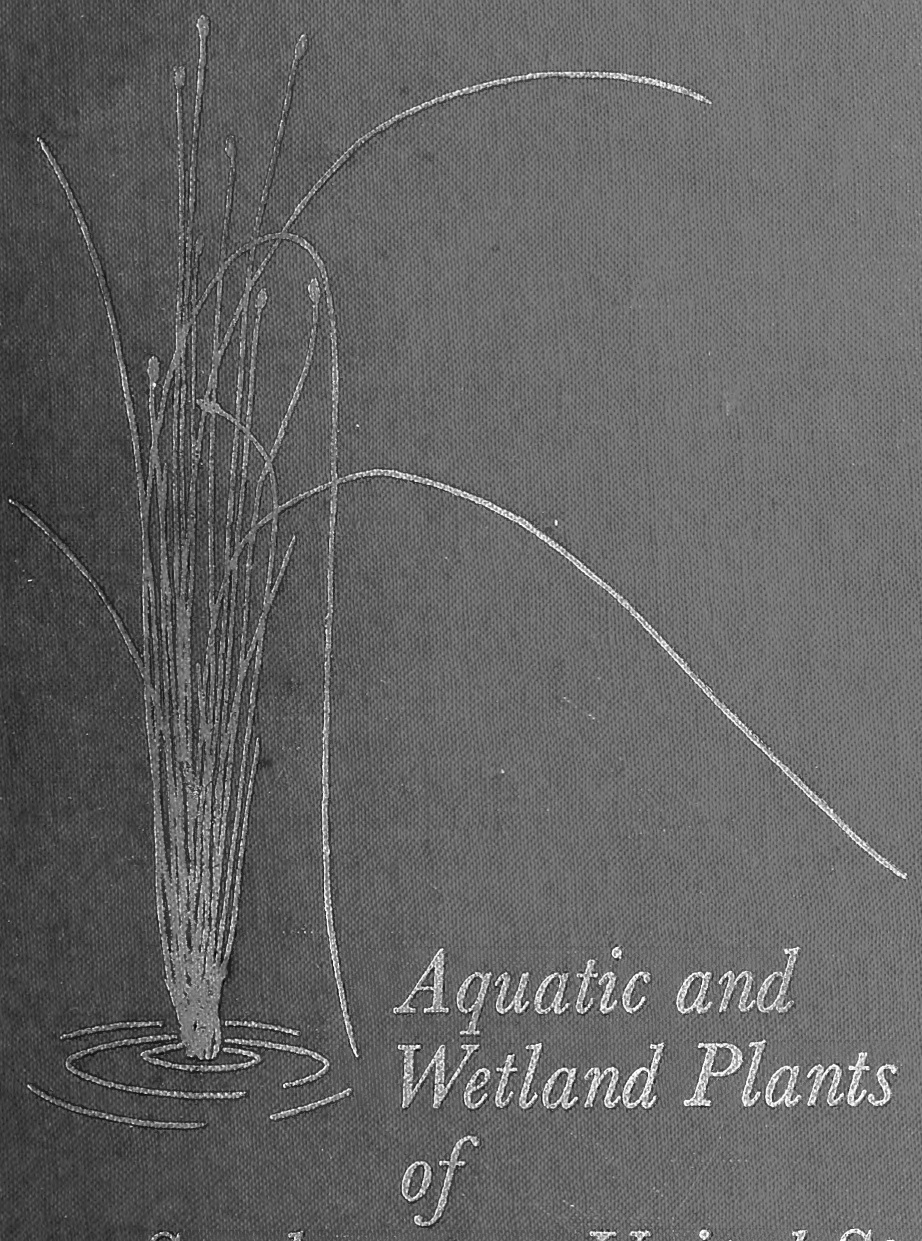

Southwesterm United States 



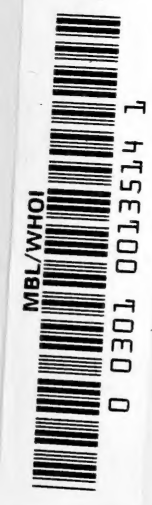





\section{Aquatic and Wetland \\ Plants of Southwestern \\ United States}




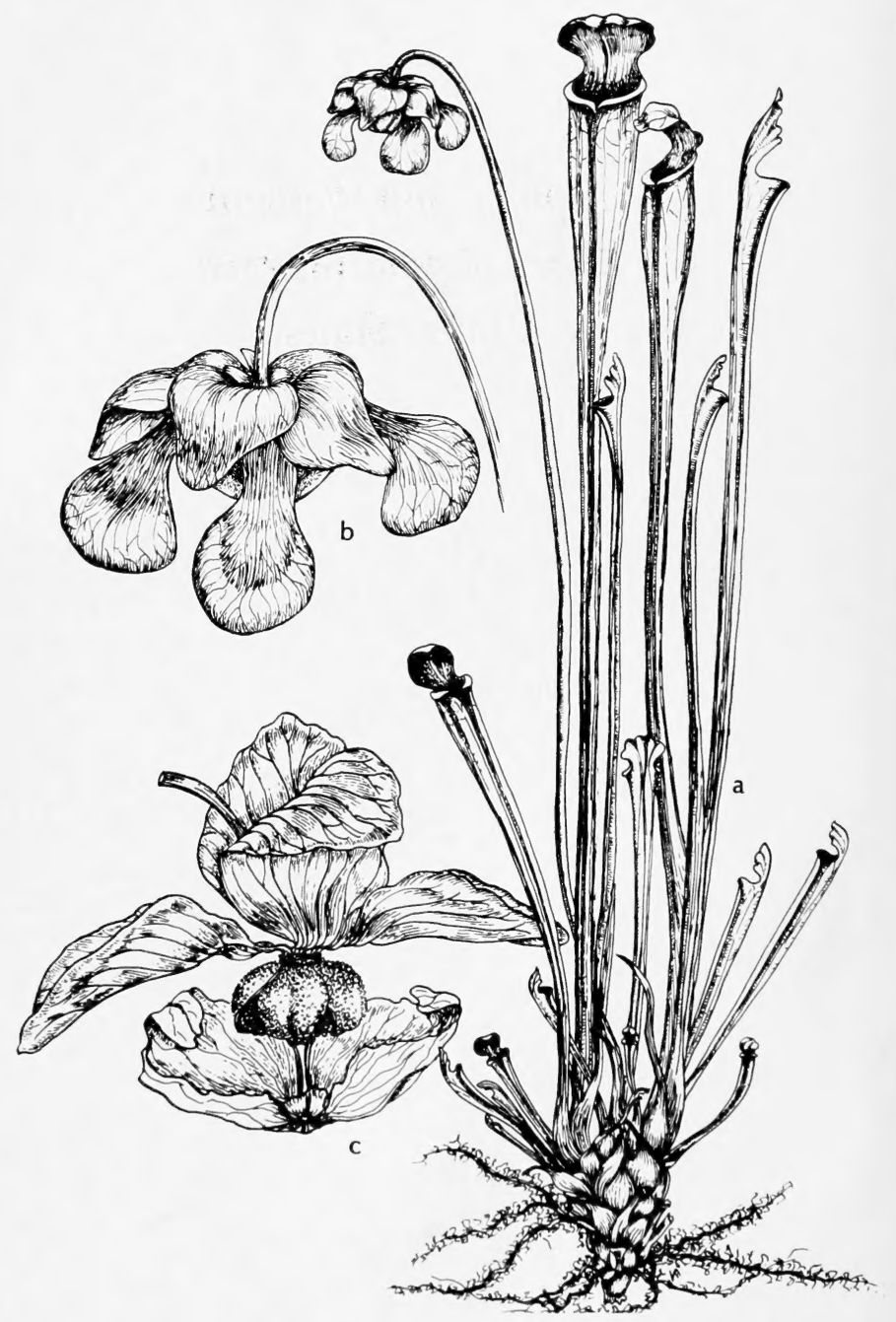

Frontispiece: Sarracenia alata: a, habit, x 1/2; b, flower, x 1; c, fruit, x 1. (V.F.). 


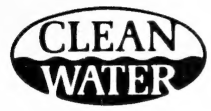

WATER POLLUTION

CONTROL RESEARCH SERIES

16030 DNL $01 / 72$

Aquatic and

Wetland Plants

of

\section{Southwestern United States}

by

Donovan S. Correll

Southern Methodist University

and

Helen B. Correll

Botanical Editor and Researcher for

Environmental Protection Agency

ENVIRONMENTAL PROTECTION AGENCY

Research and Monitoring

Grant No. 16030DNL

January 1972 
Library of Congress Catalogue Card Number 72-6000-67

For sale by the Superintendent of Documents, U.S. Government Printing Office Washington, D.C. 20402 - Price: $\$ 7.75$ Stock Number 5501-0177 


$$
\begin{gathered}
\text { To } \\
\text { Vivien FraZier } \\
\text { and } \\
\text { AileEn MadDox } \\
\text { Whose Steadfast Help } \\
\text { Made This Work Possible }
\end{gathered}
$$




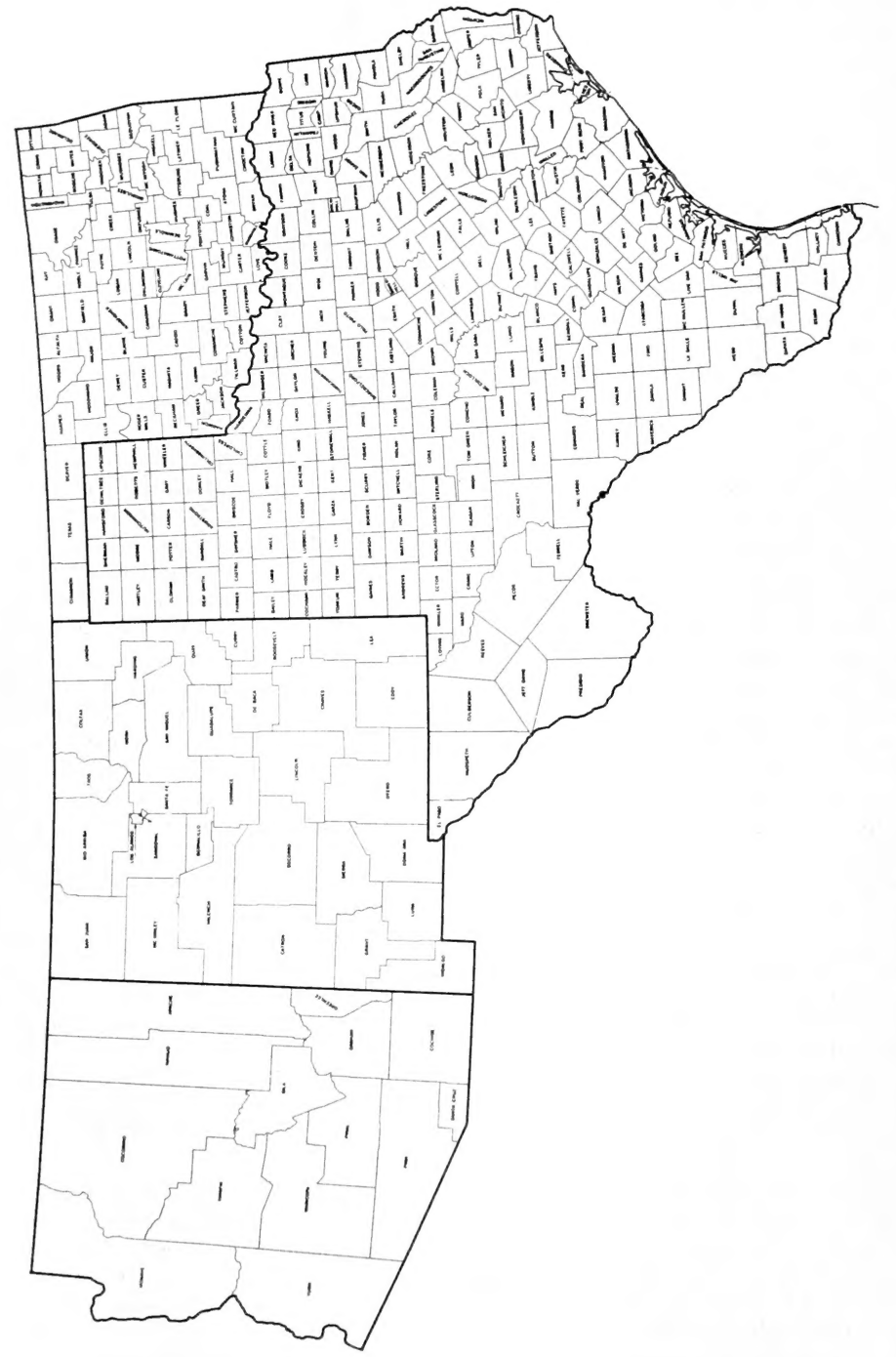

 
Upon reconsideration, however, it was decided to use the political boundaries of those states that are considered to make up southwestern United States as the boundaries of our project area; namely, Oklahoma, Texas, New Mexico and Arizona. Since there is some interplay of species where the eastern forests and the western prairies join, it was thought best to incorporate these forest areas. Their inclusion augmented considerably the number of wetland plants, as well as strictly aquatics, to be treated in our research. It was our opinion that the inclusion of species in these forested regions would make our work not only more useful in the states covered by our research but also of some use to those states to the east and northeast of our area. We also considered that since the greater part of the water that is found in the lower, more arid regions is derived not so much from rainfall but from springs and snowfields, and other such places found in the high mountains, the montane vegetation that is associated with these water sources should also be included. The inclusion of these plants of primarily seepage areas that are usually confined to high mountain regions further augmented the species that we were to treat.

This project was originally visualized, in early 1963 , to be a taxonomic-ecologic treatment, but after more than a year of vainly searching for an interested qualified ecologist to work on the project the ecological phase was reduced to what the taxonomists could contribute. Today, considering that "ecology" and "environment" are so popular with almost everyone and with nearly all phases of our life, it seems unthinkable that, in 1963, we were unable to convince those ecologicallyminded and -trained individuals whom we approached to take part in this project. We received only resistance from prospective applicants-everything from not wanting to get their feet wet, not wanting to do field work, not interested in working on aquatic plants, to "what is the need and use of doing this research?" Needless to say, we were disappointed by such lack of interest. In spite of this discouragement, a great amount of ecological and environmenal information was gained by our own observations that was supplemented by pertinent information found in literature.

Nevertheless, this work does not pretend to be a study of the ecology of hydrophytes nor of their complex physiology and morphology. Rather, it is an attempt to present a taxonomic treatment of the species that comprise what we know as hydrophytes without degenerating "into a tedious floristic catalogue," as abhorred by Sculthorpe (1967) and others.

Since no ecological studies, as such, were undertaken, field work, except in selected localities, consisted primarily in what might be termed a random sampling of various types of habitats located throughout the region covered. Locations would be visited, often more than once during any one season, observations recorded, and herbarium vouchers prepared. Approximately 9,000 field collections were made during the course of the work, the first set of which is in the Herbarium of Texas Research Foundation (LL), Renner, Texas. Additional specimens are in the Gray Herbarium (GH) of Harvard University, The University of California Herbarium (UC) at Berkeley, Rancho Santa Ana Botanic Garden Herbarium (RSA) in California, Florida State University Herbarium (FSU), Tallahassee, and elsewhere.

Distribution information within our area of study is based primarily upon the 9,000 botanical vouchers that were collected during the course of this project, and upon those that were examined, where possible, in various herbaria. These distribution data are supplemented by a discriminate and judicial adaptation of distributional information provided by published monographs, revisions, Floras and other such basic literature that are included in our Bibliography. 
The descriptions of families and genera, while they definitely include the plants in our area, have, in many instances, been written so as to include plants that might eventually be found in southwestern United States.

In giving habitat data for the species, in most cases only habitats that fall within the province of our interest are given. In other words, in the case of those species that are tolerant to a wide range of habitats only the aquatic or wetland habitats are usually cited.

We early realized that the scope of our work could become prodigious, especially when we discovered that similarly appearing habitats in proximity more frequently than not had a dissimilar floral composition. This meant that if we expected to obtain a complete knowledge of the occurrence and distribution of species within our region it would be necessary for us to investigate as many localities as possible in a given area rather than to depend solely upon random sampling in few specific localities.

We also realize that there are distinct possibilities that some researchers or otherwise interested individuals may find species that they consider should have been included in this work. These omissions could be due to a number of reasons, foremost of which would be a lack of information or a difference in interpretation as to what should or should not be included, or to an oversight on our part. If such an omitted species is found we recommend that its identity be sought in some one of the standard Floras that covers the particular region in which the plant is found. These Floras are cited in the Bibliography.

It is also possible that some of our colleagues may question our inclusion of certain species, especially the woody ones. Among these might be Cephalanthus occidentalis, Gleditsia aquatica, Nyssa aquatica, Salix spp., Quercus spp., Platanus spp. and Tamarix spp. Since this treatise is not solely a biologic one but is also concerned with the economics of water and its utilization by plants, species such as the above have been included. Also, since they grow either directly in water, in saturated soils or along water courses they must be considered to be heavy users of water. The same principle is applied for the inclusion of plants that grow in such places as alpine and subalpine wet meadows, on seepage slopes below snowfields, and in seepage along streams and about springs. These plants draw heavily upon the very source of water that ultimately makes up the streams and rivers at lower elevations. They also form turf that aids in the control of water flow from such places.

When originally proposed, this project was intended to be concerned with aquatic and wetland plants in every type of habitat that fitted into these categories. However, when support was first obtained from the National Institutes of Health, officials of that agency suggested an administrative change for the title so as to be more in line with the work and purpose of their organization. The title change was to be "Aquatic and marsh plants of polluted waters in southwestern United States." With this new title, we considered having the subtitle read "Paludal Plants of Polluted Places."

So as to live up to the administrative title as much as possible we have paid particular attention to the sewage effluents from small and large cities, essentially open cesspools of villages and small towns and even the seepage from large septic tanks of motels, homesite developments and other such places that often were flowing into lakes within a few yards of beaches where children and their parents were playing and swimming. We never felt delinquent when we worked along rivers or streams, and in and about lakes and other impounded waters, because we realized that we were still working within the administrative bounds of our project. We considered unpolluted only those streams and water bodies from which we could drink directly. Needless to say, we would have perished from thirst if we 
had confined the quenching of thirst to such places. One should be apprised from the above that we were able to complete our project essentially as it was originally proposed.

About midway in our research that was begun in 1964, public outcry was raised against pollution and for conservation and the preservation of a balance in nature's ecology. We have, consequently, taken into consideration this biotic interest of man in his environment. Since this explosion of public interest in our environment and its ecology practically every author or would-be author has written something on these now popular subjects to the extent that there exists very little one can say without repeating what someone has already said. Neverthless, since we believe that some ecological background information to our work would be useful we have presented it in the form of summarizing what is now common knowledge with a sprinkling of our own personal observations.

This work, however, is not, and never was, intended as a treatise to cover all facets of water pollution. It does, however, attempt to deal with one of the most obvious and important factors-higher plant life-in the ecosystems of our lakes, ponds, streams, marshes, swamps, bogs and wetlands, generally. Also, since, at least administratively, this project has been officially classified as "Aquatic and Marsh Plants of Polluted Waters ....," we believe that at least a brief summary should be given of the kinds and types of pollution that is to be expected or that actually exists in most of the habitats that we have studied.

In our work we are often asked what can be done about water pollution. We always say that from this minute on no facility, whatsoever, should be permitted to be built and put into operation unless it is so planned and structured as to create no further pollution. Then, methodically and persistently, our present polluters and their pollutants should be eliminated or corrected without delay. We are pleased to note that the newly created Federal Government Environmental Protection Agency plans to do just as we have always recommended to our listeners.

One of the best means for establishing and inculcating in our people a lasting appreciation of nature is the teaching of natural history in our schools, starting with Kindergarten and carrying the program through the senior year in college. All colleges, universities and other institutions of higher learning should have established long ago a required Natural History course for all freshmen students. For many years we and others, among whom is George S. Avery, former Director of the Brooklyn Botanical Garden, have "preached" that this emphasis on natural history should be made a part of every student's educational curriculum. This would not only include touching upon certain phases of biology, especially those with which one may make daily contact, but also upon related sciences, such as geology and meteorology, that make up the total environment. The end result would be a population that would really appreciate and protect every phase of the world in which we live. The required or elected courses such as botany, zoology, entomology, mycology and so forth, that would fall into a comprehensive natural history course, are given by most college and university departments as if the student taking the course is to become a professional in that particular discipline. To teach an appreciation of nature in all its aspects to the laymen students has apparently never occurred to most teachers. For this reason, an old fashioned course in Natural History for the lay student is, and has long been, desperately needed in every institution of learning so as to not only enlighten the student but to also place emphasis upon his understanding and appreciation of the world and its inhabitants so that he will become a part of Society that will appreciate and protect our Environment. 
Perhaps, at last, there will be raised a generation of champions of Nature, or what we vulgarly call "The Environment," in spite of our adult population. Our modern day youth, in its intransigence, is rapidly becoming apprised of the fact that instead of continuing to live "on" Nature we absolutely must, before it is too late, learn to live "with" Nature.

A major problem for the conservationist in our area, as well as in all areas that support considerable wildlife, is the indiscriminate draining of marsh areas, swamps and savannahs. A more recent tendency of potentially disastrous portence to wildlife is the dredging and "straightening out" of meandering streams. Instead of flooding during high water, with consequent water renewal in adjacent or nearby marshes and wetlands, the habitations of much of our wildlife, these newly created "ditches" allow the water to rush with tremendous scouring effect down their raw troughs. This, in itself, creates a pollutant condition in that the water is usually badly clouded from silt which, in turn, is frequently dropped in lakes to build up their silted bottoms or carried out into oceans to pollute their estuaries.

We have tried to present our subject matter as objectively as possible, although, as botanists, we tend to lean toward the survival of plant life, especially when we are in the process of studying it.

Support for the initial phases of this research, begun in September, 1964, was provided by the Division of Water Supply and Pollution Control, later changed to the Federal Water Pollution Control Administration, National Institutes of Health, United States Department of Health, Education and Welfare (Grants WP 00685-01 to 04A1 and 03S1). We are especially grateful to Dr. Robert A. Littleford of the National Institutes of Health, who initially approved our project for support. In September 1966 this agency was transferred to The United States Department of the Interior as the Water Quality Control Administration, where, thanks to Dr. J. Frances Allen, support for our project was continued until December 31, 1970 (Grant 16030 DNL), after which it was transferred on January 1, 1971 to the Environmental Protection Agency. We are, indeed, grateful to each of these government agencies and their administrators for the support we have received during the course of this research. We are also grateful to the Environmental Protection Agency and its administrators for support to publish the work.

Without the cooperation and help of various individuals and institutions it would have been most difficult for us to pursue and complete this work. The officers and trustees of Texas Research Foundation tolerated our stay at their institution so that we could complete this task. We are especially indebted to John R. Crutchfield who worked with us from May 1965 through July 1967 as a plant collector, and to Richard S. Mitchell who collected plants for our project during the summer of 1967.

The generosity of Herbert L. Mason, of the University of California at Berkeley, in permitting us to use a great many illustrations from his excellent work, "A Flora of the Marshes of California" (1957), is gratefully acknowledged. Dr. Mason also generously permitted us to use some of the information and data in his treatise.

We are especially fortunate to be able to use, through the generosity of Robert K. Godfrey, of the Florida State University at Tallahassee, a large number of the drawings that he had made for his temporarily suspended project on the aquatic and marsh plants of Florida. We were thus able to illustrate many of the species in eastern Texas and Oklahoma that are also common to Florida. We are, indeed, most grateful to Dr. Godfrey for the privilege of using these excellent drawings which he plans to use eventually when his work is published.

In undertaking a problem of this magnitude we have had to resort to a considerable amount of judicious compilation from the published work of many of 
our colleagues. Especially to be mentioned here are the various Manuals and Floras that cover to some extent plant species that occur in our region of investigation. By way of acknowledgment and also as a ready reference, all of these works that were consulted have been included in the Bibliography. We are most grateful to have had these publications available to us. Since the subject matter covered has been expanded to a considerable degree beyond the scope of that of most past workers in this field, these ready references were especially helpful.

We would like to note especially the work of C. D. Sculthorpe (1967), "The Biology of Aquatic Vascular Plants." It is a most lucidly written treatise, and one from which we have derived much help and information. A great amount of pertinent and valuable information regarding these plants has been compiled in this most useful work, and it is here highly recommended to all interested parties.

Research on this project ran concurrently for several years with work on the preparation of Correll's and Johnston's recently published (1970) "Manual of the Vascular Plants of Texas." We are, indeed, grateful to our fellow-author of the Manual, Marshall C. Johnston, of the University of Texas at Austin, and to the many collaborators for the privilege of using in this work some parts of their contribution to the Manual, where they and their individual contributions are acknowledged. We are equally grateful to those individuals whose published materials were adapted for use in the Manual, and acknowledged there, for the use of some parts of their material in this work. Where new material has been adapted for this work it is acknowledged where this adaptation occurs.

There are many individuals, too numerous to mention by name, who have been directly or indirectly helpful to us in our research, and to whom we are most grateful. Foremost among these are the curators of various herbaria in which specimens from our region are deposited. In regard to specimens, we wish to acknowledge especially those that were received from several individuals who made a special effort to collect aquatic plants for us. These are Frederick R. Gehlbach, of Baylor University, who also joined us in some field work in Arizona, Jimmy R. Massey, of Texas A\&M University, Charles R. Hutchins, of Albuquerque, New Mexico, and Elray S. Nixon, of Stephen F. Austin State College. We are also grateful to Alan R. Smith, of the University of California at Berkeley, for his having clarified for us a part of the difficult genus Thelypteris, and to Neil Hotchkiss, now retired from the Patuxent Wildlife Research Center, U. S. Dept. of the Interior, for his thoughtfulness in sharing his experience with us at the beginning of this project, and for his continued interest in our work.

Two botanists who accompanied us on field trips and were especially helpful are Eugene C. Ogden, New York State Botanist, Albany, and Henry K. Svenson, United States Geological Survey, now retired.

In addition to help received from professional botanists, several highly skilled amateurs in Texas have either directed us to new e!ements in our aquatic flora or have provided assistance in one way or another. Among these are Geraldine E. Watson of Silsbee, Peggy A. Amerson of Mt. Pleasant, Jim D. Bowmer of Temple, and Raymond J. Fleetwood of Angleton.

It is impossible to thank sufficiently the artists who have patiently and painstakingly delineated the often intricate and complex species. We are especially indebted to Vivien Frazier, with whom we have been associated in botanical art work for many years, for her faithful attention to the most exacting details in the rendition of her drawings. She has been of inestimable help to us. We are also grateful to Jane W. Roller and Phoebejane Horning who prepared several of the drawings used in this publication for works previously published by the senior author, and to Regina O. Hughes, who previously made drawings for the senior author's work on tuberous Solanum species of North America and Central America, for several of her plates that were recently published in Clyde Reed's "Selected Weeds 
of the United States" (1970), and several plates of Hibiscus. We are most grateful for the privilege of using some of the grass spikelet drawings by Agnes Chase, published in Hitchcock and Chase's "Manual of the Grasses of the United States" (1935, 1951). We are grateful for the privilege of using drawings of several orchids by Blanche Ames Ames and Gordon W. Dillon, and of several species of Umbelliferae by Mildred E. Mathias. To the various artists whom we have not known personally but whose work we admire and are grateful to include in our publication, we extend our most sincere thanks. These are Mary Wright Gill and Edna May Whitehorn who made most of the drawings published in Hitchcock and Chase's grass manual; Mary Barnas Pomeroy, Patricia Verret Reinholtz, Robert Mill and Emily Patterson Reid, who prepared the drawings published in Mason's "A Flora of the Marshes of California" (1957); Barbara N. Culbertson and M. Grady Reinert, who prepared the drawings for Godfrey's yet unpublished research on the aquatic and marsh plants of Florida. We are, indeed, grateful to each of these individuals for his or her contribution to this project.

The careful and exacting work of Mrs. Aileen Maddox in typing the manuscript and her assistance in all other phases of the research we gratefully acknowledge. Her enthusiasm for the project frequently lifted our sagging spirits.

As noted before, the main purpose of this work, as is that of any such manual, is to provide a means for the identification of the aquatic and wetland plants in the region under consideration; namely, southwestern United States. For the most part, we believe that the text is uncomplicated and straightforward and needs no explanation. Several points, however, should be clarified. Although the families are arranged phylogenetically essentially in accordance with the Engler and Prantl System, many of the genera and the species within a family or genus, respectively, are not arranged in phylogenetic order. This phase needs more study than time allowed for the present. In the Keys the first number in each couplet, except for the first pair, is accompanied by a number in parenthesis. This number in parenthesis refers back to the previous couplet from which the present one was derived. With this aid one can quickly and readily retrace one's steps back to the very beginning of the Key if need be. The branches or "legs" of each couplet are terminated either by a plant name or by a number in parenthesis that refers to a subsequent couplet. In regard to the measurements and numbers of parts given in some sections of the text, as "petals (5-) 7-9 (-12) $\mathrm{mm}$. long," such may be interpreted as "petals usually 7-9 $\mathrm{mm}$. long but sometimes as short as $5 \mathrm{~mm}$. or as much as $12 \mathrm{~mm}$. long." The less common extremes in measurements and numbers of parts are enclosed in parentheses.

We can not over-emphasize the need for exerting the most strenuous effort to clean up our total environment. Our close observation of much of the aquatic and wetland habitats in southwestern United States has indelibly impressed upon us the appalling conditions that now exist in many of these places that are of vital interest to plants and animals, and to the general well-being of mankind. Alung with the present cleaning, and the future protection, of our environment will come conservation. One follows the other!

Finally, we believe that any kind of work such as ours should represent a combination of our efforts and those of our many colleagues. We are grateful for their work which has contributed immensely to the fulfillment of the present task. 


\section{Contents}

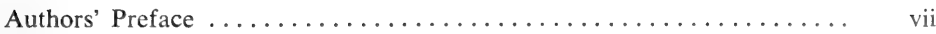

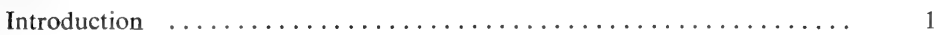

I. Habitats of Aquatic and Wetland Vascular Plants .......... 2

II. Peculiarities and Distribution of Aquatic and Wetland Vascular Plants............................... 6

III. Economics and Control of Aquatic and Wetland Vascular Plants 10

IV. Pollution in Aquatic and Wetland Habitats ............ 12

Key to the Major Groups and Families of Aquatic and Wetland Vascular Plants

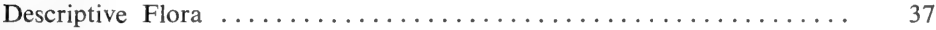

I. Pteridophyta ........................... 37

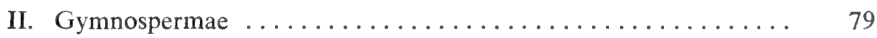

III. Monocotyledoneae ........................ 85

IV. Dicotyledoneae ......................... 734

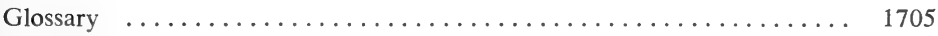

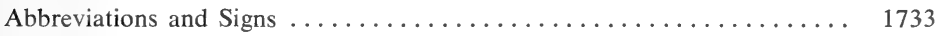

Selected References ........................... 1737

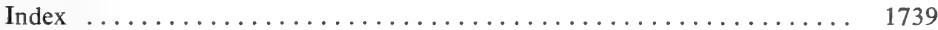





\section{Introduction}

Southwestern United States, as we have come to know it, is a vast and complex region that includes practically any ecosystem that can be found in the world today, exclusive of polar regions. The area studied extends from the warmtemperate mesophytic forests and Gulf Coastal Plain of southeastern Texas, and the subtropical Rio Grande Valley, to the alpine summits of the Rocky Mountains in New Mexico and Arizona, and the Sonoran Desert of southwestern Arizona.

For the most part, our region is one of high evaporation which, even in a single season, can greatly affect the composition of various plant communities. This high rate of evaporation that causes drastic fluctuations in the water level of a water body can quickly alter or change entirely its ecology. Through desiccation, with the lowering of the water level, much of the vegetation occupying the marginal zone can perish, while the submersed and floating vegetation may be adversely affected by lack of light and oxygen sufficient to carry on the life processes.

In addition to this drastic evaporation from open water surfaces and land, vast quantities of water are transpired from plants. Our work, which we consider to be a water-economy oriented botanical treatise, is concerned primarily with these plants that have the greatest impact upon our water resources. For this reason not only those plants that live in open water or marsh areas are treated but also those plants that are known as phreatophytes, or those plants whose roots tap the ground water. These latter plants are considered by some authorities to pose a definite threat to the meager water resources in some parts of southwestern United States. Many government and private foresters consider that such plants as the salt cedars (Tamarix) that grow especially in alkaline or saline floodplains, about lakes and on streams and river banks use water wastefully and are of little or no benefit. These foresters advocate the cutting and rooting out of these plants. This, of course, would be the simplest and probably the costliest procedure. We believe, however, that more consideration should be given to a long-range, more permanent control.

Surface waters of southwestern United States are almost entirely utilized, and ground water is being pumped at a rate that exceeds the estimated recharge. In some areas in this vast region the average depth to ground water has been found to be increasing at an annual rate in excess of $20 \mathrm{feet}$. In the light of such frightening statistics we should realize that we should delay no longer in learning all we can about our water resources and every factor that may have any kind of influence upon them, no matter how trivial such may seem to be.

Our decision as to what plants should be included in this work has been influenced as much by practical and utilitarian factors as by strictly biological considerations. In respect to interpretations, we have found that the most exasperating and frustrating part of the work is that which involved decisions as to what species to include; in other words, what should the limits be? After being certain that all strictly aquatic and wetland species have been included, we found that the periphery of inclusion had a tendency to spread to the margin of 
mesophytism. Since all vascular plants depend more or less upon water for their very existence, and are thus biologically "aquatic" to a greater or lesser degree, a premise to determine just how much effect a particular species has upon the water resources of a given area could be carried to a ridiculous extreme.

In the Introduction to his "A Flora of the Marshes of California," Mason has expressed in unequivocable terms the way we feel about the limitation or lack of limitation that should be placed upon plant species to be included in a work such as this. We agree with him entirely when he says that the circumscription of the field of research in this type of problem is not clear cut and that its boundaries are usually highly artificial. We not only include the wholly aquatic species but also the important and frequently critical amphibious species. But, as Mason succinctly states, when we include ".... the amphibious species, we are drawn immediately up on the shore, where the naturalness of the communities and the overlapping of their species lead us farther and farther away from water."

For convenience and simplicity, the term "vascular hydrophytes" has frequently been used here to include both aquatic and wetland plants.

\section{Habitats of Aquatic and Wetland Vascular Plants}

Several outlines have been proposed to cover the various habitats in which aquatic and wetland plants are to be found. For our purpose, and because it is more far-reaching than most others, the one proposed by Mason, in 1957, is the best yet devised. With some reorganization and the addition of several habitats peculiar to our region, Mason's outline is as follows:

I. Water standing or essentially so.

A. Presence of water permanent and level fairly persistent.

1. Open water surface the most conspicuous feature.

a. Fresh water: lakes, ponds, reservoirs.

b. Salt water: salt lakes, bays and oceans, estuaries, lagoons.

2. Vegetation more conspicuous than water surface.

a. Vegetation dominantly herbaceous.

aa. Marshes: alkaline marshes, salt marshes, brackish marshes, freshwater marshes.

bb. Bogs: quaking bogs, floating bogs, evergreen shrub bogs.

b. Vegetation dominated by trees and/or shrubs.

aa. Swamps, bay-galls.

B. Presence of water intermittent or at least the level widely fluctuating.

1. Intermittence seasonal: vernal pools, playa lakes, vernal marshes, savannahs.

2. Intermittence tidal: Salt-water marshes, seasonally salt and fresh-water marshes, fresh-water marshes subject to tidal influence.

II. Water flowing: live streams, intermittent streams, irrigation ditches, drainage canals, hillside bogs, streamside marshes.

III. Wet soil adjacent to habitats with standing or flowing water: strand areas, riparian lands, lacustrine lands, wet meadows, seasonally wet floodlands.

There are very few natural lakes in southwestern United States, and these are to be found mostly at high elevations in the mountains. Their creation is solely the result of local conditions. The great ice sheets that formed lakes such as those found in Wisconsin never reached this region. There are, however, innumerable man-made lakes, reservoirs, ponds and stock tanks to be found in southwestern United States, and many great and small rivers with numerous tribu- 
taries dissect this region. In eastern and southeastern Texas are to be found evergreen shrub bogs and savannahs. In this same area as well as in Oklahoma are to be found swamps, alluvial woodlands and floodplains, and along coastal Texas are to be found vast fresh and brackish marshlands, rice paddies, ocean beaches and shores, drainage canals, bays, reefs, estuaries and sluggish streams. Inland, especially in areas of low rainfall throughout our region, are to be found irrigation ditches, lakes on salt deposits, and saline and alkaline flats that are periodically inundated. In these more arid regions are to be found rivers and streams that may have their beginnings in springs and artesian wells at high mountain elevations but which disappear as dry beds as they flow into the lowlands.

When a body of water is created by man, usually the first obvious plant invaders are cat-tails (Typha); their essentially weightless wind-blown seeds would appear to be hovering nearby. Next, or occasionally invading simultaneous with cat-tails, are bulrushes (Scirpus). These early invaders first establish themselves in shallow water and then, through clonal growth by means of rhizomes and stolons, migrate out into deeper water where they form dense conspicuous colonies that provide a habitat for small floating plants and they give protection and shelter to various wildlife.

As noted above, similarly to natural lakes in the North, these southwestern artificial lakes and ponds, when stabilized, also typically have several zones of vegetation. The outermost zone is one of emergent vegetation, wherein the plants are rooted in the lake substrate and the photosynthetic organs stand above the surface of the water. Here we find primarily grasses, rushes and sedges, among which are spike rush (Eleocharis), sedge (Carex), bulrush (Scirpus), bur-reed (Sparganium), cat-tail (Typha), water plantain (Alisma) and arrowhead (Sagittaria).

The next zone, moving lakeward, is that of floating-leaf plants. These plants may be rooted in the lake substrate or they may be free-floating. In either case, they have their leaves floating on the surface of the water, or, in some instances, with some leaves raised above the surface of the water. Among these plants are water shield (Brasenia), yellow water lily (Nuphar), white water lily (Nymphaea), pondweed (Potamogeton), water ferns (Azolla and Ceratopteris), water hyacinth (Eichhornia crassipes), water lettuce (Pistia Stratiotes), duckweed (Lemna), duckmeat (Spirodela) and water meal (Wolffia).

The innermost zone is composed of entirely submersed plants or those with only their flowering and fruiting parts emersed or floating. These plants are characterized by having long, sinuous or straplike leaves and with a bunched growth habit and finely dissected highly branched leaves. These plants derive gases and nutrients from the water in order to survive. Among these plants are milfoil (Myriophyllum), hornwort (Ceratophyllum), naid (Najas), waterweed (Egeria, Elodea) and fanwort (Cabomba caroliniana). The non-vascular plants, stonewort (Chara and Nitella), are also frequently abundant in this zone.

This phenomenon in nature that can be "a thing of beauty," the zonation of life forms of undisturbed, natural aquatic vegetation that becomes established and is so prevalent about the shores of lakes, ponds, canals and slow-moving streams, when once destroyed or disturbed by man's "improvements," or his propensity for gross pollution, is essentially impossible to re-establish. Since this zonation is the result of natural succession by plants in this type of habitat, they should be left undisturbed if man is to maintain his aquatic environment as it should be in such places.

Coastal marshes, known to support numerous species of plant and animal life, are among the most important of all natural habitats. In these areas a very slight change in elevation will also mean somewhat of a change in the vegetative cover. 
Our only development of coastal marshlands occur on the Gulf Coast of Texas. The area is characterized not only by salt meadows, salt marshes, tidal flats and estuaries, but also by fresh-water marshes, swamps, meandering bayous and resacas, and sloughs. Some of the nation's largest wild-life reservations, especially for waterfowl, are to be found in this region.

The salt marsh areas typically support species of Carex, Cyperus, Eleocharis, Rhynchospora, Scirpus, several cordgrasses (Spartina) and seashore saltgrass (Distichlis spicata).

Aquatic plants abound in this region. Among these are Wolffia, Wolffiella lingulata, parrot's feather (Myriophyllum), pondweeds (Potamogeton), duckweeds (Lemna), duck meat (Spirodela), water-lilies (Nymphaea), cow-lily (Nuphar luteum), Hygrophila lacustris and arrowheads (Sagittaria). The beneficial aquatic plant species as well as open water for fish and wildlife in many of the streams, canals, lakes and ponds are threatened by several introduced noxious, aggressive species. Foremost among these are the water hyacinth (Eichhornia crassipes) and alligator weed (Alternanthera philoxeroides). The native cat-tails (Typha) also belong here. Other species that can and may prove to be troublesome in this and other parts of our region are aquatic species of water-primrose (Ludwigia), water-lettuce (Pistia Stratiotes), common frogbit (Limnobium Spongia) and American featherfoil (Hottonia inflata). In bays and open waters along the Gulf Coast are to be found such marine species as Cymodocea filiformis, Thalassia testudinum, Halophila Engelmannii, Halodule Beaudettei, and rarely Posidonia oceania. Some of these are often washed up on the beaches along the coast.

Shallow ponds and backwaters of river margins are usually the beginnings of fresh-water marshes. These marshlands are treeless expanses, often with dense growths of herbaceous plants such at cat-tails, grasses and sedges. In marsh pools, where the water is deeper, water lilies, pondweeds and other plants become established.

Plants such as cat-tails, bulrushes, bur-reeds, Sagittarias, Pickerelweed, Peltandra and button-bush are rooted in mud in shallow water on the edge of ponds and quiet backwaters of rivers. In ponds, for instance, plants grow outward from the bank and shallow water to deeper water where water-lilies, Nuphar and Brasenia take their place. On out into the deepest open waters both rooted and free-floating plants such as the carnivorous bladderworts, pondweeds, Cabomba and Ceratophyllum are found. Through the years as the plants on the outer periphery continue to move toward the center of the pond they shade and crowd out the floating and submerged plants that die and contribute to the filling of the pond. As the filling continues the vegetative composition of the pond is affected until a marsh is evolved-a treeless tract of water and aquatic plants.

With continued filling by dead plants and silt the marsh, in turn, will give way to the sedge-filled meadow that, with the invasion of trees and shrubs, will eventually become a wooded swamp.

Littoral vegetation zones similar to those found in lakes are often found along streams, especially if shallow water areas occur. Pickerel weed (Pontederia cordata), smartweed (Polygonum) and various grasses and sedges are often to be found in such areas.

Similarly to our lack of glaciation-formed lakes, our region does not have the type of bogs that are characteristic of far northern glaciated regions. Some of the bogs developed in the high mountains of New Mexico and Arizona approach these northern bogs, but they lack most of their characteristics. In glaciated country, lakes formed by ice often have relatively steep banks and poor drainage that make them conducive for the formation of bogs. True bogs are characterized by having low-growing shrubs and sedges in sphagnum mosses. 
These often form floating or stable mats supported by a peaty mass of partly decomposed plants. The outer edge of the bog has various types of tree species, determined by that part of the world in which the bog lies.

In small lakes in eastern and southeastern Texas floating mats are occasionally formed where Decodon borders the water. Sedges, rushes, various species of Hypericum and other such plants commonly grow upon these floating or quaking, somewhat stabilized mats. Various evergreen or semievergreen shrubs and small trees often border these lakes, among which are yaupon (Ilex vomitoria), bay-gall bush (I.coriacea), leatherwood (Cyrilla racemiflora) and viburnums.

In most bogs, especially at great depths, there is little oxygen and, along with acids formed by peats, decay is slow and fallen plants deposited in them often only partly decay to become more peat. Because of their stagnant, usually highly acidic environment, most bogs have their own peculiar flora, usually dominated by thick-leaved shrubs and herbs.

Two distinctive types of habitats, the evergreen shrub bog and savannah, occur to a limited extent in our area. The savannahs are found only in southeastern Texas and the bogs in southeastern and to some extent in eastern Texas.

In pockets throughout eastern and southeastern Texas are found not only evergreen shrub bogs but also open seepage slopes and cypress-tupelo swamps. The latter also occur in southeastern Oklahoma. These usually develop in sandy, seepy areas, either on or at the bottom of slopes, in scrub oak-pinelands, or in permanently wet depressions in savannahs. They are characterized by usually having peat moss (Sphagnum) present in varying degrees. The shrubs in and about these habitats are often evergreen or semievergreen. They consist mostly of viburnums, hollies, rhododendrons, bay laurel (Magnolia virginiana), waxmyrtles, hypericums, dogwoods, vacciniums, leatherwood (Cyrilla racemiflora), Lyonia, Itea, and occasionally a sprinkling of poison sumac (Rhus vernix). Often the herbaceous vegetation is quite different from that of the surrounding country, and is represented by such uncommon species as nodding-nixie (Apteria aphylla), Bartonia texana, Viola lanceolata, grass-of-Parnassus (Parnassia asarifolia), bogmoss (Mayaca Aubletii), pitcher plant (Sarracenia alata), rose pogonia (Pogonia ophioglossoides), bearded grass-pink (Calopogon barbatus), small wood orchid (Habenaria clavellata) and yellow fringed orchid (H. ciliaris).

In extreme southeastern Texas, centered in Jasper, Tyler and Newton counties, are savannahs of broad, level, grassy, open pinelands. These are characterized by a fluctuating water-table, often found at or near the surface, and they support a rather distinctive and interesting marshy and wetland flora. This includes several orchids, as the snowy orchid (Habenaria nivea), crested fringed orchid (H. cristata), grass-pink (Calopogon pulchellus) and several species of ladies' tresses (Spiranthes), yellow stargrass (Aletris aurea), pipeworts (Eriocaulon), whitehead bog-button (Lachnocaulon anceps), several meadow beauties (Rhexia), clubmosses (Lycopodium), milkworts (Polygala), small butterwort (Pinguicula pumila), bluehearts (Buchnera), sundews (Drosera), seedboxes (Ludwigia) and numerous sedges, grasses and bulrushes that are indigenous to this type of community. The savannahs and shrub bogs, where they occur in proximity, commonly grade into one another. Plants in this border-zone are often a mixture of those in the two communities.

The swamp, a wetland covered with trees and shrubs, is usually developed from a marsh. Typically wet and occasionally flooded, swamp forests often persist for a long time, especially when they are associated with streams that periodically overflow.

Originally an effort was made to coordinate $\mathrm{pH}$ and water temperature with the exact place of growth for a species, such as those of Potamogeton, but it was soon realized that such data, as we had intended using it, were essentially mean- 
ingless. After we discovered that $\mathrm{pH}$ and water temperature often varied at minute distances, both laterally and vertically, this time-consuming routine was discontinued.

\section{Peculiarities and Distribution of Aquatic and Wetland Vascu- lar Plants}

Aquatic plants are paradoxical in that while many are of great economic import in relation to the existence, reproduction and conservation of wild life they may simultaneously be a hindrance and detriment to man's hydrological activities such as those involving navigation and irrigation.

The establishment and existence of wetland plants in their particular habitat is much less complicated than that for strictly aquatic plants. To exist under water, vascular plants must have sufficient light and critical gases to carry on photosynthesis. The depth at which they grow depends largely upon the intensity and spectral composition of light. This becomes especially critical in waters that are variously polluted. Sedimentation created by floods and erosion, and turbidity as a result of dissolved organic matter and suspended organic and inorganic particles, may cloud and discolor the water and reduce to a bare minimum the possibility of a plant carrying on the photosynthetic process.

As has been noted by other researchers, individuals of some species grow under a single set of environmental conditions, while the individuals of other species will occur under the selective regime of different sets of environmental conditions. These latter species exhibit a wide degree of tolerance, such as cat-tails (Typha), Zannichellia, Najas, and Ruppia, usually found in fresh-water situations but that also can tolerate saline and alkaline conditions. The quality of water often, but not always, determines the plant community that will be developed in the environs. There is little question, however, that salinity has a critical and intricate influence upon the composition and development of maritime and littoral ecosystems.

While various physical and chemical factors of the aquatic environment have a definite influence upon the life activities of vascular hydrophytes, the converse is also true as has been succinctly stated by Sculthorpe (1967, p. 415).

"As a result of the relatively restricted volume of any inhabited body of water, aquatic vegetation exserts a much more profound influence upon its environment than does terrestrial vegetation. Through their photosynthesis and respiration, and their manner and rate of growth, vascular hydrophytes may have very significant effects upon such environmental factors as the concentrations of dissolved oxygen, carbon dioxide and ammonia, mineral nutrient supplies, $\mathrm{pH}$ value, light penetration, current velocity and rate of silting. These effects can wield a direct or indirect influence on the lives of other aquatic organisms, notably the microflora and fauna for which the hydrophytes may provide support, shelter or food. The impact of hydrophytes on the environment and on biotic relationships increases as the volume of the water-body diminishes; plants are most significant in ponds, canals and stagnant swamps, and in most rivers, which are usually shallow compared to lakes and so contain a relatively greater concentration of plants. Analysis of these ecological interactions presents a formidable problem: the tremendous variation in local edaphic and biotic conditions invalidates all but a very few generalisations."

The ecosystems of aquatic and wetland habitats, though not at all consistent as to their floral content, are made up of characteristic ecotypes for each kind of system. In other words, the species composition of a given ecosystem may vary in accordance to its geographical location but each kind of habitat usually has its characteristic type of flora. 
Although most species readily fall into one or another ecotype, in some instances individuals belonging to the same species, such as in Potamogeton nodosus and Polygonum amphibium, may occur as submersed or floating aquatics to amphibious, riparian or strand plants rooted in mud. These plants usually, but not always, differ somewhat in habit, in accordance to the ecotype in which they are found.

We have found, as other have found before us, that aquatic and wetland plants are not always dependable and of long-endurance in their particular habitats. A species abundant in one season may disappear for one or more seasons only to reappear in a later season. There are various possibilities as to why these plants behave thusly. A close approach to temporary extermination might result from overfeeding by wildlife; a change in the ionic composition of the water might be critical; especially in the case of vegetative reproduction, some water plants, as in many orchids, might have a longer resting period than just one year; fluctuating water levels might create physiological problems for the species.

Analagous habitats may be found in entirely different parts of our region and under an entirely different set of factors, but they may reveal certain similarities. For instance, the Weches fossil formation near San Augustine, Texas that is seepy and wet only in the spring long enough to support to maturity the annual crucifer, Leavenworthia aurea, is comparable to tidal zones where the usually perennial plants that occupy such zones must have a periodic replenishment of water in order to thrive. Under both situations the water needs of the plant are met at critical times to assure propagation and/or continued survival.

Vascular plants that are strictly aquatic, although relatively few in number when compared to their dryland terrestrial relatives, offer a multitude of taxonomic difficulties because of their diversity of habit and bewildering variations that include heterophylly and peculiar modifications in sexual and vegetative reproduction.

Heterophylly, the presence on a single individual of two or more distinct types of leaves, in habit, shape and/or anatomy is prominently displayed in many aquatic species in such genera as Callitriche, Potamogeton, Sagittaria, Ranunculus, Cabomba, Myriophyllum, Proserpinaca, Alisma, Armoracia and Echinodorus. This leaf difference in the same individual has created problems in the identification of many species in the above, as well as other, genera. This unique characteristic must be taken into consideration in dealing taxonomically with these species.

Peltate leaves, as in Nelumbo (Fig. 447), are considered to be the most mechanically efficient of all types of floating leaves. Although the leaves of Nymphoides (Fig. 1) do not have the thickness and toughness of such species as in Nymphaea, (Fig. 442) and Nuphar (Fig. 443), they do demonstrate the characteristic leaf of many floating leaved plants in their rounded blade and entire margins. The wax bloom of the cuticle on the upper surface, as in all plants with floating leaves, prevents excessive wetting of the leaf. The petioles that support these leaves are strong and pliable, and their buoyance and support are further enhanced by air-filled lacunae on the lower surface which are centered and more prominent along the midrib and near or about the petiole.

Floating leaves, in being exposed to both air and water at the same time, are rather unique and they have developed features that enable them to better withstand the hazards of their environment.

Most of our emergent hydrophytes produce aerenchyma-a spongy tissue developed mostly on the stems and branches at or below water level. This tissue may have several functions as for buoyancy for weak, arching stems of Decodon verticillatus, for storage of oxygen or for insulation and protection. Development of aerenchyma has not been noted by us in any emergent monocot species, even 


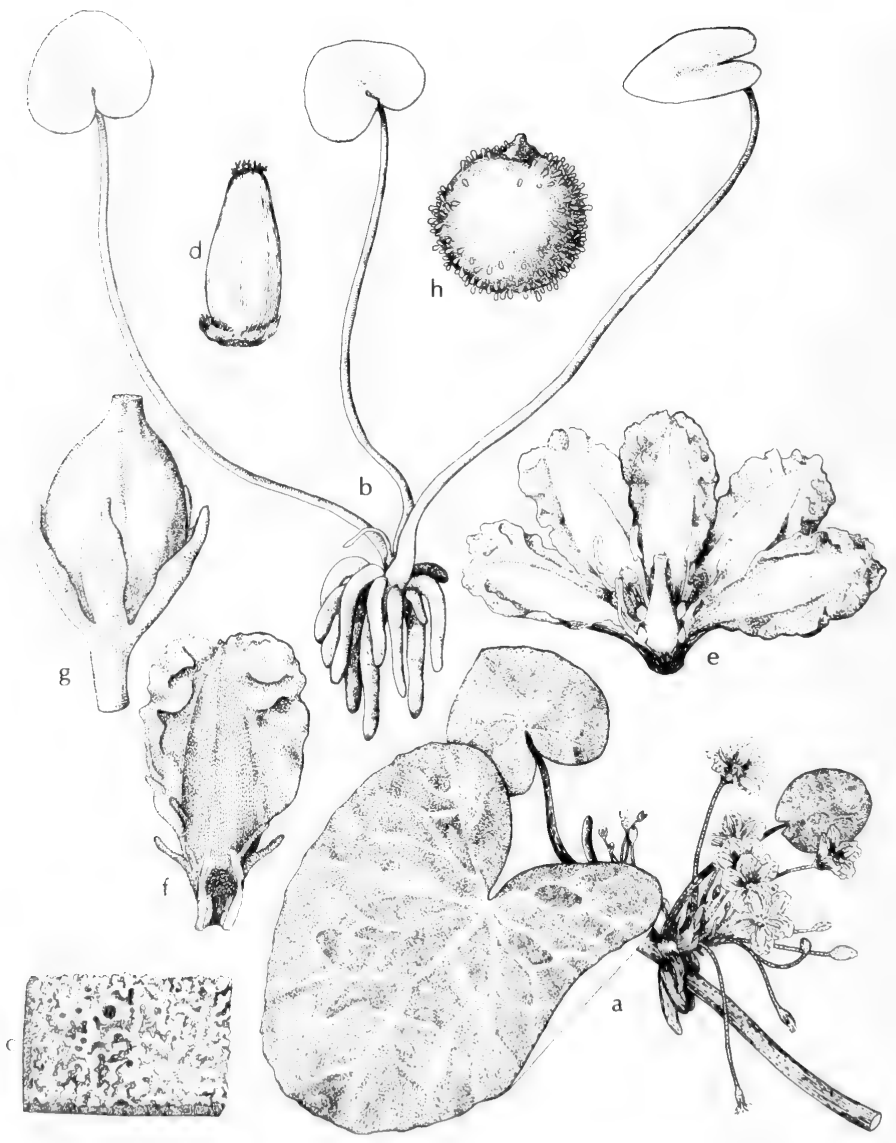

Fig. 1: Nymphoides aquatica: a, leaf and cluster of flowers and spurlike roots on the petiole, $x \frac{1}{2} ; b$, spurlike roots and young leaves separated from parent plant, $x \quad 1 / 2 ; c$, portion of leaf (under side) showing spongy tissue, greatly enlarged; $d$, immalure ovary dissected from bud, x 8; e, flower, corolla spread out, x 4; $f$, petal, x 5; g, fruit, x 5; h, seed, x 20. (Courtesy of R. K. Godfrey). 
in the conspicuous Habenaria repens. It is commonly formed on species of Ludwigia, Aeschynomone, Lythrum, Ammannia, Peplis and Sesbania.

The organs and means of sexual reproduction in the vast majority of vascular hydrophytes are not unlike those of strictly terrestrial plants. Only a relatively few of our hydrophytes have wholly submerged hydrophilous flowers. Of these, those occurring in our region are Ceratophyllum, Najas, Ruppia, Zannichellia, Posidonia, Cymodocea, Halophila, Thalassia, Halodule and several species of Callitriche.

Besides sexual reproduction many hydrophytes have a capacity for vigorous vegetative reproduction, and this has been found to be exceptionally high in many genera. The means, however, of vegetative reproduction is apparently no different from those found in strictly terrestrial species. These include the capacity to regenerate from small vegetative fragments, especially if they have attached buds, and the production of tubers, rhizomes, stolons, turions, dormant apices and offsets. The ease of dispersal of these propagules by various agents, such as floods, waterfowl, animals, motorboat propellors, irrigation activities and the other direct actions of man account for the wide distribution of many aquatic plants.

The stems, rhizomes, stolons, runners, petioles and peduncles of most submerged aquatic plants are notoriously brittle. Because of this brittleness even a slight disturbance, much less a violent one, will frequently cause fragmentation of the plant body. This is especially true of species in the genera Ceratophyllum, Egeria, Elodea, Myriophyllum and Najas. The same is also true to some extent for species of Callitriche, Azolla, Utricularia and in the Lemnaceae. Another method of vegetative reproduction is exhibited by Ceratopteris (Fig. 22), wherein plants, by means of gemmipary, arise from buds near vein-endings at the base of marginal notches in mature leaves. This method of vegetative reproduction is also common to some cruciferous species, such as in Armoracia, Cardamine and Rorippa.

All types of rhizomes may be found in aquatic plants. These may be woody or herbaceous, spongy or firm, slender or enlarged, widely creeping or much-abbreviated. Some species, especially in Cyperus, Potamogeton and Sagittaria produce stem tubers from which they perennate. These tubers, which are frequently near or just below the surface of mud, provide food for water fowl, especially geese.

In Nymphoides (Fig. 1), the buried rootstock gives rise to long stems that trail through the water and gradually ascending to the surface to produce shortpetioled leaves from their terminal nodes along with clusters of aerial flowers. A cluster of adventitious swollen, banana-shaped roots is produced from the node at the base of this floating rosette. Upon decay of the ascending stem the cluster of tuberous roots is set free and subsequently regenerates a new plant.

Among those ordinarily dryland plants that apparently depend upon an excess of water during at least a part of their life-span are Heliotropium molle and $\boldsymbol{H}$. glabriusculum, which grow where water temporarily accumulates after rains. These plants have evolved abundant corky tissue in their seeds that make them welladapted for water dispersal. When observed during much of their life-span, however, one might wonder why these species should be included in a work on aquatic and wetland plants for they grow in usually somewhat desertic situations.

The principal agents that influence plant dispersal are water, animals, wind and man. Dispersal of strictly aquatic plants are undoubtedly influenced more by water and animals than by wind and man. Buoyant fruits and seeds, and vegetative propagules broken from plants by turbulence may be carried great distances by currents and wave action.

The transmission of vegetative fragments and seeds in the plumage and on the muddy feet of waterfowl undoubtedly accounts for the wide distribution of some 
fresh-water plants. Local distribution is further enhanced by the actions and activities of other types of animal life, such as amphibians, reptiles and small and large mammals. Seeds of some species that are eaten by various bird and animal life pass through their alimentary tract essentially unharmed. These are often dropped at some distance from their intake, thus adding to the distribution of the species.

Our area lies in two of the flyways known to exist for migratory birds in North America. Arizona is in the Pacific Flyway while Texas, Oklahoma and New Mexico lie in the Central Flyway. Any kinds of water bodies found along these flyways are of importance to migratory birds for resting, feeding and protection. There is little doubt that north-south dissemination of some plant species occurs as a result of the activities of these migratory birds.

\section{Economics and Control of Aquatic and Wetland Vascular Plants}

Except for their aesthetic value in natural settings or as ornamentals, and their value to wildlife, strictly aquatic vascular plants, as such, have very little economic value in the modern-day world. They are, however, more or less involved in the general economics of such facets as wildlife, sports fishing, water utilization and weed control. Rice, which we consider to be a wetland or subaquatic plant, is undoubtedly the most important cereal plant grown by man. This plant would have to be an exception to the above statement.

The ultimate goal to be obtained in the treatment or handling of vegetation in a water body depends upon the interest of the individual or organization concerned. Those interested in waterfowl and bird life, generally, would hope to maintain submerged and floating species of Potamogeton, Najas, Zannichellia and other important food plants of like nature as well as many of the erect emergent species, such as in Scirpus, Sparganium, Typha and Sagittaria. Those interested solely in fish and fish production might wish to exterminate all plant life except plankton. And so it goes.

Our making various statements in the text, such as this or that plant provides excellent protection for fish, does not imply that this is a good thing. It is merely a statement of fact or an observation. Perhaps the fish needs no protection or should not be protected!

According to knowledgeable wildlife personnel the signficance of hydrophytic environments in relation to wildlife scarcely can be over-emphasized, and studies such as this that will lead to a better knowledge of the kinds and distribution of plants of aquatic and wetland habitats are of great interest and usefulness to all personnel involved in wildlife management. For instance, wildlife management personnel will want to know the identity of the plants under which waterfowl, fish, mammals, invertebrates, and other inhabitants of marsh and aquatic habitats feed and use for nesting and resting sites, coverage and protection. Also, wildlife personnel need to know the plant species to help them better assess a particular area in regard to the types and abundance of plant foods present and to be able to create conditions that will control and improve the food supply. A similar need is present for the health engineer, who, for instance, may want to know the identity of the plants that are associated with the breeding grounds of such pests and disease-carriers as mosquitoes, and for the hydrologist who needs to know what plants contribute to water-pollution and -contamination, and those that contribute to its clarification and potability. 
Many species of plants have a beneficial effect upon water in contrast to those that have a deleterious effect. For instance, it is realized that depletion of vegetation with accelerated stream-channel erosion decreases or entirely prevents fish production through the reduction of available food and cover, the increasing of water temperatures, and through sedimentation of spawning beds. To maintain a continuity of fish and wildlife, generally, it is essential to know how to maintain their habitat and to determine the biological requirements and relationship of each species, especially in regard to cover and food for its normal growth.

Another function of plant life in relation to water is its restraining action upon rapidly moving streams so as to prevent excessive erosion of their banks. Only those species that can tolerate having their roots submerged or that can grow in saturated soils can survive on the margins of streams and lakes. Without such species to exert control there would be no limit to the amount of erosion that might occur. The knowledge to be gained from the study of aquatic and wetland vegetation can thus be directed to the control of channel- and bank-erosion to improve fish habitats and their food supply.

In 1970, Boyd published a paper in which he pointed out the apparent potential of using aquatic angiosperms for the wholesale removal of nutrients from effluents and natural waters. He further suggested that because of their food qualities aquatic angiosperms could be harvested, dried and used as a feedstuff.

Boyd found that the most suitable species for possible nutrient removal from water were water hyacinth (Eichhornia crassipes), alligator weed (Alternanthera philoxeroides), water willow (Justicia americana) and cat-tail (Typha latifolia). All of these plants could be harvested by relatively simple means and they had a relatively high nutritive value for use as feedstuff. A series of small holding ponds into which effluents would be directed and in which plants would be grown for nutrient removal were thought to be more satisfactory than just one large body of water.

There are problems in this proposed use of these aggressive aquatic angiosperms, foremost of which is the fact that, with the possible exception of Justicia americana, they can become pernicious weeds.

It is entirely possible that with more research man will be able to manipulate native vegetation, even more than he does at present, for his welfare. The most obvious and a long-standing practice has been the use of plants in erosion control. There are many and various uses that might be made of aquatic angiosperms.

There are numerous troublesome aquatic weeds throughout the world, and there is no question whatsoever about the necessity to control the rampant growth of many of these noxious vascular hydrophytes. The main question revolves around how this should be done. Anyone who has seen a waterway that was once open and clear but is now essentially dessicated and clogged by water-hyacinth (Eichhornia crassipes) or alligator weed (Alternanthera philoxeroides) must realize that such is a situation that should and must be corrected.

An improper balance of the flora and fauna, frequently caused by the undue aggressiveness of such plants as Alternanthera and Eichhornia, can result in pollution and/or stagnation. Observations on the tolerance and aggressiveness of individual species must be undertaken so as to understand better why some species are limited in distribution while others are widely distributed. A detailed study of the reproduction by seeds and vegetative means of some hitherto neglected species will supplement that which is already known about other species. Mobility, aggressiveness, and various methods of distribution, such as the requirements needed for dissemination, and the viability of seeds under different conditions should be studied so as to better understand some of the yet unanswered problems of the specialized adaptation of these plants to their environment. 
With identification of species in a particular plant community, it will be possible to determine their optimum needs to attain their best growth and reproductive capacity, or likewise through investigation and research find some means for their control that could be recommended elsewhere. Without the identity of these organisms it would be impossible to accomplish this work.

Various methods have been used to control aquatic weeds, but undoubtedly the most efficacious though potentially dangerous to the world's life is the use of the many various herbicides. The use of herbicides in the elimination of nuisance aquatic angiosperms occasionally kill fish and desirable organisms. The decay of dead plants, too, can deplete the dissolved oxygen to the extent of killing all aerobic organisms. Often, also, the destruction of one nuisance organism only makes room for invasion of another equally noxious organism.

The oldest method of combatting aquatic weeds is that of manual and mechanical control. This is still practiced, especially where small bodies of water and streamways are involved. These methods include cutting and harvesting the plants by hand, draining and drying out plus bulldozing the water areas to be cleaned, mechanically mowing with cutters along banks or attached to boats, and dragging and dredging the area to be cleaned. In line with these mechanical methods, on Caddo Lake in northeastern Texas an unsuccessful, or rather unprofitable, attempt was made to mechanically harvest the tremendous overgrowth of water plants and to use the dried processed plants as peat or as a soil conditioner. If this activity had been successful this would have been a direct economic way to control aquatic weeds.

The most idyllic type of aquatic weed control would be biological. Each noxious species, however, would necessitate an individual study to discover in what way it might be controlled - either parasitically by a fungus or insect, or by aquatic herbivores such as certain African and Chinese fish. The manatee or sea cow is the classic example of an aquatic herbivore in that it can consume huge amounts of rooting and floating vegetation. Thus far, however, it has proved impractical or biologically impossible to manipulate the manatee as a trained grazer.

\section{Pollution in Aquatic and Wetland Habitats.}

Certainly there are no greater problems facing our civilization today than those of contending with water and air pollution. Everything that we can learn that will help us ultimately to manage these problems will be to our advantage. It is hoped that the results of this research will provide us with some phase of knowledge that will help us in combatting the corrosive situation of water pollution.

As has been noted in our Preface, from the very beginning of this research consideration of the environment has had an overwhelming influence upon our interpretation of what plants were to be included in this work. This consideration was long in progress before "environment" and "ecology" became household words in the United States. This consideration of the environment was guided mainly by our initial interest in this project: water as a critical resource in southwestern United States. Since this resource is so critical in this part of the country, and it will doubtless become more so with time, we thought that a knowledge of the plants that are associated with water should be made available to everyone who might be concerned with this vital commodity. We also hoped that our work would encourage more appreciation for water as a vital resource and thus create more respect for and a greater care of this rapidly vanishing and very necessary asset.

Perhaps one of the most frustrating phases of this project was our not being able to find areas that we could consider as "controls" for each of the ecosystems 
that we expected to observe and study during various seasons and over a period of several years. Because of man's omnipresent interference with everything natural, no lake, pond, river, marsh, bog or swamp could be designated as having never been disturbed or the way Mother Nature would have wanted it without man's disturbing and polluting influence. We early forewent the idea of establishing "controls," and decided, instead, to accept conditions as we found them to exist. We realized that pollution had become so thoroughly spread, and it had unquestionably affected or so changed the various ecosystems that it would be impossible to determine what species comprised the original vegetation of most of the area studied.

We have tried to summarize below the primary water pollutants and to point out some of the deliterious effects of their pollution upon the environment. These data are a combination of personal observations and those taken from numerous articles, papers and books that have been published on the subject during the last few years, but primarily from an article by Young (1970).

Doubtlessly, the chief causes of water pollution are inadequately treated sewage and manufacturing wastes, oil from ships and drilling leaks, fertilizer runoff, pesticide residues and acid drainage from mines. These wastes, plus sediment, have ruined practically every major river in the Nation, and have converted them from what was once unadulterated assets to the Nation into liabilities and a real menace to much of the world's population. The pollutants they transport to the sea are endangering our estuaries, wetlands and coastal waters-nurseries for most of our commercially important fish and shellfish.

Though chemical fertilizers have greatly increased crop production, and longlasting pesticides have achieved their goal in protecting our crops, wind and rain have carried these pollutants into our rivers, lakes and ponds where the fertilizer, plus sewage, has contributed to an enormous overgrowth of algae. This overgrowth of algae in the upper zone suffocates the lower layers of algae by depriving them of light for photosynthesis. This lower layer dies and decays, and in doing so uses oxygen that is needed by fish which, in turn, die. The pesticides, upon reaching the oceans, are carried up the food chain through fish to thwart the reproduction of eagles, ospreys, pelicans and other fish-eating birds.

Mercury waste has been flushed into many lakes and rivers by industry. Bacteria convert some of it into highly toxic methyl mercury, which is passed along the food chain into fish, such as sword and tuna, that man now can not eat with knowledge of absolute impunity. Various mercury compounds used in agriculture are known to have poisoned game birds in many parts of the world.

Stripping the forests for lumber, excessively wide highways and our paralytic housing developments encourage soil erosion and the steady erosion of one of our major sources of oxygen-producing greenery, while strip-mining scars the countryside and allows mine acids to wash and spread out to kill adjacent and surrounding vegetation.

Our rapidly increasing nuclear power plants create thermal pollution in the water used for cooling. The heated water holds less oxygen and can thus disrupt the life cycle of aquatic organisms.

Oil spills foul beaches throughout the world, as can be attested by anyone who has walked along practically any of our beaches during the last several years. The blotches of black oil that accumulate on the bottom of feet is only a harmless visual pollutant compared to the toxic chemicals released that can kill fish and birds, and, by forming a film over the water, oil can inhibit the intake of oxygen by the water to smother life on the bottom. Millions of tons of petroleum each year are flushed from ships, spilled at fueling ports, and poured into the sea from leaking or runaway offshore wells and wrecked tankers. 
The sad fact is that we not only continue to pour these wastes into our environment but we also continue to add new herbicidal and pesticidal chemicals without their being properly tested to learn what long-range effects they will have upon life on our planet.

Sculthorpe, in 1967, has the following to say about the use of herbicides in England: "The toxity of numerous herbicides necessitates stringent precautions for their use in aquatic habitats. It is an appalling and terrifying truth that all too many aquatic herbicides have come into general use despite colossal ignorance of their toxicology and biological side-effects. Although the situation is not perhaps quite as devastating as that created by the indiscriminate use of certain insecticides in the U.S.A. and Europe, it is nevertheless deplorable. The principal dangers inherent in the use of toxic herbicides for eradicating aquatic weeds are: (a) the hazard, to the persons applying the chemical or to others in the vicinity, of oral intake or cutaneous absorption; (b) the contamination of domestic water supplies; (c) the poisoning of plankton, invertebrates, fish and animals living in or around the water; and (d) the contamination of surrounding land bearing sensitive food crops or grazing livestock."

A useful bibliography of work on the harmful effects of herbicides and insecticides on aquatic life has been compiled by Ingram and Tarzwell (1954). There is no doubt that this bibliography could be greatly augmented if a revision were published today.

We have found literally appalling situations where herbicides of any and all types are indiscriminately dumped directly into lakes, fish ponds and stock tanks. We learned that in many such instances a fast-talking herbicide salesman was usually dealing with a customer who was grossly uninformed, misinformed or just totally ignorant of the possible damage that might be done to his water body. Most customers could not even remember the name of the herbicide they used nor its composition. They were merely assured by the glib salesman that "it" would "kill" all plant life. Many sadly learned that "it" often also contributed to the killing of their fish and possibly every other form of animal and plant life with which "it" came in contact.

In line with the indiscriminate direct and indirect dumping of chemicals into our water bodies, we have often wondered what the eventual effect will be upon man who persists in catching and eating those fish that "got away" from the potentially deadly concentration of chemicals. Though we have asked this question of many learned individuals none profess to know what may be the eventual longrange effect upon man. They seem to think it is too soon to know the answer. Meanwhile, man may be literally eating himself into oblivion.

We have noted with dismay the perversion of some of our state as well as national wildlife refuges from their original intent and purpose to preserve and protect every aspect of nature and wildlife to the dictum of making available to pillaging and irresponsible man facilities for his abuse at the expense of all else. The prevailing philosophy of certain personnel that are responsible for the management of wildlife preserves was dramatically demonstrated to us in 1968 . In 1967 we had examined the plant-life in several of the then beautiful lakes in one of the fine national reservations in our area with the thought of continuing over a several-year period the study of some ecological phases of our project. Imagine our chagrin and disappointment when we returned in 1968 to find that all of the lakes we were planning to study had only very recently been treated with a potent herbicide-nothing but rotting plant remains with a few small mammals floating here and there were to be found in and about the edges of these once very beautiful and biologically balanced lakes. The chemical stench in the air only added to our extreme displeasure. As taxpayers, we were angry and appalled that a total disregard for the wildlife of these lakes should be so blatantly 
displayed by so-called responsible administrators of the Nation's resources. The superintendent explained to us that the destruction of all aquatic plant life, irrespective of the long-range ill-effect it would have on the lakes, was necessary so that people who wanted to swim in the lakes would not risk being entangled in the underwater growth! We wondered-what is the need of setting aside a "wildlife refuge" if its main purpose is to be prostituted!

For decades we have blindly swept our filth beneath the surface of our waters, and just as blindly we have assumed that it would remain well hidden under the "rug." Until rather recently the best of authorities have assumed that sewage and garbage that we have assigned to the depths of our lakes and oceans would be like the proverbial sleeping dog. It is now known, however, that even at the greatest depths some turbulence occurs, and we learn that our "sleeping dogs" have never lain placidly; they are now coming home to haunt us in the form of poison fish and dying wildlife. In view of the fact that ocean currents have been known for such a long time the assumption that no such phenomena would occur in inland coastal waters seems strange.

The debris left in lowlands and forests that border lakes and rivers after high water is astronomical. In some such areas we have traversed it was literally impossible for us to take a step without stepping upon some sort of extraneous object such as the ubiquitous bottles and cans, plastic containers, old tires, shoes and every other type of rubbish. These had not only recently been water pollutants but now they were deposited on land where they had become visual pollutants.

It may be of interest to others that our experience from the very beginning of this project has been one of frustration. We have felt, and at times been treated, like interlopers because of our interest in and desire to work on the biological, particularly botanical, aspects of aquatic pollution. We have found that most research funds for pollution and water quality research have largely been taken over by inorganic scientists, primarily chemically trained and oriented, most of whom either have no interest in nor feeling for biological research. We would have greatly appreciated the opportunity to work with a team of scientists on a biological approach to our various problems involving aquatic pollution.

We can only say "amen" to Sculthorpe's statement on page 28 (1967) : "Pollution by sewage and other domestic products, poisonous industrial effluents, pesticides and radioactive wastes has been steadily increasing and must now be treated as an integral feature of the aquatic environment. So far, it has been treated principally, indeed too often exclusively, as a physiochemical phenomenon. Its biological, and particularly botanical, consequences have been much neglected."

It has been said by some wise individual that the environment is almost as much a product of the community as the community is of the environment. This might be carried a step further to say that the condition of the environment is a realistic measure of the kind of civilization that exists to inhabit that environment. 


\section{KEY TO MONOCOTYLEDONS AND DICOTYLEDONS}

FLOWERS WITH PARTS USUALLY IN MULTIDLES OF 3 (RARELY MORE OR LESS)

LEAVES USUALLY PARALLEL VEINED (RARELY NET VEINED)

VASCULAR BUNDLES DISTINCT AND SCATTERED

\section{COTYLEDONS I}

\section{MONOCOTYLEDONEAE}

SOME FLOWER TYPES
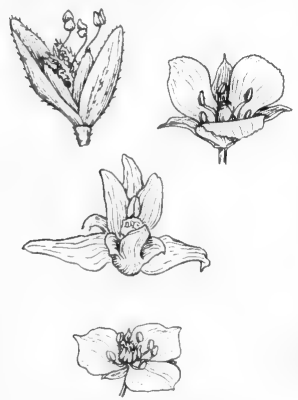

SOME LEAF TYPES
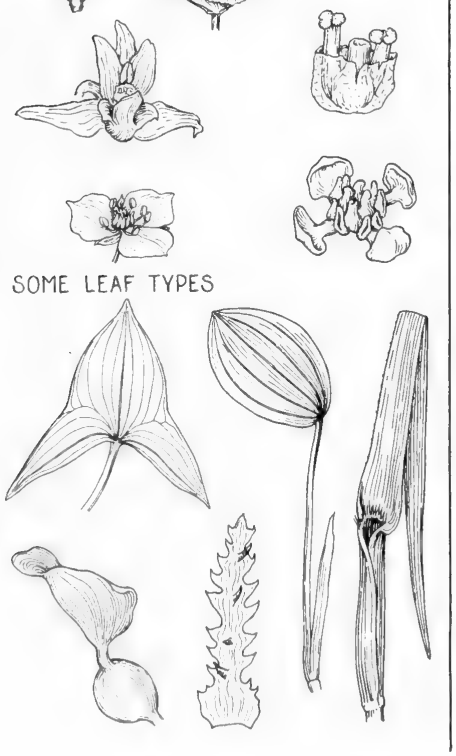

FLOWERS WITH PARTS USUALLY IN MULTIPLES OF 2,5 OR MANY (RARELY 3)

LEAVES PINNATELY OR PALMATELY VEINED (RARELY PARALLEL VEINED OR RIBBED)

VASCULAR BUNDLES OF STEMS USUALLY IN A RING (SCATTERED IN A FEW AQUATICS)

COTYLEDONS 2 (RARELY REDUCED TO 1 IN A VERY FEW AQUATICS) DICOTYLEDONEAE

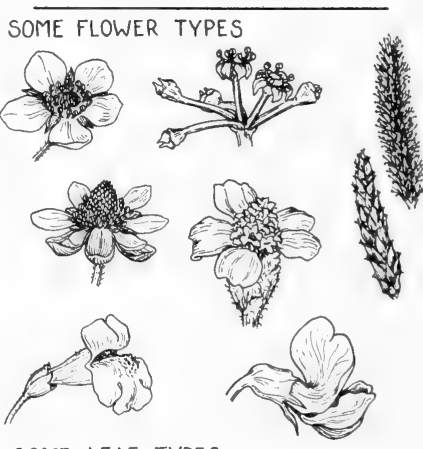

SOME LEAF TYPES
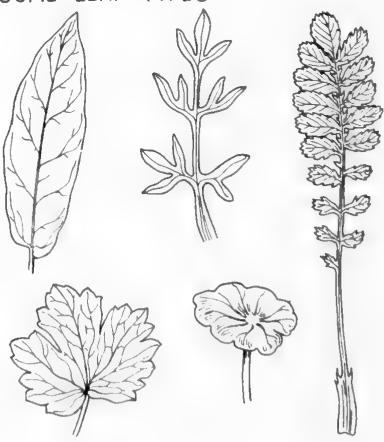

Fig. 2: Illustrated key to monocotyledons and dicotyledons. (From Mason, Fig. 1). 


\section{Artificial Analytical Key to the Higher Taxa of Aquatic and Wetland Vascular Plants}

\section{Key to the Major Groups}

1. Rushlike, fernlike, mosslike or quill-leaved plants without true seeds or flowers, reproducing chiefly by spores .I. Pteridophyta, p. 17

1. Habit various; plants producing seeds (2)

2(1). Plants producing seeds but not true flowers, i.e., either having "cones" (with seeds borne more or less exposed on the upper surfaces of the scales of the cones) or fleshy structures with the basic structures of cones (as juniper "berries"), or cones with only a few thin scales (as in Ephedraceae)......................II. Gymnospermae, p. 19

2. Plants producing true flowers, i.e., the seeds borne enclosed in specialized structures (ovaries) (Angiospermae) (3)

3(2). Plants with several if not all of the following characters: vascular bundles scattered in the usually solid internodes (these bundles can be seen as scattered dots in the stem-transection); cotyledon (seed leaf) solitary; when flower parts in whorls then some in whorls of 3 , at least not in whorls of 5 parts; leaves parallel-veined; root system fibrous (i.e., most roots adventitious); plants nearly always herbaceous ...............................................III. Monocotyledoneae, p. 19

3. Plants with several if not all of the following characters: vascular bundles of young stems forming an interrupted cylinder (seen as a ring of dots in stem-transection); cotyledons usually 2 , rarely more or one; flower parts (when in whorls) often in 4's or 5's, less often in 3's, 2's, 6's, etc.; leaves usually reticulate-veined; roots either fibrous or not; plants herbaceous or woody, the wood forming concentric layers when present; young stems nearly always hollow or with a pithy zone in the center. IV. Dicotyledoneae, p. 23

\section{Pteridophyta (p. 37 of text)}

1. Foliage leaves scalelike or long-subulate, sometimes united into toothed sheaths (2)

1. Foliage leaves or entire frond with broad or narrow, entire, toothed, pinnate, pinnatifid or variously dissected blades (6)

2(1). Stems hollow, fluted, jointed; sporangia borne under peltate scales in a cone.

5. Equisetaceae, p. 45

2. Stems solid, not fluted or jointed; sporangia borne in the axils of scalelike or small leaflike or long-subulate bracts (3)

$3(2)$. Leaves rushlike, long-subulate, more than $3 \mathrm{~cm}$. long, borne in a tuft on a short cormlike stem........................................... Isoetaceae, p. 41

3. Leaves scalelike, flat, sometimes concave or cymbiform, less than $3 \mathrm{~cm}$. long, borne on erect or creeping elongate stems and branches (4) 


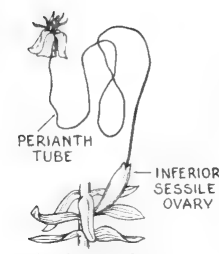

WHORLED OR OPPOSITE LEAVES OVARY INFERIOR
THE MAJOR GROUPS OF MONOCOTYLEDONS
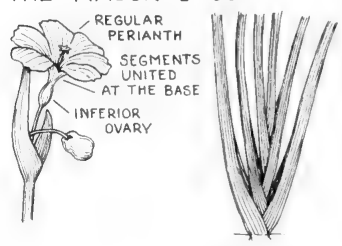

EQUITANT LEAVES

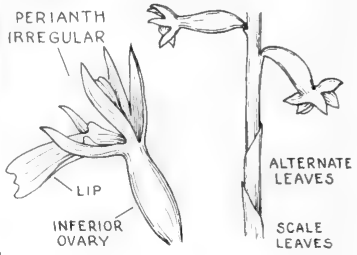

OVARY SUPERIOR

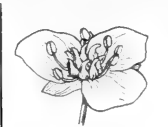

PISTILS MORE THAN ONE

PERIANTH OF

TWO SERIES

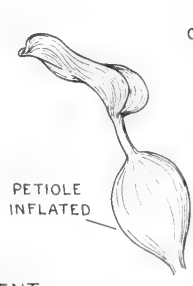

FLOWERS
CROWDED ON

SPADIX

PERIANTH PRESENT
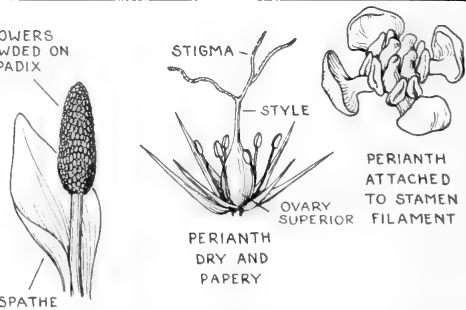

PERIANTH

DRY AND

PAPERY

PERIANTH ABSENT OR REDUCED TO BRISTLES OR SCALES, SOMETIMES FLOWERS IN A PERIANTH-LIKE

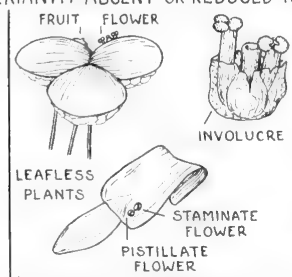

\section{FLOATING OR SUBMERSED AQUATICS}

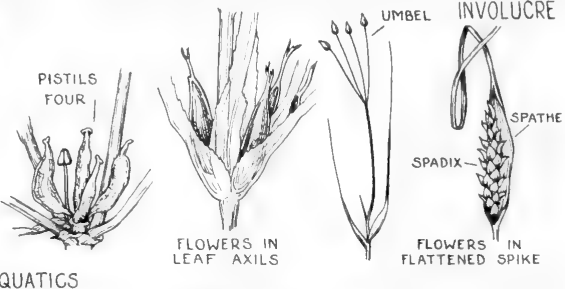

TERRESTRIAL OR, IF AQUATIC, ONLY BASE OF PLANT IN WATER

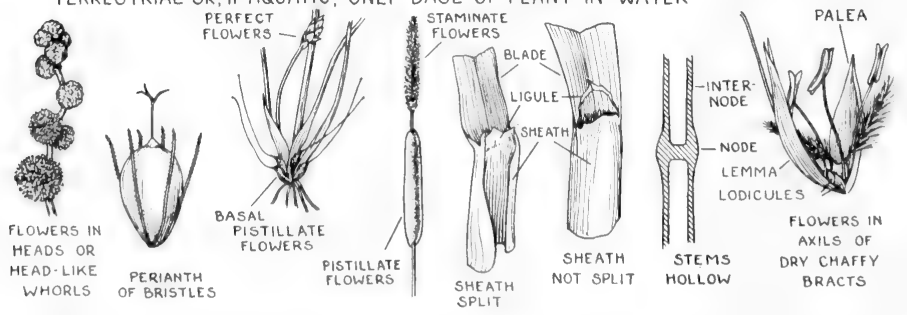

Fig. 3A: The major groups of monocotyledons. (From Mason, Fig. 2). 
4(3). Plants often forming broomlike clumps; stem naked except for distantly placed minute scalelike leaves; sporangia subtended by 2 minute scale leaves and scattered on upper part of branches....

1. Psilotaceae, p. 37

4. Plants not in broomlike clumps; stem with closely placed or imbricated leaves; sporophylls not bifid, borne in cones (5)

5(4). Plants with erect fruiting stems; cones cylindric; spores of 1 kind

2. Lycopodiaceae, p. 39

5. Plants with ascending or spreading fruiting branches; cones more or less quadrangular; spores of 2 kinds.................... Selaginellaceae, p. 41

6(1). Plants usually large and conspicuous, growing in soil or on rocks or trees, or (if free-floating or submerged) large and dendroid; spores of 1 kind, minute (7)

6. Plants small, free-floating or partially submerged or rooted in mud; spores of 2 kinds, borne in sporocarps (10)

7(6). Fertile fronds with 2 distinct parts, the fertile part being in the form of a spike or panicle and arising from the petioles, the sterile part of the frond being either entire or pinnately dissected.

6. Ophioglossaceae, p. 47

7. Fronds not as in Ophioglossaceae (8)

8(7). Sporangia in panicles or (sometimes fingerlike) spikes developed from the modified blade or parts of the blade................7. Osmundaceae, p. 51

8. Sporangia borne on the back of (the lower side of) or on the margin of the blade (9)

9(8). Plants never free-floating nor dendroid; sporangia usually long-stalked........ 10. Polypodiaceae, p. 61

9. Plants usually free-floating or very rarely deeply submerged, the sterile leaves forming a floating sterile rosette; sporangia sessile or nearly so........

11. Parkeriaceae, p. 77

10(6). Plants rooting in mud or on muddy bottoms; rootstocks creeping; leaves quadrifoliolate or filiform, not imbricate nor matted, distant.

8. Marsileaceae, p. 53

10. Plants free-floating or resting on mud; rootstocks pinnately branched; leaves deeply 2-lobed, imbricate, matted.

9. Salviniaceae, p. 57

\section{Gymnospermae (p. 79 of text)}

Leaves spreading in 2 ranks, usually seasonally deciduous; cones globose; cone scales club-shaped, without distinct bracts, flat or peltate, with two 3-angled or somewhat 3-winged seeds.

12. Taxodiaceae, p. 79

\section{Monocotyledoneae (p. 85 of text)}

1. Plants $1 \mathrm{~cm}$. long or usualy less, thalluslike, stemless, usually floating or resting on mud or some type of extraneous matter such as leaves and pieces of wood. 28. Lemnaceae, p. 563

1. Plants usually larger, not with above combination of characters (2) 
2(1). Each pistillate flower with 4 free carpels each of which at fruiting time is long-stipitate; submerged aquatics with linear leaves......

2. Carpels either coalescent or if free then not stipitate (3)

17. Ruppiaceae, p. 123

3 (2). Carpels 2 to numerous, free from each other (4)

3. Carpels solitary or if more than 1 then these (at base or throughout) coalescent for more than a third their length (7)

4(3). Carpels numerous per female flower.

21. Alismataceae, p. 133

4. Carpels 2 to 9 per flower (5)

5(4). Ovules numerous; flowers showy, yellow....

22. Butomaceae, p. 153

5. Ovules solitary; flowers inconspicuous (6)

$6(5)$. Perianth of 4 free rounded shortly clawed valvate segments $1-4 \mathrm{~mm}$. long 15. Potamogetonaceae, p. 95

6. Perianth absent (genus Zannichellia of) 16. Zannichelliaceae, p. 117

7(3). Ovary inferior; perianth clearly epigynous (8)

7. Ovary superior or apparently so, in some taxa the perianth reduced or absent, in some the perianth adnate to the ovary for a very short distance basally (14)

8(7). Partly or wholly submerged plants; ovules numerous, spread all over the inner surface of the carpels or on the intrusive septa.

23. Hydrocharitaceae, p. 156

8. Plants not submerged or if partly so the ovules confined to placentary areas (9)

9 (8). At least the inner 3 tepals dissimilar to one another, the flower thus not radially symmetrical (10)

9. At least the inner 3 tepals (and usually the outer one, too) equal to each other or nearly so, the flower thus approaching true radial symmetry (12)

10(9). Ovule solitary in each cell.

39. Marantaceae, p. 686

10. Ovules more numerous (11)

11(10). Flowers only slightly zygomorphic, reddish or orange, in terminal thyrses on erect stems to $12 \mathrm{dm}$. tall.

38. Cannaceae, p. 684

11. Flowers strongly zygomorphic, the lower (or rarely uppermost) of the 3 inner tepals strikingly different from the other 2 , forming a labellum; stems usually less than $5 \mathrm{dm}$. long.....41. Orchidaceae, p. 690

12(9). Leaves equitant, distichous and folded along the midrib; stamens 3

37. Iridaceae, p. 673

12. Leaves not equitant; stamens 3 or 6 (13)

13(12). Stamens 3; basal leaves usually linear and grasslike and stem or scape leaves scalelike.................................40. Burmanniaceae, p. 686

13. Stamens usually 6 ; basal leaves usually broader; plants very diverse in habit.... 36. Amaryllidaceae, p. 664

14(7). Palmlike plants with perennial stem $5-70 \mathrm{~cm}$. thick at ground level and fanlike leaves $4-12 \mathrm{dm}$. broad..........................26. Palmae, p. 555

14. Habit otherwise (15) 
15(14). Submerged plants mainly of salt-water gulfs and bays, occasionally inland in brackish or fresh-water (16)

15. Plants terrestrial or (if in water) at least partly or wholly emersed (18)

16(15). Plants perennial, entirely marine; leaves strap-shaped, leathery, at least $5 \mathrm{~mm}$. wide, essentially entire; rhizome and stem thick and woody, the rhizome with persistent fibers from the nodes, the stem adorned with the persistent fibrous leaf bases; flowers spicate.

19. Posidoniaceae, p. 129

16. Plants of fresh, brackish or salt-water; leaves linear, entire or toothed; rhizome and stem not thick and woody, not provided with fibers or persistent fibrous leaf bases; flowers axillary, solitary or cymose (17)

17(16). Carpels 2 or more, rarely solitary; ovule pendulous; perennials.

16. Zannichelliaceae, p. 117

17. Carpels solitary; ovule basal, erect; annuals. 18. Najadaceae, p. 123

18(15). Flowers ebracteate; small herbs with narrow grasslike basal leaves and slender spikelike racemes of small usually greenish flowers.

20. Juncaginaceae, p. 129

18. Flowers with bracts, bractlets, scales or glumes (19)

19(18). Proper perianth absent or nearly so, the flowers borne in dense heads, spikes or racemes or thickly crowded on a fleshy axis or else variously disposed in panicles, when genitalia subtended by scalelike structures these never numbering precisely 3 in 1 series or 6 in 2 series (20)

19. Proper perianth present, often in 2 series of 3 members each (in some families the outer or inner or both series scalelike (25)

20(19). Flowers crowded on a terminal elongate fleshy axis which below the flowering zone usually has a large foliaceous partially or wholly sheathing bract (spathe) which covers the inflorescence during its early development...........................................27. Araceae, p. 556

20. Axis of inflorescence not fleshy; bract (if present) not so large and not covering the young inflorescence (21)

21(20). Inflorescence a series of globose heads at the upper nodes, the uppermost heads of staminate flowers, the lower ones of pistillate flowers.

14. Sparganiaceae, p. 89

21. Inflorescence otherwise (22)

22(21). Inflorescence solitary, terminal, globose or hemispheric, 2-15 mm. thick, exceedingly dense, not subtended by large bracts (bracts only 1-4 $\mathrm{mm}$. long) ............................................31. Eriocaulaceae, p. 588

22. Inflorescences not globose nor hemispheric or if so (as in some Cyperaceae) then closely subtended by several bracts several times as long as the inflorescence is thick (23)

23(22). Inflorescence a very dense brownish spike $12-40 \mathrm{~cm}$. long and $1-2 \mathrm{~cm}$. thick with thousands of minute flowers, the male above, the female below; "cat-tails".

13. Typhaceae, p. 85

23. Inflorescence otherwise (24)

24(23). Leaves distichous (and sometimes equitant); with rare exceptions each floret subtended by 2 scales (the lower or lemma abaxial and with 1 midvein; the upper or palea adaxial and with 2 unequal nonmedial nerves) 24. Gramineae, p. 169 


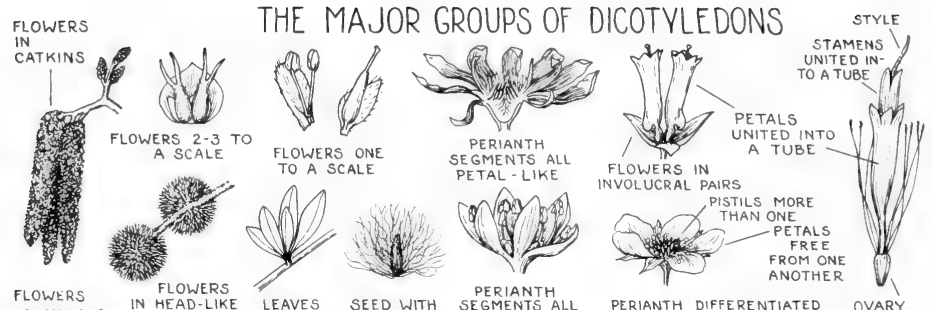

FLOWERS IN HEAD-LIKE LEAVES SEED WITH SEGMENTS ALL PERIANTH DIFFERENTIATED OVARY MONOECIOUS CLUSTERS FASCICLED LONG HAIRS SEPAL-LIKE INTO PETALS ANDSEPALS INFERIOR PLANTS WOODY AT BASE (TREES, SHRUBS, OR VINES)
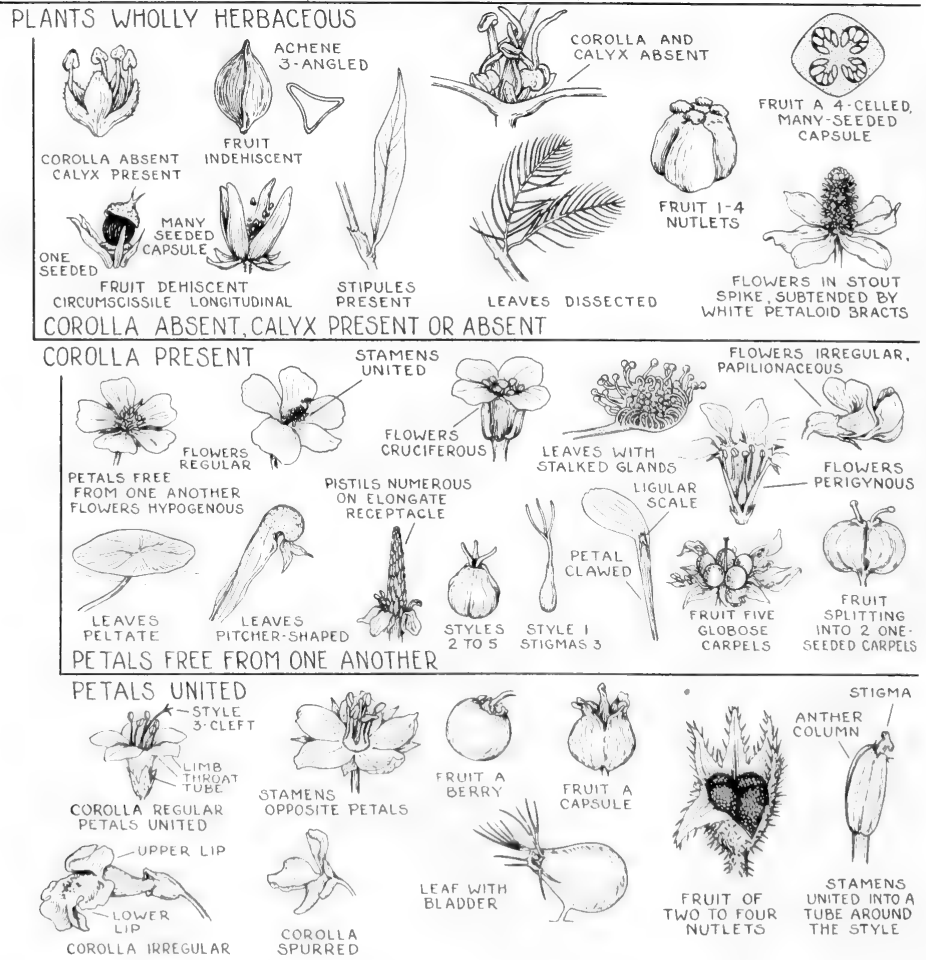

Fig. 3B: The major groups of dicotyledons. (From Mason, Fig. 3). 
24. Leaves tristichous; each floret subtended by a single abaxial scale (seemingly 2 scales in Hemicarpha, or by a sac in Carex, or by bristles in addition to the scale in some genera).

25. Cyperaceae, p. 341

25(19). Calyx irregular, glumaceous, the 2 persistent lateral sepals cymbiform and dorsally keeled or winged, the third sepal larger, obovate and enfolding or forming a hood over the corolla in bud and deciduous with it

30. Xyridaceae, p. 578

25. Calyx otherwise (26)

26(25). The 3 inner tepals (petals) quite distinct in color and/or texture from the 3 outer ones (sepals) (27)

26. The 6 tepals all rather similar in color and texture, either all dry and scalelike or all corolline (28)

27(26). Ovary completely 3-celled; lower part of leaves sheathing the internodes 32. Commelinaceae, p. 593

27. Ovary incompletely 3-celled or 1-celled; leaves not sheathing..... 29. Mayacaceae, p. 578

28(26). Perianth of 6 scalelike dry brown noncorolline tepals

28. Perianth of 6 corolline tepals or with 6 corolline segments (29)

34. Juncaceae, p. 604

29(28). Usually floating, partly submerged or at least rooting in mud; inflorescence subtended by spathelike leaf sheaths; seeds usually ribbed; flowers usually somewhat zygomorphic....33. Pontederiaceae, p. 597

29. Dryland to marshland plants; inflorescence usually not subtended by a spathelike leaf sheath; seeds various, usually not ribbed; flowers almost always radially symmetrical...................35. Liliaceae, p. 646

\section{Dicotyledoneae (p. 734 of text)}

1. Flowers with all the petals united at their edges (at least near the base) into a single structure, this corolla often deciduous as a unit and often shaped like a saucer, a cup or a trumpet (2)

1. Flowers not as above, if any petals joined then not all of them involved or else not joined at their edges (occasionally the petals may seem to be joined somewhat in bud but not in the mature flower), or petals absent (48)

2(1). Flowers epigynous or partly so, i.e., the perianth and stamens when present appearing to be attached to the top or near the middle of the sides of the ovary (3)

2. Flowers hypogynous or perigynous, the sides of the ovary free from the perianth or the floral cup, the perianth attached below the ovary (12)

3(2). Anthers 5 or 4 , coalescent but filaments free (anthers exceptionally free in the genera Ambrosia, Xanthium, Iva); fruit an achene and usually crowned by the modified calyx of bristles or scales; style branches usually 2, usually divergent; flowers usually very small and aggregated in involute heads...............129. Compositae, p. 1586

3. Anthers usually free (exceptions: Curcurbitaceae; 1 genus of Campanulaceae); fruit diverse but rarely an achene (exception: Valerianaceae); style branches 1 to 20; flowers rarely aggregated in involucrate heads (4) 
4(3). Stems trailing or twining, often vinelike, often scabrous, often with lobed leaves; fruits with a leathery or tougher rind and fleshy placental tissue inside and numerous flattish seeds either buried in flesh (as in the watermelon) or in 2 to many longitudinal rows on the several ( 3 to 5, usually) placentas which are on the walls of the chamber (as in pumpkins and gourds); stamens often united.

127. Cucurbitaceae, p. 1569

4. Plants not with the cucurbitaceous character-combination (5)

5(4). Anthers 8 or more (6)

5. Anthers 5 or fewer (rarely 6 in Ericaceae) (8)

$6(5)$. Stamens numerous, a cluster of them present at the base of each petal 105. Symplocaceae, p. 1301

6. Stamens 8 to $16(7)$

7(6). Leaves and branchlets nearly glabrous, at least never with stellate or lepidote vestiture; fruit a many-seeded berry; anthers appendaged (genus Vaccinium of) ...............................101. Ericaceae, p. 1267

7. Leaves and branchlets with at least some stellate or lepidote vestiture; fruit winged or few-seeded, round and dry; anthers unappendaged.

104. Styracaceae, p. 1296

8(5). Placenta free, central, attached to base of locule (genus Samolus of)......... 102. Primulaceae, p. 1276

8. Placenta when axile not free from the sides (in a few taxa the placenta is apical) (9)

9(8). Leaves alternate.

128. Campanulaceae, p. 1571

9. Leaves opposite or whorled (10)

10(9). Fruit an achene or an achenelike structure or at least indehiscent and with a single maturing ovule................126. Valerianaceae, p. 1562

10. Fruit a capsule, berry, drupe or schizocarp (11)

11(10). Stipules present (these sometimes in the form of leaflike structures which add to the number of "leaves" at a node).

124. Rubiaceae, p. 1538

11. Stipules absent but stipular lines sometimes evident.

125. Caprifoliaceae, p. 1555

12(2). Corolla forming a cap over the tiny flower and falling as a unit at the onset of anthesis, the petals separating from each other only at the base; stamens opposite petals but not attached to the corolla, persistent after the corolla falls (genus Vitis of)...86. Vitaceae, p. 1108

12. Corolla not behaving as in grape flowers (13)

13(12). Gynoecium at anthesis or shortly before anthesis with a 2-lobed ovary (or appearing as 2 carpels or 2 ovaries) but only a single style owing to fusion of the styles above the ovary lobes; 1 or each lobe of the ovary maturing into a folliclelike structure; stigma massive (14)

13. Ovary entire or if deeply 2-lobed then styles not united or if so the single style gynobasic; stigmas not often massive (15)

14(13). Sap milky or not; stigma free from or only loosely coherent to antherand/or corolla-tissue 109. Apocynaceae, p. 1331 
14. Sap always milky; stigma massive and united to anther-tissue and often to some corolla-tissue to form a "crown" or gynostegium".

110. Asclepiadaceae, p. 1339

15(13). Leaves pinnately twice-compound

74. Leguminosae, p. 1039

15. Leaves simple to pinnately once-compound or palmately compound (16)

16(15). Anthers more than 3 times as numerous as the petals (or as the corolla lobes) (17)

16. Anthers numbering from 3 times as numerous as the petals or corolla lobes to as few as 2 per flower (19)

17(16). Filaments either coalescent to form a tube or at least coalescent at base 87. Malvaceae, p. 1113

17. Filaments not coalescent (18)

18(17). Herbs with deeply dissected leaves and highly zygomorphic flowers.

61. Ranunculaceae, p. 913

18. Woody plants with mostly entire leaves and actinomorphic flowers.

105. Symplocaceae, p. 1301

19(16). Stamens ( 6 or) 7 to 18 , usually precisely 2 or 3 times as numerous as the petals or corolla lobes (20)

19. Stamens 2 to 5 (or very rarely 6 ), as many as the petals or corolla lobes or fewer than them (24)

20(19). Carpels free, equal in number to the calyx segments or corolla lobes, each matciring into a follicle.

69. Crassulaceae, p. 994

20. Carpeis coalescent into a compound pistil (21)

21(20). Petals typically 3; flowers extremely zygomorphic; stamens 8 or rarely

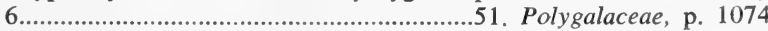

21. Petals or corolla lobes 4 to 7 ; flowers only slightly if at all zygomorphic; stamens ( 6 or) 7 to 18 (22)

22(21). Anthers often with little hornlike appendages and dehiscing by apical slits, clefts or pores.

101. Ericaceae, p. 1267

22. Anthers unappendaged, usually opening longitudinally (23)

23(22). Woody plants with stellate or lepidote vestiture.

104. Styracaceae, p. 1296

23. Plants herbaceous, vestiture absent or else not stellate nor lepidote

78. Euphorbiaceae, p. 1082

24(19). Ovule viviparous, i.e., germinating while still on the parent-plant; opposite-leaved mangrovelike small rhizomatous shrubs growing on salty mud flats along the Texas coast....115. Avicenniaceae, p. 1392

24. Ovule not viviparous; plants not growing in salty mud or if so then not shrubby (25)

25(24). Fruit an incompletely celled capsule (i.e., 1-celled with incomplete partitions), dehiscing apically.

58. Caryophyllaceae, p. 884

25. Fruit otherwise, if capsular then dehiscing differently (26)

26(25). Fruit a circumscissile capsule; herbs with leaves nearly all basal and flowers in dense spikes terminating the scapes.

123. Plantaginaceae, p. 1533

26. Fruit not a circumscissile capsule or if so then habit otherwise (27) 
27(26). Fruit a capsule terminated by 2 prominent curved and incurved beaks, $1-3 \mathrm{dm}$. long..

120. Martyniaceae, p. 1508

27. Fruit not as above (28)

28(27). Herbs with opposite leaves and the odor of wet wool (or a wet dog); stamens 3 (rarely 2); flowers minute, white, in terminal dichasia or compound cymes; calyx minute, annular, involute (often unrolling after anthesis) or with minute teeth; fruit a 1-seeded achenelike structure..........................................126. Valerianaceae, p. 1562

28. Plants not as above, usually with 2,4 or 5 stamens and with the calyx usually better-developed (29)

29(28). Herbs usually with linear leaves; fruit a capsule, more or less completely 10 -celled, at maturity splitting into 5 or 10 parts which fall away separately..... 76. Linaceae, p. 1073

29. Herbs, shrubs or trees; fruit not as in flax (30)

30(29). Leaves alternate and stipulate (the stipules sometimes small, deciduous) (31)

30. Leaves alternate, opposite or whorled, either not having stipules or if with stipules then opposite (32)

31(30). Fruit subglobose, drupaceous (with several stones), reddish to yellowish or black, usually $5-10 \mathrm{~mm}$. thick........82. Aquifoliaceae, p. 1097

31. Fruit a capsule or schizocarp. 88. Sterculiaceae, p. 1125

32(30). Leaves opposite or whorled and with stipules, the evidence of stipules sometimes reduced to mere stipular lines or membranes at the sides of the node (here may also be sought certain Rubiaceae whose essential epigyny has been overlooked) ....107. Loganiaceae, p. 1308

32. Leaves opposite or alternate, without the slightest evidence of stipules (33)

33(32). Stamens 2 or 4 , fewer than the 5 corolla lobes (the number of corolla lobes may be obscure in highly zygomorphic corollas) (34)

33. Stamens 5 in flowers with 5 corolla lobes or 4 in flowers with 4 corolla lobes (this usually easily ascertained) (40)

34(33). Fruit not capsular, either schizocarpous and breaking into 1-seeded achenelike parts or else drupaceous; leaves always opposite (35)

34. Fruit a capsule or a samara; leaves opposite or alternate (37)

35(34). Flowers strongly zygomorphic; style usually manifestly bifurcate near the apex (lower branches usually shorter than the upper); fruit a schizocarp.................................................117. Labiatae, p. 1407

35. Flowers usually only slightly if at all zygomorphic; style usually microscopically if at all bifurcate at apex; fruit schizocarpous or drupaceous (36)

36(35). Fruit a 1-seeded drupe.

106. Oleaceae, p. 1301

36. Fruit a schizocarp or a drupe with 2 or more seeds. 116. Verbenaceae, p. 1393

37(34). Seeds minute, attached to a free central placenta in the 1-celled ovary; fruit a 2 - or 4-valved capsule; small herbs.

121. Lentibulariaceae, p. 1510

37. Seeds attached to axile or nearly axile placentas in the 2-celled ovary; fruit a capsule or samara (38) 
38(37). Corolla lobes usually convolute in bud; capsule elastically dehiscent, the seeds ballistically ejected at dehiscence......122. Acanthaceae, p. 1525

38. Corolla lobes usually imbricate or valvate in bud; capsule not elastically dehiscent (or fruit a samara in some taxa), the seeds not ballistic (39)

39(38). The 2 stamens opposite each other or at least widely separated on the nearly actinomorphic corolla.........................106. Oleaceae, p. 1301

39. The 2 or 4 stamens not widely separated in the usually strongly zygomorphic corolla............................................119. Scrophulariaceae, p. 1456

40(33). Only a single seed maturing in each flower

40. At least 2 and commonly more seeds produced by each flower (41)

41(40). Placenta obviously free-central, attached at base of the single cell of the ovary; stamens opposite the corolla lobes.

102. Primulaceae, p. 1276

41. Placenta axile or parietal, or if basal then the ovary with more than 1 cell, or if placentation difficult to determine at least not obviously freecentral; stamens alternate with the corolla lobes (but this very obscure in some flowers) (42)

42(41). Ovary 3-celled; style usually 3-cleft at apex; plant never twining; sepals united by translucent webbing tissue....112. Polemoniaceae, p. 1369

42. Ovary usually 2 - or 4-celled, rarely 1 -celled (43)

43(42). Placentae parietal (but often intruded deeply into the chamber and meeting at the center, their parietal nature then revealed only by very careful dissection); seeds small and numerous; anthers after anthesis shriveling into a spiral or helix; leaves opposite (except in genus Nymphoides); cymes never scorpioid.

108. Gentianaceae, p. 1312

43. Placentae axile or axile-basal (except parietal in some Hydrophyllaceae with scorpioid cymes and more than 1 stigma); seeds few to numerous; anthers after anthesis not shriveling into a spiral or a helix; leaves opposite or alternate (44)

44(43). Fruit drupaceous or a deeply lobed schizocarp of 2 to 4 achenelike mericarps.

114. Boraginaceae, p. 1383

44. Fruit a capsule or berry (45)

45(44). Each flower with a single (sometimes shallowly 2-lobed) stigma (46)

45. Each flower with 1 or 2 styles and at least 2 stigmas (47)

46(45). Herbs or shrubs; leaves alternate (sometimes fascicled); flowers almost exclusively radially symmetrical; fruit a capsule or berry.....

118. Solanaceae, p. 1449

46. Opposite-leaved herbs with strongly zygomorphic corollas; fruit a capsule.... 119. Scrophulariaceae, p. 1456

47(45). Often herbaceous twining vines or rhizomatous or stoloniferous creeping herbs; flowers usually solitary from the axils; ovary usually 2or 3- or 4-celled...............................111. Convolvulaceae, p. 1350

47. Never twining, usually small erect taprooted herbs; flowers in cymes or helicoid or scorpioid cymes, or solitary; ovary usually 1-celled (2celled in Nama).

113. Hydrophyllaceae, p. 1375

48(1). Completely submerged fresh-water aquatics with much-reduced flowers and very peculiar habits (cf. also Haloragaceae and Lemnaceae) (49) 
48. Either terrestrial plants or if aquatic then not completely submerged (or only briefly so at some seasons), the flowers always aerial or with a less bizarre habit (50)

49(48). Leaves whorled; plants usually secmingly free-floating 60. Ceratophyllaceae, p. 912

49. Leaves alternate, distichous; plants attached to rocks and usually in swiftflowing water. 68. Podostemaceae, p. 993

$50(48)$. Stem-parasites not in contact with the soil; vegetative parts threadlike.... 63. Lauraceae, p. 961

50. Nonparasitic or if parasitic then appearing rooted in soil (51)

51(50). Shrublets or subshrubs with creeping underground organs, forming colonies on low salty ground near and along the Texas coast; leaves well-developed (cf. Salicornia where they are mere scales), opposite, fleshy, linear; pistillate flowers aggregated into and largely sunken in the axes of short axillary inflorescences; staminate flowers in spikelike axillary inflorescences..................54. Bataceae, p. 868

51. Habitally diverse, if fleshy then having leaves reduced to scales or alternate leaves or the inflorescences different from Batis (52)

52(51). Corolla absent, the flower either with no perianth or with only one series of perianth parts (sepals or "tepals"); (also see here Rumex with 2 dissimilar whorls or sepals) (53)

52. Each flower with both calyx and corolla or occasionally in families with unisexual flowers the petals absent from the pistillate ones, or in some taxa petals present only in the chasmogamous flower but absent from cleistogamous ones (95)

53(52). Trees with flowers and fruits small and numerous in spherical heads; leaves palmately lobed (54)

53. Trees, shrubs, herbs or vines with flowers not in spherical heads or if so then leaves not palmately lobed (55)

54(53). Bark furrowed; leaves deeply 5- or 7-lobed to resemble a star, smooth and shiny (genus Liquidambar of)...71. Hamamelidaceae, p. 1011

54. Bark exfoliating in thin sheets; leaves 3- or 5-lobed, usually with broad rounded shallo sinuses, the undersurfaces usually pubescent..........

72. Platanaceae, p. 1012

55(53). Sepals coalescent at least near their bases either above the receptacle in hypogynous flowers or above the floral cup or hypanthium in perigynous flowers or above the ovary in epigynous ones (56)

55. Sepals free from each other either completely to the receptacle in hypogynous flowers or above the ovary in epigynous ones, or sepals absent (67)

56(55). Ovary completely inferior (57)

56. Ovary superior or only partly inferior near the base (60)

$57(56)$. Herbs usually growing partially submerged or in mud but the flowers aerial (58)

57. Plants never aquatic (59)

58(57). Leaves (at least the immersed ones) pinnatifid to capillary-dissected; staments more than 1; ovary 2- to 4-celled.

96. Haloragaceae, p. 1201

58. Leaves all entire; stamen 1; ovary 1 -celled.....

97. Hippuridaceae, p. 1208 
59(57). Erect herbs with merely opposite leaves and a pungently fetid odor (like that of a wet dog)

126. Valerianaceae, p. 1562

59. Erect or often trailing herbs with whorled leaves and not strongly odoriferous (genus Galium of)

124. Rubiaceae, p. 1538

60(56). Pistils several, free from each other

61. Ranunculaceae, p. 913

60. Pistil solitary (61)

61(60). Seeds (or ovules) campylotropous, with embryo curved around the periphery surrounding the perisperm or endosperm (62)

61. Seeds not as above (64)

62(61). Seeds solitary

53. Amaranthaceae, p. 857

62. Seeds several to numerous $(63)$

63(62). Stamens more numerous than sepals

56. Aizoaceae, p. 870

63. Stamens as many as the sepals.

58. Caryophyllaceae, p. 884

64(61). Branches of inflorescence scorpioid (genus Penthorum of)

64. Branches of inflorescence (if any) not scorpioid (65)

70. Saxifragaceae, p. 999

65(64). Leaves pinnately compound (genus Fraxinus of)

65. Leaves simple $(66)$

106. Oleaceae, p. 1301

66(65). Ovary 1-celled; stigma solitary; stamens 2 to 5.....50. Urticaceae, p. 788 66. Ovary usually 3-celled; stigma usually more than 1; stamens usually more than 5 .

78. Euphorbiaceae, p. 1082

67(55). Stamen solitary; leaves opposite; low-growing subaquatics or aquatics; perianth absent.

79. Callitrichaceae, p. 1085

67. Stamens more numerous or if only 1 then the leaves alternate or else the plants woody; calyx often present (68)

68(67). Carpels several, distinct

61. Ranunculaceae, p. 913

68. Carpels (when more than 1) united at least at their bases (at least at anthesis)

(69)

69(68). Ovary completely inferior as shown by micro- or macroscopic scales or sepals at top (use strong lens) and/or in some taxa by stamens at the very top of the ovary (70)

69. Ovary superior or at least half-superior (75)

70(69). Plants herbaceous (71)

70. Plants woody; fruit a nutlike structure (72)

71(70). Ovary of several folliclelike structures partially or almost wholly immersed in the inflorescence axis and associated floral tissue (genus Anemopsis of)

42. Saururaceae, p. 734

71. Ovary not as in Anemopsis 98. Umbelliferae, p. 1211

72(70). Nut subtended by a cupule of more or less consolidated bracts

72. Nut not having a basal cupule of bracts (73)

48. Fagaceae, p. 783

73(72). Leaves compound

46. Juglandaceae, p. 769

73. Leaves simple (74) 
74(73). Stipules present; leaves usually serrate.

47. Betulaceae, p. 777

74. Stipules absent; leaves usually entire-margined.

99. Cornaceae, p. 1262

75(69). Annual herbs; sepals 4; fruit a compressed-flattened 2-celled pod with a thin narrow vertical septum parallel to the direction of compression 64. Cruciferae, p. 962

75. Annual or perennial herbs or shrubs, trees or vines (76)

76(75). Plants herbaceous (include in this category woody-based vines and herbs which may have slightly woody stems at base but which die back to near the base every year) (77)

76. Plants woody, never vinelike (88)

77(76). Embryo curved, occupying the periphery of the rounded ovule and surrounding the perisperm and/or endosperm (78)

77. Embryo otherwise (84)

78(77). Each pistillate or perfect flower maturing only 1 seed (79)

78. Each pistillate or perfect flower maturing several seeds (81)

79(78). Sepals dry, scalelike, for the most part not green.

79. Sepals herbaceous in texture (80)

80 (79). Stipules absent. 53. Amaranthaceae, p. 857

80. Stipules present.

52. Chenopodiaceae, p. 834

81(78). Leaves alternate; flowers in terminal racemes....55. Phytolaccaceae, p. 870 81. Leaves alternate or opposite; flowers not in terminal racemes (82)

82(81). Leaves usually opposite; ovary never even slightly inferior; fruit usually dehiscent by terminal valves

58. Caryophyllaceae, p. 884

82. Leaves alternate or if opposite then the fruit opening otherwise and not uncommonly at least slightly inferior (83)

83(82). Each flower with 2 bracteoles (or "sepals") at base which often enclose the bud; ovary 1-celled or incompletely several-celled.

57. Portulacaceae, p. 879

83. Flowers rarely bibracteolate; ovary completely several-celled.

56. Aizoaceae, p. 870

84(77). Fruit a capsule of several folliclelike parts, each part dehiscing through the apical portion of the ventral suture.......42. Saururaceae, p. 734

84. Fruit not as in Saururaceae (85)

85(84). Flowers unisexual; fruits capsular, 3-celled....78. Euphorbiaceae, p. 1082 85. Flowers usually bisexual; fruits achenelike, indehiscent (86)

$86(85)$. Leaves palmately lobed or palmately or pinnately compound.

73. Rosaceae, p. 1015

86. Leaves not palmately lobed (87)

87(86). Stipules usually present, usually deciduous, never sheathing nor scarious; placenta apical; ovule anatropous; achene usually not shiny, often neither lenticular nor trigonous.

50. Urticaceae, p. 788

87. Stipules (when present) usually sheathing; placenta basal; ovule orthotropous; achene usually smooth and shiny, either lenticular or trigonous.

51. Polygonaceae, p. 795 
88(76). Embryo curved, occupying the periphery of the rounded ovule and surrounding the perisperm and/or endosperm (go back to couplet 79).

88. Embryo not as above (89)

$89(88)$. Leaves opposite (90)

89. Leaves alternate (91)

90(89). Fruit a drupe or a simple samara

106. Oleaceae, p. 1301

90. Fruit a double samara, with the seed-bearing bases connate and the 2 blades diverging as in maple fruit.

84. Aceraceae, p. 1104

91(89). Seeds numerous, each surrounded by a basal coma of hairs.

43. Salicaceae, p. 737

91. Seeds often 1 or few, with coma absent (92)

92(91). Androecium of 4 series, each series of 3 stamens whose anthers open by 2 or 4 uplifting valves, often an additional 3 staminodia present.

63. Lauraceae, p. 961

92. Androecium otherwise, usually the stamens fewer than 12; anther dehiscence usually by longitudinal slits (93)

93(92). Flowers perfect or unisexual with both sexes on the same plant, solitary or in few-flowered fascicles; calyx 4- or 5-merous; fruit a samara, a roundish drupe or a nutlike structure.

49. Ulmaceae, p. 788

93. Flowers unisexual, usually with male and female flowers on separate plants or sometimes on the same plant, in small spikes or aments; calyx absent at least in staminate flowers; fruit either a small wax-coated sphere or an elongate drupe (94)

94(93). Fruit a small wax-coated sphere; leaves subpersistent, usually toothed or lobulate above the middle 44. Myricaceae, p. 767

94. Fruit an elongate leathery-skinned drupe; leaves deciduous, usually entiremargined. 45. Leitneriaceae, p. 769

95(52). Ovary inferior or mostly so (96)

95: Ovary superior or mostly so (here also see Nelumbo of the Nyphaeaceae whose separate ovaries are mostly immersed in the receptacle and Euonymus in the Celastraceae in which the massive disk may appear to adhere lightly to the side of the ovary) (102)

96(95). Fruit consisting of 2 achenelike mericarps which at maturity separate from each other and from the receptacle....98. Umbelliferae, p. 1211

96. Fruit otherwise (97)

97(96). Embryo curved, forming the periphery of the roundish or disklike ovule, surrounding the perisperm and/or endosperm (go back to couplet $83)$.

97. Embryo and ovule otherwise (98)

98(97). Fruit a pome.

73. Rosaceae, p. 1015

98. Fruit not a pome or if resembling one then seeds numerous (99)

99(98). Fruit a drupe. 99. Cornaceae, p. 1262

99. Fruit a berry, capsule or follicetum (100) 
100(99). Usually a long hypanthium present and prolonged above and completely obscuring the top of the ovary; stamens (often 8) usually precisely twice as numerous as the petals; fruit a capsule.

95. Onagraceae, p. 1175

100. Top of ovary plainly visible at or slightly above the point of attachment of the stamens and perianth; fruit a capsule, berry or follicetum (101)

101(100). Plants partially submerged weak-stemmed aquatics (genus Myriophyllum of ) ..........................................96. Haloragaceae, p. 1201

101. Plants not partially submerged. 70. Saxifragaceae p. 999

102(95). Filaments monadelphous or diadelphous, or confluent with a gynophore (anthers free or united) (103)

102. Filaments distinct from each other or joined into more than 2 groups (108)

103(102). Pistil solitary and simple, often folliclelike at maturity; stigma solitary

74. Leguminosae, p. 1039

103. Pistil solitary but compound, rarely folliclelike; stigmas mostly more than 1 (104)

104(103). Flowers strongly bilaterally symmetrical; carpels usually 2; stamens monadelphous or diadelphous...................77. Polygalaceae, p. 1074

104. Flowers nearly radially symmetrical; carpels more than 2 ; stamens monadelphous (105)

105(104). Filament tube elongate and forming a more or less loose sheath not only around the ovary but also around the elongate style(s); stamens numerous; flowers perfect...............87. Malvaceae, p. 1113

105. Filament tube not so elongate (or if so then stamens only 10); stamens numerous or fewer; flowers perfect or unisexual (106)

106(105). Carpels 3 as shown by number of stigmas or placentas.

78. Euphorbiaceae, p. 1082

106. Carpels 5 (107)

107(106). Fruit separating at maturity into 5 or 10 uni- or biovulate mericarps which fall separately.

76. Linaceae, p. 1073

107. Fruit not a schizocarp or if so then the cells several-seeded.

88. Sterculiaceae, p. 1125

108(102). Aquatic perennial herbs with thick horizontal rhizomes, rooted in mud at bottom of water; leaves (at least those borne at or near the surface of the water) usually peltate or very deeply roundedcordate.

59. Nymphaeaceae, p. 900

108. Habit not as in the water-lily family (109)

109(108). Pistils several (each simple) and quite separate (even at base) at all stages of development (110)

109. Pistil 1, either simple or compound (in some taxa the carpels united only near their bases as for example the Magnoliaceae, Saxifragaceae and Hamamelidaceae) (112)

110(109). Flowers with a floral cup (or "hypanthium") at the rim of which are attached the sepals, petals and stamens; stipules usually present; endosperm absent

73. Rosaceae, p. 1015

110. Calyx, corolla and androecium hypogynous or nearly so; stipules present or often absent; endosperm usually present (111) 
111(110). Leaves usually fleshy and succulent, simple, unlobed or usually so, with entire or toothed margins...................69. Crassulaceae, p. 994

111. Leaves not succulent, usually deeply lobed or compound.....

61. Ranunculaceae, p. 913

12(109). Carpels numerous, crowded together to cover the prolonged floral axis, cohering to each other and in fruit forming a fleshy or rather woody conelike fruit, each folliclelike carpel opening longitudinally by a dorsal slit and each carpel uni- or biovulate; trees or shrubs

62. Magnoliaceae, p. 958

112. Gynoecium and fruit not as in the Magnoliaceae (113)

113(112). Flowers bilaterally symmetrical; petals 3, bilobed; stamens 5, each filament with a scale and all 5 scales connivent over the stigma; capsules explosively dehiscent...............85. Balsaminaceae, p. 1105

113. Character combination not as above (114)

114(113). Flowers bilaterally symmetrical; lowermost petal spurred or gibbous; fruit a capsule with 3 valves and 3 parietal placentae.

92. Violaceae, p. 1151

114. Character combination not as above (115)

115(114). Embryo curved around the periphery of the roundish or disklike seeds, surrounding the perisperm and/or endosperm (go back to couplet 78).

115. Ovules and seeds not as in centrospermous plants (116)

116(115). Fertile stamens precisely as many as sepals and alternate with them and/or as many as petals and opposite them (117)

116. Fertile stamens either more numerous than petals or sepals or if as few as petals or sepals then opposite the sepals and alternate with the petals (119)

117(116). Vines; fruit a several-seeded berry

86. Vitaceae, p. 1108

117. Mostly trees, shrubs or herbs; fruit mostly drupes or capsules or (if vines) then fruit a drupe (118)

118(117). Opposite-leaved herbs; capsule circumscissile (genus Anagallis of)...... 102. Primulaceae, p. 1276

118. Alternate-leaved plants; capsule not circumscissile....88. Sterculiaceae, p. 1125

119(116). Fruit a specialized capsule completely divided into 2 cells by a thin partition, each cell then with 2 placentae situated at the juncture of the partition and the walls, at dehiscence the 2 valves separating from the persistent partition (starting at base) and falling free........ 64. Cruciferae, p. 962

119. Fruit not a silique or silicle (120)

120(119). Leaves tubiform, basal, trumpet-shaped, dilated upward, to $7 \mathrm{dm}$. long, partially filled with fluid, with a ridge on the adaxial side and terminated by an expanded hood to $8 \mathrm{~cm}$. long; stamens numerous 66. Sarraceniaceae, p. 990

120. Character combination not as above (121)

121(120). Rosettelike low nearly acaulous herbs; leaf blades usually rotund, the margins with gland-tipped hairs that exude drops of clear glittering glutinous fluid; insectivorous by means of folding leaf blades............

67. Droseraceae, p. 990

121. Character combination not as above (122) 
122(121). Tree with opposite palmately lobed leaves on long slender reddish petioles; fruit of geminate samaras (Acer rubrum of)

84. Aceraceae, p. 1104

122. Character combination not as above (123)

123(122). Shrub or tree with alternate simple stipulate leaves; flowers usually perfect, small, borne in small axillary pedunculate clusters or heads, with 3 each of sepals, petals, stamens and staminodes and 2 long styles; capsule bivalvate, opening loculicidally from the top; seed 1 in each cell.

71. Hamamelidaceae, p. 1011

123. Character combination not as above (124)

124(123). Ovary with a slender axis $1-5 \mathrm{~cm}$. long, at the base of which are 5 small cells, each with 2 ovules; at maturity when dry the cells suddenly separating from the axis and coiling up on their styles which are also adnate to the full length of the axis.

75. Geraniaceae, p. 1071

124. Character combination not as above (125)

125(124). Pistil simple, folliclelike with a single style and stigma and a single ventral placenta......................................74. Leguminosae, p. 1039

125. Pistil not simple as shown by 2 or more stigmas, 2 or more cells, or 2 or more placentae (126)

126(125). Flowers unisexual; carpels 3 ; fruit usually a capsule and usually with a well-developed central axis (columella) which persists after dehiscence; ovules 1 or 2 in each of the 1, 2 or usually 3 cells, attached to an apical-axial (columellar) placenta

78. Euphorbiaceae, p. 1082

126. Flowers usually bisexual; carpels 2 to 10 , if 3 then character combination not as above (127)

127(126). Herbs with alternate palmately compound leaves (rarely reduced to 1 leaflet); flowers hypogynous, often somewhat bilaterally symmetrical; stamens 6 to 27 or more, as long as or usually longer than the petals; ovary borne on a slender gynophore (rarely nearly sessile), 1 -celled (2-celled in Wislizenia), usually capsular with 2 valves and many seeds

65. Capparidaceae, p. 987

127. Character combination not as above (128)

128(127). Petals and stamens either definitely perigynous, i.e., inserted in a floral cup or "calyx tube" or very slightly epigynous (the cup attached to the very basal part of the ovary) (129)

128. Petals and stamens hypogynous (rarely very slightly or obscurely perigynous as in some Celastraceae) (132)

129(128). Leaves opposite; hypanthium urceolate; petals 4, fugacious, rose-color to purple (rarely white or yellow); stamens 8, basally appendiculate; anthers dehiscing by apical pores

94. Melastomataceae, p. 1169

129. Character combination not as above (130)

130(129). Herbs; leaves mostly basal; ovary very shortly at base adnate to a floral cup; stigmas 4; capsule 1-celled, 4-valved; stamens 5, plus 5 staminodes (genus Parnassia of) ............70. Saxifragaceae, p. 999

130. Ovary superior; style $1,2,3$ or 5 , never 4 ; stamens 4 to numerous (131) 
131(130). Flowers usually uniformly 5-merous; stamens 10 to 40 , inserted near the rim of the floral cup not very far from where the petals are inserted; stipules present..............................73. Rosaceae, p. 1015

131. Flowers 4- to 7-merous; stamens 4 to numerous, usually inserted well down into the calyx tube or floral cup, whereas the petals are inserted near the rim between the short calyx teeth; stipules minute or usually absent.

93. Lythraceae, p. 1154

132(128). Shrubs or trees with numerous twigs and very numerous alternate scalelike or nearly terete leaves only about $1 \mathrm{~mm}$. long, the entire plant often appearing grayish; flowers pink or white, very small, inconspicuous. 91. Tamaricaceae, p. 1148

132. Character combination not as above (133)

133(132). Leaves opposite, simple and gland-dotted (as seen with transmitted light); styles often separate or nearly so or only lightly cohering until after anthesis; mostly herbs or weak-stemmed shrubs; sepals, petals and stamens free and hypogynous or stamens in 5 phalanges opposite the petals; placentae parietal or usually axile; ovules usually numerous; fruit a capsule; stamens 6 to numerous, when numerous tending to be in as many groups as there are petals

89. Hypericaceae, p. 1127

133. Character combination not as above but if most of the characters are similar then the leaves mostly alternate or the styles permanently united (134)

134(133). Shrubs or small trees of eastern Texas; flowers usually white, in elongate racemes usually $5-20 \mathrm{~cm}$. long and only $1 \mathrm{~cm}$. thick (135)

134. Habit various but if flowers in elongate racemes then plants herbaceous (136)

135(134). Fruit dehiscent.

100. Clethraceae, p. 1267

135. Fruit indehiscent

81. Cyrillaceae, p. 1095

136(134). Fruit indehiscent and usually fleshy, usually 1 -seeded (137)

136. Fruit dehiscent, usually dry at maturity (138)

137(136). Leaves simple, usually stipulate; stamens never more numerous than petals; drupes usually nearly circular in transection, not resinous, usually glabrous....................................82. Aquifoliaceae, p. 1097

137. Leaves usually compound, usually exstipulate; stamens as many as or rarely twice as many as the petals; drupes usually somewhat flattened, resinous, often pubescent......................80. Anacardiaceae, p. 1091

138(136). Flowers with thick-lobed disk that fills the bottom of the calyx and sometimes hides much of the ovary; plants woody, with 4 sided green-barked branchlets; seeds with bright-red arils (genus Euonymus of) 83. Celastraceae, p. 1103

138. Disk (if present) not so thick; plants various in habit but usually mostly herbaceous in texture; seeds not with bright-red arils 


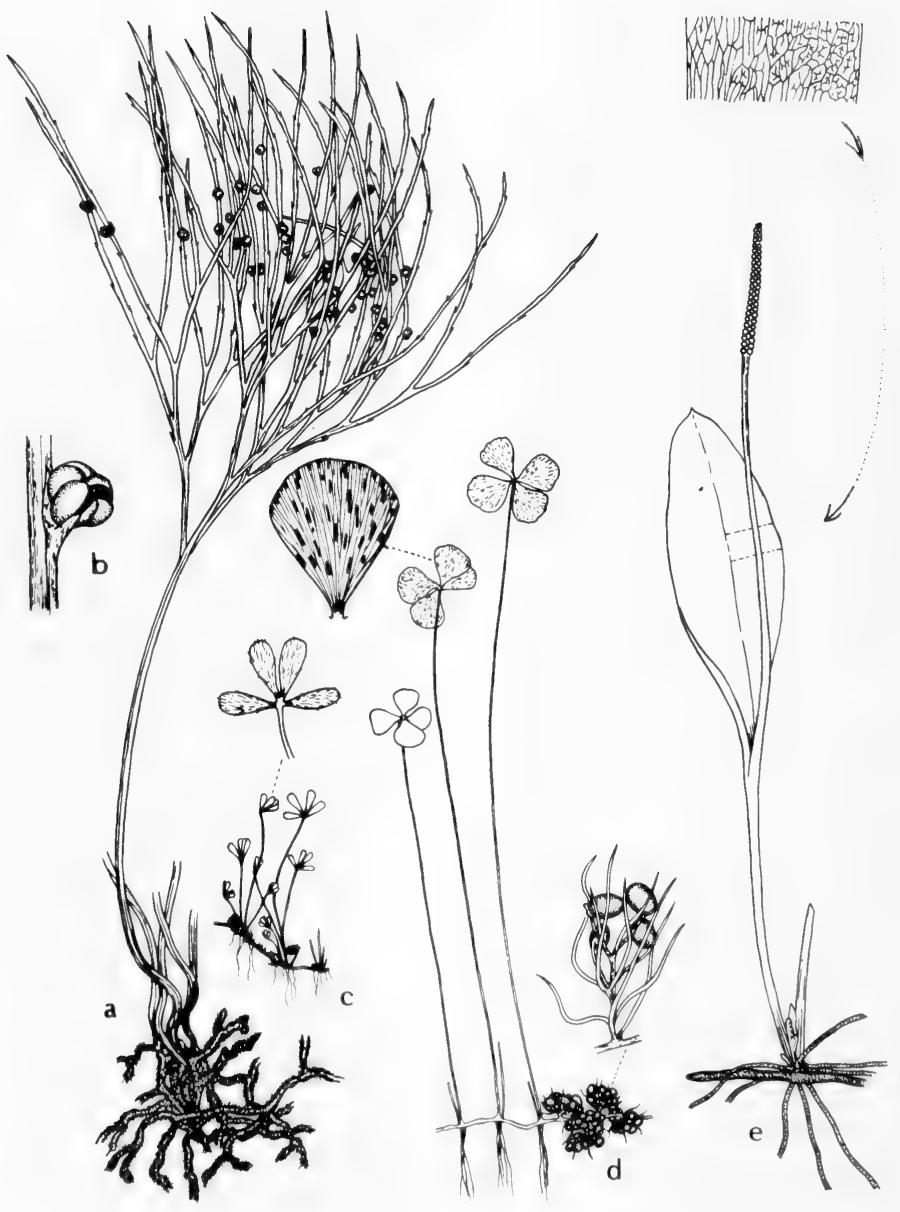

Fig. 4: a and b, Psilotum nudum: a, habit, x 1/2; b, sporangium, x 4. c, Marsilea Fournieri: c, habit, x $2 \% 3$, with leaf, x 2. d, Marsilea mexicana: d, habit, x 2/3, with leaf, x 2, and sporocarps, about x 21/2. e, Ophioglossum Engelmannii: e, habit, x 2/3, with section of sterile leaf blade enlarged. 


\section{Division I. Pteridophyta}

\section{Ferns and Fern Allies}

Terrestrial, epiphytic, saxicolous or occasionally aquatic plants with a life cycle of two distinct phases-Sporophyte and Gametophyte. The sporophyte is usually differentiated into root, stem and leaf provided with vascular tissue (phloem and xylem), and produces spores asexually that are either alike (plants homosporous) or of two very unlike kinds called microspores and megaspores (plants heterosporous). The spores germinate to produce the gametophyte or minute inconspicuous sexual stage (prothallium). In the homosporous series the prothallia are similar but may be either monoecious or dioecious; in the heterosporous series they are dissimilar and dioecious-the ones developing from microspores bearing only male reproductive organs (antheridia), and those from megaspores only female organs (archegonia). Fertilization consists of the impregnation of an egg cell (archegonia) by the coiled motile male cell (spermatozoid); the resulting growth is the sporophyte or usually conspicuous asexual stage commonly known as a fern or fern ally.

The Pteridophyta include more than 9,000 species in about 215 genera. Although world-wide in distribution, they attain their greatest number and luxuriant development in the tropics and subtropics. Approximately 345 species in about 60 genera are found in North America north of Mexico.

\section{Fam. 1. Psilotaceae Eichler}

\section{WHISK FERN FAMILY}

Terrestrial or more or less epiphytic perennial plants with short creeping coralloid rhizomes; aerial stems and branches wiry, dichotomously branched, with minute remote alternate scalelike leaves; sporangia somewhat depressed-globose and 3-celled, opening at the apex into 2 or 3 valves, sessile in the axils of the usually 2-lobed minute sporophylls on the upper part of the numerous branches; spores all alike, numerous.

A small family of two genera, Tmesipteris of Oceania and Australasia, with several species, and Psilotum.

\section{Psilotum Sw.}

Characters of the family. About 3 species that are widely distributed in tropical or warm temperate regions throughout the world.

1. Psilotum nudum (L.) Beauv. Fig. 4.

Plants dichotomously branched 3 to 5 times, usually about $25 \mathrm{~cm}$. tall, rarely to $5 \mathrm{dm}$. tall; common stalk simple, 3 -angled, to $4 \mathrm{~mm}$. thick; branches lightly winged along the 3 angles; scalelike leaves about $1 \mathrm{~mm}$. long; sporophylls rudimentary.

In swamps and low wet woods about base of trees and stumps, more or less partly saprophytic, in s.e. Tex., summer; from Fla., n. to S.C., w. to Tex., through Mex. and C. A. to S. S. A. and in W.I.; also widely distributed in the Old World trop. 


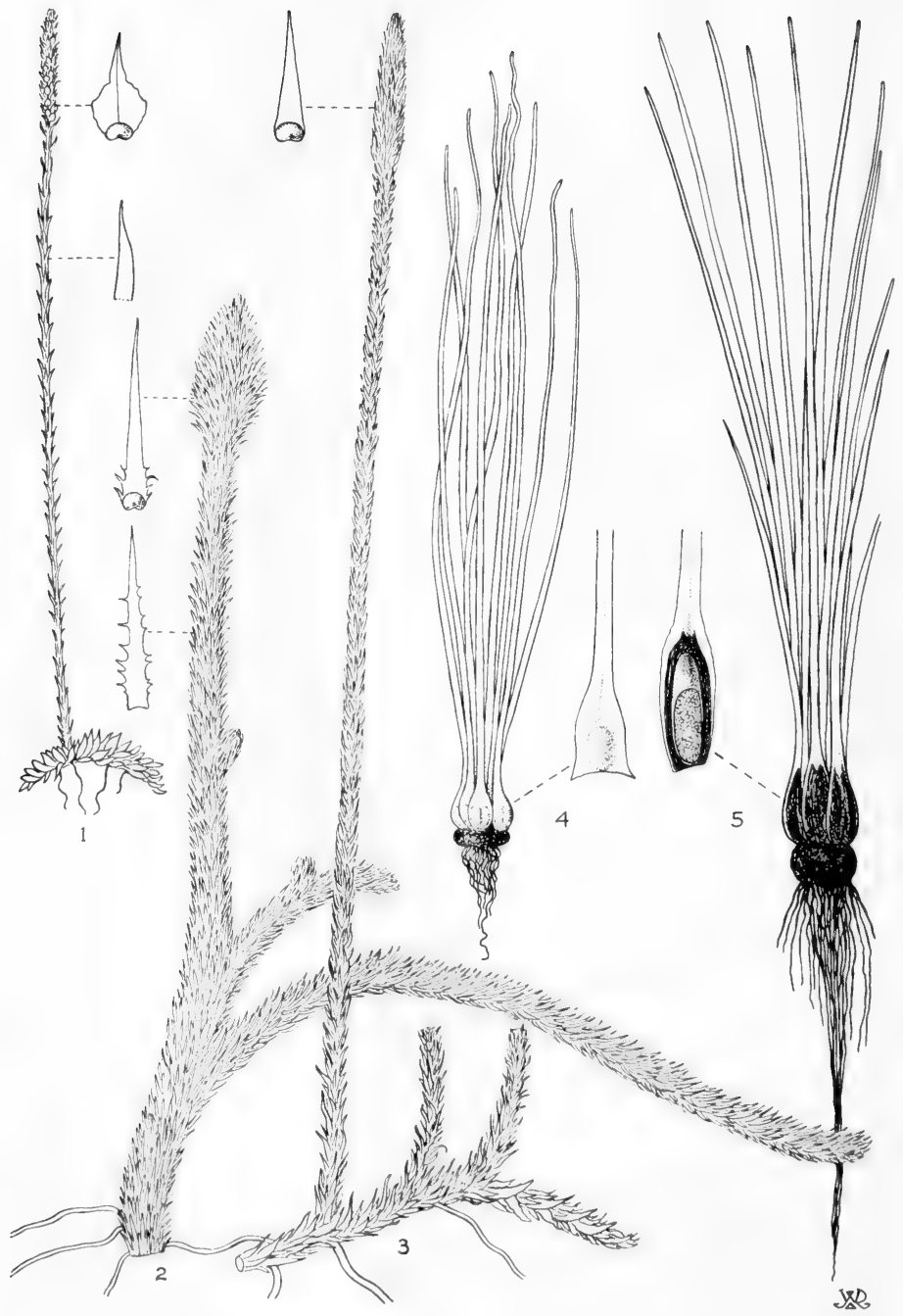

Fig. 5: 1, Lycopodium carolinianum: 1, plant, $x \quad 2 / 3$, with enlarged peduncle leaf and sporophyll. 2, Lycopodium alopecuroides: 2, plant, $\mathrm{x} 2 / 3$, with enlarged peduncle leaf and sporophyll. 3, Lycopodium adpressum: 3, plant, $\mathrm{x} 2 / 3$, and enlarged sporangium. 4, Isoetes lithophylla: 4, plant, $\mathrm{x} 1$, and enlarged sporangium. 5, Isoetes melanopoda: 5, plant, $\mathrm{x}$ 1, and enlarged sporangium. (From Correll in Lundell's Flora of Texas, Vol. 1, Pl. 3.) 


\section{Fam. 2. Lycopodiaceae ReIchB.}

\section{Clubmoss Family}

Low terrestrial erect or trailing perennial plants; stems mostly prostrate or arching and giving rise to aerial peduncles or branches, alternately branched or repeatedly dichotomous, densely or sparsely covered with small leaves; leaves numerous, mostly small and thin, 1-nerved, usually uniform and imbricate, severalto many-ranked, rigidly ascending to spreading-reflexed; sporophylls similar to the vegetative leaves or more or less modified, crowded into a cone at the apex of the aerial stems; sporangia large, in the axils of the sporophylls, uniform. 1-celled; spores all alike (plants homosporous), small, globose, light yellow; prothallia fleshy, tuberous, monoecious.

This family is composed of two genera, the monotypic genus Phylloglossum, of Australia and New Zealand, and Lycopodium.

\section{Lycopodium L. Clubmoss}

Characters same as those of the family. About 450 species that are found mainly in temperate and mountanous tropical regions.

1. Stems arching and rooting, not truly prostrate; stem leaves spreading radially..

1. Stems prostrate (2)

1. L. alopecuroides var. alopecuroides.

2(1). Foliage leaves unlike sporophylls; stem leaves spreading, arranged so as to appear 2-ranked. 3. L. carolinianum.

2. Foliage leaves and sporophylls similar (3)

3(2). Sporophylls incurved, appressed; cone slender, only slightly thicker than the supporting peduncle.

2. L. adpressum.

3. Sporophylls more or less spreading; cone stout, 2 to 3 times the diameter of the supporting peduncle. 1. L. alopecuroides var. pinnatum.

1. Lycopodium alopecuroides L. var. alopecuroides. FoxtAIL CLUBMOSS. Fig. 5.

Peduncles to $35 \mathrm{~cm}$. tall; cone 2-10 cm. long; leaves linear-lanceolate, bristletoothed below, 6-8 mm. long; sporophylls similar to leaves in shape and size.

In wet places in savannahs and boggy areas in low open pinelands in s.e. Tex., July-Nov.; from Fla., in the Coastal Plain, n. to N.Y. and w. to Tex.; also S.A.

The outstanding characteristic by which var. alopecuroides is most easily recognized in the field is the arching stem that usually roots at the tip when it touches the ground, and the several more or less erect peduncles.

Var. pinnatum (Chapm.) Lloyd \& Underw. Creeping Foxtail Clubmoss. The prostrate habit of this variety is the only characteristic separating it from var. alopecuroides. L. prostratum Harper. Apparently isolated in Travis Co., Tex.; also from cen. La., e. to Fla. and n. along the coast to N.C.

2. Lycopodium adpressum (Chapm.) Lloyd \& Underw. Southern ClubMoss. Fig. 5.

Peduncles to $3 \mathrm{dm}$. tall and about $3 \mathrm{~mm}$. in diameter; cone slender, $2-7 \mathrm{~cm}$. long; leaves linear-lanceolate to lanceolate, entire or slightly toothed below, 6-7 $\mathrm{mm}$. long; sporophylls similar to the leaves. L. alopecuroides var. adpressum Chapm.

In depressions in savannahs and flat open pinelands, bogs and sphagnous habitats in e. and s.e. Tex., June-Oct.; mostly on Coastal Plain from Fla., n. to N.Y. and w. to Tex.

The incurved appressed leaves on the peduncle and the slight difference in size between the peduncle and cone are distinctive. 


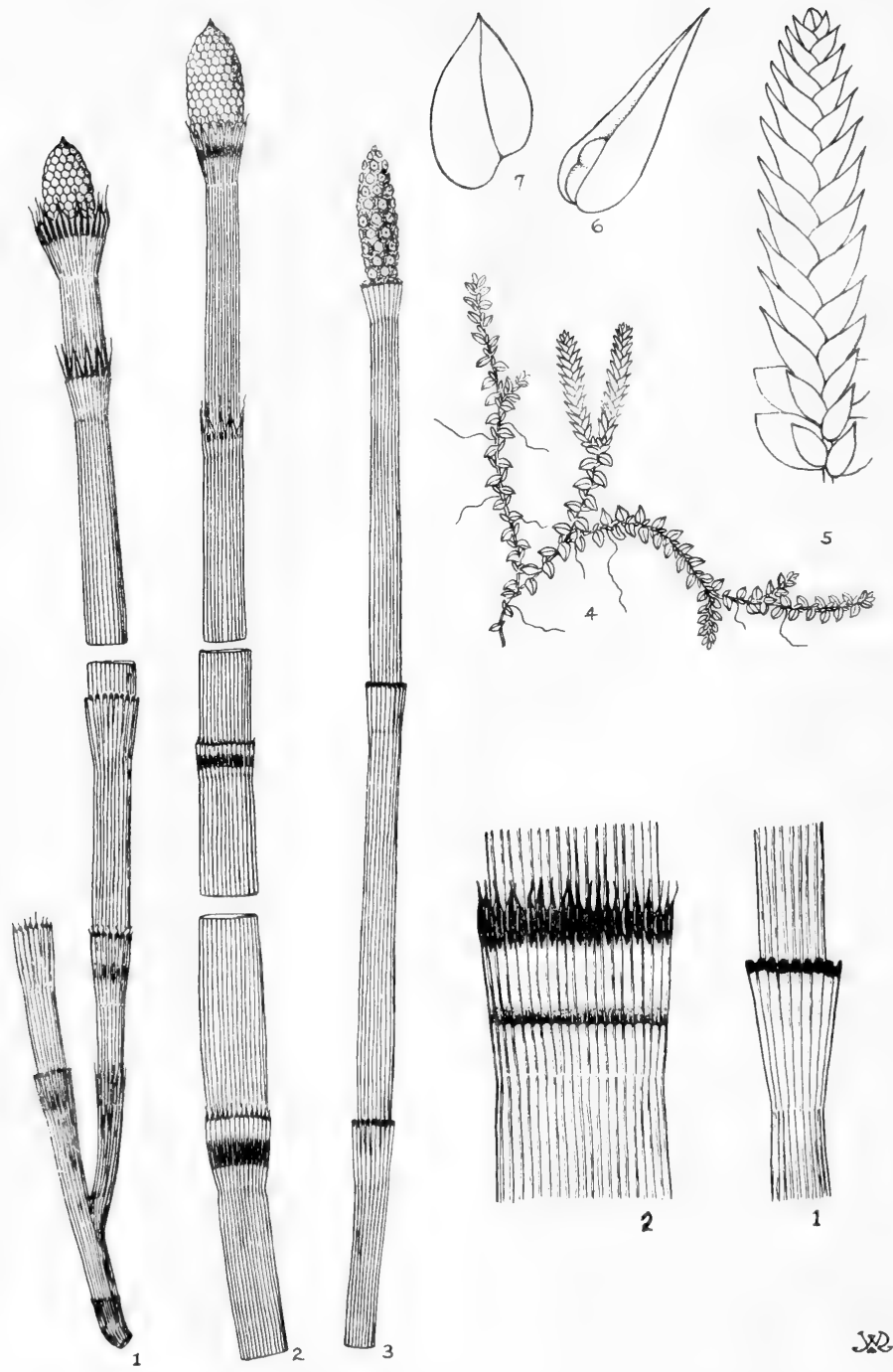

Fig. 6: 1, Equisetum laevigatum: 1, basal and upper sections of fertile stem (x 1) and somewhat enlarged sheath. 2, Equisetum hyemale var. affine: 2, several sections of fertile stem (x 1) and somewhat enlarged sheath. 3, Equisetum kansanum: 3, upper section of fertile stem, x 1.4-7. Selaginella apoda: 4, fertile plant, x 1; 5, fertile spike, $\mathrm{x} 5 ; 6$, sporophyll, x 10; 7, foliage leaf, x 10. (In part from Correll in Lundell's Flora of Texas, Vol. 1, P1. 2.). 


\section{Lycopodium carolinianum L. Slender Clubmoss. Fig. 5.}

Peduncles slender, rigidly erect, to $25 \mathrm{~cm}$. tall and $1.5 \mathrm{~mm}$. in diameter; cones 1-5 cm. long and about twice the diameter of the peduncle; leaves of the peduncle subulate, in whorls or scattered, about $5 \mathrm{~mm}$. long; sporophylls broadly ovate to deltoid, acuminate, about as long as the peduncle leaves.

Rare in depressions in savannahs, seepage areas and open flat pinelands in s.e. Tex., July-Sept.; from Fla., n. to N.Y., w. to Tex.; also occurring as variants in S.A., Asia, Afr., Austral. and N.Zeal.

The erect slender peduncle with scattered small leaves and sporophylls different from the foliage leaves is distinctive.

\section{Fam. 3. Selaginellaceae MEtr.}

\section{SPIKEMOSS FAMILY}

Small terrestrial or saxicolous plants of spreading habit, prostrate to ascending or suberect, usually profusely branched, with slender stems; stems leafy, usually producing wiry elongate rhizophores at some or all the nodes; leaves all alike or of two kinds, elliptic to lanceolate, several-ranked or in two planes, numerous, minute, 1-nerved, obscurely ligulate, approximate to widely imbricate; sporophylls somewhat modified, borne in compact sessile cones at the apex of branches; sporangia of two kinds (plants heterosporous), solitary in the axils of sporophylls, 1-celled; megasporangia containing 1 to 4 rather large megaspores; microsporangia containing numerous microspores.

Only one genus in the family.

\section{Selaginella Beauv.}

Characters same as those of the family. About 700 species are recognized in this complex genus that is highly developed in tropical and subtropical regions of both hemispheres.

\section{Selaginella apoda (L.) Spring. Meadow spikemoss. Fig. 6.}

Plants prostrate-creeping or ascending (especially when in dense shade), paleto dark-green, flaccid, frequently forming large mats, annual; stems very slender, filamentous, somewhat angled, much-branched, to $25 \mathrm{~cm}$. long or more; leaves dimorphic, membranous, spreading in 2 planes; lateral leaves 2-ranked, alternate, distant, spreading, obliquely ovate to ovate-elliptic, obtuse to acute, with the margins serrulate, $1.5-2 \mathrm{~mm}$. long, about $1 \mathrm{~mm}$. wide; dorsal leaves smaller than the lateral leaves, ovate to ovate-lanceolate, shortly cuspidate, with the margins serrulate, about $1.2 \mathrm{~mm}$. long, less than $1 \mathrm{~mm}$. wide; spikes obscurely quadrangular, 5-20 $\mathrm{mm}$. long, 2-4 $\mathrm{mm}$. in diameter; sporophylls about as long as the lateral stem leaves, ovate to ovate-lanceolate, acute to subacuminate, keeled in the upper half; megasporangia yellowish, 0.5-0.9 $\mathrm{mm}$. in diameter, most abundant toward base of spike; microsporangia reddish, very small, less than $0.1 \mathrm{~mm}$. in diameter. S. ludoviciana $\mathrm{A}$. Br.

In moist or wet places, usually in partial shade, in e. Okla. and e. and s.e. Tex., w. into the Edwards Plateau and Rio Grande Plains, May-Dec.; from Me.w. to B.C., s. to Fla. and Tex.

\section{Fam. 4. Isoetaceae Reichb. QUILlwort FAMILY}

Small herbaceous perennial aquatic or terrestrial sedgelike plants with short unbranched 2- to 5-lobed subterranean cormlike rhizomes that produce numerous branched roots and a tuft of compact erect or recurved rushlike leaves (sporophylls); leaves bearing a small membranous ligule on the inner surface just above the sporangium; sporangia of two kinds, sunken in the axils of the leaf bases, more 

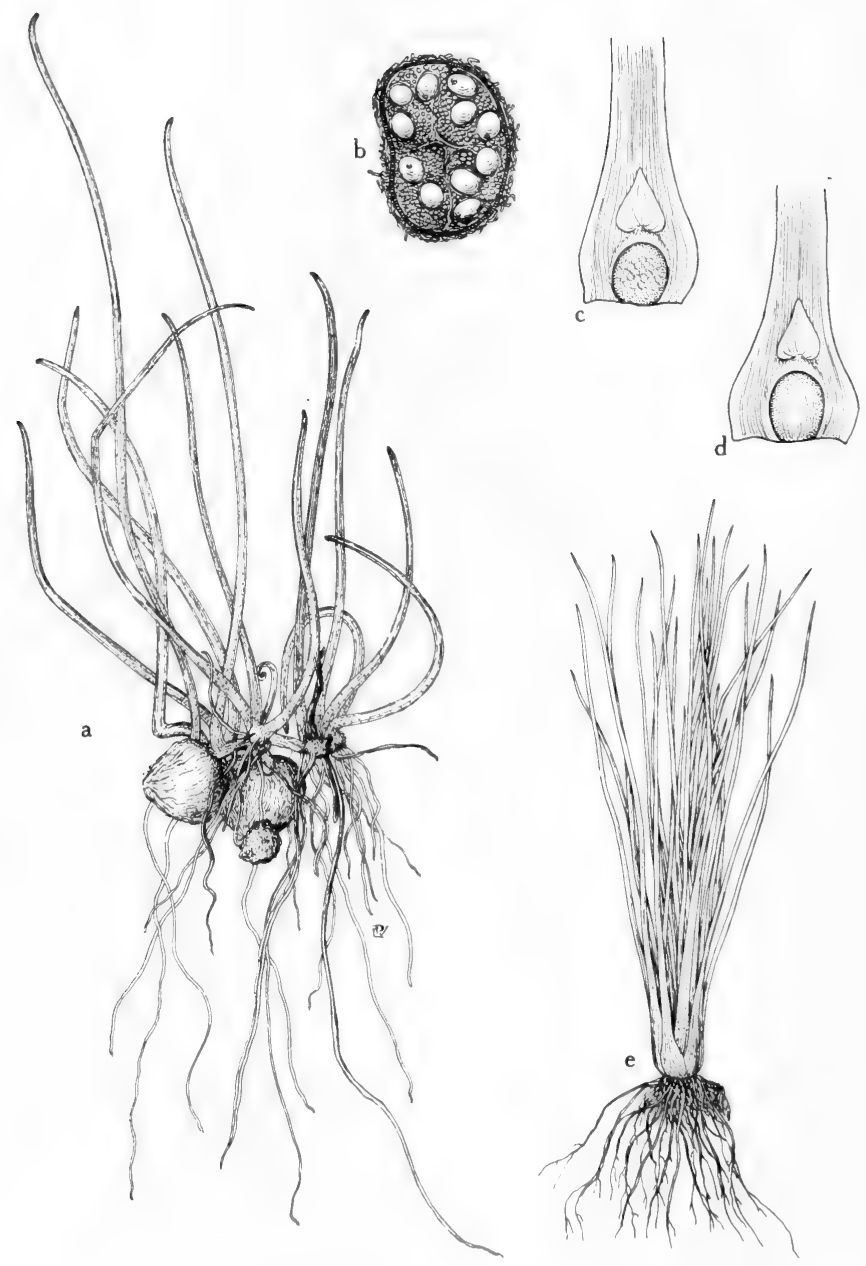

Fig. 7: a and b, Pilularia americana: a, habit, showing the filiform bladeless leaves, the young ones coiled, and the stalked sporocarps, $x 6$; b, sporocarp (cross section), showing the sporangia, x 12. c-e, Isoetes Bolanderi: c, megasporangium on adaxial side of leaf base, the upper part partially covered by the velum, the ligule free, $x$ 3; $\mathrm{d}$, microsporangium on adaxial side of leaf base, the upper portion partially covered by the velum, the ligule free, x 3; e, habit, x 4/5. (From Mason, Fig. 5). 
or less covered by a velum; the microspores germinate into prothallia that bear only a solitary antheridium; the megaspores germinate into prothallia that bear only archegonia.

This family is represented by two genera, Isoetes and Stylites.

\section{Isoetes L. QUILLWORT}

Characters same as those of the family. About 75 species that are widespread in temperate and tropical regions of both hemispheres.

A compound microscope is usually necessary in order to determine species.

It has been noted that ducks seek out and eat the cormlike rhizomes and sporangia masses at the base of the plant, and muskrats are known to eat the crisp rhizomes. Wildfowl and grazing animals are also known to eat the grasslike sporophylls.

1. Velum complete; megaspores dark-brown when wet, small-tuberculate; leaves $12 \mathrm{~cm}$. long or less; plants light-brown at base........1. I. lithophylla.

1. Velum narrow, usually covering not more than one third of sporangium (2)

2(1). Megaspores with tubercles frequently confluent into wrinkles; distribution Arizona..........................................................2. I. Bolanderi.

2. Megaspores with chiefly simple tubercles; distribution Oklahoma and Texas (3)

3(2). Megaspores less than 480 microns in diameter; sporangia 5-30 mm. long, brown-spotted, with narrow to broad velum..........3. I. melanopoda.

3. Megaspores more than 480 microns in diameter; sporangia 6-7 mm. long, usually brown-lineolate, the velum wanting or very narrow......

4. I. Butleri.

\section{Isoetes lithophylla Pfeiffer. Fig. 5.}

Corm 2-lobed, small; leaves 6 to $14,10-12 \mathrm{~cm}$. long, slender but not filiform, flexuous; stomata numerous; peripheral strands variable, none or 3 , weak; ligule very small, cordate-triangular; sporangium $2.5-4 \mathrm{~mm}$. long, orbicular to oblong, completely covered by velum; megaspores 290-360 microns in diameter, with prominent high rather narrow commissural ridges; surface of megaspores gray when dry, brown when wet, smooth or faintly marked with low short or somewhat extended usually distant ridges; microspores dark brown, chiefly 30-33 microns long, high-tuberculate or spiny.

In shallow depressions and temporary pools on rock outcrops and mts. of granite, found only in Burnet and Llano cos. on the Edwards Plateau in Tex. where it is apparently endemic, Apr.-June.

\section{Isoetes Bolanderi Engelm. Fig. 7.}

Corm usually conspicuously 2-lobed; leaves 6 to 25 , conspicuously quill-like, $6-15 \mathrm{~cm}$. long, rarely more; stomata very few; ligule small, cordate; sporangium 3-4 mm. long, orbicular to oblong, at most one-third covered by velum; megaspores white to bluish, 300-480 microns in diameter, the tubercles sometimes aggregated into wrinkles; microspores 23-30 microns long, more or less spinulose.

Submersed in bottom of lakes and ponds in shallow to deep water, rare in Ariz. (Apache and Coconino cos.); B.C. s. to Mex.

Plants small in all characters have been recognized as var. pygmaea (Engelm.) Clute. Calif., Nev. and Ariz.

\section{Isoetes melanopoda Gay \& Dur. Fig. 5.}

Corm 2-lobed; leaves 15 to 60 , slender, erect, firm, bright green, $15-40 \mathrm{~cm}$. long, usually black and shining at base, with usually pale membranaceous border, little $(2-3 \mathrm{~cm}$.) extended above sporangium level; stomata present; peripheral strands 4 or 6 cardinal, plus as many as 14 accessory groups; ligule subulatetriangular; sporangia oblong, 5-30 mm. long, marked by numerous brown spots; 


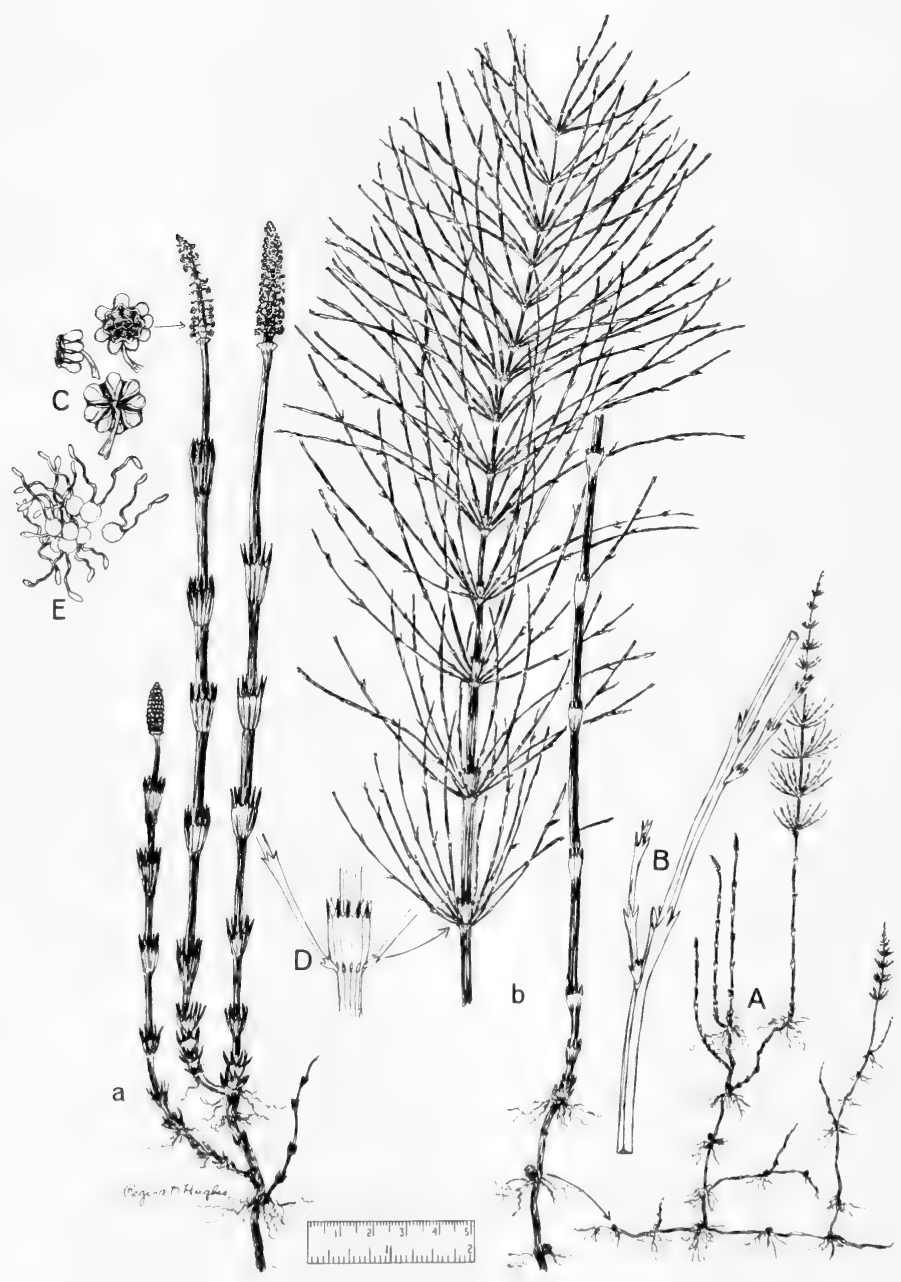

Fig. 8: Equisetum arvense: A, habit; a, early sporophyll-bearing plant; b, later, vegetative stem; B, enlarged branch; $\mathbf{C}$, sporangiophores; D, sheath; $\mathbf{E}$. spores, showing elators. (From Reed, Selected Weeds of the United States, Fig. 2). 
velum variable, from very narrow to covering nearly one half of sporangium; megaspores 280-440 microns in diameter, marked with low tubercles, frequently confluent into short low wrinkles; microspores frequently ashy-gray, 20-30 microns long, finely spinulose. Incl. var. pallida Engelm.

In shallow ponds, bogs, old buffalo wallows, wet thickets and woods (especially pinelands), in seasonal streams and temporary sedge-grass puddles in meadows and prairies, and in temporary pools on granite outcrops, rare in Okla. (Atoka Co.), widely distributed but uncommon in e. Tex., w. to Mason Co. on Edwards Plateau, Mar.-Oct.; from N.J., w. to Minn., Ill. and S.D., s. to Ga., La., Okla. and Tex.

\section{Isoetes Butleri Engelm.}

Superficially resembling a pale-based form of 1 . melanopoda, smaller, dioecious; leaves 8 to 30 , almost bristleform, with triangular cross section, $8-22 \mathrm{~cm}$. long, $0.5-1.2 \mathrm{~mm}$. broad, pale at base, with broad dissepiments, slender air-canals and 4 bast-bundles, the pale sheaths granular on the back; sporangia 6-7 $\mathrm{mm}$. long, commonly covered with brown lines, with velum wanting or very narrow; ligule subulate, with the base cordate; megaspores (360-) 480-650 microns in diameter, covered with many low and distinct (sometimes confluent) wartlike tubercles; microspores 27-37 microns long, covered with papillae.

Rocky slopes, springy places, seepage areas, flats and depressions in Okla. (Atoka Co.); Tenn., Mo. and e. Kan., s. to Ark. and Okla.

\section{Fam. 5. Equisetaceae Rich. FAMILY}

Large or small terrestrial rushlike plants with wide-creeping branching perennial rhizomes; roots felted, annual; aerial stems usually erect, perennial or annual, cylindric, fluted, stout or slender, jointed, simple or with whorls of branches at the solid nodes, with usually hollow internodes, often roughened by a coating of silex; stomata arranged in regular rows or broad bands in the grooves; stem leaves minute, reduced and united to form toothed sheaths at the nodes, the free or connivent apical teeth persistent or deciduous; sporophylls aggregated into a cone or strobile at the summit of the main stem or at the apex of the branches, modified as stalked peltate scales; sporangia 6 or 7 under each scale, opening down the inner side; spores all alike, numerous, green; prothallia in damp places above ground, green, monoecious or dioecious, variously lobed.

The family is represented only by the following genus.

Our species are of lesser importance to animal and bird life than those found farther north. The plants are incidentally browsed and eaten by cattle, deer and muskrats, and some waterfowl are known to eat the rootstocks and stems.

\section{Equisetum L.}

Characters same as those of the family. A complex genus consisting of about 23 species that are widespread in both hemispheres.

1. Aerial stems dimorphic; fertile stems light-brown, early-withering; sterile stems green, with regular whorls of branches...................... E. arvense.

1. Aerial stems uniform, without regular whorls of branches (2)

2(1). Cones rounded at the summit, without a firm sharp tip; stems annual, soft and easily crushed.

2. E. kansanum.

2. Cones tipped by a firm dark point; stems perennial (evergreen), firm and resistant or somewhat soft (3) 
3(2). Sheaths dilated upward, green (when young), with a narrow black band at the summit below the promptly deciduous teeth, frequently with a second irregular band below; stems smoothish, only slightly scabrous............................................................. E. laevigatum.

3. Sheaths cylindric, tightly pressed to the stem, ashy-gray, usually with 2 black bands, sometimes entirely black, the teeth mostly subpersistent or irregularly deciduous; stems firm, scabrous

4. E. hyemale var. affine.

1. Equisetum arvense L. Bottle brush. Fig. 8.

Rhizome extensively creeping and branching, dark-felted and tuberiferous; aerial stems dimorphic, with scattered stomata; fertile stems appearing in early spring, erect, usually thick and succulent, light-brown to yellowish-white, simple, to about $3 \mathrm{dm}$. tall, soon withering, provided with conspicuous lax scarious somewhat dilated nodal sheaths that have 8 to 12 brown lance-acuminate teeth; cones cylindric to ovoid, obtuse, to $4 \mathrm{~cm}$. long and $1 \mathrm{~cm}$. diameter; sterile stems appearing as the fertile stems wither, erect to ascending, slender, green, 8- to 14-furrowed, with whorls of branches at the upper nodes, to about $7.5 \mathrm{dm}$. tall, usually smaller, the nodal sheaths tipped with about 12 sharp brown teeth; branches numerous in dense verticils, spreading to ascending, solid, mostly simple and $2.5 \mathrm{dm}$. long or less, about $1 \mathrm{~mm}$. thick, 3- or 5-angled, provided with sheaths that have erect triangular-lanceolate sharp teeth.

In sandy or clayey soil along streams and about lakes, in meadows, low ground and open woodlands, and on railroad embankments, in Tex. found only at Buffalo Spring (now known as Buffalo Lakes) in Lubbock Co., in the Plains Country, rather widespread and frequent in the mts. of N.M. (Colfax, Catron, Sandoval, Mora, San Miguel, Taos and Rio Arriba cos.) and Ariz. (Apache, Navajo, Coconino, Graham and Gila cos.); from Nfld. w. to Alas. and s. to N.C., Ala., Tex., N.M., Ariz. and Calif.; also Euras. and N.Afr.

Forma ramulosum (Rupr.) Klinge has been found in Arizona (Gila Co.). Its branchlets are again branched.

\section{Equisetum kansanum J. H. Schaffn. Summer scouring-Rush. Fig. 6.}

Stems 3-10 dm. tall, 2-7 mm. in diameter, usually very smooth to the touch, light-green; sheaths elongate, dilated upward, pale-green except for a narrow black band at summit, the articulate teeth soon deciduous; cone sessile or shortly pedunculate, $1-2.5 \mathrm{~cm}$. long, $5-8 \mathrm{~mm}$. in diameter.

In moist or dry sandy or clayey soil, on bluffs, along irrigation ditches and lakeshores, in prairies, ditches, sloughs and among grasses and shrubs in marsh and swamp areas, in Tex. mostly in the Plains Country, Trans-Pecos and s.e. Edwards Plateau, with a lone station in Somervell Co. in the Blackland Prairies; from Mich. to B.C., s.w. through the Lake States to Mo., Tex., N.M. and s. Calif.; also n. Mex.

Except for the absence of the hard blackish apicule on its cone, the smoother texture of its cone, and its annual habit, this species approaches very closely $E$. laevigatum. Its obvious relationship to that species has resulted in its being recently relegated to it as subsp. Funstonii (A.A.Eat.) Hartman.

Two rather insignificant growth forms of this species occur in our area; $f$. caespitosum (A.A.Eat.) Broun, with many small rough stems clustered around a large central one, and f. variegatoides (A.A.Eat.) Broun, with 6 to many small prostrate to ascending stems arising from the apex of the rhizome or about the old stems of the previous year.

3. Equisetum laevigatum A. Br. Cola de caballo, Cañuela, smooth scouringRUSH. Fig. 6.

Rhizome creeping and ascending, dark-brown to blackish, naked, with felted 
roots; aerial stems evergreen, simple or occasionally sparingly and irregularly branched, frail to somewhat stout, pale-green, mostly clustered, 3-15 dm. tall, to $8 \mathrm{~mm}$. in diameter, longitudinally 14 - to 30 -grooved, with the ridges smooth or slightly scabrous; sheaths elongate, dilated upward, marked with a black girdle at the base of the mostly deciduous white-margined subulate brownish teeth and rarely also at the base of the sheaths, with the ridges of the sheaths 1- to 3-keeled, the lowermost sheaths 5-12 mm. long; cones ellipsoid, sharp pointed, 1-2 cm. long, 7-10 mm. in diameter.

Distinguished from $E$. hyemale, which it closely resembles, by its smoothness, long green sheaths with a narrow black limb, and darker green color. Forma scabrellum (Engelm.) Broun has more prominent cross bands of silex on the ridges than in $\mathrm{f}$. laevigatum.

In sandy soil or sandy loam along streams and lake banks, on seepage slopes, in alluvial thickets, marshes, meadows, prairies, sandy barrens and rocky creek beds of canyons, rather generally distributed in Okla., w. and cen. Tex., e. to Somervell and Waller cos. in the Blackland Prairies and s. to Starr Co. in the Rio Grande Plains, throughout N.M. and Ariz. (Navajo and Coconino, s. to Cochise, Santa Cruz and Pima cos.); from Anticosti Is. and Que. to B.C., s. to N.C., La., Tex., N.M., Ariz. and Calif.; also Mex. and Guat.

4. Equisetum hyemale L. var. affine (Engelm.) A.A. Eat. Cañuela, tall SCOURING-RUSH. Fig. 6.

Rhizome slender, creeping, blackish, with a ferruginous tomentum covering the fibrous roots; aerial stems erect, evergreen, stout, solitary or cespitose, fluted with many ridges that are scabrous with bands of siliceous tubercles, to $3 \mathrm{~m}$. tall and $2.5 \mathrm{~cm}$. in diameter, simple or proliferous-branching near the apex; branches fertile, similar to the primary stems but conspicuously reduced in size; sheaths cylindric, not dilated above, variable, usually with a black band at the base and apex, with the central portion whitish-gray to pinkish, the ridges obscurely keeled, 5-12 mm. long; marginal teeth of the sheaths long and flexuous, reddish-brown to almost black, usually with a narrow whitish hyaline border, subpersistent to deciduous; cones ovoid to cylindric-ellipsoid, apiculate, 1.5-2.5 $\mathrm{cm}$. long, 5-10 $\mathrm{mm}$. in diameter. E. prealtum Raf., E. robustum A. Br., E. hyemale var. robustum (A.Br.) A.A. Eat.

In sandy or loamy soil in open or wooded areas along streams and on alluvial flats, in seepage and on wet ledges, rather generally distributed throughout Okla. and Tex. but most frequent in the Blackland Prairies and on the Edwards Plateau in the latter state, through N.M. to Ariz. (Apache, Navajo and Coconio, s. to Cochise, Santa Cruz and Pima cos.); represented in most of the U.S. and Can. as well as in Mex. and Euras.

Two insignificant forms of this species occur in Texas; f. Drummondii (Milde) Broun having very tight sheaths adorned with black and white rings, and $f$. texanum (Milde) Broun with long green ampliated sheaths.

This is our largest species in the genus Equisetum. It is one of a number of species in the genus that assimilate a large amount of silica. Because of the abundant storage of silica in the stem, they were at one time utilized in rural districts in this country and in the Old World to scour metal kitchen utensils, giving rise to the name "scouring-rush."

\section{Fam. 6. Ophioglossaceae Presl. Adder's-Tongue Family}

Succulent or herbaceous terrestrial or occasionally epiphytic plants with short fleshy rhizomes bearing numerous fibrous to tuberous-thickened roots; fronds solitary or clustered, the blade erect or bent in bud (not circinate), erect or 


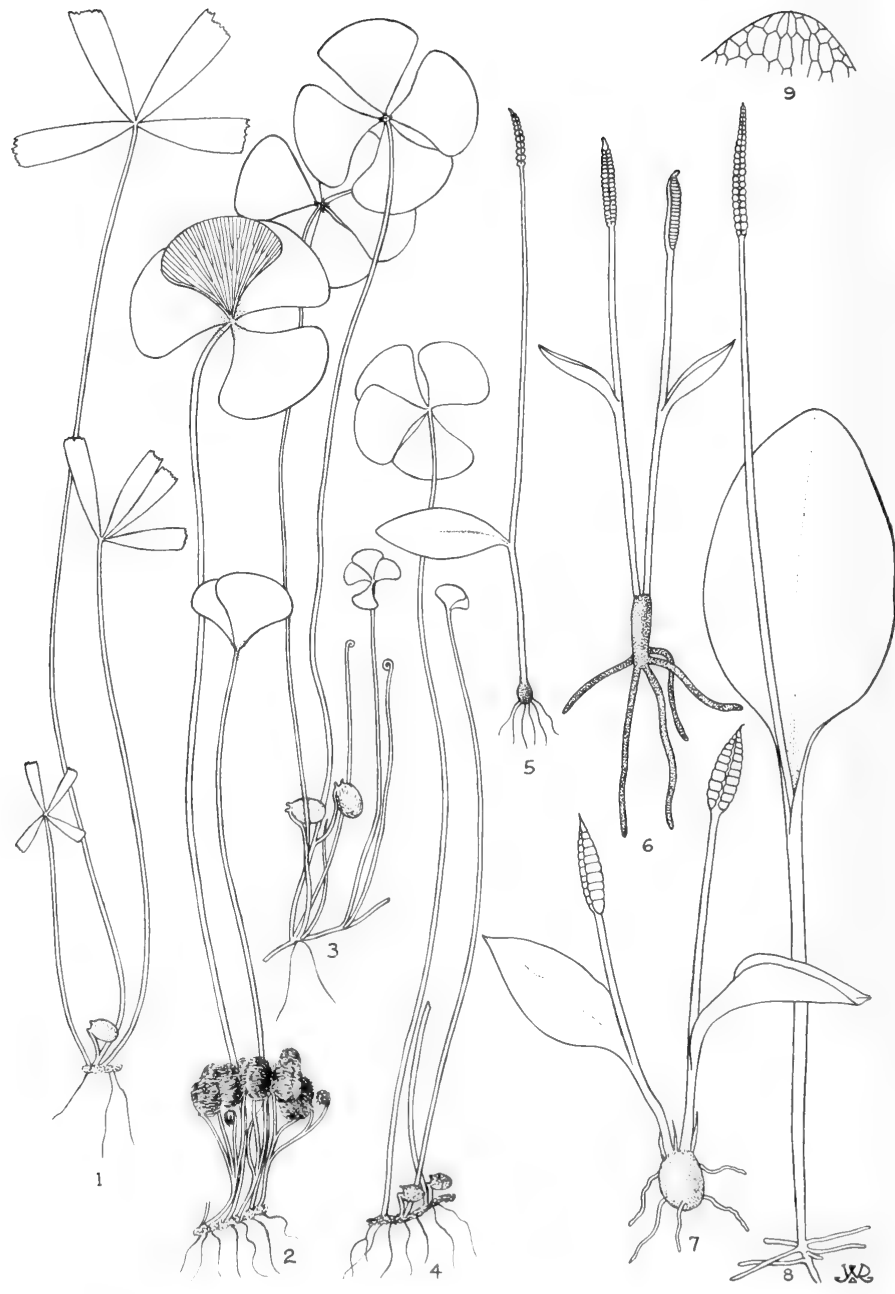

Fig. 9: 1, Marsilea tenuifolia: 1, plant, x 2/3. 2, Marsilea macropoda: 2, plant, x 2/3. 3, Marsilea uncinata: 3, plant, x 2/3. 4, Marsilea mucronata: 4, plant, x 2/3. 5, Ophioglossum nudicaule var. tenerum: 5, plant, x 1. 6, Ophioglossum petiolatum: 6, plant, x 1. 7, Ophioglossum crotalophoroides: 7, plant, x 1.8 and 9, Ophioglossum vulgatum: 8 , plant, $\mathrm{x} 2 / 3 ; 9$, tip of leaf, slightly enlarged. (From Correll in Lundell's Flora of Texas, Vol. 1, Pl. 8). 
pendent when epiphytic, consisting of a basal common stalk bearing at its apex a simple to variously compounded sessile or stalked sterile blade and (if fertile) one or more erect or pendent stalked spore-bearing spikes or panicles; sporangia in two rows, naked, opening by a transverse slit, formed from the interior tissue of the sporophyll; spores numerous, all alike, yellowish; prothallia subterranean, not green.

This family is composed of four genera and about 70 species in tropical and temperate regions throughout the world.

\section{Ophioglossum L. Adder's-Tongue}

Small fleshy-succulent terrestrial or epiphytic plants of wet or moist soils, with short (sometimes bulbous) subterranean rhizomes bearing fibrous roots; fronds one or more from the same rhizome, erect in vernation, glabrous; common stalks slender, terete; sterile blades simple or palmatifid (in the Floridian $O$. palmatum L.), sessile or short-stalked, with the veins profusely reticulate; fertile spikes slender, erect, long-stalked; sporangia large, coalescent in two ranks, subglobose; spores numerous, yellow; buds of the following season borne at the apex of the rhizomes, exposed, free.

About 40 species of wide distribution in both hemispheres.

1. Rootstocks globose-bulbous; leaf blades (when spread out) with a cordate to very broadly cuneate base............................ 1.0 . crotalophoroides.

1. Rootstocks cylindric to subglobose, not globose-bulbous; leaf blades with a rounded to cuneate base (2)

2(1). Blade distinctly and prominently apiculate; principal veins characteristically forming large primary areoles in which are included numerous veinlets forming secondary areoles...................... 4. O. Engelmannii.

2. Blade rounded to acute at apex, rarely minutely apiculate; principal veins forming areoles not enclosing smaller secondary areoles but sometimes with included free veinlets (3)

3(2). Blade inserted near base of plant; rootstocks subglobose

2. O. nudicaule var, tenerum.

3. Blade inserted towards middle of plant; rootstocks cylindric (4)

4(3). Blade small, usually less than $5 \mathrm{~cm}$. long, typically ovate-lanceolate and acute, with 4 to 8 parallel veins passing down through base of blade

3. $O$. petiolatum.

4. Blade larger, usually more than $5 \mathrm{~cm}$. long, broadly elliptic to oblong-elliptic or very rarely ovate, rounded at apex, typically with 8 to 20 parallel veins passing down through base of blade.

5. O. vulgatum.

\section{Ophioglossum crotalophoroides Walt. Bulbous adder's-tongue. Fig. 9.}

Plants usually short, fleshy, to about $15 \mathrm{~cm}$. tall; rootstock tuberous, globose, hard when dry, averaging about $8 \mathrm{~mm}$. in diameter, producing several fronds during a single growing season; common stalk mostly less than $3 \mathrm{~cm}$. long; sterile blade orbicular-ovate to ovate, when spread out cordate to sometimes very broadly cuneate at base, rounded to subacute at apex, abruptly contracted to a short petiolulate base, often conduplicate and clasping the stalk of the spike, thickherbaceous, to $3.5 \mathrm{~cm}$. long and $2.5 \mathrm{~cm}$. wide; venation mostly obscured by the thick texture of the blade, forming very unequal areoles with very few included free veinlets; fruiting spike usually on a short stalk that is to $7 \mathrm{~cm}$. long, thick and abbreviated, sharp at the apex, 3-4 mm. in diameter; sporangia 3 to 12 , partly imbedded in the rachis. $O$. pusillum Nutt.

In damp or wet pastures, moist sandy soil of open pine forests, and on grassy slopes, only in Tex. in our region, rare in s.-cen. and s.e. Tex. (Bastrop, Hardin 
and Harris cos.), found once on top of Enchanted Rock (Llano Co.), reported by Reverchon from Newton $\mathrm{Co}$. in the Timber Belt; from cen. peninsular Fla. to S.C. and w. to Tex.; also from Mex. to S.A.

2. Ophioglossum nudicaule L. f. var. tenerum (Prantl) Clausen. Fragile ADDER'S TONGUE. Fig. 9.

Plants mostly small and inconspicuous, to $12 \mathrm{~cm}$. tall, usually much smaller; rootstock subglobose, less than $5 \mathrm{~mm}$. in diameter; common stalk very short, mostly less than $1 \mathrm{~cm}$. long; sterile blade near base of plant, sessile to somewhat petioled, ovate to elliptic or occasionally somewhat oblanceolate, subobtuse to narrowly acute at apex, to $1.5 \mathrm{~cm}$. long and $8 \mathrm{~mm}$. wide; veins forming rather long irregular areoles without included veinlets; fruiting spike on a very slender elongate weak stalk, much-exceeding the sterile blade, with a sharp tip, to $2 \mathrm{~mm}$. in diameter; sporangia as many as $\mathbf{1 2}$ on each side of the rachis.

On grassy slopes and in wet meadows, damp depressions in pinelands, moist open woods, and on the edge of bogs, rare in Hardin Co. in s.e. Tex.; from Fla. and Ga., w. to Tex.; also Mex. to Arg., the W.I., Sumatra and the Phil.

\section{Ophioglossum petiolatum Hook. Fig. 9.}

Plants 6-21 cm. tall; rootstock short, cylindric, slender, erect, bearing several long fleshy roots and one or usually several fronds during a single growing season, commonly reproducing vegetatively by means of modified long slender roots whose buds give rise to new plants; common stalk 2-9 $\mathrm{cm}$. long; sterile blade sessile or cuneate into a short petiole, inserted toward middle of plant, ovate to ovate-lanceolate or elliptic-ovate, acute at the apex, thin in texture, $1.5-6 \mathrm{~cm}$. long, to about $1.7 \mathrm{~cm}$. wide; veins few, forming large areoles; fertile stalk to $9 \mathrm{~cm}$. long; fruiting spike $1-4 \mathrm{~cm}$. long; sporangia $0.5-1 \mathrm{~mm}$. in diameter.

In moist meadows, damp grassy places, depressions in old inland or coastal dunes, occasionally in moist woodlands and thickets, in Tex. only in Winkler Co. in dunes about $10 \mathrm{mi}$. n.e. of Kermit, in the Plains Country; in Fla., S.C. and Tex., Mex., the W.I. and n. S.A.; also in tropical Afr., Asia and Oceania.

\section{Ophioglossum Engelmannii Prantl. Limestone AdDER's-Tongue. Fig. 4.}

Plants resembling $O$. vulgatum, slender to somewhat stout, to $25 \mathrm{~cm}$. tall; rootstock cylindric, erect, producing 2 to 3 or rarely more fronds in a single season, with long brown roots; common stalk to $10 \mathrm{~cm}$. long, mostly below ground; sterile blade sessile or sheathing the stalk of the spike, mostly elliptic, acute and apiculate at apex, to $10 \mathrm{~cm}$. long and $3.5 \mathrm{~cm}$. wide; veins forming wide oblique areoles in which are included secondary veinlets that form secondary areoles; fruiting spike on a slender elongate stalk that is to $10 \mathrm{~cm}$. long, cylindric, apiculate, to about $3 \mathrm{~cm}$. long and $4 \mathrm{~mm}$. in diameter; sporangia to about 30 on each side of the rachis. O. vulgatum f. Engelmannii (Prantl) Clute.

Usually found in large colonies in thin black soil on limestone barrens or ledges in seepy areas, rocky woodland slopes, in cedar brakes or in clayey soil along streams, occasionally invading pastures and old fields, rare in Okla., in Tex. generally distributed and rather frequent in the Blackland Prairies, with a few stations in the Timber Belt, uncommon in Ariz. (Cochise and Santa Cruz cos.); from Va. to cen. Fla., w. to s. Ill., Kan. and Ariz.; also Mex.

\section{Ophioglossum vulgatum L. COMMON ADDER's-TONGUE. Fig. 9.}

Plants often tall and slender, to about $35 \mathrm{~cm}$. tall; rootstock erect, nearly cylindric, bearing numerous fleshy roots and one to several fronds; common stalk to about $9 \mathrm{~cm}$. long, half or more above ground; sterile blade sessile or sheathing the stalk of the spike, variable in shape, ovate to lanceolate or oblong-elliptic to oblanceolate, subtruncate to narrowly obtuse at the apex, to $12 \mathrm{~cm}$. long and 
$5 \mathrm{~cm}$. wide; venation regularly forming areoles without included secondary areoles; fruiting spike on a slender elongate stalk that is to $17 \mathrm{~cm}$. long, compressedcylindric, apiculate, to $4 \mathrm{~cm}$. long and $3-5 \mathrm{~mm}$. in diameter; sporangia to about 30 on each side of the rachis.

In moist open woods, meadows, alluvial woodlands and swamps, in Tex. rare in several cos. in the n. Timber Belt of e. Tex. and in Jefferson Co. in the Coastal Prairies, reported (fide Clausen) from Denton and Harris cos., reported from Ariz.; from P. E. I. and N. S., s. to Fla., w. to Ont., Tex. and (?) Ariz.; also Mex., Alas. and Euras.

\section{Fam. 7. Osmundaceae R. BR.}

\section{Cinnamon Fern Family}

Large terrestrial to subaquatic plants of low moist soils and wet places with creeping to erect woody rhizomes, rarely arborescent, the roots hard and fibrous; fronds erect-spreading, occasionally as much as $18 \mathrm{dm}$. or more tall, clustered; stipes scaleless; blades bipinnatifid to bipinnate, rather coarse, uniform to entirely dimorphic or with some of the pinnae dimorphic, with the usually forked veins free and extending to the margins of the ultimate segments; sporangia in dense paniculate clusters, entirely replacing the vegetative tissue of certain pinnae or whole fronds, naked, large, globose, usually short-stalked, longitudinally cleft into two halves, with the ring or annulus few-celled or wanting; spores green.

This family comprises three genera, the following and two Old World genera, that include about 20 species.

\section{Osmunda L.}

Rather coarse plants; fronds in a large crown from a woody rhizome, arranged in two circles, the inner circle fertile, erect and developing first, the outer circle sterile and spreading; blades wholly spore-bearing or with part of the pinnae spore-bearing either near the middle or at the apex, the spore-bearing tissue red or brown; sporangia short-stalked, densely clustered on the ultimate veinlets; spores copious, green.

About 10 species, mostly in the north temperate regions of both hemispheres.

1. Sterile blades pinnate-pinnatifid, the ultimate segments entire; fertile fronds separate, cinnamon-colored at maturity............... O. cinnamomea.

1. Sterile blades bipinnate, the pinnules serrulate; upper pinnae modified for spore production...............................2. O. regalis var. spectabilis.

\section{Osmunda cinnamomea L. Cinnamon fern. Fig. 10.}

Fronds several, erect, dimorphic, to $15 \mathrm{dm}$. tall; stipes irregularly coated with a loose cinnamon-colored tomentum; sterile blades lanceolate to oblong-lanceolate, acuminate, to $1 \mathrm{~m}$. long and $35 \mathrm{~cm}$. wide; pinnae opposite to subopposite, deeply pinnatifid, with a tuft of tomentum persisting at the base of each pinna; fertile blades succulent, nonfoliose, soon withering.

Usually in moist or wet soil of swamps, marshes, on open or wooded seepage slopes, along streams, on the edge of lakes and bogs and occasionally on wet ledges in e. Okla. and in Tex. rather generally distributed in the Timber Belt, s. to Orange Co. in the Coastal Prairies, w. to Gonzales, Lee and Milam cos. in the Blackland Prairies, with a lone station in Uvalde Co. on the Edwards Plateau; throughout e. N. A. from Nfid. to Minn., s. to cen. Fla, and Tex.

\section{Osmunda regalis L. var. spectabilis (Willd.) Gray. Royal FERN. Fig. 10.}

Fronds clustered, to $18 \mathrm{dm}$. tall; stipes slender, glabrous; blades broadly elliptic to oblong-ovate, with the lower 2 to 6 pairs of pinnae sterile, the upper pinnae transformed into fertile ones. 


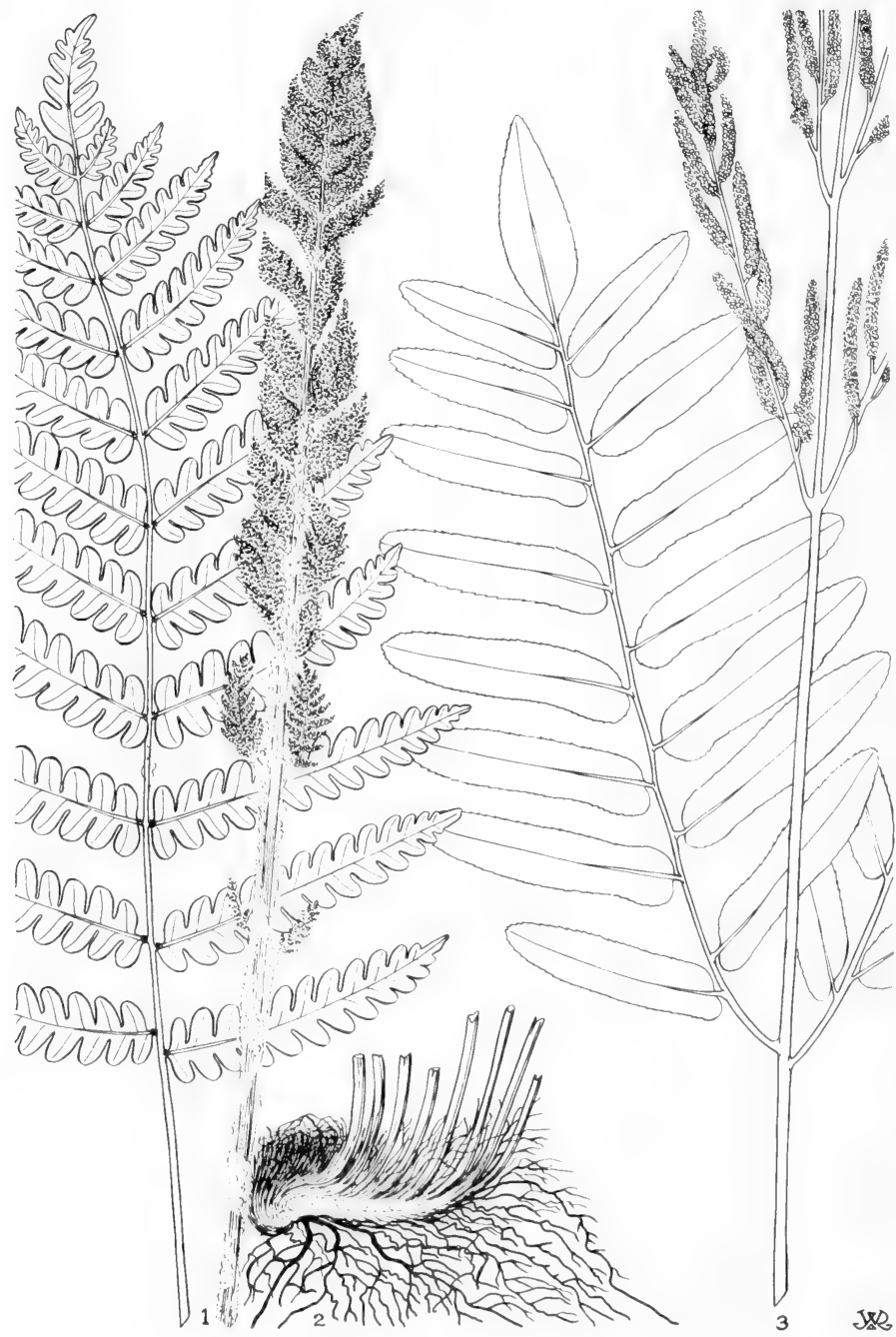

Fig. 10: 1 and 2, Osmunda cinnamomea: 1, sterile and fertile fronds, x $2 / 3 ; 2$, longitudinal section of rhizome, x 2/3. 3, Osmunda regalis var. spectabilis: 3, upper part of frond, x 2/3. (From Correll in Lundell's Flora of Texas, Vol. 1, Pl. 9). 
In swamps, marshes, moist woods, depressions in savannahs and prairies, on stream banks and seepage slopes, and in or on the edge of lakes in e. Okla., in Tex. generally distributed and common in the Timber Belt, s. and s.w. to Jefferson and Victoria cos. on the Coastal Prairies, w. to Travis Co. in the Blackland Prairies, adj. to the Edwards Plateau; from Nfld. to Sask., s. to Fla. and Tex.; also Berm., the W. I., Mex., C. A. and S. A.

\section{Fam. 8. Marsileaceae R. Br. Pepperwort Family}

Plants herbaceous, rooting in mud, creeping, often partly submerged, rarely floating, with slender branched rhizomes; leaves erect or floating, distichous, more or less remote, filiform or with long-petiolate 2- to 4-foliolate blades; leaflets (when present) of a cuneate type, with close dichotomous venation; sporocarps hard, bony, globose to ellipsoid, pilose or essentially glabrous, pedunculate, one to several borne on the rhizome near the base of the petiole or upon the petiole; sori solitary within the compartments, each producing both megaspores and microspores; megaspores germinate into prothallia that bear mostly archegonia; microspores germinate into prothallia that bear antheridia.

This family comprises three genera containing more than 70 species that are found chiefly in the Old World.

1. Leaf with distinct blade and petiole, the blade 4-foliolate.................1. Marsilea 1. Leaves filiform, without distinct blades, the tips uncoiling as the plant matures 2. Pilularia

\section{Marsilea L. WATer Clover}

Small plants forming dense colonies; leaves long-petiolate, with cruciform (4-foliolate) blades; sporocarps subglobose to ellipsoid, mostly with 2 teeth near the base, commonly provided with coarse or paleaceous hairs, splitting into 2 valves at maturity and emitting numerous sori on a gelatinous receptacle; sori including both megasporangia and microsporangia.

About 60 species of wide distribution, mainly in the Old World.

The plants of some species provide shade and shelter for fish, and the sporocarps are known to be eaten by ducks.

1. Sporocarps several on a special branch or from a common peduncle (2)

1. Sporocarps solitary, with paleaceous hairs or naked; leaves and petioles naked or sparsely pubescent (3)

2(1). Leaflets (and petioles) with long loose hairs, without colored stripes; sporocarps densely covered with reddish hairs that are to $3 \mathrm{~mm}$. long 1. M. macropoda.

2. Leaflets (and petioles) essentially glabrous, usually developing (with age) reddish-brown stripes on the lower surface; sporocarps losing (with age) its light-brown hairs.

2. M. mexicana.

3(1). Leaflets flabellate to broadly cuneate (4)

3. Leaflets narrowly and obliquely cuneate to cuneate-oblanceolate (5)

4(3). Rhizome without conspicuous fascicled branches; peduncle usually very short, often scarcely as long as the sporocarp, usually free from the petiole or attached at its very base; sporocarp with rather long coarse reddish hairs.

3. M. mucronata.

4. Rhizome producing fascicled branches that are paleaceous at their tips; peduncle about twice the length of the sporocarp or more, usually attached above the base of the petiole; sporocarp sparsely provided with short coarse hairs. 4. M. uncinata. 


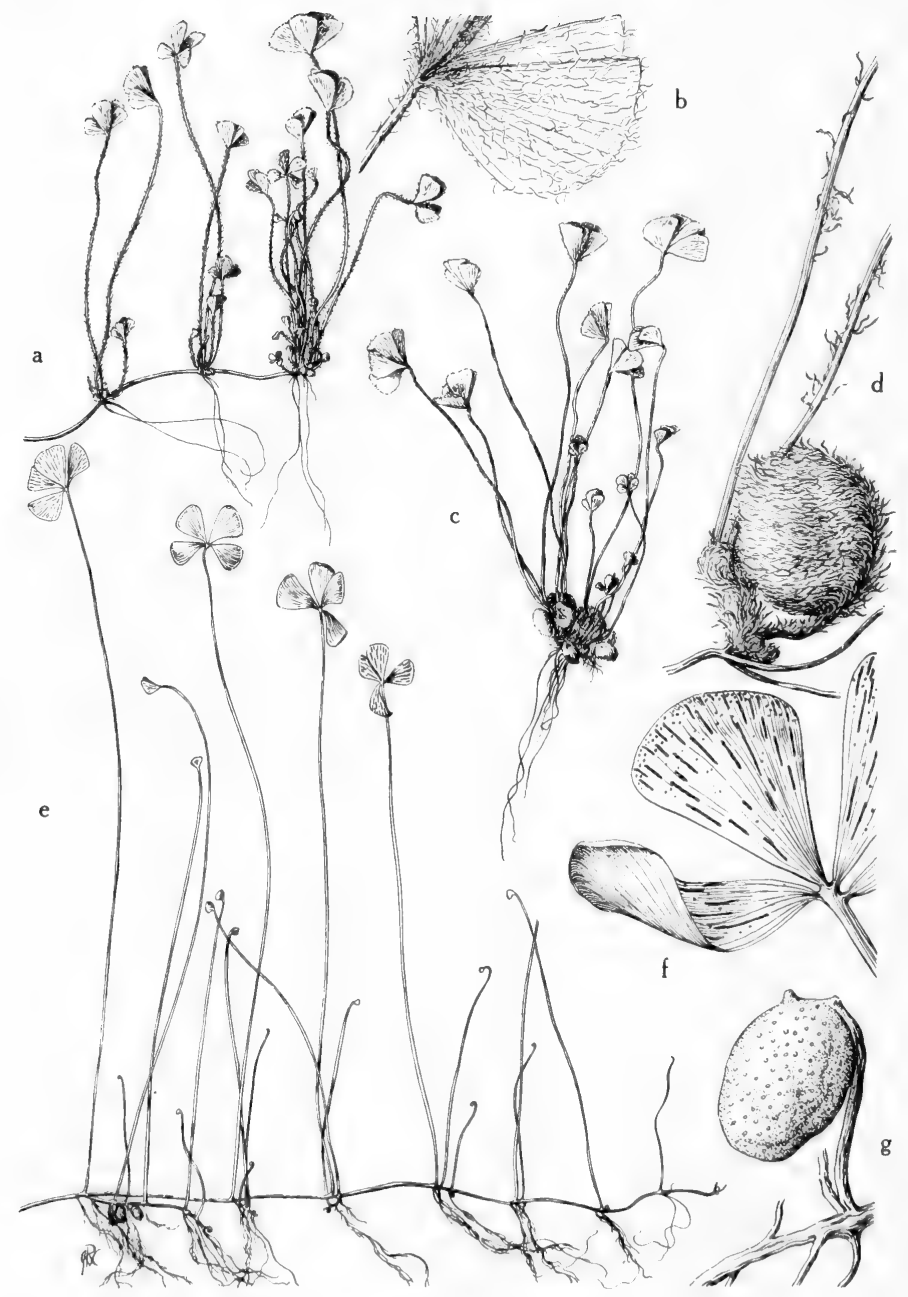

Fig. 11: Marsilea mucronata: a, habit, terrestrial plant, with densely pubescent leaves and petioles, arising from slender rhizomes, $\mathrm{x} 11 \mathrm{k} ; \mathrm{b}$, leaf detail, terrestrial plant, x $2 \frac{1}{2}$; c, habit, terrestrial plant showing sporocarps, $x_{2}^{2 / 3} ; \mathrm{d}$, sporocarp, terrestrial plant showing dense pubescence, $\mathrm{x} 4$; e, habit, aquatic plant with elongate slender completely submersed petioles, their glabrous leaf blades floating, $\mathrm{x} 2 \% ; \mathrm{f}$, leaf detail, aquatic plant, $\mathrm{x} 21 \frac{2}{2} ; \mathrm{g}$, sporocarp, aquatic form, showing blunt teeth near junction with stalk, $\mathrm{x} 4$. (From Mason, Fig. 4.). 
5(3). Leaflets usually more than $10 \mathrm{~mm}$. long, truncate and typically irregularly toothed at apex....................................................5. M. tenuifolia.

5. Leaflets less than $8 \mathrm{~mm}$. long, lightly rounded to subtruncate and entire at apex.

6. M. Fournieri.

1. Marsilea macropoda Engelm. ex A. Br. Fig. 9.

Plants robust, 10-25 cm. tall, forming large mats, adorned with bright reddish hairs at the tips of the branches of the subglabrous rhizomes; petioles slender, with long shaggy hairs; leaflets large, broadly cuneate, entire, usually undulate, clothed on both side with long lax whitish hairs (especially when young), becoming less pubescent with age, to $5 \mathrm{~cm}$. long and $2 \mathrm{~cm}$. wide; sporocarps 2 to 6 on erect or ascending branched peduncles that are $2-3 \mathrm{~cm}$. long, obliquely obovate, densely villous with the reddish hairs to $3 \mathrm{~mm}$. long or more, 6-8 $\mathrm{mm}$. long, 5-6 $\mathrm{mm}$. in diameter, the raphe short, lower tooth obtuse, upper tooth inconspicuous or wanting; sori 10 in each valve.

In mud or sandy soil and water of swamps, marshes, woodland bogs, ditches, streams, and on the edge of ponds and lakes, apparently endemic to Tex. where it is widespread and rather frequent in the Rio Grande Plains, n. and e. to Jackson Co. in the Coastal Prairies, Travis Co. in the Blackland Prairies, and in the cos. bordering the Edwards Plateau.

The several sporocarps borne on each peduncle and the large hairy leaflets are characteristics that readily distinguish this species.

\section{Marsilea mexicana A. Br. Fig. 4.}

Plants to $2 \mathrm{dm}$. tall or more; rhizomes slender, widely creeping and muchbranched, greenish-brown to light-brown; petioles filiform, channeled, glabrous, to about $18 \mathrm{~cm}$. long; leaflets broadly cuneiform or obovate-flabellate, rounded and slightly undulate at apex, $1-1.5 \mathrm{~cm}$. long, green, typically marked with reddish-brown stripes (or glands?) parallel with the veins on the lower surface, glabrous or sometimes with a few hairs near base; peduncle (free part) approximately as long as the sporocarp or slightly longer, pubescent at first; sporocarps not scattered but densely clustered on special branchlets that also give rise to slender terete rigid rootlike structures, obovoid to ellipsoid, about $4 \mathrm{~mm}$. long, somewhat compressed laterally, dark-colored, at first covered with matted light-brown hairs and terminated with long dark-brown hairs that are deciduous with age, the raphe and basal tooth obsolescent; sori approximately 12 or 13 in each sporocarp.

In shallow water or on mud flats of pools and ponds in Aransas Co. on the Tex. coast; from Tex. and Mex., s. to Hond.

This species is distinctive in that at least some of its leaflets have reddishbrown stripes, or possibly glands, on their lower surface parallel with the veins. Also, the sporocarps are borne in clusters on modified branchlets that also give rise to terete, rigid, rootlike structures that possibly might be considered as rhizophores.

\section{Marsilea mucronata A. Br. HAIRY PEPPERWORT. Figs. 9 and 11.}

Plants 6-20 cm. tall; rhizomes slender, widely creeping, branched but without conspicuous fascicled branches; petioles filiform, to $18 \mathrm{~cm}$. long; leaflets spreading, spatulate to obovate, truncate to rounded and entire or somewhat toothed at the apex, sparsely pubescent (especially beneath) with short and broad appressed hairs, to $15 \mathrm{~mm}$. long, about as wide as long; peduncles free, axillary at base of leaves or from the very base of the petiole, ascending, usually very short, mostly scarcely as long as the sporocarp; sporocarps solitary, oval to ellipsoid, slightly oblique and compressed, purplish punctate, coarsely strigose-pubescent with reddish hairs, to $8 \mathrm{~mm}$. long, usually much smaller, 3-6 $\mathrm{mm}$. in diameter, the raphe 
short, the upper tooth only slightly curved, lower tooth blunt and shorter than the upper tooth; sori 6 to 11 in each valve. $M$. vestita of auth.

Usually in black waxy mud along streams and rivers, in and about ponds, in silt of lakes, and in ditches or depressions such as old buffalo wallows in prairies that are periodically inundated, our most widespread Marsilea occurring throughout Okla. and in every section of Tex. but the Timber Belt, most frequent and abundant in the Blackland Prairies and on the Edwards Plateau, through N.M. (Lea and Sierra cos.) to Ariz. (Navajo, Coconino, Yavapai, Pinal, Cochise and Pima cos.); from s. Sask. and Alta., s. to Tex., N.M., Ariz., Calif. and Coah. e. to Fla.

Some plants of $M$. mucronata closely resemble those of $M$. macropoda, with which they are occasionally confused. The solitary sporocarp, however, readily distinguishes them from that species.

Although a temporary pool in which this species may occur may become powdery dry in season, the bony sporocarps remain undamaged until water again makes the depression a quagmire.

\section{Marsilea uncinata A. Br. Fig. 9.}

Plants 6-20 cm. tall; rhizomes slender, filiform, producing fascicled branches that are paleaceous at their tips; petioles filiform, to $19 \mathrm{~cm}$. long; leaflets spreading, obovate to broadly flabellate, subtruncate to rounded at the apex, entire, to 3 $\mathrm{cm}$. long, about as wide as long, glabrous to sparsely strigose-pubescent; peduncles usually attached to the petioles above their base, about twice or more the length of the sporocarps, $1.5-3 \mathrm{~cm}$. long; sporocarps subglobose to ellipsoid, more or less covered by short coarse reddish hairs, 4-8 $\mathrm{mm}$. long, 3-6 $\mathrm{mm}$. in diameter, the raphe long, upper tooth longer than the lower tooth and mostly uncinately curved; sori 13 or 14 in each valve.

In or on the edge of permanent ponds, along spring branches and in shallow water of brooks, ditches and bayous, rather generally distributed but uncommon in the Blackland Prairies and in several isolated localities in every section of Tex. except the Timber Belt; apparently confined to Tex. and La.

This species, unlike $M$. mucronata and $M$. tenuifolia, apparently needs a constant supply of water for optimum development, if not for survival.

A characteristic that superficially separates this species from the closely allied M. mucronata is the usual attachment of the long peduncle to the leaf petiole above its base. The much shorter peduncle of $M$. mucronata is usually either free from, in the axil of, or from the very base of the leaf petiole.

\section{Marsilea tenuifolia Engelm. ex Kunze. Fig. 9.}

Plants slender, 5-17 cm. tall; petioles glabrous or essentially so; leaflets narrowly cuneate, truncate and usually irregularly toothed at apex, more or less falcate, villous with appressed hairs, to $25 \mathrm{~mm}$. long, 2-8 $\mathrm{mm}$. wide; sporocarps on short slender peduncles, with divergent subequal teeth, 5-8 $\mathrm{mm}$. long, 4-5 $\mathrm{mm}$. in diameter; sori 9 to 11 in each valve. $M$. vestita var. tenuifolia (Engelm.) Underw. $\&$ Cook.

On the edge of lakes, in shallow beds of creeks, and in periodically inundated depressions, especially in old buffalo wallows, in Tex. rare on the Edwards Plateau, in Travis Co. in the Blackland Prairies and in the s. part of the Plains Country; apparently confined to Tex. and Okla. (unverified).

The narrowly cuneate leaflets with usually irregularly toothed apex are distinctive of this species.

\section{Marsilea Fournieri C. Chr. Fig. 4.}

Plants small, usually about $8 \mathrm{~cm}$. tall or less, villous throughout; rhizome stout for the plant, compact and sometimes sending off short thick branches; petioles 
filiform, to about $7 \mathrm{~cm}$. long, villous but eventually glabrescent; leaflets asymmetric, cuneate-oblanceolate to cuneate-obovate or linear-oblanceolate, subtruncate to lightly rounded at the entire apex, about $7 \mathrm{~mm}$. long, villous; peduncle shorter than the sporocarp; sporocarps crowded, broadly ellipsoid to suborbicularoval, lightly compressed, invested with brownish hairs that soon turn grayish and are eventually deciduous, about $4 \mathrm{~mm}$. long, the raphe short and blunt, the upper tooth sharp and prominent; sori 15 , with 4 to 7 white sporangia in each sorus.

In wet places or depressions such as playa lakes that are periodically inundated, rare in N.M. (Lea Co.), more frequent in Mex. (Coah., Chih., S.L.P. and Jal.); to be expected in Tex.

\section{Prisularia L. PILLWORT}

Six widely distributed species.

\section{Pilularia americana A. Br. American pillwort. Fig. 7.}

Very small inconspicuous plants of muddy situations, with slender wide-creeping rhizomes bearing at the nodes one to several leaves, forming dense mats; leaves setiform, solitary or sometimes several together from the nodes, glabrous, $2-6 \mathrm{~cm}$. long, rarely to $1 \mathrm{dm}$. long; sporocarps produced just below surface of ground, axillary, pedunculate, globose, brownish-yellow, 2-3 $\mathrm{mm}$. in diameter.

In shallow temporary muddy pools on rock flats and depressions in clayey prairies and in mud on edge of lakes, in our region only in Comanche Co. in s. w. Okla. and in Burnet Co. on the Edwards Plateau in Tex.; from s. Calif. to Ore., also isolated in s.-cen. Kan., w. Ark. and cen. Ga.

\section{Fam. 9. Salviniaceae Dum. SAlvinia Family}

Plants minute or small, aquatic, free-floating or on mud, with a branched rhizome bearing simple roots (Azolla) or essentially stemless with some of the leaves modified as roots (Salvinia); leaves 2-ranked or in whorls, opposite or alternate, simple or lobulate; sporocarps soft, thin-walled, borne singly or two or more on a common stalk at the base of the leaves, 1-celled, with a central often branched receptacle, unisexual, bearing either megasporangia containing a solitary megaspore or microsporangia containing numerous microspores; massulae within macrosporangia bearing septate or non-septate glochidia with barbed tips; megaspores germinate into prothallia bearing archegonia; microspores germinate into prothallia bearing antheridia.

This family comprises 2 genera of wide distribution-Salvinia and Azolla with about 16 species.

\section{Azolla Lam. Water Fern. Mosquito Fern}

Minute reddish or green free-floating plants, occasionally on mud, mostly densely matted and resembling some species of liverworts, with the stems pinnately branched and concealed by pendent roots and imbricating leaves; leaves distichous, 2-lobed, with the upper lobe floating and the lower lobe submersed; sporocarps borne in one or two pairs on the lower leaf lobe.

This genus consists of about 6 species of wide distribution.

The dense cover often formed by these plants over the surface of ponds and lagoons provides shade and shelter for fish. The plants are incidentally eaten by ducks and other wild fowl.

A compound microscope is needed in order to identify species in this genus with any certainty. 


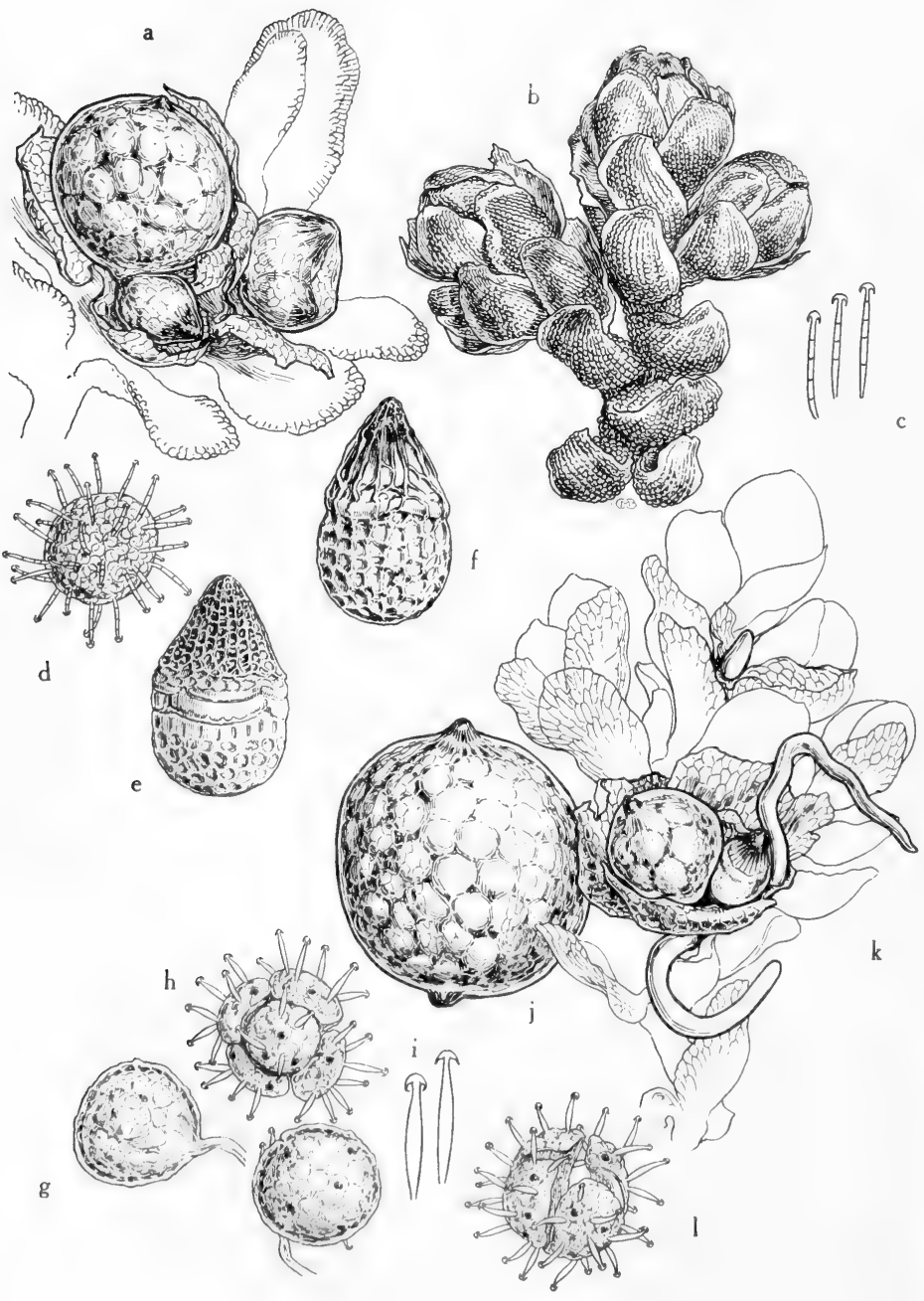


1. Glochidia with several scattered septa; basal portion of the megaspore pitted; plant usually more than $1 \mathrm{~cm}$. in diameter; leaves $0.7 \mathrm{~mm}$. long or more, closely imbricate............................................ A. mexicana.

1. Glochidia without septa or rarely with 1 or 2 septa mostly just beneath the tip (2)

2(1). Plants elongate, $2 \mathrm{~cm}$. long or more; leaves oblong to ovate, closely appressed and imbricate, papillose, about $1 \mathrm{~mm}$. long; basal portion of the megaspore tesselate-reticulate.....................2. A. filiculoides.

2. Plants small, to $1 \mathrm{~cm}$. in diameter; leaves suborbicular, divaricate, nearly smooth, about $0.5 \mathrm{~mm}$. long; megaspore unknown.

3. A. caroliniana.

1. Azolla mexicana Presl. Fig. 12.

Plants flattened, dichotomously branched, 1-3 cm. in diameter; upper leaf lobes imbricated, somewhat irregular in shape, usually broadly rhombic-ovate to suborbicular, broadly rounded to obtuse at apex, mostly less than $1 \mathrm{~mm}$. long, usually profusely tinged purplish-cerise, papillose, with narrow hyaline cellularpapiilose margins, under leaf lobes usually much larger than the upper ones; microsporangia usually with 4 massulae; megaspores pitted on the basal portion; glochidia of massulae always septate.

Floating on surface of lakes and ponds and in quiet waters of streams and irrigation canals in the Rio Grande Valley of s. Tex. and in N.M.; from s. Tex., Calif. and Mex., s. to n. S.A., n. to Ut., B.C., Wisc. and Ill.

\section{Azolla•filiculoides Lam. Fig. 12.}

Plants elongate, dichotomously branched, 2-6 cm. long; upper leaf lobes closely appressed, imbricated, minutely papillose, oblong to ovate, obtuse at apex, about $1 \mathrm{~mm}$. long, with rather broad thin hyaline margins that are usually only slightly cellular-papillose, brownish and somewhat sparingly tinged with red; under leaf lobe about as large as the upper one; microsporangia with 4 to 6 massulae; megasporangia with the basal portion tesselate-reticulate; glochidia of massulae not septate or rarely septate only at the apex.

In fresh-water ponds and ditches in Ariz. (Pima, Santa Cruz, Mohave and Yuma cos.); from Alas. to Guat.; also S.A., Eur. and H.I.

\section{Azolla caroliniana Willd. Fig. 13.}

Plants forming floating mats to $3 \mathrm{~cm}$. across; leaves minute, deeply bilobed, imbricate, mostly with hyaline margins, to $0.9 \mathrm{~mm}$. long and $0.6 \mathrm{~mm}$. wide, the upper emersed lobes oval or suborbicular-quadrate, deep-green to purplish-red, somewhat convex, hollow, provided with numerous 2-celled hairs, the lower submersed lobes glabrous, larger and paler than the upper lobes.

On still water of swamps, ponds, lakes and in slow-moving water of streams and resting on mud, up to 5,500 ft. alt., Okla. (McCurtain Co.) and in Tex. sporadically distributed from Wood Co. in the n.e. Timber Belt, s. to Orange Co. on the Coastal Prairies and Cameron Co. in the Rio Grande Plains, w. to

Fig. 12: Azolla. a-e, A. mexicana: a, part of a fertile plant: (left) globose microsporocarp with megasporocarp at its base, (right) pair of megasporocarps enclosed in one indusium (uncommon), x 20; b, habit, top view, $\mathrm{x} 12 ; \mathrm{c}$, septate glochidia of microsporic massulae, x 100; d, microsporic massula, x 40; e, megaspore covered by tip of indusium, X $40 . \mathrm{f}-1, A$. filiculoides: $\mathrm{f}$, megaspore covered by tip of indusium, $\mathrm{x} 40$; $\mathrm{g}$, young stalked microsporangia, showing a few glochidia of the massulae protruding from ruptured wall, $40 ; \mathrm{h}$, separating massulae, $\mathrm{x} 40 ; \mathrm{i}$, nonseptate glochidia, $\mathrm{x} 100 ; \mathrm{j}$, microsporocarp containing a large number of microsporangia (from same plant as k), x 20: k, part of fertile plant viewed from below and showing the roots and a small microsporocarp with a megasporocarp at its base, $\mathrm{x} 20$; 1 , separating massulae, x 40. (From Mason, Fig. 6.). 

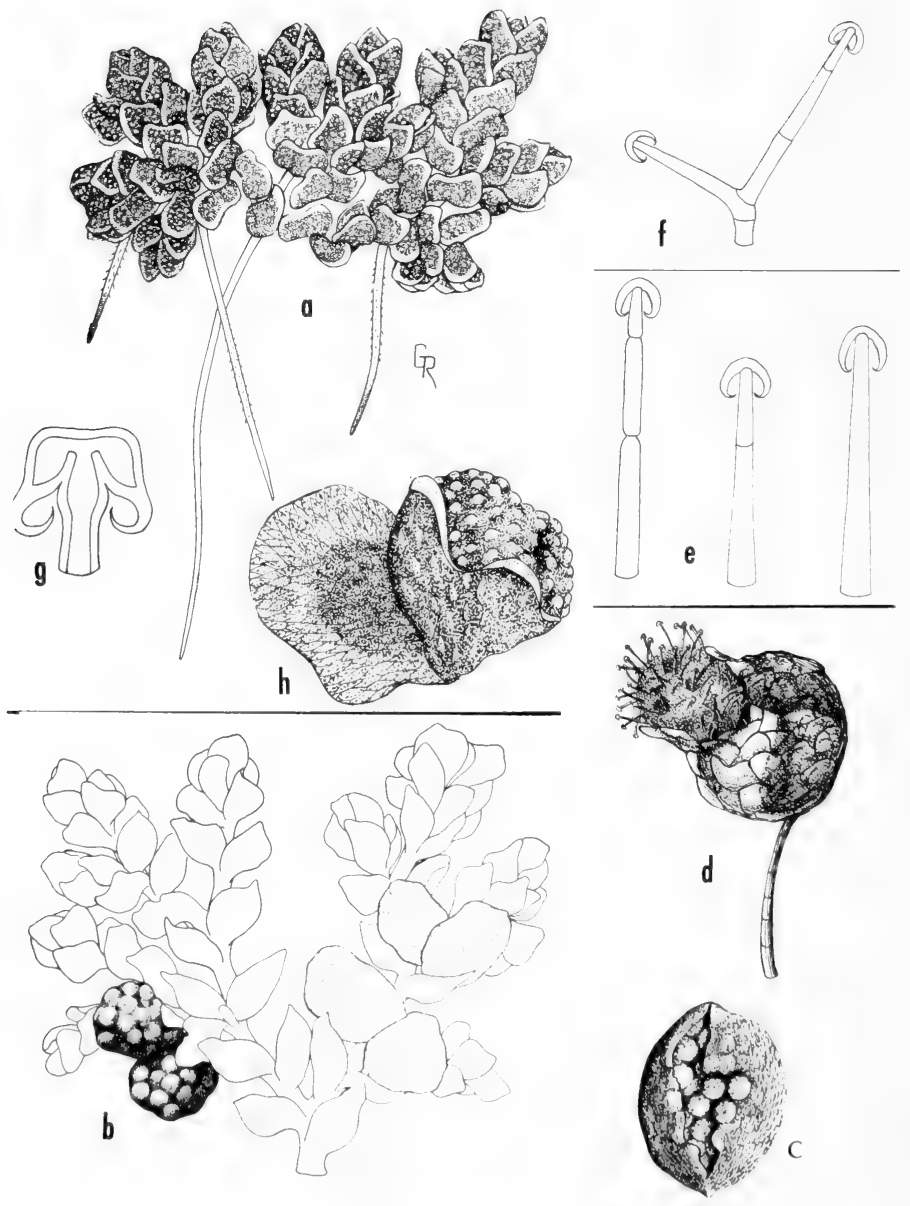

Fig. 13: Azolla caroliniana: all greatly magnified. a, habit, upper surface of sterile plant; b, lower surface, plant with microsporocarps; c, microsporocarp; d, microsporangium with massula being discharged; $\mathrm{e}$, glochida types from a single massula; $f$, one branched glochidium: g, tip of glochidium highly magnified; $h$, the two-lobed leaf. (From R. K. Godfrey et al. Am. Fern Journ., Vol. 51, p. 90, 1961). 
Jeff Davis and Presidio cos. in the Trans-Pecos, reported from N. M. (Sierra Co.); from Fla. w. to Tex., N.M. (?) and Okla., n. to N. C., O. and Alas.; also the W. I. and Mex. to Patagonia.

\section{Fam. 10. Polypodiaceae S. F. GraY}

\section{True Fern FAmily}

Usually large terrestrial or epiphytic plants of diverse habits with short or elongate creeping to suberect rhizomes; fronds clustered or remote, pendent to erect-spreading, commonly stalked, occasionally dimorphic; blades simple to much decompounded and variously dissected, with the veins simple to mostly forked, free or united and forming areoles with or without included veinlets; sporangia long-stalked, provided with an incomplete vertical annulus and opening transversely, borne either upon the veins on the lower surface or near the margins of ordinary leaf blades in lines or clusters (sori), occasionally borne on wholly fertile fronds or on partially sterile blades; sori naked or covered by a membrane (indusium) that develops from either the vein or modified leaf-margin; prothallia green.

This family, that includes about 50 genera and several thousand species, is by far the largest family of ferns in that it includes more than two thirds of the living ferns. They are found throughout the world from arctic to tropical regions in dense rain forests to desert areas.

1. Blades simple, pinnatifid or once-pinnate; pinnae or primary divisions entire, toothed or pinnatifid (2)

1. Blades twice-pinnate or more dissected (7)

2(1). Primary divisions or pinnae with the margins entire, undulate, irregularly toothed or incised, never distinctly pinnatifid (3)

2. Primary divisions or pinnae distinctly pinnatifid (4)

3(2). Primary segments with entire to undulate margins; sterile blade with the pinnae commonly opposite or essentially so; sporophylls with the divisions tightly rolled together, beadlike.........................2. Onoclea

3. Primary segments with serrulate margins; sterile blades with the pinnae commonly alternate; sporophylls with the divisions narrowly linear........

4. Lorinseria

4(2). Sori orbicular to reniform-orbicular (5)

4. Sori linear to elliptic, never orbicular (6)

5(4). Acicular unicellular hairs present on the costae above; segments of the fronds ciliate; stipe bundles 2, these united below the base of the blade; rhizome scales ciliate (sometimes sparingly so); rhizomes slender, mostly creeping; fronds membranous, mostly deciduous; veins reaching the margin.......................................6. Thelypteris

5. Acicular hairs absent on the costae above; segments of the fronds not ciliate; stipe bundles 3 to 7 , free to above the base of the blade; rhizome scales not ciliate, sometimes toothed; rhizomes massive, shortcreeping to erect; fronds herbaceous to coriaceous, sometimes evergreen; veins ending short of the margin in elongate hydathodes

7. Dryopteris

6(4). Sori parallel to and contiguous to the midrib of the leaf segments on specialized veins....................................................... Woodwardia

6. Sori borne obliquely to and away from the midrib of the leaf segments on ordinary veins 5. Athyrium

7(1). Sori borne on the under surface of the recurved portion of the ultimate segments; blades with only the apical margin of the ultimate segments recurved. 1. Adiantum 


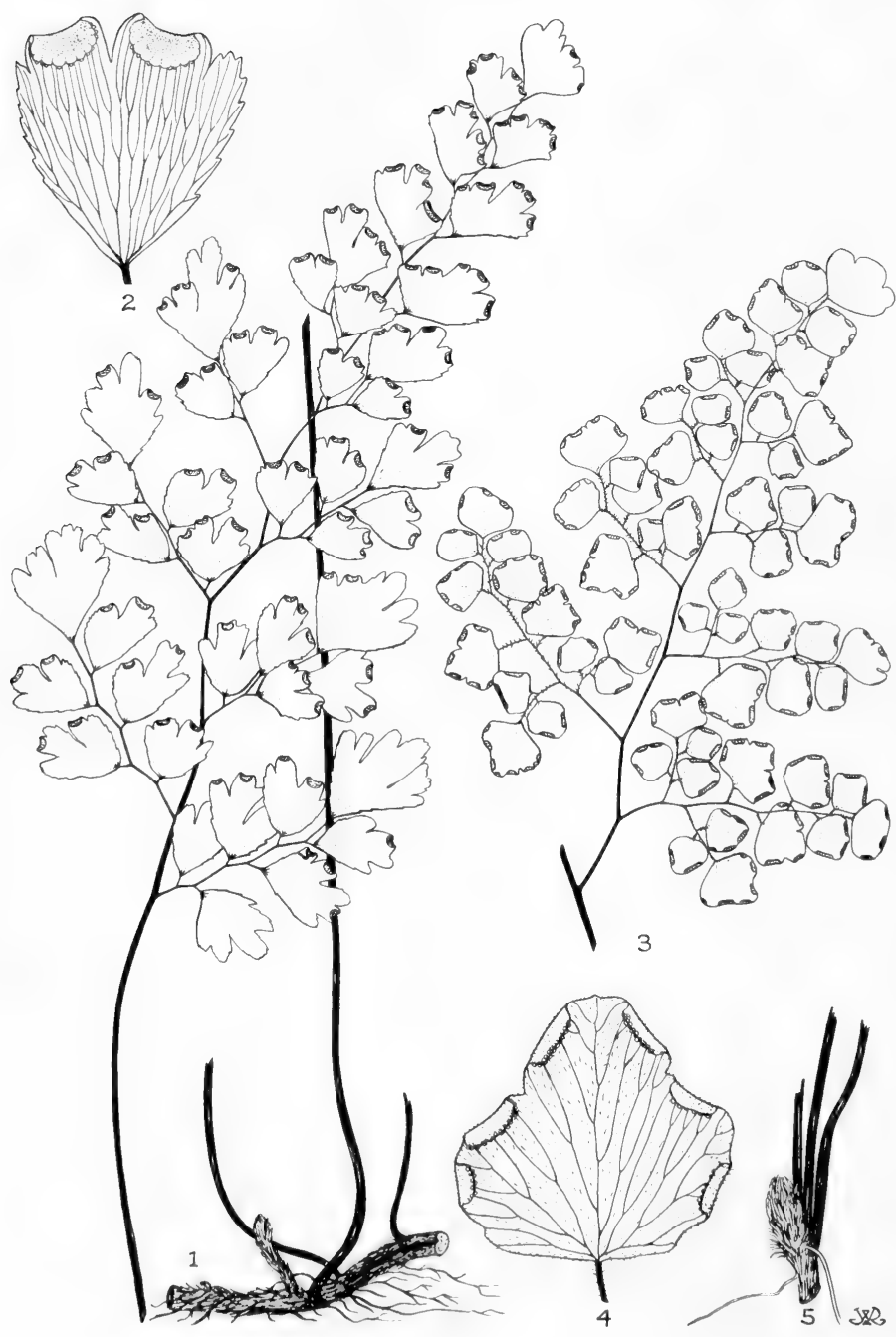

Fig. 14: 1 and 2, Adiantum Capillus-Veneris: 1, frond and rhizome, $\mathrm{x} 2 / 3 ; 2$, fertile pinnule, x 3. 3-5, Adiantum tricholepis: 3 , pinna, x 2/3; 4, fertile segment, x $3 ; 5$, erectascending rhizome, x \%3. (From Correll in Lundell's Flora of Texas. Vol. 1, PI. 13.). 
7. Sori not borne on the under surface of a recurved marginal lobule but on the leaf surface under a recurved marginal lobule (when this is present) (8)

$8(7)$. Sori linear-elliptic; indusia curved and crescentiform. 5. Athyrium

8. Sori round; indusia not curved or crescentiform (9)

9(8). Acicular unicellular hairs present on the costae above; segments of the fronds ciliate; stipe bundles 2, these united below the base of the blade; rhizome scales ciliate (sometimes sparingly so); rhizomes slender, mostly creeping; fronds membranous, mostly deciduous; veins reaching the margin.......................................6. Thelypteris

9. Acicular hairs absent on the costae above; segments of the fronds not ciliate; stipe bundles 3 to 7 , free to above the base of the blade; rhizome scales not ciliate, sometimes toothed; rhizomes massive, shortcreeping to erect; fronds herbaceous to coriaceous, sometimes evergreen; veins ending short of the margin in elongate hydathodes.

7. Dryopteris

\section{Adiantum L. Maidenhair Fern}

Delicate terrestrial or rock-inhabiting plants of moist wooded slopes, ravines and stream banks, with slender creeping to short and ascending scaly rhizomes; fronds suberect to pendent, distichous or in several ranks; stipes slender, strong, usually blackish and lustrous, glabrous or rarely pubescent, scaly at base only; blades pedately or pinnately decompound, variously dissected, rarely simple; ultimate segments oblique, petiolate or subsessile, articulate and deciduous in some species, membranous to subcoriaceous, mostly glabrous, with veins free and forking or rarely anastomosing; sori borne along or rarely between the ends of the ultimate veins, appearing marginal on the back of the reflexed apex of the lobules of the pinnules or ultimate segments; indusia formed in part by the reflexed margins of the lobules.

About 200 species, mainly in tropical America. Many species are cultivated.

1. Fronds smooth; ultimate segments obovate-cuneate or rhombic, usually prominently incised............................................... Capillus-Veneris.

1. Fronds pilose with whitish hairs; ultimate segments suborbicular, not prominently incised.

2. A. tricholepis.

1. Adiantum Capillus-Veneris L. Culantrillo. Fig. 14.

Rhizomes horizontal, creeping, cordlike, laxly scaly; rhizome scales thin, lightbrown, linear-lanceolate, attenuate, entire; fronds numerous, clustered or scattered along the rhizome, laxly ascending to pendulous, 1.3-7 dm. tall; stipes reddishbrown to purplish-black, lustrous, sulcate, glabrous, mostly shorter than the blades; blades broadly ovate to lanceolate, attenuate at apex, bipinnate to tripinnate or occasionally quadripinnate, glabrous, $1.5-4 \mathrm{dm}$. long, to $3.5 \mathrm{dm}$. wide; pinnae alternate, laxly spreading, petiolate, to $18 \mathrm{~cm}$. long; ultimate segments numerous, petiolulate, not jointed, membranous to thin-herbaceous, bright-green, variable in size and shape, obliquely obovate to semiorbicular, truncate to obliquely cuneate at the base, the outer margin more or less incised or deeply lobulate, $7-30 \mathrm{~mm}$. long, about as wide as long; sterile segments regularly denticulate with the teeth acute to long-acuminate; sori borne on the margins of the lobules of the ultimate segments, somewhat lunate; modified indusial margin of the lobules glabrous, prominent, scarious, with crenate margins. A. modestum Underw., A. tricholepis f. glabrum Clute.

Limestone rocks, ledges and cliffs, especially along streams and about pools in canyons and ravines, rare in Okla., in Tex. frequent on the Edwards Plateau and in the Trans-Pecos, e. to Harris Co. on the Coastal Plain and s.w. to Zavala Co. in 


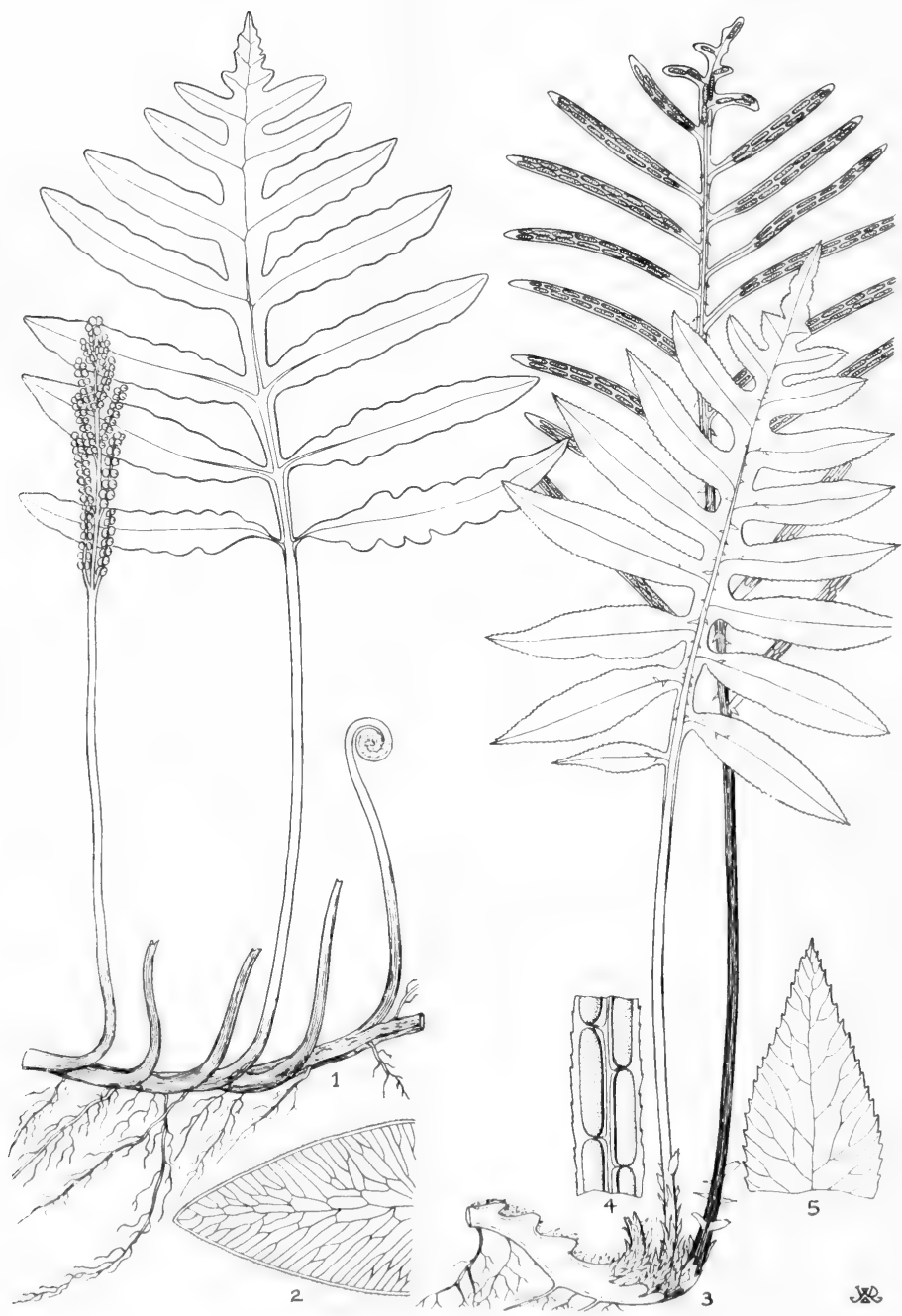

Fig. 15: 1 and 2, Onoclea sensibilis: 1, plant with fertile and sterile fronds, $\mathrm{x} 1 / 3$ : 2 , details of upper portion of sterile segment, x 2. 3-5, Lorinseria areolata: 3, plant with fertile and sterile fronds, $x 1 / 3 ; 4$, section of segment with sori, $x 2$; 5 , details of upper portion of sterile segments, x 2. (From Correll in Lundell's Flora of Texas, Vol. 1, PI. 28). 
the Rio Grande Plains, with a few stations in the Blackland Prairies and n.-cen. Plains Country, westw. through N.M. (throughout most of the state) to Ariz.; from Va., s. to Fla., w. to Ky., Tenn., Mo., Ariz. and Mex. to n. S. A.; also Euras.

\section{Adiantum tricholepis Fée. Hairy maidenhair fern. Fig. 14.}

Rhizome short, stout, erect or ascending, scaly; rhizome scales deep reddishbrown, narrowly lanceolate, attenuate and usually terminated by an early fugacious contorted seta at the apex, ciliolate; fronds several, cespitose, erect-recurved to pendulous, to $7 \mathrm{dm}$. tall or more; stipes smooth, vernicose, deep reddish-brown to blackish, to $3 \mathrm{dm}$. long or more; blades oval to ovate in outline, bipinnate to quadripinnate, pilose throughout with whitish hairs (especially on the veins beneath), 2-4 dm. long, 1.5-3.5 dm. wide; pinnae alternate, suberect to horizontal, petiolate, to $2 \mathrm{dm}$. long; ultimate segments small, numerous, petioled, membranous to rigidly herbaceous, orbicular-rhombic, subentire to obscurely tricrenate at the broadly rounded apex, truncate to broadly cuneate at the base; sori 3 to 10 , marginal; modified indusial margin of the ultimate segments inconspicuous, pubescent, scarious, with undulate margins.

On moist limestone cliffs along wooded streams on the Edwards Plateau in Tex.; uncommon in Tex., Mex. and Guat.

This species is not as dependent upon a continuous, permanent source of water as is A. Capillus-Veneris. It is, however, occasionally found in seepage areas. Our only other species, $A$. pedatum $\mathrm{L}$, is definitely a terrestrial with erect fronds. It is usually found in rich, moist, loamy soil.

\section{Onoclea L. Sensitive FERN}

\section{A monotypic genus, native in the Northern Hemisphere.}

\section{Onoclea sensibilis L. Fig. 15.}

Coarse herbaceous plant with slender branching rhizome to about $7 \mathrm{~mm}$. thick and copiously rooting and with few light-brown elliptic fugacious scales; fronds conspicuously dimorphic, erect-ascending, scattered along the rhizome; stipes slender, greenish or tinged with brown; sterile frond to $13 \mathrm{dm}$. high, glabrous, thin-herbaceous, withering with frost; blades broadly triangular, deeply pinnatifid, the rachis winged; pinnae few, subopposite (especially the lowermost pinnae), oblong-lanceolate to elliptic-lanceolate, obtuse to acute, entire to undulate or the lower and sometimes the middle pinnae sinuately lobed; veins freely anastomosing; fertile frond to $8 \mathrm{dm}$. high, rigidly erect, persistent over winter; blades bipinnate, with the pinnae much-contracted; pinnules rolled into close berrylike bodies (sporangia) and forming a narrow close panicle.

In swamps, open flooded woodlands, meadows, sandy bogs, thickets along streams and about lakes, and on seepage slopes, in e. Okla. and in Tex. widespread and rather frequent in the Timber Belt s. to Jefferson Co. in the Coastal Prairies, w. to apparently disjunct stations in Burnet Co. on the Edwards Plateau and Wilson Co. in the Rio Grande Plains; from Nfld. to Ont., Minn. and S.D., s. to n. Fla. and Tex.

\section{Woodwardia SM.}

\section{VIRGINIA Chain FERN}

About 12 species found mainly in the temperate regions of both hemispheres.

\section{Woodwardia virginica (L.) Sm. Fig. 16.}

Rather large coarse terrestrial plants; rhizome woody, ropelike, creepingelongate and branching, black, to about $2 \mathrm{~cm}$. thick, naked to densely chaffy (especially at apex) with brownish broadly lanceolate scales; fronds erectascending, uniform, borne at intervals along the rhizome, 4-15 $\mathrm{dm}$. high; stipes 

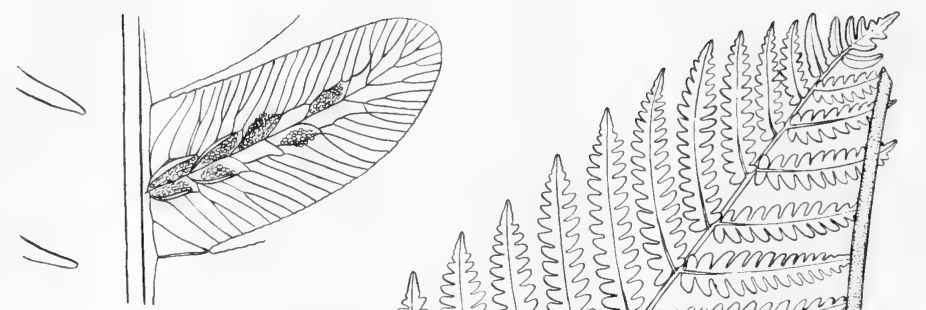

2

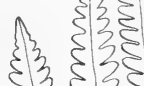

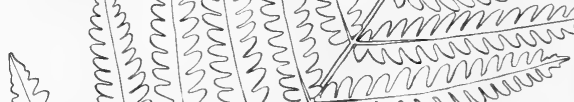

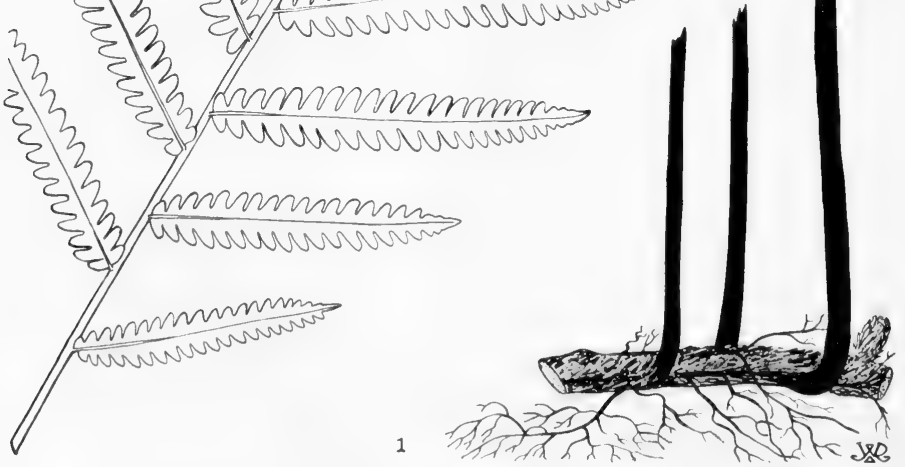

Fig. 16: Woodwardia virginica: 1, frond and rhizome, $\mathrm{x} 1 / 3 ; 2$, segment showing sori, x 3. (From Correll in Lundell's Flora of Texas, Vol. 1, PI. 29). 
black to chestnut-brown at the base, green or reddish-brown above, glabrous, lustrous, 3-9 dm. long; blades broadly ovate to oblong-elliptic or elliptic-lanceolate, bluntly acute, pinnate-pinnatifid, subcoriaceous, 3-6 dm. long. $12-30 \mathrm{~cm}$. wide; pinnae linear-lanceolate to elliptic-lanceolate, acuminate, with small brown scales along the midrib, $7.5-15 \mathrm{~cm}$. long, 12-35 mm. wide, deeply pinnatifid; ultimate segments obliquely ovate to oblong-lanceolate, obtuse to acute, 5-6 $\mathrm{mm}$. wide, with the margins somewhat reflexed; sori double, contiguous to confluent, borne on the transverse veins forming the outer side of the areoles, oblong-linear, chainlike. Anchistea virginica (L.) Presl.

In sphagnous bogs, swamps, moist thickets and meadows, and along streams, rather generally distributed in Tex. in the Timber Belt and in the extreme s.e. border cos. in the Coastal Prairies, w. to Gonzales, Lee and Milam cos. in the Blackland Prairies; from Fla. to Tex., n. to N.S., Ont. and Ill.; also Berm.

\section{Lorinseria Presl Chain FERn}

A monotypic genus.

1. Lorinseria areolata (L.) Presl. Fig. 15.

Slender herbaceous plants; rhizomes slender, widely creeping, chaffy with brown ovate-lanceolate to lanceolate scales, to $4 \mathrm{~mm}$. thick; fronds dimorphic, scattered on the rhizome; sterile fronds spreading, to $75 \mathrm{~cm}$. high; stipes slender, greenish or stramineous, sometimes purplish-brown toward the base, $15-35 \mathrm{~cm}$. long; blades ovate-oblong to ovate-deltoid, acuminate, usually deeply pinnatifid, sometimes pinnate below, membranous, 1.5-4 dm. long; ultimate segments alternate, linearlanceolate to oblong-lanceolate, acute to acuminate, lightly or sometimes deeply sinuate, serrulate, usually connected by wings on the rachis or the lower pairs free, to $13 \mathrm{~cm}$. long and $2 \mathrm{~cm}$. wide, the veins joined in the numerous hexagonal areoles; fertile fronds erect, usually surpassing the sterile ones; stipes stout, purplish-brown, lustrous, 3-6 dm. long; blades ovate-oblong, obscurely pinnatifid or pinnate, 1.5-3 dm. long; pinnae alternate, distant, linear, often connected by a slight wing along the rachis, mostly less than $5 \mathrm{~mm}$. wide; sori linear to elliptic, in a single row on each side of the midrib. Woodwardia angustifolia Sm., W. areolata (L.) Moore.

In sandy bogs and low sandy woods, swamps, marshes, thickets, on seepage slopes and along streams in s.e. Okla. and in Tex. generally distributed and rather frequent in the Timber Belt s. to Jefferson Co. in the Coastal Prairies and Bastrop and Gonzales cos. in the Blackland Prairies; from Fla. to Tex., Okla., Ark. and Mo., n. to N.S. and Mich.

\section{Athyrium Roth LAdy Fern}

About 200 species that are in tropical and subtropical regions throughout the world.

\section{Athyrium Filix-femina (L). Roth var. asplenioides (Michx.) Farw. SoutherN} LADY FERN. Fig. 17.

Rather large terrestrial plant; rhizome shortly creeping, with light-brown scales, about $7 \mathrm{~mm}$. in diameter; fronds clustered, to $12 \mathrm{dm}$. high; stipes yellowish-green, often tinged with red or brown, stramineous when dry, sparingly scaly below; blades ovate-lanceolate to elliptic-lanceolate, acuminate, pinnate-pinnatifid to rarely subtripinnate (at least below), thin-herbaceous to subcoriaceous, essentially glabrous throughout, usually exceeding the length of the stipe, to $35 \mathrm{~cm}$. wide; pinnae shortly stalked, elliptic-lanceolate to narrowly lanceolate, acuminate, spreading horizontally or curved-ascending with age, to $4 \mathrm{~cm}$. wide; pinnules or ultimate segments mostly decurrent on the rachis, sometimes subpetiolate, oblonglanceolate, obtuse to shortly acuminate, incised to serrate or lobulate with the 

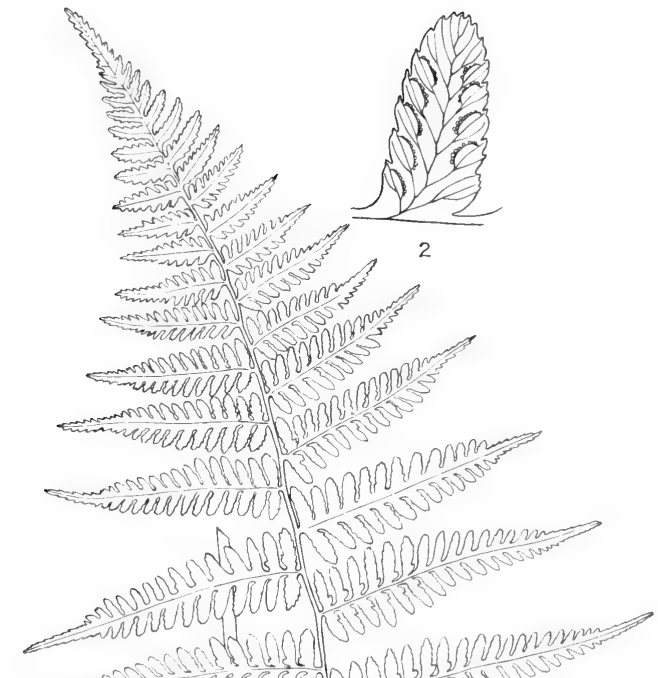

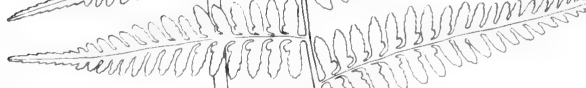

reMNOAD
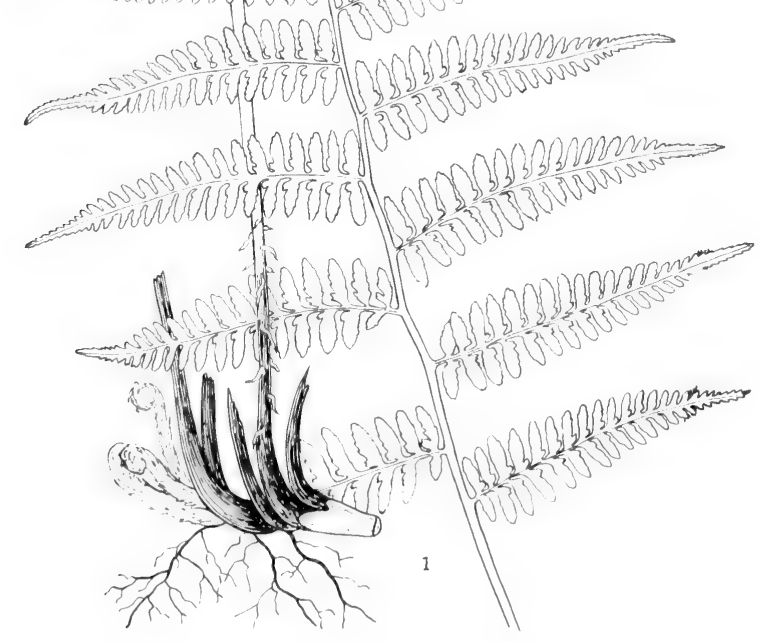

W

Fig. 17: Athyrium Filix-femina var. asplenioides: 1, plant, $x 2 \frac{3}{3} ; 2$, pinnule with sori, $x$ 3. (From Correll in Lundell's Flora of Texas. Vol. 1, Pl. 31 ). 
lobules often again toothed; sori short, 3 to 10 pairs in each segment; indusia mostly curved, with gland-tipped cilia. A. asplenioides (Michx.) Eat.

In sandy bogs, moist sandy woods, swamps, wet thickets and on stream banks in s.e. Okla. and in Tex. generally distributed and rather common in the Timber Belt and in several $\mathbf{n}$. border cos. in the Coastal Prairies, w. to Williamson Co. in the Blackland Prairies; from Fla. to Tex., n. to e. Mass., Ind. and Mo.

Var. californicum Butters. Characterized by its dark scales, indusia short ciliate or merely toothed, and large spores with a distinct, wrinkled and reticulate exospore.

In habitats similar to those of var. asplenioides in N.M. (Socorro, Grant, San Miquel and Rio Arriba cos.) and Ariz. (Apache, Graham, Cochise and Pima cos.); Ida. and w. Wyo., s. to N.M., Ariz. and Calif.

\section{Thelypteris SCHMID.}

Terrestrial plants of moist woodlands and rocky places, with stout or mostly slender strong long-creeping sparsely scaly rhizomes; scales of the rhizome ciliate, entire, fibrous; fronds erect-ascending, somewhat distant, deciduous; stipes stramineous, essentially scaleless, with two bundles at the base; blades uniform, thinmembranous, bipinnatifid to pinnate-pinnatifid or bipinnate-pinnatifid, pubescent with acicular unicellular hairs on the costae above, rarely sparsely scaly; ultimate segments usually entire or nearly so, rarely serrate or coarsely toothed, ciliate; veins few, simple or once-forked, reaching the margins; sori dorsal on the veins, median or supramedial; indusia small or sometimes absent, reniform, usually glandular or ciliate.

A large world-wide genus of several hundred species that attains its optimum development in temperate and subtropical Asia.

1. Ultimate segments with the margins serrate or coarsely toothed.

1. Ultimate segments with the margins entire to crenate or nearly pinnatifid, never serrate nor toothed (2)

2(1). Blades strongly triangular, pinnatifid (the rachis winged throughout); indusia wanting.............................................. $2 . T$. hexagonoptera.

2. Blades lanceolate to elliptic-lanceolate or sometimes ovate-lanceolate, pinnate; indusia present (3)

3(2). Veins of ultimate segments once- or twice-forked; indusia glabrous.

3. T. palustris var. Haleana.

3. Veins of ultimate segments simple; indusia variously pubescent (section Cyclosorus) (4)

4(3). Basal veins of adjacent segments united below the sinus with an excurrent vein leading toward the sinus; costules, veins and often lamina above hairy (5)

4. Basal veins of adjacent segments free below or connivent at the sinus; costules, veins and lamina above with or without hairs (6)

5(4). Costae below with predominately short hairs which are uniform in length (less than $0.2 \mathrm{~mm}$. and often less than $0.1 \mathrm{~mm}$. long); excurrent veins mostly greater than $2 \mathrm{~mm}$. long; stipe purplish; frond with usually more than 2 pairs of greatly reduced pinnae at the base........ 4. T. dentata.

5. Costae below with most hairs greater than $0.3 \mathrm{~mm}$. long with some exceeding $0.5 \mathrm{~mm}$; excurrent veins less than $2 \mathrm{~mm}$. long; stipe stramineous; fronds with 0 to 2 pairs of reduced pinnae at the base.

5. T. quadrangularis var, versicolor. 

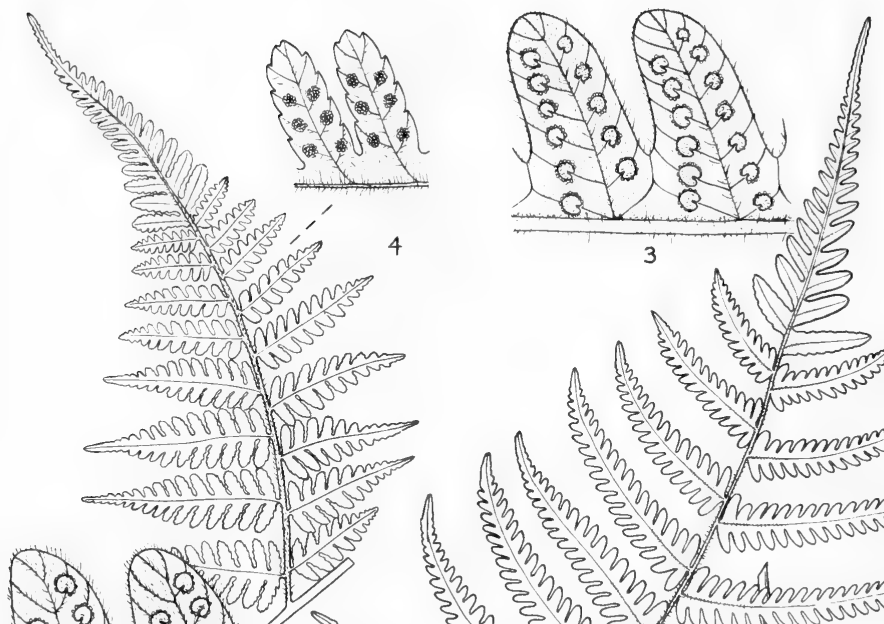

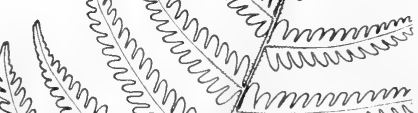
है है? है? 2 inmmm

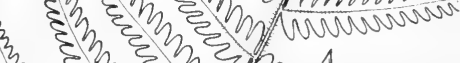
है, है? है?

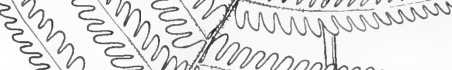

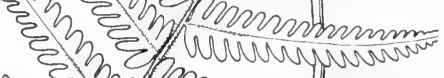

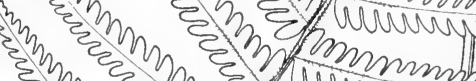

है?

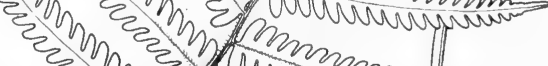
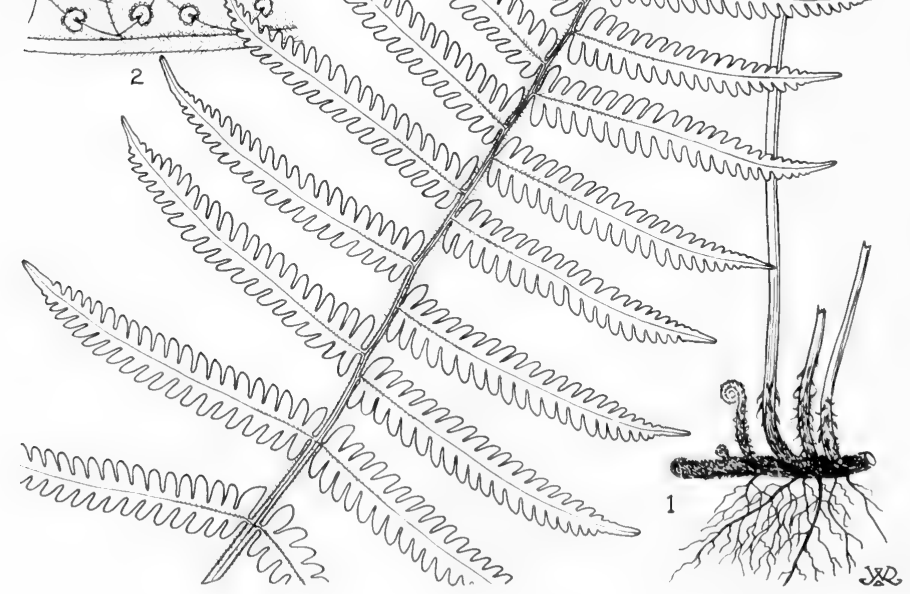

Fig. 18: 1 and 2, Thelypteris normalis: 1, frond and rhizome, $x 2 / 3 ; 2$, segments with sori, x 3. 3, Thelypteris dentata: 3, segments with sori, x 3. 4, Thelypteris Torresiana: 4, pinna (x 2/3) and segments with sori, x 3. (From Correll in Lundell's Flora of Texas, Vol. 1, Pl. 34). 

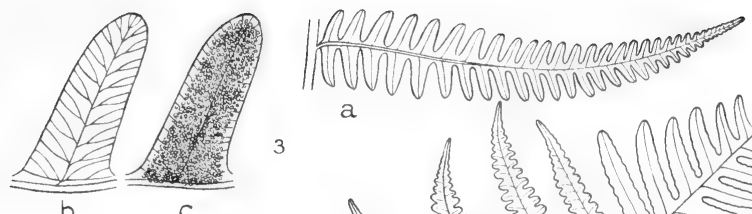

3

a

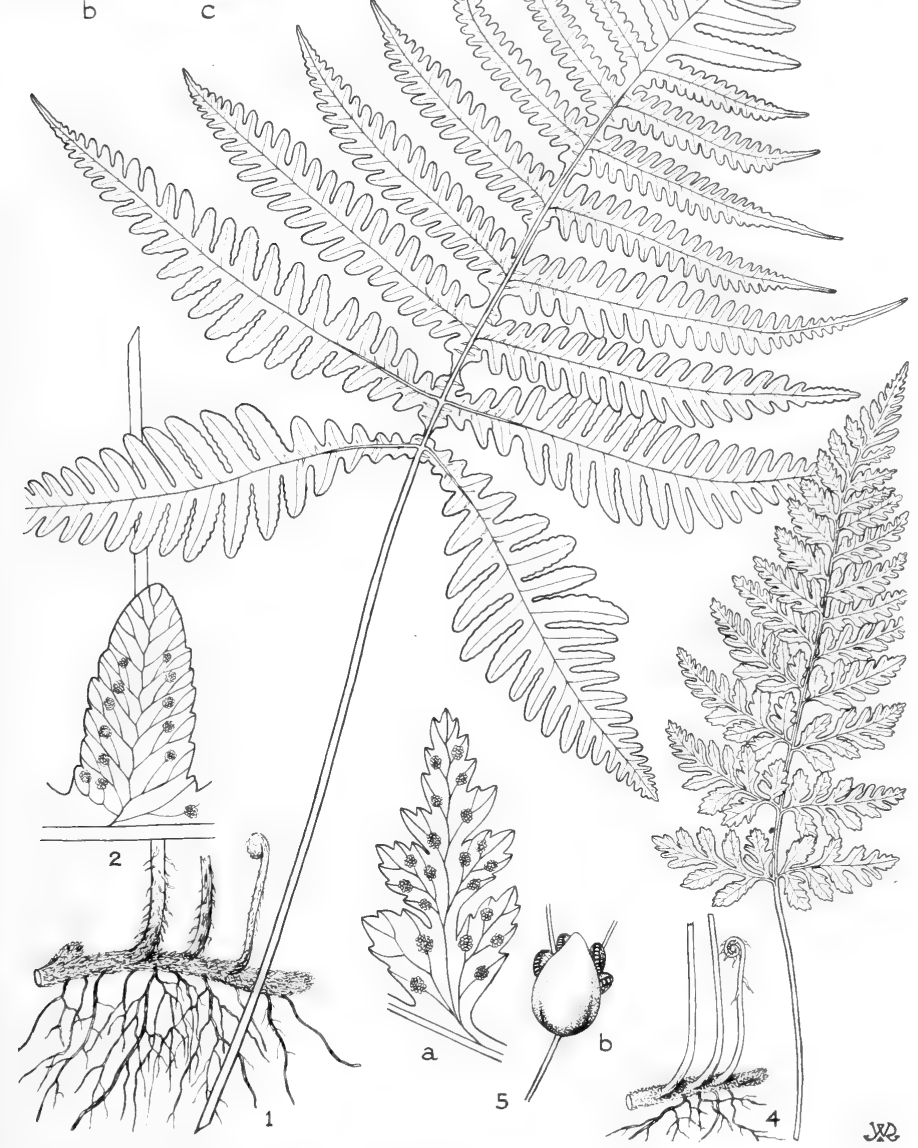

Fig. 19: 1 and 2, Thelypteris hexagonoptera: 1 , frond and rhizome, X $2 / 3 ; 2$, segment with sori, X $3 ; 3 \mathrm{a}-3 \mathrm{c}$, Thelypteris palustris var. Haleana: $3 \mathrm{a}$, pinna, X $2 / 3 ; 3 \mathrm{~b}$, sterile segment, X 3; 3c, lower surface of fertile segment, X 3. 4-5b, Cystopteris fragilis var. protrusa: (not usually considered a wetland plant) 4 , frond and rhizome, $\mathrm{X} 2 / 3 ; 5 \mathrm{a}$, segment with sori, X $3 ; 5 \mathrm{~b}$, sorus, $\mathrm{X} 25$. (From Correll in Lundell's Flora of Texas, Vol. 1, Pl. 35). 
6(4). Costae, costules and veins above glabrous, or with very thin short hairs mostly less than $0.2 \mathrm{~mm}$. long; lamina above eglandular; a few very narrow scales $1-3 \mathrm{~mm}$. long persistent on the rachis and sometimes on the costae below; sori submarginal on the veins.

6. T. ovata var. Lindheimeri.

6. Costae, costules and often veins above with at least a few rather stout hairs mostly greater than $0.3 \mathrm{~mm}$. long; lamina above often with a few minute glands; scales absent on the rachis and costae below; sori medial to submarginal on the veins....

7(6). One or two pairs of pinnae below somewhat reduced; rhizome shortcreeping, sometimes appearing suberect; venation variable (even on the same frond), from anastomosing with a short excurrent vein to connivent at the sinus; lamina above often somewhat hairy; veins above always with stout hairs many of which are greater than $0.4 \mathrm{~mm}$. long....................5.T. quadrangularis var, versicolor.

7. Lowermost pinnae usually not reduced; rhizome short-creeping to frequently long-creeping; veins connivent at the sinus or the distal one of each pair meeting the margin slightly above the sinus; lamina above glabrous or sparsely hairy; veins above with or without long stout hairs.

7. $T$. normalis.

\section{Thelypteris Torresiana (Gaudich.) Alston. Fig. 18.}

Fronds clustered on a stout rhizome, to $2 \mathrm{dm}$. tall or more; rhizome scales linear-lanceolate, acuminate-attenuate, castaneous, long-ciliate, to about $8 \mathrm{~mm}$. long; stipes slender to stoutish, stramineous, to $6 \mathrm{dm}$. long, scaly at base, glabrous to sparingly setose; blades deltoid-ovate to triangular-lanceolate, acuminate, bipinnate-pinnatifid, membranous, setaceous with silvery-white hairs, to $9 \mathrm{dm}$. long and $4 \mathrm{dm}$. wide; pinnae triangular-lanceolate to narrowly elliptic, acuminate, pinnate; pinnules sessile, lanceolate, acute to acuminate, deeply pinnatifid, confluent at apex, to about $5 \mathrm{~cm}$. long and $1.5 \mathrm{~cm}$. wide; ultimate segments rounded, coarsely toothed, about $2 \mathrm{~mm}$. wide; sori solitary at the anterior margin of a tooth, 1 to 6 per segment; indusia obsolete, early fugacious.

Along streams in pinelands, in swamps, marshes and on moist wooded banks, in e. Tex. (Newton and Hardin cos.); nat. of Asia and adj. I., escaped from cult. and more or less established in cen. peninsula Fla., Ala. to Tex. and trop. Am.

\section{Thelypteris hexagonoptera (Michx.) Weath. BroAd BEECH FERN. Fig. 19.}

Fronds distant, erect, arising at $5-15 \mathrm{~mm}$. intervals on a slender creeping rhizome, to about $8 \mathrm{dm}$. tall; rhizome scales light-brown, ovate-lanceolate to linearlanceolate, often long-ciliolate, 3-5 mm. long; stipes weak, slender, stramineous or greenish, $2-4.5 \mathrm{dm}$. long; blades broadly triangular, acute to acuminate, bipinnatifid, $15-38 \mathrm{~cm}$. long, about as broad as long or broader, slightly pubescent and frequently glandular on lower surface; rachis irregularly winged throughout; primary segments elliptic-lanceolate, acuminate, tapering at both ends, pinnatifid, with the lower usually larger pair of segments directed downward and away from the rachis at a different angle from the upper segments; ultimate segments obliquely oblong, obtuse, subentire to deeply crenate or sometimes nearly pinnatifid; sori naked, mostly near the margin.

On sandy-loamy wooded slopes and in ravines along streams, in open rocky thickets, and on the edge of low swampy woods and bogs, rare in e. Okla. and in the e. Tex. Timber Belt; from Fla. to e. Tex, and Okla., n. to Que. and Minn.

\section{Thelypteris palustris Schott var. Haleana Fern. SOUTHERN MARSH FERN. Figs.} 19 and 20.

Fronds erect from a slender widely creeping rhizome, to $12 \mathrm{dm}$. tall; rhizomes blackish; stipes slender, glabrous or nearly so, stramineous above, purplish toward base, about as long as the blade; blades lanceolate to elliptic-lanceolate, short- 


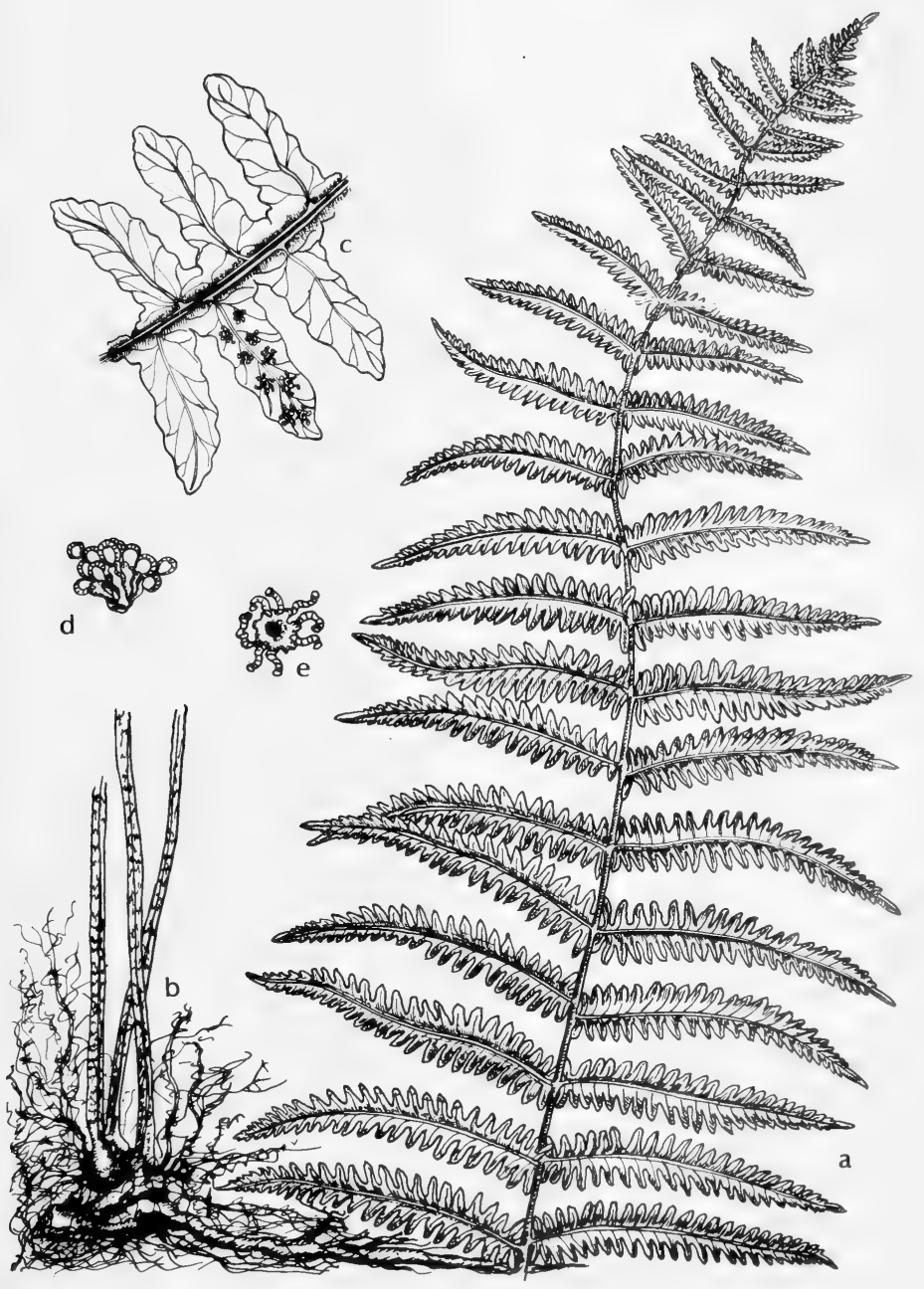

Fig. 20: Thelypteris palustris: a, upper part of frond, X 1/2; b, rootstock, X 1/2; c, pinnae showing one fertile pinnule, $\mathrm{X} 5$; $\mathrm{d}$, sporangia before spores are released, $\mathrm{X}$ 10; e, sporangia after rupturing and releasing spores, X 10, (V.F.). 
acuminate, pinnate-pinnatifid to rarely bipinnate, slightly pubescent (especially the rachises), 9-20 cm. wide, membranous to herbaceous; pinnae numerous, linearlanceolate to lanceolate, somewhat acuminate, sessile or nearly so, deeply pinnatifid to rarely pinnate, to $3 \mathrm{~cm}$. wide, the midrib beneath mostly with broad brown or tawny scales at the base of the ultimate segments; pinnules or ultimate segments mostly linear-oblong, numerous and closely set, entire or with minutely undulate margins, obtuse or appearing to be acute because of the revolute margins, to 1.5 $\mathrm{cm}$. long, with all the veins (including those of the fertile segments) commonly once- or twice-forked; sori medial, numerous, sometimes confluent; indusia small, glabrous.

In open sandy bogs, swamps and meadows, or in open low woodlands, seepage about lakes and ponds, and along streams, rare in several cos, in the e. Tex. Timber Belt and in Jefferson Co. in the Coastal Prairies and Waller and Colorado cos. in the Post Oak Prairies; from Fla. to e. Tex., n. to (?) $\mathbf{P a}$.

\section{Thelypteris dentata (Forsk.) E. St. John. Downy SHiEld FERN. Fig. 18.}

Fronds clustered, erect-ascending from a thick rhizome, to $12 \mathrm{dm}$. tall; stipe and rachis purplish; blades ovate-oblong to lanceolate, to $8 \mathrm{dm}$. long and $28 \mathrm{~cm}$. wide; pinnate-pinnatifid, with usually more than 2 pair of greatly reduced pinnae at the base, costae below with predominantly short hairs which are uniform in length (less than $0.2 \mathrm{~mm}$. and often less than $0.1 \mathrm{~mm}$. long); excurrent veins mostly greater than $2 \mathrm{~mm}$. long. Dryopteris dentata (Forsk.) C. Chr.

On rocky wooded slopes, on hummocks in swamps, and along wooded streams at low elev., rare in the Tex. Timber Belt; from Fla. to Tex., in part escaped from cult.; also from Mex. to Arg., the W.I., Asia and Afr.

\section{Thelypteris quadrangularis (Fée) Schelpe var. versicolor (R. St. John) A. R. Smith.}

Fronds erect, arching, mostly 3-10 dm. tall; rhizomes short-creeping to suberect, obscured by the persistent leaf bases; stipes $1.5-5 \mathrm{~mm}$. in diameter, pubescent, stramineous above, sometimes darkened at the base, nearly as long as the blades, with lanceolate shining dark-brown to castaneous pubescent scales at the base; blades elliptic-lanceolate, usually with 1 or 2 pair(s) of somewhat reduced pinnae below, occasionally the pinnae very little reduced below, auricled or not, 1-3 dm. wide, herbaceous; pinnae numerous, linear-lanceolate, sessile, pinnatifid two thirds to four fifths of their width, to $2 \mathrm{~cm}$. wide; pinnules linear-oblong, somewhat oblique, rounded at the apex, entire; the veins simple, mostly 6 to 9 pairs per segment, the basal pair from adjacent segments united below the sinus with an excurrent veinlet less than $1 \mathrm{~mm}$. long to the sinus or the lower pair of veins not uniting at all but approaching each other below the sinus and turning abruptly toward the sinus; costae, costules, veins and leaf tissue pubescent above and below, the hairs often stout and to $0.8 \mathrm{~mm}$. long; stipitate yellow glands often present on both surfaces of the blade; sori medial, numerous or sometimes confined to the basal pair of veins, discrete; indusia persistent, pubescent; sporangial stalks with minute glands. $T$. versicolor $\mathrm{R}$. St. John.

On the edge of sandy creeks, boggy or swampy areas and wooded slopes in e. Tex.; S.C. to e. Tex.; also Cuba; other vars. in Latin Am. and Afr.

\section{Thelypteris ovata R. St. John var. Lindheimeri (C.Chr.) A. R. Smith}

Fronds erect, arching, mostly 5-14 dm. tall; rhizomes widely creeping, brownish, 3-6 $\mathrm{mm}$. in diameter; stipes $2-6 \mathrm{~mm}$. in diameter, arising from the rhizome in a more or less bilinear series $1-4 \mathrm{~cm}$. apart, glabrous or nearly so, stramineous above, darkened at the base, about as long as the blades, paleate at the base, the light-brown scales narrowly lanceolate and short-ciliate at the margin; blades deltoid-lanceolate, mostly $30-75 \mathrm{~cm}$. long, $15-50 \mathrm{~cm}$. wide, pinnate-pinnatifid, 
tapering evenly toward the pinnatifid apex, chartaceous; rachis sparsely to densely pubescent, nearly always with a few persistent narrowly lanceolate light-brown scales; pinnae numerous, linear-lanceolate, sessile, deeply pinnatifid three fifths to usually more than four fifths of their width, $8-20 \mathrm{~mm}$. wide, the veins and leaf tissue glabrous above or sometimes with minute hairs about $0.1 \mathrm{~mm}$. long on the leaf tissue above, the costae above and below with longer hairs to $0.5 \mathrm{~mm}$. long; costae below usually with a few attenuate scales to $1 \mathrm{~mm}$. long; pinnules linearoblong, often strongly oblique, subfalcate, the margin entire, rounded or usually appearing acute because of the revolute margin, the basal segments of the medial pinnae frequently narrower and slightly longer than more distal pinnules; veins simple, 6-13 pairs per segment, the basal pair meeting the margin at or slightly above the sinus; sori supramedial to submarginal, numerous, discrete; indusia persistent, pubescent, often glandular; sporangial stalks eglandular. Dryopteris normalis var. Lindheimeri C. Chr.

On wet bluffs and ledges in canyons, especially at the base of dripping limestone bluffs, about springs and along water courses, on the Edwards Plateau in cen. Tex. s. to n. Ver. and Pue.

\section{Thelypteris normalis (C. Chr.) Moxley. Fig. 18.}

Fronds erect, arching, mostly 5-15 dm. tall; rhizomes creeping, brownish, 4-8 $\mathrm{mm}$. in diameter; stipes usually $3-6 \mathrm{~mm}$. in diameter, arising from the rhizome at $1-3 \mathrm{~cm}$. intervals in a more or less bilinear series (infrequently the stipes clustered), stramineous above, darkened at the base, about as long as the blade, glabrous to moderately hairy, paleate at the base; rhizome scales castaneous, shining, lanceolate, more or less pubescent; blades lanceolate (the lowest pair of pinnae the longest or only slightly shorter than the next pair of pinnae), mostly 3-7 dm. long, 16-30 cm. wide, pinnate-pinnatifid, herbaceous to chartaceous, the rachis pubescent and often stipitate-glandular, rarely with a few persistent scales; pinnae numerous, sessile, linear-lanceolate, to $2 \mathrm{~cm}$. wide, pinnatifid three fifths to three fourths of their width, the costae, costules and sometimes the veins above more or less pubescent with hairs mos!ly $0.2-0.5 \mathrm{~mm}$. long, the tissue between the veins above glabrous; pinnules numerous, linear-oblong, somewhat oblique, rounded at the tip or appearing acute because of the revolute margins, entire except for the basal pinnae segments of the lower pinnae which may be slightly enlarged with a crenate margin (auricles present); veins simple (except those of the auricles which may be once-forked), 6 to 11 pairs per segment, connivent at the sinus or the distal one of each pair meeting the margin slightly above the sinus; sori medial, numerous, usually discrete; indusia large, persistent, moderately to densely hairy; sporangial stalks with minute stipitate glands. $T$. Kunthii of auth., Dryopteris normalis C. Chr.

On the edge of sandy creeks, in swamps, low wet woods and slopes in e. Tex.; W. I. and Mex. to n. S.A.

\section{Dryopteris AdANS.}

Rhizomes stout, erect or short-creeping; scales fibrous, glabrous, entire to toothed, not ciliate; fronds and pinnae sometimes more or less dimorphic; blades pinnate-pinnatifid to tripinnate; stipes stout, stramineous, shorter than the blades, with 3 to 7 free bundles; ultimate segments mostly toothed, often subspinulose, glabrous, not ciliate, occasionally capitate-glandular, sparingly to densely scaly, the minor axes decurrent on the major ones to form the sides of the dorsal grooves; veins free, simple or mostly forked, ending short of the margin in elongate hydathodes; sori dorsal on the veins, inframedial to submarginal; indusium reniform, large, persistent, glabrous, sometimes glandular on margin or back.

A large world-wide genus of about 150 species that are found mainly in tropical and subtropical regions of both hemispheres. 

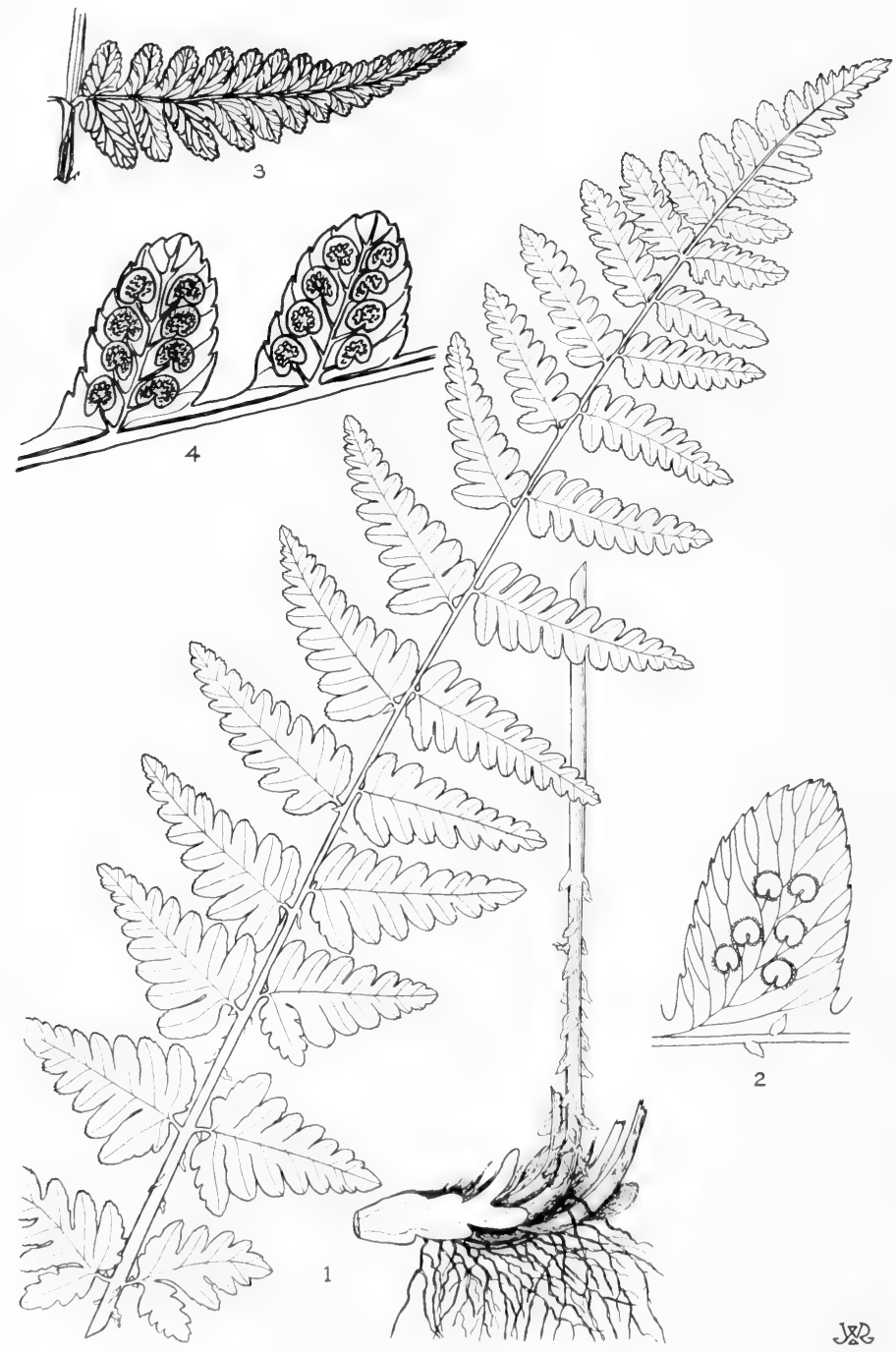

Fig. 21: 1 and 2, Dryopteris cristata: 1, frond and rhizome, X $2 / 3 ; 2$, enlarged pinna, X 3. 3 and 4, Dryopteris ludoviciana: 3 , pinna, X $2 / 3 ; 4$, detail of pinnules, $X$ 3. (From Correll in Lundell's Flora of Texas, Vol. 1, Pl. 33). 
1. Fertile segments not contracted; fertile fronds with most or all of the pinnae fertile, erect, 2 to 3 times as long as the spreading sterile fronds......

1. D. cristata.

1. Fertile segments sharply contracted to about one half the width of the sterile segments; fertile fronds with fertile pinnae only in upper half, 2 times or less the length of the sterile fronds..........2. D. ludoviciana.

\section{Dryopteris cristata (L.) Gray. Crested Shield fern. Fig. 21.}

Fronds inconspicuously dimorphic, clustered on a thick rhizome, glabrous on upper surface, sparsely scaly on lower surface, to $12 \mathrm{dm}$. tall; sterile fronds broad and spreading, usually evergreen; fertile fronds narrow and erect; blades (of both types of fronds) subcoriaceous, linear-oblong to lanceolate or narrowly ellipticlanceolate, to $8 \mathrm{dm}$. long and $15 \mathrm{~cm}$. wide, pinnate-pinnatifid to nearly bipinnate; ultimate segments mostly toothed, often subspinulose, glabrous, not ciliate, sometimes capitate-glandular, sparingly or densely scaly; veins free, simple or mostly forked, ending short of the margin in elongate hydathodes; sori dorsal on the veins.

In marshes, bogs, swamps, thickets and meadows, and on springy wooded slopes, at low elevations, if extant in our region, only in the n.e. corner of the Tex. Timber Belt (Bowie Co., "margin of sandy bog near Texarkana," October 27, 1925 , E. J. Palmer 29404 , p. p.); from Nfld. to Ida., s. to e. Va., N.C., s.e. Ark., n.-cen. La. and n.e. Tex.

\section{Dryopteris ludoviciana (Kunze) Small. Fig. 21.}

Rhizomes horizontal, with cinnamon-colored scales; fronds arising in a short row behind a cluster of apical buds; blades oblong, 5-10 dm. long, 1.5-3 dm. wide, pinnate-pinnatifid to almost bipinnate; pinnae lanceolate, about 4 times as long as wide, the basal pinnae triangular and one half to less as long as longest pinnae, their ultimate segments more or less dimorphic and serrate; fertile pinnae with more widely spaced segments that are constricted to about one half the width of the sterile segments; sori inframedial; indusia nonglandular.

In swamps, in seepage at base of bluffs, low wet woods and on stream banks, in s.e. Tex (Hardin and Tyler Cos.); from e. N.C. s. to Fla. and w. to s.e. Tex.

\section{Fam. 11. Parkeriaceae Hook. Floating Fern Family}

Aquatic or semiaquatic plants with roots on the stipes; stems creeping, sparsely scaly, reduced; fronds alternate, successive, viviparous, fleshy-herbaceous, dimorphic, reticulate-veined, floating or emergent; sporophylls erect, taller and more finely divided than the sterile fronds, the linear ultimate segments with the margins evenly and narrowly revolute; sporangia solitary.

Only one genus.

\section{Ceratopteris BrongN.}

Characteristics of the family. Three species, mostly in the tropics and subtropics of both hemispheres; edible aquatic plants.

\section{Ceratopteris thalictroides (L.) Brongn. Fig. 22.}

Fronds erect, strict, to $75 \mathrm{~cm}$. long, usually much smaller; stipes 4-27 cm. long; lamina of sterile frond narrowly deltoid to oblong, to $28 \mathrm{~cm}$. long and $13 \mathrm{~cm}$. wide, 1- or 2-pinnate or -pinnatifid with the pinnae ovate-lanceolate; segments linear-lanceolate to oblong, acute, to $25 \mathrm{~mm}$. long and $5 \mathrm{~mm}$. wide; sporophylls taller than the sterile fronds, the oblong lamina 2- to 5-pinnately divided with the pinnae and smaller divisions distant; ultimate segments flagelliform, 1-5 cm. long, the margins narrowly revolute to cover 1 or 2 rows of areolae and sporangia. 


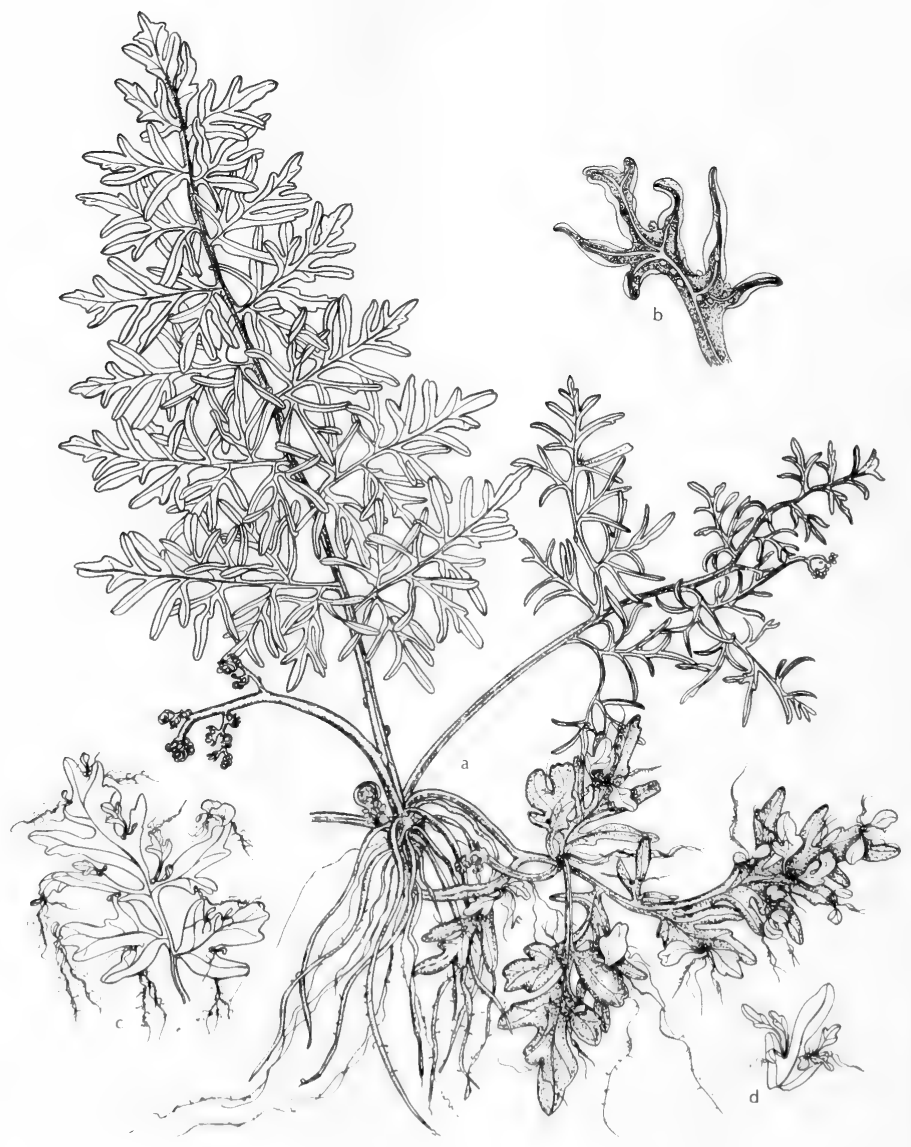

Fig. 22: Ceratopteris thalictroides: a, habit, X $1 / 3 ; \mathrm{b}$, enlargement of part of fertile frond; c, enlargement of viviparous pinna; $d$, enlargement of viviparous pinnule. (V.F.). 
Well established in spring-fed back-waters of the San Marcos River in Hays Co., Tex. where it was originally introd. (probably about 1960); nat. apparently to both hemispheres; also in s. Fla.

It is quite possible that the other two species in this genus, $C$. pteridoides (Hook.) Hieron. and $C$. deltoidea Benedict, may be introduced in Texas rivers. In contrast to $C$. thalictroides, they both have broadly deltoid fronds. The sterile fronds of $C$. pteridoides are usually simple with broad basal lobes and short, often swollen, stipes that are widest at base of blade and tapered downward, while the sterile fronds of $C$. deltoidea are pinnately divided, with long, slender stipes.

\section{Division II. Spermatophyta}

\section{Seed-Bearing or Flowering Plants}

Plants producing seeds that contain the young plants in a dormant condition until germination. Sporophylls arranged in groups (flowers) of definite or indefinite numbers, heterosporous, those bearing microsporangia (anther sacs) termed stamens, those producing macrosporangia (ovules) carpels. The gametophytes very much reduced, the female being confined within the macrosporangia where its egg-cell is fertilized by the spermatozoid of the male gametophyte (pollen tube), the sporophyte thus beginning its development while still attached to the sporophyte of the preceding generation. Eventually detached in an embryonic stage, together with the enclosing tissues, as a seed.

The seed-bearing plants form the most numerous plant group in existence, more than 200,000 species being known. The seed-habit, now restricted to the Spermatophyta, is also known to have occurred in ancient fernlike plants. This category is now considered essentially one of convenience rather than distinction because of the apparent diverse ancestry of its component members.

\section{Class 1. Gymnospermae}

Plants monoecious or dioecious, more or less resinous trees or shrubs; ovules and seeds not enclosed in an ovary, typically borne on scales that are arranged in a cone or strobilus, or sometimes terminal on naked or bracteate stalks, microsporangia mostly embedded in microphylls that are arranged in a cone or strobilus; male and female cones distinct, dissimilar.

The Gymnosperms comprise an ancient remnant of about 700 species of trees and shrubs that are considered to have been most abundant in the Mesozoic. The group contains such relicts as the Cycads, the Ginkgo tree, Metasequoia and Araucarias.

\section{Fam. 12. Taxodiaceae WARMING}

\section{TAXODIUM FAMILY}

Deciduous or essentially evergreen trees with light-brown furrowed and scaly bark and upright or spreading branches; branchlets of two kinds, those near the 


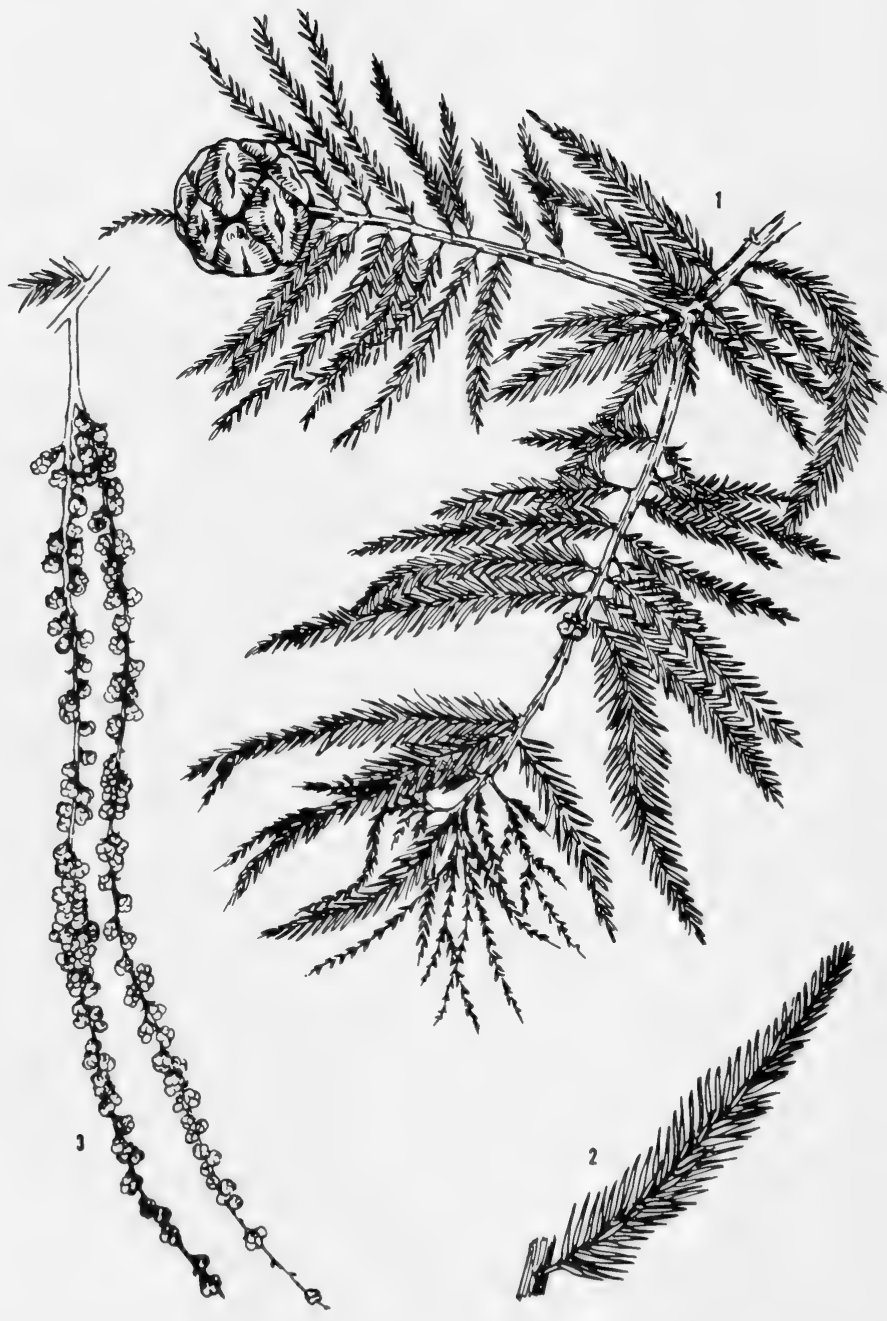

Fig. 23: 1 and 2, Taxodium distichum: 1, leafy branchlet with mature cones, X 3/4; 2, twig, X 1. 3, Taxodium mucronatum: 3, spikes of staminate cones, X $3 / 4$. 
apex of the shoot persistent and with axillary buds, those on the lower part of the shoot without axillary buds and deciduous; winter-buds globose, scaly; leaves alternate, subulate or flat and linear with stomatic bands below, those of the deciduous branchlets usually spreading in two ranks, those of the persistent branchlets spreading radially; staminate flowers ovoid, consisting of 6 to 8 stamens and forming terminal drooping panicles; pistillate flowers scattered near the ends of the branches of the preceding year, subglobose, consisting of 2-ovuled scales; fruit a short-stalked globose or ovoid cone that ripens the first year, consisting of many thick coriaceous peltate scales that are dilated from a slender sirre into an irregularly 4 -sided often mucronate disk; each fertile scale with 2 unequally 3angled seeds with 3 thick wings.

About 16 species in 10 genera in both hemispheres.

\section{Taxodium Rich. Bald Cypress}

Trees with light-green deciduous leaves and slender leafy branchlets of the season that are deciduous in autumn, monoecious, often with erect columnar "knees" produced from the roots in areas of frequent flooding; flowers unisexual, the two kinds on the same branches; staminate flowers in panicles of short or slender spikes, with few stamens; filaments scalelike, peltate, bearing 2 to 5 anther cells; pistillate aments ovoid, in small clusters, scaly, with a pair of ovules at the base of each scale; cone closed, globular, composed of thick and angular somewhat peltate scales that bear two 3 -angled seeds at their bases.

Three species in southern United States and Mexico. Important timber trees that are commonly grown for their ornamental qualities.

1. Distribution in Oklahoma and Texas north of the Rio Grande Valley; deciduous; branches of staminate flowers short and crowded, the flowers commonly in short compact secondary branches......1. T. distichum.

1. Distribution in Texas confined to the Rio Grande Valley; essentially evergreen; branches of staminate flowers long and slender, open, composed of single flowers or tight clusters of several flowers

2. T. mucronatum.

1. Taxodium distichum (L.) Rich. Bald CyPress, southern CyPress. Fig. 23.

Tree occasionally to $50 \mathrm{~m}$. tall, with a tapering trunk strongly buttressed at the swollen base, pyramidal when young, in old age usually spreading to form a broad rounded head; bark reddish-brown or gray, with long fibrous or scaly ridges; young branchlets green, becoming brown the first winter; the 2-ranked feathery leaves linear to linear-lanceolate, flat, apiculate, $1-1.5 \mathrm{~cm}$. long, softbright-green to yellowish-green or whitish below, turning dull-orange-brown before falling; panicle of staminate flowers 10-12 cm. long; cone globose or obovoid, about $25 \mathrm{~mm}$. across; disk of hard scales, rugose, usually without a mucro; seeds heavy, angular, about $1 \mathrm{~cm}$. long.

In swamps and along rivers and streams in Okla. (McCurtain Co.) and in e. Tex., w. from Brazoria Co. to Real and Uvalde cos. on the Edwards Plateau in cen. Tex.; from Del. to Fla., w. to Ill., Mo., Okla. and Tex.

Especially in wet and frequently inundated areas the roots produce woody cylindrical projections to $2 \mathrm{~m}$. tall and $3 \mathrm{dm}$. in diameter that are called "cypressknees." An important timber tree that is sometimes grown for its ornamental value. Individuals of this species exhibit some remarkable genetic differences. For example, near Saratoga (Hardin Co., Tex.) two trees growing side by side have the appearance of two entirely different species. One, with open crown, has its branches ascending, while the other, with a dense closed crown, has spreading and descending branches. 
2. Taxodium mucronatum Ten. Montezuma bald cypress, sabino, ahuehuete, CIPRÉs. Fig. 23.

Large tree with straight trunk enlarged near the base, to $30 \mathrm{~m}$. high; bark brownish-red, relatively smooth to shallowly furrowed, fibrous, more or less shredded; leaves linear, 6-12 mm. long, spreading in nearly 2-ranked sprays, these and some young branchlets falling with appearance of new growth; staminate cones small, ovoid, $1.5-2.5 \mathrm{~mm}$. long, in slender spikes 5-15 cm. long; ovulate cones subglobose, $15-25 \mathrm{~mm}$. in diameter; seeds dark-reddish-brown, 4-8 mm. long, irregularly angular because of crowding.

Along the Rio Grande and occasionally along resacas in Cameron and Hidalgo cos. in the Rio Grande Valley of Tex.; from s. Tex., s. on the Mex. tableland and along the coast of the Gulf of Mex.

This species is the famous large tree of Santa María del Tule, Oaxaca, Mexico, which, according to the best authority, has a height of about 39 meters and a trunk circumference of 52 meters, with the spread of its branches about 42 meters.

\section{Class 2. Angiospermae}

Plants diverse in habit, structure, form, size, habitat and sexualization; ovules and seeds borne enclosed in carpels that are at the center of flowers and which are interpreted as fertile fronds with megasporangia on the upper surfaces, these fronds are loosely folded along a median zone in such a way that the margins meet to form a more or less firmly sealed ventral (adaxial) suture; carpels either free (constituting a simple pistil) or often several united into a compound pistil; ovule-bearing portion of the pistil (the ovary) maturing into the fruit; gametophytic stage of the plant of very short duration (a matter of only a few hours) as compared to the gymnospermous counterparts, and the male gamete reaching the female gamete (in the ovule) by means of a tube that penetrates the tissues of the carpel; fertilization consisting of a double process: not only does the sperm-nucleus fertilize the egg-nucleus to form a diploid zygote which develops into the embryonic sporophyte in the seed, but another simultaneous fertilization in the same female gametophyte results in a triploid or higher polyploid nucleus which in many members of the class produces a nutritive tissue called endosperm closely associated with the embryonic sporophyte.

A stupendous array of about 200,000 species including all of the important sources of food and fiber, and including all the plants which the man in the street calls flowers.

Fig. 24: Typha latifolia: a, pistillate spike, $\mathrm{X}$ \%; $\mathrm{b}$, single compound pedicel of pistillate spike, X 20 ; c, upper part of plant, showing distichously arranged leaves and young contiguous spike with staminate flowers (above) and pistillate flowers (below), X $1 / \%$; d, somewhat older spike, X $2 \%$; e, variation in spike size X $2 \%$; $\mathbf{f}$, 4-celled pollen grains; g, group of compound pedicels of pistillate spike, X 4 ; h, young pistillate flowers, the pedicel not yet elongated, and fascicled hairlike bracts, $X 12$; $\mathrm{i}$ and $\mathrm{j}$, stamens on branched filaments, X $6 ; \mathrm{k}$, staminate bracts, commonly white or brown-tipped, X $6 ; 1$, oblanceolate fleshy stigma, X $12 ; \mathrm{m}$, sterile pistillate flower with ellipsoid aborted ovary tipped by rudimentary style, the surrounding hairs, like those of fertile flower, originating at base, $X 4 ; n$. sterile ovary, light-brown, $X$ 12; 0 , pistillate flower with mature functional ovary, X 4. (From Mason, Fig. 8). 


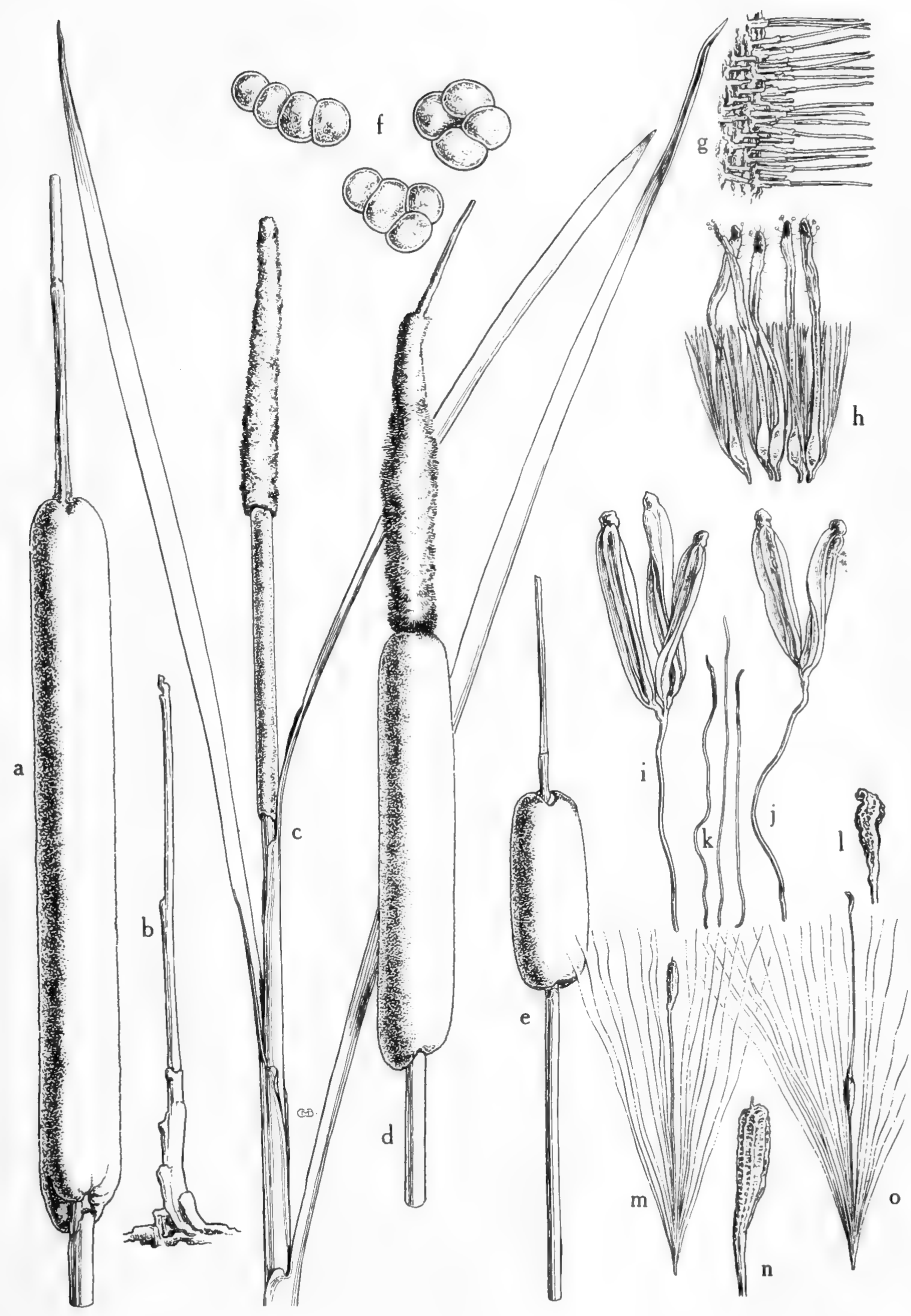




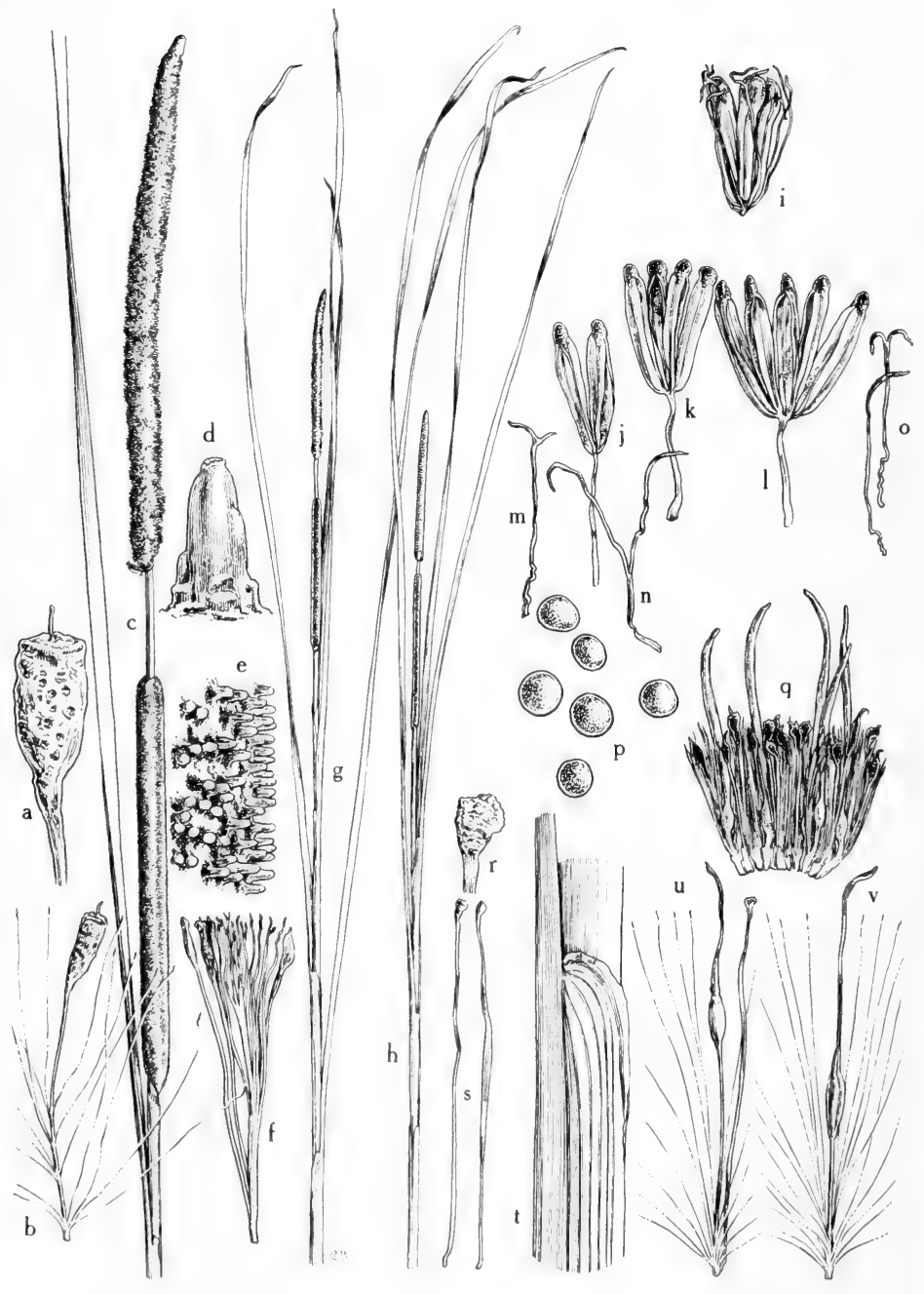




\section{Subclass 1. Monocotyledoneae}

Cotyledons usually solitary; embryonic radicle usually developing only to a very limited extent, most of the roots being adventitious on the lower part of the stem, resulting in a so-called fibrous root system; vascular strands of the stem usually not in any cylindrical pattern, the stem-transection revealing a number of scattered strands; vascular strands (nerves, veins) of the leaves usually not forming a network but parallel for most of their length; sepals, petals, stamens and carpels usually in multiples of three, but many exceptions.

Plants with long, narrow leaves such as grasses, sedges and lilies are characteristic of this subclass; but such bizarre plants as palms, yuccas and century plants also belong here. About 50,000 species, roughly a fourth of all angiosperms, fall into this group.

\section{Fam. 13. Typhaceae Juss.}

\section{Cat-Tail Family}

Aquatic or paludal monoecious perennial herbs with a creeping rhizome and distichously arranged erect leaves; leaves sessile, linear, nerved, glabrous, sheathing the base of the simple jointless stems; flowers unisexual, in a long dense cylindrical spike terminating the stem, without proper floral envelopes; staminate flowers forming the upper portion of the spike, consisting of stamens inserted directly on the axis and intermixed with long hairs or slender bracts; pistillate flowers forming the lower portion of the spike, consisting of stipitate 1-celled fertile or abortive ovaries with their stipes provided with ascending or spreading slenderly clavellate bristles that form the copious down of the fruit; ovary 1-celled and 1-ovuled, with usually persistent linear style and elongated 1-sided linear or linear-lanceolate stigma; fruit a long-stalked minute nutlet; seed suspended, anatropous.

A solitary genus.

\section{Typha L. CAT-TAIL}

Characters of the family. About 15 species of worldwide distribution.

The stalks, thick rootstocks and roots are important foods for muskrats and beaver. The rootstocks and, in some instances, the minute seeds are known to be eaten by geese and teal. The thick shelter and nesting cover afforded and the insects supported by these plants attract marsh birds, wildfowl and song birds. The plants also provide shelter for young fish and a spawning ground for sunfish. On the whole, however, these plants are considered as undesirable because they often displace more desirable species and, uncontrolled, they can rapidly cover

Fig. 25: Typha angustifolia: a, swollen aborted ovary with rudimentary style, $\mathrm{X} 20$; b, sterile long-stipitate flower with terminal aborted ovary, the hairs on stipe in whorls, terminating in club-shaped or ligulate tips, $\mathrm{X} 8$; $\mathrm{c}$, young spike, showing area of separation between staminate spikes (above) and pistillate spikes (below), $\mathrm{X} 2 / 5 ; \mathrm{d}$, single compound pedicel of pistillate spike, $\mathrm{X} 40 ; \mathrm{e}$, group of compound pedicels, appearing smooth, X $8 ; \mathrm{f}$, cluster of spatulate truncate bracts, with transitional forms resembling abortive ovaries, occurring frequently among flowers, $\mathrm{X}$ 8; $\mathrm{g}$ and $\mathrm{h}$, upper part of plant, showing distichous leaf arrangement and young flowering spikes, $\mathrm{X} 1 / 8$; i, cluster of young anthers surrounded by bracts, filament not yet elongated, $X$ 6; $\mathrm{j}-1$, mature stamens, 2 to 6 anthers in a cluster sessile on a single filament, X 6; m-o, staminate bracts-linear, simple, and forked types, X 6; p, 1-celled pollen grains; q, group of young fertile and sterile pistillate flowers, the pedicels not yet elongate, $X 12 ; \mathrm{r}$, swollen tip of pistillate bract, $\mathrm{X} 40 ; \mathrm{s}$, pistillate bracts, X $8 ; \mathrm{t}$, auricle of sheath, $\mathrm{X} 4 / 5 ; \mathrm{u}$ and $\mathrm{v}$, mature pistillate flowers with functional ovaries, long styles and linear stigmas, the pedicels of varying length and surrounded by basal hairs, X 8. (From Mason, Fig. 9). 


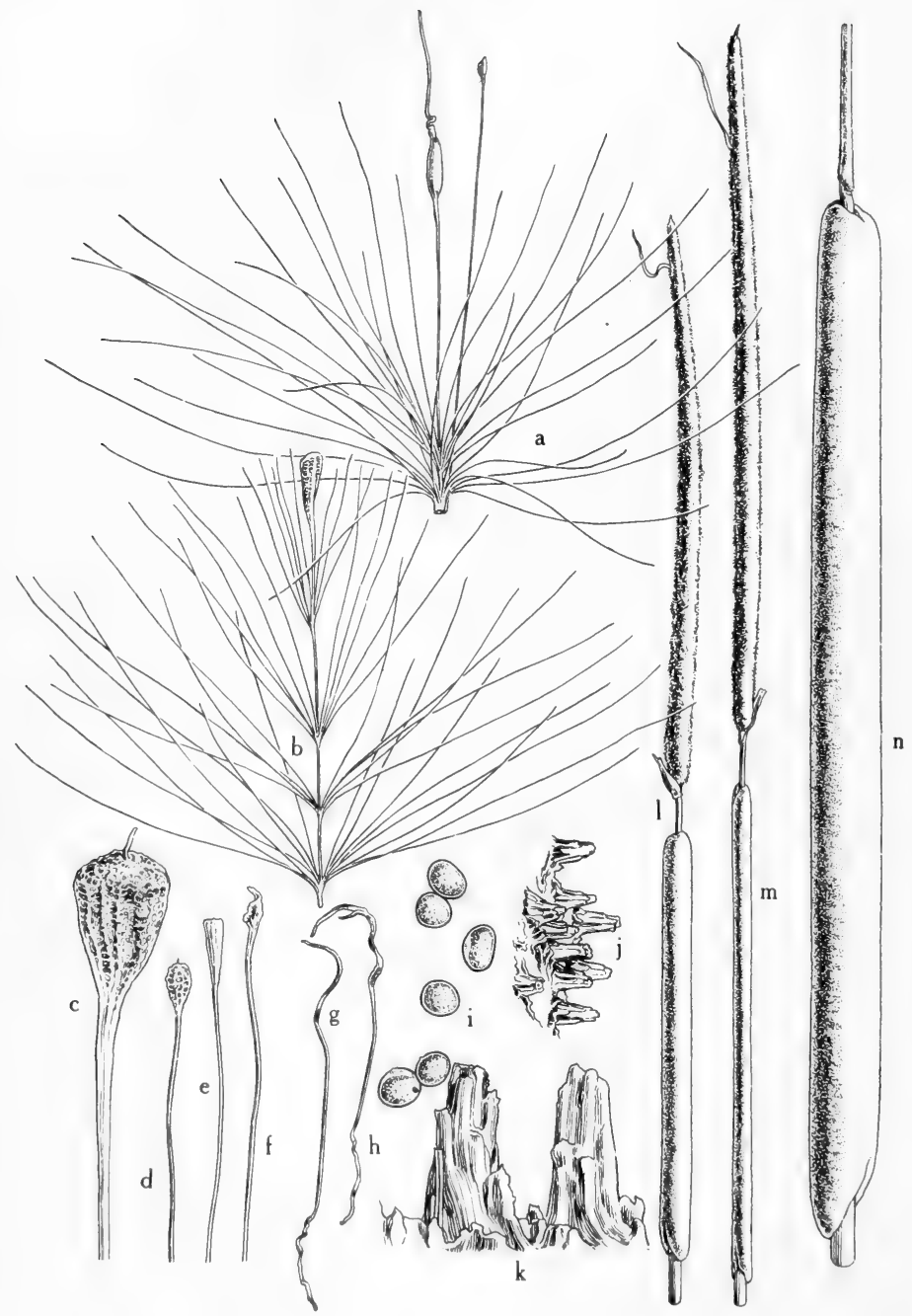


over and desiccate a water area, especially if the area is small and shallow. It has been found that mowing cat-tails after their heads are formed but still immature, followed by a second mowing a few weeks later, will control these plants to a considerable degree.

1. Staminate and pistillate portions of spike usually contiguous; stigmas ligulate to lanceolate; sterile ovary ellipsoid, tipped at the rounded apex by a rudimentary style; leaves flat on back...................... 1 . T. latifolia.

1. Staminate and pistillate portions of spike usually separated by an interval; stigmas linear to filiform; sterile ovary not ellipsoid; leaves commonly convex on back (2)

2(1). Leaves 5-8 mm. wide, dark-green; sterile ovary cuneate, with a rudimentary style on the truncate-flattened apex...............2. T. angustifolia.

2. Leaves $7-15 \mathrm{~mm}$. wide, light-yellowish-green; sterile ovary obovoid, the rounded apex tipped by a short rudimentary style.

3. T. domingensis.

\section{Typha latifolia L. Common cat-tail, tule espadilla. Fig. 24.}

Plant coarse and stout, to about $3 \mathrm{~m}$. tall; pith of the stem base white; leaves essentially flat, sheathing, pale- or grayish-green, 6-23 mm. wide, often exceeding the stem; sheaths cylindrical but open to base, the scarious upper margin tapering to blade, rarely truncate or slightly auricled; the staminate and dark-brown pistillate parts of the spike usually contiguous, the staminate portion to $12 \mathrm{~cm}$. long, the pistillate portion to $2 \mathrm{dm}$. long, when in fruit $15-35 \mathrm{~mm}$. thick, its surface (when magnified) appearing minutely pebbled with crowded persistent stigmas and scarcely bristly; pistillate flowers without bractlets among the bristles; stigma ovate-lanceolate, fleshy, persistent; pollen grains in fours; denuded axis of old spike retaining slender pedicels that are 1-2 $\mathrm{mm}$. long.

In marshes or shallow water and along streams throughout most of our area, Mar.-May; from Nfld. to Alas., through most of the U. S. into Mex.

\section{Typha angustifolia L. NARROW-LEAVED CAT-TAIL. Fig. 25.}

Plant slender, to about $15 \mathrm{dm}$. tall, the stem pith white; leaves mostly less than 10 , somewhat convex on back, dark-green, 3-7 $\mathrm{mm}$. wide; sheaths appearing cylindrical below but actually open to base, usually conspicuously auriculate above, rarely with some sheaths tapering to the blade, the auricles scariousmargined; pistillate and staminate parts of spike usually separated by a short interval; pistillate portion of spike reddish-brown, in fruit to $15 \mathrm{~cm}$. long and $15 \mathrm{~mm}$. thick, its surface minutely bristly with persistent linear stigmas; staminate portion of spike to $2 \mathrm{dm}$. long; pollen grains simple; pistillate flowers with a linear fleshy stigma and usually with a hairlike bractlet with dilated blunt tips among the bristles; the denuded old axis covered with stout blunt compound papillate pedicels that are $0.5-0.7 \mathrm{~mm}$. long.

In coastal and inland marshes in Okla. and mainly in s. Tex.; from N.S. and s. Me. to s. Que. and Ont., s. to S. C., W. Va., Ky., Mo., Neb. and Tex.; also Calif. and Euras.

Fig. 26: Typha domingensis: a, fertile pistillate flower, showing mature ovary and the surrounding hairs originating at base of stipe, bract attached, X 8; b, sterile pistillate flower terminating in a swollen aborted ovary, hairs surrounding stipe in whorls, X 8; c, aborted obovoid ovary tipped by rudimentary style, x 20 ; d-f, typical bracts, showing variations in the swollen tips, $\mathrm{X} 12 ; \mathrm{g}$ and $\mathrm{h}$, bracts of staminate flowers, slender, simple or laciniate, with dark-brown shiny tips, $X 12 ; i, 1$-celled pollen grains, grains occasionally in pairs; $j$ and $k$, compound pedicels of pistillate spike, $j, X$, $\mathrm{k}, \mathrm{X} 40 ; 1$ and $\mathrm{m}$, spike, showing area of separation between the staminate part (above) and the pistillate part (below), $X 1 / 4 ; n$, pistillate spike, $X 2 / 5$. (From Mason, Fig. 7). 


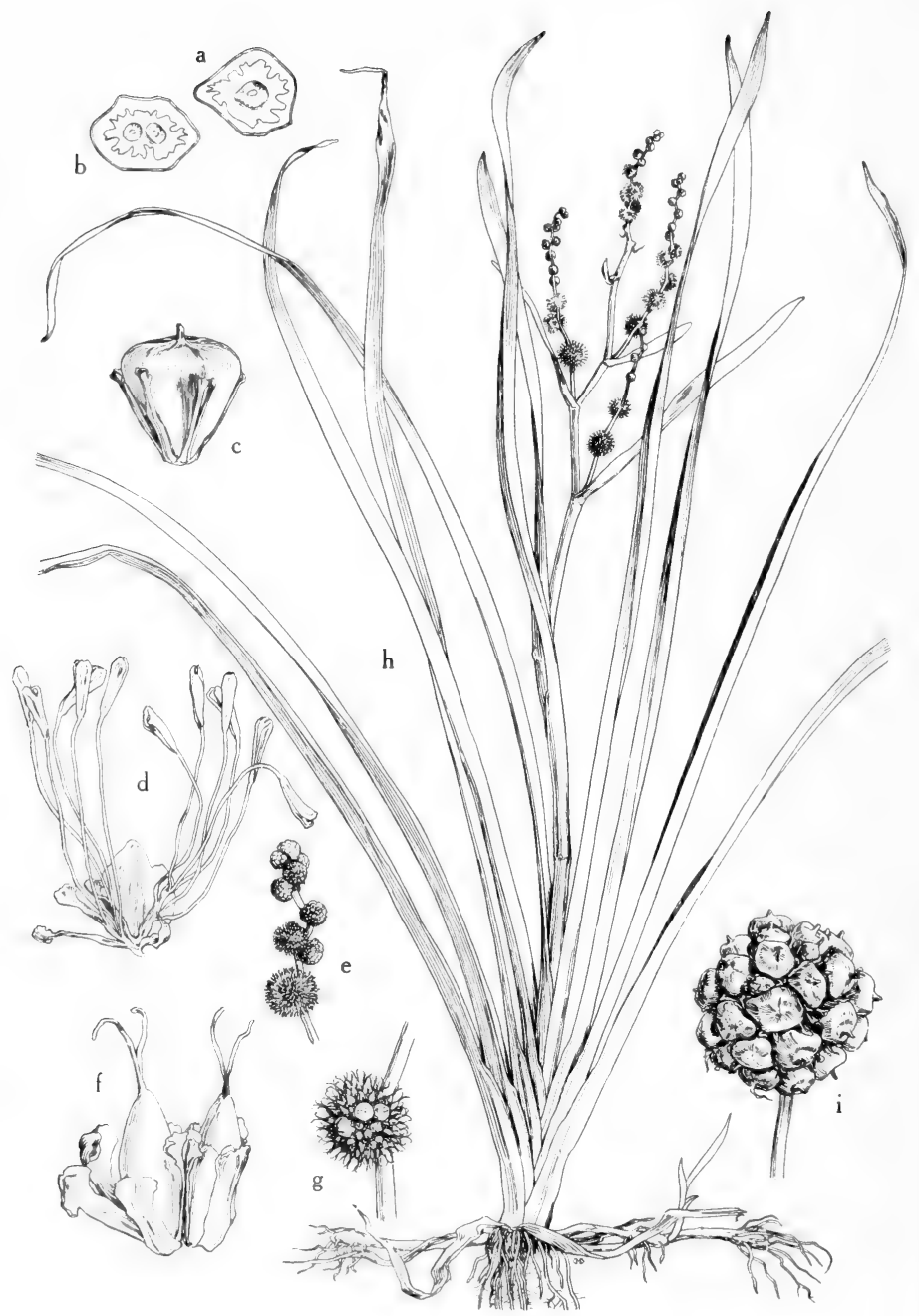

Fig. 27: Sparganium eurycarpum: a and b, 1-seeded and 2-seeded fruits (cross sections), X $11 \frac{1}{2} ; \mathrm{c}$, mature fruit, $\mathrm{X} 11 \frac{1}{2} ; \mathrm{d}$, paired staminate flowers, usually with 1 broad perianth scale and several long-clawed scales expanding into a spatulate apex, the anthers elliptic-clavate, X 6; e, staminate inflorescence showing globose heads, $\mathrm{X} \%$; $\mathrm{f}$, young sessile pistillate flowers, showing the perianth scales with spatulate apex, the scales broader than those of the staminate flowers, X 4; g, young fruiting bur, showing the long 2 -lobed style branches, $X_{2 / 3}^{2 /} h$, habit of plant, $X_{1 / 8 ;} i$, mature fruiting head, the styles broken off, $\mathrm{X}^{4 / 5}$. (From Mason, Fig. 10). 


\section{Typha domingensis Pers. TulE. Fig. 26.}

Plant slender, to about $3 \mathrm{~m}$. tall, the stem pith white; leaves 6 to 10 , usually flat, yellowish-green, firm or coriaceous, 7-15 mm. wide, usually shorter than the inflorescence; sheaths tapering at throat to the blade, scarious-margined above; staminate portion of spike 2-4 dm. long, more or less separated (sometimes by as much as $6 \mathrm{~cm}$.) from the whitish-brown pistillate portion; surface of spike similar to that of $T$. angustifolia; stigmas linear, interspersed with many apiculatebladed bractlets, soon deciduous; compound pedicels $0.5-0.8 \mathrm{~mm}$. long. $T$. truxillensis H.B.K.

In brackish or fresh marshes and pools throughout most of our area, Apr.-May; from Fla. to Tex. and s. Calif., n. along the coast to Del. and e. Md. and inland to Kan., Ut., Nev. and n. Calif.; also trop. Am.

\section{Fam. 14. Sparganiaceae RUDOLPHI}

\section{BUR-REED FAMILY}

Perennial marsh or aquatic monoecious plants with horizontal rootstocks and alternate sessile 2-ranked linear leaves on an erect simple or branched stem; flowers in distant somewhat regularly disposed globular sessile or pedunculate heads on the upper part of the stem or its branches; upper heads bearing sessile staminate naked flowers and minute scales irregularly interposed; lower heads composed of numerous sessile or shortly pedicelled pistillate flowers with a calyxlike perianth of 3 to 6 linear to spatulate or obovate-flabellate scales; bracts caducous or the lower ones persisting and leaflike; ovary 1- to 2-celled; achenes suborbicular to obovoid to fusiform, 1- or 2-seeded.

A monotypic family.

\section{Sparganium L. BUR-REED}

Characters of the family. Pistillate heads becoming burlike from the divergent beaks but the achenes at maturity falling separately in summer and autumn.

About 20 species in the temperate and cold regions of both hemispheres.

Waterfowl and marsh birds are known to eat the achenes, and muskrats eat the basal parts or even the entire plant of all our species. They are also eaten by deer. Their primary value, however, is as cover plants that attract marsh birds and waterfowl.

1. Mature achenes sessile, typically broadly cuneiform to obpyramidal, usually more than $4 \mathrm{~mm}$. thick across top, truncate to broadly rounded at apex with the stout beak produced rather abruptly; stigmas usually 2 but (in our region) 1 not uncommon; inflorescence usually branched ........................................................... 1. . eurycarpum.

1. Mature achenes more or less stipitate, typically fusiform or rarely somewhat fusiform-obovoid, somewhat tapered at both ends, usually less than $3 \mathrm{~mm}$. thick, gradually tapered to the rather slender beak, occasionally somewhat constricted at about the middle; stigma always 1 ; inflorescence simple or branched (2)

2(1). Staminate head usually single; fruiting heads to $1.5 \mathrm{~cm}$. in diameter; beak of achene usually about $1 \mathrm{~mm}$. long, rarely to $1.5 \mathrm{~mm}$.

2. S. minimum.

2. Staminate heads usually 2 or more; fruiting heads usually $2 \mathrm{~cm}$. or more in diameter, rarely less; beak of achene $2 \mathrm{~mm}$. long or more (3)

3(2). Heads (or at least one of them) supra-axillary; distribution New Mexico and Arizona (4)

3. Heads or branches of inflorescence all axillary; distribution Oklahoma and Texas (5) 

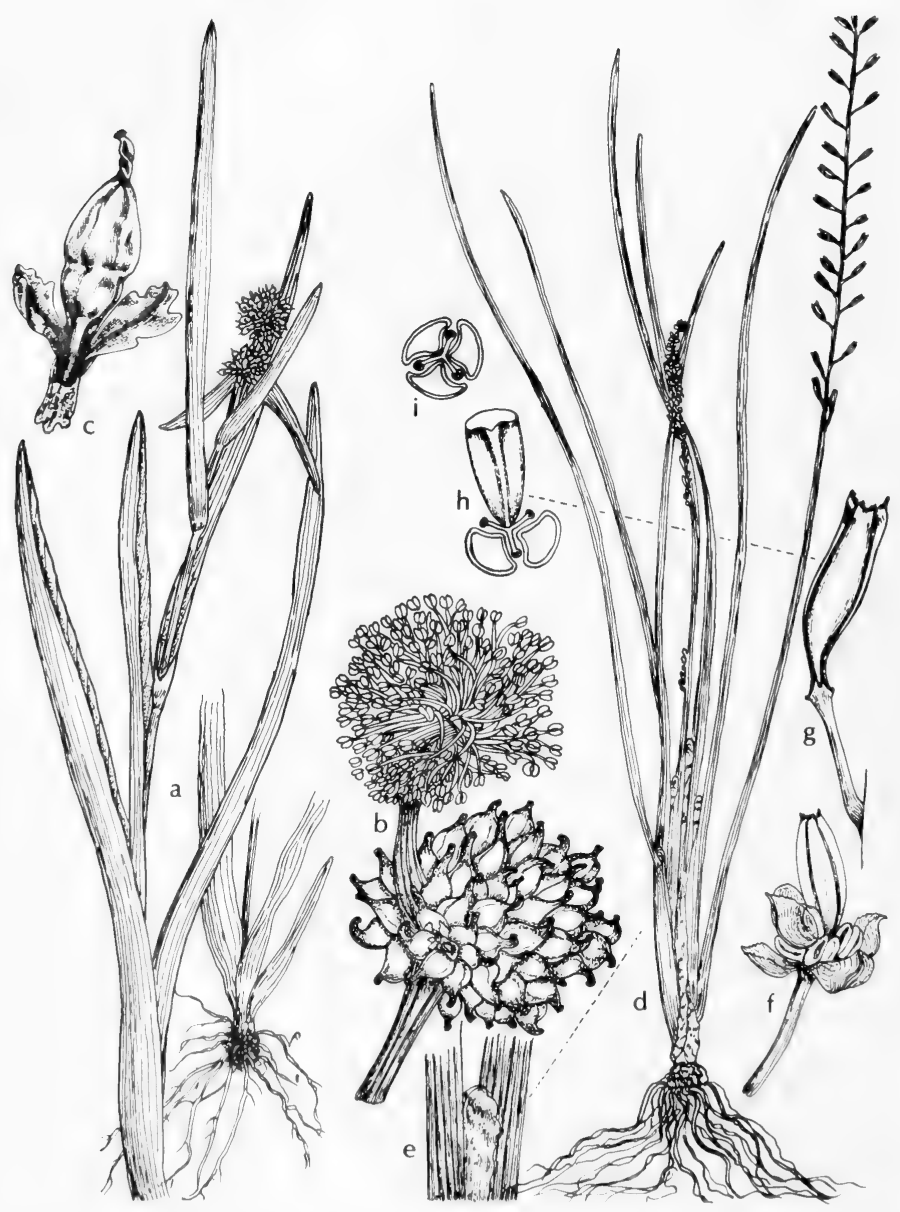

Fig. 28: a-c, Sparganium minimum: a, habit, X 1/2; b, enlargement showing separate staminate and pistillate heads, X $2 \frac{1}{2} ; \mathrm{c}$, fruit, X 5 . d-i, Triglochin palustre: $\mathrm{d}$, habit, X $1 / 2$; e, ligule, X $5 ;$ f, flower, X $5 ; \mathrm{g}$, fruit, X 5; h, fruit showing 3 carpels with 2 carpels in section, $X 5$; $i$, cross section of fruit showing 3 carpels, X 5. (V.F.). 
4(3). Stems and leaves mostly partially emersed; leaves typically more than 5 $\mathrm{mm}$. wide, sometimes scarious-margined near the base; fruiting heads usually $2 \mathrm{~cm}$. thick or more; stigma about $1.5 \mathrm{~mm}$. long; achene beak (including the stigma) well over $2 \mathrm{~mm}$. long.....

3. S. emersum.

4. Stems and leaves typically submersed or floating; leaves mostly less than 5 $\mathrm{mm}$. wide, not scarious-margined; fruiting heads usually less than $2 \mathrm{~cm}$. thick; stigma scarcely $1 \mathrm{~mm}$. long; achene beak (including stigma) about $2 \mathrm{~mm}$. long.............................4. S. angustifolium.

5(3). Leaves soft and flaccid; inflorescence simple or the branches strict and bearing 1 to 6 staminate heads; bracts mostly spreading; fruiting heads $1.5-2.5 \mathrm{~cm}$. thick; stigma $1-1.5 \mathrm{~mm}$. long; achenes usually somewhat stipitate, the body $3-5 \mathrm{~mm}$. long, not noticeably constricted; receptacle scarcely alveolate..................5. S. americanum.

5. Leaves firm and rigid; inflorescense commonly branched, the branches zig-zag and bearing 3 or more staminate heads and as many as 2 pistillate heads; bracts ascending; fruiting heads $2.5-3.5 \mathrm{~cm}$. thick; stigma 1.5-3 mm. long; achenes subsessile, the body $5.5-7 \mathrm{~mm}$. long, usually strongly constricted at middle; receptacle fimbrillatealveolate.

.6. S. androcladum.

\section{Sparganium eurycarpum Engelm. BROADFRUITED BUR-REED. Fig. 27.}

Stem stout, erect, branching, 5-18 dm. tall; leaves 5-10 dm. long, 7-17 mm. wide, flat, somewhat keeled below, as long as or slightly shorter than the branched inflorescence; pistillate heads 2 to 6 on the main stem or on branches, sessile or usually peduncled, $2-2.5 \mathrm{~cm}$. in diameter in fruit; staminate heads 8 to 12 ; anthers 1-1.5 mm. long, elliptic-clavate; perianth scales long-clawed, expanding into a spatulate apex, irregularly shallowly lobed and hyaline-margined at apex, two thirds to three fourths as long as the fruits; style branches usually 2 but often 1 in our area, filiform, about $2 \mathrm{~mm}$. long; achenes sessile, hard and thick at maturity, cuneate-obpyramidal, irregularly and obtusely 3- to 5-angled, 6-10 $\mathrm{mm}$. long and 4-8 $\mathrm{mm}$. wide at apex, the top truncate to depressed or very shallowly rounded, the stout beak $2-3 \mathrm{~mm}$. long.

Fresh-water or brackish marshes, meadows, ponds, lakes and streams in Okla. (reported from), N.M. (Lincoln and Otero cos.) and Ariz. (Apache and Navajo cos.), May-Oct.; Nfld. to B. C., s. to Va., Mo., Okla., N.M., Ariz. and Calif.

\section{Sparganium minimum (Hartm.) Fries. Fig. 28.}

Slender submersed or suberect plants, 1-8 dm. long; leaves flat, 2-8 mm. wide, without an evident keel; inflorescence simple, rarely over $6 \mathrm{~cm}$. long; fruiting heads 2 to 4 , all sessile or the lowest one short-stalked in axils of bracts, $8-15 \mathrm{~mm}$. in diameter; staminate head solitary; perianth scales elliptic to cuneate-spatulate, one half to two thirds as long as the body of the achene; achene with its ellipsoid to obovoid-fusiform somewhat centrally constricted body about $3 \mathrm{~mm}$. long and with a short stipe scarcely $1 \mathrm{~mm}$. long, the beak $1-1.5 \mathrm{~mm}$. long.

Submerged in shallow water of mt. lake in n. Ariz. (Coconino Co.), June-Sept.; Lab. to Alas., s. to N.J., Tenn., Ariz. and Calif.

\section{Sparganium emersum Rehm. Fig. 29.}

Stem rather stout but sometimes slender, 3-10 dm. tall; leaves 2-8 dm. long, 4-8 (-15) $\mathrm{mm}$. wide, slightly keeled to triangular-keeled especially toward the somewhat expanded scarious-margined base, usually well-overtopping the usually simple inflorescence; pistillate heads 2 to 5 , the lowest ones peduncled, the upper ones sessile, at least some of them supra-axillary; staminate heads 3 to 8 , congested or confluent; anthers 1-1.5 mm. long, elliptic-clavate; perianth scales oblanceolate, erose at broadened apex; stigma linear, about $1.5 \mathrm{~mm}$. long; fruiting 


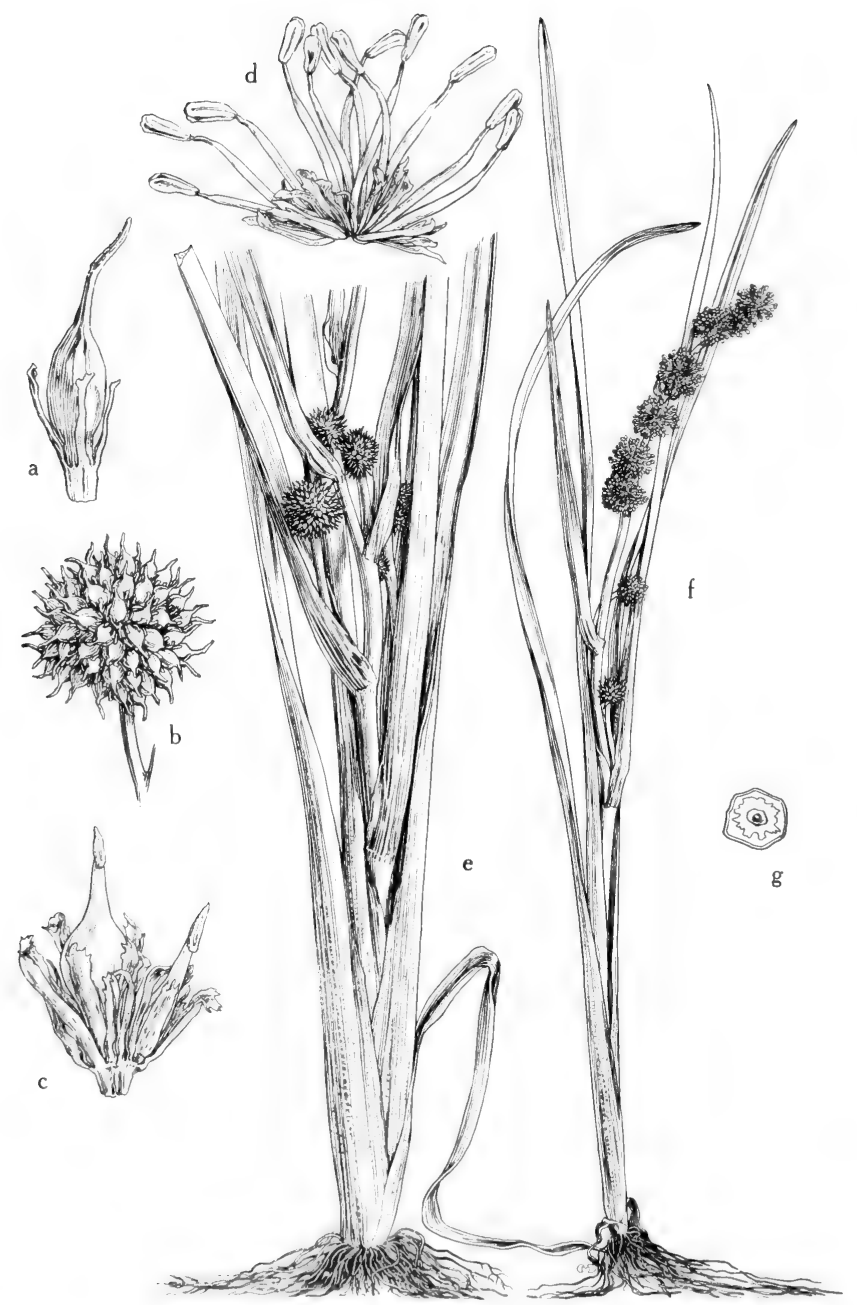

Fig. 29: Sparganium emersum var. multipedunculatum: a, mature fruit, X 4; b, mature fruiting head, $\mathrm{X} 45 \mathrm{c}$, young pistillate flowers, stipitate, X 4 ; d, group of staminate flowers with irregular perianth scales, $X$ 6; e, habit, showing the triangular-keeled leaves and bracts and the fruiting burs, $X \%$, young plant with leaves over-topping the staminate inflorescence, $X \%, g, 1$-seeded fruit (cross section), X 4. (From Mason, Fig. 12). 
heads $2-3 \mathrm{~cm}$. in diameter; achenes brown or greenish-brown, prominently stipitate, the fusiform body 4-6 $\mathrm{mm}$. long and often constricted at the middle, the beak (including the stigma) 3-5 mm. long. S. simplex of Am. auth., illegit. name.

Mucky bottoms of shallow ponds, along streams and sloughs, in N.M. (Sandoval, San Miguel and Taos cos.) and Ariz. (Coconino Co.), June-Oct.; La. to Alas., s. to Pa., N.M., Ariz. and Calif.; Euras.

The North American plant is referred to var. multipedunculatum (Morong) Reveal [S. multipendunculatum (Morong) Rydb.] with not so strongly keeled basal leaves, somewhat $\mathrm{V}$-shaped in cross section, and with mature achenes (including the stipe and beak) about $10 \mathrm{~mm}$. long.

\section{Sparganium angustifolium Michx.}

Slender usually submersed aquatic, the leaves and stems floating or below the surface, 3-10 dm. long; leaves usually 2-6 mm. wide, often very long, curved on the back; inflorescence usually simple but the lower 1 or 2 pistillate heads longstalked and borne in the axil or above the axil of a bract; pistillate heads 2 to 4; staminate heads usually 2 to 5 , somewhat confluent; perianth scales borne at base of the constricted part of the ovary or at base of stipe; stigma scarcely $1 \mathrm{~mm}$. long; fruiting heads less than $2 \mathrm{~cm}$. in diameter; achenes sessile or stipitate, often both kinds in the same head, the fusiform body $2.5-3 \mathrm{~mm}$. long, the beak (including stigma) about $2 \mathrm{~mm}$. long.

Usually in shallow or deep water in high montane lakes in n. N.M. (Rio Arriba and Colfax cos.) and n. Ariz., June-Oct, Lab. to Alas., s. to Pa., N.M., Ariz. and Calif.; Euras.

It is quite possible that this concept should be united with $S$. emersum. Their separation, based primarily on size differences of various organs, is most tenuous.

\section{Sparganium americanum Nutt. Fig. 30.}

Plants stout to slender, to $1 \mathrm{~m}$. tall; leaves soft, thin, flat, translucent, loosely ascending or occasionally floating, to $2 \mathrm{~cm}$. wide; lower bract similar to leaves, spreading-ascending, scarious-margined at base; inflorescence simple or sometimes branched, the heads or branches axillary, the primary axis with 1 to 5 pistillate heads and 5 to 9 staminate heads, the branches (when present) with 1 to 6 staminate heads and 1 to 3 (rarely 0 ) pistillate heads; anthers $0.8-1.2 \mathrm{~mm}$. long; stigma linear-oblong to lanceolate, 1-2 mm. long; fruiting heads $1.5-2.5 \mathrm{~cm}$. in diameter; achenes dull or but slightly lustrous, the body $2 \mathrm{~mm}$. thick, the beak 1.5-5 mm. long; anthers about $1 \mathrm{~mm}$. long.

In shallow water in e. Okla. (Delaware and Le Flore cos.) and e. Tex., Apr.June; from Nfld. to Ont., Wisc., Minn. and N. D., s. to Fla., Ala., Tex. and Mo.

See note under $S$. androcladum.

\section{Sparganium androcladum (Engelm.) Morong.}

Plants stout, to $12 \mathrm{dm}$. tall; leaves stiffish, strongly ascending, elongate, nearly flat but keeled below, 4-15 mm. wide; lower bracts similar to the leaves, slightly scarious-margined at base; inflorescence branched or rarely simple, the primary axis with 1 to 4 mostly sessile axillary pistillate heads and 4 to 10 staminate heads, the 1 to 3 filiform strongly arched geniculate branches with 3 to 8 staminate heads and rarely 1 pistillate head; stigma filiform, 2-4 mm. long; fruiting heads $2.5-3.5$ $\mathrm{cm}$. in diameter; achenes lustrous, the body $2.5-3 \mathrm{~mm}$. thick, the beak $4.5-6 \mathrm{~mm}$. long; anthers 1-1.5 mm. long; receptacle fimbrillate-alveolate.

In swamps and shallow water of streams in e. Okla. (Ottawa Co.) and e. Tex., Apr.-June; from Que. to Minn., s. to Va., e. Ky., Ill., Mo., Okla. and Tex.

Plants that comprise $S$. americanum and $S$. androcladum, which have the heads or branches of their inflorescence all axillary, are restricted in our area to eastern Oklahoma and eastern Texas. Voucher specimens of plants that we have examined, 

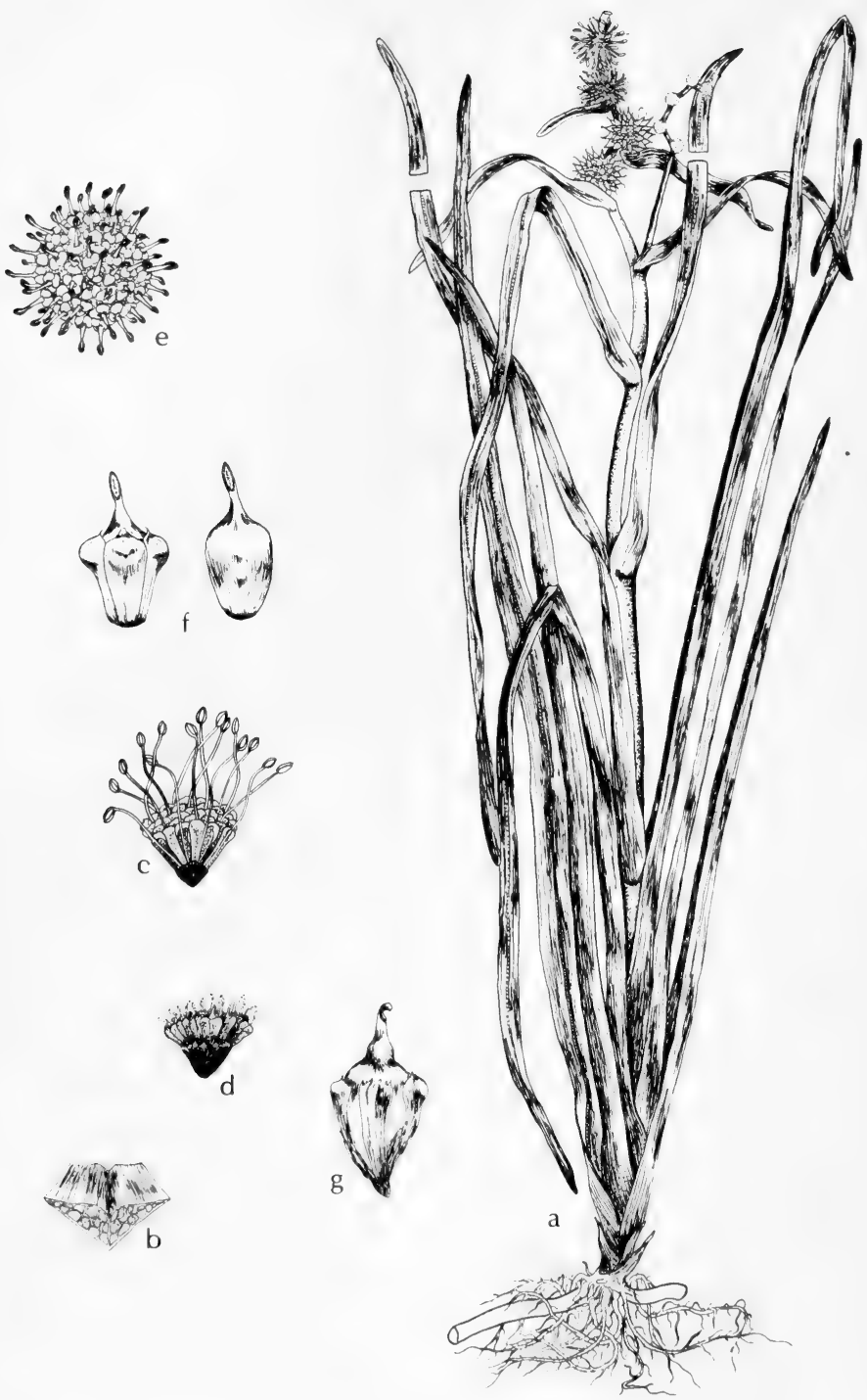

Fig. 30: Sparganium americanum: a, habit, $\mathrm{X} 1 / 4 ; \mathrm{b}$, cross section of leaf, $\mathrm{X} 1$; c, section of staminate head, X 11/2; e, pistillate head, about X 1; f, fruits, one with and one without perianth scales, $X 3 ; \mathrm{g}$, mature fruit, $X 3$. (Courtesy of $\mathbf{R}$. $\mathbf{K}$. Godfrey). 
not only from our region but from elsewhere, do not readily fall into either of these categories, although they have some characteristics attributed to one or the other of these plants. Although we would not be adverse to considering these plants as one complex entity, we have followed their traditional treatment as maintained by Fernald.

\section{Fam. 15. Potamogetonaceae Dum. Pondweed Family}

Aquatic herbs of fresh or sometimes brackish or alkaline water; leaves alternate or imperfectly opposite, those immersed thin, those above water often leathery, sheathing at the base, the sheath free or partially adnate to the petiole; flowers bisexual, small, arranged in pedunculate axillary spikes; peduncle surrounded by a sheath at the base; bracts absent; perianth comprised of 4 free rounded shortiy clawed valvate segments; stamens 4 , inserted on the claws of the segments; anthers extrorse, 2-celled, sessile; gynoecium of 4 sessile free 1-celled carpels; stigmas sessile or on short styles; ovule solitary, attached to the adaxial angle of the carpel, campylotropous; fruiting carpels sessile, free, 1-seeded, indehiscent; seeds without endosperm, the embryo with large "foot", the plumule enclosed by the cotyledon.

A family of two widespread genera, the following and Groenlandia.

\section{Potamogeton L. Pondweed}

Annual or perennial aquatic herbs propagated from seeds, winter-buds (hibernacula) or rhizomes; stems variable in length according to water depth, branched or unbranched, terete or flattened; leaves all submersed or with both submersed and floating blades; submersed leaves usually flaccid, sessile or petioled, linear or orbicular, acute to obtuse at apex, the margins entire to denticulate or serrate, the nerves 1 to 35 ; stipules fused to form a single structure with 2 midveins, arising from the axil of the stem and leaf, free or adnate to the leaf base, often sheathing the stem and sometimes with the outer margins partially fused (connate); floating leaves usually coriaceous, petioled, elliptic to ovate, cuneate to rounded or cordate at base, the nerves 3 to 51 , the margins entire, the stipules like those of submersed leaves but never adnate nor connate; peduncles about same diameter as stem, terete, sometimes clavate at tip; inflorescence a spike with 1 to 20 whorls of flowers, compact or moniliform, with 2 to 4 flowers in each whorl, mostly buoyed above the water surface; flowers bisexual, perianth of 4 free rounded short-clawed greenish segments; stamens 4 ; anthers sessile on the claws, 2-celled, extrorse; carpels 4, free, sessile; fruits dryish drupelets or achenes with spongy mesocarp and bony endocarp, one-seeded, embryo coiled, cotyledon one, endosperm absent.

A genus of 90 to 100 species found in all parts of the world, except the polar regions, but mostly in the North Temperate areas. Nearly 40 species occur in North America, all but one being indigenous; about half of these are widespread, common and often locally abundant.

Pondweeds are found primarily in shallow ponds, lakes and quiet waters of rivers and streams, and they are an important element in the ecology of such places. The achenes of all our species provide a favorite and important food for wildfowl. In addition, plant parts, especially of the more delicate species, are also eaten by wildfowl that include most waterfowl, marsh birds and shorebirds. The plants are also commonly eaten by muskrats, beaver and deer. The most important species, mainly because of its tolerance to brackish water, its abundant seed production, and the edibility of its vegetative parts, is the sago pondweed ( $P$. pectinatus). Most of the species provide food, shelter and shade for fish and minute animal life. They provide, in particular, an excellent haven for insect life that, in turn, provide food for fish. 


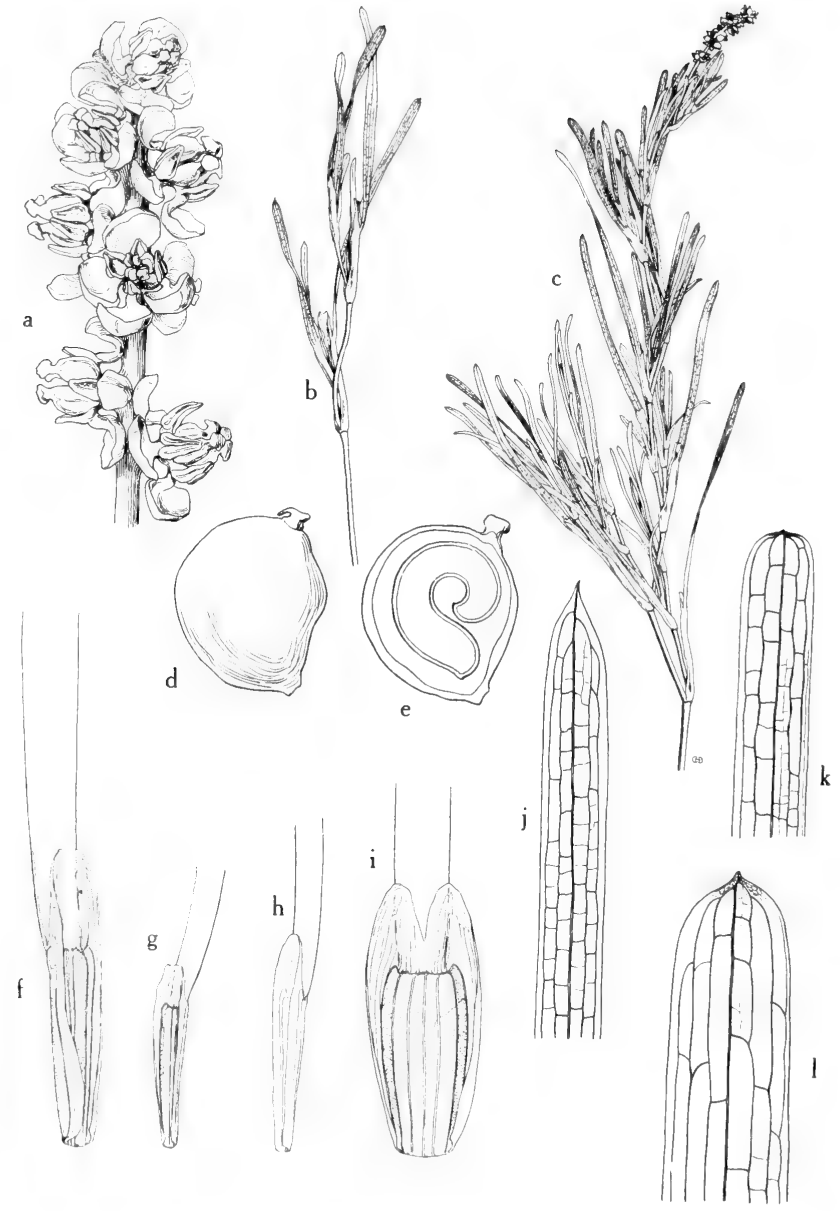

Fig. 31: Potamogeton latifolius: a, interrupted flowering spike, showing the reflexed sepaloid connectives, X 2 ; b , young branch, X $3 \% 5$; , habit, X $35 ;$; d, achene, X 6; e, achene (longitudinal section), showing tip of curved embryo directed toward base of seed, $X 6 ; \mathrm{f}-\mathrm{i}$, sheaths and ligules, showing variation in ligule apices, $\mathrm{X} 11 \frac{1}{2} ; \mathrm{j}-1$, leaf tips, showing variation in apices and venation, X 4. (From Mason, Fig. 15). 
1. Submersed leaves linear, mostly more than 10 times as long as wide (2)

1. Submersed leaves lanceolate to ovate, mostly less than 10 times as long as wide (12)

2(1). Stipules united with the base of the leaf for a distance of $7 \mathrm{~mm}$. or more; floating leaves often absent (3)

2. Stipules free from the leaf or united for a distance of less than $6 \mathrm{~mm}$. (6)

3(2). Plants with submersed leaves only; fruiting spikes slender (4)

3. Plants with long-petioled floating leaves and sessile linear submersed leaves; if floating leaves absent the fruiting spikes of submersed parts capitate and sessile or on very short peduncles.

9. P. diversifolius.

4(3). Leaves more than $1 \mathrm{~mm}$. broad, the apex rounded to broadly obtuse and apiculate, the veins 3 to 7 ......

4. Leaves all linear-filiform, less than $1 \mathrm{~mm}$. broad (5)

5(4). Stigma disc-shaped, sessile or short-stalked; leaves blunt or submucronate 2. P. filiformis.

5. Stigma not discoid, the stigmatic tip prolonged and with little evident swelling; leaves acute at the apex.

3. $P$. pectinatus.

6(2). Floating leaves absent (7)

6. Floating leaves usually present, with broad blades and long petioles (11)

7(6). Fruits with dorsal keel prominent, thin, alate, undulate or toothed (8)

7. Fruits with dorsal keel rounded or acute but never thin and alate (9)

$8(7)$. Leaves $1.4-2.7 \mathrm{~mm}$. wide, the veins 3 to 5 ; fruits $2-2.5 \mathrm{~mm}$. long. 5. P. foliosus var. foliosus.

8. Leaves $0.3-1.5 \mathrm{~mm}$. wide, the veins 1 to 3 ; fruits $1.8-2.3 \mathrm{~mm}$. long. $5 . P$ foliosus var. macelius.

9(7). Fruits tuberculate (especially at base), 2.5-2.8 $\mathrm{mm}$. long, the lateral keels prominent.........................................................7. P. clystocarpus.

9. Fruits smooth, $2-2.5 \mathrm{~mm}$. long, the lateral keels rounded or obscure (10)

$10(9)$. Stipules connate when young; peduncles $1.5-8 \mathrm{~cm}$. long; spikes $6-12 \mathrm{~mm}$. long, of 3 to 5 separated whorls...............................6. P. pusillus.

10. Stipules not connate; peduncles rarely more than $3 \mathrm{~cm}$. long; spikes $2.8 \mathrm{~mm}$. long, of 1 to 3 adjacent whorls.

8. P. Berchtoldii var. tenuissimus.

11(6). Submersed leaves linear, usually bladeless and filiform, 0.8-2 mm. wide; blade (when present) linear-lanceolate and on a very long petiole; floating leaves broad, many-veined, base of blade subcordate.

15. P. natans.

11. Submersed leaves linear to linear-obovate, often very unequal in size, usually tapering to tip and base, $3-12 \mathrm{~cm}$. long, to $15 \mathrm{~mm}$. wide.

14. P. gramineus.

12(1). Leaves mostly all submersed and essentially alike; petioles short or absent (13)

12. Leaves of two kinds, submersed and floating, the floating leaves with broad blades and long petioles (14)

13(12). Leaves broadly lanceolate-attenuate, large, serrulate only at tip.

13. Leaves oblong and crisped, serrulate throughout, rounded at tip

13. $P$. illinoensis.

4. P. crispus.

14(12). Submersed leaves ovate-lanceolate, arcuately folded or falcate in outline, sessile or on short petioles; floating leaves mostly with more than 30 nerves. 11. P. amplifolius. 


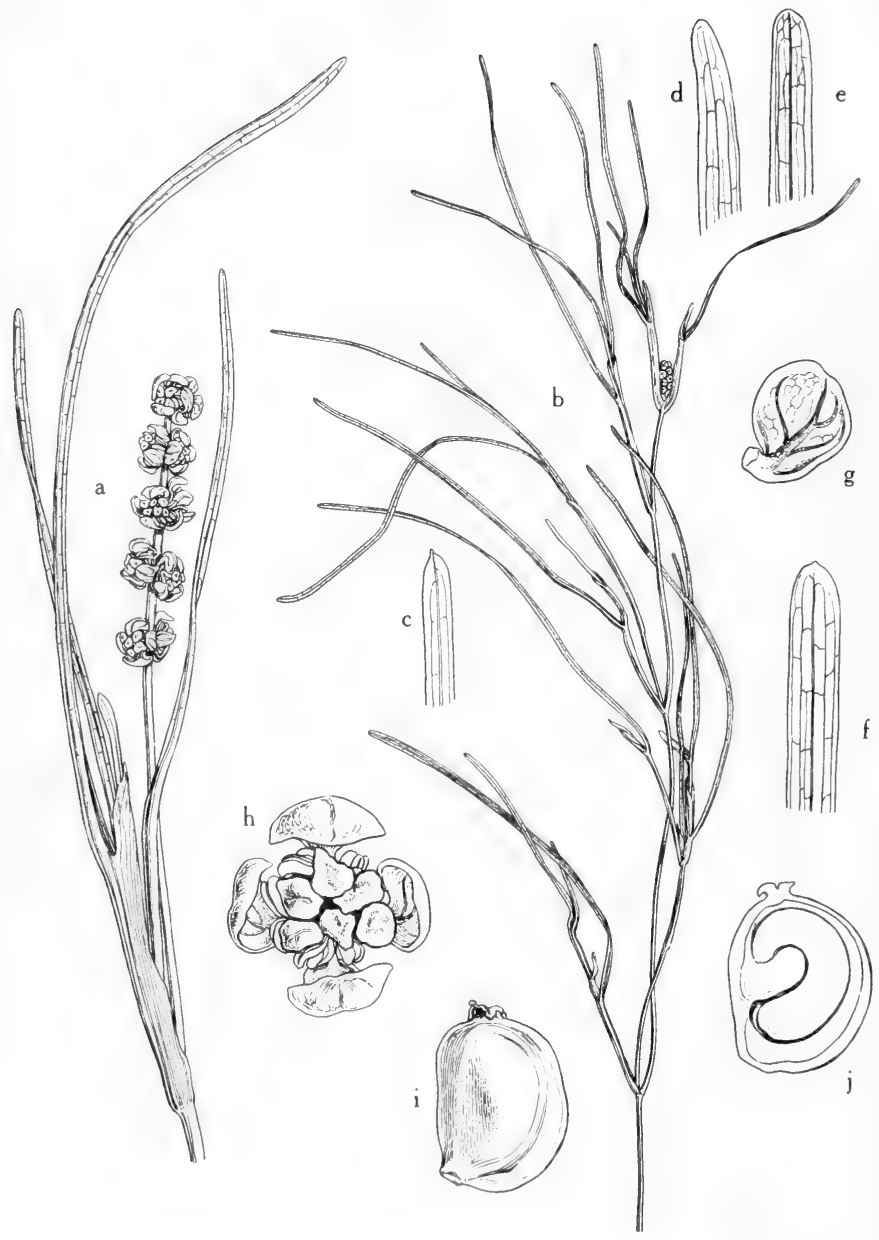

Fig. 32: Potamogeton filiformis: a, apical part of plant, showing the fleshy linear leaves with adnate stipules sheathing the young leaf blades and the 5 regularly spaced flower whorls, X 2 ; b, habit, X 4/;; c-f, leaf tips, showing variation from blunt to submucronate, X 4; g, sepaloid connective, showing pronounced veins, X $8 ; \mathrm{h}$, flower, $X 8 ; i$, achene, showing rounded back and nearly central, wartlike beak, $X 8 ; j$, achene (longitudinal section), X 8. (From Mason, Fig. 13). 


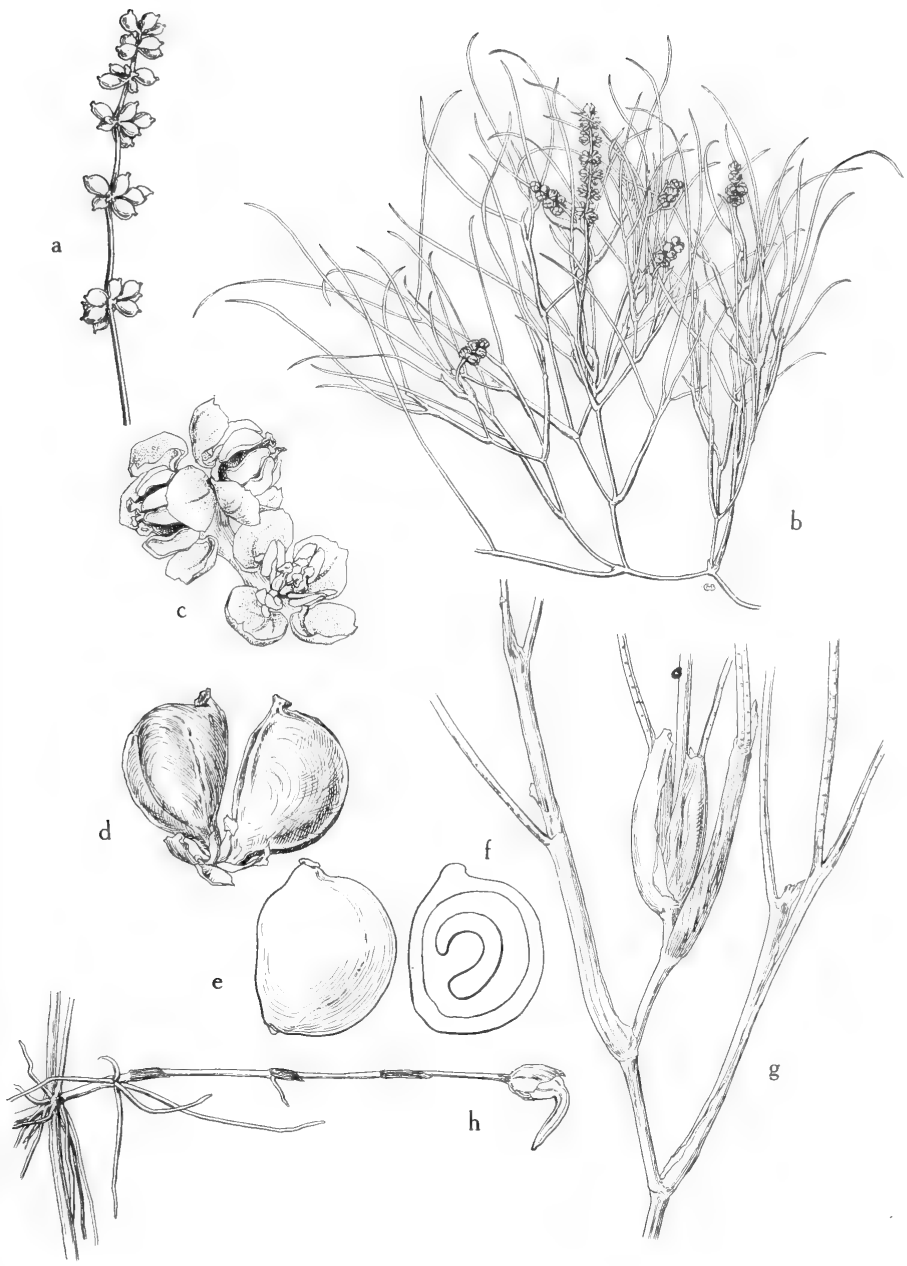

Fig. 33: Potamogeton pectinatus: a, moniliform spike with mature achenes, X 11/5; $\mathrm{b}$, habit, showing slender branching stems and linear-filiform submersed leaves, arising from rhizome, X $2 / 3$; c, upper flowers of spike, X 4 ; d and $e$, variation in achenes (usually obliquely ovoid, with a short wartlike beak), d, X 51/2, e, X 5; f, achene (longitudinal section), X $5 ; \mathrm{g}$, stipules sheathing stem or loosely investing it and somewhat inflated, the linear leaf appearing to originate at the top of the sheath, $\mathrm{X} 3 ; \mathrm{h}$, rhizome with winter corm, X 11/5. (From Mason, Fig. 14). 
14. Submersed leaves lanceolate to oblong; floating leaves mostly with fewer than 30 nerves (15)

15(14). Floating leaf blades usually cordate, rarely rounded at base, with 21 to 29 (sometimes more) veins; submersed leaves tapering rather abruptly to a sessile base or short petiole to $1.5 \mathrm{~cm}$. long; mature fruit light-brown to olive-green, 3-3.5 mm. long.......10. P. pulcher.

15. Floating leaf blades cuneate or rounded at base, with 9 to 21 veins; submersed leaves tapering gradually to a petiole $2-13 \mathrm{~cm}$. long; mature fruit usually reddish, $3.5-4 \mathrm{~mm}$. long.....

12. P. nodosus.

\section{Potamogeton latifolius (Robbins) Morong. Western POndweed. Fig. 31.}

Rhizome creeping, rooting freely at the nodes; stem whitish, simple below, repeatedly branched above; stele of the one-bundled-type or oblong-type; endodermis of U-cells; interlacunar bundles present in the outer interlacunar circle; subepidermal bundles absent; pseudohypodermis absent or partly 1 cell thick; leaves all submersed, linear, entire, green to bronze, rather opaque, to $7 \mathrm{~cm}$. long and $7 \mathrm{~mm}$. wide, the apex obtuse to rounded or shortly apiculate to acutish on the upper leaves; nerves 3 to 5 , with strong crossveins making a rectangular pattern; stipules prominent, $8-12 \mathrm{~mm}$. long, adnate to the base of the leaf to form a broad sheath, hyaline along the margin, the free portion 1-4 $\mathrm{mm}$. long; peduncles 2-25 cm. long; spikes with 4 to 6 whorls, contiguous when young but soon becoming moniliform; basal internodes 5-12 $\mathrm{mm}$. long, the upper shorter, in fruit 2-4 cm. long; flowers sessile; perianth semiorbicular, slightly wider than long, to $5.2 \mathrm{~mm}$. wide; anthers about $1.8 \mathrm{~mm}$. long; fruits obliquely obovate, the sides convex but somewhat compressed, 3-4 mm. long, 2-4 mm. wide; dorsal keel obscure, lateral keels rounded; beak facial, slightly recurved, about $1 \mathrm{~mm}$. long; exocarp olive-green to fulvous; endocarp loop solid or with a spongy area; apex of seed pointing above the basal end.

In quiet or flowing fresh or brackish water, in s.w. Tex. (Cameron, Pecos, Reeves and Val Verde cos.) and Ariz. (Mohave Co.), flowers and mature fruit from May to Sept.; rare in s.w. U.S.

\section{Potamogeton filiformis Pers. Fig. 32.}

Slender much-branched wholly submersed plant of brackish waters, with horizontal stolons bearing white tubers $1-2 \mathrm{~cm}$. long; stipules adnate to leaf and sheathing the stem, the sheaths $0.4-2.2 \mathrm{~cm}$. long, connate below, the tips free, scarious, 1-5 mm. long; leaves setaceous, to $12 \mathrm{~cm}$. long, 0.2-0.5 mm. wide, blunt; peduncles filiform, flexuous, to $1 \mathrm{dm}$. long; spike moniliform, $1.5-5 \mathrm{~cm}$. long, with 2 to 5 whorls, the upper whorls $3-12 \mathrm{~mm}$. apart, the lower ones $0.7-2.5 \mathrm{~cm}$. apart; connectives $0.5-1 \mathrm{~mm}$. long; styles almost wanting; nutlets sessile, 2-2.7 $\mathrm{mm}$. long, 1.5-2 $\mathrm{mm}$. wide, rounded on back, the beak short, wartlike, nearly central.

Ponds, slow streams and ditches in N.M. (Rio Arriba Co.) and Ariz. (Pinal Co.), Apr.-Sept.; Greenl. to Alas., s. to Pa., Mich., N.M., Ariz. and Calif.; Euras., Afr, and Austral.

\section{Potamogeton pectinatus L. Sago pondweed. Fig. 33.}

Rhizome creeping, much-branched, $1-1.5 \mathrm{~mm}$. in diameter, bearing terminal tuberous bulblets; stem terete or slightly compressed, about $1 \mathrm{~mm}$. in diameter, mostly simple near base but abundantly branched near summit; stele with the oblong pattern or one-bundled in slender branches; endodermis of U-cells; interlacunar bundles present; subepidermal bundles present or absent; pseudohypodermis 1 or 2 cells thick; leaves all submersed, filiform to narrowly linear, entire, to 15 $\mathrm{cm}$. long and $1 \mathrm{~mm}$. wide, occasionally wider on robust forms, the apex tapering to a narrowly acute point (sometimes obtuse on young seedlings); nerves 1 to 3 , 


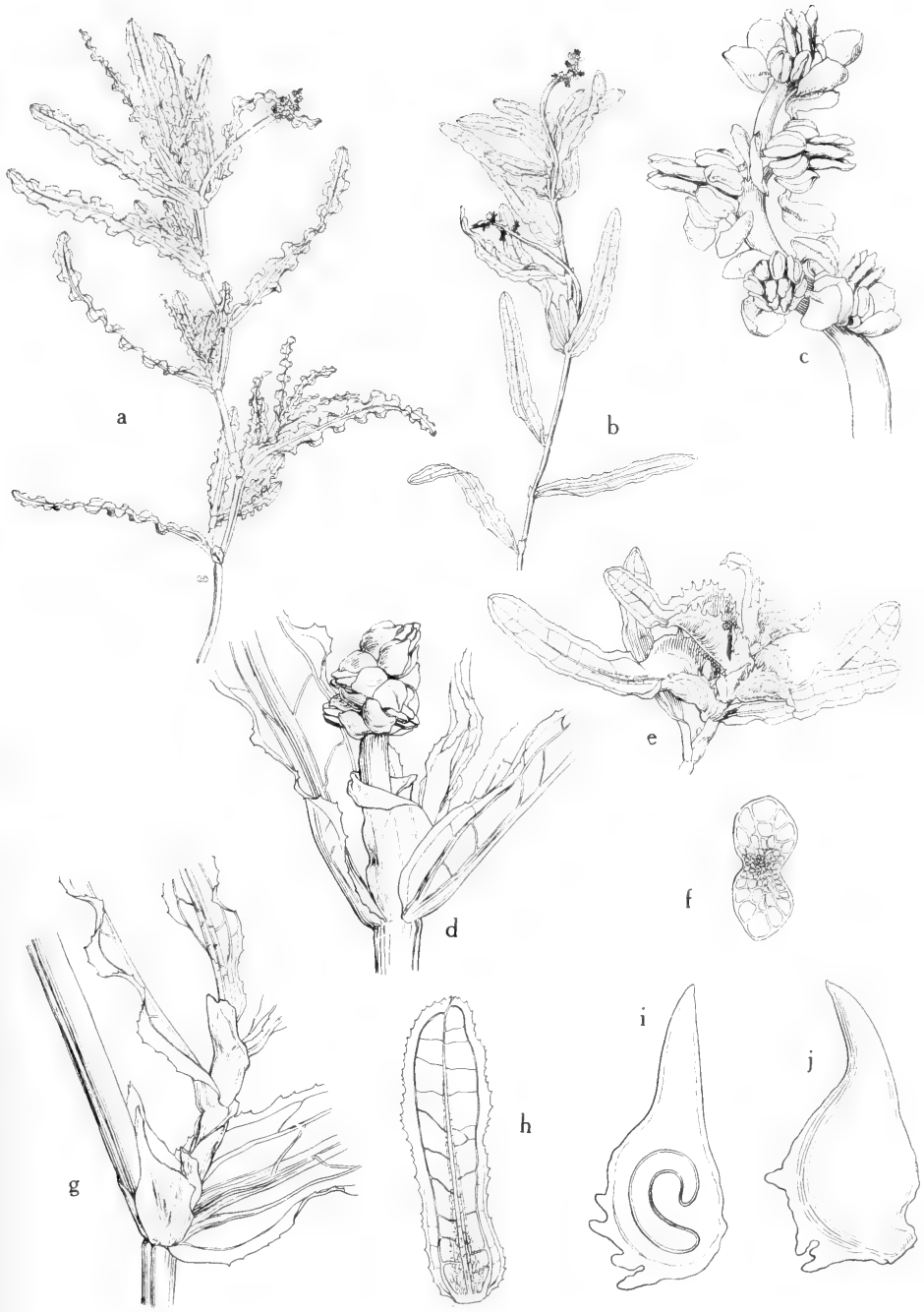

Fig. 34: Potamogeton crispus: a, habit, X $2 / 5 ; \mathrm{b}$, branch with maturing spikes, X $2 \%$; c, few-flowered spike, X 4; d, young flowering spike, emerging from sheathing stipules, X 3; e, winter bud, showing fleshy stems, short internodes and thickened foliaceous bud scales with strongly dentate broadened bases, X 11/5; f, stem (cross section), X 6; g, ligulate stipule, $X 1 \frac{1}{2} ; \mathrm{h}$, young leaf, showing venation, $\mathrm{X} 3$, $\mathrm{i}$, achene, (longitudinal section), $X 6 ; j$, achene, showing the somewhat curved beak and variation in the denticulate dorsal keel, X 6. (From Mason, Fig. 21). 

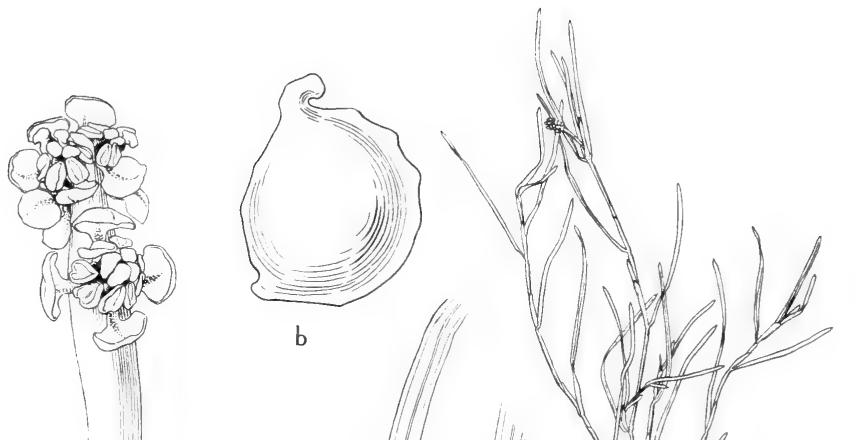

a

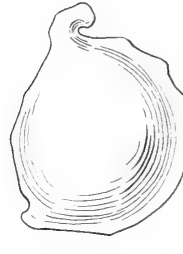

b
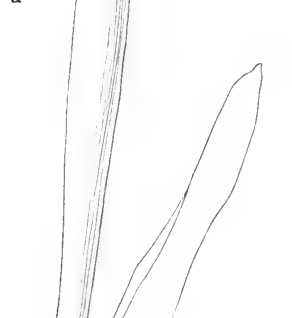

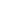

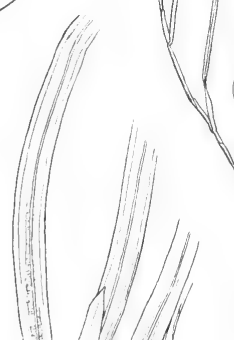

$\mathrm{d}$

$\sqrt{1} \mathrm{c}$
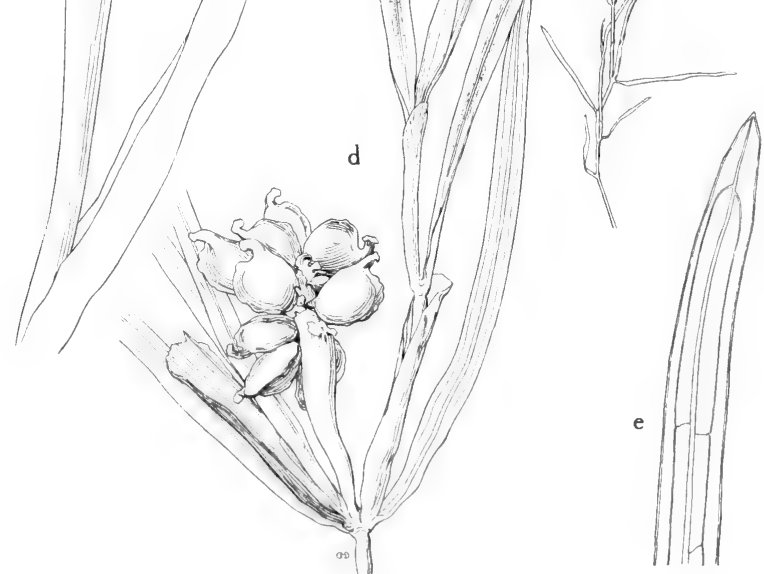

Fig. 35: Potamogeton foliosus: a, spike, showing short clavate peduncle, $\mathrm{X} 8$; b, achene, showing the thin undulate-toothed keel, X 10; c, habit, X 2/3; d, fruiting spike, showing connate and ruptured stipules, X 4; e, leaf tip, X 8. (From Mason, Fig. 23). 
with strong crossveins, the lateral nerve usually marginal; stipules prominent, 2-5 cm. long, the base adnate to the leaf to form a sheath slightly wider than the stem, greenish or whitish, the free portion less than half the length of the sheath; peduncles 3-25 cm. long, flexuous; spikes with 2 to 5 whorls of flowers, soon becoming widely and unequally spaced (moniliform), in fruit to $5 \mathrm{~cm}$. long; flowers sessile or nearly so; perianth greenish, the blades orbicular to elliptical, 1-2 mm. wide; anthers $0.5-1 \mathrm{~mm}$. long; fruits obliquely obovate, plump, narrow at base, rounded on the dorsal side, 2.5-4 mm. long, 2-3 $\mathrm{mm}$. wide; dorsal keel absent, the lateral keels obscure; beak facial, usually recurved, about $0.6 \mathrm{~mm}$. long; exocarp light tan, yellowish or pale-olive-green; endocarp loop solid, apex of seed pointing toward the basal end or slightly above.

In alkaline, brackish or saline water of ponds, quiet rivers, marshes and ocean shores, often occurring in great masses, in most of Okla., throughout Tex. except perhaps the e. Timber Belt and Blackland Prairies, and throughout most of N. M. and Ariz., mature fruit from May to Oct.; throughout much of e. half of U. S. and Can., w. to Alas., s. to Mex.

\section{Potamogeton crispus L. Curled Pondweed. Fig. 34.}

Rhizome buff or reddish, about the same thickness as the stem; stem simple or branched, laterally compressed and somewat 4-angled with the broader sides furrowed, $0.5-2.5 \mathrm{~mm}$. in greatest diameter; stele of the oblong-type pattern with but 1 central bundle and 1 lateral bundle on each side; endodermis of 0 -cells; interlacunar bundles absent; subepidermal bundles absent; pseudohypodermis 1 cell thick; leaves all submersed, bright-green to dark-green or occasionally slightly reddish, translucent, linear-oblong to linear-oblanceolate, to $1 \mathrm{dm}$. long and $1 \mathrm{~cm}$. wide, the apex broadly rounded, the base semiclasping; nerves 3 to 7 , the laterals close to the margin; lacunae of 1 or 2 rows on each side of midrib; margins finely and irregularly dentate and often undulate; stipules $5-15 \mathrm{~mm}$. long, slightly adnate at base, the upper part fraying early to leave papery or shreddy bases; peduncles 2-7 cm. long; spikes of 3 to 5 whorls of flowers, compact or moniliform, in fruit $1-2 \mathrm{~cm}$. long, $1-1.3 \mathrm{~cm}$. wide; flowers sessile or on very short pedicels; perianth blades orbicular, $1.2-2.1 \mathrm{~mm}$. wide; anthers $0.7-1.3 \mathrm{~mm}$. long; fruits ovate, 2-3.6 mm. long (excluding beak), 1.5-2.8 mm. wide; keels obtuse but prominent, the dorsal one strongly developed below and with a small tooth near the base; beak prominent, straight or incurved, as long as the fruit body; exocarp dark-olive or brownish; endocarp loop solid and near the base; apex of seed pointing toward the basal end; winter-buds burlike, hard and horny, 1-2.5 cm. thick.

In ponds and streams, often abundant in quiet muddy calcareous water; seldom found fruiting but does not produce fruits in shallow warm non-fluctuating water, in Okla. (Alfalfa, Choctaw, Comanche, Garfield and Ottawa cos.), Tex. (Dallas, Grayson, Hemphill, Randall and Travis cos.), N. M. (Hidalgo and Taos cos.) and Ariz. (Yavapai Co.), Apr.-Aug.; nat. of Eur.

When thoroughly established this species may become a very aggressive weed.

\section{Potamogeton foliosus Raf. Fig. 35.}

Rhizome freely branching, rooting at the nodes; stem subsimple below, muchbranched above, filiform, laterally compressed, usually without glands at the nodes; stele of the one-bundled-type; endodermis of 0 -cells; interlacunar bundles absent; subepidermal bundles present; pseudohypodermis absent; leaves all submersed, narrowly linear, green to bronze, to $1 \mathrm{dm}$. long and $2.7 \mathrm{~mm}$. wide, slightly tapering to a sessile base, entire-margined, acute or subacute at apex; nerves 3 to 5 , the midrib prominent, without bordering lacunae or with 1 to 3 rows on each side at the base, lateral nerves joining the midrib 1 to 3 leaf-widths below the apex, in broad leaves with 5 nerves the marginal ones may join the 


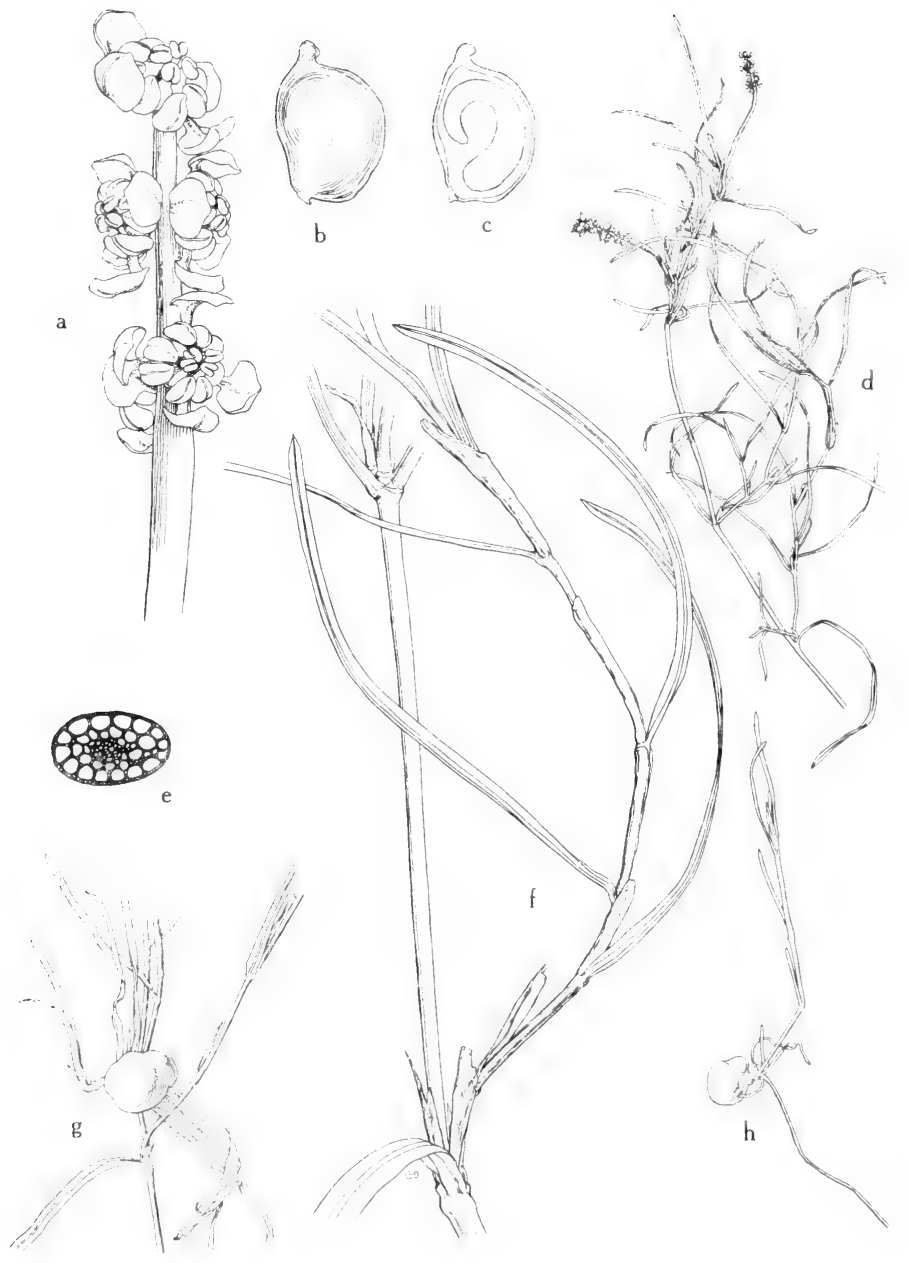

Fig. 36: Potamogeton pusillus: a, flowering spike, X 6; b, achene, obliquely obovoid, smooth, with slightly recurved beak, X 8 ; c, achene (longitudinal section), X 8; d, habit, showing narrowly linear submersed leaves, $X \%_{3}$; e, stem (cross section), X 20; f, part of stem, showing young tubular stipules in upper part and split disintegrating stipules at base, X 2; g and h, winter buds, X $1 \frac{1}{2}$. (From Mason, Fig. 24). 
laterals farther down; stipules 7-18 mm. long, with connate margins when young to form tubular delicately fibrous blunt sheaths, soon tearing and deciduous; peduncles slightly thickened upward, to $3 \mathrm{~cm}$. long; spikes subcapitate or cylindric, of 1 to 3 contiguous whorls of 2 flowers each; perianth blades flabellate, brownish, 0.6-1 mm. long; fruits obliquely suborbicular, laterally compressed, 2-2.5 mm. in diameter; dorsal keel with a thin undulate to dentate wing; lateral keels obscure; beak erect, broad at base, 0.2-0.4 mm. long; exocarp fulvous or olive-brown; embryo with apex pointing toward the basal end or slightly above; winter-buds sessile in the axils or on short branches.

In fresh (mostly calcareous) or brackish water of ponds, irrigation ditches and slow or swift streams throughout most of Okla., Tex., N.M. and Ariz., mature fruit from May to Oct.; throughout Can. and the U.S. to Mex. and the W.I.

Var. macellus Fern. Similar to var. foliosus but smaller and more bushybranched; leaves bright-green, to $7 \mathrm{~cm}$. long and $1.5 \mathrm{~mm}$. wide; nerves 1 to 3 ; midrib without adjacent lacunae or with a single row on each side below the middle; fruits green, obliquely obovoid, 1.8-2.3 $\mathrm{mm}$. long, the body longer than broad; beak slender; $0.3-0.8 \mathrm{~mm}$. long; winter-buds terminating elongate branches. Same habitats as var. foliosus. This poorly-marked variety that differs only in size is apparently rare in our region.

\section{Potamogeton pusillus L. Fig. 36 .}

Plants often with winter-bud at base; rhizome absent; stem usually muchbranched, slender, terete or slightly compressed, usually with a pair of small translucent glands at the nodes; branches (late in the season) often terminated by winter-buds; stele of the one-bundled-type or oblong-type; endodermis of 0-cells; interlacunar bundles absent; subepidermal bundles present; pseudohypodermis absent; leaves all submersed, linear to linear-setaceous, entire, light-green, to 7 $\mathrm{cm}$. long and $3 \mathrm{~mm}$. wide, acute to obtuse at apex; nerves 3 to 5 , the lateral nerves obscure in narrow extremes, joining the midrib one-half to 2 leaf widths below the tip; midrib usually not bordered by lacunae but they are sometimes evident on the young uppermost leaves; stipules scarious-membranaceous, 6-17 mm. long, clasping the stem and with margins united at base to above the middle, this union tearing with age; peduncles axillary, filiform, $1.5-8 \mathrm{~cm}$. long; spikes cylindrical, with 3 to 5 separate few-flowered whorls, 6-12 $\mathrm{mm}$. long; flowers with perianth round-flabelliform and with slender claw, 1.2-2 $\mathrm{mm}$. long; anthers $0.5-0.8 \mathrm{~mm}$. long; fruits obliquely obovoid, $1.9-2.8 \mathrm{~mm}$. long, $1-1.8 \mathrm{~mm}$. wide; dorsal keel obscure, very low and broad; lateral keels absent; beak facial, prominent, erect or slightly recurving, $0.2-0.6 \mathrm{~mm}$. long; exocarp olive-green, smooth; endocarp loop solid; apex of seed pointing slightly above the basal end or between the base and the middle of the opposite side.

In neutral or slightly alkaline or slightly brackish water of ponds and rivers, often forming large masses, in Okla. (Beaver Co.), throughout Tex., in N.M. (Colfax, Rio Arriba and Sandoval cos.) and Ariz. (Apache, Coconino and Santa Cruz cos.), mature fruit from May to Oct.; throughout much of U.S. and Can., s. to e. Mex.; Euras.

\section{Potamogeton clystocarpus Fern. Fig. 37.}

Stem much-branched, slender, terete or slightly compressed, usually with a pair of small translucent glands at the nodes; stele of the one-bundled-type; endodermis of 0 -cells; interlacunar bundles absent; subepidermal bundles present; pseudohypodermis absent; leaves all submersed, linear, entire, light-green, translucent to subopaque, to $9 \mathrm{~cm}$. long and $3 \mathrm{~mm}$. wide, the acute apex often with a sharp mucro; nerves 3 (5), often obscure, laterals joining the midrib near the apex or disappearing in the apical area; midrib bordered on each side by one or two rows of lacunae; stipules hyaline to subherbaceous, $0.5-1 \mathrm{~mm}$. long, usually 

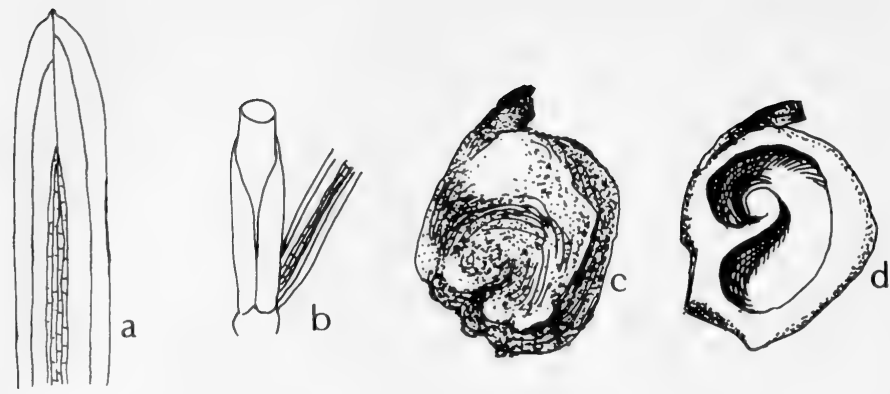

Fig. 37: Potamogeton clystocarpus: a, upper portion of leaf to show venation and apex, X $5 ; b$, portion of plant to show free margins of stipule, X $2 \frac{1}{2}$; c, fruit, X 10 ; d, fruit cut to show coil of embryo, X 10.

clasping the stem but with margins free, becoming lacerate at the apex; peduncles filiform, $15-65 \mathrm{~mm}$. long; spikes short-cylindric, $8-10 \mathrm{~mm}$. long, with 2 or 3 whorls of flowers; flowers with perianth broad-flabelliform and with slender claw, 2.5-3 mm. long, $1.5-2.5 \mathrm{~mm}$. wide; anthers $0.8-1.2 \mathrm{~mm}$. long; fruits obliquely obovate to suborbicular, with 2 or more verrucose protuberances near the base, $2.5-2.8 \mathrm{~mm}$. long, $1.8-2 \mathrm{~mm}$. wide; dorsal keel rounded to prominently developed and gibbous at base; lateral keels rounded or obscure; beak facial, recurved, 0.2$0.5 \mathrm{~mm}$. long; exocarp dark-olive-green; endocarp loop solid; apex of seed pointing slightly above the basal end or between the base and the middle of the opposite side.

In quiet pools and flowing streams, known only from Little Aguja Canyon, Davis Mts., Jeff Davis Co., Tex., where it is endemic, in fruit from May to Oct. and perhaps later.

\section{Potamogeton Berchtoldii Fieb. var. tenuissimus (Mert. \& Koch) Fern. Fig. 38.}

Plants often with winter-bud at base; rhizome absent; stem usually muchbranched, slender, terete or nearly so, usually with a pair of small translucent glands at the nodes; branches (late in the season) often terminated by winterbuds; stele of the one-bundled-type; endodermis of 0-cells; interlacunar bundles absent; subepidermal bundles present; pseudohypodermis absent; leaves all submersed, linear to linear-setaceous, acute at apex, entire, light-green to deep-green, translucent and flaccid, to $85 \mathrm{~mm}$. long and $1 \mathrm{~mm}$. wide; nerves 3 , laterals often obscure and (when not evanescent) joining the midrib one-fourth to 2 leaf-widths below the tip; midrib bordered on each side (at least in the lower half) by a single row of lacunae; stipules hyaline to subherbaceous, 3-14 $\mathrm{mm}$. long, usually clasping the stem but with margins free (or adhering because of adhesive materials in the water); peduncles axillary, filiform, to 3 (rarely -4.5 ) $\mathrm{cm}$. long; spikes subglobose, with 1 to 3 few-flowered whorls, $2-8 \mathrm{~mm}$. long; flowers with perianth round-flabelliform and with slender claw, $1-2 \mathrm{~mm}$. long; anthers $0.5-0.8 \mathrm{~mm}$. long; fruits obliquely obovoid, $2-2.5 \mathrm{~mm}$. long, $1.2-1.9 \mathrm{~mm}$. wide; dorsal keel obscure, very low and broad; lateral keels absent; beak facial, prominent, erect or slightly recurving, $0.1-0.5 \mathrm{~mm}$. long; exocarp dark-olive-green, smooth or faintly rugulose when dry; endocarp loop solid; apex of seed pointing slightly 


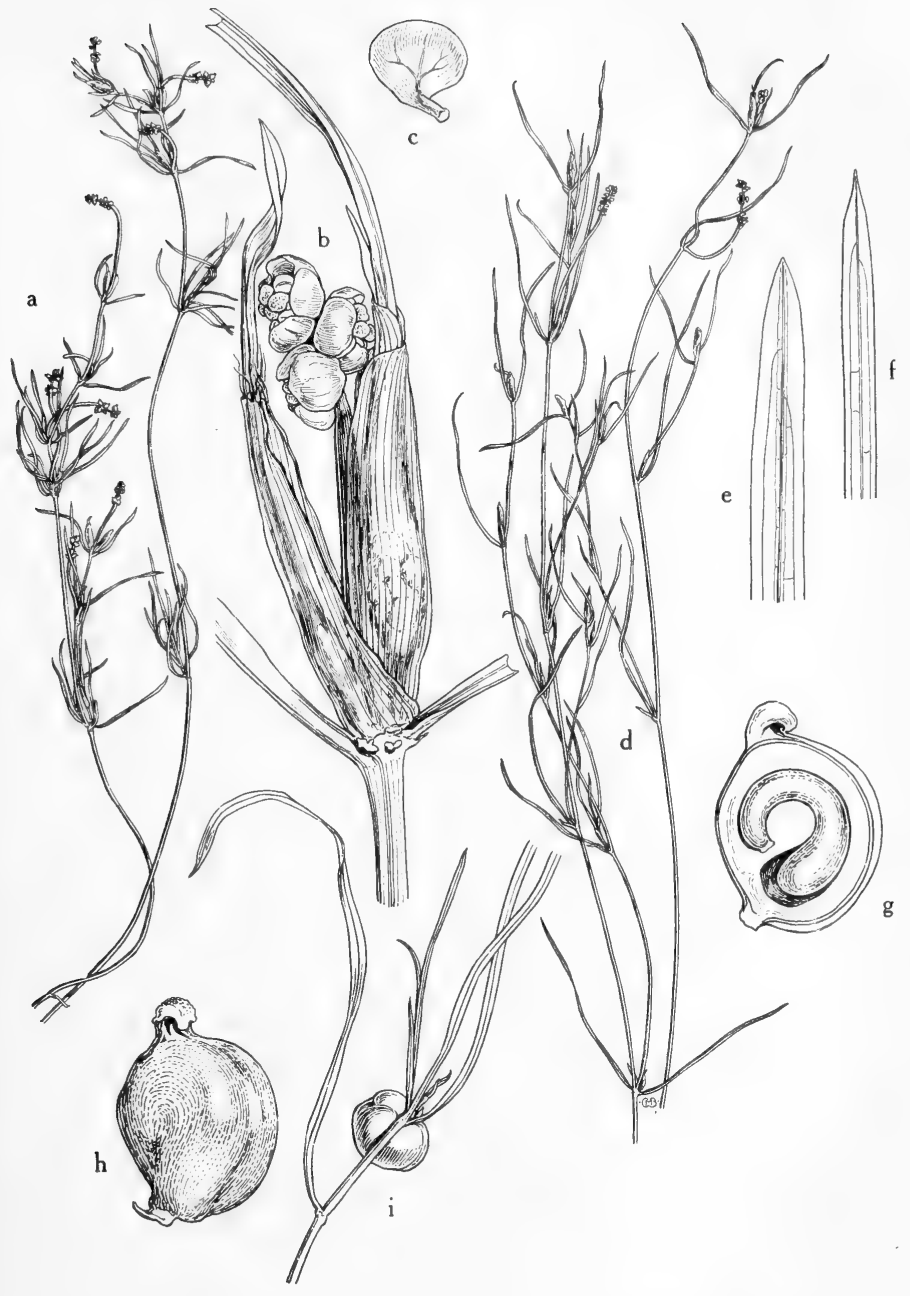

Fig. 38: Potamogeton Berchtoldii: a, habit, showing dense, short, somewhat spreading leaves, $\mathrm{X} 2 / 5$; b, young flowering spike surrounded by sheathing stipules, $\mathrm{X} 5$; c, sepaloid connective, $\mathrm{X} 12$; d, habit of a plant with leaves longer and more linearsetaceous than those of plant in $a, \mathrm{X} 2 \% 5 ; \mathrm{e}$ and $\mathrm{f}$, typical leaf tips, showing venation, $\mathrm{X} 8 ; \mathrm{g}$, achene (longitudinal section), $\mathrm{x} 12 ; \mathrm{h}$, achene, showing the rounded obscurely keeled back and the marginal erect beak, X 12; i, winter bud, X 2. (From Mason, Fig. 25). 
above the basal end or between the base and the middle of the opposite side.

In neutral to acid water of ponds and rivers in Okla. (Waterfall), n.e. Tex. (Bowie Co.), N. M. (Rio Arriba Co.) and Ariz. (Coconino Co.), May-Oct.; throughout much of N. A.

\section{Potanogeton diversifolius Raf. var. diversifolius. Fig. 39.}

Rhizome freely branching, rooting at the nodes; stem filiform, terete, muchbranched; stele of the oblong-type with one or two median bundles; endodermis of 0 -cells; interlacunar bundles absent; subepidermal bundles absent or occasionally with faint mechanical strands; pseudohypodermis present or absent; submersed leaves narrowly linear, entire, pale-green, mostly $2-6 \mathrm{~cm}$. long, $0.5-1.5 \mathrm{~mm}$. wide, slightly tapering to a sessile base, acute to obtuse at apex; nerves 3 , laterals inconspicuous; midrib usually bordered by 1 to 4 rows of lacunae; stipules delicately fibrous, adnate to the base of the leaf blade; floating leaves coriaceous, elliptic to oval or narrowly obovate, rounded at apex, cuneate or rounded at base; petioles usually shorter than the blades; blades to $4 \mathrm{~cm}$. long and $2 \mathrm{~cm}$. wide; nerves 5 to 15 ; stipules free from the petioles, $6-30 \mathrm{~mm}$. long, delicately fibrous, persistent; peduncles usually slender, often clavate, $1-4 \mathrm{~mm}$. long from the axils of submersed leaves and $2-30 \mathrm{~mm}$. long from the axils of floating leaves, ascending or arching; submersed spikes few-flowered, subglobose; emersed spikes elongate, 5-20 mm. long, in fruit 3-4 mm. wide; flowers sessile or nearly so; perianth suborbicular to broadly rhombic, $0.7-1 \mathrm{~mm}$. long, with a short claw; fruits suborbicular, the sides flattened or slightly concave and often cochleate-sulcate, $1-1.5 \mathrm{~mm}$. in diameter; dorsal keel prominent, alate, $0.2-0.4 \mathrm{~mm}$. wide, undulate or with a few very low teeth; lateral keels low and fine but evident, entire or slightly dentate; beak facial, minute but usually definite; exocarp greenish to brownish, endocarp with loop solid; embryo coil more than one complete revolution; winter-buds may form late in the growing season, being short branches with crowded internodes.

In pools, tanks and small streams, throughout most of Okla., common in e. Tex. and in the mts. of the Trans-Pecos to Ariz. (Coconino Co.), freely fruiting throughout the summer; mostly in s. U.S. and Mex.

Var. trichophyllus Morong. Similar to var. diversifolius except submersed leaves flaccid, setaceous or setaceous-linear, $0.1-0.6 \mathrm{~mm}$. wide, tapering to an acute $a: \mathrm{x}$, the nerves 1 or obscurely 3 ; stipules delicate, free or partially adnate to the uase of the leaf blade, deciduous with age; floating leaves lance-elliptic to oval-elliptic, acutish or (if rounded) at least submucronate at apex; blades 7-26 mm. long, 1-10 mm. wide; nerves 3 to 9; stipules $3-10 \mathrm{~mm}$. long; peduncles 1-4 $\mathrm{mm}$. long from the axils of submersed leaves and $2-30 \mathrm{~mm}$. from the axils of the floating leaves; fruits with dorsal keel entire or with 3 to 12 small teeth. In the same habitats as var. diversifolius.

\section{Potamogeton pulcher Tuckerm. Fig. 40.}

Rhizome pale-buff, often with dark-red spots; stem simple, terete, $1-2.5 \mathrm{~mm}$. in diameter, usually conspicuously dark-spotted; stele with the prototype pattern; endodermis of 0 -cells; interlacular and subepidermal bundles absent; pseudohypodermis mostly 1 cell thick; submersed leaves of two intergrading types, those of the lower part of the stem semiopaque and oblong with rounded apices, those of the upper part of the stem translucent and lanceolate to lance-linear, with an acutish but not sharp-pointed apex, both types tapering at base to petioles to 35 $\mathrm{mm}$. long; blades entire, to $18 \mathrm{~cm}$. long and $35 \mathrm{~mm}$. wide, usually smaller; nerves 11 to 21 , the outer ones marginal; lacunae 4 to 8 rows on each side of midrib; floating leaves coriaceous, ovate to rotund, rounded to bluntly mucronate at apex, cordate or rounded at base; petioles $4-18 \mathrm{~cm}$. long; blades to $11 \mathrm{~cm}$. long and $85 \mathrm{~mm}$. wide, with 19 to 35 nerves; stipules of the submersed leaves decaying early, those of the floating leaves persistent, narrowly triangular, obtuse when 


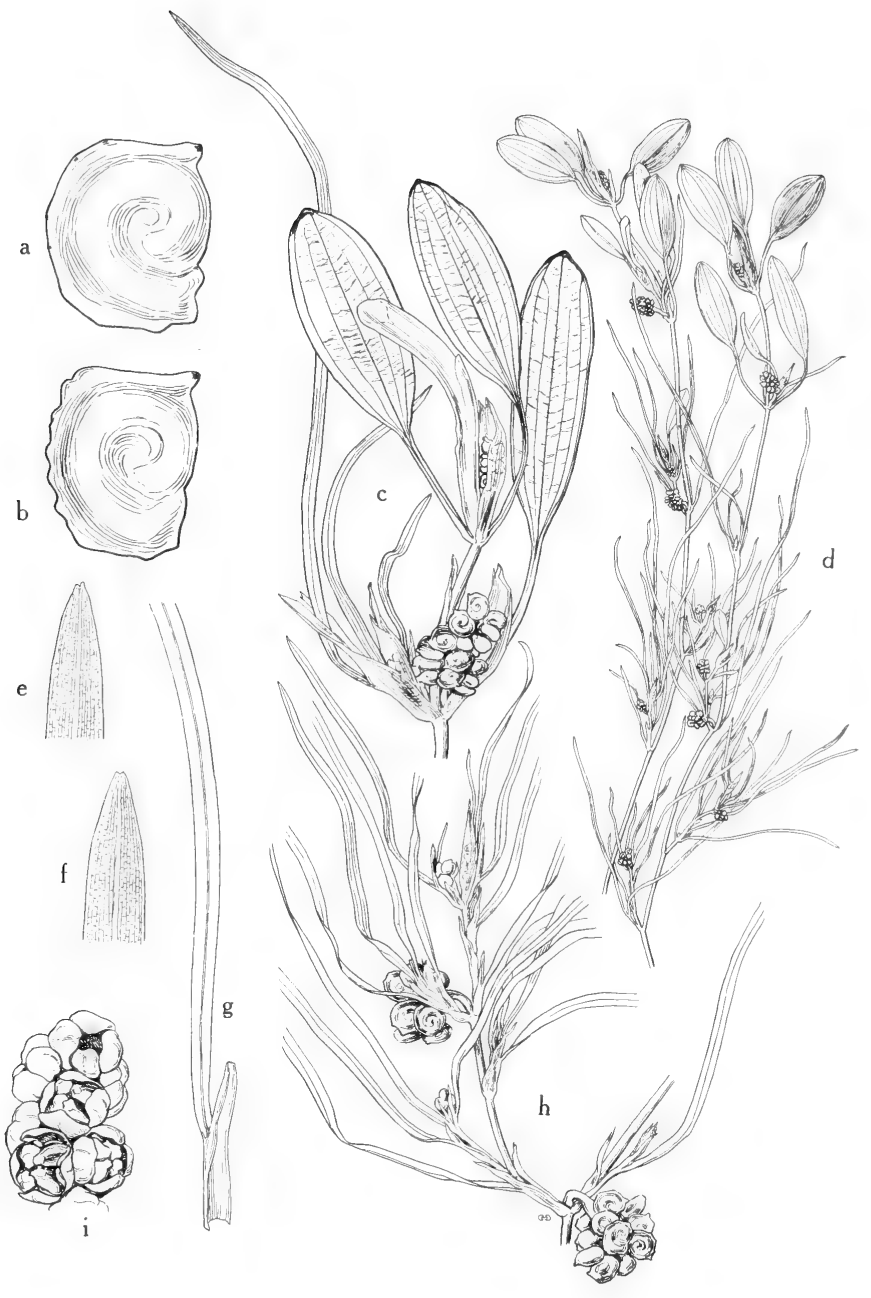

Fig. 39: Potamogeton diversifolius: $\mathrm{a}$ and $\mathrm{b}$, achenes, showing the angular often denticulate outline of the dorsal keel and the strongly coiled embryo, X 16; c, upper part of stem, the floating leaves elliptic, the submersed leaves linear, X 2; d, habit, showing the numerous capitate subsessile spikes, $\mathrm{X} 2 / 3$, e and $\mathrm{f}$, tips of submersed leaves, $\mathrm{X} 10 ; \mathrm{g}$, linear leaf blade arising from stipule, and the long free ligule, X $4 ; \mathrm{h}$, mature capitate spikes, showing reflexed peduncles in axils of submersed leaves, X 2; i, flowers in spike, X 8. (From Mason, Fig. 17). 


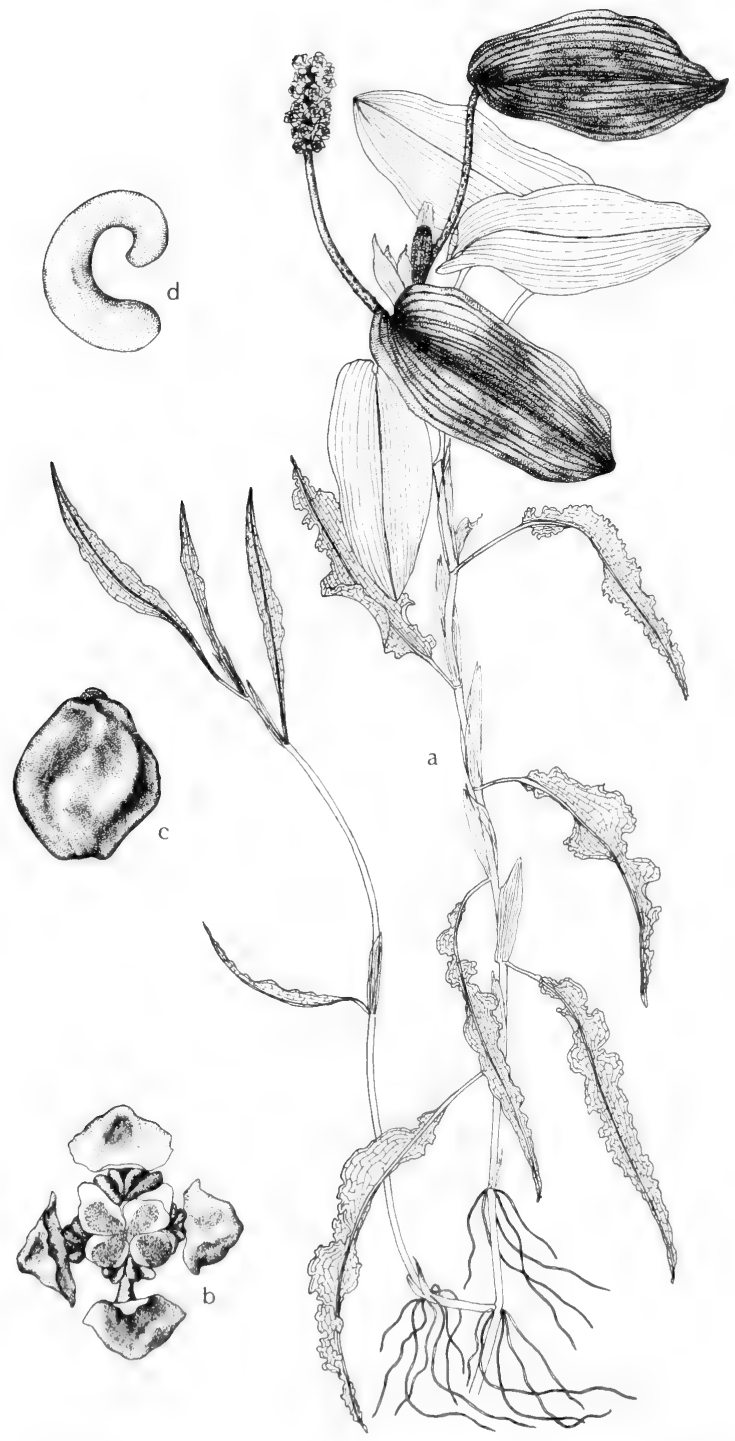

Fig. 40: Potamogeton pulcher: a, habit, X 1/3; b, flower, X 5; c, achene, X 5; d, coil of embryo, X 5. (Courtesy of R. K. Godfrey). 
young, acutish with age, 2-5 cm. long, 2-keeled; peduncles 5-11 cm. long; spikes with about 10 whorls, in fruit $2-3.5 \mathrm{~cm}$. long, $8-11 \mathrm{~mm}$. thick; flowers sessile or nearly so; perianth greenish, blades orbicular to elliptical and $1.2-3 \mathrm{~mm}$. wide; anthers $0.8-1.4 \mathrm{~mm}$. long; fruits obliquely ovate, rounded or cuneate at base, the sides flat or slightly concave, 2.7-4 mm. long, 2.3-3.4 mm. wide; keels usually prominent, acutish, the dorsal one often strongly developed and sometimes with a basal lobe projecting below the point of attachment; beak often prominent, to $0.8 \mathrm{~mm}$. long; exocarp light-brown to olive-green; endocarp with 3 prominent acutish and somewhat muricate keels; beak linear, facial, about $1 \mathrm{~mm}$. long; loop solid; apex of seed pointing $0.5-1.2 \mathrm{~mm}$. above the basal end.

In muddy pools, boggy streams, lakes and occasionally in clear water in sandy bottoms in Okla. (McCurtain, Payne and Pushmataha cos.) and in Tex. mostly in the Timber Belt, flowers in Apr. and May, mature fruit by mid-May; in the e. half of U. S.

\section{Potamogeton amplifolius Tuckerm. Fig. 41.}

Plant from stout rhizomes; stems simple or branched near the top, often rufous; submersed leaves variable, from short-lived (lanceolate and short-petioled) to persistent (broadly lanceolate to ovate and folded along the midvein), the blade $8-20 \mathrm{~cm}$. long, 25-75 $\mathrm{mm}$. broad, tapering to petiole $1-6 \mathrm{~mm}$. long, the stipules becoming fibrous and stringy, 3-10 cm. long; floating leaves similar to the upper submersed leaves to ovate or elliptic, round-tipped, rounded or tapering to the base, 5-10 cm. long, 25-50 mm. wide, the stipules usually 2-keeled; peduncles often thickened apically, 5-11 cm. long; spikes with 9 to 16 whorls of flowers, 4-8 $\mathrm{gm}$. long when mature; nutlets $3-5 \mathrm{~mm}$. long, obovate, rounded on back, cuneate at base, the sides flat, the beak prominent.

Lakes, ponds, still water of creeks, at middle and lower altitudes, in rather deep water, in Okla. (Comanche, McCurtain and Osage cos.), Apr.-Sept.; from Nfld. to B. C., s. to Va., Ark., Okla., and Calif.

\section{Potamogeton nodosus Poir. Fig. 42.}

Rhizome white, suffused or spotted with rusty red; stem simple, terete, often pressing very flat, $1-2 \mathrm{~mm}$. in diameter; stele with the triotype pattern, with the phloem on the inner face of the trio-bundle appearing as one patch; endodermis of 0-cells; interlacunar and subepidermal bundles absent; pseudohypodermis absent; submersed leaves thin, linear-lanceolate to broadly lance-elliptic, to $2 \mathrm{dm}$. long and $35 \mathrm{~mm}$. wide, tapering gradually at base into a petiole $2-13 \mathrm{~cm}$. long, tapering gradually to an acutish but not sharp-pointed apex; nerves 7 to 15 ; lacunae of 2 to 5 rows along the midrib; margin of young blades with fugacious translucent denticles; floating leaves coriaceous, with long petioles; blades lenticular to elliptic, cuneate or somewhat rounded at base, acutish to rounded at apex and sometimes with an obtuse mucro, to $11 \mathrm{~cm}$. long and $45 \mathrm{~mm}$. wide; nerves 9 to 21; lacunae rarely present; stipules of submersed leaves brownish, often delicate and decaying early, linear, acute or obtuse, 3-9 $\mathrm{cm}$. long, those of the floating leaves similar but usually broader at base and more or less 2-keeled; peduncles usually thicker than the stem, 3-15 cm. long; young spikes compact but becoming loose at anthesis, of 10 to 17 whorls of flowers, at maturity usually not densely fruited, $3-7 \mathrm{~cm}$. long, 8-10 $\mathrm{mm}$. thick; flowers sessile; perianth greenish or brownish, orbicular or elliptical, 1.4-2.6 mm. wide; anthers 1-1.4 mm. long; fruits obovate, $3.5-4.3 \mathrm{~mm}$. long, $2.5-3 \mathrm{~mm}$. wide; keels prominent, the dorsal strongly developed (especially upward), the laterals often muricate; beak facial, short; exocarp of mature fruits brownish or reddish; endocarp with keels strongly developed, the dorsal often $0.5 \mathrm{~mm}$. wide, the laterals strongly muricate; 


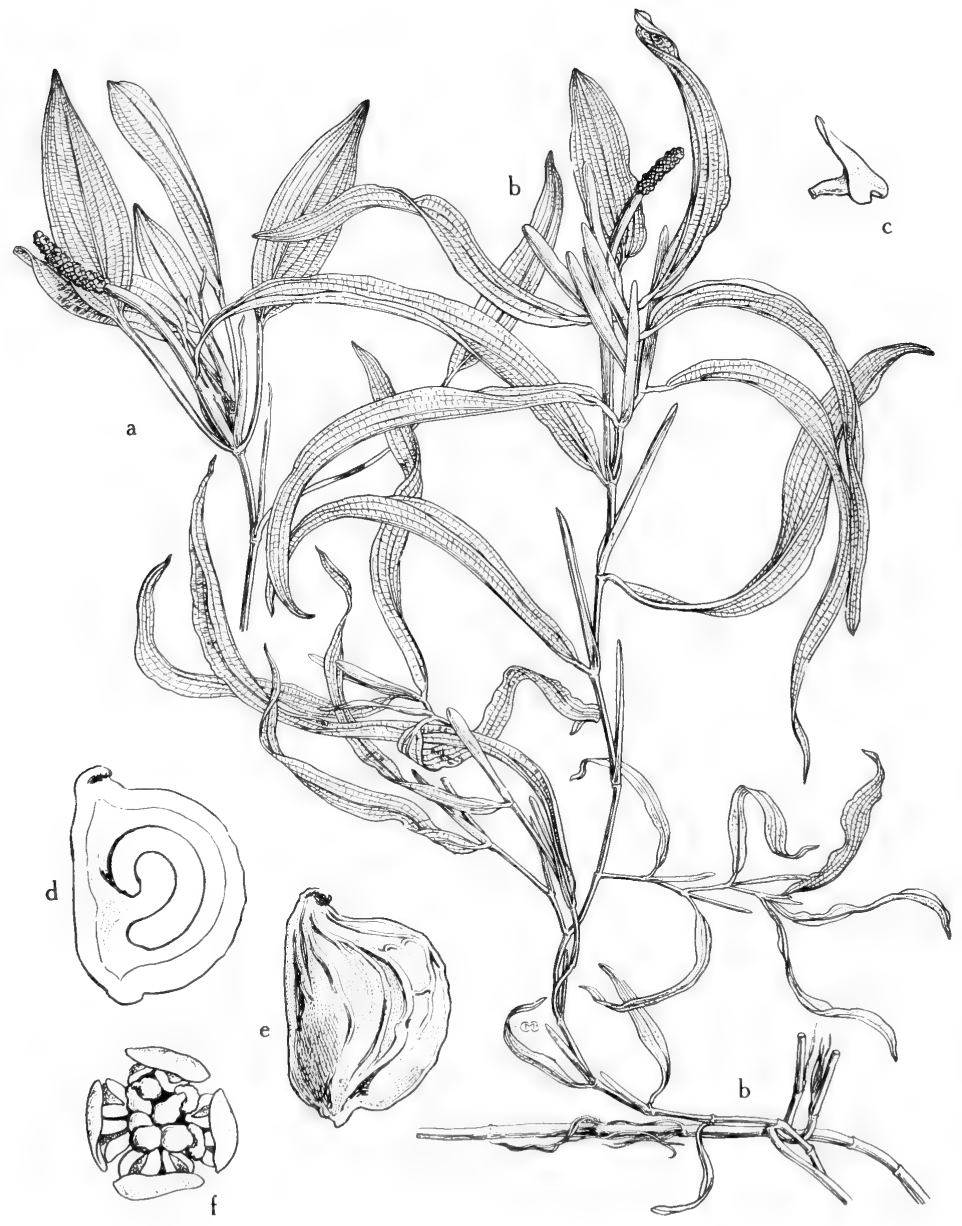

Fig. 41: Potamogeton amplifolius: a, upper part of stem, showing floating leaves, the stout upwardly thickened peduncle and acute stipules, X $2 \%$; b, habit, showing rhizome, arcuate submersed leaves, broad stipules and densely whorled flowers, $X 2 / 5$; c, sepaloid connective, X 6; d, achene (longitudinal section), X 6; e, achene, showing the flat sides and prominent beak, X 6; f, single flower, X 6 (From Mason, Fig. 27). 


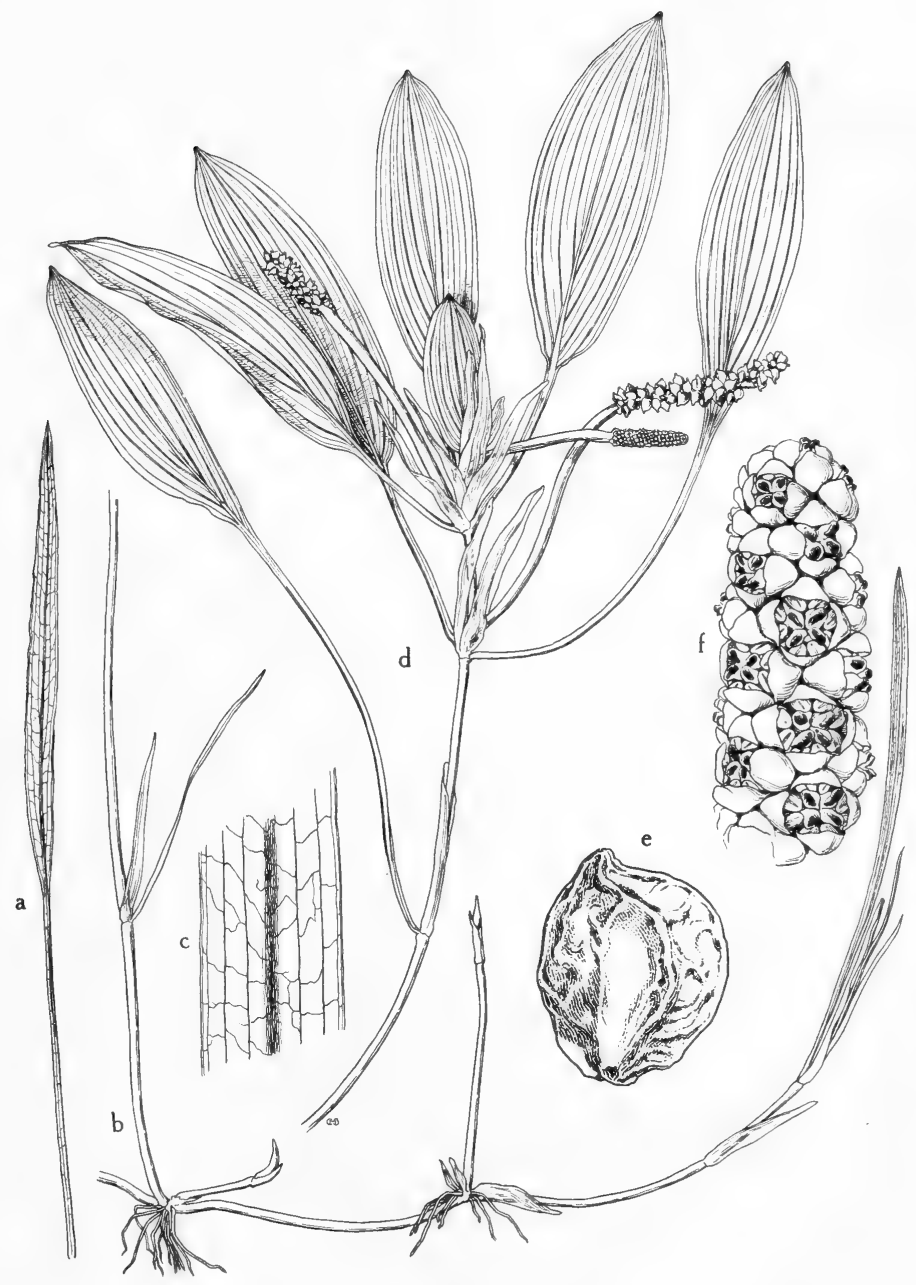

Fig. 42: Potamogeton nodosus: a, submersed leaf, X $2 / 5 ; \mathrm{b}$, rhizome and young shoot, showing stipules and attenuate scales, X $2 \%$; c, venation in submersed leaf blade, $\mathbf{X} 2$; d, upper part of stem, showing elliptic long-petioled floating leaves, X $2 / 5$; e, achene, showing strongly developed dorsal and lateral keels and sculptured surface, $X \quad 8 ; f$, spike, X 4. (From Mason, Fig. 28). 
beak linear, erect, to $1 \mathrm{~mm}$. long; loop solid; apex of seed pointing a little above the basal end. $P$. americanus Cham. \& Schlecht.

In streams and lakes throughout Okla. and Tex. to N. M. (Colfax, Sandoval and San Miguel cos.) and Ariz. (Coconino, Gila, Maricopa, Navajo and Yavapai cos.), mature fruits in late spring and summer; in much of the U. S., Can. and n. Mex.

\section{Potamogeton illinoensis Morong. Fig. 43.}

Rhizome buff, spotted or suffused with red; stem simple or branched, terete, 1-5 $\mathrm{mm}$. in diameter; stele with the prototype, triotype or oblong-type pattern; endodermis of U-cells; interlacunar bundles in the outer interlacunar circle, sometimes a few in the next to the outer circle; subepidermal bundles present or absent; pseudohypodermis absent or of 1 cell thick; submersed leaves thin, elliptic to lanceolate, often somewhat arcuate; blades to $2 \mathrm{dm}$. long and $45 \mathrm{~mm}$. wide, sessile or tapering into a petiole to $4 \mathrm{~cm}$. long, acute and usually somewhat mucronate at apex; nerves 7 to 19 ; lacunae of 2 to 5 rows along midrib and larger nerves; margin entire or with fugacious 1-celled translucent denticles; floating leaves (often absent) more or less coriaceous, transition to submersed leaves usually gradual; blades elliptic to ovate-elliptic or oblong-elliptic, to $19 \mathrm{~cm}$. long and 65 $\mathrm{mm}$. wide, obtuse-mucronate at apex, cuneate or rounded at base; petioles $2-9 \mathrm{~cm}$. long, shorter than the blade; nerves 13 to 29 ; lacunae of 2 or 3 rows of cells along midrib, sometimes obscure; stipules persistent, divergent and conspicuous, obtuse, those of the submersed leaves 1-8 cm. long and 3-12 mm. wide at base, prominently 2-keeled, with 15 to 35 finer nerves; those of the floating leaves broader; peduncles as thick as or thicker than the stem, 4-30 cm. long; spikes in anthesis compact, of 8 to 15 whorls of flowers, at maturity cylindric and crowded, 2.5-7 cm. long, 8-10 mm. thick; flowers sessile or on pedicels to $0.5 \mathrm{~mm}$. long; perianth orbicular to oval, $1.3-3.2 \mathrm{~mm}$. wide; anthers $0.6-2 \mathrm{~mm}$. long; fruits obovate to orbicular or ovate, 2.5-3.6 mm. long (excluding beak), 2.1-3 mm. wide, the sides flat; keels prominent and acute, the dorsal strongly developed above and below, the laterals less strongly developed but often each with a projecting knob at the base; beak facial, short, erect or curved toward the back; exocarp gray-green to olive-green or brownish, sometimes reddish; endocarp with keels low but prominent or with dorsal keel thin and very weak; beak deltoid and weak, about $0.5 \mathrm{~mm}$. long; loop solid; apex of seed pointing at the middle of the opposite side or between middle and base. P. lucens L., P, angustifolius Bercht. \& Presl.

In quiet or flowering water of ponds, canals and rivers in s.-cen. Tex., especially on the Edwards Plateau and in the Guadalupe Mts., w. to N. M. (Eddy Co.) and Ariz. (Coconino Co.), fruiting by early May; throughout much of U.S. and Can.

A variable species due, in part, to habitat. Hybrids may occur between this species and $P$. nodosus, especially where the two are found together.

\section{Potamogeton gramineus L. Fig. 44.}

Plant from a mass of rhizomes; stems slender, occasionally fistulose, 2-15 dm. long; submersed leaves abundant, typically sessile (occasionally petioled), linear to lanceolate or oblanceolate, 3-12 cm. long, 1-15 mm. wide, acute and often with a short-attenuate tip, the stipules persistent; floating leaves on slender petioles, the blades ovate to elliptic, $1.5-7 \mathrm{~cm}$. long, 1-3 cm. broad, usually shorter than petioles; stipules lanceolate, somewhat keeled, persistent, 5-30 mm. long; peduncles stout, 2-10 cm. long; spikes compact, 1-4 cm. long when mature; nutlets obovate, 1.5-3 $\mathrm{mm}$. long, obscurely keeled, the beak somewhat recurved.

Ponds, lakes, marshes and sluggish streams in N.M. (San Juan and Sandoval cos.) and Ariz. (Coconino and Maricopa cos.), May-Sept.; Greenl. to Alas., s. to Pa., N. Y., III., Ia., N.M., Ariz. and Calif.; Euras. 


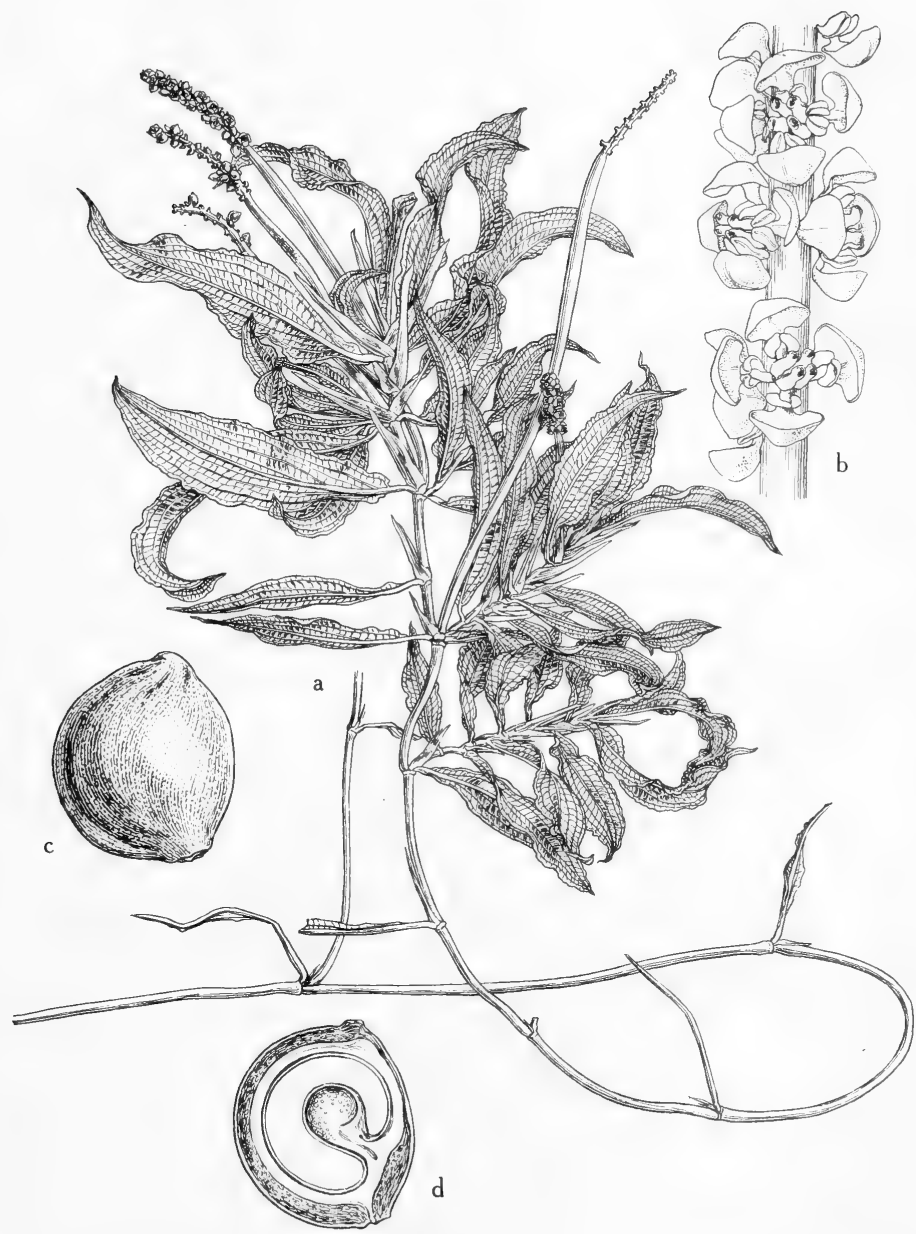

Fig. 43: Potamogeton illinoensis: a, habit, showing profusion of crowded leaves, conspicuous stipules and long stout peduncles, X $2 / \%$; , part of flowering spike, X 4; c, achene, showing strong dorsal keel, smooth face and short beak, X 6; d, achene (longitudinal section), X 6. (From Mason, Fig. 20). 


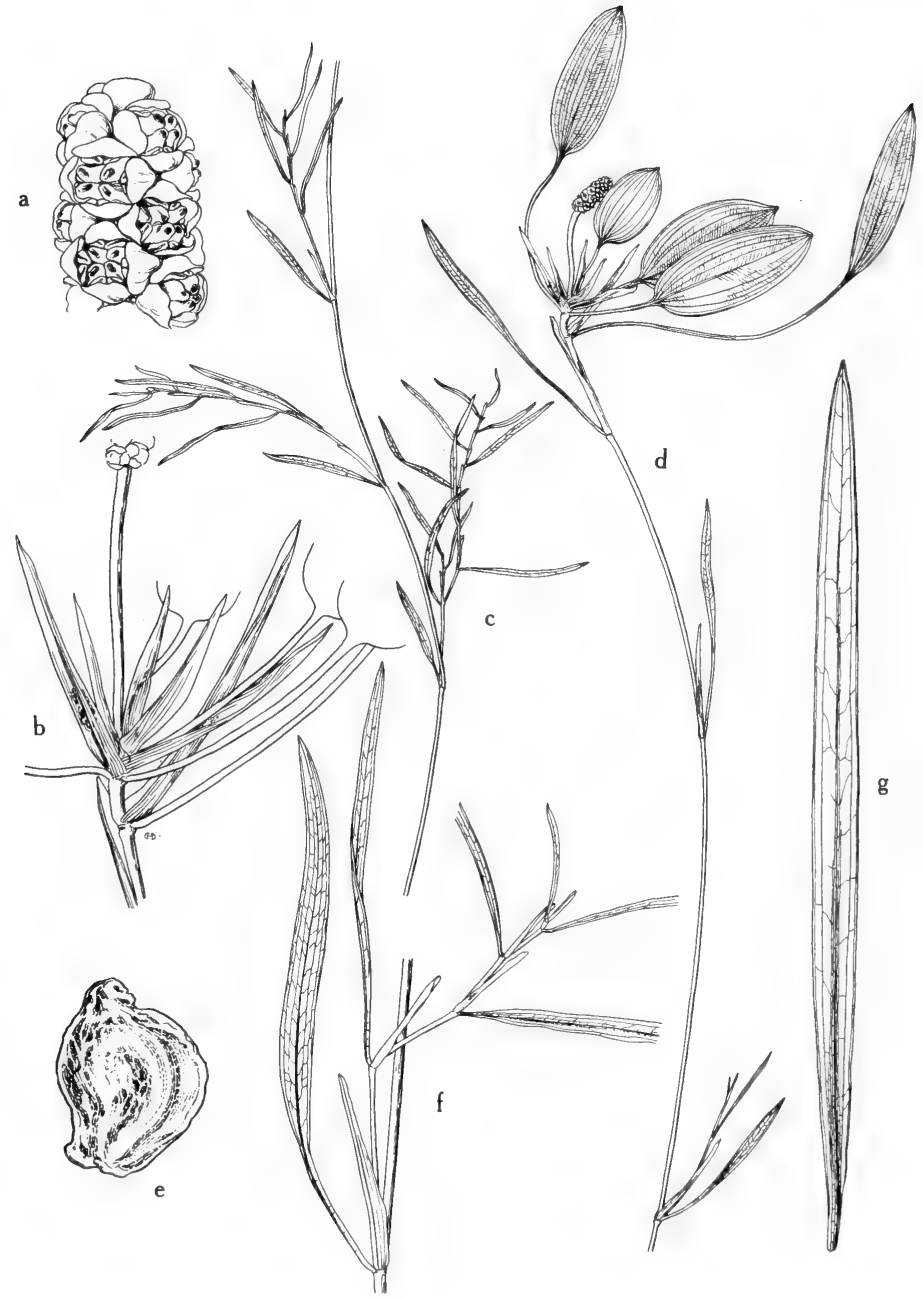

Fig. 44: Potamogeton gramineus: a, tip of compact flowering spike, X 4; b, keeled stipules on flowering branch, $X 11 \%$; c, submersed lower part of stem, showing the sterile branches with leaf variations and the young stipules clasping the stem, X $2 \% ;$, upper part of stem, showing submersed as well as floating leaves, X $2 \%$; e, achene with obscure keels, X 8 ; f, submersed foliage, showing transitional forms, X 11\%; g, young linear leaf, showing venation and tip, X 3. (From Mason, Fig. 31 ). 


\section{Potamogeton natans L. Broad-LeAved PondweEd. Fig. 45.}

Stems branching from a horizontal rhizome, otherwise usually simple; submersed leaves without blades, 1-3 dm. long, 0.8-2 $\mathrm{mm}$. wide, rarely with a poorly developed blade, the linear stipules $6-8 \mathrm{~cm}$. long; floating leaves broadly elliptic to oblong, often subcordate at base, broadly rounded at apex, 25- to 27nerved, the petiole longer than blade, the stipules $5-12 \mathrm{~cm}$. long, linear-lanceolate: membranous; spikes in the axils of floating leaves, 3-6 cm. long on stout peduncles, $1 \frac{1}{2}$ to 3 times as long as the spike; nutlets $3-5 \mathrm{~mm}$. long, strongly keeled on the back, the lateral angles scarcely evident, the beak erect.

Marshy ponds and lakes, often brackish, in Okla. (Choctaw Co.), N. M. (San Juan and Sandoval cos.) and Ariz. (Apache and Coconino cos.), May-Sept.; Greenl. to Alas., s. to N. J., Pa., O., Ind., Ill., Ia., Neb., N.M., Ariz. and Calif.

A sterile specimen in the U. S. National Herbarium might possibly be $P$. alpinus Balbis. It was collected by R. O. Studhalter, etc. (S3874) at Glacial Lake near Tres Ritos, Taos Co., New Mexico, at 9,500 ft. elevation. It is distinguished from $P$. amplifolius, which it superficially resembles, by its usually smaller, sessile, submersed leaves, more slender rhizome and usually reddish stems and peduncles. Its floating leaves, when present, are also delicate and thin with no sharp distinction between blade and petiole.

\section{Fam. 16. Zannichelliaceae DuM.}

\section{Horned Pondweed FAMILY}

Submerged aquatic dioecious or monoecious herbs, with a slender creeping rhizome; leaves alternate or opposite or crowded at the nodes, linear, sheathing at the base, the sheaths mostly ligulate at the apex, the floral leaves sometimes reduced to sheaths; flowers minute, bisexual or unisexual, axillary, solitary or in cymes; perianth of 3 small free scales or absent; stamens 1 to 3 , the anthers 1 - or 2-celled and opening lengthwise; pollen globose or threadlike; gynoecium of 1 to 9 free carpels; style short or long, simple and with a capitate to peltate or spatulate stigma, sometimes 2- to 4-lobed; ovule solitary, pendulous; fruiting carpels sessile or stipitate, indehiscent; seed pendulous, without endosperm.

Widely distributed, mainly in salt or brackish water; 3 genera and 6 species.

1. Pollen spheroid; carpels several, free; plants of fresh or brackish water; leaves filiform...........................................................1. Zannichellia

1. Pollen threadlike; gynoecium 1- or 2-carpellate; plants of marine habitats (2)

2(1). Leaves flat, tridentate at apex; styles simple; one anther attached higher than the other. 2. Halodule

2. Leaves terete or semiterete, acute or pointed at apex; styles 2- to 4-lobed; anthers at an equal height........................................ Cymodocea

\section{Zannichellia L. Horned Pondweed}

A genus of two species, the other in Africa. Placed by some authors in the Najadaceae.

\section{Zannichellia palustris L. CoMmon POOLMAT. Fig. 46.}

Submerged aquatic plant, monoecious, rooted on bottom and floating below surface of water; rhizome creeping; stem slender, simple or much-branched; leaves mostly opposite, linear-filiform, entire, to $1 \mathrm{dm}$. long, acute or almost pungent at the apex, 1-nerved; stipules scarious, free from the leaf bases, scarcely $2 \mathrm{~cm}$. long; flowers unisexual, sessile, usually both kinds from the same axil, enclosed in a hyaline deciduous spathe, the perianth wanting; staminate flower consisting of 


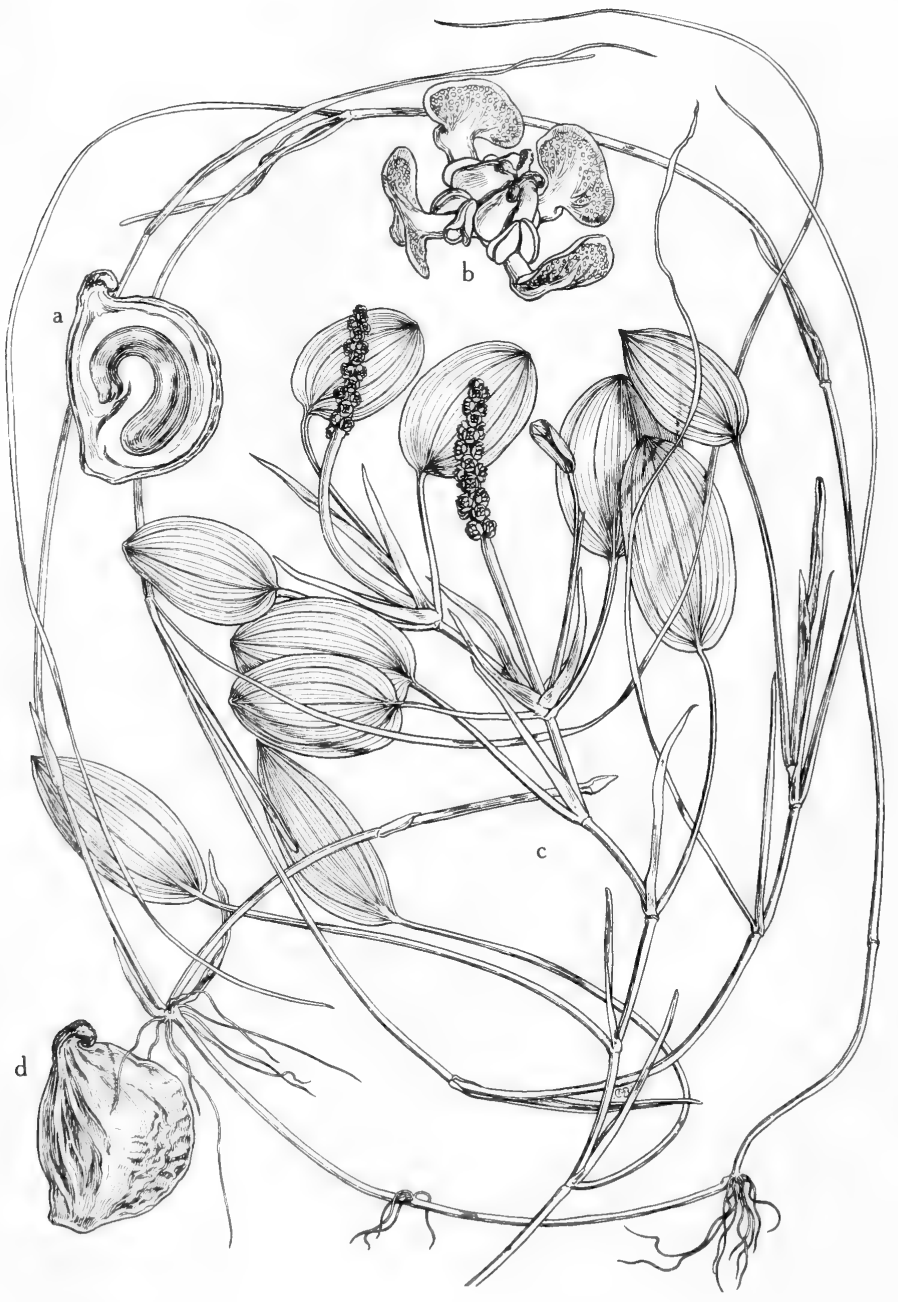

Fig. 45: Potamogeton natans: a, achene (longitudinal section), X 6; b, flower, X 4; $c$, habit, showing the long linear submersed leaves and broadly elliptic floating leaves, and the linear-lanceolate stipules, X $2 \%$; achene, showing strong keel on the back, X 6. (From Mason, Fig. 29). 


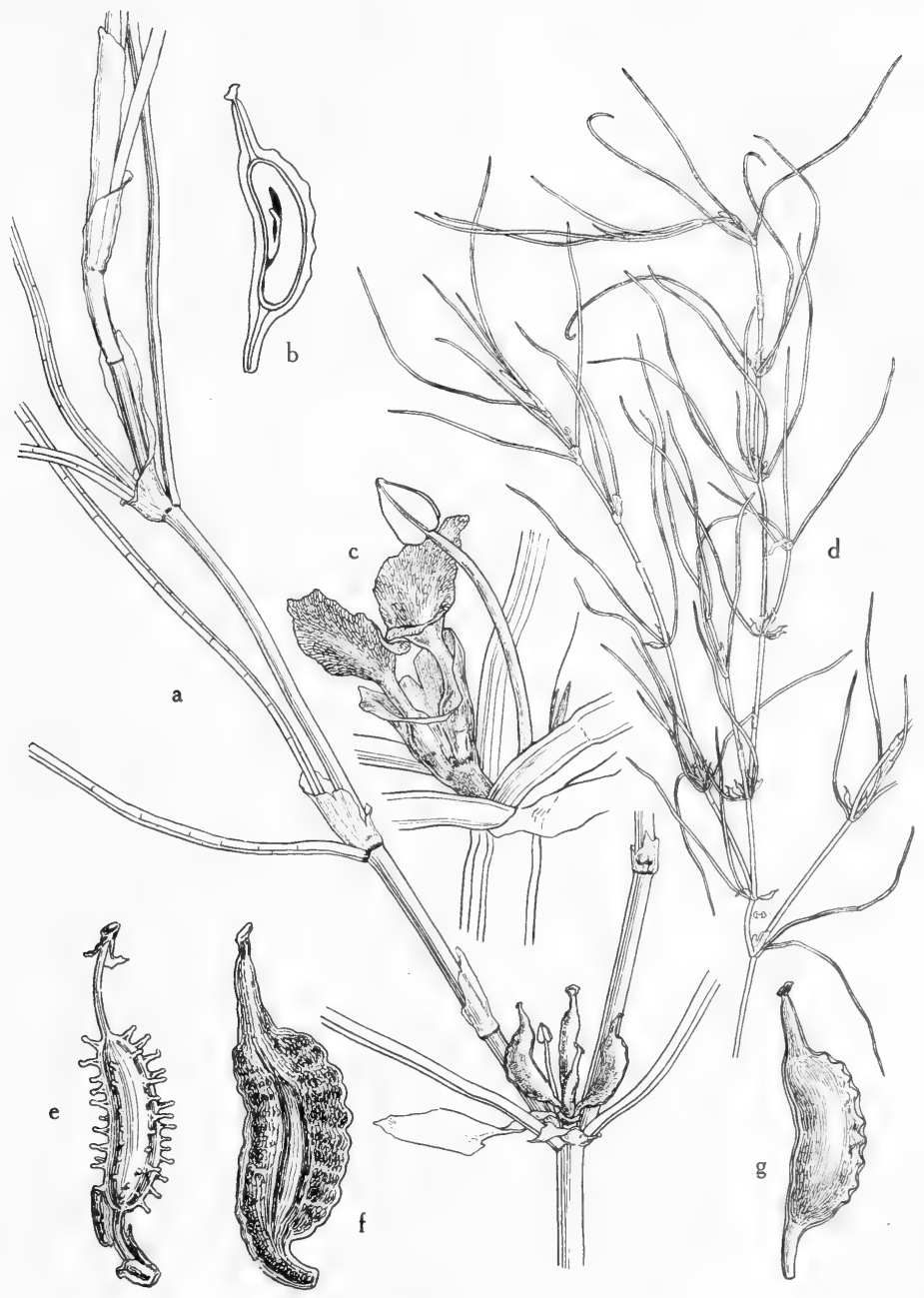

Fig. 46: Zannichellia palustris: a, branch with submersed filiform 1-nerved leaves, showing stipular sheaths and flowers in lower axil, the staminate flower comprised of a single stamen arising at the base of the short stout peduncle which bears 4 (usually 2 to 5) pistils arrounded by a spathe, $\mathrm{X} 4$; b, fruit (longitudinal section), X 8; c, involucre or spathe with 2 young pistillate flowers and a single staminate flower, all from the same axil, X 16; d, habit, showing the long opposite filiform submersed leaves and maturing fruits in the axils, $\mathrm{X} 4 / \%$; e, fruit, showing toothed ridges as revealed by normal deterioration of outer coat in old fruits, $X 8 ; \mathrm{f}$ and $\mathrm{g}$, mature undried fruits before deterioration of coat, X 8. (From Mason, Fig. 37). 
a single 2- to 4-celled anther on a slender filament; pistillate flowers sessile at first, often pedicellate after anthesis; carpels 2 to 8 , flask-shaped, ribbed or toothed on the margins, or sometimes smooth; style recurved, persistent; mature fruit 2-4 mm. long, rarely pitted, flattened, slightly incurved, smooth or slightly dentate on the convex back, the body $2-3 \mathrm{~mm}$. long, the beak to $1.5 \mathrm{~mm}$ long.

In fresh or brackish water in pools, marshes, streams and irrigation canals, in Tex. mainly in the Edwards Plateau and in the Trans-Pecos but widespread in Okla., N.M. and Ariz., Apr.-Sept.; nearly throughout N. A., except the extreme n., also S. A., Euras. and Afr.

The fruits as well as the foliage are eaten by wildfowl, the fruits by some marshbirds and shorebirds, and the plants are considered to be a fair food producer for trout.

\section{Halodule ENDL.}

Several species of marine waters mainly in tropical regions.

\section{Halodule Beaudettei (den Hartog) den Hartog. Fig. 47.}

Submerged dioecious perennial, with creeping rootstocks; rootstocks branching, articulated and rooting at the nodes, the roots often terminating in fleshy starchy tuberlike swellings, with a short erect stem at each node; internodes $5-40 \mathrm{~mm}$. long; scales elliptic, 5-10 mm. long; sheaths $1.5-6 \mathrm{~cm}$. long; leaves mostly crowded on short erect lateral branches, all linear, grasslike, more or less narrowed and sheathing at the base, 5-20 cm. long, $0.8-1.2 \mathrm{~mm}$. wide, midrib conspicuous, widening and often furcate near the tip; leaf tip with a very prominent acute median tooth which is 1 to 10 times as long as the narrow linear lateral teeth; flowers without perianth, subtended by a hyaline perianthlike bract; staminate flowers consisting of two anthers on the end of a stout stalk; anthers oblong, about $4 \mathrm{~mm}$. long, unequally attached, 2-celled; pistillate flowers of 2 unequal carpels on a stout stalk, the largest carpel about $3.5 \mathrm{~mm}$. long (including the single elongate-attenuate style). Diplanthera Beaudettei den Hartog, D. Wrightii of auth., Halodule Wrightii of auth.

In salt water of bays along the Gulf Coast in Tex., frequent in sea drift; widely distributed in the Carib. and also in the Gulf of Mex., along the Atl. Coast of N.A. n. to N.C.; also along the Pac. Coast of Pan. and Nic.

\section{Cymodocea KöNIG}

Several species of marine waters mainly in tropical regions. Sometimes placed in a separate family, Cymodoceaceae.

\section{Cymodocea filiformis (Kütz.) Correll. Manatee-grass. Fig. 48.}

Submerged acaulescent dioecious perennial, with creeping rootstocks branching and rooting at the nodes; leaves all submerged, grasslike, terete or semiterete, acute at the apex and sheathing at the base, the sheaths more or less auriculate, to $35 \mathrm{~cm}$. long and $2 \mathrm{~mm}$. wide; stipular sheaths completely surrounding the leaf bases, scarious, to $45 \mathrm{~mm}$. long; flowers unisexual, solitary or in simple or dichotomous cymes; staminate flowers consisting of two anthers on the end of a long pedicel, the anthers equally attached, both the same height, 2-celled; pistillate flower of 2 carpels, without perianth but subtended by a hyaline perianthlike bract; style 2- to 4-lobed; stigmas 2, hairlike; mature fruit 1-seeded, $3 \mathrm{~mm}$. long, beaked by the persistent style. Cymodocea manatorum Asch., Syringodium filiforme Kütz.

In shallow salt water of bays along the Gulf Coast of Tex., frequent in sea drift; from Fla. and Tex. to Berm., Cuba and Martinique. 

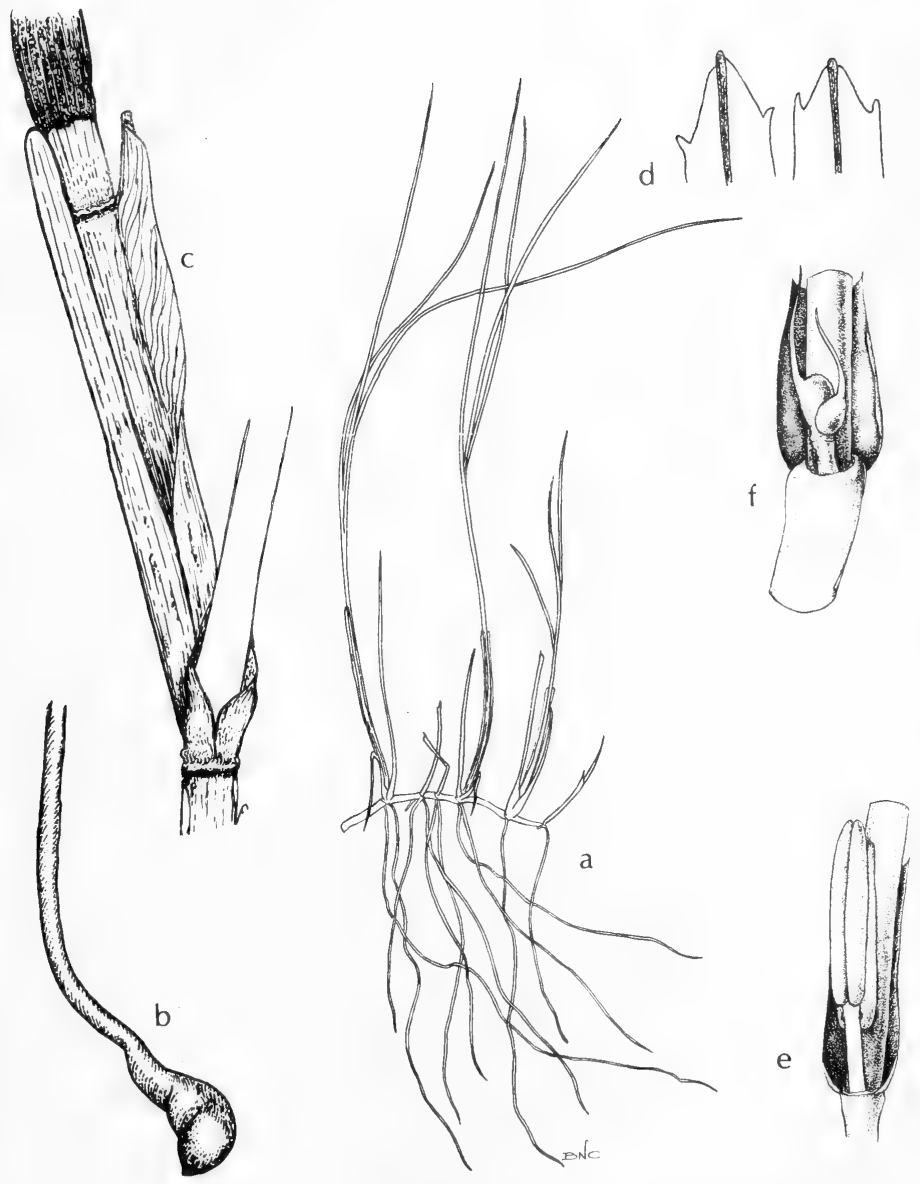

Fig. 47: Halodule Beaudettei: a, habit, $\mathrm{x} 1 / 2$; b, enlarged fleshy root; c, sheath, X 5; d, enlarged tips of leaves; e, staminate flower, X 5 ; $\mathrm{f}$, pistillate flower, X 5 . (a, e, f, Courtesy of R. K. Godfrey. b, c, d, V. F.) 


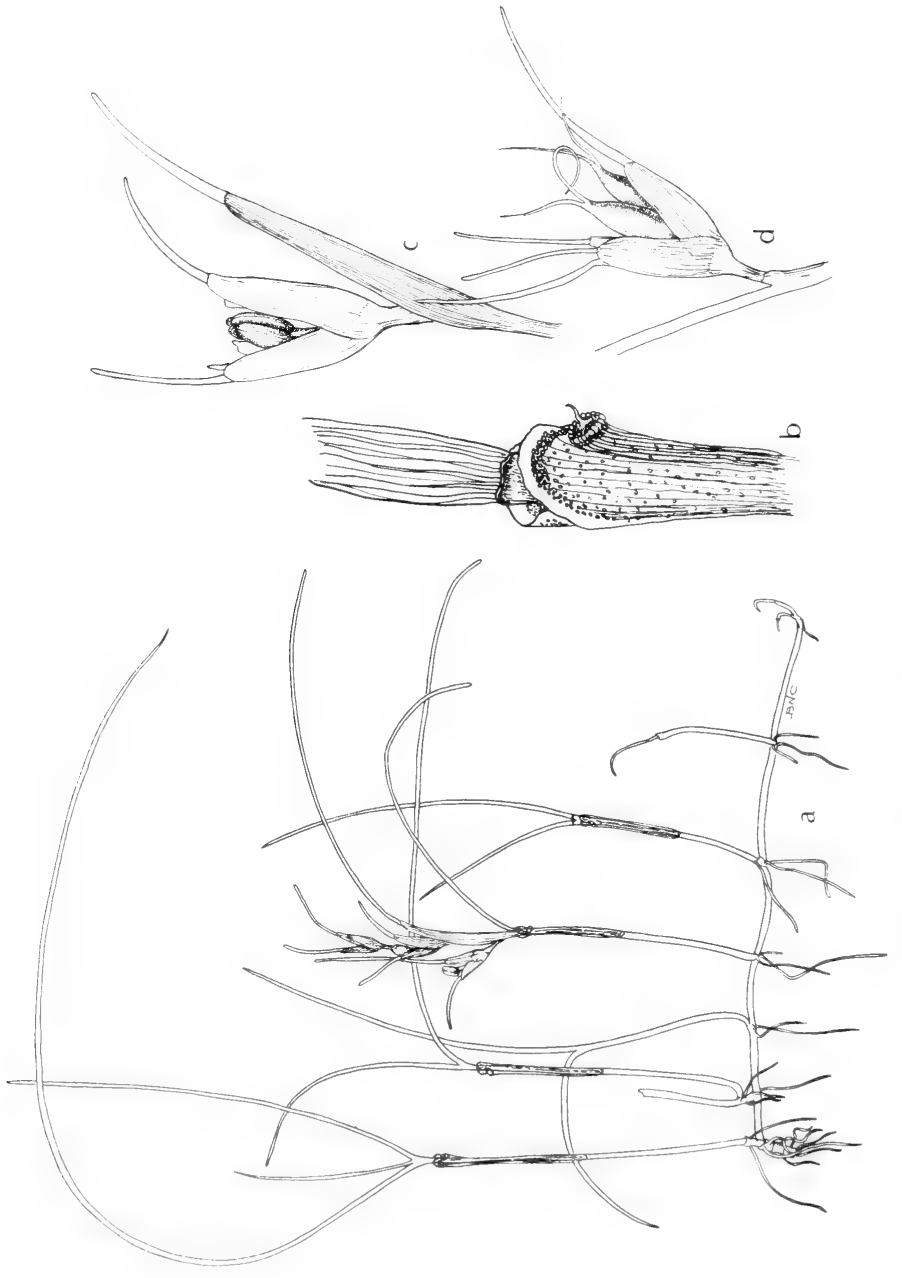

نे

D)

$\therefore$

$\times$

苛㻤

تص

..

है

है

$\approx 3$

0

ธัن

$8 x$

है

屯े

. $\stackrel{\infty}{\frac{1}{3}}$

进宓 ซீ 
Aquatic herbs of brackish or saline waters; stems simple or branched, submerged; leaves opposite or alternate, linear or setaceous, with a stipular sheath at the base; flowers perfect, small, few, arranged in terminal spikes that are at first enclosed by the sheathing leaf bases, at length much-elongated to the surface of the water; bracts absent; perianth wanting; stamens 2, opposite each other, with very short broad filaments; anthers extrorse, the 2 cells reniform and separated by the connective; carpels 4, with peltate or umbonate stigmas; ovule solitary, pendulous from the apex of the carpel, campylotropous; nutlets long-stipitate, with spirally twisted stalks, indehiscent; seeds pendulous, without endosperm.

Only one genus distrlbuted throughout temperate and subtropical regions.

\section{Ruppia L.}

Characters of the family; 2 species.

\section{Ruppia maritima L. Widgeon-GRAss. Fig. 49.}

Stem whitish or green, to $1 \mathrm{~m}$. long; leaves all submerged, threadlike, entire, 1 -nerved, to $1 \mathrm{dm}$. long and $0.3 \mathrm{~mm}$. wide, with a sharp pointed or more or less pungent apex; stipular sheath 6-10 $\mathrm{mm}$. long, membranous, the free part very short or wanting; flowers on a short peduncle that elongates after anthesis and ultimately becomes a loosely coiled spiral; stamens without a filament, early deciduous; anthers 2, sessile, 2-celled; mature carpels ovoid, equilateral or gibbous and oblique, about $2 \mathrm{~mm}$. long, long-stipitate; style short and stout or finely attenuate, straight or hooked; pedicellate stipe of the black nutlet to $3 \mathrm{~cm}$. long.

On the Tex. Gulf Coast and in saline waters of pools, rivers and marshes in the interior to Okla. (Alfalfa Co.), N.M. (Chaves Co.) and Ariz. (Maricopa, Mohave and Navajo cos.), Apr.-Aug.; from Can. s. to Mex.

This species is considered to be one of the most valuable of all submerged aquatics, especially in saline habitats, for the maintenance of wild life. It provides excellent food and cover for fish, and all parts of the plant, including its rootstock and stems, are relished by many species of waterfowl, while marshbirds and shorebirds eat its fruit and foliage.

\section{Fam. 18. Najadaceae Juss. WATER-NYMPH FAMILY}

Submerged annual monoecious or dioecious herbs of fresh or brackish waters, with fibrous roots; stems slender, much-branched; internodes spiny or unarmed; leaves small, sessile, subopposite to somewhat alternate or verticillate, with a sheathing base and linear entire or toothed blade; within the sheath a pair of minute scales; flowers unisexual, very small, borne at the base of the branches; staminate flowers with 1 stamen, mostly subsessile and included in a spathe, the perianth bilabiate at the apex; anther sessile, 1- to 4-celled, opening by slits lengthwise; pistillate flowers without a perianth or this very thin and adhering to the carpel; ovary of 1 carpel, 1-celled, with 2 to 4 linear stigmas; ovule solitary, erect from the base, anatropous; nutlet usually embraced by the leaf sheath, indehiscent, enclosed in a loose and separable membranous coat, smooth and shining or reticulate with angled or roundish areolae.

Contains only the following genus and about 50 species widely distributed in temperate and warm regions. 


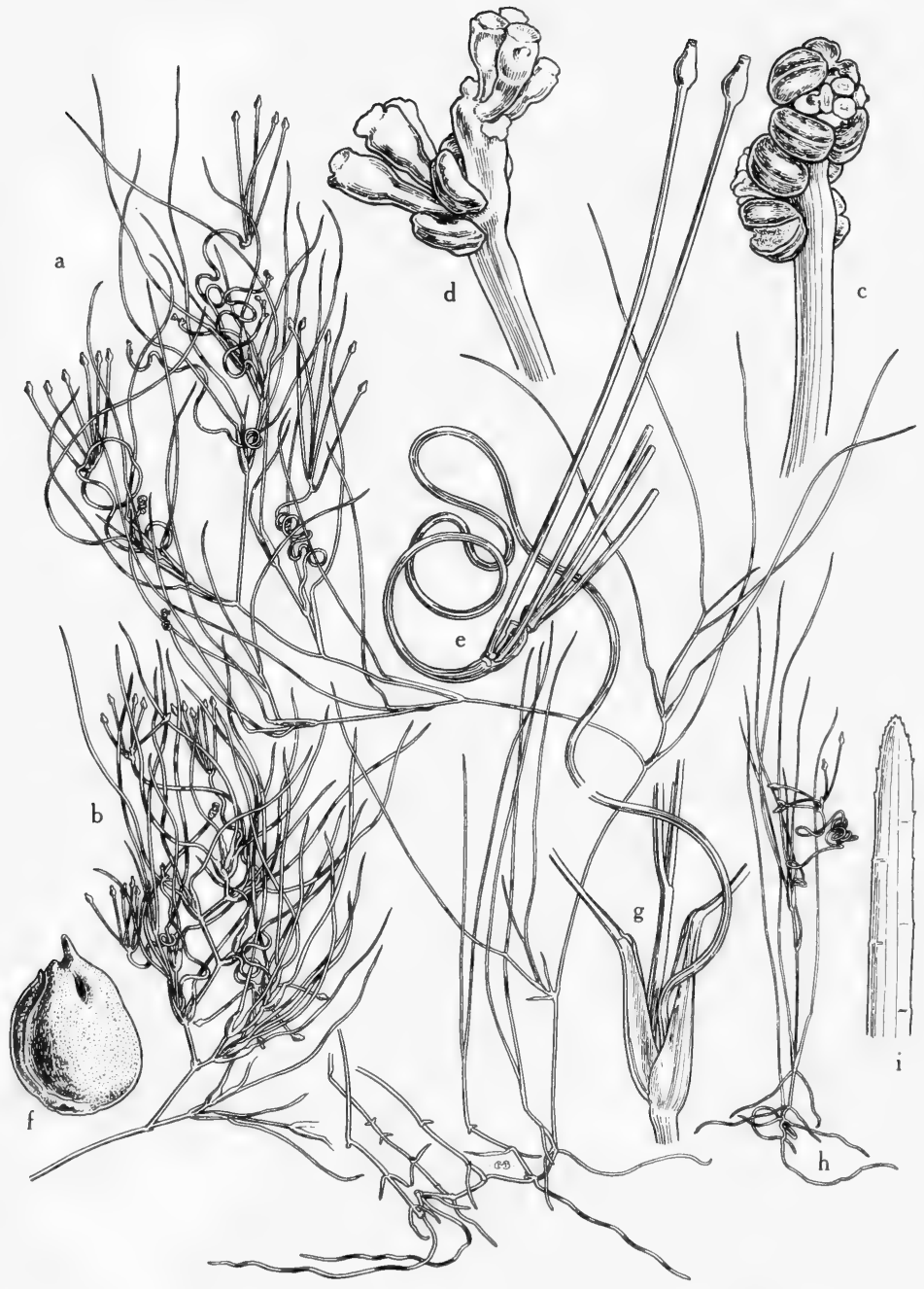

Fig. 49: Ruppia maritima: a and b, variations in habit, the stems sometimes very long and slender or sometimes with short fractiflex nodes, X $2 \%$; c, peduncle bearing 2 young flowers, each consisting of 2 large bicellular anthers and 4 pistils, $X 8 ; d, 2$ flowers, after fertilization, $X$ 8; e, development of the long-pediceled fruits following fertilization of the 2 flowers ( note elongate, coiled peduncle), X 2 ; f, mature nutlet, hard and black, X 8;g, 2 stipular sheaths of the alternate capillary succulent leaves, X 2 ; h, habit variation, X $\% \% ;$ i, serrate leaf tip, X 20. (From Mason, Fig. 32). 

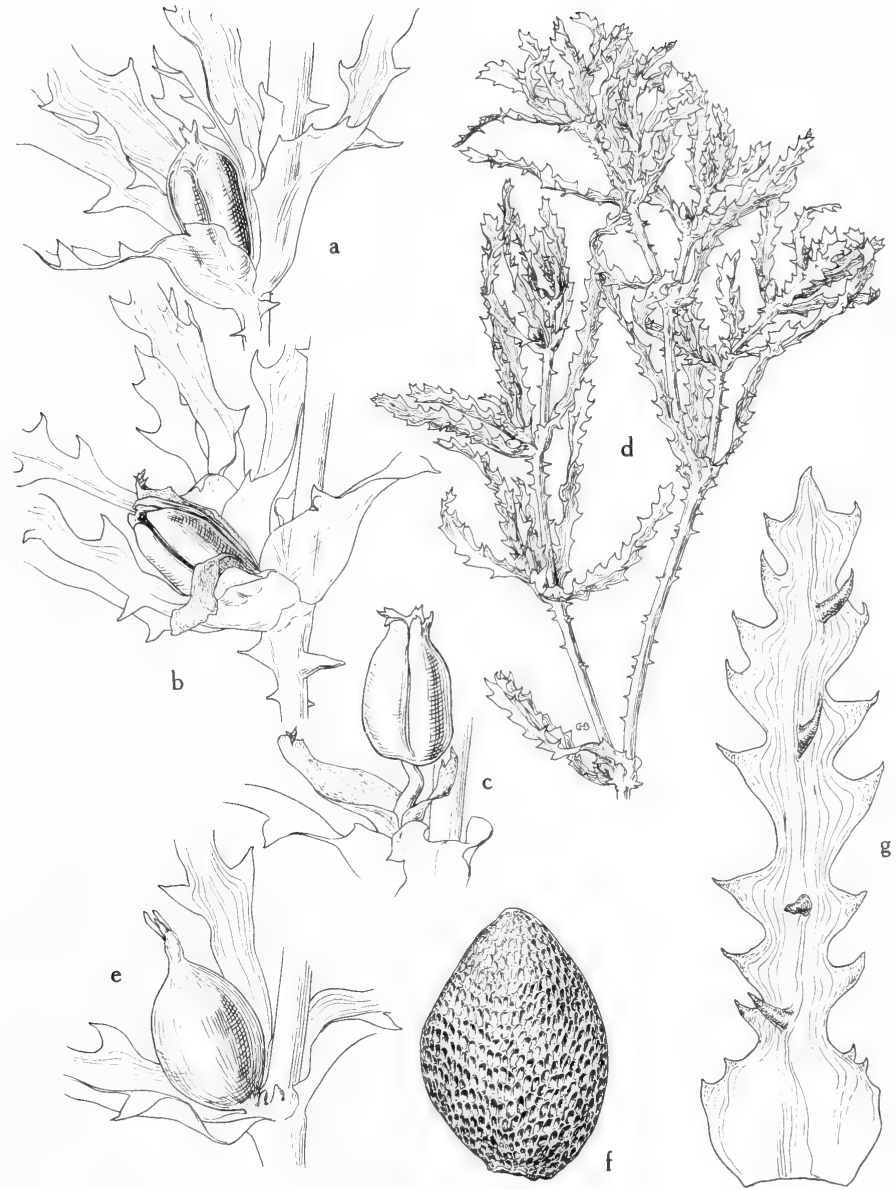

Fig. 50: Najas marina: a-c, development of anther: a, anther enclosed in sessile spathe in leaf axil, X 8; b, anther beginning to elongate and rupture spathe, $\mathrm{X} 8$; c, mature anther, showing short filament, X 8; d, habit, showing the stems beset with prickles, and the spiny-toothed leaves, $X 11 \%$; e, mature pistillate flower, showing the 3 stigmas and the intravaginal scales at base, X 8; $\mathrm{f}$, mature seed, X 10: $\mathrm{g}$, leaf blade, showing the coarse, spiny-toothed margins, the spines on the outer side along the midrib, and the rounded shoulders of the leaf sheaths, X 6. (From Mason, Fig. 33). 
Characters of the family.

The species in this genus, along with those in Potamogeton, are considered by knowledgeable wildlife personnel to provide the most important source of all foods for wildfowl, marshbirds and shorebirds. Ducks and other waterfowl not only eat the seeds but also the stems and leaves of most of the species. The species are also considered to be good food producers for fish and to provide shelter.

1. Male and female flowers on different plants; leaves coarsely toothed; internodes and back of the leaf spiny....

1. N. marina.

1. Male and female flowers on same plant; leaves minutely denticulate; internodes and back of leaf unarmed (2)

2(1). Seeds dull, with distinct squarish pitted reticulations; leaves tapered for 2-3 $\mathrm{mm}$. to an acute to obtuse apex...................... . guadalupensis.

2. Seeds apparently smooth and shining (but finely reticulate under magnification); leaves tapered from near middle to a long slender point......... 3. N. flexilis.

1. Najas marina L. Holly-Leaved Water-NYMPh. Fig. 50.

Plants brittle; stems branched, sometimes dichotomously so, armed with brownish spinulose teeth on the internodes; leaves linear, opposite to somewhat alternate, stiffish or recurved, to $45 \mathrm{~mm}$. long and $3 \mathrm{~mm}$. wide, with toothed margins and sometimes dorsally toothed on the midrib, the usually triangular teeth apiculate and $1 \mathrm{~mm}$. long or more; basal leaf sheaths rounded, without teeth or rarely with a few short teeth; male and female flowers on different plants; staminate flowers 3-4 mm. long, the anther 4-celled; pistillate flowers 3-4 mm. long; stigmas 3 , sometimes one shorter than the others; mature seeds ovoid, apparently tesselated in dried specimens, smooth when fresh.

In lakes and ponds, rare in s. Tex. and Ariz. (Mohave, Navajo, Pima, Santa Cruz and Yuma cos.), May-Sept.; from N.Y. to Calif., s. to Fla., Tex., Ariz., Mex. and Cuba; also Euras. and Austral.

\section{Najas guadalupensis (Spreng.) Magnus. COMMON WATER-NYMPH. Fig. 51.}

Plants monoecious, flaccid; stems slender, branched, to about $6 \mathrm{dm}$. long; leaves all submerged, linear, to $25 \mathrm{~mm}$. long and $2 \mathrm{~mm}$. wide, tapered for 2-3 $\mathrm{mm}$. to an acute to obtuse apex and usually tipped with 1 or 2 spines, the 20 to 40 marginal teeth inconspicuous or often apparently wanting; basal leaf sheaths sloping or rounded, not auriculate, spinulose; male and female flowers on same plant; staminate flowers $2-3 \mathrm{~mm}$. long, the anthers 4-celled; pistillate flowers 2-3 $\mathrm{mm}$. long; mature fruit crowned with 2 or 3 stigmas and usually with 1 or 2 spiny sterile stigmatic processes; seeds ellipsoid, dull, reticulate with numerous 4-sided areolae.

Attached to bottom and floating just below surface of water in ponds, lakes, springs, ditches and streams, in fresh or sometimes brackish water, often forming large mats, rather common throughout Tex. and Okla., rare in N.M. (Rio Arriba Co.) and Ariz. (Santa Cruz and Yavapai cos.), Apr.-Sept.; from Pa.w. to Ore., s. to Fla., Tex., N.M., Ariz., Mex., C.A., the W.I., Jam. and Guadeloupe.

\section{Najas flexilis Rostkov. \& Schmidt. Slender water-Nymph. Fig. 52.}

Plants monoecious; stems freely branched, slender, to $2 \mathrm{~m}$. long; leaves narrowly linear, $1-3 \mathrm{~cm}$. long, less than $1 \mathrm{~mm}$. wide tapered from about the middle to a long slender point, thin and translucent, very minutely toothed, numerous and crowded on the upper parts of the branches, the teeth consisting of protrusions of usually 1 marginal cell; leaf sheaths with obliquely sloping shoulders, the margins bearing 


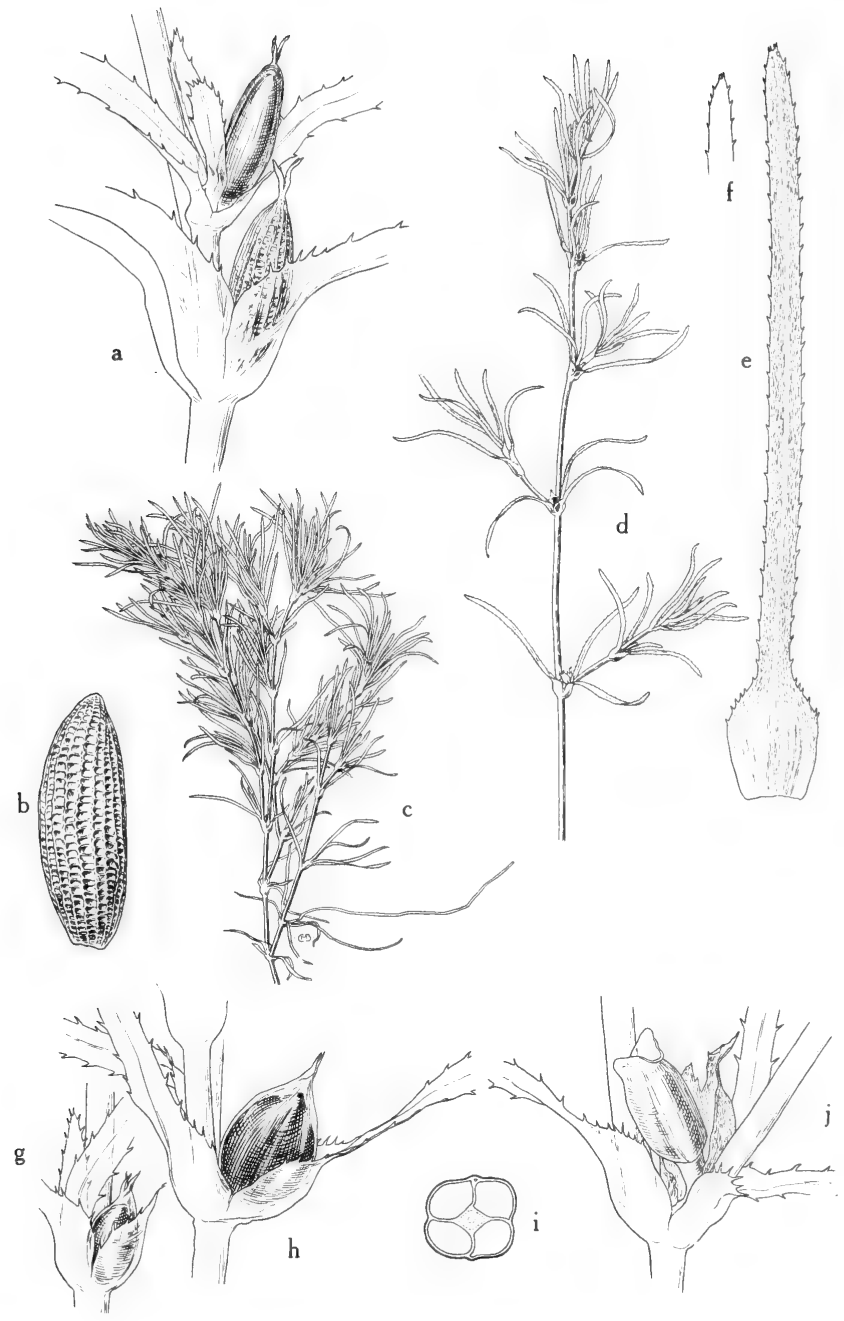

Fig. 51: Najas guadalupensis: a, young and mature pistillate flowers, borne singly in leaf-sheath axils, X 8; b, mature seed, dull but distinctly reticulate, $X$ 16; c, habit, showing plant with threadlike crowded leaves, $\mathrm{X} 4 / 5 ; \mathrm{d}$, habit, showing plant with less crowded leaves, X 11/5; e and f, leaf blade, showing marginal and apical teeth, X 61/2; $\mathrm{g}$ and $\mathrm{h}$, young staminate flowers borne singly in leaf-sheath axils, the anthers still enveloped by the spathe, X $8 ; \mathrm{i}$, anther (cross section), $\mathrm{X} 12 ; \mathrm{j}$, mature anther at anthesis, showing ruptured spathe, X 8. (From Mason, Fig. 36). 


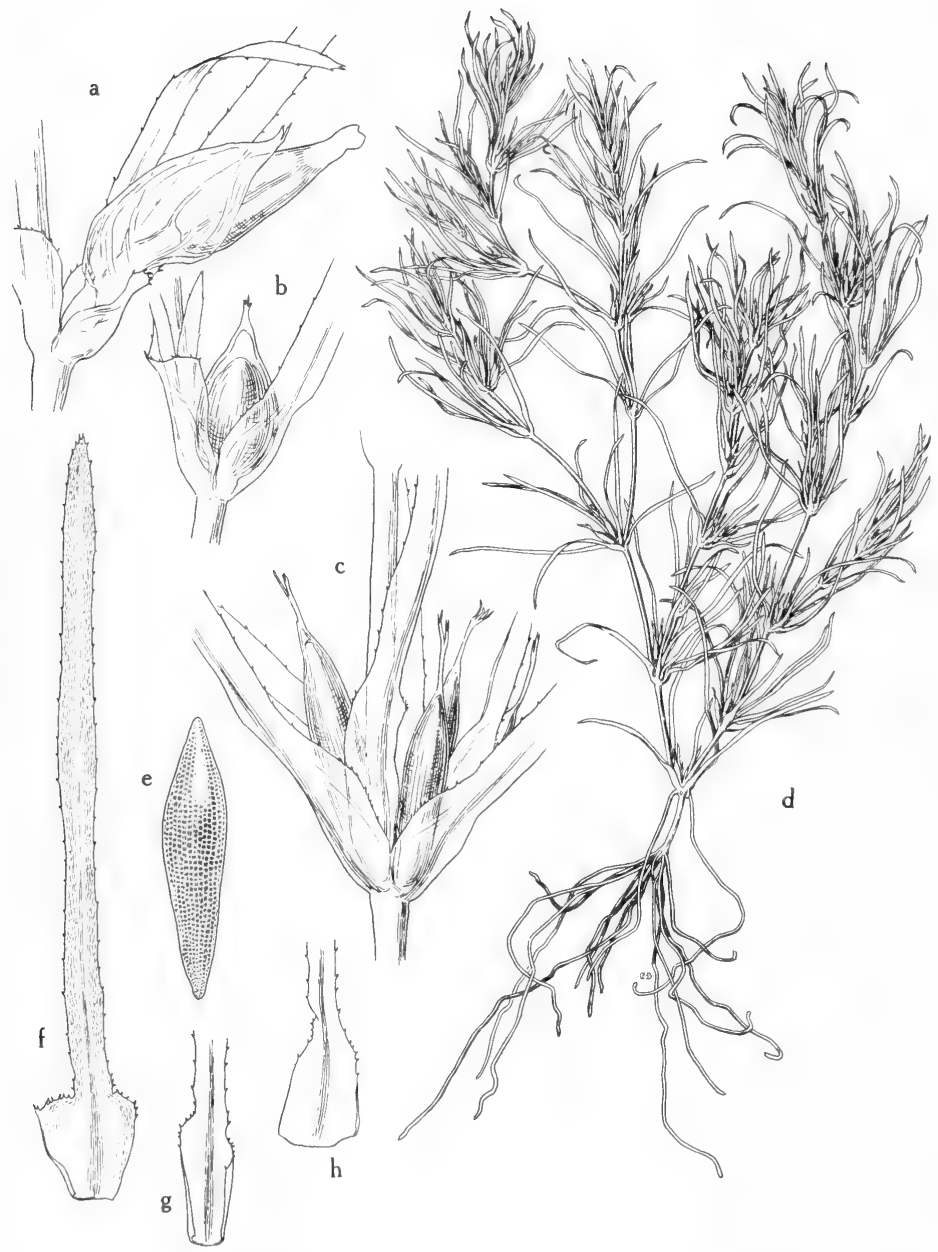

Fig. 52: Najas flexilis: a, mature staminate flower, showing dehisced anther and ruptured spathe, $X 8$; b, young sessile, staminate flower enveloped by spathe, X 8 ; c, pistillate flowers in axil of leaf sheath, showing variations in stigmas, X 8; $\mathrm{d}$, habit, plant completely submersed, showing the fascicled leaves, X 11/5; e, mature seed, shiny yet finely reticulate under magnification, X $12 ; \mathrm{f}-\mathrm{h}$, leaf blades, showing minute teeth and obliquely sloping somewhat unequally shouldered leaf sheaths, X 5. (From Mason, Fig. 35). 
several very minute teeth; intravaginal scales filiform, less than $1 \mathrm{~mm}$. long; staminate flowers $2.5-3 \mathrm{~mm}$. long, the anther 1-celled; pistillate flowers about $3 \mathrm{~mm}$. long; stigmas 2 to 4 , usually 3 ; seed narrowly elliptic to lanceolate-ovoid, about $3 \mathrm{~mm}$. long, apparently smooth and shining but finely reticulate under magnification.

In fresh to somewhat brackish water, reported by Mason from w. Ariz., MayAug.; n. e. Can. to B. C., s. to Md., Ariz. and Calif.; also Eur.

The occurrence of this species in our region needs verification. We have seen no material.

\section{Fam. 19. Posidoniaceae Lotsy}

Submerged marine perennials; rhizome and stem densely covered with the persistent fibrous leaf bases; leaves sheathing at the base, the sheaths open and ligulate; blades linear, flat, rounded at the apex, leathery, entire to serrulate; flowers perfect, spicate, on long axillary and terminal peduncles; spikes several, subtended by reduced leaves; floral bracts absent; perianth absent or of 3 caducous scales; stamens 3 or 4, hypogynous; anthers extrorse, large, sessile, with a thick connective produced beyond the cells, the latter widely separated; pollen threadlike; ovary superior, 1-celled, with a sessile lacerate or muricate stigma; ovule elongated, parietal, the micropyle inferior; fruit ovoid, fleshy, indehiscent; seed without endosperm; embryo with a straight cotyledon.

A monotypic family, considered to be confined to Australia and the Mediterranean region.

\section{Posidonia KönIG.}

A genus of 2 species. Characters of the family. Sometimes placed in the Najadaceae or Potamogetonaceae.

\section{Posidonia oceania König. Fig. 53.}

Characterized by the rhizome and stem being densely covered with the persistent fibrous leaf bases; leaves linear, rounded at apex, to $5 \mathrm{dm}$. long and $7 \mathrm{~mm}$. wide, about 13-nerved; inflorescence a 3-flowered spike, 2 flowers of which are perfect and one staminate; staminal connective broad, abruptly long-aristate; fruit semioval, fleshy, indehiscent.

This species is included here with some reservations since it is known from Texas only by plants being washed up on the beaches along the coast in Cameron, Galveston and Nueces counties. Since, however, species in the marine genera Cymodocea, Halodule, Thalassia and Halophila are not only frequent in sea drift but are also known to grow along the Texas coast, it is quite possible that Posidonia may also eventually be found to grow along the Texas coast.

\section{Fam. 20. Juncaginaceae RicH.}

\section{Arrow-WeEd Family}

Annual or perennial marsh herbs from rhizomes or tubers; leaves basal, linear, sheathing, ours with blade terete or semiterete; inflorescence a spikelike raceme borne on a naked scape; flowers with short slender or stout pedicels, unisexual or perfect, regular to slightly irregular, bractless; bractiform perianthlike appendages usually 6 , in 2 series, each appendage bearing a stamen attached to its base or on some the stamen absent; anthers 2-celled, subsessile, opening by slits; pistil superior, of 6 or 4 (or 3) connate to weakly united carpels, these sometimes separating in fruit; styles short or absent; stigmas often papillate or plumose; ovule 1 per carpel, basal, erect; fruit of distinct or weakly united dehiscent or indehiscent 

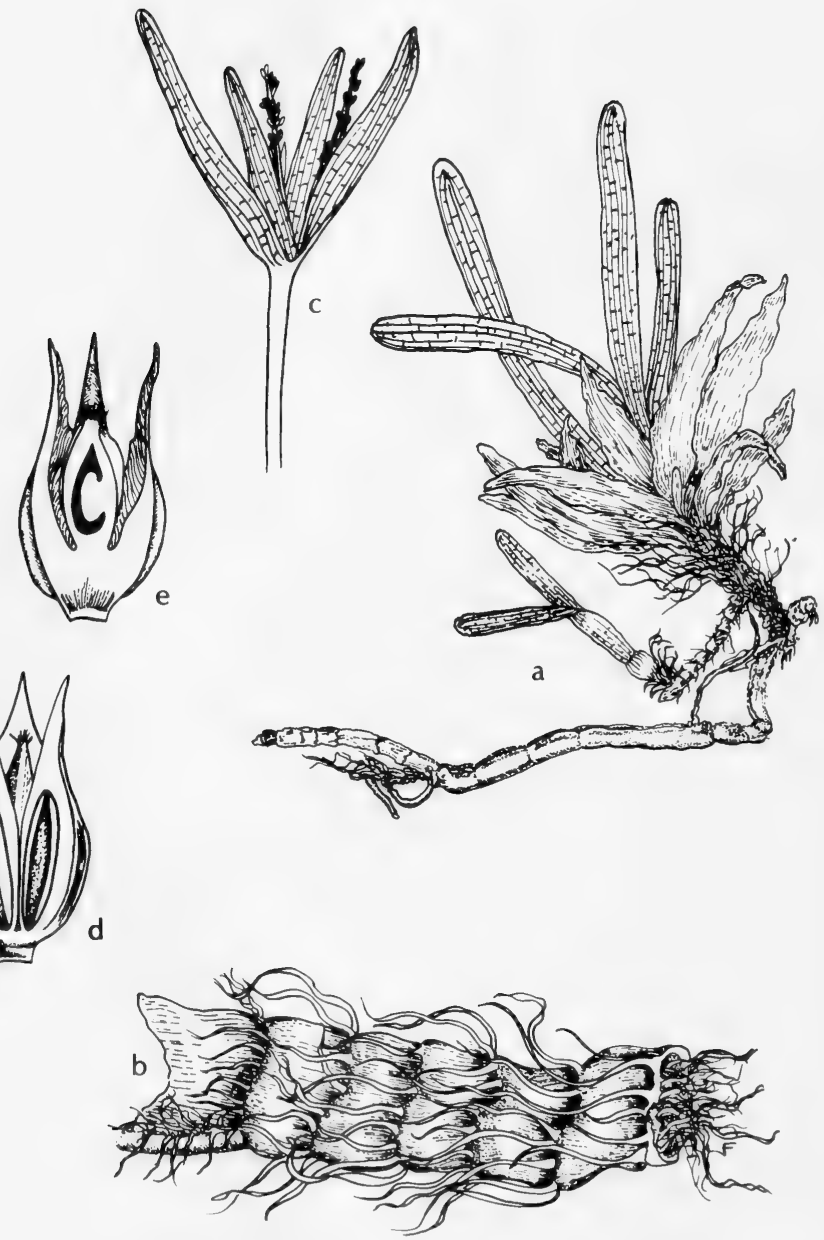

Fig. 53: Posidonia oceania: a, habit, X 1/2; b, rhizome, X 2; c, inflorescence, enlarged; d, flower, enlarged; e, vertical section of flower, enlarged. (a, b, V. F. c-e, from Hutchinson, The Families of Flowering Plants, Vol. 2, Fig. 351). 
carpels, these erect or recurved only at apex, sometimes with hooked spines at base.

About 25 species in 3 genera in temperate and cold regions in both hemispheres.

\section{Triglochin L.}

Herbaceous perennial; leaves broadly sheathing at base, the sheath culminating above in an entire or 2-lobed ligule, the blade semiterete; scapes and racemes longer than or shorter than the leaves; each perianthlike appendage of the flower usually deciduous with its attached stamen and often leaving a conspicuous enlarged scar which simulates a reflexed perianth part at the base of the fruit; stamens 6 to 3 (or 1), subsessile, the anthers often broader than high, rarely much longer than broad; carpels joined to a central carpophore from which only the fertile carpels separate at maturity; stigmas of slender papillae; seed linear, loosely enclosed in the indehiscent carpel.

About 15 species, cosmopolitan, especially Australia and temperate South America.

1. Carpels and stigmas 3 ; fruit linear-clavate, the axis 3-winged; carpels subulate at the base.......................................................... 1. T. palustre.

1. Carpels and stigmas typically 6 , occasionally 3 ; fruit narrowly oblong-elliptic to ovate-prismatic, the axis terete; carpels not subulate at base (2)

2(1). Rootstock covered with persistent whitish leaf bases; ligules entire or essentially so, 1-5 mm. long; leaf blades somewhat obcompressed, mostly $1.5-2.5 \mathrm{~mm}$. wide, rarely more; fruits usually $3.5-4.5 \mathrm{~mm}$. long and 2-3 mm. thick...................................2. T. maritimum.

2. Rootstock usually covered with coarse brownish fibers of the old leaf bases; ligules deeply bilobed, $0.5-1 \mathrm{~mm}$. long; leaf blades almost terete, $1.5 \mathrm{~mm}$. wide or less; fruits usually $3-3.5 \mathrm{~mm}$. long and 1-2 mm. thick. 3. T. debilis.

\section{Triglochin palustre L. Fig. 28.}

Rootstock short, emitting filiform bulb-bearing stolons; scape to $7 \mathrm{dm}$. high, terminated by an elongate laxly flowered raceme; leaves one half to three fourths as long as scape, 1-2 $\mathrm{mm}$. wide, sharp-pointed, the ligule $0.5-1.5 \mathrm{~mm}$. long and parted to the base; pedicels slender, erect in fruit and then 4-6 $\mathrm{mm}$. long; perianth segments about $1.5(-2) \mathrm{mm}$. long, slightly exceeding the stamens; fruit linearclavate, mostly $6-8 \mathrm{~mm}$. long, the 3 carpels separating from below upward and remaining suspended from the tip, subulate at base.

Wet meadows, bogs, mud flats and gravelly stream margins, often brackish or alkaline, in N. M. (Otero, Sandoval, San Miguel and Taos cos.), June-Sept.; Greenl. and Lab. to Alas., s. to Me., N. Y., Ill., Ia., N. M., Ida. and Calif.; also S. A. and Euras.

\section{Triglochin maritimum L. Fig. 54 .}

Coarse or slender plant with few to many tufted scapes 1-10 dm. tall from a proliferating caudex or stout short rhizome covered with persistent whitish leaf bases; leaves thick, 1-8 dm. long, 2-5 mm. wide, the ligule entire and 1-5 $\mathrm{mm}$. long; scape terminated by a raceme of numerous pedicellate flowers; pedicels somewhat ascending to decurrent, 2-6 mm. long; flowers with 6 perianthlike appendages each bearing an attached stamen; pistil of 6 (rarely 3 ) fertile carpels rounded at base and united around the slender carpophore; mature fruit ovoidprismatic, 3-4.5 $\mathrm{mm}$. long, 2-3 $\mathrm{mm}$. thick, with carpels united, the edges acutish and reflexed, the beaks recurved, indehiscent; seeds linear. Incl. var. elata (Nutt.) Gray.

Saline and alkaline wet meadows and marshes in N.M. (Colfax, Grant, Otero, Sandoval, San Juan, Taos and Valencia cos.) and Ariz. (Coconino Co.), MayOct.; Lab. to Alas., s. to Pa., Ind., Ill., Ia., N.M., Calif. and Mex.; also S.A. and Euras. 


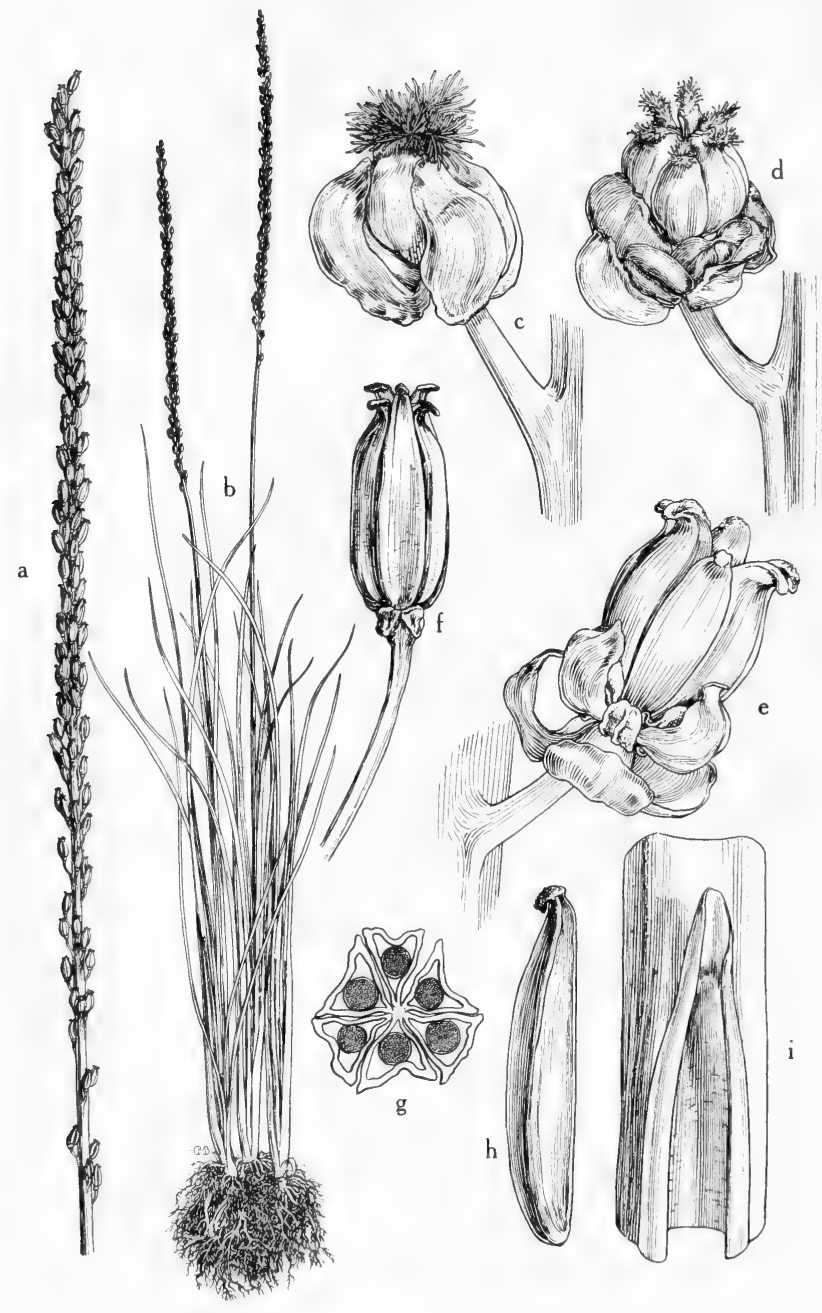

Fig. 54: Triglochin maritima: a, inflorescence, $\mathrm{X} 2 \%$; , habit, showing racemes raised above the leaves, $\mathrm{X} 1 / \mathrm{s} ; \mathrm{c}$, young flower, showing bractiform perianthlike appendages (anthers enclosed) and stigmas of slender papillae, X 8; d, flower, showing maturing anthers, each within a perianthlike appendage, and maturing carpels, X 8; e, flower, showing the 2 series of perianthlike appendages, each appendage with a dehisced anther, the fruit nearly mature, $X 8$; $\mathrm{f}$, mature fruit, showing the conspicuous appendage scars below, X $4 ; \mathrm{g}$, fruit (cross section), all carpels fertile, $\mathrm{X} 6 ; \mathrm{h}$, separate mature carpel, X 6; i, entire ligule, X 4. (From Mason, Fig. 39). 


\section{Triglochin debilis (M.E. Jones) Löve \& Löve.}

Plant slender, 1-3 dm. tall, usually well-spaced and erect-spreading from a slender elongate rootstock, the base covered with coarse brownish fibers of the leaf bases, the rootstock with conspicuous internodes and bracteate nodes; leaves $8-20 \mathrm{~cm}$. long, the sheaths membranous-margined, terminating above in a 2 -lobed ligule $0.5-1 \mathrm{~mm}$. long; scapes longer than the leaves, terminated by a strict raceme, the rachis may be either straight or fractiflex; pedicels slender; flower with 6 perianthlike appendages each bearing an attached anther; mature fruit composed of 6 united carpels about $3-3.5 \mathrm{~mm}$. long and 1-2 mm. thick, usually all fertile; fruiting carpels separating readily from the slender carpophore, indehiscent; seeds slender, needlelike. T. concinnum Davy var. debilis (M.E. Jones) J. T. Howell.

In wet meadows and marshes along streams, in brackish to saline or alkaline situations, in Ariz. (Coconino and Navajo cos.), May-Oct.; from Ore. to Calif., e. to and beyond the Rocky Mts., from N. D. to Colo. and Ariz.

\section{Fam. 21. Alismataceae Vent. Water Plantain Family}

Annual or perennial lacticiferous aquatic or marsh plants with fibrous roots from a usually somewhat thickened rootstock and a cluster of basal leaves with their long petioles sheathing a scape; leaves at first typically bladeless but soon developing either a linear or sagittate type of blade with prominent nerves and transverse veinlets; scape erect or arching, with a simple or branched bracteate inflorescence; flowers perfect or unisexual, regular, borne in verticils; perianth segments imbricate or involute in bud; sepals 3 , green, persistent; petals 3 , deciduous; stamens 6 to many, included, the filaments distinct, the anthers 2-celled and dehiscing by longitudinal slits; carpels numerous, distinct, 1-celled and mostly 1-ovuled, arranged in a ring or crowded on a receptable to produce a headlike fruit of flat or turgid achenes that are usually provided with resin ducts and/or wings.

A family of about 13 genera and 90 species of worldwide distribution.

Species that comprise this family are known to attract marsh and song birds and to provide shade and shelter for young fish, while the tubers formed by many species, as well as the achenes, are eaten by wildfowl. Mammals, such as muskrats, beavers and porcupines, are known to eat the vegetative parts of many species of Sagittaria.

Seeds of most of our species are ideally suited for dissemination by birds and animals in that the beak formed by the style can readily become hooked in feathers and furs, and even to minute particles of soil that may remain on muddy feet. Also, the resin ducts and suberous wings and excrescences of the achenes of many species enable them to float great distances.

1. Achenes arranged in a single ring on the receptacle, strongly flattened;

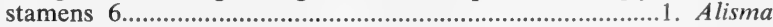

1. Achenes densely crowded over the surface of the receptacle; stamens more than 6 (2)

2(1). Flowers all perfect; achenes plump; fruiting heads simulating a bur

2. Echinodorus

2. Flowers perfect or unisexual, the upper ones mostly staminate; achenes flattened; fruiting heads not burlike 3. Sagittaria 


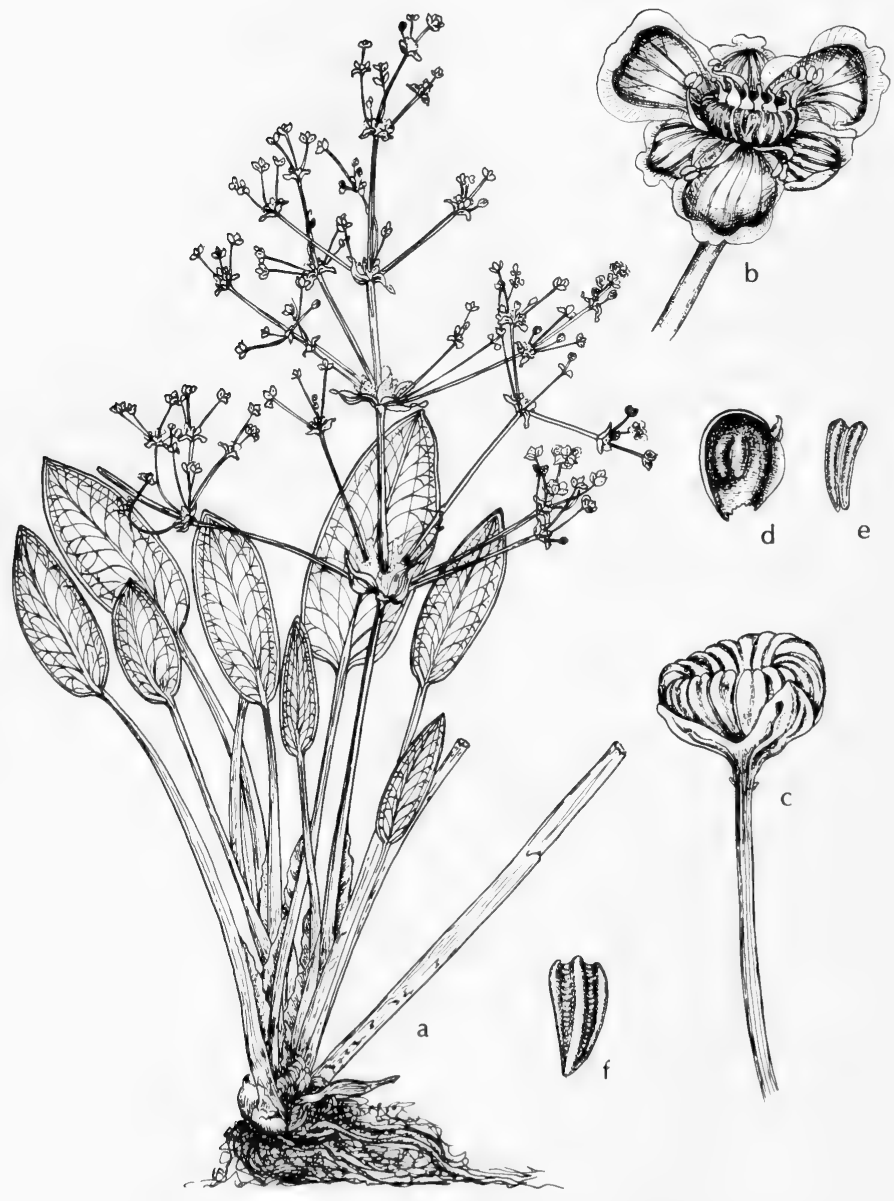

Fig. 55: a-e, Alisma triviale: a, habit, about X 1/3; b, flower, X 5; c, fruit head, X 5; d, seed, side view, X 5; e, seed, dorsal view, X 5. f, Alisma gramineum: f, seed, dorsal view, X 5. (V.F.). 


\section{Alisma L. Water Plantain. Mud Plantain}

Aquatic herbs, perennial or sometimes behaving as annuals, emersed or growing on wet mud, rarely submersed, from an apically flattened corm and fibrous roots; leaves basal, erect or rarely floating, with lanceolate or oblong-ovate to broadly ovate blades, rarely reduced to ribbonlike phyllodes; inflorescence a large open panicle; flowers small, 3-10 mm. broad, perfect, numerous, on 3-bracteate pedicels unequal in length; sepals 3 , green, persistent; petals 3 , white or occasionally rose or pink; stamens 6 to 9; pistils separate, arranged in a more or less 3 -sided whorl on the receptacle; fruit an achene, with 1 or 2 grooves to almost plane on the back.

About 10 species mostly in the North Temperate Zone.

1. Achenes about as wide as long, distinctly bisulcate on the back with the median rib typically broad and rounded; pedicels stout; petioles 4-6 mm. wide; leaf blade elliptic-lanceolate to narrowly lanceolate, to about $2.5 \mathrm{~cm}$. wide......................................... A. Aramineum.

1. Achenes longer than wide, with a solitary groove to almost plane on the back; pedicels slender; petioles less than $4 \mathrm{~mm}$. wide; leaf blade typically broadly elliptic and usually much more than $2.5 \mathrm{~cm}$. wide (2)

2(1). Achenes $2 \mathrm{~mm}$. long or less, the dorsal groove shallow or with a somewhat depressed slight thickening in the trough; fruiting heads $3.5 \mathrm{~mm}$. or less in diameter; distribution in Oklahoma and Texas.

2. A. subcordatum.

2. Achenes more than $2 \mathrm{~mm}$. long, the dorsal groove deep; fruiting heads more than $3.5 \mathrm{~mm}$. in diameter; distribution in New Mexico and Arizona 3. A. triviale.

1. Alisma gramineum Gmel. Fig. 55.

Submersed or amphibious perennial herb $5-20 \mathrm{~cm}$. high, erect or ascending or (when plant submersed) leaves and stems floating; leaves usually erect, with long broad petioles (4-6 $\mathrm{mm}$. wide) and linear-lanceolate to lanceolate blades (these rarely absent), to about $2.5 \mathrm{~cm}$. wide; inflorescence a scapose verticillate panicle to $2 \mathrm{dm}$. long, sometimes shorter than the leaves; branchlets and pedicels subtended by 2 or 3 lanceolate papery bracts; pedicels stout, often recurved in fruit; flowers $5-7 \mathrm{~mm}$. broad; sepals green, persistent; petals usually white, rhombic, entire to somewhat erose; stamens 6 to 9 ; pistils in an obscurely 3 -sided whorl; fruiting heads $3-4 \mathrm{~mm}$. in diameter; achenes often orbicular to orbicularcuneate in outline, about $2.5 \mathrm{~mm}$. in diameter, the beak on the inner margin, distinctly bisulcate on the back with the median rib broad and rounded. A. Geyeri Torr., A. gramineum var. Geyeri (Torr.) Samuelsson.

On mud and in shallow water of lakes in N.M. (Rio Arriba and Sandoval cos.) and Ariz (Coconino Co.), June-Sept.; from Calif., Ariz, and N.M., n. to Wash. and e. to Minn.

Our material is usually referred to var. angustissimum (DC.) Hendricks.

\section{Alisma subcordatum Raf.}

Erect perennial herb with a basal cluster of erect long-petioled laminated leaves surrounding a scape, essentially glabrous; leaf blades ovate to elliptic, cuneate to cordate at base, abruptly acute at apex, to $12 \mathrm{~cm}$. long and $8 \mathrm{~cm}$. wide, usually shorter than the petioles; scape to $6 \mathrm{dm}$. tall, with whorled panicled branches of small white or pinkish flowers; bracts lanceolate, acuminate, about $1 \mathrm{~cm}$. long; pedicels filiform; flowers perfect, numerous; sepals broadly ovate to suborbicular, obtuse, to $2.5 \mathrm{~mm}$. long; petals to $2.5 \mathrm{~mm}$. long; anthers spherical, $0.3-0.5 \mathrm{~mm}$. long; ovaries many in a simple circle on a small flattened receptacle; style $0.2-0.4$ $\mathrm{mm}$. long, about one fourth as long as ovaries; fruiting heads $3.5 \mathrm{~mm}$. or less in 


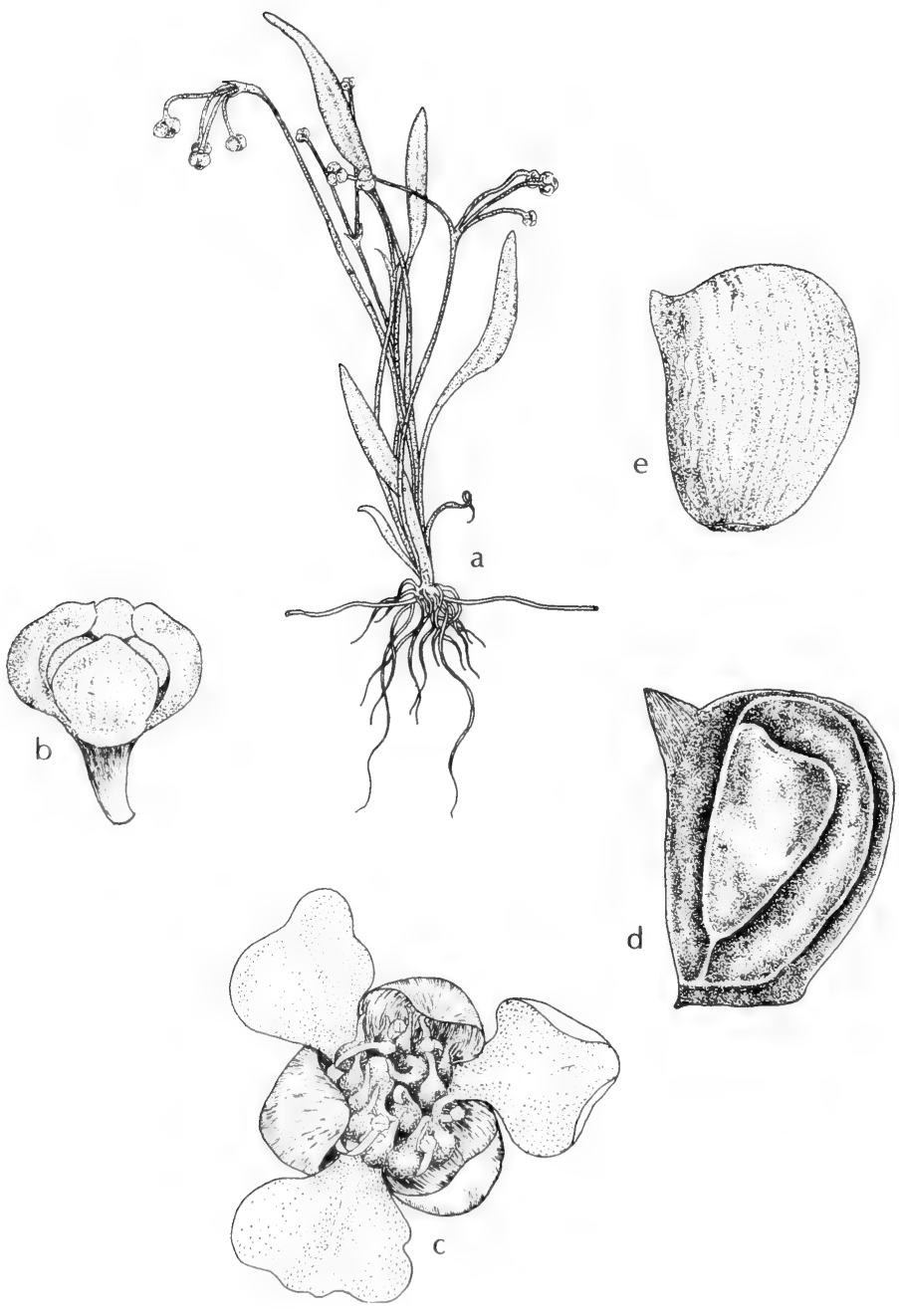

Fig. 56: Echinodorus parvulus: a, habit, X 1; b, bud, X 6; c, flower, X 9; d, achene, X 40 ; e, seed, X 30. (Courtesy of R. K. Godfrey). 
diameter; achenes obliquely obovate, 1.5-2 mm. long, the solitary dorsal groove shallow or with a somewhat depressed slight thickening in the trough, the minute beak ascending. A. parviflorum Pursh, A. Plantago-aquatica var. parviflorum (Pursh) Farw.

Usually in shallow water of marshes, streams and ponds in Okla. (Delaware, McCurtain, Mayes, Johnston, Murry and Craig cos.), n.e. Tex. (Bowie Co.) and the Tex. Panhandle (Hemphill Co.), June-Sept.; Ont., N. E. and N. Y., w. to Minn. and Neb., s. to Fla. and Tex.

Though reported from Arizona, we have seen no material of this species from the state.

\section{Alisma triviale Pursh. Fig. 55.}

Erect perennial to $12 \mathrm{dm}$. tall; leaves usually long-petioled, linear-lanceolate to broadly elliptic, 5-20 cm. long, cuneate to truncate or subcordate at base, subobtuse to abruptly acute at apex; inflorescence on an erect scape with several whorls of branches, each with 1 or more whorls of flowers or further compounded into verticillate branches much longer than the leaves, each branch and each pedicel subtended by 2 or 3 lanceolate papery bracts; flowers hypogynous; sepals 3 , plane or somewhat gibbous, obtuse, green, 3-4 $\mathrm{mm}$. long; petals 3, white or sometimes rose to pink, 3-6 $\mathrm{mm}$. long, rhombic in outline, margins entire or minutely erose; stamens 6 to 9 , much-surpassing the ovary; filaments glabrous; anthers $0.6-1 \mathrm{~mm}$. long; pistils numerous, in a single often obscurely 3 -sided whorl; styles 1-1.5 mm. long, as long as or longer than ovary; fruiting heads more than $3.5 \mathrm{~mm}$. in diameter; achenes with a solitary deep groove on back, 2-3 mm. long, 1.5-2 mm. wide, the beak on the inner angle, erect or suberect. A. brevipes Greene, A. Plantago-aquatica subsp. brevipes (Greene) Samuelsson, and var. americanum Schult. \& Schult., and var. Michaletii (Asch. \& Grabn.) Buch.

In shallow water or on wet mud in N.M. (Rio Arriba, Valencia and Taos cos.) and Ariz. (Coconino, Navajo and Cochise cos.), May-Sept.; Que. to B.C., s. to Md., W.Va., Mich., Ia., Neb., N.M., Ariz. and n. Mex.

\section{Echinodorus Rich. BurHeAd}

Annuals or short-lived perennials of wet habitats, with basal leaves and naked erect or repent scapes that are sparingly branched or occasionally simple; flowers pedicellate, perfect, usually in remote whorls; sepals 3, persistent; petals 3 , imbricated in the bud, white, deciduous; stamens 6 to usually many more; filaments elongate, usually exceeding the anthers in length; achenes forming a head, turgid, ribbed or ridged, beaked or beakless.

A dozen or more species in America, Europe and Africa.

1. Achenes 20 or fewer in a loose head, essentially beakless; stamens 9; anthers basifixed.

1. E. parvulus.

1. Achenes 30 or more in a dense tight head, prominently beaked; stamens 12 or more; anthers versatile (2)

2(1). Sepals with papillose ridges; scape erect when young but soon repent; achenes with summit or keel often crested and the beak ascending; pellucid lines of leaves mostly $1 \mathrm{~mm}$. or more apart and rarely exceeding $1 \mathrm{~mm}$. in length..................................... E. cordifolius.

2. Sepals with smooth veins; scape rigidly erect at maturity; achenes with keel entire and the beak erect or nearly so; pellucid lines of leaves mostly less than $1 \mathrm{~mm}$. apart and often several $\mathrm{mm}$. long (3)

3 (2). Plants robust, usually much more than $2 \mathrm{dm}$. tall; leaves typically broadly ovate, broadly cuneate to cordate at base; beak of achenes $1.2-2$ mm. long. 


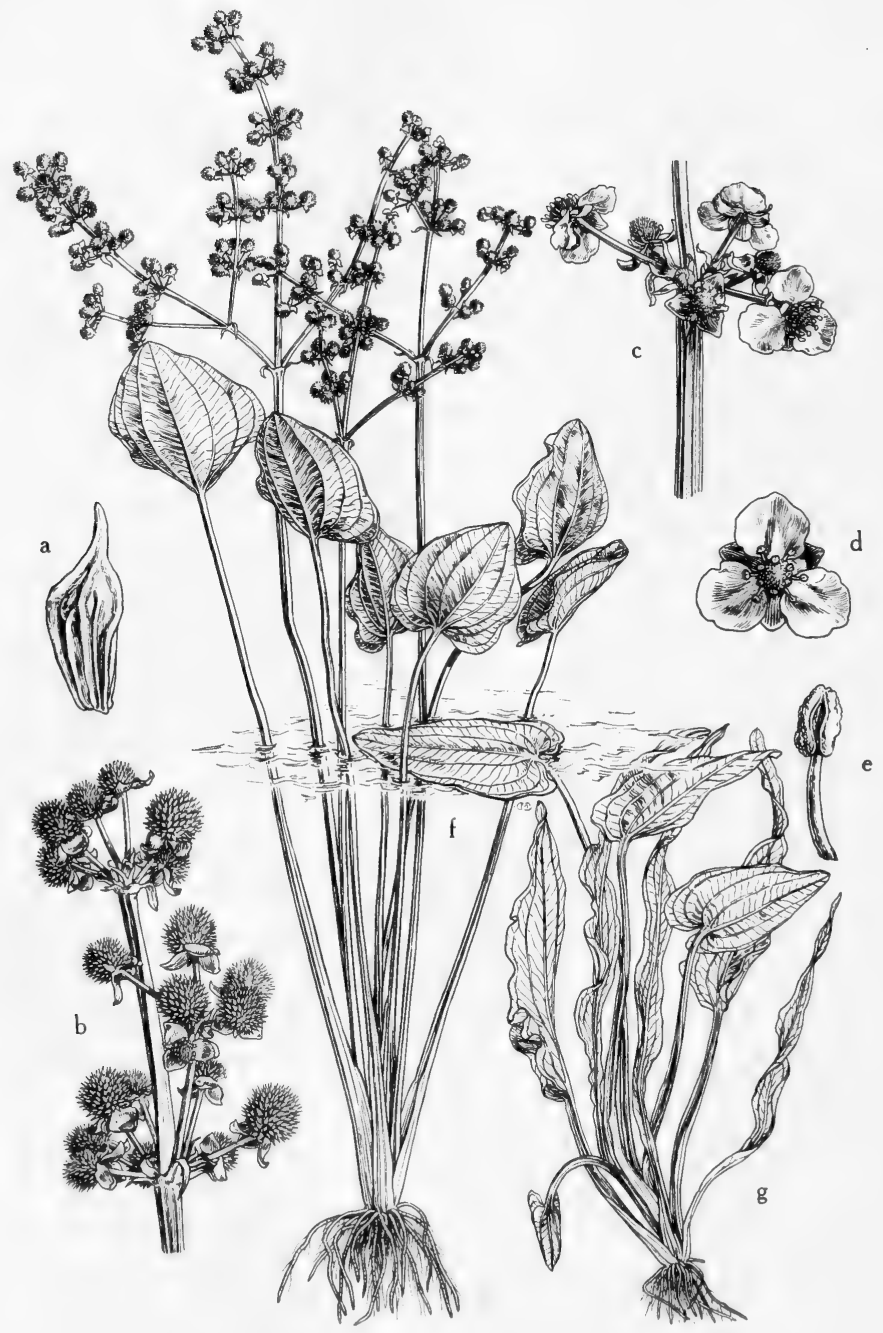

Fig. 57: Echinodorus rostratus: a, mature achene, $X 8, \mathrm{~b}$, upper part of inflorescence, showing maturing burlike fruits, $\mathrm{X} 4 \% \mathrm{c}$, whorl of flowers, $\mathrm{X} 4 \% \mathrm{~d}$, flower, showing the arrangement of the 12 stamens, $X 1 \frac{1}{2}$; e, stamen, X 8; f, habit of mature plant, X $1 / 5 ; \mathrm{g}$, habit of young submersed plant, showing transition stages from early linear to mature cordate leaf blades, X 1/5. (From Mason, Fig. 46). 

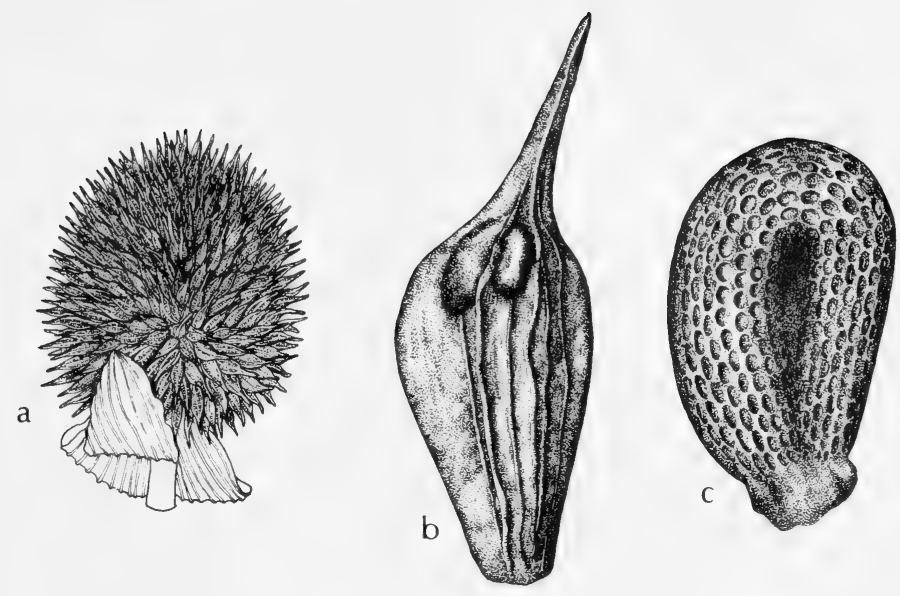

Fig. 58: Echinodorus rostratus: a, head, X 5; b, achene, X 25; c, seed, X 60 . (Courtesy of R. K. Godfrey).

3. Plants delicate, rarely more than $2 \mathrm{dm}$. tall; leaves typically lanceolate, narrowly cuneate to somewhat rounded at base; beak of achenes $0.5-1$ $\mathrm{mm}$. long............................................... E. E rostratus var. lanceolatus.

1. Echinodorus parvulus Engelm. Fig. 56.

Plants small and delicate, with the shoots often creeping and proliferous; scapes to $1 \mathrm{dm}$. tall, supporting a single umbellate inflorescence of 2 or more flowers; leaves with a petiole to $5 \mathrm{~cm}$. long, the blade (to $3 \mathrm{~cm}$. long and $8 \mathrm{~mm}$. wide) narrowly elliptic and acutely tapered at both ends; pedicels slender, to $3 \mathrm{~cm}$. long, reflexed in fruit; flowers white, about $6 \mathrm{~mm}$. across; achenes 8-ribbed, reddishbrown, glandless. E. tenellus var. parvulus (Engelm.) Fassett, Helianthium parvulum (Engelm.) Small.

Among grasses in wet sandy soils about ponds in s. Tex., Mar.-Sept.; from Fla. and Tex., locally n. to Mass., Ill. and Mo.

2. Echinodorus rostratus (Nutt.) Engelm. Figs. 57 and 58.

Plants usually coarse; scapes rigidly erect, to $6 \mathrm{dm}$. tall, exceeding the leaves; leaves broadly ovate, cordate to broadly rounded-cuneate at base, obtuse at apex, to $15 \mathrm{~cm}$. long and often as broad; umbels proliferous, in a branched panicle; flowers white, about $1 \mathrm{~cm}$. across; achenes with 2 glands at base of the conspicuous erect beak; seeds brown, obliquely oval, with rows of murications. E. cordifolius, misapplied; E. Berteroi (Spreng.) Fassett, as to descr.

In mud and shallow water about lakes, ponds and along streams mostly in s. Tex. but sparingly throughout most of the state, in Okla. (Alfalfa and Kay cos.) and apparently isolated in Yuma Co., Ariz., May-Oct.; from Ont., w. to Calif. and s. to Fla., Tex. and Mex. 


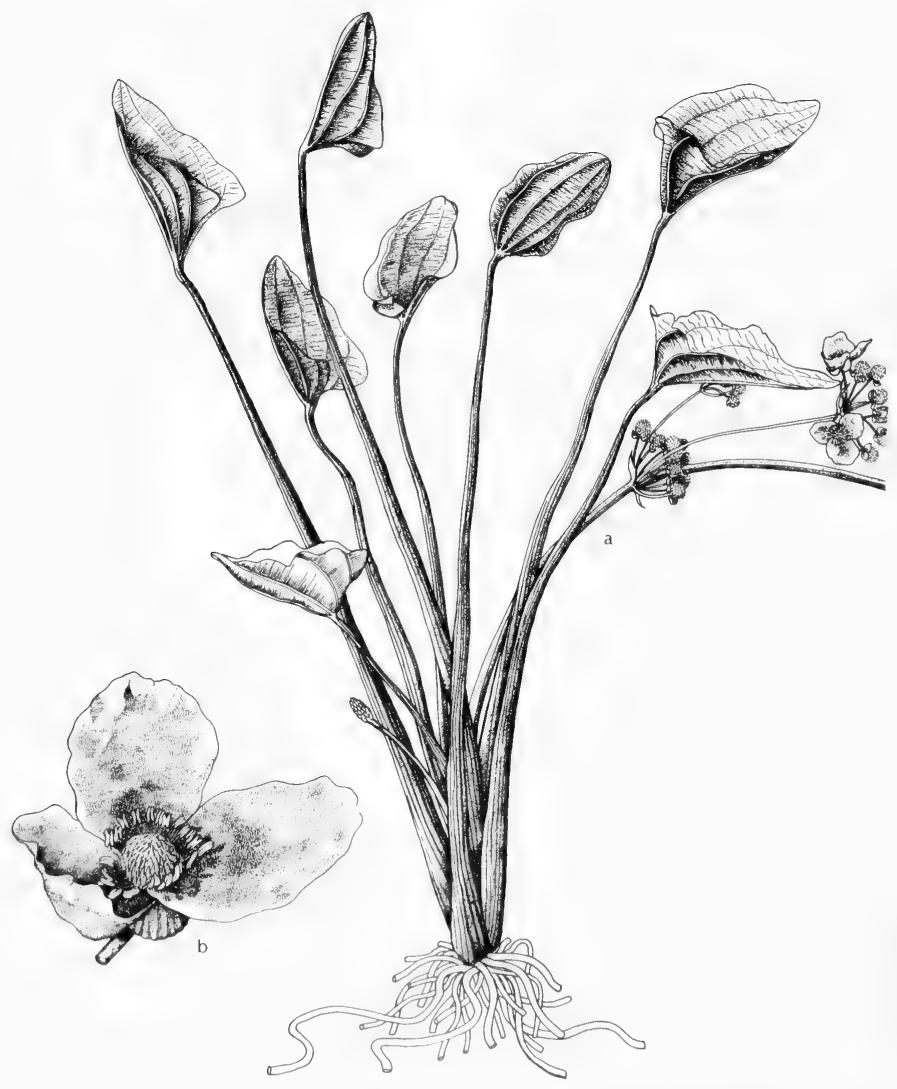

Fig. 59: Echinodorus cordifolius: a, habit, X 1/3; b, flower, X 12/3. 

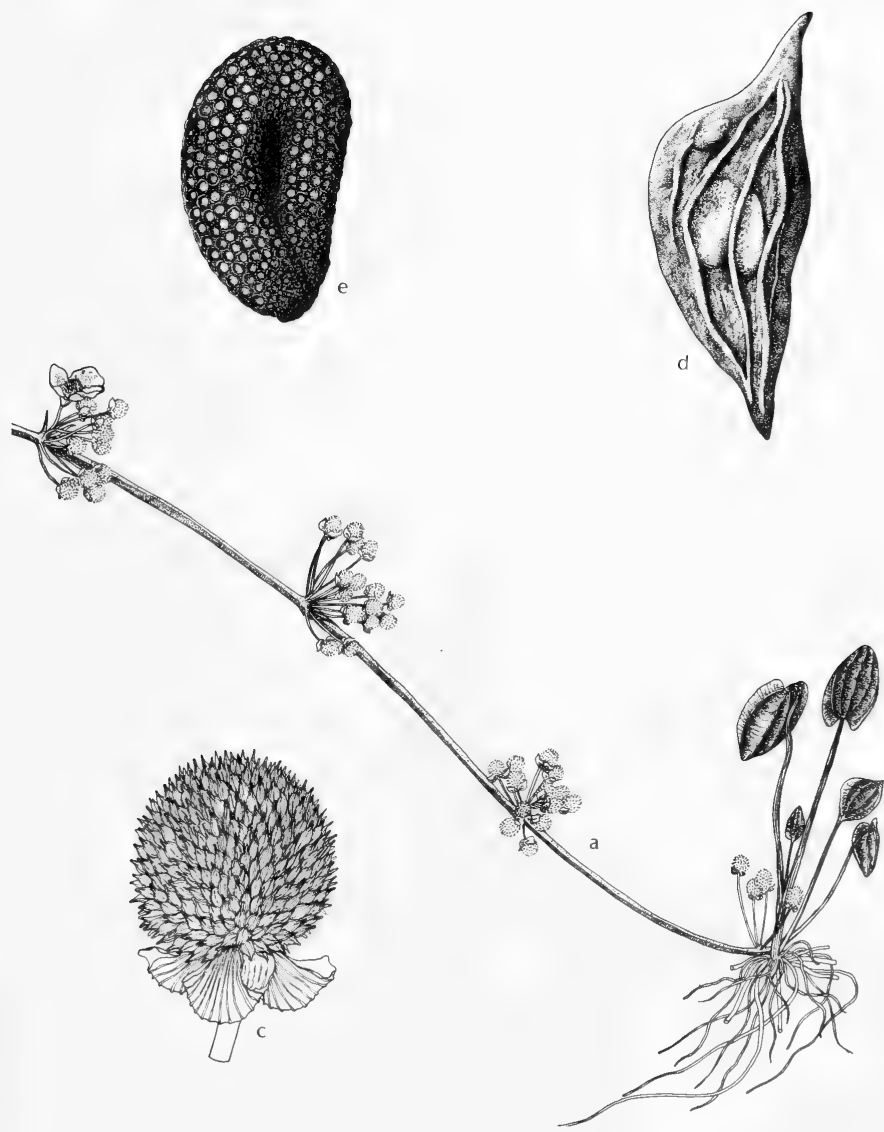

Fig. 60: Echinodorus cordifolius: a, habit, X 1/3; c, head of achenes, X 5; d, achene, X 18; e, seed, X 33. (Courtesy of R. K. Godfrey). 
Var. lanceolatus Engelm. Plants small and delicate, with typically lanceolate leaves. Echinodorous Berteroi var. lanceolatus (Engelm.) Fassett, as to descr. Habitat and distribution similar to that of var. rostratus.

In deeper water the plants rarely produce normal adult foliage leaves and never flower, but develop large, ribbonlike submersed leaves.

\section{Echinodorus cordifolius (L.) Griseb. Figs. 59 and 60.}

Plants coarse and usually stout; scapes prostrate, arching and creeping, to 12 $\mathrm{dm}$. long, proliferous and bearing numerous whorls of flowers, also sometimes producing leaves with the flowers; leaves with a petiole to $2 \mathrm{dm}$. or more long, the blade (to $2 \mathrm{dm}$. long and nearly as broad) broadly ovate and truncately cordate at base and obtuse at apex; flowers white, $12 \mathrm{~mm}$. or more across; achenes with the keeled back denticulate. E. radicans (Nutt.) Engelm.

In mud and shallow water of ponds and quiet streams of e. Tex. and e. Okla. (LeFlore and Muskogee cos.), Apr.-June; from s.e. Va., Ill., Mo. and Kan., s. to Fla., Tex. and Mex.

\section{Sagittaria L. ARrowheAD}

Paludal or aquatic mostly perennial erect or lax stoloniferous herbs, with milky juice, monoecious or rarely dioecious, sometimes tuber-bearing; leaves submersed or emersed, with long cellular petioles, bladeless (i.e., phyllodia) or with unlobed or sagittate blades; scapes erect or laxly ascending, sheathed at base by the bases of the leaf petioles, supporting a narrow verticillate inflorescence that is simple or sparingly branched; flowers produced all summer, pedicellate, in whorls of three, mostly unisexual, subtended by membranous bracts, the staminate flowers typically uppermost in the inflorescence; sepals 3, persistent, in fruit appressed, loosely spreading or reflexed; petals 3 , white or rarely pink, imbricated in the bud, usually exceeding the sepals, deciduous; stamens whorled, mostly numerous; carpels numerous, spirally arranged in a crowded spherical head on a dome-shaped receptacle, 1-celled and 1-ovuled; achenes flattened, membranous-winged, more or less beaked.

About 20 species, mostly in America.

1. Pistillate flowers (in fruit) with sepals appressed or spreading and pedicels recurved and noticeably thickened..................... S. montevidensis.

1. Pistillate flowers (in fruit) with reflexed sepals and pedicels ascending or (if recurved) not noticeably thickened (2)

2(1). Filaments pubescent or minutely scaly (3)

2. Filaments smooth (5)

3(2). Bracts of inflorescence thinly membranous, smooth, more or less connate; filaments dilated (4)

3. Bracts of inflorescence somewhat thickened, papillose or coarsely ridged, nearly free; filaments linear. 4. S. lancifolia.

4(3). Pistillate pedicels ascending, if recurved the achene beak less than $0.3 \mathrm{~mm}$. long; leaves typically narrow................................ S. graminea.

4. Pistillate pedicels recurved; subulate beak of mature achenes $0.3 \mathrm{~mm}$. or more long; leaves typically broad................................. S. platyphylla.

5(2). Bracts of inflorescence papillose; leaves never sagittate (6)

5. Bracts of inflorescence smooth or at most pubescent; leaves sagittate (7)

6(5). Bracts densely papillose, $7 \mathrm{~mm}$. long or less, obtuse; achenes $1.5 \mathrm{~mm}$. long or less; Texas in our area...........................................5. S papillosa.

6. Bracts sparsely papillose, longer, attenuate; achenes larger; Oklahoma in our area. .6. S. ambigua. 


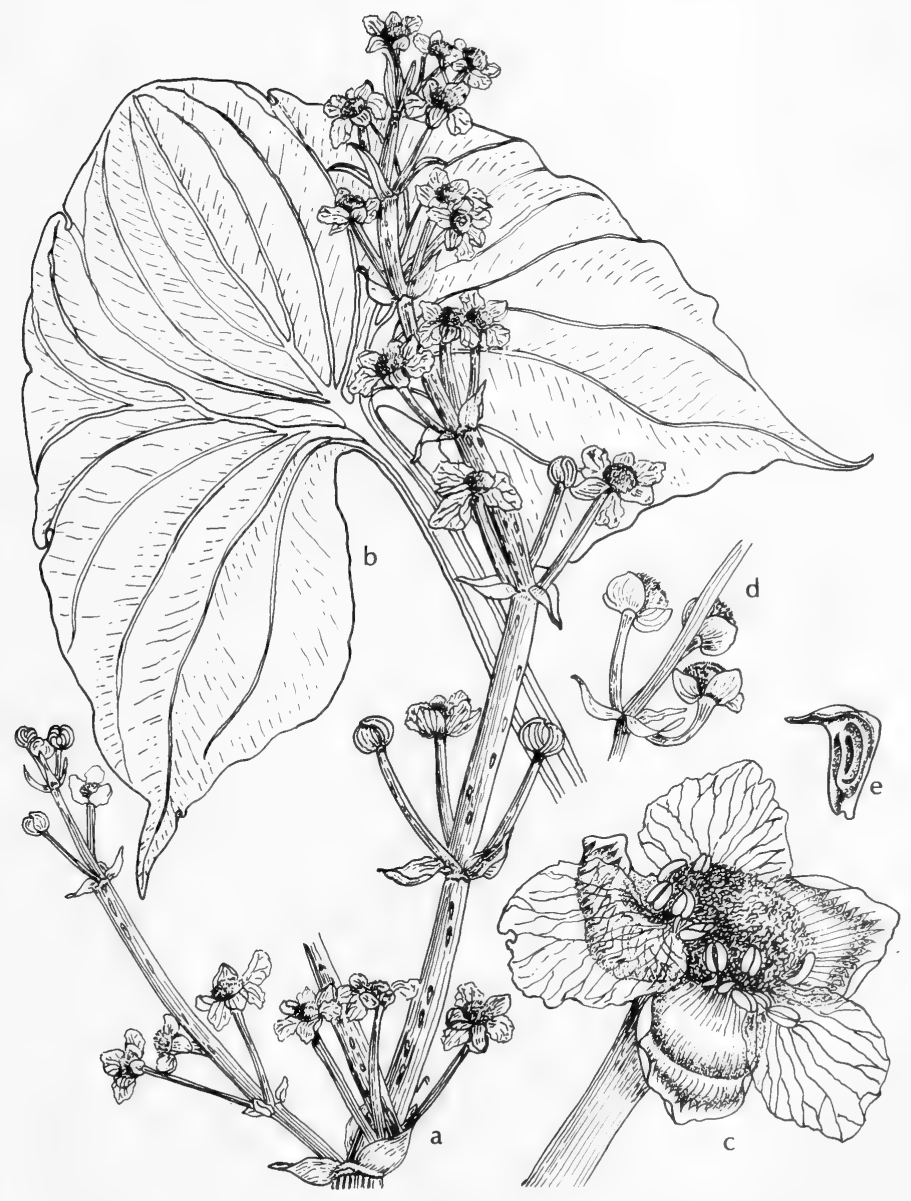

Fig. 61: Sagittaria montevidensis: a, habit, X 1/3; b, leaf, X 1/3; c, flower, X $2 \frac{1}{2}$; d, fruit, X 1/3; e, achene, X 5. (V. F.). 


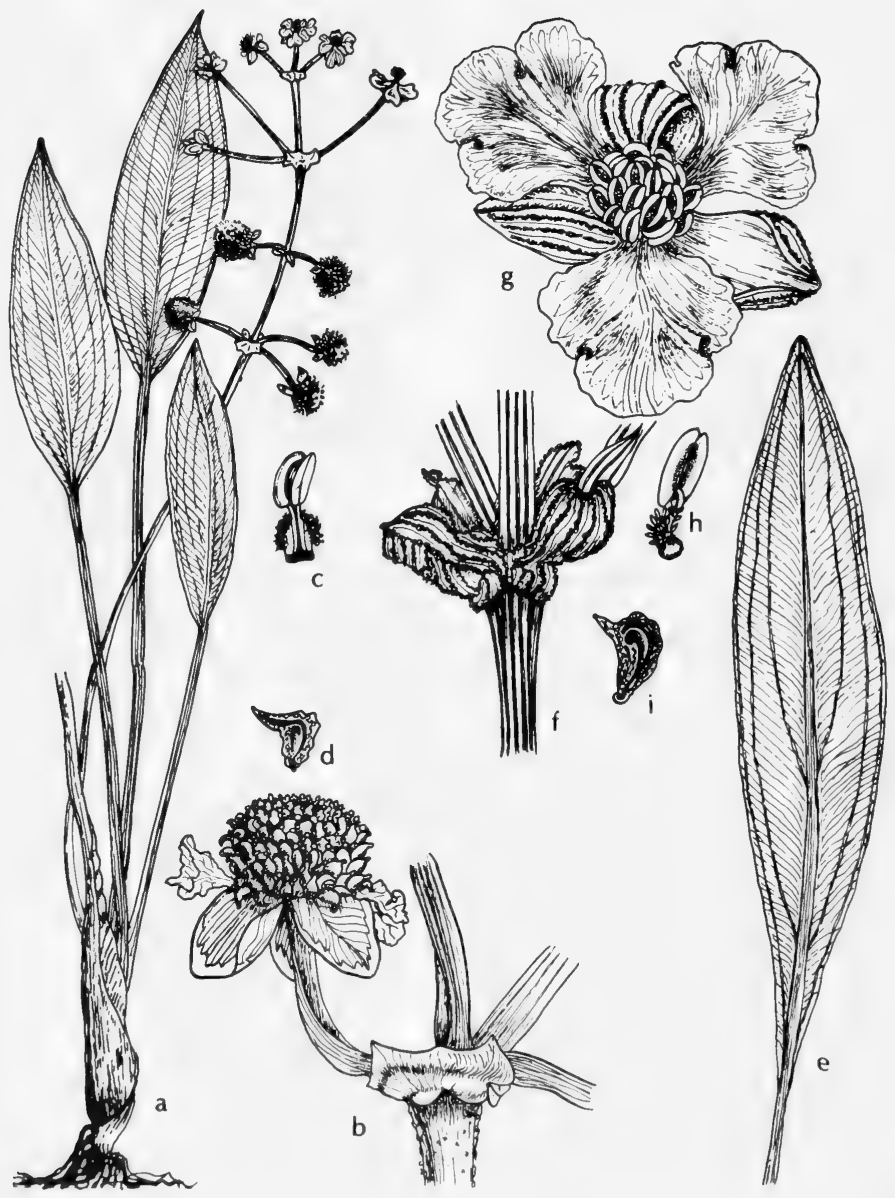

Fig. 62: a-d, Sagittaria graminea: a, habit, X 11/2; b, fruit, X 21/2; c, anther, X 5; d, achene, X 5. e-i, Sagittaria lancifolia: e, leaf, X $1 \frac{1}{2} ;$ f, bracts, X $2 \frac{1}{2} ; \mathrm{g}$, flower, X $2 \frac{1}{2}$; h, anther, X 5; i, achene, X 5. (V. F.). 
7. Achene beak apically inserted, more or less erect (10)

8(7). Bracts of inflorescence cymbiform, obtuse to acute, rather firm, sometimes pubescent; achene beak $0.5 \mathrm{~mm}$. long or more............7. S. latifolia.

8. Bracts of inflorescence almost plane, at least not cymbiform, acuminate to attenuate, membranous, never pubescent; achene beak less than 0.5 $\mathrm{mm}$. long (9)

9(8). Achenes without or with solitary facial wings; leaf blades not more than $2.5 \mathrm{dm}$. long, the terminal lobe linear to lanceolate, usualiy longacuminate, commony less than half as long as the basal lobes; scape usually simple............................................. 8. S. longiloba.

9. Achenes with facial wings and tuberculations; leaf blades typically $2-4 \mathrm{dm}$. long, the terminal lobe ovate to broadly lanceolate, acute to shortacuminate, more than half as long as the basal lobes; scape sometimes branched ..................................................... . S. Greggii.

10(7). Achene usually with one narrow facial wing or keel, the beak somewhat curved and $0.5 \mathrm{~mm}$. or more long.......................10. S. brevirostra.

10. Achene face wingless, typically with a large resin duct, the minute to obsolescent beak erect..............................................11. S. cuneata.

1. Sagittaria montevidensis Cham. \& Schlecht. Fig. 61.

Emersed aquatic annual, only the early stages completely submersed, erect, to $5 \mathrm{dm}$. tall; leaves erect-spreading, usually with stout spongy petioles; leaf blades broadly ovate, sagittate, to $2 \mathrm{dm}$. or more long and wide; scape erect or reflexed, simple or occasionally branched below, with up to 10 whorls; bracts membranous, ovate to ovate-lanceolate, acute to attenuate, connate, about $1 \mathrm{~cm}$. long; pistillate flowers usually with a ring of functional stamens; sepals orbicular-ovate, concave, about $13 \mathrm{~mm}$. long, covering most of the fruiting head; stamens with linear pubescent filaments; heads of carpels to $2 \mathrm{~cm}$. in diameter; achenes cuneateobovate, to $2.5 \mathrm{~mm}$. long and $1.3 \mathrm{~mm}$. wide, the faces usually with a resin duct, the horizontal or oblique beak about as long as the breadth of the achene and narrowly winged on the margin. S. calycina Engelm., Lophotocarpus calycinus (Engelm.) J. G. Sm.

Sloughs, lakes and ponds in e., cen. and w. Tex., Okla. (Adair, Sequoyah, Cherokee, Murray and Johnston cos.) and N.M., June-Oct.; O. and Mich., w. to N.D., Calif. and N.M., s. to Va., Tenn., La. and Tex.

Our plants have been segregated as subsp. calycina (Engelm.) Bogin.

\section{Sagittaria graminea Michx. Fig. 62 .}

Leaves erect, either represented by thin broadly linear (strap-shaped) acute to shortly acuminate phyllodia or with the slender petioles bladeless or with narrowly lanceolate tapering blades to $2 \mathrm{dm}$. long and $25 \mathrm{~mm}$. wide; scape simple, usually surpassed by the leaves, with as many as 10 whorls, the flowers with filiform ascending or spreading pedicels to $3 \mathrm{~cm}$. long, the lower one or two whorls of pistillate flowers or sometimes all staminate; bracts ovate, obtuse to subacute, to $6 \mathrm{~mm}$. long, more or less connate, membranous; sepals ovate, obtuse, to $5 \mathrm{~mm}$. long; petals white or rarely pinkish, to $6 \mathrm{~mm}$. long; stamens with dilated pubescent filaments to $1 \mathrm{~mm}$. long; fruiting heads to $1 \mathrm{~cm}$. in diameter; achenes obovate, to $2 \mathrm{~mm}$. long and $1.2 \mathrm{~mm}$. wide, the narrow-winged back strongly rounded to a high shoulder, the sides plane or with 1 or 2 narrow ridges, the subulate beak to $0.3 \mathrm{~mm}$. long, obliquely inserted below the summit of the achene. S. cycloptera (J. G. Sm.) Mohr.

Rooted in mud or in shallow water of ditches, ponds, marshes and streams in e. and s.-cen. Tex. and Okla. (Osage Co.) to s.e. Ariz., flowering throughout the year but mostly Apr.-Nov.; throughout e. N. A., w. to the Great Plains; also Cuba. 


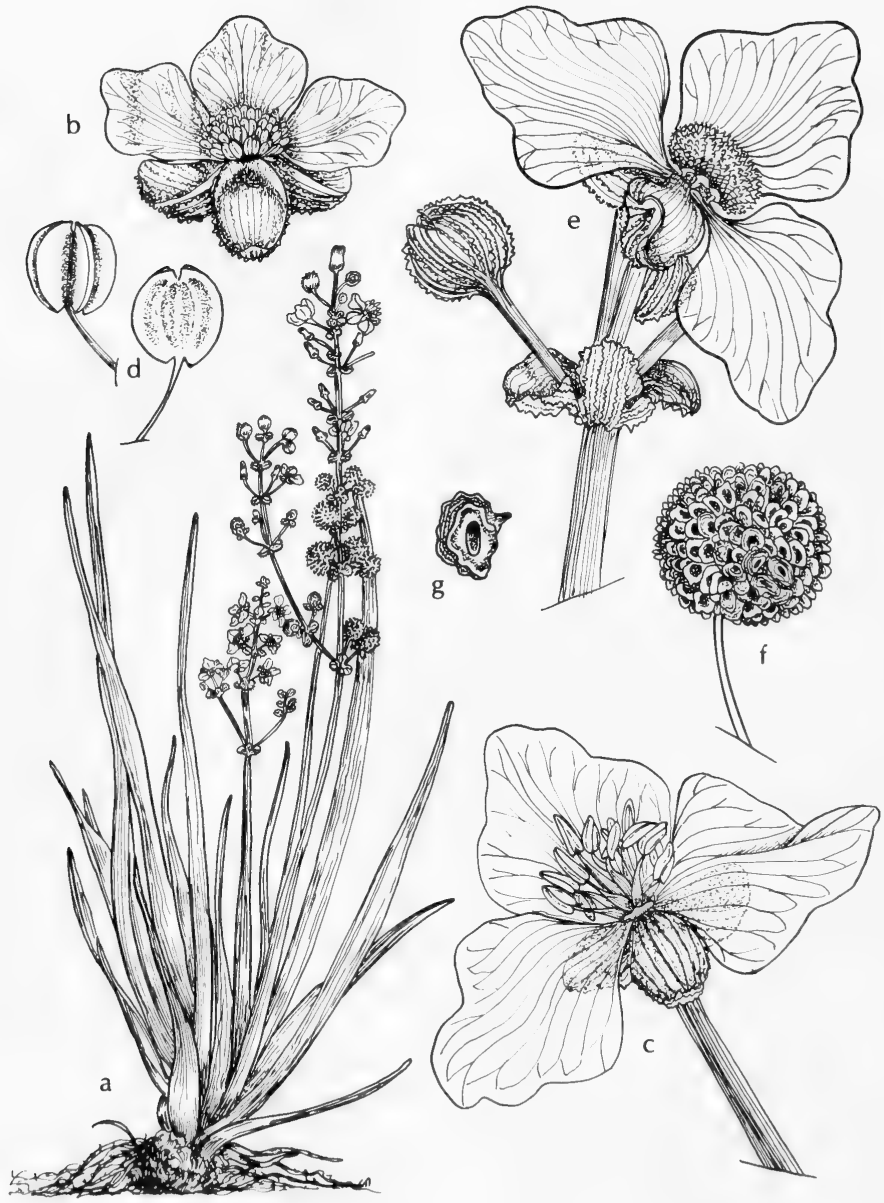

Fig. 63: Sagittaria papillosa: a, habit, X 1/4; b, staminate flower (young), X 21/2 c, staminate flower, $X 2 \frac{1}{2}$; d, stamen (two views), X 5 ; e, pistillate flower, X $2 \frac{1}{2}$; f, fruiting head, X $2 \frac{1}{2} ; \mathrm{g}$, achene, X 6 . (V.F.). 


\section{Sagittaria platyphylla (Engelm.) J. G. Sm.}

Leaves erect, overtopping the scape; leaf blades ovate to elliptic or lanceolate, unlobed, to $18 \mathrm{~cm}$. long and $8 \mathrm{~cm}$. wide; scape simple, with as many as 8 whorls, the 1 to 4 lower whorls pistillate and with their thickish pedicels to $25 \mathrm{~mm}$. long and soon recurving; bracts ovate, obtuse, scarious, strongly connate, to $8 \mathrm{~mm}$. long; stamens with dilated pubescent filaments that are mostly longer than the anthers; fruiting heads to $15 \mathrm{~mm}$. in diameter; achenes cuneate-obovate, to $2 \mathrm{~mm}$. long and $1.2 \mathrm{~mm}$. wide, the dorsal keel rounded to the subtruncate summit, the faces with 1 to 3 narrow ridges; beak subulate, $0.3 \mathrm{~mm}$. or more long, obliquely ascending. S. graminea var. platyphylla (Engelm.) J. G. Sm.

In mud or shallow water of marshes, streams, sloughs, swamps and ponds in e. Tex. and Okla. (Atoka, Murray, Pushmataha, Choctaw, Latimer and Mc-Curtain cos.), Apr.-Oct.; Mo. w. to Kan., s. to Tex. and Ala.; adv. in the Pan. Canal Zone.

\section{Sagittaria lancifolia L. Fig. 62.}

Leaves erect; leaf blades ovate to elliptic or narrowly lanceolate, unlobed, tapering to both ends, firm, to $4 \mathrm{dm}$. long and $1 \mathrm{dm}$. wide; scapes simple or branching at lower nodes, the main axis with as many as 10 whorls, the lower 1 to 4 whorls pistillate with pedicels to $25 \mathrm{~mm}$. long, the staminate pedicels to $35 \mathrm{~mm}$. long; bracts ovate, obtuse, strongly papillose, to $15 \mathrm{~mm}$. long, connate; sepals more or less papillose; stamens with slender arachnoid filaments that are longer than the anthers; fruiting heads about $15 \mathrm{~mm}$. in diameter; achenes cuneate-oblanceolate, falcate, to $2.5 \mathrm{~mm}$. long and $1 \mathrm{~mm}$. wide, dorsally narrowly winged, usually with 1 or 2 low facial ridges; beak obliquely inserted, subulate from a thick base, to $0.8 \mathrm{~mm}$. long, ascending. S. falcata Pursh.

In fresh-water and brackish tidal marshes, swamps, and along streams in s.e. Tex. and Okla., May-Nov.; Fla. to Tex., n. to Del.; also Mex. and C.A.

Our plants, as described here, have been segregated as subsp. media (Mich.) Bogin.

\section{Sagittaria papillosa Buch. Fig. 63.}

Leaves erect; leaf blades linear to narrowly lanceolate, to $25 \mathrm{~cm}$. long and $5 \mathrm{~cm}$. wide; scapes typically branching from the lowest whorl, the main axis with as many as 10 whorls, the lower 1 to 4 whorls pistillate with pedicels much shorter that those of the staminate; bracts ovate, obtuse, somewhat connate, densely papillose, to $1 \mathrm{~cm}$. long; sepals to $6 \mathrm{~mm}$. long, more or less papillose; petals about twice as long as the sepals; stamens with linear glabrous filaments to $1.6 \mathrm{~mm}$. long; fruiting heads about $1 \mathrm{~cm}$. in diameter; achenes cuneate, to $1.5 \mathrm{~mm}$. long and $1 \mathrm{~mm}$. wide, with the remotely crested dorsal wing about $0.2 \mathrm{~mm}$. wide and the ventral wing somewhat narrower, the faces plane; beak broad-based, laterally inserted above the middle of the achene body, more or less recurving, about 0.2 mm. long.

In swamps, marshes, bogs, ditches, small ponds and depressions in prairies in e. and s. Tex. and e. Okla. (McCurtain Co.), Mar.-Nov.; Ark., La., Okla. and Tex.

\section{Sagittaria ambigua J. G. Sm.}

Plant erect; leaves lanceolate to ovate, $12-20 \mathrm{~cm}$. long, 4-10 cm. wide, the petioles to $35 \mathrm{~cm}$. long; scape erect, 3-9 dm. tall, with 2 to 10 whorls of flowers; pistillate pedicels $15-35 \mathrm{~mm}$. long, longer than the staminate pedicels; bracts linear to lanceolate, acuminate, slightly papillose, mostly $1-3 \mathrm{~cm}$. long, nearly free; pedicels ascending, 1-2.5 cm. long; sepals oblong, 5-7 $\mathrm{mm}$. long, remotely papillose; petals ovate, $8-10 \mathrm{~mm}$. long; filaments slender, glabrous; fruiting heads $1-1.5 \mathrm{~cm}$. in diameter; achenes cuneate-obovate, $1.5-2 \mathrm{~mm}$. long, $0.8-1.4 \mathrm{~mm}$. broad, narrowly thin-winged, the faces smooth or with a longitudina! thin keel; 


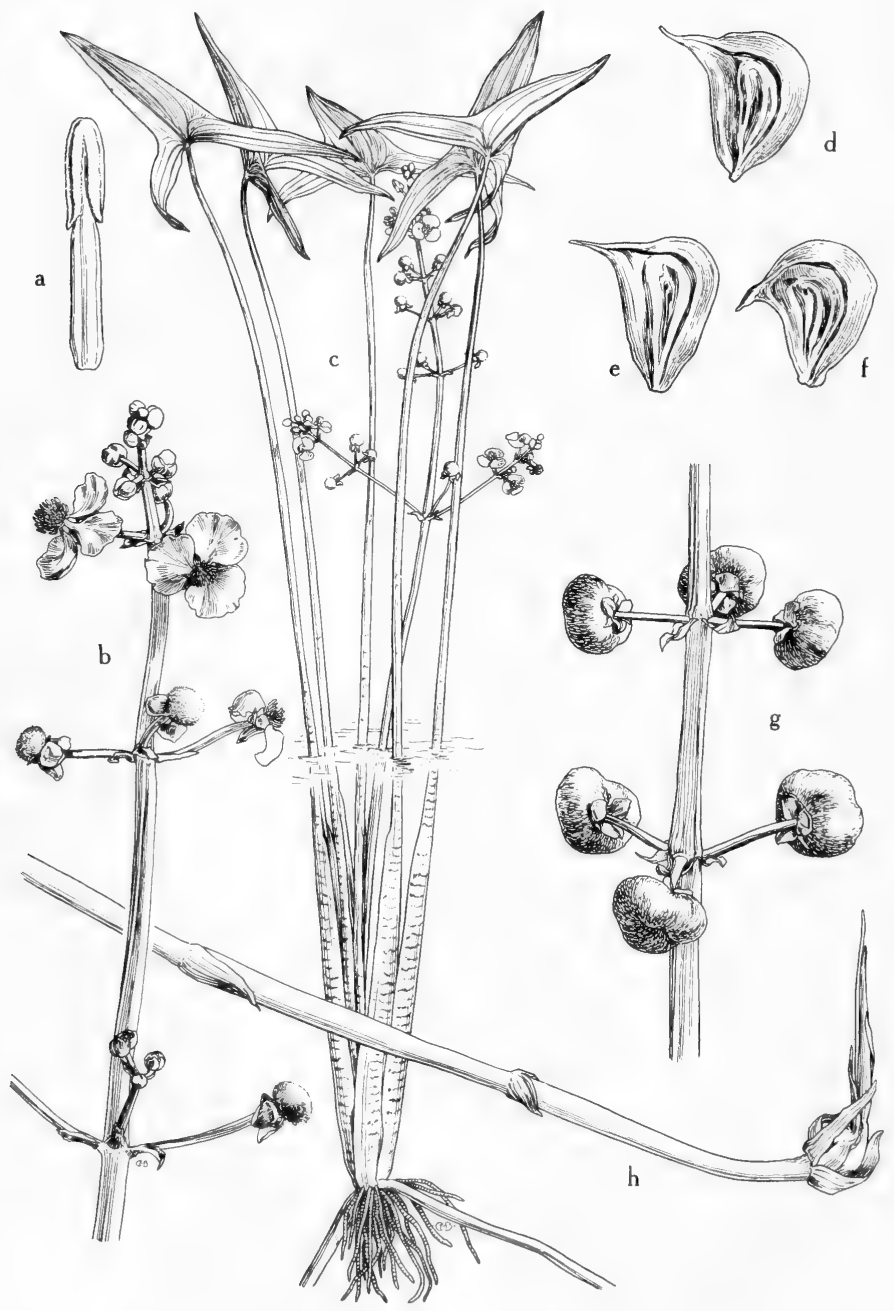

Fig. 64: Sagittaria latifolia: a, stamen, showing glabrous filament which is longer than anther, X 8; b, inflorescence, showing whorls of staminate flowers and of pistillate flowers, the sepals reflexed, X $2 / 3$; c, habit, showing rhizomes and branched inflorescence, $\mathrm{X} 1 / \mathrm{a} ; \mathrm{d}-\mathrm{f}$, mature achenes, the margins with broad corky and laterally disposed wings, $\mathrm{X} 6$; g, part of inflorescence, showing whorls of mature fruits, $\mathrm{X} 2 / 3 ; \mathrm{h}$, corm at the end of rhizome, $X \%$. (From Mason, Fig. 51). 


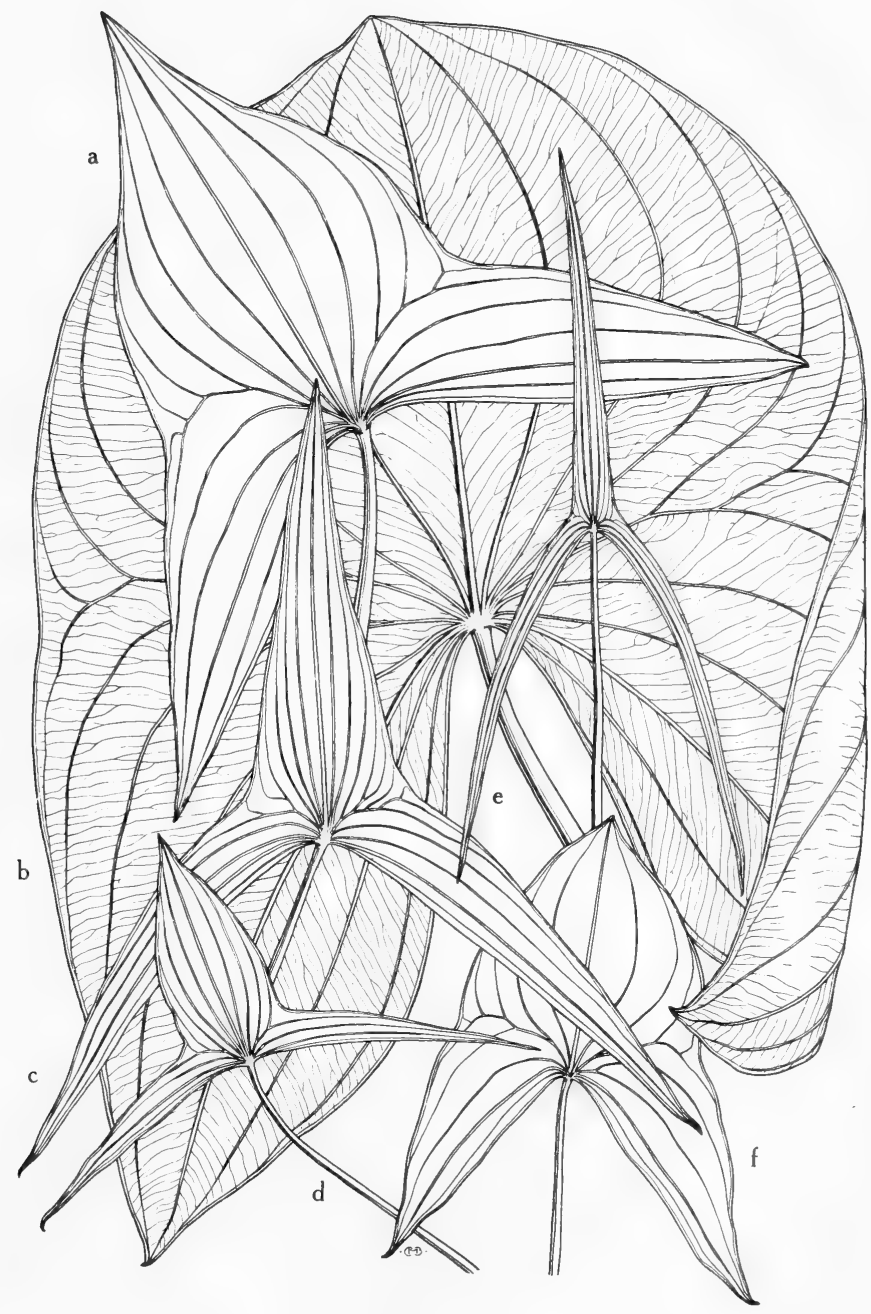

Fig. 65: Sagittaria latifolia: variation in leaf blades. a, c-f, S. latifolia: e, early seasonal phase, and $\mathrm{f}$, late seasonal phase of same plant; $\mathrm{b}, S$. latifolia var. obtusa. All $\mathrm{X} 2 / 5$. (From Mason, Fig. 52). 
beak minute, 0.1-0.2 mm. long, horizontal or incurved.

Swamps and lake shores, Okla.; s.w. Mo., Kan. and Okla.

\section{Sagittaria latifolia Willd. Wapato, Duck-Potato. Figs. 64 and 65.}

Leaves erect or erect-spreading; leaf blades triangular-ovate, obtuse to acute at apex, sagittate, the portion above the basal lobes to $25 \mathrm{~cm}$. long and wide, the linear to ovate-triangular basal lobes one half as long as or longer than the body of the blade; scapes angled, occasionally branching from the lowest whorls, the main axis with as many as 10 whorls, with one or more of the lower whorls pistillate or all unisexual; pedicels of pistillate flowers typically shorter than those of the staminate flowers; sepals to $1 \mathrm{~cm}$. long, glabrous to densely pubescent; bracts cymbiform, distinctly or only slightly connate, thin, somewhat scarious, obtuse to acute, glabrous to densely pubescent; stamens with slender filaments that are usually longer than the anthers; fruiting heads to $25 \mathrm{~mm}$. in diameter; achenes obovate, to $3.5 \mathrm{~mm}$. long and $3 \mathrm{~mm}$. wide, with broad marginal wings but no facial keels; beak broad-based, subhorizontal to slightly incurved, to $2 \mathrm{~mm}$. long. Incl. var. obtusa (Muhl.) Wieg.

In water or wet places from s.e. to n. Tex. and Okla. (Washita, Logan, Ottawa, Delaware, Woodward, Adair and Choctaw cos.), w. through N.M. (Sandoval Co.) to Ariz. (Navajo Co.), May-Sept.; throughout most of the U. S. and much of Latin Am.

Both the entirely glabrous widespread var. latifolia and the southern var. pubescens (Muhl.) J. G. Sm. (S. pubescens Muhl.), with densely pubescent bracts and calyx, are rare in our area. Several variants, such as f. hastata (Pursh) Robins. and var. obtusa (Muhl.) Wieg., have been proposed, based on leaf variations.

\section{Sagittaria longiloba Engelm. ex Torr. in J. G. Sm. FlechA DE AguA. Fig. 66.}

Leaves erect or erect-spreading; leaf blades ovate-triangular, acute at apex, sagittate, the portion above the basal lobes to $15 \mathrm{~cm}$. long and $1 \mathrm{dm}$. wide, the conspicuously long linear to lanceolate basal lobes always longer than and commonly twice as long as the body of the blade; scapes commonly branching at the lowest whorl, the main axis with as many as 12 whorls; pedicels to $35 \mathrm{~mm}$. long, ascending; bracts ovate-lanceolate to narrowly lanceolate, attenuate, to $25 \mathrm{~mm}$. long, connate at base; stamens with glabrous linear filaments to $3 \mathrm{~mm}$. long and exceeding the anthers; fruiting heads to $12 \mathrm{~mm}$. in diameter; achenes obovate, to $2.3 \mathrm{~mm}$. long and $1.3 \mathrm{~mm}$. wide, the narrow dorsal wing to $0.3 \mathrm{~mm}$. wide, the ventral wing nearly obsolete, the faces commonly 1-winged; beak laterally inserted, triangular, to $0.15 \mathrm{~mm}$. long or obsolete.

In shallow water of sloughs, ditches, ponds and swamps, especially common in roadside ditches in s. Tex. and extending to $\mathrm{n}$. and w. Tex., Okla., N. M. and Ariz., Apr.-Nov.; Ariz., N. M., Calif.(?), Colo., Kan., Neb., Okla., Tex., and Mex.

\section{Sagittaria Greggii J. G. Sm. Fig. 67.}

Erect aquatic of shallow water, to $1 \mathrm{~m}$. tall; tip of ephemeral rhizome at length becoming a globose perennial corm, or plant behaving as an annual; leaves erect, the blades sagittate, 2-4 dm. long, the basal lobes 2 to 3 times as long as the terminal, linear to linear-lanceolate, sometimes acuminate, the submersed juvenile leaves with blades entire or lacking; inflorescence simple or branched, subequal to or longer than leaves; lower flowers pistillate, upper ones staminate, occasionally a few flowers perfect; pistillate flowers on slender ascending often unequal pedicels, the pedicels $1-3 \mathrm{~cm}$. long; sepals becoming reflexed, not growing with fruit; petals white, blades orbicular, claws cuneate; rudimentary stamens in a single whorl, sometimes a few with pollen; staminate flowers withering-persistent, rarely with rudimentary pistils; stamens numerous, the filaments longer than 


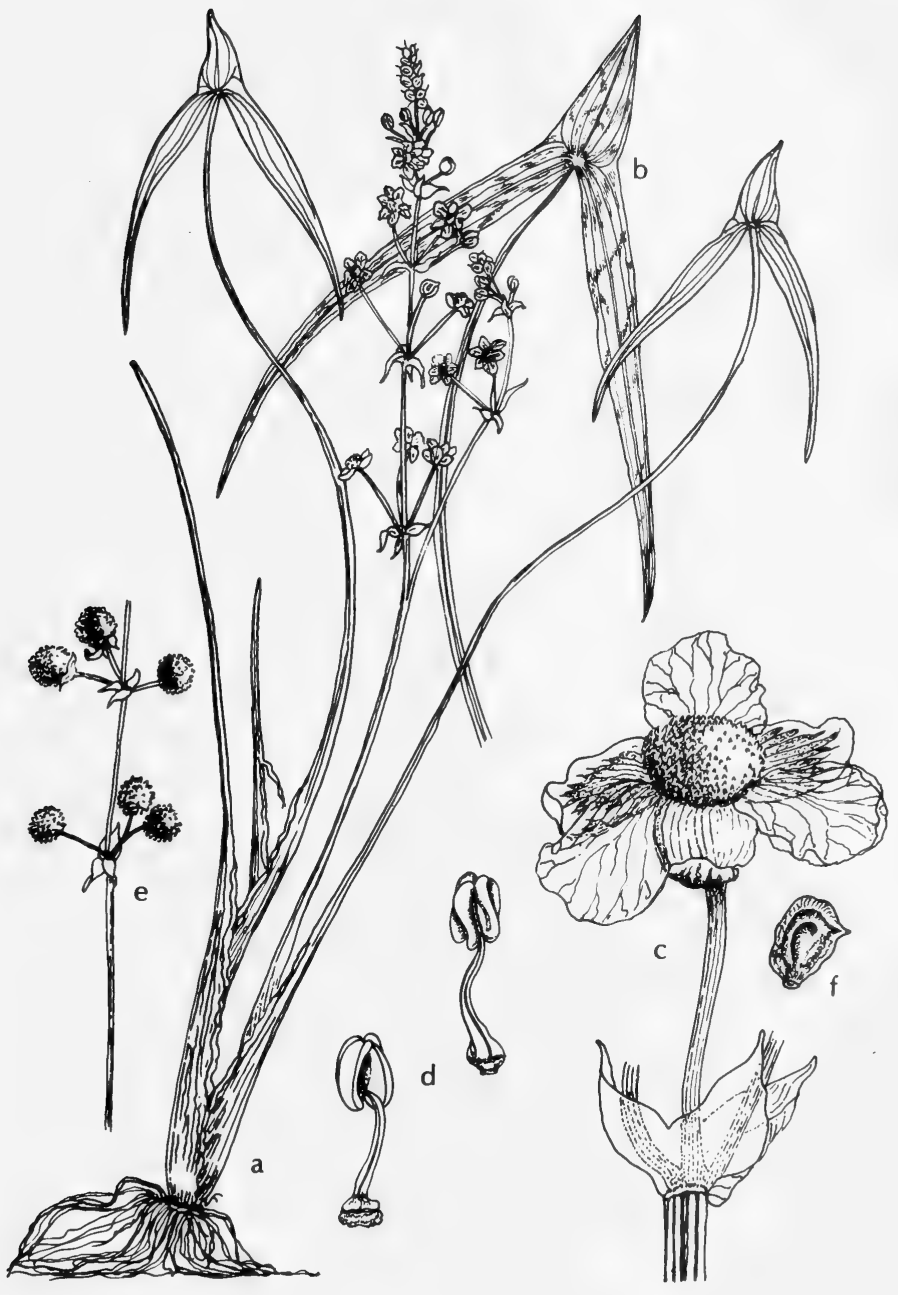

Fig. 66: Sagittaria longiloba: a, habit, X 1/4; b, single leaf, X 1/2; c, flower, X 21/2; d, stamens, X 5; e, fruit, X 1/4; f, achene, X 5. (V. F.). 


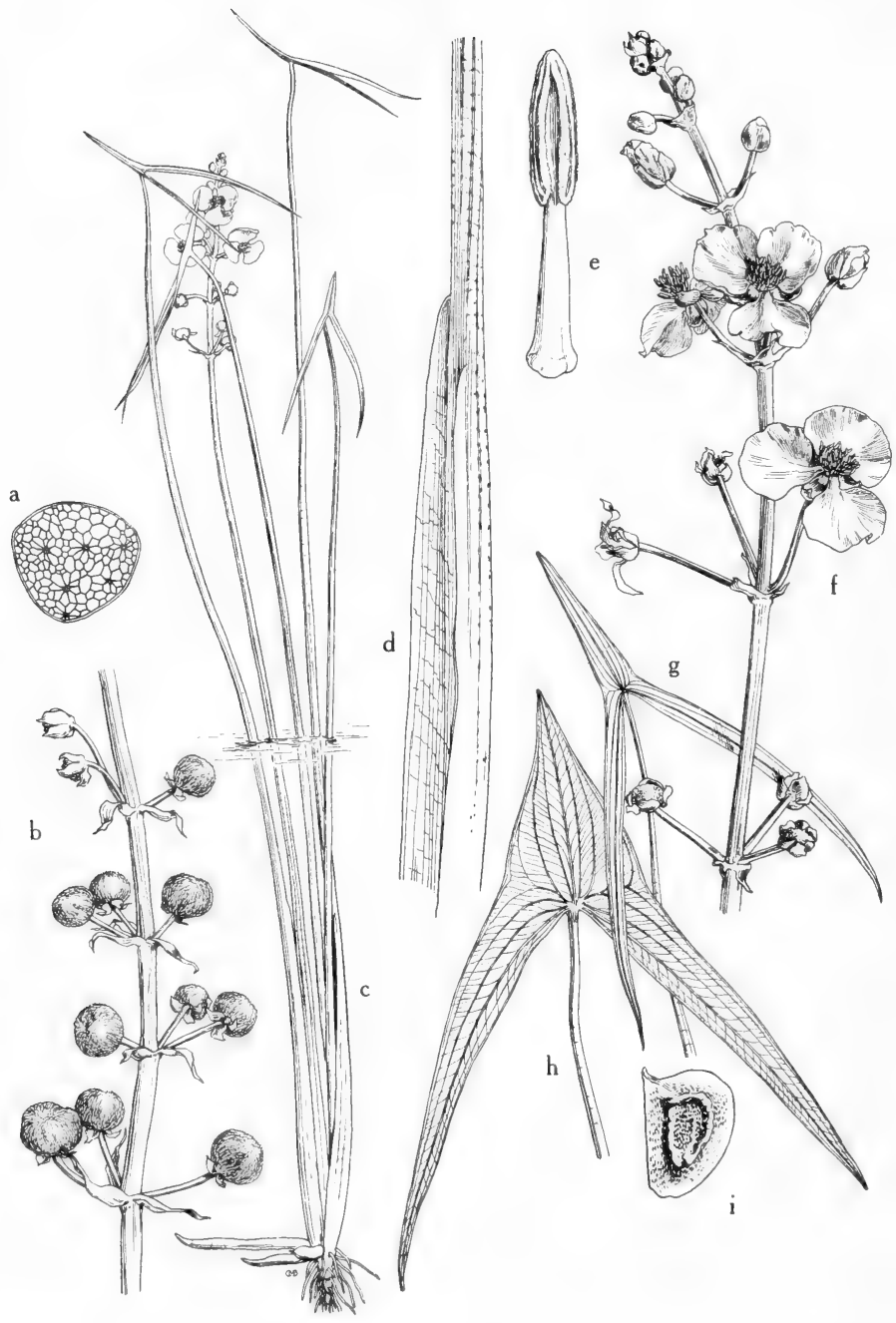

Fig. 67: Sagittaria Greggii: a, scape (cross section), X 11/2; b, whorls of maturing fruits, showing the reflexed sepals and long bracts subtending the pedicels, X $2 / 3 ; \mathrm{c}$, habit, showing narrowly sagittate leaf blades, X 1\%; d, leaf base sheath, X $2 \%$; e, stamen, showing glabrous filament with dilated base, X 8; $\mathrm{f}$, tip of inflorescence, showing whorls of staminate flowers and pistillate flowers below beginning to mature, $\mathrm{X} 2 / 3 ; \mathrm{g}$ and $\mathrm{h}$, leaf blade variations, $X \%$ i. mature achene, showing the tubercled irregularly thickened lateral ribs, X 8. (From Mason, Fig. 49). 
anthers, glabrous, somewhat dilated at base; fruiting heads depressed-globose; achenes obovate, 2-3 $\mathrm{mm}$. long, winged, the lateral ribs irregularly thickened and winged or tubercled, curved to orbicular in outline, the style beak short and erect, occasionally pushed in a lateral direction as the achene matures.

In shallow water of irrigation ditches and rice fields in Ariz. and N. M., Apr.-Nov.; also Calif. and n. Mex.

Closely related to $S$. longiloba, with which it apparently intergrades, or more likely, with which it is probably conspecific. We are in agreement with Mason, however, who chose to maintain these two concepts until further field studies can be made.

\section{Sagittaria brevirostra Mack. \& Bush. Fig. 68.}

Leaves erect; leaf blades broadly ovate to lanceolate, obtuse to acute at apex, sagittate, the portion above the basal lobes to $2 \mathrm{dm}$. long and usually about as wide, the ovate to ovate-lanceolate and acute basal lobes about equaling the body of the blade; scapes simple or branched at base, the main axis with as many as 12 whorls, the lower 2 to 6 whorls pistillate with pedicels to $2 \mathrm{~cm}$. long, the staminate with slightly longer pedicels; bracts firm, lanceolate, longattenuate, to $25 \mathrm{~mm}$. long; stamens with slender glabrous filaments about as long as the anthers; fruiting heads depressed, not noticeably echinate, to $2 \mathrm{~cm}$. in diameter; achenes cuneate-obovate to quadrate, to $3 \mathrm{~mm}$. long and $2 \mathrm{~mm}$. wide, with an often dentate or serrate dorsal keel and usually with a narrow facial ridge; beak broad-based, obliquely ascending, to $1.5 \mathrm{~mm}$. long, terminating the straight ventral margin. S. Engelmanniana J. G. Sm. subsp. brevirostra (Mack. \& Bush) Bogin.

Along rivers, ditches and sloughs in cen. Tex. to Okla. and n. N. M. (Taos Co.), June-Aug.; O. and Mich., w. to S.D. and s. to Tex. and N. M.

\section{Sagittaria cuneata Sheld. Fig. 69.}

Leaves erect or erect-spreading; leaf blades broadly ovate to ovate-triangular, obtuse to acute at apex, sagittate, the portion above the basal lobes to $15 \mathrm{~cm}$. long and $1 \mathrm{dm}$. wide, the deltoid basal lobes somewhat smaller than the body of the blade; scapes erect or arching, simple or sometimes branched, the main axis with as many as 7 whorls, the lower 1 or 2 (or sometimes all) whorls pistillate and subsessile or on pedicels to $2 \mathrm{~cm}$. long, the staminate pedicels somewhat longer; bracts narrowly ovate to lanceolate, acute to attenuate, usually connate at base, to $2 \mathrm{~cm}$. long; stamens with glabrous subulate filaments that about equal the anthers; fruiting heads to $15 \mathrm{~mm}$. in diameter; achenes obovate, to $2.5 \mathrm{~mm}$. long and $2 \mathrm{~mm}$. wide, the wide dorsal keel rounded, the faces usually with a low narrow ridge; beak subulate, usually recurved. erect to suberect, to $0.4 \mathrm{~mm}$. long, terminating the strongly rounded ventral keel. S. arifolia Nutt. ex J. G. Sm.

Along rivers and streams in the Tex. High Plains, Okla., N.M. and Ariz., June-Sept.; n.e. Can., s. to N.E., N.Y., O., Ind., Ill., Ia., Kan., Tex., N.M., Ariz. and Calif.

\section{Fam. 22. Butomaceae RICH.}

\section{FLOWERING-RUSH FAMILY}

Perennial aquatic or marsh herbs with stout short or elongate rhizomes and usually with milky juice; leaves cauline or basal; flowers perfect in involucrate umbels or solitary; sepals 3, persistent; petals 3, showy; stamens 6 to many, free, the outer ones usually sterile; anthers basifixed, 2-celled, laterally dehiscent; pistils 4 to 8 , free or basally coherent, with numerous ovules attached over the inner surface; fruit a many-seeded follicle, dehiscing on the inner side; seeds without endosperm. 


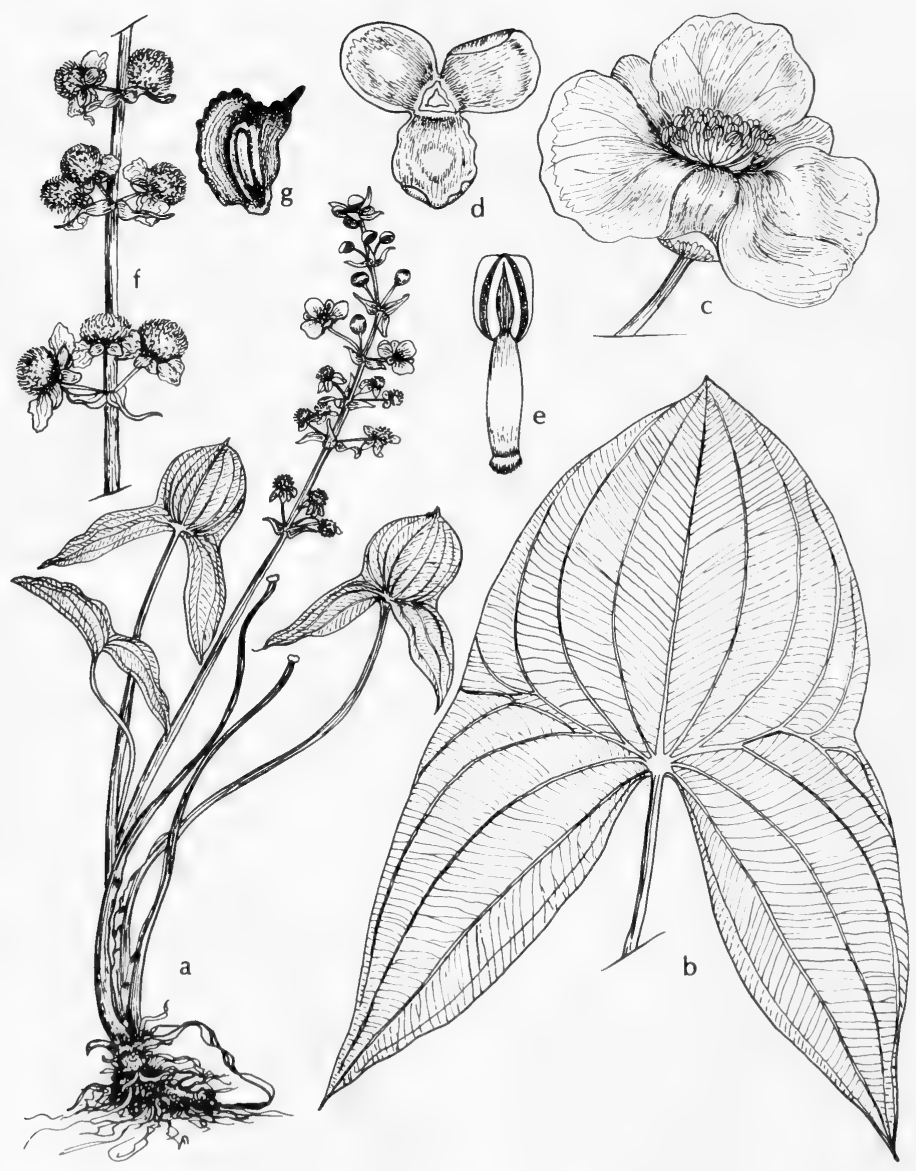

Fig. 68: Sagittaria brevirostra: a, habit, X 1/4; b, leaf, X 1/2; c, flower, X 11/2; d, calyx, X 11\%; e, stamen, X 5; f, fruit, X 1/2; g, achene, X 5. (V. F.). 


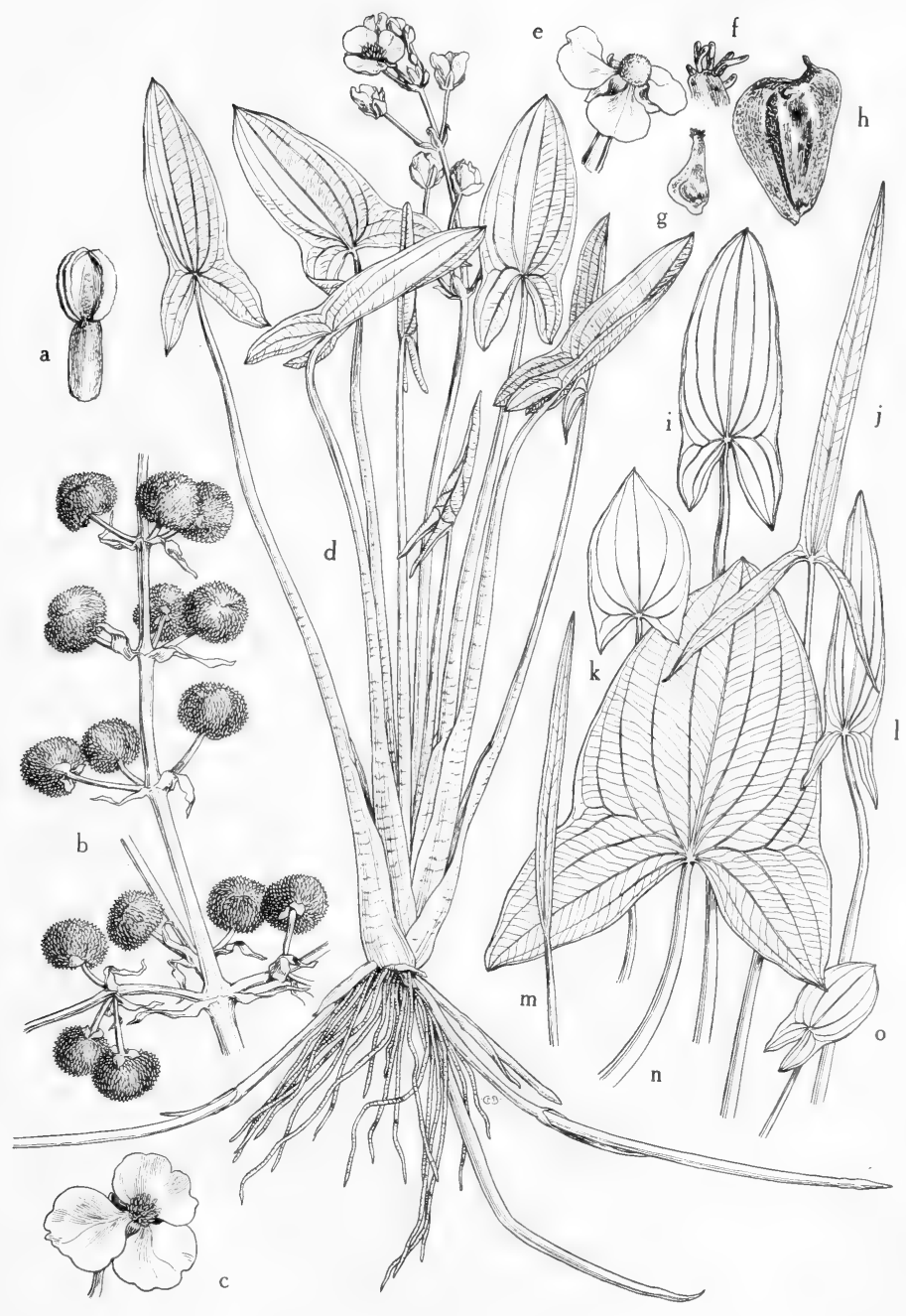

Fig. 69: Sagittaria cuneata: a, stamen, showing short glabrous filament, X 6; b, whorls of maturing fruits, X 25 ; c, staminate flower, X $4 / 5$; d, habit, showing rhizomes, inflorescence and the somewhat spreading leaves, $X 2 / 5$; e, pistillate flower, $X 4 / 5$; $f$, papillate stigma, X $40 ; \mathrm{g}$, ovary terminating in stout style with papillate stigma, X 8 ; $\mathrm{h}$, mature achene, showing wings and the erect beaklike persistent style, X 6 ; i-o, leaf blade variations (note that the basal lobes are generally shorter than terminal lobe), $\mathrm{X} \%$. (From Mason, Fig. 50). 
Several genera containing about 10 species, mostly of warm regions.

\section{Hydrocleys Rich.}

Characteristics of family. Four species, all native to Brazil.

\section{Hydrocleys nymphoides (Willd.) Buch. WATER-POPPY. Fig. 70.}

Rhizomes rooting at the nodes; leaves alternate, long-petioled; leaf blades broadly ovate, cordate at base, rounded at apex, $5 \mathrm{~cm}$. long or more, entire, glossy on upper surface, somewhat spongy along the midrib and sparsely pubescent on lower surface, usually floating; flowers axillary on long peduncles, raised well above the water and lasting only one day; petals light-yellow, obovate, $2-3 \mathrm{~cm}$. long; stamens numerous, the outer ones sterile, fertile stamens purple or violetcolor; pistils usually 6 , gradually tapering into the style.

Cult. in ponds and pools in s. U.S., including e. Tex., and becoming somewhat naturalized, summer; nat. of Braz.

Included here on the basis of Muenscher's report of its occurrence in Texas; we have seen no specimens.

\section{Fam. 23. Hydrocharitaceae Juss.}

\section{FroG'S-BIT FAMILY}

Fresh- or salt-water herbs, partly or wholly submerged, dioecious to polygamo-monoecious, with terrestrial or floating roots; leaves radical and crowded or dispersed on elongated stems, alternate to opposite or whorled; flowers regular, usually unisexual, arranged in a bifid spathaceous bract or within 2 opposite bracts, the staminate usually more than 1, the pistillate solitary; spathe sessile to long-pedunculate, the peduncle sometimes spirally twisted; perianth segments free to the base, 1- or 2-seriate, 3 or rarely 2 in each series, the outer often green and valvate, the inner imbricate and petaloid; stamens 1 to numerous; anthers with 2 parallel cells that open by longitudinal slits; rudimentary ovary present in the staminate flowers; staminodes sometimes present in the pistillate flower; ovary inferior, sometimes beaked, 1 -celled, with 3 to 6 or rarely more parietal placentas that sometimes protrude nearly to the middle of the ovary; styles as many as placentas, entire or 2- or 3-branched; ovules numerous on the placentas; fruit globose to linear, dry or pulpy, rupturing irregularly; seeds numerous, without endosperm; embryo straight, with a thick radicle and usually inconspicuous plumule.

About 16 genera and 80 species, mainly of tropical and warm temperate regions.

1. Fresh-water plants that are pollinated at or above the surface of the water: pollen spheroid (2)

1. Marine plants that are pollinated beneath the surface of the water; pollen confervoid or united in strings (5)

2(1). Plant floating; leaves broadly ovate to reniform, distinctly petiolate, emersed or floating; spathe composed of 1 or 2 free bracts.

2. Plants attached to bottom; leaves linear or straplike, without a petiole, submersed; spathe composed of 2 bracts connate into a tube (3)

3(2). Leaves clustered at the base, straplike, more than $15 \mathrm{~cm}$. long; petals rudimentary and much smaller than the sepals..................2. Vallisneria

3. Leaves opposite or in approximate whoris on an elongated stem, less than $5 \mathrm{~cm}$. long; petals well-developed and much larger than the sepals (4) 


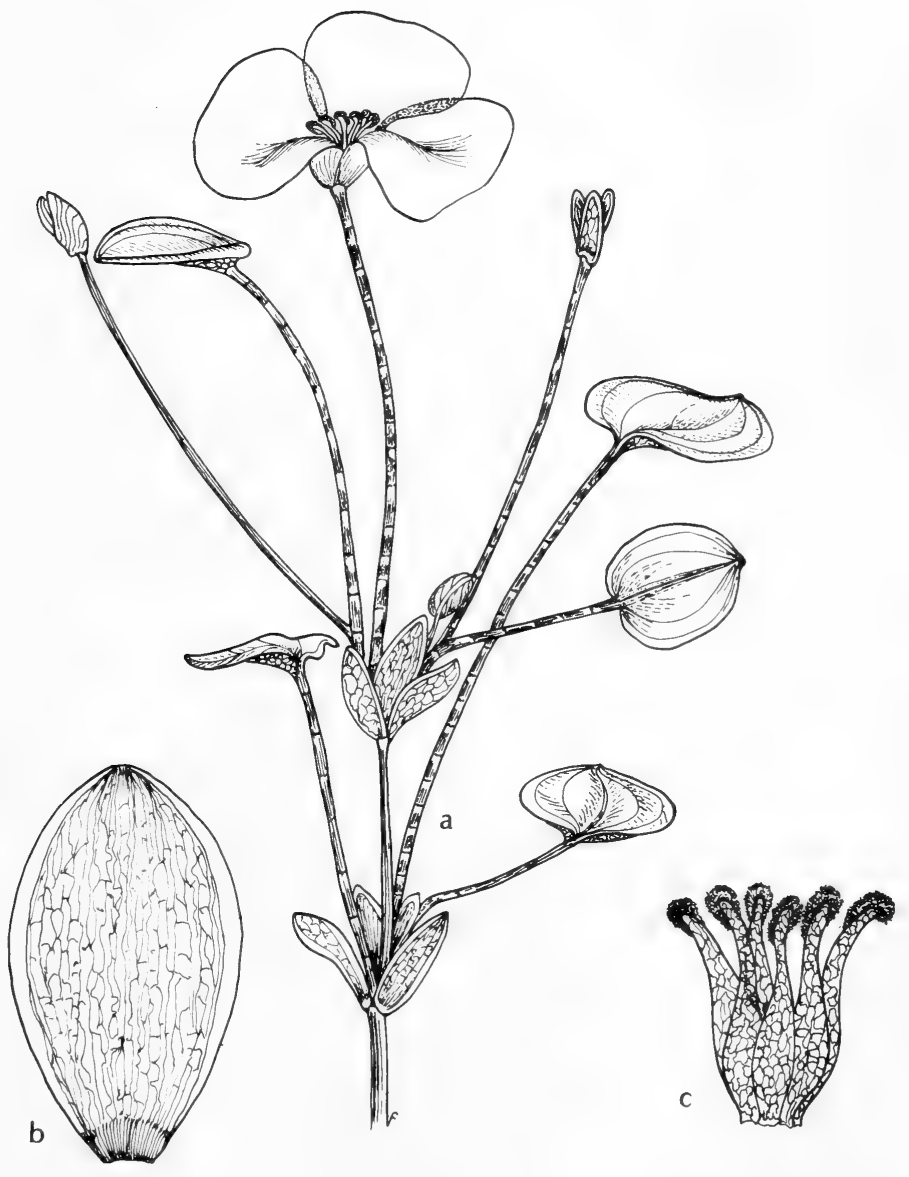

Fig. 70: Hydrocleis nymphoides: a, top of plant, X 1/2; b, sepal, X 21/2; c, carpels, X $21 / 2$. (V. F.). 


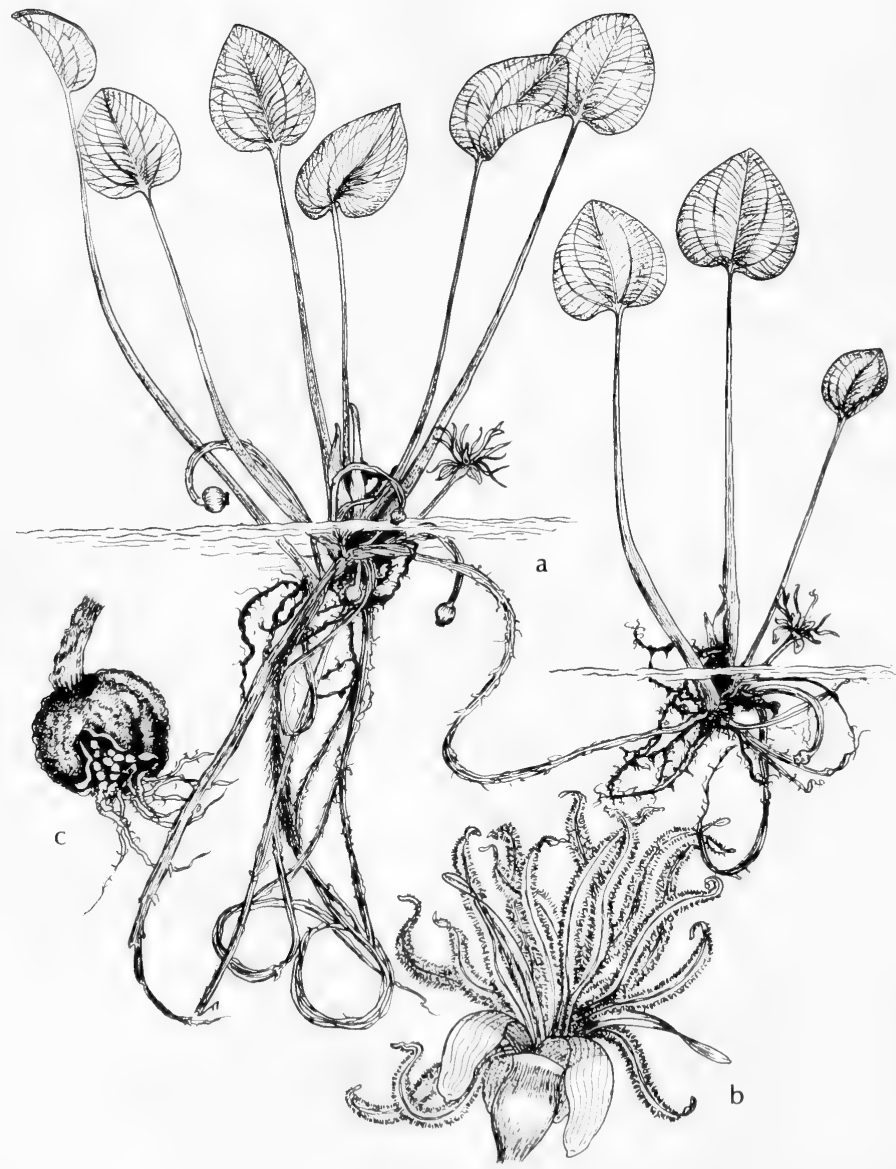

Fig. 71A: Limnobium Spongia: a, habit, X 1/2; b, pistillate flower, X 21/2; c, fruit with seeds sprouting, X 21/2. (V. F.). 

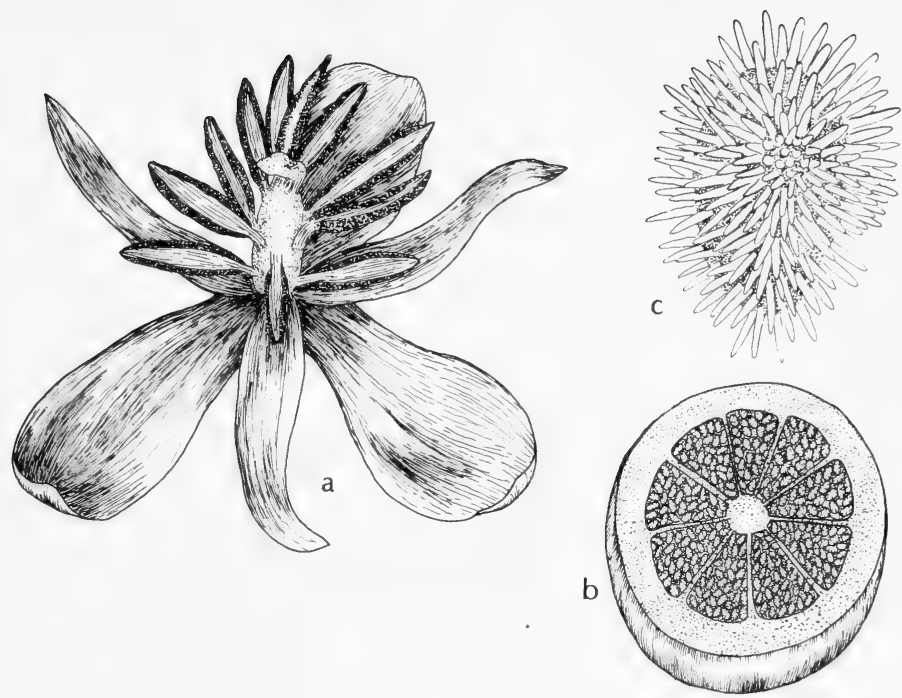

Fig. 71B: Limnobium Spongia: a, staminate flower, X 10; b, section of capsule, X $2 \frac{1}{2}$; c, seed, X 42. (Courtesy of R. K. Godfrey).

4(3). Middle and upper leaves in whorls of 4 to 6 , averaging about $2.5 \mathrm{~cm}$. long; staminate spathes 2 - to 4 -flowered; petals about $8 \mathrm{~mm}$. wide...

3. Egeria

4. Middle and upper leaves opposite or in whorls of 3 (rarely with some 4), rarely more than $2 \mathrm{~cm}$. long; staminate spathes 1 -flowered; petals $1.5 \mathrm{~mm}$. wide or less. 4. Elodea

5(1). Leaves alternate on a short stout concealed stem, ribbonlike, more than $1 \mathrm{dm}$. long; spathe composed of 2 bracts connate at the base to form a tube...............................................................5. Thalassia

5. Leaves opposite at summit of slender nearly naked stem, mostly oblongelliptic, less than $5 \mathrm{~cm}$. long; spathe composed of 2 free bracts. 6. Halophila

\section{Limnobium Rich. AMERICAN Frog's-Bit}

Three species centered in tropical America.

1. Limnobium Spongia (Bosc.) Steud. Common frog's-BIT. Figs. 71A and 71B.

Floating aquatic with pendent roots and stolons; leaves in a basal rosette, erect or ascending, with petioles to $15 \mathrm{~cm}$. long, ovate to suborbicular or the earlier ones reniform, to $5 \mathrm{~cm}$. broad, obtuse at the apex, truncate to cordate at base, entire, faintly 5-nerved, purplish and spongy beneath; flowers unisexual; staminate scapes to $1 \mathrm{dm}$. long, producing 3 or more flowers, filiform, the lanceovoid spathe $3-5 \mathrm{~cm}$. long; pistillate scapes 2-leaved, with 1 or 2 short-pedicelled flowers, about $25 \mathrm{~mm}$. long in flower, stout, strongly recurved and elongated in fruit; sepals $3,7-10 \mathrm{~mm}$. long; petals $3,8-10 \mathrm{~mm}$. long; stamens represented by 


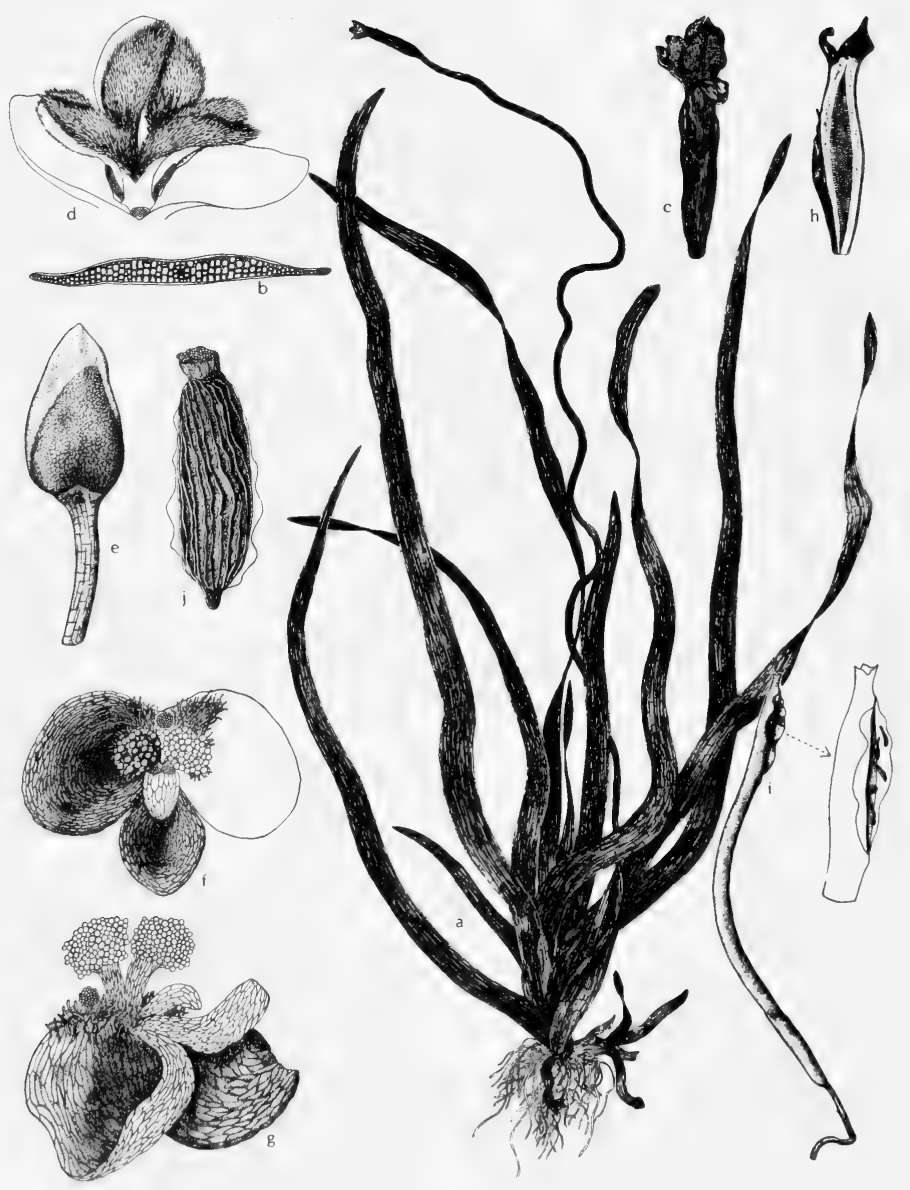

Fig. 72: Vallisneria americana: a, pistillate plant, $\mathrm{X} 1 / 3$; b, cross section of leaf, X i; c, pistillate flower, X 11/3; d, top of flower showing stigmas, X 4; e, spathe of staminate flowers, $X 1 \frac{1,2}{\mathrm{f}} \mathrm{f}$ and $\mathrm{g}$, two views of staminate flower, $\mathrm{X} 28 ; \mathrm{h}$, capsule, $\mathrm{X} 11 \frac{1}{3}$; $\mathrm{i}$, young fruit, $\mathrm{X} 2 / 3$ with fruit enlarged; $\mathrm{j}$, seed, greatly enlarged. (Courtesy of $\mathbf{R}$. K. Godfrey). 
3 to 6 subulate rudiments; anthers linear, apiculate, $2-4 \mathrm{~mm}$. long; ovary inferior, 6- to 9-celled; stigmas filiform, as many as the cells, deeply 2-parted, $1-1.5 \mathrm{~cm}$. long, papillose-ciliate; berry ovoid, many-seeded, $1-1.5 \mathrm{~cm}$. long, on a stout recurved peduncle.

In shallow mostly stagnant water of quiet lakes, ponds, lagoons and ditches in e. Tex., June-Oct.; from Ont. and N.J., s. to Fla., Tex., Mo. and Ill.

The dense growth often formed by this species provides an excellent habitat for small animal life, which apparently attracts marshbirds. The seeds are eaten by wildfowl.

\section{Vallisneria L. TAPEgrass. Eelgrass}

Two species, one native to America, another in the Old World.

\section{Vallisneria americana Michx. WATER-CELERY. Fig. 72.}

Aquatic dioecious submerged plant from perennial stoloniferous rootstocks with fibrous roots and fleshy propagating buds; leaves in basal clusters, linear, obtuse, thin, ribbonlike, flaccid, entirely submerged or with the upper part floating, to about $6 \mathrm{dm}$. long and $2 \mathrm{~cm}$. wide, somewhat nerved and netted-veined, often minutely denticulate on the margin; staminate spathes 2- or 3-parted, bluntly acuminate, $1-2 \mathrm{~cm}$. long, on thick clavate scapes to $5 \mathrm{~cm}$. long; staminate flowers numerous, crowded on a short-pedunculate spadix, enclosed in the spathe, detached at maturity and floating and expanding on the surface of the water; perianth of 3 sepals; stamens 1 to 3 ; peduncles of the pistillate plant to $1 \mathrm{~m}$. long, curved but scarcely spirally twisted in fruit; spathe 2-cleft, $2-2.5 \mathrm{~cm}$. long, rather loose; pistillate flowers solitary in the spathe, floating on the water; hypanthium linear-cylindric, in flower $2.5-3 \mathrm{~cm}$. long, fully $2 \mathrm{~mm}$. thick, in fruit about $1 \mathrm{dm}$. long; sepals 3 , fused to the inferior ovary, oval, 5-6 $\mathrm{mm}$. long, rounded at the apex; petals 3, about $2 \mathrm{~mm}$. long; ovary 1-celled, cylindric; stigmas 3, large, about $5 \mathrm{~mm}$. long, 2-cleft to near the base with each division obliquely obovate and abruptly short-acuminate; fruits cylindric, indehiscent, $8-18 \mathrm{~cm}$. long. V. spiralis of auth.

In lakes and beds of flowing streams, rare in the e. half of Tex., N.M. (Rio Arriba Co.) and recently discovered in Ariz. (Maricopa Co.), Apr.-July; from N.B., w. to N.D., N.M. and Ariz., s. in Fla. and Tex.

In our region, this species is too rare to be of much value to wild life. However, where it occurs abundantly in the north all parts of the plant are relished by many species of waterfowl. It is also eaten by muskrats and is a valuable food for fish. Diving ducks are said to be especially fond of the growing tips of the rootstocks. The plants also attract various marsh- and shore-birds, and they also provide a habitat for minute animal life.

\section{Egeria Planch.}

Two species that are native to South America.

\section{Egeria densa Planch. Fig. 73.}

Perennial submerged aquatic herb of fresh water, dioecious, rooting on the bottom or drifting when broken loose; stems terete, slender, $2-3 \mathrm{~mm}$. thick, ascending, simple or sparingly dichotomously branched; lower leaves opposite or in whorls of 3 ; middle and upper leaves in whorls of 4 to 6 , sessile, crowded, pellucid, linear-elliptic to linear-lanceolate, subobtuse to acuminate, serrulate, to $4 \mathrm{~cm}$. long and $5 \mathrm{~mm}$. wide, much longer than the internodes; flowers unisexual; staminate spathes funnelform, sessile, 2- to 4-flowered, borne in the upper axils, to $12 \mathrm{~mm}$. long and $3.5 \mathrm{~mm}$. broad, cleft on one side, the apex bifid; flowers stipitate, borne to the surface of the water on a threadlike hypanthium $3-6 \mathrm{~cm}$. 

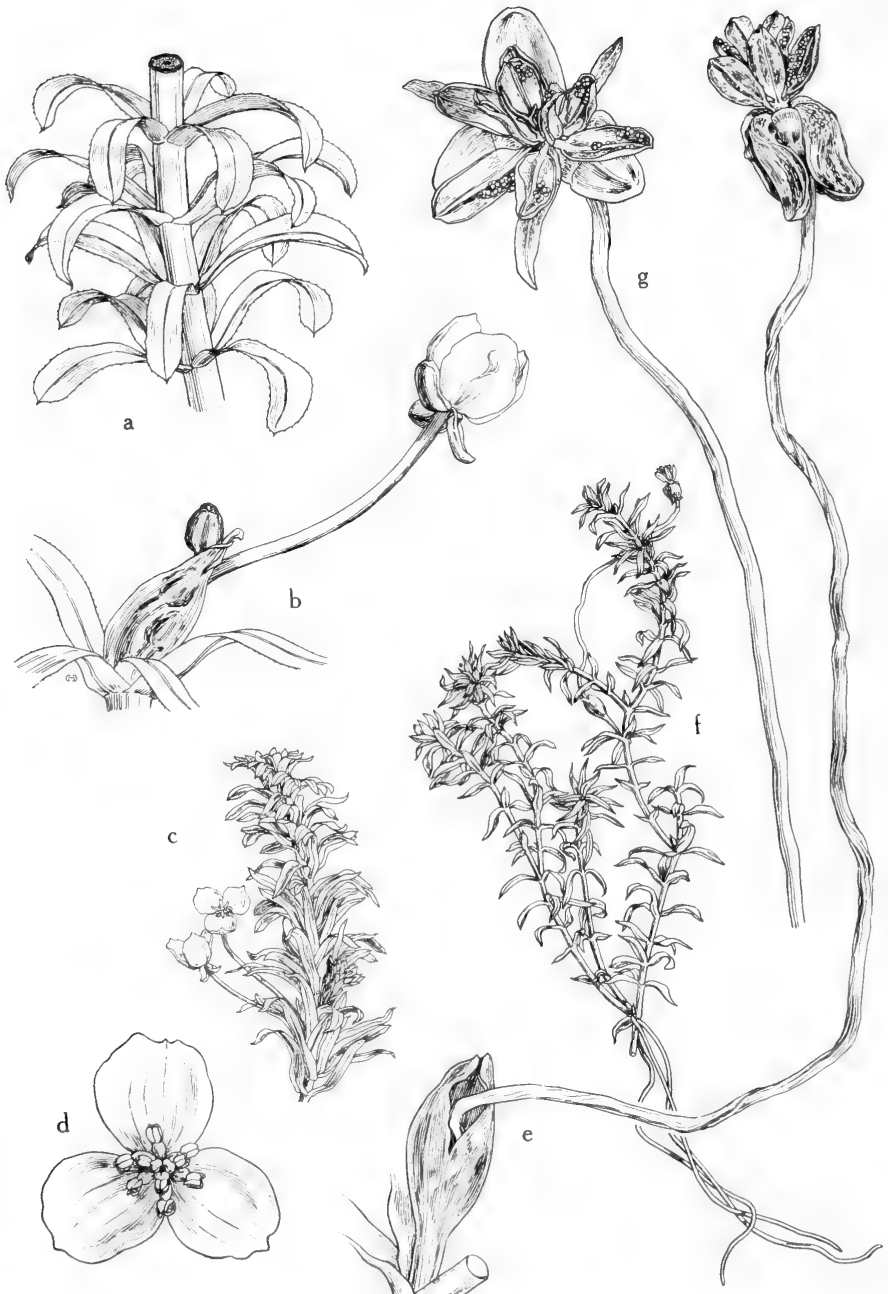

Fig. 73: a-d, Egeria densa: a, stem with whorls of lanceolate leaves, showing their minutely serrate margins, X 11/\%; b, spathe and the flowers, X 11/2; c, habit, showing long-peduncled staminate flowers, X $2 \%$; d staminate flower, X 2. e-g, Elodea canadensis: e, obovoid-clavate spathe with staminate flower on long thread-like peduncle, X 4; $\mathrm{f}$, habit, the staminate flower at the surface of the water in anthesis, $\mathrm{X} 2 / 3 ; \mathrm{g}$, mature staminate flower, showing the 9 anthers and 3 rudimentary stigmas, X 5. (From Mason, Fig. 53). 
long; sepals 3, herbaceous, elliptic-oblong, 3-4 mm. long; petals 3, white, obovate to suborbicular, membranous, about $1 \mathrm{~cm}$. long and $8 \mathrm{~mm}$. wide; stamens 9 , distinct; anthers loculicidal; filaments glandular-papillose above; nectary central, 3-lobed, small; pistillate plants not seen. Elodea densa (Planch.) Casp., Anacharis densa (Planch.) Vict.

In lakes, ponds, pools, ditches and quiet streams in Okla. (Comanche Co.) and in cen. and e. Tex., also Ariz. (Cochise and Santa Cruz cos.), Apr.-Oct.; a nat. of S.A. that has escaped from cult. in various places in the U.S. and Eur.

The relationship of this species to animal life is similar to that for species of Elodea.

\section{Elodea Michx. Waterweed. Ditchmoss}

Submersed dioecious (ours) perennials, adapted for cross-pollination at the surface of water, with dichotomously branching and usually nodally rooting slender stems; leaves sessile, opposite or in whorls of 3, 1-nerved, usually minutely denticulate; flowers mostly unisexual or occasionally in part perfect, borne in sessile to pedunculate bilobed spathes, the sepals and petals 3 each; staminate flowers 1 from a somewhat globose spathe, sessile or with a very short pedicellate hypanthium, when sessile deciduous from the plant at anthesis and floating on surface of water; stamens 3 to 9 ; pistillate flowers solitary in the tubular spathes, the pedicel-like hypanthium elongated to carry the rest of the flower to the water surface; stigmas 3 , simple or bilobed, tending to float, the styles slender; fruit ovoid to cylindric, several-seeded.

About 12 species in temperate and tropical America; one introduced into Europe.

The young, tender leafy stems of species in this genus are apparently only incidentally eaten by ducks, beaver and muskrats. The dense herbage that is frequently developed provides a sheltered habitat for small aquatic life but at the same time it may suppress the growth of more desirable species.

1. Middle and upper leaves opposite or occasionally with at least some in whorls of 3 , rounded to broadly obtuse at apex (2)

1. Middle and upper leaves always in whorls of 3 , obtuse-apiculate to acute at apex (3)

2(1). Largest leaves usually $1 \mathrm{~cm}$. long or less; pistillate spathe $2-2.2 \mathrm{~cm}$. long, the apical teeth erect; in New Mexico in our region....1. E. bifoliata.

2. Largest leaves usually $1.5 \mathrm{~cm}$. long or more; pistillate spathe $3-7 \mathrm{~cm}$. long, the apical teeth divergent; in Arizona in our region....2.E. longivaginata.

3(1). Leaves rarely less than $1.5 \mathrm{~mm}$. wide, obtuse-apiculate at apex; staminate flowers with a slender stalk (hypanthium), not deciduous at anthesis; pistillate sepals $2-3 \mathrm{~mm}$. long...................... E. canadensis.

3. Leaves rarely more than $1.5 \mathrm{~mm}$. wide, acute at apex; staminate flowers sessile, deciduous from plant at anthesis and floating on the surface of the water; pistillate sepals about $1 \mathrm{~mm}$. long.................... 4 . E. Nuttallii.

\section{Elodea bifoliata St. John.}

Stems slender, dichotomously branched; middle and upper leaves opposite or occasionally with at least some in whorls of 3 , linear to lance-linear, rounded to broadly obtuse at apex, finely serrulate, the longer ones $6-10 \mathrm{~mm}$. long and 1-1.5 mm. wide, bright green and flaccid; staminate spathe narrowed below into a slender petiolelike base $6-8 \mathrm{~mm}$. long, the upper portion ellipsoid-inflated and $5 \mathrm{~mm}$. long; flower peduncled by the slender threadlike hypanthium; sepals and petals $3.5 \mathrm{~mm}$. long; stamens 9, raised on a very short common stalk; pistillate spathe $2-2.2 \mathrm{~cm}$. long, the flower exserted by the very slender threadlike elongated hypanthium that becomes $9-12 \mathrm{~cm}$. in length; sepals $1.4 \mathrm{~mm}$. long and petals 1.8 


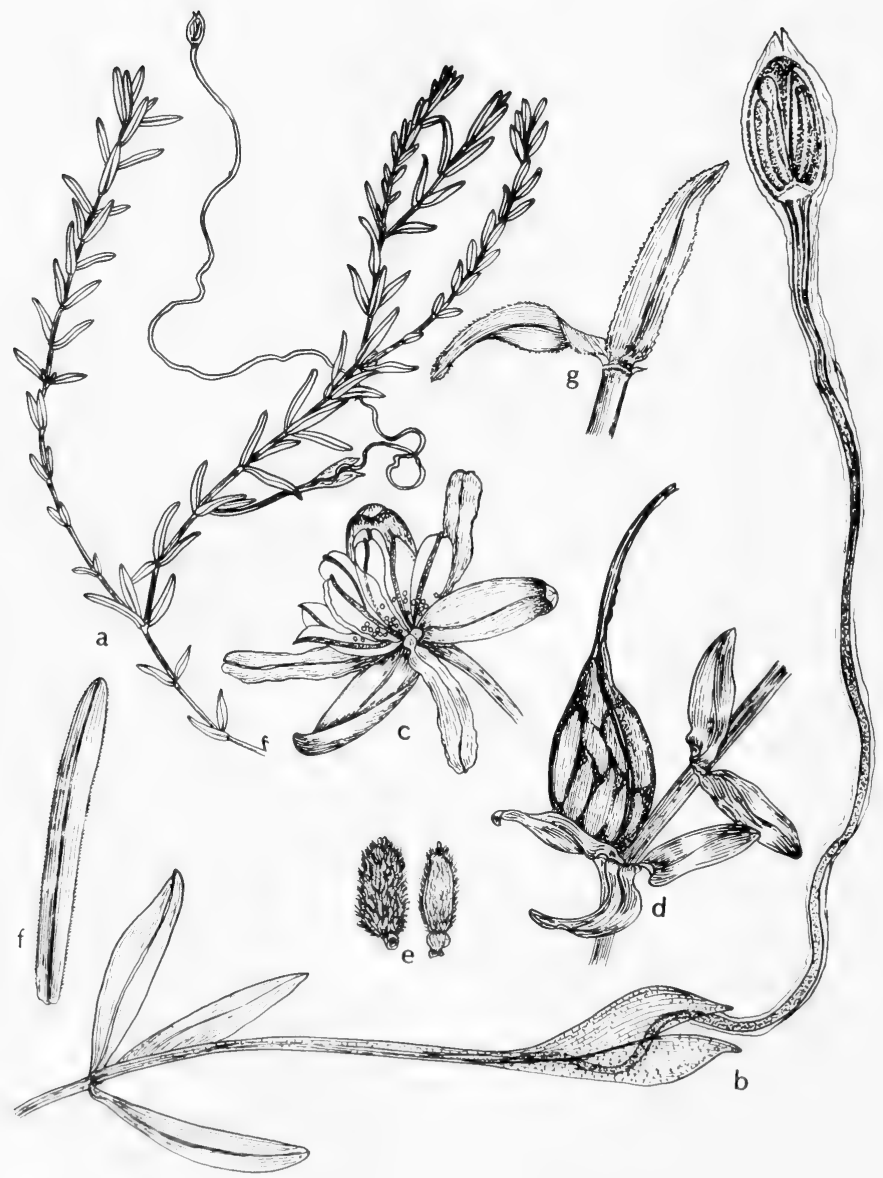

Fig. 74:- a-f, Elodea longivaginata: a, habit, X 1/2; b, young staminate flower and spathe, X 3; c, mature staminate flower, X 3 ; d, mature capsule, X 3; e, seeds, X 3; f, leaf, X 21/2. g, Elodea Nuttallii: g, leaf, X $2 \frac{1}{2}$. (V. F.). 
mm. long; staminodia 3, linear, obtuse; stigmas 3, bidentate, papillose.

In ponds and sloughs in Ariz. (Coconino Co.), May-Oct.; apparently endemic.

\section{Elodea longivaginata St. John. Fig. 74.}

Stems elongate, slender, sparingly dichotomously branched; middle and upper leaves opposite or occasionally with at least some in whorls of 3 , linear, rounded to broadly obtuse at apex, finely serrulate especially near and at the tip, the longer ones 1.5-2.6 cm. long and 1-2.5 mm. wide, bright green and flaccid, scarcely imbricate; staminate spathe short- to long-pedunculate, $6-10 \mathrm{~mm}$. long, 1-flowered; flower with an elongate threadlike hypanthium to about $3 \mathrm{dm}$. long, with sepals about $4 \mathrm{~mm}$. long and petals $5 \mathrm{~mm}$. long; stamens 9 , all attached at the summit of the hypanthium; pistillate spathe (and stalk) 3-7 cm. long, the flower with a threadlike hypanthium that elongates to about $3 \mathrm{dm}$. long so as to bear the flower to the surface of the water; sepals $2.8 \mathrm{~mm}$. long and petals $4 \mathrm{~mm}$. long; staminodia 3 , ligulate; stigmas 3 , oblong, undivided; capsule about $1 \mathrm{~cm}$. long; seeds cylindric, $6 \mathrm{~mm}$. long.

Submersed in water of lakes, ponds, sloughs and quiet running water in N.M. (Mora, Rio Arriba and San Miguel cos.), June-Oct.; from Alta. to N. D., s. to Mont., Wyo., Colo., N. M. and Ut.

\section{.3. Elodea canadensis Rich. in Michx. Fig. 73.}

Stems elongate, slender dichotomously branched; middle and upper leaves in whorls of 3 , linear to lance-oblong, mostly $8-15 \mathrm{~mm}$. long and $1.5-3 \mathrm{~mm}$. wide, rarely larger, bright green, thin, flaccid, finely serrulate, strongly imbricate at tip of stems (especially in pistillate plants); staminate spathe with a narrowed pedunculate base, inflated, ellipsoid to ovoid, $7 \mathrm{~mm}$. long and $4 \mathrm{~mm}$. wide; flowers peduncled by the slender threadlike elongate base of hypanthium, with the sepals $3.5-5 \mathrm{~mm}$. long and petals $5 \mathrm{~mm}$. long; stamens 9, with the 3 inner ones raised on a common fused stalk; pistillate spathe cylindric; flowers exserted from the spathe by the threadlike elongate base of the hypanthium which is to $15 \mathrm{~cm}$. long; sepals and petals 2-3 mm. long; staminodia 3, acicular; stigmas $3,4 \mathrm{~mm}$. long, broad, 2-cleft at apex; capsule ovoid, $6 \mathrm{~mm}$. long; seeds narrowly cylindric, $4.5 \mathrm{~mm}$. long, glabrous. Anacharis canadensis (Rich. in Michx.) Rich.

In lakes, ponds and slow-moving streams, especially in calcareous areas, reported (but not seen) from Okla., in N. M. (Sandoval and Taos cos.) and Ariz. (Coconino and Navajo cos.), June-Oct.; from Que. to Sask., s. to Va., Ala., (?) Okla., N. M., Ariz. and Calif.; also introd. in Eur.

\section{Elodea Nuttallii (Planch.) St. John. Fig. 74.}

Stems slender, dichotomously branched, often freely so; middle and upper leaves in whorls of 3 or occasionally with some in 4's, linear to narrowly lance-linear, 6-13 mm. long, 0.3-1.5 mm. wide, rarely more, acute at apex, green and flaccid, finely serrulate; staminate spathe borne at the median axils, sessile, ovoid, apiculate, 2-parted to well below the middle, the 2 acuminate teeth often twisted to form the apiculate tip, the body $2 \mathrm{~mm}$. long; flower single in each spathe, sessile, at maturity breaking loose to float to the surface and there opening; sepals about $2 \mathrm{~mm}$. long and $1.6 \mathrm{~mm}$. wide; petals usually wanting or (when occasionally present) $0.5 \mathrm{~mm}$. long; stamens 9 , the 3 central ones slightly elevated on a common stalk, the 6 outer ones at a lower level and with separate filaments; pistillate spathe narrowly cylindric, somewhat ovoid at base, usually $1-1.5 \mathrm{~cm}$. long; flower stalked by a slender threadlike elongated hypanthium as much as $9 \mathrm{~cm}$. in length; sepals $1.1 \mathrm{~mm}$. long and petals $1.3 \mathrm{~mm}$. long; staminodia $3,0.5 \mathrm{~mm}$. long, acicular; stigmas 3, slender, bifid, somewhat exceeding the sepals; capsule sessile, narrowly ovoid to fusiform, 5-7 mm. long, 1.5-2 mm. in diameter; seeds cylindric, short-beaked, 3.5-4.5 mm. long, pilose. Anacharis Nuttallii Planch., A. occidentalis (Pursh) Marie-Vict. 


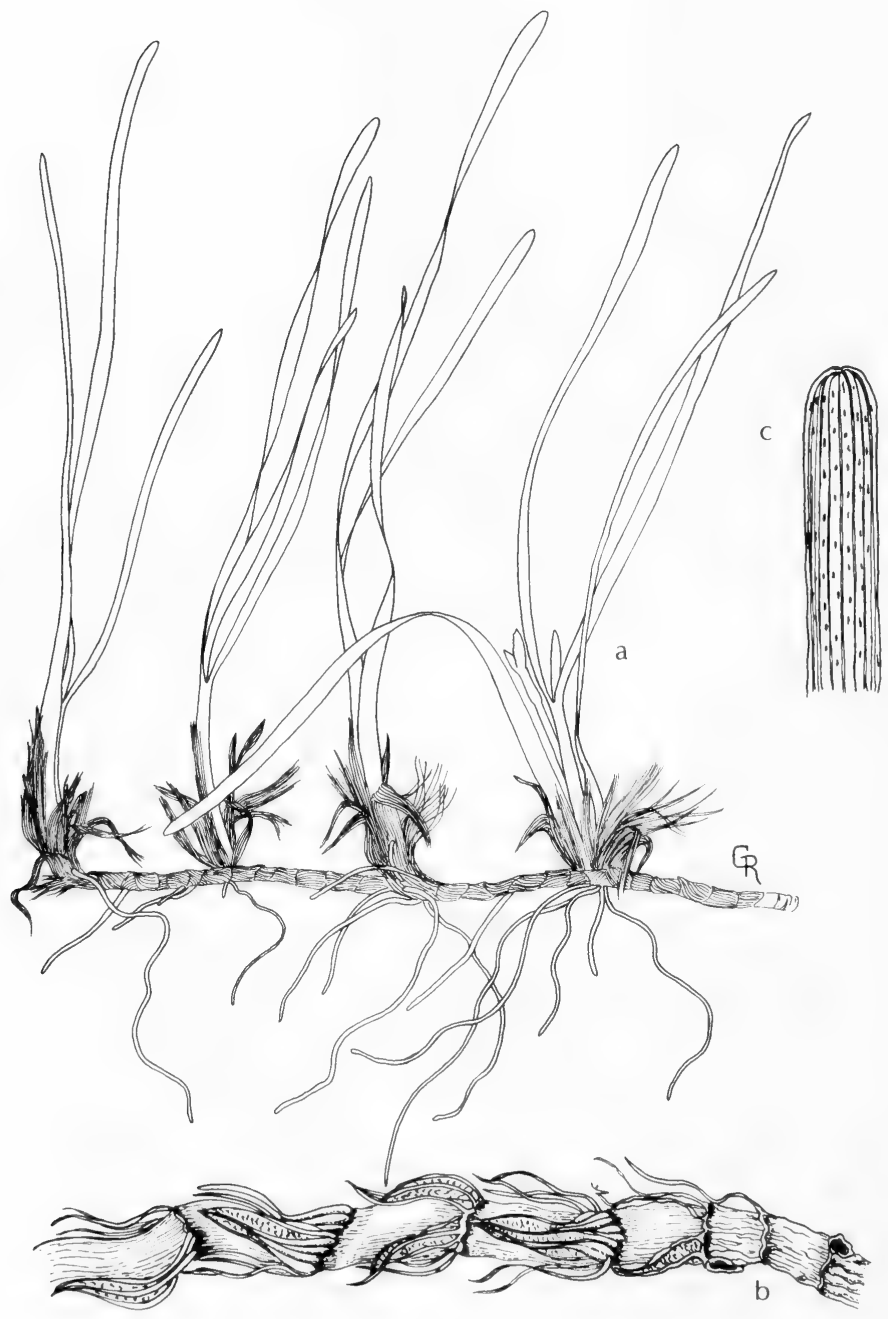

Fig. 75A: Thalassia testudinum: a, habit, $\mathrm{X} 1 / 2 ; \mathrm{b}$, rhizome showing sheaths and fibers, X 2; c, leaf tip, X 11/2. (a, Courtesy of R. K. Godfrey, b, c, V. F.). 

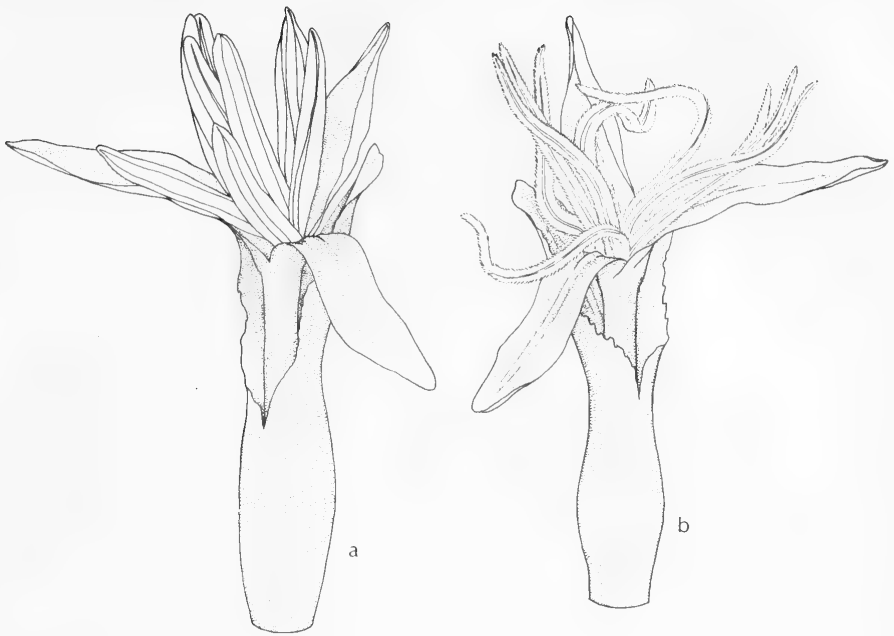

Fig. 75B: Thalassia testudinum: a, staminate flower, enlarged; b, pistillate flower, enlarged. (Courtesy of R. K. Godfrey).

In fresh or rarely brackish water, commonly in still water of streams, in Okla. (Alfalfa, Delaware, Ottawa and Sequoyah cos.) and N. M. (Taos Co.), May-Oct.; Que. to N. C., westw. to Minn., Okla. and N. M.; also Ida.

\section{Thalassia Soland. Turtle-grass}

Several species in marine waters of tropical and warm temperate regions.

1. Thalassia testudinum König, PALMAS DEL MAR. Figs. $75 \mathrm{~A}$ and $75 \mathrm{~B}$.

Submersed perennial herb with thick creeping scaly rhizome $3-5 \mathrm{~mm}$. thick, dioecious; the short stems covered by the fibrous remains of old leaves; leaves several, 2-ranked, clustered on short erect branches, sheathing at base, linear, to $35 \mathrm{~cm}$. long and $1 \mathrm{~cm}$. wide, glabrous, minutely serrulate at the obtuserounded apex, withering-persistent; scapes arising from the leaf axils, bearing a solitary unisexual flower in a 2-cleft tubular spathe whose lobes are elliptic and papillose-dentate on the margins; staminate flowers pedicelled; pistillate flower nearly sessile in the spathe; perianth lobes 6 , in both kinds of flowers oblong, rounded above, 1-1.2 cm. long; stamens 9; anthers about $8 \mathrm{~mm}$. long, linear, opening laterally; stigmas 9 to 12 , linear-filiform, pilose, grooved on the inside, about $1 \mathrm{~cm}$. long; fruit oval to ellipsoid-fusiform, short-stalked and short-beaked, densely warty-mammillate, opening by valves, $2 \mathrm{~cm}$. or more long.

In shallow salt water along the Gulf Coast where it forms dense and extensive marine meadows in bays and about reefs, occasional in beach drift; from Fla. to Tex., s. to n. S. A. 


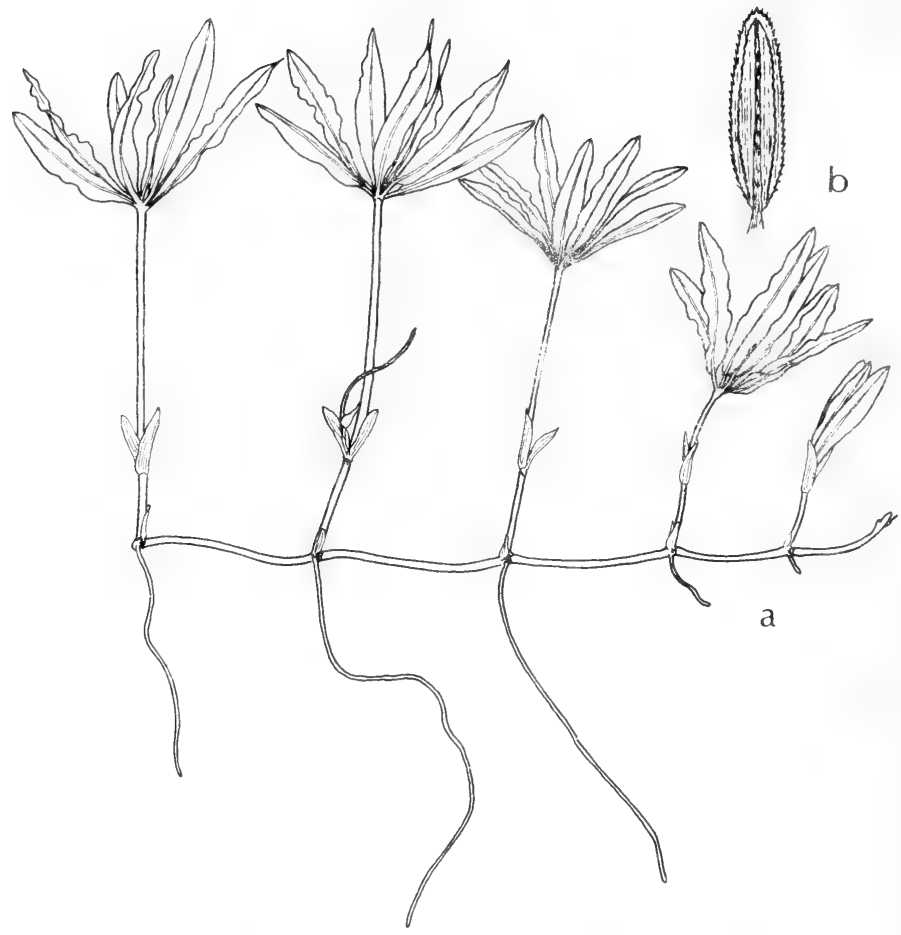

Fig. 76: Halophila Engelmannii: a, habit, X 1/2; b, young leaf, X 1. (Courtesy of R. K. Godfrey).

\section{Halophila Thou.}

Several species widespread in marine waters of tropical and warm temperate regions.

1. Halophila Engelmannii Asch. Fig. 76.

Submersed peronnial with horizontal slender creeping scaly branching stoloniferous stems $1-1.5 \mathrm{~mm}$. thick that root at the nodes and produce short erect leafy branches; internodes 2-4 cm. long; scales and leaves in pairs, opposite; scales broadly obovate, glabrous, to about $1 \mathrm{~cm}$. long; erect shoots $2-4 \mathrm{~cm}$. long, with 1 pair of scales at the middle and 2 or 3 pairs of leaves clustered at the summit; leaves sessile or with a very short thick petiole $2 \mathrm{~mm}$. long or less, linearoblong to oblong-elliptic, obtuse to subacute at apex, tapering at base, to $4 \mathrm{~cm}$. long and $8 \mathrm{~mm}$. wide, rather thick, faintly 3-ribbed and with 6 to 8 pairs of lateral veins, reticulate-roughened, finely serrulate on the margins; flowers 1 or 2 enclosed in a bifoliate sheath, both kinds often in the same sheath; pistillate flowers sessile in the axils of the leaves; hypanthium ovoid, 3-4 mm. long, its neck about $5 \mathrm{~mm}$. 
long; sepals 3, minute; stigmas 3, filiform, sessile, channeled and with usually 2 rows of papillae; fruit a membranous capsule with 3 parietal placentae, enclosed in the sheath; seeds numerous; staminate flowers not seen.

In shallow salt water along the Gulf Coast, occasional in beach drift; from Fla to Tex., the Bah. I. and W. I.

Ottelia alismoides (L.) Pers. Vegetatively resembling a large, coarse Plantago; leaves thin, submerged or partly emersed, broadly ovate to suborbicular or cordatereniform, to $21 \mathrm{~cm}$. in diameter, with 7 to 11 prominent parallel curved veins; peduncle several-angular, to $3 \mathrm{dm}$. tall; spathe elliptic to ovate, with 2 acute tips, 1 -flowered; flowers sessile, fragrant; sepals linear to oblong, obtuse, 1-nerved, to $16 \mathrm{~mm}$. long and $4 \mathrm{~mm}$. wide; petals obovate, $2-3 \mathrm{~cm}$. long, white to very pale pink, slightly darker distally yellow-based; anthers bright yellow; fruit oblong, rostrate, $2-4 \mathrm{~cm}$. long, crowned by the sepals, bursting irregularly.

This Afro-Asian plant has recently been found in Cameron Parish, Louisiana, in shallow, clear water in McCain's Fishing Lake, about 3 miles southwest of Sweet Lake (15 miles south of Lake Charles), about 30 miles east of the Texas state line. It probably is only a matter of time before it is found in similar locations in Texas.

\section{Fam. 24. Gramineae JUSS. GRASS FAMILY}

Herbs or less commonly woody reedlike plants; roots fibrous; leaves distichous, each with a more or less sheathing lower portion ("sheath") and a terminal usually more or less linear blade, often at the juncture of sheath and blade an adaxial fringe- or scalelike structure ("ligule"); in each axil often a small 2-nerved asymmetric (in transection often H-shaped) structure ("prophyll"); leaves often with a meristem near the ligule that permits continued elongation; flowers (florets) very much reduced, perfect or neuter, less commonly staminate or pistillate, usually aggregated distichously in small clusters known as spikelets, each flower comprising the genitalia (when present) at the base of which are usually 2 minute bulbs or scales ("lodicules"), this floret subtended usually by a minute adaxial prophyll-like bract scale (palea) and a slightly larger abaxial bract scale (lemma); lemmas (when more than one present) distichous on the spikelet axis (rachilla); base of spikelet usually with 2 empty bract scales (glumes), or one of these sometimes obsolete or rarely both glumes absent; perianth absent; stamens 1 to 6 (usually 3); ovary a usually dorsiventrally flattened 1-celled uniovulate structure; style deeply divided into 2 (rarely 3) long feathery stigmas; fruit ("grain," "caryopsis") an achenelike structure but with the ovary wall usually tightly coherent to the solitary endosperm-containing seed (ovary wall apparently not persistently tightly adherent to seed in Sporobolus and some species of Muhlenbergia), or in some genera (e.g., Panicum, etc.) the word "fruit" is used to refer to the lemma and its contents since in these plants the lemma tightly and persistently clasps the grain and thus constitutes a spurious outer fruit layer. Poaceae Barnh.

One of the largest families of flowering plants, the Gramineae are the most important economically as measured by several criteria. They produce the dietary staples of most of the world's population. One species, rice, is the most important of all the grasses and probably the single most important plant species in the world.

(Many data, including an adaptation of the generic key, have been derived from the work of A. S. Hitchcock, Manual of the Grasses of the United States, U. S. Dept. Agric. Misc. Publ. No. 200, 2nd ed. revised by Agnes Chase, 1055 pp. 1950.) 
1. Spikelets with 1 perfect terminal floret and a sterile or staminate floret below, usually represented by a sterile lemma only, 1 glume sometimes wanting; the rachilla articulated below the spikelets, the spikelets thus falling entire (2)

1. Spikelets 1- to many-flowered, the reduced florets (if any) above the perfect florets (except in Phalaris); the rachilla usually articulated above the glumes (except in Leersia, Polypogon, Alopecurus, Spartina and Agrostis semiverticillata) (16)

2(1). Glumes membranaceous, the sterile lemma like the glumes in texture (3)

2. Glumes indurate; fertile lemma and palea hyaline or membranaceous, the sterile lemma like the fertile one in texture (12)

$3(2)$. Spikelets subtended or surrounded by 1 to many distinct or more or less connate bristles forming an involucre (4)

3. Spikelets not subtended by bristles (5)

4(3). Bristles persistent, the spikelets deciduous

55. Setaria

4. Bristles falling with the spikelets at maturity 56. Cenchrus

5(3). Glumes or sterile lemma awned (awn reduced to a point in Echinochloa colonum) 54. Echinochloa

5. Glumes and sterile lemma awnless (6)

6(5). Fruit cartilaginous-indurate, flexible, usually dark-colored, the lemma with more or less prominent white hyaline margins that are not inrolled (7)

6. Fruit chartaceous-indurate, rigid (8)

7(6). Spikelets in slender racemes more or less digitate at the summit of the culms. 48. Digitaria

7. Spikelets in panicles 47. Anthaenantia

$8(6)$. Spikelets placed with the back of the fruit turned away from the rachis of the racemes, usually solitary (not in pairs) (9)

8. Spikelets placed with the back of the fruit turned toward the rachis (first glume, when present, away from the rachis) of the spikelike racemes or pedicellate in panicles (10)

9(8). First glume and the rachilla joint forming a swollen ringlike callus below the spikelet...................................................................49. Eriochloa

9. First glume present or wanting, not forming a ringlike callus below the spikelet 50. Axonopus

10(8). First glume typically wanting; spikelets plano-convex, subsessile in spikelike racemes.

51. Paspalum

10. First glume present; spikelets usually in panicles (11)

11(10). Second glume inflated-saccate, this and the sterile lemma much exceeding the stipitate fruit.

11. Second glume not inflated-saccate. .53 Sacciolepis

12(2). Spikelets unisexual, the pistillate below, the staminate above, in the same inflorescence or in separate inflorescences.

61. Tripsacum

12. Spikelets in pairs, one sessile and perfect, the other pedicellate and usually staminate or neuter (the pedicellate one sometimes obsolete, rarely both pedicellate); lemmas nyaline (13)

13(12). Spikelets alike, all perfect.

57. Erianthus

13. Spikelets unlike, the sessile perfect, the pedicellate sterile (14)

14(13). Pedicel thickened, appressed to the thickened rachis joint (at least parallel to it) or adnate to it; spikelets awnless, appressed to the joint

60. Manisuris 
14. Pedicel not thickened (if slightly so the spikelets awned), neither appressed nor adnate to the rachis ioint, this usually slender; spikelets usually awned (15)

15(14). Fertile spikelet with a hairy-pointed callus, formed of the attached supporting rachis joint or pedicel; awns strong......

58. Andropogon

15. Fertile spikelet without a callus, the rachis disarticulating immediately below the spikelet; awns slender. 50. Sorghum

16(1). Culms woody, perennial; leaf blades articulated with sheaths

..1. Arundinaria

16. Culms herbaceous, annual (somewhat woody and persistent in Arundo); leaf blades and sheaths continuous (17)

17(16). Spikelets with 2 (rarely 1 ) staminate, neuter or rudimentary lemmas unlike and below the fertile lemma; no sterile nor rudimentary floret above (18)

17. Spikelets without sterile lemmas below the perfect floret (19)

18(17). Lower florets staminate; spikelets brown, shining.

18. Lower florets neuter; spikelet green or yellowish.

40. Hierochlö

19(17). Spikelets unisexual, falling entire, 1-flowered, terete or nearly so (20)

19. Spikelets perfect (rarely unisexual but then not as above), usually articulate above the glumes (22)

20(19). Culms slender; floating aquatic; staminate and pistillate spikelets borne in separate inflorescences ...................................46. Hydrochloa

20. Culms robust; plants tall, usually standing in water; staminate and pistillate spikelets borne in the same panicle (21)

21(20). Pistillate spikelets on the ascending upper branches, the staminate on the spreading lower branches of the panicle; annual or perennial.... 44. Zizania

21. Pistillate spikelets at the ends, the staminate below on the same branches of the panicle; perennial. 45. Zizaniopsis

22(19). Spikelets articulate below the glumes, 1-flowered, very flat, the lemma and palea about equal, both keeled; glumes small or wanting (23)

22. Spikelets articulate above the glumes (rarely below, but at least one of the glumes well-developed) (24)

23(22). Glumes minute; lemma often awned.

23. Glumes wanting; lemma awnless.

42. Oryza

24(22). Spikelets sessile on a usually continuous rachis (short-pedicellate in Leptochloa; the rachis disarticulating in Hordeum) (25)

24. Spikelets pedicellate in open or contracted sometimes spikelike panicles, rarely racemes (34)

25(24). Spikelets on opposite sides of the rachis; spike terminal, solitary (26)

25 . Spikelets on one side of the rachis; spikes usually more than 1 , digitate or racemose $(30)$

26(25). Spikelets solitary at each node of the rachis (rarely 2 in species of Agropyron, but never throughout) (27)

26. Spikelets more than 1 at each node of the rachis (solitary in part of the spike in some species of Elymus) (29)

27(26). Spikelets 1-flowered, sunken in hollows of the rachis; spikes slender, cylindric; low annuals. 20. Parapholis

27. Spikelets 2- to several-flowered, not sunken in the rachis (28) 
28(27). Spikelets placed edgewise to the rachis; first glume wanting except in the terminal spikelet.

19. Lolium

28. Spikelets placed flatwise to the rachis.

16. Agropyron

29(26). Spikelets 3 at each node of the rachis, 1-flowered, the lateral pair pediceled, usually reduced to awns............................18. Hordeum

29. Spikelets 2 or more (occasionally solitary) at each node of the rachis, alike, 2- to 6-flowered.

17. Elymus

$30(25)$. Spikelets wtih more than 1 perfect floret.

35. Leptochloa

30. Spikelets with only 1 perfect floret, often with additional imperfect florets above or below (31)

31(30). Spikelets with 1 or more modified florets above the perfect one

39. Trichloris

31. Spikelets without additional modified florets, the rachilla sometimes prolonged (32)

32(31). Rachilla articulate above the glumes.

32. Rachilla articulate below the glume, the spikelets falling entire (33)

33(32). Glumes unequal, narrow.

38. Spartina

33. Glumes equal, broad, boat-shaped.

37. Beckmannia

34(24). Spikelets 1-flowered (occasionally some of the spikelets 2-flowered in a few species of Muhlenbergia) (35)

34. Spikelets 2- to many-flowered (44)

35(34). Articulation below the glumes, the spikelets falling entire (36)

35. Articulation above the glumes (38)

36(35). Glumes long-awned.

30. Polypogon

36. Glumes awnless (37)

37(36). Rachilla prolonged behind the palea; panicle narrow or open. not dense; glumes not united, not ciliate on the keel.

28. Cinna

37. Rachilla not prolonged behind the palea; panicle dense. 29. Alopecurus

38(35). Glumes longer than the lemma (39)

38. Glvmes not longer than the lemma, usually shorter (the awn tips longer in Muhlenbergia racemosa) (42)

39(38). Glumes compressed-carinate, stiff-ciliate on the keel; panicle dense, cylindric or ellipsoid....

39. Glumes not compressed-carinate, not ciliate (40)

40(39). Glumes saccate at base; lemma long-awned; panicle contracted, shining 32. Gastridium

40. Glumes not saccate at base; lemma awned or awnless; panicle open or contracted (41)

41(40). Floret bearing a tuft of hairs at the base from the short callus; palea well-developed, the rachilla prolonged behind the palen as a hairy bristle............................................................26. Calamagrostis

41. Floret without hairs at the base or with short hairs; palea usually small or obsolete. 27. Agrostis

42(38). Lemma awned from the tip or mucronate, 3- to 5-nerved or obscure in some species..................................................33. Muhlenbergia

42. Lemma awnless or awned from the back (43)

43(42). Caryopsis at maturity falling from the lemma and palea; seed loose in the pericarp, this usually opening when ripe; lemma 1 -nerved........ 34. Sporobolus 
43. Caryopsis not falling from the lemma and palea, remaining permanently enclosed in them; seed adnate to the pericarp............33. Muhlenbergia

44(34). Glumes as long as the lowest floret, usually as long as the spikelet (sometimes shorter in Sphenopholis); lemmas awned from the back (spikelets awnless in species of Trisetum and Sphenopholis) (45)

44. Glumes shorter than the first floret (except in Tridens strictus); lemmas awnless or awned from the tip or from a bifid apex (50)

45(44). Florets 2, one perfect, the other staminate.

24. Holcus

45. Florets 2 or more, all alike except the reduced upper ones (46)

46(45). Articulation below the glumes, the spikelets falling entire (47)

46. Articulation above the glumes, the glumes similar in shape (48)

47(46). Lemmas (at least the upper) with a conspicuous bent awn; glumes nearly alike.........................................................22. Trisetum

47. Lemmas awnless or the upper with a short awn; second glume much wider than the first..................................................21. Sphenopholis

48(46). Lemmas biñd at apex, awned or mucronate between the lobes; spikelets several-flowered................................................25. Danthonia

48. Lemmas toothed but not bifid and awned or mucronate between the lobes (49)

49(48). Lemmas keeled, the awn when present from above the middle

22. Trisetum

49. Lemmas convex, awned from below the middle.

23. Deschampsia

50(44). Tall stout reeds with large plumelike panicles; lemmas and rachilla with long silky hairs as long as the lemmas (51)

50. Low or rather tall grasses, rarely more than $1.5 \mathrm{~m}$. tall; panicles not as above (52)

51(50). Lemmas naked; rachilla hairy

14. Phragmites

51. Lemmas hairy; rachilla naked.

13. Arundo

52(50). Plants dioecious, perennial (53)

52. Plants not dioecious (except in the annual Eragrostis reptans) (54)

53(52). Plants low, stoloniferous; spikelets obscure, scarcely differentiated from the short crowded rigid leaves............................9. Monanthochloë

53. Plants erect from creeping rhizomes; spikelets in narrow simple exserted panicles.

10. Distichlis

54(52). Lemmas 3-nerved, the nerves prominent, often hairy (55)

54. Lemmas 5- to many-nerved, the nerves sometimes obscure (57)

55(54). Inflorescence a few-flowered head or capitate panicle overtopped by the leaves or partly concealed in them; lemmas toothed or cleft; low plants of usually arid regions.

15. Tridens

55. Inflorescence an exserted open or spikelike panicle (56)

56(55). Lemmas pubescent on the nerves or callus, the midnerve usually exserted as an awn or mucro.

15. Tridens

56. Lemmas not pubescent on the nerves nor callus (the internerves sometimes pubescent), awnless.

8. Eragrostis

57(54). Spikelets with 1 to 4 empty lemmas below the fertile florets; nerves obscure; lemmas firm.

11. Chasmanthium

57. Spikelets with no empty lemmas below the fertile florets; nerves usually prominent; lemmas membranous (firm in a few species of Bromus and Festuca) (58) 


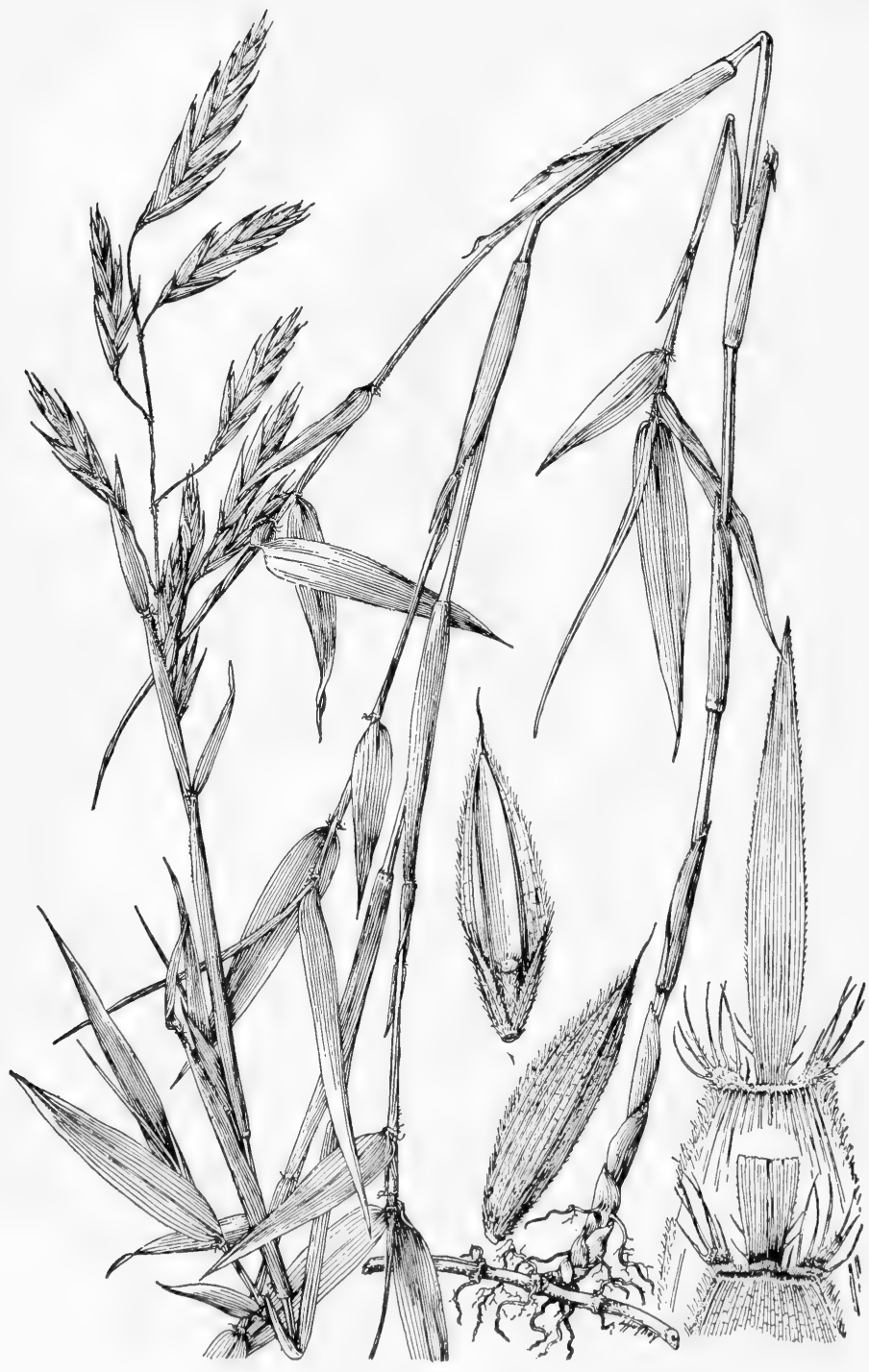

Fig. 77: Arundinaria gigantea: flowering shoot, X 1/2; summit of culm sheath, outer and inner face, showing auricles and ligule, and two views of floret, X 2. (From Hitchcock \& Chase). 
58(57). Lemmas as broad as long, the margins outspread; florets closely imbricate, horizontally spreading.....

58. Lemmas longer than broad, the margins clasping the palea; florets not horizontally spreading (59)

59(58). Lemmas keeled on the back (60)

59. Lemmas rounded on the back (slightly keeled toward the summit in Festuca and Bromus) (62)

60(59). Spikelets strongly compressed, crowded in 1-sided clusters at the ends of the stiff naked panicle branches. 12. Dactylis

60. Spikelets not strongly compressed, not crowded in 1 -sided clusters (61)

61(60). Lemmas awned from a minutely bifid apex; spikelets large......2. Bromus 61. Lemmas awnless; spikelets small........................................................ Poa

62(59). Nerves of lemma parallel, not converging at summit or but slightly so (63)

62. Nerves of lemma converging toward the summit, the lemmas narrowed at apex (64)

63(62). Nerves prominent; plants usually rather tall, growing in fresh-water marshes or wet woodlands...........................................5. Glyceria

63. Nerves faint; plants low, usually growing in saline soils................4. Puccinellia

64(62). Lemmas awned or awn-tipped from a minutely bifid apex; palea adhering to the caryopsis................................................2. Bromus

64. Lemmas entire, pointed, awnless or awned from the tip (65)

$65(64)$. Spikelets awned (awnless in a few perennial species); lemmas pointed....

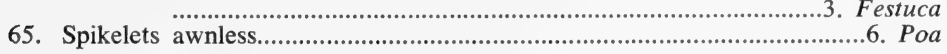

\section{Arundinaria MichX.}

About 150 species in warmer parts of the world; one species in our area.

1. Arundinaria gigantea (Walt.) Muhl. Giant cane. Fig. 77.

Mostly glabrous robust rhizomatous cane-grass forming dense brakes; primary aerial culms perennial (not usually freezing back), 2-8 m. tall, 2-20 mm. thick, erect, with some ascending or appressed branches along the length; sheath margins ciliate; small sheath auricles usually with a few spreading bristles; blades very shortly petiolate, of two size-classes, larger ones on the primary aerial culms $12-20 \mathrm{~cm}$. long and 10-25 mm. broad, smaller ones on the branches; inflorescences narrowly paniculate, the lower pedicels mostly included in the sheath and the upper ones free (most of them nearly as long as their spikelets); spikelets few, 5-8 cm. long, about $8 \mathrm{~mm}$. broad, 9- to 13-flowered, lax enough so that the internodes of rachis are often visible; zone of abscission at lower part of each lemma node; lower lemmas 22-25 mm. long, cymbiform, finely pubescent, obscurely 11-nerved, with fine awnlike tips.

Locally forming brakes in low areas near sloughs, bayous and rivers, in s.e. Okla. (Waterfall) and in e. and s.e. Tex., s.w. to Wharton Co., spring; s.e. U. S., n. to N. C., O. and Ind.

Giant cane formerly covered many square miles in east and southeast Texas but with the introduction of domestic stock it has almost disappeared and is now relatively rare.

\section{Bromus L. Chess. Brome}

Plant diverse in habit; inflorescense an open or dense panicle; spikelets diverse, large, either strongly compressed or turgid, several-flowered with all the flowers 


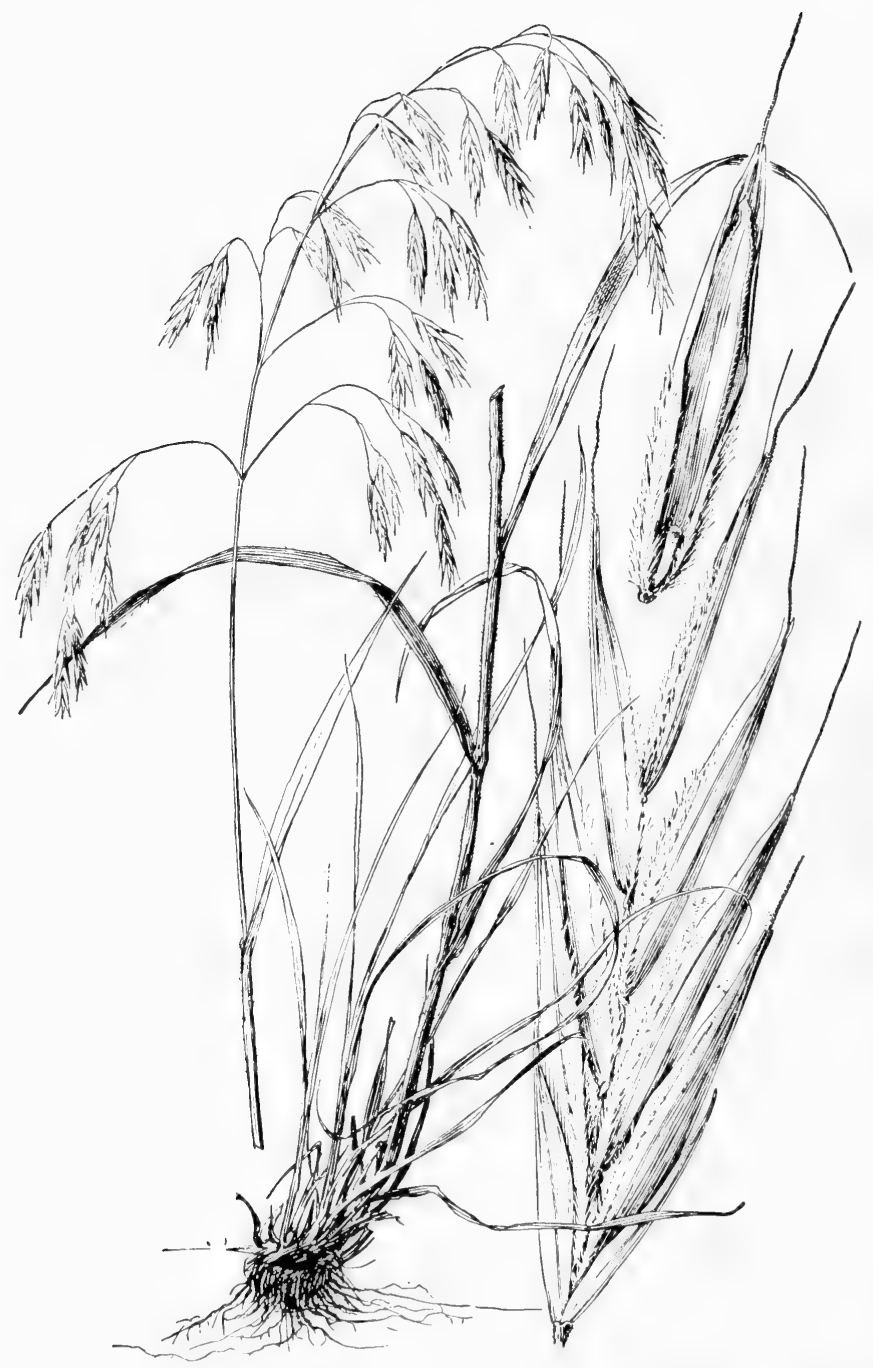

Fig. 78: Bromus Richardsonii: plant, X 1/2; spikelet and floret, X 5. (From Hitchcock \& Chase). 
perfect; rachilla glabrous, abscising above the glumes and below the florets; glumes 1- to 5-nerved, shorter than the lower lemma; lemmas basally not calloused or else with a glabrous callus, 5- to 9-nerved, apically narrowed or bifid, the nerves converging toward the summit, mucronate or awned either between the teeth or from the back shortly below the apex.

A genus of about 150 species in temperate regions. Some European authors split Bromus into several genera, perhaps justly.

1. Panicle branches elongate, drooping; lemmas mostly 5-6 mm. wide, at first membranous, eventually becoming slightly chartaceous and only the lower part of the margin becoming revolute, the back rather evenly pubescent.

1. B. japonicus.

1. Panicle branches relatively short, ascending; lemmas mostly $6-8 \mathrm{~mm}$. wide, at first membranous but soon becoming chartaceous and the margin partly revolute, the upper portion of back glabrous

2. B. Richardsonii.

\section{Bromus japonicus L. JAPANESE CHESS.}

Annual; culms 3-8 dm. long, ascending, slender, sheaths and blades usually shortly pilose; blades mostly 2-5 $\mathrm{mm}$. broad; panicle 1-2 $\mathrm{dm}$. long, 1-sided (when mature) nodding with several long curved drooping few-flowered branches at the base; spikelets turgid, 7- to 10-flowered; lemmas with awns 5-11 mm. long, (at first straight or eventually slightly curved and spreading) and bodies 7-9 $\mathrm{mm}$. long and 5-6 $\mathrm{mm}$. broad, broadly overlapping, the thin margins conspicuous and eventually (very late in maturation) becoming chartaceous and the margins revolute to clasp the palea which is conspicuously shorter; anthers $0.6-1.2 \mathrm{~mm}$. long.

Abundant weed in wet meadows and ditches, in Okla. (Waterfall) and in scattered parts of Tex. (rare in Trans-Pecos), and Ariz. (Apache, Navajo, Coconino, Gila, Cochise and Pima cos.), spring; widespread in temp. parts of Euras. and N.A.

\section{Bromus Richardsonii Link. Fig. 78.}

Tufted perennial; culms 4-8 dm. long, about $2 \mathrm{~mm}$. thick, often decumbent in the lower part and geniculate; sheaths usually glabrous; blades $5-15 \mathrm{~mm}$. broad, mostly flat, the lower corners (where joining sheath) minutely round-auricled; panicles nodding, 1-2 dm. long, very open and diffuse; spikelets 6- or 7-flowered; first glume 1-nerved, the second 3-nerved; lemmas not at all keeled (except when very immature), cymbiform with a body $10-13 \mathrm{~mm}$. long and an awn $3-5 \mathrm{~mm}$. long, densely pubescent near the lateral margins but the median portion glabrous. Zerna Richardsonii (Link) Nevskii. These plants have usually been called $B$. ciliatus $\mathrm{L}$.

On lake and pond margins, in seepage areas and along wettish river banks, also moist woods and rocky slopes, in higher parts of mts. in the Tex. Trans-Pecos, N. M. (rather widespread) and Ariz. (Apache, Coconino, Yavapai, Graham, Cochise and Pima cos.), summer; Rocky Mts. and s. to Tex.

\section{Festuca L. Perennial Fescue}

Tufted perennials $1-11 \mathrm{dm}$. tall; spikelets very slightly if at all laterally compressed, 2- to 8-flowered, most of the flowers perfect and chasmogamous but the uppermost staminate or rudimentary; lower glume usually well-developed, 1-nerved; upper glume usually merely pointed though less commonly awned, usually 3-nerved (but the lateral nerves obscure); spikelet rachilla disarticulating at the lower part of each node (i.e., top of each internode); lemmas usually ovate or elliptic, blunt to acute, awned or awnless, cymbiform and/or convex, not keeled (except slightly in $F$. rubra), revolute, 5-nerved (lateral nerves obscured); anthers 3, free, exserted; grains ellipsoid or ovoid. 


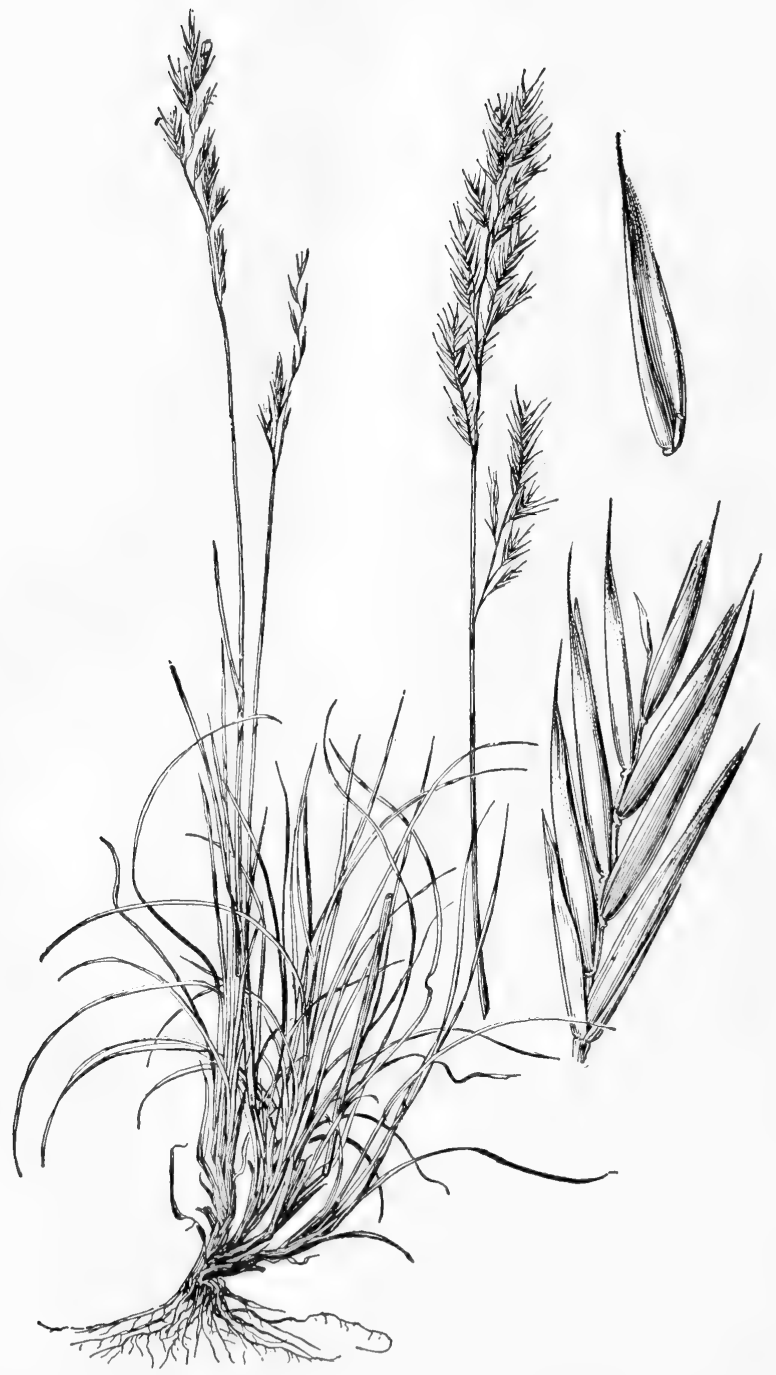

Fig. 79: Festuca rubra: plant, X 1/2; spikelet and floret, X 5. (From Hitchcock \& Chase). 
A moderately large genus of temperate regions of the world.

1. Blades involute; lemmas lanceolate, with awns 1-4 mm. long.......... 1. . rubra.

1. Blades flat for at least a part of their length; lemmas elliptic, awnless, acute

2. F. obtusa.

\section{Festuca rubra L. Red fescue. Fig. 79.}

Tufted perennial; culms 1-5 dm. long, 0.5-1 mm. thick, usually decumbent at the base, reddish-fibrillose and subrhizomatous, otherwise erect; ligules extremely short to obsolete; panicles interrupted-spikelike (or more lax with a few very short ascending branches in the lower part floriferous nearly to their bases), 4-12 cm. long; pedicels 1-2 mm. long, appressed; spikelets laterally compressed, 3- to 5-flowered; lemmas lanceolate, very slightly (if at all) keeled near the apex, marginally thin and revolute, apically long-tapered, acute with an awn 1-4 mm. long, the lowest with bodies 5-7 $\mathrm{mm}$. long.

In wet meadows, bogs and marshes, rare in highest parts of Madera Canyon, Davis Mts. in the Tex. Trans-Pecos and Ariz. (Apache and Coconino cos.), summer; widespread in the cooler parts of the N. Hemis., in Am. s. in the mts. to S. C., Ala. and Mex.

\section{Festuca obtusa Biehler. Nodding fescue.}

Tufted perennial; culms 5-11 dm. long, 1-2 mm. thick, basally shortly decumbent, usually geniculate at the lower nodes; blades $3-8 \mathrm{~mm}$. broad, flat at least part of their length; panicles $12-25 \mathrm{~cm}$. long, usually less than half as thick, more or less open, nodding, with several branches, the long lower ones naked in at least the basal two-thirds to three-fourths their lengths; pedicels 2-4 mm. long, appressed; spikelets turgid, 2- to 5-flowered; lemmas elliptical, not at all keeled, convex, marginally thin, eventually revolute, the lowest lemmas $3.5-4.5 \mathrm{~mm}$. long, awnless, apically acute (the angle broad, blunt), eventually turning greenishstramineous, the lateral nerves very obscure.

Scarce in woods, on shores of ponds and alluvial soil along streams, in Okla. (Alfalfa Co.) and in e. Tex., spring; e. U.S., w. to N.D., S.D., Neb., Kan., Okla. and Tex.

\section{Puccinellia Parl. Alkali-grass}

Low pale smooth tufted annuals or perennials with narrow to open panicles; spikelets several-flowered, usually terete or subterete, the rachilla disarticulating above the glumes and between the florets; glumes unequal, shorter than the first lemma, obtuse or acute, rather firm, often scarious at the tip, the first 1-nerved or sometimes 3-nerved, the second 3-nerved; lemmas usually firm, rounded on the back, obtuse or acute, rarely acuminate, usually scarious and often erose at the tip, glabrous or puberulent toward base, rarely pubescent on the nerves, 5-nerved, the parallel nerves indistinct or rarely prominent; palea about as long as the lemma or somewhat shorter.

About 100 species in the North Temperate Zone and in South Africa.

1. Lemmas pubescent on the nerves for one half to three fourths their length; dwarf annual............................................................1. P. Parishii.

1. Lemmas glabrous or (if pubescent) the hairs not confined to the nerves; perennials (2)

2(1). Lemmas $2 \mathrm{~mm}$. long or less; anthers $0.5-0.8 \mathrm{~mm}$. long; lower panicle branches usually reflexed, spikelet-bearing mainly near the tip.

2. $P$. distans.

2. Lemmas usually $2.5-3.2 \mathrm{~mm}$. long; anthers usually more than $0.8 \mathrm{~mm}$. long; lower panicle branches often erect, usually spikelet-bearing most of their length. 3. P. Nuttalliana. 


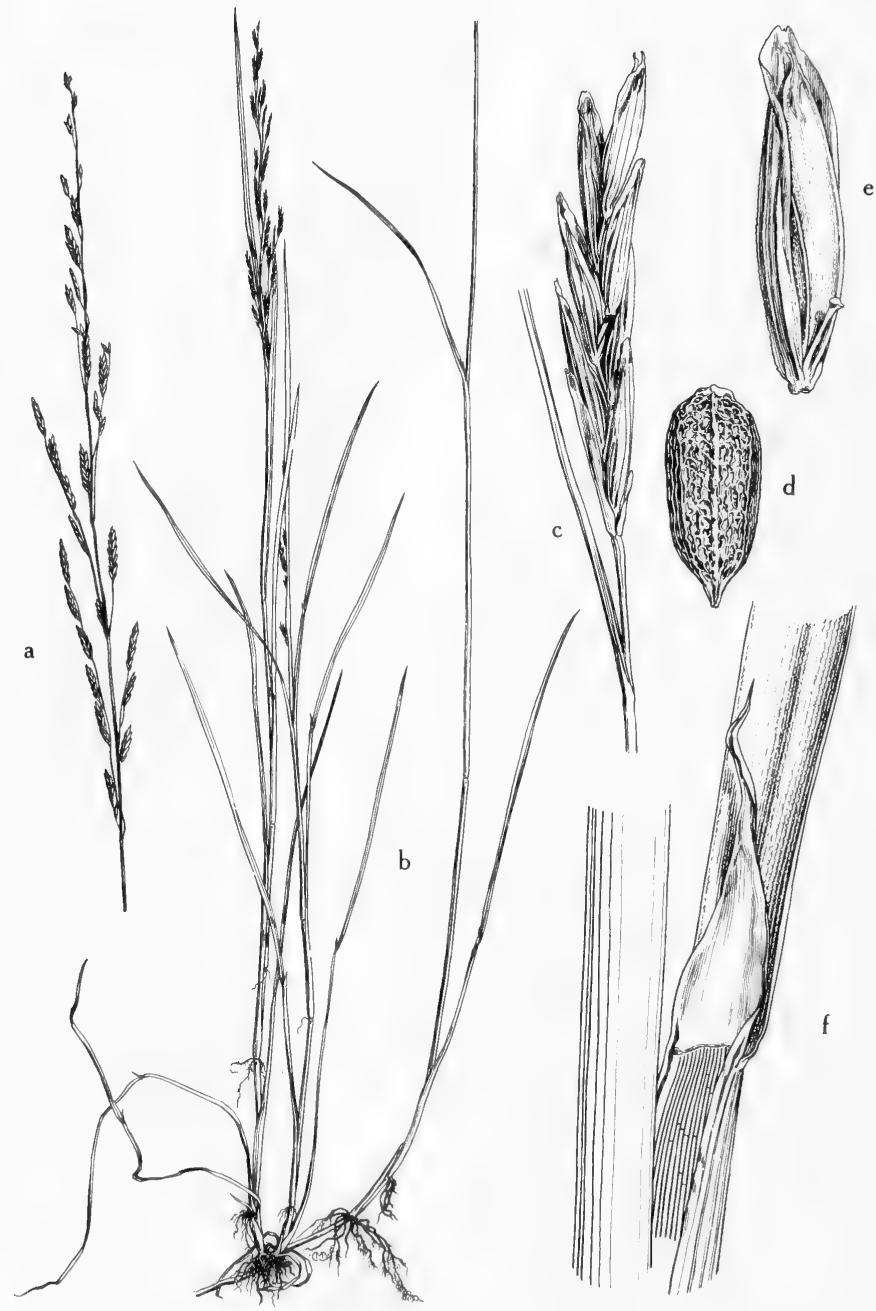

Fig. 80: Glyceria borcalis: a, panicle, X 2\%; b, habit, showing the slender culms, leaves and the panicles, $X 1 / 5$; c, spikelet, X 6 ; d, grain, X 20; e, floret, showing the palea and broadly scarious tip of lemma, X 12; $\mathrm{f}$, leaf sheath, blade and ligule, X 4 . (From Mason, Fig. 68). 


\section{Puccinellia Parishii Hitchc.}

Annual; culms $3-10 \mathrm{~cm}$. tall; blades flat to subinvolute, less than $1 \mathrm{~mm}$. wide; panicle narrow, few-flowered, 1-4 cm. long; spikelets 3- to 6-flowered, 3-5 mm. long; lemmas about $2 \mathrm{~mm}$. long, obtuse to truncate, scarious and somewhat erose at the tip, pubescent on the mid and lateral nerves nearly to the apex and on the intermediate nerves about half way.

In marshy ground in N. M. (Taos Co.) and Ariz. (Navajo and Coconino cos.); also s. Calif.

\section{Puccinellia distans (L.) Parl.}

Perennial; culms erect or decumbent at base, 2-4 dm. tall, sometimes taller; blades flat or more or less involute, mostly $2-4 \mathrm{~mm}$. wide; panicle pyramidal, loose, 5-15 cm. long, the branches fascicled, rather distant, the lower spreading or finally reflexed, the longer ones naked half their length or more; spikelets 4- to 6-flowered, 4-5 mm. long; glumes 1-2 mm. long; lemmas rather thin, obtuse or truncate, $1.5-2 \mathrm{~mm}$. long, with a few short hairs at base; anthers about $0.8 \mathrm{~mm}$. long.

In wet meadows, marshes and wet more or less alkaline soils, in N. M. (San Juan, Rio Arriba and Taos cos.); Que. to B.C., s. to Md., Mich., Wisc. and N.D., s. to N.M. and Calif.

\section{Puccinellia Nuttalliana (Schult.) Hitchc.}

Perennial; culms usually erect, slender, rather stiff and firm at base, mostly 3-6 (-10) dm. tall; blades $1-3 \mathrm{~mm}$. wide, flat or becoming involute; panicle pyramidal, open, mostly 1-2 dm. long, the distant scabrous branches fascicled, spreading and naked below, as much as $1 \mathrm{dm}$. long; spikelets 3- to 6-flowered, 4-7 $\mathrm{mm}$. long, the florets rather distant, the rachilla often exposed; pedicels scabrous; glumes 1.5-2 mm. long; lemmas 2-3 mm. long, rather narrow, somewhat narrowed into an obtuse apex; anthers about $0.7 \mathrm{~mm}$. long. $P$. airoides (Nutt.) Wats. \& Coult.

In wet usually alkaline soils, in N. M. (San Juan and San Miguel cos.) and Ariz. (Apache and Coconino cos.); Wisc. to B.C., s. to Kan., N. M., Ariz. and Calif.

\section{Glyceria R. BR. MANNA-Grass}

Perennials, tufted or subrhizomatous, culms simple; ligule a hyaline scale; blades flat, thin; panicles open; spikelets turgid or only slightly laterally compressed, 3- to 14-flowered; all flowers perfect or the terminal one usually abortive or rudimentary; glumes scarious to hyaline, the first usually shorter, acutish and 1-nerved, the second obtuse, almost equaling the lowest lemma and obscurely 3-nerved; rachilla eventually abscising at the lower part of each node; lemmas firm to membranous, green, broadly ovate or obovate, usually blunt and scariousmargined apically, usually awnless, 7-nerved, the nerves not converging to the apex but terminating severally near the distal margin.

About 40 species, cosmopolitan in distribution.

1. Spikelets linear, nearly terete, usually $1 \mathrm{~cm}$. long or more, appressed on short pedicels; panicles narrow, erect (2)

1. Spikelets ovate to oblong, more or less compressed, usually not more than $5 \mathrm{~mm}$. long; panicles usually nodding (4)

2(1). Lemmas glabrous between the slightly scabrous nerves.......... 1. . borealis. 2. Lemmas scaberulous or hirtellous between the usually distinctly scabrous nerves (3)

3(2). Lemmas about $3 \mathrm{~mm}$. long, broadly rounded at the apex...2. G. arkansana. 3. Lemmas about $4 \mathrm{~mm}$. long, slightly narrowed at apex........ 3. G. septentrionalis. 


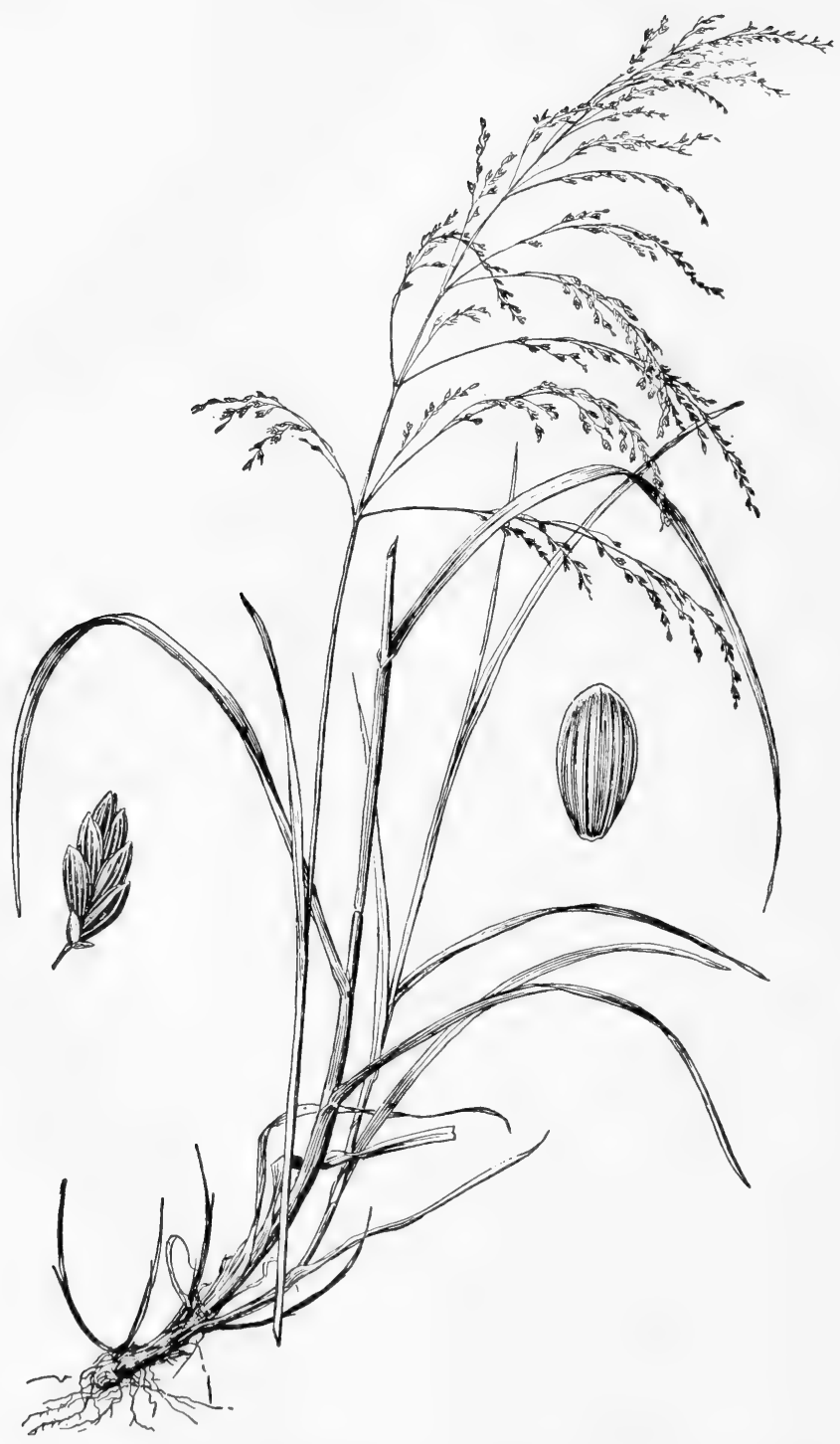

Fig. 81: Glyceria striata: plant, X 1/2; spikelet, X 5; floret, X 10. (From Hitchcock \& Chase). 
4(1). Lemmas with 5 prominent nerves; second glume 3-nerved; sheaths open 7. G. pauciflora.

4. Lemmas with 7 usually prominent nerves; second glume 1-nerved; sheaths (at least the upper) closed from below the summit (5)

5(4). First glume more than $1 \mathrm{~mm}$. long, usually about $1.5 \mathrm{~mm}$. long.

5. First glume not more than $1 \mathrm{~mm}$. long (6)

6(5). Blades $2-4 \mathrm{~mm}$. wide, sometimes to $8 \mathrm{~mm}$., rather firm, often folded; first glume $0.5 \mathrm{~mm}$. long. 4. G. striata.

6. Blades $6-12 \mathrm{~mm}$. wide, flat, thin, lax; first glume about $1 \mathrm{~mm}$. long..

5. G. elata.

1. Glyceria borealis (Nash) Batchelder. Northern MANNA-Grass. Fig. 80.

Culms erect or decumbent and rooting at the base, slender, 3-10 dm. tall; sheaths smooth or slightly scabrous, keeled; blades flat or folded, usually 2-6 mm. wide, very narrow; panicle mostly $2-4 \mathrm{dm}$. long, very narrow, the branches as much as $1 \mathrm{dm}$. long, bearing several closely appressed spikelets; spikelets mostly 6- to 12-flowered, $1-1.5 \mathrm{~cm}$. long; glumes oblong, scarious, the first glume 1.5-2 $\mathrm{mm}$. long, the second 3-4 mm. long; lemmas rather thin, obtuse, 3-4 mm. long, strongly 7-nerved, broadly scarious at the tip, minutely scabrous on the nerves, otherwise glabrous.

Shallow water in wet meadows or lake margins, in N. M. (Hitchcock) and Ariz. (Coconino, Apache, Cochise and Pima cos.); Nfld. to Alas., s. to Pa., Ill., Minn. and Wash., in mts. to N. M., Ariz. and Calif.

\section{Glyceria arkansana Fern.}

Tufted perennial; culms stout, 10-15 dm. long, erect; panicles $35-50 \mathrm{~cm}$. long, with a number of ascending floriferous branches $0.4-1 \mathrm{~mm}$. thick, rather rigidly straight; spikelets 10 - to 14-flowered, nearly sessile, appressed, remote; lemmas 2.5-3.5 mm. long, minutely pubescent. Probably only a form of $G$. septentrionalis.

In marshy areas, roadside ditches, along sloughs and in swampy ground, in Okla. (McCurtain Co.) and possibly Tex., spring-summer; also La. and Ark.

\section{Glyceria septentrionalis Hitchc.}

Like $G$. arkansana but lemmas merely minutely scabrous and $3.5-5 \mathrm{~mm}$. long. In shallow water and borders of sloughs and lakes and in marshy areas and roadside ditches in e. and s.e. Tex., spring-summer; e. N.A. w. to Wisc., Ia., Mo., Ark. and Tex.

\section{Glyceria striata (Lam.) Hitchc. Fowl ManNA-GRAss. Fig. 81.}

Perennial forming mats by means of short rhizomes; panicles 1-2 dm. long, with numerous slender ascending-diverging branches about $0.2 \mathrm{~mm}$. thick (in turn bearing even more slender floriferous branchlets); pedicels $0.5-1 \mathrm{~mm}$. long, appressed; spikelets 3- to 7-flowered, ovate in outline; lemmas $1.5-2.1 \mathrm{~mm}$. long.

Rare at the margins of clear permanent streams in limestone areas, in wet meadows, bogs and shallow water of ponds and lakes, drainage ditches and sloughs in Okla. (Johnston and Murray cos.) and in the Tex. Trans-Pecos (Guadalupe Mts.) and e. part of Edwards Plateau, N.M. (Otero, Taos, San Miguel and Sandoval cos.) and Ariz. (Coconino, Apache, Navajo and Gila cos.), spring-summer; most of the temp. parts of N. A.

\section{Glyceria elata (Nash) Hitchc.}

Culms erect, smooth, succulent, dark green, 1-2 m. tall; sheaths scabrous; blades flat, usually $6-9 \mathrm{~mm}$. or sometimes only $4 \mathrm{~mm}$. wide, scabrous; panicle large and diffuse, becoming oblong, 15-30 cm. long, the branches naked below, the lower ones usually reflexed at maturity; spikelets $3-5 \mathrm{~mm}$. long, oblong or 


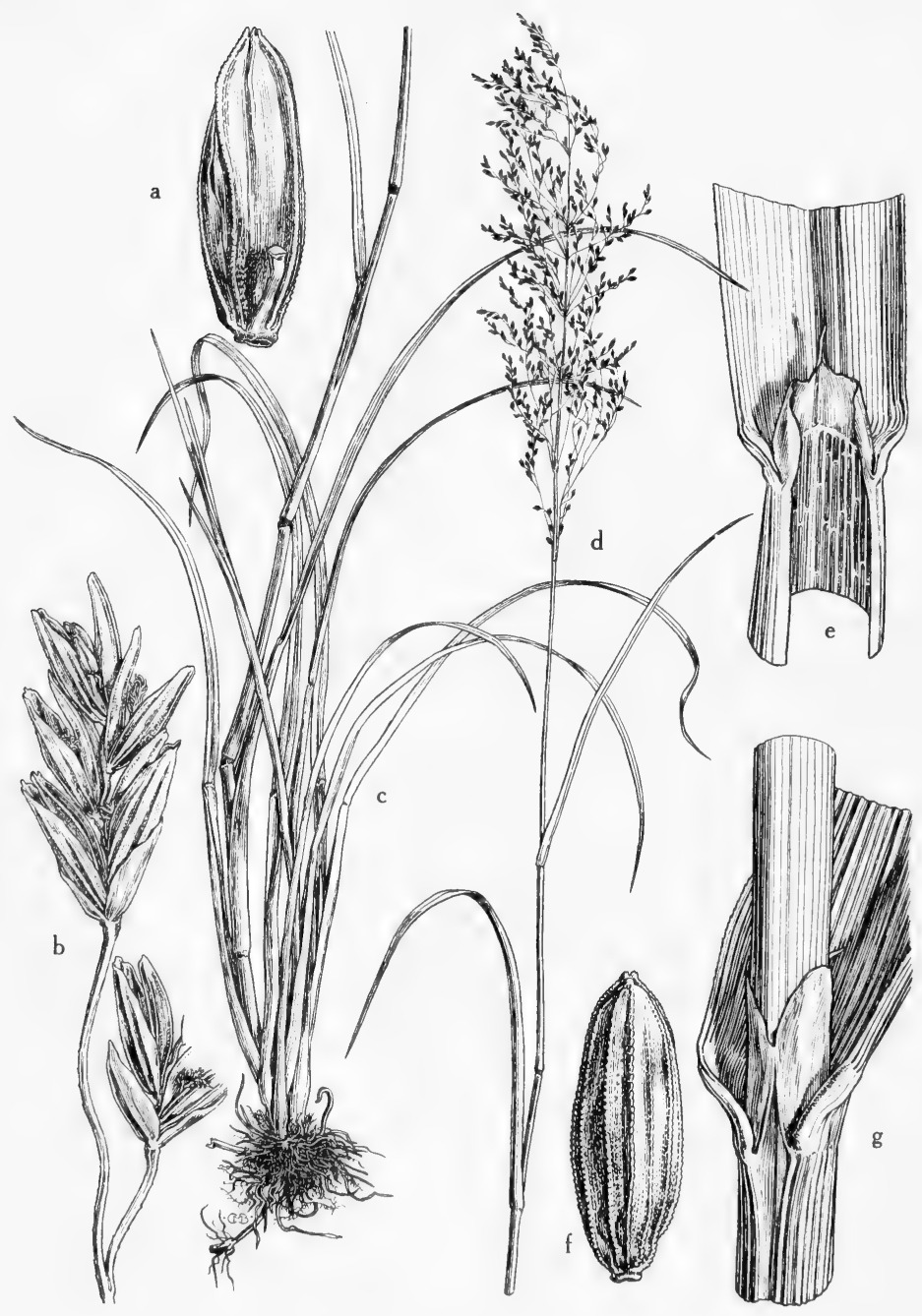

Fig. 82: Glyceria grandis: a, floret, showing palea, X 16; b, spikelets, solitary on tips of branchlets, X 8; c, habit, lower part showing the conspicuous joints of culm and the long lax leaf blades, X 1/5; d, habit, upper part of culm, showing panicle, $\mathrm{X} 1 / \ldots$; e, leaf sheath, blade and ruptured ligule, $\mathrm{X} 4$; $\mathrm{f}$, floret, showing lemma, the strong nerves papillose, X 16; g, young upper leaf, the sheath and ligule enclosing culm, X 4 . (From Mason, Fig. 67). 
Jvate-oblong, usually 6- to 8-flowered; glumes broad, obtuse, much shorter than the lower lemmas, often nerveless, the first glume about $1 \mathrm{~mm}$. long, the second nearly $2 \mathrm{~mm}$. long; lemmas firm, 2-2.5 mm. long, obovoid, obtuse or acutish, prominently 7-nerved, the apex distinctly scarious; stamens 2 ; palea apex with a narrow slit.

In wet meadows, swampy woods or along streams, in N.M. (Lincoln Co.) and Ariz. (Apache, Coconino, Graham, Cochise and Pima cos.); Mont. to B.C., s. in mts. to N. M., Ariz. and Calif.

\section{Glyceria grandis Wats. ex Gray. AmERICAN MANNA-GRASs. Fig. 82.}

Culms stout, $1-1.5 \mathrm{~m}$. tall from a perennial base; leaf blades flat, 6-12 mm. wide; panicle large, compound, $20-40 \mathrm{~cm}$. long, somewhat nodding at tip; spikelets 4- to 7-fiowered, 5-6 $\mathrm{mm}$. long; glumes $1.5-2 \mathrm{~mm}$. long; lemmas purplish, 2-2.5 $\mathrm{mm}$. long; palea slightly longer than lemma.

Marshes, stream banks, wet meadows, and in mud and shallow water of ponds, lakes and slow-flowing streams, in N. M. (Colfax, San Miguel and Taos cos.) and Ariz. (Apache and Graham cos.); P.E.I. to Alas., s. to Va., Tenn., Ia., Neb., N.M., Ariz. and Ore.

\section{Glyceria pauciflora Presl. WeaK manNa-grass. Fig. 83.}

Culms 3-12 dm. tall, from a decumbent rooting base; sheaths smooth or minutely scabrous, free and overlapping; blades thin, flat, lax, minutely scabrous, mostly 8-20 cm. long, 5-15 mm. wide; panicle oblong or pyramidal, open or rather dense and spikelike, nodding, 8-20 (or -25$) \mathrm{cm}$. long, the branches ascending or spreading, rather flexuous, naked below, the spikelets crowded on the upper half; spikelets 4- to 7-fiowered (usually 5- or 6-flowered), 4-6 mm. long; glumes broadly ovate or oval, purplish-tinged, the first glume $1-1.5 \mathrm{~mm}$. long, the second glume 1.5-2 mm. long, 3-nerved, the nerves sometimes obscure, the margins erose-scarious; lemmas oblong, 2-3 mm. (usually $2.5 \mathrm{~mm}$.) long, with 5 prominent nerves and an outer short faint pair near the margins, minutely scabrous on the nerves and somewhat so between them, the tip rounded, scarious, somewhat erose, usually with a purplish band below the scarious tip; caryopsis with a sub-basal and oblong hilum. Torreyochloa pauciflora (Presl) Church, Puccinellia pauciflora (Presl) Munz.

Marshes, shallow water, and wet meadows, in N.M. (Sandoval and Taos cos.); Alas. to S.D., N.M. and Calif.

\section{Poa L. Bluegrass}

Inflorescence paniculate; spikelets 2- to several-flowered, laterally compressed, all the flowers functional except usually the terminal one reduced, in some species the flowers unisexual and in some the male and female flowers on separate plants (at least in some populations); rachilla abscising above the glumes and at the lower part of each node; glumes usually shorter than first lemma, thin (marginally often hyaline), keeled, the first usually 1-nerved, the second 3-nerved; lemmas keeled, ovate-lanceolate, awnless, thin (marginally often hyaline), 5-nerved (or often appearing only 3-nerved, one pair of nerves being obscure).

A genus of about 300 species in cool and temperate regions of the world.

1. Rhizomes present, often very extensively developed (2)

1. Rhizomes lacking although plants sometimes stoloniferous (8)

2(1). Culms strongly flattened, 2-edged; plants strongly rhizomatous; lemmas sparsely if at all webbed............................................ . compressa.

2. Culms slightly if at all flattened, not 2-edged; plants often either only weakly rhizomatous or with strongly webbed lemmas (3) 


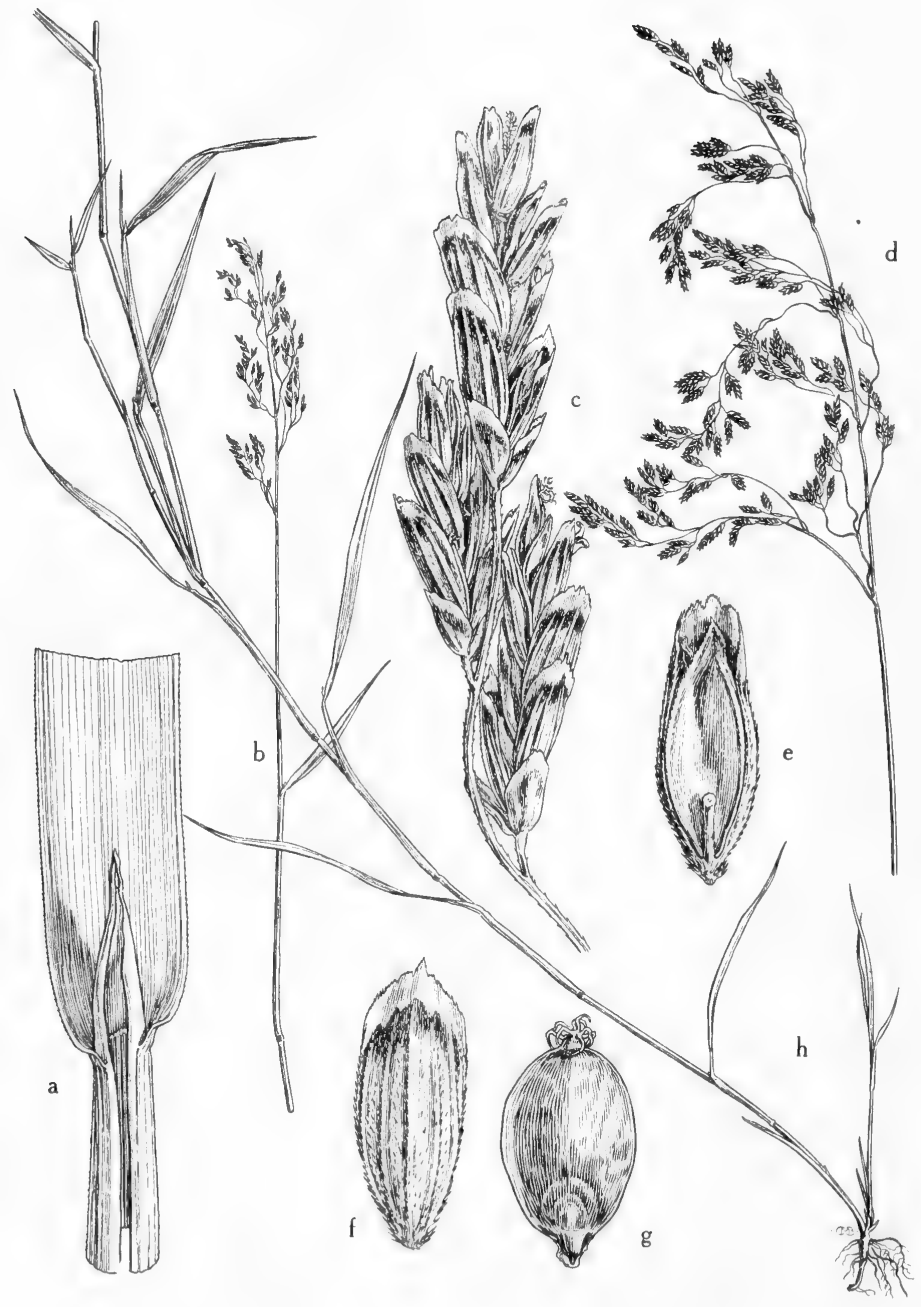

Fig. 83: Glyceria pauciflora: a, leaf sheath, blade and ligule, X $2 ; \mathrm{b}$, upper part of culm, showing panicle, X $1 / 2 ; c$, branch of panicle, the spikelets crowded on the upper half, X 6; d, panicle, X 2/3; e, floret, showing palea and rachilla, X 12; f, floret, showing lemma, X $12 ; \mathrm{g}$, grain, showing subbasal oblong hilum, X $20 ; \mathrm{h}$, habit, lower part of culm, showing the flat, lax leaf blades, X 1/\%. (From Mason, Fig. 66). 
3(2). Panicle narrow, the branches ascending or appressed; lemmas scabrous to pubescent on all the nerves but not webbed............. . glaucifolia.

3. Panicle open, the branches mostly spreading; lemmas often webbed at base or glabrous on the internerves (4)

4(3). Plants alpine or subalpine; lemmas pubescent over the back and silky on the 5 nerves, usually webbed.

4. P. Grayana.

4. Plants often of lower elevations; lemmas sometimes glabrous on the internerves or not webbed (5)

5(4). Anthers mostly $0.5-0.9 \mathrm{~mm}$. long; lower panicle branches mostly in twos

5. Anthers at least $1 \mathrm{~mm}$. long; lower panicle branches usually in threes or fives (6)

6(5). Lemmas not webbed at base.

3. P. glaucifolia.

6. Lemmas more or less strongly webbed at base (7)

7(6). Ligules mostly not over $1.5 \mathrm{~mm}$. long, rarely with the uppermost much longer, truncate; lemmas more than $3 \mathrm{~mm}$. long........2. P. pratensis.

7. Ligules mostly (2-) 3-5 mm. long, often acute; lemmas $2.5-3 \mathrm{~mm}$. long....... 7. P. palustris.

8(1). Lemmas with long tangled cobwebby hairs at base (9)

8. Lemmas not cobwebby at base (13)

9(8). Panicle loose, the lower slender branches 1 to 3 per node and spreading or reflexed; spikelets usually purplish; ligules glabrous, usually over $1 \mathrm{~mm}$. long; anthers not over $1 \mathrm{~mm}$. long (10)

9. Panicle very narrow, the branches ascending or more than 3 per node; spikelets usually greenish; ligules often puberulent-scabridulous, sometimes less than $1 \mathrm{~mm}$. long; anthers often over $1 \mathrm{~mm}$. long (11)

10(9). Lower panicle branches reflexed, 1 to 3 per node. 5. $P$. reflexa. 10. Lower panicle branches usually not reflexed, generally in pairs.

6. P. leptocoma.

11(9). Spikelets averaging about $6 \mathrm{~mm}$. long, the lemmas $4-5 \mathrm{~mm}$. long. 4. P. Grayana.

11. Spikelets usually less than $5 \mathrm{~mm}$. long, the lemmas less than $4 \mathrm{~mm}$. long (12)

12(11). Plants of the lowlands or low mountains; culms decumbent and usually stoloniferous, 4-12 dm. tall; ligules (2-) 3-5 mm. long.

7. $P$. palustris.

12. Plants montane to subalpine; culms erect, not at all stoloniferous; ligules rarely as much as $2 \mathrm{~mm}$. and never so much as $3 \mathrm{~mm}$. long.

8. $P$. interior.

13(8). Spikelets compressed, at anthesis usually less than twice as long as broad; lemmas rather strongly keeled (14)

13. Spikelets only slightly compressed, at anthesis over twice as long as broad; lemmas rounded on the back or only slightly keeled (15)

14(13). Ligules usually truncate, $0.3-1$ (or rarely to 2) $\mathrm{mm}$. long; spikelets mostly 2- to 3- (4-) flowered; second glume $2.5-3.5 \mathrm{~mm}$. long........

8. $P$. interior.

14. Ligules usually obtuse to acute, generally at least 1 (the longest 4) $\mathrm{mm}$. long; spikelets mostly 3 - to 5-flowered; second glume rarely less than $4 \mathrm{~mm}$. long.

4. P. Grayana.

15(13). Ligules thickish, strongly ciliolate, truncate to roundish, those of the innovations and basal culm leaves scarcely visible from the side, mostly not over 0.5 (to 1) $\mathrm{mm}$. long, those of the upper culm leaves mostly $1-1.5$ (rarely to $2.5 \mathrm{~mm}$.) long........10. P. juncifolia. 


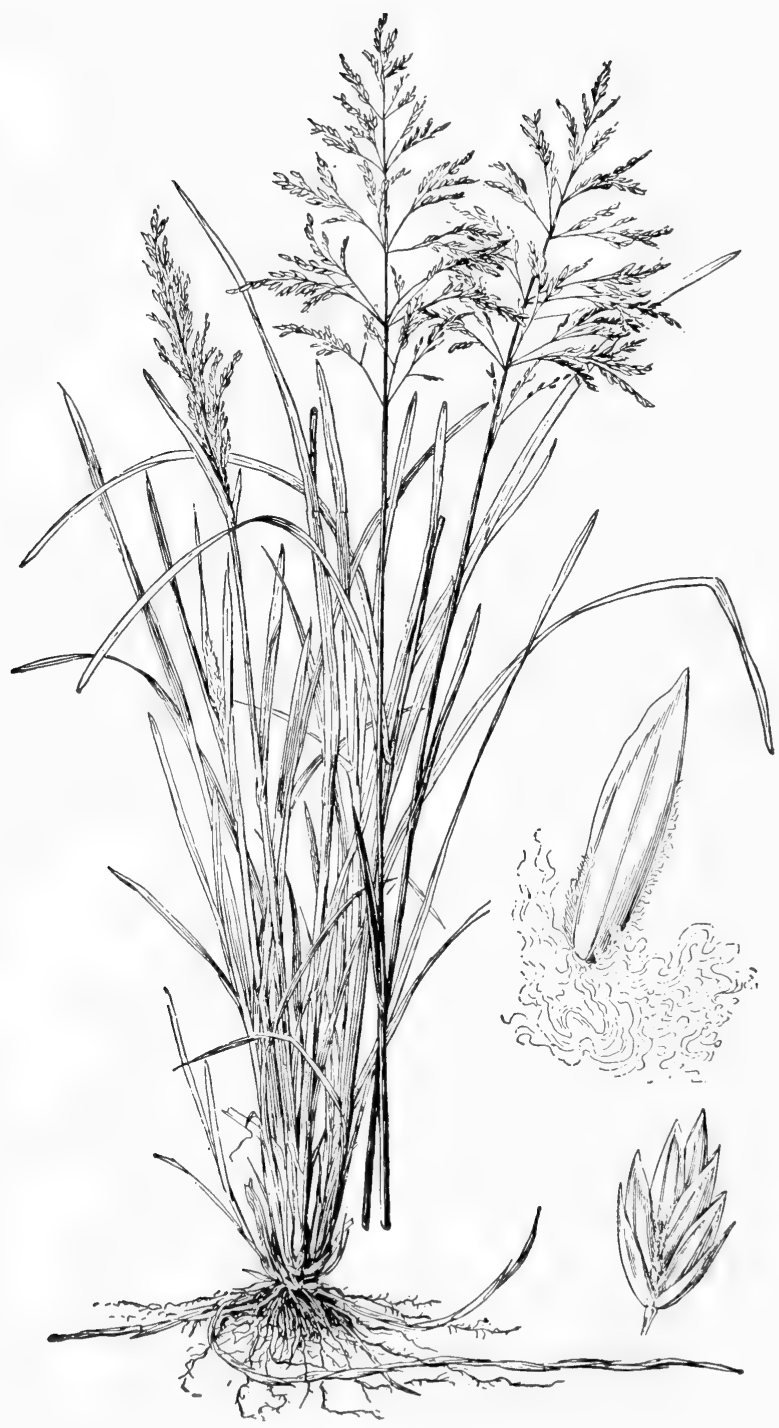

Fig. 84: 'Poa pratensis: plant, X 1/2; spikelet, X 5; floret, X 10. (From Hitchcock \& Chase). 
15. Ligules thin and membranous, rarely ciliolate, usually acute, those of the innovations and lower culm leaves usually over $1 \mathrm{~mm}$. long, those of the upper culm leaves mostly $2-7 \mathrm{~mm}$. long.......9. P. nevadensis.

\section{Poa compressa L. Canada bluegrass.}

Perennial; culms basally long-decumbent, stoloniform or subrhizomatous, strongly compressed, 1-2.5 mm. broad, with 2 longitudinal keels; aerial culms ascending, somewhat geniculate; lower sheaths shorter than the internodes; blades $3-12 \mathrm{~cm}$. long, $1-3 \mathrm{~mm}$. broad, flat or folded; panicles conic-cylindric, $3-10 \mathrm{~cm}$. long, open with few short branches per whorl rather strikingly ascending; pedicels 5-10 $\mathrm{mm}$. long; spikelets crowded, laterally compressed, 3- to 6-flowered; lowest lemma 2-3 mm. long, firm, green-stramineous, keeled, 5-nerved, the lower part of the midnerve and marginal nerves minutely pubescent, the very obscure intermediate nerves and internerve areas glabrous, basally with very short scant tuft of silky hair or this absent.

Tame pastures, wet meadows and in marshy soil, in Okla. (Waterfall) and n.-cen. Tex. and the Rio Grande Plains, probably elsewhere, not persistent but repeatedly introd., N.M. (Taos, San Miguel and Colfax cos.) and Ariz. (Apache, Navajo, Coconino, Graham and Gila cos.), spring; nat. of Eur., now widely introd. in Am.

\section{Poa pratensis L. Kentucky bluegrass. Fig. 84.}

Tufted perennial with fragile rhizomes 1-2 $\mathrm{mm}$. thick and to $2 \mathrm{dm}$. long; aerial culms 3-6 dm. long, mostly erect, slightly flattened but not two-keeled; ligule a short usually erose scale; blades thin, 2-4 $\mathrm{mm}$. broad, flat or folded, basally not markedly broader than the top of the sheath; panicles $5-13 \mathrm{~cm}$. long, conical, usually open and with a whorl of 5 flexuous basally naked branches at the lowest node, the successively higher nodes with fewer branches; pedicels 0.5-1.5 mm. long; spikelets somewhat laterally compressed, crowded, 4- to 6-flowered; lowest lemma 3-4 $\mathrm{mm}$. long, green with a broad thin whitish margin, dorsally keeled, 5-nerved, the lower part of the midnerve and marginal nerves pubescent, the intermediate nerves and internerve area glabrous, basally with a long tuft of flexuous silky hairs.

Meadows and tame pastures, and in wet soil on edge of lakes and ponds, in n.-cen., e. and Trans-Pecos Tex., infrequent and probably not persistent, N. M. (Sandoval Co.) and Ariz. (Apache to Mohave, s. to Cochise, Santa Cruz and Pima cos.), spring; nat. of Euras., now widely introd. in moist temp. areas of N.A. and S.A.

\section{Poa glaucifolia Scribn. \& Williams.}

Plants glaucous; culms in loose tufts, 6-10 dm. tall; blades $2-3 \mathrm{~mm}$. wide; panicle narrow, open, mostly 1-2 dm. long, the branches usually in somewhat distant whorls, mostly in threes, ascending, very scabrous, naked below; spikelets 2- to 4-flowered; glumes 4-5 $\mathrm{mm}$. long; lemmas about $4 \mathrm{~mm}$. long, villous on the lower half of the keel and marginal nerves and more or less so on the intermediate nerves below.

In wet meadows, ditches and stream bottoms, in N.M. (Hitchcock) and Ariz. (Coconino Co.), July-Aug.; B.C. and Alta. to Minn., Neb., N.M., Ariz. and Nev.

\section{Poa Grayana Vasey Arctic bluegrass.}

Culms loosely tufted, erect from a decumbent base, 1-3 dm. tall; ligule pointed, to $4 \mathrm{~mm}$. long; blades mostly basal, flat or folded, mostly $2-3 \mathrm{~mm}$. wide, with one short blade about the middle of the culm; panicle open, pyramidal, $5-10 \mathrm{~cm}$. long, the lower branches usually 2 and spreading or sometimes reflexed, bearing a few spikelets toward the tip; spikelets 5-8 $\mathrm{mm}$. long, 3- or 4-flowered; lemmas densely villous on the keel and marginal nerves and pubescent on the lower part 
of the internerves, the base often webbed. $P$. arctica of Am. Auth., not R. Br.

In wet meadows, shallow water of lakes and ponds, and on wet stream banks, mostly above timberline, in N. M. (Rio and Taos cos.); from arctic regions s. to N.S. and in the Rocky Mts. to N.M., Nev. and Calif.

\section{Poa reflexa Vasey \& Scribn. Nodding bluegrass.}

Culms solitary or in small tufts, erect, 2-4 dm. tall; blades rather short, 1-4 $\mathrm{mm}$. wide; panicle nodding, 5-15 cm. long, the branches naked below, solitary, in pairs or in threes, the lower usually reflexed, sometimes strongly so; spikelets 2- to 4-flowered; lemmas about $3 \mathrm{~mm}$. long, oblong-elliptic, webbed at base, villous on keel and marginal nerves and sometimes on intermediate nerves.

In wet meadows and on wet stream banks, in N. M. (Santa Fe Co.) and Ariz. (Coconino Co.); Mont. to e. B.C., s. in mts. to N.M. and Ariz.

\section{Poa leptocoma Trin. Bog bluegrass.}

Culms slender, solitary or few in a tuft, $2-5 \mathrm{dm}$. tall, often decumbent at the base; sheaths usually slightly scabrous; ligule acute, the uppermost $3-4 \mathrm{~mm}$. long; blades short, lax, mostly $2-4 \mathrm{~mm}$. wide; panicle nodding, delicate, fewflowered, the branches capillary and ascending or spreading, subflexuous, the lower mostly in pairs; spikelets narrow, 2- to 4-flowered; glumes narrow, acuminate; lemmas 3.5-4.5 $\mathrm{mm}$. long, acuminate, webbed at base, pubescent on the keel and marginal nerves or sometimes nearly glabrous, the intermediate nerves distinct.

In bogs and wet meadows and wet places along streams, in N.M. (Hitchcock); Alas., s. in mts. to N.M. and Calif.

\section{Poa palustris L. Fowl bluegrass.}

Culms loosely tufted, glabrous, decumbent at the flattened purplish base, 3-15 $\mathrm{dm}$. tall; sheaths keeled, sometimes scaberulous; ligule 3-5 mm. long or only 1 $\mathrm{mm}$. on the innovations; blades 1-2 $\mathrm{mm}$. wide; panicle pyramidal or oblong, nodding, yellowish green or purplish, 1-3 dm. long, the branches in rather distant fascicles, naked below; spikelets 2- to 4-flowered, about $4 \mathrm{~mm}$. long; glumes lanceolate, acute, shorter than the first floret; lemmas $2.5-3 \mathrm{~mm}$. long, usually bronzed at the tip, webbed at base, villous on the keel and marginal nerves.

Wet meadows and wet open soils, in N.M. (Hitchcook) and Ariz. (Graham Co.); Nfld. and Que. to Alas., s. to Va., Mo., Neb., N.M., Ariz. and Calif.; Euras.

\section{Poa interior Rydb.}

Tightly tufted perennial; culms numerous, 2-5 dm. long, about $1 \mathrm{~mm}$. thick, strictly erect; blades short, about $1 \mathrm{~mm}$. broad, flat, erect; panicles 4-8 $\mathrm{cm}$. long, 1-2 cm. broad, rather dense, almost spiciform, strictly erect, the lower node with 2 (rarely 3 ) strictly erect basally naked branches; spikelets crowded, laterally compressed, 2- to 4-flowered; lowest lemmas 3-4 mm. long, keeled, stramineous, firm, 5-nerved, the midnerve and marginal nerves pubescent at least in the lower part, the intermediate nerves very obscure, the internerve areas glabrous, the base with a weak tuft of long flexuous silky white hair.

In water of streams, edge of lakes and ponds, and in marshes, in N.M. (Sandoval and Taos cos.) and Ariz. (Coconino Co.), reported to occur in Tex.; if present then rare at highest elev. in the Trans-Pecos mts.. summer; forested $\mathrm{mt}$. slopes, Que. to B.C. and s. in the mts. to Ariz. and N.M.

\section{Poa nevadensis Vasey ex Scribn. Nevada bluegrass.}

Culms erect, 5-10 dm. tall; sheaths scabrous, sometimes only slightly so; ligule about $4 \mathrm{~mm}$. long, shorter on the innovations, decurrent; blades usually elongate, narrow, involute, sometimes almost capillary, rather stiff; panicle narrow, 


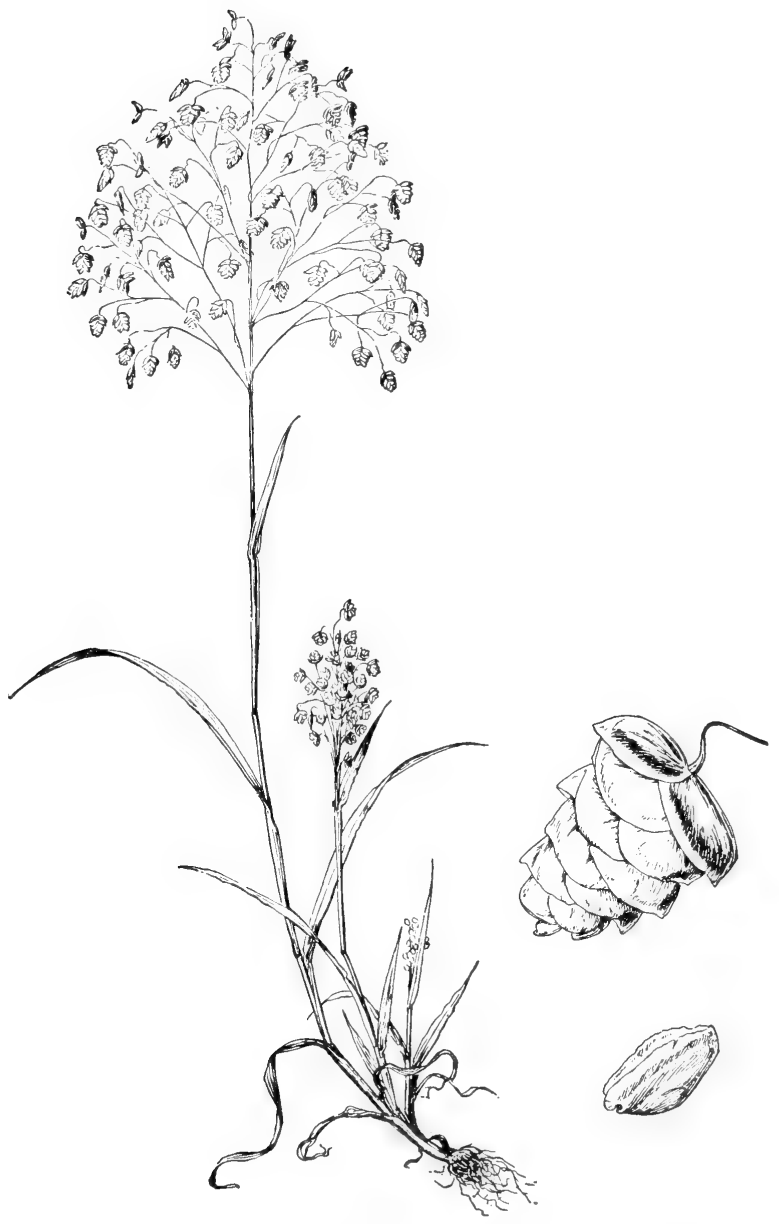

Fig. 85: Briza minor: plant, X 1/2; spikelet and floret, X 5. (From Hitchcock \& Chase). 
10-15 cm. long, pale, rather loose, the branches short-appressed; spikelets 3 - to 5-flowered, 6-8 $\mathrm{mm}$. long; glumes narrow, the second about as long as the lowest floret; lemmas 4-5 $\mathrm{mm}$. long, rather obtuse at the scarious tip.

Low meadows and other such wet places, in Ariz. (Kearney \& Peebles); Mont. to Wash. and Yuk., s. to Colo., Ariz. and Calif.

\section{Poa juncifolia Scribn.}

Strongly tufted perennial sometimes producing rhizomes, 4-12 dm. tall; sheaths smooth to scaberulous, rarely closed as much as one fourth their length; innovations usually numerous, their blades often $1-3 \mathrm{~cm}$. long, from involute and almost filiform to flat and as much as $3 \mathrm{~mm}$. wide; culm leaves usually shorter than those of the innovations; ligules rather thick, truncate to rounded, strongly scaberulous-puberulent and finely ciliolate, from $0.5 \mathrm{~mm}$. long on the innovations to as much as 2 or $3 \mathrm{~mm}$. long on the upper culm leaves; panicle narrow, usually 6-20 cm. long, the branches mostly erect; spikelets 3- to 7-flowered, (5-) 7-10 mm. long; glumes slightly unequal, usually 3-nerved, the first mostly 3.5-4.5 $\mathrm{mm}$. long, the second 4-5 $\mathrm{mm}$. long; lemmas slightly keeled, 4-6 mm. long, without a basal web and usually either finely scaberulous over the back or glabrous over the lower half, sometimes scabrous above and very finely crisp-puberulent on the lower fourth; anthers $2-3 \mathrm{~mm}$. long; lodicules about $0.7 \mathrm{~mm}$. long. $P$. ampla Merrill.

In marshes, wet alkaline meadows and rocky open slopes, in N.M. (Hitchcock) and Ariz. (Santa Cruz Co.); Alta., Neb., the Dakotas to B.C., s. to N.M. and Calif.

\section{Briza L. Quaking Grass}

A genus of 20 species in temperate North America and South America; we have only a single species. Another species, B. maxima L., the big quaking grass, is occasionally cultivated but does not persist or escape.

\section{Briza minor L. LitTle QUAKING GRASS. Fig. 85.}

Annual; culms 1-4 dm. long, erect or at the very base shortly decumbent; ligule a long hyaline scale sheath shorter than the internodes, having an inverted $\mathrm{V}$-shaped juncture to the blade; blades $5-10 \mathrm{~mm}$. broad, flat; panicle broadly ovoid, 5-12 cm. long, about as broad, open, diffuse, with ascending-spreading branches that are twice trichotomous and naked; spikelets pendulous from the ultimate capillary pedicels at the periphery of the panicle, 3-5 $\mathrm{mm}$. long, 6- to 8 -flowered, broader than long, markedly tapered, only very slightly laterally compressed; glumes 2, very broad, spreading, 3-nerved, with broad hyaline margins; lemmas 1.5-2 mm. long, spreading cymbiform, 5-nerved, marginally broadly hyaline, basally auriculate and thus basally overlapping each other; rachilla abscising above the glumes and at the lower part of each node.

Infrequent in swales and in woods or open sandy soil, in marshes, wet meadows and seepage areas, in e. and s.e. Tex., spring; nat. of Eur., widely introd. in the U.S.

\section{Eragrostis Beauv. Lovegrass}

Variable in habit and foliage; panicles usually much-branched (the branches in some species very short and closely appressed); spikelets usually somewhat laterally compressed, several-flowered; glumes shorter than the lowest lemma, 1-nerved; lemmas 3-nerved (lateral nerves sometimes obscure); rachilla either remaining intact (lemmas then deciduous) or abscising above the glumes and either at the upper or lower part of each lemma-node or breaking irregularly between the florets under mechanical pressure during tumbling of the panicle. 


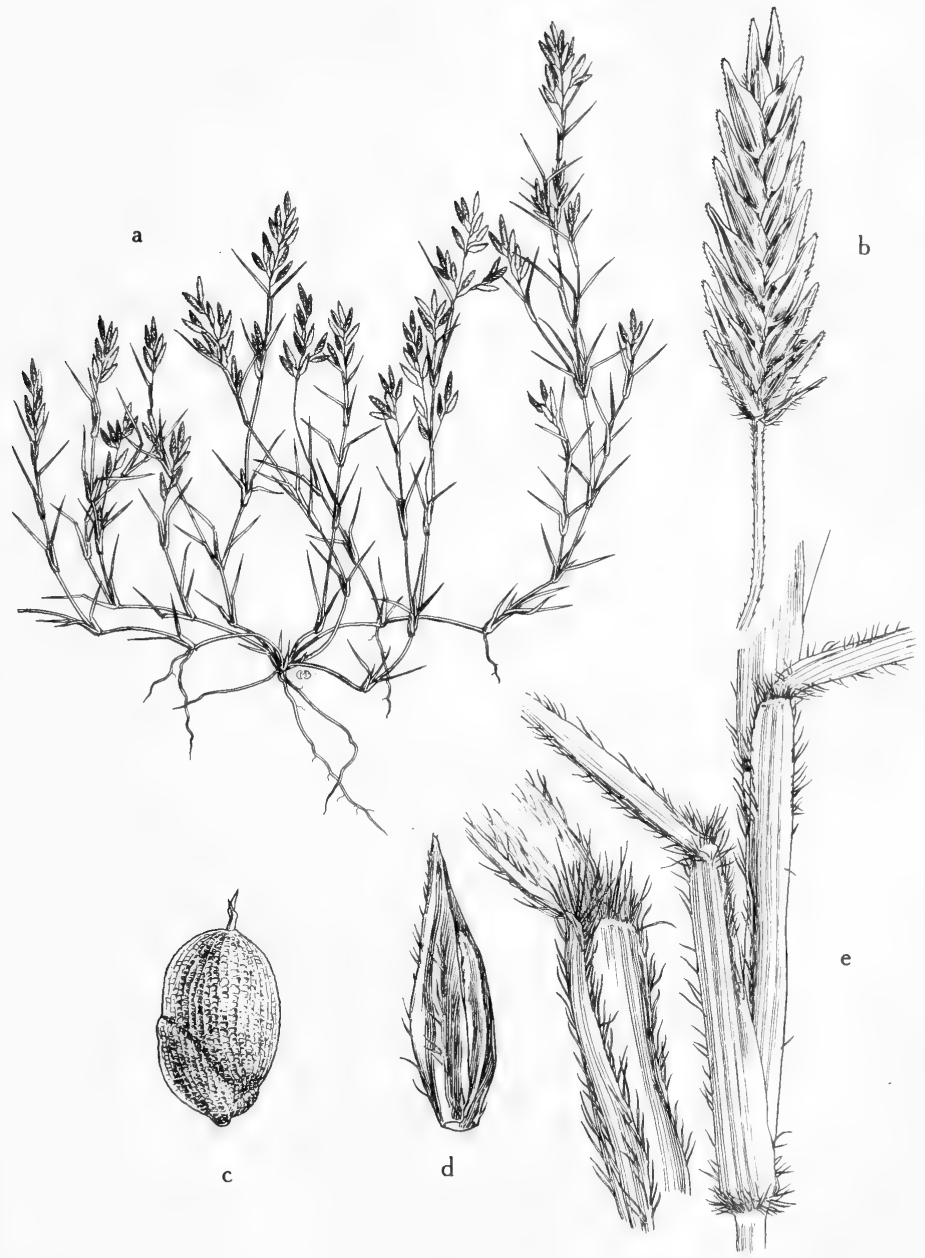

Fig. 86: Eragrostis hypnoides: a, habit, showing slender creeping culms, divergent leaf blades and elliptic panicles, X $2 / 5 ; b$, spikelet, showing hairs on backs of glumes and lemmas, X 8; c, mature seed, X 40; d, floret, X 20; e, leaf sheaths and blades, X 8 . (From Mason, Fig. 65). 
A genus of about 300 species widely distributed in warm regions. Some lovegrasses are difficult to determine, the characters useful in distinguishing them being subtle, quantitative ones which tend to grade from one species to another. This probably is evidence of past hybridization and genetic contamination of many species.

1. Mat-forming annuals creeping by stolons (2)

1. Not mat-forming (3)

2(1). Flowers unisexual, staminate ones on some plants, pistillate on others; lemmas about $3 \mathrm{~mm}$. long, persistent on the rachilla....1. E. reptans.

2. Flowers perfect; lemmas $1.5-2 \mathrm{~mm}$. long, falling individually from the rachilla to expose the minute paleas which persist on the rachilla.

..2. E. hypnoides.

3(1). Spikelets (the lateral ones, not those terminal on the panicle branches) subsessile, their pedicels averaging less than $1 \mathrm{~mm}$. long (4)

3. Spikelets (the lateral ones) with pedicels averaging more than $1 \mathrm{~mm}$. long, often much more (5)

4(3). Lemmas about $1 \mathrm{~mm}$. long.

4. Lemmas $1.5-5.5 \mathrm{~mm}$. long.

..8. E. glomerata.

4. E. cilianensis.

5(3). Pedicels of individual spikelets 10-30 mm. long, averaging about 15-20 $\mathrm{mm}$. long, rather stiff and straight.

7. E. Elliottii.

5. Pedicels of individual spikelets $1-18 \mathrm{~mm}$. long, averaging usually less than $10 \mathrm{~mm}$. long, stiffish to weak and flexible (6)

6(5). Perennial

6. E. hirsuta.

6. Annuals (7)

7(6). Lemmas about $1 \mathrm{~mm}$. long.

7. Lemmas $1.5-2.5 \mathrm{~mm}$. long.

3. E. pilosa.

1. Eragrostis reptans (Michx.) Nees.

Mat-forming annual, extensively creeping by stolons, rooting at the numerous nodes; sheaths about $5 \mathrm{~mm}$. long; blades $1-4 \mathrm{~cm}$. long; panicles $1-3 \mathrm{~cm}$. long, about as thick, of several glomerules of spikelets, often subcapitate, of 2 sexes, the staminate panicles on some plants, the pistillate on others; spikelets laterally compressed, curvilinear, 4-17 mm. long, 6- to 32-flowered, the rachilla remaining intact; lemmas often pubescent, about $3 \mathrm{~mm}$. long, not falling individually from the rachilla. Neeragrostis reptans (Michx.) Nicora.

Locally abundant in swales and lake- and river-beds, and muddy shores of lakes, streams and ponds, usually in tight clay-loam soil, in Okla. (Waterfall) and in n.-cen., e. and s.e. Tex. and Rio Grande Plains, spring-fall; cen. U. S. from S.D. e. to Ill. and Ky. and s. to Coah. and Tam.; also Fla.

\section{Eragrostis hypnoides (Lam.)B.S.P. Fig. 86.}

Annual, creeping over small areas by short stolons; culms very slender and short; sheaths and blades very short as in E. reptans; panicles often subcapitate or occasionally elongate to interrupted-spikelike or even more open, diffusely oblong, with short branches; pedicels $1-3 \mathrm{~mm}$. long, capillary, somewhat flexuous; spikelets approximate or even glomerulate, linear, 2-20 mm. long, 4- to 44flowered, the flowers all perfect, the rachilla remaining intact; lemmas lanceovate, 1.5-2 mm. long, falling individually (starting at the bottom of the spikelet) to liberate the grains and to leave the minute paleas persistent on the rachilla.

Locally abundant in swales, borrow ditches, on margin of ponds, sloughs and streams, and on mud flats, streambars and banks, in Okla. (Pittsburg Co.), e. and s.e. Tex., rare in coastal parts of Rio Grande Plains (Cameron Co.) and N.M. (Taos Co.), spring-fall; widespread from s. Can. nearly throughout the U.S. to Mex. and W.I.; Arg. 


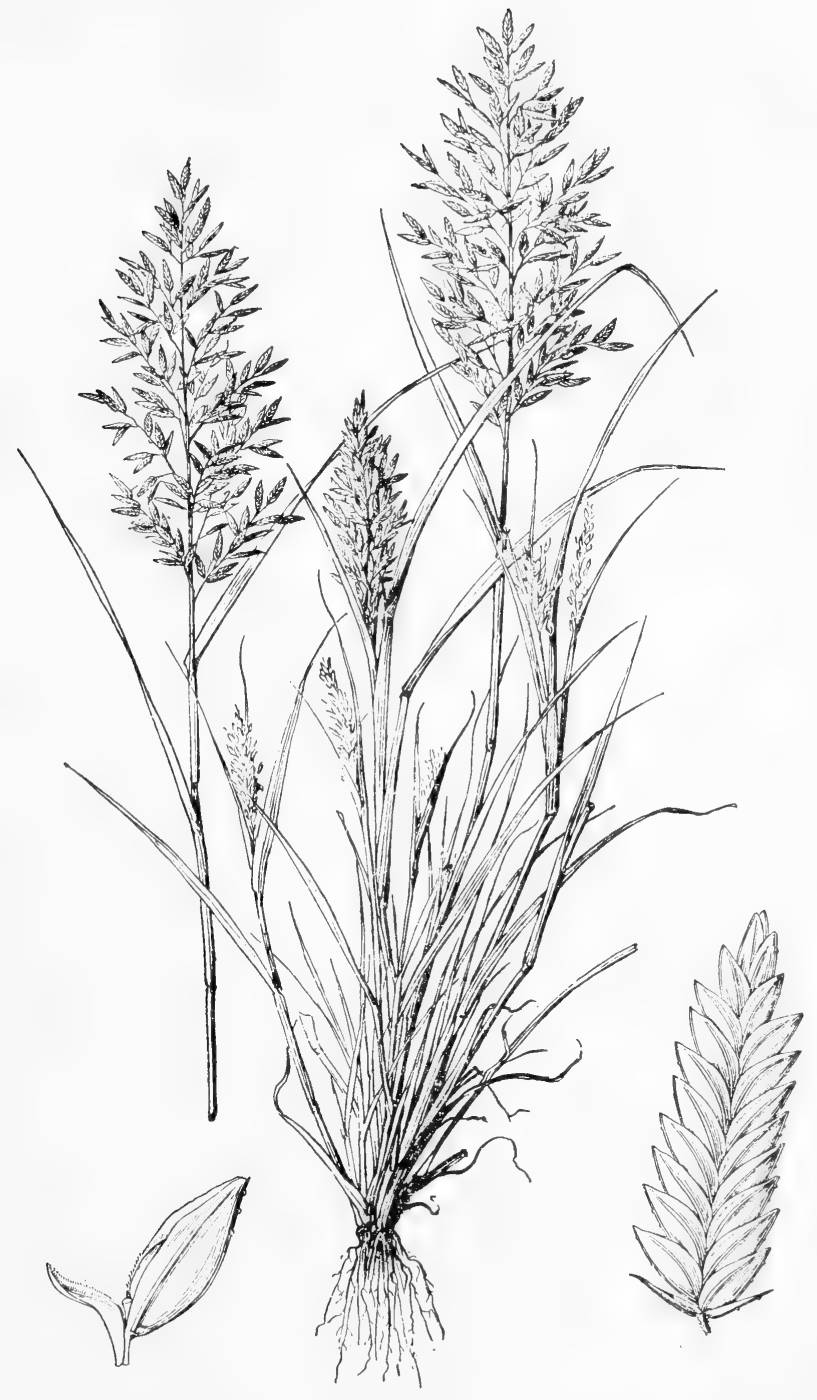

Fig. 87: Eragrostis cilianensis: plant, X 1/2; spikelet, X 5; floret, X 10. (From Hitchcock \& Chase). 


\section{Eragrostis pilosa (L.) Beauv. India LOVEgRAss.}

Loosely tufted annual; culms 1-5 dm. long, very slender, pronouncedly geniculate and sparingly or not branched near the base; sheaths much shorter than the internodes, mostly glabrous except at the corners; blades short, 1-3 mm. broad, often flat; panicles mostly pyramidal, long-exserted, very diffuse, $5-20 \mathrm{~cm}$. long, with a few widely spreading capillary branches which in turn bear the capillary pedicellary branchlets that are mostly deflexed and 3-8 $\mathrm{mm}$. long; spikelets linear, 3-6 mm. long, about $1 \mathrm{~mm}$. broad, 3- to 10-flowered; lemmas about $1 \mathrm{~mm}$. long, gray with dark purple tip, falling individually from the slightly fractiflex intact rachilla.

On muddy or wet sandy banks along streams and wet meadows, a rare weed in Okla. (LeFlore Co.) and n.-cen. and e. Tex., summer; nat. of s. Eur., now scattered in warmer parts of the New World.

\section{Eragrostis cilianensis (All.) E. Mosher. StinkgRass. Fig. 87.}

Loosely tufted annual, odoriferous when fresh; culms $5-50 \mathrm{~cm}$. long, mostly decumbent and geniculate basally, ascending distally, rarely branched, with an obscure yellow glandular (often broken) ring shortly below each node; sheaths mostly shorter than their internodes and often pilose on the corners, with microscopic glands along the keel and near the base also along the nerves; blades 3-7 $\mathrm{mm}$. broad, mostly flat, often papillose-pilose along the margins basally; panicles 3-20 cm. long, 1-7 cm. broad, narrowly oblong or ovoid, rather dense (spikelets touching), with a number of short ascending branches (glabrous in the axils) bearing in turn the glomerules of spikelets on individual pedicels $0.5-1 \mathrm{~mm}$. long, the branches and pedicels often gland-dotted; spikelets 8- to 40-flowered, 5-15 $\mathrm{mm}$. long, slightly tapering; lemmas $2-2.8 \mathrm{~mm}$. long, membranous, suborbicular, with conspicuous lateral veins and rounded apex, falling individually from the intact rachilla, the keel scabrous and with a few glands toward the apex. $E$. megastachya (Koel.) Link.

Edge of playa lakes and pond margins, in wettish sandy alkali among Tamarix, in Okla. (Alfalfa Co.) and in the Tex. Trans-Pecos and Plains Country, infrequent e. to n.-cen. Tex. and Rio Grande Plains, rare in s.e. Tex. to Ariz. (rather wide-spread), spring-fall; nearly throughout the warmer parts of the world, introd. from the Old World.

\section{Eragrostis pectinacea (Michx.) Nees.}

Loosely tufted diffuse annual; culms numerous, $15-30 \mathrm{~cm}$. long, ascending or usually spreading and geniculate in the lower part where also sparingly branched; sheaths usually folded, softly keeled, pilose at the corners; blades $2-5 \mathrm{~mm}$. broad, mostly flat; panicles ascending or often nodding or even altogether inclined, obovoid, usually open and diffuse when mature, 5-40 cm. long, with numerous ascending branches bearing along the distal two-thirds of their length the appressed flexuous pedicellary branchlets (1-5 $\mathrm{mm}$. long) or in larger specimens the lower main branches with ascending secondary branchlets that in turn bear the appressed pedicellary branchlets; spikelets mostly appressed or nearly so, slightly tapered, plumbeous, 3-10 mm. long; lemmas $1.5-2 \mathrm{~mm}$. long, blunt, all plumbeous, eventually falling from the intact rachilla (the lowest lemma falling first). E. diffusa Buckl., E. perplexa L. H. Harvey.

Frequent in a variety of habitats, most abundant in disturbed loamy soil near roads, fields and streams, in water and mud on edge of streams, ponds and lakes, in Okla. (Mayes Co.) and throughout Tex., spring-fall; essentially throughout the U.S. and s. into Mex.

\section{Eragrostis hirsuta (Michx.) Nees.}

Tightly tufted perennial; culms 4-10 dm. long, erect, unbranched; sheaths 


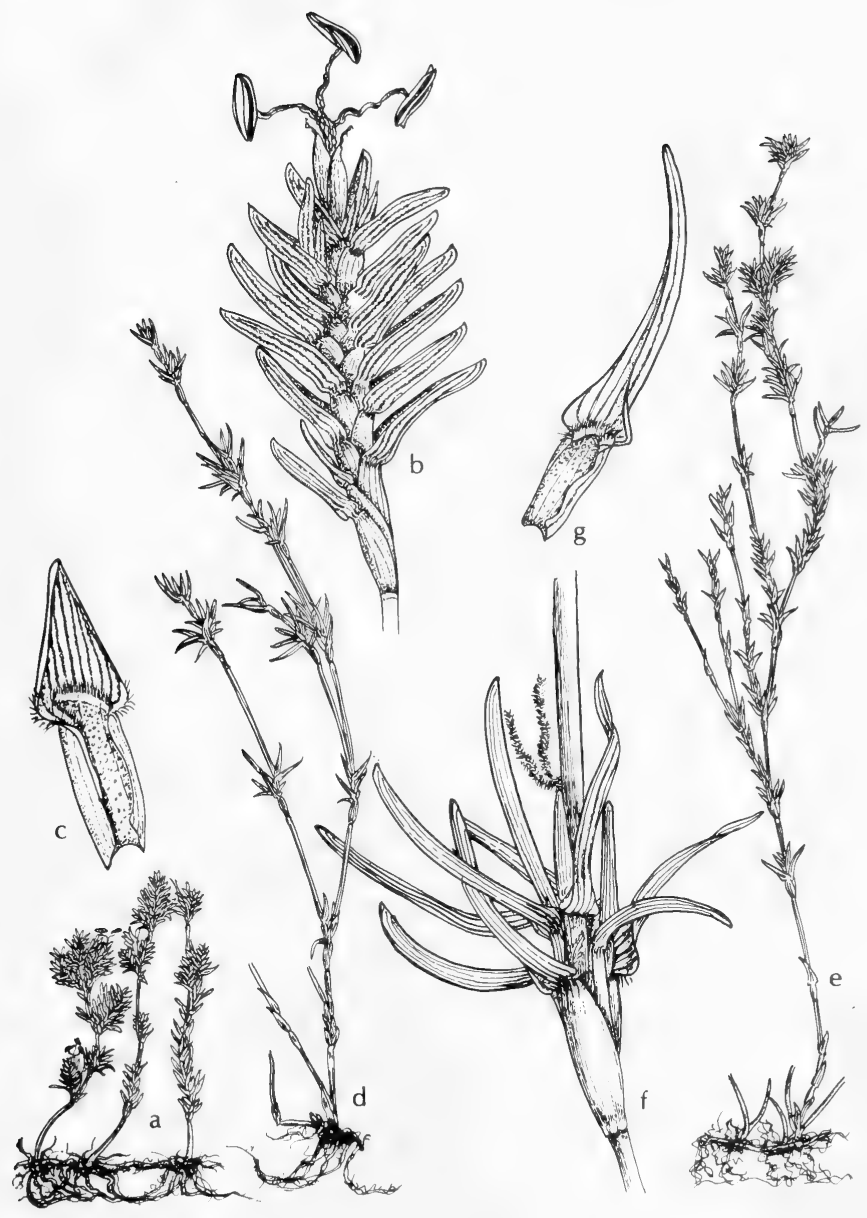

Fig. 88: Monanthochloë littoralis: a, habit, staminate plant, $\mathrm{X} 1 / 2 ; \mathrm{b}$, staminate inflorescence, X 5; c, leaf and sheath, X 5; d, habit, pistillate plant, X 1/2; e, plant later in the season after flowering, $X 1 / 2 ; \mathrm{f}$, pistillate inflorescence, $X 5 ; \mathrm{g}$, leaf and sheath of plant after flowering, X 5. (V.F.). 
much longer than their internodes, shortly ascending-pilose in the upper part and long erect-pilose at the apex dorsally, or rarely nearly glabrous; blades elongate-arcuate, the upper ones nearly surpassing the panicle, folded or eventually involute, 5-10 $\mathrm{mm}$. broad when flattened; panicle 2-6 dm. long, 8-30 cm. broad, open and diffuse, of numerous usually slightly to markedly ascending branches bearing several secondary branches (these often deflexed) which in turn bear the long capillary spreading pedicels $(8-18 \mathrm{~mm}$. long); spikelets $2-4 \mathrm{~mm}$. long, markedly tapered, (1- or) 2- to 4-flowered; lemmas 1.7-2.2 mm. long, ovate, blunt, with obscure lateral nerves, falling individually from the intact rachilla.

In marshy areas, alluvial areas, and in open sandy woods, in Okla. (Nowata Co.) and in e. and s.e. Tex., s.w. to San Patricio Co., summer-fall; Coastal States, Me. to Tex. and inland to Tenn., Ark. and Okla.; Br. Hond.

\section{Eragrostis Elliottii Wats.}

Tufted perennial (not knotty basally); culms 4-8 dm. long, erect; ligule a minute lacerate-fringed scale; sheaths long, shortly pilose at the corners, otherwise glabrous; blades rolled up marginally, stiffly ascending to a very slender tip; panicles erect, $25-50 \mathrm{~cm}$. long, nearly as broad as long, very diffuse, with numerous long stiff antrorsely scabrous capillary branches that in turn bear long straight mostly deflexed capillary pedicellary branchlets $1-3 \mathrm{~cm}$. long (these bearing spikelets only at the end, not along the length); part of the panicle often included in the uppermost sheath; spikelets strongly laterally compressed, remote, linear, 5-12 mm. long, mostly 8- to 15 -flowered, about $1.5 \mathrm{~mm}$. broad; lemmas ovate, about $1.5 \mathrm{~mm}$. long, not falling away individually but the rachilla of the spikelet eventually breaking up by mechanical action.

Rare in wet sandy open woods, wet meadows and low grounds, in extreme s.e. Tex. near the coast, summer-fall; Coastal States, from N.C. to Tex.; W.I., Mex.; Br. Hond.

\section{Eragrostis glomerata (Walt.) L. H. Dewey.}

Annual; cuims 2-10 dm. long, erect, sparingly branched and geniculate in the lower third; panicles erect or slightly nodding, $5-50 \mathrm{~cm}$. long, only $1-4 \mathrm{~cm}$. broad, with numerous long main branches and these in turn further branched, all the branches strictly ascending; spikelets nearly sessile, 2-3 $\mathrm{mm}$. long, 6- to 8flowered; lemmas about $1 \mathrm{~mm}$. long; palea glabrous or merely scabrous on the keels; rachilla eventually abscising above the glumes and between the florets.

Rare in roadside ditches, on wet banks of ponds, streams and lakes, in Okla. (LeFlore Co.) and in e. Tex., summer-fall; widespread in warmer parts of the New World n. to S.C. and the Gulf States; also waifed n. to Mo.

\section{Monanthochloë ENGELM.}

A monotypic North American genus.

\section{Monanthochloë littoralis Engelm. Fig. 88.}

Perennial forming extensive mats by rhizomes and/or stolons; flowering culms ascending, 5-25 cm. long; branches of 2 size-classes; few-noded elongate culms with leaves $10-15 \mathrm{~cm}$. long, bearing in the axils many-noded short shoots with crowded leaves 5-10 $\mathrm{mm}$. long: sheaths and blades extremely short, very firm, indurate-wiry, folded-falcate, grayish-green; male and female flowers on separate plants; panicles reduced to solitary 3- to 5-flowered spikelets, appearing terminal and embedded in the masses of leaves of the short shoots, difficult to find; glumes apparently absent; lemmas coriaceous or in the pistillate spikelet like the leaves; upper florets rudimentary; rachilla of pistillate floret tardily abscising at the lower part of the nodes. 


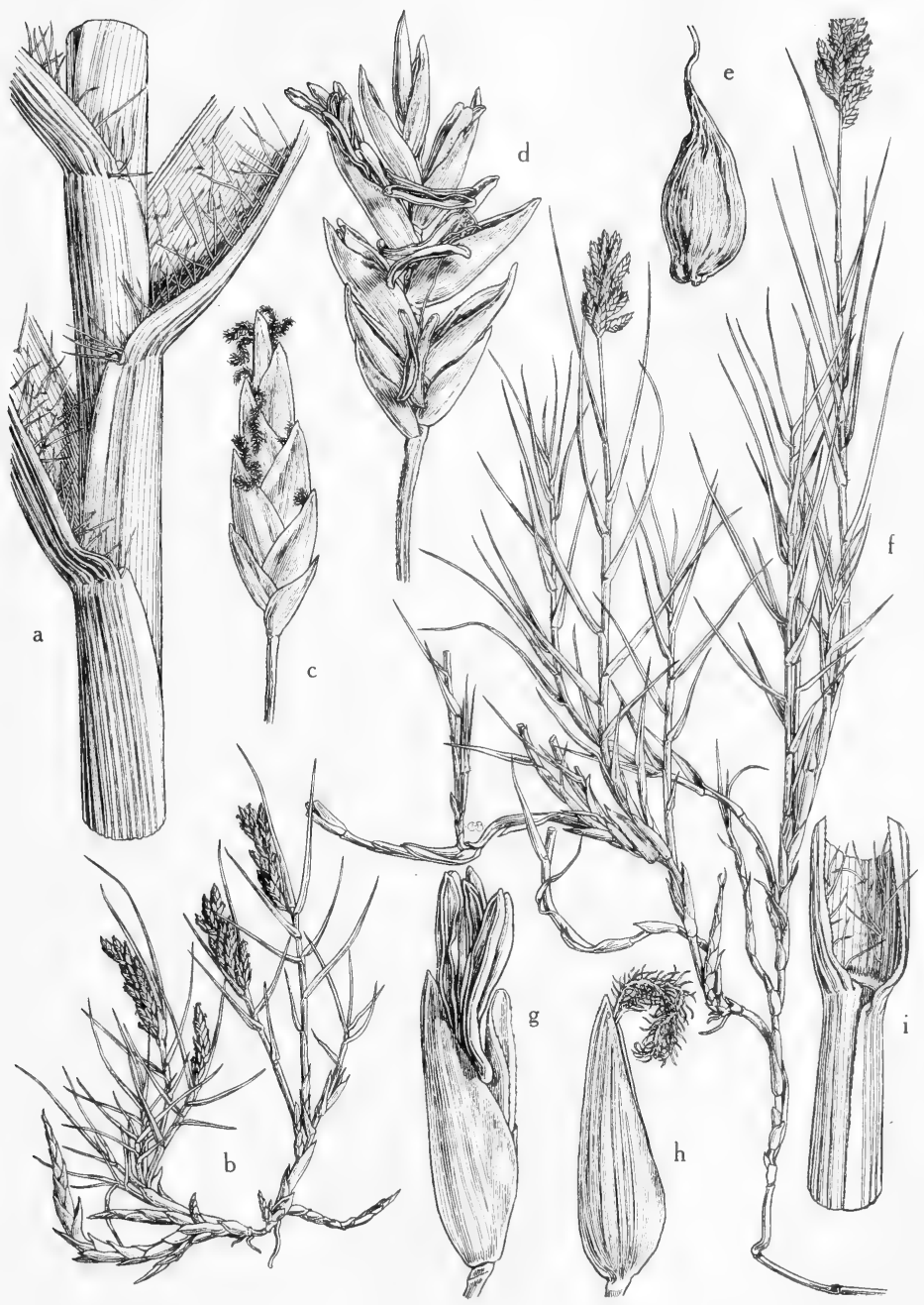

Fig. 89: Distichlis spicata: a, culm, leaf sheaths and ciliate base of leaf blades, X 4; b, habit, pistillate plant, X 2\%; c, pistillate spikelet, X 4; d, staminate spikelet, X 4; e, mature grain, hard and nutlike, X $8 ; \mathrm{f}$, habit, pistillate plant, $X 2 / 5 ; \mathrm{g}$, staminate floret, $\mathrm{X} 8 ; \mathrm{h}$, pistillate floret, $\mathrm{X} 6 ; \mathrm{i}$, leaf sheath, base of blade and ciliate ligule, $\mathrm{X} 6$. (From Mason, Fig. 61). 
Localiy abundant in poorly drained brackish or tidal saline flats or cayos near the coast, s.e. Tex. and Rio Grande Plains, also in Gonzales Co., spring; Fla. to Cuba; Tex. to Tam. and Coah.; Calif. to Baja Calif., Son. and Sin.

\section{Distichlis RaF.}

A small American genus of perhaps 3 or 4 species.

\section{Distichlis spicata (L.) Greene. Saltgrass. Fig. 89.}

Perennial, rarely more than $3 \mathrm{dm}$. tall, forming tight colonies in saline mud by means of very tough slender whitish scaly rhizomes; culms erect, $1-3(-5)$ $\mathrm{dm}$. tall, tough and wiry; leaves usually noticeably 2-ranked, narrow (1-3 mm. broad), usually mostly involute, tough, pungent, only $2-6(-10) \mathrm{cm}$. long, ascending; male and female flowers on separate plants; spikelets rather similar on both kinds of plants, in terminal erect spikes or spikelike racemes; pistillate racemes often shorter than staminate (the staminate ones often overtopping the foliate); spikelets 5- to 15-flowered, usually 6-10 $\mathrm{mm}$. long; rachilla of the pistillate spikelets disarticulating above the glumes and between the florets; glumes unequal, broad, acute, keeled, 3- to 7-nerved, the lateral nerves sometimes faint; lemmas closely imbricate, firm, the coriaceous pistillate ones acute or subacute and 3-6 $\mathrm{mm}$. long, the pistillate ones more coriaceous and more closely imbricate than the staminate, with 9 to 11 mostly faint nerves; palea as long as the lemma or shorter, the margins bowed out near the base, rather soft, narrow, the keels narrowly winged, the pistillate lemmas coriaceous and enclosing the grain which is brown.

Represented with us by two varieties as follows:

Var. spicata. Culms 1-6 dm. tall, slender, erect; blades erect, to $15 \mathrm{~cm}$. long, 10-25 $\mathrm{mm}$. apart on the culm, equaling or exceeding the pistillate spikes and rarely exceeded by the staminate spikes; pistillate spikes pale green, 1-6 cm. long, of 8 to 36 congested spikelets that are 5- to 9-flowered, up to but not exceeding $1 \mathrm{~cm}$. long, $4 \mathrm{~mm}$. broad; first glume $3 \mathrm{~mm}$. long; second glume $4 \mathrm{~mm}$. long; lemmas 6- to 10-nerved, 3.5-4 $\mathrm{mm}$. long, closely imbricate; palea keels minutely evenly serrate, the 4 nerves often excurrent; grain about $2 \mathrm{~mm}$. long, somewhat truncate at the tip; staminate spikes pale green, $1-6 \mathrm{~cm}$. long, of 6 to 30 congested spikelets that are 7 - to 10 -flowered, about $1 \mathrm{~cm}$. long, $4 \mathrm{~mm}$. broad; first glume to $3 \mathrm{~mm}$. long; second glume to $4 \mathrm{~mm}$. long; lemmas 6 - to 10 -nerved, $3 \mathrm{~mm}$. long; palea 2-keeled but otherwise nerveless, about $3 \mathrm{~mm}$. long.

Salt marshes near the coast, very abundant, rare in salt marshy areas inland in e. Tex., summer-fall; Can. to Mex. along the coast; also W.I.

Var. stricta (Torr.) Beetle. Culms $10-35 \mathrm{~cm}$. tall, erect or rarely decumbent; blades to $2 \mathrm{dm}$. long, the upper equaling or exceeding the pistillate spikes but exceeded by the staminate ones; pistillate spike green drying stramineous-brown, 2-7 cm. long, of 5 to 40 approximate spikelets that are 5- to 20-flowered, 5-20 $\mathrm{mm}$. long and 4-7 $\mathrm{mm}$. broad, the mature florets often strongly reflexed, usually not closely imbricate; first glume 2-3 $\mathrm{mm}$. long; second glume 3-4 $\mathrm{mm}$. long; lemma $2.5-6 \mathrm{~mm}$. long, firm, with a broad hyaline margin; palea $3-5 \mathrm{~mm}$. long, the keels conspicuously serrate to the base, often dentate, narrowed or winged at base, occasionally with a few long hairs on back; grain $2-5 \mathrm{~mm}$. long, sometimes slenderly tapered to a single beak, sometimes truncate with a double beak; staminate spike green or rarely purplish, drying stramineous-brown, $2-5 \mathrm{~cm}$. long, of 5 to 25 approximate spikelets that are 5- to 20 -flowered, $5-20 \mathrm{~mm}$. long and 4-7 mm. broad, closely imbricate; first glume 2-3 $\mathrm{mm}$. long; second glume 3-4 mm. long; lemmas 5-6 mm. long, firm, equalled by the palea; palea 5-6 $\mathrm{mm}$. long, the keels conspicuously serrate to the base, infrequently dentate, rarely broadly winged, usually with at least one prominent marginal vein. $D$. stricta (Torr.) Rydb. 


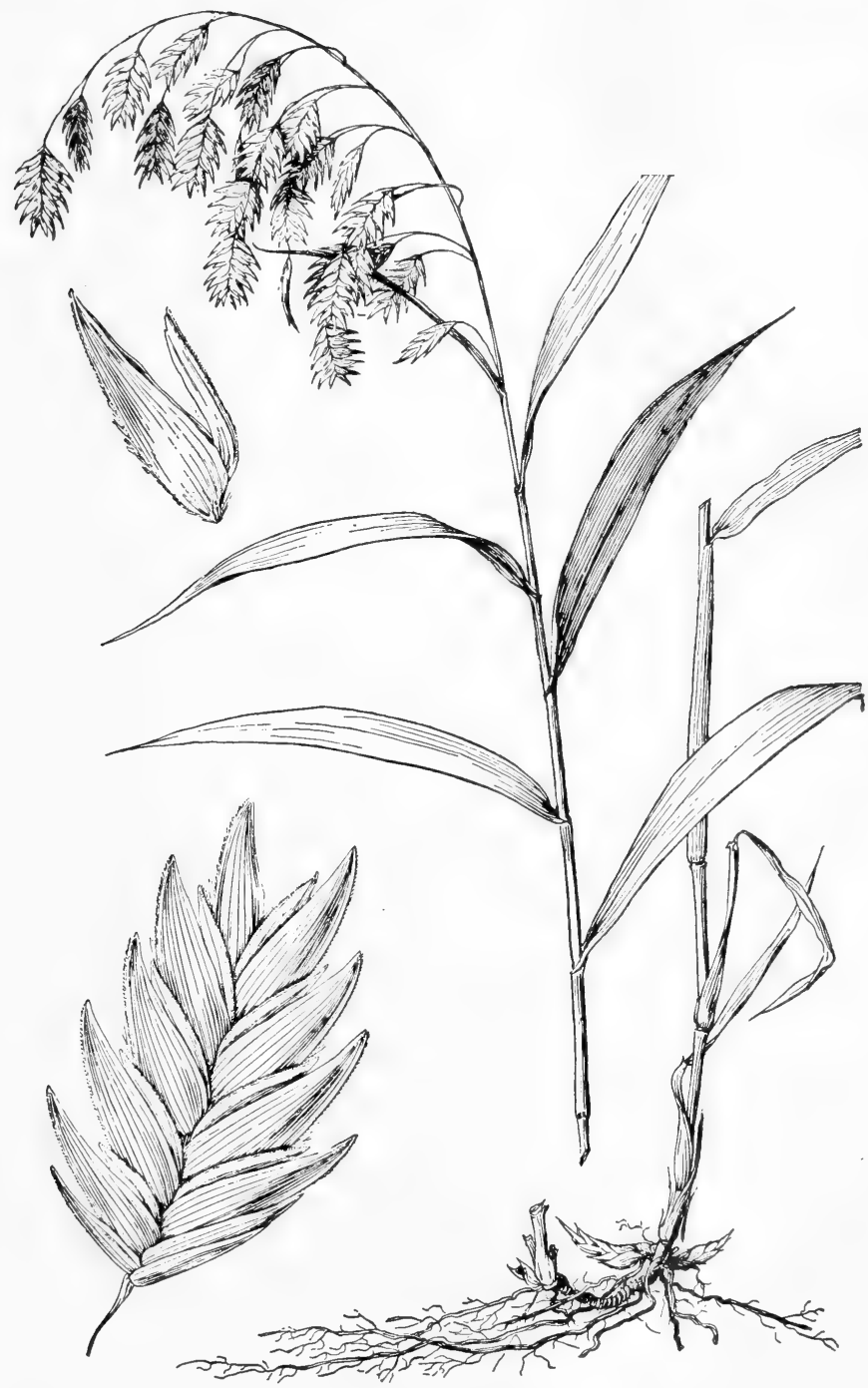

Fig. 90: Chasmanthium latifolium: plant, $X \quad 1 / 2$; spikelet and floret, $X$ 3. (From Hitchcock \& Chase). 
Locally abundant in alkaline or alkaline-saline areas such as marshes, lakes and irrigation ditches, in Okla. (Alfalfa Co.) and w. half of Tex., N. M. (Guadalupe, Sandoval, Chaves and Valencia cos.) and Ariz. (Coconino Co.), summer-fall; w. U. S. e. to the Dakotas, Neb., Kan., Okla., Tex., Coah. and Chih.

\section{Chasmanthium LINK}

A North American genus of 5 species.

1. Chasmanthium latifolium (Michx.) Yates. INLAND SEA OATs. Fig. 90.

Essentially glabrous rhizomatous perennial; rhizomes short, indurated, forming mats; culms rising singly from the mats, 5-13 dm. long, $1.5-3 \mathrm{~mm}$. thick, usually purplish, reclining and geniculate below, above erect, simple and stramineous, terete; sheaths considerably shorter than the internodes and tightly clasping them; blades lanceolate, 1-2 dm. long, $8-16 \mathrm{~mm}$. broad, divergent, acute, striate-veined; panicles very lax, $15-30 \mathrm{~cm}$. long, of 10 to 30 (to 50 ) large spikelets drooping at the ends of mostly naked capillary branches $3-10 \mathrm{~cm}$. long; spikelets very strongly laterally compressed, 12- to 18-flowered, 25-45 $\mathrm{mm}$. long, 13-16 mm. broad; rachis of spikelet with zone of abscission at the lower part of each node; glumes subequal, 5-7 mm. long, about $1 \mathrm{~mm}$. broad, cymbiform, shorter than the lowest lemma; lemmas broadly lanceolate, 9-13 $\mathrm{mm}$. long, 5-7 $\mathrm{mm}$. broad when unfolded, apically slightly incurved and acutish, grayish to bluish-green, firm, marginally very narrowly hyaline with 3 to 6 nerves on each side, minutely scabrellate, on the keels minutely pectinately scabrous; paleas only two thirds as long as the lemmas and of the same texture, doubly strongly keeled (the keels minutely pectinate), falcate; grain laterally compressed, black, rough, about 3 $\mathrm{mm}$. long. Uniola latifolia Michx.

Locally abundant in moist loamy soils of creek bottoms, in marshes, in mud and shallow water of streams and ponds, in Okla. (McCurtain, Washington, Murray, Ottawa and Cherokee cos.) and in e. and s.e. Tex., less common w. to n.-cen. Tex., e. Edwards Plateau and n. part of Rio Grande Plains, summer-fall; most of s.e. U.S., n. to Pa., O., Ill. and Neb.; also N. L.

\section{Dactylis L.}

A genus of 5 species indigenous to temperate Eurasia.

1. Dactylis glomerata L. ORCHARD GRASs. Fig. 91.

Densely tufted perennial; culms geniculate, ascending, 6-10 dm. long; ligule a lacerate hyaline scale; sheaths and blades soft, the blades flat and mostly aggregated toward the base; panicles long-exserted, mostly narrow, erect, with few mostly ascending branches, each of which bears apically a very dense aggregation (about $1 \mathrm{~cm}$. thick) of secund nearly sessile fascicles of spikelets; spikelets fewflowered, laterally compressed; rachilla abscising at the lower part of each node; glumes and lemmas keeled, the keels hispid; lemmas 5-nerved, about $7 \mathrm{~mm}$. long, narrowly lanceolate, mucronate.

In stream beds and wet meadows, rare in farm pastures and roadsides in Okla. (Waterfall), the Tex. Plains Country (Lubbock Co.) and N. M. (Taos Co.), spring-summer; widespread in temp. areas, nat. to Euras.

\section{Arundo L.}

About 8 species in the Old World tropics; we have one.

1. Arundo Donax L. Giant reed, Georgia cane, Carrizo. Fig. 92.

Canelike grass from thick short rhizomes, forming large clumps; aerial culms 2-6 m. long, to $5 \mathrm{~cm}$. thick, erect, rarely branched, perennial or in the northern extremes mostly freezing down annually or every few years; ligule a short scale; 


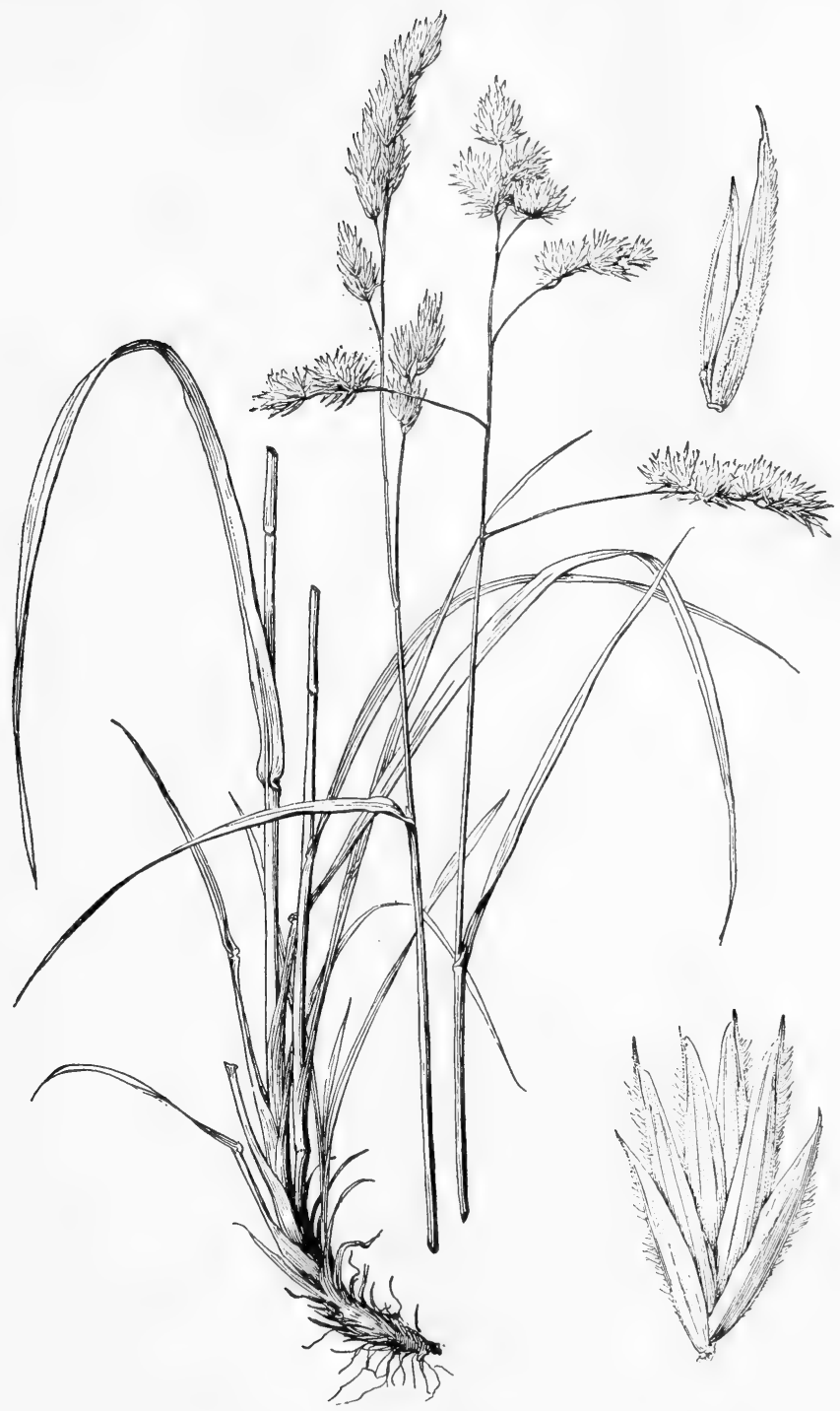

Fig. 91: Dactylis glomerata: plant, X 1/2; spikelet and floret, X 5. (From Hitchcock \& Chase). 


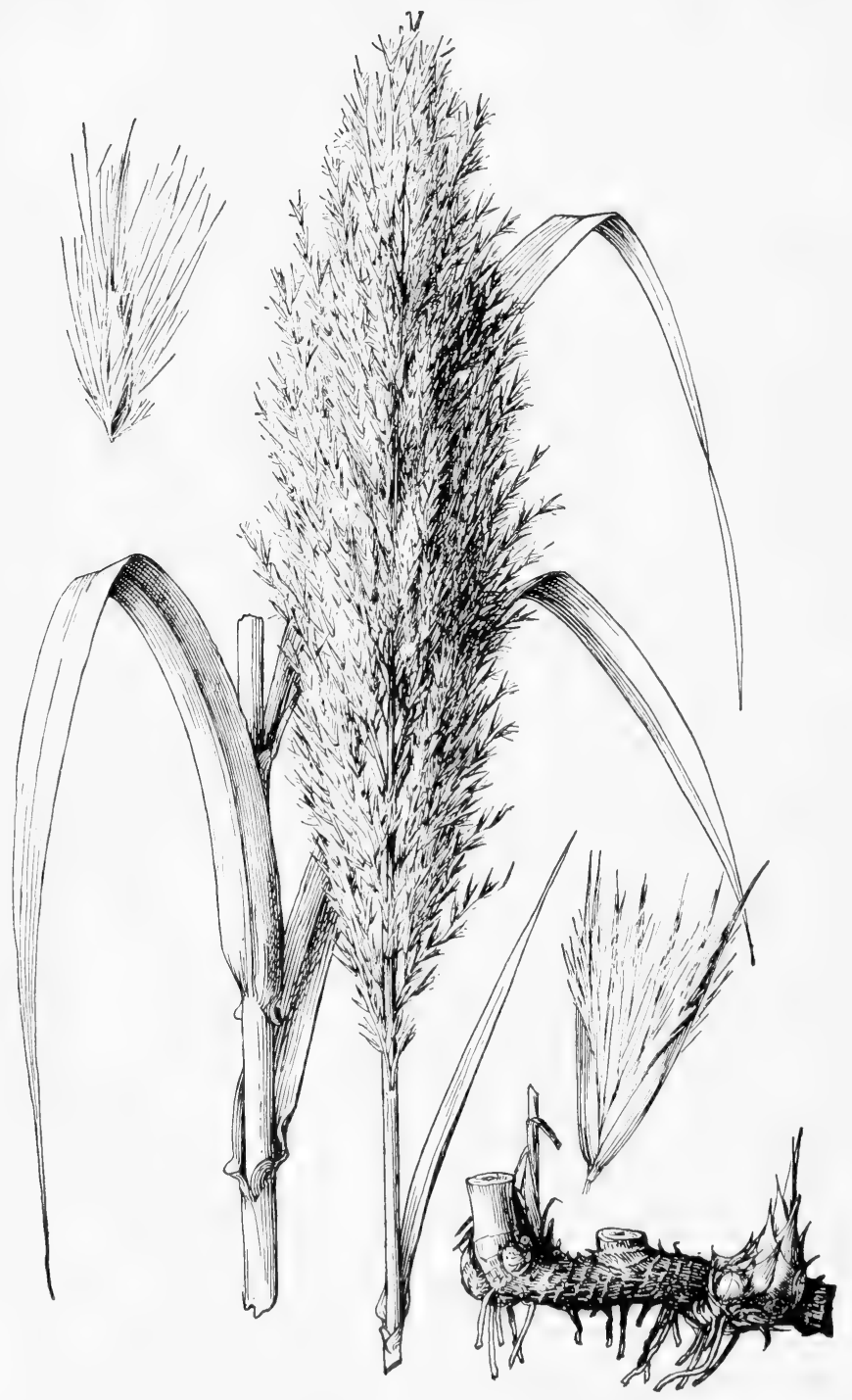

Fig. 92: Arundo donax: plant, X $1 / 3$; spikelet and floret, X 3. (From Hitchcock \& \& Chase). 
blades mostly 3-6 dm. long, 2-5 cm. broad or larger, often glaucous, firm; inflorescence a thick narowly ellipsoid buffy-white panicle 3-6 dm. long; spikelets 13-15 mm. long, usually 3-flowered; rachilla glabrous, with zones of abscission at lower part of each node; glumes subequal, cymbiform, thin, nearly as long as the spikelet, each 3-nerved; lemmas (including the small calloused base) longpilose, 3-nerved, thin, cymbiform, obscurely round-keeled, long-attenuate to very fine points.

Established along irrigation ditches and streams (occasional in marshes), on sand bars and levees of the Rio Grande in Rio Grande Plains, w. to the TransPecos and near rivers and lakes in s.e. and cen. Tex., summer-fall; widespread in warmer areas, nat. to Old World, adv. in Tex.

Planted for erosion control along roads in dune areas.

\section{Phragmites TRIN.}

A genus of 3 species, cosmopolitan; we have one.

\section{Phragmites communis Trin. CoMmon ReEd. Figs. 93 and 94.}

Perennial reed with thick rhizomes; culms 1-3 m. tall, 5-15 mm. thick; ligule a short tough lacerate fringe; blades flat, $1-4 \mathrm{~cm}$. broad; panicle a large terminal plume, many-branched and densely flowered; spikelets few-flowered, the lower flowers empty or merely staminate, the rest perfect; rachilla abscising at the upper part of each node, the fragments thus consisting of one floret with a portion of the densely long-silky-villous rachilla below (not above) the node; glumes lanceolate, shorter than the lowest lemma; lemmas lanceolate, glabrous, about $11 \mathrm{~mm}$. long.

Locally abundant in marshes, seeps, along rivers, at streamsides and canal banks, scattered throughout our region, fall; in most of the warmer parts of the world.

\section{Tridens R. \& S. TRIDENS}

Tufted or rarely shortly rhizomatous perennials; culms erect (or in one species scandent); ligule a white fringe or short fringed scale; blades mostly flat, elongate; panicles terminal, diffuse or spikelike; spikelets not much laterally compressed, several-flowered, all the florets perfect or the pistil of the uppermost usually abortive; rachilla abscising just below the lemma nodes; lemmas broad, mostly apically obtuse, emarginate and/or very shallowly cleft, 3-nerved (the midnerve and/or the laterals in some species minutely excurrent), usually pubescent on the lower half to two-thirds of the nerves (glabrous in $T$. albescens); paleas either glabrous or short silky-hairy on the nerves and dorsally.

A North American genus of about a dozen species, in some works enlarged to include the related genus Erioneuron.

1. Glumes as long as the spikelets or nearly so...

1. Glumes about equaling the lowest lemma (2)

2(1). Lemmas essentially glabrous (hair, if present, only at the basal callus of the lemma); panicles spikelike, $8-23 \mathrm{~cm}$. long.........2. T. albescens.

2. Lemmas pubescent, at least at the base of the lateral nerves.

3. T. ambiguus.

\section{Tridens strictus (Nutt.) Nash.}

Culms $8-17 \mathrm{dm}$. long, erect; sheaths not keeled; blades $3-8 \mathrm{~mm}$. broad; panicle spikelike, 1-3 dm. long, 9-15 mm. thick, with a few short appressed branches near the base; glumes as long as to longer than the rest of the spikelet, viscid, acuminate to a fine point, conspicuous in the panicle; lemmas about $3 \mathrm{~mm}$. long, the lateral nerves reaching the distal margin and in some specimens excurrent, all 3 nerves hairy in the distal two-thirds the length. 


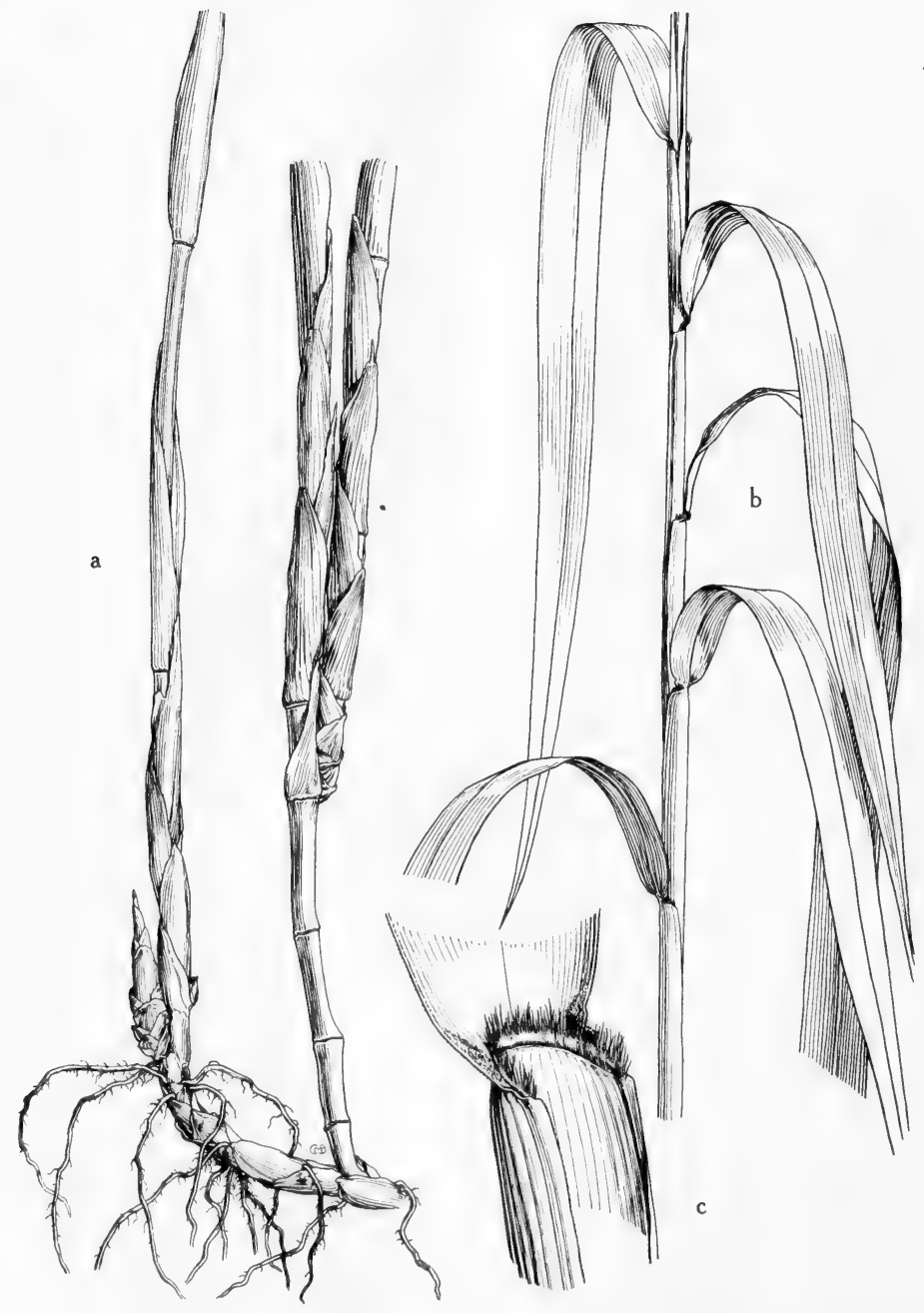

Fig. 93: Phragmites communis: a, habit, lower part of culm and rhizome, $\mathrm{X} 26$; $\mathrm{b}$, habit, culm and leaves, $\mathrm{X} 2 \%$; $\mathrm{c}$, leaf sheath, base of blade and ciliate ligule, $\mathrm{X} 11 \frac{1}{2}$. (From Mason, Fig. 80). 


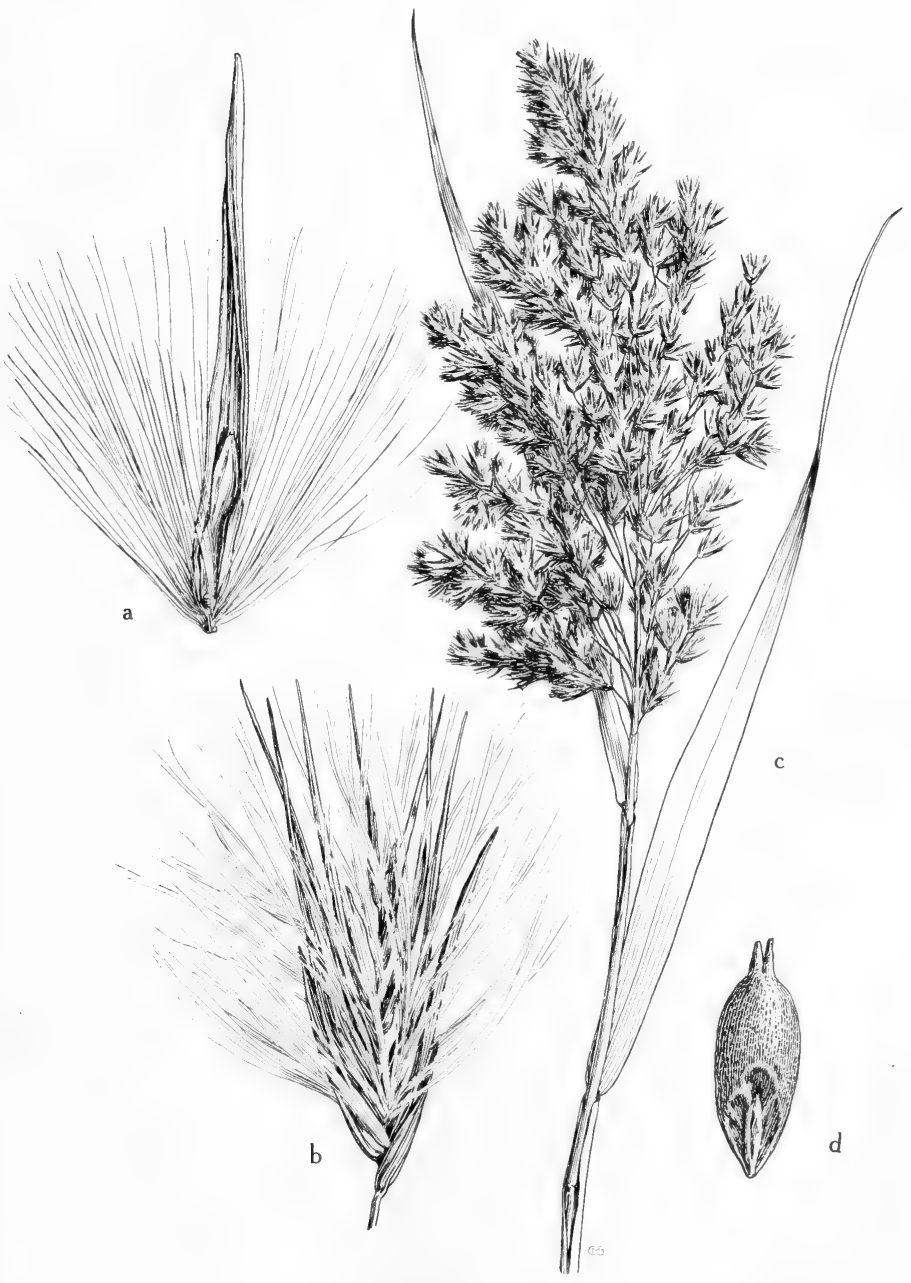

Fig. 94: Phragmites communis: a, floret, showing the long-acuminate lemma, the short palea and the long silky hairs on rachilla joint, $X$ 6; b, spikelet, showing the glumes and the florets successively smaller, $X 4$; c, habit, upper part of culm and panicle, X 2\%; d, grain, X 16. (From Mason, Fig. 81). 
Infrequent in open forests on sandy soil, in mud at edge of ponds and lakes, along streams and low wet ground, in Okla. (Mayes Co.) and e., s.e. and n.-cen. Tex., summer-fall; s.e. U.S. n. to N.C., Tenn., Ill. and Mo., w. to Kan., Okla. and Tex.

\section{Tridens albescens (Vasey) Woot. \& Standl. White TRIDENS.}

Tufts robust; culms $3-10 \mathrm{dm}$. long, erect; basal sheaths not or obscurely keeled; panicles spikelike, $8-25 \mathrm{~cm}$. long, 5-13 $\mathrm{mm}$. broad, very pale in color; lemmas about $3 \mathrm{~mm}$. long, 3-nerved, the nerves ending well within the distal margin and glabrous (hair, if present, confined to the basal callus of the lemma.

Abundant in roadside ditches, streamsides, overflows, in playa lakes, draws and low-lying prairies throughout Okla and Tex. to N.M. (Lea Co.), summerfall; Okla. and Colo., s. to Tam., N.L. and Coah.

\section{Tridens ambiguus (Ell.) Schult.}

Tufted; culms 6-10 dm. long, erect; basal sheaths keeled; panicle broadly to narrowly obovoid, $8-15 \mathrm{~cm}$. long, the branches stiffly ascending; most pedicels (of lateral spikelets) about $1 \mathrm{~mm}$. long; spikelets erect, appressed to the branches; lemmas 3-4 $\mathrm{mm}$. long, the 3 nerves usually minutely excurrent and pubescent in the lower two-thirds the length, or the lateral nerves scarcely excurrent in many specimens.

Infrequent to rare, wet pinelands, boggy areas and wet savannahs, extreme e. Tex., late summer-fall; Coastal States, S.C. to Tex.

\section{Agropyron Gaertn. Wheatgrass}

Perennials; corners of base of blades discolored and minutely auriculate or pointed; inflorescences spikelike, the axis usually slightly zigzag, unbranched, remaining intact; spikelets several-flowered, solitary (rarely in pairs) at each node, sessile, laterally compressed, turned with one side appressed to the rachis (or to the next spikelet above when crowded); all florets perfect or usually the terminal 1 or 2 reduced; rachilla abscising above the glume and at the lower part of each node; glumes lanceolate, acute, persistent, roundly keeled, equal, firm, several-nerved (the nerves obscure in some species); lemmas roundly keeled, 5- to 7-nerved (nerves obscure in some species at some stages of maturity), firm to subindurate, lanceolae, acute or in some species awned, eventually the lateral margins revolute.

A genus of about 100 or more species in temperate regions.

1. Plants normally cespitose, non-rhizomatous

1. A. subsecundum.

1. Plants with creeping rhizomes; blades firm and strongly nerved (2)

2(1). Glumes rigid, gradually tapering into a short awn, more or less asymmetric, the lateral nerves usually obscure.....................2. A. Smithii.

2. Glumes not rigid, acute or abruptly awn-pointed, symmetric, the lateral nerves evident. 3. A. repens.

\section{Agropyron subsecundum (Link) Hitchc. BeARded Wheatgrass.}

Green or glaucous, without creeping rhizomes; culms erect, tufted, 5-10 dm. tall; sheaths glabrous or rarely pubescent; blades flat, 3-8 $\mathrm{mm}$. wide; spike erect or slightly nodding, 6-15 cm. long, sometimes unilateral from twisting of the spikelets to one side, the rachis scabrous to scabrous-ciliate on the angles, sometimes disarticulating; spikelets rather closely imbricate, few-flowered, the rachilla villous, the callus of the florets short-pilose; glumes broad, rather prominently 4- to 7-nerved, nearly as long as the spikelet, tapering into an awn; lemmas obscurely 5-nerved, the nerves becoming prominent toward the tip, the awn straight or nearly so, usually $1-3 \mathrm{~cm}$. long. 


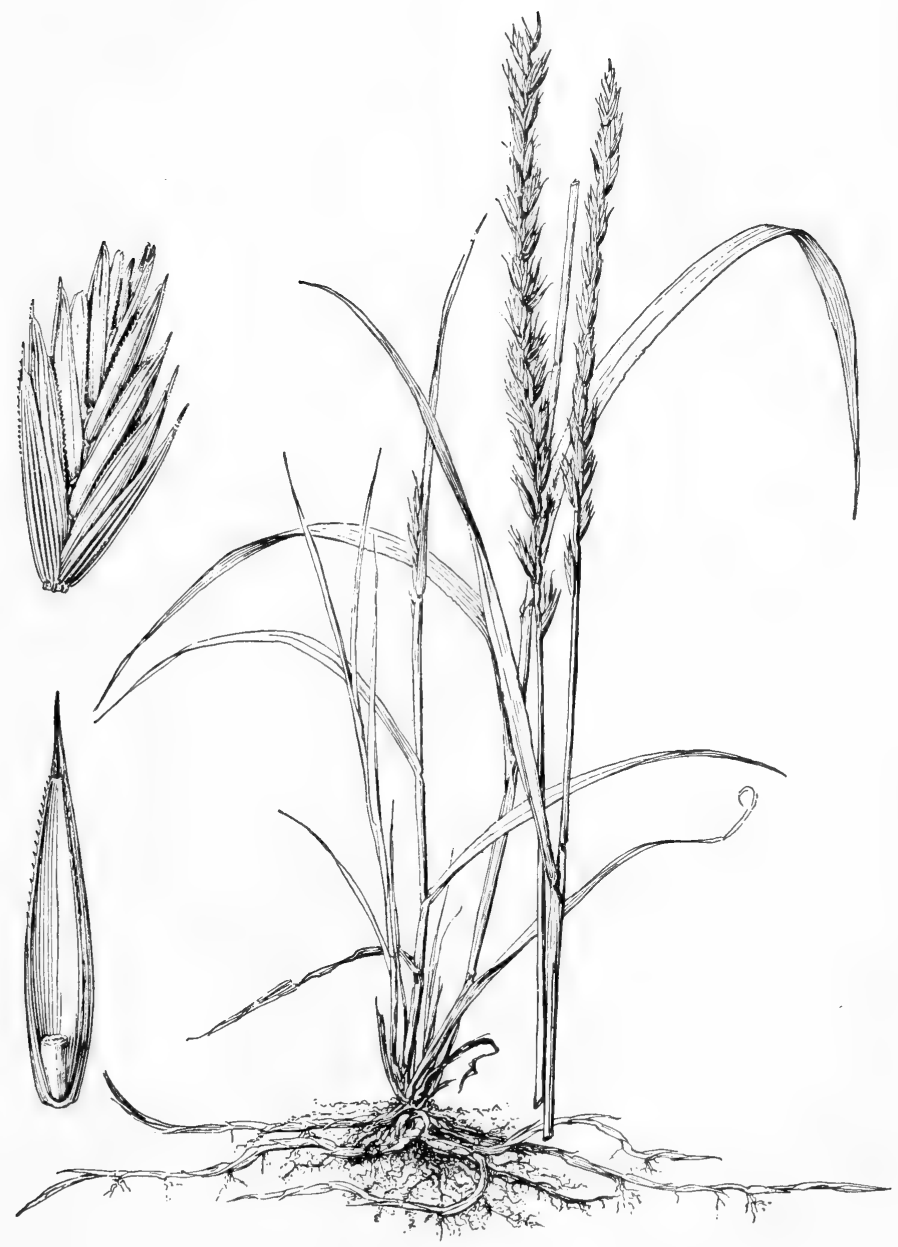

Fig. 95: Agropyron repens: plant, X 1/2; spikelet and floret, X 3. (From Hitchcock \& Chase). 
Moist or wet meadows, in water on edge of lakes and in open woods, in N. M. (Taos Co.) and Ariz. (Apache, Coconino and Gila cos.); Nfld. to Alas., s. to the mts. of Md., w. to Wash. and Calif., s. to N. M. and Ariz.

\section{Agropyron Smithii Rydb. Western wheatgrass.}

Forming large colonies by means of slender fragile easily detached rhizomes, the aerial culms erect even at the base; spikes strictly erect, rather dense, the spikelets overlapping usually more than their lengths. Elymus Smithii (Rydb.) Gould.

In marshes and edge of water about lakes, along streams and ponds, occasionally in flowing water, in Okla. (Cimarron Co.), abundant (formerly) in the prairies of the higher parts of the Tex. Plains Country, infrequent e. to n.-cen. Tex. and w. to the Trans-Pecos, N. M. (Grant and Colfax cos.) and Ariz. (Apache, Navajo, Coconino, Yavapai and Pima cos.), late spring-summer; w. U.S. e. to O., Ky., Tenn., Ark. and Tex.

This species apparently tends to disappear under grazing.

Var. molle (Scribn. \& Smith) M. E. Jones has pubescent lemmas.

Var. Palmeri (Scribn. \& Smith) Heller has densely pubescent sheaths.

\section{Agropyron repens (L.) Beauv. Quackgrass. Fig. 95.}

Green or glaucous; culms erect or curved at base, 5-10 dm. tall, sometimes taller, with creeping yellowish rhizomes; sheaths of the innovations often pubescent; blades relatively thin, flat, usually sparsely pilose on the upper surface, mostly 6-10 mm. wide; spike $5-15 \mathrm{~cm}$. long, the rachis scabrous on the angles; spikelets mostly 4- to 6 -flowered, $1-1.5 \mathrm{~cm}$. long, the rachilla glabrous or scaberulous; glumes 3- to 7-nerved, awn-pointed; lemmas mostly 8-10 $\mathrm{mm}$. long, the awn from less than $1 \mathrm{~mm}$. to as long as the lemma; palea obtuse, nearly as long as the lemma, scabrous on the keels.

Waste places, meadows and pastures, also in seepage areas and wet meadows, in N. M. (Otero and Taos cos.) and Ariz. (Coconino Co.) Nfld. to Alas., s. to N.C., Ark., Ut. and Calif.; Mex.; introd. from Euras.

A troublesome weed in cultivated ground.

\section{Elymus L. WILD-RYE}

Perennials; culms slender; minute pointed auricles present at juncture of blade and sheath; inflorescence a terminal spike, the axis slender with short internodes, remaining intact; spikelets collaterally paired at each node, each basally only slightly laterally compressed and with one side toward the axis but each distally (due to contortion of rachilla) with 1 keel toward the axis; spikelets 2- to 6flowered, all the flowers perfect except the terminal 1 or 2 ; glumes equal, firm to subindurate, lanceolate to subulate, 1- to several-nerved; lemmas lanceolate, cymbiform, not keeled, eventually subindurate, obscurely 5-nerved, awned from the tip in most species.

A genus of about 70 species in temperate North America and South America.

1. Rhizomes present; awns of lemmas $0-2 \mathrm{~mm}$. long................... E. triticoides.

1. Rhizomes absent but base of culm usually decumbent; awns of lemmas 5-45 mm. long (2)

2(1). Glumes basally discolored, indurate, roundish in transection and diverging from the axis at a large angle, becoming broader and flatter toward the middle and then tapering to the awn................. E. virginicus.

2. Glumes basally flat, neither discolored, indurate nor rounded, diverging at a low angle, broadest near the base and tapering the full length to the awn..... 3. E canadensis. 

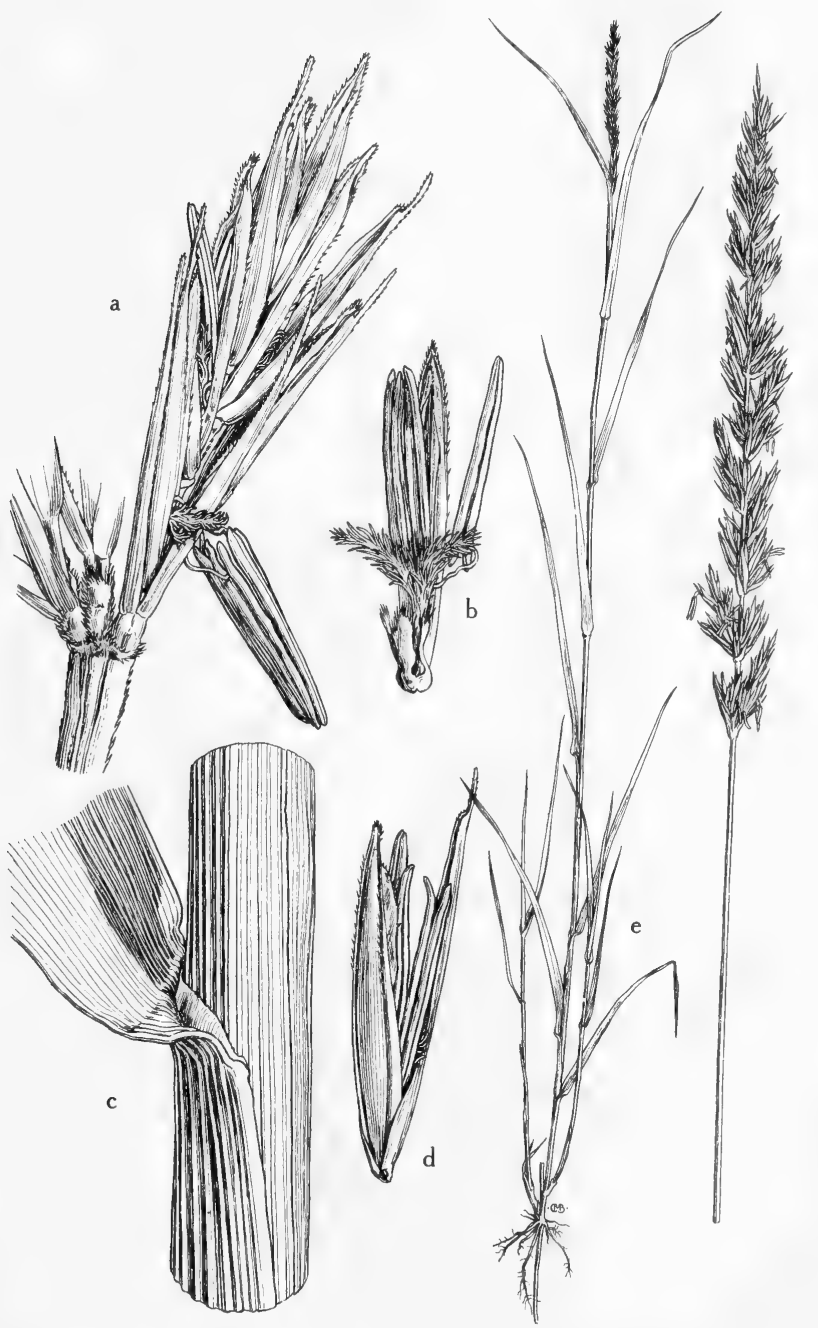

Fig. 96: Elymus triticoides: a, node, showing group of spikelets, $\mathrm{X} 4$; b, floret, the lemma removed to show the lodicules, $X 4$; c, leaf sheath and ligule, $X$ 4; $d$, floret, X 4; e, habit, X 1/8; f, inflorescence, X $2 / 5$. (From Mason, Fig. 64). 


\section{Elymus triticoides Buckl. Beardless wild-RyE. Fig. 96.}

Perennial from creeping rhizomes; aerial culms erect, 6-12 dm. long; spikes erect, 7-20 cm. long, slender, the spikelets of successive nodes overlapping only a sixth to a half their lengths; spikelets paired; glumes subulate, much shorter than the body of the lemma; lemma tapering into a mucro or awn only 1-2 mm. long.

On the dried or moist edges of meadows and flats, and in marshes about ponds, usually in heavy often alkaline soil, also flourishing as a weed in waste places, reported to occur in the Tex. Plains Country and Trans-Pecos; if present exceedingly rare and probably not nat., in N. M. (Dona Ana, Otero and Taos cos.) and Ariz. (Navajo, Coconino, Mohave, Yavapai, Greenlee and Pima cos.), spring; abundant in Pac. States, less frequent e. to the mts. of Mont., Wyo., Colo. and N. M.

This species is apparently more closely related to species included in the genus Agropyron than it is to the other 2 species of Elymus below.

\section{Elymus virginicus $L$.}

Perennial; culms basally erect or very shortly decumbent, mostly erect, 6-12 dm. long, peduncles (at maturity of the spike!) 7-30 cm. long; spikes 3-12 $\mathrm{cm}$. long, mostly erect or at least ascending; spikelets paired; glumes linear-elliptic, at the very base discolored, tending to be terete in transection, strongly indurate and diverging at a large angle from the axis but upward broader, flatter and less thoroughly indurate, $1.2-2.2 \mathrm{~mm}$. broad near the middle and becoming more erect, tapered upward to a straightish ascending or slightly divergent awn 5-25 $\mathrm{mm}$. long. Incl. forms that have been called var. australis (Scribn. \& Ball) Hitchc., var. glabriflorus (Vasey) Bush and var. intermedius (Vasey) Bush.

In mud and water of streams, ponds and marshy areas, in Okla. (Murray and Pittsburg cos.) and rather frequent in e., s.e., and n.-cen. Tex., less abundant in n. parts of Rio Grande Plains, Edwards Plateau and Plains Country, and Ariz. (Yavapai Co.), spring-summer; e. U.S. w. to Wash., Ida., Ut. and n. N. M., rare to n. Ariz.

This species is highly variable. Many plants referred here show some characters of $E$. canadensis, with which this species undoubtedly intergrades.

\section{Elymus canadensis L. Canada WILD-RYe. Fig. 97.}

Perennial; culms basally decumbent, mostly ascending, 8-15 dm. long; peduncles (at maturity of the spike!) typically $25-45 \mathrm{~cm}$. long, spikes $8-15 \mathrm{~cm}$. long, nodding; spikelets usually paired or less commonly in threes at each node; glumes basally $0.7-1.2(-1.4) \mathrm{mm}$. broad, ridge-keeled and fairly straight and diverging at a low angle, tapering into a slender scabrous outbowed awn, never becoming completely indurate but remaining flexible; lemmas glabrous to pubescent, with awns mostly 20-35 $(-45) \mathrm{mm}$. long that diverge or curve away from the axis slightly or greatly. Incl. forms that have been called var. brachystachys (Scribn. \& Ball) Farw., var. robustus (Scribn. \& Sm.) Mack. \& Bush and var. villosus (Muhl.) Shinners (E. villosus Muhl.).

On wet mud along sluggish streams, in seepage areas, marshes and along streams, in Okla. (Haskell Co.), nearly throughout Tex. except s. part of Rio Grande Plains, N. M. (widespread) and Ariz. (Coconino, Apache, Navajo, s. to Cochise and Pima cos.); spring (less commonly summer), nearly throughout temp. N. A. (except Ala., Ga., Fla. and S. C.).

This species is somewhat variable and grades into E. virginicus. 


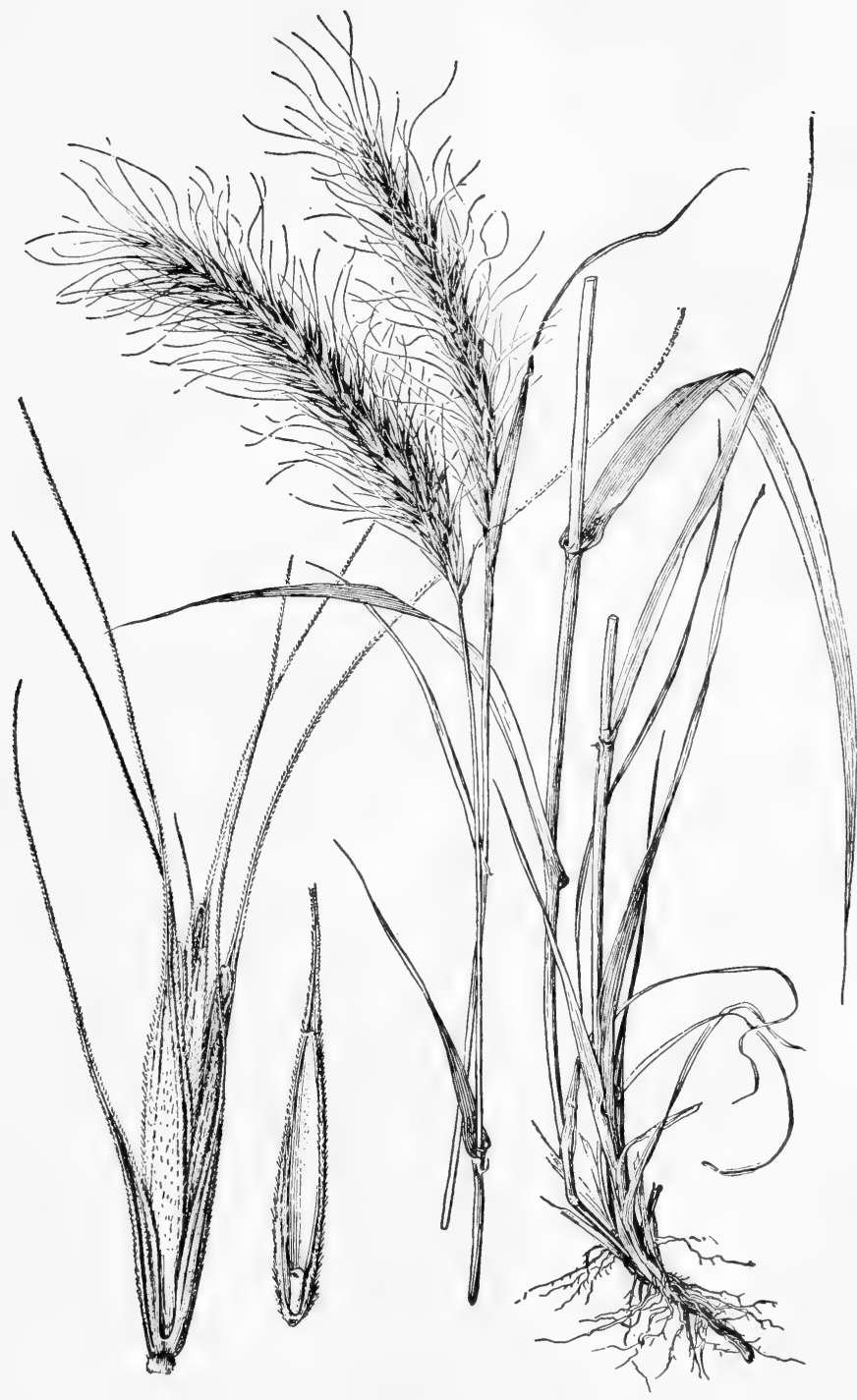

Fig. 97: Elymus canadensis: plant, X 1/2; spikelet and floret, X 5. (From Hitchcock \& Chase). 


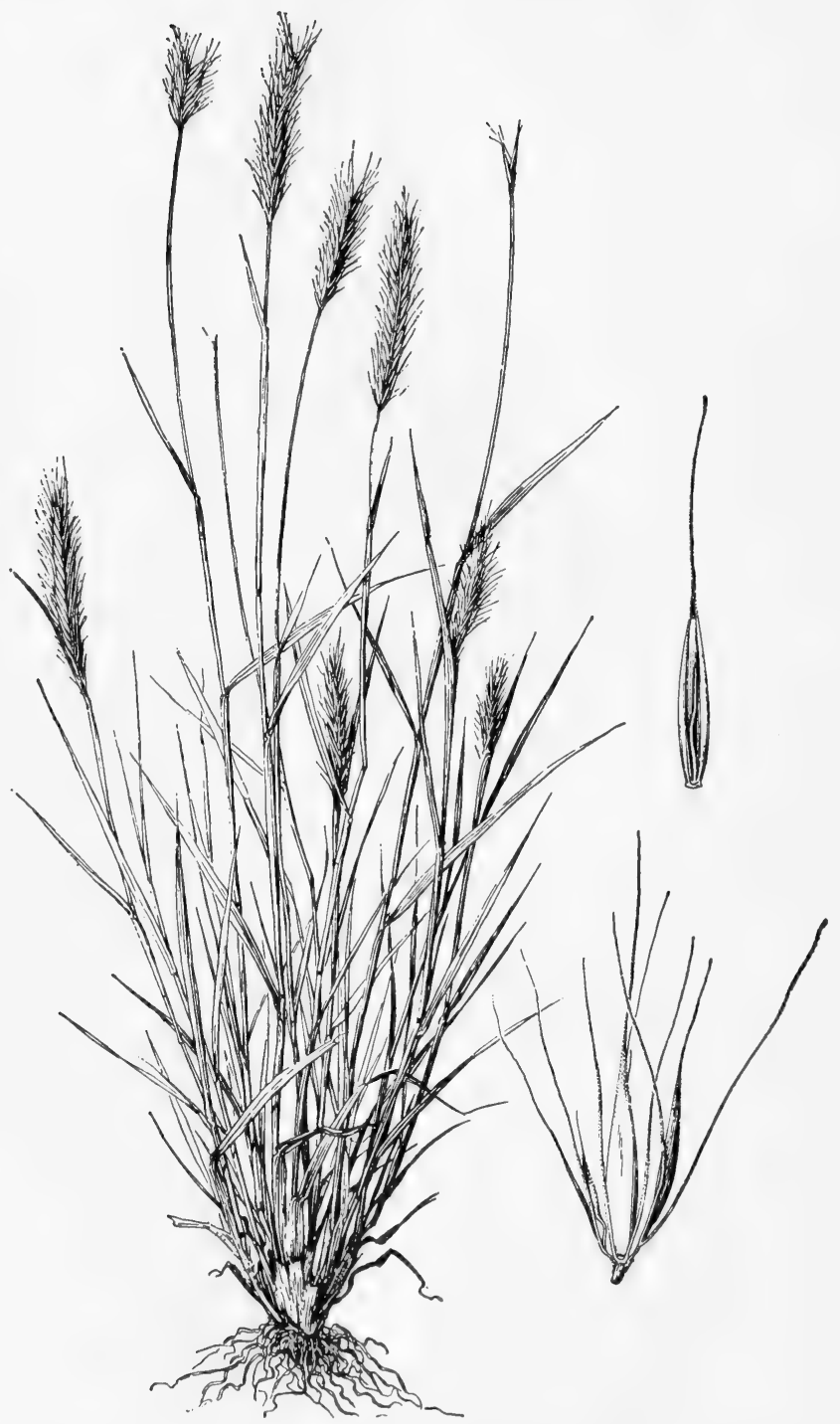

Fig. 98: Hordeum brachyantherum: plant, X 1/2; group of spikelets and floret, X 3 . (From Hitchcock \& Chase). 


\section{Hordeum L. BARLEY}

Tufted annuals (frequently some perennial); inflorescences dense terminal spikes; rachis abscising at the lower part of each node; spikelets in threes at each node, the central one largest, the lateral ones reduced and pedicellate, 1-flowered; lemma contorted so that its back is abaxial; rachilla produced beyond the lemma node as a point; glumes setaceous, produced into awns; lemmas cymbiform or flatter, not keeled, obscurely 5-nerved, tapering into an awn.

A genus of about 20 species of temperate regions.

1. Awns 2-5 cm. long; spike nodding. 1. H. jubatum.

1. Awns mostly less than $1 \mathrm{~cm}$. long; spike erect 2. H. brachyantherum.

\section{Hordeum jubatum L. Foxtail barley.}

Short-lived perennial or often behaving as a spring annual; culms basally decumbent, mostly ascending, 30-65 cm. long; spikes $2-11 \mathrm{~cm}$. long (not including awns) and about $1 \mathrm{~cm}$. thick (not including awns), nodding, dense, the rachis abscising at the lower part of each node; spikelets in threes at each node, the lateral ones pedicelled and with slightly smaller lemmas than the central one and merely staminate; awns of the various glumes and lemmas not curved at maturity, 25-60 mm. long.

Moist open ground, along ditches, in marshes and seepage areas, in shallow water streams, and in waste places, often on alkaline or saline soils; a troublesome weed, especially in irrigated lands, in Okla. (Waterfall) and in Tex. Plains Country and Trans-Pecos, in N. M. (Colfax, Taos, DeBaca, San Juan, Valencia and McKinley cos.) and Ariz. (Coconino, Navajo, Apache and Maricopa cos.), spring; w. U. S. e. to Plains States and as a weed e. to N. E.

Var. caespitosum (Scribn.) Hitchc. has awns $1.5-3 \mathrm{~cm}$. long.

\section{Hordeum brachyantherum Nevski. Meadow barley. Fig. 98.}

Perennial; culms tufted, erect or sometimes spreading, 1-5 dm. tall; blades soft, usually glabrous, sometimes scabrous or shortly pubescent, 3-9 $\mathrm{mm}$. wide; spike slender, 2-8 cm. long; glumes all setaceous, $8-15 \mathrm{~mm}$. long, those of the central spikelet often scarcely longer than the palea; the rachilla prolonged, usually extending beyond the middle of the palea; lateral spikelets pediceled, the pedicels usually curved, the florets much-reduced.

Wet meadows, flats, marshes, lakes or ponds and their borders, often in subalkaline or saline soils, in N. M. (San Juan, Rio Arriba, Taos, McKinley and Valencia cos.) and Ariz. (Coconino, Apache, Greenlee, Maricopa, Cochise and Pima cos.); Nfld. to Alas., s. to N. M., Ariz. and Calif.

\section{Lolium L.}

Inflorescences elongate, terminal, lax spikes; axis sculptured with a niche for a spikelet on one side of each internode, the axis remaining intact; spikelets 2-ranked, solitary, each fitting within the niche of the internode, slightly if at all laterally compressed, 5- to 20-flowered, all the florets perfect except the terminal one; rachilla eventually abscising above the glume(s) and at the lower part of each node; first glume obsolete or much reduced, adaxial when present (thus hidden except on terminal spikelet), 3- to 5-nerved; second glume abaxial, strongly 5- to 7-nerved, membranous, obtuse; lemmas broadly ovate, 5- to 7-nerved, eventually marginally revolute.

A genus of perhaps 12 species in temperate Eurasia.

1. Lolium perenne L. Ryegrass. Fig. 99.

Tufted perennial; culms 3-10 dm. long, mostly erect; spikes 7-25 cm. long, 


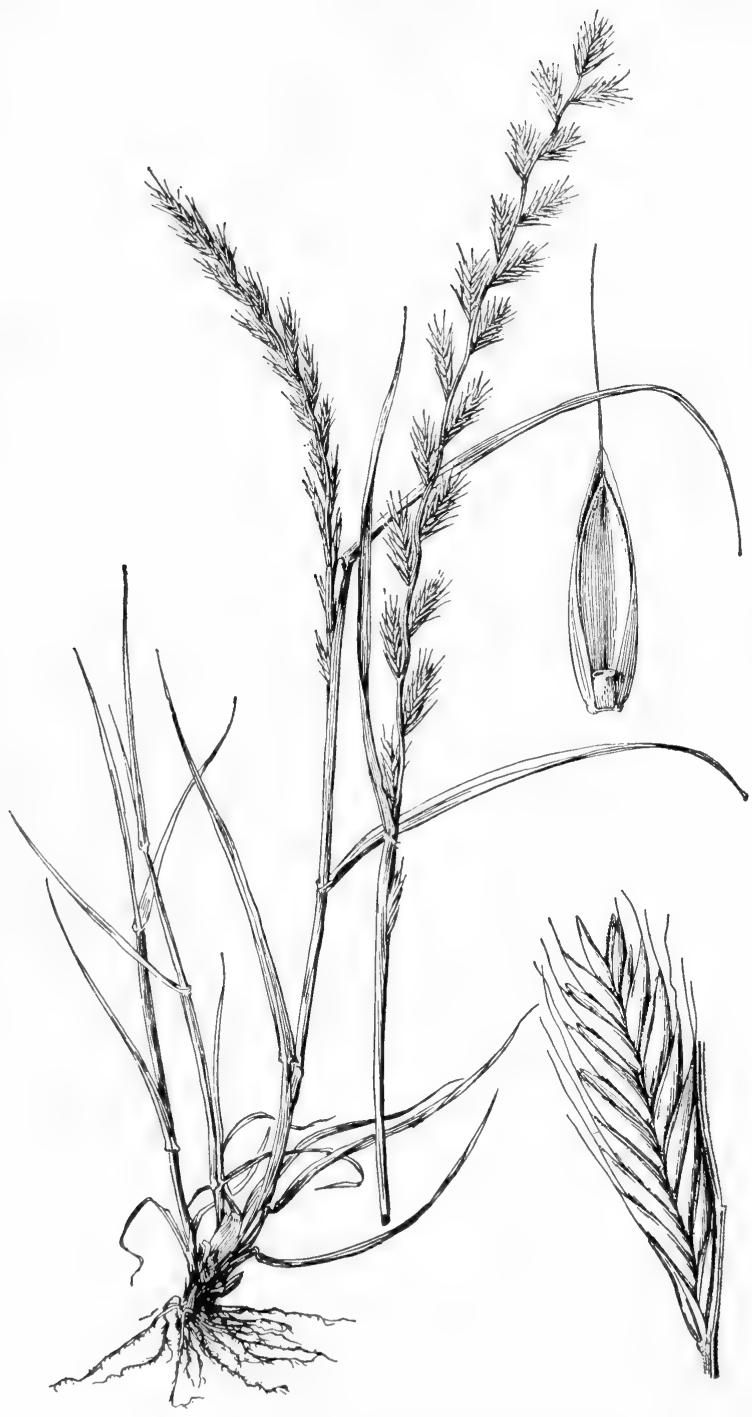

Fig. 99: Lolium perenne: plant, X 1/2; spikelet, X 3; floret, X 5. (From Hitchcock \& Chase). 


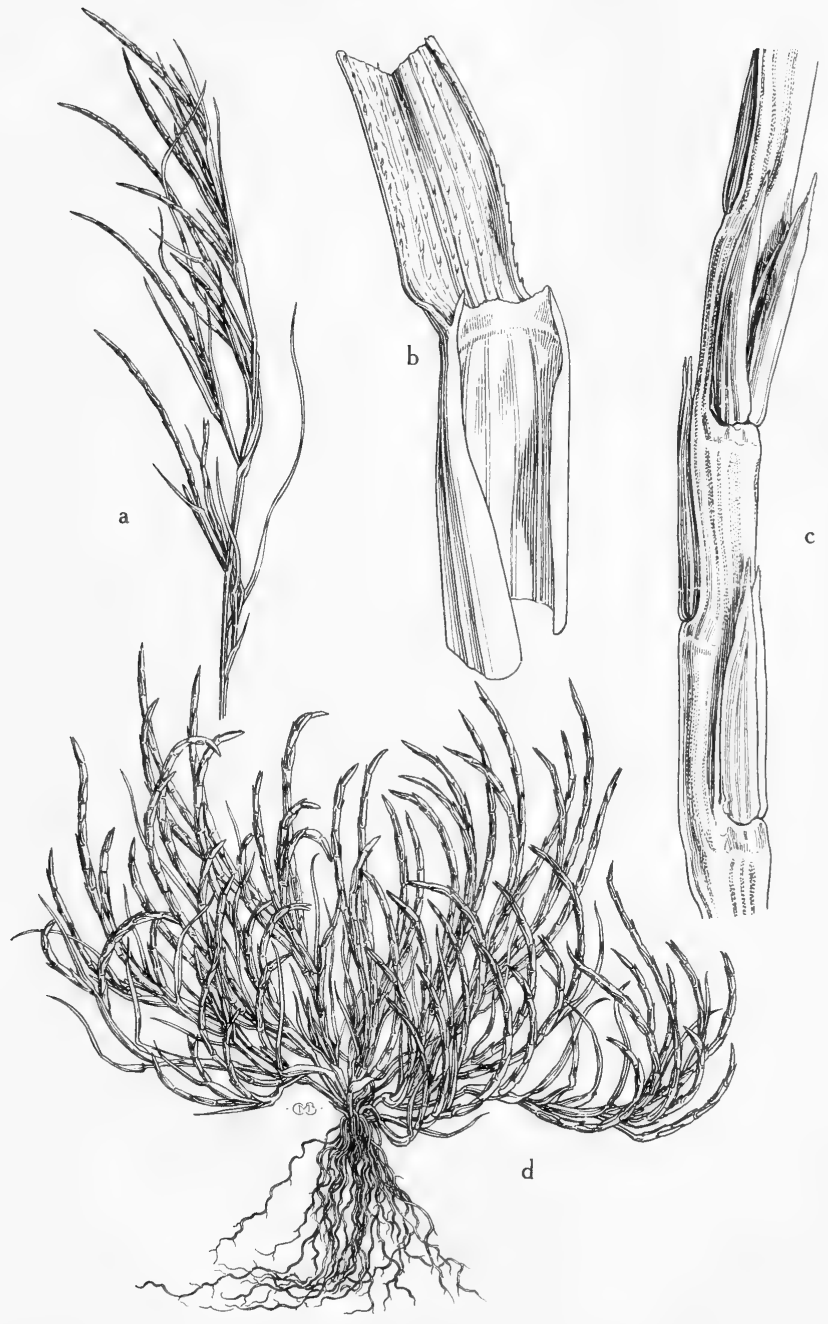

Fig. 100: Parapholis incurva: a, habit variation, culm erect, $\mathrm{X} \%$; b, leaf sheath, ligule and blade, X 8; c, part of spike, showing spikelets embedded in the cylindric articulate rachis, $X$ 6; d, habit, the culms decumbent and the spikes strongly curved, $\mathrm{X} 2 / 5$. (From Mason, Fig. 76). 
compressed; spikelets 4- to 20-flowered; second (only) glume 6-10 (-14) mm. long, from less than a third to nearly as long as the rest of the spikelet; lemmas awnless or short-awned. L. multiflorum Lam.

Scattered in lawns and other disturbed areas, in mud and shallow water of ponds and lakes, in Okla. (McCurtain Co.), over most of Tex. except the Rio Grande Plains, N. M. (San Juan Co.) and Ariz. (Coconino, Pinal, Cochise, Santa Cruz and Pima cos.), spring; nat. of Eur., now widely introd. in temp. parts of N. A. and S. A.

\section{Parapholis C. E. HubB.}

A genus of 4 species in the Old World.

\section{Parapholis incurva (L.) C. E. Hubb. Sicklegrass. Fig. 100.}

Tufted annual; culms 1-3 dm. long, decumbent most of their length, terminally arcuate upward; internodes short; sheaths loose, departing from and revealing the internodes which they only slightly exceed in length; blades of upper leaves shorter than their sheaths; inflorescences not fully exserted, arcuate, terminal, lax, nearly terete or somewhat compressed-cylindrical; spikes $3-10 \mathrm{~cm}$. long and only about $3 \mathrm{~mm}$. thick; rachis of spikes eventually abscising at the lower part of each node, the internodes sculptured, each with a niche for a spikelet; spikelets 2-ranked, solitary at each node, 1-flowered, the only parts visible being the halves of the 2 strongly nerved lanceolate-acute glumes; lemma adaxial, flattened, fitting into the niche of the internode, 4-7 mm. long. Pholiurus incurvus (L.) Schinz \& Thell.

Brackish shores and ditches, salt marshes and tidal mud flats along the coast of s.e. Tex., s.w. to San Patricio Co., spring; nat. of Eur., now established in many coastal areas of $\mathrm{N}$. A.

\section{Sphenopholis SCRIBN.}

\section{WEDGEGRASS}

Soft tufted perennials; culms ascending, inflorescence a terminal panicle with much-branched main branches, these usually appressed or at least ascending; pedicels abscising just below the spikelets; spikelets slightly laterally compressed, 2- or 3-flowered, all flowers perfect (?); rachilla extended beyond the last lemmas as a bristle; first glume linear-filiform, green; second glume usually slightly exceeding the first in length, broadly obovate, truncate to slightly acute apically, marginally broadly hyaline or at least thin, medially green and obscurely 3- to 5-nerved, the median nervate portion in some species coriaceous or even thickly verrucose and scabrous along the veins, clasping the second lemma; first lemma lanceolate, thin-chartaceous or marginally hyaline, shiny, in almost all species perfectly glabrous; second lemma shorter than the first, similar in texture but in several species scabrous (at least toward the tip), often cellulose under high magnification; paleae hyaline, as long as the lemmas, shiny.

A North American genus of about a dozen species.

1. Panicle dense, often spikelike, erect; second glume very broad, obtuse

1. Panicle rather ioose, nodding, never spikelike; second glume subacute

1. S. obtusata. ..2. S. intermedia.

1. Sphenopholis obtusata (Michx.) Scribn. Prairie wedgescale. Fig. 101.

Perennial; culms leafy, 1-10 dm. long, basally $1-2.5 \mathrm{~mm}$. thick, shortly decumbent, geniculate at the lower nodes, mostly ascending or erect; blades 3-12 mm. broad, flat; panicle dense, usually interrupted-spiciform or slightly more open, $3-18 \mathrm{~cm}$. long, 5-20 mm. broad, with pedicels about $0.5 \mathrm{~mm}$. long, a $1-\mathrm{cm}$. transection through the middle enclosing about (20) 30 to 75 spikelets; spikelets rarely gaping, usually yellowish; first glume $1.3-2.3 \mathrm{~mm}$. long; second glume very 


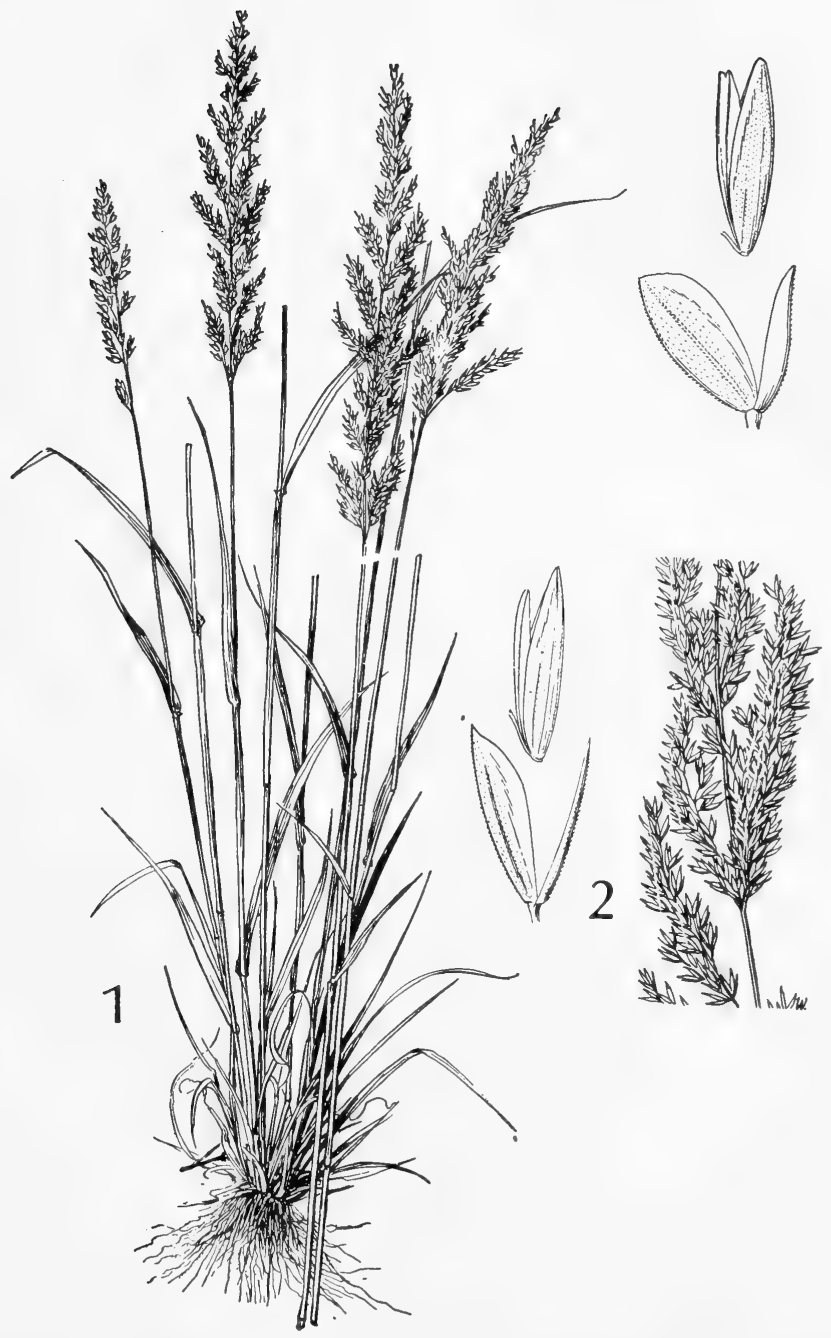

Fig. 101: 1, Sphenopholis obtusata: plant, X 1/2; glumes and floret, X 10.2, Sphenopholis intermedia: panicle, X 1; glumes and floret, X 10. (From Hitchcock \& Chase). 
blunt, almost cucullate, with a distinct line separating the chartaceous to subcoriaceous convex median portion from the flat thin margins, 1.7-2.4 $\mathrm{mm}$. long; lowest lemma usually microscopically cellulose-pustulate or scaberulous toward the apex, 1.9-2.7 mm. long; second lemma often more scabrous than the first.

In moist swales, in water of creeks, in seepage areas and wet soils, Okla. (Waterfall), essentially throughout Tex., N.M. (Colfax, DeBaca, Eddy and Guadalupe cos.) and Ariz. (Apache, Navajo, Coconino, Yavapai, Pinal, Cochise and Pima cos.), spring; s. Can. and nearly all of U. S. and higher parts of Mex.

\section{Sphenopholis intermedia (Rydb.) Rydb. Fig. 101.}

Cespitose short-lived perennial, sometimes flowering as a winter annual, usually 3-10 dm. tall, glabrous or scabrous to pubescent; ligules $1.5-2.5 \mathrm{~mm}$. long, finely erose-ciliate and irregularly toothed, glabrous or sometimes scabridulous externally; blades flat, 2-5 mm. wide, scabridulous; panicle 7-20 cm. long, narrow but the individual crowded erect branches usually plainly distinguishable; first glume narrowly linear, 1.6-2.5 $\mathrm{mm}$. long; second glume oblanceolate, obtuse to subacute, 2.2 $-2.5 \mathrm{~mm}$. long, about one fourth as wide as the first; lemmas $2.5-3 \mathrm{~mm}$. long; anthers about $0.6 \mathrm{~mm}$. long.

On the edge of water of lakes, ponds and along streams, in Ariz. (Navajo and Cochise cos.); Nfld. to B. C., s. to Fla. and Ariz.

\section{Trisetum PERS.}

Tufted perennials with flat blades and open or usually contracted or spikelike shining panicles; spikelets usually 2-flowered, sometimes 3- to 5-flowered, the rachilla prolonged behind the upper floret, usually villous; glumes somewhat unequal, acute, the second usually longer than the first floret; lemmas usually shortbearded at base, 2-toothed at apex with the teeth awned, bearing from the back below the cleft apex a straight and included or usually bent and exserted awn (rarely essentially awnless in $\boldsymbol{T}$. Wolfii).

A genus of 75 species in temperate regions.

1. Awn essentially wanting, included within the glumes................... 1. T. Wolfii.

1. Awn exserted (2)

2(1). Panicle open, ratior densely flowered but not spikelike......2. T. montanum.

2. Panicle dense, spikelike, i:ore or less interrupted below 3. T. spicatum.

1. Trisetum Wolfii Vasey. Wolf's trisetum.

Perennial; culms erect, 5-10 dm. tall, loosely tufted, sometimes with short rhizomes; sheaths scabrous, rarely with the lower pilose; blades flat, scabrous, rarely pilose on the upper surface, 2-4 $\mathrm{mm}$. wide; panicle erect, rather dense but scarcely spikelike, green or pale, sometimes a little purplish, $8-15 \mathrm{~cm}$. long; spikelets 5-7 mm. long, 2-flowered or sometimes 3-flowered; glumes nearly equal, acuminate, about $5 \mathrm{~mm}$. long; lemmas obtusish, scaberulous, 4-5 mm. long, awnless or with a minute awn below the tip, the callus hairs scant, about $0.5 \mathrm{~mm}$. long, the rachilla internode about $2 \mathrm{~mm}$. long, rather sparingly long-villous.

In wet meadows and wet soil along mt. streams, in N. M. (Hitchcock); Mont. to Wash., s. to N. M. and Calif.

\section{Trisetum montanum Vasey.}

Perennial about $5 \mathrm{dm}$. tall, with narrow blades; sheaths from nearly glabrous to softly retrorsely pubescent; panicle open, rather densely flowered but not spikelike, often purple-tinged; spikelets 5-6 mm. long, disarticulating above the thinnish glumes; awns delicate, $5-8 \mathrm{~mm}$. long; rachilla villous. 


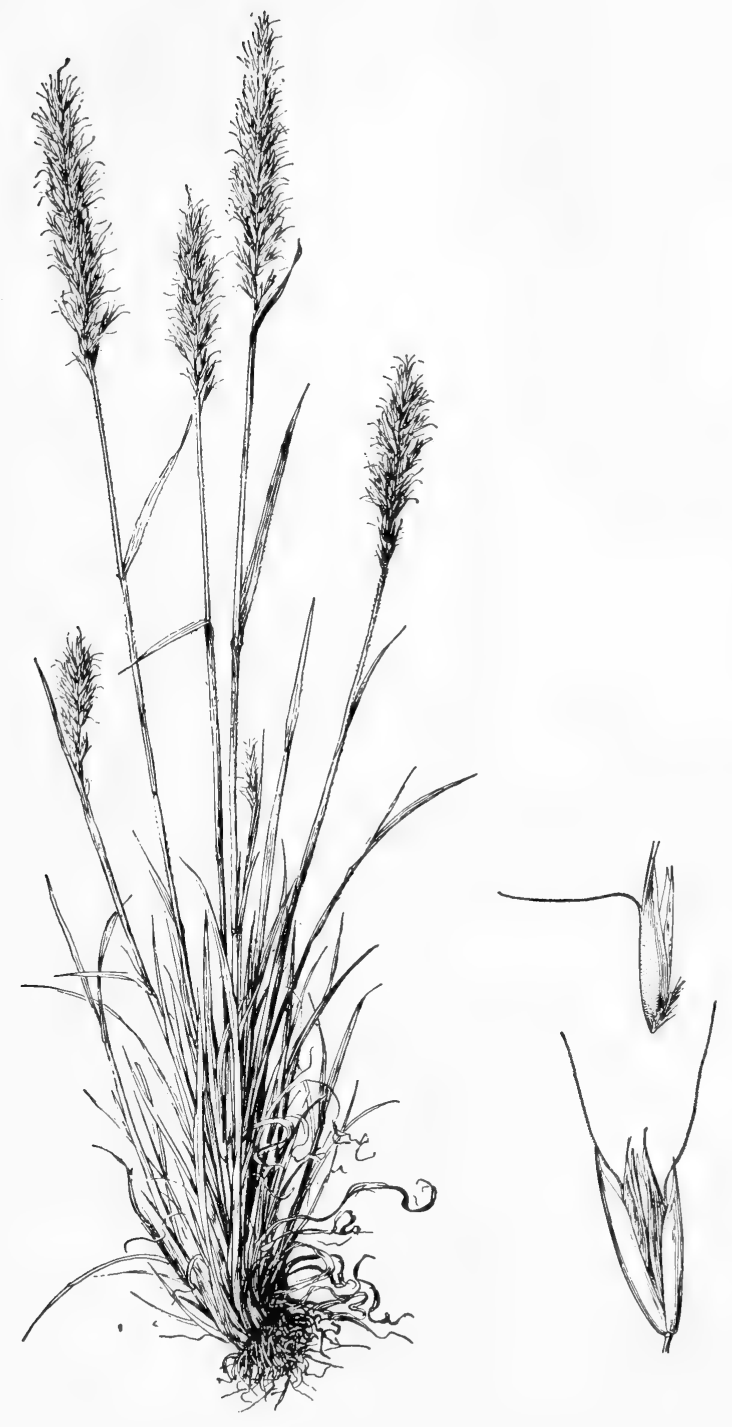

Fig. 102: Trisetum spicatum: plant, X 1/2; spikelet and floret, X 5. (From Hitchcock \& Chase). 
Wet mt. meadows, gulches and moist places on mt. slopes, in N. M. (San Miguel, Taos, and Lincoln cos.) and Ariz. (Graham Co.); Colo., Ut., N. M. and Ariz.

\section{Trisetum spicatum (L.) Richt. Spike TRISETUM. Fig. 102.}

Culms densely tufted, erect, $15-50 \mathrm{~cm}$. tall, glabrous to puberulent; sheaths and usually the blades puberulent; panicle dense, usually spikelike, often interrupted at base, pale or often dark purple, $5-15 \mathrm{~cm}$. long; spikelets $4-6 \mathrm{~mm}$. long; glumes somewhat unequal in length, glabrous or scabrous except the keels, or sometimes pilose, the first narrow, acuminate and 1-nerved, the second broader, acute and 3-nerved; lemmas scaberulous, $5 \mathrm{~mm}$. long, the first longer than the glumes, the teeth setaceous; awn attached about one third below the tip, 5-6 mm. long, geniculate, exserted.

Wet alpine meadows and slopes, in N. M. (Mora, Rio Arriba and Sandoval cos.) and Ariz. (Apache and Coconino cos.); Arctic America, southw. to Conn., Pa., Mich. and Minn., in the mts. to N. M., Ariz. and Calif.; also w. N. C.; through Mex. to the Antarctic regions of S. A.; arctic and alpine regions of the Old World.

\section{Deschampsia Beauv. HaIR-Grass}

Low or moderately tall annuals or usually perennials with shining pale or purplish spikelets in narrow or open panicles; spikelets 2-flowered, disarticulating above the glumes and between the florets, the hairy rachilla prolonged beyond the upper floret and sometimes bearing a reduced floret; glumes about equal, acute or acutish, membranaceous; lemmas thin, truncate and 2- to 4-toothed at summit, bearded at base, bearing a slender awn from or below the middle, the awn straight, bent or twisted.

About 60 species in temperate and cold regions, and in tropical mountains, in both hemispheres.

1. Annual; panicle open, the stiffly ascending capillary branches usually in twos............................................................ D. danthonioides.

1. Perennials; panicle narrow or open, the slender branches appressed or drooping (2)

2(1). Glumes usually longer than the florets; panicle usually narrow, as much as $3 \mathrm{dm}$. long, the branches appressed; blades filiform, lax

2. D. elongata.

2. Glumes shorter than the florets; panicle open, nodding, 1-2.5 dm. long, the branches drooping; blades firm, flat or folded........3. D. caespitosa.

\section{Deschampsia danthonioides (Trin.) Munro ex Benth. Annual hairgrass.}

Annual; culms slender, erect, 15-60 cm. tall; blades few, short, narrow; panicle open, 7-25 cm. long, the capillary branches commonly in twos, stiffly ascending, naked below, bearing a few short-pediceled spikelets toward the ends; glumes 4-8 mm. long, 3-nerved, acuminate, smooth except the keel, exceeding the florets; lemmas smooth and shining, somewhat indurate, $2-3 \mathrm{~mm}$. long, the base of the florets and the rachilla pilose, the geniculate awns 4-6 $\mathrm{mm}$. long.

In mud about lakes and ponds, along streams and wet meadows, in Ariz. (Coconino and Cochise cos.); Mont, to Alas., s. to Ariz. and Baja Calif.; Arg. and Chile.

\section{Deschampsia elongata (Hook.) Munro ex Benth. SLender HaIR GRASS.}

Perennial; culms densely tufted, slender, erect, 3-12 dm. tall; blades soft, 1-1.5 mm. wide, flat or folded, those of the basal tuft filiform-involute; panicle very narrow, 15-30 cm. long, the capillary branches strictly appressed; spikelets on short appressed pedicels; glumes 4-6 mm. long, 3-nerved, as long as or 


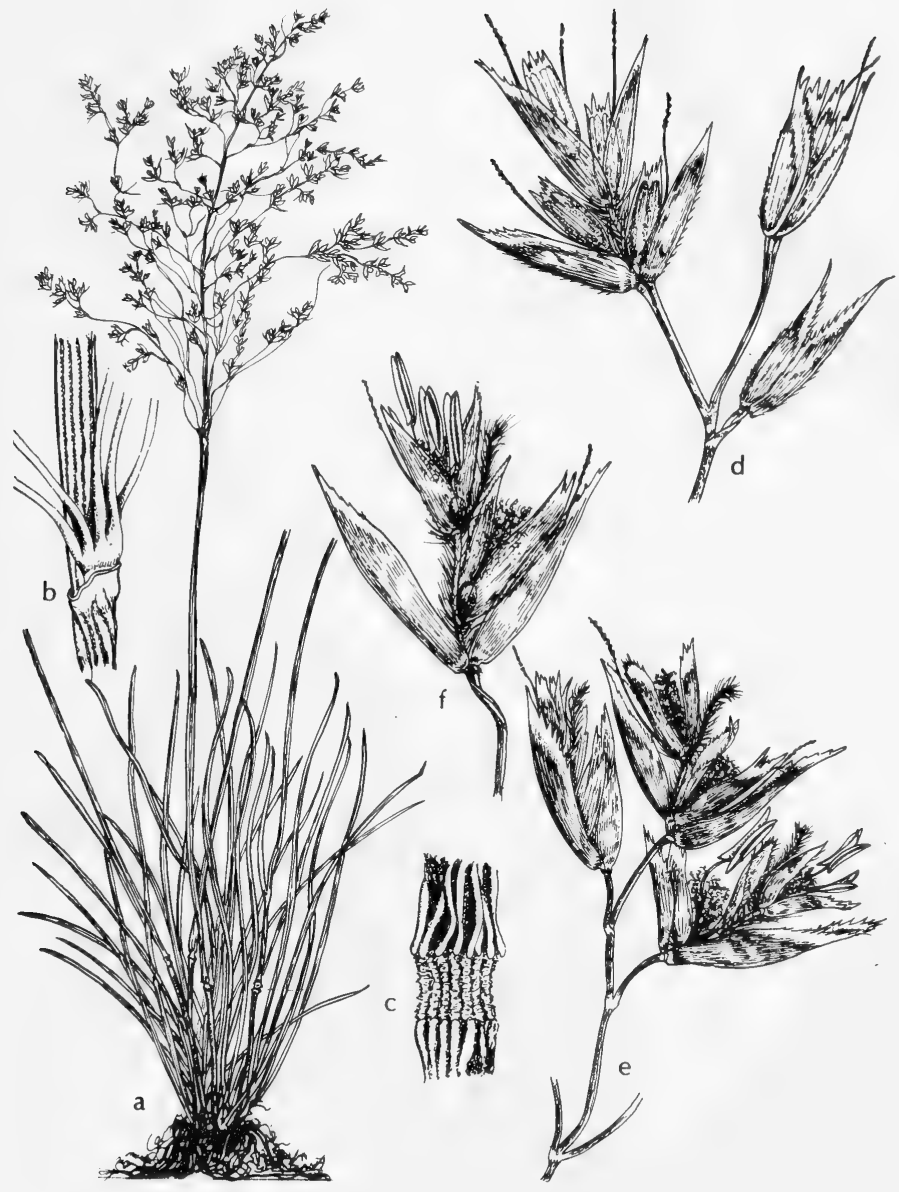

Fig. 103: Deschampsia caespitosa: a, habit, X 1/4; b, rachis section, X 5; c, node section, X 5. d-f, branchlets and spikelets with florets in progressive stages of development, X 5. (V. F.). 
slightly longer than the florets, more or less purplish-tinged; lemmas $2-3 \mathrm{~mm}$. long, smooth and shining, somewhat indurate, the awns straight, to twice as long as the glumes.

Moist or wet soil in meadows, along streams, on open or wooded slopes, in Ariz. (Mohave, Graham and Pima cos.); Alas. to Wyo., s. to Ariz., Calif. and Mex.; Chile.

\section{Deschampsia caespitosa (L.) Beauv. Tufted hair GRass. Fig. 103.}

Perennial; culms densely tufted, erect, 5-15 dm. tall (alpine forms reduced); leaves mostly basal, flat or folded, $1.5-4 \mathrm{~mm}$. wide, short or often elongate; panicle open, nodding (condensed, with short, usually appressed branches in Deschampsia caespitosa subsp. holciformis), 10-25 cm. long, capillary, the scabrous branches spikelet-bearing toward the ends; spikelets $3.5-7 \mathrm{~mm}$. long, green or purple-tinged, the florets distant, the rachilla joint one half as long as the lower floret; glumes acute, glabrous or minutely scabrous; lemmas smooth, the awns from near the base, from straight and included to slightly bent and twice as long as the spikelet.

Bogs, wet $\mathrm{mt}$. meadows, edges of marshes and in shallow water, in $\mathbf{N}$. $\mathbf{M}$. (Otero and Taos cos.) and Ariz. (Apache, Coconino and Cochise cos.); Greenl. to Alas., s. to N. C., Ill., N. D., N. M., Ariz. and Calif.; s. Arg. and Chile; also the Old World.

\section{Holcus L.}

About 8 species in the Canaries, Eurasia and North Africa and South Africa.

\section{Holcus lanatus L. Velvet grass. Fig. 104.}

Plant grayish, velvety-pubescent; culms erect, 3-10 dm. tall, rarely taller; blades 4-8 $\mathrm{mm}$. wide; panicles $8-15 \mathrm{~cm}$. long, contracted, pale, purplish-tinged; spikelets $4 \mathrm{~mm}$. long; glumes villous, hirsute on the nerves, the second broader than the first, 3-nerved; lemmas smooth and shining, the awn of the second hooklike.

Open ground, wet meadows and wet or moist places, in Okla. (Delaware Co.) and Ariz. (Coconino Co.); Me. to Okla. and Colo. s. to Ga. and La.: common on the Pac. coast, B.C. and Mont. to Ariz. and Calif.; introd. from Eur., widespread in Can. and U.S.

\section{Danthonia LAM. \& DC. OATgRASS}

About 10 species in warm regions.

\section{Danthonia intermedia Vasey. TIMBER OATGRASS.}

Culms 1-5 dm. tall; sheaths glabrous (the lower rather pilose) with long hairs in the throat; blades subinvolute or those of the culm flat, glabrous or sparsely pilose; panicle purplish, narrow, few-flowered, 2-5 cm. long, the branches appressed, bearing a single spikelet; glumes about $15 \mathrm{~mm}$. long; lemmas 7-8 $\mathrm{mm}$. long, appressed-pilose along the margin below and on the callus, the summit scaberulous, the acuminate teeth aristate-tipped; terminal segment of awn $5-8 \mathrm{~mm}$. long; palea narrowed above, notched at the apex.

Wet meadows and bogs in N. M. (Pecos National Forest) and Ariz. (Apache, Coconino and Graham cos.); Nfld. and Que. to Alas., s. to n. Mich., N. M., Ariz. and Calif.

\section{Calamagrostis Adans. ReED-Grass}

Perennial usually moderately tall grasses, mostly with creeping rhizomes, with small spikelets in open or usually narrow sometimes spikelike panicles; spikelets 1 -flowered, the rachilla disarticulating above the glumes, prolonged behind the 


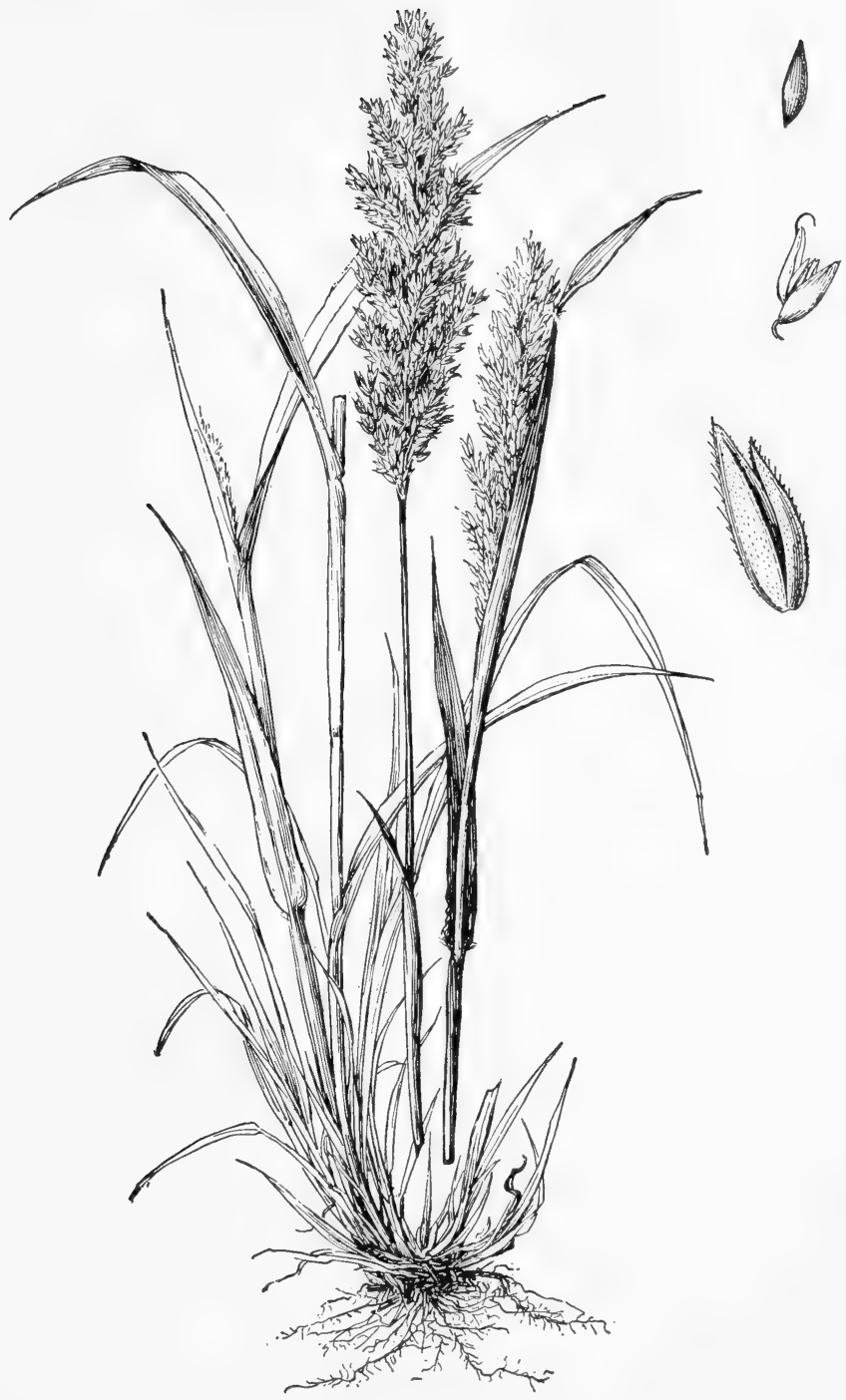

Fig. 104: Holcus lanatus: plant, X 1/2; spikelet, florets and mature fertile floret, X 5. (From Hitchcock \& Chase). 
palea as a short commonly hairy bristle; glumes about equal, acute to acuminate; lemmas shorter and usually more delicate than the glumes, usually 5-nerved with the midnerve exserted as an awn, the callus bearing a tuft of hairs that are often copious and as long as the lemma.

About 80 species in temperate and cold regions of the world; especially abundant in the South American Andes.

1. Panicle nodding, rather loose and open; callus hairs copious, about as long as the lemma.......................................................... C. canadensis.

1. Panicle erect, dense or spikelike, more or less interrupted below; callus hairs shorter than the lemma....

2. C. inexpansa.

1. Calamagrostis canadensis (Michx.) Beauv. Blue-JoINT. Fig. 105.

In small or large tussocks; culms suberect, 6-15 dm. tall, with numerous creeping rhizomes; sheaths glabrous or rarely obscurely pubescent; blades numerous, elongate, flat, rather lax, scabrous, 4-8 $\mathrm{mm}$. wide; panicle nodding, from narrow and rather dense to loose and relatively open (especially at base), 10-25 $\mathrm{cm}$. long; glumes usually 3-4 $\mathrm{mm}$. long, smooth or more commonly scabrous, acute to acuminate; lemma nearly as long as the glumes, smooth, thin in texture, the awn delicate, straight, attached, near or just below the middle and extending to or slightly beyond its tip, the callus hairs abundant, about as long as the lemma; rachilla delicate, sparsely long-pilose.

Marshes, wet places, open woods and wet meadows, in N.M. (Taos Co.) and Ariz. (Apache, Coconino, Graham and Pima cos.), spring-fall; Greenl. to Alas., s. to W.Va., N.C., Mo., Kan., N.M. and Calif.

A variable species that comprises several varieties. We have two segregated by Fernald as follows:

1. Spikelets $2-3.8 \mathrm{~mm}$. long; glumes rounded on the back, weakly keeled, acute or acuminate; lemma 1.7-3 mm. long; awn inserted near middle of lemma var. canadensis.

1. Spikelets 3.8-6 mm. long; glumes narrow, strongly keeled, distinctly acuminate; lemma 3-4.2 mm. long; awn inserted on lower third of lemma var. robusta Vasey.

\section{Calamagrostis inexpansa Gray. Northern REedgrass. Fig. 105.}

Culms tufted, 4-12 dm. tall, with rather slender rhizomes, often scabrous below the panicle; sheaths smooth or somewhat scabrous, the basal ones numerous, withering but persistent; ligule 4-6 $\mathrm{mm}$. long; blades firm, rather rigid, flat or loosely involute, very scabrous, $2-4 \mathrm{~mm}$. wide; panicle narrow, dense, the branches mostly erect and spikelet-bearing from the base, $5-15 \mathrm{~cm}$. long; glumes 3-4 mm. long, abruptly acuminate, scaberulous; lemma as long as glumes, scabrous, the awn attached about the middle, straight or nearly so, about as long as glumes, the callus hairs $1 / 2$ to $3 / 4$ as long; rachilla $0.5 \mathrm{~mm}$. long, some of the hairs reaching to tip of lemma.

Meadows, marshes and wet places, in N. M. (San Juan and San Miguel cos.) and Ariz. (Coconino and Apache cos.), spring-fall; Greenl. to Alas., s. to Me., Va., Wash., N. M. and Calif.

Our plant has been designated as var. brevior (Vasey) Stebbins with smaller parts than in var. inexpansa; these being spikelets 3-4.5 mm. long; lemma 2.5-3.5 $\mathrm{mm}$. long; palea $1.7-2.6 \mathrm{~mm}$. long.

\section{Agrostis L. Bentgrass}

Annual or usually perennial herbs; culms glabrous; blades flat; inflorescences paniculate; spikelets one-flowered, very slightly laterally compressed; zone of abscission between the glumes and the lemma (in $A$. semiverticillata a zone of abscission also in the pedicel below the glumes); lemma shorter than the glumes, awned or awnless. 


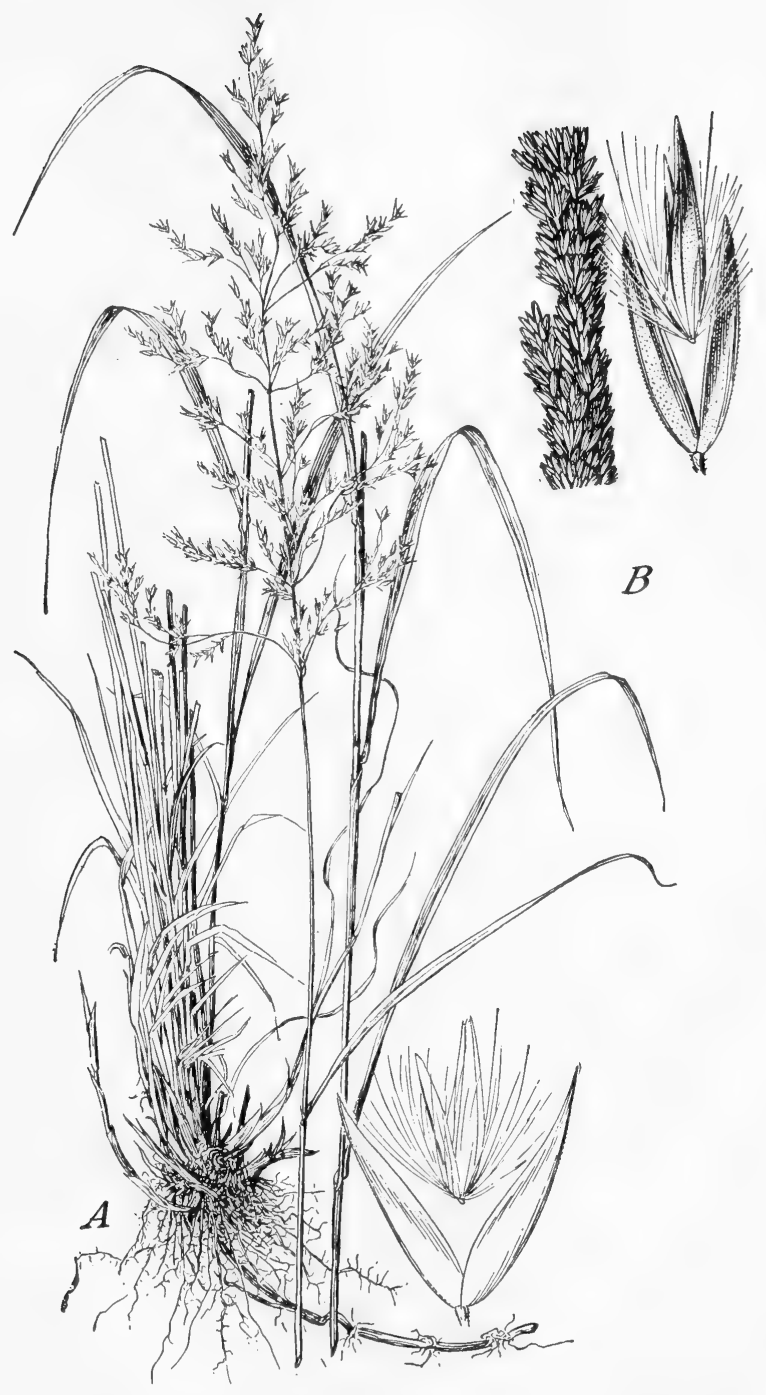

Fig. 105: A, Calamagrostis canadensis: plant, X 1/2; glumes and floret, X 10. B, Calamagrostis inexpansa: panicle, X 1; glumes and floret, X 10. (From Hitchcock \& Chase). 
A genus of 150 to 200 species, chiefly in the North Temperate Zone.

1. Longest glume shorter than $2 \mathrm{~mm}$. (2)

1. Longest glume longer than $2 \mathrm{~mm}$. (3)

2(1). Panicle very dense with short scabrous branchlets that are many-flowered nearly to the base; stolons present................... A. A. semiverticillata.

2. Panicle very diffuse; branchlets long and naked most of their length, the spikelets crowded toward the tips; stolons absent.....

2. A. hyemalis.

3(1). Tufted perennials without rhizomes or stolons; panicles open and/or diffuse, the branches mostly naked (4)

3. Perennials with stolons or rhizomes or the lower internodes reclining and subrhizomatous; panicles sometimes open but not diffuse, the branches bearing flowers for at least half their length (6)

4(3). Panicle very diffuse, irregularly rounded, the main branches forking toward the end or above the middle, the pedicels short, the spikelets crowded near the end of the branches............................ 3. A. scabra.

4. Panicle open but not diffuse, subpyramidal, the main branches forking at or below the middle; pedicels and spikelets not as above (5)

5(4). Spikelets about $2 \mathrm{~mm}$. long; plants of high altitudes, delicate, mostly 1-3 $\mathrm{dm}$. tall........................................................4. A. idahoensis.

5. Spikelets $2-3 \mathrm{~mm}$. long; plants somewhat robust, of lower elevations.

5. A. perennans.

6(3). Panicles more than $25 \mathrm{~mm}$. broad, the branches spreading; rhizomes present, $2-3 \mathrm{~mm}$. thick.

..6. A. stolonifera.

6. Panicles less than $25 \mathrm{~mm}$. broad, the branches ascending or appressed; rhizomes absent but stolons often present (7)

7(6). Palea present

7. A. palustris.

7. Palea absent.

8. A. exarata.

1. Agrostis semiverticillata (Forsk.) Christ. Water Bentgrass. Fig. 106.

Stoloniferous perennial freely rooting at the nodes; aerial culms $2-5 \mathrm{dm}$. long, 1-2 mm. thick, leafy; ligule a thin scale 2-7 mm. long; blades $4-14 \mathrm{~cm}$. long, 2-7 $\mathrm{mm}$. broad, flat; panicle $3-10 \mathrm{~cm}$. long, 1-3 cm. thick, ellipsoidal, very dense; swollen zone of abscission present on the scabrous pedicellary branchlets below the spikelets; glumes 1.3-2 mm. long, scabrous; lemma about $1 \mathrm{~mm}$. long or shorter, truncate; palea narrow, as long as lemma. Polypogon semiverticillatus (Forsk.) Hylander.

At the edges of streams in calcareous mud, along irrigation ditches, seepage and in shallow water, in Okla. (Cimarron Co.), n.-cen. Tex., Edwards Plateau, Plains Country and Trans-Pecos, locally abundant, N.M. (Guadalupe, De Baca and Eddy cos.) and Ariz. (Apache to Mohave, s. to Cochise, Santa Cruz and Pima cos.), Apr.-June and continuing now and then into Nov.; warmer parts of the world, in N. A. n. to Wash., Nev., Ut., Colo., and Tex., introd. from the Old World.

\section{Agrostis hyemalis (Walt.) B.S.P. SPring Bentgrass. Fig. 107.}

Tufted perennial; culms 1-6 dm. long, 0.5-1 mm. thick, leafy, erect or the lowermost internodes reclining; ligule a thin scale $1-4 \mathrm{~mm}$. long; blades $3-9 \mathrm{~cm}$. long, 1-2 mm. broad, flat; panicle $5-30 \mathrm{~cm}$. long, at least half as broad at maturity, open and very diffuse, the long branches capillary and mostly naked, branched in the outer third; spikelets crowded at the ends of the branchlets, appressed; glumes 1.5-2.1 mm. long, subequal; lemma 1-1.3 (-1.5) mm. long, awnless; palea absent. 


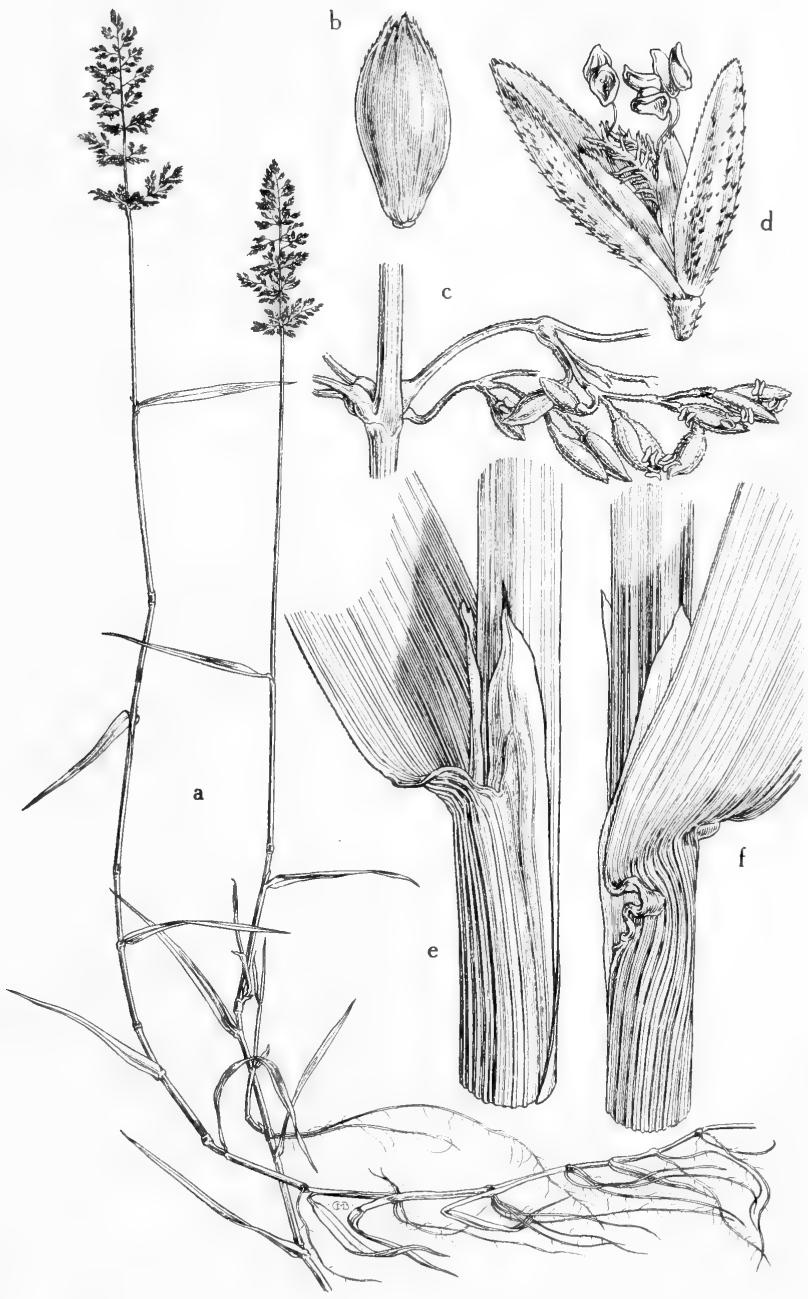

Fig. 106: Agrostis semiverticillata: a, habit, showing culms with decumbent base, short horizontal leaf blades and panicles, $X 1 / \% ; b$, young floret, showing the truncate lemma toothed at apex, X 12; c, branchlets of panicle, showing inflated base, X 4; d, flowering spikelet, the glumes scabrous, X 20; e and $f$, leaf sheath, dentate ligule and scabrous blade, X 4. (From Mason, Fig. 56). 


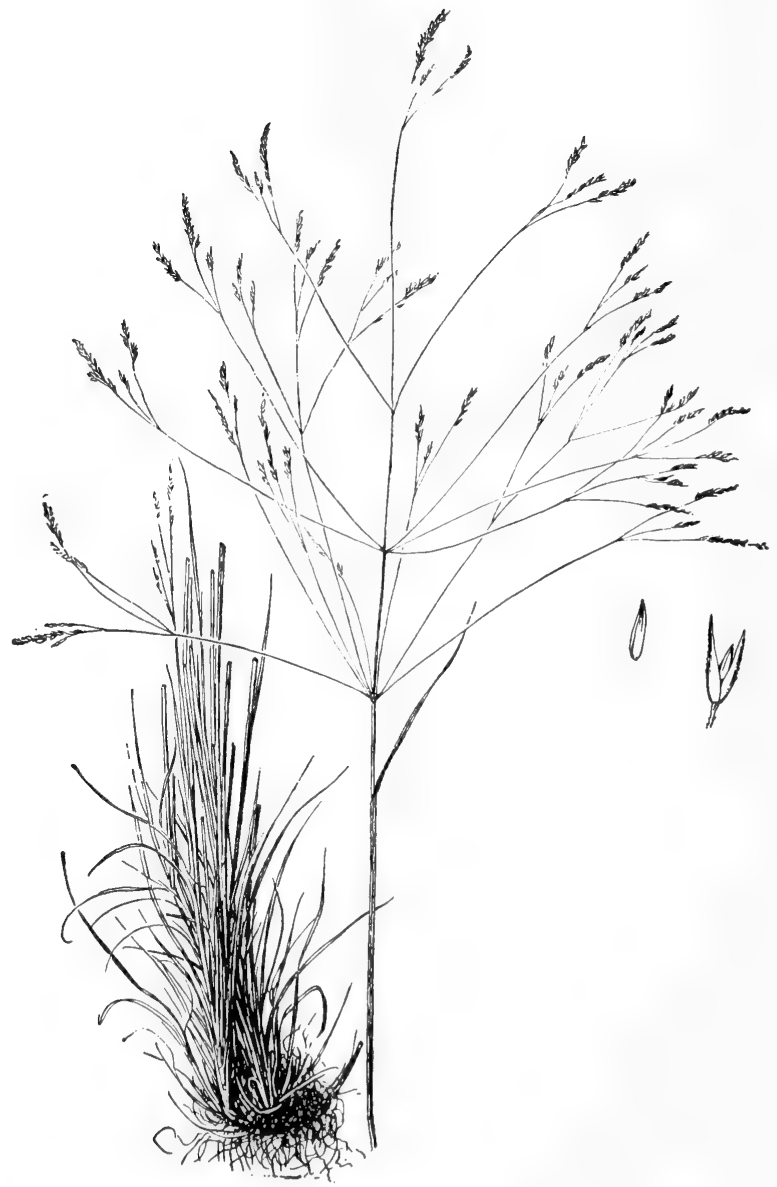

Fig. 107: Agrostis hyemalis: plant, X 1/2; glumes and floret, X 5. (From Hitchcock \& Chase). 
Usually moist sandy soil, in water of ponds and lakes, and seepage along streams, roadsides and other open places in Okla. (Waterfall) and in most of Tex. except w. Plains Country, scattered, Mar.-May, rarely to June; e. U.S. w. to Kan., Okla. and Tex.

\section{Agrostis scabra Willd.}

Similar to $A$. hyemalis but the glumes $2-2.6 \mathrm{~mm}$. long, some of them on any plant at least $2.2 \mathrm{~mm}$. long; lemma $1.3-1.6 \mathrm{~mm}$. long, rarely as short as $1.2 \mathrm{~mm}$; palea absent. A. hyemalis var. tenuis (Tuckerm.) Gl.

Moist soil, in flowing water of streams, wet meadows and in mud on edge of ponds and lakes, and openings in forests, at elev. of $6,000-8,300 \mathrm{ft}$. in the Tex. Trans-Pecos mts. where probably nat., also scattered in other parts of the state (Dallas, Hardin and Harris cos., etc.) where introd., N.M. (Taos and Colfax cos.) and Ariz. (Pima, Coconino, Apache, Navajo, Yavapai, Graham, Santa Cruz and Cochise cos.), July-Sept. in the mts., Apr.-May elsewhere; most of cool temp. N.A.

\section{Agrostis idahoensis Nash.}

Tufted delicate perennial 1-4 dm. tall; ligules 1-2 (-3) $\mathrm{mm}$. long, acute to obtuse, erose-ciliolate and often lacerate; blades mostly lax and flat but sometimes folded, 0.5-1.5 mm. wide; panicle narrow but not compressed, usually 5-10 cm. long, the capillary branches ascending and forking below the middle and bearing few spikelets; glumes green or purplish, acute, scabridulous on the keel but not on back, usually $1.6-2.4$ or sometimes $2.6 \mathrm{~mm}$. long, the first somewhat the longest; lemma about three fourths as long as the glumes, unawned, only slightly bearded (at most) on the callus; palea lacking or not over $0.2 \mathrm{~mm}$. long; anthers about $0.3 \mathrm{~mm}$. long; lodicules $0.2-0.3 \mathrm{~mm}$. long.

In wet mt. meadows, swamps, shallow water of ponds, lakes, along streams and on sand-gravel bars in river beds, in N. M. (Rio Arriba and Taos cos.) and Ariz. (Apache and Coconino cos.); Mont. to Wash., s. to N.M., Ariz. and Calif.; Alas.

\section{Agrostis perennans (Walt.) Tuckerm. Autumn Bentgrass.}

Tufted perennial; culms $25-100 \mathrm{~cm}$. long, $0.5-2.5 \mathrm{~mm}$. thick, leafy, erect or the lowest internodes reclining; ligule a scale $1-3 \mathrm{~mm}$. long; blades $5-22 \mathrm{~cm}$. long, 1-6 mm. broad, flat; panicle 1-3 dm. long, about half as broad, often subpyramidal, very diffuse, open, some of the main branches branched near the middle or slightly above, the pedicellary branchlets appressed or often more divaricate; glumes 2-3.2 $\mathrm{mm}$. long; lemma shorter, awnless (in ours, elsewhere rarely awned); palea absent.

Moist sandy soils along streams and about ponds, in marshes and wet meadows, in Okla. (Waterfall), e. Tex. and N. M. (Otero and Sandoval cos.), infrequent, Oct.; Que. and e. U.S. w. to Neb., Kan., Okla., Tex. and N. M.; also Mex.

\section{Agrostis stolonifera L. Redtop bentgrass. Fig. 108.}

Perennial from rhizomes $2-3 \mathrm{~mm}$. thick; aerial culms $35-100 \mathrm{~cm}$. long, $1.5-2.5$ $\mathrm{mm}$. thick, the lower internodes usually decumbent, leafy; ligule a thin scale 4-8 $\mathrm{mm}$. long; blades $6-20 \mathrm{~cm}$. long, $3-8 \mathrm{~mm}$. broad, flat; panicle $12-25 \mathrm{~cm}$. long, less than half as broad, the branches spreading; glumes equal, 2-3 mm. long, gaping; lemma nearly as long as the glumes, not awned; palea about two thirds as long as the lemma. Often called $A$. alba $\mathrm{L}$. but that name pertains to a species of Poa. A. gigantea Roth.

Wet meadows and stream banks, swampy prairies, Typha marshes and ditches, in Okla. (Alfalfa Co.) and e. and n.-cen. Tex., the Plains Country and Trans-Pecos mts., scattered, mostly in tame pastures, in N. M. (Sandoval and Colfax cos.) and 


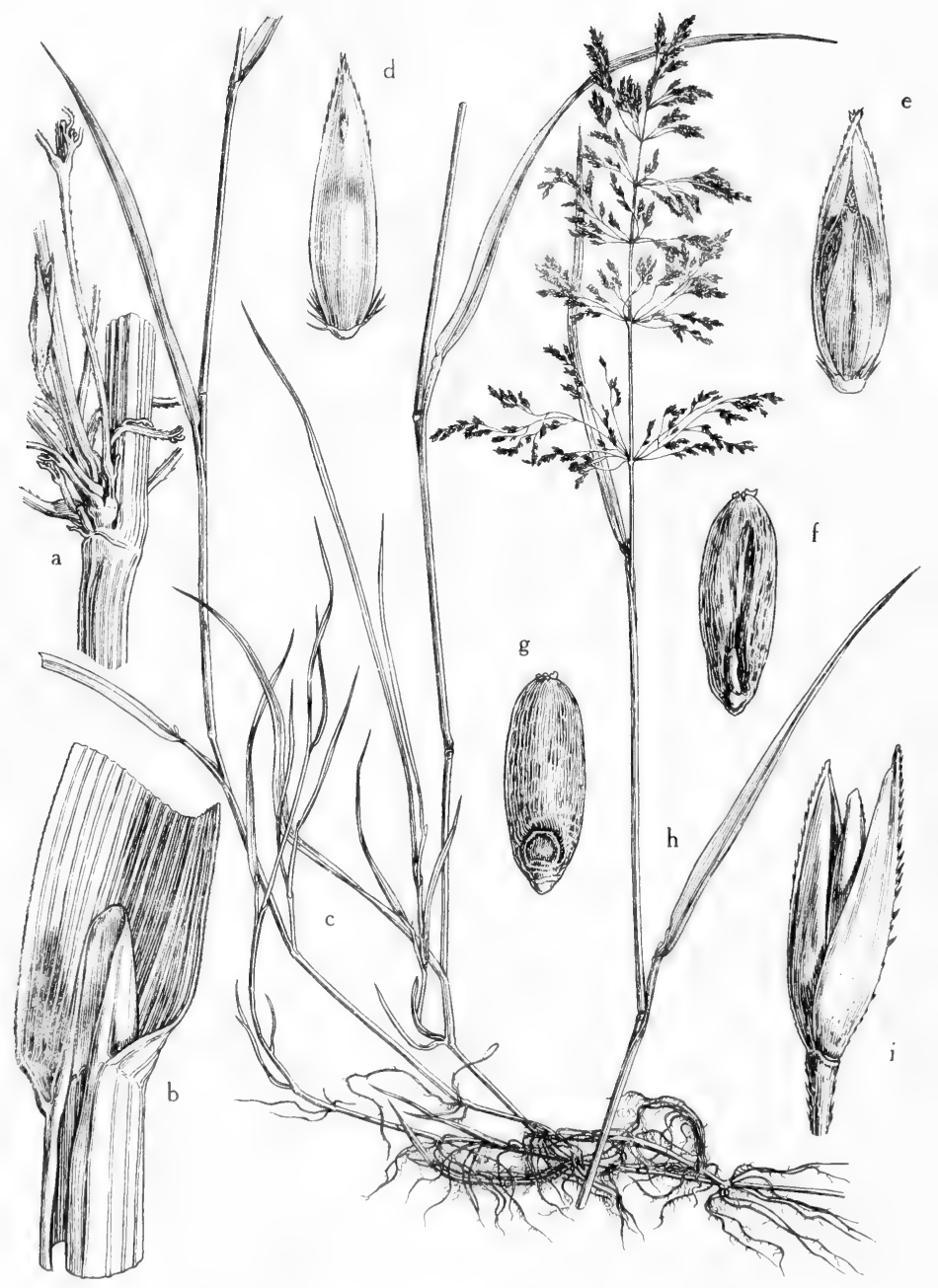

Fig. 108: Agrostis stolonifera: a, scabrous branchlets of panicle, X 6; b, leaf sheath, ligule and blade, $X$ 6; c, habit, showing the decumbent culms and flat leaf blades, $X 1 / 3$; d, floret, showing lemma, X 20; e, floret, showing the short, emarginate palea, $X 20$; $f$ and $g$, grains (caryopses), X 20; h, habit, upper part of culm showing panicle, $X 1 / 3$; i, spikelet, showing the glumes, each with scabrous keel, X 16. (From Mason, Fig. 55). 


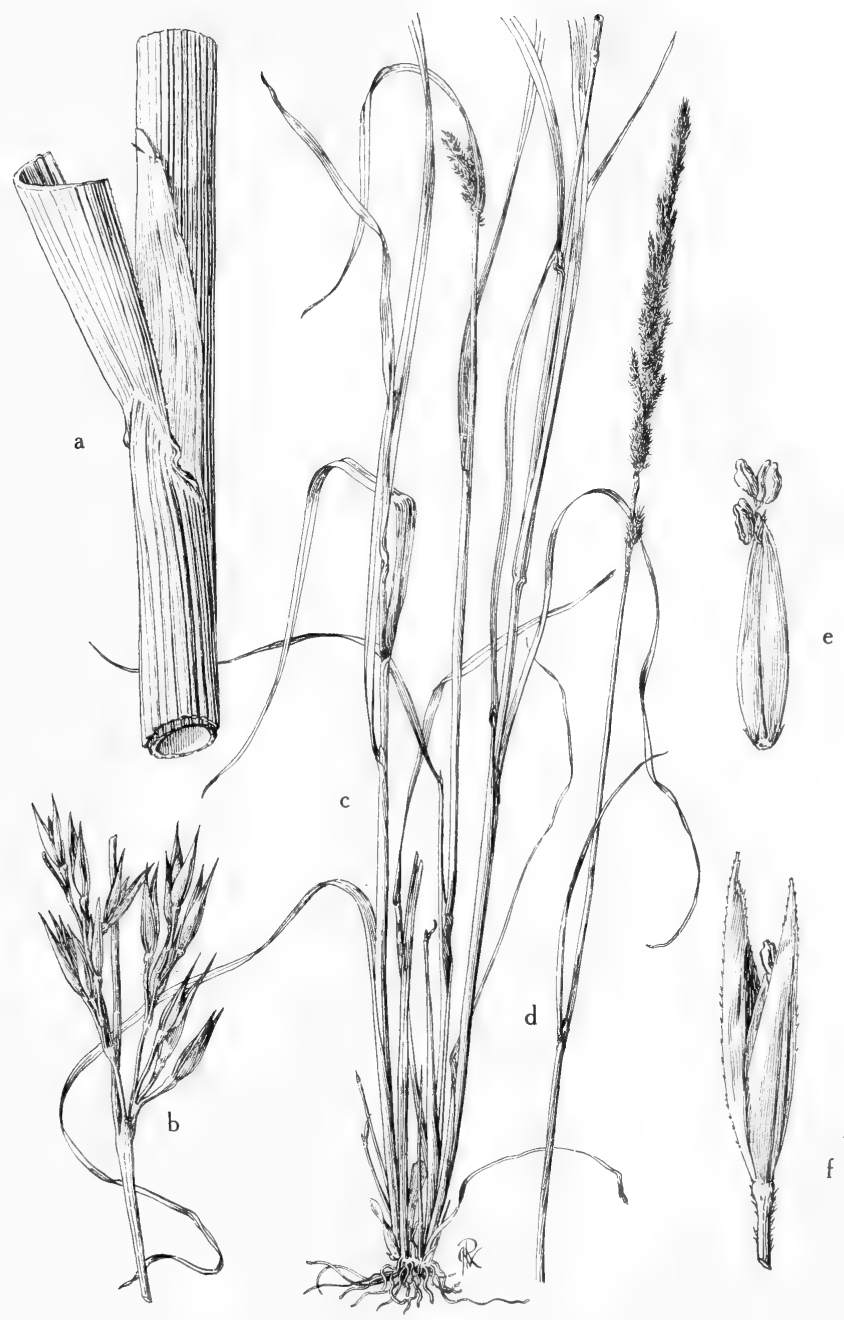

Fig. 109: Agrostis exarata: a, leaf sheath, ligule and blade, X 5; b, spikelet in lower part of panicle, $X 3 ; \mathrm{c}$, habit, showing the leafy culms and young close panicle, $X 2 \%$; $\mathrm{d}$, upper part of culm, showing panicle, $X$ \%; $\mathrm{e}$, floret, $X 14$; $\mathrm{f}$, spikelet, the glumes each with a scabrous keel, X 14. (From Mason, Fig. 54). 
Ariz. (Apache, Navajo, Coconino, Yavapai, Greenlee and Cochise cos.), summer; widespread in temp. N. A., introd. from Euras.

\section{Agrostis palustris Huds. Creeping bentgrass.}

Perennial; culms decumbent, often long-stoloniferous, the aerial ones erect, 3-5 dm. long, 1-2 mm. thick, leafy; ligule a thin scale 2-4 mm. long; blades 4-10 $\mathrm{cm}$. long, 1-3.5 mm. broad, flat; panicles 5-15 cm. long, 1-2 cm. thick, the short branches ascending; glumes $2-3 \mathrm{~mm}$. long; lemma about two thirds as long as the glumes, not awned; palea about two thirds as long as the lemma.

Fresh-water shores of lakes and ponds, along streams and ditches, in wet meadows and marshes in s.e. Tex., N.M. (Taos Co.) and Ariz. (Coconino, Yavapai, Gila and Pinal cos.), scattered or rare, summer; widely introd. in temp. N. A. from Euras.

\section{Agrostis exarata Trin. Spike bentgrass. Fig. 109.}

Tufted perennial; culms 3-9 dm. long, 1-2 mm. thick (in ours; more robust elsewhere), leafy, mostly erect or the lower internodes reclining and substoloniferous; ligule a scale $3-5 \mathrm{~mm}$. long; blades $4-20 \mathrm{~cm}$. long, 2-8 mm. broad, flat; panicle 1-3 dm. long, 10-25 mm. thick, rather lax and often somewhat interrupted toward the base, the branches many-flowered, appressed; glumes $2.5-3 \mathrm{~mm}$. long, narrowly acuminate; lemma 1.7-2.3 mm. long, not awned (in ours; elsewhere apically awned); palea absent.

Wet places such as marshes, wet meadows, flowing water and along streams, at high elev. in Tex. Trans-Pecos mts., rare, in N. M. (Union, Guadalupe and Otero cos.) and Ariz. (Apache to Coconino, s. to Cochise and Pima cos.), late summer; w. Can. and w. U. S. (including Alas.), e. to S. D., Neb. and in the mts. to w. Mex.

\section{Cinna L. Woodreed}

Tall perennials with flat blades and close or open panicles; spikelets 1-flowered, disarticulating below the glumes, the rachilla forming a stipe below the floret and produced behind the galea as a minute bristle; glumes equal or subequal, 1- to 3-nerved; lemma similar to the glumes, nearly as long, 3-nerved, bearing a minute short straight awn just below the apex or rarely awnless; palea 1-keeled.

A genus of 4 species in Eurasia, North America and South America.

1. Spikelets $5 \mathrm{~mm}$. long; panicle rather dense, the branches ascending. 1. C. arundinacea.

1. Spikelets $3.5-4 \mathrm{~mm}$. long; panicle loose, the branches spreading or drooping 2. C. latifolia.

\section{Cinna arundinacea L. Stout woodreed. Fig. 110.}

Clumped perennial with short thick rhizomes; aerial culms erect, 7-15 dm. tall, 2-5 mm. thick, leafy; ligule a stramineous scale $2-3 \mathrm{~mm}$. long centrally and with long auricles laterally; blades $15-37 \mathrm{~cm}$. long, 7-14 $\mathrm{mm}$. broad near the middle, tapering to both ends, flat; panicles $15-32 \mathrm{~cm}$. long, ellipsoidal, the numerous branches ascending or rarely spreading, densely-flowered; zone of abscission just below the glumes; spikelets one-flowered, falling as a unit, strongly laterally compressed, with keeled scales; first glume 4-4.5 long; second glume 5-5.5 mm. long; lemma 5.5-6 mm. long, bearing dorsally just below the tip a minute awn equaling the tip of the lemma (use lens).

Moist usually sandy soil, floodplains and stream banks in forests, in wet meadows and along sluggish streams, in Okla. (Sequoyah Co.) and e. Tex., infrequent, Aug.-Sept.; all of e. U. S. w. to S. D., Neb., Kan., Okla. and Tex. 


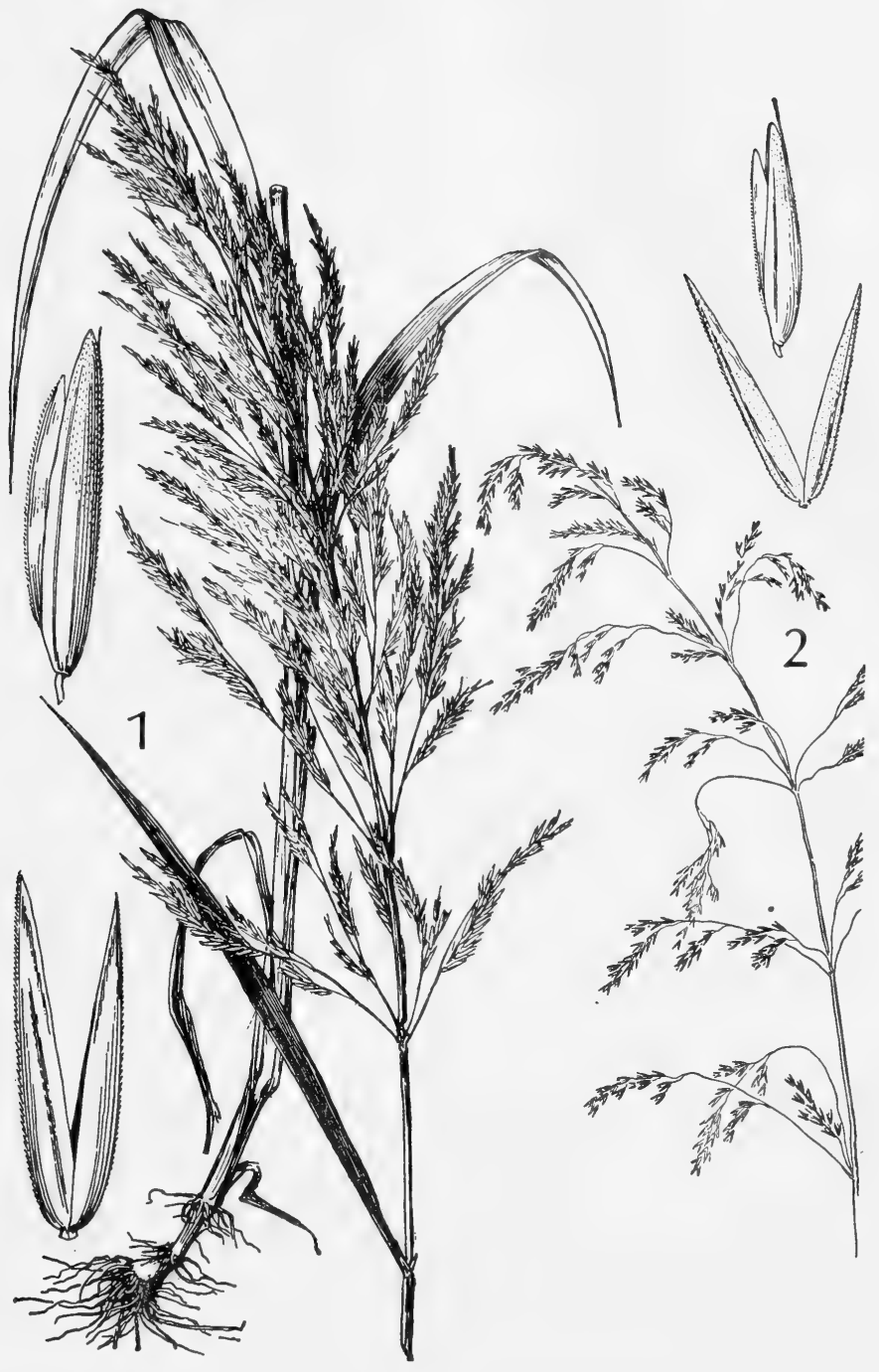

Fig. 110: 1, Cinna arundinacea: plant, X 1/2; glumes and floret, X 10, 2, Cinna latifolia: panicle, X 1; glumes and floret, X 10. (From Hitchcock \& Chase). 
2. Cinna latifolia (Trev.) Griseb. Fig. 110.

Rhizomatous perennial 7-20 dm. tall; sheaths glabrous to finely scabridulous; ligules pubescent, 3-8 $\mathrm{mm}$. long, erose and intact or usually more or less strongly lacerate; blades flat, $7-15 \mathrm{~mm}$. wide, the veins very unequal in size; panicle 15-30 $\mathrm{cm}$. long, loose, the branches spreading to drooping; glumes slender, acuminate, (2-) 3-4 mm. long, the second somewhat the longest, scabridulouspuberulent on the keel and often over the back; lemma strongly compressed, 2-3.2 mm. long, puberulent over the back, awnless or awned, the subterminal awn scarcely to $1 \mathrm{~mm}$. long; palea almost as long as the lemma; rachilla bristlelike, mostly about $0.6 \mathrm{~mm}$. long; anthers about $1 \mathrm{~mm}$. long; lodicules cuneate-obovate, dentate, about $0.3 \mathrm{~mm}$. long.

In wet meadows, and wet soil along streams, and moist or wettish woods, in N. M. (Bernalillo Co.); Nfld. and Lab. to Alas., s. to N. C., Tenn., N.M. and Calif.; n. Euras.

\section{Alopecurus L. FoxtaIL}

Annuals or perennials; blades flat; panicles dense, straight, spikelike; zone of abscission just below the glumes; spikelets falling as a unit, one-flowered, strongly laterally compressed; glumes equal, united by the margins basally, keeled dorsally; lemma about as long as glumes, the margins united to each other basally, bearing an awn dorsally below the middle, this once-geniculate, the lower portion twisted; palea absent.

About 50 species in temperate Eurasia, North America and South America.

1. Spikelets 5-6 mm. long; introduced species.......................... A. myosuroides.

1. Spikelets $2-4 \mathrm{~mm}$. long; native species (2)

2(1). Awns straight, included or only slightly longer than the glumes; perennial

2. Awns geniculate, twisted below, much longer than the glumes (3)

3(2). Perennial; anthers $1.5 \mathrm{~mm}$. long.

3. A. geniculatus.

3. Annual; anthers about $0.5 \mathrm{~mm}$. long

4. A. carolinianus.

\section{Alopecurus myosuroides Huds.}

Tufted annual; culms 2-7 dm. long, 1.5-3 mm. thick, erect or the lower few internor es reclining; ligule a scale 2-4 mm. long; blades $5-30 \mathrm{~cm}$. long, 3-7 mm. broad, flat; spike 5-11 cm. long, 5-10 mm. thick; glumes 6-7 $\mathrm{mm}$. long, the keel merely scabrous, not ciliate except basally; awn of lemma 5-8 $\mathrm{mm}$. long.

Moist or wet meadows in e. Tex., occurring only as waif brought in with hay, May; Euras., adv. and widespread in n.e. U. S.; also Wash. and Ore.

Other European species are to be expected in our area as introductions, notably A. pratensis $\mathbf{L}$., the meadow foxtail, rather similar to $A$. myosuroides but perennial and the keels of the glumes ciliate.

\section{Alopecurus aequalis Sobol. ShORT-Awn foxtAil, Fig. 111.}

Perennial; culms erect or somewhat decumbent below and rooting at the nodes, glabrous, 2-6 dm. tall (or taller in some aquatic forms); sheaths glabrous, usually somewhat inflated; ligules 3-5 mm. long; blades slightly scabrous, $1-4 \mathrm{~mm}$. wide, sometimes tufted at base; panicles more or less exserted, narrow-cylindric, 2-7 $\mathrm{cm}$. long, 4-5 mm. wide; glumes 2-2.5 mm. long, ciliate on the keel, appressedpubescent on the sides, especially below; lemma glabrous, the awn attached at or slightly below the middle, straight or slightly bent, included or exserted about $1 \mathrm{~mm}$; ; anthers about $1 \mathrm{~mm}$. long.

In mud and shallow water of ponds, sloughs, lakes and streams, swampy ground, marshy areas, bogs, in N. M. (Lincoln, San Miguel, Taos, San Juan, Rio Arriba, McKinley, Socorro and Grant cos.) and Ariz. (Coconino, Apache and Yavapai 

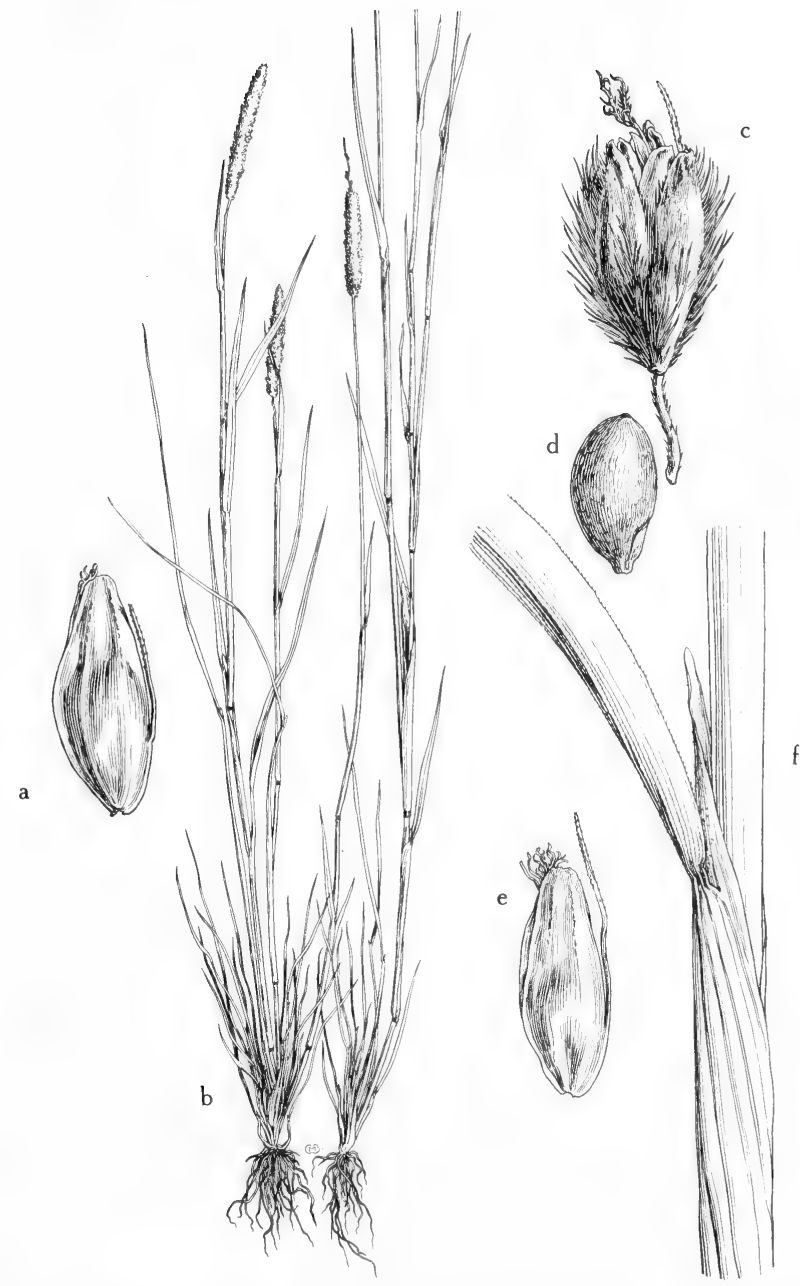

Fig. 111: Alopecurus aequalis: a, floret, the lemma bearing an awn below the middle, $\mathrm{X} 12$; $\mathrm{b}$, habit, showing short basal leaves, the tall culms and narrow-cylindric panicles, $\mathrm{X} \% \overline{\mathrm{j}}$; c, spikelet, showing the ciliate glumes, the awn of lemma protruding, $\mathrm{X} \mathrm{12}$; d, grain, X 12; e, floret, variation in the awn of lemma, X 12; $\mathrm{f}$, leaf sheath, ligule and scabrous blade, X 4. (From Mason, Fig. 57). 
cos.); Greenl. to Alas., s. to Pa., Ill., Kan., N.M., Ariz. and Calif.; Euras.

\section{Alopecurus geniculatus L. WATER fOXTAIL. Fig. 112.}

Perennial; culms decumbent or long-decumbent at base, rooting at the lower nodes, glabrous, often bent above (only erect in dwarf forms), 1-6 dm. long above the rooting base; sheaths glabrous, usually somewhat inflated; ligules usually 2-4 mm. long; blades minutely scabrous above, $1-4 \mathrm{~mm}$. wide; panicles $2-7 \mathrm{~cm}$. long, 4-6 $\mathrm{mm}$. wide; glumes 2.5-3 $\mathrm{mm}$. long, the tips often purplish, ciliate on the keel, glabrous or appressed-pubescent on the lateral margins; lemma glabrous, the often purplish awn bent, exserted about the length of the spikelet or farther; anthers about $1.5 \mathrm{~mm}$. long.

In mud and shallow water of lakes, ponds and waterways, and in marshes, in N. M. (Grant Co.) and Ariz. (Apache, Coconino, Santa Cruz, Yavapai and Pima cos.); Nfld. to Sask. and B. C., s. to Va., Pa., Mich., Wisc., Kan., Wyo., N. M., Ariz. and Calif.; Euras.

\section{Alopecurus carolinianus Walt.}

Tufted annual; culm 1-5 dm. long, 1-2 mm. thick, the lower internodes commonly not erect, the remainder erect; ligule a scale $1-3 \mathrm{~mm}$. long; blades $2-15 \mathrm{~cm}$. long, $1.5-5 \mathrm{~mm}$. broad, flat; spikes $2-5 \mathrm{~cm}$. long, 4-6 mm. thick; glumes 2-2.5 $\mathrm{mm}$. long, densely ciliate on the keels; awn of lemma $3-5 \mathrm{~mm}$. long.

Moist soil near ponds and streams, wet meadows, in Okla. (Johnston Co.), e., s.e. and n.-cen. Tex., infrequent and rare w. to Bexar, Burnet, Llano and Wichita cos., N. M. (San Miguel Co.) and Ariz. (Coconino, Gila and Pima cos.), Mar.May; B. C. and practically throughout the U. S. except n. N.E.

\section{Polypogon DESF.}

Annual or perennial usually decumbent herbs; blades flat, scabrous; lower internodes reclining on mud, the nodes with adventitious roots; panicles dense; zone of abscission below the glumes; glumes nearly equal, both persistent, awned, united at the very base, scabrous or pubescent; lemma much shorter than glumes, involute, ellipsoidal, with a dorsal readily deciduous awn; palea membranous, enclosed by the lemma.

A genus of about 15 species in warm regions of the world.

1. Annual; glumes minutely lobed, the very slender awns (4-) 6-8 $\mathrm{mm}$. long; panicles very dense, spikelike............................1. P. monspeliensis.

1. Perennials; glumes not lobed, the awn not more than $5 \mathrm{~mm}$. long; panicles moderately dense (2)

2(1). Glumes abruptly narrowed above, the awns $2.5-5 \mathrm{~mm}$. long. 2. $P$. interruptus.

2. Glumes gradually tapering into a short awn that is $1-2 \mathrm{~mm}$. long.

3. P. elongatus.

1. Polypogon monspeliensis (L.) Desf. RabBitfoot grass. Fig. 113.

Annual; culms often rooting at the lower nodes or less commonly totally erect, 1-7 dm. long, 1-3 mm. thick; ligule a scale 3-10 mm. long; blades 4-16 cm. long, 2.5-11 mm. broad, flat; panicle $2-15 \mathrm{~cm}$. long, $1-2 \mathrm{~cm}$. thick, either narrow and spikelike or broader and ellipsoidal and somewhat interrupted, stramineous at maturity; glumes $2 \mathrm{~mm}$. long, apically notched and in the notch each bearing an awn 5-9 mm. long; lemma less than $1 \mathrm{~mm}$. long, with a deciduous awn less than $1 \mathrm{~mm}$. long.

Moist soil near fresh water, in brackish ponds, seepage and boggy areas, marshes, wet meadows and along streams, throughout most of our region, scattered and local, Mar.-July; Eur., introd. and now widespread in temp. N. A.; of local forage value. 

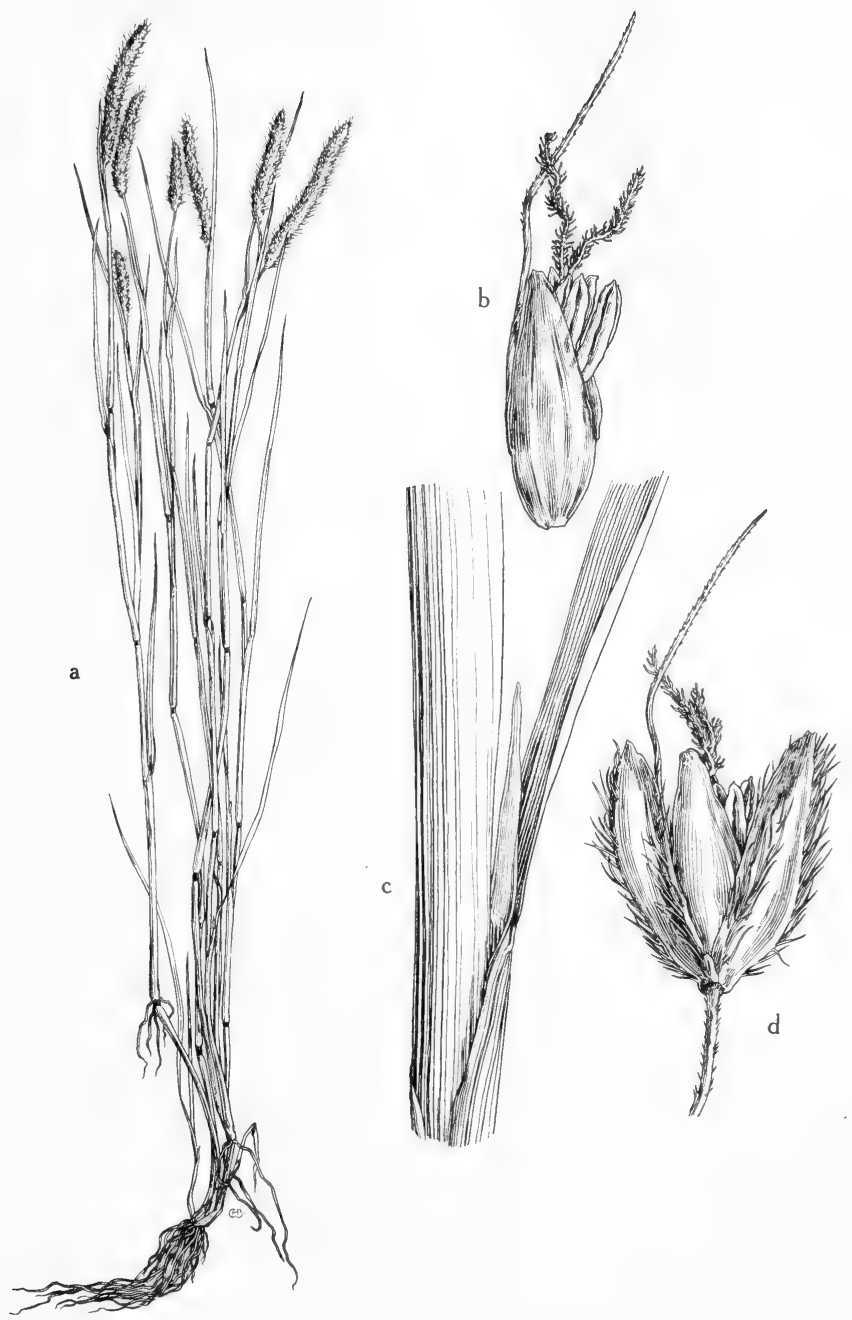

Fig. 112: Alopecurus geniculatus: a, habit, showing the cylindric panicles, the awns of lemmas conspicuous, $\mathrm{X} 2 / 5 ; \mathrm{b}$, floret, showing the long curved awn of lemma attached below the middle, X 12; c, leaf sheath, ligule and scabrous blade, X 4; d, spikelet, showing the cilitate glumes and the long awn of lemma, X 12. (From Mason, Fig. 58). 


\section{Polypogon interruptus H.B.K. Ditch Polypogon. Fig. 113.}

Perennial; culms rooting at the lower nodes, 2-10 dm. long, 1-4 mm. thick; ligule a scale 4-10 mm. long; blades 4-22 cm. long, 2-12 mm. broad; panicle 3-20 cm. long, 1-5 cm. thick, occasionally narrowed and somewhat spikelike but usually broad, interrupted, with whorled branches $1-5 \mathrm{~cm}$. long; glumes $2 \mathrm{~mm}$. long, apically entire, each bearing an awn about $2 \mathrm{~mm}$. long; lemma a little longer than $1 \mathrm{~mm}$. with a deciduous awn $2-3 \mathrm{~mm}$. long.

Calcareous mud along streams and irrigation ditches and low wet places, in Okla. (Waterfall) and on Tex. Edwards Plateau, rare (known only from Val Verde Co.), to Ariz. (Apache, Navajo, Coconino, Santa Cruz and Pima cos.), Apr.; widespread in temp. N. A. and S. A., n. to B.C. and Neb.

\section{Polypogon elongatus H.B.K. Fig. 114.}

Perennial; culms erect or often decumbent at base, glabrous, rather stout, as much as $1 \mathrm{~m}$. tall; sheaths glabrous, somewhat nerved, lacerate at the rather broad summit, to $8 \mathrm{~mm}$. long; blades scabrous on the margins, glabrous or somewhat scabrous on the surfaces, to $20 \mathrm{~cm}$. long and $1 \mathrm{~cm}$. wide; panicle erect, in ours rather dense and spikelike but somewhat interrupted in the lower part, $15-30 \mathrm{~cm}$. long, the branches closely flowered to base; glumes hispidulous (especially on keel), 2-3 mm. long, gradually narrowed to an awn 2-3 mm. long; lemma $1.5 \mathrm{~mm}$. long, the awn arising from below the tip, 1-2 $\mathrm{mm}$. long or sometimes obsolete.

In salt marshes, along streams and ditches, in Ariz. (Santa Cruz and Pima cos.); also Mex. to Arg.

\section{Phleum L.}

Annuals or perennials with erect culms, flat blades and dense cylindric panicles; spikelets 1-flowered, laterally compressed, disarticulating above the glumes; glumes equal, membranaceous, keeled, abruptly mucronate or awned or gradually acute; lemma shorter than the glumes, hyaline, broadly truncate, 3- to 5-nerved; palea narrow, nearly as long as the lemma.

A genus of 15 species in temperate Eurasia, North America and South America: probably all Eurasian in origin.

1. Culms mostly more than $5 \mathrm{dm}$. tall, erect from a swollen bulblike base; panicle narrow, several times longer than wide......................1. P. pratense.

1. Culms 2-5 dm. tall, from a decumbent somewhat creeping base; panicle usually not more than twice as long as wide, bristly....2. P. alpinum.

\section{Phleum pratense L. Tiмотну. Fig. 115.}

Perennial from very short bulbously thickened rhizomes; aerial culms 5-10 dm. long, 2-3 $\mathrm{mm}$. thick, the lowest internodes often reclining, otherwise erect, leafy; ligule a thin scale $2-4 \mathrm{~mm}$. long; blades $6-26 \mathrm{~cm}$. long, 5-10 $\mathrm{mm}$. broad, tapered to a long point, flat; panicle 5-20 $\mathrm{cm}$. long, 5-8 $\mathrm{mm}$. thick, terete, spikelike; spikelets 1-flowered, strongly laterally compressed; glumes equal $3-3.5 \mathrm{~mm}$. long, oblong, hyaline but each with a firm keel prolonged into a short spreading awn, the keel ciliate; zone of abscission between the glumes and the lemma; lemma and palea about half as long as the glumes, hyaline, the palea very narrow.

Occasional as a waif in marshes, wet meadows, seepage areas and in mud along streams, in the e. half of Tex., not persisting, brought in with hay, and N. M. (Colfax, Otero, Santa Fe, San Miguel and Sandoval cos.) and Ariz. (Coconino and Apache, s. to Graham and Pima cos.), summer; widespread in moist temp. parts of N. A., introd. from Euras.

2. Phleum alpinum L. Alpine timothy. Fig. 115.

Culms 2-6 dm. tall, glabrous, from a decumbent somewhat creeping densely 


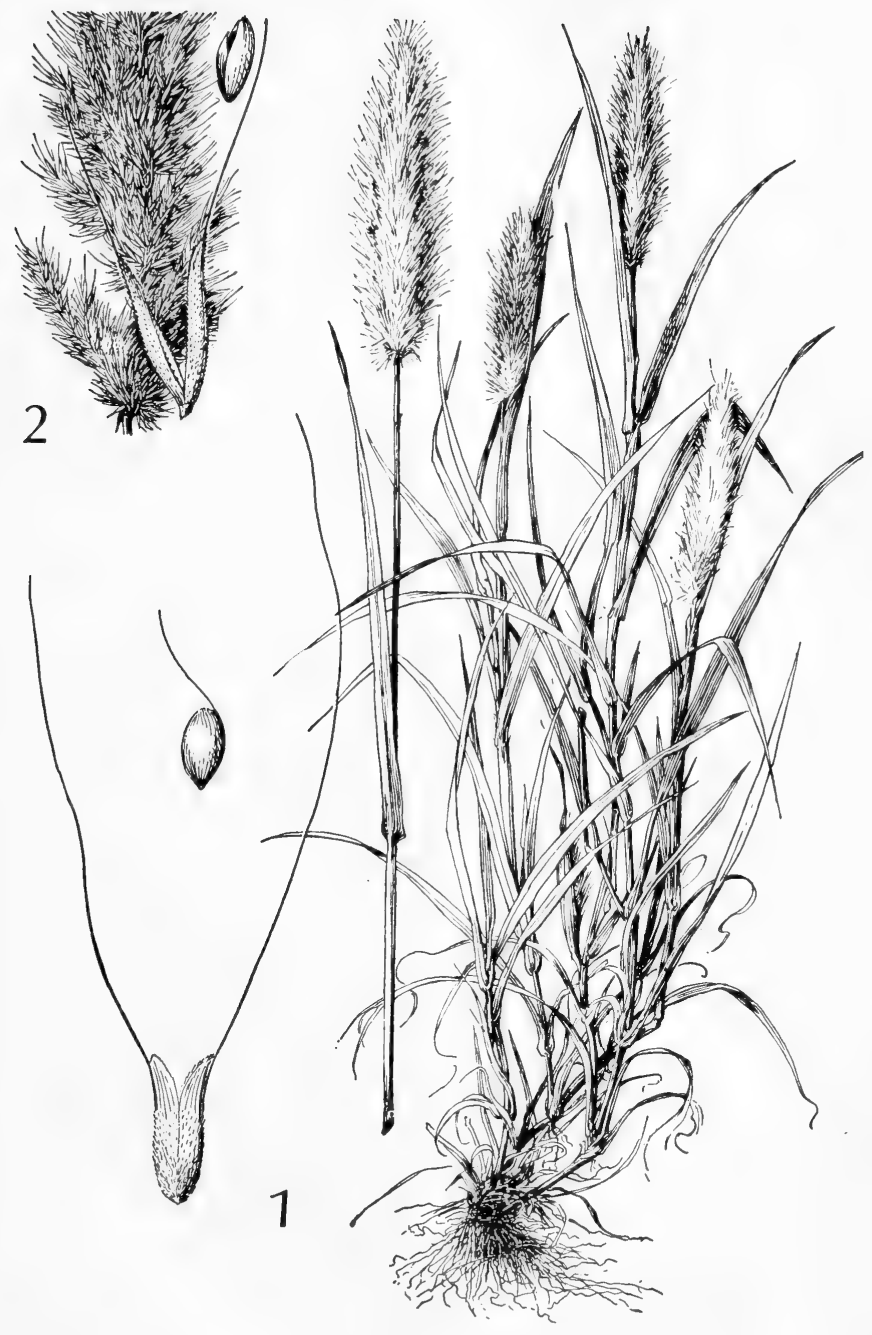

Fig. 113: 1, Polypogon monspeliensis: plant, X 1/2; glumes and floret, X 10.2 , Polypogon interruptus: panicle, X 1; glumes and floret, X 10. (From Hitchcock \& Chase). 


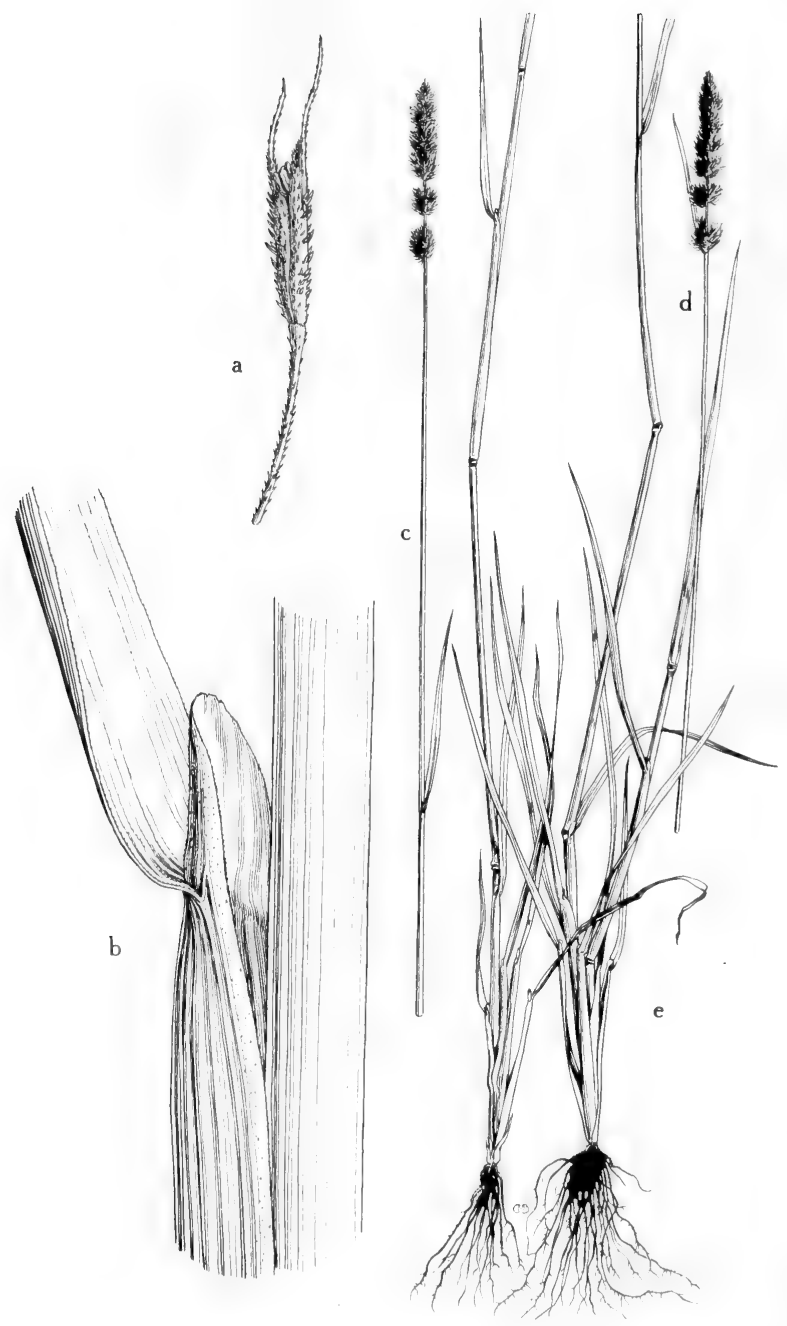

Fig. 114: Polypogon elongatus: a, spikelet, showing the hispidulous awned glumes, $\mathrm{X} 8$; b, leaf sheath, ligule, and blade, X 4; c and d, upper parts of culms with spikelike, interrupted panicles, $X{ }_{1 / 5}$; e, habit, lower part of plant, $X 1 / \%$. (From Mason, Fig. 82). 
tufted base; blades mostly less than $15 \mathrm{~cm}$. long, 3-6 mm. wide; panicle $1-5 \mathrm{~cm}$. long or broadly cylindric; glumes 5 (sometimes 7) $\mathrm{mm}$. long, oblong, hispidciliate on the keel, the stoutish awns $2 \mathrm{~mm}$. long to give the head a bristly appearance.

In wet mt. meadows, bogs, marshes and mud on edge of lakes and ponds, in N. M. (Rio Arriba, San Juan, Santa Fe, San Miguel and Taos cos.) and Ariz. (Apache and Coconino cos.); Greenl. to Alas., s, to N. H., Mich., N. M., Ariz. and Calif.; Euras.

\section{Gastridium Beauv.}

Two species in the Canaries, western Europe and the Mediterranean region.

\section{Gastridium ventricosum (Gouan) Schinz \& Thell. Nit Grass. Fig. 116.}

Plants annual; culms 1-5 dm. tall; foliage scant, the blades flat, scabrous; panicle 3-8 cm. long (or in robust specimens $10-14 \mathrm{~cm}$. long), dense, shining, spikelike; spikelets 1 -flowered, slender, about $5 \mathrm{~mm}$. long; glumes long-acuminate, somewhat swollen at the base, scabrous on the keels, the second glume about threefourths as long as the first; lemmas much shorter than the glumes, hyaline, globular, pubescent, truncate, with a delicate, somewhat bent awn $5 \mathrm{~mm}$. long; palea about as long as the lemma.

Established usually on open, dry ground, but occasionally found in marshy sites along streams or around vernal pools, in Ariz. (Pima Co.); Ore. to Calif. and Ariz.; introd. from Eur.

\section{Muhlenbergia Schreb. MUHLY}

Perennial or rarely annual low or moderately tall or rarely robust grasses, tufted or rhizomatous; culms simple or much-branched; inflorescence a narrow sometimes spikelike or open panicle; spikelets 1-flowered or occasionally 2 -flowered, the rachilla disarticulating above the glumes; glumes usually shorter than the lemma or sometimes as long, obtuse to acuminate or awned, keeled or convex on the back, the first sometimes small or rarely obsolete; lemma firm-membranaceous, 3-nerved with the nerves sometimes obscure or rarely an obscure additional pair, with a very short callus, rarely long-pilose, usually minutely pilose, the apex acute, awned from the tip or just below it or from between very short lobes, sometimes only mucronate, the awn straight or flexuous.

A genus of more than 100 species that occur from the Himalaya Mts. to Japan, and from North America to the Andes. The genus, as now interpreted, is very diverse, being a taxonomic dumping ground. Some of the muhlys are quite abundant and are valuable forage.

1. Annuals (doubtful cases should be keyed under both alternatives) (2)

1. Perennials (4)

2(1). Lemma with awn 1-3 cm. long.

2. Lemma awnless (3)

3(2). Pedicels capillary, elongate; glumes minutely pilose........ 1. M. minutissima.

3. Pedicels short, appressed; glumes glabrous. 3. M. filiformis.

4(1). Rhizomes developed, usually prominent, scaly, creeping, often branching (5)

4. Rhizomes wanting; culms tufted, usually erect (12)

5(4). Blades $2 \mathrm{~mm}$. wide or less, mostly short and involute (6)

5. Blades flat, at least some of them more than $3 \mathrm{~mm}$. wide, usually $5 \mathrm{~mm}$. wide or more (8) 


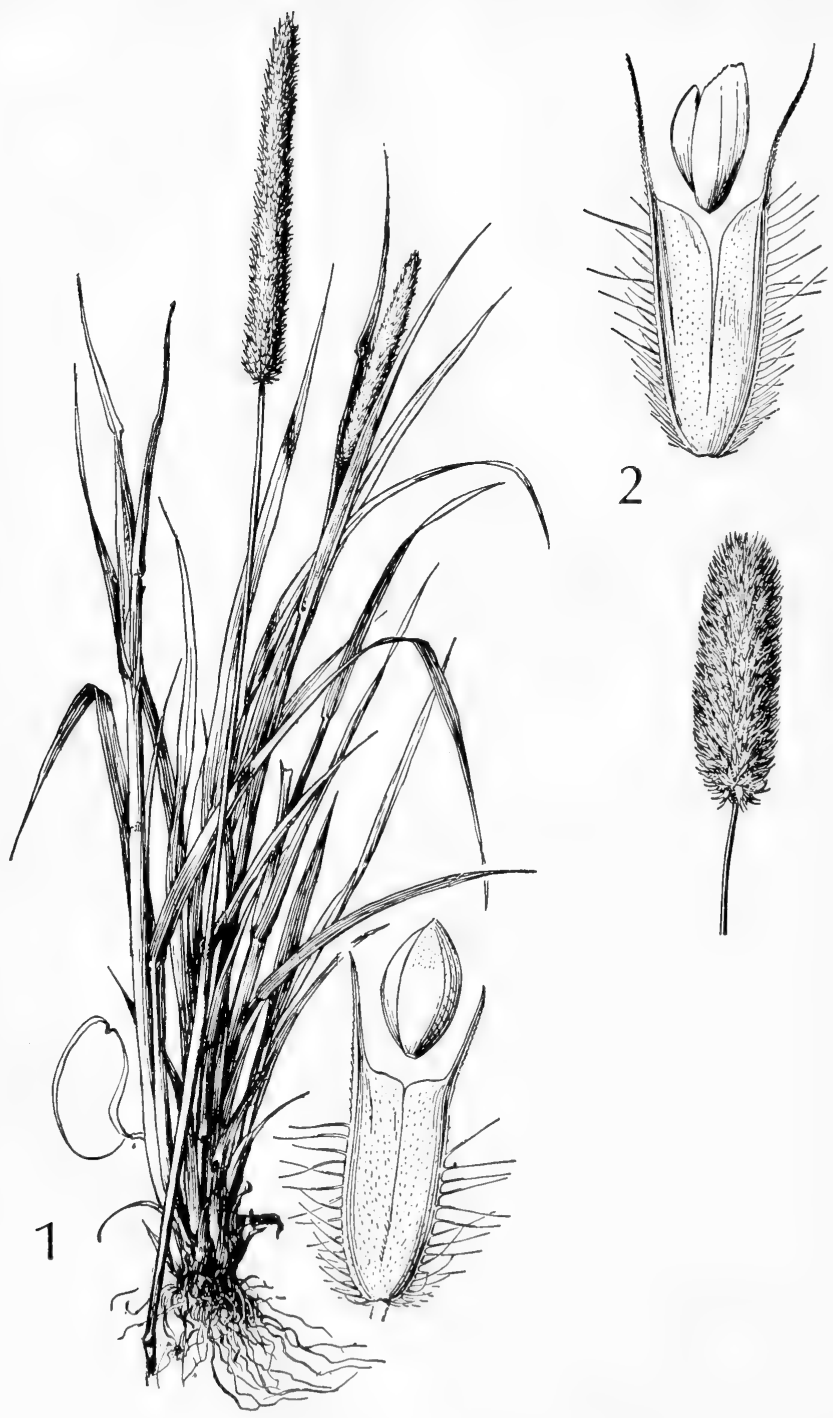

Fig. 115: 1, Phleum pratense: plant, X 1/2; glumes and floret, X 10. 2, Phleum alpinum: panicle, X 1; glumes and floret, X 10. (From Hitchcock \& Chase). 


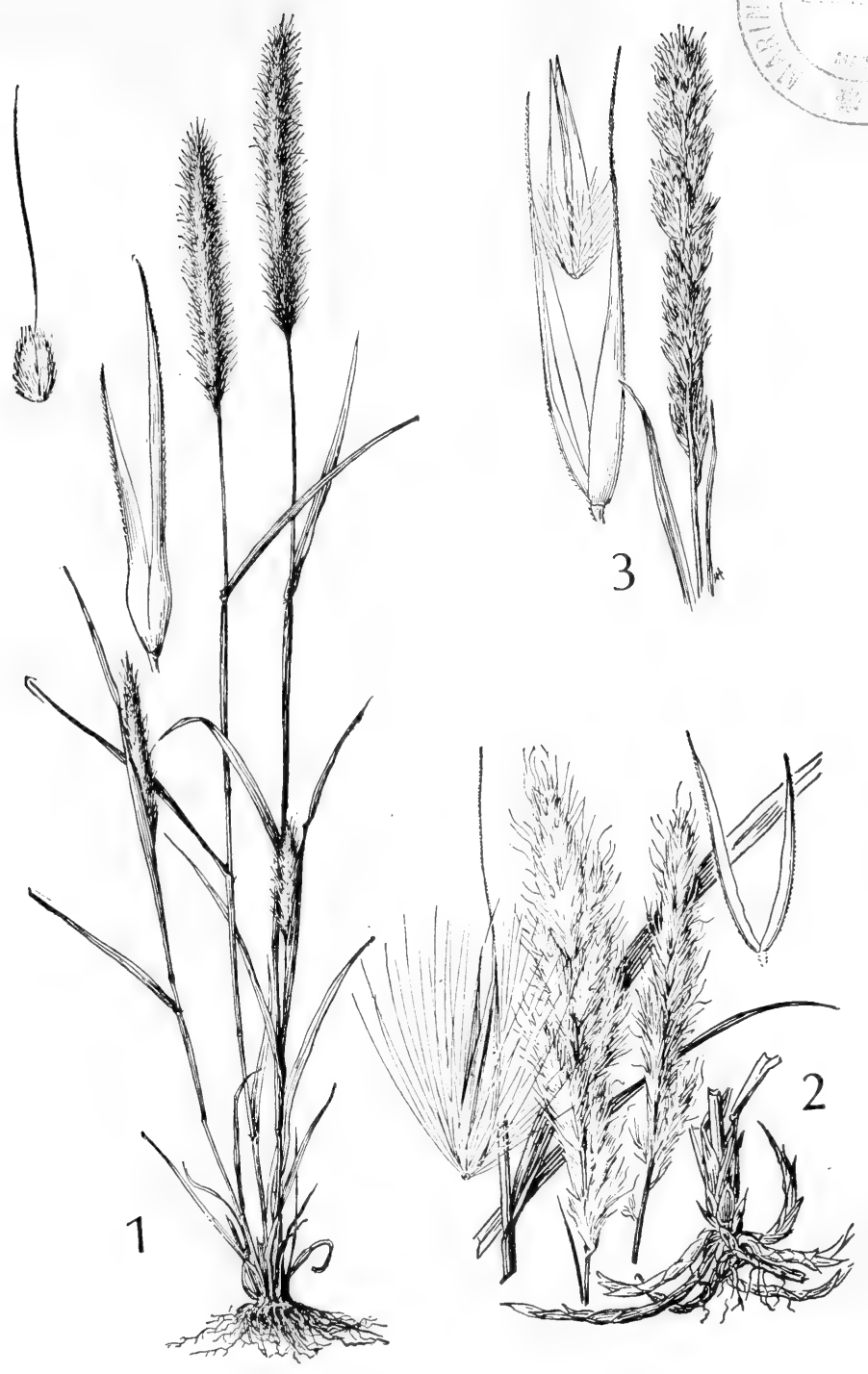

Fig. 116: 1, Gastridium ventricosum: plant, X 1/2; glumes and floret, X 10. 2, Muhlenbergia andina: plant, X 1; glumes and floret, X 10. 3, Muhlenbergia racemosa: panicle, X 1; glumes and floret, X 10. (From Hitchcock \& Chase). 
6(5). Panicles open, the spikelets on slender pedicels. 6. M. asperifolia.

6. Panicles narrow, more or less condensed, the spikelets on short pedicels (7)

7(6). Culms smooth, widely creeping, the blades fine, conspicuously recurved, spreading................................................................ 4. . utilis.

7. Culms nodulose-roughened, erect or decumbent at base, sometimes spreading but not widely creeping................................5. M. Richardsonis.

8(5). Hairs at base of floret copious, as long as the body of the lemma.

7. $M$. andina.

8. Hairs at base of floret inconspicuous, not more than half as long as the lemma (9)

9(8). Glumes with stiff scabrous awn-tips, much-exceeding the awnless lemma; panicles terminal on the culm or leafy branches, compact interrupted, bristly...................................................8. $M$. racemosa.

9. Glumes acuminate, sometimes awn-tipped but not stiff and exceeding the lemma; panicles terminal and axillary, numerous, not bristly (10)

10(9). Culms glabrous below the nodes; panicles not compact, the branches ascending; plants sprawling, top-heavy, the branchlets geniculatespreading.

9. M. frondosa.

10. Culms strigose below the nodes; panicles compact or (if not) the branches erect or nearly so; plants often bushy-branching but not sprawling with geniculate branchlets (11)

11(10). Panicles not compactly flowered; lemma with awn as much as $1 \mathrm{~cm}$. long or more; some of the blades $1-1.5 \mathrm{dm}$. long or more....

10. $M$. sylvatica.

11. Panicles compactly flowered or (if not) lemma awnless; blades commonly less than $1 \mathrm{dm}$. long but sometimes longer...........11. M. mexicana.

12(4). Culms decumbent and rooting at the nodes.

12. M. Schreberi.

12. Culms erect or spreading but not rooting at nodes.

3. M. filiformis.

1. Muhlenbergia minutissima (Steud.) Swall. Fig. 117.

Tufted annual; culms $10-35 \mathrm{~cm}$. long, 0.4-1 mm. thick, geniculately branched near the base; ligule a hyaline soon lacerate scale about $2 \mathrm{~mm}$. long, not auricled; blades 3-10 cm. long, 1-2 mm. broad, usually flat, folded or involute on drying, minutely pubescent; panicles 1-2 dm. long, 2-3 cm. broad, open and diffuse, the numerous main branches often flexuous, ascending, much-branched secondarily; glumes $0.6-1 \mathrm{~mm}$. long, minutely pubescent (use strong lens); lemma 1.2-2 mm. long, very finely pubescent, broadly elliptical, blunt or apically minutely bifid, awnless or with an awn to about $1 \mathrm{~mm}$. long; palea about equaling lemma. M. texana Buckl., M. sinuosa Swall.

Rocky grassy slopes, border of marshes and wet canyon walls, in the Tex. Trans-Pecos (Davis Mts.), rare, N. M. (Hitchcock) and Ariz. (Apache, Navajo, Coconino, Yavapai, Gila and Pima cos.), late summer-fall; Mont. to Wash. and s. to Mex.

\section{Muhlenbergia pectinata $\mathrm{C}$. O. Goodd.}

Culms 1-2.5 dm. tall or long, erect to decumbent, sometimes rooting at the lower nodes, freely branching, angular; sheath margins often ciliate; ligule erose to ciliate, about $0.5 \mathrm{~mm}$. long; blades flat to involute, $1-6 \mathrm{~cm}$. long, $1-2 \mathrm{~mm}$. wide, pubescent or sparsely pilose; panicles numerous, narrow, 2-12 cm. long; spikelets $3.5-4.5 \mathrm{~mm}$. long; glumes abruptly acute to acuminate, commonly aristate, 1.5-2 (-3) $\mathrm{mm}$. long, the awn about half the entire length; lemma 3- to 5-nerved, scabrous to prominently ciliate on the lateral nerves, the callus appressedpubescent; awn 1-3 cm. long. 


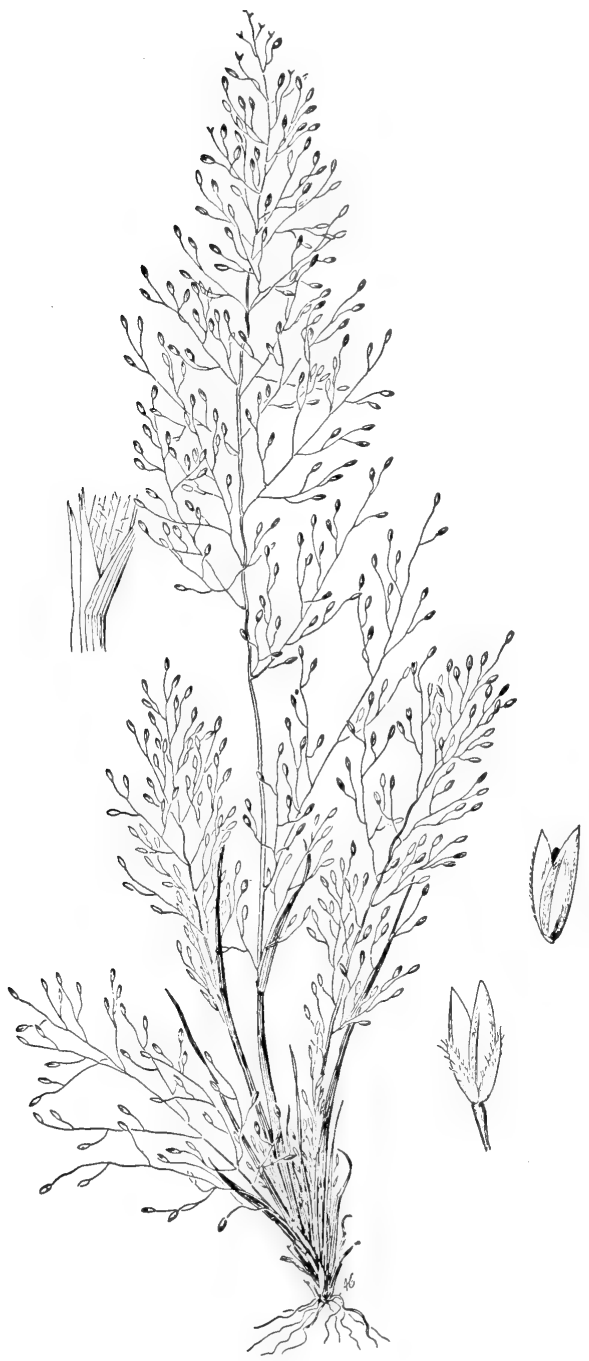

Fig. 117: Muhlenbergia minutissima: plant, X 1; spikelet, floret and ligule, X 10 . (From Hitchcock \& Chase). 
In wet places below or on face of cliffs, moist or wettish rocky hills, in Ariz. (Cochise and Santa Cruz cos.); also Jal.

\section{Muhlenbergia filiformis (Thurb.) Rydb. Pull-UP MuHly.}

Perennial or sometimes apparently annual, with fibrous roots or decumbent creeping bases; culms tufted, erect or somewhat spreading, glabrous, filiform, usually $0.5-1.5 \mathrm{dm}$. or sometimes as much as $3 \mathrm{dm}$. tall; ligules thin, hyaline, 1-2 mm. long; blades flat, glabrous beneath, scabrous-pubescent on the upper surface, 1-3 cm. long, $1 \mathrm{~mm}$. wide; panicles numerous, narrow, interrupted, fewflowered, usually less than $5 \mathrm{~cm}$. long; glumes ovate, about equal in size, obtuse or acutish, awnless, $1 \mathrm{~mm}$. long; lemma lanceolate, acute, $2 \mathrm{~mm}$. long, mucronate, minutely pubescent, minutely scabrous at the tip, $1 \mathrm{~mm}$. long, the callus glabrous.

In wet meadows, springy or seepage areas, old lake beds and moist open woods, in N. M. (Hitchcock) and Ariz. (Apache and Coconino cos.); S. D. and Kan. to B. C., s. to N. M., Ariz. and Calif.

\section{Muhlenbergia utilis (Torr.) Hitchc. Aparejo Muhly.}

Perennial from firm creeping rhizome; culms 1-3.5 dm. long; ligule a scale 0.5-1 mm. long; blades $15-35 \mathrm{~mm}$. long, about $1 \mathrm{~mm}$. broad and mostly involute, the smaller blades 5-20 mm. long and closely involute and arcuate, $0.2-0.4 \mathrm{~mm}$. thick as rolled; glumes $0.6-1.5 \mathrm{~mm}$. long; lemma 1.6-2 mm. long, scarcely mucronate.

Calcareous seasonally muddy soil along streams, marshy places and about springs in the Tex. Edwards Plateau, N. M. (widespread in s. half) and Ariz. (Santa Cruz Co.), locally abundant, usually fall-early winter, occasionally springsummer; also Calif. and Nev.

\section{Muhlenbergia Richardsonis (Trin.) Rydb. MAT MUHLY.}

Perennial from numerous hard creeping rhizomes; culms wiry, noduloseroughened, erect or decumbent at base, 1-6 dm. tall; ligule 2-3 mm. long; blades usually involute, $1-5 \mathrm{~cm}$. long or rarely longer; panicle narrow, interrupted or sometimes rather close and spikelike, 2-10 cm. long; spikelets $2-3 \mathrm{~mm}$. long, the glumes about half as long, ovate; lemma lanceolate, acute, mucronate.

In wet meadows, dry or wettish often alkaline soils and low open ground, in Ariz. (Coconino Co.); N. B. to Alta., s. to S.D., N. M., Ariz., Calif. and Baja Calif.

\section{Muhlenbergia asperifolia (Nees \& Mey.) Parodi. Scratchgrass MuhLy.}

Perennial from elongate scaly rhizomes $1.5-2 \mathrm{~mm}$. thick; aerial culms $1-6 \mathrm{dm}$. long, about $1 \mathrm{~mm}$. thick, mostly weak and reclining, ascending only at the floriferous ends, sparsely branched; ligule a muticous scale about $0.5 \mathrm{~mm}$. long, not auricled; blades 2-7 (-14) $\mathrm{cm}$. long, 1-3 mm. broad, flat or folded, mostly rapidly ascending; panicle 5-18 cm. long, $4-15 \mathrm{~cm}$. broad, ovoid, very open, diffuse, fewflowered; glumes $0.6-1$ ( rarely to 1.5 ) $\mathrm{mm}$. long, acute; lemma $1.2-1.5 \mathrm{~mm}$. long, dark, awnless; palea about equaling lemma.

Moist alluvial soil near streams and ditches, occasional in marshy, wet, or often alkaline soil, in water of cat-tail swamps and mud about pools and lakes, in w. Okla. (Waterfall) and the Tex. Plains Country and Trans-Pecos, N. M. (San Juan and Valencia cos.) and Ariz. (Apache to Coconino, s. to Pima cos.) infrequent, late summer-fall; w. N. A. e. to Ill., Okla. and Tex.; s. S. A.

\section{Muhlenbergia andina (Nutt.) Hitchc. Foxtall MuHLy. Fig. 116.}

Perennial from scaly white rhizomes $1-2 \mathrm{~mm}$. thick; aerial culms $25-80 \mathrm{~cm}$. long, 1-1.5 mm. thick, erect, leafy, sparingly branched; ligule a scale about $1 \mathrm{~mm}$. long, laterally with very short auricular points; blades $5-18 \mathrm{~cm}$. long, 1-3 mm. broad (rarely to $5 \mathrm{~mm}$.), flat; panicle $4-12 \mathrm{~cm}$. long, 6-15 $\mathrm{mm}$. thick, spikelike 
but usually interrupted; glumes 3-4 mm. long, shining, grayish, keeled, awnless; lemma 2-3 $\mathrm{mm}$. long, linear, grayish, glabrous but with a basal callus bearing a beard of hairs 2-3 $\mathrm{mm}$. long and an apical awn 4-8 $\mathrm{mm}$. long; palea nearly equaling lemma.

In wet meadows, moist thickets and river beds, in the (?) Tex. Trans-Pecos and N. M. (San Miguel Co.); w. U.S., e. to Wyo., Colo., N.M. and possibly Tex.

\section{Muhlenbergia racemosa (Michx.) B.S.P. Fig. 116.}

Perennial from scaly white rhizomes 1-2 mm. thick; aerial culms 3-7 dm. long, 0.5-2.5 mm. thick, erect, leafy, sparingly branched; ligule an erose scale $0.5-1 \mathrm{~mm}$. long, without auricles; blades 4-16 cm. long, 1-7 mm. broad, flat, rather stiffly erect; panicles 2-14 cm. long, 4-11 mm. thick, spikelike but usually interrupted; glumes $1.5-2 \mathrm{~mm}$. long, lanceolate, apically with a stiff awn 2-5 $\mathrm{mm}$. long; lemma 2.5-3.5 mm. long, short-pilose on the lower half, acuminate or the apical portion awnlike; palea nearly equaling lemma.

Moist ground, wet meadows, swamps, alluvial soil along rivers, streams and irrigation ditches, in Okla. (Waterfall) and the Tex. Plains Country, rare (one collection from Perryton, Ochiltree Co.), N. M. (widespread) and Ariz. (Apache and Coconino cos.), Sept.-Oct.; most of U. S. w. of Miss. River.

\section{Muhlenbergia frondosa (Poir.) Fern. Wirestem muhly.}

Perennial from scaly white rhizomes $1-2 \mathrm{~mm}$. thick; aerial culms $3-10 \mathrm{dm}$. long, 1-2 mm. thick, leafy, profusely geniculately branched near the middle, topheavy and falling over (then often rooting at the nodes), the naked pedunculiform terminal internodes only $1-4 \mathrm{~cm}$. long or absent; ligule an erose scale $0.5-1 \mathrm{~mm}$. long, not auricled; blades 4-11 cm. long, 1.5-5 mm. broad, flat, ascending or appressed; panicles 3-10 $\mathrm{cm}$. long, when only $1-2 \mathrm{~mm}$. thick then linear but when 3-6 mm. thick tapered to both ends, loose and interrupted; glumes 2.5-3.5 $\mathrm{mm}$. long including the awnlike tip, linear-lanceolate; lemma about $3 \mathrm{~mm}$. long, awnless, pubescent on the lower part; palea about $3 \mathrm{~mm}$. long.

Woods, sandbars along streams, muddy banks of streams and swales, low wet soils and thickets, in Okla. (Waterfall) and n.-cen. Tex., rare (Dallas and Grayson cos.) Oct.; e. Can. s. to n. Ala., Tex. and Okla.

\section{Muhlenbergia sylvatica (Torr.) Torr.}

Perennial from scaly rhizomes $1-2.5 \mathrm{~mm}$. thick; aerial culms 4-10 dm. long, 1-3 mm. thick, leafy, moderately branched near the middle, weak and often reclining, the lower nodes rooting, the internodes minutely strigose in a zone just below the nodes (use lens), the terminal internodes short and not pedunculiform; ligule an erose scale $0.5-1.2 \mathrm{~mm}$. long; blades $6-18 \mathrm{~cm}$. long, 2-7 mm. broad, flat, ascending; panicles 4-10 cm. long, 3-5 mm. thick, somewhat spikelike, interrupted, nodding; glumes about $2 \mathrm{~mm}$. long, awnless or with an awnlike tip 0.1-1 mm. long; lemma about $3 \mathrm{~mm}$. long, pubescent in the lower part, with an awn 3-10 $\mathrm{mm}$. long; palea about $3 \mathrm{~mm}$. long.

Dense woods and swampy meadows, in Okla. (Waterfall) and n.-cen. Tex. and e. Edwards Plateau, rare, Aug,-Sept.; s.e. Can. s. to n. Ala. and Tex.

\section{Muhlenbergia mexicana (L.) Trin.}

Resembling $M$. frondosa; culms erect or ascending, usually simple below, less freely branching, scaberulous below the nodes; blades lax, 1-2 dm. long, mostly 2-4 mm. wide; panicles mostly long-exserted, narrow, the upper often $10-15 \mathrm{~cm}$. long, of numerous short appressed densely flowered somewhat aggregate branches; spikelets 2-3 mm. long; glumes narrow, attenuate, awn-tipped, about equaling the pointed or awn-tipped lemma, the lemma long-pilose below. 
In wet meadows, swales, springy places along streams and about pools, damp thickets and wettish low open ground, in N. M. (San Miguel and Socorro cos.) and Ariz. (Cochise Co.); Me. and Que. to Wash., s. to N. C., Ark., N.M. and Ariz.

\section{Muhlenbergia Schreberi J. F. Gmel. Nimblewill MUhly.}

Perennial with stolons about $1 \mathrm{~mm}$. thick, freely rooting; flowering culms $1-4$ $\mathrm{dm}$. long, $0.5-1 \mathrm{~mm}$. thick, weak, ascending; ligule an erose scale about $0.5 \mathrm{~mm}$. long, not auricled; blades 3-8 cm. long, 1-4 mm. broad, weak, flat, diverging from culm at right angles; panicles 5-12 cm. long, 1-3 mm. thick, spikelike but lax and interrupted, weak and nodding; glumes minute, $0.1-0.3 \mathrm{~mm}$. long, muticous; lemma about $2 \mathrm{~mm}$. long, linear-lanceolate, with an awn 1.5-6 $\mathrm{mm}$. long; palea about $2 \mathrm{~mm}$. long.

Moist usually shaded ground near streams and marshy areas, wet meadows and wet sandy-clay about ponds, in Okla. (Waterfall) and e., s.e. and n.-cen. Tex. and e. Edwards Plateau and n. Rio Grande Plains, scattered but locally abundant, spring-fall; e. U.S., w. to Neb., Kan., Okla. and Tex.

\section{Sporobolus R. BR. DRopseed}

Perennials (except in 1 species); inflorescences paniculate, either open and diffuse or spiciform; spikelets 1-flowered, slightly laterally compressed, with membranous to scarious parts; rachilla with zone of abscission just above the glume node and below the lemma nodes in most species; palea often splitting at maturity; grain usually falling readily, often reddish, with a coat (ovary wall) that imbibes water, becoming loose and easily detached from the remainder of the grain.

A genus of about 150 species of the warmer regions of the world.

1. Mature panicles more than $9 \mathrm{~cm}$. broad.

1. S. texanus.

1. Mature panicles less than $9 \mathrm{~cm}$. broad (2)

2(1). Collar of sheath (dorsal summit where it joins the blade) abundantly furnished with soft white hairs; panicle more than $2 \mathrm{~cm}$. broad

2. S. flexuosus.

2. Collar of sheath glabrous (but the corners commonly pilose); panicle less than $1.5 \mathrm{~cm}$. broad (3)

3(2). Mature panicles less than $5 \mathrm{~cm}$. long.

3. S. virginicus.

3. Mature panicles more than $5 \mathrm{~cm}$. long.

4. S. indicus.

\section{Sporobolus texanus Vasey. Fig. 118.}

Tufted perennial from short very firm rhizomes $1.5-2 \mathrm{~mm}$. thick, or these often apparently absent; aerial culms numerous, 3-7 dm. long, 1-2 mm. thick, leafy; ligule a very dense line of cilia about $0.5 \mathrm{~mm}$. long; blades $1-12(-20) \mathrm{cm}$. long, 2-4 $\mathrm{mm}$. broad near the base, flat or drying involute, pointed; summit of sheath glabrous but the corners and margins often sparsely long-pilose; panicle 15-30 cm. long, 1-2 dm. broad, vaguely obovoid, open and diffuse, the branches not whorled but bearing numerous somewhat flexuous capillary ultimate branchlets 5-20 mm. long, each terminating in a single spikelet; first glume $0.7-1.5 \mathrm{~mm}$. long; second glume 2.1-2.8 $\mathrm{mm}$. long; lemma 2.3-2.9 mm. long; palea about equaling lemma.

Seasonally moist and often subsaline low areas, salt marshes, mesas and valley, in Okla. (Waterfall), the Tex. Plains Country and Trans-Pecos, infrequent or rare, N.M. (Chaves and Eddy cos.) and Ariz. (Coconino Co.), summer-fall; w. Kan. to Tex. and w. to Ariz. 


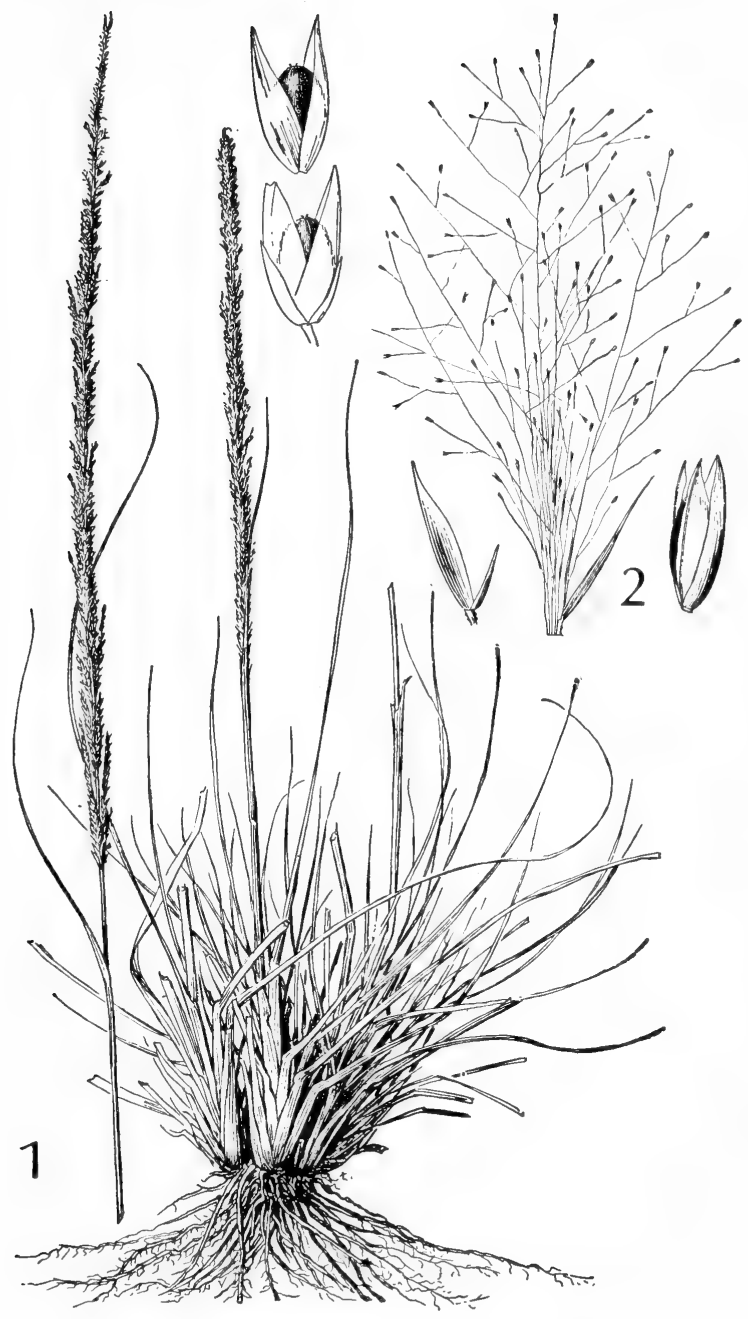

Fig. 118: 1, Sporobolus indicus: plant, X 1/2; spikelet and floret, X 10. 2, Sporobolus texanus: panicle, X 1/2; glumes and floret with caryopsis, X 10. (From Hitchcock \& Chase). 


\section{Sporobolus flexuosus (Thurb.) Rydb. MESA DROPSEED.}

Tufted perennial; culms 3-10 dm. long, 1-2 mm. thick, erect, unbranched; ligule a ciliate fringe $0.3-0.5 \mathrm{~mm}$. long; blades $5-23 \mathrm{~cm}$. long, $2.4 \mathrm{~mm}$. broad at the base where flat but usually soon involute; sheaths obscurely round-keeled apically, the corners with some soft white hairs but the dorsal summit or collar glabrous or only very sparsely furnished with hairs, 1-1.5 $\mathrm{mm}$. long; panicles $12-30 \mathrm{~cm}$. long, 4-9 cm. broad, basally sometimes partially included in the uppermost sheath, open, the branches not whorled, divaricate or even somewhat deflexed and then arcuately reflexed distally, the floriferous branchlets subsecund on the lower side of the branches, mostly widely divergent from the branches, the spikelets borne on tertiary pedicellary branchlets about $1 \mathrm{~mm}$. long which are subsecund along the proximal side of the secondary branchlets; first glume 1-1.3 mm. long; second glume 1.9-2.5 mm. long; lemma 1.9-2.3 mm. long; palea about equaling lemma.

Loose usually blowing sand in dune areas, also in marshes and wet seepage areas, in the Tex. Trans-Pecos, locally frequent, N. M. (widespread) and Ariz. (Apache, Navajo, Coconino, Yavapai, Graham, Cochise and Pima cos.), Sept.Nov., rarely also in spring; w. Tex. to s. Ut., Nev., s. Calif. and n. Mex.

\section{Sporobolus virginicus (L.) Kunth. CoAstal DROPSEEd.}

Perennial from scaly creeping stramineous rhizomes 1-3 $\mathrm{mm}$. thick; aerial culms mostly ascending or the lowermost internodes stoloniform, 7-40 cm. long, 1-3 mm. thick, leafy; ligule a ciliate scale $0.2-0.4 \mathrm{~mm}$. long; blades $3-20 \mathrm{~cm}$. long, usually flat at the very base or rounded-keeled and $2.5-4 \mathrm{~mm}$. broad, tapering to an involute point; corners of sheaths sparsely pilose and upper part of sheath dorsally keeled; panicle 25-80 $\mathrm{mm}$. long, 6-10 $\mathrm{mm}$. broad, dense, spikelike or usually narrowly ellipsoidal or oblong-ellipsoidal; first glume 1.3-2.8 $\mathrm{mm}$. long; second glume $1.8-3 \mathrm{~mm}$. long; lemma $2.1-3 \mathrm{~mm}$. long; palea about as long as lemma.

Packed loamy somewhat saline soil, in saline marshes, sandy or muddy seashores and wettish coastal prairies, all along the Tex. coast, common, summerfall; warmer Atl. and Carib. coasts, s. to Braz. and n. to Va.

\section{Sporobolus indicus (L.) R. Br. Smutgrass. Fig. 118.}

Tufted perennial; culms 3-11 dm. long, 1-3 mm. thick, erect, unbranched; ligule obsolete or only a scale $0.1 \mathrm{~mm}$. long; blades aggregated at the base of the plant, $15-25(-50) \mathrm{cm}$. long, at the base usually flat or sharply folded, 3-5 $\mathrm{mm}$. broad, tapering to a long involute arcuate tip; upper part of the sheaths usually dorsally keeled; panicles 1-4 dm. long, 5-10 mm. thick, dense, spikelike, often somewhat interrupted in the lower part; first glume $0.4-0.9 \mathrm{~mm}$. long; second glume $0.8-1.3 \mathrm{~mm}$. long; lemma 1.4-2 mm. long; palea $1.2-1.8 \mathrm{~mm}$. long; pericarp mucilaginous, the grain often sticking persistently instead of falling readily as in many dropseeds. In some works erroneously called $S$. Poiretii.

Mud and moist loam, low prairies and swales, in shallow water and mud about ponds and springy areas, in s.e. Okla. (Waterfall) and e. and s.e. Tex., s.w. to Bexar, DeWitt, Goliad and Aransas cos., frequent, late spring-Nov.; widely distributed in the warmer parts of the world, nat. to the Old World; in Am. occurring n. to Va., Tenn., Ark. and Okla.

\section{Leptochloa BEAUV.}

\section{SPRANGletoP}

Annuals; spikelets 3- to 12-flowered, the lower 1 or 2 florets perfect, the rest staminate or neutral; spikelets sessile and overlapping, appressed in two rows along one side of a nearly terete rachis (the rachis with its two rows of spikelets being called a "raceme," the total inflorescence being a panicle of 4 to 90 of 
these racemes attached along an axis, the axis being elongate); zone of abscission just below each lemma, the marginal basal portion of the lemma pubescent or nearly glabrous.

A genus of about 27 species in the warmer parts of the world.

1. Lemma $1-1.5 \mathrm{~mm}$. long (2)

1. Lemma at least $1.8 \mathrm{~mm}$. long (3)

2(1). Panicles more than 10 times as long as broad; racemes stiffly ascending or appressed. 4. L. Nealleyi.

2. Panicles much less than 10 times as long as broad 5. L. filiformis.

3(1). Recemes usually more than 40 per panicle; spikelets $3.5-4.5 \mathrm{~mm}$. long; lemmas about $2 \mathrm{~mm}$. long, acute............................ L. panicoides.

3. Racemes usually fewer than 40 per panicle; spikelets $4-10 \mathrm{~mm}$. long; lemmas 1.8-4 $\mathrm{mm}$. long (4)

4(3). Lemmas lance-elliptic, acute and acuminate, $2.5-4 \mathrm{~mm}$. long.

4. Lemmas obovate, blunt, $1.8-3 \mathrm{~mm}$. long.

1. L. fascicularis. 2. L. uninervia.

\section{Leptochloa fascicularis (Lam.) Gray. Bearded SPRAngletop. Fig. 119.}

Tufted annual; culms 2-9 dm. long, 2-3 mm. thick, erect or geniculately ascending, sparingly branched, leafy, soft; ligule a hyaline scale $2.5-6 \mathrm{~mm}$. long, usually lacerate into several strap-shaped parts, the lateral portions resembling auricles on the sheaths; blades $5-35 \mathrm{~cm}$. long, 2-10 $\mathrm{mm}$. broad, flat or soon involute; panicles $15-30 \mathrm{~cm}$. long, 2-5 cm. broad, usually partly included in the sheath; racemes 14 to 35 , widely spaced on the panicle axis but appressed or ascending and overlapping, 3-11 cm. long, 3-5 mm. thick; spikelets scarcely laterally compressed, overlapping, 5-10 mm. long, 6- to 12-flowered; glumes 1.5-3.5 mm. long, acute; lemma lance-elliptic, 2.5-4 mm. long, acute or acuminate to mucronate or short-awned, pubescent near the margin in the lower half, the hairs conspicuous from the side of the spikelet under a lens.

Muddy areas, sometimes alkaline or subsaline mud, brackish marshes, about playa lakes, in seepage areas, and in shallow water of ponds and streams, in Okla. (Logan and Pawnee cos.), in the Tex. Plains Country, Trans-Pecos, Rio Grande Plains, and n.-cen. and s.e. Tex., scattered but locally abundant, N. M. (Lea, Socorro, Dona Ana, Chaves and Eddy cos.) and Ariz. (Coconino, Navajo, Graham, Gila, Pinal, Cochise and Pima cos.) summer-fall; widespread in the warmer parts of the New World, n. to N. E., N. D. and Wash. (See remark under L. uninervia.)

\section{Leptochloa uninervia (Presl) Hitchc. \& Chase. Fig. 120.}

Much like $L$. fascicularis, identical in habit; racemes 20 to $40,2-8 \mathrm{~cm}$. long; spikelets 4-9 mm. long; glumes and lemmas much less acute, the latter $1.8-3 \mathrm{~mm}$. long, obovate and obtuse or muticous, sometimes mucronate, the pubescence inconspicuous or hidden when spikelet is viewed from the side.

Mud, sometimes alkaline or subsaline mud, in ditches, along and in sloughs and river sand bars, in Okla. (Love Co.) and in the Tex. Edwards Plateau, Rio Grande Plains, s.e. and Trans-Pecos Tex., to be expected in n.-cen. Tex. and the Plains Country, scattered, spring-summer, rarely into fall; widespread but scattered in the warmer parts of the New World n. to N. E., Okla., Colo., Ut. and Ore. Perhaps only a form of $L$. fascicularis.

\section{Leptochloa panicoides (Presl) Hitchc.}

Tufted annual; culms 5-10 dm. long. 2-6 mm. thick, erect, sparingly or not branched, leafy, soft; ligule a hyaline usually lacerate scale $2-4 \mathrm{~mm}$. long; blades 2-5 dm. long, 3-10 mm. broad, folded or drying involute; sheaths sharply keeled; 


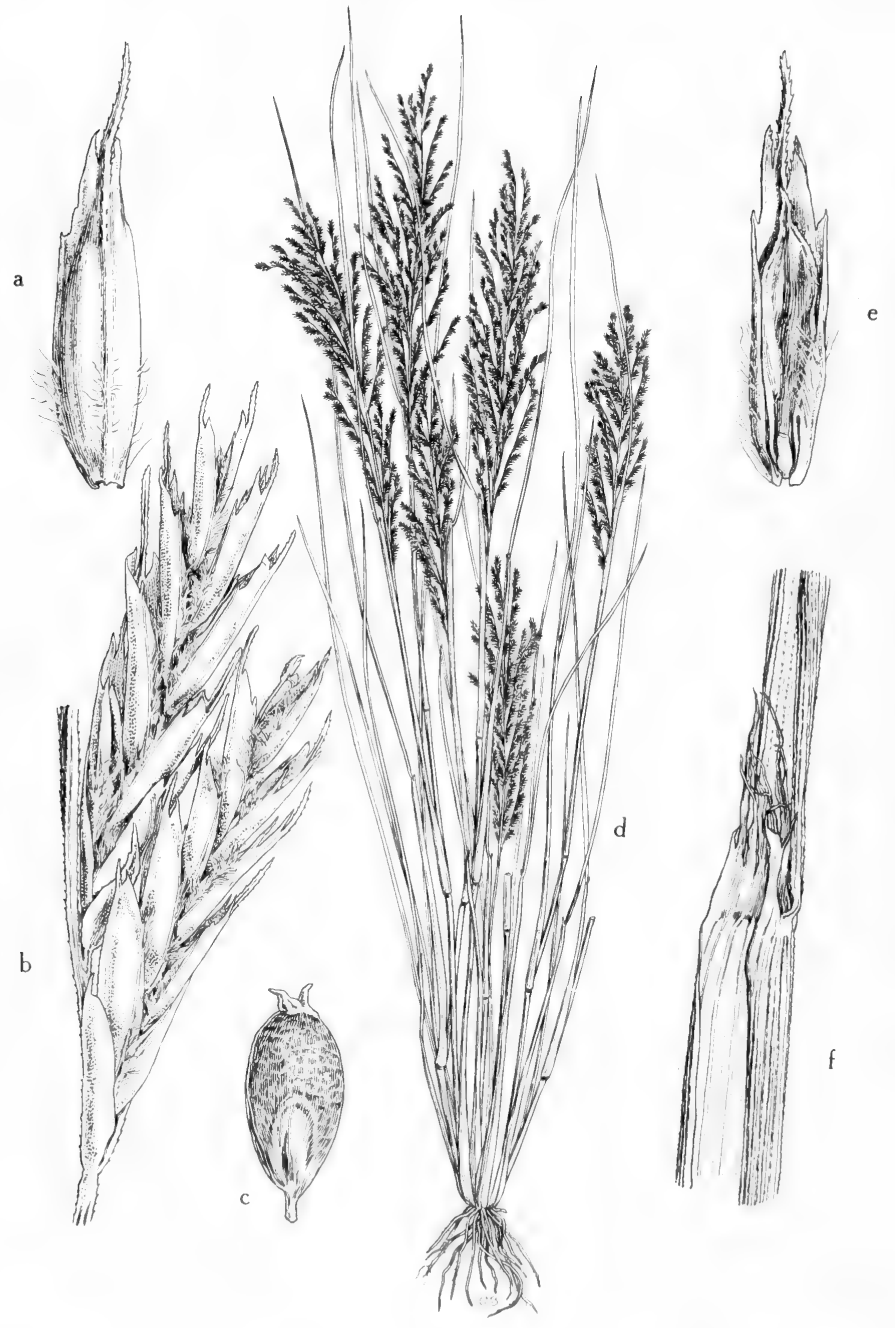

Fig. 119: Leptochloa fascicularis: a, floret, showing awned lemma with bifid apex, $X 12 ; b$, spikelets, $X 8$; c, grain, $X 20$; d, habit, showing the branching culms and the panicles, $X 1 / 4 ;$ e, floret, showing palea, $X 12 ; \mathrm{f}$, leaf sheath and fimbriate ligule, $X 4$. (From Mason, Fig. 73). 


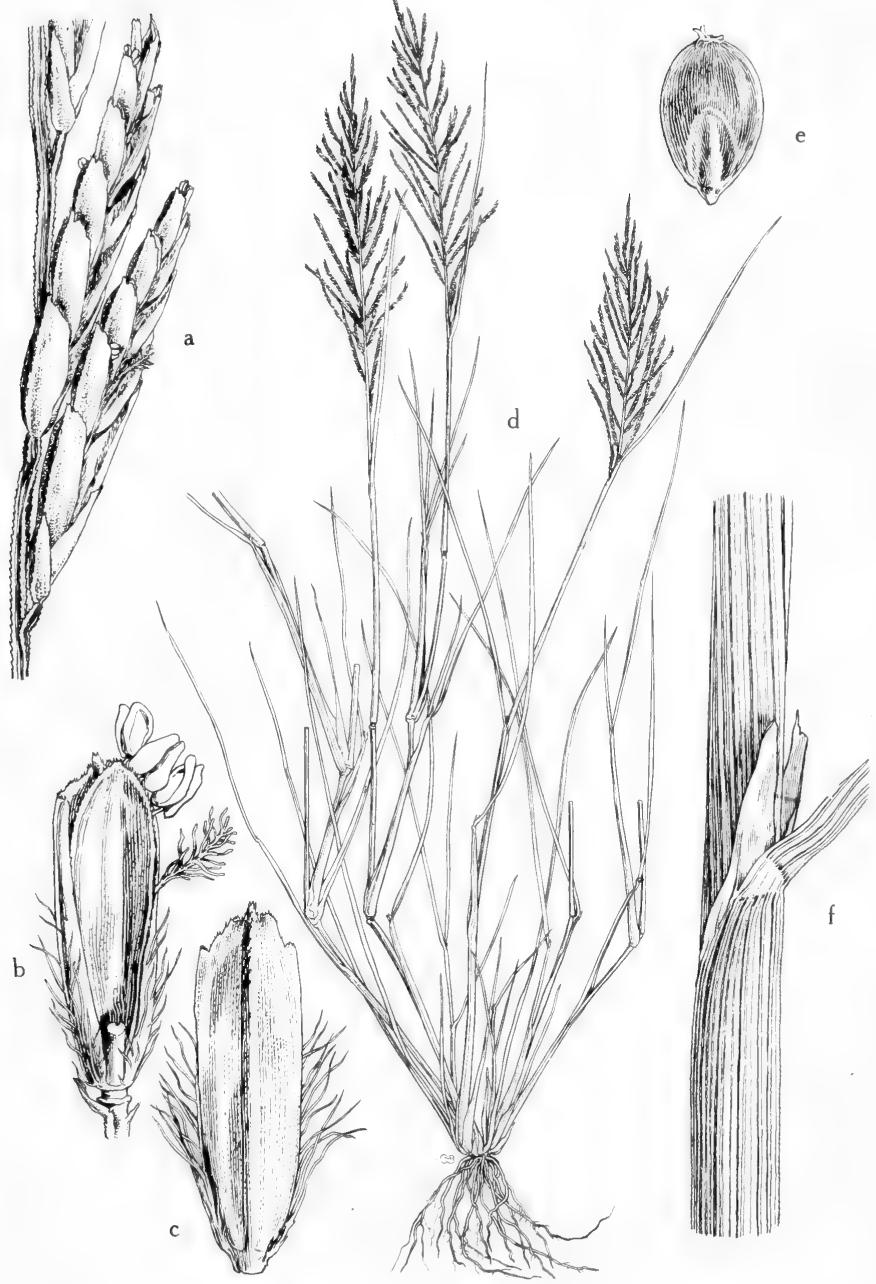

Fig. 120: Leptochloa uninervia: a, spikelets, X 8; b and c, floret, showing palea and the apiculate lemma, the margins basally pubescent, X 16; d, habit, X 1/5; e, grain, $X 16 ; f$, leaf sheath and the bilobed ligule, $X$ 4. (From Mason, Fig. 74). 
panicles 1-2 dm. long, 3-6 cm. wide; racemes 40 to 90 , crowded, ascending, 2-5 $\mathrm{cm}$. long, 2-3 mm. thick; spikelets laterally compressed, closely overlapping, 5- to 7-flowered, 3.5-4.5 mm. long; glumes and lemma acute, about $2 \mathrm{~mm}$. long, mucronate, pubescent laterally on the lower part.

Mud, e. and s.e. Tex., rare, spring-fall; nat. of Braz.; Mo. to Miss., Ark. and Tex.; adv. in India.

\section{Leptochloa Nealleyi Vasey.}

Tufted annual; culms 5-15 dm. long, 1.5-6 mm. thick, erect, unbranched, leafy; ligule a somewhat lacerate scale 1-3 mm. long; blades 1-4 dm. long, 2-7 $\mathrm{mm}$. broad, flat or basally folded or drying involute; sheaths sharply keeled; panicles 2-5 dm. long, $1-3 \mathrm{~cm}$. broad; racemes 25 to 85 , overlapping, $1-10 \mathrm{~cm}$. long, about $2 \mathrm{~mm}$. thick, stiffly ascending or appressed; spikelets laterally compressed, closely overlapping, 3- or 4-flowered, 2-3 mm. long; glumes and lemmas about $1 \mathrm{~mm}$. long, the former acute, the latter blunt and awnless with slightly pubescent nerves.

Mud, near the coast, in marshes and in mud and water of sloughs, s.e. Tex. and Rio Grande Plains, scattered, spring-fall; coastal areas, Tam. to La.

5. Leptochloa filiformis (Lam.) Beauv. Red SPRAngletor. Fig. 121.

Tufted annual; culms 2-9 dm. long, 1-3 mm. thick, geniculate and occasionally rooting at lower nodes, sparingly branched, ascending, leafy, soft; ligule a hyaline somewhat lacerate scale about $1 \mathrm{~mm}$. long; blades 2-20 cm. long, $1.5-10 \mathrm{~mm}$. broad, flat; sheaths papillose-pilose; panicles $7-35 \mathrm{~cm}$. long, 2-21 cm. broad; racemes 7 to 70 , remote, $1-15 \mathrm{~cm}$. long, 1-2 $\mathrm{mm}$. thick, diverging from axis at angles of $40^{\circ}-90^{\circ}$; spikelets not much-compressed laterally, 1.4-2.6 mm. long, 3- or 4-flowered, barely overlapping; glumes lanceolate, the second one surpassing the lowest lemma; lemma blunt, 1-1.5 $\mathrm{mm}$. long, awnless, pubescent on the nerves.

Moist soil and mud, along streams, on flats, and alluvial banks, in Okla. (Waterfall) and in e., s.e. and n.-cen. Tex., Rio Grande Plains and rarely w. to e. Plains Country, scattered, in N. M. (Dona Ana and Sierra cos.) and Ariz. (Apache, Navajo and Coconino, s. to Cochise, Santa Cruz, Pima and Yuma cos.), late spring-fall; widely distributed in the warmer parts of the New World $\mathbf{n}$, to Va., Ind., Ill., Mo., Kan., N.M., Ariz. and Calif.

\section{Cynodon Rich.}

A genus of perhaps 10 species of the warmer parts of the Old World; one species now nearly ubiquitous in warmer parts of the whole world.

\section{Cynodon Dactylon (L.) Pers. Bermuda grass, pata de gallo. Fig. 122.}

Rhizomatous and stoloniferous perennial; aerial culms 1-4 (10) dm. long, 1-2 $\mathrm{mm}$. thick, the lower portions stoloniferous and much-branched, distal portions ascending; ligule a double fringe of cilia, a shorter denser fringe about $0.5 \mathrm{~mm}$. long and sparser hairs 1-2 mm. long; blades $1-8(-13) \mathrm{cm}$. long, 1-4 mm. broad, mostly flat or folded, ascending; sheaths pilose at the corners; panicles flabellate, of digitate spikes; spikes 3 to 7 (usually 4 or 5 ) per panicle, $1-6 \mathrm{~cm}$. long, about $1 \mathrm{~mm}$. thick, ascending; spikelets sessile, very crowded, 1-flowered, $1.5-2(-2.5) \mathrm{mm}$. long, strongly compressed, arranged in 2 rows along and appressed to one side of the very narrow rachis; glumes $1-1.5 \mathrm{~mm}$. long, narrow, acute, persistent, the single nerve forming a keel; zone of abscission below the lemma; lemma 1.5-2 mm. long, awnless, slightly cartilaginous, pubescent on the dorsal keel, with lateral nerves very near the margin. C. maritimus H.B.K.

Loamy, usually alluvial, seasonally moist, sometimes alkaline or subsaline, soils, capable of surviving periodic submersion about hot springs, nearly throughout Tex. to Ariz. (Graham Co.), most abundant in the coastal areas of s.e. Tex. 


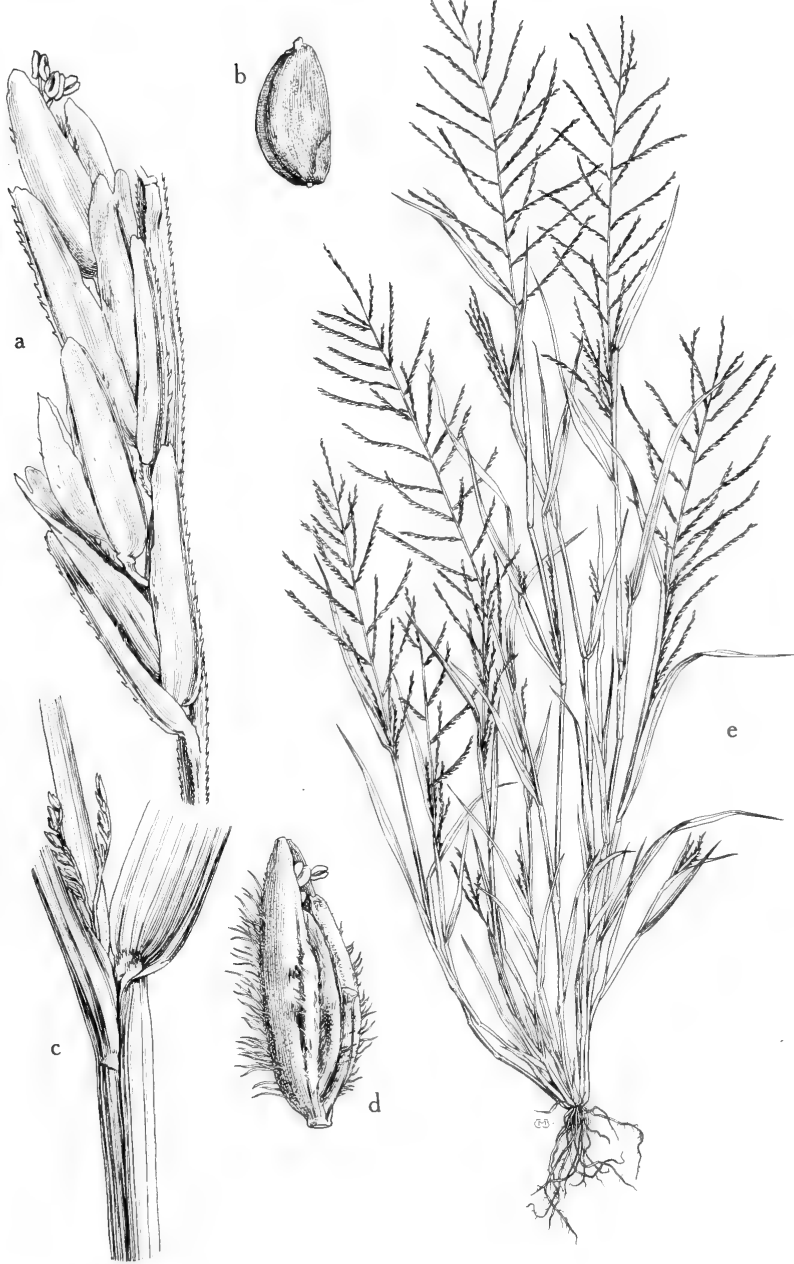

Fig. 121: Leptochloa filiformis: a, spikelets on rachis, X 20; b, seed, X 20; c, leaf sheath and ligule, $X 4$; d, floret, $X 20$; e, habit, showing the long panicles and spreading-ascending spikes, $\mathrm{X} \% 5$. (From Mason, Fig. 72). 


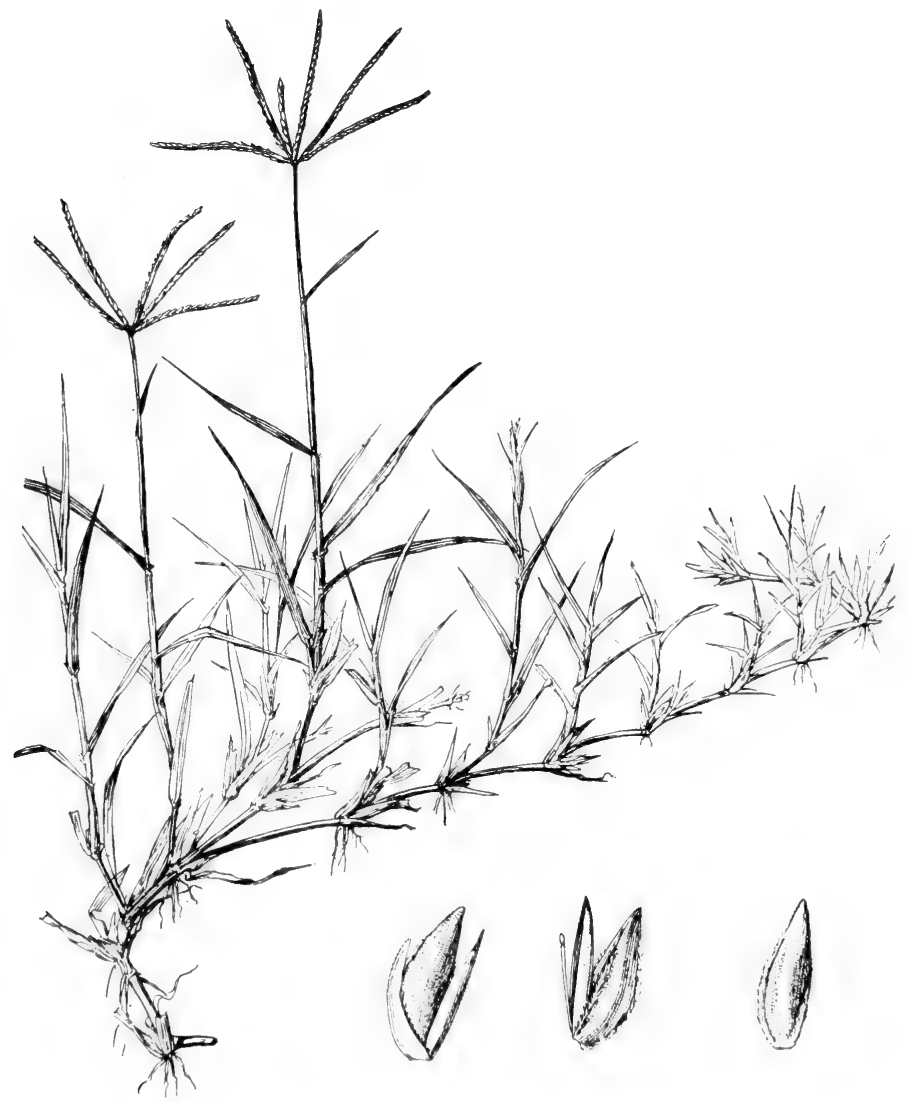

Fig. 122: Cynodon Dactylon: plant, X $1 / 2$; spikelet and two views of floret, $\mathrm{X} 5$. (From Hitchcock \& Chase). 
and Rio Grande Plains, spring-fall and in the extreme s. in winter; nat. of Euras., introd. and ubiquitous in disturbed areas, warmer parts of Am. n. to N. E., Mich., Ia., Colo., Ut., Nev. and Ore.

Very important as a forage in tame pastures, and as a lawngrass.

\section{Beckmannia Host.}

Two species confined to the North Temperate Zone.

\section{Beckmannia Sysigachne (Steud.) Fern. American Slough grass. Fig. 123.}

Annual; culms light green, erect, rather stout, 3-10 dm. tall; blades flat; panicle 10-25 cm. long, narrow, more or less interrupted; spikes crowded, 1-2 cm. long, appressed or ascending; spikelets 1-flowered, laterally compressed, subcircular, nearly sessile and closely imbricate, in 2 rows along one side of a slender continuous rachis, disarticulating below the glumes, falling entire, $3 \mathrm{~mm}$. long; glumes equal in size, inflated, obovate, 3-nerved, transversely wrinkled and with a deep keel; lemma narrow, 5-nerved, acuminate with the apex protruding beyond the glumes; palea nearly as long as the lemma.

Marshy flats, ditches, swampy grounds, wet meadows, in mud of irrigated fields and edge of lakes and ponds, in N. M. (Rio Arriba, San Juan and Taos cos); Man. to Alas.; N. Y. and O. to Pac. Coast, s. to Kan. and N.M.; Asia.

\section{Spartina Schreb. Cordgrass}

Perennials; ligule a fringe of cilia; panicle of several spikes; zone of abscission at the base of the spikelet; spikelet strongly laterally compressed, very closely imbricate, arranged in 2 rows on the abaxial side of the flattened rachis of the spike, 1-flowered, firm; glumes very unequal, the first shorter than the lemma, the second longer than the lemma; palea often longer than the lemma but shorter than the second glume.

A genus of about 16 species, mostly American but a few on the coasts of Europe and Africa.

These plants afford protection for wildlife in coastal and inland marshes. Their seeds are eaten by some species of ducks, marsh birds and songbirds, and the rootstocks also provide valuable winter food for geese. Muskrats are also known to feed on their underground parts.

1. Spikelets $15-25 \mathrm{~mm}$. long, including the awn; second glume with an awnlike tip a third to a half its entire length; keels of second glume and lemma with bristles $0.2-0.4 \mathrm{~mm}$. long...................... S. S. pectinata.

1. Spikelets 5-15 mm. long, awnless; keel of second glume and lemma often minutely pubescent but not pectinate (2)

2(1). Spikes numbering only 2 to 7 (to 10 ) per panicle, often remote (the panicle axis being 9-20 $\mathrm{cm}$. long); culms only 2-4 $\mathrm{mm}$. thick and rhizomes present (3)

2. Spikes more numerous per panicle and more crowded or if few then culms thicker and/or rhizomes absent (4)

3(2). Blades usually flat but becoming involute; glumes conspicuously hispidciliate on the keels; spikes 4 to 8 , appressed................4. S. gracilis.

3. Blades usually involute; glumes scabrous on the keels; spikes 2 to several, ascending to spreading.............................................5. S. patens.

4(2). Spikes 1-3.5 $\mathrm{cm}$. long; panicle spikelike, 5-10 $\mathrm{mm}$. thick; rhizomes absent; leaf blades nearly wholly involute, $2-5 \mathrm{~mm}$. broad at base....

4. Spikes 4-15 cm. long; panicles 7-70 mm. broad; rhizomes present; leaf blades 4-25 mm. broad at base, mostly flat (5) 


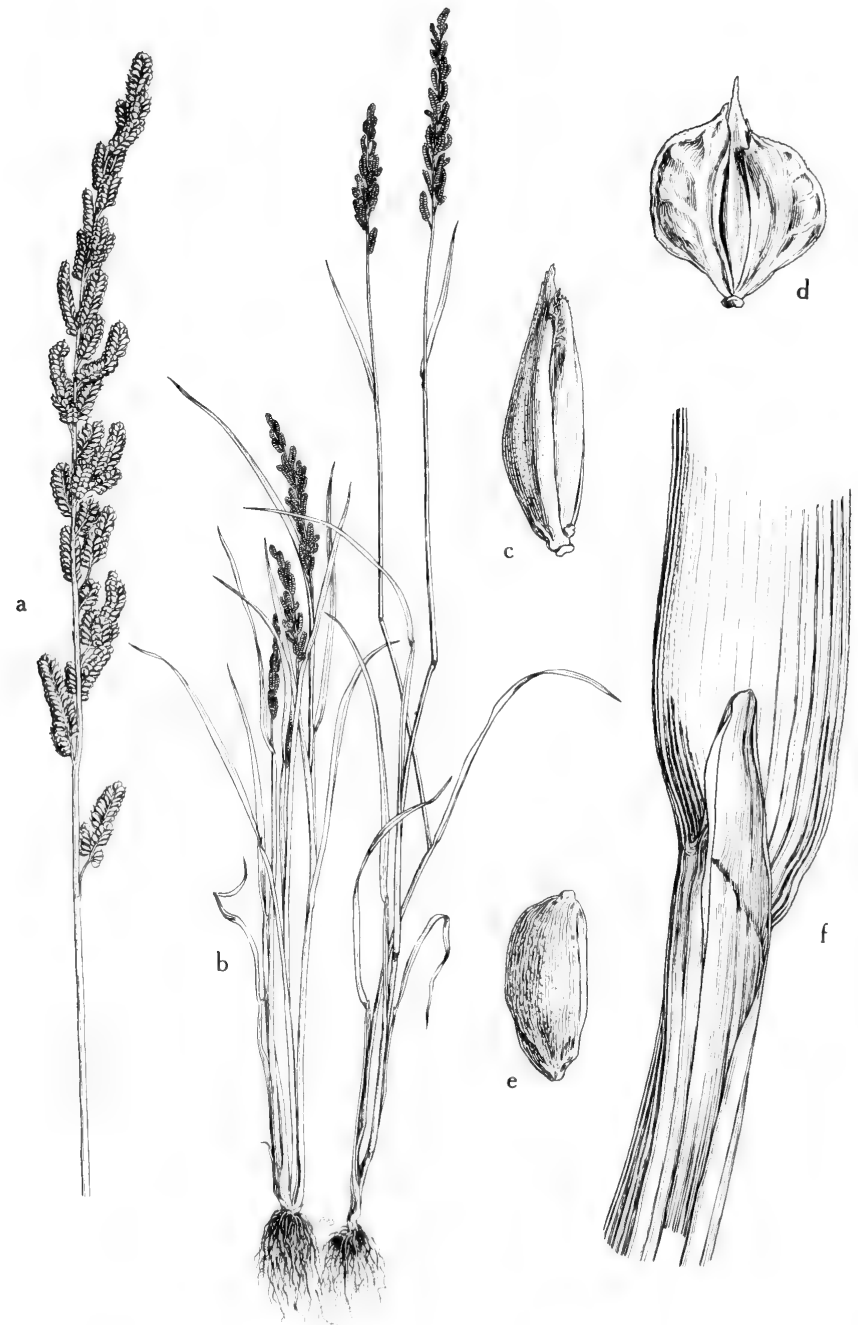

Fig. 123: Beckmannia Syzigachne: a, panicle, showing the ascending spikes, X 2/3; $\mathrm{b}$, habit, $\mathrm{X} 1 / \mathrm{k}$; , floret, $\mathrm{X} 12$ : d, spikelet, laterally compressed, $\mathrm{X} 8$; e, grain, $\mathrm{X} 12$; f, leaf sheath and ligule, X 4. (From Mason, Fig. 59). 

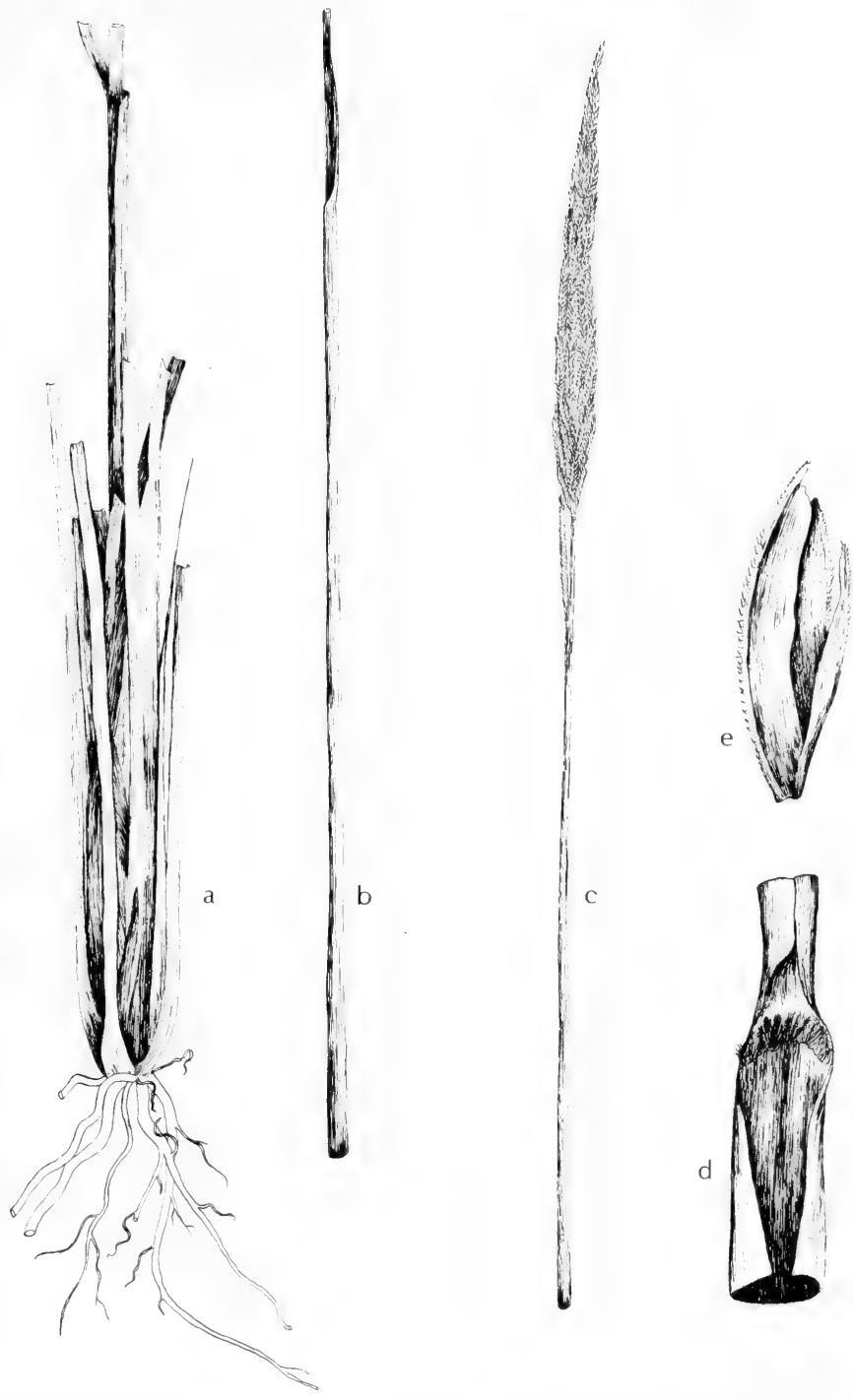

Fig. 124: Spartina spartinae: a, basal part of plant, $\mathrm{X} 1 \frac{1}{2} ; \mathrm{b}$, middle section of plant, $\mathrm{X} 1 / 2$; c, upper part of plant, $\mathrm{X} 1 / 2$; d, ligule, $\mathrm{X} 2$; e, spikelet, $\mathrm{X} 6$. (Courtesy of $\mathrm{R}$. K. Godfrey). 
5(4). Panicle mostly less than $3 \mathrm{~cm}$. broad; spikes only 5 to 30 per panicle; rhizomes soft; culms $6-15 \mathrm{dm}$. long......................2. S. alterniflora.

5. Panicle mostly more than $3 \mathrm{~cm}$. broad; spikes usually 25 to 45 per panicle; rhizomes firm; culm firm and tough, 9-30 dm. long.

3. S. cynosuroides.

1. Spartina spartinae (Trin.) Hitchc. Sacahuista, Gulf cordgrass. Fig. 124.

Tufted perennial; lowermost internodes occasionally shortly subrhizomatous toward the outside of the large tuft but true rhizomes absent; culms numerous, 5-20 dm. long, $2.4 \mathrm{~mm}$. thick, erect, unbranched; ligule 1-2 mm. long; blades 2-7 dm. long, 2-5 $\mathrm{mm}$. broad at the base, closely involute essentially the entire length, the tips sharp and spinelike; panicle spikelike, 6-40 $\mathrm{cm}$. long, 5-9 mm. thick, usually tapered to both ends; spikes 10 to 75 per panicle, $10-35 \mathrm{~mm}$. long, 3-4 mm. thick, closely appressed and overlapping; spikelets 16 to 40 per spike, 5-8 mm. long; first glume 2-6 $\mathrm{mm}$. long; second glume 4-8 $\mathrm{mm}$. long; lemma about equaling second glume; keels of glumes and lemma minutely hispid.

Abundant in tight loamy somewhat saline poorly drained flats, marshes, swamps and wet coastal prairies, in s.e. Tex. and Rio Grande Plains, extremely abundant near the coast, rare and scattered inland (e.g. Gonzales Co.), spring-summer, rarely fall; Gulf and Carib. shores, U.S., Mex. and C.A.; also inland in S.L.P., Coah. and N. L.; also inland in Arg. and Parag.

The young shoots emerging after fires are good forage but the older shoots are much too tough even for horses. Formerly vast acreage of sacahuista were therefore burned over purposely in the ranches of southern Texas; the practice is less common now.

\section{Spartina alterniflora Lois. SMOоTH CORdgrass. Fig. 125.}

Perennial from relatively soft deeply buried (and seldom collected) branched rhizomes 4-7 mm. thick; aerial culms 6-15 dm. long, 3-14 mm. thick, erect, unbranched, leafy; ligule 1-2 mm. long; blades 20-55 cm. long, 4-16 (-25) mm. broad at the very base, flat, distally involute and wholly involute on drying; panicle 1-4 dm. long, 7-22 mm. thick, tapered to both ends, somewhat spikelike but lax; spikes 5 to 30 per panicle, $4-10 \mathrm{~cm}$. long, 3-5 mm. thick, appressed or usually diverging at angles of $10^{\circ}-20^{\circ}$, closely overlapping; spikelets 10 to 40 per spike, 8-14 mm. long; first glume $4-10 \mathrm{~mm}$. long; second glume as long as spikelet, the lemma a little shorter; keels of glumes and lemma with some minute pubescence. Incl. var. glabra (Muhl.) Fern.

Abundant in colonies at the tidally-innundated shores of brackish to hypersaline bays and river-mouths, along the Tex. coast, locally common, summer-fall; nat. to the e. coast of N.A. from the Maritime Provinces to Tex., and also S.A. from Gui. to Arg.; introd. in Wash., and in Fr. and Eng.

\section{Spartina cynosuroides (L.) Roth. Big CORdgrass. Fig. 126.}

Perennial from deeply buried (rarely collected) rhizomes 7-15 mm. thick; aerial culms 9-30 dm. long, 4-25 mm. thick, erect, unbranched, leafy; ligule 1-3 $\mathrm{mm}$. long; blades $25-70 \mathrm{~cm}$. long, $10-22 \mathrm{~mm}$. broad at base, flat, at the tip involute; panicle 15-30 cm. long, 4-7 cm. broad, more or less ellipsoidal; spikes 5 to 67 (usually 25 to 45 ) per panicle, $5-15 \mathrm{~cm}$. long, 3-6 cm thick. basally shortly naked, usually diverging at angles of $20^{\circ}-30^{\circ}$, overlapping; spikelets 30 to 70 per spike, 9-14 mm. long; first glume 3-7 mm. long; second glume as long as spikelets, the lemma a little shorter; glumes and lemmas minutely pubescent on the keels or wholly glabrous.

Locally abundant in colonies in muck at tidally submerged shores of brackish bays and river-mouths, also in marshes, in s.e. Tex. (Chambers, Galveston and Harris cos.), summer; coasts from Mass. to Tex. 


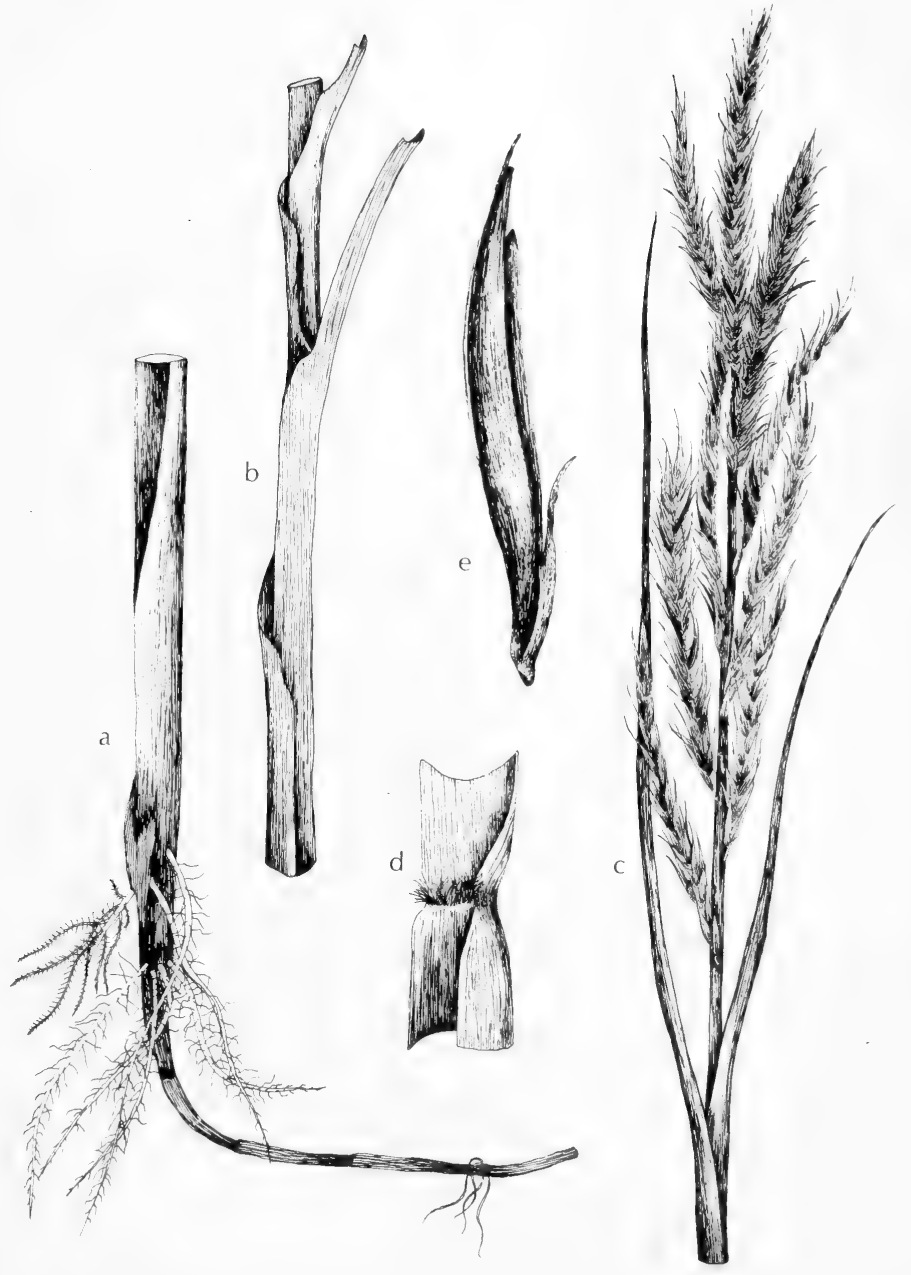

Fig. 125: Spartina alternifolia: a, basal part of plant, $\mathrm{X} \frac{1}{2} ; \mathrm{b}$, section of center of plant, $X 1 / 2$; c, top of plant, $X 1 / 2$; d, ligule, $X 4$; e, spikelet, $X 5$. (Courtesy of $R$. K. Godfrey). 


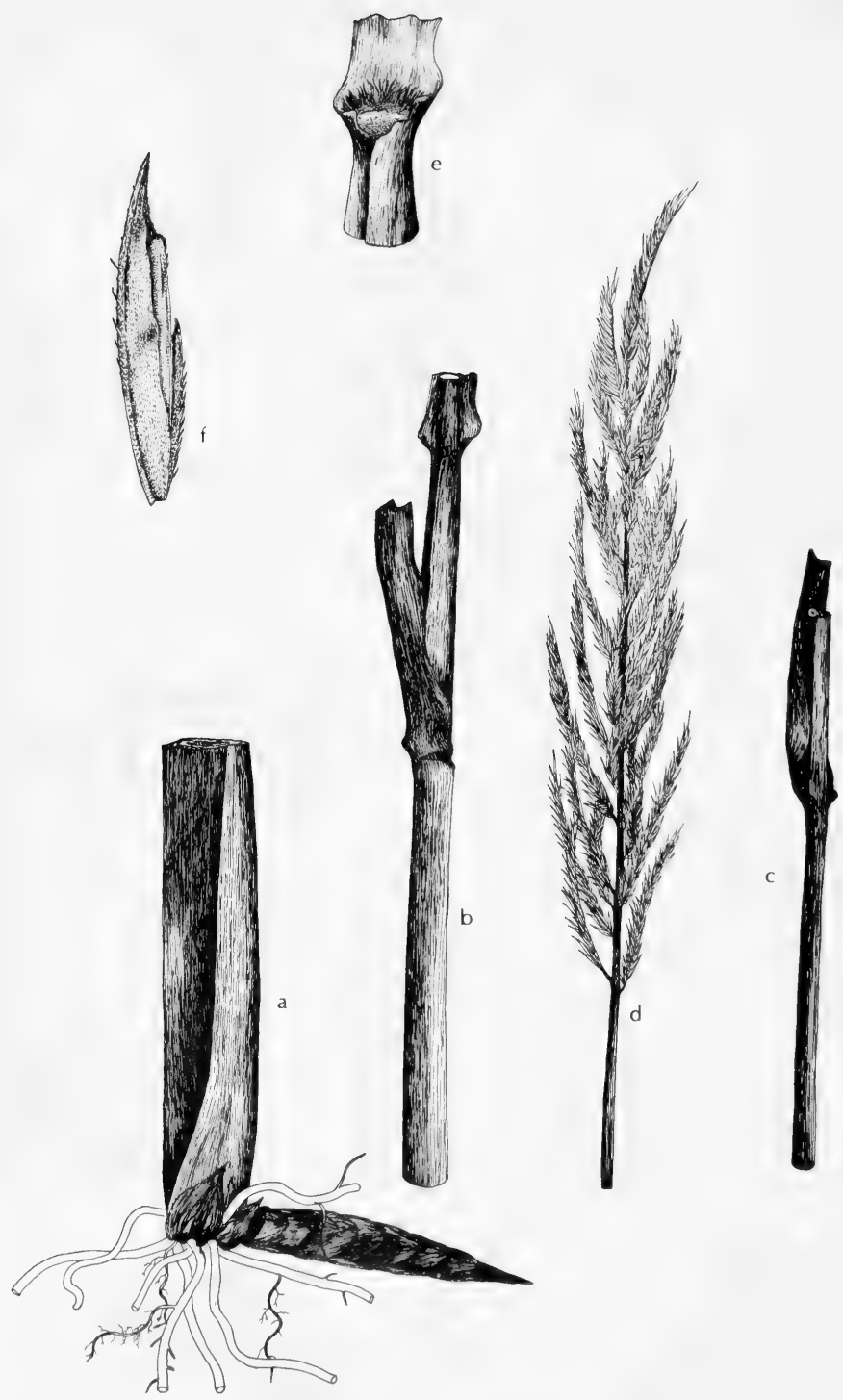

Fig. 126: Spartina cynosuroides: a, basal part of plant, X 1/3; b, lower center section of stem, X $1 / 3$; c, upper center section of stem, X $1 / 3$; d, inflorescence, X $1 / 3 ;$ e, ligule, X 1; f, spikelet, X 31/3. (Courtesy of R. Godfrey). 


\section{Spartina gracilis Trin. Alkali cordgrass. Fig. 127.}

Culms 3-10 $\mathrm{dm}$. tall; ligules about $1 \mathrm{~mm}$. long; blades flat, becoming involute, $15-20 \mathrm{~cm}$. long, very scabrous above, mostly less than $5 \mathrm{~mm}$. wide; spikes 4 to 8 , closely appressed, $2-4 \mathrm{~cm}$. long; spikelets $6-8 \mathrm{~mm}$. long; glumes long-ciliate on the keel, acute, the first 5-6 mm. long, about half as long as the second; lemma nearly as long as second glume, ciliate on the keel; palea as long as lemma, obtuse.

Alkaline meadows and saline marshes and ditches, plains, in Ariz. (Apache and Navajo cos.); B. C. to Wash., s. to Kan., N.M. (Hitchcock) and Ariz.

\section{Spartina patens (Ait.) Muhl. Saltmeadow cordgrass. Fig. 128.}

Perennial from creeping rhizomes $2-4 \mathrm{~mm}$. thick; aerial culms $25-29 \mathrm{~cm}$. long, 1-3 mm. thick, erect, unbranched; ligule about $0.5 \mathrm{~mm}$. long; blades $15-40 \mathrm{~cm}$. long, $1.5-3 \mathrm{~mm}$. broad, mostly involute. the tip subspinose; panicle $9-20 \mathrm{~cm}$. long, about $1 \mathrm{~cm}$. broad; spikes 2 to 7 per panicle, $1-7 \mathrm{~cm}$. long, $2-3 \mathrm{~mm}$. thick, usually diverging at angles of $5^{\circ}-45^{\circ}$, remote; spikelets 24 to 50 per spike, 7-12 $\mathrm{mm}$. long; first glume 3-8 mm, long; second glume 7-12 mm. long; lemma shorter than second glume; glumes and lemma hispid on keel, at least distally.

Sandy seasonally moist soil near the coast, salt marshes and wet sandy meadows, in s.e. Tex. and Rio Grande Plains, common, summer-fall; shores of Great Lakes, Atl. and Gulf coasts, cont. N.A. and W.I.; also s. Fr., Corsica and It.

\section{Spartina pectinata Link. Prairie cordgrass. Fig. 127.}

Perennial from firm creeping rhizomes $3-8 \mathrm{~mm}$. thick; aerial culms $75-200 \mathrm{~cm}$. long, 3-10 mm. thick, erect, unbranched, leafy; ligule 1-3 mm. long; blades 2-6 $\mathrm{dm}$. long. 5-10 mm. broad at base and flat, involute toward the tip and more extensively involute on drying; panicle $1-3 \mathrm{dm}$. long. 2-6 cm. broad; spikes 5 to 20 (rarely more) per panicle, 2-15 cm. long, 3-7 mm. thick, appressed or usually diverging at angles of $10^{\circ}-20^{\circ}$, overlapping; spikelets 40 to 80 (rarely fewer) per spike; first glume $5-10 \mathrm{~mm}$. long including an awnlike tip, the keel minutely hispid; second glume $15-25 \mathrm{~mm}$. long including an awn-tip about a third to half the entire length, the keel pectinate with erect bristles $0.2-0.4 \mathrm{~mm}$. long; lemma much shorter than the second glume, apically narrowed and bidentate, on the upper half of the dorsal keel pectinate. Incl. var. Suttiei (Farw.) Fern.

In wet meadows, swampy ground, fresh-water or saline marshes, seepage areas, edge of ponds and streams, in Okla. (Ottawa and Alfalfa cos.) and n.-cen. and e. Tex., Plains Country and Trans-Pecos, scattered or rare, summer; s. Can., s. to N.C., Tenn., Ark., Tex., N.M. (Hitchcock), Ut. and Ore.

\section{Trichloris FoURN.}

A very small American genus, included by some authors in Chloris.

\section{Trichloris crinita (Lag.) Parodi. Fig. 129.}

Tufted coarse perennial; culms 4-12 dm. long; blades elongate, 2-4 mm. broad, pilose near the ligule; spikes digitate, 8 to 25 per panicle, $5-12 \mathrm{~cm}$. long, feathery, nearly straight, strictly ascending; spikelets each with one fertile floret and one staminate or neutral; fertile lemma about $3 \mathrm{~mm}$. long, both lemmas with 3 awns about $1 \mathrm{~cm}$. long.

Deep alluvial silty soil along or near intermittent creeks and along ditc ${ }^{2}$ infrequent in the Tex. Trans-Pecos and rare in w. Rio Grande Plains, N. (Dona Ana Co.) and Ariz. (Graham, Pinal, Maricopa, Cochise and Pima cos. spring-fall; Tex. to Ariz. and s. to Dgo. and Coah.; also arid-temp. areas in S. A. 


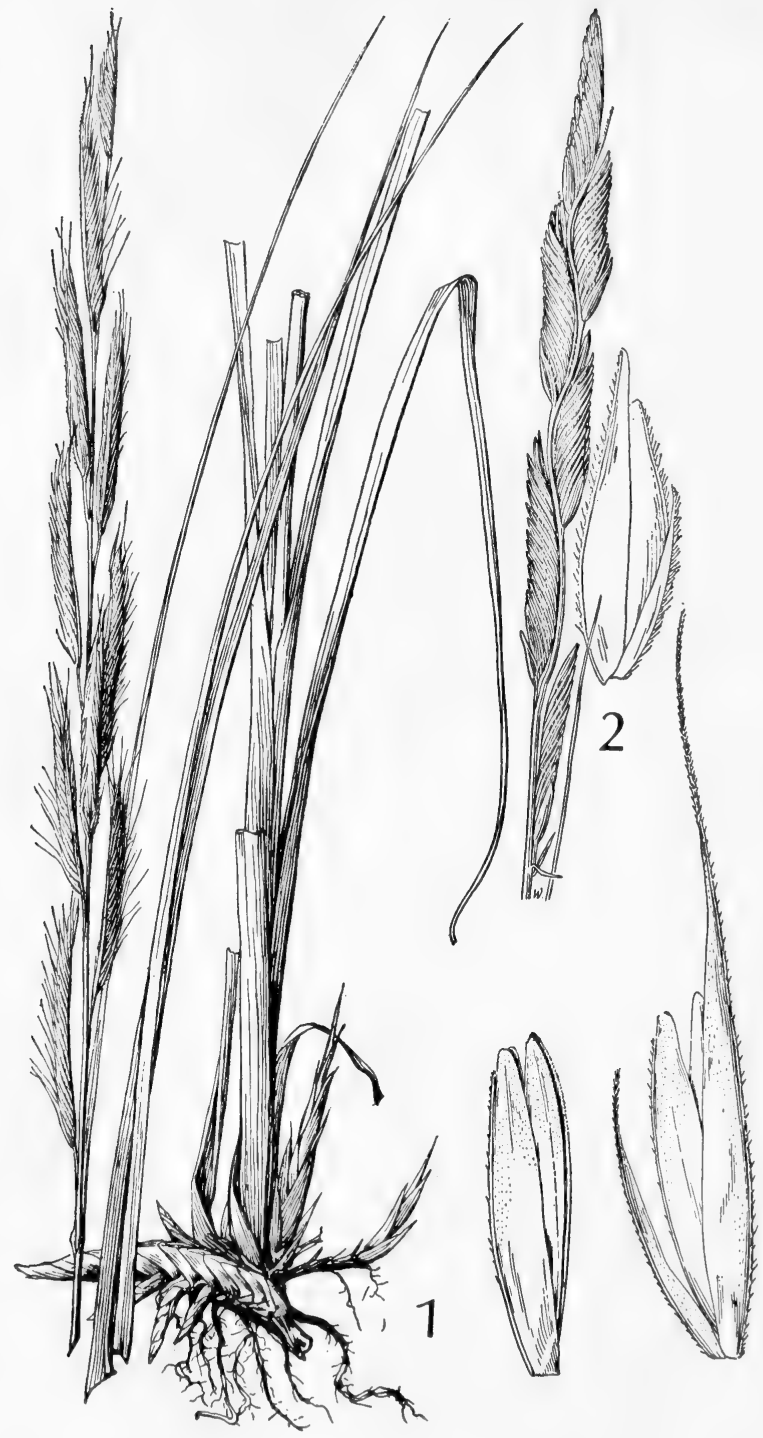

Fig. 127: 1, Spartina pectinata: plant, X 1/2; spikelet and floret, X 5. 2, Spartina gracilis: panicle, X 1; spikelet, X 5. (From Hitchcock \& Chase). 


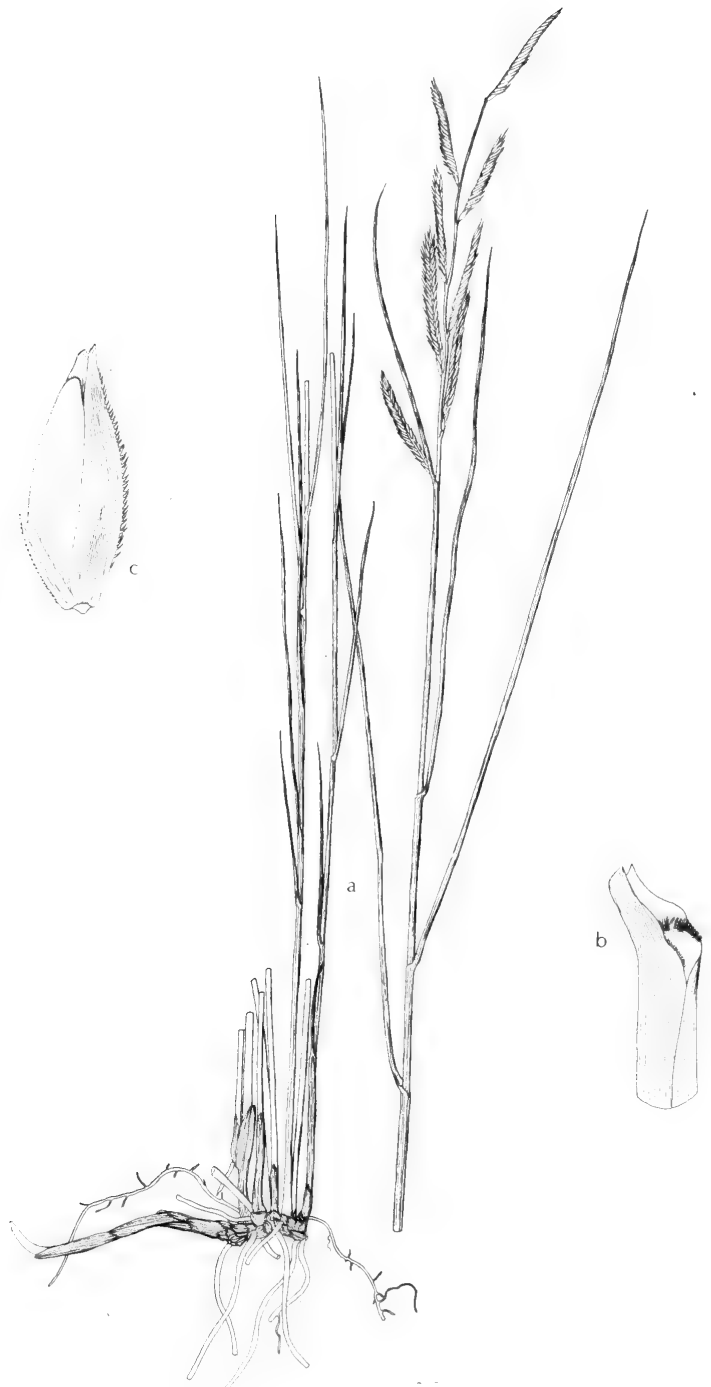

Fig. 128: Spartina patens: a, habit, X 1/3: b, ligule, X 2; c, spikelet, X 4. (Courtesy of R. K. Godfrey). 
About 30 species in temperate and cold regions as well as tropical mountains in both hemispheres.

\section{Hierochloë odorata (L.) Beauv. SweEt grass. Fig. 130.}

Culms 3-6 dm. tall, with few to several leafy shoots and slender creeping rhizomes; blades 2-5 $\mathrm{mm}$. wide, sometimes wider, those of the sterile shoots elongate, those of the culm mostly less than $5 \mathrm{~cm}$. long, rarely to $10 \mathrm{~cm}$. long; panicle pyramidal, 4-12 cm. long, from somewhat compact to loose with slender drooping branches; spikelets mostly short-pediceled, $5 \mathrm{~mm}$. long; staminate lemmas awnless or nearly so; fertile lemma pubescent toward the apex.

Wet meadows, bogs and moist places, in N. M. (San Miguel and Mora cos.) and Ariz. (Apache, Navajo, Coconino and Pima cos.); Lab. to Alas., s. to N. J., Ind., Ia., Ore., and in the mts. to N. M. and Ariz.; Euras.

This plant, also known as holy grass, vanilla grass, and seneca grass, is said to be used by the Indians in some parts of the United States for making fragrant baskets.

\section{Phalaris L. Canary Grass}

Soft tufted annuals or perennials with broad flat blades and large hyaline scalelike ligules; inflorescences terminal dense capitate ovoid or spikelike panicles; spikelets sessile, 90 to 800 per panicle, strongly laterally compressed (the plane of the glumes perpendicular or at an angle to the axis of the panicle, in transection tangential to the panicle); glumes nearly equal, large, cymbiform, enclosing and hiding the rest of the spikelet, strongly keeled and usually with wings on the upper part of the keels, usually with a strong lateral nerve on each side; zone of abscission just above the glumes; fertile floret solitary (persistently subtended at the base by 2 awns or scales or glandlike structures representing the remains of reduced sterile florets); lemma compressed-ovoid, cartilaginous, nerveless, enclosing and falling with the palea and caryopsis (grain), usually antrorsely strigose.

About 20 species in temperate regions.

1. Perennial with creeping rhizomes; panicle interrupted below, the branches 1. Annuals (2) spreading in anthesis........................................ $P$. arundinacea.

2(1). Panicle mostly 2-6 cm. long, tapering to each end; glumes 5-6 mm. long.... ..2. P. caroliniana.

2. Panicle mostly $2-17 \mathrm{~cm}$. long, subcylindric; glumes $3.5-4 \mathrm{~mm}$. long. 3. P. angusta.

\section{Phalaris arundinacea L. Reed Canary Grass. Fig. 131.}

Perennial with creeping rhizomes, glaucous; culms erect, 6-15 dm. tall, glabrous; panicle $5-20 \mathrm{~cm}$. long, pale green or tinged with purple, narrow and dense or interrupted below, the branches spreading during anthesis, the lower ones as much as $5 \mathrm{~cm}$. long; spikelets $5-6 \mathrm{~mm}$. long; glumes about $5 \mathrm{~mm}$. long, sharply keeled, narrow, acute, longer than the lemmas, the keels scabrous, wingless or very narrowly winged; fertile lemma lancolate, 3-4 $\mathrm{mm}$. long, shining, with a few appressed hairs in upper part; narrow, scale-like sterile lemmas villous, $1 \mathrm{~mm}$. long.

Sloughs, marshes, wet meadows, in mud and shallow water of ponds, lakes and streams, in N. M. (Sandoval Co.) and Ariz. (Coconino Co.); N.B. to Alas., s. to N. C., Ky., N.M., Ariz. and Calif.; Euras.

\section{Phalaris caroliniana Walt. Fig. 130.}

Tufted annual; culms 23-100 cm. long, 1-4 mm. thick, erect, sparingly branched in the lower part; ligule a hyaline scale $1-5 \mathrm{~mm}$. long; blades $5-12(-20) \mathrm{cm}$. long, 


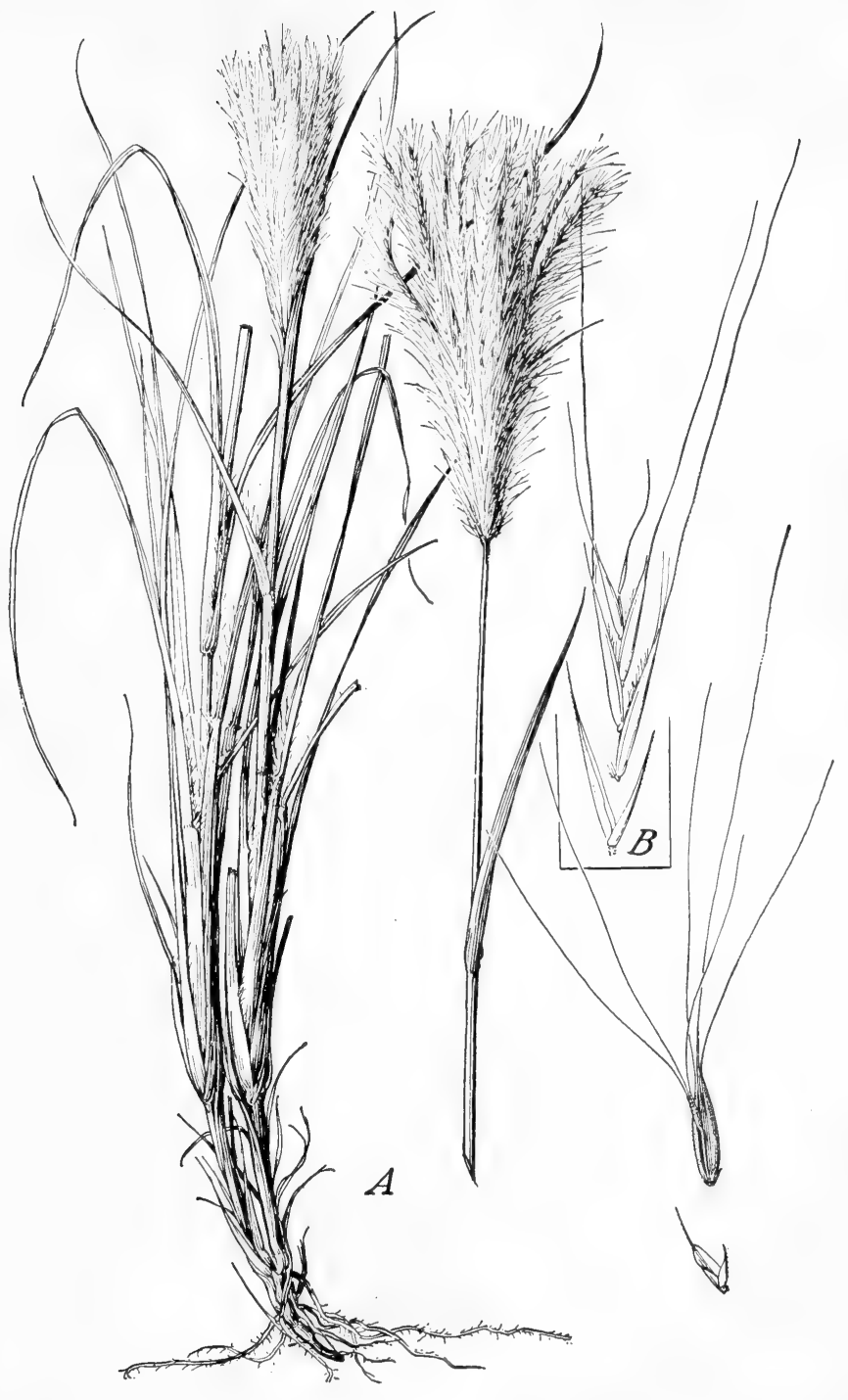

Fig. 129: A, Trichloris crinita: plant, X 1/2; glumes and florets, X 5. B, T. pluriflora (not included here.). (From Hitchcock \& Chase). 


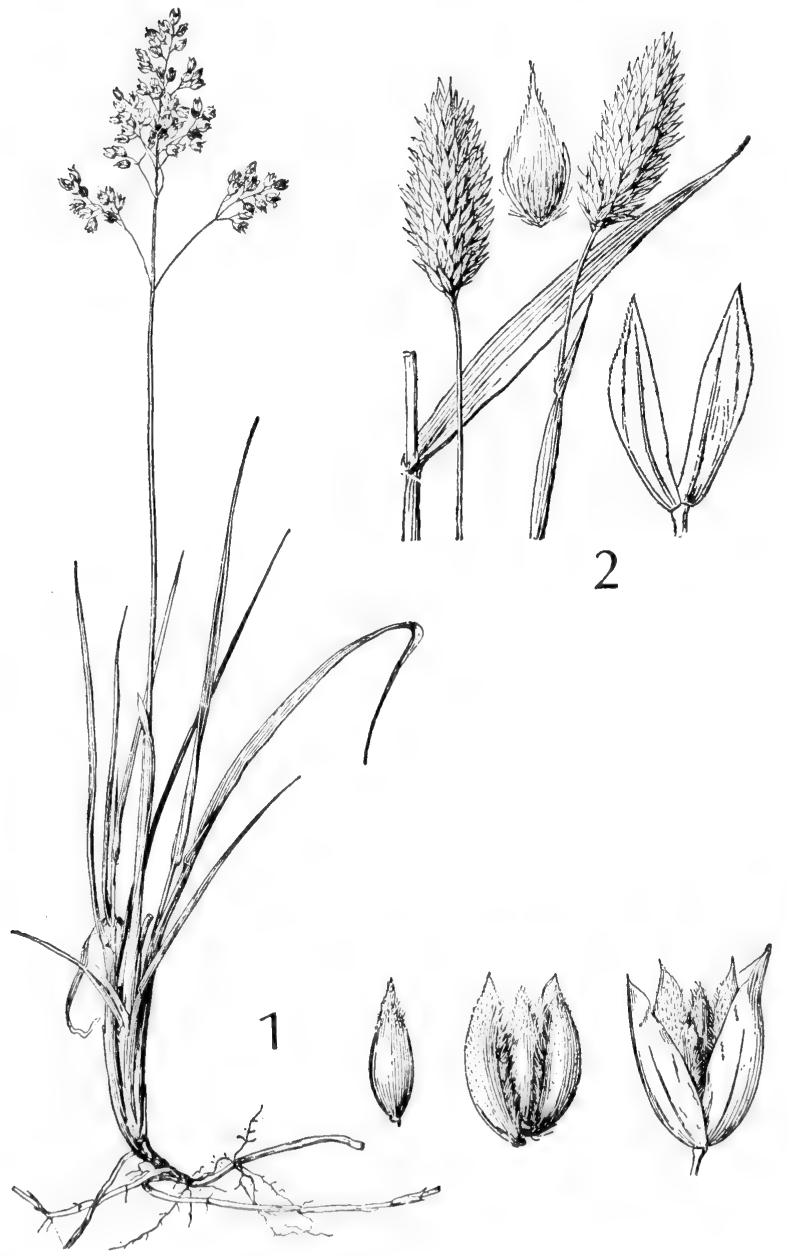

Fig. 130: 1, Hierochlö̈ odorata: plant, X 1/2; spikelets, florets and fertile florets, $X$ 5. 2, Phalaris caroliniana: plant, X 1; glumes and floret, X 5. (From Hitchcock \& Chase). 
2-9 (-13) mm. broad, flat; panicle 1-6 (-9) $\mathrm{cm}$. long, 8-20 mm. thick. ovoid to subcylindric, glumes $4.2-6.7 \mathrm{~mm}$. long, narrowly winged, as viewed from the side 3 or 4 times as long as broad; "sterile florets" subulate, $1.5-2.5 \mathrm{~mm}$. long; fertile floret 3-4.7 mm. long; grain $2-2.3 \mathrm{~mm}$. long.

Abundant in loamy usually alluvial soils near creeks, in disturbed soils along roadsides and in fallow fields and pastures, in shallow water and in wet sandy edge of ponds and lakes, in Okla. (Waterfall), throughout Tex., common toward the coast, rare in the Trans-Pecos and w. Plains Country, N. M. (Grant Co.) and Ariz. (Graham, Gila and Yavapai to Cochise, Pima and Yuma cos.), spring; Va. to Okla. and s. to the Gulf States; also Ore., Calif., s. Nev., Ariz. and N.M., s. to Son., Chih. and Coah.

\section{Phalaris angusta Trin.}

Tufted annual; culms $55-150 \mathrm{~cm}$. long, 2-6 mm. thick, erect, sparıngly branched in the lower part; ligule a hyaline scale $1-3 \mathrm{~mm}$. long; blades $2-25 \mathrm{~cm}$. long, 3-10 $\mathrm{mm}$. broad, flat; panicle $2.5-17 \mathrm{~cm}$. long, 6-15 mm. broad, cylindrical; glumes 3-5.5 mm. long, narrowly winged, as viewed from the side nearly 4 times as long as broad; "sterile florets" subulate, $0.7-1.5 \mathrm{~mm}$. long; fertile floret $2.1-3.8 \mathrm{~mm}$. long; grain 1.4-1.6 mm. long.

Locally abundant in moist loamy soil near and in ditches, creeks and bayous, in s.e. Tex., also Ariz. (Pinal Co.), Mar.-Apr.; Ga. to Tex., w. Ariz., Calif., S. A.; introd. into S. Afr.

\section{Oryza L.}

About 25 species in the Old World tropics and subtropics; we have one.

\section{Oryza sativa L. RicE. Fig. 132.}

Robust annual; culms 6-20 dm. long, 4-20 mm. thick, erect, often rooting from lower nodes; ligule a firm lacerate scale 2-6 mm. long; blades 1-6 dm. long, 4-14 $\mathrm{mm}$. broad, flat; inflorescence an open branched drooping panicle $15-40 \mathrm{~cm}$. long, each branch bearing a number of large spikelets; zone of abscission below each spikelet; spikelets sessile or usually on very short pedicels, appressed to the branches, slightly laterally compressed; lowermost parts of spikelets (interpreted either as two sterile lemmas or two glumes) small, lance-subulate, scalelike, 2-3 $\mathrm{mm}$. long; fertile floret solitary; lemma and palea fitting closely together, 7-10 $\mathrm{mm}$. long, pubescent, brownish, shining, cartilaginous-indurate, the lemma mucronate (or in some varieties awned).

Volunteering in ditches and other muddy and seasonally flooded areas in s.e. Okla. (McCurtain Co.) and s.-cen. and s.e. Tex., late summer-fall; warm parts of the world, indigenous to Old World trop.; in Am. n. to Va. and the Gulf States.

Economically and for the direct use of mankind this is undoubtedly the single most important plant species in the world.

\section{Leersia Sw.}

Perennials with few slender wiry culms; inflorescences lax open panicles with capillary branches; zone of abscission at the base of the spikelet; spikelets secund along the abaxial sides of the distal portions of the branchlets, overlapping, each consisting of a solitary naked fertile floret (glumes or sterile florets absent), laterally compressed (both lemma and palea keeled), cartilaginous, with obscure or conspicuous nerves.

About 15 species in warmer regions of the world.

1. Floret only 1 to 1.5 times as long as broad.

1. Floret at least twice as long as broad (2)

2(1). Spikelets $2.5-3 \mathrm{~mm}$. long, closely imbricate and usually parallel with the branches of the panicle.

.4. L. virginica. 

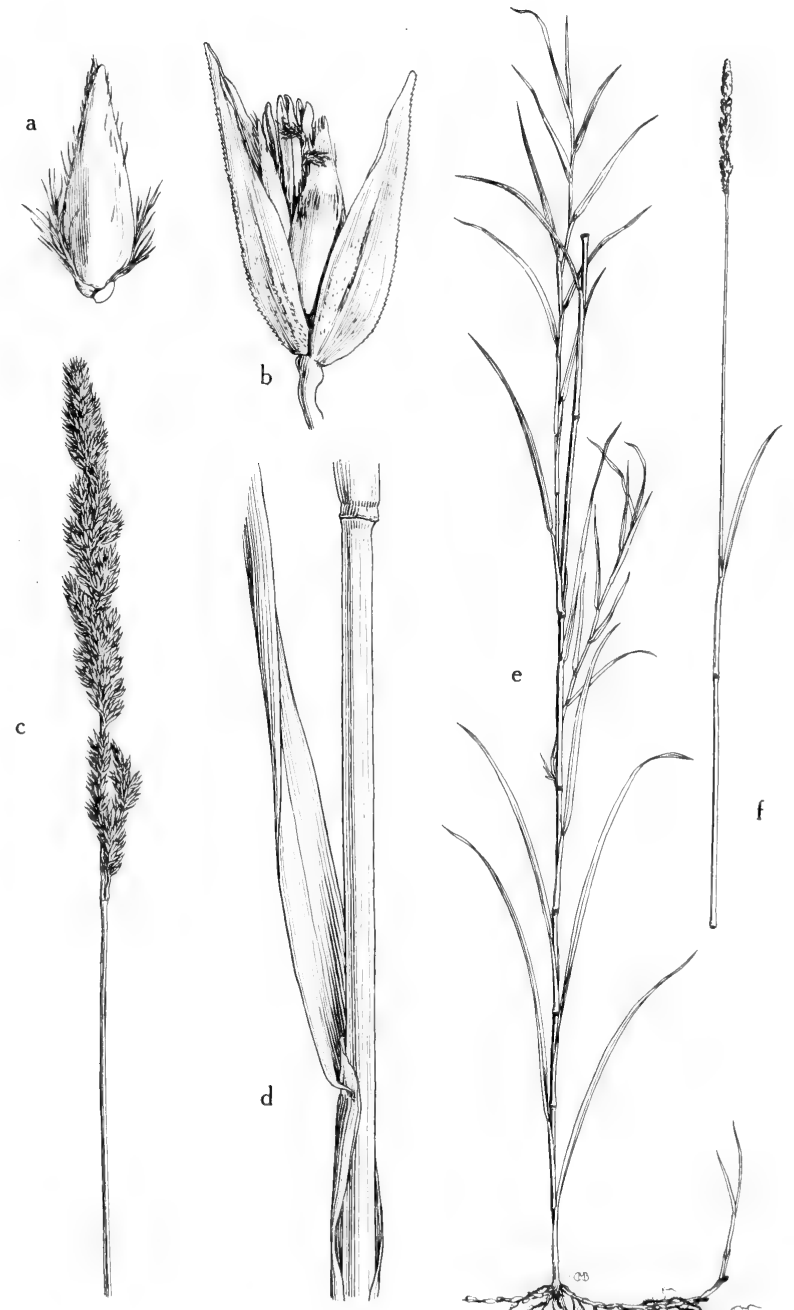

Fig. 131: Phalaris arundinacea: a, floret, showing fertile and sterile lemmas, X 8; b, spikelet, showing the strongly keeled glumes, fertile lemma and palea, X 8; c, panicle, interrupted below, $\mathrm{X} \%$; , leaf sheath, ligule, blade and mode, $\mathrm{X}_{4} /$, ; , habit, showing creeping rhizome, $\mathrm{X} 1 / 8 ; \mathrm{f}$, upper part of culm, showing panicle, $\mathrm{X} 1 / \mathrm{r}$. (From Mason, Fig. 79). 


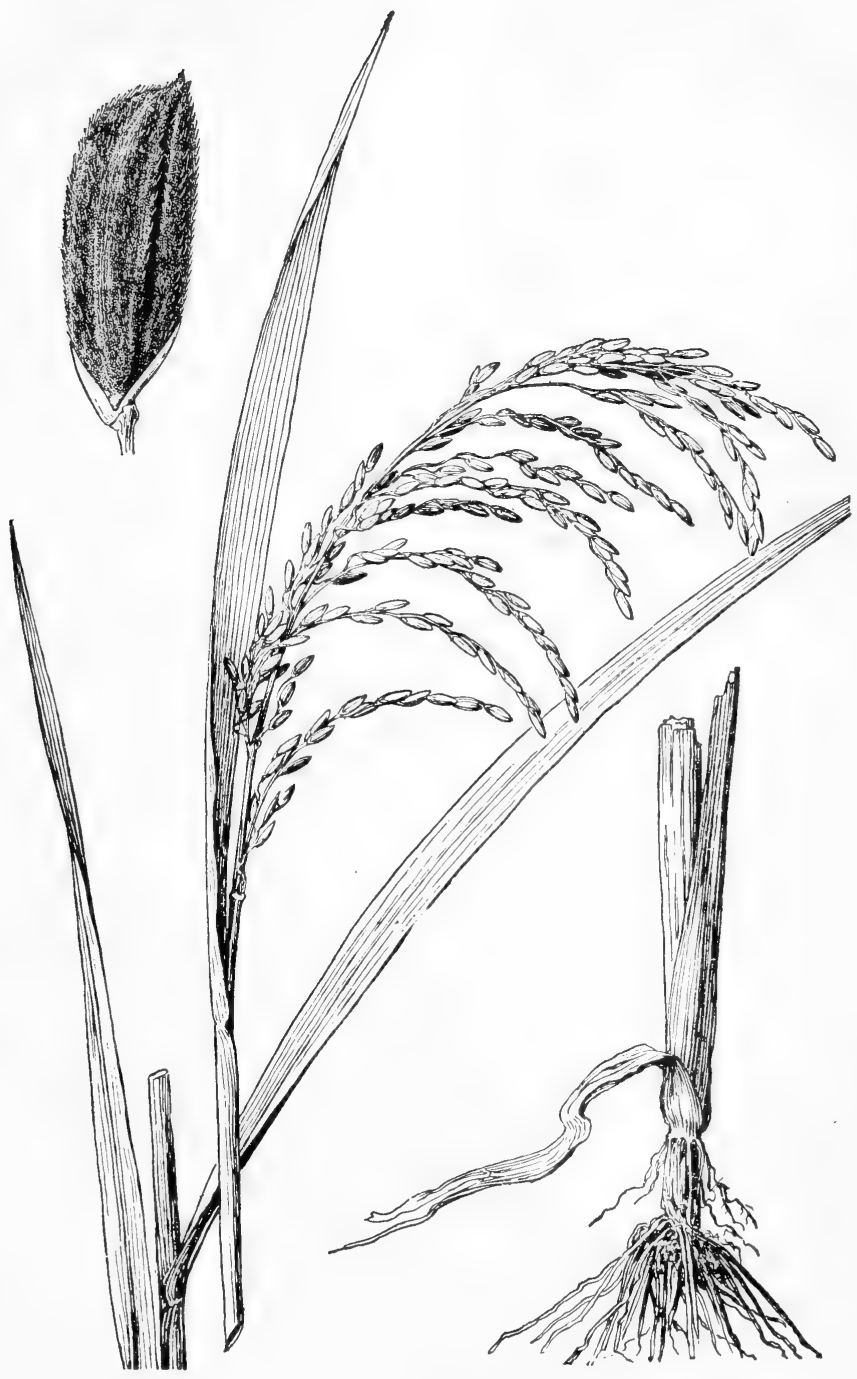

Fig. 132: Oryza sativa: plant, X 1/2; spikelet, X 5. (From Hitchcock \& Chase). 
2. Spikelets about $4 \mathrm{~mm}$. long, loosely imbricate and usually pendulous and pectinately arranged at an angle to the branches of the panicle (3)

3(2). Panicles 10-20 cm. long, open, the branches diverging.......2. L. oryzoides. 3. Panicles $5-10 \mathrm{~cm}$. long, narrow, the branches ascending or appressed.....

3. L. hexandra.

\section{Leersia lenticularis Michx. CATChFLy gRass. Fig. 133.}

Perennial with short scaly rhizomes (these seldom present on prepared specimens); aerial culms 7-15 dm. long, 1-3 mm. thick, erect or often sprawling and distally ascending; ligule a tough scale about $0.5 \mathrm{~mm}$. long; blades $13-40 \mathrm{~cm}$. long, 1-2 cm. broad, flat; panicle 1-2 dm. long, very open and subpyramidal, often nodding, the branches naked about half their length; florets 4-5 $\mathrm{mm}$. long, nearly or quite as broad as long, sparsely pubescent, the keels comb-toothed.

Sloughs, bayous, ditches, swamps and in mud and shallow water, and marshy prairies in Okla. (Waterfall) and e. and s.e. Tex., infrequent or locally abundant, late summer-fall; Md. to Minn., s. to the Gulf States.

\section{Leersia oryzoides (L.) Sw. Rice CutgRass. Fig. 134.}

Perennial with short slender scaly rhizomes; culms 7-15 dm. long, 2-3 mm. thick, often decumbent and rooting at the lower nodes or erect, shortly bearded at the nodes; ligule a firm scale about $0.5 \mathrm{~mm}$. long; blades (3-) 7-25 cm. long, 6-11 mm. broad, flat; panicle 1-2 dm. long, open, the branches diverging, naked for less than half their length; florets $3.7-5.5 \mathrm{~mm}$. long, about 2.5 times as long as broad, pubescent, the keels comb-toothed.

Near and along creeks, in marshes, swamps, muddy borders of ponds, ditches and rivers, often forming dense zones, in Okla. (McCurtain, Ottawa and Stephens cos.) and in e. and n.-cen. Tex., Edwards Plateau, n.w. part of Rio Grande Plains and Plains Country, and Ariz. (Navajo Co.), infrequent, mostly spring-fall; most of U. S. n. to Que. and B. C. (not known from Mont., Wyo., Nev. or Mex.)

The seeds and rootstocks of this species are a favorite food of various ducks, marsh birds and shore birds.

\section{Leersia hexandra Sw. Fig. 135.}

Perennial with short slender scaly rhizomes; culms 5-10 dm. long, 1.5-3 mm. thick, usually long-decumbent and rooting at the lower nodes, shorily bearded at the nodes; ligule a firm scale about $0.5 \mathrm{~mm}$. long; blades $5-18 \mathrm{~cm}$. long, 3-7 $(-10)$ $\mathrm{mm}$. broad, flat; panicle 5-9 $(-12) \mathrm{cm}$. long, 1-2 $\mathrm{cm}$. broad, the few branches acending or appressed, naked for less than half their length; florets $3.3-4.5 \mathrm{~mm}$. long, about 2.5 times as long as broad, sparsely pubescent, the keels minutely comb-toothed.

Near creeks, in shallow water of ditches and wet places, and in rivers and resacas in e. and s.e. Tex. and coastal parts of the Rio Grande Plains, infrequent, spring-fall; widely distributed in warmer parts of the world, in Am. n. to. Va. and the Gulf States.

\section{Leersia virginica Willd. White gRASS. Fig. 135.}

Perennial with short rhizomes $2-4 \mathrm{~mm}$. thick (these seldom present on prepared specimens); culms $25-120 \mathrm{~cm}$. long, 1-1.5 mm. thick, often geniculate and rooting at a few of the lower nodes but mostly ascending or erect, upper nodes minutely bearded; ligule a scale about $1 \mathrm{~mm}$. long; blades $4-10(-13) \mathrm{cm}$. long, 3-8 $\mathrm{mm}$. broad, flat; panicle 5-10 $(-18) \mathrm{cm}$. long, the very few branches diverging, naked for more than half their length; florets $2.5-3 \mathrm{~mm}$. long closely appressed and parallel to the branches, 2 to 3 times as long as broad, microscopically pubescent on sides and keels. 


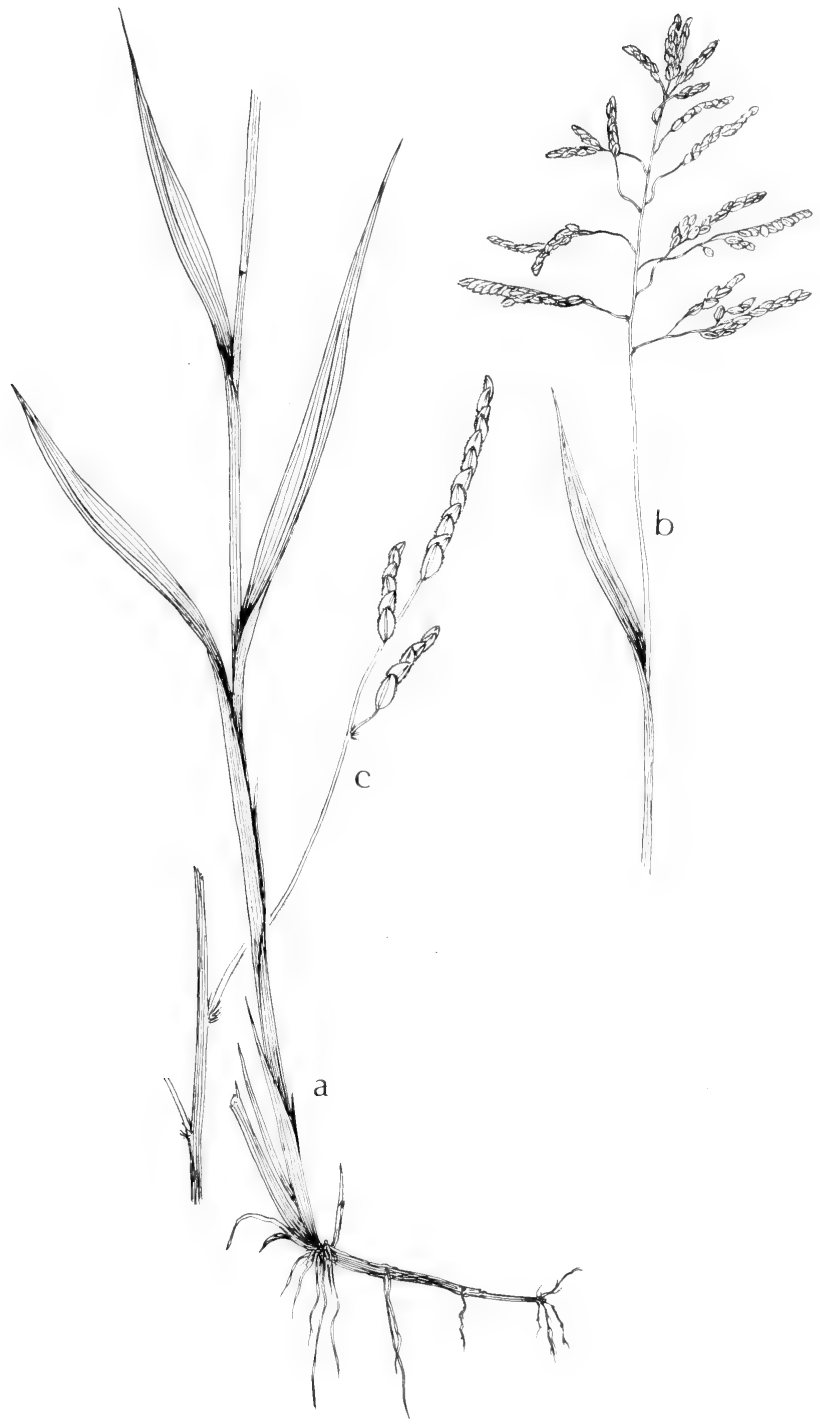

Fig. 133: Leersia lenticularis: a, basal part of plant, $X_{1 / 4}^{1 / 4}$ b, top of plant, X 1/4; c, branch of panicle, X 1. (Courtesy of R. K. Godfrey). 


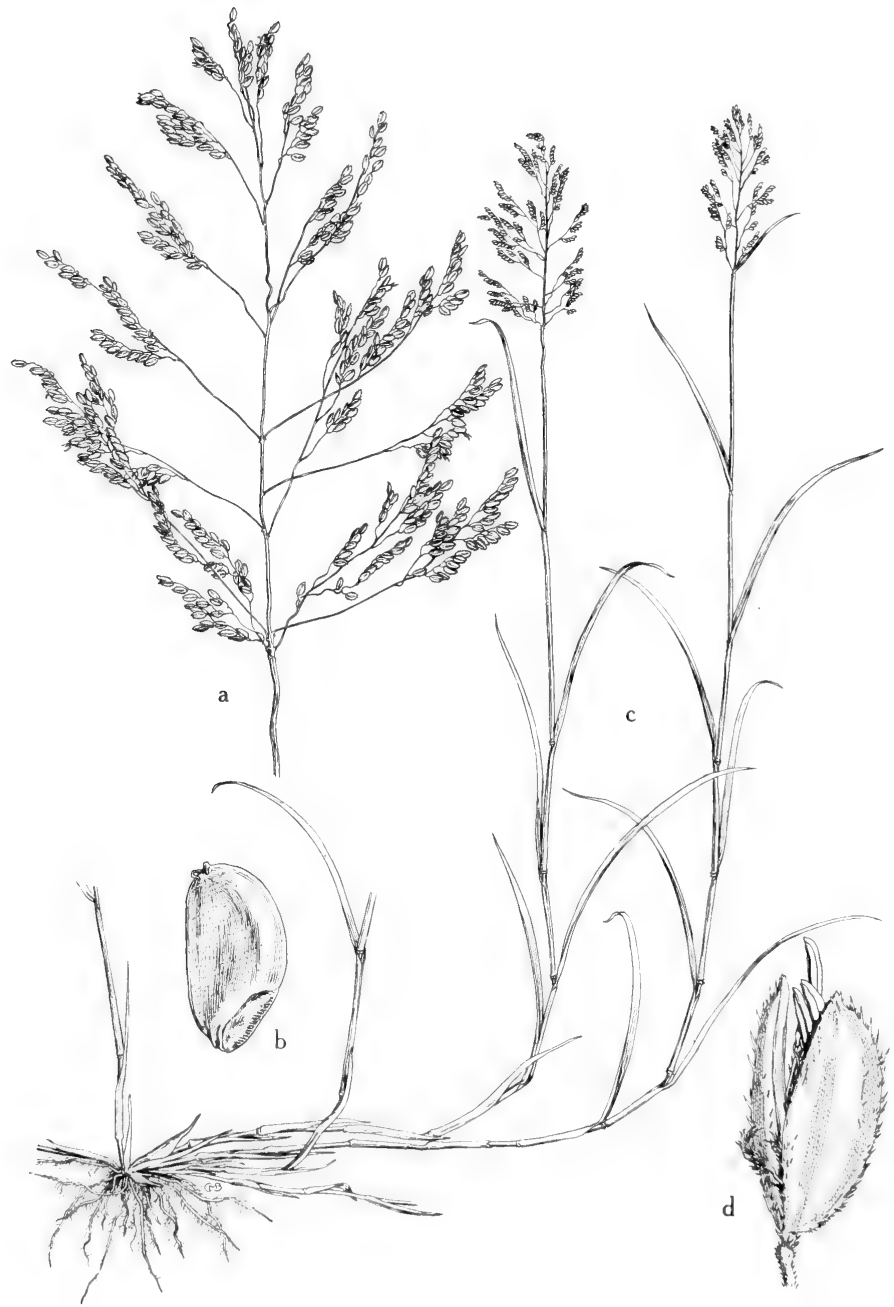

Fig. 134: Leersia oryzoides: a, panicle, X 2\%; b, seed, X 8; c, habit, showing the slender creeping rhizomes and the culms with decumbent bases, $X 1 / \mathrm{s} ; \mathrm{d}$, spikelet, laterally compressed, the glumes wanting, X 8. (From Mason, Fig. 71). 
Swamps and bogs along bayous, rivers and streams, and sand flats on the edge of ponds and lakes, in Okla. (Creek Co.) and in e., s.e. and n.-cen. Tex., infrequent to rare, spring-fall; e. U.S. w. to S.D., Neb., Kan., Okla. and Tex.

\section{Zizania L. WILD-RICE}

Tall aquatic annuals or perennials with flat blades; panicles large, terminal, the lower branches ascending or spreading and bearing the pendulous early deciduous staminate spikelets, the upper branches ascending (at maturity erect) and bearing the appressed tardily deciduous pistillate spikelets; spikelets 1-flowered, disarticulating from the pedicel; glumes obsolete, represented by a small collarlike ridge; staminate spikelet soft; lemma 5-nerved, membranaceous, linear, acuminate or awn-pointed; palea about as long as the lemma, 3-nerved; stamens 6; pistillate spikelet terete, angled at maturity; lemma chartaceous, 3-nerved, tapering into a long slender awn; palea 2-nerved, closely clasped by the lemma; grain cylindric. $1-2 \mathrm{~cm}$. long.

A genus of 2 species in North America and one in Asia.

1. Perennial, long-decumbent at base, growing in rapidly flowing water.

1. Z. texana.

1. Annual, erect, growing usually in shallow still water.

2. Z. aquatica.

\section{Zizania texana Hitchc. Texas WILD-RICE. Fig. 135.}

Coarse perennial; culms long-decumbent and rooting at nodes. stoloniform, distally ascending, 1-3 m. long, 3-13 mm. thick; ligule a scale 5-15 mm. long; blades $12-110 \mathrm{~cm}$. long, 5-23 mm. broad, flat, forming long streamers beneath surface of water; panicle 2-3 dm. long, the lower portion with spreading branches bearing staminate spikelets, the upper part with ascending or appressed branches bearing pistillate spikelets; zone of abscission below the floret or spikelet; spikelets consisting of a single naked floret (glumes obsolete or absent); staminate spikelets pendulous, 7-9 $\mathrm{mm}$. long, $1.5 \mathrm{~mm}$. broad, not indurated nor awned; pistillate spikelets erect, about $10 \mathrm{~mm}$. long and $1 \mathrm{~mm}$. broad, terete or at least not laterally compressed, the lemma indurate at maturity and bearing an awn 10-23 mm. long.

In clear cool fast-flowing spring-water in the San Marcos River, Hays Co., Tex., where it is becoming rare, fall-spring, usually early spring; endemic.

\section{Zizania aquatica L. NORTHERN WILD-RICE. Fig. 136.}

Tall annual; culms robust, to $1.5 \mathrm{~m}$. long, often long-decumbent at base and rooting at the nodes, spongy, but usually thickened at the nodes; sheaths glabrous, somewhat inflated above; blades flat 5-12 (to 50) $\mathrm{mm}$. wide, densely pubescent at the base on both surfaces and on the nodes, otherwise minutely scabrous; ligules 5-10 mm. long, ovate, hyaline, acute or somewhat lacerate at the summit; panicles large, 3-5 dm. long, terminal, monoecious, the lower branches ascending or spreading, bearing 1 to 15 pendulous reddish staminate spikelets on short capillary pedicels, the upper branches ascending, at maturity erect, bearing 2 to 6 appressed pistillate spikelets on short club-shaped pedicels: the staminate spikelets earlydeciduous and the pistillate spikelets tardily deciduous; spikelets 1-flowered, disarticulating from the pedicel; glumes obsolete, represented by a small collarlike ridge; pistillate spikelet terete, angled at maturity, $4.5-8 \mathrm{~cm}$. long, bearing a long bristlelike awn $2.5-6 \mathrm{~cm}$. long (the body of the spikelet $2-3 \mathrm{~cm}$. long); pistillate lemma rather firm and tough to thin and papery, strawlike with a somewhat lustrous glabrous surface, appressed-scabrous over the entire surface or on the margins, at the base and summit, along the awn and sometimes on the 3 nerves, the lemma closely clasping the palea by a pair of strong lateral nerves; aborted spikelets are very slender and shriveled, without a definite body; caryopsis narrowly cylindrical, about $1.5 \mathrm{~cm}$. long, pale brown to dark brown. 

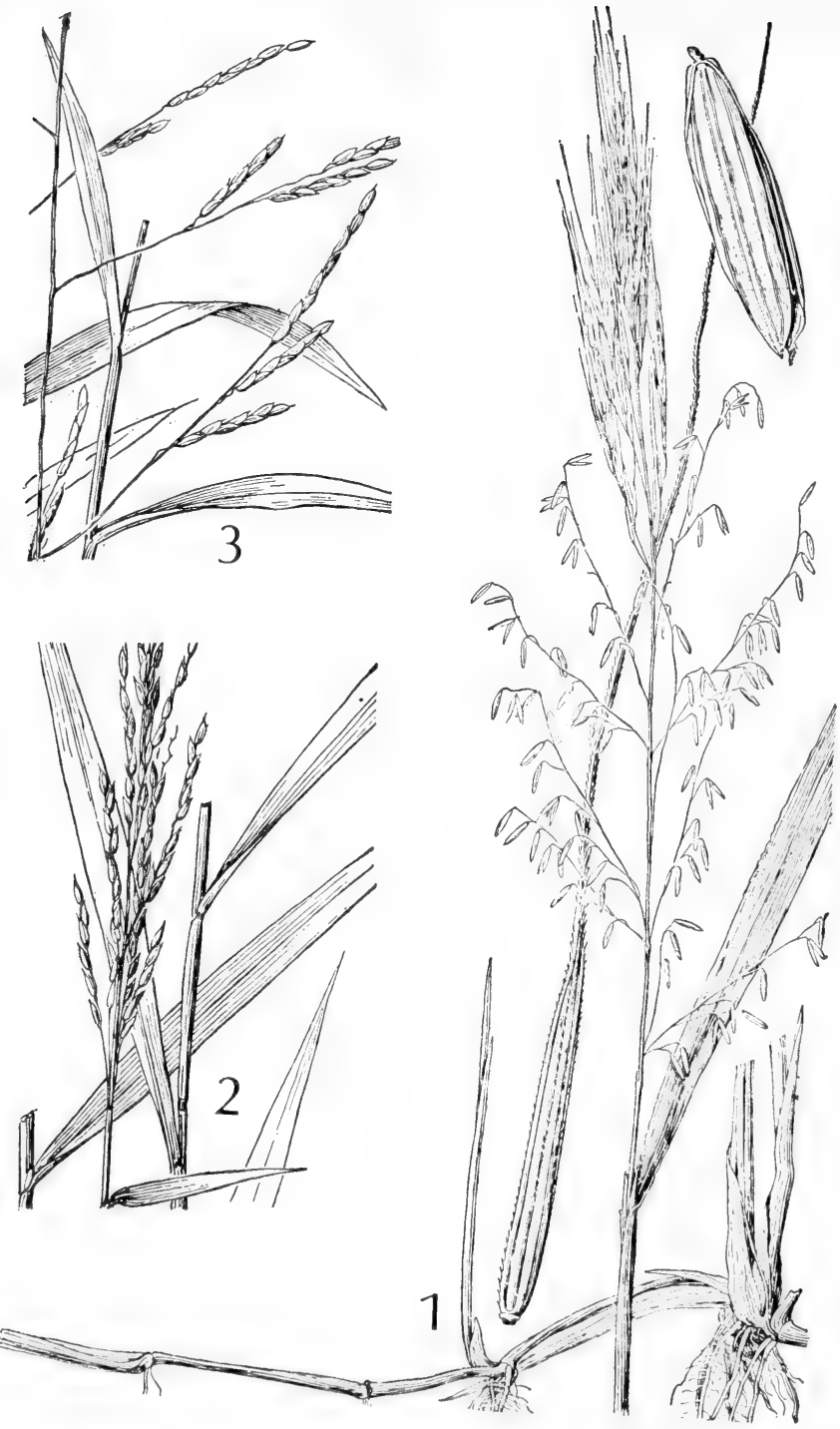

Fig. 135: 1, Zizania texana: plant, X 1/2; pistillate and staminate spikelets, X 5. 2, Leersia hexandra: X 1. 3, Leersia virginica: X 1. (From Hitchcock \& Chase). 


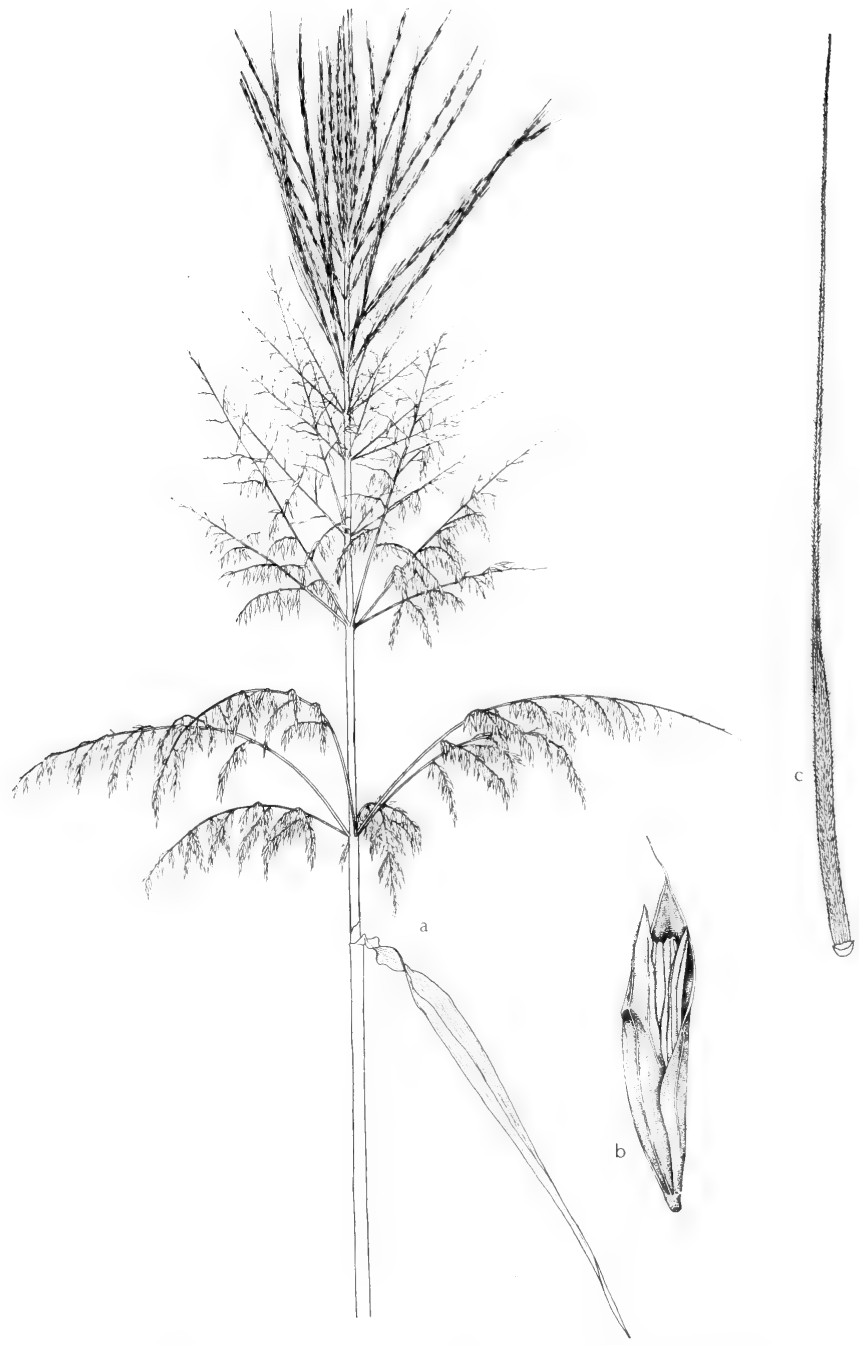

Fig. 136: Zizania aquatica: a, top of plant, X 1/3; b, staminate spikelet, X 4; c, pistillate spikelet, X 4. (Courtesy of R. K. Godfrey). 
In water and mud of springs, marshes, lakes and ponds, in Ariz. (Coconino Co., s. of Flagstaff), June-Sept.; in most of s. Can. and e. U.S., w. to Minn., Ariz. and Mo.

Several varieties are recognized. Our plant is referred to var. augustifolia Hitchc., characterized by having leaves $4-15 \mathrm{~mm}$. wide, ligules $3-10 \mathrm{~mm}$. long, and lower pistillate branches with 2 to 6 spikelets.

This provides the "wild rice" of commerce, and it is still harvested to some extent in the Great Lakes region. The seeds are a favorite food of ducks, rails, blackbirds, bobolinks and other birdlife, and it is especially valuable in northern United States and Canada where it thrives in mud and water of quiet lakes and ponds.

\section{Zizaniopsis DOELL \& ASCH.}

A genus of 4 species in North America and South America; we have one species.

\section{Zizaniopsis miliacea (Michx.) Doell \& Asch. Southern Wild-RICE. Fig. 137.}

Coarse perennial from creeping rhizomes, 5-11 mm. thick; culms 9-30 dm. long, 5-15 mm. thick, rooting at some of the lower nodes, mostly erect and unbranched; ligule a scale 5-15 mm. long; blades $15-100 \mathrm{~cm}$. long, 8-22 mm. broad, flat; panicle 3-6 dm. long, 10-17 cm. broad, the main branches verticillate and ascending, much verticillately rebranched with each branchlet bearing some pistillate spikelets and some staminate ones, both kinds ascending and appressed and superficially similar; zone of abscission below the floret; each spikelet consisting of a single naked floret (glumes obsolete or absent), 6-8 mm. long, ellipsoidal, acuminate, not at all laterally compressed; lemma 7-nerved, mucronate or with an awn 2-3 $\mathrm{mm}$. long.

At the edges of streams, in marshes, along sloughs and in shallow water of ponds and lakes, in Okla. (McCurtain and Pushmataha cos.) and s.e., e. and n.-cen. Tex., Edwards Plateau and extreme n. Rio Grande Plains, locally abundant, spring-fall; Coastal States, Md. to Tex., n. to Ky., Ark. and Okla.

\section{Hydrochloa BeAuv.}

\section{A monotypic genus of southern United States.}

\section{Hydrochloa caroliniensis Beauv. Fig. 138.}

Mostly submerged bottom-rooted aquatic perennial; culms 3-10 dm. long, about $0.5 \mathrm{~mm}$. thick, often rooted at most nodes, somewhat branched; ligule a scale of 0.5-1 mm. long; blades floating near surface or usually emergent a few $\mathrm{cm}$., 2-4 (-6) cm. long, 2-3 (-5) $\mathrm{mm}$. broad; panicles 5-20 $\mathrm{mm}$. long, racemiform, few-flowered, the terminal ones with staminate spikelets, the subterminal axillary ones with pistillate spikelets; zone of abscission below the floret; each spikelet consisting of a single naked floret (glumes obsolete or absent), not indurated and scarcely compressed; staminate floret about $4 \mathrm{~mm}$. long, pistillate ones about 2 $\mathrm{mm}$. long.

Ponds, lakes and slow-flowing streams in e. Tex., rare, late summer; Coastal States, N. C. to Tex.

This is a very inconspicuous grass and may well be more common than is indicated by the few collections. It sometimes becomes so thick where it grows as to become a nuisance.

\section{Anthaenantia BEAUV.}

Erect perennials with short creeping rhizomes; blades narrow, firm, flat, the uppermost much-reduced; panicles terminal, narrow, the slender branches ascending or appressed; spikelets obovoid, 2-flowered, the lower flower reduced; first 


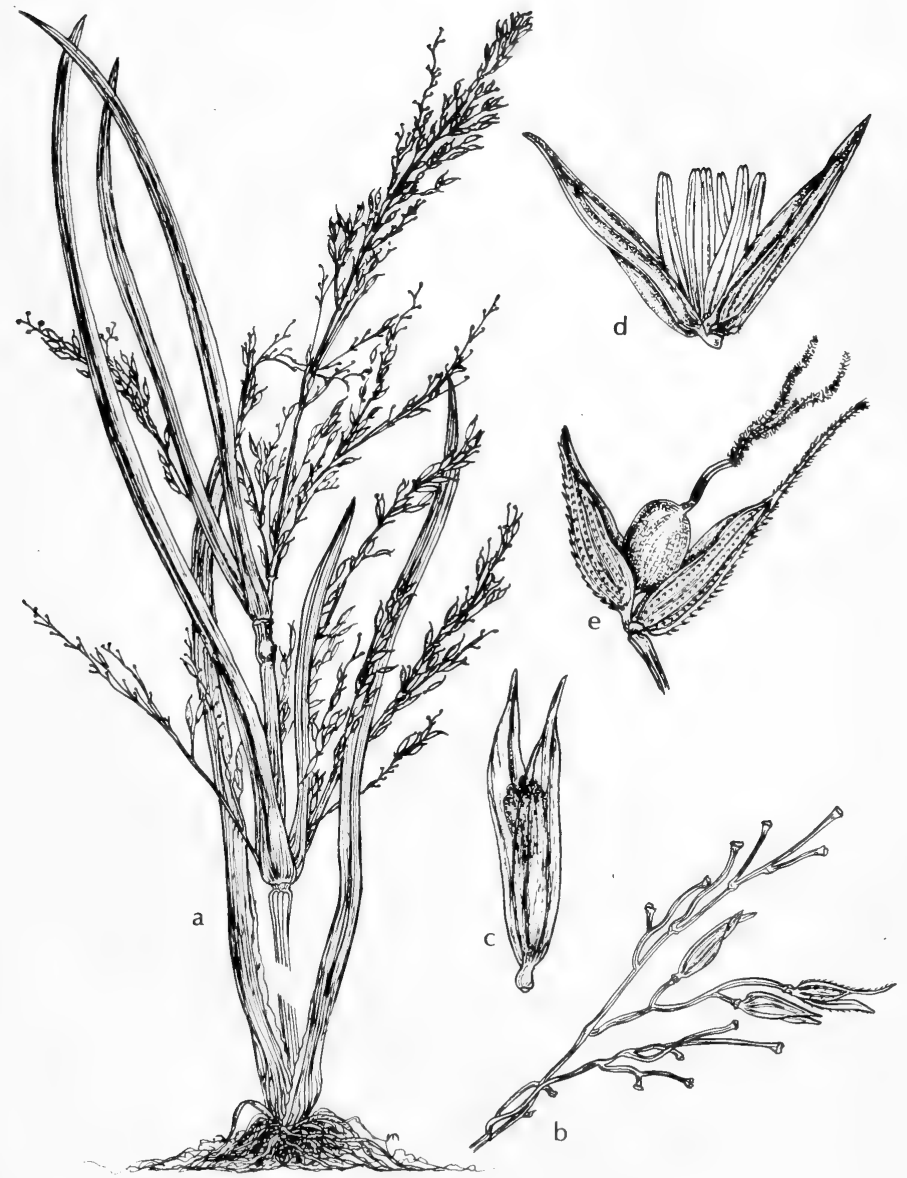

Fig. 137: Zizaniopsis miliacea: a, habit, about X 1/8; b, branch, $\mathrm{X} \mathrm{1;}$, young staminate spikelets, X $5 ; 6$, staminate spikelet, X 5 ; e, pistillate spikelet, X 5 . (V. F.). 


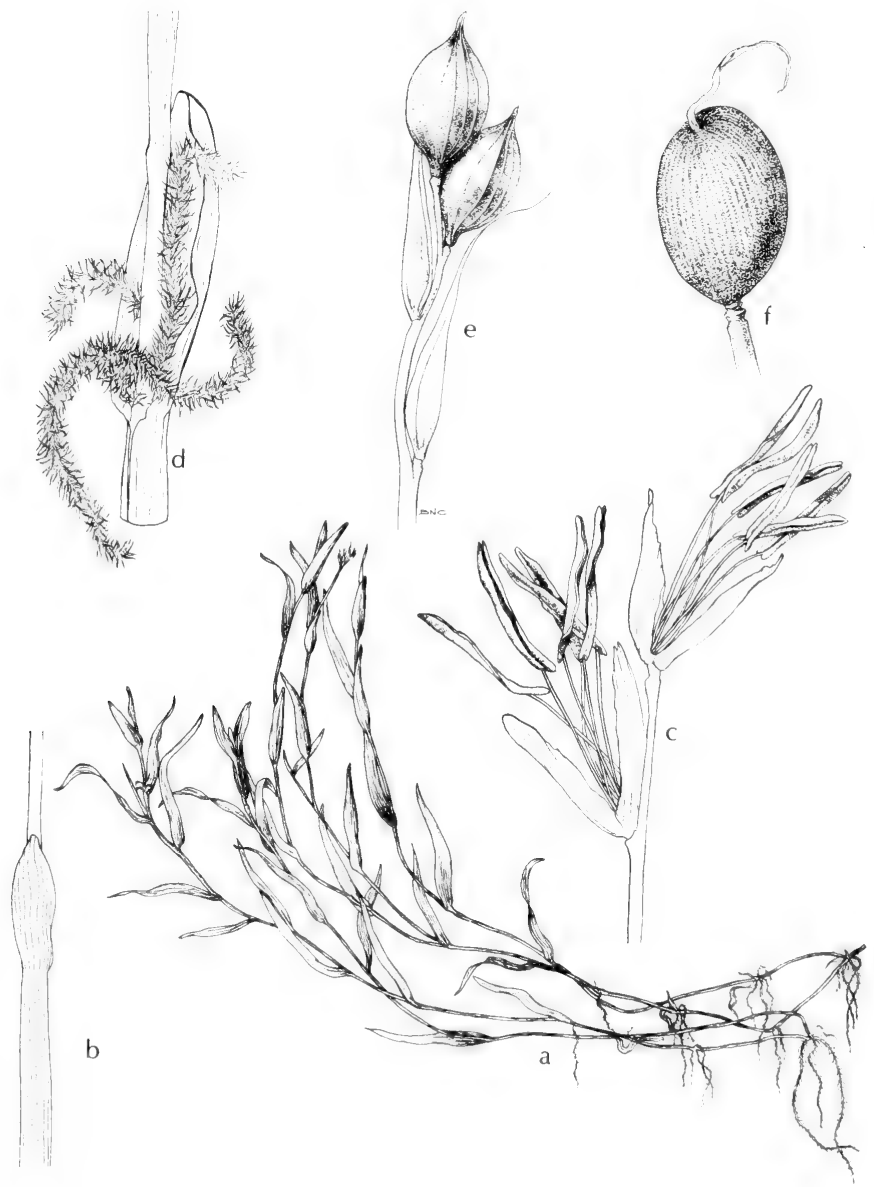

Fig. 138: Hydrochloa caroliniensis: a, habit, X 1/2; b, young staminate spikelet, X 5 ; c, staminate spikelet, X 5; d, young pistillate spikelet, X 10; e, mature pistillate spikelet, X 10; f, caryopsis, X 18. (Courtesy of R. K. Godfrey). 
glume absent; second glume and sterile lemma about equal, 5-nerved, the broad internerves infolded, densely villous; sterile lemma with a small palea and sometimes with a staminate flower; fertile lemma cartilaginous, brown, with narrow pale hyaline margins, cymbiform, 3-nerved, subacute.

An American genus of 2 species.

1. Blades erect or spreading, rather blunt or rounded at apex, linear, folded at base; panicle usually purple... 1. A. rufa.

1. Blades ascending or spreading (on the average shorter and broader than in A. $r u f a$ ), tapering to apex, rounded at base; panicle usually pale... 2. A. villosa.

1. Anthaenantia rufa (Ell.) Schult. Fig. 139.

Culms slender, 6-12 dm. tall; blades elongate, 3-5 $\mathrm{mm}$. broad, often scabrous; panicle $8-15 \mathrm{~cm}$. long, usually purple; spikelets $3-4 \mathrm{~mm}$. long.

Infrequent in wet savannahs and sandy woodlands, e. and s.e. Tex., summerfall; Coastal States, N. C. to Tex.

2. Anthaenantia villosa (Michx.) Beauv. Fig. 139.

Differing from $A$. rufa in the broader, mostly shorter, spreading blades and in the usually pale panicles.

Rare in sandy woodlands and wet savannahs, in mud on edge of ponds, s.e. and e. Tex., summer-fall; Coastal States, N.C. to Tex.

\section{Digitaria FABR. CRABGRASS}

A genus of several hundred species in warm regions, sometimes made to include the related genera Trichachne and Leptoloma. The introduced annual crabgrasses, $D$. sanguinalis, and the more abundant native $D$. adscendens and $D$. diversiflora are persistent and pernicious weeds in the loamy soil of plowed fields, lawns and flowerbeds.

\section{Digitaria sanguinalis (L.) Scop. Northern CRABgrass. Fig. 140.}

Tufted and/or usually stoloniferous annual freely rooting at the nodes; culms 15-90 cm. long, 1-3 mm. thick, usually long-decumbent, ascending only at the ends; ligule a thin scale 1-2 mm. long; blades 2-7 cm. long, 3-10 mm. broad, flat, usually crisped, sparsely or usually densely papillose-pilose; sheaths papillosepilose; panicle axis $1-15(-30) \mathrm{mm}$. long; racemes 2 to $11,4-12 \mathrm{~cm}$. long, 1-2 $\mathrm{mm}$. thick, often purplish, the wing of the rachis as broad as the central rib; spikelet 2.3-3.2 mm. long; first glume present but minute; second glume 1-1.9 mm. long, narrow, a third to three fifths (usually half) as long as the spikelet; sterile lemma as long as the spikelet, usually with a sparse short antrorse-appressed silky fringe on the margins and the 2 to 4 lateral nerves usually with minute inflexible pointed cilia (as seen under a powerful lens); "fruit" (the lemmas and its enclosures) often pale-plumbeous.

Disturbed soil along roads, in fields and gardens, along irrigation ditches, margin of ponds and spring branches and wet gravel bars, in Okla. (LeFlore, Ottawa and Mayes cos.), frequent in the Tex. Plains country and infrequent to Trans-Pecos, n.-cen. and e. Tex., s. as far as Travis and Gonzales cos., summerfall; s. Can., N. E., s. to Va., w. and s.w. to Wash., Calif. and Tex.; scattered in U. S.; also Son., Chih. and Dgo.; introd. from n. Eur., now widespread in temp. areas.

\section{Eriochloa H. B. K. Cupgrass}

Tufted annuals or perennials; inflorescence an elongate panicle of racemes attached in 2 rows along 1 side of a more or less flattened axis (or on 2 sides when the axis is vaguely broadly triangular in transection); racemes with more 


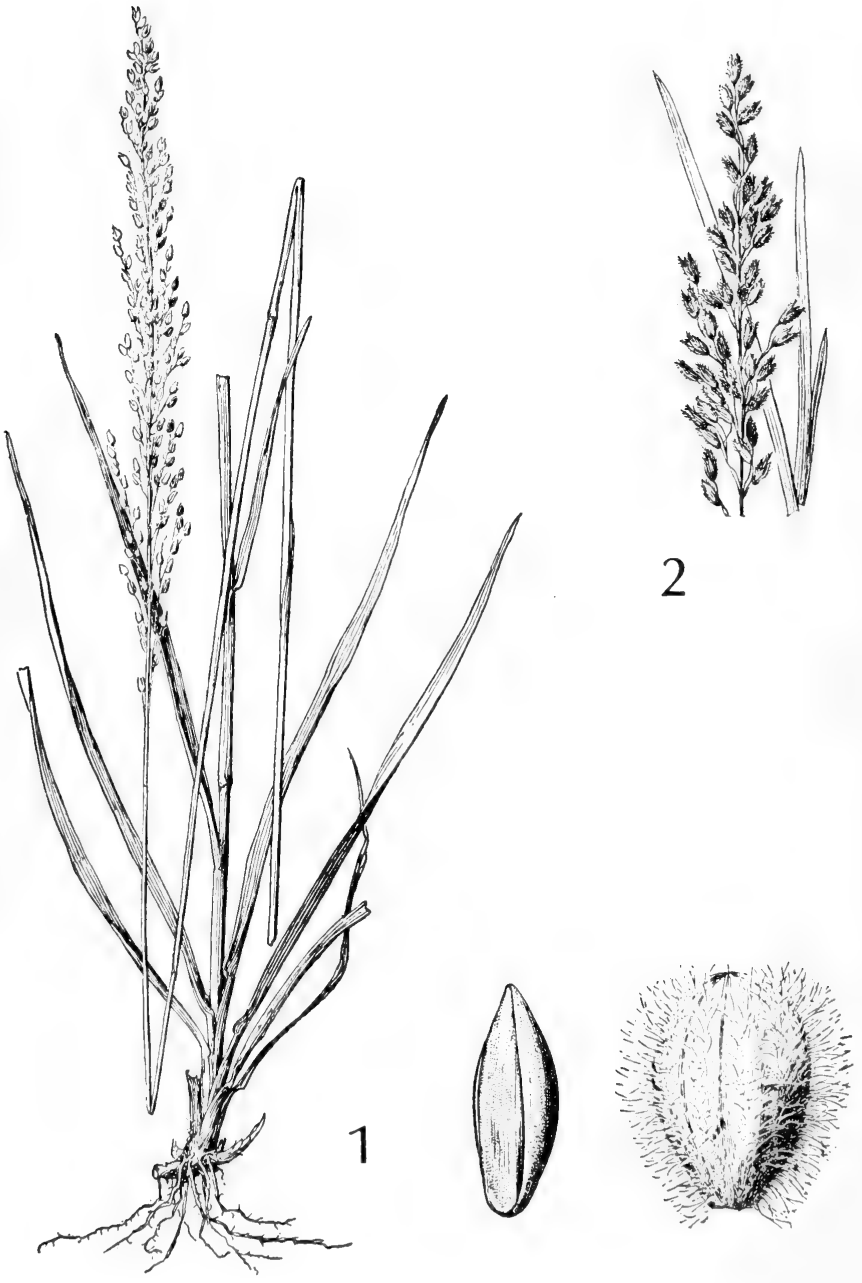

Fig. 139: 1, Anthaenantia villosa: plant, X 1/2; spikelet and floret, X 10, 2, Anthaenanthia rufa: spike, X 1. (From Hitchcock \& Chase). 
or less flattened (or in transection broadly triangular) rachises; zone of abscission at the base of the spikelet below the callus; spikelets attached in 2 rows abaxially on the rachis, strongly dorsally compressed, each with one perfect floret, solitary or paired or at the bases of the raceme in racemelets of 3 (in extralimital species the basal racemelets have up to 15 spikelets in 2 rows along the abaxial side of a flattened rachilla, the "raceme" then being a small panicle), commonly the uppermost spikelets solitary even when the lower ones are paired and the pedicelled one slightly larger than the sterile one of the same pair; first glume truncate, about $0.1 \mathrm{~mm}$. long, discolored, closely investing the minute swollen portion of the rachilla below the second glume, the swelling and the glume constituting the "callus"; second glume as large as the spikelet, abaxial, marginally often revolute; sterile lemma toward the rachis, nearly as large as the second glume; fertile lemma abaxial, thin-cartilaginous but not indurate, stramineous, elliptic-oblong, shorter than the second glume, marginally revolute and clasping the palea of the same texture, surficially with microscopic transverse rugae or puncticulate and apically mucronate or with an antrorsely scabrous awn.

About 20 species in warm regions. The spikelet measurements given below do not include the "callus".

1. Plant perennial (but flowering the first year); foliage essentially glabrous; spikelets slightly acuminate or usually merely tapered to a point, usually with a purplish tinge; fertile lemma with an awn 0.9-1.5 $\mathrm{mm}$. long

1. E. punctata.

1. Plant annual; foliage finely pubescent (as seen under a lens), rarely glabrate; spikelets distinctly acuminate to a very fine point, usually greenish; fertile lemma with an awn $0.3-0.8(-1) \mathrm{mm}$. long....2. E. contracta.

\section{Eriochloa punctata (L.) Desv. Fig. 140.}

Tufted weak perennial but flowering the first year; culms 3-10 dm. long, 2-5 mm. thick, commonly geniculate and stoloniform basally, distally ascending, leafy; ligule a fringe about $1 \mathrm{~mm}$. long; blades (3-) $10-27 \mathrm{~cm}$. long, 3-10 mm. broad, mostly flat or folded, essentially glabrous; panicle dense and elongate with numerous broadly overlapping ascending racemes; pedicels merely scabrous, without any longer hairs; spikelets solitary or paired or in threes, 4-6 mm. long, tapered to the slightly or not acuminate apex, purplish when mature; fertile lemma with an awn $0.9-1.5 \mathrm{~mm}$. long.

Tight loamy moist soil near ponds or seasonally muddy areas, in marshes and on river banks in s.e. Tex. and coastal parts of the Rio Grande Plains, frequent, spring-fall; warmer parts of Am., n. to La. and Tex.

Some plants seem intermediate between this species and $E$. contracta.

\section{Eriochloa contracta Hitchc. PRAIRIE CUPGRASS. Fig. 140.}

Tufted annual; culms 2-8 dm. long, 1-4 mm. thick, geniculate and infrequently shortly stoloniform basally, mostly ascending, leafy; ligule a fringe 1-2 mm. long; blades 3-20 cm. long, 2-6 mm. broad, mostly flat or folded, or eventually involute, shortly pubescent (like the sheaths); panicle narrow, with overlapping erect racemes; pedicels scabrous and also apically with some long erect cilia a third to half as long as the spikelet; spikelets solitary or paired, (3.1-) 3.7-4 (-5) $\mathrm{mm}$. long, somewhat shaggy-pubescent, acuminate to a long fine point, greenish to stramineous at maturity; fertile lemma with an awn $0.3-0.8(-1) \mathrm{mm}$. long.

Tight loamy usually seasonally moist soil near swales in prairies and at edges of fields and roadsides and lawns, in ditches, marshy areas and wet depressions, in Okla. (Nowata Co.) and s.e. Tex. and Rio Grande Plains n. to. n.-cen. Tex., infrequent w. to e. Plains Country, and Ariz. (Santa Cruz, Pima and Yuma cos), spring-fall; Neb. s. to Tex. and La., w. to Colo. and Ariz.; adv. in Mo. and Va. 


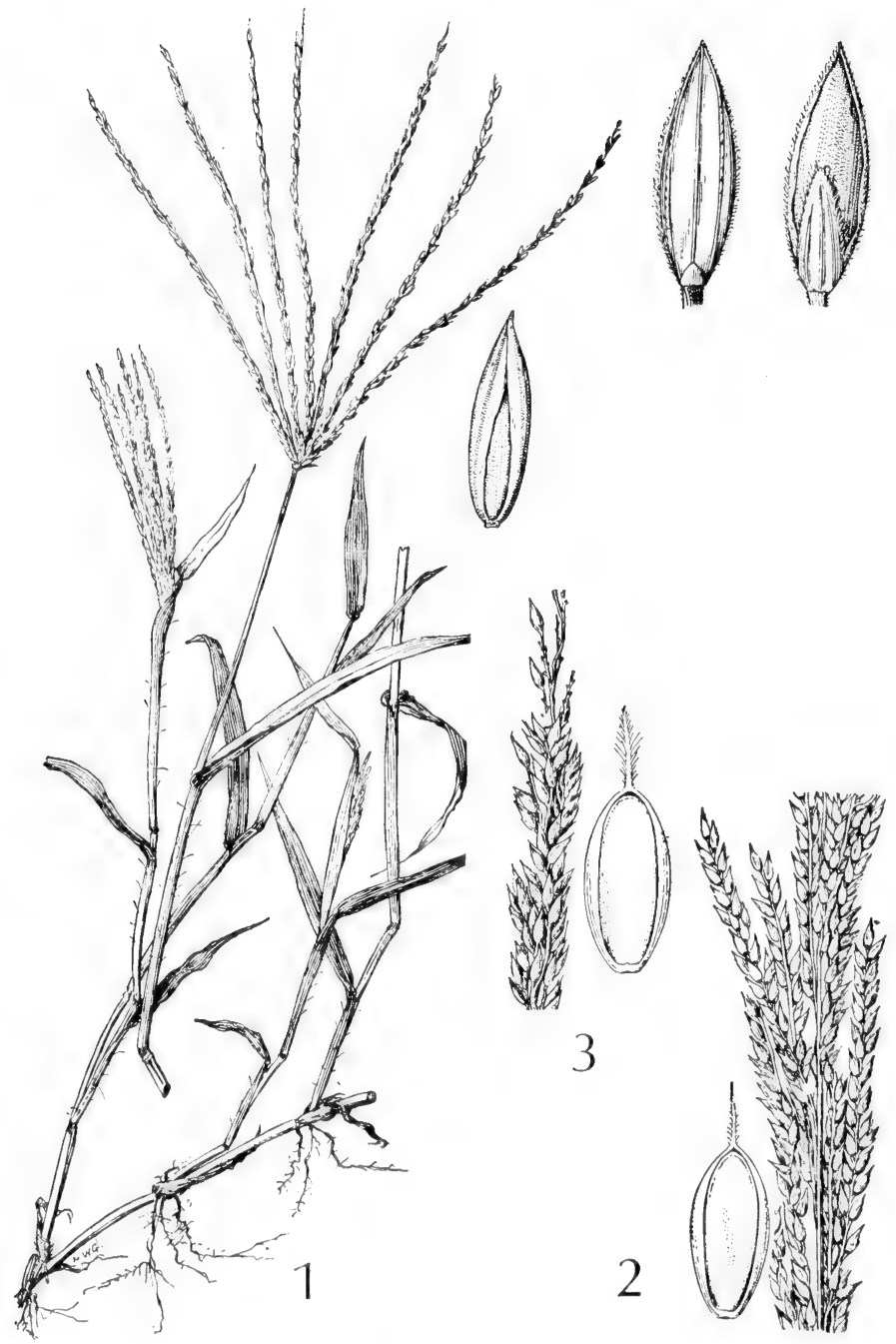

Fig. 140: 1, Digitaria sanguinalis: plant, X 1/2; two views of spikelets and floret, X 10. 2, Eriochloa punctata: panicle, X 1; floret, X 10. 3, Eriochloa contracta: panicle, X 1; floret, X 10. (From Hitchcock \& Chase). 


\section{Axonopus Beauv.}

Tufted and usually stoloniferous perennials; blades broad and flat; floriferous culm at anthesis short, after anthesis greatly elongating, filiform; panicle a terminal pair of ascending divergent linear spikes, with or without another 1 or 2 spikes attached to the axis subterminally; spikes with flattened or even narrowly winged rachises; zone of abscission at the base of the spikelet; spikelets solitary, in 2 rows on the abaxial side of (and appressed to) the rachis, considerably dorsally compressed; first glume absent; "second" (or only) glume abaxial (away from the rachis), as large as the spikelet; sterile lemma appressed to the rachis (sterile palea absent); fertile lemma oblong, abaxial, thin-cartilaginous but not indurate, the margins revolute and clasping the palea of the same texture; fertile floret perfect.

A genus of warm parts of America, with perhaps as many as 75 species. They are of considerable importance in pastures near the coast in east and southeast Texas.

1. Spikelets 4.5-6 $\mathrm{mm}$. long; spikes about $2 \mathrm{~mm}$. thick

1. A. furcatus.

1. Spikelets $1.7-3 \mathrm{~mm}$. long; spikes about $1 \mathrm{~mm}$. thick (2)

2(1). Spikelets (2.3-) 2.5-3 mm. long

2. Spikelets $1.7-2.2 \mathrm{~mm}$. long.......

2. A. compressus. 3. A. affinis.

1. Axonopus furcatus (Flügge) Hitchc. Fig. 141.

Stoloniferous perennial with floriferous tufts at the nodes; culms 4-10 dm. long, compressed, 2-4 mm. wide on the broad axis; ligule a minute firm scale or obsolete; blades 5-15 (-25) cm. long, 5-10 (-13) $\mathrm{mm}$. broad, blunt; spikes 2, digitate, 4-10 cm. long, about $2 \mathrm{~mm}$. thick; spikelets $4.5-6 \mathrm{~mm}$. long, glabrous, apically pointed.

Moist sand, in marshes, on river banks and wet pine barrens, e. and s.e. Tex., infrequent, summer-fall; Coastal States, Va. to Tex.; also Ark.

\section{Axonopus compressus (Sw.) Beauv. Fig. 141.}

Tufted perennial; culms $20-75 \mathrm{~cm}$. long, compressed, about $2 \mathrm{~mm}$. broad on the long axis, often rather long-stoloniferous basally, the tufted floriferous culms erect and unbranched; ligule a scale about $0.5 \mathrm{~mm}$. long; blades $8-25 \mathrm{~cm}$. long (shorter on stolons), 5-7 (-10) mm. broad; spikes 2 to $4,4-10 \mathrm{~cm}$. long, $1 \mathrm{~mm}$. thick; spikelets (2.3-) 2.5-3 mm. long, minutely pubescent basally, apically pointed, the point prolonged beyond the blunt end of the fruit.

Moist or wet sand, s.e. Tex., rare (near Anahuac, Chambers Co.), mostly in the fall; widespread in warmer parts of Am., n. to Fla., La. and Tex.

\section{Axonopus affinis Chase. Carpet grass. Fig. 141.}

Tufted perennial; culms 20-75 $\mathrm{cm}$. long, compressed, about $2 \mathrm{~mm}$. broad on the long axis, often rather long-stoloniferous basally, forming carpets but the tufted floriferous culms erect and unbranched; ligule a scale about $0.3 \mathrm{~mm}$. long; blades 6-17 $(-28) \mathrm{cm}$. long, shorter on the stolons, 3-6 (-9) $\mathrm{mm}$. broad, flat, blunt; sheaths keeled, spikes 2 to $4,2-10 \mathrm{~cm}$. long, about $1 \mathrm{~mm}$. broad; spikelets $1.7-2.2$ $\mathrm{mm}$. long, very minutely pubescent around the edges, apically rather blunt, the "second" glume not much if any prolonged beyond the fruit.

Moist sand, in wet mucky or sandy meadows, openings in forests, roadsides, in s.e. Okla. (Waterfall) and e. and s.e. Tex., very frequent, spring-fall (in Calhoun, Jackson and Aransas cos. even as late as Dec. and as early as Feb.); widespread in warmer parts of Am. n. to N. C. and the Gulf States, Ark. and Okla. 


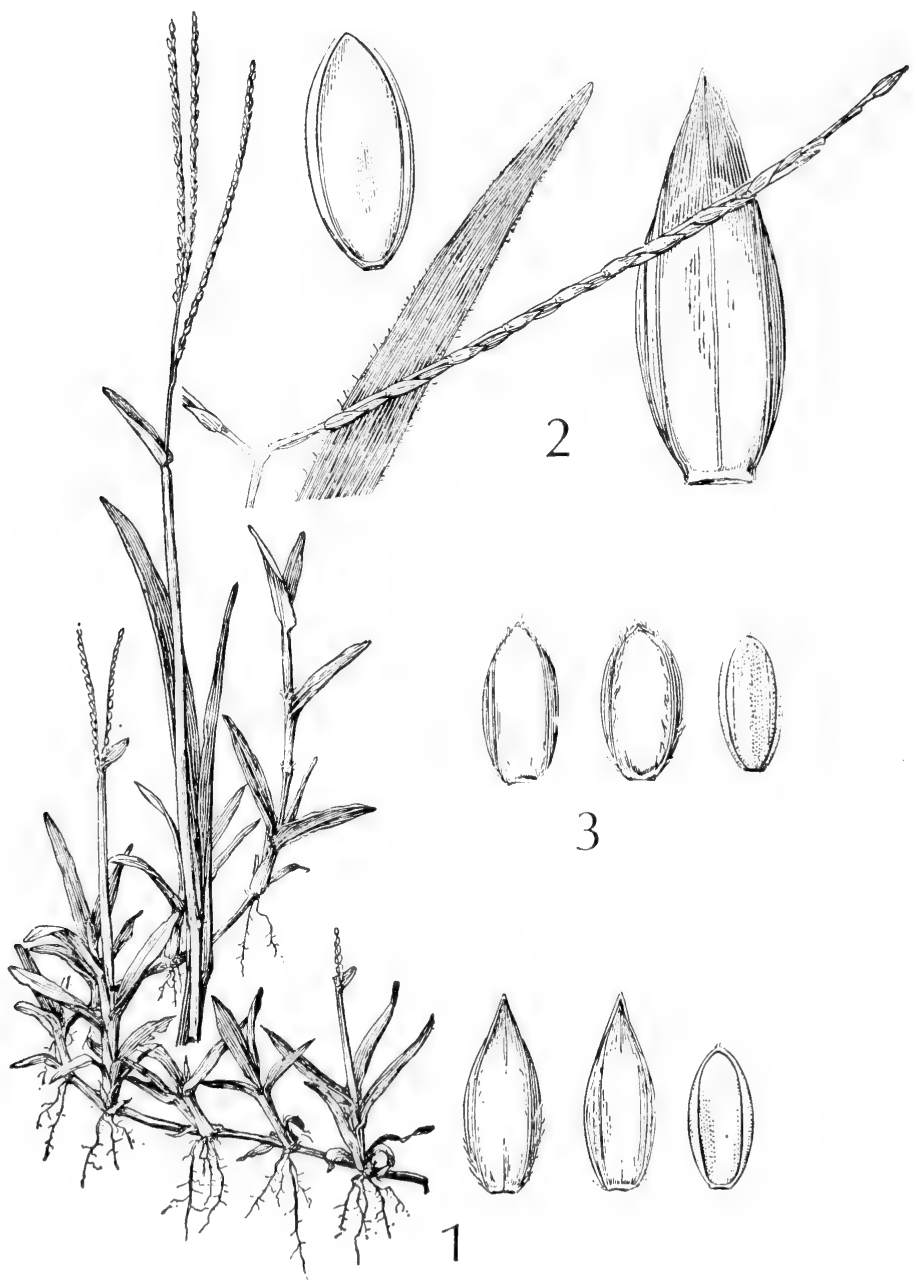

Fig. 141: 1, Axonopus compressus: plant, X 1/2; two views of spikelet and floret, $\mathrm{X}$ 10.2, Axonopus furcatus: plant, X 1; spikelet and floret, X 10. 3, Axonopus affinis: two views of spikelet and floret, X 10. (From Hitchcock \& Chase). 


\section{Paspalum L. Paspalum}

Mostly perennials; ligule a scale; inflorescence a panicle of 1 to several racemes on the common axis; raceme with a more or less flattened rachis; the numerous spikelets borne in pairs or singly in 2 rows on the abaxial side of the rachis, the pedicels of the pairs short and unequal in length; zone of abscission at the base of the spikelet at the end of the pedicel; spikelets each with a single perfect floret subtended by 2 or 3 scales, when 3 then the lowest one being a minute abaxial first glume; next highest one of the adaxial second glume as large or nearly as large as the spikelet; the abaxial sterile lemma representing the sole remains of a neutral lower floret; fertile lemma adaxial, chartaceous-indurate, convex, the margins revolute, clasping the fertile palea of similar texture, the fertile lemma and palea and their enclosures and appendages constituting the "fruit."

A genus of about 250 species in warm regions. Most Paspalums are of great economic importance as forage plants.

1. Racemes 20 to 50 per panicle, eventually deciduous from the panicle axis; commonly attached and floating aquatics; spikelets solitary, 1.2-1.7 $\mathrm{mm}$. long, pubescent.......................................................16. P. fluitans.

1. Racemes fewer, persistent (2)

2(1). "Second" (only) glume and sterile lemma abruptly pointed beyond the blunt fruit (3)

2. Second (only) glume and sterile lemma not abruptly pointed beyond the fruit (5)

3(2). Spikelets solitary (that is, not paired) and glabrous; fruit with microscopic cilia apically.....

14. P. acuminatum.

3. Spikelets paired and silky-fringed (4)

4(3). Racemes ( 8 to) 12 to 22 per panicle; spikelets $2-3 \mathrm{~mm}$. long.

5. P. Urvillei.

4. Racemes 3 to 6 (to 11 ) per panicle; spikelets $2.8-4.1 \mathrm{~mm}$. long

6. P. dilatatum.

5(2). Spikelets $3.6-5 \mathrm{~mm}$. long (6)

5. Spikelets less than $3.6 \mathrm{~mm}$ long (8)

6(5). Spikelets solitary

13. P. vaginatum.

6. Spikelets paired; fruit brown (7)

7(6). Spikelet pairs remote, usually not overlapping; first glume present on at least some of the spikelets; rachis of raceme $0.5-0.8 \mathrm{~mm}$. broad......

1. P. bifidum.

7. Spikelet pairs approximate, overlapping; first glume absent; rachis $1-1.5 \mathrm{~mm}$. broad

2. P. floridanum.

$8(5)$. All the spikelets solitary, never paired (9)

8. Some and usually nearly all the spikelets paired (12)

9(8). Spikelets $1.4-2.3 \mathrm{~mm}$. long

15. P. dissectum.

9. Spikelets $2.4-3.6 \mathrm{~mm}$. long (10)

10(9). Panicle axis 3-10 (-19) cm. long; racemes 2 to 9 per panicle

7. P. laeve.

10. Panicle axis obsolete or only to $2.5 \mathrm{~cm}$. long; racemes 1 to 3 per panicle (11)

11(10). Spikelets $2.5-3.2 \mathrm{~mm}$. long; second glume minutely pubescent; first glume usually present................................................12. P. distichum.

11. Spikelets $3.1-4.5 \mathrm{~mm}$. long; second glume nearly glabrous; first glume usually absent.

13. $P$. vaginatum. 
13(12). Panicle axis $12-25 \mathrm{~cm}$. long; racemes 7 to 25 per panicle; spikelets conspicuously pubescent; fruits pale-brown. 4. P. virgatum.

13. Panicle axis to $13 \mathrm{~cm}$. long; racemes 1 to 15 per panicle; spikelets essentially glabrous or minutely pubescent; fruits quite brown..3 P. Boscianum.

14(12). Spikelets orbicular or suborbicular, glabrous.

14. Spikelets longer than broad (15)

15(14). Spikelets thickly turgidly plano-convex, usually pubescent; rachis rarely with purplish coloration; racemes only 1 to 6 per panicle

15. Spikelets .................................................................11. P. pubiflorum. fatly compressed plano-convex; rachis usually with a distinct pur(16)

16(15). Spikelets (2.1-) 2.3-2.7 (-2.9) mm. long, glabrous.............9. P. lividum. 16. Spikelets (2.2-) 2.5-2.9 (-3.2) mm. long, pubescent.....10. P. Hartwegianum.

1. Paspalum bifidum (Bert.) Nash. Fig. 142.

Perennial from rhizomes 3-4 mm. thick with pubescent scales; aerial culms 5-12 dm. long, 2-3 mm. thick, erect, unbranched; ligule a thin brownish scale 1-5 mm. long; blades 1-5 dm. long, 3-14 mm. broad, flat or folded, densely pilose at least near the ligule and often on both surfaces; sheaths pilose; panicle axis 12-20 cm. long; racemes 2 to $6,4-16 \mathrm{~cm}$. long, ascending or somewhat spreading; rachis $0.5-0.8 \mathrm{~mm}$. broad, triangular in transection, often markedly zigzag; spikelets paired or by abortion a few solitary in the same raceme (the pairs remote from each other and not much if at all overlapping), 3.6-4.2 $\mathrm{mm}$. long, ovate to obovate, brownish, turgidly plano-convex, glabrous; first glume present as a minute triangle at the base of the sterile lemma; second glume and sterile lemma firm-membranous; fruit brownish-green or olivaceous. Incl. var. projectum Fern.

In moist acid sand near bogs and open woods, in mud and shallow water of bayous, sloughs, streams and ponds, in Okla. (Waterfall), infrequent or rare in e. Tex., Sept.-Oct.; Coastai States, from Va. to Tex. and inland to Ark. and Okla.

\section{Paspalum floridanum Michx. Fig. 142.}

Robust perennial from short rhizomes $3-6 \mathrm{~mm}$. thick with pubescent scales; aerial culms (5-) 8-15 (-20) dm. long, 2-5 mm. thick, erect, unbranched; ligule a brownish scale 1-2 mm. long; blades 1-5 dm. long, 4-13 mm. broad, firm, flat or folded, glabrous to pilose; sheaths keeled, glabrous to pilose; panicle axis (when racemes not solitary) 4-13 (-20) cm. long; racemes (1 or) 2 to 4 (to 6), $4-15 \mathrm{~cm}$. long, ascending or somewhat spreading; rachis $1-1.5 \mathrm{~mm}$. broad, usually strongly zigzag, the central rib to which the pedicels are attached even more markedly zigzag, the very narrow margins thus interrupted; spikelets paired or by abortion some solitary on the same raceme, 3.6-5 $\mathrm{mm}$. long, ovate to obovate, usually broadly so, brownish, turgidly plano-convex, glabrous; first glume always absent or present as a mere minute line at the base of the sterile lemma; second glume and sterile lemma firm-membranous, sometimes the latter slightly wrinkled; fruit pale-brownish. Incl. var. glabratum Engelm.

Permanently or seasonally moist clay or sandy loam, seepage areas, flatwoods, in and about lakes and marshes, in shallow water in depressions in savannahs, and in cat-tail ponds, in Okla. (Pittsburg, Ottawa, Love, Osage, Le Flore and Mayes cos.) and e., s.e. and n.-cen. Tex. and extreme n.e. Rio Grande Plains, frequent, summer-fall; N. J. to Ill., Mo. and Kan., s. to the Gulf States. 

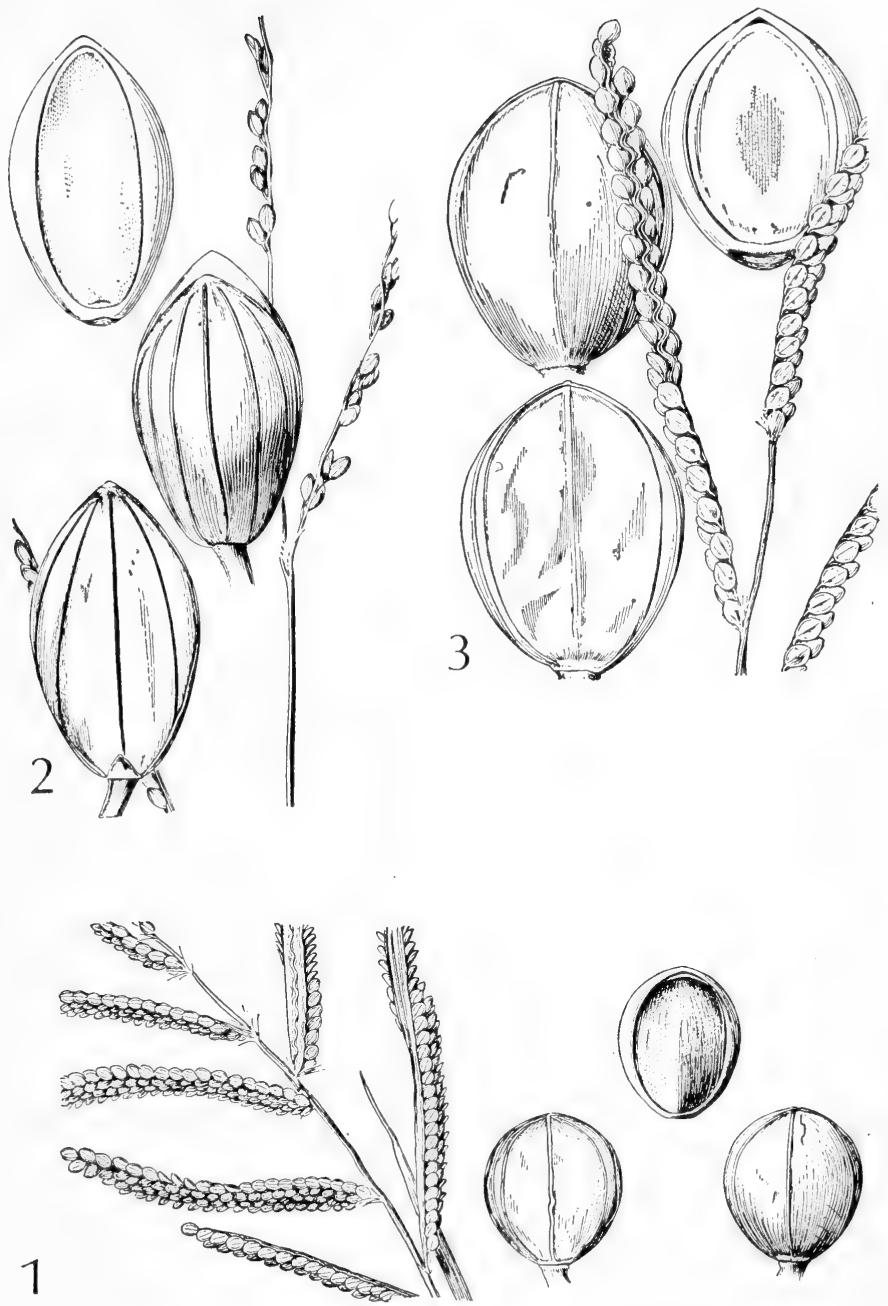

Fig. 142: 1, Paspalum Boscianum: panicle, X 1; two views of spikelet and floret, $\mathrm{X}$ 10. 2, Paspalum bifidum: panicle, $\mathrm{X} 1$; two views of spikelet and floret, $\mathrm{X} 10.3$, Paspalum floridanum: panicle, X 1; two views of spikelet, and floret, X 10. (From Hitchcock \& Chase). 


\section{Paspalum Boscianum Flügge. Bull paspalum. Fig. 142.}

Tufted annual; culms 3-10 dm. long, 2-7 mm. thick, ascending, often prostrate basally, rooting and genuflexed at the nodes, purple; ligule a brown scale 2-4 mm. long; blades 1-4 dm. long, 5-13 mm. broad, flat or folded, pilose near the ligule; lowermost sheaths inconspicuously pilose; axis of panicle $5-10 \mathrm{~cm}$. long; racemes (2 to) 4 to 11 (to 15 ), $2-9 \mathrm{~cm}$. long, ascending, arcuate, pilose in the axils; rachis 2-2.5 mm. broad, olivaceous, the pedicels attached in a narrow central rib, the marginal winglike portions mostly broader than the rib; spikelets paired or by abortion a few in the same raceme solitary, 2-2.3 $\mathrm{mm}$. long, plano-convex, brownish, obovate-orbicular, glabrous; first glume always absent; second glume and sterile lemma thin; fruit brown and shining at maturity.

In moist or wet open ground, along margins of ditches and ponds, reported to occur in e. Tex., summer-fall; Coastal States, Va. to Tex. and inland to Tenn. and Ark.; W. I.

\section{Paspalum virgatum L. Fig. 143.}

Robust tufted perennial; culms 1-2 m. long, 2-8 mm. thick erect, unbranched; ligule a scale $0.5-2.5 \mathrm{~mm}$. long; blades $30-75 \mathrm{~cm}$. long, $10-25 \mathrm{~mm}$. broad, firm, flat, marginally serrulate, pilose near the ligule; sheaths pilose at the summit; axis of panicle $12-25 \mathrm{~cm}$. long; racemes 7 to $25,3-15 \mathrm{~cm}$. long, ascending; rachis 1-1.5 mm. broad, purplish-olive or olive-purple, the central rib (to which the pedicels are attached) narrow, the winglike margins slightly broader than the rib, commonly with some few scattered cilia; spikelets paired, $2.5-3.2 \mathrm{~mm}$. long, brownish or purplish-brown, elliptic to narrowly obovate, much-compressed, plano-convex; first glume always absent; second glume softly spreading pubescent, the hairs longer near the margin; sterile lemma often nearly glabrous; fruit pale-brownish.

Moist clay loam, disturbed places, in wet or swampy ground, in the Tex. s. Rio Grande Plains, rare (Cameron Co.); widespread in trop. Am. n. to Tex. and Cuba.

\section{Paspalum Urvillei Steud. VASEY GRASS. Fig. 144.}

Tufted perennial, often shortly subrhizomatous basally; culms 7-20 dm. long, 2.5-8 mm. thick, mostly strictly erect; ligule a scale $3-6 \mathrm{~mm}$. long (base of blade pilose); blades 1-4 dm. long, 4-13 mm. broad, flat, essentially glabrous except near the ligule; lowermost sheaths densely pilose; panicle axis $8-25 \mathrm{~cm}$. long; racemes ( 8 to) 12 to $22,2-13 \mathrm{~cm}$. long, pilose at the axils; rachis about $1 \mathrm{~mm}$. broad, greenish and purplish, flattened, the pedicels attached at the central rib, the marginal portions about as broad as the rib; spikelets paired, (2-) 2.2-2.7 (-3) $\mathrm{mm}$. long, broadly obovate, greenish-stramineous, much-flattened, plano-convex, extended in the broad triangular point beyond the fruit; first glume always absent; second glume softly silky-pubescent, this pubescence much longer near the margins than in the center; sterile lemma nearly glabrous at the center; fruit elliptic-oblong, slightly obovate.

Loamy disturbed usually very moist soil, in wet savannahs, in ponds and along ditches and streams, in s.e. Okla. (Waterfall), e., s.e. and n.-cen. Tex., rare w. to Edwards Plateau, spring-fall; nat. of S. A., now distributed in N. A., n. to N. C., the Gulf States and Ark.; Calif.

\section{Paspalum dilatatum Poir. Dallis grass. Fig. 145.}

Tufted perennial, shortly subrhizomatous basally: culms 3-15 dm. long, 2-6 $\mathrm{mm}$ thick, erect or somewhat sprawling and slightly genuflexed and rarely rooting at the lower 1 or 2 nodes; ligule a scale $2-5 \mathrm{~mm}$. long (base of blade pilose); blades 7-36 cm. long, 4-12 mm. broad, flat, essentially glabrous except near the ligule; lowermost sheaths pilose; panicle axis $(3-) 5-10(-15) \mathrm{cm}$. long; racemes 3 to 6 (to 11), 4-12 cm. long, pilose at the axils; rachis $0.8-1.7 \mathrm{~mm}$. broad, 

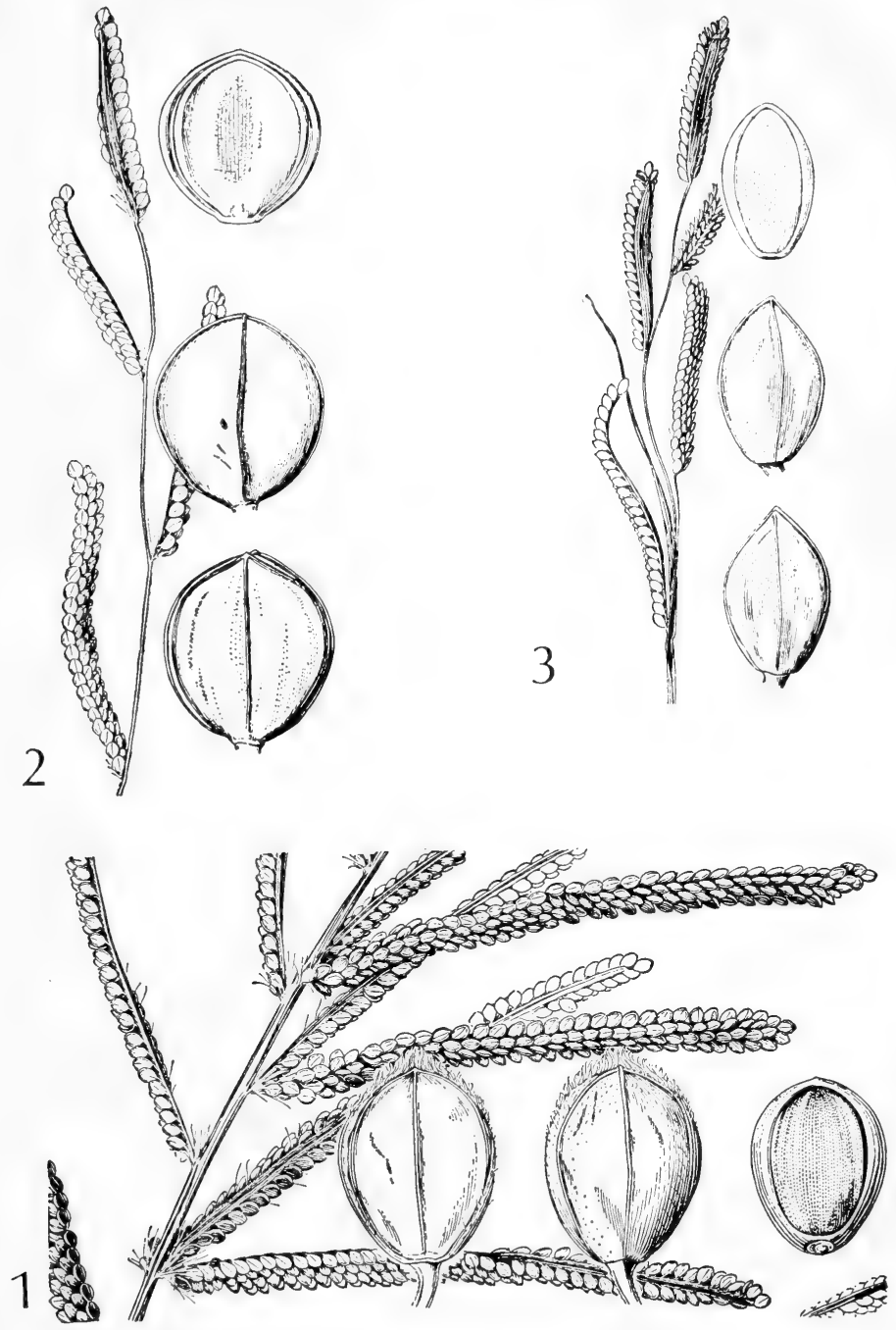

Fig. 143: 1, Paspalum virgatum: panicle, X 1; two views of spikelet and floret, $\mathrm{X}$ 10. 2, Paspalum praecox: panicle, X 1; two views of spikelet and floret, $\mathrm{X} 10.3$, Paspalum lividum: panicle, X 1; two views of spikelet and floret, X 10. (From Hitchcock \& Chase). 


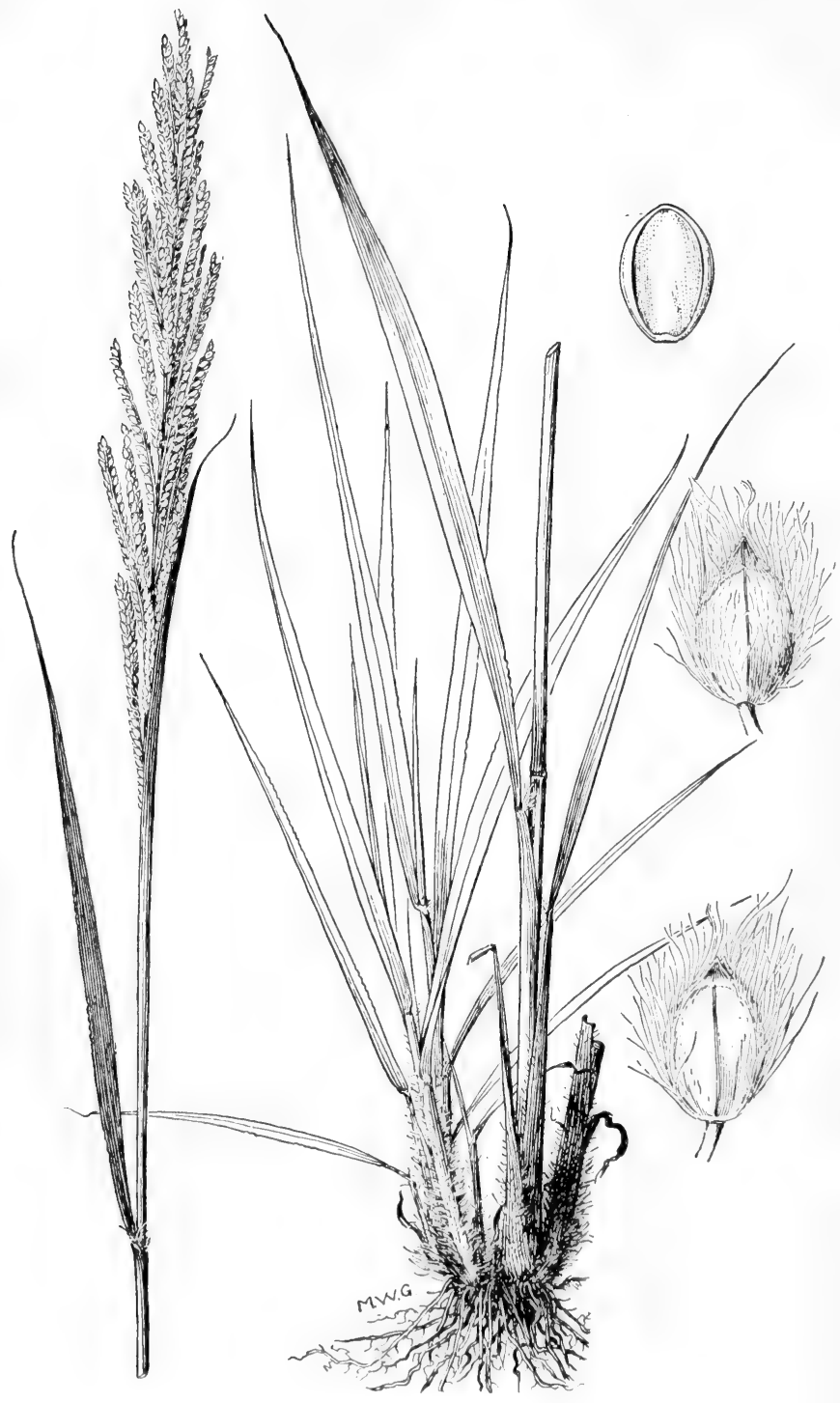

Fig. 144: Paspalum Urvillei: plant, X 1/2; two views of spikelet and floret, $X 10$. (From Hitchcock \& Chase). 
greenish or purplish-olive, flattened, the pedicels attached at the narrow central rib, the marginal portions winglike and at least as broad as the rib; spikelets paired, (2.8-) 3.2-3.5 (-4.1) $\mathrm{mm}$. long, basally obovate, greenish-stramineous, very flattened, compressed plano-convex, extended in a broad triangular point beyond the fruit; first glume always absent; second glume softly pubescent, shortly so in the middle but near the margins with a long silky fringe; sterile lemma softly pubescent; fruit nearly orbicular.

Loamy disturbed soils in marshy meadows, along streams and irrigation ditches, in mud and water of marshes, lakes and ponds. in Okla. (McCurtain and Comanche cos.), abundant in e., s.e. and n.-cen. Tex., infrequent in Rio Grande Plains, Edwards Plateau and Trans-Pecos, and Ariz. (Santa Cruz, Pima and Mohave cos.), spring-fall; nat. of S. A., now rather widely distributed in warm-temp. areas n. to N. J., Tenn., Ark., Okla. and Ore.

A persistent weed in lawns, almost impossible to eradicate once it has become established. It is an important forage plant.

\section{Paspalum laeve Michx. Fig. 146.}

Tufted perennial, very shortly subrhizomatous basally; culms 3-9 dm. long, about $2 \mathrm{~mm}$. thick, erect, unbranched; ligule a brown scale 1-2 $\mathrm{mm}$. long; blades 6-40 cm. long, 3-10 mm. broad, flat or folded, glabrous or pilose; sheaths somewhat keeled, glabrous or pilose; panicle axis 3-10 $(-19) \mathrm{cm}$. long; racemes $(2$ to $)$ 3 to 6 (to 9), 3-11 cm. long, spreading, pilose in the axils; rachis about $1 \mathrm{~mm}$. broad, dark-olive-green, with a zigzag central rib, the pedicels attached on this rib where it is nearest the margin, the narrow winglike margins interrupted; spikelets solitary, 2.4-3.1 $\mathrm{mm}$. long, very broadly obovate to orbicular, pale or stramineous-olive, plano-convex, blunt; first glume always absent; second glume and sterile lemma firm-membranous, glabrous. $P$. longipilum Nash, $P$. circulare Nash.

Sandy loam, prairies and open forests, wet pine barrens, marshy ground along ditches and borders of lakes, ponds and bayous, wet savannahs, in Okla. (McCurtain Co.) and in e. and s.e. Tex. and extreme n.e. Rio Grande Plains (Nueces Co.), infrequent, summer-fall; Coastal States, Mass. to Tex. and inland to O., Ind., Ill., Mo., Kan. and Okla.

\section{Paspalum praecox Walt. Fig. 143.}

Tufted perennial, very shortly rhizomatous basally, culms 5-15 dm. long, 1-3 $\mathrm{mm}$. thick, erect, unbranched; ligule a brown scale 1-3 mm. long; blades 1-3 (-4) $\mathrm{dm}$. long, 3-10 $\mathrm{mm}$. broad, flat or usually folded, glabrous to pilose; sheaths glabrous to pilose, keeled; panicle axis $5-17 \mathrm{~cm}$. long; racemes (2 to) 4 to 6 (to 9), 2-7 (-9) cm. long, arcuate, ascending or spreading, shortly bearded and sometimes also pilose at the axils; rachis $1.3-2 \mathrm{~mm}$. broad, purplish-olive, with a broad central rib to which the pedicels are attached, the marginal winglike portions firm and narrower than the central rib; spikelets paired or a few by abortion solitary on the same raceme, 2.2-3.2 $\mathrm{mm}$. long, orbicular to suborbicular, yellowish-green, occasionally with a purplish-tinge, highly compressed planoconvex; first glume always absent; second glume and sterile lemma membranous, glabrous. $P$. lentiferum Lam.

Sandy loam, open pine flats, in wet savannahs, cypress swamps, wet pine barrens and flatwoods, in s.e. Tex., infrequent, summer-fall; Coastal States, Va. to Tex.

\section{Paspalum lividum Trin. Longtom. Fig. 143.}

Tufted perennial; culms $50-175 \mathrm{~cm}$. long, compressed, 2-4 mm. thick on the long axis, often basally decumbent and freely rooting for up to $1 \mathrm{~m}$., then ascending at the floriferous ends; ligule a scale 1-3 mm. long; blades $10-23 \mathrm{~cm}$. 


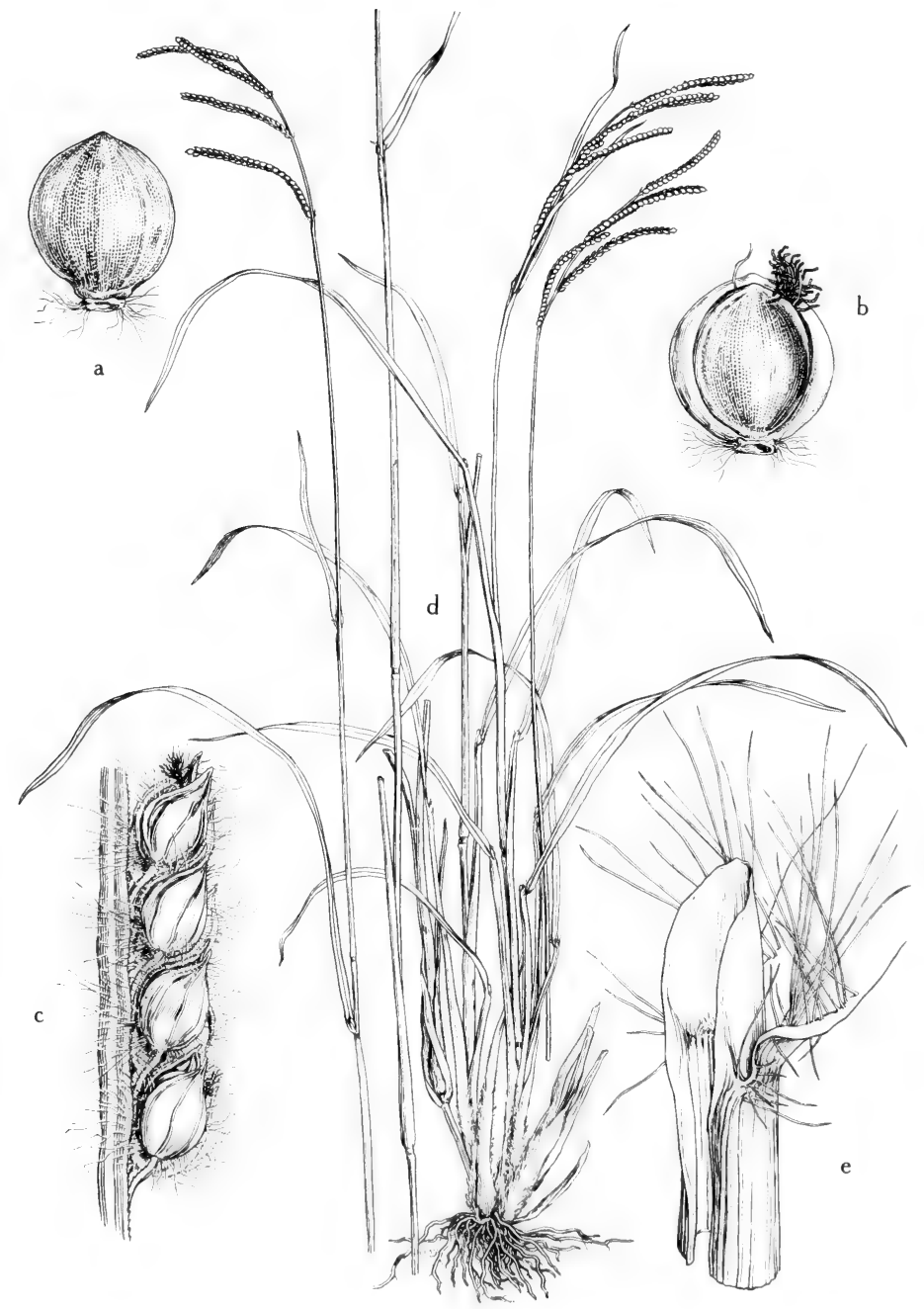

Fig. 145: Paspalum dilatatum: a, floret, showing lemma, X 8; b, floret, showing palea. X 8; c, rachis, showing the 2 rows of hairy spikelets, X 4; d, habit, showing the noticeably pubescent lowest sheaths, the arching leaves and the spreading racemes, $\mathrm{X} 1 \%$; e, upper sheath, pubescent only around ligule and on base of blade, X 4. (From Mason, Fig. 78 ). 


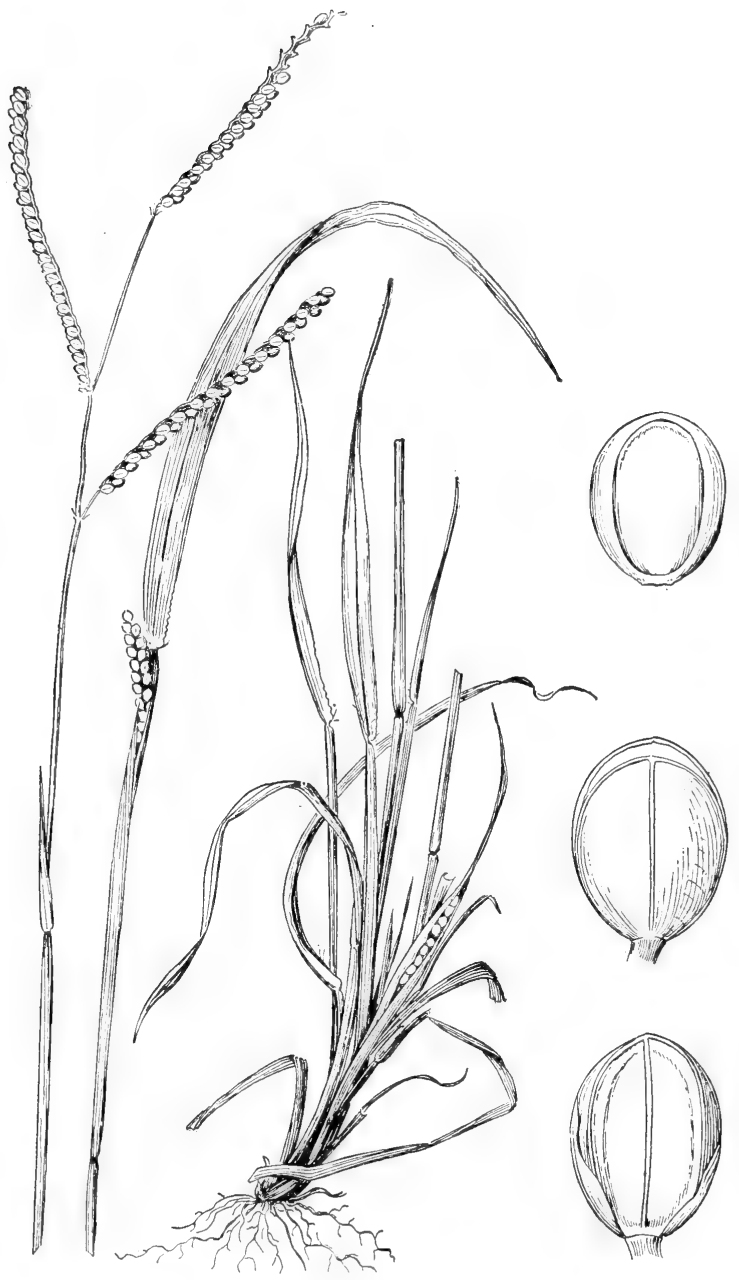

Fig. 146: Paspalum laeve: plant, $\mathrm{X}$ 1/2; two views of spikelet and floret, $\mathrm{X} 10$. (From Hitchcock \& Chase). 
long, 3-5 mm. broad, flat or folded; panicle axis $3-12 \mathrm{~cm}$. long, curviflexuous; racemes 3 to $8,15-50 \mathrm{~mm}$. long, ascending and curved, floriferous to the base, the lower racemes with a few hairs in the axils; rachises $1.5-2.5 \mathrm{~mm}$. broad, thin, purplish-olive to olive-purple, rather elongate, spreading, the rather elongate spreading pedicels attached along a very narrow central rib, the lateral portions of the rachis foliaceous and winglike and usually sparsely papillose-pilose marginally; spikelets paired or rarely a few also solitary in the same raceme, (2.1-) 2.3-2.7 (-2.9) $\mathrm{mm}$. long, obovate, bluntly pointed, with nearly parallel plane surfaces or at least very compressed plano-convex, yellowish-green or occasionally with a purplish cast; first glume always absent; second glume and sterile lemma essentially glabrous.

Moist tight clay loam in ditches, tanks, wet savannahs, swamps and flooded pasturelands, and in resacas and shallow lakes, s.e. Tex. and coastal parts of Rio Grande Plains, frequent, spring-fall; widespread in warmer parts of Am., n. to Ala., La. and Tex.

\section{Paspalum Hartwegianum Fourn. Fig. 147.}

Tufted stoloniferous perennial; floriferous culms 5-15 dm. long, slightly compressed, 2-5 $\mathrm{mm}$. thick on the long axis, ligule a scale 1-3 $\mathrm{mm}$. long; blades $10-35 \mathrm{~cm}$. long, 2-6 mm. broad, flat or folded; sheaths keeled; panicle axis 5-15 $\mathrm{cm}$. long, mostly straight and slender; racemes ( 3 or) 4 to $8,2-9 \mathrm{~cm}$. long, ascending or somewhat spreading, often slightly curved, floriferous to the base, the lower ones usually with a few long hairs in the axils; rachises $1.5-2 \mathrm{~mm}$. broad, thin, olive or purplish-olive, the rather elongate spreading pedicels attached along a very narrow central rib, the lateral portions of the rachis foliaceous and winglike; spikelets paired, rarely also a few in the same raceme solitary, (2.2-) 2.5-2.9 (-3.2) $\mathrm{mm}$. long, obovate, slightly pointed, with nearly parallel plane surfaces or at least very compressed plano-convex, yellowish-green; first glume always absent; second glume and sterile lemma shortly and uniformly pubescent.

Moist tight soil, wet prairies, alkaline meadows, in mud and shallow water of irrigation ditches and streams, in the Tex. Rio Grande Plains, frequent, springfall; much of Mex. n.w. to Son.; Tex.

\section{Paspalum pubiflorum Fourn. Fig. 147.}

Loosely tufted perennial; culms 3-15 dm. long, compressed, 2-3 mm. thick on the long axis, decumbent and freely rooting in the basal third to half the length but usually mostly ascending; ligule a scale $1-3 \mathrm{~mm}$. long; blades 6-30 $\mathrm{cm}$. long, 5-13 $\mathrm{mm}$. broad, mostly flat, marginally crisped and basally papillosepilose; lower sheaths usualy papillose-pilose; panicle axis $8-62 \mathrm{~mm}$. long; racemes 2 to 4 (to 6 ), 2-10 $\mathrm{cm}$. long, ascending or spreading, floriferous to the base or infrequently with a naked basal portion 1-3 $\mathrm{mm}$. long and a few long hairs in the axil; rachises $1.5-2 \mathrm{~mm}$. broad, broadly triangular, olive-green; spikelets attached even along the margins, paired or rarely in the same raceme a few of them solitary, (2.3-) 2.7-2.9 (-3.2) $\mathrm{mm}$. long, obovate, turgidly plano-convex, greenish to stramineous or with a purplish cast, blunt to very slightly pointed; first glume small, triangular, usually absent or much-reduced; second glume and sterile lemma microscopically pubescent to rarely glabrate. Incl. var. glabrum Scribn.

Moist garden loam and moist usually calcareous soil at edges of streams, ponds and lakes, along streams and irrigation ditches, in wet meadows, in Okla. (Hughes and Cherokee cos.), throughout Tex. (but rare in Plains Country), spring-fall; lowlands of s.e. U.S. n. to N.C., O., Ind., III., Mo. and Kan.; much of Mex.; Cuba.

\section{Paspalum distichum L. Knotgrass. Fig. 148.}

Long-decumbent perennial; culms 5-15 dm. long, compressed, 2-3 mm. thick on the long axis, extensively creeping, freely rooting, somewhat branched, ascend- 

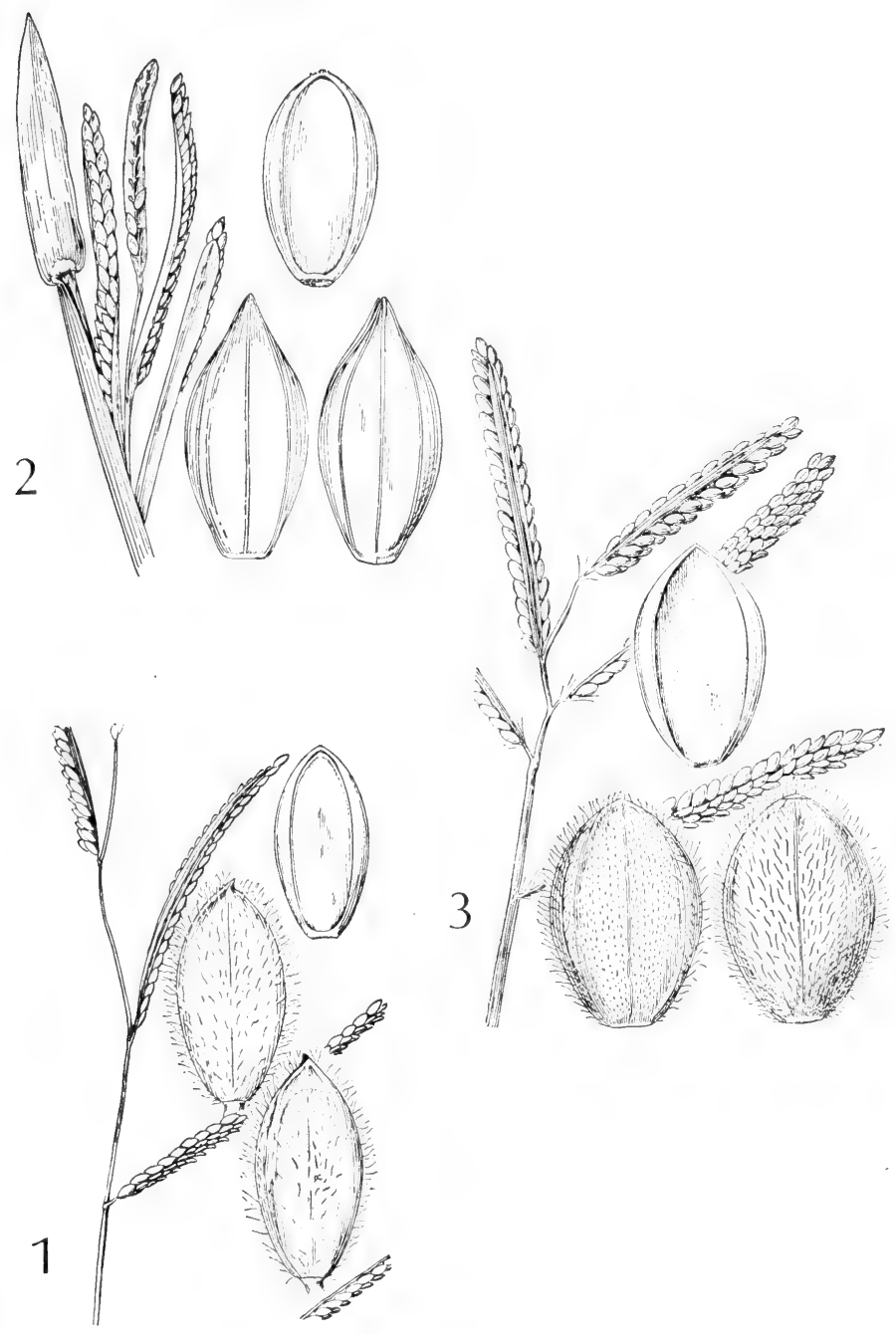

Fig. 147: 1, Paspalum Hartwegianum: panicle, X 1; two views of spikelet and floret, $\mathrm{X}$ 10. 2, Paspalum acuminatum: panicle, $\mathrm{X} 1$; two views of spikelet and floret, $\mathrm{X}$ 10. 3, Paspalum pubiflorum; panicle, $\mathrm{X} 1$; two views of spikelet and floret, $\mathrm{X} 10$. (From Hitchcock \& Chase). 


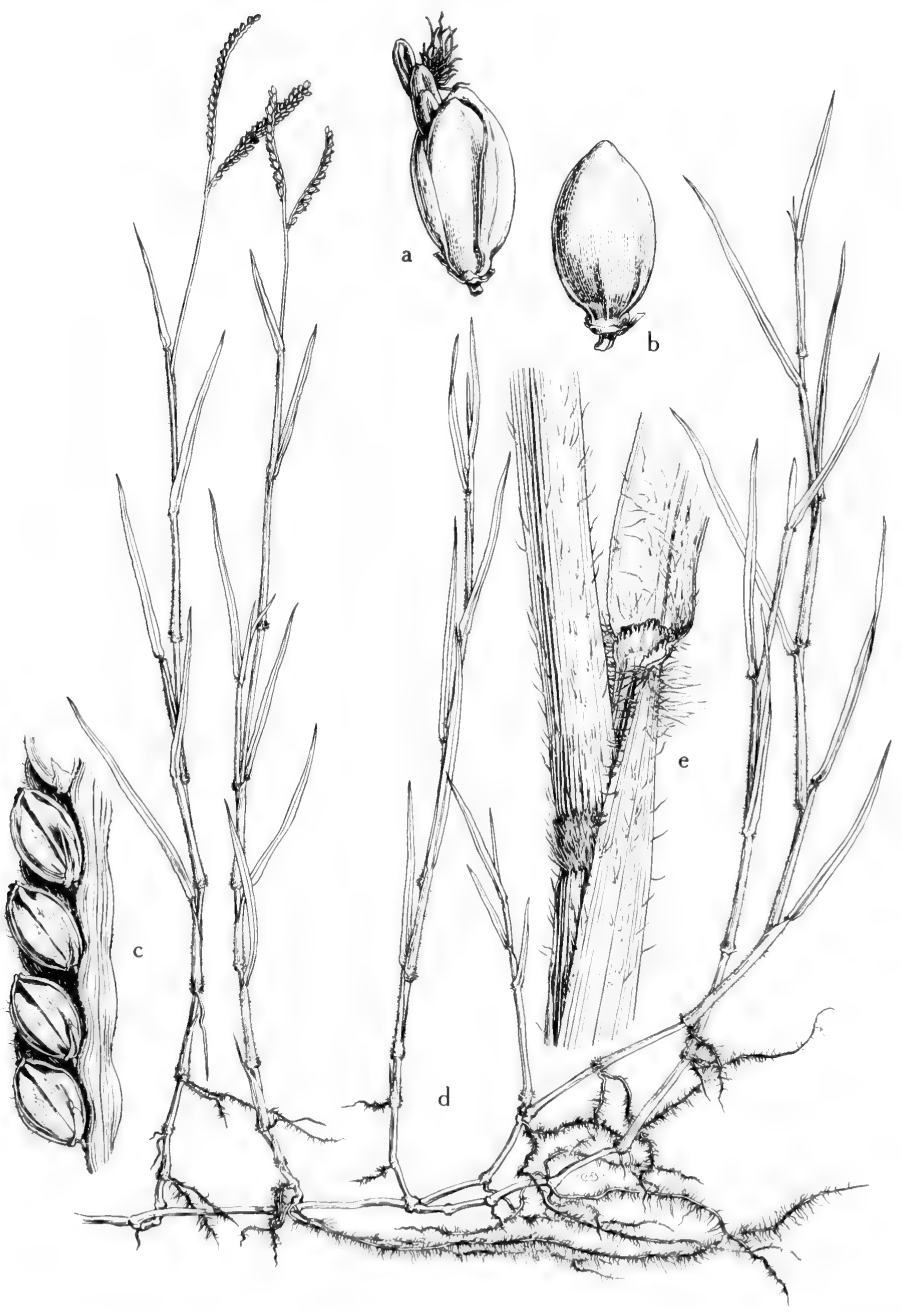

Fig. 148: Paspalum distichum: a, floret, showing palea, X 8; b, floret, showing lemma, X 8; c, rachis, showing 2 rows of spikelets, $X$ 4; d, habit, showing the decumbent rooting base, the flat leaf blades and the paired racemes, $X_{1 / 4}$; e, leaf sheath, ligule and node, densely pubescent, X 2\%.2. (From Mason, Fig. 77). 
ing at the simple floriferous ends; ligule a scale $0.5-1 \mathrm{~mm}$. long; blades $3-12 \mathrm{~cm}$. long, 2-6 mm. broad, membranous and usually flat or folded, or the tip on drying loosely involute, basally broader than the summit of the sheath; sheaths slightly keeled at summit, the corner with a few soft hairs and often the lower sheaths (when emergent) visibly pubescent ("var. indutum") but these usually lost in specimens; racemes usually 2 , rarely 1 or $3,15-70 \mathrm{~mm}$. long, erect or somewhat spreading, often arcuate, floriferous essentially to the base; rachises broadly triangular in transection, $1-1.5(-2) \mathrm{mm}$. broad; spikelets attached nearly at the margin by the short pedicels, solitary, elliptic, (2.5-) 2.7-3 (-3.2) $\mathrm{mm}$. long, greenish to stramineous, blunt to somewhat pointed; first glume usually present, minute, triangular; second glume microscopically pubescent; sterile lemma glabrous or rarely with a few microscopic hairs near midrib. Incl. var. indutum Shinners,

Margins of fresh ponds, streams and lakes, in marshes and on mud and in shallow water, sometimes in brackish areas, in Okla. (Grady and Washita cos.), frequent in e., s.e. and n.-cen. Tex., Edwards Plateau and Trans-Pecos, infrequent in Rio Grande Plains and Plains Country, N. M. (Dona Ana and DeBaca cos.) and Ariz. (Pinal, Santa Cruz and Mohave cos.), summer-fall; widespread in the warmer parts of the world, in Am. n. to N. J., Tenn., Ark., Okla., Ut., Ida. and Wash.

\section{Paspalum vaginatum Sw. Fig. 149.}

Long-decumbent perennial; culms 5-25 dm. long, compressed, 3-4 mm. thick on the long axis, extensively creeping and freely rooting, branched, ascending only at the simple floriferous ends; ligule a scale about $1 \mathrm{~mm}$. long; blades $2.5-15$ $\mathrm{cm}$. long, 3-8 mm. broad, firm and stiffly straight, basally narrower than the summit of the sheath and folded, tapering to a long-involute tip (occasionally near semibrackish water the blades persistently flat); sheaths keeled, the corners ciliate; panicle axis 1-10 (-15) mm. long; racemes 1 or 2 (or 3), 2-8 cm. long, divaricate; rachises often naked for the basal 2-5 mm., 1-2 $\mathrm{mm}$. broadly triangular or occasionally very narrowly winged; spikelets attached nearly at the margin by the broad short pedicels, solitary, ovate-elliptical, 3.1-4.2 (-4.5) mm. long, glabrous, stramineous, pointed; first glume very rarely present; sterile lemma thin and often transversely wrinkled; fruit pointed, nearly as long as spikelet, apically glabrous.

Moist saline to brackish sands at edges of lagoons, bays and river-mouths, rarely in sub-brackish ponds near the coast, s.e. Tex. and Rio Grande Plains, frequent, summer-fall-early winter; widespread in warm coastal areas of the world, in Am., n. to N. C. and the Gulf States.

\section{Paspalum acuminatum Raddi. Fig. 147.}

Long-decumbent aquatic or subaquatic perennial; culms 3-10 dm. long, 1-3.5 $\mathrm{mm}$. thick, soft, freely rooting and rather freely branching, ascending and emergent only at the end; ligule a membranous scale 1-3 mm. long; blades 3-20 $\mathrm{cm}$. long, 2-12 mm. broad, flat, thin; panicle axis $1-3 \mathrm{~cm}$. long; racemes 2 or 3 (to 5?), 3-7 cm. long, ascending, usually somewhat arcuate; rachis $3-3.5 \mathrm{~mm}$. broad, with the spikelets borne in a very narrow central rib, the remainder of the rachis forming foliaceous wings; spikelets solitary, elliptic, 3.3-3.5 mm. long, glabrous, greenish, apically abruptly pointed beyond the fruit; first glume absent; fruit blunt, apically with some minute cilia.

In fresh water ponds or wet open ground, in the Tex. Rio Grande Plains, rare (Cameron and Brooks cos.), spring-fall; lowlands, widespread but scattered in trop Am., n. to s. La. and s. Tex. 


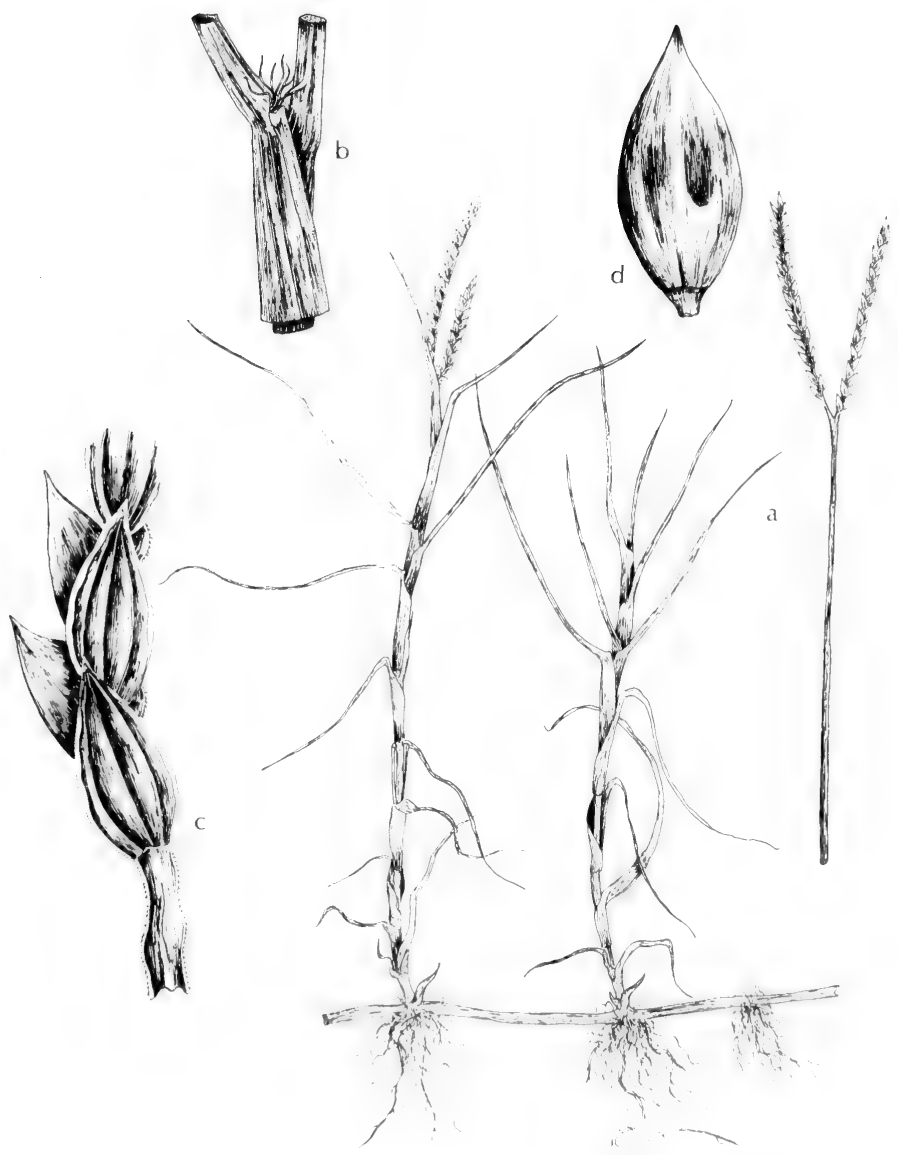

Fig. 149: Paspalum vaginatum: a, habit, about $\mathrm{X} 1 / 2 ; \mathrm{b}$, ligule, $\mathrm{X} 1$; $\mathrm{c}$, portion of rachis, X 6; d, spikelet, X 10. (Courtesy of $R$. K. Godfrey). 


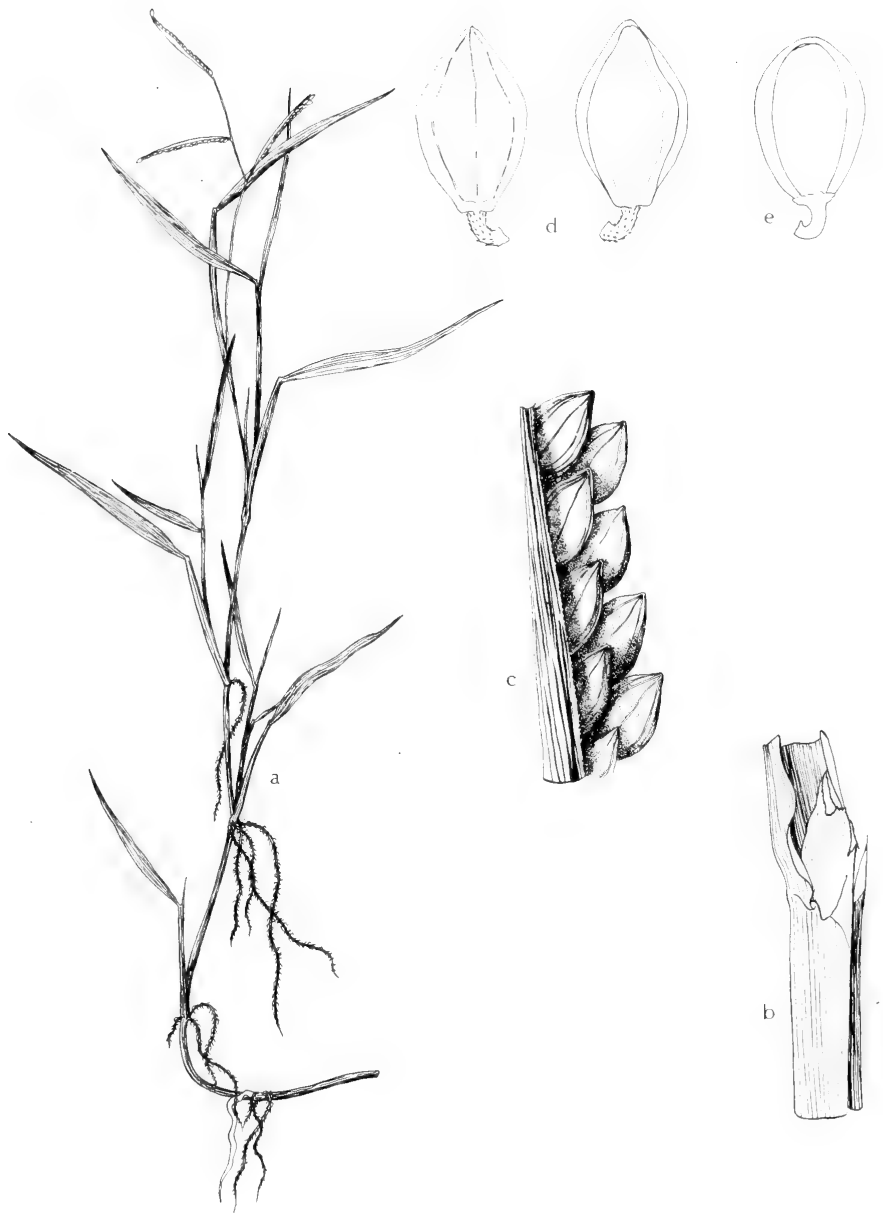

Fig. 150: Paspalum dissectum: a, habit, X 1/3; b, ligule, X 5; c, part of rachis with spikelets, X 6; d, two views of spikelet, X 10; e, floret, X 10. (Courtesy of R. K. Godfrey). 
15. Paspalum dissectum (L.) L. Fig. 150.

Long-decumbent mat-forming perennial; culms $20-75 \mathrm{~cm}$. long, compressed, 1.5-2 $\mathrm{mm}$. thick on the long axis, freely rooting in the mud, rather freely branched; ligule a membranous scale 1-2 mm. long; blades $2-9(-12) \mathrm{cm}$. long, 2-5 $\mathrm{mm}$. broad, thin, flat or folded; panicle axis $3-8 \mathrm{~cm}$. long, slender and grooved, $0.2-0.4 \mathrm{~mm}$. thick; racemes 2 to $4,1-5 \mathrm{~cm}$. long, ascending and slightly arcuate; rachis $1.8-3 \mathrm{~mm}$. broad, with the spikelets borne on a very narrow central rib, the remainder of the rachis forming foliaceous wings; spikelets solitary. broadly elliptic, 1.7-2 mm. long, 1-1.2 mm. broad, essentially glabrous, greenish to stramineous, apically blunt; first glume absent; fruit blunt.

Forming mats in moist sand at the margins of seeps, bogs and lakes, on muddy and sandy banks of ponds and ditches or in shallow water, in Okla. (Okfuskee Co.) and e. Tex., infrequent, summer-fall; lowlands of s. U.S., n. to N.J. and Ill.; Cuba.

\section{Paspalum fluitans (Ell.) Kunth. Fig. 151.}

Long-decumbent or floating aquatic grasses said to be annual; culms 3-10 dm. long, 2-5 mm. thick, soft (with much gas-holding tissue), mostly submerged, only the floriferous ends emergent; ligule a membranous scale $2-4 \mathrm{~mm}$. long; aerial blades $10-25 \mathrm{~cm}$. long, 9-20 mm. broad, very thin and flat; sheaths pubescent, their corners triangular-auricled; panicle axis $6-16 \mathrm{~cm}$. long, $0.5-1 \mathrm{~mm}$. thick; racemes (20 to) 30 to $50,25-75 \mathrm{~mm}$. long, ascending or usually arcuatespreading, at maturity deciduous from the axis; rachis $1-1.7 \mathrm{~mm}$. broad, the spikelets borne on a very narrow central rib, the remainder of the rachis forming thin foliaceous wings; spikelets solitary, $1.2-1.7 \mathrm{~mm}$. long, only about $0.7-0.9 \mathrm{~mm}$. broad, pubescent, pale-stramineous, often with a discolored or stained spot at the base of the sterile lemma and apically acute; first glume absent. P. repens Berg.

Forming colonies in fresh water, in mud and water on edge of lakes, sloughs and ponds and floating in sluggish streams or standing water, in e. Okla. (Waterfall) and s.e. Tex., infrequent, summer-fall; widespread in trop. Am., n. to N.C., Ill., Ind., Mo. and Neb.

\section{Panicum L. Panic Grass}

Annuals or perennials, widely diverse in habit; spikelets in panicles or less commonly in racemes (rarely in spikelike panicles and then sometimes with a bristle-like sterile branch subtending some spikelets); pedicels usually present; each spikelet falling as a unit, 2-flowered, the lower floret staminate or completely reduced, the upper perfect; first glume much shorter than the spikelet, severalnerved, membranous; second glume as long as the spikelet or nearly as long; lower "sterile" lemma several-nerved, membranous, usually as long as the spikelet or essentially so; sterile palea usually obsolete but occasionally (as in P. hians) very strongly developed and cupped and/or hooded; fertile lemma usually somewhat indurate, strongly convex, the margins revolute and clasping the palea of the same texture, usually smooth and shining like white cartilage, rarely transversely rugose.

A large extremely complex genus (perhaps 500 species) of warm parts of the world, made particularly difficult in North America because of the occurrence of cleistogamy and occasional wide outcrossing among the "Dichantheliums" or dichotomous panic grasses. 


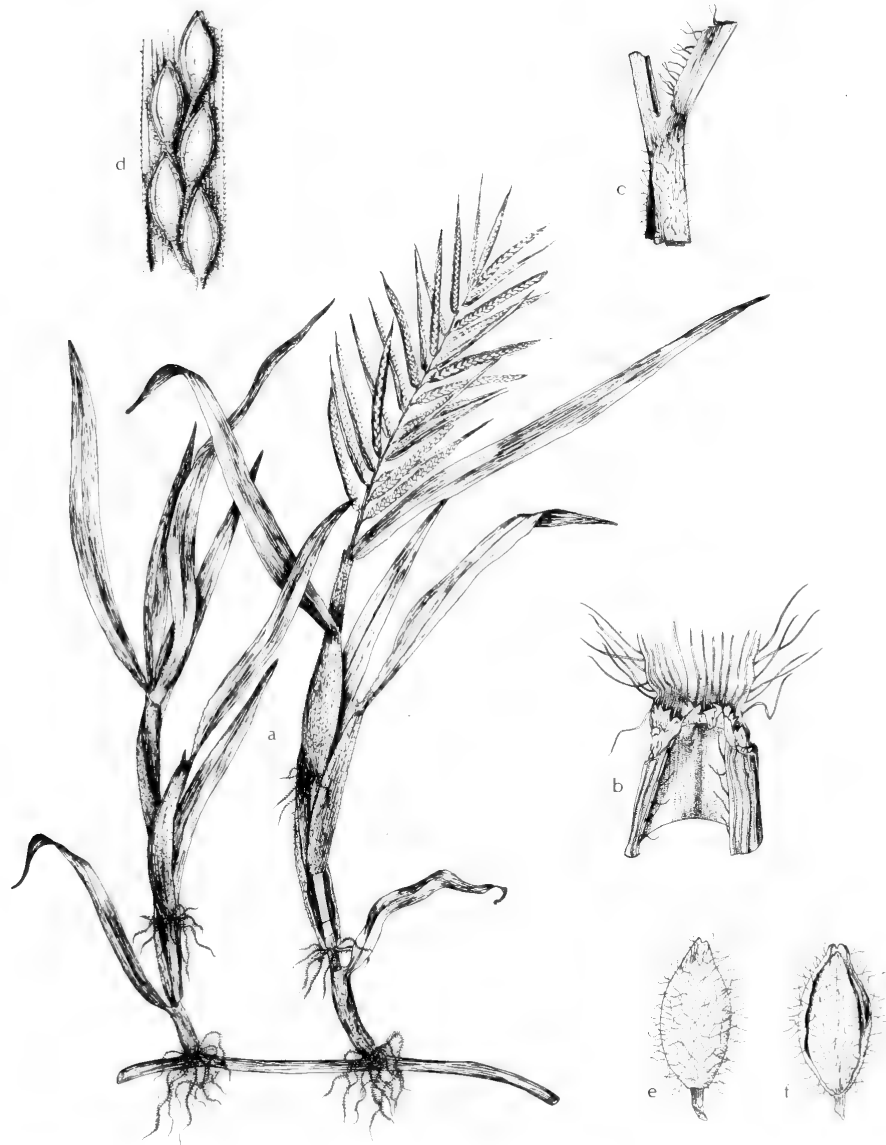

Fig. 151: Paspalum fluitans: a, habit, X 1/3; b, ligule, $X 2$; c, ligule, about $\mathrm{X} \mathrm{11/2}$; d, portion of rachis, $X 10$; e and $f$, two views of spikelet, $X 12$. (Courtesy of $R$. $K$. Godfrey). 
1. Basal leaves usually distinctly different from those of the culm, forming a winter rosette; plants perennial, in spring producing simple culms with mostly narrowly lanceolate blades and terminal panicles with numerous spikelets (in most species these not producing viable seed); later culms often much-reduced and much-branched, producing an autumnal phase usually quite different from the vernal phase and with reduced axillary panicles (2)

1. Basal leaves similar to though usually smaller than those of the stem leaves; winter rosette absent; plants annual or perennial; spikelets usually nearly all fertile (9)

2(1). Spikelets blunt and strongly nerved; blades rarely as much as $20 \mathrm{~mm}$. broad. 6. P. Ravenelii.

2. Spikelets rarely if ever both blunt and strongly nerved (3)

3(2). Ligule (or at least a ligulelike tuft at the extreme base of the blade) of conspicuous hairs usually (2-) 3-5 mm. long (4)

3. Ligule less than $2 \mathrm{~mm}$. long to obsolete (5)

4(3). Spikelets $0.9-1.3 \mathrm{~mm}$. long; "ligule" $2-3 \mathrm{~mm}$. long.

4. Spikelets $1.3-2.9 \mathrm{~mm}$ long; "ligule" (2-) 3-5 mm. long.

2. P. leucothrix.

5 (3). Spikelets nearly spherical at maturity; blades glabrous, firm, cordate; ligule obsolete.

5. $P$. polyanthes.

5. Spikelets usually obovoid or ellipsoid; ligule usually developed (obsolete in $P$. commutatum and allies) $(6)$

6(5). Spikelets $2.3-3.2 \mathrm{~mm}$. long (7)

6. Spikelets $1.2-2.2 \mathrm{~mm}$. long (8)

7(6). Ligule obsolete; blade only 5-10 $(-15) \mathrm{cm}$. long, 8-25 mm. wide, glabrous, at base cordate and ciliate; spikelets slenderly ellipsoid, $2.4-3.1 \mathrm{~mm}$. long, never turgid..........................................8. P. commutatum.

7. Ligule a muticous scale or a short fringe; blades $10-23 \mathrm{~cm}$. long, 9-30 $\mathrm{mtm}$. wide, glabrous or scabrous, at base only slightly if at all cordate; spikelet turgidly ellipsoid to obovoid or ovoid, $2.3-3.2 \mathrm{~mm}$. long 7. P. scoparium.

8(6). Culms delicate, usually less than 30 (rarely to 40 ) $\mathrm{cm}$. tall; blades filmy, usually only $1-3 \mathrm{~cm}$. long and $1-3 \mathrm{~mm}$. wide, often reflexed.

4. $P$. ensifolium.

8. Culms delicate or not so delicate, (15-) 20-100 cm. tall; blades firmer (membranous or more firm), 3-12 cm. long, 3-15 mm. wide, reflexed or ascending. 1. P. dichotomum.

9(1). Plants annual (doubtful cases should be keyed under both alternatives) (10)

9. Plants perennial (11)

10(9). First glume about a fourth as long as the spikelet.

10. First glume usually proportionately longer.

21. P. dichotomiflorum.

11(9). Spikelets short-pedicelled along one side of the rachises to form spikelike racemes; fertile lemma transversely rugose (except in $P$. hemitomum) (12)

11. Spikelets in open or sometimes contracted or congested panicles (somewhat 1 -sided in $P$. anceps and $P$. rigidulum) (16)

12(11). First glume nearly equaling the sterile lemma (13)

12. First glume much shorter than the sterile lemma (14)

13(12). Racemes spreading; fertile lemma not more than one third the total length of the spikelet...................................11.P. gymnocarpon. 
14(12). Fertile lemma not transversely rugose 12. P. hemitomum.

14. Fertile lemma transversely rugose (15)

15(14). Spikelets $2.2-2.4 \mathrm{~mm}$. long. 9. P. geminatum.

15. Spikelets $2.5-3 \mathrm{~mm}$. long. 10. $P$. paludivagum.

16(11). Sterile palea enlarged and indurate at maturity, expanding the spikelet; blades scarcely broader than their sheaths; spikelets about $2.3 \mathrm{~mm}$. long, borne toward the ends of the few slender branches.

14. P. hians.

16. Sterile palea usually absent or (if present) minute (17)

17(16). Plants with conspicuous creeping scaly rhizomes (18)

17. Plants without creeping scaly rhizomes (20)

18(17). Spikelets shont-pedicelled, more or less secund along the nearly simple panicle branches..................................................15. P. anceps.

18. Spikelets long-pedicelled, not secund, arranged in an open or contracted panicle (19)

19(18). Panicle compact, strongly contracted, elongate and nodding; plants of coastal sands..................................................18. P. amarulum.

19. Panicle diffuse or only slightly contracted..........................19. P. virgatum.

20(17). Panicles narrow and few-flowered; culms erect and wiry; blades drying involute.

17. P. tenerum.

20. Panicles open or contracted, many-flowered. 16. $P$. rigidulum.

\section{Panicum dichotomum L. Fig. 152.}

Perennial; vernal phase (Apr.-Aug.) culms tufted, erect or ascending from a knotted or loose crown, 3-5 $(-10) \mathrm{dm}$. tall, glabrous but the nodes very often with a grayish retrorse beard about $1(-2) \mathrm{mm}$. long and often the lower nodes geniculate; sheaths essentially glabrous; ligules minute; blades usually spreading, the upper often reflexed, 3-12 cm. long, 4-15 mm. broad, glabrous or sparsely papillose-ciliate at base, green (often bright, rarely olivaceous) and thin, quite flat; panicle usually elongate-ovoid, usually many-spikeletted, 5-12 cm. long, with the slightly spreading. very slender and often flexuous branches usually copiously branched; spikelets 1.4-2.2 mm. long, elliptic, glabrous or pubescent, 5- to 7-nerved; second glume usually shorter than fertile lemma; autumnal phase (June-Dec.) much-reduced, much-branched at some nodes, the lower part usually ascending (or reclining from the heavy weight of the top) and bladeless like a slender tree-trunk, the upper part copiously bushy-branched with numerous small blades 2-4 cm. long and 1-3 mm. broad (thin, green, flat or often involute). $\boldsymbol{P}$. nitidum Lam., $\boldsymbol{P}$. barbulatum Michx., $\boldsymbol{P}$. microcarpon Muhl., $\boldsymbol{P}$. lucidum Ashe, $P$. yadkinense Ashe.

In swampy and marshy grounds, bogs, wet peaty meadows and margins of streams, also in moist sandy woodlands, in Okla. (LeFlore Co.) and in e. and s.e. Tex., rare w. to n.-cen. Tex., spring-fall; s.e. Can., e. U.S., Bah. I., Cuba.

\section{Panicum leucothrix Nash. Fig. 152.}

Perennial; vernal phase light olive-green to dark-green; culms $1-5(-7) \mathrm{dm}$. tall, ascending (often decumbent at base and somewhat geniculate) weak, slender, glabrous or appressed papillose-pilose, the nodes pubescent or glabrous; sheaths papillose-pilose to puberulent or glabrous; ligule minute but blade at base with a ligulelike tuft or hairs $2-3 \mathrm{~mm}$. long; blades $3-8 \mathrm{~mm}$. broad, about $2-5 \mathrm{~cm}$. long, glabrous or sparsely villous above, puberulent or glabrous beneath, or even velvety-puberulent beneath; panicle $3-8 \mathrm{~cm}$. long, rather densely flowered; spike- 


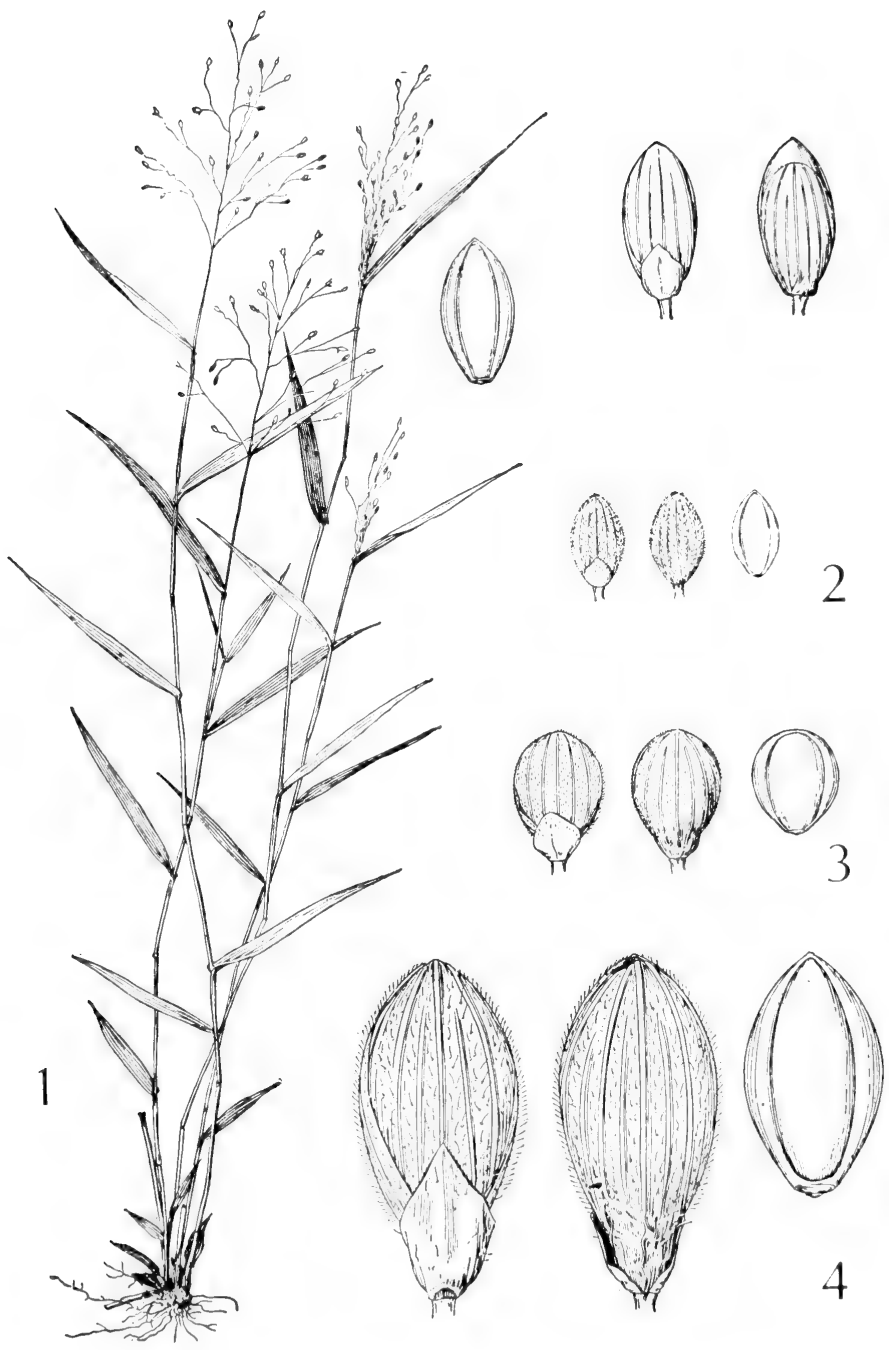

Fig. 152: 1, Panicum dichotomum: plant, X 1/2; two views of spikelet, and floret, $X$ 10. 2, Panicum lencothrix: two views of spikelet and floret, X 10. 3, Panicum polyanthes: two views of spikelet and floret, X 10,4, Panicum Ravenelii: two views of spikelet and floret, X 10. (From Hitchcock \& Chase). 

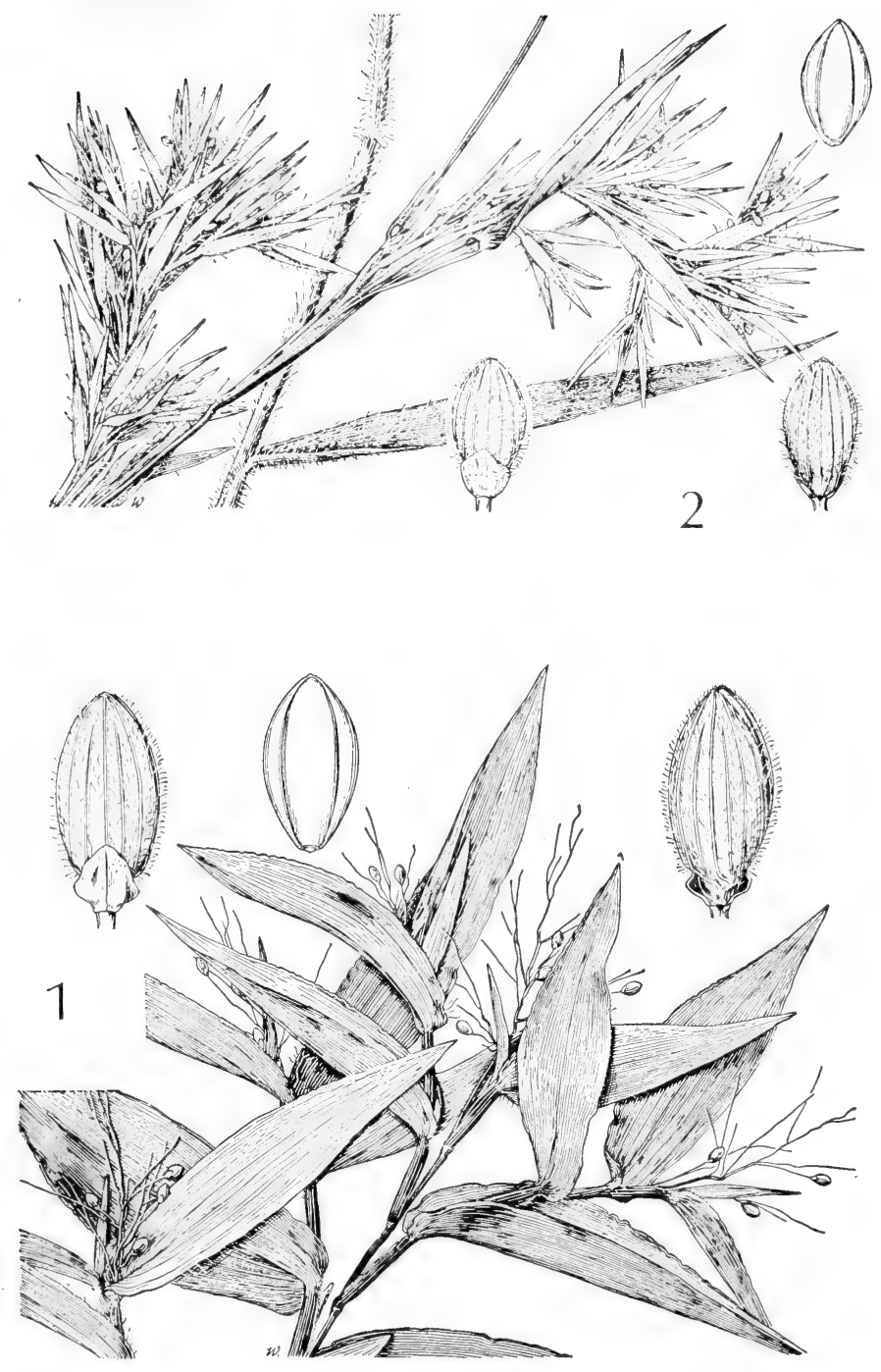

Fig. 153: 1, Panicum commutatum: plant, X 1; two views of spikelet and floret, $\mathrm{X}$ 10. 2, Panicum lanuginosum: plant, $\mathrm{X} 1$; two views of spikelet and floret, $\mathrm{X} 10$. (From Hitchcock \& Chase). 
lets $0.9-1.3 \mathrm{~mm}$. long, pubescent, elliptic; autumnal phase: stems reclining or decumbent-spreading, occasionally the culms at first sending out from lower and middle nodes long branches similar to primary culms, later producing more or less fascicled branches, or usually the culms with crowded branchlets, the whole somewhat bushy-branched; blades flat or subinvolute. P. Wrightianum Scribn., $P$. longiligulatum Nash.

Infrequent in sandy woodlands, often in boggy or moist low places, in pine barrens and swamps, in e. and s.e. Tex., spring-fall; Coastal States, Mass. to Tex.; also Tenn.; W.I., C.A., Col.

\section{Panicum lanuginosum Ell. Fig. 153.}

Perennial; vernal phase (usually grayish) olive-green or bluish-green, velvetyvillous to densely spreading-villous throughout or the upper parts of the culm or the various parts of the leaves glabrate; culms usually in large clumps, 2-7 dm. tall, spreading, often with a glabrous ring below the nodes, the nodes themselves usually with a retrorse gray beard; sheaths like the midstems in pubescence; ligule a short fringe but blade at base with a ligulelike tuft of hair 3-5 mm. long; blades thickish, sometimes stiff, often somewhat incurved or spoon-shaped (when fresh), from nearly glabrous to densely velvety or densely villous, 4-10 cm. long, 5-12 mm. broad, sometimes with a very thin firm margin; panicle (4-) 6-12 cm. long, the axis and also often the branches pubescent; spikelets $1.6-2.1 \mathrm{~mm}$. long, pubescent, 5- to 9-nerved; autumnal culms widely spreading to matted-decumbent or ascending or rarely erect, freely branching from the middle nodes, the branches repeatedly branching and much-exceeding the internodes, the ultimate branchlets forming flabellate fascicles; blades much-reduced, 2-3 cm. long, usually muchexceeding the panicles. P. Thurowii Scribn. \& Sm.

In wet meadows, swales, seepage areas, and wet soil along streams, about ponds and lakes, in sandy woodlands and prairies, in Okla. (Waterfall), e. half of Tex., to Ariz. (Pima Co.), spring-fall; N. S. and Que. to Mont., s. to Gulf States, N.M., Ariz. and Calif. (rare w. of the 100th meridian).

\section{Panicum ensifolium Ell. Fig. 154.}

Perennial, glabrous throughout; vernal culms 2-4 dm. tall, erect or reclining; ligule a very minute fringe or obsolete; blades distant, often reflexed, $1-3 \mathrm{~cm}$. long, 1.5-3 mm. broad, puberulent beneath (at least toward the tip); panicle 15-40 mm. long; spikelets 1.2-1.7 mm. long, glabrous or puberulent, 5- to 7 nerved; autumnal culms spreading or reclining, sparingly branching from the middle nodes, the branches mostly simple.

Rare in moist sand, boggy soil and shady wettish places, in e. Tex. (Nacogdoches and Newton cos.), spring-fall; Coastal States, N. J. to Tex.

\section{Panicum polyanthes Schult. Fig. 152.}

Perennial, completely glabrous (except spikelets); vernal culms erect, 3-9 dm. tall, the nodes glabrous or nearly so; ligules absent or a minute fringe in genetically contaminated plants; blades $12-33 \mathrm{~cm}$. long, $15-25 \mathrm{~mm}$. broad, firm, cartilage-margined, at base cordate and ciliate, the upper scarcely reduced; panicle $8-25 \mathrm{~cm}$. long, a fourth to half as wide as long, densely flowered, the branches mostly viscid; spikelets $1.3-1.8 \mathrm{~mm}$. long, minutely puberulent, obovoid-spherical at maturity, broadly ellipsoid when young, 5- to 7-nerved; autumnal phase remaining erect, producing simple branches from the lower and middle nodes, the thick white-margined blades of the winter rosette conspicuous.

In shallow water of streams, in seepage areas and in sandy moist woodlands, in Okla. (McCurtain Co.) and in e. Tex., spring-fall; s.e. U.S. n. to Conn., Pa., III., Mo. and Okla. 

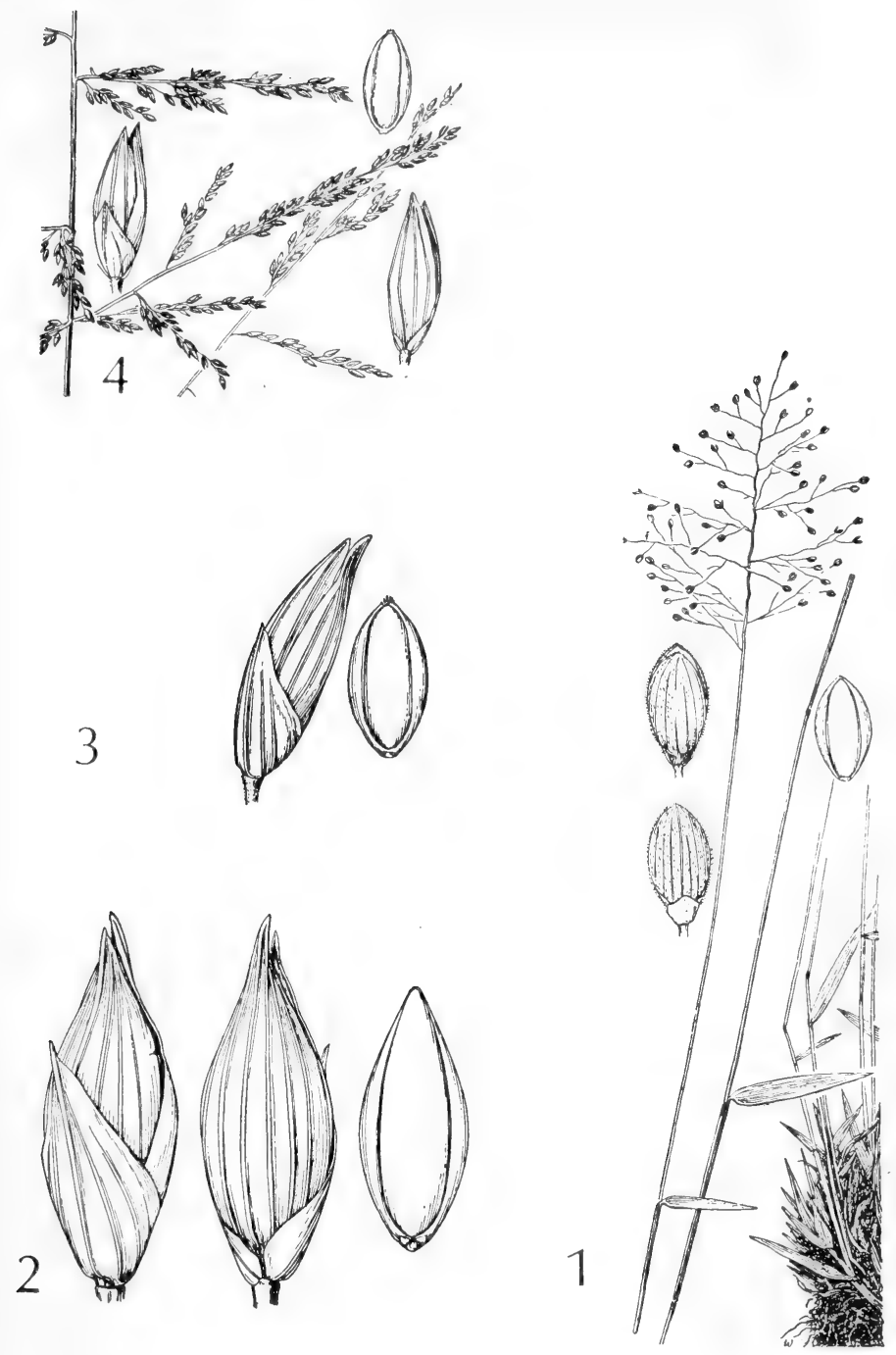

Fig. 154: 1, Panicum ensifolium: plant, X 1; two views of spikelet and floret, X 10 . 2, Panicum amarulum: two views of spikelet and floret, X 10. 3, Panicum anceps: spikelet and floret, $\mathrm{X} 10.4$, Panicum rigidulum: panicle, $\mathrm{X} 1$; two views of spikelet and floret, $\mathrm{X} 10$. (From Hitchcock \& Chase). 


\section{Panicum Ravenelii Scribn. \& Merr. Fig. 152.}

Perennial; vernal culms fairly stout and erect, 3-7 dm. tall, densely papillosehirsute with ascending hairs, the nodes short-bearded; sheaths hirsute like the culms; ligule a fringe or tuft $3-4 \mathrm{~mm}$. long, on the larger leaves grading into additional tuft at blade base; blades thick and firm, $8-15 \mathrm{~cm}$. long, 1-2 cm. broad, glabrous above, densely velvety-hirsute beneath; panicle 7-12 cm. long; spikelets 3.7-4.3 $\mathrm{mm}$. long, sparsely papillose-pubescent, strongly 7- to 9-nerved; autumnal phase more or less spreading, branching from the middle and upper nodes, the short branches crowded at the summit.

Sandy woodlands, in wet sandy loam, and in water and mud of lakes and ponds, in Okla. (Cherokee and Haskell cos.) and e. and s.e. Tex., spring-fall; Del. to Mo., s. to Fla. and Tex.

\section{Panicum scoparium Lam. Fig. 155.}

Perennial; vernal phase grayish-olive-green, velvety-pubescent throughout except on a viscid ring below the nodes and at the summit of the sheath; culms 8-15 $\mathrm{dm}$. long, stout, usually 2-3 (-4) $\mathrm{mm}$. thick, erect or ascending, usually geniculate basally, sometimes scabrous below the nodes, sometimes puberulent; sheaths glabrous or hispid, often mottled or white-spotted, commonly swollen basally and contracted upward; ligule a fringe $0.5-1.3(-1.4) \mathrm{mm}$. long (more than $1 \mathrm{~mm}$. long only in the best-developed leaves); blades rather thick, $12-25 \mathrm{~cm}$. long, 9-18 $\mathrm{mm}$. broad, often stiffish, ascending or spreading, glabrous or scabrous, sometimes more or less pubescent beneath; panicle $8-20 \mathrm{~cm}$. long, the axis and branches with viscid blotches or these absent; spikelets 2.3-2.6 mm. long, ovate to obovate, turgid, papillose-pubescent to obscurely puberulent to glabrous, pointed (not sharply), 7- to 9-nerved; autumnal phase erect, leaning or spreading, freely branching from the middle and upper nodes, forming flabellate fascicles. $P$. scabriusculum Ell.

Sandy woodlands, usually in moist or even boggy areas, in swamps, marshmeadows, and wet soil along ditches, streams and about ponds, in Okla. (LeFlore Co.) and e. and s.e. Tex., spring-fall; Mass. to Fla. w. thorugh Ky. to Mo., Okla. and Tex.; Cuba.

\section{Panicum commutatum Schult. Fig. 153.}

Perennial; vernal culms erect or decumbent often from somewhat knotty bases, 25-75 cm. long, sometimes purplish-tinged; nodes never bearded; sheaths glabrous or nearly so; ligule a minute scale or usually essentially absent; blades 5-10 (-15) $\mathrm{cm}$. long, (6-) 8-25 mm. broad, glabrous on both surfaces but often slightly cordate and marginally ciliate near base; panicle $5-12 \mathrm{~cm}$. long, loosely flowered, not much or often incompletely exserted from the upper sheath; spikelets 2.4-3.1 $\mathrm{mm}$. long, 7- to 9-nerved, pubescent, ellipsoid, not very turgid; autumnal culms erect or leaning, often widely spreading, not much-branched, the winter rosette leaves often with a minute cartilaginous margin. P. Joorii Vasey, P. Ashei Pearson.

Low or swampy woods in Okla. (Waterfall) and e. Tex.; e. U.S. w. to Mo., Okla. and Tex.; Mex.

\section{Panicum geminatum Forsk. Fig. 156.}

Perennial, glabrous; culms terete, tufted, $25-80 \mathrm{~cm}$. long, rarely decumbent basally and rooting at the nodes, usually slightly geniculate basally and essentially erect; blades 1-2 dm. long, 3-6 mm. broad, flat or toward the apex involute; panicle 12-30 cm. long, extremely narrow; appressed spikelike racemes (3 to) 8 to 18 , lower racemes $25-30 \mathrm{~mm}$. long, upper gradually shorter; raceme rachis ending in a short naked point; spikelets 2.2-2.4 mm. long, 5-nerved, subsessile, abruptly pointed, glabrous, the first glume truncate; fertile lemma and palea 

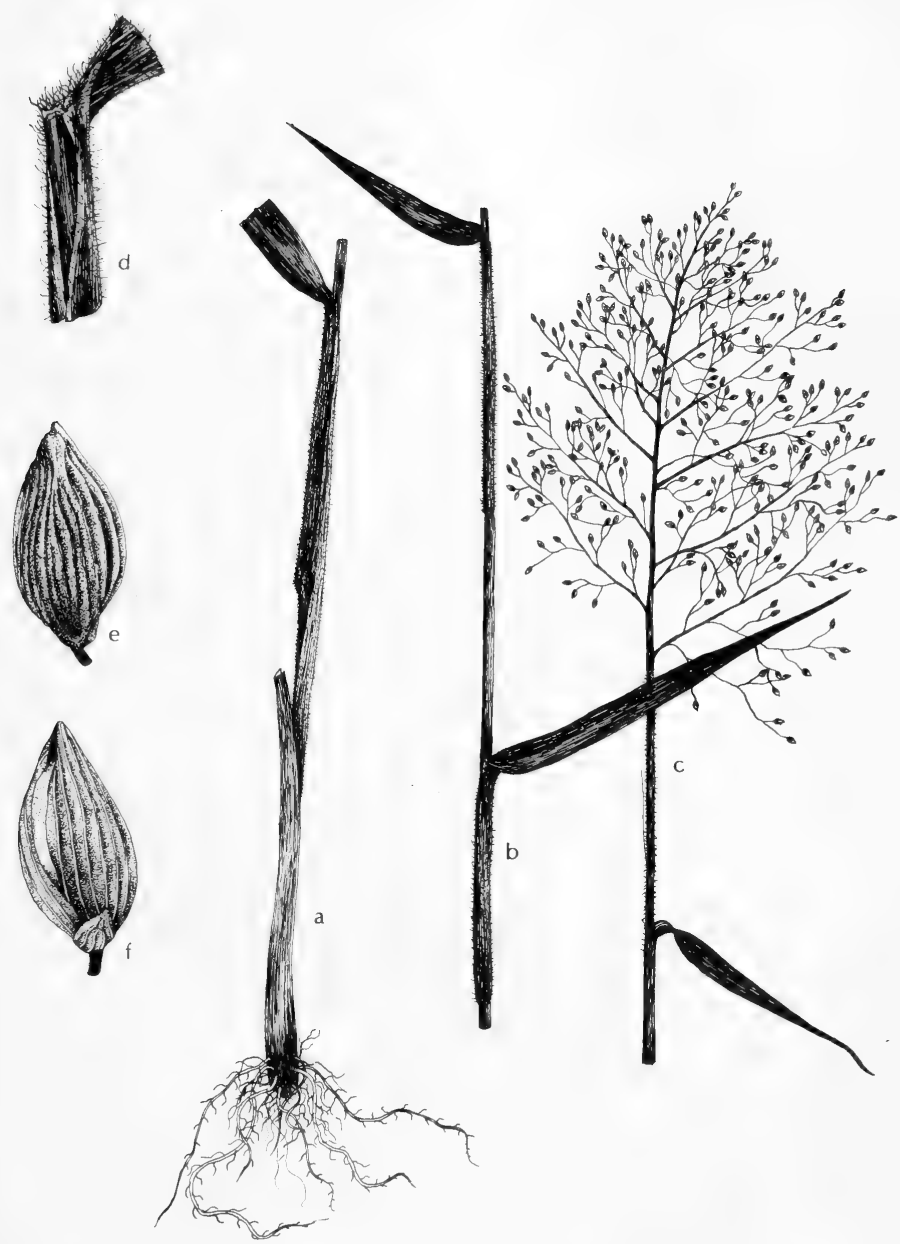

Fig. 155: Panicum scoparium: a, basal part of plant, X $1 / 3 ; \mathrm{b}$, middle section of stem, X 1/3; c, upper part of plant, $\mathrm{X} 1 / 3$; d, ligule, about $\mathrm{X} 2$; e and $\mathrm{f}$, two views of spikelet, X 10. (Courtesy of R. K. Godfrey). 
transversely rugose. Paspalidium geminatum (Forsk.) Stapf.

Moist or wet ground or in shallow water, in Okla. (Jefferson Co.) and in e. half of Tex., frequent nearest the coast, summer-fall; Fla., La., Tex., Okla. and warmer regions of the world.

10. Panicum paludivagum Hitchc. \& Chase. Fig. 157.

Perennial; vernal culms erect or decumbent often from somewhat knotty bases, creeping, rooting, rather succulent, as much as $2 \mathrm{~m}$. long, the lower part often submerged, loosely branching; blades $15-40 \mathrm{~cm}$. long, scabrous on the upper surface; spikelets $2.5-3 \mathrm{~mm}$. long, faintly 3-nerved; fertile lemma obscurely to obsoletely transversely rugose. Paspalidium paludivagum (Hitchc. \& Chase) Parodi.

Scattered in wet places, in shallow water of ponds, lakes and streams, in s. Tex. (Cameron, Hidalgo, Brazoria and San Patricio cos.), summer-fall; Fla., Tex., Mex.; Guat.

This is not adequately separable from $P$. geminatum, being scarcely more than a form of that species.

\section{Panicum gymnocarpon Ell. Fig. 158.}

Perennial, rooting at the lower nodes; culms basally prostrate, terminally ascending, 3-7 mm. thick; blades $14-25 \mathrm{~mm}$. broad, basally with pronounced corners, marginally finely serrate; ligule a thin scale $1 \mathrm{~mm}$. long; inflorescence paniculoid, 12-40 cm. long, $7-25 \mathrm{~cm}$. broad, of 14 to 35 loosely ascending remote or remotely whorled branches ("racemes" of some descriptions) with each secundly bearing a number of closely set appressed nearly sessile spikelets or (toward the base) usually compound with short appressed secondary branchlets (each bearing several appressed sessile spikelets); spikelets 5.5-7 mm. long, narrow; first glume nearly as long as the sterile lemma, the second glume strongly 3- to 5-nerved and surpassing the sterile lemma, both of them acuminate and glabrous; fertile lemma $2 \mathrm{~mm}$. long, smooth, shiny.

Local in wet sand along streams or in shallow water, in mud about lakes and ponds, in e. and s.e. Tex. (w. to Anderson and Colorado cos.), fall; Coastal States, S.C. to Tex. and inland to Ark.

\section{Panicum hemitomon Schult. Maidencane. Fig. 159.}

Aquatic or subaquatic perennial from extensively creeping rhizomes, often producing numerous sterile shoots with overlapping sometimes densely hirsute sheaths; culms 5-15 dm. tall, usually hard; sheaths of fertile culms usually glabrous; blades 10-25 cm. long, 7-15 mm. broad, usually scabrous on the upper surface and smooth beneath; panicles elongate, very narrow, $15-30 \mathrm{~cm}$. long, the branches erect, the lower branches distant, the upper ones approximate, $2-10 \mathrm{~cm}$. long; spikelets subsessile, 2.4-2.7 mm. long, lanceolate, acute, 3- to 5-nerved, glabrous; first glume about half the length of the spikelet; fertile lemma less indurate than usual in Panicum; apex of fertile palea scarcely enclosed by the margin of the fertile lemma.

Frequent (rarely flowering) on margin of lakes, ponds and streams, and in shallow water of lakes and ponds, in e. and s.e. Tex., spring (usually May); Coastal States, N.J. to Tex.; also Tenn.; Braz.

\section{Panicum obtusum H.B.K. Vine-Mesquite. Fig. 160.}

Perennial forming large colonies from extensive stolons; culms in tufts from a knotty base at intervals along the stolon, wiry, compressed, $2-8 \mathrm{dm}$. tall; ligules about $1 \mathrm{~mm}$. long; blades mostly elongate, 2-7 mm. broad, glabrous or nearly so; panicles narrow, 3-12 cm. long, about $1 \mathrm{~cm}$. broad, the few appressed branches densely flowered, the short pedicels secund; spikelets $3-3.8 \mathrm{~mm}$. long, obovoid, brownish, blunt, scabrous; first glume nearly as long as the spikelet; 


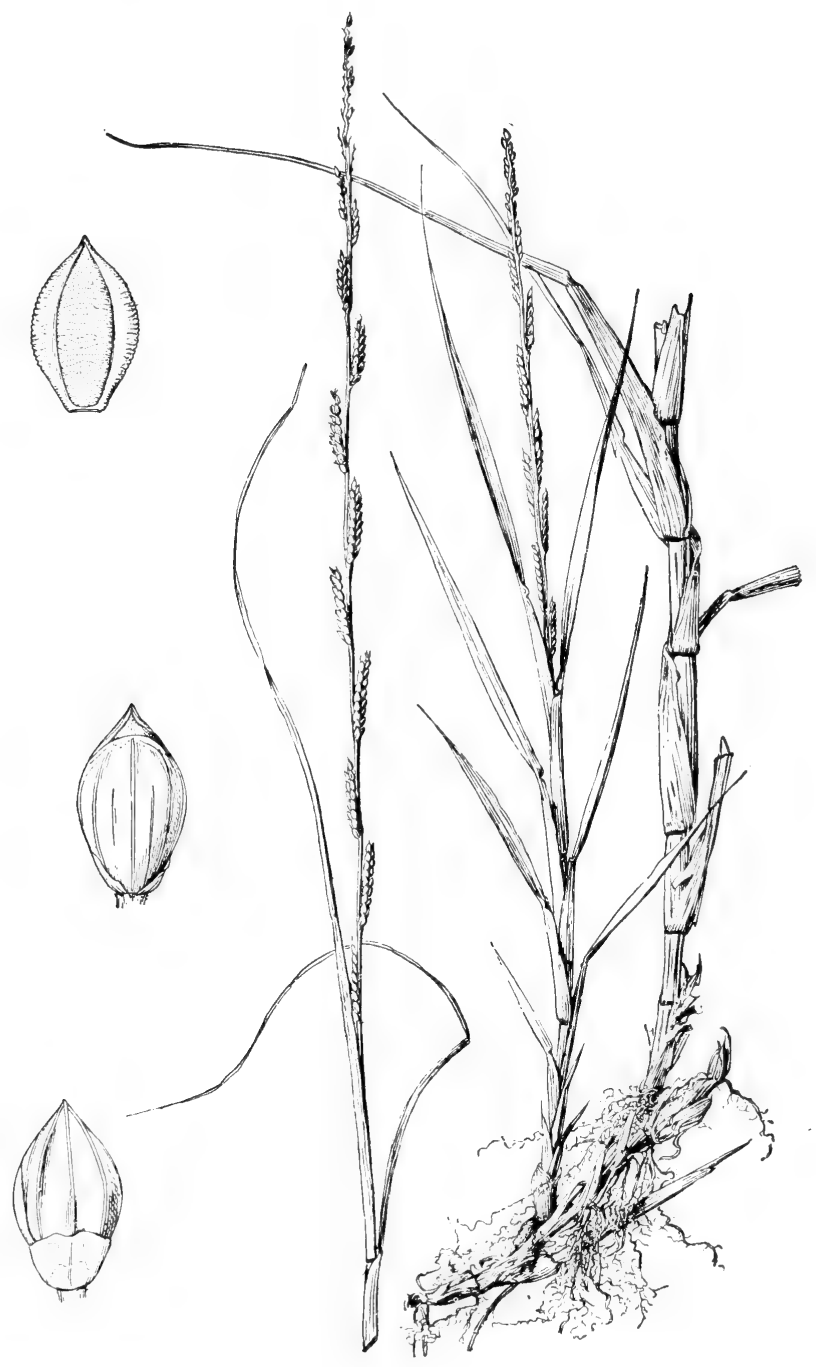

Fig. 156: Panicum geminatum: plant, $\mathrm{X} \frac{1}{1} 2$; two views of spikelet and floret, $\mathrm{X} 10$. (From Hitchcock \& Chase). 


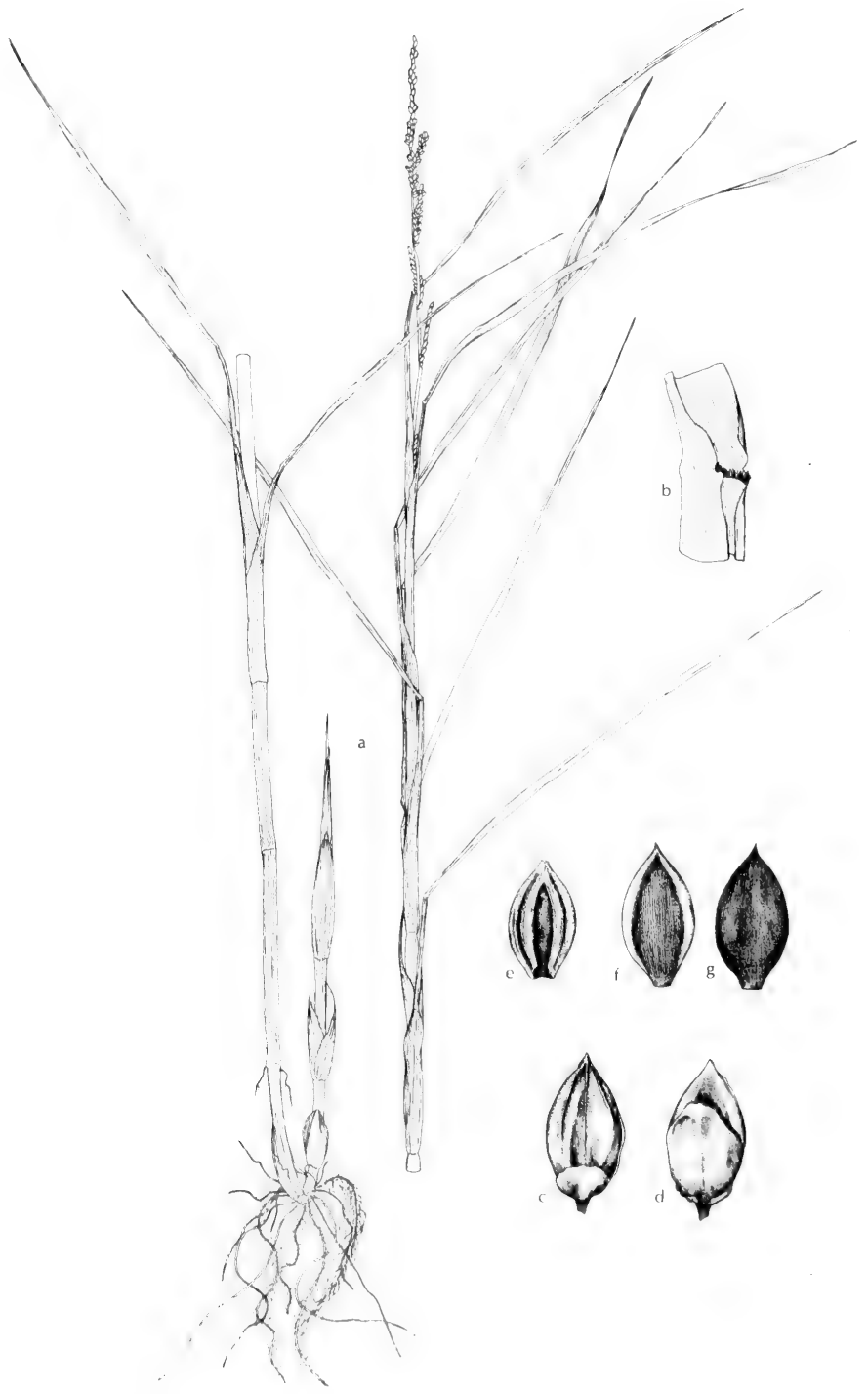

Fig. 157: Panicum paludivagum: a, habit, X 1/3; b, ligule, X 4; c, spikelet showing 1 st glume, $X 7$; d, spikelet showing 2 nd glume, $X 7$; e, palea of staminate flower, $X 7$; f, floret showing palea, X 7; g, floret showing lemma, X 7. (Courtesy of R. K. Godfrey). 
fertile lemma smooth and shiny.

In marshes, seepage areas, about playa lakes, along sloughs, often forming large colonies near water or in sporadic overflow areas, in Okla. (Waterfall), the w. half of Tex., e. to n.-cen. Tex. and the Coastal Bend area, N. M. (Colfax and Valencia cos.) and Ariz. (throughout the state), spring-fall; Mo. to Colo., s. to Ark. and cen. Mex.

\section{Panicum hians Ell. Fig. 161.}

Tufted perennial; culms compressed, 2-6 dm. tall, mostly erect, sometimes more or less decumbent or prostrate with erect branches; ligules minute; blades 5-15 cm. long, 1-5 mm. broad, flat or folded, pilose on the upper surface near base; panicles 5-20 cm. long, usually loose and open, the primary branches few, slender, distant, spreading or drooping, the branchlets borne on the upper half or toward the ends only; spikelets in more or less secund clusters, short-pedicelled, 2.2-2.4 mm. long, 5-nerved, glabrous; palea of the sterile floret becoming enlarged and indurate, expanding the spikelet to twice as thick as wide at maturity; fertile lemma minutely papillose-roughened, relatively thin for this genus.

Usually in low places, damp soil, in swamps, marshes, seepage areas, bogs, sloughs and about ponds and lakes, Okla. (LeFlore, McCurtain, Atoka and Johnston cos.) and e., s.e. and n.-cen. Tex. and Rio Grande Plains, rare w. to Llano region, spring-fall; Coastal States, Va. to Tex.; also Mo., Ark., Okla. and Mex.

\section{Panicum anceps Michx. Fig. 154.}

Perennial from branching scaly rhizomes $2-4 \mathrm{~mm}$. thick; culms $3-10 \mathrm{dm}$. long, erect, compressed; sheaths keeled, glabrous to pilose or densely to sparsely villous (especially at summit); ligule a scale $0.2-0.6 \mathrm{~mm}$. long, firm; blades elongate, 4-12 mm. broad, pilose near base or often pubescent on both surfaces; panicles $15-40 \mathrm{~cm}$. long, the branches ascending or spreading, slender, remote, bearing short mostly appressed rather densely flowered branchlets; spikelets slightly oblique to the pedicels, 2.4-3.8 mm. long, short-pedicelled, lanceolate, pointed, glabrous, often gaping; sterile lemma 5- to 7-nerved; glumes and sterile lemma mostly keeled; fertile lemma smooth and shiny and with a very minute tuft of thickish hairs at apex. P. rhizomatum Hitchc. \& Chase.

Abundant in sandy well-drained usually forested uplands, in wet prairies, swampy meadows, and on edge of streams and ponds, in Okla. (Pushmataha Co.) and in e. and s.e. Tex., infrequent w. to n.-cen. Tex., late summer-fall; s.e. U.S. w. to Kan., Okla. and Tex.

\section{Panicum rigidulum Nees. Fig. 154.}

Tufted perennial in dense clumps from a short multinoded crown, with numerous short-leaved innovations at base; culms 5-10 dm. tall, erect, compressed; sheaths keeled; ligules membranous, about $1 \mathrm{~mm}$. long or less; blades erect, folded basally, flat distally, 2-5 dm. long, 5-12 mm. broad, glabrous or sparsely pilose on the upper side at the folded base; panicles terminal and axillary, 1-3 dm. long, a fifth to nearly as broad as long, the long branches erect or spreading, naked at base, the appressed to spreading densely flowered branchlets mostly borne on the underside of the branches, the pedicels glabrous or bearing near the summit 1 or several hairs; spikelets $1.8-2.8 \mathrm{~mm}$. long, short-pedicelled, lanceolate, pointed, glabrous; sterile lemma 5- to 7-nerved; glumes and sterile lemma mostly keeled; fertile lemma and palea smooth and shiny, the fertile lemma sessile or rarely with a very minute stipe and with a minute tuft of thickish hairs at apex. $P$. agrostoides Spreng. and var. ramosius (Mohr) Fern., $\boldsymbol{P}$. condensum Nash, $\boldsymbol{P}$. stipitatum Nash. 


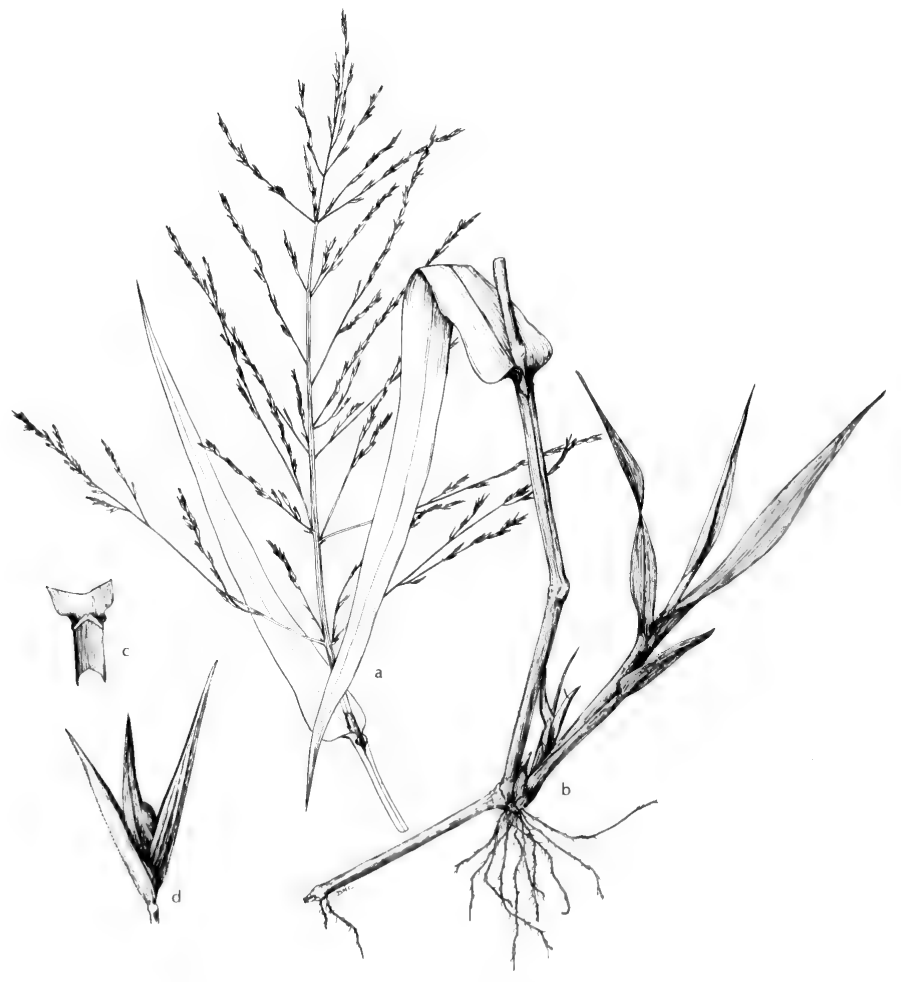
Fig. 158: Panicum gymnocarpum: a and b, habit, X 1/3; c, ligule, X 1/3; d, spikelet,
X 5. (Courtesy of R. K. Godfrey). 


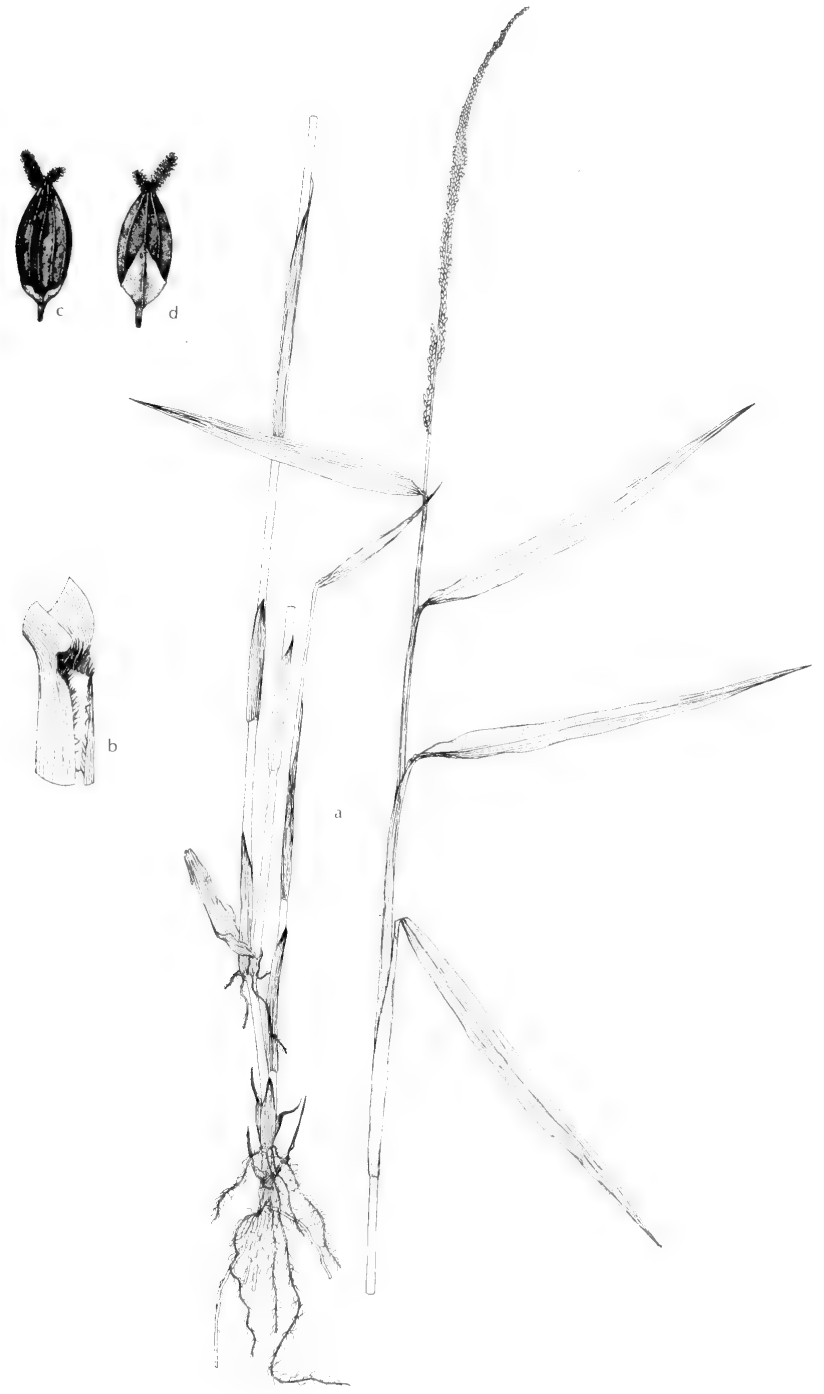

Fig. 159: Panicum hemitomon: a, habit, $\mathrm{X} 1 \frac{1}{3}$; b, ligule, $\mathrm{X} 3$; c, spikelet showing 2nd glume, X 10; d, spikelet showing 1st glume, X 10. (Courtesy of R. K. Godfrey). 
Abundant in moist or poorly drained areas, in wet meadows, on muddy banks of ponds, lakes and streams, in shallow water of ponds and lakes, swampy areas and along sloughs, in Okla. (McCurtain, Adair, Atoka, LeFlore, Osage and Mayes cos.) and e. and s.e. Tex., infrequent w. to n.-cen. Tex., late summer-fall; most of e. U.S.; W.I.; Coah.

\section{Panicum tenerum Beyr. Fig. 161.}

Perennial from knotty crowns; culms several, subcompressed, wiry, erect, 4-9 $\mathrm{dm}$. tall; lower sheaths pubescent toward the summit, with spreading hairs; ligule minute; blades 4-15 cm. long, 2-4 mm. broad, erect, firm, subinvolute, pilose on upper surfaces toward the base; panicle $3-8 \mathrm{~cm}$. long, very slender, terminal and axillary; spikelets short-pedicelled (the pedicel usually with a few long hairs), 2.2-2.8 mm. long, pointed, glabrous; fertile lemma and palea smooth and shiny.

Rare in wet places, margins of swamps and wet places in pine barrens, in s.e. Tex., rarer still in e. Tex., summer-fall; Coastal States, N.C. to Tex.; W.I.

\section{Panicum amarulum Hitchc. \& Chase. BEACH PANIC. Fig. 154.}

Perennial from extensive decumbent subrhizomatous to rhizomatous bases, forming clumps as much as $3 \mathrm{~m}$. across; ascending aerial portions of the numerous culms to $1 \mathrm{~m}$. long and $1 \mathrm{~cm}$. thick, glaucous, glabrous throughout; ligule a fringe about $2 \mathrm{~mm}$. long or at the extreme base of the fringe a firm minute scale; blades linear, firm, 2-5 dm. long, 5-12 mm. broad, involute near the tip, pilose on the upper surface near the base; panicle large, rather compact, $3-10 \mathrm{~cm}$. broad, slightly nodding, densely flowered; spikelets $4.3-5.5 \mathrm{~mm}$. long, acuminatepointed, glabrous; sterile lemma strongly 5- to 9-nerved; lower floret staminate; fertile lemma and palea smooth and shiny.

All along the Gulf beaches in loose dune sand, also on margin of swamps and wet places in pine barrens, fall; beaches, N.J. to Mex.; W.I.

Very doubtfully distinct from $P$. amarum Ell., which occurs on beaches from Connecticut to Georgia, and has been reported to occur in Texas. $P$. amarum supposedly differs in more definitely rhizomatous habit, with culms rising singly at intervals, panicle a fourth to a third the entire height of the plant and not more than $3 \mathrm{~cm}$. broad and spikelets $5-6.5 \mathrm{~mm}$. long.

Panicum amarulum intergrades with $P$. virgatum inland.

\section{Panicum virgatum L. Switchgrass. Fig. 162.}

Perennial from strong branching scaly horizontal rhizomes; culms stout, robust, in large bunches, green or glaucous, tough, 1-2 (-3) $\mathrm{m}$. tall; sheaths glabrous; ligule membranous, ciliate; blades 1-6 dm. long, 3-15 mm. broad, flat, glabrous or sometimes pilose above near base, rarely pilose all over; panicle $15-50 \mathrm{~cm}$. long, open and diffuse; spikelets turgid, often gaping, glabrous, (2.8-) 3.5-5 mm. long, acuminate-pointed; first glume clasping, two thirds to three fourths as long as the spikelet, acuminate or cuspidate; sterile lemma 5- to 9-nerved; lower floret usually staminate; fertile lemma narrowly ovate, smooth and shiny, the margins inrolled only in the lower part.

In moist or seasonally moist open places, fresh or brackish marshes, seepage areas, swamps about lakes, edge of ponds and in shallow water of pools, in Okla. (Ottawa, Woodward, Creek. LeFlore and McCurtain cos.), nearly throughout Tex, but infrequent or rare in the Trans-Pecos, and N. M. (Colfax, Guadalupe and Quay cos.), late summer-fall; N.S. and Ont. to N.D. and Wyo., s. to Gulf States; Cuba; reported in Jal. and Gro. but perhaps based on misdeterminations; reports of its occurrence in Coah. and Chih. are based on specimens of $P$. bulbosum. 


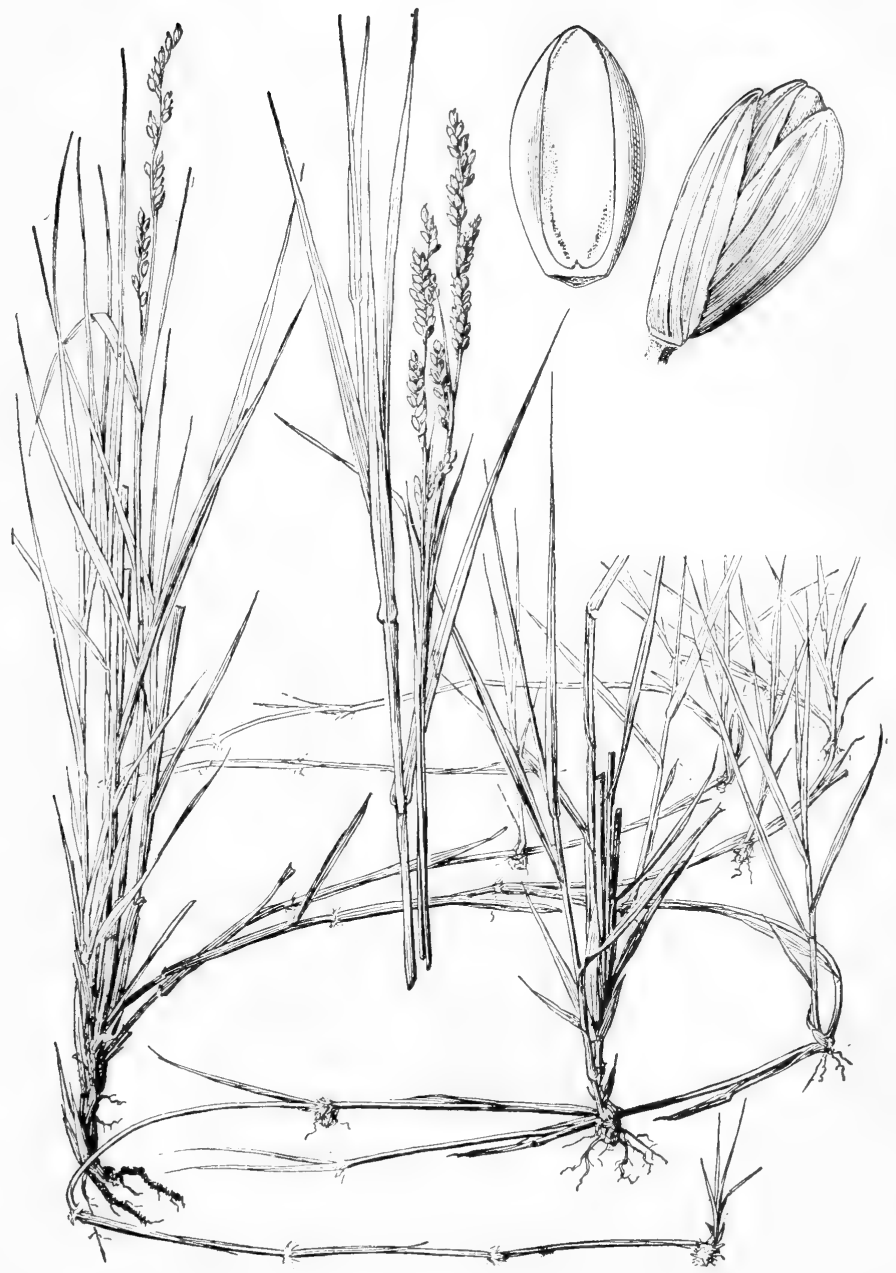

Fig. 160: Panicum obtusum: plant, X $1 / 2$; spikelet and floret, X 10. (From Hitchcock \& Chase). 

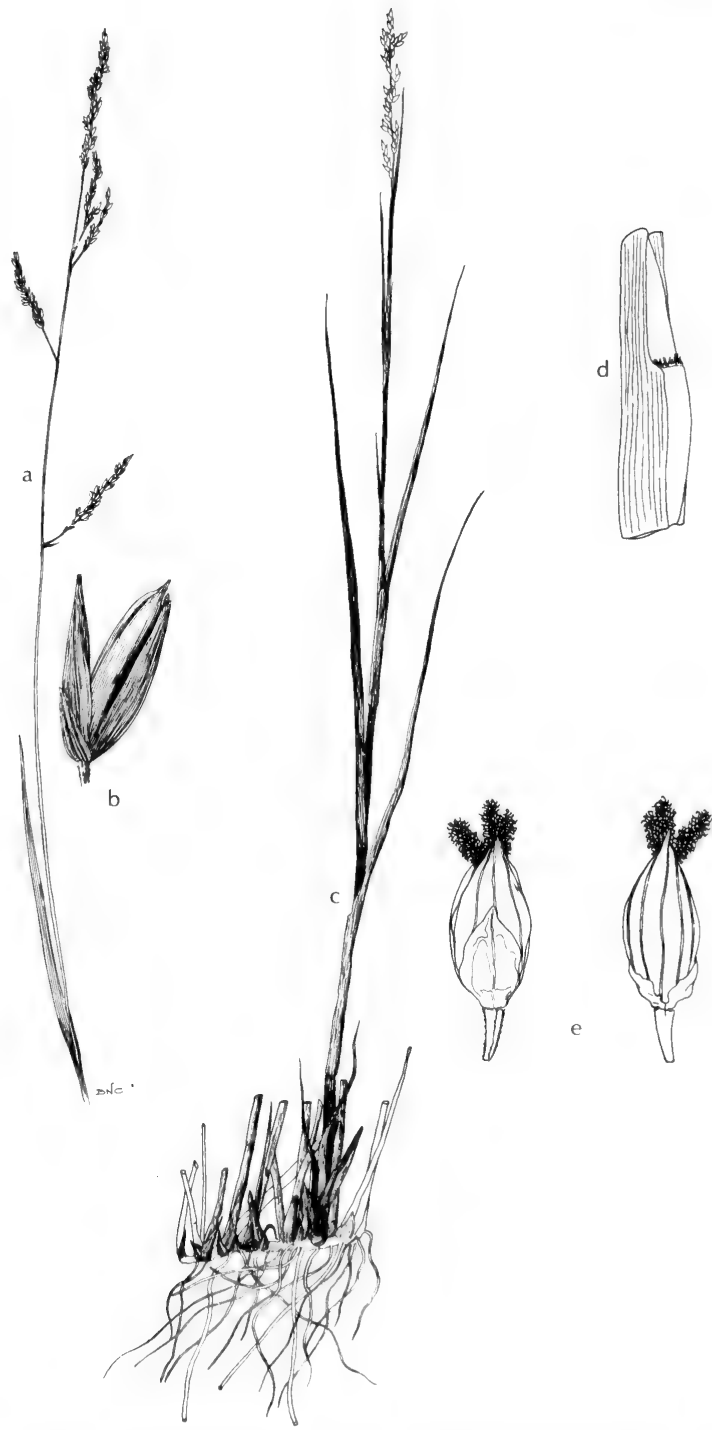

Fig. 161: a and b, Panicum hians: a, top of plant, $\mathrm{X} 2 / 3$; b, spikelet, $\mathrm{X} 10$. c-e, Panicum tenerum: c, habit, X $1 / 3$; d, ligule, X 2 ; e, two views of spikelet, $X 7$. (Courtesy of R. K. Godfrey). 
Annual, freely branched from the base; culms usually somewhat spreading from the base, 2-8 dm. long, papillose-hispid to rarely nearly glabrous; sheaths hispid; ligule 1-3 mm. long; blades 10-25 cm. long, 5-15 $\mathrm{mm}$. broad, hispid on both surfaces; panicles many-flowered, diffuse, often making up half the total length of the plant, included at base until maturity, the branches finally divaricately spreading, the whole panicle breaking away and rolling before the wind; spikelets 2-3.3 $\mathrm{mm}$. long, pointed or attenuate at the tip, 7- to 9-nerved, glabrous; first glume large, clasping; fertile lemma and palea smooth and shining, usually olive-brown at maturity. Incl. var. occidentale Rydb.

Moist soil in waste and cultivated lands, along irrigation ditches, and in wet sandy places along streams, about playa lakes and low alluvial soils in Okla. (Alfalfa Co.) and in the Tex. Trans-Pecos and Plains Country, infrequent e. to n.-cen. Tex. and N. M. (San Miguel and Sierra cos.), often in disturbed ground, summer-fall; most of N.A.

\section{Panicum dichotomiflorum Michx. Fall Panic. Fig. 164.}

Somewhat succulent branching annual; culms ascending or spreading from a geniculate base, $5-10 \mathrm{dm}$. tall or in robust specimens to $2 \mathrm{~m}$. long; ligule a dense ring of white hairs 1-2 mm. long; blades flat, scaberulous and sometimes sparsely pilose on the upper surface, 1-5 dm. long, 3-20 mm. broad, the white midrib usually prominent; panicles many-flowered, terminal and axillary, mostly included in the upper sheath at the base, 1-4 dm. long or more, the main branches rather stiff, ascending, the branchlets short and appressed along the main branches; spikelets short-pedicelled, narrowly oblong-ovate, 2-3 mm. long, acute, 7-nerved, glabrous; first glume only about a fourth as long as the spikelet; fertile lemma smooth and shining.

Moist ground along streams and in disturbed soil, marshy areas, in sluggish streams and seepage areas, in Okla. (McCurtain, Nowata, Kay and Pittsburg cos.) and in e. half of Tex., more common in low areas near the coast such as rice fields, rare in e. part of Plains Country, late summer-fall; N.S. and Me. to Minn., s. to Fla. and Tex., occasionally introd. farther w.; W.I.

\section{Sacciolepis NASH}

A genus of about 30 species in warm regions.

\section{Sacciolepis striata (L.) Nash. Fig. 165.}

Perennial; culms extensively creeping, the lower internodes $2-4 \mathrm{~mm}$. thick; sheaths usually shortly papillose-pilose; ligule obsolete; blades with conspicuous nervature; panicles terminal, not much-exserted, spiciform, 6-15 (-25) cm. long, about $1 \mathrm{~cm}$. thick, with numerous appressed branches, the minute ultimate pedicels abscising just below the glumes; spikelets not much-compressed, 2-flowered, the lower floret staminiferous, the upper perfect; rachilla abscising just below the fertile lemma; first glume minute, triangular, 3- to 5-nerved; second glume lanceolate, gibbous basally, 4-5 mm. long, strongly several-nerved; lower lemma as long as the second glume, with obscure nerves and a well-developed palea and 3-stamens; fertile lemma about half as long as the spikelet, very thin-cartilaginous, oblong, blunt, the margins revolute, enclosing the palea of the same texture.

In moist sands near streams, marshes and bogs, in shallow water of lakes and ponds, in Okla. (Johnston Co.) and infrequent to rare in e. and s.e. Tex. (Jasper Marion, Houston, Cherokee and Wood cos.), late summer-fall; Coastal States, N. J. to Tex.; Okla. and Tenn. 


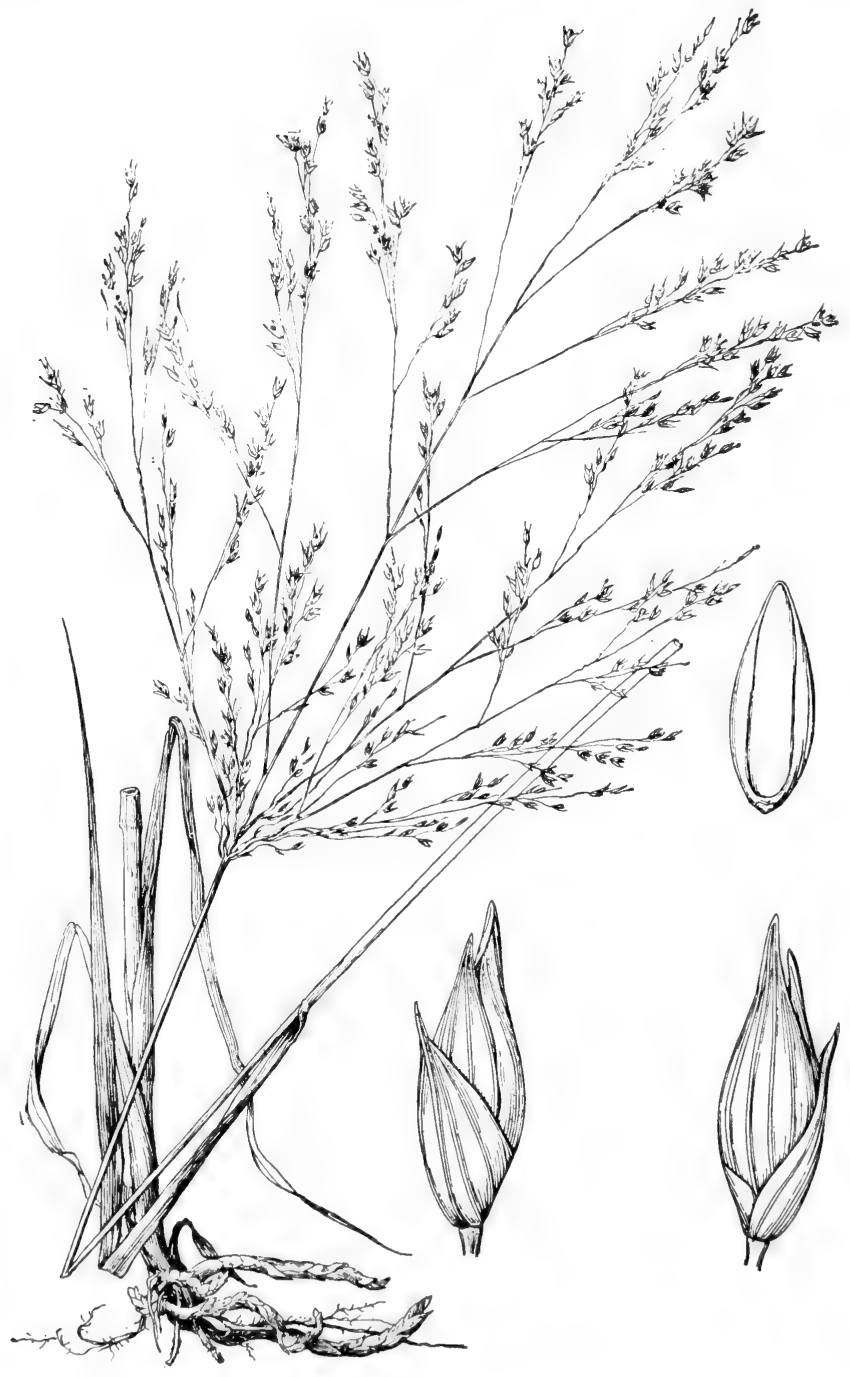

Fig. 162: Panicum virgatum: plant, X $1 / 2$; two views of spikelet and floret, $\mathrm{X} 10$. (From Hitchcock \& Chase). 


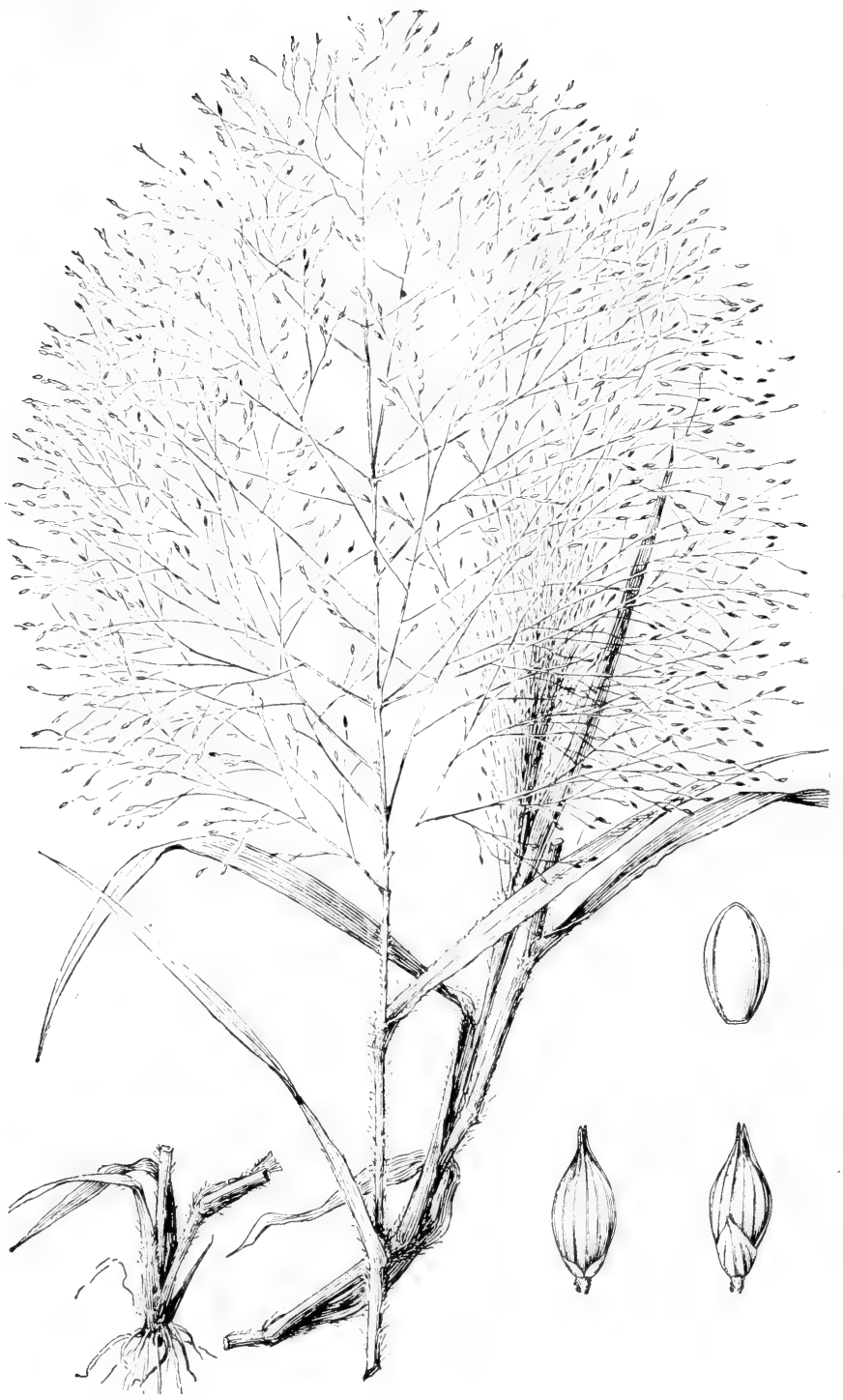

Fig. 163: Panicum capillare: plant, X 1/2; two views of spikelet and floret. X 10 . (From Hitchcock \& Chase). 


\section{Echinochloa BeAuv.}

Annual or rarely perennial; culms rarely erect, often rooting at the nodes; leaves membranous, flat; ligule absent in most species; inflorescence an elongate terminal panicle of numerous ascending spikelike branchlets that are secundly flowered on the abaxial side; spikelets paired in the upper nodes of the spikelike branchlets and in several-flowered secondary panicles in the lower part, not at all compressed, 2-flowered (the lower floret usually completely reduced, rarely staminiferous), turgidly plano-convex; first glume about half as long as the spikelet, acute; second glume and sterile lemma membranous, equal, about as long as the spikelet, usually stiffly hispidulous along the several nerves, acute; glume usually coarsely mucronate or awned (if awned, the awn of the second glume much longer than that of the first); sterile lemma enclosing a thin palea and rarely 3 stamens and often awned; fertile lemma broadly elliptical, cartilaginous-indurate, acuminate, the lateral margins revolute, clasping the lateral margins of the similarly textured palea but not its acute free tip.

A genus of perhaps 25 species of warm regions. They are excluded from Panicum on the bases of the form of the inflorescence, the usually very coarsely pubescent spikelets and the coarsely mucronate or awned glumes. Probably they represent merely a part of the very diverse genus Panicum, and should be placed therein. These plants are commonly found in muddy places and provide good forage locally.

The seeds of these species provide important food for ducks and many other kinds of birdlife.

1. Ligule a row of stiff yellowish hairs; body of sterile lemma 4-5 mm. long....

1. Ligule obsolete or absent; body of sterile lemma $2.5-4 \mathrm{~mm}$. long (2)

2(1). "Spikes" of inflorescence 3-20 $(-40) \mathrm{mm}$. long, ascending, often diverging from the axis at angles of $20^{\circ}-45^{\circ}$, only shortly if at all overlapping; blades 3-6 mm. broad............................................ E. colonum.

2. "Spikes" of inflorescence $10-100 \mathrm{~mm}$. long, ascending or slightly diverging, often overlapping a considerable portion of their lengths; blades mostly broader than $5 \mathrm{~mm}$. (3)

3(2). Inflorescence thick, if slender then erect; sterile lemmas unawned or with awns to $10 \mathrm{~mm}$. long..................................................... E. crusgalli.

3. Inflorescence slender, nodding, dense; sterile lemmas with awns, 4-43 mm. long (4)

4(3). Sheaths usually papillose-pilose or papillose-hispid; spinulose cilia of the nerves of the second glume and sterile lemma conspicuously papillose ....................................................................... E. Walteri.

4. Sheaths glabrous; spinulose cilia of the nerves of the second glume and sterile lemma not conspicuously papillose. 3. E. cruspavonis.

1. Echinochloa colonum (L.) Link. JUnGi E-RICE. Fig. 166.

Diffuse annual; culms erect or procumbent and rooting at the nodes, 1-2 (-3) $\mathrm{mm}$. thick basally; ligule obsolete; "spikes" 3-20 (-40) $\mathrm{mm}$. long, ascending, appressed or often diverging from the axis at angles of $20^{\circ}-45^{\circ}$, remote on the axis, only shortly if at all overlapping; second glume and sterile lemma simply strongly acuminate, not awned, hispid along the nerves (use lens), about $3 \mathrm{~mm}$. long. Panicum colonum $\mathrm{L}$.

In water of freshwater canals, ditches and pools, in marshes, Okla. (McCurtain, Johnston and Cherokee cos.), nearly throughout Tex. (infrequent in Plains Country) in moist loamy often disturbed soil, N. M. (Lea and San Juan cos.) and Ariz. (Yavapai, Graham, Pinal, Maricopa, Cochise, Santa Cruz, Pima and 


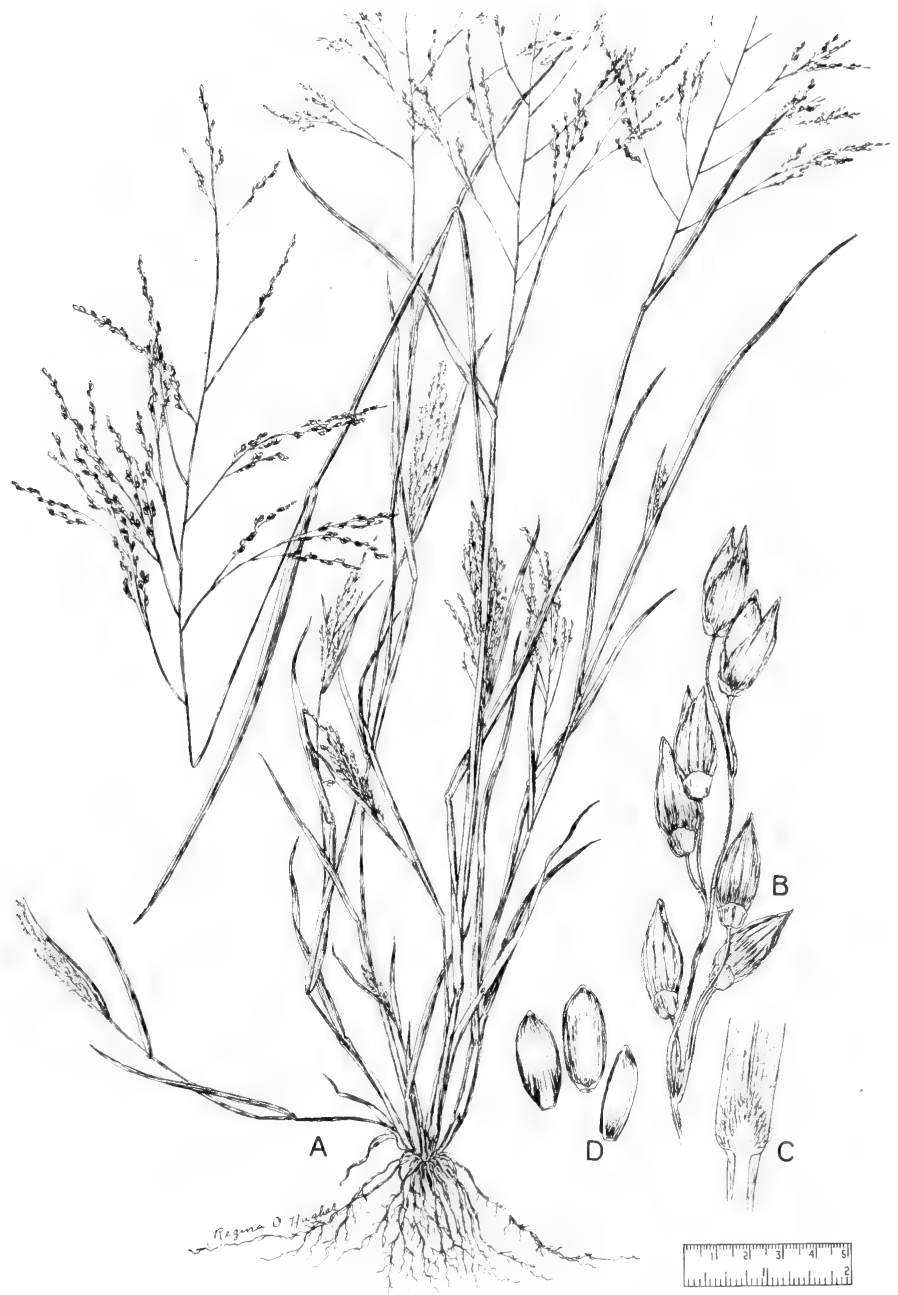

Fig. 164: Panicum dichotomiflorum: A, habit, $x$ 1/2; B, spikelet, showing the dichotomous florets, x 7; C, ligule, x 4; D, caryopses, x 7. (From Reed, Selected Weeds of the United States, Fig. 35). 


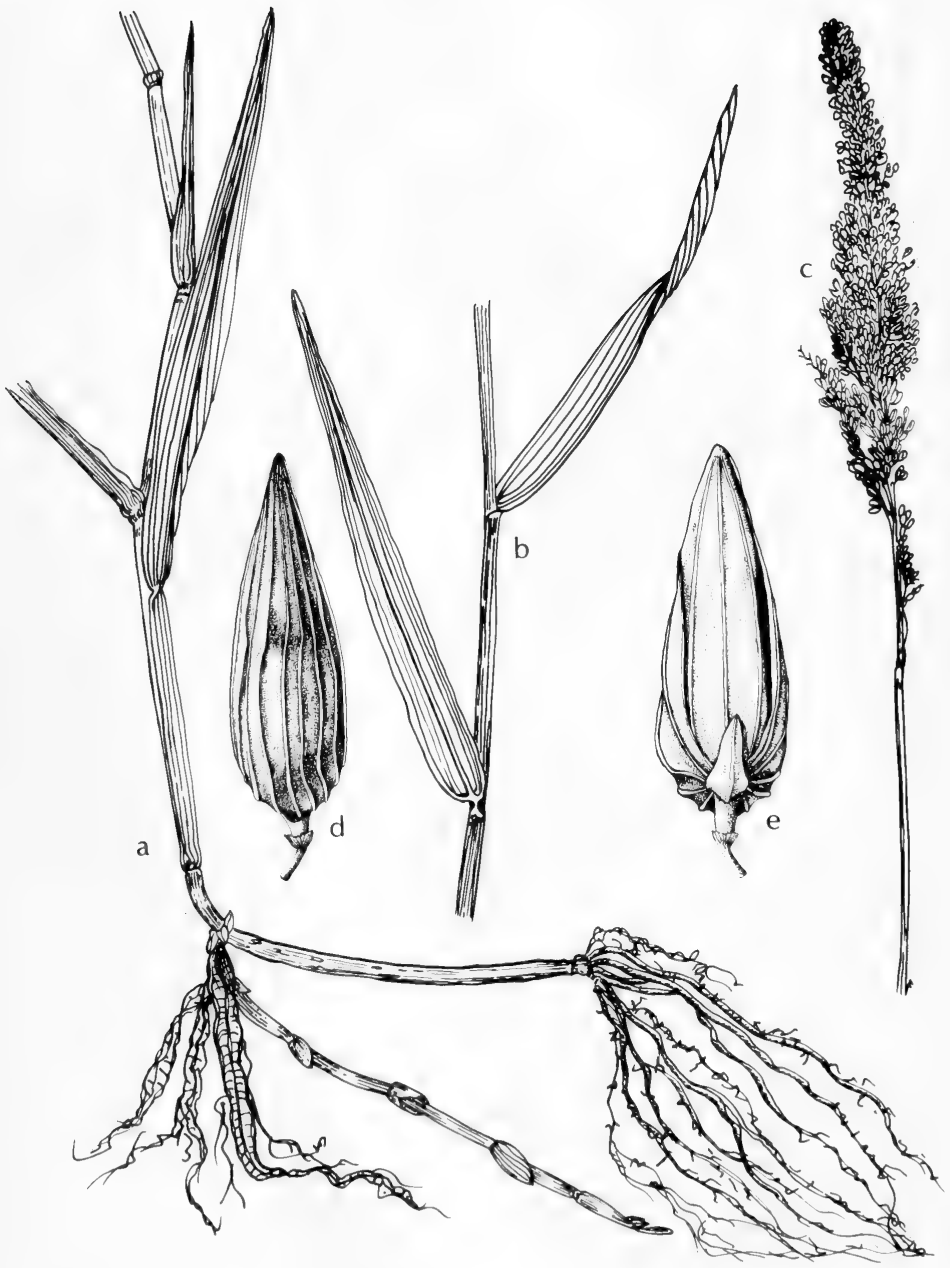

Fig. 165: Sacciolepis striata: a-c, habit, $\mathrm{X} 1 \frac{1}{2} ; \mathrm{d}$ and e, two views of spikelet, $\mathrm{X} 14$. (a-c, V. F.; d and e, Courtesy of R. K. Godfrey). 
Yuma cos.), summer-fall; nat. to the Old World trop., now widespread in warm regions of the world.

\section{Echinochloa crusgalli (L.) Beauv. BARNYARD GRASS. Fig. 167.}

Erect or diffuse annual; culms $2.5-10 \mathrm{~mm}$. thick basally; sheaths smooth; ligule obsolete; panicle erect or slightly nodding; "spikes" $1-10 \mathrm{~cm}$. long, ascending, lengthily overlapping, often with stiff bristlelike hairs; second glume and sterile lemma mucronate or awned, the nerves hispid or spinose-hirsute, $2.5-4 \mathrm{~mm}$. long. Panicum crusgalli $\mathrm{L}$.

Nearly throughout our area in moist often disturbed loamy soil, in marshes, seepage areas, and in mud and water of lakes, ditches and floodplains, summerfall; widespread in temp. and trop. areas of the world.

Variable species; we have two fairly well-marked but intergrading varities:

Var. crusgalli, with long, somewhat spreading, papillose cilia at the summits of the internodes and bases of the branches in the inflorescence and short, very thick, papillose cilia along the lateral nerves of the second glume and sterile lemma, and somewhat spreading "spikes", and sterile lemmas with awns 0-10 mm. long; synonyms include E. crusgalli subsp. muricata (Michx.) Shinners, var. muricata (Michx.) Shinners and var, microstachya (Wieg.) Shinners, and perhaps var. mitis (Pursh) Peterm.

Var. zelayensis (H.B.K.) Hitchc., with non-papillate ascending cilia in the inflorescence or these absent, and short, thinner, not-so-markedly papillose cilia along the nerves of the second glume and sterile lemma, usually strictly ascending "spikes", and sterile lemma rarely short-awned; synonyms include E. crusgalli subsp. zelayensis (H.B.K.) Shinners and var. macera (Wieg.) Shinners.

Japanese millet is planted in places and occasionally escapes; it is usually called E. crusgalli var. frumentacea (Link) W. Wight but is no doubt merely a cultivar of var. crusgalli.

One specimen from near Brownsville, Cameron Co. in the Texas Rio Grande Valley, has staminiferous lower florets and therefore corresponds to E. paludigena Wieg., which is otherwise identical to, and is to be referred to, E. crusgalli var. crusgalli.

\section{Echinochloa cruspavonis (H.B.K.) Schult.}

Diffuse annual, the lower parts of the culms long-trailing in water and mud and rooting at the nodes, the lower internodes 4-12 mm. thick; sheaths smooth; ligule obsolete; panicles long, slender, conspicuously nodding; "spikes" ascending or appressed, 1-4 cm. long, lengthily overlapping, often with stiff bristlelike hairs; second glume and sterile lemma with bodies $3-4 \mathrm{~mm}$. long and awns, the awn of the lemma 4-29 mm. long, the nerves with spinulose cilia but these not conspicuously papillose. Panicum cruspavonis (H.B.K.) Nees, E. crusgalli var. cruspavonis (H.B.K.) Nees.

Marshy margins of streams and lakes, infrequent in s.e. Tex. and n. parts of Rio Grande Plains, rare in the Trans-Pecos, summer-fall; trop. areas of Afr. and Am., n. to Ala., La. and Tex.; also rare in Va.

\section{Echinochloa Walteri (Pursh) Heller.}

Mostly erect annual; culms 4-17 mm. thick basally; sheaths papillose-pilose or papillose-hispid at least part of the length or rarely wholly glabrous; ligule obsolete; panicles elongate, nodding; "spikes" 2-10 cm. long, ascending or spreading, lengthily overlapping, often with stiff bristlelike hairs; second glume and sterile lemma with bodies $3-4 \mathrm{~mm}$. long and awns, the awns of the lemma 10-43 $\mathrm{mm}$. long, the nerves (especially the lateral) with conspicuously papillose-spinulose cilia. Panicum Walteri Pursh. 


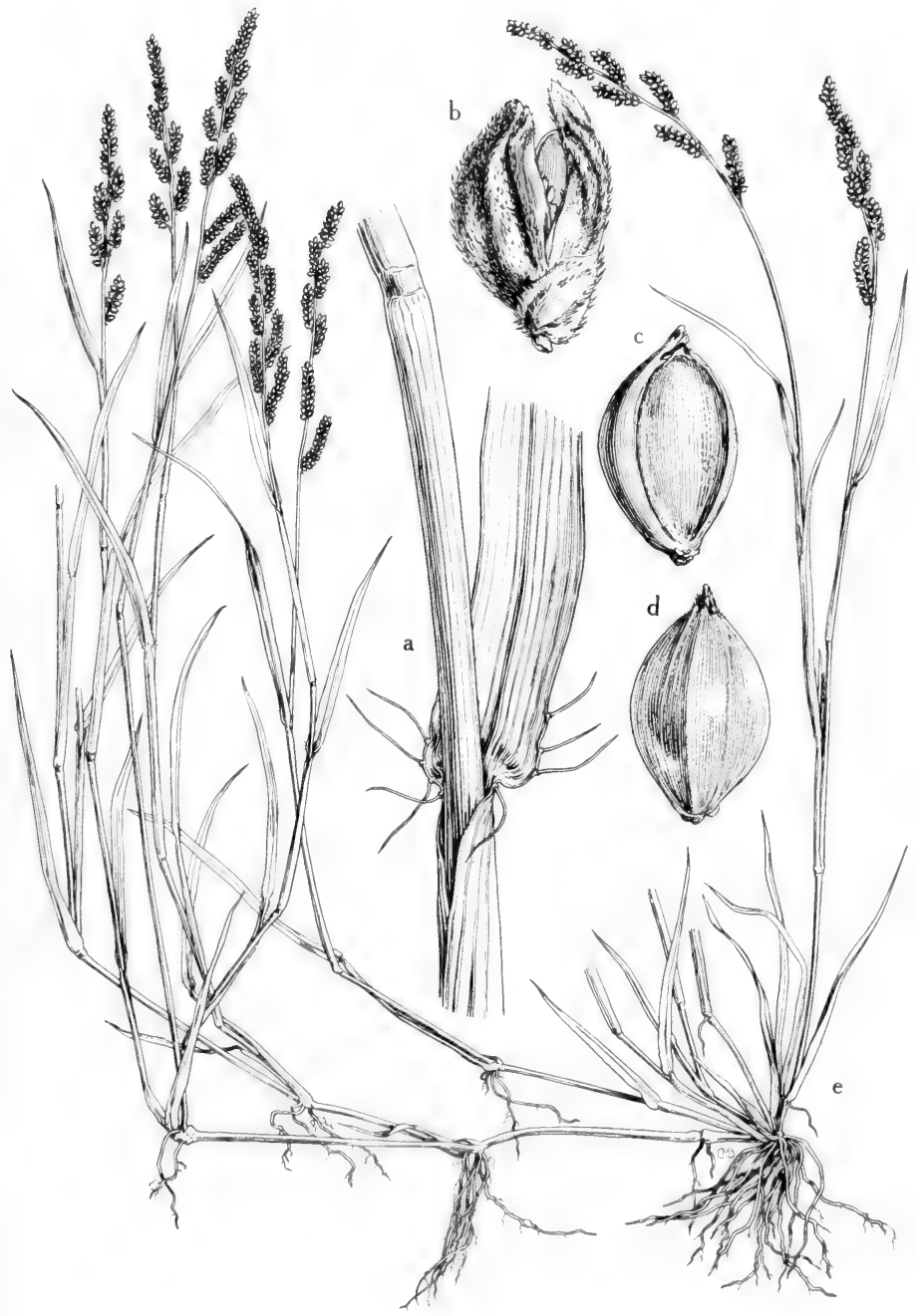

Fig. 166: Echinochloa colonum: a, culm, leaf sheath and ciliate leaf base, X 3; b, spikelet, $\mathrm{X} 12$; c, floret, adaxial view, showing indurated pales, $\mathrm{X} 12$; d, floret, abaxial view, showing indurated lemma, X 12; e, habit, showing decumbent stems rooting at the nodes, $X 1 / 4$. (From Mason, Fig. 62). 


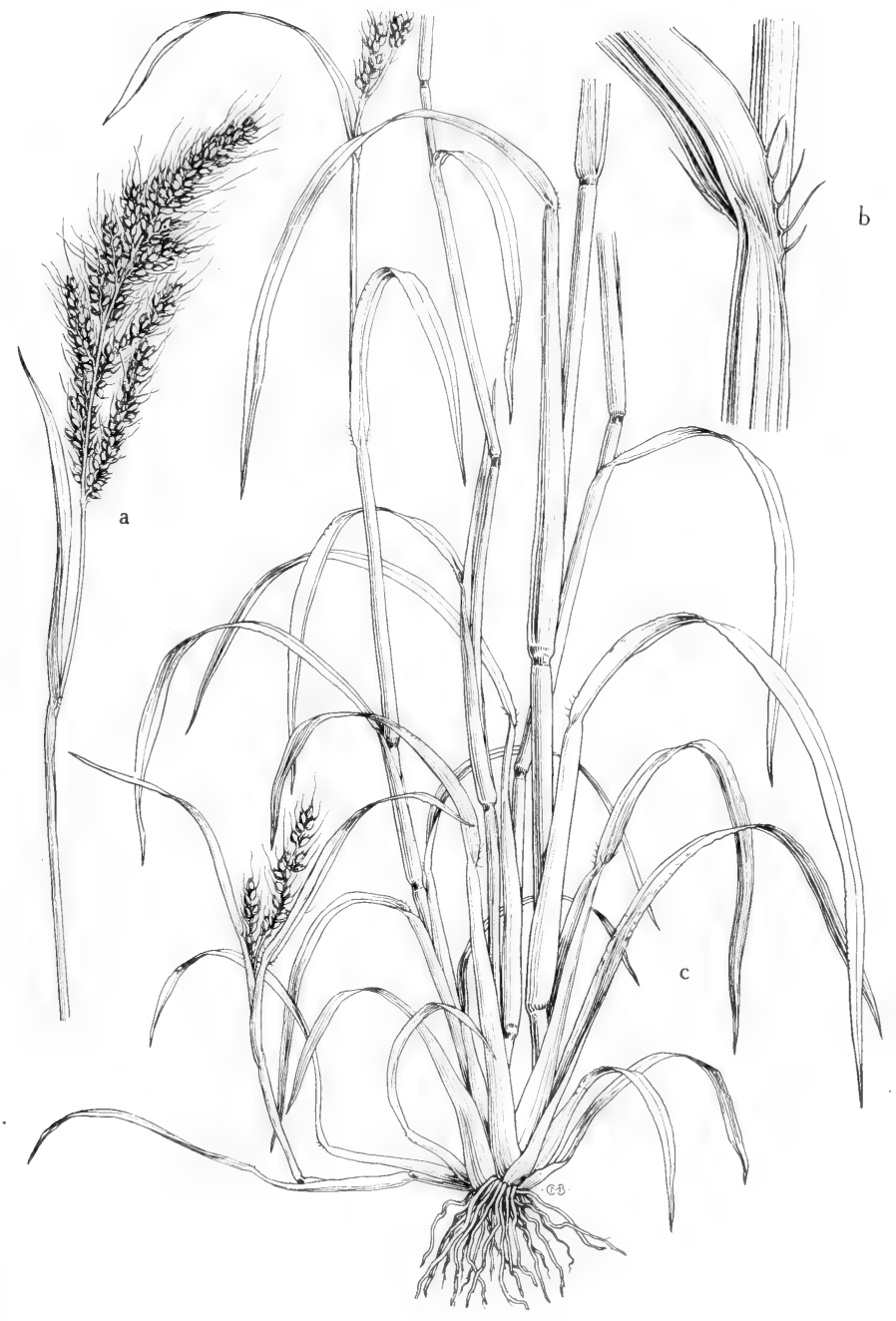

Fig. 167: Echinochloa crusgalli: a, panicle, X $2 \%$; b, leaf sheath and ciliate leaf base, X 3; c, habit, X \%). (From Mason, Fig. 63). 
Margins of streams and irrigation ditches, swampy places, in shallow water of ponds and in brackish marshes, in Okla. (Murray and Kay cos.) and extreme n. edge of Tex. Rio Grande Plains, s. parts of n.-cen. Tex. and e. Tex., infrequent, summer; Wisc., Va., S.C., Ark., La., Okla., Tex. and Coah.

\section{Echinochloa polystachya (H.B.K.) Hitchc.}

Long-creeping perennial, some of the lower internodes 3-6 mm. thick; nodes villous; sheaths smooth; ligule a row of stiff yellowish hairs (use lens); panicles slender and usually nodding; "spikes" 2-5 mm. long, strictly ascending and appressed, the lower ones only slightly overlapping, often with stiff bristlelike hairs; second glume and sterile lemma with bodies 4-5 $\mathrm{mm}$. long and awns, the awn of the lemma 4-18 $\mathrm{mm}$. long, the nerves (especially the lateral ones) with spinulose cilia but these not conspicuously pilose. Panicum polystachyum H.B.K.

Infrequent in moist clay loam, in shallow water, swamps and ditches, coastal parts of Tex. Rio Grande Plains and s. part of s.e. Tex., Mar.-Nov.; warm-temp. and trop. parts of Am., n. to Cuba and Tex.

\section{Setaria Beauv. Bristle Grass. Millet}

Panicles with many nodes and short branches, each branch system exhibiting numerous reduced sterile branchlets which are seen as bristles subtending the spikelets; spikelets essentially sessile, each falling as a unit, 2-flowered, the lower floret staminate or completely reduced, the upper perfect; first glume much shorter than the spikelet, several-nerved, membranous; second glume nearly as long as the spikelet, several-nerved, membranous; lower ("sterile") lemma several-nerved, membranous, usually not quite as long as the fertile lemma; sterile palea nearly obsolete to well-developed and as long as the sterile lemma; fertile lemma indurate, strongly convex, the margins revolute and clasping the palea of the same texture, smooth or usually faintly to strongly transversely rugose.

A genus of about 140 species in the warmer parts of the world; closely related to certain species of Panicum and probably best treated as a subgenus of that genus.

1. Bristles 4 to 12 below each spikelet; panicles spiciform, not tapering nor interrupted (2)

1. Bristles 1 to 3 below each spikelet; panicles tapering or if spiciform then usually interrupted in the lower part (3)

2(1). Plants perennial, from hard knotty subrhizomatous bases; spikelets mostly $1.2-1.6 \mathrm{~mm}$. broad, elliptic.

1. S. geniculata.

2. Plants annual, from bases that are not hard knotty or subrhizomatous; spikelets mostly $1.5-1.9 \mathrm{~mm}$. broad, turgid.

2. S. glauca.

3(1). Bristles retrorsely scabrous

3. Bristles antrorsely scabrous only

3. S. verticillata. 4. S. magna.

\section{Setaria geniculata (Lam.) Beauv. Fig. 168}

Perennial from hard knotty subrhizomatous bases; aerial culms $2-10 \mathrm{dm}$. long, geniculate at the lower nodes, mostly erect; blades $3-8 \mathrm{~mm}$. broad, mostly rather strictly erect; panicles $1-8 \mathrm{~cm}$. long, cylindric, about $15 \mathrm{~mm}$. thick, dense, a $1-\mathrm{cm}$. transection including 13 to 25 spikelets; spikelets subtended by numerous stiff bristles, mostly $2.5-3 \mathrm{~mm}$. long, $1.2-1.6 \mathrm{~mm}$. broad, elliptic to elliptic-ovate: lower (sterile) floret usually staminiferous with a well-developed palea.

Most common in disturbed moist areas, in mud along streams, salt and freshwater marshes, in mud and shallow water about ponds and lakes, in Okla. (Alfalfa, Pittsburg, Mayes and LeFlore cos.), throughout Tex., N.M. (Hitchcock) and Ariz. (Santa Cruz Co.), spring-fall; in warmer parts of Am. n. to Calif., Ariz., N.M., Kan., Ia., W.Va. and Mass. 

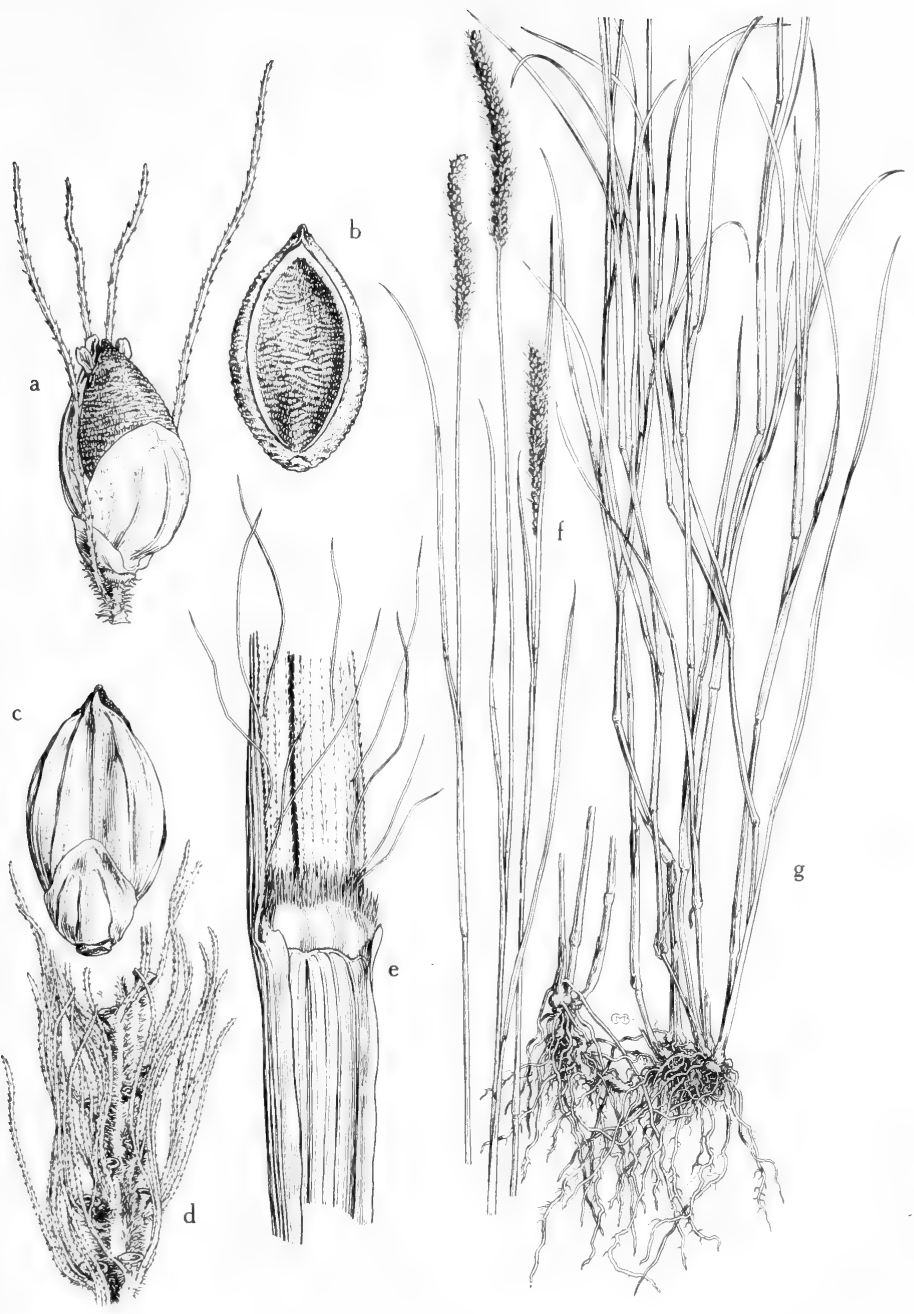

Fig. 168: Setaria geniculata: a, spikelet, showing fertile lemma and the few upwardly barbed bristles on branchlet, $\mathrm{X} 12$; $\mathrm{b}$, floret, showing palea, $\mathrm{X} 12$; $\mathrm{c}$, spikelet, showing first glume and sterile lemma, X 12; d, rachilla, the bristles remaining and the spikelets having fallen off from the branchlets, X 6; e, leaf sheath, showing long-ciliate ligule and the sparsely set long hairs at base of the scabrous blade, X 6 ; $\mathrm{f}$, habit, upper part, showing the slender linear panicles, X $2 \%$; , habit, lower part, showing the knotty branching rhizomes and the erect, ascending leaf blades, X $2 / 5$. (From Mason, Fig. 84). 
2. Setaria glauca (L.) Beauv. Yellow foxtail. Fig. 169.

Loosely-tufted annual; culms 2-10 dm. long, often geniculate and decumbent basally, ascending distally; blades $4-10 \mathrm{~mm}$. broad, ascending; panicles $1-8 \mathrm{~cm}$. long, cylindric, about $1 \mathrm{~cm}$. thick, fairly dense, a $1-\mathrm{cm}$. transection near the middle including 11 to 20 spikelets; each spikelet subtended by numerous bristles, mostly $2.5-3.2 \mathrm{~mm}$. long, 1.4-2.1 mm. broad, rotundly ovate, turgid; lower (sterile) floret usually staminiferous with a well-developed palea. S. lutescens (Weig.) F. T. Hubb.

In wet soil on edge of ponds, lakes and streams, in wet meadows, ditches and on gravel bars along streams, in Okla. (Waterfall), nearly throughout Tex. but absent from Rio Grande Plains and Plains Country, rare in the Trans-Pecos, in N. M. (Sierra Co.) and Ariz. (Apache, Coconino, Gila, Maricopa, Cochise, Yavapai, Pima and Yuma cos.), summer-fall; nearly throughout the temp. and trop. areas of the world, introd. from Eur.

\section{Setaria verticillata (L.) Beauv. Fig. 170.}

Plants annual; culms to $1 \mathrm{~m}$. long, simple or more often much-branched at base, geniculately spreading and rooting at nodes; leaf blades flat, thin, scabrous and sparingly pilose, 5-10 $\mathrm{mm}$. wide, $10-20 \mathrm{~cm}$. long; panicle erect, not rigid, slightly tapered, sometimes interrupted at base, 5-15 cm. long, 7-15 mm. thick, bristles 1 below each spikelet, retrorsely scabrous and 1 to 3 times as long as the spikelet; spikelet $2 \mathrm{~mm}$. long; fruit finely rugose.

Along ditch banks and in muddy or waste places, in Okla. (Muskogee Co.) and Ariz. (Coconino, Mohave, Cochise and Pima cos.); Mass. to N.D., s. to Ala., Mo. and Okla., w. to Ariz. and Calif., introd. from Eur.

\section{Setaria magna Griseb.}

Robust annual; culms 1-4 m. tall, 5-20 mm. thick basally, prop-rooting from the lower nodes but erect and simple; panicles $25-60 \mathrm{~cm}$. long, 2-3 cm. thick, dense (the axis mostly hidden); spikelets very numerous, about $2 \mathrm{~mm}$. long; fertile lemma smooth, shiny.

In marshes, wet places, moist ditches, bayous, etc., s.e. Tex., summer-fall; Coastal States, N.J. to Tex.; W.I., Yuc., C. R.

\section{Cenchrus L.}

About 160 species in warmer parts of the world. Individuals of this genus are exceedingly abundant, especially so in disturbed, sandy, non-forested areas and at elevations below 4,000 feet. Several species have been introduced, including Pearl Millet and Napier Grass. Some authors segregate the genus into two genera on trivial technical grounds. The spiny burs cause pain and sometimes infection when they penetrate the skin, and they are noxious to animals when mixed with hay.

\section{Cenchrus myosuroides H.B.K.}

Perennial from hard knotty subrhizomatous bases; culms 6-20 dm. long, erect; panicle (6-) 10-23 cm. long, 6-12 mm. thick, interrupted at the very base, otherwise rather dense, a $1-\mathrm{cm}$. transection near the middle containing 7 to 10 burs; internodes of axis about $1-1.5 \mathrm{~mm}$. long; burs about $3 \mathrm{~mm}$. thick basally, the bristles numerous (about 35 to 60 per bur), united only basally in the short cup which does not equal the spikelets, greatly unequal (outer ones shortest), spreading (outer) or ascending (inner ones), the inner ones stiff, none plumose.

In ditches and near creeks or springs, infrequent in the Tex. Rio Grande Plains, rare in the Trans-Pecos, summer-fall; Col., Ecu., Bol., Chile, Parag., Arg. and extreme s. Braz.; also W.I. n. to Fla. Keys; Mex.; Tex. 


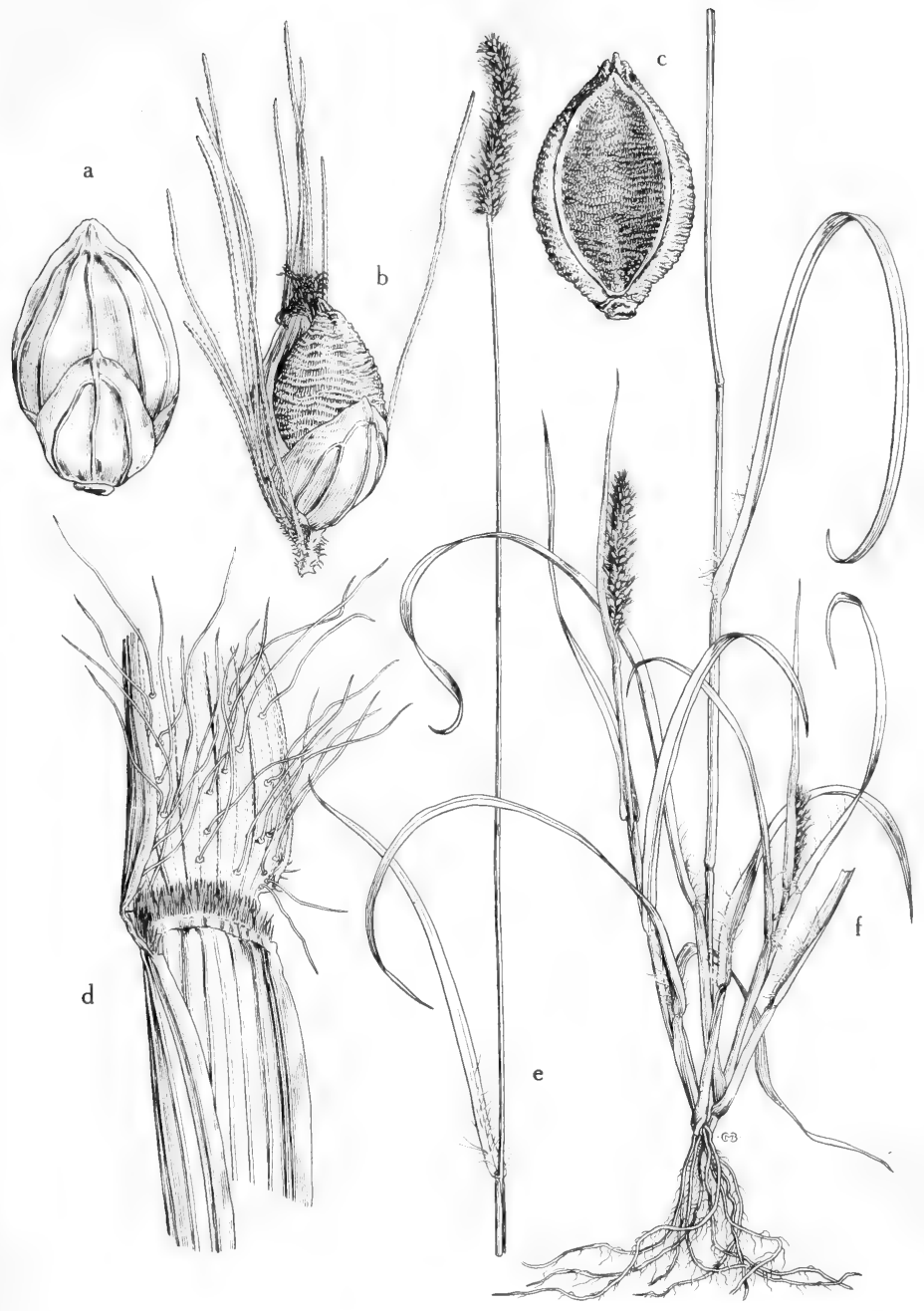

Fig. 169: Setaria glauca: a, spikelet, showing first glume and sterile lemma, X 10; $\mathrm{b}$, spikelet, showing fertile lemma and the upwardly barbed slender bristles on branchlet, X 10; c, floret, showing palea, X 10; d, leaf sheath and ciliate ligule, X 6; e, habit, upper part of culm, showing spikelike panicle, $X 2 \% ; \mathrm{f}$, habit, lower part, showing the leaf blades with villous base above sheath, X $2 \%$. (From Mason, Fig. 83). 


\section{Erianthus Michx. Plumegrass}

Perennials, 1-3 m. tall, forming robust clumps; leaves elongate; ligules narrow, usually hippocrepiform; panicle 1-9 dm. long, terminal, often pyramidal to clavate or even slender; spikelets in pairs, one of each pair sessile, one pedicelled, both perfect, usually 4-6 mm. long (not including awn), typically membranous to coriaceous, usually dorsally villous with long hairs; sterile lemma hyaline, shorter, with usually 1 median nerve; fertile lemma narrow, ovate-lanceolate, hyaline, with usually a prominent straight or twisted exserted awn 4-20 mm. long; palea (if present) hyaline.

A genus of 28 species of southeast Asia to southeast Europe, Madagascar, and the warmer parts of America.

1. Culm appressed-hairy below the panicle (2)

1. Culm glabrous below the panicle (3)

2(1). Awn straight or slightly flexuous

2. Awn loosely twisted.

4. E. giganteus. 3. E. alopecuroides.

3(1). Hairs subtending the spikelet few and short or absent; panicle nearly completely glabrous; awn straight. 1. E. strictus.

3. Hairs subtending the spikelet as long as or longer than the spikelet; panicle very hairy; awn $2 \mathrm{~cm}$. long, coiled. 2. E. contortus.

\section{Erianthus strictus Baldw. Narrow plumegrass.}

Perennial; culms 1-2 m. tall, relatively slender, glabrous; nodes sometimes hirsute with stiff erect deciduous hairs; internode below the panicle glabrous; foliage glabrous; lower sheaths narrow and crowded; blades mostly 4-12 mm. broad; panicle 2-4 dm. (rarely $8 \mathrm{dm}$.) long, strict (about $1-2 \mathrm{~cm}$. thick), the branches closely appressed; spikelets brown, about $8-11 \mathrm{~mm}$. long (not including awn), scabrous, nearly naked to sparsely short-hairy at base; awn straight, 15-20 $\mathrm{mm}$. long; rachis joint and pedicel scabrous.

Rare in moist sandy places, marshes and swamps, in Okla. (Waterfall), e. and s.e. Tex., fall; Va. to Fla. and Tex., n. to Tenn. and Mo.

\section{Erianthus contortus Baldw. BENT-AWN PL.UMEgRASS.}

Perennial; culms 1-2 m. tall, glabrous or sometimes sparsely appressed-pilose below the panicle; nodes glabrous or pubescent with erect deciduous hairs; internodes below the panicle glabrous; sheaths sparsely pilose at summit or glabrous; blades $10-15 \mathrm{~mm}$. broad, scabrous; panicle $15-30 \mathrm{~cm}$. long, narrow, the branches ascending but not closely appressed; spikelets 6-8 $\mathrm{mm}$. (excluding awn) long, brownish, the basal hairs nearly or about as long as the spikelet; awn about $2 \mathrm{~cm}$. long, spirally coiled at base; rachis joint and pedicel villous.

Rare in moist sandy places, especially wet pinelands, in Okla. (Waterfall), e. and s.e. Tex., fall; Md. to Fla. and Tex., n. to Tenn. and Okla.

\section{Erianthus alopecuroides (L.) Ell. Silver PLUMEgrass.}

Perennial; culms robust, $15-30 \mathrm{dm}$. tall, appressed-villous below the panicle and usually on the nodes; sheaths pilose at the summit; blades 12-20 mm. wide, scabrous, pilose on upper surface toward base; panicle 2-3 dm. long, silvery to tawny or purplish; spikelets 5-6 mm. long, pale, sparsely villous, shorter than the copious basal hairs; awn 10-15 mm. ing, flat, loosely twisted; rachis joint and pedicel long-villous. E. divaricatus Hitchc.

Infrequent in sandy woodlands, usually near water or in seepage, in Okla. (Waterfall), e. and s.e. Tex., fall; N.J. to Ill., s. Mo. and Okla., s. to Gulf States. 


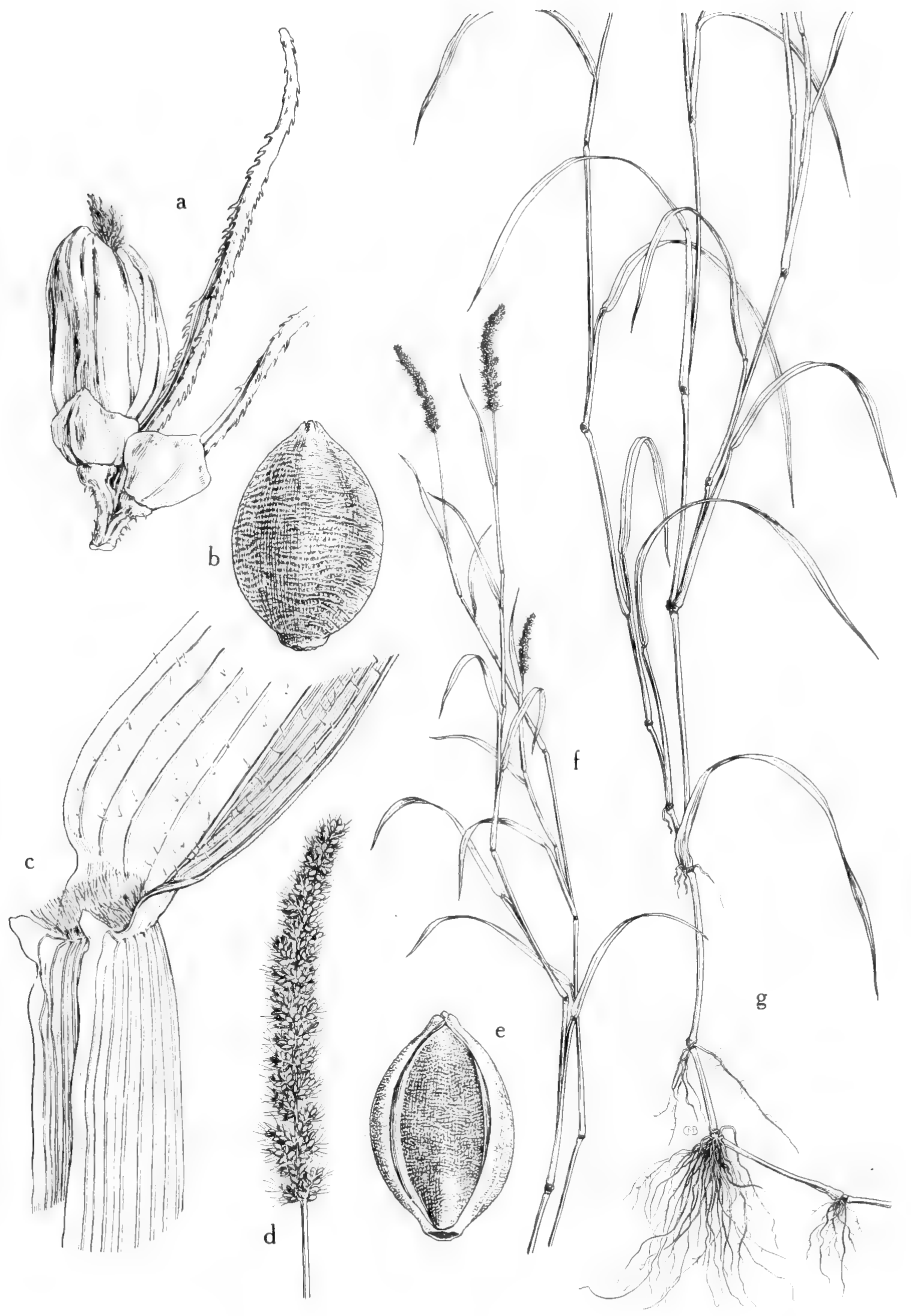

Fig. 170: Setaria verticillata: a, spikelet, showing short first glumes and the single downwardly barbed bristles on branchlets, X 16; b, floret, showing lemma, X 16; c, auricled leaf sheath and ciliate ligule, X 4; d, panicle, X 4\%; e, floret, showing palea, $\mathrm{X} 16$; f, habit, upper part, showing panicles, $\mathrm{X} 1 / 1 ; \mathrm{g}$, habit, lower part, showing the lax arching leaf blades and roots at the nodes, $X$ 1/5. (From Mason, Fig. 85). 
4. Erianthus giganteus (Walt.) Muhl. Sugarcane Plumegrass. Fig. 171.

Perennial; culms 1-3 m. tall, appressed-villous below the panicle, the nodes appressed-hispid, the hairs deciduous; sheaths and blades from nearly glabrous to shaggy appressed-villous; blades $4-15 \mathrm{~mm}$. broad; panicle 10-15 $(-40) \mathrm{cm}$. long, oblong or ovoid, tawny to purplish; spikelets 5-6 (-7) $\mathrm{mm}$. long, sparsely longvillous on the upper part, shorter than the copious basal hairs; awn 10-25 mm. long, terete, straight or rarely slightly flexuous; rachis joint and pedicel longpilose. E. saccharoides Michx., E. Tracyi Nash, E. laxus Nash, E. compactus Nash.

Infrequent in sandy soil, usually near moisture, often in marshes or seepage areas, in Okla. (Waterfall), e. and s.e. Tex., fall; N. Y. to Tex.; Cuba; probably elsewhere in trop. Am.

\section{Andropogon L. Bluestem}

In the present strict sense this is a genus of some few dozens of species of the temperate and subtropical areas of the Old World and New World.

\section{Andropogon glomeratus (Walt.) B. S. P. BUSHY BEARDgRass.}

Perennial; culms erect, 5-15 dm. tall, compressed, with broad keeled overlapping lower sheaths, the flat tufts often forming dense usually glaucous clumps, the culms from freely to bushy-branching toward the summit; sheaths occasionally villous; blades elongate, $3-8 \mathrm{~mm}$. wide; inflorescence dense, feathery, from flabellate to oblong, the paired racemes 1-3 cm. long, about equaling the slightly dilated spathes, the enclosed peduncle and ultimate branchlets long-villous, the peduncle at least $5 \mathrm{~mm}$. long or often longer; rachis very slender, flexuous, longvillous; sessile spikelets 3-4 $\mathrm{mm}$. long, the awn straight, 10-15 $\mathrm{mm}$. long; sterile spikelet reduced to a subulate glume or wanting, the slender pedicel long-villous. A. virginicus var. abbreviatus (Hack.) Fern. \& Grisc.

Frequent in moist areas, in marshes and swamps, on wet springy slopes and in seepage areas, on edge of water about springs and ponds, in Okla. (Haskell Co.), e. half of Tex., rare westw., in N. M. (Eddy Co.) and Ariz. (Coconino, Mohave, Maricopa, Pinal and Santa Cruz cos.), late summer-fall; s.e. U.S. n. to N.E., Ky., Okla.; also N.M., Ariz., Nev., Calif., Mex., W.I. and C.A.

\section{Sorghum MOENCH}

A large genus centered in the Near East; at least 2 species are cultivated and escaped in Texas.

\section{Sorghum halepense (L.) Pers. Johnson grass. Fig. 172.}

Robust perennial; culms 5-15 dm. tall, from extensively creeping scaly rhizomes; blades mostly less than $2 \mathrm{~cm}$. wide; panicle open, terminal, of several to numerous racemes, $15-50 \mathrm{~cm}$. long; spikelets tardily disarticulating just below each sessile spikelet; fertile sessile spikelet $4.5-5.5 \mathrm{~mm}$. long, ovate, appressed-silky, the readily deciduous awn $10-15 \mathrm{~mm}$. long, geniculate, twisted below; sterile pedicellate spikelet 5-7 $\mathrm{mm}$. long, lanceolate.

Open ground, fields and waste places, along irrigation ditches and in wet depressions, Mass. to Ia. and Kan., s. to Fla. and Tex., w. to s. Calif.; nat. of the Medit. region but in the trop. and warmer regions of both hemispheres.

Cultivated for forage, but because of the difficulty of eradication it becomes a troublesome weed.

\section{Manisuris L. JoINT-TaIL}

Perennial moderately tall plants; racemes nearly cylindrical, their rachises glabrous or nearly so and quite thick, the base of each internode on one side sculptured with a niche into which the spikelets fit closely; pedicellate spikelets reduced, 


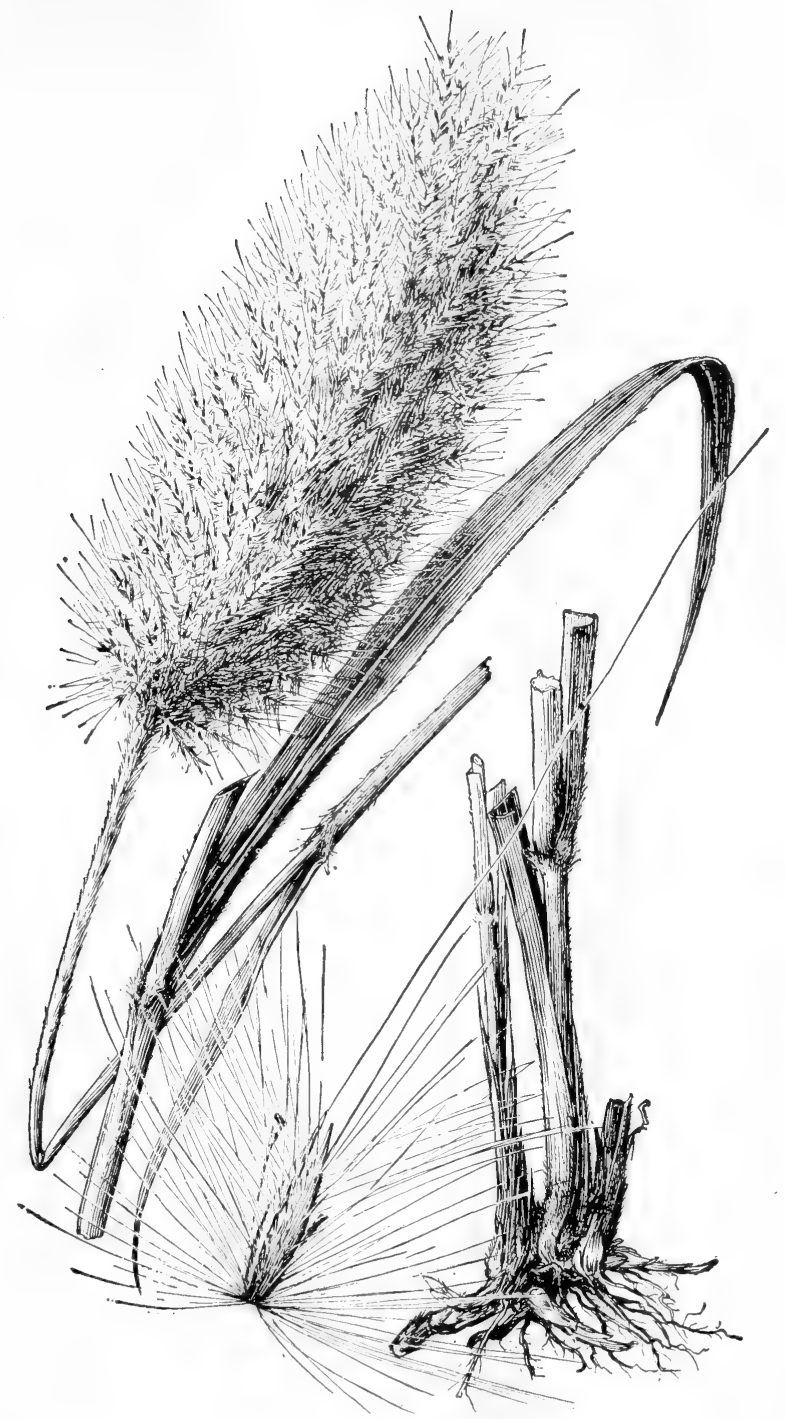

Fig. 171: Erianthus giganteus: plant, X 1/2; spikelet with pedicel and rachis joint, X 5. (From Hitchcock \& Chase). 

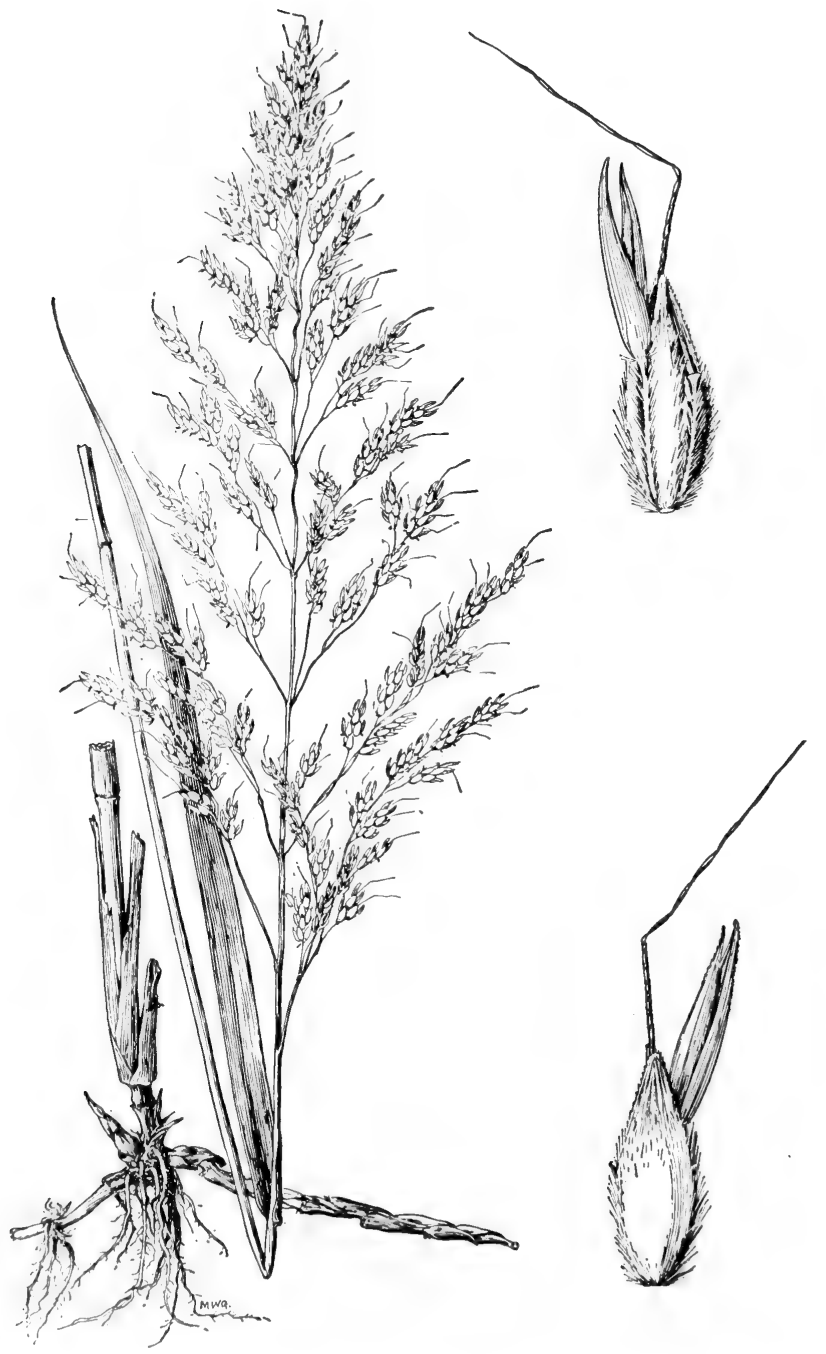

Fig. 172: Sorghum halepense: Plant, X 1/2; two views of terminal raceme, X 5. (From Hitchcock \& Chase). 
often rudimentary.

A small genus of the warmer parts of the world.

1. Racemes flattened, tardily disarticulating; first glume of sessile spikelet smooth 1. M. altissima.

1. Racemes nearly cylindric, readily disarticulating at maturity; first glume of sessile spikelet marked with pits or wrinkles...............2. M. rugosa.

\section{Manisuris altissima (Poir.) Hitchc.}

Perennial; culms ascending from a long creeping base, compressed and 2-edged, 4-8 dm. long, freely branching toward the ends; blades flat, 3-8 mm. wide; flowering branches often short and fascicled; racemes $3-5 \mathrm{~cm}$. or sometimes $1 \mathrm{dm}$. long, compressed; pedicel free or partly adnate to the rachis joint; sessile spikelet 5-7 $\mathrm{mm}$. long, the keels of the first glume very narrowly winged toward the apex; pedicellate spikelet 5-6 $\mathrm{mm}$. long, acute.

Rare in coastal s. Tex., where repeatedly introd. in ponds, ditches and on edge of water in the Rio Grande, spring-fall; warmer parts of the world, introd. in Am.

\section{Manisuris rugosa (Nutt.) $\mathrm{O}$. Ktze.}

Perennial; culms mostly rather stout, 7-12 dm. tall, freely branching; sheaths compressed-keeled; blades commonly folded, $3-8 \mathrm{~mm}$. wide; flowering branches often numerous; racemes $4-8 \mathrm{~cm}$. long, partly included in brownish sheaths; rachis joint and pedicel contracted in the middle; sessile spikelet $3.5-5 \mathrm{~mm}$. long, the first glume strongly and irregularly transversely ridged, the keels narrowly winged toward the summit.

Infrequent in open woodlands on low often moist or wet sandy loam, in wet savannahs and wettish pine woods, in e. and s.e. Tex., summer-fall; Coastal States, Va. to Tex.; Ark.

\section{Tripsacum L.}

A small American genus of which we have one species.

\section{Tripsacum dactyloides (L.) L. EASTern gamagrass. Fig. 173.}

Very robust perennial, usually $15-30 \mathrm{dm}$. tall, often with rhizomes, glabrous throughout; blades elongate, 1-2 cm. broad, flat; inflorescence 15-25 cm. long, terminal, subdigitate group of a few androgynous spikelike racemes, each with a few lower solitary pistillate fertile spikelets at the base and many paired staminate spikelets above; pistillate spikelets $7-10 \mathrm{~mm}$. long, occasionally subtended by a rudimentary pedicel, arranged on opposite sides at each joint of the thick hard articulate lower part of the rachis, sunken in niches of the sculptured rachis, consisting of one perfect floret and a sterile lemma; first glume coriaceous, nearly infolding the spikelet, fitting into and closing the hollow of the rachis; second glume similar to the first but smaller, infolding the remainder of the spikelet; sterile and fertile lemmas and palea very thin and hyaline; staminate spikelets 7-11 mm. long, paired and 2-flowered; glumes firm, acute; lemma and palea hyaline. Incl. var. occidentale Cutler \& Anders.

In marsh-meadows, wet grasslands, seepage areas, in wet mud along streams and about ponds, in Okla. (LeFlore Co.), frequent in scattered parts of Tex. but more common in the e. half, very rare in the Plains Country, summer-fall; W.I.; e. U.S., Coah., N.L., Tam., S.L.P.

\section{Fam. 25. Cyperaceae Juss.}

\section{Sedge FAmily}

Herbs with tristichous leaves and often triangular stems; blades grasslike, often long and linear or gradually tapered; inflorescences diverse; florets often borne grouped into spikelets, each floret subtended by a single abaxial scale (apparently 


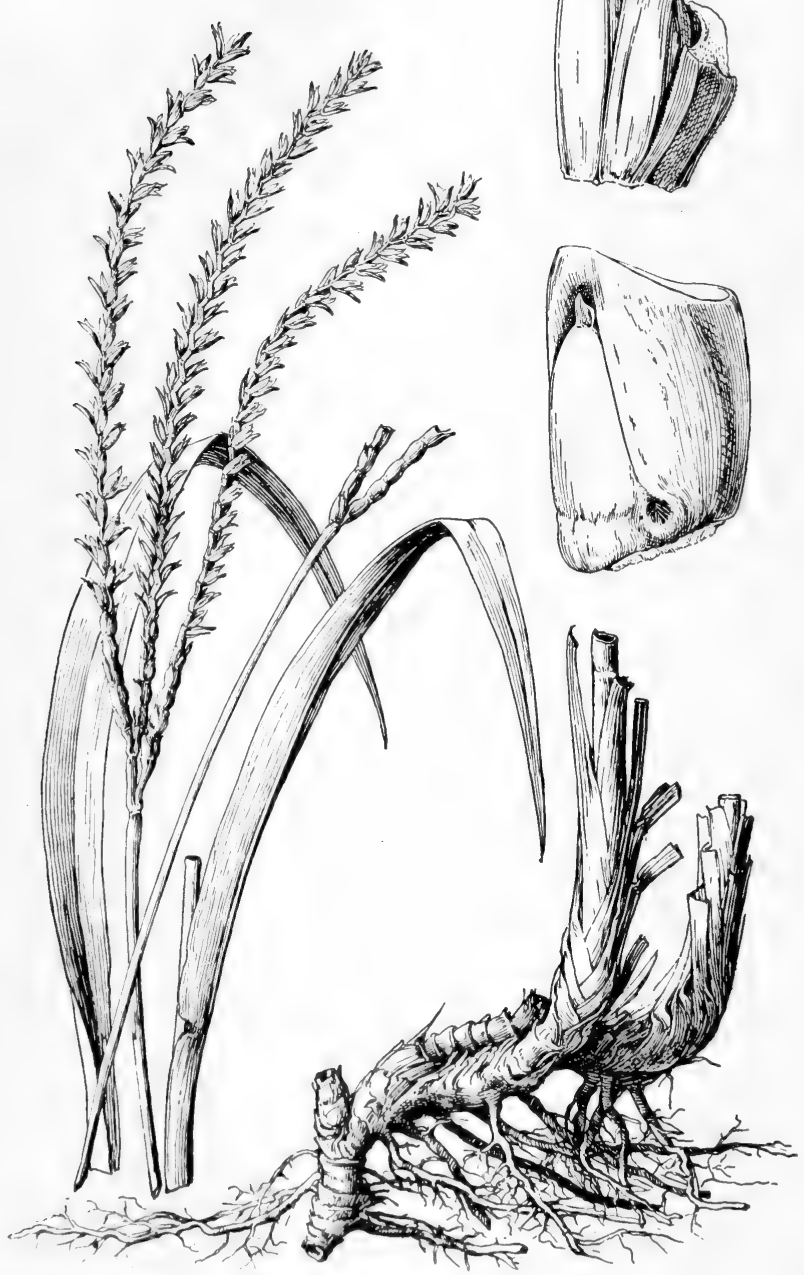

Fig. 173: Tripsacum dactyloides: plant, X 1/6; pistillate spikelets with rachis joint and pair of staminate spikelets with rachis joint, X 5. (From Hitchcock \& Chase). 
2 scales in Hemicarpha; pistillate flower surrounded by a sac in Carex); perianth either of bristles or plumes or more elaborate structures or absent; fruit an achene.

About 4000 species in 90 genera of world-wide distribution.

1. The unit of the infructescence (i.e., the object bearing one seed and which falls from the plant at maturity) comprising not only an achene and usually a portion of the style but also a thin bag surrounding those structures; monoecious or dioecious.... 16. Carex

1. The unit of the infructescence merely an achene with or without attached stylar or other floral tissue, but never surrounded by a sac (2)

2(1). Perianth of 3 stalked scalelike or paddlelike structures, often thickened at maturity, with or without 3 bristles in addition. 4. Fuirena

2. Perianth of bristles or plumose structures or absent (3)

3(2). All or virtually all florets of each spikelet perfect (4)

3. In each spikelet either the florets all pistillate or all staminate or merely some of them strictly staminate (12)

4(3). Each achene subtended by 2 scales, the lower scale easily visible, the adaxial one hyaline, very inconspicuous and often split or torn by the growing achene or adhering to it..............................8. Hemicarpha

4. Each achene subtended only by one abaxial scale (5)

5(4). Culms naked, the sheath solitary on the extreme base of the culms and entirely bladeless........................................................5. Eleocharis

5. Culms not so naked, if some of the sheaths bladeless then each culm with several of them (6)

$6(5)$. Scales of spikelets distichous and perianth bristles present; base of style not much swollen but almost the entire style below the fork persistent on the achene.

1. Dulichium

6. Scales of spikelet distichous or spirally imbricate and perianth bristles present or absent, but if scales distichous then bristles absent; base of style swollen or not, persistent or deciduous (7)

7(6). Swollen style base persistent on the achene as a tubercle of a color and texture distinct from those of the achenial body (8)

7. Style swollen or not but not persistent on the achene (9)

8(7). Style 3-branched; achene trigonous.

6. Bulbostylis

8. Style 2-branched; achene biconvex.

14. Psilocarya

$9(7)$. Scales of spikelets distichous on the spikelet axis (this obscure in C. sesquiflorus, $C$. tenuifolius and $C$. brevifolius)

9. Cyperus

9. Scales of spikelets spirally arranged (10)

10(9). Style base swollen.

7. Fimbristylis

10. Style terete, slender, not dilated at the base (11)

11(10). Perianth of 1 to 8 bristles or wanting.

..2. Scirpus

11. Perianth of numerous elongate silky or woolly bristles

3. Eriophorum

12(3). Inflorescence bracts basally white, distally green.............12. Dichromena

12. Inflorescence bracts essentially unicolored, green (13)

13(12). Scales of spikelets visibly distichous; spikelets agglomerated into a tight head 11. Schoenus

13. Scales of spikelets spirally disposed (this obscure in Scleria) or at least not definitely distichous (14)

14(13). Style base enlarged and persistent as a tubercle of a color and texture distinct from those of the achenial body; perianth bristles or plumes usually present. 13. Rhynchospora 
14. Style base not persistent; perianth absent (15)

15(14). Achene often bony, pearly or crustaceous, supported on a disk or appearing sculptured basally; pistillate flowers solitary and borne in separate spikelets...................................................15. Scleria

15. Achene otherwise; spikelets all alike and borne in very large inflorescences 10. Cladium

\section{Dulichium PERS.}

The genus comprises only one species; confined to North America.

\section{Dulichium arundinaceum (L.) Britt. ThreE-WAy SEDGE. Fig. 174.}

Perennial with creeping rhizomes $2-3 \mathrm{~mm}$. thick and with internodes $2-5 \mathrm{~cm}$. long; culms simple, solitary from the nodes of the rhizomes, 2-10 dm. long, 2-5 $\mathrm{mm}$. thick, erect, with short internodes; lowest leaves with nearly bladeless sheaths, the upper with short stiff pointed ascending blades $2-10 \mathrm{~cm}$. long, the upper 5 to 20 leaves functioning as bracts, each subtending a peduncled spike; peduncle of spike only slightly longer than the bract sheath; spike $2-6 \mathrm{~cm}$. long, $15-50 \mathrm{~mm}$. thick, of 6 to 15 ascending to eventually spreading spikelets; spikelets of 5 to 10 distichous scales, the axis with each internode thickened and concave (niched) on the fertile side and with 2 narrow vertical wings at the edges of the niche; perianth bristles 6 to 9 , coarse, longer than the achene, retrorsely serrate; style branches 2 ; achene flattened, beaked with the long persistent style.

Infrequent or rare in boggy places, edge of streams and swamps, e. Tex. (Leon, Robertson, Cass, Madison, Henderson and Wood cos.), fall; wet places and in shallow water over much of the lowlands of U.S., n. to Nfld., Que., Ont. and B.C., s. to the Gulf States and Calif.

\section{Scirpus L. BUlRUSH}

Annual or perennial herbs, usually aquatic; leaves either well-developed or the blades much-reduced in some species; inflorescences very variable; scales of spikelets spirally imbricate; each flower with only a single subtending scale; bristles present or rarely absent; styles 2- or 3-branched; achenes plano-convex, biconvex or trigonous, usually apiculate but the apex of the same texture and color as the rest of the achene (not differentiated as a "tubercle"); style completely deciduous.

About 300 species, cosmopolitan.

1. Bracts leaflike, none appearing as a continuation of the culm (2)

1. Primary bract appearing as a continuation of the culm and similar to it in texture, color and usually in transectional outline (10)

2(1). Spikelets in dense spherical or prolate heads $1-2 \mathrm{~cm}$. thick

1. S. cubensis.

2. Spikelets either solitary on their peduncles or in small fascicles or glomerules. never in dense heads (3)

3(2). Achene 3-5 mm. long (4)

3. Achene about $1 \mathrm{~mm}$. long (5)

4(3). Achene dull gray-brown, 4-5 mm. long; bristles 6, stiff, retrorsely barbed 2. S. fluviatilis.

4. Achene dark-brown to black, $3-4 \mathrm{~mm}$. long; bristles 2 to 6 , fragile or deciduous.

3. S. maritimus.

5(3). Bristles very long and far-surpassing the scales, conspicuous in fruit

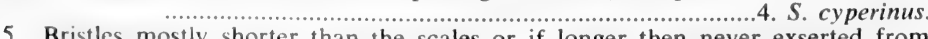

5. Bristles mostly shorter than the scales or if longer then never exserted from the spikelet (6) 


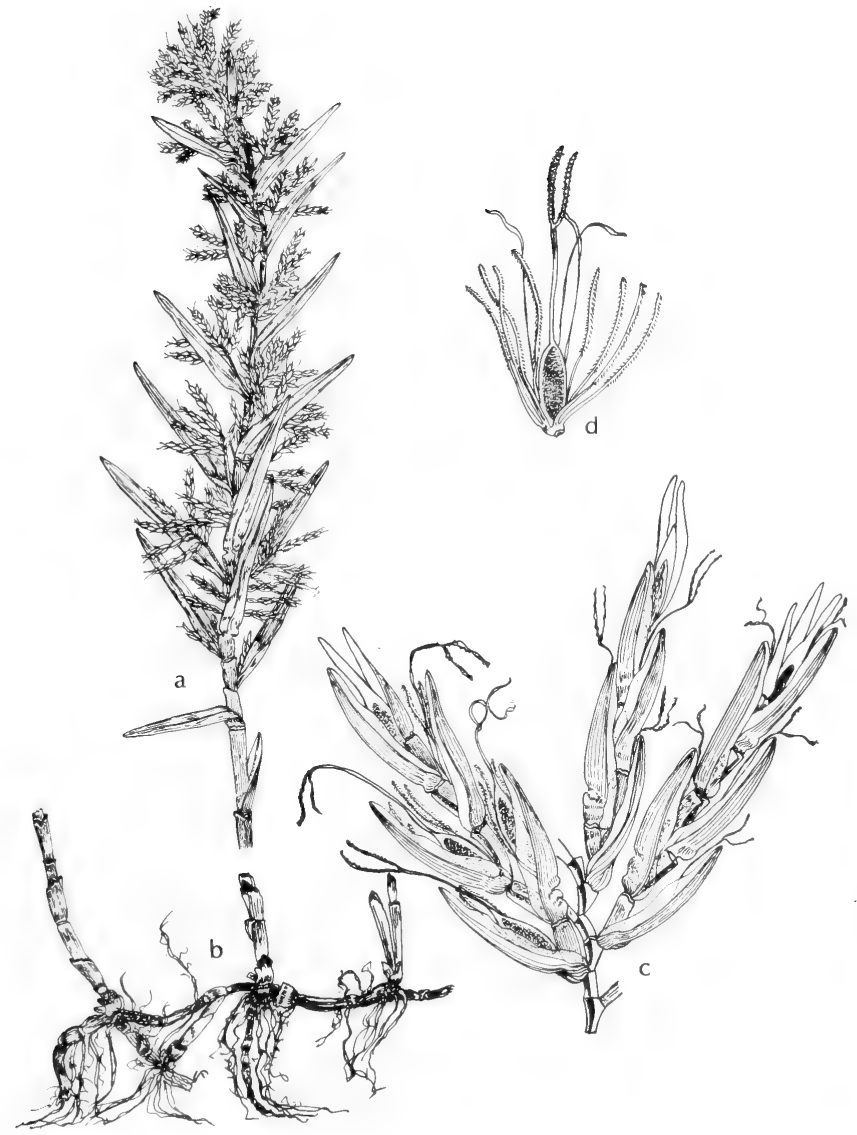

Fig. 174: Dulichium arundinaceum: a, inflorescence, $\mathrm{X} 1 / 2 ; \mathrm{b}$, base of stems and rhizomes, X 1/2; c, several spikelets, X 3; d, flower with scales removed, X 3. (V. F.). 
6(5). Bristles straight or slightly curved or none (7)

6. Bristles strongly curved (9)

$7(6)$. Inflorescence usually 2 or more times compound, the clusters loose; achene lenticular or plano-convex; style bifid

5. S. microcarpus.

7. Inflorescence usually only once compound, the clusters of spikelets commonly dense; achene obtusely trigonous; style trifid (8).

$8(7)$. Rhizomatous; bracts as long as or exceeding the inflorescence; each spikelet with 20 to 40 florets.

6. S. atrovirens.

8. Not distinctly rhizomatous; bracts shorter than the inflorescence; each spikelet with 70 to 200 florets.

7. S. georgianus.

9(6). Principal leaves $3-8 \mathrm{~mm}$. wide; sessile spikelets usually glomerate; curling bristles mostly much longer than the achene.

..8. S. lineatus.

9. Principal leaves $8-12 \mathrm{~mm}$. wide, sessile spikelets usually solitary; curling bristles rarely exceeding tne achene.

9. S. fontinalis.

10(1). Achene 0.8-0.9 mm. long.

10. Achene $1.3-4 \mathrm{~mm}$. long (11)

10. S. molestus.

11(10). Achene 1.3-1.5 mm. long; culms 0.3-1.8 mm. thick; tufted annuals (12) 11. Achene 1.5-4 mm. long; culms usually thicker; rhizomatous perennials (13)

12(11). Achene with vertical rows of minute pits.

11. S. koilolepis.

12. Achene with horizontal ridges.

12. S. supinus.

13(11). Culms 3-20 dm. long, often sharply triquetrous, $2-8 \mathrm{~mm}$. thick, often arcuate (14)

13. Culms $10-30 \mathrm{dm}$. long, either terete or only obscurely trigonous, $8-23 \mathrm{~mm}$. thick near the base, $2-4 \mathrm{~mm}$. thick just beneath the inflorescence, usually rigidly erect (15)

14(13). Achene 2.5-3 mm. long; lower scales or the spikelets often much longer than the rest and with strong venation, bracteolelike; inflorescence a solitary spikelet or glomerule of 2 to 4 spikelets.

13. S. americanus.

14. Achene 1.8-2.6 mm. long; lower scales of the spikelets not differentiated; inflorescence a dense glomerule of 5 to 15 spikelets

14. S. Olneyi.

15(13). Achene bristles 2 to 4 (16)

15. Achene bristles 4 to 6 (17)

16(15). Sheaths (near base of culm) at margins rather regularly retrorsely fimbriate-filiferous; bristles ciliate or plumose, not barbed.

15. S. californicus.

16. Sheaths smooth or merely lacerate; bristles fragile, barbellate or smooth.

16. S. heterochaetus.

17(15). Culm obscurely trigonous or flattened; at least the upper sheath with a well-developed blade; achene usually more than $3 \mathrm{~mm}$. long........

17. S. etuberculatus.

17. Cuim terete; sheaths without blades or a much-reduced blade only; achene less than $3 \mathrm{~mm}$. long (18)

18(17). Scales about $5 \mathrm{~mm}$. long, thin-membranous, pale-brown and with conspicuous elongate reddish glutinous spots (seen under a lens), the distal margin lacerate; achene $1.8-2.9 \mathrm{~mm}$. long.........18. S. acutus.

18. Scale 3-4 mm. long, firm-membranous, dark-brown, nearly smooth (occasionally with a few reddish gummy spots near the midveins), the distal margin nearly smooth to slightly lacerate; achene 1.5-2.2 $\mathrm{mm}$. long...................................................................... validus. 


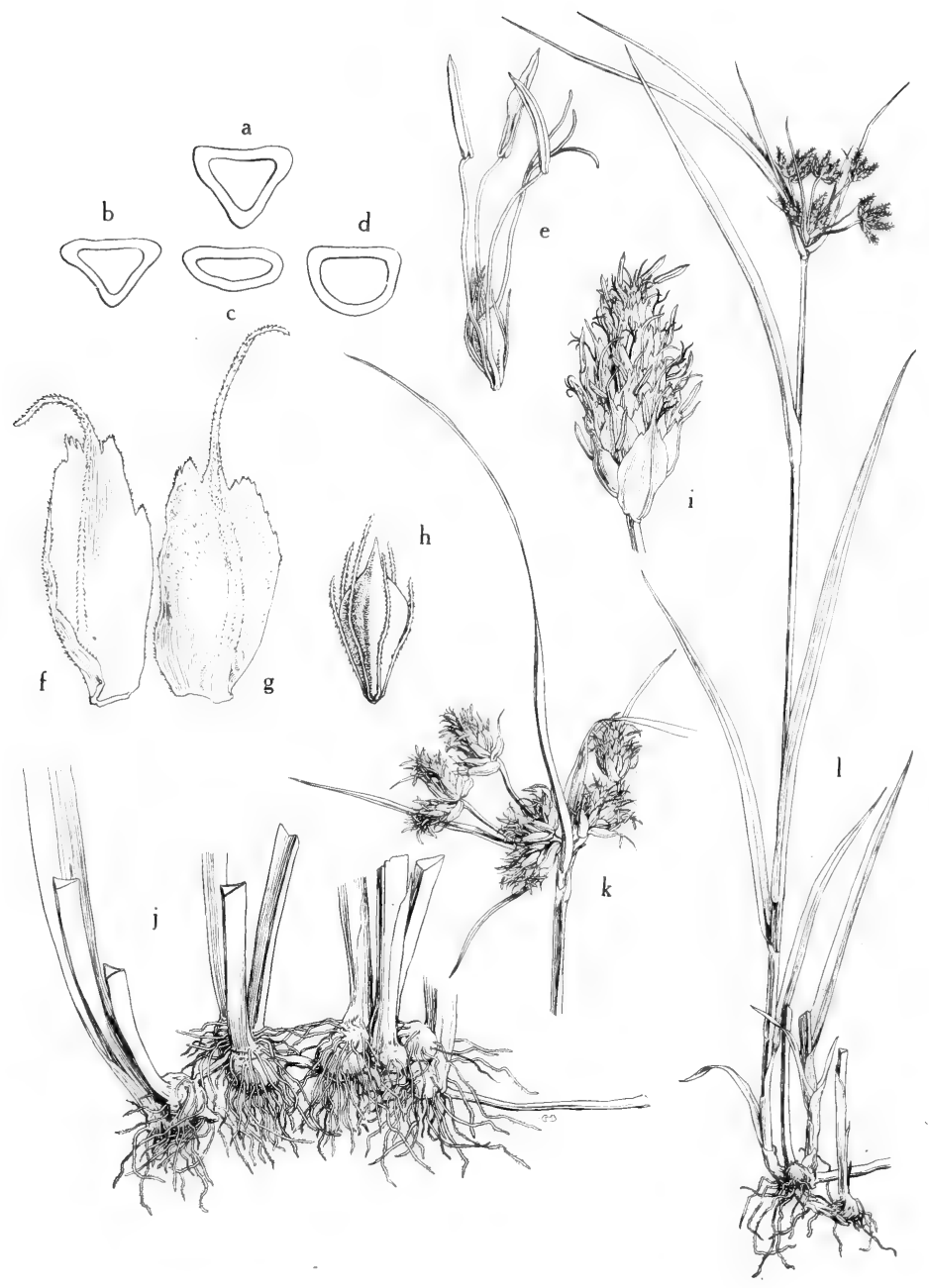

Fig. 175: Scirpus fluviatilis: a-d, achenes, showing variation in shape (cross section), $\mathrm{X} \mathrm{6}$; e, flower, style slender and trifid, the bristles unequal in length, $\mathrm{X} 3 ; \mathrm{f}$ and $\mathrm{g}$, awned scales, $X 4 ; \mathrm{h}$, achene, the subtending bristles unequal in length, $\mathrm{X} 4$; $\mathrm{i}$, spikelet, $\mathrm{X} 11 / 5 ; \mathrm{j}$, rhizome, tubers and sharply triangular culms, X 2/5; $\mathrm{k}$, inflorescence with nearly sessile rays and longer primary rays, X $2 \% 1$, habit, showing rhizomes, tubers, sheathing culm leaves and umbellate inflorescence with the involucral leaves unequal in length, $\mathrm{X} \frac{1}{1 / 6}$. (From Mason, Fig. 148). 


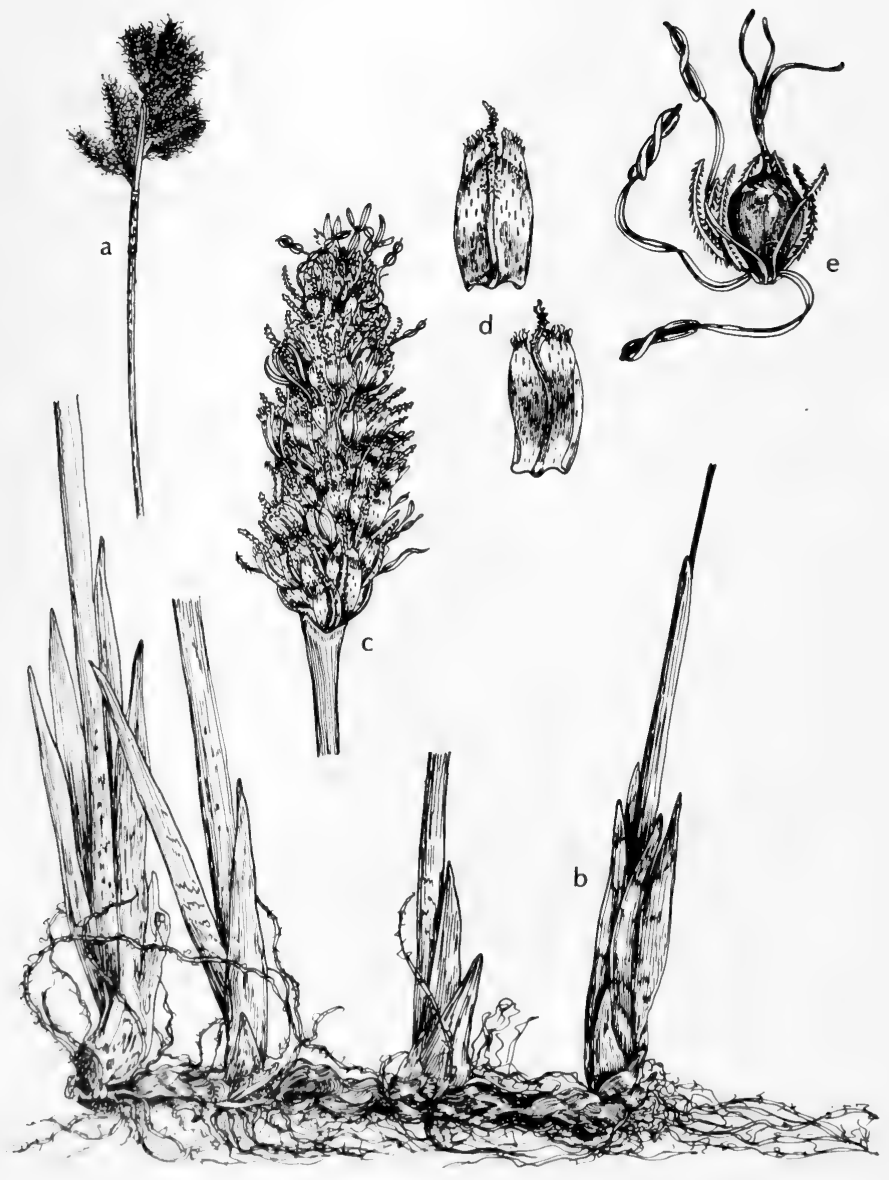

Fig. 176: Scirpus maritimus var. paludosus: $\mathrm{a}$, inflorescence, $\mathrm{X} \mathrm{1/2}$; b, lower part of stems and rhizomes, X 1/2; c, spikelet, X 3; d, scales, X 5; e, achene, X 5. (V. F.). 


\section{Scirpus cubensis Poepp. \& Kunth.}

Rhizomatous perennial; rhizome 1-5 mm. thick; aerial culms solitary at the nodes of the rhizome, to $1 \mathrm{~m}$. tall, sharply trigonous, smooth; leaves all basal with blades to $15 \mathrm{~mm}$. broad; inflorescence involucrate, umbel-like; bracts 2 to 5, leaflike, spreading, unequal, often much-elongate, far-surpassing the umbel; branches of umbel very unequal ( 1 head usually quite sessile), usually $1-3 \mathrm{~cm}$. long; each branch terminated by a dense spherical or somewhat prolate head 1-2 $\mathrm{cm}$. thick; each head of many spikelets; scales about $3 \mathrm{~mm}$. long, reddish, spreading, tapered to the acute reflexed tip; bristles absent; style bifid; achene about 3 $\mathrm{mm}$. long, lenticular, apiculate.

Very rare, known only from Eagle Nest Lake, Brazoria Co., Tex. where collected once in 1958, summer-fall; warmer parts of Am., n. to Gulf States; also Afr.

\section{Scirpus fluviatilis (Torr.) Gray. RIVER BUlRush. Fig. 175.}

Perennial sedge with horizontal rhizomes forming tubers; culms stout, sharply triangular, erect, $1-1.5 \mathrm{~m}$. tall; leaves $8-16 \mathrm{~mm}$. wide; involucral leaves 3 to 5 , unequal in length, to $20 \mathrm{~cm}$. long; inflorescence umbellate, rays 5 to 12 , elongate. recurved-spreading, up to $12 \mathrm{~cm}$. long; spikelets acute, $1.6-4 \mathrm{~cm}$. long; bristles 6 , retrorsely barbed, stiff, unequal in length, nearly as long as the achene; anthers 2.5-4.5 mm. long; style trifid; achene usually sharply triangular, angled on back, dull gray-brown, 4-5 mm. long.

In shallow water and wet mud of sloughs, swamps, lakes, and along rivers and streams, in N. M. (Fernald); Que. to Sask. and Wash., s. to Va., Ind., Ill., Mo., Kan., N.M. and Calif.

\section{Scirpus maritimus L. Salt-Marsh bulrush.}

Rhizomatous perennial; rhizome several $\mathrm{mm}$. thick, extensive; culms tufted along the rhizome, often with tuberlike enlargements basally, 5-20 $\mathrm{mm}$. thick above the tuber, $30-100 \mathrm{~cm}$. long, erect, triquetrous; leaves several, welldeveloped; bracts several, flat, leaflike, ascending or usually spreading; inflorescence of 3 to 15 ovoid to ovoid-cylindric erect or ascending spikelets, either all sessile or some variously sessile and others peduncled, quite variable; scales 6-10 $\mathrm{mm}$. long, almost as broad, apically mostly retuse and the midnerve prolonged into a point $1-3 \mathrm{~mm}$. long; achenes obovate-apiculate, $3-4 \mathrm{~mm}$. long, about $2 \mathrm{~mm}$. broad, in transection biconvex or one of the sides more convex or bifaceted than the other, ripening to a dark-brown. The species is nearly world-wide.

We have 2 varieties:

Var. macrostachyus Michx. Scales firm, maturing to a dark-brown; styles usually 3-branched. S. robustus Pursh.

Coastal marshes, s.e. Tex. and Rio Grande Plains, spring-summer-fall.

Var. paludosus (A. Nels.) Koyama. Fig. 176. Scales thin, translucent, whitish to pallid-buff; styles uniformly 2-branched. S. paludosus A. Nels.

Marshes, salt flats and in mud about ponds and lakes, and along streams, in Okla. (Ottawa, San Juan, Colfax, Washita, Blaine and Alfalfa cos.), n.-cen. and Trans-Pecos Tex., the Plains Country, Edwards Plateau and Rio Grande Plains, N. M. (Dona Ana, San Juan, Chaves, Colfax, Quay and Eddy cos.) and Ariz. (Apache, Navajo, Coconino and Mohave to Pinal and Maricopa cos.)

\section{Scirpus cyperinus (L.) Kunth var. rubricosus (Fern.) Gilly. Fig. 177.}

Perennial probably from short thick rhizomes; culms 8-20 dm. long, 6-13 $\mathrm{mm}$. thick basally, 3-4 $\mathrm{mm}$. thick apically where obscurely trigonous; leaves numerous; bracts several, leaflike, basally brownish or reddish-brown, ascending, the lowest one about as long as or slightly surpassing the inflorescence, the rest much shorter; inflorescence a dense decompound panicle (some of the longer primary branches $5-11 \mathrm{~cm}$. long), somewhat droopy, of 200 to 500 spikelets, 

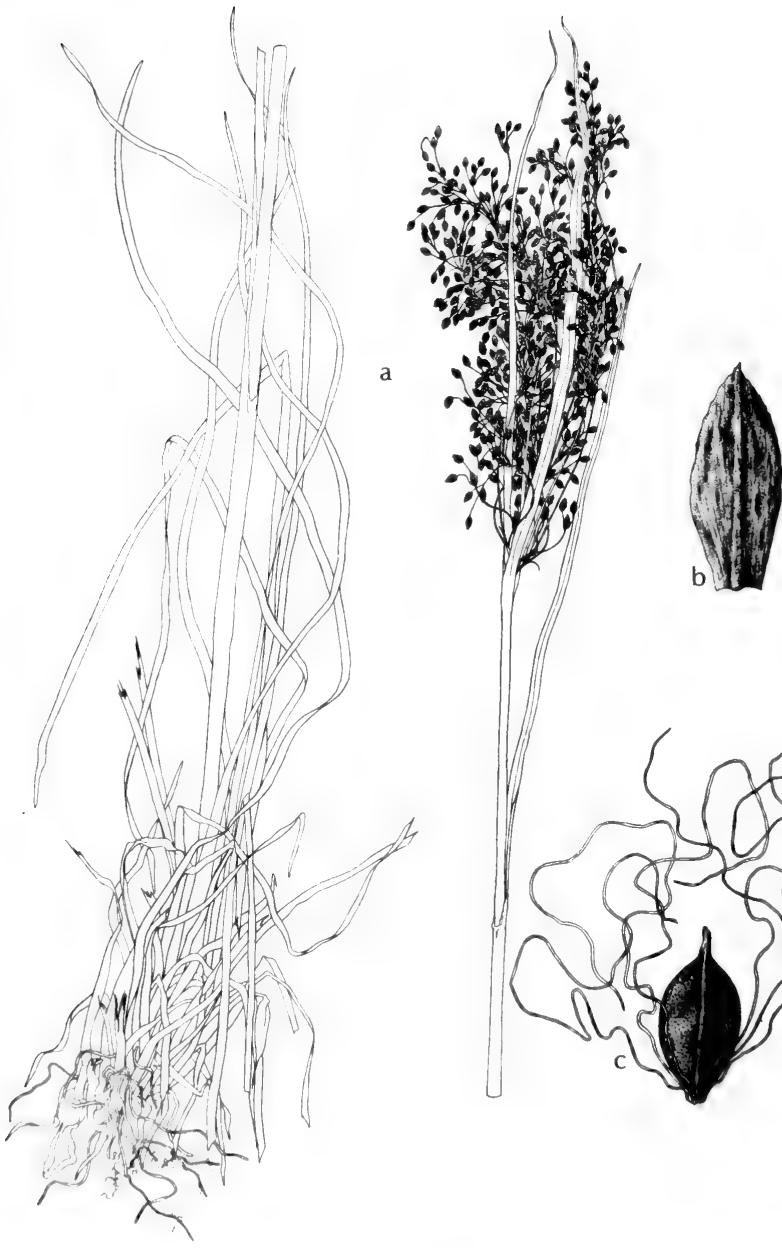

Fig. 177: Scirpus cyperinus var. rubricosus: a, habit, X 1/3; b, scale, X 15; c, achene, about X 15. (Courtesy of R. K. Godfrey). 


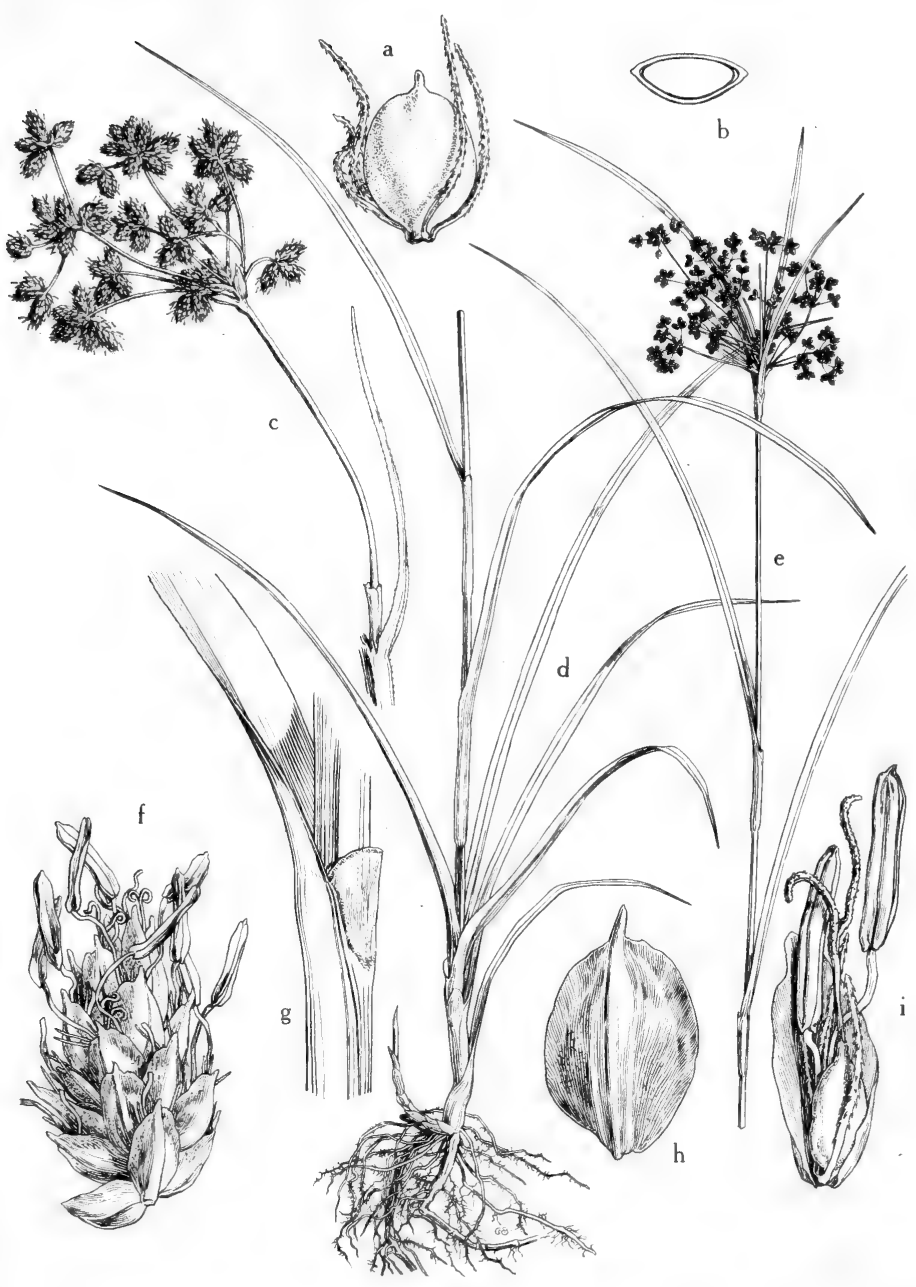

Fig. 178: Scirpus microcarpus: a, achene and retrorsely barbed subtending bristles, $\mathrm{X} 12$; b, achene (cross section), X 12 ; c, primary ray of umbel, X $4 / 5$; d, habit, showing the spreading leaf blades and their basal sheaths, the culm cut off, $X 1 / 5 ; \mathrm{e}$, upper part of culm, with entire leaf sheaths and compound inflorescence, the involucral leaves extending beyond the inflorescence, $\mathrm{X} 1 / 5 ; \mathrm{f}$, spikelet, $\mathrm{X} 8 ; \mathrm{g}$, young leaf sheath, $\mathrm{X} 2$; h, ovate acute scale with prominent midrib, $X 16$; $\mathrm{i}$, flower, the style 2 -cleft, $X 16$. (From Mason, Fig. 146). 
most of them on slender peduncles 4-10 mm. long, not in glomerules; spikelets ovoid to ellipsoid, brown, $3-5 \mathrm{~mm}$. long, of 40 to 100 flowers; scales elliptic, 1.5-2 mm. long, brown, acute; bristles several, very long, brown, far-surpassing the scales; achenes about $1 \mathrm{~mm}$. long, oblong-apiculate, whitish, flattened-triangular (the abaxial angle blunt, the inner 2 sharp). S. rubricosus Fern.

Wet or boggy places, in water and muddy places, in Okla. (Waterfall) and e. Tex., summer; the var. cyperinus is widespread in e. U.S. and Can.; the var. rubricosus is found mostly in s.e. U.S. but occurs n. to Mich. and N.E.

\section{Scirpus microcarpus Presl. Fig. 178.}

Perennial with stout rhizomes; culms stout, erect, leafy, subterete, 7-17 dm. tall; leaves flat, broad, 1-2 cm. wide, margins scabrous, the blades acuminate, often overtopping the stem; involucral leaves 2 to 5 , the longer ones usually extending beyond the heads; inflorescence a loose spreading compound umbel, the primary rays to $10 \mathrm{~cm}$. long; scales green to brown, acute, ovate, with a prominent midrib, not awned; bristles 4 , downwardly barbed, somewhat longer than the achene; stamens 2; style 2-cleft; achene whitish, ovate, lenticular, with an obscure dorsal crest, mucronate, $1 \mathrm{~mm}$. long.

Along boggy streams, about springs and in mud at edge of stream, in N. M. (Catron, Colfax, Taos and Rio Arriba cos.) and Ariz. (Apache, Navajo, Coconino, Yavapai, Gila, Cochise and Pima cos.); Alas. to N.M., Ariz. and Calif.

\section{Scirpus atrovirens Willd. Fig. 179.}

Rhizomatous perennial; rhizome 2-6 mm. thick; culms 5-8 $\mathrm{mm}$. thick basally, 8-15 dm. long, erect, somewhat trigonous in the upper portion, leafy; bracts several, well-developed, leaflike, ascending or spreading, as long as or exceeding the inflorescence; inflorescence complicatedly decompound, of 100 to 250 (to 500) spikelets in glomerules which in turn are disposed in dense compound panicles, some of the primary branches that bear the panicles $5-14 \mathrm{~cm}$. long; spikelets ovoid to narrowly ovoid, dark-brown to fuscous, of 20 to 40 flowers; bristles almost as long as the achene; scales $1.5-3 \mathrm{~mm}$. long, ovate, acute, with a strong midrib; achene oblong, about $1 \mathrm{~mm}$. long, in transection flattened-trigonous (the abaxial angle blunt, the others sharp).

Most of the U.S. (except Pac. States), in and along streams and in wet meadows, about lakes and in sloughs.

We have 2 varieties:

Var. atrovirens. Scales with a minute mucro only. Rare in moist loam, e. Tex. (Angelina Co.), summer; otherwise in e. U.S. and e. Can., one station in Ariz.

Var. pallidus Britt. Scales with a strong mucro or very short awn. S. pallidus (Britt.) Fern. Rare in Tex. Plains Country (Panhandle), Okla. (Osage, Adair, Caddo and Woodward cos.), N. M. (Catron, Union, Colfax, Otero and San Miguel cos.) and Ariz. (Apache and Navajo cos.), summer; in cen. and w. U.S.

\section{Scirpus georgianus Harper.}

Tufted perennial from thick ascending ligneous caudexes but not distinctly rhizomatous; culms 5-15 dm. long, erect (some very shortly decumbent basally), 3-6 mm. thick just above the caudex, obscurely trigonous above, leafy; bracts several, leaflike but reduced in size, ascending, shorter than the inflorescence; inflorescence a decompound often droopy panicle, some of the longer branches 3-7 $\mathrm{cm}$. long, the 50 to 120 spikelets not in glomerules but most of them on pedicels 2-8 $\mathrm{mm}$. long; spikelets ovoid to usually cylindric, of 70 to 150 (to 200 ) flowers at maturity; scales ovate, ahout $2 \mathrm{~mm}$. long, acute, brown with very strongly pronounced green or buffy midnerve; bristles several, about twice as long as the achenes or as long as the scales but mostly crumpled and entangled and never 


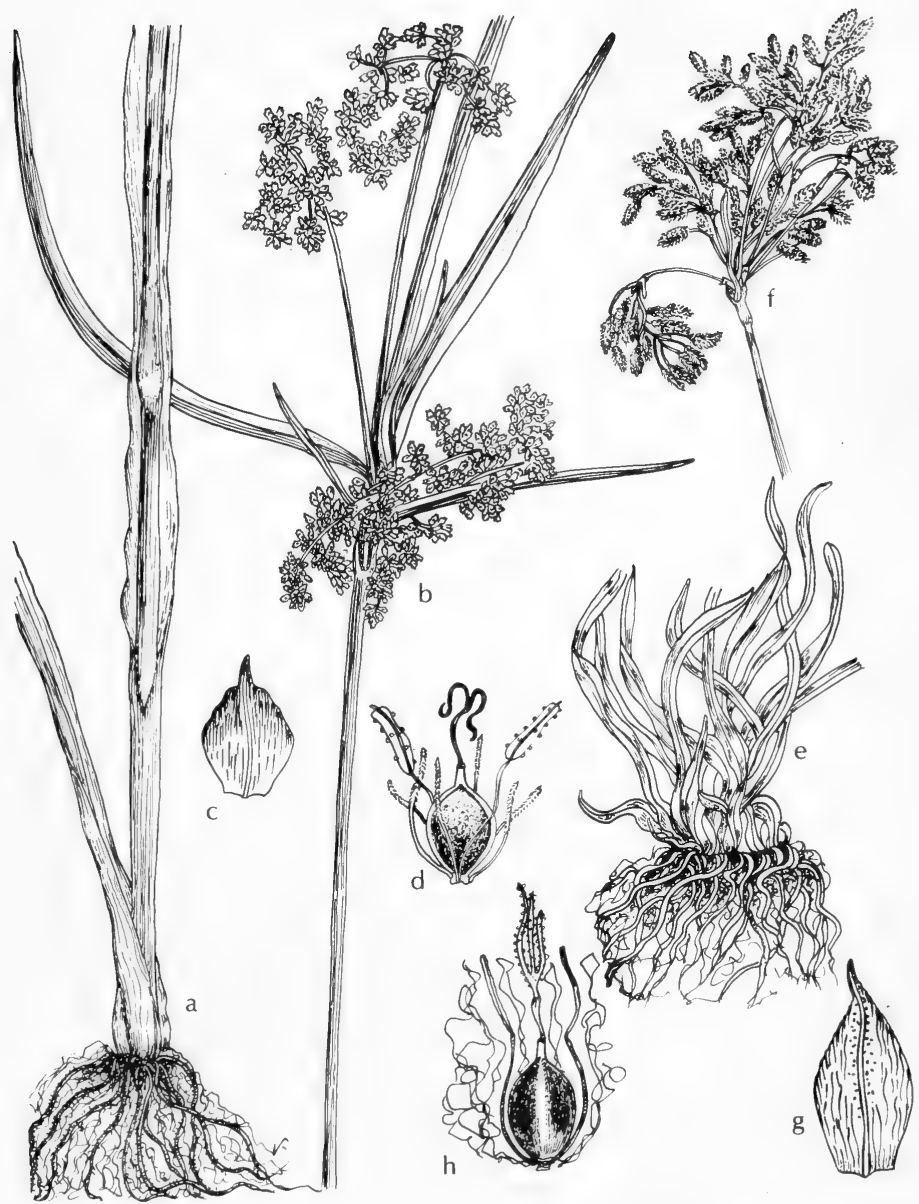

Fig. 179: a-d, Scirpus atrovirens: a, basal part of plant, X 1/2; b, upper part of plant, $\mathrm{X} 1 \frac{2}{2}$; c, scale, X 10; d, achene, X 10. e-h, Scirpus lineatus: e, basal part of plant, X 1/2; f, inflorescence X 1/2; g, scale, X 10; h, achene, X 10. (V. F.). 
exserted from the spikelet; achene oblong, about $1 \mathrm{~mm}$. long, in transection flattened-trigonous (the abaxial angle blunt, the others sharp). S. atrovirens var. georgianus (Harper) Fern.

In bogs and wet mud along streams and about ponds and lakes, infrequent in n.-cen. Tex., rare in e. Tex., spring; P.E.I. s. to Ga. and w. to Neb. and Tex.

\section{Scirpus lineatus Michx. Fig. 179.}

Culms strongly ascending, firm, remotely 5- to 10-leaved, with long internodes; leaves 3-8 (-10) $\mathrm{mm}$. wide, pale-green, firm; involucre and involucels pale-brown at base; umbels terminal and sometimes axillary, loose, 5-20 cm. high, subsecund, the terminal with a 1- to 3-leaved involucre much shorter than the long slender nodding-tipped rays; spikelets oblong, becoming cylindrical, $5-10 \mathrm{~mm}$. long, 2-3.5 $\mathrm{mm}$. thick, the lateral ones of each group on smooth pedicels; scales pale-brown to rufescent, ovate, sharply and slenderly green-keeled, the sharp tips ascending; achene obscurely 3-angled, narrowly ellipsoid to fusiform, long-beaked, papillate; bristles curling, mostly longer than achene.

Meadows, swales, edge of water of lakes and ponds, and in low wettish thickets, in Okla. (Murray, Love, Adair, Stephens, Choctaw, Johnston and Alfalfa cos.) and Tex. (San Augustine Co.); Me. to Ia., s. to Va., Ala., Miss., Tex. and Okla.

\section{Scirpus fontinalis Harper.}

Resembling $S$. lineatus, tufted short-lived perennial; culms 9-12 dm. tall, obtusely angled; leaves basal and cauline, the cauline 10 or less per culms; blades to $5 \mathrm{dm}$. long, $8-12 \mathrm{~mm}$. wide; sheath ventral surface purple spotted; inflorescence decompound, the branches mostly ascending; bracts reduced or largest similar to blades, 1 per branch, tubular-sheathing; spikelets solitary, ovoid to lanceolate, 4-8 mm. long, about $2 \mathrm{~mm}$. broad, sessile or scaberulous-pedicellate; scales brown or reddish, lustrous, green-keeled, 1.5-2 mm. long, acuminate to cuspidate; achenes yellowish or brownish, smooth, trigonous or plano-convex, ellipsoid, 0.7-1 mm. long, stipitate; bristles numerous, reddish, crinkly, smoothish, shorter than to slightly exceeding achene.

Swamp forests, usually over marl, Coastal Plain, Va. to Fla., w. to Okla. (Waterfall).

\section{Scirpus molestus M C. Johnst.}

Tufted annual; culms 5-16 cm. long, grayish-green, compressed, $0.2-0.25 \mathrm{~mm}$. thick, minutely striate, ascending, often somewhat flexuous or arcuate; sheaths short, slightly loose, quite smooth at the hyaline apical-ventral orifice, grayishgreen, eventually turning brownish-stramineous, never red or purple; blades 2-3 $\mathrm{cm}$. long, tightly involute, arcuate-setaceous, about as thick as the culms; bract solitary, appearing as a continuation of (and as thick as) the culm, 5-10 (-23) $\mathrm{mm}$. long; inflorescence a glomerule of 2 or 3 spikelets, less commonly a solitary spikelet; spikelet $2-7 \mathrm{~mm}$. long, ovoid to lance-ovoid, of (10 to) 20 to 30 flowers; scales never purplish or reddish, promptly and serially deciduous after anthesis, beginning at the bottom of the spikelet, the lowest scale larger than the rest; the second or third scale from the bottom $1-1.3 \mathrm{~mm}$. long, gibbous, strongly arcuate-convex, broadly ovate, acute, the midnerve forming a broad grayishgreen keel and mucro, the sides translucent, thin-membranous, unpigmented, cellular, with 1 or 2 acrodome veins near the keel on each side; perianth bristles absent; stamens 2; filaments about as long as the achenes; anthers minute; style 3-branched; achene globose-trigonous, basally rounded or minutely stipitate, apically rounded or extremely minutely apiculate, $0.8-0.9 \mathrm{~mm}$. long, the 3 angles about equally prominent, the sides flat or slightly concave, surficially pinkishbrownish with numerous vertical rows of very minute pits, this pattern and color obscured by a more or less thick whitish-waxy coat. 
Frequent in moist or wet sand, often associated with $S$. koilolepis, e. and s.e. Tex., spring; Ark., La. and Tex.

\section{Scirpus koilolepis (Steud.) Gl.}

Tufted annual; roots fibrous; culms cespitose, 4-22 cm. long, dark-grayishgreen, compressed, $0.3-0.35 \mathrm{~mm}$. thick, minutely striate, ascending, often somewhat flexuous or arcuate; blades $2-5 \mathrm{~cm}$. long, arcuate-setaceous; bract solitary, appearing as a continuation of (and as thick as) the culm, (13-) 17-33 mm. long; inflorescence of 1 or less commonly 2 spikelets; spikelets $3-7 \mathrm{~mm}$. long, narrowly ovoid, acute, of ( 7 to) 10 to 14 flowers; scales never purplish or reddish, tardily serially deciduous; lowest scale larger than the rest; second or third scale from the bottom 2-2.5 mm. long, ovate, acuminate, strongly gibbous, arcuate-convex, the midnerve forming a broad grayish-green keel and mucro or apiculus, the sides translucent, membranous, cellular, with 1 to 3 acrodome veins near the keel on each side; perianth bristles absent; style 3-branched; achene globose to globoseoblong, trigonous, basally rounded or shortly stipitate, apically rounded or usually minutely apiculate, $1.3-1.5 \mathrm{~mm}$. long, the 3 angles about equally prominent, the sides flat or slightly convex, surficially brownish, with numerous vertical rows of very minute pits and a thin whitish-waxy-bloom.

Frequent in moist sandy loam, in bogs about lakes and ponds, depressions and marshes in coastal prairies and seepage areas, in Okla. (Johnston Co.), e., s.e., and n.-cen. Tex., rare in Edwards Plateau (Burnet Co.), spring; Ga., Tenn, and Ala. to Okla. and Tex.; Calif.

\section{Scirpus supinus L. Fig. 180 .}

Tufted annual; culms $3-35 \mathrm{~cm}$. long, $0.6-1.8 \mathrm{~mm}$. thick, essentially terete (ridged on drying), not or only obscurely and bluntly trigonous; sheaths somewhat loose, apically oblique and acute, essentially bladeless; lower bract appearing as a continuation of the culm, (1-) 3-10 (-15) cm. long; other bracts muchreduced, very inconspicuous; inflorescence a glomerule of 2 to 8 spikelets or occasionally some of these extended on peduncles 1-3 cm. long; spikelets lance-ovate, 4-11 mm. long, of 16 to 36 flowers; scales somewhat convex basally, ovate, acuminate, acute, with a very strong keel (green turning stramineous) and sides which are green-membranous turning firm and buffy to purple; style 2-branched [var. Hallii (Gray) Gray] or 3-branched [var. saximontanus (Fern.) Koyama]; bristles variable; achenes $1.3-1.5 \mathrm{~mm}$. long, glabrous, to broadly elliptic, in transection either plano-convex (var. Hallii) or strongly trigonous (var. saximontanus) and surficially with horizontal ridges or wrinkles.

Frequent in moist areas near the coast and in mud about lakes and ponds, s.e. Tex. and Rio Grande Plains (both varieties), rare in n.-cen. Tex. and Plains Country (var. saximontanus), spring-summer; var. supinus is widespread in temp. parts of the world; var. Hallii in e. U.S. mainly Coastal Plain; var. saximontanus in Great Plains, N.D. to Tex.

Scirpus "supinus," in the present broad sense, has only recently been treated as several narrowly defined species, of which three are attributed to our area and are characterized as follows:

S. Wilkensii Schuyler. Styles mostly 2-parted and achenes 2-angled; scales mostly $1.9-2.3 \mathrm{~mm}$. wide, the cells at the upper margin of the ventral surface 2 to 5 times as long as wide; spikelet achenes mostly $1-1.2 \mathrm{~mm}$. wide, with narrow acute transverse ridges.

Ditches, swales and pond margins, s. Tex. (Aransas, Atascosa, Kleberg, Nueces and Willacy cos.) spr.-fall; also Tam.

S. saximontanus Fern. Style mostly 3-parted and achenes 3-angled; scales usually longer than wide; spikelet achenes with more than 15 narrow transverse ridges. 


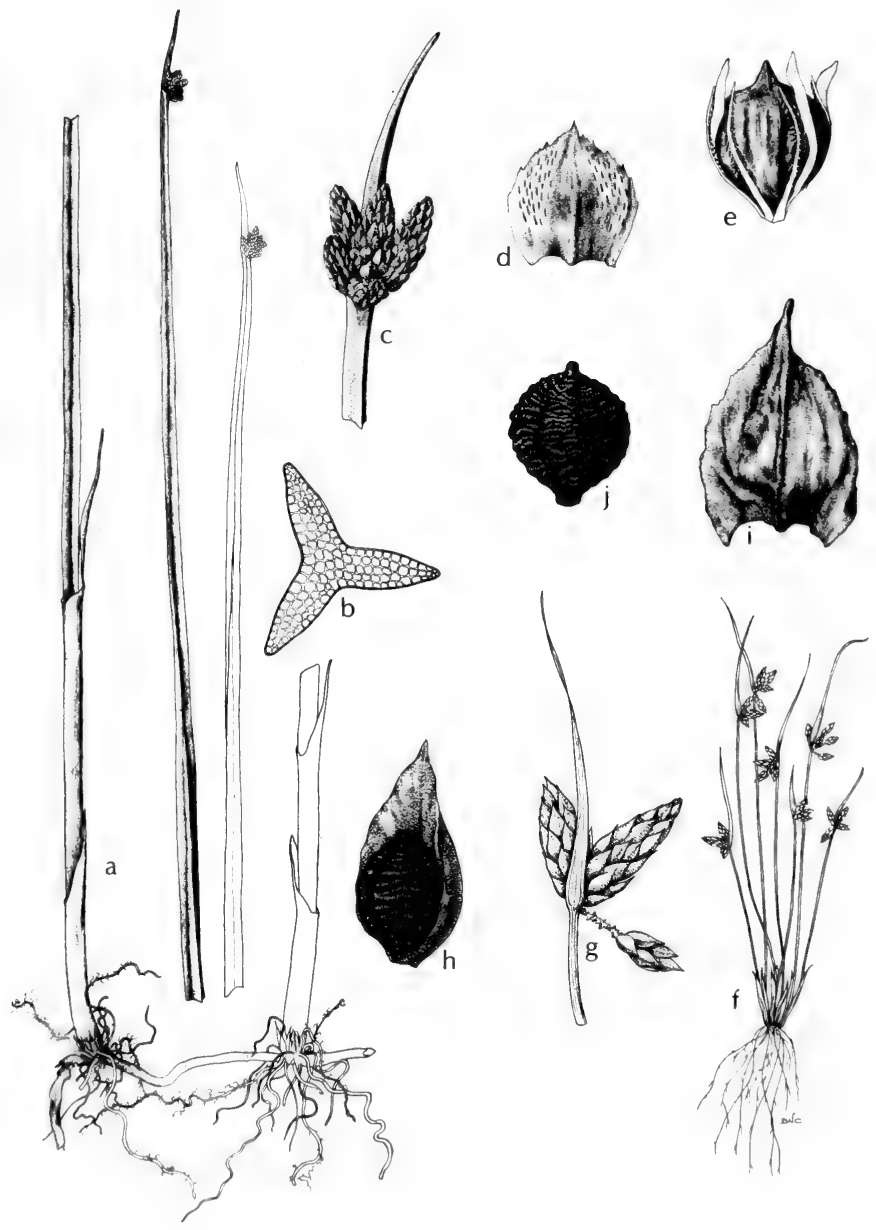

Fig. 180: a-e, Scirpus Olneyi: a, habit, X 1/3; b, cross section of culm, X 4; c, inflorescence, X 1; d, scale, X 5; e, achene, X 8. f-j, Scirpus supinus var. Hallii: f, habit, $X 1 / 3 ; g$, inflorescence, $X 12 ;, h$, achene in scale, $X 12 ; i$, scale spread out, $X 12 ; j$, achene, $X$ 12. (Courtesy of R. K. Godfrey). 
Local in ditches, sink-lakes, ponds and wet prairies, e. (Austin Co.) and s. (Aransas, Bexar, Cameron, Hidalgo, Nueces and San Patricio cos.) Tex., Plains Country (Tom Green Co.) and Panhandle (Hale and Lynn cos.), spr.-fall; Kan., Mo., Neb., O., Okla. (Comanche Co.), S.D., Tex., Wyo., S.L.P. and Tam.

S. Bergsonii Schuyler. Styles mostly 3-parted and achenes 3-angled; scales broadly ovate, mostly 2.1-2.9 $\mathrm{mm}$. long and 2.2-3 mm. wide; spikelet achenes with fewer than 15 firm undulating transverse ridges.

Local in ditches and on pond margins in s. Tex., (Kenedy, Kleberg and Nueces cos.), summer-fall; endemic. Said to hybridize with $S$. Wilkensii in Kenedy and Nueces counties.

13. Scirpus americanus Pers. var. longispicatus Britt. SWORD-GRASS, THREE-SQUARE BULRUSH. Fig. 181

Rhizomatous perennial; rhizomes extensively creeping, reddish-brown, 2-3 mm. thick; culms rising at short intervals, (1-) 3-15 dm. long, 2-6 mm. thick, ascending in the distal half sharply triquetrous and often somewhat nodding; leaves 2 to 4 , usually 2 , with involute blades several $\mathrm{cm}$. long; principal bract solitary, appearing as a continuation of the stem, (15-) 30-50 (-155) $\mathrm{mm}$. long; (lower scales of the spikelets often much longer than the rest and with strong venation, bractlike); inflorescence a solitary spikelet or a glomerule of 2 to 4 spikelets; spikelets sessile, 7-17 mm. long, 4-5 mm. thick, narrowly ovoid or lance-ovoid, of 28 to 50 flowers; scales (except lowest) obovoid, brown, 4-5 $\mathrm{mm}$. long, lower ones emarginate, with a well-marked buffy midnerve (prolonged into a short awn) and firm to membranous deep-brown sides; bristles about 4 , about equaling the achene, retrorsely barbellate; style 3-branched, less commonly 2-branched; achene 2.5-3 $\mathrm{mm}$. long, 1.8-2.5 mm. broad, broadly obovate, apiculate, plano-convex, smooth, dark-brown when mature. Some of our plants have been known incorrectly as var. polyphyllus (Boeck.) Beetle.

Essentially throughout our region in low often moist ground, in water and about seepage areas, spring-summer; nearly throughout temp. parts of the world.

\section{Scirpus Olneyi E. \& G. Fig. 180 .}

Rhizomatous perennial; rhizomes extensive, 2-4 $\mathrm{mm}$. thick; culms rising at intervals, 6-20 dm. long, 4-8 mm. thick, sharply triquetrous most of the length (the sides often concave); leaves crowded at the base, usually 2 or 3 , the lowest ones with loose membranous sheaths and reduced or obsolete, the upper one (which still appears basal) with a slightly longer blade; principal bract solitary, appearing as a continuation of the stem, 1-4 (-15) $\mathrm{cm}$. long; (lower scales of the spikelets not differentiated from the rest); inflorescence a dense glomerule of 5 to 15 spikelets; spikelets sessile, 5-8 (-12) mm. long, 3-5 mm. thick, mostly ovoid, of 24 to 30 (to 40 ) flowers; scales $3-4 \mathrm{~mm}$. long, the lower ones emarginate, brown, the midrib paler, prolonged as a mucro; bristles about 4 , about equaling the achene, retrorsely barbellate; style usually 2-branched, less commonly -3branched; achene 1.8-2.6 $\mathrm{mm}$. long, $1.5-1.8 \mathrm{~mm}$. broad, obovate, apiculate, planoconvex or unequally biconvex. Our plants have been known incorrectly as S. chilensis Nees.

Rare and scattered, wet alkaline or marshy soil, s.e. and e. Tex., Trans-Pecos, Plains Country and probably elsewhere, N.M. (Grant, Otero and Socorro cos.) and Ariz. (Apache and Coconino, s. to Cochise, Santa Cruz and Pima cos.), spring-summer; temp. N.A.; also Br. Hond., Venez. and Chile.

15. Scirpus californicus (C.A. Mey.) Steud. Giant Bulrush, Tule. Fig. 182.

Perennial from tight subrhizomatous knots; culms closely tufted, 1-2 mm. long, 8-22 mm. thick near the base, $2-4 \mathrm{~mm}$. thick near the inflorescence, bluntly tri- 


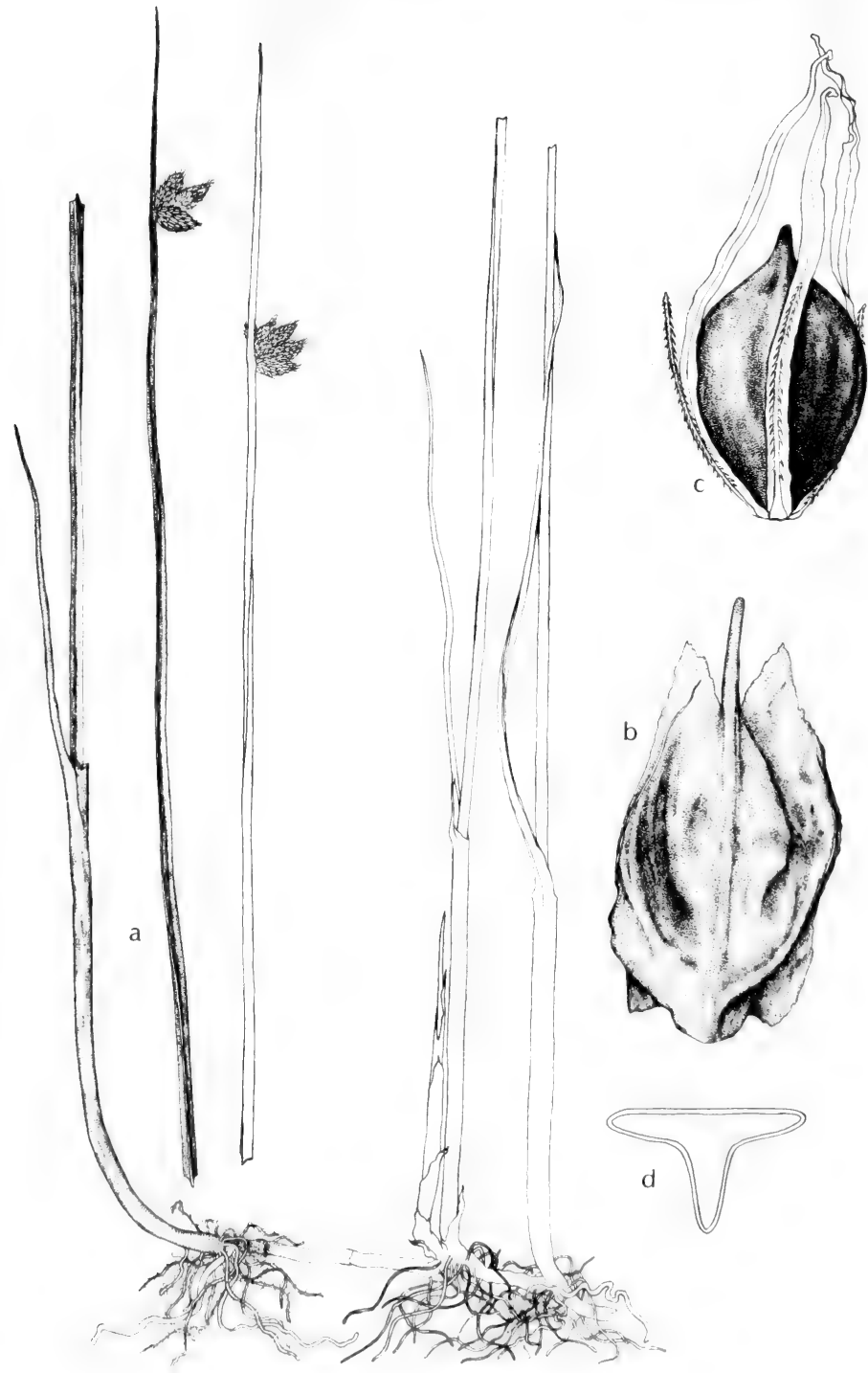

Fig. 181: Scirpus americanus: a, habit, X 1/2; b, scale, X 12; c, achene, X 12; d, cross section of stem, X 14. (Courtesy of R. K. Godfrey). 


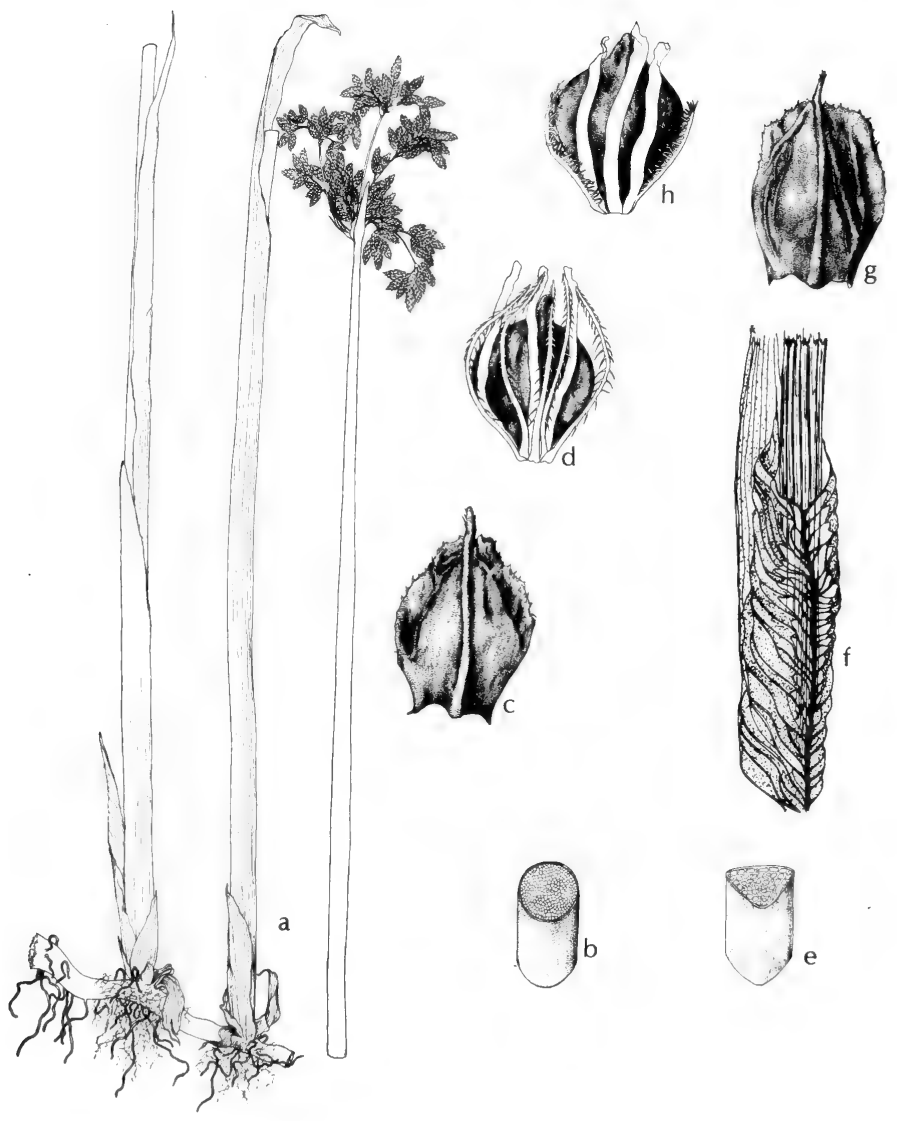

Fig. 182: a-d, Scirpus validus: a, habit, X $1 / 3 ;$ b, cross section of upper stem, X 1 ; c, scale, X 7; d, achene, X 10. e-h, Scirpus californicus: e, cross section of upper stem, X 1; f, sheath, X 1; g, scale, X 7; h, achene, X 10. (Courtesy of R. K. Godfrey). 
gonous; leaves few, basal, consisting only of mostly open brownish sheaths whose margins are rather regularly retrorsely fimbriate-filiferous; primary bract appearing as a continuation of the culm, $18-70 \mathrm{~mm}$. long (other bracts reduced, scalelike), shorter than the inflorescence; inflorescence 4-12 cm. long, decompound with a number of usually drooping branches, altogether with 50 to 150 spikelets; spikelets lance-ovoid, $6-11 \mathrm{~mm}$. long, of 30 to 50 flowers; scales about $3 \mathrm{~mm}$. long, ovate to obovate, dark-brown, some of them emarginate, mucronate, the distal margins essentially entire; bristles 2 to 4 , subligulate, reddish-brown, each one on each side with 15 to 20 reddish-brown closely spaced spreading or often somewhat retrorse projections (not barbellate); styles mostly bifid; achene obovate, apiculate, about $2 \mathrm{~mm}$. long, brown, plano-convex or biconvex.

Scattered in mud and shallow water of ponds and lakes throughout Tex. except the Plains Country, Okla. (Creek, Sequoyah and Stephens cos.), N. M. (McKinley and Rio Arriba cos.) and Ariz. (Mohave, Maricopa, Pima, Santa Cruz and Yuma cos.), spring-summer; warmer parts of Am., n. to Gulf States, s. Ariz. and s. Calif.

\section{Scirpus heterochaetus Chase.}

Similar to $S$. acutus; culms slender, rarely $1 \mathrm{~cm}$. thick, pale green, firm; panicle with ascending to spreading very slender smooth to barely scabrous rays; bractlets whitish-brown, glabrous; spikelets mostly solitary, pale-brown to drab or whitish-green, lance-acuminate to slenderly ellipsoid, acute to subacuminate, 7.5-23 mm. long; scales firm or subcoriaceous, deeply emarginate, often slightly red-dotted, glabrous; bristles 2 to 4 (mostly 2), fragile, unequal, shorter than achene, barbellate or smooth; filaments broad; style 3-cleft; achene trigonous but twice as broad as thick.

Calcareous or other basic deadwaters, shores and swamps, in Okla. (Waterfall), June-Sept; e. Mass., s.w. Que., w. Vt. and n. N.Y., Wisc. to N.D., s. to cen. Ky., Ill., Mo. and Okla.; n.w. Ida., Wash. and Ore.

\section{Scirpus etuberculatus (Steud.) O. Ktze. Fig. 183.}

Culm 1-2 m. tall, 3-angled (usually sharply so above, obtusely so below), the sheath at base extended into a long slender triangular and channeled leaf; involucral leaf similar (1-2.5 dm. long), continuing the culm; spikelets cylindric (1-2 cm. long), single or sometimes proliferously 2 or 3 together, nodding on the apices of the 5 to 9 long filiform and flattened peduncles or rays of the dichotomous umbel-like corymb, or the central one nearly sessile; scales loosely imbricated oblong-ovate, acute, pale, thin and scarious, with a greenish nerved back; bristles 6 , firm, furnished above with spreading hairs rather than barbs, equaling the slender abrupt beak of the obovoid-triangular shining achene $2.5-3 \mathrm{~mm}$. (-4) long.

Ponds (in 1 to $3 \mathrm{ft}$. of water) and fresh to brackish marshes, very local, Fla. to s.e. Tex. (Hardin Co.), n. to Del. and Mo.

Often with a 2nd involucral bract, in this character and in its achene and bristles showing alliance with $S$. fluviatilis.

18. Scirpus acutus Muhl. Hard-stem bulrush, Tule, great bulrush. Fig. 184.

Rhizomatous perennial forming extensive colonies; culms 1-3 m. long, rising at close intervals from the rhizomes, $8-23 \mathrm{~mm}$. thick near the base, long-tapered, 2-4 mm. thick just under the inflorescence, essentially terete to very obscurely trigonous; leaves 1 or 2 per culm, confined to the very base, consisting of short mostly open sheaths with nearly smooth to lacerate margins; blades obsolescent; bract appearing as a continuation of the culm, (5-) 10-30 (-55) $\mathrm{mm}$. long, shorter than the inflorescence; inflorescence $3-10 \mathrm{~cm}$. long, decompound, with several drooping primary branches and 10 to 35 spikelets; spikelets lance-ovoid, at maturity $8-15 \mathrm{~mm}$. long, of 20 to 50 flowers; scales about $5 \mathrm{~mm}$. long (the lower 

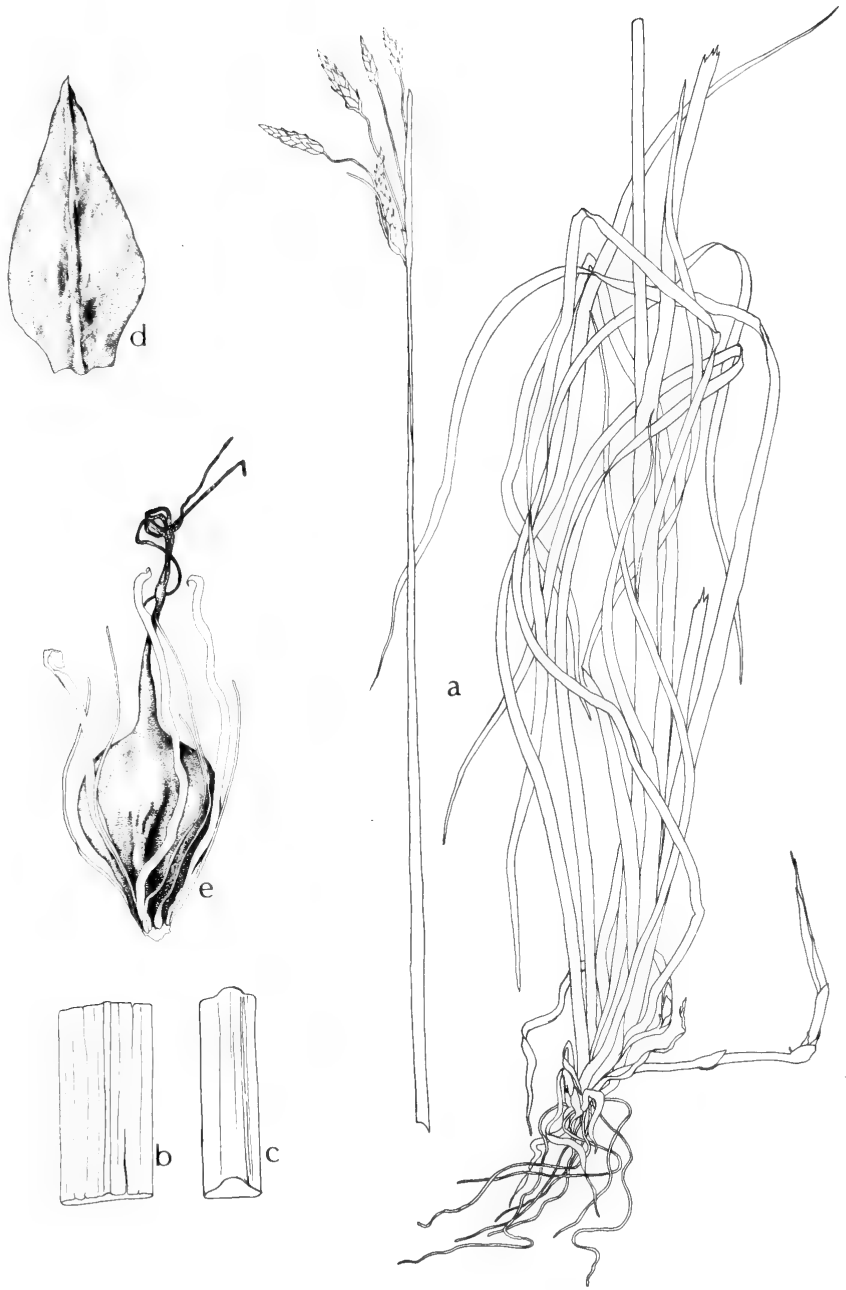

Fig. 183: Scirpus etuberculatus: a, habit, X 1/3; b, section of aquatic leaf; c, section of terrestrial leaf; d, scale, X 6; achene, X 8. (Courtesy of R. K. Godfrey). 

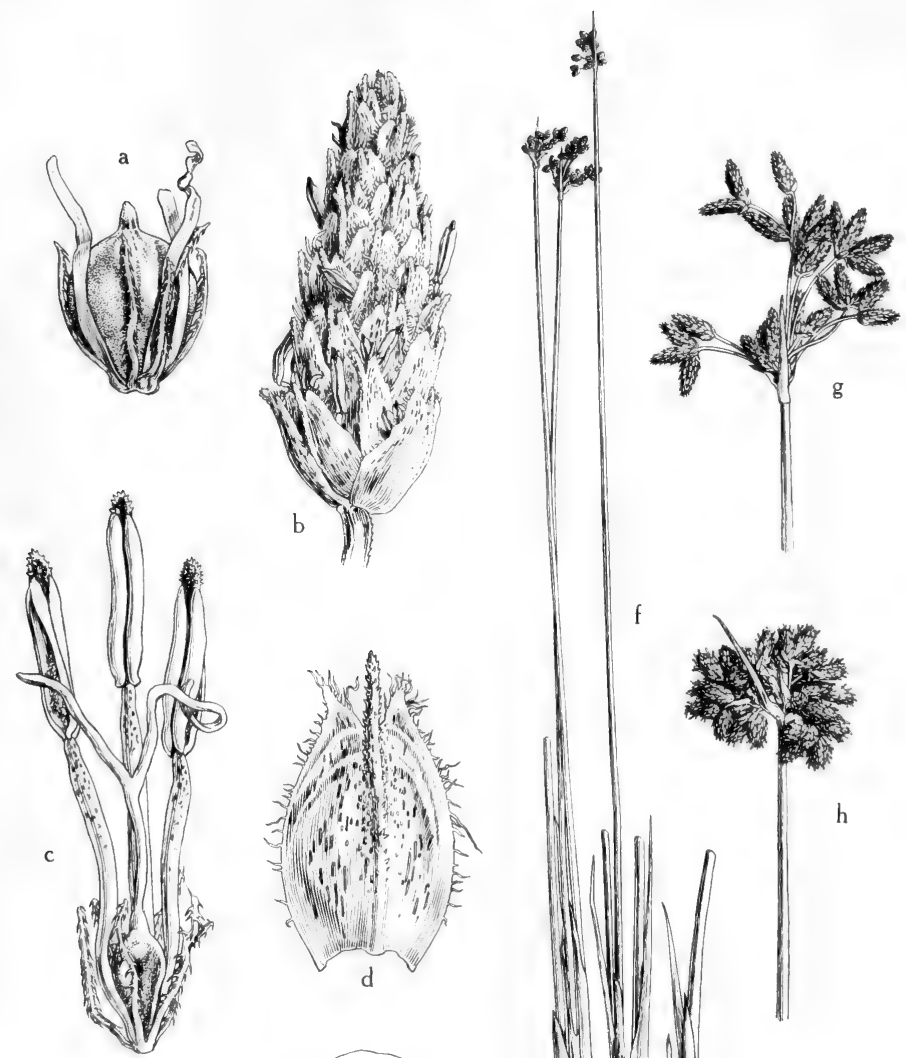

e
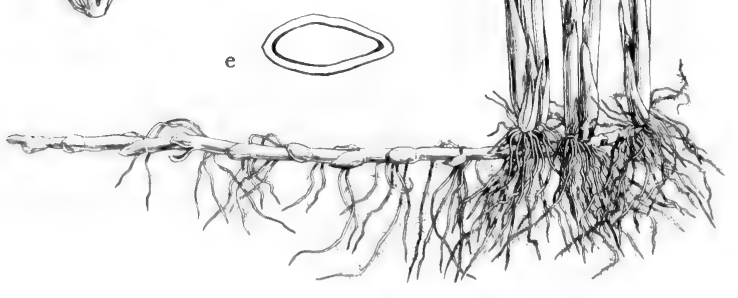

Fig. 184: Scirpus acutus: a, mature achene, the subtending bristles with conspicuous retrorse barbs, X 8; b, spikelet, X 4; c, flower without the scale, X 12; d, carinate scale, showing the short awn and the cleft ciliate apex, X 8; e, achene (cross section), X 8; $\mathrm{f}$, habit, showing stout rhizome, basal sheaths and erect culms, $\mathrm{X} 1 \% \mathrm{~g}$ and $\mathrm{h}$, inflorescences, showing variation, X\%. (From Mason, Fig. 157). 
ones emarginate), thin-membranous, pale-brown and with conspicuous elongate reddish glutinous spots (seen under a lens), the distal margin lacerate, the midnerve scabrous and projected as a mucro or short awn; bristles 4 to 6 , about equaling the achene, retrorsely barbed, on each side of the bristle 10 to 16 wellspaced barbs; styles mostly 2-branched; achene obovate, apiculate, plano-convex or very unequally biconvex, (1.8-) 2.1-2.4 (-2.9) mm. long. S. lacustris L. subsp. glaucus (Sm.) Hartm., S. Tabernaemontani Gmel., S. lacustris var. occidentalis Wats.

Alkaline or calcareous mud, marshes, usually in water, in Okla. (Le Flore, Ottawa, Blaine, Cimarron, Comanche, Bryan and Texas cos.) in the Tex. Plains Country and Trans-Pecos, rare e. to n.-cen. Tex., widespread in N.M. and Ariz., spring-fall; Eur., much of temp. N. A. s. to Gulf States, Chih., Coah. and Calif.

This is perhaps only a variety of $S$. lacustris. Some specimens from the Texas lower Rio Grande Plains seem to be intermediate between $S$. acutus and $S$. validus.

\section{Scirpus validus Vahl. Great or Soft-stem Bulrush. Fig. 182.}

Rhizomatous perennial forming extensive colonies; culms 1-3 $\mathrm{m}$. long, rising at close intervals from the rhizomes, $8-23 \mathrm{~mm}$. thick near the base, long-tapered, 2-4 $\mathrm{mm}$. thick just under the inflorescence, essentially terete or very obscurely trigonous; leaves 1 or 2 per culm, confined to the very base, consisting of short mostly open sheaths with nearly smooth to lacerate margins; blades obsolescent; bract appearing as a continuation of the culm, (5-) 10-30 (-55) $\mathrm{mm}$. long, shorter than the inflorescence; inflorescence $3-10 \mathrm{~cm}$. long, decompound, with several drooping primary branches and 20 to 120 spikelets; spikelets ovoid, 5-10 mm. long, of 20 to 50 flowers; scales obovate, $3-4 \mathrm{~mm}$. long, firm-membranous, darkbrown, nearly smooth (occasionally with a few reddish gummy spots near the midnerve), the distal margin nearly smooth to slightly lacerate, the midnerve projected as a mucro or short awn; bristles 4 to 6 , mostly slightly surpassing the achene, retrorsely barbed (on each side of each bristle 10 to 16 well-spaced barbs); styles mostly 2-branched; achenes obovate, apiculate, plano-convex or very unequally biconvex, (1.5-) 1.9-2.1 (-2.2) mm. long. S. lacustris var. condensatus Peck.

In mud and usually in shallow water, Okla. (Alfalfa, Grady, Johnston and Stephens cos.), infrequent in scattered parts of e, s.e. and n.-cen. Tex. and Rio Grande Plains, N. M. (San Miguel and Taos cos.) and Ariz. (Coconino, Yavapai, Gila, Pinal, Cochise and Santa Cruz cos.), spring-fall; temp. N.A. s. to S.A.

Perhaps only a variety of $S$. lacustris.

\section{Eriophorum L. COTTON-GRASS}

About 20 species in North Temperate and Arctic areas, with one in South Africa.

\section{Eriophorum polystachion L.}

Colonial from widely creeping rhizomes; culms subterete, mostly 2-6 dm. tall; leaves basal and cauline; blade well-developed, the lower ones usually somewhat elongate, 2-6 mm. wide, flat or essentially so for most of its length, becoming narrow and triangular or channeled toward the tip; uppermost culm leaf with welldeveloped blade usually equaling or exceeding the sheath; involucral bracts several, unequal, 2 or more of them noticeably foliaceous at least above the broadened more chartaceous base, the longest one usually surpassing or equaling the inflorescence; spikelets 2 to 8 , most or all of them individually pedunculate, in a compact to open umbelliform cyme, the peduncle more or less compressed, smooth or sometimes minutely scabrous-hirtellous; scales tawny to brownish or blackishgreen, very thin distally, the slender midrib attenuated distally and not reaching 


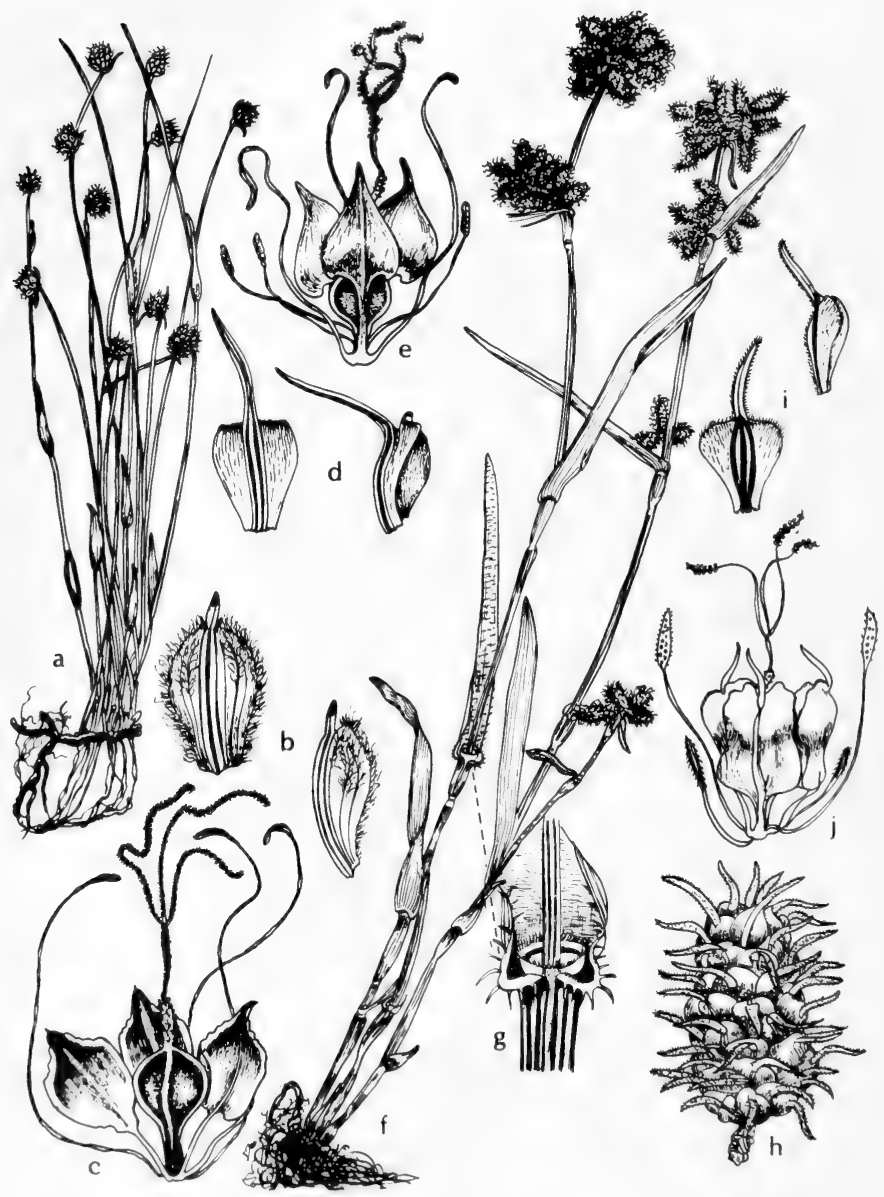

Fig. 185: a-c, Fuirena scirpoidea: a, habit, X 1/2; b, two views of scale, X 5 ; c, ovary and perianth scales, X 10. d and e, Fuirena squarrosa: d, two views of scale, X 5; e, ovary and perianth scales, $X 10$. f-j, Fuirena simplex: $\mathrm{f}$, habit, $\mathrm{X} 16 \mathrm{~g} ; \mathrm{g}$, sheath and ligule, $X 21 ; h$, spikelet, $X 3 ; i$, two view of scale, $X 5 ; j$, ovary and perianth scales, $X 10$. (V.F.). 
the tip; anthers usually to about $4 \mathrm{~mm}$. long; bristles numerous, white or nearly so; achenes blackish, 2-3 mm. long, broadly oblanceolate to obovate, 2 to 3 times as long as wide. E. angustifolium Honck.

In wet bogs, cold swamps and marshes, in N. M. (Taos Co.), Apr.-Aug.; Nfld. to Ore. and N.M.

\section{Fuirena Rottb. Umbrella-grass}

Perennials, usually rhizomatous, the lowest leaves often with reduced blades, the upper 1, 2 or 3 leaves functioning as bracts with each subtending a very much condensed often glomerulelike inflorescence of 1 to 10 spikelets; spikelets globose to oblong-cylindric; scales numerous, spirally imbricate, usually pubescent, all fertile, usually obovate and awn-tipped (awn short in one species); perianth of 3 stalked scalelike or paddlelike structures often thickened at maturity, often additionally three perianth bristles alternating with these stalked structures; style branches 3; achene plumply trigonous, shiny, apically tapering into a more or less persistent indurate linear style base often nearly as long as the achenial body itself.

The genus is related to, and should be included within, Scirpus, according to some authors. A small genus of 40 species in warmer regions of the world.

1. All or nearly all blades reduced; awns of spikelet scales only about $1 \mathrm{~mm}$. long, ascending............................................................ F. scirpoidea.

1. Nearly all blades well-developed, only the lowest reduced; awns of spikelet scales usually $2-4 \mathrm{~mm}$. long, often spreading apically (2)

2(1). Each of the 3 prominent perianth parts with an acuminate apex which often arches toward the style...........................................2. F. squarrosa.

2. Each of the 3 prominent perianth parts with an acute, blunt or even emarginate apex and often subapically on the dorsal side with a mucro or a minute awn........................................................... F. F. simplex.

\section{Fuirena scirpoidea Michx. Fig. 185 .}

Strongly rhizomatous; only the middle sheaths with small blades; inflorescences often only at the uppermost node and reduced to 1 to 3 spikelets; scales of spikelets with very short straight awns; the 3 expanded perianth parts tapering to their acumens.

Rare in wet sand, s.e. Tex. (Aransas and San Patricio.cos.), summer; coastwise, Fla. and Ga. to Tex.; Cuba.

\section{Fuirena squarrosa Michx. Fig. 185 .}

Scales of spikelet with long often decurved awns; expanded perianth parts tapering to the nonmucronate acumen which is often incurved to the style. F. hispida Ell., F . breviseta Cov.

Frequently in usually acid soils of marshes and bogs, e. and s.e. Tex., s. to Aransas Co. and Okla. (Waterfall), summer; parts of e. U.S. w. to e. Okla. and Tex.; Cuba, P.R.

\section{Fuirena simplex Vahl. Fig. 185.}

Scales of spikelet with long awns; expanded perianth parts variable but usually apically blunt or retuse and dorsally just below the tip with a mucro or minute awn.

Frequent in wet areas, about springs, in shallow water on edge of ponds and lakes, usually in calcareous mud, Okla. (Love, Stephens, McCurtain, Comanche and Grady cos.), w. part of Tex., e. to n.-cen. Tex. and Rio Grande Plains and N. M. (Eddy co.), later summer-fall; Guat. and Br. Hond. n.w. to Mo., Neb., N.M., Son. and Baja Calif. 


\section{Eleocharis R. BR. SPIKERUSH}

Annual or perennial broomlike sedges usually in aquatic environments; leaves reduced to mere bladeless sheaths; inflorescence solitary, terminal, spiciform (the bract reduced to a mere basal scale or usually absent), bearing few to many perfect flowers crowded in 3 to many ranks; scales spirally imbricate or rarely distichous (as in E. Baldwinii and perhaps E. minima), usually closely crowded, remaining so even when the achenes mature in some species (in others serially deciduous starting at the base of the spike), of various textures but always glabrous; perianth bristles 6 to 9 (or in some species reduced or absent); stamens usually 3, in some species often reduced to 2 or 1; styles 2- or 3-branched, basally enlarged into a persistent base (called the "tubercle") capping the achene, with a postanthetic zone of abscission between this base and the more slender portion, variously shaped and textured, either well-demarcated from the body of the achene or appearing to merge with it (as in E. parvula and E. obtusa, etc.); achene body plano-convex or isolaterally or isosceleslike trigonous (the trigony often obscure) to nearly terete, of various shapes, textures, colors and surficial sculpturing.

A cosmopolitan genus said to comprise about 200 species.

1. Tubercle $1.2-1.7 \mathrm{~mm}$. long, about as broad as the body of the achene.

1. Tubercle less than $1.1 \mathrm{~mm}$. long (2)

2(1). Achenes with about 6 longitudinal ridges with fine horizontal lines (trabeculae) between the ridges (3)

2. Achenes various but not trabeculate (6)

3(2). Culms strongly compressed, 2-edged, often C-shaped in transection, 0.6-1.3 $\mathrm{mm}$. broad.

2. E. Wolfii.

3. Culms neither strongly compressed nor 2-edged (4)

4(3). Anthers $0.5-1 \mathrm{~mm}$. long.

3. E. acicularis.

4. Anthers less than $0.5 \mathrm{~mm}$. long (5)

5(4). Anthers $0.3-0.4 \mathrm{~mm}$. long; perennial with creeping rootstocks.

5. Anthers $0.25-0.4 \mathrm{~mm}$. long; annual, forming dense tufts

4. $E$. radicans. 5. E. bella.

6(2). Culms sharply triquetrous or quadrangular in transection, $2.5-4 \mathrm{~mm}$. broad across each side, 5-8 dm. long (7)

6. Culms not as above, if triquetrous or quadrangular then much less coarse (8)

7(6). Culms quadrangular; achenial body 1.7-2.3 mm. long; tubercle 1-1.5 mm. long......

6. E. quadrangulata.

7. Culms triquetrous; achenial body $1.4-1.7 \mathrm{~mm}$. long; tubercle $0.7-1 \mathrm{~mm}$. long 7. E. fistulosa.

8(6). Tubercle coronalike, $0.3-0.5 \mathrm{~mm}$. high, $0.8-1 \mathrm{~mm}$. broad, capping and often broader than the trigonous obpyramidal body

8. E. melanocarpa.

8. Tubercle not as above, if coronalike then the body not trigonous (9)

$9(8)$. Achene biconvex, lustrous, brown when mature; style branches 2 ; tubercle forming a narrow lamelliform cap on and in outline confluent with the body (10)

9. Achene trigonous or biconvex, if biconvex then the style branches 3 and/or the tubercle not lamelliform (11)

10(9). Spikelets lanceolate, acuminate; scales acute 9. E. lanceolata.

10. Spikelets broadly ovoid to ovoid-cylindric, obtuse; scales obtuse...10. E. obtusa. 
11(9). Culms 1.5-9 mm. thick; spikelets of 40 to 350 flowers; achenes biconvex (12)

11. Culms $0.1-1.4 \mathrm{~mm}$. thick; spikelets of 5 to 80 flowers; achenes either biconvex or trigonous (16)

12(11). Culms with complete septa (as revealed by dissection) (13)

12. Culms not septate or irregularly and incompletely septate (15)

13(12). Culms 1.5-3.5 mm. thick; septa 2-5 mm. apart; tubercle depressed, 0.1-0.2 mm. high, in outline confluent with the body; body of achene $0.9-1.1 \mathrm{~mm}$. long....................................11. E. montana.

13. Culms 4-9 mm. thick; septa mostly farther apart; tubercle conic, $1-1.2 \mathrm{~mm}$. long; body of achene $1.8-2.2 \mathrm{~mm}$. long (14)

14(13). Septa very crowded just below the spikelet. 12. E. interstincta.

14. Septa not very crowded just below the spikelet 13. E. equisetoides.

15(12). Body of achene about $2 \mathrm{~mm}$. long, the surface cellular, appearing as if embedded in plastic; scales obtuse; spikelet 19-36 mm. long, cylindric. 14. E. cellulosa.

15. Body of achene 1.2-1.8 mm. long, surface smooth or micropunctate; scales usually acute; spikelets $8-25 \mathrm{~mm}$. long. 15. E. macrostachya.

16(11). Achenes biconvex, lustrous, black when mature, the bodies $0.5-1 \mathrm{~mm}$. long; tubercles $0.05-0.2 \mathrm{~mm}$. long; style branches 2 (17)

16. Achenes trigonous or if obscurely so then not black when mature (19)

17(16). Perennial usually with slender rhizomes; flowers 15 to 25 per spikelet; scales obviously keeled

16. E. flavescens.

17. Annuals, densely tufted; flowers 28 to 80 per spikelet; scales not or inconspicuously keeled (18)

18(17). Body of achene 0.7-1 mm. long; tubercle 0.1-0.2 mm. long; culms 0.4-1 mm. thick.

17. E. caribaea.

18. Body of achene $0.5-0.6 \mathrm{~mm}$. long; tubercle $0.05 \mathrm{~mm}$. long; culms $0.2-0.3$ $\mathrm{mm}$. thick 18. E. atropurpurea.

19(16). Body of achene rather sharply trigonous, broadest near the middle, apically confluent in outline with the tubercle which is pyramidal and $0.1-0.2 \mathrm{~mm}$. long; rhizomatous mat-formers; culms $2-12 \mathrm{~cm}$. long, $0.1-0.4 \mathrm{~mm}$. thick.

19. E. parvula.

19. Body of achene either not sharply trigonous or (if so) not confluent with the tubercle, or else plants otherwise habitally (20)

20(19). Tubercle columnar or slightly tapered, blunt, 0.6-1 mm. long, confluent with the body of the achene (21)

20. Tubercle shorter or if as much as $0.6-1 \mathrm{~mm}$. long then constricted basally, not confluent (22)

21(20). Culms usually less than $1 \mathrm{~mm}$. wide, not flattened; spikelets 4-7 mm. long, mostly of 2 to 7 flowers; achene reticulate......20. E. pauciflora.

21. Culms usually over $1 \mathrm{~mm}$. wide, flattened; spikelets $8-17 \mathrm{~mm}$. long, mostly of 12 to 30 flowers; achene smooth. 21. E. rostellata.

22(20). Tubercle $0.6-1 \mathrm{~mm}$. long, high-pyramidal, basally truncate; body of achene $1.2-1.7 \mathrm{~mm}$. long, surficially cellular (the cells with prominent margins) and olivaceous brown to olivaceous gray when mature....................................................................22. E. tortilis.

22. Tubercle $0.05-0.7 \mathrm{~mm}$. long, mostly pyramidal, low to depressed-pyramidal or globose; body of achene $0.5-1.8 \mathrm{~mm}$. long, surficially smooth to warty or punctate but not cancellate, variously colored (23) 
23(22). Spikelets of 5 to 20 flowers; culms $0.1-0.3 \mathrm{~mm}$. thick; achenes rather sharply trigonous, mostly whitish or maturing to shades of olive, surficially smooth; sheaths long-oblique apically (24)

23. Spikelets of 20 to 110 flowers; culms $0.2-1.4 \mathrm{~mm}$. thick; achenes mostly not so sharply trigonous (except in $E$. tenuis, $E$. cylindrica and $E$. austrotexana), maturing (except in E. tenuis and E. elongata) through shades of yellow to golden-brown or brown; sheaths truncate or only very slightly oblique apically (26)

24. Spikelets ovoid, $2-5 \mathrm{~mm}$. long; scales rarely appearing distichous (except in lance-elliptic, 3-4.5 $\mathrm{mm}$. long, buffy to ferruginous-buff.

23. E. Baldwinii.

24. Spikelets ovoid, 2-5 mm. long; scales rarely appearing distichous (except in E. minima?), ovate, shorter, usually whitish to purplish (25)

25(24). Culms about $0.1 \mathrm{~mm}$. thick, strongly recurved, 3-7 $(-10) \mathrm{cm}$. long; spikelets of 5 to 10 flowers; body of achene $0.7-0.8 \mathrm{~mm}$. long, maturing through whitish or olive to olive-gray; tubercle pyramidal, $0.15-0.3 \mathrm{~mm}$. high.............................................24. E. minima.

25. Culms $0.1-0.3 \mathrm{~mm}$. thick, mostly erect, $4-28 \mathrm{~cm}$. long; spikelets of 8 to 15 flowers; body of achene $0.5-0.6 \mathrm{~mm}$. long, pearly white; tubercle depressed-pyramidal, $0.05-0.15 \mathrm{~mm}$. high...........25. E. microcarpa.

26(23). Scales broadly ovate, subcartilaginous medially, firm-membranous marginally, stramineous in color, somewhat lustrous; body of achene ripening through shades of olive-whitish to brownish-olive and finally to a rich dark-chocolate-brown; bristles conspicuous, reddishbrown at maturity..... 26. E. albida.

26. Scales mostly thinner, membranous and usually with some dark pigmentation (27)

27(26). Body of achene light-green, with about 12 rows of coarse transversely linear cells; bristles 6 or 7 , equaling the achene, greenish; culms often floating on the surface of water...................27. E. elongata.

27. Body of achene (except in E. tenuis) ripening through shades of yellow to golden-brown; bristles various but not as above (28)

28(27). Body of achene minutely but pronouncedly warty or pitted in vertical lines, $0.6-0.8 \mathrm{~mm}$. long, ripening through shades of ivory to greenish-olive; tubercle pronouncedly depressed, $0.1-0.2 \mathrm{~mm}$. high, not much-constricted basally; culms $0.2-0.3 \mathrm{~mm}$. thick.

28. E. tenuis.

28. Body of achene minutely punctate-reticulate to smooth but not warty, $0.6-1.8$ $\mathrm{mm}$. long, ripening through shades of yellow to brown; tubercle usually conic-globular, usually constricted basally; culms $0.4-1.4$ mm. thick (29)

29(28). Scales of spikelet apically rounded, hyaline only in a very narrow rounded border at the apex (30)

29. Scales of spikelet deltoid or ovate-acute to lance-acuminate, with a more or less acute more or less extensive hyaline apex (32)

30(29). Spikelet linear-cylindric, acute; body of achene distinctly trigonous, smooth and satiny.............................................29. E. cylindrica.

30. Spikelet linear-lanceolate or narrowly ovoid to oblong and apically blunt: body of achene obscurely trigonous (31)

31(30). Spikelets linear to narrowly lanceolate, acuminate; achenes smooth or finely pitted; scales acute or acutish. 30. E. Parishii.

31. Spikelets ovoid to oblong, usually apically blunt; achenes punctulate-reticulate to nearly smooth; scales mostly obtuse. 31. E. montevidensis. 
32(29). Body of achene $1.2-1.8 \mathrm{~mm}$. long; tubercle $0.2-0.7 \mathrm{~mm}$. long; styles mostly 2-branched, rarely 3 -branched (33)

32. Body of achene $0.7-1.2 \mathrm{~mm}$. long; tubercle $0.1-0.2 \mathrm{~mm}$. long; styles $3-$ branched (34)

33(32). Styles always 2-branched; body of achenes very faintly reticulatepunctulate to essentially smooth; common.......15. E. macrostachya.

33. Styles 2- or 3-branched; body of achene distinctly reticulate-punctulate; exceedingly rare............................................................ E. fallax.

34(32). Culms 30-45 cm. long, with complete septa at regular short intervals (as revealed by dissection); body of achene with at least 2 distinct angles, the third sometimes also fairly sharp, the surface essentially smooth; scales merely acute, about $2 \mathrm{~mm}$. long.

33. E. austrotexana.

34. Culms $8-28 \mathrm{~cm}$. long, not septate; body of achene obscurely trigonous, the surface somewhat punctulate-reticulate; scales with long-acuminate scarious or hyaline apexes which often become split (bifid) during elongation (35)

35(34). Culms strongly compressed, 0.6-1 mm. thick in the flat dimension; deep east Texas.......................................................34. E. compresisa.

35. Culms variable, somewhat to not at all compressed, $0.3-0.8 \mathrm{~mm}$. thick; Edwards Plateau, Plains Country, s.e. Tex. and Okla......

35. E. acutisquamata.

1. Eleocharis tuberculosa (Michx.) R. \& S. Fig. 186.

Tufted perennial, often with ascending rhizomes 3-6 $\mathrm{mm}$. thick; culms 15-80 $\mathrm{cm}$. long, compressed, $0.5-1 \mathrm{~mm}$. thick in the longer dimension, erect, wiry, sulcate, grayish-yellow; sheaths grayish-yellow, shortly oblique and acute; spikelets ovoid to lance-ovoid, 5-15 mm. long, blunt to acute, with 25 to 40 flowers; scales ovate to nearly orbicular, about $3 \mathrm{~mm}$. long, blunt, grayish-yellow to stramineous, firm (chartaceous to subcartilaginous), not keeled, marginally slightly thinner than medially; bristles several, brownish, usually surpassing the achenial body; style 3-branched; achenial body broadly obovoid, 1.2-1.7 $\mathrm{mm}$. long, obscurely trigonous, stramineous to olivaceous, surficially with pronounced large cells (the cellwalls prominent), lustrous; tubercle $1.2-1.7 \mathrm{~mm}$. long, irregularly stele-shapedconic, apically rounded, toward the base flared out mushroomlike and as broad as the body, very strongly truncate, the connection to the body very thin.

Frequent in moist sand, wet meadows, about lakes and ponds, and along streams, in s.e. and e. Tex., May-Nov.; coastal provinces and states, N.S. and N.H. to Tex.; also Tenn. and Ark.

\section{Eleocharis Wolfii (Gray) Patt.}

Perennial (?); rhizomes slender, creeping, fragile; culms tufted, 2-edged, somewhat concavo-convex or C-shaped in transection, $12-30 \mathrm{~cm}$. long, $0.6-1.3$ $\mathrm{mm}$. broad, erect; sheaths apically scarious, oblique; spikelets ovoid-lanceolate, acute, 5-10 mm. long, 18- to 34-flowered; scales narrowly ovate, acute, usually with 2 purple longitudinal stripes and the rest stramineous, firm or marginally scarious; bristles absent; style 3-branched; achenial bodies narrowly obovoid, $0.8-0.9 \mathrm{~mm}$. long, pearly, obscurely trigonous to terete, with about 9 longitudinal ridges and between each 2 ridges about 40 close horizontally elongate cells (trabeculae); tubercle depressed-conic, about $0.1 \mathrm{~mm}$. long, much narrower than the body.

Rare in wet sand and wet swales in prairies, Plains Country and s.e. Tex., probably scattered elsewhere, spring-summer; Sask., Ind., Ill., Mo., Kan., Colo., (?) Okla., Tenn., La. and Tex. 

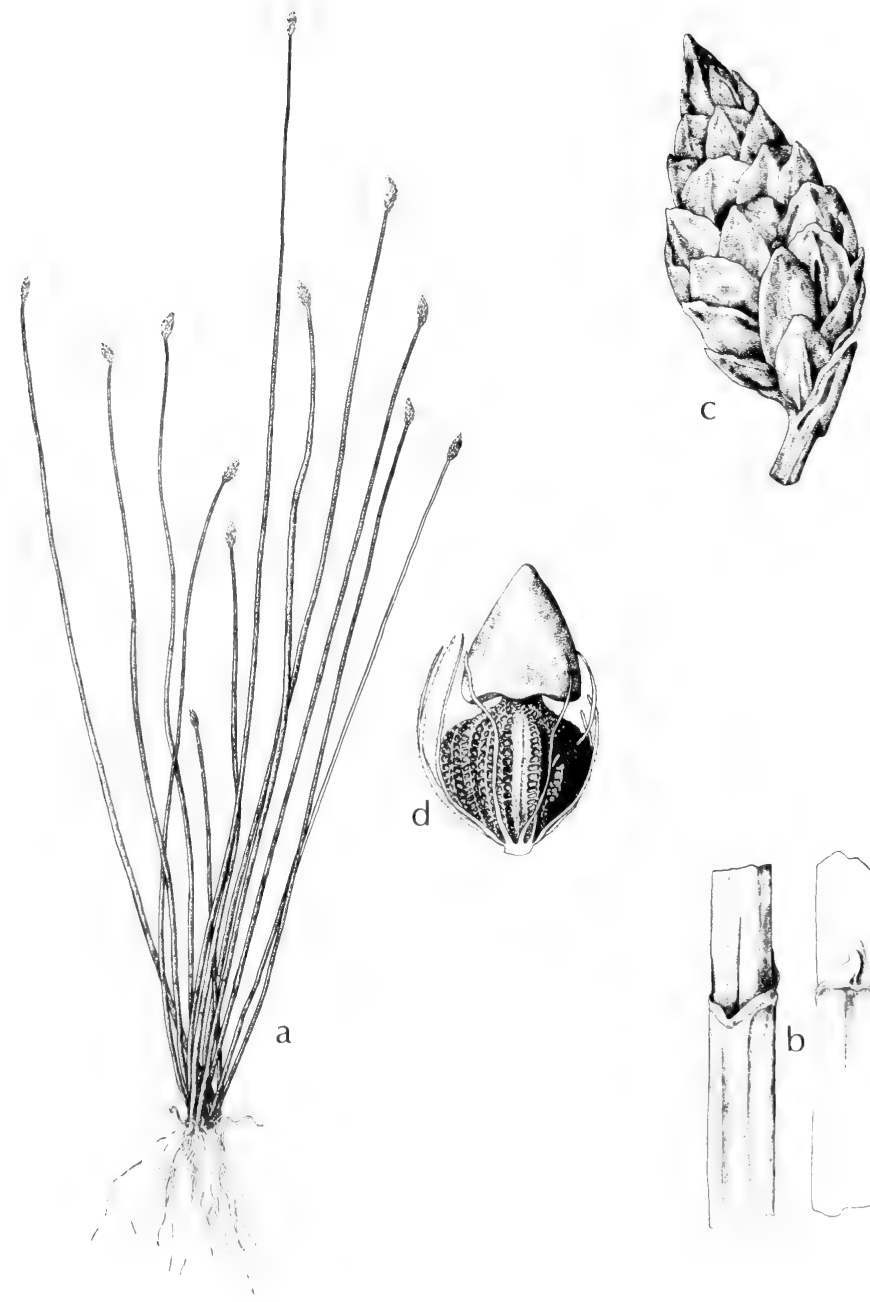

Fig. 186: Eleocharis tuherculosa: a, habit, about X 1/2; b, sheath, about X 5; spikelet, about X 8; d, achene, about X 15. (Courtesy of R. $\vec{K}$. Godfrey). 

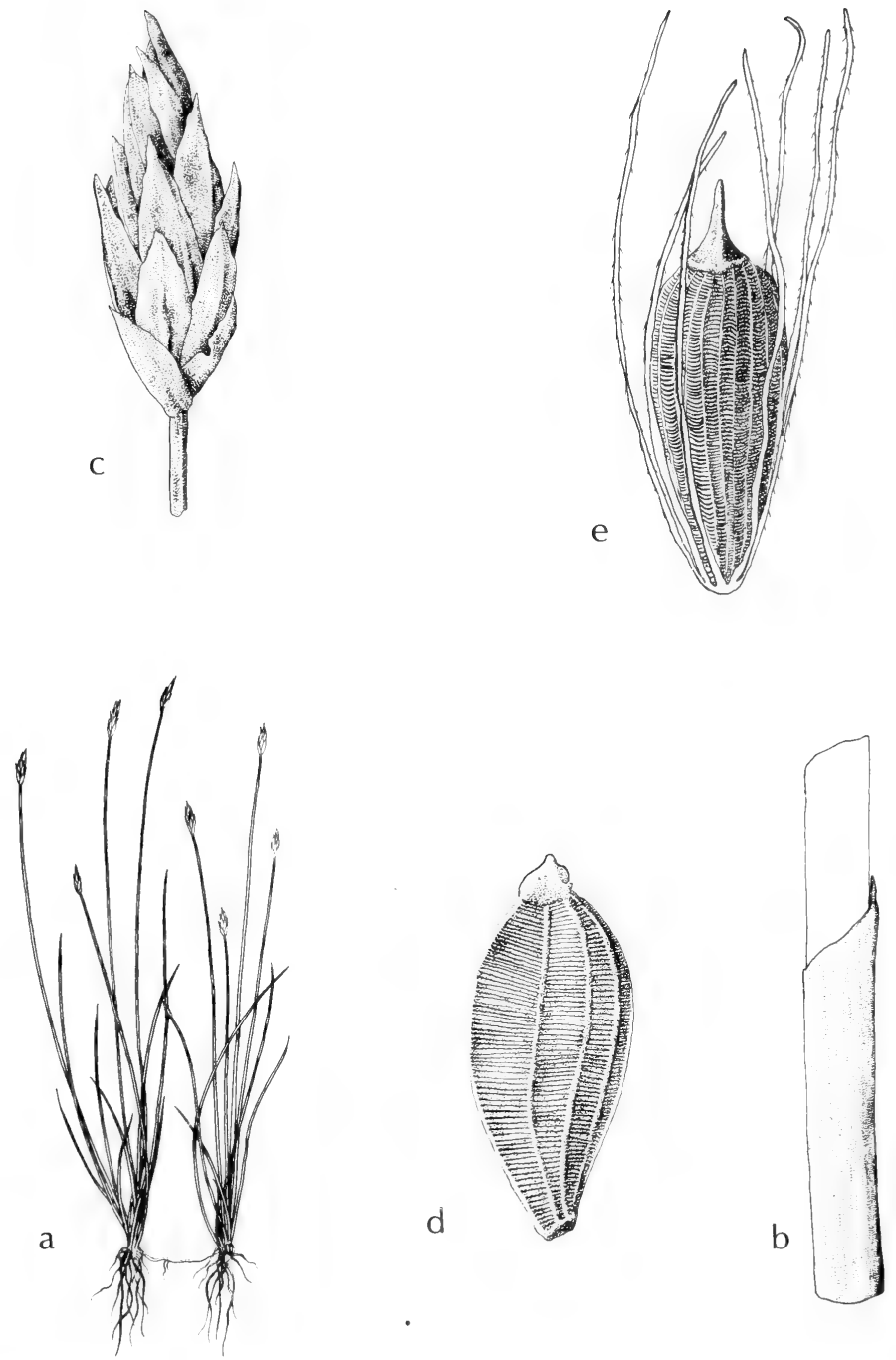

Fig. 187: a-d, Eleocharis acicularis: a, habit, X 1/2; b, sheath, X 12; c, spikelet, X 8 ; d, achene, X 50. e, Eleocharis radicans: e, achene, X 50. (Courtesy of R. K. Godfrey). 
3. Eleocharis acicularis (L.) R. \& S. Fig. 187.

Rhizomatous perennial forming mats; roots not fleshy; rhizomes $0.3-0.6 \mathrm{~mm}$. thick, extensively creeping; aerial culms $2-23 \mathrm{~cm}$. long, $0.2-0.4 \mathrm{~mm}$. thick, about 8-costate and-sulcate, often somewhat flattened or angulate; sheaths thin, reddish below, pallid and membranous or hyaline terminally, oblique; spikelets narrowly ovoid to ovoid-elliptic, 2-5 mm. long, 5- to 15-flowered; scales membranous, whitish to usually dark-purplish-red (or marginally pallid), ovate, $1.5-2 \mathrm{~mm}$. long, rather truncate to acute; bristles 3 or 4 , or usually (in Texas material) reduced or absent; stamens 3, anthers $0.5-1 \mathrm{~mm}$. long; styles 3-branched; achenial body obovoid, obscurely trigonous to usually nearly terete because of the turgid sides, 0.5-0.7 mm. long, pearly-white, with a number of longitudinal ribs and between each 2 ribs 25 to 40 close horizontally elongate facets or cells; tubercle conic, $0.075-0.15 \mathrm{~mm}$. long, constricted basally, much narrower than the achenial body. E. Reverchonii Svens.

Muddy river banks, meadows, vernal pools, edge of lakes and marshes, in Okla. (Kay and Alfalfa cos.), nearly throughout Tex. except Trans-Pecos and e. Tex., N. M. (San Miguel, Rio Arriba, Catron, San Juan, Socorro and Grant cos.) and Ariz. (Apache and Coconino cos.), infrequent or locally abundant, Feb.-summer; most n.-temp. areas of the world, in Am. s. to Calif., Chih., and the Gulf States.

\section{Eleocharis radicans (A. Dietr.) Kunth. Fig. 187.}

Densely matted perennial, the rhizomes very short; culms succulent (pressed flat in specimens), only 3-8 cm. long, 0.6-1 mm. thick, erect; sheaths membranous, tight; spikelets ovoid, 3-4 mm. long, 6- to 12-flowered; scales ovatelanceolate, greenish-stramineous; bristles usually 4, slender, white, retrorsely toothed, variable in length, in some specimens reduced or absent; stamens 2, anthers $0.3-0.4 \mathrm{~mm}$. long; style 3-branched; achenial bodies narrowly obovoid, $0.7-0.9 \mathrm{~mm}$. long, pearly, obscurely trigonous or usually essentially terete, with several longitudinal ridges and (between them) many (30 to 40) close horizontally elongate cells (trabeculae) in each longitudinal series; tubercle conic, $0.1-0.2$ $\mathrm{mm}$. long, much narrower than the body. Scirpus radicans Poir. (an illegit. name), Eleogiton radicans A. Dietr., Eleocharis Lindheimeri (Clarke) Svens.

Rare in marshy areas, wet sand and gravelly stream banks, in Okla. (Waterfall), e. and s.e. Tex. and Ariz. (Coconino, Pinal and Cochise cos.), spring (-summer?); Va., Mich., Tex., Okla., Ariz., Calif., Son., Gr. Ant., S.A.; H.I.

\section{Eleocharis bella (Piper) Svens.}

Dwarf annual with fibrous roots and caespitose culms, often forming dense round tufts $5-10 \mathrm{~cm}$. in diameter; culms capillary, furrowed, $2-6 \mathrm{~cm}$. tall, light green; basal leaf sheaths loose, obliquely truncated; spikelets $1-3 \mathrm{~mm}$. long, 3- to 15-flowered; scales with purplish brown sides and green midrib; bristles none; stamens 2, anthers $0.25-0.4 \mathrm{~mm}$. long; stigmas 3; achenes white or cream-colored, $0.6-0.8 \mathrm{~mm}$. long, with numerous longitudinal ribs, about 30 fine transverse lines between the ribs; tubercle compressed-conical.

Montane meadows, borders of marshes and lakes, wet, muddy or springy places, in Ariz. (Apache, Coconino and Cochise cos.); Mont., Ida. and Wash., s. to N.M. and Ariz.

\section{Eleocharis quadrangulata (Michx.) R. \& S. Fig. 188.}

Tufted perennial; culms 5-8 dm. long, 2.5-4 mm. thick, erect, sharply 4-angled, not septate; sheaths membranous, brownish or less commonly reddish, apically oblique; spikelets cylindric, $20-42 \mathrm{~mm}$. long, 3.5-4.5 mm. thick, with 40 to 90 flowers; scales rotundly obovate to ovate, 5.5-6 mm. long, 3-5 mm. broad, medially nearly flat, stramineous and subcartilaginous, laterally broadly chartace- 


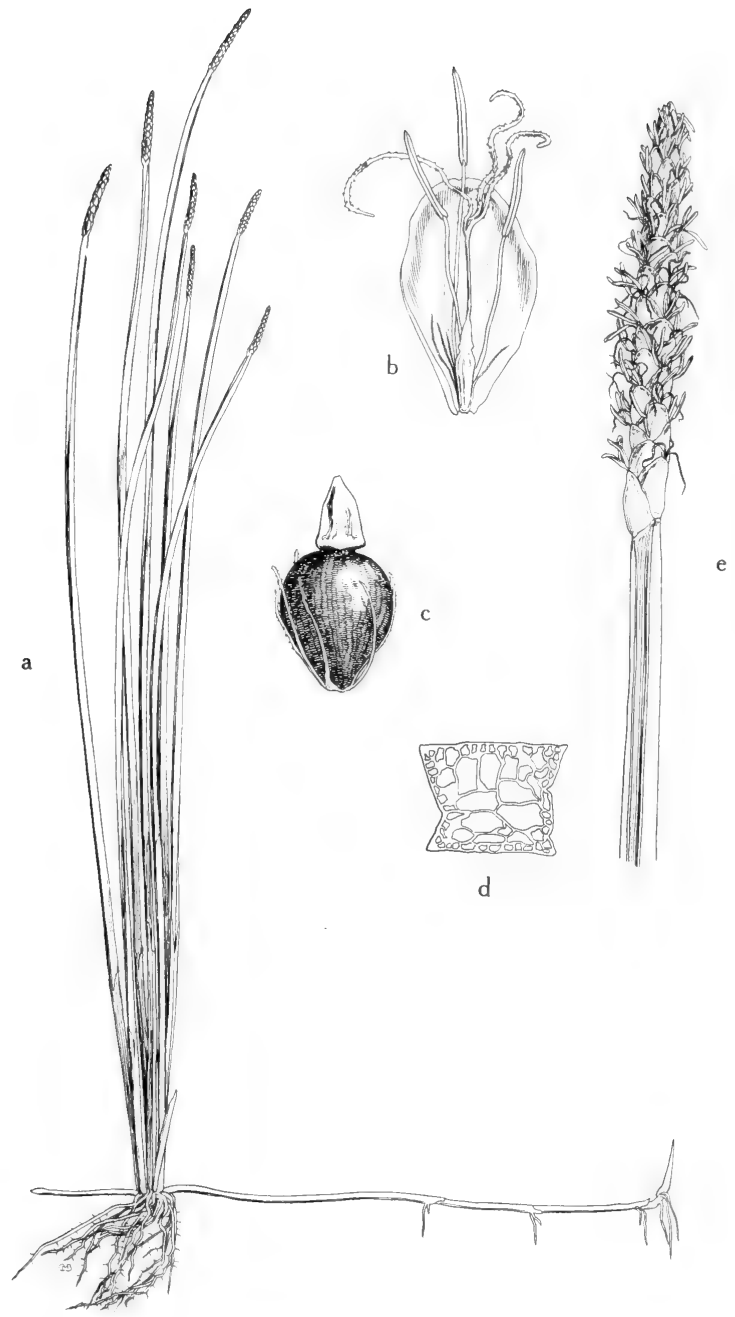

Fig. 188: Eleocharis quadrangulata: a, habit, showing the rhizome, the basal leaf sheaths, the tall 4 -angled culms, and the cylindric spikelets, $X 1 / 5 ; b$, flower, showing the rounded scale, the 3 stamens and the trifid style, X 6; c, mature achene, the tubercle elongated and triangular, and the slender subtending bristles, X 8; d, culm, showing the sharp angles (cross section), X 6; e, spikelet, X 11/2. (From Mason, Fig. 144). 


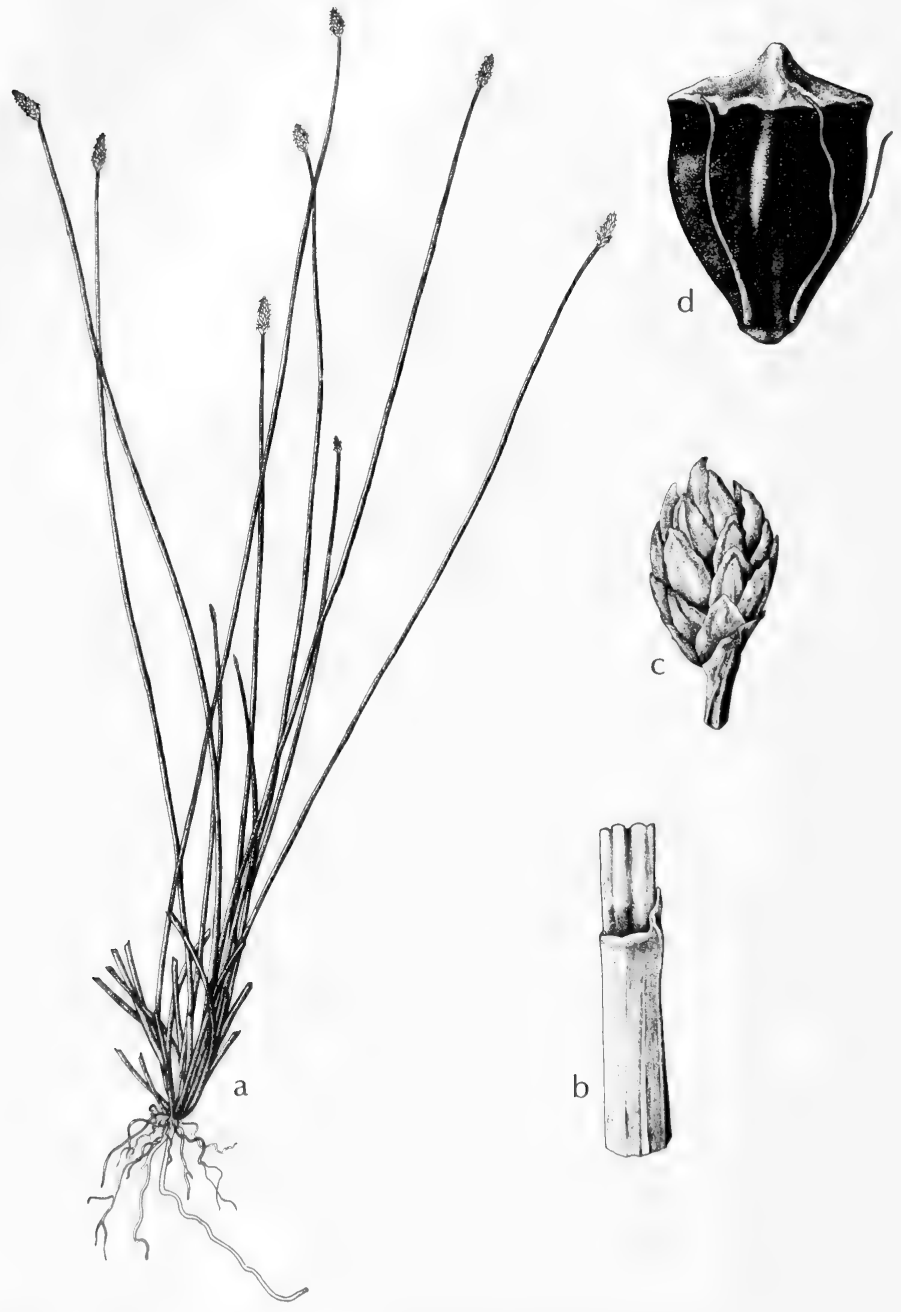

Fig. 189: Elencharis melanocarpa: a, habit, X 1/3; b, sheath, X 3; c, spikelet, X 3 ; d, achene, X 30. (Courtesy of R. K. Godfrey). 
ous to hyaline, the distal margin with slightly darker coloration; bristles about 6 , slender, unequal, some equaling the body, others surpassing the tubercle, with minute retrorse serrulations; style 2- or 3-branched; achene body biconvex to turgidly biconvex, 1.7-2.3 $\mathrm{mm}$. long, brown (yellow when immature), shiny; tubercle high-conic to deltoid or oblong, 1-1.5 mm. long, 0.8-1 mm. broad, basally constricted, dark.

Infrequent in mud and in shallow water at edge of ponds and lakes in Okla. (Le Flore, Pushmataha, Muskogee, Ottawa, Latimer and Atoka cos.) and in e. and s.e. Tex., rare in n. part of Rio Grande Plains, late spring-fall; most of e. U.S., w. to Wisc., Mo., Okla. and Tex.; also Jal.

\section{Eleocharis fistulosa (Poir.) Schult.}

Tufted perennial, apparently rather similar to $E$. quadrangulata but the culms sharply triangular and the spikelets and scales averaging slightly smaller; achene body $1.4-1.7 \mathrm{~mm}$. long; tubercle $0.7-1 \mathrm{~mm}$. long.

Rare in Tex., Rio Grande Plains, summer-fall (?); widely distributed in the warmer parts of the world, in Am. n. to Cuba and Tex.

\section{Eleocharis melanocarpa Torr. Fig. 189.}

Densely tufted perennial; culms 2-6 dm. long, flattened, about $1 \mathrm{~mm}$. thick in the larger dimension, on each side paucicostate and paucisulcate; sheaths apically firm and thickened, mucronate; spikelets narrowly ovoid, obtuse, 6-12 $\mathrm{mm}$. long, 4-5 mm. thick, with 20 to 40 flowers; scales ovate, $3-3.5 \mathrm{~mm}$. long, with a pale buffy very firm midrib, passing laterally through firm-brown to membranous-stramineous marginally; bristles dark-brown, shorter than the achene tubercle, retrorsely toothed or much-reduced; style 3-branched; achenial body obpyramidal-trigonous, $0.8-1 \mathrm{~mm}$. long, apically truncate, ripening through fuscous to black, glossy; tubercle paler, caplike, $0.3-0.5 \mathrm{~mm}$. long, $0.8-1 \mathrm{~mm}$. broad, often broader than the body and overhanging its truncate apex, depressed centrally with a slight pointed umbo.

Rare in moist sandy often boggy loam, e. Tex. (Leon and Upshur cos.), summer-fall (?); Coastal States, Mass. to Tex.; also Ind. and Mich.

Plants of this species appear to combine some characters of E. rostellata and some of $E$. obtusa.

\section{Eleocharis lanceolata Fern.}

Densely tufted annual; culms 1-2 dm. long, 0.3-0.9 mm. thick, erect; sheaths apically firm and oblique; spikelets lanceolate to lance-ovoid, of 30 to 80 flowers, acute; scales ovate, firm, brownish-stramineous, with a narrow scarious margin, acute, falling promptly in series from bottom to top of spikelet; bristles 6 or 7 , usually surpassing the tubercle; style 2- or 3-branched; achenial body 0.9-1.1 $\mathrm{mm}$. long, $0.7-0.8 \mathrm{~mm}$. broad, biconvex, pyriform in outline, smooth, shiny, ripening to a brownish color; tubercle forming a dark broad low-deltoid crown on the body and in outline merging with it, not constricted basally, about $0.4 \mathrm{~mm}$. long, 0.5-0.6 mm. broad. E. obtusa var. lanceolata (Fern.) Gilly.

In moist or wet loamy soils and muddy margins of ponds and lakes, in Okla. (McIntosh, Pittsburg, McCurtain, Atoka and Ottawa cos.) and in n.-cen. and n.e. Tex. (Grayson and Bowie cos.), summer-fall (?); Mo., Kan., Ark., Okla. and Tex.

10. Eleocharis obtusa (Willd.) Schult. Fig. 190.

Densely tufted annual (rarely persisting more than 1 season); culms $3-50 \mathrm{~cm}$. long, $0.3-1.6 \mathrm{~mm}$. thick (fleshy and sometimes seemingly broader when pressed flat), erect, striate; sheaths often slightly purplish basally, apically firm and 

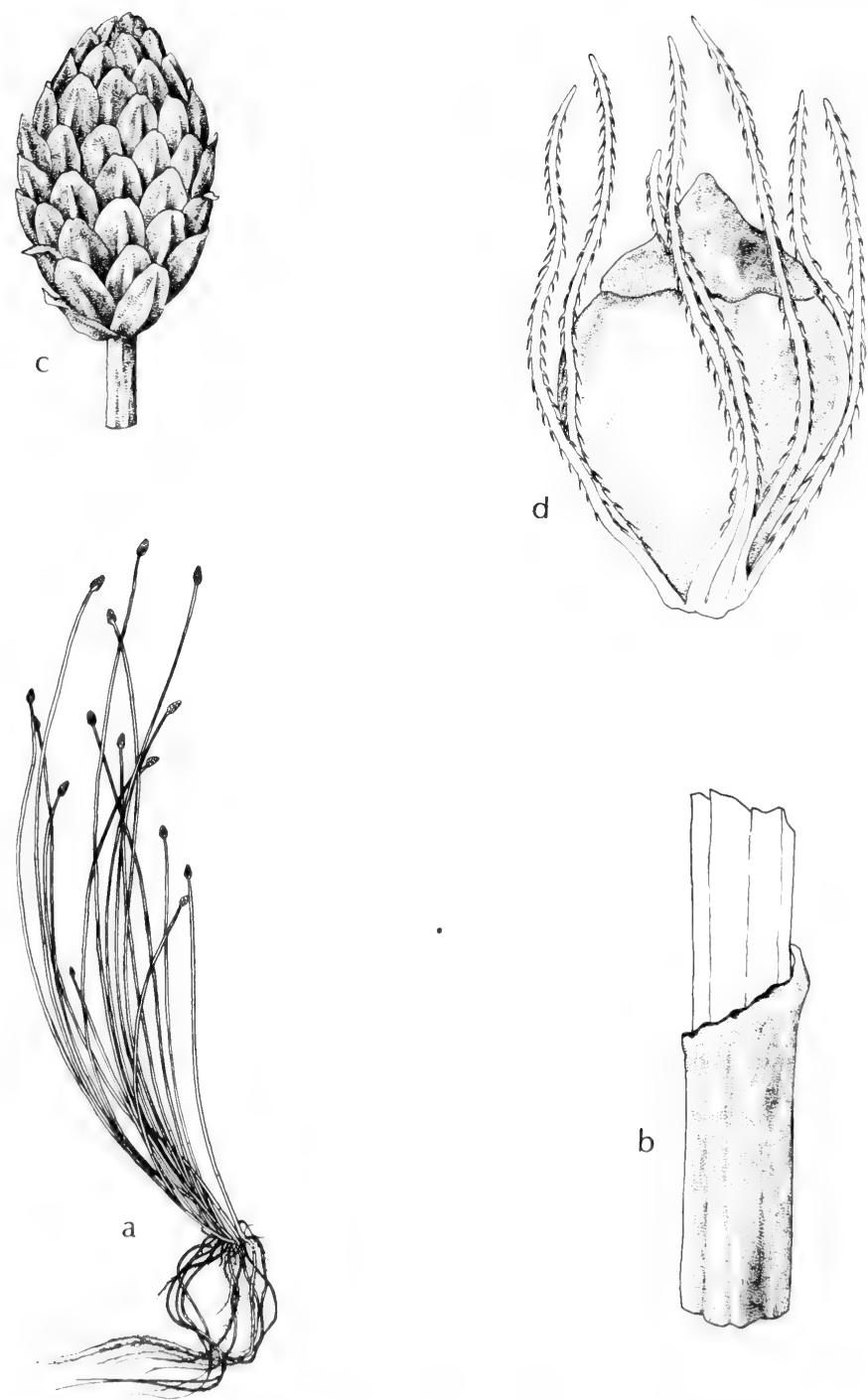

Fig. 190: Eleocharis obtusa: a, habit, X 1/2; b, sheath, X 12; c, spikelet, X 8; d, achene, X 40. (Courtesy of R. K. Godfrey). 


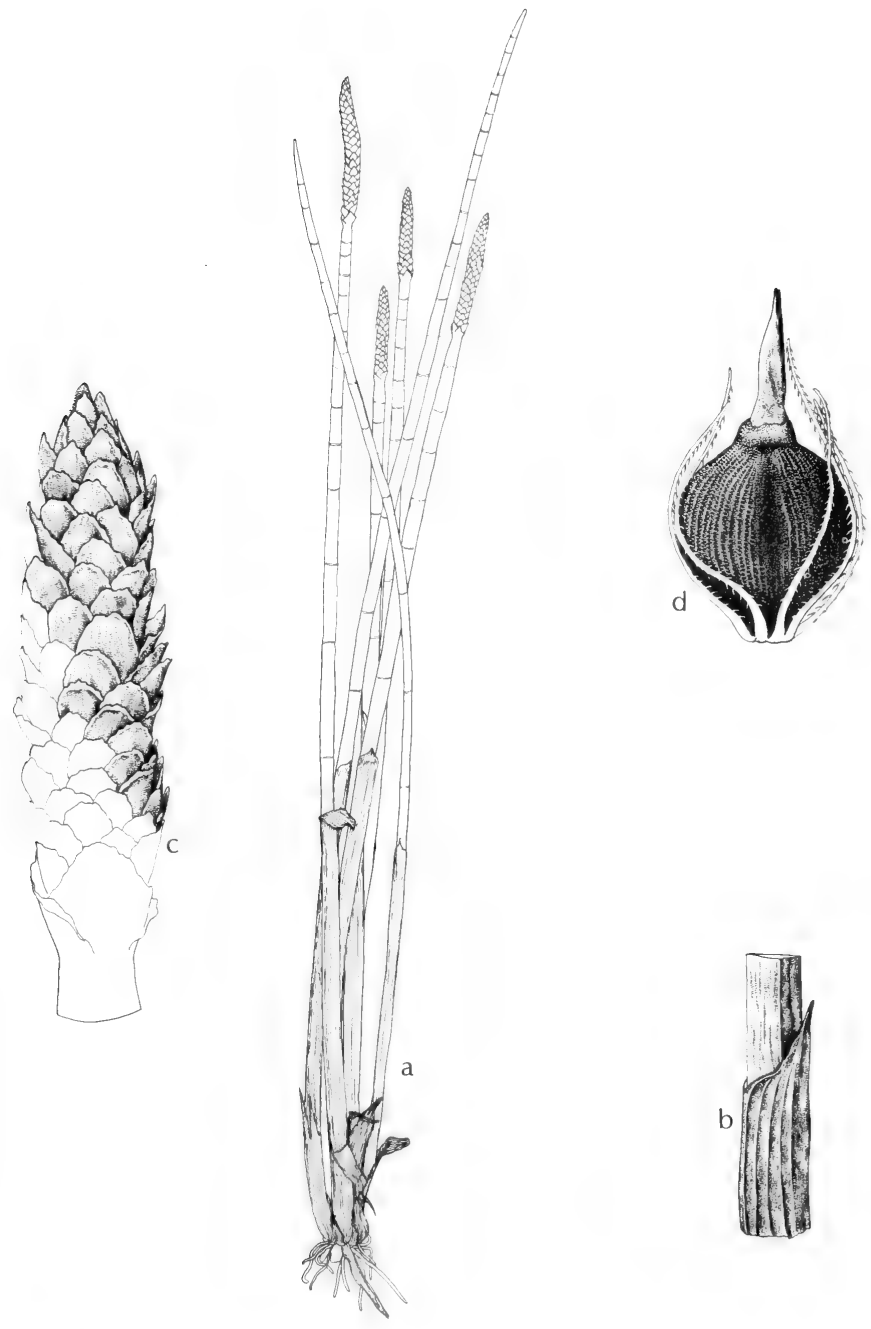

Fig. 191: Eleocharis interstincta: a, habit, X 1/3; b, sheath, X 3; c, spikelet, X 2; d, achene, X 10. (Courtesy of R. K. Godfrey). 
oblique; spikelets broadly ovoid to nearly cylindric, of 50 to 100 flowers (50 to 80 in var. obtusa, 60 to 100 in var, detonsa). obtuse; scales oblong to suborbicular, firm, drab-stramineous with a narrow scarious margin, obtuse, falling promptly in series from bottom to top of spikelet: bristles several, varying from surpassing the tubercle to essentially absent: style 2- to 3-branched; achenial body biconvex, pyriform, 0.8-1.2 mm. long. $0.7-1 \mathrm{~mm}$. broad, smooth and shiny, ripening through shades of yellow-green to brown; tubercle forming a dark broad low-deltoid crown on the body and in outline merging with it, not constricted basally, $0.1-4 \mathrm{~mm}$. long. $0.5-1 \mathrm{~mm}$. broad (in var. ohtusa the tubercle 1.7 to 3 times broader than long; in var. detonsa 2.8 to 4.5 times broader than long). E. Engelmannii Steud.

Locally abundant in moist sandy soils, in wet meadows, shallow water of ponds and edge of lakes, and mud of swamps, in Okla. (widespread), N.M. (Catron, Eddy and Socorro cos.) and Ariz. (Apache and Coconino cos.), the var. obtusa in e. and s.e. Tex, passing into var. detonsa (Gray) Drapalik \& Mohlenbrock in n.-cen. Tex. and Edwards Plateau (Enchanted Rock area only), spring-summer; over much of temp. N.A. [and perhaps including the Euras. E. ovata (Roth) R. \& S. as var. olata (Roth) Drapalik \& Mohlenbrock].

\section{Eleocharis montana (H.B.K.) R. \& S.}

Perennial, hasally subrhizomatous but not extensive; culms densely tufted, 3-8 dm. long. $1.5-3.5 \mathrm{~mm}$. thick, erect, terete, with complete septa $2-3 \mathrm{~mm}$. apart; sheaths basally reddish, apically lineolate, very firm, only very slightly oblique, mucronate: spikelets lanceolate, $8-24 \mathrm{~mm}$. long, acute, with 110 to 240 (to 350 ) flowers; scales ovate and acute to broadly lanceolate, about $2 \mathrm{~mm}$. long. medially huffy-brown and membranous, marginally hyaline and paler: bristles 6 to 8 , brownish, unequal, the longer ones about equaling the achenial body; style 2-branched (in Texas material); achenial body $0.9-1.1 \mathrm{~mm}$. long, obovate, biconvex (not turgidly so), with 2 definite angles (in Texas material), ripening through shades of pallid chartreuse and yellow to olive-brown, surficially punctulate-reticulate; tubercle $0.1-0.2 \mathrm{~mm}$. long. depressed-deltoid, about half as broad as the body and scarcely restricted basally, almost merging with the body.

Scarce in wet places, s.e. Tex. and s, as far as Nueces Co., N.M. (rather widespread) and Ariz. (Pima and Pinal cos.), summer: widespread in S.A. and C.A., W.I., n. to Ariz., N.M., Tex., La. and Fla.

\section{Eleocharis interstincta (Vahl) R. \& S. Fig. 191.}

Tufted perennial: culms 5-10 dm. long. 4-9 mm. thick. erect, essentially terete, septate. the septa closer together as the spikelet is approached; sheaths often tinged dark-red, apically firm, oblique; spikelets cylindric, 22-42 mm. long, 5-7 $\mathrm{mm}$. thick, with 80 to 140 flowers: scales (sub) cartilaginous, $3.5-5 \mathrm{~mm}$. long and hroad, obtuse, rounded, stramineous to buffy-stramineous, marginally darker and thinner. medially flat with a faint narrow midvein which is more heavily pigmented distally; bristles 6. exceeding the achene, brownish, stout, subcartilaginous, thattened, with (usually retrorse) serrulations; styles 2- or 3-branched; achene hoty hiconvex, $1.8-2.2 \mathrm{~mm}$. long, brown (yellow when immature), shiny: tuhercle high-conic, $1-1.2 \mathrm{~mm}$. long. $0.8 \mathrm{~mm}$, broad, dark, slightly constricted basally.

Infrequent to rare in mud and in water on edge of streams, lakes and ponds. in e. Tex.. Rio Grande Plains and Edwards Plateau, probably elsewhere, summerfall: Fla., Tex.. Berm., W.I. s. to Bol. and Braz.

\section{Eleocharis equisetoides (FII.) Torr. Fig. 192.}

Tufted perennial, exceedingly similar to $E$. interstincta but the septa not as crowded just below the spikelet and the bristles slightly shorter and thinner on the average. 


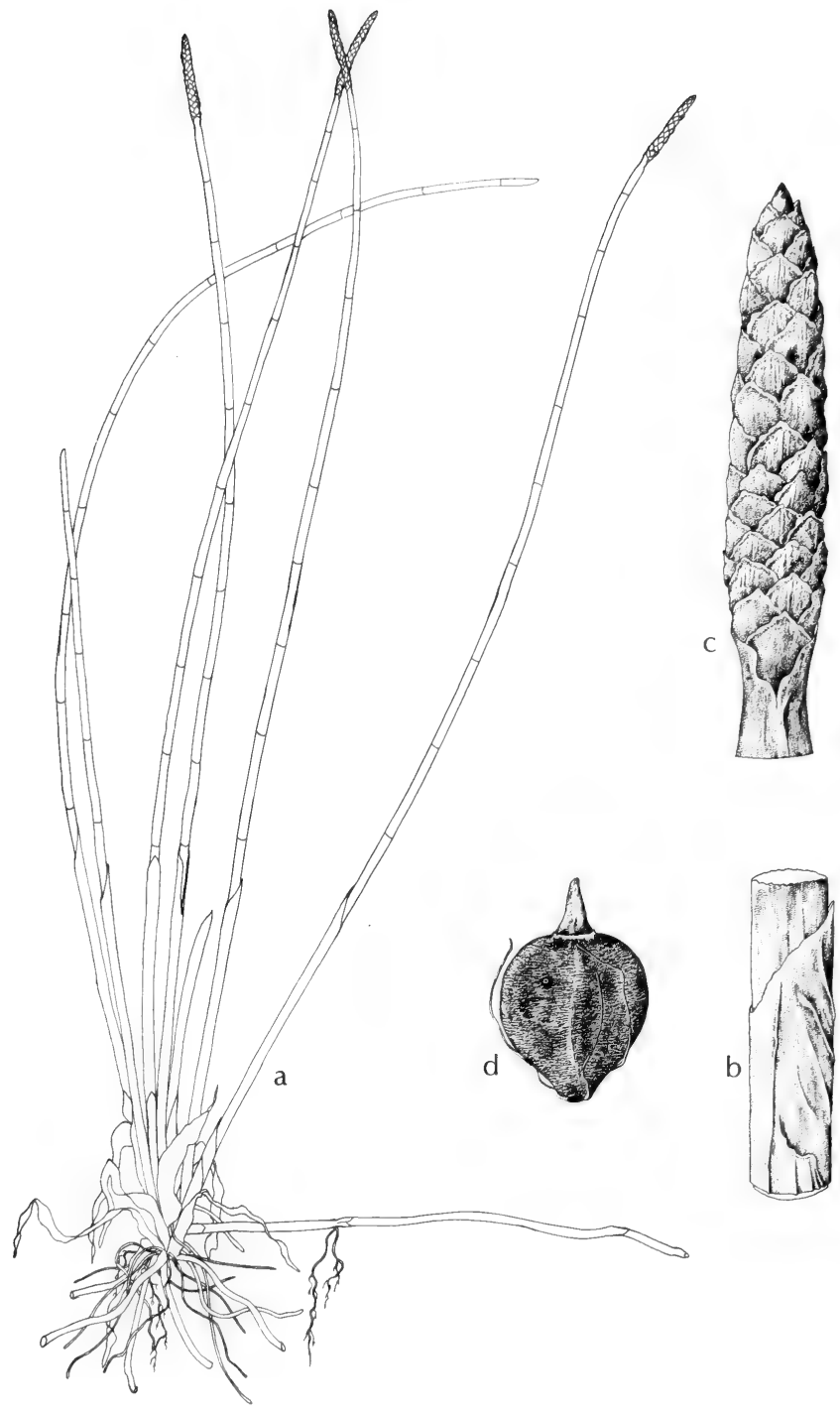

Fig. 192: Eleocharis equisetoides: a, habit, X 1/3; b, sheath, X 3; c, spikelet, X 2; d, achene, X 8. (Courtesy of R. K. Godfrey). 


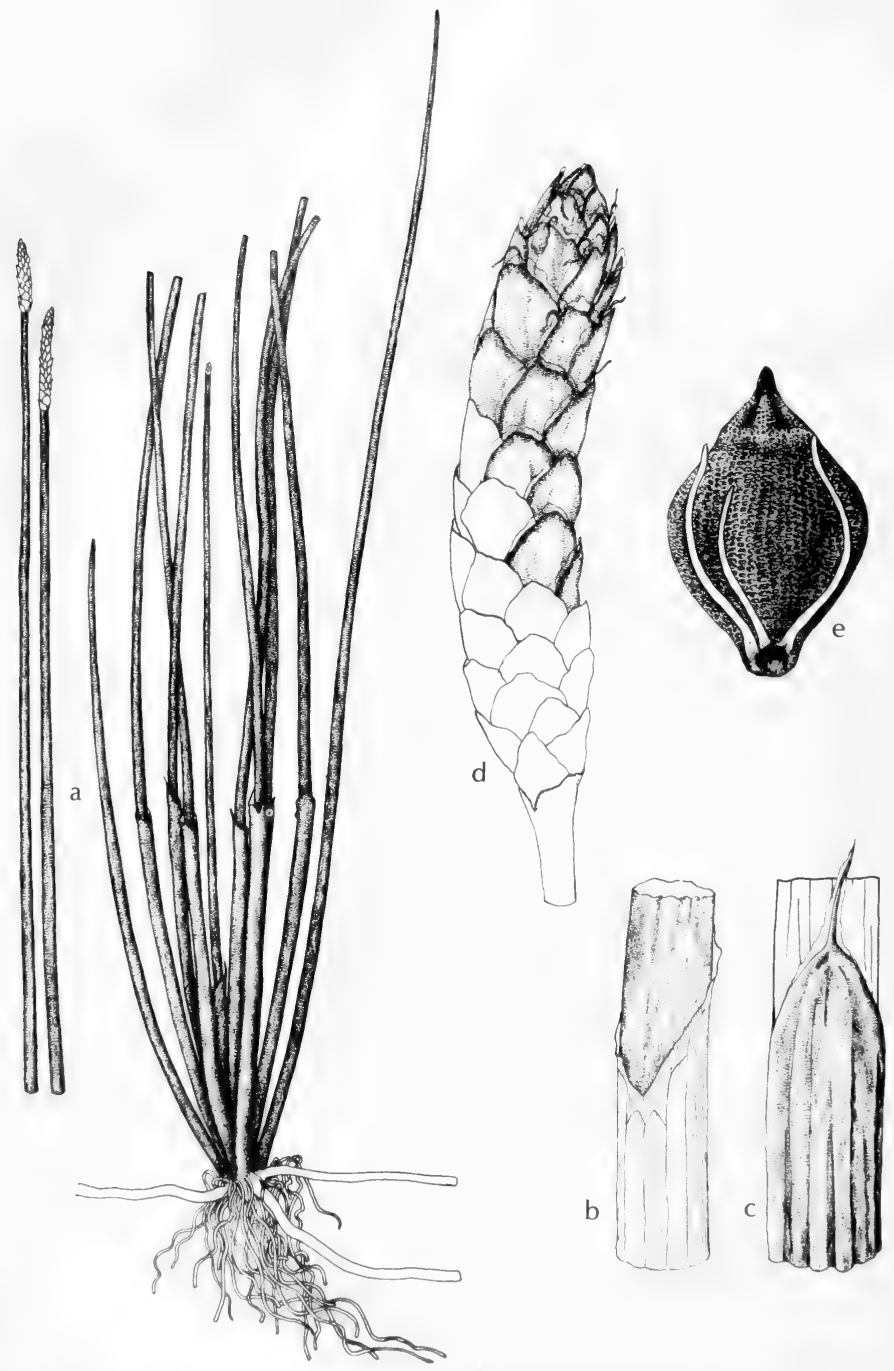

Fig. 193: Elencharis cellulosa: a, habit, $\mathrm{X}$ 1/2; b and c, two views of sheath, X 3; d, spike, X 4; e, achene, X 15 . (Courtesy of R. K. Godfrey). 
Rare in water of lakes and ponds, in e. and s.e. Tex., summer-fall; Coastal States, Mass. to Tex.; also Ind., Mich., Wisc. and Mo.

14. Eleocharis cellulosa Torr. Fig. 193.

Tufted perennial; culms 5-8 dm. long, 2-5 mm. thick, erect, essentially terete or irregularly compressed and striate; sheaths usually reddish, apically oblique, membranous; spikelets cylindric, $19-36 \mathrm{~cm}$. long, 3.5-5 mm. thick, with 50 to 90 flowers; scales broadly ovate to obovate, 5-6 $\mathrm{mm}$. long, 3-3.5 $\mathrm{mm}$. broad, medially with a prominent midrib and subcartilaginous and stramineous, striate and brownpenicillate, in texture passing laterally to chartaceous and finally to hyaline, in color to pallid-buff, the distal margin finely white-hyaline, submarginally with a thin brown line; bristles about 6, slender, mostly exceeding the achene and not serrulate; style 3-branched; achene body biconvex, about $2 \mathrm{~mm}$. long, brownish, surficially distinctly cellular (the cells quadrangular, appearing as if embedded in clear plastic), apically umbonate (forming a buttonlike base which is the podium for and merges into the tubercle); tubercle conic-deltoid, 0.6-1 mm. long, 0.4-0.6 $\mathrm{mm}$. broad, dark, not at all constricted basally but appearing as a continuation of the umbo of the body although differing texturally (being noncellular).

Infrequent in fresh-water and mud, occasionally forming mats in shallow water, and in depressions, in the Tex. Edwards Plateau, rare in Rio Grande Plains, exceedingly rare in e. Tex., spring-fall; Coastal States, N.C. to Tex.; Mex.; W.I.; Berm.

\section{Eleocharis macrostachya Britt. CREEPING SPIKE RUSH. Fig. 194.}

Rhizomatous perennial; rhizomes $1-2.5 \mathrm{~mm}$. thick, often reddish; culms in tufts along the rhizome, $18-50 \mathrm{~cm}$. long, $0.9-3 \mathrm{~mm}$. thick, erect, often appearing slightly spongiose and irregularly sulcate on drying, occasionally compressed; sheaths tight, apically truncate or very slightly oblique, very firm, in many specimens mucronate, basally dark-reddish-brown; spikelets $8-25 \mathrm{~mm}$. long, $3 \mathrm{~mm}$. thick, lanceolate or linear-lanceolate, acute, of 40 to 100 flowers; lowest 1 to 3 scales sterile, firm, obtuse, the lowest one sometimes completely encircling the base of the spikelet; fertile scales lanceolate to broadly lanceolate, more or less acute, about $3 \mathrm{~mm}$. long, with a green or stramineous midrib (which does not reach the apex), a firm buffy to castaneous lateral and subapical zone and a hyaline margin and apex; bristles 7 or 8 , brownish, unequal, the longest usually as long as the tubercle; style 2-branched, the upper part promptly deciduous from the base; achenial body obovate to pyriform, 1.2-1.8 $\mathrm{mm}$. long, usually more turgidly convex on one (abaxial) side than on the other, surficially nearly smooth or very faintly reticulate-punctate in an open pattern, lustrous, ripening through shades of yellow to golden-brown; tubercle $0.3-0.7 \mathrm{~mm}$. long, conic to depressed or even subglobular, grayish, texturally like pumice or rotted bone, usually about half as broad as the body, basally constricted. Some workers refer these plants to the Old World complex known by the name E. palustris (L.) R. \& S., (?) E. calva Torr., E. xyridiformis Fern. \& Brack.

Common and widespread in most of our area, in marshes, vernal pools, wet meadows, ditches, flooded lands and alkaline mud, spring-summer; Minn. to Ill., Mo., Kan., Okla. and Tex., w. to s. Alas., Calif. and s. to cen. Mex.; Col.

\section{Eleocharis flavescens (Poir.) Urban. Fig. 195.}

Perennial, often with elongate fleshy rhizomes $0.5-1 \mathrm{~mm}$. thick; culms either densely tufted or rising singly from the nodes of the rhizome, $4-35 \mathrm{~cm}$. long, $0.3-$ $1 \mathrm{~mm}$. thick, ascending, firm to flaccid, often sulcate when dried; sheaths apically oblique, hyaline, fragile, promptly becoming loose and withered on drying; spikelets 3-6 mm. long, ovoid, acute or blunt, with 15 to 25 flowers at maturity (the 


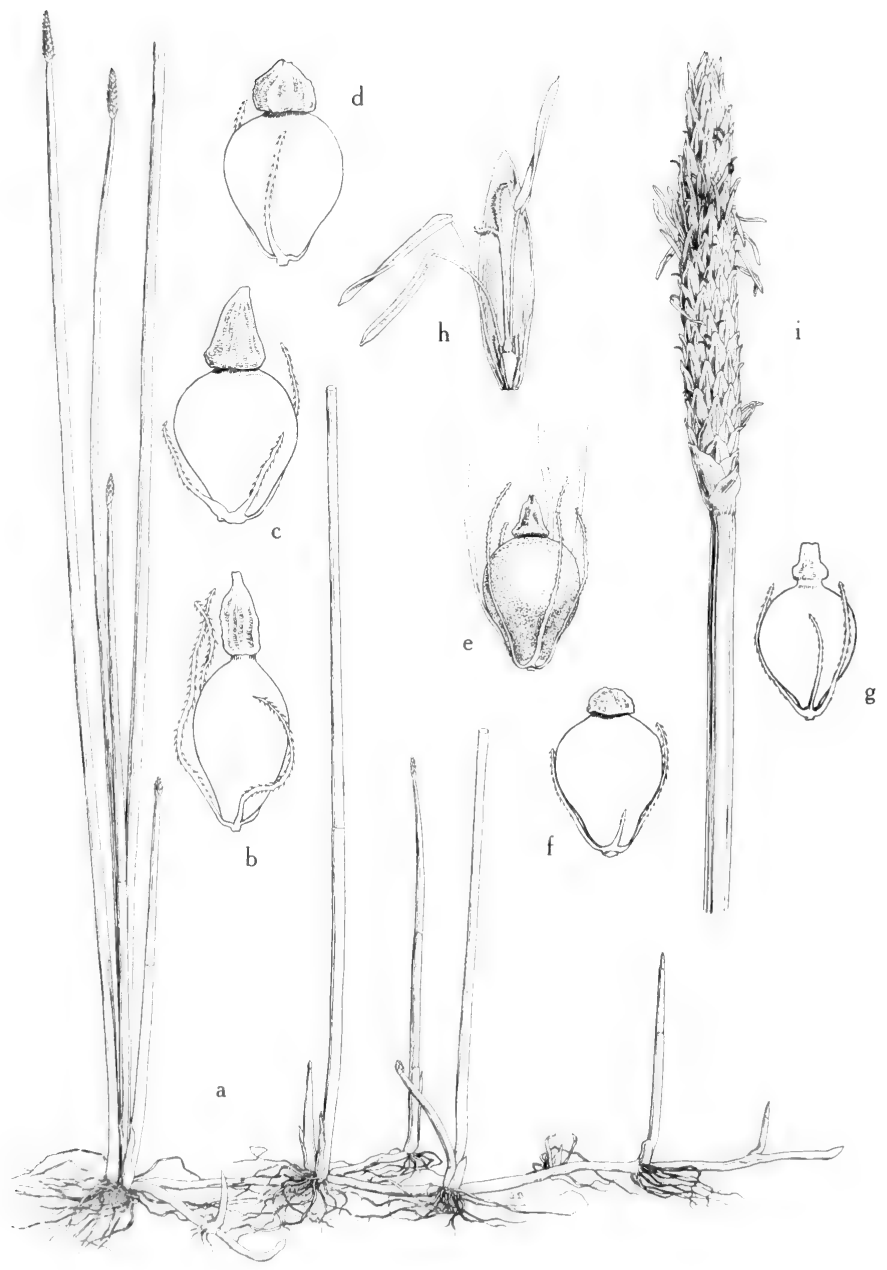

Fig. 194: Eleocharis macrostachya: a, habit, showing the tall erect culms with truncate hasal leaf sheaths and the creeping rhizomes, $X-2 ; \mathrm{b}-\mathrm{g}$, variations in form and size of achene, tuhercle and subtending bristles, X $12 ; \mathrm{h}$, flowers, showing the lanceolate scale, X 6; i, terminal spike, the lower scales empty, X 2. (From Mason, Fig. 143). 


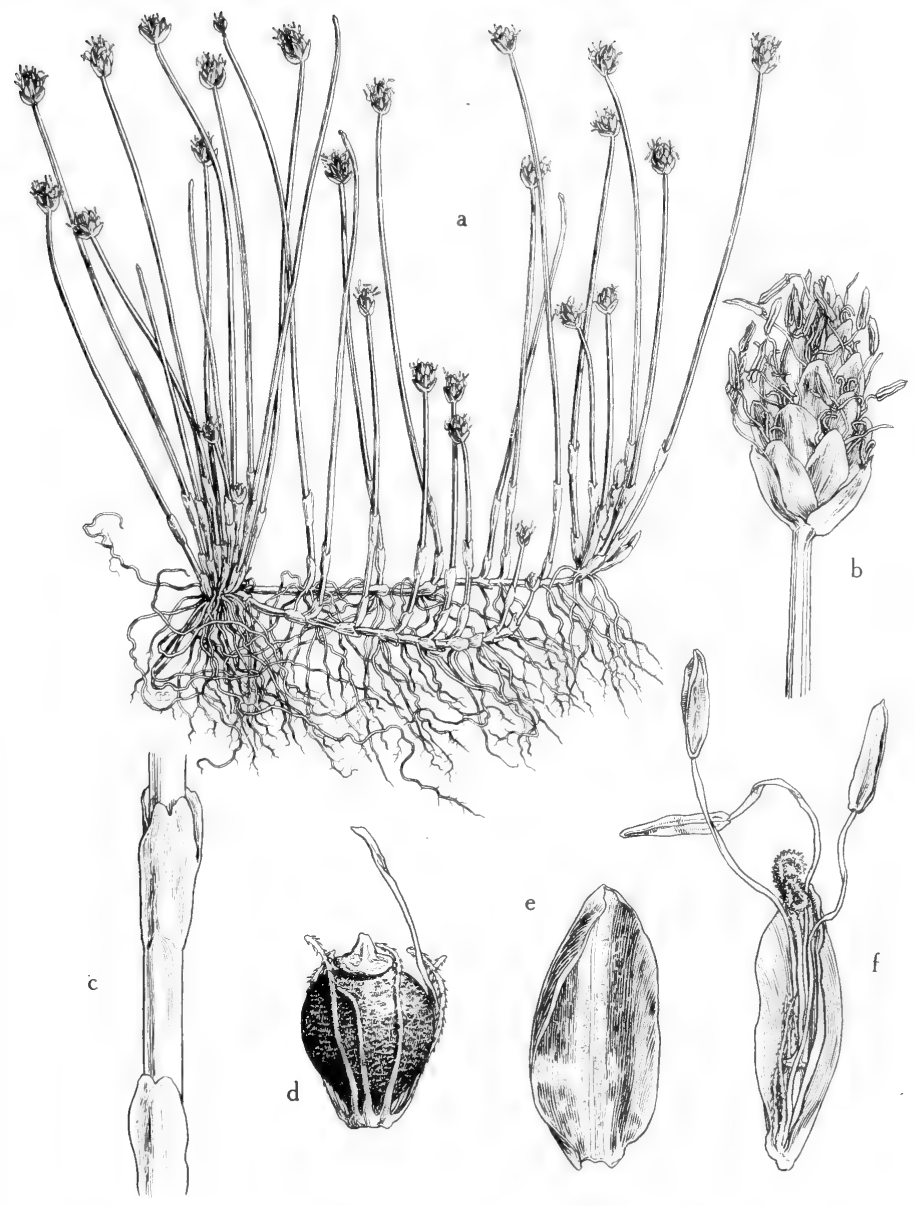

Fig. 195: Eleocharis flavescens: a, habit, showing a tufted plant and rhizomes with single culms arising from the nodes, $\mathrm{X} 4 \%$; b, ovate obtuse spikelet, $\mathrm{X} 6$; c, emarginate basal leaf sheaths, X 6; d, mature achene, the tubercle conic and acute, the subtending bristles as long as or slightly longer than achene, X 24; e, elliptic scale with pale midvein, $X 20 ; \mathrm{f}$, flower, showing the bifid style and the 3 stamens, X 20. (From Mason, Fig. 139). 
numerous more apically situated primordia never maturing); scales ovate to ovateoblong, firm to membranous, somewhat striate, with a strong greenish keel-like midrib and brown-stramineous sides; bristles about 7 , pallid to pure white, quite variable in length but usually about equaling the tubercle; style 2-branched; achenial body obovate to pyriform, 0.8-0.9 (-1) $\mathrm{mm}$. long, biconvex, shining, microscopically pitted, ripening through shades of chartreuse and olive brown to purplish-brown or even purplish-black; tubercle conic, yellow to greenish-white, acute, $0.1-0.2 \mathrm{~mm}$. long, about $0.1 \mathrm{~mm}$. broad, basally very slightly constricted. E. olivacea Torr., E. ocreata (Nees) Steud.

Rare in moist soil, on mud and in shallow water, sometimes on floating logs, in e. and s.e. Tex. and Edwards Plateau, probably elsewhere, and Ariz. (Pima Co.), spring-fall; e. N.A. w. to Minn. and Tex.; Ariz. and Calif.; W.I., Mex., S.A. Easily confused with E. caribaea.

17. Eleocharis caribaea (Rottb.) Blake. Fig. 196.

Densely tufted annual (when plants are covered slowly with shifting sand the bases elongating upward somewhat like rhizomes) or perhaps rarely perennial; culms 4-30 cm. long, 0.4-1 mm. thick, terete (or striate and sulcate on drying); sheaths apically oblique, firm; spikelet 3-6 $\mathrm{mm}$. long, ovoid to broadly ovoid, obtuse, of 28 to 50 flowers; scales broadly ovate, $1.5-2 \mathrm{~mm}$. long, firm, when mature stramineous to pallid-buffy and with inconspicuous midrib, obtuse, eventually serially deciduous from lowest to highest; bristles about 7, dark-colored, usually about equaling the tubercle; style 2-branched; achenial body (0.7-) 0.8-1 mm. long, obovate to pyriform in outline, biconvex, ripening through shades of pale-green to purplish-black, shiny; tubercle conic (depressed or acute), (0.05-) $0.1-0.2 \mathrm{~mm}$. long, pallid-greenish or whitish, slightly constricted basally.

Locally abundant in moist calcareous soil, wet mud, wet lake shore and streams, in Okla. (Carter, Love and Stephens cos.), in most parts of Tex. (absent from Plains Country and e. Tex.), and Ariz. (Gila and Pima cos.), summer-fall; widespread in warmer parts of the world; in Am. n. to Gulf States, casual elsewhere.

Has been known incorrectly as E. geniculata (L.) R. \& S.; the latter is a species of coarse, tropical perennials not occurring in our region.

18. Eleocharis atropurpurea (Retz.) J. \& C. Presl. Fig. 196.

Densely tufted annual; culms $3-12 \mathrm{~cm}$. long, $0.2-0.3 \mathrm{~mm}$. thick, arcuateerect, terete (sulcate or striate on drying); sheaths apically oblique, firm; spikelet narrowly ovoid, 2-4 mm. long, of 40 to 80 flowers; scales ovate to narrowly so. about $1 \mathrm{~mm}$. long, obtuse to abruptly acute, firm-membranous, with a green midrib, brown to purplish laterally: bristles several, usually colorless, translucent, about equaling the achenial body or much-reduced; style 2-branched; achenial body $0.5-0.6(-0.7) \mathrm{mm}$. long, obovate to pyriform in outline, biconvex, when mature quite jet black, shiny; tubercle conic, about $0.05 \mathrm{~mm}$. long, whitish, constricted basally.

Rare and local in moist sandy soil, in mud along streams and marshes in Okla. (Blaine and Alfalfa cos.), e. Tex. (Bastrop Co.), Edwards Plateau (Burnet Co.), Plains Country (Hale Co.) and Rio Grande Plains (Hidalgo Co.), and N. M. (Sandoval Co.), scattered, summer; scattered in warmer parts of both hemispheres, in Am. n. to Ia., Neb., Colo. and Wash.

\section{Eleocharis parvula (R. \& S.) Link. Fig. 197.}

Tufted annual (?) spreading by short stolons or rhizomes $0.2-0.5 \mathrm{~mm}$. thick, forming mats in mud; culms 2-7 (-12) cm. long, $0.1-0.4 \mathrm{~mm}$. thick, usually sulcate or irregularly flattened; sheaths extremely short and inconspicuous, hyaline, often slightly reddish; spikelets ovoid to cylindric, 2-9 $\mathrm{mm}$. long, stramineous, 


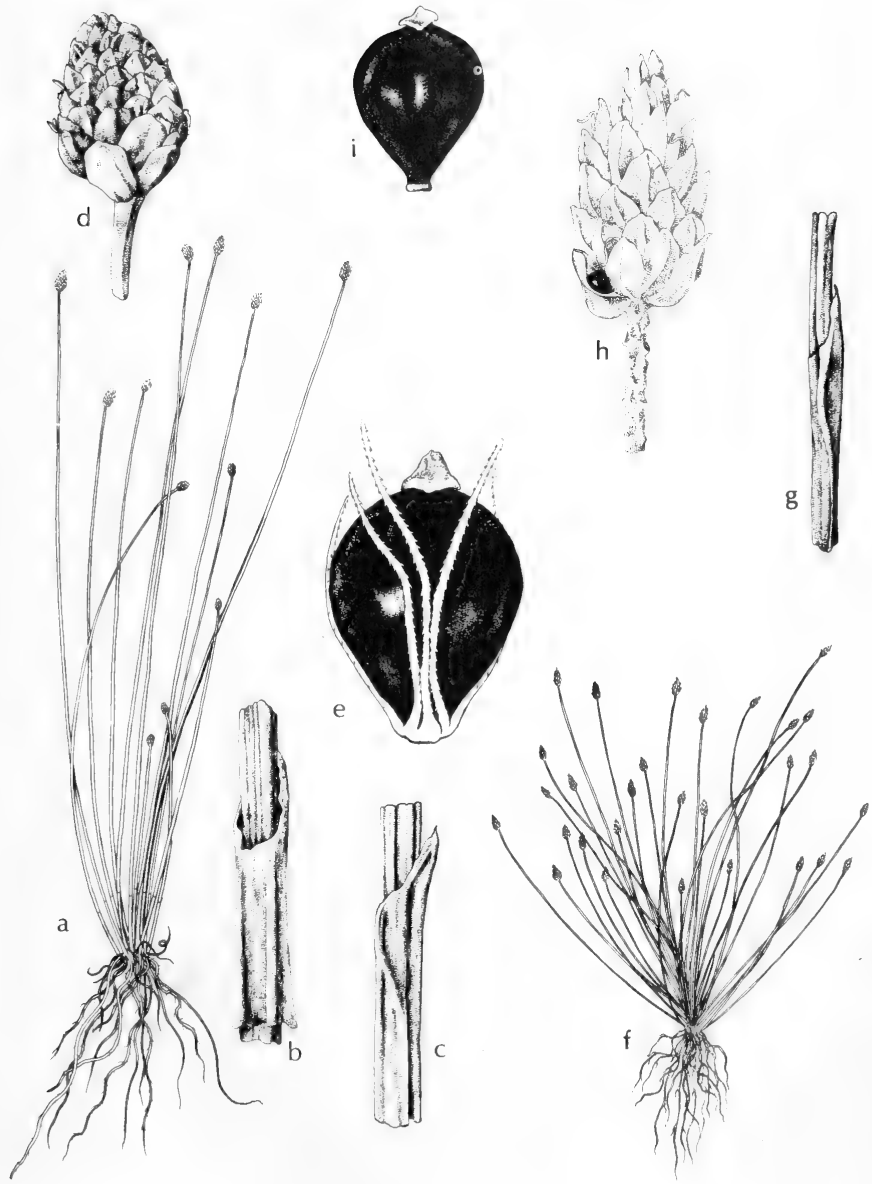

Fig. 196: a-e, Eleocharis caribaea: a, habit, X 1/2; b and c, two views of sheath, X 5; d, spikelet, X 5; e, achene, X 40. f-i, Eleocharis atropurpurea: f, habit, X 1/2; g, sheath, X 8; h, spikelet, X 5; i, achene, X 40. (Courtesy of R. K. Godfrey). 

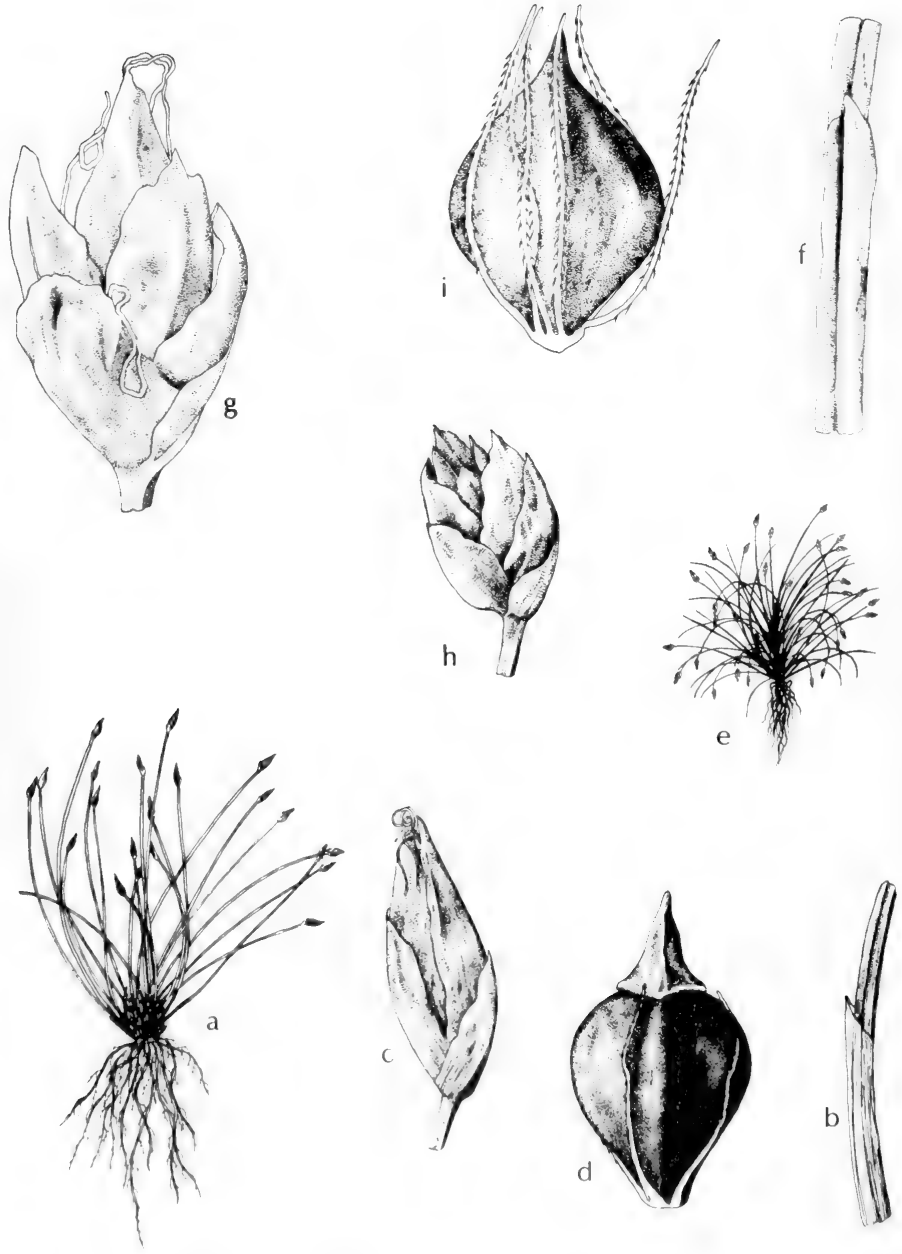

Fig. 197: a-d, Elcocharis Baldwinii: a, habit, X 12; b, sheath, X 12; c, spikelet, X 8; d, achene, X 35. e-i, Eleocharis parvula: e, habit, X 1/2; f, sheath, X 12; g and h, spikelets, showing variation, about X 25 ; i, achene, X 40 . (Courtesy of R. K. Godfrey). 
medially chartaceous, laterally membranous and marginally hyaline; bristles usually reduced and essentially obsolete in our plants, most of which are of the var. anachaeta (Torr.) Svens.; stamens 3; style 3-branched; achenial body ovoid to obovoid, trigonous, $0.8-1 \mathrm{~mm}$. long, passing through shades of gray to fuscous or black at maturity, smooth, usually somewhat shiny; tubercle conic-trigonous, much narrower than the body of the achene and confluent with it, scarcely differentiable except under high magnification, 0.1-0.2 $\mathrm{mm}$. long. Scirpus nanus Spreng. (non-Poir.), E. membranacea (Buckl.) Gilly.

In mud and shallow water of lakes, ponds and stream banks, occasionally in salt marshes, infrequent to locally abundant, essentially throughout Tex., in Okla. (Kay, Stephens, Grady, San Miguel and Garvin cos.), N.M. (Chaves and Eddy cos.) and Ariz. (Navajo Co.), spring-fall; var. parvula is widespread in Eur., N. Afr., the Near East and N.A.; var. anachaeta is scattered in w. N.A.

\section{Eleocharis pauciflora (Lightf.) Link.}

Perennial with filiform rhizomes bearing small leafy tubers; culms capillary, grooved, erect, 7-14 cm. tall or sometimes $40 \mathrm{~cm}$. tall, usually less than $1 \mathrm{~mm}$. thick, not proliferous; basal leaf sheaths $2-3 \mathrm{~cm}$. long, truncate; spikelets 4-7 $\mathrm{mm}$. long, ovate 2- to 7-flowered; scales lanceolate, acuminate, purplish-brown bristles 2 to 6 , shorter than to as long as or longer than the achene; style trifid; achene trigonous, the surface finely reticulate, yellowish-brown, about $2 \mathrm{~mm}$. long; tubercle a subulate beak merging into the dark base of the style.

Boggy or otherwise wet places at high elevations in the mts., tolerant of salt and alkali, Ariz. (Apache and Coconino cos.), circumboreal, e. to Ill. and N. J.

\section{Eleocharis rostellata (Torr.) Torr. Fig. 198.}

Tufted perennial with short often erect rhizomes to $5 \mathrm{~mm}$. thick; culms $25-80$ $(-150) \mathrm{cm}$. long, flattened (1-1.4 mm. thick in the broader dimension), on each side usually 3- or 4-costate, wiry, tough, erect or the more elongate ones arching and taking root as the spikelet touches the ground, thus stoloniform; sheaths firm, apically slightly oblique; spikelets lanceolate, acute, $8-17 \mathrm{~mm}$. long, 2.5-4.5 $\mathrm{mm}$. thick, with 12 to 30 flowers; scales ovate, $3-3.5 \mathrm{~mm}$. long, the upper ones more acute than the lower, medially rigid and with a strong stramineous midrib, passing laterally through chartaceous to membranous texture and in color through shades of brown to pale-brown or stramineous marginally; bristles firm, regularly serrulate, pale-brown, about equaling the tubercle; style 3-branched; achene body obscurely trigonous or turgidly plano-convex, obovoid, brownish, shiny, 1.5-1.7 $\mathrm{mm}$. long, apically narrowed and merging with the tubercle; tubercle oblong or stelelike, $0.7-1 \mathrm{~mm}$. long, $0.3-0.4 \mathrm{~mm}$. thick basally (at attachment but narrower most of the length).

Mud in upland areas, springs, alkaline marshes and seeping wet meadows, in Okla. (Texas Co.), frequent in Tex. Plains Country, infrequent on Edwards Plateau, N. M. (Otero, DeBaca, San Juan, Valencia, Sandoval, Eddy and Grant cos.) and Ariz. (Coconino, Yavapai, Graham, Cochise and Santa Cruz cos.), summer-fall; N.S. and Me. to Fla., inland in Ont. to N.J., Mich., Wisc., Ill., Kan., Okla., Tex., Coah., B.C. to Wyo., Ut., Calif., N.M.; Berm, Cuba, Hisp., n. Mex., mts. of Ecu. and Arg.

\section{Eleocharis tortilis (Link) Schult. Fig. 199.}

Tufted perennial; rhizomes ascending, 2-3 mm. thick; culms $15-50 \mathrm{~cm}$. long, 0.5-1 mm. thick, usually flattened or irregularly 3-costate and -sided, often twisted, wiry, grayish to yellowish; sheaths grayish or yellowish, shortly oblique and acute or blunt, firm; spikelets ovoid to lance-ovoid or cylindric-ovoid, 6-14 mm long, of 13 to 38 flowers; scales ovate to suborbicular, about $3 \mathrm{~mm}$. long, blunt, firm (subcartilaginous medially to chartaceous marginally), yellowish or grayish-strami- 


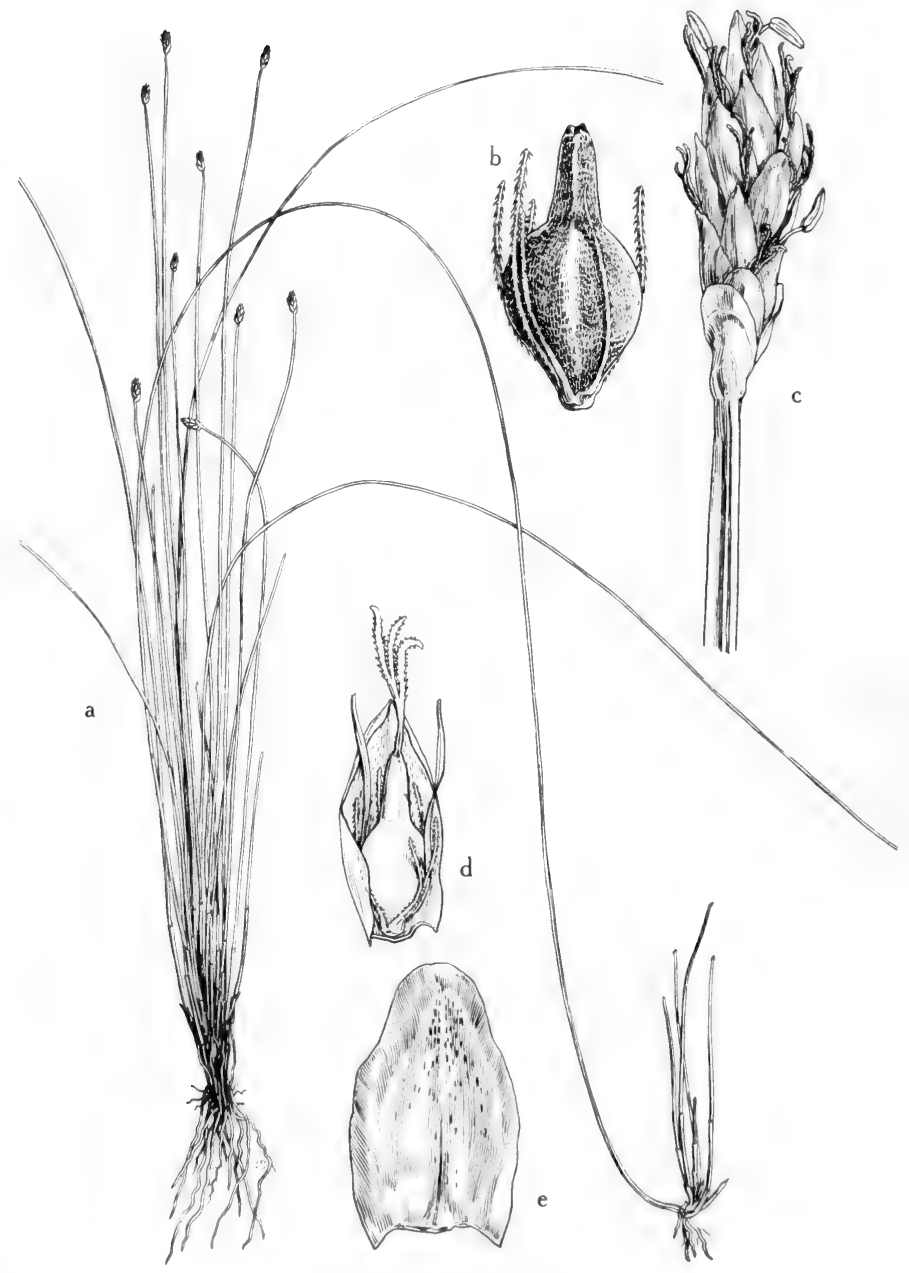

Fig. 198: Eleocharis rostellata: a, habit showing the wiry culms, some procumbent and rooting at the tips, $\mathrm{X}_{1, ;} \mathrm{b}$, mature obtusely trigonous achene with surface finely reticulate, the tubercle subulate and continuous with the apex of the achene, X 12; c, spikelet, X 4; d, flower, X 8; e, scale, X 8. (From Mason, Fig. 137). 

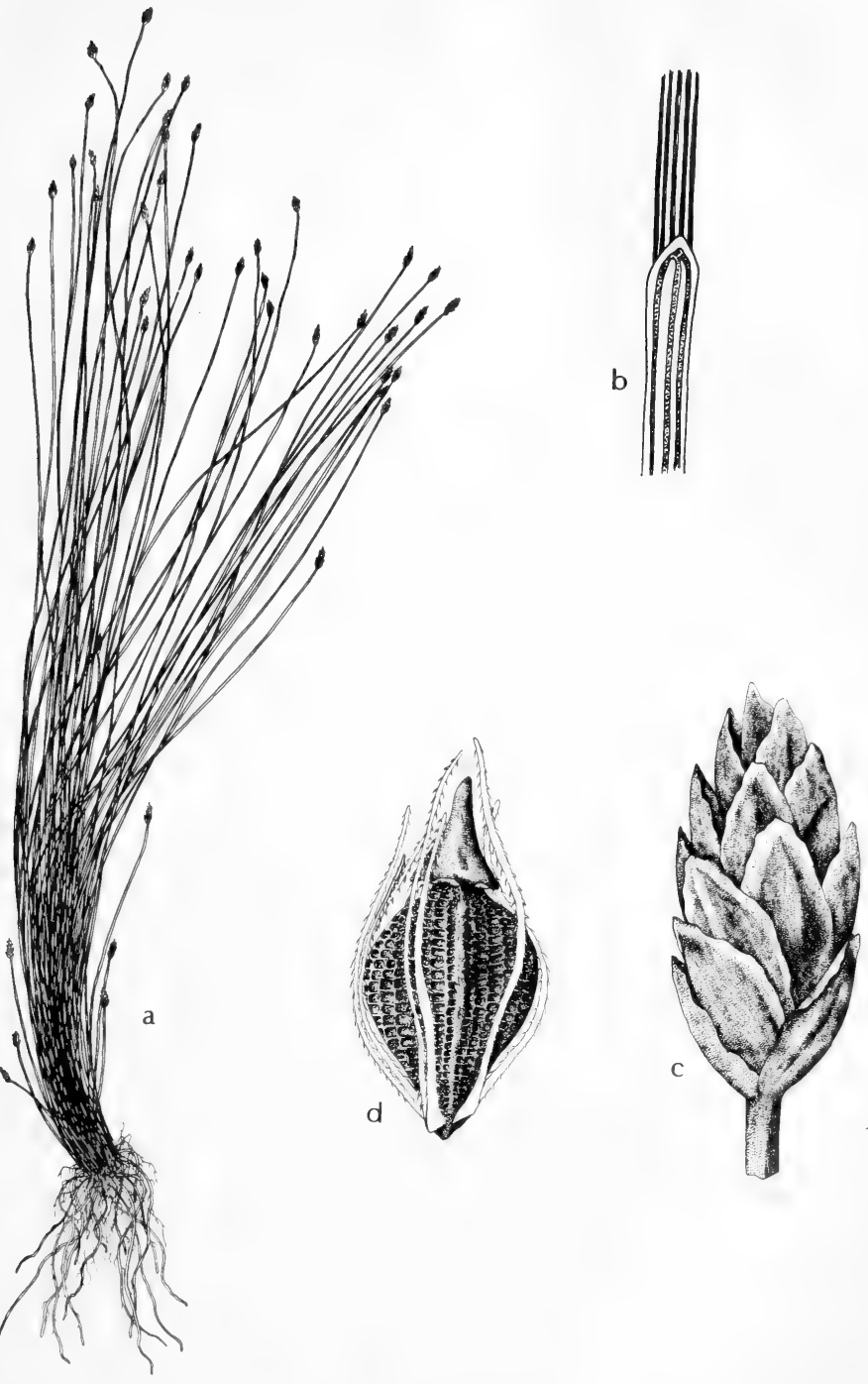

Fig. 199: Eleocharis tortilis: a, habit, X 1/2; b, sheath, X 5; c, spikelet, X 5; d, achene, X 20. (Courtesy of R. K. Godfrey; b, V.F.). 
neous, sometimes with a subterminal purplish splotch especially when immature; bristles several, brownish, often surpassing the achenial body; style 3-branched; achenial body broadly obovoid, $1.2-1.7 \mathrm{~mm}$. long, obscurely trigonous, the sides convex, surficially pronouncedly large-cellular (the cell walls prominent), lustrous, olivaceous-brown or gray; tubercle pyramidal, 0.6-1 $\mathrm{mm}$. long, usually acute, basally narrower than the body, truncately constricted to the very narrow attachment.

Infrequent in moist or wet sandy soil and seepage areas in e. Tex., May-Nov.; coastal areas, N. Y. to Tex.

\section{Eleocharis Baldwinii (Torr.) Chapm. Fig. 197.}

Tufted annual; culms $6-20 \mathrm{~cm}$. long, $0.1-0.25 \mathrm{~mm}$. thick, ascending or often strongly recurved and stoloniform; sheaths mostly reddish, long-oblique, blunt, hyaline; cleistogamous few-flowered spikelets usually abundant at base of plant among the sheaths; ordinary spikelets mostly narrowly elliptic, 4-7 $\mathrm{mm}$. long, of 5 to 10 flowers, frequently proliferating when the recurved culm (stolon) touches the ground; scales pseudodistichous, the lowest linear and with a strong green midnerve, the others progressively broader toward the top of the spikelet, lanceelliptic, 3-4.5 mm. long, buffy to ferruginous-buff, membranous, strictly appressed, acute; bristles several, pallid, about equaling the achenial body or reduced; style 3-branched; achenial body ovate, $0.7-0.8 \mathrm{~mm}$. long, whitish-buffy to olive or brownish-olive, trigonous (angles distinct and sides nearly flat), smooth; tubercle pyramidal-trigonous, $0.2-0.3 \mathrm{~mm}$. long, acute, constricted basally.

In bogs and about pools, near Caddo Lake, La. (part of this lake extends into e. Tex.), summer-fall; N.C., Ga., Fla., La., (Tex.?).

\section{Eleocharis minima Kunth. Fig. 200.}

Tufted annual; culms 3-7 $(-10) \mathrm{cm}$. long, about $0.1 \mathrm{~mm}$. thick, extremely weak, often flexuous and recurved, quadrangulate-sulcate; sheaths dark-reddish, apically long-oblique, blunt, hyaline; reduced (cleistogamous?) spikelets often present at the base of the plant among the culms; ordinary spikelets $2-4 \mathrm{~mm}$. long, ovoid, 5to 10 -flowered, usually blunt; scales ovate to narrowly ovate, blunt or shortly acute, 1.5-2 mm. long, brown and membranous (midrib paler), marginally hyaline; bristles about 5 to 7 , whitish, about as long as the body of the achene; style 3-branched; achenial body obovoid, $0.7-0.8 \mathrm{~mm}$. long, sharply trigonous (the 3 sides slightly convex), ripening through olive-whitish to pale-olive or even darkolive-gray, often somewhat mottled, darker near the angles and the ends, essentially smooth; tubercle sharply pyramidal-trigunous, $0.15-0.3 \mathrm{~mm}$. long and broad, slightly constricted basally.

Rare in mud and shallow water of lakes, ponds and slow-flowing streams, cypress swamps, in s.e. Tex. (Aransas and Jackson cos.), spring and fall; trop. Am. s, to s. Braz. and $\mathbf{n}$. to Ga., Tex. and Calif.

\section{Eleocharis microcarpa Torr. Fig. 200.}

Tufted annual; culms $4-28 \mathrm{~cm}$. long, $(0.1-) \quad 0.15-0.3 \mathrm{~mm}$. thick, mostly erect or ascending (less commonly weak and somewhat flexuous), often quadrangulatesulcate (at least when dry); sheaths short, stramineous or slightly tinged with pink basally, apically long-oblique, blunt and hyaline; spikelets never at the base of the plant, always terminal on elongate culms, ovoid, 2-5 mm. long, 8- to 15-flowered, often proliferous (sending out culms instead of flowers, usually from the axil of the lowest scale), the spikelet then slightly inclined; lowest scale differentiated, bractlike, sterile, lanceolate to linear, often a third to three fourths the entire length of the spikelet, consisting mostly of a prominent green midnerve with reduced membranous sides; other scales ovate, about $1.5 \mathrm{~mm}$. long, blunt, the 

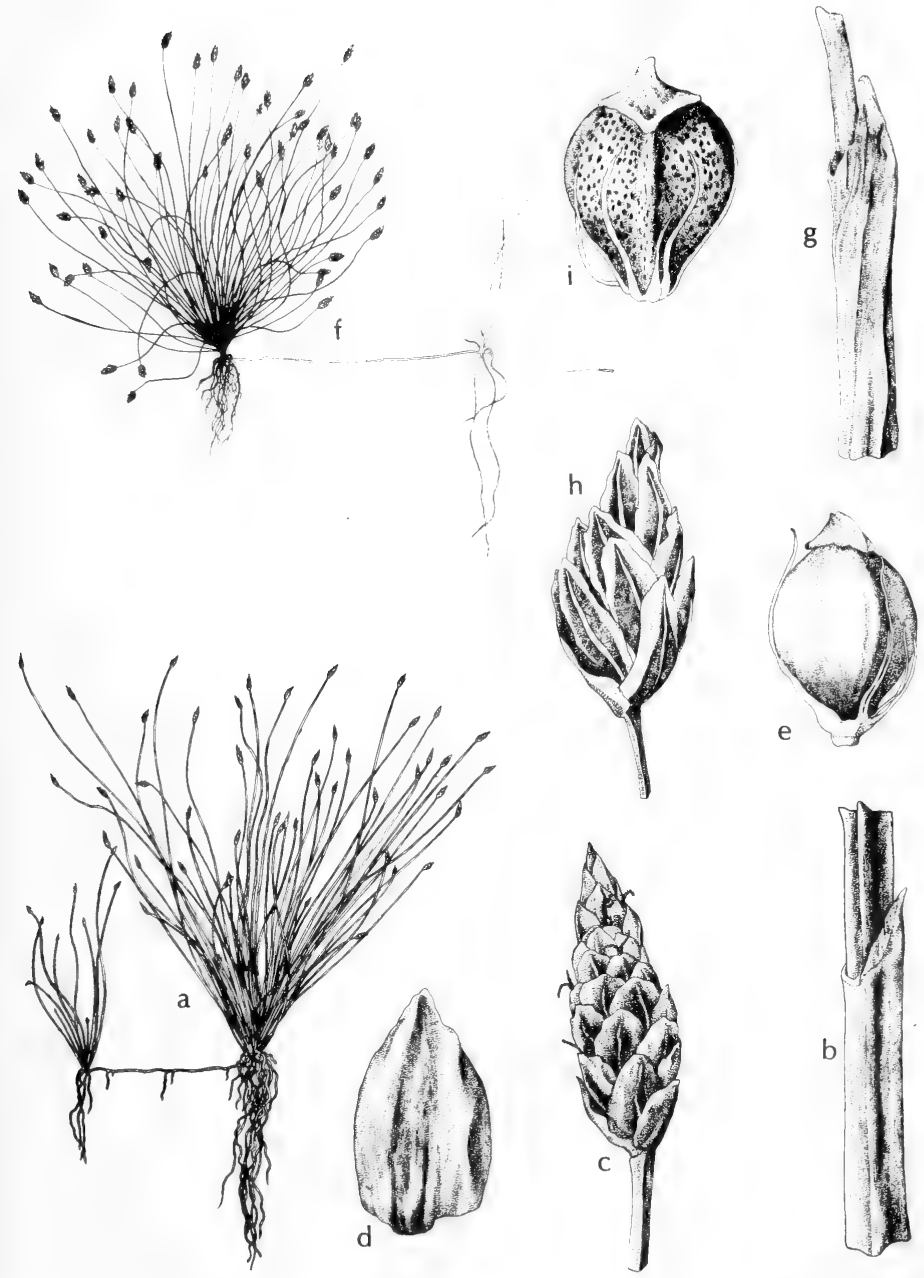

Fig. 200: a-e, Eleocharis microcarpa: a, habit, X 1/2; b, sheath, X 12; c, spikelet, $\mathrm{X} 10$; d, scale, X 20; e, achene, about X 50. f-i, Eleocharis minima: f, habit, X 1/2; g, sheath, X 16; h, spikelet, X 8; i, achene, about X 35. (Courtesy of R. K. Godfrey). 

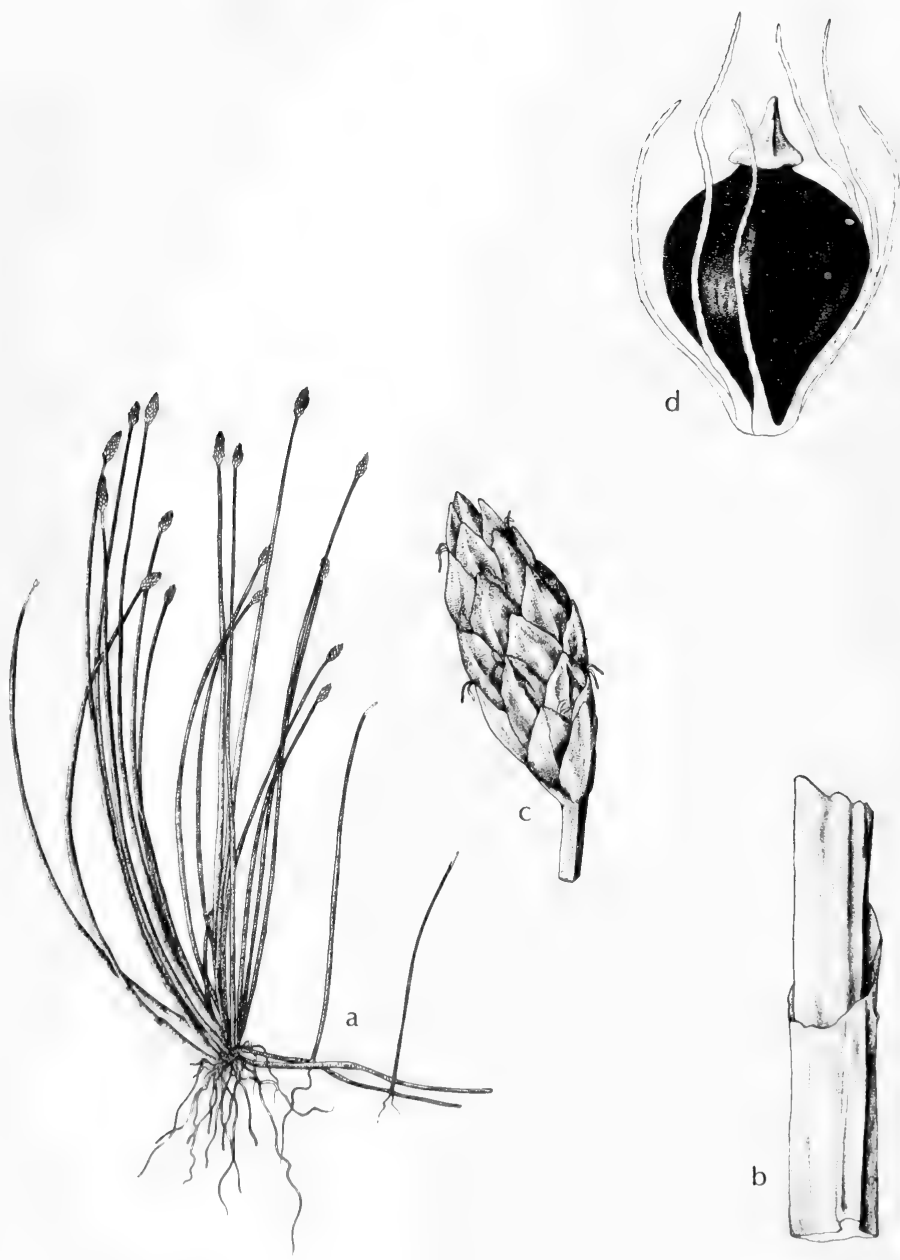

Fig. 201: Eleocharis albida: a, habit, X 1/2; b, sheath, X 12; c, spikelet, X 5; d, achene, X 40. (Courtesy of R. K. Godfrey). 
median distal portion purplish (midrib paler) and membranous, the median proximal portion whitish, the margins white-hyaline; bristles somewhat variable, in our specimens much reduced or usually absent; styles 3-branched; achenial body 0.5$0.6 \mathrm{~mm}$. long, obovoid, trigonous (angles not very prominent, sides convex), pearly-white, lustrous, smooth; tubercle 0.05-0.1 (-0.15) $\mathrm{mm}$. long, depressedpyramidal, buffy-white, slightly constricted basally. E. Brittonii Small, E. Lundellii Svens.

On sandy loams, in mud and shallow water of ponds and streams, and depressions in savannahs, frequent in s.e. Tex., infrequent in e. Tex., spring-fall; coastal areas, Conn. and N.J. to Tex.; also Tenn. and Ind.

\section{Eleocharis albida Torr. Fig. 201.}

Rhizomatous perennial; rhizomes extensive, 1-2 mm. thick, orangish-brown; culms tufted at intervals along the rhizome, $5-30 \mathrm{~cm}$. long, about $1 \mathrm{~mm}$. thick, erect, essentially terete, stramineous or basally slightly pinkish; sheaths apically truncate or shortly oblique and firm but membranous, basally often pinkish to red; spikelets ovoid to ovoid-cylindric, 5-16 mm. long, of 30 to 90 flowers, rarely proliferating; scales broadly ovate, subcartilaginous medially, firm-membranous marginally, stramineous, shiny; bristles 5 to 8 , when mature reddish-brown, some often surpassing the achenial body, others half as long; style 3-branched; achenial body broadly obovoid, $0.8-1 \mathrm{~mm}$. long, trigonous (the 2 inner angles sharper and more definite than the abaxial one, the faces only slightly convex), maturing through shades of olive-whitish to brownish-olive and finally to a rich darkchocolate-brown, lustrous; tubercle varying from conic to globular, $0.15-0.3$ $\mathrm{mm}$. long, paler than the body at maturity, constricted basally.

Frequent in moist perhaps brackish sand and on lake margin and in water, in coastal parts of Rio Grande Plains and s.e. Tex., spring-summer; coastal areas, Md. to Mex.; Berm.

\section{Eleocharis elongata Chapm. Fig. 202.}

Culms very slender, usually less than $1 \mathrm{~mm}$. wide, elongate, $5-8 \mathrm{dm}$. long, often floating on the surface of the water, flattened or obscurely angled; roots fibrous; stolons abundant, brown or straw-colored, elongate, with culms rising from the nodes; spikelets $1-1.5 \mathrm{~cm}$. long, about $2 \mathrm{~mm}$. wide, acute; style 3-branched; stamens 3; scales linear, obtuse, $3.5 \mathrm{~mm}$. long, striate, greenish, conspicuously broadened with brown just within the hyaline margin; achenes $1.5 \mathrm{~mm}$. long including the style base, triangular, light-green, obovate (the inner face broadest, with about 12 rows of coarse transversely linear cells), abruptly narrowed at the summit to a short acute neck one-fourth the width of the achene from which rises the short acute deep-brown style base; bristles 6 or 7 , equalling the achene, greenish, prominently toothed.

In quiet water of lakes and ponds in Tex. (Hardin Co.); Fla. to Tex.

\section{Eleocharis tenuis (Willd.) Schult. var. verrucosa (Svens.) Svens.}

Rhizomatous perennial; rhizomes 1-2 mm. thick, scaly-fibrous, castaneousfuscous; culms tufted at intervals along the rhizomes, $15-50 \mathrm{~cm}$. long, $0.2-0.3$ $\mathrm{mm}$. thick, weakly ascending, 4- or 5-sulcate or simply angled; sheaths basally purplish-red, apically firm, truncate to very slightly oblique, usually with a minute mucro; spikelets oblong or narrowly ovoid to lance-ovoid, 3-9 $\mathrm{mm}$. long, of 20 to 40 flowers; scales ovate to obovate, obtuse, about $2 \mathrm{~mm}$. long, with a greenish or stramineous midrib and firm castaneous to purplish-black sides, marginally very narrowly scarious; bristles 2 or 3 , promptly deciduous, very short; styles 3-branched; achenial body broadly obovoid to suborbicular, distinctly trigonous, $0.6-0.8 \mathrm{~mm}$. long, ripening through shades of ivory to greenish-olive, surficially minutely but pronouncedly warty or pitted in vertical lines; tubercle 

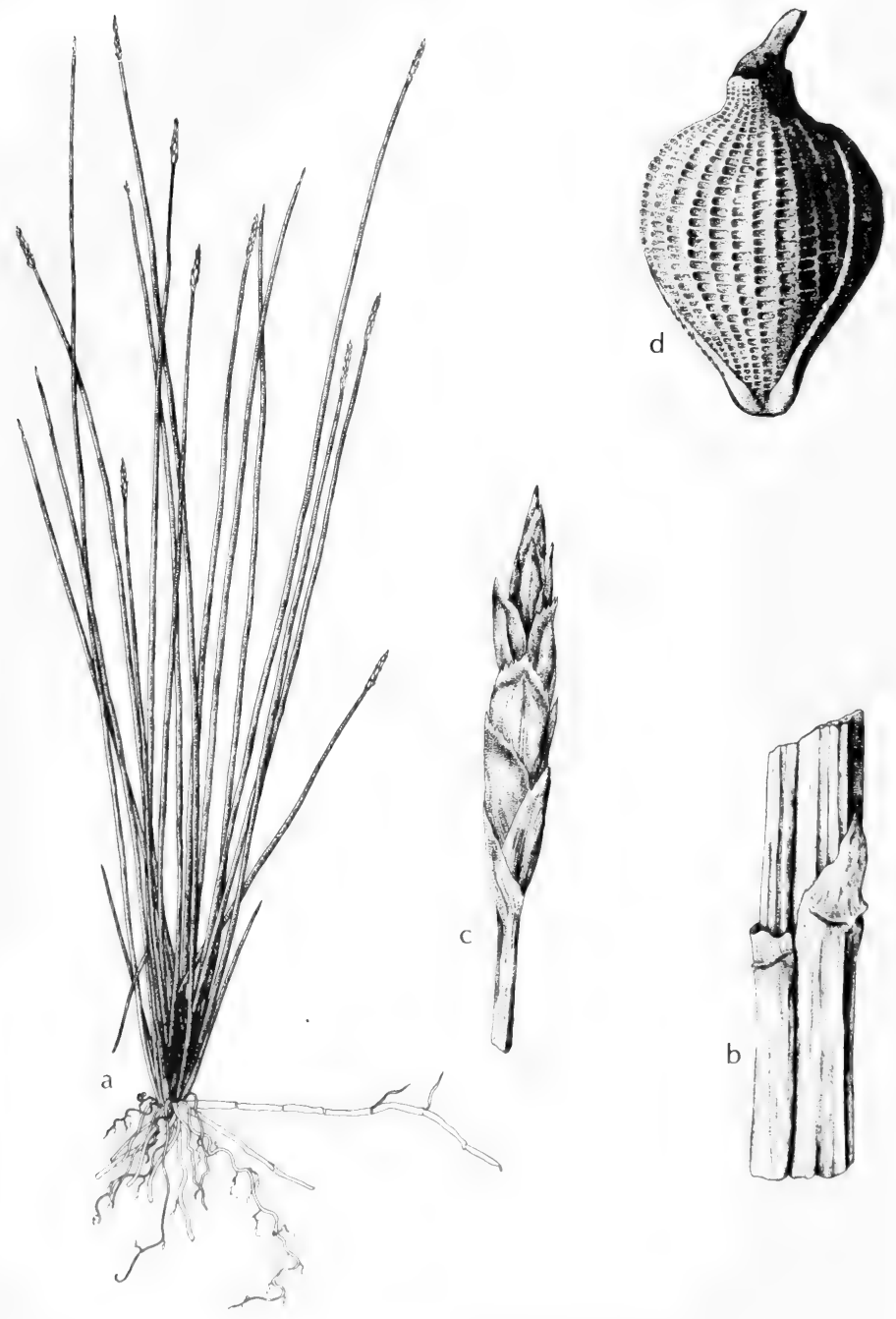

Fig. 202: Eleocharis elongata: a, habit, X 1/2; b, sheath, X 12; c, spikelet, X 5; d, achene, X 35. (Courtesy of R. K. Godfrey). 


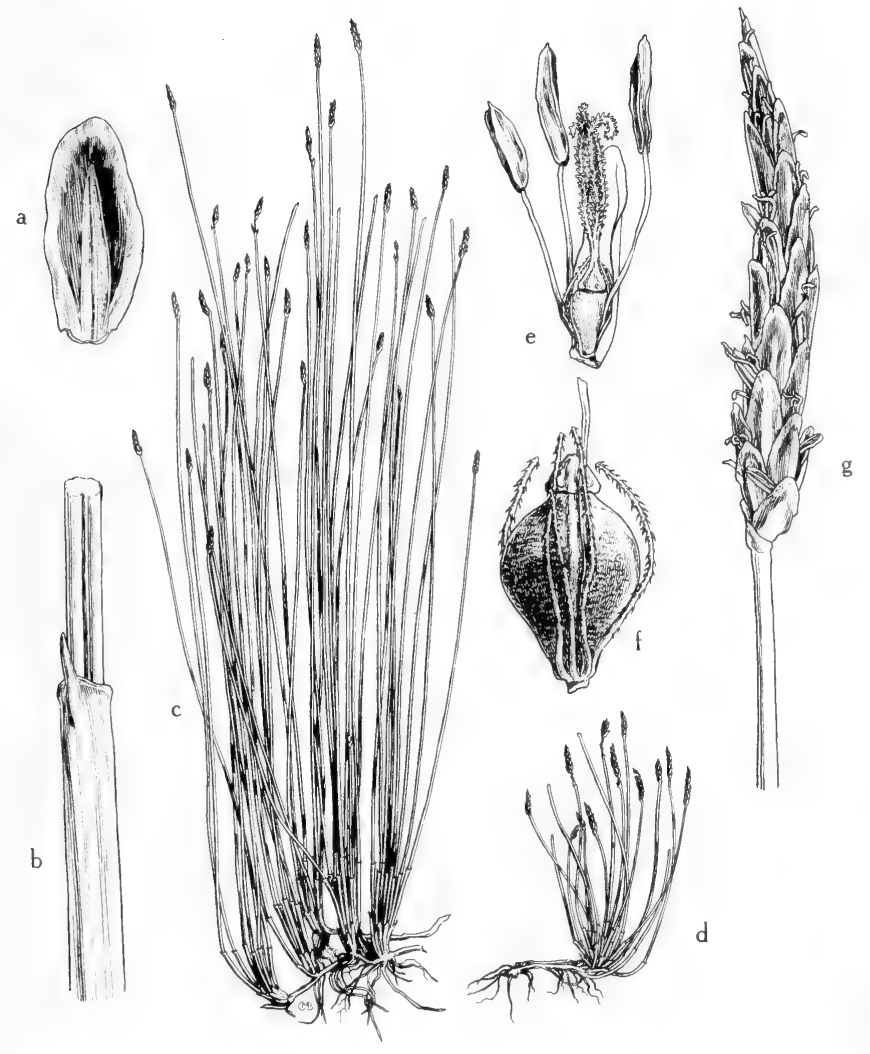

Fig. 203: Eleocharis Parishii: a, scale, X 10; b, toothed truncate leaf sheath, X 6; $\mathrm{c}$ and $\mathrm{d}$, habit, showing average and small plants, the slender erect fascicled culms and the creeping rhizomes, $X 2 / 5 ; \mathrm{e}$, flower, $\mathrm{X} 10 ; \mathrm{f}$, trigonous obovoid achene, the surface faintly reticulate, the tubercle conic and the subtending bristles longer than the achene, X 20; g, spikelet, linear-lanceolate, acute, X 6. (From Mason, Fig. 138). 
strongly depressed-pyramidal, $0.1-0.2 \mathrm{~mm}$. long, slightly constricted basally.

Infrequent in moist or wet sand, wet forested areas, along ditches and in wet mud along sloughs, in Okla. (Payne Co.) and e. Tex., rare in s.e. Tex., spring; temp. e. N.A., w. to Ill., Mo., Okla. and Tex. (the var. verrucosa in the w. part of that distribution area).

\section{Eleocharis cylindrica Buckl.}

Rhizomatous perennial; rhizomes slender (1-2 mm. thick); culms $15-30 \mathrm{~cm}$. long, 0.4-0.5 mm. thick, about 4-sulcate and -angled, erect; sheaths faintly reddish-brown basally, apically firm, truncate or very slightly oblique, mucronate; spikelets linear-cylindric, $8-17 \mathrm{~mm}$. long, 2-2.5 mm. thick, acute, of 50 to 60 flowers; scales about $2 \mathrm{~mm}$. long, ovate, acute, medially thin-membranous, brown (the midnerve pale), marginally white-hyaline, slightly convex abaxially; bristles pale-brown, 0.05-0.1 mm. long, extremely inconspicuous; style 3-branched; achenial body $0.6-0.8(-1) \mathrm{mm}$. long, obovoid, strongly and obviously trigonous (the sides slightly concave, the angles prominent but not sharp), ripening through canary-yellow to golden-brown or dark-brown, essentially smooth and satiny, apically conspicuously and abruptly narrowed to a short cylindric pedestal; tubercle depressed-pyramidal, about $0.1 \mathrm{~mm}$. long and about as wide or pyramidal and about $0.3 \mathrm{~mm}$. long.

Rare, probably in shallow water or calcareous mud, in Tex. Plains Country (Lubbock Co.) and Trans-Pecos (Presidio Co.), June-July; endemic, to be sought in N.M. and Chih.

\section{Eleocharis Parishii Britt. Fig. 203.}

Perennial (or sometimes annual?) with slender creeping reddish rhizomes; culms slender, striate, erect, 1-3 dm. tall, in fascicles or tufted; leaf sheaths reddish-brown at base, usually becoming straw-colored at the obliquely truncate apex, usually with a minute tooth; spikelets linear-lanceolate, acute, $10-15 \mathrm{~mm}$. long, many-flowered; scales ovate-oblong, acute to obtuse, chestnut-brown or dark-brown, with a short hyaline tip; bristles 6 or 7 , as long as to longer or shorter than the achene; style trifid; achene trigonous, ellipsoid or obovoid, yellow to light-brown, smooth or faintly reticulate under magnification; tubercle shortsubulate to conic.

Moist soil, wet meadows or rooted in shallow water to form small mats in N.M. (Grant and Valencia cos.) and Ariz. (widely distributed); Ore. to N.M., Ariz., Calif. and n. Mex.

\section{Eleocharis montevidensis Kunth. Fig. 204.}

Rhizomatous perennial; rhizomes extensive, 1-2 (-2.5) $\mathrm{mm}$. thick, usually darkreddish; culms $1-5 \mathrm{dm}$. long, 0.4-1 $\mathrm{mm}$. thick, erect, rather soft, sometimes slightly compressed, in pressed specimens often irregularly sulcate and showing incomplete and weak septa; sheaths basally dark-reddish, apically quite firm, truncate or only very slightly oblique and weakly mucronate; spikelets very variable in shape, from globular to cylindric or ovoid to elliptic, apically blunt, 3-14 mm. long, with 24 to 70 (to 110 ) flowers; scales mostly oblong to oblong-ovate, $2-3 \mathrm{~mm}$. long, obtuse to slightly emarginate, the median portion membranous and brownish to atrocastaneous (with or without a paler midnerve), marginally scarious, often somewhat convex abaxially, concave adaxially (this true even before the achenes mature, so the spikelets appear filled out soon after anthesis); bristles 4 to 6 , some of them usually equaling the tubercle; style 3-branched; achenial body obovoid to pyriform-obovoid, $(0.8-)$ 0.9-1.1 $(-1.2) \mathrm{mm}$. long, turgid, obscurely trigonous, ripening through shades of yellow to golden-brown or even dark-brown, punctuatereticulate surficially (varying from as rough as in $E$. compressa to nearly smooth as in the plant called $E$. Palmeri), lustrous; tubercle precisely to irregularly conic, 

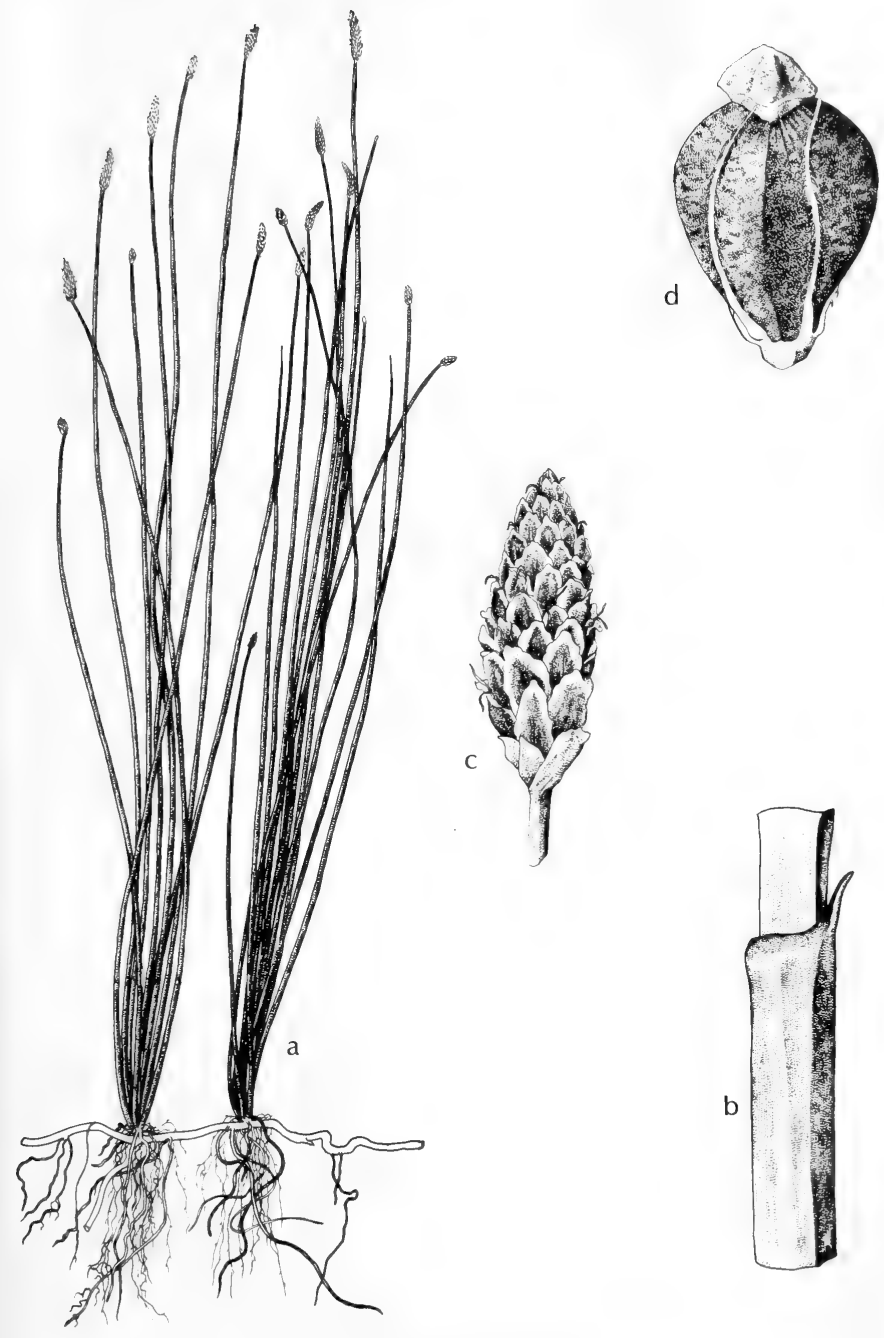

Fig. 204. Eleocharis montevidensis: a, habit, X 1/2; b, sheath, X 10; c, spikelet, X 5; d, achene, X 40. (Courtesy of R. K. Godfrey). 

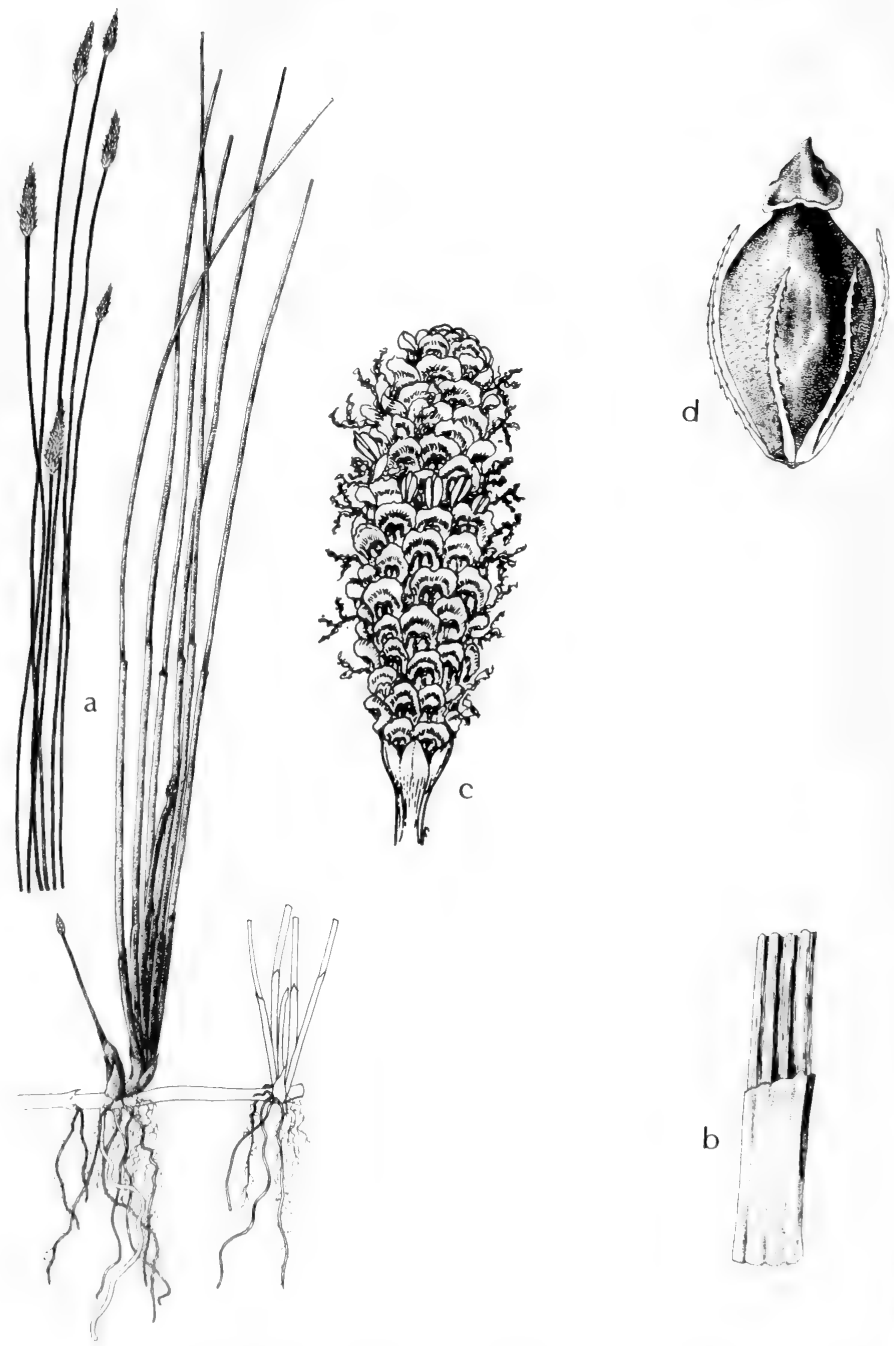

Fig. 205: Eleocharis fallax: a, habit, X 1/2; b, sheath, X 5; c, spikelet, X 5; d, achene, X 20. (Courtesy of R. K. Godfrey). 


\section{(0.1-) 0.2-0.3 (-0.4) mm. long. E. arenicola Torr., E. Palmeri Svens.}

In moist soil, in shallow water of streams and ponds and in wet granitic sands, in Okla. (Roger Mills, Alfalfa, Grady, Johnston and Bryan cos.), essentially throughout Tex. (rare in extreme e. and extreme w.), N. M. (Sandoval Co.) and Ariz. (Coconino, Yavapai, Pima, Cochise and Santa Cruz cos.), spring (-summer); cen. Mex. n. to Ore., Ida., N.M., Okla., the Gulf States and S.C.; also s. Braz., Urug. and Arg.

\section{Eleocharis fallax Weath. Fig. 205.}

Perennial much like E. macrostachya but styles 2- or 3-branched, the achenes averaging smaller (body $1.2-1.7 \mathrm{~mm}$. long and tubercle $0.2-0.5 \mathrm{~mm}$. long) and the body more distinctly and regularly punctate (much as in E. montevidensis).

Rare in (brackish?) mud, s.e. Tex. (collected once in Matagorda Co.), summer (?); coastwise, Mass. to Tex.; Cuba.

\section{Eleocharis austrotexana M. C. Johnst.}

Densely tufted perennial (probably with short slender matted reddish rhizomes); culms $30-45 \mathrm{~cm}$. long, erect, $0.8-1.1 \mathrm{~mm}$. thick, essentially terete, with 12 to 15 minute striae in dried specimens and very weak but complete transverse septa 2-3 $\mathrm{mm}$. apart (otherwise hollow); sheaths $2-5 \mathrm{~cm}$. long, tight, mostly reddish, apically quite firm, truncate or only very slightly oblique and with a seta or mucro to $1 \mathrm{~mm}$. long; spikelets lanceolate, acuminate, acute, $8-13 \mathrm{~mm}$. long, of about 50 to 70 flowers; scales ovate and acute to broadly lanceolate, about $2 \mathrm{~mm}$. long, medially buffy-brown (midnerve paler) and membranous, marginally hyaline, whitish; bristles about 6 to 8 , pale-brown, translucent, inconspicuous, persistent, unequal, the longer ones about equaling the achenial body; style 3-branched; achenial body obovoid-pyriform, 0.7-0.9 $\mathrm{mm}$. long, obscurely trigonous (the 2 inner angles definite, though not sharp, the abaxial one obscure), ripening through shades of yellow to golden-brown, surficially nearly smooth, slightly lustrous (under very high magnification punctulate-reticulate); tubercle depressed-pyramidal, about 0.2 $\mathrm{mm}$. long and broad, slightly constricted basally.

Rare in Rio Grande Plains and s.e. Tex., Apr.; endemic.

\section{Eleocharis compressa Sulliv.}

Rhizomatous perennial; rhizomes 2-4 (-6) mm. thick, usually short and forking, forming dense thick mats; culms tufted along the rhizome, 9-20 cm. long, erect, strongly compressed, $0.6-1 \mathrm{~mm}$. broad in the flat dimension, several-striate on each side; sheaths usually reddish basally, apically firm and truncate or only very slightly oblique, with a mucro; spikelets ovoid to narrowly ovoid, 5-12 mm. long, with 20 to 40 flowers; scales broadly lanceolate, the lower medial portion chestnutbrown or chestnut-fuscous (the mid-nerve somewhat paler), the margins and the long-attenuate sometimes bifid (split) apex translucent-scarious; bristles 1 to 5 , promptly deciduous, very short; style 3-branched; achenial body broadly obovoid, turgid, obscurely trigonous, about $1 \mathrm{~mm}$. long, ripening through yellow to a goldenbrown, surficially granular-roughened or reticulate (rougher than in the following species but not as rough as in E. tenuis); tubercle $0.1-0.2 \mathrm{~mm}$. long, depressedto globose-conic, usually slightly constructed basally. E. elliptica Kunth var. compressa (Sulliv.) Drapalik \& Mohlenbrock.

Rare in loamy usually moist soil and in shallow water of ponds and streams in Okla. (Latimer Co.) and in e. Tex. (San Augustine Co.), spring; most of n.e. U.S.; also Ont., Sask., Ga., Okla. and Tex.

\section{Eleocharis acutisquamata Buckl.}

Rhizomatous perennial; rhizomes 2-4 (-6) mm. thick, usually short and forking, forming dense thick mats; culms tufted along the rhizomes, $8-20(-2.8) \mathrm{cm}$. long, 
0.3-0.8 mm. thick, slightly compressed or usually merely irregularly several-angled; sheaths usually slightly pinkish basally, apically firm and truncate or only very slightly oblique, not mucronate; spikelets narrowly oblong or cylindric to narrowly elliptic, usually with a blunt point, 3-11 mm. long, of 24 to 44 flowers; scales broadly lanceolate, the lower medial portion brown (the midnerve slightly paler), the margin and the long-attenuate sometimes bifid (split) apex translucent-scarious; bristles several, extremely short and promptly deciduous; style 3-branched; achenial body broadly obovoid-pyriform, turgid, obscurely trigonous, $0.9-1.2 \mathrm{~mm}$. long, ripening through yellow to golden-brown, surficially very minutely granular-roughened and obscurely reticulate; tubercle conic to essentially globular, 0.1 $\mathrm{mm}$. long (rarely to $0.2 \mathrm{~mm}$.), basally constricted. Probably conspecific with E. compressa.

In calcareous loamy (usually slightly moist) soil, in water of ponds and lake margins, seepage areas, in Okla. (Waterfall) and on Tex. Edwards Plateau and n.-cen. Tex., infrequent s. to s.e. Tex. (Refugio Co.) and in e. Plains Country, spring.

\section{Bulbostylis KUNTH}

Essentially glabrous perennial forming tight swards of limited extent or less commonly annual herbs; culms closely tufted, $4-30 \mathrm{~cm}$. long, $0.2-0.6 \mathrm{~mm}$. thick, wiry, erect; leaves setaceous, about half as high as and even thinner than the culm; primary brach setaceous, often appearing as a continuation of the culm or spreading, 3-22 mm. long; other bracts setaceous, much-reduced; inflorescence umbelliform or cymose, simple or compound, $5-40 \mathrm{~mm}$. long or occasionally reduced to a glomerule or even rarely a single spikelet; spikelets lance-cylindric, dark-brown, of 7 to 25 perfect flowers; scales spirally imbricate, ovate, obtuse to acute or rarely retuse, dark-brown, 1-2 mm. long, strongly keeled (the keel paler), occasionally slightly gibbous, glabrous to strigose or puberulent, marginally smooth to slightly fimbriate; perianth bristles absent; style 3-branched, the base enlarged and persistent as a tubercle $0.5-1 \mathrm{~mm}$. long, differentiated in texture and color from the achenial body; achenial body obovoid or usually obpyramidal, strongly triquetrous, $0.7-0.9 \mathrm{~mm}$. long, maturing through shades of white to pale-buffy-white or grayish, with papillae or transverse ridges. Stenophyllus Raf. (a rejected name). Many authors, with much justification, include Bulbostylis in Fimbristylis.

About 100 species in warm regions.

1. Achenes papillose, maturing yellowish or grayish; cyne typically compound

1. Achenes transversely ridged or rugose; cyme simple (2)

2(1). Strong perennial; achene with about 20 minute but (under a lens!) conspicuous and pronounced transverse rugae on each face, maturing to a grayish color........................................................ B. juncoides.

2. Annual; achenes with about 10 indistinct transverse ridges on each face, maturing to a buffy-white (3)

3(2). Spikelets 2 or more in each inflorescence, at the apex of the culms, not sessile in axils of basal leaves; leave sheaths usually sparsely villous, at least at the summit; achenes all alike..................... 3. B. capillaris.

3. Spikelets usually solitary at the apex of the culms and others sessile in axils of leaves; leaf sheaths glabrous; middle achenes of basal spikelets larger than those of the culms. 4. C. Funckii.

1. Bulbostylis ciliatifolia (Ell.) Fern. Fig. 206.

Characters given in the generic description and the key.

Uncommon in periodically wet sandy soil of open woods and hillsides in Okla. 

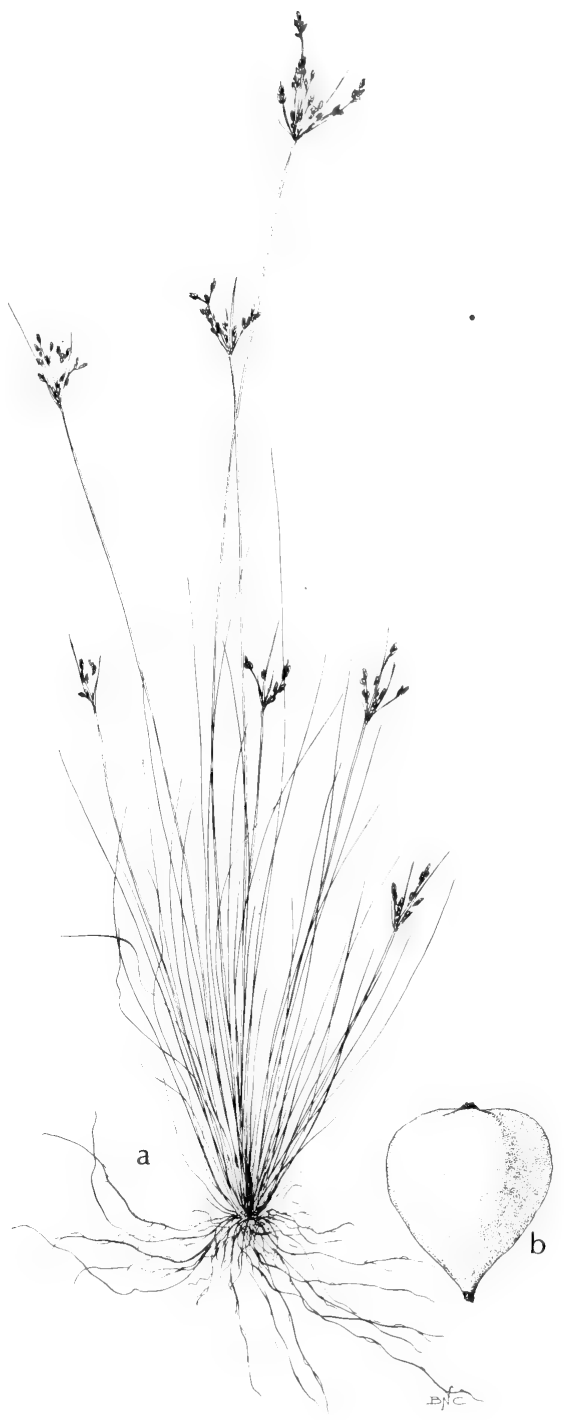

Fig. 206: Bulbostylis ciliatifolia: a, habit, X 1/2; b, achene, X 30. (Courtesy of R. K. Godfrey). 
(Waterfall) and e. and s.e. Tex., summer-fall; from Va. s. to Fla., w. to Tex. and Okla.

\section{Bulbostylis juncoides (Vahl) Kükenth. Fig. 207.}

Characters given in the generic description and the key.

Locally frequent in rock crevices and seepy areas in Chisos and Davis Mts. in the Tex. Trans-Pecos, rare in granite area of Edwards Plateau, w. to Ariz. (Yavapai, Cochise, Santa Cruz and Pima cos.), summer; Tex. and Ariz., s.e. to Guat.; Hisp., Bol. to Urug. and Arg.

Our plants are referable to the var. ampliceps Kükenth. (which name is probably not the earliest applicable one in the varietal rank).

\section{Bulbostylis capillaris (L.) Clarke.}

Characters given in the generic description and the key. Fimbristylis capillaris (L.) Gray.

Infrequent in sandy soil and in crevices of granitelike rocks which decompose to sandy soil, seepage areas, in Okla. (Johnston Co.), e., s.e., and n.-cen. Tex. and Edwards Plateau (Central Mineral Region), rare in Tex. Trans-Pecos, N.M. (Dona Ana, Grant and Socorro cos.) and Ariz. (Yavapai, Greenlee, Gila, Cochise, Santa Cruz and Pima cos.), spring-summer; widespread in warm-temp. N.A., s. to Calif., Ariz., N.M., Okla. and the Gulf States; Tam., Cuba, reported in Chih.

\section{Bulbostylis Funckii (Steud.) C. B. Clarke.}

Similar to $B$. capillaris except that the spikelets are usually solitary, apical and sessile in the axils of the leaves with achenes 1-1.2 $\mathrm{mm}$. long, and that the leaf sheaths are glabrous.

Wet soil, in canyons, N.M. (Socorro Co.), Ariz. (Mohave, Gila, Cochise and Pima cos.) and Chih., s. to cen. S.A. and the W.I.

\section{Fimbristylis VAHL}

Perennial or annual, the culms solitary or in tufts, or variously rhizomatous, rigid or lax, leafy toward the base; leaves filiform to narrowly or broadly linear, glabrous to pubescent, flat or involute, ligulate or eligulate, the sheaths closed or partly open at maturity of the leaf; spikelets lanceolate or oblong to ovoid or round in outline, terete or somewhat flattened or angled, either solitary and terminal on the scapes or in simple or compound umbelliform systems involving pedunculate and sessile spikelets of cymules, the whole inflorescence as well as the cymules composing it often subtended by a leafy involucre; fertile scales glabrous or variously pubescent, subdistichous to more often spirally arranged, deciduous, all but the lowermost fertile; florets perfect; perianth absent (the flower produced on a short pedicel joint which usually disarticulates with the achene); stamens one to three; anthers oblong, basifixed, sometimes apiculate, the two thecae at maturity longitudinally and laterally dehiscing; style 2- or 3-branched, the unbranched portion flattened and fimbriate for at least a portion of its length or (more rarely) subterete or angled, the style base either flattened or swollen but in any event not persistent at the summit of the achene; achene lenticular or trigonous; surface of achene smoothish, cancellate or warty, usually made up of isodiametric or horizontally arranged rectangular cells, these either concave or protuberant.

Over 200 described species, in a variety of habitats in warm temperate to tropical regions of the world.

(Adapted from Robert Kral in Sida 4, No. 2. 1971.)

1. Style 3-branched (2)

1. Style 2-branched (3) 

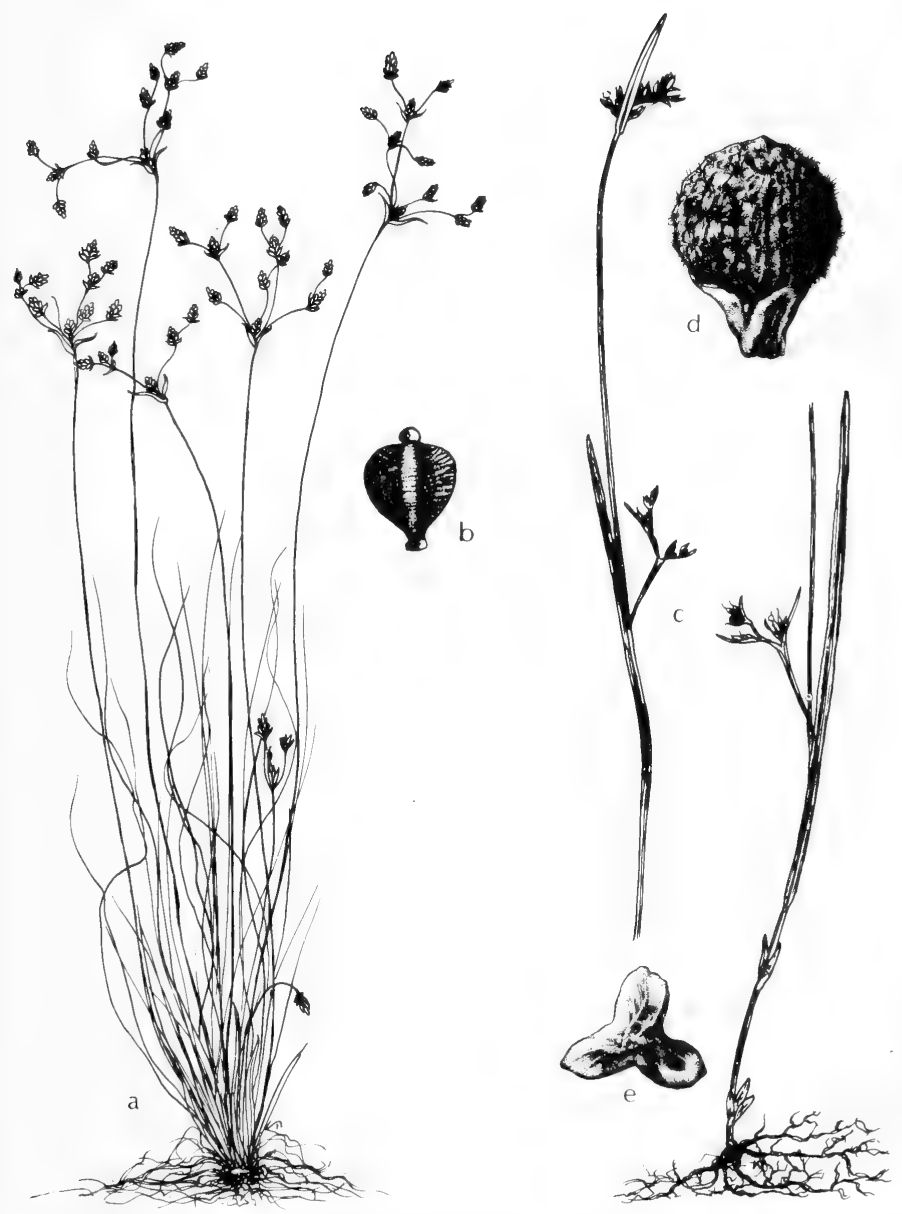

Fig. 207: a and b, Bulbostylis juncoides: a, habit, $\mathrm{X} \frac{1}{1} 2 ; \mathrm{b}$, achene, $\mathrm{X} 10$. c-e, Scleria Muhlenbergia: c, habit, X 1/2; d, achene, X 12; e, hypogynium from below, X 12. (a-c, V. F.; d and e, Courtesy of R. K. Godfrey). 
2(1). Achene trigonous, the surfaces smooth or warty; ligule of short hairs present 1. F. autumnalis.

2. Achene not trigonous or only obscurely so, obovoid, the surfaces usually warty; ligule absent.

2. F. miliacea.

3(1). Ligule of short hairs present (this characteristic is most noticeable in those entities that have broadly linear flattened leaf blades but is difficult to detect in those extremes that have very involute narrow leaf blades) (4)

3. Ligule absent (9)

4(3). A system of slender pale or reddish rhizomes present; robust perennials with tall wandlike culms (5)

4. Rhizomes absent or (if present) thickened and composed of stout contiguous culm-bases; perennial or annual species (7)

5(4). Outer surface of spikelet scales uniformly pubescent; spikelets ellipticoblong, the apices of the bracts acutish and with the midrib exserted as a prominent mucro; backs of leaf bases often pubescent

3. F. thermalis.

5. Outer surface of spikelet scales glabrous or puberulent apically; spikelets ovoid to lance-ovoid, rarely oblong, the apices of the bracts rounded with the midrib somewhat exserted; backs of the leaf bases seldom pubescent (6)

6(5). Fertile scales puberulent toward the tip; scapes usually flattened, often scabrous-edged distally; edges of leaves (especially toward the tip) scabrid; achene finely but definitely reticulate; in upper edges of salt marshes, dune swales or fresh marshes on the Coastal Plain 4. $F$. caroliniana.

6. Fertile scales usually smooth; scapes more slender, terete or broadly oval in cross section and smooth distally; edges of leaves usually not scabrid; achene smoothish or with longitudinal rows of shallow isodiametric pits; moist or wet prairies, river sloughs, marshes and springy places in west Texas. 11. F. puberula var. interior.

7(4). Face (one side) of achene smoothish or with many (15 or more) longitudinal row of shallow pits or cells (thus finely striate)

5. F. tomentosa.

7. Face (one side) of achene more closely reticulate, usually with 12 or less longitudinal rows of horizontally oriented rectangular cells (8)

8(7). Perennial with spreading hard pale-green leaves; achenes lacking warts...... 6. F. dichotoma.

8. Annual with spreading or ascending leaves; achenes with warts

7. F. annua.

9(3). Low often densely tufted weedy annual; leaf blades linear-filiform 8. F, Vahlii.

9. Taller more robust wider-leaved perennials (10)

10(9). Plants densely cespitose; bases of leaves hard, leathery, usually verv darkbrown or castaneous, often quite lustrous, deeply set in substrate; common to brackish coastal habitats.

9. F. castanea.

10. Plants in small tufts or culms solitary; bases of leaves thickened and hard or culm bases bulbous but in any case more shallow-set in substrate; either with stout contracted rhizomes or with fasciculate clusters of narrow orange-brown rhizomes; from sandy acid pineland savannahs or oak barrens to heavy prairie soils but not in brackish coastal habitats (11) 
11(10). Base of culms bulbous, often joined together into a stout knotty rhizome; old leaf bases often persisting as shreddy remnants; outer surface of fertile scales usually with some puberulence.

10. F. puberula.

11. Base of culms rarely bulbous, usually producing fascicles of slender orangish rhizomes; old leaf bases not persisting as shreddy remnants; outer surface of fertile scales seldom with any puberulence.

11. F. puberula var. interior.

\section{Fimbristylis autumnalis (L.) R. \& S. Fig. 208.}

Cespitose annual, usually 5-20 cm. tall; leaves glabrous, spreading, subdistichous, from half as long as the culms to equaling the culms; blades linear (to $4 \mathrm{~mm}$. broad), flat, the backs with numerous raised veins, the margin a pale cartilaginous ciliate-scabrid border; sheaths broader, keeled, with a broad scarious tan entire margin, joining the blade at an acute angle or truncate; ligule present as a line of short pale hairs; scapes flat, similar to the leaf blades, the edges often harsh; longest involucral bract with blade similar to that of the leaves, seemingly a continuation of the scape, shorter to longer than the inflorescence; spikelets linear-oblong to lanceolate, usually 3-7 $\mathrm{mm}$. long, pale- to dark-brown, in an open to densely paniculate system of cymes, the primary rays usually ascending; fertile scales ovate-lanceolate, usually keeled, entire, the midrib excurrent as a mucro; stamens usually 2 , rarely $1,0.2-0.3 \mathrm{~mm}$. long; style 3 -branched, much longer than the achene, trigonous at the base, subterete above toward the branches, entirely smooth; achene trigonous-obovoid, apiculate, about $1 \mathrm{~mm}$. long, palebrown, the surface smooth to quite verrucose.

Moist to wet sands, peats, silts or clays, primarily of disturbed sunny ground, in marshes, and mud and water at edge of streams, ponds and lakes, in Okla. (Mayes, Ottawa, Love, McIntosh, LeFlore, McCurtain and Sequoyah cos.) and most of Tex.; various provinces of e. N.A.; Carib., I., Mex. and C.A.; also Old and New World trop.

\section{Fimbristylis miliacea (L.) Vahl. Fig. 209.}

Cespitose annual to $5 \mathrm{dm}$. tall (rarely to $1 \mathrm{~m}$.); leaves equitant, distichous, from one half the length of the plant to nearly as long, rigid, smooth, flabellately spreading, tapering evenly from broad clasping sheaths into the blade, thence continuing to taper into a slender tip, the numerous veins raised and evenly spaced; margin of the blade narrow, pale, cartilaginous, antrorsely ciliate-scabrid, the margin of the sheath somewhat broader, scarious and entire; sheaths keeled, often bladeless; ligule not evident; scapes slender but rigid, flattened or somewhat angled in cross section toward the base, more flattened distally but often with a double margin along each edge; spikelets subglobose to ovoid or short-cylindrical, 2-4 mm. long, on flattened scabrous pedicels in a compound loose to congested system of cymes; longest involucral bract usually shorter than the inflorescence; fertile scales ovate, pale- to (usually) dark-brown, smooth, the apex obtuse to rounded or emarginate, the margin entire, the midrib paler by contrast or greenish and rarely excurrent; stamens 1 or 2 , the anthers less than $1 \mathrm{~mm}$. long; style 3-branched, the unbranched portion not much longer than the achene, subterete below, more flattened and fimbriate above toward the branches; achene obovoid (usually narrowly so), apiculate, about $1 \mathrm{~mm}$. long, pale-brown, reticulate, the cells narrowly rectangular and horizontally oriented in 4 to 6 rows on a face, the longitudinal ribs usually more prominent and usually verrucose.

Sandy peat, peat-muck and silt of open areas such as savannahs, pond, lake or river shores, cult. areas (particularly rice fields), in the U.S. from N.C. s. in the Coastal Plain into peninsular Fla., w. along the Gulf Coast into Tex.; throughout the Carib. I., Mex. and C.A. 


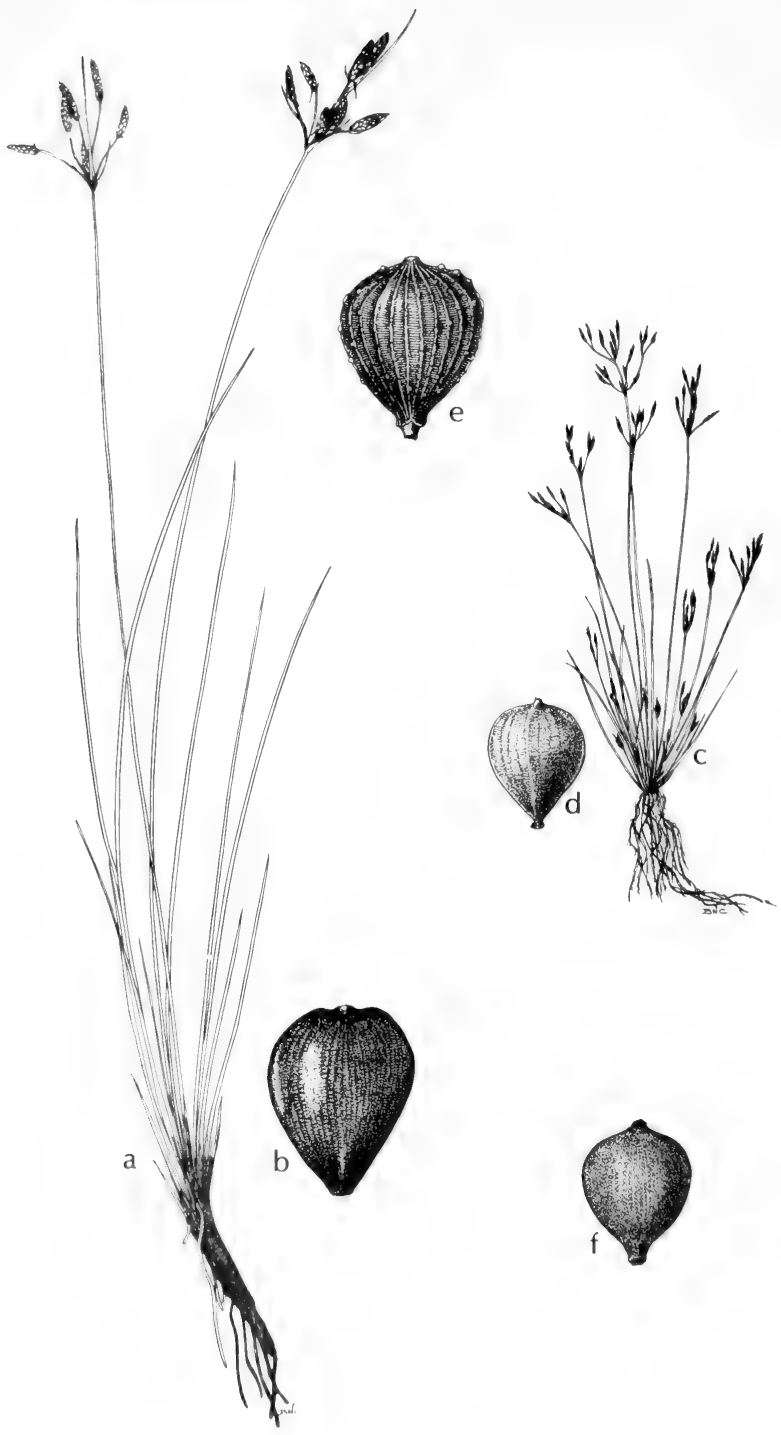

Fig. 208: a and b, Fimbristylis castanea: a, habit, X 2/3; b, achene, X 13. c and d, Fimbristylis autumnalis: c, babit, X 1/3; d, achene, X 15 . e, Fimbristylis dichotoma: e, achene, X 16. f, Fimbristylis caroliniana: f, achene, X 16. (Courtesy of R. K. Godfrey). 


\section{Fimbristylis thermalis Wats.}

Rhizomatous perennial, solitary or in small tufts, to about $1.5 \mathrm{~m}$. tall; leaves one third to one half the length of the scapes; blades linear, 1-4 mm. broad, flat to somewhat involute, glabrous or with some pubescence toward the sheath and apex on lower surface, upper surface just above ligule usually puberulent, veins numerous and prominent on the lower surface, the pale marginal vein or veins cartilaginous and ciliate-scabrid; sheath much broader, clasping, indurate, usually with some pubescence, stramineous to dull-brown, with a broad and scarious margin that is usually entire and converging to the blade at an acute angle; ligule of short pale hairs present; spikelets oblong-cylindric to lance ovoid, $1-2 \mathrm{~cm}$. long, pale dull-brown, 1 to many in a closed to rather open paniculate system of cymes; longest bract of the inflorescence shorter than the inflorescence; scapes rather rigid, about the width of the leaves, glabrous, many-ridged, subterete below, progressively flattened toward the inflorescence, the edges of the flattened portion scabrous; fertile scales ovate, subentire, pale dull-brown, dorsally uniformly puberulent, the midrib by contrast paler and exserted as a prominent cusp; stamens 3 , the anthers about $2 \mathrm{~mm}$. long; style branches 2 , the style flattened and fimbriate from the base to above the point of branching; achene lenticular-obovoid, about $1.5 \mathrm{~mm}$. long, dark lustrous-brown, finely reticulate, the individual foveae horizontally rectangular and arranged in numerous vertical lines; joint of achene short, persistent on fruit.

On usually highly mineralized sandy substrate of marshes and about hot springs in Ariz. (Coconino Co.); s. Calif., Nev., Ut. and Ariz., s. to B. Calif. and Coah.

\section{Fimbristylis caroliniana (Lam.) Fern. Fig. 208.}

Rhizomatous perennial, $1.5(-2) \mathrm{m}$. tall; culms solitary or in small tufts, the bases rather shallowly set in the substrate; leaves subdistichous, usually spreading, about half as long as the scapes; blades firm, linear, $2.5(-7) \mathrm{mm}$. wide, the surfaces smooth or in some cases pubescent near the ligule or the upper face, the backs with several raised nerves, the pale margin hyaline and scabrid; leaf-sheath broader, clasping, firm, pale- to dark-brown, glabrous to sparsely pubescent, with a wide stramineous to tan or reddish-brown scarious margin (this gradually or abruptly passing into the blade and often ciliate at this point); ligule of appressed hairs, usually complete; scapes about the width of the leaf blade, glabrous, manyribbed, subterete toward the base, usually flattened toward the apex (in which case the edges scabrid); longest bract of the involucre much shorter than the inflorescence to but slightly exceeding it, the back glabrous to puberulent, the margin harsh; spikelets ellipsoidal to lance-ovoid or oblong, 5-15 $\mathrm{mm}$. long, blunt to acute, pale-dull-brown to reddish-brown, a few to many in a compound umbellate system of cymes, the edges of the peduncles scabrid; fertile bracts ovate, glabrous or puberulent on the backs toward the apex, the margin entire, the surface marked by a thick usually paler area of midrib (this sometimes excurrent as a short mucro); stamens 3 , the apex of the flattened filaments narrowed, the anthers about $3 \mathrm{~mm}$. long; style 2-branched, flat, fimbriate from near the base to slightly beyond the point of branching; achene lenticular-obovoid, about $1 \mathrm{~mm}$. long, pale- to deep-brown, often lustrous, finely reticulate with the reticule composed of several fine rows of foveae or horizontally oriented rectangular cells; pedicel joint very short, usually persistent.

Brackish, alkaline or mildly acid sands or sandy peats of beaches, dune swales, lake shores, roadside ditches, more rarely savannahs or flatwoods, Coastal Plain from N.J. s. into the Fla. Keys and w. along the Gulf Coast to Tab.; Cuba.

\section{Fimbristylis tomentosa Vahl.}

Cespitose annual to $7.5 \mathrm{dm}$. tall; leaves from half as long to nearly the length 
of the mature culms; blades linear, 2-4 (-5) $\mathrm{mm}$. broad, usually flat but sometimes slightly involute, spreading to ascending, the surfaces pubescent, the backs with several prominent raised nerves, the margin evident as a pale cartilaginous narrow border which is ciliate-scabrid; leaf sheath broad, usually tomentose, with a wide brownish subscarious margin (this long-ciliate and truncate above at juncture with blade); ligule present as horizontal line of short pale hairs; scapes rather rigid, subterete basally, usually flattened or oval in cross section just below inflorescence, smooth or variously pubescent; spikelets at maturity a rich-reddishbrown, lance-ovoid, 4-6 mm. long, acute, usually many in a rather dense paniculate system of cymes the primary branches of which are usually ascending, pubescent (spikelets solitary in depauperate specimens); longest involucral bract exceeding inflorescence, leaflifle in its vestiture, always with a prominently hairy sheath; fertile bracts ovate, at maturity glabrous, reddish-brown except for a paler often greenish area of midrib (this usually exserted as a short cusp, backs of the midrib of lowermost scales often with some hairs); anthers 2, 0.7-1 mm. long; style 2-branched, flattened, the edges fimbriate from near the base to the base of the branches; achene obovoid, slightly apiculate, including the pedicel 1.7-2 $\mathrm{mm}$. long, lenticular, finely foveate (pitted) with the pits arranged in many vertical rows, sometimes slightly umbonate, at maturity a dark- to pale-brown except for the pale margin; pedicel joint persistent, to $0.5 \mathrm{~mm}$. long.

Moist to wet sands, silts or clays of disturbed habitats such as pond or river banks, roadside ditches, canals or agricultural grounds, Coastal Plain from N.C. s. to n. Fla. and w. into Tex.

\section{Fimbristylis dichotoma (L.) Vahl. Fig. 208.}

Tufted perennial to $5 \mathrm{dm}$. tall or more; leaves from half as long to nearly the length of the culms; blades linear, 2-5 $\mathrm{mm}$. broad, flat to somewhat involute, often glaucous and spreading, usually glabrous or rarely the lower surface pubescent, with several prominent nerves, the margin evident as a pale cartilaginous border that is ciliate-scabrid; sheaths broad, usually appressed-pubescent, with a wide $\tan$ or reddish-brown subscarious margin that is ciliate and subtruncate apically; ligule present as a horizontal line of short hairs; scapes rigid, subterete basally, usually flattened or oval in cross section just below the inflorescence, the flattened edges usually scabrid; longest involucral bract usually longer than the inflorescence, the blade similar to a leaf blade, the sheathing base sometimes pubescent and ciliate; spikelets drab to brownish or reddish-brown, usually lanceovoid to oblong, 4-8 $\mathrm{mm}$. long, acute, in an open to dense simple or compound umbellate system of cymes (spikelets solitary in depauperate specimens); fertile bracts broadly oblong to ovate, acute to obtuse at apex, the margin entire, the surface smooth and pale- to dark-brown except for a paler often greenish midrib that terminates at the apex or is excurrent as a short cusp; anthers 1 or 2, about $1 \mathrm{~mm}$. long; style 2-branched, flattened with the edges fimbriate toward the point of branching; achene lenticular-obovoid, sometimes fairly tumid, about 1 $\mathrm{mm}$. long or slightly longer, apiculate, white to brownish, striate-reticulate, the cells rectangular, shallowly concave, horizontally arranged in (5) 10 to 12 longitudinally rows.

In moist or wet sunny savannahs, fields, grasslands and along roadsides in s.e. Tex.; Old World species fast becoming a weed throughout the lower Coastal Plain of s.e. U.S.

\section{Fimbristylis annua (All.) R. \& S. Fig. 210.}

Cespitose, decumbent to ascending or erect annual, to $5 \mathrm{dm}$. tall (usually much lower): leaves from half as long to nearly the length of the mature culms; blades usually narrowly linear, glabrous to tomentose, 1-2 (-4) $\mathrm{mm}$. wide, the backs 


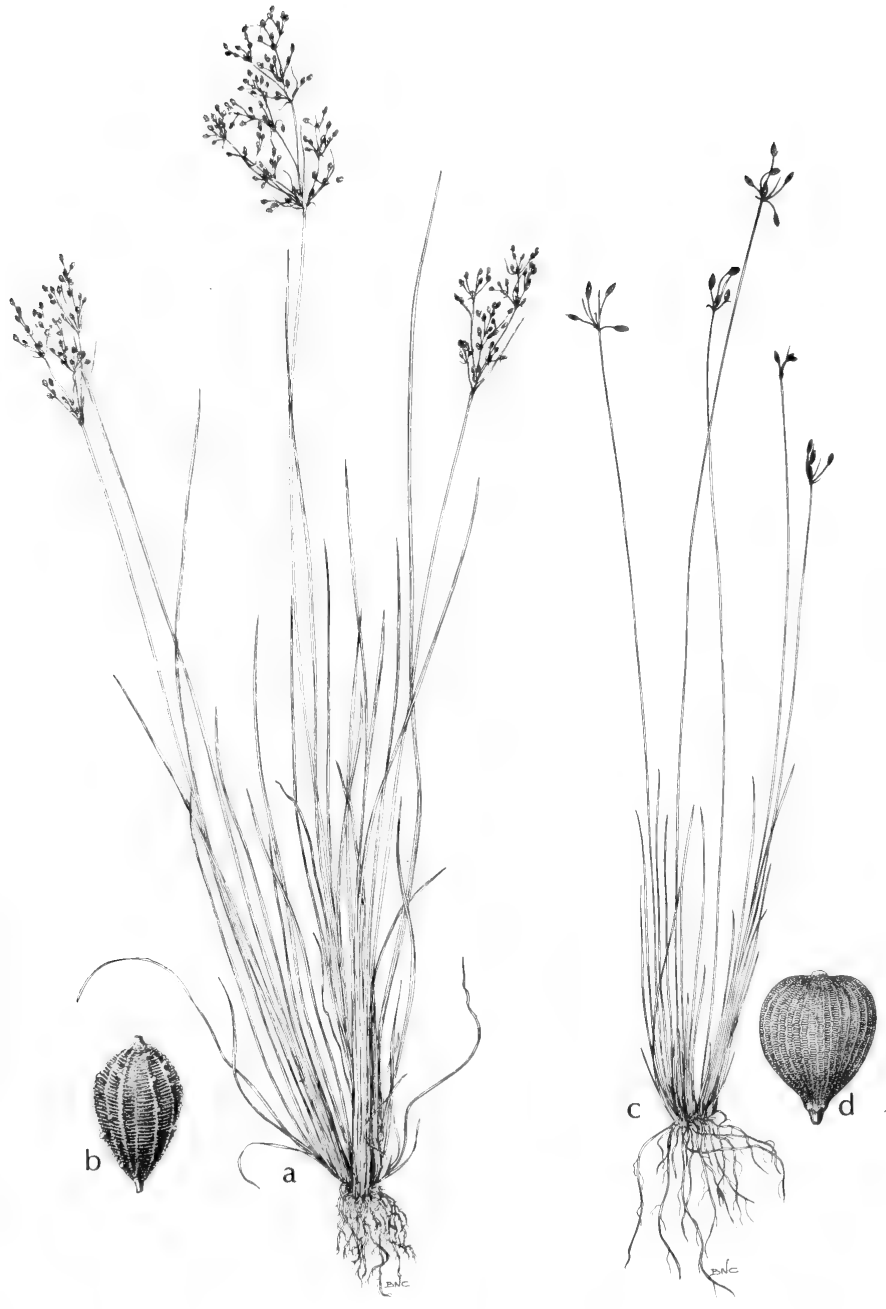

Fig. 209: a and b, Fimbristylis miliacea: a, habit, X 1/3; b, achene, X 20. c and d, Fimbristylis puberula: c, habit, X 1/6; d, achene, X 16. (Courtesy of R. K. Godfrey). 


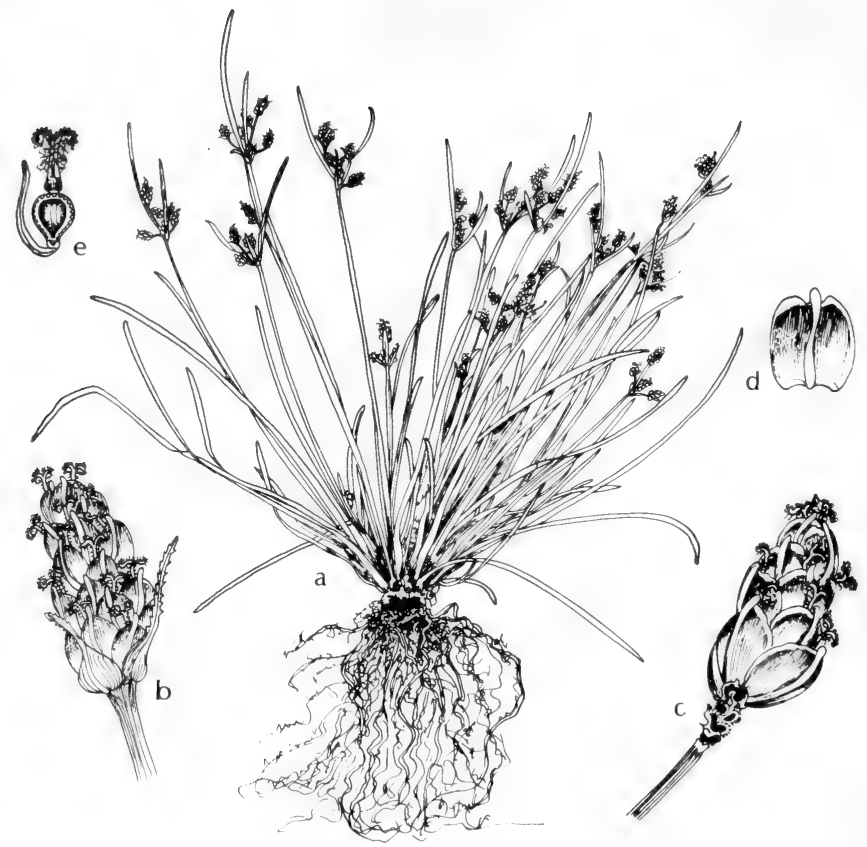

Fig. 210: Fimbristylis annua: a, habit, X 1/2; b, spikelet, X 5; c, spikelet with lower achenes fallen, X 5; d, scale, X 5; e, achene, X 5. (V. F.).

with several prominent raised nerves, the often pale margin cartilaginous and usually ciliate-scabrid; sheaths broad, smooth or pubescent, with a wide subscarious margin that is smooth or pubescent, pale brown, toward its apex ciliate and truncate or acute; ligule present as a horizontal line of short hairs; scapes lax to rigid, ascending or erect, subterete basally, flattened or subterete above at juncture with inflorescence; longest involucral bract similar to leaves in its width and indument, shorter or longer than the inflorescence, the sheathing base smooth or hirsute; spikelets lance-ovoid or oblong, 3-8 mm. long, acute, greenish to tan or brown to a dark-reddish-brown, in a few- to many-spikeletted simple or compound umbellate system of cymes (spikelets solitary in depauperate specimens); fertile bracts broadly oblong to ovate, the apex acute to obtuse, the margin entire, the surface smooth, the paler midrib seldom excurrent; anthers 1 or rarely 2, about $1 \mathrm{~mm}$. long; style 2-branched, flattened, ahe edges fimbriate from the base to the branches or entire basally; achene lenticular, ovoid or obovoid and quite tumid, about $1 \mathrm{~mm}$. long, apiculate, white to brownish, often iridescent, striate-reticulate, the rectangular cells shallowly concave and horizontally arranged in from 5 to 12 longitudinal rows per side, the longitudinal ribs more conspicuous than the horizontal; surface of achene often verrucose, the warts forming either along the longitudinal ribs or over entire cells. F. Baldwiniana 
(Schult.) Torr., F. alamosa Fern.

On a variety of moist sunny substrates such as savannahs, roadsides, grasslands and disturbed or cultivated areas, in mud on edge of ponds and streams, in Okla. (Adair and Mayes cos.) and mostly s.e. Tex.; in temp. to trop. climates of both hemispheres.

\section{Fimbristylis Vahlii (Lam.) Link. Fig. 211.}

Cespitose low annual, the culms to $1.5 \mathrm{dm}$. tall (usually much lower); leaves one third as long as the scape to equaling or exceeding it; blades linear-filiform, spreading-recurved, less than $1 \mathrm{~mm}$. broad, somewhat involute, the backs with several prominent raised veins, often with small stiff ascending hairs, the margin somewhat thickened and similarly hairy; leaf sheath broad, stramineous or palebrown, usually smooth or with a scattering of small hairs, the margin scarious, entire, passing gradually into the blade; ligule absent; scapes stiffly ascending, wiry, slightly broader than the leaves, glabrous, many-ribbed, subterete; spikelets lance-ovoid to linear-ellipsoidal or oblong, 5-10 $\mathrm{mm}$. long, usually acute, palegreenish-brown, 3 to 8 in a dense terminal cluster that are subtended by several leaflike involucral bracts (these always exceeding the inflorescence and usually at least the length of the basal leaves); fertile bracts ovate-lanceolate or oblonglanceolate, glabrous, stramineous or pale-green, the midrib conspicuous, darkgreen and pointed beyond the scale as a short erect or slightly recurved mucro; stamen 1, the anther less than $0.5 \mathrm{~mm}$. long; style 2-branched, much longer than the achene, subterete, the base swollen, the surface smooth or papillate from about the midpoint to the point of branching; achene obovoid, tumid, $0.5-0.7 \mathrm{~mm}$. long, pale, sometimes slightly iridescent, reticulate, the individual rectangular cells arranged horizontally in 5 to 7 vertical rows on a side.

Fine sands, silts or clays, usually alluvial or shoreline situations, of ten on areas of disturbed bottomland, in mud and wet sand on edge of ponds and lakes, in Okla. (LeFlore, Pittsburg, Stephens, McIntosh and McCurtain cos.), e. and s. Tex. and Ariz. (Kearney \& Peebles); S. C. s. to n. Fla., w. to Tex.; scattered localities in inland states; in w. U.S., Calif. and Ariz.; Mex. and C.A.

\section{Fimbristylis castanea (Michx.) Vahl. Fig. 208.}

Densely cespitose perennial to $1.5(-2) \mathrm{m}$. tall, the bases of the plants castaneous, deep-set in substratum, the outer leaves of a tuft and the older leaves persistent as imbricated scales; leaves from one third the length of the culms to nearly as long; blades usually very narrowly linear (rarely to 2 or $3 \mathrm{~mm}$. broad), ascending, thick (often semicircular in cross section), most frequently involute, smooth (particularly toward the base), the nerves on the back numerous and indistinct but the marginal nerve or nerves ciliate-scabrid with ascending stout-based hairs; sheathing portion of the leaf broad (broadening gradually toward the base), pale-brown to dark-brown or very deep-lustrous-reddish-brown, thick and rigid, the broad margin thin or even scarious, entire except for the truncate or rounded ciliate apex; ligule of hairs either absent or incomplete but a color change evident on the upper surface of the leaf at the collar; scapes slender, wandlike, as wide as the blades or somewhat wider, many-ribbed, terete toward the base of the plant, subterete to oval or elliptical in cross section upwardly; longest bract of the involucre usually shorter than the inflorescence or about the length of the inflorescence (rarely longer), the blade somewhat flattened, ciliate-scabrid; spikelets usually ovoid or lance-ovoid, very rarely cylindrical, 5-10 $\mathrm{mm}$. long, rarely longer, the mature ones usually pale- to dark-brown, dull, in a dense to open ascending or spreading umbellate compound system of cymes; fertile bracts broadly ovate, smooth, brown, usually dull, the margin entire or becoming erose with age, the apex rounded; veins of the mid-portion of the scale obscure or visible as faint pale lines that 


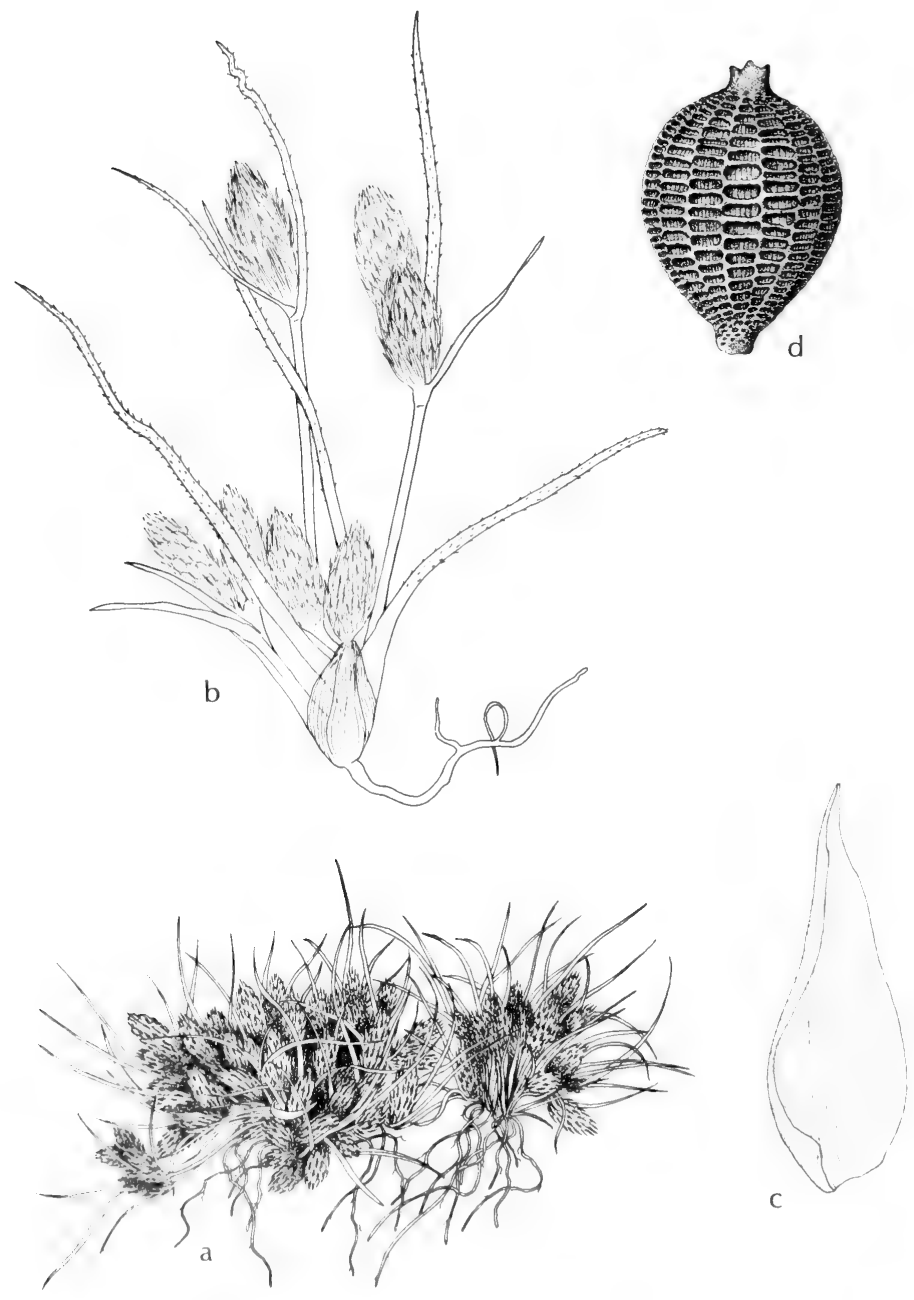

Fig. 211: Fimbristylis Vahlii: a, habit, X 1; b, habit, X 2; c, scale, X 50; d, achene, X 50. (Courtesy of R. K. Godfrey). 
converge apically to form a short mucro; stamens 2 or 3 , the anthers about $2 \mathrm{~mm}$. long; style 2-branched, flattened, fimbriate from the base to the point of branching; achene lenticular-obovoid or obpyriform, 1.5-2 mm. long, reddish-brown or dark-brown, often lustrous, scalariform-foveate or reticulate, the individual cells almost isodiametric or horizontally rectangular and usually arranged in numerous fine vertical rows.

Moist sands or muck of coastal marshes, dune swales or estuary banks (rarely alkaline situations inland), L.I., s. along the Atl. Coast into the Fla. Keys, along the Gulf Coast s. and w. into Tam. and the Yuc. Peninsula; Bah. I., Cuba.

\section{Fimbristylis puberula (Michx.) Vahl. Fig. 209.}

Perennial to $1 \mathrm{~m}$. tall; culms solitary or in small tufts, the bases often hard, knotty and jointed together into short thick rhizomes on which the old leaf bases often persist as shreddy remnants; leaves from one third as long to nearly equaling the culms; blades narrowly linear, usually involute at least toward the base, about $1 \mathrm{~mm}$. wide, the backs with several raised nerves, smooth to variously pubescent, the upper surface smooth or variously pubescent, the pale margin cartilaginous and ciliate-scabrid (this most noticeable toward the blade-base and -apex); sheaths hard, thick, fibrous, pale- to dark-brown, the broad margin scarious and entire except for long cilia at apex; ligule inconspicuous, incomplete or absent; longest bract of inflorescence erect, the blade flattened, usually much-surpassed by the inflorescence; spikelets lance-ovoid to ovoid or ellipsoidal, 5-10 $\mathrm{mm}$. long, reddish-brown, in a usually few-flowered compact to open system of pedunculate cymules or a simple umbel-like cyme; fertile scales ovate to obovate or even reniform, reddish brown to dull-brown or flavescent, the backs rounded, the scarious rounded margin entire and ciliate or somewhat lacerate, the inconspicuous nerves flavescent to pale-brown or sometimes the central ones slightly raised, greenish and slightly excurrent as a short mucro; outer surface of at least the lower scales puberulent at least toward the apex; stamens 3, the anthers 2-2.5 $\mathrm{mm}$. long; style 2-branched, flattened, the edges usually fimbriate from about the midpoint to the base of the style branches; achene lenticular-obovoid, about $1 \mathrm{~mm}$. long, rather flat to stmewhat tumid, sometimes umbonate, flavescent to dark-brown, the surface distinctly to faintly reticulate, the rectangular cells usually arranged in several longitudinal lines (11 to 20 on a face) in a few cases with very many longitudinal lines with the cells isodiametric, the longitudinal lines prominently to slightly raised.

Sands, sandy peats or clays of savannahs, edge of ponds, open pinelands, upper edges of grass-sedge bogs, meadows and prairies, throughout the Atl. and Gulf Coastal Plain from L.I. s. into peninsular Fla. and w. to Tex. nearly to the Mex. border; scattered from the cen. Piedmont to its southwest edge; scattered in the interior highlands and of frequent occurrence in the moist meadows and prairies of the cen. lowlands, particularly along the Great Lakes on the Pleistocene shores and $w$. into the tall and mid-grass prairies of Tex., Okla., Kan. and Neb.; Can.

\section{Fimbristylis puberula var, interior (Britt.) Kral.}

As var. puberula but plant base less bulbous and producing dense clusters of short slender twisted pale-reddish-brown rhizomes; foliage pale-green, sometimes appearing glaucous; blade margins distantly to approximately ciliate-scabrid; ligule inconspicuous or present at a narrow line of short ascending hairs; longest involucral bract usually longer than the inflorescence; spikelets ovoid to cylindrical or ellipsoidal, 5-10 $\mathrm{mm}$. long, stramineous to reddish-brown, the backs of the scales usually smooth, the central nerve of at least the lower scales excurrent as a definite terete mucro; achene with several prominent to rather obscure longitudinal ridges that are interconnected with finer horizontal lines, hence the surface composed of longitudinal rows of roughly isodiametric shallowly concave cells. 

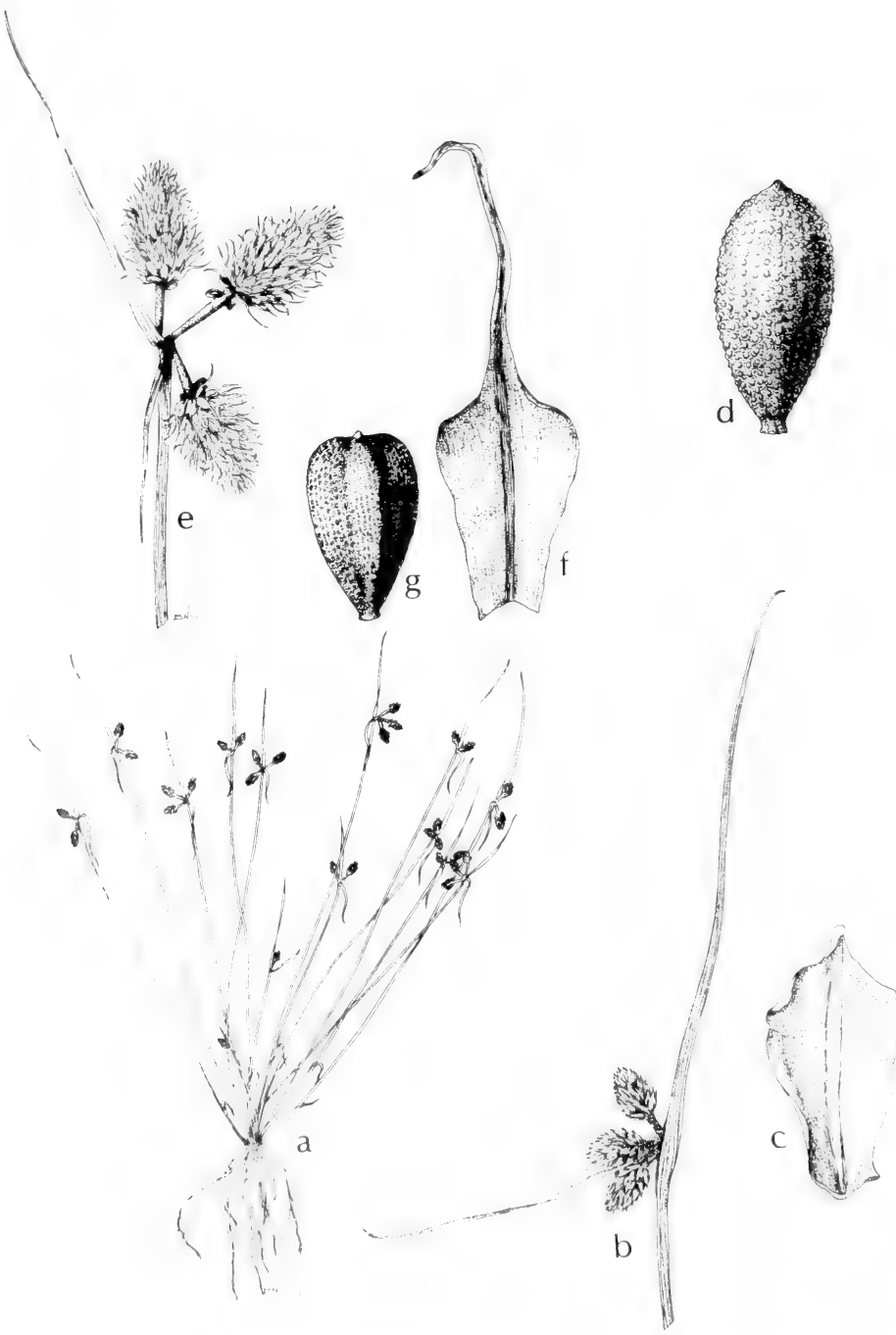

Fig. 212: a-d, Hemicarpha micramha var. micrantha: a, habit, X $2 / 3$; b, inflorescence, X 2; c, scale, X 36; d, achene, X 46. e-g, Hemicarpha micrantha var. aristulata: e, inflorescence, X 2; f, scale, X 36; g, achene, X 36. (Courtesy of R. K. Godfrey). 
Sandy sloughs in prairie provinces, particularly in w. Kan. and Neb. but extending s. into w. Tex. and southw. to Ariz.

\section{Hemicarpha Nees \& ARN.}

A genus of a few species (perhaps as many as 6) of warm regions. Hemicarpha is closely related to Cyperus subgenus $K y$ llinga but the inflorescence and flowers are much-reduced. Some authors include Hemicarpha in Scirpus but this has very little merit.

\section{Hemicarpha micrantha (Vahl) Britt. Fig. 212.}

Essentially glabrous densely tufted annuals; culms 1-22 cm. long, 0.2-0.6 mm. thick, essentially leafless; leaves usually 2 per culm at its base; upper sheath purplish or brownish, its blade linear to setaceous; lower sheath much-reduced, its blade absent; lower bract often appearing as a continuation of the culm, 7-37 $\mathrm{mm}$. long; 1 or 2 other much-reduced bracts present; inflorescence a glomerule of 2 (rarely 3 ) sessile heads or head solitary; heads broadly ovoid, 2-8 $\mathrm{mm}$. long, of 60 to 140 uniflorus spikelets in tight spirals; scale solitary per spikelet,e()?t,d of 60 to 140 uniflorus spikelets arranged in tight spirals; scale solitary per spikelet, abaxial, ovate to lanceolate, $0.8-2.3 \mathrm{~mm}$. long, the midrib conspicuous often as a keel in the lower part and a mucro or awn apically, the sides membranous, convex; "perianth" (actually the wings of the reduced spikelet axis) of a single hyaline adaxial scale, often split and torn by or adhering to the achene, very inconspicuous; stamens 1 or 2; styles 2-branched; achene oblong, nearly terete or elliptic in transection, $0.5-0.8 \mathrm{~mm}$. long, very minutely apiculate, surficially miscroscopically papillate. Scirpus micranthus Vahl.

The species is widespread in wet or moist soils in warm temp. and trop. areas of Am. We have 3 varieties as follows:

Var. micrantha. "Perianth" scale much shorter than the achene, often bifid or reduced or absent. Infrequent or rare in moist or wet soils along streams, s. part of e. Tex., Rio Grande Plains and Trans-Pecos; widespread in trop. Am., Calif., Wash., Gulf States and n.e. U.S.

Var. aristulata Cov. "Perianth" scale equaling or surpassing the achene and often cupped around it distally and adaxially, with no definite vascular tissue (use magnification of 40 diameters); awn of floral scale two thirds as long as to a little longer than the body of the scale. Infrequent in moist soil, throughout most of Tex. to Ariz.; Neb. and Wyo., s. to Tex., N.M. and Ariz.

Var. Drummondii (Nees) Friedl. "Perianth" scale equaling or surpassing the achene and often cupped around it distally and adaxially, with 3 to 5 vascular strands; mucro of floral scales less than two thirds as long as the body of the scale. In Okla. (Comanche Co.), e. and n.-cen. Tex., N. M. (Bernalillo Co.) and Ariz. (Pima Co.); from Mo. and Neb. s. and s.w. to Tex., N.M. and Ariz.; intergrading with the last variety.

Var. minor (Schrad.) Friedl. Mucro shorter than body of glume; "perianth" scale shorter than the achene and usually more or less bifid. Ariz. (Cochise and Pima cos.).

\section{Cyperus L. Flatsedge}

Herbs, usually with culms leafy near the base, often subscapose; inflorescence terminal, an umbel-like aggregation of primary peduncles (each subtended by a bract, usually) bearing spikes or heads of spikelets or the longer of the peduncles each bearing smaller umbel-like aggregations of secondary peduncles (with or without bractlets) each bearing spikes or head of spikelets or the whole inflorescence contracted into a dense flowering mass with the true form obliterated; spikelets usually borne in several rows on the spike or head axis, with a minute bract basally and either with several to many fertile scales distichously arranged or else reduced 
to a single fertile scale plus one or more sterile scales above, when several scales present the spikelet usually discernibly laterally compressed (i.e., as if the 2 margins of the folded scale were pushed toward each other and the scale creased at the usually keel-like median portion, the breadth of the spikelets then measured from keel to keel of alternating scales and the thickness from side to side of the same folded scale), the spikelet axis either disarticulating at the top of each internode or only at its base or often completely persistent, each internode of the spikelet axis often with 2 thin "wings" on each side of the flower (the decurrent lower margins of the next superjacent scale); scales usually folded, either persistent or deciduous; perianth absent; stamens 1 to 3; styles 2- or 3-branched; achenes lenticular or trigonous, often stipitate and/or apiculate, jointed with the style usually at the very top of the achene, the achenial body there with or without a minute apiculus but the latter (if present) of the same color and texture as the main part of the achene.

With upwards of 900 species in warm regions, Cyperus, a vast, difficult genus, is often made more confusing by a very unsatisfactory and arbitrary segregation of smaller "genera," such as Mariscus Vahl, Pycreus Beauv., Kyllinga Rottb.

1. Achene lenticular, biconvex or concavo-convex (2)

1. Achene trigonous or vaguely so, occasionally appearing nearly terete but definitely not biconvex nor concavo-convex (9)

2(1). Achene dorsiventrally compressed, i.e., with one of the sides appressed to the spikelet axis, the other appressed to the inner surface of the scale, the latter not keeled.

1. C. laevigatus.

2. Achene laterally compressed, i.e., with one angle next to the spikelet axis and the 2 slightly convex sides parallel with the 2 sides of the scale, the scale being folded and creased at the keel-like median (3)

3(2). Each spikelet with only 2 scales and only one achene (4)

3. Each spikelet with 6 to 60 scales, usually several of them fertile (6)

4(3). Stamens solitary; plants rhizomatous, the culms rising at intervals of 3-10

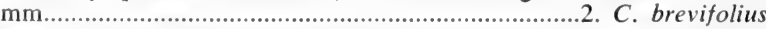

4. Stamens paired; culms densely tufted or plants mat-forming (5)

5(4). Densely tufted with a culm density of 4 to 20 per square $\mathrm{cm}$. in the tufts; culms about $0.7 \mathrm{~mm}$. thick basally; inflorescence $3-8 \mathrm{~mm}$. long; bracts with translucent corners at the very base; spikelets $2-2.5 \mathrm{~mm}$. long, $0.7-0.8 \mathrm{~mm}$. broad, sordid-whitish or very pale-brownish; lower (fertile) scale 1.7-2.4 mm. long; achene elliptic, $0.9-1.1 \mathrm{~mm}$. long (not including the apiculus), $0.5-0.6 \mathrm{~mm}$. broad, ripening to a very dark brown.................................................. 3 C. tenuifolius.

5. Culm density in the mat 1 to 4 per square $\mathrm{cm}$; culms $0.8-1.8 \mathrm{~mm}$. thick basally; inflorescence 7-14 $\mathrm{mm}$. long; bracts without translucent corners; spikelets $2.3-3 \mathrm{~mm}$. long, $1.2-1.3 \mathrm{~mm}$. broad, buffy-white to white; lower (fertile) scale 2.2-2.9 mm. long; achene obovate, $1-1.4 \mathrm{~mm}$. long (not including the apiculus), 0.75-0.9 $\mathrm{mm}$. broad, ripening black.

4. C. sesquiflorus.

6(3). Spikelets borne in lax spikes $12-40 \mathrm{~mm}$. long and 12-23 mm. thick; scales with broad white-hyaline margins markedly contrasting with the brownish sides; achenes $1.2-1.5 \mathrm{~mm}$. long........5. C. albomarginatus.

6. Spikelets borne in heads or glomerules; scales with thin but not hyaline nor white margins; achenes mostly less than $1.2 \mathrm{~mm}$. long (7)

7(6). The lower part of the edges of the internodal niches of the spikelet axis with minute persistent wings which become narrowed and join abaxially forming a minute cup at the base of the achene 
7. The edges of the internodal niches essentially wingless (8)

8(7). Achenial surface with rectangular-linear cells oriented vertically in horizontal rows, these rows marked off by horizontal wavy usually discolored sutures.

7. C. flavescens.

8. Achenial surface with vertical rows of minute essentially isodiametric usually somewhat hexagonal cells; spikelets $7-12 \mathrm{~mm}$. long; scales about $2 \mathrm{~mm}$. long........................................................... . . niger.

9(1). The spikelet axis at maturity disarticulating at the base of each internode (just above each node), thus breaking into units consisting of a scale, the next lowest internode and the attached wings and clasped achene; internodes postanthetically on the sterile side becoming thickened and assuming a white cartilaginous texture......

9. C. odoratus.

9. The spikelet axis either persistent as a unit or else deciduous as a unit, not disarticulating spontaneously at maturity (10)

10(9). Culms stiffly erect with complete septa at intervals of 5-50 mm.

10. Culms non-septate (11)

10. C. articulatus

11(10). Each of the 5 to 8 extremely unequal primary peduncles with an irregular panicle of several spikes each with a number of ascending spikelets; the total inflorescence with 100 to 600 spikelets; scales when spread out nearly orbicular, about $1.5 \mathrm{~mm}$. long; spikelet axes wingless.........................................................................11. C. Iria.

11. Each primary peduncle either reduced or bearing a head or spike or a glomerule, or bearing several short secondary peduncles but never an irregular panicle; scales usually considerably longer than broad or if nearly as long as broad then longer than $1.5 \mathrm{~mm}$. (12)

12(11). Stamens 1 or 2; spikelet axis wingless or essentially so (13)

12. Stamens 3 ; spikelet axis winged or wingless (22)

13(12). Scales less than $1 \mathrm{~mm}$. long, rounded or truncate at apex, the lateral nerves indistinct, hyaline-margined, 3-nerved, caducous, annual........

12. C. difformis.

13. Scales $1 \mathrm{~mm}$. or longer, acuminate at apex, the lateral nerves prominent (14)

14(13). Scales with 7 to 9 strong evenly distributed nerves and a wholly keel-like median portion, terminating in a spreading recurved awn; annual, reddish-brown at base.....................................13. C. aristatus.

14. Scales with 3 or 5 nerves and these sometimes obscure and concentrated in the median portion, the tip mostly either incurved or straight (15)

15(14). Scales 3-nerved, acuminate to cuspidate or aristate (16)

15. Scales 5-nerved, (3-nerved if culm has retrorse projections) apex blunt, rounded or acute (18)

16(15). Bracts 3 to 6 , scarcely if at all surpassing the inflorescence; rays up to 10 ; spikelets to $18 \mathrm{~mm}$. long, reddish-brown, digitate-radiate; scales aristate....................................14. C. amabilis var. macrostachyos.

16. Bracts 2 to 4 , much-surpassing the inflorescence; rays up to 5 ; spikelets not more than $10 \mathrm{~mm}$. long, in dense heads, white to pale-brown; scales mucronate to acuminate (17)

17(16). Matted perennial with a tuberiferous rhizome, to $3 \mathrm{~cm}$. long; culm muchthickened and fibrous-coated at the base; leaf sheaths nearly black; bracts more or less reflexed; inflorescence contracted into a single head; achene nearly black. 15. C. seslerioides. 
17. Annual or biennial; rhizome wanting; stems scarcely thickened or fibrouscoated basally; leaf sheaths often reddish-brown or purplish-brown at base; bracts erect or ascending; inflorescence with 2 to 5 rays, rarely a single head; achenes brown or purplish-brown.

16. C. acuminatus.

18(15). Achenes only $0.7-0.8 \mathrm{~mm}$. long; culms with scattered microscopic retrorse projections like shark's teeth................17. C. surinamensis.

18. Achenes $0.9-1.5 \mathrm{~mm}$. long; culms either smooth or with antrorse or horizontal projections (19)

19(18). Culms 5-12 mm. thick basally, apically 3-8 mm. thick and with microscopic antrorse projections like shark's teeth; scales $2-2.4 \mathrm{~mm}$. long, when spread out $1.2-1.5 \mathrm{~mm}$. broad at the broadest point (just below the middle).

18. C. virens.

19. Culms $0.7-5 \mathrm{~mm}$. thick basally, apically $0.4-2.7 \mathrm{~mm}$. thick, either smooth or with microscopic knobs (very rarely with antrorse projections in C. pseudovegetus); scales $1.3-1.9 \mathrm{~mm}$. long (20)

$20(19)$. Scales with the dorsal basal flat portion or groove continuing a third to half the total length of a scale and $0.3-0.5 \mathrm{~mm}$. broad; scales when spread out $1.5-1.9 \mathrm{~mm}$. broad near the base and tapering all the way to the apex; achene 1.3-1.5 $\mathrm{mm}$. long, $0.5-0.6 \mathrm{~mm}$. thick, maturing to a nearly black color.......................19. C. ochraceus.

20. Scales with the dorsal basal flat portion or groove continuing only a fifth to a third the total length and only $0.1-0.2(-0.3) \mathrm{mm}$. broad; scales when spread out $0.6-1.2 \mathrm{~mm}$. broad at the broadest (near the middle or shortly below); achene $0.9-1.3 \mathrm{~mm}$. long, $0.2-0.45 \mathrm{~mm}$. thick, maturing to a brownish color (21)

21(20). Scales essentially linear for most of the length, only $0.6-0.7 \mathrm{~mm}$. broad and (as folded in place) the whole scale incurved-falcate; achene linear, $0.2-0.3 \mathrm{~mm}$. thick.............................20. C. pseudovegetus.

21. Scales ovate, reddish with greenish keels, $0.8-1.1 \mathrm{~mm}$. broad at the broadest point, as folded in place the lower part of the keel incurved but the upper part straight........................................21. C. reflexus.

22(12). Most leaves reduced to mere bladeless sheaths or occasionally the uppermost sheaths with short blades very rarely to $10 \mathrm{~cm}$. long (23)

22. Even the lower leaves with well-developed blades (26)

23(22). Inflorescence (not including bracts) 1-2 cm. long.......22. C. phaeolepis.

23. Inflorescence (not including bracts) $3-35 \mathrm{~cm}$. long (24)

24(23). Bracts usually 2, 1 of them 0.3 to 1 (to 2 ) times as long as the inflorescence.................................................................23, C. Haspan.

24. Bracts 10 to 25 , often much-surpassing the inflorescence (25)

25(24). Internodes of spikelet axes with deciduous wings about $1 \mathrm{~mm}$. long and $0.2-0.3 \mathrm{~mm}$. broad. 24. C. giganteus.

25. Spikelet axes wingless. 25. C. alternifolius.

26(22). Achene 0.4-0.7 mm. long, 0.4-0.5 mm. thick, subglobose, white; bracts usually only 2 in number......................................23. C. Haspan.

26. Achene $0.7-3 \mathrm{~mm}$. long, usually considerably longer than thick; bracts 3 to 13 (27)

27(26). Scales 1.3-2 mm. long; achenes 0.8-1 mm. long, 0.3-0.6 mm. thick, unequally trigonous; spikelet axis with readily deciduous wings, $0.2-0.3 \mathrm{~mm}$. broad; spikelets only $1 \mathrm{~mm}$. broad, much-compressed, borne 15 to 70 together in spikes (28) 
27. Scales (at least the fertile ones) $2.3-5.5 \mathrm{~mm}$. long; spikelet axis either wingless or with more or less persistent wings; spikelets variously borne but if only $1 \mathrm{~mm}$. broad then not much-compressed (29)

28(27). Internodes of spikes to $0.5 \mathrm{~mm}$. long; scales $1.3-1.5 \mathrm{~mm}$. long. 26. C. erythrorhizos. 28. Internodes of spikes $0.6-2 \mathrm{~mm}$. long; scales $1.5-2 \mathrm{~mm}$. long..27. C. digitatus. 29(27). Achene $0.25-0.3 \mathrm{~mm}$. thick 28. C. onerosus. 29. Achene 0.4-1.2 mm thick (30)

30(29). Achene 1-1.3 mm. long (31)

30. Achene 1.3-3 mm. long, much longer than thick (32)

31(30). Achene 1-1.3 mm. long, nearly as thick as long; pale or brown; spikelets much-compressed; scales 3-3.5 mm. long, acuminate, the keel grayish-white, the broad margins pale and hyaline

29. C. compressus.

31. Achene 1-1.2 mm. long, about half as thick, nearly black; scales $2-3 \mathrm{~mm}$. long, obtuse, the keel green, the sides reddish-brown.

30. C. Parishii.

32(30). Spikelet axis internodes essentially wingless, occasionally with wings to $0.2 \mathrm{~mm}$. broad (33)

32. Spikelet axis internodes with wings $0.3-1.2 \mathrm{~mm}$. broad (35)

33(32). Nonviscid perennial, tufted and usually with extensive knotty subrhizomatous bases; secondary peduncles absent; leaves neither spongy nor septate basally; inflorescence a single dense sessile head 1-3 $\mathrm{cm}$. thick with 15 to 55 spikelets.........................31. C. filiculmis.

33. Viscid tufted perennials with culms 3-7 mm. thick, the longer peduncles in most inflorescences with secondary peduncles each bearing a head similar to those of the shorter primary peduncles; leaves spongy at base, when dried their incomplete septa visible, the leaf apexes involute (34)

34(33). Spikelets grayish-ochraceous turning grayish-brown; achene thickest (0.7-0.8 mm.) near the apex, long-tapered to the base, 1.4-1.8 $\mathrm{mm}$. long, only slightly apiculate...........................32. C. elegans.

34. Spikelets grayish-yellow becoming rich-golden-brown; achene nearly cylindrical or very slightly thickened in the upper part, long-tapered below, the main part $1.5 \mathrm{~mm}$. long and $0.5 \mathrm{~mm}$. thick but also with the persistent style base (or very large apiculus) adding almost $1 \mathrm{~mm}$. to the length..............................................33. C. oxylepis.

35(32). Rhizomatous perennials; spikelets with 6 to 40 eventually deciduous scales; spikelet axes persistent on the axis of the cluster or spike (36)

35. Tufted perennials (occasionally with knotty subrhizomatous bases in $C$. huarmensis); spikelets with 2 to 8 scales (up to 20 in C. strigosus) and these persistent (deciduous in some specimens of $C$. strigosus); spikelet axis deciduous (more or less so in C. strigosus) (38)

36(35). Bracts 3 or 4 , about equaling the inflorescence; inflorescence with 20 to 65 spikelets altogether, usually even the longer primary peduncles bearing a simple cluster or spike of spikelets just as do the shorter peduncles; each cluster or spike with 3 to 9 spikelets; wings of spikelet axis 2-3 $\mathrm{mm}$. long; achenes $0.9-1 \mathrm{~mm}$. thick

34. C. rotundus.

36. Bracts 5 to 13 , usually much-surpassing the inflorescence; inflorescence with 70 to 350 spikelets altogether; the longer primary peduncles usually with several nearly sessile clusters or spikes of spikelets; each cluster or spike with 10 to 50 spikelets; wings of spikelet axis $1-1.5 \mathrm{~mm}$. long; achenes $0.4-0.8 \mathrm{~mm}$. thick (37) 
37(36). Culms (60-) $75-110 \mathrm{~cm}$. tall; bracts 9 to 13 ; primary peduncles 9 to 13; spikelets reddish-brown; achenes $0.4-0.5 \mathrm{~mm}$. thick.

35. C. setigerus.

37. Culms $15-50(-65) \mathrm{cm}$. tall; bracts 5 to 10 ; primary peduncles 5 to 10 ; spikelets brown, buffy-brown or golden-brown; achenes $0.6-0.8$ $\mathrm{mm}$. thick. 36. C. esculentus.

38(35). Achenes mostly 0.3 to 0.5 times as long as the scales; spikelets $10-29$ $\mathrm{mm}$. long, 1-2 $\mathrm{mm}$. broad, usually less than half as thick as broad (39)

38. Achenes mostly 0.6 to 0.8 times as long as the scales; spikelets $3.5-11 \mathrm{~mm}$. long, $0.5-1(-1.3) \mathrm{mm}$. broad, usually more than half as thick as broad (40)

39(38). Blades $2-8 \mathrm{~mm}$. broad; most inflorescences with the longer peduncles bearing a few short secondary ones; spikes 13-35 mm. long, 20-45 $\mathrm{mm}$. thick, thus usually thicker than long, with 20 to 70 spikelets 1-2 mm. broad, golden- or tawny-brown, with 5 to 20 scales.

37. C. strigosus.

39. Blades $1.5-5 \mathrm{~mm}$. broad; secondary peduncle formation rare; spikes $20-40$ $\mathrm{mm}$. long, 15-27 mm. thick, thus usually longer than thick, with 14-45 spikelets $0.7-1.3 \mathrm{~mm}$. broad, grayish-brown, with 3 to 6 scales 38. C. tenuis.

40(38). Perennial from black knotty subrhizomatous bases; inflorescence only $2-3(-4) \mathrm{cm}$. long, of 3 to 6 essentially sessile spikes $10-25 \mathrm{~mm}$. long and 7-10 mm. thick, with 40 to 80 three-scaled spikelets; only the lowest scale of each spikelet fertile and it enclosing the achene (1.5-2.1 mm. long, 0.8-1 mm. thick) .................39. C. huarmensis.

40. Tufted perennials; inflorescence (1-) $2-15 \mathrm{~cm}$. long, of 1 to 14 usually peduncled heads or spikes 7-30 $\mathrm{mm}$. long and 7-20 $\mathrm{mm}$. thick, with 8 to 2402 - to 8 -scaled spikelets in which only the terminal scale is sterile, the rest all fertile; achenes $0.5-0.8 \mathrm{~mm}$. thick (41)

41(40). Spikes lax, $10-30 \mathrm{~mm}$. long, with 8 to 30 spikelets (42)

41. Heads or spikes dense (the spikelets touching), 7-15 mm. long, with 25 to 240 spikelets (43)

42(41). Scales $2.2-2.5 \mathrm{~mm}$. long, $1.5-2 \mathrm{~mm}$. wide; achene olive-brown, minutely punctulate 40. C. Pringlei.

42. Scales $2.5-3.5 \mathrm{~mm}$. long, about $1 \mathrm{~mm}$. wide; achene yellow-brown to brown., 41. C. hermaphroditus.

43(41). Achenes 1.8-2.2 mm. long; wings 1-2 mm. long; scales $1.2-2 \mathrm{~mm}$. broad; spikelets 50 to 240 per head or spike, $0.5-1 \mathrm{~mm}$. broad, with 2 to 4 scales, straw-brown to dark-brown (to tawny-ochraceous).... 42. C ovularis.

43. Achenes $1.3-1.7 \mathrm{~mm}$. long; wings $0.8-1.4 \mathrm{~mm}$. long; scales $1-1.3 \mathrm{~mm}$. broad; spikelets 25 to 70 per head, with 3 to 8 scales, greenish-brown to ochraceous-brown or olive. 43. C. globulosus.

\section{Cyperus laevigatus L. Fig. 213.}

Densely tufted or mat-forming perennial; culms soft, $5-25 \mathrm{~cm}$. long, $1-1.5 \mathrm{~mm}$. thick; leaves reduced to basal sheaths with subulate or setaceous blades $3-30 \mathrm{~mm}$. long: inflorescence $5-10 \mathrm{~mm}$. long, of a single head of 4 to 8 spikelets; bracts 2 , the longer one $2-8 \mathrm{~cm}$. long. appearing as a continuation of the culm; spikelet straw-white or often white with atropurpureous blotches medially, 4-7 mm. long, 2-3 $\mathrm{mm}$. broad, $0.7-1 \mathrm{~mm}$. thick, with 8 to 30 scales, the axis persistent, essentially wingless, somewhat flattened; achene lenticular (often concavo-convex) with one of the flat sides against the flattened spikelet axis. 


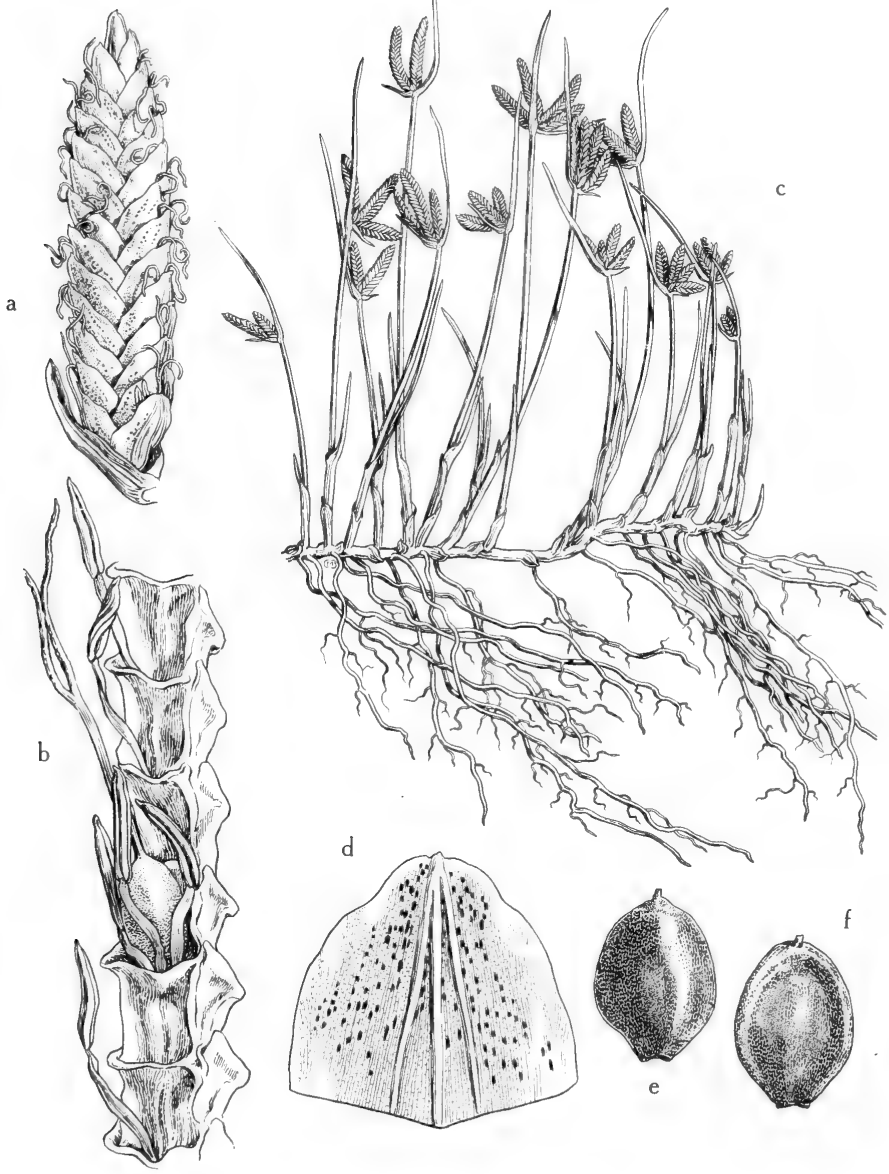

Fig. 213: Cyperus laevigatus: a, compressed spikelet, $\mathrm{X}$ 6; $\mathrm{b}$, rachis, showing the persistent stamens and an achene with bifid style, X 20; c, habit, the culms arising singly from a horizontal rhizome, X 4/5; d, obtuse scale, X 3 ; e and $\mathrm{f}$, achenes, showing minutely reticulate surface, abaxial and adaxial views, X 12. (From Mason, Fig. 126). 


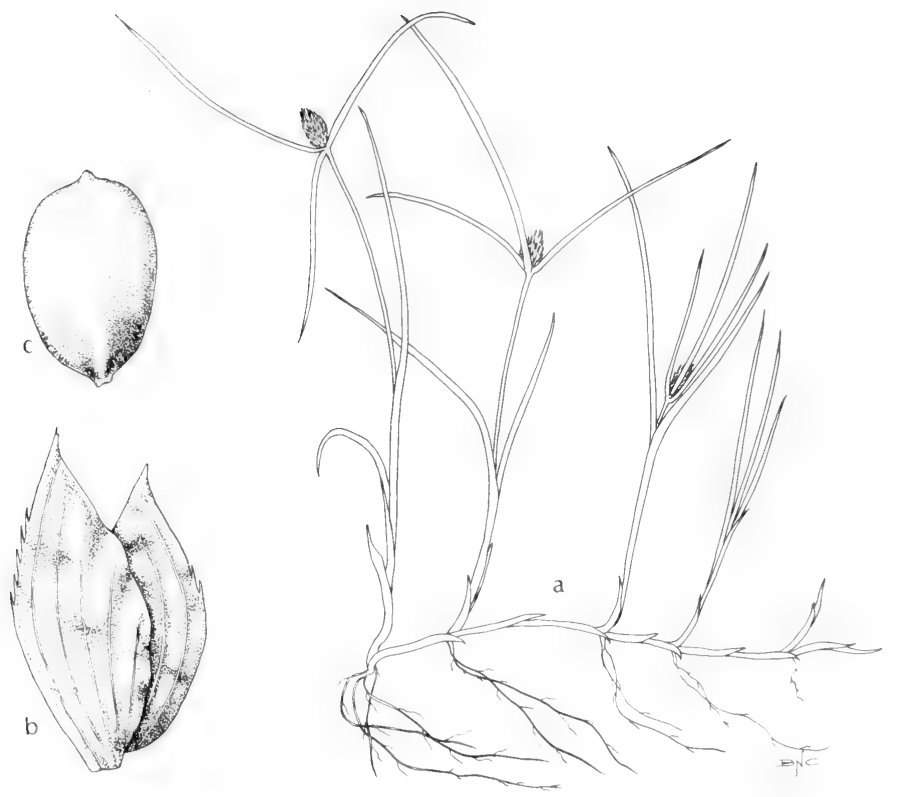

Fig. 214: Cyperus brevifolius: a, habit, X 1; b, scale, X 30; c, achene, X 25. (Courtesy of R. K. Godfrey).

Infrequent in fresh or subsaline or gypseous mud in water on edge of canals and streams, and wet sandy flats, in the Tex. Trans-Pecos, and Ariz. (Pima, Yuma, Mohave and Cochise cos.), Feb.-Oct.; widely distributed in warm-temp. and trop. regions.

2. Cyperus brevifolius (Rottb.) Hassk. Fig. 214.

Perennial with creeping branching reddish-brown rhizomes to $20 \mathrm{~cm}$. long and 1--2 mm. thick; flowering culms rising from the rhizomes $3-10 \mathrm{~mm}$. apart, 4-20 $(-38) \mathrm{cm}$. long, 0.4-1 mm. thick; leaves with sheaths $5-30 \mathrm{~mm}$. long and membranous; flaccid blades $1-3(-10) \mathrm{cm}$. long, 1-3 $\mathrm{mm}$. broad, mostly much shorter than the culms except when the latter are dwarfed; inflorescence a single roundish seemingly simple congested head 4-6 mm. long and broad, with 38 to 100 spikelets; bracts 3 (or 4 ), the longest one usually nearly vertical or ultimately reflexed, membranous, 15-120 mm. long, 1-2 mm. broad; spikelets each deciduous as a unit, 2-2.9 mm. long, $0.8-1.1 \mathrm{~mm}$. broad, about $0.3 \mathrm{~mm}$. thick, sordid- or buffywhitish or very pale-brownish, with 2 scales, the lower one enclosing a fertile floret, the upper empty, the single short internode with very broad hyaline wings clasping the achene and continuous with the lower part of the higher scales; scales persistent (the lower one $1.9-2.4 \mathrm{~mm}$. long), with green keels and translucent sides, each side with a couple of inconspicuous well-distributed nerves; stamens 1 (very rarely 2 in isolated spikelets, never many on the same head), at the abaxial angle of the achene; stigmas 2; achene lenticular with an adaxial angle 
against the internode and abaxial one at the keel of the lower scale, obovate or oblong-obovate, 1-1.2 mm. long (plus an apicule 0.05-0.1 mm. long), (0.6-) $0.7-0.8 \mathrm{~mm}$. broad, ripening to a rich-brown. Kyllinga brevifolia Rottb.

Common weeds in moist or wettish loam, s.e. Tex., less common in e. Tex., rare in Edwards Plateau and Brownsville region, and Okla. (Waterfall), Apr-Nov.; widespread in warn regions.

\section{Cyperus tenuifolius (Steud.) Dandy. Fig. 215.}

Densely tufted fragrant annual (or short-lived perennial ?) with density of about 4 to 20 culms per square $\mathrm{cm}$; culms $1-21 \mathrm{~cm}$. long, $0.5-0.7 \mathrm{~mm}$. thick throughout; leaves with sheaths $8-45 \mathrm{~mm}$. long and membranous; flaccid blades 2-11 cm. long, 1-1.8 $\mathrm{mm}$. broad, often more than two thirds as long as the culms; inflorescence a single roundish 3-lobed compound headlike mass $3-8 \mathrm{~mm}$. long and 5-6 mm. broad in the upper obtuse lobe, with 40 to 170 spikelets altogether; bracts 3 (or 4 ), ultimately spreading or slightly reflexed, flaccid, 2-10 cm. long, 1-2 $\mathrm{mm}$. broad, at the very base with broad translucent membranous corners; spikelets each deciduous as a unit, 2-2.5 mm. long, 0.7-0.8 mm. broad, about 0.3 $\mathrm{mm}$. thick, sordid-whitish or very pale-brownish, with 2 scales, the lower one enclosing a fertile floret, the upper empty, the single short internode with very broad hyaline wings clasping the achene and continuous with the lower part of the higher scale; scales persistent (the lower one $1.7-2.4 \mathrm{~mm}$. long) with green keels and translucent sides, each side with a couple of inconspicuous welldistributed longitudinal nerves; stamens uniformly 2 at the abaxial angle of the achene; stigmas 2; achene lenticular, with the adaxial angle against the internode, the abaxial one at the keel of the lower scale, elliptic, $0.9-1.1 \mathrm{~mm}$. long (plus an apicule $0.1 \mathrm{~mm}$. long), $0.5-0.6 \mathrm{~mm}$. broad, ripening to a very dark-brown. Kyllinga pumila Michx., Cyperus densicaespitosus Mattf. \& Kükenth.

Infrequent in moist loam, in marshes along streams, edge of ponds and other wet areas, e. Tex. (Bowie, Cass, Hardin and Polk cos.), rare in n.-cen. Tex. (Grayson Co.), and Okla. (McCurtain Co.), Sept.-Nov.; widespread in warmer moister parts of Am.; also Afr. and Madag.

The name is incorrectly said by some writers to be illegitimate.

\section{Cyperus sesquiflorus (Torr.) Mattf. \& Kükenth.}

Annual (?) or usually perennial mat-formers, emitting a strong citronellalike odor when bruised, with a culm density of 1 to 4 flowering culms per square $\mathrm{cm}$. in the mat; culms $5-30 \mathrm{~cm}$. long, basally $0.8-1.8 \mathrm{~mm}$. thick, apically $0.5-1 \mathrm{~mm}$. thick; leaves essentially basal, with sheaths $1-2(-3) \mathrm{cm}$. long and firm-membranous, ascending blades $3-12 \mathrm{~cm}$. long and $2-3.5(-5) \mathrm{mm}$. broad, mostly much shorter than the scapelike culms; inflorescence a single prolate few-lobed compound congested headlike mass 7-14 $\mathrm{mm}$. long and 6-8 $\mathrm{mm}$. broad in the upper cylindrical lobe, with 50 to 200 spikelets altogether; bracts 3 (or 4), ultimately slightly to strongly reflexed, firm-membranous, $2-8 \mathrm{~cm}$. long, $1-3 \mathrm{~mm}$. broad, at the very base discolored whitish-green but not hyaline at corners; spikelets each deciduous as a unit, 2.3-3 mm. long, $1.2-1.3 \mathrm{~mm}$. broad, about $0.4 \mathrm{~mm}$. thick, with 2 scales, buffy-white to white laterally, the lower scale enclosing a fertile floret, the upper one empty, the single short internode with very broad hyaline wings clasping the achene and continuous with the lower part of the higher scale; scales persistent (the lower one 2.2-2.9 $\mathrm{mm}$. long) with green keels and buffy-white to white sides, each side with a couple of inconspicuous welldistributed longitudinal nerves; stamens uniformly 2 at the abaxial angle of the achene; stigmas 2; achene lenticular with the adaxial angle against the internode, the abaxial one at the keel of the lower scale, obovate, $1-1.4 \mathrm{~mm}$. long, plus an apicule $0.05-0.15 \mathrm{~mm}$. long, $0.75-0.9 \mathrm{~mm}$. broad, ripening to jet-black. Kyllinga 

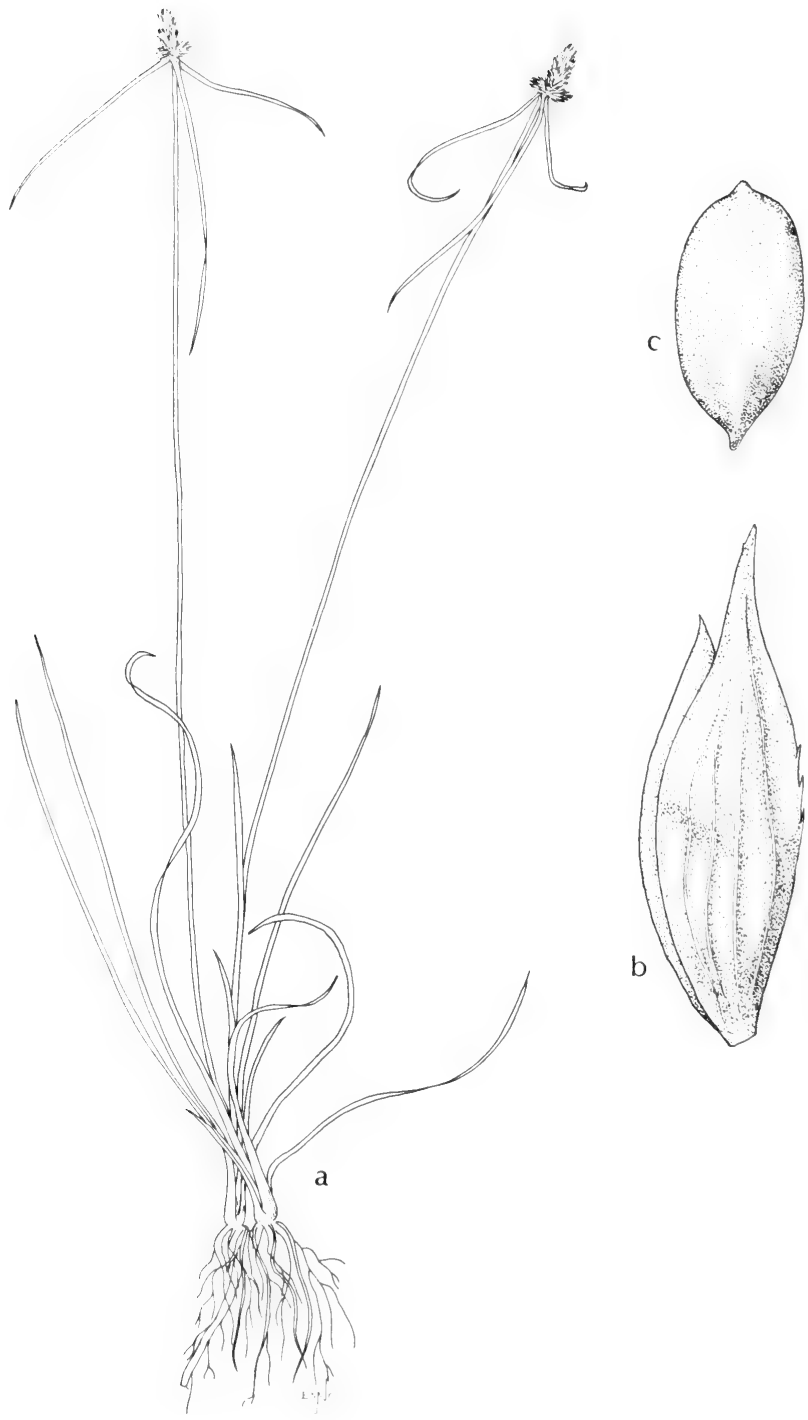

Fig. 215: Cyperus tenuifolius: a, habit, X 1/2; b, scale, X 30; c, achene, X 30. (Courtesy of R. K. Godfrey). 


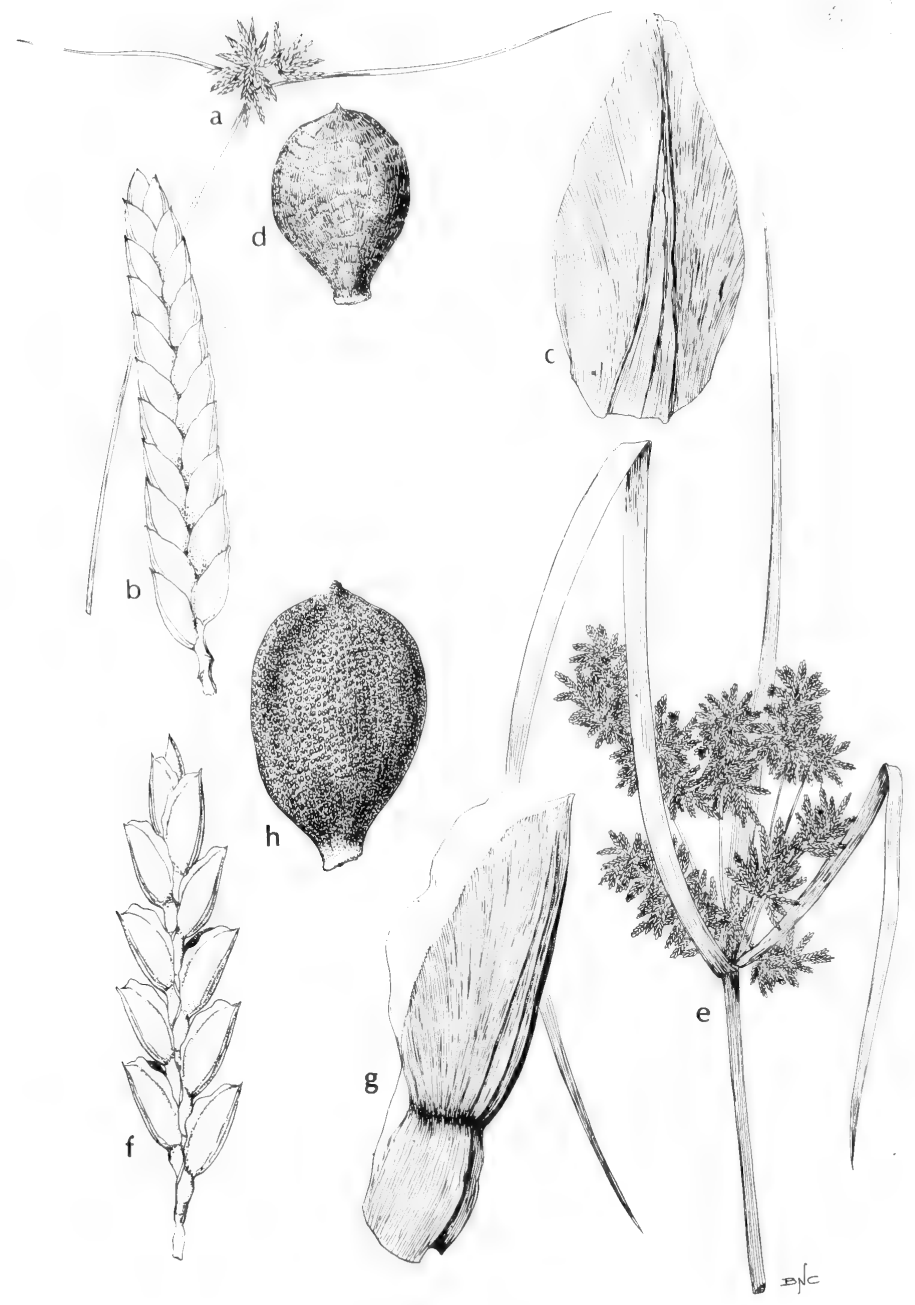

Fig. 216: a-d, Cyperus flavescens: a, habit, X 1/2; b, spikelet, X 5; c, scale, X 25; $\mathrm{d}$, achene, X 25, e-h, Cyperus albomarginatus: e, habit, X 1/2; f, spikelet, X 7; g, scale, X 25; h, achene, X 25. (Courtesy of R. K. Godfrey). 
odorata Vahl.

Frequent in moist sandy loam, and on seepage slopes in e. Tex. (Angelina, Austin, Gonzales, Hardin, Lavaca and Newton cos.), June-Oct.; widespread in warm regions.

\section{Cyperus albomarginatus Mart. \& Schrad. Fig. 216.}

Tufted annual; culms 2-9 dm. long, basally leafy and 2-8 $\mathrm{mm}$. thick, apically $0.7-4 \mathrm{~mm}$. thick; inflorescences $2-13 \mathrm{~cm}$. long, of 3 to 12 very unequal peduncles each bearing a lax spike $12-40 \mathrm{~mm}$. long and $12-23 \mathrm{~mm}$. thick, of 10 to 60 spreading spikelets or the longer peduncles bearing secondary peduncles with such spikes; bracts 3 to 7 , far-surpassing the inflorescence; spikelets $5-12 \mathrm{~mm}$. long, $1.7-3 \mathrm{~mm}$. broad, about $0.7 \mathrm{~mm}$. thick, with 6 to 18 scales, straw-brown to dark-chocolate-brown, straight, the axis somewhat 4-angled, at maturity persistent, each internode on the fertile side with a niche for an edge of the achene and on the edges (at the sides of the achene) with minute winglike margins; scales 1.4$1.7 \mathrm{~mm}$. long, 1.4-2 mm. broad, obovate, membranous, with 5 nerves at the keellike median and marginally with a broad hyaline zone (albomargin) markedly contrasting with the brownish sides, deciduous, not much overlapping, clasping the achene; stamens 2 or 3 ; achenes lenticular, with an angle fitting into the niche of the internode, nearly as long as the scale, broadly obovate, apiculate, 1.2-1.5 $\mathrm{mm}$. long, $0.6-1 \mathrm{~mm}$. broad, maturing to black.

Infrequent or rare, on rocky slopes, washes and along streams, scattered in s.e. and Trans-Pecos Tex. and Ariz. (Cochise, Pima and Santa Cruz cos.), summer; Afr., Madag., India, Burma, Austral.; in Am. from Arg. and Bol. n. to Va., N.C., S.C., Ala., La., Tex. and Ariz.

\section{Cyperus polystachyos Rottb. var. texensis (Torr.) Fern. Fig. 217.}

Tufted perennial (flowering the first year); culms $3-35 \mathrm{~cm}$. long, basally $0.8-3$ $\mathrm{mm}$. thick, apically $0.5-1.5 \mathrm{~mm}$. thick, wiry; leaves basal, mostly shorter than the culms; inflorescence $12-60 \mathrm{~mm}$. long, of several unequal peduncles (these, especially in coastal populations, suppressed so that inflorescence is congested) with glomerules or short lax spikes, or rarely the longer ones with secondary peduncles 1-3 $\mathrm{mm}$. long each with a glomerule or lax spike; glomerules or lax spikes with 5 to 10 mostly spreading spikelets; bracts 1 to 6 , the longer ones usually about twice as long as the inflorescence; spikelets 4-25 (-43) $\mathrm{mm}$. long, 0.7-2 $\mathrm{mm}$. broad, about $0.5 \mathrm{~mm}$. thick, with 10 to 40 (to 60 ) scales, brownish-buff to tawnystramineous, straight, the axis slightly 4 -angled, at maturity persistent, each internode on its fertile side with a niche for one edge of the achene, near the base of the niche with minute hyaline wings that narrow and join abaxially forming a minute cup at the base of the achene (use a strong lens!); scales 1.4-2 mm. long, about $1 \mathrm{~mm}$. broad, ovate, appressed, much-overlapping, with 3 obscure nerves at the keel-like median, deciduous; stamens 2; achene lenticular, with an angle fitting the niche of the internode, about $1 \mathrm{~mm}$. long, oblong to narrowly oblong, ripening through brown to black. Incl. var. leptostachyus Boeck.

Locally abundant in seasonally moist sand, in muddy shallows, on vegetation mats in lakes, and at edge of stream, in Okla. (McCurtain and Johnston cos.), e. and s.e. Tex. and coastal part of Rio Grande Plains, spring-fall; widespread in Am. n. to Mass., Pa., Mo., Ark., Okla. and Tex.; the var. polystachyos $(C$. filicinus Vahl) occurs in coastal areas, Mass. to Va.; the var. paniculatus ( $C$. vulgaris var. teretifructus (Steud.) Miq.) occurs widely in trop. of both hemispheres.

\section{Cyperus flavescens L. Fig. 216.}

Tufted annual; culms $10-25 \mathrm{~cm}$. long, basally $0.8-1.9 \mathrm{~mm}$. thick, apically 0.7-1.1 mm. thick; inflorescence a congested (compound) sessile head of 10 to 35 


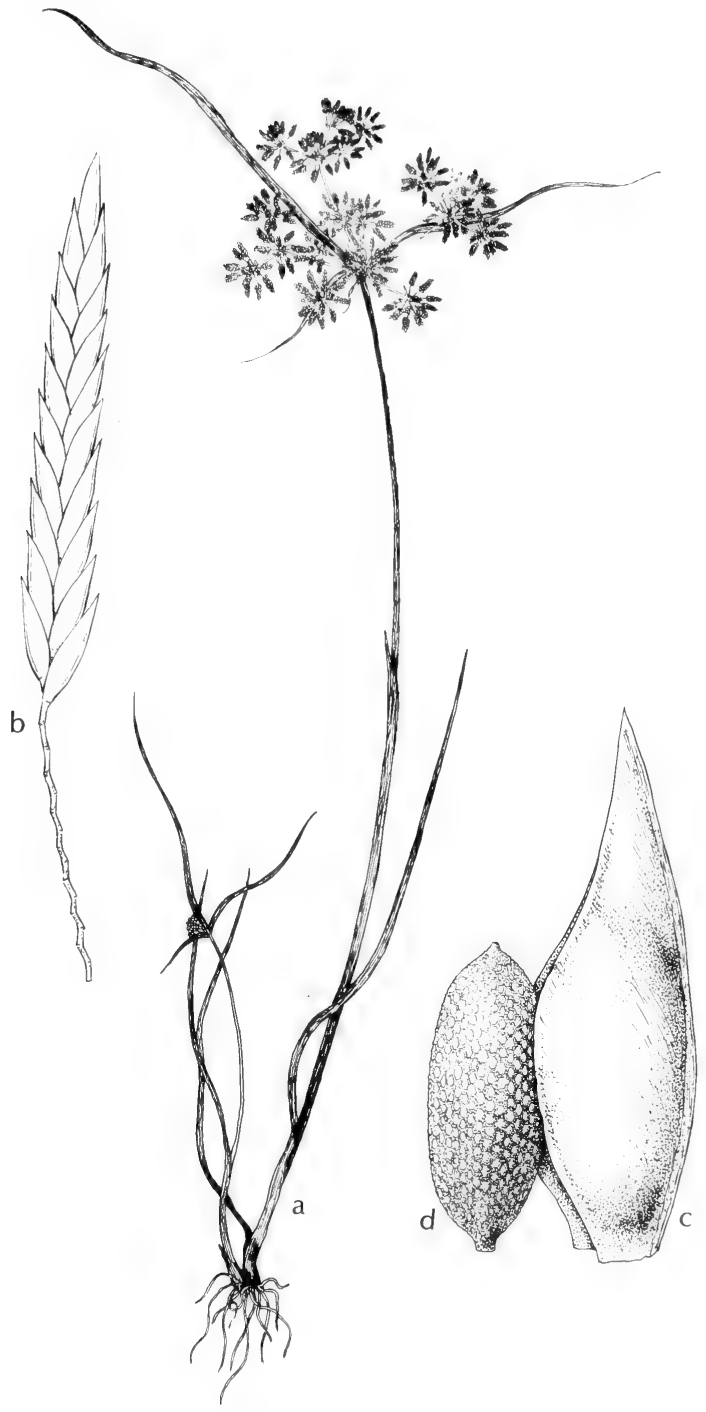

Fig. 217: Cyperus polystachyos var. texensis: a, habit, about $\mathrm{X} 1 / 2 ; \mathrm{b}$, spikelet, about X 8; c, scale, X 40; d, achene, X 40. (Courtesy of R. K. Godfrey). 


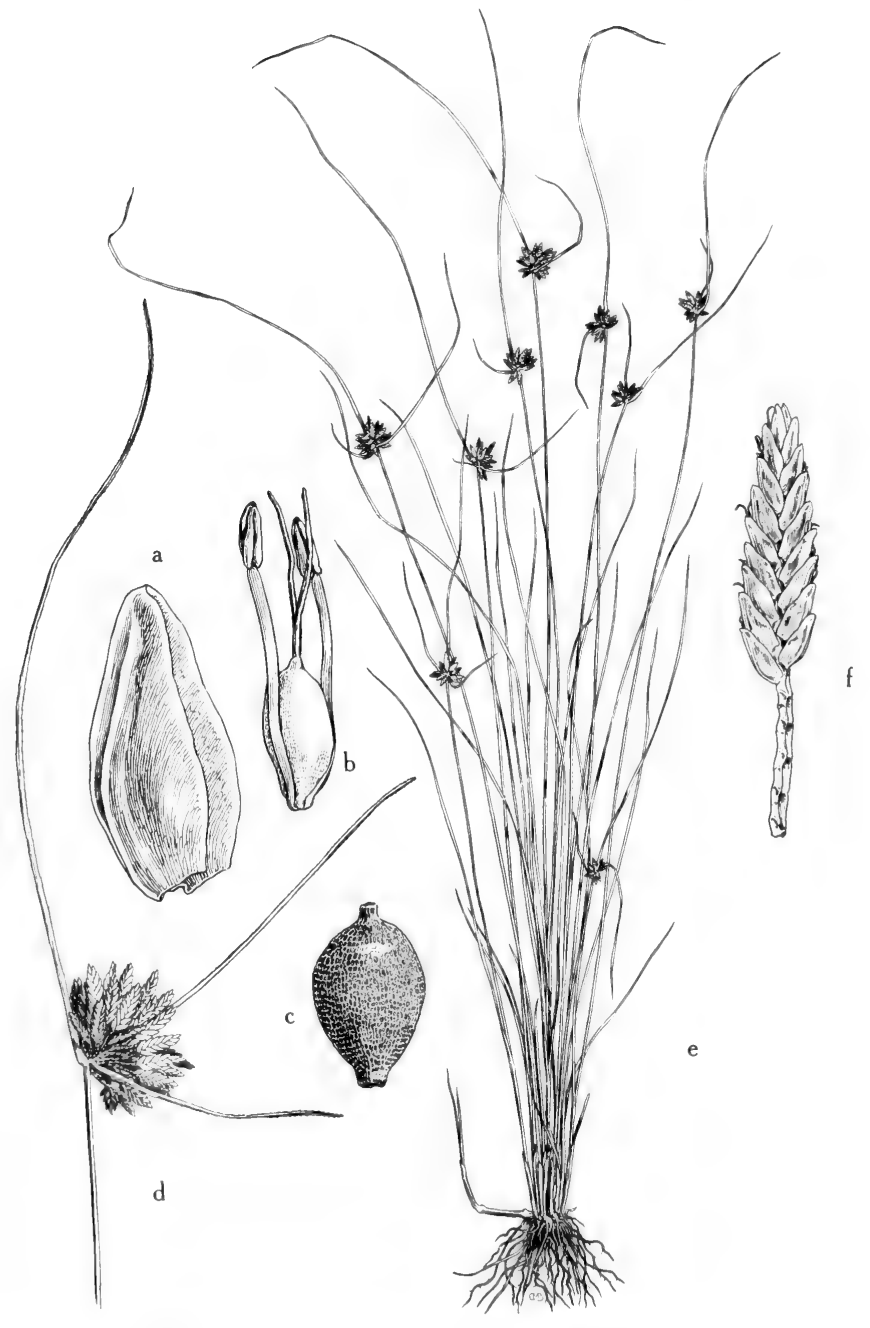

Fig. 218: Cyperus niger var. capitatus: a, scale, showing keel and obtuse apex, $X 16$; b, flower with scale removed, showing the bifid style and the 2 stamens, $X 16$; $c$, mature achene, showing puncticulate surface, $X 16$; d, capitate inflorescence and the involucral leaves unequal in length, $\mathrm{X}=3 ; \mathrm{e}$, habit, showing the short rhizome and the slender erect culms and leaf blades, $X$ i $f$, spikelet, with lower scales removed to show the fractiflex rachis, X 4. (From Mason, Fig. 124). 
spikelets plus occasionally 1 to 3 peduncles $1-3 \mathrm{~cm}$. long each with a head of 4 to 10 spikelets; bracts 1 to 4 , the longer ones usually surpassing the inflorescence; spikelets 6-20 mm. long, $1.8-3 \mathrm{~mm}$. broad, about $0.8 \mathrm{~mm}$. thick, with 22 to 40 scales, mostly straight, uniformly stramineous to ochre-stramineous, the axis persistent straightish, flattened, essentially wingless, each internode with a niche into which fits an angle of the achene; scales deciduous, $1.5-2 \mathrm{~mm}$. long, $1.2-1.6 \mathrm{~mm}$. broad, ovate, with 3 nerves in the keel-like median; stamens normally 3 ; achene lenticular (biconvex), about $0.9 \mathrm{~mm}$. long and $0.6 \mathrm{~mm}$. broad, obovate, substipitate, short-apiculate, ripening to black, surficially shiny and with rectangular linear (vertical) cells (the rows of these cells marked off by horizontal wavy usually discolored sutures). Incl. var, poaeformis (Pursh) Fern.

Infrequent or rare in moist or wet sand, wet meadows, ditches and on seepage slopes, in Okla. (Waterfall), e., s.e. and n.-cen. Tex., July-Nov.; widespread (in several varieties) in warm regions; in Am. n. to N.Y., Pa., Mich., Mo. and Kan.

\section{Cyperus niger R. \& P. Fig. 218.}

Annual or usually weak perennial occasionally forming mats by rooting or very shortly decumbent culms; aerial parts 1-4 (-6) dm. long, mostly erect, subbasally 1-2 $\mathrm{mm}$. thick, apically $0.4-1.4 \mathrm{~mm}$. thick; leaves few, mostly much shorter than the culms; inflorescence commonly of a single sessile irregular head $1-2 \mathrm{~cm}$. thick of 3 to 30 spikelets, rarely more elaborate with a sessile head plus 2 or 3 peduncles to $4 \mathrm{~cm}$. long each with a lax irregular head or glomerule of up to 20 spikelets; bracts 1 to 3 , the longest far-surpassing the inflorescence and (when young) commonly erect (like a continuation of the culm), later spreading; spikelets 7-12 mm. long, $1.7-2.2 \mathrm{~mm}$. broad, about $0.7 \mathrm{~mm}$. thick, with 10 to 22 scales, straight, pale-chestnut-brown or often with darker blotches of chestnut on each scale, rarely almost totally dark-brown, the axis persistent, somewhat 4-angled but essentially wingless, each internode on the fertile side with a niche into which fits an angle of the achene; scales about $2 \mathrm{~mm}$. long, much-overlapping, with about 3 nerves crowded in the arcuate keel-like median, otherwise smooth and shiny, deciduous; stamens 2; achene lenticular (biconvex) about $1 \mathrm{~mm}$. long, elliptic, apiculate, surficially nearly featureless, ripening through shades of brown to nearly black, oriented so an angle fits into the internode niche. C. melanostachys H.B.K.

We have two varieties.

Var. castaneus (Pursh) Kükenth. With usually lax elaborate inflorescences. $C$. bipartitus Torr., $C$. rivularis Kunth. Rare in moist or wet sandy loam in e. Tex. (Austin and Washington cos.); from Que. w. to Minn. and Neb., s. to Ga., Ala., Miss. and Tex.; also Calif. and Ore.

Var. capitatus (Britt.) O'Neill. Fig. 218. With relatively light-colored (chestnutbrown) glumes and strongly apiculate achenes. Local in creeks in igneous TransPecos Tex. mts. at elev. of more than 4,000 ft., and Ariz. (Apache, Navajo, Yavapai, Greenlee, Gila, Cochise, Santa Cruz and Pima cos.), summer-fall; from Cuba and C.A. n.w. to Calif., Ariz. and Colorado.

\section{Cyperus odoratus L. Fig. 219.}

Tufted perennial, rarely rhizomatous or often flowering the first year and behaving annual; culms often slightly tuberous-thickened basally, to $9 \mathrm{dm}$. long, subbasally 1-6 mm. thick, just beneath the inflorescence $0.3-3 \mathrm{~mm}$. thick; inflorescence $1-45 \mathrm{~cm}$. long, of numerous very unequal spreading or ascending primary peduncles the longer of which usually bear several unequal secondary peduncles, all eventually bearing lax to subdense spikes of rather numerous spreading spikelets; bracts 3 to 10 , the longer far-surpassing the inflorescence; spikelets quite variable in size (about $1 \mathrm{~mm}$. broad and thick) and number of scales (4 to 30 ), each internode of the axis unilaterally (on the sterile side) postanthetically bulbous 


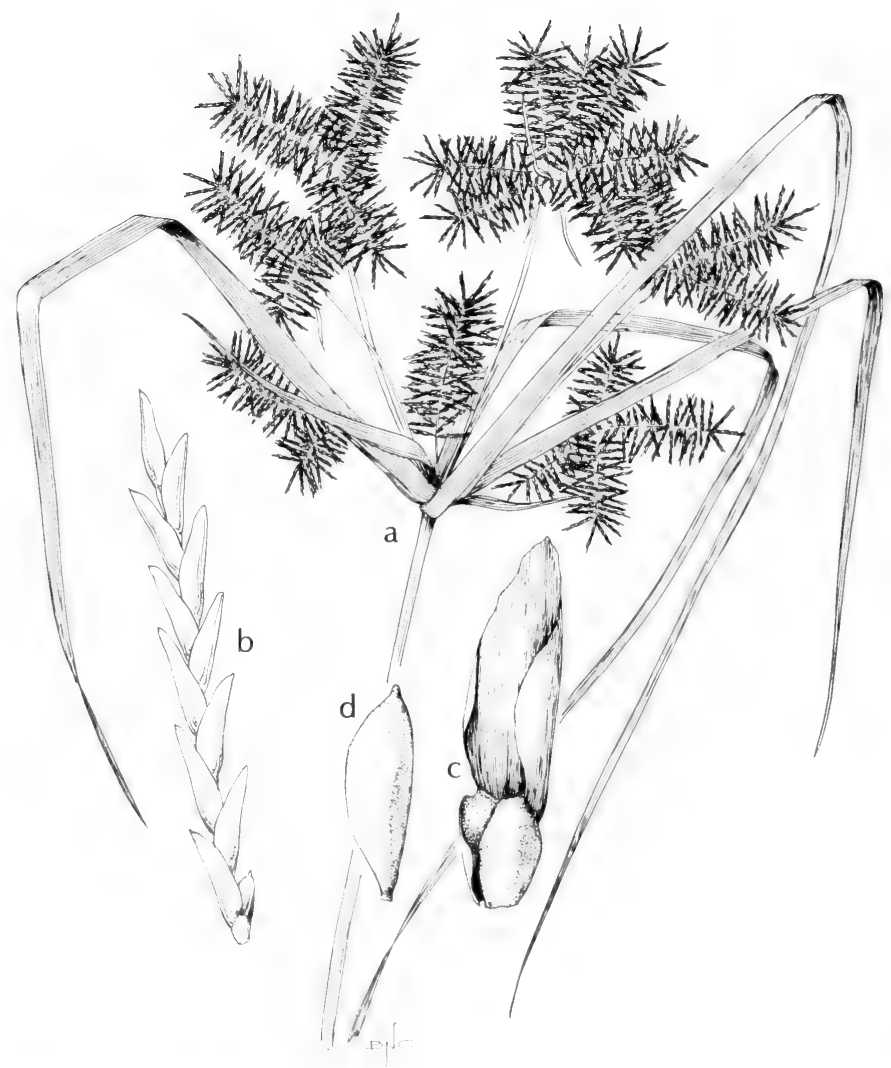

Fig. 219: Cyperus odoratus: a, habit, X 1/2; b, spikelet, X 5 ; c, scale, X 15; d, achene, X 15. (Courtesy of R. K. Godfrey). 


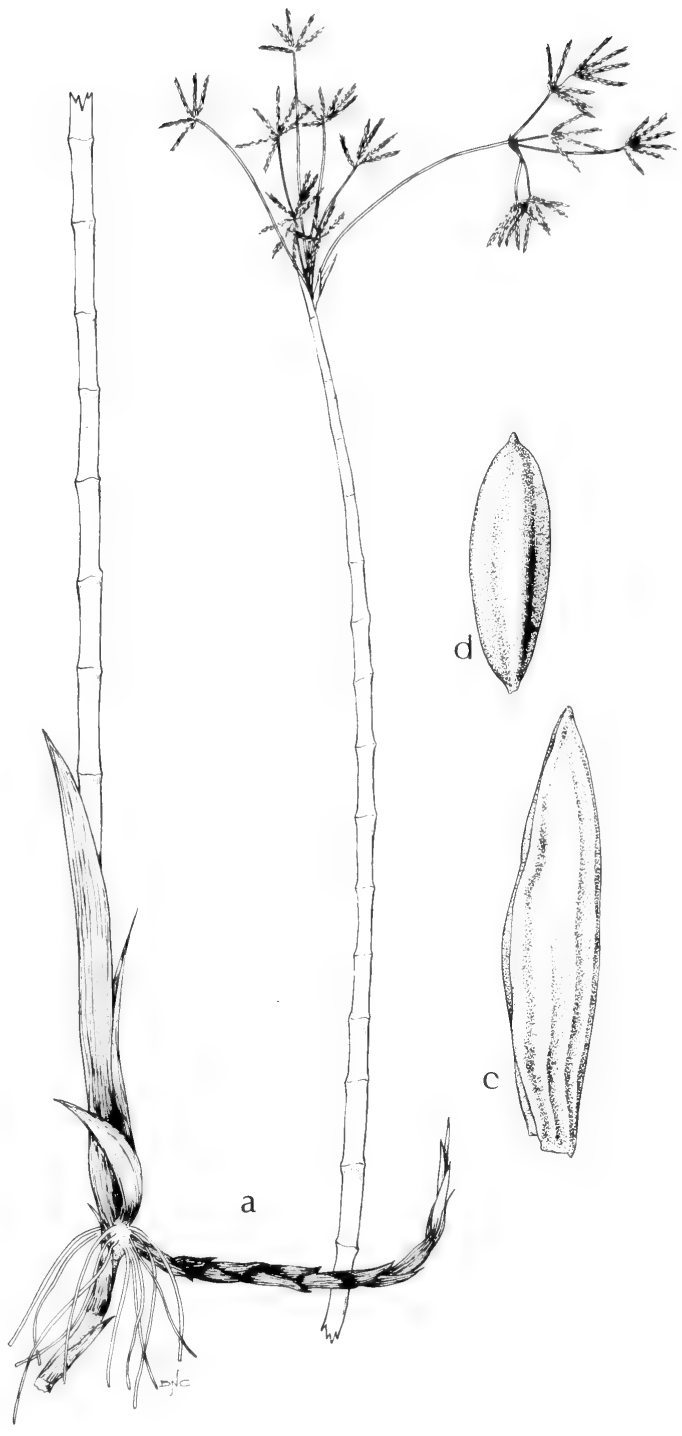

Fig. 220: Cyperus articulatus: a, habit, X 1/2; b, spikelet, X 4; c, scale, X 20; d, achene, X 25. (Courtesy of R. K. Godfrey). 
with white cartilaginous thickening and on the fertile side with 2 hyaline wings (eventually becoming papery) clasping the achene and at the base of each internode (above each node) abscising so that the whole spikelet breaks un into joints each comprising a scale, the next lower internode and the attached wings and achene; scales small, brownish, with a number of nerves, each persistent on its joint; stamens 3; achenes brownish, unequally trigonous, the 2 smaller (sharper) angles adaxial, clasped by the wings. C. ferax Rich., C. speciosus Vahl, C. ferruginescens Buckl.

In mud of swamps, ditches and streams, at edge of lakes and creeks. abundant in all parts of Tex. and Okla., N.M. (San Juan Co.) and Ariz. (widespread); perhaps our most abundant flatsedge and one of the most variable, but it is impossible to distinguish segregate taxa, spring-fall, occasionally, winter; semicosmopolitan in temp. and trop. regions. Passing through the form called $C$. Eggersii Boeck. to $C$. macrocephalus Liebm. with a headlike inflorescence.

\section{Cyperus articulatus L. Chintul. Fig. 220.}

Perennial forming colonies with creeping scaly rhizomes $1.5-6 \mathrm{~mm}$. thick; culms rising at intervals 7-50 mm. apart on the rhizomes, erect, 5-14 dm. long, 2-8 $\mathrm{mm}$. thick, nearly terete or only vaguely triangular, septate at intervals of 5-50 mm.; leaves only few, toward the base, reduced to small essentially bladeless sheaths; bracts few, 3-11 mm. long; inflorescence comprising 4 to 12 glomerules of spikelets, some glomerules nearly sessile and some on slender nodding peduncles to $12 \mathrm{~cm}$. long; glomerules with up to 20 spikelets, essentially bractless; spikelets $6-25 \mathrm{~mm}$. long, about $2 \mathrm{~mm}$. brozd, laterally compressed, the axis remaining intact after the scales and achenes fall; scales keeled, the lower sides decurrent on the spikelet axis as readily deciduous wings $0.2-0.4 \mathrm{~mm}$. wide and about $1 \mathrm{~mm}$. long; stamens 3 ; connective very minutely prolonged beyond the end of the anther; achene unequally trigonous.

Abundant in moist or wet clay meadows, in mud on edge of lakes, along streams and above inlets, s.e. Tex. and Rio Grande Plains, rare n. to s. part of n.-cen. Tex. (Comal, Travis and McLennan cos.), May-Oct.; Braz. and Col. n. to Gulf States.

\section{Cyperus Iria L. Fig. 221.}

Tufted annual; culms 8-60 cm. long, erect; leaves crowded near the base, shorter than the culm; inflorescence 4-12 cm. long (not including the bracts), an umbel-like aggregation of 5 to 8 extremely unequal peduncles each bearing an irregular panicle of several spikes each with a number of ascending spikelets the total inflorescence with 100 to 600 spikelets; bracts about 4 , much longer than the inflorescence; spikelets 3-10 mm. long, $1.3-1.8 \mathrm{~mm}$. broad, with 2 to 22 flowers, the axis persisting and remaining intact even after the achenes and scales fall; scales nearly orbicular or as seen laterally and folded appearing obovate, about $1.5 \mathrm{~mm}$. long, rounded to emarginate, mucronulate, with about 4 nerves in the incurved weakly keel-like median, brownish or golden-brown, the hyaline margins tending to fold in and meet on the adaxial side of the achene, decurrent below as thin striations but not as wings; stamens 2 or 3 ; achene trigonous, 1.2$1.3 \mathrm{~mm}$. long.

Wet clay in coastal rice-growing areas, in water of freshwater canals and on edge of ponds, in Okla. (McCurtain, LeFlore and Pittsburgh cos.) and s.e. Tex. (Colorado, Harris, Jackson and Matagorda cos.), locally common, July-Sept.; s.e. Asia (n. to Korea and Mongolia), N. Austral., Malaysia, India, Afr. Madag., Iran, Afghan., adv. in scattered parts of Am., especially in the Gulf and s. Atl. States; W.I. 


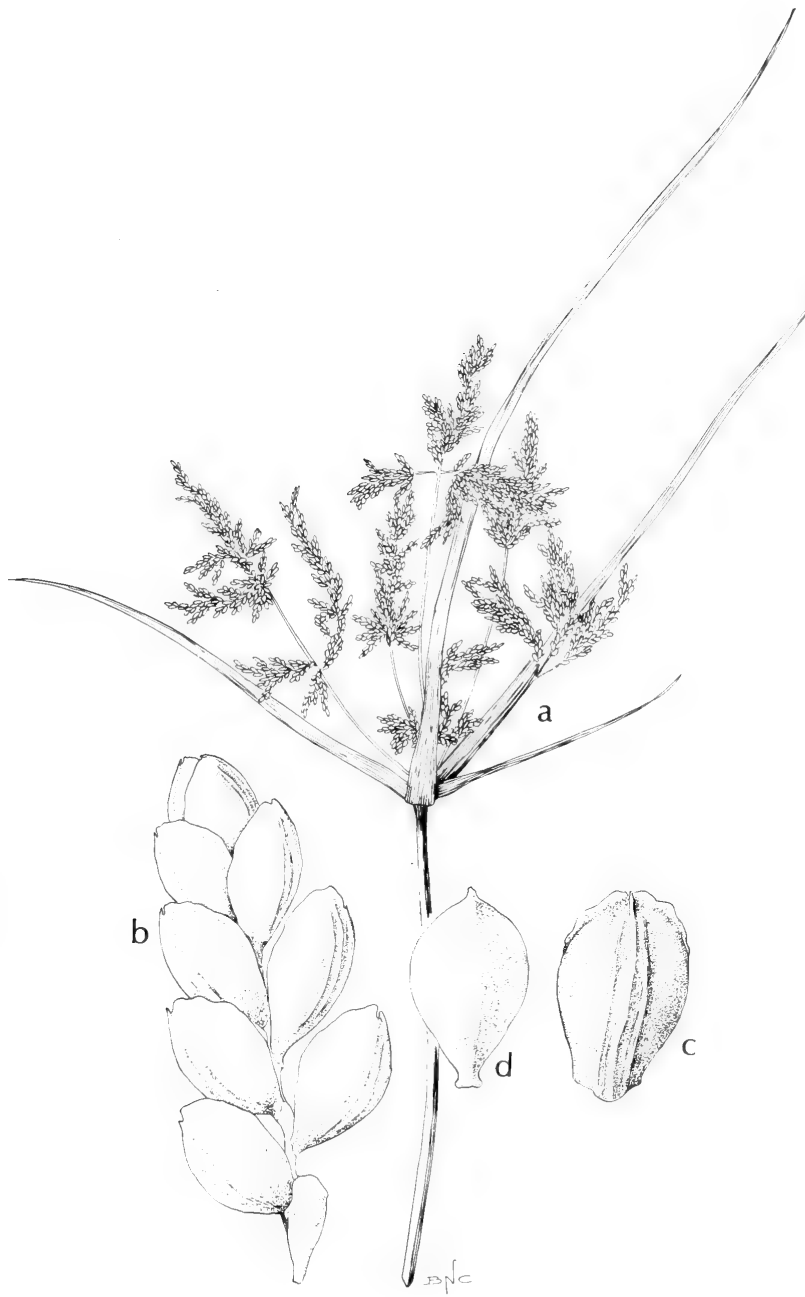

Fig. 221: Cyperus Iria: a, habit, X 1/2; b, spikelet, X 10; c, scale, X 17; d, achene, X 19. (Courtesy of R. K. Godfrey). 

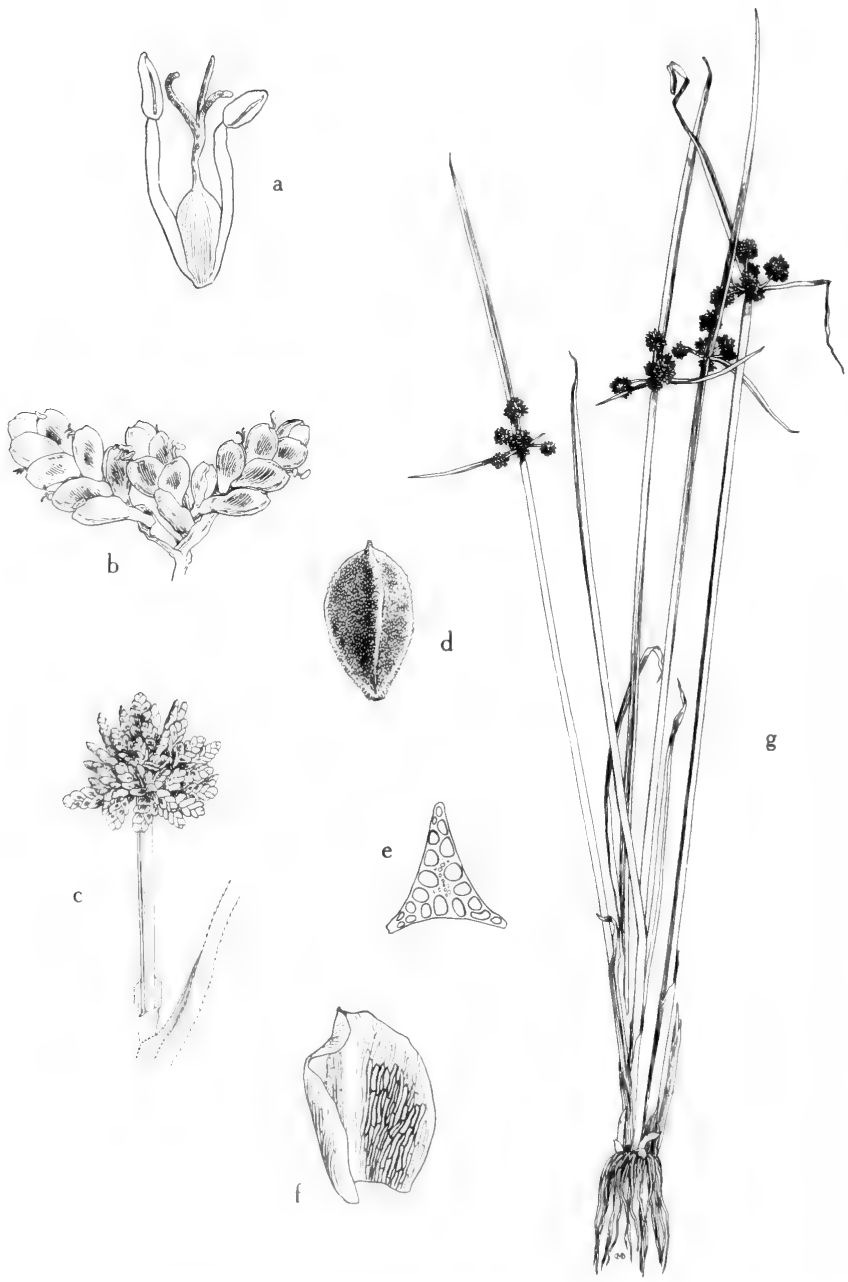

Fig. 222: Cyperus difformis: a, flower without scale, X 40; b, group of spikelets, $\mathrm{X} 8$; $\mathrm{c}$, ray of inflorescence, showing globose head of spikelets and part of scabrellate margin of involucral leaf, $X 2$; d trigonous achene, showing the minutely cellular surface, X 28; e, culm (cross section), X 6; f, scale, X 40; $\mathrm{g}$, habit, showing the umbellate inflorescences with involucral leaves of unequal length, X 1/3. (From Mason, Fig. 130). 


\section{Cyperus difformis L. Fig. 222.}

Annual sedge with fibrous roots and cespitose culms; culms smooth, $15-50 \mathrm{~cm}$. tall; leaves 2 to 4 on a culm, about as long as the culm, 1-4 mm. wide, scaberulous on margins near apex; involucral leaves 2 or 3 , unequal in length; inflorescence umbellate, the globose heads of spikelets sessile or on rays to $7 \mathrm{~cm}$. long; spikelets linear, obtuse, subcompressed, 4-8 mm. long; rachis straight, unwinged; scales roundish, obtuse, $0.6-0.8 \mathrm{~mm}$. long, membranous, green with brown sides, readily deciduous; stamens 1 or 2 ; achene trigonous, obovate, minutely mucronulate, $0.5 \mathrm{~mm}$. long, pale-greenish-brown, the surface minutely cellular.

Common weed in rice fields, Okla. (LeFlore Co.) and Ariz. (Mohave Co.); Okla., N.M., Ariz., Calif. and Mex., nat. of Asia.

\section{Cyperus aristatus Rottb. Fig. 223.}

Tufted annual with persistent coffee-and-chicory or curry powder odor (like Ulmus rubra, Phyllanthus ericoides, Gnaphalium obtusifolium, flowers of Bombacaceae, etc.); culms 1-20 cm. long, the longer leaves often equaling or surpassing them; inflorescence of 1 to 3 heads, essentially sessile at the summit, often with 1 to 6 additional shortly peduncled ones; bracts 2 to 4 , the longer ones farsurpassing the inflorescence, often ascending; heads $5-20 \mathrm{~mm}$. thick, often slightly prolate, with 2 to 50 spikelets; spikelets $4-14 \mathrm{~mm}$. long, 2-3 mm. broad, about $0.5 \mathrm{~mm}$. thick, laterally compressed, straight, with 5 to 30 scales, brown to yellowbrown to tawny-brown, the axis essentially wingless, at maturity eventually deciduous as a unit from the head axis; scales deciduous either before or after fall of the spikelet axis, 2-2.5 mm. long, about in the distal third the length being a very slender sharp acuminate-subulate prominently recurved tip, with 7 or 9 evenly distributed nerves; stamen 1 ; achene $0.7-1 \mathrm{~mm}$. long, $0.2-0.5 \mathrm{~mm}$. broad, from nearly linear-oblong to obovoid, dark-brown. C. inflexus Muhl.

In wet soils, on edge of lakes and ponds and marshes, in Okla. (Stephens, McIntosh, Alfalfa, LeFlore and Johnston cos.) to Ariz. (Navajo and Coconino, s. to Cochise, Santa Cruz and Pima cos.) throughout Tex. (except Plains Country), scattered, spring-early winter; nearly cosmopolitan in temp. and trop. areas.

In extreme south coastal Texas occurs the var. Runyonii O'Neill with the achenes at the extremes of greatest length and narrowness allowed here.

\section{Cyperus amabilis Vahl var. macrostachyus (Boeck.) Kükenth.}

Rachilla articulated with the rachis at the base, wingless; bracts 3 to 6 , scarcely if at all exceeding the inflorescence; rays 0 to 10 ; spikelets $10-18 \mathrm{~mm}$. long, 1.5-2.5 mm. wide, lustrous, reddish-brown, digitate-radiate in heads; scales 3nerved, aristate, 1.5-2.7 mm. long; achene trigonous; style branches 3 ; stamen 1 (rarely 2).

Ariz. (Santa Cruz Co.); to S.A.

\section{Cyperus seslerioides H.B.K.}

Tufted perennial forming tough fibrous black mats (bulblike bases connected by extremely short branching rhizomes); culms $10-25 \mathrm{~cm}$. long, erect, basally about $1 \mathrm{~mm}$. thick, apically about $0.5 \mathrm{~mm}$. thick; leaves 2 or 3 per culm, basal, 1-2 mm. broad; inflorescence (excluding bracts) 6-12 $\mathrm{mm}$. long, contracted into a single densely flowered several-lobed subhemispheric whitish or pallid-brownish (Dichromena-like) head; bracts 3 or 4 , linear, 2 to 10 times as long as the head, spreading or reflexed; spikelets 3-7 mm. long, 2-2.5 $\mathrm{mm}$. broad, compressed, with 10 to 20 flowers, the axis wingless and persistent as a unit after the scales have fallen; scales 1.5-2.7 mm. long, 1.1-1.6 mm. broad, membranous, 3-nerved, acuminate, sharp; stamen 1 ; achene $0.7-1 \mathrm{~mm}$. long and nearly as thick, suborbicular, strongly 3 -angled with concave sides, maturing to a very dark-brown. 


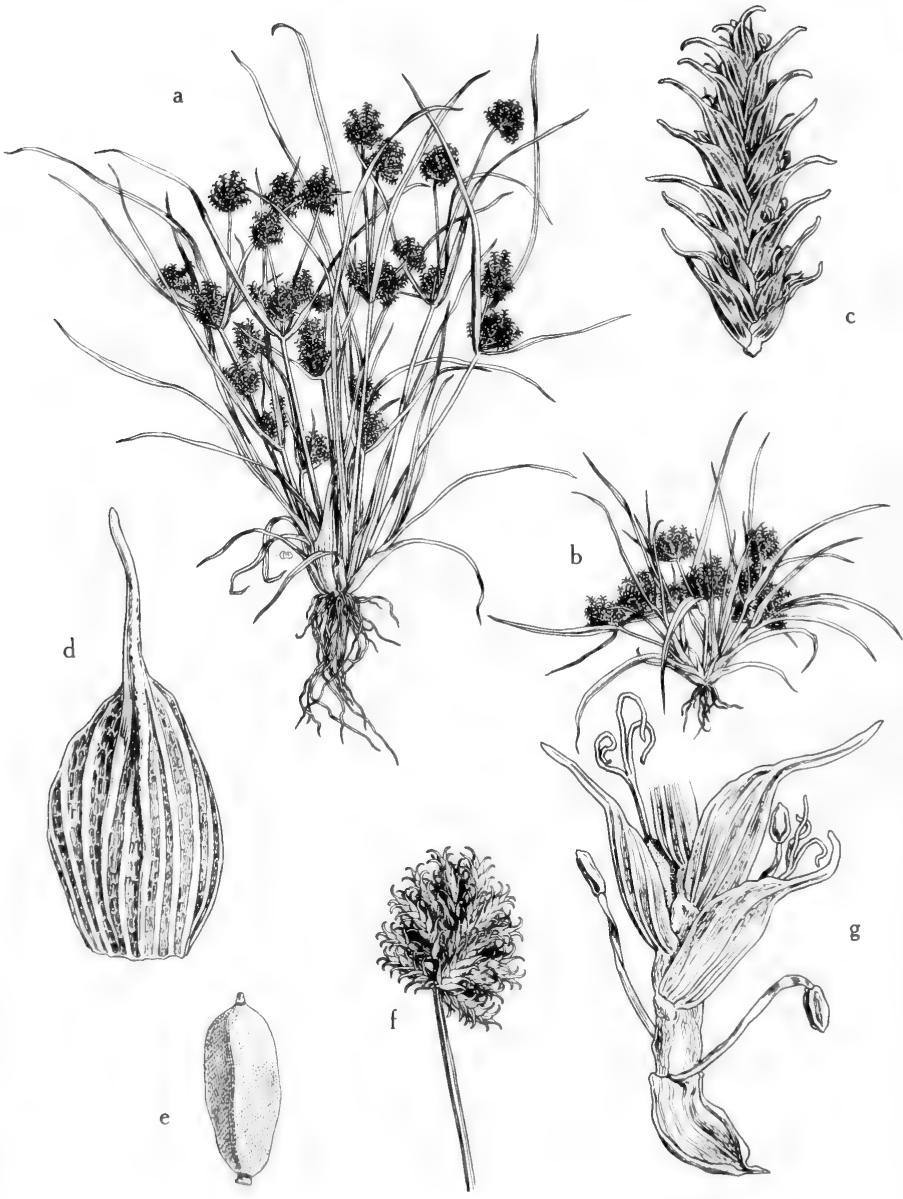

Fig. 223: Cyperus aristatus: a and b, habit, showing the umbellate inflorescences, each ray bearing a capitate cluster of spikelets, $X_{2 / 3}$; c, compressed spikelet, showing the recurved awns of scales, X 8; d, scale, showing the strong nerves, X 32; e, mature achene with puncticulate surface, $X 24 ; f$, ray of inflorescence, showing capitate arrangement of spikelets, $X \quad 1_{2}^{1} ; \mathrm{g}$, rachis, showing persistent stamens, arrangement of achenes and the trifid styles, X 20. (From Mason, Fig. 128). 


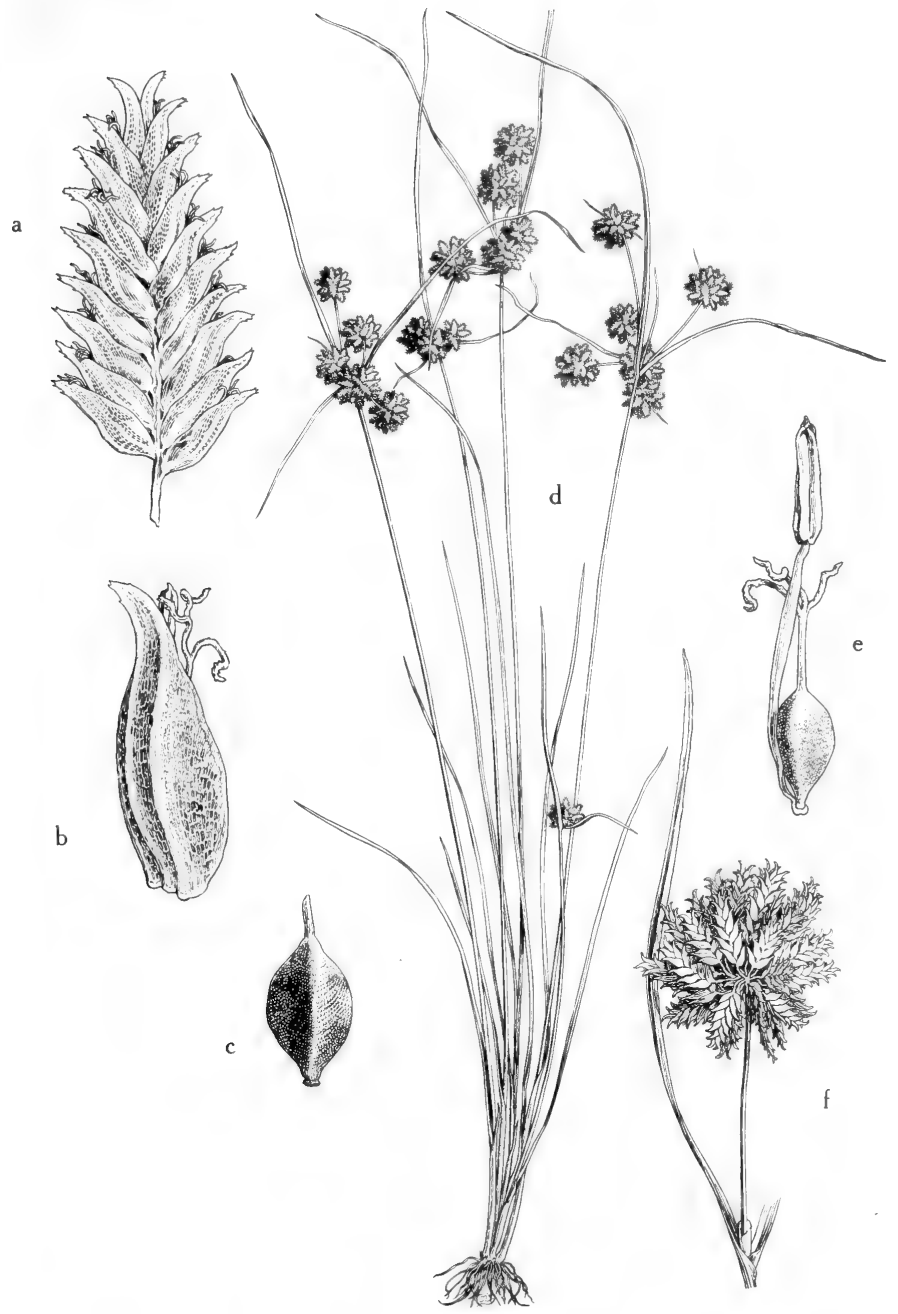

Fig. 224: Cyperus acuminatus: a, spikelet, showing the recurved tips of scales, X 8; b, scale, 3-nerved, the surface cellular-reticulate, X 20; c, trigonous achene, X 20; d, habit, showing the globose heads of spikelets on rays of unequal length, $X 1 / 3$; e, flower without scale, X $20 ; \mathrm{f}$, ray of inflorescence, showing globose head of spikelets, $X 11 \%$. (From Mason, Fig. 129). 
Scarce in shaded moist ravines high in the Chisos Mts. in the Tex. Trans-Pecos and Ariz. (Cochise and Santa Cruz cos.), summer; Venez., Guat., Mex., Ariz. and Tex.

\section{Cyperus acuminatus T. \& H. Fig. 224.}

Short-lived perennial, flowering the first year, tufted; culms $1-4 \mathrm{dm}$. long, erect, basally with a few leaves and $0.7-1.2 \mathrm{~mm}$. thick, just beneath the inflorescence $0.4-0.8 \mathrm{~mm}$. thick, roundly triquetrous, smooth or with more or less abundant microscopic knobs more or less at right angles to the culm; leaves few, $0.5-2 \mathrm{~mm}$. broad, the longer ones sometimes equaling the culms, basally not septate; inflorescence (excluding bracts) $2-8 \mathrm{~cm}$. long, of 2 to 5 very unequal primary peduricles, the shorter of which bear nearly hemispherical to spherical glomerules of 13 to 25 spikelets, the longer ones with such glomerules (rarely compound or with secondary peduncles) of up to 55 spikelets; bracts 3 or 4 , the longer ones nearly erect and far-surpassing the inflorescence; spikelets 4-10 mm. long, 1.5-2.5 mm. broad, nearly linear, with 12 to 44 flowers, stramineous to brownish-stramineous or rarely tawny-stramineous, laterally compressed, the axis slightly flattened, wingless and persistent as a unit after the scales and achenes have fallen; scales laterally membranous, inconspicuously cellular, medially firmmembranous, $1.3-1.9 \mathrm{~mm}$. long, in the proximal fifth to fourth the length with a flattish area about $0.2 \mathrm{~mm}$. broad dorsally (abaxially), the 2 lateral parts $0.4-0.6$ $\mathrm{mm}$. broad (the scale spread out $0.8-1.2 \mathrm{~mm}$. broad, ovate or narrowly so), tapering distally to the acute apex, with 3 nerves (the inconspicuous midnerve plus on each side a conspicuous nerve about three eighths to two fifths the distance from the midnerve to the margin), the dorsal (median) portion of the scale (as the scale is folded in position in the spikelet) incurved in the lower part, in the distal part either straight or usually with a slight to marked excurvature so that the whole is weakly S-shaped; stamen 1; achene elliptic, 0.9-1.1 mm. long, $0.35-0.45 \mathrm{~mm}$. thick, sharply trigonous, basally short-stipitate, apically prolongedacuminate, pale-brown, occasionally maturing to brown. C. cyrtolepis T. \& $\mathbf{H}$.

Abundant in moist places, wet soil and sandy shore of lakes and ponds, and in shallow water, in Okla. (Stephens, Love, Ottawa, Comanche, McCurtain and Mayes cos.), e., s.e., n.-cen. Tex. and Rio Grande Plains, rare in Edwards Plateau (Central Mineral Region only) and the Trans-Pecos (Jeff Davis and Presidio cos.) and Ariz. (Graham, Gila, Cochise and Pima cos.), almost all year; Mo. and N.C., s. to La., Tex. and Coah.; also Ga., Ariz., Nev., Calif. and Ore.

Young specimens strongly simulate dwarf specimens of $C$. reflexus.

\section{Cyperus surinamensis Rottb. Fig. 225.}

Short-lived tufted perennial, flowering the first year; culms 1-4 (-8) dm. long, with scattered microscopic retrorse projections like shark's teeth, erect, basally with a few leaves and $0.8-3.5(-4.5) \mathrm{mm}$. thick, just beneath the inflorescence 0.4-1.5 mm. thick and bluntly triquetrous; leaves few, the longer ones nearly as long as the culm, basally usually with scattered microscopic transverse septa between the nerves; inflorescence (excluding bracts) $1-8 \mathrm{~cm}$. long, of (4 to) 7 to 12 very unequal primary peduncles the shorter of which bear nearly spherical glomerules of 8 to 25 spikelets, the longer usually with several very unequal secondary peduncles each with a nearly spherical head of 11 to 35 spikelets; bracts 5 to 7 , the longer ones far-surpassing the inflorescence; spikelets 3-6 $(-14)$ $\mathrm{mm}$. long, 1.8-2.5 $\mathrm{mm}$. broad, nearly linear, with 10 to 20 (to 30 ) flowers, stramineous to chartreuse or ochraceous, laterally compressed, the axis slightly flattened, wingless and persistent as a unit after the scales and achenes have fallen; scales laterally membranous, inconspicuously cellular, medially slightly firmer, $1-1.5 \mathrm{~mm}$. long, in the proximal third to three fifths the length with a flat abaxial (dorsal) area $0.15-0.2 \mathrm{~mm}$. broad, the 2 lateral parts $0.4-0.6 \mathrm{~mm}$. broad (the 


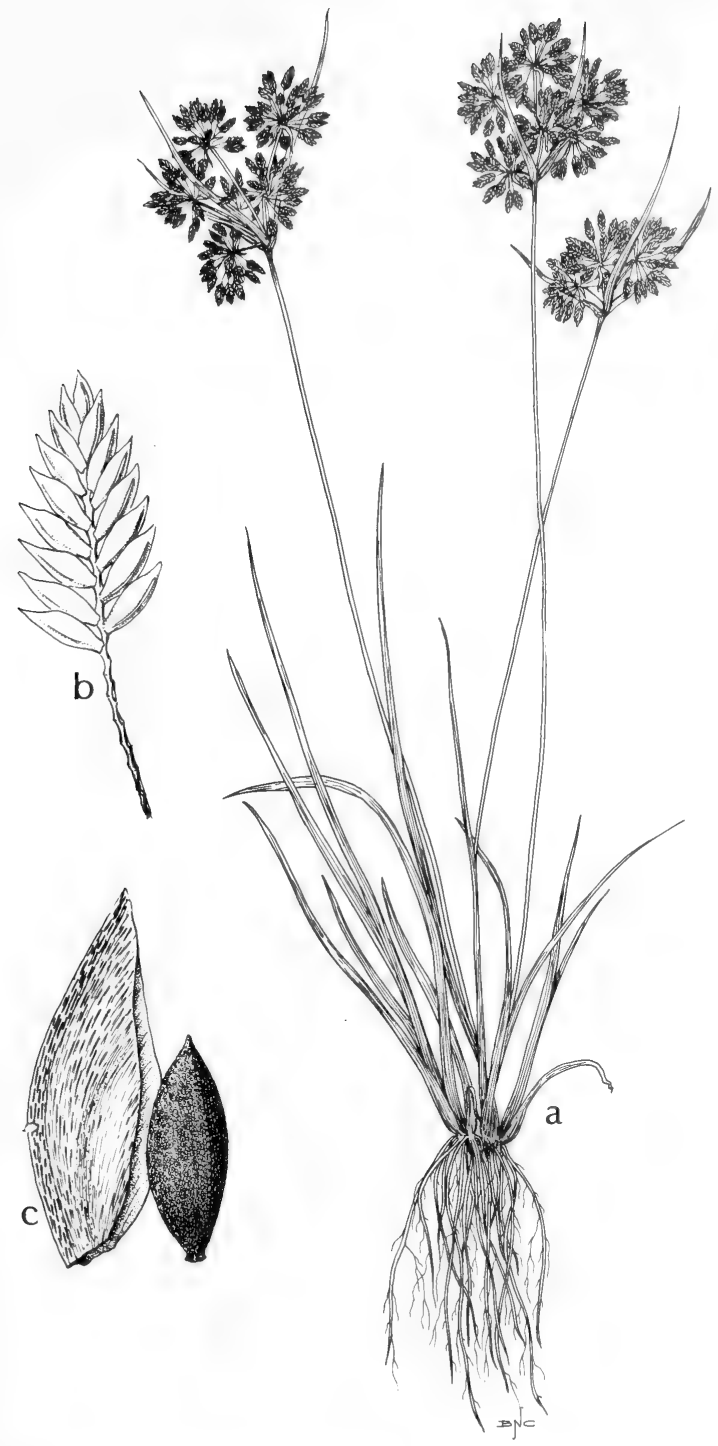

Fig. 225: Cyperus surinamensis: a, habit, X 1/2; b, spikelet, X 10; c, scale and achene, X 40. (Courtesy of R. K. Godfrey). 


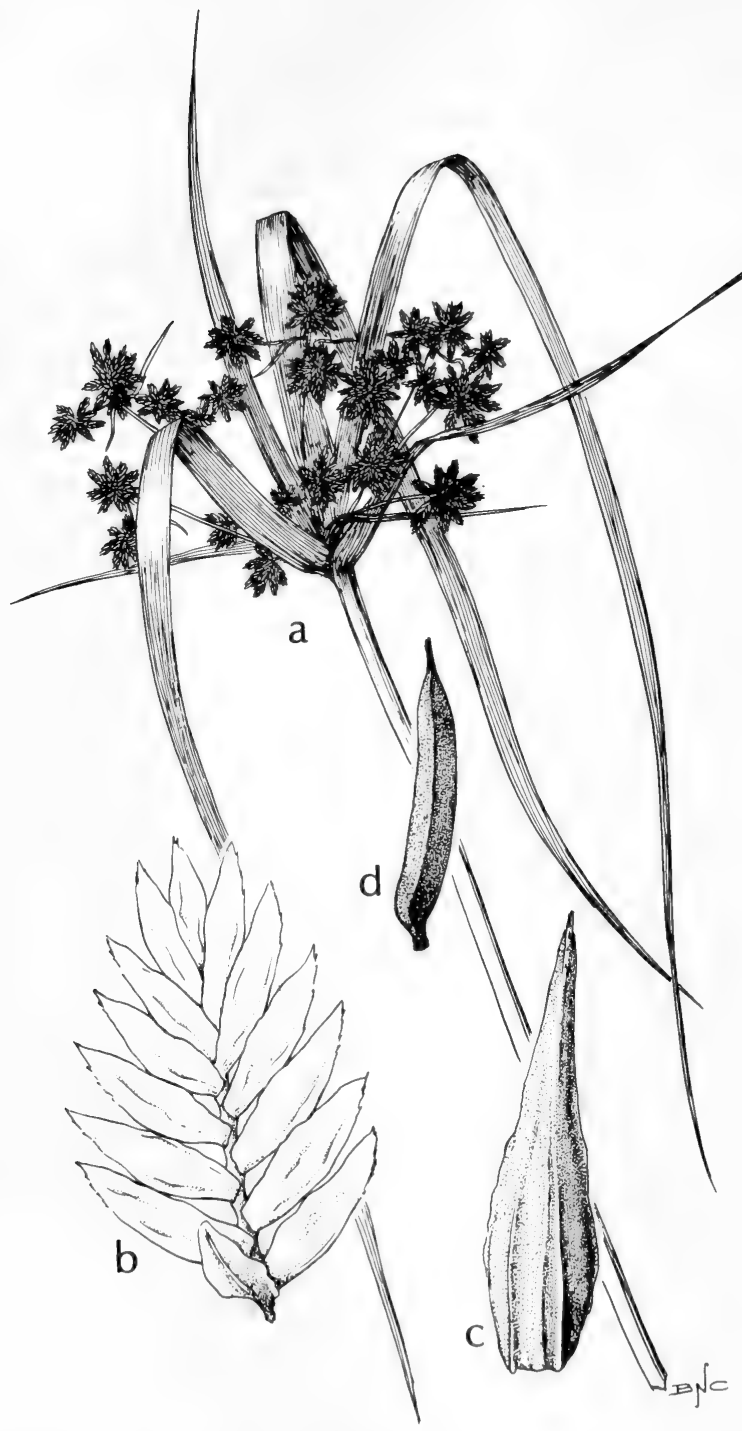

Fig. 226: Cyperus virens: a, habit, X 1/2; b, spikelet, X 8; c, scale, X 26; d, achene, X 26. (Courtesy of R. K. Godfrey). 
scale when spread out $0.9-1.2 \mathrm{~mm}$. broad, ovate), rounded or slightly acute, with 3 nerves (the inconspicuous midnerve plus the 2 prominent laterals which form the proximal keels); dorsum of the scale as it is folded in position in the spikelet gently incurved in the proximal part, nearly straight distally; stamen 1; achene elliptic-oblong or oblong, $0.7-0.8 \mathrm{~mm}$. long, $0.25-0.3 \mathrm{~mm}$. thick, bluntly trigonous, dark-rosy-brown, basally minutely stipitate, apiculate or shortly acuminate.

Infrequent in moist places, wet meadows and pastures, s.e. Tex. and coastal parts of Rio Grande Plains, rare in n.-cen. and e. Tex., July-Nov., rarely spring; Arg. and Bol. n. to Fla., La. and Tex.

\section{Cyperus virens Michx. Fig. 226.}

Tufted perennial; culms 5-11 dm. long, erect, basally leafy and 5-12 mm. thick, just beneath the inflorescence $3-8 \mathrm{~mm}$. thick, sharply triquetrous and often with microscopic rigid antrorse projections like shark's teeth especially on the angles; leaves several, the longer ones almost as long as the culm, basally usually with numerous short incomplete transverse septa visible after pressing and drying; inflorescence (excluding bracts) 3-13 $\mathrm{cm}$. long, of 6 to 14 very unequal primary peduncles, the shorter of which bear nearly spherical heads of 12 to 30 spikelets, the longer ones bearing some shorter unequal secondary peduncles each with a head of 16 to 40 spikelets; bracts 5 to 9 , the longer ones far-surpassing the inflorescence; spikelets $6-13 \mathrm{~mm}$. long, 2.5-3.3 broad, linear, acute, with 10 to 36 flowers, stramineous (young) to olive-brown or grayish-brown (mature), laterally compressed, the axis flat, wingless and persistent as a unit after the scales and achenes have fallen; scales laterally firm-membranous and with visible cells, medially chartaceous (to eventually subcartilaginous), 2-2.4 $\mathrm{mm}$. long, in the proximal third to five eighths the length definitely bicarinate with a flat area or shallow groove $0.25-0.4 \mathrm{~mm}$. broad dorsally (abaxially), the 2 lateral parts $0.5-0.6 \mathrm{~mm}$. broad (therefore the scale spread out $1.2-1.5 \mathrm{~mm}$. broad just below the middle), in the lower half linear, gently tapering distally, with 5 nerves ( 1 of these being the inconspicuous midvein between the keels), including 1 nerve at each keel and 1 on each lateral face about a fourth to a third the distance from the keel to the margin, the whole scale (as folded in the spikelet) incurved slightly in the distal half; stamen 1; achene linear, triquetrous, basally stipitate, apically acuminate, $1-1.5 \mathrm{~mm}$. long, $0.3-0.5 \mathrm{~mm}$. thick, brownish with a very thin translucent surficial layer of cells.

Abundant in moist places, in shallow water and on edge of streams, ponds and lakes, in Okla. (McCurtain, Sequoyah, Muskogee, LeFlore and Osage cos.) and s.e. Tex., frequent in e. Tex. and coastal parts of Rio Grande Plains, May-Oct.; Urug. and Ecu. n. to N.C. and the Gulf States, adv. in Calif.

Through error, the name $C$. virens has been widely misapplied to $C$. pseudovegetus. The 2 taxa are extremely closely related and occasionally hybridize. Young specimens of $C$. virens greatly resemble $C$. pseudovegetus.

\section{Cyperus ochraceus Vahl. Fig. 227.}

Perennial, tufted; culms $11-80 \mathrm{~cm}$. long, basally $2-5 \mathrm{~mm}$. thick, apically bluntly trigonous, 1-2.7 mm. thick, erect, smooth; leaves several, basally aggregated, the longer ones about as long as the culm, not septate-nodulose; inflorescence (excluding bracts) $25-185 \mathrm{~mm}$. long, of 6 to 12 very unequal primary peduncles, the shorter of which bear nearly spherical lax heads of 4 to 15 spikelets, the longer ones bearing some short unequal secondary peduncles each with a head of 4 to 24 spikelets; bracts 5 to 8 , the longer ones far-surpassing the inflorescence; spikelets 5-20 mm. long, 2-2.5 (-3) $\mathrm{mm}$. broad, linear, acute, with 10 to 30 (to 40 ) flowers, olive-stramineous (young) to olive-yellow or yellowishbrown (mature), laterally compressed, the axis flat, wingless and persistent as a 


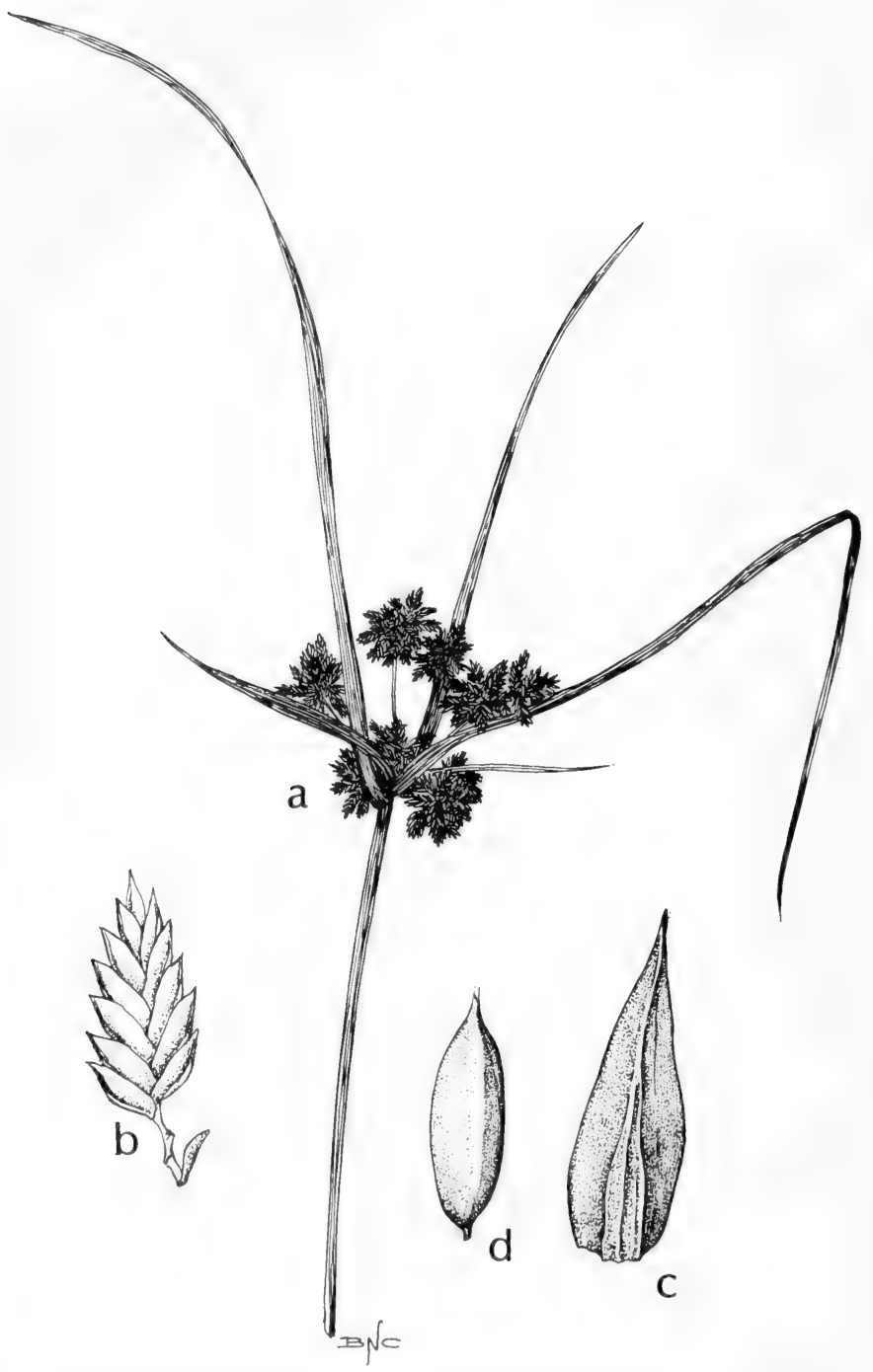

Fig. 227: Cyperus ochraceus: a, habit, X 1/2; b, spikelet, X 3; c, scale, X 25; d, achene, X 20. (Courtesy of R. K. Godfrey). 
unit after the scales and achenes have fallen; scales laterally membranous and with visible cells, medially chartaceous (eventually subcartilaginous), 1.5-2 mm. long, in the proximal half to two thirds definitely bicarinate with a flat area or shallow groove $(0.3-0.5 \mathrm{~mm}$. broad) dorsaliy (abaxially), the 2 lateral parts $0.6-0.7 \mathrm{~mm}$. broad (therefore the scale when spread out $1.5-1.9 \mathrm{~mm}$. broad at the very base, tapering all the way to the blunt apex), with 5 nerves (the midvein in the channel between the keels inconspicuous) including a nerve at each keel and one on each lateral face about a third the distance from the keel to the margin, the whole scale as folded in position in the spikelet incurved slightly in the distal half; stamen solitary; achene ovoid, $1.3-1.5 \mathrm{~mm}$. long, 0.5-0.6 mim. thick, nearly terete or obscurely triangular, slightly stipitate, apically acuminate and passing imperceptibly into the style, black when mature but appearing dark-iridescentgray because of outer 1-cell thick covering of translucent cells; stigmas 3 .

Abundant in shallow water and mud, and edge of lakes and ponds, Rio Grande Plains (n. to Bexar Co.) and s.e. Tex., throughout year, most profuse Sept.-Nov.; C.A., W.I., Mex., n. to Cuba and La.

\section{Cyperus pseudovegetus Steud.}

Tufted perennial, often slightly more loosely tufted than in $C$. virens by elongation of rhizomes 2-5 $\mathrm{mm}$. between culms; culms 3-8 dm. long, erect basally with a few leaves and $2-5 \mathrm{~mm}$. thick, just beneath the inflorescence $1-2.2 \mathrm{~mm}$. thick, roundly triquetrous, smooth or rarely with microscopic antrorse scabrousness; leaves few to several, the larger ones almost as long as the culms, basally often with minute transverse septa between the close veins; inflorescence (excluding bracts) $2-9 \mathrm{~cm}$. long, of 3 to 10 very unequal primary peduncles, the shorter of which bear dense strongly 3- to 8-lobed glomerules or heads of 15 to 50 spikelets, the longer ones bearing some shorter unequal secondary peduncles each with such a head; bracts 3 to 6 , the longer ones far-surpassing the inflorescence; spikelets 2.5-4 mm. long, 2.3-3 mm. broad, narrowly ovate, blunt or slightly acute, with 6 to 14 flowers, tawny stramineous to (very slightly reddish-) brown, laterally compressed, the axis flat, wingless and persistent as a unit after the scales and achenes have fallen; scales laterally membranous with visible cells, medially firm to chartaceous, $1.8-2.5 \mathrm{~mm}$. long, in the proximal fourth to third the length bicarinate with a flat or shallowly groovelike area $0.1-0.2(-0.3) \mathrm{mm}$. broad dorsally (abaxially), the 2 lateral parts $0.2-0.4 \mathrm{~mm}$. broad (therefore the scale spread out is $0.6-0.7 \mathrm{~mm}$. broad near the middle, almost linear), tapering only at the very tip, with 5 inconspicuous nerves in the median portion, the whole scale (as folded in the spikelet) incurved-falcate; stamen 1; achene linear, 1-1.3 $\mathrm{mm}$. long, $0.2-0.3 \mathrm{~mm}$. thick, bluntly trigonous, basally short-stipitate apically acuminate, often slightly falcate, brown with a very thin translucent-iridescent surficial layer of cells. C. arenicola Steud.

Locally frequent in moist places, about lakes and ponds, in marshy areas and seepage areas, in Okla. (Pushmataha, McCurtain, Pittsburgh, Atoka, Love and LeFlore cos.), e. and s.e. Tex., infrequent in n.-cen. Tex., May-Sept.; Gulf States and n. to N.J., Ind., Ill., Mo. and Kan.

Through error this species, in some works, has been called $C$. virens.

\section{Cyperus reflexus Vahl.}

Perennial with scaly creeping rhizomes $1-1.5 \mathrm{~mm}$. thick; culms contiguous or several $\mathrm{mm}$. apart along the rhizome, 3-7 dm. long, erect, basally with a slightly bulblike enlargement, with a few leaves and 1-2.5 $\mathrm{mm}$. thick (just above the "bulb"), just beneath the inflorescence $0.5-1.3 \mathrm{~mm}$. thick, roundly triquetrous, smooth; leaves few, the longer ones about as long as the culms or shorter, basally not septate; inflorescence (excluding bracts) 15-50 $\mathrm{mm}$. long, of 3 to 8 very 


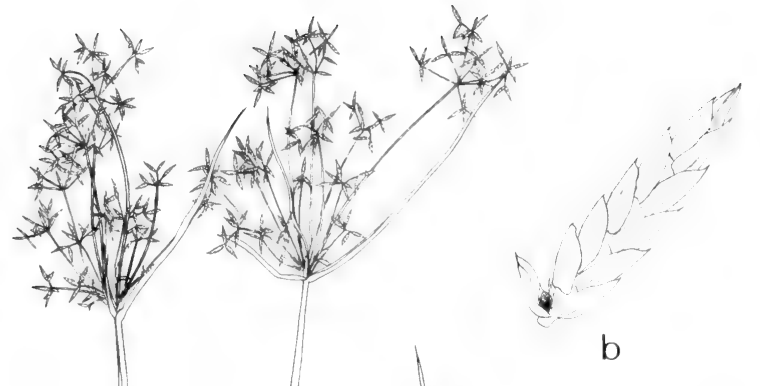


unequal primary peduncles the shorter of which bear very dense strongly 3- to 8 -lobed glomerules of 25 to 50 spikelets, the longer ones (more than $15 \mathrm{~mm}$. long) with dense strongly 15 - to 30 -lobed compound glomerules of up to 100 spikelets; bracts 3 to 5 , the longer ones far-surpassing the inflorescence; spikelets $3-5 \mathrm{~mm}$. long, 1.5-2.2 $\mathrm{mm}$. broad, nearly linear in the lower part, distally tapered and apically crowded, with 8 to 12 flowers, red and green, laterally compressed, the axis flat, wingless and persistent as a unit after the scales and achenes have fallen; scales laterally red, membranous, inconspicuously cellular, medially firmmembranous, $1.5-2 \mathrm{~mm}$. long, in the proximal fourth the length with a narrow flat area about $0.2 \mathrm{~mm}$. broad dorsally (abaxially), the 2 lateral parts red, $0.5-$ $0.6 \mathrm{~mm}$. broad (therefore the scale spread out is about $1.1 \mathrm{~mm}$. broad, narrowly ovate), tapering distally to the slightly acute tip, with 5 inconspicuous nerves in the median portion, the median portion of the scale (as folded in position in the spikelet) with a distinct curve in the proximal part but distally nearly straight; stamen 1; achene oblong or elliptic-oblong, 0.9-1 (-1.2) $\mathrm{mm}$. long, 0.3-0.4 mm. thick, sharply trigonous, basally short-stipitate, apically shortly acuminate or pyramidal, pale-brown (finally dark-fuscous beneath the outer cellular layer). $C$. rufescens Torr.

Rare in e. and s.e. Tex., inland to Houston, Bastrop and DeWitt cos., in moist or wet sand, spring-summer; otherwise scattered in S.A., Mex., La. and Okla.

Only mature material can be determined with confidence.

\section{Cyperus phaeolepis Cherm.}

Densely tufted perennial; culm 3-5 (-9) dm. long, erect, basally 2-3 mm. thick, just beneath the inflorescence $1.7-2 \mathrm{~mm}$. thick, irregularly striate; leaves few, basal, reduced to usually reddish-brown sheaths with diagonal orifices, the "blades" only a few mm. long; inflorescences (excluding bracts) $1-2 \mathrm{~cm}$. long, of 8 to 12 unequal peduncles each bearing a headlike (occasionally compound) glomerule of 8 to 15 spikelets; bracts 9 to 13 , spreading, $3-10 \mathrm{~cm}$. long, (1-) 3-5 mm. broad, abruptly acute; spikelets $3-6 \mathrm{~mm}$. long, $1.5-2 \mathrm{~mm}$. broad, with 12 to 18 flowers, compressed slightly, the axis flat, wingless and remaining intact as a unit after the scales have fallen (achenes sometimes more persistent); scales 1.3-1.5 mm. long, about as broad, broadly ovate when unfolded, obtuse, laterally membranous, whitish or with a chestnut-tawny splotch, dorsally-proximally flat, the midnerve obscure and the 2 other nerves forming keels on each side of the flat area for about three eighths the total length; stamens 3 ; achenes $0.7-0.8 \mathrm{~mm}$. long, ellipsoid, obscurely trigonous, pallid-brown turning brown. C. albiflorus Cherm.

Rare in moist or wet places, s.e. (Galveston Co.) and Trans-Pecos (Pecos Co.) Tex., escaped, Apr.-June; Madag.; Tex.

\section{Cyperus Haspan L. Fig. 228.}

Short-lived tufted perennial, flowering the first year; culms 1-7 dm. long, erect, basally $2-5 \mathrm{~mm}$. thick, just beneath the inflorescence $1.5-3 \mathrm{~mm}$. thick, sharply trigonous but soft and easily pressed flat; leaves basal, the lowest ones bladeless, some of the upper ones consisting of sheaths with oblique orifices or even with soft blades $1-10 \mathrm{~cm}$. long; inflorescence (excluding bracts) $4-12 \mathrm{~cm}$. long, of 10 to 15 extremely unequal primary peduncles the shorter of which each bears a lax glomerule of 3 to 12 spikelets and the longer with several secondary peduncles each with a lax glomerule (or occasionally bearing unequal tertiary peduncles with glomerules); bracts usually 2, one of them 0.3 to 1 (to 2) times as long as the inflorescence, the other much shorter and inconspicuous; spikelets 4-10 $\mathrm{mm}$. long, about $1 \mathrm{~mm}$. broad, linear, compressed, brown, with 8 to 30 flowers, the axis persistent as a unit after the scales have fallen (the achenes and 


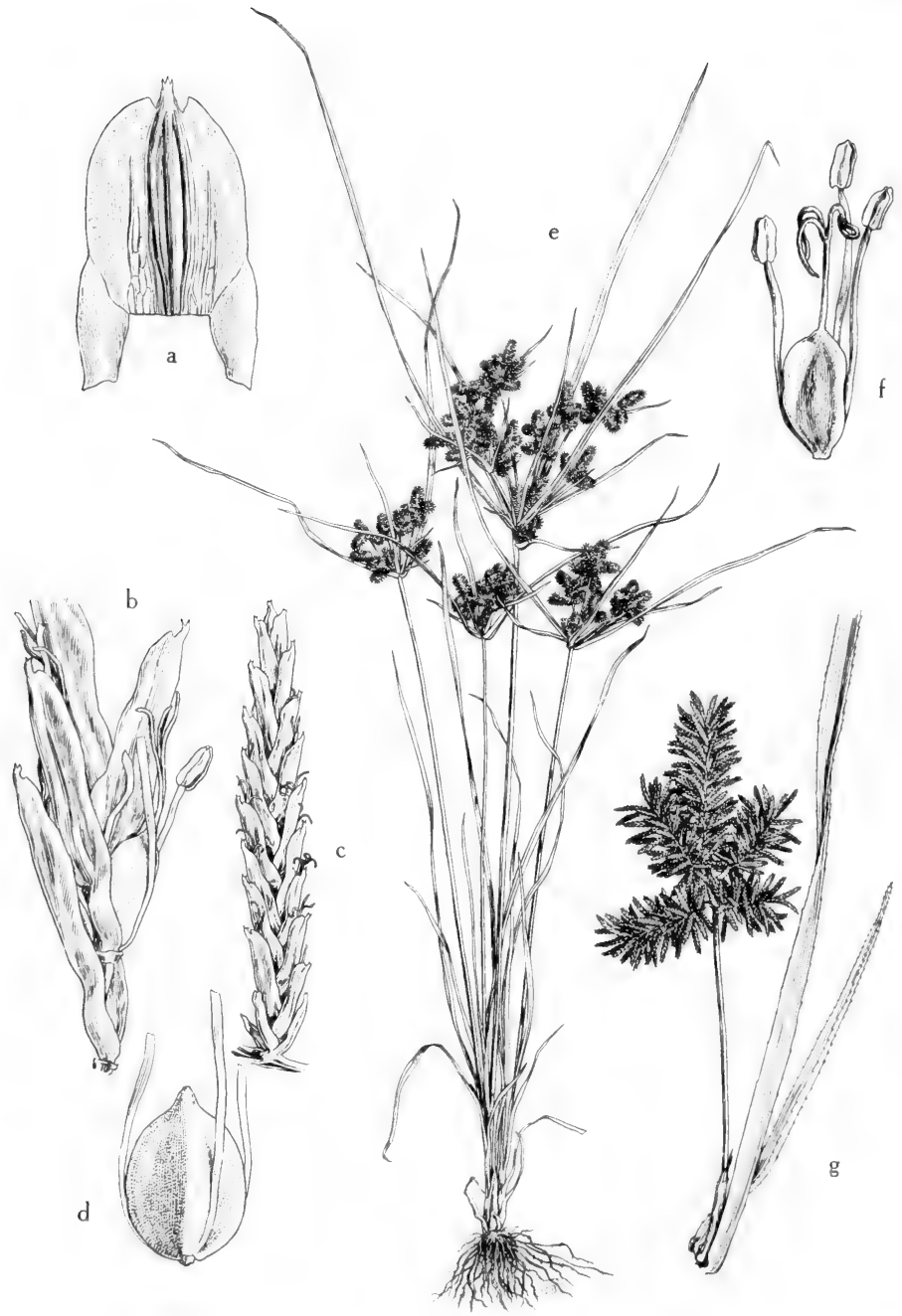

Fig. 229: Cyperus erythrorhizos: a, scale with rachis wings attached, X 20; b, part of spikelet, with some scales removed to show inner hyaline membranes forming wings on rachis, X 20; c, linear spikelet, X 8; d, mature achene, trigonous and with surface finely cellular, $X 28$; e, habit, showing the compound umbels and their numerous involucral leaves which are unequal in length, $X$ 1/s; f, flower, $X 20$; $g$, ray of inflorescence, showing hranches of divaricate spikelets and scabrellate involucral leaves, $\mathrm{X} 4 / \%$. (From Mason, Fig. 133). 
filaments often less readily caducous than the scales); scales $1.2-1.6 \mathrm{~mm}$. long, 0.8-1 mm. broad, obtuse, fragile-membranous, 3-nerved (actually with 5 nerves but the ones nearest the margin extremely inconspicuous and in some specimens weakly developed); stamens 3; achene globose-obovate to subglobose, obscurely trigonous, 0.4-0.7 mm. long, 0.4-0.5 mm. thick, whitish, roughened. Incl. var. americanus Boeck., C. juncoides Lam.

Infrequent in moist places, in water of swift stream, in wet meadows, on seepage slopes, in e. and s.e. Tex. and coastal parts of Rio Grande Plains, inland to Guadalupe Co., June-Oct.; widely distributed in warm regions.

\section{Cyperus giganteus Vahl.}

Perennial, densely tufted, culms $4-15 \mathrm{dm}$. long; leaves reduced to mere long brown sheaths at the base of the culm; inflorescence an umbel-like aggregation of 10 to 25 primary peduncles (the longest only about twice as long as the shortest), each bearing an umbellule of 4 to 8 peduncled lax spikes with elongate axes and 10 to 20 (reportedly up to 50 ) spreading spikelets; spikelets about $1 \mathrm{~mm}$. broad or narrower, laterally much-compressed, 4-10 mm. long, with 8 to 18 flowers; bracts of umbel about as many as the primary peduncles and surpassing the umbel; bracts of umbellules as many as the spikes and mostly exceeding them; spikelet axis persistent as a unit after the achenes and scales fall; lower margins of scales decurrent on the spikelet axis as hyaline readily deciduous wings $0.2-0.3 \mathrm{~mm}$. broad and more than $1 \mathrm{~mm}$. long; stamens 3 ; anthers with 2 cells, the connective between the cells prolonged $0.2-0.5 \mathrm{~mm}$. beyond the end of the anthers; achene unequally trigonous, the 2 adaxial angles much smaller (sharper) than the abaxial one.

Rare in extreme s.e. Tex. (Orange Co.) in marshes, probably not a persistent member of our flora; Parag., Urug. and Col. n. to Hond. and Gr. Ant.

\section{Cyperus alternifolius L. Umbrella flatsedge, Umbrella Plant.}

Tufted perennial; culm 3-15 dm. long, erect, basally 5-20 mm. thick, just below the apex 1-5 mm. thick, triangular; leaves few, basal, reduced to sheaths, apically with a diagonal orifice and a short flat triangular blade 5-50 (-100) $\mathrm{mm}$. long; inflorescence (excluding bracts) $3-10 \mathrm{~cm}$. long, of 15 to 25 slightly unequal primary peduncles each bearing a short headlike raceme of 8 to 15 shortpeduncled spikelets; bracts 15 to $25,15-40 \mathrm{~cm}$. long, 1-15 $\mathrm{mm}$. broad, spreading (forming an umbrella); spikelets 5-10 mm. long, 1.5-2 mm. broad, with 12 to 30 flowers, compressed, the axis wingless and remaining intact as a unit after the scales have fallen (achenes often more persistent); scales 1.6-2 mm. long, 1.4-1.6 $\mathrm{mm}$. broad when unfolded, several-nerved; stamens 3 ; achene trigonous, 0.6-0.9 $\mathrm{mm}$. long, 0.5-0.6 mm. thick, brown, elliptic-oblong.

S.e. Tex., cult. in moist or wet ground and rarely escaping, summer-fall; nat. of the Old World, probably Afr. or Madag., widely cult. and escaping in warm regions.

\section{Cyperus erythrorhizos Muhl. Fig. 229.}

Tufted annual or becoming a definite perennial in s. Tex.; culms 5-14 dm. long; inflorescence an umbel-like aggregation of 4 to 10 long markedly unequal peduncles each bearing an irregular cluster of several nearly sessile spikes with elongate axes (with internodes $0-0.5 \mathrm{~mm}$. long) and 15 to 70 spreading spikelets; spikelets about $1 \mathrm{~mm}$. broad or narrower, laterally much-compressed, very thin, 3-10 $(-15) \mathrm{mm}$. long with 6 to 34 or more flowers; bracts of umbel about as many as primary peduncles and some about as long as the inflorescence; bracts of the spike clusters considerably reduced, inconspicuous; spikelet axes persistent as a unit after the achenes and scales have fallen; scales keeled, the lower margins decurrent on the spikelet axis as readily deciduous hyaline wings about $0.8 \mathrm{~mm}$. 


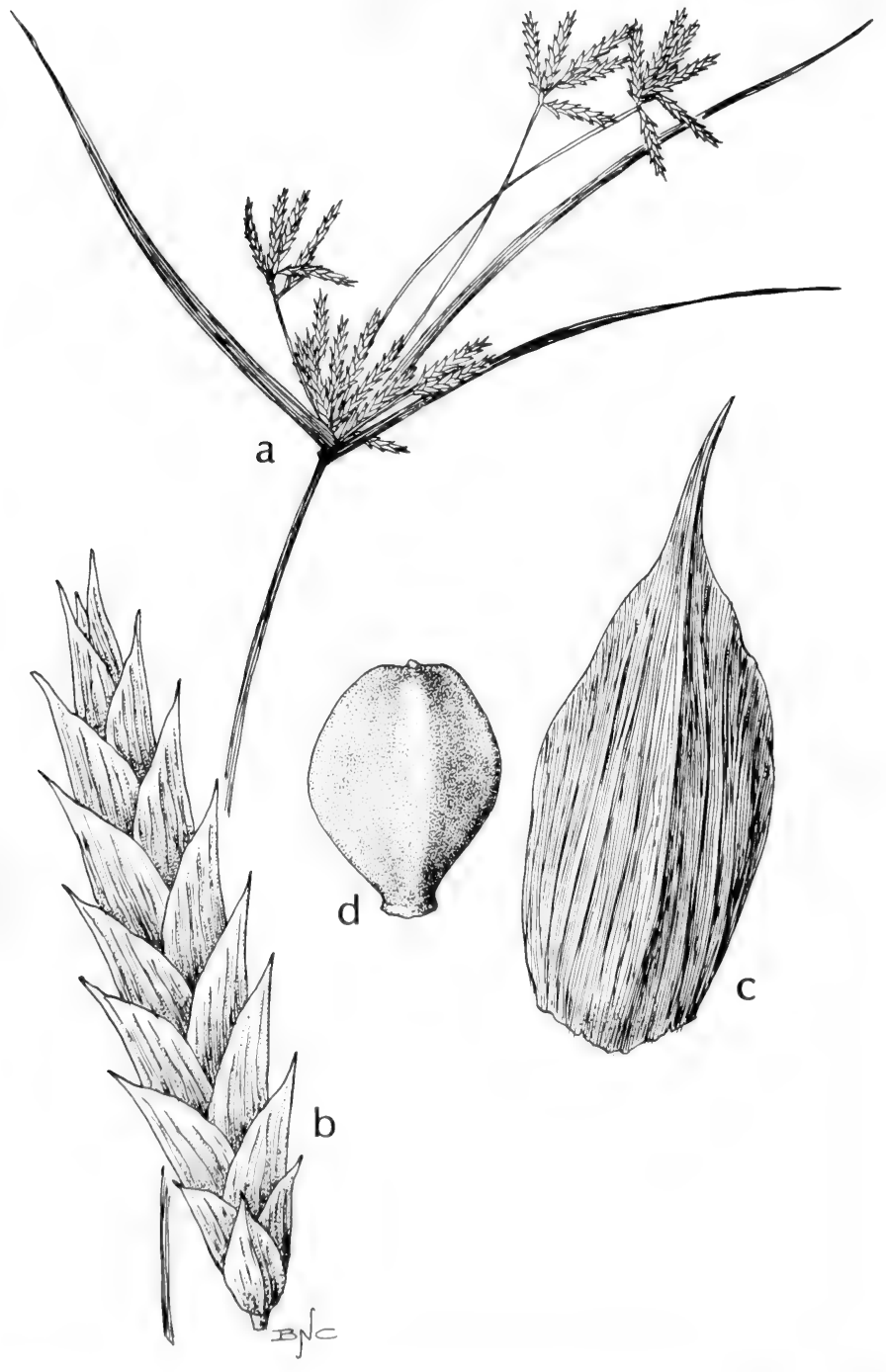

Fig, 230: Cyperus compressus: a, habit, X $1 \frac{1}{2}$; b, spikelet, X 5; c, scale, X 25; d, achené, X 25. (Courtesy of R. K. Godfrey). 
long and $0.2-0.3 \mathrm{~mm}$. broad; stamens 3 ; connective of anthers not surpassing the anther cells themselves or else projected as a red point only $0.05-0.1 \mathrm{~mm}$. long; achene unequally trigonous.

Abundant in marshy places, sand flats and in shallow water of lakes and ponds, along creeks, in Okla. (widespread), s.e. Tex., infrequent in Rio Grande Plains, n.-cen. and e. Tex., probably elsewhere, N. M. (Dona Ana Co.) and Ariz. (Coconino, Mohave and Yuma cos.), July-Dec.; Ont. and e. U.S. w. to N.D., S.D., Neb., Kan., Okla. and N.M.; also Wash., Ore., Calif., Ariz. and Ut.; presumably also Tam.

Probably not sufficiently distinct from $C$. digitatus.

\section{Cyperus digitatus Roxb.}

Tufted perennial; culms 5-15 dm. long; inflorescence an umbel-like aggregation of 5 to 13 long markedly unequal peduncles each bearing an irregular cluster of several nearly sessile spikes with elongate axes (internodes of spike axis $0.6-2$ $\mathrm{mm}$. long) and 15 to 35 spreading spikelets; spikelets about $1 \mathrm{~mm}$. broad, laterally compressed, $7-15 \mathrm{~mm}$. long, with 8 to 35 flowers; bracts of umbel about as many as peduncles and some as long as or longer than the inflorescence; bracts of spike clusters considerably reduced, inconspicuous; spikelet axes persistent as units after the achenes and scales have fallen; scales keeled, the lower sides decurrent down the spikelet axis as readily deciduous hyaline wings $0.2-0.3 \mathrm{~mm}$. broad and about $0.8 \mathrm{~mm}$. long; stamens 3 ; connective of anther not surpassing the anther cells themselves or else merely a red point $0.05-0.1 \mathrm{~mm}$. long; achene unequally trigonous.

Local in marshy places near Brownsville, Laredo and Corpus Christi in Rio Grande Plains, July-Dec.; Braz., Col., Mex., W.I. and Tex.

\section{Cyperus onerosus M. C. Johnst.}

Perennial with scaly rhizomes $5-80 \mathrm{~mm}$. long and 1-2 mm. thick; culms $20-49 \mathrm{~cm}$. long, erect, basally leafy and $2-4 \mathrm{~mm}$. thick, just beneath the inflorescence smooth, sharply triquetrous and $1.5-2 \mathrm{~mm}$. thick; leaves few, basally with no transverse septation, some of the longer ones usually surpassing the inflorescence; inflorescence (excluding bracts) 2-12 cm. long, with 7 to 15 very unequal primary peduncles, the shorter of these bearing nearly spherical heads of 8 to 25 spikelets, the longer ones bearing 3 to 12 unequal secondary peduncles each bearing a head of 20 to 35 spikelets; bracts about 4 , the longer one nearly erect, exceeding the inflorescence; spikelets $7-13 \mathrm{~mm}$. long, 2.5-3.5 $\mathrm{mm}$. broad, linear, with (10 to) 16 to 26 (to 42 ) flowers, brownish to tawny-brown, laterally compressed; the axis wingless, thick, dorsiventrally slightly flattened, persistent as a unit after the scales and achenes have fallen, the internodes sculptured (with a niche for each achene); scales 2.3-2.9 mm. long, 1.2-1.4 mm. broad, ovateelliptic when unfolded, basally slightly gibbous, laterally firm-membranous, medially chartaceous and with a midnerve and on each side 2 (rarely 3 ) nerves (the total number obscure except when the scale is young and translucent), the medial nerved keel-like zone (as seen in place in the spikelet) except for the curve at the gibbous base mostly straight or very slightly excurved to the very acute apex; stamens 3 ; achene elliptic to narrowly so, trigonous, acuminate at both ends, $0.7-0.8 \mathrm{~mm}$. long, $0.25-0.3 \mathrm{~mm}$. thick, whitish or eventually turning brownish.

Locally frequent in moist or wet loose sand and pools between sand dunes, s.w. part of Plains Country of Tex. (Ward and Winkler cos.), June-Nov.; endemic.

\section{Cyperus compressus L. Fig. 230.}

Tufted annual (or occasionally appearing as a short-lived perennial); leaves few, clustered near the base, little shorter than the culms; inflorescence (not 


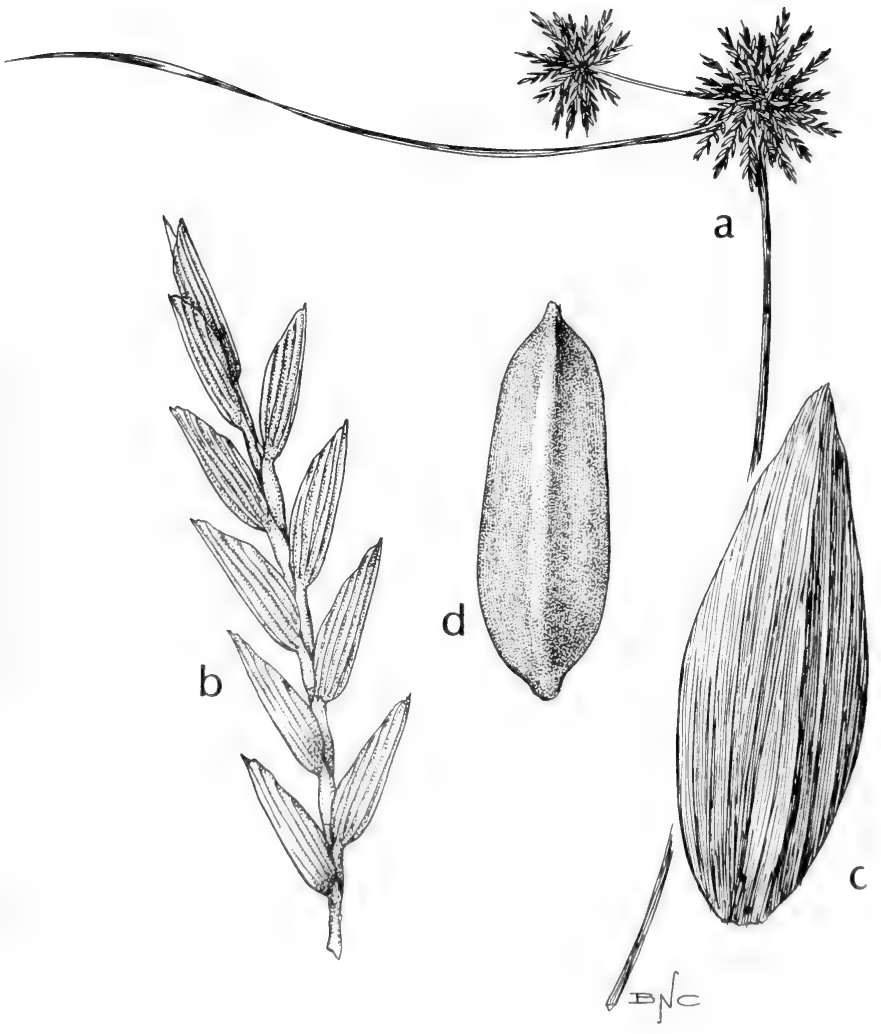

Fig. 231: Cyperus filiculmis: a, habit, X 1/2; b, spikelet, X 7; c, scale, X 23; d, achene, X 23. (Courtesy of R. K. Godfrey). 
including bracts) 1-7 cm. long, either of a single nearly sessile head or an umbellike aggregation of 2 to 6 very unequal peduncles each bearing a head of more or less spreading spikelets, the total inflorescence with 5 to 38 spikelets; bracts 3 to 5 , the longer ones far-surpassing the inflorescence; spikelets $10-24 \mathrm{~mm}$. long, 2-3 mm. broad, laterally compressed, with 12 to 24 flowers, the axis persistent and remaining intact even after the achenes and scales have fallen; scales 3-3.5 $\mathrm{mm}$. long, acuminate, the keel-like median somewhat excurved in the distal half and with 9 to 13 nerves, grayish-white with very pale broad hyaline margins (so the entire spikelet appears to have a white mid-stripe), decurrent below as definite wings but these persistent until the scale next below falls; stamens 3; achene trigonous, $1-1.3 \mathrm{~mm}$. long, almost as thick as long.

In moist or wet sand and swampy ground, in Okla. (McCurtain Co.), infrequent in s.e. Tex., rare in e. Tex., July-Sept.; Afr., Madag., s.e. Asia, Malaysia, N. Austral., Micronesia; in Am. from Ecu., Bol. and Braz. n. to N.Y., Pa., O., Okla. and Tex.

\section{Cyperus Parishii Britt.}

Perennial sedge with short rhizomes and fibrous roots; culms subtrigonous, smooth, 10-25 cm. tall; leaves several, much shorter than the culm, 3-5 mm. wide, minutely scabrellate on the margins and midrib; involucral leaves 3 or 4 , scabrellate; inflorescence umbellate, the rays $0.5-5 \mathrm{~cm}$. long; spikelets linear, acute, 12-20 mm. long, about $2 \mathrm{~mm}$. wide; rachis with a pair of hyaline wings at each node, these early deciduous; scales ovate, acute, $2-3 \mathrm{~mm}$. long, strongly several-nerved, the keel green and the sides reddish brown; stamens 3; style trifid; achene trigonous, obovoid-ellipsoid, 1-1.2 $\mathrm{mm}$. long, mucronulate, nearly black.

Wet meadows in N.M. (Dona Ana Co.) and Ariz. (Yavapai, Maricopa and Cochise cos.); N.M., Ariz. and Calif.

\section{Cyperus filiculmis Vahl. Fig. 231.}

Tufted or very loosely tufted perennial; culms basally tuberous-thickened or with short thick rhizomes, 10-35 $(-50) \mathrm{cm}$. long, subbasally $1-2(-2.3) \mathrm{mm}$. thick, just beneath the inflorescence $0.5-1 \mathrm{~mm}$. thick; leaves $1-2 \mathrm{~mm}$. broad, even the longer ones mostly shorter than the culms; inflorescence $1-3 \mathrm{~cm}$. long, of a single nearly spherical head of 15 to 55 spikelets or (usually in contaminated plants) the inflorescences with such a head plus a few peduncles $1-5 \mathrm{~cm}$. long each with a head or glomerule of 8 to 20 spikelets; bracts 3 or $4,0.5-1 \mathrm{~mm}$. broad, much-exceeding the inflorescence, usually spreading or reflexed; spikelets 6-16 mm. long, 2.5-4 mm. broad, about $1 \mathrm{~mm}$. thick, grayish-brown to darktawny-grayish-brown, with 7 to 20 scales (the terminal one sterile or staminate and slightly reduced), straight, the axis noticeably dorsiventrally flattened, at maturity either persistent or commonly tardily deciduous as a unit from the head axis, the flat sculptured internodes commonly wingless or with wings only to 0.2 $\mathrm{mm}$. broad; scales spreading at a $45^{\circ}$ angle (the spikelet axis thus exposed), most much-overlapping, $2.5-3.5 \mathrm{~mm}$. long, 2-2.5 $\mathrm{mm}$. broad, broadly ovate, with 9 to 11 nerves; stamens 3 ; achene $1.5-2.2 \mathrm{~mm}$. long, $0.8-1.1 \mathrm{~mm}$. thick, broadly oblong, trigonous, dark-brown. C. Houghtonii Torr. var. Bushii (Britt.) Kükenth.

Infrequent, scattered in seasonally moist sandy loam in open-wooded areas, wet sandy banks, in drying stream beds, in Okla. (Alfalfa Co.), n.-cen. Tex., Plains Country and Edwards Plateau, rare in the Trans-Pecos (i.e., genetically dilute plants in Glass Mts.), spring-fall; e. U.S. and s.e. Can. w. to the Rocky Mts.

\section{Cyperus elegans L. Fig. 232.}

Tufted perennial; culms 3-7 dm. long, erect; leaves viscid, crowded near the base, basally stramineous and somewhat spongy when fresh and upon drying the 


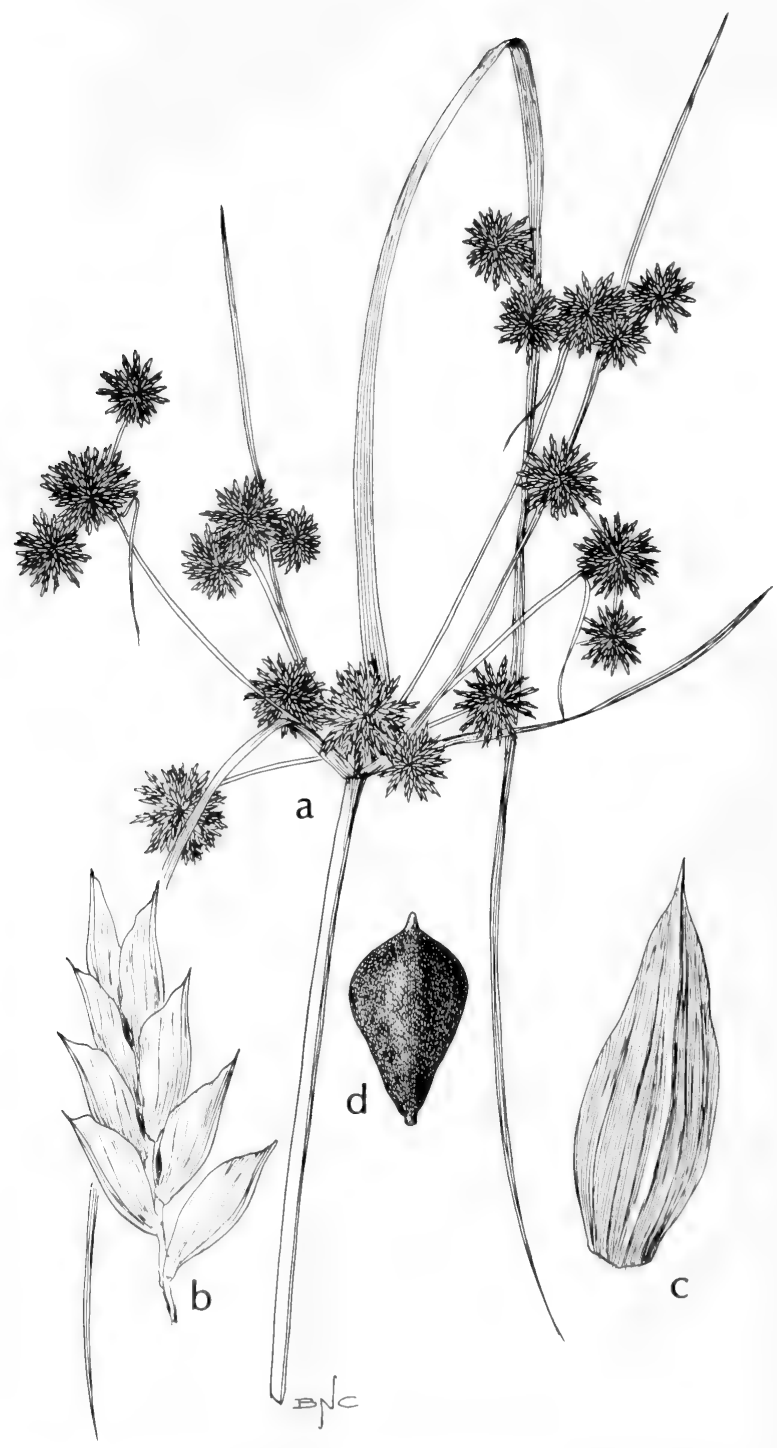

Fig. 232: Cyperus elegans: a, habit, X 1/2; b, spikelet, X 5; c, scale, X 12; d, achene, X 14. (Courtesy of R. K. Godfrey). 


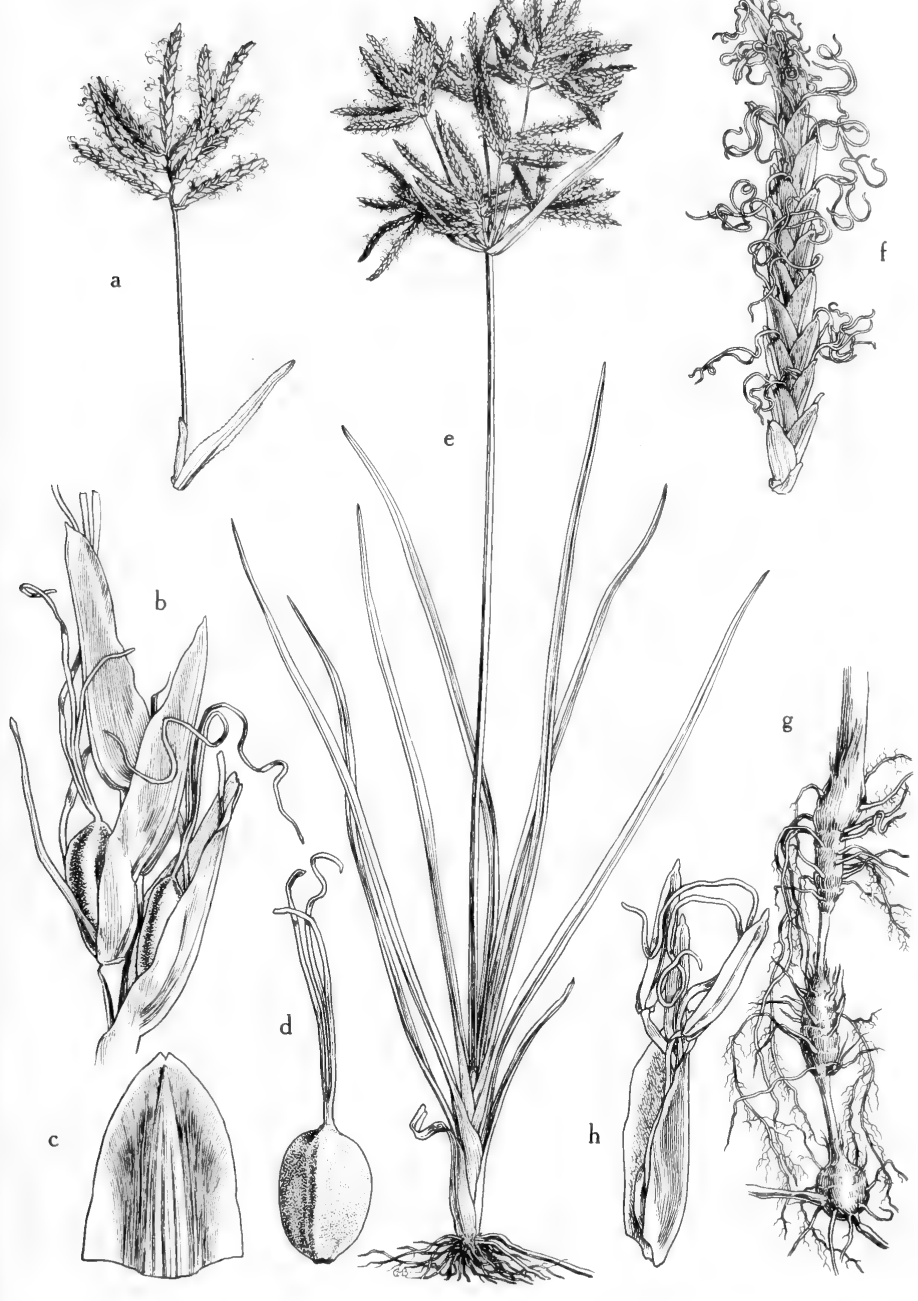

Fig. 233: Cyperus rotundus: a, ray, showing linear spikelets, $\mathrm{X} 4 / 5$; b, part of spikelet, 1 scale and wing removed to show wing on rachis continuous on either side of scale, X 12; c, scale, X 8 ; d, puncticulate trigonous achene, X 12; e, habit, showing the large umbellate inflorescence and short scabrellate involucral leaves, $X 2 / 5$; spikelet, showing the very long filiform trifid styles, X $3 ; \mathrm{g}$, stolon with tubers, $\mathrm{X} 4 / 5 ; \mathrm{h}$, flower, X 11. (From Mason, Fig. 132). 
incomplete septa becoming conspicuous, the upper part involute; inflorescence (excluding bracts) 5-15 (-22) $\mathrm{cm}$. long, of 3 to 10 extremely unequal primary peduncles, the shorter ones each bearing a head of spikelets, the longer ones often with several short secondary peduncles each bearing a head; each head with 5 to 13 spikelets; bracts 3 to 5 , the longer ones much-exceeding the inflorescence; spikelets 3-15 mm. long, 2.5-4 mm. broad, with 6 to 20 flowers, viscid, grayishochraceous turning grayish-brown at maturity, the axis persistent and remaining intact even after the scales and achenes have fallen, wingless; scales firm, 3-4.2 $\mathrm{mm}$. long, with 3 strong nerves close together on the weakly keel-like median and farther apart on each side 2 or 3 less conspicuous ones ( 7 to 9 altogether), the very sharp tip slightly excurved, the lower sides not decurrent (the scales measured as folded in the spikelet is $1-1.2 \mathrm{~mm}$. broad); stamens 3 ; achene $1.4-1.8 \mathrm{~mm}$. long, black at maturity, trigonous, widest near the apex and long-tapered to the base.

In moist calcareous soil, edge of lakes, ponds and tanks, and wet gravel-sand of creek beds, frequent in s.e. Tex. and Rio Grande Plains, infrequent to rare in Edwards Plateau and Trans-Pecos, Aug.-Nov., rarely in spring or early summer; W.I., Trin., C.A., Mex., Fla., La. and Tex.; a var. major Kükenth. in Peru.

\section{Cyperus oxylepis Steud.}

Tufted perennial; culms 3-7 dm. long, erect; leaves viscid, crowded near the base, basally stramineous splotched with red, somewhat spongy when fresh and upon drying the incomplete septa becoming conspicuous, the upper part involute; inflorescence (excluding bracts) $5-15 \mathrm{~cm}$. long, of 3 to 10 extremely unequal primary peduncles, the shorter ones each bearing a head of spikelets, the longer ones often with several short secondary peduncles each bearing a head, each head with 6 to 18 spikelets; bracts 3 to 5 , the longer ones much-exceeding the inflorescence; spikelets $8-22 \mathrm{~mm}$. long, $2.5-3.5 \mathrm{~mm}$. broad, with 10 to 24 flowers, viscid, grayish-yellow becoming at maturity a rich golden-brown, the axis persistent and remaining intact even after the scales and achenes fall, wingless; scales firm-membranous, $3.3-3.7 \mathrm{~mm}$. long, with 3 strong nerves together on the weakly keel-like median and farther apart on each side 2 less conspicuous ones (7 altogether), the sharp point very slightly excurved, the lower sides not decurrent on the axis (the half-scale measured as it is folded in the spikelet is $0.8 \mathrm{~mm}$. broad): stamens 3; achene 1.4-2 $\mathrm{mm}$. long, dark-brown at maturity, trigonous. nearly cylindric or very slightly thickened in the upper part and long-tapered below, capped by the beaklike persistent style base about $1 \mathrm{~mm}$. long.

Infrequent in coastal s.e. Tex. (Harris, Nueces, Refugio and San Patricio cos.) in clay ditches and ponds, May-Aug.; Arg., Parag., Ecu., Col., Br. Gui., Jam., Virg. I., Oax., Sin., Son., Tex. and La.

\section{Cyperus rotundus L. Nut-grass, tulillo. Fig. 233.}

Perennial forming colonies with creeping rhizomes about $1 \mathrm{~mm}$. thick, at intervals with tuberlike thickenings to $1 \mathrm{~cm}$. thick; culms $8-30(-75) \mathrm{cm}$. long, just beneath the inflorescence $0.8-1.8 \mathrm{~mm}$. thick; leaves crowded in the basal few $\mathrm{cm}$., much shorter than the culm and usually spreading; inflorescence $3-11 \mathrm{~cm}$. long, of 3 to 8 extremely unequal peduncles each bearing a (rarely compound) cluster or short spike of divaricate spikelets. each cluster or spike with 3 to 9 spikelets, the total inflorescence with 20 to 65 spikelets; bracts usually about 3 or 4 and ahout as long as the inflorescence; spikelets $4-30 \mathrm{~mm}$. long, 1-2 mm. broad, laterally much-comnressed, with 12 to 36 flowers; scales keeled, straight, darkreddish, dark-purplish or dark-purplish-brown, 3-3.5 $\mathrm{mm}$. long, with about 7 paler nerves crowded near the median so that each of the halves is nerveless in the marginal half to five eighths the width, the sides decurrent basally as hyaline 


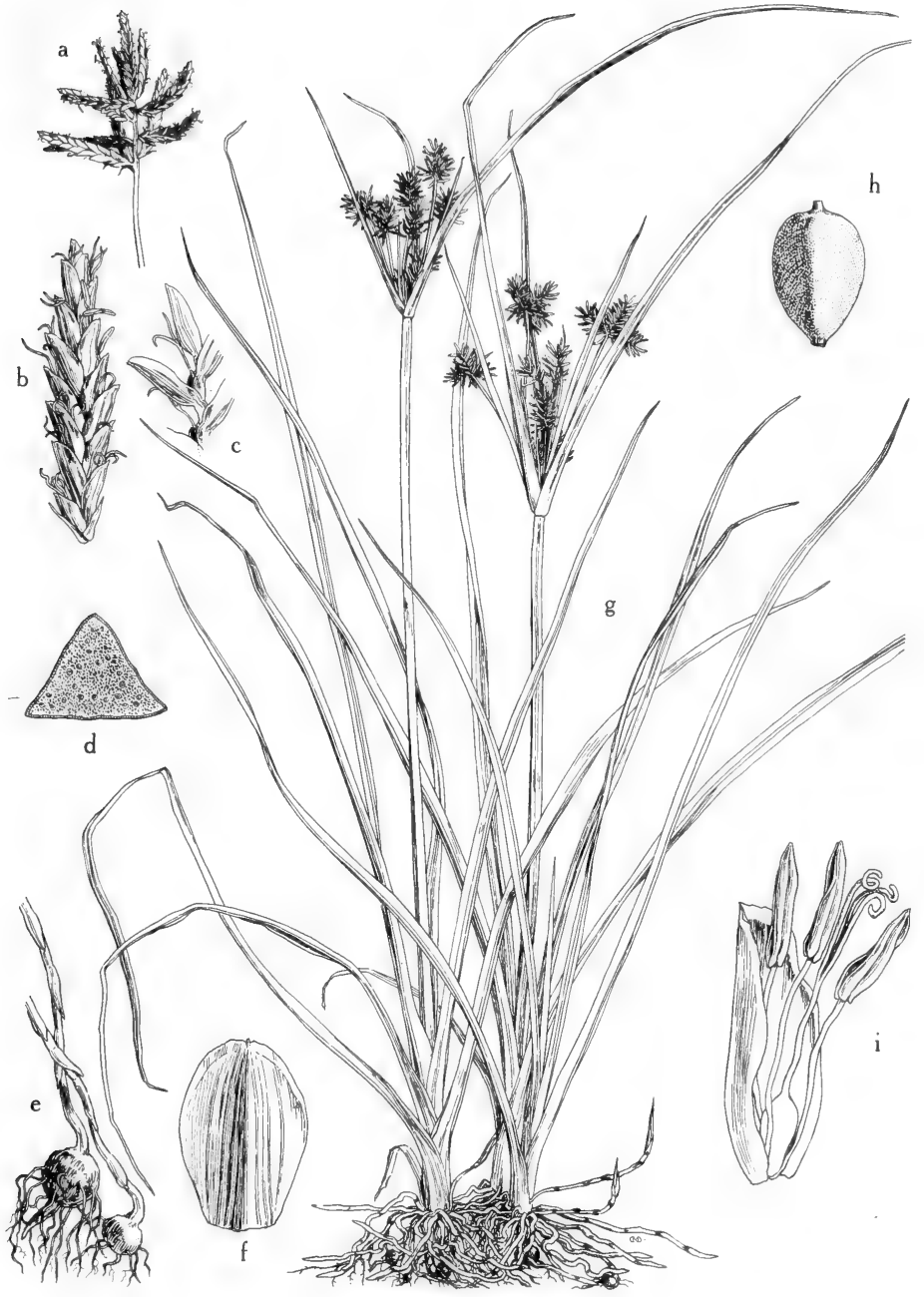

Fig. 234: Cyperus esculentus: a, ray, showing remote divaricate spikelets, $\mathrm{X} 4 / 5 ; \mathrm{b}$, spikelet, X 3; c, part of spikelet, with some flowers removed, showing the hyaline persistent wings of rachis, X 3 ; d, culm (cross section), X 2 ; e, stolons terminating in tubers, $\mathrm{X} 4 / 5 ; \mathrm{f}$, ovate scale, showing mucronulate apex, $\mathrm{X} 8$; $\mathrm{g}$, habit, showing stolons, tubers, numerous flat leaves and umbellate inflorescences with broad ascending involucral leaves, X 4/5; h, achene, showing surface puncticulate, X 12; i, flower, X 12 . (From Mason, Fig. 131). 
persistent wings on the spikelet axis which remains intact even after the scales and achenes have fallen; stamens 3 ; the prominent long-exserted anthers with the connective slightly prolonged into a minute reddish knob; achenes trigonous.

Abundant in loamy soils, wet meadows and lawns, in Okla. (Waterfall), s.e., n.-cen. Tex. and Rio Grande Plains, rare in Plains Country and Trans-Pecos, a pernicious lawn-weed, adv. with us, July-Dec., less commonly Jan.-Apr.; widespread in the warmer parts of the world, nat. to Euras.

\section{Cyperus setigerus $T$. \& $H$.}

Perennial forming small colonies with creeping rhizomes (1-) $1.5-5 \mathrm{~mm}$. thick or slighly thicker at the culm bases; culms (60-) $75-110 \mathrm{~cm}$. long, just beneath the inflorescence (1.5-) 2.3-3.3 mm. thick; leaves few, attached in the basal third of the culm, shorter than the culm, ascending; inflorescence (not including bracts) (7-) 10-16 (-20) $\mathrm{cm}$. long, of 9 to 13 extremely unequal peduncles each bearing a compound cluster or short spike of divaricate spikelets, each cluster or spike with 10 to 30 spikelets, the total inflorescence with 120 to 350 spikelets; bracts about as many as the primary peduncles, the longer ones far-surpassing the inflorescence; spikelets $6-40 \mathrm{~mm}$. long, $1.5-2 \mathrm{~mm}$. broad, laterally much-compressed, with 6 to 40 flowers; scales keeled, reddish-brown, straight, 3-4 mm. long, with 5 to 7 nerves either crowded medially or somewhat spread out so that each of the halves is nerveless in the marginal fifth to three eighths the width, the sides decurrent basally as hyaline persistent wings on the spikelets axis which remains intact even after the scales and achenes have fallen; stamens 3; anther connective sometimes minutely prolonged achenes trigonous.

Scattered and local in moist clay meadows and ditches, about lakes and ponds in Okla. (Comanche, Craig and Kay cos.), n.-cen. Tex., Rio Grande Plains, Edwards Plateau (Mason Co.) and Plains Country, summer; Kan., Mo., Okla. and Tex.

\section{Cyperus esculentus L. Yellow nut-grass. Fig. 234.}

Perennial forming colonies with creeping rhizomes $1-1.5(-2) \mathrm{mm}$. thick (some forms have tuberlike thickenings on the rhizomes; these forms rarely flower); culms $15-50(-65) \mathrm{cm}$. long, just below the inflorescence 1.5-3 (-3.8) $\mathrm{mm}$. thick; leaves several, attached in the basal half of the culm, the upper ones ascending, almost equaling or surpassing the inflorescence; inflorescence (not including bracts) 4-14 $(-24) \mathrm{cm}$. long, of 5 to 10 extremely unequal peduncles each bearing a short spike (or the longer peduncles a cluster of short spikes) of divaricate spikelets, each spike or cluster with 12 to 50 spikelets, the total inflorescence with 70 to 350 spikelets; bracts about as many as the primary peduncles, the longer ones farsurpassing the inflorescence; spikelets 6-30 $\mathrm{mm}$. long, 1-2 $\mathrm{mm}$. broad, somewhat laterally compressed, with 8 to 40 flowers; scales keeled, straight, brown, buffybrown or golden-brown, $2.6-4 \mathrm{~mm}$. long, hyaline, with 7 to 9 nerves which are about equidistant and so spaced out that only about the marginal third of each side of the scale is nerveless, the sides decurrent basally as hyaline persistent wings on the spikelet axis which remains intact even after the scales and achenes have fallen; stamens 3 ; anther connective prolonged into a red dot $0.05-0.1 \mathrm{~mm}$. long; achenes trigonous. Incl. var. angustispicatus Britt. and var. macrostachyus Boeckl.

Locally abundant and weedy in occasionally moistened sandy usually disturbed or unstable or loamy soil, in shallow water of ponds and lakes, gravel bars along streams and on seepage banks, in Okla. (LeFlore, Ottawa, Pushmataha and Alfalfa cos.), scattered all over Tex. but rare in Edwards Plateau and higher parts of the Plains Country, N. M. (widespread) and Ariz. (Apache, Navajo and Coconino, s. to Cochise, Santa Cruz and Pima cos.), summer-fall (through Dec. in extreme 
s.); scattered in the warmer parts of the world, in Am. n. to Que., Ont., Minn., Ore. and Alas.; probably adv. in Tex.

\section{Cyperus strigosus L. Fig. 235.}

Tufted perennial (occasionally flowering the first year); culms 4-10 dm. long, subbasally 3-9 mm. thick (at the extreme base swollen tuberlike), just below the inflorescence trigonous and $1.7-3 \mathrm{~mm}$. thick; leaves $2-8 \mathrm{~mm}$. broad, firm, the longer ones about equaling the culm; inflorescence $7-30(-40) \mathrm{cm}$. long, of 4 to 11 very unequal primary peduncles the shorter of which bear spikes $13-25 \mathrm{~mm}$. long and $2-4 \mathrm{~cm}$. thick, each spike with 20 to 40 divaricately spreading spikelets in several ranks, the longer peduncles in turn bearing a few secondary peduncles (often very short) each with a spike $15-35 \mathrm{~mm}$. long and $20-45 \mathrm{~mm}$. thick, each spike with 25 to 70 spreading spikelets; bracts 3 to 10 , the longer ones far-surpassing the inflorescence; spikelets linear, straight, (10-) 12-25 (-29) $\mathrm{mm}$. long, 1-2 mm. broad, less than half as thick as broad, golden-brown or tawny-brown, with 5 to 20 scales (the terminal one sterile, tending to become involuted and forming a short point), the axis at maturity detaching as a unit from the spike axis, the internodes on the fertile side with 2 narrow hyaline wings $1.5-2 \mathrm{~mm}$. long, about $0.4 \mathrm{~mm}$. broad; scales $3.7-4.5 \mathrm{~mm}$. long, $1.2-1.8 \mathrm{~mm}$. broad, with 7 or 9 nerves, overlapping, usually persistent or less commonly belatedly deciduous either before or after the axis falls from the plant; stamens 3 ; achene $1.5-2 \mathrm{~mm}$. long (usually about half as long as the scale), 0.5-0.6 mm. thick, trigonous, linearoblong, brown, basally substipitate, short-apiculate.

Frequent in bogs and marshy areas, in shallow water of ponds and lakes and in mud, in Okla. (McCurtain, LeFlore, Ottawa, Sequoyah, Craig, Johnston, Alfalfa and Mayes cos.), e. and s.e. Tex., less frequent in n.-cen. Tex. and rare in the Panhandle (genetically dilute plants rare elsewhere), and Ariz. (Pima Co.), summer-fall; e. U.S. n. to Que., Ont., Minn., w. to Neb., Kan., Okla. and Tex.; also Pac. States.

\section{Cyperus tenuis Sw.}

Tufted perennial; culms 3-8 dm. long, basally 2-7 mm. thick, just below the inflorescence $1.1-2.8 \mathrm{~mm}$. thick; leaves $1.5-5 \mathrm{~mm}$. broad, the longer ones about equaling the culms; inflorescence $6-20 \mathrm{~cm}$. long, of 4 to 11 extremely unequal primary peduncles the shorter of which bear spikes $2-3 \mathrm{~cm}$. long and $15-25 \mathrm{~mm}$. thick, each spike with 14 to 30 divaricately spreading spikelets in 3 or 4 ranks, the longer peduncles each with a spike $25-40 \mathrm{~mm}$. long and $18-27 \mathrm{~mm}$. thick, each spike with 19 to 45 spikelets, the spikes occasionally compound with 1 or 2 smaller nearly sessile spikes basally; bracts 3 to 11 , the longer ones far-surpassing the inflorescence; spikelets linear, straight, $10-15 \mathrm{~mm}$. long, 0.7-1.3 mm. broad, about half as thick as broad, grayish-brown, with 3 to 6 scales (the terminal 1 sterile, tending to become involute and forming a short point), the axis at maturity detaching as a unit from the spike axis, the internodes on the fertile side with 2 narrow hyaline wings $1.5-2 \mathrm{~mm}$. long and $0.3-0.5 \mathrm{~mm}$. broad; scales $3.5-5 \mathrm{~mm}$. long, 1-1.6 mm. broad, with 7 or 9 nerves, overlapping, persistent; stamens 3; achene $1.3-1.6 \mathrm{~mm}$. long, less than half as long as the scale, $0.5-0.6 \mathrm{~mm}$. thick, trigonous, ellipsoid to obovoid-ellipsoid, brown, very minutely stipitate, apiculate. Incl. var. lentiginosus (Millsp. \& Chase) Kükenth., C. strigosus var. gracilis Britt., C. lentiginosus Millsp. \& Chase.

Infrequent in s. part of s.e. Tex. (San Patricio and Nueces cos.) and coastal parts of Rio Grande Plains (Duval, Karnes and Cameron cos.), in wet or moist clayey loam, summer-fall; n. S.A. w. to C.A. and Mex., n. to Sin. and Tex.; also (?) Afr. 


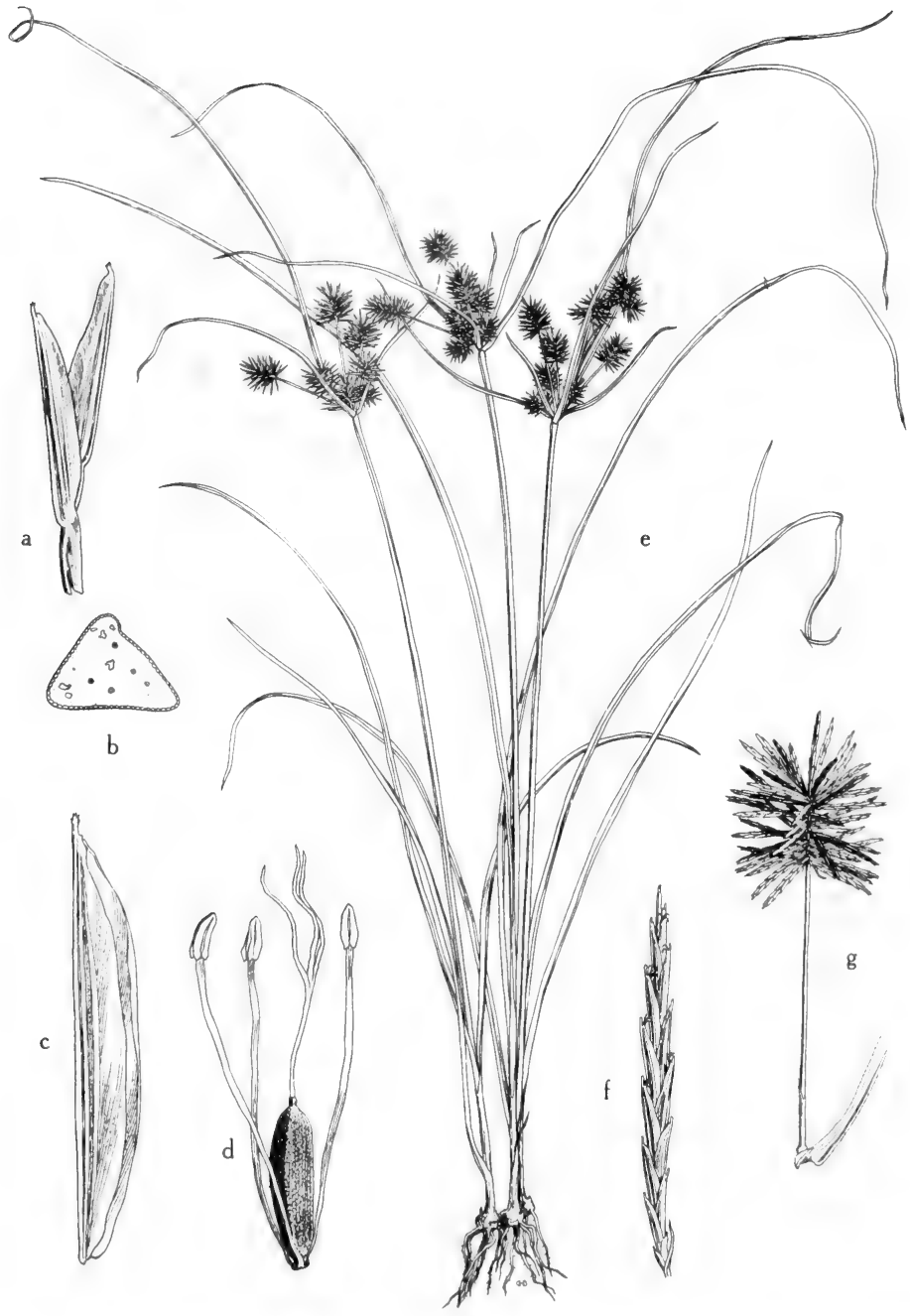

Fig. 235: Cyperus strigosus: a, part of a winged rachis, X 6; b, culm (cross section), X 5; c, scale, strongly nerved, X 12; d, linear puncticulate achene, with trifid style and 3 stamens, X 12; e, habit, showing corms swollen at base, the umbellate inflorescence and the involucral leaves which are unequal in length, $X 1<;$, linear spikelets, X $2 \frac{1}{2} ; \mathrm{g}$, ray of inflorescence, showing loose divaricate cluster of spikelets, $\mathrm{X} 2 / 3$. (From Mason, Fig. 134). 


\section{Cyperus huarmensis (H.B.K.) M. C. Johnst.}

(Often loosely) tufted perennial from black knotty subrhizomatous bases; culms 1-4 dm. long, sub-basally $1.5-3 \mathrm{~mm}$. thick, just beneath the inflorescence $0.7-1.3$ $\mathrm{mm}$. thick; leaves $2-4 \mathrm{~mm}$. broad, firm, shorter than the culms; inflorescence 2-3 $(-4) \mathrm{cm}$. long, of 3 to 6 essentially sessile (or occasionally 1 or 2 of them on peduncles 1-2 cm. long) dense spikes 10-25 $\mathrm{mm}$. long and 7-10 $\mathrm{mm}$. thick, with 40 to 80 ascending spikelets; bracts 3 to 6 , spreading, the longer ones 3 to 10 times as long as the inflorescence; spikelets $4-7 \mathrm{~mm}$. long, about $1 \mathrm{~mm}$. broad and almost as thick, ochraceous gray-brown to tawny-gray, with 3 scales (usually only the lowest one fertile and it slightly longer than the others), straight, the axis at maturity detaching as a unit from the spike axis, the internodes of the fertile side with 2 hyaline wings $1.5-2.2 \mathrm{~mm}$. long and $0.6-0.8 \mathrm{~mm}$. broad, clasping the achene; fertile scale $3-4 \mathrm{~mm}$. long, about $2 \mathrm{~mm}$. broad, with about 9 nerves, almost completely overlapping the higher scales; stamens 3 ; achene $1.5-2.1 \mathrm{~mm}$. long, 0.8-1 mm. thick, oblong-obovoid, trigonous, very dark-brown, substipitate, apiculate. C. cayennensis (Lam.) Britt., non Link, C. flavus (Vahl) Nees, non J. \& C. Presl, Mariscus huarmensis H.B.K., C. obesus Liebm.

Rare in s.e. Tex. (Aransas and San Patricio cos.) to Ariz. (Gila, Cochise, Pima and Santa Cruz cos.), spring-fall; widespread in the warmer parts of Am. s. to Arg. and n. to Ariz., N.M., Tex. and La.

\section{Cyperus Pringlei Britt.}

Perennial; culm erect, triangular, glabrous, to $6 \mathrm{dm}$. long, with swollen base from short nodose rhizomes; leaf sheaths thin, subscarious, yellowish to reddishbrown, to $12 \mathrm{~cm}$. long; leaf blades flat, $3-8 \mathrm{~mm}$. wide, glabrous or slightly scabrous along the midrib and margins, to $3 \mathrm{dm}$. long; bracts 5 to 8 , to $2 \mathrm{dm}$. long, surpassing the inflorescence; umbels simple or somewhat compound of 5 to 6 rays, 1-12 cm. long, spreading; spikes cylindric-oblong, rather loose, 7-10 $\mathrm{mm}$. in diameter, 1.5-3 cm. long; spikelets terete-oblong, $1 \mathrm{~mm}$. in diameter or less, 3-5 $\mathrm{mm}$. long, 3- to 5-flowered; scales pale yellow to light-brown, 2.2-2.5 $\mathrm{mm}$. long, 1.5-2 mm. wide, distinctly 7 to 11 -nerved; rachilla scariously winged; stamens 3 ; style deeply 3-cleft; achenes ellipsoid-oblong, trigonous, basal one-third of margin enfolded by scarious rachilla wings, olive-brown, sublustrous, minutely punctate.

Canyons, wet meadows and mt. slopes in Ariz. (Pima Co.), Aug.-Sept.; also Chih. and Son.

\section{Cyperus hermaphroditus (Jacq.) Standl.}

Tufted perennial; culms very slightly thickened, $15-80 \mathrm{~cm}$. long, sub-basally 1-3 $\mathrm{mm}$. thick, just below the inflorescence $0.7-2 \mathrm{~mm}$. thick; leaves $1-3 \mathrm{~mm}$. broad, the longer ones about as long as the culm; inflorescences $3-15 \mathrm{~cm}$. long, of 4 to 8 or more slender very unequal peduncles each with a lax spike $1-3 \mathrm{~cm}$. long and $1-2 \mathrm{~cm}$. thick, of 8 to 30 or more divaricately spreading spikelets in 3 or 4 ranks, secondary peduncles absent; bracts 3 to 8 , the longer ones far-surpassing the inflorescence; spikelets linear, 5-11 mm. long, $0.5-1 \mathrm{~mm}$. broad, more than half as thick as broad, dull-brown, with 3 to 7 scales (the terminal one sterile, tending to become involute and forming a short point), the axis at maturity detaching as a unit from the spike axis, the internodes on their fertile side with 2 narrow hyaline wings $1.3-2 \mathrm{~mm}$. long and $0.3-0.5 \mathrm{~mm}$. broad; scales $2.5-3.5 \mathrm{~mm}$. long, $0.8-1.3 \mathrm{~mm}$. broad, with about 9 nerves, overlapping, persistent; stamens 3 ; achene 1.6-1.8 (-2) mm. long, $0.6-0.8 \mathrm{~mm}$. thick, trigonous, oblong to ellipsoid, yellowish-brown to brown, substipitate, apiculate. Incl. var. angustior (Clarke) Kükenth., C. thyrsiflorus Schlecht. \& Cham., C. dissitiflorus Torr.

Rare in rich loam, shaded river woods, s.e. Tex. (Brazoria, Colorado, Harris and Jackson cos.), and Ariz. (Pima Co.), summer; widespread in warmer parts of Am., n. to Ala., La., Tex., Coah. and Ariz. 


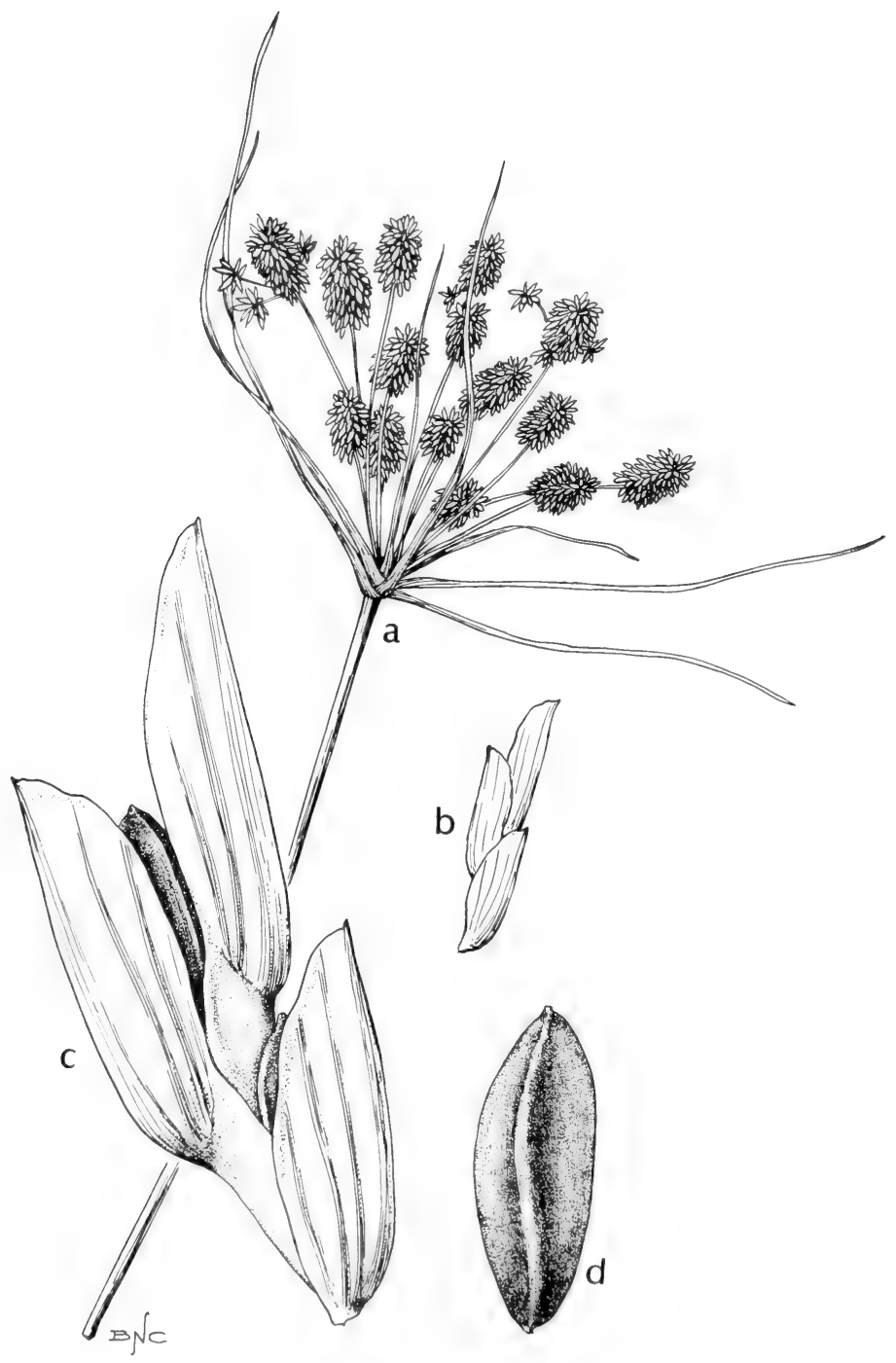

Fig. 236: Cyperus ovularis: a, habit, X 1/2; b, spikelet, X 5; c, spikelet, X 15; d, achene, X 15. (Courtesy of R. K. Godfrey). 
42. Cyperus ovularis (Michx.) Torr. Figs. 236 and 237.

Tufted perennial; culms, basally with tuberous enlargements, $25-80 \mathrm{~cm}$. long, sub-basally 1-3 mm. thick, just beneath the inflorescence $0.6-2 \mathrm{~mm}$. thick; leaves 1.5-5 mm. broad, the longer ones about equaling the culms; inflorescence (1-) $3-12 \mathrm{~cm}$. long, of ( 1 to ) 3 to 8 very unequal peduncles each with a dense spherical or prolate-spherical head $7-19 \mathrm{~mm}$. long and $7-18 \mathrm{~mm}$. thick, with (70 to) 100 to 240 spikelets borne spirally or in many ranks, about equally dense at top and bottom, the upper spikelets ascending, middle ones spreading and lower ones retrorsely appressed; secondary peduncles absent; bracts ( 2 or) 3 to 7 , the longer ones far-exceeding the inflorescence; spikelets $3.5-9 \mathrm{~mm}$. long, $0.5-1 \mathrm{~mm}$. broad, about half to three fourths as thick as broad, straw-brown to dark-brown, with 2 to 4 scales ( the terminal one or two sterile and forming a blunt point, not an awn), straight, the axis at maturity detaching a unit from the head axis, the internodes on the fertile side with hyaline wings $1-2 \mathrm{~mm}$. long and $0.3-0.7 \mathrm{~mm}$. broad, usually not clasping the achene; fertile scales $2.5-4 \mathrm{~mm}$. long, $1.2-2 \mathrm{~mm}$. broad, obtuse, with about 9 nerves well-distributed over the width, overlapping, persistent; stamens 3 ; achene narrowly oblong, $1.8-2.2 \mathrm{~mm}$. long, $0.5-0.7 \mathrm{~mm}$. thick, trigonous, brown substipitate, apiculate. Inc. var. sphaericus Boeck. and var. robustus Britt., $C$. Wolfi Wood.

Infrequent in moist or wet sand, wet soil on edge of lake and banks of ditches, in Okla. (Carter, Pittsburg, Pushmataha and LeFlore cos.), e., s.e. and n.-cen. Tex., spring-fall; e. U.S. n. to N.Y., Pa., O., Ind., Ill. and Mo., w. to Kan., Okla. and Tex.

The description above applies to the typical form. A more common form is the var. cylindricus (Ell.) Torr. (C. retrorsus Chapm.) with narrower and proportionally more elongate heads (actually short spikes), paler and with a slightly more tawny-ochraceous tinge, with fewer spikelets on the average (50 to 100), only 2 or 3 scales per spikelet, the wings averaging slightly narrower, the wings, scales and achene averaging shorter.

\section{Cyperus globulosus Aubl. Fig. 238.}

Tufted perennial; culms slightly tuberous-enlarged basally, 1-8 dm. long, subbasally $1.5-2.5 \mathrm{~mm}$. thick, just beneath the inflorescence $1-1.7 \mathrm{~mm}$. thick; leaves $1.5-3 \mathrm{~mm}$. broad, the longer ones about equaling the culms; inflorescences $2-8$ $\mathrm{cm}$. long, of 3 to 14 very unequal peduncles each with a dense head $7-15 \mathrm{~mm}$. long and $8-17 \mathrm{~mm}$. thick, with 25 to 70 spikelets borne spirally or in a number of ranks, about equally dense throughout, the upper spikelets ascending, the middle ones spreading, the lower spreading or slightly descending but never retrorsely appressed; secondary peduncles absent; bracts 4 to 11 , the longer ones far-exceeding the inflorescences; spikelets $5-10 \mathrm{~mm}$. long, $0.7-1.3 \mathrm{~mm}$. broad, almost as thick as broad, greenish-brown to ochraceous-brown or olive, with 3 to 8 scales (the terminal one sterile or staminate and forming a short point, or blunt), straight, the axis at maturity detaching as a unit from the head axis, the internodes with hyaline wings $0.8-1.4 \mathrm{~mm}$. long and $0.25-0.6 \mathrm{~mm}$. broad and not clasping the achene; scales 2.5-3 mm. long, 1-1.3 mm. broad, obtuse, with usually 9 well-distributed nerves, overlapping, persistent; stamens 3; achene narrowly oblong, 1.3-1.6 mm. long, about $0.6 \mathrm{~mm}$. thick, trigonous, brown, substipitate, subapiculate.

Frequent in moist or dry sandy soil, wet clay meadows and wet depressions, in Okla. (Waterfall), e. and s.e. Tex., rare and in genetically dilute from inland to $n$.-cen. Tex., summer-fall; $\mathrm{n}$. reputedly to Va. and Mo.

\section{Cladium P. BR.}

About 55 species of tropical and temperate regions, especially Australia; our species almost cosmopolitan. 


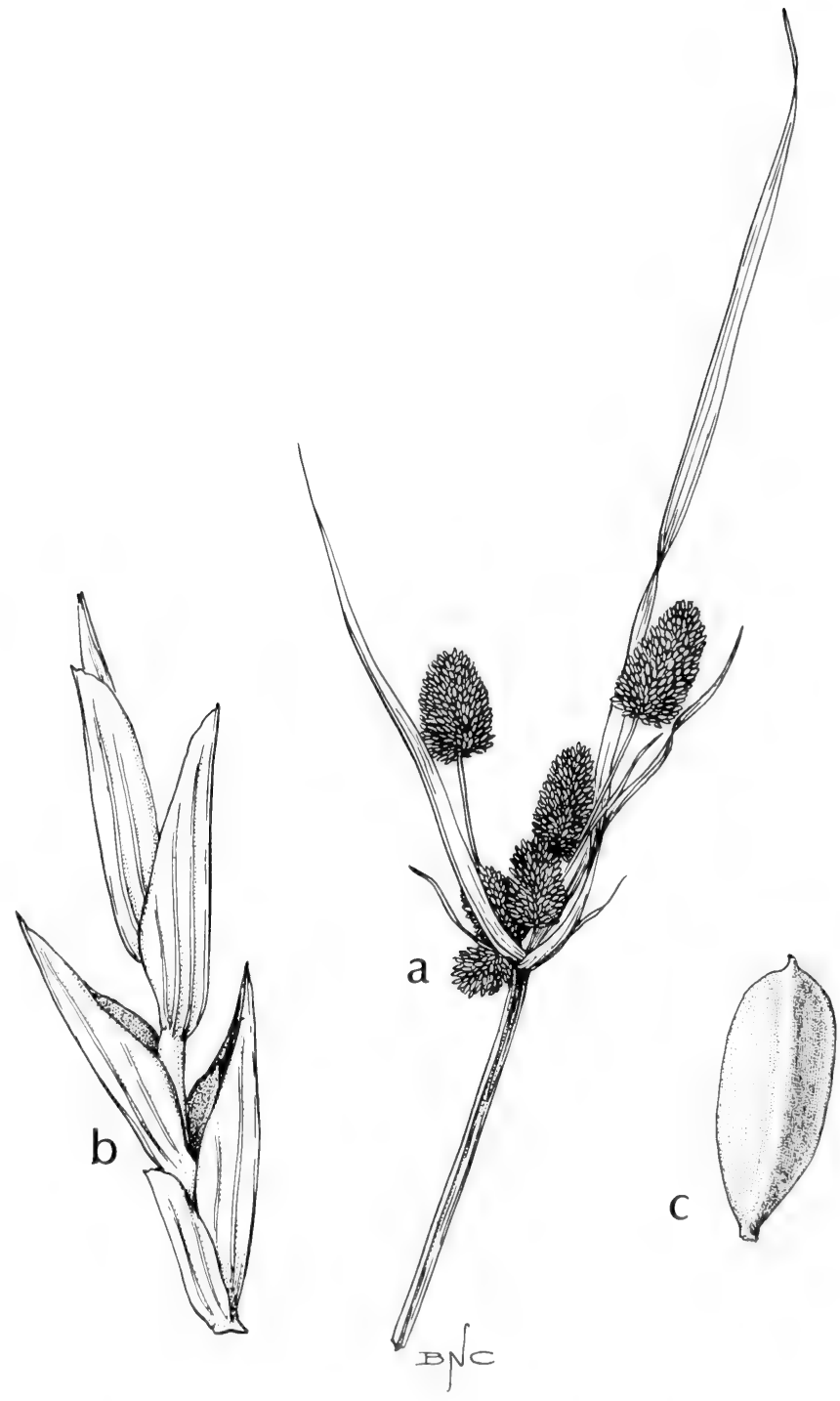

Fig. 237: Cyperus ovularis var. cylindricus: a, habit, X 1/2; b, spikelet, X 10; c, achene, X 15. (Courtesy of R. K. Godfrey). 


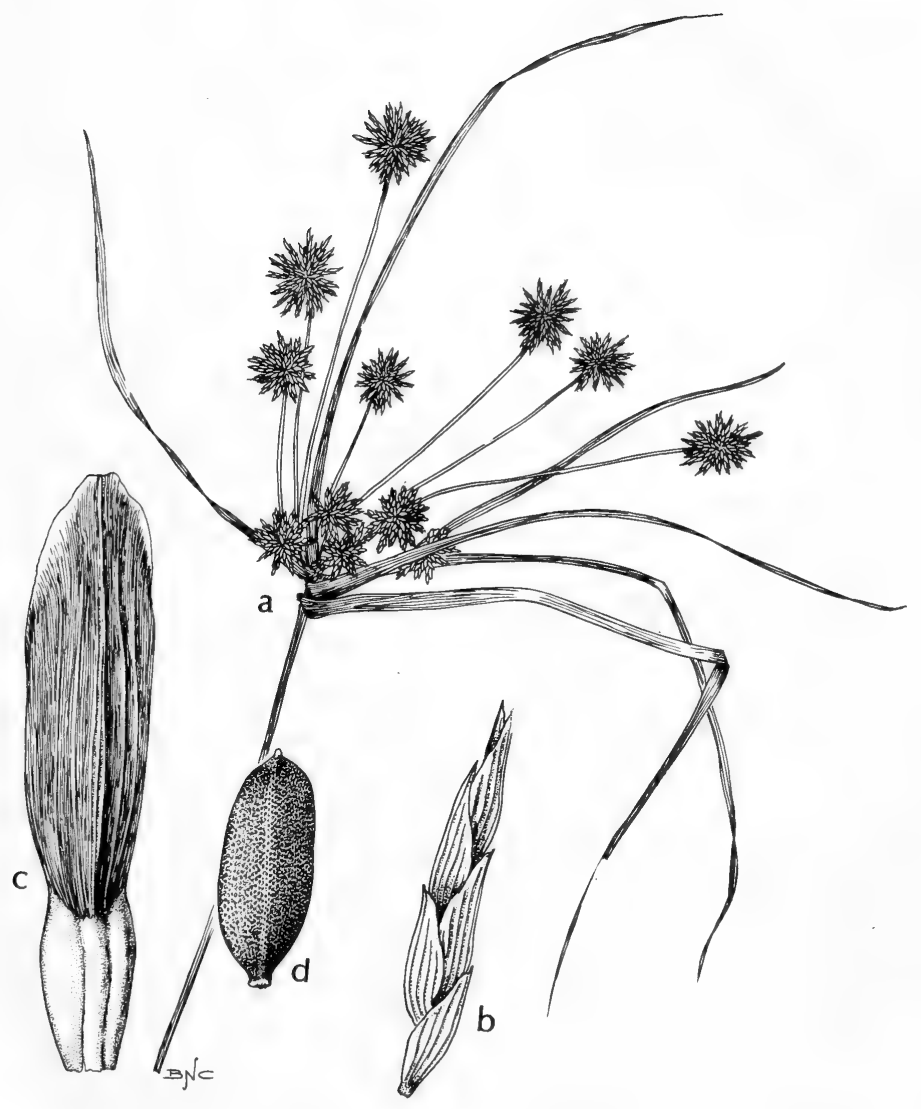

Fig. 238: Cyperus globulosus: a, habit, X 1/2; b, spikelet, X 5; c, scale, X 15; d, achene, X 15. (Courtesy of R. K. Godfrey). 


\section{Cladium jamaicense Crantz. SAW-GRASS. Fig. 239.}

Coarse erect reed 1-2.5 m. tall, with short rhizomes; leaves long, very tough, channeled ventrally, with dangerous saw-toothed cutting margins; inflorescences ample, 2-5 dm. long, much-branched, often droopy; spikelets ovoid, chestnutbrown, 3-5 mm. long, in fascicles of 2 to 6 at ends of the branchlets, each with a single fertile floret and below it 2 or 3 other spirally imbricate scales, all but the lowest enclosing stamens; perianth absent; achene obovoid, apiculate, somewhat lustrous, brownish, the obovoid body $2-2.5 \mathrm{~mm}$. long, the apiculate $0.6-1 \mathrm{~mm}$. long.

Locally abundant in fresh water on margins of streams, ponds and lakes, mostly in areas of calcareous soil, s.e. Tex., Rio Grande Plains, Edwards Plateau and Trans-Pecos, summer; widespread in Carib. region, n. to Gulf States and Va. The var. chinense (Nees) Koyama occurs in China and Japan.

Most of the plants of Arizona, Nevada and New Mexico, and some plants of the Edwards Plateau and the Trans-Pecos, Texas, have, on the average, slightly smaller, proportionately shorter and more numerous spikelets and denser inflorescences than the plants described above. These have been segregated as a separate species, $C$. californicum (Wats.) O'Neill. These differences are not well marked but usually the plants from the above states, California and Coahuila are thought to be $C$. californicum.

\section{Schoenus L.}

About 100 species, world-wide in distribution.

\section{Schoenus nigricans L. BLACK SEDGE. Fig. 240.}

Coarsely tufted perennial; culms slender, wiry, erect, simple, 2-6 dm. long, about $1 \mathrm{~mm}$. thick; leaves basally crowded, the lower sheaths chestnut-black and shiny, the upper blades tough, thin, wiry, involute, shorter than the culms, apically spinose; bracts 1 or 2 , the lower one far-surpassing the inflorescence, involute and wiry like the leaves; inflorescence a single sessile glomerule of about 10 sessile spikelets; spikelets laterally compressed, of about 5 to 10 distichous much-overlapping dark-chestnut to blackish scales of which only the upper few produce mature fruit; perianth bristles few, much shorter than the achene, minutely plumose at the very base; style 3-branched; achene shortly obovoid-trigonous with convex sides, pearly- or bony-white, shiny, jointed abruptly with the differently-textured style which thus does not leave a tubercle.

Infrequent or rare in creek canyons, about hot springs and other wet places, s. part of Tex. Edwards Plateau, spring; widespread in warm-temp. usually semiarid parts of the world.

\section{Dichromena MichX White-top Sedge}

Tufted or rhizomatous perennials with stems leafy basally, the blades ascending; flowering culms terminating in an involucrate headlike agglomeration of spikelets, the bracts white basally but green distally; spikelets usually whitish: scales several, spirally imbricated or irregularly distichous, the terminal ones enclosing a fertile floret, the lower ones staminate or empty; perianth absent; achenes lenticular, transversely rugose, crowned with the broad persistent base of the style (tubercle) as in Rhynchospora. Some authors would include Dichromena within Rhynchospora.

One of the more easily recognizable of the sedges because of the white bases of the bracts; these apparently function to attract insects. Most sedges, on the contrary, are thought to be wind-pollinated. About 60 species in the Western Hemisphere. 


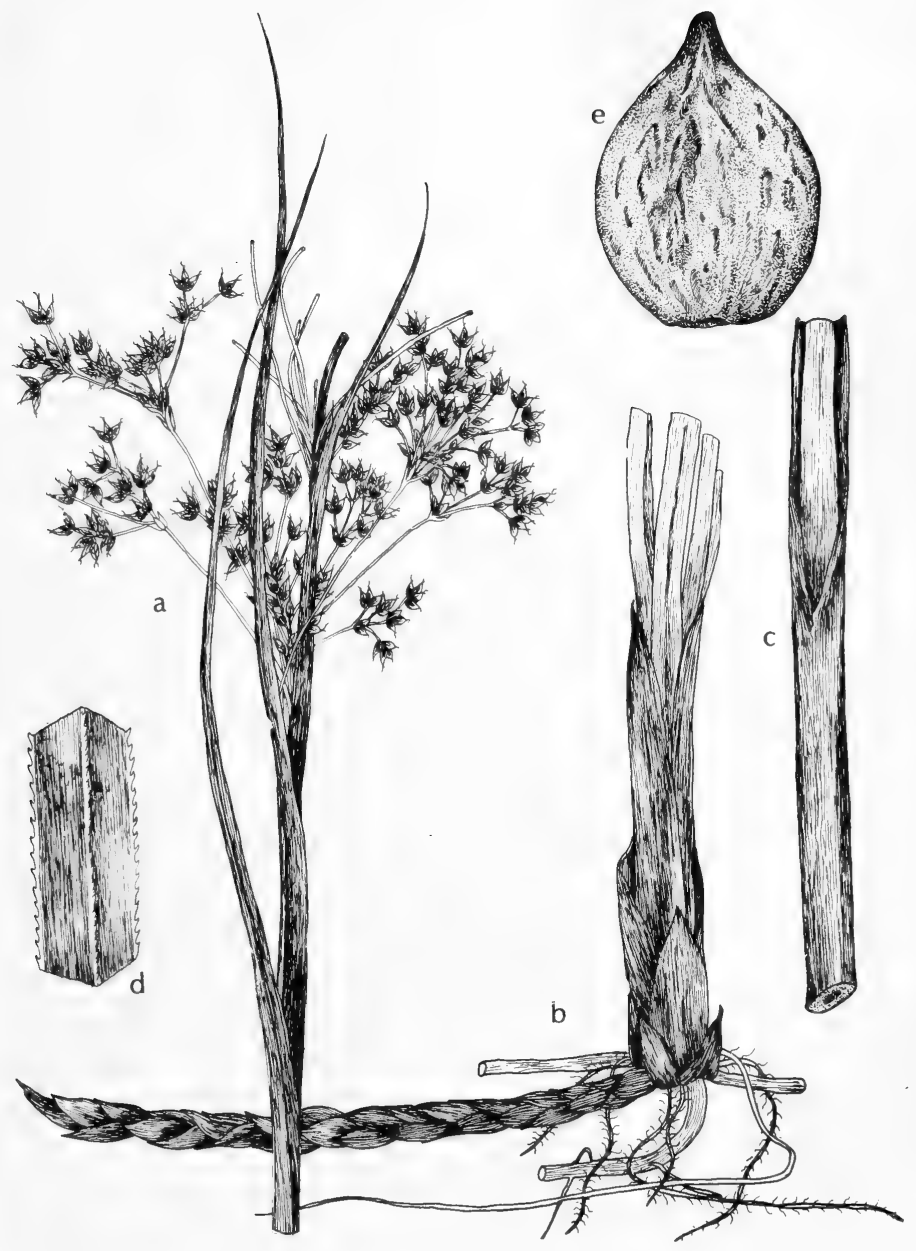

Fig. 239: Cladium jamaicense: a, top of plant, X 1/2; b, base of plant, X $1 / 2$; c, central part of culm and sheath, X $1 \frac{1}{2}$; $\mathrm{d}$, section of leaf, $\mathrm{X} 1 \frac{112}{2}$; e, achene, about X 12 . (Courtesy of R. K. Godfrey). 


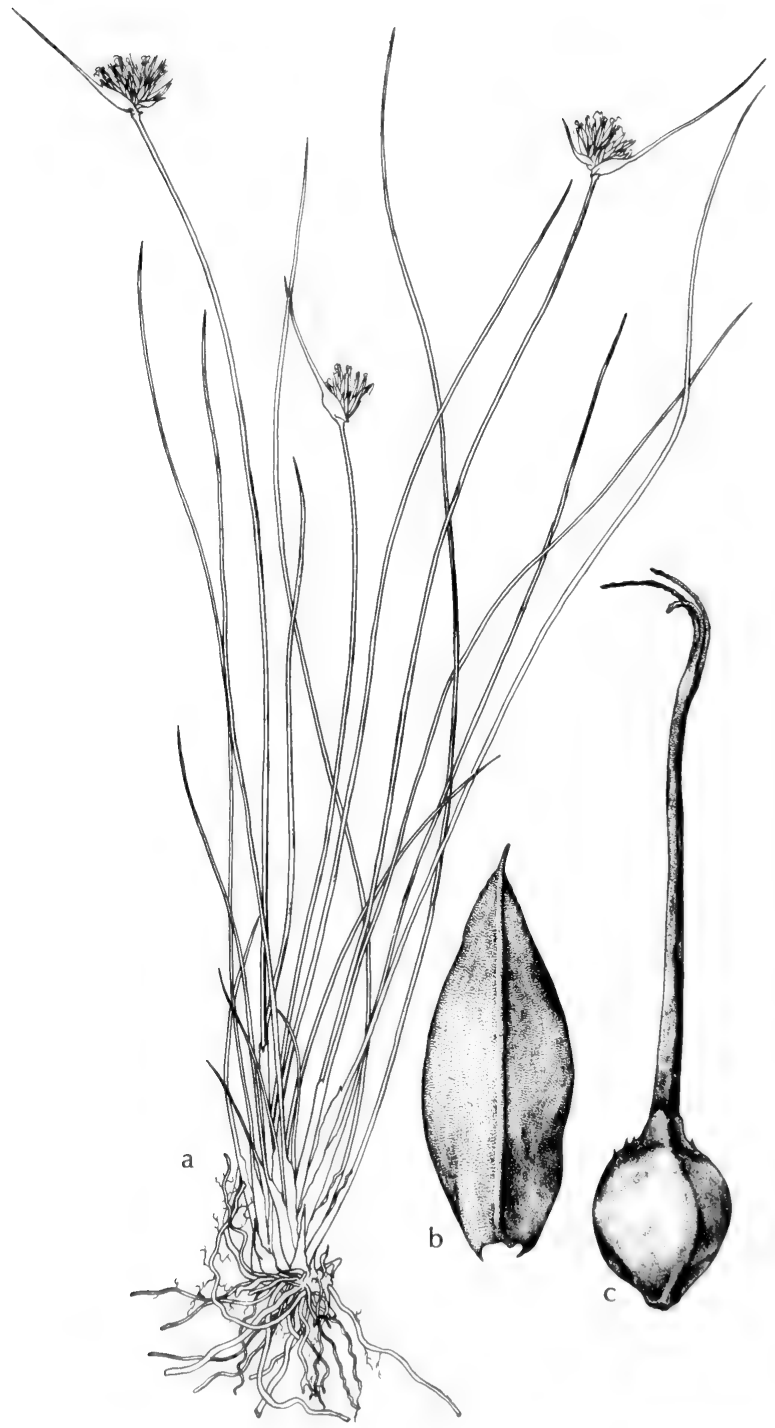

Fig. 240: Schoenus nigricans: a, habit, X 1/2; b, scale, X 15; c, achene, X 15 . (Courtesy of R. K. Godfrey). 
1. Plants densely tufted; rhizomes absent; culms $1 \mathrm{~mm}$. or less thick; blades 3-7 $\mathrm{cm}$. long, $1 \mathrm{~mm}$. broad basally, arcuate-filiform in the distal part; bracts 2 (rarely 3 ), the longer ones $17-37 \mathrm{~mm}$. long, filiform most of the length.

3. D. nivea.

1. Plants with extensively creeping orangish or whitish rhizomes; culms $1.5-3$ $\mathrm{mm}$. thick basally; blades $6-25 \mathrm{~cm}$. long, $1.2-4 \mathrm{~mm}$. broad basally and at least $1 \mathrm{~mm}$. broad even in the distal part; bracts several, the longer ones (20-) 40-130 $\mathrm{mm}$. long, not filiform except perhaps at the extreme apex (2)

2(1). The white spot at the base of the longer bracts 5-20 (-25) $\mathrm{mm}$. long, a (third to a) fifth to a tenth as long as the bracts; bracts 3 to 6 (or 7) 1. D. colorata.

2. The white spot at the base of the longer bracts $25-50 \mathrm{~mm}$. long, about half as long as the bracts; bracts 6 to 10 .

2. D. latifolia.

1. Dichromena colorata (L.) Hitchc. White-TOPPED UMBrella grass. Figs. 241 and 242.

Rhizomes usually orangish, 2-3 mm. thick, extensively creeping, scaly; culms $12-56 \mathrm{~cm}$. long, erect or often decumbent at the very base; leaves crowded basally, mostly rather stiffly ascending, 2-6 $\mathrm{mm}$. broad, linear-involute at the tip; bracts 3 to 6 (or 7), mostly basally ascending but for the most of the length spreading or slightly reflexed, lanceolate, very unequal, the longer ones (3-) $5-15 \mathrm{~cm}$. long, (1.5-) 2.5-5 mm. broad basally, with a white spot 5-20 (-25) mm. long.

Locally frequent in swales, ditches and wet places generally, s.e. Tex., Rio Grande Plains and Edwards Plateau, rare in s. part of e. Tex., w. to Terrell Co. in the Trans-Pecos, (spring-) summer widespread in Carib. region, n. to Va. and the Gulf States; e. Mex.

\section{Dichromena latifolia Ell. Figs. 241 and 242.}

Perennial with rhizomes 2-3 $\mathrm{mm}$. thick; culms rather stiffly erect the full length, 4-8 $(-10) \mathrm{dm}$. long, 2-4 mm. thick basally; leaves crowded basally, ascending, 4-6 mm. broad basally, tapered upward and involute in the distal third, apically pointed; bracts 6 to 10 mostly basally ascending but for most of the length spreading or slightly reflexed, lanceolate, very unequal, the longer ones $5-10 \mathrm{~cm}$. long, 4-10 $\mathrm{mm}$. broad in the lower half, with a white spot $25-50 \mathrm{~mm}$. long (about half as long as the bract).

Locally frequent in poorly drained pine savannahs, s.e. Tex (Hardin and Jefferson cos. only), summer; Gulf States and n. to N.C.

\section{Dichromena nivea (Boeck.) Britt. Fig. 241.}

Densely tufted; rhizomes absent; culms weak, ascending, 1-3 (-4) dm. long, about $1 \mathrm{~mm}$. thick or less; leaves in the lower part, flaccid, 3-7 cm. long, about $1 \mathrm{~mm}$. broad basally, arcuate-filiform; bracts 2 (rarely 3), weak, the longer ones 17-37 mm. long, filiform most of the length, with a white spot only at the very base, D. Reverchonii S. H. Wright, Rhynchospora nivea Boeck.

Locally frequent in creek beds through limestone on Tex. Edwards Plateau, rare in n.-cen. Tex. and Okla. (Marshall Co.), summer; also Ark.

\section{Rhynchospora Vahl (corr. Willd.) BeaK-RUSH}

Perennials (rarely annuals); culms leafy; inflorescence of each culm usually divided into several discontinuous parts (branches of the culm), the largest part (appearing terminal) usually subumbelliform (occasionally much-reduced) with several unequal primary branches (each subtended by a bracteal leaf) and these in turn bearing spikelets or glomerules or corymbs of spikelets; the several axillary parts of the inflorescence below usually reduced as compared to the terminal part, 


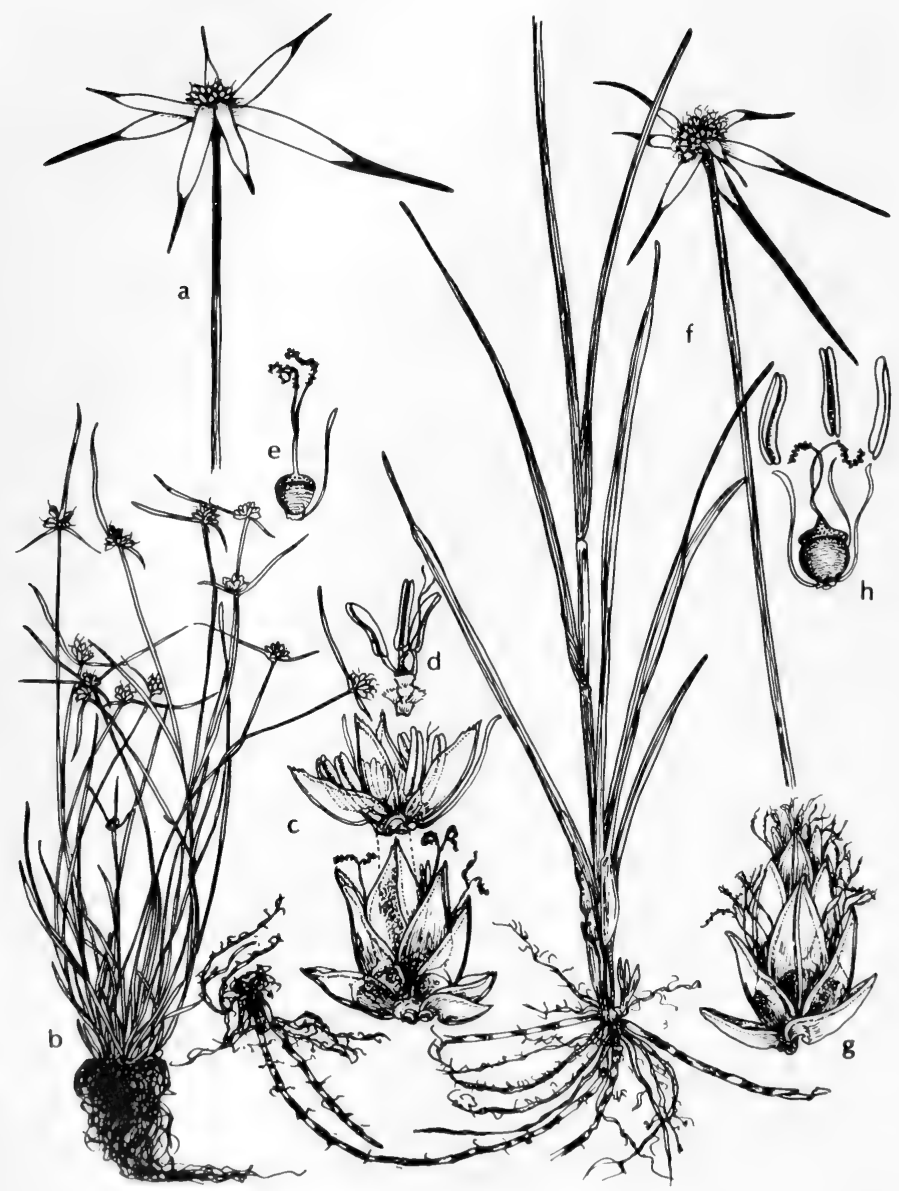

Fig. 241: a, Dichromena latifolia: a, infiorescence, X $1 / 2$, b-e, Dichromena nivea: b, habit, $X$ 1;: c, spikelet pulled apart to show flowers, $X \quad 5$; flower with scales removed, X 5; e, achene, X 5. f-h, Dichromena colorata: f, habit, X 1/2; g, spikelet, X 5; h, achene, X 5. (V.F.). 

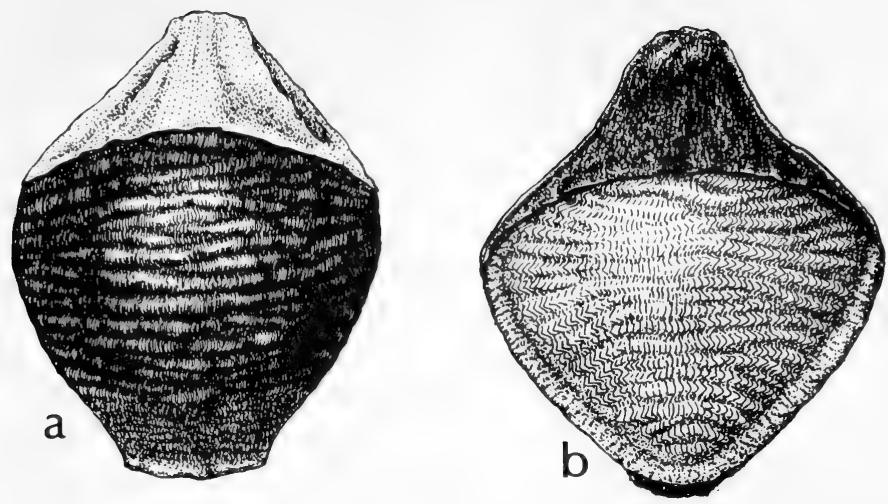

Fig. 242: a, Dichromena colorata: a, achene, X 25 b, Dichromena latifolia: b, achene, X 20. (Courtesy of R. K. Godfrey).

occasionally reduced to virtual absence; spikelets with several spirally-disposed scales, the axils of the lowest 1 (or 2) scales empty, the 1 to 10 axils above with perfect flowers, and usually above that 1 or 2 scales enclosing staminate or rudimentary flowers; scales usually broad, membranous, usually brownish with very indistinct midnerves and no other nervation; bristles usually above 6 or 8 (or up to 20 ) or reduced to virtual absence; stamens usually 1 or 2 or 3 ; style bifurcate either at the very tip or usually much farther down, its base becoming indurate and persisting on the achenial body as a tubercle of distinctly different texture; achenial body usually distinctly biconvex, varying to nearly flat or nearly turgid, the cells of the face usually variously sculptured and elongated, the walls often prominent.

About 200 species, cosmopolitan in distribution, especially tropical, The name has been misspelled as Rynchospora and Rhyncospora in various works.

1. Style nearly simple or very shortly 2-branched at the summit; achenial bodies $3.5-6 \mathrm{~mm}$. long; tubercle $3.5-18 \mathrm{~mm}$. long (2)

1. Style with 2 long branches; achenial bodies and tubercles mostly shorter (4)

2(1). Mature spikelet 7-10 $\mathrm{mm}$. long; achenial body $3.5-4 \mathrm{~mm}$. long; tubercle 3.5-4 mm. long.......................................... $R$. indianolensis.

2. Mature spikelet $15-23 \mathrm{~mm}$. long; achenial body 4-5 $\mathrm{mm}$. long; tubercle 13-18 $\mathrm{mm}$. long (3)

3(2). Bristles (at least most of them) much-exceeding the achenial body.

..1. R. macrostachya.

3. Bristles shorter than the achenial body, stout and closely appressed.....

2. $R$. corniculata.

4(1). Achenial bodies pearly-white, $0.7-0.8 \mathrm{~mm}$. long; tubercles $0.1-0.2 \mathrm{~mm}$. long, $0.15-0.2 \mathrm{~mm}$. broad; spikelets with 5 to 8 fertile flowers; perianth bristles absent (5)

4. Achenial bodies and/or tubercles considerably larger and often brownish in color; spikelets with fewer fertile flowers; perianth bristles usually present (6) 
5(4). Achenial body smooth under low magnification or faintly cellular-reticulate under high magnification, the 2 faces strongly convex.

4. $R$. divergens.

5. Achenial body with transverse ridges, the 2 faces only slightly convex.

5. R. pusilla.

6(4). Bristles conspicuously retrorsely barbed (7)

6. Bristles antrorsely barbed or plumose or absent or smooth (10)

7(6). Bristles 10 to 20 per achene; spikelets with only 1 fertile flower and this appearing terminal (no rudimentary flower above it); inflorescence usually merely a dense terminal fascicle.

9. R. macra.

7. Bristles fewer; spikelets usually with 2 fertile flowers or one fertile flower and a reduced one above it; each culm with several fascicles, one terminal and several axillary, or if only one fascicle then culm capillary (8)

8(7). Culms capillary; achenes inconspicuously margined, finely granulate to slightly rugulose, achene body $1.7-2.6 \mathrm{~mm}$. long, less than half as wide as long.................................................... $R$. capillacea.

8. Culms 1-3.5 mm. thick basally; achenes with conspicuous pale wire-like margins, smooth, castaneous, usually lustrous, achene body 1.3-1.7 $\mathrm{mm}$. long, one half to three fourths as wide as long (9)

$9(8)$. Central portions of the 2 sides of the achenial body abruptly raised in a hump and polished-buffy, contrasting with the dark chestnut-brown submarginal flat portions, the margins themselves pale and wirelike; leaves basally 5-6 mm. broad; culms basally $2-3.5 \mathrm{~mm}$. thick.

7. R. glomerata.

9. The 2 sides of the achenial body rather evenly convex all over, grading from buffy centrally to darker brownish marginally, the margins themselves slightly paler and wirelike; leaves basally $2-3 \mathrm{~mm}$. broad; culms basally $1-2 \mathrm{~mm}$. thick. 8. R. capitellata.

10(6). Bristles heavily plumose basally (11)

10. Bristles antrorsely serrulate or barbed, smooth or these absent (12)

11(10). Spikelets 4-7 $\mathrm{mm}$. long, 1 to 5 present per culm, remote on slender pedicels; achene 2.3-2.6 $\mathrm{mm}$. long (excluding tubercle).

10. $R$. oliganthra.

11. Spikelets $3-4 \mathrm{~mm}$. long, more numerous, congested in spikelike fascicles; achene 1.4-1.8 mm. long (excluding tubercle)........11. R. plumosa.

12(10). Achenial body smooth (13)

12. Achenial body with traverse wrinkles or traverse rows of cells with sculptured walls (15)

13(12). Achenial body $0.9-1 \mathrm{~mm}$. long; tubercle $0.4-0.6 \mathrm{~mm}$. long.

13. Achenial body $1.3-1.8 \mathrm{~mm}$. long; tubercle $0.4-2 \mathrm{~mm}$. long (14)

14(13). Tubercle $0.4-0.7 \mathrm{~mm}$. long.

13. R. fascicularis.

14. Tubercle 1-2 $\mathrm{mm}$. long. 14. R. gracilenta.

15(12). Terminal part of inflorescence of each culm very lax, with only 6 to 12 ( to 20) spikelets each on a capillary pedicel 3-12 mm. long: culms only $0.6-1 \mathrm{~mm}$. thick.

17. $R$. rariflora.

15. Terminal fascicle denser with more spikelets or if as few as 12 then either denser or else the culm thicker than $1 \mathrm{~mm}$. basally (16) 
16(15). Horizontal rows of cells counted in vertical series near the middle of one face of the achenial body numbering (14 to) 16 to 30 and all the cells nearly isodiametric, the horizontal cell walls only slightly if at all raised more than the vertical walls; achenes turgid, $1 \mathrm{~mm}$. or more thick from the middle of one face to the middle of the other (17)

16. Horizontal rows of cells usually 11 to 15 ; (except in $R$. mixta) those cells near the middle of the face greatly vertically elongated and their horizontal walls very prominent and forming horizontal wrinkles on the achene, but those cells near the base and top of the body nearly isodiametric; achenes less turgid, less than $1 \mathrm{~mm}$. thick from face to face (18)

17(16). Achenial body $2-2.4 \mathrm{~mm}$. long, $1.5-1.8 \mathrm{~mm}$. thick from face to face; horizontal rows of cells 25 to 30 or more; spikelets $4-5.5 \mathrm{~mm}$. long..............................................................15. R. Grayi.

17. Achenial body $1.5-1.8 \mathrm{~mm}$. long, $1-1.5 \mathrm{~mm}$. thick from face to face; horizontal rows of cells ( 14 to) 16 to 20 ; spikelets $2.5-3 \mathrm{~mm}$. long........ 16. R. Harveyi.

18(16). Achenial body twice as long as broad. 18. $R$. inexpansa.

18. Achenial body less than twice as long as broad (19)

19(18). Bristles (most of them) surpassing the tubercle (20)

19. Bristles not surpassing the tubercle (22)

20(19). Achenial body $1.2-1.3 \mathrm{~mm}$. long, the 2 faces nearly flat; plants never rhizomatous; tubercle $0.3-0.4 \mathrm{~mm}$. long. 20. R. Elliottii.

20. Achenial body $1.3-1.7 \mathrm{~mm}$. long, the 2 faces distinctly convex at least in the upper part; plants rhizomatous (this often obscure in exsiccatae); tubercle $0.4-0.9 \mathrm{~mm}$. long (21)

21(20). Achenial body only $0.8-0.9 \mathrm{~mm}$. broad, with numerous indistinct transverse lines. 19. R. mixtra.

21. Achenial body $1.2-1.6 \mathrm{~mm}$. broad, with strong transverse wrinkles

23. R. caduca.

22(19). Primary branches of the terminal part of the inflorescence straight, stiffly ascending; faces of the achenial body definitely convex at least in the upper half....................................24. $R$. globularis.

22. Primary branches of the terminal part of the inflorescence arcuate, often slightly droopy; faces of the achenial body nearly flat or only very slightly convex (23)

23(22). Bristles half as long as to nearly as long as the achenial body; blades usually flat basally. 21. R. microcarpa.

23. Bristles less than half as long as the achenial body; blades usually nearly all strongly involute. 22. $R$. perplexa.

\section{Rhynchospora macrostachya Torr. HoRned-RUSH. Fig. 243.}

Tufted perennial; culms 5-10 dm. long, erect, 3-7 $\mathrm{mm}$. thick basally, triquetrous, leafy; basal sheaths becoming markedly fibrous; inflorescence (at maturity) clavate, 3-6 cm. thick, the branches numerous but rather short, erect; spikelets subulate, rich-brown, $15-23 \mathrm{~mm}$. long, the distal third consisting merely of the protruding distal part of the tubercle; bristles; several (4 to 7), about 1.5 to 2.5 times as long as the achenial body, stiff, brownish, antrorsely barbed; achenial body 4-5 $\mathrm{mm}$. long, obovate, nearly flat on the 2 faces, dark-brown; tubercle subulate, consisting of the indurated entire portion of the style, $13-18 \mathrm{~mm}$. long, pale-brownish to buffy. $R$. corniculata var. macrostachya (Torr.) Britt. 


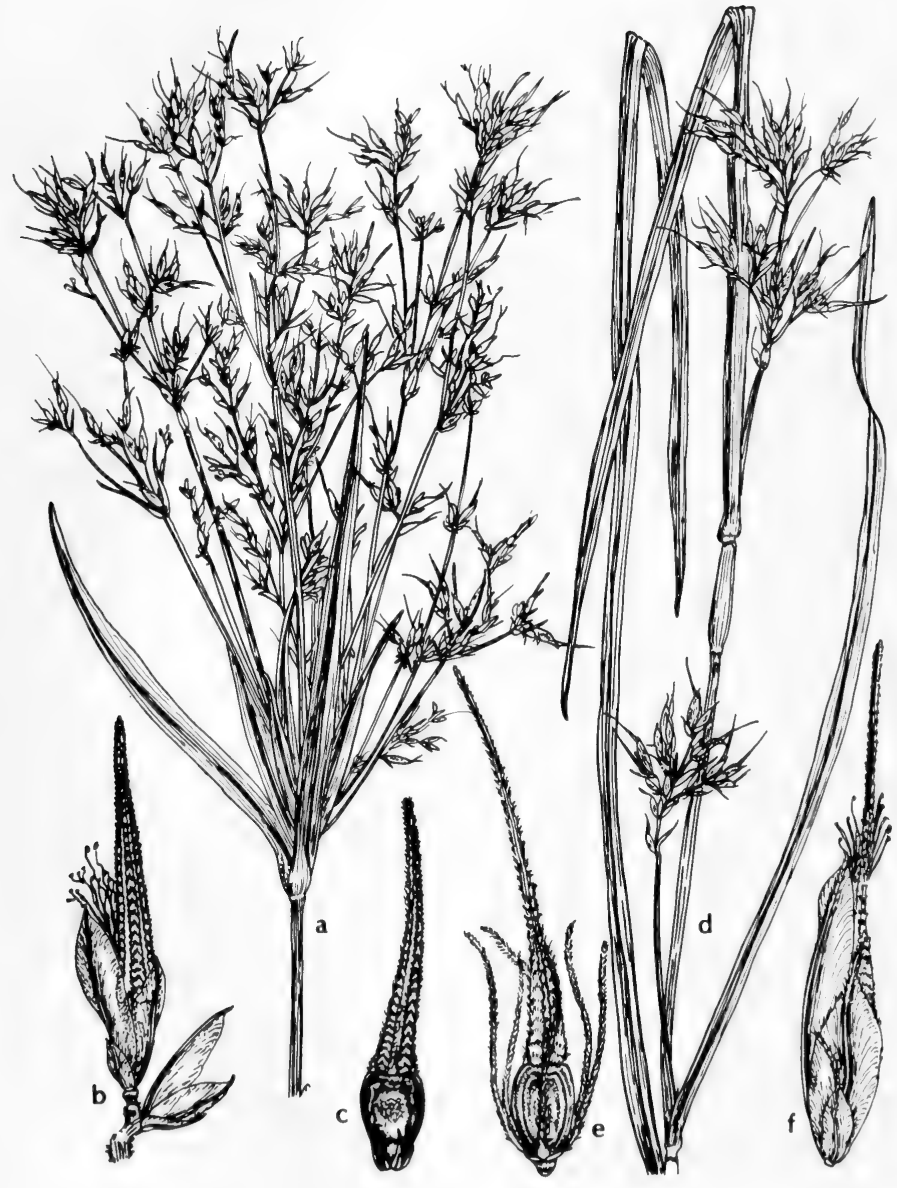

Fig. 243: a-c, Rhynchospora corniculata: a, terminal inflorescence, $\mathrm{X}$ 1/2; b, flower, X $2 \frac{1}{2}$; c, achene, X $2 \frac{1}{2}$. d-f, Rhynchospora macrostachya: d, upper part of plant, X $1 / 2$; e, achene, X 21/2; f, flower, X 21/2. (V.F.). 
In mud about ponds and along ditches, and in and on edge of lakes, infrequent in s.e. Tex., rare in e. Tex., and Okla. (LeFlore, Atoka and Pushmataha cos.), summer; s.e. U.S. n. to N.E., N.Y. and Mo., w. to Kan., Okla. and Tex.

\section{Rhynchospora corniculata (Lam.) Gray. HoRnED-RUSH. Fig. 243.}

Perennial, either tufted or usually with thick scaly rhizomes (these often broken off in specimens); culms 6-11 dm. long, erect, 3-9 mm. thick basally, triquetrous, very leafy; basal sheaths becoming only slightly fibrous; inflorescence at maturity loose-obovoid, ample, $7-15 \mathrm{~cm}$. thick, the numerous branches ascending to spreading; spikelets subulate, rich-brown, $15-23 \mathrm{~mm}$. long, the distal third to half consisting merely of the protruding distal part of the tubercle; bristles 2 to 4 (or 5), about a third to two thirds as long as the achenial body, stiff, brownish, closely appressed; achenial body $4-5 \mathrm{~mm}$. long, obovate, nearly flat on the 2 faces, dark-brown; tubercle subulate, consisting of the indurated entire portion of the style, 13-18 mm. long; pale buffy.

Frequent in mud, on edge of lakes, along edge of swamps and in water of ditches, in Okla. (Choctaw, McCurtain, Bowie, LeFlore and Sequoyah cos.), e. and s.e. Tex., spring-summer, (fruiting into fall); s.e. U.S., n. to Del., Ky., Ind. and Mo., w. to Okla. and Tex.; W.I.

Ours are nearly all of the var. interior Fern. in which the achenial body is only about 1.5 times as broad as the base of the tubercle; a few are of the var. corniculata in which the body is about twice as broad as the tubercle.

\section{Rhynchospora indianolensis Small.}

Tufted perennial; culms 5-9 dm. long, erect, 3-6 $\mathrm{mm}$. thick basally, triquetrous, leafy (especially in the basal part); terminal part of the inflorescence somewhat umbelliform, Cyperus-like, 4-9 cm. long, with several ascending rays each bearing a dense roundish glomerule or capitulum of nearly sessile spikelets, usually a reduced axillary part of the inflorescence present; spikelets $7-10 \mathrm{~mm}$. long, lanceolate, brown, acute, the tubercle only slightly if at all exserted; bristles 3 to 5 , about equaling the achenial body, stiff, appressed; achenial body $3.5-4 \mathrm{~mm}$. long, obovate, nearly flat on the 2 faces, dark brown; tubercle $3.5-4 \mathrm{~mm}$. long, brown, elongate-deltoid, acute or slightly acuminate.

Locally frequent in mud, s.e. Tex., summer; endemic.

\section{Rhynchospora divergens M.A. Curtis.}

Tufted short-lived perennial (or annual?); culms 18-42 cm. long, 0.3-0.9 mm. thick, erect; leaves numerous, $5-10 \mathrm{~cm}$. long, setaceous-involute; terminal part of the inflorescence umbel-like, 1-2 cm. long, and $1 \mathrm{~cm}$. broad, occasionally 1 or 2 reduced axillary parts of the inflorescence present below; spikelets linear, 3 - to 10 -flowered, about $1 \mathrm{~mm}$. thick, the fruits very quickly maturing in succession acropetally as the spikelet elongates, the scales and achenes falling as the achenes mature, eventually as many as 5 to 8 fruits maturing from a single spikelet but only 1 or 2 visible at any one time; scales brownish, about $1.5 \mathrm{~mm}$. long; bristles absent; achenial body $0.7 \mathrm{~mm}$. long, obovate, white, the 2 faces convex and under low magnification appearing smooth, under higher magnification faintly cellular-reticulate; tubercle about $0.15 \mathrm{~mm}$. long and $2 \mathrm{~mm}$. broad, whitish, blunt.

Rare in moist or wet sand, s.e. Tex. (Aransas and Montgomery cos.), summer; S.C., Ga., Fla., Bah. I. and Tex.

\section{Rhynchospora pusilla M. A. Curtis.}

Tufted short-lived Bulbostylis-like perennial; culms $15-30 \mathrm{~cm}$. long, 0.2-0.7 $\mathrm{mm}$. thick, erect; leaves numerous, $5-10 \mathrm{~cm}$. long, setaceous-involute, terminal part of the inflorescence reduced, somewhat umbel-like or corymbose, 6-20 $\mathrm{mm}$. long, 5-10 mm. broad, often reduced parts of the inflorescence also present from 


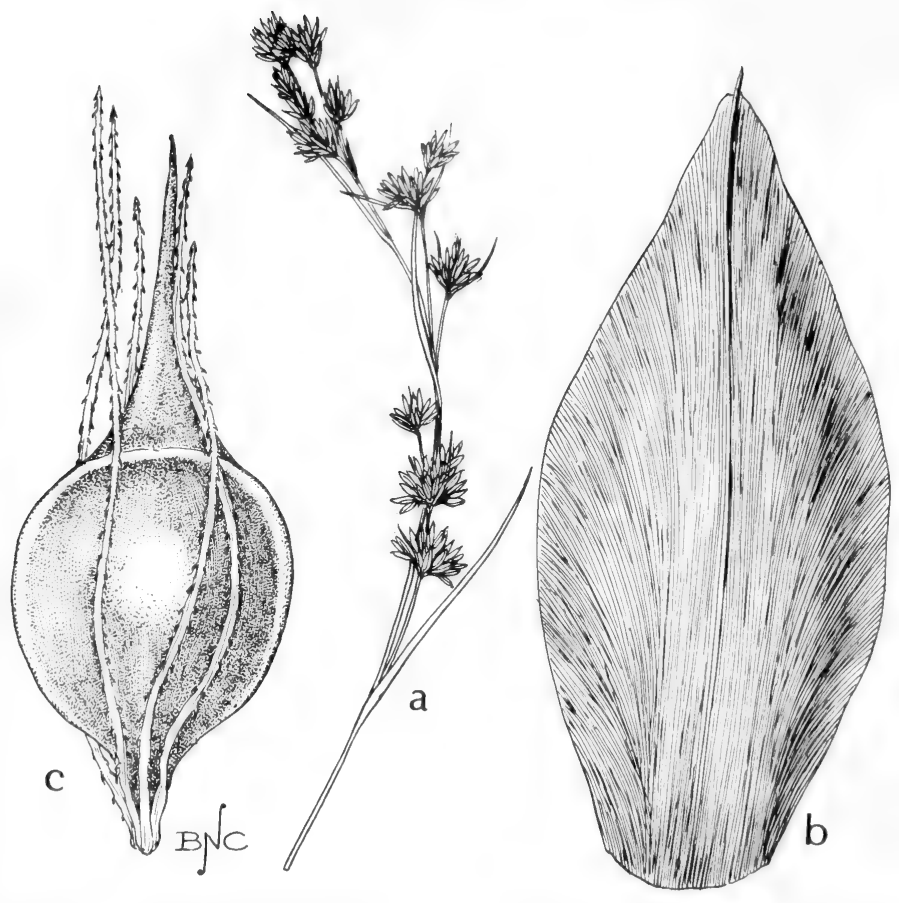

Fig. 244: Rhynchospora glomerata: a, top of plant, X 1/2; b, scale, X 25; c, achene, X 15. (Courtesy of R. K. Godfrey).

the penultimate axils; spikelets, linear, 3- to 10 -flowered, about $1 \mathrm{~mm}$. thick, the fruits very quickly maturing in acropetal succession and falling with the scales, as many as 5 to 8 fruits maturing from a single spikelet but only 1 or 2 visible at any one time; scales brownish, about 1:5 mm. long; bristles absent; achenial body $0.7-0.8 \mathrm{~mm}$. long, obovate, whitish, the 2 faces nearly flat, with transverse rugae; tubercle $0.1-0.15 \mathrm{~mm}$. long, $0.15-0.2 \mathrm{~mm}$. broad, whitish, blunt.

Rare in moist or wet sand, s. part of e. Tex. (Hardin Co.), summer; Fla. to Tex.; W.I.

Some authors have referred these plants to $R$. intermixta Wright.

\section{Rhynchospora capillacea Torr.}

Tufted perennial; culms capillary, $1-4 \mathrm{dm}$. tall; leaves filiform, 0.2-0.4 mm. wide, often as long as the inflorescence; inflorescence ellipsoid or ovoid, of 1-10 spikelets, the terminal $2-8 \mathrm{~mm}$. broad, the 1 axillary fascicle subsessile or short, peduncled; spikelets lanceolate, sessile or subsessile, brown, 5-7 mm. long, 1- to 5-fruited; scales with a pale margin; bristles 6 (or rarely more), retrorsely barbed, as long as or longer than the tubercle; achenes obovate-oblong, marked horizontally or rugose, $1.7-2.6 \mathrm{~mm}$. long, less than half as wide, narrowed toward the base; tubercle lanceolate, $0.8-1.6 \mathrm{~mm}$. long. 
In calcareous meadows or calcoreous swamps and seepage areas, reported from Bryan Co., Okla. by Waterfall; Nfld. to Sask., s. to N.J., Pa., Va., Tenn., Mo., Okla. and S.D.

\section{Rhynchospora glomerata (L). Vahl. Fig. 244.}

Tufted perennial; culms 6-11 dm. long, erect, 2-3.5 mm. thick basally, triquetrous, leafy; larger leaves 5-6 mm. broad near the base of the plant; inflorescence variable, either of a number of subcapitate glomerules scattered along the upper half of the culm ("var. glomerata") or a few more discretely grouped glomerules ("var. angusta Gale"): spikelets lanceolate, 4.5-6 mm. long, richdark-brown, with usually 2 fruits (less commonly 3 or 1 , if with 1 then with a terminal rudimentary flower); bristles about 6 , exceeding the achene and often about equaling the tubercle, somewhat dorsiventrally compressed, conspicuously retrorsely barbed; achenial body pyriform, 1.5-1.7 $\mathrm{mm}$. long, the 2 sides with an abruptly raised central hump which is polished and buffy, contrasting with the dark-chestnut-brown submarginal flat portion, the margins themselves pale like the umbo; tubercle 1.3-1.8 mm. long, elongate-deltoid, much compressed, grayish.

In moist sand, wet sandy drainage area, ponds on edge of woods, in water of seepage bog, in Okla. (LeFlore, McCurtain, pushmataha and Pittsburg cos.), frequent in e. Tex., infrequent in s.e. Tex., summer; Gulf States, n. to Del., Va., Tenn. and Ark., w. to Okla. and Tex.

\section{Rhynchospora capitellata (Michx.) Vahl. Fig. 245.}

Tufted perennial; culms 2-9 dm. long, erect, 1-2 mm. thick basally, bluntly 3-angled, leafy; larger leaves $2-3 \mathrm{~mm}$. broad near the base of the plant; inflorescence of a few turbinate fascicles scattered along the uppor half of the culm; spikelets lanceolate, $3.5-5 \mathrm{~mm}$. long, usually with 2 fruits (less commonly 3 or 1 , if with 1 then also with a terminal rudimentary flower); bristles about 6 , exceeding the achene, usually about equaling the tubercle, somewhat dorsiventrally compressed, conspicuously retrorsely barbed; achenial body pyriform or obovate, basally cuneate, $1.3-1.6 \mathrm{~mm}$. long, the 2 sides merely convex (the central portions paler, grading off into the darker brown submarginal zones, the margins themselves pale like the center); tubercle elongate-deltoid, $0.9-1.6 \mathrm{~mm}$. long, grayish, muchcompressed.

On banks of streams and spring branches and wet places in uplands, infrequent or rare in Okla. (Adair and McCurtain cos.) and e. Tex. (Austin, Guadalupe, Angelina, Henderson and Leon cos.), apparently always in acid boggy ground, summer; e. U.S. n.e. to N.S., w. to Wisc., Mo., Okla. and Tex.

\section{Rhynchospora macra (Clarke) Small. Fig. 245.}

Tufted (?) or with rhizomes about $1 \mathrm{~mm}$. thick; culms 3-7 dm. long, erect, triquetrous, $1.5-2 \mathrm{~mm}$. thick near the base; leaves several, the blades $2-3.5 \mathrm{~mm}$. broad near the base of the plant; inflorescence primarily a large terminal turbinatecorymbose fascicle $1-3 \mathrm{~cm}$. broad, 1 or 2 extremly reduced axillary fascicles also present; spikelets linear-lanceolate, 4-5 $\mathrm{mm}$. long, pale brown, each with a single fertile flower and never a higher rudimentary one; bristles 10 to 20 per achene, much-surpassing the body, conspicuously retrorsely barbed; achenial body pyriform 1.8-2 $\mathrm{mm}$. long, brown (the raised central portions of the 2 sides paler, buffy), the submarginal surfaces with very faint transverse wrinkles; tubercle elongate-deltoid, much-compressed, about $1 \mathrm{~mm}$. long.

Very rare in bogs in e. Tex. (Houston and Robertson cos.), summer; Ga., Fla., Miss. and Tex. 

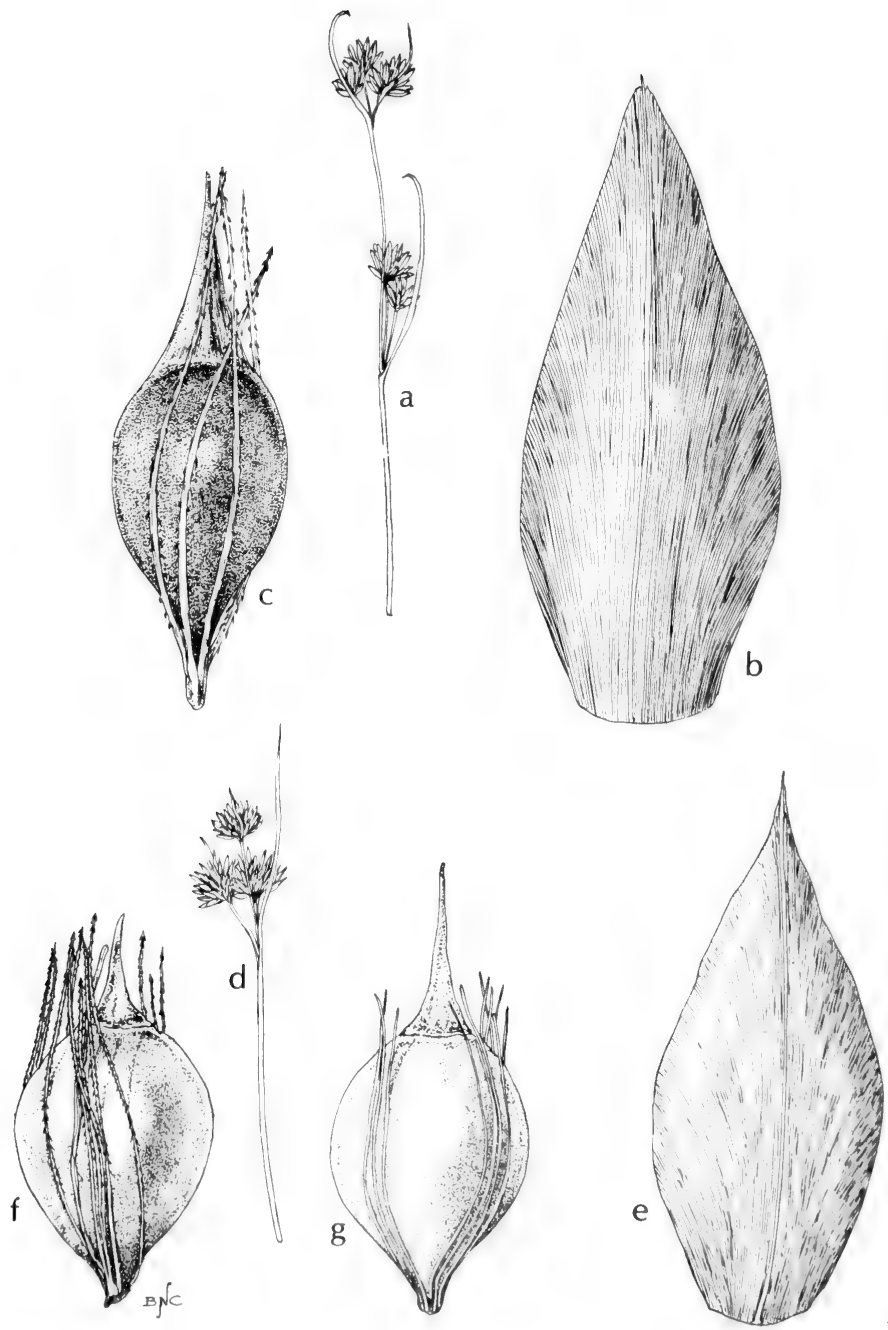

Fig. 245: a-c, Rhynchospora capitellata: a, top of plant, X 1/2; b, scale, X 15; c, achene, X 15. d-g, Rhynchospora macra: d, top of plant, X 1; e, scale, X 15; f, achene with usual bristles, X 15; g, achene with unusual smooth bristles, X 15. (Courtesy of R. K. Godfrey). 

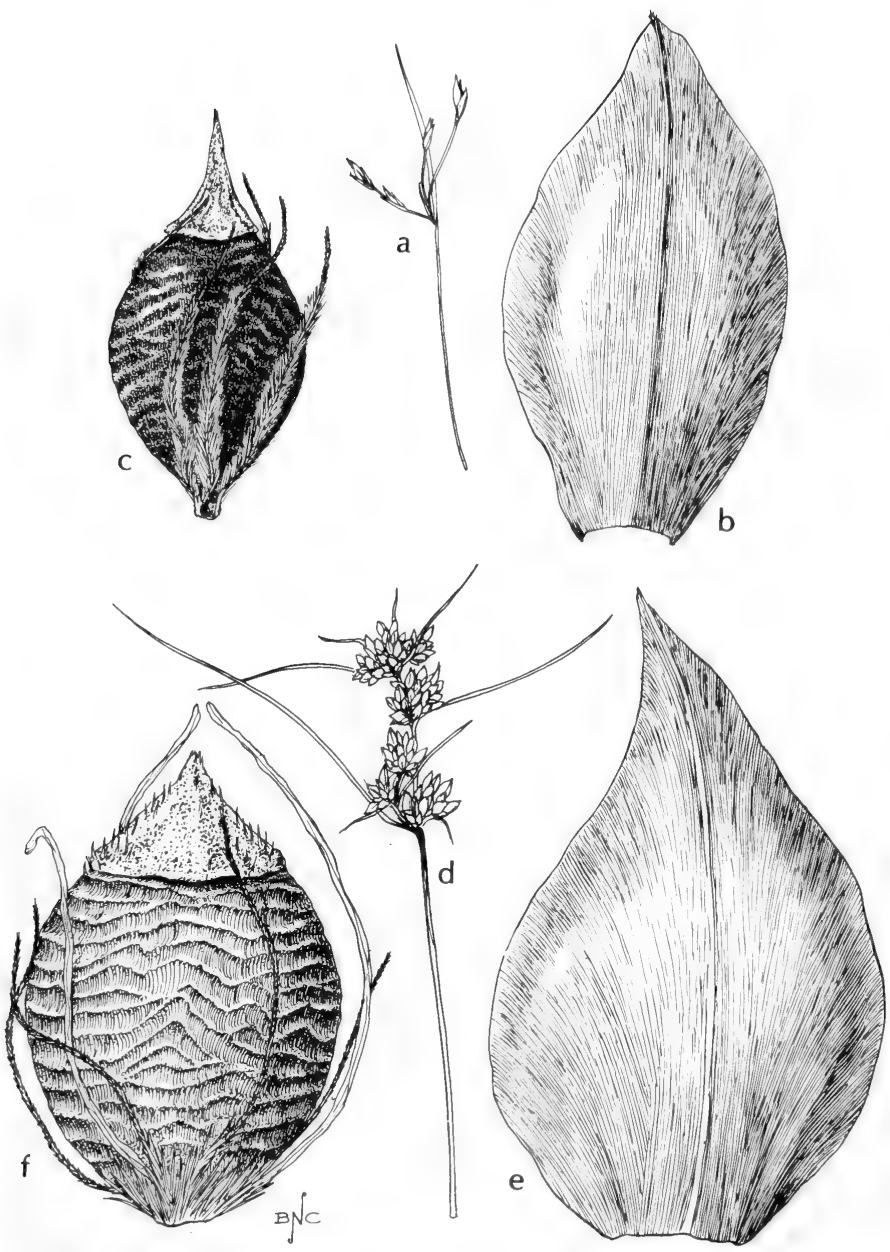

Fig. 246: a-c, Rhynchospora oligantha: a, top of plant, X 1; b, scale, X 15; c, achene, X 15. d-f, Rhynchospora plumosa: d, top of plant, X 1; e, scale, X 25; f, achene, X 25. (Courtesy of R. K. Godfrey). 


\section{Rhynchospora oligantha Gray. Fig. 246.}

Tufted perennial; culms $15-45 \mathrm{~cm}$. long, erect or ascending, 0.3-0.6 mm. thick; leaves filiform-setaceous, resembling the stems; inflorescence of a lax terminal fascicle and usually a remote reduced axillary one, each fascicle with only 1 to 3 spikelets; spikelets on slender individual pedicles $3-10 \mathrm{~mm}$. long, narrowly ovoid, pale-brown, 4-7 mm. long, usually with 2 fruit (1 to 3); bristles 6 , in the lower half densely plumose, slightly shorter than the body; achenial body $2.3-2.6 \mathrm{~mm}$. long, broadly ovate, dark-brown when mature, very turgidly biconvex, transversely wrinkled, apically prounoncedly narrowed into a definite hour-glassed-shaped turbercle base, tubercle very short-conic, $0.3-0.6 \mathrm{~mm}$. long.

Rare in bogs and open seepage slopes, in e. Tex. (Austin, Henderson, Smith and Waller cos.), spring (May-early June); N.J., Del., N.C., Ga. and Gulf States; Gr. Ant.; C.A.

\section{Rhynchospora plumosa Ell. Fig. 246.}

Tufted perennial; culms wiry, 2-4 dm. long, erect, 0.6-1.1 mm. thick, basally, stamineous; leaves setaceous-filiform, numerous, often curling toward the ends; lower bracts of the fascicles elongate, wiry, like the leaves, far-surpassing the inflorescence; inflorescence compact, congested, terminal, 1-3 cm. long, about $1 \mathrm{~cm}$. thick, often spikelike; spikelets pale- to dark-brown, lance-elliptic, 3-4 mm. long, usually with 1 or 2 fruits; bristles 6 , densely plumose in the lower part; achenial body broadly obovate, 1.4-1.8 $\mathrm{mm}$. long, brown, turgid, transversely wrinkled, not narrowed apically; tubercle short-conic, about $0.5 \mathrm{~mm}$. long, brown. R. semiplumosa Gray.

Infrequent in wet soils along streams and in savannah-evergreen shrub bogs, in s.e. Tex. (Hardin, Tyler and Newton cos.), Apr.-May; coastal flats, N.C. to Tex.; Cuba.

\section{Rhynchospora filifolia Gray. Fig. 247.}

Tufted perennial; culms 3-6 dm. long, about $1 \mathrm{~mm}$. thick near the base, erect, wiry; leaves mostly involute, resembling the culms; inflorescence a terminal very dense round-topped fascicle $10-15 \mathrm{~mm}$. broad, plus usually one reduced fascicle in the next lowest axil; spikelets cinnamon-brown, lanceolate, 3-5 $\mathrm{mm}$. long, with 3 to 10 flowers, the 2 to 6 achenes and their scales quickly falling in acropetal succession, upon maturation only 1 or 2 mature achenes present at any one time and these usually exposed by the rapid shedding of the scales; bristles 6 , usually surpassing the tubercle, minutely antrorsely barbed; achenial bodies obovate, 0.9-1 mm. long, biconvex, the 2 polished smooth faces brown or the central portions paler, buffy, tubercle deltoid, grayish, compressed, acute, 0.4-0.6 mm. long.

Rare in moist loam and wet areas in savannahs, in e. Tex. (Hardin and Waller cos.), summer; coastal areas, N.J. to Tex.; Cuba.

\section{Rhynchospora fascicularis (Michx.) Vahl. Fig. 248.}

Tufted perennial; culms 5-13 dm. long, 1.5-2.5 mm. thick basally, subterete or obtusely 3-angled, leafy; leaves $1-4 \mathrm{~mm}$. broad; inflorescence a crowded terminal group of 1 to 3 fascicles (about $1 \mathrm{~cm}$. broad and overtopped by the setaceous bracts) plus usually 1 (rarely 2) remote similar axillary fascicles below; spikelets 3.5-5 mm. long, lanceolate, cinnamon-brown, several-flowered and -fruited, the scales caducous in acropetal succession, each falling just before maturation of its achene; bristles about 6 , minutely antrorsely serrulate or barbed; achenial body nearly orbicular, biconvex, very dark-brown or fuscous except for a buffy spot in the center of each of the 2 smooth faces, 1.4-1.5 mm. long; tubercle deltoid, 0.4-0.7 mm. long, much-compressed, grayish. 


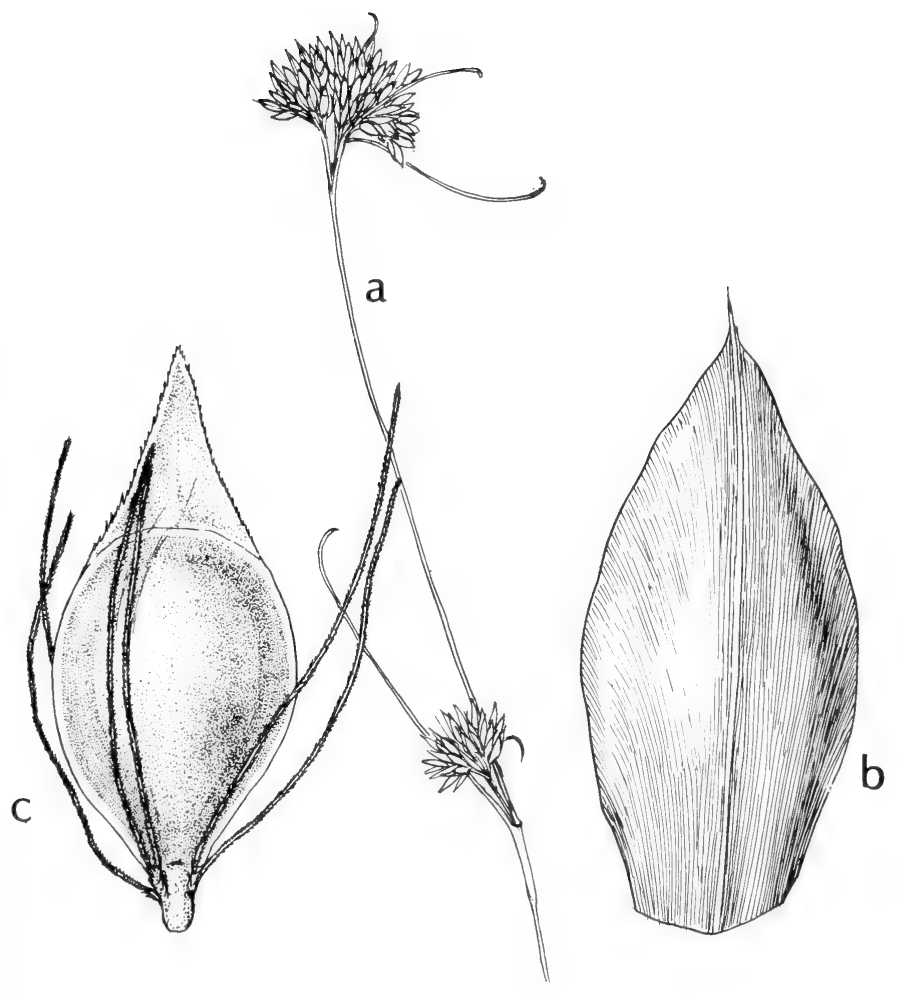

Fig. 247: Rhynchospora filifolia: a, top of plant, X 11/2; b, scale, X 40; c. achene, X 40. (Courtesy of R. K. Godfrey). 

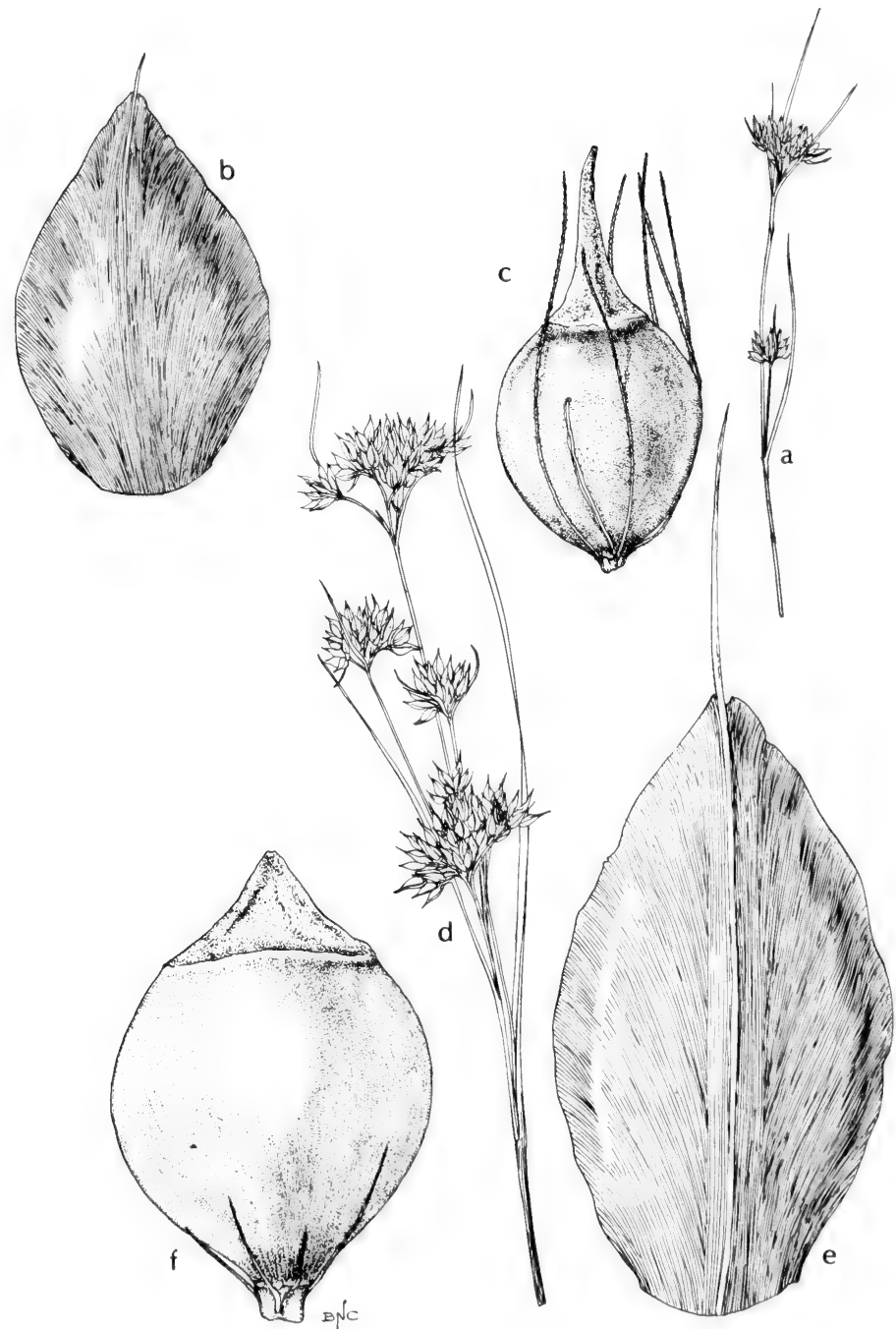

Fig. 248: a-c, Rhynchospora gracilenta: a, top of plant, X 1/2; b, scale, X 15; c, achene, X 15, d-f, Rhynchospora fascicularis: d, top of plant, X 11/2; e, scale, X 25; f, achene, x 25. (Courtesy of R. K. Godfrey). 
Infrequent in moist sand, savannahs and bogs in pinelands, in s.e. Tex. (Arkansas, Tyler, Chambers and Jefferson cos.), summer; low coastal areas, Va. to Tex.; Berm., Gr. Ant.

\section{Rhynchospora gracilenta Gray. Fig. 248.}

Tufted perennial; culms 5-9 dm. long, erect, 1-1.5 mm. thick basally, essentially terete; leaves mostly confined to the base of the plant, the blades proximally only $1-2.5 \mathrm{~mm}$. broad, distally involute; inflorescence a terminal fascicle about $1 \mathrm{~cm}$. broad and usually a remote slightly smaller axillary one a few $\mathrm{cm}$. below; spikelets broadly lanceolate, 3-4 mm. long, cinnamon-brown, with 2 or 3 flowers, when 3 flowers present usually only the middle one or the upper 2 bearing fruit; bristles about 6 , about equaling the body or tubercle, minutely antrorsely serrulate or barbed; achenial body broadly obovate or nearly orbicular, turgidly biconvex, 1.3-1.8 mm. long, smooth, dark-brown (or a central spot on each of the 2 faces slightly paler); tubercle much-compressed, whitish, 1-2 $\mathrm{mm}$. long including the straplike prolongation.

Infrequent in boggy ground and pitcher plant bogs, e. and s.e. Tex., summer (-fall?); s.e. U.S. mainly near the coast, N.J. to Tex., less frequent inland to Tenn. and Ark.

\section{Rhynchospora Grayi Kunch. Fig. 249.}

Tufted perennial; culms 4-7 dm. long, 1.5-2 mm. thick başally, erect; leaves mostly crowded toward the base, curly, 2-4 $\mathrm{mm}$. broad; inflorescence a dense terminal fascicle about $1 \mathrm{~cm}$. broad and long, of essentially sessile spikelets, plus sometimes a reduced fascicle lower down; spikelets cinnamon-brown, 4-5.5 mm. long, narrowly ovoid to broadly lanceolate, of 2 to 3 flowers, but usually maturing only 1 fruit; bristles 6 , minutely antrorsely serrulate; achenial body broadly obovate, $2-2.4 \mathrm{~mm}$. long, $1.8-2.2 \mathrm{~mm}$. broad, $1.5-1.8 \mathrm{~mm}$. thick from face to face, turgid, at maturity dark-brown, each face with 25 to 30 or more horizontal rows of minute nearly isodiametric cells whose horizontal walls are only slightly more prominent than the verticle walls; tubercle conic, $0.4-0.6 \mathrm{~mm}$. high, basally not wider than (but often appearing embedded in) the top of the body.

Rare in moist or wet sand, e. Tex. (Jasper and Liberty cos.), Mar.-May (earlier-flowering than most beak-rushes); lowlands near the coast, Va. to Tex.; Cuba.

\section{Rhynchospora Harveyi W. Boott. Fig. 250.}

Tufted perennial; culms 15-60 $\mathrm{cm}$. long, 1-2 mm. thick near the base, erect, obtusely triquetrous, leafy; leaves $1.5-3 \mathrm{~mm}$. broad; inflorescence a dense terminal fascicle about $5 \mathrm{~mm}$. high and $5-10 \mathrm{~mm}$. broad, of essentially sessile spikelets plus usually 1 or 2 reduced similarly dense glomerules lower down; spikelets cinnamon-brown, ovoid, 2.5-3 mm. long, usually with 2 flowers and setting 1 fruit; bristles 6 , minutely antrorsely serrulate achenial body broadly obovate, $1.5-1.8 \mathrm{~mm}$. long, $1.3-1.6 \mathrm{~mm}$. broad, $1-1.5 \mathrm{~mm}$. thick from face to face, turgid, at maturity rick-dark-brown, each face with (14 to) 16 to 20 horizontal rows of minute nearly isodiametric cells with prominent walls; tubercle conic, 0.4-0.5 $\mathrm{mm}$. long, basally no wider than (but often appearing embedded in) the top of the body. R. Plankii Small.

Frequent to abundant in low places in open woods and prairies, wet soils on edge of streams, e., s.e. and n.-cen. Tex., and Okla. (Pushmataha Co.), Apr.Sept.; s.e. U.S. n. to Va., Tenn. and Mo., w. to Okla. and Tex.

\section{Rhynchospora rariflora (Michx.) Ell. Fig. 251.}

Tufted perennial; culms 3-6 dm. long, 0.6-0.9 mm. thick near the base, ascending but often flexuous, essentially trete; leaves in lower half of plant, 


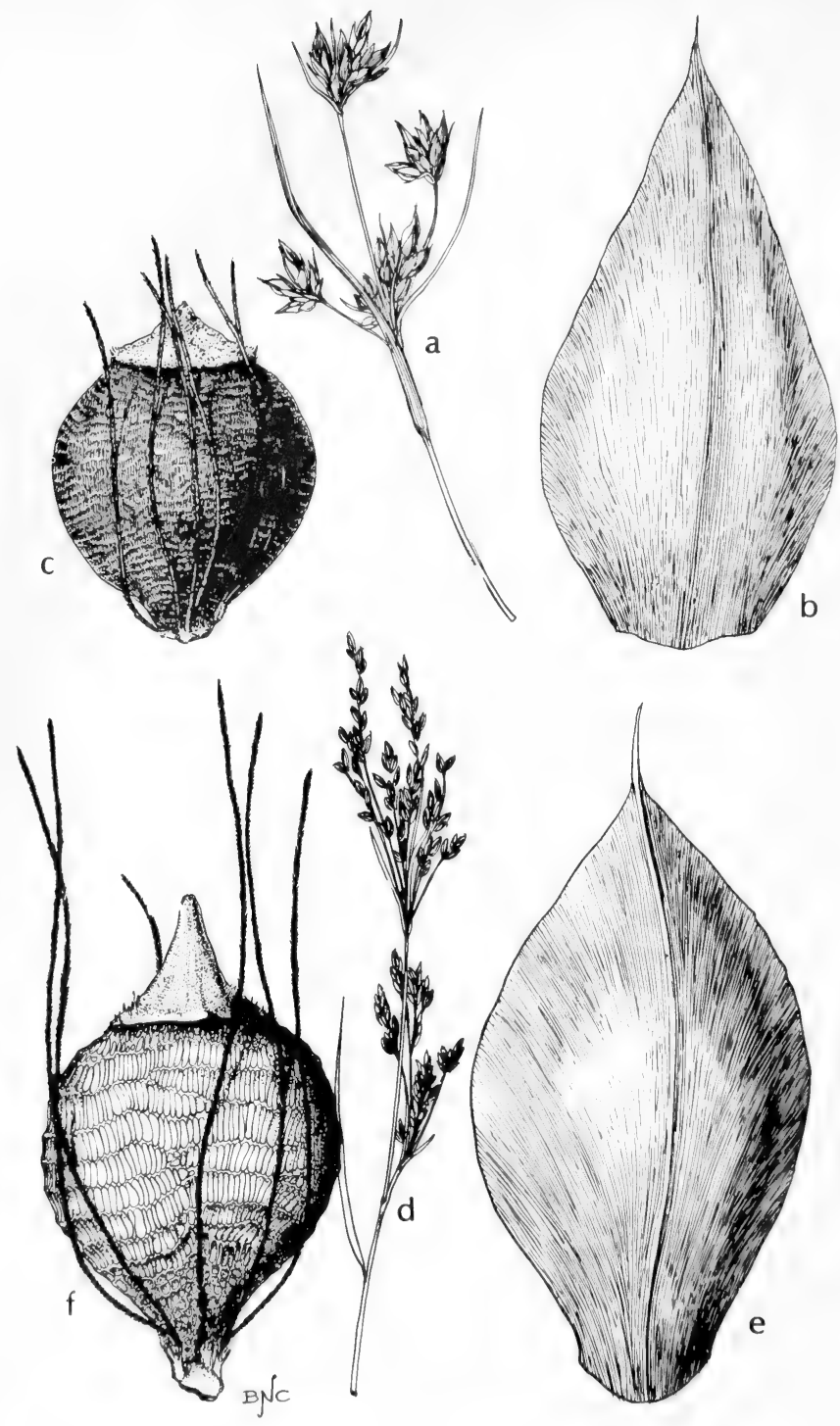

Fig. 249: a-c, Rhynchospora Grayi: a, top of plant, X 1; b, scale, X 12; c, achene, $\mathrm{X}$ 12. d-f, Rhynchospora caduca: d, top of plant, $\mathrm{X} 1 / 2 ; \mathrm{e}$, scale, $\mathrm{X} 25$; $\mathrm{f}$, achene, $\mathrm{X} 25$. (Courtesy of R. K. Godfrey). 


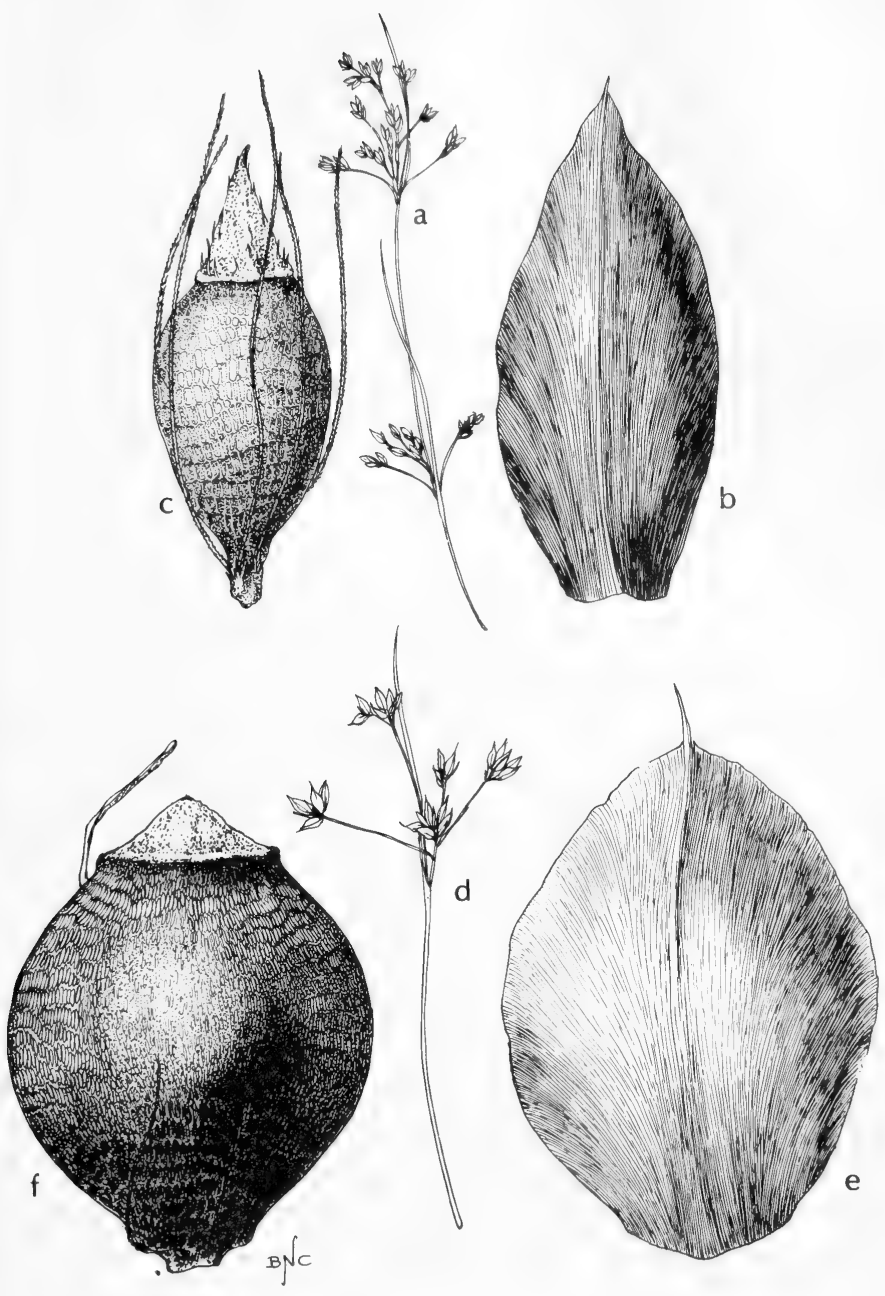

Fig. 250: a-c, Rhynchospora mixta: a, top of plant, X 1/2; b, scale, X 25; c, achene, $\mathrm{X} 25$. d-f, Rhynchospora Harveyi: d, top of plant, X 1; e, scale, X 25 ; $\mathrm{f}$, achene, X 25 . (Courtesy of R. K. Godfrey). 
capillary-setaceus; inflorescence of a terminal 6- to 12- (to 20-) spikeletted lax subumbelliform unit $1-3 \mathrm{~cm}$. broad, the individual capillary pedicels $3-12 \mathrm{~mm}$. long; spikelets narrowly ovoid, subacute, pale-cinnamon-brown, 3-4 mm. long, with 2 to 4 flowers and maturing 1 to 3 fruits; bristles 6 , shorter than the achenial body, minutely antrorsely serrulate; achenial body broadly obovate, 1.1-1.4 mm. long, biconvex, pale-brown, the 2 faces with strong transverse ridges, tubercle deltoid, compressed, 0.3-0.6 $\mathrm{mm}$. long.

Rare in bogs or piny crayfish-land, savannahs, e. and s.e. Tex. (Austin, Harris, Henderson, Anderson, Tyler, Leon, Orange and Waller cos.) May-June; coastal areas, N.J. to Tex.; also Tenn., Gr. Ant. and C.A.

\section{Rhynchospora inexpansa (Michx.) Vahl.}

Tufted perennial; culms 5-8 dm. long, erect (or terminally drooping), wiry, 1.5-2 $\mathrm{mm}$. thick near the base; leaves mostly basal, with long tough somewhat curly blades; inflorescence fairly narrow, elongate and drooping; spikelets lanceolate, brown, $4.5-6 \mathrm{~mm}$. long, with 2 to 5 flowers, setting 1 to 4 fruits; bristles about 6 , surpassing the tubercle, minutely antrorsely serrulate; achenial body elliptic-obovate, $2-2.2 \mathrm{~mm}$. long, $0.8-1 \mathrm{~mm}$. broad, much-compressed, the 2 flat faces transversely rigid; tubercle deltoid, 0.9-1.2 $\mathrm{mm}$. long.

Locally frequent in open pinelands, swamps, ditches, marches, in ponds, savannahs and pineland bogs, e. and s.e. Tex. (Angelina, Hardin, Jasper, Jefferson and Liberty cos.), summer; Coastal States, Va. to Tex.; also Ark. and (?) Okla.

19. Rhynchospora mixta Small. Fig. 250.

Rhizomatous perennial; culms about $1 \mathrm{~m}$. long, about $2 \mathrm{~mm}$. or more thick basally, leafy, erect or ascending (flexuous in the distal floriferous portion); blades 3-4 $\mathrm{mm}$. broad; inflorescence decomposed, open, the terminal portion 3-4 cm. broad, very lax, of about 25 spikelets, some of the ultimate glomerules on long spreading arculate-erect peduncles $10-15 \mathrm{~mm}$. long; spikelets narrowly ovoid, 4-6 mm. long, brown, with 2 or more (rarely as many as 10) flowers, 1 (rarely as many as 10) fruit produced; bristles about 6, surpassing the tubercle, upwardly minutely barbed; achenial body narrowly obovate, 1.3-1.4 mm. long, $0.8-0.9 \mathrm{~mm}$. broad, turgidly biconvex, with very numerous faint transverse lines; tubercle deltoid-attenuate, 0.4-0.9 mm. long, compressed.

Rare in sandy forested areas near streams, e. Tex. (Nacogdoches Co.), summer; near the cost, N.C. to s.e. La.; Tex.

\section{Rhynchospora Elliottii A. Dietr.}

Tufted perennial; culms 8-15 dm. long, 2.5-5 mm. thick basally, erect except slightly nodding distally; leaf blades 4-5 mm. wide basally, mostly long-tapered, strictly erect and appressed; inflorescence of 2 to 5 dense decomposed separate portions, the terminal portion irregularly corymbiform, $2-6 \mathrm{~cm}$. broad, of 150 to 300 spikelets; spikelets ovoid, rich-dark-brown, $2.5-3.2 \mathrm{~mm}$. long, with 3 to 6 flowers and setting 2 to 4 fruits; bristles 6 , surpassing the tubercle, minutely antrorsely serrulate, not closely appressed to the achene but slightly spreading basally and arcuate-erect; achenial body obovate, tawny-brown, 1.2-1.3 mm. long, 0.9-1.1 mm. broad, with very pronounced traverse ridges on the 2 nearly flat faces; tubercle deltoid, 0.3-0.4 mm. long. $R$. schoenoides (Ell.) Wood, an illegit. name.

Frequent in moist or wet sand in savannahs, in e. and s.e. Tex., summer; near the coast, N.C. to Tex. (except Fla.)

\section{Rhynchospora microcarpa Gray. Fig. 251.}

Tufted perennial; culms 5-8 dm. long, 2-3 mm. thick basally, erect; leaves mostly appressed or curly, 2-3 mm. broad basally; inflorescence in (1 or) 2 to 4 

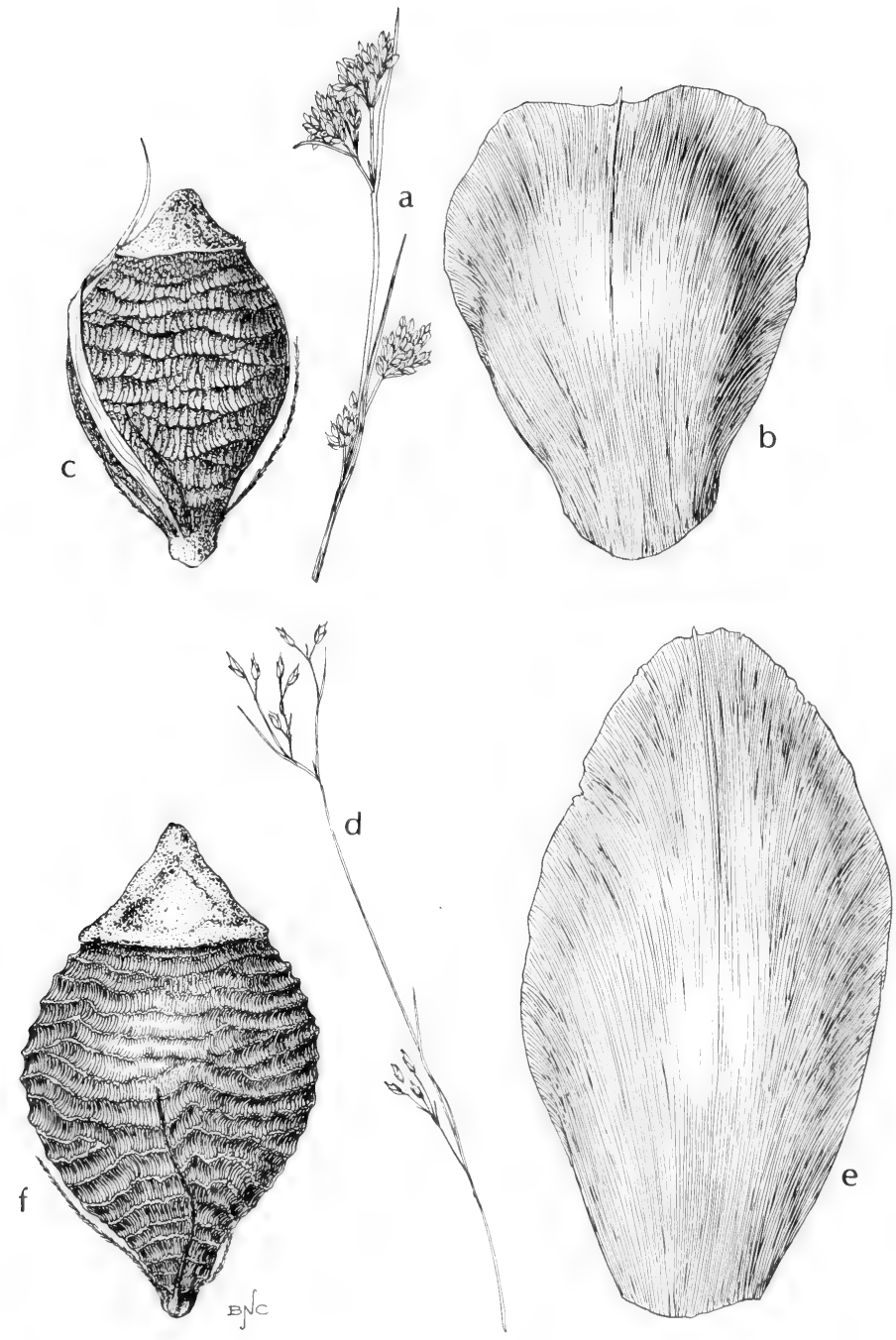

Fig. 251: a-c, Rhynchospora microcarpa: a, top of plant, X 1; b, scale, X 25; c, achene, X 25. d-f, Rhynchospora rariflora: d, top of plant, X 1/2; e, scale, X 25; f, achene, X 25. (Courtesy of R. K. Godfrey). 


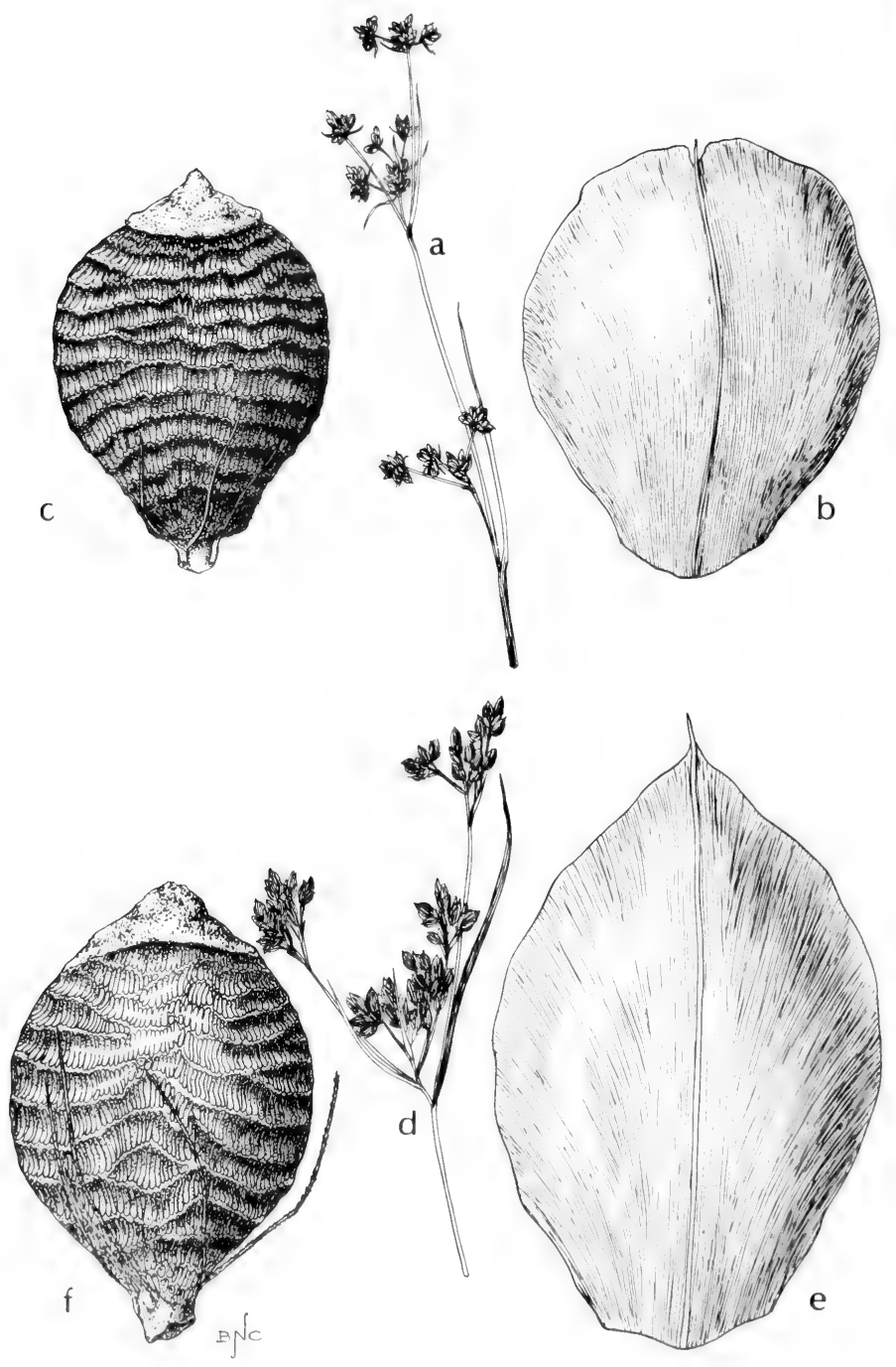

Fig. 253: a-c, Rhynchospora glohularis: a, top of plant, X 1/2; b, scale, X 25; c, achene, X 25. d-f, Rhynchospora perplexa: d, top of plant, X 1 ; e, scale, X 30; f, achene, X 30. (Courtesy of R. K. Godfrey). 
parts per culm, the terminal part irregularly corymbiform, dense, nearly erect, 2-6 cm. broad, of 100 to 200 spikelets or less commonly fewer; spikelets ovoid to narrowly ovoid, 2.5-3 mm. long, dark-rich-brown, with 3 or 4 flowers and setting 2 or 3 fruits; bristles about 6, from half as long as to as long as the body or rarely nearly equaling the tubercle, stiffly erect and mostly appressed to the body, minutely antrorsely serrulate; achenial body obovate, $1-1.2 \mathrm{~mm}$. long, $0.8-1.2$ $\mathrm{mm}$. broad, the 2 nearly flat or very slightly convex faces with strong transverse wrinkles; tubercle deltoid, $0.2-0.5 \mathrm{~mm}$. long.

Rare in moist or wet sand, s.e. Tex. (Aransas Co.), summer; near the coast, Fla. and Ga. to Tex.; Bah. I., Hisp. and Cuba.

\section{Rhynchospora perplexa Small.}

Tufted perennial; culms 5-11 dm. long, 1.5-2 mm. thick basally, wiry, erect or very slightly flexuous in the floriferous region; leaf blades $1-2 \mathrm{~mm}$. broad basally, mostly strongly involute; inflorescence in 1 to 3 parts per culm, the terminal part very irregularly cormbiform, 1-4 $\mathrm{mm}$. broad, usually dense and with upwards of 100 to 200 spikelets; spikelets ovoid, rich-dark-brown, $2.5-3 \mathrm{~mm}$. long; bristles about 6 or fewer, less than half as long as the body to which they are appressed or reduced to virtual absence; achenial body obovate, 1-1.3 mm. long, 0.9-1.2 $\mathrm{mm}$. broad, tawny, the 2 nearly flat or very slightly convex faces with strong transverse wrinkles; tubercle deltoid, $0.2-0.3 \mathrm{~mm}$. long.

Rare in moist or wet sand in e. and s.e. Tex. (Aransas, Hardin, Tyler and Waller cos.), late spring-summer; Coastal States, s.e. Va. to Tex.; Tenn.; Gr. Ant.

Probably not specifically distinct from $R$. microcarpa.

\section{Rhynchospora caduca Ell. Fig. 249.}

Rhizomatous perennial; culms 7-13 dm. long, 2-4 mm. thick near the base, ascending but quite flexuous in the upper part; leaves $4-7 \mathrm{~mm}$. broad below the middle, tapering in both directions; inflorescence of 3 to 5 parts per culm, the terminal part obovoid, irregularly corymbiform, 2-4 cm. broad, with 60 to 125 spikelets, some of the primary branches commonly elongate, erect and 1-2 cm. long; spikelets rich-dark-brown, ovoid, $4-4.5 \mathrm{~mm}$. long, with 3 to 6 flowers and setting 2 to 5 fruits; bristles about 6 , surpassing the tubercle and somewhat stiffly spreading away from the body basally, minutely antrorsely serrulate; achenial body obovate, 1.4-1.7 $\mathrm{mm}$. long, $1.2-1.6 \mathrm{~mm}$. broad, the 2 faces with strong transverse wrinkles and at least in the upper part pronouncedly convex; tubercle deltoid, 0.6-0.8 mm. long.

Frequent in moist or wet sand in Okla. (McCurtain Co.) and s.e. Tex. (Liberty and Polk cos.), less frequent in e. Tex. (Bowie Co.) and very local in Burnet and Llano cos. on the Edwards Plateau, summer; Coastal States, Va. to Tex.; also Ark. and Okla.

\section{Rhynchospora globularis (Chapm.) Small. Fig. 253.}

Tufted perennial; culms (15-) 30-75 (-90) cm. long, 1-1.8 (-2.5) mm. thick near the base, basally often shortly reclining, mostly erect, leafy with the old sheaths basally becoming somewhat fibrous; blades $1.5-4 \mathrm{~mm}$. broad; inflorescence in 1 to 4 parts per culm, the terminal part usually strictly erect, of several straight stiffly ascending unequal branches each topped by a corymbiform glomerule 8-15 mm. broad (broader than high) and often with stiffly erect setaceous protruding bracts; spikelets ovoid, 2.5-4 mm. long, cinnamon-brown, with 1 to 4 flowers and setting 1 to 3 fruits; bristles about 6 , shorter than the body of the achene, minutely antrorsely serrulate; achenial body obovate, $1.2-1.6$ $\mathrm{mm}$. long, 1-1.5 $\mathrm{mm}$. broad, castaneous, with 2 faces which are convex at least in the upper part and have strong transverse wrinkles; tubercle deltoid, $0.3-0.6 \mathrm{~mm}$. 


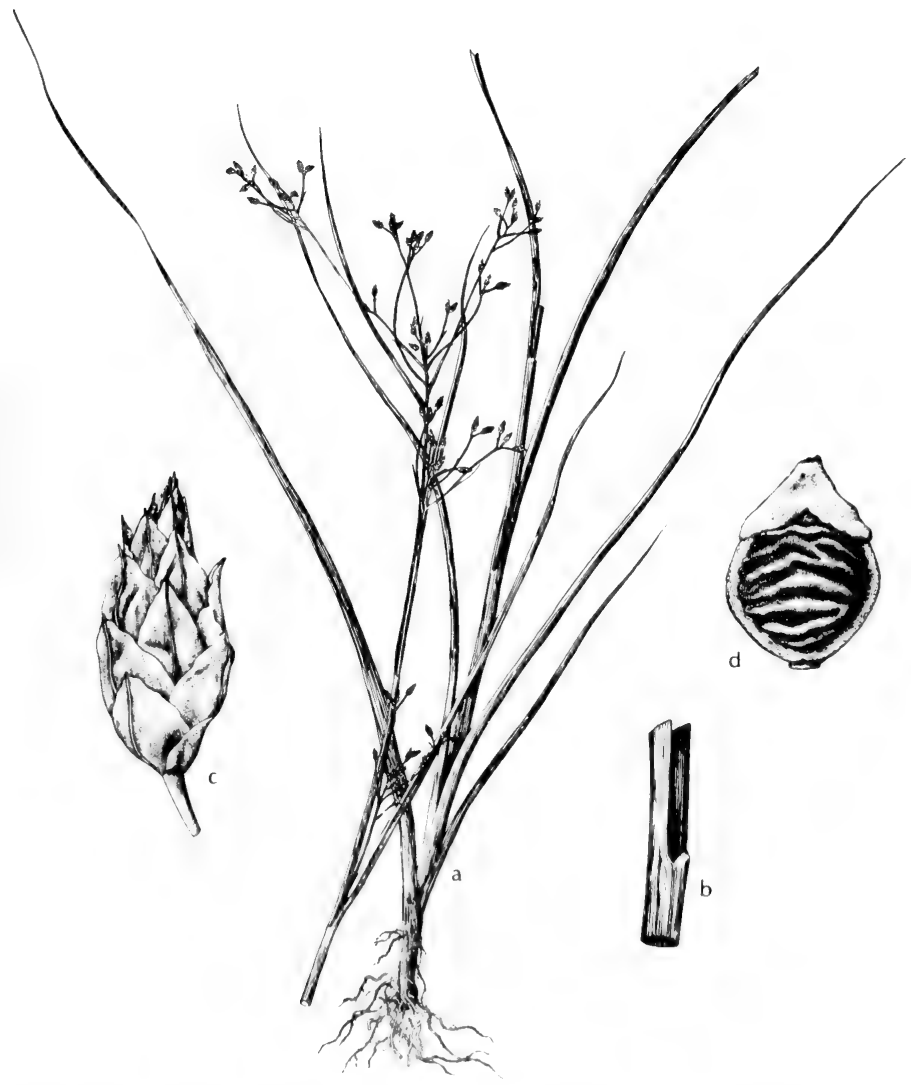

Fig. 254: Psilocarya nitens: a, habit, X 1/2; b, sheath, X 3; c, spikelet, X 5; d, achene, X 25. (Courtesy of R. K. Godfrey). 
long. $R$. cymosa of many auth., not (Willd.) Ell., $R$. globularis var. recognita Gale, $R$. obliterata Gale.

Moist sandy soil, bogs, seepage areas, ditches, wet coastal savannah-prairie, in Okla. (McCurtain, Sequoyah and Pushmataha cos.), frequent in e. Tex., infrequent in s.e. Tex. and rare inland to n.-cen. Tex., late spring-summer; widespread in s.e. U.S., n. to N.J., Tenn. and Mo., w. to Okla. and Tex.; also Calif., W.I. and C.A.

\section{Psilocarya TORR. BALD RUSH}

An American and Australian genus of about 6 species, included by several workers in Rhynchospora.

\section{Psilocarya nitens (Vahl) Wood. Fig. 254.}

Said to be annual but occasionally with weak short rhizomes and often rooting from the lower nodes; culms few, erect, soft, 3-8 dm. long, 1-4 mm. thick, usually with 1 to 3 weakly exserted ascending branches in the middle part; leaves crowded in lower half of culm, with long acute ascending blades; main panicle lax, terminal on main stem, smaller panicles terminating the branches; bracts several, attached at close intervals along the panicle axis, shorter than the inflorescence; inflorescence axis about $1 \mathrm{~cm}$. long, with several unequal divergent mostly naked branches bearing racemes of spikelets; spikelets $5-9 \mathrm{~mm}$. long, narrowly ovoid, acute; scales numerous, spirally attached, strongly imbricate, brown, ovate, acute, all fertile; perianth absent; style branches 2; base of style becoming indurated and persistent on the achene as a low grayish tubercle almost as broad as the achene itself (but not as thick); achene plumply biconvex, Rhynchospora-like, strongly transversely wrinkled.

Infrequent or rare, usually in marshy places, in mud at edge of water and on vegetation mats in lakes, in s.e. Tex. (Hardin, Houston and Madison to Aransas cos.) ; coastwise, Mass. to Tex.; local in n.w. Ind.

\section{Scleria Berg. Stone-RUSh. NUt-RUSH}

About 200 species, mostly tropical and subtropical.

\section{Scleria Muhlenbergii Steud. Fig. 207.}

Annual with fibrous roots or perennial with very short rhizomes; culms 15-80 $\mathrm{cm}$. long, 1-1.6 mm. thick, trigonous or somewhat compressed, tufted, weak and diffuse; sheaths sometimes somewhat winged; blades $15-25 \mathrm{~cm}$. long, 1-4 (-8) $\mathrm{mm}$. broad, flat, often with cartilaginous margins, sometimes scabrous marginally and on the nerves beneath; inflorescence terminal and axillary (the lateral ones very remote, on long setaceous-filiform compressed often recurved or drooping peduncles), loosely flowered, the clusters $1-3 \mathrm{~cm}$. long; spikelets 2-4 mm. long; hypogynium deeply 3-lobed, the lobes ovate-lanceolate, subacute, appressed; achene $2 \mathrm{~mm}$. long, more or less reticulate, the transverse ridges pilose, sordidwhite, globose-elliptic, umbonate, the ridges somewhat spirally disposed. S. setacea of many auth., non Poir.

Moist sand, about lakes, edge of water, pitcher plant bogs, pineland bogs, and seepage slopes, infrequent in e. Tex. (Angelina, Tyler and Henderson cos.), rare in n. part of Rio Grande Plains (Guadalupe Co.); N.Y. to Ind. and s. to Gulf States; W.I., Mex., C.A., s. to Braz. and Bol.

\section{Carex L. Sedge. Caric-Sedge}

Perennials with well-developed leaves, mostly monoecious; inflorescence of several to many more or less spikelike spikelets emerging singly from the axils of the upper leaves (herein called bracts) (in C. leptalea the spikelet solitary), in some species the spikelets so numerous and crowded and the bracts so reduced 
that the inflorescence appears headlike or spikelike; spikelets of few to many unisexual flowers arranged spirally around the axis (rarely in definite rows) either wholly staminate or pistillate or androgynous (with staminate flowers at top, pistillate below) or gynecandrous (reverse order); staminate flowers comprising merely 3 stamens (rarely 2) subtended by a scale; pistillate flowers merely a scale subtending a "perigynium" that encloses an achene; perigynium an indehiscent bag or envelop completely enclosing the achene (but not adherent to it) except at the minute apical orifice through which the stigmas protrude at anthesis, falling with the mature achene and thus a spurious outer portion of the fruit which is unique to this genus.

An enormous, technical genus occurring in moist temperate and moist cool tropical regions. Carex is in dire need of critical taxonomic study bolstered by cytology and by field and garden studies which might elucidate many of the problems arising from hybridization or introgression. The keys and descriptions can be used only when the material to be determined is complete with underground parts and has fully mature achenes, the latter to be examined carefully at a magnification of at least 15 diameters.

Presumably caric-sedges provide some forage for stock.

(Part of treatment adapted from F. J. Hermann "Manual of the Carices of the Rocky Mountains and Colorado Basin." Agr. Handb. No. 374, Forest Service, U.S. Dept. Agric. 1970).

1. Achenes lenticular or plano-convex; stigmas 2 (2)

1. Achenes trigonous; stigmas 3 (43)

2(1). Terminal spike androgynous or gynecandrous (except $C$. Douglasii which is dioecious); lateral spikes short and sessile (3)

2. Terminal spike staminate, (rarely gynecandrous or androgynous); lateral spikes peduncled or elongate and sessile (35)

3(2). Some or all spikes androgynous, not gynecandrous (or plants dioecious) (4)

3. Some (especially the terminal) or all spikes gynecandrous, with staminate flowers at base or scattered, not at apex (15)

4(3). Rhizomes slender, elongating; culms mostly solitary; spikes (at least the lower) distinct (5)

4. Rhizomes short, not freely stoloniferous, with short internodes; culms or leafy tufts approximate (8)

5(4). Plants dioecious or nearly so; perigynium beak nearly as long as the body 1. C. Douglasii.

5. Plants not dioecious, the spikes mostly androgynous; perigynium beak shorter (6)

6(5). Perigynia plump, unequally biconvex, rounded to the summit with fine nerves on both surfaces, white-punctate................4. C. disperma.

6. Perigynia broadly ovate to ovate-lanceolate, nerveless or nearly so, winged (7)

7(6). Perigynia yellowish, brown to chestnut-brown, 1.7-2.7 $\mathrm{mm}$. long, hyalinewinged at the center; rootstock and lower sheaths light-brown........

2. C. simulata.

7. Perigynia brownish-black, $3-4 \mathrm{~mm}$. long, thin-coriaceous with sharp coriaceous margins; rootstocks blackish, fibrous..................... 3. C. praegracilis.

8(4). Spikes 2 to 15 in an ovoid, bractless head, 10-15 mm. long and 4-9 $\mathrm{mm}$. thick..........................................................6. C. cephalophora.

8. Spikes numerous, in paniculate spikelike heads, usually 2 to several on each lateral branch (9) 
9(8). Leaf sheaths close; blades firm; culms slender and firm; perigynia firm, flat or merely convex on inner surface (10)

9. Leaf sheaths loose; blades soft to firm; culms soft, flattened under pressure; perigynia spongy or corky at base, thin and soft, more or less inflated (13)

10(9). Inner nerveless ventral band of leaf sheath not cross-puckered; perigynia broadly compressed, obovoid or obpyramidal, abruptly beaked........

7. C. decomposita.

10. Inner nerveless ventral band of leaf sheath cross-puckered and/or red-dotted; perigynia flat on inner face (11)

11(10). Leaves flat, exceeding the culm; perigynia ascending, 1.7-3 mm. long; scales, ovate, the 3-nerved center green, terminating in a long rough awn.................................................... $8 . C$. vulpinoidea.

11. Leaves thickish, flat or channeled, usually not exceeding the culm; perigynia ascending or spreading, $3.5-4 \mathrm{~mm}$. long; scales acute or cuspidate (12)

12(11). Perigynia $1.6-1.8 \mathrm{~mm}$. wide, almost black at maturity; achenes $1.5 \mathrm{~mm}$. long (Ariz.)

9. C. alma.

12. Perigynia $2 \mathrm{~mm}$. wide, light-green or brown; achene $2 \mathrm{~mm}$. long (Okla.)...... 10. C. fissa.

13(9). Bases of perigynia disklike; beak 2 to 3 times length of body. 11. C. crus-corvi.

13. Bases of perigynia not disklike; beak 1 to 2 times length of body (14)

14(13). Leaf sheaths cross-puckered ventrally, without band at the orifice.

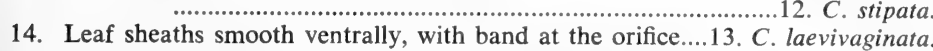

15(13). Perigynia with rounded to very narrow margins or edges, without definite winged margins, thickened or corky at the base (16)

15. Perigynia with thin or winged margins, mostly with concave inner faces, not spongy or corky at the base (20)

16(15). Perigynia with rounded margins, ascending or merely spreading-ascending, of soft or membranaceous texture (17)

16. Perigynia with thin but scarcely winged margins, ascending to horizontally divergent or reflexed in maturity, firm, very spongy at base (19)

17(16). Perigynia ovoid-oblong, $1.8-3 \mathrm{~mm}$. long, more or less nerved on both surfaces; beak very short or obsolete.

5. C. canescens.

17. Perigynia ovate-lanceolate or lanceolate, $3.5-4.5 \mathrm{~mm}$. long; beak half the length of the body (18)

18(17). Perigynia shallowly bidentate, $3.5-4 \mathrm{~mm}$. long; spikes ovoid or oblong, the lateral pistillate.

14. C. leptopoda.

18. Perigynia deeply bidentate, 4-4.5 mm. long; spikes linear-oblong, all gynecandrous.

15. C. Bolanderi.

19(16). Beak of perigynia only minutely notched; perigynia 1-2 mm. wide, nerveless or essentially so; heads $1-3 \mathrm{~cm}$. long, of subglobose spikes about $4 \mathrm{~mm}$. in diameter.

16. C. interior.

19. Beak of perigynia sharply bidentate at tip; perigynia $2-2.5 \mathrm{~mm}$. wide, strongly nerved on both surfaces; heads $2-6 \mathrm{~cm}$. long, of 3 to 6 echinate spikes mostly 7-12 mm. long and 6-8 mm thick......17. C. atlantica.

20(15). Spikes $1.5-2.5 \mathrm{~cm}$. long, long-cylindric; perigynia 7-10 $\mathrm{mm}$. long, thin and scalelike.............................................18. C. muskingumensis.

20. Spikes less than $1.5 \mathrm{~cm}$. long; perigynia less than $7.7 \mathrm{~mm}$. long (21) 
21. Perigynia more than $2 \mathrm{~mm}$. wide (28)

22(21). Bracts conspicuously exceeding the head but not leaflike.

22. Bracts wanting or setaceous (23)

19. C. athrostachya.

23(22). Perigynia barely distended over the achene, thin and scalelike (24)

23. Perigynia obviously distended over achene, firm (26)

24(23). Sheaths loose and loosely ribbed, veined ventrally with a hyaline summit; wings of perigynia abruptly narrowed above the base (Tex. and Okla.) ..........................................................20. C. tribuloides.

24. Sheaths close, ventrally hyaline; wings of perigynia extending continuously to the base (Ariz. \& N.M.) (25)

25(24). Perigynia 3.5-5 mm. long; beak of perigynium slender and terete, not serrulate (or only slightly) at the usually dark-colored tip; spikes distinguishable but aggregated into an ovoid or suborbicular truncate-based head................................................21. C. microptera.

25. Perigynia 4-7 $\mathrm{mm}$. long; beak of perigynium flattened and serrulate to the pale tip; spikes aggregated into an oblong or linear-oblong head......

22. C. scoparia.

26(23). Perigynia ovate, broadest below the middle; spikes often clavate at base.. 23. C. festucacea.

26. Perigynia obovate to suborbicular or elliptic to rhombic, broadest at or above the middle (27)

27(26). Inflorescence $6-10 \mathrm{~mm}$. thick; spikes ovoid, each with 30 to 50 perigynia which are $2.8-3.2(-3.5) \mathrm{mm}$. long and 1.6-2.2 $\mathrm{mm}$. broad.

24. C. albolutescens.

27. Inflorescence $12-15 \mathrm{~mm}$. thick; spikes narrowly ovoid, each with 55 to 80 perigynia which are (3-) $3.5-4.2(-4.5) \mathrm{mm}$. long and 1.7-2.5 $\mathrm{mm}$. broad.....................................................25. C. Longii.

28(21). Scales acute to blunt, without awn-tips (29)

28. Scales awn-tipped; body of perigynium broadest near the summit

26. C. alata.

29(28). Perigynia thin and scalelike, barely distended over the achene, lanceolate to narrowly ovate, $1.2-2.6 \mathrm{~mm}$. wide. 22. C. scoparia.

29. Perigynia firmer and thicker, usually well-distended over the achene (30)

$30(29)$. Beak of perigynium short and broad, gradually tapering into the firm broadly elliptic to rhombic body of the perigynium which is $3-4.5$ $\mathrm{mm}$. long and $1.7-2.5 \mathrm{~mm}$ wide.

25. C. Longii.

30. Beak of perigynium elongate and narrow above, more abruptly differentiated from the obovate or suborbicular body of the perigynium which is 3.5-7.7 $\mathrm{mm}$. long (31)

31 (30). Perigynia pale-green to dull-brown, 2.8-3.5 mm. long, 1.6-2.2 mm. wide, the obovate to suborbicular bodies broadest above the middle.

24. $C$. albolutescens.

31. Perigynia stramineous or greenish, 3.5-8.5 mm. long, 2.3-6 mm. wide, the bodies broadest below the middle (32)

32(31). Perigynia strongly nerved on ventral surface (33)

32. Perigynia ventrally essentially nerveless or nerves few (34)

33(32). Perigynia 15 to 30 per spike, broadly ovate, with transverse wrinkles between the veins on the ventral side; perigynia $2.5-3.2 \mathrm{~mm}$. wide....

27. C. hyalina. 
33. Perigynia more numerous per spike, ovate, broadly winged, nerved dorsally and ventrally; perigynia $2.7-4.8 \mathrm{~mm}$. wide.............28. C. Bicknellii.

34(32). Larger perigynia (including beaks) $5.5-8.5 \mathrm{~mm}$. long

34. Larger perigynia (including beaks) $2.8-5.5 \mathrm{~mm}$. long...

29. C. Brittoniana.

35(2). Bracts long-sheathing; perigynia golden-yellow or whitish-pulverulent at maturity (36)

35. Bracts nearly or quite sheathless; perigynia not golden-yellow nor pulverulent at maturity (37)

36(35). Mature perigynia whitish-pulverulent, elliptic-obovoid, not fleshy nor translucent, rather obscurely ribbed; scales appressed..31. C. Hassei.

36. Mature perigynia golden-orange to rich dark-brown, orbicular-obovoid, fleshy, translucent, coarsely ribbed; scales spreading.

32. C. aurea.

$37(35)$. Scales aristate, subulate-tipped; equaling or longer than the perigynia......

37. Scales obtuse to acute, not aristate (38)

33. C. crinita.

38 (37). Flowering culms from the center of a tuft of leaves of the previous year (39)

38. Flowering culms all or mostly arising laterally, not from the center of a tuft of leaves from the previous year (42)

39(38). Leaf sheaths breaking and becoming filamentose.

34. C. senta.

39. Leaf sheaths not becoming filamentose when breaking (40)

40(39). Perigynia conspicuously veined or ribbed ventrally (41)

40. Perigynia nerveless ventrally or with obscure impressed nerves; scales appressed.

35. C. aquatilis.

41(40). Perigynia early-deciduous, membranaceous, conspicuously stipitate, the apiculate beak entire; lowest bract exceeding the inflorescence......

36. C. Kelloggii.

41. Perigynia persistent, coriaceous, strongly ribbed, the broad beak bidentate; lowest bract equaling the inflorescence.

37. C. nebraskensis.

42(38). Lower sheaths fibrillose; juncture of sheath and blade V-shape.

38 C stricta.

42. Lower sheaths not fibrillose; juncture of sheath and blade flat or slightly arcuate.

39. C. Emoryi.

43(1). Lower part of style hard, texturally similar to the achene, persistent (44)

43. Lower part of style jointed to achene, texturally different, withering and becoming detached from mature achene (59)

44(43). Perigynia obconic or broadly obovoid, truncate or abruptly rounded to a long subulate beak (45)

44. Perigynia subulate to ovoid or subglobose, gradually tapering to a beak (48)

45(44). Spikes elongate, linear-cylindric; achene silvery-black, minutely pitted....

40. C. ultra.

45. Spikes subglobose to thick-cylindric or ellipsoid; achene yellow to brown, granular (46)

46(45). Terminal spike staminate; pistillate rough-awned scales longer than the perigynia

41. C. Frankii.

46. Terminal spike gynecandrous; pistillate scales shorter than the bodies of the perigynia (47)

47(46). Pistillate scales obtuse; style straight.

42. C. typhina.

47. Pistillate scales acuminate or awned; style curved. 43. C. squarrosa. 
48. Pergynia thin or papery, acuminate (49)

49(48). Perigynia finely and closely ribbed; pistillate scales with scabrous awns equal to or longer than the body of the scales (50)

49. Perigynia coarsely ribbed; pistillate scales blunt to cuspidate or short-awned (53)

50(49). Perigynia closely investing base of achenes, not inflated, greenish, becoming pale-brown, the teeth arched-divergent; leaves strongly septate-nodose; ligules prolonged................................45. C. comosa.

50. Perigynia loosely investing achenes, inflated, straw color or yellow-green; leaves less conspicuously septate-nodose; ligules about as broad as long (51)

51(50). Perigynia 2.5-4 mm. thick, about 10-nerved.

48. C. lurida.

51. Perigynia less than $2 \mathrm{~mm}$. thick, with 12 to 20 nerves (52)

52(51). Perigynia 5-7 mm. long, inflated, the beak about $2 \mathrm{~mm}$. long; body of pistillate scales small.

46. C. hystericina.

52. Perigynia 4-5 mm. long, slightly inflated, the beak $1.5 \mathrm{~mm}$. long; body of pistillate scales large. 47. C. Thurberi.

53(49). Perigynia $8-20 \mathrm{~mm}$. long (54)

53. Perigynia $3.5-8 \mathrm{~mm}$. long (58)

54(53). Perigynia subulate to slenderly lanceolate, 1-3 $\mathrm{mm}$. thick, delicately nerved, barely inflated.......................................51. C. folliculata.

54. Perigynia lanceolate to ovoid or flask-shaped, $3-8 \mathrm{~mm}$. thick, strongly nerved, usually much inflated (55)

55(54). Plants densely cespitose, without elongate stolons; pistillate spikes globose or nearly so; style straight or slightly bent (56)

55. Plants stout and leafy, with creeping stolons; pistillate spikes thick-cylindric or ellipsoid; style spirally bent (57)

56(55). Perigynia cuneate at base, firm, opaque, dull-green, often hispidulous 52. C. Grayi.

56. Perigynia rounded at base, membranous, lustrous, glabrous.

53. C. intumescens.

57(55). Achene longer than wide, the angles prominent but not really knobby 54. C. lupulina.

57. Achene wider than long, the angle definitely knobby.

55. C. gigantea.

58(53). Rhizomes without horizontal stolons; culms slender, rarely spongy-based; leaves not conspicuously septate-nodulose; ligule longer than wide 49. $C$. vesicaria.

58. Rhizomes with long horizontal stolons; culms mostly thick and spongy at base; leaves prominently septate-nodulose; ligule as wide as long.... 50. C. rostrata.

59(43). Spike solitary per culm. 56. C. leptalea.

59. Spikes 2 to numerous per culm (60)

60(59). Achenes only obscurely 3 -angled, with rounded or convex sides, slightly pubescent, closely filling the bodies of the perigynia (61)

60. Achenes definitely 3 -angled, with flat or concave sides (62)

61(60). Most of the culms short and hidden among the leaves: perigynia 3-4 $\mathrm{mm}$. long...............................................57. C. nigromarginata.

61. Most of the culms not hidden among the leaves; perigynia $2.5-3 \mathrm{~mm}$. long 58. C. physorhyncha. 
62(60). Perigynia tightly filled to tip by achenes; base of style bulbous-thickened 59. C. eburnea.

62. Perigynia not tightly filled by achenes, at least the summit usually empty (except for the style) (63)

63(62). Bract at base of inflorescence (excluding rare basal spikes) sheathless or barely sheathing (64)

63. Bract at base of inflorescence with a prolonged closed and tubular sheath (76)

64(63). Leaves and perigynia glabrous (65)

64. Leaves (or sheaths) or perigynia or both pubescent (73)

65(64). Perigynia compressed (C. serratodens may be plump), 1-2 mm. thick, strongly appressed-ascending (at least before maturity) (66)

65. Perigynia plump, 1.7-3.5 $\mathrm{mm}$. thick, spreading to spreading-ascending (71)

66(65). Pistillate scales small, acute to obtuse, 1.5-2.5 mm. long, persistent, purplish-black; perigynia 2-2.5 (-3.5) mm. long.......60. C. media.

66. Pistillate scales larger or sharp-pointed or both; perigynia $3 \mathrm{~mm}$. long or more (67)

67(66). Terminal spike staminate

67. Terminal spike gynecandrous, the terminal flowers pistillate (68)

68(67). Perigynia densely papillose, glaucous-green, trigonous-bíconvex; pistillate scales usually aristate, their tips exceeding the perigynia.

68. Perigynia puncticulate or granular but not papillose; pistillate scales not aristate (69)

69(68). Perigynia not granular-roughened, the margins smooth; lower spikes on long slender peduncles.........................................63. C. bella.

69. Perigynia granular-roughed, especially on the upper margins; spikes sessile or short-peduncled (70)

70(69). Lowest spike slightly separate, short-peduncled; scales rough-papillose, with very conspicuous white-hyaline apex and upper margins; apex of perigynium body obtuse..................................64. C. albonigra.

70. All spikes densely aggregated, sessile; scales with very inconspicuous hyaline margins; apex of perigynium body acute...................65. C. nova.

71(65). Terminal spike pistillate except at base; perigynia as broad as long, transversely rugose............................................66.C. Shortiana.

71. Terminal spike staminate; perigynia not transversely rugose (72)

72(71). Pistillate scales gradually tapering or rounded to the awn; perigynia 4-5 $\mathrm{mm}$. long, strongly ribbed.

67. C. Joorii.

72. Pistillate scales retuse and notched below the awn; perigynia $2.8-3.5 \mathrm{~mm}$. long, essentially nerveless. 68. C. glaucescens.

73(64). Leaves septate-nodulose; perigynia densely soft-hairy.

73. Leaves or sheaths pubescent; perigynia not pubescent (74)

74(73). Spikes usually 2 per culm, the lower ones $7-10 \mathrm{~mm}$. thick; scales of the lower part of the ovoid pistillate portion of the terminal spike strongly cuspidate, 4-5 $\mathrm{mm}$. long, longer than the perigynia; perigynia $3-5 \mathrm{~mm}$. long........................................70. C. Bushii.

74. Spikes usually 3 (sometimes 4) per culm, the lower ones 4-6 mm. thick; scales of lower part of the ovoid-cylindric to cylindric pistillate portion of the terminal spike $1.5-3 \mathrm{~mm}$. long, shorter than or equaling the mature perigynia; perigynia $1.8-2.8 \mathrm{~mm}$. long (75) 
75(74). Perigynia in transection flattened-triangular to unequally biconvex, 2.3-2.8 $\mathrm{mm}$. long, ascending.

71. C. complanata.

75. Perigynia in transection nearly round, $1.8-2.3 \mathrm{~mm}$. long, spreading 72. C. caroliniana.

76(63). Perigynia ascending or not strongly divergent; the orifice entire, oblique or but slightly notched (77)

76. Perigynia usually soon divergent, many-ribbed, $2-3 \mathrm{~mm}$. long, the beak onethird as long as the body; beak minutely bidentate.

73. C. viridula.

77(76). Terminal spike regularly pistillate except at base.

77. Terminal spike regularly staminate throughout (78)

78(77). Culms from lateral buds or sometimes central, relatively weak, readily compressed, soon shriveling after maturity of fruit; perigynia ellipsoid-obovoid, 3-4.5 $\mathrm{mm}$. long, strongly asymmetrical.

75. C. blanda.

78. Culms from centers of leafy tufts, slender and firm, not easily compressed, long-persistent after falling of fruit (79)

79(78). Pistillate spikes linear- to oblong-cylindric, the lower peduncled and usually drooping or loosely spreading; perigynia lanceolate to fusiform or ovoid $(80)$

79. Pistillate spikes oblong-cylindric, erect or ascending, only rarely with elongated peduncles; perigynia ellipsoid to oblong-ovoid or subglobose (81)

80(79). Bases purple or purplish; lowest sheaths at base of culm without green blades; perigynia fusiform-lanceolate, 4-10 $\mathrm{mm}$. long.

76. C. debilis.

80. Bases drab or brown; lowest sheaths at base of culms with elongate green blades; perigynia lance-ovoid, subfusiform, 2-3 $\mathrm{mm}$. long....

77. C. capillaris.

81(79). Perigynia with elevated ribs, $2-3.6 \mathrm{~mm}$. long (82)

81. Perigynia with impressed nerves, $4-6 \mathrm{~mm}$. long (84)

82(81). Plant cespitose with several culms from a crown; leaves flat, flaccid; staminate spikes sessile or short-peduncled...........78. C. granularis.

82. Plant loosely stoloniferous with culms solitary; leaves often folded, firm; staminate spike long-peduncled (83)

83(82). Pistillate spikes 4-6 $\mathrm{mm}$. thick; perigynia 3-3.5 mm. long, many-nerved, with minute hyaline-tipped beak............................79. C. Crawei.

83. Pistillate spikes $7.5 \mathrm{~mm}$. thick; perigynia $3-4.5 \mathrm{~mm}$. long, definitely ribbed, the beak strongly bidentate...............................8. 8 . . microdonta.

84(81). Leaves thin and flaccid to firm, green, rarely glaucous, $1.5-4 \mathrm{~mm}$. wide; lower spike 8-13 (-20) $\mathrm{mm}$. long. with 3 to 6 (to 10) perigynia...........................................................81. C. amphibola.

84. Leaves firm to coriaccous, usually glaucous, 4-10 $\mathrm{mm}$. wide: lower spike 12-50 $\mathrm{mm}$. long, with 8 to 32 perigynia...........82. C. flaccosperma.

\section{Carex Douglasii Boott. Fig. 255.}

Rhizomes 1-2 mm. thick, tough; culms $6-30 \mathrm{~cm}$. tall, slender but stiff, obtusely triangular, smooth, usually overtopping the leaves but sometimes shorter; leaves clustered near the base, 5-15 cm. long, $1-2.5 \mathrm{~mm}$. wide, involute above and flat or channeled toward base; heads usually dioecious, the many spikes closely aggregated but usually distinguishable; pistillate heads suborbicular to oblong, 1.5-5 $\mathrm{cm}$. long. 1-2.5 cm. thick; scales yellowish-brown with broad hyaline margins and 


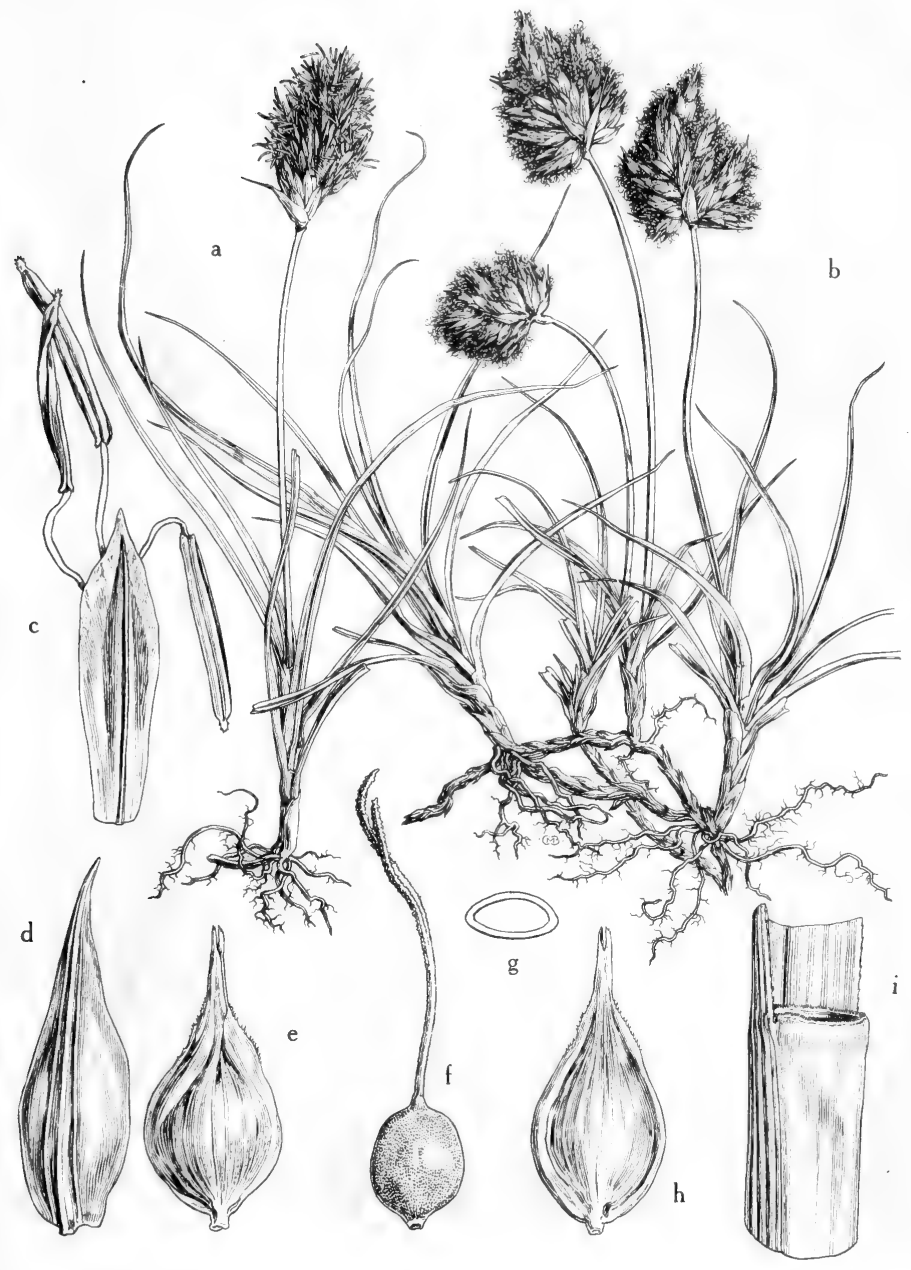

Fig. 255: Carex Douglasii: a, habit, staminate plant, X 2/3; b habit, pistillate plant, $\mathrm{X} 2 \% 3$; c staminate flower with subtending scale, X 8; d, scale of pistillate flower, X 8 , e, perigynium, strongly nerved, abaxial view, X $8 ; \mathrm{f}$, pistillate flower with perigynium removed, X 8; g, achene (cross section), X $8 ; \mathrm{h}$, perigynium, lightly nerved, adaxial view, X 8; i, ligule, truncate with ciliate margin, X 8. (From Mason, Fig. 96). 


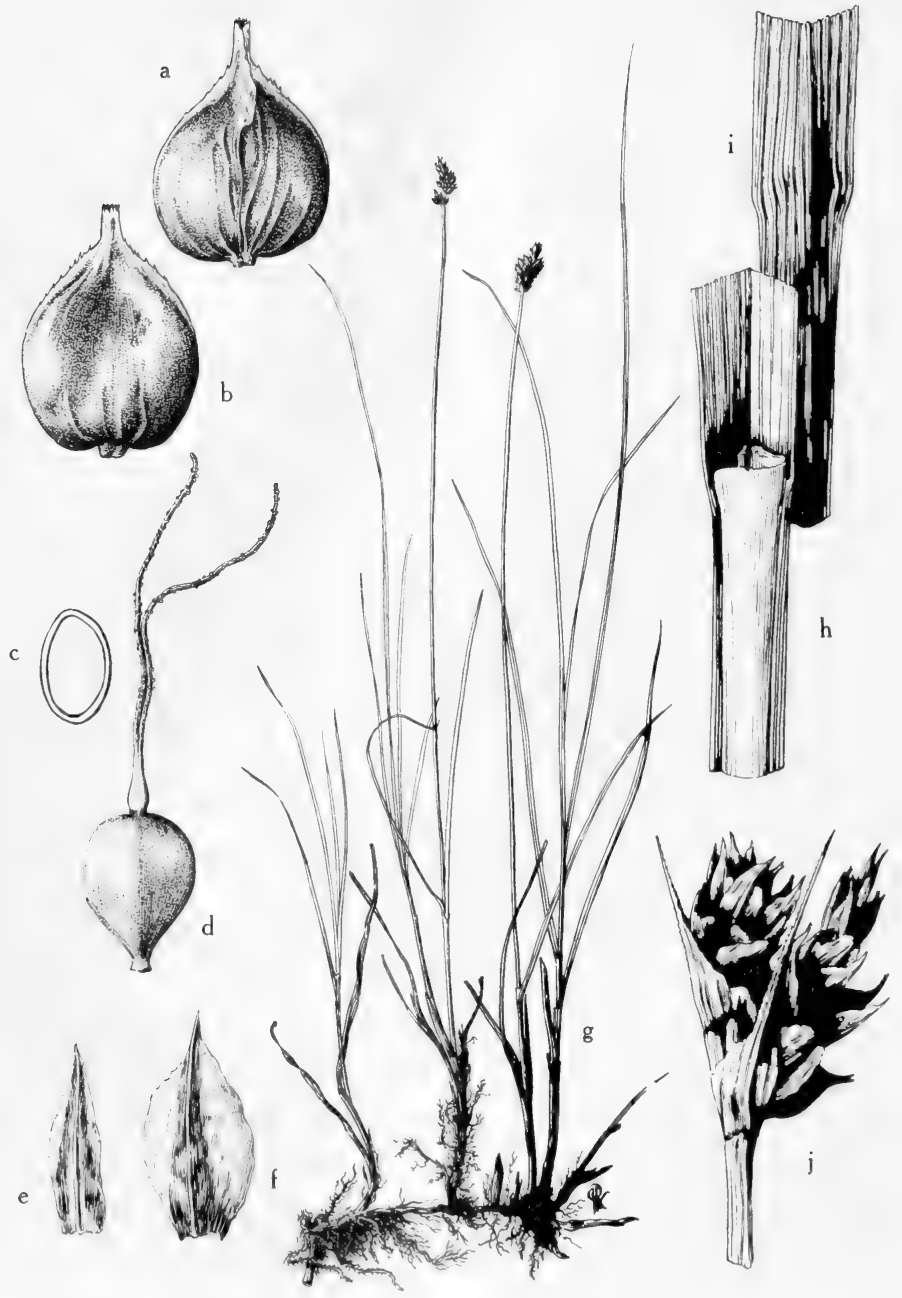

Fig. 256: Carex simulata: a, perigynium, abaxial view, $\mathrm{X} 12 ; \mathrm{b}$, perigynium, adaxial view, X 12; c, achene (cross section), X 12; d, pistillate flower with perigynium removed, X 12; e, scale of staminate flower, X 12; f, scale of pistillate flower, X $12 ; \mathbf{g}$, habit, showing bractless pistillate heads, $X 2 \%$, ligule (on adaxial side of blade), X 8, i, ligular region of leaf, abaxial view, X 8; j, pistillate inflorescence, showing subtending bracts, $X$ 4. (From Mason, Fig. 97). 
green center, acuminate to cuspidate, concealing perigynia; staminate heads similar but somewhat narrower; lowest bract short-cuspidate, not extending beyond tip of inflorescence; perigynia appressed-ascending, ovate-lanceolate, 3-4.5 mm. long, $1.7 \mathrm{~mm}$. wide, straw-colored to brownish, plano-convex, coriaceous, lightly nerved ventrally, strongly nerved dorsally, rounded and short-stipitate at base, sharpedged, serrulate above middle, the beak obliquely cut dorsally, in age minutely bidentate, the apex hyaline; achenes lenticular, obovate, brown, shiny, about 1.7 $\mathrm{mm}$. long, $1.2 \mathrm{~mm}$. wide; style and 2 stigmas conspicuous at flowering time.

Wet meadows, in wet mud and on seepage banks or dryish alkaline flats, in N.M. (Taos Co.) and Ariz. (Coconino, Mohave and Cochise cos.); Can. to N.M., Ariz. and Calif.

\section{Carex simulata Mack. Short-Beaked sedge. Fig. 256.}

Culms 2.5-5.5 dm. tall, sharply triangular and roughened on the angles above, overtopping the leaves; leaf blades $2-4 \mathrm{~mm}$. wide, flat or channeled, light-green; spikes densely aggregated into a linear-oblong or oblong-ovoid head 12-25 mm. long and $5-10 \mathrm{~mm}$. thick, wholly pistillate, wholly staminate or pistillate and partly staminate above, the lower spikes distinguishable; bracts absent or if present then shorter than head, cuspidate and enlarged at base; pistillate scales concealing perigynia, cuspidate or short-awned, brown with narrow hyaline margin and prominent lighter midvein; perigynia ascending, unequally biconvex to plano-convex, broadly ovate, smooth, shining, coriaceous, yellowish brown to chestnut-colored, $1.75-2.25 \mathrm{~mm}$. long, $1.5 \mathrm{~mm}$. wide, rounded and short-stipitate at base, sharpedged, nerveless ventrally, slenderly few-nerved dorsally, the upper part of the body and beak serrulate (sometimes only sparingly so), the beak obliquely cut dorsally, its apex at length minutely bidentate and slightly hyaline; achenes lenticular, obovoid, yellowish-brown, $1 \mathrm{~mm}$. long.

Wet meadows, streams, swales, or marshes, in N.M. (Grant and Sandoval cos.) and Ariz. (Apache and Santa Cruz cos.); Mont. to Wash., s. to N.M., Ariz. and Calif.

\section{Carex praegracilis W. Boott. Clustered field sedge. Fig. 257.}

Perennial; rhizomes 2-4 mm. thick, blackish, fibrous, creeping (but with internodes only $1 \mathrm{~mm}$. long); culms rising at close intervals, $12-30 \mathrm{~cm}$. long, $1-3 \mathrm{~mm}$. thick, leafy; blades mostly folded, long-tapered to a fine point, the uppermost ones usually slightly exceeding the inflorescence; inflorescence $15-45 \mathrm{~mm}$. long, 6-10 $\mathrm{mm}$. thick, of about 6 to 15 short glomeriform androgynous spikes, the lower 1 or 2 spikes usually weakly separated from the rest; scales hyaline marginally, acuminate, longer than the perigynia; perigynia (about 10 per spike) plano-convex, ascending, thin-coriaceous and brownish black when mature and with sharp coriaceous margins, the body obovate or ovate, 3-4 mm. long, 1.5-2 mm. broad, tapering into a serrulate beak half the length of the body or more; achene lenticular, about $1.3 \mathrm{~mm}$. long, $1 \mathrm{~mm}$. wide.

In wet meadows and water of streams and lakes, infrequent in moist canyons of basaltic mts. at elev. of 4,000-8,000 ft. in the Tex. Trans-Pecos (Chisos and Davis mts.), N.M. (Grant and Sandoval cos.) and Ariz. (Apache to Mohave, s. to Cochise and Pima cos.), spring-early summer; temp. w. N.A., in mts. s. to Mexico City.

\section{Carex disperma Dewey.}

Loosely tufted from long slender rhizomes; culms very slender and weak, 6-60 $\mathrm{cm}$. high, mostly exceeding the leaves, usually nodding; leaves thin, soft and flat, $0.75-2 \mathrm{~mm}$. wide; sheaths tight, very thin and hyaline ventrally; spikes 2 to 4 , androgynous, the lower separate, the upper aggregated, with 1 to 3 (or the terminal with 3 to 6 ) perigynia and 1 or 2 apical inconspicuous staminate flowers; 


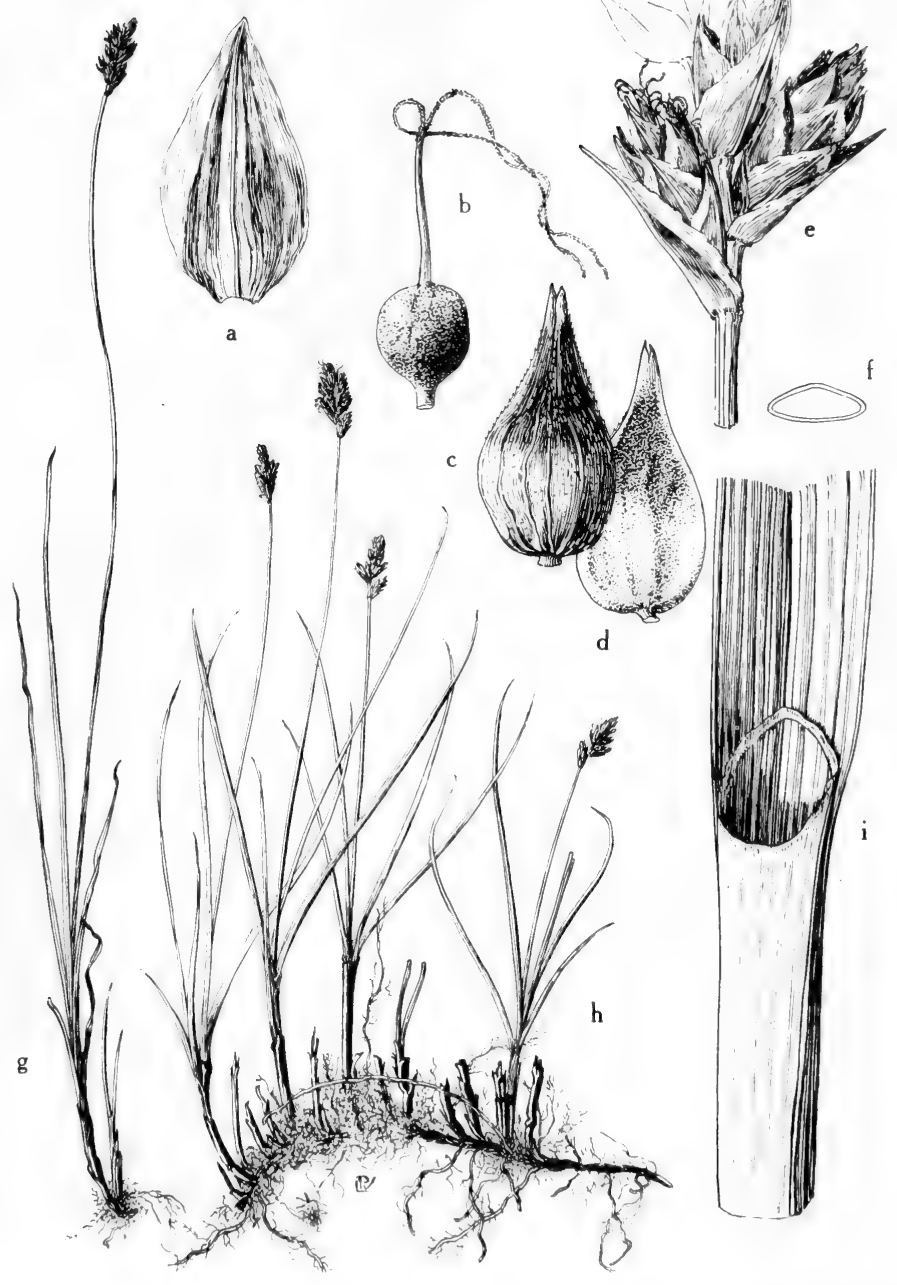

Fig. 257: Carex praegracilis: a, scale of upper pistillate flower, $\mathbf{X} 10 ; \mathrm{b}$, pistillate flower with perigynium removed, $X 10 ; c$, perigynium, lightly several-nerved, beak obliquely cut, abaxial view, X 10; d, perigynium, adaxial view, X 10; e, lower pistillate spikes with short subtending bracts, $X \quad 4 ; f$, achene (cross section), $X 10 ; \mathrm{g}$, habit, showing the erect-ascending leaf blades, $X \%$, habit, showing the dark basal sheaths and the culms extending above the leaves, X $\%$ i, ligule, X 10. (From Mason, Fig. 98). 

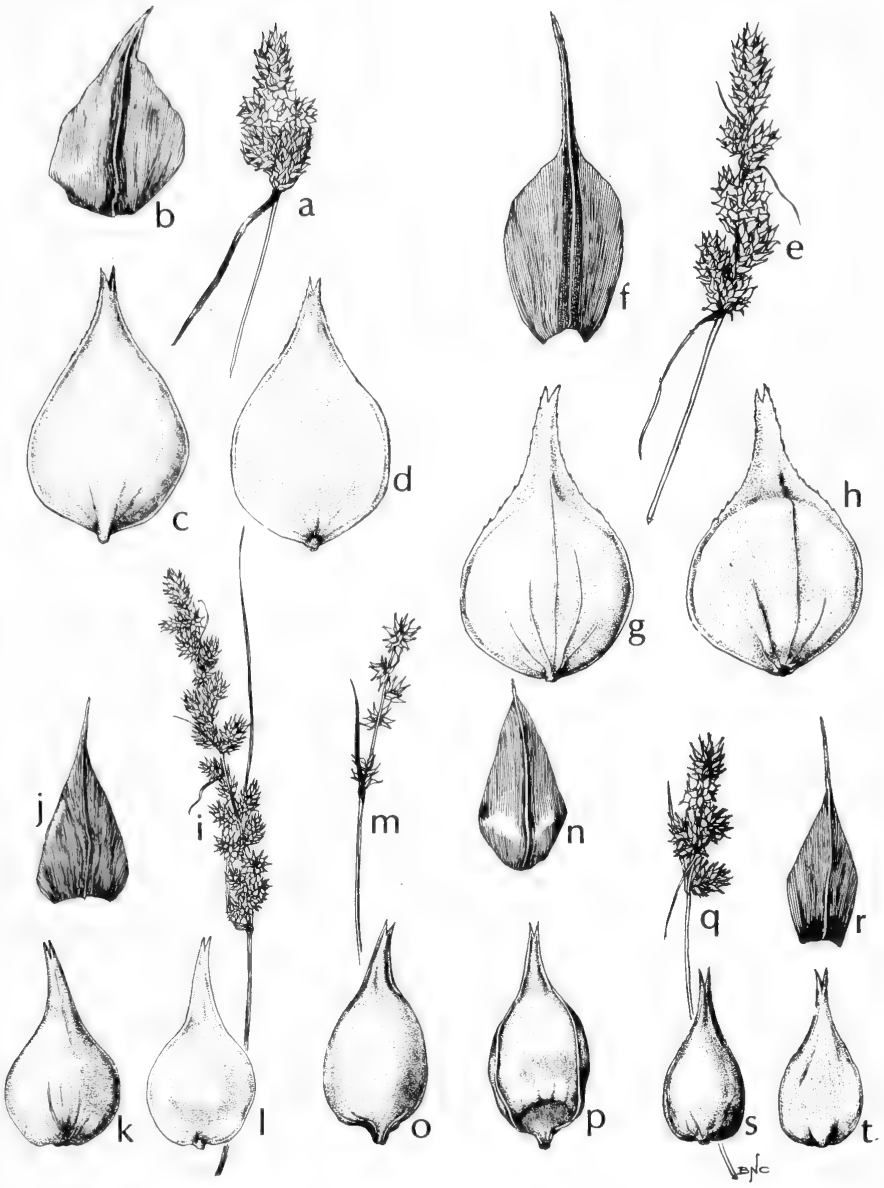

Fig. 258: a-d, Carcx cephalophora: a, inflorescence, X 11/2; b, pistillate scale, X 15 ; c, perigynium, dorsal view, X 15; d, perigynium, ventral view, $\mathrm{X} 15$. e-h, Carex fissa: $\mathrm{e}$, inflorescence, X 1; f, pistillate scale, X 10; g, perigynium, dorsal view, X 10; $\mathrm{h}$, perigynium, ventral view, $X 10$, $\mathrm{i}-1$, Carex vulpinoidea: $\mathrm{i}$, inflorescence, $\mathrm{X} 1 ; \mathrm{j}$, pistillate scale, $\mathrm{X} 12 ; \mathrm{k}$, perigynium, dorsal view, $\mathrm{X} 12 ; 1$, perigynium, ventral view, $\mathrm{X} 12$. $\mathrm{m}-\mathrm{p}$, Carex retroflexa: (woodland species). q-t, Carex Muhlenbergia: (woodland species). (Courtesy of R. K. Godfrey). 
scales ovate-triangular, white-hyaline with green midrib, narrower and shorter than the perigynia; perigynia plump, unequally biconvex, elliptic-ovoid, 2-2.8 $\mathrm{mm}$. long, $1.5 \mathrm{~mm}$. wide, light-green to yellow-green, finely many-nerved on both surfaces, white-punctate, short-stipitate, abruptly contracted into a minute entire beak; achenes lenticular, oblong-elliptic, brownish-yellow, glossy, $1.7 \mathrm{~mm}$. long, $1 \mathrm{~mm}$. wide.

In boggy meadows, coniferous woods, and on peaty banks of streams and lakes, in N. M. (Sandoval, San Miguel, Santa Fe and Taos cos.); Lab. to Alas., southw. to N.J., Ind., N.M., Ariz. and Calif.; also Euras.

\section{Carex canescens $\mathrm{L}$.}

Plants densely cespitose from short rootstocks, often in large tussocks; culms 1-8 dm. high, soft, sharply triangular, often lax and widely spreading; leaves glaucous-green, soft, flat, $2-4 \mathrm{~mm}$. wide; sheaths tight, thin and hyaline ventrally; spikes 4 to 8 , silvery-brown, the upper approximate, the lower separate, containing 10 to 30 appressed-ascending perigynia, the terminal generally clavate at the staminate base; scales broadly ovate, hyaline with a green center, shorter than the perigynia; perigynia plano-convex, ovoid-oblong, $1.8-3 \mathrm{~mm}$. long, $1.25-1.75$ $\mathrm{mm}$. wide, pale-green to whitish-brown, more or less nerved on both surfaces, the sharp margin smooth throughout or only minutely serrulate at the base of the very short inconspicuous or obsolete beak; achenes lenticular, oblong-obovate, substipitate, $1.5 \mathrm{~mm}$. long, $0.9 \mathrm{~mm}$. wide.

Locally abundant on lake margins and shallow water, and in swamps and bogs, in N.M. (Taos Co.) and Ariz. (Apache Co.); Nfld. to Alas., s. to N.J., N.M., Ariz. and Calif.; also Euras. and Austral.

\section{Carex cephalophora Muhl. Fig. 258.}

(Sub-) rhizomatous perennial; rhizomes $2-10 \mathrm{~cm}$. long, much-branched, about $2 \mathrm{~mm}$. thick, with very short internodes; culms $15-30(-45) \mathrm{cm}$. long, 1-2 mm. thick, ascending; leaves 2 to 4 per culm, mostly basal; blades about $15 \mathrm{~cm}$. long and $2 \mathrm{~mm}$. broad, the sheaths ventrally smooth, rather tight-fitting, stramineous, the orifice broadly U-shaped; spikes 5 to 10 , each with about 10 perigynia, very short, sessile, androgynous, aggregated in a narrow more or less ovoid nearly or usually quite bractless head 10-15 $(-17) \mathrm{mm}$. long and 4-9 $\mathrm{mm}$. broad; scales inconspicuous, shorter than the perigynia; perigynia ascending, much-flattened, broadly ovate, the body $1.5-2.5 \mathrm{~mm}$. long and $1-1.5 \mathrm{~mm}$. broad, plano-convex, ventrally quite smooth and with raised margins, basally not differentiated or else discoloring brown in the basal third to fourth the length, firm-membranous, with inconspicuous only slightly tougher margins and with a very short triangular beak less than half as long as the body; achene lenticular, about $1.7 \mathrm{~mm}$. long, $1.5 \mathrm{~mm}$. wide. Incl. var. angustifolia Boott and some plants referred to C. "mesochorea" Mack., C. Leavenworthii Dew.

Frequent in usually moist sandy soil at base of bluffs, in wettish pasturelands, in Okla. (Cherokee and Muskogee cos.) and in e., s.e. and n.-cen. Tex., rare in parts of Edwards Plateau (Enchanted Rock), spring; e. N.A., w. to Mich., Ia., Mo., Okla. and Tex.

\section{Carex decomposita Muhl. Fig. 259.}

Perennial, the branching fibrous blackish rhizomes with internodes several $\mathrm{mm}$. to several $\mathrm{cm}$. long; culms weakly arcuately ascending, soft, 5-15 dm. long, 3-7 $\mathrm{mm}$. thick, nearly terete; lower sheaths brownish or reddish-brown, 1-2 cm. long; sheath venters papery, tending to split at maturity, not at all wrinkled, orifice weakly rounded; upper leaves long, much-surpassing the inflorescence; inflorescence a decompound panicle of 5 to 10 spiciform erect branches (the lower branches longer than the upper ones), each branch bearing 5 to 20 short ovoid 


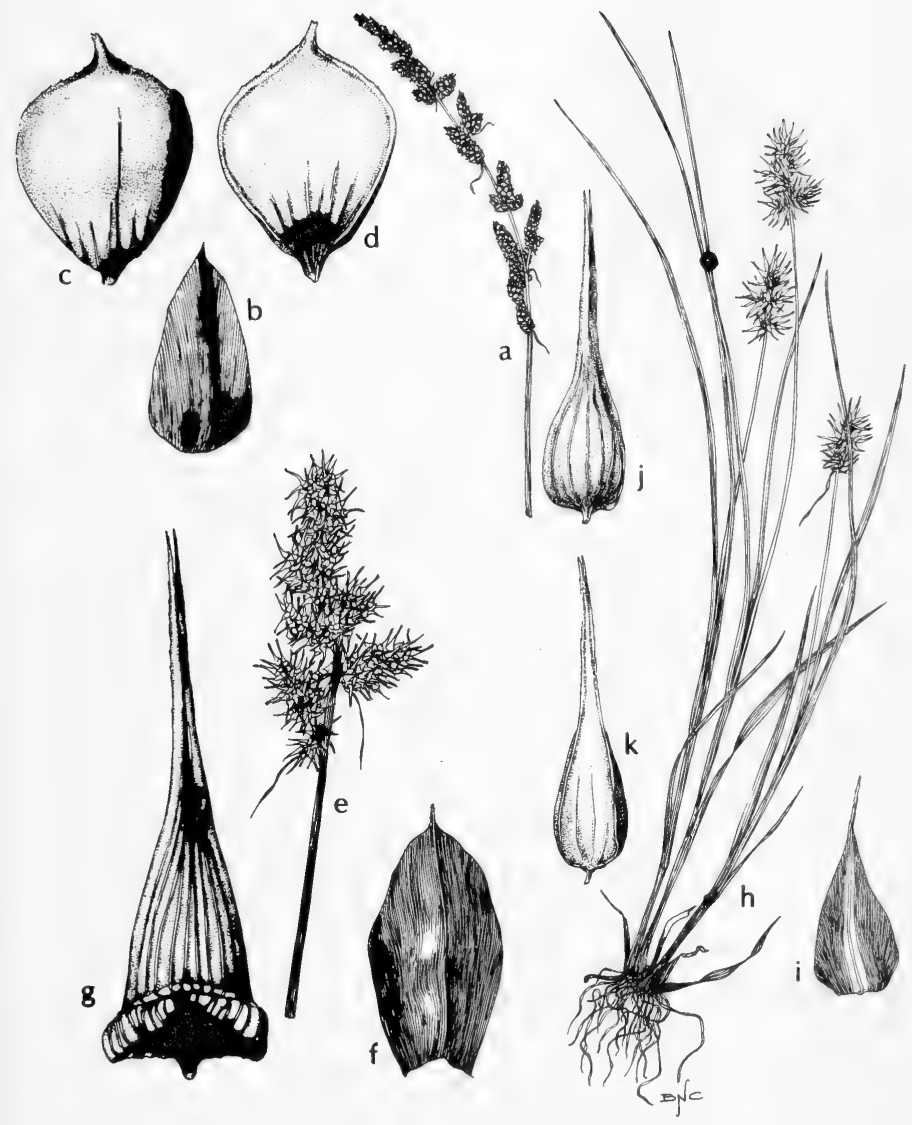

Fig. 259: a-d, Carex decomposita: a, inflorescence, X 1/2; b, scale, X 12; c, perigynium, dorsal view, $\mathrm{X} 12$; d, perigynium, ventral view, $\mathrm{X} 12$. e-g, Carex crus-corvi: $\mathrm{e}$, inflorescence, $\mathrm{X} 1 / 2 ; \mathrm{f}$, scale, X $10 ; \mathrm{g}$, perigynium, X 10 . h-k, Carex laevivaginata: h, habit, X 1/2; i, scale, X 7; j, perigynium, dorsal view, X 7; perigynium, ventral view, X 7. (Courtesy of R. K. Godfrey). 
sessile androgynous brownish essentially bractless spikes each with 8 to 13 perigynia; scales narrower and shorter than the perigynia; perigynia bodies obovate or obpyramidal, plano-convex, firm, $1.5-2.5 \mathrm{~mm}$. long, nearly as broad, sharpedged laterally; beak abrupt, $0.3-0.5 \mathrm{~mm}$. long, bidentate; achene lenticular, very closely enveloped, about $1 \mathrm{~mm}$. long and wide.

Rare in wet areas, usually on rotten logs at lake-margins, n.e. Tex. (Marion and Wood cos.), spring; e. U.S. n. to N.Y. and Mich., w. to Mo. and Tex.

\section{Carex vulpinoidea Michx. Fig. 258.}

Densely matted rhizomatous perennial; rhizomes $2-4 \mathrm{~mm}$. thick, dark-brown or black, fibrous, internodes only 1-2 mm. long; culms $35-70(-90) \mathrm{cm}$. long, 1.5-3.5 mm. thick, erect; sheaths tight, ventrally papery, strongly and closely transversely wrinkled, at the orifice firm and rounded; leaf blades diverse, the lower ones only $5-10 \mathrm{~cm}$. long, the upper very long and equaling or surpassing the heads, tapered to a setaceous tip; inflorescence interrupted-spiciform, $35-80 \mathrm{~mm}$. long, 7-13 mm. thick, of 10 to 15 short sessile androgynous spikes (each with 15 to 30 perigynia), all except the lowermost bractless (in var. platycarpa Hall) or with setaceous bracts 10-30 (-80) $\mathrm{mm}$. long (in var. vulpinoidea); scales papery, lanceolate, acute, about equaling or usually a little shorter than their perigynia; perigynial bodies ovate to suborbicular, 2.5-3 $\mathrm{mm}$. long, 2-3 $\mathrm{mm}$. broad, strongly compressed, mostly flat ventrally, very slightly convex dorsally, smooth or usually serrulate marginally, ventrally usually with a few veins and often on both faces at maturity becoming brownish and firm-membranous; beak of perigynium either abruptly differentiated from and only about a third as long as the body (var. platycarpa) or less abrupt and about half as long as the body (var. vulpinoidea), bidentate, serrulate or entire-margined; achene lenticular, about $1.3 \mathrm{~mm}$. long, $1 \mathrm{~mm}$. wide. C. triangularis Boeck., C. annectans Bickn.

In low wet woods and swamps in wet mud on edge of lakes, ponds and streams; the var. platycarpa Hall is frequent in Okla. (Johnston, Alfalfa, McCurtain, Adair, Caddo, Haskell and Atoka cos.) and in e. and s.e. Tex., rare in n.-cen. Tex. (Denton Co.); var. vulpinoidea is rare in the Tex. Plains Country (Dallam and Hemphill cos.), N.M. (San Miguel Co.) and Ariz. (Apache and Cochise cos.), spring (var. platycarpa) or summer (var. vulpinoidea); e. temp. N.A. w. to the Rocky Mts.; also B.C., Wash. and Ore.

\section{Carex alma Bailey.}

Cespitose from short-prolonged stout rootstocks; culms aphyllopodic, 3-12 dm. high, roughened above, exceeding the leaves; leaves clustered toward the base, thickish, flat or channeled, 3-6 $\mathrm{mm}$. wide, the margins strongly serrulate; sheaths tight, somewhat septate-nodulose dorsally, thin and purplish-dotted ventrally, the ligule about as wide as long; spikes densely aggregated into an oblong head 3-12 $\mathrm{cm}$. long, the lower sometimes separate, the individual spikes seldom distinguishable, the perigynia appressed; scales ovate, about the size of the perigynia, strawcolored or brownish with white-hyaline margins, the midrib prominent, awned to acute; perigynia plano-convex, ovate to oblong-ovate, $3.5-4 \mathrm{~mm}$. long, 1.6-1.8 $\mathrm{mm}$. wide, almost black at maturity, obscurely nerved on both surfaces, roundtruncate at the base, substipitate, narrowly sharp-margined and serrulate above, more or less abruptly contracted into a serrulate bidentate beak about one-third the length of the body, the triangular teeth very short; achenes lenticular, ovoid, $1.5 \mathrm{~mm}$. long, substipitate.

In wet soil along streams, in Ariz. (Gila, Maricopa and Cochise cos.); also Nev, and Calif. 


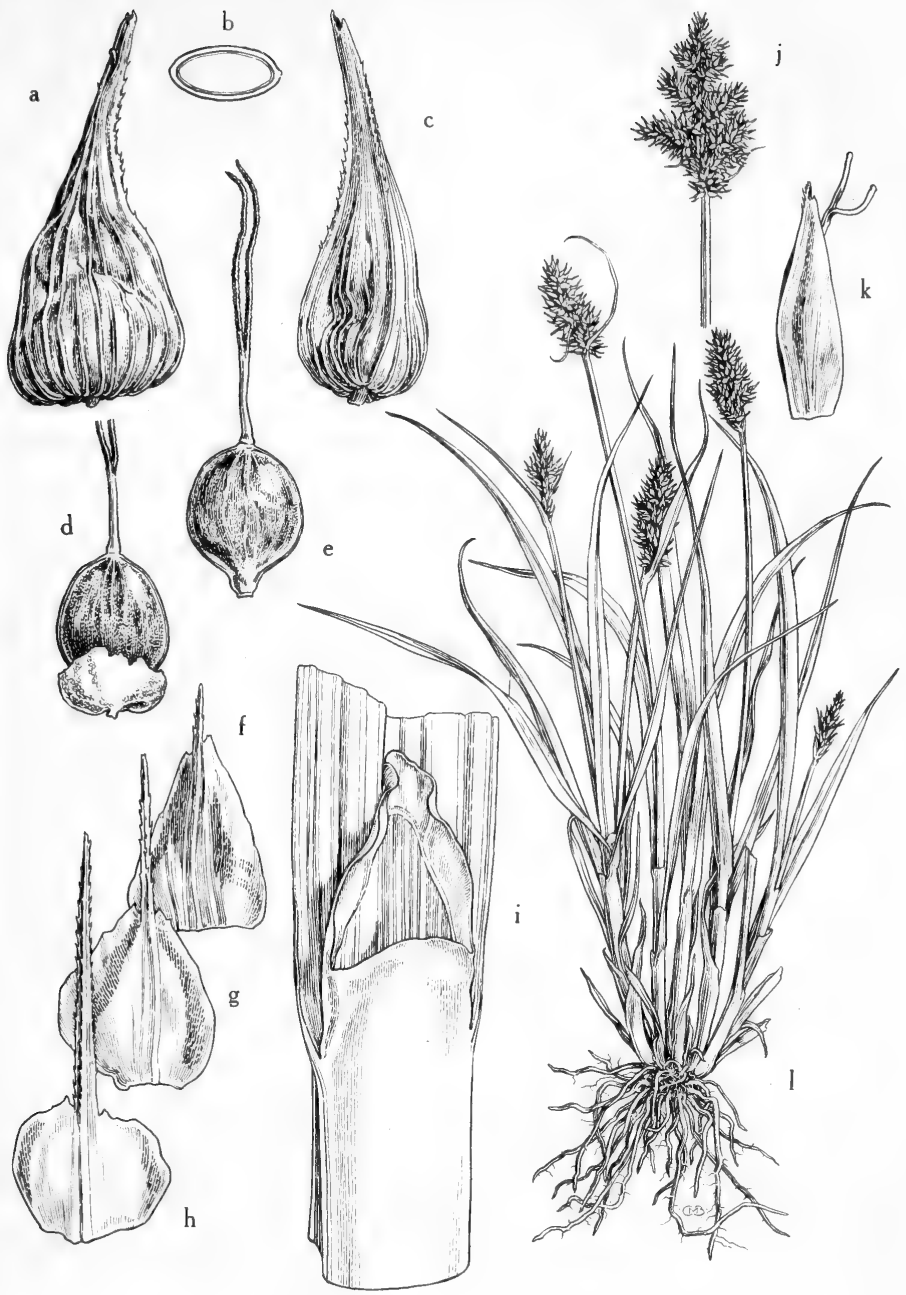

Fig. 260: Carex stipata: a, perigynium, abaxial view, showing the strong nerves and the round-cordate spongy base, X $10 ; \mathrm{b}$, achene (cross section), X 10; c, perigynium, adaxial view, the nerves less developed than on abaxial side, $X 10$; $d$, achene, showing the spongy base of the perigynium, X 10; e, pistillate flower with perigynium removed, showing the stipitate achene, the short style and 2 long stigmas, X 10; $\mathrm{f}-\mathrm{h}$, scales of pistillate flowers, showing variation in shape of scale and in length of awn, $\mathrm{X} 10 ; \mathrm{i}$, ligule, $\mathrm{X} 4 ; \mathrm{j}$, infiorescence, the spikes not crowded, the bracts bristlelike, $\mathrm{X} 25 ; \mathbf{k}$, staminate flower and subtending scale (lowermost flower in spike), X 10;1, habit, showing the conspicuous leaf sheaths and flat flaccid blades, X $2 \%$. (From Mason, Fig. 104). 


\section{Carex fissa Mack. Fig. 258.}

Cespitose; rootstock short, stout, black, fibrillose; culms 2.5-7.5 dm. long, 4-7 $\mathrm{mm}$. wide at base, bluntly triangular, smooth or roughened beneath head, lightbrown at base; well developed leaves 4 to 6 to a culm, on lower third; blades 1-2 $\mathrm{dm}$. long, 3-5 mm. wide, flat or channeled, thick, light-green; sheaths thin and cross-rugulose ventrally, prolonged, red-dotted near mouth; ligule wider than long; spikes 10 to 20 , androgynous, in a head $2.5-4 \mathrm{~cm}$. long and $8-18 \mathrm{~mm}$. wide; lower bracts setaceous, the upper scalelike; scales acute or cuspidate, hyaline, lightyellowish-brown-tinged with green midvein; staminate flowers inconspicuous; perigynia 8 to 20 in a spike, $3.5 \mathrm{~mm}$. long and $2 \mathrm{~mm}$. wide, ascending or spreading, plano- or concavo-convex, submembranous, light-green or yellowish-brown-tinged, few-nerved dorsally, sharp-margined, serrulate above, substipitate; beak $1 \mathrm{~mm}$. long, serrulate, dorsally cleft, bidentate, light-reddish-brown-tinged; achenes $2 \mathrm{~mm}$. long, $1.7 \mathrm{~mm}$. wide, lenticular, substipitate, apiculate, jointed with the short style which is enlarged at base; stigmas 2 , reddish-brown.

On wet ditch banks in Okla. (Waterfall).

\section{Carex crus-corvi Kunze. Fig. 259.}

Densely tufted perennial (the internodes of the rhizomes very short); culms 4-9 dm. long, 4-12 mm. thick basally, soft; sheaths soft, ventrally thin-papery and easily splitting, the orifice horizontal or shallowly U-shaped, not thickened; blades long, often surpassing the inflorescence; inflorescence a decompound panicle $6-15(-19) \mathrm{cm}$. long and $15-40 \mathrm{~mm}$. thick, with 7 to 13 ascending or erect short branches (the lower-middle branches the longest), each branch with 3 to 10 burlike sessile androgynous bractless spikes each with only a few perigynia; scales lanceolate, about as long as or slightly exceeding the body; perigynial body triangular, largely plano-convex, 2-3 mm. long, firm, brownish, basally inflated, discolored whitish, truncately narrowed to the minute stipelike base, apically passing into the linear strongly bidentate beak (3-4 $\mathrm{mm}$. long); achene lenticular, up to $2 \mathrm{~mm}$. long, $1.3 \mathrm{~mm}$. wide.

In mud on edge of lakes, ponds and streams, and in shallow water, in Okla. (McCurtain, Choctaw and Love cos.), frequent in e. Tex., infrequent in s.e. and n.-cen. Tex., rare in the Plains Country (Wichita Co.), spring; Gulf States and n. in cen. U.S. to O., Mich., Minn. and Wisc.

\section{Carex stipata Muhl. Fig. 260.}

Densely tufted perennial, the internodes of the rootstocks very short; culms 3-10 dm. long, 3-7 (-12) mm. thick basally, rather soft, triangular above with concave sides; sheaths soft, ventrally not transversely wrinkled, easily splitting, orifice horizontal or slightly prolonged and rounded, not thickened; upper blades usually about equaling the inflorescence; inflorescence a dense decompound panicle 3-10 $\mathrm{cm}$. long and $10-25 \mathrm{~mm}$. thick, with several ascending branches (the lower branches longer), each branch with 2 to 10 sessile subglobose essentially bractless androgynous spikes each with 8 to 15 perigynia; scales ovate, acuminate, about equaling the perigynia; perigynia 4-6 $\mathrm{mm}$. long, the bodies plano-convex, ovate, firm, 2-3 mm. long, basally more or less discolored brownish-stramineous, firmer, abruptly narrowed to a minute stipe, apically passing into the linear beak which is strongly bidentate and $2-3 \mathrm{~mm}$. long; achene lenticular, about $1.7 \mathrm{~mm}$. long, $1.5 \mathrm{~mm}$. wide. Incl. var. maxima Chapm., C. uberior (Mohr) Mack.

In mud on edge of streams and ponds, wet meadows and marshes, in Okla. (McCurtain Co.), rare in e. Tex. (Austin and Leon cos.), N.M. (Catron, San Miguel, Colfax and Sandoval cos.) and Ariz. (Apache, Navajo, Coconino, Graham and Gila cos.), spring: most of temp. N.A. (except extreme s.w. U.S. and Mex.). 


\section{Carex laevivaginata (Kükenth.) Mack. Fig. 259.}

Closely resembling $C$. stipata in general habit and size; sheaths not cross-puckered, at the mouth distinctly concave and thickened, hence not easily torn and well-preserved in most herbarium material; spike shorter and less compound, 2-5 $\mathrm{cm}$. long, 10-15 mm. thick, green or tinged with straw-color at maturity; scales acuminate, shorter than the perigynia; perigynia lance-ovoid, plano-convex, 4.9-6.2 $\mathrm{mm}$. long, averaging $5.2 \mathrm{~mm}$. and usually less than a third as wide; achene lenticular, stipitate, ovate, $2 \mathrm{~mm}$. long (including stipe), $1.3 \mathrm{~mm}$. wide.

Boggy or swampy woods and meadows, in Okla. (Waterfall); Mass. to Mich. and Minn., s. to n. Fla. cen. Ga., Tenn., Okla. and Mo.

\section{Carex leptopoda Mack.}

Loosely cespitose from slender elongate rootstocks; culms slender, 2-8 dm. high, sharply triangular and roughened below the head, exceeding the leaves; leaves yellowish-green to light-green, flat or the margins somewhat revolute, 2-5 $\mathrm{mm}$. wide; sheaths rather loose, hyaline ventrally, the ligule acuminate and prolonged; spikes 4 to 7 , ovoid or oblong, aggregated into a loose head 2-4 cm. long, but the lower 1 to 3 usually separate, the lateral pistillate, the terminal gynecandrous; scales oblong-ovate, obtuse to acute or cuspidate, about the length of the perigynium bodies, greenish-white with green center; perigynia plano-convex, ovate-lanceolate, $3.5-4 \mathrm{~mm}$. long, $1.5 \mathrm{~mm}$. wide, greenish to greenish-white, several-nerved toward the base dorsally, nerveless to very few- and short-nerved ventrally, contracted into a serrulate bidentate beak half the length of the body; achenes lenticular, suborbicular, about $1.5 \mathrm{~mm}$. long and $1.25 \mathrm{~mm}$. wide, yellowish-brown.

On moist or wet soil of wooded slopes and flats, and in low swampy places, from near sea level to $10,000 \mathrm{ft}$., in Ariz. (Apache, Coconino and Pima cos.); Mont. to B.C., s. to Ariz. and Calif.

\section{Carex Bolanderi Olney.}

Cespitose from slender short-prolonged rootstocks; culms slender, 1.5-9 dm. high, sharply triangular, smooth or somewhat roughened below the head, exceeding the leaves; leaves yellowish-green to pale-green, flat, 2-5 $\mathrm{mm}$. wide; sheaths rather loose, hyaline ventrally, the acuminate ligule much longer than wide; spikes 5 to 8 , linear-oblong, the lower 1 to 5 more or less separate, the rest aggregated into a head $3-8 \mathrm{~cm}$. long, gynecandrous but the staminate flowers inconspicuous; scales ovate to lanceolate-ovate, acute to short-awned, brownish with green center, exceeding the perigynium bodies; perigynia plano-convex, lanceolate, 4-4.5 mm. long, 1-1.25 mm. wide, yellowish-green, strongly severalnerved dorsally, lightly several-nerved (at least at the base) ventrally, tapering somewhat abruptly into a serrulate deeply bidentate beak more than half the length of the body; achenes lenticular, suborbicular or obovate, about $1.75 \mathrm{~mm}$. long and $1.25 \mathrm{~mm}$. wide, yellowish-brown.

Along streams, in wet meadows and on edge of marshes, from sea level to 8,500 ft., in N.M. (Mora Co.) and Ariz. (Coconino, Pinal, Cochise, Santa Cruz and Pima cos.); Mont. to B.C., s. to N.M., Ariz. and s. Calif.

\section{Carex interior Bailey.}

Densely cespitose from short dark-colored rootstocks; culms erect or ascending, slender but firm, wiry and strict, sharply triangular, $1.5-5 \mathrm{dm}$. high, usually longer than the leaves; leaves about 3 to a culm, thin, flat or slightly channeled, 1-3 mm. wide; sheaths tight, the ligule wider than long; spikes 2 to 4 (6), somewhat but not closely crowded into an oblong head, the terminal usually gynecandrous and long-clavate but sometimes entirely staminate and narrowly 
linear or almost entirely pistillate and oblong, the 1 to 10 perigynia of the lateral spikes widely spreading at maturity; scales broadly ovate, very obtuse, yellowishbrown with broad white-hyaline margins and green center, half the length of the bodies of the perigynia; perigynia concavo-convex, oblong-ovoid to deltoid, 2.25-3.25 mm. long, $1.5-2 \mathrm{~mm}$. wide, plump and firm, the body broadest just above the base, thick-margined, olive-green becoming brown, several-nerved dorsally, nerveless to definitely nerved ventrally, rather abruptly narrowed into a sparingly serrulate shallowly bidentate beak about one-third or one-fourth the length of the body, the ventral false suture inconspicuous; achenes lenticular, broadly ovate-orbicular, $1.3 \mathrm{~mm}$. long and about as wide just below the middle.

In swampy meadows, calcareous bogs, and on springy banks, at moderate elevations (mostly 7,000-11,000 ft.) in Ariz. (Apache Co.); Lab. to B. C., s. to Pa., Kan., n. Calif. and cen. Mex.

\section{Carex atlantica Bailey. Fig. 261.}

Tufted perennial (internodes of the branching rhizomes less than $1 \mathrm{~mm}$. long); culms 2-5 dm. long, about $1(-2) \mathrm{mm}$. thick; sheaths stramineous, tight, ventrally papery, tending to split, the orifice horizontal or shallowly U-shaped; inflorescence interrupted-spiciform, 3-5 cm. long, 5-8 mm. thick, of 3 or 4 subglobose bractless spikes each with 8 to 20 perigynia (rarely as many as 40 ) and separated by bare axis internodes $5-14 \mathrm{~mm}$. long, the terminal spike attenuate basally (in the staminate portion), gynecandrous, the rest usually wholly pistillate; scales slightly shorter than the perigynia; perigynial bodies spreading at maturity, 1.5-1.8 $\mathrm{mm}$. long, broadly ovate to nearly orbicular, plano-convex, firm, marginally sharp but not winged, shiny, stramineous, with several strong nerves ventrally (use lens), abruptly narrowed to the beak which is linear, $0.7-0.9 \mathrm{~mm}$. long and bidentate; achene lenticular, about $1.7 \mathrm{~mm}$. long and wide. C. incomperta Bickn., C. Howei Mack.

Infrequent or rare at edge of clear acid streams, edge of lakes, swamps along streams and seepage areas, in Okla. (McCurtain Co.) and in e. and s.e. Tex. (Hardin, Nacogdoches, Cass, Wood, Newton and Tyler cos.), spring; e. N.A., w. to Mich., Ind., Tenn. and Tex.

\section{Carex muskingumensis $\mathrm{Schw}$.}

Cespitose with numerous very leafy sterile culms; fertile culms stout, 5-10 $\mathrm{dm}$. tall; principal leaf blades 3-5 $\mathrm{mm}$. wide; spikes 5 to 10 , fusiform, pointed at both ends, 15-25 $\mathrm{mm}$. long, 4-6 $\mathrm{mm}$. thick, closely aggregated in a dense cluster 4-8 cm. long; pistillate scales lanceolate, about half as long as the perigynia, pale-brown with hyaline margins; perigynia appressed, lanceolate, thin, 7-10 mm. long, about a fourth as wide, finely nerved on both sides, gradually tapering to the beak; achene lenticular, narrowly oblong, 2-2.5 mm. long, $0.8 \mathrm{~mm}$. wide.

Low woods and wet meadows, swamps and alluvial floodplains, in Okla. (fide Fernald and Gleason); Mich., O. and Ky., w. to Kan. and Okla.

\section{Carex athrostachya Olney. Fig. 262.}

Culms cespitose, 1-8 dm. tall; leaves 2 to 4 ; blades flat, 1-3 mm. wide, yellowish green; head ovoid, $1-2.5 \mathrm{~cm}$. long, the spikes 4 to 20 , closely aggregated, the staminate basal flowers inconspicuous; bracts usually well developed, the lowest exceeding the head; scales ovate or lanceolate-ovate, shorter than perigynia, acute or short-cuspidate, brownish with hyaline margins; perigynia ovate-lanceolate, 3-4 mm. long, light-green, becoming straw-colored or brownish, substipitate, ciliate-serrulate above, tapering into a slender terete brownish-tipped beak, the margins of the orifice hyaline; achenes lenticular, oblong-oval, about $1.5 \mathrm{~mm}$. long and $1 \mathrm{~mm}$. wide. 

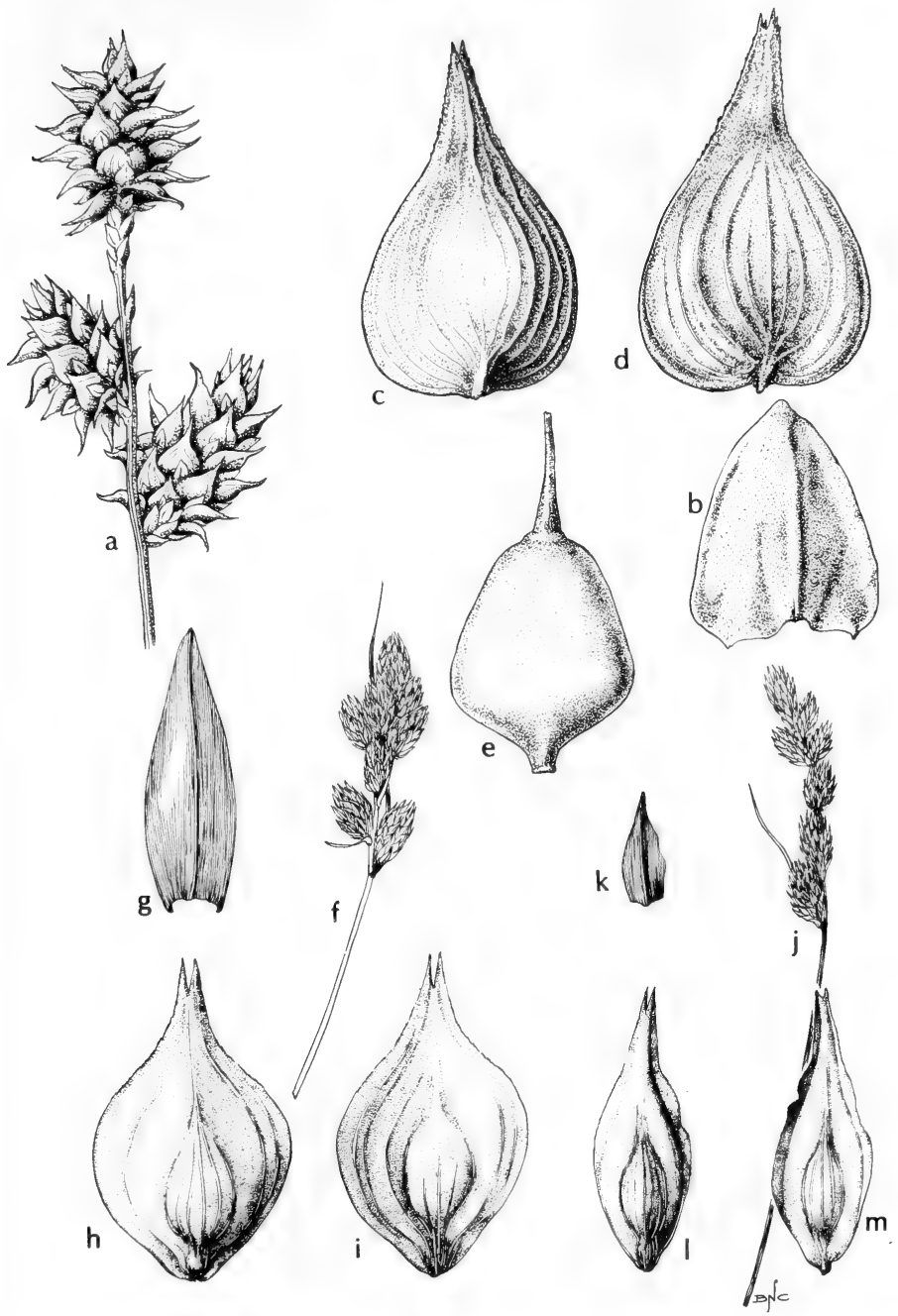

Fig. 261: a-e, Carex atlantica: a, inflorescence, X 5; b, scale, X 17; c, perigynium, dorsal view, X 17; d, perigynium, ventral view, X 17; e, achene, X 17. f-i, Carex albolutescens: $\mathrm{f}$, inflorescence, X 1; g, scale, X 10; h, perigynium, dorsal view, X 10; $\mathrm{i}$, perigynium, ventral view, X 10. j-m. Carex tribuloides: $\mathrm{j}$, inflorescence, X 1; $\mathrm{k}$, scale, $\mathrm{X} 10 ; 1$, perigynium, dorsal view, $\mathrm{X} 10 ; \mathrm{m}$. perigynium, ventral view, $\mathrm{X} 10$. (Courtesy of R. K. Godfrey). 


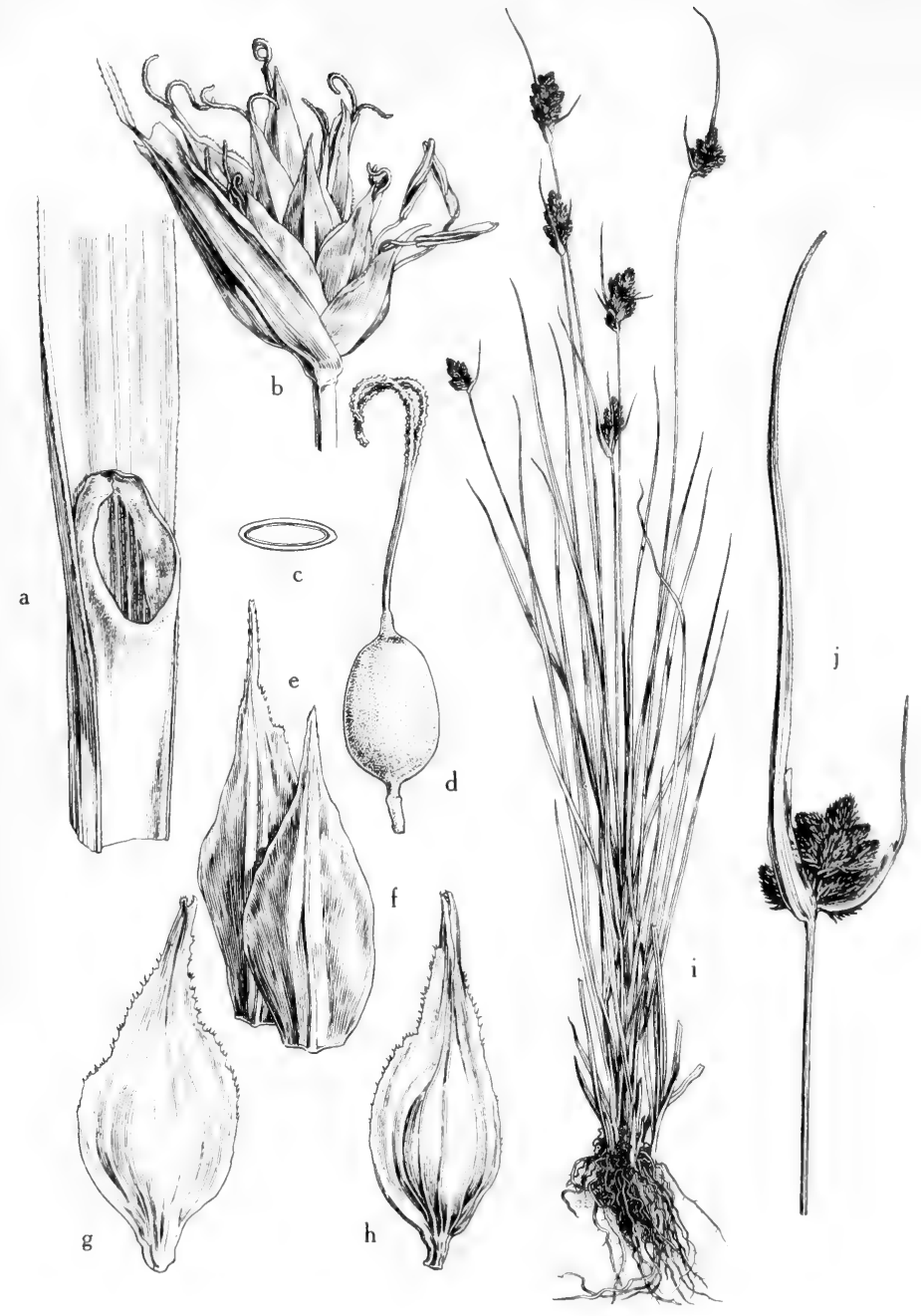

Fig. 262: Carex athrostachya: a, ligule, bilobed, X 8; b. lowermost spike of an inflorescence, showing subtending bract with auricled hyaline base and elongate, serrulate midvein and the inconspicuous staminate flowers at base of spike, X 6; c, achene (cross section), X 12; d, pistillate flower, showing stipitate achene, $\mathrm{X} 12$; e and $\mathrm{f}$, scales, showing variation in size and shape, X $12 ; \mathrm{g}$. perigynium, adaxial view, X 12; $\mathrm{h}$, perigynium, abaxial view, $\mathrm{X} 12 ; \mathrm{i}$, habit, showing the slender culms and the closely aggregated spikes, $X \quad 1 / 4 ;$, inflorescence with auricled subtending bracts, the uppermost much reduced, $X t_{\ldots}$ (From Mason, Fig. 101). 
Wet meadows and thickets, in mud on edge of ponds and lakes, and in seepage areas, in N. M. (Taos Co.) and Ariz. (Navajo, Coconino and Pima cos.); Sask. to Alas., s. to N.M., Ariz. and Calif.

\section{Carex tribuloides Wahl. Fig. 261.}

Tufted perennial; culms 3-8 dm. long, 1-2 mm. thick, basally slightly arcuateascending, mostly ascending, apically strongly angled; sheaths short, the venters mostly veiny except for the hyaline area near the orifice; blades (1-) $2.5-5 \mathrm{~mm}$. broad, shorter than the culms and at least the lower ones often relatively stiff and diverging from the culm at an angle of $10-30^{\circ}\left(-50^{\circ}\right)$; inflorescence elongate, capitate or shortly subspicate, 25-50 mm. long, 9-15 mm. thick, of 5 to 15 closely set sessile burlike obovoid to oblong ascending gynecandrous spikes 7-10 $\mathrm{mm}$. long and 3-5 $\mathrm{mm}$. thick; bracts absent except occasionally a small setaceous one at the base of the lowest spike; scales half to two thirds as long as their perigynia; perigynia 50 to 80 per spike, much-flattened and scalelike, distended only over the achene, winged, 3.5-5.2 $\mathrm{mm}$. long (including the bidentate beak which is about $1 \mathrm{~mm}$. long), $1-1.5 \mathrm{~mm}$. broad including the wings (broadest near the middle, i.e., in the upper half of the "body"), stramineous-brown, ventrally veiny, stiffly ascending and apically not appressed nor incurved; achene lenticular, about $1.5 \mathrm{~mm}$. long, $0.7 \mathrm{~mm}$. wide.

In swampy or low wet meadows and woods of alluvial soils, in mud on edge of ponds, lakes and streams, in Okla. (McCurtain and Alfalfa cos.) and s.e. Tex. (Jefferson, Panola, Gregg, Rusk, Sabine and Montgomery cos.), May; e. temp. N.A. w. to Minn., Mo., Okla. and Tex.

\section{Carex microptera Mack.}

Very densely cespitose from short stout rootstocks; culms 3-10 dm. high, 2.5-4 $\mathrm{mm}$. thick at the base, conspicuously striate, sharply triangular above and roughened below the head, much-exceeding the leaves; leaves 3 to 5 to a culm, on the lower third, flat, firm, 2-6 mm. wide; sheaths tight, white-hyaline ventrally; spikes 5 to 20 , gynecandrous, distinguishable but densely aggregated into an ovoid or suborbicular, truncate-based head, 12-18 (-25) mm. long, 10-18 mm. wide; lowest bract short-awned; scales ovate-lanceolate, acute, dull-brown, with faint lighter midrib, narrower and shorter than the perigynia; perigynia thin and flattened except where distended by the achene, lanceolate-ovate to lanceolate, 3.4-5 mm. long, 1-2 $\mathrm{mm}$. wide, spreading-ascending, light-green to lightbrown, lightly several-nerved on both surfaces, very narrowly wing-margined to the round-tapering base, serrulate to the middle, tapering into a terete serrulate (smooth at the tip) bidentate beak one-third to one-half the length of the body; achenes lenticular, broadly obovoid, to $1.5 \mathrm{~mm}$. long, about $1 \mathrm{~mm}$. wide; anthers long-persistent, linear-oblong, spinulose apiculate, $1.3-2 \mathrm{~mm}$. long. C. festivella Mack.

Moist or wet places, in N.M. (Taos, Grant, San Miguel, Catron, Rio Arriba and Sandoval cos.) and Ariz. (Coconino, Pima and Graham cos.); B.C. to Sask. and Man., s. to Calif., N.M., Ariz. and in the Black Hills of S.D.

\section{Carex scoparia Schkuhr.}

Densely cespitose from short fibrillose rootstocks; culms $1.5-10 \mathrm{dm}$. high, usually much-exceeding the leaves, sharply triangular, the angles very rough below the inflorescence; leaves 2 to 6 , on the lower half, flat or canaliculate, 1-3 $\mathrm{mm}$. wide, yellowish-green; spikes 3 to 12 , distinct, aggregated into an oblong to linear-oblong or globose head (or sometimes a moniliform flexuous inflorescence), gynecandrous, straw-colored, the numerous erect-ascending perigynia with appressed-erect beaks; scales ovate to oblong-ovate, dull, light-brownish with green center and narrow white-hyaline margins, nearly as wide as the 
perigynia but conspicuously exceeded by the beaks; perigynia flat, thin and scalelike, barely distended over the achene, 4-7 mm. long, 1.2-2.6 mm. wide, lanceolate to narrowly ovate-lanceolate, greenish-white to straw-colored, wingmargined to the base, serrulate to below the middle, nerved on both faces, tapering into a flat serrulate shallowly bidentate beak $1.2-2 \mathrm{~mm}$. long; achenes lenticular, oval-oblong, 1-1.5 mm. long, 0.5-0.7 mm. wide, brownish, short-stipitate.

In open usually swampy places in seepage along streams and about ponds in Ariz. (Apache and Pima cos.); Nfld. to B.C., s. to S.C., Ark., N.M., Ariz. and Ore.

Carex Bebbii Olney (in Colfax Co., N.M.) is similar to this species but the perigynia are only about $3 \mathrm{~mm}$. long.

\section{Carex festucacea Schkuhr.}

Culms cespitose, slender, erect, exceeding the leaves; principal leaf blades 2-5 $\mathrm{mm}$. wide; spikes ovoid to subglobose, 6-10 $\mathrm{mm}$. long, often distinctly clavate at base, distinct but crowded in a compact cluster or separate in an inflorescence 3-6 cm. long; pistillate scales ovate, much shorter and narrower than the perigynia, hyaline and lightly tinged with brown, acute or acuminate; perigynia $2.7-4$ $\mathrm{mm}$. long, half to three-fourths as wide, broadest at a third to half of their length, the body broadly ovate to obovate, finely nerved on both faces, abruptly narrowed to the beak; achenes lenticular, elliptic, light-brown, about $1.3 \mathrm{~mm}$. long, $1 \mathrm{~mm}$. wide. ? C. normalis Mack.

In wooded swamps and bottomlands, in mud along streams and in swales, in Okla. (fide Fernald and Gleason); N.S. to N.Y., s. Mich. and Ia., s. to Fla. and Okla.

\section{Carex albolutescens Schwein. Fig. 261.}

Tufted perennial; culms $25-75 \mathrm{~cm}$. long, 1-2 mm. thick, sharply triangular, erect; sheath venters broadly stramineous-hyaline; blades $1.5-3 \mathrm{~mm}$. broad, shorter than the culms, in most specimens rather stiffly ascending, the lower ones extremely short; inflorescence interrupted-spiciform to moniliform-spiciform, 25-45 mm. long, 6-10 mm. thick, of 3 to 10 sessile basally attenuate ovoid apically rounded ascending gynecandrous spikes 6-11 $\mathrm{mm}$. long and 5-6 $\mathrm{mm}$. thick; bracts absent; scales shorter than the perigynia; perigynia 30 to 50 per spike, 2.8-3.2 $(-3.5) \mathrm{mm}$. long, 1.6-2.2 $\mathrm{mm}$. broad, widest below the middle, the body broadly obovate, widest above the middle, at anthesis stramineous, very thin and distended only over the achene, winged, at maturity stramineous and firmer, somewhat plano-convex, ventrally nearly veinless; beak $0.6-1 \mathrm{~mm}$. long, flat, bidentate, serrulate, at anthesis green, at maturity brownish, contrasting with the body; achene lenticular, about $1.3 \mathrm{~mm}$. long, $1 \mathrm{~mm}$. wide.

Infrequent or rare in moist or wet sand in bogs, low wooded swamps, edge of water and in mud along streams and about ponds in e. (Polk, Leon and Sabine cos.) and s.e. (Jefferson Co.) Tex., Apr.; otherwise said to occur in Coastal States, N.S. to Fla.; also Mich., III., Ind., Mo., Tenn. and La.

\section{Carex Longii Mack.}

Tufted perennial, the rootstocks with very short internodes; culms sharply triangular, 3-8 dm. long, erect, 1.5-2 mm. thick: sheaths short, the venters mostly green and veiny except for the immediate vicinity of the orifice; blades $1.5-4 \mathrm{~mm}$. broad, shorter than the culms, at least the lower ones often relatively stiff and diverging slightly from the stem; inflorescence moniliform-spicate, 3-5 $\mathrm{cm}$. long, 12-15 mm. thick, of 5 to 10 sessile basally abruptly attenuate narrowly ovoid ascending gynecandrous spikes 7-11 $\mathrm{mm}$. long and 5-8 $\mathrm{mm}$. thick; bracts absent except occasionally a small setaceous one at the base of the lowest spike; scales shorter and narrower than their perigynia; perigynia 55 to 80 per spike, 
winged, when immature silvery-green, scalelike and subappressed, at maturity brownish and plano-convex, very firm, with tip erect, ventrally veiny, (3-) 3.5-4.2 $(-4.5) \mathrm{mm}$. long, 1.7-2.5 $\mathrm{mm}$. broad (including the wings), broadest near the middle (meaning in the upper half of the "body"), the broadly triangular "beak" about $1 \mathrm{~mm}$. long and scarcely differentiable from the "body"; achene lenticular, about $1.5 \mathrm{~mm}$. long, $0.8 \mathrm{~mm}$. wide.

Infrequent in mud and shallow water in e. and s.e. Tex., Apr.-early June; Coastal States, Mass. to Tex., Ind., Mich.; Mex., Berm., also reported in Venez.

\section{Carex alata Torr. Fig. 263.}

Tufted perennial rather like $C$. Longii but the inflorescence perhaps on the average with the spikes a little more separated from each other; perigynia (3.7-) 4-5 mm. long, 3.1-3.5 mm. broad, thus averaging longer and proportionately broader than in $C$. Longii, and with the ventral veins slightly less conspicuous.

Rare in mud and wet sandy loam, e. Tex. (Anderson Co.) and Edwards Plateau (Sterling Co.), Apr.; otherwise attributed to Coastal States, Mass. to Fla. and Ind., Mich. and $\mathrm{O}$.

\section{Carex hyalina Boott.}

Rhizomes 2-3.5 mm. thick, branching, black-fibrous, with internodes 0.5-1 $\mathrm{mm}$. long; culms $25-60 \mathrm{~cm}$. long, about $1 \mathrm{~mm}$. thick, erect, sharply triangular; sheath venters pale-hyaline; blades $1-2 \mathrm{~mm}$. broad, shorter than (or the uppermost equaling) the culms; inflorescence $15-35 \mathrm{~mm}$. long, 8-11 $\mathrm{mm}$. thick, of 2 to 4 noticeably separated sessile ascending gynecandrous subglobose (burlike) to prolate basally abruptly attenuate heads $8-12 \mathrm{~mm}$. long and 8-11 $\mathrm{mm}$. broad; scales much shorter than their perigynia; perigynia 15 to 30 per spike, divaricate, 5.5-6.5 mm. long (including the beak), 2.5-3.2 mm. broad, widest well below the middle, the body (poorly differentiated) broadly ovate, widest near the middle, at anthesis pale-greenish-stramineous, membranous and distended only over the achene, at maturity very firm, unequally biconvex centrally and with the margins and wings strongly curved toward the ventral surface, stramineous with a brownish submarginal zone, strongly veined ventrally, with transverse wrinkles between the veins and in the margins and wings; beak poorly differentiated, elongate-triangular, 1.5-2 mm. long, green turning brownish; achene lenticular, about $2 \mathrm{~mm}$. long, $1 \mathrm{~mm}$. wide.

Infrequent to rare in mud, Okla. (McCurtain Co.) and e. Tex. (Cass, Houston and Waiker cos.), very rare in n.-cen. Tex. (Dallas Co.), Apr.-May; Ark., Okla. and Tex.

\section{Carex Bicknellii Britt.}

Culms cespitose, slender, erect, exceeding the leaves, 5-10 dm. tall; principal leaf blades $2-4.5 \mathrm{~mm}$. wide; spikes usually 4 to 6 , the pistillate portion globose to ovoid, 8-12 mm. long, often distinctly clavate at base and to $18 \mathrm{~mm}$. long (including the staminate portion), separate or somewhat aggregated in an oblong to linear cluster 3-7 cm. long; pistillate scales lance-ovate, shorter (1-2 mm.) and much narrower than the perigynia, pale-brown with green midnerve and narrow hyaline margins; perigynia broadly ovate, straw-color, $4.2-7.7 \mathrm{~mm}$. long, 2.7-4.8 $\mathrm{mm}$. wide, very flat, thin and almost translucent, broadly winged, sharply severalnerved on both faces, abruptly contracted into the beak; achene lenticular, obovate, about $2 \mathrm{~mm}$. long and $1.5 \mathrm{~mm}$. wide.

In wet or dry meadows, fields and open woods, in Okla. (Waterfall) and N.M.; Me. to Sask., s. to Del., O., Mo., Okla. and N.M. 


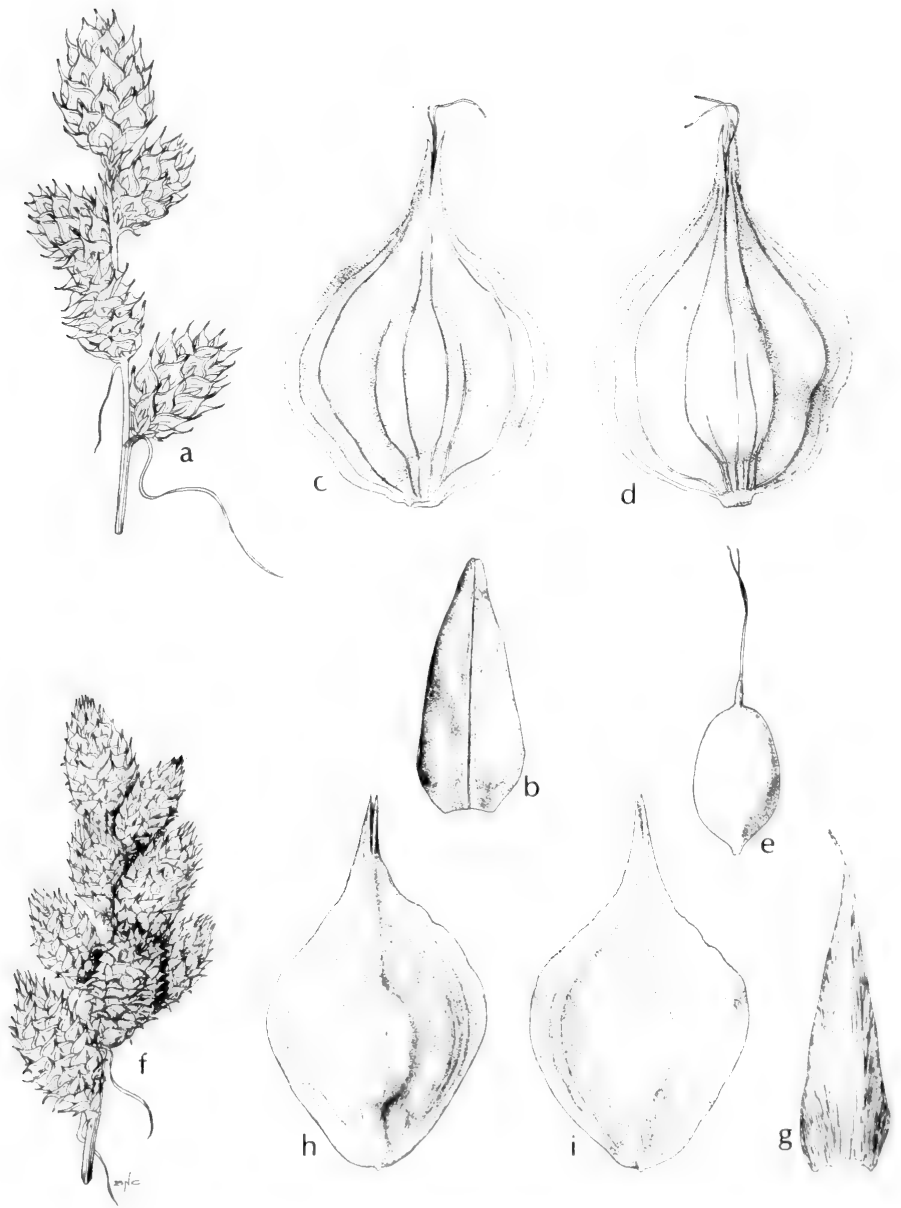

Fig. 263. a-e, Carex reniformis: a, inflorescence, X 12/3; b, pistillate scale, X 8; c, perigynium, ventral view, $X 8$; d, perigynium, dorsal view, $X 8$; e, achene, $X 8$. f-i, Carex alata: $\mathrm{f}$, inflorescence, $X 1 \% 3 ; \mathrm{g}$, pistillate scale, $\mathrm{X} 8 ; \mathrm{h}$, perigynium, dorsal view, X 8 ; i, perigynium, ventral view. X 8. (Courtesy of R. K. Godfrey). 


\section{Carex Brittoniana Bailey.}

Tufted perennial; rhizomes $2-4 \mathrm{~mm}$. thick, black-fibrous, with internodes about $1 \mathrm{~mm}$. long, branching; culms 35-75 (-90) cm. long, 2-2.5 (-3) mm. thick, erect, sharply triangular; sheath venters stramineous-hyaline; blades $2.5-5 \mathrm{~mm}$. broad, flat, shorter than the culms; inflorescence $25-50 \mathrm{~mm}$. long, $10-25 \mathrm{~mm}$. broad, of 2 to 5 clumped or slightly separated ascending nearly globose to ovoid burlike basally strongly attenuate gynecandrous sessile spikes 11-16 mm. long; bracts essentially absent; perigynia (30 to) 40 to 50 (to 65) per bur, (5.5-) 6-8 (-8.5) mm. long (including the beak), (3.7-) 4-5.5 (-6) $\mathrm{mm}$. broad (including the wings), at maturity divaricate, the body very broadly ovate to very broadly elliptic to nearly orbicular, occasionally broader than long, basally broadly rounded to slightly cordate, at anthesis thin-membranous, pale-greenish-stramineous, distended only over the achene, at maturity firm to subcoriaceous, plano-convex centrally, stramineous with a submarginal brown zone, ventrally nearly veinless; beak $2.5-3(-3.5) \mathrm{mm}$. long, strongly differentiated, at anthesis green, at maturity brown, bidentate; achene lenticular, $2.5 \mathrm{~mm}$. long, $2 \mathrm{~mm}$. wide.

In wet mud on edge of lakes, ponds and streams, in depressions in fields and in resacas, in Okla. (Waterfall) and in Rio Grande Plains, s.e. and n.-cen. Tex., infrequent in Edwards Plateau, Plains Country and e. Tex., Mar.-May.

\section{Carex reniformis (Bailey) Small. Fig. 263.}

Tufted perennial; culms 2-7 dm. long, 1-2 mm. thick, sharply triangular; sheath venters stramineous-hyaline; lower blades very short, upper ones 1.5-4 $\mathrm{mm}$. broad, shorter than the culms; inflorescence (1.5-) 3-4.5 (-5) cm. long, 7-10 $\mathrm{mm}$. thick, of 3 to 7 more or less strongly separate gynecandrous erect subglobose apically rounded basally abruptly attenuate spikes $6-10(-13) \mathrm{mm}$. long and 5-8 (-9) $\mathrm{mm}$. broad; bracts essentially absent; scales half to two thirds as long as their perigynia; perigynia 25 to 40 per spike, erect, (3.3-) $3.8-5(-5.5) \mathrm{mm}$. long (including the beak), (2.3-) 2.6-3.5 (-4.5) $\mathrm{mm}$. broad, broadest near or below the middle, the bodies nearly orbicular to broadly oblong to obovate, winged, at anthesis extremely thin, distended only over the achene, membranous but at maturity firm to subcoriaceous, nearly plano-convex or concavo-convex, stramineous or with brownish submarginal staining, ventrally shiny and essentially veinless; beak well-differentiated from body, green turning pale-brownish, 1-1.7 mm. long, bidentate; achene lenticular, $2 \mathrm{~mm}$. long, $1.5 \mathrm{~mm}$. wide. C. brevior (Dew.) Mack.

Frequent in s.e., e., and n.-cen. Tex., and N.M. (San Miguel Co.), in mud, occasionally in woodlands, usually in open places, Apr-May; e. N.A. w. to B.C., Wash., Ore., Colo., N.M. and Tex.

\section{Carex Hassei Bailey. Fig. 264.}

Rhizomes slender; culms 1-6 dm. tall, sharply triangular, roughened above, overtopping the leaves; leaves clustered near the base, channeled, 2-4 mm. wide, flat above; staminate spike terminal, solitary, peduncled, $6-15 \mathrm{~mm}$. long, often pistillate at apex; pistillate spikes 2 to 4, linear-oblong, 8-20 mm. long, 3.5-4.5 $\mathrm{mm}$. wide, the upper spikes approximate and short-peduncled, the lower ones strongly separate and long-peduncled; lowest bract extending beyond the tip of the culm, scales broadly or narrowly ovate, the tips obtuse to acute or acuminate or often aristate with a scabrid awn, all these variations occurring within the same spike, the scales reddish-brown-tinged with green center and narrow hyaline margins; perigynia obovoid, at first greenish or straw-colored, becoming whitish and minutely granular, rounded and nearly beakless, the orifice entire; achenes lenticular, $1.5 \mathrm{~mm}$. long, $1.2 \mathrm{~mm}$. wide.

Along streams, in wet meadows and in bogs, in Ariz. (Navajo and Coconino cos.); Alas. s. to Ariz. and Baja Calif. 


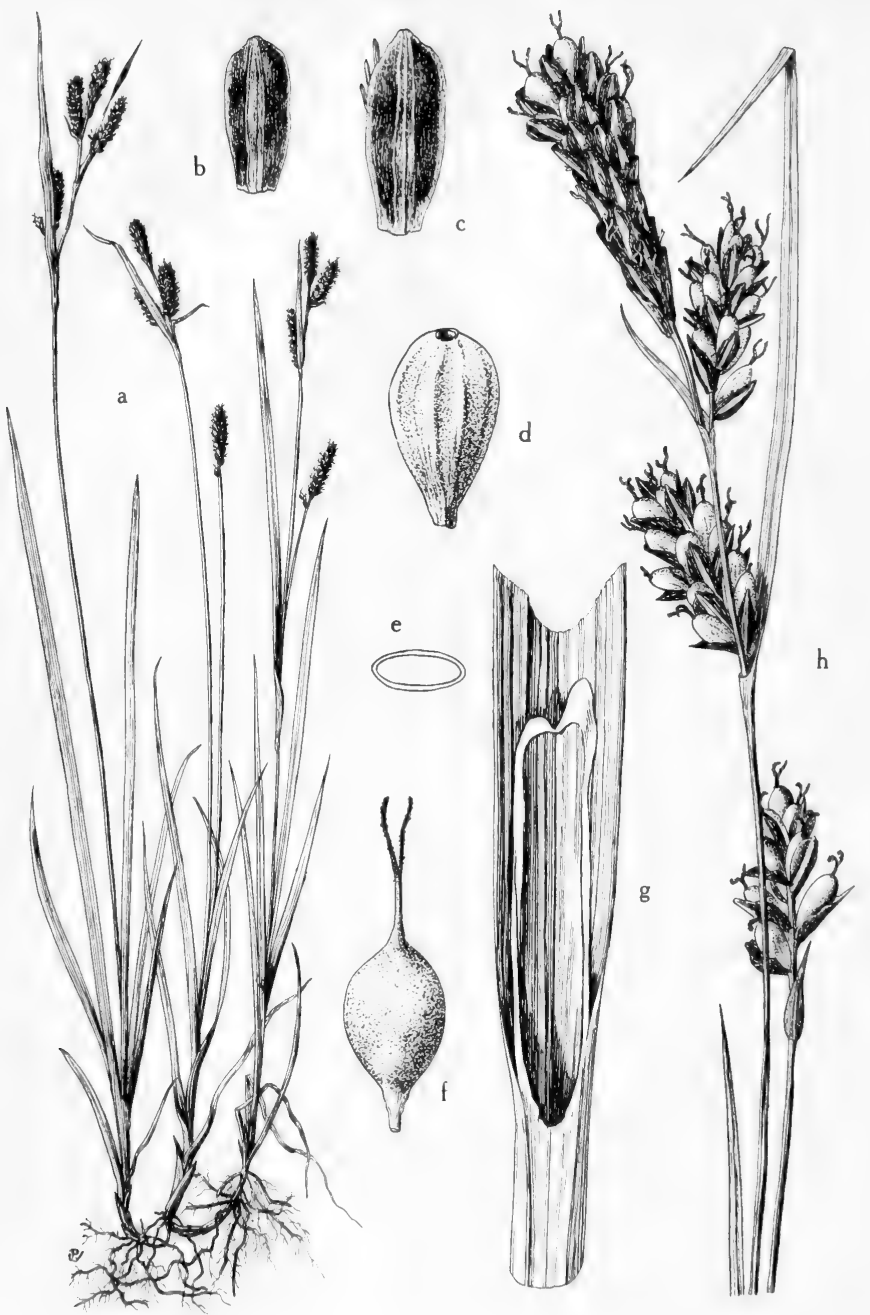

Fig. 264: Carex Hassei: a, habit, showing separate pistillate and staminate spikes, the staminate spikes above, $X{ }_{3} ;$ b , scale of pistillate flower, $X \quad 6$; c, scale of staminate flower, X 6 ; d, perigynium, rounded at apex, X 12; e, achene (cross section), X 12; f, pistillate flower with perigynium removed, $X 12 ; \mathrm{g}$, ligule, $X 8 ; \mathrm{h}$, inflorescence, the terminal spike staminate at base and pistillate at apex, the other spikes pistillate, $\mathrm{X} 3$. (From Mason, Fig. 86). 


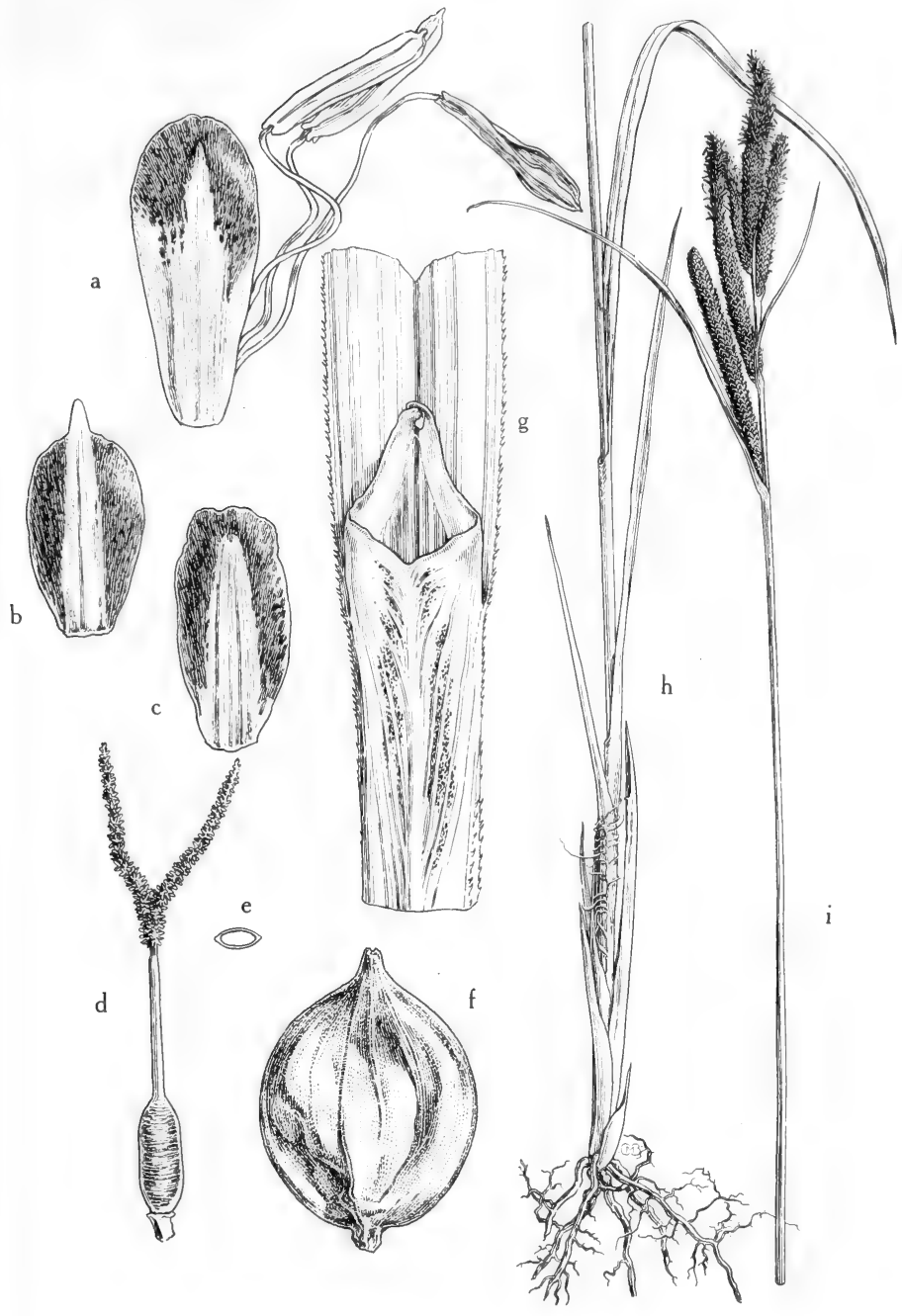

Fig. 265: Carex senta: a, staminate flower with subtending scale, X 10; b and c, scales of pistillate flowers, showing variation, $X 10 ; \mathrm{d}$, pistillate flower with perigynium removed, $\mathrm{X} 12$; e, achene (cross section), X 12; $\mathrm{f}$, perigynium, broadly ovate, $\mathrm{X} 12$; $\mathrm{g}$, ligule, showing the long auricles, $X$ 6; h, lower part of plant, showing filamentose lower sheaths, $X 2 / 5 ; \mathbf{i}$, upper part of culm, with short subtending bract, the lower spike pistillate, the upper spikes pistillate below and staminate above, $\mathbf{X} 2 / 5$. (From Mason, Fig. 92). 


\section{Carex aurea Nutt.}

Perennial with extensive rhizomes several $\mathrm{cm}$. long and $1 \mathrm{~mm}$. thick; culms often weak and reclining basally, distally ascending, $7-20 \mathrm{~cm}$. long, $0.5-0.8 \mathrm{~mm}$. thick; leaves few, clustered basally; blades $15-25 \mathrm{~cm}$. long and about $2 \mathrm{~mm}$. broad, often surpassing the inflorescence; inflorescence of a terminal staminate spike and 2 or 3 subterminal weakly ascending peduncled (peduncle of lowest filiform one 1-2 cm. long, of upper ones shorter) lax pistillate spikes about $1 \mathrm{~cm}$. long; bract of lowest spike leaflike, $3-10 \mathrm{~cm}$. long, those of the higher spikes smaller; scales hyaline, minute, much smaller than their perigynia; perigynia 5 to 8 per spike, broadly ovate, plano-convex or lenticular, 2-2.5 $\mathrm{mm}$. long, basally slightly narrowed, apically rounded, quite beakless, with a number of faint veins ( 2 of them less faint than the rest), membranous (when fresh somewhat succulent or baccate and translucent but drying firm, opaque in specimens), orange (in dried specimens rich-dark-brown); achene not quite filling the top of the perigynium (at least in dried specimens) but laterally filling it, lenticular, $1.5 \mathrm{~mm}$. long, 1.3 $\mathrm{mm}$. wide, ovate, minutely apiculate, dark-brown, jointed with the style.

Rare in seepy areas on shaded hillsides, and on edge of water of streams and ponds, in the Tex. Plains Country (Randall Co., Ceta Canyon), N.M. (Taos Co.) and Ariz. (Apache and Coconino cos.), June; temp. N.A., s. to Conn., Mich. and Neb. and at moderate elev, to Tex., N.M., Ut., Nev. and Calif.

\section{Carex crinita Lam,}

Tufted essentially glabrous perennial with branching scaly brownish rhizomes 2-4 mm. thick; culms 6-12 dm. long, 2.5-5 mm. thick basally; basal sheaths dark brown, bladeless; blades of cauline leaves $5-11 \mathrm{~mm}$. broad; spikes 4 or 5 per culm, overlapping, mostly nodding; terminal spike staminate, $3-5 \mathrm{~cm}$. long, $2-3 \mathrm{~mm}$. thick; subterminal spikes androgynous and progressively longer-peduncled downward; lowest spike essentially all pistillate or with only a very small terminal staminate portion, 4-9 $\mathrm{cm}$. long, 5-10 $\mathrm{mm}$. thick (including the scale cusps), with 75 to 130 close ascending perigynia, the scales with hyaline oblong bodies shorter than the perigynia but with the midnerve elongated into a spreading cusp surpassing the perigynium; bract of lowest spike sheathless, erect and usually much-surpassing the terminal spike, the higher bracts progressively reduced; perigynia obovate, 3-3.5 $\mathrm{mm}$. long, biconvex, membranous, somewhat inflated, with 2 strong marginal nerves and a few vanishingly faint ones, stramineous to brownish, basally tapered, apically rounded or tapered and giving away abruptly to the minute tubular beak with entire orifice; achene biconvex, only half filling the perigynium, $1.5 \mathrm{~mm}$. long, $1.3 \mathrm{~mm}$. wide, apiculate, jointed with the 2-branched style which entirely withers after anthesis. Incl. var. Mitchelliana (M.A. Curtis) Gl. and var. brevicrinis Fern.

Infrequent in wet places, usually in water, e. Tex. (Cass, Wood, Gregg and Morris cos.), May-June; e. N.A. w. to Man., Minn., Mo. and Tex.

\section{Carex senta Boott. Fig. 265.}

Cespitose from long stout horizontal rhizomes; culms rather slender but stiff, 3-10 dm. high, sharply triangular and roughened on the angles, exceeding the leaves, brownish or reddish-brown at the base, the dried leaves of the previous year conspicuous; leaves 4 to 8 to a culm, septate-nodulose, clustered near the base, flat, channeled toward the base, the margins revolute toward the apex, 3-5 $\mathrm{mm}$. wide, the lower reduced, the upper much longer, papillate, ciliate-serrulate; sheaths hirsutulous, the lower breaking and becoming filamentose, the ligule longer than wide and acuminate; staminate spikes 2 or 3 , somewhat scattered, the terminal peduncled, $3-4.5 \mathrm{~cm}$. long, $5 \mathrm{~mm}$. wide, the lateral sessile, often with a few perigynia at the base; pistillate spikes 1 or 2 , remote or approximate, 
sessile or slightly peduncled, linear to oblong, $2.5-5 \mathrm{~cm}$. long, 5-9 mm. wide, sometimes staminate at the apex, densely 25 - to 100 -flowered, the perigynia appressed-ascending; lowest bract leaflike, sheathless, usually exceeding the spike; scales linear-oblong to oblong-lanceolate, reddish-black with narrow one-nerved center, shorter than and about half as wide as the perigynia; perigynia muchflattened, plano-convex, broadly ovate to broadly obovate, 3-3.5 mm. long, 2-2.3 $\mathrm{mm}$. wide, granular-roughened, puncticulate, straw-colored, often strongly reddish-brown-tinged, slenderly few-nerved on both surfaces and with two marginal ribs, round-tapering to truncate at the short-stipitate or sessile base, round-tapering at the apex, the margins entire or minutely serrulate, abruptly apiculate, the dark-tinged beak $0.25 \mathrm{~mm}$. long, the orifice entire; achenes lenticular, broadly obovoid, $1.5 \mathrm{~mm}$. long, $1 \mathrm{~mm}$. wide, apiculate.

Swampy habitats, in water of ponds and on wet cliffs in N.M. (Catron Co.) and Ariz. (Apache, Coconino, Maricopa and Cochise cos.); also Calif.

\section{Carex aquatilis Wahl.}

Cespitose, often in large clumps, sending forth scaly horizontal rhizomes; culms erect, slender, 1-10 dm. high, from obtusely triangular and smooth to sharply triangular and smooth or scabrous above, usually exceeding the leaves, phyllopodic, reddish-tinged at the base, the dried leaves of the previous year usually conspicuous; leaves 8 to 15 to a culm, on the lower third, often more or less septate-nodulose (especially the sheaths), flat or channeled at the base, light-green or glaucousgreen, erect-ascending, long-tapering, 2.5-8 $\mathrm{mm}$. wide; sheaths slightly hispidulous or smooth dorsally, thin, reddish- or brownish-dotted arid early ruptured ventrally, the ligule longer than wide; staminate spikes 1 to 3 , linear, the upper peduncled, $1.25 \mathrm{~cm}$. long, 2-3 mm. wide, the others sessile or nearly so and shorter, sometimes pistillate at the base; pistillate spikes 2 to 6 , the upper often staminate at the apex, the lowest often strongly separate and occasionally on very long peduncles arising from near the base of the plant, the upper more or less approximate, and sessile to short-peduncled, erect, linear to oblong, 1-4 cm. long, 2.5-4 mm. wide, densely 20- to 100-flowered or somewhat attenuate at the base, the perigynia appressed-ascending; lowest bract leaflike, sheathless, normally exceeding the culm, the upper reduced; scales ovate to oblong-ovate, 1-2 $\mathrm{mm}$. wide, obtuse and normally much narrower and shorter than the perigynia, blackish with lighter midrib and very narrow hyaline margins, not puncticulate and not enveloping the perigynia; perigynia unequally biconvex, strongly flattened, not at all turgid, oval to obovate, $2.5-3 \mathrm{~mm}$. long, $1.25-1.75 \mathrm{~mm}$. wide, nerveless or obscurely fewnerved except for the two marginal ribs, puncticulate, glandular-dotted, lightgreen to straw-colored or brownish, rounded and substipitate at the base, rounded at the apex and abruptly apiculate, the beak entire, $0.1-0.3 \mathrm{~mm}$. long; achenes lenticular, broadly obovoid, about $1.6 \mathrm{~mm}$. long and $1.2 \mathrm{~mm}$. wide, yellowish and broadly substipitate, abruptly short-apiculate.

In swamps, marshes, wet meadows, lake and pond shores and stream banks, often in shallow water, in N.M. (Colfax and Taos cos.) and Ariz. (Apache Co.); Greenl. to Alas., s. to Que., N.M., Ariz. and Calif.; Euras.

\section{Carex Kelloggii W. Boott.}

Cespitose, forming medium size to large clumps, the slender rootstocks short to more or less elongate; culms 1-6 dm. high, erect, slender, usually shorter than but sometimes exceeding the leaves, phyllopodic (sterile shoots aphyllopodic), brownish and somewhat fibrillose at the base, the dried leaves of the previous year conspicuous; leaves 5 to 10 to a culm, more or less clustered on the lower onethird, erect, thin, flat above, channeled toward the base, 1.5-2.5 $\mathrm{mm}$. wide, longattenuate; sheaths yellowish-brown-dotted ventrally, concave at the mouth, the ligule longer than wide; terminal spike staminate, rarely somewhat pistillate, more 


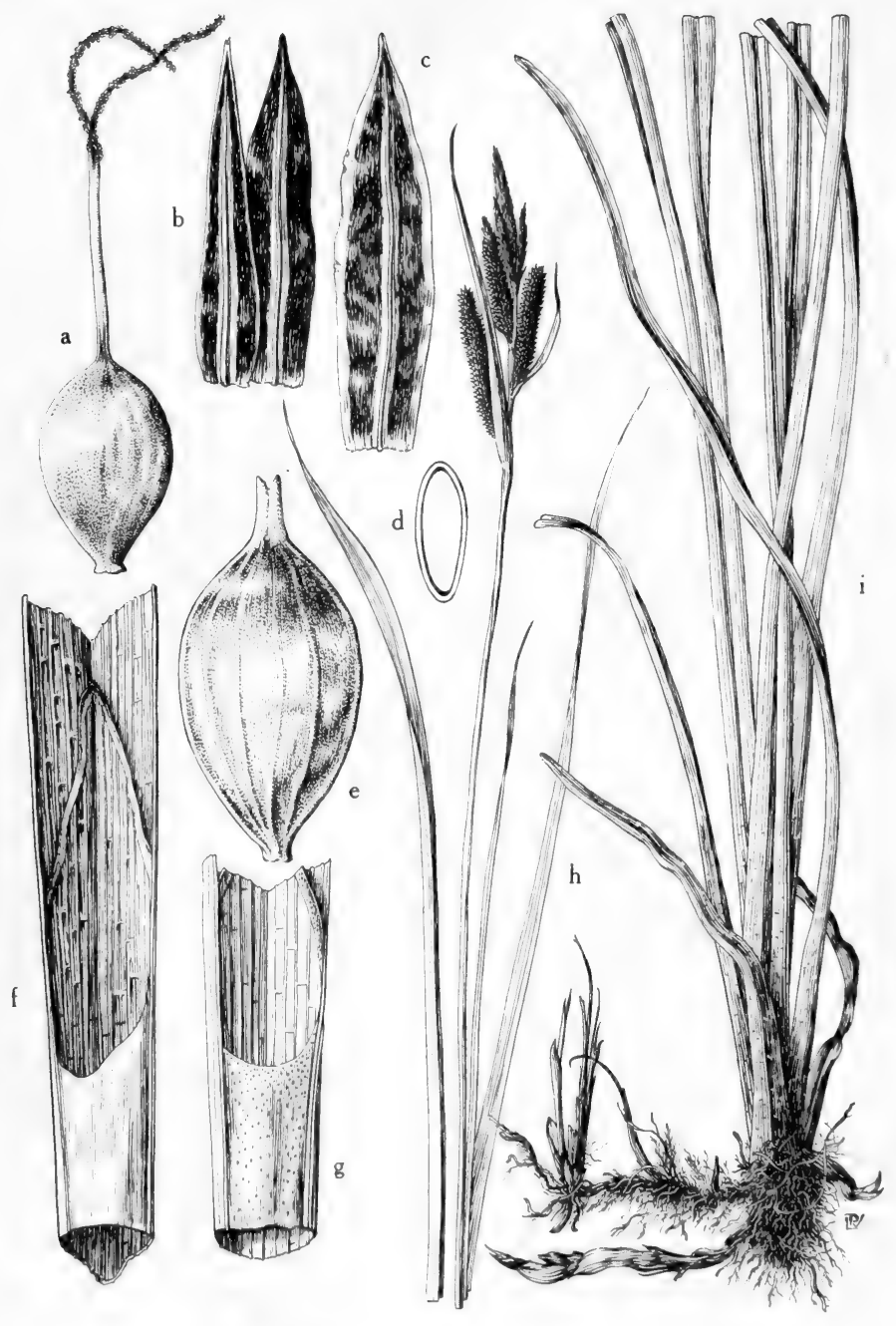

Fig. 266: Carex nebraskensis: a, pistillate flower with perigynium removed, X 12; $\mathrm{b}$, scales of pistillate flowers, X 12; c, scales of staminate flower, X 12; d, achene (cross section), $\mathrm{X} 12 ; \mathrm{e}$, perigynium, flattened and strongly many-ribbed, $\mathrm{X} 12 ; \mathrm{f}$ and $\mathrm{g}$. ligules, sometimes punctate, $X$ 6; b, habit, upper part of plant, showing the leaves, the culm and the inflorescence with the spikes staminate above and pistillate below, the subtending bracts short, $\mathbf{X} \%$ i. lower part of plant, showing the stout horizontal rhizomes, X 2/5. (From Mason, Fig. 94). 
or less strongly peduncled, 1-4 cm. long, 3-4 mm. wide; pistillate spikes 3 to 5 , approximate or slightly separate, erect, the lower short-peduncled, the upper sessile or subsessile, linear-cylindric, often attenuate at the base, $1.5-3.5 \mathrm{~cm}$. long, about $4.5 \mathrm{~mm}$. wide, the numerous perigynia appressed-ascending; lowest bract leaflike, much-exceeding the inflorescence, usually sheathless or nearly so, the upper reduced, auriculate; scales oblong-ovate, obtuse or somewhat acute, darkreddish-brown with narrow hyaline margins and a broad lighter usually one-nerved center not extending to the apex, narrower and shorter than to equaling the perigynia; perigynia early-deciduous, ovate, flattened-biconvex, sharply 2-edged, 1.5-3 mm. long, $1.25 \mathrm{~mm}$. wide, light-green, granular, membranaceous, 2-ribbed, truncate at the slenderly stipitate base, rounded at the abruptly apiculate-beaked apex, the beak $0.1-0.25 \mathrm{~mm}$. long, entire, usually conspicuously black-tipped; achenes lenticular, suborbicular, about $1 \mathrm{~mm}$. long, blackish, granular, substipitate, abruptly short-apiculate.

On rocky lake margins, wet banks and in moist to marshy meadows, in Ariz. (Coconino Co.); Alta. to Colo. and Ariz., w. to Alas. and Calif.

\section{Carex nebraskensis Dewey. Fig. 266.}

Cespitose with long stout horizontal rhizomes; culms 2-10 dm. tall, papillate, sharply triangular, roughened or smooth above; leaf blades pale-green, 3-8 $\mathrm{mm}$. wide, flat, the lower sheaths usually prominently septate-nodulose; terminal staminate spike $1.5-4 \mathrm{~cm}$. long, 3-6 mm. wide, often with 1 or 2 smaller ones near its base, the lateral ones sessile or short-peduncled; pistillate spikes 2 to 4 , erect, the upper one sessile or nearly so, the lower ones short- or long-peduncled, all contiguous or the lower ones somewhat separate, oblong to cylindric, $1.5-5 \mathrm{~cm}$. long, 5-9 $\mathrm{mm}$. wide; lowest bract leaflike, not sheathing, often dark- or lightauricled, varying from extending slightly beyond to not reaching the tip of the inflorescence; scales lanceolate, obtusish to acute or acuminate, narrower than and from shorter than to longer than perigynia, purplish or brownish-black with lighter center and often with narrower hyaline margins; perigynia flattened, oblong-ovate to broadly ovate or obovate, $3-3.5 \mathrm{~mm}$. long, $2 \mathrm{~mm}$. wide, strongly many-ribbed on both faces, greenish to straw-colored or brownish at maturity, abruptly apiculate at apex, the beak often dark-tipped; achenes lenticular, nearly orbicular, $1.5 \mathrm{~mm}$. long.

In mud along sloughs, streams and in seepage areas, wet meadows and marshes, in N.M. (Taos and Rio Arriba cos:) and Ariz. (Apache, Coconino and Mohave cos.) ; S.D. to B.C., s. to Kan., N.M., Ariz. and Calif.

\section{Carex stricta Lam.}

Perennial in large tufts, with slender easily detached rhizomes; culms 3-8 dm. long, 1-2 mm. thick basally, the basal sheaths chestnut-black; juncture of sheath and blade V-shaped; spikes usually 4 per culm, overlapping or occasionally the lowermost slightly remote; uppermost spike erect and usually entirely staminate, 2-4 cm. long, 2.5-4 mm. thick, buffy-brown; subterminal spikes usually sessile, androgynous and slightly nodding (at maturity); lower spikes usually almost entirely pistillate, $2-4 \mathrm{~cm}$. long, 3-4 mm. thick, with 45 to 65 overlapping ascending perigynia (borne in elegant rows) and brownish oblong blunt scales with paler mid-nerve and slightly shorter than their perigynia to which they are closely appressed; bracts sheathless, that of the lowest spike often attaining the uppermost spike in length, those of higher spikes progressively drastically reduced; perigyn: ovate, flattened (biconvex), 2.5-3 mm. long, olivaceous, with 2 strong (marginal) nerves and a few vanishingly obscure ones, firm-membranous, basally rounded, shortly tapered to an essentially beakless or minutely beaked apex, the orifice essentially entire; stigmas 2 ; achene lenticular, only about half filling the perigyn- 
ium, $1.7 \mathrm{~mm}$. long, $1.3 \mathrm{~mm}$. wide, apiculate, jointed with the style which entirely withers after anthesis.

Rare in moist sandy forests and bogs, e. Tex. (Freestone and Walker cos.), Apr.-May; N.E., N.Y. and Pa. s. to N.C.; also Ind., Mich., Wisc., Ill., Minn. and Tex.

Our plants have longer, fewer perigynia than plants from most of the range in northeastern United States and perhaps should be a different name.

\section{Carex Emoryi Dew.}

Perennial in large tufts and in tufts with extensively creeping scaly rhizomes 2-3 mm. thick; culms 4-10 dm. long, 2-3 mm. thick basally, remainder of leaves mostly clustered basally; basal sheaths light chestnut to purplish; juncture of sheath and blade flat or slightly arcuate; spikes 4 to 7 per culm, overlapping or rarely slightly remote; uppermost spike nearly erect and usually entirely or nearly entirely staminate, $2.5-7 \mathrm{~cm}$. long, $2.5-4 \mathrm{~mm}$. thick, brownish-stramineous; lower spikes usually sessile, androgynous, slightly nodding (at maturity); lowest spikes usually almost entirely pistillate, $3-10 \mathrm{~cm}$. long, $3.5-5 \mathrm{~mm}$. thick, with 65 to 165 overlapping ascending perigynia (borne in rows); bracts sheathless, that of the lowest spike $1.5-4 \mathrm{~mm}$. broad and (in length) often attaining the uppermost spike, the higher bracts progressively drastically reduced; scales brownish-hyaline, oblong, blunt, with paler broad midnerves, shorter than the perigynia to which they are closely appressed; perigynia ovate to obovate, flattened (biconvex), 2.3-3.3 mm. long, stramineous, with 2 strong (marginal) nerves and a few vanishingly obscure ones, firm-membranous, basally rounded, shortly tapered to an essentially beakless or minutely beaked apex, the orifice essentially entire; stigmas 2; achene lenticular, only about half filling the perigynium, $1.5 \mathrm{~mm}$. long, $1 \mathrm{~mm}$. wide, apiculate, jointed with the style which entirely withers after anthesis.

Frequent in calcareous mud, n.-cen. and Trans-Pecos Tex. and Edwards Plateau, and N. M. (Mora Co.), Apr.-May; Man. and N.D. s. to Coah. and Tex., e. to N.Y., N.J., D.C. and Va.

Perhaps only a variety of $C$. stricta.

\section{Carex ultra Bailey.}

Densely cespitose from very stout rootstocks; culms stout, erect, much-exceeding the leaves, 5-15 dm. high, $1.5 \mathrm{~cm}$. thick at the base, smooth on the obtuse angles below, serrulate on the sharp angles in the inflorescence, brownish-tinged at the base; leaves 6 to 15 to a culm, not septate-nodulose, thick, glaucous, 6-12 $\mathrm{mm}$. wide, channeled at the base, flat above with more or less revolute margins, conspicuously striate-nerved, strongly rough-serrulate on the margins; lower sheaths rough, scabrous and filamentose ventrally, concave at the mouth, the ligule longer than wide; staminate spikes 2 to 4 , approximate or more or less separate, 3-12 $\mathrm{cm}$. long, 4-6 mm. wide, the lateral sessile or short-peduncled; pistillate spikes 3 to 6 , sometimes staminate at the apex, the upper sessile and overlapping, the lower more or less strongly peduncled and separate, erect, elongate, linear-cylindric, $2.5-15 \mathrm{~cm}$. long, 6-12 mm. wide, containing very numerous appressed-ascending perigynia; bracts leaflike, the lower short-sheathing and sometimes exceeding the inflorescence, the upper shorter; scales lanceolate, acute to acuminate or tapering into a short rough awn, reddish-brown, the center several-nerved and green or straw-colored, half as wide as the perigynia; perigynia compressed-trigonous, broadly obovoid, 3.5-4.5 $\mathrm{mm}$. long, $2 \mathrm{~mm}$. wide, little-inflated, subcoriaceous, glabrous, light-brown, red-striolate at maturity, obscurely several-nerved on both surfaces, rounded at the base and apex, abruptly short-beaked, the beak $0.3 \mathrm{~mm}$. long, the apex emarginate; achenes trigonous with blunt angles, elliptic-obovoid, 


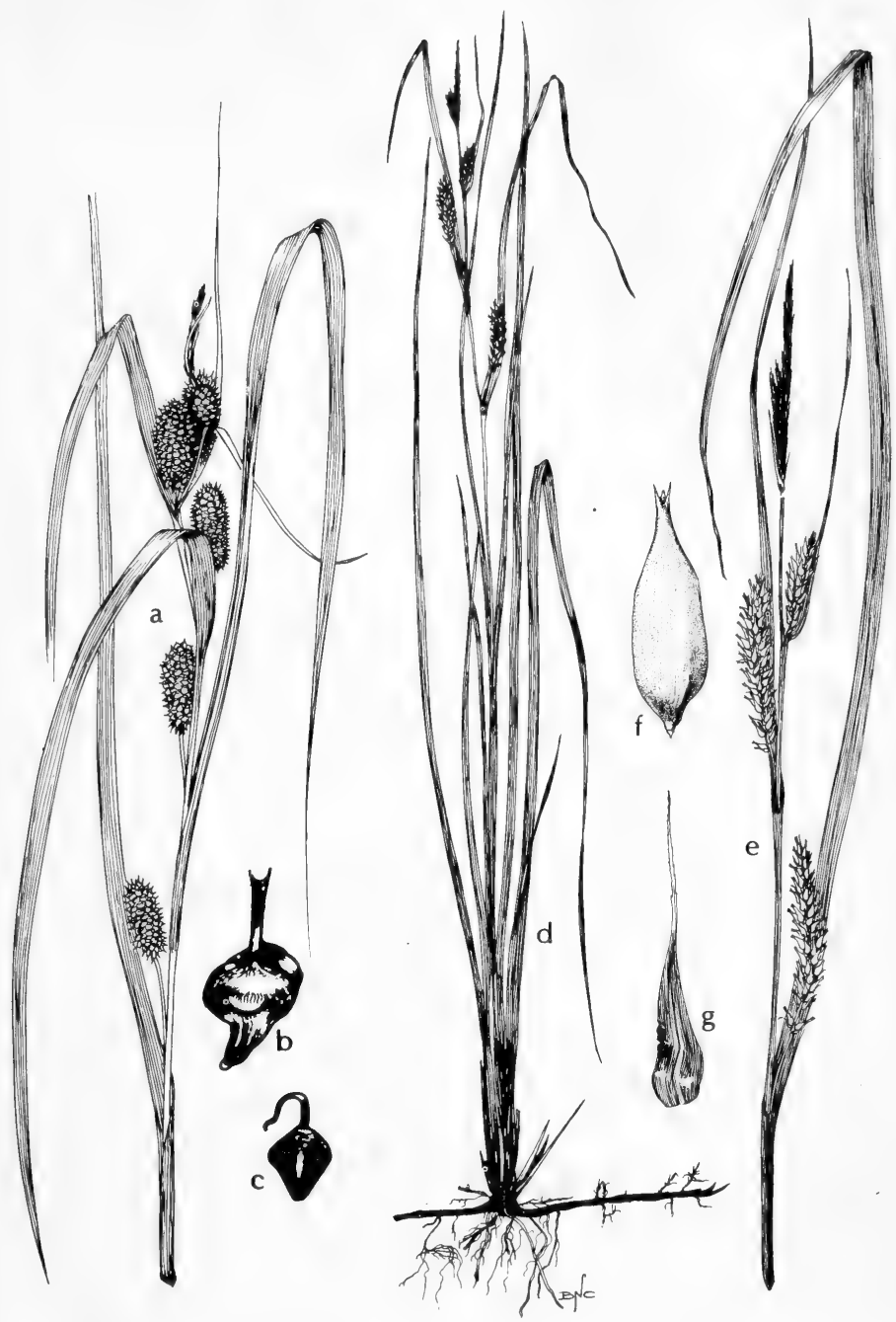

Fig. 267: a-c, Carex Frankii: a, top of plant, X 1/2; b, perigynium, X 5; c, achene, X 5. d-g, Carex hyalinolepis: d, habit, X $1 \frac{1}{6}$; e, top of plant, X $1 \frac{2}{2} ; \mathrm{f}$, perigynium, X 5 ; g, scale, X 5. (a, d-g, Courtesy of R. K. Godfrey; b and c, V. F.). 


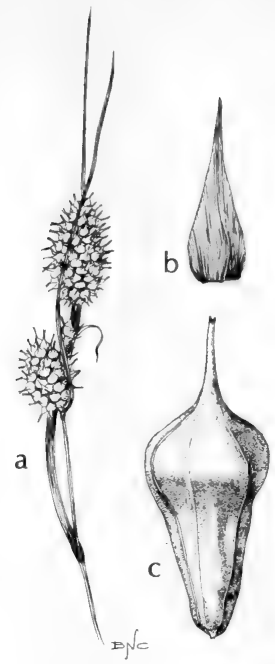

Fig. 268: Carex typhina: a, inflorescence, X 1/2; b, scale, X 5; c, perigynium, X 5 . (Courtesy of R. K. Godfrey).

about $2.5 \mathrm{~mm}$. long and $1.25 \mathrm{~mm}$. wide, silvery-black, minutely pitted, substipitate, abruptly contracted into the slender straight style.

Springy places in N. M. (Grant Co.), and Ariz. (Apache, Pinal, Cochise and Santa Cruz cos.); also n. Mex.

41. Carex Frankii Kunth. Fig. 267.

Perennial with extensively creeping rhizomes 1-2 mm. thick; culms 2-7 dm. long, 1.5-5 mm. thick basally; basal sheaths brownish, rarely rosy; blades 4-11 $\mathrm{mm}$. broad; inflorescence of 4 to 6 ascending spikes; terminal (often exceedingly inconspicuous) spike staminate, 3-50 mm. long, 1.5-5 mm. thick, stramineous or brown; the remaining spikes pistillate, the upper ones overlapping and shortpeduncled but the lowest commonly remote with a peduncle to $15 \mathrm{~cm}$. long, $1-4$ $\mathrm{cm}$. long, 8-15 mm. thick, bristly, with 25 to 130 very close spreading perigynia; bracts sheathing, foliaceous, the blade of the lowest one commonly far-exceeding the inflorescence, the higher ones progressively reduced; scales as long as or longer than the perigynia with the distal part being a wiry awn or bristle; perigynia 3.5-5.5 mm. long, with obovoid bodies 2-4 mm. long, olivaceous, inflated, membranous, with 10 to 15 nerves much more slender than the internerve spaces, basally tapered and narrowly rounded, apically abruptly short-conic and welldifferentiated from the subulate beak (about $1.5 \mathrm{~mm}$. long) and with a strongly bidentate orifice; achenes triangular, 1.5-2.2 mm. long, about $1.5 \mathrm{~mm}$. wide, continuous with the persistent very slender usually straight style which in its lower half has much the same texture as the achene.

In marshes, boggy areas and mud in seepage areas, edge of streams and about ponds, in Okla. (Johnston, Adair, Murray, Mayes, Washington, Haskell, Atoka, Pittsburg, Pushmataha and Cherokee cos.) and in e. and s.e. Tex., infrequent in n.-cen. Tex., rare in the Trans-Pecos (Franklin and Davis Mts.), in seeps and 
springs, Apr.-June (to July in Trans-Pecos); s.e. U.S. n. to N.Y., Ill. and Kan.; also Coah. and parts of s. S.A.

\section{Carex typhina Michx. Fig. 268.}

Perennial; rhizomes black, scaly, 2-5 mm. thick, 1-4 cm. long between culmtufts; culms 3-8 dm. long, 1.5-4 mm. thick basally; lower sheaths brown; blades 3-7 mm. broad; spikes 1 to several, terminal gynecandrous, 3-4 cm. long, 12-15 mm. thick including the beaks, with a cylindric (slightly ovoid) terminal pistillate portion of 60 to 110 closely packed spreading perigynia, basally abruptly acuminate to the inconspicuous staminate portion; bracts sheathless, the blade surpassing the spike; pistillate scales narrowly obovate to oblanceolate, apically acute but not mucronate, laterally hyaline; perigynia about $6 \mathrm{~mm}$. long, the obovoid bodies 4-5 mm. long, inflated, brownish, brittle-membranous, shiny, with 2 faint nerves distally, basally narrowed and shortly rounded, apically abruptly short-conic to the subulate or linear bidentate spreading or usually very slightly ascending beak; achene triangular, $3 \mathrm{~mm}$. long, $1.5 \mathrm{~mm}$. wide, occupying only a small portion of the perigynium, apically acute, continuous with the persistent slender abruptly sinuous style whose proximal part is texturally like the achene. C. squarrosa $\mathrm{L}$. var. typhina (Michx.) Nutt.

In swamps and low wet woodlands, river bottomlands and wet sandy loam, rare in e. Tex. (Harrison and Shelby cos.), July-Sept.; Que. and n.e. U.S. s. to S.C., Ky. and La., w. to Wisc., Ia., Mo. and Tex.

May not be specifically distinct from C. squarrosa.

\section{Carex squarrosa $L$.}

Culms cespitose, 3-8 dm. tall; principal blades 3-6 mm. wide; spikes usually solitary, occasionally 2 , rarely 3 , the upper two-thirds pistillate, the lower third staminate; pistillate portion elliptic, 1-3 cm. long, 1-2 cm. thick, rounded at both ends, very densely flowered; lateral spikes (if present) pistillate, smaller, erect on short peduncles; bracts of the terminal spike short and narrow, of the lateral ones foliaceous; staminate scales acute or acuminate; pistillate scales mostly concealed, acuminate or short-awned; perigynia obconic or conic-obovoid, 3.5-7 $\mathrm{mm}$. long, its summit with two strong ribs (the lateral) and a few obscure nerves; beak 2-3.5 mm. long, its teeth $0.2 \mathrm{~mm}$. long; achenes trigonous, blackish with iridescent superficial cells (when fully mature), $3 \mathrm{~mm}$. long, $1.5 \mathrm{~mm}$. wide, base of the style greatly curved.

In wet meadows, swamps, wet swales and alluvial floodplains in Okla. (Waterfall); w. Que. and Conn. to Wisc. and Neb. s. to N. C., Ark. and Okla.

\section{Carex hyalinolepis Steud. Fig. 267.}

Perennial with extensively creeping rhizomes $2-5 \mathrm{~mm}$. thick; culms single at the nodes of the rhizome, 4-8 dm. long, 5-8 mm. thick basally; leaves mostly crowded toward the base; basal sheaths yellowish-stramineous; blades 4-13 mm. broad, tough, with noxious serrulate edges; spikes 4 to 6 (to 8 ) per culm, the upper 1 to 3 staminate and sessile, the lower 1 to 4 short-peduncled, erect and pistillate, often with an androgynous spike at an intermediate level; terminal spike 3-6 cm. long, 3-6 mm. thick; lowest pistillate spike 3-8 cm. long, 11-15 $\mathrm{mm}$. thick, with 70 to 100 ascending perigynia (overlapping closely except occasionally the lowest 2 or 3 ), the scales much shorter than their perigynia; bracts foliaceous, short-sheathing, that of the lowest commonly surpassing the entire inflorescence, the higher ones progressively reduced; perigynia $6-9 \mathrm{~mm}$. long, ampulelike or very narrowly ovate, in transection elliptic, stramineous-brown to olive-brown, tough-membranous, eventually becoming tough-chartaceous, with 20 to 25 very faint (vanishing in some specimens) nerves much narrower than the spaces between them, slightly inflated, basally rounded, in the upper half slightly acuminate to a scarcely beaklike firm bidentate apex; achene triangular, up to 


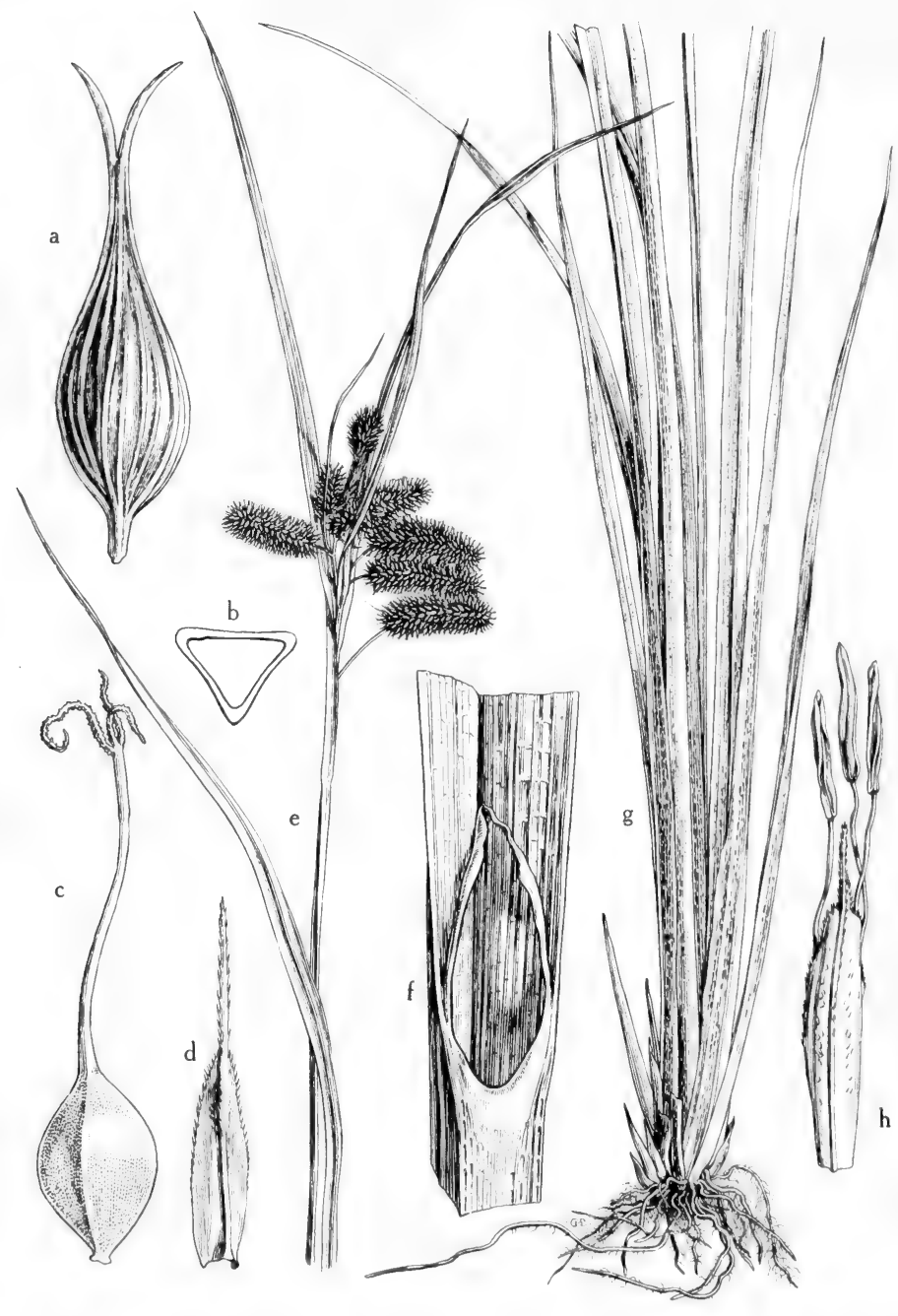

Fig. 269: Carex comosa: a, perigynium, showing the numerous strong ribs and the spreading bidentate beak, X $8 ; b$, achene (cross section), X 12; c, pistillate flower with perigynium removed, showing the very long style and the 3 short stigmas, $X 12$; $d$, scale of pistillate flower, showing the long scabrid awn, X 12; e upper part of culm. showing the leaflike bracts and the nodding pistillate spikes, $X 1_{4} ; \mathrm{f}$, ligule, $\mathrm{X} 2 ; \mathrm{g}$. lower part of plant, showing the stout erect culms and leaf blades, $X 1 / 4 ; \mathrm{h}$, staminate flower, the subtending scale scabrid, X 6. (From Mason, Fig. 120). 
$2.5 \mathrm{~mm}$. long, $1.5 \mathrm{~mm}$. wide, continuous with the basally curved style which basally has the same porcelaneous texture as the achene.

In wet meadows, swamps, ditches, edge of sloughs, lakes and ponds, and in mud of streams in Okla. (Waterfall) and in s.e. (Brazoria and Colorado cos.), e. (Bowie and Gonzales cos.) and n.-cen. (Dallas and Tarrant cos.) Tex., Apr-May; Ont. and e. U.S. w. to Mich., Neb., Okla. and Tex.

45. Carex comosa Boott. Bristly sedge. Fig. 269.

Mat-forming perennial with short branching rhizomes; culms 5-13 dm. long, erect, 3-10 mm. thick basally; lower sheaths brownish-stramineous; blades 6-12 $\mathrm{mm}$. broad; spikes 4 or 5 per culm, overlapping for most of their lengths; uppermost spike staminate, 25-50 mm. long, 3-5 mm. thick, brownish-stramineous; lower spikes pistillate, nearly horizontal by virtue of a sharp bend at the top of each peduncle, bristly, the lowest one 35-50 mm. long, 12-15 mm. thick, with 65 to 130 spreading or even slightly deflexed close perigynia; bracts sheathless, the lowest one with a blade far-surpassing the inflorescence the rest progressively reduced; pistillate scales with very small pale brown bodies with the pale midveins extending into rough awns usually shorter than the perigynia, deciduous with the perigynia; perigynia lance-acuminate, in transection vaguely triangular or somewhat dorsiventrally flattened, 4-7 mm. long, stramineous, firm-membranous, with 2 ribs and 14 or 15 prominent nerves slightly narrower than the spaces between, basally narrowly rounded, acuminate into a slender beak almost as long as the very slightly inflated body and with 2 terminal arcuate-divaricate teeth; achene triangular, about $1.5 \mathrm{~mm}$. long, $1 \mathrm{~mm}$. wide, apically continuous with the long slender persistent style which proximally has much the same porcelaneous texture as the achene itself.

Rare in lakes, marshes and ponds, in e. Tex. (Wood Co.), Apr.-June; otherwise s.e. Can. and e. U.S. w. to Minn., Neb., Mo. and Tex.; also Ida., Wash., Ore. and Calif.

46. Carex hystericina Muhl. Porcupine Caric-Sedge, BotTle-Brush CARIC-Sedge.

Perennial with rhizomes $1.5-2.5 \mathrm{~mm}$. thick and several $\mathrm{cm}$. long; culms tufted at intervals along the rhizome, 2-8 dm. long, 1-3.5 mm. thick, erect; lower sheaths stramineous, rarely with a reddish-tinge; blades $2.5-9 \mathrm{~mm}$. broad; spikes 3 to 4 (to 6) per culm, mostly overlapping or the lower one or 2 somewhat remote; uppermost spike staminate (rarely androgynous), $15-35 \mathrm{~mm}$. long, 3-4 mm. thick, stramineous; lower spikes pistillate (some upper ones infrequently androgynous), bristly, the lowest one erect or nodding slightly, 15-35 mm. long, 8-12 mm. thick, with 35 to 70 close spreading (at maturity) perigynia; bracts sheathless, the blades of the lowest one often surpassing the terminal spikes, the higher ones progressively much-reduced; the stramineous scales almost as long as the perigynia and with ovate hyaline bodies and long subulate cusps or awns; perigynia lance-acuminate, in transection nearly round or (when immature or pressed) dorsiventrally flattened, 5-7 mm. long, stramineous-membranous, with 2 nerves or weak ribs and 12 to 14 fine nerves much narrower than the spaces between them, basally narrowly rounded, acuminate into a slender strongly bidentate beak about half as long as the inflated body; achene triangular, about $1.8 \mathrm{~mm}$. long, $1.2 \mathrm{~mm}$. wide, the sides concave in the lower part, continuous with the long persistent slender style which basally has much the same porcelaneous texture as the achene itself.

In swampy meadows and in calcareous mud of stream beds in Okla. (Waterfall) and Tex., in the mts. of the Trans-Pecos, rare e. to the Plains Country and Edwards Plateau, N. M. (San Miguel Co.) and Ariz. (Apache, Navajo, Coconino and Maricopa cos.), summer; s. Can. and n. U.S. s. to Va., Ky., Okla., Tex., N.M., Ariz. and Calif; Coah. Sometimes incorrectly spelled "hystricina". 


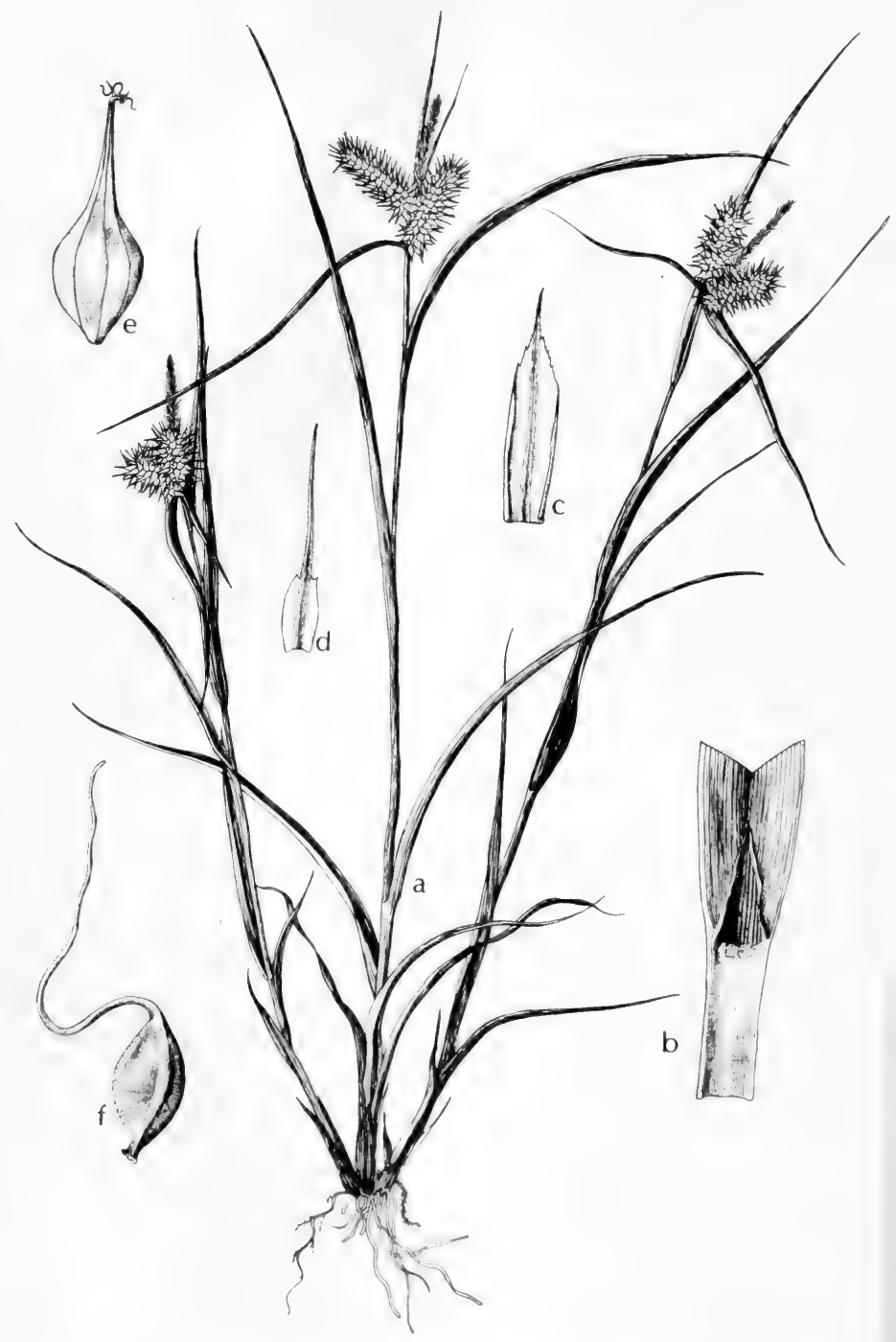

Fig. 270: Carex lurida: a, habit, X 1/3; b, ligule, X 11/3; c, staminate scale, X 4; d, pistillate scale, X 4; e, perigynium, X 4; f, achene, X 8. (Courtesy of R. K. Godfrey). 


\section{Carex Thurberi Dewey.}

Cespitose from stout rootstocks; culms 6-12 dm. high, phyllopodic, erect, stout, shorter than the leaves and bracts, sharply triangular, reddish-tinged at the base, the lower sheaths breaking and becoming filamentose; leaves 5 to 10 to a culm, obscurely septate-nodulose, the blades flat with revolute margins, thin but rather stiff, 4-8 mm. wide, long-attenuate, very rough toward the apex; sheaths sparsely hispidulous dorsally, concave and short-hispid at the mouth, the short ligule much wider than long; terminal spike staminate, erect, short-peduncled, linear, 4-8 cm. long, 3-5 mm. wide; pistillate spikes 3 or 4 , approximate or more or less separate, drooping or the upper weakly erect on rough slender peduncles mostly shorter (except the lowest) than the spikes, the spikes oblong-cylindric or cylindric, $3.5-7 \mathrm{~cm}$. long, 8-10 mm. wide, densely 50 - to 100 -flowered, the perigynia ascending or spreading-ascending; bracts leaflike, sheathless or very nearly so, much-exceeding the inflorescence; scales ovate, often emarginate, strongly roughawned, the body large, ciliate-serrulate above, hyaline and slightly reddish-browntinged, the green center three-nerved, nearly as wide as but much shorter than the perigynia; perigynia elliptic-ovoid, $4-5 \mathrm{~mm}$. long, $1.5 \mathrm{~mm}$. wide, slightly inflated, suborbicular to obscurely triangular in cross section, submembranaceous, puncticulate, yellowish-green, finely several-ribbed, rounded at the short-stipitate base, tapering into a smooth strongly bidentate beak $1.5 \mathrm{~mm}$. long, the slender stiff teeth slightly spreading, $0.5-0.75 \mathrm{~mm}$. long; achenes trigonous with blunt angles, oblong-obovoid, about $1.75 \mathrm{~mm}$. long and $0.75 \mathrm{~mm}$. wide, substipitate, continuous with the slender abruptly bent persistent style.

In moist or wet ravines and swampy habitats, in Ariz. (Coconino, Gila, Cochise, Santa Cruz. and Pima cos.); Ariz. to Guat.; W.I.

\section{Carex lurida Wahl. Fig. 270.}

Tufted perennial with very short rhizomes; culms 3-10 dm. long, 1.5-6.5 mm. thick, erect, leafy; basal sheaths brown (occasionally faintly reddish); blades 4-10 $\mathrm{mm}$. broad; spikes 3 to 5 , mostly overlapping or occasionally the lower 1 or 2 slightly removed; terminal spike staminate, erect, 3-6 cm. long, 1-2 mm. thick; rest of spikes pistillate, nearly sessile (or the lower occasionally on flexuous peduncles to $19 \mathrm{~cm}$. long), often arcuate-nodding, the lowest 25-40 (-60) $\mathrm{mm}$. long, 14-18 (-20) mm. thick including beaks, with 50 to 80 (to 100 ) close somewhat ascending perigynia; bracts foliaceous, sheathing, the blade of the lowest one much-surpassing the entire inflorescence; the scales about as long as the bodies of the perigynia and subulate or awnlike in their distal part; perigynia ampule-shaped, 7-11 $\mathrm{mm}$. long, the bodies ovoid or obovoid, $2.3 \mathrm{~mm}$. thick, 4-6 mm. long, inflated, membranous, olive-green, drying to olive-brown or olive-stramineous, with 8 to 11 nerves ( 2 slightly stronger than the rest) much narrower than the internerve spaces, basally tapered and shortly rounded, apically tapered or long-conic and passing gradually into the linear-subulate bidentate beak; achene triangular, about $2.5 \mathrm{~mm}$. long, $1.5 \mathrm{~mm}$. wide, granular, continuous with the sinous-flexuous persistent style the lower half of which is texturally similar to the achene.

Wet meadows, marshes, seepage, edge of streams and ponds in sand and mud, in Okla. (McCurtain and LeFlore cos.) and e. Tex., May-June; e. temp. N.A.w. to Minn., Mo., Okla. and Tex.; also Ver.

\section{Carex vesicaria L. Inflated sedge. Fig. 271.}

Rhizomes short-creeping, stout; culms 3-9 dm. tall, sharply triangular and rough above, the lower leaves more or less bladeless; leaf blades flat, 2-6 mm. wide, more or less strongly nodulose on abaxial surface; staminate spikes 2 to 4 , 2-4 cm. long, 2.5-4 mm. wide, the upper one peduncled, the lateral ones sessile; pistillate spikes 1 to 3 (usually 2), 2-7.5 cm. long, 5-15 mm. wide, oblong- 

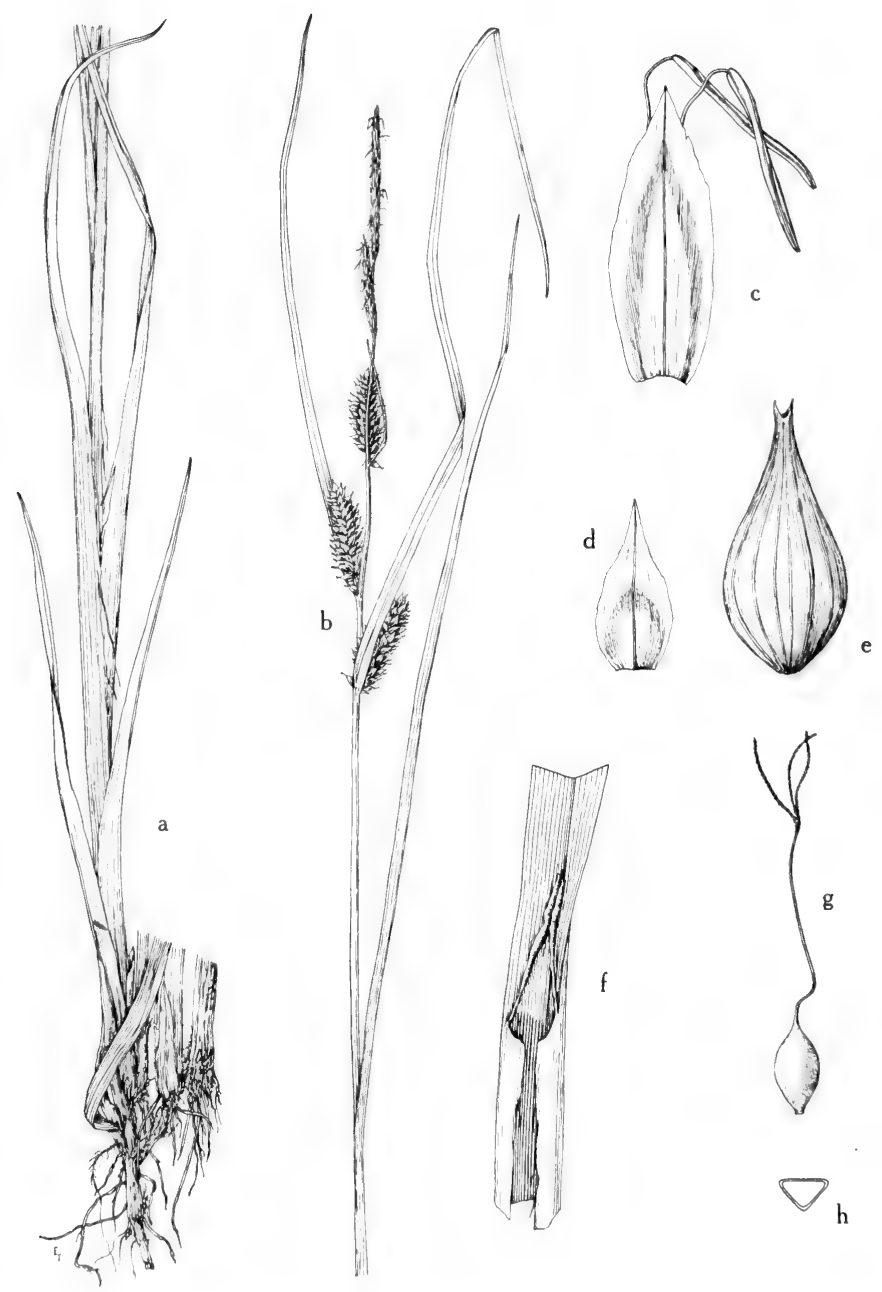

Fig. 271: Carex vesicaria: a, lower part of plant, showing the bladeless lower leaves and the rhizomatous base of plant, $\mathrm{X} \% \mathrm{~b}$, upper part of culm, showing the long bracts, the sessile pistillate spikes below and the terminal staminate spikes above, $\mathrm{X} \%$; c, staminate flower and subtending scale, X $5 ; \mathrm{d}$, scale of pistillate flower, X 5; $\mathrm{e}$, perigynium, showing bidentate beak with erect teeth, $X 5 ; \mathrm{f}$, ligule, $\mathrm{X} 11 \% \mathrm{~g}$, pistillate flower with perigynium removed, showing the very long and flexuous style, $X 5 ; \mathrm{h}$, achene (cross section), X 5. (From Mason, Fig. 121). 


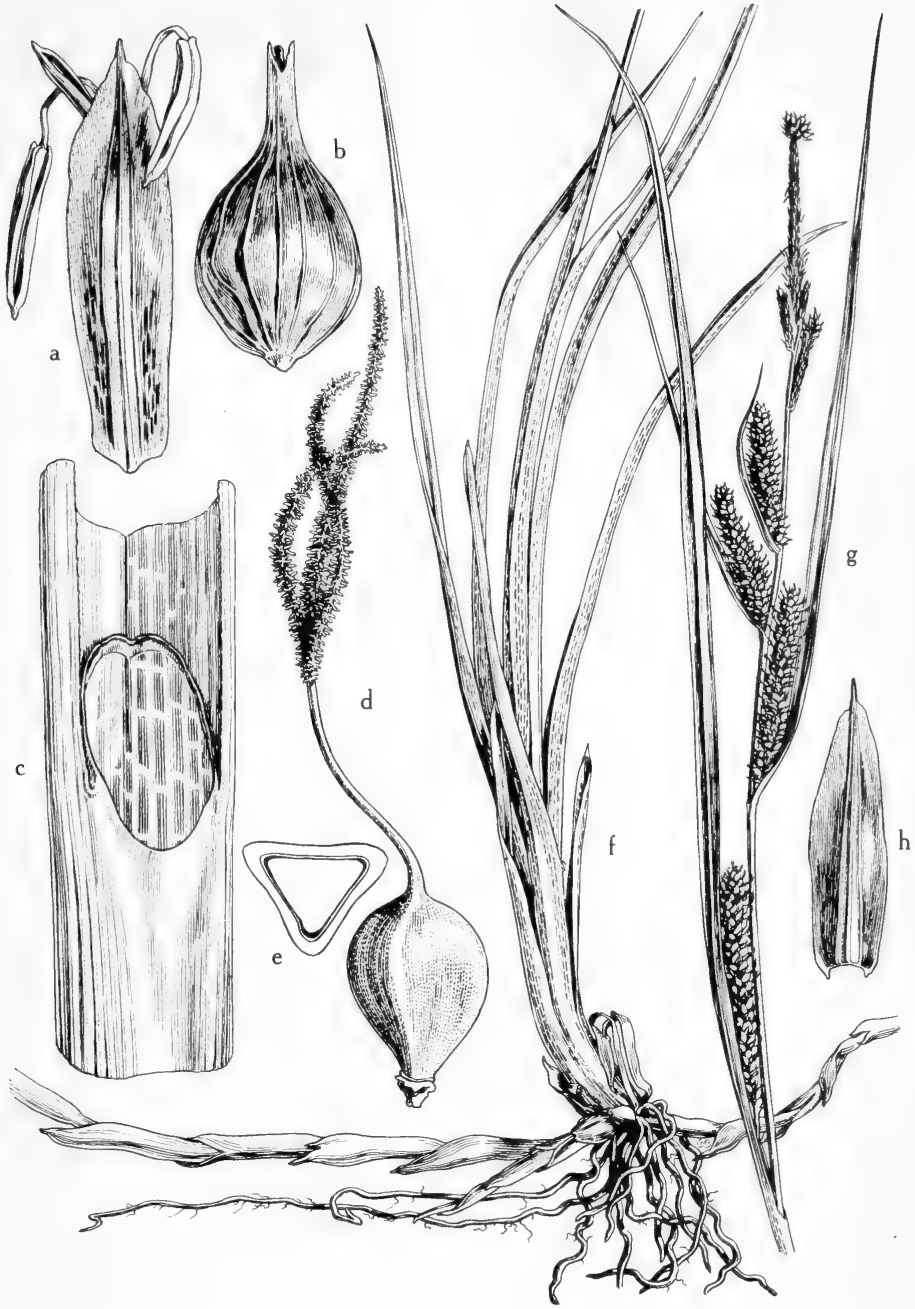

Fig. 272: Carex rostrata: a, staminate flower and subtending scale, $\mathrm{X}$ 8; b, perigynium, showing the slender erect bidentate beak, X 8; c, ligule, X 6; d, pistillate flower with perigynium removed, showing the substipitate achene and curved style, X 12; e, achene (cross section), X 12; f, habit, lower part of plant, showing the long horizontal rhizomes, X $2 \% ; \mathrm{g}$, upper part of culm, the lower spikes pistillate, the staminate spikes terminal, some of the staminate spikes bearing perigynia at apex, X $25 ; \mathrm{h}$, scale of pistillate flower, X 8. (From Mason, Fig. 122). 
cylindric, sessile or short-peduncled, widely separate; bracts leaflike, not sheathing, the lowest extending well beyond the tip of the culm; scales ovate-lanceolate, acute to acuminate or short-awned, reddish-brown-tinged with green center and narrow hyaline margins, one half to nearly as long as the perigynia; perigynia ovoid, inflated, 4-8 $\mathrm{mm}$. long, $3 \mathrm{~mm}$. wide, yellowish-green or brownish, ascending or ascending-spreading at maturity, the smooth bidentate beak 1.5-2 $\mathrm{mm}$. long, the erect teeth $0.5-1 \mathrm{~mm}$. long; achene trigonous, with blunt angles, $2.5 \mathrm{~mm}$. long, $1.7 \mathrm{~mm}$. wide, obovoid, substipitate, contracted at the apex into the persistent abruptly bent style.

Wet meadows, swampy open ground or woods, forested floodplains, low wet river bottoms, in N.M. (Otero, Sandoval, Rio Arriba and Taos cos.) and Ariz. Coconino Co.); Nfld. to B.C., s. to Del., Ind., Mo., N.M., Ariz. and Calif.; Euras.

\section{Carex rostrata Stokes. Beaked sedge. Fig. 272.}

Closely resembling $C$. vesicaria, with which it possibly intergrades, but differing, at least in its typical aspect, in the following features: rhizomes producing long horizontal stolons; culms obtusely angled; lower leaves with well-developed blades; leaves more or less strongly septate-nodulose (at least on the sheaths), the blades 2-12 mm. wide; basal sheaths little if at all filamentose; perigynia $3.5-8 \mathrm{~mm}$. long, 2.5-3.5 mm. wide, at maturity ascending-spreading or spreading, the lowest sometimes reflexed; achenes trigonous with blunt angles, obovoid, $2 \mathrm{~mm}$. long, $1.2 \mathrm{~mm}$. wide. $C$. inflata Huds.

In marshes and bogs, in water of pools, ponds and lakes, along streams and in seepage area about springs, in N.M. (Rio Arriba and Taos cos.) and Ariz. (Apache and Coconino cos.); Greenl. to Alas., s. to Del., Ind., N.M., Ariz. and Calif.

\section{Carex folliculata L. var. australis Bailey. Fig. 273.}

Tufted perennial; culms 4-8 dm. long, 2-4 mm. thick basally, erect; basal sheaths whitish, nodulose; blades $5-10 \mathrm{~mm}$. broad; spikes 3 or 4 per culm, remote except for sometimes the 2 upper ones; the uppermost spike staminate, $2-4 \mathrm{~cm}$. long, 2-3 mm. thick, stramineous; next lowest spike pistillate (or with a very short terminal staminate portion), nearly sessile; lower spikes progressively longerpeduncled and all pistillate, erect; lowest spike 15-27 mm. long, 15-23 mm. broad, with 12 to 20 spreading perigynia (internodes of rachis about $1 \mathrm{~mm}$. long); bracts leaflike, that of the lowest spike $15-25 \mathrm{~cm}$. long including the sheath; higher bracts progressively reduced; the lance-acuminate scales hyaline-stramineous and 5-7 mm. long; perigynia lance-subulate, not at all acuminate, nearly round in transection, 11-14 mm. long, greenish (drying stramineous), membranous, with 15 to 25 strong nerves narrower than the internerve spaces, inflated; achene rounded-triangular with concave sides, up to $3.5 \mathrm{~mm}$. long, $2 \mathrm{~mm}$. wide, continuous with the long persistent slender style which basally has much the same porcelaneous texture as the achene itself. C. lonchocarpa Willd.

Infrequent or rare in e. Tex. (Hardin, Jasper, Newton and Tyler cos.), in wet sand or mud, Apr.-May, rarely as late as June, a few perigynia persistent into July; Coastal States, Va. to Tex.

\section{Carex Grayi Carey.}

Plants cespitose, usually 3-8 dm. tall; principal blades usually 2-3 dm. long, 6-12 mm. wide; pistillate spikes 1 or 2 (rarely 3 ), when 2 close together, globose or nearly so, $2.5-4 \mathrm{~cm}$. in diameter; pistillate scales ovate, much shorter than and mostly concealed by the perigynia; perigynia crowded, usually 15 to 20 , dull, lance-ovoid, radiating in all directions, $12-18 \mathrm{~mm}$. long, obconic from the base to the widest portion, thence tapering to the beak, usually hispidulous below the 

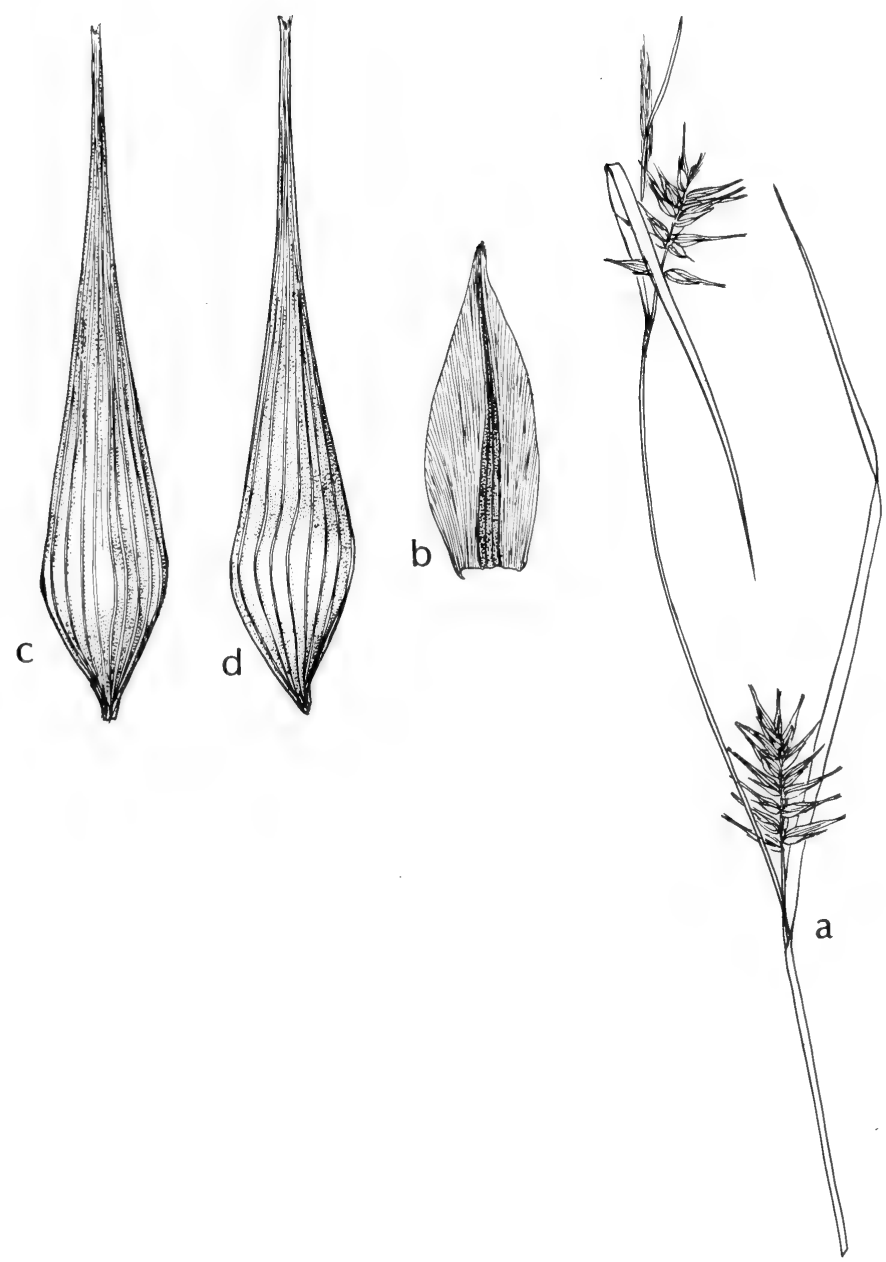

Fig. 273: Carex folliculata var. australis: a, inflorescence, $\mathrm{X} 1 / 2 ; \mathrm{b}$, scale, $\mathrm{X} 7$; c, perigynium, dorsal view, $X 7 ; \mathrm{d}$, perigynium, ventral view, $\mathrm{X} 7$. (Courtesy of $\mathrm{R}$. K. Godfrey). 


$$
\begin{aligned}
& 4 \\
& \text { do }
\end{aligned}
$$


middle; achenes trigonous with rounded angles, the body about $4 \mathrm{~mm}$. long, $3 \mathrm{~mm}$. wide; style persistent, straight or loosely contorted above the middle.

Swampy woods, forested alluvial floodplains, and low wet river bottomland, in Okla. (Waterfall); Vt. to Wisc., s. to Ga., Mo. and Okla.

\section{Carex intumescens Rudge. Fig. 274}

Tufted perennial; culms 3-7 dm. long, basally $1.5-3 \mathrm{~mm}$. thick, erect; basal sheaths reddish-brown; blades $2-5 \mathrm{~mm}$. broad; spikes 2 to 4 per culm, clustered or remote; terminal spike staminate, 2-5 cm. long, 2-3 mm. thick, brownish; the remaining spikes pistillate, ascending, 13-22 $\mathrm{mm}$. long, 14-25 $\mathrm{mm}$. broad, with 8 to 15 close spreading perigynia; bracts sheathing, foliaceous, surpassing the inflorescence; the narrowly ovate scales acute and only about half as long as their perigynia; perigynia 11-16 $\mathrm{mm}$. long, the body three-fourths to five-sixths the total length, ovoid to narrowly so, olivaceous, crusty-membranous, much-inflated, with 14 to 19 slender nerves, basally rounded, apically tapered and passing gradually into the proportionally short bidentate beak; achene longer than thick, triangular, the angles not prominent and totally knobless, about $4 \mathrm{~mm}$. long, 25 $\mathrm{mm}$. wide, passing into the slender often looped style (the lower persistent part of which texturally resembles the achene).

In moist areas, floodplain woods along streams, wooded swamps and alluvial plains, in Okla. (Waterfall) and e. and s.e. Tex., Apr.-June; s.e. Can. and e. U.S. w. to Minn., Ia., Mo., Ark. and Tex.

\section{Carex lupulina Muhl.}

Perennial, usually very loosely tufted and with creeping rhizomes $1-3 \mathrm{~mm}$. thick; culms 3-10 dm. long, erect, basally 1.5-10 mm. thick, the lower sheaths brownish, occasionally with a slight rosy hue; blades $3-12 \mathrm{~mm}$. broad; spikes 3 to 6 per culm, either clustered and overlapping or the lower remote, occasionally all rather remote and the lower ones long-peduncled; upper spike (rarely upper 2) staminate, 3-8 $\mathrm{cm}$. long, 2-4 mm. thick, brownish; lower spikes pistillate, usually cylindrical, less commonly oblong or ellipsoid-oblong, often slightly nodding terminally, 2-5 cm. long, 15-24 mm. thick, the lowest with 25 to 80 close ascending or somewhat spreading perigynia; bracts sheathing, foliaceous, that of the lowest spike commonly far-surbassing the inflorescence; scales mostly hyalinetranslucent, broadly lanceolate, acute, often mucronate, less commonly with an awn about $2 \mathrm{~mm}$. long, the whole only about half to two thirds as long as the perigynia; perigynia 11-20 $\mathrm{mm}$. long, the body about half to five eighths the total length, broadly ovoid, stramineous to olivaceous, crusty-membranous, with 14 to 21 slender nerves, inflated, basally rounded, apically acuminate and passing gradually into the long slender bidentate beak; achene longer than broad, about $3 \mathrm{~mm}$. long, $2.5 \mathrm{~mm}$. wide, triangular with more or less pronounced angles (making the sides seem concave) and with more or less of a process or knob on each angle (very indistinct in some plants), apically continuous with the violently looped style whose lower persistent part texturally resembles the achene. $C$. lupuliformis Sartw., C. louisianica Bailey.

In mud and shallow water of streams, in marshes and swamps, low roadside ditches, in e. Okla. (Adair, Delaware, LeFlore, McCurtain, Ottawa, Pushmataha, Creek, Osage and Haskell cos.) and e. and s.e. Tex., Apr.-May, occasionally into early summer; N.S., Que. and Ont., e. U.S. w. to Minn., Ia., Mo., Okla. and Tex.

\section{Carex gigantea Rudge. Fig. 274.}

Loosely tufted perennial with creeping scaly rhizomes $1.5-3 \mathrm{~mm}$. thick; culms $35-80 \mathrm{~cm}$. long; basal sheaths brownish to stramineous; blades 4-12 mm. broad; spikes 3 or 4 (rarely 5) per culm, usually all but the lowermost overlapping; terminal spike staminate, 3-6 $\mathrm{cm}$. long, 2-4 $\mathrm{mm}$. thick; the remaining spikes 


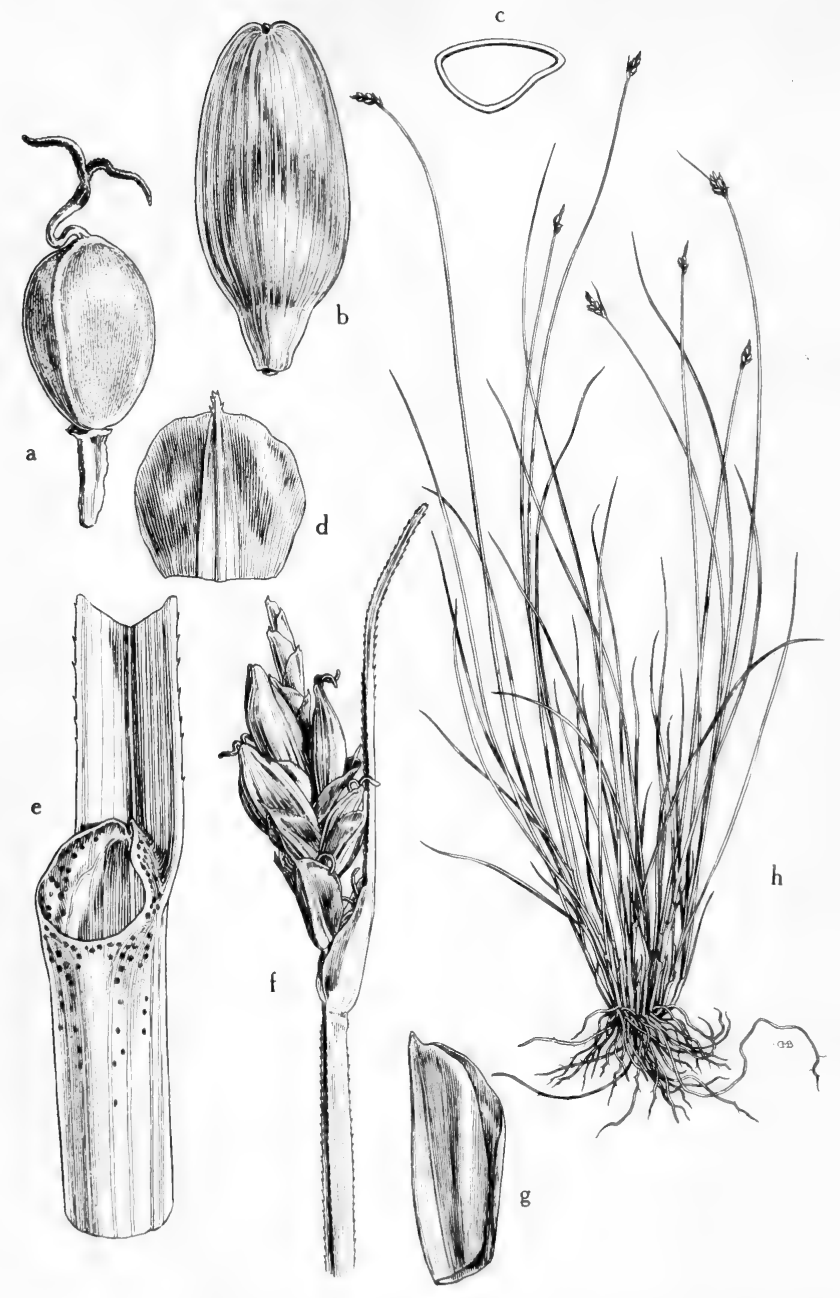

Fig. 275: Carex leptalea: a, pistillate flower with a part of the stipitate perigynium attached, the achene obscurely trigonous, the style flexuous and the stigma bifid, $X 16$; $\mathrm{b}$, perigynium, many-striate and beakless, $\mathrm{X} 12$; $\mathrm{c}$, achene (cross section), X 16; d, scale of pistillate flower, $X 12$; e, ligule, X $24 ; \mathrm{f}$, spike subtended by bractlike scale, the inconspicuous staminate flowers at apex, X 6; g, scale of staminate flower, X 16; h, habit, showing the very slender densely tufted culms extending above the leaves, $X \quad \%$. (From Mason, Fig. 108). 
pistillate, cylindric, the lowest $3-5 \mathrm{~cm}$. long, 14-22 mm. thick (including beaks), with 30 to 65 close spreading perigynia; bracts sheathing, foliaceous, that of the lowest spike far-exceeding the inflorescence; the lanceolate scales acute or acuminate and about half to three fourths as long as the perigynia; perigynia $12-15 \mathrm{~mm}$. long, the body about three eighths the total length, ovoid, crusty-membranous, inflated, olive-stramineous, with 14 to 17 slender nerves, basally rounded, apically acuminate and passing into the long subulate bidentate beak; achene about as broad as or usually broader than long, rhombic-triangular with very prominent angles each with a pronounced knob near the middle, about $2 \mathrm{~mm}$. long, $2.5 \mathrm{~mm}$. wide, apically continuous with the violently looped style whose persistent lower part texturally resembles the achene.

In wooded swamps, alluvial floodplain woods, in and about ponds, lakes and pools, in Okla. (Waterfall) and e. and s.e. Tex. (Harris and Polk cos.), MayJuly; lowlands of s.e. U.S. n. to Del., Ky., Ind., Mo. and Okla.

\section{Carex leptalea Wahl. Fig. 275.}

Perennial with creeping scaly rhizomes $0.5-1 \mathrm{~mm}$. thick; culms in tight tufts along the rhizome, $1-4 \mathrm{dm}$. long, $0.5-1 \mathrm{~mm}$. thick, erect; sheath venters broadly hyaline, splitting lengthwise; blades narrower than their sheaths, $0.5-1 \mathrm{~mm}$. broad, shorter than to occasionally equaling the culms; inflorescence a solitary androgynous spike $5-18 \mathrm{~mm}$. long and $2-3 \mathrm{~mm}$. thick; scales red-dotted, those of the staminate flowers with edges connate on lower part; bract absent; perigynia compressed-triangular in transection, almost flat (flat in prepared specimens, appearing 2-edged), oblong-elliptic, 3.9-5 $\mathrm{mm}$. long, 1 to 10 per spike, appearing to be tristichous, the lower ones maturing first and falling early in succession (with their scales!), appressed-erect, membranous, many-nerved, the upper part empty, basally spongy, substipitate, beakless, apically rounded; achenes triangular with concave sides, $1.5 \mathrm{~mm}$. long, $1 \mathrm{~mm}$. wide, apically truncate, jointed with the flexuous style which all withers away after anthesis. Incl. var. Harperi (Fern.) Stone.

In sphagnum areas, bogs, marshes and wet meadows, in e. and s.e. Tex. (Anderson, Angelina, Hardin, Jasper, Nacogdoches, Newton, Shelby and Tyler cos.) and N. M. (Taos Co.), Apr.-early June; e. temp. N.A. s. and w. to n. Calif., Colo., N.M. and Tex.

\section{Carex nigromarginata Schwein. var. floridana (Schwein.) Kükenth.}

Tufted perennial, often with scaly slender rhizomes; culms $4-20 \mathrm{~cm}$. long, $0.3-0.5 \mathrm{~mm}$. thick; leaves largely clustered near the base; lowest sheaths of the new shoots bladeless; blades $8-30 \mathrm{~cm}$. long, far-exceeding the culms, $2-2.5 \mathrm{~mm}$. broad; inflorescence subcapitate, 9-12 mm. long, 3-7 mm. thick, composed of one terminal staminate spike and a few subterminal sessile ascending-appressed pistillate ones so closely placed that they overlap for most of their lengths; bracts of lowest spike 6-9 mm. long, foliaceous, those of rest of spikes smaller; scales about as long as the perigynia and mostly concealing them, often with a faint purplish marginal zone, otherwise thin-membranous; perigynia 5 to 12 per spike, ascending-appressed, about $3.3 \mathrm{~mm}$. long, the bodies narrowly obovate and about $2.8 \mathrm{~mm}$. long, vaguely triangular in transection (the inner "angle" blunt), longtapered basally (at the extreme base discolored), apically narrowed, minutely pubescent, with 2 prominent veins; membranous; beak about $0.5 \mathrm{~mm}$. long, oblique or minutely bidentate; achene completely filling the upper part of the body of the perigynium, in transection with 2 definitely small angles and one ventral indefinite blunt one, with convex sides, $1.5 \mathrm{~mm}$. long, $1 \mathrm{~mm}$. wide, apiculate, jointed with the style which completely withers after anthesis. 
Rare in wet sandy forests, e. Tex. (Nacogdoches and Newton cos.), Feb.-Mar.; Ga., Fla., Miss., La. and Tex. (the var. nigromarginata from Gulf States except Tex., n. to N.E.).

\section{Carex physorhyncha Liebm.}

Tufted perennial, with scaly reddish brown rhizomes about $2 \mathrm{~mm}$. thick; culms $15-30 \mathrm{~cm}$. long, $0.3-0.6 \mathrm{~mm}$. thick; lowest sheaths of flowering culms with blades, those of sterile shoots bladeless; blades 2-3 mm. broad, shorter than the culms; inflorescence interrupted-spiciform, 15-25 $\mathrm{mm}$. long, 4-7 $\mathrm{mm}$. thick, composed of one terminal staminate spike and 2 to 3 subterminal sessile ascending-appressed pistillate ones, the 2 lowest pistillate spikes only $3-10 \mathrm{~mm}$. apart on the axis; bracts of lowest spike setaceous to subfoliaceous, 5-44 $\mathrm{mm}$. long, ascending, those of the rest of the spikes smaller; scales nearly as long as the perigynia, 3-veined medially, marginally hyaline; perigynia 6 to 12 per spike, ascending-appressed, 2.5-3 mm. long (the bodies narrowly obovoid, bluntly triangular, $1.8-2.3 \mathrm{~mm}$. long, about $1 \mathrm{~mm}$. thick), basally strongly stipitate-narrowed and at the very base discolored, with 2 prominent veins, minutely pubescent, membranous; beak 0.5 $0.7 \mathrm{~mm}$. long, thin-membranous, shallowly bidentate; achene completely filling the upper part of the perigynium, triangular, apiculate with convex sides, $1.5 \mathrm{~mm}$. long, $1 \mathrm{~mm}$. wide, jointed with the style which completely withers after anthesis.

Rare in e. (Smith and Walker cos.), s.e. (Jefferson Co.) and n.-cen. (Dallas Co.) Tex. and Okla. (Payne Co.), in wet sandy soil, Mar.-May; S.C., Ala., Miss., La., Ark., Okla., Tex. and Hgo.

\section{Carex eburnea Boott.}

Perennial; rhizomes extensively creeping, scaly, about $1 \mathrm{~mm}$. thick; culms in small tufts at intervals along the rhizome, $20-35 \mathrm{~cm}$. long, $0.2-0.3 \mathrm{~mm}$. thick, wiry, grayish-green; leaves involute-filiform, 15-20 cm. long, $0.2-0.3 \mathrm{~mm}$. thick, mostly shorter than the culms, grayish-green, basally clustered; inflorescence essentially bractless except for a minute nearly bladeless hyaline sheath at the node of the subterminal spikes, composed of a terminal erect staminate spike and usually 2 subterminal erect peduncled (peduncles filiform, erect, 1-2 cm. long) pistillate spikes about $8 \mathrm{~mm}$. long and $2 \mathrm{~mm}$. thick, the nodes of attachment of spikes being separated by internodes 8-12 (upper ones) or 13-27 (lower ones) $\mathrm{mm}$. long; scales hyaline, very slightly shorter than their perigynia; perigynia 5 to 8 per spike, fusiform, $2.5-2.7 \mathrm{~mm}$. long, the bodies narrowly obovoid-triangular (the angles blunt, the sides flat), 2-2.1 mm. long, membranous or subhyaline, glabrous, with 2 prominent veins and a number of faint ones, apically narrowed; beak $0.5-0.6 \mathrm{~mm}$. long, not well-defined, thick basally, oblique and the orifice oblique; achenes 1.6-1.8 mm. long, dark-brown, obovoid, rather sharply trigonous, essentially filling the bodies of the perigynia, apiculate, jointed with the style which wholly withers after anthesis.

Rare in seepage areas of limestone cliffs at alt. of $5,000-6,000 \mathrm{ft}$. in the Trans-Pecos (Guadalupe Mts.), July; temp. N.A. s. to Va., Tenn., Mo., Neb. and in $\mathrm{mts}$. to Tex.

Our plants may be varietally distinct in that the perigynia and achenes average slightly larger than in more northern plants.

\section{Carex media R. Br.}

Loosely cespitose from rather short slender rhizomes; culms 2-8 dm. high, slender, smooth or slightly scabrous above, not stiff, sharply triangular above. much-exceeding the leaves, red-tinged at the base, the dried leaves of the preceding year conspicuous: leaves 7 to 15 to a culm, mostly aggregated toward the base, thin, pale-green, flat or with slightly revolute margins, $2-3 \mathrm{~mm}$. wide, 
long-attenuate, roughened on the margins, the ventrally hyaline sheaths concave at the mouth, the ligule much wider than long; spikes usually 3 , the lateral pistillate, the terminal gynecandrous, closely aggregated or approximate, erect, short-oblong to suborbicular, $3.5-8 \mathrm{~mm}$. long, 2.75-4.5 $\mathrm{mm}$. wide, the lower shortpeduncled, the upper sessile, closely 8 - to 25-flowered, the perigynia ascending; lowest bract usually shorter than the head, little or not at all sheathing, the upper much shorter; scales small, 1.5-2.5 mm. long, persistent, purplish-black; staminate scales ovate-lanceolate, rather acute, with lighter midrib and whitehyaline margins; pistillate scales broadly ovate, somewhat acute to obtuse, the midrib essentially obsolete, the margins white-hyaline, nearly as wide as but much shorter than the perigynia; perigynia obovoid or oblong-obovoid, $2-2.5(-3.5)$ $\mathrm{mm}$. long, $1.25 \mathrm{~mm}$. wide, obtusely trigonous, slightly inflated, membranaceous, yellowish-green to yellowish-brown, granular and conspicuously puncticulate, glabrous, 2-ribbed, otherwise nerveless, occasionally somewhat serrulate, tapering at the base, sessile, rounded and abruptly beaked above, the beak short $(0.5 \mathrm{~mm}$. long) but prominent, minutely bidentate, dark-reddish-tinged, not ciliate at the mouth; achenes trigonous with concave sides, obovoid, and $1.75 \mathrm{~mm}$. long and $1 \mathrm{~mm}$. wide, granular, yellowish-brown, substipitate, abruptly apiculate. .

In moist or wet open or partially open habitats in the mts., especially along drainage courses in spruce-fir forests, in N.M. (Taos Co.); Lab. to Alas., s. to Que., n. Mich., N.M. and Wash.

\section{Carex serratodens W. Boott.}

Loosely cespitose from short rootstocks; culms $3-12 \mathrm{dm}$. high, slender, aphyllopodic, strongly red-tinged at the base, the basal sheaths breaking and becoming filamentose; sterile shoots phyllopodic, conspicuous; leaves 2 to 5 to a culm, clustered toward the base, $1.75-4 \mathrm{~mm}$. wide, flat, pale-green, longattenuate, the ligule conspicuously red-dotted, as long as wide; terminal spike staminate or gynecandrous, slightly peduncled or nearly sessile, linear, $1.5-3 \mathrm{~cm}$. long, 3-4.5 $\mathrm{mm}$. wide; pistillate spikes 2 to 5 , the lower 1 or 2 more or less separate, the other closely approximate, erect, sessile or the lowest slightly peduncled, oblong, 6-18 $\mathrm{mm}$. long, 5-8 $\mathrm{mm}$. wide, densely 20 - to 40 -flowered, the ascending perigynia at length spreading or squarrose; lowest bract leaflike, from shorter than to exceeding the culm, scarcely sheathing, the other bracts much-reduced; scales ovate, acute to short-mucronate, somewhat narrower and shorter than the perigynia, reddish-brown with lighter center; perigynia oblongovate to ovate, trigonous, slightly flattened above, $3-5 \mathrm{~mm}$. long, $1.5-2.5 \mathrm{~mm}$. wide, strongly many-nerved, light-green, reddish-dotted, puncticulate, rounded and sessile at the base, rather abruptly tapering at the apex into a slender bidentate hispidulous to serrulate beak $0.5-1 \mathrm{~mm}$. long; achenes obtusely trigonous, obovoid, about $2 \mathrm{~mm}$. long and $1.5 \mathrm{~mm}$. wide, short-stipitate and abruptly apiculate.

Moist or wet meadows and rocky wettish places near streams and seepages, in Ariz. (Gila Co.); s. Ore. and Calif.; Ariz.

\section{Carex Buxbaumii Wahl.}

Cespitose, rhizomatous; culms 2-10 dm. tall, slender but stiff, sharply angled, rough above, red-tinged at the base; basal leaf sheaths breaking and becoming conspicuously filamentose; leaf blades $1.5-4 \mathrm{~mm}$. wide, light-green, more or less glaucous, flat, channeled toward base, sharply keeled, long-attenuate; spikes 2 to 4 , erect, 1-4 cm. long, sessile or short-peduncled, the lateral ones pistillate, ovoid or oblong-ovoid 5-20 mm. long, 6-10 $\mathrm{mm}$. wide; bracts scalelike, the lowest one not reaching the tip of the culm to extending slightly beyond it; scales ovate, longer than the perigynia, long-acuminate or aristate, purplish-black or purplishbrown with light midvein; perigynia oblong-obovoid, 3-4 mm. long, $1.5-2 \mathrm{~mm}$. 
wide, glaucous-green, papillose, marginally 2-ribbed and finely many-nerved, shortstipitate, abruptly very minutely bidentate, purplish-tipped; achenes trigonous, suborbicular-obovoid, $1.7 \mathrm{~mm}$. long, $1.5 \mathrm{~mm}$. wide, brownish, punctate.

In bogs and swales, wet meadows, swampy woods and wet river bottoms, in Okla. (Waterfall); Nfld. to Alas., s. to e. Va. and w. N.C., Ky., Ark., Okla., Colo. and Calif.

\section{Carex bella Bailey.}

Cespitose from short-creeping fibrillose rootstocks; culms very slender, 5-9 $\mathrm{dm}$. high, much-exceeding the leaves, phyllopodic, cinnamon-brown and more or less strongly red-tinged at the base, the dried leaves of the previous year conspicuous; leaves usually 8 to 12 to a culm, scattered on the lower half, erect, flat, 3-6 mm. wide, long-attenuate; sheaths ventrally dull-reddish-brown-tinged or dotted, the ligule as wide as long; spikes 3 or 4 , the lower more or less drooping on slender roughish peduncles $1.5-4 \mathrm{~cm}$. long, the upper spikes erect, short-peduncled or subsessile, the uppermost contiguous, the others more or less strongly separate, gynecandrous, the terminal spike half-staminate, the lateral with only a few staminate flowers, linear to oblong-linear, 12-25 $\mathrm{mm}$. long, 4-5.5 mm. wide, closely 15- to 30-flowered, the perigynia appressed, the terminal spike slightly wider; lowest bract short $(2.5 \mathrm{~mm}$. long), leaflike, sheathing, exceeding the head; upper bracts much-reduced; pistillate scales ovate, obtuse to acute, dark-reddishbrown with lighter midrib usually conspicuous to the tip and shining white-hyaline margins, nearly as wide as (but shorter than) the mature perigynia; perigynia strongiy flattened but swollen by the ripening achene, broadly oval to oblong-oval, 3-4 mm. long, 1.75-2 mm. wide, nerveless (except for the two marginal ribs) or lightly 2- to 3-nerved, whitish-green, little or not at all red-tinged, membranaceous, smooth, puncticulate, rounded at the base, substipitate, rounded at the apex and abruptly beaked, the beak $0.3 \mathrm{~mm}$. long, apiculate, shallowly bidentate; achenes obovoid or oblong-obovoid, about $2.2 \mathrm{~mm}$. long and $1.7 \mathrm{~mm}$. wide, trigonous, yellowish-brown, granular, substipitate, strongly apiculate.

Along streams and in moist or wet open woods and open parks in the spruce-fir zone, and in wet alpine meadows in Ariz. (Apache, Navajo, Coconino and Graham cos.); S.D. and Colo. to Ut., s. to N.M., Ariz. and N.L.

\section{Carex albonigra Mack.}

Cespitose from short slender rootstocks; culms 1-3 dm. high, stiff and erect, phyllopodic, much-exceeding the leaves, red-tinged toward the base, the dried leaves of the previous year conspicuous; leaves 6 to 12 to a culm, clustered at the base, firm, flat with slightly revolute margins, $2.5-5 \mathrm{~mm}$. wide, roughened toward the strongly attenuate apex, the ligule as wide as long; spikes usually 3 , the upper approximate and sessile, the lowest usually slightly separate on an erect peduncle shorter than the spike, the lateral pistillate, narrowly oblong, very closely 8- to 20-flowered, 8-10 $\mathrm{mm}$. long, $4 \mathrm{~mm}$. wide, the perigynia appressed, the terminal gynecandrous, clavate at the base, 10-12 mm. long, $6 \mathrm{~mm}$. wide, with 25 to 30 appressed perigynia; lowest bract leaflike, about equaling the inflorescence, brownish-red-tinged and short-sheathing at the base, the others scalelike; scales broadly ovate, obtuse or acutish, reddish-black, rough-papillose, conspicuously whitehyaline at the apex and on the margins, the midrib usually more or less obsolete, nearly equaling and generally wider than the perigynia; perigynia much-flattened, broadly ovate or obovate, 3-3.5 mm. long, $2 \mathrm{~mm}$. wide, nerveless (except for the two marginal ribs) or nearly so, membranaceous, granular, reddish-black, rounded at the base, substipitate, rounded at the apex and very abruptly contracted into a minute apiculate, shallowly bidentate beak scarcely $0.5 \mathrm{~mm}$. long; achenes 
obovoid, about $1.25 \mathrm{~mm}$. long and $0.75 \mathrm{~mm}$. wide, trigonous, granular, lightyellowish-brown, substipitate, apiculate.

In seepage, edge of water in streams and ponds, in N. M. (Taos Co.) and Ariz. (Coconino Co.); Alta. to Wash., s. to Ariz., N.M. and Calif.

\section{Carex nova Bailey.}

Cespitose from short-creeping rootstock; culms stiffly erect, $1.5-6 \mathrm{dm}$. high, exceeding the leaves, strongly red-tinged at the base, the dried leaves of the previous year conspicuous; leaves 8 to 15 to a culm, mostly bunched near the base, firm, erect, flat with slightly revolute margins $2.5-5 \mathrm{~mm}$. wide, roughened at the attenuate apex, the ligule as long as wide; spikes 3 or 4 , the lateral pistillate, the terminal gynecandrous, sessile, very closely aggregated into a dense, terminal head $8-18 \mathrm{~mm}$. long and about as wide, the spikes suborbicular, 7-12 $\mathrm{mm}$. long, 6-10 $\mathrm{mm}$. wide, very closely flowered, the perigynia spreadingascending, at length squarrose; an empty bract $2-30 \mathrm{~mm}$. below the head, littlesheathing, from shorter than to exceeding the head, other bracts obsolete; scales lanceolate to obovate, rather obtuse or acute to short-cuspidate, dark-reddish-black with very narrow hyaline margins above, the midrib almost obsolete, shorter and narrower than the perigynia; perigynia strongly flattened but conspicuously distended by the ripening achene, ovate-suborbicular to obovoid, 3-4 $\mathrm{mm}$. long, 2-3.5 mm. wide, nerveless except for the two marginal ribs, membranaceous, granular, remotely and sparingly ciliate-scabrous, reddish-black with green margins and straw-colored base, rounded at the base and substipitate, rounded at the apex and abruptly short-beaked; beak apiculate, 0.5-1 mm. long, reddish-black, sharply bidentate; achenes trigonous, narrowly obovoid, about $2 \mathrm{~mm}$. long, $1 \mathrm{~mm}$. wide, yellowish-brown, granular, short-stipitate and abruptly apiculate.

In wet mt. meadows, upland marshes and on stream banks, in N.M. (Taos Co.); Mont. and Ore. to N.M. and Nev.

\section{Carex Shortiana Dewey}

Cespitose, the stout culms 4-8 dm. tall, usually shorter than the leaves; principal blades 4-8 $\mathrm{mm}$. wide; spikes 4 to 6 , cylindric, erect, $1.5-4 \mathrm{~cm}$. long, 4-6 $\mathrm{mm}$. thick, the terminal pistillate above, staminate below, the lateral pistillate, the lowest on long slender peduncles, the others on progressively shorter peduncles to nearly sessile; bracts leaflike, sheathless or nearly so; pistillate scales ovate, nearly or quite as long as the perigynia, reddish-brown, acute or rounded and mucronate; perigynia flattened-triangular, broadly obovate, 1.8-2.6 $\mathrm{mm}$. long, nearly as wide, cuneate to the base, transversely rugose, conspicuously 2-ribbed at the lateral angles, otherwise nerveless, minutely apiculate; achene trigonous-ellipsoid, minutely papillate, $1.8 \mathrm{~mm}$. long, $1 \mathrm{~mm}$. wide.

Wet woods and wet meadows, in Okla. (Waterfall); $\mathrm{Pa}$. to Ind., Ia., and $\mathrm{Kan}$. s. to Tenn. and Okla.

\section{Carex Joorii Bailey. Fig. 276.}

Loosely tufted glabrous perennial with short blackish scaly rhizomes 3-8 mm. thick; culms 6-10 dm. long, erect; blades $4-8 \mathrm{~mm}$. broad at the broadest point; spikes ( 5 or) 6 (rarely up to 8 ); the upper 1 (or 2 ) spikes staminate and erect, the lower ones pistillate (or the 2 nd and 3 rd from the top androgynous with a very short staminate portion) and downward progressively longer-peduncled and more nodding (at maturity!); terminal staminate spike $3-6 \mathrm{~cm}$. long, 4-6 mm. thick, with mucronate scales 5-6 mm. long; lowest pistillate spike $25-40 \mathrm{~mm}$. long, 6-9 mm. thick, with 25 to 60 close spreading perigynia and obovate or ovate strongly cuspidate hyaline scales about as long as the perigynia; lowest bract sheathless, the blade $2-4 \mathrm{~mm}$. broad, often surpassing the staminate spike, the bracts of the higher spikes progressively very strongly reduced; perigynia rhom- 


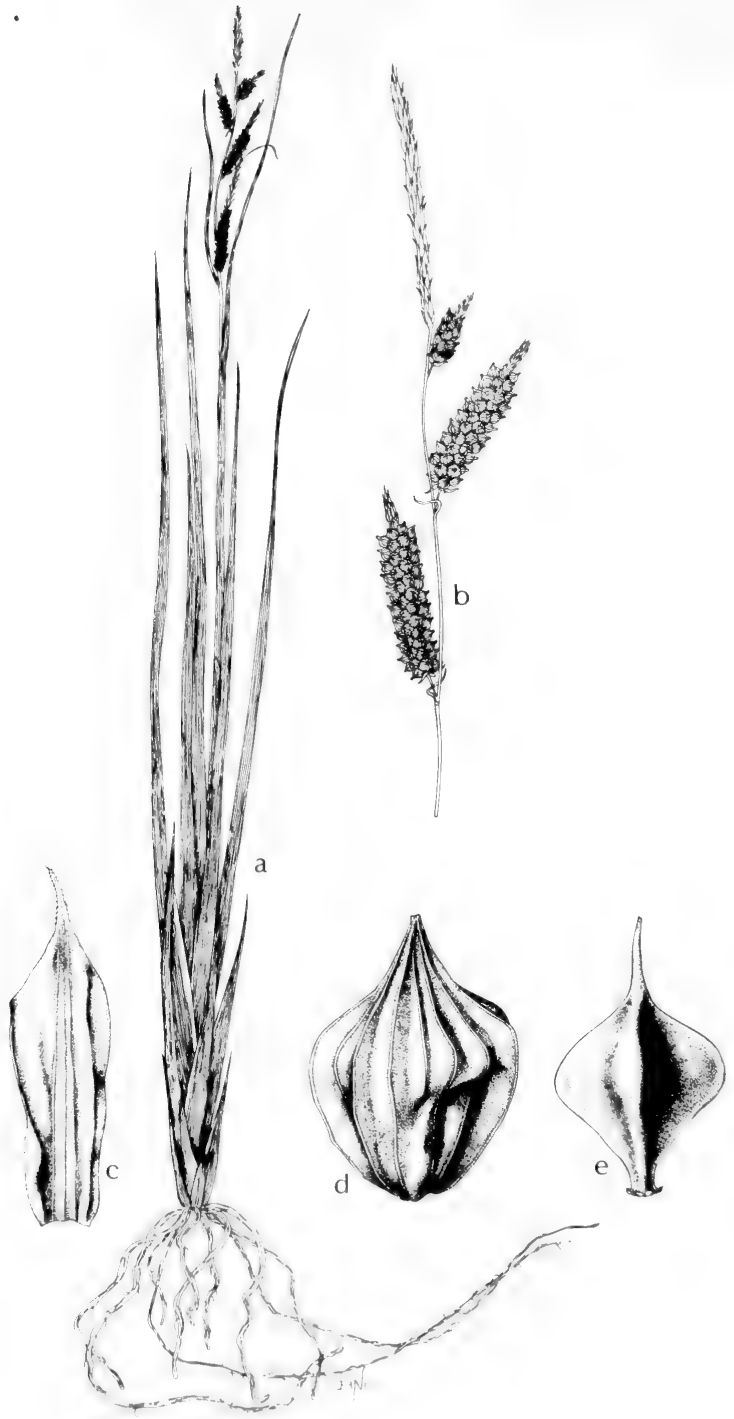

Fig. 276: Carex Joorii: a, habit, X $1 \%$; b, inflorescence, X $2 / 3$; c, scale, X 8; d, perigynium, X 8; e, achene, X 8. (Courtesy of R. K. Godfrey). 

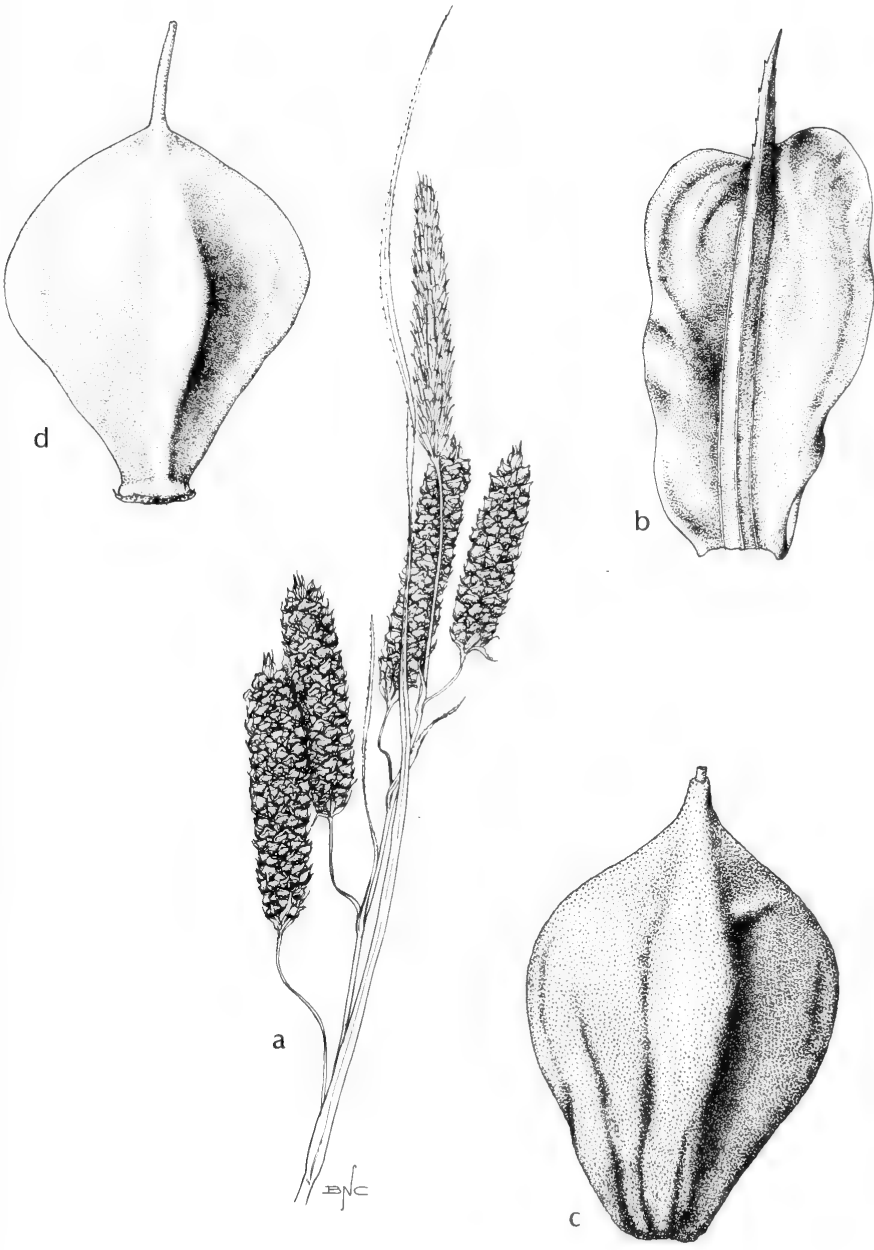

Fig. 277: Carex glaucescens: a, inflorescence, X 1; b, scale, X 17; c, perigynium, X 17; d, achene, X 17. (Courtesy of R. K. Godfrey). 
boid-ovoid to -obovoid, in transection nearly round (fresh) to obscurely triangular (dried), 4-5 mm. long, inflated, firm-membranous, dark brown, with 2 strong pale nerves (or ribs) and 9 to 12 slightly less strong ones, basally rounded, apically pyramidal-acuminate, passing into the definite slender beak (about $0.5 \mathrm{~mm}$. long) with an entire orifice; achene triangular with concave sides, about $2.3 \mathrm{~mm}$. long, $2.8 \mathrm{~mm}$. wide, apiculate, jointed with the style which entirely withers after anthesis.

In mud and water of streams, ponds and lakes, seepage areas, in Okla. (Waterfall ) and in e. and s.e. Tex., July-Oct.; Coastal States, Md. to Tex.; also Ark., Tenn. and Mo.

\section{Carex glaucescens Ell. Fig. 277.}

Tufted glabrous perennial with short blackish rhizomes 2-3 mm. thick; culms 5-12 dm. long, erect, leafy; blades 4-8 mm. broad at the broadest point; spikes 4 to 7 , the upper one staminate and erect, the lower ones pistillate (or some of them androgynous with very short staminate portions) and downward progressively longer peduncled and more nodding (at maturity!; at anthesis many of them ascending); terminal staminate spike 25-40 $\mathrm{mm}$. long, 5-7 $\mathrm{mm}$. thick, with mucronate scales $5-7 \mathrm{~mm}$. long; lowest pistillate spike $2-5 \mathrm{~cm}$. long, 7-9 $\mathrm{mm}$. thick, with 60 to 100 very close ascending perigynia and obovate reddish-brown hyaline scales (with greenish midnerves subulately exserted from an emarginate apex) about equaling the perigynia; lowest bract sheathless, the blade $1-4.5 \mathrm{~mm}$. broad and from very short to surpassing the staminate spike, the bracts of the higher spikes progressively strongly reduced; perigynia elliptic to obovate in the larger plane, in transection elliptic or obscurely very unequally triangular, 3-4 $\mathrm{mm}$. long, somewhat inflated, membranous, purplish-brown with a very pronounced whitish bloom, with 2 strong nerves and 2 or 3 extremely weak scarcely visible ones, basally tapered and rounded, apically tapered to a very short beak $(0.2-0.3$ $\mathrm{mm}$. long) and a nearly entire orifice; achene triangular with concave sides, 2.5 $\mathrm{mm}$. long, $2 \mathrm{~mm}$. wide, apiculate, jointed with the style which entirely withers after anthesis. C. verrucosa var. glaucescens (Ell.) Wood.

In wet savannahs, in mud on the edge of lakes, ponds and streams, rather frequent in e. Tex., rare in s.e. Tex., late spring-summer; Coastal States, Va. to Tex.

\section{Carex lanuginosa Michx. Woolly SEDGe. Fig. 278.}

Perennial with branching rhizomes about $1.5 \mathrm{~mm}$. thick and several $\mathrm{cm}$. long (often broken off in prepared specimens); culms 3-6 dm. long, strictly erect, simple, in slender clumps, 2-4 mm. thick basally; blades 3-4 mm. broad, the sheath-orifices U-shaped, brownish-discolored and thickened; sheaths ventrally pale-brownish, basally with transverse septation between the nerves; spikes about 3 or 4 , sessile or on very short peduncles, the upper 2 usually overlapping slightly, the upper one or 2 completely or almost completely staminate or with a few female flowers at the very base; female spike $25-30 \mathrm{~mm}$. long, 5-7 mm. thick, with 30 to 60 spreading-ascending spikes; bract of lowest spike not sheathing, its blade about $2 \mathrm{~mm}$. broad and equaling or exceeding the staminate spike; scales lanceolate, hyaline with green midrib, the body $1.5-2 \mathrm{~mm}$. long and with a subulate mucro about $1 \mathrm{~mm}$. long; perigynial body broadly ellipsoid, brown, firmmembranous, slightly inflated, about $2.5 \mathrm{~mm}$. long. densely hirsutulous as seen under a lens (the nervature obscured), the beak about $1 \mathrm{~mm}$. long and strongly bidentate apically; achene triangular with concave sides, 1.7-2 $\mathrm{mm}$. long, 1.3 $\mathrm{mm}$. wide, sessile, short-apiculate, jointed with the very short straight style which entirely withers after anthesis. 

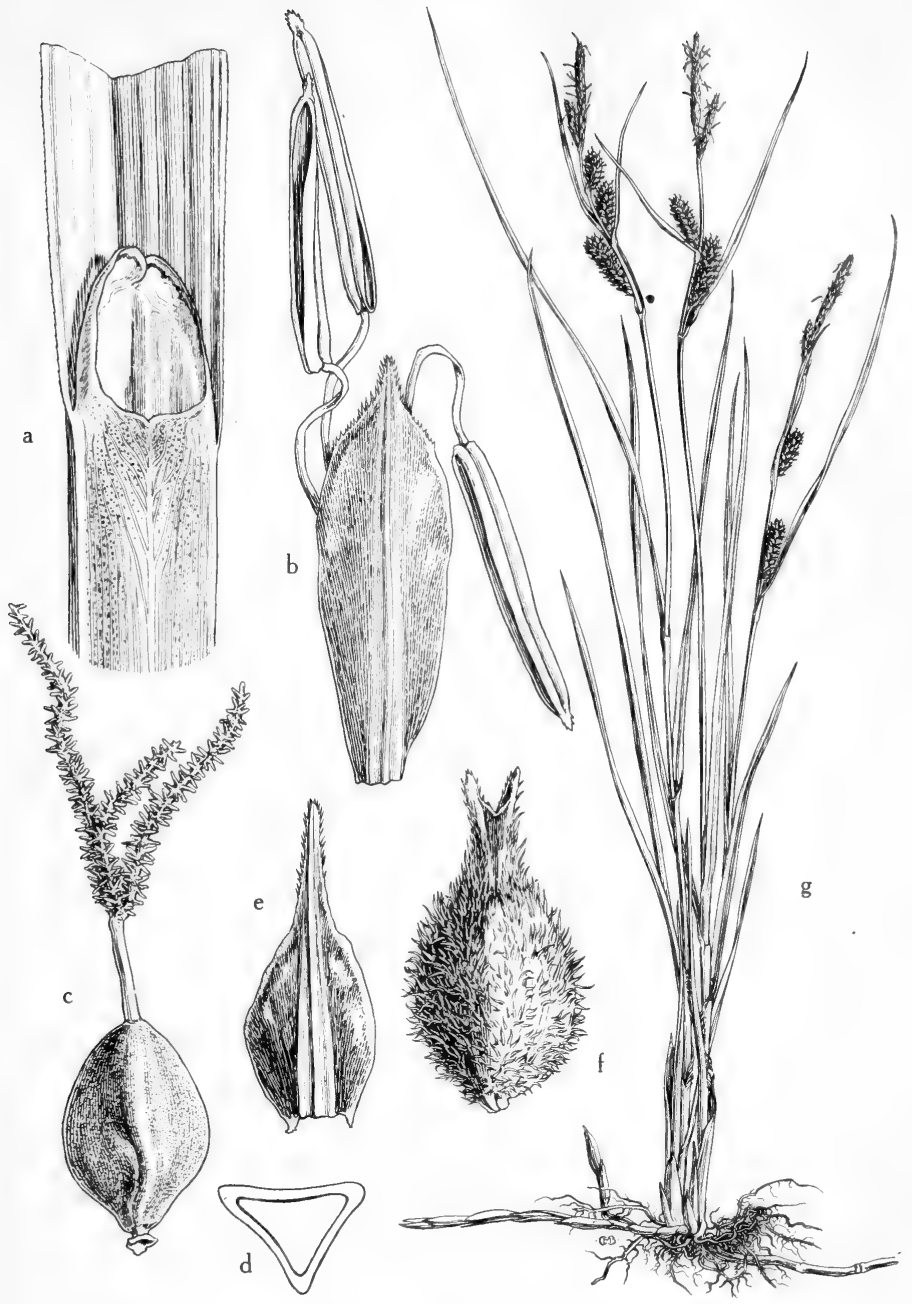

Fig. 278: Carex lanuginosa: a, ligule, X 6; b, staminate flower, the subtending scale acuminate and ciliate toward apex, $\mathrm{X} 12 ; \mathrm{c}$, pistillate flower with perigynium removed, showing the trigonous achene, X 12; d, achene (cross section), X 12; e, scale of pistillate flower, awned and ciliate upward (shorter than staminate scale), X 12; f, perigynium, showing the deeply bidentate beak and the dense ascending pubescence, $\mathrm{X} 12$. $\mathrm{g}$, habit, showing the rhizome, the basal leaf sheaths which become filamentose in age and the inflorescences with staminate spikes at apex, X $\%$. (From Mason, Fig. 109). 
Sloughs of river bottoms, wet meadows, marshes, seepage areas, and in mud and water of ponds and lakes in Tex. Panhandle of Plains Country (Hemphill Co.), rare, in N.M. (Colfax, Catron, Otero, Rio Arriba and Taos cos.) and Ariz. (Coconino, Santa Cruz, Navajo, Apache, Mohave and Yavapai cos.); N.B. to B.C., s. to Tenn., Tex., N.M., Ariz. and Calif., late spring-early summer; most of temp. N.A.

\section{Carex Bushii Mack.}

Tufted perennial; culms 3-9 dm. long, basally $1.5-2.5 \mathrm{~mm}$. thick, erect, the basal sheaths rich-brown and quickly fading; foliage usually shortly pilose or hirsute at least on the sheaths; blades $2.5-5 \mathrm{~mm}$. broad at the broadest point, the uppermost one usually surpassing the spikes; spikes usually 2 , less commonly 3 , overlapping; terminal spike gynecandrous, with an ovoid distal pistillate portion 7-10 $\mathrm{mm}$. long and 7-9 $\mathrm{mm}$. thick (including the scales), with ovate scales in the widest part pale-hyaline, strongly cuspidate and 4-5. mm. long (longer than the perigynia even at maturity), with an obconic basal staminate portion with elliptic acuminate whitish hyaline scales about $4 \mathrm{~mm}$. long; the lower spike(s) all pistillate, ovoid, 9-14 mm. long, 7-10 mm. thick (including scales), with 12 to 25 ascending perigynia; lowest bract not sheathing, about $1 \mathrm{~mm}$. broad, usually about equaling the terminal spike, the higher bracts greatly reduced; perigynia obovoid, in transection usually very slightly unequally triangular, 3-5 $\mathrm{mm}$. long, brown, firmmembranous, with 2 strong nerves and 7 to 13 weaker slender ones (scarcely visible at maturity), basally obconical and shortly rounded, apically shortpyramidal and abruptly passing into the very short beak (some specimens essentially beakless) with essentially entire orifice; achenes triangular, $2.5 \mathrm{~mm}$. long, $1.8 \mathrm{~mm}$. wide, bent-apiculate, jointed with the style which entirely withers after anthesis. C. caroliniana var. cuspidata (Dew.) Shinners.

In wet or moist sandy soil, wet meadows, swamps, ditches and borders of ponds in Okla. (Waterfall), rather frequent in e. Tex., infrequent in n.-cen. Tex., spring; N.E. s. to D.C. and s.w. to Kan., Okla. and Tex.

\section{Carex complanata T. \& H. Fig. 279.}

Tufted perennial; culms 3-8 dm. long, basally 1-2 mm. thick, erect, the basal sheaths dark-purplish; foliage often shortly pilose to hirsute on the sheaths and often also on the lower parts or all of the blade; blades $1.5-3 \mathrm{~mm}$. broad at the broadest point, usually the uppermost one surpassing the spikes; spikes usually 3 , less often 4 , overlapping; terminal spike gynecandrous, with an ovoid-cylindrical distal pistillate portion $8-11 \mathrm{~mm}$. long and 5-6 mm. broad (with brownish-white hyaline ovate scales, the lower ones more strongly acuminate than the upper, slightly longer than the immature perigynia but about equaling the mature ones), with a short obconic staminate portion with ovate acuminate brownish-white hyaline scales 3-4 mm. long; lower spikes pistillate, ovoid to cylindrical, 5-12 mm. long, 5-6 mm. thick, with 11 to 25 close ascending perigynia; bracts not sheathing, that of the lowest spike $0.5-1.5 \mathrm{~mm}$. broad and usually exceeding the terminal spikes, that of the middle spike much-reduced, that of the terminal spike essentially absent; perigynia obovoid, in transection flattened-triangular to unequally biconvex, 2.3-2.8 mm. long, ascending, olive-brown, firm-membranous, with 2 strong and 7 to 14 weak (at full maturity scarcely visible) nerves, scarcely inflated, basally rounded, apically shortly acute to a nearly entire orifice; achene triangular, $1.7 \mathrm{~mm}$. long, $1.2 \mathrm{~mm}$. wide, bent-apiculate, jointed with the style which entirely withers after anthesis. C. hirsutella Mack.

In wet sand in bogs, wet soil at edge of ponds and in moist sandy woods, in Okla. (McCurtain Co.), e. and s.e. Tex., spring; Ont. and e. U.S. w. to Mich., Mo., Okla. and Tex. 

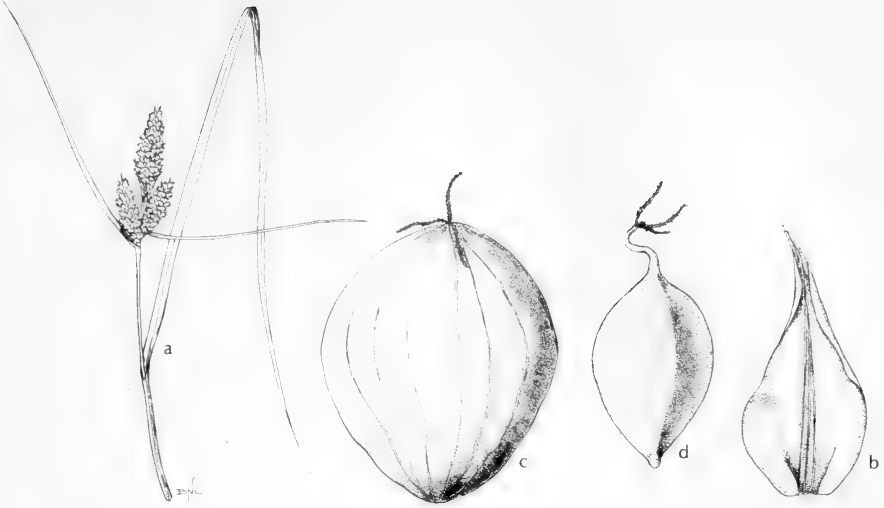

Fig. 279: Carex complanata: a, top of plant, X 1; b, scale, X 17; c, perigynium, X 17; d, achene, X 17. (Courtesy of R. K. Godfrey).

\section{Carex caroliniana Schwein.}

Tufted perennial; culms 3-6 dm. long, basally about $1 \mathrm{~mm}$. thick, erect, the basal sheaths dark-purplish-black quickly fading to brown; foliage essentially glabrous; blades $1.5-3 \mathrm{~mm}$. broad at the broadest point, usually the uppermost one surpassing the spikes; spikes usually 3 , overlapping; terminal spike gynecandrous with a cylindrical distal pistillate portion 8-13 $\mathrm{mm}$. long and 4-4.5 $\mathrm{mm}$. thick (with scales ovate, brownish-white, hyaline, 1.5-2 $\mathrm{mm}$. long, shorter than the perigynia) and a long-attenuate basal staminate portion 2-3 mm. thick with ellipsoid acute brownish-white-hyaline scales $2-2.5 \mathrm{~mm}$. long; the lower spikes all pistillate, cylindrical, 6-20 mm. long, 4-4.5 $\mathrm{mm}$. thick, with 16 to 40 closely packed spreading perigynia; bracts not sheathing, that of the lowest spike $1-2 \mathrm{~mm}$. broad, usually exceeding the terminal spike, that of the middle spike muchreduced, that of the terminal one essentially absent; perigynia obovoid, nearly round in transection, $1.8-2.3 \mathrm{~mm}$. long, spreading, fuscous or reddish-brown, membranous, with 8 to 15 nerves ( 2 stronger than the rest), inflated, basally rounded, apically short-conic and passing abruptly to the short tubular bidentate beak or in some specimens essentially beakless; achene triangular, $2 \mathrm{~mm}$. long, $1.5 \mathrm{~mm}$. wide, bent-apiculate, jointed with the style which entirely withers after anthesis.

In rich open woods near streams in sandy soil, wet lowlands, swamps, river flood plain forests, in Okla. (Waterfall), in e., s.e. and n.-cen. Tex. (Jasper, Jefferson, Kaufman and Walker cos.), spring; Pa. to Ind. and s. to N.C., Tenn., Ark., Okla. and Tex. (probably also La.).

\section{Carex viridula Michx. Green SEDGE. Fig. 280.}

Culms densely cespitose, 1-4 dm. tall, smooth, bluntly triangular; leaf blades dull-green, grooved, $1.5-3 \mathrm{~mm}$. wide; terminal spike usually staminate, sessile or short-peduncled, 3-15 mm. long, 1.2-3 mm. wide; pistillate spikes 2 to 6 , closely aggregated and sessile or the lower ones separate and short-peduncled, oblong or globose-oblong, 5-11 mm. long, 4-7 $\mathrm{mm}$. wide; bracts leaflike, the lower one extending well beyond the tips of the culms, strongly sheathing; scales broadly ovate, shorter than perigynia, obtuse to acute or short-cuspidate, hyaline with 


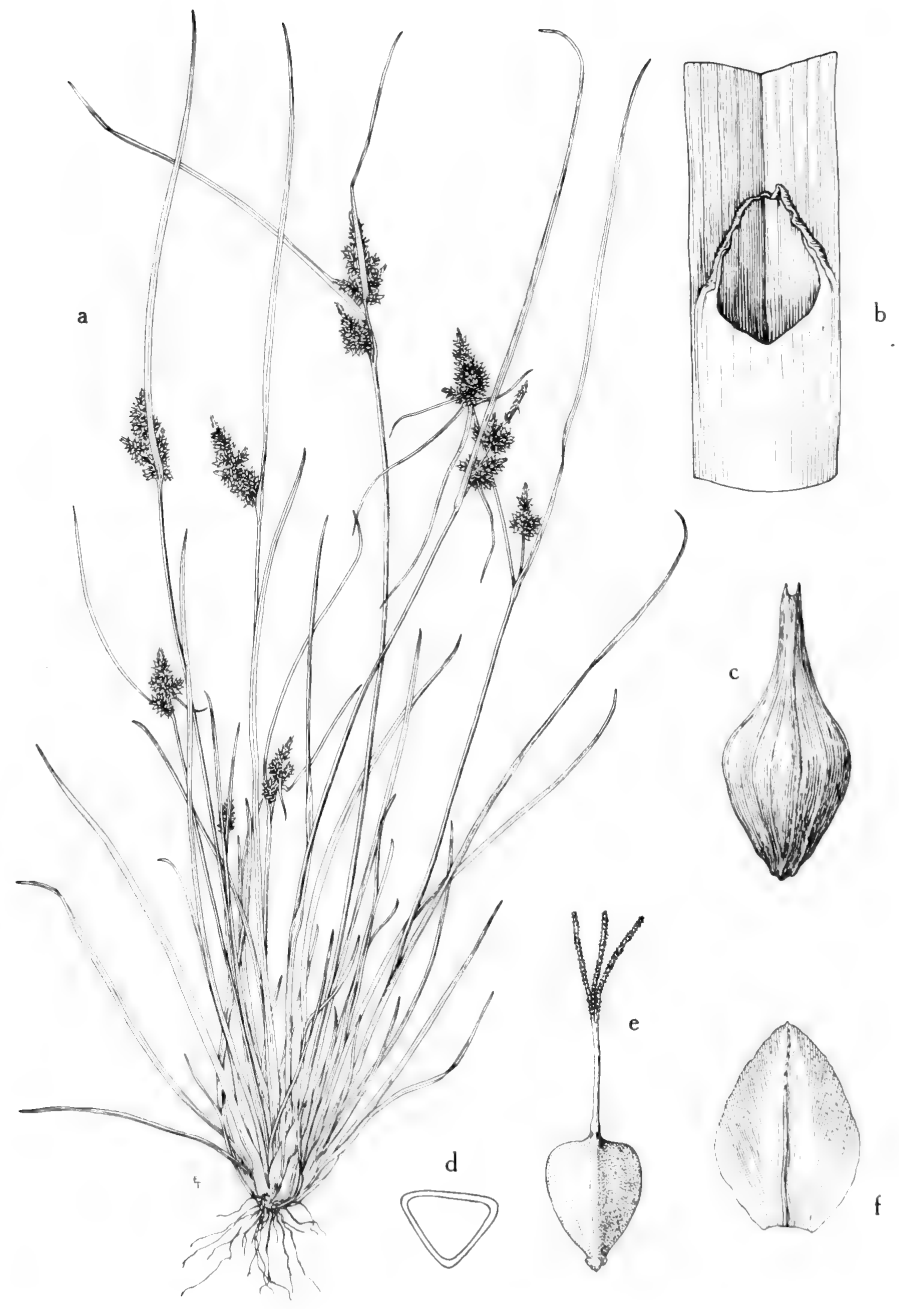

Fig. 280; Carex viridula: a, habit, showing the densely caespitose culms and leaves and the long bracts subtending the inflorescences, $X 25 ; b$, ligule, $X$ 6; c, perigynium, $X 12 ; d$, achene (cross section), X 12; e, pistillate flower with perigynium removed, $\mathrm{X} 12 ; \mathrm{f}$, scale, X 12. (From Mason, Fig. 114.) 


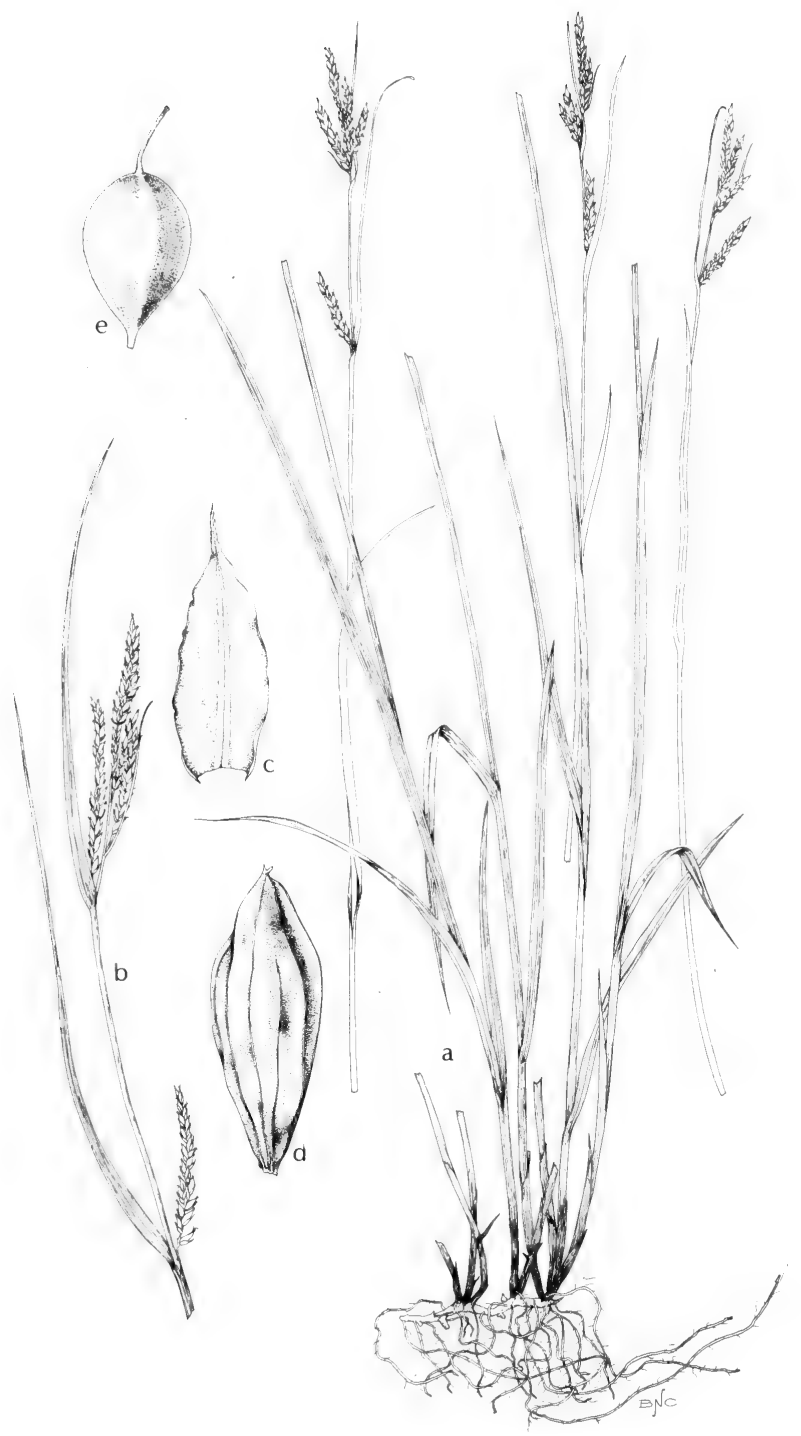

Fig. 281: Carex oxylepis: a habit, X 1/4; b, inflorescence, X 1/2; c, scale, X 15; d, perigynium, X 15; e, achene, X 15. (Courtesy of R. K. Godfrey). 
greenish midvein, reddish-brown-tinged; perigynia 2-3 $\mathrm{mm}$. long, $1.3 \mathrm{~mm}$. wide, obovoid, many-nerved, yellowish-green, tapering at base, abruptly beaked; beak minutely bidentate, reddish-tinged; achenes trigonous, obovoid, $1.3 \mathrm{~mm}$. long, $0.9 \mathrm{~mm}$. wide, black and glossy at maturity.

Marshes and bogs, on border of streams, ponds and lakes in N.M. (Otero Co.); Nfld. to Alas., s. to N.J., Ind., Colo., N.M. and Calif.

\section{Carex oxylepis T. \& H. Fig. 281.}

Loosely tufted perennial or with short purplish-black scaly rhizomes $2-3 \mathrm{~mm}$. thick; culms 4-7 dm. long, 1-2 mm. thick, erect, basally with reduced blades and purplish-black sheaths; cauline leaves $2.5-6 \mathrm{~mm}$. broad, pale-green, erect; spikes usually 4 per culm; terminal spike gynecandrous, on a slender nodding peduncle 2-4 cm. long, $2-5 \mathrm{~cm}$. long, with a short terminal pistillate portion and a long staminate portion about $2 \mathrm{~mm}$. thick, with lanceolate hyaline stramineous scales; other spikes pistillate, with slender nodding or flexuous peduncles usually only 2-4 cm. long, 4-5 $\mathrm{mm}$. thick, with 20 to 44 ascending perigynia which are close enough to overlap (except occasionally the lowermost); lower bract with definite sheath and a long blade $1-3 \mathrm{~mm}$. broad, almost equaling the uppermost spike, the higher bracts progressively much-reduced; scales hyaline, ovate, long-subulatecuspidate, about three fourths as long as the perigynia; perigynia fusiform-ellipsoid, in transection nearly round when fresh or obtusely triangular after drying, 3.5-4 $\mathrm{mm}$. long, green, membranous, inflated, with 6 to 8 slender nerves ( 2 stronger than the rest), basally and apically tapered, with a beak $0.2-0.3 \mathrm{~mm}$. long and a nearly entire orifice; achene triangular with concave sides, $2 \mathrm{~mm}$. long, $1.5 \mathrm{~mm}$. wide, apiculate, jointed with the style which entirely withers after anthesis.

In low moist rich woods near streams, wet soil along streams in Okla. (Ouachita Mts., McCurtain Co.), in e. and s.e. Tex., Mar.-Apr.; Fla., the Gulf States to Tex., S.C., N.C., Tenn., Mo., Ark. and Okla.

\section{Carex blanda Dew. Fig. 282.}

Tufted perennial (rhizomes very short); culms 15-55 cm. long, ascending, 0.8$1.5 \mathrm{~mm}$. thick; basal sheaths brownish at base and rather loose; basal blades 4-11 $\mathrm{mm}$. broad, the cauline ones 3-5 mm. broad, thin-membranous; upper 2 or 3 spikes usually close or even overlapping, nearly sessile, the lowest (usually fourth and/or fifth) spike usually widely separate and exserted on an erect filiform peduncle 2-8 $\mathrm{cm}$. long; terminal spike staminate, 1-2 $\mathrm{cm}$. long, 2-3 $\mathrm{mm}$. thick, stramineous, the scales acute to acuminate or cuspidate; remainder of spikes pistillate, $5-20 \mathrm{~mm}$. long, 4-6 mm. thick, with 4 to 20 closely set overlapping perigynia, the ovate or obovate scales either mucronate (and shorter than their perigynia) or with a long subulate projection (this often equaling or exceeding the perigynium) and whitehyaline; bracts foliaceous, with definite sheaths (the edges of which are minutely fimbriate), the blades of the bract of the third or fourth spike from the apex often equaling or surpassing the staminate spike; perigynia turgidly obovoid, vaguely triangular, 3-4 mm. long, closely investing the achene not only laterally but in much of the apex as well, membranous, with 2 ribs and 23 to 30 nerves (much more slender than the internerve spaces), basally tapering and substipitate, apically rounded, abruptly very short-beaked, the beak about $0.5 \mathrm{~mm}$. long and bent or recurved nearly at right angles to the axis of the perigynium, the orifice hyaline and entire; achenes triangular, $2.5 \mathrm{~mm}$. long, $1.5 \mathrm{~mm}$. wide, bent-apiculate, jointed with the style which wholly withers after anthesis.

In moist or wet woods, alluvial thickets, wet soil along rivers, in Okla. (Waterfall), in e. and n.-cen. Tex., rare w. to Edwards Plateau (San Saba Co.), Apr.-May; e. temp. N.A. w. to the Dakotas, Neb., Kan., Okla, and Tex. 


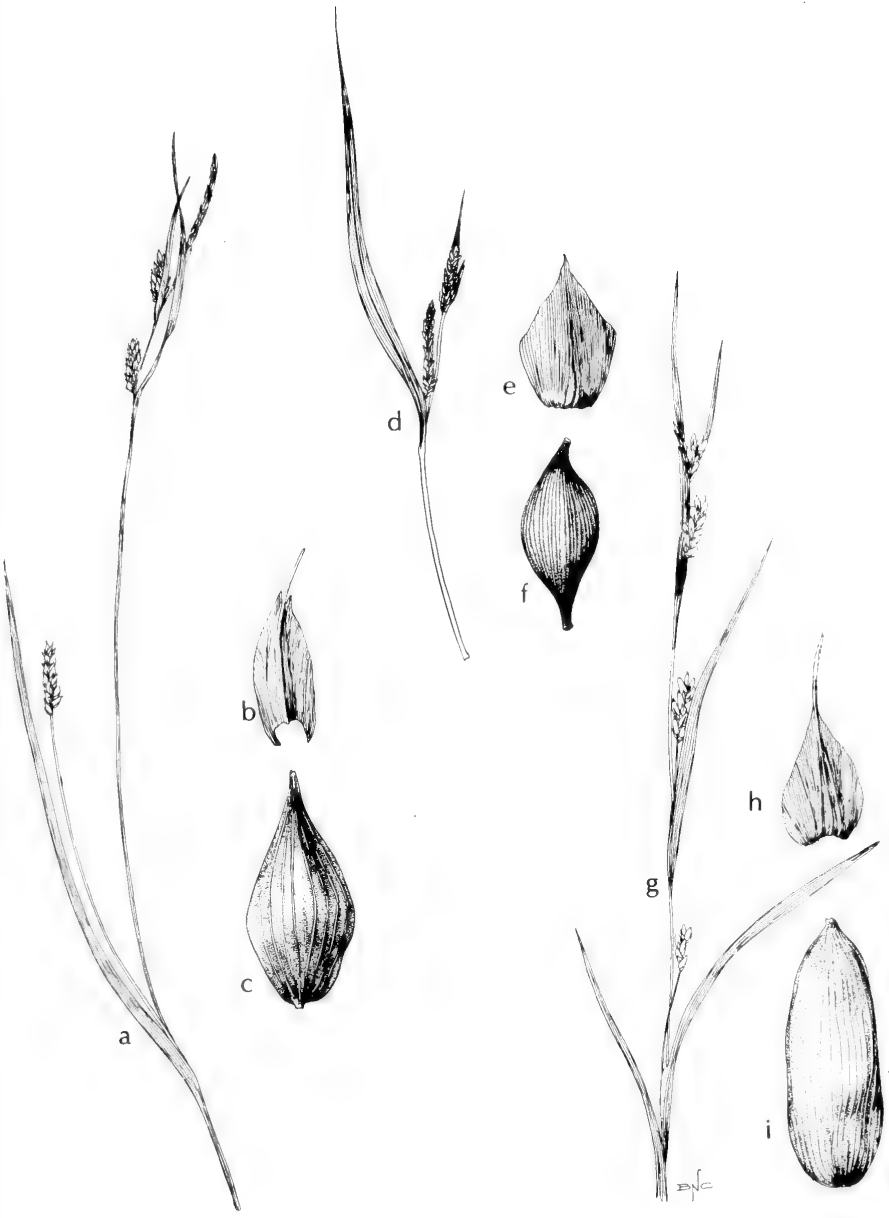

Fig. 282: a-c, Carex granularis: a, top of plant, X 1/a; bcales, X 10; c, perigynium, $\mathrm{X} 10$. d-f, Carex blanda: d, top of plant, X 1/2; e, scale, $\mathrm{X} 7 ; \mathrm{f}$, perigynium, X $7 . \mathrm{g}-\mathrm{i}$, Carex faccosperma: $\mathrm{g}$, top of plant, $\mathrm{X} 1 / 2 ; \mathrm{h}$, scale, $\mathrm{X} 7 ; \mathrm{i}$, perigynium, X 7 . (Courtesy of R. K. Godfrey). 


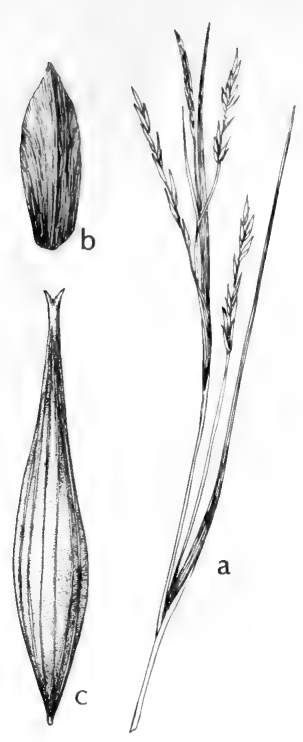

Fig. 283: Carex debilis: a, top of plant, X 1/2; b, scale, X 7; c, perigynium, X 7 . (Courtesy of R. K. Godfrey).

\section{Carex debilis Michx. Fig. 283.}

Loosely tufted perennial; culms $15-60 \mathrm{~cm}$. long, 0.6-1 mm. thick; basally with reduced blades and purplish red sheaths; cauline leaves $2-4 \mathrm{~mm}$. broad, ascending, pale-green, membranous; spikes 4 or 5 per culm, the terminal one (rarely the terminal 2) staminate in Texas material (some non-Texan specimens have gynecandrous terminal spikes), 2-5 cm. long, about $1 \mathrm{~mm}$. thick, erect or often nodding on a peduncle $2-5 \mathrm{~cm}$. long, the scales stramineous-hyaline; the remaining spikes pistillate, nodding on slender flexuous peduncles $2-5 \mathrm{~cm}$. long, crowded or the lower ones usually remote, $3-6 \mathrm{~cm}$. long, $4-6 \mathrm{~mm}$. thick, with 12 to 25 ascending perigynia which are usually close enough to overlap a little (except the lowermost); lower bract long-sheathing, foliaceous, the blade 1-2 mm. broad and often equaling or surpassing the pistillate spike; scales subulate, hyaline, inconspicuous, about half as long as the perigynia and deciduous with them; perigynia narrowly fusiform, in transection nearly round when fresh, 6-9 $\mathrm{mm}$. long, 1.2-1.7 $\mathrm{mm}$. thick, stramineous-brown, membranous, inflated, with 2 strong nerves and 10 to 18 weak slender ones, long-tapered basally and apically and passing into a beak about $1 \mathrm{~mm}$. long and very deeply bidentate; achene triangular with concave sides and thickened angles $2 \mathrm{~mm}$. long, $1.5 \mathrm{~mm}$. wide, stipitate, apiculate, jointed with the style which entirely withers after anthesis.

Near brooks and in low poorly drained pinewoods, swampy woods, along sluggish streams in Okla. (McCurtain Co.) and in e. and s.e. Tex. (Cass, Cherokee, Hardin, Nacogdoches, Panola and Polk cos.), Apr.-May; e. temp. N.A., w. to Wisc., Mo. and Tex. 


\section{Carex capillaris $\mathrm{L}$.}

Densely cespitose from short rootstocks; culms usually very slender, to $6 \mathrm{dm}$. high, generally much exceeding the leaves, obtusely triangular and smooth, somewhat fibrillose at the base, the dried leaves of the previous year conspicuous; leaves clustered toward the base, usually 5 to 8 to a culm, flat or somewhat channeled toward the base, thin but firm, $0.5-4 \mathrm{~mm}$. wide, the tight sheaths truncate at the mouth, the ligule very short; terminal spike staminate, very slender, 4-8 $\mathrm{mm}$. long, $0.75-1 \mathrm{~mm}$. wide, usually shorter than the uppermost pistillate spike, on a short slender roughish peduncle; pistillate spikes 2 or 3, linear-oblong, 4-17 $\mathrm{mm}$. long, 3-4 mm. wide, containing 3 to 20 ascending loosely arranged perigynia, on elongate very slender drooping peduncles; bracts long-sheathing, the blades leaflike, usually strongly exceeding the culm; scales orbicular-ovate, thin, closely appressed, early-deciduous, somewhat wider but much shorter than the perigynia, light-chestnut with conspicuous white-hyaline apex; perigynia ovoid-lanceolate, obtusely trigonous, slightly inflated, 2-4 mm. long, $0.75 \mathrm{~mm}$. wide, serrulate and slightly ciliate, greenish-brown, nerveless except for the 2 ribs, conspicuously stipitate, contracted into a straight entire minutely white-hyaline-tipped conic beak $1 \mathrm{~mm}$. long; achenes trigonous, obovoid, $1.5 \mathrm{~mm}$. long, $0.7 \mathrm{~mm}$. wide, brownish with blunt green angles, granular, substipitate.

In woods, thickets, wooded swamps and on shores, in N. M. (Rio Arriba and San Miguel cos.), from arctic Am. s. to Vt., N.Y., Mich., N.M. and Nev.

\section{Carex granularis Muhl. Fig. 282.}

Tufted perennial; culms $18-55 \mathrm{~cm}$. long, $0.5-1.1 \mathrm{~mm}$. thick, erect, leafy; basal sheaths brown; cauline blades $2-4 \mathrm{~mm}$. broad, olive-green, membranous, erect, long-tapered; spikes 4 or 5 per culm, the upper 2 or 3 usually essentially sessile and approximate, the rest remote and on slender peduncles; terminal spike staminate, 15-25 $(-35) \mathrm{mm}$. long, about $1 \mathrm{~mm}$. thick, the ovate scales awned to cuspidate or acuminate, closely appressed and brownish; rest of spikes pistillate, 5-20 mm. long, 3.5-5 mm. thick, with 10 to 40 close widely spreading perigynia, the ovate scales little over half as long as the perigynia; bracts foliaceous, with definite sheaths, the lower bracts (of fourth or fifth spike) often equaling or exceeding the staminate spike; perigynia broadly ovoid to broadly obovoid, round in transection, 2-2.5 $\mathrm{mm}$. long, about $1.3 \mathrm{~mm}$. thick, membranous, brownish, with 2 ribs and about 10 nerves (these much more slender than the internerve spaces), inflated, not closely investing the achene at any point, basally obtuse, (either rounded or very shortly tapered), apically abruptly contracted into a minute entire straight (though often distorted in prepared specimens) tubular beak with a nearly entire orifice; achenes triangular with concave sides, about $2 \mathrm{~mm}$. long, $1.2 \mathrm{~mm}$. wide, bent-apiculate, jointed with the style which entirely withers after anthesis. Incl. var. Haleana (Olney) Porter.

In water of flowing streams, wet meadows, wooded swamps, prairie swales, in ditches, in Okla. (Waterfall) and e. (San Augustine Co.) and n.e. (Bowie Co.) Tex., May; e. U.S. and Que. and Ont., w. to Minn., Kan., Okla. and Tex.

\section{Carex Crawei Dewey.}

Culms arising one to few together from slender long-creeping rootstocks, 1-3 $\mathrm{dm}$. high, slender but stiff, phyllopodic, exceeding the leaves, the dried leaves of the previous year conspicuous at their base; leaves 6 to 12 to a culm, thick, stiff, usually recurved-spreading, $1.5-3 \mathrm{~mm}$. wide, roughened on the margins toward the apex, the tight sheaths hyaline ventrally, the ligule longer than wide; staminate spike solitary, erect, long-peduncled, linear, $1-3 \mathrm{~cm}$. long, 2-3 mm. wide; pistillate spikes 2 to 4 , widely separate, the lowest often nearly basal, the peduncles little or not at all exserted, oblong-cylindric, 1-3 cm. long, 5-6 mm. 
wide, closely 10 - to 45 -flowered, the perigynia ascending; bracts leaflike, the upper reduced, usually shorter than the culms, the sheaths tight; scales broadly ovate, narrower than and about half the length of the perigynia, reddish-brown with hyaline margins and green center; perigynia ovoid or oblong-ovoid, almost terete, scarcely inflated, 3-3.5 mm. long, 1.25-2 mm. wide, many-nerved, light-green or yellowish-green, rounded at the sessile base, rather abruptly contracted into a very short straight entire or minutely bidentulate beak; achenes trigonous, obovoid, small, filling only the lower two-thirds of the perigynium, about $1.8 \mathrm{~mm}$. long and $1.2 \mathrm{~mm}$. wide.

Boggy meadows and wet thin soil underlaid by rock, especially in limestone regions, in Okla. (Waterfall); Que. to Alta. and Wash., s. to N.J., Ala., Okla. and $\mathrm{Ut}$.

\section{Carex microdonta T. \& H.}

Perennial; rhizomes $2-15 \mathrm{~cm}$. long, $1 \mathrm{~mm}$. thick, brown; culms rising singly or in small tufts from the rhizomes, $9-50 \mathrm{~cm}$. long, $0.7-1.1 \mathrm{~mm}$. thick; leaves mostly crowded at the base, the basal sheaths brown; blades $2-7 \mathrm{~mm}$. broad, shorter than the culm, shortly tapered apically; spikes 3 to 5 per culm, the terminal one staminate (rarely androgynous), usually with the sessile staminate or androgynous second spike attached near its base and overlapping it; rest of spikes usually more remote, erect, on pedicels $2-10 \mathrm{~cm}$. long and nearly all pistillate (the upper one occasionally with a few terminal staminate flowers); staminate spikes prominent, 2-5 cm. long, 4-8 mm. thick, often with prominent subpersistent anthers, greenish or brownish, the narrowly obovate scales $3-8 \mathrm{~mm}$. long and brownish to reddish-brown and hyaline with 3 prominent green midnerves; pistillate spikes 1-5 $\mathrm{cm}$. long, 5-6 mm. thick, with 20 to 40 close spreading perigynia, the ovate scales acuminate and half as long as the perigynia, reddish-brown with hyaline margins and prominent 3-nerved median; perigynia ovoid to narrowly ovoid, $2.6-3.6 \mathrm{~mm}$. long (including beak), reddish-brown, firm-membranous, with 2 ribs and 12 to 15 less prominent nerves, rather closely investing the achene except at the rounded or very shortly tapered base and the conical apex which abruptly passes into the tubular beak $(0.5-0.7 \mathrm{~mm}$. long with a minutely 2-toothed apex); achene triangular with concave sides, up to $2.5 \mathrm{~mm}$. long, $1.7 \mathrm{~mm}$. wide, bent-apiculate, jointed with the style which entirely withers after anthesis.

In moist open places, usually calcareous areas on wet seeping limestone banks and on wet granite ledges in depressions in prairies, in Okla. (Waterfall) and n.-cen. and s.e. Tex., Edwards Plateau, infrequent in e. Tex., rare in the TransPecos, Mar.-May (June-Aug. in Trans-Pecos); Miss., La., Tex., Okla. and Mo.

\section{Carex amphibola Steud.}

Tufted perennial; culms $15-30(-40) \mathrm{cm}$. long, erect; basal sheaths purplishbrown with reduced blades; cauline leaves few, $1.5-3.5(-4.5) \mathrm{mm}$. broad, membranous, green; spikes usually 4 , less commonly 3 ; terminal spikes inconspicuous and staminate, nearly sessile, 6-20 $\mathrm{mm}$. long, 1.5-2.5 $\mathrm{mm}$. thick, stramineous, the scales broadly hyaline; rest of spikes pistillate (the highest one subterminal and sessile at the base of the staminate spike, the others on slender short peduncles and more or less remote), 8-13 (-20) $\mathrm{mm}$. long, about $5 \mathrm{~mm}$. thick, with 3 to 6 (to 10 ) ascending perigynia which are close enough to overlap (except occasionally the lowermost), the scales with the hyaline broadly ovate main portion about a third to half as long as the perigynia but the abrupt subulate cusp almost equaling it; bracts narrowly foliaceous with definite close sheaths, the blades greatly surpassing the spikes; perigynia turgidly to slenderly obovoid, in transection nearly round when fresh but less so after drying, often obtusely triangular, $4-5 \mathrm{~mm}$. long, inflated, brown-membranous, in the lower half with about 50 or 60 nerves which 
are so close they are only a little narrower than the internerve spaces (some of these ending so the upper part with fewer nerves than the lower), basally slightly tapered and narrowly rounded, apically broadly rounded or very obtuse, essentially beakless with a nearly entire orifice (after drying the apex often somewhat conical instead of rounded but still essentially beakless); achene triangular, apiculate, up to $3 \mathrm{~mm}$. long, $2 \mathrm{~mm}$. wide, jointed with the style which entirely withers after anthesis. Incl. var. globosa (Bailey) Bailey, var. rigida Fern. and var. turgida Fern., "C. grisea" of many authors, not Wahl., C. Bulbostylis Mack.

In moist soil and woodlands, in wet soil along streams in forests, alluvial forests and ravines, in Okla. (Waterfall), in e., s.e. and n.-cen. Tex., infrequent to rare in moist areas of e. part of Edwards Plateau, spring; from Fla. to Tex., n. to Del., Pa., Tenn. and Ark. Seeming to grade somewhat into C. flaccosperma.

\section{Carex flaccosperma Dew. Fig. 282.}

Tufted perennial; culms (14-) 25-40 (-60) cm. long, erect; basal sheaths usually glaucous to pale-brownish with reduced blades; cauline leaves few, 4-10 $\mathrm{mm}$. broad, membranous, pale-green or glaucous-green; spikes usually 5, less commonly 4; terminal spike very inconspicuous, staminate, nearly sessile or short-peduncled, 7-35 mm. long, 1-3 mm. thick, stramineous, the scales broadly hyaline; other spikes pistillate (the highest one subterminal and nearly sessile or short-peduncled and attached near the base of the staminate spike, the others more or less remote on slender peduncles 1-15 cm. long), 12-50 mm. long, about $7 \mathrm{~mm}$. thick, with 8 to 32 ascending perigynia which are close enough to overlap (except occasionally the lowermost); bracts foliaceous, with definite loose sheaths, the blades greatly surpassing the spikes; scales brownish-hyaline, ovate, less than half as long as the perigynia, acute to very short-cuspidate; perigynia slenderly obovoid to ovoidfusiform, in transection nearly round when fresh (but after drying often obtusely triangular), 4-5 mm. long, inflated, brown-membranous, in the lower half with 47 to 60 nerves which are so close they are only a little (if at all) narrower than the internerve spaces (some of them ending so the upper part has fewer than the lower), basally slightly tapered and narrowly rounded, apically tapered and narrowly rounded or acute, essentially beakless, with a nearly entire orifice; achene triangular, up to $2.5 \mathrm{~mm}$. long, $1.7 \mathrm{~mm}$. wide, apiculate, jointed with the style which entirely withers after anthesis.

In moist sandy soil in wooded areas, swampy grounds, wet rocky stream banks, wet woodlands, in Okla. (Pittsburg Co.), in e. and s.e. Tex., infrequent in n.-cen. Tex., spring; s.e. U.S. n. to Va., Tenn. and Mo., w. to Okla. and Tex.

\section{Fam. 26. Palmae Juss.}

\section{Palm Family}

Trees, shrubs or perennial vines, endogenous in growth; leaves persistent and often shedding after withering and natural breaking of the petioles, in some detaching cleanly from sheathing base of the petiole and leaving rings on the trunk; leaf blades firm and durable, sometimes entire but mostly pinnate or palmate, the ultimate divisions with strong midrib and lesser parallel lateral veins; inflorescence or spadix various, ordinarily a long branching structure issuing from axils of present or of fallen leaves, each branch subtended by a bract or nodifrond or in some cases enclosed in a woody spathelike structure or cymba; flowers paleaceous and very small in proportion to size of plant, perfect or unisexual, usually 3-merous or multiples thereof; calyx 3-parted or tridentate, sometimes subtended by involucral bracts; corolla polypetalous or gamopetalous; stamens 3,6 or multiples thereof; pistils 1 to 3 in most species, ripening into a drupelike or fleshy fruit of many sizes and shapes, the exterior pulp sometimes edible, commonly with only 1 seed coming to maturity; seed a hard body often 
inseparably attached to carpellary parts; albumen sometimes partly liquid at maturity but commonly firm and hard and either continuous and plain in structure or ruminate by intrusion of lateral walls, placement of the embryo from basal to apical.

The genera and species are many, the latter in the thousands and often limited in distribution; mostly in tropical regions, with only one genus in Texas. Plants of most palms are highly ornamental, and several species are cultivated in the warmer areas of southern Texas, especially in the Rio Grande Valley. Among these are species of Phoenix, Sabal and Washingtonia.

\section{Sabal AdAns.}

A small genus of about 25 species confined to the Western Hemisphere.

\section{Sabal minor (Jacq.) Pers. Bush Palmetto, DWarf palmetto.}

Usually acaulescent, only occasionally developing an abbreviated stem that might become $6 \mathrm{~m}$. tall; leaf blade palmate, bluish, not glaucous, stiff in appearance, to $15 \mathrm{dm}$. wide, divided to about two-thirds its length into numerous segments; petiole extending on lower side of blade as a midrib; spadices intrafoliar, with many narrow acuminate nodifronds from which the separate flower clusters issue; flowers perfect; stamens 6; ovary solitary; superior; fruits black, globular or oblate, dull or shining, 8-13 mm. in diameter. S. louisiana (Darby) Bomhard.

In lowlands, swamps, river terraces and floodplains, reported (but not seen) from Okla., in e. Tex., w. to the Edwards Plateau and s. to Aransas Co.; from n.e. N.C., s. to s. Fla., w. to s.w. Ark. and Tex.

According to Bailey, the conspicuously caulescent plants, such as those found in Brazoria County, Texas, represent the optimum emergence of this species. Other than size, there seems to be no botanical difference between the dwarf acaulescent plants and those that develop a prominent trunk. The arborescent plants have been given the name S. louisiana.

The fruits of this species are eaten by various songbirds and by squirrels and raccoons.

\section{Fam. 27. Araceae Juss.}

\section{ARUM FAMILY}

Perennial herbs from corms, rhizomes or thick roots, with soft succulent stems and leaves, usually with slender raphides and frequently with acrid or pungent juices; the veiny leaves simple or compound; flowers unisexual or perfect, crowded on a spadix which is usually subtended by a foliaceous or colored spathe; perianth none or composed of 4 to 6 similar hypogynous segments; stamens usually 4 to 6 , hypogynous, opposite the perianth segments when these are present; ovary superior; fruit usually a berry, indehiscent or rupturing irregularly; seeds with fleshy albumen or none.

A large family, chiefly tropical, of about 115 genera and 2,000 species.

1. Plants floating on water; pistillate flowers solitary at base of inflorescence......

1. Plants rooted in soil; pistillate or perfect flowers several to many (2)

2(1). Spathe-well-developed, fleshy or petaloid (3)

2. Spathe obscure or like the foliage leaves; flowers perfect, with perianths of 6 segments (4)

3(2). Flowers covering only the base of the spadix; leaves compound.

3. Flowers almost completely covering the spadix; leaves simple.......2. Peltandra 
4. Spadix much-overtopped by the swordlike spathe that resembles the foliage leaves; leaf blades linear and more or less ensiform..........4. Acorus

\section{Arisaema Mart. Indian-TURNIP}

Low perennial monoecious herbs; the tuberous rhizome, tuber or corm sending up a simple scape sheathed with the petioles of the veiny leaves, with several sheaths surrounding base of plant; spathe convolute below and mostly expanded and arched over the spadix; flowers unisexual; perianth none; staminate flowers above the pistillate on the spadix, composed of a cluster of almost sessile 2- to 4celled anthers that open by terminal slits and pores; pistillate flowers consisting of a 1-celled ovary that contains as many as 6 erect orthotropous ovules and a broad stigma; fruit a 1 - to few-seeded globose scarlet berry.

About 150 species in America, Asia and Africa.

The fruits and, to some extent, the leaves are eaten by several species of birds.

1. Primary leaf pedately divided into 5 to 15 very unequal leaflets; the oblong summit of the spathe with inrolled margins; spadix slender, tapering, long-exserted; fruiting head conical..............1. A. Dracontium.

1. Primary leaf palmately divided into 3 or 5 segments; the ovate to lanceolate arching hood or spathe flat; spadix cylindric-tapering to clavate, included; fruiting head ovoid or subglobose (2)

2(1). Primary leaf with 3 segments, the lateral segments rarely bilobed; spathe typically suffused or striped with purple or red-brown; hood narrowly ovate to lanceolate, acute-acuminate, $2-3 \mathrm{~cm}$. wide; spadix cylindric to somewhat clavate, straight..................2. A. triphyllum.

2. Primary leaf with 5 segments, the lateral segments sometimes partly united; spathes green or yellowish-green; hood broadly ovate, abruptly pointed, 3-5 cm. wide; spadix cylindric-tapering, curved.

3. A. quinatum.

\section{Arisaema Dracontium (L.) Schott. Green Dragon, Dragon-Root.}

Leaf usually solitary, with a petiole to $5 \mathrm{dm}$. long at anthesis; leaflets sometimes confluent at base, elliptic to oblanceolate, acuminate, the central one to $2 \mathrm{dm}$. long, the outer ones successively smaller, with veins similar to those of $A$. triphyllum; peduncle to $25 \mathrm{~cm}$. long; spathe thin, about $6 \mathrm{~cm}$. long, light green; spadix with long tapering tip to $15 \mathrm{~cm}$. long or more; berries about $1 \mathrm{~cm}$. in diameter. Muricauda Dracontium (L.) Small.

Rich wet woodlands and alluvial soils in woods and thickets in Okla. (Johnston Co.) and in e. and s.e. Tex., w. onto the Edwards Plateau, May-June; Fla. w. to Okla. and Tex., n. to N. H., Vt. and s.w. Que., s. Ont., Mich. and Wisc.

2. Arisaema triphyllum (L.) Schott. JACK-IN-THE-PUlpit, Indian-TURnip. Fig. 284.

Leaves mostly 2, with petioles to $4 \mathrm{dm}$. long at anthesis; leaflets 3 , elliptic to rhombic-ovate, acute to acuminate, the lateral ones asymmetrical, with veins parallel from midrib to margin; peduncle to $2 \mathrm{dm}$. long; spathe suffused or striped with purple or red-brown; hood 2-3 cm. wide; spadix straight; berries about $1 \mathrm{~cm}$. in diameter.

Wet woods, swamps and boggy areas in e. Okla. and e. and s.e. Tex., MayJune; from Ga., w. to Tex., n. to s.e. N.Y., Conn. and s.e. Mass.

Several segregates have been proposed in this species, which are probably found in our area. The most significant are var. pusillum Peck with lateral leaflets almost symmetrical and with the expanded limb of the spathe $1.5-3 \mathrm{~cm}$. wide and usually all brown or red within; var. Stewardsonii (Britt.) Stevens with the inrolled tubular half of the spathe sharply and deeply corrugated. 


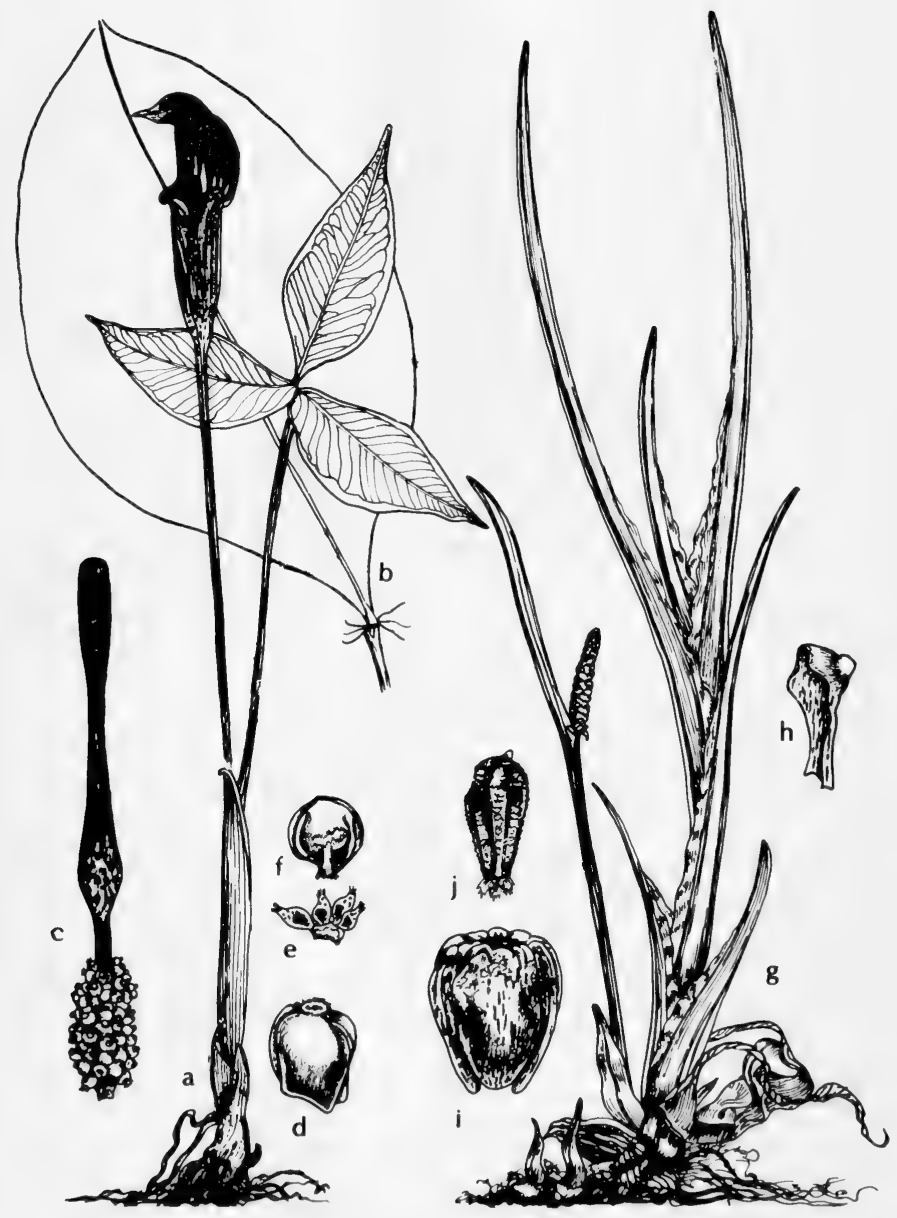

Fig. 284: a-f, Arisaema triphyllum: a, habit, X 1\%; b, outline of one leaflet, X 1/\%; c, spadix, X 11/2; d and f, berries, X 21/2; e, seeds, X 21/2. g-j. Acorus Calamus: g, habit, X $1 / 4 ;$ h, bract, X 10 ; i, fruit, X 5; j, seed, X 5. (V. F.). 


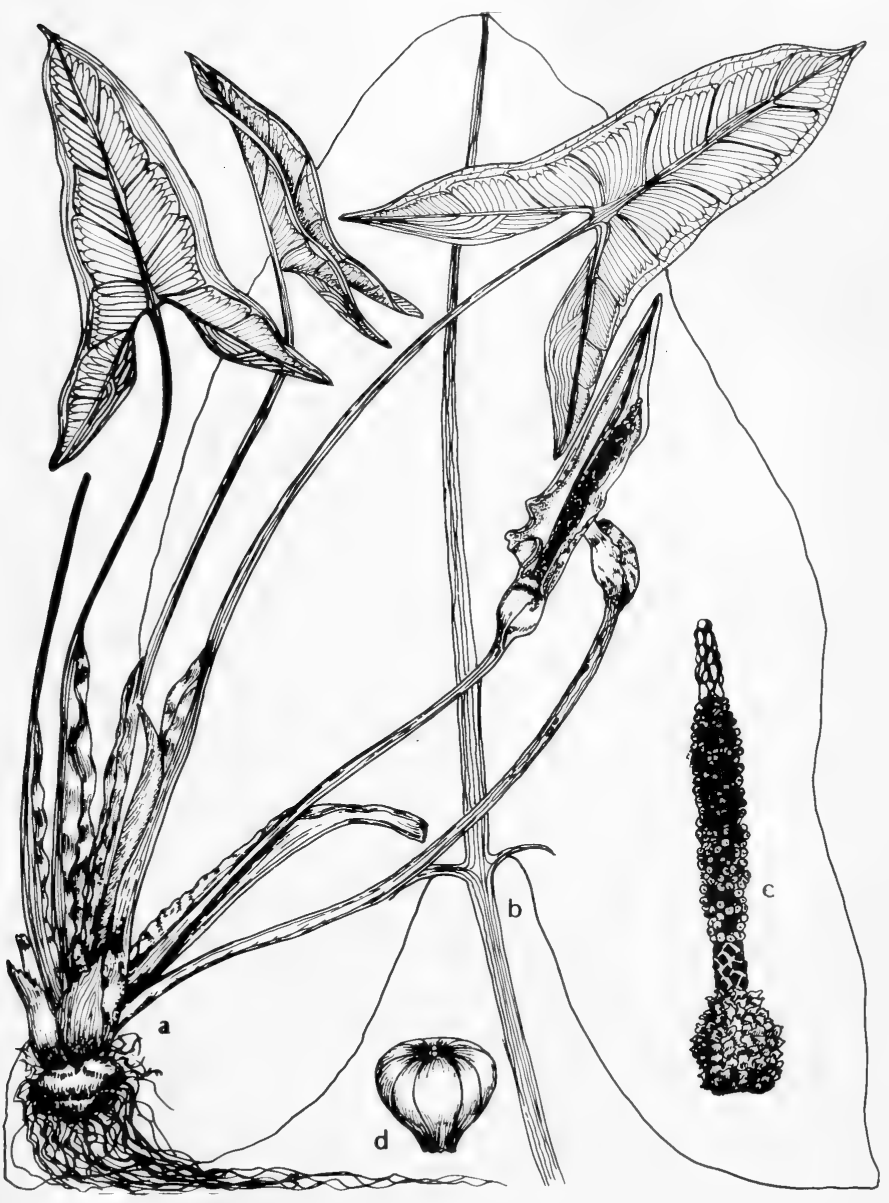

Fig. 285: Peltandra virginica: a, habit, X $1 / 3$; b, outline of leaf, X 1/2; c, spadix, X 1; d, berry (submersed), X 1. (V.F.). 


\section{Arisaema quinatum (Nutt.) Schott.}

Leaves mostly 1 , with petioles to about $3 \mathrm{dm}$. long at anthesis; leaf segments 5 , broadly ovate-elliptic to suborbicular-oval, tapering at the somewhat oblique base, abruptly acuminate at apex, glaucous beneath, to about $16 \mathrm{~cm}$. long and 10 $\mathrm{cm}$. wide, the lower 2 conspicuously the smallest; peduncle to $2 \mathrm{dm}$. long; spathe green or yellowish-green, the tube $5-6 \mathrm{~cm}$. long; hood broadly ovate and abruptly acuminate, about as long as the tube and $3-6 \mathrm{~cm}$. wide; spadix noticeably broadened near base, tapered to apex, curved; fruit 6-7 $\mathrm{mm}$. thick.

Moist wooded slopes and along stream in woods in e. Tex., Apr.-May; from Tex. e. to Ga. and n. to Tenn. and N.C.

\section{Peltandra Raf. Arrow-Arum}

An American genus of several species.

\section{Peltandra virginica (L.) Kunth. Tuckahoe. Fig. 285.}

Plants monoecious, from thick fibrous or subtuberous roots, consisting of palmately 3-nerved and pinnately veined leaves produced at base along with one or more simple scapes; petiole to about $4 \mathrm{dm}$. long; leaf blade oblong to broadly triangular, with more or less divergent well-developed basal lobes narrowed to the tip, to $2 \mathrm{dm}$. long and $15 \mathrm{~cm}$. wide, the basal lobes to $75 \mathrm{~mm}$. wide, shorter than width of blade; scape to $35 \mathrm{~cm}$. tall, in anthesis about equaling the leaves; spathe green with pale or whitish margins, somewhat leathery, to $1 \mathrm{dm}$. long; flowers unisexual, thickly covering the slender and tapering spadix throughout (or only its apex naked); perianth none; anther masses sessile, naked, covering the upper part of the spadix, each of 4 to 6 pairs of cells embedded in the margin of a thick and shield-shaped connective, opening by terminal pores; ovaries at the base of the spadix, each surrounded by several distinct scalelike staminodia, 1 -celled; berry in an ovoid fleshy head, green or light-brown, to about $1 \mathrm{~cm}$. long when dried. P. Tharpii Barkl.

Swamps, moist woodlands, bogs, along streams and about and in bodies of water in s.e. Okla. (Choctaw Co.) and e. Tex., Apr.-May; from Fla., w. to Tex., n. to s. Me., N.H., Vt., s.w. Que., n. N.Y. and s. Ont.

A number of varietal segregates have been proposed based mainly on the shape and size of the leaf blades.

The seeds are eaten by wood duck, marshbirds and shorebirds, and to some extent by muskrats.

\section{Orontium L. Golden Club}

\section{A monotypic genus of eastern North America.}

\section{Orontium aquaticum L. Fig. 286.}

Plants aquatic, with a deep stout rhizome and basal long-petioled entire leaves; petioles to $2 \mathrm{dm}$. long; leaf blade with veins parallel from base to apex, to $2 \mathrm{dm}$. long, about a third as wide; scape to $4 \mathrm{dm}$. long; spathe incomplete and distant, merely a leaf sheath investing the lower part of the slender scape and bearing a small and imperfect bractlike blade; spadix $2-5 \mathrm{~cm}$. long; flowers perfect, the lower ones with 6 concave sepals and 6 stamens, the uppermost flowers with 4; filaments wide and thin; anthers 2-celled, opening obliquely lengthwise; ovary 1celled, with an anatropous ovule; fruit a blue-green or brownish utricle.

Sandy, muddy and peaty shores and shallow water in e. (?) Tex., Apr.-June; from Fla. w. to La. (Cameron Parish) and probably Tex., n. to Mass., cen. N.Y., W.Va, and Ky.

This species has not yet been found in our area, but since it occurs in Cameron Parish, La. adjacent to Jefferson and Orange counties, Texas, there is a good possi- 


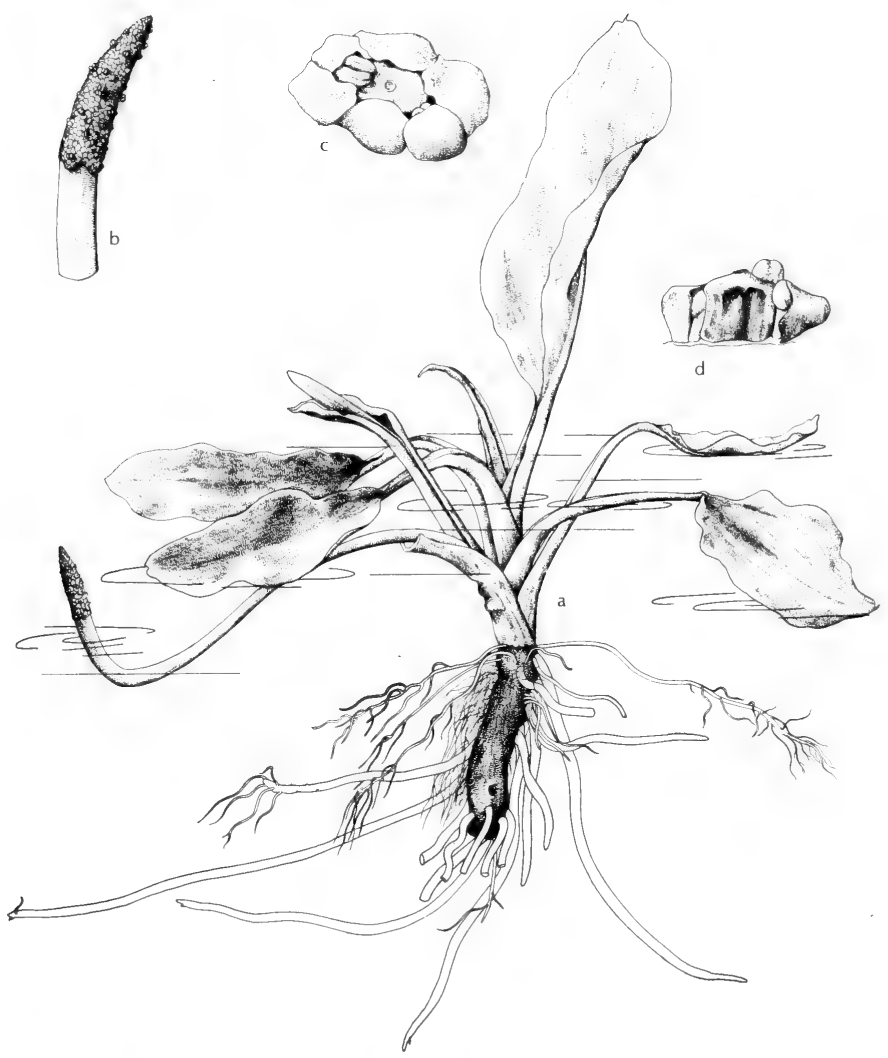

Fig. 286: Orontium aquaticum: a, habit, X 1/3; b, spadix, X $2 / 3$; c, lower flower with 6 perianth parts, $X 4$; d, side view of flower dissected showing utricle, $X 4$. (Courtesy of R. K. Godfrey). 

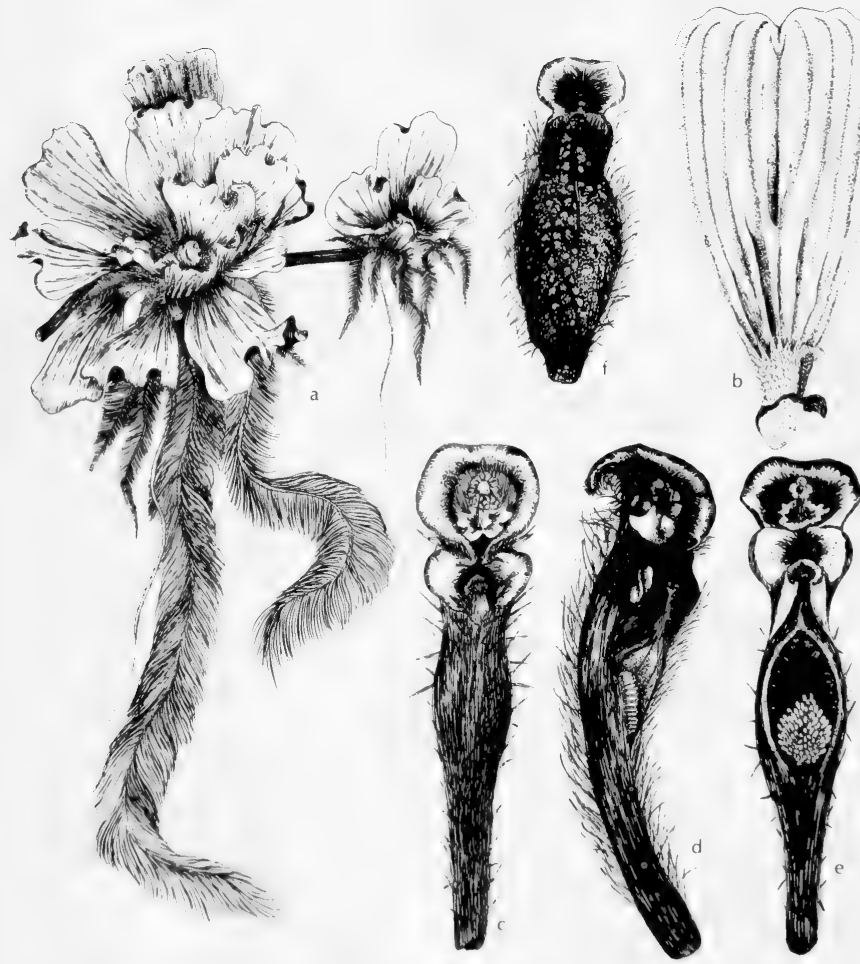

Fig. 287: Pistia Stratiotes: a, habit, X 1/3; b, large leaf, X 1/3; c-e, three views: spathe with two cavities, the upper with a whorl of 3 to 8 stamens with fused filaments, the lower with a pistil, X 4; f, pistil with seeds, X 4. (Courtesy of R. K. Godfery). 
bility that it occurs in marshes along the Sabine River in Texas.

A specimen of Lysichitum americanum Hult. \& St. John in the University of Texas herbarium bears the label "Gregg Co., March 20, 1943, Mrs. C. L. York." This typically far northern species, which was probably under cultivation at this Texas locality, resembles $O$. aquaticum but differs from it superficially by the more slender peduncle that is distinctly demarcated from the spadix.

\section{Acorus L. Sweetflag. Calamus}

A genus of 2 species in the Northern Hemisphere.

\section{Acorus Calamus L. Fig. 284.}

Aromatic plants with thick creeping rhizome and ensiform leaves crowded at the base, erect, linear and more or less ensiform, to $2 \mathrm{~m}$. long and $25 \mathrm{~mm}$. wide; scape resembling the leaves; spadix cylindrical, diverging laterally from a tall 3-angled scape, the upper and more foliaceous prolongation of the scape may be considered as a kind of open spathe, covered with yellowish-brown perfect flowers, to $1 \mathrm{dm}$. long and $1 \mathrm{~cm}$. thick at anthesis, to as much as $2 \mathrm{~cm}$. thick at maturity; perianth of 6 short concave segments; stamens 6 , the linear filaments thin and flat, with 1-celled anthers reniform and opening transversely; ovary 2- or 3-celled; fruit obpyramidal, about $4 \mathrm{~mm}$. long.

Wet places and borders of quiet water, reported (but not seen) from Okla., in n -cen. and n.e. (Marion Co.) Tex.. May-Aug.; from P.E.I., s. to Fla., w. to Mont., Ore. and Tex.; early introd. from Eur. and naturalized.

Muskrats are known to eat the plants.

\section{Pistia L. Water-lettuce. Water-Bonnet}

A monotypic genus in southern United States and Latin America.

\section{Pistia Stratiotes L. Fig. 287.}

Plants monoecious, floating herbs; leaves clustered on very short branches at the nodes of the rootstock; leaf blades entire, cuneate to obovate-cuneate, to about $25 \mathrm{~cm}$. long, strongly ribbed, dilated upward; spadix adnate to the axillary spathe; spathe about $15 \mathrm{~mm}$. long, pubescent, the upper part ovate; flowers unisexual, the pistillate solitary and the staminate above the pistillate; perianth none.

Streams, lakes and ponds in s. and s.w. Tex. (Fort Bend and Val Verde cos.); spring; from Fla., w. along the coast to Tex., through Latin Am. to S.A.

\section{Fam. 28. Lemnaceae S. F. Gray Duckweed Family}

Minute green aquatic herbs floating on or below surface of water, often forming a solid cover over the surface, occasionally in wet seepage places, muchreduced and simplified in structure, stemless, rootless or with few nonfunctional roots, vascular tissue lacking in many of the species, reproducing chiefly by budding from a single basal pouch or 2 lateral pouches, many successive generations sometimes remaining attached by short stipes; flowers from a saclike spathe in a pouch at the basal margin of the frond or breaking through the surface to one side of the spathe, consisting either of a single stamen or a single pistil, often 2 staminate flowers and 1 pistillate flower to a spathe; fruit a 1- or 2-seeded utricle; seed large, smooth or ribbed.

A family consisting of 4 well-defined genera and including about 40 species.

All of the species that comprise this family, especially Lemna minor, are used more or less by wildlife. Many species of duck as well as marsh birds and shorebirds scoop up these tiny plants along with associated minute animal organisms 
to bolster their diet. The myriad plants often form a floating sheet that smothers out much of the submerged plant life.

1. Thallus with 1 or more roots and 2 lateral reproductive pouches; inflorescence of 2 staminate and 1 pistillate flowers surrounded by a membranaceous spathe (2)

1. Thallus rootless, each with a single basal reproductive pouch; inflorescence of 1 staminate and 1 pistillate flowers with a spathe (3)

2(1). Roots usually 2 or more on each thallus; mature thallus usually obscurely or conspicuously 3- to 11-nerved, the ventral surface usually reddish-purple............................................................. Spirodela

2. Roots solitary on each thallus; mature thallus 1- to 3-nerved or apparently nerveless, the ventral surface typically green or rarely streaked or tinged with brown...................................................... Lemna

3(1). Thallus globose to ellipsoid, more or less obviously 3-dimensional, usually only mother- and daughter-thalluses connected; stipe attachment within the reproductive pouch........................................ Wolffia

3. Thallus flat, thin, lingulate or ligulate, usually falcate, appearing 2-dimensional, solitary or united in stellate colonies; stipe attachment on one side of the reproductive pouch.

4. Wolffiella

\section{Spirodela SchleID. DUCK-MEAT}

Thallus floating, solitary or usually in clusters of 2 to 5 or more, orbicular to obovate or oblong-elliptic, sometimes slightly curved, with 2 to numerous roots fascicled on ventral surface, palmately 3- to 11-nerved; reproductive pouches 2 , one on either side of the basal end; inflorescence arising from a pouch that consists of a saclike spathe enclosing 1 pistillate and 2 or 3 staminate flowers; ovary somewhat winged on the shoulders, 1- to 4-ovuled; fruit a utricle, slightly winged; seed longitudinally ribbed and transversely striate or smooth with a spongy outer layer.

About 6 species, cosmopolitan.

1. Thallus broadly obovate, usually almost as wide as long, with 5 or more nerves radiating from above the root attachment................ $1 . S$. polyrhiza.

1. Thallus oblong-elliptic to narrowly obovate, longer than wide, sometimes slightly curved, seemingly nerveless or usually with a lateral branch on each side of a central nerve just below the middle at the root attachment. 2. S, oligorhiza.

\section{Spirodela polyrhiza (L.) Schleid. Fig. 288.}

Thallus with 4 to 12 fascicled roots, conspicuously orbicular-obovate, 3-10 $\mathrm{mm}$. long, almost as broad as long, dark-glossy-green above, usually reddish-purple beneath, with 5 to 11 conspicuous radiating nerves that create a peltate appearance, the stipe marginal or submarginal and the reproductive pouches on either side; roots provided with a single vascular strand and a long pointed rootcap; forming turions at all seasons but abundantly so in the fall.

In ponds, lakes, bayous and sluggish streams throughout Okla. and Tex., through N. M. (Bernalillo Co.) and Ariz. (Navajo Co.); cosmospolitan but apparently lacking in S. A.

This is the largest of the surface-floating duckweeds. It is often present as scattered, large thalluses in masses of Lemna, Wolffiella and Azolla, and occasionally in almost pure stands. The plants winter by producing buds that are dense and sink to the bottom of the pond.

2. Spirodela oligorhiza (Kurtz) Hegelm. Fig. 289.

Thallus with 2 to 5 roots, oblong-elliptic to oblong-obovate or somewhat elliptic-reniform, 2.5-5 mm. long, $1.5-3 \mathrm{~mm}$. broad, obscurely 3 - to 5-nerved, 


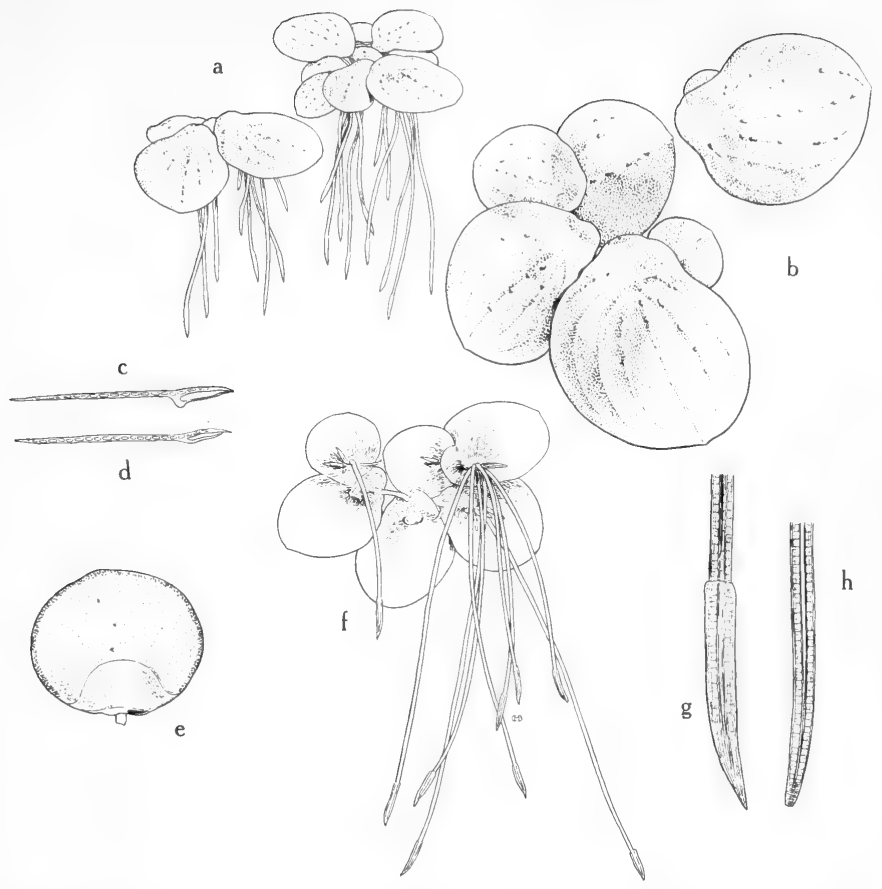

Fig. 288: Spirodela polyrhiza: a, habit, showing group of fronds, each with numerous roots, $\mathrm{X} 2$; $\mathrm{b}$, fronds producing buds, top view, showing the conspicuous nerves radiating from the reproductive pouches, $\mathrm{X} 4 ; \mathrm{c}$ and $\mathrm{d}$, fronds (longitudinal section), showing air chambers, X 4; e, winter bud, X 12; f, fronds, lower surface, showing the slender stipes by which they are attached to one another and the clustered roots, $\mathrm{X} 3 ; \mathrm{g}$ and $\mathrm{h}$, root tips, with and without rootcaps, the rootcap $0.9-1.5 \mathrm{~mm}$. long, X 20. (From Mason, Fig. 164).

closely resembling in size and shape some species of Lemna; dorsal surface yellowgreen, flat to convex; ventral surface convex, frequently somewhat inflated, commonly red-purple-pigmented.

On lakes and ponds, rare in e. Tex. (Shelby Co.); in the Far East, S. Pac. and U.S.

\section{Lemna L. DUCKWEED. DUCK-MEAT}

Diminutive free-floating aquatics or growing on wet surfaces; thallus solitary or in groups of 2 or more, with 1 to 3 nerves and a single root without vascular tissue, bearing on either side a meristematic pouch in which are vegetative and flower buds; vegetative buds usually disarticulate to form independent plants (in L. trisulca often remaining attached); flowers unisexual, produced in a membranous spathe; staminate flowers usually 2 to a spathe, each flower consisting 

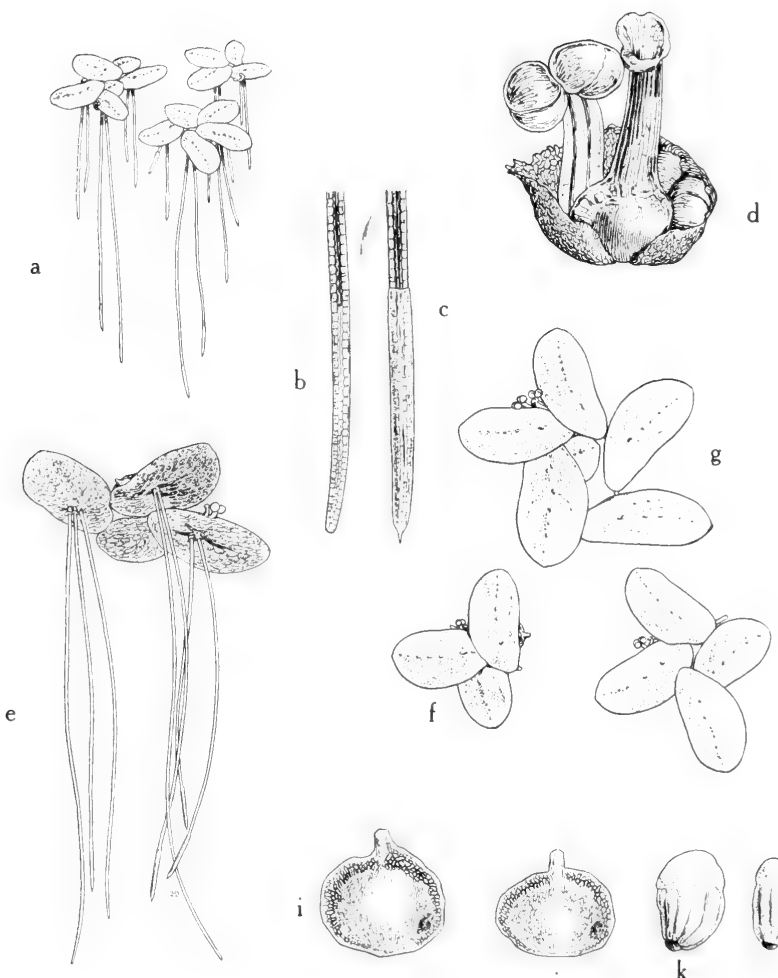

C

b
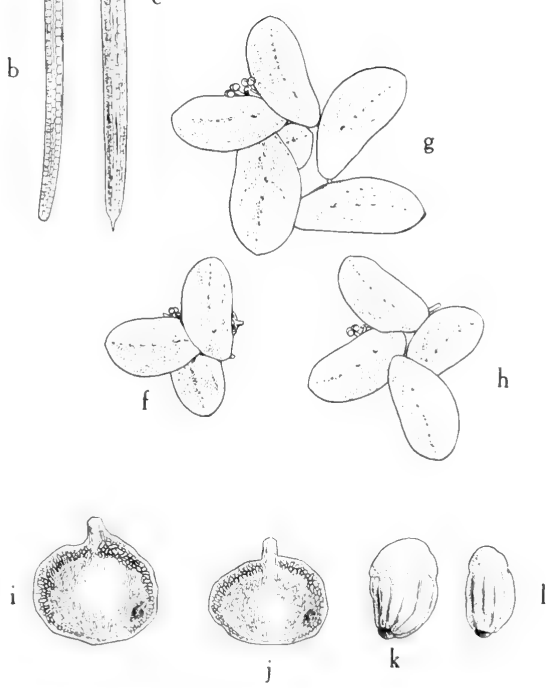

$\mathrm{m}$

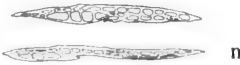

Fig. 289: Spirodela oligorhiza: a, habit, X 2; b and c, root tips, with and without rootcaps, the rootcap $1.2-1.9 \mathrm{~mm}$. long, $X 20$; d, pistillate flowers and pair of staminate flowers enclosed by short spathe open on one side, X 40; e, habit. lower surface, showing the large netlike air spaces and the flowers and fruit arising from pouch, $X \quad 4 ; f$, fronds, top view, with flowers and fruit, $X 4 ; \mathrm{g}$ and $\mathrm{h}$, fronds remaining attached to one another by slender stipes, $X 4 ; \mathrm{i}$ and $\mathrm{j}$, fruits, showing the winged shoulders, $X 16$; $k$ and $I$, seeds, ribbed and minutely reticulate, $X 16 ; m$ and $n$, frond (longitudinal section), showing air chambers, X 8. (From Mason, Fig. 163) 
of a single stamen; pistillate flowers usually 1 to a spathe and having a single pistil; ovary 1- to 3-ovuled; seeds usually early-ribbed and containing a distinct operculum.

About 15 species, mostly world-wide in distribution.

Identification of the species can be more certain when live, fresh plants are available. Although the highest power of a dissecting microscope can be used in studying the flowers and fruits, best results can be obtained by using a somewhat higher magnification.

1. Thallus elliptic to lanceolate, commonly dilated below middle, usually submersed, long-stipitate, frequently with many remaining attached to form long chains, commonly denticulate near and at apex.

1. L trisulca.

1. Thallus obovate to oblong or oblong-elliptic, usually floating, short-stipitate or sessile, characteristically 2 to 5 attached, entire (2)

2(1). Thallus typically oblong to oblong-elliptic; dorsal surface flat, smooth, with no prominent protuberances, nerveless or very obscurely 1nerved (3)

2. Thallus typically obovate to suborbicular; dorsal surface with more or less prominent protuberances, indistinctly to prominently 3-nerved (4)

3(2). Thalluses often 8 to 10 attached, obliquely oblong, thin and flat, without papules, the surface texture uniform throughout.....2. L. valdiviana.

3. Thalluses seldom more than 2 remaining attached, oval, symmetrical, thick, with a low median ridge bearing 2 or more papules, usually with a thin margin.

3. L. minima.

4(2). Root sheath with definite wings or appendages; thallus thin or somewhat thickened and light green, typically without pigmentation (5)

4. Root sheath without wings or appendages; thallus thickish, yellow- or darkgreen and typically with some pigmentation (6)

5(4). Thallus usually not prominently nerved, generally biconvex, the apical papilla prominent.

4. L. perpusilla.

5. Thallus distinctly 3-nerved, flat, thin.

5. L. trinervis.

6(4). Thallus usually much less than $3 \mathrm{~mm}$. long and $2 \mathrm{~mm}$. wide, symmetric at apex.

6. L. obscura.

6. Thallus usually more than $3.5 \mathrm{~mm}$. long and $2 \mathrm{~mm}$. wide (7)

7(6). Thallus symmetric at apex; ventral surface of thallus flat or slightly convex but not inflated; dorsal surface of thallus dark-green, the air spaces not prominent; fruits broad but not winged at the shoulders; seed 1.................................................... . L. minor.

7. Thallus asymmetric at apex; ventral surface of thallus noticeably convex, usually inflated; dorsal surface of thallus mottled yellow-green, the air spaces prominent; both surfaces of thallus showing red-purple coloring; fruits winged at the shoulder; seeds usually 2...8. L. gibba.

1. Lemna trisulca L. Ivy DUCKWEED. Fig. 290.

Often forming dense masses, usually floating just beneath the surface except when flowering, mother- and daughter-thalluses often remaining attached for several generations by long attenuate stipes; thallus $5-15 \mathrm{~mm}$. long, $2.5-5 \mathrm{~mm}$. wide, lanceolate-elliptic to oblanceolate, flat on both surfaces, translucent, attenuate below into a slender stipe, entire or mostly denticulate at the apex, each with a solitary root or in some thalluses the root lacking; rootcap acutely pointed.

In ponds and slow-moving streams, reported from Tex. and in N. M. (Catron, Grant and Socorro cos.) and Ariz. (Apache Co.); in temp. zones of the N. Hemis. 


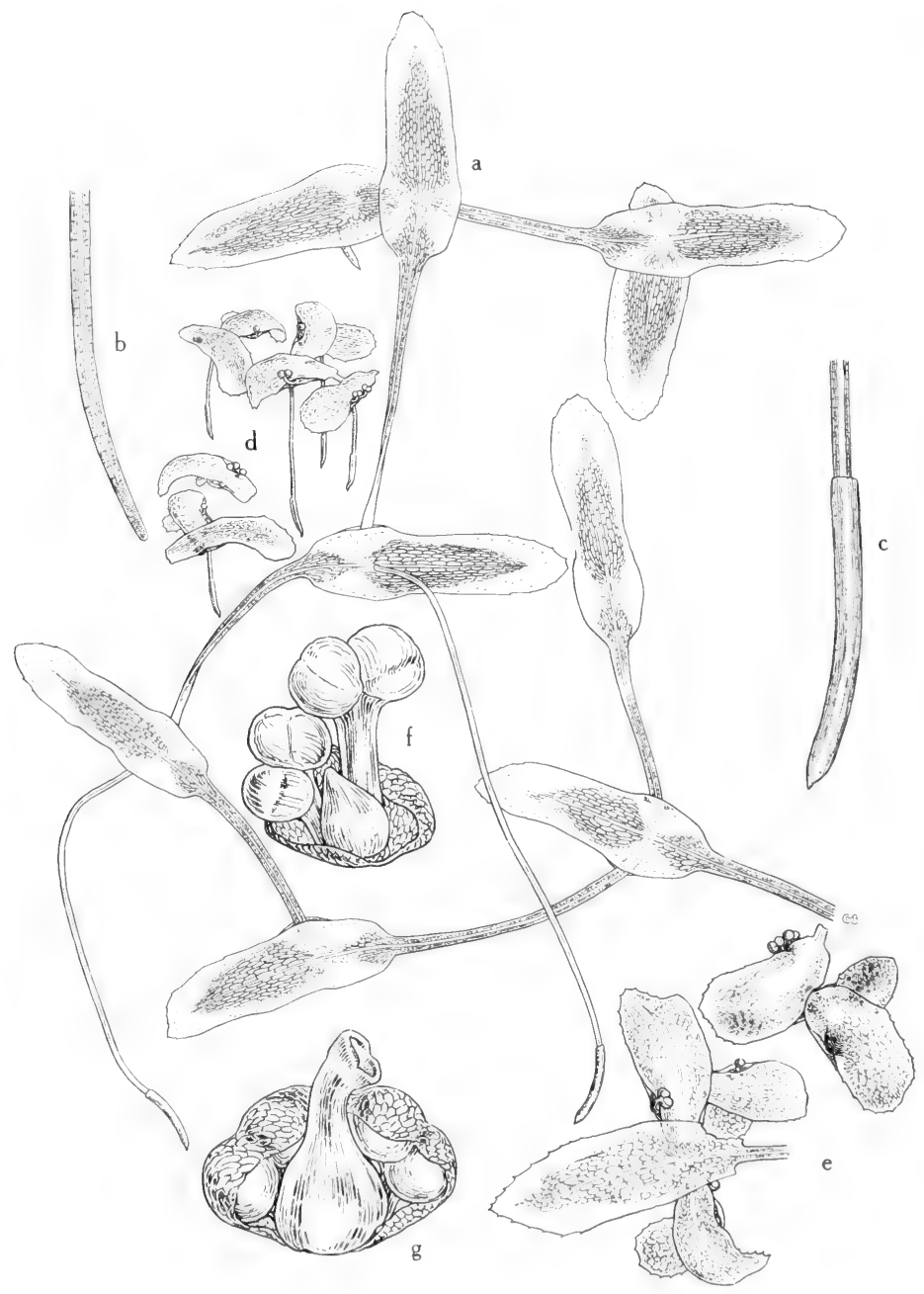

Fig. 290: Lemna trisulca: a, habit, vegetative plant, showing mother and daughter fronds remaining attached by long attenuate stipes, some fronds with solitary root, $\mathrm{X} 4$; b, root tip without the rootcap, X 20; c, root with rootcap, X 20; d, habit, flowering plants, $X 2$; e, flowering plants, showing flowers emerging from lateral pouches, $X$ 4; $\mathrm{f}$, spathe at time of development of staminate flowers, X $40 ; \mathrm{g}$, spathe at time of development of pistillate flowers, X 40. (From Mason, Fig. 159) 

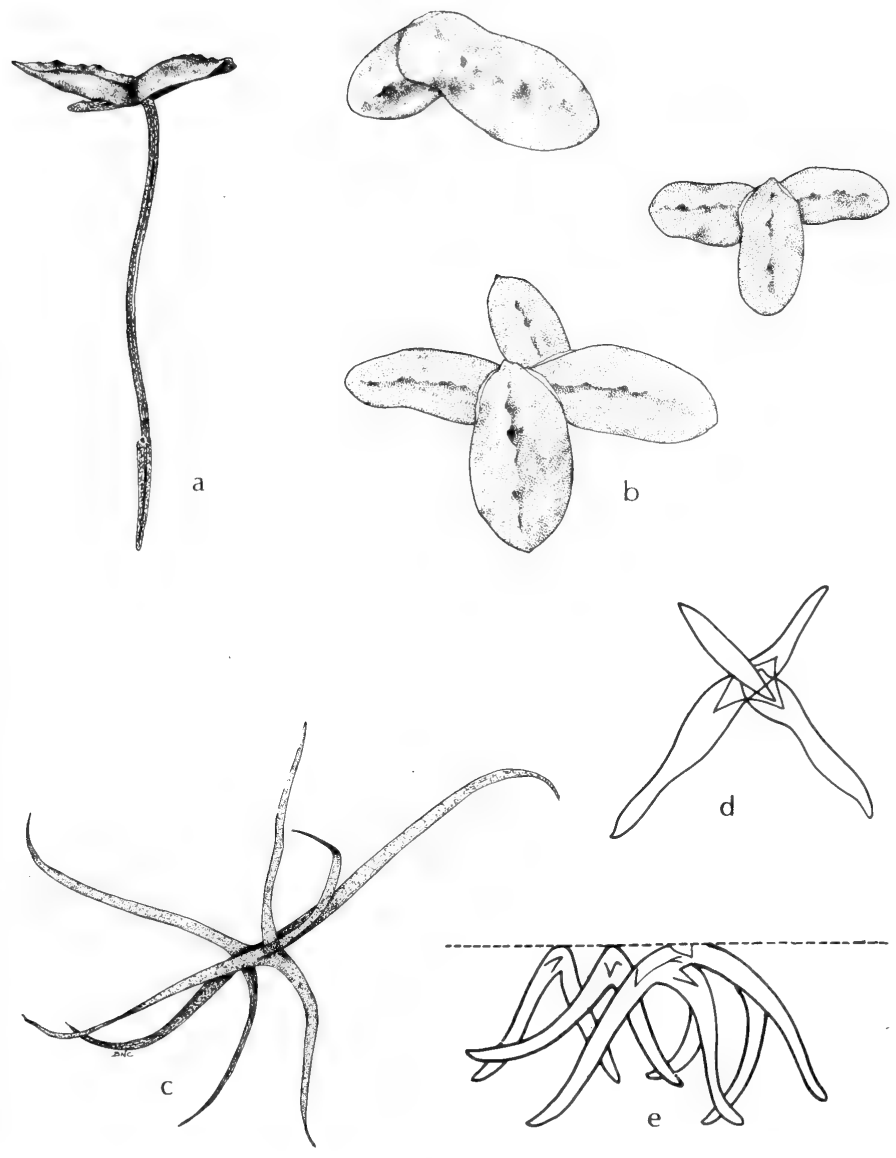

Fig. 291: a and b, Lemna valdiviana: a, fronds and root, X 5; b, group of fronds from above, X 8. c, Wolffiella floridana: c, colony of plants, X 5. d and e, Wolffiella gladiata: d, typical shape and habit of growth, X $31 \frac{1}{2}$; e, colony of plants in water, X $3 \frac{1}{2}$. (a-c, Courtesy of R. K. Godfrey; d and e, from Daubs). 


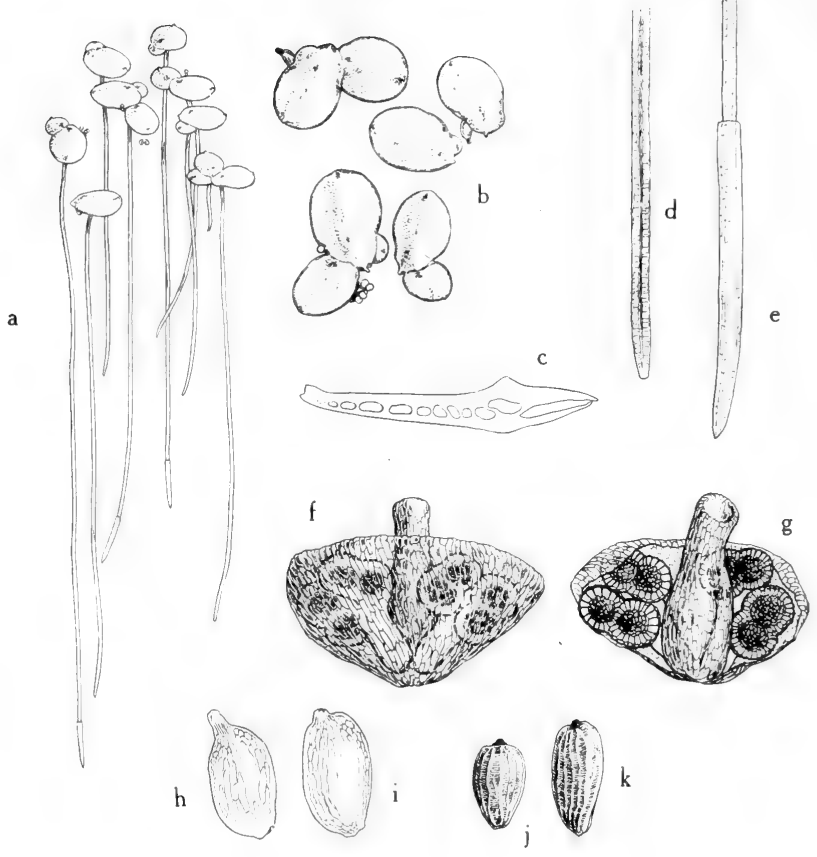

Fig. 292: Lemna minima: a, habit, showing flowering fronds with long, solitary roots, X 2; b, habit, top view of fronds with flowers and fruits, X 4; c, frond (longitudinal section), the air spaces in a single layer, $X 12 ; \mathrm{d}$ and $\mathrm{e}$, root tips, with and without rootcap, X 20; f and g, pistillate and staminate flowers, the broad enclosing spathe reniform and open on one side, $X 48 ; \mathrm{h}$ and $\mathrm{i}$, fruits, slightly flattened, $\mathrm{X} 16 ; \mathrm{j}$ and $\mathrm{k}$. mature seeds, longitudinally ribbed and cross-striate, X 16. (From Mason, Fig. 162).

\section{Lemna valdiviana Phil. Fig. 291.}

Thallus narrowly elliptic to oblong or oval, solitary or several together, 2-5 $\mathrm{mm}$. long, 0.5-2 $\mathrm{mm}$. wide, symmetrical to somewhat falcate, obscurely 1 -nerved or nerveless, the dorsal surface of conspicuously uniform texture throughout, light green and often translucent.

In ponds, lakes, ditches and about springs in s.e. Okla. (McCurtain Co.), throughout Tex. and Ariz. (Coconino, Greenlee, Pima and Yavapai cos.); widespread in the W. Hemis.

\section{Lemna minima Phil. Fig. 292.}

Thallus solitary or in small clusters, oblong to elliptic or somewhat ovoid, 1-2.5 mm. long, 0.7-1.5 mm. wide, sometimes with only occasional members larger, thick, the dorsal surface convex, commonly nerveless or with an obscure nerve and a row of papules along the middle, usually with a thin margin around 
the thallus that becomes hyaline near the base, the air chambers in 1 layer.

In ponds, lakes, canals and lagoons in s.e. Okla. (McCurtain Co.), general but mostly in the w. half of Tex., N.M. (Grant, Sandoval and Socorro cos.) and Ariz. (Maricopa and Santa Cruz cos.); in w. U.S. and S.A.

Vegetatively, what one might consider to be the largest thallus of this species could easily be taken for the smallest thallus of $L$. valdiviana. An arbitrary separation of species based on size differences is most unsatisfactory, but in this case this condition exists.

\section{Lemna perpusilla Torr. Fig. 293.}

Thallus solitary or in small clusters, obovate to orbicular-obovate, oblique, 1-2.5 mm. long, 0.7-2 mm. wide, obscurely 1- to 3-nerved, rather thick, usually light-green, not pigmented, with large air spaces within that are in 1 layer, the apical papilla usually prominent, sometimes with a row of papules along the mid-nerve. L. aequinoctiales Welwitch.

In ponds and lakes in e. Okla. (Johnston, McCurtain and Washington cos.) e., cen. and s. Tex. and Ariz. (Pima and Santa Clara cos.); distributed more or less throughout the world.

\section{Lemna trinervis (Aust.) Small.}

Thallus solitary or several attached, 2.5-5 mm. long, $1.5-3 \mathrm{~mm}$. wide, obovate to elliptic-obovate, with an obtuse to rounded apex and subacute base, very nearly symmetrical, thin and membranous, flat on both surfaces, light to medium green, typically not pigmented but occasionally with some pigment, papillae lacking or at least not prominent, with 3 distinct and prominent nerves; root sheath winged, the rootcap acute. $L$. perpusilla var. trinervis Aust.

In lakes, streams, ditches and canals in Okla. (Adair, Alfalfa, Blaine, Bryan, Comanche, Harper and Ottawa cos.), throughout Tex., in N. M. (Catron, Mora, Rio Arriba, San Juan and Taos cos.) and Ariz. (Maricopa, Navajo and Yavapai cos.); mostly in the W. Hemis.

\section{Lemna obscura (Austin) Daubs.}

Thallus solitary or only 2 or 3 attached, 1.5-3.5 mm. long, 1-2.5 mm. wide, usually toward the smaller range, obovate to suborbicular, slightly asymmetrical at the obtuse to rounded apex, nerveless or indistinctly nerved, the margin entire, thin and frequently curling when dried; dorsal surface medium green, slightly laterally convex; ventral surface strongly red-purple, rounded-convex slightly inflated; root sheath short, the young root usually lying in a furrow similarly to L. minor.

In sluggish streams, sloughs, quiet lakes and ponds in s.e. Okla. (McCurtain Co.), e., cen. and s. Tex., N. M. (Grant and Valencia cos.) and Ariz. (Apache and Navajo cos.); e. and s. U.S., w. to Calif. and Mex.

Those plants whose thallus is less than $3 \mathrm{~mm}$. long and is somewhat ventrally convex and inflated are arbitrarily referred here. There is little doubt that it is part of a complex involving $L$. gibba and $L$. minor. It is more probable that these plants should be considered as merely small forms of $L$. minor.

\section{Lemna minor L. WATER Lentil. Fig. 293.}

Thallus solitary or clustered, suborbicular to elliptic-obovate, 2-4 mm. long, 1.5-3 mm. wide, opaque, with 2 layers of air spaces within that are not inflated, nearly flat on both sides, obscurely 1 -nerved above, the dark-green surface often suffused with red or purple, a low median ridge often terminated by a conspicuous papilla or sometimes with a row of papules along the median ridge.

In quiet waters of sloughs, lakes, canals and ponds in Okla. (Beaver, McCurtain and Texas cos.), general but mostly in the w. half of Tex., N.M. (Catron, Grant, 

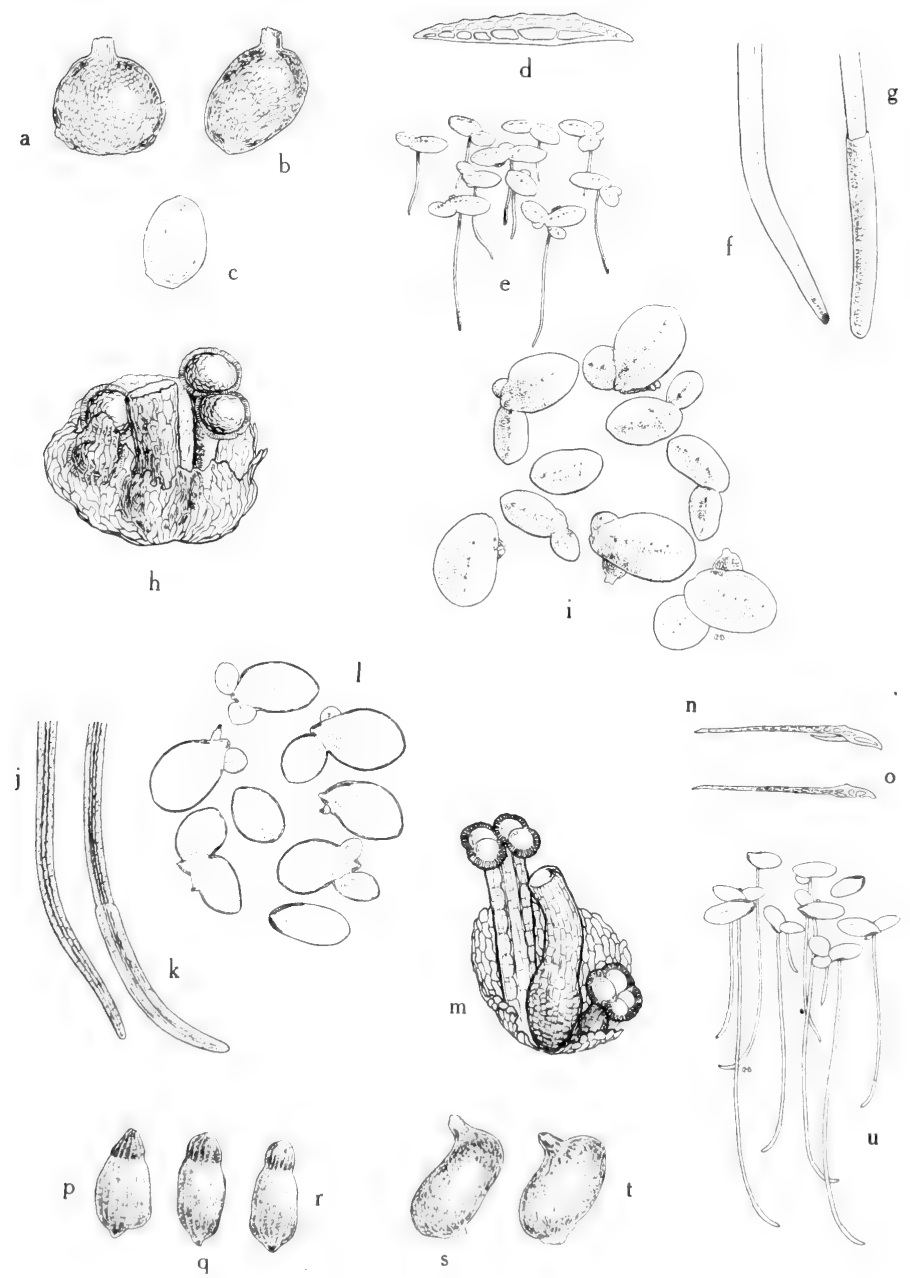
Rio Arriba, Sandoval, San Juan and Valencia cos.) and Ariz. (Apache, Maricopa, Mohave, Navajo, Pima, Pinal and Yavapai cos.); distributed throughout the world.

Those plants whose thallus is not or is scarcely inflated and is 3-6 $\mathrm{mm}$. long are placed here. It has never been made entirely clear, even by the most recent monographer of the genus, as to how this plant really differs from the so-called "flattened form" of $L$. gibba.

\section{Lemna gibba L. InfLATEd dUCKWEed, Wind-Bags. Fig. 294.}

Thallus solitary or few in a group, orbicular-obovate, $2-5 \mathrm{~mm}$. long, $2-4 \mathrm{~mm}$. wide, thick, with 2 layers of air spaces within, dark-green above and often suffused with red or purple, with a slight ridge and 1- to 3-nerved above and conspicuously round, usually inflated-gibbous on the ventral side because of the enlargement of the lower tier of air spaces or these not much enlarged and the thallus merely convex below.

In ponds, marshes and slow streams in w. Tex., N.M. (Grant and Hidalgo cos.) and Ariz. (Cochise, Maricopa, Mohave, Pima, Pinal, Santa Cruz and Yavapai cos.); widely distributed throughout most of the world.

\section{Wolffia Horkel WATER-MeAL}

Diminutive floating rootless herbs, scarcely visible to the naked eye as individuals and often forming uninterrupted green masses on the surface of the water as a thin green scum; thallus spheroid to ellipsoid, sometimes flattened above, with a single funnel-shaped reproductive pouch at one end that bears asexually successive daughter-fronds, sometimes bearing masses of red pigment bodies in each epidermal cell; inflorescence breaking through the upper surface of the frond, composed of 1 staminate flower consisting of a single stamen and 1 pistillate flower consisting of a single pistil; utricle spherical, smooth.

About 10 species, mainly in the tropics and subtropics.

The thallus, about the size of a pinhead, is the smallest seed plant known. Identification of the species can be more certain when live, fresh plants are available. Although the highest power of a dissecting microscope can be used in studying the flowers and fruits, best results can be obtained by using a higher magnification.

1. Thallus mostly globular, the dorsal surface strongly convex and without a papilla, without pigmented cells in epidermis......... $W$. columbiana.

1. Thallus typically ellipsoidal or broadly ovoid, commonly punctate on all surfaces, with brown or reddish-brown pigment cells in epidermis (2)

2(1). Thallus with a prominent conical papilla in center of dorsal surface 2. W. papulifera.

2. Thallus with dorsal surface flat or slightly rounded and without a papilla........ 3. W. punctata.

Fig. 293: Lemna. a-i, L. minor: a and b, shouldered fruits, $a$ showing remains of spathe, X 16; c, seed, X 16; d, frond (longitudinal section), X 8; e, group habit, showing the papules along median ridge and the solitary roots, $\mathrm{X} 2$; f and $\mathrm{g}$, roots with and without rootcap, $X 28 ; \mathrm{h}$, pistillate and staminate flowers in short saclike spathe, $\mathrm{X} 36$; i, habit, top view showing young, flowering, and fruiting fronds, $\mathrm{X} 4$. $\mathrm{j}-\mathrm{u}, L$. perpusilla: $\mathrm{j}$ and $\mathrm{k}$, roots, with and without rootcap, $\mathrm{X} 12 ; 1$ habit, showing top view of fruiting fronds, $\mathrm{X} 4 ; \mathrm{m}$, pistillate and staminate flowers. the surrounding spathe open on one side, $\mathrm{X} 40 ; \mathrm{n}$ and $\mathrm{o}$, fronds (longitudinal section), the air spaces in a single layer, $\mathrm{X} 8$; p-r, mature seeds, ribbed, cross-striate between ribs, X 20; s and t, fruits asymmetrical, $\mathrm{X} 20$; u, group habit, the roots long, X 2. (From Mason, Fig. 161). 

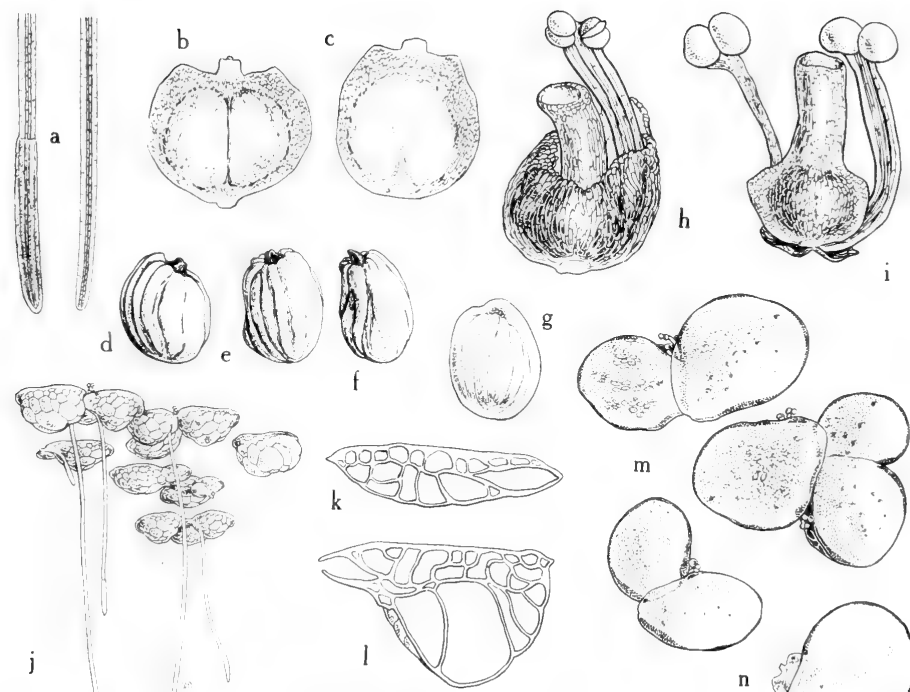

j
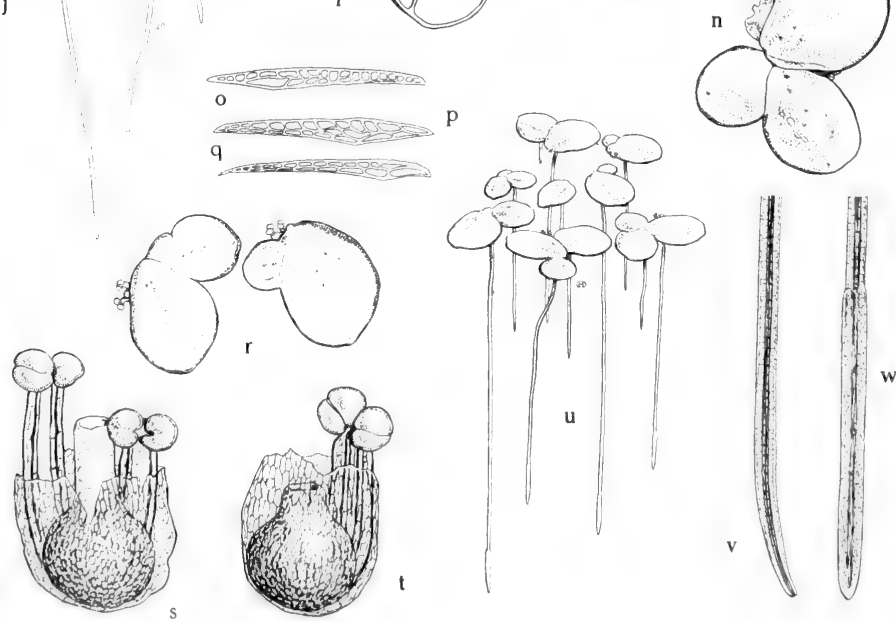
1. Wolffia columbiana Karst. Fig. 295.

Thallus solitary or paired, globular or rarely ellipsoidal, $0.8-1.4 \mathrm{~mm}$. long, $0.4-0.8 \mathrm{~mm}$. wide, scarcely if at all flattened, green on all surfaces, not conspicuously punctate, the dorsal surface not flattened and without a papilla.

On lakes and sloughs of Okla. (Choctaw and McCurtain cos.) and e. and s. Tex.; from N. E. to Calif., s, to n. S.A.

\section{Wolffia papulifera Thomps. Fig. 295.}

Thallus solitary or paired, mostly broadly ovoid, $0.5-1.5 \mathrm{~mm}$. long, $0.3-1 \mathrm{~mm}$. wide, green, brown-punctate on all surfaces, the dorsal surface flattened and bearing a conspicuous papilla.

On surface of lakes and ponds in Okla. (Choctaw and McCurtain cos.) and in e. Tex. and on the Edwards Plateau; from Va. s. to Fla., w. to Tex., Kan. and Ill.

\section{Wolffia punctata Griseb.}

Thallus ellipsoid to ovoid-oblong, usually tapering to an acutish apex, 0.7-1.2 $\mathrm{mm}$. long, $0.4-0.7 \mathrm{~mm}$. wide, the dorsal surface flattened and without a papilla, punctate on all surfaces with brown pigment cells.

In marshes, lakes and sloughs in s.e. Okla. (McCurtain Co.) and e. Tex. (Bowie, Cherokee, Harrison and Henderson cos.); from Conn. to Ont. and Minn., s. to Tex. and the W. I.

\section{Wolffiella Hegelm. MUd-Midget. Bog-Mat}

Thalluses flat, thin, membranous, elongate or straplike, frequently falcate, solitary or commonly 2 remaining attached, sometimes many remaining connected to form extensive colonies, rootless, usually floating submersed except for a small area at the base, more or less punctate with brown pigment cells in epidermis of all surfaces, commonly reproducing by budding from a single triangular (in outline) basal pouch, rarely flowering; flowering cavities on dorsal surface at one side of median line; flowers not enclosed in a spathe, unisexual, consisting of a single stamen or a single pistil, the pistillate flower with a single orthotropous ovule; fruit a slightly laterally compressed utricle with the style persistent; seed smooth, with spongy outer coat, the prominent operculum flattened.

About 8 species, primarily in the New World.

1. Thallus lingulate (tongue-shaped), strongly curved, up to 4 times as long as wide, usually 2 attached to form a circle................. W. lingulata.

1. Thallus more or less sickle-shaped, mostly 5 times or more longer than wide, usually several to many cohering in colonies (2)

2(1). Thallus broad at base, abruptly tapered to the obtuse-rounded apex, slightly falcate 2. $W$. gladiata.

2. Thallus narrow at base, gradually tapered to a slender sharp point, usually doubly falcate.....................................................$W$. floridana.

Fig. 294: Lemna gibba: a, roots, with and without rootcap, X 12; b and c, winged fruits, the ovules 1 to $3 ; \mathrm{X} 12 ; \mathrm{d}-\mathrm{f}$, mature seeds, showing corky ribs and conspicuous operculum, X 16; g, young seed, X 16; h, staminate and pistillate flowers surrounded by saclike spathe, $\mathrm{X} 23$; i, flowers with spathe removed, showing the pistillate flower with winged shoulders and a pair of staminate flowers, $X 25 ; \mathrm{j}$, flowering and fruiting fronds with inflated gibbous lower side and solitary roots, $\mathrm{X} 2 ; \mathrm{k}$ and 1 , fronds (longitudinal section), showing variation in the air spaces, $X 8 ; \mathrm{m}$, habit, top view of flowering fronds, X $4 ; \mathrm{n}$, habit, top view of fronds, the parent frond with fruit, X 4 . $0-w$, non-gibbous plants; o-q, fronds (longitudinal section), X 8; r, habit, flowering fronds, $\mathrm{X}-4 ; \mathrm{s}$ and $\mathrm{t}$, pistillate and staminate flowers surrounded by spathe, $\mathrm{X} 28$; u, habit, showing group of plants, X 2; v and $w$, roots, with and without rootcap, X 20. (From Mason, Fig. 160). 

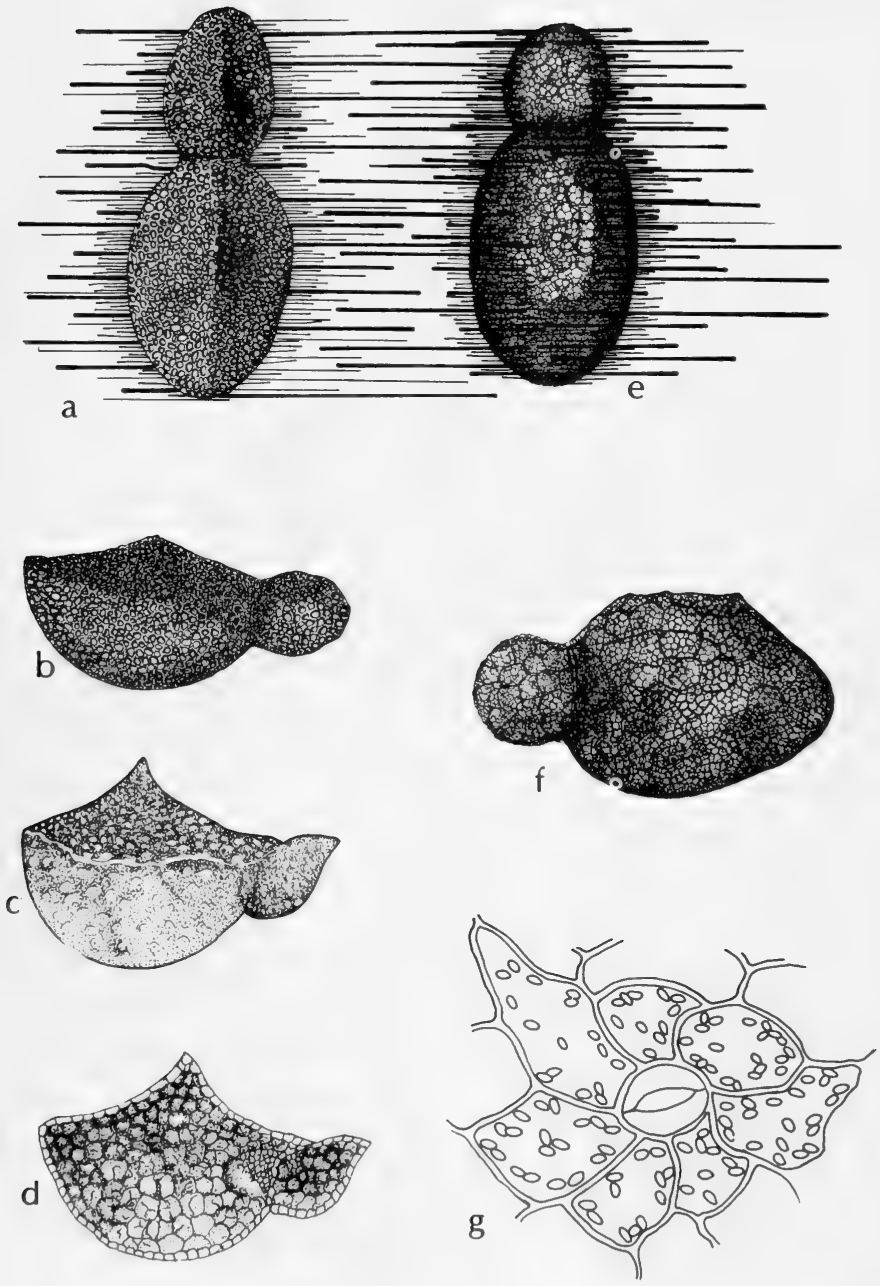

Fig. 295: a-d, Wolffia papulifera: a, dorsal view, about X 40; b and c, lateral view, X 40; d, longitudinal section, X 40. e-g, Wolffia columbiana: e, dorsal view, about X 40; $\mathrm{f}$, lateral view, X 40; g, cell, greatly enlarged to show stoma. (Courtesy of R. K. Godfrey). 

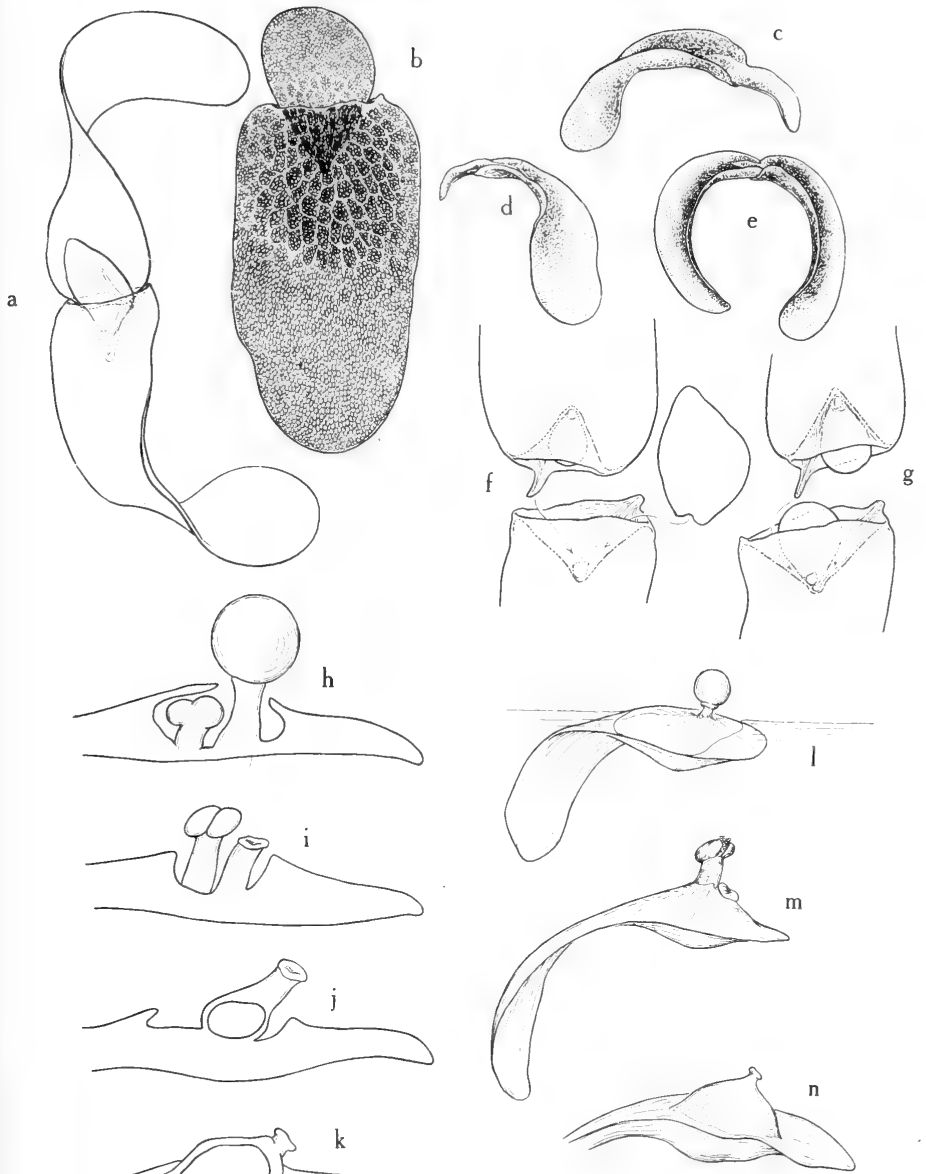

Fig. 296: Wolffiella lingulata: a, parent and daughter fronds forming recurved band, $\mathrm{X} 8$ : b, parent frond and young daughter frond, top view, $\mathrm{X} 8$; c-e, side view of fronds, $\mathrm{X} \mathrm{4;} \mathrm{f}$ and $\mathrm{g}$, parent and daughter fronds dividing, $\mathrm{X} 8$; h-k, diagrammatic representation of development of flower and fruit; 1 , frond, side view, showing stigma with a spherical globule of liquid; $\mathrm{m}$, frond, side view, the single anther protruding beyond the stigma; $n$, fruit embedded in frond. (From Mason, Fig. 166). 


\section{Wolffiella lingulata (Hegelm.) Hegelm. Fig. 296.}

Thalluses broadly oblong to linear, somewhat curved, 5-10 $\mathrm{mm}$. long, 1-5 $\mathrm{mm}$. wide, the surfaces concave or channelled, the parent- and daughter-thalluses often recurved and together appearing like a segment of a band.

In freshwater pond in Tex. (Brazoria Co.); in La., Tex. and Calif., s. through Latin Am. to Urug.

\section{Wolffiella gladiata (Hegelm.) Hegelm. Fig. 291.}

Thalluses $3.5-8 \mathrm{~mm}$. long, 1-2 mm. wide at the broad base, tapered to an obtuse-rounded apex, usually several or many cohering to form submerged colonies, somewhat falcate.

Growing in fresh nitrogenous water pond on Brazoria National Wildlife Refuge, s.e. of Angleton, Brazoria Co., Tex., associated with Lemna, Riccia fluitans and Ricciacarpus natans (fide R. J. Fleetwood), spring-summer; La. and Tex., s. through Latin Am. to Urug.

3. Wolffiella floridana (J.D. Sm.) Thomps. Fig. 291.

Thalluses fistulose, usually several in a group, sometimes paired or solitary, thin, sickle-shaped or conically elongated, attenuate to an acuminate apex, 5-10 $\mathrm{mm}$. long, 0.4-0.7 mm. wide, green on all surfaces, often brown-punctate.

On lakes and ponds in s.e. Okla. (McCurtain Co.) and e. Tex.; in inland waters of the U.S. along the Atl. and Gulf coasts, and in the Miss. Valley n. to Mo.

\section{Fam. 29. Mayacaceae KunTH}

\section{Bogmoss FAMILY}

Small mosslike plants of wet soils and shallow flowing water; leaves cauline, numerous, crowded on stem; peduncles axillary, 1-flowered, arising along stem; flowers perfect, regular, hypogynous, 3-merous; sepals and petals each 3, quite distinct from each other; stamens 3, opposite the sepals; filaments filiform; anthers oblong to ovoid, basifixed, opening by a terminal pore; ovary 1-celled, superior; ovules several; style filiform; fruit a 3-celled and 3-valved capsule, dehiscent between the placentae.

A monogeneric family.

\section{Mayaca Aubl.}

Characters of the family. About 10 species in tropical and warm-temperate America, one in tropical Africa.

1. Mayaca Aubletii Michx. Bogmoss. Fig. 297.

Stems tufted or matted, to $2 \mathrm{dm}$. long, usually much less; leaves linearlanceolate, 3-5 mm. long, 1-nerved; pedicels much-exceeding the leaves in length; sepals lanceolate, about $4 \mathrm{~mm}$. long; petals pink or whitish, obovate, about $4 \mathrm{~mm}$. long, persistent with sepals; capsule subglobose, about $4 \mathrm{~mm}$. in diameter. $M$. Michauxii Schott \& Endl.

Springy and seepage areas, mainly along and in streams, and about ponds in s.e. Tex., May-July; on Coastal Plain from Va. (?) s. to Fla. and w. to Tex.

A second species, $M$. fluviatilis Aubl., with pedicels shorter than the leaves and its capsule more ellipsoid, occurs east of Texas. It may eventually be discovered in seepage areas in extreme southeast Texas.

\section{Fam. 30. Xyridaceae Agardh}

\section{Yellow-eyed Grass Family}

Perennial or sometimes annual rushlike herbs with narrow mostly basal and tufted leaves that sheath the lower part of a naked scape which is terminated by 

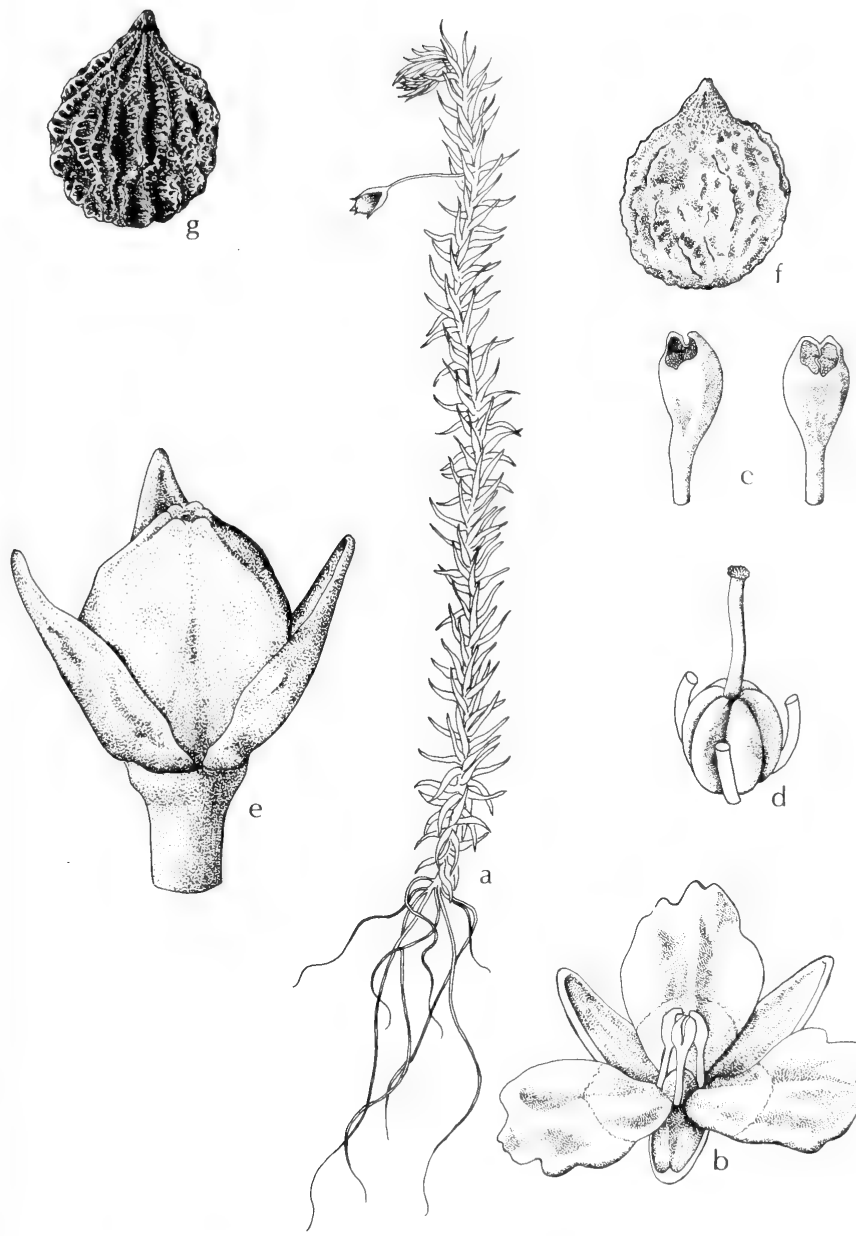

Fig. 297: Mayaca Aubletii: a, habit, X 1; b, flower. X 4; c, anthers, X 15; d, ovary and style, X 9; e, capsule, X 9; f, young seed, X 25; g, mature seed, X 25 . (Courtesy of R. K. Godfrey). 
a globose to cylindrical headlike spike of perfect trimerous flowers; floral bracts usually densely spirally imbricate, coriaceous or rigid, typically concave and dorsally marked with a blotch of different color or texture, the upper bracts subtending a solitary flower, the lower ones often sterile and forming an involucre; calyx irregular, glumaceous, the 2 persistent lateral sepals cymbiform and dorsally keeled or winged, the larger anterior sepal obovate and enfolding the corolla in bud and deciduous with it; petals yellow or rarely whitish, obovate, with claws that are more or less coherent, fugacious; stamens inserted on the petal claws, the basifixed anthers extrorse; staminodes (when present) alternate with the petals, bifid and bearded at apex; style 3-cleft; capsule ellipsoid, free, 1-celled, with 3 parietal somewhat projecting placentae, 3-valved, with numerous more or less ribbed ellipsoid to fusiform orthotropous seeds.

A family of two genera, mostly in tropical regions.

\section{Xyris L. Yellow-eyed Grass}

Characters of the family. A genus of about 250 species distributed mostly in tropical and subtropical regions in America, Africa and Australia.

1. Keel of lateral sepals ciliate or fimbriate (2)

1. Keel of lateral sepals lacerate, usually quite thin, rarely entire (4)

2(1). Tips of lateral sepals exserted beyond the subtending bract, fimbriate (usually crisped); spikes seldom shorter than $1 \mathrm{~cm}$.; seeds seldom shorter than $0.8 \mathrm{~mm}$., fusiform, with broad flat longitudinal ridges; sheaths of the scape exceeded by the leaves........... $X$. caroliniana.

2. Tips of lateral sepals not exserted beyond the subtending bract and not fimbriate (in old or dried spikes the lateral sepals may separate from the bracts and appear to be exserted but exsertion is supposed to mean that bracts are shorter than sepals); seed lengths and shapes various but the seeds without broad flat longitudinal ridges; sheath lengths various (3)

3(2). Leaves ascending, twisted, strongly grooved; spikes ovoid, the bracts and lateral sepals with a small apical tuft of short reddish-brown hairs; bases of leaves abruptly expanded, pinkish or purplish, becoming dark-brown, the bases of the plants therefore bulbous and the outermost leaves often scalelike. 5. X. torta.

3. Leaves spreading, scarcely twisted; spikes lance-ovoid to ellipsoidal; bracts and sepals not as above; bases of leaves longitudinally striate (the innermost fresh leaf bases white, the striae in dark contrast) and with the bases of the plants often invested by a stubble or ramentum of fibrous dead leaf bases.....................................2. X. ambigua.

4(1). Leaves filiform or rarely somewhat linear, the blades gradually expanding below into lustrous rich-brown or tan hard bases; plants densely cespitose; spikes ovoid and seldom longer than $1 \mathrm{~cm}$. 1. X. Baldwiniana.

4. Leaves broader or not as above, the bases softer or of a different color; plants or spikes not as above (5)

5(4). Bases of the leaves rather abruptly expanded into thickened flaring equitant zones, thus the plant bulbous-based (the outer leaves are often shorter, darker and scalelike); scapes often flexuous, usually quite twisted, the green upper portion of leaf blades often conspicuously twisted; flowers opening in the afternoon................. $4 . X$. platylepis.

5. Bases of the leaves and the plant bases not as above; scapes usually not flexuous, the blades not conspicuously twisted; flowers opening in the early or late morning (6) 
$7(6)$. Summit of scape not flattened and broad relative to the spike; scape ridges usually more than 3 and therefore the upper scape broadly oval or almost round in oultine (except for projecting ridges); habitats various, usually not alluvial; foliage pinkish- or purplish-based but the surfaces (particularly of the outermost leaves) papillose or tuberculate-scabrid.............................. 8. X. difformis var. Curtissii.

7. Summit of scape quite evidently flattened and broad relative to the spike (at least on living specimens); scape ridges few, usually 2 or 3 , the 2 most prominent ones along the scape edges and therefore the upper scape narrowly ellipsoidal or fusiform in cross section; plants commonly of wet situations in sun or shade; foliage smooth, a very deep-rich-green except for the reddish or purplish color of the leaf bases (8)

$8(7)$. The two principal scape ridges noticeably and abruptly flattened and winglike below the spike and in the plane of the flattened scape, their combined width (on live specimens) broader than the scape, thus the outline of the cross section of the scape bicaudate; fruiting spikes seldom longer than $15 \mathrm{~mm}$., ovoid, acute; seeds translucent, ovoid or ellipsoidal, seldom longer than $0.6 \mathrm{~mm}$

8. $X$. difformis var. difformis.

8. The two principal scape ridges not abruptly fiattened, the scape itself flattened and 2-edged and (in cross section) narrowly elliptic; fruiting spikes seldom shorter than $15 \mathrm{~mm}$., broadly ellipsoidal or oblong, blunt; seeds farinose, dark when ripe, fusiform or narrowly oblong and never as short as $0.6 \mathrm{~mm}$.

6. X. iridifolia.

\section{Xyris Baldwiniana Schult. Fig. 298.}

In large tufts, the leaf bases usually brownish, lustrous; leaves filiform to linearfiliform, 1-3 dm. long, straight or slightly twisted, green, expanding more or less abruptly toward the lustrous base; sheath of the scape from one half as long to nearly as long as the principal leaves, tightly investing the scape except for the the loose orifice and a short blade; scape 2-4 (-5) dm. long, usually broader than the leaf, terete below, one-ridged and tending to be terete above; spikes at the seed-bearing time ovoid to ellipsoidal, 4-7 $\mathrm{mm}$. long, acute or blunt, of a few tightly imbricate bracts; fertile bracts ovate to obovate, $4-5 \mathrm{~mm}$. long, not keeled, the apex rounded, the exposed margin entire, becoming erose with age, the matrix dull- to dark-brown or reddish-brown, the dorsal area elliptic and dull-green; lateral sepals included, slightly shorter than the bracts, linear but slightly curvate, reddish-brown, the keel lacerate from the tip to about the middle or slightly beyond; petal blades cuneate-obovate, about 3-4 $\mathrm{mm}$. long, unfolding in morning; seeds oblong to narrowly ellipsoidal, $0.8-1 \mathrm{~mm}$. long, the longitudinal lines evident, translucent, yellowish or pale-amber. Atypical plants erroneously reported from Texas as $X$. Elliottii Chapm.

In moist sands or sandy peats of pine flatwoods, hillside bogs, roadside ditches, and savannahs in e. Tex., May-July; in Coastal Plain, N.C. s. into n. Fla. and w. to Tex.

Plants now referred here with extremely narrow and flat leaves, apparently the var. tenuifolia (Chapm.) Malme (X. tenuifolia $C$ hapm.), could possibly be a hybrid of this species and $X$. Elliottii Chapm. if it were not for the fact that the latter species is thought not to occur farther west than southern Mississippi.

\section{Xyris ambigua Kunth.}

Solitary or in small tufts, the base hard, often fibrous; leaves broadly linear, spreading, 1-4 dm. long, 3-20 mm. broad, a dark- and lustrous-green above the 


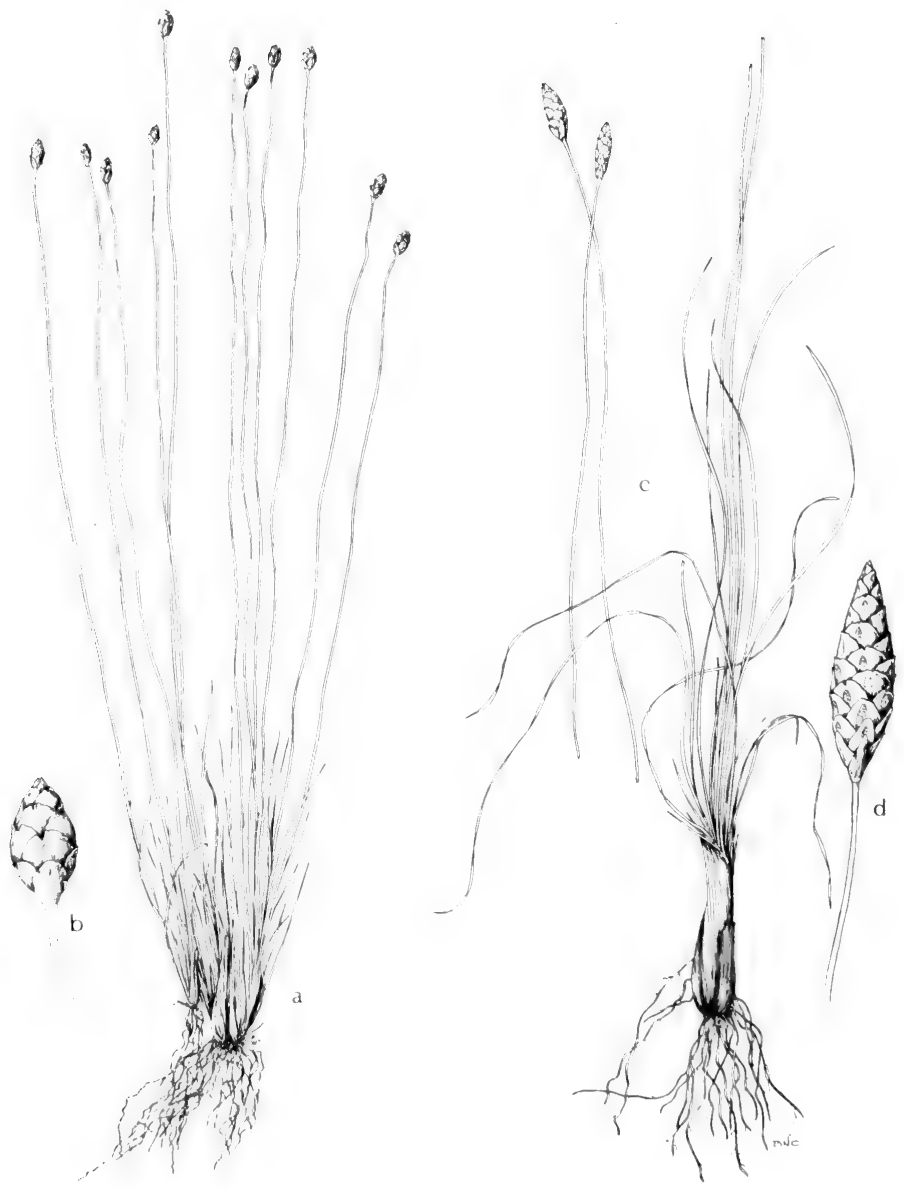

Fig. 298: a and b, Xyris Baldwiniana: a, habit, X 1/3; b, head, X 1\%. c and d, Xyris caroliniana: c, habit, X 1/3; d, head, X 1. (Courtesy of R. K. Godfrey). 
equitant portion (about two thirds the total leaf length), the basal equitant portion stramineous, brownish or pinkish, narrowing more or less gradually to an abrupt slightly incurved tip, the surface smooth or slightly papillose, the margins papillose and rather harshly scabrous; sheaths of the scapes from one third to nearly as long as the principal leaves, rather loosely investing the scape except for a distal bladelike portion, their bases usually lustrous, stramineous to castaneous; scape (1.5-) 7-10 dm. long, twisted but rarely flexuous, many ribbed below, becoming flattened and 2-edged above; spikes at seed bearing time ellipsoidal to lance-ovoid, 1-3 cm. long, of many tightly imbricated bracts; fertile bracts broadly obovate to suborbicular, 5-8 mm. long, not keeled, the apex rounded, the exposed margin subentire or erose with age, the matrix reddish-brown or pale-brown, the dorsal area roughly rectangular and olive to dark-brown; lateral sepals included, curvate, dark-lustrous-brown, the thickened keel nearly as broad as the sepal sides and ciliate-scabrid; petal blades obovate, about $8 \mathrm{~mm}$. long, unfolding in morning; seeds ellipsoid to broadly ovoid, caudate at one end, $0.5-$ $0.6 \mathrm{~mm}$. long, lustrous, with 20 or 22 distinct papillose longitudinal lines and several faint cross lines.

Moist sands or sandy-peats of bog margins, savannahs, pine flatwoods, lake shores and roadside ditches in e. Tex., May-July; in Coastal Plain from Va. s. to Fla. and w. to Tex.

\section{Xyris caroliniana Walt. Fig. 298.}

Solitary or in small tufts, the bases deeply set in the substrate; outer leaves scaly, castaneous; principal leaves linear, 2-5 dm. long, 2-5 mm. broad, twisted and flexuous, fleshy, minutely tuberculate along the margins, otherwise smooth and lustrous, blunt to acute at tip, the base abruptly dilated, dark-brown, shiny, long-persistent as scales; sheaths of the scapes shorter than the leaves, tight below, loose toward the oblique orifice which is tipped by a short $(2-4 \mathrm{~mm}$.) blade; scapes linear, 5-11 dm. long, twisted, flexuous, smooth, terete and minutely ridged below, becoming oval in cross section and smooth to 1-ridged above, the ridges (if present) minutely tuberculate; spikes (13-) 15-30 $\mathrm{mm}$. long, elliptic to narrowly oblanceolate in outline, blunt to broadly acute, of few to many closely imbricate bracts; fertile bracts 5-10 (-13) $\mathrm{mm}$. long, oblong to obovate, entire or emarginate, becoming erose, the matrix reddish-brown to tan with an elliptic or rectangular gray-green or brown dorsal area; lateral sepals linear, slightly to conspicuously exserted, tan to reddish-brown with a broad keel which is entire below but fimbriate at its exserted apex; petal blades obovate, $8-9 \mathrm{~mm}$. long, yellow or white, in most populations opening in the afternoon; seeds fusiform, narrow, 0.8-1 mm. long, translucent, with about 20 pale longitudinal lines, the vertical lines not evident. $X$. flexuosa Muhl., $X$. torta Kunth, $X$, arenicola Small.

Moist sands of pine flatwoods or savannahs, in well-drained sands or lower reaches of scrub oak-pine barrens in e. Tex., June-Aug.; from N. J. s. to Fla. and w. to Tex.

\section{Xyris platylepis Chapm. Fig. 299.}

Solitary or in small tufts, the bases shallowly set on the substrate, perennating by means of pale fleshy lateral buds; outer leaves scaly, pinkish, becoming dullgray-brown; principal leaves linear, 2-4 (-5) dm. long, 5-10 mm. broad, twisted, ascending, flexuous, fleshy, minutely tuberculate or smooth along the margin, otherwise smooth, blunt to acute at tip; equitant portion of leaves dilated, fleshy, ivory-white or pink or purplish toward the base; sheaths of the scape shorter than the leaves, castaneous or pale-brown and tight toward the base, more lax toward the oblique short bladed orifice; scapes 5-11 dm. long, twisted, flexuous, smooth to minutely ridged and terete below, oval in cross section and smooth to 1 - 


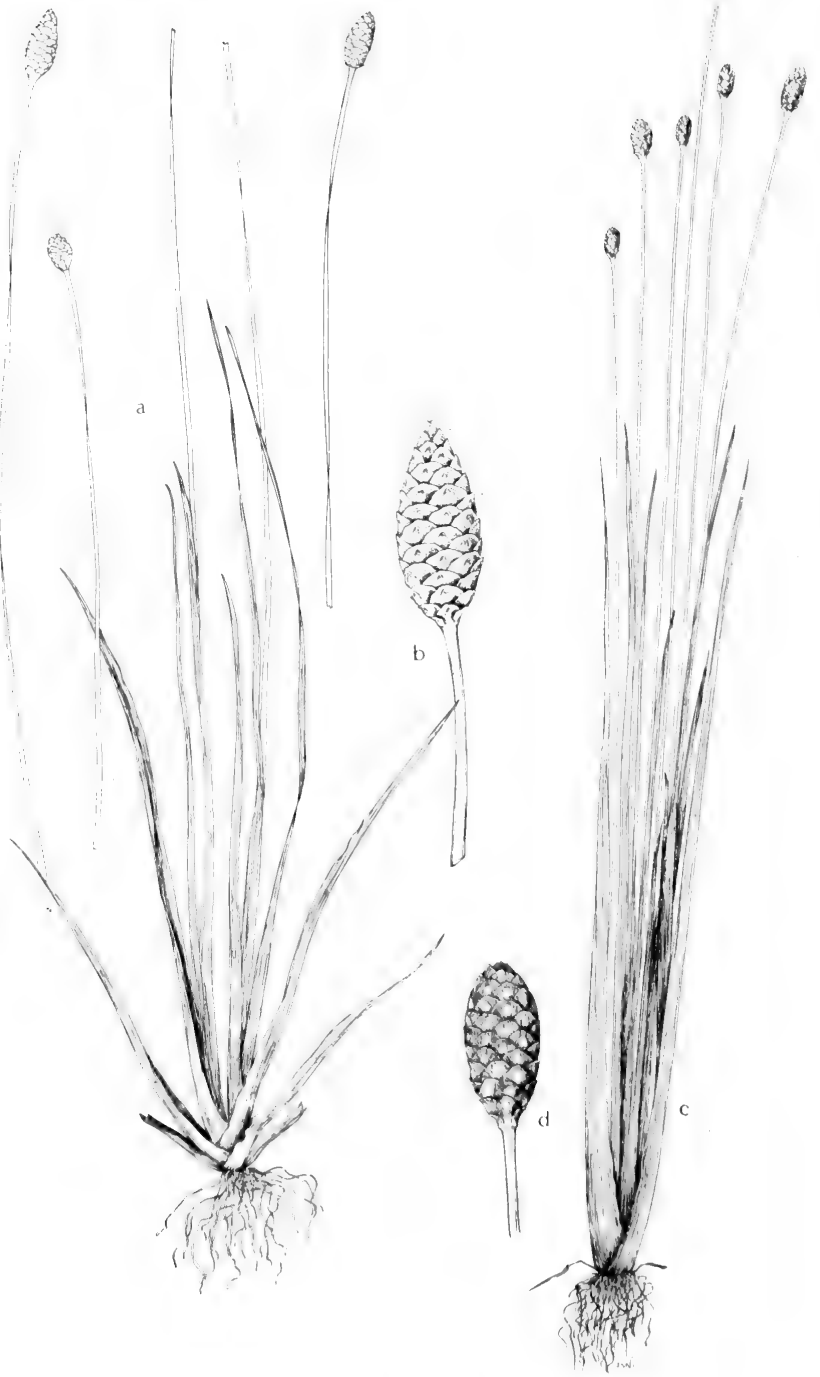

Fig. 299: a and b, Xyris platylepis: a, habit, X 1/3: b, head, X 1, c and d, Xyris iridifolia: c, habit, X 1/6; d, head, X 2/3. (Courtesy of R. K. Godfrey). 
ridged above the ridges (if present), papillate; spikes elliptic to ovoid or oblong, $1.5-3(-4) \mathrm{cm}$. long, of numerous closely imbricate bracts; fertile bracts obovate, 5-7 mm. long, entire (becoming slightly erose with age), brownish or pale-tan with an oblong to deltoid dark-green dorsal area; lateral sepals included, lightbrown, about the length of the subtending bracts, linear, the keel narrow except toward the apex where it is lacerate; petal blades broadly obovate, about $5 \mathrm{~mm}$. long, yellow or white, opening in the afternoon; seeds ellipsoidal, 0.5-0.6 mm. long, translucent, with 10 to 12 rather irregular longitudinal lines together with a scattering of less distinct vertical lines.

In moist to wet sands or sandy peats of pineland pond-margins, savannahs, bogs and roadsides ditches in e. Tex., summer; Coastal Plain, Va. to s. Fla., w. to Tex.

\section{Xyris torta $\mathrm{Sm}$.}

Solitary or in tufts of a few individuals, bulbous-based; leaves of 2 sorts, the outer scalelike (from the bud scales), the inner elongate-linear; principal leaves linear, ascending, 2-5 dm. long, 2-5 mm. wide, twisted, grooved longitudinally, the upper (blade) portion dark-green, lustrous, narrowing rather abruptly to a blunt incurved thickened tip, the equitant portion pinkish, purplish or yellow-green, flaring rather abruptly to the fleshy pale or castaneous base, the surfaces smooth or papillose, the margins narrowly incrassate and smooth or papillose; outer leaves usually much shorter than the inner, maroon or more commonly a dark-lustrous-brown, often scalelike with very dilated bases and slender often acuminate tips; sheaths of the scape shorter than the principal leaves, tightly clasping below, becoming looser toward the orifice which has a short erect slightly divergent blade at its tip; scapes $1.5-8(-10) \mathrm{dm}$. long, 1-1.5 $(-2) \mathrm{mm}$. broad, slightly to very twisted and flexuous above toward the spike; spikes at seeding time broadly ovoid or ellipsoidal to lance-ovoid or rarely oblong, 8-25 mm. long, 6-10 mm. broad, of many tightly imbricated bracts; fertile bracts broadly obovate to suborbicular, 5-7 $\mathrm{mm}$. long, deep-lustrous-brown within, dull-brown on the outer surface except for a pale-gray-green elliptical subapical dorsal area, exposed margin of the bract entire or sparingly ciliate. except for a short-fimbriate usually slightly emarginate apex; lateral sepals included, slightly shorter than the subtending bract, lustrous-brown, lunate, the brown thickened keel ciliate-scabrid from near the base to the apex where appears a small tuft of reddish-brown or blonde trichomes; petal blades obovate, about 4 $\mathrm{mm}$. long, unfolding in the morning; seeds ellipsoidal, about $0.5 \mathrm{~mm}$. long, caudate, with 14 to 18 prominent longitudinal lines (these under high magnification a series of contiguous papillae) and indistinct narrower cross lines, translucent except for the region of the embryo. Incl. var. occidentalis Malme.

Sphagnous bogs, stream banks, lake and pond shores, wet sandy swales and acid sandy swamps in e. Tex., June-July; from Can., s. to Ga., Tex. and (?) Okla.

\section{Xyris iridifolia Chapm. Fig. 299.}

Solitary or in small tufts, the pinkish or purplish keeled bases shallowly set on a mucky substratum; leaves linear, iridiform, 4-7 dm. long, 10-25 mm. broad, flat or slightly twisted, smooth, a deep-rich-green, broadly acute to blunt and incurved at tip, the base slightly dilated and keeled, pink or pale-maroon with a broadly hyaline margin; sheaths of the scape shorter than the leaves, deep-brown or reddish-brown and tight below, becoming somewhat looser and green above, the oblique orifice with a short cusplike blade; scapes $6-8 \mathrm{dm}$. tall, linear, straight or slightly twisted, terete and 2-ridged below, conspicuously broadened and flattened above, the edges smooth; spikes oblong to broadly oblanceolate, rarely ovoid, 20-35 mm. long, blunt, of numerous closely imbricate bracts with the 


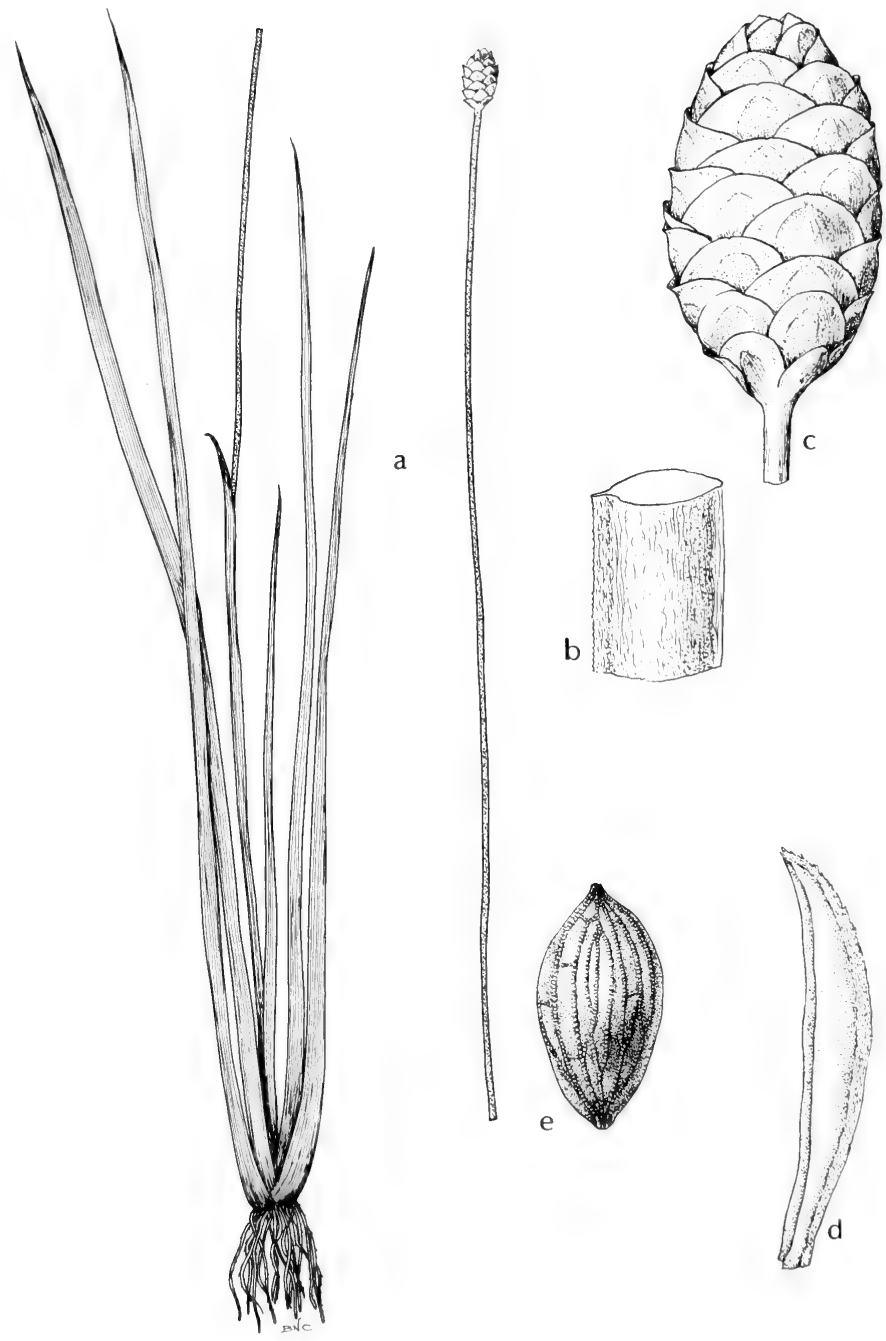

Fig. 300: Xyris Jupicai: a, habit, about X 1/2; b, section of peduncle, X 9; c, spike, X 3; d, lateral sepal, X 10; e, seed, X 75. (Courtesy of R. K. Godfrey). 
lowest ones barren; fertile bracts $6-7 \mathrm{~mm}$. long, broadly obovate to suborbicular, entire, the outer surfaces dark-purplish- or reddish-brown, shining except for a paler-green or gray-green oval or triangular dorsal area; lateral sepals included, linear, about the length of the bracts, castaneous, with a broad lacerate keel; petal blades cuneate, about $3 \mathrm{~mm}$. long, opening in the morning; seeds oblongfusiform, 0.8-1 mm. long, opaque, dark, farinose, the regularly arranged longitudinal lines obscured by the farina.

Wet sands but more commonly wet sandy clay, sandy peat, peat muck or alluvium of stream banks, cypress swamps, marshes or pineland pond margins with the bases commonly submersed, e. Tex., July-Sept.; in Coastal Plain from s.e. Va. s. to n. Fla. and w. to Tex.

\section{Xyris Jupicai Rich. Fig. 300.}

Short-lived perennial, solitary or in small tufts, dying completely after one year from seed or perennating from bulbous lateral over-wintering buds; leaves linear, 1-6 dm. long, 5-10 mm. broad, ascending, lustrous, yellow-green, pale or stramineous toward the base; sheaths of the scape shorter than the principal leaves, somewhat loose toward the oblique orifice which terminates in a short cusplike blade; scapes 2-7 (-9) dm. long, terete and many-ridged below, becoming somewhat flattened and narrower and usually one- or two-edged above; spikes at seeding time ovoid to ellipsoidal or oblong, 5-15 mm. long, of numerous rather loosely imbricated bracts; fertile bracts obovate to oval, 5-7 $\mathrm{mm}$. long, the exposed margins subentire, the outer surface pale- to dark-brown and dull, the dorsal area rectangular to elliptic and green or brownish on old spikes; lateral sepals included, about the length of the bracts, linear and slightly curvate, the thin wings broad, the somewhat thicker keel lacerate for the upper two thirds or one half its length; petal blades cuneate, about $3 \mathrm{~mm}$. long, opening in the morning; seeds broadly ellipsoidal, 4-5 $\mathrm{mm}$. long, the longitudinal ribs numerous but faint, cross lines not evident.

Wet sands or sandy peat or alluvium of roadside ditches, flatwoods, pond margins, cypress swamps and lake shores, but particularly in mechanically disturbed wet lands in e. Tex., June -Aug.; in Coastal Plain from N. J. s. to Fla. and w. to Tex. and Ark.

\section{Xyris difformis Chapm.}

Solitary or in small tufts, the soft pinkish or purplish (rarely greenish) bases rooted on wet sand or muck; principal leaves broadly linear or linear-elliptic, 1-5 $\mathrm{dm}$. long, 5-15 mm. broad, usually flabellate-spreading, dark and lustrous-green but toward the bases becoming pinkish, purplish or reddish, apex acute and slightly incurved, the surface smooth, the margin above the equitant portion usually papillose or rarely smooth; sheaths of the scapes shorter than most of the leaves, thin, tight except at the slightly loosened oblique orifice whose upper margin converges to a short cusplike blade; scape linear, $15-70 \mathrm{~cm}$. long, terete, brownish and twisted below, straightening and becoming deep-green and oval in cross section above with 2 prominent broad thin ridges whose combined breadth is at least equal to that of the scape and whose margins are papillose; spikes at seed-bearing time ovoid, about $1 \mathrm{~cm}$. long, acute, dark, of many usually tightly imbricated bracts of which the lower few are barren; fertile bracts $5-7 \mathrm{~mm}$. long, obovate to oval, not keeled, the apex rounded and subentire, the outer surface usually deep-brown, lustrous, the dorsal area greenish or gray-green, rectangular to round or elliptic; lateral sepals included, about the length of the bracts, the broad wings thin and pale-brown, the keel slightly thicker and darker with its margin jagged from about the middle to the apex; petal blades cuneate, about $4 \mathrm{~mm}$. long or less, unfolding in the morning; seeds broadly ellipsoidal, 
about $0.5 \mathrm{~mm}$. long, translucent, with 24 to 28 very fine straight longitudinal lines of small papillae, the vertical lines straight but indistinct. (?) $X$. elata Chapm.

Wet sands or sandy peats of flatwoods, pond margins, ditches and lake shores, but more often on alluvial situations (often in fairly heavy shade) in e. Tex., spring-summer; primarily on the Coastal Plain from Tex. to s.e. Can. and the Great Lakes system.

Var. Curtissii (Malme) Kral. Similar to var. difformis but smaller, usually less than $2 \mathrm{dm}$. high, more tufted and with the margins of the equitant portion of the leaves very broad and pinkish-translucent, the surfaces papillose or lowtuberculate with the papillae or tubercles in slightly diagonal lines, the bases pinkish or purplish and similarly papillate; sheaths of the scape looser with the bases a rich-brown or sometimes castaneous; scapes rarely to $2 \mathrm{dm}$., terete with many low ridges below, the margins of the ridges papillate or scabrid; spikes at seed-bearing time broadly ovoid to ellipsoidal, seldom longer than $5 \mathrm{~mm}$., of but few bracts; fertile bracts $3-4 \mathrm{~mm}$. long, suborbicular to broadly obovate, the outer surfaces pale to deep brown and lustrous, the ellipsoidal dorsal areas graygreen and becoming brown and indistinct with age; lateral sepals included, about the length of the bracts, linear-curvate, a lustrous-brown, the thin wings broad, the slightly thicker keel broadened and somewhat lacerate toward its tip or even entire; petal blades obovate to cuneate, slightly less than $3 \mathrm{~mm}$. long, unfolding in the early morning; seeds oblong to ellipsoidal, about $0.5 \mathrm{~mm}$. long, translucent, with 12 or 14 faint longitudinal lines, the vertical lines even more faint.

Sandy peats of ditches and bogs, flatwoods or acid seepage areas in e. Tex., spring-summer; from the Great Lakes system and s.e. Can. s. to Fla. and Tex.

\section{Fam. 31. Eriocaulaceae Desv.}

\section{PIPEWORT FAMILY}

Perennial or rarely annual aquatic or marsh herbs, mostly short-stemmed; roots tufted, fibrous, knotty or spongy, often septate; leaves mostly basal and tufted, narrow, grasslike; inflorescence capitate, in terminal solitary or umbellately aggregate involucrate heads, borne on long slender scapose peduncles that are sheathed at the base; florets numerous, small, sessile or short-pedicellate on a variously shaped receptacle, each borne in the axil of a scarious scalelike colored or colorless receptacular bractlet, unisexual, mostly androgynous, the staminate and pistillate mixed together or the staminate in the center and the pistillate on the periphery, the sexes very rarely in separate heads; perianth scarious or membranous, rarely hyaline, 2- or 3-merous, usually in 2 distinct series, the outer (calyx) free or rarely partially connate, the inner (corolla) often united in an infundibular fashion, rarely absent; stamens as many or twice as many as the outer perianth segments and alternate with them, inserted on the corolla (when present); filaments distinct; anthers small, 2- or 4-celled, composed of 1 or 2 thecae, opening by longitudinal slits, introrse; ovary superior, 2- or 3-celled; style terminal, often appendaged; stigmas 2 or 3 , simple or lobed; ovules solitary and pendulous in each cell, orthotropous; fruit a 2-or 3-celled and 2-or 3-seeded membranous capsule, loculicidally dehiscent; seeds solitary, pendulous.

About 1,150 species in 13 genera, mostly tropical and subtropical.

1. Stamens 4 or 6 , twice as many as the outer perianth segments; peduncles glabrous or at most puberulent.

1. Eriocaulon

1. Stamens 2 or 3 , as many as the outer perianth segments; peduncle villous above

2. Lachnocaulon

\section{Eriocaulon L. PIPEWORT}

Stems short; leaves tufted, membranous or very thin and pellucid, more or less linear or linear-lanceolate and grasslike, sessile and clasping at base, very 


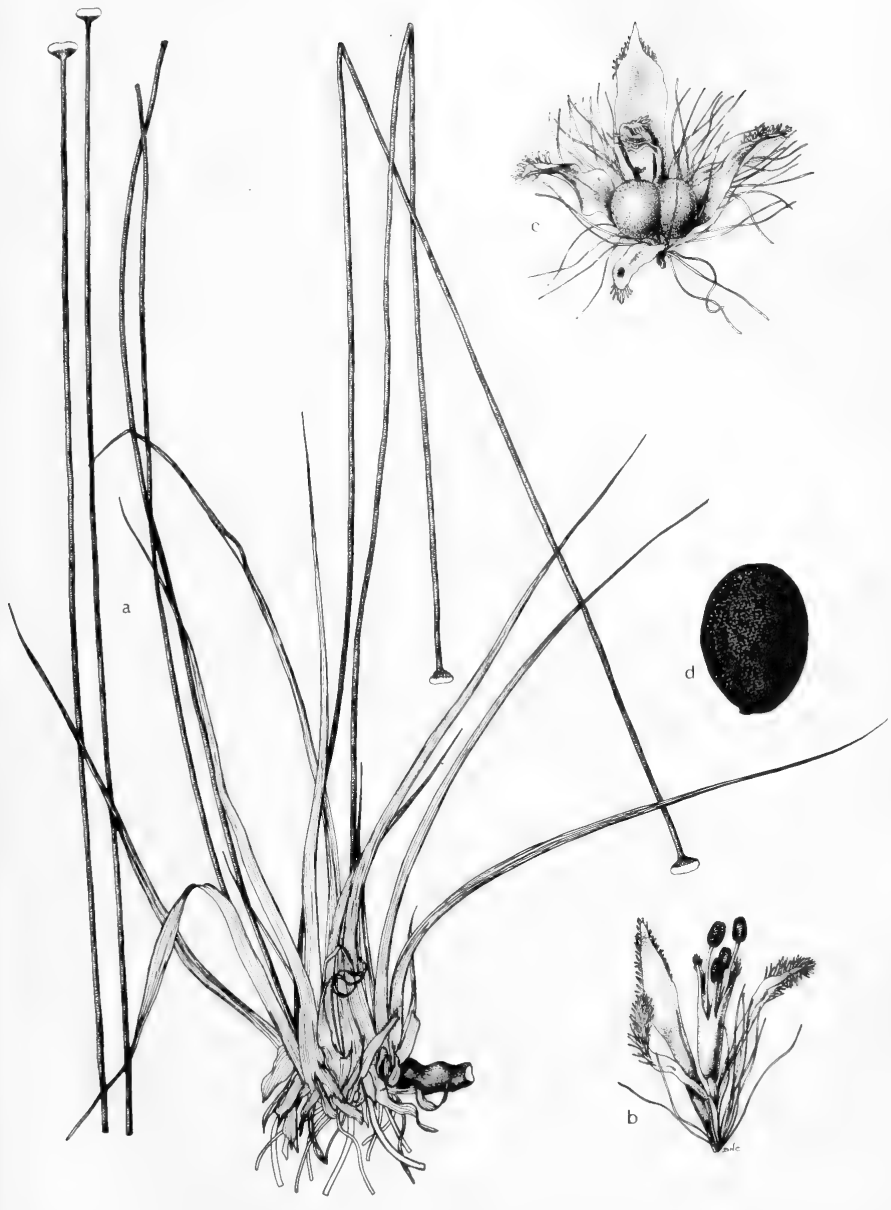

Fig. 301: Eriocaulon decangulare: a, habit, X 1; b, staminate flower, X 7; c, pistillate flower, X 7; d, seed, X 27. (Courtesy of R. K. Godfrey). 
often fenestrate; peduncles solitary or aggregate, slender, sheathed, usually glabrous and several-costate; florets dimerous or trimerous, the staminate mixed with the pistillate or segregated on separate heads or (rarely) on separate plants; perigonium almost always double; staminate florets with the sepals free at the base and often more or less connate into a split spathe, or the 2 or 3 petals united below into a tube, free at apex, the lobes usually bearing a small black gland on the inner surface near the apex; stamens twice as many as the sepals (or rarely 3) and exserted; anthers 4-celled, mostly black, composed of 2 thecae; pistillate florets with free or (rarely) spathaceous-connate sepals; petals free or rarely none, usually each bearing a small black gland slightly below the apex within; style appendages none; stigmas 2 or 3 , simple.

A genus of about 400 species, widely distributed in marshy places in tropical and subtropical regions, the greatest number in tropical America; numerous also in tropical Asia and Africa; one species in northwestern Europe and northeastern North America; several on the Coastal Plain of eastern and southern United States.

The leaves of some species are said to be eaten by ducks.

1. Heads when mature glabrous or subglabrous, olivaceous, not white-villous

1. Heads when mature always white-villous at the summit (2)

2(1). Receptacular bractlets surpassing the florets, long-acuminate; heads very tough and hard, not at all compressed in drying; leaves mostly rigid..............................................................2. E. decangulare.

2. Receptacular bractlets about equaling or shorter than the florets; heads more or less compressed in drying; leaves mostly lax (3)

3(2). Staminate florets with the anterior petal much larger than the posterior one; plants mostly dioecious or practically so; heads $5-14 \mathrm{~mm}$. in diameter........................................................... E. compressum.

3. Staminate florets with the petals equal or subequal; plants always plainly monoecious; heads 3-7 mm. in diameter (4)

4(3). Heads loose-flowered, greatly compressed in drying.......4. E. septangulare. 4. Heads dense-flowered, scarcely compressed in drying..... 5. E. texense.

\section{Eriocaulon Körnickianum Van Heurck \& Muell. Arg.}

Leaves erect, to $25 \mathrm{~mm}$. long, $1 \mathrm{~mm}$. wide, glabrous, 3-nerved; peduncles aggregate, as many as 25 , to $1 \mathrm{dm}$. tall, pale-green, 3- or 4-costate, twisted, the basal sheath to $25 \mathrm{~mm}$. long; heads globose or hemispheric, $2-4 \mathrm{~mm}$. in diameter, compressed in drying.

In springy places on prairies and wet sandy soil in e. Okla., spring; also Ark. and probably Tex.

No Texas material has been seen but the type is considered to have been collected in "East Texas" (Tyler Co.) by Charles Wright.

\section{Eriocaulon decangulare L. Fig. 301.}

Plants monoecious; leaves to $35 \mathrm{~cm}$. long and $1 \mathrm{~cm}$. wide at the middle, manynerved, the margin often revolute; peduncles 1 to 3 per plant, rigid, to $1 \mathrm{~m}$. tall, usually much smaller, many-costate, not noticeably twisted, the basal sheath to $16 \mathrm{~cm}$. long; heads globose or hemispheric, 7-12 $\mathrm{mm}$. in diameter.

In moist meadows and pinelands, savannahs, bogs, swamps and pond-margins in e. Tex., spring; from N. J. to Fla. and w. along Gulf Coast to e. Tex.

Plants with binary heads are sometimes found.

\section{Eriocaulon compressum Lam. Fig. 302.}

Plants rarely monoecious; leaves dull, to $25 \mathrm{~cm}$. long and $6.5 \mathrm{~mm}$. wide, manynerved; peduncles mostly solitary, rarely 2 or 3 , to $85 \mathrm{~cm}$. tall, 10 -striate, more or less twisted, the basal sheath about as long as leaves. 

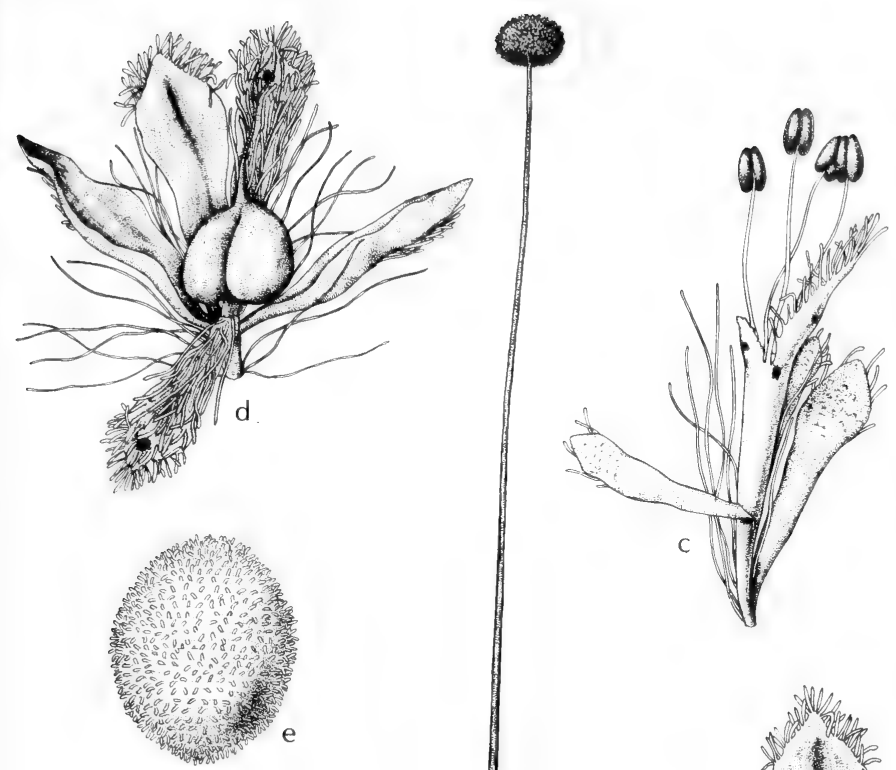


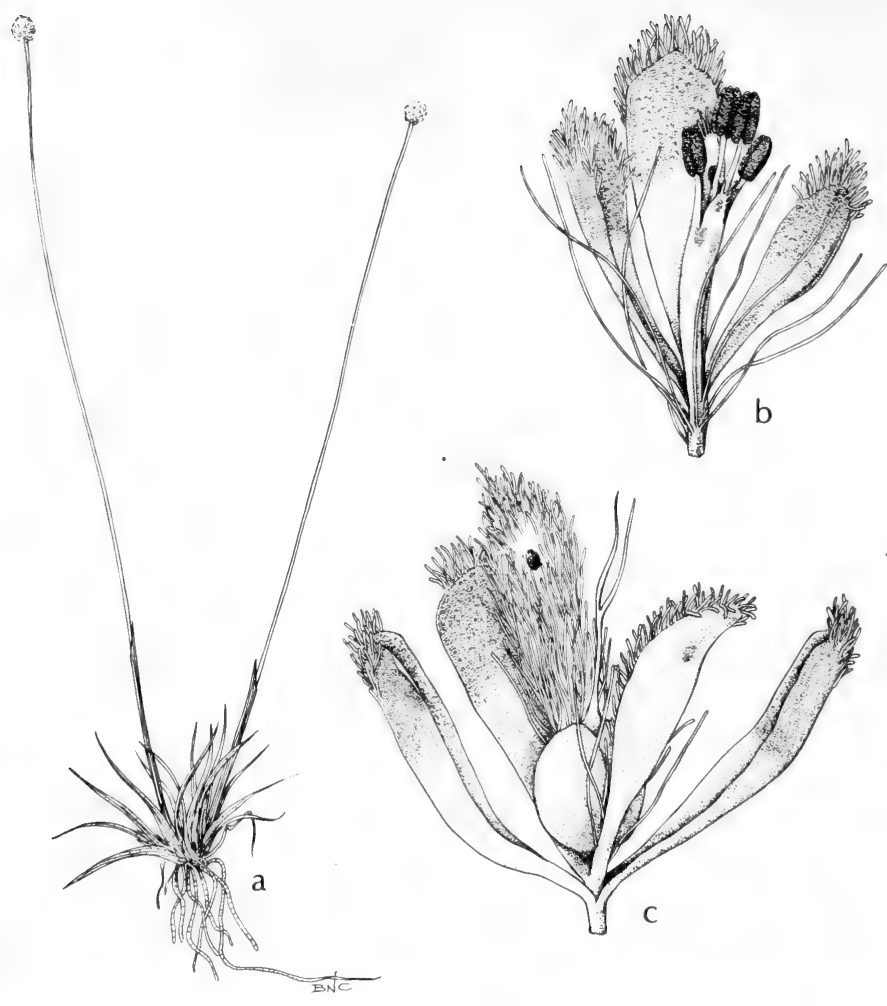

Fig. 303: Eriocaulon texense: a, habit, X 1;: b, staminate flower, X 20; c, pistillate flower, X 20. (Courtesy of R. K. Godfrey).

In still shallow water of acid ponds, swamps and low pinelands, and in streams in e. Tex., spring; from s. N.J. to Fla., w. to La. and e. Tex.

\section{Eriocaulon septangulare With.}

Leaves to $18 \mathrm{~cm}$. long and $3.5 \mathrm{~mm}$. wide, usually much smaller, 3- to 8-nerved; peduncles mostly solitary, to $55 \mathrm{~cm}$. tall or more in deep water, 7-costate, usually not twisted.

In still water and on shores of ponds in (?) e. Tex., spring; from Nfld. to Va., w. to Ont., Minn. and Ind., reported from Tex. but doubtfully in the state; also in the Hebrides and adj. is., $\mathbf{n}$. Scot. and Ire.

5. Eriocaulon texense Körn. Fig. 303.

Leaves spreading, plane, to $65 \mathrm{~mm}$. long and $3 \mathrm{~mm}$. wide, 10 - to 13-nerved; 
peduncles solitary or 2 to 4 , to $35 \mathrm{~cm}$. tall, 5- or 6-costate, slightly twisted, glabrous, the basal sheaths longer than the leaves.

In bogs, swamps and moist pinelands in e. Tex., Apr.-June; from e. Tex. to s.w. Ala.

\section{Lachnocaulon KUNTH}

A genus of about 10 species, all North American.

1. Lachnocaulon anceps (Walt.) Morong. HAIRY PIPEWORT, WHITEHEAD BOGBUTTON. Fig. 304.

Stems short; leaves tufted, bright-green, olivaceous in age, linear-lanceolate, to $7 \mathrm{~cm}$. long and $2.5 \mathrm{~mm}$. wide; peduncle rarely more than $3 \mathrm{dm}$. tall, 3-costate, twisted, densely villous above, the sheaths to $7 \mathrm{~cm}$. long; heads obconic-globose or hemispheric, 3-6 mm. in diameter; involucral bractlets fuscous or olivaceousgrayish, ovate to obovate, obtuse to subacute, long-villous on the back at the apex; receptacular bractlets olivaceous-fuscous, spatulate, very obtuse, pilose on the back at the apex; florets trimerous; staminate florets with 3 sepals, no petals, 3 stamens, the filaments united below and coalescent with a rudimentary corolla or pistil, free above, and with oblong 2-celled anthers composed of 1 theca; staminate sepals fuscous, oblong-obovate, connate at the base, rounded-obtuse and comose at the apex; pistillate florets with 3 free sepals, petals reduced to hairs, a single style, 2 or 3 style appendages, 2 or 3 simple or bifid stigmas and a 2 - or 3-locular ovary; pistillate sepals free, whitish, oblong-spatulate, longer than the receptacular hairs, obtuse to acute, pilose at the apex.

In wet places in s.e. Tex., May-Oct.; Va. s. to Fla., along the Gulf Coast to Tex.; also Isle of Pines, Cuba.

The white pistillate flowers mingled with the brown staminate ones impart a mixed gray and dark appearance to the heads.

\section{Fam. 32. Commelinaceae R. BR. SPIDERWORT FAMILY}

Succulent perennial or annual herbs, acaulescent or with nodose stems, the roots fibrous or sometimes much-thickened and tuberlike; leaves alternate, flat or somewhat channeled, entire, parallel-veined, sheathing by a basal membranous and often closed sheath; inflorescence terminal and/or axillary, a simple or compound cyme or thyrse, occasionally 1-flowered, sometimes attended by a cymbiform spathe or foliaceous bracts; flowers usually actinomorphic but sometimes zygomorphic, bisexual; calyx of 3 usually free and imbricated herbaceous sepals; corolla mostly ephemeral and deliquescent, the 3 colored petals equal or unequal and free or united into a tube, the third petal sometimes much-reduced; stamens typically 6 but sometimes fewer or only one, some occasionally reduced to staminodes; filaments usually distinct, often bearded with moniliform hairs; ovary superior, sessile or stipitate, usually 3-celled; fruit a loculicidal capsule, sometimes enclosed by fleshy sepals, rarely fleshy and indehiscent.

A large family mainly in tropical and subtropical regions. About 600 species in nearly 40 genera.

The seeds of some species in this family, especially those of Commelina, are eaten by various songbirds and game birds, and deer are known to browse the plants.

1. Flowers several, borne in a folded floral bract that is abruptly different from the stem leaves....................................................... Commelina

1. Flowers in an umbellate dichotomous helicoid terminal or lateral cyme, subtended by 2 or 3 subequal or unequal foliaceous or rarely scarious bracts.

2. Tradescantia 

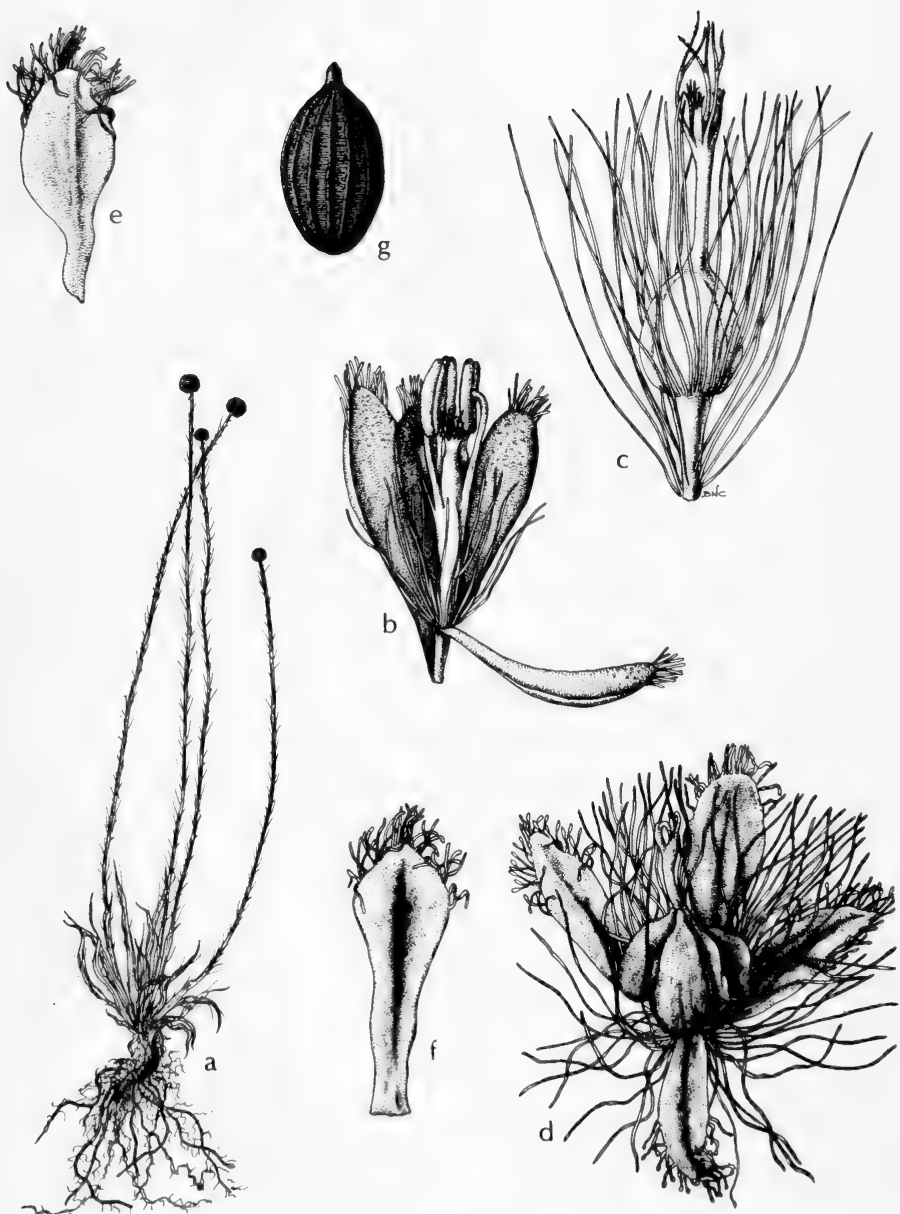

Fig. 304: Lachnocaulon anceps: a, habit, X 1/, b, staminate flower, X 25; c, pistillate flower, without sepals, X 26; d, pistillate flower, X 25; e, bract, X 25; f, sepal, X 25; g, seed, X 50. (Courtesy of R. K. Godfrey). 


\section{Commelina L. Widow's-TEARs. DaY-FLower}

Plants herbaceous, annuals or perennials; stems at first erect, in some species eventually decumbent; leaves ovate to linear, forming a sheath at the base, margin of leaf and throat of sheath often lined with white or reddish trichomes; flower buds borne inside of a cymbiform spathe that is open across the top, 3 to 5 buds are produced in each spathe, the buds opening in succession 3 or 4 days apart; flowers blue or sometimes paler, exserted above the spathe shortly after dawn to remain until midday after which they recede into the spathe as a juicy mass; sepals 3 , one subequal to the other 2; petals 3 , one of which is subequal to the other 2 and often paler; stamens 3, the smaller staminodia 3; ovary 3carpellate; fruits usually 1 or 2 or sometimes 3 per spathe; seeds 1 to 3 per fruit.

About 225 species, mainly in tropical and subtropical regions of both hemispheres.

1. Spathes open across the top but closed down the adaxial side, the margins connate at base. 1. C. virginica.

1. Spathes open across the top and down adaxial side to spathe stalk, the margins not connate at base (2)

2(1). Two posterior petals blue; anterior petal much smaller, white, lanceolate; capsule 2-celled, 4-seeded (no rudiment of third cell); anthers $6 . . . .$.

2. C. communis.

2. All three petals blue; anterior petal ovate, slightly smaller; capsule 3-celled, 5-seeded (posterior cell 1-seeded, indehiscent); anthers 5 (posterior lacking)

3. C. diffusa.

\section{Commelina virginica $L$.}

Plant perennial, overwintering by a tuberous root system, commonly producing new plants by elongated prostrate rhizomes that turn up at the ends; stem erect to decumbent, 3-6 mm. in diameter at base, the longest internodes usually 8-18 $\mathrm{cm}$., leaves broadly lanceolate, when mature to $2 \mathrm{dm}$. long and $65 \mathrm{~mm}$. wide, finely pubescent, especially scabrous to the touch when rubbed from the tip toward the base; leaf sheaths heavily pubescent at throat and down the open edge, the hairs sandy-red to dark-red in color; spathes terminal and usually clustered, occasionally produced singly at top, glabrous to very finely pubescent, to $35 \mathrm{~mm}$. long and $2 \mathrm{~cm}$. high, closed down the adaxial side, open across the top, tapering to a point on abaxial side.

In low woods, about and in water of pools, in s.e. Okla. (Pushmataha Co.) and in e. and n.-cen. Tex., May-Oct.; from e. Tex. and Okla., n. to Ill. and Md., e. to the Atl. Ocean.

\section{Commelina communis $\mathrm{L}$.}

Plant annual, with a fibrous root system, to $5 \mathrm{dm}$. tall; stems erect at first, later becoming prostrate and spreading due to numerous branches being produced, to $4 \mathrm{~mm}$. in diameter, some internodes as much as $16 \mathrm{~cm}$. long; leaves broadly lanceolate, smooth beneath, scabrous and often with scattered white hairs above, to $12 \mathrm{~cm}$. long and $4 \mathrm{~cm}$. wide; throat of leaf sheath with or without pubescence; spathe stalk to $7 \mathrm{~cm}$. long; spathes glabrous to very slightly pubescent with long white hairs, 2-3 cm. long, 8-13 mm. high, open across top and down the side to the spathe stalk, tapering to a blunt tip on abaxial end, the bottom forming a straight line while the top is curved.

On stream banks and in low thickets, a common garden weed, in e. Okla. (McCurtain Co.) and e. Tex., May-Oct.; from S.D. to Tex., e. to the Atl. Ocean. 


\section{Commelina diffusa Burm. $f$.}

Plant annual, with a fibrous root system; stems at first erect, later becoming decumbent because of profuse branching and layering, rarely more than $1.5 \mathrm{~mm}$. in diameter, the larger internodes to $10 \mathrm{~cm}$. long; leaves broadly lanceolate, glabrous beneath, glabrous to slightly scabrous above, $3.5-11 \mathrm{~cm}$. long, 9-22 mm. wide; leaf sheaths $5-10 \mathrm{~mm}$. long, the throat usually lined with long white hairs or sometimes with only short hairs; spathe stalk 1-2 cm. long; spathe glabrous, open across top, tapering to a slightly attenuated tip at the abaxial end and open down the adaxial side to the point of attachment to the stalk, the bottom usually decurved at the tip.

In floodplain woods, stream beds and wet clays about ponds in s.e. Okla. (LeFlore Co.) and e. and s. Tex., Apr.-Nov.; in s.e. U.S., w. to Tex., Okla. and Kan.

\section{Tradescantia L. SPIDER LILY. SPIDERWORT}

Subsucculent perennial herbs; stem erect to trailing, herbaceous, frequently producing subterranean stolons; leaves alternate, sessile, linear to oblong-elliptic (in our species), the blade basally produced into a perfoliate sheath; inflorescence an umbellate dichotomous helicoid cyme, terminal or lateral, subtended by 2 or infrequently 3 subequal or unequal foliaceous or rarely scarious bracts; pedicels subtended by solitary or paired hyaline or slightly foliaceous bracteoles; sepals 3, separate, equal, more or less concave or navicular, foliaceous to petalaceous or hyaline; petals 3 , separate, equal, ephemeral; stamen 6 , fertile, equal, hypogynous; anther sacs reniform (in our species), dehiscing longitudinally, united by a broadly trapezoid connective; filaments (in our species) abundantly pilose; ovary 3-celled; ovules 3 to 6 , uniseriate, orthotropous; style filiform; stigma capitate; capsule dry, loculicidally 3-valved; seeds naked, roughly oblongoid to subtrigonal or subspherical, more or less rugose and radiately ridged, the micropyle persistently pitted, the funicular scar linear to punctiform.

About 60 species in temperate and tropical America.

1. Leaf blade broader than the sheath (at least the upper ones); endemic to south-central Texas.

1. T. edwardsiana.

1. Leaf blade narrower than the sheath or about as broad (2)

2(1). Sepals glabrous or only the tips eglandular-barbate; distribution in eastern two thirds of Texas and Oklahoma.

2. $T$. ohioensis.

2. Sepals glabrous or rarely with a few glandular hairs at the base; endemic to Trans-Pecos Texas. 3. T. Wrightii.

\section{Tradescantia edwardsiana Tharp.}

Roots long and slender, relatively fleshy, very inconspicuously and irregularly pilose; stems erect or ascending, relatively stout, straight, not flexuose, densely and minutely puberulent to glabrate; nodes 3 to 6 ; internodes to $11 \mathrm{~cm}$. long; leaves relatively firm, somewhat subsucculent and crisp, light-green, not glaucous nor subglaucous, the anastomosing secondary veins not evident in desiccation, elliptic-lanceolate, acuminate, gradually constricted into the sheath, $7-30 \mathrm{~cm}$. long, $15-45 \mathrm{~mm}$. broad, minutely puberulent to essentially glabrate, the sheath to $3 \mathrm{~cm}$. long and $2 \mathrm{~cm}$. broad; cymes umbellate, few- to several-flowered, terminal, usually also lateral at the upper nodes, the lateral inflorescences with a definite peduncle; bracts foliaceous, 4-18 $\mathrm{cm}$. long, to $35 \mathrm{~mm}$. broad, widely spreading; pedicels $1.5-3 \mathrm{~cm}$. long, reflexed and somewhat accrescent in fruit, green, minutely and densely puberulent; sepals elliptic, acuminate, 6-9 $\mathrm{mm}$. long, green, not inflated, glandular-puberulent; petals broadly ovate, $1-1.2 \mathrm{~cm}$. long, white to pale-mauve, rarely bright-pink; filaments abundantly pilose, the connective 
broadly trapezoid; ovary ovoid, glandular-puberulent; capsules obovoid-trigonal, 8-10 mm. long; seeds 3-4 $\mathrm{mm}$. long, roughly compressed-oblongoid, the linear funicular scar about as long as the seed.

Rich woods and along moist alluvial terraces and ravines, s.-cen. Tex., FebMay; endemic.

\section{Tradescantia ohioensis Raf.}

Roots relatively slender, somewhat fleshy, irregularly pilose to glabrate; stems erect or ascending, straight or slightly flexuose, glabrous, glaucous and subsucculent; nodes 3 to 8 ; internodes to $18 \mathrm{~cm}$. long; leaves firmly membranaceous, glaucous, linear-lanceolate, long-acuminate, to $45 \mathrm{~cm}$. long and $45 \mathrm{~mm}$. broad, glabrous or infrequently more or less pilose at the sheath; sheath rather turgid and inflated, to $4 \mathrm{~cm}$. long and $45 \mathrm{~mm}$. broad; cymes umbellate, few- to many-flowered, terminal, solitary, frequently accompanied at the upper nodes by lateral pedunculate inflorescences; bracts foliaceous, glaucous, glabrous or minutely barbate at the tips, to $25 \mathrm{~cm}$. long and $22 \mathrm{~mm}$. broad, sharply reflexed or divaricate; pedicels to $25 \mathrm{~mm}$. long, glabrous, more or less reflexed and somewhat accrescent in fruit; sepals elliptic, acute to acuminate, to $15 \mathrm{~mm}$. long, glaucous, infrequently somewhat suffused wtih rose or purple, glabrous or more or less eglandular-barbate at the tips; petals broadly ovate, to $2 \mathrm{~cm}$. long, blue to rose or magenta, rarely white; filaments abundantly pilose, the connective broadly trapezoid; ovary ovoid, glabrous or with a tuft of weak eglandular hairs at the base of the style; capsules obovoid-trigonal, 4-6 mm. long; seeds roughly compressed-oblongoid, 2-3 mm. long, the linear funicular scar about as long as the seed. T. canaliculata Raf., T. reflexa $\mathrm{Raf}$.

In wet meadows, prairies and thickets, less frequently in woods, commonly spreading to roadsides and railroad right-of-ways in e. Okla. (Ottawa Co.) and e. two thirds of Tex., Feb.-May; from s. N.E. to Fla., and w. to Minn. and Tex.

The most common and widespread species in the U. S. where it is frequently cultivated and escapes to become naturalized.

\section{Tradescantia Wrightii Rose \& Bush.}

Roots relatively slender, somewhat fleshy, irregularly and inconspicuously pilose to glabrate; stems erect or ascending, straight, simple, glabrous, glaucous or glaucescent, somewhat subsucculent; nodes 1 to 3 ; internodes to $15 \mathrm{~cm}$. long; leaves firmly membranaceous or somewhat subsucculent, glabrous, glaucous or glaucescent, linear-lanceolate, long-acuminate, to $1 \mathrm{dm}$. long and $2-5 \mathrm{~mm}$. broad, spreading or ascending; sheath 1-2 cm. long, to $1 \mathrm{~cm}$. broad; cymes umbellate, few- to several-flowered, terminal, solitary; bracts foliaceous, glabrous, glaucous or glaucescent, spreading or ascending, to $7 \mathrm{~cm}$. long, 3-6 $\mathrm{mm}$. broad; pedicels 12-17 $\mathrm{mm}$. long, glabrous or rarely with a very few glandular hairs, reflexed and somewhat accrescent in fruit; sepals elliptic, acute to acuminate, 5-6 mm. long, glaucous or glaucescent, glabrous or rarely with a few glandular hairs at the base; petals broadly ovate, about $1 \mathrm{~cm}$. long, rose to magenta and purple; filaments abundantly pilose, the connective broadly trapezoid; ovary ovoid, glabrous or rarely with a very few glandular hairs at the base of the style; capsules obovoidtrigonal, 3-4 mm. long; seeds broadly compressed-oblongoid to oblongoid-trigonal, about $2 \mathrm{~mm}$. long, the linear funicular scar much shorter than the seed.

On moist canyon stream banks in Trans-Pecos Tex., May-Sept.; endemic.

\section{Fam. 33. Pontederiaceae H. B. K.}

\section{Pickerel-Weed FAMily}

Perennial aquatic or bog plants with floating or creeping rootstocks and sheathing leaves; leaves alternate, straplike or differentiated into petiole and blade; 
inflorescence axillary from the stem or rootstock, from a spathe; flowers solitary or in several- to many-flowered spikes or panicles, perfect, more or less irregular; perianth salverform of funnelform, the tube mostly well-developed, free from the ovary, the 6 lobes similarly colored; stamens 3 or 6 , inserted in throat of perianth, mostly unequal or dissimilar, the anthers introrse; style 1; stigma 3-lobed or 6-toothed; ovary superior; fruit a perfect or incompletely 3-celled many-seeded capsule or a 1-seeded utricle; seeds ribbed.

About 30 species in a half dozen genera in temperate and tropical regions.

1. Stamens 6 ; perianth funnelform (2)

1. Stamens 3 ; perianth salverform (3)

2(1). Plants typically free-floating; fruit a many-seeded dehiscent capsule

2. Plants rooted in mud; fruit a 1 -seeded utricle

1. Eichhornia

3(1). Perianth regular or nearly so; style usually stout, about as long as or shorter than the short stamens. 3. Heteranthera

3. Perianth markedly zygomorphic; style slender, almost as long as the long stamen.

4. Eurystemon

\section{Eichhornia KUnTH}

\section{WATER-HYACINTH}

Floating aquatic herbs, rooting at nodes; submersed leaves (when present) long and narrow; aerial leaves broad, the petiole usually spongy-inflated; inflorescence pedunculate, spicate to paniculate, from a spathe, the spathe subtended by a sheath that often has a small dilated blade; perianth funnelform, slightly 2-lipped; stamens 6, the 3 upper all included, the 3 lower more exserted; anthers oblong, basifixed; filaments irregularly adnate to the perianth; ovary 3-celled; capsule membranaceous, many-seeded. Also spelled Eichornia.

About six species in the tropics and warm temperate regions of America and Africa.

The plants provide an ideal haven for minute animal life that provide food for fish and bird life. Their aggressive weediness, however, offsets any value that they may otherwise have. They are notorious for clogging and desiccating canals and waterways in the southern United States. They are a favorite food of the manatee.

1. Petioles inflated at the base; plants with a short naked stem bearing new plants at the nodes; peduncle below the flowers exserted from the spathe; perianth lobes entire.

1. E. crassipes.

1. Petioles not inflated; plants with a continually growing stem, bearing leaves for its entire length; peduncle below the flowers included in the spathe; perianth lobes marginally erose.

2. E. azurea.

\section{Eichhornia crassipes (Mart.) Solms. Fig. 305.}

Leaf blade suborbicular to broadly elliptic, leathery, to $1.5 \mathrm{dm}$. long and wide; inflorescence a loose terminal spike; flowers showy, light-blue to bluishpurple, 4-6 cm. long and broad. Piaropus crassipes (Mart.) Britt.

Ponds, streams and ditches in s. and e. Tex., Apr.-July; from Va. s. to Fla., w. to Mo. and Tex.; also Calif., Mex., W.I., C.A. and S.A.

A beautiful, noxious weed!

\section{Eichhornia azurea (Sw.) Kunth.}

Except for the uninflated petioles and cross-margined perianth lobes, this species is quite similar in habit to $E$. crassipes.

It also grows in the same kind of habitats. Rather widespread in Latin Am., apparently introd. in s. Tex., July. 


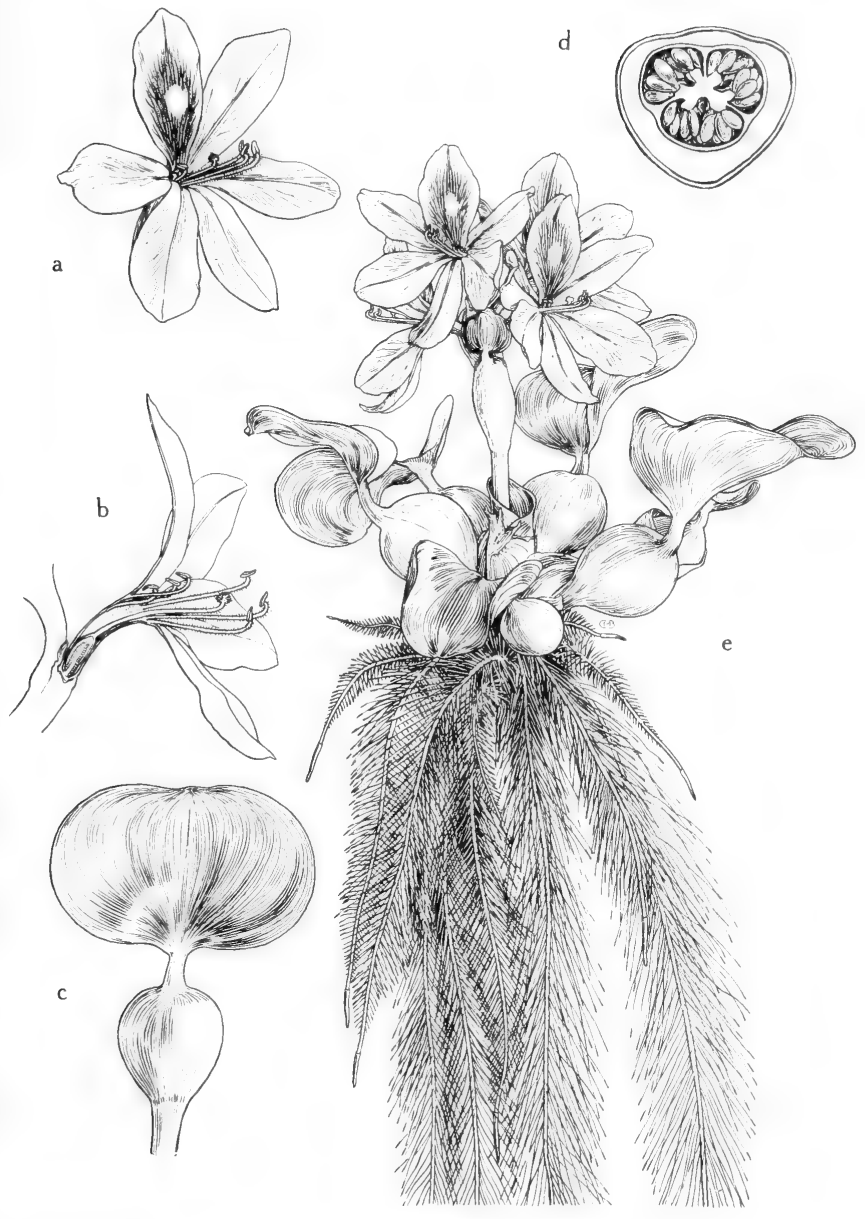

Fig. 305: Eichhornia crassipes: a, flower, X $2 / 3$; b, flower (longitudinal section), showing the irregularly adnate stamens, $\mathrm{X} 4 / 5 ; \mathrm{c}$, leaf, showing its orbicular leathery blade and inflated petiole, X $2 / 5$; d, ovary (cross section), X 8 ; e, habit, showing the loose terminal spike of flowers, the floating leaves and the roots, $\mathrm{X} \%$. (From Mason, Fig. 167). 


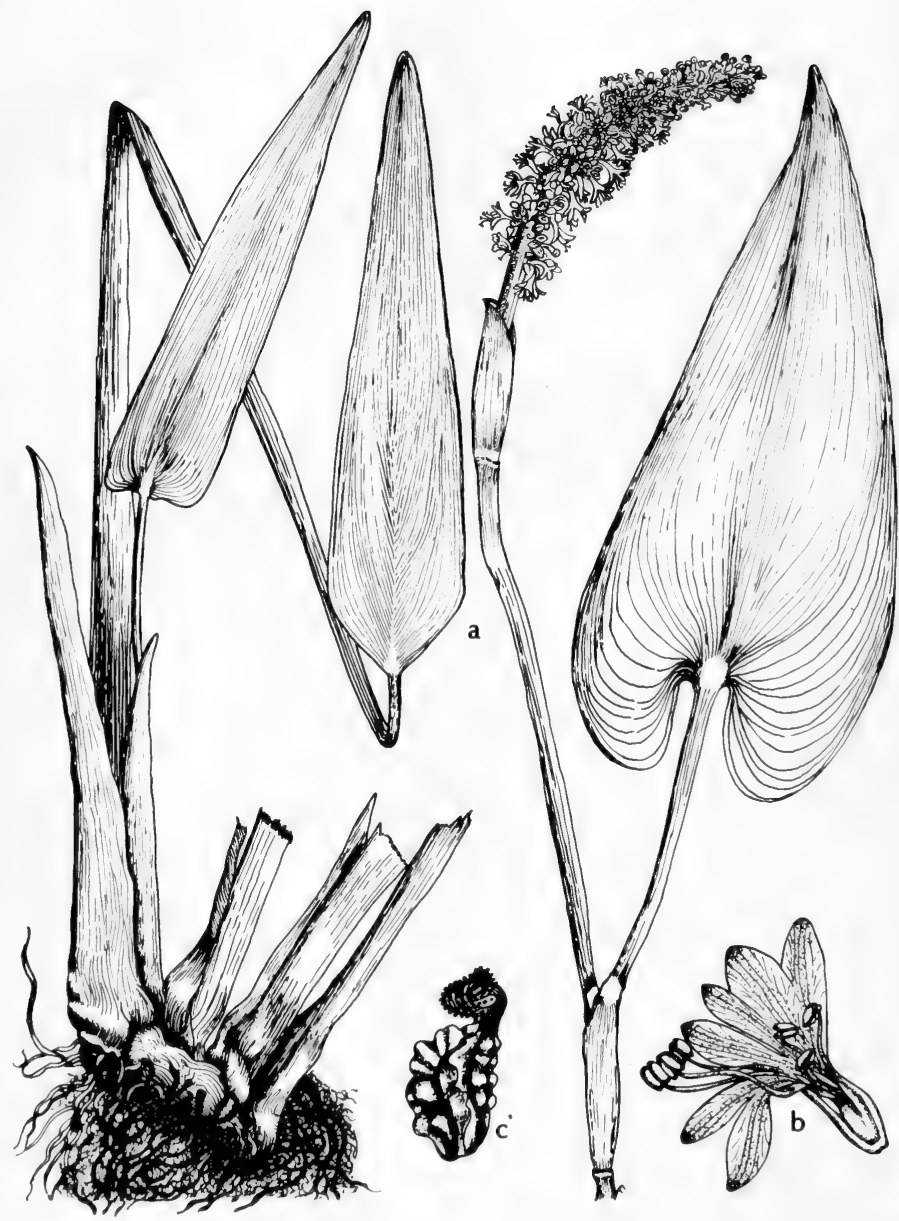

Fig. 306: Pontederia cordata: a, habit, X 1/2; b, flower, X 21/2; c, revolute-coiled perianth, after flowering, X $2 \frac{1 \%}{1}$. (V.F.). 


\section{Pontederia L. Pickerel-weed}

Stout herbs with thick creeping rhizomes rooted in mud; leaves erect, longpetioled, with a sheathing stipule within the petiole; leaf blades variable, broad or narrow; inflorescence an erect spike of violet-blue ephemeral flowers from a sheathing spathe, with a solitary leaf on the flowering stem; perianth funnelform, 2-lipped, the tube revolute-coiled after flowering; stamens 6, the 3 upper unequally inserted, the 3 lower long-exserted; anther elliptic, blue, versatile; ovary 3-celled; fruit a 1-seeded utricle.

About 6 species in warm regions of the Western Hemisphere.

The seeds are sometimes eaten by ducks and muskrats.

1. Perianth villous in bud, becoming glabrate with age, rarely sparsely glandular

1. Perianth persistently pubescent with short glandular hairs. 1. P. cordata var. cordata. 1. P. cordata var. lanceolata.

\section{Pontederia cordata L. var cordata. Fig. 306.}

Stem up to $1 \mathrm{~m}$. tall; leaf blades varying from deltoid-ovate to triangularlanceolate, prominently and deeply cordate to truncate or rarely narrowed at base, to $2 \mathrm{dm}$. long; spike to $15 \mathrm{~cm}$. long.

In marshes, sluggish streams and ditches in shallow water of n.-cen. and e. Okla. (Alfalfa, Cherokee and McCurtain cos.) and e. Tex., June-Sept.; P.E.I. and N.S., s. to Fla., w. to Mo., Okla. and Tex.

Var. lanceolata (Nutt.) Griseb. Similar to var. cordata in habit and habitat; leaf blade usually somewhat firmer than in that variety. P. lanceolata Nutt. Fla. w. to e. Tex. and e. Okla. (McCurtain and Payne cos.), locally n. to Del.

\section{Heteranthera R. \& P. Mud-Plantain}

Herbs submersed, floating or rooted in mud, forming a rosette or with elongate simple or branched stems; leaves sessile or petiolate; leaf blades straplike to ovate or lanceolate to reniform, leathery to thin and pellucid; flowers solitary or several in a spike, from a spathe that arises from the sheathing side of a petiole or in the axis of leaves; - perianth salverform, the limb more or less equally 6-parted, ephemeral; stamens 3, equal or unequal; anthers ovate to sagittate, basifixed; capsule 1- or incompletely 3-celled by intrusion of the placentae, many-seeded.

About a dozen species in America and Africa, mostly tropical.

Ducks are known to eat the seeds, and the dense growth occasionally formed by $\boldsymbol{H}$. dubia provide food and shelter for fish.

1. Leaves sessile, linear, grasslike, pellucid; spathe sessile in axils of leaves; stamens all alike; anthers coiled with age (2)

1. Leaves petiolate, with an expanded thickish blade; spathe peduncled; stamens dimorphic; anthers not coiled (3)

2(1). Perianth tube much less than twice as long as the spathe; seeds ellipsoid, yellow-brown, the 10 to 12 membranaceous wings evanescent........ .1. H. dubia.

2. Perianth tube twice as long as the spathe or longer; seeds nearly globose, black-brown, the 14 to 16 wings persistent...........2. H. Liebmannii.

3(1). Spathe 1-flowered; leaf blade ovate to elliptic or elliptic-lanceolate.

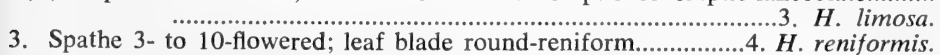

1. Heteranthera dubia (Jacq.) MacM. WATER STAR grass. Fig. 307.

Submersed grasslike herb, with slender branching stems often rooting at the nodes; leaves linear or ribbonlike, thin, sessile, finely parallel-veined and without 


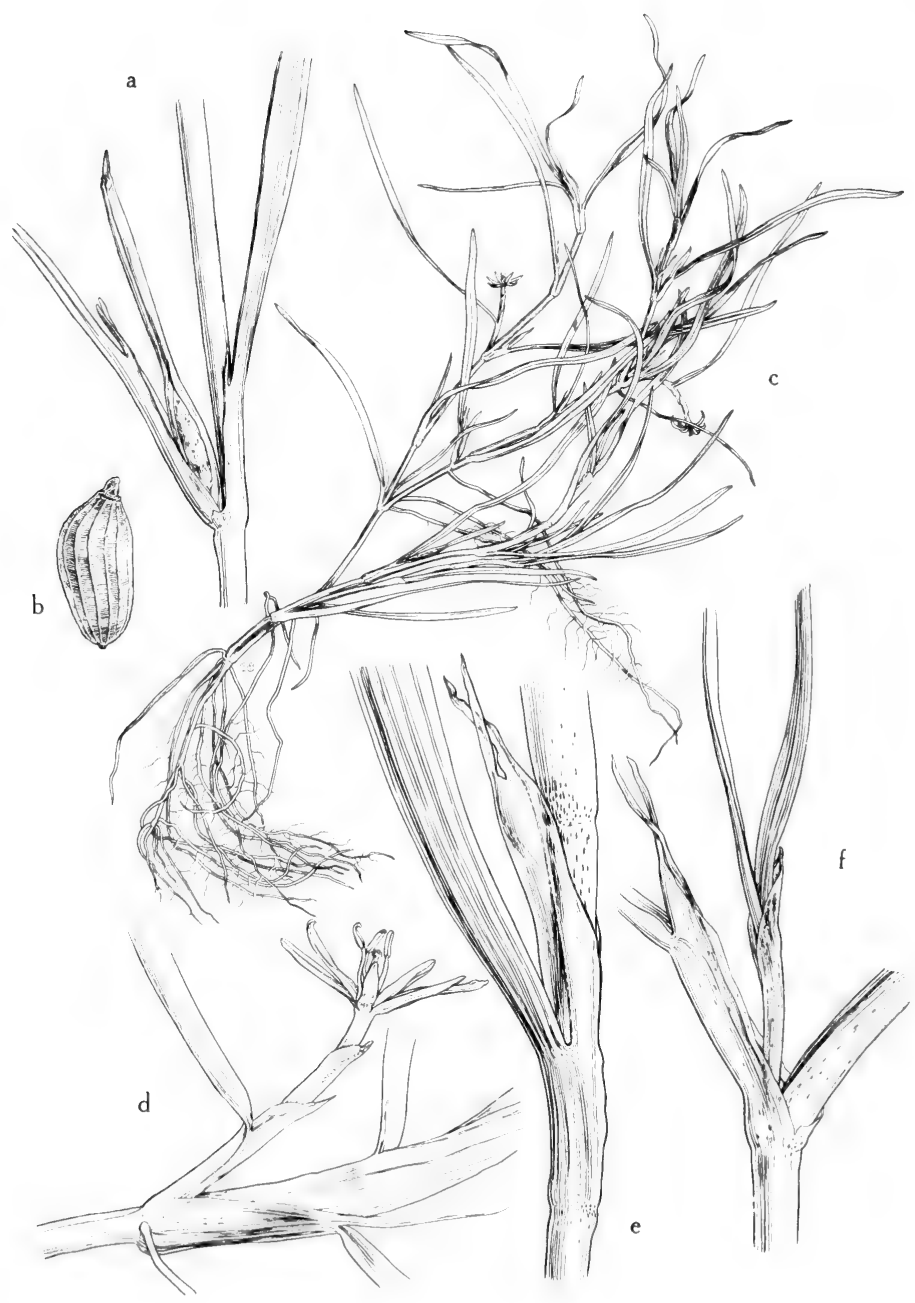

Fig. 307: Heteranthera dubia: a, capsule, sessile in leaf axil and enclosed by spathe, $X 1_{1} ; b$, mature seed. finely cross-striate and with membranous longitudinal ribs, $X$ 12; c, habit, showing the ribbonlike leaves, sessile flowers and fruit and roots at the nodes, $X$ stipulelike appendages, X 4. (From Mason, Fig. 168). 


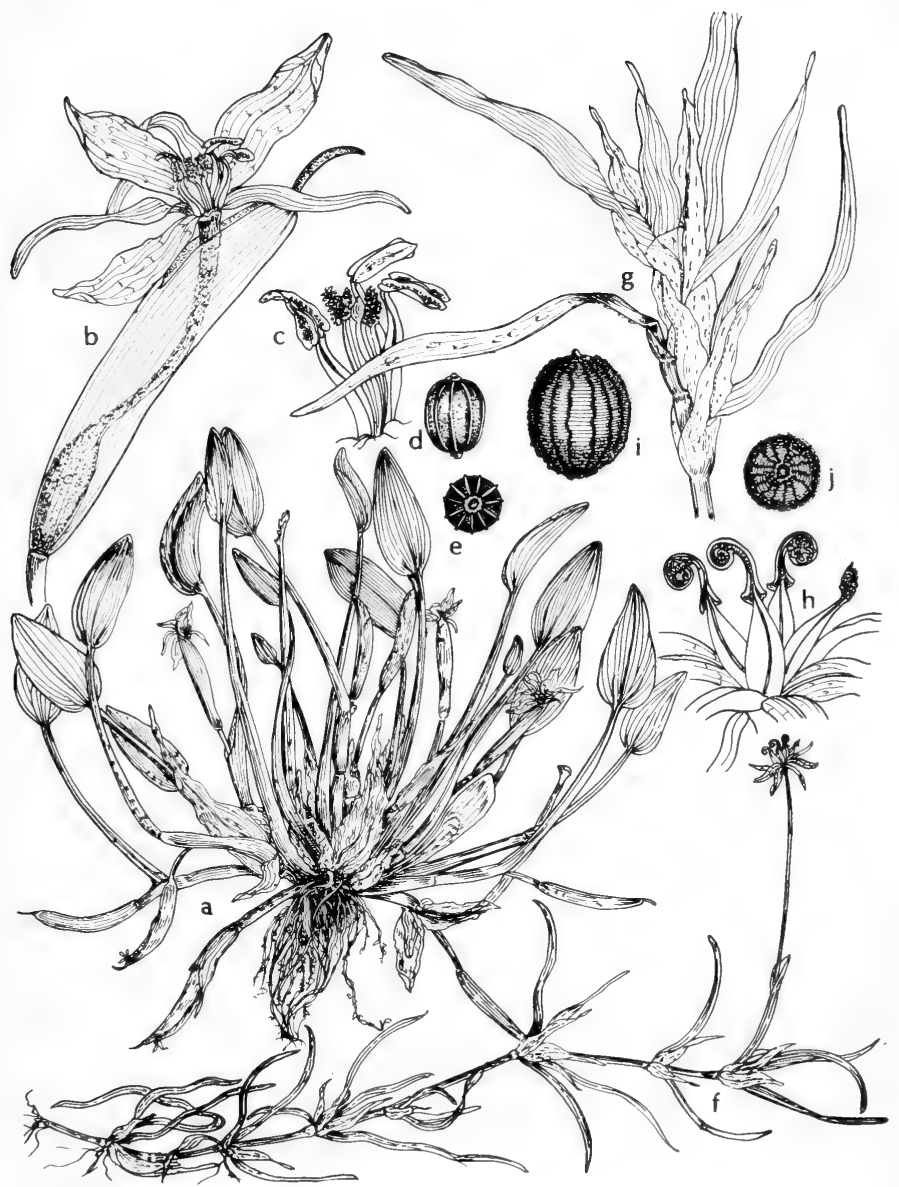

Fig. 308: a-e, Heteranthera limosa: a, habit, X 1/3; b, flower, X 2; c, stamens, X 5; d, seed, side view, X 12; e, seed, top view, X 12. f-j, Heteranthera Liebmanii: f, habit, X 1/2; g, node showing sheaths, X 1; h, stamens, X 5; i, seed, side view, X 12; j, seed, top view, X 12. (V. F.). 
a distinct midvein, to $15 \mathrm{~cm}$. long; sheaths thin, tipped on either side with small acute stipulelike appendages; spathe terminal, 1-flowered, rarely more than 2 $\mathrm{cm}$. long, exposed above the water; perianth pale yellow, with an elongated filiform tube rarely more than $3 \mathrm{~cm}$. long and a rotate 6-parted limb, the segments linear-lanceolate and to about $1 \mathrm{~cm}$. long; stamens 3 , equal in size, the filaments dilated below; stigma several-lobed; capsule 1-celled, with 3 parietal placentae; seeds oblong-ovoid, finely crosslined, with prominent raised membranous longitudinal ribs. Zosterella dubia (Jacq.) Small.

Streams, canals and quiet waters in e. Okla. (Mayes Co.), s. and s.-cen. Tex. and Ariz. (Maricopa and Yavapai cos.), Apr.-June; Fla. to Tex., Ariz., Calif. and Mex., n. to Que. and Ont., w. to Ore.

2. Heteranthera Liebmannii (Buch.) Shinners. Fig. 308.

Plant similar in habit and habitat to $H$. dubia; spathe to $6 \mathrm{~cm}$. long; perianth tube to $12 \mathrm{~cm}$. long. Zosterella longituba Alex.

On mud or floating in ponds and ditches in s. and w. Tex., Apr.-July; Tex. and Ala., s. to Mex. and W.I.

This species is more abundant in Texas than the closely allied $\boldsymbol{H}$. dubia.

\section{Heteranthera limosa (Sw.) Willd. Fig. 308.}

Plants rooted in mud to form rosettes, also represented by another distinct form with an elongated creeping stem that roots at the nodes; leaf blade ovate to elliptic or elliptic-lanceolate, to $1 \mathrm{dm}$. long, usually much shorter; spathe conspicuously peduncled, 1 -flowered; flowers white to purplish-blue.

Ponds, tanks and in wet soil of low woods in Okla. (Aifalfa, Cherokee, Comanche and Johnston cos.), s., cen. and w. Tex., rare in e. Tex., w. to N. M. (Grant and Socorro cos.) and Ariz. (Graham, Cochise and Santa Clara cos.), May-Oct.; Fla., w. to Ariz. and Mex., n. to Minn., Neb. Colo.; also trop. Am.

What we consider to be two forms of this species, as noted above, might prove to be distinct entities with further study.

4. Heteranthera reniformis R. \& P. Fig. 309.

Plants creeping in mud or floating in shallow water; leaf blades round-reniform, to $3 \mathrm{~cm}$. long and $5 \mathrm{~cm}$. wide; spathe short-peduncled, 3- to 10-flowered; flowers white or pale-blue. $H$. peduncularis Benth.

In streams in w. and s.e. Tex., Aug.-Sept.; Fla., w. to Tex. and Mex., n. to Conn., Ill. and Neb.

\section{Eurystemon Alex.}

A monotypic genus.

\section{Eurystemon mexicanum (Wats.) Alex. Fig. 309.}

Erect herb rooted in mud, to $4 \mathrm{dm}$. tall, noticeably glandular-pubescent above; leaves sessile, sheathing the stem, to $15 \mathrm{~cm}$. long, straplike; flowers about 12 in open spike that appears to be terminal, pale-blue to indigo-blue, from a spreading foliaceous spathe; perianth salverform, the limb conspicuously zygomorphic; stamens 3, strikingly dissimilar; anthers basifixed, anther on longest filament bluish and much larger than those on the two short inflated filaments; capsule 3-celled, many-seeded. Heteranthera mexicana Wats.

In ditches and about ponds in s. and n.w. Tex., June-Aug.; also n. Mex.

\section{Fam. 34. Juncaceae Juss. Rush FAmily}

Annual or perennial grasslike or sedgelike herbs, usually growing in wet places; leaves (like those of Cyperaceae and Gramincae) definitely formed into a lower sheath and an upper blade or the latter reduced in some species; inflorescence a ter- 


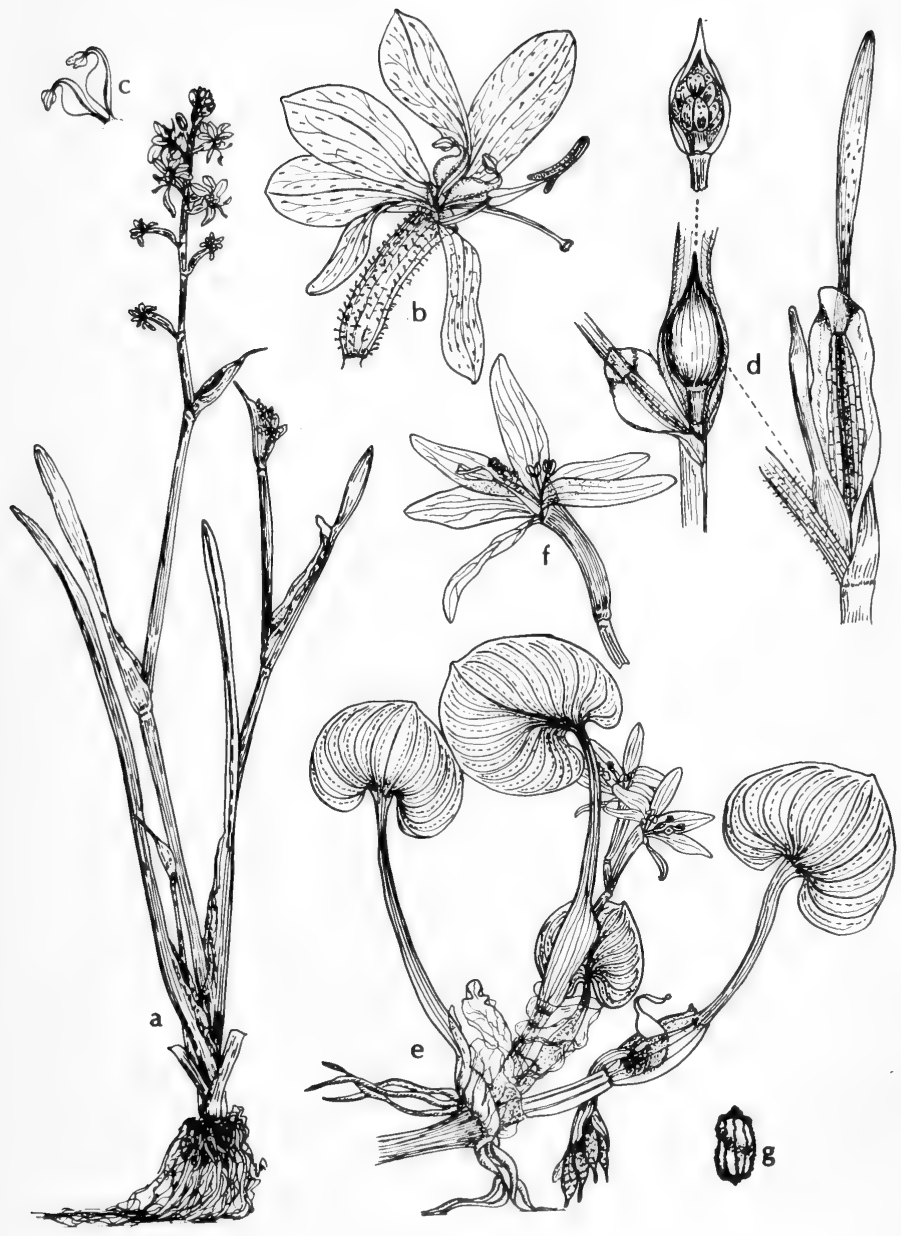

Fig. 309: a-d, Eurystemon mexicanum: a, habit, X 1/2; b, flower, X 21/2; c, stamens,

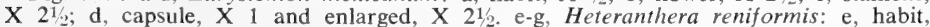
$X 1$; f, flowers, $X 2 \frac{1}{2}$; g, seed, X 10. (V. F.). 
minal (or in a few species apparently lateral) flaring panicle either of individual flowers subtended by pairs of scalelike bracts or usually of glomerules or heads of flowers, the flowers of the heads being subtended by 3 or only a single scalelike bract or occasionally the inflorescence reduced to only a single glomerule or head; perianth of 6 separate scales in 2 series, an outer whorl of 3 (sepals) and an inner whorl of 3 (petals), these all usually of about the same scalelike chartaceous to hyaline texture, narrowly ovate to lanceolate or subulate, usually sharply acute; stamens 3 or 6 , when 3 then opposite the sepals (at the corners of the capsule); filaments basally united into a minute flange around (but free from) the ovary; carpels 3 ; styles 3 ; placentas 3 ; ovary superior, 1- to 3-locular; placentas axile or by reduction of the septa more or less parietal; capsules loculicidal; ovules and seeds minute, 3 to many.

A family of about 9 genera and 400 species very widely distributed but not as common in the tropics as in cool, wet climates.

1. Seeds numerous

1. Juncus

1. Seeds 3

2. Luzula

\section{Juncus L. RUSH. Bog-RUSH}

Characters of the family but seeds numerous, never only 3. Rushes and sedges (Cyperaceae) are often confused by those who do not take the trouble to look at the flowers, which are diagnostic. The certain identification of any species (of sedge or rush) requires mature or nearly mature fruit and usually the examination of it under a strong lens.

A cosmopolitan genus of perhaps 300 species. Rushes have some forage value, but are nowhere abundant enough to be of much economic importance.

The seeds of many species are eaten by various bird life and the vegetative parts of some species, such as $J$. effusus, are sparingly eaten by muskrats, deer and, to some extent, by wildfowl.

1. Inflorescence pseudolateral, the stem appearing to continue beyond it; leaves never septate (2)

1. Inflorescence terminal or both terminal and lateral with either long or short leafy bracts (10)

2(1). Flowers 1 to 3 (rarely more); seeds with long white tails at each end; alpine plants 15 to $35 \mathrm{~cm}$. tall.............................. J. Drummondii.

2. Flowers many; seeds not tailed or only slightly so; plants usually taller than $30 \mathrm{~cm}$. (3)

3(2). Stems relatively slender, not very rigid; inflorescence not glomerate; flowers mostly solitary, subtended by a pair of bracteoles in addition to the bracteole at the floriferous node (4)

3. Stems coarse, rigid; inflorescence in head-like clusters or glomerules; basal leaf sheaths with terete, pungent blades (8)

4(3). Rhizomes much-branched, forming extensive mats in the mud; stamens 6 ; capsule narrowly ovoid, acute (5)

4. Rhizomes (if present) very short and not extensively creeping or branching, the plants thus essentially tufted; stamens 3, the anthers about equalling the filaments; capsules obovoid and obtuse or nearly spherical (7)

5(4). Perianth segments 2.5-3.5 mm. long; anthers shorter than the filaments.... 2. J. filiformis.

5. Perianth segments $3.5-5 \mathrm{~mm}$. long: anthers about 4 times as long as the filaments (6)

6(5). Culms essentially terete, $1-2.5 \mathrm{~mm}$. thick basally, not twisted; bract 3 to 8 times as long as the inflorescence........................... J. balticus. 
6. Culms compressed, $2.3 \mathrm{~mm}$. thick basally, often twisted; bract 2 or 3 times as long as the inflorescence. 4. J. mexicanus.

7(4). Capsules obovoid, obtuse or even depressed apically; flowers numerous, 30 to 100 per panicle; upper sheaths bladeless................5. J. effusus.

7. Capsule nearly spherical or slightly ovoid, apically turgid; flowers few, 2 to 25 per panicle; upper sheaths bearing blades..............6. J. coriaceus.

8(3). Flowers in glomerules of 2 to 5 flowers, each glomerule subtended by as many bracteoles as there are flowers, or an occasional flower also with an extra bracteole at the base of the perianth.

..7. J. Roemerianus.

8. Flowers in headlike clusters arranged in open panicles, from the axil of a single bractlet but without bracteoles (9)

9(8). Perianth segments acutish to acuminate, narrowly scarious-margined, greenish or straw-colored, 4 to $6 \mathrm{~mm}$. long, nearly equaling the narrowly ovoid, acute or acuminate capsule..

8. J. Cooperi.

9. Perianth segments (at least the inner ones) obtuse or truncate, broadly scarious-margined, brown, 2 to $4 \mathrm{~mm}$. long, much shorter than the subglobose, obtuse mucronate capsule....................9. J. acutus.

10(1). Individual flowers with a pair of braceoles in addition to the bractlet at the base of the pedicel (11)

10. Individual flower with only one bractlet at the base of the very short pedicel (17)

11(10). Annual 5-30 $\mathrm{cm}$. tall; inflorescence more than half the height of the plant; flowers scattered along the loosely forking branches (12)

11. Perennials $8-125 \mathrm{~cm}$. tall; inflorescence much less than half of the height of the plants; leaf sheaths auricled and/or prolonged (13)

12(11). Capsule oblong, 3 to $4.5 \mathrm{~mm}$. long; perianth 4 to $6 \mathrm{~mm}$. long.

12. Capsule subglobose to broadly ovoid; perianth 3 to $4 \mathrm{~mm}$. long.

10. J. bufonius.

11. J. sphaerocarpus

13(11). Capsule completely 3 -celled, retuse.

12. J. confusus.

13. Capsule 1-celled, with septa extending halfway to the center, acutish to obtuse, not retuse (14)

14(13). Leaf auricles scarious or broadly scarious-margined, 1-2.5 mm. long, prolonged, distinctly longer than broad; plant $8-45 \mathrm{~cm}$. tall.

13. J. tenuis.

14. Leaf auricles membranous or subcoriaceus, white to brown, 0.3-1 mm. long, not prolonged; plants $20-125 \mathrm{~cm}$. tall (15)

15(14). Leaf blades strongly involute, appearing channeled on the ventral side; bractlets acute or acuminate; inflorescence diffuse.

14. J. dichotomus.

15. Leaf blades flat or involute; bractlets obtuse or acute; inflorescence crowded (16)

16(15). Perianth 4-5 mm. long; some flowers solitary, some in heads

15. J. Dudleyi.

16. Perianth $3.3-4.2 \mathrm{~mm}$. long; flowers solitary, not in true heads

16. J. interior.

17(10). Leaf blades not septate or with only incomplete partitions (18)

17. Leaf blades septate, nodulose or cross-partitioned (26)

18(17). Blade non-septate entirely (19)

18. Blades with incomplete septa; leaves ensiform (23) 
19(18). Stems first ascending $5-20 \mathrm{~cm}$, then stoloniform-creeping or floating and greatly elongate; capsule very narrow but obtuse.

17. J. repens.

19. Stems erect or nearly so; capsule obovoid or tapering at the apex into a beak (20)

20(19). Perianth 2-5 mm. long (21)

20. Perianth 5-6 mm. long (22)

21(20). Perianth 4-5 mm. long, half again as long as the capsule; anthers yellow; largest transverse dimension of the compressed culm $0.5-1$ mm...............................................................18. J. filipendulus.

21. Perianth $2.5-3.5 \mathrm{~mm}$. long, about equaling the capsule; anthers orangish to reddish brown; culms $1.5-3 \mathrm{~mm}$. broad...............19. J. marginatus.

22(20). Sepals equaling or slightly exceeding the petals; auricles of the leaf sheaths 0.5 to $1.5 \mathrm{~mm}$. long; leaf blades flat; anthers cream-colored or pale yellow...................................................20. J. longistylis.

22. Sepals shorter than the petals; auricles $1.5-3 \mathrm{~mm}$. long; leaf blades channeled; anthers brownish.............................................21. J: macrophyllus.

23(18). Stamens $6(24)$

23. Stamens 3; bract ensiform, more than half the length of the inflorescence 22. J. ensifolius.

24(23). Perianth segments equal in length, very narrow, often shorter than the oblong, acute capsule, spreading; blades of the larger leaves 3 to $12 \mathrm{~mm}$. wide; stems stout.

23. J. xiphioides.

24. Perianth segments unequal, the inner ones shorter, the segments broader and firmer in texture, usually exceeding the oblong-obovoid capsule, appressed; blades of the larger leaves seldom more than $5 \mathrm{~mm}$. wide; stems relatively slender (25)

25(24). Seeds tailed; styles long-exserted

24. J. Tracyi.

25. Seeds not tailed; styles usually little if at all exserted.

25. J. saximontanus.

26(17). Seeds caudate (27)

26. Seeds not caudate (30)

27(26). Stamens 3 (said to be 6 sometimes in J. trigonocarpus)

27. Stamens 6 (29)

28(27). Stems slender, densely cespitose, 1-5 dm. tall; inflorescence strict with ascending branches, with few to many heads each with 2 to 7 flowers; seeds (with tails) about $1 \mathrm{~mm}$. long....26. J. brevicaudatus.

28. Stems simple, tough, wiry, 5-9 dm. long; inflorescence a compound panicle with fascicles of short branches bearing turbinate heads with 6 to 15 flowers; seeds (with tails) $1.5-2 \mathrm{~mm}$. long.....

27. J. trigonocarpus.

29(27). Stems $10-40 \mathrm{~cm}$. tall, leaves mostly basal; sheaths not auriculate; inflorescence of 1 to 3 heads; perianth segments $4-7 \mathrm{~mm}$. long; capsule longer than the perianth.....................................28. J. castaneus.

29. Stems $5-15 \mathrm{~cm}$. tall, leaves 1 to 5 ; sheaths auriculate; inflorescence a capitate cluster of 1 to 5 flowers; perianth segments $3-4 \mathrm{~mm}$. long; capsule about equaling the perianth. 29. J. albescens.

$30(26)$. Stamens $6(31)$

30. Stamens 3 (36)

31(30). Culms 30-100 cm. tall, 2-4 mm. thick (32)

31. Culms $5-45 \mathrm{~cm}$. tall (rarely taller in J. texanus), 0.7-2 mm. thick (33) 
32(31). Inflorescence of spherical many-flowered heads in a cluster subtended by a long pointed bract; capsule subulate, 4-5 $\mathrm{mm}$. long.

30. J. Torreyi.

32. Inflorescence of hemispheric or top-shaped heads on spreading branches; capsule 3 -angled, ovate, tapering to a conspicuous tip, $3 \mathrm{~mm}$. long 31. J. articulatus.

33(31). Capsule trigonous and oval or obovoid (34)

33. Capsule subulate-pointed (35)

34(33). Heads usually solitary, densely many-flowered; perianth dark brown, 3.5-4 mm. long; capsule narrowly oval, emarginate.

32. J. Mertensianus.

34. Heads 4 to 12,5 - to 10 -flowered; perianth brown, $2-3 \mathrm{~mm}$. long,

33. J. badius.

$35(33)$. Inflorescence $2-5 \mathrm{~cm}$. long; capsule slightly exserted, 3 to 4 times as long as broad; anthers a little shorter than their filaments; plants of $w$. Texas and New Mexico......................................34. J. nodosus.

35. Inflorescence at maturity mostly $5-10 \mathrm{~cm}$. long; capsule at maturity subulatebeaked, more than 4 times as long as broad, much-exserted; anthers much longer than their filaments; endemic to n.-cen. Tex. and the Edwards Plateau 35. J. texanus.

36(30). Heads nearly spherical when mature, 15- to 100-flowered (37)

36. Heads or glomerules hemispherical or narrower at maturity, 2- to 10-flowered (42)

37(36). Capsules 1.5-2.2 mm. long.

37. Capsules longer (38)

36. J. brachycarpus,

38(37). Capsules narrowly ovoid to elliptic-ovoid, 2.5-3.3 mm. long, about equaling the petals but usually shorter than the sepals, apically blunt and sometimes apiculate; sepals and petals paleaceus, drying semirigid................................37. J. acuminatus f. sphaerocephalus.

38. Capsules usually subulate (at least terminally), usually at least $3.5 \mathrm{~mm}$. long, apically acute; sepals and petals semirigid and subspinescent (39)

39(38). Uppermost sheath (not that of the bract of the inflorescence) much longer than its blade......................................38. J. megacephalus.

39. Uppermost sheath shorter than its blade (40)

40(39). Flowering culms $1-1.5 \mathrm{~mm}$. thick near the middle, arising erect and separately from short whitish rhizomes; leaves few, scattered on the culm, the blades essentially terete and about $1 \mathrm{~mm}$. thick near the middle; sepals $0.5-0.8 \mathrm{~mm}$. broad; petals $0.3-0.5 \mathrm{~mm}$. broad 39. J. scirpoides.

40. Flowering culms $2-4 \mathrm{~mm}$. thick near the middle, a few ascending in a tuft from a non- or sub-rhizomatous base; leaves several in a basal cluster and also scattered on the culm, the blades laterally flattened and 3-7 $\mathrm{mm}$. thick in the larger (dorsiventral) dimension; sepals $0.7-1.4 \mathrm{~mm}$. broad; petals $0.5-1 \mathrm{~mm}$. broad (41)

41(40). Blades 4-7 mm. thick in the larger dimension, with many weak incomplete septa; leaves and stems greenish, mostly crushed flat in prepared specimens; culms $6-10 \mathrm{~mm}$. thick basally

40. J. polycephalus.

41. Blades 3-6 mm. thick in the larger dimension, with several tough complete septa; herbage grayish or olivaceous, mostly tough and resistant to crushing; culms $3-5 \mathrm{~mm}$. thick basally................41. J. validus.

42(36). Capsules at least half again as long as the petals, 4-5.2 mm. long....... 42. J. diffusissimus. 
45(44). Sepals 2-2.5 mm. long, 0.6-0.8 mm. broad; petals $1.9-2.3 \mathrm{~mm}$. long, 0.4-0.6 mm, broad; capsule golden-brown, 2.3-2.5 $\mathrm{mm}$. long; septa of blades conspicuous.

44. J. nodatus.

45. Sepals 2.6-2.9 mm. long, 0.9-1.1 mm. broad; petals 2.4-2.8 mm. long, $0.6-0.8 \mathrm{~mm}$. broad; capsule dark golden-brown to fuscous, 2.4-2.9 $\mathrm{mm}$. long; septa of blades inconspicuous..

45. J. Elliottii.

\section{Juncus Drummondii E. Mey.}

Stems tufted, mostly $15-35 \mathrm{~cm}$. high, from matted rootstocks; basal leaf sheaths all bladeless or with the mere rudiments of blades; inflorescence 1- to 3-flowered, rarely 4- or 5-flowered, the flowers inserted singly and each with a pair of bractlets at the base; lowest leaf of the inflorescence mostly $2-3 \mathrm{~cm}$. long; perianth $6 \mathrm{~mm}$. long, its segments lanceolate, acute to acuminate, with broad brown margins, the inner equaling the outer or nearly so; stamens 6 , scarcely half the length of the segments; anthers longer than the filaments; capsule oblong, retuse at apex, equaling the segments; seeds ovate, $2 \mathrm{~mm}$. long, caudate, very finely striate.

Moist or wet alpine slopes, bogs and seepage in mts. of N.M. (Taos, Santa Fe, San Miguel and Rio Arriba cos.) and Ariz. (Coconino Co.); from Alas. s to s. Calif., N. M. and Ariz.

\section{Juncus filiformis $\mathrm{L}$.}

Perennial plants; stems $7-50 \mathrm{~cm}$. long, arising from a matted rootstock, erect, slender, finely striate; sheaths purplish-tinged, obtuse, with a short bristlelike remnant of a blade of ten present or this absent entirely; panicle 5- to 10-flowered, 1-3 cm. high; bract terete, appearing like a continuation of the stem, usually longer than the stem proper; perianth 2.5-3.5 mm. long; bractlets obtuse; segments of perianth lanceolate, greenish or stramineous in age, margins hyaline, equal or outer somewhat longer, acute to acuminate, the inner usually less pointed, sometimes almost obtuse; stamens 6; capsule obovoid, green to stramineous in age, somewhat pointed, three fourths to nearly as long as the petals.

Moist or wet places and seepage along streams, in N. M. (Taos Co.); Greenl. to Alas., s. to Pa., N.M., Ut. and Wash.; Euras.

\section{Juncus balticus Willd. Wire Rush. Fig. 310.}

Stems in small clusters or arising singly from creeping rootstocks, 2-9 dm. tall, strict, terete or compressed, moderately stout; basal leaf sheaths bladeless; panicle lateral, lax or somewhat compact, few- or many-flowered, its branches disposed to be secund; perianth segments $3.5-5 \mathrm{~mm}$. long, lanceolate, the outer segments acuminate, the inner ones acute and slightly shorter, greenish or strawcolored or brownish with a green midrib, the hyaline margins usually rather broad and well developed on the inner segments; stamens about two thirds as long as the perianth, the anthers much longer than the filaments; capsule as long as or slightly shorter than the perianth, oblong-ovoid, mucronate, pale or dark brown; seeds oblong-cylindric, faintly reticulate, often with a whitish, membranous surface. Incl. var. littoralis Engelm. and var. montanus Engelm.

In marshes, scepage areas and in shallow water of ponds and pools, in Okla. (Black Mesa, Waterfall), N.M. (widespread) and Ariz. (Santa Cruz, Coconino, Cochise, Pima and Navajo cos.); widespread in N.A. and the Old World. 


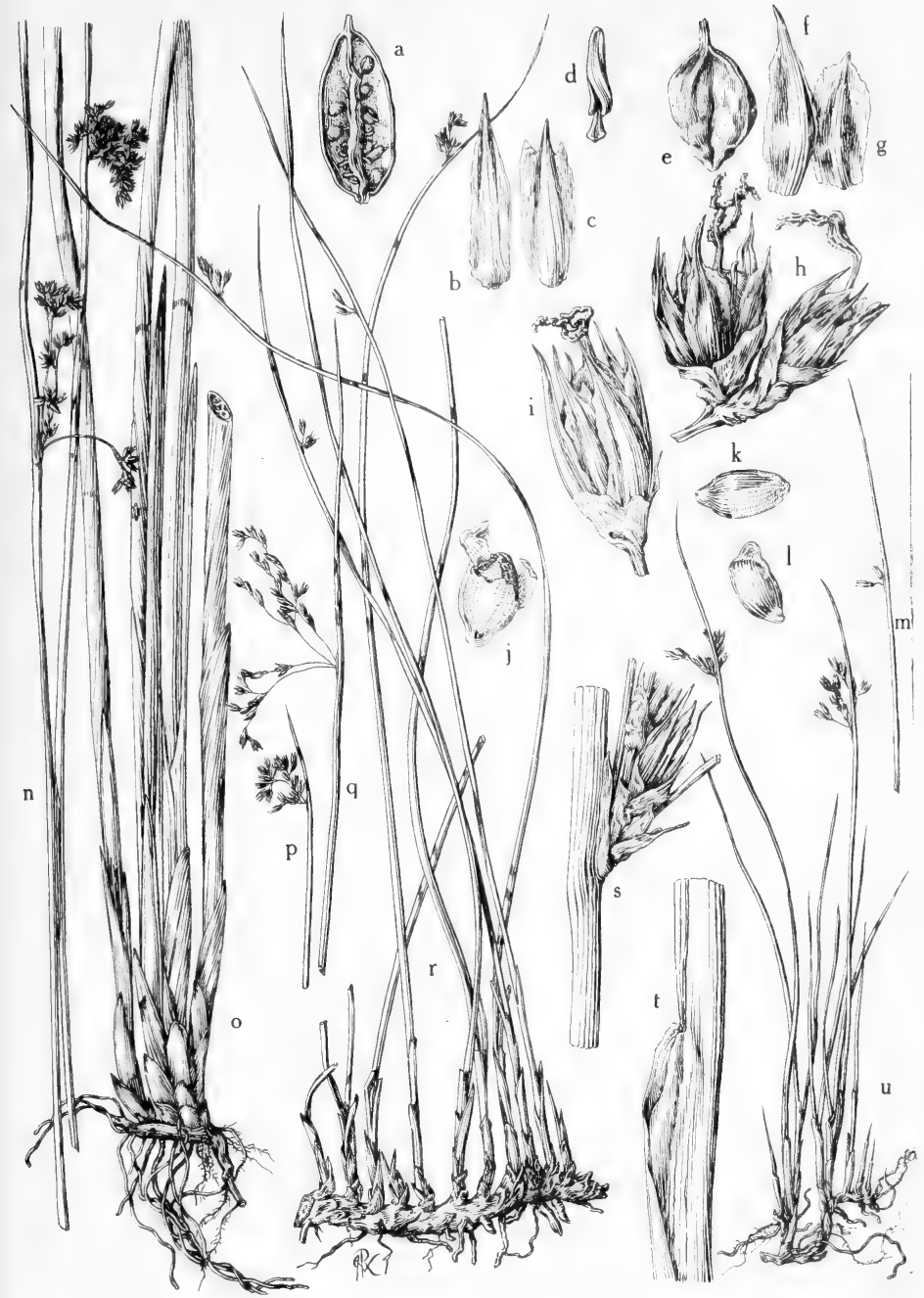

Fig. 310: Juncus balticus: a, capsule valve, showing seeds, X 5; b, outer perianth segment, X 5; c, inner perianth segment, X 5; d, stamen, X 5; e, mature capsule, X 5; f, outer perianth segment, X $5 ; \mathrm{g}$, inner perianth segment, X 5; h, part of inflorescence, X 5 ; i, flower, X 5; j-1, seeds, some with and some without membranous coat, X 16; $\mathrm{m}$, simple inflorescence, $\mathrm{X} \% ; \mathrm{n}$, habit, upper part of plant, showing inflorescences, $\mathrm{X}$ $2 \% ; \mathrm{o}$, habit, basal part of plant, showing rootstock and sheaths, $\mathrm{X} 24 ; \mathrm{p}$ and $\mathrm{q}$, variation in inflorescences, $\mathrm{X} 2 \%$; $\mathrm{r}$, habit, showing creeping rootstock, $\mathrm{X} 2 \% ; \mathrm{s}$ and $\mathrm{t}$, enclosing sheath of inflorescence, X $3 ; \mathrm{u}$, habit variation, X 2\%. (From Mason, Fig. 171). 


\section{Juncus mexicanus R. \& S.}

Almost identical to J. balticus but culms compressed and usually twisted, and averaging thicker; bract only 2 to 3 times as long as the panicle. J. balticus var. mexicanus (R. \& S.) O. Ktze.

In wet sandy soil on edge of ponds and lakes, infrequent to rare in buffalowallow lakes in the High Plains Country and formerly near springs in the TransPecos of Tex., in N. M. (San Miguel, Sandoval, Grant, Lincoln and Otero cos.) and Ariz. (Apache, Navajo, Coconino, Yavapai, Cochise and Santa Cruz cos.), early summer; Tex. to Calif. and s. to cen. Mex. In Mexico and elsewhere the populations of this species usually show a few blades on the upper sheaths, but our populations do not.

\section{Juncus effusus L. var. solutus Fern. \& Wieg. Soft RUsh. Fig. 311.}

Rhizomes very short, thick, chestnut-color; aerial culms (plus bract) 6-12 dm. long, 2-4 mm. thick, strictly erect, very crowded in thick stands, essentially terete; basal sheaths chestnut-brown, bladeless, $5-15 \mathrm{~cm}$. long, apically rounded; panicles 30 to 100 -flowered, appearing as if emerging subterminally from the side of the culm (actually terminal, far-overtopped by the terete pungent bract which is 5 to 10 times as long as the panicle and which appears as a continuation of the culm), of a few densely-flowered much-branched unequal branches; bracteoles 3 beneath each flower; perianth parts $2.7-3.3 \mathrm{~mm}$. long, usually brownish; stamens 3 , the anthers about equaling the filaments; capsule obovoid, apically obtuse, truncate or even depressed, about equaling or slightly exceeding the perianth.

Moist sandy soil or shallow fresh water, about ponds and lakes, along streams, sloughs and in marshes and wet depressions, in Okla. (Atoka, Adair, McCurtain, Haskell, Ottawa and Bryan cos.), e. and s.e. Tex., locally abundant, N.M. (San Miguel, Eddy and Taos cos.) and Ariz. (Navajo, Coconino, Gila and Pima cos.), spring.

This European species is represented in America by several varieties, the commonest of which is considered to be var. solutus in the eastern states.

Var. brunneus Engelm. is characterized by having a dark-brown perianth which is firm to almost rigid in texture, appressed to and from slightly shorter than to slightly exceeding the capsule; its segments with narrow scarious scarcely or not at all involute margins.

Var. exiguus Fern. \& Wieg. has a pale-brown perianth that is thin in texture, spreading and about one and one half times as long as the capsule; the segments with broadly scarious more or less involute margins.

\section{Juncus coriaceus Mack. Fig. 312.}

Culms essentially tufted from dark knotty bases, (with bracts) 3-10 dm. long. 1-1.5 mm. thick, often arcuate, crowded or not, essentially terete; sheaths buffy or tawny, the lower bladeless or with setaceous rudiments a few $\mathrm{mm}$. long, the upper with long weak curving blades 1-2 mm. broad and strongly involute, terminally pungent; panicle 2- to 25-flowered, appearing as if emerging from the side of the culm (actually terminal, far-overtopped by the terete or slightly compressed bract which is 3 to 20 times as long as the panicle and which appears as a continuation of the culm), of a few laxly flowered unequal branches; bracteoles 3 beneath each flower; perianth parts $3-4 \mathrm{~mm}$. long, brownish, firm, ascending (fl.) or spreading (fr.); stamens 3, the anthers about equaling the filaments; capsule nearly spherical or ovoid-spherical, about equaling or slightly exceeding the perianth.

Moist sand on edge of streams, in water and along edge of lakes and ponds, and in marshes, in Okla. (McCurtain, Pushmataha and Choctaw cos.) and e. Tex., summer; Coastal States, N.J. to Tex. and inland to Ky., Ark. and Okla. 


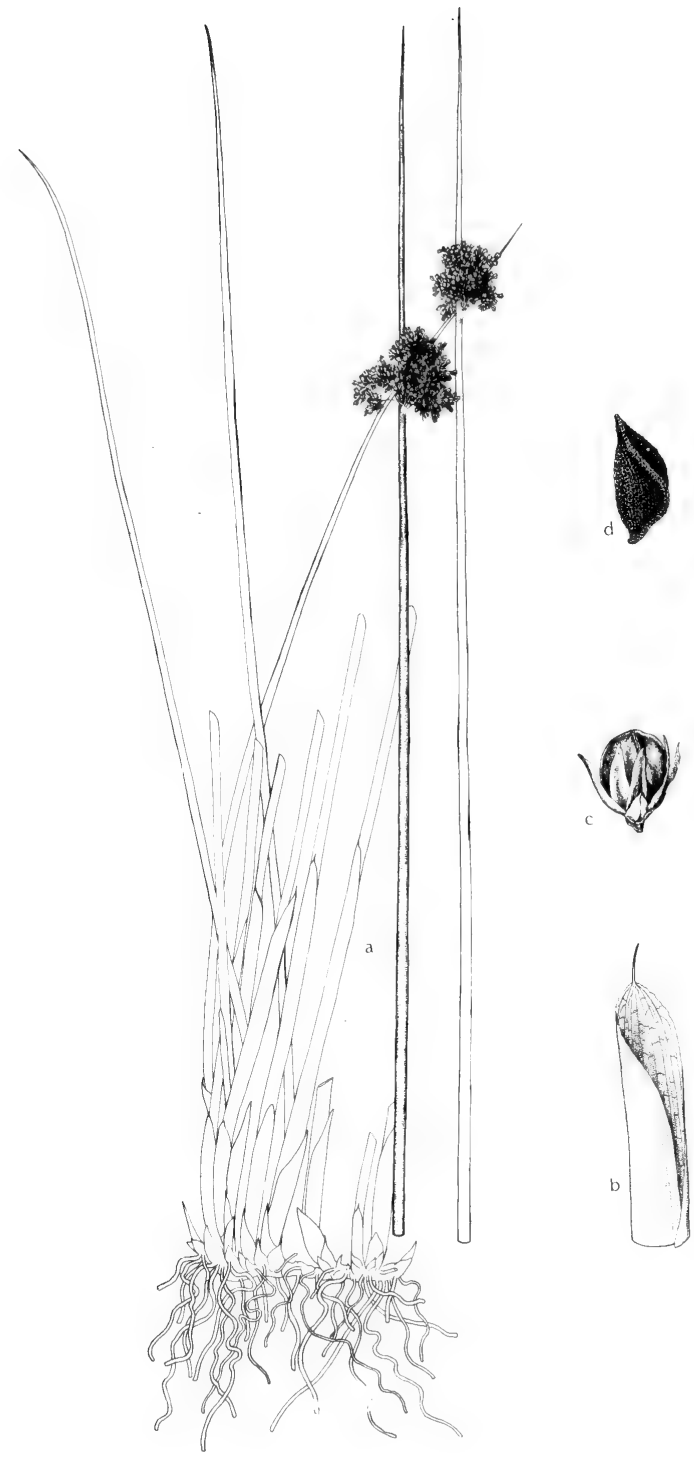

Fig. 311: Juncus effusus: a, habit, X 1/3; b, sheath, X 12/3; c, perianth and capsule, X $31 / 3$; d, seed, X 33. (Courtesy of R. K. Godfrey). 


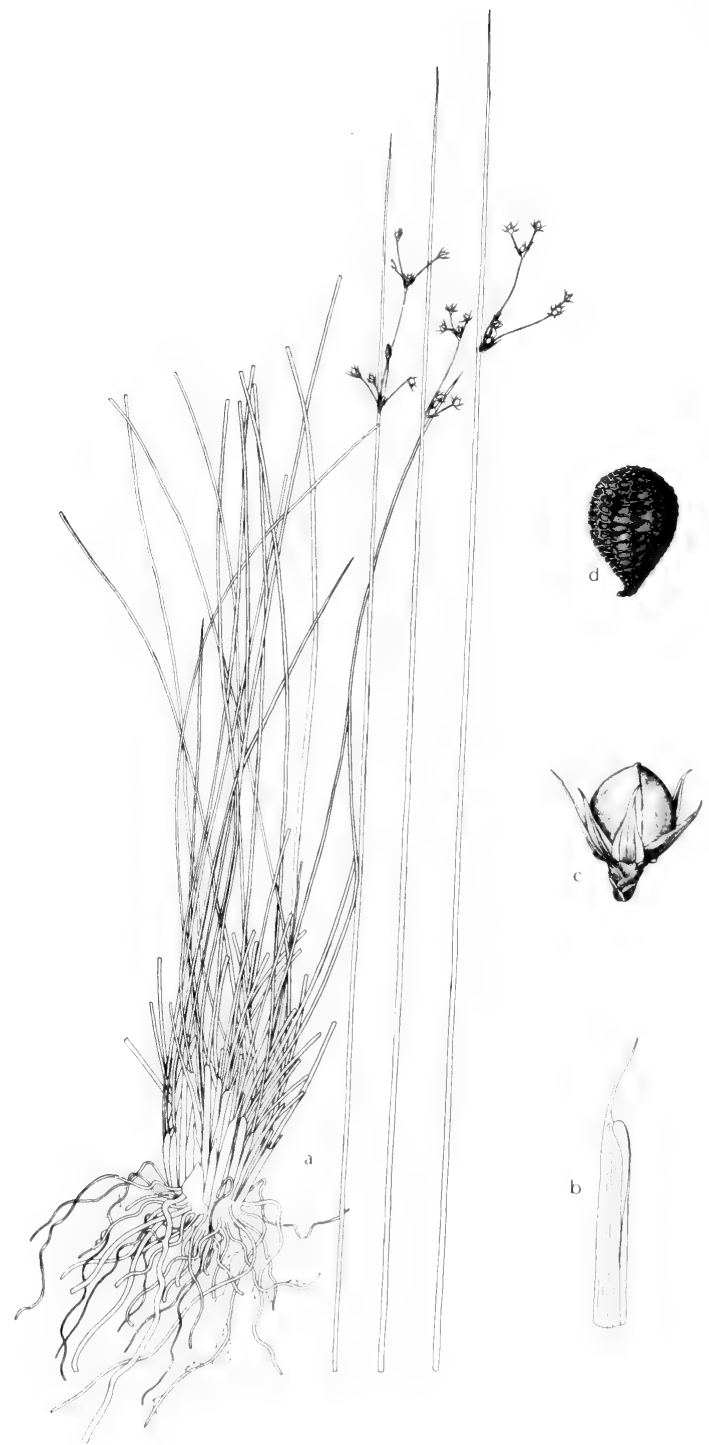

Fig. 312: Juncus coriaceus: A, habit. X 1/3; b, sheath, X 2; c, perianth and capsule, X $31 / 3$; d, seed, X 35 . (Courtesy of R. K. Godfrey). 


\section{Juncus Roemerianus Scheele. Fig. 313.}

Tufted perennial; culms with bracts 5-15 dm. long, 2-4 mm. thick, erect, simple, essentially terete; sheaths chestnut-color, with long wiry terete pungent erect blades; panicle much-branched and compound, 7-12 cm. long, appearing as if emerging from the sides of the culm (actually terminal, far-overtopped by the terete pungent bract which is about 3 times as long as the inflorescence and which appears as a continuation of the culm), the ultimate branchlets bearing glomerules of 2 to 5 flowers, each glomerule subtended by as many bracteoles as it has flowers or an occasional flower subtended by one additional bracteole; perianth 2.8-3.5 $\mathrm{mm}$. long, brown, the apexes of the parts often slightly spreading; stamens 6 , the anthers about 5 times as long as the filaments; capsule obovoid to ellipticobovoid, apiculate, brown, shining, about equaling or shorter than the perianth.

Infrequent in brackish-water ditches and coastal marshes, s.e. Tex., spring; Coastal States, Md. to Tex.

\section{Juncus Cooperi Engelm.}

Stems in large tufts from stout, much-branched rootstocks, 4-8 dm. tall, stout, pungent, terete, finely striate; leaves from basal sheaths with terete, stout, pungent blades, short or nearly as long as the stems; involucral bract $5-10 \mathrm{~cm}$. long, stout, pungent; panicle compound, with branches very unequal in length, the longer ones to $10 \mathrm{~cm}$. long; flowers 2 to several in a cluster; perianth pale green or strawcolored, 4-6 mm. long, the segments oblong-lanceolate, broadly hyaline-margined, the outer ones prominently cuspidate and longer than the inner ones; stamens 6 , about as long as the inner perianth segments, the anthers much longer than the filaments; capsule ovate-oblong, acute, extending slightly beyond the perianth; seeds with white appendage at each end, slightly margined on the side, finely reticulate.

Alkaline and saline flats in deserts, and marshy areas below springs and along streams, in Ariz. (Kearney \& Peebles); also Ut., Nev. and Calif.

\section{Juncus acutus var. sphaerocarpus Engelm. SPINY RUSH. Fig. 314.}

Stems in large tufts, 6-12 dm. tall, stout, pungent, terete or slightly compressed; leaves from basal sheaths terete, nearly as long as and resembling the stems; involucral bract $5-15 \mathrm{~cm}$. long, stout, pungent; panicle compound, with branches very unequal in length, the longer ones $10-20 \mathrm{~cm}$. long; flower clusters 2- to 4-flowered; perianth 2-4 $\mathrm{mm}$. long, yellowish-brown, the outer segments broadly lanceolate, acute, scarious-margined, the inner ones shorter, retuse at the very broad, scariousmargined apex; stamens slightly shorter than the perianth, the anthers much longer than the filaments; capsule broadly obovate or subglobose, apiculate, brown, extending well beyond the perianth; seeds acute at each end or slightly tailed, finely reticulate.

Coastal salt marshes and inland on alkaline or saline sinks and seepy areas about springs, in Ariz. (Coconino, Yavapai, Mohave and Yuma cos.); nat. of Eur. also introd. into s. Calif. and Baja Calif.

\section{Juncus bufonius L. ToAD-RUSH. Fig. 315.}

Tufted annual 4-18 $(-30) \mathrm{cm}$. tall; culms $0.4-0.7 \mathrm{~mm}$. thick, erect, mostly simple, often reddish-tinged; sheaths often swollen basally, thicker than the blades, hyaline-margined; blades involute-filiform, often arcuate especially terminally; panicles a fourth to four fifths the entire height of the plant, of a few ascending usually weak and somewhat arcuate branches (each with a few remote flowers), the subterminal flowers appressed or nearly so; bracteoles 3 beneath each flower, the lowest opposite the minute pedicel; perianth 4-6 (-8) $\mathrm{mm}$. long, the parts erect, sharp-pointed, medially green, marginally broadly white-membranous; stamens 6 or less commonly reduced to 3 ; capsule turgid-ellipsoid. 

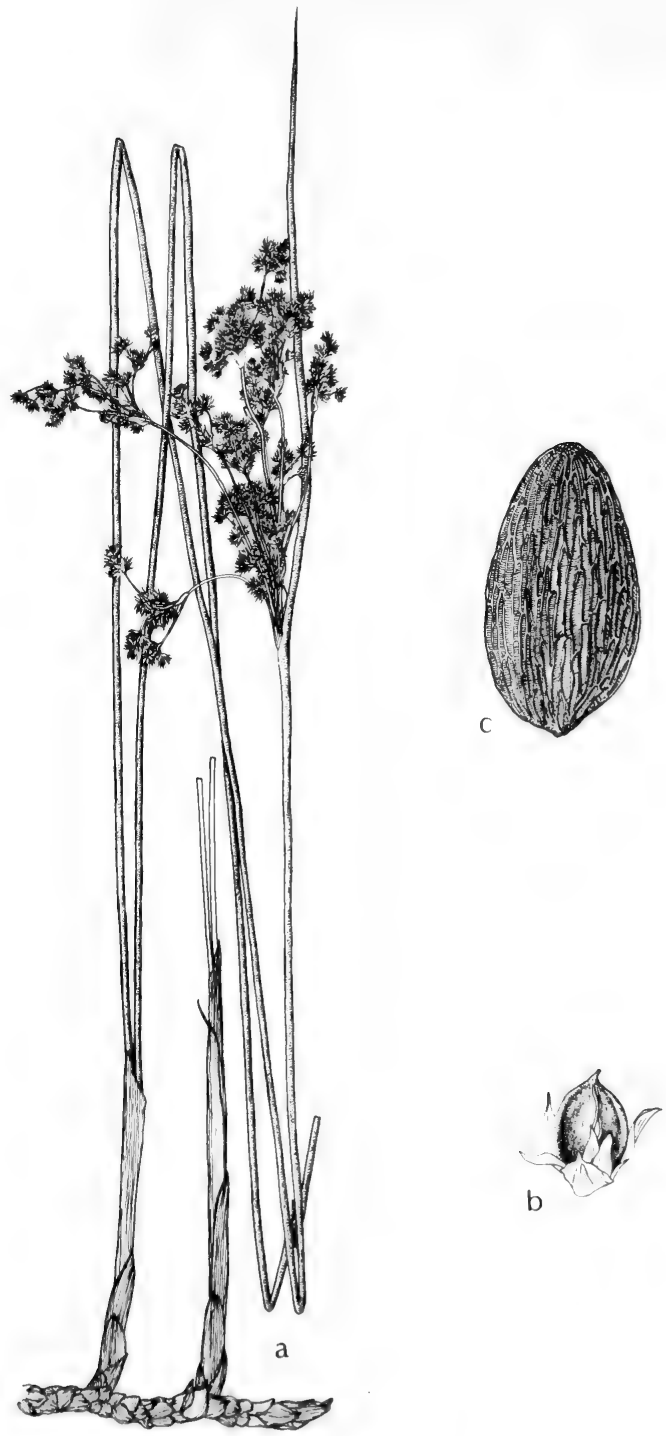

Fig. 313: Juncus Roemerianus: a, habit, X 1/2; b, perianth and capsule, X 5; c, seed, about X 40. (Courtesy of R. K. Godfrey). 


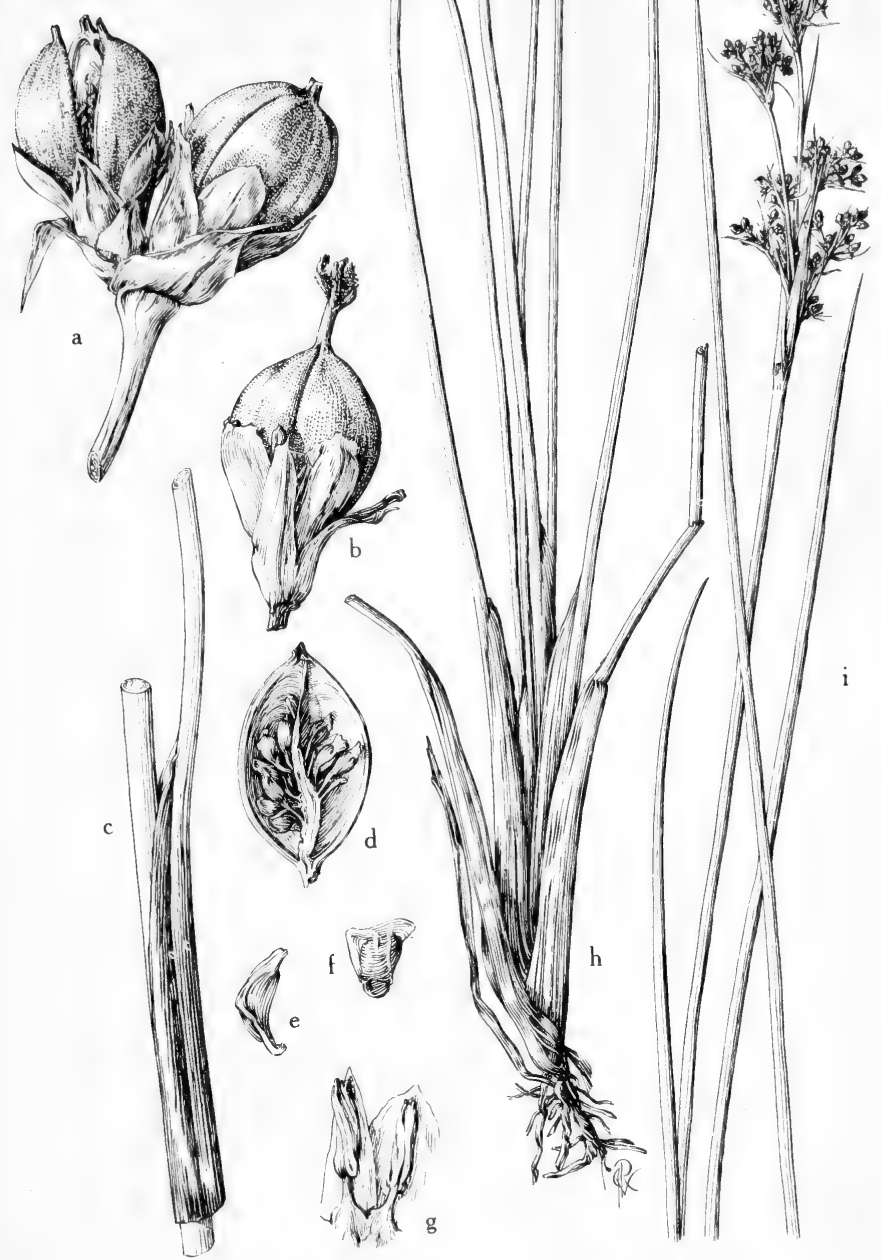

Fig. 314: Juncus acutus var. sphaerocarpus: a, single panicle cluster, showing mature capsules, X $61^{1 / 4} ;$ b, capsule, X $6{ }^{1 \%}$; c, part of stem, enclosed by basal sheath, showing the terete stemlike leaf, $\mathrm{X}+\frac{1}{5}$; $\mathrm{d}$, capsule valve, showing the tailed seeds, $\mathrm{X} 61 \frac{1}{2}$; $\mathrm{e}$ and $\mathrm{f}$, seeds, X 12; g, stamens, X $6 \frac{1 \% 2}{2}$ h, lower part of plant, showing basal sheaths and tufted stems, $\mathrm{X} 2 \% ; \mathrm{i}$, upper part of plant, showing leaves, stem and the compound panicle, X 2\%. (From Mason, Fig. 169). 
In mud and wet sand about pools, ponds and along streams, in marshes and boggy areas about springs and in flowing water, in Okla. (Cimarron Co.) and in most of Tex. except extreme Panhandle and Rio Grande Plains, N. M. (widespread) and Ariz. (throughout state), scattered, locally abundant, spring; temp. regions, nearly throughout the world, not nat. with us.

Var. halophilus Buch. \& Fern. of brackish soils has been reported from Arizona.

\section{Juncus sphaerocarpus Nees. ROUND-FRUITED TOAD-RUSH.}

Annual, branching at the base, 4-20 cm. tall, the branches filiform; leaves narrow, the blades flat or involute, 1 to 3 on the stem; inflorescence usually occupying more than half the length of the stem; flowers inserted singly on the branches and more or less remote; perianth 3-4 mm. long, the segments lanceolate, acuminate, greenish with white scarious margins, subequal in length (or the outer segments slightly longer), spreading at maturity; stamens 6 , about one half as long as the segments, the anthers shorter than the filaments; capsule oblong-ovoid or subglobose, about two thirds as long as the perianth; seeds oblong, faintly reticulate.

On edge of small ponds, pools and streams in Ariz. (Coconino, Yavapai and Pima cos.), July-Aug.; an Old World species now rather widespread in Am.

This species is very similar in many of its characters to J. bufonius, but it can usually be distinguished by its slender, smaller habit, smaller flowers, the length and arrangement of the inflorescence, and its broader capsule.

\section{Juncus confusus Coville.}

Perennial, sparingly tufted; stems $35-50 \mathrm{~cm}$. tall, slender, erect; leaves narrow, almost filiform, flat or involute; auricles produced beyond insertion, scarious; inflorescence $0.5-2 \mathrm{~cm}$. long, short and compact, pale; bract of inflorescence 2-7 $\mathrm{cm}$. long, exceeding the inflorescence; bracteoles present, large, ovate, scarious, obtuse or acutish; perianth $3.5-4 \mathrm{~mm}$. long, parts nearly equal, appressed, segments stramineous with dark stripes on each side, lanceolate, acutish, scarious at margins; stamens 6; capsule oblong, a little shorter than perianth, triangular, retuse at apex, completely 3 -celled; seeds oblong, apiculate.

In wet meadows and wet soil about lakes and ponds, in N. M. (Rio Arriba Co.) and Ariz. (Coconino and Santa Cruz cos.); Mont. and Sask. to B.C., s. to N.M., Ariz. and Calif.

\section{Juncus tenuis Willd. Slender-Rush. Fig. 316.}

Tufted perennial $8-30(-45) \mathrm{cm}$. tall; culms erect, simple, about $1 \mathrm{~mm}$. thick; leaf blades flat, $0.5-0.9 \mathrm{~mm}$. broad, occasionally slightly involute marginally, soft, often almost as long as the culms; auricles of sheaths scarious or broadly scarious margined, 1-2.5 $\mathrm{mm}$. long on the longer leaves, distinctly prolonged laterally more than centrally; panicle terminal, 3-6 (-9) $\mathrm{cm}$. long, about a fourth or a fifth the total height of the plant, 15 to 25 (to 30 ) -flowered, with branches $0.15-0.2$ $\mathrm{mm}$. thick and ascending; bracts slender, soft, usually much-exceeding the panicle; bracteoles 3 beneath each flower (the lowest opposite the flower on the floriferous node); flowers solitary or occasionally several of them approximate; sepals 3-4 $\mathrm{mm}$. long, greenish-white, long-tapered to the sharp point, soft, spreading in fruit (the almost setaceous tip then often broadly spreading); stamens 6; capsule oblong-ovoid, shorter than to rarely equaling the perianth. Incl. var. anthelatus Wieg.

Wet sands in woods, in wet soils on edge of ponds, lakes and streams, in Okla. (McCurtain and Adair cos.), e. and s.e. Tex., N.M. (Colfax Co.) and Ariz. (Coconino, Graham, Cochise and Pima cos.), infrequent, spring, rarely summer; 


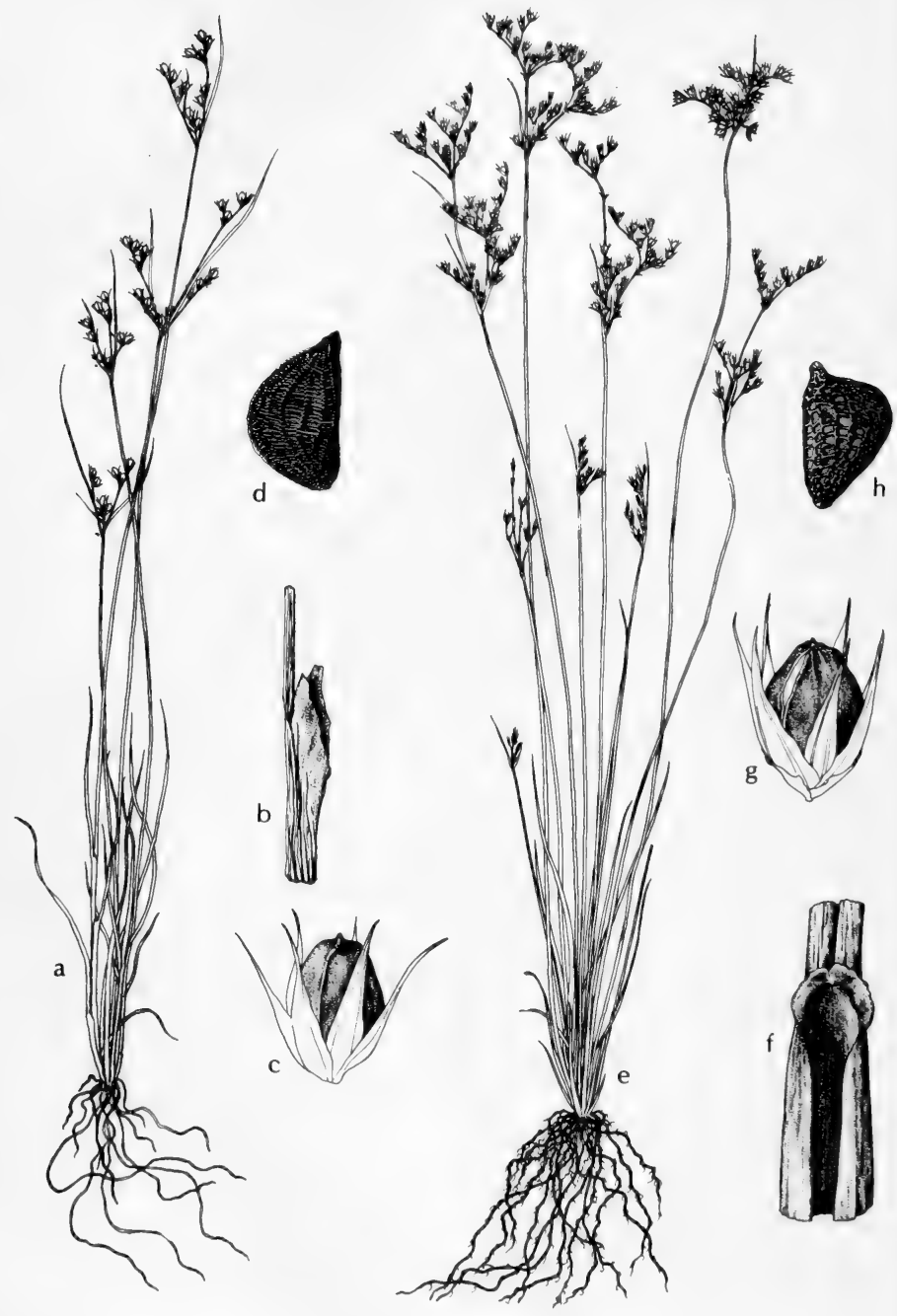

Fig. 316: a-d, Juncus tenuis: a, habit, X 1/2; b, sheath, X 5; c, perianth and capsule, X 5; d, seed, X 75, e-h, Juncus dichotomus: e, habit, X 1; f, sheath, X 10; g, perianth and capsule, X 5; h, not unusual asymmetrical seed, X 50. (Courtesy of R. K. Godfrey). 
e. temp. N.A., w. to Minn., Ia., Mo., Okla., Tex., N.M. and Ariz.; Euras.; also reputedly in Mex., S.A. and N. Afr.

14. Juncus dichotomus Ell. Fig. 316.

Tufted perennial much like J. interior but the panicles more diffuse (3-) 5-10 cm. long.

In seepage areas, edge of water about lakes, ponds and streams, and wet lowland forests, in Okla. (McCurtain Co.), e. (and probably s.e.) Tex. and (?) N.M. (San Miguel and Grant cos.), infrequent to rare, apparently grading into J. interior, with which it is probably conspecific, spring; Coastal States, Mass. to Okla. and Tex.; also reputedly N.M. and Mex.

\section{Juncus Dudleyi Wieg.}

Tufted perennial much like $J$. interior but the auricles averaging even firmer; panicle very compact, 1-2 (-3) cm. long, 7- to 25-flowered; flowers approximate in 1 to 3 glomerules but not true heads; sepals $4-5.5 \mathrm{~mm}$. long, very firm to cartilaginous; capsule distinctly shorter than the perianth. J. tenuis var. Dudleyi (Wieg.) Herm.

Moist calcareous soil, in swamps, borders of streams, lakes and ponds, marshes, wet meadows, seepage areas, in Okla. (Murray, Ottawa, Mayes, Cherokee and Adair cos.), n.-cen. Tex., w. part of e. Tex. and Edwards Plateau, N.M. (Union, Taos, Lincoln, Otero, San Miguel, Santa Fe, Socorro and McKinley cos.) and Ariz. (Santa Cruz, Coconino, Yavapai, Maricopa, Pinal and Cochise cos.), rare or scattered, spring-summer; s. Can. s. to Va., Tenn., N.M., Ariz. and Calif.; also n. Mex.

\section{Juncus interior Wieg.}

Tufted perennial 3-8 dm. tall; culms erect, simple, $1.3-2.5 \mathrm{~mm}$. thick (rarely more slender), tough, wiry; leaf blades flat and $1-1.5 \mathrm{~mm}$. broad or usually somewhat involute marginally (making them narrower and more wiry) and prolonged to a sharp involute tip, usually about $1 / 2$ as long as the culms; auricles of sheaths firm-membranous, not scarious, whitish to yellowish, rounded, not at all prolonged; panicle $1-4(-6) \mathrm{cm}$. long, ( 3 to) 10 to 25 (to 50 ) -flowered, more densely flowered than in $J$. tenuis, with branches $0.3-0.5 \mathrm{~mm}$. thick, wiry and ascending; bracts slender, wiry, rather stiffly erect, equaling (or the lowest usually much-exceeding) the panicle, involute-tipped; bracteoles 3 beneath each flower (the lowest opposite the flower at the floriferous node); flowers solitary; sepals $3-5 \mathrm{~mm}$. long, stramineous, long-tapered to the sharp point, firm, stiffly ascending (even at the tip and even in fruit); stamens 6; capsule narrowly oblong-ovoid, about equaling the perianth. Incl. var. arizonicus (Wieg.) Herm. and var. neomexicanus (Wieg.) Herm., J. arizonicus Wieg. and var. curtiflorus Wieg., J. neomexicanus Wieg.

Moist usually calcareous soil, marshes, wet meadows, in water of ditches, pools and depression in savannahs, and seepage areas, in Okla. (Grady, McCurtain, Haskell, Comanche and Alfalfa cos.), n.-cen. and s.e. Tex., w. portion of e. Tex. and coastal part of Rio Grande Plains, w. through Edwards Plateau, Plains Country and the Trans-Pecos, N. M. (Sierra, Colfax, Sandoval, Rio Arriba, Lincoln, Grant and Socorro cos.) and Ariz. (Coconino, Navajo and Pima cos.), rather frequent, spring-summer; O. and Mich., s.w. to Tex. and w. to Mont., Colo. and Ariz.; n. Mex.

Some specimens seem intermediate between this species and $J$. Dudleyi, and others between it and $J$. dichotomus, of which $J$. interior is perhaps only a variety.

\section{Juncus repens Michx. Fig. 317.}

Perennial but vegetative culms largely annual, weak, compressed, at first ascending but then arcuate-stoloniferous and creeping or floating, or growing along the 

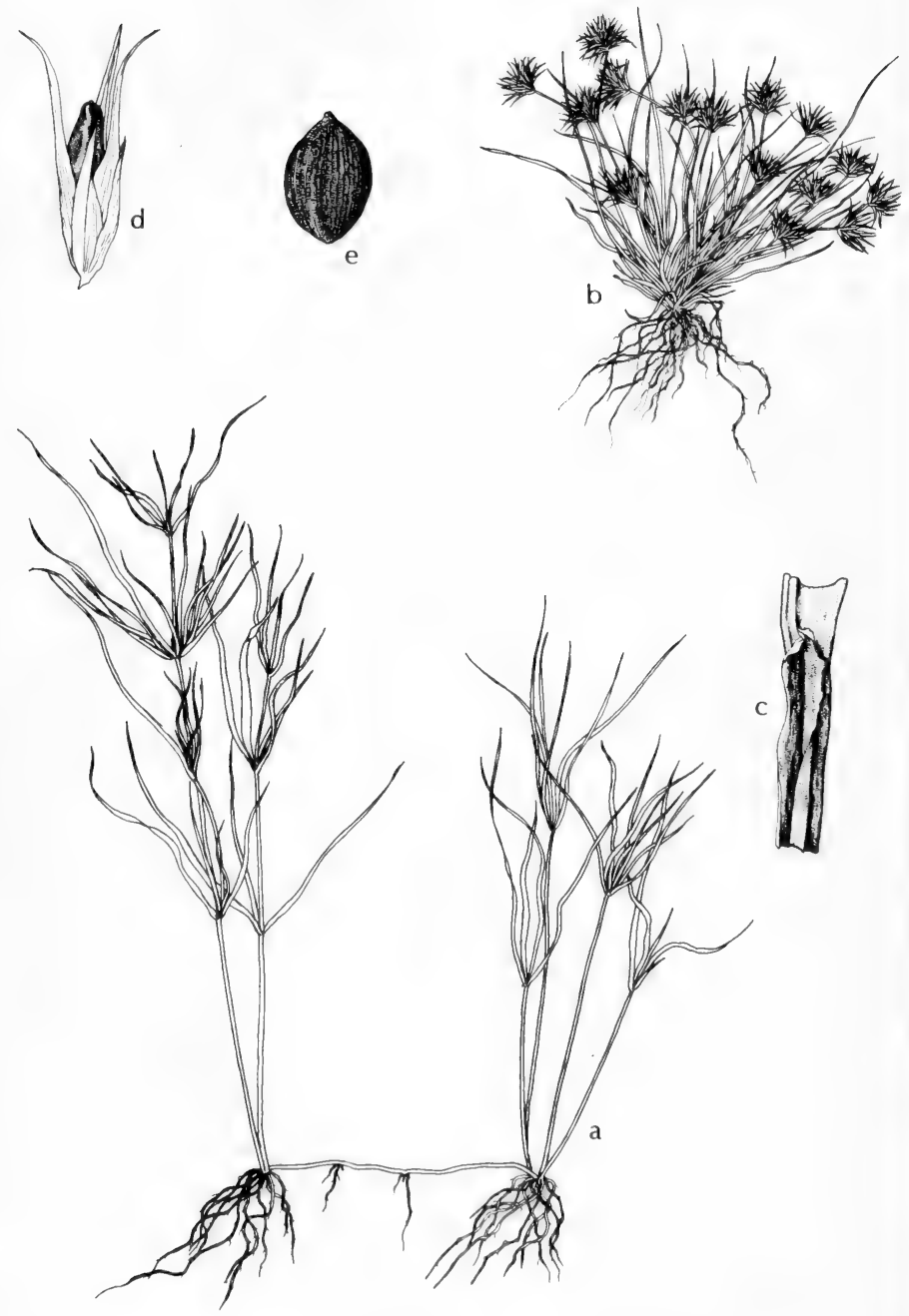

Fig. 317: Juncus repens: a, sterile plant, $\mathrm{X} 1 / 2 ; \mathrm{b}$, fruiting plant, $\mathrm{X} 1 / 2 ; \mathrm{c}$, sheath, X 5; d, perianth and capsule, X 5; e, seed, X 30. (Courtesy of R. K. Godfrey). 


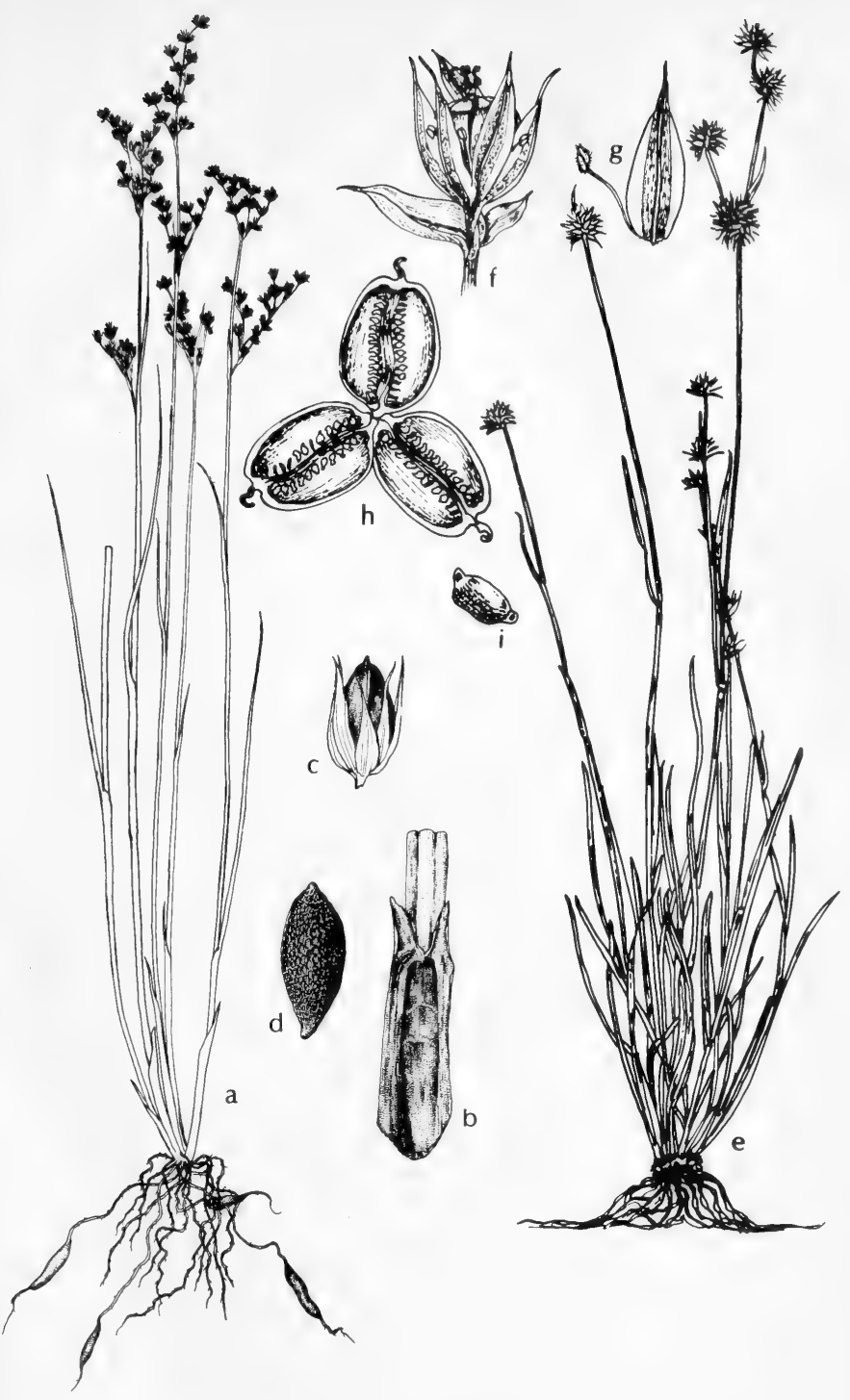

Fig. 318: a-d, Juncus Elliottii: a, habit, X 1/2; b, sheath, X 5; c, perianth and capsule, X 5; d, seed, X 60 . e-i, Juncus filipendulus: e, habit, X 1/2; f, flower, X 3; g, outer perianth segment, X 5 ; h, open capsule, X 5; i, seed, X 20 . (a-d, Courtesy of R. K. Godfrey). 
bottom submerged, at each node with a cluster of basal leaves and fibrous roots and eventually at each emergent (not submerged) terrestrial node with an ascending floriferous culm (5-) $10-30 \mathrm{~cm}$. long, this with only 1 or 2 nodes and these lower nodes bearing clusters of leaves; blades weak, ascending, more or less flat, 5-10 $\mathrm{cm}$. long, 2-3 $\mathrm{mm}$. broad, not septate, tapering to a fine point; panicle terminal, 7-13 cm. long, simple or few-branched, of 2 to ten 3- to 12-flowered rotate-turbinate glomerules which are terminal on the branches or else appearing sessile at the nodes; individual flowers 5-10 mm. long, subtended by only 1 bractlet at the base of the pedicel; sepals and petals rigid, lance-subulate, setaceous-tipped, the petals much longer than the sepals; stamens 3; capsule linear or at least very narrow, apically obtuse, about as long as the sepals.

Margins of fresh water ponds and sandy loam soil, in swamps and bogs, in Okla. (LeFlore Co.) and e. Tex., infrequent to rare, summer; Coastal States, Del. to Tex. and inland to Tenn., Ark. and Okla.

\section{Juncus filipendulus Buckl. Fig. 318.}

Perennial, tufted or from masses of slightly swollen bulbil-like bases; culms 15-30 $\mathrm{cm}$. long, compressed, 0.5-1 mm. broad (in largest transverse dimension), leafy, erect or some of them basally shortly decumbent; sheaths shorter than their internodes; blades flat, soft, membranous, 2-10 cm. long, 1-2.5 mm. broad, mostly ascending; panicle terminal, few-branched, of 2 to 5 (to rarely 10 ) headlike glomerules or reduced to a single glomerule; glomerules hemispherical, 7-10 mm. across, stramineous, of 6 to 15 essentially sessile flowers, each subtended by 1 (rarely 2) bracteoles; perianth 4-5 $\mathrm{mm}$. long, whitish to stramineous; stamens 3; capsule obovoid, much shorter than the perianth.

Moist calcareous soil or shallow water along streams, in Okla. (Arbuckle Mts., Waterfall), infrequent in Edwards Plateau, rare in n.-cen. Tex. and e. part of Plains Country, spring-summer.

\section{Juncus marginatus Rostk. Fig. 319.}

Perennial from enlarged, bulblike bases (these often connected by short rhizomes); aerial culms 1 to 3 from each bulb, 15-100 cm. long, compressed, 1.5-3 $\mathrm{mm}$. broad (in largest transverse dimension), leafy, erect or some culms basally shortly decumbent; sheaths much shorter than their internodes, with narrow hyaline margins near the corners; blades flat, soft, membranous, $3-15 \mathrm{~cm}$. long, 2-5 $\mathrm{mm}$. broad, mostly erect or distally decurved-arcuate, abruptly acute; panicles terminal, much-branched and compound, the branches ascending, each of the 10 to 80 ultimate branches bearing a glomerule of 2 to 12 essentially sessile flowers; each glomerule subtended by as many bracteoles as it has flowers or a few more; perianth 2.5-3.5 mm. long, brownish; stamens 3; capsule rotundly obovoid, about equaling the perianth, brown. Incl. var. paucicapitatus Engelm., J. aristulatus Michx., J. biflorus Ell.

In marshes, wet meadows, seepage areas, on edge of lakes, ponds and streams, in most of Okla and Tex., common in e. half, infrequent to rare in w. part, and Ariz. (Santa Cruz, Graham and Pima cos.), spring-summer; e. half of temp. N.A., rare w. to Ariz.

Var. setosus (Small) Cov. with glossy capsules and aristate inner perianth segments occurs in Arizona.

\section{Juncus longistylis Torr.}

Perennial plants from short rootstocks; stems $20-50 \mathrm{~cm}$. tall, loosely cespitose; basal leaves flat, with well-developed auricles; stem leaves $1-4 \mathrm{~mm}$. wide, flat or somewhat involute, the flat edges inserted next to the sheaths with scarious 


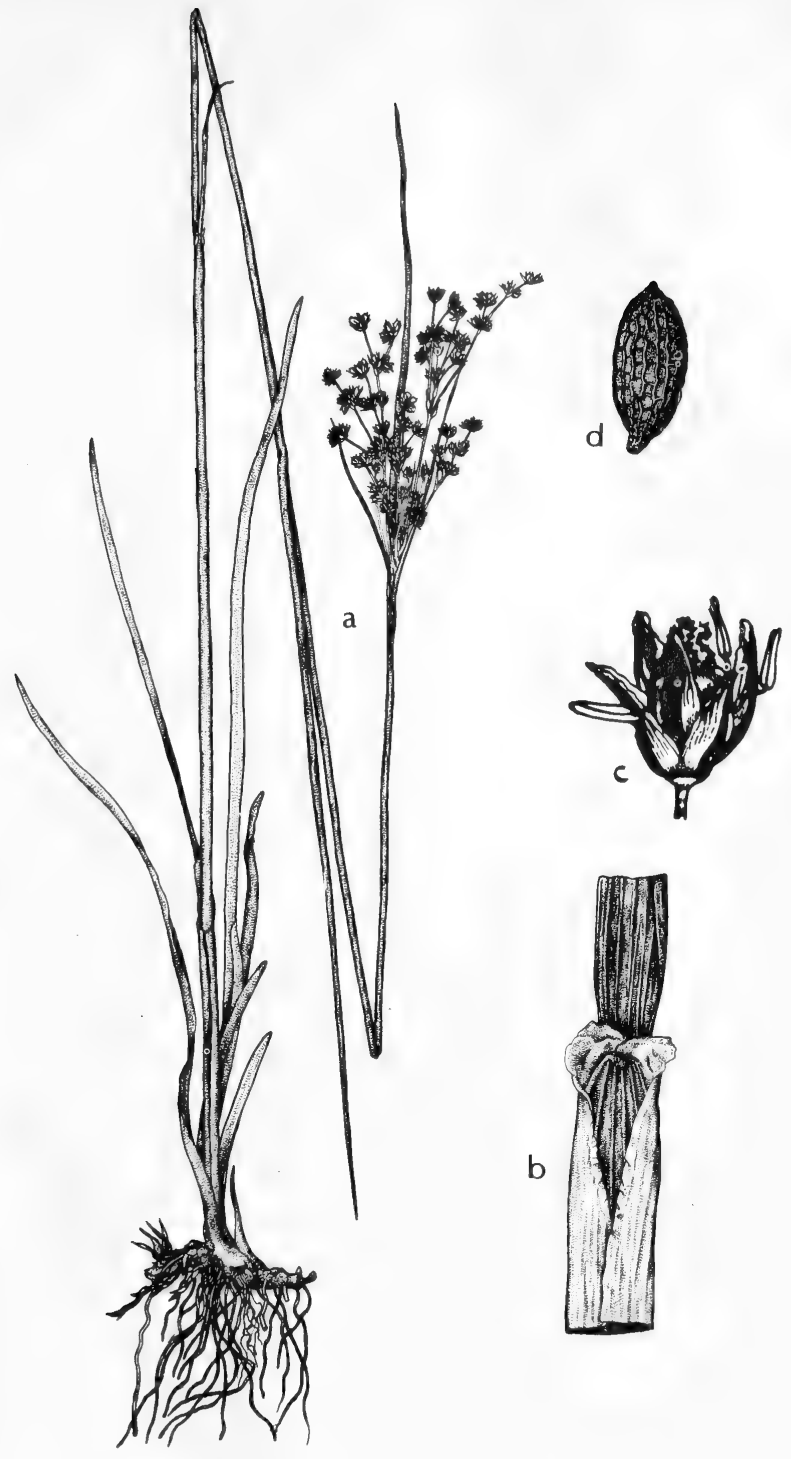

Fig. 319: Juncus marginatus: a, habit, X 1/2; b, sheath, X 3; c, flower, X 5; d, seed, X 60. (Courtesy of R. K. Godfrey; c. by V. F.). 


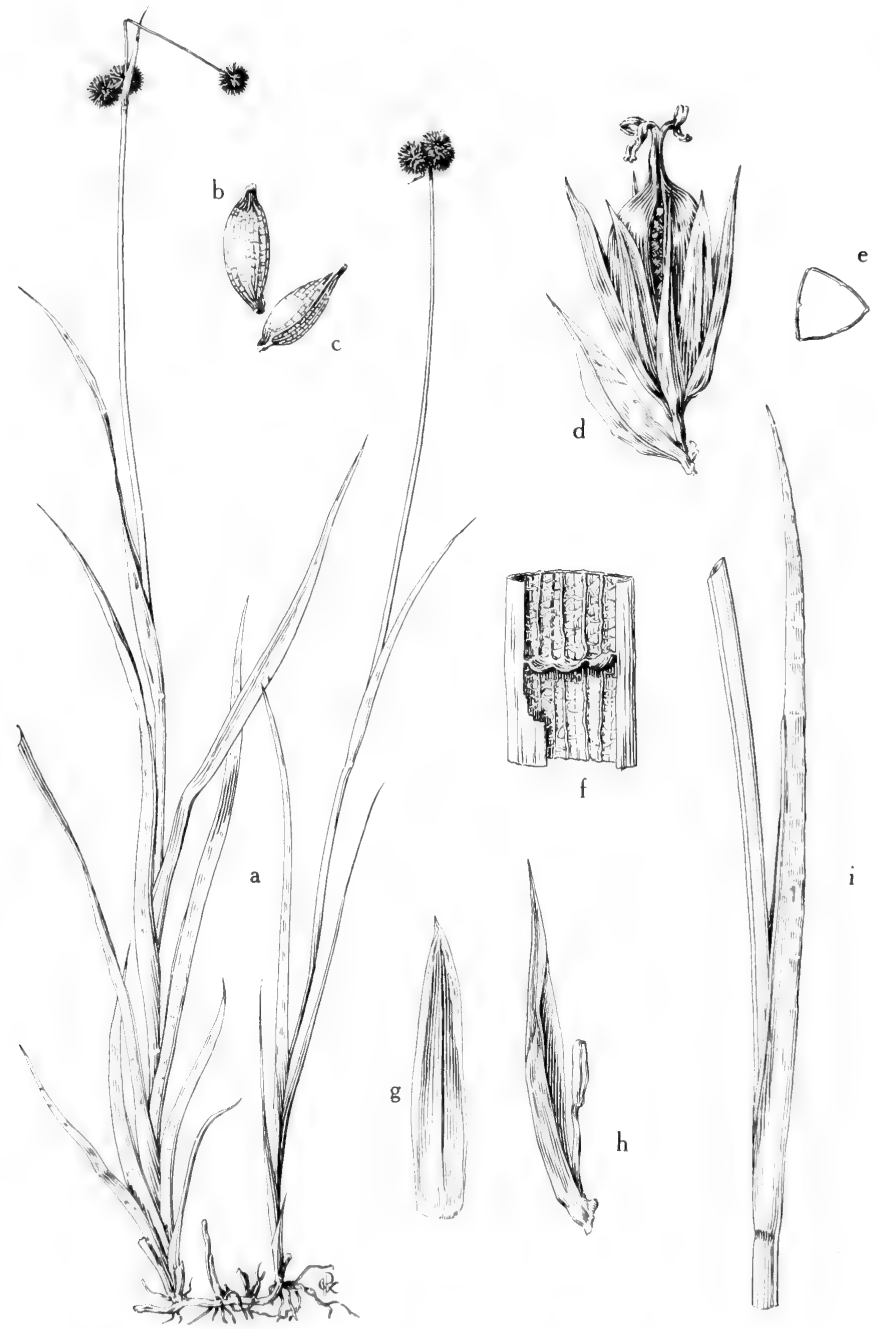

Fig 320: Juncus ensifolius: a, habit, showing the slender rootstock, the equitant septate leaves and the densely flowered heads, X $2 ;$; b and $c$, mature seeds, X $24 ; d$, perianth and mature capsule, X 10; e, capsule (cross section), X 8; f, leaf, with a part of surface removed to show septum, X $3 ; \mathrm{g}$, inner perianth segment, X 14; h, outer perianth segment and stamen, X 14; i, leaf, equitant and septate, X 4/5. (From Mason, Fig. 180). 
margins; inflorescence of 2 to 8 heads, each 3- to 8- (rarely less) flowered; perianth 5-6 $\mathrm{mm}$. long, segments greenish or light brown in center, brown on the sides and with broad hyaline margins, lanceolate, acuminate; flowers not bracteolate; stamens 6; capsule 3-celled, oblong, from somewhat shorter to somewhat longer than the perianth, mucronate; seeds oblong, apiculate.

In wet meadows, seepage areas and wet soils generally, in N.M. (San Miguel, Union, Taos, Colfax, Sandoval and Otero cos.) and Ariz. (Apache, Navajo, Coconino, Yavapai, Greenlee, Graham, Santa Cruz and Gila cos.), spring-summer; Alta. to B.C., s. to N.M. and Calif.

Var. scabratus Herm. with vegetation strongly scabrous and the auricles tending to be prolonged, free and acute, is the common plant in Arizona.

\section{Juncus macrophyllus Coville.}

Stems erect, 3-9 dm. high, rather stiff, compressed; basal leaves equaling or about half the length of the stems; sheath scarious-margined and more or less distinctly auriculate; blades flat but rather thick and firm, 1.5-4 mm. wide, striate, long attenuate and pungent; stem leaves 1 to 3 , their blades mostly 8-15 $\mathrm{cm}$. long; inflorescence loosely paniculate; heads usually 12 to 25,3 - to 5-flowered; perianth green tinged with light brown, 5-6 $\mathrm{mm}$. long, the segments ovate, acute or obtuse, hyaline-margined, the outer distinctly shorter than the inner; stamens 6, half the length of the segments; anthers reddish-brown, much longer than the filaments; capsule shorter than the perianth, tapering at the apex into a short beak; seeds $0.5 \mathrm{~mm}$. long, obliquely obovate, about 30-ribbed, the reticulations lineolate.

Dry hillsides, wet soils and marshes, in Ariz. (Yavapai, Maricopa and Pinal cos.); also Baja Calif.

\section{Juncus ensifolius Wiks. Three-STEMmed Rush. Fig. 320.}

Stems from slender rootstocks, 2-5 dm. tall, compressed; leaves distinctly equitant, 2-5 $\mathrm{mm}$. wide, incompletely septate, the upper ones often nearly equaling the inflorescence in height; heads 1- to 3-glomerate, densely flowered, dark-reddish brown; perianth $2.5-3.5 \mathrm{~mm}$. long, the segments nearly equal in size, lanceolate, acuminate; stamens $3,1 / 2-2 / 3$ as long as the perianth, the filaments longer than the anthers; capsule dark-reddish-brown, longer than the perianth, oblong, obtuse or shortly acute at the summit with a short mucro; seeds sharply reticulate.

Wet ground, commonly near the coast, inland to Ariz. (Kearney \& Peebles); Sask. to Alas., s. to Ariz. and Calif.

It is frequently confused with $J$. xiphioides, but the few, densely flowered, glomerate, and dark-colored heads distinguish it from that species.

\section{Juncus xiphioides E. Mey. Fig. 321.}

Stems compressed, acutely 2-edged, 4-8 dm. tall, from stout, creeping rootstocks; leaves flattened laterally, the sheaths without auricles, the blades $3-12 \mathrm{~mm}$. wide, more or less distinctly ribbed by transverse septa; inflorescence variable, commonly of numerous heads in a loose or compact compound panicle, but sometimes with a few relatively large heads; perianth brownish or reddish-tinged, 2.5-3 $\mathrm{mm}$. long, the segments lanceolate, acuminate (prominently subulate in immature plants); stamens 3 or 6 , one half (or sometimes more) as long as the perianth, the anthers shorter than or of about the same length as the filaments; style usually included; capsule oblong, shortly acute or slightly tapering below the mucronation, as long as to slightly longer than the perianth; seeds reticulate.

Streams, meadows and marshes, in N. M. (Catron Co.) and Ariz. (Coconino, Gila, Mohave, Pima, Yavapai, Maricopa and Santa Cruz cos.); also Calif. and Baja Calif. 


\section{Juncus Tracyi Rydb.}

Stem stout, 3-6 dm. high, compressed; blades 5-20 cm. long, 2-4 mm. wide; sheaths with a scarious margin which usually is produced into a very short auricle; inflorescence of 5 to 9 heads, these about $1 \mathrm{~cm}$. in diameter; sepals and petals lanceolate, acute, light brown, 3-4 mm. long, slightly scarious-margined; capsule oblong, mucronate, shorter than the perianth, imperfectly 3 -celled.

In wet meadows in Ariz. (Apache and Coconino cos.); Mont. and Ida. to Ariz. and Nev.

\section{Juncus saximontanus A. Nels. Fig. 322.}

Culms basally shortly decumbent and/or subrhizomatous but tuber-bearing enlargements absent; flowering culms mostly in loose clumps, erect, $25-45 \mathrm{~cm}$. long, compressed, 1-2 mm. thick near the middle; blades membranous, weakly septate (the septae often incomplete and not tangible in well-pressed specimens), laterally flattened, gladiate, tapering to a point; panicle terminal, 4-7 cm. long, sparsely branched, either of 6 to twenty 6- to 19-flowered turbinate glomerules (f. brunnescens (Rydb.) Herm.) or else the glomerules congested into fewer (2 to 5) pleianthous (20- to 40-flowered) nearly round heads (typical form); bracteole solitary at the base of the pedicel; sepals $3-4 \mathrm{~mm}$. long, lanceolate, acute, stramineous or usually brown to chestnut-color, chaffy; petals similar to sepals but shorter; anthers 6 , much shorter than the filaments; capsules oblong, mucronate, a little shorter than the sepals, usually chestnut-brown at maturity. J. parous Rydb., J. brunnescens Rydb.

Along creeks in water and wet meadows, in the Tex. Trans-Pecos mts. (Chisos and Davis), N.M. (Taos, San Miguel, Catron, Otero, Colfax, Union, Grant, Sandoval and Rio Arriba cos.) and Ariz. (Coconino, Yavapai, Greenlee, Graham, Chochise and Pima cos.), infrequent; B.C., s. to Dgo. and e. to Colo., N.M., Tex. and Coah.

\section{Juncus brevicaudatus (Engelm.) Fern.}

Stems slender, densely cespitose, 1-5 dm. tall; leaves erect, 1-2 mm. in diameter; inflorescence strict, 3 to 6 times as long as wide, $3-12 \mathrm{~cm}$. long, with few to many erect or ascending branches and few to many heads, each with 2 to 7 flowers; perianth-segments lance-subulate, 3-nerved, the sepals $2.3-2.9 \mathrm{~mm}$. long, the petals $2.6-3.2 \mathrm{~mm}$. long; capsule prismatic, $3.5-4.8 \mathrm{~mm}$. long, abruptly tapering into a very short beak or merely acute; seeds fusiform, 0.9-1.2 $\mathrm{mm}$. long, the body occupying about three fifths of the total length.

Marshes, wet meadows and shores, in Ariz. (Coconino Co.); Que. and N.S, to w. Ont. and Minn., s. to Mass. and N.Y., in the mts. to W. Va. and Ariz.

\section{Juncus trigonocarpus Steud. Fig. 323.}

Perennial; culms erect or ascending, simple, tough, wiry, terete, 5-9 dm. long, 2-2.5 mm. thick, basally often trailing and rooting in the mire; leaves few, remote, subappressed; blades terete, wiry, nodulose, 7-20 cm. long, about $2 \mathrm{~mm}$. thick; panicle terminal, compound-branched, $5-15 \mathrm{~cm}$. long, about a fourth to a third as broad; primary branches of panicle erect, 1-9 $\mathrm{cm}$. long, bearing nodes with short bracts and fascicles of short branches each of which bears a hemispheric or turbinate 6- to 15-flowered glomerule; bracteole solitary at the base of each pedicel; sepals and petals about $3 \mathrm{~mm}$. long, lanceolate, rigidly subspinescent, strongly nerved, mostly green or stramineous with a chestnut-brown tip; stamens 3 or said to be sometimes 6 ; capsule 3.5-5 mm. long, exserted, narrow, tapered at both ends, acuminate apically, shining chestnut-brown, eventually completely dehiscent (even the tip); seeds with brown bodies $0.6-0.7 \mathrm{~mm}$. long and white to stramineous "tails" on either end, the tail on the upper end slender and $0.5-0.6 \mathrm{~mm}$. long, 


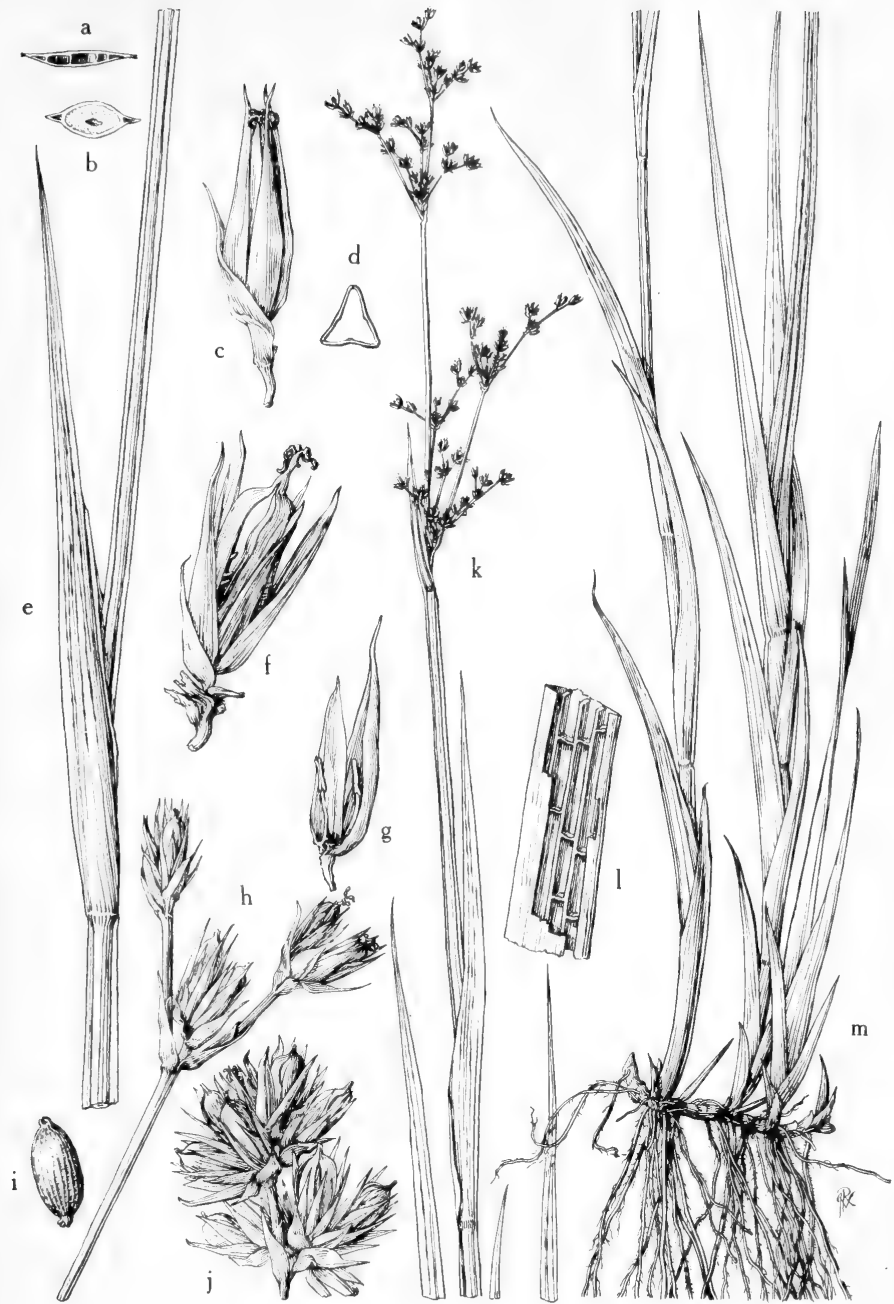

Fig. 321: Juncus xiphioides: a, leaf (cross section), X 11/2; b, stem (cross section), $\mathrm{X} 11 \%$; , flower, $\mathrm{X} 10$; d, capsule (cross section), X 10; e, leaf, the sheath without auricles, $\mathrm{X} 4 \%$; $\mathrm{f}$, perianth and mature capsule, $\mathrm{X} 10$; $\mathrm{g}$, inner and outer perianth segments and stamens, the anthers shorte: than filaments, X $10 ; \mathrm{h}$, branch of inflorescence, $X 4 ; i$, mature seed, X $24 ; j$, variation in inflorescence, the heads larger, X 4; $k$, habit, upper part of plant, showing inflorescence, $X 2 \% ; 1$, leaf, with a part of epidermis removed to show septa, X $1 \frac{1}{2} ; \mathrm{m}$, habit, lower part of plant, showing the stout creeping rootstock and the flattened leaf blades, X $2 \%$. (From Mason, Fig. 183). 


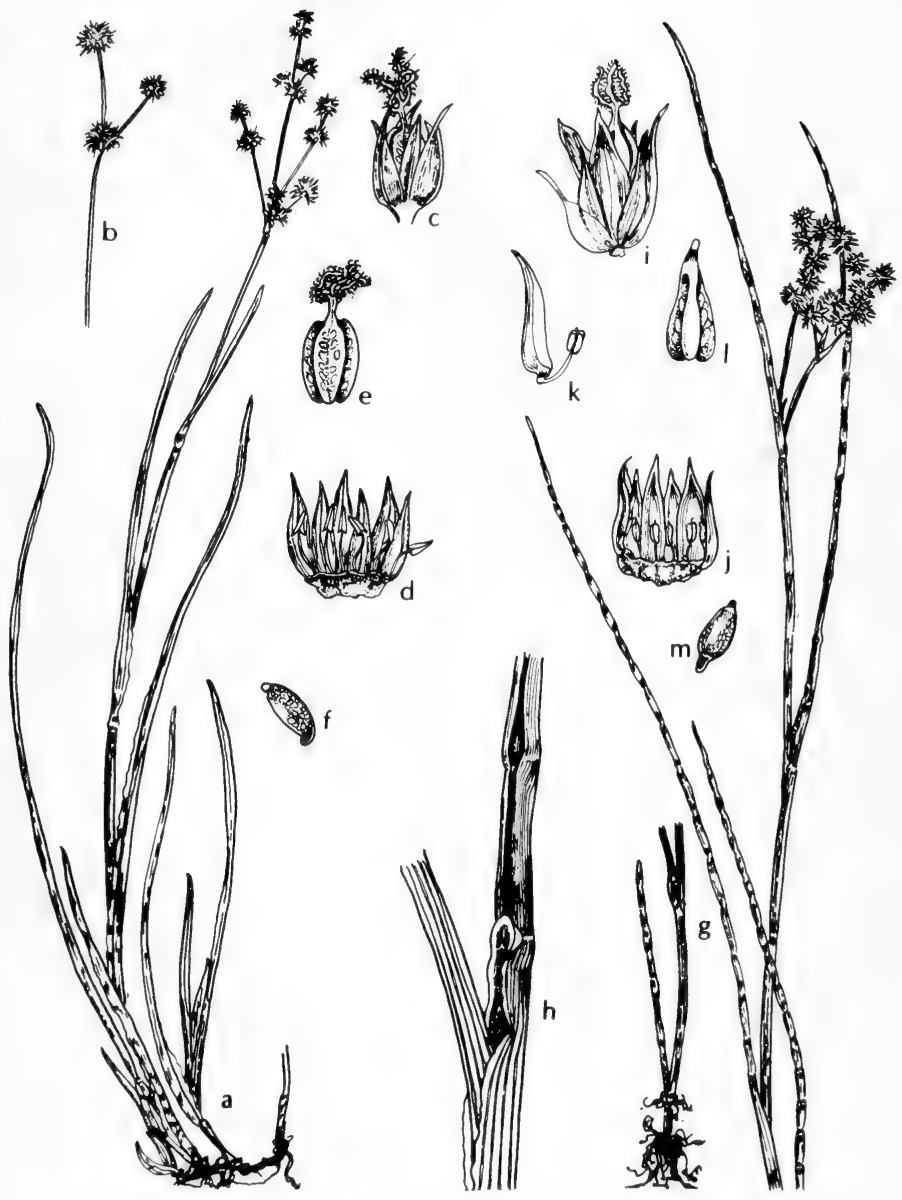

Fig. 322: a-f, Juncus saximontanus: a, habit, $\mathrm{X} 1 / 2$; b, three flower heads, $\mathrm{X} 1$; c, flower, X 5; d, perianth and stamens spread out, X 5; e, capsule, X 5; f, seed, X 20 . $\mathrm{g}-\mathrm{m}$, Juncus nodosus: $\mathrm{g}$, habit, $\mathrm{X} 1 / \mathrm{g} ; \mathrm{h}$, stem showing sheath, $\mathrm{X} 3$; $\mathrm{i}$, flower, $\mathrm{X} 5 ; \mathrm{j}$, perianth and stamen spread out, $X-5 ; k$, inner perianth segment and anther, $X$ 5; 1 , capsule, X 5; m, seed, X 10 . (V. F.). 
that on the lower end shorter and stouter. J. caudatus Chapm.

Rare in seeps and bogs on sandy soil, e. Tex. (Henderson, Jasper and Tyler cos.), Sept.-Nov.; Coastal States, S.C. to Tex.

\section{Juncus castaneus Smith.}

Perennial plants; stems $10-40 \mathrm{~cm}$. tall, terete, leaves mostly basal; leaves tapering from an involute tubular base to a slender channeled apex, the general effect being terete, the upper epidermis being membranous, 1-2 $\mathrm{mm}$. thick; sheaths not auriculate; lowest bract usually exceeding the inflorescence; inflorescence of 1 to 3 heads, few-flowered, no bractlets present; segments of perianth 4-7 mm. long, lanceolate, acute, chestnut-brown, petals somewhat shorter and often almost obtuse; stamens 6; capsule one and a half to two times as long as perianth, brown, tapering to an acute apex, narrowly oblong; seeds long-caudate.

In wet meadows and seepage areas in N.M. (Taos and Rio Arriba cos.); Greenl. to Alas., s. to N.M.; Euras.

\section{Juncus albescens (Lange) Fern.}

Plants perennial; stems $5-15 \mathrm{~cm}$. tall, loosely tufted from branching rootstocks, erect, terete; leaves $1-7 \mathrm{~cm}$. long, 1 to 5 in number, terete; sheaths auriculate; inflorescence a capitate cluster of 1 to 5 (mostly 3 ) flowers; bracts almost as long as the flowers, the lower acuminate; perianth $3-4 \mathrm{~mm}$. long, brown, segments ovate-lanceolate or oblong-lanceolate, nearly or quite obtuse, about equal; stamens 6 ; capsule equaling or slightly exceeding the perianth, obtuse or mucronate, 3angled, imperfectly 3-celled; seeds about $2 \mathrm{~mm}$. long, caudate.

In wet meadows and seepage areas, in N.M. (Taos Co.); Greenl. to Alas., s. to N.Y. and N.M.

\section{Juncus Torreyi Cov. Fig. 324.}

Perennial with slender elongate rhizomes bearing tuberlike enlargements; flowering culms colonial, erect, 3-10 dm. long, 2-4 $\mathrm{mm}$. thick near the middle; blades terete, ascending, with complete septa; inflorescence terminal, usually farsurpassed by the subtending terete bract, $2-5(-10) \mathrm{cm}$. long, of 5 to 10 (to 17) heads which are mostly closely crowded, $8-15 \mathrm{~mm}$. thick, 25 - to 50 -flowered; bractlet solitary at base of pedicel; sepals lanceolate, stramineous, 4-5 mm. long, with semirigid brownish subulate tips; petals similar to sepals but shorter; anthers 6 , shorter than their filaments; capsule at maturity brownish, linear-subulate, trigonous, equaling or slightly surpassing the sepals, wholly dehiscent; seeds not tailed.

Marshy margins of lakes, ponds and streams, wet meadows, ditches and seepage areas in Okla. (Cimarron, Grady, Alfalfa, Osage, Logan and Stephens cos.), N. M. (widespread) and Ariz. (Navajo to Mohave, s. to Pima and Yuma cos.), abundant in the Tex. Trans-Pecos and Plains Country, less frequent in Edwards Plateau and n.-cen. Tex., rare in e. Tex., summer; N.Y. to Sask. and Wash., s. to D.C., Ala., Miss., Coah. and Calif.

\section{Juncus articulatus L. JOINTED RUSH. Fig. 325.}

Stems erect or spreading from short rootstocks, 2-6 dm. tall; stem leaves with, rather loose sheaths and strongly septate terete blades $5-10 \mathrm{~cm}$. long; inflorescence $3-10 \mathrm{~cm}$. high, loose, the branches stiffly spreading; heads hemispheric to topshaped, 3- to 12-flowered; perianth 2-3 $\mathrm{mm}$. long, the segments nearly equal in size, lanceolate, acuminate, reddish brown with a greenish midrib; stamens 6 , one half to three fourths as long as the perianth, the anthers shorter than the filaments; capsule dark brown, shining, longer than the perianth, 3-angled, ovate, sharply acute, tapering to a conspicuous tip; seeds reticulate.

In marshes, saline flats and edge of water of streams, in N.M. (Rio Arriba and San Juan cos.) and Ariz. (Yavapai and Maricopa cos.); Nfld. to B.C., s. to N.E., 


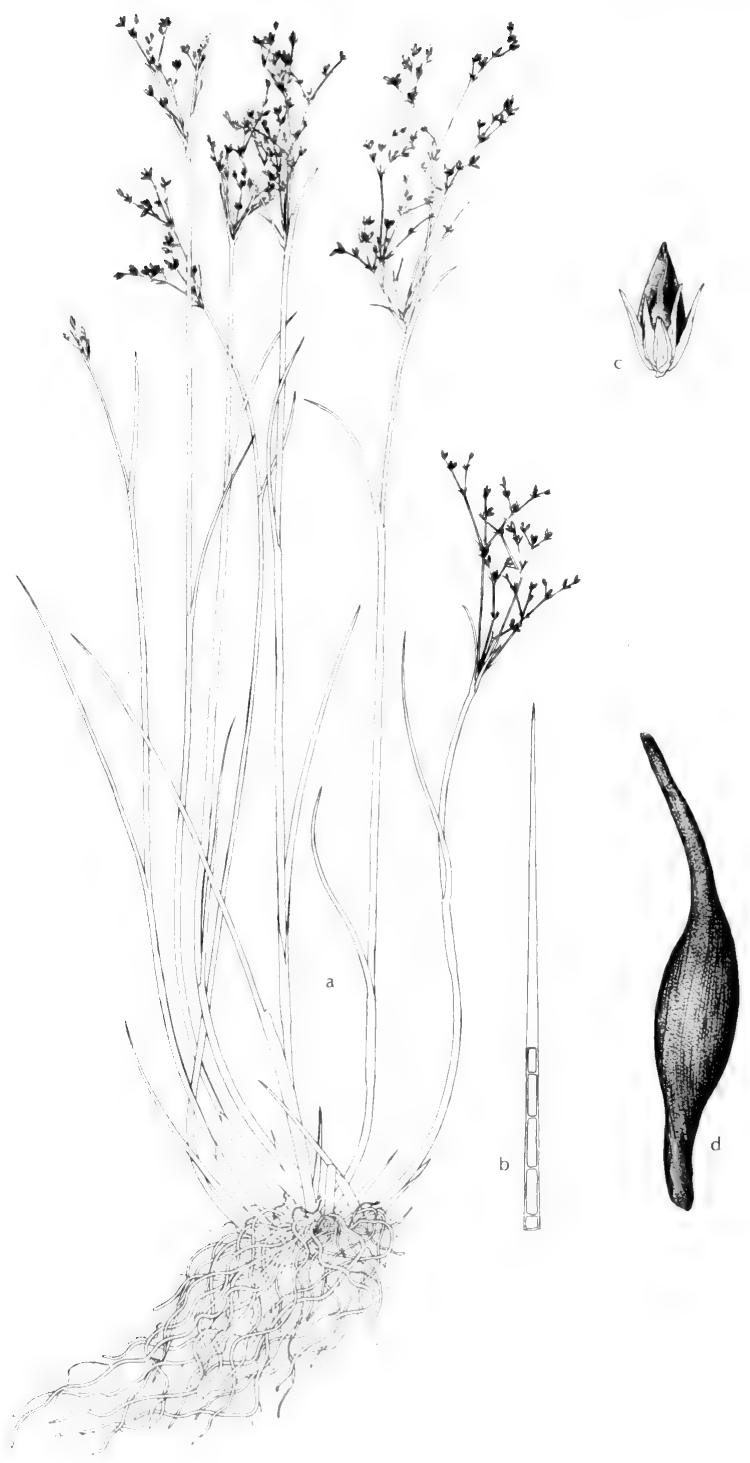

Fig. 323: Juncos trigonocarpus: a, habit, $\mathrm{X}^{1 / 3}$; b, leaf cut to show septa; $\mathrm{c}$, perianth and capsule, X 31/3; d, seed, X 30. (Courtesy of R. K. Godfrey). 


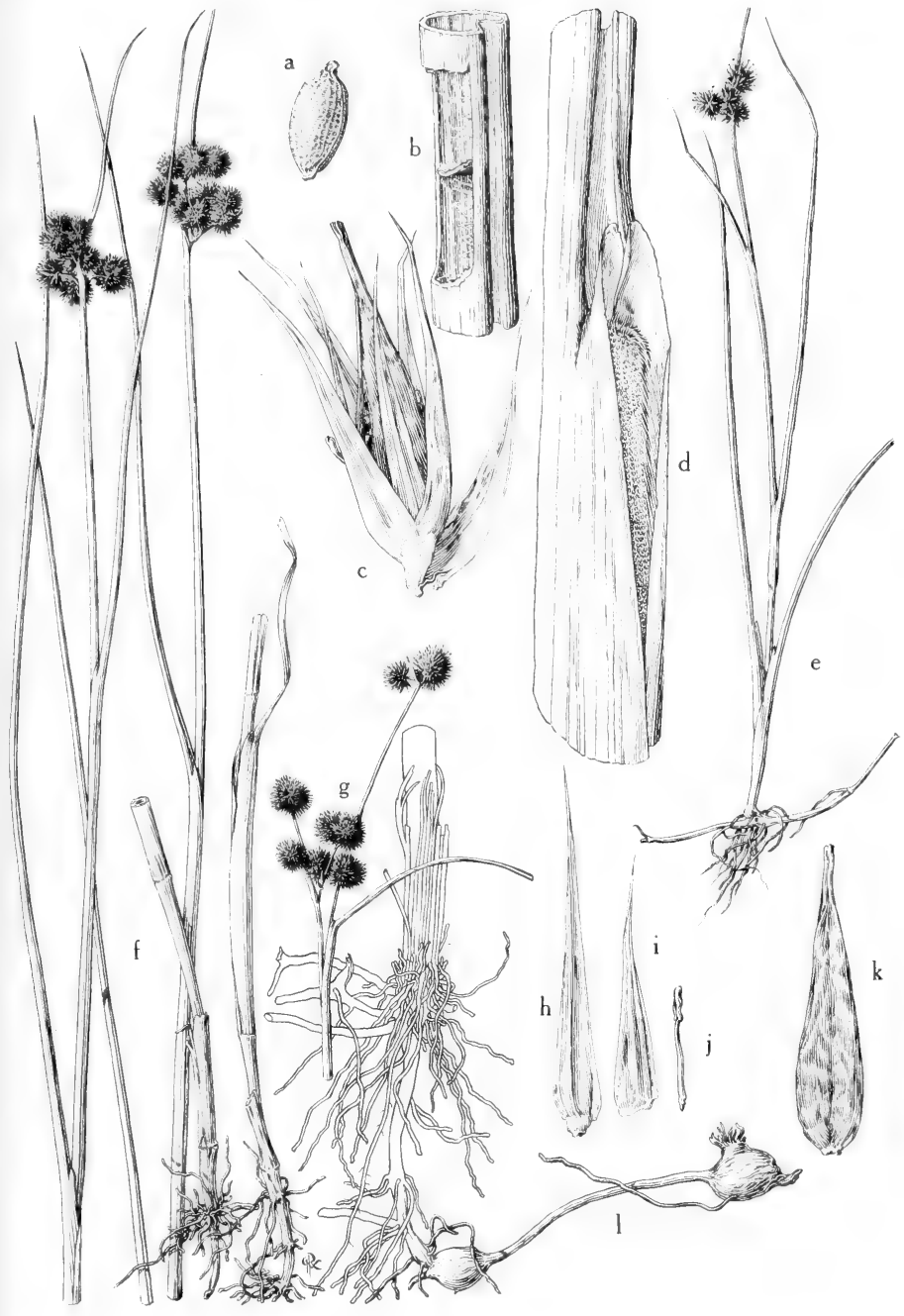

Fig. 324: Juncus Torreyi: a, mature seed, X 24; b, leaf, with a part of it removed to show septum, X 3; c, flower, X 8; d, ligulate auricled leaf sheath, X 3; e, habit,

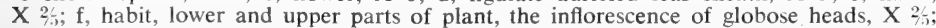
$\mathrm{g}$, inflorescence, more branched type, $\mathrm{X} 2 \% ; \mathrm{h}$, outer perianth segment, $\mathrm{X} 8$; $\mathrm{i}$, inner perianth segment, X 8 ; j, stamen, $X 8 ; \mathrm{k}$, capsule, $X 8 ; 1$, basal part of plant, showing slender rootstock and tuberlike thickenings, X 11/5. (From Mason, Fig. 175). 
W. Va., N.M. Ariz. and Calif.; S. A., Afr. and Austral.

\section{Juncus Mertensianus Bong.}

Perennial plants; stems $10-40 \mathrm{~cm}$. tall, slender, cespitose from slender matted rootstocks; leaves $1-3 \mathrm{~mm}$. wide, terete, 2 to 3 to a stem, somewhat compressed, septate but often obscurely so; sheaths with scarious margins and bearing auricles; inflorescence usually a solitary head, this becoming spherical, about 10-12 mm. in diameter, many-flowered; perianth $3.5-4 \mathrm{~mm}$. long, dark brown to brownishblack, segments about equal, lanceolate, acute to acuminate especially the outer; stamens 6; capsule trigonous, oval, obtuse to mucronate, equaling or slightly shorter than the perianth, reportedly 1-celled; seeds caudate or not caudate.

In moist or wet places, bogs, in mud of streams and edge of lakes, in N. M. (Taos, Colfax, Santa Fe and San Miguel cos.) and Ariz. (Coconino Co.); Alta. to Alas., s. to N.M., Ariz. and Calif.

\section{Juncus badius Suksdorf.}

Perennial plants with slender rhizomes; stems $20-50 \mathrm{~cm}$. tall, nearly or quite terete; leaves 1-2 mm. in diameter, terete or somewhat flattened laterally, septate, 1 short leaf present over one half way up stem; sheaths with scarious margins and rounded rather scarious auricles; inflorescence open, $2-5 \mathrm{~cm}$. long with 4 to 12 heads, these 6-9 mm. across and 5- to 10-flowered; bracts 5-30 $\mathrm{mm}$. long; perianth 2-3 mm. long, dark brown, the segments lanceolate, acuminate, about equal; bractlets ovate; capsule slightly shorter than the perianth, obovoid, truncate or broadly rounded at apex; seeds not caudate.

Moist or wet ground, on edge of lakes and streams, in N.M. (Taos and Rio Arriba cos.) and Ariz. (Coconino, Apache and Yavapai cos.); Wyo. to Wash., s. to N.M. and Ariz.

\section{Juncus nodosus L. Fig. 322.}

Perennial with long creeping rhizomes bearing tuberlike enlargements; flowering culms colonial, $11-30 \mathrm{~cm}$. long, $0.7-1.2 \mathrm{~mm}$. thick, erect, terete or slightly compressed; blades 2 or 3 per culm, terete, $0.5-1 \mathrm{~mm}$. thick near the middle, long-tapered to a thin point, with some complete but sometimes weak and inconspicuous septa; inflorescence terminal, 2-5 cm. long, sparingly branched, of 2 to 4 heads; basal bract of inflorescence leaflike, about equaling the inflorescence or exceeding it by $1-3 \mathrm{~cm}$. at most; heads mostly well-separated from each other, 7-10 mm. thick, 15- to 30-flowered; sepals and petals lanceolate, 3-4 mm. long, brownish-stramineous, with acute semirigid tips; bractlets solitary at the base of each pedicel; stamens 6 (occasionally 3, fide F. J. Hermann), the anthers shorter than the filaments; capsules at maturity slightly exserted, narrowly ellipsoidtrigonous, 3 to 4 times as long as thick, brownish, shining, wholly dehiscent (even the abruptly acute apex); seeds not tailed. Incl. var. meridianus Herm.

Mud along creeks and streams, in flowing water and on wet sandbars along streams, in the Tex. Trans-Pecos and N. M. (Rio Arriba, Union, Colfax, San Juan and San Migeul cos.), summer; temp. N.A. s. to Va., O., Ind., Ill., Ia. and Neb., at higher elev. to Coah., Chih., Nev, and Calif.

\section{Juncus texanus (Engelm.) Cov.}

Perennial with elongate slender rhizomes bearing tuberlike enlargements; flowering culms colonial, erect, essentially terete, 2-4 (-6) dm. long, 1-2 mm. thick near the middle, simple; leaves few; blades essentially terete, with several complete (though in some specimens weak) septa: inflorescence terminal (subtended by a bract shorter than or only slightly surpassing it), at maturity $5-10 \mathrm{~cm}$. long, of 3 to 12 (to 19) 15- to 25-flowered heads which are remote from each other at the ends of the short branches and $8-10(-11) \mathrm{mm}$. thick; bractlet solitary at 


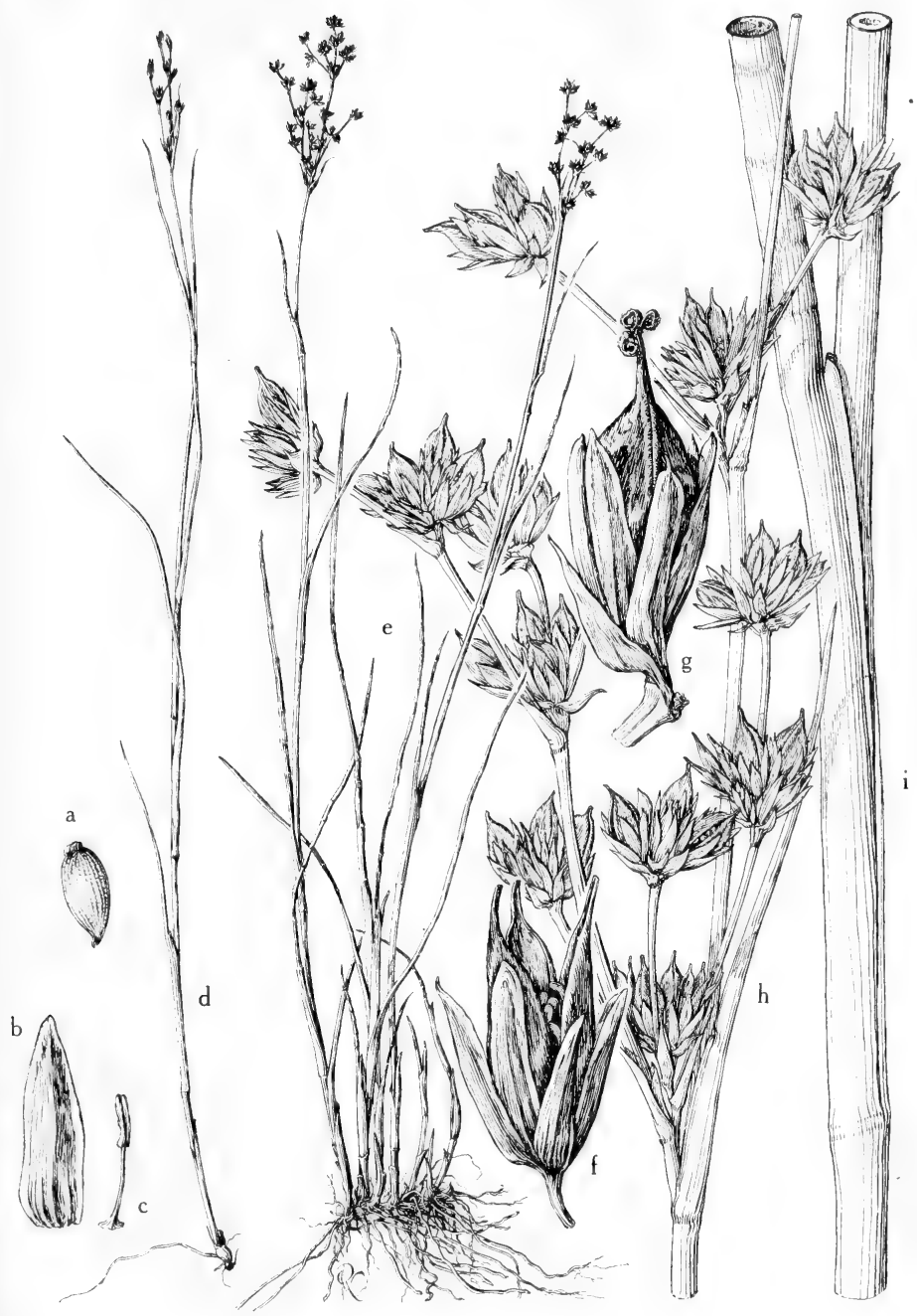

Fig. 325: Juncus articulatus: a, mature seed, X 40; b, perianth segment, X 10; c, stamen, X 10; d, and e, habit, showing the septate leaves and the loose inflorescence, $\mathrm{X} 2 \%$; f, mature capsule, after dehiscence, $\mathrm{X} 10 ; \mathrm{g}$, perianth and mature capsule, $\mathrm{X} 10$; $\mathrm{h}$, inflorescence, showing the heads on stiffly spreading branches, X 3 ; $\mathrm{i}$, ieaf sheath and part of septate leaf, X 3. (From Mason, Fig. 178). 

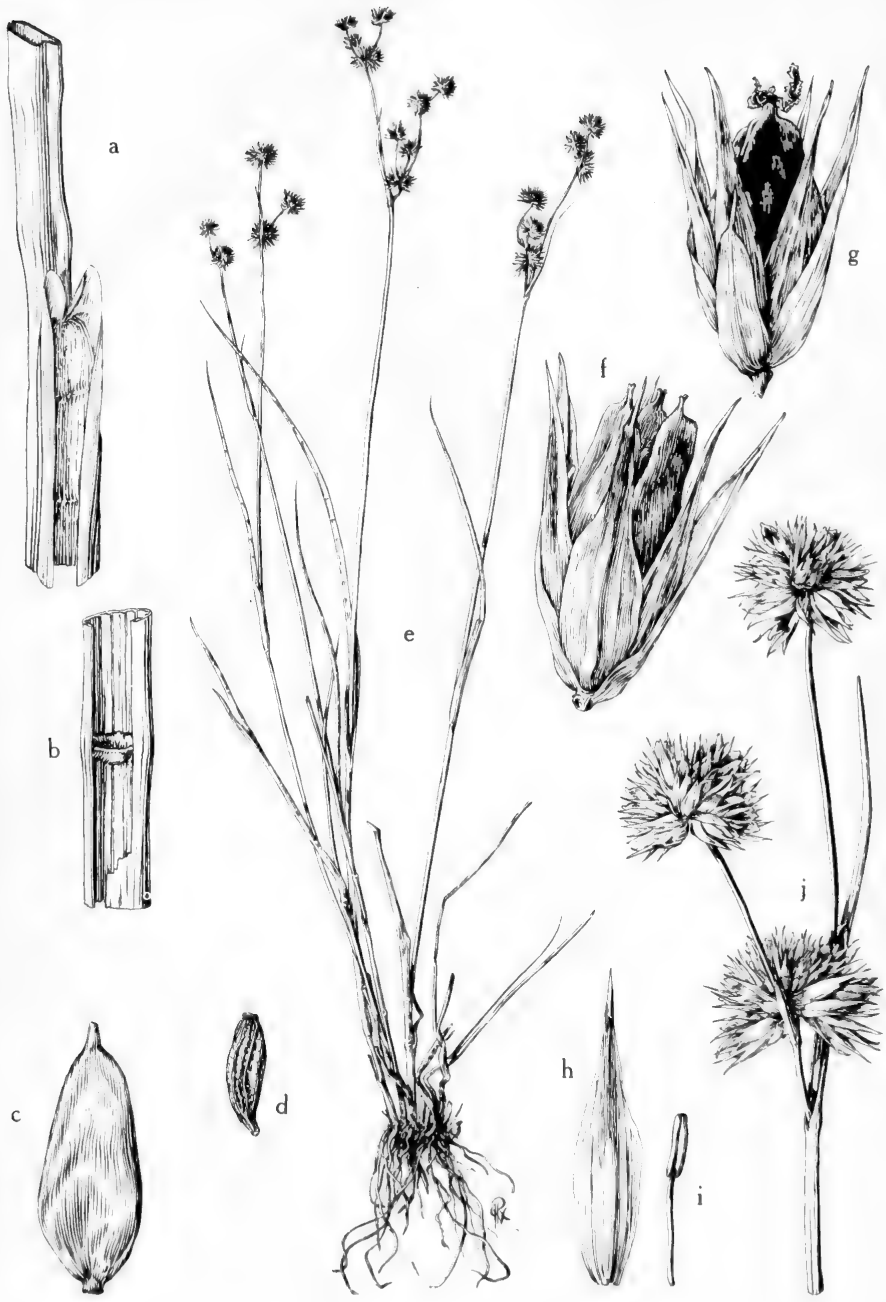

Fig. 326: Juncus acuminatus: a, auricles of leaf sheath, X 21/2; b, leaf, with a part removed to show septum, X 21/2; c, capsule, showing beak, X 10; d, mature seed, X 40; e, habit, showing the septate leaves, cespitose stems and open panicles, $\mathbf{X} 2 \% \mathrm{f}$, mature capsule, after dehiscence, X 10; g, perianth and mature capsule, X 10; h, perianth segment, X 10; i, stamen, X 10; j, inflorescence, showing the spherical heads of flowers, $X 11 / 2$. (From Mason, Fig. 177). 
the base of the pedicel; sepals and petals linear-lanceolate; stamens 6 , the anthers longer than (often 2 to 3 times as long as) their filaments; capsules at maturity 4 to 8 times as long as thick, including the exserted prolonged slender-subulate beak which remains intact with dehiscence; seeds not tailed. J. nodosus var. texanus Engelm.

Infrequent along ponds, lakes and streams, in mud of sloughs and on gravelsand bars of rivers, in n.-cen. Tex. and the Edwards Plateau, summer; endemic.

\section{Juncus brachycarpus Engelm.}

Perennial, the bases subrhizomatous to shortly rhizomatous, whitish; flowering culms stiffly erect, 20-75 cm. long, 1-2 mm. thick near the middle; leaves scattered and subappressed along the culms; blades ascending, only slightly arcuate, essentially terete or basally laterally compressed, 1-2 mm. thick near the middle, with strong complete septa and always longer than their sheaths; bract shorter than or equaling the inflorescence; inflorescence terminal, 2-6 $(-13) \mathrm{cm}$. long, of 2 to 10 (to 25 ) heads, sparingly branched; heads round, 7-9 mm. thick, with 25 to 60 flowers; bractlet solitary at the base of the short pedicel; sepals $2.7-3.4 \mathrm{~mm}$. long, about $0.8 \mathrm{~mm}$. broad; petals $2.2-2.3 \mathrm{~mm}$. long, about $0.4 \mathrm{~mm}$. broad; sepals and petals greenish with broad hyaline margins, turning golden brown medially at maturity or slightly darker terminally; stamens 3 ; capsule obovoid, $1.5-2.2 \mathrm{~mm}$. long, about $1 \mathrm{~mm}$. thick, abruptly apiculate, promptly and completely dehiscent; seeds not tailed.

Frequent in moist loamy soils, coastal savannah, roadside depressions, marshes, and in water of small ponds and seepy areas, in Okla. (Waterfall), e. and s.e. Tex., rare inland to n.-cen. Tex. and n. part of Rio Grande Plains, spring-early summer; e. and s.e. U.S. inland to O., Mich., Ill., Mo. and Okla.

\section{Juncus acuminatus Michx. Fig. 326.}

Tufted perennial; culms $14-80 \mathrm{~cm}$. long, erect, 1-3 mm. thick near the middle; leaves few at the base, mostly scattered on the culm; blades strongly laterally compressed, 1-3 mm. thick near the middle, toward the tip very narrow and nearly terete, with complete but rather weak septa; bract much shorter than the inflorescence; inflorescence terminal, variable, $3-15 \mathrm{~cm}$. long, not or sparingly or much and repeatedly branched, in the typical form of (25 to) 40 to 60 hemispherical to turbinate 2 to 10 -flowered glomerules, in the f. sphaerocephalus Herm. of 2 to 25 nearly round 15 - to 60-flowered heads; bractlet solitary at the base of the short pedicel; sepals $3.3-4 \mathrm{~mm}$. long, $0.7-1.2 \mathrm{~mm}$. broad; petals $2.5-3.5 \mathrm{~mm}$. long, $0.3-0.4 \mathrm{~mm}$. broad in the typical form or $0.5-0.7 \mathrm{~mm}$. broad in $\mathrm{f}$. sphaerocephalus; sepals and petals paleaceous, drying semirigid, stramineous or often terminally a rich-reddish-brown; stamens 3; capsule narrowly ovoid to ellipticovoid, $2.5-3.3 \mathrm{~mm}$. long, apically blunt or very bluntly apiculate, completely and promptly dehiscent.

The typical form is infrequent in wet places in e. Tex., the f. sphaerocephalus locally frequent in wet meadows, on margin of ponds, sloughs and streams, marshes and springy areas, in Okla. (Adair, Atoka, Mayes and Osage cos.), e. s.e. and n.-cen. Tex., the n. parts of the Rio Grande Plains, Edwards Plateau and Trans-Pecos, and Ariz. (Navajo, Coconino, Santa Cruz and Pima cos.), late spring-summer; the typical form in most of e. U.S. w. to Wisc. and Tex.; f. sphaerocephalus from N.Y., Pa., Mich., Ind., Mo., Tex., Wash., Calif., Ariz., Chih., Michoac. and probably scattered elsewhere.

\section{Juncus megacephalus M.A. Curtis. Fig. 327.}

Perennial from subrhizomatous bases; flowering culms $45-110 \mathrm{~cm}$. long, 2-2.2 $\mathrm{mm}$. thick near the middle; leaves few and mostly scattered along the culm, not crowded basally; blades terete, mostly about $1 \mathrm{~mm}$. thick near the middle, 


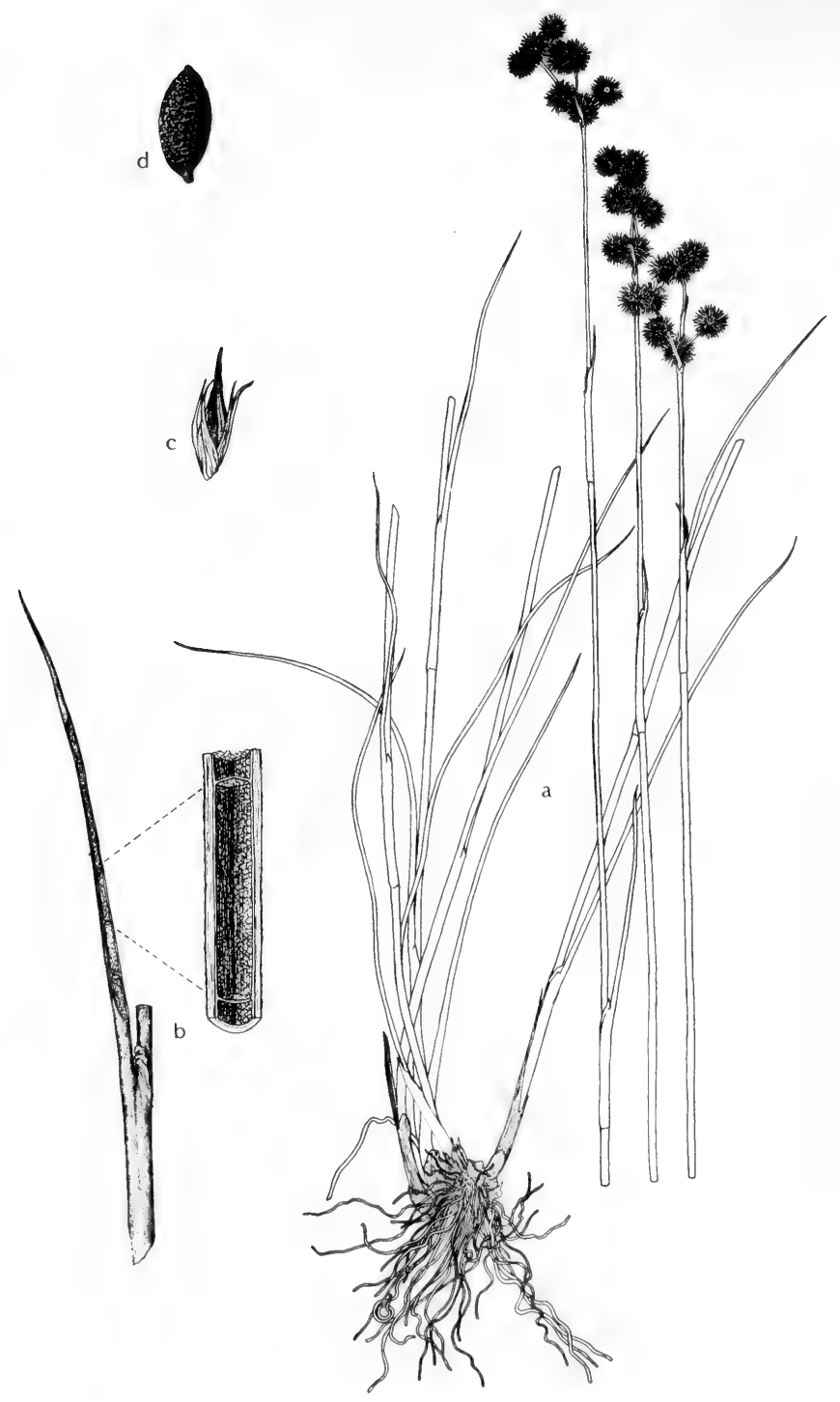

Fig. 327: Juncus megacephalus: a, habit, $\mathrm{X} 1 / 3: \mathrm{b}$, sheath and leaf with section of leaf enlarged to show septa; c, perianth and capsule, X 31/3; d, seed, X 33. (Courtesy of R. K. Godfrey). 


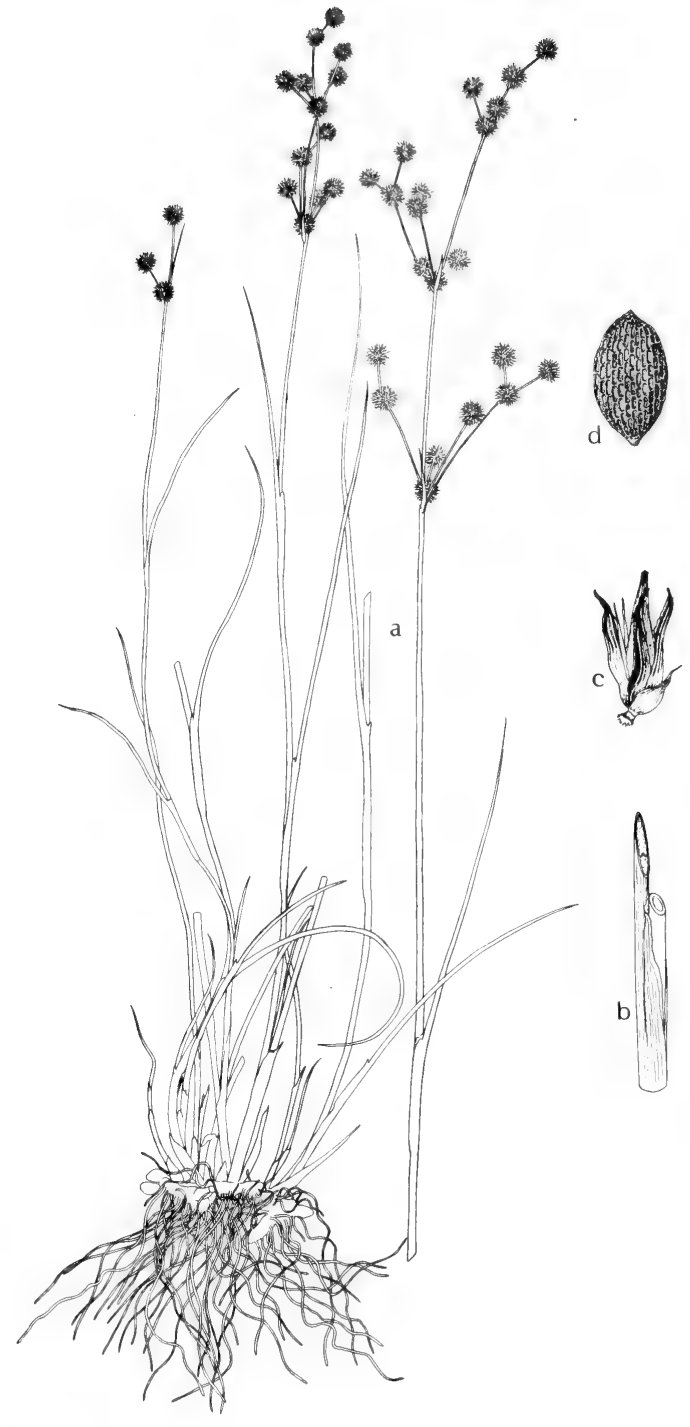

Fig. 328: Juncus scirpoides: a, habit, X 1/3; b, sheath, about X 1; c, capsule and perianth, X 5; d, seed, X 60 . (Courtesy of R. K. Godfrey). 
ascending, only slightly arcuate, having strong complete septa; blade of the uppermost leaf (but not the bract!) much shorter than its sheath, sometimes reduced to a mucro; bract much shorter than the inflorescence; inflorescence terminal, sparingly branched, 2-5 $(-10) \mathrm{cm}$. long, of 3 to 7 (to 15 ) heads which are $10-15$ $\mathrm{mm}$. thick and 40- to 100-flowered; bractlet solitary at the base of the short pedicel; sepals $4.1-4.3 \mathrm{~mm}$. long, $0.6-0.8 \mathrm{~mm}$. broad; petals about $3.5 \mathrm{~mm}$. long, 0.3-0.4 mm. broad; sepals and petals usually (reddish)-brown apically, stramineous basally; stamens 3 ; capsule about $0.8 \mathrm{~mm}$. thick, lance-subulate, trigonous, golden-brown, not or only very slightly exserted, usually about equaling the sepals, laterally dehiscent but the three valves coalescent apically into an indehiscent beak.

Infrequent to rare in deep sands and depressions very near the coast, s.e. Tex. (Aransas and Galveston cos.), summer; Coastal States, (Md.? and) Va. to Tex.

\section{Juncus scirpoides Lam. Fig. 328.}

Perennial from whitish rhizomes $3-15 \mathrm{~mm}$. long, the internodes of the rhizomes 1-2 mm. long; flowering culms $20-45 \mathrm{~cm}$. long, erect, $1-1.5 \mathrm{~mm}$. thick near the middle; leaves few and mostly scattered along the flowering culm, not crowded basally; blades with strong complete septa, terete, rarely very slightly laterally compressed on drying, mostly about $1 \mathrm{~mm}$. thick near the middle, ascending, only slightly arcuate; bract usually shorter than to only slightly surpassing the inflorescence; inflorescence 1-5 (-11) $\mathrm{cm}$. long, terminal, unbranched or very sparingly branched; heads (solitary to) 2 to 5 (to 12 ), rounded or somewhat lobulate, 7-10 mm. thick, with 25 to 60 flowers; bractlet solitary at the base of the short pedicel; sepals $2.7-4 \mathrm{~mm}$. long, $0.5-0.8 \mathrm{~mm}$. broad; petals $2-3 \mathrm{~mm}$. long, $0.3-$ $0.5 \mathrm{~mm}$. broad; sepals and petals green turning stramineous to stramineous-brown, semirigid to subspinescent; stamens 3 ; capsule $0.5-0.8 \mathrm{~mm}$. thick, exserted usually even when immature, the tip long-subulate and its 3 valves fused into a perdurant indehiscent beak; seeds not tailed. Incl. var. meridionalis Buch.

In swampy places, in mud and water of ponds, streams and lakes, in Okla. (LeFlore, Sequoyah and Ottawa cos.), frequent in e. Tex., infrequent in s.e. Tex., uncommon to rare $w$. to $n$.-cen. Tex. and $n$. and coastal parts of Rio Grande Plains and Edwards Plateau, also in Winkler Co. in the Trans-Pecos, always in deep sandy soils, summer; e. U.S., n. to N.Y., Pa., Ind., Mich. and w. to Okla. and Tex.

Some robust Texas specimens seem to show intergradation to J. validus var. fascinatus.

\section{Juncus polycephalus Michx. Fig. 329.}

Tufted perennials from subrhizomatous bases; culms $5-10 \mathrm{dm}$. long, erect, basally $6-10 \mathrm{~mm}$. thick, 2-4 mm. thick near the middle, greenish; leaves several in a basal cluster and scattered along the stem; blades strongly laterally compressed, arcuate, 4-7 $\mathrm{mm}$. thick near the middle in the larger (dorsiventral) dimension, greenish, with weak incomplete septa; inflorescence terminal, usually widely branched, 7-25 cm. long, to $12 \mathrm{~mm}$. thick; heads few to 20 , of 40 to 80 flowers; bractlet solitary at the base of the short pedicel; sepals $3.5-4 \mathrm{~mm}$. long, $0.7-0.8 \mathrm{~mm}$. broad; petals $3-3.3 \mathrm{~mm}$. long, about $0.5 \mathrm{~mm}$. broad, marginally hyaline, greenish-brown turning stramineous to dark-brown, semirigid at maturity and subspinescent; stamens 3; capsule slightly exserted, tapering uniformly, dehiscing laterally but not at the short beaklike apex; seeds not tailed.

In wet places, often in or on edge of water of streams, lakes and ponds, infrequent, Jasper and Tyler cos. in extreme s.e. Tex., summer; Coastal States, N. C. to Tex. 


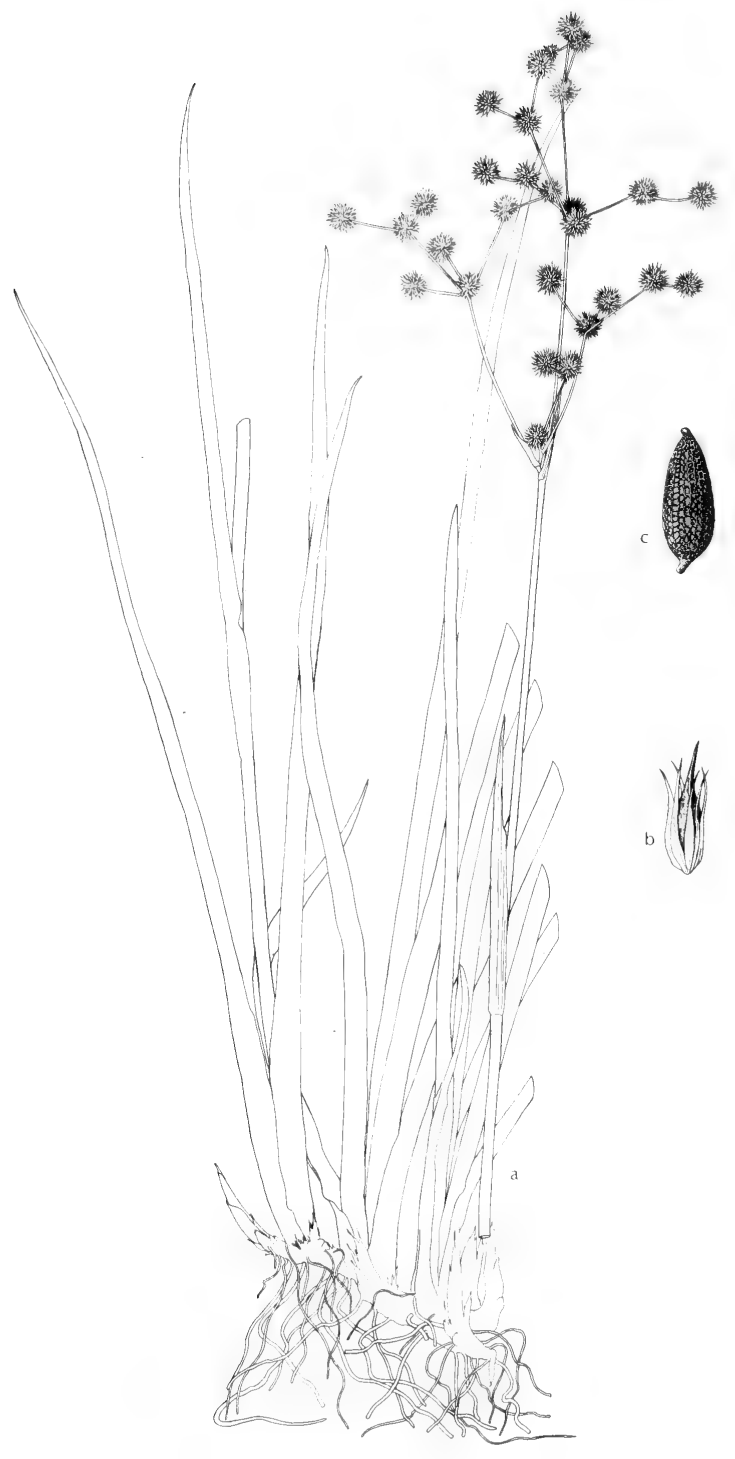

Fig. 329: Juncus polycephalus: a, habit, X 1/3; b, perianth and capsule, X $31 \frac{1}{3}$; c, seed, X 33. (Courtesy of R. K. Godfrey). 


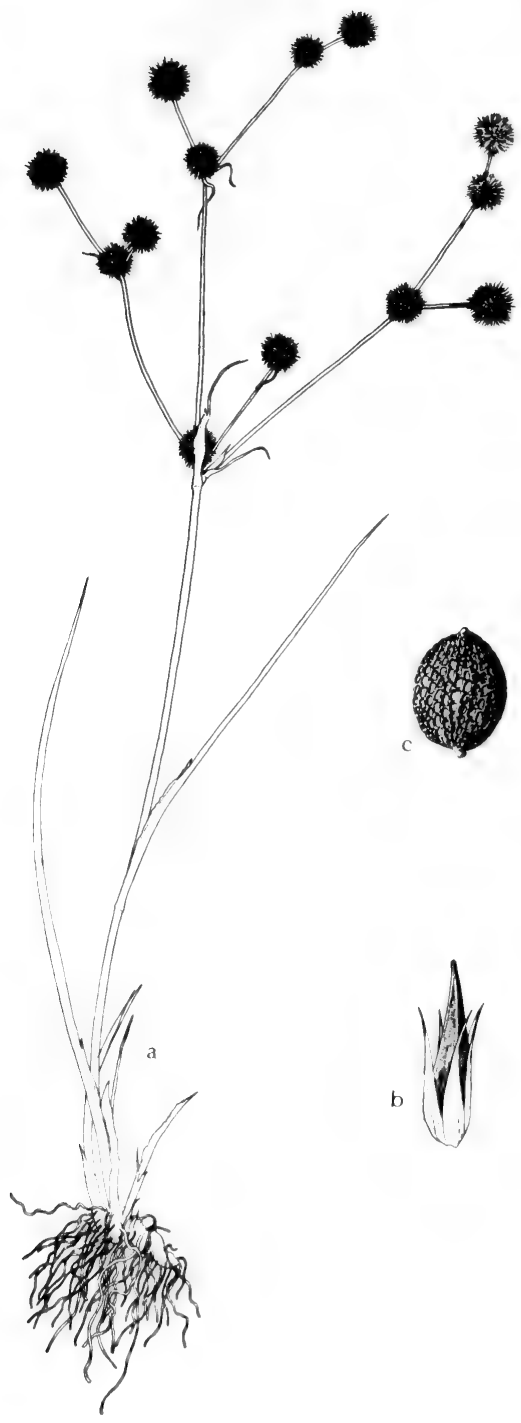

Fig. 330: Juncus validus: a, habit, X 1/3; b, perianth and capsule, X $31 \frac{1}{3}$; c, seed, X 40. (Courtesy of R. K. Godfrey). 


\section{Juncus validus Cov. Fig. 330 .}

Tufted perennial from a non- or subrhizomatous base; culms 2-10 dm. long, ascending or erect, basally $3-5 \mathrm{~mm}$. thick, mostly $2-4 \mathrm{~mm}$. thick near the middle, olive-gray; leaves several in a basal cluster and scattered along the culm, laterally compressed, slightly arcuate, 3-6 (-8) mm. thick in larger (dorsiventral) dimension, with strong complete septa; bract much shorter than the inflorescence; inflorescence terminal; heads 6 to 76 , rounded or often lobulate, $10-15 \mathrm{~mm}$. thick, each with (30 to) 40 to 50 (to 80 ) flowers; bractlet solitary at the base of the short pedicel; sepals (3-) 3.4-4.2 (-4.5) $\mathrm{mm}$. long, 0.7-1.4 mm. broad; petals (2-) 2.5-3.5 (-4.3) $\mathrm{mm}$. long, $0.5-1 \mathrm{~mm}$. broad; both petals and sepals marginally hyaline (the petals sometimes broadly so) and both semirigid and subspinose at maturity, stramineous-brown or turning dark-brown; stamens 3; capsule $4.5-5 \mathrm{~mm}$. long, brown or golden-brown, subulate; seeds not tailed.

In swampy ground, seepage areas, on edge of ponds, lakes and streams. We have two varieties.

Var. validus. Inflorescence widely spreading, 5-25 cm. long, of (12 to) 15 to 76 heads and completely promptly dehiscent capsules. In Okla. (Love, Pittsburg, Osage and LeFlore cos.), abundant in e. and s.e. Tex. and less so w. to n.-cen. Tex. and n. part of Rio Grande Plains; in Coastal States, Ga. to Tex. and inland to Okla. and Mo.

Var. fascinatus M. C. Johnst. Inflorescences mostly 2-5 cm. long, of 6 to 15 heads, with capsules usually tardily dehiscent apically or even with an indehiscent beak. In Tex. in Edwards Plateau area (Central Mineral Region) and s. to $\mathrm{n}$. part of Rio Grande Plains and n.-cen. Tex., uncommon e. to s.e. Tex., summer; endemic.

\section{Juncus diffusissimus Buckl. Fig. 331.}

Tufted weak perennial; culms $25-65 \mathrm{~cm}$. long, erect, 1-2 $\mathrm{mm}$. thick near the middle; leaves few, scattered on the culm; blades ascending, strongly laterally compressed, 1-2 mm. broad in the larger (dorsiventral) dimension, long-tapered to a setaceous tip, with some complete but rather inconspicuous septa; bract much shorter than the inflorescence; inflorescence terminal, widely and repeatedly branched, 5-20 cm. long; glomerules numbering 30 to 70 (to 130) per inflorescence, hemispherical or narrower, (1- or) 2- to 10-flowered; bractlet solitary at the base of the short pedicel; sepals (2-) $2.6-3.2 \mathrm{~mm}$. long, $0.6-0.8 \mathrm{~mm}$. broad; petals (1.8-) 2.3-3 mm. long, 0.4-0.5 mm. broad; petals and sepals paleaceous, acute but not subspinescent; stamens 3; capsules linear-lanceolate, trigonous, 4-5 (-5.2) $\mathrm{mm}$. long, minutely apiculate, 1.5 to 2 times as long as the perianth, golden-brown, completely dehiscent.

Swampy meadows, margin of ponds, sloughs, streams, and in shallow water in Okla. (widespread), frequent in e. Tex., less so w. to n.-cen. Tex., rare in Edwards Plateau (Central Mineral Region), in moist loamy soil, summer; Coastal States, Ga. to Tex. and inland to Ind., Mo. and Kan.

\section{Juncus debilis Gray. Fig. 331.}

Tufted weak perennial (or annual?); culms 15-30 cm. long, ascending, 0.5-1 $\mathrm{mm}$. thick near the middle; leaves few, scattered on the culm; blades ascending, basally slightly laterally compressed, about $1 \mathrm{~mm}$. broad near the middle, with some complete but inconspicuous septa; bract only 1-2 cm. long; inflorescence terminal, repeatedly branched, $3-10 \mathrm{~cm}$. long, with 5 to 35 glomerules which are hemispherical or narrower and 2- to 10 -flowered; bractlet solitary at the base of the short pedicel; sepals $2.2-2.8 \mathrm{~mm}$. long, $0.6-0.8 \mathrm{~mm}$. broad; petals $2.3-2.5$ $\mathrm{mm}$. long, $0.5-0.7 \mathrm{~mm}$. broad; sepals and petals paleaceous, acute but not sub- 


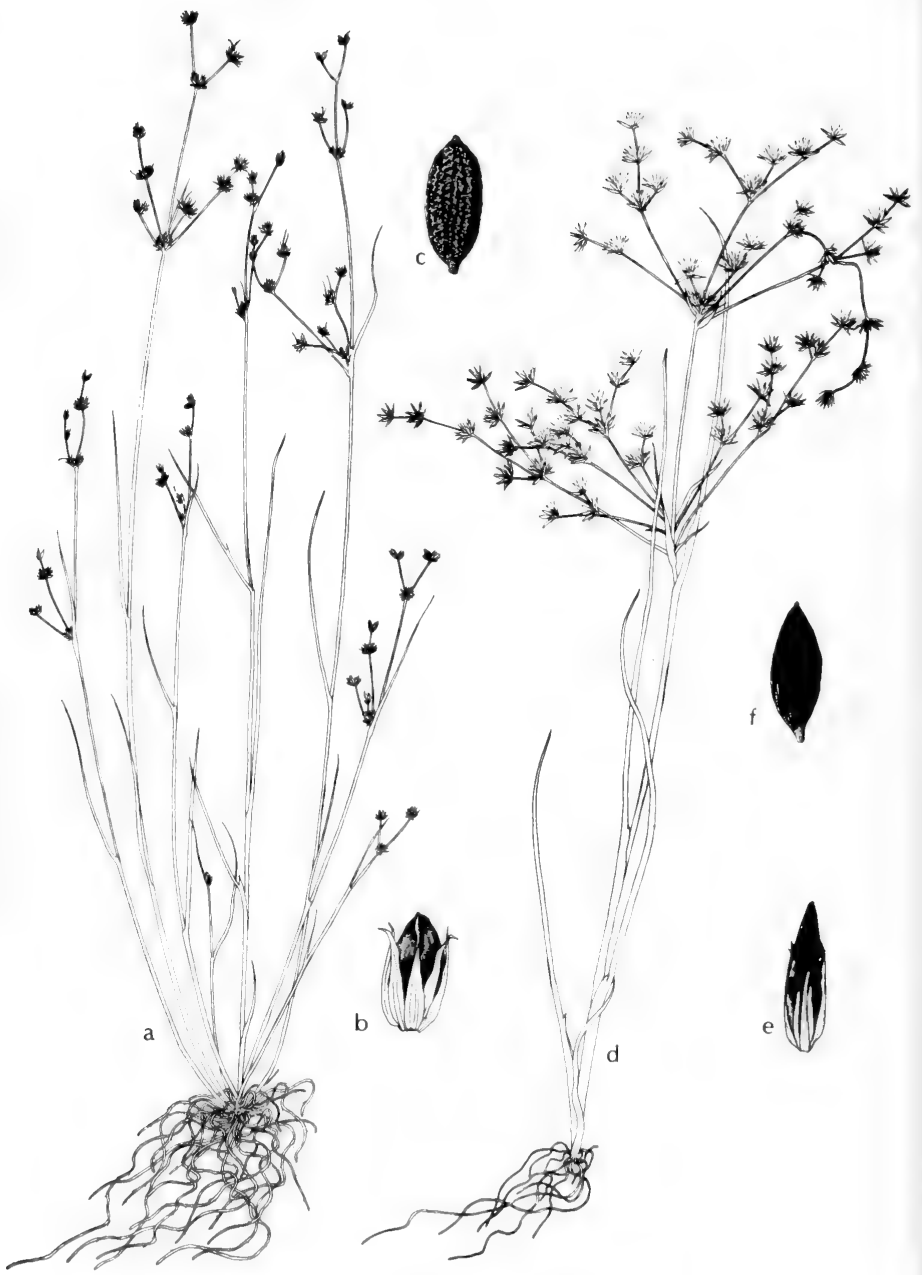

Fig. 331: a-c, Juncus debilis: a, habit, X 1/2; b, perianth and capsule, X 5; c, seed, $\mathrm{X} 60$. d-f, Juncus diffusissimus: d, habit, X 1/2; e, perianth and capsule, X 5; $\mathrm{f}$, seed, X 60. (Courtesy of R. K. Godfrey). 
spinescent; stamens 3 ; capsule broadly to narrowly ovoid, bluntly apiculate, 2.2-3 $\mathrm{mm}$. long.

Infrequent to rare in moist sand, in mud of streams, and in quiet shallow water, in extreme e. Tex. (Newton and Polk cos.), summer; Coastal States, Conn. to Tex., inland to Tenn. and Mo.

\section{Juncus nodatus Cov.}

Perennial; roots not bearing tuberlike enlargements; culms erect, 6-12 dm. long, 3-5 $\mathrm{mm}$. thick near the middle (as much as $1 \mathrm{~cm}$. thick basally); basal sheaths of culm 6-15 mm. broad; blades 2-5 mm. thick near the middle, essentially terete to flattened; septa of blades complete, tough, conspicuous; bract much shorter than the inflorescence; inflorescence terminal, repeatedly much-branched, 7-16 cm. long; glomerules 40 to 200 per inflorescence, hemispherical or narrower, 2- to 10-flowered; bractlet solitary at the base of the short pedicel; sepals 2-2.5 mm. long, 0.6-0.8 mm. broad; petals $1.9-2.3 \mathrm{~mm}$. long, 0.4-0.6 mm. broad; sepals and petals membranous, medially brown, marginally broadly hyaline; stamens 3; capsule obpyriform to narrowly ovoid, minutely apiculate, $2.3-2.5 \mathrm{~mm}$. long, golden-brown.

In marshes, wet savannahs and meadows, in mud and shallow water of sloughs, streams, ditches, ponds and lakes, in Okla. (Atoka, Comanche, Muskogee, Sequoyah, Love, LeFlore and McCurtain cos.), infrequent, e. and s.e. Tex., rare w. to n.-cen. Tex., extreme n. edge of Rio Grande Plains and n. part of Plains Country (Wichita Co.), late spring-summer; La. to Tex., n. to Ind., Ill., Mo. and Kan.

45. Juncus Elliottii Chapm. Fig. 318.

Perennial; roots often ending in tuberlike enlargements; culms erect or arcuate, 3-9 dm. long, 1.5-2 mm. thick near the middle; basal sheaths of culm 4-8 mm. broad; blades 1-2 mm. thick near the middle, laterally compressed; septa of blades present, complete but weak and inconspicuous in prepared specimens; inflorescence terminal, repeatedly much-branched, $5-14 \mathrm{~cm}$. long; glomerules 40 to 100 per inflorescence, 2- to 10-flowered, hemispherical or narrower; bractlet solitary at the base of the short pedicel; sepals $2.6-2.9 \mathrm{~mm}$. long, $0.9-1.1 \mathrm{~mm}$. broad; petals $2.4-2.8 \mathrm{~mm}$. long, $0.6-0.8 \mathrm{~mm}$. broad; sepals and petals dark-golden-brown to fuscous, chartaceous medially, narrowly white-hyaline marginally, becoming semirigid and subspinescent; stamens 3; capsule narrowly obpyriform to narrowly ovoid, 2.4-2.9 mm. long, minutely apiculate, at maturity fuscous.

In moist or wet areas in savannahs and wet coastal prairies in s.e. Tex., MayAug.; Coastal States, Del. to La. and Tex.

\section{Luzula DC. WOODRUSH}

Tufted low perennials with weak pubescent foliage; inflorescence terminal, of a number of simple or nearly simple unequal branches topped by heads or short spikes of flowers; seeds only 3 per capsule.

A cosmopolitan genus of about 80 species.

1. Flowers on slender pedicels, in a loose, somewhat drooping decompound cyme; seeds not appendaged.......................................... L. parviflora.

1. Flowers crowded in spikes or glomerules; seeds with a caruncle or appendage (2)

2(1). Base of plant bearing firm whitish coralline tubers. 1. L. bulbosa.

2. Plant without white coralline tubers.................. L. campestris var. multiflora.

1. Luzula bulbosa (Wood) Rydb. Fig. 332.

Weak tufted perennial, just underground with numerous slightly elongate whitish tuberlike structures (rhizomes?) 2-4 mm. thick; culms $10-25(-35) \mathrm{cm}$. long, 
ascending, about $1 \mathrm{~mm}$. thick; leaves few, only a few or none clustered basally; blades membranous, flat, flaccid, 5-10 (-20) cm. long, 2-6 mm. broad, longtapered, long-pilose marginally especially near juncture with sheath; bract shorter than the inflorescence, leaflike; inflorescence terminal, 3-6 cm. long, of 5 to 10 (to 13) branches which are mostly simple (a few of the longer ones with subsidiary branches) and ascending; bractlets 3 beneath each flower ( 2 at the base of the calyx and one at the base of the extremely short pedicel); flowers in 20 - to 40 flowered ovoid-cylindric spikes or racemes which are 6-10 $\mathrm{mm}$. long and 4-6 mm. thick (rarely almost round and capitate); sepals $3,2.3-2.5 \mathrm{~mm}$. long, ovatedeltoid, membranous and brownish medially, broadly hyaline marginally, acute; petals similar to sepals but only 1.9-2.2 mm. long; stamens 6, shorter than the sepals; style at anthesis about $0.5 \mathrm{~mm}$. long, with 3 branches $1-1.5 \mathrm{~mm}$. long (postanthetically deciduous); capsule nearly globose to broadly obovoid, about equaling the sepals, terminally truncate and minutely apiculate, completely and promptly deciduous; seeds 3. L. campestris L. var. bulbosa Wood, L. multiflora (Retz.) Lej. var. bulbosa (Wood) Herm.

Locally frequent in forested sandy soils and on grassy seepage banks in Okla. (Waterfall) and e. Tex., rare to s.e. Tex., spring; Coastal States, Mass. to Tex., inland to Ind., Ill., Mo., Kan. and Okla.

\section{Luzula parviflora (Ehrh.) Desv. Fig. 332.}

Stems stoloniferous, single or few in a tuft, erect, 1-3 dm. high, 2- to 5-leaved; leaves glabrous, their blades $3-10 \mathrm{~mm}$. wide, tapering to a sharp or blunt apex; inflorescence a nodding decompound panicle, commonly $6-10 \mathrm{~cm}$. long; lowest bract foliose, one fourth to one half the length of the panicle; flowers borne singly or sometimes 2 or 3 together, on very slender pedicels; bractlets ovate, entire or lacerate; perianth $2-2.5 \mathrm{~mm}$. long, the segments lanceolate, acute, green or more or less tinged with brown; capsule ovoid, slightly exceeding the perianth, green or brownish; seeds ellipsoid, brown.

Moist woods and meadows, from coastal rain-forest to alpine slopes, seepage banks, marshes and wet meadows, in N.M. (Mora, San Miguel and Taos cos.) and Ariz. (Coconino and Apache cos.), Lab. and Nfld. to Alas., s. to N.Y., Minn., N.M., Ariz. and s. Calif.; Greenl.; Euras.

\section{Luzula campestris (L.) D.C. var. multiflora (Ehrh.) Cĕlak.}

Stems loosely cespitose, $2-5 \mathrm{dm}$. tall; basal leaves several, cauline leaves usually pilose, 2 to 4 , flat, except toward the callous, blunt tip, 2-6 mm. wide; inflorescence usually with a few slender peduncles and 1 or more sessile, capitate or short-cylindric spikes; bracts usually scarious toward the acute apex; perianth segments $2-3.5 \mathrm{~mm}$. long, ovate-lanceolate, acuminate; capsule obovoid, mucronulate, shorter than the perianth; seeds ellipsoid, 1-1.4 $\mathrm{mm}$. long, with a prominent basal, white, spongy cellular appendage, up to half the length of the body of the seed.

Dry or moist woodlands, streambanks, creek bottoms and wet meadows in N.M. (Taos Co.) and Ariz. (Pima Co.).

We have apparently only the var. multiflora in our region. The species with many varieties is widespread in North America except the lower central and southern United States.

\section{Fam. 35. Liliaceae JuSS. LILY FAMILY}

Mostly perennial herbs, infrequently or only occasionally woody; rootstock a rhizome, bulb, corm or tuber; stems erect or climbing, often modified into fleshy subterranean storage organs or cladophylls; leaves basal or cauline, alternate or whorled, mostly lamellate but sometimes reduced to scales or sheaths, 


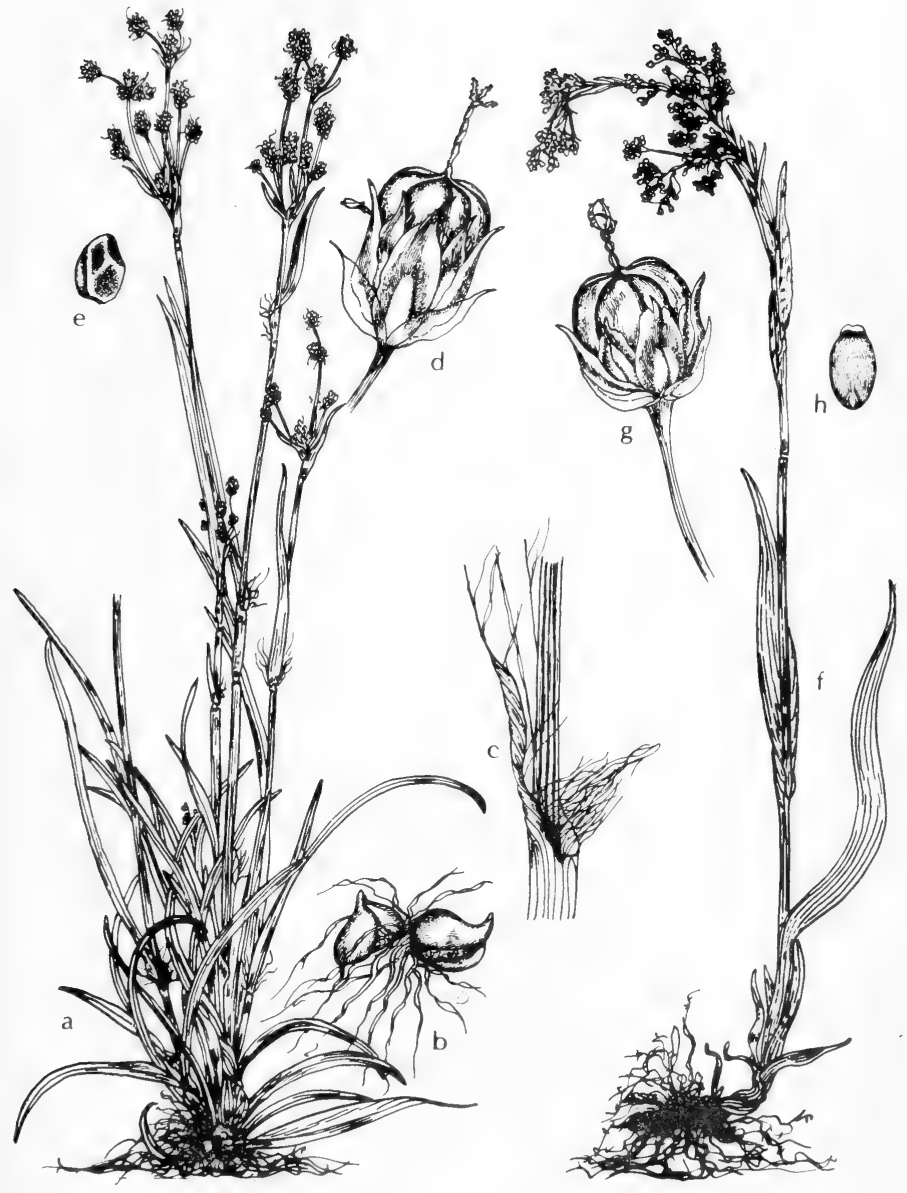

Fig. 332: a-e, Luzula bulbosa: a, habit, X 1/2; b, bulblike tubers, X 2; c, sheath enlarged to show long-pilose margin of the leaf. $X 2$; $d$, capsule and perianth, $X 10$; e, seed. X 10. f-h, Luzula parviflora: f, habit, X 1, g, capsule and perianth, X 10; h, seed, X 10. (V. F.). 
sometimes fleshy or with prickly margins, occasionally fibrous, the venation mostly parallel but also reticulate-parallel in some genera; inflorescence various; flowers bisexual or rarely unisexual (with the plants mostly dioecious), regular (in ours); perianth often large and showy, in 2 series of 3 segments each, very rarely fewer or more, usually undifferentiated into corolla and calyx, the segments imbricate or the outer series valvate, sometimes connate into a tube; stamens 6 , rarely fewer or more, hypogynous or adnate to the perianth; filaments distinct or connate; anthers 2-celled, extrorse or antrorse, versatile or basifixed, dehiscing usually by vertical slits; pistil 1; ovary usually 3-celled; styles 1 or 3 , sometimes divided or trifid; fruit a septicidal or loculicidal capsule or a berry; seeds various.

More than 4,000 species in about 250 genera throughout the world. Many are of great economic and horticultural importance.

1. Flowers or inflorescences in the axils of alternate stem leaves (2)

1. Flowers or inflorescences terminal (3)

2(1). Plant erect, without tendrils; leaves cordate-clasping at base.

10. Streptopus

2. Plant viny, with tendrils; leaves petiolate.

13. Smilax

3(1). Flowers usually 1 or 2 (4)

3. Flowers more than 5 , variously arranged (5)

4(3). Leaves in a terminal whorl of 3; perianth purple, yellowish-green, pink or white. 11. Trillium

4. Leaves in several whorls on the stem; perianth pale lemon-yellow and minutely dotted

7. Lilium

5(3). Flowers in umbels.

6. Allium

5. Flowers in racemes, corymbs or panicles (6)

6(5). Floral segments united except at apex into a tubular or campanulate perianth. 12. Aletris

6. Floral segments distinct or slightly united only at base, the perianth lobes then much longer than the tube (7)

7(6). Style single, sometimes cleft at tip (8)

7. Styles $3(10)$

8(7). Leaves ovate to lanceolate, alternate on the stem; flowers white; fruit a berry.

9. Smilacina

8. Leaves linear, grasslike, in a basal tuft; flowers yellow to orange or blue; fruit a capsule (9)

9(8). Flowers blue or purplish-blue; filaments filiform.

8. Camassia

9. Flowers yellow to orange; filaments somewhat flattened below the middle.

3. Schoenolirion

10(7). Anthers ovate-cordate, 2-celled; leaves 2-ranked and equitant; inflorescence glutinous......................................................... Tofieldia

10. Anthers peltate or reniform, with confluent cells; leaves and inflorescence not as above (11)

11(10). Axis of inflorescence glabrous; seeds not flat, narrowly winged or wingless......................................................................2. Zigadenus

11. Axis of inflorescence pubescent; seeds flat, broadly winged (12)

12(11). Perianth segments with narrow claws and conspicuous glands (nectaries) at base of blade, free from ovary

4. Melanthium

12. Perianth segments clawless and glandless, usually adnate to base of ovary 5. Veratrum 


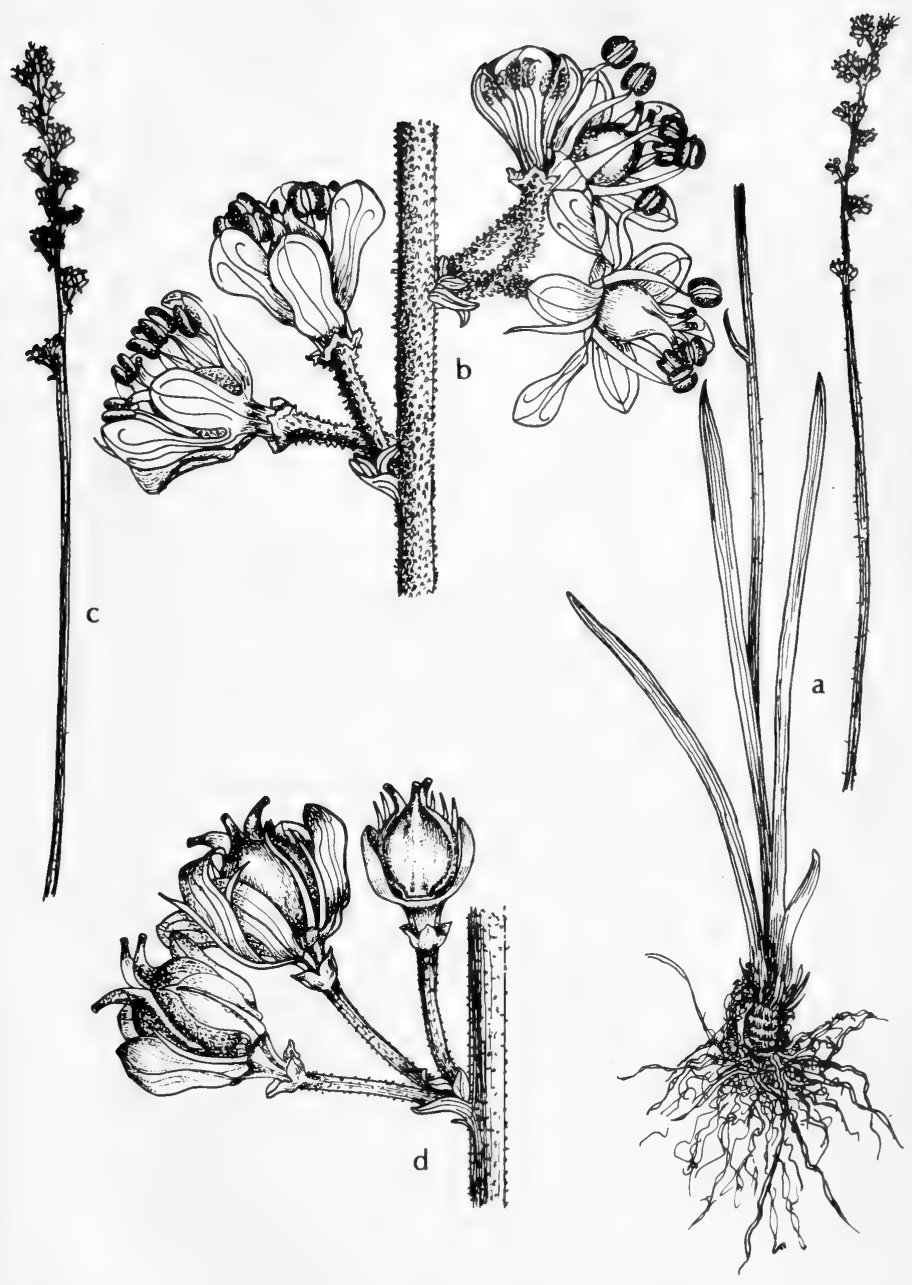

Fig. 333: Tofielda racemosa: a, habit, X $1 \frac{1}{2}$; b, flowers, X 5; c, top of plant in fruit, X 1/2; d, fruit, X 5. (V. F.). 


\section{Tofieldia Huds. False Asphodel}

About 20 species in the North Temperate Zone and Andes.

\section{Tofieldia racemosa (Walt.) Small. Fig. 333.}

Slender perennial, mostly tufted, with short or creeping rhizomes and simple usually 1-foliate stems that are surrounded by a tuft of grasslike leaves at the base; basal leaves erect, equitant, linear, to $4 \mathrm{dm}$. long and 3-5 mm. wide; cauline leaf usually single and bractlike, inserted below middle of stem; scape 3-7 dm. high, minutely but distinctly pubescent, increasingly so above, bearing a racemose inflorescence to $15 \mathrm{~cm}$. long; flowers creamy-white, the segments separate and spreading, 2 or 3 together at each node, with pubescent pedicels, subtended immediately below the perianth by a small perfoliate bractlet having 3 ovate lobes; terminal flowers opening first; perianth segments oblong to broadly ellipticoblanceolate, concave, 3-nerved, obtuse, 4-5 mm. long; stamens 6, exceeding the perianth; anthers ovate-cordate, 2-celled; filaments flattened, subulate; capsule narrowly obovoid, firm-walled, about $3 \mathrm{~mm}$. long, subtended by the persistent perianth and tipped by the 3 enlarged divergent styles; seeds narrowly ellipsoid, appendaged at both ends, about $2 \mathrm{~mm}$. long.

In wet sandy soils on pine savannahs and in pitcher plant bogs in s.e. Tex., June-Sept.; from Fla. to Tex., n. to N.J.

\section{Zigadenus Michx. Death Camas. Poison Sego}

Smooth and often glaucous perennials with rhizomes or bulbs, leafy stems and rather large panicled or racemed white to yellow or greenish to bronze perfect or polygamous flowers; perianth withering-persistent spreading; floral segments oblong or oval, 1- or 2-glandular near the more or less narrowed but rarely definitely unguiculate base; stamens free from the floral segments and about as long as them; anthers cordate or reniform; capsules 3-lobed, 3-celled, dehiscent to the base; seeds oblong or linear, angled.

About 15 species in the Northern Hemisphere of America and Asia. When grazed, most of the species are usually fatal to sheep and some species even to cattle. The bulbs are also poisonous.

1. Perianth segments $8-17 \mathrm{~mm}$. long, bearing a bilobed gland or 2 glands well above the base; filaments widened at the base (2)

1. Perianth segments $3-7 \mathrm{~mm}$. long, bearing a single basal gland (3)

2(1). Stem from bulbous-thickened base; perianth segments obtuse, 8-12 mm. long; gland bilobed............................................. Z. elegans.

2. Stem from creeping rhizome; perianth segments acuminate, $12-17 \mathrm{~mm}$. long; bearing 2 glands...........................................2. Z. glaberrimus.

3(1). Pedicels usually $2 \mathrm{~cm}$. long or more; filaments widened at base; bracts 8-12 $\mathrm{mm}$. long; distribution in New Mexico and Arizona...

3. Z. virescens.

3. Pedicels usually less than $1 \mathrm{~cm}$. long; filaments slender throughout; bracts $2-5 \mathrm{~mm}$. long; distribution in Texas (4)

4(3). Flowers polygamous; inflorescence always paniculate.

4. Z. leimanthoides.

4. Flowers perfect, usually in a simple raceme.

5. Z. densus.

1. Zigadenus elegans Pursh. White camas, alkali-grass. Fig. 334.

Stem rather stout, erect, to about $8 \mathrm{dm}$. high; leaves crowded toward base, narrowly to broadly linear, to about $4 \mathrm{dm}$. long and $1 \mathrm{~cm}$. wide, thin, attenuate at tip; inflorescence commonly a slender loose cylindric raceme, rarely a panicle; middle and upper bracts with scarious margins and summits, blunt to mucronate; pedicels usually slender; perianth pale or slightly suffused with purple or brown 


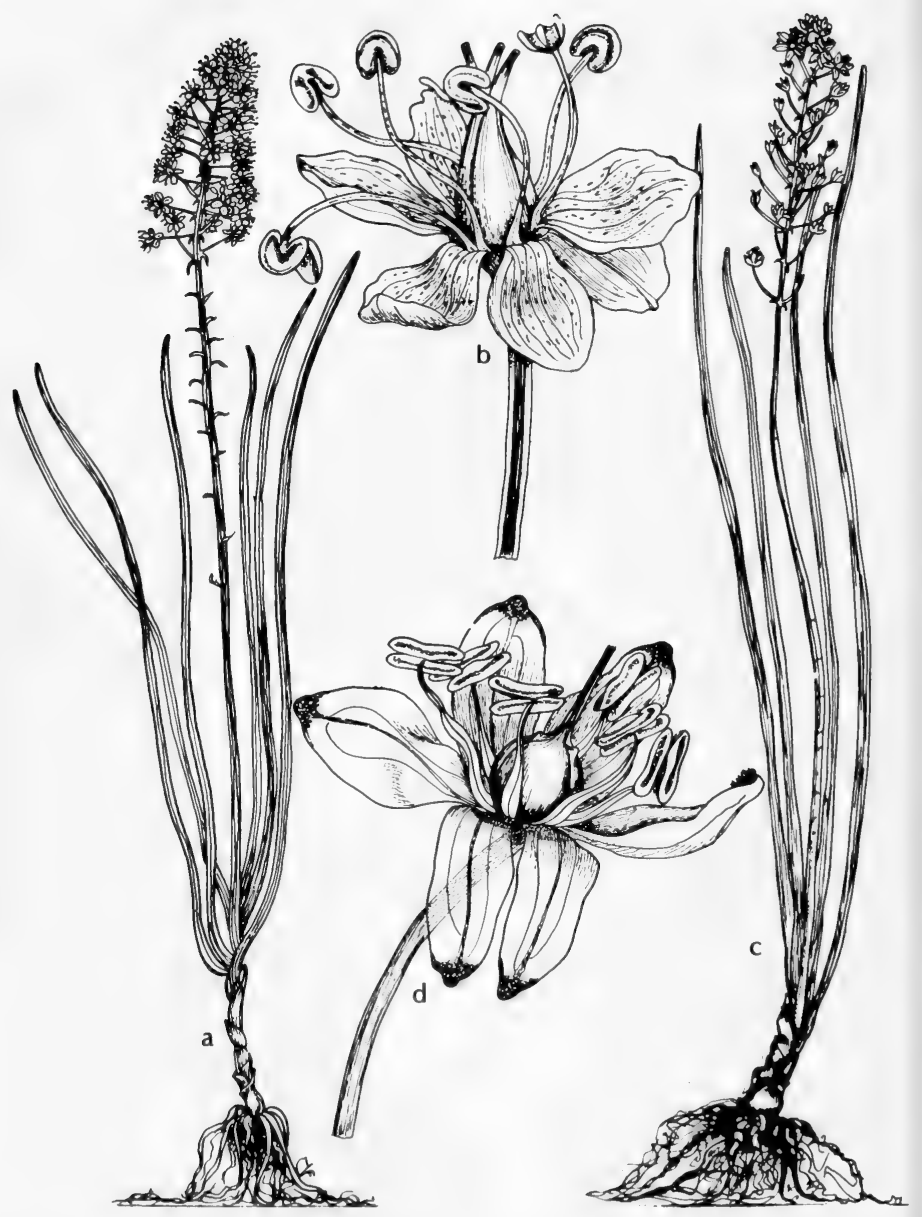

Fig. 335: a and b, Zygadenus densus: a, habit, X 1/;; b, flower, X 5. c-d, Schoenolirion croceum: $\mathrm{c}$, habit, $\mathrm{X} 1 / 5$; $\mathrm{d}$, flower, $\mathrm{X}$ 5. (V. F.). 
below, without or with only a small darkened spot outside at base; capsule lanceconic, 13-22 mm. long, 4-6 mm. in diameter, about twice as long as the persistent perianth; seeds $5-6 \mathrm{~mm}$. long.

On wet ledges and seepage in canyons of Guadalupe Mts. in the Trans-Pecos of Tex. and in N. M. (Taos Co.), June-Sept.; from Alas. to Ariz., Tex. and N. M., e. to Man., Minn., Ia. and Mo.

\section{Zigadenus glaberrimus Michx.}

Rhizome subligneous, blackish, horizontal, elongate; stem slender, to $12 \mathrm{dm}$. high, leafy; basal leaves elongate, linear, attenuate, firm, to $4 \mathrm{dm}$. long and 15 $\mathrm{mm}$. wide; panicle loosely pyramidal, to $3 \mathrm{dm}$. long; bracts ovate, acuminate, about $5 \mathrm{~mm}$. long; pedicels $5-10 \mathrm{~mm}$. long; flowers perfect; perianth segments $1-1.5 \mathrm{~cm}$. long, white, lanceolate or lance-ovate, acute to acuminate, with 2 distinct glands just above the short but definite claw; filaments widened at base; capsule lance-conic, about $1 \mathrm{~cm}$. long, barely equaling the connivent persistent perianth.

Savannahs, bogs and wet pinelands, June-Sept.; from Fla. to Tex. (?), n. to s.e. $\mathrm{Va}$.

This species is included here based solely upon a report of its occurrence in the state. It should occur in southeast Texas.

\section{Zigadenus virescens (H.B.K.) Macbr.}

Plant ascending from a slender bulb; leaves in a basal tuft, grasslike, to about $2 \mathrm{dm}$. long and $1 \mathrm{~cm}$. wide; scape and inflorescence scarcely exceeding the leaves, paniculate, the branches widely spreading; floral bracts $8-12 \mathrm{~mm}$. long, scarious; pedicels as much as $2 \mathrm{~cm}$. long or more, slender, divergent, often decurved; perianth segments whitish, sometimes tinged greenish, purplish or yellowish, elliptic, obtuse, 5-6 mm. long, somewhat cuneate at base, the gland obcordate with a sharply defined upper margin; stamens about $7 \mathrm{~mm}$. long, moderately exserted, the filaments widened at base; ovary partly inferior. Z. porrifolius Greene.

On wet ledges and in rich moist woods in N. M. (Catron and San Juan cos.) and Ariz. (Apache and Cochise cos.), May-Sept.; N. M. and Ariz. s. to C. A.

\section{Zigadenus leimanthoides Gray.}

Outer bulb coats fibrous; stem slender, erect, to about $15 \mathrm{dm}$. high; leaves elongate-linear, mostly crowded near the base, to $5 \mathrm{dm}$. long and $1 \mathrm{~cm}$. wide; flowers crowded in panicled racemes (central axis to $3 \mathrm{dm}$. long); lower and middle bracts of panicle herbaceous; pedicels to $12 \mathrm{~mm}$. long; perianth segments creamy or yellow to somewhat greenish-white, ovate-elliptic, 3-4 mm. long, each with a deeper yellowish spot on the contracted base; filaments subulate, slightly exceeding the perianth; capsules slender-conic, about $1 \mathrm{~cm}$. long, with pedicels to $15 \mathrm{~mm}$. long.

Sandy pinelands and bogs of the Coastal Plain and Piedmont, very rare in n.e. Tex., May-Aug.; Ga. to Tex., n. to N. J. and L. I.

\section{Zigadenus densus (Desr.) Fern. Black SNAKEROot, Crow-POISON. Fig. 335.}

The barely thickened bulbs with smooth coats; stem slender, erect, to $15 \mathrm{dm}$. high, remotely bracted; leaves narrowly linear, mostly near the base, to $5 \mathrm{dm}$. long and $7 \mathrm{~mm}$. wide; raceme simple (rarely branching below), densely subcylindric, to about $2 \mathrm{dm}$. long and $3-5 \mathrm{~cm}$. thick; bracts small, firm, brownish, persistent; perianth creamy-white to pink, nearly or wholly free; perianth segments 4-5 $\mathrm{mm}$. long, elliptic-obovate, obtuse, each usually with a very small obscure gland at base; capsules slenderly conical, with pedicels $1-2 \mathrm{~cm}$. long.

Damp pinelands and bogs in e. Tex., Apr.-June; from Fla. to Tex., n. to s.e. Va., N.C. and Tenn.

The bulb of this plant is very poisonous. 


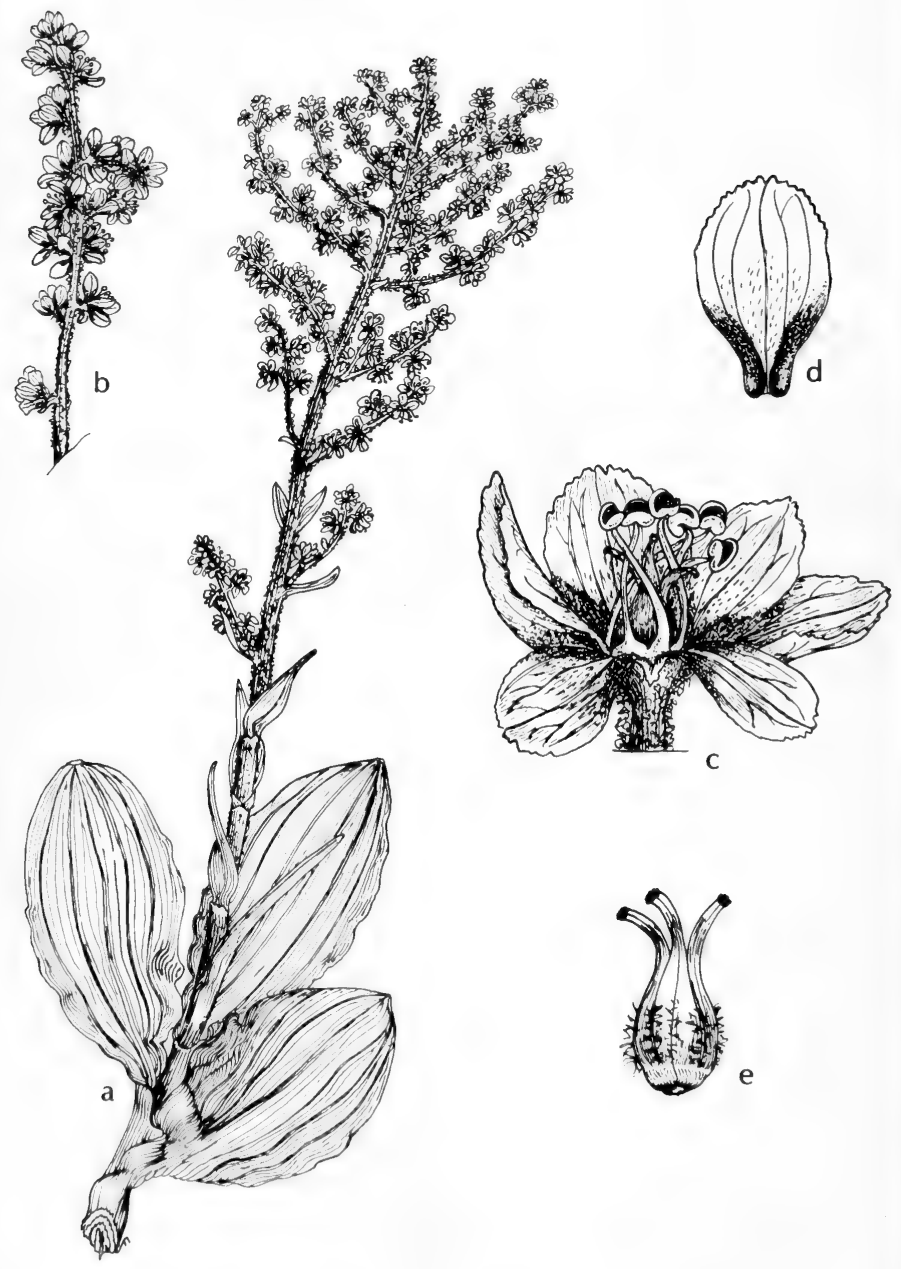

Fig. 336: Veratrum californicum: a, top of plant, X 1\%; b, branch, X 1/2; c, flower, X 3 ; d, segment of perianth, X 3; e, capsule, X 4. (V. F.). 


\section{Schoenolirion Durand}

Three species in southern United States; one in California.

1. Schoenolirion croceum (Michx.) Wood. Yellow sunny-Bell. Fig. 335.

Perennial herb; scape very slender, about $3 \mathrm{dm}$. high, scaly and somewhat thickened at base, from a thick rootstock and fleshy-fibrous cluster of roots; leaves in a basal tuft, elongate, flat, the principal leaves $4-8 \mathrm{~mm}$. wide, strongly ribbed; raceme simple, to $15 \mathrm{~cm}$. long and $4 \mathrm{~cm}$. in diameter; bracts ovate to elliptic, concave, mostly obtuse, often tinged with purple; flowers yellow and mostly tinged with red; floral segments 6, elliptic-oblong, distinctly 3-nerved, 5-7 mm. long; capsule depressed-globose,. deeply 3-lobed; seeds subglobose, shining, nearly $4 \mathrm{~mm}$. long. Oxytria crocea (Michx.) Raf.

In wet savannahs, marshy pinelands, bogs and on seepage slopes in s.e. Tex., Mar.-May; from Fla. to Tex., n. to N. C.

\section{Melanthium L.}

Five species all native of North America.

\section{Melanthium virginicum L. BUNCHFLOWER.}

Perennial from a thick rootstock; stem to about $1.5 \mathrm{~m}$. high, scurfy above; leaves firm, broadly linear, acuminate-attenuate, to $3 \mathrm{~cm}$. broad; panicle to $45 \mathrm{~cm}$. long, usually much shorter, somewhat scurfy, with ascending to spreading lateral branches; flowers creamy, changing to green or purplish, scurfy outside; floral segments 6, broadly oblong to ovate, rounded to cordate or hastate at base, flat, obtuse, $5-8 \mathrm{~mm}$. long, 2 or 3 times the length of the slender claw, with 2 dark glands at base; stamens borne at or above middle of each claw; capsule erect, ovoid, with furrows between the round-backed carpels, 13-18 $\mathrm{mm}$. high, 3-beaked; seeds whitish, narrowly obovate, flat, broadly winged, about 10 in each cell, 5-7 $\mathrm{mm}$. long.

Meadows, bogs, swales, savannahs, edge of woodlands and low thickets in e. and s.e. Tex., May-July; from n. Fla. to Tex., n. to s. N. Y., O., Ind., Ill. and Ia.

\section{Veratrum L. FALSE-Hellebore}

About 25 species in the North Temperate region.

\section{Veratrum californicum Durand. Skunk-CAbbage. Fig. 336.}

Stout, tall, leafy perennial 1-2 m. tall, with a short thick poisonous rootstock; leaves sheathing at base, 2-5 dm. long, 1-2 dm. wide, ovate or the upper ones narrower, lightly pubescent, plaited, prominently nerved; panicle 2-5 dm. long, tomentose; pedicels 2-6 mm. long; flowers dull white; perianth segments $8-15 \mathrm{~mm}$. long, 5-8 mm. wide, greenish-margined, with a greenish spot at base; stamens 6 , opposite perianth segments, free, short, curved, the anthers cordate, with confluent polien sacs; styles 3, persistent; capsule 2-3 cm. long, 3-celled, 3-lobed; seeds numerous, wing-margined.

Wet meadows and bogs in N. M. (Sandoval and Taos cos.) and Ariz. (Apache, Cochise, Coconino, Graham and Navajo cos.), June-Sept.; Mont. to Wash., s. to N. M., Ariz. and Calif.

\section{Allium L. Onion. Garlic. Leek}

Biennial or perennial herbs; scapes from a tunicated bulb, with mostly narrowly linear basal leaves; herbage usually with the characteristic odor and taste of onions or garlic; flowers in a terminal simple umbel, subtended by 2 to 4 membranous separate or united bracts, some or all of the flowers occasionally replaced by 
bulblets; pedicels slender, not jointed; perianth persistent, its 6 segments white to purple and distinct or united at the base: stamens inserted on the bases of the perianth segments; filaments filiform or dilated, sometimes toothed; style filiform, jointed; capsule obovate-globose, obtusely 3-lobed, often crested, loculicidally dehiscent; seeds obovoid or ovoid-reniform, wrinkled, black.

A genus of 450 or more species widely distributed in the North Temperate Zone. Sometimes segregated, with a few other liliaceous genera, as a separate family, the Alliaceae.

1. Flowering pedicels mostly or entirely replaced by bulbils; flowers rarely producing capsules or seeds.......................................... A. canadense.

1. Umbels floriferous and capsuliferous; bulbils unknown................ A. Geyeri.

\section{Allium canadense L. var. canadense. CANADA GARLIC.}

Bulb ovoid, without basal bulblets, often one of a cluster; inner bulb coats whitish, the epidermal cells obscure, vertically elongate, regular or nearly so; outer bulb coats persisting as a series of grayish or brownish fibrous fine- to coarse-meshed open reticula, enclosing 1 or more bulbs or soon disintegrating; fleshy scales 2 to 5 , with mild to strong garlic flavor; leaves usually 3 or more per bulb, channeled, concavo-convex in cross section, 1-5 mm. broad, usually with entire margins, shorter than the scape, green at anthesis; scape $1.5-5 \mathrm{dm}$. tall, terete, solitary; spathe membranaceous, caudate, breaking before anthesis into usually 3 separate or partially united 3- to 7-nerved bracts that are ovate to lanceolate and acuminate; umbel with few or no flowers, the pedicels being replaced (all or in part) by ovoid bulbils, some of which may in turn bear secondary umbels; pedicels (when present) 2 to several times the length of the perianth, elongating and becoming rigid when fruit is produced; perianth broadly campanulate; perianth segments 4-7 $\mathrm{mm}$. long, elliptic-lanceolate, obtuse to acute, entire, spreading, white or pink, withering in fruit, the midribs somewhat thickened; stamens shorter than the perianth; fllaments subulate, dilated and united into a cup at base; anthers oblong, obtuse to acute; ovary crestless style linear, about equaling the filaments in length; stigma capitate, entire or obscurely lobed; seeds black, shining, finely alveolate, and alveoli each with a minute pustule in the center. A. mutabile Michx.

Roadsides, wet meadows, woods and fields in the e, third of Okla. (Waterfall) and Tex., Mar.-May; generally distributed throughout e. N.A.

\section{Allium Geyeri Wats.}

Bulb ovoid or more elongate, without basal bulblets, usually one of a cluster; inner bulb coats whitish, epidermal cells vertically elongate and regular or obscure; outer bulb coats persisting as a series of gray or brown fibrous rather coarsemeshed open reticula, enclosing 1 or more bulbs; fleshy bulb scales 3 or 4 , strongly garlic-flavored; leaves ordinary 3 or more per scape, channeled, concavo-convex in cross section, 1-5 mm. broad, entire or denticulate on the margins, usually shorter than the scape, green at anthesis; scape 1-5 dm. tall, terete or somewhat angled, solitary; spathe membranaceous, acuminate, breaking before anthesis into 2 or 3 separate or partially united ovate to lanceolate acuminate 1-nerved bracts; umbel 10- to 25- (sometimes more-) flowered, erect; pedicels nearly equal in length, often less than twice that of the perianth, becoming rigid and stiffly spreading in fruit, usually not flexuous; perianth urccolate-campanulate; perianth segments 4-10 (usually 6-8) $\mathrm{mm}$. long, ovate to lanceolate, obtuse to acuminate, erect, pink or white, often obscurely toothed on the margins and papillose on the midribs, becoming callous-keeled and permanently investing the fruit; stamens usually shorter than the perianth; filaments subulate, dilated and united into a cup at base; anthers oblong, obtuse or umbonate; ovary inconspicuously crested with 6 
low rounded knobs that are separate or united in pairs across the septa, becoming variously developed or obsolete in fruit, usually not more than $0.5 \mathrm{~mm}$. high; style linear, about equaling the filaments in length; stigma capitate, entire or obscurely lobed; seeds black, shining, finely alveolate, the alveoli each with a minute pustule in the center.

Moist open slopes, meadows or stream banks in the Guadalupe Mts. of Tex., through N. M. (Bernalillo, Lincoln, Otero, Rio Arriba, Sandoval, Union and Valencia cos.) and Ariz. (Apache, Cochise, Coconino, Gila, Navajo, Pima and Santa Cruz cos.), June-Aug.; from Tex. to Ariz., Ida., Wash. and s. Alta.

\section{Lilium L. LILY}

About 80 species that are widely distributed over the North Temperate Zone.

\section{Lilium Parryi Wats. Lemon LILY.}

Bulb small, about $2.5 \mathrm{~cm}$. in diameter, somewhat rhizomatous, with numerous jointed scales, 12-20 mm. long; stem slender, 6-12 dm. high, glabrous; leaves usually scattered, linear-oblanceolate, $10-15 \mathrm{~cm}$. long, 6-10 $\mathrm{mm}$. wide, mostly acuminate; flowers 1 or 2 , rarely more, horizontal, funnelform, pale lemon-yellow and minutely dotted, very fragrant; pedicels stout, erect, usually $8-10 \mathrm{~cm}$. long; perianth segments $6-10 \mathrm{~cm}$. long, $8-11 \mathrm{~mm}$. wide, acuminate, the upper third spreading or the tips finally recurved; anthers oblong, brownish, 6-8 mm. long; stigma 3-lobed; capsule 4-5 cm. long, about $12 \mathrm{~mm}$. wide, narrowly oblong, acutish, the lobes not winged nor angled; seeds densely packed in 2 rows in each cell.

Wet places about mt. springs, meadows and along streams, rare in s. Ariz. (Cochise and Santa Cruz cos.), May-July; also s. Calif.

\section{Camassia lindl. Wild Hyacinth}

About 6 species in North America.

\section{Camassia scilloides (Raf.) Cory.}

Perennial from a tunicated bulb; leaves crowded at base of scape, their bases clasping and surrounded by a sheathing scarious bract, keeled, elongate, grasslike, to about $15 \mathrm{~mm}$. wide; scape to $8 \mathrm{dm}$. high, exceeding the leaves; raceme elongated and cylindrical; bracts setaceous, usually longer than the pedicels; flowers sweetscented, lavender to pale-blue; floral segments distinct, 1-1.4 cm. long, 3-nerved, spreading or erect; capsule acutely triangular-globose, 3-valved, about $1 \mathrm{~cm}$. long; seeds roundish, angled, black and shining. Quamasia hyacinthina (Raf.) Britt.

In sandy or rocky soils in fields, wet meadows, prairies and open woodlands from cen. Tex. northw. through e.-cen. Okla. (Waterfall), Mar.-May; from Ala. to Tex., n.e. and n. to Pa., s. Ont., Mich., Wisc., Ia. and Kan.

A phase that blooms later and has small flowers with erect segments is sometimes referred to as $C$. angustata (Engelm. \& Gray) Blank.

\section{Smilacina Desf. False Solomon's Seal}

About 25 species mostly in temperate regions of both hemispheres.

\section{Smilacina stellata (L.) Desf. Starflower. Fig. 337.}

Herbaceous perennial from creeping scaly rootstock; stem ascending or usually erect, 2-6 dm. tall, leafy, finely pubescent or glabrous; leaves spreading or usually strongly ascending, mostly folded along midvein, sessile and somewhat clasping, lanceolate to oblong-lanceolate, $6-15 \mathrm{~cm}$. long, 2-5 cm. wide, acuminate or gradually tapering to the acute apex, finely pubescent beneath; raceme shortpeduncled to nearly sessile, $2-5 \mathrm{~cm}$. long, with 2 to several flowers; perianth segments narrowly lanceolate, white, about $5 \mathrm{~mm}$. long, exceeding the 6 stamens; 


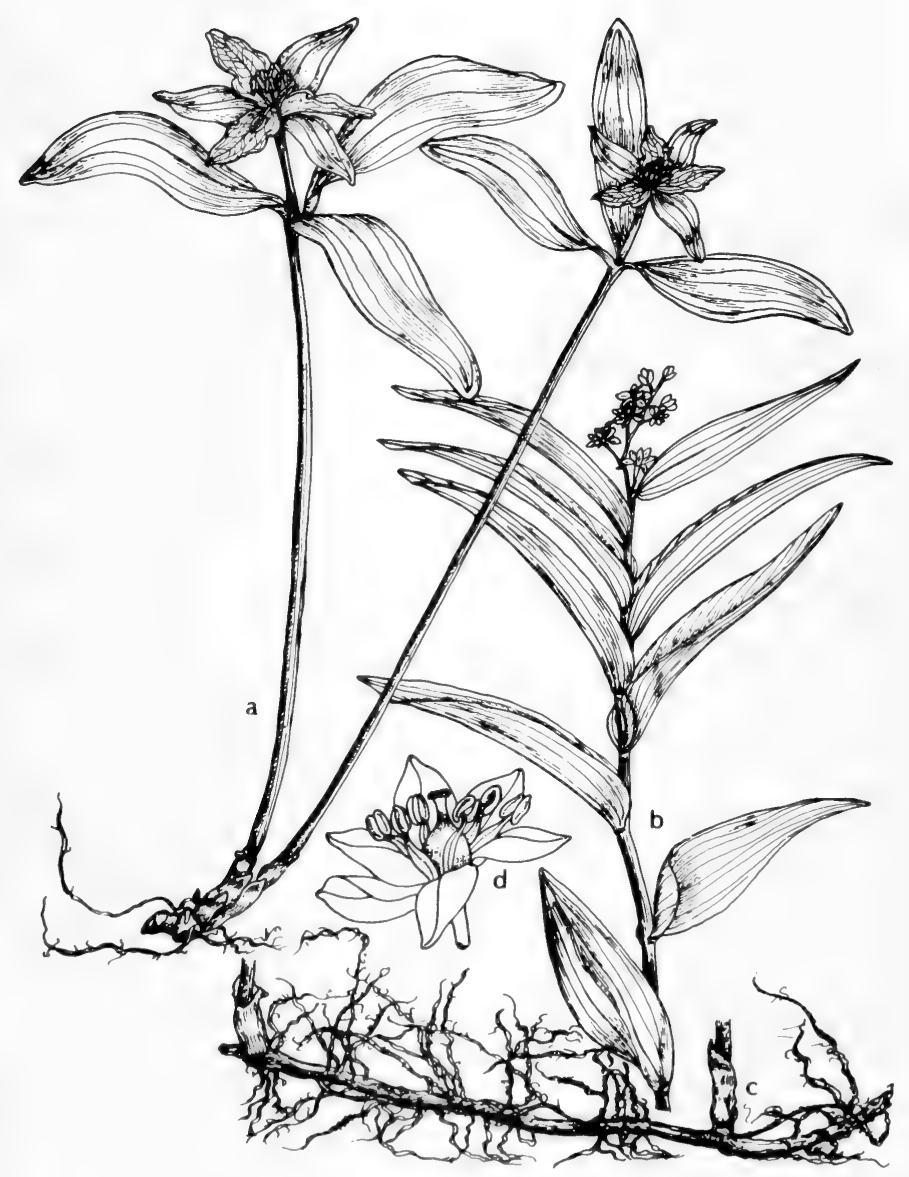

Fig. 337: a, Trillium texanum: a, habit, X 1/2. b-d, Smilacina stellata: b, upper part of plant, $X 1 \frac{1}{2}$; c, rhizome, $X 1 \frac{1}{2}$; d, flower, X 3. (V. F.). 
fruit orbicular, black or green with black stripes, 6-10 $\mathrm{mm}$. in diameter.

In seepage areas, wet meadows, sandy woodlands, shores and prairies, reported from Okla. (Waterfall), in N. M. (Colfax, Grant and Taos cos.) and Ariz. (Apache, Cochise, Coconino, Graham and Pima cos.), May-July; Nfld. to B.C., s. to w. Va., O., Ind., Ill., Mo., Kan., N.M., Ariz. and Calif.

\section{Streptopus Michx. Twisted-Stalk}

Seven species of temperate North America and Eurasia.

\section{Streptopus amplexifolius (L.) DC.}

Perennial herb; rootstock short, stout, horizontal, covered with thick fibrous roots; stem erect, usually branching below the middle, 4-10 dm. high, glabrous; leaves ovate to lanceolate, $5-15 \mathrm{~cm}$. long, $2.5-5 \mathrm{~cm}$. wide, acuminate at apex, cordate-clasping at base, glabrous, glaucous beneath; peduncles $2.5-5 \mathrm{~cm}$. long, 1- or 2-flowered; flowers 8-12 mm. long, greenish-white; perianth segments narrowly lanceolate, acuminate, widely spreading or recurved above; anthers subulatepointed; stigma entire, obtuse to truncate; berry oval, $10-18 \mathrm{~mm}$. long.

In moist or wet woods, reported from Okla. (Waterfall), in mts. of N. M. (San Miguel and Taos cos.) and Ariz. (Apache Co.), June-July; Alas. and Lab. s. to Pa., N. M., Ariz. and Calif.

\section{Trillium L. Trillium. WaKe-Robin}

Perennial scapose herbs with subterranean or creeping tuberlike rhizomes, rarely producing rhizomatal leaves; scapes 1 or 2 (very rarely 3 or more), each with a whorl of 3 large foliaceous bracts subtending a solitary perfect flower at the summit; flowers pedicellate or sessile, 3-merous (occasionally 2-, 4-, or irregularly parted), with the perianth in 2 distinct series; sepals distinct, usually green, sometimes suffused with purple adaxially; petals distinct, white, pink, yellow, greenish or purple; anthers linear, adnate to the sides of connective or terminal; ovary sessile, 3- or 6-angled or -winged; stigmas 3, sessile or on a distinct style; berry 3-locular, few- to many-seeded, indehiscent.

About 40 species in temperate wooded regions of North America and eastern Asia. Segregated with three closely allied genera by some authors as the family Trilliaceae.

1. Flowers pedicellate; corolla white or pink; gynoecium with a distinct style........ ..1. T. texanum. 1. Flowers sessile; corolla purple or yellowish-green; gynoecium with sessile stigmas. 2. $T$, recurvatum.

\section{Trillium texanum Buckl. Fig. 337.}

Scapes 1-3 dm. tall; bracts sessile or abruptly narrowed into short petioles, narrowly lanceolate to elliptic-lanceolate or oblong, obtuse to rounded, upper surface somewhat farinose by the presence of numerous stomates, (3-) 4-6 $(-8) \mathrm{cm}$. long, (1-) 1.3-2 $(-3) \mathrm{cm}$. wide; flowers on erect pedicels $(2.5-) 3-4(-4.5) \mathrm{cm}$. long; sepals spreading, lanceolate, green, usually larger than the petals; petals spreading, narrowly lanceolate to lanceolate, acute, often with a short claw, white, becoming pink and finally reddish with age, $(1.5-) 2-2.5(-3) \mathrm{cm}$. long, 7-10 $(-14)$ $\mathrm{mm}$. wide; stamens $10-14 \mathrm{~mm}$. long, the anthers slightly longer than the white or pale-green filaments, the connectives often purple; gynoecium about as long as the stamens, with a distinct style about as long as the ovary and stigmas equal to or longer than the style; berry triangular-ovoid, sharply 6-ridged at base of persistent style, 8 - to 15 -seeded.

Extremely rare in low moist woods, bogs and stream banks in Tex. [Cass, Houston and Panola (type locality) cos.], Mar.-May; replaced in Ark. and s.w. 
Mo. by T. pusillum Michx. var. ozarkanum (Palm. \& Steyerm.) Steyerm., which lacks the upper epidermal stomates in the bracts, has thicker rhizomes, and grows in relatively dry rocky woods.

\section{Trillium recurvatum Beck.}

Scapes (1.5-) 2-4 (-5) dm. tall; bracts with a petiole $1-3 \mathrm{~cm}$. long, narrowly lanceolate to ovate, acute to slightly acumirate, obscurely mottled with darkgreen, (5-) 7-11 (-18) cm. long, (2-) 4-8 (-12) cm. wide; flower sessile or subsessile (pedicel not more than $3 \mathrm{~mm}$. long); sepals abruptly recurved, narrowly lanceolate, acute, (1.5-) 2-3 (-4) cm. long, 5-10 mm. wide; petals erect, lanceolate to oblanceolate, acute, distinctly clawed, purple or yellowish-green, (2-) 2.5-4 (-5) cm. long, (6-) 10-20 (-26) mm. wide; stamens erect, (8-) 10-15 (-20) $\mathrm{mm}$. long, the filaments straight and almost as long as the strongly incurved anther connectives; gynoecium height about even with the bases of the anthers, the prominently 6-winged angular-ovoid ovary (3-) 4-6 (-8) $\mathrm{mm}$. in height and the divergent-spreading stigmas about as long; fruit transversely angular-ovoid, distinctly winged, about $15 \mathrm{~mm}$. in diameter.

Rare on alluvial banks in rich woods and along streams in e. Okla. and e. Tex. (Nacogdoches and Rusk cos.), Mar.-May; widespread n. into Ia. and Wis., n.e. into $\mathrm{Ky}$. and Ind.

Forma Shayi Palm. \& Steyerm. Flowers lacking purple pigments; petals yellow or greenish-yellow; stamens and carpels greenish; occurring with the typical form.

\section{Aletris L. COLIC-ROOT. Star-grass}

Perennial and smooth stemless herbs, very bitter, with a short and thick rhizome and a spreading rosette of thin and flat lanceolate leaves; flowers small, in a spikelike raceme that terminates a slender nearly naked scape; perianth tubular to campanulate, wrinkled and roughened outside by thickly set points, the tube adhering to the base of the ovary, 6-cleft at the summit; stamens 6 , inserted at the summit of the perianth tube; filaments and anthers short, included; style subulate, 3-cleft at the apex; stigmas minutely 2-lobed; capsule ovoid, beaked, enclosed in the persistent withered perianth; seeds numerous, minute, costate.

About 25 species in Asia and North America.

1. Perianth white, $8-9 \mathrm{~mm}$. long, the lance-oblong lobes recurved-spreading........

1. Perianth yellow, about $7 \mathrm{~mm}$. long, the ovate lobes erect. 1. A. farinosa. 2. A. aurea.

\section{Aletris farinosa L. Unicorn-ROot. Fig. 338.}

Leaves firm, to $2 \mathrm{dm}$. long; scapes to $1 \mathrm{~m}$. high, usually much smaller, with remote small bracts; raceme to $3 \mathrm{dm}$. long, densely to subremotely flowered; bracts linear or clavate; perianth tubular, $8-9 \mathrm{~mm}$. long, whitish, with granulate surface, its lance-oblong lobes somewhat recurved-spreading, marcescent, shrinking at maturity and thus often exposing the long abrupt beaks that are about as long as the plump body of the capsule.

Dry or moist peats, savannahs and boggy areas, sands and gravels, rare in e. Okla. (Delaware Co.) and s.e. Tex., Mar-May; from Fla. to Tex., n. to s.w. Me., s. N.H., cen. Mass., s.e. N.Y., s. Ont., Mich. and Wisc.

\section{Aletris aurea Walt. Yellow star-Grass. Fig. 338.}

Very similar to $A$. farinosa; leaves membranaceous, to $12 \mathrm{~cm}$. long; scape to $8 \mathrm{dm}$. tall or more; raceme remotely flowered; perianth broadly campanulate, about $7 \mathrm{~mm}$. long, orange-yellow, not so roughened, its short-ovate lobes erect; beaks of capsules included, about as long as the plump body. 


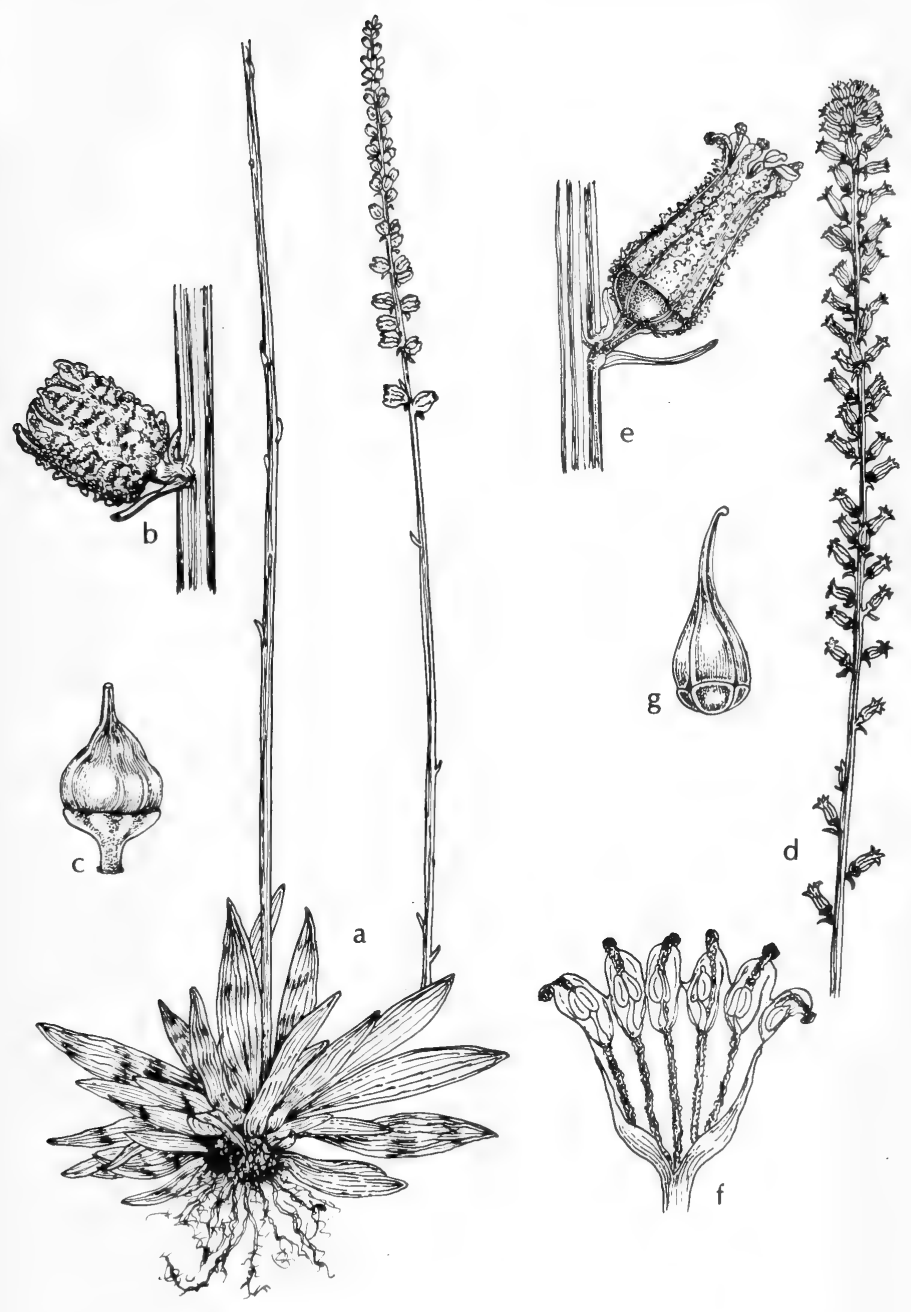

Fig. 338: a-c, Aletris aurea: a, habit, X 1/2; b, flower, X 3; c, capsule, X 3. d-g, Aletris farinosa: d, upper part of plant, X $1 / 2$; e, flower, X $3 ; \mathrm{f}$, corolla split longitudinally, X 3; g, capsule, X 3. (V. F.). 


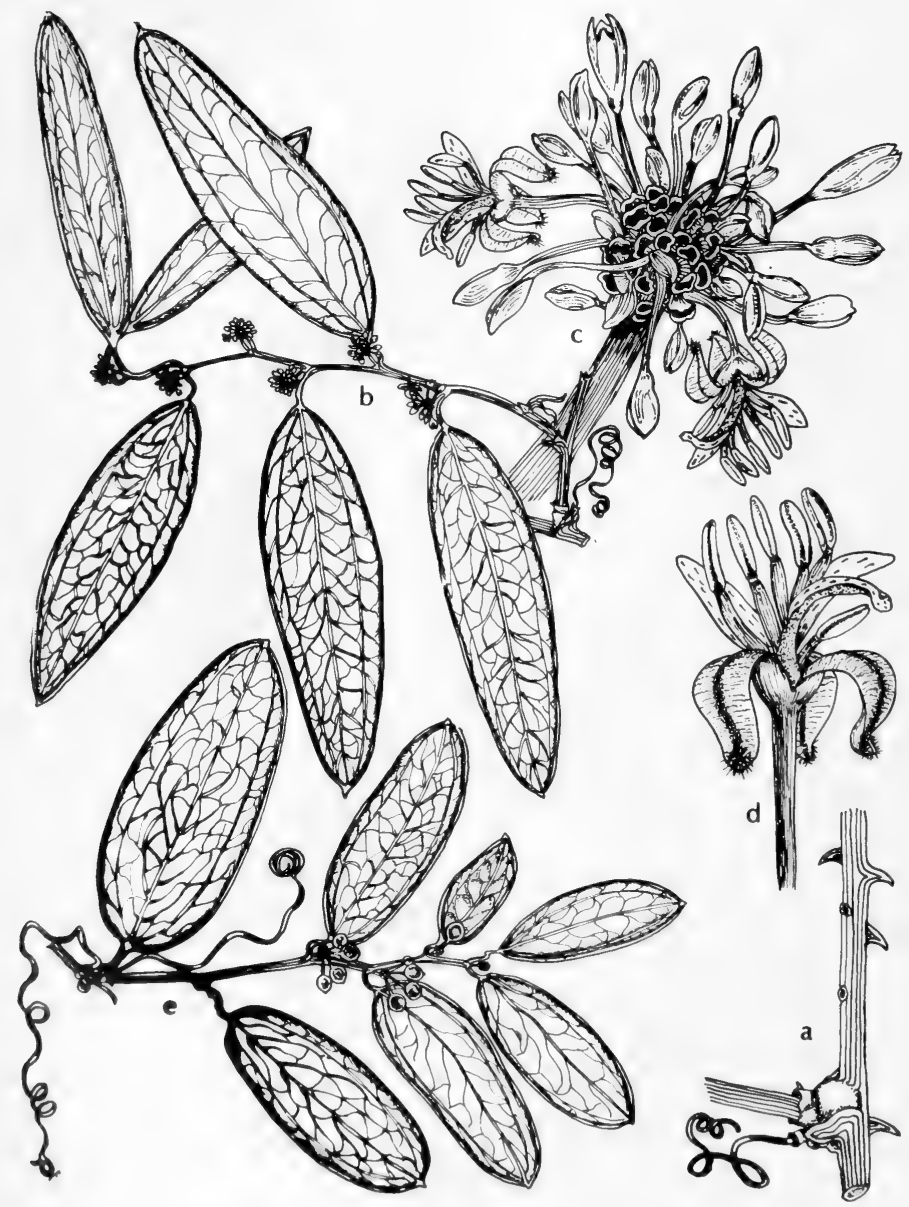

Fig. 339: Smilax laurifolia: a, part of stem showing thorns and tendril, $\mathrm{X} 1$; b branch with clusters of flowers, $X$ 1.; c, cluster of flowers, X 3; d, staminate flower, $\mathrm{X} 5$; e, branch with fruit, X $1 \%$ (V. F.). 
Damp pine-barrens, bogs and savannahs in s.e. Okla. (McCurtain Co.) and e. Tex., May-July; from Fla. to Tex. and Okla., n. to s.e. Va. and Md.

\section{Smilax L. Green-brier. CAt-brier}

Shrubby or herbaceous dioecious plants usually climbing or supported by a pair of tendrils on the petiole of the broad-ribbed and netted-veined simple leaves; flowers unisexual, the staminate often the larger, in umbels in axillary peduncles, small, greenish, yellowish or bronze, regular; perianth segments distinct, similar, deciduous; stamens in the staminate flower 6; filaments slender or flattened, inserted on the very base of the perianth; the introrse anthers linear or oblong, fixed by the base, apparently 1-celled; ovary of fertile flowers 3-celled (1-cell with single stigma in $S$. laurifolia); stigmas thick and spreading, almost sessile; ovules 1 or 2 in each cell, pendulous, orthotropous; fruit a small berry.

About 350 species, mostly tropical with few in the Temperate Zone in North America and eastern Asia. Segregated by some authors as a separate family, Smilacaceae.

The fruits of green-briers provide winter food for many species of songbirds, game birds and wild animals, and the herbage is browsed by deer and is occasionally eaten by wildfowl.

1. Leaves evergreen, thick-coriaceous, oblong to oblong-linear or oblong-lanceolate to rarely broadly linear, on the underside the midvein in its lower third more prominent than the laterals, a lateral vein closely and evenly submarginal; stigma 1; berries black, 1 -seeded, ripening late in the second season after flowering in the previous summer or fall....................................................................... S. laurifolia.

1. Leaves deciduous, firm-membranous, ovate to triangular-lanceolate, the veins not as above; stigmas 2 or 3 ; berries black or red, 1 - to 3 -seeded, ripening the same year after flowering in the spring (2)

2(1). Berries black or bluish-black (when glaucous); principal stems and main branches with stout flattened prickles; leaf blades usually ovate, abruptly acute to short-acuminate at apex............2. S. rotundifolia.

2. Berries bright-red; stems prickly mostly at the base, the prickles usually subulate; leaf blades usually ovate-lanceolate to narrowly triangularlanceolate, rounded to obtuse and mucronate at apex.

3. S. Walteri.

1. Smilax laurifolia L. Bamboo-vine, Blaspheme-vine. Fig. 339.

Evergreen high-climbing rampant vine, often forming impenetrable entanglements, with knotty-thickened subligneous rhizomes and with strong terete stems armed (especially below and on vigorous sprouts) with rigid terete prickles; tendrils intermittent, few or wanting on flowering branchlets; leaves heavily coriaceous, short-petioled, with the thick midrib much more prominent beneath than the 2 to 4 lateral ones, oblong to oblong-linear or -lanceolate, usually coarsely mucronate, provided with a prominent and evenly submarginal vein, $6-20 \mathrm{~cm}$. long and 1-7.5 cm. broad; umbels sort-stalked, often crowded and subpaniculate along the branchlets; stigma solitary, ovary 1-celled; berries becoming black, about $8 \mathrm{~mm}$. in diameter.

Swamps, seepage slopes and low ground in s.e. Okla. (McCurtain Co.) and e. Tex., flowering in late summer and autumn of 1 st season, lasting over winter; from Fla. to Tex., n. to N.J. and Tenn.; also W.I.

The leaf margin is often inrolled so that there appear to be 2 closely parallel veins at the margin.

2. Smilax rotundifolia L. COMMON GREEN-BRIER, HORSE-BRIER.

Tough woody high-climbing vine, from long slender rhizomes, with strong 
greenish subrigid terete to 4-angled stems and branches bearing stout flattened prickles; tendrils numerous; leaves shortly petioled, narrowly ovate to suborbicular or reniform, with rounded to cordate bases, bright-green on both sides, lustrous, thinnish, becoming subcoriaceous, mostly $4.5-10 \mathrm{~cm}$. long, often muriculate on back near base; peduncles to $15 \mathrm{~mm}$. long, ascending to divergent; pedicels 2-7 mm. long; flowers greenish to bronze; berries blue-black, with bloom, mostly 2- to 3-seeded. Incl. var. quadrangularis (Muhl.) Wood.

Moist to dryish thickets and woods, evergreen shrub bogs, often a noxious pest in e. Okla, and e. Tex., Mar.-June; from Fla. to Tex., n. to N.S., s. Me., s. N.H., N.Y., s. Ont., O., Ind., s. Ill, s.e. Mo. and Okla.

\section{Smilax Walteri Pursh. Coral green-brier, Red-Berried bamboo.}

Slender and lithe woody vine, with widely creeping slender rhizomes, clambering over bushes; lower half of the stem with scattered subulate prickles, the terete branches nearly or quite without prickles; tendrils numerous; leaves submembranaceous, smooth, green on both sides, when dried very lightly orange-tinged with brown, ovate to ovate-oblong or triangular-ovate, with rounded bases, rounded to obtuse and mucronate at apex, mostly $6-12 \mathrm{~cm}$. long and 3-7 cm. broad; peduncles mostly shorter than petioles; flowers greenish to bronze; berries brightred, handsome, persistent over the winter.

Swampy or boggy thickets, low pinelands, rare in e. Tex., Mar.-June; from Fla. to Tex., n. to N.J.

\section{Fam. 36. Amaryllidaceae ST. HiL.}

\section{AMARYLLis FAMILY}

Mostly perennial herbs, herbaceous or sometimes with a woody base or with somewhat woody stems; flowering stems scapose, from a bulb or corm, a short rootstock or a large woody caudex; leaves of a linear type and entire; flowers perfect, regular or nearly so; perianth segments 6 , distinct or mostly united below into a tube that is adnate to the ovary; stamens 6 , rarely more or only 3 , inserted on the perianth, the filaments free or united in a cup; anthers basifixed or versatile, dehiscing usually by introrse longitudinal slits; ovary inferior, 3-celled; style 3-lobed; fruit usually a 3-valved capsule with loculicidal dehiscence or sometimes indehiscent; seeds usually numerous.

Broadly interpreted the family probably has nearly 2,000 species in about 100 genera, rather cosmopolitan but mostly in tropical and subtropical regions of both hemispheres. Some of the species are highly ornamental while others, such as Agaves, are important economically.

The commonly cultivated Amaryllis Belladonna L., a native of Latin America, occasionally escapes. It is abundantly spread in and along a slough on the west edge of Edna in Jackson County, Texas, where it is well-established. It is readily distinguished by its umbellate cluster of large (to $15 \mathrm{~cm}$. long) reddish to salmoncolor bell-shaped flowers, and its basal cluster of broad, fleshy, strap-shaped leaves.

1. Flowers with a conspicuous corona above the perianth.

1. Flowers without a corona (2)

2(1). Perianth segments pilose on the outer surface; foliage grasslike, herbaceous, usually villous or pilose................................................2. Hypoxis

2. Perianth segments glabrous; foliage mostly broad and fleshy-thickened, rarely grasslike, glabrous or essentially so (3)

$3(2)$. Flowers several in an umbel; spathes 2, large and broad 6. Crinum

3. Flower solitary; spathe solitary, narrow (4) 


\section{Hymenocallis SaLisB.}

\section{SPIDER-LILY}

Herbs with scapes and leaves from a rather large tunicated bulb; flowers white (in ours), showy, essentially sessile in a terminal umbel subtended by 2 or more usually scarious bracts; perianth tube very slender, elongate, the limb with linear to narrowly lanceolate spreading segments; crown showy, forming a large conspicuous cup that connects the bases of elongate filaments; anthers versatile; capsule firm, few-seeded.

Forty or mcre species in the warmer parts of the Western Hemisphere. $\boldsymbol{H}$. caymanensis Herb. has been reported from coastal Texas but no material has been seen. The long $(12-16 \mathrm{~cm}$.) perianth tube is characteristic of this species.

1. Flowering from July to September after the leaves begin to wither...... 1. H. Eulae.

1. Flowering from March to May or sporadically to July, with the leaves (2)

2(1). Free part of filaments $20 \mathrm{~mm}$. long or less; larger perianth segments usually $5 \mathrm{~mm}$. wide or less; crown $25-35 \mathrm{~mm}$. long; leaves commonly less than $20 \mathrm{~mm}$. wide.

2. H. Liriosme.

2. Free part of filaments $23-35 \mathrm{~mm}$. long; larger perianth segments usually more than $5 \mathrm{~mm}$. wide; crown $33-40 \mathrm{~mm}$. long; leaves $18-42 \mathrm{~mm}$. wide 3. H. caroliniana.

\section{Hymenocallis Eulae Shinners.}

Bulb about $5 \mathrm{~cm}$. in diameter, to $75 \mathrm{~mm}$. long (including neck); scape 6-9 dm. high; leaves glaucous-green, oblanceolate, to $6 \mathrm{dm}$. long and $5 \mathrm{~cm}$. wide, slightly recurved, appearing in late winter and dying off in late spring; spathes lanceolate, to $4 \mathrm{~cm}$. long; umbel mostly 6- to 9-flowered; flowers snow-white, about $2 \mathrm{dm}$. across, fragrant (especially at night); perianth tube $8-12 \mathrm{~cm}$. long, the segments to $1 \mathrm{dm}$. long; staminal cup about $65 \mathrm{~mm}$. in diameter, the edges somewhat lacerate, with sharp points; ovary sessile, about $1 \mathrm{~cm}$. long; filaments $3-4 \mathrm{~cm}$. long; anthers introrse.

In heavy soils near streams that periodically overflow and seepage slopes in s.e. Tex., July-Sept.; also La.

\section{Hymenocallis Liriosme (Raf.) Shinners.}

Bulb with black outer and white inner coat; scape sharply 2-edged, biconvex, spongy, shriveling to less than half its original width and less than a fourth its thickness in drying; leaves shining, light-green, to about $4 \mathrm{~cm}$. wide, appearing in the spring; flowers snowy-white (tinged lemon-yellow in the center and greenish or yellowish on perianth tube), blooming simultaneously with appearance of leaves, about $2 \mathrm{dm}$. in diameter; perianth tube $6-8 \mathrm{~cm}$. long. $H$. galvestonensis of auth.

Common on stream banks, in ditches and wet places in e. Tex., w. to Red River, Van Zandt, Kaufman and Victoria cos., Mar.-May; from La. and Tex. to Ark. and (?) Okla.

\section{Hymenocallis caroliniana (L.) Herb. Fig. 340.}

Scape $35-53 \mathrm{~cm}$. high; leaves narrowly oblanceolate to elliptic-ligulate, 1.8-4 $\mathrm{cm}$. wide; umbel 3- to 9-flowered; spathe bracts lanceolate, acute to obtusely acute, to $6 \mathrm{~cm}$. long; flowers sweetly fragrant; perianth segments greenish-white below, to $1 \mathrm{dm}$. long: crown $3.3-4 \mathrm{~cm}$. long, the margins irregularly incised; filaments 23-35 mm. long; style exceeding the stamens; fruit globose, usually with 
2 ovules in each cell. $\boldsymbol{H}$. occidentalis of auth.

In wet sandy areas, meadows, swamps and marshes in s.e. Okla. (Waterfall) and e. and s.-cen. Tex., Mar.-May or sporadically to July; from Ga. to Tex., n. to Ky., Mo. and Ark.

\section{Hypoxis L. Yellow StaR-Grass}

Stemless small herbs with grasslike usually hairy linear or narrowly lanceolate leaves and slender 1 - to several-flowered peduncles from a cormlike short vertical rhizome; perianth mostly pilose without, its tube completely coherent with the ovary; perianth segments yellow to whitish within, usually green on the back, connivent at least after anthesis, usually forming a beaklike crown to the fruit or rarely deciduous; anthers versatile or rarely basifixed; capsule indehiscent or longitudinally dehiscent; seeds globular to ellipsoid, with pebbled to muricate or variously sculptured testa.

More than 100 species, mostly in the Southern Hemisphere.

1. Seeds sharply muricate, the projections somewhat awl-shaped and acute 1. $H$. hirsuta.

1. Seeds reticulate, covered with low smooth rounded pebbling or blunt murications (2)

2(1). Leaves thin and flaccid, glabrous, narrowly linear-lanceolate, usually more than $5 \mathrm{~mm}$. wide at about the middle; peduncles mostly 2 -flowered; perianth segments 5-7 mm. long.......................2. H. leptocarpa.

2. Leaves firm, linear, pilose, $1-4 \mathrm{~mm}$. wide; peduncles usually 1 -flowered; perianth segments $7-12 \mathrm{~mm}$. long.............................. H. rigida.

\section{Hypoxis hirsuta (L.) Cov. Fig. 341.}

Corm subglobose to ellipsoid, 5-20 mm. thick, covered with membranaceous pale or brown-tinged stieaths that do not become fibrillous; leaves linear, rather firm, 1-6 dm. long, 1-8 mm. wide; peduncles filiform, stiffish or spreading, 4-35 cm. long, 2- to 7-flowered; pedicels elongate; ovary and capsule densely pilose; perianth segments lanceolate to elliptic or narrowly ovate, 5-15 $\mathrm{mm}$. long; capsule ellipsoid, 2-6 mm. long; seeds $0.8-1.3 \mathrm{~mm}$. in diameter, black, lustrous, the outer coat closely covered with sharp murications. $H$. erecta $\mathrm{L}$.

In open woods, wet meadows, prairies and pastures in e. half of Okla. and e. Tex., w. to Wise and Bastrop cos., Mar.-May; from s. N.H. to Man., s. to Fla. and Tex.

\section{Hypoxis leptocarpa Engelm. Fig. 341.}

Corm ovoid-cylindric, $10-15 \mathrm{~cm}$. thick; leaves very thin and flaccid, narrowly linear-lanceolate, tapering below, acuminate and long-attenuate at apex, often quite glabrous, 2-9 dm. long, about $12 \mathrm{~mm}$. broad; peduncles very slender and lax, mostly 1- to 3- (rarely 4-) flowered; perianth segments 5-7 $\mathrm{mm}$. long, subglabrous to dorsally pilose; mature capsules $4-10 \mathrm{~mm}$. long, slightly pubescent to glabrate; seeds black, with blunt murications. H. hirsuta var. leptocarpa (Engelm.) Brackett.

Wet woods, swamps and bottomlands, often along streams, in s.e. Tex., MayAug.; from N. C. to Fla. and Tex.

3. Hypoxis rigida Chapm. Fig. 341.

Corm subcylindric to ellipsoid, 6-15 mm. thick, covered with the stiff bristly bases of the old sheaths or rarely with membranous slightly disintegrating leaf bases; leaves rather rigid, linear, 1-4 dm. long, 1-4 mm. wide; peduncles glabrate, to $3 \mathrm{dm}$. long, 1- or rarely more-flowered; ovary and capsule pilose; perianth segments 7-12 mm. long, oblong to lanceolate, acutish, densely pubescent without; 


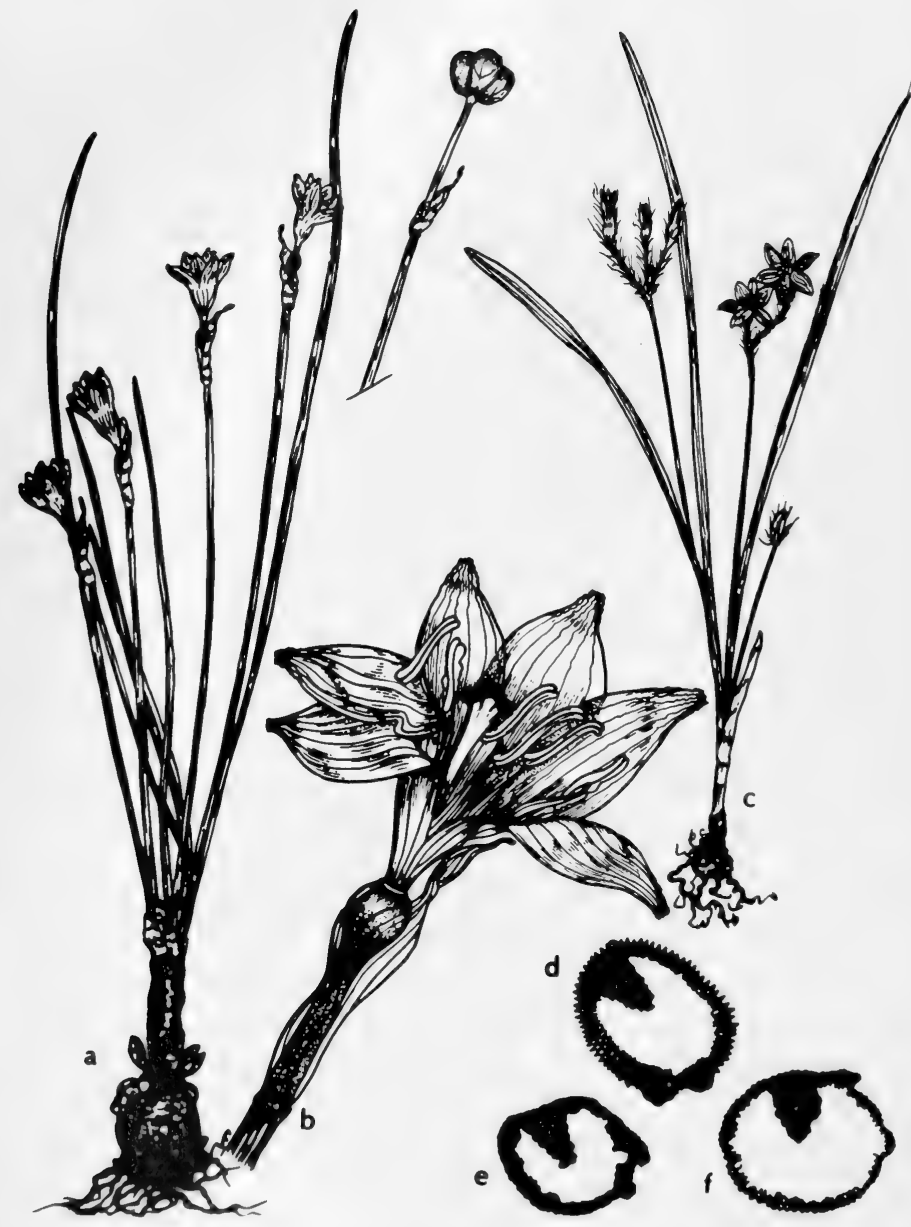

Fig. 341: a and b, Zephyranthes pulchella: a, habit, X 1/2; b, flower, X 21/2, c and d, Hypoxis hirsuta: c, hahit, $X 1_{2}$; d, seed (with detail drawn to show surface only at the edge and in a section), X 20. e, Hypoxis rigida: e, seed (with detail drawn to show surface only at the edge and in a section), x 20. f, Hypoxis leptocarpa: f, seed (with detail drawn to show surface only at the edge and in a section), X 20. (V. F.). 
capsule narrowly obovoid, 1-9 $\mathrm{mm}$. long; seeds about $1 \mathrm{~mm}$. in diameter, black, opaque or slightly lustrous, covered with short rounded approximate pebbling. $H$. humilis Tharp.

Low pine barrens, sandy soil in prairies and on edge of bogs in s.e. Tex., Apr.July; from Fla. to Tex., n. to N.C.

\section{Cooperia Herb. RAIN-Lily}

About 6 or 7 species, one in South America, the others from northern Mexico, through Texas to Kansas, west to New Mexico and east to southwestern Louisiana.

\section{Cooperia Drummondii Herb. Cebolleta. Fig. 342.}

Quite variable; bulb large, subglobose, $2 \times 3 \mathrm{~cm}$., the neck 2-9 $\mathrm{cm}$. long, the tunics black; leaves 2 to 5, narrow-linear, gray-green, tending to be glaucous, erect or declinate, $3 \mathrm{dm}$. long; scape $10-33 \mathrm{~cm}$. high; spathe about $4 \mathrm{~cm}$. long, slit or looped at the tip, with its tube about $11 \mathrm{~cm}$ long and greenish, often fading red; stipe none; flowers most frequently in the fall, sometimes in the summer, less frequently in the spring, white, the very slender tube $8-18 \mathrm{~cm}$. long; perianth limb opening flat, white, pink-tinted on the outer surface; calyx lobes ovate to lanceolate, $24 \mathrm{~mm}$. long, $13 \mathrm{~mm}$. wide, with blunt tips, the corolla lobes just slightly smaller; flower expanding in the evening, sometimes lasting up to 4 days before it withers; anthers erect, creamy-yellow, $9 \mathrm{~mm}$. long, attached one-third of length from base, filaments $4-8 \mathrm{~mm}$. long; style white, sometimes shorter than the tube, sometimes exceeding the stamens; capsule trilocular; seeds flat, black D-shaped. Zephyranthes Herbertiana D. Dietr., Z. brazosensis (Herb.) Traub. The most widely distributed Cooperia known, with its greatest frequency in Tex., but occurring from n. Mex. to Kan., N.M. and La., in low wet areas, swales and depressions, sometimes on saline flats, May-Sept.

\section{Zephyranthes HERB.}

\section{RAIN-LILY. ZEPHYR-LILY}

Bulb globose or subglobose, tunicated, usually dark-brown; leaves linear, grasslike, with margins essentially parallel; scape hollow, slender, single-flowered, from a tubular spathe that is sometimes fenestrate but usually is 2-notched at apex; flower regular, erect to suberect, funnelform with short to long tube, the limb segments about equal; anthers erect to suberect, becoming versatile after anthesis, orange, affixed below the middle; stigma trifid, the lobes filiform to globose; capsule tricolor, rarely 4-celled; seeds few or many per cell, black, flat, D-shaped.

About 50 species in the warmer parts of the Western Hemisphere. The South American $Z$. candida Herb. escapes from cultivation and tends to become naturalized in southeast Texas (Liberty, Orange and Jefferson cos.). It has white flowers that are usually tinged rose on the outside, and leaves that are slightly thickened or raised on the edges.

1. Flowers bright (buttercup)-yellow, unscented; perianth tube $5 \mathrm{~mm}$. long; stigma capitate and distinctly 3 -lobed....................... Z. pulchella.

1. Flowers a lighter yellow, with decided fragrance; perianth tube $15-24 \mathrm{~mm}$. long; stigma shortly 3- lobed. 2. Z. refugiensis.

\section{Zephyranthes pulchella J. G. Sm. Fig. 341 .}

Bulbs globose, 1-2 cm. in diameter; leaves 3 or 4 , appearing with flower, usually $2 \mathrm{dm}$. long or less but occasionally to $3 \mathrm{dm}$. long, to $3.5 \mathrm{~mm}$. wide; flowers yellow, usually appearing after heavy rains, unscented; perianth erect, $2 \mathrm{~cm}$. long; tube $5 \mathrm{~mm}$. long; stamens inserted at the throat, about $1 \mathrm{~cm}$. long; suberect anthers curved; filaments diverse at anthesis; style equal to the stamens; stigma capitate, 3-lobed. Atamosco pulchella (J. G. Sm.) Greene, Z. chrysantha Greenm. \& Thomps. 

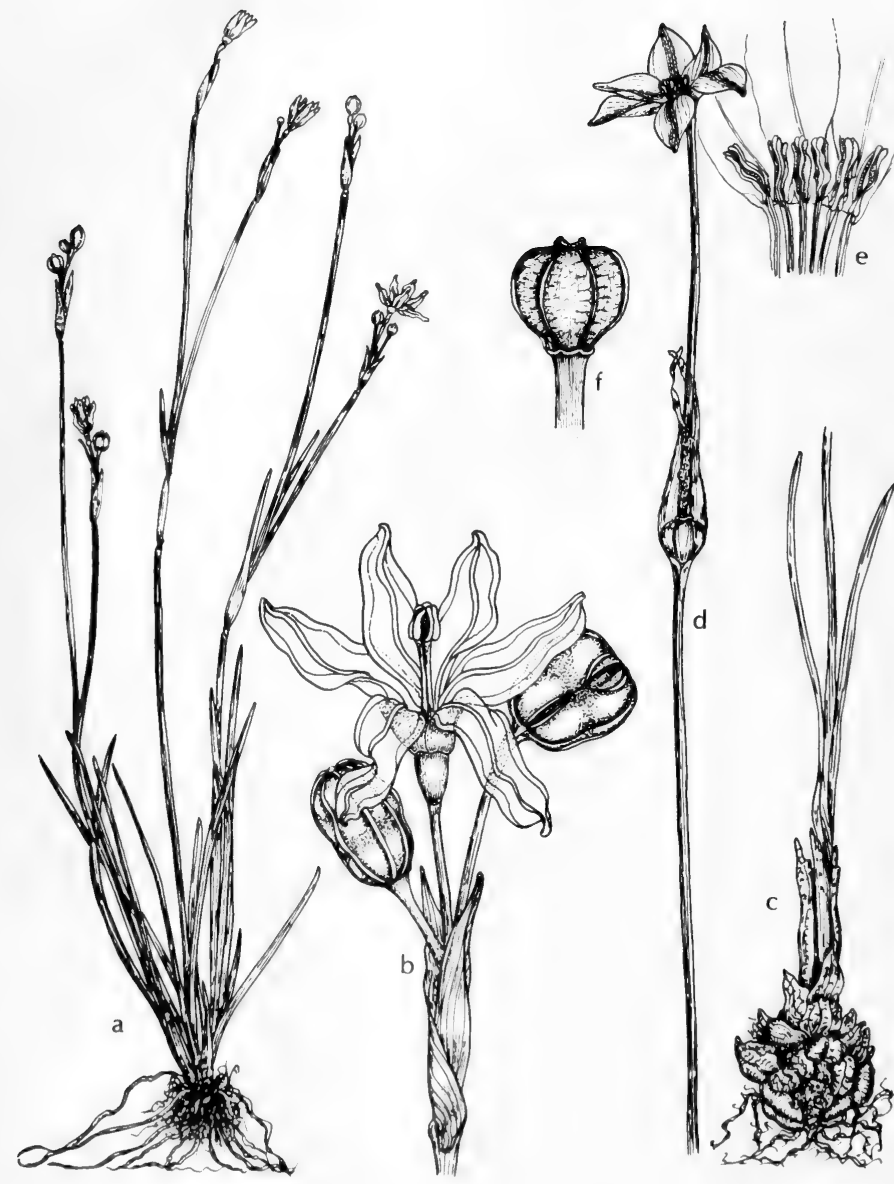
Most often in swales and roadside ditches, throughout s. Tex. Coastal Prairies from Corpus Christi to Brownsville and westw., May-Oct.; endemic.

\section{Zephyranthes rufugiensis $F$. B. Jones}

Bulb subglobose, 2-2.5 cm. in diameter, slightly broader than high, the neck 4-5 cm. long; leaves to $25 \mathrm{~cm}$. long, 2-3 mm. wide at base and to $4 \mathrm{~mm}$. at widest point; flowers dark-lemon-yellow (but lighter in color than those of Z. pulchella), appearing after heavy rains from July to Nov., reported to be fragrant; perianth erect, to $45 \mathrm{~mm}$. long, the limb funnelform, the yellowish-green tube 15-23 $\mathrm{mm}$. long; anthers suberect and curved, the filaments semipatent; stigma shortly 3-lobed.

In open swales on prairies or in brushy pastures over a 200 square mile area mostly in Refugio Co., but to some extent in adjoining Goliad Co., Texas.

A hybrid close to $Z$. pulchella with some introgression from Cooperia Drummondii; endemic.

\section{Habranthus Herb. Copper Lily}

About 20 species in subtropical and warm temperate regions, mostly South America; we have one species.

1. Habranthus texanus (Herb.) Steud.

Bulb ovoid, about $2 \mathrm{~cm}$. in diameter; leaves basal, following the flower, short, narrowly linear; scape slender, to about $3 \mathrm{dm}$. tall, 1-flowered; spathe bifid, about $25 \mathrm{~mm}$. long; perianth orange-yellow, sometimes tinged reddish on outer surface, 25-30 mm. long, broadly infundibuliform, somewhat zygomorphic and declinate, the subequal linear-oblong segments to $1 \mathrm{~cm}$. wide and rounded-apiculate at apex; stamens fasciculate, unequal, of 4 different lengths; capsule subglobose, 3-lobed and -angled, about $15 \mathrm{~mm}$. wide. Zephyranthes texana Herb., Atamosco texana (Herb.) Greene.

In water among grasses, swales, moist pasturelands and other such places in e. Tex., w. to the Edwards Plateau and along the coast to the Rio Grande Plains, Aug.-Oct.; endemic.

\section{Crinum L.}

Bulbous, the neck of the bulb often columnar like a caudex; leaves basal, often persistent, broad and thick, strap-shaped, not narrowed at base; flowers white or whitish, in some species striped or tinged with red, few or many in an umbel subtended by 2 large broad spathe valves, the pedicels short or none, the scape solid; perianth tube equaling or exceeding the essentially equal segments; stamens inserted at throat; fllaments long and usually declinate; ovary inferior, globose to oblong or oval, with few ovules in each cell; style long, slender; stigma small, capitate; capsules bursting irregularly; seeds large, green.

About 100 species in warm temperate or tropical regions in both hemispheres.

Crinum bulbispermum (Burm.) Milne-Redhead \& Schweickerdt has been reported from Texas but no material has been seen of this plant. This species, a native of South Africa, is commonly cultivated. It may be distinguished by its outward-curved or even drooping flowers with contiguous and often declinate stamens and styles.

1. Perianth segments much shorter than the tube..................... C. americanum.

1. Perianth segments longer than the tube...................................... . C. strictum.

1. Crinum americanum L. Southern swamplily. Fig. 343.

Bulbs stoloniferous, $5-12 \mathrm{~cm}$. in diameter, the neck short; scape to $9 \mathrm{dm}$. tall or more; leaves narrowly liguliform, to $15 \mathrm{dm}$. long and $5 \mathrm{~cm}$. wide, sparingly denticulate; flowers white, sometimes marked with pink, fragrant, salverform, 


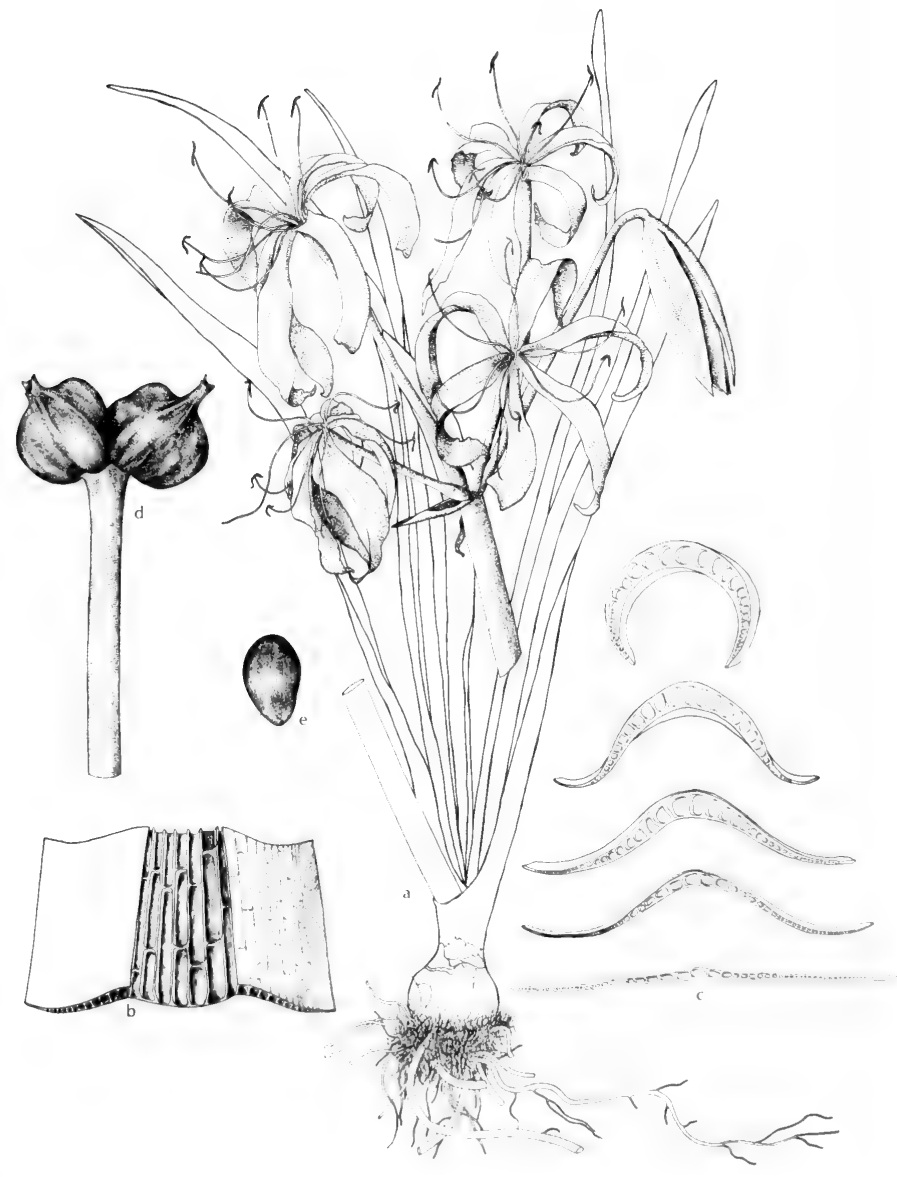

Fig. 343: Crinum americanum: a, habit, x 1/3; b, section of leaf, x 4; c, sections of leaf at different levels to show leaf shape, with the curved section at top showing the leaf at the base to the flat section toward the tip of the leaf, $x 5$; d, capsules, $x 1 / 3$; e, seed, $x{ }^{1 / 3}$. (Courtesy of R. K. Godfrey). 
2 to 6 in an umbel, essentially sessile; spathe valves broadly lanceolate, acuminate, 5-9 cm. long; perianth tube very slender, greenish, 10-12 cm. long; perianth segments much shorter than the tube, to about $15 \mathrm{~mm}$. wide; stamens spreading, prominent; capsule globose, about $3 \mathrm{~cm}$. in diameter, strongly beaked.

In swamps, marshes, edge of water in ditches and lakes, in s.e. and s.-coastal Tex., May-Nov.; from Fla. and Ga. to Tex.

\section{Crinum strictum Herb.}

Bulb small, ovoid, without a distinct neck; leaves 6 , evergreen, suberect, to about $4 \mathrm{dm}$. long and $5 \mathrm{~cm}$. wide, narrowly linear-lanceolate, bluntly acute at apex, with hyaline margins that are minutely toothed at varying intervals to 8 $\mathrm{mm}$. apart; scape flattish, with rounded edges, rusty-reddish in lower third, to 3 $\mathrm{dm}$. long; spathe valves lanceolate, the margins infolded, streaked reddish over moderate yellow-green, to $9 \mathrm{~cm}$. long and $25 \mathrm{~mm}$. wide at base, tapering to a bluntly acute to truncately notched apex; umbel 3- or 4-flowered; buds creamywhite streaked reddish for the most part on outside, upright at first then nodding slightly below; flowers fragrant, on pedicels 3-4 mm. long; perianth tube permanently slightly curved in upper fourth, $85 \mathrm{~mm}$. long, 5-7 $\mathrm{mm}$. in diameter; perianth segments white and streaked reddish on outer surface, narrowly lanceolate, acute-apiculate, about $11 \mathrm{~cm}$. long and $15 \mathrm{~mm}$. wide; stamens and styles red in upper three-fourths, prominently exserted; stamens $65 \mathrm{~mm}$. long; anthers 13 $\mathrm{mm}$. long; ovary oblong, $14 \mathrm{~cm}$. long, about $9 \mathrm{~mm}$. in diameter; style $32 \mathrm{~mm}$. longer than the stamens; stigma minute.

In wet soils, rare in s.e. Tex.

Var. Traubii Moldenke differs from var. strictum in its 7-flowered umbel, longer foliage that is deeper green in color, and flowers not so erect. Occurring with the species.

\section{Fam. 37. Iridaceae Juss.}

\section{IRIS FAMILY}

Perennial or annual mostly caulescent herbs with short or long rootstocks; leaves equitant, mostly elongate; flowers perfect, mostly regular, arising from spathelike bracts; perianth composed of an outer and inner series of 3 segments each; stamens 3 , the filaments partially adnate to the perianth; carpels 3 , united; ovary inferior; styles entire or variously divided, sometimes petal-like; ovules few to many; fruit a loculicidal 3-valved capsule.

About 1,000 species in nearly 60 genera of wide geographic distribution.

1. Roots clustered at base of plant, fibrous or tuberous-thickened; plants delicate, mostly less than $4 \mathrm{dm}$. tall; leaves grasslike; perianth tube absent 1. Sisyrinchium

1. Rootstock a rhizome; plants coarse, usually much more than $4 \mathrm{dm}$. tall; leaves broad; perianth tube present.

2. Iris

\section{Sisyrinchium L. BLUE-EYEd GRASS}

Annual or perennial herbs; roots fibrous to tuberlike; leaves grasslike; flowers single or in small clusters; perianth regular; tepals similar, often alternating wide and narrow; stamens united into a column or free to the base.

About 125 species in the Western Hemisphere.

1. Flowers variously colored, not blue; plants usually annual (2)

1. Flowers blue to blue-purple, sometimes white in blue populations or white; plants perennial, with simple stems or sessile spathes (6) 
3(2). Pedicels erect or ascending; perianth $8-12 \mathrm{~mm}$. long; anthers 2-3 $\mathrm{mm}$. long.

1. S. longipes.

3. Pedicels spreading or recurved; perianth $3-5 \mathrm{~mm}$. long; anthers $0.5-1.5 \mathrm{~mm}$. long.

2. S. cernuum.

4(2). Ovaries and capsules 1.5 times as long as broad.

3. S. minus.

4. Ovaries and capsules subglobose to broadly oblong (5)

5(4). Flower variously colored, not yellow; tepals 9-16 mm. long; capsules $3-4.2 \mathrm{~mm}$. wide.............................................4. S. rosulatum.

5. Flowers yellow with red-brown eye ring; tepals $5-10 \mathrm{~mm}$. long; capsules 2.7-3.5 mm. wide 5. S exile.

6(1). Stems without leafy bracts (7)

6. Stems with leafy bracts (10)

7(6). Spathes dry and brown, often tinged violet.

6. S. sagittiferum.

7. Spathes dark-green to yellow-green, sometimes purple at nodes (8)

$8(7)$. Floral bracts about the same length.

11. S. biforme.

8. Outer floral bract much longer than the inner (9)

9(8). Plants of central and south Texas, drying olive-green.

9. Plants of north Texas, drying light-green.

12. S. dimorphum. 7. S. montanum.

$10(6)$. Stems broadly winged with each wing as broad as the stem and at least $1 \mathrm{~mm}$. wide.

8. S. angustifolium.

10. Stems not broadly winged (11)

11(10). Plants very erect; stems 5 to 7 times as long as the peduncles.

9. S. atlanticum.

11. Plants spreading to erect; stems shorter to 3 times as long as the peduncles (12)

12(11). Spathes dry and brown, usually tinged violet.

12. Spathes green, sometimes purple at nodes (13)

6. S. sagittiferum.

13(12). Pedicels 6-11 mm. longer than the spathes; capsules upright; plants erect; stems few or solitary...............................10. S. demissum.

13. Pedicels shorter, to $4-5(-10) \mathrm{mm}$. longer than the spathes; capsules spreading to pendent; plants spreading to erect; stems often numerous (14)

14(13). Mature capsules broadly oblong, 5-7 mm. high; tepals 7-13 mm. long; wings and stems drying about the same color.

11. S. biforme.

14. Capsules globose to subglobose, 4-5 mm. high; tepals $5-8 \mathrm{~mm}$. long; wings drying dark, the stems light. 12. S. dimorphum.

1. Sisyrinchium longipes (Bickn.) Kearn. \& Peeb.

Plants 1.5-3 dm. tall, dull green and glaucescent; leaves about half the height of the plant; flowers several on pedicels much-exserted from bracts; tepals 8-12 $\mathrm{mm}$. long, orange-yellow with orange or brownish veins; capsules broadly oblong to oblong-obovoid, 5-7 mm. high, 4-5 mm. wide, erect and contiguous.

In springy places and open spruce and pine woods in Ariz. (Apache, Cochise, Coconino, Graham and Pima cos.), July-Sept.; also n. Mex.

\section{Sisyrinchium cernuum (Bickn.) Kearn.}

Plants in small tufts $7-18 \mathrm{~cm}$. tall, dull green and glaucescent, from a cluster of delicate roots; leaves equal to or shorter than the stems; flowers small; tepals 3-5 mm. long, yellow, obtuse, dark-lineate; capsules subglobose to somewhat pyriform, 3-5 mm. high, nodding on slender recurved pedicels that are exserted from the bracts.

Along a stream in Ariz. (Cochise Co.), Mar.; also Mex. 
3. Sisyrinchium minus Engelm. \& Gray.

Plants prostrate to erect, 4-22 cm. tall, often forming rosettes; stems with 1 or 2 leafy nodes and a leafy bract; spathes often broad and foliaceous; outer floral bract 5-10 $\mathrm{mm}$. longer than inner; pedicels usually shorter than floral bracts; flowers usually lavender-pink to purple-rose, occasionally white, rarely yellow; capsule 4-5 mm. high, recurving to pendent. S. Thurowii Coult. \& Fish.

In sandy or silty soil, occasionally in bogs, in s. Coastal Plains to cen. Tex., Mar.-May; also La., introd. elsewhere.

\section{Sisyrinchium rosulatum Bickn.}

Plants usually erect, $13-36 \mathrm{~cm}$. tall; leaves $2-4 \mathrm{~mm}$. wide, one fourth to one half the height of plant; flowers vary from white to lavender-rose, with rose-purple eye ring; filaments free about $0.5 \mathrm{~mm}$; base of staminal column urn-shaped. $S$. laxum of auth.

Weedy along roadsides and old fields, sometimes in bogs or wet meadows, from Gulf Coast to s.e. Tex., Apr.-May; Fla. to Tex., n. to N.C., Ark.; nat. of S.A. Hybridizes with $S$. exile giving flower colors of mauve, scarlet or yellow, with or without variously colored eye ring and stripes along veins.

\section{Sisyrinchium exile Bickn.}

Plants 5-19 cm. tall, usually erect; stems sometimes simple; leaves $0.5-3 \mathrm{~mm}$. wide; filaments free about $0.5 \mathrm{~mm}$; staminal column urn-shaped at base. $S$. Brownii Small, S. micranthum of auth.

Sandy roadsides and old fields, occasionally in bogs and wet soils, from Gulf Coast to s.e. Tex., Apr.-May; Fla. to Tex.; nat. to S.A.

Hybridizes with $S$. rosulatum.

\section{Sisyrinchium sagittiferum Bickn.}

Plants 1-3 dm tall, with fibrillose fibers at base; leaves erect, one half to three fourths height of plant; floral bracts equal or outer to $3 \mathrm{~cm}$. longer than inner; flowers blue-purple; capsules $3-4 \mathrm{~mm}$. high, on spreading pedicels. S. texanum Bickn. (hybrid form).

In low wet areas in e. Tex., occurs mostly in hybrid form n. of Gulf Coast, Mar.-Apr.; also La.

\section{Sisyrinchium montanum Greene.}

Plants $20-35 \mathrm{~cm}$. tall; leaves $2-3 \mathrm{~mm}$. wide and one third to as tall as the plant; flowers blue; tepals $8-10 \mathrm{~mm}$. long; capsules $6-7 \mathrm{~mm}$. high.

River bottoms in e. Panhandle of Tex., Apr.-June; Nfld. to n. B.C., s. to Que., s. Ont., N.Y., n. Ind., n. Ill., Neb. and Tex.

\section{Sisyrinchium angustifolium Mill.}

Plants $15-30 \mathrm{~cm}$. tall, erect to slightly spreading, branched or simple and branched on same plant, drying olive-green, darkening with age; basal leaves erect, one fourth to three fourths as high as the plant; peduncles 1 to $3,1-5 \mathrm{~mm}$. longer than the subtending leafy bract; outer floral bract longer than inner; flowers blue to blue-violet, rarely white; capsules $4-5.5 \mathrm{~mm}$. high, on erect or recurving pedicels. S. bermudianum of auth., S. graminoides Bickn., S. gramineum Curt. Differs somewhat from plants of e. U.S.

In low wet areas in e. Okla. (Adair and McCurtain cos.) and e. Tex., Apr.May; Fla. to Tex., n. to s.e. Nfld., s. Que., s. Ont., O., Ind., Ill., Mo. and e. Kan.

\section{Sisyrinchium atlanticum Bickn.}

Plants erect from coarse roots, 23-57 cm. tall, drying light-green, fibers present or absent at base; stems $17-43 \mathrm{~cm}$. long; peduncles $3-7 \mathrm{~cm}$. long; flowers blue, 
occasionally white; tepals 8-11 mm. long; capsules 4-5 mm. high, drying dark.

In wet areas of s.e. Tex., Apr.-May; Fla. to Tex., n. to n. N. S., N. Y., n. O., s. Mich. and Ark.

\section{Sisyrinchium demissum Greene. Fig. 342.}

Plants 22-72 cm. tall, drying light-green; stems erect, $1-3 \mathrm{~mm}$. wide, the wings about one half the width of stems; leaves $2-3 \mathrm{~mm}$. wide, less than one half the height of plant; peduncles to $17 \mathrm{~cm}$. long; tepals blue, $1 \mathrm{~cm}$. long; capsules 6-7 mm. high. S. longipedunculatum Bickn.

Along streams in wet meadows and grasslands and springy places in Guadalupe Mts. (Culberson Co.) and High Plains (Hemphill Co.) of Tex., w. through N. M. (rather widespread) and Ariz. (Apache and Greenlee cos. to Coconino and Yavapai cos.), June-Sept.; from Tex. to Calif., n. to Ore., Colo.; also n. Mex.

\section{Sisyrinchium biforme Bickn.}

Plants erect, 14-38 cm. tall; roots coarse; stems very narrowly winged; leaves 1-3 mm. wide; capsules 6-7 mm. high.

In sandy, usually wettish, soil of beaches and offshore islands of Tex., Dec-June; also La. ?; Mex.

\section{Sisyrinchium dimorphum $\mathrm{R}$. Oliv.}

Plants 9-32 cm. tall, drying olive-green; roots coarse; stems with or without leafy bracts, the wings less than one half the width of stem; leaves one half to three fourths the height of plant; flowers blue, sometimes white; tepals $5-9 \mathrm{~mm}$. long, 1.5-3 mm. wide; capsules about $5 \mathrm{~mm}$. high.

Along streams in Edwards Plateau and Trans-Pecos of Tex., Apr.-July; also n. Mex.

\section{Iris L. IRIS. FLEUR-DE-LIS}

Perennials from a creeping more or less tuberous rhizome; leaves ensiform or lanceolate, commonly broadly grasslike; flowers large and showy, mostly purplish or bluish (in ours); tube of the perianth commonly extended beyond the ovary; stamens distinct, the linear or oblong anthers sheltered under the over-arching petal-like branches of the style that bear the stigma in the form of a thin lip or plate under the apex; most of the style connate with the perianth segments to form a tube; capsule 3- or 6-angled, usually coriaceous; seeds depressed-flattened or plump, usually in 2 rows in each cell.

More than 200 species in the Northern Hemisphere, most frequent in Asia. Cultivated Iris tend to maintain themselves about abandoned farms and homesteads, the most common of these are I. pallida Lam., I. tingitana Boiss. \& Reut. and 1 . xiphium $\mathbf{L}$.

Muskrats and beavers, as well as wildfowl and marsh birds, are known to eat various parts of some species.

1. Distribution in mountains of New Mexico and Arizona in our region.

1. Distribution in eastern Oklahoma and Texas eastward (2)

2(1). Flowers bright- to golden-yellow throughout or dark-red to reddish-brown (3)

2. Flowers in shades of blue to purplish-blue or rarely whitish (4)

3(2). Flowers bright- to golden-yellow throughout; tepals entire at apex; capsule 3-angled; introduced species................................2. I. Pseudacorus.

3. Flowers dark-red to reddish- or coppery-brown; tepals notched at apex; capsule 6-angled; native species. 3. I. fulva. 


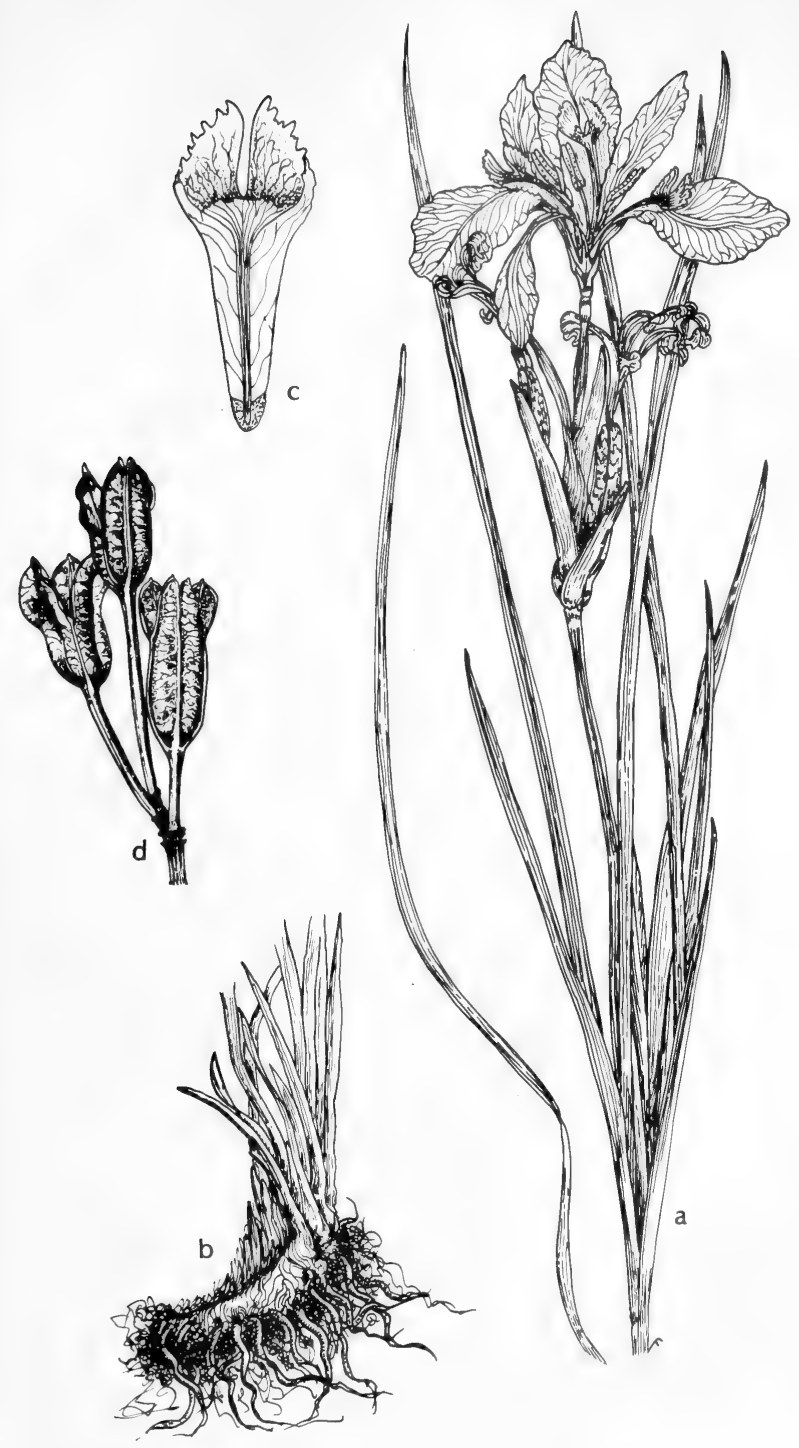

Fig. 344: Iris missouriensis: a, top of plant, $\mathrm{x} 1 \frac{1}{2}$; b, rhizome, $\mathrm{x} 1 / 2$; c, style, $\mathrm{x} 1$; d, capsules, $x$ 1/2. (V. F.). 


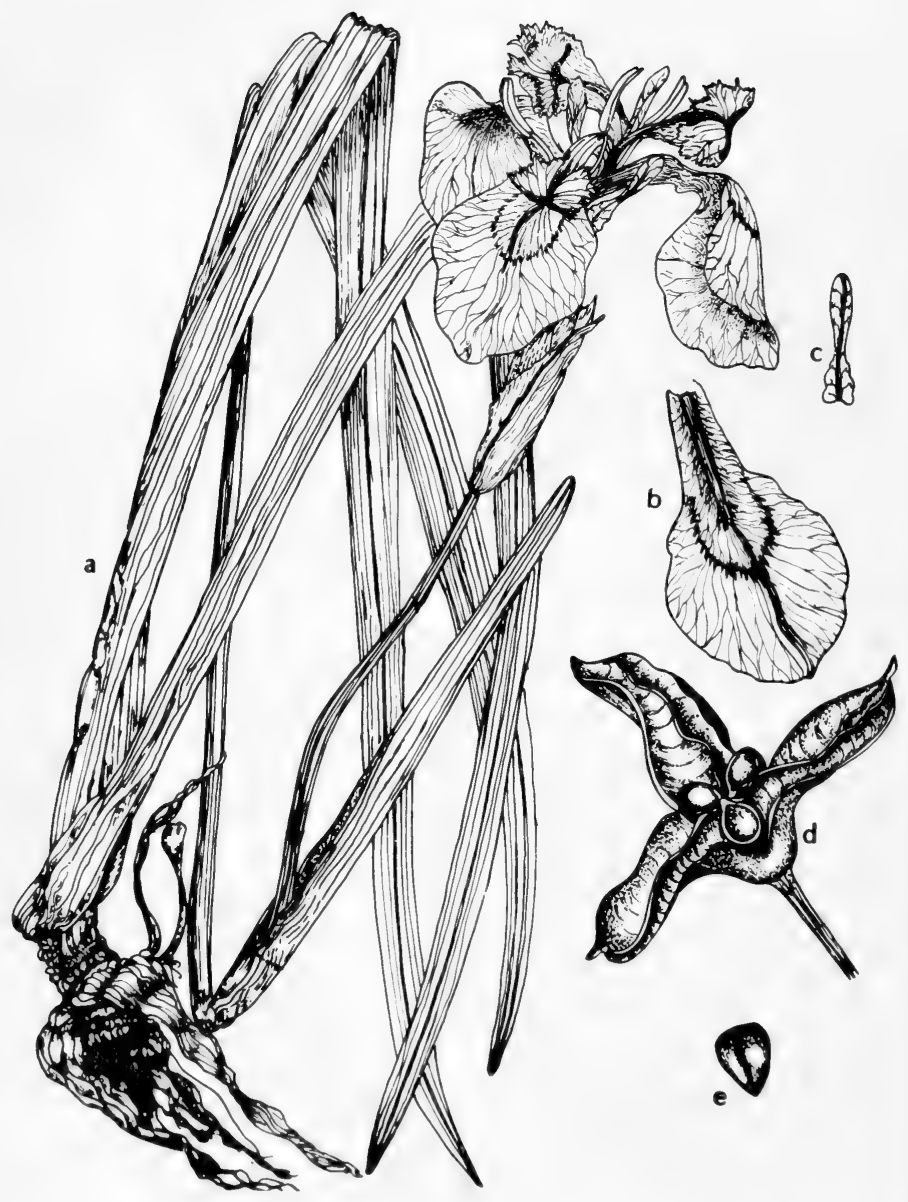

Fig. 345: Iris pseudacorus: a, habit, X 1/2; b, outer segment, x 1/2; c, inner segment, x 1/2; d, capsule open, $x$ 1/2; e, seed, x 1. (V.F.; in part from Small in Addisonia 12: Pl. 386). 
4(2). Leafy bract subtending spathes less than or slightly longer than the spathes, or absent; ovary and capsule 3 -angled........................ 4 . I. virginica.

4. Leafy bract subtending spathes usually more than twice as long as the spathes; ovary and capsule 6-angled (5)

5(4). Largest leaves mostly about $15 \mathrm{~mm}$. wide, essentially erect; inner 3 segments usually notched at apex.

5. I. hexagona var. flexicaulis.

5. Largest leaves more than $20 \mathrm{~mm}$. wide, arcuate-spreading; inner 3 perianth segments rounded to subacute at apex...................6. I. brevicaulis.

\section{Iris missouriensis Nutt. WeStern IRIS. Fig. 344.}

Perennial herb with stout, creeping rootstock; stem slender, simple, terete, 3-5 dm. tall; equitant leaves usually basal, shorter than or as long as the stem, 4-10 $\mathrm{mm}$. wide; bracts scarious, $4-7 \mathrm{~cm}$. long, acute; pedicels $2-8 \mathrm{~cm}$. long; perianth segments 6-clawed, united below into a tube $5-8 \mathrm{~mm}$. long, the 3 outer segments broad, spreading or reflexed, 5-7 cm. long, glabrous, without crest, the 3 inner segments somewhat shorter, erect, narrow, white to blue, often with darker veins; capsule 3-7 cm. long, 6-angled; seeds $4 \mathrm{~mm}$. long, obovate.

Wet mt. meadows in N. M. (widespread) and Ariz. (Apache, Navajo, Cochise and Coconino cos.), May-Sept.; N. D. to B.C., s. to N.M., Ariz. and Calif.

2. Iris Pseudacorus L. Yellow-Flag. Fig. 345.

Rhizome stout and extensively spreading; leaves erect, somewhat arched and nodding at tip, linear-attenuate, about $2 \mathrm{~cm}$. wide, forming clumps to about $1 \mathrm{~m}$. tall; flowering stalk stout, erect, about as tall as clump of leaves, with 1 or 2 short leafy bracts; flowers 1 or 2 together at apex of flower stalk, also often in the axil of the upper leaf; involucral bracts 2 , shorter than flower; the 3 outer perianth segments 5-8 cm. long and arching, clear-yellow or sometimes with flecks of brown at base and on claw, with suborbicular to ovate blade and a broad claw with involute edges; the 3 inner perianth segments yellow, linear to linearpandurate, obtuse, to about $25 \mathrm{~mm}$. long; capsule cylindric-prismatic to ellipsoid, 5-8 cm. long, bright-green, often lustrous, turgid, bluntly 3 -angled; seeds suborbicular or somewhat angular from pressure, corky, about $7 \mathrm{~mm}$. in diameter.

Usually standing in 1 to 3 feet of water in ponds, in open woods, rare in s.e. Tex. (known only from Hardin Co.), Apr.-May; introd. from Euras. and Afr., rather aggressive as an escape from cult.

3. Iris fulva Ker. Red-FLAG. Fig. 346.

Rhizome rather stout, widely spreading, with scars or fibers of decayed leaves; leaves erect, linear-attenuate, to about $9 \mathrm{dm}$. long; flower stalk rather slender, erect, slightly fractiflex, often overtopping the leaves; flowers 1 or 2 at summit of flower stalk, often also in axils of 1 or 2 upper stem leaves; involucral bracts 2 , the longer attenuate one exceeding the flower; the 3 outer perianth segments red to copper-colored, spreading-arching, 45-55 $\mathrm{mm}$. long, with oval to obovate-oval apically notched blade and a short paler claw; the 3 inner perianth segments red to copper-colored, narrowly obovate to elliptic-obovate, cuneate at base and notched at apex, about two thirds as long as outer perianth segments; capsule ellipsoid to oval, 45-55 mm. long, green, not beaked but sometimes constricted near apex, 6-angled, rather thick-walled; seeds orbicular to semiorbicular, about $7 \mathrm{~mm}$. in diameter.

In marshes and wet meadows, ditches and on stream banks, reported from e. Tex. but no specimen seen, spring; Ga. to e. Tex. (?), Mo. and Ky. 


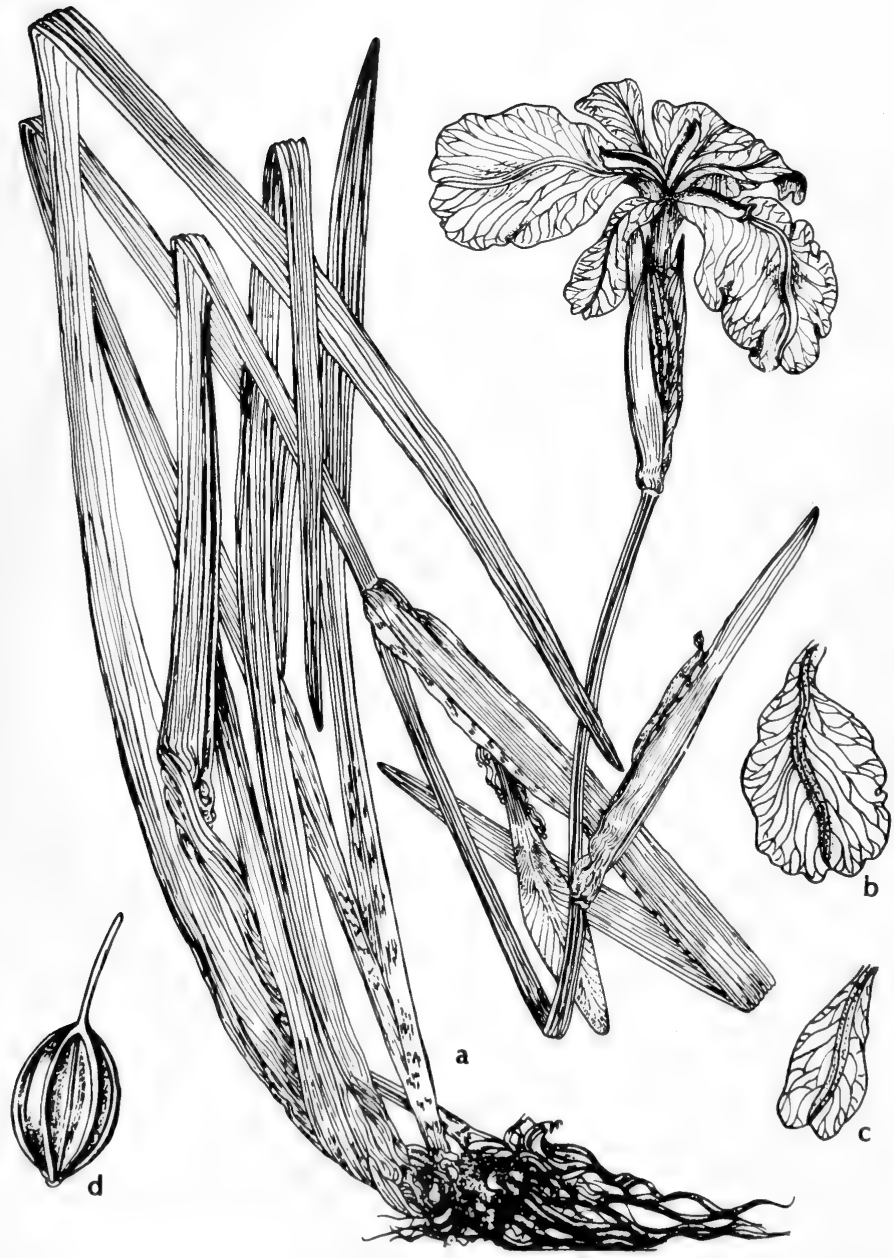

Fig. 346: Iris fulva: a, habit, $\mathrm{x} 1 \frac{1}{2}$; b, outer segment, $\times 1 / 2$; $\mathrm{c}$, inner segment, $\mathrm{x} 1 / 2$; d, fruit, $x$ 1/2. (V. F.). 


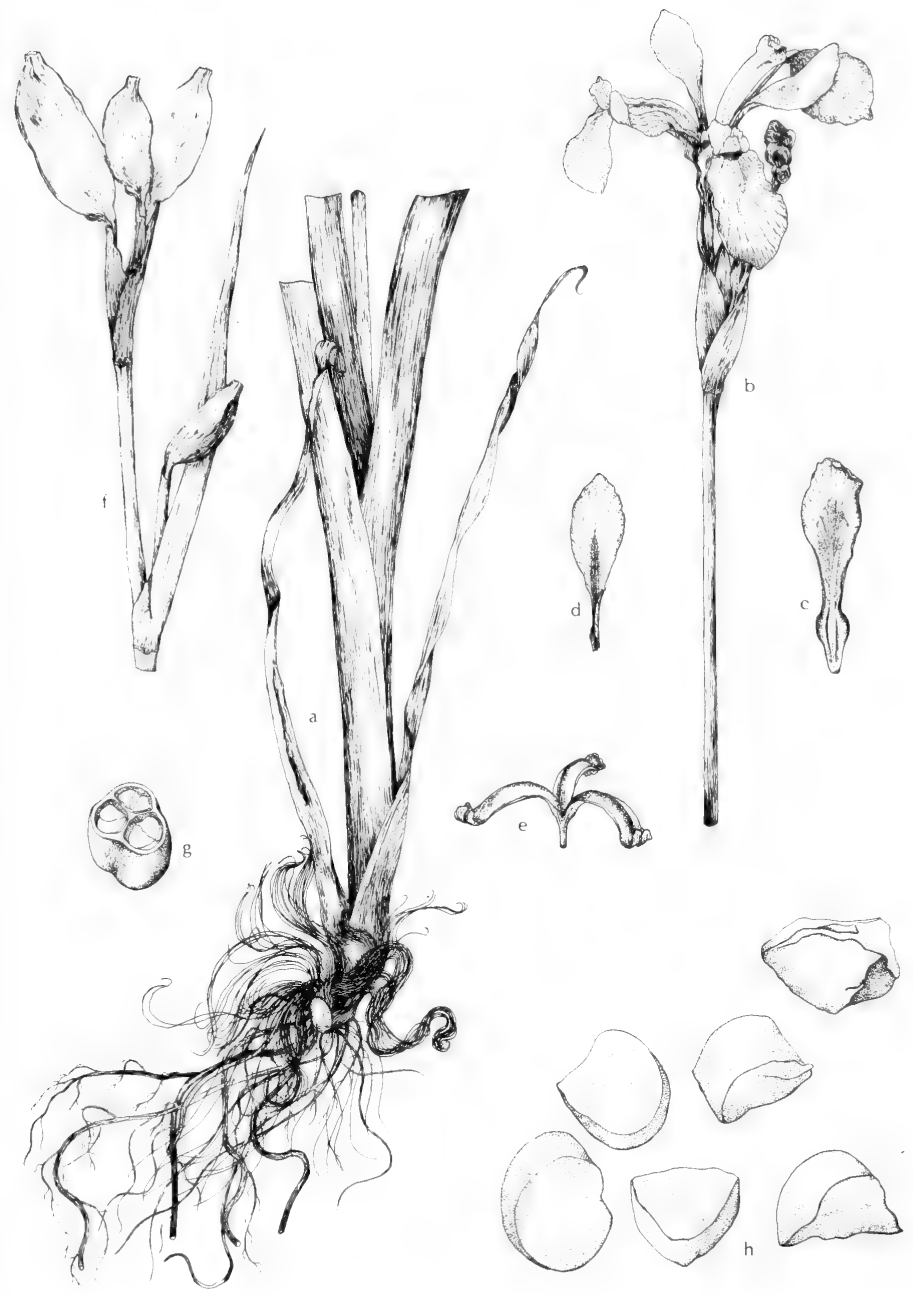

Fig. 347: Iris virginica: $\mathrm{a}$, base of plant, $\mathrm{x} 1 / 3$; $\mathrm{b}$, flowering stem, $\mathrm{x} 1 / 3 ; \mathrm{c}$, outer segment, $\mathrm{x} 1 / 3 ; \mathrm{d}$, inner segment, $\mathrm{x} 1 / 3$; e, style branches, $\mathrm{x} 1 / 3 ; \mathrm{f}$, fruiting stem, $\mathrm{x} 1 / 3 ; \mathrm{g}$, section of capsule, $x \frac{1}{3} ; \mathrm{h}$, seeds, x $1 \frac{1}{3}$. (Courtesy of R. K. Godfrey). 


\section{Iris virginica L. SOUthern BLUE FlaG. Fig. 347.}

Rhizome stout; leaves rather flaccid; basal leaves buff or pale-brown at base, soon arched-recurving or falling to ground; flowering stem weak, to $1 \mathrm{~m}$. high, simple or somewhat branched in the inflorescence, soon low-arching and maturing fruit on the ground or in water; spathe bracts firm, usually subherbaceous, to 14 $\mathrm{cm}$. long; the 3 outer perianth segments with obovate to oval-obovate blade 3-4 $\mathrm{cm}$. wide, with prominent yellow midrib expanding to a broad bright-yellow pubescent patch at base (the elongate hairs as long as thickness of blade); the 3 inner perianth segments obovate to obovate-spatulate, two thirds or four fifths as large as sepals; capsule ovoid to ellipsoid or thick-cylindric, $3-11 \mathrm{~cm}$. long, 13-25 mm. thick, 3-angled, often asymmetrical, brittle-walled, dull or scarcely lustrous on inner surface, early disintegrating; seeds rounded to irregularly Dshaped, 3-6 mm. thick at back, 5-8 $\mathrm{mm}$. wide, with an irregularly deep-pitted brittle corky coat. I. caroliniana Wats., I, versicolor of auth.

In marshes, wet savannahs and pinelands, shallow water in ditches and in soggy meadows in e. Okla. (Cherokee and Ottawa cos) and e. Tex., Apr.-June; from Fla. to Tex, and Okla., n. to e. Va.

Those plants with a branched, not simple, inflorescence and with capsules 7-11 $\mathrm{cm}$. long have been segregated as var. Shrevei (Small) Anders. (I. Shrevei Small).

\section{Iris hexagona Walt. var. flexicaulis (Small) Foster. Fig. 348.}

Rhizome rather stout; leaves erect, mostly 3 to 5 together, pale-green and more or less glaucous, linear-attenuate, mostly 1-2 cm. wide; flower stalk erect, rather stout or slender, shorter than the basal leaves, exceptionally leafy, fractiflex, glaucescent; flowers paired or 3 together at top of stem or sometimes solitary and 1 and 2 together in the axils of the stem leaves; involucral bracts 2 , not foliaceous, exceeded by the flowers; perianth tube cylindric-prismatic, almost $13 \mathrm{~mm}$. long; the 3 outer perianth segments broadly spatulate, obovate, $5-7 \mathrm{~cm}$. long, about $25 \mathrm{~mm}$. wide, spreading or recurved at tip, bright-violet except basal part which is yellowish-green; inner 3 perianth segments shorter than the outer ones, narrowly spatulate, notched at apex, somewhat spreading, deep-violet, the claw somewhat brownish; style branches nearly $5 \mathrm{~cm}$. long, broadly linear, reddishviolet except the paler margins; anthers shorter than filaments; capsule ellipsoid to oval or somewhat obovoid, 5-7.5 $\mathrm{cm}$. long, 6-angled, somewhat glaucous, the walls thick; seeds brown, corky.

Lowland and marshy areas in s.e. Tex., Mar.-May; also La.

\section{Iris brevicaulis Raf.}

Rhizomes rather slender, $10-25 \mathrm{~mm}$, in diameter; stem fractiflex, loosely ascending to depressed, compressed, $15-53 \mathrm{~cm}$. high; basal leaves lax, 3-6 dm. long or more, 15-35 mm. wide; spathes terminal and subsessile or short-peduncled from all but lowest axils, subtended by broad and very prolonged leafy bracts $2-6 \mathrm{dm}$. long or more; spathe bracts subequal, to $5 \mathrm{~cm}$. long, the outer pair green, the inner pair scarious-margined; flower deep-blue or blue-purple; ovary prominently 6 -angled; the 3 outer perianth segments $7-9.5 \mathrm{~cm}$. long, $2.5-3 \mathrm{~cm}$. wide, the ovate blade slightly longer than the greenish-yellow dark-striped claw, the latter with a yellowish-white summit; the 3 inner perianth segments oblanceolate, slightly shorter than the sepals; style branches greenish, with entire or toothed subquadrate to semiovate crests; capsule 6-angled, ovoid to ellipsoid, $3-5 \mathrm{~cm}$. long; seeds irregularly circular, with thick coat. 1 . foliosa Mack. \& Bush.

Swamps, wet meadows, damp woods, marshes and bottomlands in e. Tex., Apr.June; from Ala. to Tex., n. to O., Ind., Ill., Mo. and Kan. 


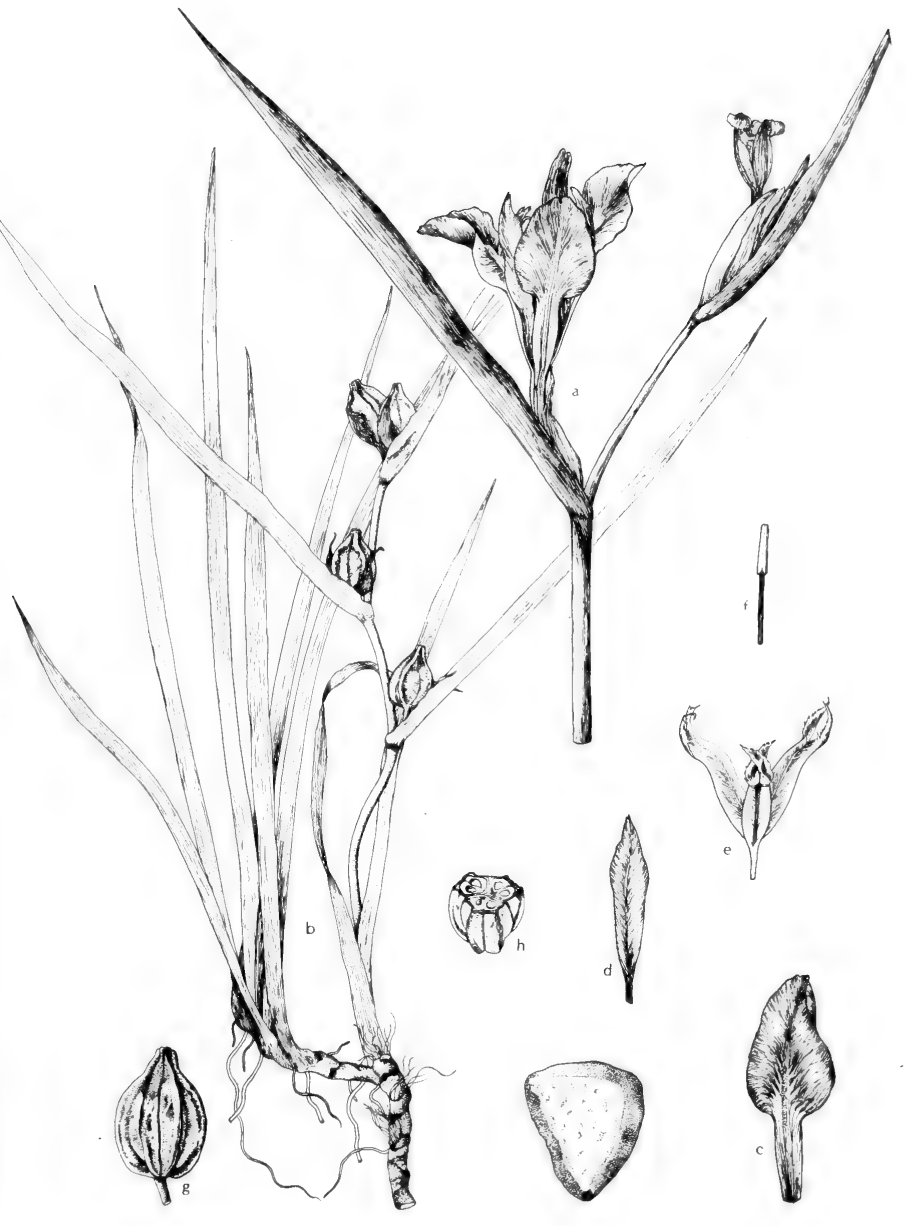

Fig. 348: Iris hexagona: a, top of plant, $\mathrm{x} \frac{1}{6} ; \mathrm{b}$, habit, fruiting plant, $\mathrm{x} 1 / 6$; c, sepal,

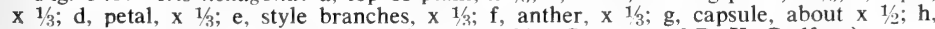
cross section of capsule, about X 1/2; i, seed, x 22. (Courtesy of R. K. Godfrey). 
Perennial erect herbs with branched or unbranched stems and large alternate leaves with sheathing petioles; flowers perfect, zygomorphic, mostly showy, borne in terminal thyrsoid panicles; sepals 3, erect, greenish and bractlike; petals 3, more or less united to form a tube; stamens more or less adnate to the corolla, with one filament anther-bearing, the others becoming showy staminodia; ovary inferior, 3-celled, with the placentae parietal; style petaloid, the stigma marginal.

A solitary genus of about 55 species, mostly in tropical America.

\section{Canna L. CANnA. Indian-Shot}

Characters of the family.

1. Flowers red; plant not glaucous; leaves rounded at base....

1. C. indica.

1. Flowers yellow; leaves tapered at base (2)

2(1). Petals becoming reflexed; tube about $5 \mathrm{~cm}$. long, prominent; plant green; leaves oblong-lanceolate.

2. C. flaccida.

2. Petals remaining erect or strongly ascending; tube about $2 \mathrm{~cm}$. long; plant glaucous; leaves narrowly lanceolate.

3. C. glauca.

\section{Canna indica L. INDIAN-SHOT}

Plant slender, to about $12 \mathrm{dm}$. tall, the herbage deep-green and glabrous; leaves oblong-elliptic, 2-4 dm. long, to about $2 \mathrm{dm}$. wide; flowers small, usually in pairs, red or reddish, not especially showy; floral bracts suborbicular; sepals $1-1.5 \mathrm{~cm}$. long, exceeding the perianth tube; corolla lobes $3-3.5 \mathrm{~cm}$. long, much longer than the tube; staminodia linear to narrowly spatulate or oblanceolate, flat, about $5 \mathrm{~cm}$. long; capsule $25-35 \mathrm{~mm}$. long.

Commonly cult, and escaped to low wet grounds along the Gulf Coastal Plain from Fla. to Tex., summer-fall; nat. of E. I.

\section{Canna flaccida Salisb. Fig. 349 .}

Plant to $75 \mathrm{~cm}$. high, the herbage green throughout; leaves oblong-lanceolate, to $6 \mathrm{dm}$. long and $13 \mathrm{~cm}$. wide; raceme simple, loose and few-flowered, with very small bracts, erect; flowers yellow, showy, soft or flaccid in texture; sepals about $25 \mathrm{~mm}$. long; corolla tube about $5 \mathrm{~cm}$. long; petals yellow, strongly reflexed, nearly as long as the tube; upper staminodia 3 , rounded, $5-7.5 \mathrm{~cm}$. long, the lip orbicular.

About lakes and in marshes and swamps along the coast in s. Tex., Apr.-June; from S. C. to Fla. and Tex.

\section{Canna glauca $L$.}

Plant to $9 \mathrm{dm}$. high, the herbage green and glaucous; leaves narrowly lanceolate, to at least $6 \mathrm{dm}$. long and usually $1 \mathrm{dm}$. or less wide, tapering both to the base and to the long-acuminate apex, typically white hyaline-edged; raceme rather loose, erect, simple or forked, little-exceeding the leaves; floral bracts orbicular; flowers clear-yellow, narrow and erect; sepals green, about $12 \mathrm{~mm}$. long; petals 4-5 $\mathrm{cm}$. long, the tube about $2 \mathrm{~cm}$. long; upper staminodia 3, entire, to $75 \mathrm{~mm}$. long and $2 \mathrm{~cm}$. broad; lip narrow, emarginate.

In marshes and swamps along the coast in s. Tex., Apr.-July; from s. Tex. and Mex. s. to S.A. and W.I. 


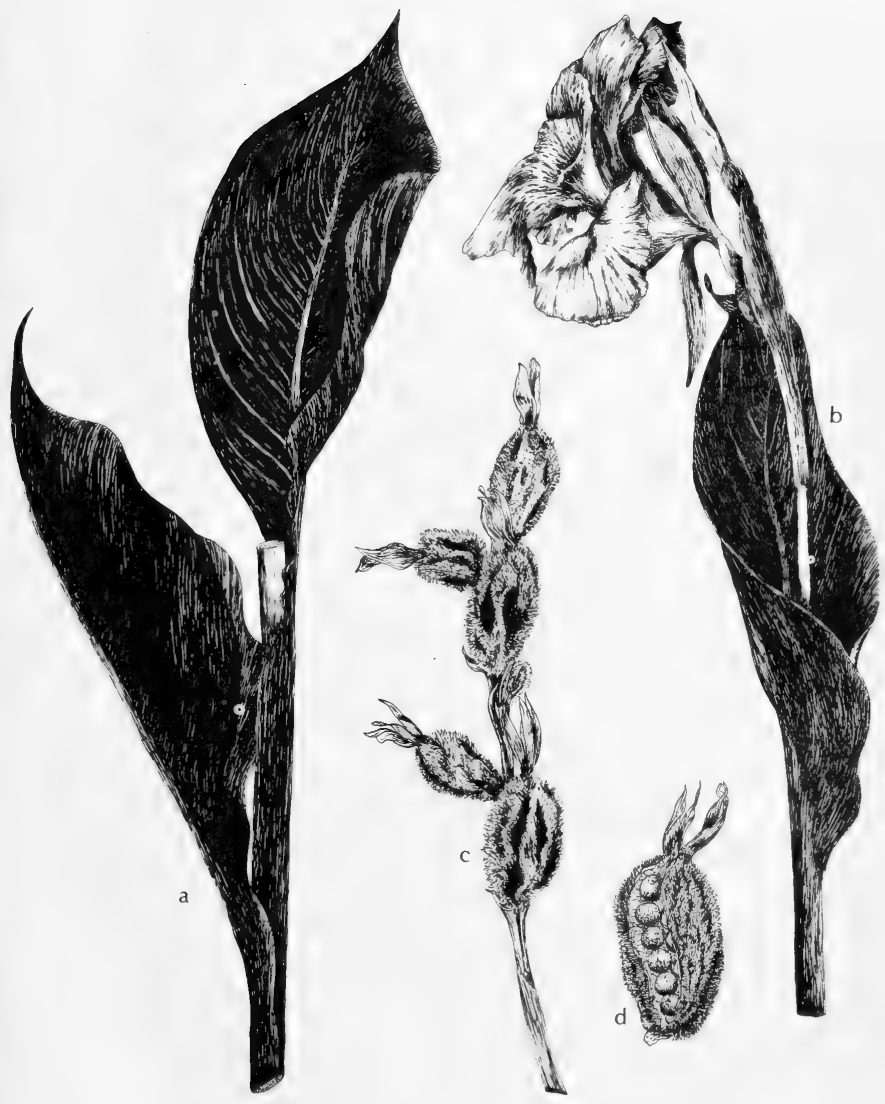

Fig. 349: Canna flaccida: a, part of stem, x 1/2; b, top of plant, x 1/2; c, capsules, x $1 / 2$; d, capsule showing seed, about x 1 . (Courtesy of R. K. Godfrey). 
Herbs with alternate or basal sheathing leaves provided with a joint at the summit of the petiole; flowers perfect, typically 3-merous; sepals separate, usually green and similar or only slightly dissimilar; petals 3, separate or united at base, forming an irregular corolla; stamens of the outer circle reduced to 2 or 1 , these modified into staminodia and often petaloid; stamens of the inner circle 3,2 staminodes, the third only half-staminode and half-fertile; ovary inferior, 3-celled or by abortion 1-celled; ovule solitary and erect in each cell; fruit fleshy or capsular; seeds arillate.

About 26 genera and 400 species, all tropical except ours.

\section{Thalia L.}

Characteristics of the family. About a dozen species found in America and Africa.

1. Thalia dealbata Roscoe. Powdery-thalia. Fig. 350.

Erect scapose herbs from strong rhizomes, with large basal long-petioled leaves; leaves 3, the blades ovate-lanceolate or elliptic-lanceolate and 2-4 dm. long; scapes 1-2 dm. tall; inflorescence more or less white-powdery; flowers purplish, in panicled spikes, each surrounded by several coriaceous bracts; corolla tube short; staminodia petaloid, somewhat connate, the largest deflexed and lip-like; ovary 1-celled; fruit a capsule. T. barbata Small.

In water of ditches, edge of ponds and in swamps in s.e. Okla. (Johnston and McCurtain cos.), e. and s e. Tex., Oct.-Nov.; from Fla. to Tex. and Okla., n. to S. C. and s.e. Mo.

\section{Fam. 40. Burmanniaceae BL.}

\section{Burmannia FAMily}

Small annual or perennial herbs, commonly with grasslike basal leaves and/or alternate minute bractlike leaves on the stem, saprophytic or autophytic; flowers solitary or several in a terminal cluster or cyme, or racemosely scattered on upper part of stem, perfect, with a 6-cleft perianth whose tube adheres to the 1- or 3celled ovary; stamens 3 or 6 , attached to the perianth tube about the middle or near its summit; anthers with broad connectives; capsule usually irregularly dehiscent, with numerous minute seeds.

About 17 genera comprising more than 125 species, mostly tropical and subtropical.

1. Hypanthium 3-angled or 3-winged; ovary 3-celled; capsule 3-valved from the apex or irregularly rupturing.

1. Hypanthium terete; ovary 1-celled; capsule 3 -valved from the base 1. Burmannia

2. Apteria

\section{Burmannia L.}

Mostly small herbs with linear or scalelike leaves and solitary, capitate, racemose or cymose flowers; perianth 3-angled or 3-winged, with the outer 3 lobes much larger than the minute or essentially lacking 3 inner lobes; stamens 3 , sessile in the throat of perianth; ovary 3-celled; capsule crowned by the persistent perianth.

A genus of nearly 60 species, mainly in the tropics of both hemispheres.

1. Flowers 1 or several in a raceme; hypanthium broadly 3 -winged....1. B. biflora.

1. Flowers several in a terminal cluster; hypanthium merely 3 -angled. 


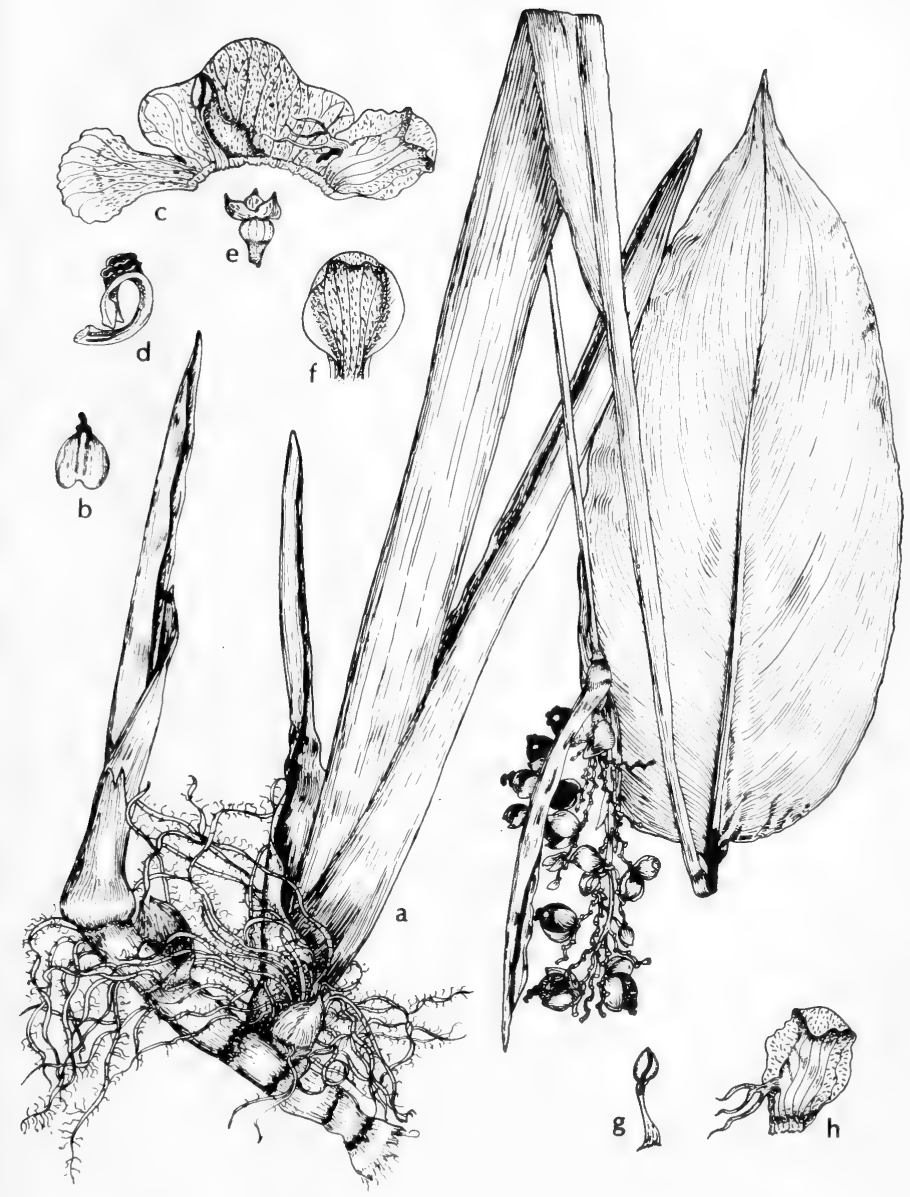

Fig. 350: Thalia dealbata: a, habit, $\mathrm{x}$ 1/20: $\mathrm{b}$, individual bract with drying apex, $\mathrm{x}$ 5; c, combined outer staminode, stamen, calloused staminode, cucullate staminode, $x$

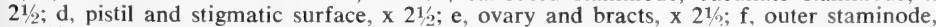
x $2 \frac{1}{2} ; \mathrm{g}$, stamen separated from flower, $\times 2 \frac{1}{2} ; \mathrm{h}$, cucullate staminode, $\times 2 \frac{11}{2}$. V. F.). 


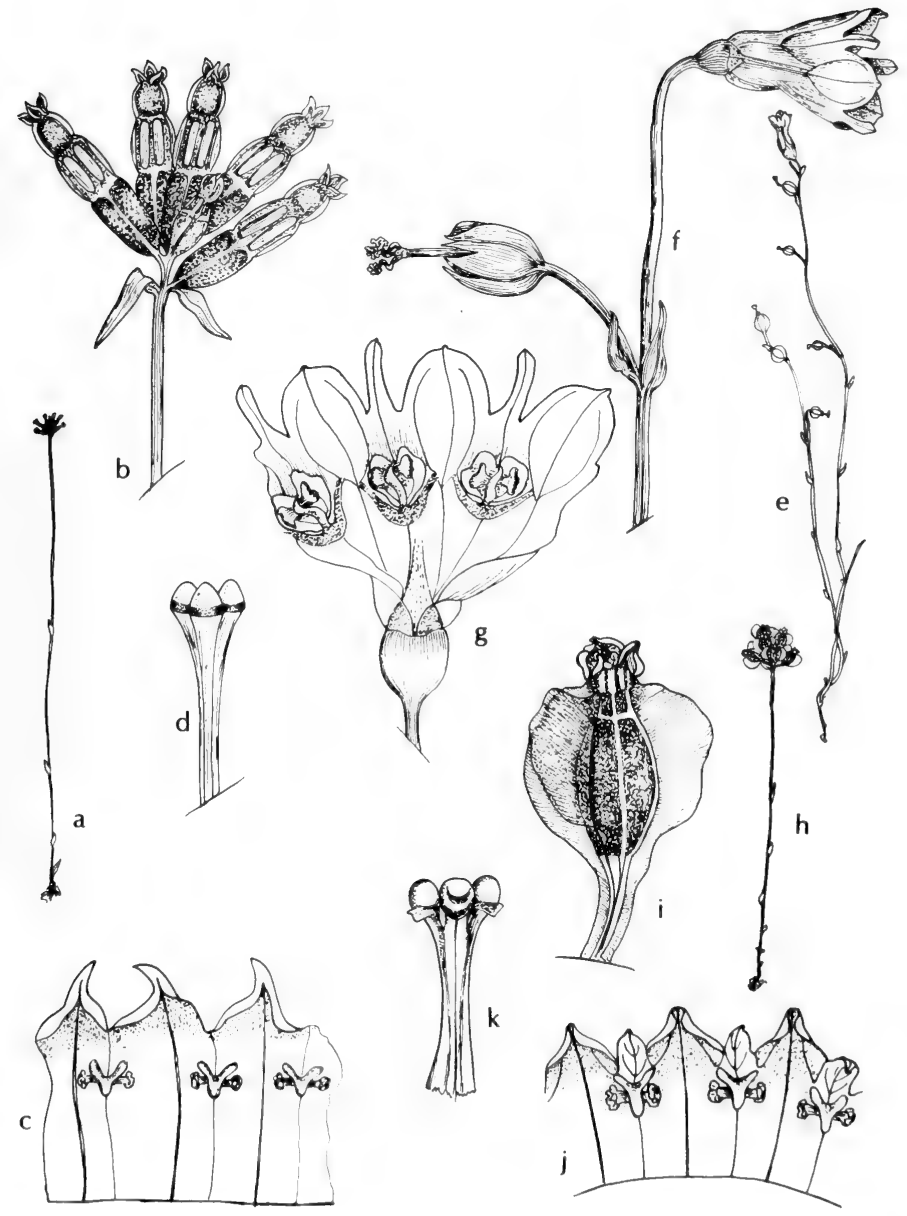

Fig. 351: a-d, Burmannia capitata: a, habit, $x$ 16; b, flowers with developing capsules, x 5; c, flower open, x 10; d, style and stigmas, x 10. e-g, Apteria aphylla: e, habit, $x$ 1; ff flowers, $x 21 \frac{1}{2}$ g, flower open, x 5. h-k, Burmannia biflora: h, habit, $\mathrm{x} 1,2 ; \mathrm{i}$, flower showing wings of the perianth tube surrounding the ovary, $\mathrm{x} 5$; $\mathrm{j}$, flower open, x 10; k, style and stigmas, x 10. (V. F.). 

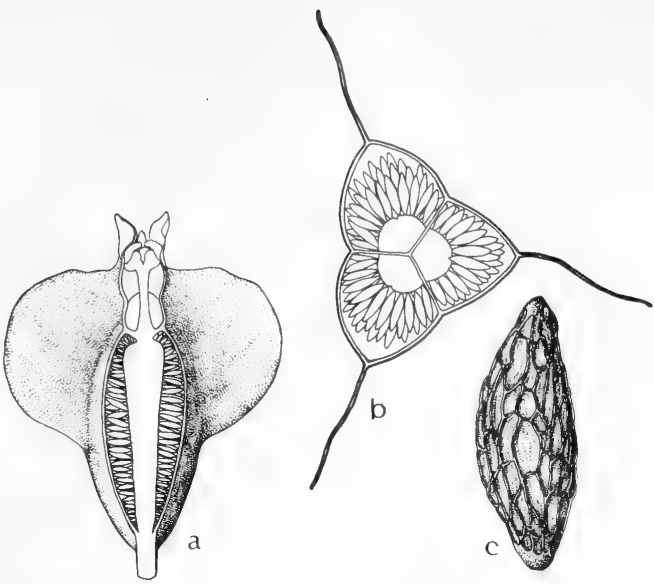

Fig. 352: Burmania biflora: a, flower with ovary opened, $x$ 9; b, cross section of ovary showing thin wings, x 12; c, seed, x 175. (Courtesy of R. K. Godfrey).

1. Burmannia biflora L. Figs. 351 and 352 .

Stem threadlike, to $15 \mathrm{~cm}$. tall; scalelike stem leaves to $3 \mathrm{~mm}$. long; perianth about $5 \mathrm{~mm}$. long, bright-blue, the lobes narrow; capsule 4-5 $\mathrm{mm}$. long.

In moist woodlands and bogs in e. Tex. (Hardin and Houston cos.), Aug.-Oct.; Fla., n. to Va. and w. to Tex.

2. Burmannia capitata (Walt.) Mart. Fig. 351.

Stem threadlike, to $2 \mathrm{dm}$. tall; scalelike stem leaves to $5 \mathrm{~mm}$. long; perianth about $5 \mathrm{~mm}$. long, whitish or bluish-white, the lobes minute to obsolescent; capsule $2-3 \mathrm{~mm}$. long.

In moist woodlands and bog areas in e. Tex. (Anderson and Smith cos.), Aug.-Nov.; Fla., n. to N.C. and w. to Tex.

\section{Apteria NutT.}

Several species in tropical and warm regions of America.

1. Apteria aphylla (Nutt.) Barnh. Nodding-NixiE. Fig. 351.

Stem slender, threadlike, to $2 \mathrm{dm}$. tall, simple or branched; scalelike stem leaves to $3 \mathrm{~mm}$. long; flowers small, nodding, with long pedicels; perianth 1-1.5 $\mathrm{cm}$. long, whitish or purple; outer 3 perianth lobes much larger than the 3 narrow inner lobes, the lobes $2-3 \mathrm{~mm}$. long; stamens attached deep in throat of perianth; filaments with winglike appendages; connective not prolonged beyond the anther sacs; capsule 3-4 mm. long. $A$. setacea Nutt.

In decaying leaves of moist woods and on edge of bogs in e. Tex. (Tyler Co.), Aug.-Oct.; Fla. and Ga., w. to Tex. 


\section{Fam. 41. Orchidaceae Juss.}

\section{ORCHID FAMILY}

Perennial herbs of various habits and habitats, terrestrial, semiaquatic or epiphytic, autophytic or saprophytic, hermaphroditic, produced from a short or elongated (rarely) coralloid rhizome; roots subterranean or aerial, fibrous, fleshy or tuberous, fasciculate or adventitious and scattered on the rhizome or stem; stems terete, much-abbreviated to elongated, slender to very stout, naked, bracteate or leafy; leaves simple, radical or cauline or both, persistent, deciduous or fugacious, occasionally altogether lacking, varying from sheathing bracts to a broad or narrow lamina; lamina linear to broadly elliptic, membranaceous to somewhat fleshy; inflorescence terminal, supported by an abbreviated to greatly elongated peduncle, composed of one or more flowers, commonly a spike or simple raceme; flowers small and inconspicuous to rather showy, zygomorphic, perfect; perianth composed of three outer segments (sepals) and three inner segments (petals), the segments free or more or less united, adnate to the 1- or 3-celled inferior ovary, one petal (the lip or labellum) usually complex in structure and differing only slightly or greatly in form, size and coloration from the other segments; lip often extended to form a spur or nectary; stamens and pistils (including the filaments and styles) united to form an organ (the column) in the center of the flower; column various, bearing at or near its summit or laterally 1 or 2 mobile or rigidly attached anthers, producing in front on the ventral surface the somewhat confluent stigmas, with one stigma usually modifled to form the rostellum; anthers situated behind the rostellum, resting in a bed or clinandrium, perfectly or abortively 2-celled, containing a mass of pollen or 2 to 8 distinct pollen masses or pollinia; pollen powdery, granular-mealy, waxy or cartilaginous; fruit a dry capsule or fleshy pod, commonly ovoid, ellipsoid or cylindrical, dehiscing along 1 , 2 or 3 longitudinal sutures; seeds numerous, scobicular.

A cosmopolitan family that attains its highest development in the tropics of both hemispheres and is one of the largest families of flowering plants in the world, consisting of several hundred genera and 15,000 or more species. It is also considered to be among the most advanced families in the Monocotyledoneae. The column, formed by the united stamens and pistils, is distinctive of the family.

1. Flowers with a distinct saccate or elongated spur.

1. Habenaria

1. Flowers without a conspicuous spur, at most producing a short mentum (2)

2(1). Lip broadly saccate or cymbiform; leaves rather large (3)

2. Lip not saccate; leaves small, often grasslike (4)

3(2). Leaves forming a basal rosette, shining and fleshy; lip uppermost in flower.. 7. Ponthieva

3. Leaves scattered on the stem, plicate; lip lowermost in flower.

3. Epipactis

4(2). Lip crested or bearded on the face (5)

4. Lip not crested or bearded on the face (7)

5(4). Leaf linear to linear-lanceolate, grasslike, plicate, sheathing the scape near the base; column broadly winged at the apex; lip forming the uppermost segment of the perianth.....................................6. Calopogon

5. Leaf ovate to ovate-elliptic, fleshy; column not winged, clavate; lip forming the lowermost segment of the perianth (6)

6(5). Lip $25 \mathrm{~mm}$. long or less, bearded on the face. 4. Pogonia 6. Lip more than $30 \mathrm{~mm}$. long, with a central crest 5. Cleistes

7(4). Leaves several, basal or cauline, narrow and grasslike or (if broad) basal.. 8. Spiranthes 
7. Leaf solitary or 2 oppositely placed on the stem, attached to or spreading near middle of stem, broad and short (8)

8(7). Stem produced from a small bulbous corm; leaves 1 or 2 ; lip broad and short, obliquely tridentate or acutish at the apex............9. Malaxis

8. Stem produced from a slender rhizome; leaves always 2 , opposite; lip narrow and elongated, deeply bilobed.

2. Listera

\section{Habenaria WILLD.}

Terrestrial or semiaquatic herbs with fleshy or tuberous roots; roots ovoid to fusiform-elongated or rarely palmate; plants erect, simple, glabrous; stem leafy or merely bracted; leaves one or more, basal or cauline, essentially sessile, with the basal part sheathing the stem; flowers usually small, in showy or inconspicuous racemes; sepals free, similar or dissimilar; dorsal sepal erect or incurved to form a hood over the column; lateral sepals spreading or deflexed; petals free, erect, usually connivent with the dorsal sepal, simple or bipartite; lip lowermost or occasionally uppermost, simple or tripartite (the divisions cuneate to filiformsetaceous, entire or variously toothed or fringed), entire, toothed or fringed, extended at the base to form a spur; spur elongated and filiform or filiformclavellate, shorter to much longer than the pedicellate ovary; column short; stigmas with or without papillose processes; anther cells two, separate, relatively distant; pollen granular, attached to exposed glands (not contained in a pouch); capsules narrowly cylindrical to ellipsoid.

A polymorphic genus of approximately 500 species native mainly to the warmer regions of the world.

1. Lip deeply 3-parted, that is divided at least halfway to the base of the lamina (2)

1. Lip simple (not 3-parted), linguiform, ligulate, linear or lanceolate, at most fringed, angled, notched or lobed (4)

2(1). Divisions of the lip fringed; petals simple (not 2-parted), crenate at most.. ..1. H. lacera.

2. Divisions of the lip not fringed, entire, linear or linear-filiform; petals 2-parted (3)

3(2). Spur more than $4 \mathrm{~cm}$. long, much longer than the pedicellate ovary (often as much as 6 times as long); lateral divisions of the lip $1.5 \mathrm{~cm}$. long or more.

2. H. quinqueseta.

3. Spur less than $2 \mathrm{~cm}$. long, about as long as the pedicellate ovary; lateral divisions of the lip less than $1.3 \mathrm{~cm}$. long...

3. H. repens.

4(1). Lip copiously ciliate-fringed (5)

4. Lip not fringed, at most coarsely erose (8)

5(4). Flowers white, occasionally tinged with cream-color; lip narrowly ovateoblong.

4. H. Blephariglottis.

5. Flowers yellow or orange-color; lip ovate to oblong (6)

6(5). Lip oblong, more than $8 \mathrm{~mm}$. long; spur longer than the pedicellate ovary.. 5. H. ciliaris.

6. Lip ovate, less than $6 \mathrm{~mm}$. long; spur shorter than the pedicellate ovary (7)

7(6). Spur less than $1 \mathrm{~cm}$. long.

7. Spur more than $1.1 \mathrm{~cm}$. long

6. H. cristata.

8(4). Lip entire or only crenate, not noticeably lobed nor notched (9)

8. Lip angled or lobed at the base (rarely entire) or trilobulate or tridentate at the apex (19) 
9. Flowers white or greenish (10)

10(9). Lip uppermost in the snowy-white flowers.

9. H. nivea.

10. Lip lowermost in the flower; flowers greenish or white (11)

11(10). Lip with a small tubercle or cushionlike callus in the center at or near the base, usually strongly arcuate at the base (12)

11. Lip sometimes with a thickened keel but never with a tubercle at or near the base, pendent, spreading or upcurved (13)

12(11). Lip subquadrate; petals usually crenulate on the margins.....10. H. flava. 12. Lip linear or linear-ligulate; petals entire. 11. H. limosa.

13(11). Spur scrotiform or strongly saccate to thick-cylindric, usually (but not always) less than two-thirds the length of the lip (14)

13. Spur slender-cylindric, only slightly clavellate, variable in length, as long as or longer than the lip (15)

14(13). Raceme densely flowered, usually short, thick, congested

12. H. hyperborea.

14. Raceme laxly flowered, elongate, often with the flowers scattered

13. H. saccata.

15(13). Leaves very short, ovate, less than $9 \mathrm{~cm}$. long, usually reduced to clasping tubular sheaths.........................14. H. sparsiflora var. brevifolia.

15. Leaves ample, usually broadly elliptic to lanceolate, variable in length, never reduced entirely to sheaths (16)

16(15). Lip rhombic-lanceolate, prominently dilated at the base; flowers usually white, rarely greenish.

15. H. dilatata.

16. Lip linear to linear-elliptic or broadly lanceolate, not prominently dilated at the base; flowers always greenish, sometimes marked with purple (17)

17(16). Flowers usually in a densely or loosely flowered slender cylindrical raceme; lip characteristically lanceolate (sometimes broadly lanceolate)

12. $H$. hyperborea.

17. Flowers usually scattered, rarely approximate or produced in an elongate raceme; lip characteristically linear (18)

18(17). Flowers rather small, usually marked or suffused with purple; lip 4-7.5 $\mathrm{mm}$. long, fleshy but usually without a central ridge; column small, usually with a narrow connective, about one-third the length of the dorsal sepal.............................14. $H$. sparsiflora var. laxiflora.

18. Flowers rather large, light green; lip 6-14 $\mathrm{mm}$. long, usually with a fleshy ridge in the center below the middle; column large, with a broad connective, usually about one-half as long as the dorsal sepal.

14. H. sparsiflora.

19(8). Lip lobed or angled (sometimes truncate) at the base 10. H. flava.

19. Lip neither lobed nor angled at the base, either trilobulate or tridentate at the apex (20)

20(19). Spur slender, clavellate, longer than the pedicellate ovary; lip shallowly notched at the apex with 3 short equal rounded lobules

16. $H$. clavellata.

20. Spur scrotiform, much shorter than the pedicellate ovary; lip unequally 3-lobed at the apex, the acute lateral lobes prolonged beyond the obsolescent middle lobe. 17. $H$. viridis var. bracteata. 


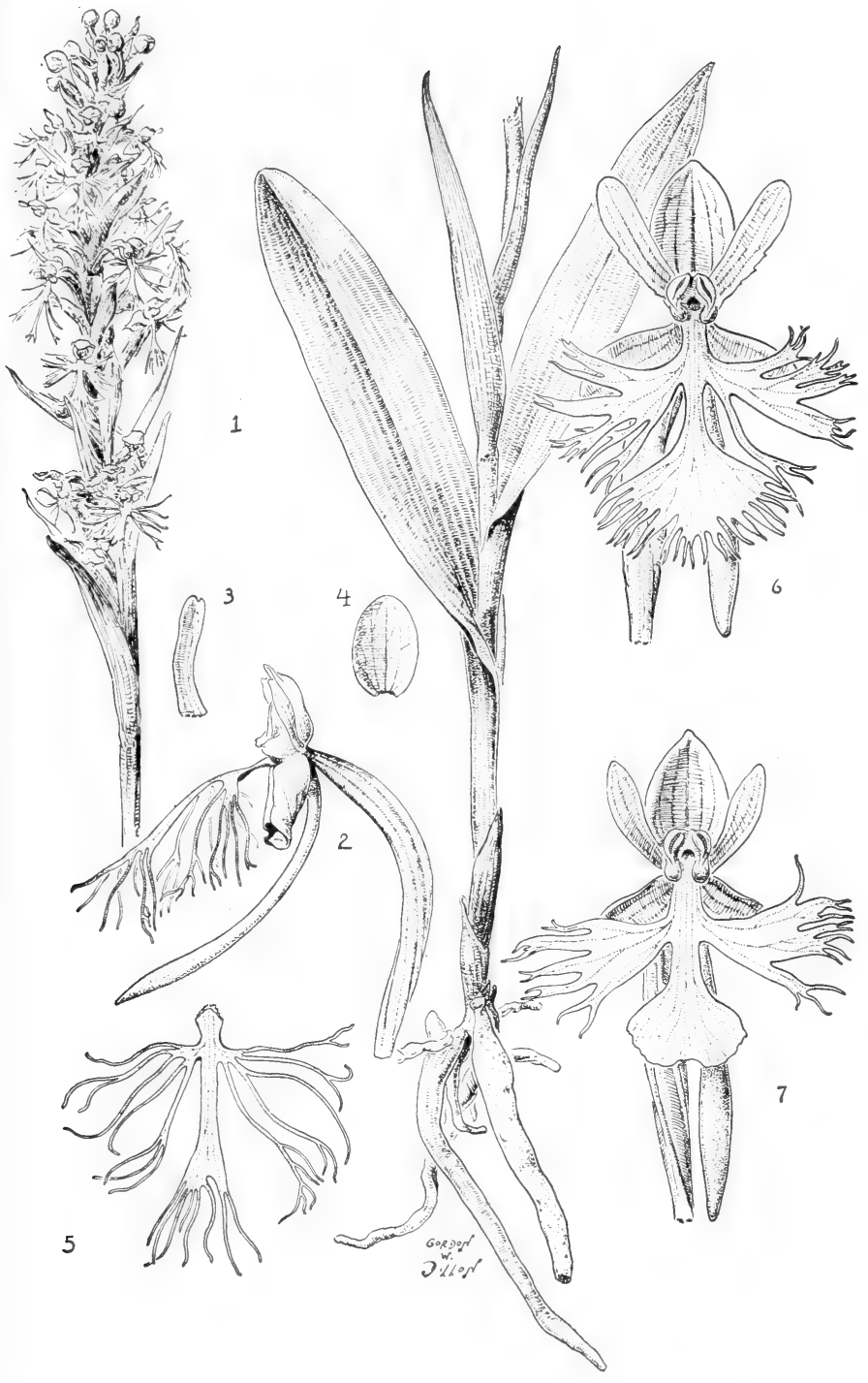

Fig. 353: Habenaria lacera: 1, plant, x 1; 2, flower, side view, x 2; 3, petal, x 2; 4 , dorsal sepal, x $2 ; 5$, lip, from above, $\times 2 ; 6$ and 7 , flowers, front view, hybrids, $x 2$. 


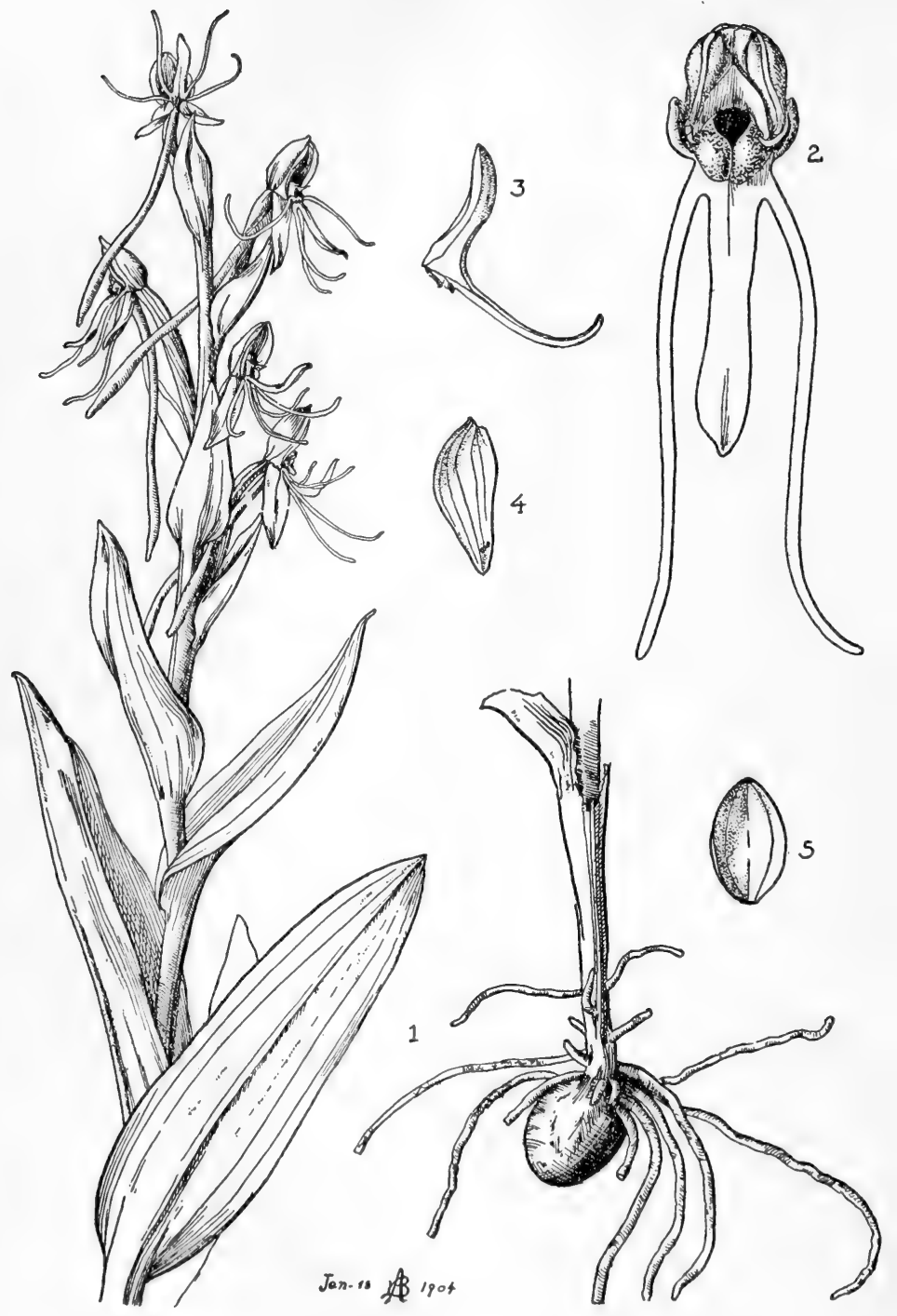

Fig. 354: Habenaria quinqueseta: 1 , plant, $x 2 / 3 ; 2$, lip and column, front view, $x$ $2 ; 3$, petal, x $2 ; 4$, lateral sepal, x $2 ; 5$, dorsal sepal, x 2 . 
1. Habenaria lacera (Michx.) Lodd. RAGged FRINGED ORCHID. Fig. 353.

Plant glabrous, rather stout, $2.5-7.5 \mathrm{dm}$. tall (often propagating by means of root-shoots); roots slender, fleshy, from thickened tuberoids; stem somewhat ribbed, leafy below, bracted above; leaves rather rigid, erect, oblong-linear to oblong-obovate or linear-lanceolate, with the basal part sheathing the stem, 7-21 $\mathrm{cm}$ long, 1.5-5 cm. wide; raceme loosely or densely flowered, 3-26 cm. long, $3-4.5 \mathrm{~cm}$. in diameter; floral bracts usually equaling the pedicellate ovaries, rarely exceeding the flowers, narrowly lanceolate to linear-lanceolate, acuminate, $1-4 \mathrm{~cm}$. long; flowers pale yellowish-green or whitish-green, with rather stout curving pedicellate ovaries which are $1.5-2 \mathrm{~cm}$. long; dorsal sepal ovate to elliptic, concave, 4-5 mm. long, 3-4 mm. wide; lateral sepals obliquely ovate, obtuse, 4-6 $\mathrm{mm}$. long, about $3 \mathrm{~mm}$. wide; petals linear-oblong to narrowly oblong-spatulate, entire or rarely toothed at the truncate or rounded apex, rarely obtuse, slightly oblique, 5-7 mm. long, mostly less than $2 \mathrm{~mm}$. wide; lip deeply tripartite, 10-16 mm. long, 13-17 mm. wide across the lateral lobes; lateral lobes deeply cut (usually to the base) into three divisions, with the divisions subdivided again; mid-lobe slender, clavate to narrowly cuneate or linear-spatulate, somewhat spreading above into irregular slender or coarse fringes, rarely erose to shortfringed at the apex, often laciniate halfway or more to the base; spur curved, slender or clavellate, as long as or longer than the pedicellate ovary, $1-2.3 \mathrm{~cm}$. long; capsule ellipsoid, erect, about $1.5 \mathrm{~cm}$. long.

The fringed deeply 3-lobed lip of the yellowish-green flowers is distinctive.

In open woods along streams, in open sedge marshes and meadows in Okla. (Waterfall) and n.e. Tex., rare, May-Aug.; from Nfld., s. to Ga., w. to Tex., Ark., Mo., I!l., Wisc., Minn.

2. Habenaria quinqueseta (Michx.) Sw. Long-horned Habenaria. Fig. 354.

Plant slender or stout, erect, leafy, (occasionally with the leaves mostly basal), glabrous throughout, 2-9 dm. tall; roots slender-fibrous, with tuberous swellings (usually with an ovoid tuber at the base of the stem); leaves mainly cauline, thin and chartaceous when dry, oblong-elliptic to elliptic-lanceolate or oblong-obovate, broadly rounded to acute or acuminate at the apex, reduced above to clasping ovate acuminate bracts, $6-25 \mathrm{~cm}$. long, $2.5-6 \mathrm{~cm}$. wide; raceme elongated, laxly few- to many-flowered, $7-25 \mathrm{~cm}$. long, $5-6 \mathrm{~cm}$. in diameter; floral bracts ovatelanceolate, acuminate, semitranslucent as long as or shorter than the pedicellate ovaries, $1.5-2.8 \mathrm{~cm}$. long, 7-15 $\mathrm{mm}$. wide below the middle; flowers greenishwhite, with slender pedicellate ovaries which are 2-3 cm. long; dorsal sepal oblong-elliptic to suborbicular, obtuse to rarely acute, concave, $6-13 \mathrm{~mm}$. long, 5-10 $\mathrm{mm}$. wide at the middle; lateral sepals ovate-oblong to oblong-lanceolate or oblong-elliptic, obtuse to acute, oblique, 8-16 mm. long, 4-7 mm. wide below the middle; petals 2-parted; posterior lobe erect, linear-oblong, falcate, obtuse to acute, 6-15 mm. long, about $2 \mathrm{~mm}$. wide; anterior lobe filiform, almost twice as long as the posterior division, recurved, 1.3-2.5 cm. long; lip 3-parted; lateral lobes filiform, recurved at the apex, $1.5-3 \mathrm{~cm}$. long; midlobe linear with revolute margins, 8-20 mm. long, 2-3 mm. wide; spur varying from slender to strongly clavellate, recurved, $4-18 \mathrm{~cm}$. long.

Represented in Tex. by a collection by Charles Wright, without a definite locality but doubtless in the Coastal Prairies in the s.e. part of the state. It should be looked for in swamps, margin of ponds, and similar wet places; locally distributed from Fla., n. to S.C. and w. to Tex., also in the W.I. and Latin Am., July-Nov. 

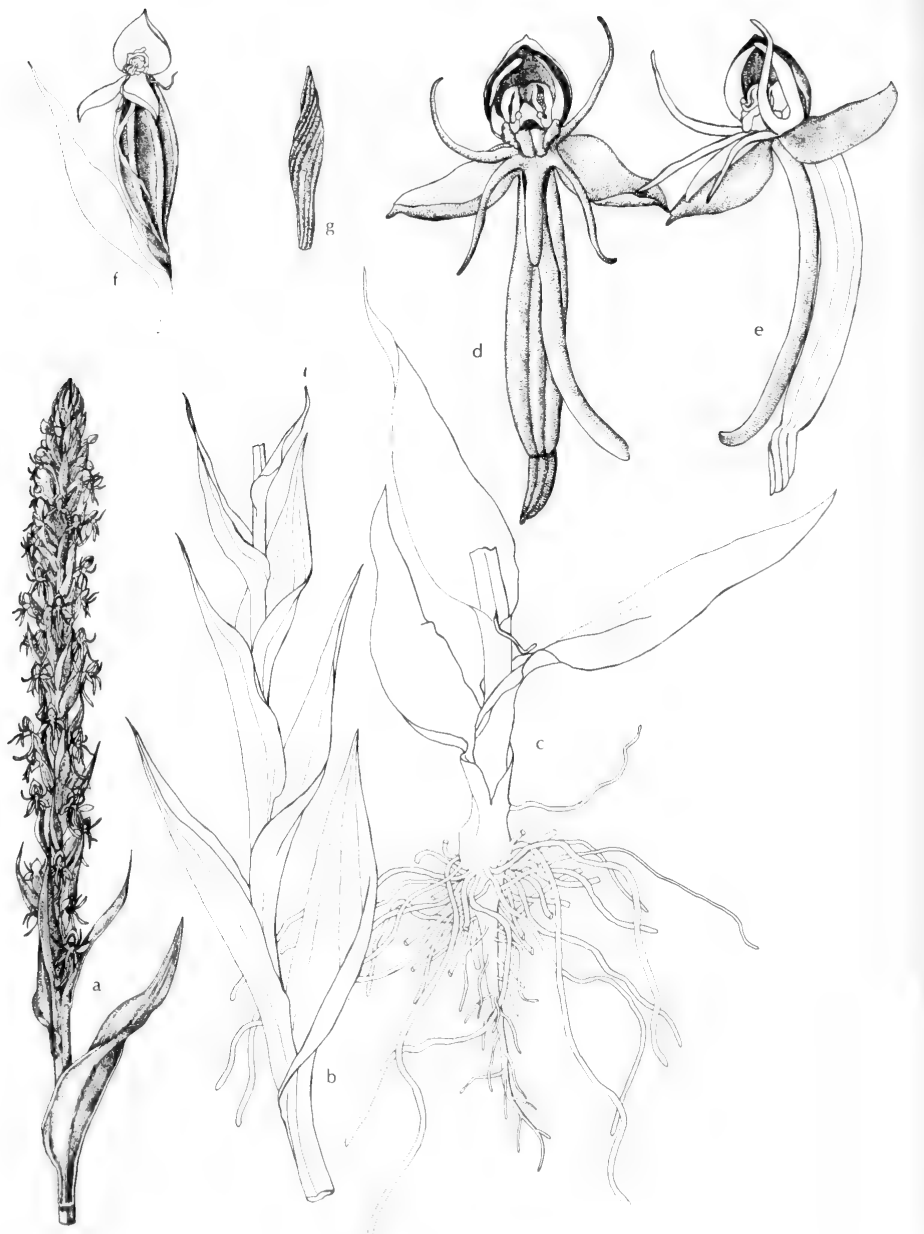


\section{Habenaria repens Nutt. WATER-SPIDER ORCHID. Fig. 355.}

Plant slender or stout, leafy, glabrous, 1-9 dm. tall; roots slender, fibrous, often with tuberous swellings; leaves linear-oblong to linear-lanceolate, acute to acuminate, thin and chartaceous, 3-ribbed, strongly veined, sheathing the stem below, 5-24 cm. long, 3.5-20 $\mathrm{mm}$. wide; raceme densely flowered, rarely consisting of a few scattered flowers, 6-28 cm. long, $2.5-3 \mathrm{~cm}$. in diameter; floral bracts oblong-lanceolate to lanceolate, acute to acuminate, exceeding the flowers at maturity (rarely shorter than the flowers), $1.5-9 \mathrm{~cm}$. long, about $1 \mathrm{~cm}$. wide near the base; flowers small, greenish, with slender pedicellate ovaries which are 9-14 $\mathrm{mm}$. long; dorsal sepal oval to suborbicular-ovate, mucronate, concave, 3-7 mm. long, about $3 \mathrm{~mm}$. wide; lateral sepals ovate to ovate-oblong, mucronate, 4-7 mm. long, about $3 \mathrm{~mm}$. wide; petals 2-parted; posterior lobe erect, falcate, oblong-lanceolate to lanceolate, acute, 3-7 $\mathrm{mm}$. long; anterior lobe filiform, falcate, erect, 4-7.5 mm. long; lip deeply 3-parted to within $2 \mathrm{~mm}$. of the base, strongly deflexed; lateral lobes filiform, 5-11 mm. long; midlobe linear to linearoblong, 4-7 mm. long; spur slender, about as long as the pedicellate ovary, 9-14 mm. long. H. Nuttallii Small.

In streams, ditches, swamps, on the margins of ponds and lakes, often floating on mats of other vegetation on surface of water in cen., s. and e. Tex., May-Nov.; from Fla., n. to N.C. and Va. (?), w. to Tex.; also throughout the W.I. and Latin Am.

\section{Habenaria Blephariglottis (Willd.) Hook. WHITE FRINGED ORCHID.}

Plant stout, leafy below, bracted above, glabrous, $0.8-11 \mathrm{dm}$. tall; roots fleshy, tuberous-thickened; stem strongly ribbed; leaves ovate-lanceolate to elliptic-lanceolate or linear-lanceolate, acute to acuminate, with the lower part sheathing the stem, 5-35 $\mathrm{cm}$. long, $1-5 \mathrm{~cm}$. wide; raceme densely or laxly flowered, 3-20 cm. long, $2.5-8 \mathrm{~cm}$. in diameter; floral bracts narrowly lanceolate, shorter than the pedicellate ovaries, $1.5-2.5 \mathrm{~cm}$. long; flowers white, often tinged with cream, with slender pedicellate ovaries which are about $2 \mathrm{~cm}$. long; dorsal sepal oblong-elliptic to orbicular, obtuse to rounded at the apex, concave, 5-10 $\mathrm{mm}$. long, 4-8 mm. wide; lateral sepals broadly ovate-orbicular, oblique, 5-11 $\mathrm{mm}$. long, 4-9 $\mathrm{mm}$. wide; petals linear to narrowly oblong-spatulate or oblanceolate, truncate and retuse to denticulate at the apex, 3-8 $\mathrm{mm}$. long, 1-3 mm. wide at the widest point; lip with the undivided portion linguiform, ovate-oblong to oblong-elliptic or oblong-quadrate, rarely suborbicular, 4-13 mm. long, 2-4 mm. wide, copiously and coarsely fringed; fringes less than $8 \mathrm{~mm}$. long, with the segments often branched; spur slender, as long as or longer than the pedicellate ovary, 1.5-5 cm. long. Blephariglottis Blephariglottis (Willd) Rydb.

In marshes, meadows, edge of swamps and depressions in savannahs and prairies in s.e. Tex., June-Sept.; widely distributed and locally abundant from Nfld., s. to Fla., w. to O., Mich. and Tex.

\section{Habenaria ciliaris (L.) R. Br. Yellow fringed orchid. Fig. 356.}

Similar to $H$. Blephariglottis except for its bright- to deep-orange-color flowers with more copiously and finely fringed lips. Plant to $1 \mathrm{~m}$. tall; petals linear-oblong to linear-cuneate, 6-7 mm. long 1-2 mm. wide; lip 8-12 $\mathrm{mm}$. long; spur 2-3.3 cm. long. Blephariglottis ciliaris (L.) Rydb.

In moist woodlands, along streams, seepage slopes in forests and open areas, bogs, savannahs and prairies in e. and s.e. Tex., June-Oct.; from Ont., s. to Fla., w. to Ill., Mo., Ark. and Tex. 


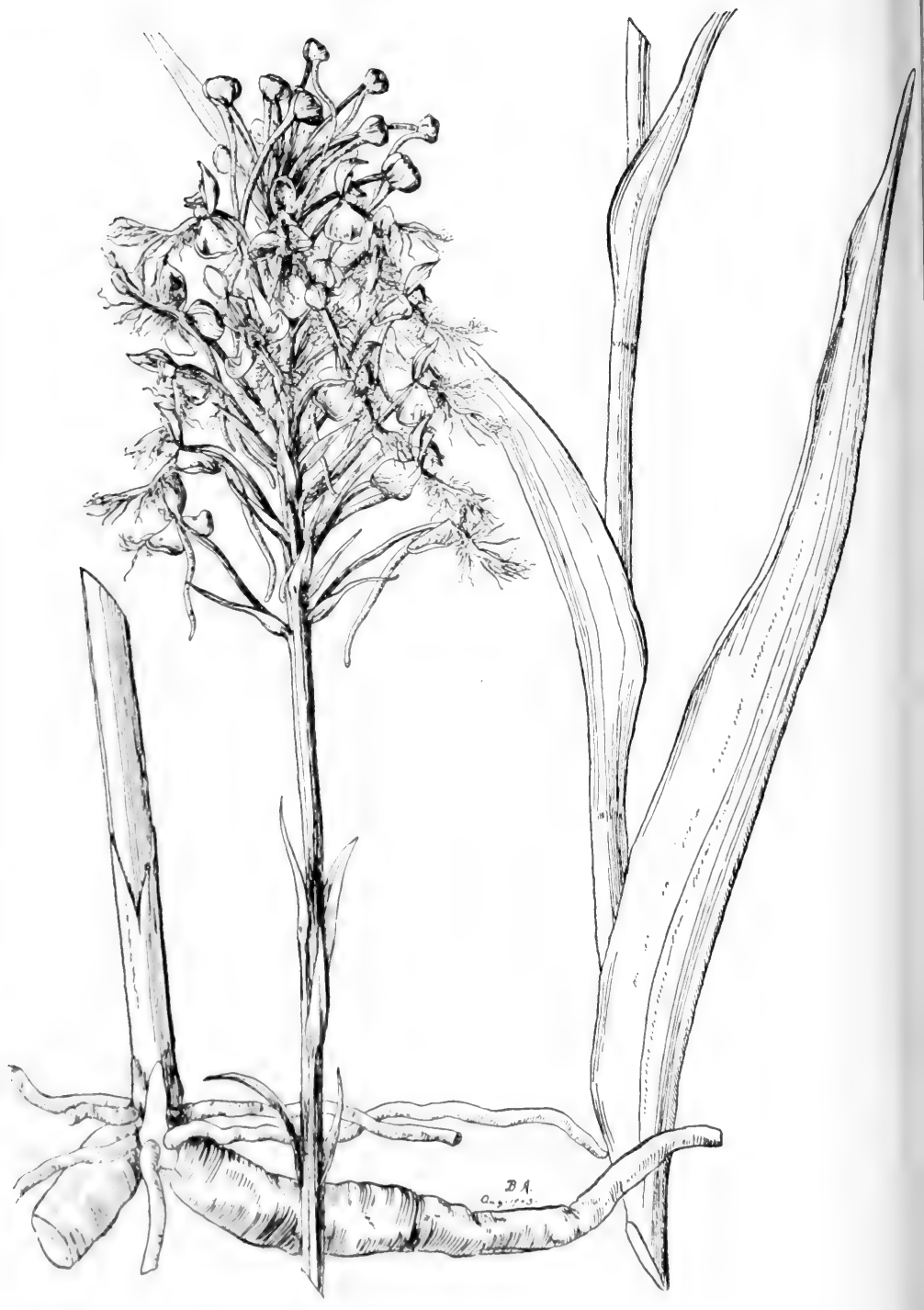

Fig. 356: Hahenaria ciliaris: plant, x 1. 


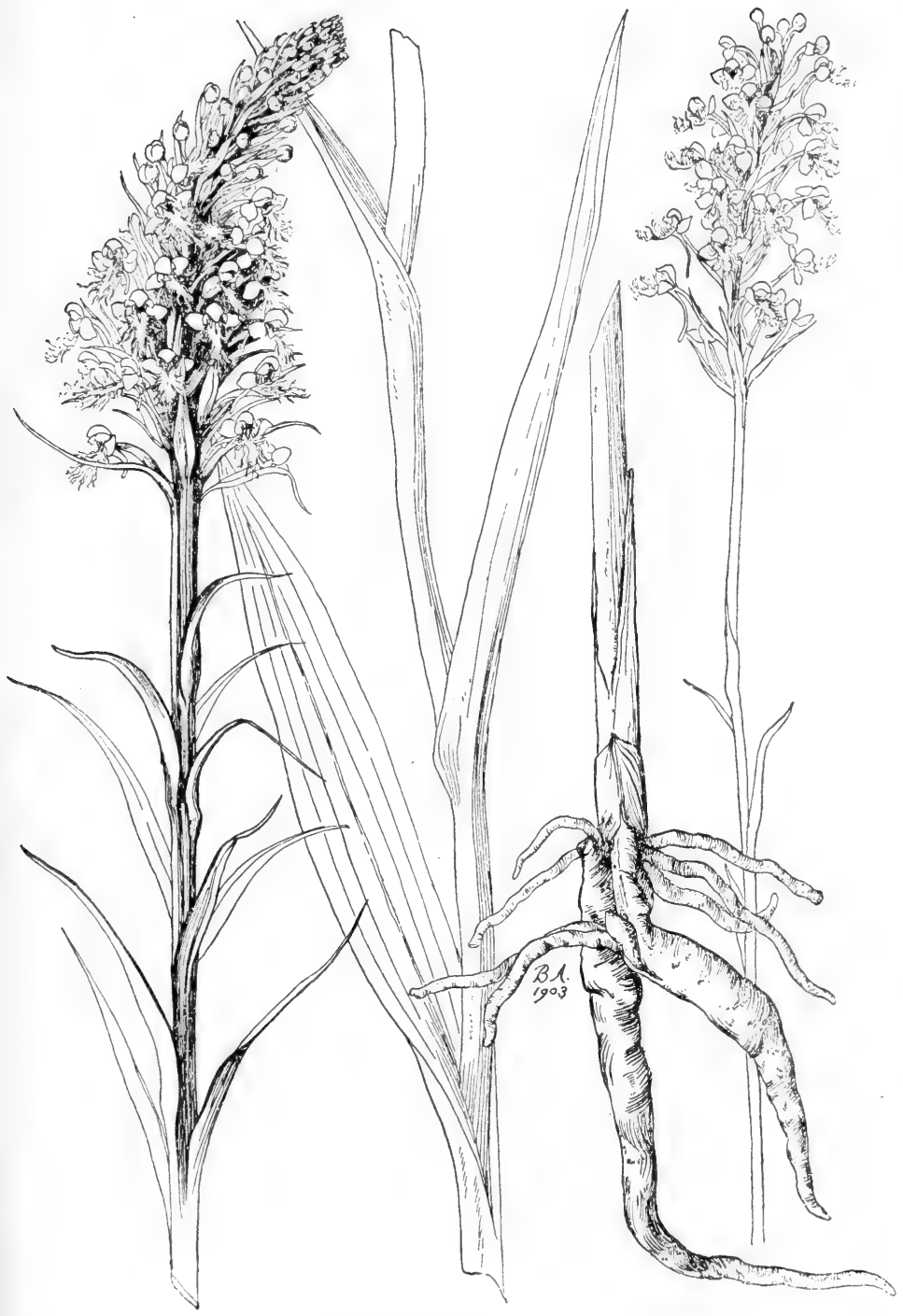

Fig. 357: Habenaria cristata: plant, x 1. 


\section{Habenaria cristata (Michx.) R. Br. CRested FrInged orchid. Fig. 357.}

Plant stout, glabrous, leafy below, bracted above, 1.8-9 dm. tall; roots fleshy, tuberous-thickened; leaves oblong-lanceolate to linear-lanceolate, acute to acuminate, sheathing the stem below, 7-21 cm. long, 1-2.5 cm. wide; floral bracts narrowly lanceolate, acuminate, about as long as or shorter than the pedicellate ovary, 1-2.5 cm. long; raceme cylindrical, densely flowered, $2-15 \mathrm{~cm}$. long, 2-4 $\mathrm{cm}$. in diameter; flowers bright orange-colored, with slender pedicellate ovaries which are 1.2-1.7 cm. long; dorsal sepal oblong-elliptic to suborbicular, often slightly notched at the obtuse apex, concave, $3-5 \mathrm{~mm}$. long, 2-3 mm. wide; lateral sepals suborbicular to orbicular, rounded at the apex, 3-4 $\mathrm{mm}$. long, 2-3 $\mathrm{mm}$. wide; petals oblong-elliptic, often narrowly cuneate, fringed at the apex, 2-4 mm. long, 1-2 $\mathrm{mm}$. wide; lip ovate to ovate-oblong, 4-6 $\mathrm{mm}$. long, copiously ciliate-fringed, with the segments usually branched (often a confusion of fringes); spur 5-10 (averaging 6) $\mathrm{mm}$. long, slender, much shorter than the pedicellate ovary.

In bogs, meadows, wet prairies and savannahs, along streams in woods, in depressions in pine lands, and on wooded seepage slopes, in e. and s.e. Tex., June-Sept.; from e. Mass. (rare), s. to cen. Fla., w. to Tex., Ark. and Tenn.

Except for their smaller size and usually deeper color the flowers of this species are similar to those of $\boldsymbol{H}$. ciliaris.

\section{Habenaria X Chapmanii (Small) Ames.}

The size of the lemon-yellow to orange-color flowers of this plant are intermediate between $H$. cristata and $H$. Blephariglottis, its putative parents. The spur is usually about $12 \mathrm{~mm}$. long. Blephariglottis Chapmanii Small.

In habitats similar to those of $H$. ciliaris in s.e. Tex. (Hardin and Jefferson cos.), July-Aug.; from N.J. and Del., s. to n. Fla., w. to Tex.

\section{Habenaria integra (Nutt.) Spreng. Yellow fringeless orCHID. Fig. 358.}

Plant glabrous, with several leaves below, bracted above, $3-6.2 \mathrm{~cm}$. tall; roots fleshy, tuberous, swollen near the base of the stem; stem angled; leaves oblonglanceolate to narrowly lanceolate, acuminate, with the lower part sheathing the stem, 10-19 cm. long, 1-3 cm. or more wide; raceme densely many-flowered, cylindrical, 2-10.5 cm. long, 2-3 cm. in diameter; floral bracts narrowly lanceolate, acuminate, $1-1.7 \mathrm{~cm}$. long; flowers light lemon-orange to dull-orange in color, with stout pedicellate ovaries which are $5-10 \mathrm{~mm}$. long; dorsal sepal suborbicular to orbicular, rarely toothed at the rounded apex, concave, 3-4 mm. long, 2-3 mm. wide; lateral sepals ovate-orbicular, subobtuse, oblique, 4-5 $\mathrm{mm}$. long, 3-4 mm. wide; petals narrowly oblong, obtuse, 3-4 $\mathrm{mm}$. long, about $2 \mathrm{~mm}$. wide; lip ovate-elliptic to obovate, obtuse to acute, crenulate to rarely entire on the margins, 4-5 mm. long, 3-4 mm. wide; spur descending, tapering from a thickened base, about $5 \mathrm{~mm}$. long. Gymnadeniopsis integra (Nutt.) Rydb.

Represented in Tex. by a collection of Thomas Drummond without a definite locality but doubtless in boggy savannahs or prairies in the s.e. part of the state, July-Sept. along the coast from N. J. s. to n.-cen. Fla., w. to Tex.; also e.-cen. Tenn.

Except for its lack of fringes on the lip the flowers of this species are quite similar in color, size and appearance to those of $H$. cristata.

9. Habenaria nivea (Nutt.) Spreng. SNOWy ORCHID. Fig. 359.

Plant erect, slender, rigid, glabrous, 2-9 dm. tall; roots few, coarse, with one or more hard ellipsoidal tubers which are to $3 \mathrm{~cm}$. long and $8 \mathrm{~mm}$. in diameter; leaves 2 or 3, near base of stem, rigidly suberect, linear to linear-lanceolate, acuminate-attenuate, conduplicate, strongly keeled, with the lower part sheathing 


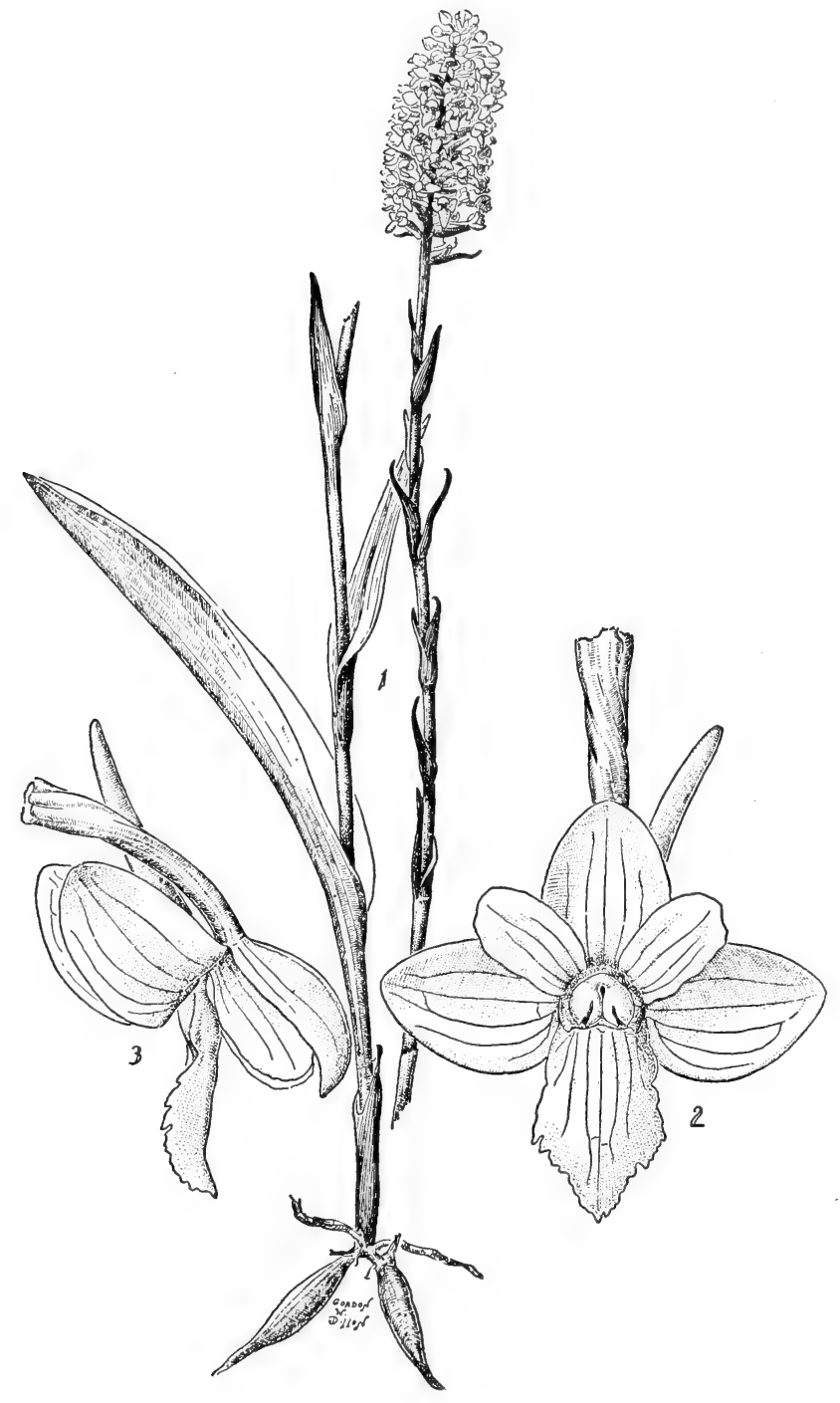

Fig. 358: Habenaria integra: 1, plant, x 1/2; 2, flower, front view, spread open, x 5; 3 , flower, side view, $x 5$. 


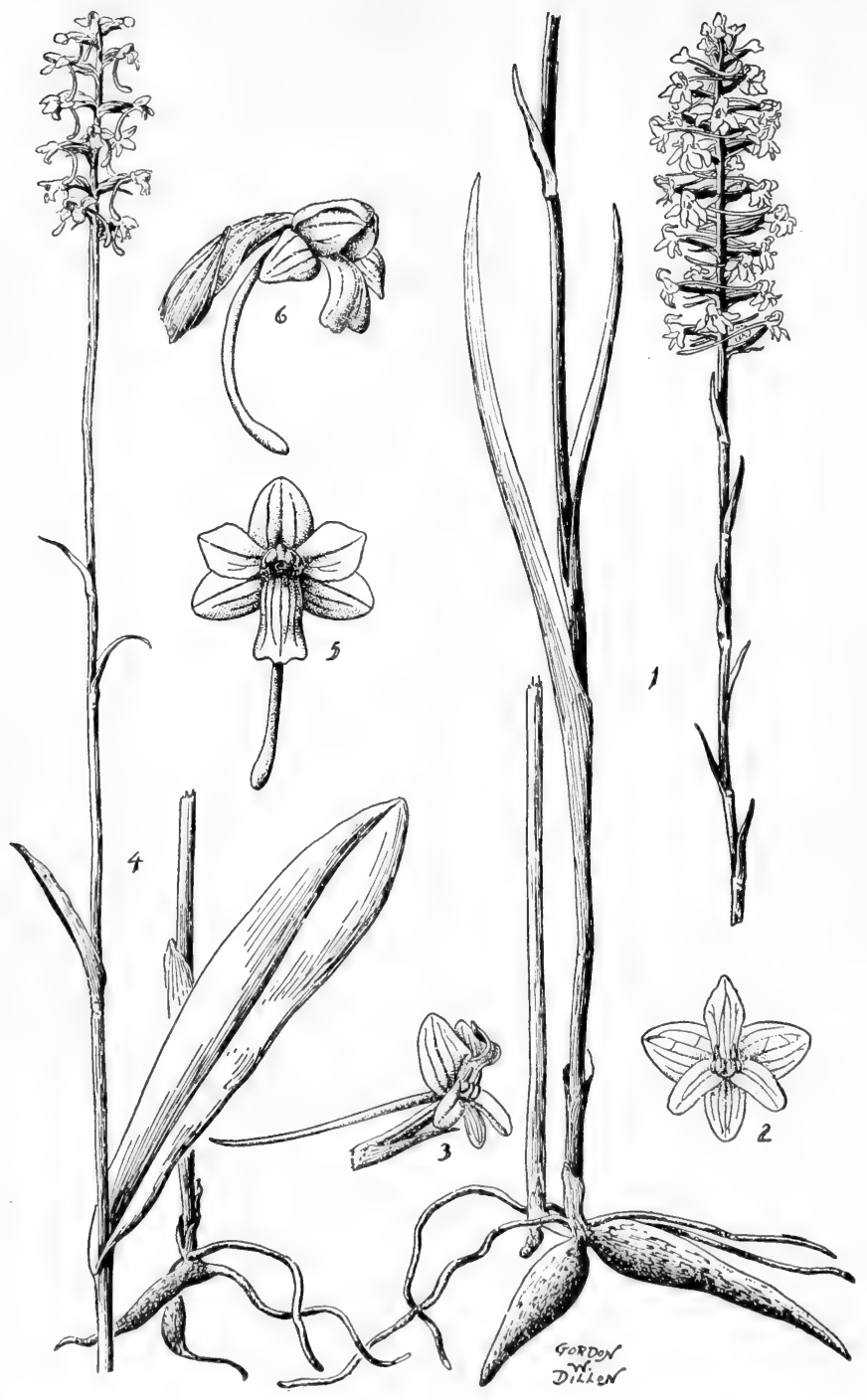

Fig. 359: 1-3, Hahenaria nivea: 1, plant, $x$ 1\%:2, flower front view, spread out, $\mathrm{x}$ $21 \frac{2}{2} ; 3$, flower, side view, x 21/2. 4-6, Habenaria clavellata: 4, plant, 1/2; 5, flower, front view, spread open, x $2 \frac{1}{2} ; 6$, flower, side view, $x 2^{1 / 2}$. 
the stem, reduced above to slender acuminate bracts, 7-26 cm. long, about $8 \mathrm{~mm}$. wide near the base; raceme many-flowered, cylindrical, conical at the apex, slender, 3-15 cm. long, $1.3-3 \mathrm{~cm}$. in diameter; floral bracts mostly longer than the pedicellate ovaries, linear-lanceolate, acuminate, 6-10 $\mathrm{mm}$. long; flowers snowy-white, rarely tinged with pink, with slender pedicellate ovaries which are about $8 \mathrm{~mm}$. long; dorsal sepal oval-oblong to suborbicular, obtuse, $2-5 \mathrm{~mm}$. long, 1-4 mm. wide; lateral sepals ovate-oblong to oblong-elliptic, auriculate or dilated at the base on the posterior margin, obtuse, 4-6 $\mathrm{mm}$. long, 2-4 mm. wide; petals linear-oblong to elliptic, obtuse, somewhat falcate, 2-5 mm. long, 1-2 $\mathrm{mm}$. wide; lip uppermost, linear-oblong to linear-elliptic, often somewhat contracted at the apex, 3-8 $\mathrm{mm}$. long, 1-3 $\mathrm{mm}$. wide; spur slender, rarely clavellate, almost horizontal, curved upward, $1-1.6 \mathrm{~cm}$. long; capsule cylindrical, strongly ribbed and tuberculate, 8-12 mm. long. Gymnadeniopsis nivea (Nutt.) Rydb.

In wet prairies, savannahs and bogs, mainly in s.e. Tex., May-Aug.; locally distributed from N.J. and Del., s. along the coast to Fla., w. to Tex. and Ark.

The small white flowers with lip uppermost distinguishes this species.

\section{Habenaria flava (L.) R. Br. Southern ReIN-OrChid. Fig. 360.}

Plant slender or stout, glabrous, leafy below, bracted above, 1-6 dm. tall, commonly reproducing by underground stolons; roots short, fleshy, tuberous; leaves 1 to 3 , usually 2 , expanded just below the middle of the stem or toward the base, ovate-oblong to narrowly lanceolate, acuminate, sheathing the stem below, light-green, lucid, 5-23 cm. long, 1-5 cm. wide, abruptly reduced to bracts above; raceme usually densely flowered (often composed of loosely scattered isolated flowers), stout or wandlike, $3-21 \mathrm{~cm}$. long, 1-2 cm. in diameter; floral bracts very variable in length, shorter to somewhat longer than the flowers, linear-lanceolate, long-acuminate, to $3.5 \mathrm{~cm}$. long; flowers yellow-green, small, with stout pedicellate ovaries which are 5-10 $\mathrm{mm}$. long; dorsal sepal ovate-oval, obtuse, 3-4 mm. long, about $1.5 \mathrm{~mm}$. wide; lateral sepals ovate-oblong to suborbicular, obtuse, $2-4 \mathrm{~mm}$. long, about $1.5 \mathrm{~mm}$. wide; petals ovate to oblong or suborbicular, rarely subquadrate, oblique, broadly rounded to obtuse at the apex, often crenulate on the margins, 2-5 mm. long, 1.5-3.5 mm. wide; lip very variable in shape, broadly oblong to suborbicular, hastate to subhastate or entire, often with the margins undulate-crenulate, broadly rounded to truncate and occasionally retuse at the apex, strongly arcuate-decurved in natural position, adorned with a tubercle on the median line at or near the base, $2.2-6 \mathrm{~mm}$. long, 2-4.5 mm. wide across the basal lateral teeth or lobules (when these are present); spur slender, rarely clavellate, 4-11 mm. long. Perularia bidentata (Ell.) Small, $P$. scutellata (Nutt.) Small.

In mud of densely wooded floodplain swamplands, thickets, wet savannahs, prairies and marshes in Okla. (Waterfall) and in e. and s.e. Tex., Apr.-Aug.; primarily in the coastal regions and lowlands from Md., s. to cen. Fla., w. to Tex., Ark., Mo., Ill. and Ind.

The tubercle or callus on the disk of the lip near its base is characteristic. of this species.

\section{Habenaria limosa (Lindl.) Hemsl. Thurber's Bog-ORCHID. Fig. 361}

Plant slender or stout, glabrous throughout, 3-16.5 dm. tall; roots fibrous, from dilated tuberous bases; stem leafy, provided at the base with tubular sheaths; leaves lanceolate, acuminate, suberect, 9-28 cm. long, 1.2-3.5 cm. wide; raceme cylindrical, laxly or densely flowered, with the flowers distant or approximate to compact, elongated, $6-45 \mathrm{~cm}$. long, $1-2.5 \mathrm{~cm}$. in diameter; floral bracts narrowly lanceolate, the lowermost to $4 \mathrm{~cm}$. long and greatly exceeding the flowers; flowers small, green, fragrant; dorsal sepal ovate-oblong to elliptic, obtuse, con- 


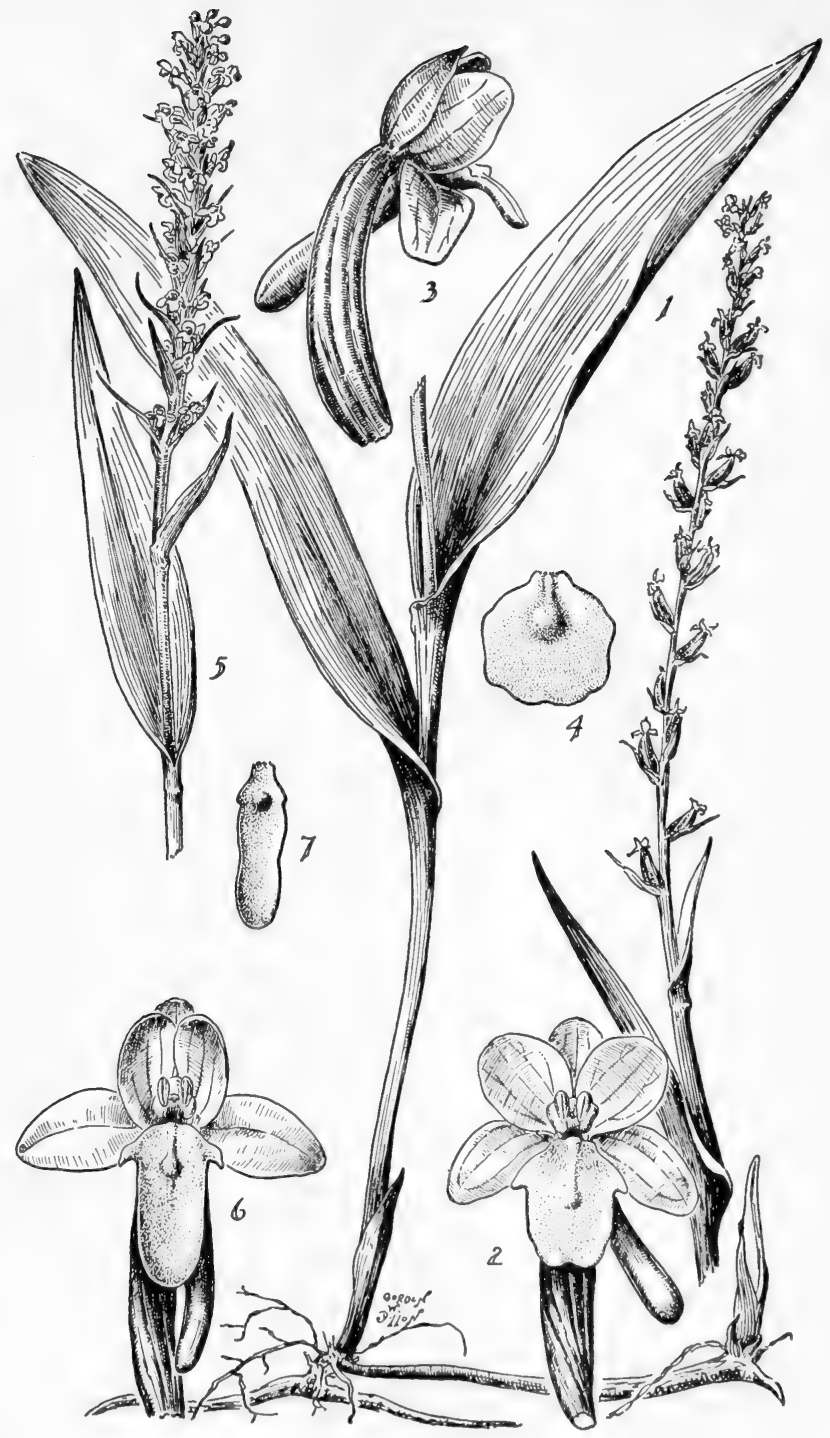

Fig. 360: 1-4. Habenaria flava: 1, plant $x$ 1/2; 2, flower, front view, spread open, x 5; 3, flower, side view x 5; 4, lip, an entire toothless form, x 5. 5-7, Habenaria flava var. herhiola: 5 , inflorescence, $x \quad 1,6$, flower front view, $x 5 ; 7$, lip, an unusual subentire form, x 5 . 


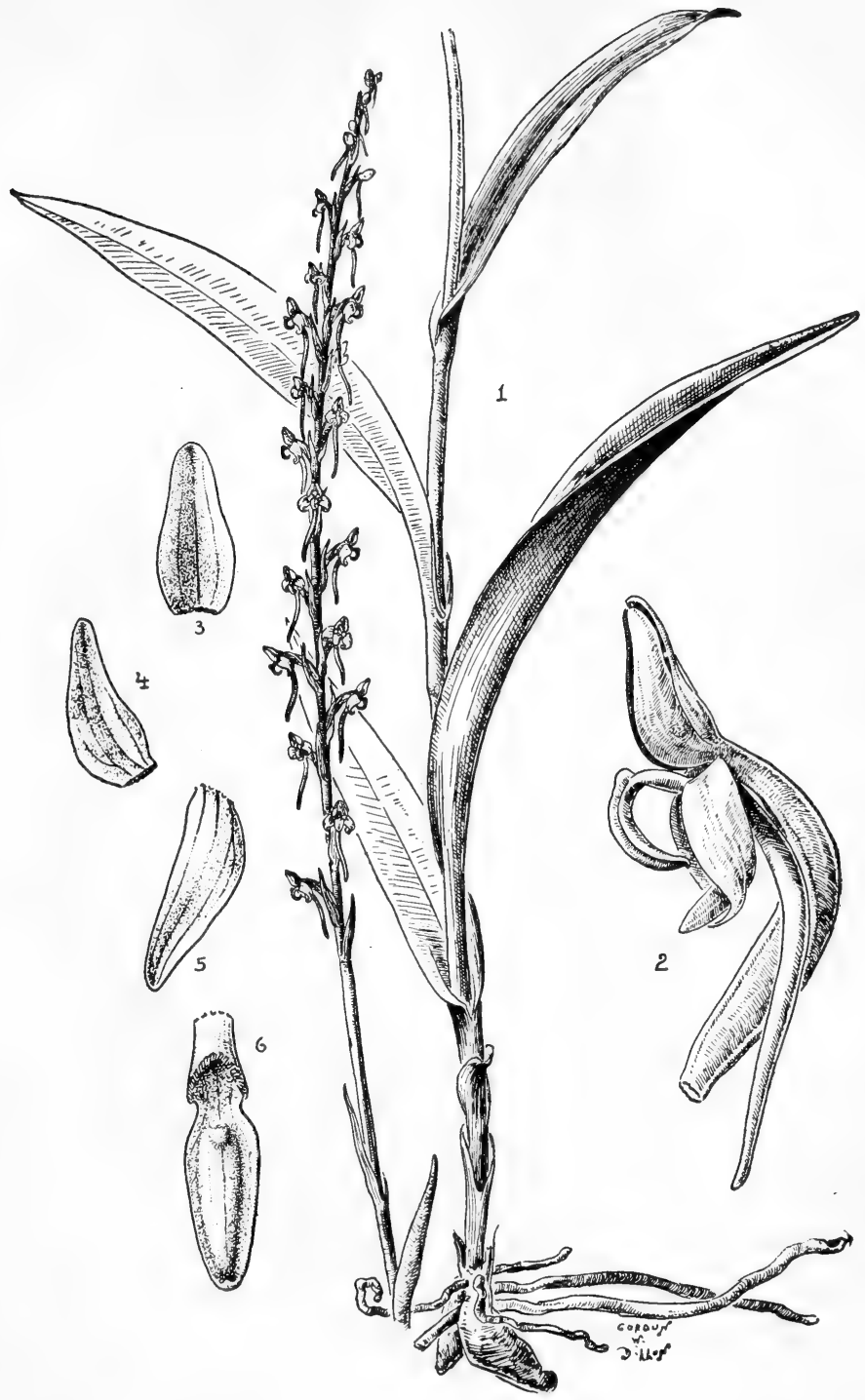

Fig. 361: Habenaria limosa: 1, plant, x 1/2; 2, flower, side view, $x$ 4; 3, dorsal sepal, x $4 ; 4$, petal, x 4; 5, lateral sepal, x 4; 6, lip, x 4 . 
cave, connivent with the petals to form a hood over the column, 3-nerved, 3-6 $\mathrm{mm}$. long, 2-3 mm. wide below the middle; lateral sepals strongly reflexed, ovatelanceolate to linear-elliptic, oblique, obtuse to subacute, 3-nerved, 4-8 $\mathrm{mm}$. long, $1.8-2.5 \mathrm{~mm}$. wide; petals ovate to ovate-oblong or lanceolate, more or less falcate or oblique, obtuse to subacute, $3.2-6.5 \mathrm{~mm}$. long, $1.5-3 \mathrm{~mm}$. wide at the obliquely dilated base; lip linear-elliptic to somewhat elliptic-lanceolate or triangularovate, obtuse at the apex, tapering or rounded to somewhat angled on each side at the base, strongly arcuate-recurved in natural position, with a thick cushioncallus or tubercle in the middle near the base, often with lightly revolute margins, 4-8.5 mm. long, 1.5-3.5 mm. wide below the middle; spur cylindrical, filiform, tapering at the apex, usually about twice as long as the lip, 1-2.5 cm. long; column stout, short, 1-2 mm. long.

In boggy soil about springs in gulches and canyons, but it is also rather frequent in mossy ground in open woods, along cold brooks and in open sedge marshes, in N. M. (Socorro Co.) and Ariz. (Cochise and Pima cos.), June-Sept.; s. through Mex. to Guat.

\section{Habenaria hyperborea (L.) R. Br. TALL NORTHERN GREEN-ORCHID, TALL LEAFY} GREEN-ORCHID, GREEN-FLOWERED BOG-ORCHID. Fig. 362.

Plant erect, slender or stout, glabrous throughout, 1.5-10 dm. tall; roots tuberous, fusiform, elongated, 5-9 $\mathrm{mm}$. thick; stem leafy throughout or only at the base; leaves several, cauline or produced in a cluster near or at the base of the stem, variable, linear, oblong-elliptic, oblanceolate or linear-lanceolate, obtuse to acuminate, reduced above to bracts, $4.5-30 \mathrm{~cm}$. long, $0.8-4.5 \mathrm{~cm}$. wide at the widest part; raceme spicate, extremely variable in habit, cylindrical to rarely subsecund, densely or laxly few- (rarely 3-) to many-flowered, short and stout to elongated and slender, 3-25 cm. long, 1--2.5 cm. in diameter; floral bracts lanceolate to linear-lanceolate, acuminate, suberect to spreading, usually cellular-papillose on the margins, the lowermost bracts sometimes up to $3 \mathrm{~cm}$. long and greatly exceeding the flowers; flowers small, variable in size, often fragrant, green or yellowish green, sometimes marked or suffused with brownish purple, congested or remotely spaced on the rachis; dorsal sepal suborbicular-ovate to ovate-elliptic, rounded to obtuse and occasionally minutely cucullate at the apex, concave, erect and connivent with the petals to form a hood over the column, 3-nerved, 3-7 $\mathrm{mm}$. long, 1.3-4 mm. wide below the middle; lateral sepals ovate to ovate-lanceolate or elliptic-lanceolate, obtuse to subacute or sometimes minutely cucullate at the apex, oblique, spreading or strongly reflexed, 3-nerved, 3-9 $\mathrm{mm}$. long, 1-3.5 $\mathrm{mm}$. wide below the middle; petals usually fleshy, ovate-lanceolate to lanceolate, falcate, acute to acuminate, obliquely dilated at the base, erect and connivent with the dorsal sepal, 1- to 2-nerved, concave at the base, occasionally tinged or marked with brownish purple, more or less cellular-papillose on the margins, 3-7 $\mathrm{mm}$. long, 1-3 mm. wide at the base; lip fleshy, lanceolate to sublinear, not conspicuously dilated at the base, obtuse to acute at the tapering apex, reflexed or curved upward, 3- to 5-nerved, 3-9 $\mathrm{mm}$. long, $1.5-2.5 \mathrm{~mm}$. wide below the middle; spur cylindrical, slender to somewhat clavate, $2.5-7.5 \mathrm{~mm}$. long, usually shorter than the lip or at most only a little longer than the lip, occasionally only one third as long as the lip; column broad, thick, $1.5-3.5 \mathrm{~mm}$. long; capsule erect, obliquely ellipsoid, suberect, to $1.5 \mathrm{~cm}$. long.

In moist or wet soil in meadows in mud on edge of streams, turf mats, bogs, thickets, swamps, coniferous or mixed forests, canyons, marshes, in open slopes and cliffs, along streams and on gravel bars along rivers and lakes, in N. M. (Colfax and Taos cos.) and Ariz. (Apache and Greenlee cos.), June-Sept.; Greenl. and Nfld. to Alas., s. to N.Y., Pa., Neb., N.M., Ariz. and Calif.; Icel. and Asia. 


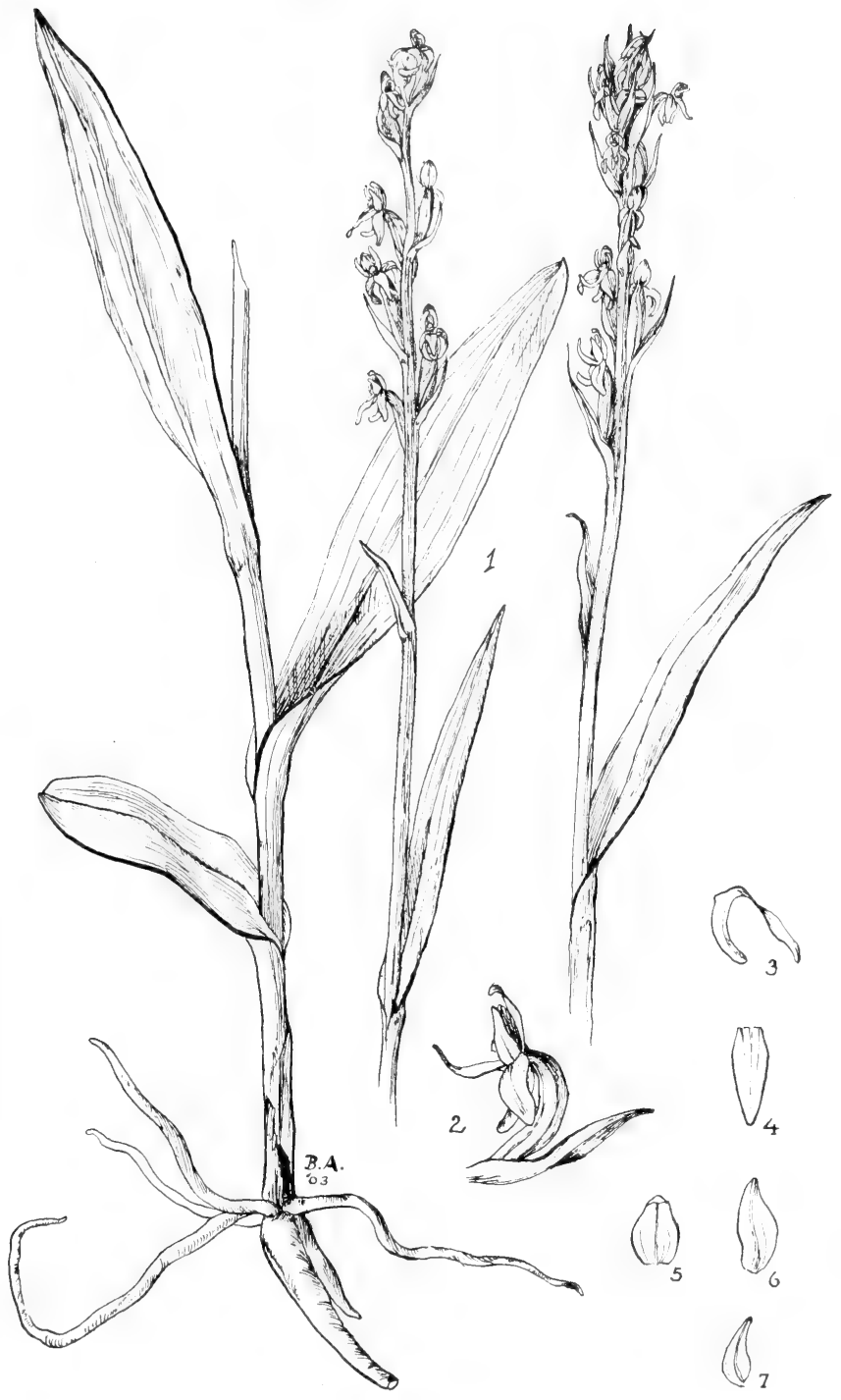

Fig. 362: Habenaria hyperborea: 1, plant $\times 1$; , flower and floral bract, side view, x $2 ; 3$, lip and spur, side view, x $2 ; 4$, lip, from above, x $2 ; 5$, dorsal sepal, x $2 ; 6$, lateral sepal, $\times 2 ; 7$, petal, x 2 . 


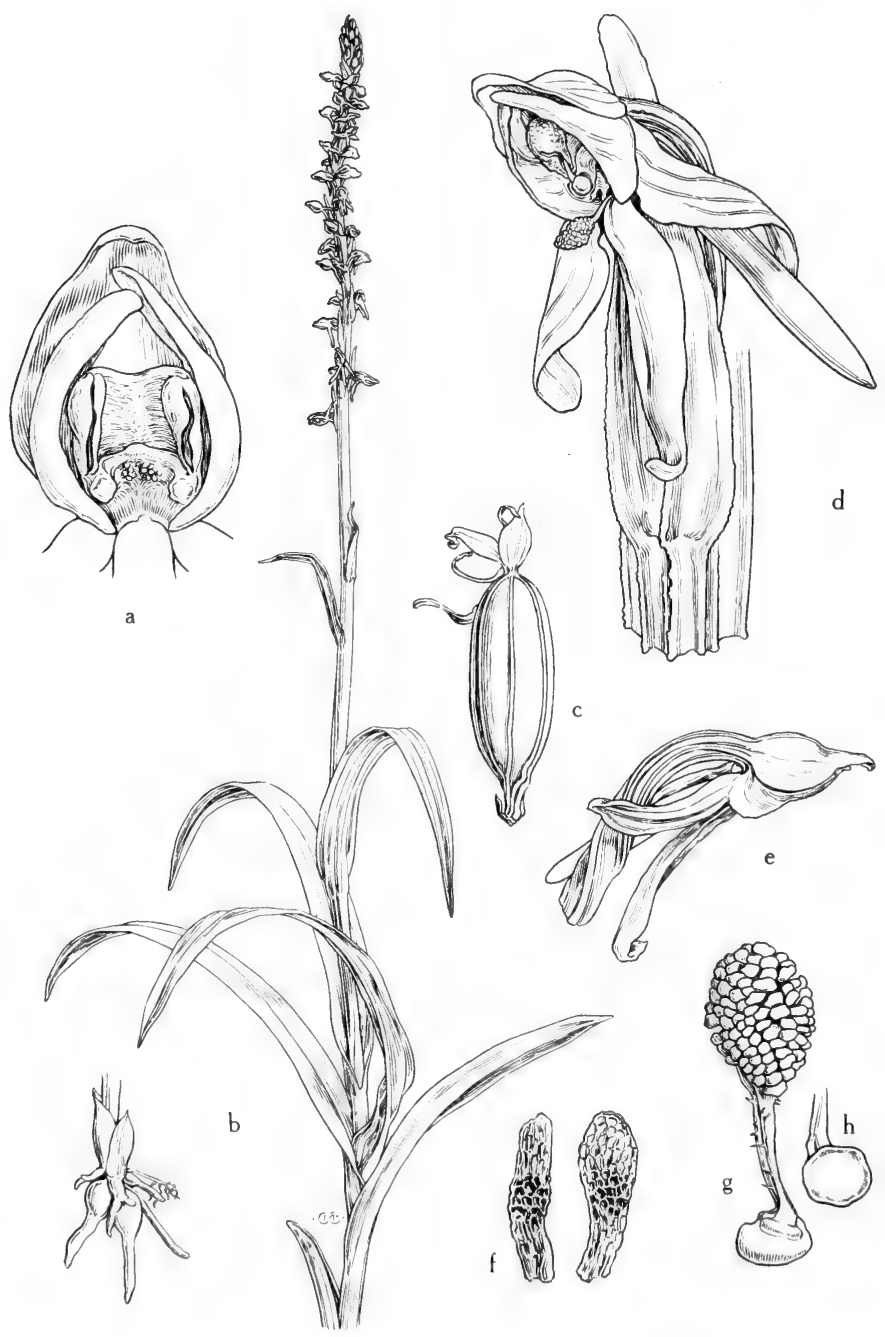

Fig. 363: Habenaria sparsiflora: a, upper sepal and petals, stigma and empty anther sacs, $\times 6$; b, habit, $\times 1$ 13; c, mature capsule, $\times 2$; , bract and flower, 1 anther still enclosed in anther sac, x 4; e. flower, lateral view, x 3; f, seeds, x 30; g, caudicle and massula (pollinium), x 16; h, base of caudicle, x 16. (From Mason, Fig. 193). 


\section{Habenaria saccata Greene. SLender BOG-ORCHID.}

Plant strictly erect, slender or stout, glabrous and light green throughout, 1.5-10 dm. tall; roots tuberous, fusiform, 5-10 mm. in diameter; stem leafy, provided below with one or more tubular sheaths; leaves scattered on the stem or occasionally clustered near the base, usually narrowly elliptic to linear-lanceolate or rarely oblanceolate, rounded to subacuminate at the apex, scarcely or not at all sheathing the stem, 4-14 cm. long, 1-4 cm. wide; raceme spicate, usually much-elongated, laxly few- to many-flowered, slender, cylindrical to subsecund, 4-42 cm. long, $0.8-2 \mathrm{~cm}$. in diameter; floral bracts linear-lanceolate, acuminate, cellular-papillose on the margins, the lowermost to $6 \mathrm{~cm}$. long and greatly exceeding the flowers; flowers small, green, commonly tinged or marked with purplish brown, usually scattered along the elongated rachis; sepals rather thin and 3nerved, the petals and lip fleshy; dorsal sepal suborbicular to ovate or ovate-elliptic, broadly rounded to obtuse and occasionally minutely cucullate at the apex, erect and connivent with the petals to form a hood over the column, 3-5 $\mathrm{mm}$. long, 3-3.5 mm. wide near the base; lateral sepals spreading or reflexed, triangular-ovate to elliptic-lanceolate, oblique, obtuse, 4-6 $\mathrm{mm}$. long, 2-3 $\mathrm{mm}$. wide near the base; petals triangular-lanceolate to elliptic-lanceolate, falcate, obtuse to acute, obliquely dilated and auriculate at the base, usually purplish, 1- to 2-nerved, 3-5 mm. long, 1.5-2.2 $\mathrm{mm}$. wide at the base; lip linear to occasionally ovate-elliptic, sometimes tapering at the apex, obtuse to acute, usually purplish, 4-7.5 $\mathrm{mm}$. long, 1-2 $\mathrm{mm}$. wide; spur broadly cylindric-clavate to scrotiform, sometimes slightly didymous, usually broadly rounded at the apex, often purplish, one-third to two-thirds the length of the lip, rarely longer; column short, thick, about $2 \mathrm{~mm}$. long, sometimes with a rather broad connective; capsule erect, obliquely ellipsoid, about $1 \mathrm{~cm}$. long.

In moist or wet soil in meadows, fields, bogs, thickets, swamps, marshes, canyons, coniferous forests, on open seepage slopes, ledges and in or along streams, in N. M. (Colfax, San Miguel, Santa Fe and Taos cos.) and Ariz. (Apache, Greenlee and Graham cos.) May-Sept.; N.M., Ariz. and Calif., n. to Alas.

\section{Habenaria sparsifiora Wats. Sparsely-Flowered Bog-orchid. Fig. 363.}

Plant strictly erect, slender or stout, glabrous and rather light green throughout, 1.5-7.5 dm. tall; roots fusiform, fleshy-thickened; stem more or less leafy, provided at the base with tubular sheaths, often several produced from the same rhizome (cespitose); leaves variable, scattered on the stem or occasionally clustered near the base, oblong-elliptic or oblanceolate-elliptic to linear-lanceolate or rarely linear, broadly rounded to acuminate at the apex, $6.5-30 \mathrm{~cm}$. long, $1-5 \mathrm{~cm}$. wide; raceme spicate, usually laxly few- to many-flowered, occasionally rather densely flowered, usually much-elongated, 1-4.5 dm. long, 1-3 cm. in diameter; floral bracts narrowly lanceolate, acuminate, usually about equaling the flowers or the lowermost bracts to $4 \mathrm{~cm}$. long and greatly exceeding the flowers; flowers lightgreen, usually scattered in an elongated raceme, the lowermost often remote; dorsal sepal suborbicular to suborbicular-ovate or ovate-elliptic, broadly rounded to obtuse at the apex, concave, erect and connivent with the petals to form a hood over the column, 3-nerved, 6-7.5 $\mathrm{mm}$. long, 4.5-6 $\mathrm{mm}$. wide near the base; lateral sepals strongly reflexed, ovate-elliptic to elliptic-lanceolate, obtuse, oblique, 3-nerved, with the margins usually revolute, 6-10 $\mathrm{mm}$. long, up to $4 \mathrm{~mm}$. wide; petals rather fleshy, triangular-lanceolate to narrowly lanceolate, falcate, obtuse to acuminate, obliquely dilated at the base and somewhat auriculate, often cellularpapillose on the margins, 1- to 2-nerved, connivent with the dorsal sepal, 6-8 $\mathrm{mm}$. long, 3-4.5 $\mathrm{mm}$. wide near the base; lip fleshy, large for the flower, conspicuously pendent, linear to linear-elliptic or sometimes linear-lanceolate, obtuse 
to acute, with a more or less fleshy-thickened ridge through the center below the middle, 6-14 mm. long, 1.5-3 mm. wide; spur cylindric, filiform or only slightly dilated above the middle, usually slightly exceeding the lip (rarely shorter than the lip), to $1.3 \mathrm{~cm}$. long; column conspicuous, usually variable in size, large for the flower, with a rather broad connective, usually one half the length of the dorsal sepal, 2.5-5 mm. long and wide; capsule obliquely ellipsoid, to $1.5 \mathrm{~cm}$. long.

In moist or wet soil in mt. meadows, marshes, swamps, bogs, open or dense forests, on stream banks and open seepage, and frequently about springs, in N. M. (Lincoln and Sandoval cos.) and Ariz. (Apache, Navajo, Coconino and Graham cos.), Apr.-Sept.; from Wash., s. to N.M., Ariz., Calif. and Baja Calif.

Var. brevifolia (Greene) Correll. Leaves very short, ovate, less than $9 \mathrm{~cm}$. long, usually reduced to clasping tubular sheaths. In N. M. (Grant, Lincoln, Socorro and Otero cos.).

Var. laxiflora (Rydb.) Correll. Flowers small, marked or suffused with purple; lip 4-7.5 mm. long, fleshy but usually without a central ridge; column about one third the length of the dorsal sepal. In N. M. (Sandoval Co.) and Ariz. (Navajo and Coconino cos.).

15. Habenaria dilatata (Pursh) Hook. TALL White BOg-ORChID, TALL WHite NORTHERN-ORCHID, FRAGRANT-ORCHID, BOREAL BOG-ORCHID.

Plant usually strictly erect and tall, glabrous, 1.5-12 dm. tall, sometimes taller; stem slender or stout, leafy; leaves linear to lanceolate or occasionally oblanceolate, obtuse to shortly acuminate, sheathing the stem below, to $30 \mathrm{~cm}$. long and 5.5 $\mathrm{cm}$. wide; raceme laxly or densely many-flowered, cylindrical, to $45 \mathrm{~cm}$. long and $3.5 \mathrm{~cm}$. in diameter; floral bracts lanceolate, acuminate, usually incurved and exceeding the flowers; flowers white or yellowish-white or greenish-white; dorsal sepal ovate to elliptic, obtuse, sometimes minutely cucullate at the apex, erect and connivent with the petals to form a hood over the column, 3-nerved, 3-7 mm. long, 2.5-4 mm. wide near the base; lateral sepals elliptic-lanceolate to narrowly lanceolate, broadly obtuse to acuminate, 3-nerved, spreading or reflexed, 4-9 mm. long, 1-3.5 mm. wide; petals ovate-lanceolate to linear-lanceolate, falcate, obtuse to acuminate-attenuate, obliquely dilated at the base, 1- or 2-nerved, connivent with the dorsal sepal, 4-8.2 mm. long, 1.8-4 mm. wide at the base, sometimes lightly notched at the apex and cellular-papillose on the margins; lip variable, rhombic-lanceolate to broadly lanceolate or with a suborbicular base and linear anterior part, usually but not always strongly dilated at the base, obtuse, sometimes minutely erose-ciliate on the margins below the middle, usually projecting outward, 5-10 $\mathrm{mm}$. long, 2-5 $\mathrm{mm}$. wide across the base; spur cylindrical, about equaling the lip in length.

In moist or wet situations in lowland or alpine meadows, swamps, bogs, marshes, coniferous forests, canyons, on moist seepage slopes and in or along streams and springs, bordering lakes and rarely on dry slopes, in N. M., Apr.Sept.; Greenl. to Alas., s. to N. J., Mich., Minn., N.M. and Calif.

16. Habenaria clavellata (Michx.) Spreng. GREEN REIN-ORCHID, SMALL woOD ORCHID. Fig. 359.

Plant usually small, glabrous, $0.8-4.5 \mathrm{dm}$. tall; roots slender, fleshy, rarely swollen near the base of the stem: stem somewhat angled and narrowly winged; leaves one or rarely two, expanded about the middle of the stem, obovateoblanceolate, obtuse, 5-18 cm. long, $1-3.5 \mathrm{~cm}$. wide, reduced above to linearlanceolate bracts; raceme few- to many-flowered, $2-9 \mathrm{~cm}$. long, 2-3.5 cm. in diameter; floral bracts lanceolate, acuminate, $3-10 \mathrm{~mm}$. long; flowers greenish or yellowish white, with stout spreading pedicellate ovaries which are about $1 \mathrm{~cm}$. 
long; sepals ovate, rounded to obtuse at the apex, 4-5 $\mathrm{mm}$. long, about $2.5 \mathrm{~mm}$. wide; lateral sepals oblique; petals ovate, obtuse, irregularly sinuate along the apical margin, 3-5 $\mathrm{mm}$. long, about $2 \mathrm{~mm}$. wide; lip narrowly oblong-cuneate, truncate and sinuately tridentate at the apex, 3-7 mm. long, 3-4 mm. wide at the apex; spur longer than the pedicellate ovary, slender-clavate (rarely cleft at the apex), curved upward, 8-12 (averaging less than 10) $\mathrm{mm}$. long. Gymnadeniopsis clavellata (Michx.) Rydb.

In water or at edge of water along streams in forests, swamps, on wooded seepage slopes and in ravines in e. Tex., June-Aug.; from Nfld., s. to n. Fla., w. to Tex., Ark., Mo. and Minn.

The narrowly oblong-cuneate lip that is truncate and sinuately tridentate at the apex is characteristic of this species.

17. Habenaria viridis (L.) $\mathrm{R}$. Br, var. bracteata (Muhl. ex Willd.) Gray. Long BRACTED HABENARIA, LONG-BRACTED ORCHID, SATYR ORCHID, FROG ORCHID, AMERICAN FROG ORCHID.

Plant stout, occasionally slender, glabrous throughout, 1-6 dm. tall; roots fleshy, palmate, from a thickened and swollen rootstock; stem leafy; leaves variable, the lower blades obovate to oblanceolate, the upper blades oblong to lanceolate, obtuse to acute, $4-15 \mathrm{~cm}$. long, 1-6.5 cm. wide; raceme densely or laxly flowered, to $20 \mathrm{~cm}$. long; floral bracts linear-lanceolate, acuminate, 1.5-5.5 $\mathrm{cm}$. long, or more, usually 2 to 4 times the length of the flower (according to the age of the plant); flowers green, with stout pedicellate ovaries which are 5-10 $\mathrm{mm}$. long; dorsal sepal ovate-orbicular to oblong-elliptic, concave, 3-6 mm. long, 2-3.5 mm. wide; lateral sepals obliquely ovate-oblong, obtuse, 4-6 mm. long, 2-4 $\mathrm{mm}$. wide below the middle; petals linear-lanceolate to linear-oblong, acute to subobtuse, 3-5 $\mathrm{mm}$. long; lip narrowly oblong-spatulate or narrowly cuneate, 2- to 3-toothed at the apex (the middle tooth short and often obscure), 5-10 mm. long, 2-4 mm. wide near the apex, with a small thickened keel along the center below the middle, occasionally tinged with reddish-brown, 2 to 3 times longer than the abbreviated saccate whitish spur; spur scrotiform; capsule ellipsoid, 7-10 $\mathrm{mm}$. long.

In moist or wet soil in dense hardwood or mixed coniferous-hardwood forests, in meadows, prairies, thickets, bogs and swamps and in open grassy slopes, in N. M. (San Miguel and Sierra cos:), Mar.-Aug.; Nfid. to Alas., s. to N. C., Ia. and N.M.; Icel., Jap. and China.

\section{Listeria R. BR.}

Small inconspicuous terrestrial herbs with fibrous roots; stems slender, more or less glandular-pubescent above the 2 opposite or subopposite leaves; leaves sessile, inserted about the middle of the stem; inflorescence a terminal raceme composed of small greenish or purplish flowers; sepals and petals free, similar and subequal; lip longer than the sepals and petals, bilobed or 2-cleft at the apex, variously toothed, auricled, lobed or sometimes entire on each side at the base; column wingless; stigmas with a rounded beak; anther borne on the back of the column near the apex; pollinia 2, powdery; capsule small, slender pedicellate.

A small genus of about 20 species widely distributed in boreal and temperate regions of the Northern Hemisphere.

1. Lip with a short slender claw, narrowly cuneate, shallowly notched at apex, 8-13 mm. long, 5-7 mm. wide rear apex; column 2.5-3 mm. long 1. L. convallarioides.

1. Lip sessile, linear-oblong, cleft halfway or more to the base into linear-filiform to linear-lanceolate lobes, not flaring at the apex; column $0.5 \mathrm{~mm}$. long or less (2) 

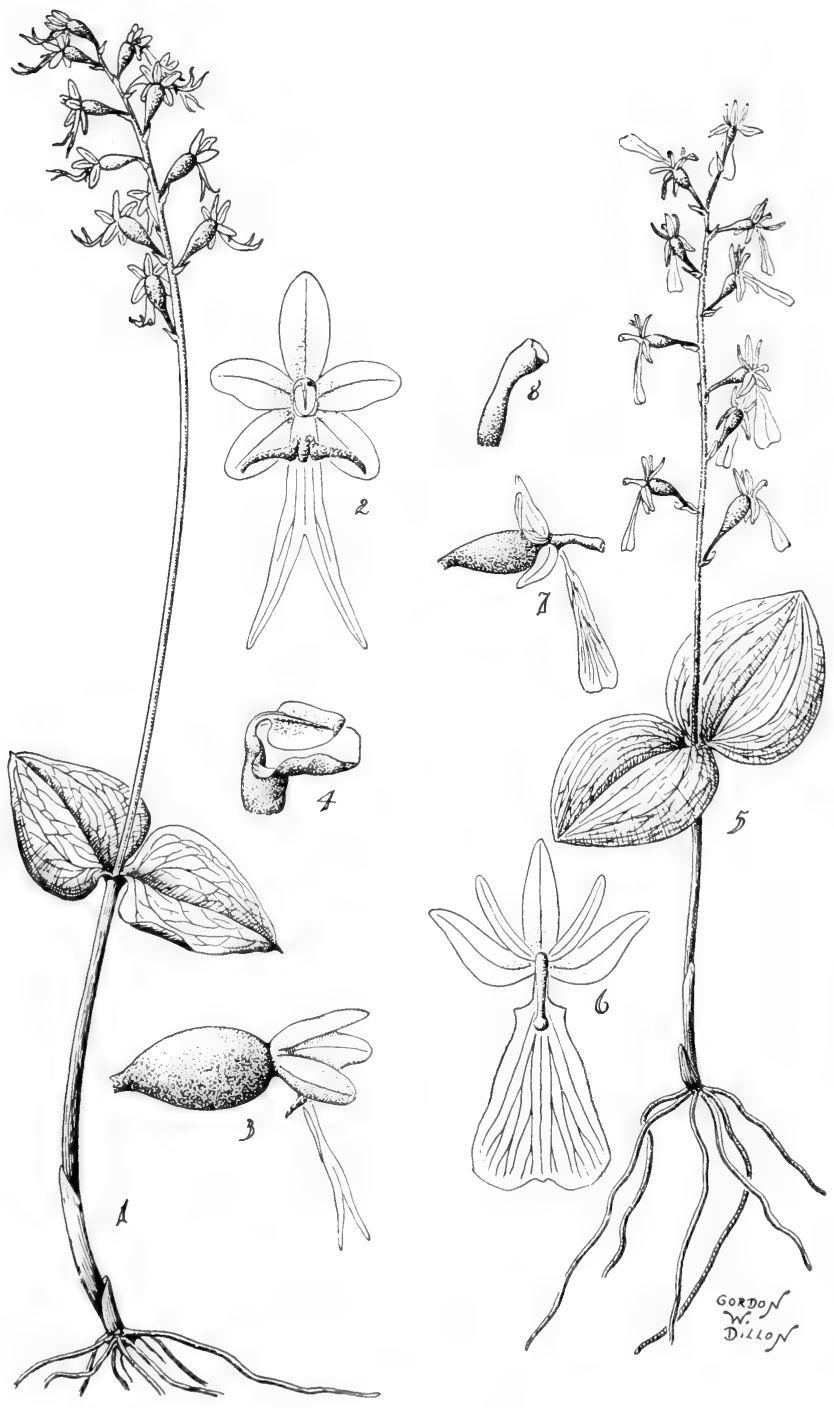

Fig. 364: 1-4. Listera cordata: 1, plant, x 1: 2, flower, front view, spread open, x 5;3, flower, side view, x 5; 4, column, side view, x 15. 5-8, Listera convallarioides: 5 , plant, $x 1 ; 6$, flower, front view, spread open x $3 ; 7$, flower, side view, x $2 ; 8$, column, side view $\times 5$. 
2(1). Lip with prominent curved basal lateral teeth; lamina less than $6 \mathrm{~mm}$. long; stem green...................................................... $2 . L$ cordata.

2. Lip slightly auriculate at the base but without lateral teeth; lamina more than $6 \mathrm{~mm}$. long; stem purplish...................................... . L. australis.

1. Listera convallarioides ( $\mathrm{Sw}$.) Nutt. BROAD-LEAvED TWAYBLADE, BROAD-LIPPED TWAYBLADE. Fig. 364.

Plants slender or occasionally stout, stoloniferous, glabrous below, densely and minutely whitish glandular-pubescent above, $6-37 \mathrm{~cm}$. tall; leaves two, opposite or occasionally subopposite, mostly above the middle of the stem, broadly ovate to elliptic, oval or suborbicular, obtuse or rarely acute to apiculate, glabrous, 2-7 cm. long, 1.5-5.8 cm. wide; raceme loose, laxly many-flowered, 2-12 cm. long, $2.5-4 \mathrm{~cm}$. in diameter; floral bracts rhombic-ovate, acute to acuminate, semitranslucent, 3-5 mm. long: flowers yellowish green, with slender pedicels which are 4-7 mm. long; dorsal sepal ovate-lanceolate, narrowly obtuse to acute, 4.5-5 mm. long, about $1.8-2 \mathrm{~mm}$. wide; lateral sepals lanceolate, strongly falcaterecurved, acute to subacute, 1-nerved, $4.5-5.5 \mathrm{~mm}$. long, 1.5-1.8 $\mathrm{mm}$. wide below the middle; petals linear-falcate, obtuse, 1-nerved, 4-5 mm. long, 0.8-1 mm. wide; lip with a short slender claw, narrowly cuneate, shallowly notched at the apex, with the lateral lobules obtusely rounded, minutely toothed in the sinus, with a short triangular tooth on each side near the base, minutely bristly-ciliate along the margins, $8-13 \mathrm{~mm}$. long, 5-7 mm. wide near the apex; column slender, slightly recurved, $2.5-3 \mathrm{~mm}$. long; capsule nearly glabrous.

In leaf mold in damp mossy coniferous or mixed coniferous-hardwood forests, bogs, meadows, various types of evergreen swamps, wet thickets in forests and in peaty barrens, in Ariz. (Pima Co.), June-Sept.; Nfld. and Ont. to Alas., s. to Ariz.

\section{Listera cordata (L.) R. Br. Heart-Leaved twayblade. Fig. 364.}

Plant slender, delicate, glabrous throughout (except for a small glandularpubescent area just above the leaves), $6.5-25 \mathrm{~cm}$. tall; roots often somewhat matted; leaves 2 , opposite, about midway up the stem, broadly to narrowly ovatecordate or deltoid, mucronate, $0.9-4 \mathrm{~cm}$. long, $0.7-3.8 \mathrm{~cm}$. wide; raceme densely or loosely flowered, slender, $2-10 \mathrm{~cm}$. long, $8-15 \mathrm{~mm}$. in diameter; floral bracts small, purplish to yellowish-green, with slender pedicels which are 1-4 mm. long; dorsal sepal ovate-oblong to oblong-elliptic, obtuse, 2-3 $\mathrm{mm}$. long, about $1 \mathrm{~mm}$. wide; lateral sepals ovate-oblong to elliptic or oblong-linear, obtuse, somewhat oblique, 2-3 $\mathrm{mm}$. long, $0.5-1.5 \mathrm{~mm}$. wide; petals elliptic to oblong-linear, obtuse or occasionally truncate, $1.5-2.5 \mathrm{~mm}$. long, $0.5-1 \mathrm{~mm}$. wide; lip linear-oblong, cleft one-half to two thirds of the distance to the base into two linear-lanceolate lobes, with a subulate transverse tooth on each side near the base, the lamina being 3-6 mm. long and $1-1.5 \mathrm{~mm}$. wide near the middle; column short, about $0.5 \mathrm{~mm}$. long.

In mossy damp coniferous or mixed coniferous-hardwood forests, sphagnum bogs, various kinds of evergreen swamps and in subalpine forests and thickets, in N. M. (Pecos River National Forest), Apr.-Sept.; Greenl. and Nfld. to Alas., s. to N.C., Wyo., N.M. and Calif.; Icel., Eur. and Jap.

\section{Listera australis Lindl. Southern twayblade. Fig. 365.}

Small inconspicuous terrestrial herb with fibrous matted roots; stem slender, rarely more than $15 \mathrm{~cm}$. high, more or less glandular-pubescent above the two opposite or subopposite leaves; leaves sessile, inserted above the middle of the stem, typically ovate-elliptic, to $4 \mathrm{~cm}$. long; inflorescence a terminal raceme composed of small reddish-purple or greenish flowers; sepals and petals free, similar 


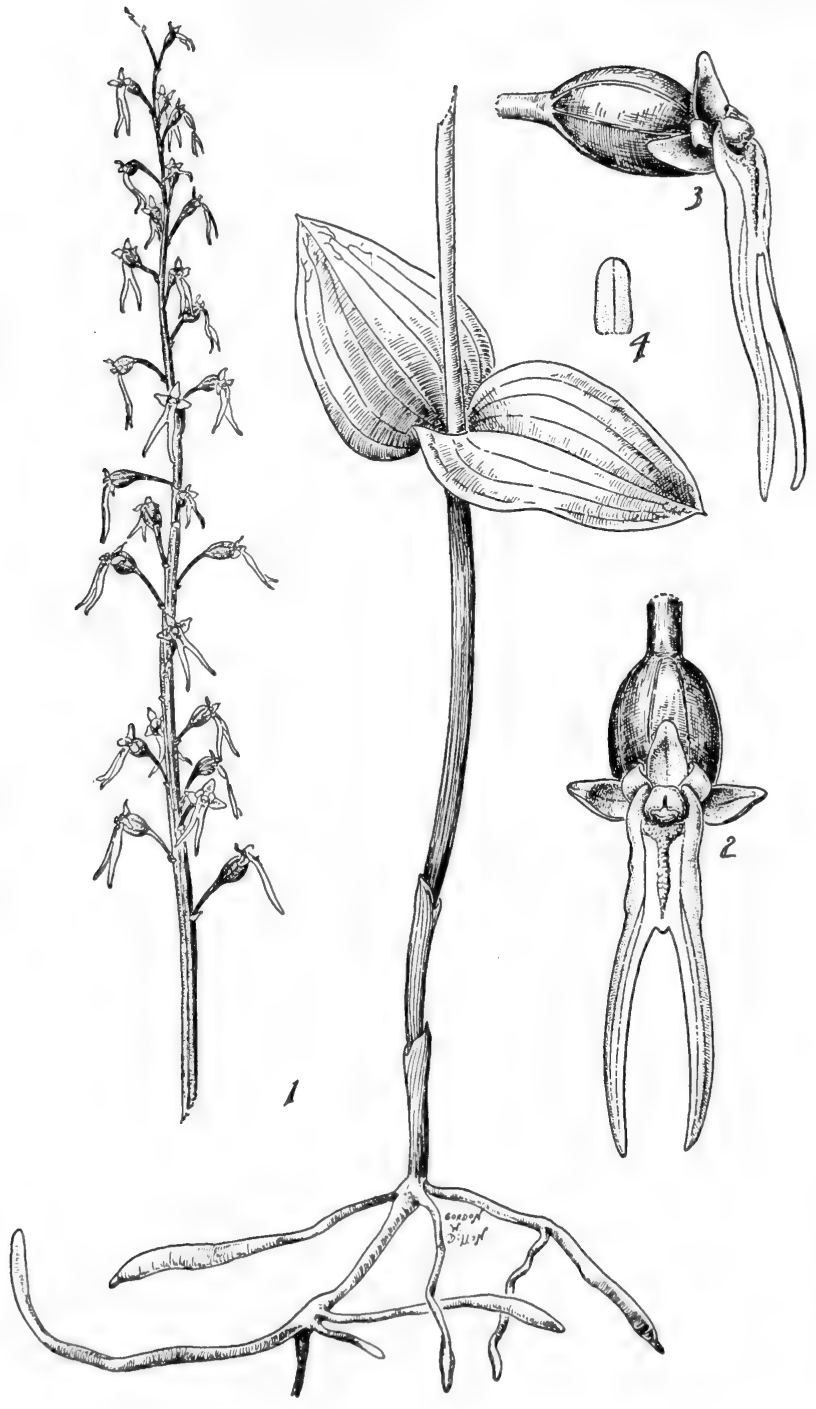

Fig. 365: Listera australis: 1, plant, x 1; 2, flower, front view, x 5; 3, flower, side view, $x 5 ; 4$, petal, $\times 6$. 


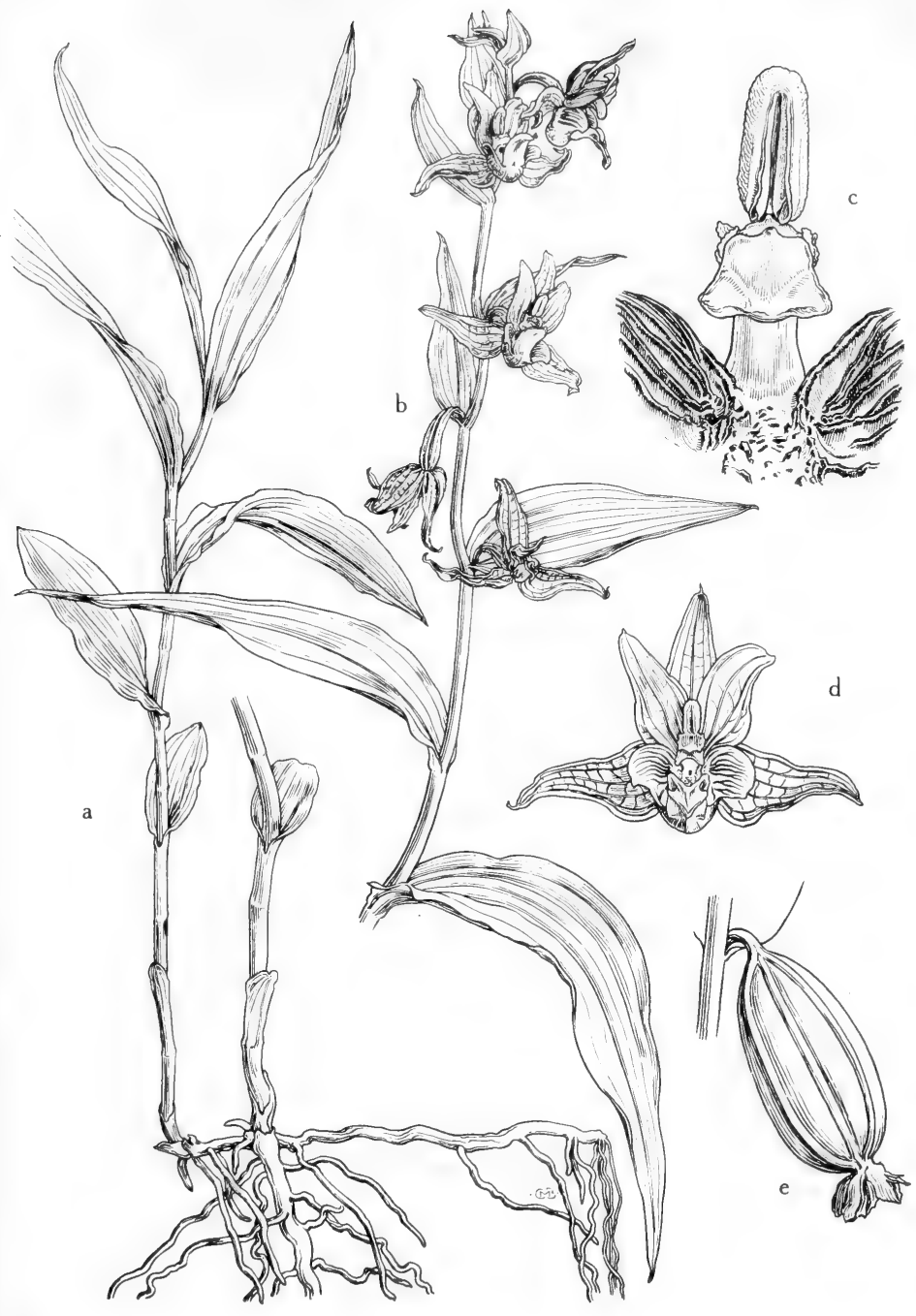

Fig. 366: Epipactis gigantea: a, habit, showing creeping rootstocks, stems and clasping leaves, $\mathrm{x} 2 \% ; \mathrm{b}$, habit, upper part of stem, showing raceme of flowers with their leaflike bracts, x $2 / 3$; c, anther and stigma, x 4; d, flower, face view, x $1 \frac{1}{5}$; e, mature capsule, x 11\%. (From Mason, Fig. 192). 
and subequal, to $2 \mathrm{~mm}$. long and $1 \mathrm{~mm}$. wide; lip longer than the sepals and petals, linear, deeply 2 -cleft, auricled on each side at the base; column wingless; capsule small, slender, pedicellate.

In humus and on mosses of low moist and swampy woods, and in ravines along streams, in s.e. Tex., Feb.-May; locally from Que. and Ont., s. to cen. Fla. and w. to Tex.

\section{Epipactis Sw.}

A genus of about 20 species mainly in temperate and mountainous regions of Europe and Asia, with 2 species in North America.

\section{Epipactis gigantea Hook. Giant helleborine. Fig. 366.}

Plant terrestrial or saxicolous, usually $5 \mathrm{dm}$. tall or more; stem simple, leafy, from a short creeping rhizome with fibrous roots; leaves clasping stem, plicatevenose, broadly elliptic to linear-lanceolate, $6-20 \mathrm{~cm}$. long, 2-7 cm. wide; inflorescence a few- to many-flowered prominently bracteose more or less secund raceme; floral bracts foliaceous, conspicuously exceeding the flowers; flowers greenish, marked with purplish or reddish nerves; sepals free, lanceolate, subequal, spreading or loosely connivent, 15-25 $\mathrm{mm}$. long, 7-9 $\mathrm{mm}$. wide; petals similar to the sepals but smaller; lip sessile on the base of the column, fleshy, saccate at the base, flattened above, distinctly 3-lobed with the lateral lobes erect to form a sac, about as long as sepals; column short, broadened above; capsule obovoid to ellipsoid, pendent, $2-2.5 \mathrm{~cm}$. long. Serapias gigantea (Hook.) A. A. Eat.

On seepage slopes, wet limestone bluffs and ledges, in swamps and marshy places, in Okla. (Murray Co.) and in cen. and w. Tex., N. M. (Eddy, Grant, Guadalupe and Socorro cos.) and Ariz. (Navajo, Coconino, Mohave, Santa Cruz and Pima cos.), Apr.-July; scattered from Mont., S.D., Colo., Okla. and Tex., w. to B.C., Wash., Ore. and Calif.; also Mex.

\section{Pogonia Juss.}

A genus of about 20 species widely dispersed over the world.

1. Pogonia ophioglossoides (L.) Ker. Rose Pogonia. Fig. 367.

Plants slender, glabrous (propagating by means of root-shoots), 1-7 dm. tall; stem green or brownish-green; leaf solitary, about halfway up the stem (occasionally with one or two long-petiolate leaves arising from the base of the stem), ovate to elliptic or broadly ovate-lanceolate, obtuse to subacute, $2-12 \mathrm{~cm}$. long, 1-3 cm. wide; inflorescence composed of one to three flowers (usually one) terminating the stem; floral bract foliaceous, oblong-elliptic to oblong-lanceolate, 1-3 cm. long, 3-8 $\mathrm{mm}$. wide; flowers rose to white, of several days' duration; dorsal sepal oblong-elliptic to linear-oblong, subobtuse, $1.5-2.3 \mathrm{~cm}$. long, 3-6 mm. wide; lateral sepals narrowly elliptic to linear-oblong or linear-lanceolate, acute to rarely obtuse, $1.5-2.7 \mathrm{~cm}$. long, 3-6 mm. wide; petals oblong-elliptic to ellipticobovate, broadly rounded at the apex, $1.5-2.5 \mathrm{~cm}$. long, 6-11 mm. wide; lip narrowly oblong-spatulate, narrowed at the base, lacerate-toothed along the apical margin, prominently bearded along the three central veins of the disk with short fleshy yellow-white bristles, $1.5-2.5 \mathrm{~cm}$. long, $8-10 \mathrm{~mm}$. wide near the apex; column about $1 \mathrm{~cm}$. long, toothed at the apex.

In swamps, bogs, marshes, wet savannahs, prairies and seepage slopes in e. and s.e. Tex., Apr.-July; from Nfld., s. to Fla., w. to Minn., III. and Tex.

The heavily bearded lip, which forms the lower segment of the flower, is distinctive. 


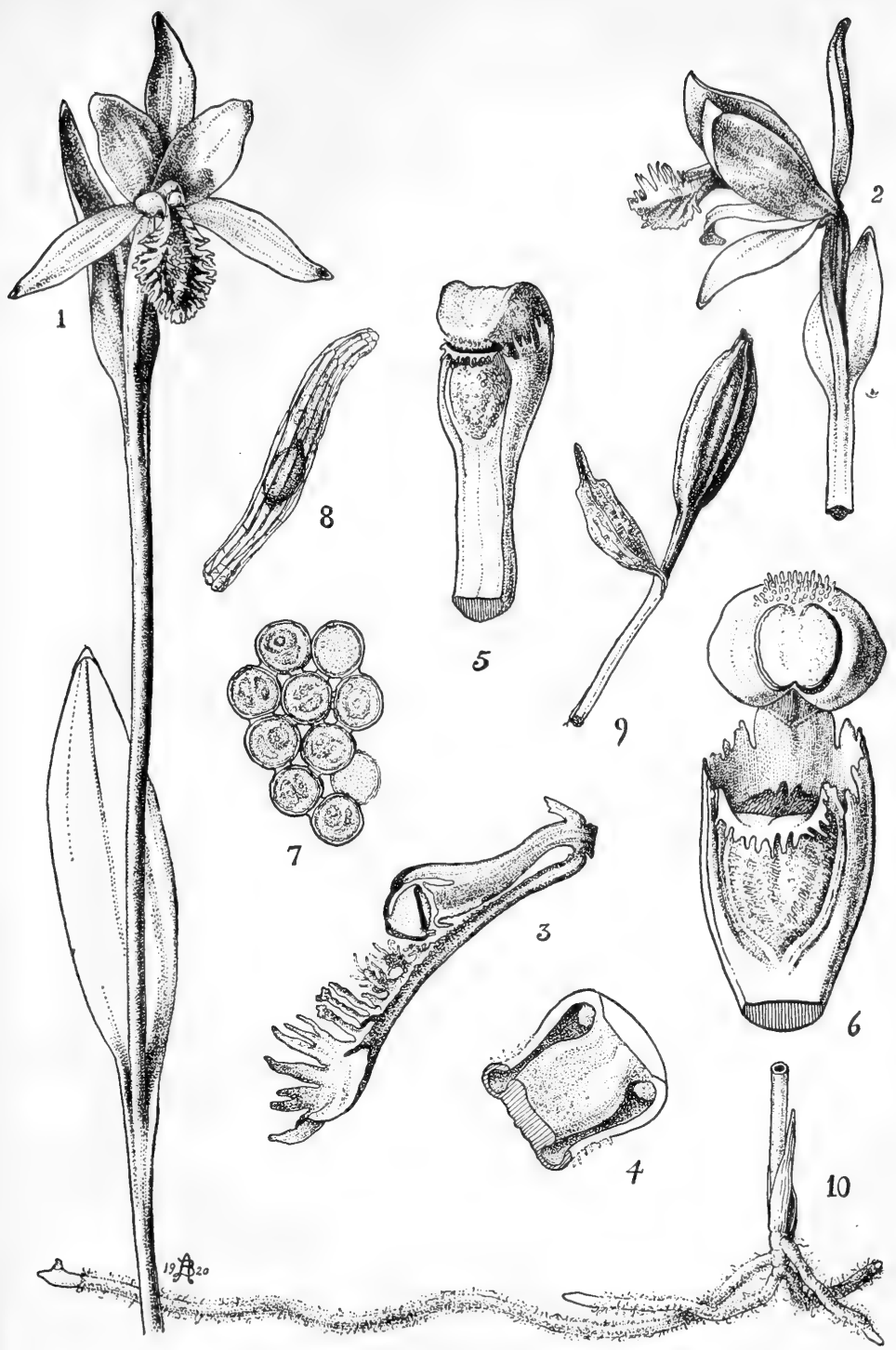

Fig. 367: Pogonia ophioglossoides: 1, upper part of plant, x 1; flower, side view, $\mathrm{x} 1 ; 3$, longitudinal section through center of lip and column, to show the structure of the median keel of the lip and the position of the anther in relation to the clinandrium, $\mathrm{x} 3 ; 4$, base of lip to show gland on each side, $\mathrm{x} 6 \frac{1}{1} ; 5$, column, with anther in normal position, $\mathrm{x} 4 \frac{1}{2} ; 6$, upper part of column, anther turned back, x $9 ; 7$, ten pollen grains, highly magnified; 8 , seed, highly magnified; 9 , capsule, $x 1 ; 10$, base of stem, $x$. 


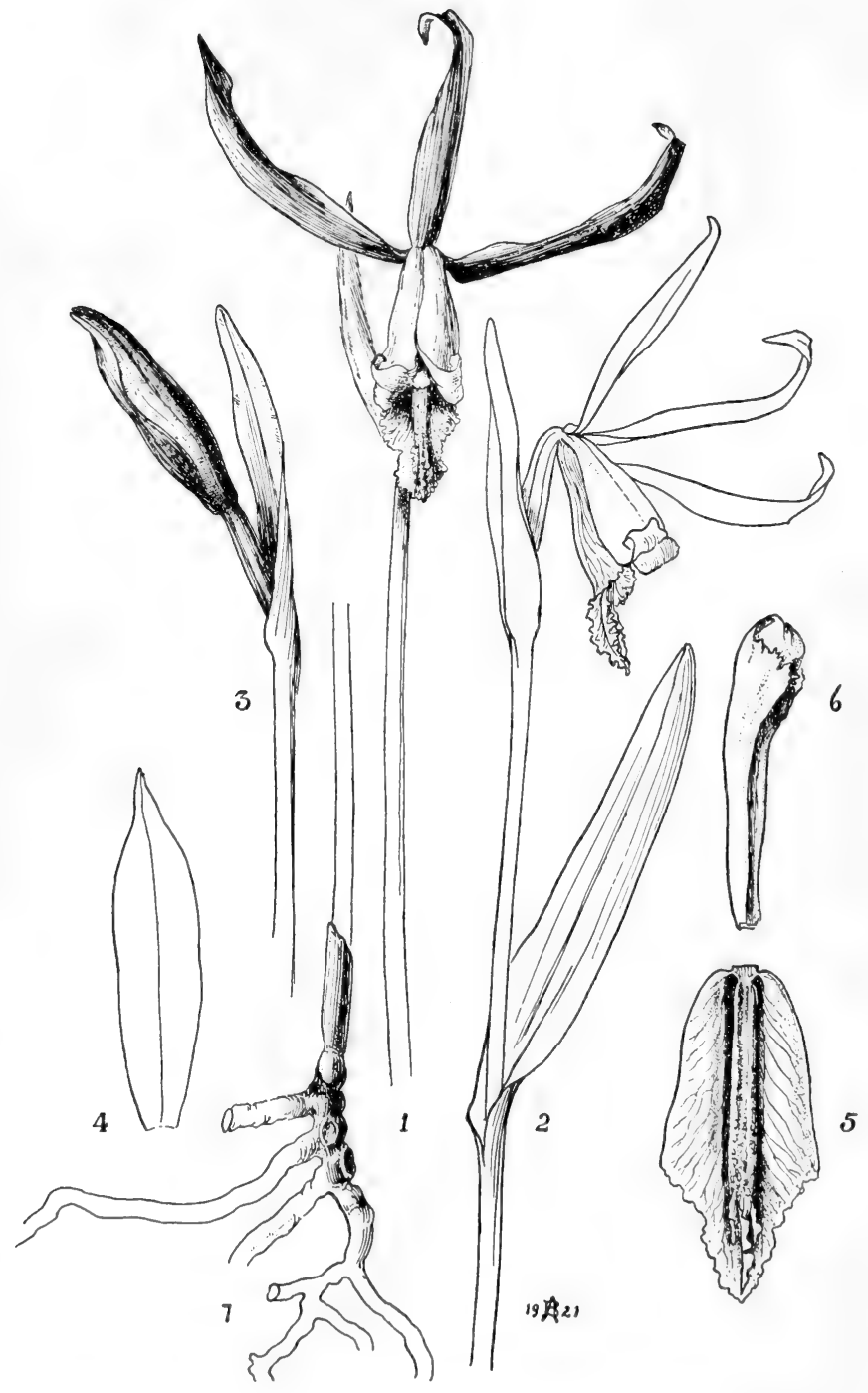

Fig. 368: Cleistes divaricata: 1 and 2, plant, $\mathrm{x} 1$; 3, flower bud, $\mathrm{x} 1$; 4 , petal, $\mathrm{x} 1$; 5 , lip, spread out, $x 1 ; 6$, column, $x 2 ; 7$, rhizome and roots, $x 1$. 


\section{Cleistes Rich.}

A genus of about 40 species in the Western Hemisphere, mainly in South America.

1. Cleistes divaricata (L.) Ames. Spreading pogonia. Fig. 368.

Terrestrial herb with slender fibrous root, rigidly erect, to $75 \mathrm{~cm}$. tall; leaf solitary, inserted above the middle of the stem, oblong-lanceolate, to $15 \mathrm{~cm}$. long and $2 \mathrm{~cm}$. wide; flowers one to rarely 3 that terminate the stem; perianth parts distinct; sepals to $65 \mathrm{~mm}$. long, about $5 \mathrm{~mm}$. wide; petals magenta-pink to white, spatulate-oblanceolate, to $45 \mathrm{~mm}$. long and $12 \mathrm{~mm}$. wide; lip crested, about as long as petals, oblong-cuneate, strongly veined, indistinctly 3-lobed, crenulate along the margins, with a linear-grooved somewhat fleshy papillose crest through the median line of the disk, 3.5-4.5 cm. long, about $2 \mathrm{~cm}$. wide above the middle; lateral lobes broadly rounded at the apex, involute to form a trough; apical lobe ovate-triangular, somewhat revolute and decurved, projecting about $1 \mathrm{~cm}$. beyond the lateral lobes; column free, 2-2.5 cm. long, eroded at apex; capsule erect, cylindrical. Pogonia divaricata (L.) R. Br.

This species is represented in Tex. by a collection made by E. J. Palmer, but the exact locality is unknown. It doubtlessly occurs in the s.e. part of the state and is to be looked for in low grassy pine barrens, savannahs, prairies, flatwoods, bogs, swamps and along stream banks; rare and of local occurrence from N. J. and Del. s. to cen. Fla., w. to Tenn., Ky. and Tex.; Apr.-July.

The ascending and often recurved linear-lanceolate brownish sepals are distinctive.

\section{Calopogon R. BR.}

Terrestrial scapose herbs arising from orbicular or ellipsoid corms, with a solitary (rarely more) grasslike leaf sheathing the stem near the base; inflorescence a dense or lax few-to several-flowered terminal raceme; flowers conspicuous, showy, varying in color from white to deep-crimson or magenta; sepals and petals free, spreading; lip forming the upper segment of the perianth, with a minute lateral lobe on each side near the base, strongly dilated and bearded above with numerous clavellate hairs and papillae at the apex; column free, slender and somewhat incurved, winged on each side at the apex; anther terminal, operculate; pollinia four, two in each anther cell, the grains connected by filaments; capsule erect, cylindrical or ellipsoid.

A small New World genus of 4 species, chiefly occurring in southeastern United States with one species widespread in eastern Canada and the United States. The bearded lip, which forms the uppermost segment of the flower, is distinctive.

1. Flowers usually 2 to 5 , opening almost simultaneously; leaves grasslike, about $2 \mathrm{~mm}$. wide........................................................... . C. barbatus.

1. Flowers usually more than 8 , opening in slow succession up the raceme to extend over a prolonged period; leaves usually much more than $5 \mathrm{~mm}$. wide. 2. C. pulchellus.

1. Calopogon barbatus (Walt.) Ames. Bearded grass-PInK.

Plant scapose, slender, erect, somewhat rigid, glabrous, $1.5-4.5 \mathrm{dm}$. tall; rootstock a bulbous corm; having a tuft of roots at the proximal end and usually the remains of the old stalks at the distal end; stem light green or tinged with reddish brown (occasionally two stems are produced from the same corm); leaves (when present) one or two, basal, narrowly linear and grasslike, long-acuminate, strongly ribbed, 5-18 cm. long, about $2 \mathrm{~mm}$. wide; raceme short, often somewhat capitate, three- to five- (or rarely more-) flowered; floral bracts subulate to shortly lanceolate, 2-4 mm. long; flowers rose-pink, rarely white, mostly opening simultaneously, 
with the slender pedicellate ovaries $6-10 \mathrm{~mm}$. long; dorsal sepal narrowly oblongelliptic to linear-oblong, acute to apiculate, $1.3-1.7 \mathrm{~cm}$. long, 4-6 $\mathrm{mm}$. wide; lateral sepals arising from a broad base, obliquely ovate-deltoid, somewhat keeled at the apex, abruptly acute or apiculate, about $1.3 \mathrm{~cm}$. long, 5-7 mm. wide; petals with a short claw, varying in shape from narrowly oblong-pandurate to ovatelanceolate or oblong-elliptic with a distinct constriction near the middle, or with an ovate-orbicular base and gradually tapering to oblong above, elongated, obtuse or abruptly acute, widest below the middle, $1.2-1.5 \mathrm{~cm}$. long, $3-5 \mathrm{~mm}$. wide; lip obscurely 3-lobed, 1-1.3 cm. long; lateral lobes near the base, inconspicuous, with a triangular apex, involute, separated from the large mid-lobe by a gradually dilated isthmus; mid-lobe broadly obovate to suborbicular, broadly rounded (sometimes retuse) at the apex, with broadly rounded lateral margins, 7-10 $\mathrm{mm}$. wide; disk bearded on the central portion with clavellate hairs, the basal and central hairs being deep rust-red and the anterior hairs (usually extending to the apical margins) being gradually reduced to pale lavender papillae; column broadly winged on each side near the apex, 7-8 $\mathrm{mm}$. long, $4.5-7.5 \mathrm{~mm}$. wide across the wings, with the pair of wings (when spread out) forming a semiorbicular lamina which is either subtruncate at the base or tapering down the sides of the column.

In moist acid sandy soils on edge of bogs, swamps and marshes, and in moist open woodlands, rare in e. Tex. (Henderson Co.), Apr--May; from N. C. along the Atl. seaboard to Fla., w. along the Gulf Coast to e. Tex.

\section{Calopogon pulchellus (Salisb.) R. Br. Grass-Pink. Fig. 369.}

Plant scapose, erect, slender to somewhat stout, glabrous, 1-13.5 dm. tall; rootstock a rather small corm having a tuft of slender whitish roots at the proximal end; leaves one or rarely two, basal, linear to linear-lanceolate, occasionally semiterete or linear-setaceous and bristly, strongly ribbed, keeled or flat, to $5 \mathrm{dm}$. or more long and $5 \mathrm{~cm}$. wide; raceme laxly flowered, elongated, composed of four to twenty showy flowers, $8-46 \mathrm{~cm}$. long; floral bracts ovate to ovate-lanceolate, acuminate, 3-9 $\mathrm{mm}$. long; flowers opening successively up the raceme, pink to rose-purple or magenta-crimson, rarely pure white; dorsal sepal narrowly oblong to oblong-elliptic, acute to apiculate, $2-2.7 \mathrm{~cm}$. long, $5.5-10 \mathrm{~mm}$. wide; lateral sepals ovate to ovate-lanceolate or oblong-elliptic, oblique, abruptly acute, often somewhat keeled and apiculate at the apex, 1.2-2.3 cm. long. 9-13 mm. wide; petals with a short claw, narrowly pandurate, oblong-pandurate, ovate-lanceolate or oblong-elliptic, usually somewhat constricted above the middle, widest near the base, broadly rounded to obtuse or rarely acute at the apex, $1.3-2.4 \mathrm{~cm}$. long, 4-9 $\mathrm{mm}$. wide; lip obsolescently 3-lobed, 1-2 cm. long; lateral lobes minute, separated from the midlobe by an elongated isthmus, the isthmus linear; midlobe broadly cuneate-flabellate to obreniform or transversely oblong-elliptic, retuse to broadly rounded and apiculate at the apex, occasionally retuse with an apicule in the sinus, 6-18 mm. wide; disk bearded on the three central veins with clavellate hairs, the filaments of the basal hairs united and deep purple, the shorter central hairs distinct and gradually becoming cream-colored with orange-colored tips, the anterior hairs gradually shortened and deep rust-red becoming fleshy-colored papillae near the apex; column strongly incurved, 1-2 cm. long, broadly winged on each side at the apex, 6-9 $\mathrm{mm}$. across the wings; with the pair of wings (when spread out) forming a suborbicular to rhombic or broadly obovate lamina; capsule ellipsoid, three-angled, prominently six-ribbed, $1.2-2.3 \mathrm{~cm}$. long, 5-19 $\mathrm{mm}$. in diameter.

In depressions in savannahs and prairies, marshes, swamps and bogs, in Okla. (Waterfall) and e. and s.e. Tex., Apr.-June; from Nfld., s. to s. Fla., w. to Minn., Ia., Mo., Okla. and Tex. 


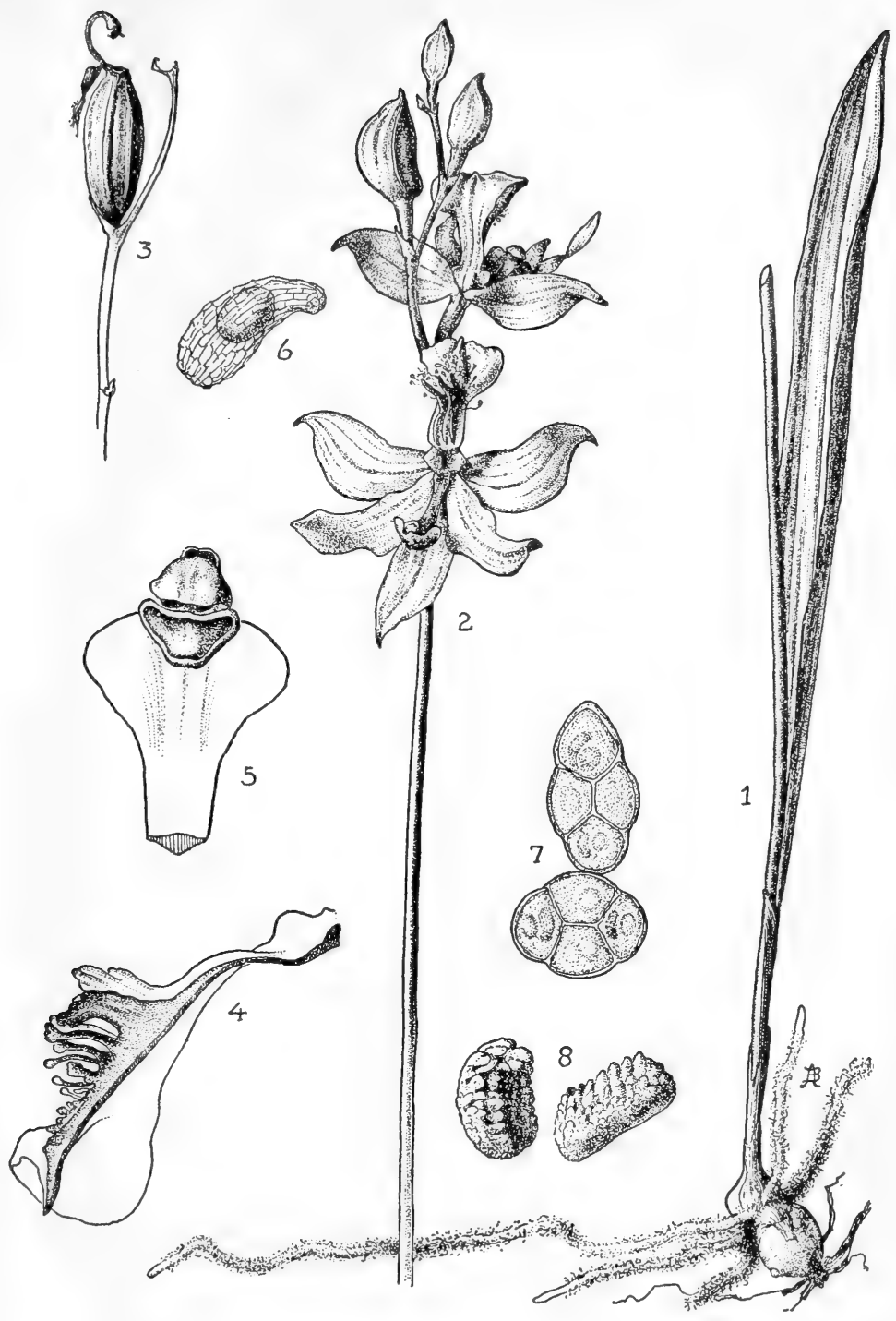

Fig. 369: Calopogon pulchellus: 1, basal part of plant, x 1; 2, inflorescence, x 1; 3 , mature capsule, to show the persistent column, $\mathrm{x} 1 ; 4$, longitudinal section through center of lip to show the papillae, x 4; 5, upper part of column, x 4 ; 6 , seed, highly magnified; 7 , two pollen tetrads, highly magnified; 8 , pollen masses, highly magnified. 


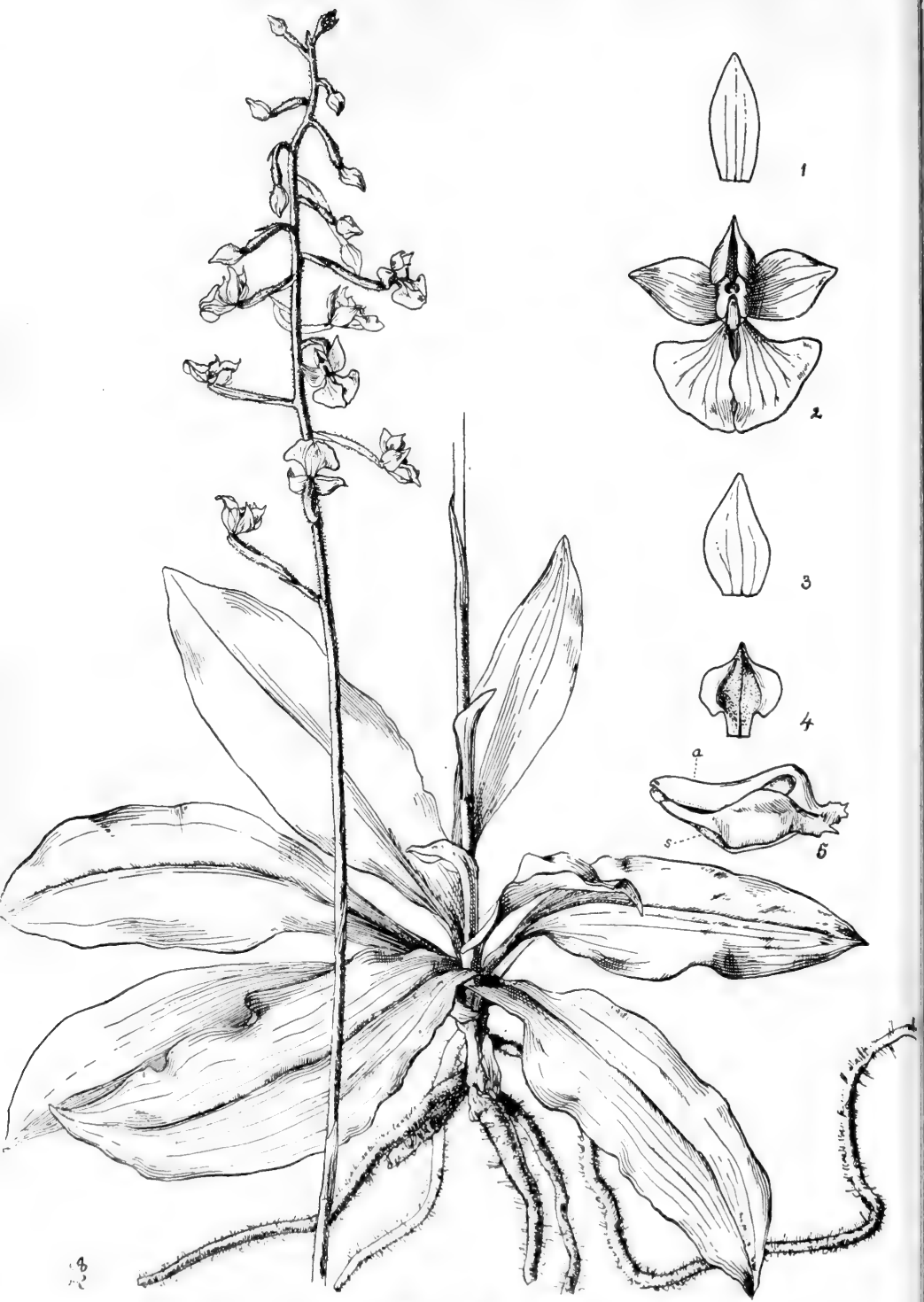

Fig. 370: Ponthicva racemosa: plant, x $2 / 3 ; 1$, dorsal sepal, $x 2$; 2 , flower, partly spread out, x $2 ; 3$, lateral sepal, x $2 ; 4$, lip, spread out, X 2; 5, column (a, anther, s, stigma) side view, $x 8$. 


\section{Ponthieva R. BR.}

In this genus there are 25 species that are found in the warmer regions of the Western Hemisphere from southeastern Virginia to Chile, including Mexico, Central America, the West Indies and South America.

\section{Ponthieva racemosa (Walt.) Mohr. Shadow-witch. Fig. 370.}

Terrestrial scapose herb with fleshy or somewhat fibrous roots, usually about $3 \mathrm{dm}$. tall; leaves in basal rosette, oblong-elliptic to oblanceolate, obtuse, to $15 \mathrm{~cm}$. long and $5 \mathrm{~cm}$. wide; flowers white-green, fragrant, nonresupinate in a lax terminal raceme; sepals ovate to elliptic-lanceolate, spreading, to $8 \mathrm{~mm}$. long and $3.5 \mathrm{~mm}$. wide; petals attached to the column above its base, oblique, often adherent to the dorsal sepal at the apex; lip on the upper part of the flower, with its claw grown to the column above its base, abruptly dilated and ascending, suborbicular, saccate-concave, to $7 \mathrm{~mm}$. long; capsule suberect, ellipsoid to obovoid-ellipsoid.

Along streams in woods or about muddy sloughs and ponds in e. and s.e. Tex., Sept.-Nov.; from s.e. Va., s. to Fla., w. to Tex.; also the W.I. and Latin Am.

The noticeably oblique petals and lip forming the uppermost segment of the flower are characteristic.

\section{Spiranthes Rich. LAdies' Tresses}

Coarse or delicate terrestrial herbs with clustered tuberous or rarely fibrous roots; leaves various, mostly basal, broadly ovate to elliptic or narrowly linear to semiterete, persistent or fugacious, reduced above to persistent sheathing bracts; flowers variously colored, usually white and variously tinged or marked with green, yellow, brown or lavender, sometimes brick-red, deep-crimson, yelloworange or yellow-scarlet, in a more or less spirally twisted showy or inconspicuous terminal spike; sepals free; dorsal sepal and petals coherent; lateral sepals usually somewhat decurrent on the ovary and gibbous at the base or extended to form a mentum; lip sessile or with a short claw, with the basal portion concave and embracing the column, spreading or arcuate-recurved at the apex, crisped, wavy or toothed, with a minute or conspicuous callosity on each side at the base, sometimes ecallose; column short, terete to clavate, essentially footless or extended into a long foot at the base; anther erect on the back of the column, 2-celled; pollinia two, powdery-granular, narrowly obovoid, their filaments coherent to the narrow viscid gland which is set in the thin beak (rostellum) terminating the column (after the removal of the gland the beak is left as a 2-toothed or forked tip); capsule erect, ellipsoid to ovoid or obovoid, sometimes 3-keeled.

A polymorphic genus of about 200 species widely dispersed throughout the North Temperate Zone and tropical Asia and America, south to Chile.

1. Flowers forming a dense cylindrical spike, apparently in several ranks; basal leaves (when present) with linear, lanceolate, oblong-elliptic or oblanceolate blades, never with a distinct petiole, having the lower part sheathing the stem (2)

1. Flowers forming a loose or dense (usually spiral) single rank, often secund; basal leaves (when present) with ovate, oblong-elliptic, lanceolate or semi-terete blades with a distinct petiole or with the lower part sheathing the stem (4)

2(1). Lip thin, panduriform in outline, deeply constricted at about the middle, with the orbicular or oblong-quadrate basal portion deeply concave; calli small; flowers ascending and ringent........1. S. Romanzoffiana.

2. Lip fleshy-thickened, only slightly or not at all constricted at about the middle, ovate-oblong to rhombic-ovate; calli large, prominent; flowers nodding perceptibly (3) 
3(2). Lip ovate-oblong, usually slightly constricted at about the middle and then somewhat dilated at the apex, mostly less than $1 \mathrm{~cm}$. long; leaves basal or only on the lower part of the stem..................2. S. cernua.

3. Lip broadly rhombic-ovate, with the basal half dilated, tapering to the obtuse or subacute apex, often as much as $1.4 \mathrm{~cm}$. long; leaves often extending up the stem..............................2. S. cernua var. odorata.

4(1). Basal leaves widely spreading, with the relatively short and broad blades having a distinct petiole, ovate to narrowly oblong-elliptic, either persistent or fugacious (marcescent) (5)

4. Basal leaves erect, ascending, narrow, linear, narrowly lanceolate or oblongelliptic, without a petiole, the lower portion sheathing the stem, either persistent or fugacious (7)

5(4). Plant with a densely pubescent spike; lip deeply fringed and with a prominent tuft of hairs on the disk near the apex; leaves usually persistent; flowering in the spring............... S. gracilis var. brevilabris.

5. Plant essentially glabrous throughout (6)

6(5). Lip with a broad green stripe on the central portion of the disk; leaves fugacious or marcescent; usually flowering in the fall.....

3. S. gracilis.

6. Lip with a broad yellow stripe on the central portion of the disk; often flecked with green; leaves mostly persistent; usually flowering in the spring..

3. S. gracilis var. floridana.

7(4). Flowers secund (rarely slightly spiraled); lip from a broad base tapering to the obtuse apex, $6-9.5 \mathrm{~mm}$. long; basal leaves fugacious.

4. S. longilabris.

7. Flowers strongly spiraled; lip ovate, orbicular-quadrate, oblong or oblongquadrate; basal leaves persistent or fugacious (8)

8(7). Lip oblong-elliptic to oblong, with parallel lateral margins or sometimes broadest at the distal end, membranaceous (9)

8. Lip ovate to ovate-oblong or ovate-elliptic, broadest at or near the base, usually fleshy-thickened; spike more or less pubescent with capitate or sharp-pointed hairs (10)

9(8). Lip usually veined with green; spike subglabrous or very sparsely pubescent with usually capitate hairs; distribution in eastern Texas.

5. S. praecox.

9. Lip not veined with green; spike densely pubescent with long hairs; distribution in southern Arizona........................................6. S. graminea.

10(8). Spike densely pubescent; ovaries usually covered by a thick mat of reddish-brown sharp-pointed hairs; lip ovate to ovate-elliptic..........

7. S. vernalis.

10. Spike more or less pubescent with capitate hairs; lip ovate-oblong, often from a suborbicular base, conspicuously laciniate along the apical margins.

8. S. X laciniata.

1. Spiranthes Romanzoffiana Cham. HoOded ladies' tresses, Western ladies' TRESSES. Fig. 371.

Plant erect, glabrous below, somewhat glandular-pubescent above, $8-55 \mathrm{~cm}$. tall; roots fasciculate, long, fleshy; leaves mostly basal, linear to oblanceolate or oblong-lanceolate, 5-26 cm. long, 6-13 mm. wide; spike densely flowered, cylindrical, composed of three spiral ranks of flowers, $3-12 \mathrm{~cm}$. long, $1.5-3 \mathrm{~cm}$. in diameter; floral bracts ovate to ovate-lanceolate, acuminate, semitranslucent, nervose, $1.2-2.5 \mathrm{~cm}$. long; flowers white or creamy white, tubular, dilated and ringent above the middle; sepals and petals connivent and forming a hood over the column; sepals $6.5-13 \mathrm{~mm}$. long, 3-4 mm. wide near the base; dorsal sepal oblong- 


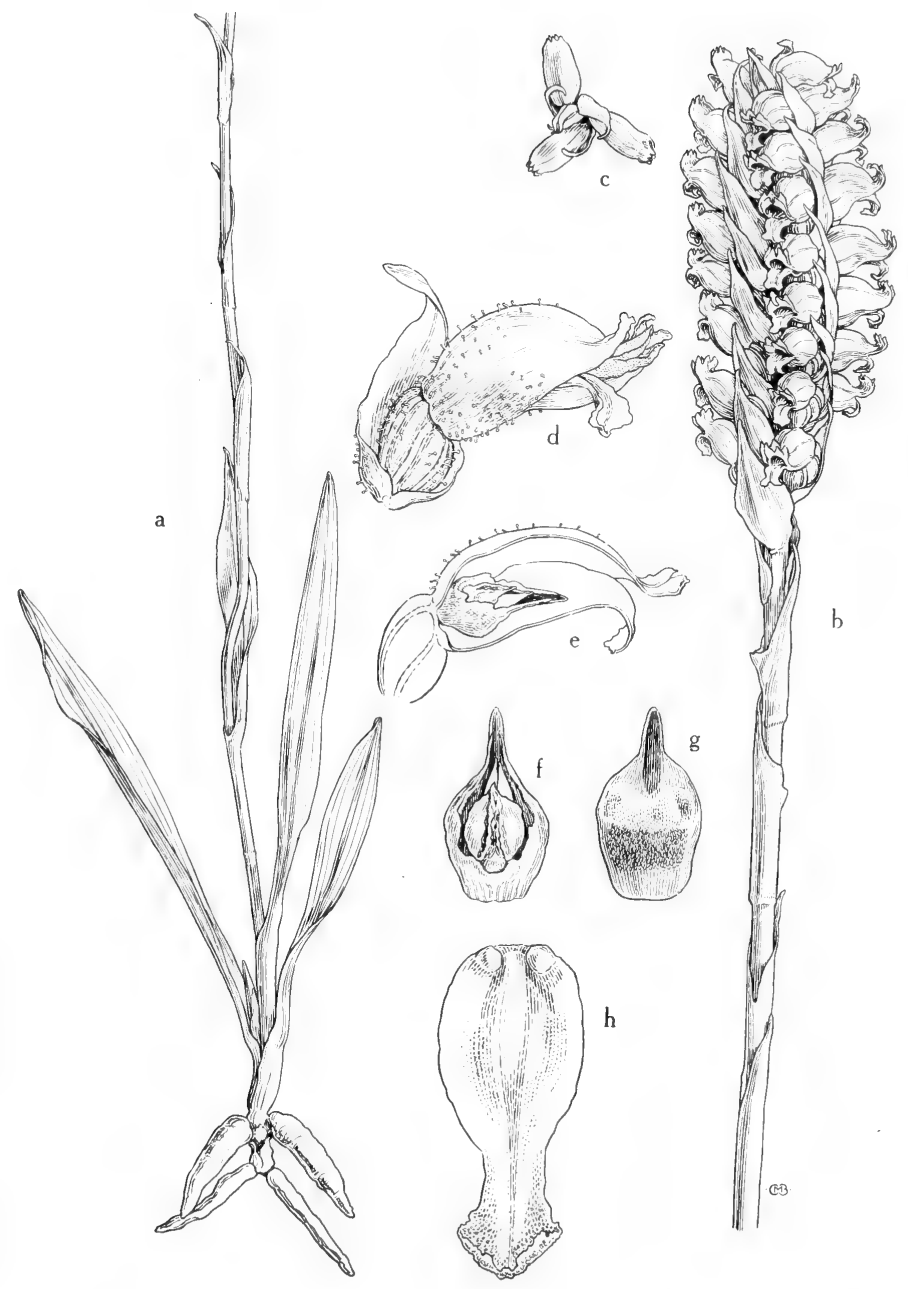

Fig. 371: Spiranthes Romanzoffiana: a, base of plant, showing linear leaves and fleshy roots, $\mathrm{x} 2 / 3 ; \mathrm{b}$, spike, $\mathrm{x} 11 \%$; , single whorl of flowers; $\mathrm{x} 11 \% \mathrm{~d}$, flower, lateral view, $\mathrm{x} \mathrm{4}$; e, flower (longitudinal section), x 4; $\mathrm{f}$, back of column, showing anther, $\mathrm{x}$ 6; g, front of column, showing stigma, x 6; h, lower lip, x 6. (From Mason, Fig. 194). 


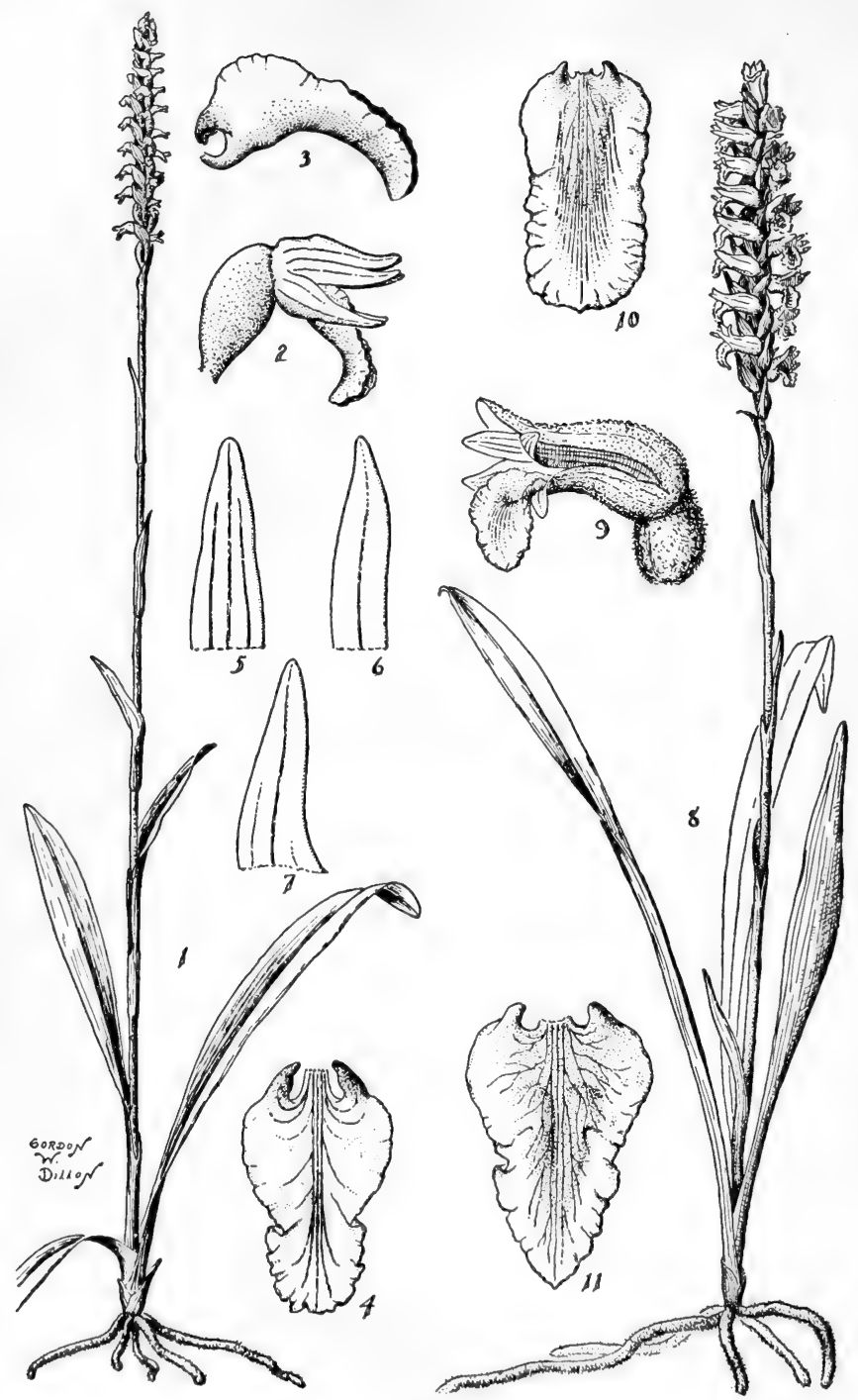

Fig. 372: 1-7, Spiranthes ovalis: (a woodland orchid). 8-10, Spiranthes cernua: 8 , plant, x 1/2; 9, flower, front-side view, x 3;10, lip, spread out, x 3.11, Spiranthes cernua var. odorata: 11, lip, spread out, x 3 . 
elliptic to oblong-lanceolate, obtuse to acute; lateral sepals oblong-lanceolate to lanceolate, somewhat falcate, obtuse to acute; petals linear, obtuse, $6.5-12 \mathrm{~mm}$. long, 1-2 $\mathrm{mm}$. wide; lip pandurate, with the thin suborbicular base strongly concave and prominently veined, conspicuously constricted above the middle, somewhat dilated above the constriction, $7-11 \mathrm{~mm}$. long, $5 \mathrm{~mm}$. wide across the lower half, strongly arcuate-recurved near the apex in natural position; basal callosities minute; column 2-3 $\mathrm{mm}$. long.

In moist or wet situations in bogs, marshes, meadows, salt flats, thickets, on sandy-gravelly beaches and occasionally in dry woods and on dry open hillsides, in N. M. (Sandoval Co.) and Ariz. (Apache, Coconino and Graham cos.), JulyOct.; Nfld. to Alas., s. to N.E., N.Y., Neb., N.M., Ariz. and Calif.; Ire.

2. Spiranthes cernua (L.) Rich. Nodding Ladies' tresses. Fig. 372.

Plant erect, glabrous below, downy-pubescent above, occasionally stoloniferous (especially in swamp areas), 1-5.5 (-9.5) dm. tall; roots slender or coarse, fleshy; leaves mostly basal or fugacious, linear to lanceolate, acute to acuminate, $5-40 \mathrm{~cm}$. long, 5-20 mm. wide; spike densely flowered, compact, consisting of rather small nodding flowers in 2 to 4 (rarely 1) spiral or vertical ranks, $3-18 \mathrm{~cm}$. long, $2-3 \mathrm{~cm}$. in diameter; floral bracts ovate to lanceolate, acuminate-attenuate, $8-15 \mathrm{~mm}$. long; flowers white, sometimes marked with green or cream-tinged, usually fragrant of vanilla; perianth parts somewhat downy on the outer surface; sepals oblonglanceolate, obtuse to subacute, 6-13.5 $\mathrm{mm}$. long, to about $3 \mathrm{~mm}$. wide, the lateral sepals free; petals coherent with the dorsal sepal, linear to linear-lanceolate, obtuse to acute, 6-13.5 $\mathrm{mm}$. long, 1-2 $\mathrm{mm}$. wide; lip ovate-oblong to oblong, arcuate-recurved, sometimes rhombic with the basal half dilated, with the apical margins erose or crisped, 6-14 mm. long, 3-8 $\mathrm{mm}$. wide across the base; basal callosities prominent, pubescent; column stout, $3-5 \mathrm{~mm}$. long.

Var. cernua. Lip ovate-oblong to oblong, mostly 6-11 mm. long. Ibidium cernuum (L.) House. In swamps, wet woods, stream bottoms, grassy seepage slopes, in Okla. (Ellis and Payne cos.), cen. and e. Tex. and N.M. (Rio Arriba Co.), JulyDec.; N.S., and Ont., s. to Fla., w. to Minn., S.D., Neb., Kan., Okla., Tex. and N. M.

Var. odorata (Nutt.) Correll. Fragrant LADIES' TRESSES. The thickish lip of var. odorata is broadly ovate instead of being oblongish as in var. cernua. Gyrostachys odorata (Nutt.) O. Ktze. This variety occurs sparingly throughout the area of distribution of var cernua. It attains its maximum development in the southeastern states where it is commonly found in stoloniferous colonies in water and mud of swamps, marshes, and along wooded rivers and streams.

3. Spiranthes gracilis (Bigel.) Beck. var. gracilis. GREEN-LiP LADIES' TRESSES. Fig. 373.

Plant slender, essentially glabrous throughout, rarely sparsely pubescent above, $1.8-7.5 \mathrm{dm}$. tall, occasionally two or three plants produced from the same rootstock; roots fasciculate, stout, short, fleshy; leaves basal, fugacious, broadly ovate to elliptic or ovate-lanceolate, short-petioled; lamina $1.5-6.5 \mathrm{~cm}$. long, $1-2.3 \mathrm{~cm}$. wide; spike slender, densely or loosely flowered, strongly spiraled or occasionally secund, rarely bifurcate, 3-26 $\mathrm{cm}$. long; floral bracts ovate to ovate-lanceolate, acute to long-acuminate, 5-10 mm. long; flowers small, white with a green stripe in the center of the lip, in a single rank; perianth 4-6 mm. long; sepals and petals about equal in length, 4-5.5 mm. long; dorsal sepal elliptic-oblong to oblonglanceolate, obtuse to acute; lateral sepals lanceolate, acute to somewhat acuminate; petals coherent with the dorsal sepal, linear, obtuse to subacute; lip oblongquadrate to elliptic-oblong, 4-6 mm. long, about $2.5 \mathrm{~mm}$. wide, with the slightly grooved central portion conspicuously green, the apical margins crenulate to somewhat fringed-erose; basal callosities short, erect; column 2-3 mm. long. 


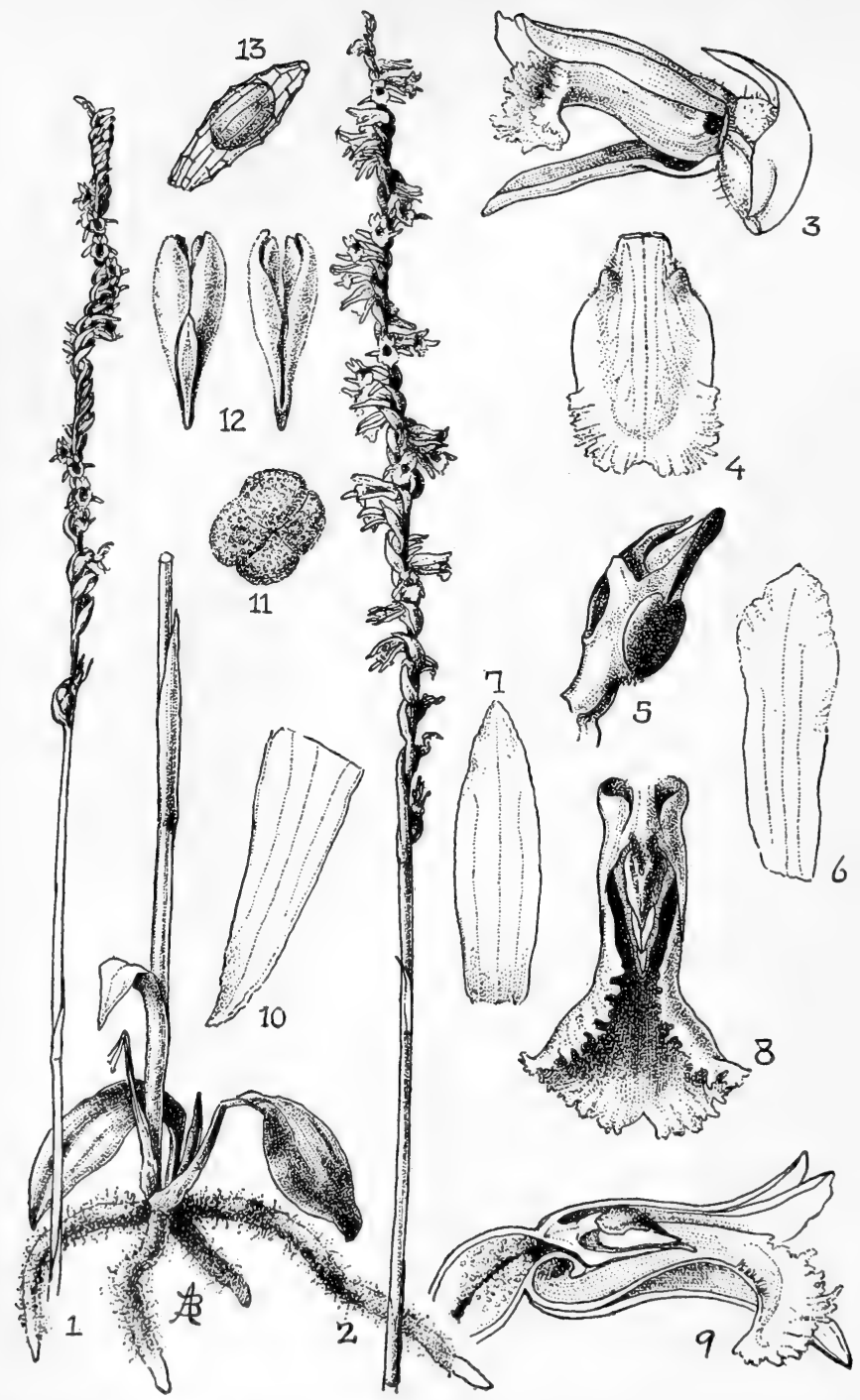

Fig. 373: Spiranthes gracilis: 1 and 2, plant $\mathrm{x} 1$; 3 , flower, side view, with one lateral sepal removed, x $6: 4$, lip, spread out, x $6 ; 5$, column, x $11 ; 6$, petal, x $11 ; 7$, dorsal sepal, $\mathrm{x} 11 ; 8$, lip and column, in natural position, front view, $\mathrm{x} 11 ; 9$, longitudinal section through center of perianth and ovary, $x 8 ; 10$, lateral sepal, $x 8 ; 11$, pollen tetrad, highly magnified; 12, pollinia, from below (at left), from above (at right), $\mathbf{x}$ $20 ; 13$, seed, highly magnified. 

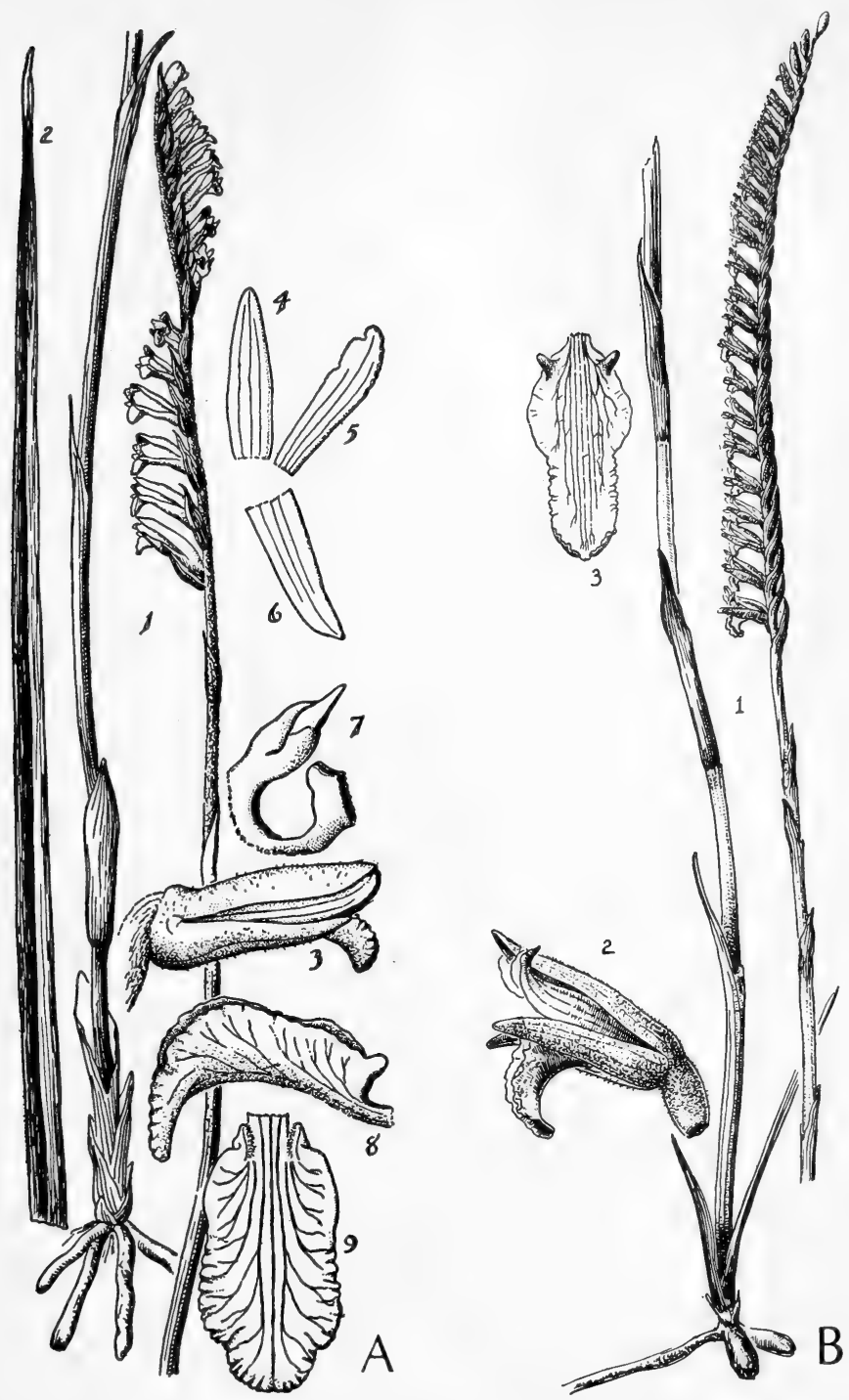

Fig. 374: A, Spiranthes praecox: 1, plant, x 1; 2, leaf, $\times 1$; , flower, side view, x $3 ; 4$, dorsal sepal, x $2 \frac{1}{2} ; 5$, petal, x 21/2;6, lateral sepal, x $2 \frac{1}{2} ; 7$, column and base of lip, side view, x 5; 8, lip, side view, x 5; 9, lip spread out, x 5. B, Spiranthes longilabris: 1 , plant, $x 1 \frac{1}{2} ; 2$, flower, side view, x $3 ; 3$, lip, spread out, $x 3$. 
Gyrostachys gracilis (Bigel.) O. Ktze., Ibidium gracile (Bigel.) House.

In sandy post oak woods, gravelly soils, on open-wooded slopes, in mucky or boggy soil in low pinelands, in savannahs and coastal prairies, swamps and evergreen shrub bogs, in fields, meadows and prairies of n.-cen., e. and s.e. Tex., July-Oct.; from N.S. and N.B., s. to s.-cen. Fla., w. to Minn., Ia., Mo., Okla. and Tex.

The broad green stripe in the center of the lip, which is rarely more than $5 \mathrm{~mm}$. long, is distinctive. Also, the usually fugacious basal leaves are ovate to ovate-lanceolate instead of being grasslike as in most of our species.

Var. brevilabris (Lindl.) Correll. TEXAS LADIEs' TRESSES. Similar to var. gracilis except for the densely pubescent spike, persistent basal leaves, and earlier flowering period in March and May. Spiranthes brevilabris Lindl. Originally described from Tex., this variety is rare from s. Tex., e. to Fla. in habitats similar to those of var. gracilis.

Var. floridana (Wherry) Correll. Florida LADIES' TRESSES. Similar to var. gracilis except for the lip having a yellow instead of green center and the much narrower and elongated basal leaves being persistent; also flowering earlier, from April to June. Ibidium floridanum Wherry. Occurring in habitats similar to var. gracilis from N.C., s, to cen. Fla. and w. to Tex.

\section{Spiranthes longilabris Lindl. Giant SPIRAL-ORCHID. Fig. 374.}

Plant erect, slender, flexuous, essentially glabrous throughout, occasionally pubescent above, 1.2-6 dm. tall; roots fleshy, numerous, fasciculate; leaves (when present) basal, linear to narrowly lanceolate, acute, $3-10 \mathrm{~cm}$. long, mostly less than $5 \mathrm{~mm}$. wide, reduced above to sheathing bracts; spike slender, secund, only slightly spiraled at most, 5-14 cm. long; floral bracts broadly ovate to ovatelanceolate, acuminate-elongate, 5-12 mm. long; flowers white or white tinged with cream-color, conspicuously ringent, tubular, projecting almost horizontally away from the rachis; sepals $6-10 \mathrm{~mm}$. long, 2-3 $\mathrm{mm}$. wide; dorsal sepal oblong-elliptic to oblong-lanceolate, subacute to acute; lateral sepals linear-lanceolate, spreading and recurved upward; petals linear, obtuse to subacute, $6.5-9 \mathrm{~mm}$. long, about 1 $\mathrm{mm}$. wide; lip yellow-white, narrowly ovate to ovate-oblong, from a broadened base, tapering to the obtuse to subacute apex, strongly arcuate-recurved, usually somewhat dentate or crenate along the apical margin, 6-10 $\mathrm{mm}$. long, 3-5.5 mm. wide near the base, callosities rather slender; column about $4 \mathrm{~mm}$. long.

Commonly in wet grassy pine barrens and flatwoods, swamps, marshes, wet savannahs and prairies, and sandy bogs in s.e. Tex., Oct-Dec.; from e. N.C., s. to Fla., and w. to Tex.

The characteristically secund inflorescence of horizontally projecting flowers separates this species from all other of our Spiranthes. Its nearest ally, S. praecox, with which it may be confused, has flowers whose lips are marked or veined with green, a character lacking in $S$. longilabris.

\section{Spiranthes praecox (Walt.) Wats. Grass-leaved ladies' tresses. Fig. 374.}

Plant usually slender, essentially glabrous throughout, occasionally sparsely pubescent above, 2-7.5 dm. tall; roots rather slender, elongated, fasciculate; leaves (when present) as many as seven, mostly basal, narrowly linear to filiform, 10-25 $\mathrm{cm}$. long, 1-5 mm. wide; spike loosely to densely flowered, spirally twisted or often nearly secund, $3-15 \mathrm{~cm}$. long, about $1.5 \mathrm{~cm}$. in diameter; floral bracts ovate-lanceolate, acuminate-attenuate, often with strongly hyaline margins, 4-15 $\mathrm{mm}$. long: flowers white, or white and veined and marked with green; sepals usually puberulent on the outer surface, 5.5-10 $\mathrm{mm}$. long, 2-3 mm. wide; dorsal sepal oblong-elliptic to lanceolate, subacute, often slightly constricted near the apex; lateral sepals lanceolate, acute; petals coherent with the dorsal sepal, linear, 

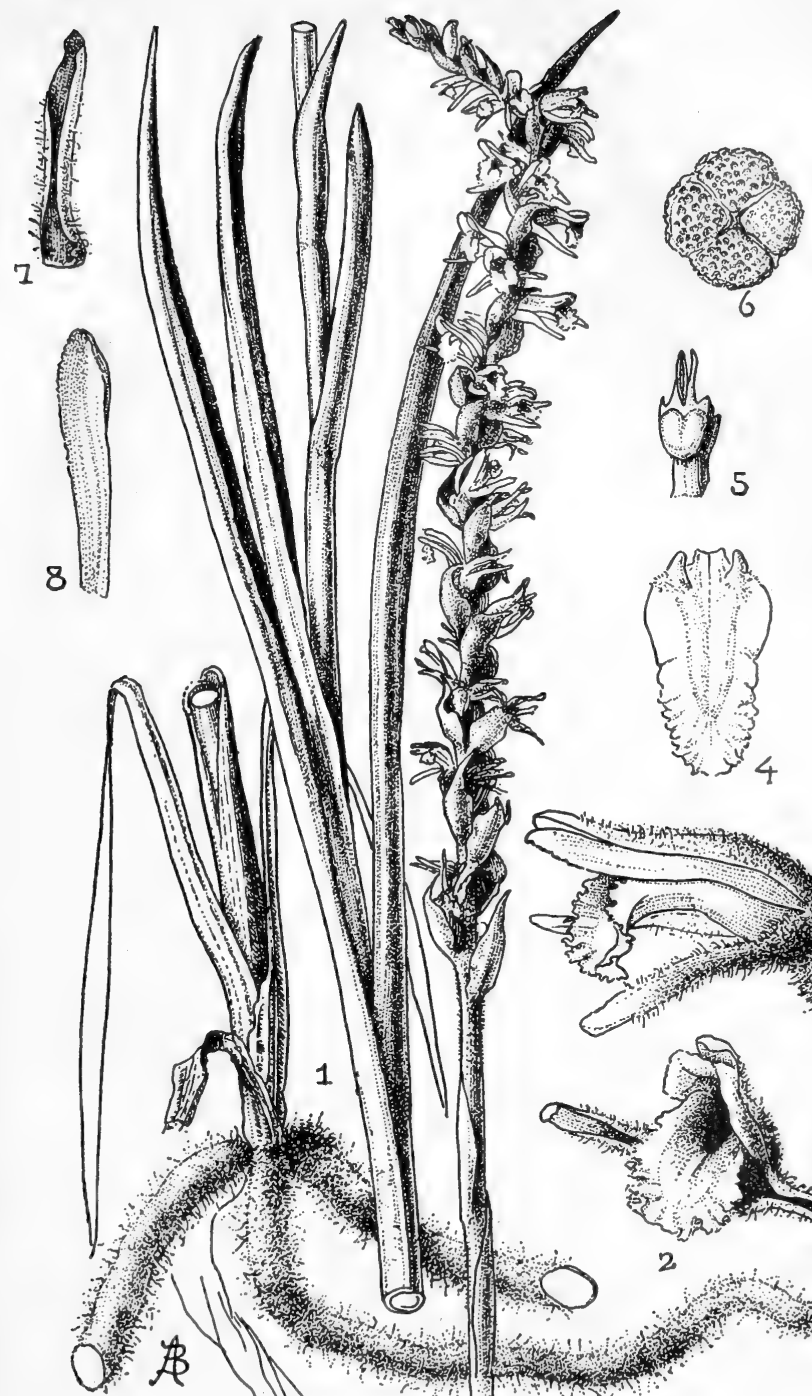
obtuse to subacute or rarely acute, 5.5-10 mm. long, 1-2 mm. wide; lip thin, with a short claw, oblong to broadly oval-elliptic, of ten dilated and broadest at the distal end, prominently veined with green or with green on the central portion of the disk, mostly wavy and slightly crenulate or toothed on the apical margin, 5.5-11 mm. long, 2-6 mm. wide; basal callosites slender or sometimes stout, straight; column 2.5-5 mm. long. Gyrostachys praecox (Walt.) O. Ktze., Ibidium praecox (Walt.) House.

In low wet grassy pinelands and flatwoods, wet prairies, savannahs and meadows, cypress swamps, in bogs and coastal marshes in e. and s.e. Tex., Mar.June; from N.J., s. to s. Fla., w. to Ark. and Tex.

The thin green-veined oblong lip, which is $5.5-10 \mathrm{~mm}$. long, is distinctive.

\section{Spiranthes graminea Lindl.}

Nearly allied to and resembling $S$. vernalis, stem to about $5 \mathrm{dm}$. tall; basal leaves longer than the stem sheaths, lax, obtuse to acute at apex; spike simply twisted, densely pubescent with long often matted hairs; floral bracts acute, about as long as the flowers; flowers white, sometimes in tight coils as to appear 4ranked; sepals more than $3 \mathrm{~mm}$. long; lip typically thin, oblong-quadrate and with a truncate apex.

In a permanently wet cienaga or marsh in Ariz. (Santa Cruz Co.), July-Sept.; s. through Mex. to Guat., Brit. Hond. and Nic.

7. Spiranthes vernalis Engelm. \& Gray. SPRING LAdIES' TRESSES. Fig. 375.

Plant stout or slender, densely and copiously pubescent above, $1.8-11 \mathrm{dm}$. tall; roots coarse, fusiform, fasciculate; leaves basal or extending partly up the stem, suberect and ascending, linear to narrowly lanceolate, acuminate, often strongly keeled or semiterete, with the basal portion sheathing the stem; spike densely flowered, spiraled, $3-15 \mathrm{~cm}$. long, about $1.5 \mathrm{~cm}$. in diameter; rachis and ovaries mostly covered by a dense mat of reddish brown hairs; floral bracts broadly ovate to oblong-lanceolate, rather abruptly acuminate-elongated, concave, 7-15 $\mathrm{mm}$. long; flowers yellowish or sometimes greenish, often white, often fragrant, in a single rank or rarely 2-ranked; parts of the perianth somewhat pubescent on the outer surface; dorsal sepal oblong-lanceolate to lanceolate, obtuse to acute, concave at the base, $5.5-10 \mathrm{~mm}$. long, $2.5-3 \mathrm{~mm}$. wide near the base; lateral sepals lanceolate, acute, 5-9.5 $\mathrm{mm}$. long; petals coherent with the dorsal sepal, linear to linear-elliptic, obtuse, 5-9 $\mathrm{mm}$. long, 1-2 $\mathrm{mm}$. wide; lip thickened, broadly ovate to rhombic-ovate or sometimes ovate-oblong, arcuate-recurved, often somewhat dilated and crenulate-wavy at the apex, $4.5-8 \mathrm{~mm}$. long, 2.5-6 mm. wide near the base; basal callosities stout, incurved, pubescent. Ibidium vernale (Engelm. \& Gray) House.

In wet prairies, savannahs and meadows, fresh and coastal salt marshes, swamps, beaches and dune areas, Okla. (Creek, Dewey and McCurtain cos.) and in the e. third of Tex., Apr.-July; from Que. and Mass., s. to s. Fla., w. to Mo.. Kan., Okla. and N.M.; also Mex. and Guat.

Characterized by its copiously pubescent rachis and ovaries that are provided with articulated, brownish, sharp-pointed hairs.

8. Spiranthes X laciniata (Small) Ames. LACE-L.IP SPIRAL-ORCHID.

Rather coarse plants that have intermediate characters between $S$. praecox and S. vernalis. Ibidium laciniatum (Small) House.

In marshes and shallow water of cypress swamps and in boggy depressions in savannahs and prairies in s.e. Tex., May-July; from N.J., s, to Fla., w. along the Gulf Coast to Tex. 

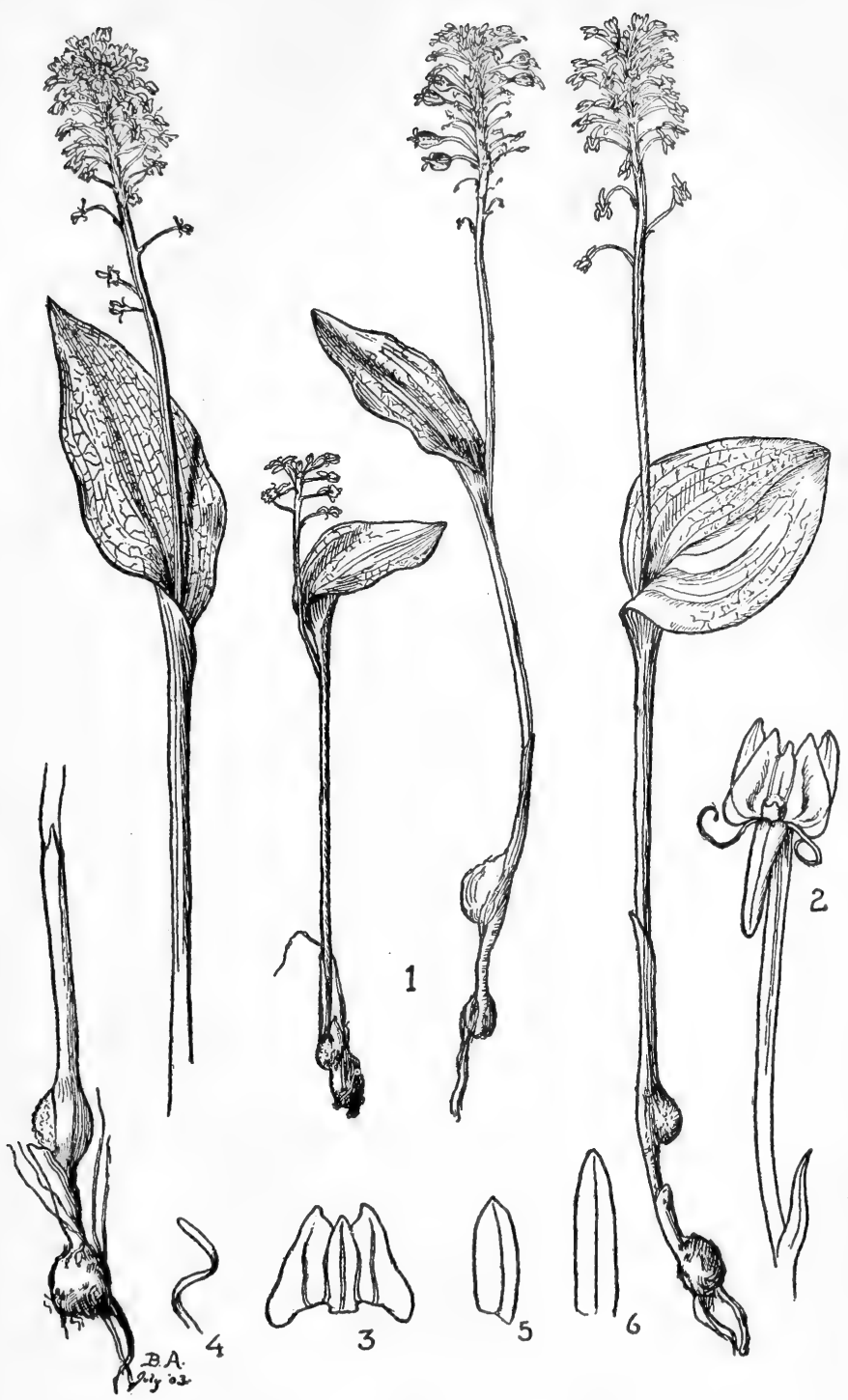

Fig. 376: Malaxis unifolia: 1, plants, x 1;2, flower, front view, x 5; 3, lip, spread out, $x 6 ; 4$, petal, $x 7 ; 5$, lateral sepal, $x 7 ; 6$, dorsal sepal, $x 7$. 


\section{Malaxis Sw.}

About 150 species that attain their greatest development in Asia and Oceania; also widely distributed in the Western Hemisphere and sparsely in Europe.

\section{Malaxis unifolia Michx. Fig. 376.}

Plant bright green, erect, 6-55 cm. tall; scape from a bulbous corm, somewhat angled and winged; leaf solitary, sheathing the stem below, expanded near the middle of the scape; blade sessile and clasping the stem, orbicular-ovate to ovatelanceolate, obtuse to acute, to $9 \mathrm{~cm}$. long and $6.5 \mathrm{~cm}$. wide, usually much smaller; raceme subcorymbose to slender-elongate, densely flowered, to $16 \mathrm{~cm}$. long and $2.5 \mathrm{~cm}$. in diameter; floral bracts minute, subulate, $1-3 \mathrm{~mm}$. long; flowers minute, green, with filiform pedicellate ovaries 3-10 $\mathrm{mm}$. long; sepals spreading, linearoblong to oblong-elliptic, subacute, 1-nerved, with the margins often somewhat involute, $1.8-3.5 \mathrm{~mm}$. long, $0.8-1.5 \mathrm{~mm}$. wide; petals narrowly linear to filiform, strongly recurved, $1.4-3 \mathrm{~mm}$. long; lip uppermost in the flower, variable in shape, cordate-deltoid to cordate-ovate or oblong-quadrate, 2-4 $\mathrm{mm}$. long, $1.5-3 \mathrm{~mm}$. wide, cordate or auricled on each side at the base with the lobules broadly rounded to acute and often deeply notched, obliquely tridentate at apex with the 2 lateral teeth more or less elongate and obtuse to acute, the minute median tooth thickened and apiculate; column minute, $0.5-1 \mathrm{~mm}$. long, with 2 short apical lateral teeth; capsule obliquely ovoid, 3-6 $\mathrm{mm}$. long, 2-3 $\mathrm{mm}$. in diameter.

In low swampy woods, peaty or sandy soil or boggy areas, moist or wettish wooded slopes along streams and in depressions of low woodlands, in e. Tex. (Cherokee, Nacogdoches and Harris cos.), Mar.-July; Nfld. w. to Man., Minn., Mo., Ark. and Tex., s. to Fla. and the Gulf Coast; Cuba, Jam. and Mex.

\section{Subclass 2. Dicotyledoneae}

Stem exogenous, of pith, wood and bark, the wood in one or more layers surrounding a central pith, traversed by medullary rays, and covered by the bark (endogenous in structure in Nymphaeaceae). Leaves usually pinnately or palmately veined, the veinlets forming a network. Parts of the flower usually in fours or fives, rarely in threes or sixes. Embryo of the seed with two cotyledons (one only in Nymphaeaceae and some species of Ranunculaceae; in Quercus and a few other genera 3 sometimes occur, and in some species of Amsinikia 4), the first leaves of the germinating plantlet opposite.

Dicotyledonous plants are first definitely known in Cretaceous time. They include more than 160,000 species and constitute nearly four fifths of all flowering plants.

\section{Fam. 42. Saururaceae E. MEY.}

\section{LIZARD'S-TAIL FAMILY}

Erect or ascending more or less aromatic perennial herbs, usually rhizomatous and stoloniferous; stems jointed; leaves alternate, simple, usually petioled; stipules adnate to petiole; flowers perfect, in congested or lax elongated spikes that may or may not be subtended by an involucre; perianth none; pistils 3 or 4 , indehiscent, 1 -seeded, free or united at the base; stamens as many as 8 , free or adnate to ovary at base or epigynous, the 2-celled anthers longitudinally dehiscent; fruit a somewhat succulent capsule, in ours dehiscing apically through the central-apical portion of the folliclelike capsule.

A small family comprised of 5 genera and about 7 species in North America and Asia. 


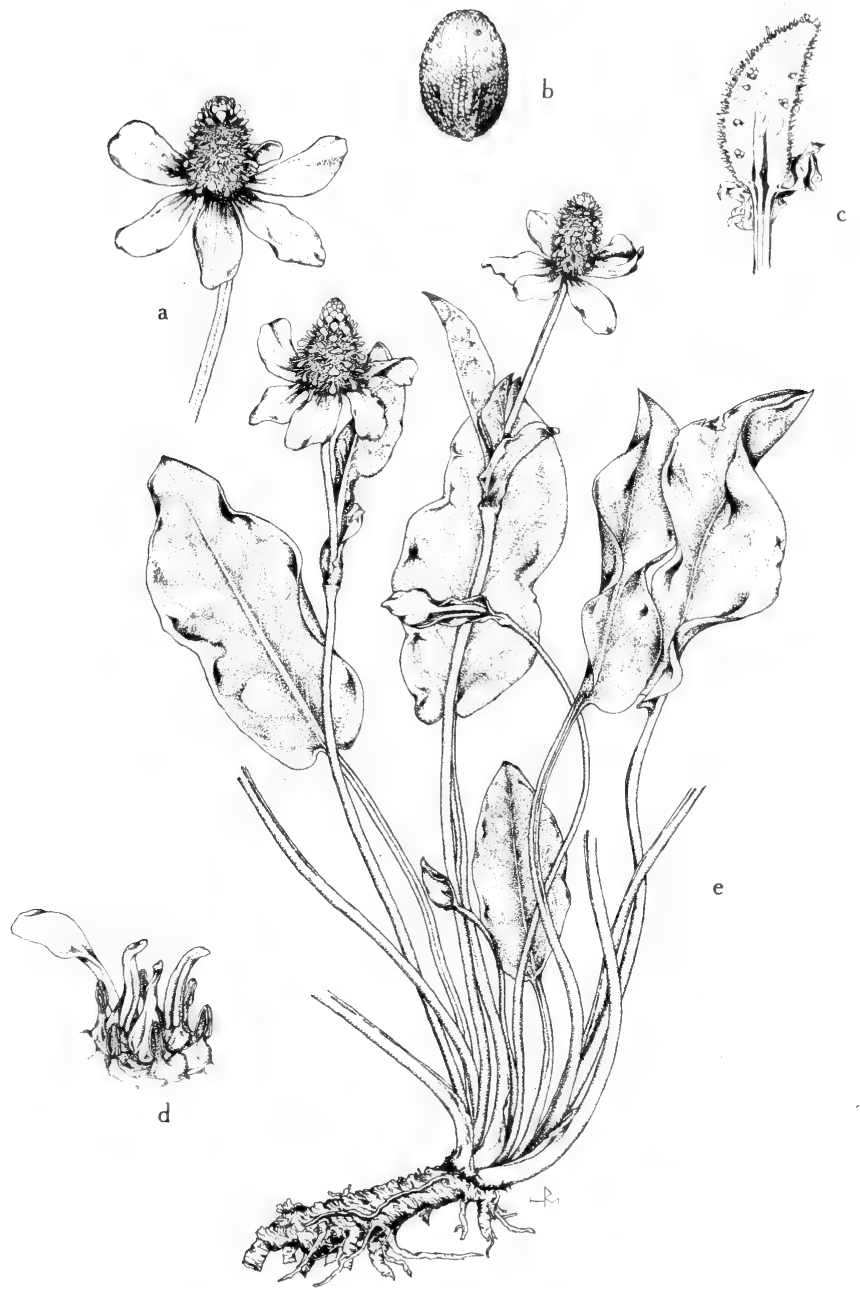

Fig. 377: Anemopsis californica: a, flowerlike inflorescence subtended by petaloid bracts, $x 4 / 5$; b, seed, x 20; c, spike, showing receptacle (longitudinal section), x 11/\%; single bracteate flower, x 8; e, habit, x \%5. (From Mason, Fig. 195). 


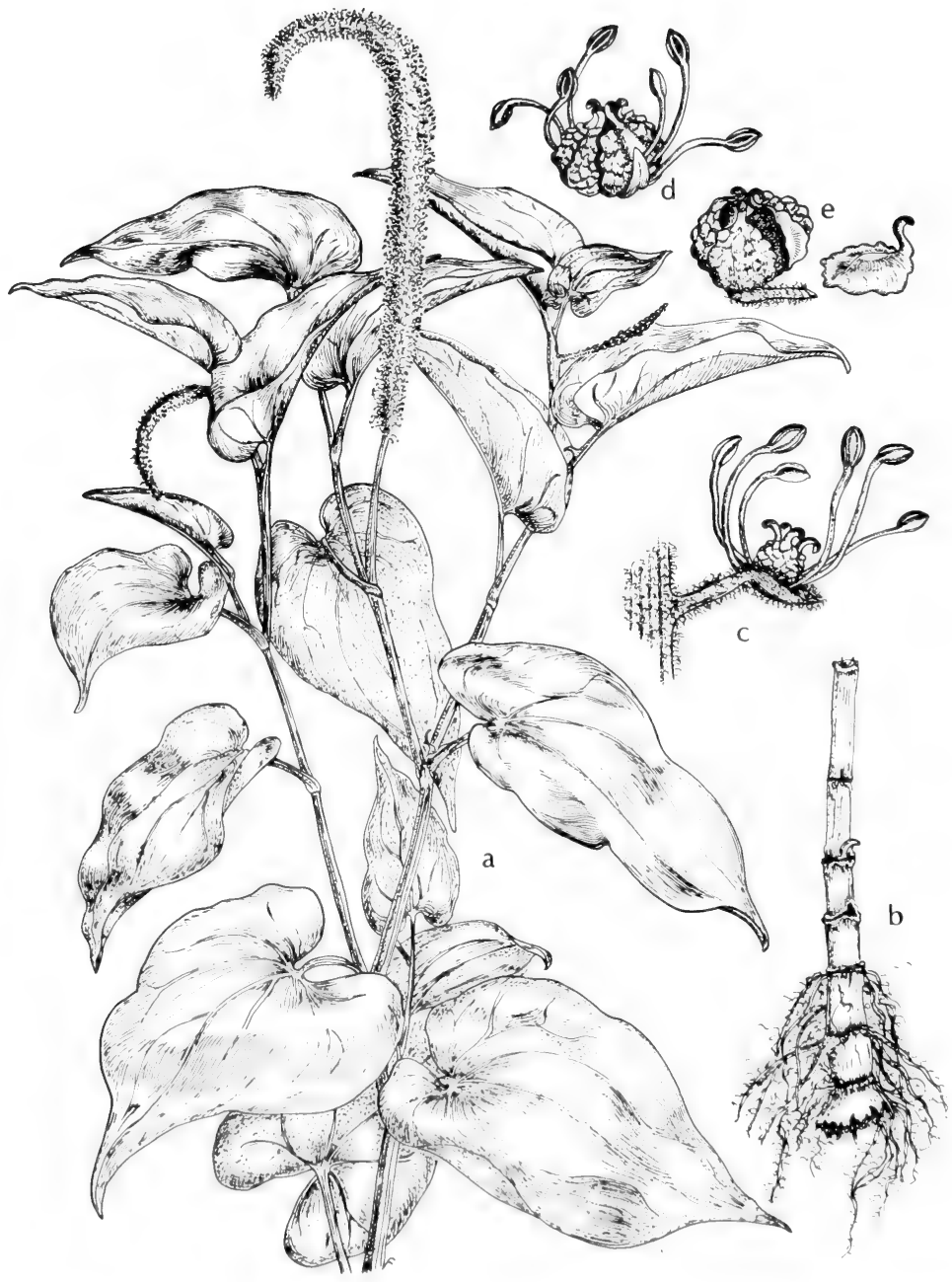

Fig. 378: Saururus cernuus: a, top portion of plant, $\mathrm{x} 1 \frac{1}{2} ; \mathrm{b}$, portion of lower stem showing adventitious roots, $x{ }^{1} ;$; flower, showing carpels united at the base only (no calyx nor corolla), x 5; d, fruit, x 5; e, carpels breaking apart, x 5. (V. F.). 
1. Leaves mostly basal; spike subtended by an involucre; western Oklahoma and Texas westward......................................................1. Anemopsis

1. Leaves all cauline; spike naked, not subtended by an involucre; eastern Oklahoma and Texas eastward.

2. Saururus

\section{Anemopsis H. \& A.}

A monotypic genus.

\section{Anemopsis californica (Nutt.) H. \& A. Yerba mansa. Fig. 377.}

Plant forming colonies, usually about $3 \mathrm{dm}$. tall; stems nodose, scapelike, from aromatic creeping rootstocks; leaves mostly basal, those on the stem subtended by a sheathing bracteose leaf, elliptic-oblong, truncate or cordate at base, to $15 \mathrm{~cm}$. long, with the petiole about as long as the blade; spike conical, $1.5-4 \mathrm{~cm}$. long, subtended by a whorl of white or reddish bracts; most of the flowers subtended by a white obovate clawed bract; ovary sunk in the rachis of spike; fruit a capsule. Incl. var. subglabra Kelso.

In alkaline or saline soils of wet meadows, fiats and along streams in $\mathrm{n}$. $\mathbf{w}$. Okla. (Woods Co.), w. to s.w. Tex. (El Paso Co.), reported from Hemphill and Lubbock cos. in the Panhandle, widespread in N. M. (Bernalillo, Dona Ana, Grant, Hidalgo, Otero, San Miguel, Sandoval, Sierra, Socorro and Valencia cos.) and Ariz. (Cochise, Pima and Yuma n. to Coconino cos.), May-July; from Calif. and Ariz., n.e. to cen. Colo. and e. to w. Okla. and Tex.; also n. Mex.

\section{Saururus L.}

Another species occurs in eastern Asia.

\section{Saururus cernuus L. Lizard's-TAll. Fig. 378.}

Plant forming colonies, to about $9 \mathrm{dm}$. tall; stem naked below, leafy above, simple or branched; leaves cauline, cordate-ovate, the veins converging, to $15 \mathrm{~cm}$. long, much longer than the petiole; stipules indistinct; spike to $3 \mathrm{dm}$. long and 15 $\mathrm{mm}$. in diameter, peduncled, wandlike, naked, pubescent, curved-nodding at tip; flowers white, crowded, provided with a small bract that is adnate to or borne on the pedicel; stamens with long slender filaments; pistils (carpels) united at base; stigmas recurved; fruit somewhat fleshy, wrinkled.

In water or muddy soils of lakes; swamps and streams in e. Okla. (Adair, Le Flore, McCurtain and Muskogee cos.) and e. and s.e. Tex., May-Aug.; from s.w. Que. and s. Ont., s. to Fla., w. to Minn., Ill., Mo., Kan., Okla. and Tex.

\section{Fam. 43. Salicaceae Mirb.}

\section{WiLlow FAMILY}

Shrubs or trees with soft light wood, bitter bark and simple alternate deciduous stipulate leaves; stipules deciduous or persistent; dioecious (sexes on separate plants); flowers in aments (catkins) which fall off as a unit (the staminate after shedding pollen, the pistillate after ripening and dispersal of seeds); flowers subtended by a single scalelike bract; stamens 2 to many; fruit a 1-celled capsule, 2- to 4-valved, containing numerous seeds that are surrounded by a tuft of long silky white or tawny hairs that arise from the base; style 1, rarely wanting; stigmas 2 to 4 , sometimes 2-lobed.

A family containing only the following two genera, both of which are widely distributed but most abundant in North Temperate and Alpine-Arctic regions.

1. Buds with several imbricated scales, often resinous; floral bracts lacerate, caducous; flowers borne on a shallow or cup-shaped disk; stamens 6 to 60 ; capsule 2 - to 4 -valved. 1. Populus 
1. Buds with a single scale; floral bracts entire or merely toothed, tardily deciduous or persistent; flowers with a ventral and sometimes a dorsal gland; disk none; stamens 2 to 7 or 8 ; capsule 2 -valved.

2. Salix

\section{Populus L. Cottonwood. Alamo}

Fast-growing and often short-lived dioecious trees with soft wood, fissured bark and mostly stout branches; branchlets slender or stout, terete or angled, pale-olivebrown or grayish- to lustrous reddish-brown, glabrous to tomentose; buds terminal and lateral, resinous or nonresinous, covered by several imbricated membranaceous scales; leaves alternate, stipulate, varying in shape from deltoid to rhombic or lanceolate, with the margins entire to variously crenate or serrate with the teeth often glandular, rarely lobulate, often bearing glands on upper surface at junction of leaf blade with petiole; petioles stout and much-abbreviated to elongate and slender, more or less terete to laterally compressed, sometimes channeled on upper side; stipules caducous; leaf scars deltoid to elliptic in shape, with 3 bundle scars; flowers without a perianth, in pendulous stalked unisexual aments, appearing before the leaves, borne singly, inserted on a shallow or cup-shaped symmetrical or oblique persistent disk and subtended by a bract; bracts stipitate, mostly cuneate or obovate, entire to variously lacerate or divided above, glabrous to villous, caducous; stamens 6 to 60 , the slender filaments free on the disk and the small yellowish-red to purplish anthers ellipsoid to ovoid; ovary sessile on the disk, with 2 to 4 parietal placentae; styles short, stigmas 2 to 4 , divided into filiform lobes or broadly dilated and more or less irregularly erose; pistillate aments mostly becoming elongated with age; fruit usually maturing before the leaves are mature, a 2- to 4-valved dehiscent capsule, globose to ellipsoid-conic, pale- to dark-brown; seeds abundant, minute, surrounded at the base by a tuft of long silky white or tawny hairs that are directed upward parallel with and encompassing the seed.

This is a genus of about 35 species, all native of the Northern Hemisphere in both the Old World and New World. Many species are widely grown as ornamental shade and street trees, especially because of their rapid growth and ease of propagation from cuttings.

According to some historians, the Alamo of Texas fame received its name from a grove of Populus that grew on the banks of the acequia, "alamo" being the Spanish word for cottonwood.

The resinous buds and aments of most species are valuable foods for game birds, such as various grouse and quail, and some songbirds, and the tender somewhat succulent bark, twigs and foliage are eaten by hoofed browsers and rabbits. The bark as well as the wood are favorite foods of beavers, porcupines and muskrats.

1. Petioles nearly terete, usually prominently channeled or somewhat flattened on the upper side; leaf blades suborbicular-ovate to rhombic-ovate or lanceolate, the margins mostly finely serrate or crenate-serrate (2)

1. Petioles conspicuously laterally compressed (especially just below the leaf blades), rarely channeled on the upper side; leaf blades typically deltoid to rhombic-ovate or suborbicular, the margins coarsely or finely crenate-serrate (4)

2(1). Leaf blades more than 3 times as long as wide, pale-green on the lower surface, mostly obtuse to acute; petioles rarely more than $20 \mathrm{~mm}$. long................................................................. $P$. angustifolia.

2. Leaf blades rarely as much as twice as long as wide, not conspicuously paler on the lower surface, mostly acuminate; petioles usually more than $25 \mathrm{~mm}$. long (3) 
3(2). Pistillate disk sessile; fruit orbicular, 2-3 mm. in diameter; leaf blade suborbicular-ovate to broadly deltoid-ovate, truncate to broadly rounded at the base, the margins sharply and unevenly serrate.

\section{..3. P. Hinckleyana.}

3. Pistillate disk on a pedicel 3-5 mm. long; fruit ellipsoid-ovoid, about $10 \mathrm{~mm}$. long; leaf blade more or less rhombic, commonly rounded-cuneate at base, the margins mostly crenate-serrate..............1.P. acuminata.

4(1). Leaf blades suborbicular to broadly ovate, abruptly apiculate to shortly acuminate at apex, the margins finely crenate-serrate; found only at high elevations in the mountains from Trans-Pecos Texas westward................................................................. 8. P. tremuloides.

4. Leaf blades deltoid to broadly rhombic-ovate, coarsely or finely crenateserrate; not confined to high elevations (5)

5(4). Bud scales glabrous; leaf blades finely or coarsely crenate-serrate with usually 10 to 20 teeth on each side.........................6. P. deltoides.

5. Bud scales pubescent to puberulent or very rarely subglabrous; leaf blades usually coarsely crenate-serrate with mostly no more than 10 teeth on each side (6)

6(5). Trees of the Texas Trans-Pecos and along the Rio Grande, westward (7) 6. Trees of the Texas Panhandle (Plains Country) and eastward (9)

7(6). Capsule typically ovoid-ellipsoid to ovoid-conic, mostly $8-18 \mathrm{~mm}$. long, about as long as or slightly longer than the slender pedicels; disk shallow, mostly $3-4 \mathrm{~mm}$. in diameter.

5. P. Wislizenii.

7. Capsule typically orbicular to orbicular-ovoid, 3-8 $(-12) \mathrm{mm}$. long, at least twice as long as the short stout pedicel; disk cup-shaped, $5-8 \mathrm{~mm}$. in diameter (8)

$8(7)$. Leaves (at least some on same tree) typically shallowly or deeply cordate at base, triangular-acute at apex.

4. P. Fremontii var. Fremontii.

8. Leaves typically broadly cuneate to rounded or truncate at base, typically tapering long-acuminate at apex.........4. P. Fremontii var. arizonica.

9(6). Leaf blades with a pair of glands on upper surface at juncture with petioles............................................... . P. Sargentii var. Sargentii.

9. Leaf blades without basal glands or rarely with rudimentary glands.

..7. P. Sargentii var. texana.

1. Populus acuminata Rydb. Lanceleaf cotTonwood, smooth-BARKed CotTonwood. Fig. 379.

Tree to about $18 \mathrm{~m}$. tall, with a trunk $2-5 \mathrm{dm}$. in diameter, the stout branches ascending and spreading to form a compact pyramidal or domelike crown; bark smooth and whitish when young, with age becoming pale grayish-brown and deeply fissured to form narrow flat ridges; branchlets slender, terete to somewhat 4-angled, pale greenish-brown, glabrous or somewhat pubescent; buds ellipticconic, sharp-pointed, curved, resinous, bright reddish-brown, subglabrous to pubescent, about $1 \mathrm{~cm}$. long; leaf blades firm, dark-green and shiny on the upper surface, only slightly paler green on the lower surface, rhombic-lanceolate to rhombic-ovate or broadly ovate, gradually or abruptly subacute to acuminateattenuate at the apex, broadly rounded to cuneate at the base, the margins usually finely (or occasionally coarsely) crenate-serrate except near apex, 5-12 cm. long, usually about half to two thirds as wide as long, rarely about as wide as long; petiole nearly terete, usually somewhat channeled on the upper side, glabrous to puberulent, $2.5-7.5 \mathrm{~cm}$. long, rarely shorter; aments $5-12 \mathrm{~cm}$. long; floral bracts glabrous, scarious, caducous, dilated and irregularly lacerate at the apex; staminate aments densely cylindric, with short pedicels and oblique disks that support numerous stamens; pistillate aments more laxly flowered, with mature pedicels 


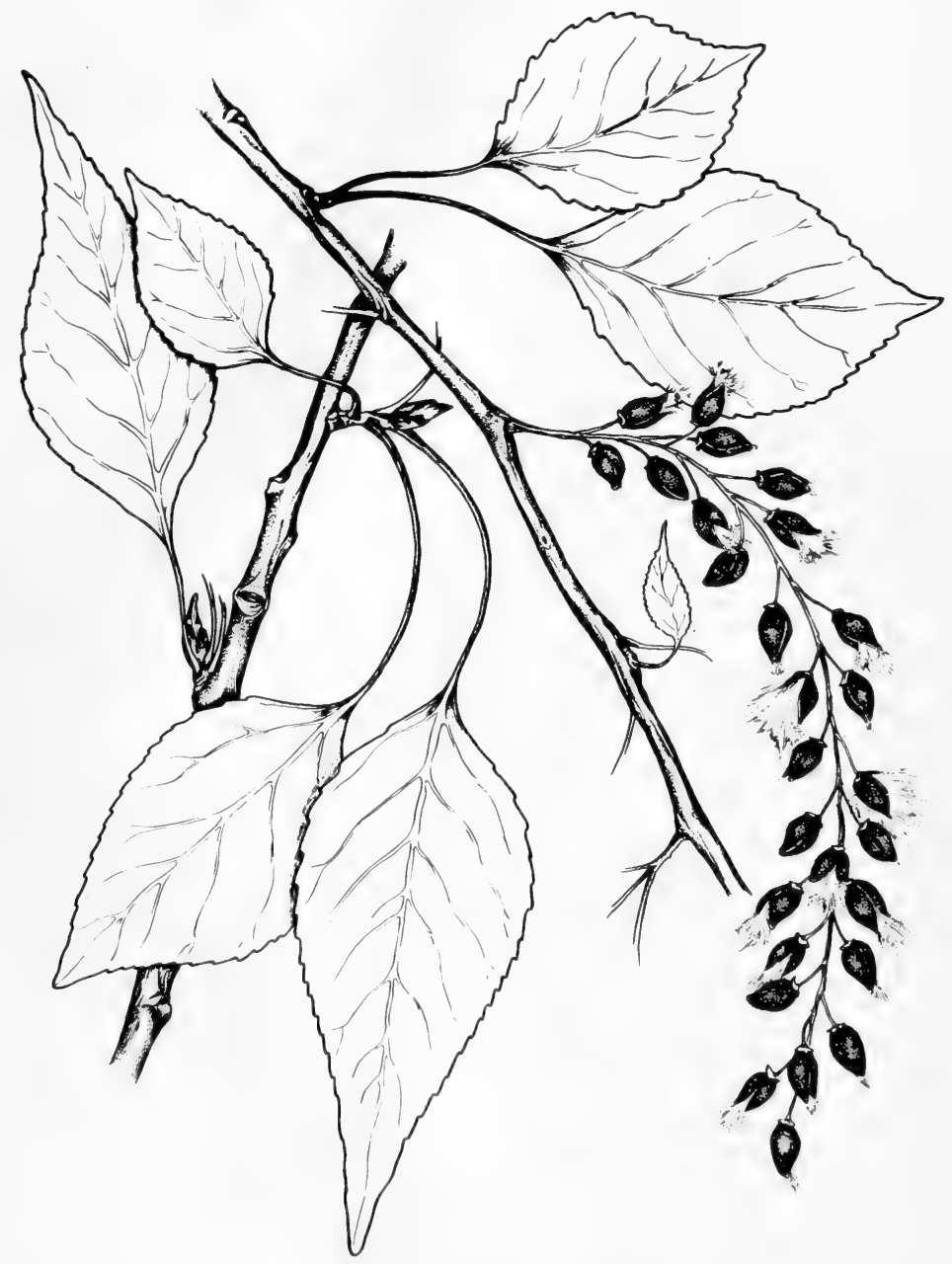

Fig. 379: Populus acuminata: sterile and fruiting branchlets, $\mathrm{x}$ 1. (From Correll in Lundell's Flora of Texas, Vol. 3, PI. 55.). 


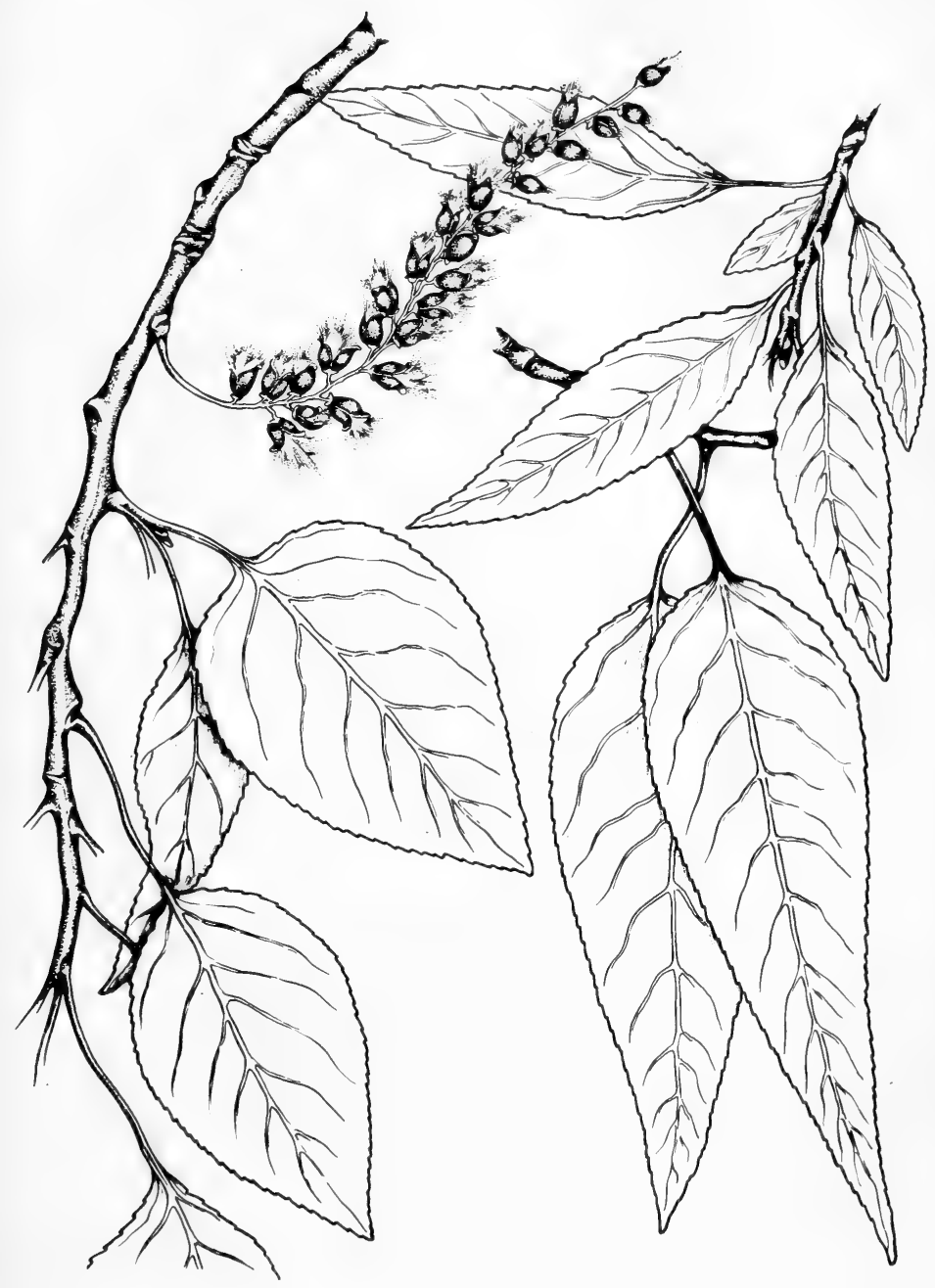

Fig. 380: Populus angustifolia: sterile and fruiting branchlets, x 1. (From Correll in Lundell's Flora of Texas, Vol. 3, Pl. 57.). 
3-5 mm. long and small cup-shaped disks 3-4 mm. in diameter; fruits ellipsoidovoid, somewhat pitted, about $1 \mathrm{~cm}$. long, 2- to 3-valved; seeds ellipsoid-obovoid, about $2 \mathrm{~mm}$. long.

In canyons and valleys, about springs and water tanks, and along streams in the Tex. S. and w. Trans-Pecos, N. M. (rather widespread) and Ariz. (Apache, Navajo, Yavapai and Greenlee cos.) Apr.-June; from s. Alta., s. to Colo., Tex., N.M. and Ariz.

\section{Populus angustifolia James. Narrowleaf cotTonwood. Fig. 380.}

Tree to about $20 \mathrm{~m}$. tall, with a slender trunk rarely more than $1.5 \mathrm{dm}$. in diameter, the slender branches erect-ascending to form a narrow more or less pyramidal crown; bark light-yellowish-green when young, shallowly fissured into broad flat plates near base of old trunks; branchlets slender, light-yellowish-green at first, later turning light-brown or orange-yellow and finally ashy-gray, glabrous to somewhat pubescent; buds ovoid-conic to ellipsoid-conic, sharp-pointed, strongly resinous, reddish-brown, glabrous to pubescent, 5-15 mm. long; leaf blades rather thin but firm, bright-yellowish-green on the upper surface, much more pale-green and sometimes puberulent on the lower surface, turning a dull-yellow in autumn, lanceolate to occasionally narrowly ovate-lanceolate, gradually narrowed to the acute to broadly obtuse apex, broadly to narrowly rounded or somewhat cuneate at the base, the margins finely or coarsely serrate with numerous teeth, $4.5-15 \mathrm{~cm}$. long, 2-3.5 cm. wide; petioles short, semiterete, more or less horizontally flattened and channeled on the upper side (especially near base of blades), puberulent to subglabrous, usually much less than $2 \mathrm{~cm}$. long, rarely longer; aments densely flowered, narrowly cylindric, 4-7 cm. long; floral bracts broadly obovate, deeply and irregularly lacerate at apex; staminate aments with subsessile or muchabbreviated pedicels and deep cup-shaped oblique disks with reflexed margins, the disks supporting 12 to 20 stamens; pistillate aments with abbreviated pedicels and shallow cup-shaped disks, the ovary with 2 oblique dilated irregularly lobed stigmas; fruits broadly ovoid to suborbicular, 4-7.5 mm. long, 2-valved; seeds ovoid to obovoid, about $3 \mathrm{~mm}$. long.

In the area of distribution this species is found along streams usually above 3,500 ft. alt., rare in the Tex. Trans-Pecos, N. M. (rather widespread) and Ariz. (Apache, Coconino and Yavapai cos.), Mar.-June; from s. Sask. and s. Alta., w. to Wash., and Ore., s. to Tex., N.M. and Ariz.; also n. Mex.

\section{Populus Hinckleyana Correll. Fig. 381.}

Tree to $20 \mathrm{~m}$. tall, with smooth light-gray bark which is deeply furrowed on the lower part of the trunk and light-gray to tan-colored bark on the young growth; twigs downy-puberulent, sometimes with some longer whitish spreading hairs; buds ellipsoid, puberulent and resinous, orange-brown, $1-1.5 \mathrm{~cm}$. long; leaf blades rather thin, essentially glabrous or sometimes slightly puberulent on the margins and on the veins on the lower surface, suborbicular-ovate to broadly deltoid-ovate, truncate to broadly rounded at the base, acute to abruptly acuminate at the apex, rather finely and irregularly (almost doubly) serrate on the margins (except at the very base and apex), darker-green on the upper surface, to $7 \mathrm{~cm}$. long and $6.5 \mathrm{~cm}$. wide, usually smaller; petiole subterete, channeled or somewhat flattened on the upper side, downy-puberulent, with age becoming glabrate, 2-4 (mostly less than 3) $\mathrm{cm}$. long; pistillate aments much-abbreviated, less than $5 \mathrm{~cm}$. long, with the rachis thick and rigid, the cup-shaped floral disks sessile and about $3 \mathrm{~mm}$. in diameter; fruits orbicular, pitted-rugose, $2-3 \mathrm{~mm}$. in diameter, 2- to 3-valved; seeds not fully developed in material examined.

In canyons and floodplain areas in the Davis Mts. in the Trans-Pecos where it is apparently endemic, Mar.-Apr. 


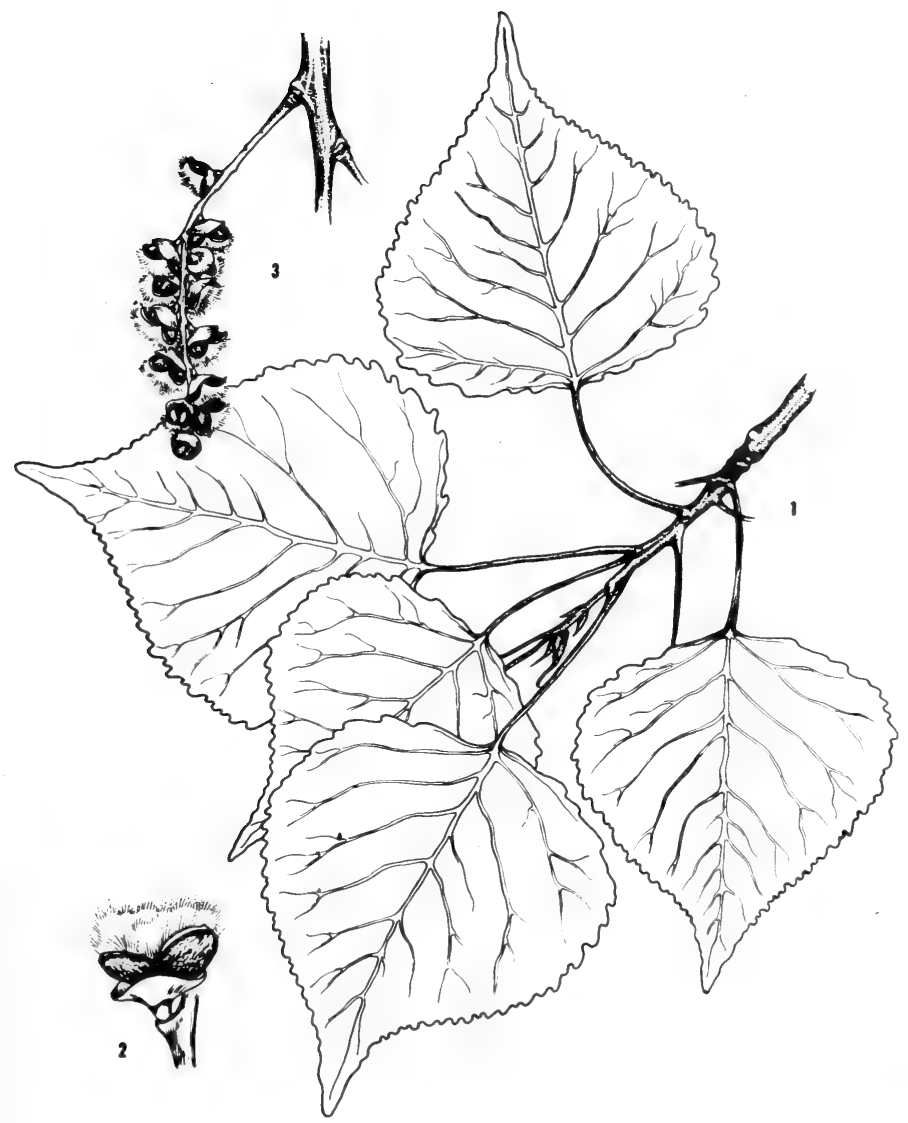

Fig. 381: Populus Hinckleyana: 1, leafy branchlet, x 1; 2, fruit and floral disk, x 3; 3, female ament, x 1. (From Correll in Lundell's Flora of Texas, Vol. 3, Pl. 60.). 


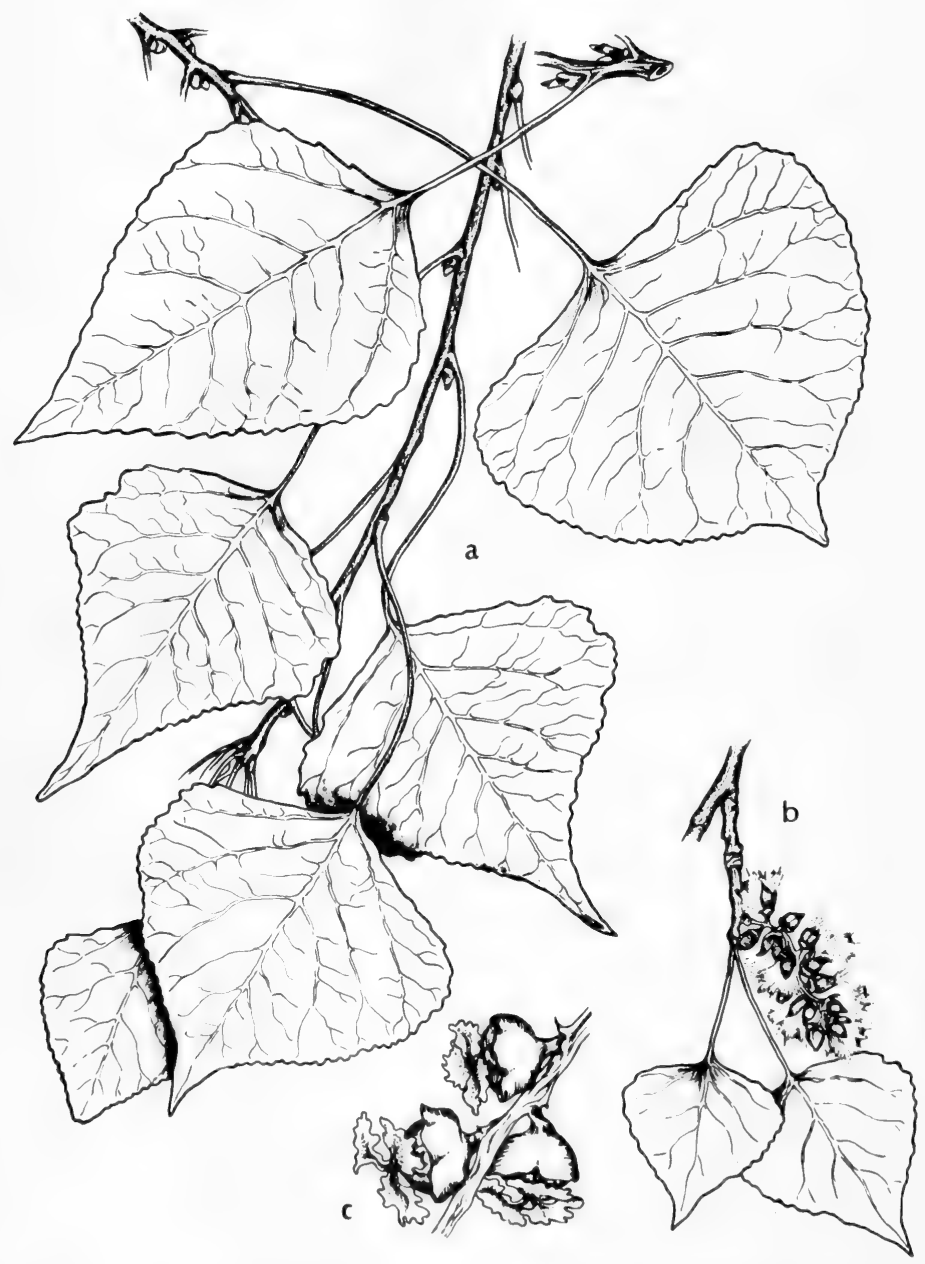

Fig. 382: Populus Fremontii var. arizonica: a, sterile branchlets to show leaf variation, $x 1 / 2 ; b$, fruiting branchlets, $x \frac{1}{2} ; c$, young fruits and floral disks, $x$ 4. (From Correll in Lundell's Flora of Texas, Vol. 3, Pl. 58.). 
The small (to $7 \mathrm{~cm}$. long) suborbicular-ovate to broadly deltoid-ovate leaf blades and much-abbreviated pistillate aments, with their sessile floral disks, are characteristics that distinguish this species from the allied $P$. angustifolia and $P$. acuminata.

\section{Populus Fremontii Wats. Fig. 382 (var. arizonica).}

Tree to about $30 \mathrm{~m}$. tall, with a thick often short trunk to $1 \mathrm{~m}$. or more in diameter, the branches large and ascending or wide-spreading to form a broad open crown; bark pale-gray or whitish, thick, in age pale-greenish and deeply fissured to form broad plates; branchlets (and sometimes older wood) noticeably pubescent to glabrous, rather slender, at first pale-green, later tan-color to yellowish or grayish; buds ovoid, only slightly resinous, pale-orange-brown, densely hirsute, $1-2 \mathrm{~cm}$. long; leaf blades leathery, glabrous to more or less pubescent or puberulent, yellowish-green and lustrous on the upper surface, paler on the lower surface, broadly deltoid to rhombic-ovate or triangular-ovate, abruptly acuteapiculate to long-acuminate at the usually entire apex, truncate to rounded or broadly cuneate to shallowly or deeply cordate at the base, the margins with few to many coarse glandular-crenate teeth, very rarely with poorly developed glands at juncture with petioles, $5-14 \mathrm{~cm}$. long, mostly about as wide as long; petioles slender, mostly somewhat pubescent, laterally compressed (especially just below the leaf blade), sometimes channeled on the upper side, $2.5-9 \mathrm{~cm}$. long; aments 6-10 cm. long; floral bracts caducous, scarious, narrowly cuneate, lacerate on the apical margin, about $2 \mathrm{~mm}$. long; staminate aments densely cylindric, with pedicels about $1 \mathrm{~cm}$. long and disks to $1 \mathrm{~cm}$. in diameter, the disks supporting 20 to 30 $(-60)$ stamens with anthers about $2 \mathrm{~mm}$. long; pistillate aments more laxly flowered, with mature stout pedicels 1-3 (rarely more) $\mathrm{mm}$. long and the large disks cup-shaped and 5-8 $\mathrm{mm}$. in diameter; stigma lobes broad, flattened, crenate; fruits orbicular to orbicular-ovoid, deeply pitted, 3-8 (-12) $\mathrm{mm}$. long, 3- to 4-valved; seeds ellipsoid, apiculate, compressed, 2-2.5 $\mathrm{mm}$. long.

Along streams, in swamps and wettish bottomlands, about springs and water tanks, Calif. and Nev., through Ariz., N.M. and (as var. arizonica) to w. Tex., Feb.-Apr.; also n. Mex.

Our two variants are distinguished in the key. It is quite possible that the Arizona cottonwood or chopo, var. arizonica (Sarg.) Jeps. ( $P$. arizonica Sarg.), should be referred to var. pubescens Sarg.

\section{Populus Wislizenii (Wats.) Sarg. Rio Grande cottonwood, alamillo.} Fig. 383.

Tree $8-25 \mathrm{~m}$. tall, with a thick trunk to about $1.5 \mathrm{~m}$. in diameter, the branches large and wide-spreading to form a broad somewhat flat-topped open crown; bark pale-grayish-brown, thick, deeply fissured to form broad flat plates; branchlets rather stout, glabrous, yellowish or light-yellowish-brown; buds ellipsoid-conic, sharp-pointed, somewhat resinous reddish-brown or greenish and brown, puberulous to densely hirsute, $1.5-2 \mathrm{~cm}$. long; leaf blades coriaceous, yellowish-green and more or less shiny on both surfaces, turning bright-yellow in autumn, broadly deltoid to deltoid-ovate, rather abruptly triangular-acuminate (rarely attenuate) at the entire apex, cordate to truncate at the base, the margins coarsely crenateserrate with usually less than 10 glandular teeth on each side, eglandular at base, $5-14 \mathrm{~cm}$. long, usually as broad as or broader than long; petioles slender, laterally compressed, 3-10 cm. long; aments 8-15 (usually about 10) cm. long; floral bracts caducous, obovate, lacerate on the apical margin, about $2 \mathrm{~mm}$. long; staminate aments densely cylindric, with pedicels $4-8 \mathrm{~mm}$. long and oblique disks about $3 \mathrm{~mm}$. in diameter, the disks supporting numerous stamens with reddish anthers $1-1.5 \mathrm{~mm}$. long; pistillate aments more laxly flowered, with mature pedi- 


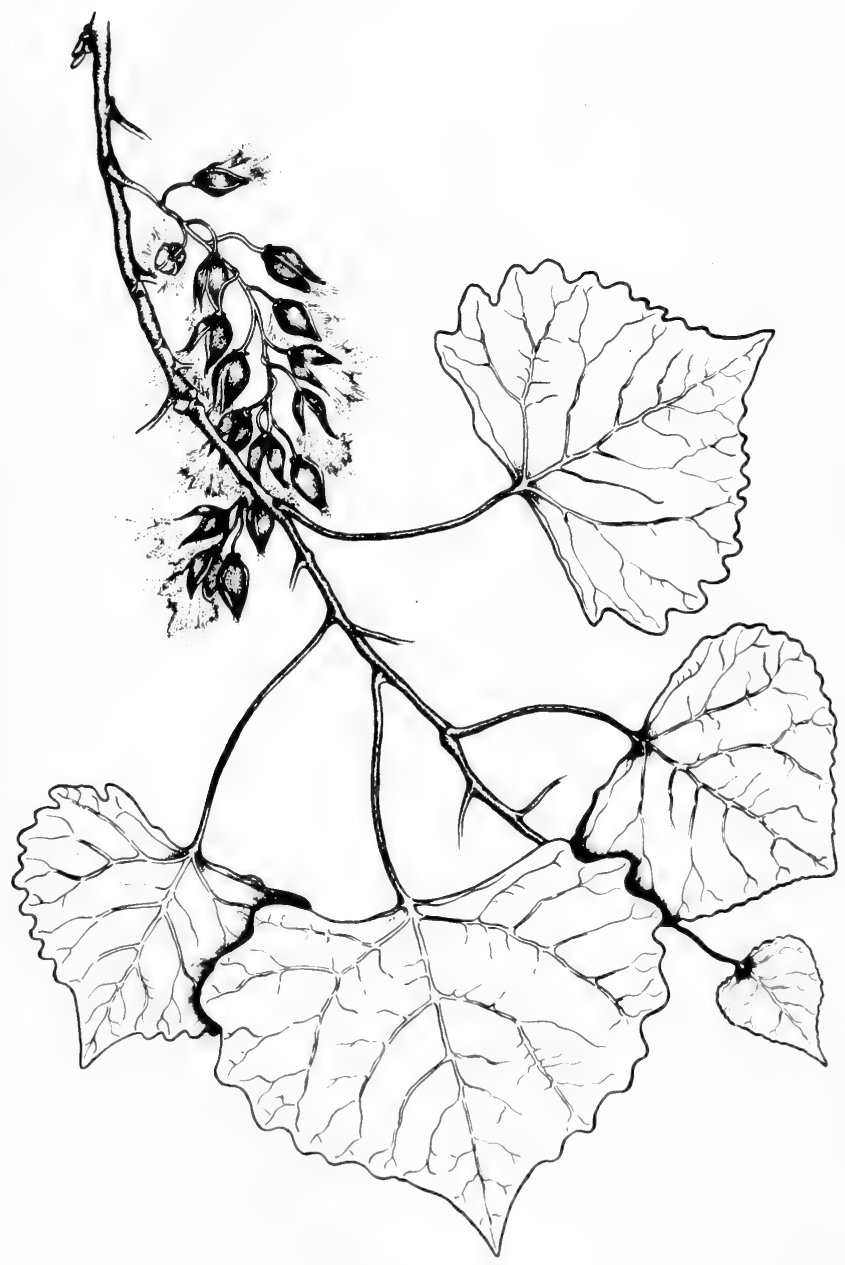

Fig. 383: Populus Wislizenii: leafy branchlet with female ament, $x$ 1/2. (From Correll in Lundell's Flora of Texas, Vol. 3, Pl. 63.). 


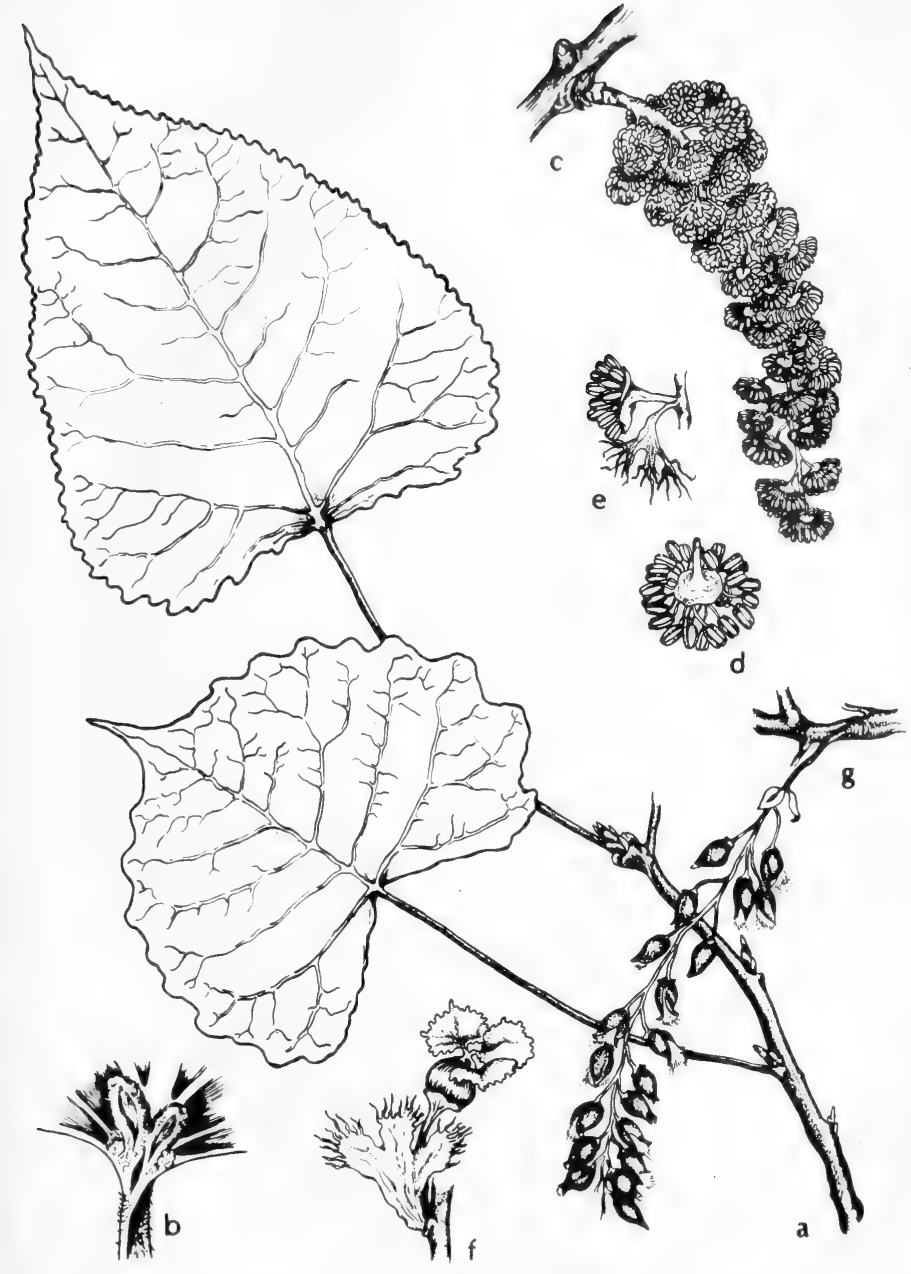

Fig. 384: Populus deltoides: a, leafy branchlet, showing leaf variation on same branch, X $1 / 2 ; b$, glands at base of leaf on upper surface, x 6 ; c, male ament, x 3/4; d, mature male flower, viewed from below, $\mathrm{x} 2 \frac{1}{2}$; e, young male flower with subtending floral bract, side view, x 3; f, young fruit with subtending floral bract, x 4; g, female ament, $x$ 1/2. (From Correll in Lundell's Flora of Texas, Vol. 3, PI. 59.). 
cels 7-15 (rarely less) $\mathrm{mm}$. long and shallow disks $3-4 \mathrm{~mm}$. in diameter; fruits broadly ovoid-ellipsoid to ovoid-conic or suborbicular, pitted, $8-18 \mathrm{~mm}$. long, rarely smaller, 3- or 4-valved; seeds ellipsoid, apiculate, compressed, 3-4 mm. long.

Along rivers, streams and irrigation canals in valleys and canyons, in rocky or deep alluvial soils, in the Tex. Trans-Pecos, Mar-July; from s. Colo. and s. Ut., s. to w. Tex., N.M. and n. Mex.

This is the common cottonwood along the Rio Grande in extreme west Texas and New Mexico. It is separated from $P$. Fremontii, which it resembles, not only by an apparent difference in distribution but also by its relatively narrower capsules and much longer pedicels.

6. Populus deltoides Marsh. Eastern cottonwood, alamo. Fig. 384.

Tree to $30 \mathrm{~m}$. or more tall, with a large erect trunk to $2 \mathrm{~m}$. or more in diameter, the branches often massive and erect-spreading or gradually wide-spreading to become pendulous at their extremities and form a wide open crown that occasionally attains a spread of $30 \mathrm{~m}$. or more in diameter; bark ashy-gray, thick, deeply fissured to form broad rounded ridges; branchlets usually stout, glabrous, terete or angular, light-yellowish-green to brownish or grayish, when young commonly sparsely hispid; buds large, ovoid to ellipsoid, acute, resinous, bright-reddishbrown, glabrous, $1.2-3 \mathrm{~cm}$. long; leaf blades thick and coriaceous, rarely thinnish, pale bright- or grayish-green and shiny on the upper surface, paler on the lower surface, turning a bright clear-yellow in autumn, deltoid to deltoid-ovate or suborbicular-ovate, abruptly or gradually triangular-acuminate (often attenute) or occasionally rounded and acute-apiculate at apex, truncate to cordate or broadly rounded to rarely somewhat broadly cuneate at base, the margins crenately serrate with few coarse or many fine teeth that are commonly ciliate, with 2 or more enlarged conspicuous glands at juncture with petioles, glutinous and fragrant of balsam when young and provided with white caducous hairs, $7-15 \mathrm{~cm}$. long, usually about as wide as long or longer than wide; petioles slender, pilose at first but soon glabrous, yellowish or tinged with red, laterally compressed, to $15 \mathrm{~cm}$. long; staminate aments densely flowered, cylindric, 7-10 cm. long, with pedicels $8-10 \mathrm{~mm}$. long and oblique disks $3-4 \mathrm{~mm}$. in diameter, the disks supporting about 60 stamens with anthers about $1 \mathrm{~mm}$. long; pistillate aments laxly flowered, to $2 \mathrm{dm}$. or more long, with mature pedicels 8-13 (rarely less) $\mathrm{mm}$. long and shallow cup-shaped disks $2.5-3 \mathrm{~mm}$. in diameter; floral bracts caducous, glabrous, light-brown, narrowly to broadly cuneate, sometimes 3-lobed, irregularly lacerate on the margins of the upper half, $2.5-5.5 \mathrm{~mm}$. long; fruits ellipsoid-conic to suborbicular-ovoid, sharp-pointed, somewhat pitted, 6-15 $\mathrm{mm}$. long, 3- to 4-valved; seeds ellipsoid-obovoid, apiculate, compressed, 3-4 mm. long.

Occurring naturally in Tex. as far n.w. as the s. Plains Country and s.w. to Uvalde Co. in the Rio Grande Plains, and Okla. (Waterfall), Mar.-July; from N.H. s. to n.w. Fla., w. to s. Sask., N.D., w. Kan., w. Okla. and Tex.

This species may be found along practically every watercourse of any size and about most of the springs and waterholes in the eastern third of Texas, commonly planted along roadways and about dwellings, growing especially well in deep alluvial soils.

\section{Populus Sargentii Dode var. Sargentii. Plains cottonwood. Fig. 385.}

Tree $8-27 \mathrm{~m}$. tall, with a heavy trunk up to about $1.5 \mathrm{~m}$. in diameter, the branches large and spreading-pendulous to form a broad open crown; bark grayish, becoming darker with age, thick, deeply fissured to form broad ridges; branchlets slender, pale yellowish brown or sometimes grayish, glabrous; buds ellipsoid-conic, sharp-pointed somewhat resinous, yellowish brown, puberulent to somewhat hirsute, $1-2.5 \mathrm{~cm}$. long; leaf blades firm, yellowish green and shiny on the upper surface, paler on the lower surface, broadly deltoid to deltoid-ovate 


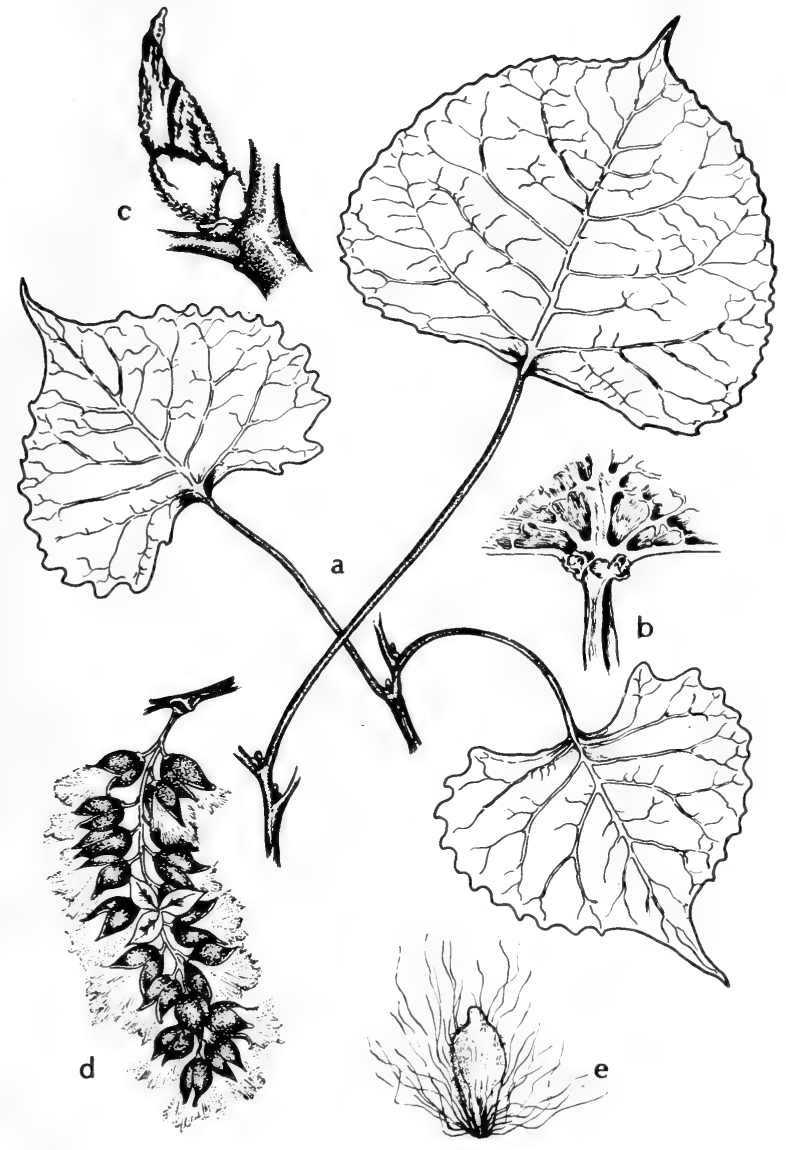

Fig. 385: Populus Sargentii: a, leafy twigs, $\mathrm{x} 1 / 2 ; \mathrm{b}$, glands on base of leaf on upper surfaces, x 6; c, vegetative bud, x 3; d, female ament, x 1/2; e, seed, x 8. (From Correll in Lundell's Flora of Texas, Vol. 3, P1. 61.). 


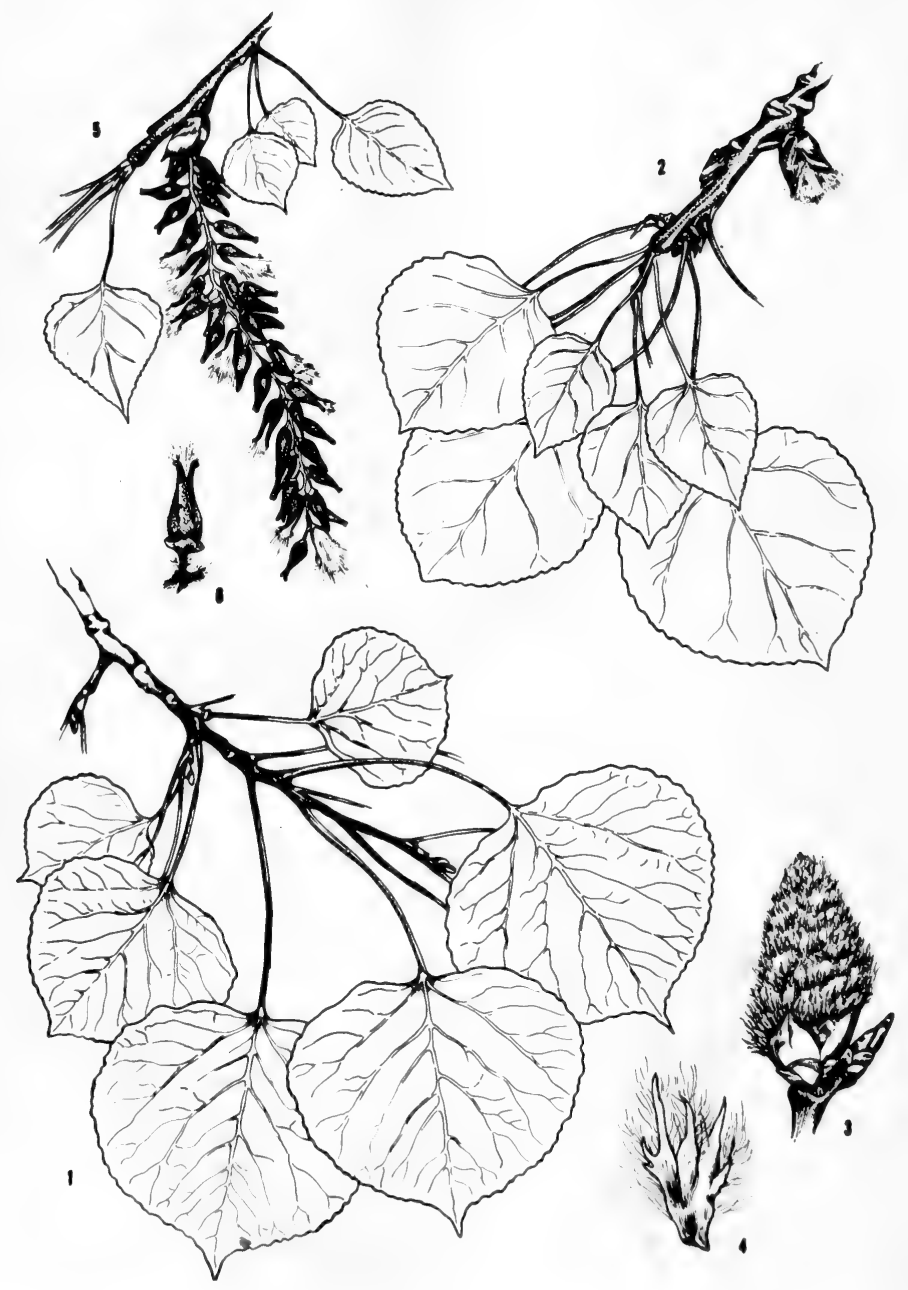

Fig. 386: Populus tremuloides: 1, leafy branchlet, $x 1 / 2 ; 2$, leafy branchlet with bursting young ament, $x 1 ; 3$, young male ament, $x 1 ; 4$, floral bract, $x 21 / 2 ; 5$, leafy twig with female ament, x 1; 6, fruit, x 21/2. (From Correll in Lundell's Flora of Texas,
Vol. 3, Pl. 62.). 
or deltoid-subreniform, mostly abruptly narrowed and acuminate-attenuate at the entire apex, truncate to shallowly cordate or sometimes widely cuneate at base, the margins coarsely serrate with usually less than 10 teeth on each side, provided with two small glands at juncture with petioles, 7-11 cm. long, usually about as broad as or broader than long; petioles slender, laterally compressed, $5-10 \mathrm{~cm}$. long; pistillate aments $6-13 \mathrm{~cm}$. long, with mature pedicels 1-6 (rarely more) $\mathrm{mm}$. long (usually $5 \mathrm{~mm}$. or less) and shallow disks $2-4 \mathrm{~mm}$. in diameter; floral bracts caducous, thin, scarious, cuneate below, dilated above and lacerate on the apical margin, 3-4 $\mathrm{mm}$. long; fruits broadly ovoid to ovoid-ellipsoidal, pitted, 1-1.5 cm. long, 3- to 4-valved; seeds ellipsoid, usually widest above the middle, apiculate, compressed, 3-4 mm. long. P. deltoides [var.] occidentalis Rydb.

In sandy alluvial soils along rivers and streams, about stock tanks and along roadside banks scattered over the Tex. Plains Country from Nolan Co. northw., and extending over into Cooke and Montague cos. in n.-cen. Tex. and into Okla., Mar.-June; from s. Sask., s. Alta. and S.D., s. to w. Okla., n. Tex. and n.e. N.M.

When in fruit, var. Sargentii is readily distinguished from both $P$. deltoides and $P$. Wislizenii by its short pedicels which are shorter than the fruits and usually less than $5 \mathrm{~mm}$. long. From $P$. deltoides it is also distinguished by its pubescent, not glabrous, buds, and from $P$. Wislizenii by the glands that are developed at the junction of the leaf blades and petioles. The glands are smaller and of a different shape than those of $P$. deltoides.

Var. texana (Sarg.) Correll. Texas cotTonwood. P. texana Sarg. Variety texana occurs in the same types of habitat and, in Texas and Oklahoma, occupies approximately the same area of distribution as var. Sargentii.

Except for the fact that var. texana rarely, if ever, has glands at the junction of the leaf blades and petioles it could be referred to var. Sargentii. This lack of well-developed glands is apparently the only characteristic that separates these two entities. Sterile specimens of var. texana resemble $P$. Wislizenii so closely that if it were not for a difference in their area of distribution it would practically be impossible to distinguish one from the other. The leaves of var. texana, however, usually have a more abruptly acuminate-attenuate apex, and some of the leaves occasionally have one or two abortive glands, a characteristic that is not evident in $P$. Wislizenii. In fruit, however, the stout pedicels of var. texana, which rarely exceed $5 \mathrm{~mm}$. in length, conveniently separate it from the longer, more slender pedicels of $\boldsymbol{P}$. Wislizenii.

\section{Populus tremuloides Michx. Quacking aspen, alamo temblón. Fig. 386.}

Tree (in our area) rarely more than $15 \mathrm{~m}$. tall, attaining a much greater size at lower elevations, with a slender erect trunk to about $1.5 \mathrm{dm}$. in diameter, the slender pendulous branches forming a narrow symmetrical domelike crown; bark smooth, firm, grayish-white to brownish or pale-green occasionally mottled with yellow, with scattered black rounded protuberances and curved scarlike marks, the older bark at base of trunk irregularly fissured and becoming blackish; branchlets slender, flexible, glabrous and shiny, reddish-brown in autumn of first year, later becoming gray, provided with scattered elliptic orange-colored lenticels; buds reddish-brown, shiny, slightly resinous, ellipsoid-conic, sharp-pointed, sometimes with the lowermost scales slightly puberulent, to about $1 \mathrm{~cm}$. long; leaf blades glabrous, suborbicular to orbicular-ovate or sometimes orbicular-subreniform, abruptly apiculate to shortly acuminate at apex, truncate to broadly rounded or shallowly cordate at base, deep-yellowish-green and lustrous on upper surface, paler on lower surface, with conspicuous yellowish veins, becoming yellowish to deep orange-color in autumn, the margins regularly and finely crenulate-serrulate, occasionally with small glands at juncture with petiole to $7.5 \mathrm{~cm}$. long, frequently wider than long; petiole slender, weak, yellow, laterally compressed just below the 
leaf blade, 4-6.5 cm. long; aments 4-6 cm. long; floral bracts cuneate, deeply divided to near the middle into 3 to 5 triangular-lanceolate lobes, fringed with long hairs; staminate aments densely flowered and cylindric, with short pedicels and small oblique disks that support 6 to 12 stamens; pistillate aments more laxly flowered, with mature pedicels $2-3 \mathrm{~mm}$. long and oblique somewhat crenulate disks 2-3 mm. in diameter; ovary conical, crowned by a thick short style and 2 erect thickened stigmas that are divided above into linear divergent lobes; fruits ellipsoid-conic, thin-walled, 6-9 mm. long, on pedicels 2-3 mm. long; seeds obovate, light-brown, about $1 \mathrm{~mm}$. long. Incl. [var.] aurea (Tidestr.) Daniels.

Apparently confined to the highest mts. in the Tex. Trans-Pecos where it grows in ravines and on talus slopes above $7,000 \mathrm{ft}$. alt.; common in high mts., in bogs, swamps and wet meadows of N. M. and Ariz.

This species is probably the most widespread tree in North America. It occurs in most of Canada and Alaska and throughout the United States, except in the southeast, and southward into northern Mexico it is found only in the high mountains. The leaves turn an intense bright yellow or orange-yellow in autumn. It flowers and fruits in the spring in its range. The slightest breeze causes movement of the leaves, hence the common name, "quaking aspen."

\section{Salix L. Willow}

Prostrate to ascending or erect shrubs to large trees, to $36 \mathrm{~m}$. or more in height; budscale one, with an adhering inner membrane; leaf blades variable, linear, lanceolate, oblanceolate, elliptic or oblong, petiolate, often persistently stipulate, green or glaucous on the lower surface, hairy to glabrous, the margins entire or somewhat revolute, denticulate, serrulate, crenate, undulate or undulate-serrulate; aments precocious, coetaneous or serotinous, ascending, divaricate or somewhat recurved (never pendulous), 1-10 cm. or more long, slender and flexuous to stout and dense; flower scales entire to erose-toothed, yellowish to black, mostly hairy, tardily deciduous or persistent; stamens 2 (sometimes united) to 7 or 8 , with 1 ventral and sometimes 1 dorsal gland; capsules with 2 valves recurving at maturity, lanceolate to ovoid, 2-9 mm. long, hairy to glabrous, sessile or pedicelled $(0.5-3$ $\mathrm{mm}$. long), with 1 ventral gland and sometimes 1 dorsal gland; style 1 (sometimes wanting), entire or more or less divided; stigmas 2, entire or more or less divided; without a disk; seeds numerous, minute, $0.8-1.2 \mathrm{~mm}$. long, oblong, bearing a tuft of silky hairs at base.

A genus of about 500 species, widely distributed throughout the North Temperate and Arctic zones, a few in the American tropics and Southern Hemisphere.

Many of the species produce vigorous shoots that may have much larger and often more toothed leaves than on the mature plant, and the stipules may be greatly enlarged and even foliaceous. The shape and measurements of all organs given in our descriptions are from mature plants.

The buds and twigs are the main parts of these plants that are eaten by various game birds and songbirds, while not only these parts but also the bark and foliage are eaten by various animal life, including, deer, elk, beaver, muskrat, rabbit and squirrel.

I. Distribution in Oklahoma and Texas (p. 752)

II. Distribution in New Mexico and Arizona (p. 755)

Key Based on Vegetative Characters (For OKlahoma and Texas species)

A. Leaves narrowly lanceolate to lanceolate, acuminate to long-acuminate, 5-10 or $12 \mathrm{~cm}$. long, finely serrulate, the vein islets beneath very small (1) 
B. Leaves linear or linear-oblong, acute, almost sessile, subentire to remotely and irregularly denticulate $(8)$

C. Leaves linear-oblong or linear-oblanceolate, $5-10 \mathrm{~cm}$. long, distinctly petioled, entire to undulate-serrate, glaucous on lower surface, more or less pubescent (14)

1(A). Leaves green beneath, linear-lanceolate, acuminate (2)

1. Leaves glaucescent to glaucous beneath (5)

2(1). Twigs all yellowish; blades narrowly lanceolate.

3. S. Gooddingii var. variabilis.

2. Twigs brown to blackish (seasonal somewhat yellowish) (3)

3(2). Capsule ovoid to ellipsoid, sculptured; leafy peduncle without a miniature shoot from the axis of its uppermost leaf; stipules glandless.

2. S. Humboldtiana.

3. Capsule ovoid-conical, unsculptured; leafy peduncle often producing a miniature shoot from the axis of the uppermost leaf; stipules more or less glandular (4)

4(3). Petioles short, averaging about $6 \mathrm{~mm}$. long, brownish, pubescent; blades broader, less narrowed at base......................... S. nigra var. nigra.

4. Petioles longer, averaging about $8 \mathrm{~mm}$. long, yellowish, glabrous; blades narrower, more narrowed at base.............. S. nigra var. Lindheimeri.

5(1). Petioles with glands near leaf base; blades lanceolate, coarsely crenateserrate, dark-green above, glabrous.

5. Petioles without glands near leaf base (6)

6(5). Twigs brownish, often pubescent; blades linear- to narrowly lanceolate, long-acuminate, often pubescent, dark-green above $(S$. longipes var.

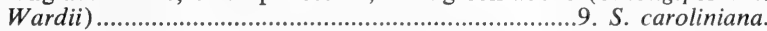

6. Twigs yellow or yellowish, glabrous; blades yellowish-green above, glabrous (7)

7(6). Blades lanceolate or somewhat ovate-lanceolate; aments lax ..4. S. amygdaloides var. amygdaloides.

7. Blades linear-lanceolate or lingulate-lanceolate; aments denser.

4. S. amygdaloides var. Wrightii.

8(B). Blades yellowish-green, somewhat translucent, glabrous (more or less thinly hairy while developing) (9)

8. Blades green, more opaque, silvery-silky or more or less gray-pubescent (10)

$9(8)$. Blades 5-10 or $12 \mathrm{~cm}$. long, 5-10 mm. wide....12. S. interior var. interior. 9. Blades $5-8$ or $10 \mathrm{~cm}$. long, 2-5 mm. wide.........12. S. interior var. pedicellata.

10(8). Blades silvery-silky, at least until full-size (11)

10. Blades more or less gray-puberulent or gray-pubescent (12)

11(10). Blades $6-10$ or $12 \mathrm{~cm}$. long, usually sharply denticulate, the hairs persisting beneath (especially on midrib.).

12. S interior var. angustissima.

11. Blades $5-8 \mathrm{~cm}$. long, mostly subentire, the hairs persisting on both surfaces.... 11. S. exigua var. stenophylla.

12(10). Blades only occasionally more than $4 \mathrm{~cm}$. long and $4 \mathrm{~mm}$. wide, usually crowded, yewlike, pubescent, often becoming glabrate.

10. S. taxifolia.

12. Blades only occasionally less than $5 \mathrm{~cm}$. long, $5 \mathrm{~mm}$. wide, not yewlike, pubescent or glabrous (13) 
13(12). Blades $5-8$ or $10 \mathrm{~cm}$. long, $5-10$ or $12 \mathrm{~mm}$. wide, permanently more or less pubescent.

11. S. exigua var. exigua.

13. Blades $4-6$ or $8 \mathrm{~cm}$. long, 3-5 or $6 \mathrm{~mm}$. wide, soon glabrate to glabrous and yellowish green.

11. S. exigua var. nevadensis.

14(C). Blades mostly linear-oblanceolate, pubescent while young, becoming glabrous, densely glaucous and veiny; distribution mostly in mountain canyons..................................17. S. lasiolepis var. Bracelinae.

14. Blades narrowly elliptic to oblanceolate, densely pubescent while young, more thinly so and somewhat rugose in age; distribution in low or upland prairies or open wasteland eastward.

23. $S$. humilis var. rigidiuscula.

\section{Key Based on Floral Characters (For Oklahoma and Texas species)}

1. Flower scales yellowish, slowly deciduous; aments leafy-pedunculate (2)

1. Flower scales blackish, persistent; aments precocious, sessile or subsessile (11)

2(1). Aments only one per peduncle, mostly coetaneous, occasionally subprecocious; capsules always glabrous (in Texas) (3)

2. Aments (especially staminate) 2 to 4 per peduncle, the supernumerary later, at base of the first, serotinous; stamens 2; ovaries (sometimes) and capsules (less frequently) more or less hairy while developing (8)

$3(2)$. Stamens 2 (occasionally 3 or 4 ); maturing fruiting aments $7-10 \mathrm{~mm}$. wide; trees introduced.

6. S. fragilis.

3. Stamens 3 to 7 or 8 ; trees native (4)

4(3). Fruiting aments. (mature) 10-15 mm. wide; capsules 4-5 or $6 \mathrm{~mm}$. long; pedicels 1-2 mm. long (5)

4. Fruiting aments (mature) $15-20 \mathrm{~mm}$. wide; capsule 5-6 or $7 \mathrm{~mm}$. long; pedicels $1.5-3 \mathrm{~mm}$. long (7)

5(4). In the Texas Plains Country (Panhandle) and western Trans-Pecos, westward........................................................... 4. . amygdaloides.

5. In Texas and/or Oklahoma east of the above regions (6)

6(5). Capsules ovoid to ellipsoid, sculptured; stipules glandless; lacking a miniature shoot from the axis of the top peduncle leaf

2. S. Humboldtiana.

6. Capsules ovoid-conical, unsculptured; stipules more or less glandular; often producing a shoot from the axis of the top peduncle leaf....

1. S. nigra.

7(4). Capsules mostly 5.5-6.5 mm. long

7. Capsules mostly $4.5-5.5 \mathrm{~mm}$. long.

3. S. Gooddingii var. variabilis. 9. S. caroliniana.

$8(2)$. Aments $1-1.5 \mathrm{~cm}$. long, crowded near the tips of twigs

8. Aments $3-6$ or $8 \mathrm{~cm}$. long, scattered along the twigs (9)

10. S. taxifolia.

9(8). Capsules 5-6 or $7 \mathrm{~mm}$. long; aments to $15 \mathrm{~mm}$. wide

9. Capsules $8-9$ or $10 \mathrm{~mm}$. long; aments to $20 \mathrm{~mm}$. wide (10)

10(9). Capsules thinly silky to glabrous when young, glabrous when mature

10. ..............12. S. interior var. interior and $S$. interior var. pedicellata.

10. Capsules densely white-hairy while young, gray-hairy when mature.

12. S interior var. angustissima.

11(1). Aments 8-12 mm. wide; capsules 4-5 mm. long, glabrous.

17. S. lasiolepis var. Bracelinae.

11. Aments 15-20 mm. wide; capsules 7-9 mm. long, pubescent

23. S. humilis var, rigidiuscula. 
1. Prostrate miniature shrub with stems on or just below surface of ground, commonly forming mats; alpine or subalpine (2)

1. Erect or ascending shrubs or trees with stems usually $5 \mathrm{dm}$. tall or more; at lower elevations, rarely alpine (3)

2(1). Aments serotinous, terminating the short leafy shoots of the season; scales pale, inconspicuously short-hairy within, otherwise glabrous; filaments inconspicuously short-hairy toward the base; style very short, it and the stigmas together less than $1 \mathrm{~mm}$. long..........13. S. nivalis.

2. Aments coetaneous, terminating short leafy lateral branches, the principal vegetative shoots of the season not ending in aments; scale dark, ordinarily conspicuously long-hairy (at least on the margins), the hairs much surpassing the body of the scale; filaments glabrous; style often longer, it and the stigmas together well over $1 \mathrm{~mm}$. long........................................................................... 14. S. arctica.

3(1). Petioles very short (not more than $3 \mathrm{~mm}$. long) or none; leaves linearlanceolate to narrowly oblanceolate, sericeous (at least beneath); seldom more and usually much less than $7 \mathrm{~mm}$. wide or rarely to $12 \mathrm{~mm}$. in $S$. exigia, the margins entire or remotely denticulate; stamens 2 (4)

3. Petioles more than $3 \mathrm{~mm}$. long or (if shorter) then the larger leaves more than $7 \mathrm{~mm}$. wide or closely serrate or serrulate (5)

4(3). Leaves oblanceolate, sessile or very nearly so, at maturity not more than $3 \mathrm{~cm}$. long; capsules silky-villous, then glabrate..........10. S. taxifolia. 4. Leaves linear-lanceolate, short-petioled, at maturity $5 \mathrm{~cm}$. long or more; capsules glabrous................................................11. S. exigua.

5(3). All leaves with entire margins (6)

5. At least some or all of leaves with serrulate to serrate or crenulate-dentate magins (7)

6(5). Leaves $2-4 \mathrm{~cm}$. long, subglaucous beneath; staminate aments $7-15 \mathrm{~mm}$. long; pistillate aments $1-2.5 \mathrm{~cm}$. long at maturity; style to about $0.4 \mathrm{~mm}$. long.....................................................22. S. Geyeriana.

6. Leaves 4-6 $(-8) \mathrm{cm}$. long, the margins often revolute, silvery appressedpubescent beneath; staminate aments $20-30 \mathrm{~mm}$. long; pistillate aments $2-6 \mathrm{~cm}$. long at maturity; style mostly $0.6-1.3 \mathrm{~mm}$. long 26. S. Drummondiana.

7(5). Margins of the leaves entire or with some obscurely serrulate (8)

7. Margins of all the leaves noticeably serrate to serrulate or dentate to crenulate (16)

$8(7)$. Leaves rounded to subcordate at base, green but paler beneath.... 19. S. myrtillifolia.

8. Leaves acutish to somewhat cuneate or attenuate at base, typically white or whitish beneath (9)

9(8). Capsules thin-hairy or silky-pubescent (10)

9. Capsules glabrous; leaves lanceolate to oblanceolate, acute to acuminate at apex, glabrous and often shiny above (14)

10(9). Stigmas elongate, mostly $0.5-1 \mathrm{~mm}$. long; twigs not glaucous, usually glabrous; leaves broadly to narrowly obovate or elliptic-obovate, glabrous above at maturity, widest above the middle (11)

10. Stigmas shorter than above, $0.2-0.5 \mathrm{~mm}$. long; twigs glaucous or more or less pubescent; leaves not broadly obovate, more or less pubescent above (especially on main veins), mostly (but not always) widest at or below the middle (12) 
11(10). Style usually $0.7-1.7 \mathrm{~mm}$. long; leaves generally glabrous by the time they are fully expanded; plants sometimes dwarf, rarely to $4 \mathrm{~m}$. tall......................................................................25. S. phylicifolia.

11. Style to 0.5 (rarely to 0.8 ) $\mathrm{mm}$. long; leaves typically reddish-strigillose beneath but sometimes more conspicuously hairy or even glabrous; plants robust, mostly more than $4 \mathrm{~m}$. tall. 24. S. Scouleriana.

12(10). Leaves 5 or more times as long as wide, usually narrowly lanceolate but sometimes oblanceolate; twigs very glaucous.........22. S. Geyeriana.

12. Leaves not more than 4 times as long as wide, typically elliptic but sometimes oblong-lanceolate or narrowly obovate; twigs usually strongly pubescent (13)

13(12). Style $0.5-0.8 \mathrm{~mm}$. long; scales light- to dark-brown or sometimes blackish......................................................................15. S. glauca.

13. Style short, to about $0.4 \mathrm{~mm}$. long; scales yellowish to light-brown...............

21. S. Bebbiana.

14(9). Shrub to about $4 \mathrm{~m}$. tall; branchlets usually dark-purple (plum-colored) and very glaucous..................................................16. S. irrorata.

14. Shrubs or trees; branchlets yellowish to dark-brown, not or but slightly glaucous (15)

15(14). Leaves oblanceolate to linear, acute to short-acuminate; stamens 2 , the filaments glabrous...........................................17. S. lasiolepis.

15. Leaves prevailingly lanceolate to oblong-lanceolate and long-acuminate; stamens more than 2 , the filaments hairy toward the base.

.8. S. laevigata.

16(7). Lower leaf surface green, slightly paler than the upper surface but seldom distinctly glaucous (17)

16. Lower leaf surface decidedly paler than the upper surface, usually glaucous (19)

17(16). Petioles and leaf bases glandular.

5. S. lasiandra.

17. Petioles and leaf bases not glandular (18)

18(17). Shrub; twigs brown; leaves seldom more than 4 times as long as wide, rounded to subcordate at base, obtuse to short-acuminate at apex 19. S. myrtillifolia.

18. Tree; twigs yellowish; leaves much more than 4 times as long as wide, attenuate at base, long-acuminate at apex.

3. S. Gooddingii.

19(16). Leaves all (or some of them) conspicuously and sharply long-acuminate at apex; stamens 3 or more, the filaments hairy toward the base; usually trees (20)

19. Leaves rounded to short-acuminate at apex (23)

20(19). Petioles slender, those of the larger leaves usually $10 \mathrm{~mm}$. long or more; leaves typically not more than 3 times as long as wide, not shiny above............................................................. 4 . S. amygdaloides.

20. Petioles stout, usually less than $10 \mathrm{~mm}$. long; leaves commonly at least 4 times as long as wide, often shiny above (21)

21(20). Margins of the leaf blades and the petioles near the apex bearing conspicuous yellowish glands; branchlets and the upper surface of the leaves very shiny.

5. S. lasiandra.

21. Margins of the leaf blades and the petioles not or not conspicuously glandular; branchlets and the upper surface of the leaves not or only moderately shiny (22) 
22(21). Leaves commonly broadly lanceolate (less than 6 times as long as wide), usually only moderately acuminate, glaucous but ordinarily not silvery-white beneath......................................... 8 . S. laevigata.

22. Leaves commonly narrowly lanceolate ( 6 or more times as long as wide), very long- and sharp-acuminate, silvery-white beneath.

7. S. Bonplandiana.

23(19). Bases of the leaves rounded or subcordate (seldom cuneate); stamens 2 , the filaments glabrous (24)

23. Bases of the leaves cuneate or attenuate (sometimes rounded in S. laevigata), the blades often shiny above and very glaucous beneath (25)

24(23). Bark of the twigs yellow or brown; leaves oblong-lanceolate to linearlanceolate, yellowish-green and usually not glossy above, moderately glaucous beneath......................................................18. S. rigida.

24. Bark of the twigs reddish-brown to dark-purple (plum-colored); leaves elliptic (often broadly so), dark-green and slightly glossy above, strongly glaucous beneath; stipules large, usually persistent....20. S. monticola.

25(23). Leaves prevailing oblanceolate to broadly obovate (26)

25 . Leaves prevailingly lanceolate to oblong-lanceolate (27)

26(25). Capsules hairy; leaves commonly obovate. 26. Capsules glabrous; leaves commonly oblanceolate.

24. S. Scouleriana.

27(25). Branchlets commonly dark-purple (plum-colored) and very glaucous; filaments glabrous.......................................................16. S. irrorata.

27. Branchlets yellow to dark-brown, not or but slightly glaucous; filaments hairy toward base.

8. S. laevigata.

1. Salix nigra Marsh. Black wilı.ow, saúz. Fig. 387.

Tree to $20 \mathrm{~m}$. tall, sometimes with several trunks and when young somewhat shrubby, with flaky dark-brown to blackish bark; branchlets and twigs brittle at base but tough and flexible above, soon glabrate; stipules semicordate, acute, glandular-serrulate, to $12 \mathrm{~mm}$. long, caducous; leaves with pubescent to glabrous petioles 4-10 $\mathrm{mm}$. long; blades (when mature) linear to narrowly lanceolate, acuminate-attenuate, broadly to narrowly cuneate at base, often falcate, $5-15 \mathrm{~cm}$. long, 5-15 mm. wide, becoming glabrous, deep green on both surfaces, glandularserrulate; aments coetaneous, terminating leafy shoots, slender-cylindric, $2-8 \mathrm{~cm}$. long; scales obovate, yellowish, crisp-villous on inner surface, caducous; staminate flowers with 2 basal glands; stamens 3 to 5, the free arching filaments pubescent below; pistillate flowers with 1 basal gland; style nearly obsolete; capsules ovoidconical, fulvous, glabrous, 3-5 mm. long.

In alluvial soils along streams and in wet meadows, also about ponds, lakes and other water bodies, in Okla. (Blaine, Caddo, Seminole and Texas cos.) and in the e. two third of Tex., w. to the 101st Meridian and s. to Cameron Co., spring; N.B. and N.E., s. to Fla., w. to s. Minn., s.e. Neb, e. Kan., Okla. and Tex.; also n.e. Mex.

Var. nigra and var. Lindheimeri Schneid, are distinguished in the key. In addition, var. Lindheimeri further differs from var. nigra in its usually narrower leaves that are at least more attenuate at the base. Its young branchlets and petioles are also glabrous or become so very soon.

\section{Salix Humboldtiana Willd.}

Very similar to $S$. nigra var. Lindheimeri, but differs from that species in having sculptured markings on the ovoid to ovoid-oblong or ellipsoid glabrous capsules and in lacking a miniature shoot from the axis of the top peduncle leaf. Also, the stipules are said to be glandless. Salix nigra has ovoid-conical unsculptured cap- 


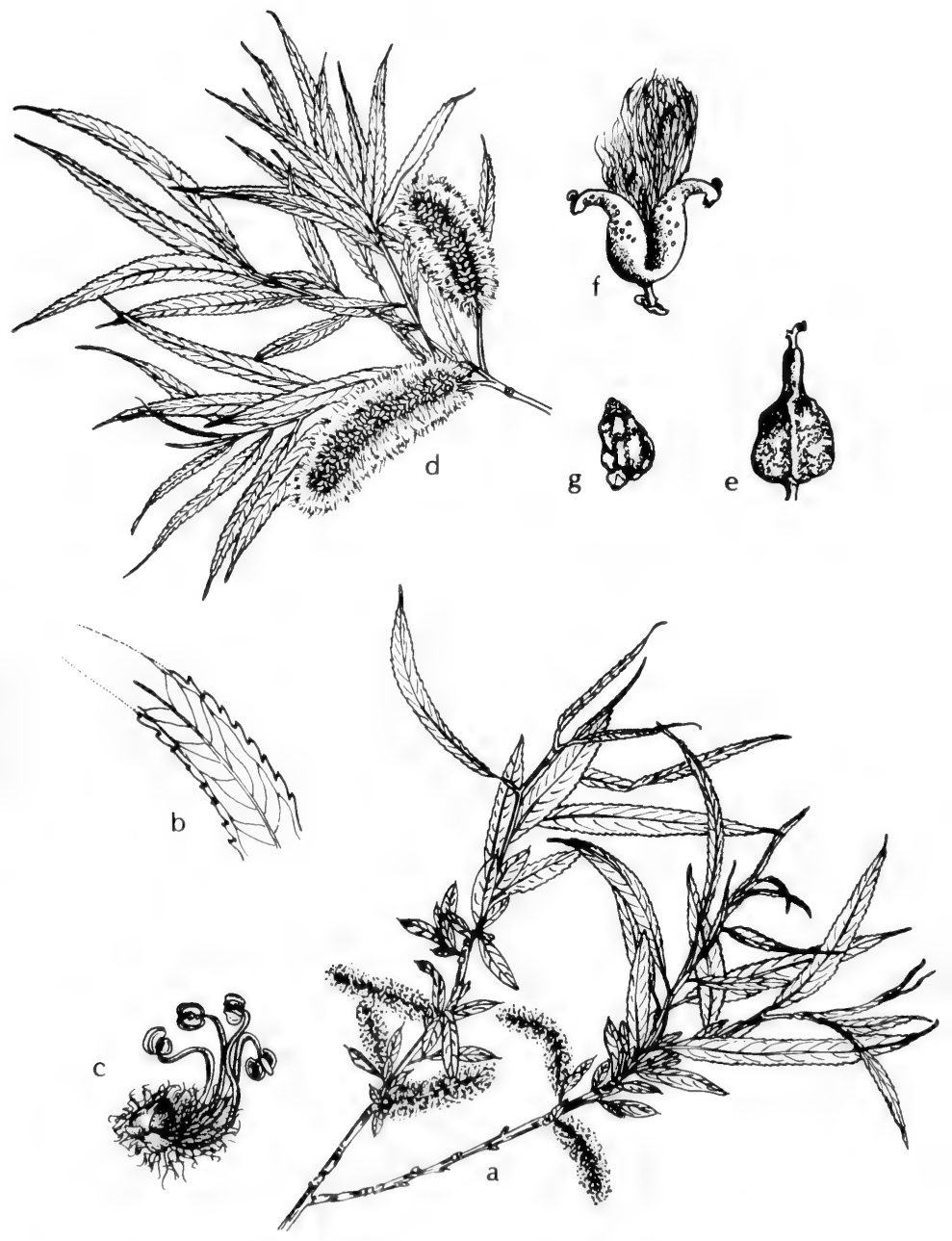

Fig. 387: Salix nigra: a, branch with male aments, $x \frac{1}{2} ; \mathrm{b}$, portion of leaf, $\mathrm{x} 2$; c, male flower, x 5; d, branch with female aments, x 1\%; e, fruit, x 5; f, fruit dehiscing, x 5; g, seed, x 10. (V. F.). 
sules and often produced a shoot from the axis of the top peduncle leaf, and the stipules are more or less glandular.

In habitats similar to those of $S$. nigra, in s. and s.w. Tex. (Hidalgo, Starr, Uvalde and Val Verde cos.); represented throughout Lat. Am. to the s. tip of S.A. by several varieties.

The above Texas collections, originally designated as this species by W. Andrew Archer, should probably be referred to var. stipulacea (Mart. \& Gal.) Schneid., of Mexico and Central America.

\section{Salix Gooddingii Ball var. variabilis Ball. SouthWESTERN BLACK WILLOW.}

Trees with 2 to 4 trunks, to about $15 \mathrm{~m}$. tall, with gray furrowed bark; branchlets slender, yellowish or yellowish-brown, pubescent to puberulous, becoming glabrous with age; bud scales $2-4 \mathrm{~mm}$. long, colored and clothed as the twigs; stipules 1-3 (-10) $\mathrm{mm}$. long, semicordate to subreniform or sublunate, glandulardenticulate, often gland-bearing on inner surface; petioles 3-6 (-10) mm. long, yellowish, pubescent, becoming glabrous; blades linear-lanceolate to narrowly lanceolate, often somewhat falcate, $6-10(-17) \mathrm{cm}$. long, $1-1.5(-3) \mathrm{cm}$. wide, acute at base, long-acuminate at apex, at first pubescent but later glabrous, green or yellowish-green, glandular-denticulate with about 8 teeth per $\mathrm{cm}$; aments coetaneous, numerous, 3-6 $(-8) \mathrm{cm}$. long, 1.2-2 cm. wide, lax, terminating lateral seasonal shoots that bear 3 to 6 small leaves; scales oblong-lanceolate to oblanceolate, sometimes toothed, $2.5-3 \mathrm{~mm}$. long, yellow, deciduous; stamens 3 to 6 , the filaments pilose on lower third; ovaries glabrous or thinly pilose; capsules ovateconic, 5.5-7 mm. long, glabrous or sometimes papillose; stigmas 2, divided; pedicels $1.5-3 \mathrm{~mm}$. long.

In alluvial soil near bodies of water, swamps and stream courses, in the w. third of Tex., across N.M. and Ariz. to Calif. and n. Mex., spring.

It is very doubtful that this plant should be maintained separately from $S$. nigra.

\section{Salix amygdaloides Anderss. PEACH-LeAF WILlow.}

Shrub or tree 3-12 m. tall, sometimes multitrunked, the fissured bark darkbrown or reddish-brown; branches gray-brown; twigs yellow to reddish-brown, glabrous, not brittle, drooping at tip; stipules wanting or semilunate and to $12 \mathrm{~mm}$. long; petioles slender, 6-20 mm. long, often twisted, glabrous, yellowish; blades lanceolate to ovate-lanceolate, 5-10 $(-12) \mathrm{cm}$. long, 7-30 mm. wide, acuminate, closely serrulate, acute or rounded at base, glabrous, yellowish, green above, glaucous beneath; aments coetaneous, linear, lax, 2.5-7 cm. long, on leafy lateral peduncles to $4 \mathrm{~cm}$. long; scales yellow, lanceolate or broader, glabrate on outer surface, villous within, deciduous; stamens 4 to 7 , the free filaments hairy below; capsules lanceolate, 4-5 mm. long, glabrous; styles $0.3-0.5 \mathrm{~mm}$. long, the stigmas shorter. S. nigra of W. \& S.

In alluvial soils along streams and near bodies of water, in Okla. (Cimarron Co.), in the Tex. Plains Country and Trans-Pecos, N.M. (Union, Dona Ana, Chaves, Grant, Sierra, Socorro, Otero, San Juan and Bernalillo cos.) and Ariz. (Apache and Pima cos.), spring; Que. to B.C., s. to Pa., s.w. Ky., Okla., w. Tex., N.M., Ariz. and Nev.; (?) Mex.

Var. amygdaloides and var. Wrightii (Anderss.) Schneid. (S. Wrightii Anderss.) are distinguished in the key. The much narrower leaves of var. Wrightii are usually $7-10$ or rarely to $15 \mathrm{~mm}$. wide and mostly $6-8 \mathrm{~cm}$. long, with an acute base and tapering acuminate apex.

\section{Salix lasiandra Benth. Yellow willow tree.}

Coarse several-stemmed shrub or small tree to about $12 \mathrm{~m}$. tall; trunk to about $6 \mathrm{dm}$. thick, usually much less, the smooth gray bark eventually fissured; leaves and twigs finely spreading-hairy when young, soon glabrate to glabrous; stipules 
usually well-developed and leafy, broadly rounded, gland-toothed, 2-10 mm. long, deciduous; petiole mostly 3-15 $(-25) \mathrm{mm}$. long, bearing 2 or more large glands or glandular processes on the upper side at or near base of blade; blades lanceolate to narrowly elliptic, gradually long-acuminate, usually $6-15 \mathrm{~cm}$. long and $1-3 \mathrm{~cm}$. wide, larger on vigorous shoots, finely and closely serrulate with some teeth callousglandular, blades of the floriferous branches smaller; aments appearing with the leaves, the axis finely and persistently spreading-hairy; scales yellowish, hairy at least on inner surface, deciduous; staminate aments $2-7 \mathrm{~cm}$. long and $1-1.5 \mathrm{~cm}$. thick; stamens 3 to 18 , the filaments hairy toward base; pistillate aments $3-12 \mathrm{~cm}$. long; capsules 4-8 mm. long, short-pedicellate, glabrous. S. caudata (Nutt.) Heller.

Along streams, in swamps and marshy thickets, in N.M. (Rio Arriba, Santa Fe, Grant, Socorro and McKinley cos.) and Ariz. (Apache, Navajo, Greenlee, Coconino and Gila cos.); Colo. to Yuk., s. to N.M., Ariz. and Calif.

\section{Salix fragilis L. CraCK-WILlow.}

Large tree to $20 \mathrm{~m}$. tall; branchlets greenish to dark-red, glabrous, very brittle at base and deciduous in strong winds; stipules wanting or small, early deciduous; petioles 7-15 mm. long, glandular above at outer end; blades narrowly lanceolate to lanceolate, $7-15 \mathrm{~cm}$. long, 2-3.5 $\mathrm{cm}$. wide, with 5 to 6 glandular serrations per $\mathrm{cm}$. of margin, dark-green above, glaucescent to glaucous beneath, glabrous at maturity; aments coetaneous, slender, lax, $4-8 \mathrm{~cm}$. long, on leafy peduncles to 5 cm. long; scales oblong, greenish-yellow, crisp-villous, deciduous; capsules narrowly conic, $4-5.5 \mathrm{~mm}$. long, glabrous; styles $0.3-0.7 \mathrm{~mm}$. long, the short stigmas notched.

Introd. from Eur., occasionally escapes to wettish meadowlands, along streams, pastures and other such places, in Can. and e. and cen. U.S.

\section{Salix Bonplandiana H.B.K.}

Tree to about $12 \mathrm{~m}$. tall, the slender branches drooping; branchlets glabrous or sparsely pilose; petioles stout, reddish, mostly more than $1 \mathrm{~cm}$. long; blades lanceolate to linear-lanceolate, sharply long-acuminate, to about $12 \mathrm{~cm}$. long and 1-2 cm. wide, 6 or more times as long as wide, yellow-green and lustrous above, essentially glabrous and silvery-white glaucous on lower surface, serrulate; staminate aments $4-6 \mathrm{~cm}$. long; stamens 3 or more, the free filaments hairy toward the base; scales broadly obovate, light-yellow, villous on outer surface, glabrous or slightly hairy above on inner surface; fruit ovoid-conical, light reddish-yellow: stigmas nearly sessile and club-shaped. Incl. var. Toumeyi (Britt.) Schneid.

Banks of streams, on edge of wet meadows, in N. M. (Grant Co.) and Ariz. (Yavapai, Greenlee, Gila, Santa Cruz and Pima cos.); s. to Guat.

\section{Salix laevigata Bebb. RED WIL Low.}

Tree to $15 \mathrm{~m}$. tall, the bark rough: twigs reddish-brown, slabrous; winter buds 5-7 mm. long, pointed; stipules minute, caducous; petioles stout, 4-10 mm. long; blades oblong-elliptic to lanceolate, acute at both ends or obtuse at base, green above, glaucous beneath; staminate aments lax, erect, $3-10 \mathrm{~cm}$. long, the peduncle leafy; stamens 4 to 7 , the filaments free; pistillate aments slender, $2-5 \mathrm{~cm}$. long. the peduncle leafy; capsule ovoid.

In swamps and along streams, in Ariz. (Navajo, Coconino, Mohave, Yavapai, Gila and Cochise cos.); also s.w. Ut., Calif. and Baja Calif.

Var. araquipa (Jeps.) Ball has pubescent young twigs, petioles and bases of the midveins, and often very large leaves.

9. Salix caroliniana Michx. LoNG-PEDICEI.LED WILLOW.

Shrub or tree to $10 \mathrm{~m}$. tall; branchlets and petioles yellowish to dark-brown, sparsely to densely white-pubescent; stipules broadly reniform, 7-15 mm. long, 
obtuse to acute, serrulate, glaucous; leaf blades linear-lanceolate to lanceolate, 7-15 cm. long, 1-3 cm. wide, long-acuminate, shallowy serrulate, acute to rounded at base, dark green above, strongly glaucous beneath and often somewhat pubescent; aments coetaneous, 3-11 cm. long; scales obovate to oblanceolate, yellowish, villous, deciduous; stamens 4 to 8 , the free filaments pubescent at base; capsules narrowly ovoid-lanceolate, 3-3.5 mm. long, glabrous; styles and stigmas minute. S. longipes Shuttlew., $S$. Wardii Bebb.

Along rocky water courses, stream bottoms and in coastal sands, in Okla. (Pushmataha Co.) and s.-cen. Tex., spring; W.I. and Fia,, w. to Tex. and Okla., n. to the Potomac Valley, the Ohio River in w. Pa. and s. Ind.

\section{Salix taxifolia Kunth. Yew-LEAF WILlow.}

Shrub or tree 4-12 m. tall, with furrowed bark, the lower branchlets somewhat drooping and the color effect in mass grayish-white; branchlets much-branched, slender, yellowish-gray or somewhat brownish, at first densely white- or silverypubescent, eventually grayish and glabrate; stipules mostly wanting; leaves shortpetiolate; blades linear to linear-oblanceolate, 1-5 cm. long, $2-5 \mathrm{~mm}$. wide, acutish at both ends, entire to remotely and minutely denticulate, densely silverypubescent when young, becoming gray-pubescent or puberulent with age, more or less densely crowded on the twigs; aments serotinous, $1-1.5 \mathrm{~cm}$. long in fruit, subglobose to ovate-oblong, usually several terminating densely-leaved seasonal shoots; scales yellowish, obovate to ovate, deciduous; stamens 2 , the free filaments pubescent on the lower third or half; ovaries usually pubescent but sometimes glabrate; capsules sessile, lanceolate, 4-5 (-5) $\mathrm{mm}$. long, thinly pubescent to glabrate; styles $0.1-0.2 \mathrm{~mm}$. long; stigmas $0.4-0.7 \mathrm{~mm}$. long, divided.

Along streams, about springs and bodies of water, in w. Tex. (Brewster, Jeff Davis and Presidio cos.), N. M. (Grant Co.) and Ariz. (Cochise, Santa Cruz and Pima cos.), spring; also Mex. to Guat.

Var. microphylla (Schlecht. \& Cham.) Schneid. has very small leaves, Santa Cruz Co., Ariz.

\section{Salix exigua Nutt. var. exigua. Gray SANDBAR willow. Fig. 388.}

Shrub 2-4 m. tall, gray-appearing; twigs pruinose to silky-tomentose; leaves without stipules; blades tapering to a short petiole, $5-12 \mathrm{~cm}$. long, linear to linear-lanceolate, remotely denticulate, canescent to silky-pubescent on both surfaces, becoming glabrate with age; staminate aments on long peduncles, $2-4 \mathrm{~cm}$. long; stamens 2, the free filaments pubescent; pistillate aments $3-6 \mathrm{~cm}$. long, on leafy peduncles; scales lanceolate, acute, white-pilose; ovary glabrous or sometimes with 2 glands (var. nevadensis (Wats.) Schneid.); stigma sessile; capsule subsessile to short-pediceled, $4.5-6.5 \mathrm{~mm}$. long, ovoid-attenuate, glabrous to sericeous and becoming glabrous.

Along streams and near bodies of water, and swamps, usually at high elevations, in the Edwards Plateau, Plains Country and Trans-Pecos of Tex., in N.M. (frequent in mts.) and Ariz. (almost throughout the state), spring; from Calif. $\mathrm{n}$. to B.C. and e. to the w. Great Plains.

\section{1a. Salix exigua var. nevadensis (Wats.) Schneid.}

Differs (in part) from var. exigua in having browner and more glabrate branchlets, narrower glabrate and yellowish-green leaves, and somewhat more glabrate flower scales. Along streams and near bodies of water, in canyons, from Calif., Ida, and Ut., e. to s. Colo. and w. Tex.

\section{1b. Salix exigua var. stenophylla (Rydb.) Schneid. Silvery DESERT WiLlow.}

Variety stenophylla differs from var, exigua in having narrower leaves and in the much more dense silvery-pubescence of all vegetal parts, and branchlets and 


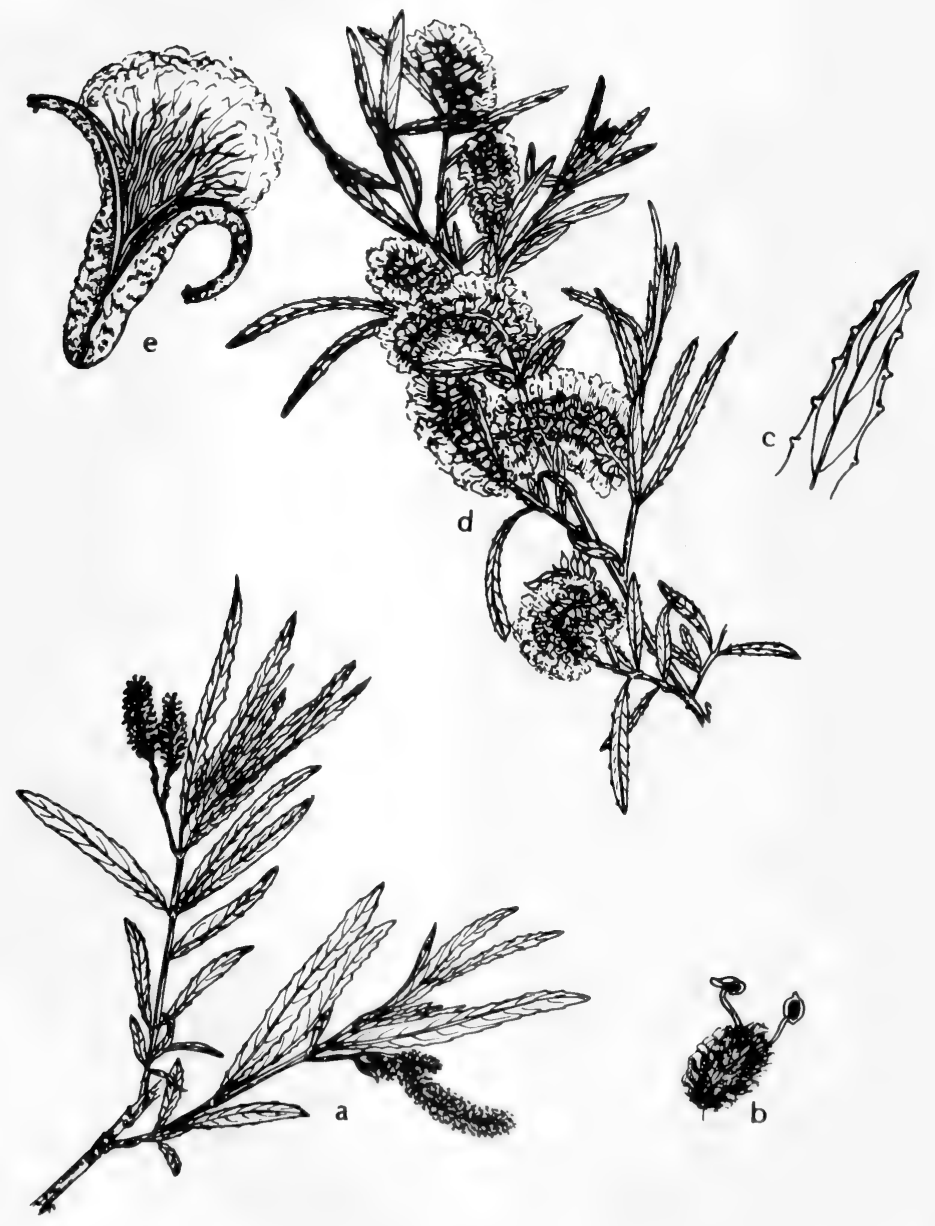

Fig. 388: Salix exigua: a, branch with male aments, x 1/2; b, male flower, x 5; c, tip of leaf, $x 2$; d, branch with female aments, $x 1 / 2$; e, fruit dehiscing, $x$ 5. (V. F.). 
bud scales more densely pilose-pubescent. From var. nevadensis it differs in its densely silvery-pubescent leaves that never become glabrate or yellowish-green in age, except on some vigorous shoots.

Along streams and near bodies of water, from w. Tex. and n. Mex. to Calif., n. to Colo. and Ida.

Indians and Mexicans use the stripped branches in basket-making.

12. Salix interior Rowlee. SAndbar Willow, taray.

Many-stemmed shrub 2-5 m. tall; branchlets slender, leafy, reddish-brown; usually glabrous; stipules none; leaves essentially sessile; blades linear to linearoblanceolate, 5-14 cm. long, 5-12 $(-18) \mathrm{mm}$. wide, acute to acuminate at both ends, remotely and irregularly spinulose-denticulate, green on both sides but paler beneath, often sericeous when young, glabrous with age; aments serotinus, 3-6 (-8) $\mathrm{cm}$. long, lax, 1 to 3 together terminating lateral leafy branchlets $3-10 \mathrm{~cm}$. long; scales lanceolate, yellowish, thinly pubescent, deciduous; stamens 2, the free filament pubescent at base; ovaries densely to thinly silvery-villous; capsules narrowly lanceolate, 7-10 mm. long, glabrous; pedicels $0.5-1.5 \mathrm{~mm}$. long; styles almost obsolete; stigmas short, divided. S. longifolia Muhl.

In alluvial soils, mostly along ditches, on sandbars and mudbars, and about bodies of water, in Okla. (Alfalfa Co.), n. Tex. s. to the Rio Grande Valley and N.M. (Grant Co.), spring; Potomac and Ohio valleys, n. to s. Can., w. from the Miss. River across the Great Plains, s. to La., Tex. and N.M., n.w. to Yuk. and Alas.; Mex.

Most of our material is referred to the following two varieties.

Var. pedicellata (Anderss.) Ball. NARRow-LEAVEd SANDBAR WILlow. Differs from var. interior in the narrowly linear leaves, $2-4 \mathrm{~mm}$. wide, and in the ovaries nearly always glabrous. $S$. linearifolia Rydb.

Var. angustissima (Anderss.) Dayton. Silvery-Fruited SANDBAR Willow. Differs from var. interior principally in the ovaries being densely white pilosepubescent and the capsules remaining gray pilose-putescent even in age.

\section{Salix nivalis Hook.}

Depressed somewhat matted shrub with woody rhizomatous stems creeping at or below the surface of ground, rarely to $1 \mathrm{dm}$. above ground level; stipules wanting or minute and caducous; petioles mostly $2-15 \mathrm{~mm}$. long; blades elliptic to obovate, rounded and sometimes retuse to acutish at apex, to about $3 \mathrm{~cm}$. long and $2 \mathrm{~cm}$. wide, glabrous, firm, dark-green above, conspicuously glaucous and reticulateveined on lower surface, entire; aments serotinous, terminating the main vegetative shoots of the season; scales pale, mostly yellowish or greenish, glabrous on outer surface, somewhat villous-puberulent within; staminate aments slender; filaments 2 , inconspicuously villous-hirsute at base; capsules $3-5 \mathrm{~mm}$. long, villous-puberulent or subtomentose; style and stigmas combined less than $1 \mathrm{~mm}$. long $S$. saximontana Rydb.

Wet meadows, seepage slopes among grasses, in N. M. (Rio Arriba and Taos cos.); Alta. and B.C., s. to N.M., Ut. and Calif.

\section{Salix arctica Pall.}

Depressed somewhat matted shrub that typically creeps along surface of ground, seldom to $1 \mathrm{dm}$. above ground level; stems yellowish or brown; stipules minute or wanting; petiole 4-13 $\mathrm{mm}$. long; blades elliptic to obovate, entire, rounded to somewhat acute at apex, usually $1.5-5 \mathrm{~cm}$. long and 5-20 mm. wide, loosely villous at first but soon glabrate, paler and somewhat glaucous on lower surface; aments appearing with leaves, on short leafy lateral branchlets, the pistillate usually 2-5 cm. long; scales brown to blackish, persistent, with long hairs mostly sur- 
passing body of scale; stamens 2 , the glabrous filaments often connate toward base; capsules 4-8 mm. long, villous-tomentose; style and stigma combined 1.5-2.5 mm. long. S. petrophila Rydb.

Wet meadows, seepage grassy slopes among rocks, in N. M. (Rio Arriba and Taos cos.); circumboreal, s, in Am. to Que., N.M. and Calif.

\section{Salix glauca $L$.}

Erect branching shrubs to about $15 \mathrm{dm}$. tall; twigs reddish and villous-tomentulose; stipules often less than $1 \mathrm{~mm}$. long, deciduous; petioles yellowish, 4-10 mm. long; blades elliptic to obovate or oblanceolate, obtuse to acute at apex, 2.5-4.5 $(-6) \mathrm{cm}$. long, 1-2 (-3) cm. wide, loosely villous-tomentulose when young, often becoming glabrate with age, essentially entire, conspicuously glaucous beneath; aments coetaneous, on short leafy-bracted peduncles to $2 \mathrm{~cm}$. long; scales lightto dark-brown or occasionally blackish; staminate aments cylindric, $1-3 \mathrm{~cm}$. long; stamens 2, the free or basally united filaments glabrous or hairy at the base; pistillate aments $2-5 \mathrm{~cm}$. long at maturity; capsules $4-8 \mathrm{~mm}$. long, hairy, on pedicels 1-2 mm. long; styles $0.5-0.8 \mathrm{~mm}$. long, longer than the bilobed stigmas.

Boggy or wet places in high mts., in N. M. (San Miguel and Taos cos.); circumboreal, s. in Am. to Que., Man., Alta., and B.C., and in Rocky Mts. to N. M.

\section{Salix irrorata Anderss.}

Shrubs to $3 \mathrm{~m}$. tall; twigs usually dark reddish-brown, usually pruinose, puberulent or glabrous; buds stout, broadly ovoid, brownish; leaf blades narrowly oblongelliptic to oblanceolate, acute to short-acuminate at apex, cuneate at base, 5-6 $(-7) \mathrm{cm}$. long, 1-1.2 cm. wide, entire or those of shoots undulate-serrate, when mature dark green and glabrous above and green or somewhat glaucous beneath; staminate aments sessile, $1.5-2 \mathrm{~cm}$. long; stamens 2 , the glabrous filaments united at base; pistillate aments subsessile, $2.5-4 \mathrm{~cm}$. long; scales ovate to obovate, blackish, with long white hairs; capsules ovoid-conic, glabrous, 3-4 mm. long; styles $0.5-0.7 \mathrm{~mm}$. long, the short stigmas entire or emarginate.

Along streams and edge of wet meadows in canyons, in N. M. (widespread in mts.) and Ariz. (Apache, Cochise and Pima cos.); also Colo.

\section{Salix lasiolepis Benth. Arroyo willow.}

Shrub or small tree usually to 6 or rarely to $12 \mathrm{~m}$. tall; twigs yellowish-olive to reddish, downy-puberulent to glabrous; stipules essentially wanting; petioles mostly 5-15 mm. long; blades thickish, revolute-margined, entire or sometimes shallowly toothed or sinuate, dark-green above, conspicuously paler and glaucous beneath, oblanceolate to oblong-elliptic, $3-11 \mathrm{~cm}$. long, 5-30 mm. wide, shorthairy when young, with age glabrous above and strigose-puberulent beneath; aments precocious, sessile or with peduncle to $1 \mathrm{~cm}$. long; scales blackish, persistent, densely long-wooly-villous; staminate aments $2.5-4.5 \mathrm{~cm}$. long; filaments 2 , glabrous; pistillate aments $2.5-6 \mathrm{~cm}$. long; capsules $3-5 \mathrm{~mm}$. long.

Along streams, in swamps and about springs, in w. Tex. to Ariz. (Apache, Navajo, Coconino, s. to Cochise and Pima cos.); Ida. and Wash., s. to w. Tex., Ariz., Calif. and n. Mex.

Our material is usually referred to the narrow-leaved var. Bracelinae Ball.

\section{Salix rigida Muhl. Yeliow willow.}

Coarse shrub usually $2-4$ or rarely to $9 \mathrm{~m}$. tall, occasionally somewhat arborescent; twigs elongate and slender, yellow to reddish-brown, puberulent but becoming glabrous; stipules foliaceous, to about $1 \mathrm{~cm}$. long, ovate to lunate, serrulate to entire; petioles to about $2 \mathrm{~cm}$. long; blades typically lanceolate and broadly rounded to somewhat cordate at base, varying to elliptic or oblanceolate-obovate, 
acuminate to acute, closely and finely toothed, eventually glabrous, glaucous beneath, 5-10 $(-15) \mathrm{cm}$. long, 1-3 $(-6) \mathrm{cm}$. wide; aments precocious to coetaneous, subsessile, terminating short lateral branches, the axis of aments white woollyvillous; scales often glabrous, light-brown to dark-brown or blackish, persistent; staminate aments $2-5 \mathrm{~cm}$. long; stamens 2 , the glabrous filaments free or somewhat connate below; pistillate aments 3-6 (-9) $\mathrm{cm}$. long; capsules glabrous, 3-7 mm. long. S. lutea Nutt.

In wet meadows and along streams, in N.M. (Lincoln, Otero, San Miguel and Valencia cos.) and Ariz. (Apache to Coconino and Yavapai cos.); Nfld. and Que., s. to Va., w. to Yuk., B.C., Wash., Calif., Ariz. and N.M.

\section{Salix myrtillifolia Anderss.}

Much-branched shrub to about $1 \mathrm{~m}$. tall, rarely somewhat arborescent and to $4 \mathrm{~m}$. tall; twigs minutely hairy; stipules insignificant, deciduous; petioles seldom to $1 \mathrm{~cm}$. long; blades firm, hairy when young but soon essentially glabrous, elliptic-oblanceolate to elliptic-obovate or elliptic, obtuse to subacuminate, finely and often glandular-crenate-serrate to entire, mostly $3-7 \mathrm{~cm}$. long and $1-2 \mathrm{~cm}$. wide, green but somewhat pale beneath; aments coetaneous, on short leafy peduncles to about $1.5 \mathrm{~cm}$. long; scales persistent, brown or blackish, thinly whitepilose or at least more or less hairy within; staminate aments $1-2 \mathrm{~cm}$. long; stamens 2, the glabrous filaments usually free; pistillate aments $2-4 \mathrm{~cm}$. long; style evident; capsules glabrous, 3-6 mm. long, ovoid-attenuate, with pedicels about 1 $\mathrm{mm}$. long. $S$. pseudocordata Anderss.

Wet meadows and wet open slopes, forming thickets in marshy ground, in N. M. (Taos Co.) and Ariz. (Apache and Navajo cos.); Nfld. to Alas., s. to N.M., Ariz. and Calif.

\section{Salix monticola Bebb. ex Coult.}

Shrub to about $4 \mathrm{~m}$. tall; twigs mostly yellowish, short-hairy when young, becoming glabrous with age; stipules small, deciduous; petioles 5-10 (-15) mm. long; blades elliptic to elliptic-obovate, obtuse to acute or even subacuminate at apex, $3.5-8 \mathrm{~cm}$. long, $1-3 \mathrm{~cm}$. wide, hairy when young but becoming glabrate with age, glaucous beneath, crenate-serrate to subentire; aments coetaneous or subprecocious, essentially sessile on short peduncles to $1 \mathrm{~cm}$. long, often subtended by small leafy bracts to $1.5 \mathrm{~cm}$. long; scales dark, long-hairy, persistent; staminate aments $2-3.5 \mathrm{~cm}$. long; filaments 2 , glabrous, free to base or sometimes connate below; pistillate aments 2-6 cm. long; capsules glabrous, 4-7 $\mathrm{mm}$. long, on a pedicel $1 \mathrm{~mm}$. long; style $0.7-1.8 \mathrm{~mm}$. long, longer than the somewhat bilobed stigmas. $S$. pseudomonticola Ball, $S$. padophylla $\mathrm{Rydb}$.

On stream banks and edge of wet meadows, in N. M. (San Miguel and Santa Fe cos.) and Ariz. (Apache Co.); Sask. to Alta., s. to N.M. and Ariz.

\section{Salix Bebbiana Sarg. BeaKed Willow.}

Shrub or small tree $2-5 \mathrm{~m}$. tall, with 1 to several stems; branchlets slender, divaricate, brownish, pubescent to glabrate; stipules wanting or small; leaf blades elliptic and acute at both ends to broadly rhombic-oblanceolate to obovate-oval, abruptly short-acuminate and rounded at base, 4-7 $(-10) \mathrm{cm}$. long, 1.5-3 (-4) $\mathrm{cm}$. wide, subentire to undulate-crenate, glaucous and rugose beneath, more or less gray-pubescent on both surfaces; aments subprecocious; staminate aments small and subsessile; stamens 2, the slender filaments free; pistillate aments $2-7 \mathrm{~cm}$. long, very lax, on bracted peduncles 5-20 mm. long; scales narrowly oblong, acute, 1-2 mm. long, greenish-yellow with reddish tips, pilose; capsules lanceolaterostrate, 7-10 mm. long, finely pubescent; styles $0.1-0.2 \mathrm{~mm}$. long; stigmas $0.1-0.3 \mathrm{~mm}$. long, entire to divided. 
In moist or wet places, mostly along streams and on edge of wet meadows, in N.M. (widespread in mts.) and Ariz. (Apache, Navajo, Coconino and Graham cos.), spring; Nfld. to Alas., s. to N.J., S.D., N.M., Ariz. and Calif.

\section{Salix Geyeriana Anderss.}

Shrub to $1 \mathrm{~m}$. tall; twigs black and pruinose, glabrous to pubescent; leaves without stipules; blades linear-oblanceolate to elliptic, acute at each end, 2-6 cm. long, dark-green above, glaucous beneath, thinly to densely pubescent on both sides, the margins entire to revolute; staminate aments oblong, $1 \mathrm{~cm}$. long, on a leafy peduncle; stamens 2, the filaments united at base; pistillate aments subglobose to oblong, 1-2 cm. long; scales with red tips; style short or none; capsule 5-7 mm. long, pubescent.

In wet meadows and along stream borders, in Ariz. (Apache, Navajo, Coconino and Yavapai cos.); Can. and Alas., s. to Pa. and Ariz.

23. Salix humilis Marsh. var. rigidiuscula (Anderss.) Robins. \& Fern. NARRowLEAVED PRAIRIE WILLOW.

Shrub 1-3 m. tall; stems clustered; branchlets yellowish to brown, pubescent to glabrate; stipules lanceolate, acute, dentate, often deciduous; leaf blades oblanceolate to narrowly obovate, 3-10 (-15) cm. long, 1-2 (-3) cm. wide, acute to abruptly short-acuminate, somewhat revolute, entire to somewhat undulate-crenate, narrowed to the base, dark-green and often puberulent above, the lower surface glaucous, somewhat rugose and more or less gray-pubescent becoming glabrate; aments precocious, sessile or subsessile, oval-obovoid, $1.5-3 \mathrm{~cm}$. long; scales oblanceolate, 1.5-2 mm. long, blackish, long-villous; stamens 2, the free filaments glabrous; capsules narrowly lanceolate-rostrate, 7-9 $\mathrm{mm}$. long, gray-pubescent; pedicels 1-2 $\mathrm{mm}$. long, pubescent; styles $0.2-0.4 \mathrm{~mm}$. long, equaling the divided stigmas.

In dry barrens, fields, open woods and swampy areas, in Okla. (Waterfall) and n.e. Tex. (Bowie Co.), spring; from the Appalachian Plateau to the edge of the Great Plains, w. to cen. N.D. and Tex.

Our material is usually referred to var. rigidiuscula (Anderss.) Robins. \& Fern. with leaves narrowly oblanceolate to subelliptic, acute to acuminate at both ends, becoming glabrate to glabrous with age.

\section{Salix Scouleriana Barratt. Fire willow.}

Large shrub or tree to $12 \mathrm{~m}$. tall and with a trunk to $4 \mathrm{dm}$. thick, usually much smaller; stipules insignificant except on vigorous young shoots, eventually deciduous; petioles 5-10 $\mathrm{mm}$. long; blades broadly oblanceolate to obovate, cuneate at base and broadly rounded to abruptly short-acuminate at apex, hairy when young, at maturity usually lustrous dark-green and glabrous above, glaucous and sparsely reddish-strigillose beneath, 4-8 (-12) cm. long, 1-3 (-5) cm. wide; aments precocious or occasionally coetaneous, sessile or with peduncle to about $1.5 \mathrm{~cm}$. long; scales blackish, persistent, conspicuously long-hairy; staminate aments 2-4 cm. long; filaments 2, distinct, glabrous or somewhat hairy toward base; pistillate aments $3-7 \mathrm{~cm}$. long; capsules narrow, long-beaked, tomentose or densely short-hairy, 5-8 $\mathrm{mm}$. long, on pedicels about $1.5 \mathrm{~mm}$. long.

In swamps and bogs, along streams, ditches and sloughs, in N.M. (widespread in mts.) and Ariz. (Apache, Coconino, Graham, Cochise and Pima cos.); Man. and S.D. to Alas., s. to N.M., Ariz. and Calif.

\section{Salix phylicifolia L.}

Shrub to about $2 \mathrm{~m}$. tall, branching; twigs shiny, brownish to deep-red, essentially glabrous; stipules small, caducous; petioles usually $2-10 \mathrm{~mm}$. long; blades 
usually elliptic to elliptic-obovate, $2.5-3.5(-5) \mathrm{cm}$. long, 1-1.5 (-2) cm. wide, thinly rufous-strigillose when young, becoming glabrous with age, more or less glaucous beneath, entire or sometimes somewhat toothed; aments precocious to coetaneous, sessile or very short-pedunculate with leafy bracts; scales blackish, long-hairy, persistent; staminate aments usually 2-4 mm. long; filaments 2, distinct, glabrous; pistillate aments usually 3-6 cm. long; capsules 4-6.5 mm. long, subsessile, short-hairy; style $0.7-1.7 \mathrm{~mm}$. long; stigmas often undivided, $0.5-0.8$ $\mathrm{mm}$. long.

Stream banks, lake shores, swamps and open woods, in N. M. (Mora, San Miguel, and Taos cos.); circumboreal, in N.A. from N.E. to N.M., Calif. and Wash.

Our plants have been referred to var. monica (Bebb) Jebs., a small shrub to about $2 \mathrm{~m}$. tall.

\section{Salix Drummondiana Barratt.}

Shrub usually 2-3 m. tall, rarely more or less; twigs dark-brown, puberulent or glabrous, soon becoming very glaucous; stipules small and caducous; petioles usually 4-10 mm. long; blades elliptic to lanceolate or occasionally oblanceolate, with entire somewhat revolute margins, densely white-hairy beneath, short-hairy but usually soon glabrate above, mostly 4-9 cm. long and 1-3 cm. wide, occasionally somewhat larger; aments precocious to coetaneous, sessile or nearly so; scales blackish or dark-brown, long-hairy; staminate aments $2-3 \mathrm{~cm}$. long; stamens 2 , the glabrous filaments often connate toward base; pistillate aments $2-6 \mathrm{~cm}$. long; capsules densely short-hairy, 3-6 $\mathrm{mm}$. long, with pedicel to $1.5 \mathrm{~mm}$. long; style to $1.3 \mathrm{~mm}$. long, sometimes cleft above. $S$. subcoerulea Piper.

Forming thickets in bogs, along streams and in wet meadows, in N.M. (Rio Arriba Co.); Wyo. to B.C. and Wash., s. to N.M., Nev. and Calif.

\section{Fam. 44. Myricaceae BL.}

\section{WAX-MYRTLE Or BAYBERRY FAMILY}

Monoecious or dioecious shrubs or small trees with both kinds of flowers in short scaly erect aments and with resinous-dotted usually fragrant alternate leaves; involucre and perianth none.

A family of about 50 species in several genera of world-wide distribution.

\section{Myrica L. WAX-MYRTLE}

Leaves coriaceous and evergreen (in ours) or tardily deciduous, entire or toothed to lobulate above the middle, without stipules; flowers typically unisexual, in the axils of small scalelike bracts and with or without 2 to 4 short entire basal bracteoles not overlapping the fruit; staminate aments ellipsoid or thick-cylindric, these from axillary scaly buds; stamens 2 to many; filaments somewhat united below; anthers 2-celled; pistillate aments ovoid or cylindric; ovary 1-celled; ovule 1, basal; stigmas 2, linear-elongate; fruit globose or ovoid, warty, commonly with a waxy coat or resinous dots.

About 35 cosmopolitan species.

1. Leaves of flowering branches typically elliptic to broadly oblanceolate, mostly $2 \mathrm{~cm}$. wide or more, their upper surface with resinous dots remote or wanting.......................................................$M$. heterophylla.

1. Leaves of flowering branches typically narrowly oblanceolate to narrowly cuneate-oblanceolate, rarely to $2 \mathrm{~cm}$. wide, their upper surface densely covered with resinous dots............................2. $M$. cerifera.

\section{Myrica heterophylla Raf. Fig. 389.}

Mostly small shrubs to about $3 \mathrm{~m}$. tall; branches blackish or dark-grayish-black, the pubescence of leafy branchlets becoming dark with age; leaves elliptic to 


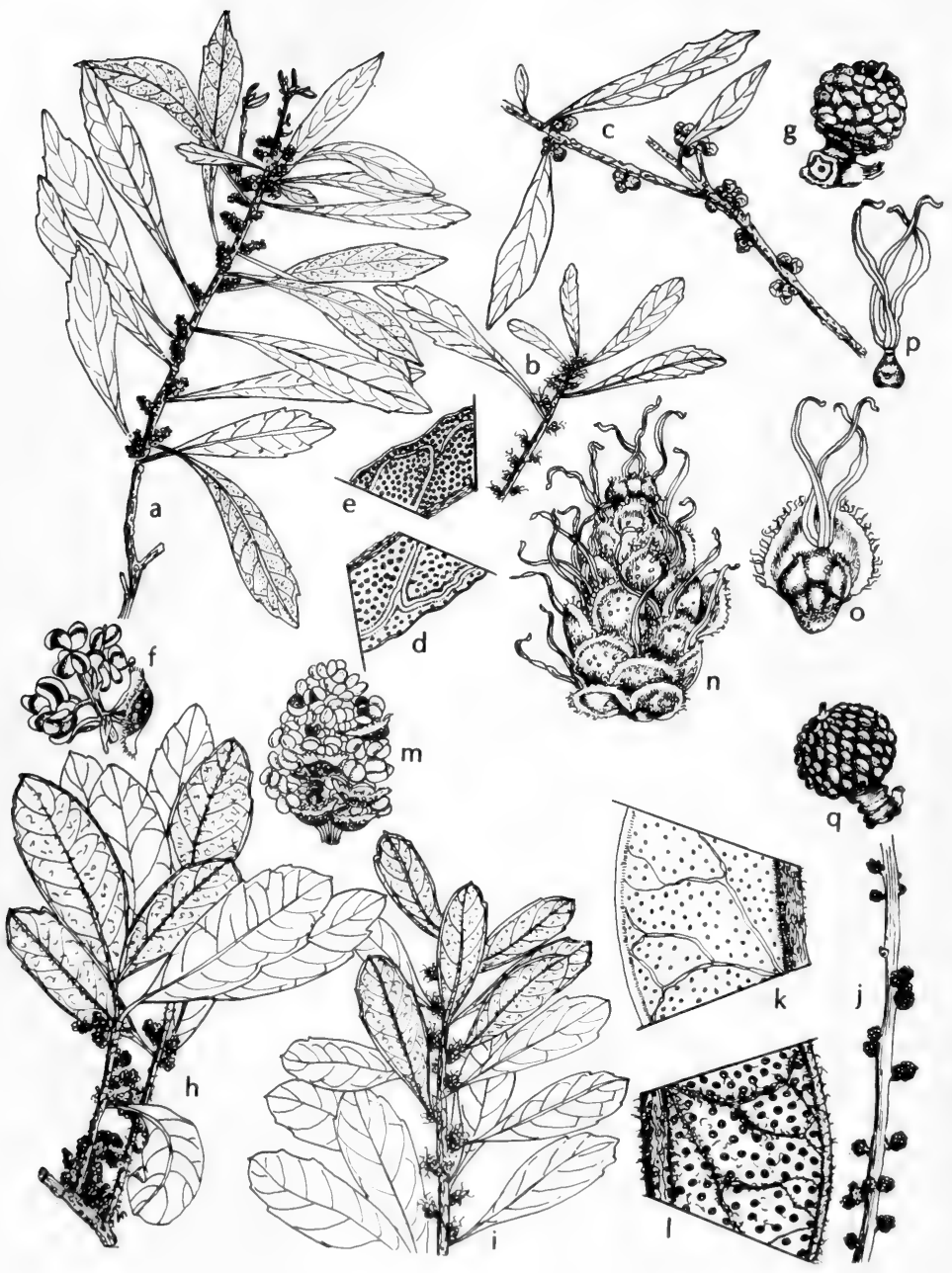

Fig. 389: a-g, Myrica cerifera: a, sprig with staminate flowers, x $1 / 2 ; b$, sprig with pistillate flowers, $x 1 \frac{1}{2} ; \mathrm{c}$, sprig with fruit, $\times 1 \frac{1}{2}$, top of leaf, $x 21 \frac{1}{2}$; e, underside of leaf, x $2 \frac{1}{2} ; \mathrm{f}$, staminate flowers, x $21, \mathrm{~g}$, fruit, x 3 . h-q. Myrica heterophylla: h, sprig with staminate flowers, $x_{12}^{1} ; i$, sprig with pistillate flowers, $x_{1 / 2} ; j$, sprig with fruit, $x$ $1 / 2 ; k$, top of leaf, $x 21 \frac{1}{2} ; 1$, underside of leaf. $x 21 \frac{1}{2} ; \mathrm{m}$, cluster of staminate flowers, $\times 2 \frac{1}{2} ; n$, cluster of pistillate flowers, x 6 ; 0 , pistillate flowers, $x 12 ; p$, pistil, x $12 ; q$, fruit, x 3. (V. F.). 
oblanceolate or occasionally obovate, tapering at base into a short petiole, broadly rounded to acute and minutely apiculate at apex, opaque, essentially glabrous and sometimes somewhat glaucous on upper surface, to $14 \mathrm{~cm}$. long and $4 \mathrm{~cm}$. wide; inflorescence either below or in the axils of the leaves; staminate aments to 15 $\mathrm{mm}$. long; fruit $3-3.5 \mathrm{~mm}$. in diameter.

In bogs and along streams in woods and thickets in e. Tex., Mar.-Apr.; from Fla., w. to Tex. and n. on inner Coastal Plain to N. J.

\section{Myrica cerifera L. WAX-Myrtle, Candle-BerRy. Fig. 389.}

Shrub or small tree to $12 \mathrm{~m}$. tall, rarely with a trunk to $2 \mathrm{dm}$. in diameter; young branchlets waxy, glabrous or sometimes pilose; leaves narrowly oblanceolate to cuneate-oblanceolate, tapering at base to short petiole, acute at apex, mostly less than $7 \mathrm{~cm}$. long and to $25 \mathrm{~mm}$. wide, fulvous or yellow-green, heavily coated on both surfaces with resinous dots; fruit $2-3 \mathrm{~mm}$. in diameter. Cerothamnus ceriferus (L.) Small.

Along streams, about lakes and in boggy grasslands and wet woodlands in s.e. Okla. (Waterfall) and e. Tex., Mar.-Apr.; from Fla., w. to Okla. and Tex., n. to N.J. and Ark.

\section{Fam. 45. Leitneriaceae Benth. \& Hook. F. CORKwood FAmily}

Shrub or small tree to $6.5 \mathrm{~m}$. tall, with very light wood; bark brown and smooth when young, fissured with age; leaves alternate, deciduous, more or less scattered, petiolate; leaf blades entire, thick and firm, prominently veiny, narrowly elliptic to elliptic-lanceolate, acute to acuminate, bright green and shining on upper surface, pubescent on lower surface; stipules wanting; flowers unisexual, male and female flowers borne on separate plants, in few- to many-flowered aments or spikes that appear before the leaves from the axils of last year's leaves; staminate flowers in a conspicuously bracted compound ament, composed of 3 to 12 stamens and without a perianth, the distinct filaments short and the anthers 2-celled; pistillate flowers in a few-flowered spike, solitary in the axils of primary bracts each of which is accompanied by 2 secondary bracts, composed of a single sessile 1-ovuled pistil and 3 to 8 diminutive bractlets; fruit a drupe, subtended by a bract, elongate, glabrous, the flesh leathery.

Represented only by the following American genus.

\section{Leitneria CHAPM.}

Characters same as those of the family. A monotypic genus of the southern United States.

1. Leitneria floridana Chapm. CoRkwood. Figs. 390 and 391.

Leaf blades to $2 \mathrm{dm}$. long; staminate aments $3-4 \mathrm{~cm}$. long; drupe elliptic, to $25 \mathrm{~mm}$. long.

In brackish or fresh water swamps and thickets in s.e. and s.-cen. Tex., spring; from n. Fla., w. to Tex. and n. to Ga. and Mo.

\section{Fam. 46. Juglandaceae KUNTH}

\section{WALNUT FAMILY}

Trees, monoecious, with alternate pinnate leaves and no stipules; leaflets usually glandular-dotted beneath; flowers unisexual; staminate flowers in aments with or without a calyx adnate to the bract and the two bractlets; pisillate flowers solitary or in a small cluster or spike, with a bract, 2 or 3 bractlets and a regular 4-lobed 


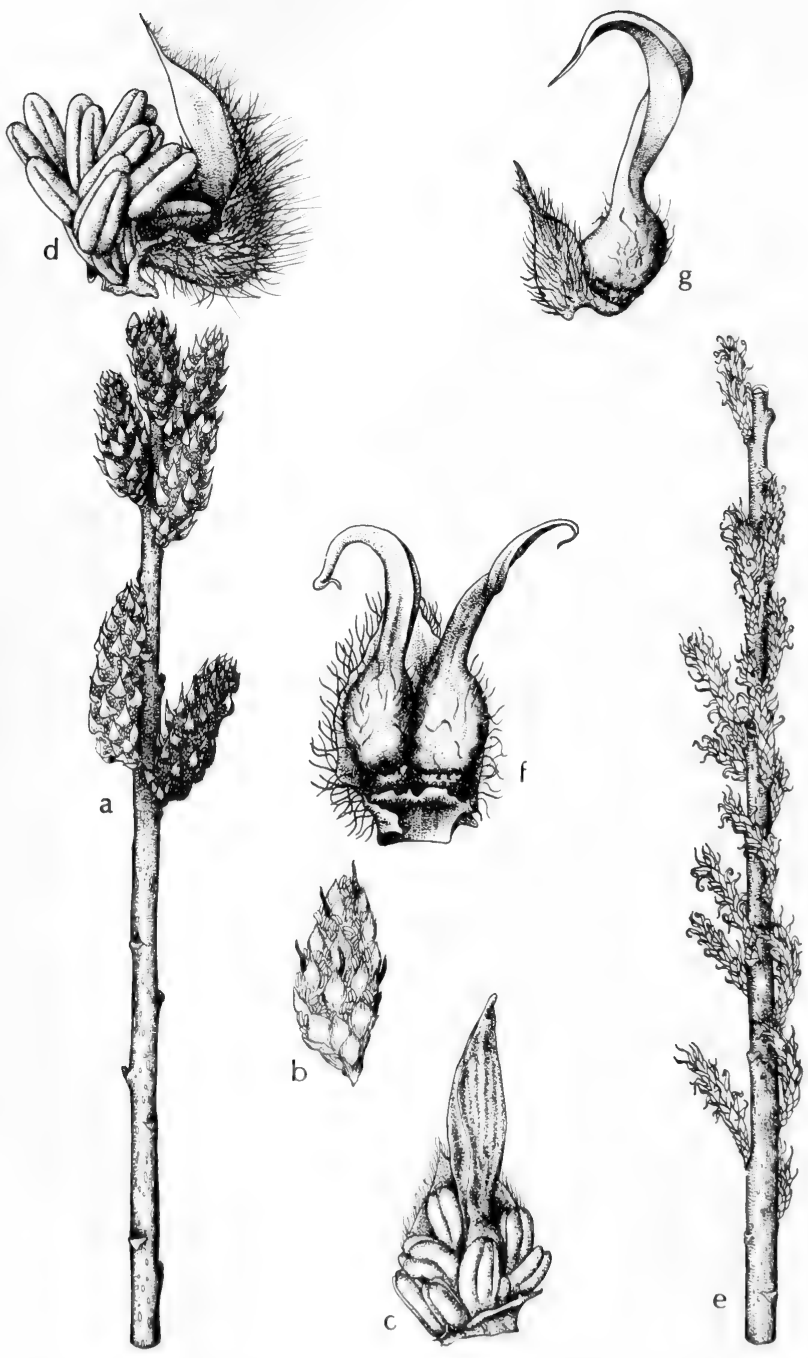

Fig. 390: Leitneria floridana: a, staminate twig, x 1/2; b, staminate catkin, about $\mathrm{x}$ 1; c, staminate flower, x 5; d, staminate flower, x 7; e, pistillate twig, x 1/2; f, two fruits together, x 6; g, single fruit, x 6. (Courtesy of R. K. Godfrey). 


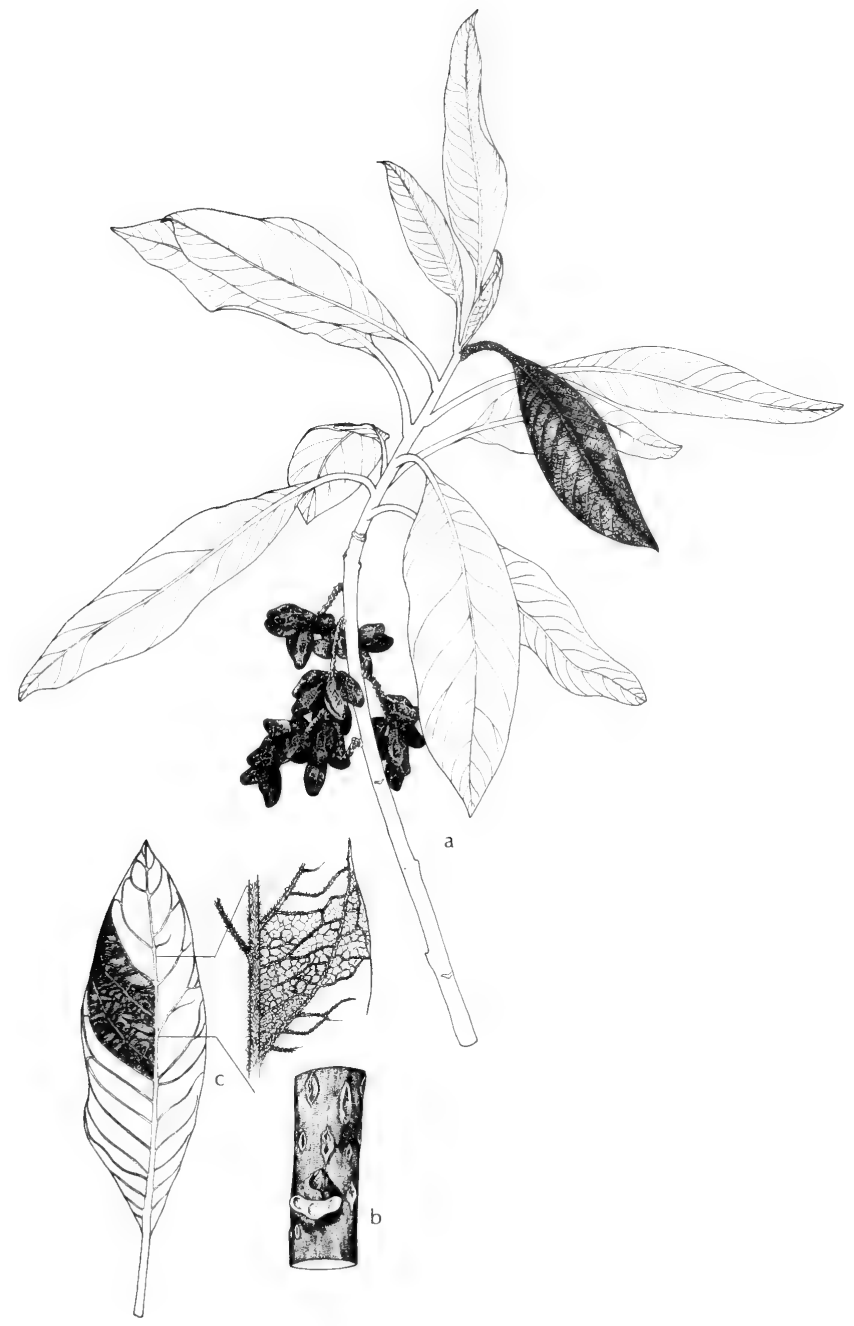

Fig. 391: Leitnera floridana: a, fruiting branch, x 1/3; b, section of branch, x 1 ; c, leaf with section enlarged to show venation. (Courtesy of R. K. Godfrey). 
calyx (when present) adherent to the incompletely 2- to 4-celled but only 1-ovulate ovary; ovule orthotropous, erect, at the apex of the incomplete primary partition; fruit similar to a dry drupe, the fibrous-fleshy or woody husk or exocarp (ripened bract and bractlets or involucre and calyx) fused at least until maturity with the crustaceous or bony endocarp or nutshell (ripened carpels), containing a 2- to 4-lobed seed.

A small family of important trees, about 50 species in 7 genera. A number of species in the family produce edible nuts, including the pecans, the Persian or "English" and black walnuts.

1. Pith of branchlets separating into thin plates; staminate aments separate, sessile, on last year's branchlets, in the axils of the fallen leaves of the previous season; stamens 8 to 40 ; staminate and pistillate flowers with 4 small sepals; style branches (stigmas) elongate; nut with indehiscent husk and irregularly furrowed shell................ Juglans

1. Pith continuous; staminate aments in fascicles of 3 , the fascicles subsessile to long-stalked in the axils of bud scales on new growth; stamens 3 to 8 ; staminate and pistillate flowers usually without sepals; stigmas short; husk of fruit splitting or partially splitting into valves, the nutshell smooth or merely reticulate...................2. Carya

\section{Juglans L. Walnut. Nogal}

Trees with furrowed scaly bark and durable dark-colored wood; branchlets stout, with laminate pith; leaves pinnate, with numerous serrate leaflets; flowers greenish, produced in spring; staminate aments sessile, separate though often superposed, near the apex of the preceding year's growth; stamens 8 to 40 , the floral receptacle adnate to the bract; bractlets 2 ; sepals usually 4 , with some occasionally reduced to minute teeth; filaments free, very short; pistillate flowers solitary or several together in a cluster or short spike on a peduncle at the end of the branch, with a bract and 2 often irregularly toothed bractlets; sepals 4, small; style short, with 2 or rarely 3 elongate style branches that have their inner surfaces deeply fringed and stigmatic; style branches carinal (above the center of the carpel); fruit with a fibrous-fleshy indehiscent husk (exocarp) and a mostly rough irregularly furrowed nutshell or endocarp.

About 20 species in both hemispheres. The timber of some species is extremely valuable for cabinet and furniture making. The fruits of most species are also edible.

1. Fruit $25 \mathrm{~mm}$. or more in diameter; leaflets usually 15 or fewer, with dentateserrate margins, mostly $15 \mathrm{~mm}$. or more wide. 1. J. major.

1. Fruit rarely more than $20 \mathrm{~mm}$. in diameter; leaflets more than 15 , with subentire to serrulate margins, rarely more than $15 \mathrm{~mm}$. wide.

2. J. microcarpa.

1. Juglans major (Torr.) Heller. Arizona walnut, nogal silvestre.

Tree to about $15 \mathrm{~m}$. high, with trunk to $12 \mathrm{dm}$. in diameter, the bark deeply furrowed and ridged on older trees; branches widely spreading to form a rounded crown; twigs reddish-brown, densely hairy when young, with age becoming ashygray; leaves to $35 \mathrm{~cm}$. long; leaflets usually 9 to 13 , rarely more, essentially sessile, lanceolate, acuminate at apex, more or less falcate, to $1 \mathrm{dm}$. long and $35 \mathrm{~mm}$. wide below the middle, coarsely dentate-serrate on margins, thin, yellowishgreen, scurfy-hairy when young, essentially hairless with age; fruit spherical, 25-35 mm. in diameter; husk brown, thin, densely hairy; nut with a thick hard shell and a small edible kernel. 
Scattered along streams and in canyons in the Edwards Plateau and Trans-Pecos of Tex. to s.w. N.M. and cen. Ariz. and n. Mex.

The durable wood is used locally for posts.

\section{Juglans microcarpa Berl. River walnut, LitTle Walnut.}

Large shrub or small tree to about $6 \mathrm{~m}$. high, rarely with trunk to $45 \mathrm{~cm}$. in diameter, the bark smoothish or lightly furrowed; branches usually arising near the ground to form a broad rounded crown; twigs reddish-brown, densely hairy when young, with age becoming ashy-gray; leaves to about $3 \mathrm{dm}$. long; leaflets usually 17 to 23 , sometimes fewer, essentially sessile, narrowly lanceolate, tapering to an acuminate apex, more or less falcate, to $75 \mathrm{~mm}$. long and $12 \mathrm{~mm}$. wide below middle, subentire to serrulate on margins, thin, yellowish-green, with age becoming essentially hairless; fruit spherical, $1.2-2 \mathrm{~cm}$. in diameter; husk brownish, thin, hairy; nut with a thick hard shell and a small edible kernel. J. rupestris Engelm.

Scattered along streams and arroyos in s. and w. Tex. and w. Okla. to s.e. N.M. and n. Mex.

The var. Stewartii (I.M.Johnst.) W. Manning with broader leaflets and larger fruits on the average, is reported to occur in the Chisos Mts. of Trans-Pecos Texas.

\section{Carya NutT. Hickory}

Trees with hard and very tough wood, and scaly buds from which in spring are produced usually both kinds of flowers with staminate flowers below the leaves and the pistillate flowers above; leaves petiolate, odd-pinnate, often glandulardotted; leaflets 5 to 25 ; staminate aments usually in fascicles of 3 in the axils of bud scales; stamens 3 to 8 , adnate to the bract and 2 bractlets; filaments short or none, free; pistillate flowers 2 to 10 in a cluster or short spike on a peduncle terminating the shoot of the season; bract and typically 3 bractlets sepal-like in flower, a true calyx absent; stigmas sessile, 2 and sometimes divided, with a stigmatic disk at their base, papillose, commisural (above the lines connecting the carpels), usually persistent; fruit with a 4-valved firm and (at length) dry husk that consists of the exocarp or involucre which usually falls away from the smooth and crustaceous or bony nutshell or endocarp; nut incompletely 2-celled and (at the base) mostly 4-celled.

Probably about 15 species in eastern North America and eastern Asia. Because of their tough, resilient wood some species are used for such purposes as the making of tool handles.

1. Bud scales valvate; bud scale scars wide, separate, not in a distinct ring; husk sutures winged or keeled (2)

1. Bud scales imbricate; bud scale scars in a distinct ring; husk sutures not winged nor keeled (5)

2(1). Shell smooth; kernel sweet; cotyledons not deeply 2-cleft (3)

2. Shell uneven; kernel bitter; cotyledons deeply 2-cleft (4)

3(2). Leaflets 5 to 9 ; fascicles of staminate aments peduncled.

3. Leaflets more than 9; fascicles of staminate aments sessile or nearly so 2. C. illinoinensis.

4(2). Bud sulphur-yellow; husk wingless at base, at maturity splitting only to just below middle; nut gray, smooth; leaflets usually fewer than 9, the lower surface pubescent and with ferruginous scales; terminal leaflet essentially sessile.

3. C. cordiformis. 
4. Bud brownish; husk winged to the base, at maturity the valves completely separating; nut reddish-brown, furrowed or wrinkled; leaflets usually more than 9, the lower surface glabrous; terminal leaflet stalked....

4. C. aquatica.

5(1). Leaflets usually 5 , rarely 7 , the margins of young leaflet densely ciliate. the older leaflet serrations with persistent tufts of hairs; branchlets light reddish-brown.................................................. . C. ovata.

5. Leaflets 7 to 9 , rarely some 5 , the margins of young leaflets not densely ciliate, the older leaflet serrations without tufts of hairs; branchlets paleorange.

6. C. laciniosa.

1. Carya myristicaeformis (Michx. f.) Nutt. NUTMEg HiCKORY, NOGAL.

Tree to about $30 \mathrm{~m}$. high, with a trunk to $6 \mathrm{dm}$. in diameter, the bark darkbrown tinged with red and broken irregularly into small thin appressed scales; branches stout and somewhat spreading to form a rather narrow open crown; branchlets at first with lustrous scales, eventually dark-reddish-brown; leaves to $35 \mathrm{~cm}$. long; leaflets 7 or 9 , occasionally 5 , short-stalked or essentially sessile, ovate-lanceolate to broadly obovate, acute at apex, cuneate or somewhat rounded at the narrow base, the margins serrate, to $12.5 \mathrm{~cm}$. long and $37 \mathrm{~mm}$. wide, thin and firm, dark-green above, more or less pubescent or nearly glabrous and silverywhite and lustrous beneath, becoming golden-bronze in the fall; fruit usually solitary, ellipsoid to somewhat obovoid, about $35 \mathrm{~mm}$. long; husk broadly 4-ridged to base, coated with a yellow-brown scurfy pubescence, not more than $1 \mathrm{~mm}$. thick, splitting nearly to the base; nut with a thick hard and bony shell, rounded and apiculate at the ends, smooth, dark-reddish-brown and marked by longitudinal small broken bands of gray covering the entire surface, the dark-brown kernel sweet. Hicoria myristicaeformis (Michx. f.) Britt.

Along banks of rivers and in swamps of e. Okla. and e. Tex.; from e. S.C. to e. Okla. and e. Tex.; (?) also in mts. of n.e. Mex.

\section{Carya illinoinensis (Wang.) K. Koch. PeCan, nogal Morado, Nuez encarce-} LADA.

Tree to about $50 \mathrm{~m}$. high, with a massive trunk to $2 \mathrm{~m}$. in diameter that is often enlarged and buttressed at the base, the thick bark light-brown tinged with red and deeply divided into irregular furrows and ridges; overwintering buds flattened, with paired and valvate narrow scales covered with articulated hairs; branches stout and spreading to form a round-topped crown; branchlets at first red-tinged and coated with a loose pale tomentum, eventually glabrous or merely puberulent; leaves to $5 \mathrm{dm}$. long; leaflets 9 to 17 , sessile, oblong-lanceolate to lanceolate, more or less falcate, acuminate at apex, cuneate to rounded at the asymmetric base, the margin coarsely and often doubly serrate, to $2 \mathrm{dm}$. long and $75 \mathrm{~mm}$. wide, dark-yellow-green and glabrous or pilose above, pale and glabrous or pubescent beneath, terminal leaflet only slightly broader than upper lateral ones; fascicles of staminate aments sessile or nearly so; fruit in clusters of 3 to 11 , ovoid to more or less ellipsoid, pointed at apex, rounded at the narrowed base, 4-winged and -keeled along the sutures, 25-65 $\mathrm{mm}$. long, 12-25 mm. thick, dark-brown and more or less thickly covered with yellow scales; husk thin, brittle, at maturity splitting nearly to the base and often persistent on the branch during the winter after dropping the nut; nut usually thin-shelled, pointed at both ends, somewhat bright-reddish-brown, the reddish-brown kernel sweet. Carya Pecan (Marsh.) Engl. \& Graebn., Hicoria Pecan (Marsh.) Britt.

In low rich grounds along streams, bottomlands and moist open woodlands, mostly in Okla. and cen. and n.w. Tex.; from Tex., n. to Ind. and Ia., e. to Ala. 
The species, in many selected varieties, is widely cultivated in the southern states. The nuts, which vary in size and shape and in the thickness of their shells, and in the quality of the kernels, are an important article of commerce. The pecan is the State Tree of Texas.

Specimens have been seen that apparently represent Carya X Lecontei Little, a hybrid that combines the compressed fruit and bitter kernel of $C$. aquatica and the sessile male catkins, hairy yellowish winter buds, and elongate nut of $C$. illinoinensis.

3. Carya cordiformis (Wang.) K. Koch. BITTERnUt HICKORY, PIGNUT HICKORY.

Tree often to $30 \mathrm{~m}$. high, with a trunk to $9 \mathrm{dm}$. in diameter, the light-brown red-tinged bark about $15 \mathrm{~mm}$. thick and broken into thin platelike scales that separate on the surface into small thin flakes; branches stout and spreading to form a broad crown; branchlets slender, marked by oblong pale lenticels, at first bright-green and covered more or less with rusty hairs, ultimately becoming light gray; leaves to $25 \mathrm{~cm}$. long; leaflets usually 7 or 9 , sessile, ovate-lanceolate to lanceolate or obovate, acuminate at apex, coarsely serrate except at the cuneate to subcordate base, thin and firm, to $15 \mathrm{~cm}$. long and $3 \mathrm{~cm}$. or more wide, darkyellow-green and glabrous above, light-green and pubescent beneath; overwintering bud-scales lanceolate, sulphur-yellow with persistent scurf; fruit usually obovoid to subglobose, 4-winged from the apex to about the middle; husk thin, puberulous, more or less covered with small yellow scales, splitting only to below the middle; nut with a thin brittle shell, often broader than long, depressed or obcordate at apex, the bright-reddish-brown kernel very bitter. Hicoria cordiformis (Wang.) Britt., H. minima (Marsh.) Britt.

In low wet woods near the borders of streams and swamps or on high rolling uplands in e. Okla. and e. Tex.; from Fla. to Tex. n. to. N. E., Minn. and Neb.

\section{Carya aquatica (Michx. f.) Nutt. Water hickory, bitter PECAN. Fig. 392.}

Tree sometimes to $30 \mathrm{~m}$. in height, with a trunk rarely exceeding $6 \mathrm{dm}$. in diameter, the bark to $15 \mathrm{~mm}$. thick and separating freely into long loose platelike light-brown scales tinged with red; overwintering buds reddish-brown, adorned with caducous yellow glands; branches slender, upright to form a narrow crown; branchlets slender, at first reddish-brown or ashy-gray and slightly glandular and coated with a loose pale tomentum, eventually gray and essentially glabrous; leaves to $33 \mathrm{~cm}$. long; leaflets 7 to 13 , sessile or stalked, ovate-lanceolate to lanceolate, falcate, acuminate at apex, rounded to cuneate at the more or less oblique base, glabrous, to $75 \mathrm{~mm}$. long and $4 \mathrm{~cm}$. wide, finely or coarsely serrate; fascicled staminate aments peduncled; fruit often in clusters of 3 or 4 , subglobose to obovoid, much-compressed, usually broadest above the middle, rounded at the slightly narrowed base, conspicuously 4-winged, dark-brown or nearly black, provided with bright-yellow scales, to $4 \mathrm{~cm}$. long and $32 \mathrm{~mm}$. wide; husk thin, brittle, splitting tardily and usually only to below the middle; nut flattened, somewhat obovoid, with a thin dark-reddish-brown somewhat wrinkled shell, rounded and abruptly short-pointed at apex, the dark-brown kernel very bitter. Hicoria aquatica (Michx. f.) Britt.

In river swamps that are periodically inundated, in e. Okla. and e. Tex.; from Fla. to Okla. and Tex., n. to. Va., s.w. Ill. and s.e. Mo.

5. Carya ovata (Mill.) K. Koch. SHagbark hickory, SHellbark.

Tree to $20 \mathrm{~m}$. or more high, with a trunk to about $1 \mathrm{~m}$. in diameter, the light- 


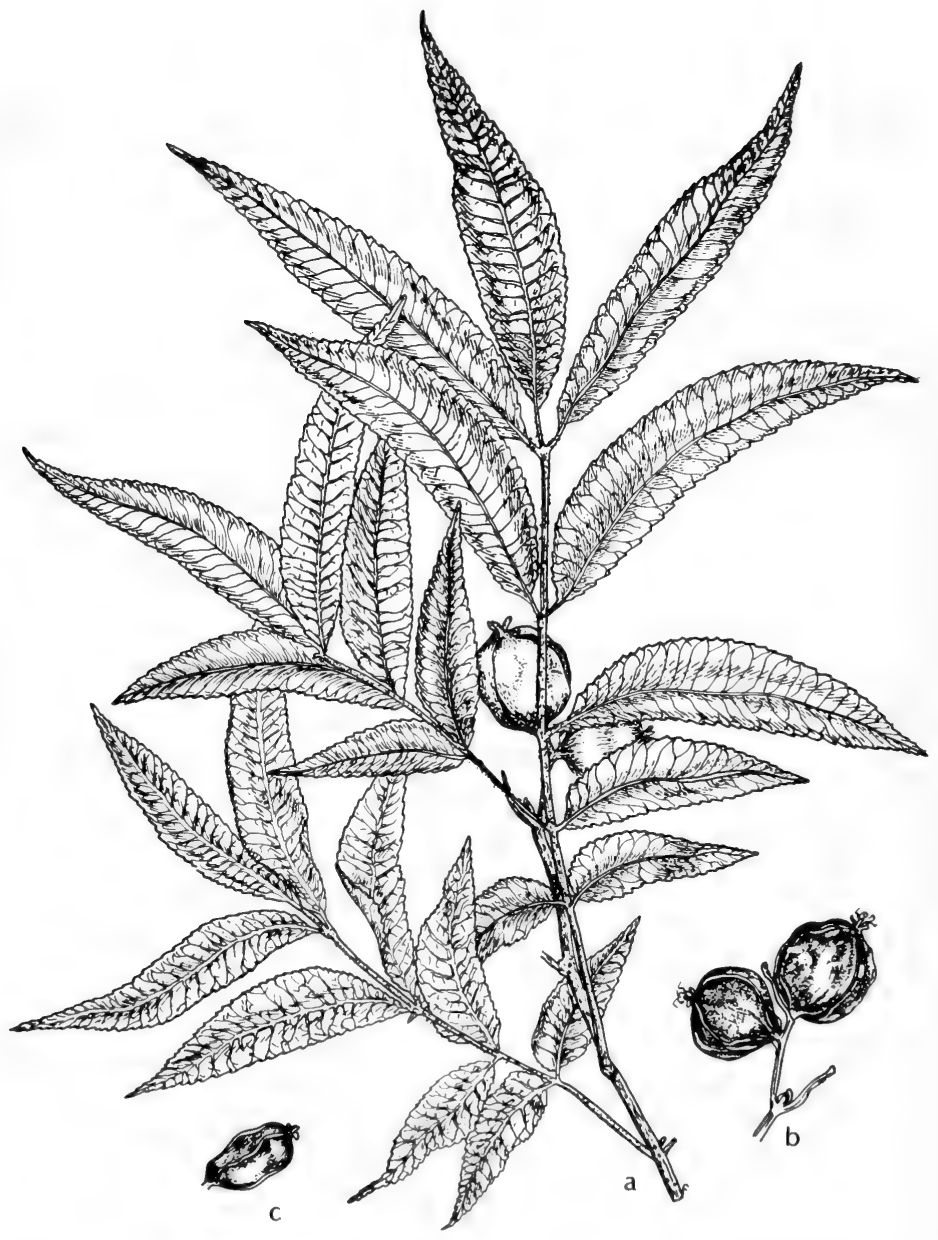

Fig. 392: Carya aquatica: a, twig, $x$ 1/2; b, fruit, $x$ 1/2; $c$, fruit, side view, $x 1 / 2$. (V. F.). 
gray bark to $25 \mathrm{~mm}$. thick and separating into thick plates often $3 \mathrm{dm}$. or more long and $2 \mathrm{dm}$. wide that are attached to the trunk by the middle; branches stout and slightly spreading to form a conic round-topped crown; branchlets at first covered with caducous brown scurf and pale glandular pubescence, soon brightreddish-brown and lustrous, glabrous or pubescent; leaves to $35 \mathrm{~cm}$. long; leaflets 5 or rarely 7 , slender-stalked, ovate to ovate-lanceolate or obovate, somewhat rounded to acuminate at apex, ciliate on the margins that are finely serrate except toward the usually cuneate base, most of the serrations with a dense tuft of persistent hairs on one or both sides near their apex, to $17 \mathrm{~cm}$. long and $75 \mathrm{~mm}$. wide above the middle, dark-yellow-green and glabrous above, paler and shiny-glabrous or puberulous beneath, the terminal leaflet largest; fascicles of staminate aments peduncled, the floral bracts much-elongated; overwintering terminal buds ovoid, to $25 \mathrm{~mm}$. long and $1 \mathrm{~cm}$. thick; fruit solitary or in pairs, subglobose to somewhat obovoid, depressed at apex, dark-reddish-brown or nearly black at maturity, glabrous or pilose, to $6 \mathrm{~cm}$. long; husk to $15 \mathrm{~mm}$. thick and splitting freely to the base; nut with a usually thin shell, more or less 4-ridged or -angled, pale or whitish, the light-brown kernel sweet and aromatic. Hicoria ovata (Mill.) Britt.

In rich woodlands, bottoms and slopes, commonly near streams and swamps in e. Okla. and e. Tex.; from Fla. to Okla. and Tex., n. to Me., Ont., Wisc., Minn. and Neb.

\section{Carya laciniosa (Michx. f.) Loud. BIg SHELlbark HICKORY, KING-NUT.}

Tree sometimes more than $30 \mathrm{~m}$. high, with a trunk to $9 \mathrm{dm}$. in diameter, the light-gray bark to $5 \mathrm{~cm}$. thick and separating into broad thick long-persistent plates to $12 \mathrm{dm}$. long; branches small and spreading to form a narrow cylindric crown; branchlets orange-brown or tan, at first pilose or covered with a pale or rufous pubescence or tomentum, eventually glabrous or puberulous; leaves to 55 $\mathrm{cm}$. long; leaflets 5 to 9 , sessile or short-stalked, ovate to oblong-lanceolate or broadly obovate, acute to acuminate at apex, asymmetrically cuneate or rounded at base; to $22 \mathrm{~cm}$. long and $12 \mathrm{~cm}$. wide, the margins finely serrate, dark-green and lustrous above, pale-yellow-green or bronze-brown and covered with soft pubescence beneath; overwintering bud short and blunt; fruit solitary or in pairs, ellipsoid to ovoid or subglobose, depressed at apex, downy or glabrous, lightorange-color or chestnut-brown at maturity, to $63 \mathrm{~mm}$. long and $5 \mathrm{~cm}$. broad; husk pale, hard and woody, about $12 \mathrm{~mm}$. thick; nut with a hard bony shell to $7 \mathrm{~mm}$. thick, more or less compressed, prominently 4-ridged or -angled, light yellow or reddish-brown, the light-chestnut-brown kernel very sweet. Hicoria laciniosa (Michx. f.) Sarg.

In rich bottomlands that are usually periodically inundated, in e. Okla., reported from n.e. Tex.; from N.Y., w. to Ia. and Neb., s. to Ala., La. and (probably) Tex.

\section{Fam. 47. Betulaceae S. F. Gray Birch or Hazel-nut Family}

Monoecious trees or shrubs with alternate simple pinnately straight-veined deciduous leaves and deciduous stipules; flowers unisexual; staminate flowers in spreading or drooping catkins, subtended by scaly bracts, with 2- to 4-parted "perianth" (or bracteoles) and 2 to many stamens; pistillate flowers in clusters, spikes or in a scaly catkin, with minute perianth or none; ovary 2-celled, with 2 pendulous anatropous ovules in each cell; styles 2; fruit a 1-celled and 1-seeded nutlet, with or without a foliaceous involucre. 
A family of 4 to 6 genera and about 140 species, mostly in the Northern Hemisphere. Sometimes divided so that Carpinus and Ostrya constitute a separate family, the Carpinaceae.

1. Staminate flowers solitary in the axil of each bract, without a calyx or bracteoles; pistillate flowers with a calyx or bracteoles; bracts of the pistillate ament deciduous; nutlets wingless, more or less enveloped by an involucre formed by the enlargement of the bract and bractlets of the flower............................................ Carpinus

1. Staminate flowers 2 or more in the axil of each bract, with a calyx or bracteoles; pistillate flowers without a calyx or bracteoles; bracts of the pistillate ament persistent or eventually deciduous; nutlets winged or with a coriaceous margin, without an involucre, borne in an ovoid to oblong-ellipsoid strobile (2)

2(1). Pistillate aments solitary; fruiting aments not persistent, the bracts thin, 3-lobed, deciduous with or soon after the nutlet; stamens 2, bifid; buds not stalked; trees with usually exfoliating bark.........2. Betula

2. Pistillate aments racemose; fruiting aments persistent, the bracts thick and semi-woody, not deeply lobed, persistent; stamens 4 , not bifid; buds stalked; shrubs with smooth or somewhat scaly bark. 3. Alnus

\section{Carpinus L. Hornbeam. Ironwood}

An Old World genus of about 35 species, with one in America.

\section{Carpinus caroliniana Walt. American hornbeam, blue-Beech, lechillo.}

Small tree to $10 \mathrm{~m}$. tall, with somewhat flattened and twisted trunk and smooth grayish bark; leaves oblong to narrowly oblong-ovate or elliptic-lanceolate, rounded at base, subobtuse to acuminate at apex, to $9 \mathrm{~cm}$. long and $45 \mathrm{~mm}$. wide, more or less doubly serrate; staminate aments pendulous, the ovate scales each subtending a solitary naked flower that is composed of several divided filaments each bearing 2 apically pilose half-anthers; fruiting aments ovoid to shortcylindric, to $5 \mathrm{~cm}$. long; bracts about $2 \mathrm{~cm}$. long, ovate, subtending 2 flowers, chartaceous, halberd-shaped, with 1 or 2 divergent basal lobes, entire or with a few blunt teeth along one side of the midlobe; nutlet ovoid, several-nerved.

Rich woods and bottomlands along streams subject to flooding, in e. Okla. (Waterfall) and e. Tex., Mar.-May; from Fla. and Tex., n. to Md., Tenn. and s. III.

\section{Betula L. BIRCH}

Trees or rarely shrubs with the outer bark often separable in sheets, the branchlets dotted; buds sessile, scaly; staminate aments terminal and lateral, sessile, formed in summer, remaining naked during winter to expand in early spring with or preceding the leaves; flowers 3 (the bractlets 2) to each peltate scale or bract of the aments, consisting each of a calyx of 1 scale bearing 4 short filaments with 1-celled anthers or strictly of 2 bipartite filaments with each division bearing an anther-cell; pistillate aments (strobiles) ovoid to cylindrical, usually terminating very short 2-leaved early lateral branches of the season (spurs); flowers 2 or 3 to each 3 -lobed bract, without bractlets or calyx, each with a naked ovary, becoming a winged and scalelike nutlet or small samara crowned by the two spreading stigmas.

About 60 species that are widely scattered in the Northern Hemisphere.

1. Bark readily exfoliating; bracts of pistillate aments subequally lobed, cuneatetapered to base; distribution in eastern Oklahoma and Texas.. 
1. Bark not readily exfoliating; bracts of pistillate aments noticeably unequally divided, broadly rounded at base; distribution in mountains of New Mexico and Arizona......

2. B. occidentalis.

\section{Betula nigra L. River BIRCH. Fig. 393.}

Tree to $30 \mathrm{~m}$. tall and a trunk to $8 \mathrm{dm}$. in diameter, with soft shaggy and freely exfoliating salmon-pink bark and reddish-dotted twigs; leaves with a tomentose petiole to $15 \mathrm{~mm}$. long, rhombic-ovate, broadly cuneate to subtruncate at base, acute at apex, to $1 \mathrm{dm}$. long and $8 \mathrm{~cm}$. wide below middle, conspicuously and often deeply doubly serrate, bright-green on upper surface, grayish-white on lower surface and when young downy; aments formed in the fall and expanding in early spring; staminate aments mostly 2 or 3 clustered, sessile, elongate, each of the ovate to suborbicular bracts subtending 3 flowers; flowers consisting of 4 stamens adnate to a 4-parted calyx, with two bractlets; the pedunculate thickcylindric pistillate aments tomentose, solitary, 25-35 $\mathrm{mm}$. long, the bracts $6-8 \mathrm{~mm}$. long, nearly equally divided into 3 oblong-linear lobes, subtending 2 or 3 flowers; flowers naked, without bractlets or calyx; fruit an erect or pendent ovoid to oblong-ellipsoid strobile, the scales deciduous from the persistent cone axis at maturity to release the compressed laterally winged nutlets.

Along streams and in bottomlands in e. Okla. (Creek Co.), e. Tex., Mar.-Apr.; from Fla. and Tex., n. to N.E., Pa., W.Va., O., s. Mich., s. Wisc., s. Minn. and e. Kan.

\section{Betula occidentalis Hook. WATER BIRCH. Fig. 393.}

Shrub or small tree to about $15 \mathrm{~m}$. tall, finely branched, with a trunk to about $3 \mathrm{dm}$. in diameter; bark smooth, reddish or copper-colored, not readily exfoliating; twigs glandular-dotted; leaves ovate, cuneate to truncate or somewhat cordate at base, 3-5 cm. long, sharply singly or doubly serrate, resinousglandular above when young, glandular-dotted below; aments spreading or pendulous; pistillate aments $2-4 \mathrm{~cm}$. long, $4-10 \mathrm{~mm}$. thick; bracts puberulent and ciliate, the lateral lobes shorter than the middle one; wings of fruit usually nearly or quite as broad as the puberulent nutlet. B. fontinalis Sarg.

Along mt. streams and wet areas in forests, often forming thickets, in N.M. (San Juan and Valencia cos.) and Ariz. (Apache and Coconino cos.); S.D. to B.C., s. to Neb., N.M., Ariz. and Calif.

\section{Alnus Mill. Alder}

Trees or shrubs with 3-angled pith and few-scaled leaf buds; leaves ovate to obovate, deciduous; aments racemose or cymose-clustered; staminate aments with 4 or 5 bractlets and 3 (rarely 6 ) flowers upon each short-stalked peltate bract; individual flowers usually with a 3-or 5-parted calyx and as many stamens; filaments short and simple; anthers 2-celled; pistillate aments ovoid to ellipsoid; bracts fleshy, each subtending 2 flowers and a group of 4 tiny scalelets adherent to the bracts of the ament, in iruit woody, cuneate-obovate and truncate or 3-or 5-lobed; fruit a small nutlet, crowned with the short persistent styles and surrounded by a membranous wing or a thin margin.

About 35 species, mostly in cool temperate regions.

1. Distribution eastern Texas and/or southeastern Oklahoma (2)

1. Distribution in mountains of New Mexico and Arizona (3)

2(1). Principal leaves typically with 9 to 12 pairs of lateral veins; pistillate aments 3 to 10 , mostly sessile, $1-1.5 \mathrm{~cm}$. long, $5-15 \mathrm{~mm}$. thick........

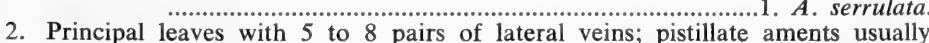
2 or 3 , rarely more or less, all peduncled, $1.5-3 \mathrm{~cm}$. long, 15-20 mm. thick.

2. A. maritima. 


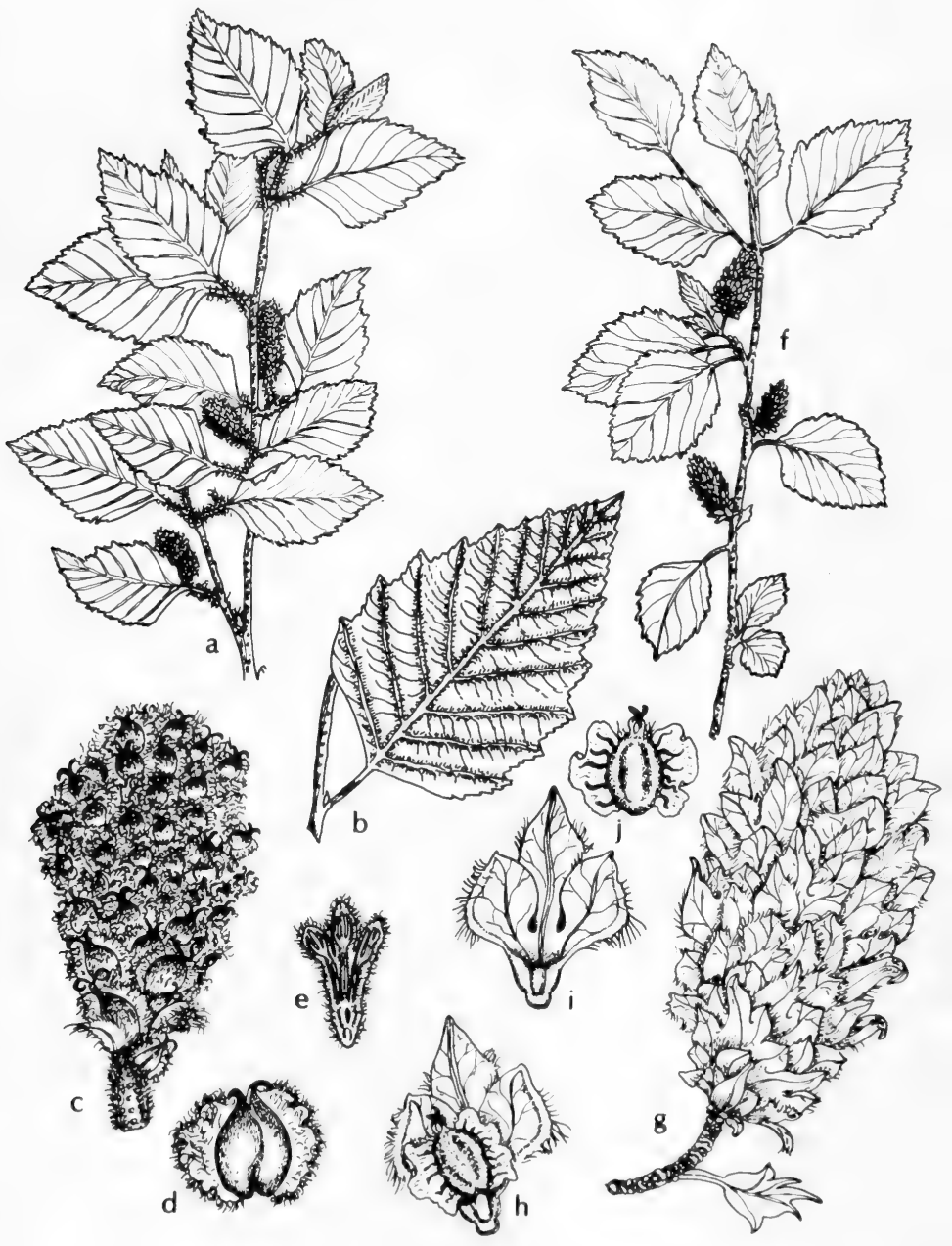

Fig. 393: a-e, Betula nigra: a, tip of branch, $x$ 1/2; b, leaf, $x 1 \frac{1}{2}$; c, pistillate catkin.

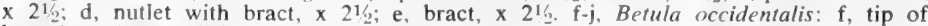
branch, $x 1 \frac{1}{2} ; \mathrm{g}$, pistillate catkin, $\mathrm{x} 2 \frac{1}{2} ; \mathrm{h}$, nutlet with bract, $\mathrm{x} 21 \frac{1}{2} ; \mathrm{i}$, bract, $\mathrm{x} 21 \frac{1}{2} ; \mathrm{j}$, nutlet, $x$ 21/2. (V. F.). 


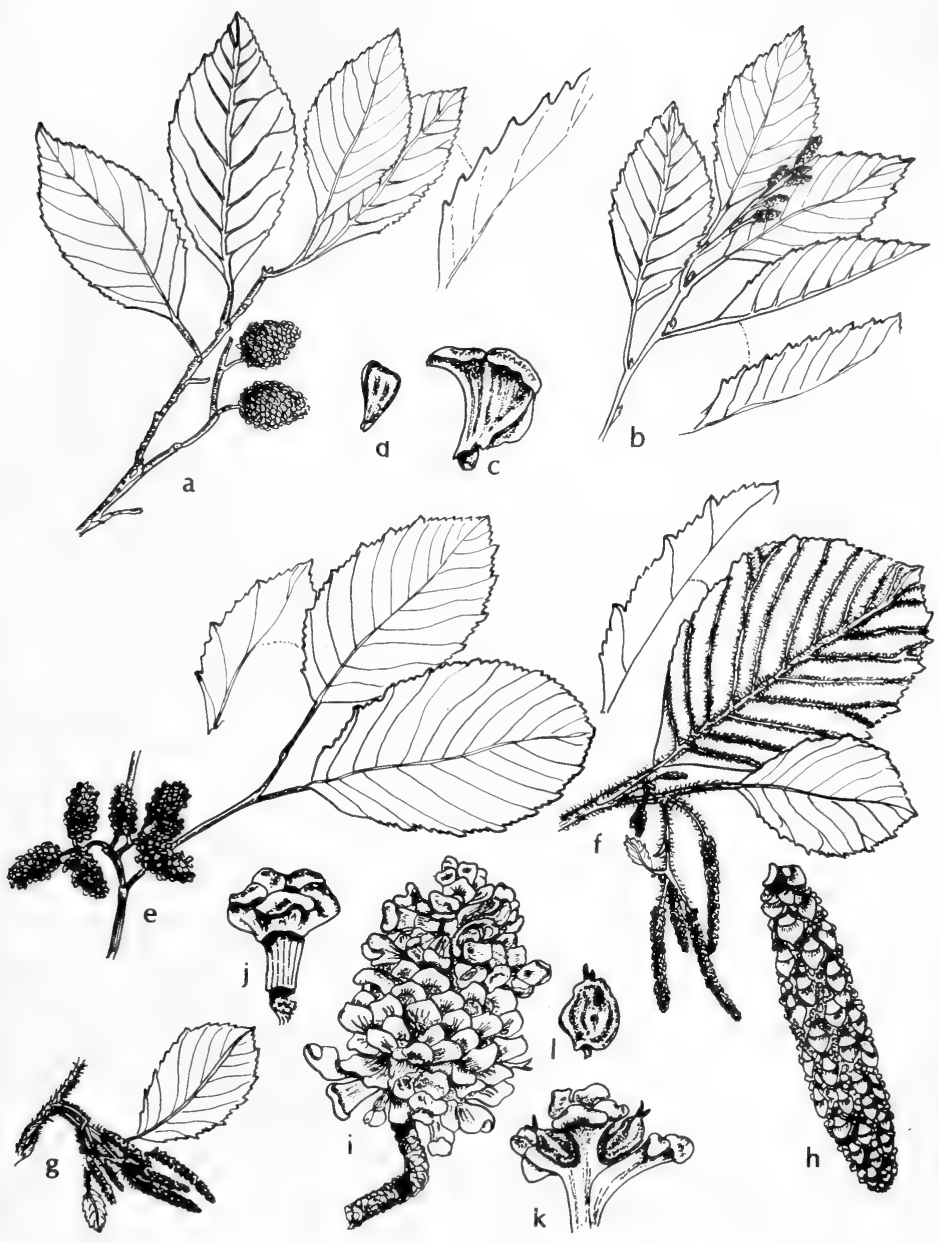

Fig. 394: a-d, Alnus maritima: a, branch with pistillate aments, $x \quad 1 / 2 ; b$, branch with staminate aments, $\times 1 \frac{1}{2}$; c, bract of pistillate ament, x $2 \frac{1}{2}$; d, nutlet, x $2 \frac{1}{2}$. e-k, Alnus serrulata: e, branch with pistillate aments, $\mathrm{x} 1 / 2 ; \mathrm{f}$, branch with staminate aments, $\mathrm{x} 1 / 2 ; \mathrm{g}$, young staminate aments, $\mathrm{x} 1 / 2 ; \mathrm{h}$, staminate ament, $\mathrm{x} 21 \frac{1}{2} ; \mathrm{i}$, pistillate ament, $\mathrm{x}$ $21 / 2 ; j$, bract of pistillate ament, $\times 2 \frac{1}{1} ; \mathrm{k}$, bracts and nutlets, $\times 2 \frac{1}{2} ; 1$, nutlet, $\times 2 \frac{1}{2}$. (V. F.). 
3(1). Leaves rounded to truncate or subcordate at base, often somewhat lobulate; stamens 4.

3. A. incana.

3. Leaves typically cuneate at base, seldom lobulate; stamens 1 to 3 (usually 2) ..4. A. oblongifolia.

1. Alnus serrulata (Ait.) Willd. Smooth ALDER. Fig. 394.

Spreading or laxly ascending deciduous shrubs or small trees to $5 \mathrm{~m}$. or more tall, the main stem to $15 \mathrm{~cm}$. in diameter; bark of trunk smooth, light grayishbrown to reddish-brown or blackish-gray, with dark lenticels; leaves with petioles to $15 \mathrm{~mm}$. long, obovate to obovate-elliptic or elliptic, narrowly to broadly cuneate at base, rounded to acute at the apex, to $1 \mathrm{dm}$. long and $6 \mathrm{~cm}$. wide, the margins simply serrulate or rarely somewhat undulate, the expanding leaves glutinous and aromatic; aments usually formed in the fall and expanding in early spring; staminate aments pendulous, in clusters of 3 to 5 , each of the bracts subtending 3 flowers; staminate flowers with a minute 4-parted calyx and 4 stamens with undivided filaments; pistillate aments in clusters of 2 or 3 , ovoid to ellipsoid, $1.5-2 \mathrm{~cm}$. long, the fleshy cuneate bracts $3-4 \mathrm{~mm}$. long, each subtending 2 flowers and a group of 4 tiny scaleiets adherent to the bracts of the aments; fruit a persistent semiwoody strobile, each cuneate to cuneate-obovate truncate or lobulate scale bearing 2 to 4 compressed laterally winged nutlets.

Along streams and in swamps and boggy situations, in s.e. Okla. (McCurtain and Pushmataha cos.) and in e. Tex., Mar.-Apr.; from N.E., s. to Fla. and Tex., Okla., Mo., Ind. and O.

Often confused with the eastern A. rugosa (Du Roi) Spreng., whose bark has linear, whitish lenticels.

\section{Alnus maritima (Marsh.) Nutt. Fig. 394.}

Shrub or small tree to about $10 \mathrm{~m}$. tall; bark reddish-brown; branchlets at first pubescent, soon glabrate; leaves oblong-elliptic to obovate, obtuse to acute or short-acuminate at apex, serrulate with low distant ascending or incurved teeth, broadly cuneate to a long petiole, to $10 \mathrm{~cm}$. long and $5 \mathrm{~cm}$. wide, dull green and glabrous beneath; aments expanding in late summer; pistillate aments 2 or 3 in a raceme, oblong-ovoid, $2-3 \mathrm{~cm}$. long, $1.5-2 \mathrm{~cm}$. thick, maturing the 2 nd year; bracts with depressed and broad terminal lobes; nutlets 3-4 $\mathrm{mm}$. long, thinmargined.

Banks of streams and ponds, and in wet woods in s.e. Okla. (Johnston and Pontotoc cos.); also Del. and Md.

\section{Alnus incana (L.) Moench. Thin-Leaf ALDER.}

Shrub or small tree to about $10 \mathrm{~m}$. tall, often forming thickets; bark grayishbrown to reddish; leaves ovate-oblong to broadly elliptic, usually $5-10 \mathrm{~cm}$. long, rounded to truncate or subcordate at base, rounded to obtuse or somewhat acute at apex, sinuate and serrate-denticulate on margins, dark-green and glabrous to pubescent above, pale and usually heavily pubescent beneath; staminate aments to $10 \mathrm{~cm}$. long; stamens 4; pistillate aments ovoid-ellipsoid, $8-12 \mathrm{~mm}$. long, with stout peduncles; scales 3 -lobed at apex; nutlets without a true wing. A. tenuifolia Nutt.

In bogs, about ponds and lakes, on stream banks and in wet woodlands, in N.M. (Rio Arriba, Sandoval, San Miguel and Taos cos.) and Ariz. (Apache, Graham and Pima cos.); Minn. and N.D. to B.C., N.M., Ariz. and B. Calif.

Our plant is referred to ssp. rugosa var. occidentalis (Dippel) C. L. Hitchc. by recent authors.

\section{Alnus oblongifolia Torr. New Mexican alder, Arizona alder.}

Tree to about $10 \mathrm{~m}$. tall, with a trunk to $2.5 \mathrm{dm}$. in diameter; bark thin, light-brown tinged with red; branches reddish-brown; leaves ovate-oblong to 
ovate-lanceolate, 4-10 cm. long, usually acute at apex, cuneate at base, sharply and doubly serrate, not lobulate or only slightly so, glabrous or puberulous beneath; staminate aments in short racemes; stamens (1) 2 or 3 ; pistillate aments $1.5-2.5 \mathrm{~cm}$. long; scales thin, slightly thickened and nearly truncate at apex; nutlets without a true wing.

Along mt. streams and low meadowlands in N.M. (Grant, Sierra and Socorro cos.) and Ariz. (Apache and Coconino cos. s. to Graham and Pima cos.); also n. Mex.

\section{Fam. 48. Fagaceae Dum.}

\section{Beech Family}

Monoecious trees or shrubs with alternate simple straight-veined deciduous or evergreen leaves and deciduous stipules; staminate flowers in aments or capitate clusters; pistillate flowers solitary or slightly clustered; the 1-celled and 1-seeded nut entirely to partly enclosed in a cupule formed by the more or less consolidated bracts that become indurated; ovary 3 - to 7-celled; ovules 1 or 2 in each cell, usually with only one ripening; styles 3 ; seed with no albumen, filled by the embryo and with 2 integuments.

About 900 species in 8 genera mostly cosmopolitan but most abundant in the Northern Hemisphere.

\section{Quercus L. OAK}

Shrubs to large trees, monoecious; pith star-shaped, continuous; wood usually hard with both uniseriate and multiseriate rays, the vessels grouped in a matrix of wood-parenchyma, either diffuse-porous or ring-porous, often plugged by tyloses; buds crowded toward the ends of the usually fluted twigs; stipules associated with the buds rather than the leaves, subulate to ligulate, promptly caducous or sometimes persistent; leaves alternate, usually distinctly petioled, never quite sessile, simple, entire or toothed or pinnately lobed, pinnately veined; staminate flowers in elongate flaccid catkins, apetalous, the calyx of 5 lobes fused into a more or less bowl-shaped perianth enclosing 5 to 10 free stamens with short anthers and slender filaments; pistillate flowers in a reduced catkin with a stiff woody rachis either short or long and 1- to several-flowered, the calyx of 6 sepals adherent to the bases of the styles and fused into a tube, the pistil of 3 carpels comprising a single 3-celled ovary (each cell containing 2 ovules) and 3 free styles which are ventrally stigmatic toward the dilated apex; fruit 1 -celled and 1 -seeded, the 5 remaining ovules aborted and adhering to the developed seed, the seed enclosed in a shell (forming a nut or acorn) and seated in a cup or involucre formed (in our species) of scales (each with a more or less aborted bud in its axil), developing from a compressed inflorescence, the cup enveloping the whole nut or covering it only at the base.

A genus of some 500 or so recognized species in the Northern Hemisphere, exclusive of the Arctic; about 250 in the New World centering in central Mexico and reaching Canada and Colombia.

1. Leaves distinctly several-lobed (2)

1. Leaves entire to merely sinuate or unevenly dilated, rarely obscurely 3 -lobed at apex (6)

2(1). Leaf lobes acute to rounded, at most mucronate-tipped (3)

2 . Leaf lobes and teeth narrowly acute to acuminate and aristate-tipped (5)

3(2). Cups thick, typically 3-6 cm. in diameter, fringed about the lip with coarsely attenuated apices of the uppermost scales.

3. Cups thin, typically less than $3 \mathrm{~cm}$. in diameter, not fringed about the lip (4) 
4(3). Mature acorns nearly enclosed in the cups, the orifice usually less than half the diameter of the acorn; petioles to $2 \mathrm{~cm}$. long, sparsely pubescent...............................................................2. $Q$. lyrata.

4. Mature acorns rarely more than half-enclosed in the cups, with orifice as great as the diameter of the acorn; petioles $1 \mathrm{~cm}$. long or less, gray-puberulent to velvety-tomentulose.......................3. $Q$. similis.

5(2). Mature leaves with a rounded to broadly cuneate base, cinereous-tomentulose beneath............................................................4. Q. falcata.

5. Mature leaves with a subtruncate base, glabrous beneath except for tufts of hair in the vein axils.............................................5. Q. palustris.

6(1). Leaves narrowly elliptic to linear-lanceolate, fully 5 times as long as broad, markedly revolute and awl-shaped upon issuing from the buds. 6. Q. Phellos.

6. Leaves elliptic to oblanceolate or clavate, scarcely more than 3 times as long as broad, flat when issuing from the buds, never awl-shaped (7)

7(6). Leaves typically narrowly oblong to oblanceolate, glossy beneath. 7. Q. laurifolia.

7. Leaves typically cuneiform to clavate or broadly obovate, occasionally shallowly 3-lobed at apex, dull green beneath.

.8. $Q$. nigra.

\section{Quercus macrocarpa Michx. BUR OAK.}

Large trees; twigs very coarse, 3-5 $\mathrm{mm}$. thick or rarely somewhat more slender, fluted, yellowish or gray, from villous to pubescent or both becoming glabrate, with few very inconspicuous lenticels; buds 4-5 $\mathrm{mm}$. long, ovoid or narrowly so, obtuse to acute, grayish-brown, sparsely pubescent to tomentose; stipules persistent or sometimes deciduous, about $1 \mathrm{~cm}$. long, awl-shaped or the lateral ones longer and obviously spatulate-dilated, the terminal ones coarsely thickened and gray-tomentose; leaves deciduous, rather thin, to $20 \mathrm{~cm}$. long and $15 \mathrm{~cm}$. broad, obovate in outline, the apices broadly rounded, the bases rounded to cuneate, rather deeply incised, with 3 or 4 sinuses on each side, these acute or narrowly rounded, usually reaching nearly to the midrib (especially below), the lobes clavate, undulate distally, the basal ones often much-shortened, margins minutely revolute, upper surfaces glabrate, dull or slightly lustrous, lower surfaces villous and gray-puberulent with a mixture of long spreading and short appressed stellate hairs or the appressed hairs rarely absent and the surface then green; petioles to $25 \mathrm{~mm}$. long, densely or sparsely pubescent; staminate catkins $3-4 \mathrm{~cm}$. long, the rachis yellow-tomentose, at length rather loosely flowered, the perianth deeply incised with narrow oblong lobes, the anthers scarcely exserted; pistillate catkins about $2 \mathrm{~cm}$. long, about 4-flowered near the end; fruit annual, solitary or paired on a peduncle $1-2 \mathrm{~cm}$. long and 2-3 mm. thick; cups $3-6 \mathrm{~cm}$. broad, $2-5 \mathrm{~cm}$. deep, moderately or deeply cup-shaped, margins woolly with attenuate apices of the uppermost scales, these sometimes closing the orifice of the cup; cup scales broad-based, the apices of the basal scales not elongate, the dorsal surface keeled (thickened), the bases broad, often appearing to be fused to adjacent scales, the whole gray-pubescent; acorns 3-5 cm. long, 2-4 cm. broad, ovoid, broadly rounded, usually one half or three fourths included, sometimes wholly or only one fourth included.

In moist forests along streams and bottomlands in e. Okla. and e. and cen. Tex.; e. to the Atl. and n. to N.B. and Sask.

\section{Quercus lyrata Walt. OVERCUP OAK, SWAMP POST-OAK.}

Moderate trees; twigs rather coarse, to $4 \mathrm{~mm}$. thick, finely fluted, from minutely villous becoming glabrate and gray or yellowish with few inconspicuous lenticels; buds about $3 \mathrm{~mm}$. long, ovoid, obtuse, gray-puberulent; stipules tardily deciduous 
from about the terminal bud, about $5 \mathrm{~mm}$. long, very finely subulate, pubescent; leaves deciduous, thin-membranous, to $20 \mathrm{~cm}$. long and $12 \mathrm{~cm}$. broad, usually smaller, narrowly obovate in outline or broadly so, apices acute or sometimes rounded, bases cuneate or attenuately acute; blades twice or thrice incised on each side, the lobes obtuse, acuminate-tipped, progressively shortened downward, the uppermost clavate and coarsely toothed, the sinuses deep, broadly rounded or angularly flattened along a line parallel to the midrib, margins minutely revolute, upper surfaces glabrous and lustrous, lower surfaces minutely villous and dullgreen or glaucous-appressed-tomentose; petioles to $2 \mathrm{~cm}$. long, sparsely pubescent; staminate catkins 4-6 cm. long, densely or loosely flowered, sparsely stellatepubescent, the perianth irregularly lobed, the anthers scarcely exserted; pistillate catkins 1-2 cm. long, 2- or 3-flowered distally, densely short-tomentose; fruit annual, solitary or rarely paired on a tomentose or glabrate peduncle to $4 \mathrm{~cm}$. long and 1-1.5 mm. thick; cups to $3 \mathrm{~cm}$. broad and $2 \mathrm{~cm}$. deep, hemispheric or spheroid, the base usually broadly flattened, the mouth much-constricted, sometimes forming a minute orifice and sometimes rather open, the lower scales coarse and much-thickened, those about the margin small, thin and appressed; acorns hemispheric or rarely ovoid, usually wholly contained in the cup but rarely only half-included.

In moist forests along streams, river swamps and depressions in bottomlands, in e. Okla. and e. Tex.; e. to the Atl., n. to Md. and Mo.

\section{Quercus similis Ashe. Bottomland POST OAK.}

Moderate to large trees; twigs $2-3 \mathrm{~mm}$. thick, only slightly fluted, persistently gray-puberulent to velvety-tomentulose; buds $2-3 \mathrm{~mm}$. long, ovoid, pubescent basally, brown; stipules 3-5 $\mathrm{mm}$. long, subulate, pubescent, caducous or only those of the terminal buds persistent; leaves deciduous, thin and membranous, about $12 \mathrm{~cm}$. long and $8 \mathrm{~cm}$. broad (as little as $5 \mathrm{~cm}$. long or to $16 \mathrm{~cm}$. long), obovate, usually 2 pairs of lateral lobes with the apical pair sometimes clavate but the blade scarcely cruciform, basally narrow, cuneate to rounded, margins minutely revolute, lower surface minutely and sparsely stellate-puberulent, somewhat gray, upper surface glabrous and glossy-green at maturity; petioles $3-10 \mathrm{~mm}$. long, pubescent like the twigs; pistillate catkins 2-10 mm. long, 1- to 3-flowered; fruit annual, solitary or paired, moderate-sized, short-peduncled, very similar to $Q$. stellata. Q. stellata var. paludosa Sarg., Q. Ashei Sterrett.

The common post oak of wet stream bottoms in e. Tex.; also s. Ark. and La., e. to S. C.

\section{Quercus falcata Michx. Southern Red oak, SPANiSh OAK.}

Large trees to $20 \mathrm{~m}$. tall, with a trunk diameter of $5 \mathrm{dm}$. and roughly furrowed hard black bark; twigs 1-3 mm. thick, fluted, from sparsely or densely fulvousstellate-tomentose tardily glabrate to persistently pubescent, brown. becoming gray the second season with conspicuous or inconspicuous lenticels; buds 4-8 $\mathrm{mm}$. long, narrowly ovoid, acute, somewhat quadrangular or round, deep-red-brown, puberulent, tomentose about the apex or all over; stipules caducous, about $1 \mathrm{~cm}$. long, ligulate, dorsally densely tomentose; leaves deciduous, rather thin and papery, to $23 \mathrm{~cm}$. long and usually smaller, $15 \mathrm{~cm}$. broad, very polymorphic, typically ovate or lanceolate in outline, frequently obovate to cuneiform, apically long-attenuate or obtusely clavate, basally cuneate to round or truncate, typically deeply falcate-lobed with broadly rounded sinuses reaching within 1 or $2 \mathrm{~cm}$. of the midrib or with a few broad lobes or entire with 3 lobes at the apex, apical lobes typically elongate, toothed at the ends, all lobes and teeth tipped with aristae, margins finely or coarsely revolute, upper surfaces from densely fulvous-stellatetomentose glabrate and dark-glossy-green or more or less persistently pubescent 
especially toward the bases, lower surfaces persistently fulvous-tomentose, some forms very sparingly stellate-villous, especially shade leaves; petioles $1-3.5 \mathrm{~cm}$. long, shorter in some shade forms, dorsally glabrate and ventrally pubescent like the blade; staminate catkins 6-8 cm. long, densely fulvous-tomentose, rather loosely or closely flowered, the anthers well-exserted from the ciliate perianth; pistillate catkins 5-10 $\mathrm{mm}$. long, 1- to 3-flowered, from fulvous-pubescent tardily glabrate like the twigs; fruit biennial, solitary or paired on peduncles to $1 \mathrm{~cm}$. long and $3 \mathrm{~mm}$. thick; cups 1-2 cm. broad, 6-8 mm. high, goblet-shaped to turbinate, basally rounded or markedly constricted, margins not inrolled; cup scales ovate, somewhat thickened basally, the apices rather loosely appressed, dorsally densely short-fulvous-tomentose except the glossy brown margins; acorns 12-15 mm. long, 8-15 mm. broad, ovoid or flattened basally, rounded apically, sparingly puberulent, dull brown, about one third included. Q. digitata (Marsh.) Sudw., $Q$. rubra var. leucophylla Ashe, $Q$. rubra Sarg., non L., $Q$. rubra var. triloba (Michx.) Sarg., Q. rubra var. pogodaefolia (Ell.) Sarg., Q. rubra var. digitata (Marsh.) Cory \& Parks.

In moist or wet forests in the timber region of e. Okla. and e. Tex., in river bottoms or uplands; ranging e. to the Atl. and n. to N.J. and Mo.

\section{Quercus palustris Muenchh. PIN OAK.}

Tree to $30 \mathrm{~m}$. tall, the lateral branches usually somewhat drooping; mature twigs glabrous; leaves deeply lobed, $8-13 \mathrm{~cm}$. long, 5-13 cm. wide, more or less subtruncate at base, shining, paler beneath, glabrous except for conspicuous tufts of stellate hairs in the vein axils; leaf lobes in 2 or 3 pairs, much longer than the width of the central body of the blade, often widened distally and toothed, bristletipped; cups saucer-shaped, 1-1.6 cm. wide, covering a fourth to a third of the acorn, with very small puberulent scales; acorn depressed-ovoid, $1-1.3 \mathrm{~cm}$. long.

In swampy woods and bottomlands in e. Okla.; Mass. to Mich., Ia., Okla., Tenn. and N. C.

Because of its tolerance to city air pollution it is often planted as a street tree.

\section{Quercus Phellos L. Willow oAK.}

Moderate or large trees to $20 \mathrm{~m}$. tall, with a trunk diameter of $7.5 \mathrm{dm}$. and hard rather smooth bark; twigs 1-2 mm. thick, fluted, glabrous or from stellatetomentose quickly glabrate or rather persistently floccose, dull-reddish-brown with inconspicuous lenticels; buds $2-4 \mathrm{~mm}$. long, $1.5-2 \mathrm{~mm}$. broad, narrowly ovoid to usually lanceolate, very acute, the scales dark-russet and glabrous except the ciliate edges; stipules caducous, $6-8 \mathrm{~mm}$. long, filiform-ligulate to spatulate, dorsally villous, apically tomentose; leaves deciduous, moderately thin but coriaceous, usually 6-12 (or rarely 16) $\mathrm{cm}$. long and 1-2.5 (or even 4) $\mathrm{cm}$. broad, linear-lanceolate to sometimes oblanceolate or even narrowly ovate or obovate, setaceously acu+e at apex or sometimes obtuse but aristate-tipped, cuneate or narrowly rounded basally, entire, strongly revolute in the bud and lengthening before unfolding (thus filiform for a time), margins eventually flat or undulate or minutely revolute, upper surfaces dark, dull- or glossy-green, glabrous to tomentose along the midrib toward the base, lower surfaces lighter dull-green, from villoustomentose to glabrate or with conspicuous axillary tufts or densely tomentose along the midrib; petioles 1-4 $\mathrm{mm}$. long, from densely stellate-tomentose promptly or tardily glabrate; staminate catkins $25-35 \mathrm{~mm}$. long, moderately closely flowered, villous, the oval anthers well-exserted from the villous-tomentose perianth; pistillate catkins 1-3 mm. long, 1- to 3-flowered; fruit biennial, solitary or paired on peduncles to $5 \mathrm{~mm}$. long or subsessile; cups 1-1.5 cm. broad, 4-8 $\mathrm{mm}$. high, saucer-shaped to goblet-shaped, the base flat or markedly constricted, the margin not inrolled; cup scales narrowly ovate, the attenuately rounded apices closely 
appressed, minutely dense-tomentose except the glabrous brown margin; acorns $1-1.5 \mathrm{~cm}$. long, nearly as broad, subrotund, broadly rounded, densely puberulent or glabrate and dull-brown, one fourth included or enclosed at base only.

In moist forests, wet borders of swamps and along streams in s.e. Okla. and e. Tex.; e. to the Atl. ocean and n. to IIl. and N.Y.

\section{Quercus laurifolia Michx. LAurel oAK, SWAMP LAURel oaK.}

Large trees to $18 \mathrm{~m}$. tall, with hard gray or black bark; twigs $1-2.5 \mathrm{~mm}$. thick, pliable, fluted or round, dark-reddish-brown, gray the second season, from densely fulvous-stellate promptly glabrate or remaining sparsely pubescent; buds about 4 $\mathrm{mm}$. long and $2 \mathrm{~mm}$. broad, very acute, slightly quadrangular, nearly glabrous, dark-reddish-brown; stipules quickly caducous, about $4 \mathrm{~mm}$. long, ligulate or spatulate, tan, villous especially about the apex; leaves evergreen, thick and coriaceous or deciduous, $5-10$ or sometimes $12-15 \mathrm{~cm}$. long, to $8 \mathrm{~cm}$. broad, characteristically oblanceolate or narrowly ovate, acute to broadly rounded at apex but aristate-tipped, cuneate to cordate at base, entire to variously undulate, margins moderately revolute, from sparsely stellate-puberulent glabrate and glossy above or persistently somewhat pubescent about the base of the midrib, similarly glabrate beneath but dull; petioles to $4 \mathrm{~mm}$. long, rose-color or dark-red, glabrate or sparsely stellate; staminate catkins $2-2.5 \mathrm{~cm}$. long, densely villous, moderately densely flowered, the small ellipsoid anthers moderately exserted from the villous perianth; pistillate catkins on peduncles 1-3 mm. long, 1- to 3-flowered; fruit biennial, solitary or paired on a short peduncle or subsessile; cups 14-18 mm. broad, 5-7 mm. high, shallowly bowl-shaped, flat basaily or turbinate; cup scales tightly appressed, ovate, minutely dense-puberulent, tan and glossy where abraded, margins not inrolled; acorns about $15 \mathrm{~mm}$. long, subglobose to broadly ovoid, apically broadly rounded, basally flattened, tan or brown, minutely and sparsely puberulent, included at base only. Q. obtusa (Willd.) Pursh, Q. rhombica Sarg.

Wet forests, particularly along streams and borders of swamps, in s.e. Tex.; e. to the Atl. ocean.

\section{Quercus nigra L. WATER OAK.}

Moderate or large trees to $15 \mathrm{~m}$. tall, with boles to $5 \mathrm{dm}$. in diameter and hard smooth or shallowly furrowed black bark; twigs 1-2 $\mathrm{mm}$. in diameter, fluted, glabrous or from scantily stellate quickly glabrate and glossy dark-reddish-brown with conspicuous pale lenticels or not, gray the second season; buds $3-5 \mathrm{~mm}$. long, 2-3 mm. broad, ovoid, subacute, dark-reddish-brown, densely fulvousstrigose above the middle; stipules caducous, 6-10 mm. long, ligulate to spatulate, tufted at apex; leaves subevergreen, rather thick and leathery, to $14 \mathrm{~cm}$. long and $5 \mathrm{~cm}$. broad, oblong to usually cuneiform or clavate, sometimes oblanceolate, entire or 3-lobed apically or variously toothed or lobed and distorted in cases of heterophylly, broadly rounded or rarely acute at the apices, attenuately cuneate or rarely narrowly rounded at the bases, margins flat or minutely revolute, from minutely puberulent glabrate and glossy above, dull green or coppery and glabrate beneath or usually with prominent axillary tufts; petioles $3-7 \mathrm{~mm}$. long, prominently winged by decurrence of the blade, from sparingly stellate-tomentose glabrate or persistently pubescent; staminate catkins $4-7 \mathrm{~cm}$. long, densely or sparsely arachnoid-tomentose, rather loosely flowered, the anthers well-exserted from the villous perianth; pistillate catkins 3-5 $\mathrm{mm}$. long, 1- to 3-flowered; fruit biennial, solitary or paired on a peduncle to $5 \mathrm{~mm}$. long or subsessile; cups 9-15 mm. broad, 2.5-5 mm. high, at most deeply saucer-shaped, basally very flat or somewhat rounded, margins not inrolled; cup scales narrowly ovate, closely appressed, densely fulvous-sericeous-tomentose; acorns 8-10 mm. long, 9-15 mm. broad, hemispheric to subglobose, very flat at base, broadly rounded apically, densely 
minute-pubescent, dull-brown where abraded, included at base only. $Q$. aquatica Walt., $Q$. nigra var. tridentifera Sarg.

In wet forests, edge of swamps and streams, and in river bottomlands in s.e. Okla. and e. Tex.; e. to the Atl. States and n. to Mo. and Del.

\section{Fam. 49. Ulmaceae Mirb. Elm FAmily}

Trees or rarely shrubs with watery sap; buds with imbricate scales; leaves simple, 2-ranked, alternate, usually oblique at base, pinnately veined, serrate or rarely entire; stipules deciduous; flowers perfect or unisexual with both sexes on the same plant; perianth 4- or 5-merous, rarely more or less, usually somewhat connate; stamens (in bud) with curved or somewhat sigmoid filaments, as many as or twice as many as the perianth lobes; filaments straight; ovary superior, 1-celled, with 1 suspended anatropous ovule; style 2-parted; fruit a samara, nut or drupe.

About 15 genera with more than 200 species in both hemispheres.

\section{Planera J. F. GMel.}

A monotypic genus.

1. Planera aquatica (Walt.) J. F. Gmel. Water-elm, Planer-Tree. Fig. 395.

Small deciduous polygamo-monoecious tree with spreading branches to form a low broad crown, to about $12 \mathrm{~m}$. high, the short trunk with reddish-brown scaly and flaky bark; branchlets puberulous; winter-buds subglobose, minute; leaves with petioles 3-6 mm. long, rhombic-ovate to ovate-oblong, 3-8 $\mathrm{cm}$. long, to 25 $\mathrm{mm}$. wide, unequal at the rounded to cuneate base, acute at apex, unequally serrate, scabrate above, pinnately veined, at maturity glabrous; calyx deeply 4- or 5-lobed; staminate flowers in clusters at base of the young branchlets; stamens 4 or 5 ; perfect flowers 1 to 3 in the axils of the young leaves; fruit ellipsoid, about $8 \mathrm{~mm}$. long, with irregularly crested fleshy ribs.

In water of streams and lakes and in alluvial floodplains subject to periodic flooding, often forming large stands, in s.e. Okla. (McCurtain Co.) and e. Tex.; from Fla. to Tex., n. to s. Ill. and Ky.

\section{Fam. 50. Urticaceae Juss. Nettle Family}

Annual or perennial herbs, sometimes with stinging hairs, frequently succulent and with watery sap; leaves simple, alternate or opposite, mostly stipulate; flowers minute, greenish, unisexual or rarely perfect, in simple or branched spikes or clusters; calyx 2- to 5-cleft or of separate sepals; petals none; stamens as many as the calyx lobes or sepals and opposite them, the filaments inflexed; ovary superior, 1-celled; style simple, with a capitate or filiform stigma; ovule solitary, erect or ascending, orthotropous; fruit an achene, often tipped with the persistent style or enclosed by the accrescent calyx.

About 45 genera and 600 species of wide geographic range, but mostly tropical and subtropical.

1. Leaves alternate.

1. Laportea

1. Leaves opposite or rarely alternate (2)

2(1). Calyx of pistillate flowers tubular or cupuliform, enclosing the achene; plants without stinging hairs. 2. Boehmeria

2. Calyx of pistillate flowers of 2 to 5 separate or nearly separate sepals (3)

3(2). Plants more or less pubescent, beset with stinging bristles; achene enclosed by the calyx. 


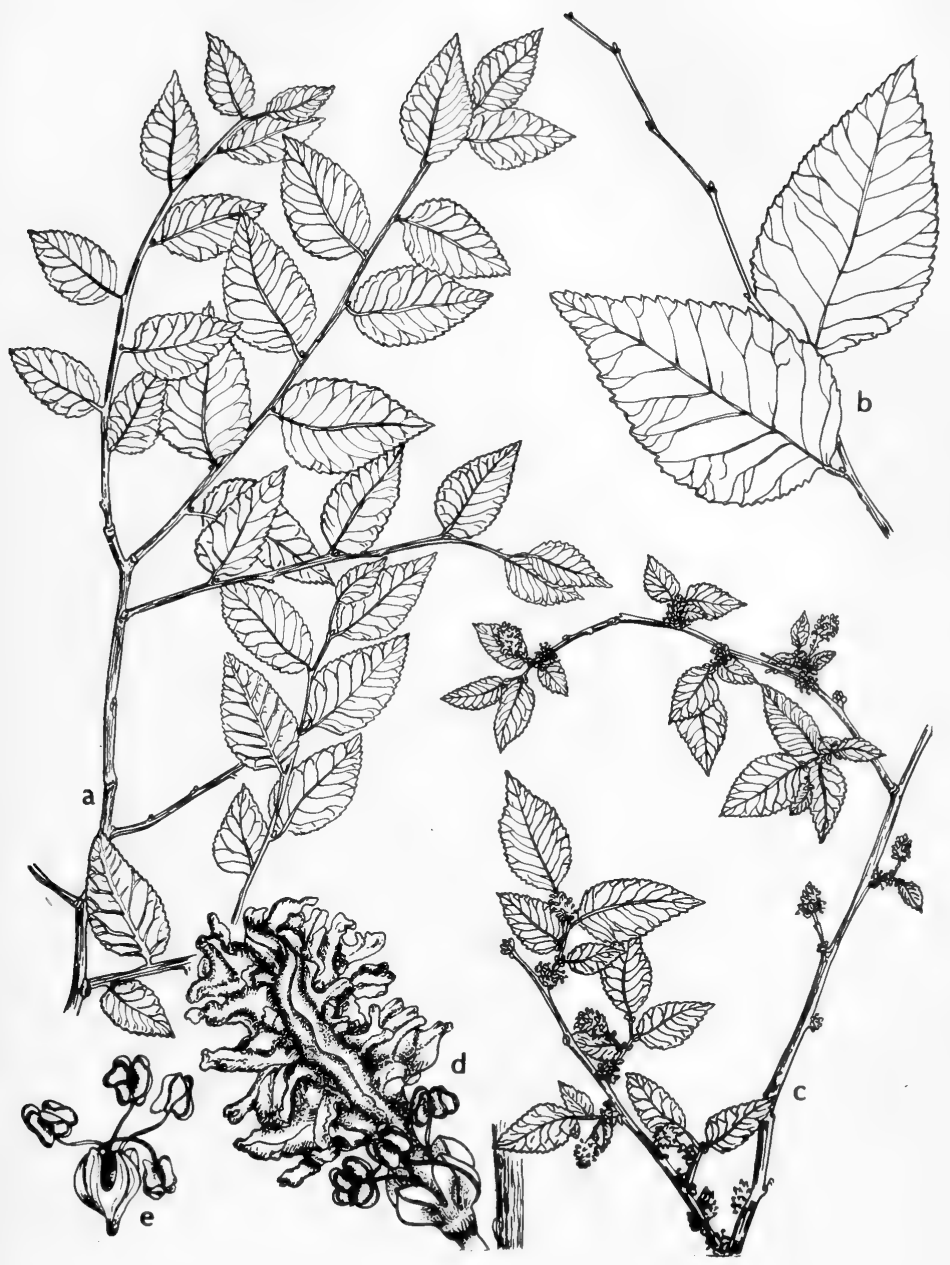

Fig. 395: Planera aquatica: a, branch showing position of leaves; $\mathrm{x} 1 / 2$; $\mathrm{b}$, two leaves, $\mathrm{x} 1$; $\mathrm{c}$, flowering branch, $\mathrm{x} 1 / 2$; $\mathrm{d}$, fruit with processes of the exocarp, $\mathrm{x} 5$; $\mathrm{e}$, staminate flower, x 5. (V. F.). 


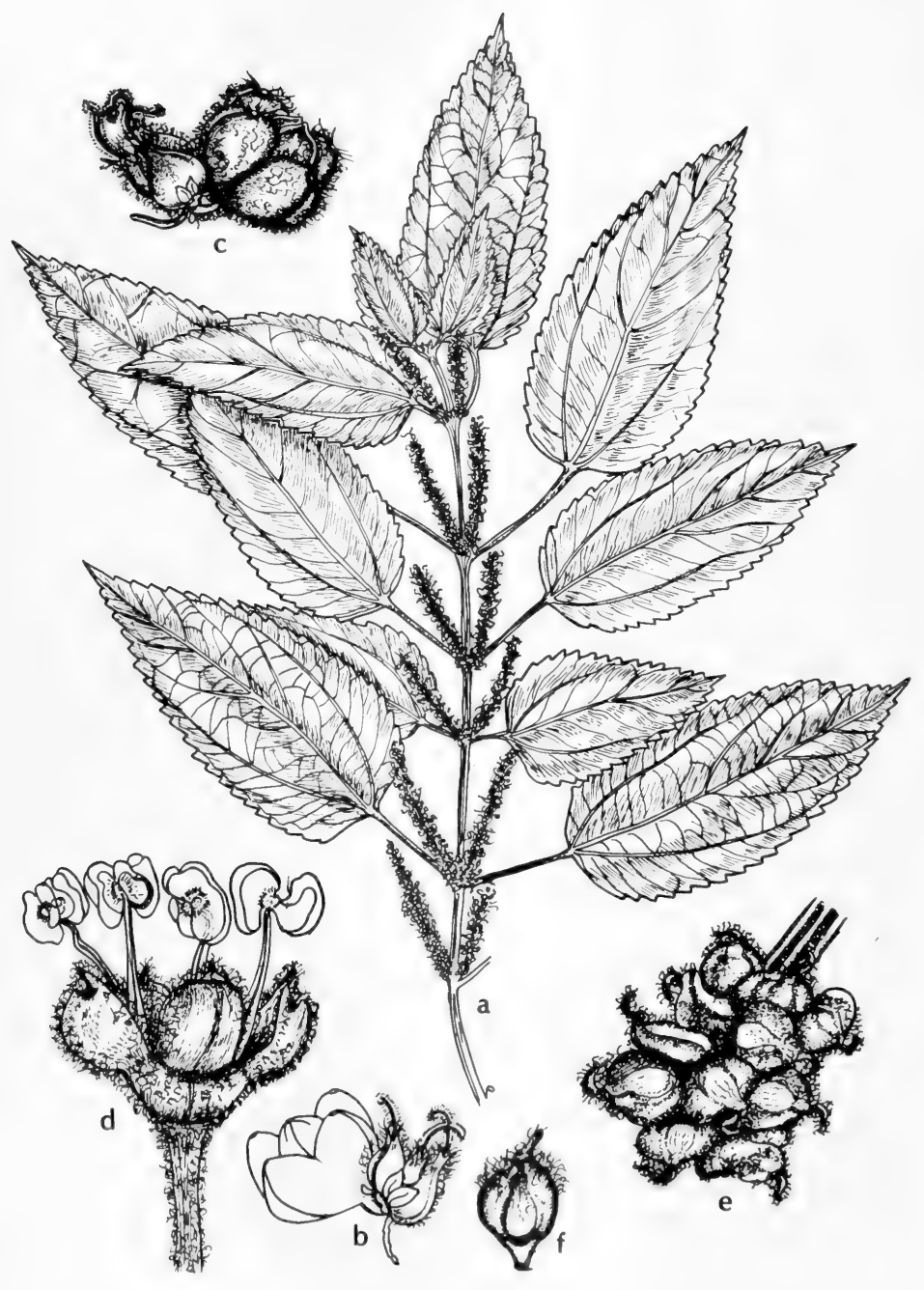

Fig. 396: Bochmeria cylindrica: a, top of plant. $x$ 16: b, staminate buds and cluster of pistillate flowers, $\mathrm{x} 5 ; \mathrm{c}$ and $\mathrm{e}$, clusters of pistillate flowers in different stages, $\mathrm{x} 5$; d, staminate flower, x 10 ; f, fruit, x 5. (V. F.). 
3. Plants glabrous, smooth and shining, without stinging bristles; achene longer than the calyx.

\section{Laportea Gaudich.}

WOOD-NETTLE

About 25 species, mostly in the tropics and subtropics of both hemispheres.

\section{Laportea canadensis (L.) Wedd.}

Monoecious perennial herb to about $1 \mathrm{~m}$. tall, usually much less, beset with stinging hairs; stem often flexuous; leaves alternate, broadly ovate, long-petioled, 7-20 cm. long, acuminate-attenuate at apex, rounded to broadly cuneate at base, coarsely serrate, strongly feather-veined; stipule single, 2-cleft; staminate flowers in cymes from the lowest leaf axils, seldom surpassing the subtending petioles; pistillate flowers in loose elongate spreading divaricately branched cymes in the upper leaf axils, usually much-surpassing the petioles; fruiting cymes divergent; achenes flat, crescent-shaped, 3-4 $\mathrm{mm}$. long.

Low alluvial woodlands and along banks of streams, often forming large colonies, in n.e. Okla., June-Aug.; N. S. to Man., s. to Ga. and Okla.

\section{Boehmeria JACQ. False Nettle}

Herbs, shrubs or small trees, devoid of stinging hairs, monoecious or dioecious; leaves opposite or alternate, stipulate; flowers clustered, axillary; staminate flowers minute, with a 4-parted calyx and 4 stamens; pistillate flowers with a tubular or urceolate entire or 2- to 4-toothed calyx enclosing the ovary; style filiformsubulate, persistent, stigmatic and papillose down one side; fruit formed by the dry accrescent calyx that closely invests the elliptic achene.

About 100 species mostly in tropical regions of both hemispheres.

1. Leaf blades thinnish, coarsely serrate; petioles usually about as long as the blades..............................................1. B. cylindrica var. cylindrica.

1. Leaf blades leathery, finely serrate; petioles much shorter than the blades......... 1. B. cylindrica var. Drummondiana.

1. Boehmeria cylindrica (L.) Sw. BoG-HEMP, FALSE NETTLE, BUtTON-HEMP. Fig. 396.

Perennial, usually dioecious, glabrous to pubescent or even scabrous, erect, to about $12 \mathrm{dm}$. high, the stem simple or rarely branched; leaves mostly longpetioled, opposite or rarely alternate, ovate to ovate-lanceolate or oblonglanceolate, the blade to about $15 \mathrm{~cm}$. long and $8 \mathrm{~cm}$. wide, rather thin to leathery, smooth to scabrous, acuminate at apex, rounded to somewhat cordate at base, serrate, 3-nerved; stipules distinct; flowers about $2 \mathrm{~mm}$. broad, unisexual, the two kinds sometimes intermixed, the small clusters densely aggregated in simple and elongated axillary spikes, the staminate spikes interrupted, the pistillate spike often continuous and frequently leaf-bearing at apex; fruit ovate to suborbicular, compressed, minutely winged, apiculate, hairy, to $1.5 \mathrm{~mm}$. wide.

In bogs, marshes, swamps, seepage areas and in wet soil and water along rivers and streams in sun or shade, throughout e. Okla., n.w. to Woodward Co., mostly in e. Tex. but extending w. to Val Verde Co. in w. Edwards Plateau and n. to Hemphill Co. in the High Plains, June-Oct.; from Fla. to Tex., n. to Ont. and Que., w. to Minn., Neb. and Ill.

Those plants that are usually in more exposed situations than var. cylindrica and have narrower, oblong-lanceolate, thicker leaves with petioles mostly $2 \mathrm{~cm}$. or less long and harshly scabrous above and pubescent beneath are segregated as var. Drummondiana Wedd. (B. scabra Small). The leaves also are commonly recurved to give the plant a drooping appearance, and the fruiting spikes are more dense and thicker and the fruits larger than in var. cylindrica. 


\section{Urtica L. NetTle}

About 30 species of wide distribution, mostly in the North Temperate Zone.

1. Urtica dioica L. ssp. gracilis (Ait.) Seland. Fig. 396A.

Strongly rhizomatous typically monoecious perennial $1-3 \mathrm{~m}$. tall, from glabrous except for a few stinging hairs to strongly bristly and sericeous-pubescent; leaves (5-) 7-15 cm. long, the petiole from nearly one half as long as to scarcely one tenth as long as the blade; stipules prominent, mostly (5-) 10-15 mm. long; leaf blades from narrowly lanceolate and rounded or cuneate at base to broadly ovate and often cordate at base, coarsely serrate; pistillate flowers usually uppermost; perianth 1-2 mm. long, pubescent; achene flattened, about $1.5 \mathrm{~mm}$. long MaySept.

We have several varieties of this complex species that are distinguished in the following key.

1. Leaf blades usually ovate-lanceolate to ovate, the length rarely as much as 3 times the width; petioles mostly at least one third or rarely only one fourth as long as the blades; inflorescence not crowded, the floral leaves not greatly reduced and usually well-exceeding the panicle branches.......................................................var. gracilis.

1. Leaf blades narrowly to broadly lanceolate, usually at least 3 times as long as broad, acute to rounded at base; petioles short, rarely as much as one third as long as the blade; inflorescence crowded above, the upper leaves reduced and usually equal to or exceeded by some of the panicle branches (2)

2(1). Plants densely pubescent, the stems and leaves usually more or less cinereous...........................................................var. holosericea.

2. Plants much less strongly pubescent, the stems and leaves often essentially glabrous with only bristles on the stems (3)

3(2). Stems (at least near the base) usually bristly only, not otherwise hairy; leaves lightly hairy.................................................var. procera.

3. Stems usually moderately hairy as well as bristly; leaves rather strongly hairy var. angustifolia.

Var. gracilis. In thickets, springy places and along streams in the Plains Country and Trans-Pecos of Tex., through N.M. to Ariz.; from B.C. s. to Ariz., eastw. to the Atl. coast. U. gracilis Ait., U. viridis Rydb.

Var. holosericea (Nutt.) C. L. Hitchc. On banks of streams and ditches, in swamps and marshes, possibly in mts. of Ariz. but yet to be verified; mostly in s.w. U.S., n. to Wash. and Ida.

Var. procera (Muhl. ex Willd.) Wedd. In wet thickets, alluvial bottomlands along streams and floodplain areas in n.e. Okla. (Ottawa Co.), w. to N.M. and Ariz.; mainly e. U.S. and s. Can.

Var. angustifolia Schlecht. Low ground and stream banks, ditches and marshes, in mts. of the Tex. Trans-Pecos, through N.M. to Ariz.; also Colo., Calif. and adj. Mex. U. Serra Bl., U. Breweri Wats., U. gracilenta Greene.

\section{Pilea Lindl. Richweed. Clearweed}

About 400 species, mainly in the tropics.

1. Pilea pumila (L.) Gray. Fig. 397.

Low annual to $7 \mathrm{dm}$. high, usually much smaller, simple to bushy-branched, the bases of large plants decumbent, essentially glabrous throughout; leaves opposite, with petioles about one third as long as to longer than the blade, to $15 \mathrm{~cm}$. wide, lustrous, translucent, ovate, rounded to cuneate at base, with a conspicuous linear entire apex, with as many as 17 coarse rounded teeth on each 


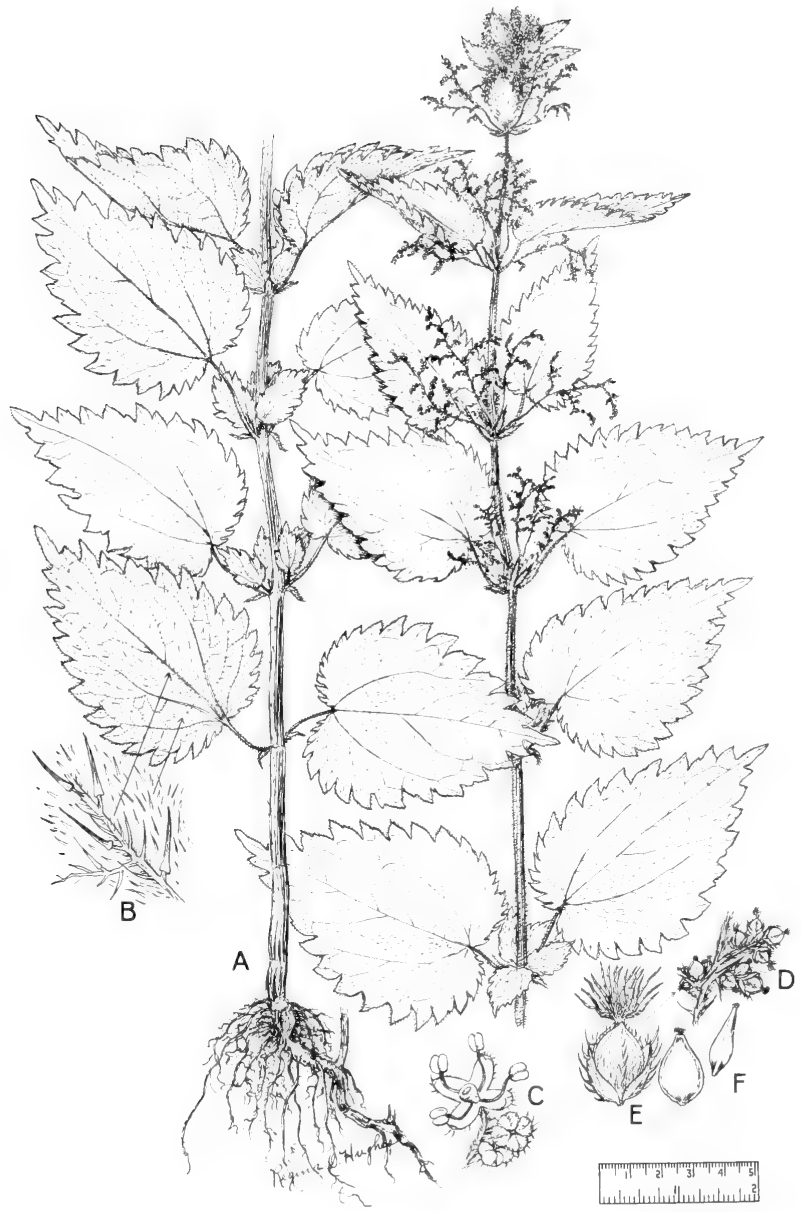

Fig. 396A: Urtica dioica: A, habit, x 1/2; B, stinging hairs, enlarged; C, flowers, closed and open, $x 71 \frac{1}{2} ; \mathrm{D}$, fruiting spike, $\mathrm{x} 11 \frac{1}{2} ; \mathrm{E}$, fruit, $\mathrm{x} 6 \frac{1}{2} ; \mathrm{F}$, achenes, face and edge views, x 71/2. (From Reed, Selected Weeds of the United States, Fig. 53). 


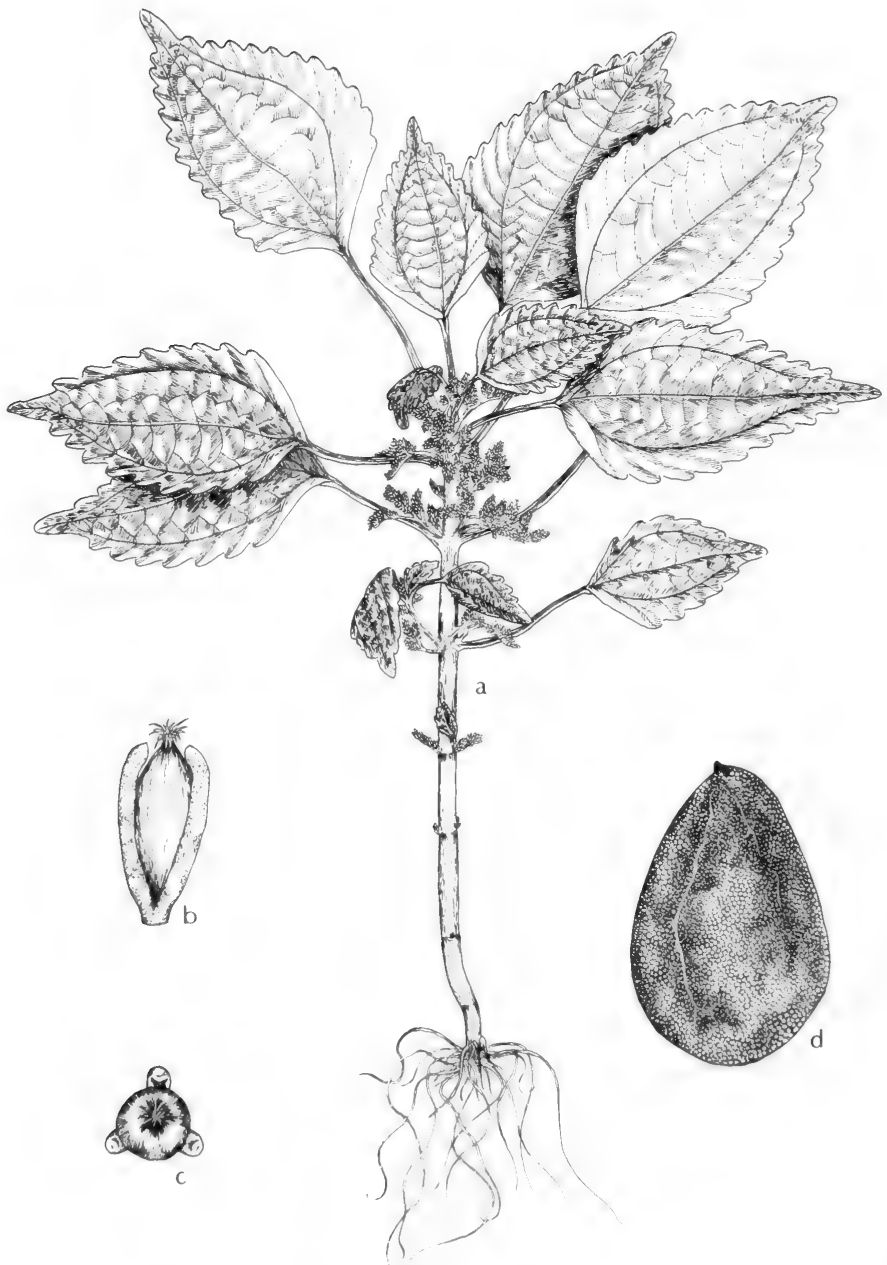

Fig. 397: Pilea pumila: a, habit, $\times 1 \frac{1}{2} ; \mathrm{b}$, pistillate flower from the side, $\mathrm{x} 50$; c, pistillate flower from the top, x 50; d, achene. x 35. (Courtesy of R. K. Godfrey). 
margin, when dried the surface covered with small whitish lines (cystoliths), the primary nerves rising from base and narrowly winged; flowers unisexual, green or whitish, in axillary cymes to $3 \mathrm{~cm}$. long; staminate flowers with 3 or 4 sepals and stamens, often mixed with the pistillate flowers; calyx of pistillate flowers deeply 3-parted, each of the unequal segments subtending a concave scalelike staminodium; ovary free, with a sessile stigma; fruit a compressed thin-walled achene that is subtended by the persistent calyx, ovate, pale green, smooth and unspotted or with purple markings, 1.3-2 mm. long. Adicea pumila (L.) Raf.

In moist or wet rich soils of woods, especially in seepage and along streams, in e. Okla. (Cherokee Co.) and e. Tex., June-Nov.; from e. Can and N.E., s. to Fla. and Tex., w. to S.D., Ia. and Kan.

Most of our material is referable to var. Deamii (Lunell) Fern. which is more southern in distribution than var. pumila, and has leaves more rounded at the base and with 11 to 17 teeth on each margin, whereas the largest leaves of var. pumila are mostly cuneate at the base and have only 3 to 11 teeth on each margin.

\section{Fam. 51. Polygonaceae Juss. Knotweed Family}

Caulescent or rarely acaulescent herbs or herbaceous vines; leaves alternate or rarely opposite or whorled, the blades entire or rarely lobed or toothed; petioles usually present; stipules (ocreae) present, usually sheathing the nodes, variously long-sheathing or short-sheathing or sometimes deeply or shallowly lobed and sometimes fringed, rarely seemingly absent (Eriogonum; Brunnichia); flowers small, hypogynous, perfect or unisexual, usually in racemes or in involucrate clusters, sometimes solitary at the nodes; perianth of 2 to 6 usually nearly entirely separate lobes, sometimes developing keeils or wings, often corolloid and whitish or pinkish; stamens 2 to 9, the filaments often dilated basally; anthers 2-celled, each cell with a longitudinal slit; ovary 1-celled, usually trigonous (3-carpellate) or less commonly lenticular (when one of the carpels is suppressed); styles 3 or 2, usually not much united; ovule solitary, orthotropous; endosperm horny or mealy, usually copious; fruit a trigonous or lenticular achene, usually falling still covered by the remains of the calyx and androecium.

A widely distributed family of about 35 conservative genera or upwards of 45 narrowly drawn ones. Some of the species are good honey plants. The Buckwheat, Fagopyrum sagittatum Gilib., is a member of this family; it does not do well in cultivation so far south as our region, but it has been grown in experimental plots.

1. Vines with tendrils; endosperm ruminate..................................... Brunnichia

1. Herbs or if viny then tendrils absent; endosperm not ruminate (2)

2(1). Leaf blades reniform; perianth 4-parted nearly to the base; pistil 2-carpellary, the ovary strongly compressed....................................2. Oxyria

2. Leaf blades never truly reniform, if cordate or hastate then the perianth 5- or 6-lobed or -parted or the pistil 3-carpellary (3)

3(2). Perianth segments usually 6 , noticeably disparate in size, the outer ones not enlarged, the 3 inner ones (valves) erect and greatly enlarged in fruit (1 or more often with a dorsal callous grain); stigmas peltate, tufted.

3. Rumex

3. Perianth segments usually 5 , not greatly disparate in size at fruiting time; stigmas not tufted. 4. Polygonum

\section{Brunnichia GaERTN. EARDROP VINe}

A monotypic North American genus.

1. Brunnichia ovata (Walt.) Shinners. Fig. 398.

Perennial vine; stems perennial at least in part, climbing by means of tendrils; 


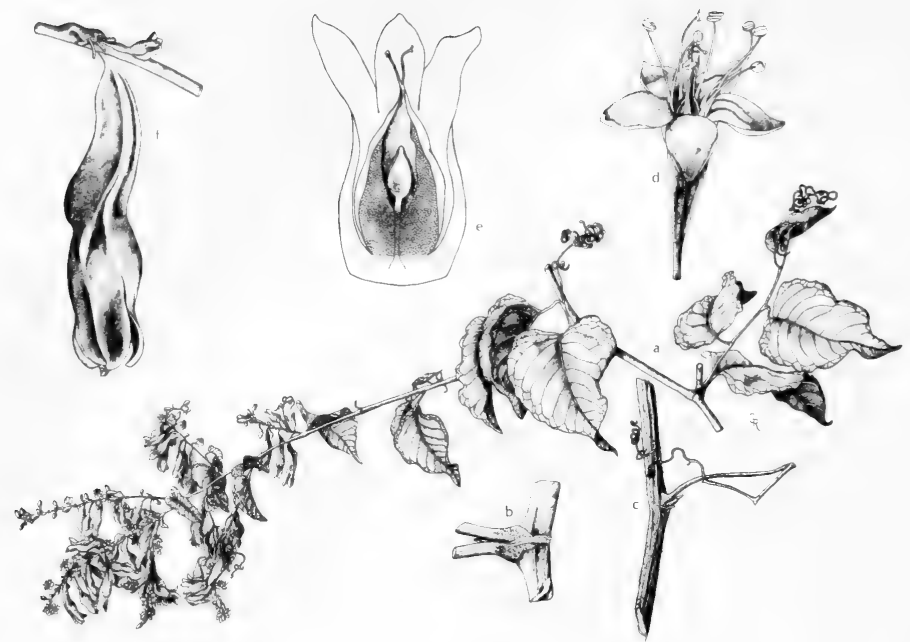

Fig. 398: Brunnichia ovata: a, portion of vine, $\mathrm{x} \mathrm{1/4;} \mathrm{b}$ and $\mathrm{c}$, portion of stem slightly enlarged to show vestiges of ocreae; d, flower, x 5; e, young fruit opened up, x 5; f, mature fruit, x 2. (Courtesy of R. K. Godfrey).

leaves alternate, entire, ovate or ovate-lanceolate, truncate or subcordate at base, acute to acuminate at apex, 3-15 cm. long; flowers in terminal panicled spikelike racemes, with perianth greenish or yellow-green; achene trigonous, about $6 \mathrm{~mm}$. long, closely invested by the accrescent and leathery somewhat winged hypanthium that becomes nearly $3 \mathrm{~cm}$. long. B. cirrhosa Gaertn.

Infrequent on edge of and in woods near streams, lakes and ponds in e. Tex. and s.e. Okla. (LeFlore and Choctaw cos.), spring-summer; Gulf States, n. to Mo., Tenn. and S.C.

There is some question regarding the name of this plant since the names "ovata" and "cirrhosa" were published within a few months of each other, and it is not certain which has priority.

\section{Oxyria Hill Mountain Sorrel}

A monotypic genus.

\section{Oxyria digyna (L.) Hill.}

Glabrous perennial herb, often reddish-tinged, from a fleshy taproot and branching crown, with strongly acrid juice; leaves chiefly basal, with a petiole to $8 \mathrm{~cm}$. long, reniform to cordate, $1-5 \mathrm{~cm}$. wide; stipules sheathing, membranous, brownish or reddish; flowering stems usually several, mostly $1-4 \mathrm{dm}$. tall, leafless or usually with a single leaf below the inflorescence; flowers perfect, in panicles $5-15 \mathrm{~cm}$. long, crowded, several in each ochreate bract, with a slender pedicel 1-3 mm. long; perianth about $1.5 \mathrm{~mm}$. long, 4-parted nearly to base, the 2 narrow segments 
strongly keeled and subtending the accrescent ovary, the other 2 erect, oblongobovate and plane; stamens 6 , the filaments shorter than the anthers; pistil 2carpellary, the ovary strongly compressed; styles 2 , short; stigma dilated, fimbriate; fruit lenticular, prominently winged, much compressed, oval, 4-6 mm. wide.

In seepage at timberline, commonly about boulders and on open wettish rockygravelly slopes, in N. M. (Colfax, Taos and Rio Arriba cos.) and Ariz. (Coconino Co.), June-Sept.; Greenl. to Alas., s. in mts. to N. H., N.M., Ariz. and Calif.; Euras.

\section{Rumex L. Dock}

Annual or perennial herbs; leaves alternate, flat, undulate or crisped, narrowed to cordate or auricled at base; ocreae thin, brittle, often brownish; flowers greenish, on pedicels that are jointed to and terminate short peduncles, in distant or approximate whorls disposed usually in elongate panicles; perianth lobes 6 , the inner 3 (valves) usually developing entire, toothed or spiny wings one or each of which usually bears a tuberclelike grain, in fruit the valves greatly increasing in size compared to their size at anthesis and erect and usually loosely coherent to the achene; the 3 outer sepals much smaller than the inner ones, usually lanceolate or subulate and slightly spreading or arcuate; stamens 6 ; ovary sessile; styles 3 , the stigmas peltate and tufted; achene trigonous.

About 200 species widespread in the world. The sap usually is quite acid and in some species has been used in tanning leather, especially the "canaigre," $\boldsymbol{R}$. hymenosepalus. The leaves of some species are cooked as greens.

Additional species in this wide-ranging, weedy genus should be found in our region. They are not an easy lot!

1. Flowers unisexual or polygamous; leaves usually hastately lobed (2)

1. Flowers usually bisexual; leaves never hastately lobed (3)

2(1). Valves (inner sepals) not larger than the achene; plant spreading by long slender rootstocks.

1. R. Acetosella.

2. Valves distinctly overtopping the achene; plants without slender rootstocks 2. R. hastatulus.

3(1). Stems erect, ascending or procumbent; axillary shoots present below inflorescence or rarely absent (doubtful cases should be keyed under both alternatives) (4)

3. Stems usually erect; axillary shoots absent (9)

4(3). Pedicels straight, conspicuously turned downward, (2) 2.5 to 5 times as long as the valves.

3. $R$, verticillatus.

4. Pedicels curved, at most twice as long as the valves (5)

5(4). Valves 7-8 mm. long, 8-12 mm. broad.

5. Valves much smaller (6)

4. $R$. spiralis.

6(5). Leaves ovate-lanceolate to elliptic-lanceolate, broadest below the middle; valves more than $4.5 \mathrm{~mm}$. long

5. $R$. altissimus.

6. Leaves usually narrower, lanceolate or linear-lanceolate, if exceptionally broad then the fruit much smaller (7)

7(6). Valves without grains

6. $R$. californicus.

7. One valve or all bearing grains (8)

8(7). Leaves small and thickish, in the dry state olive-green, often undulatecrisped, somewhat obtuse, with strongly prominent nerves beneath; panicles interrupted, most whorls remote.............7. $R$. chrysocarpus.

8. Leaves larger, rather thin, in the dry state pale-green, acute; nerves scarcely prominent; fruiting panicle not interrupted or only in the lower part

8. R. mexicanus. 
9(3). Valves without grains and as measured (including the basal lobes) altogether about $5 \mathrm{~mm}$. long and $5 \mathrm{~mm}$. broad, rarely more....9. $R$. occidentalis.

9. One or more of the valves bearing a grain dorsally (10)

10(9). Valves entire-margined to slightly erose (11)

10. Valves denticulate to setaceously toothed (12)

11(10). Leaves large, somewhat crisped or undulate, often narrowed at base, seldom truncate; valves (3.5-) 4-6 mm. long; only the lower whorls with bracteal leaves and occasionally remote...............10. $R$. crispus.

11. Leaves small, flat and truncate; valves very small, scarcely broader than the thick grains; whorls remote and nearly all with bracteal leaves........ 11. $R$. conglomeratus.

12(10). Plants glabrous throughout; leaves elliptic-lanceolate, with noticeably crenate-undulate margins; the 3 grains nearly equally developed 12. R. stenophyllus.

12. Plants with minute pubescence either on leaf stalks, lower surface of at least the lower leaves or on the stem; leaves plane, typically with smooth margins; the grains equally developed or not (13)

13(12). Perennials; basal leaves at most 2.5 times as long as broad, cordate at base; valves broadly ovate to triangular-ovate, 4-6 mm. long (14)

13. Annuals or biennials; basal leaves 3 or more times as long as broad; valves narrowly triangular-ovate, rarely to $3.5 \mathrm{~mm}$. long (15)

14(13). Leaves large; pedicels slender, nearly twice as long as the mature fruit; mature grain smooth or only lightly wrinkled.......13. R. obtusifolius.

14. Leaves small; pedicels stout, one fourth as long to nearly as long as the mature fruit; mature grain coarsely warty. 14. R. pulcher.

15(13). Pedicels stout, thickish; valves very shortly dentate; leaves obcordatelanceolate, mostly widest above the middle, about 3 times longer than broad.

15. $R$. violascens.

15. Pedicels long, slender; valves usually long-dentate; leaves linear-lanceolate, mostly many times longer than broad. 16. $R$. maritimus.

\section{Rumex Acetosella L. Sheep sorrel. Fig. 398A.}

Perennial with slender running rhizomes; stems numerous, slender, wiry, erect or decumbent at base, usually unbranched, 2-4 dm. tall, scabrous; leaves linear to lanceolate, $2.5-8 \mathrm{~cm}$. long, hastate, the basal lobes usually large, the petioles of lower leaves often longer than the blades; panicles many-branched, the glomerules without subtending leaves; flowers usually unisexual, occasionally polygamous, the pistillate flowers turning red in age; pedicels as long to twice as long as mature perianth, not articulated; valves entire, not enlarging in fruit, about $1 \mathrm{~mm}$. long, scarcely as long as the achene, lacking callous grains and without distinct nervation; achene about $1 \mathrm{~mm}$. long, almost as broad, the surface smooth and shiny, mahogany red. Acetosella acetosella (L.) Small.

Waste places, often in swampy areas, in wet mud about lakes and pools, along railroads and open fields, rare in e. Okla. (Waterfall), cen. Tex., N.M. (Lincoln Co.) and Ariz. (Coconino Co.), summer-fall; Euras. weed now widely adv.

The sour leaves, which can be used to quench thirst or prepare an acid beverage may be used similarly to water cress in salads and as a seasoning for various dishes, as well as for a potherb. Some individuals are known to have mild dermatitis from handling the plants while others may have hay fever from its profuse pollen.

Although several other species of Rumex have some value for wildlife, this species is by far the most important. Both its seeds and herbage are eaten by most kinds of wildlife. 


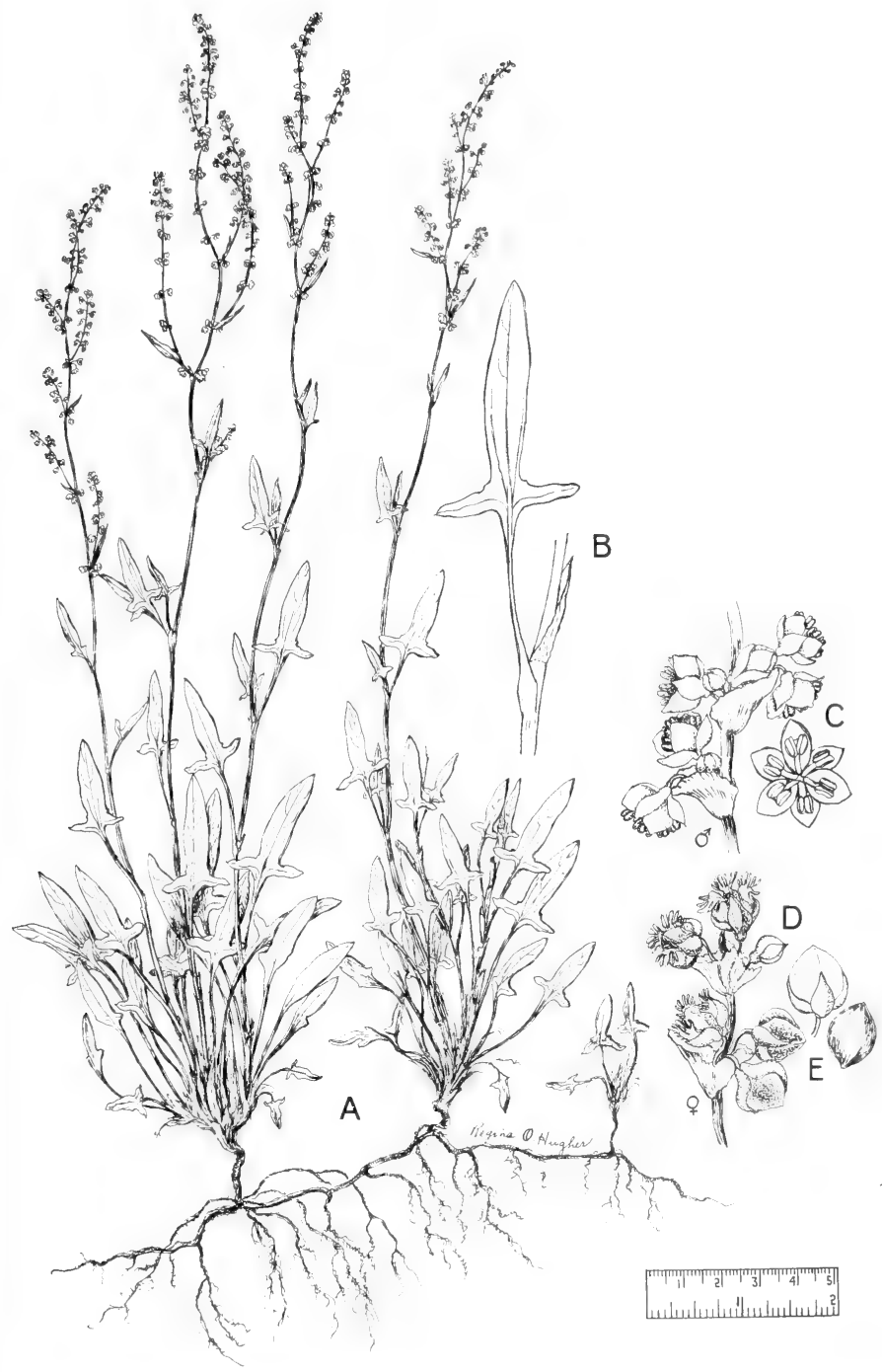

Fig. 398A: Rumex acetosella: A, habit, x 1/2; B, leaf detail, x 11/2; C, staminate flowers, $x 7 \frac{1}{2}$; D, pistillate flowers, $x 7 \frac{1}{2}$; E, achenes, in and out of calyx, $x 10$. (From Reed, Selected Weeds of the United States, Fig. 62.). 

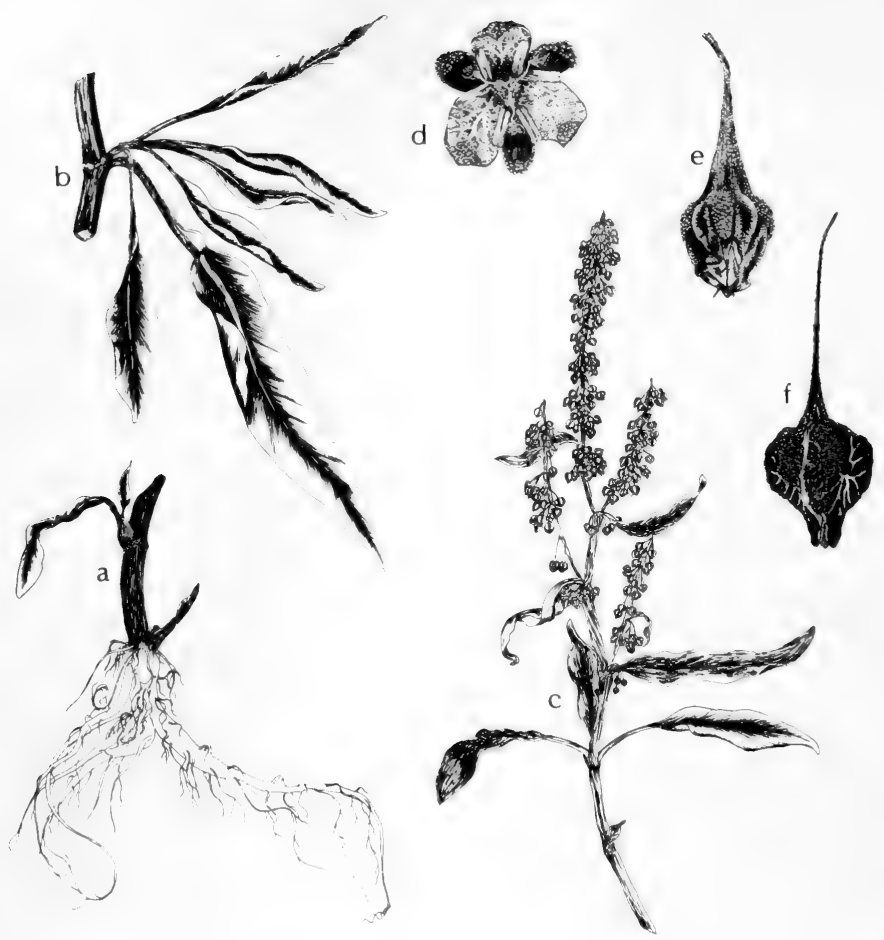

Fig. 399: Rumex verticillata: a, basal part of plant, $x 1 / 3 ; \mathrm{b}$, node, $\mathrm{x} 1 / 3 ; \mathrm{c}$, top of plant, $x 1 / 3$; d, flower, $x 4$; e, young fruit, $x 4$; , mature fruit, $x 4$. (Courtesy of $R$. K. Godfrey).

\section{Rumex hastatulus Ell. HeART SORREL.}

Perennial herb, $15-80 \mathrm{~cm}$. tall, slender, erect; leaves pale-green, often crowded near the base, the basal ones $2-10 \mathrm{~cm}$. long and $3-18 \mathrm{~mm}$. broad, lanceolate to oblong-linear or usually with hastate bladelike portion and a long narrow basal portion; inflorescence leafless, narrow; flowers unisexual; valves $2.5-3 \mathrm{~mm}$. long, 2.7-3.2 mm. broad, longer than the achene, without grains; achene $0.9-1 \mathrm{~mm}$. long, 0.6-0.7 mm. thick. $R$. Engelmannii Meisn.

Very abundant in open wet or dry sandy ground, in seepage along streams and in wet soils about lakes and ponds, in s.e. Okla. (Johnston, Pushmataha and McCurtain cos.), in e., s.e. and n.-cen. Tex. and N. M. (Sandoval and Taos cos.), spring; Gulf States, n. to N.C., Ill., Mo. and Okla., a waif even farther n.

The name, through error, has sometimes been spelled "hastulatus."

3. Rumex verticillatus L. SwAMP Dock. Fig. 399.

Perennial herb; stems erect, 4-10 dm. tall, slender, commonly purplish; basal 
leaves linear-lanceolate, 5 to 7 times as long as broad; cauline leaves narrowly linear-lanceolate, 6 to 9 times as long as broad; fruiting pedicels straight, conspicuously turned downward, (2) 2.5 to 5 times as long as the valves; valves at maturity 4-5 mm. long, 2.5-4 mm. broad, each dorsomedially with a pronounced grain.

Infrequent in low ground, often wet meadows, in water of ponds, swamps, marshes, and along edge of streams, in s.e. Okla. (McCurtain Co.), e. and s.e. Tex. and N. M. (Sandoval Co.), spring; s.e. Can. and e. U.S., w. to Mo., Ark., Okla., N.M. and Tex.

\section{Rumex spiralis Small.}

Perennial herb from creeping rootstocks; stems erect, usually purplish, to $1 \mathrm{~m}$. tall; leaves of lower part of stem ovate to oblong-lanceolate, $10-15 \mathrm{~cm}$. long, $35-55 \mathrm{~mm}$. broad, 2.5 to 5 times as long as broad; pedicels (2-) $3-5 \mathrm{~mm}$. long, even in fruit shorter than the valves; valves $7-8 \mathrm{~mm}$. long, $8-12 \mathrm{~mm}$. broad, somewhat cordate, each dorsomedially with a pronounced grain.

Local in poorly drained or seasonally moist calcareous clay soil, and on edge of lakes and ponds, in Tex. Rio Grande Plains, spring; endemic.

\section{Rumex altissimus Wood. PALE Dock.}

Perennial herb; stems erect or basally procumbent to $8 \mathrm{dm}$. tall; leaves of lower part of stem broadly ovate-lanceolate to oblong-lanceolate, $12-18 \mathrm{~cm}$. long, 40-55 mm. broad, 2.5 to 4 times as long as broad; leaves of upper part of stem smaller; inflorescences rather crowded; valves $4.5-6 \mathrm{~mm}$. long, 3-4 (-5) $\mathrm{mm}$. broad, each with or without a dorsomedial grain or 1 with and 2 without; achene about $3 \mathrm{~mm}$. long and $2 \mathrm{~mm}$. broad. $R$. ellipticus Greene.

Frequent in wet places such as marshes, shallow water of ponds, in wet meadows, wet sandy alkaline soils, along streams, rivers and ditches, in Okla. (Beaver, Johnston, Garvin, Cimarron, Payne and Cleveland cos.), in e. and n.-cen. Tex., the Plains Country and parts of Edwards Plateau, N. M. (De Baca, Grant, Chaves, Guadalupe and Taos cos.) and Ariz. (Coconino and Cochise cos.), springsummer; most of U.S. except Pac. States.

\section{Rumex californicus Rech. f.}

Perennial; stems many, finely sulcate-striate, ascending or suberect, 3-6 dm. tall, with many leafy branches arising below the middle of the plant in the axils of the leaves; leaves linear-lanceolate, the lower ones to $1 \mathrm{dm}$. long and $1.6 \mathrm{~cm}$. wide, the petiole about as long as the blade is wide; panicle large and open, the simple branches arcuately diverging from the stem or sometimes appressed, the lower glomerules remote, the upper ones nearly approximate or all of them approximate, contiguous in fruit; flowers prefect; pedicels articulate in their lower third or fourth; valves about $3 \mathrm{~mm}$. long and $2.5 \mathrm{~mm}$. wide, broadly triangular, acute, membranous, dark, irregularly and shallowly denticulate toward base, prominently reticulate-nerved with conspicuous midvein, without callous grains; achene dark-brown to black, about $2 \mathrm{~mm}$. long and $1.3 \mathrm{~mm}$. wide. (?) $R$. utahensis Rech. f.

In $\mathrm{mt}$. meadows and wet seepy soil along streams, in N. M. (DeBaca Co.) and Ariz. (Coconino, Pima and Yavapai cos.), summer-fall; also Calif.

\section{Rumex chrysocarpus Moris. Amamastla.}

Perennial herb from creeping rootstocks; stems erect or basally procumbent, usually only 4-6 dm. tall, often reddish; leaves linear-lanceolate to oblong-linear, $5-12 \mathrm{~cm}$. long, 3.5 to 5 times as long as broad, drying a rather dark olive-green; inflorescence usually interrupted, never leafy; valves dark-reddish-brown, tough 
and coarsely veined, $3.5-4.5 \mathrm{~mm}$. long, 3-4 $\mathrm{mm}$. broad, triangular to rotundtriangular, each one dorsomedially with a pronounced grain; infructescence often crowded; achene $2.5-3 \mathrm{~mm}$. long, $1.5-2 \mathrm{~mm}$. broad. $R$. Berlandieri Meisn., $R$. Langloisii Small.

Abundant in low seasonally wet places, s.e. Tex. and Rio Grande Plains, less frequent n. to n.-cen. Tex., Edwards Plateau and the Trans-Pecos, spring-summer; La., Tex., Tam., Ver. and Michoac.

\section{Rumex mexicanus Meisn.}

Very similar to $R$. chrysocarpus but the inflorescences and infructescences more crowded; leaves larger, thinner and much paler green and more acute; valves 2-5 mm long; achene only about $2 \mathrm{~mm}$. long. $R$. triangulivalvis (Danser) Rech. f.

Meadows and marsh areas, boggy soils, about playa lakes, ponds and in seepage along streams, infrequent in El Paso Co., Tex., through N.M. (Dona Ana, Union, San Miguel, Santa Fe, Taos and Rio Arriba cos.) to Ariz. (Coconino and Navajo cos.), spring-summer; Que. to B.C., s. to Mo., w. Tex., N.M., Ariz., Calif. and Mex.

\section{Rumex occidentalis Wats. WESTERN DOCK.}

Perennial from a stout taproot; stems usually simple, stout, erect, striated, glabrous, 4-20 dm. tall, reddish or suffused with purple; petioles of lower leaves from one third to nearly as long as the blade is wide, the blades from oblongtriangular to ovate-triangular, $15-40 \mathrm{~cm}$. long, 2 to 2.5 times as long as wide, somewhat crisped on margins, cordate or subcordate at base, obtuse to acute at apex; panicles dense, strict, smooth or puberulent, 3-6 dm. long, leafless or with only a few small leaves below; pedicels 1 to 2 times as long as mature perianth, obscurely articulate toward base; flowers perfect; valves round-ovate, 4-5 mm. long and 5-6 mm. wide, rarely more, prominently reticulate-veined, subcordate, the margins erose or denticulate, without callous grains (or rarely with one); achene brown, smooth, shining, 2.5-3 mm. long, $1.5 \mathrm{~mm}$. wide, acuminate at both ends, slightly more so at apex.

Bogs and marshes near fresh or brackish water, swamps, wet meadows and water about lakes, pools and along streams, in N.M. (Socorro, Rio Arriba, Taos and Catron cos.), June-Sept.; Que. to Yuk. and B.C., s. to N.M., Ariz. and Calif.

\section{Rumex crispus L. Yellow dock, sour dock, CURly dock. Fig. 400.}

Coarse perennial; stems stout, erect, straight, without axillary branches, 5-15 $\mathrm{dm}$. tall, from a deep taproot, glabrous, dark-bluish-green; lower leaves elliptical to oblong-lanceolate, 1-3 dm. long, prominently undulate and crisped on margin, cuneate at base, long-petioled, the upper smaller leaves all cordate or obtuse at base; panicles usually strict, of elongate wandlike branches with few leaves, the whorls usually dense and approximate; pedicels 1.5 to 2 times as long as the mature perianth, articulate below middle; flowers perfect; valves about $5 \mathrm{~mm}$. long and 3-4 $\mathrm{mm}$. wide, round-ovate, subcordate, the margin entire to scarcely erose, all valves with a smooth oblong dorsomedial callous grain much narrower than perianth margin, occasionally 1 or 2 valves naked; achene smooth, glossy reddish-brown, acute, $2 \mathrm{~mm}$. long.

In shallow water of streams, about ponds and lakes and marshy areas, commonly in seasonally wet places, in Okla. (Comanche, Cimarron, Murray, McCurtain and Bryan cos.), n.-cen., e. and s.e. Tex. and on the Edwards Plateau and in the Trans-Pecos, N.M. (widespread) and Ariz. (Navajo, Coconino, Mohave, Yavapai, Maricopa, Cochise, Pinal, Gila and Santa Cruz cos.), Apr.-Sept.; a Euras. weed, now widely adv. in temp. areas. 


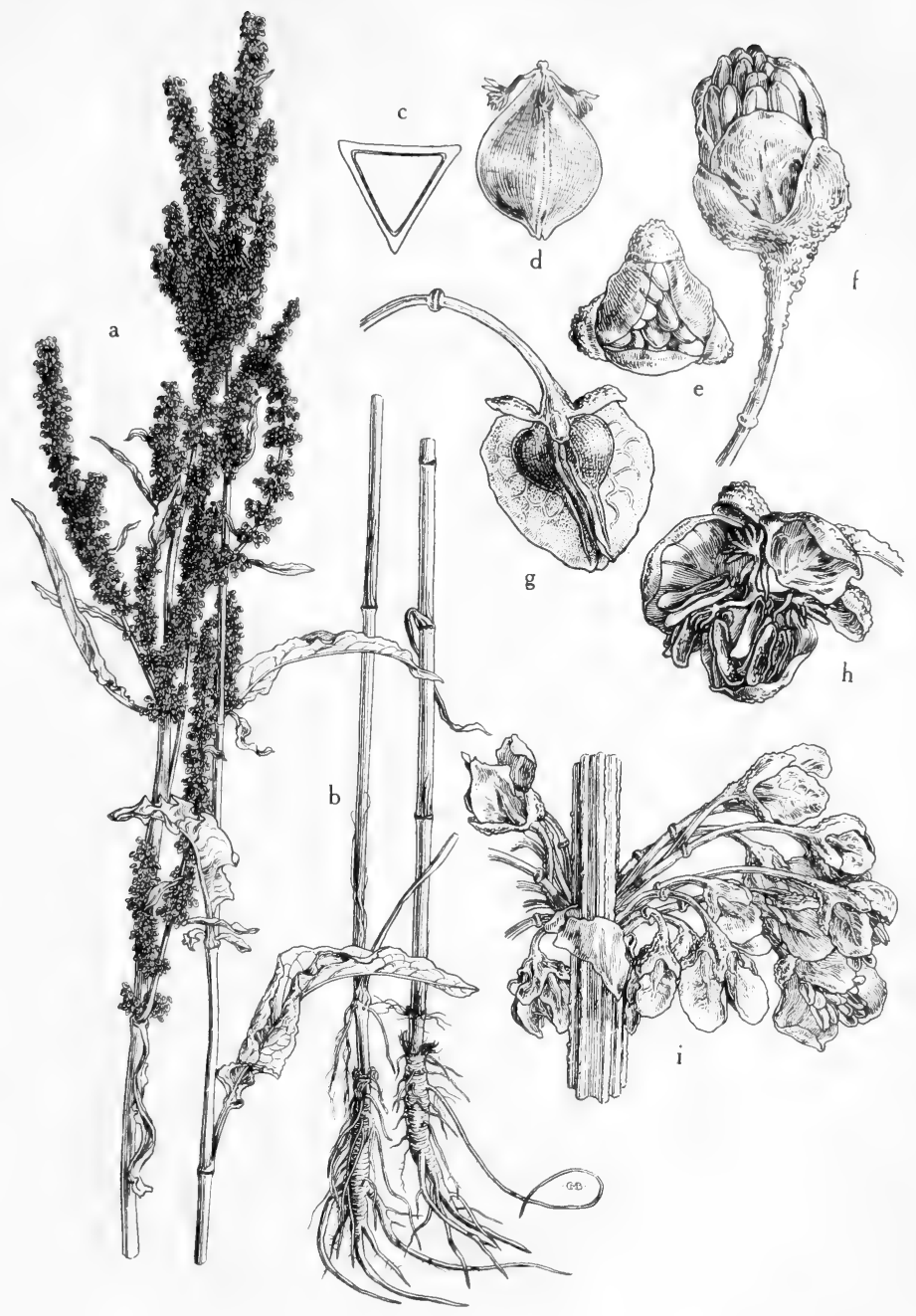

Fig. 400: Rumex crispus: a, habit, upper part of plant, showing the undulate leaves and the wandlike panicle branches, $x 1 / ;$, b habit, lower part of stem and the deep taproots, $\mathrm{x} 1 / 5 ; \mathrm{c}$, achene (cross section), x 8; d, mature achene, showing the reflexed styles with tufted stigmas, $\mathrm{x} 8$; e, young flower, top view, x 8; f, young flower, showing inner and outer perianth segments, $x$ 8; $g$, mature fruit, the achene enclosed by inner perianth segments which bear smooth callous grains, $\mathrm{x} 4$; $\mathrm{h}$, flower, showing tufted stigmas and anthers after dehiscence, $x 8$; $i$, whorl of flowers, showing the sheathing stipules (in older plants only long fibers remain), x 3. (From Mason, Fig. 211). 


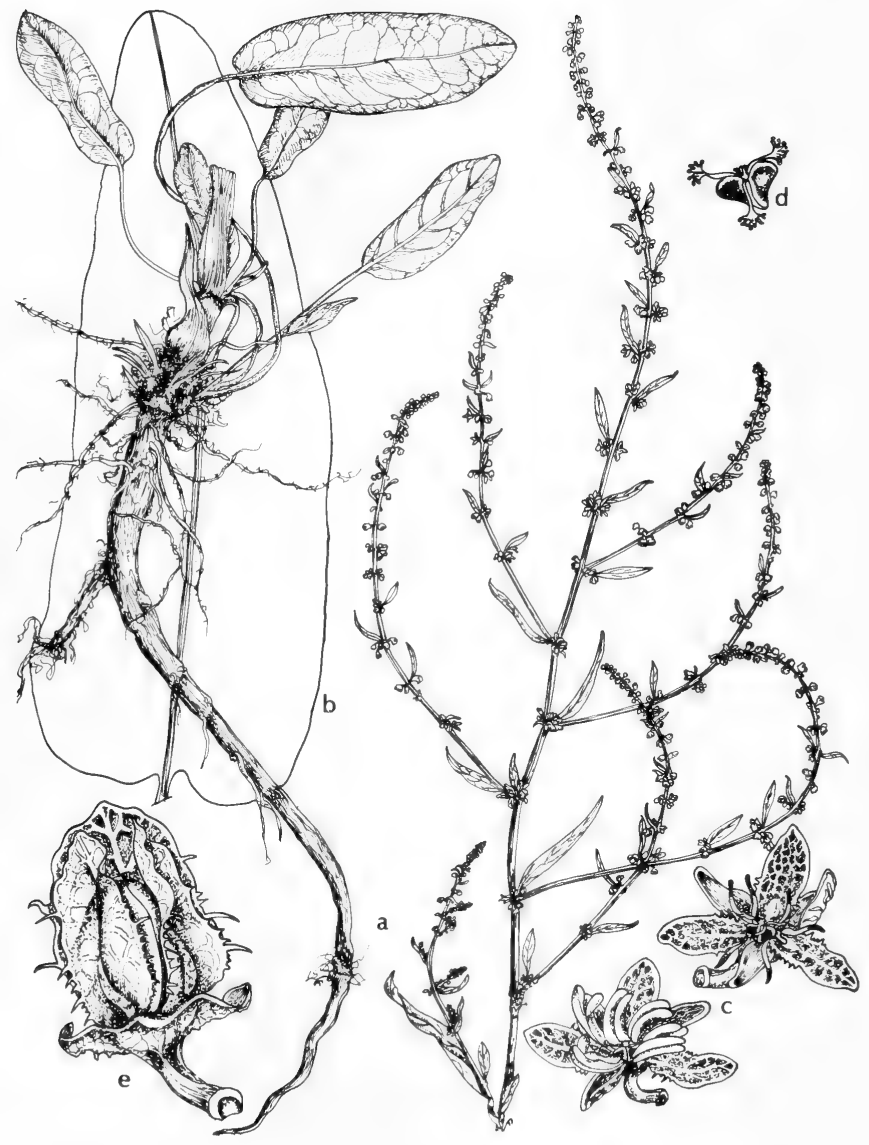

Fig. 401: Rumex pulcher: a, basal and upper part of plant $\times 1 / 2 ; b$, outline of leaf from center portion of plant, $\mathrm{x} 1 / 2$; c, two flowers, $\mathrm{x} 8$; d, ovary, $\mathrm{x} 10$, e, fruit, $\mathrm{x} 10$. (V. F.). 
The plant may cause dermatitis similar to that caused by poison ivy when handled by some individuals. At one time the root was used as medicine under the name "yellow dock."

\section{Rumex conglomeratus Murr.}

Rather similar to $\boldsymbol{R}$. crispus; lower leaves cordate at base, flat; branches of the panicle divergent, whorls of inflorescence each with a bracteal leaf, remote; pedicels usually not longer than the fruit; valves entire-margined, $2.5-3 \mathrm{~mm}$. long, each with a large grain dorsally.

Floodplain woods, ditches, stream banks and in wet sandy spots, rare in e. Tex. and perhaps elsewhere, and Ariz. (Maricopa, Santa Cruz and Pinal cos.), spring; nat. of Eur., now widely adv.

\section{Rumex stenophyllus Ledeb.}

Perennial; stems erect or ascending, 6-12 dm. tall, branching from the base; leaves petioled, papery, light-green, glabrous and smooth; lower leaves broadly linear-lanceolate, flat and marginally crisped, 3-4 dm. long, 4-10 cm. wide, narrowed at both ends, the cauline leaves and those subtending branches of the inflorescence similar to basal leaves but smaller; flowers in approximate glomerules on branches of a panicle; pedicels 4-7 mm. long, articulate at or below the middle; valves broadly triangular with a truncate base, narrowly obtuse to acute at apex, the margins spinose-dentate, all the valves with a similar prominent callous grain; achene nut-brown, about $2.5 \mathrm{~mm}$. long. $R$. alluvius Gates \& McGregor.

In marshy areas about lakes and in alluvial soils along streams, Okla. (Alfalfa Co.), May-Aug.; Man., s. to Mo. and Okla.; nat. of Euras.

As Steyermark has noted, plants of this species resemble a hybrid between $\boldsymbol{R}$. crispus and $\boldsymbol{R}$. obtusifolius. The fully developed grain on each of the 3 toothed valves, however, readily separate it from the above species.

\section{Rumex obtusifolius L. BITTER DOCK.}

Perennial; stems from a stout taproot, simple or sparingly branched at base, tall, slender, 6-12 dm. tall; lower leaves ovate-oblong to broadly oblong-lanceolate, 10-35 mm. long, somewhat undulate, margins slightly crisped, usually deeply cordate at base, somewhat papillate on lower surface, glabrous, dark green, on long petioles; panicle strict, leafless or with a few leaves at base, open, the glomerules not crowded, the lower ones remote; pedicels slender, 1 to 2.5 times as long as the mature perianth, articulate near base; flowers perfect; valves deltoidovate, 4-6 mm, long, with 3 or 4 pronounced spinose or subulate teeth on each margin, 1 valve with a small callous grain, sometimes the other 2 with very small grains; achene $2 \mathrm{~mm}$. long, reddish-brown, shining.

Wet grounds and springy stream banks, marshy areas and floodplains, in Okla. (Cherokee, Pottawattomie and Kiowa cos.), the Tex Panhandle (Castro, Hale and Randall cos.), N. M. (Sierra, Valencia and Union cos.) and Ariz. (Cochise and Pima cos.), spring-summer; nat. of Eur., now widely distributed.

\section{Rumex pulcher L. FIDDLE Dock. Fig. 401.}

Perennial herb; stems erect, 5-8 dm. tall; lower leaves small, long-petioled, 3-15 cm. long, cordate at base, somewhat crisp marginally, often pubescent beneath; branches of the panicle very divergent, often intricately enmeshed at fruiting time; some of the whorls with bracteal leaves, all remote; pedicels thick, not longer than the fruit, jointed in the middle; valves denticulate-margined, 3-6 $\mathrm{mm}$. long, $2.5-4.5 \mathrm{~mm}$. broad, usually all dorsomedially with a grain but the grains of disparate size even in the same flower; achenes $3-4 \mathrm{~mm}$. long. 


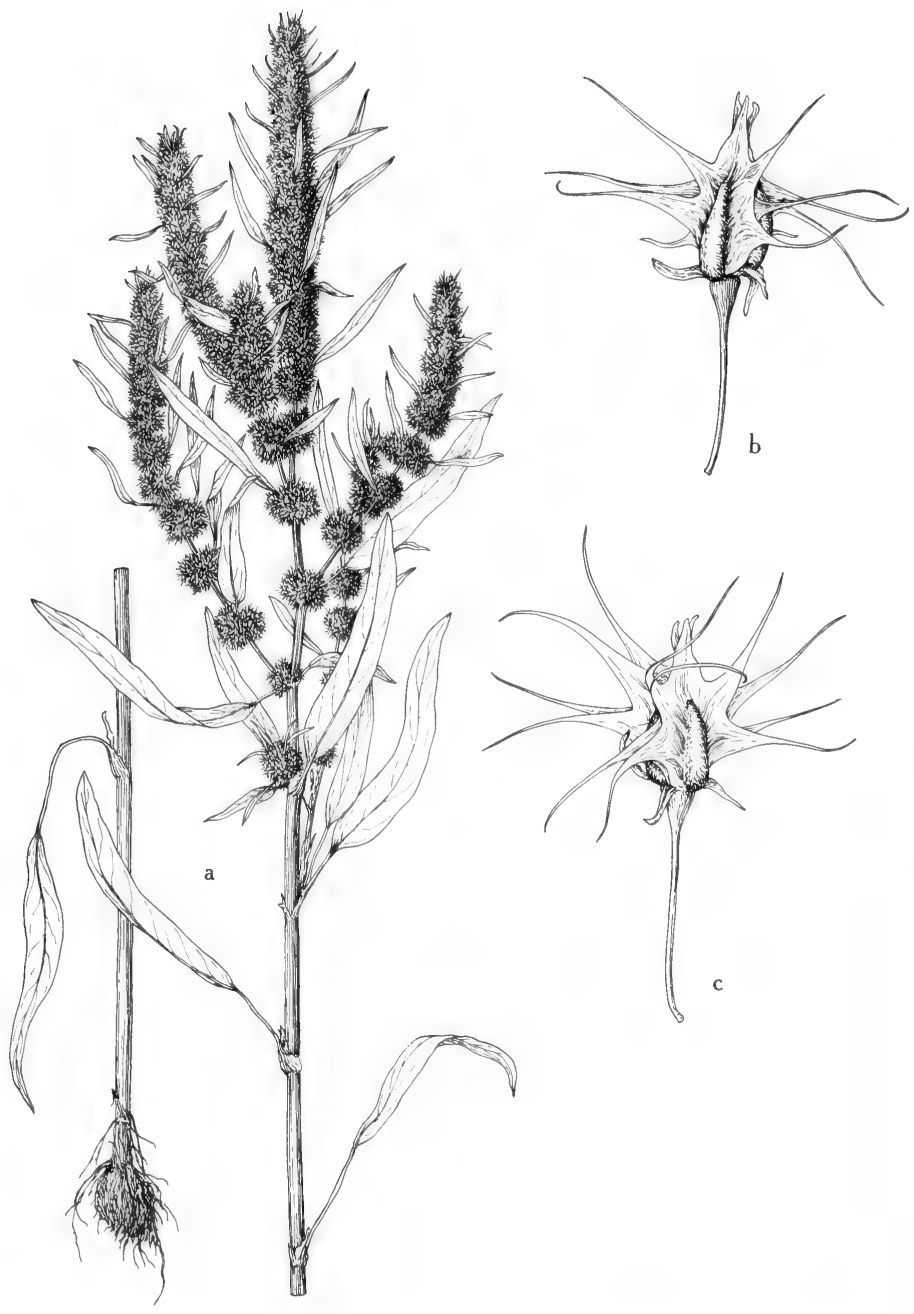

Fig. 402: Rumex maritimus: a, habit, $\mathrm{x} 2 / 5 ; \mathrm{b}$ and $\mathrm{c}$, flowers in fruit, showing the inner perianth segments with slender teeth and long narrow callous grains, $x$ 8. (From Mason, Fig. 212.). 
In mud at edge of lakes and ponds, bogs and muddy areas, most frequent in seasonally moist usually disturbed ground in e. Okla. (Bryan and McCurtain cos.) and widespread in e. half of Tex., spring; Medit. region, now widely adv. in warm-temp. regions.

\section{Rumex violascens Rech. f.}

Annual or biennial or perhaps perennial at times; stems stoutish, to $8 \mathrm{dm}$. tall, often in the upper part more or less fractiflex; basal leaves 3 times as long as broad, oblanceolate to elongate-obovate, the stem leaves smaller and proportionately narrower and longer; valves $2.5-3 \mathrm{~mm}$. long, 2-3 mm. broad, marginally denticulate and each dorsomedially with a grain but the grains often disparate in size in the same flower; achenes $1.7 \mathrm{~mm}$. long.

Low wettish lands and ditch banks, locally frequent near El Paso (El Paso Co.) in the Tex. Trans-Pecos, N.M. (Dona Ana and San Juan cos.) and Ariz. (Mohave and Gila to Pima and Yuma cos.), spring; Tex., N.M., Ariz., Calif., Son. and Coah.

\section{Rumex maritimus L. Golden docK. Fig. 402.}

Annual or occasionally biennial; stems erect or ascending, 1.5-6 dm. tall, usually strict, slender or stout, more or less striate, papillose-scabrous, glabrescent or glabrous, becoming brownish or sometimes purplish; lower leaves membranous or subcoriaceous, the margin more or less undulate-crisped, glabrous and smooth or scabrous-pubescent, linear-lanceolate, the blade 5 to 7 times as long as wide, more or less cordate or truncate at base and widened above base, the apex acute; petiole shorter than blade; upper leaves progressively smaller, narrower; panicle broad, the glomerules many-flowered, contiguous and compact above, remote below and often extending to near base of plant, leafy-bracted; pedicels slender, articulate near base, 1 to 2 times as long as mature perianth; flowers perfect; valves triangular, 1.7-2 mm. long, 0.7-0.9 mm. wide exclusive of the teeth, subcoriaceous, the apex ligulate, acute, the margins each with 2 (or 3) divergent setaceoussubulate teeth, each valve with a callous grain, these fusiform, cellular-punctate, prominent, about $1-1.4 \mathrm{~mm}$. long, $0.5-0.7 \mathrm{~mm}$. wide, the apex obtuse, narrowing into midrib; achene brown, $1.3-1.4 \mathrm{~mm}$. long, $0.5-0.7 \mathrm{~mm}$. wide, the ends usually subequally acuminate. Incl. var. fueginus (Phil.) Dusén, $R$. fueginus Phil.

Lake margins, marshy ground, in shallow water and on sandy-gravel bars along streams and about lakes and ponds, rare in the Tex. Panhandle (Randall Co.), N.M. (Colfax, Catron, Taos, Rio Arriba and San Juan cos.) and Ariz. (Apache Co.); June-Sept.; also widely distributed in Eur. and s. S.A.

A plant found on mud about Morgan Lake, San Juan County, New Mexico, that has been referred here, is possibly an undescribed species closely allied to $R$. maritimus.

\section{Polygonum L. Smartweed. Knotweed}

Aquatic, terrestrial or amphibious annual or perennial herbs, sometimes viny but without tendrils; leaves alternate, entire, with scarious sheathing (stipular sheath) often conspicuously venose stipules (ocreae); flowers on jointed pedicels clustered in the axils of leaves or bracts or more often in terminal spikelike racemes which may be solitary and terminal, in pairs or in groups of 1 to 9 at the ends of branches, or occasionally reduced in the axils of leaves; perianth 4- to 6-merous, essentially distinct or united below, pink, green or white, the essentially equal lobes erect in fruit, often closely investing the achene, usually with an evident glandular disk lining the lower part (this frequently not evident in dried material); stamens 3 to 9 , often unequally inserted, some in the sinuses of the lobes, others below on the tube or occasionally some on the margin of the gland; anthers small, linear, 
sometimes highly colored; ovary superior; style 2- or 3-cleft or -parted; stigmas capitate; achene trigonous or lenticular, 1-celled, sometimes both kinds on the same plant, light-tan through reddish-brown to black.

A cosmopolitan genus of about 320 species. Persicaria Mill.

The seeds of these species are eaten by many kinds of songbirds, upland game birds, waterfowl, marsh birds, shorebirds and small mammals. The plants are often eaten by browsers. It has been noted that where these plants are in abundance about the borders of an aquatic area the region is apt to be popular with waterfowl.

1. Flowers in terminal spikelike or narrowly racemelike inflorescences; blades never jointed to petioles; styles never indurate and persistent or if so less than $0.5 \mathrm{~mm}$ long; plants often aquatic or semiaquatic, never vinelike (12)

1. Flowers not in terminal spikelike or racemelike inflorescences, or if so then a joint (zone of abscission) present between blade and petiole or else the plants vinelike (2)

2(1). Leaf blade jointed or articulated to petiole (6)

2. Leaf blade not jointed to petiole (3)

3(2). Plants with erect or ascending stems, not at all vinelike; styles persistent, deflexed, hook- or hornlike, rigid, about $3 \mathrm{~mm}$. long.

1. P. virginianum.

3. Plants vinelike or with long weak reclining stems; styles not rigid, persistent and elongate (4)

4(3). Stems 4-angled, weak and reclining, not twining.

2. P. sagittatum.

4. Stems twining (5)

5(4). Perianth after anthesis becoming about $3.5 \mathrm{~mm}$. long, closely investing the achene, the 3 outer sepals minutely keeled but never winged.

3. $P$ Convolvulus.

5. Perianth after anthesis eventually about $6 \mathrm{~mm}$. long, the outer 3 sepals with dorsomedial wings $0.25-1 \mathrm{~mm}$. broad

4. P. cristatum.

6(2). Flowers crowded toward the ends of the branches (appearing to be terminal spikes) or else solitary or in 2's or 3's in the upper nodes (7)

6. Flowers in axillary clusters along the stem (10)

7(6). Strong perennial, often rhizomatous; flowers solitary or in 2's or 3's at the upper nodes....................................................5. P. texense.

7. Taprooted annual with the ends of the branches appearing to be terminal spikes (8)

8(7). Stems slender usually less than $1.5 \mathrm{dm}$. tall; flowers in leafy-bracted spike; anther-bearing stamens 3 (9)

8. Stems stout, with ascending branches, striate; upper leaves reduced to inconspicuous bracts; perianth lobes usually 6 ; stamens 6 to 8 ....

6. P. argyrocoleon.

9(8). Floral bracts mostly plainly white-margined, the upper ones often no longer than the flowers.................................... 7. P. confertiflorum.

9. Floral bracts only slightly or not white-margined, the upper ones usually exceeding the flowers...............................................8. P. Kelloggii.

10(6). Stems usually decumbent or prostrate, upper leaves not greatly reduced; achenes usually brown, dull and striated or roughened.

.9. P. aviculare.

10. Stems usually erect or ascending; achenes dark-brown or black (11) 
11(10). Pedicels mostly deflexed or recurved; perianth $3-4 \mathrm{~mm}$. long, the lobes 5 10. P. Douglasii.

11. Pedicels mostly erect; perianth less than $3 \mathrm{~mm}$. long, the lobes usually 6 . 11. $P$. ramosissimum.

12(1). Basal leaves well-developed; stem simple; rootstock often thickened and bulblike (13)

12. Basal leaves (if any) soon withering; stem often branched; rootstock not bulblike (14)

13(12). Inflorescences usually less than $1 \mathrm{~cm}$. wide, the lower flowers bearing bulblets.

12. $P$. viviparum.

13. Inflorescences usually more than $1 \mathrm{~cm}$. wide, with no bulblets.

13. P. bistortoides.

14(12). Ocreae (sheath around the stem) with marginal cilia less than $1 \mathrm{~mm}$. long (15)

14. Ocreae with marginal cilia $1.5 \mathrm{~mm}$. long or more (21)

15(14). Peduncles with numerous stalked glands (16)

15. Peduncles without stalked glands (sessile glands may occur) (18)

16(15). Styles and stamens of the same length (or nearly so), not exserted from perianth; achene lenticular, flat or nearly so on both surfaces; flowers white to pink; annual..........................14. P. pensylvanica.

16. Styles or stamens exserted; achene lenticular and with at least one side convex or ridged (17)

17(16). Inflorescences often solitary, all terminal or nearly so; flowers bright pink; plants aquatic or semiaquatic; perianth in fruit more than $4 \mathrm{~mm}$. long.................................................15. P. amphibium.

17. Inflorescences numerous, lateral and terminal; flowers white or light-pink; perianth in fruit usually less than $4 \mathrm{~mm}$. long; stems usually cherryred at the nodes..................................................16. P. bicorne.

18(15). Inflorescences usually nodding; perianth with prominent anchor-shaped veins near apex; achenes lenticular, flat, about $2 \mathrm{~mm}$. long.

17. P. lapathifolium.

18. Inflorescences erect; perianth without anchor-shaped veins; achene biconvex, oval in cross section (19)

19(18). Leaf blades less than 2 times as long as wide, long-petioled (usually 25 $\mathrm{mm}$. long or more); mature ocreae short, about as wide as high; petioles, stems and peduncles copiously pubescent with strigose hairs; perianth $3.3 \mathrm{~mm}$. long or more, pink to pinkish-red.

18. $P$. orientale.

19. Leaf blades more than 2.5 times as long as wide, short-petioled (less than 20 $\mathrm{mm}$. long); mature ocreae at least 1.5 times longer than broad; petioles, stems and peduncles glabrous or pubescent; perianth $2-4.5$ $\mathrm{mm}$. long, white or pinkish-red (20)

20(19). Peduncles and ocreolae strigose or stipitate-glandular; stamens or styles strongly exserted from the flowers; perianth in fruit $4 \mathrm{~mm}$. long or more, pinkish-red; inflorescences 1 or 2 , terminal..15. P. amphibium.

20. Peduncles and ocreolae not strigose nor stipitate-glandular (glands, if present, sessile); stamens and styles mostly included; perianth in fruit less than $3.5 \mathrm{~mm}$. long, white or pinkish-white; inflorescences numerous, terminal and lateral. 19. $P$. densiflorum.

21(14). Leaf blades less than twice as long as wide; petioles usually $25 \mathrm{~mm}$. or more long; mature ocreae short, about as wide as high; petioles, stems and peduncles copiously pubescent with strigose hairs; flowers pinkish-red................................................18. P. orientale. 
21. Leaf blades at least 2.5 times as long as wide; petioles usuaily less than 20 $\mathrm{mm}$. long; mature ocreae at least 1.5 times as long as broad (22)

22(21). Perianth glandular (23)

22. Perianth without glands (25)

23(22). Achenes biconvex, oval in cross section; styles 2 ; stems stout, usually over $7 \mathrm{~mm}$. in diameter at base.......................19. P. densiflorum.

23. Achenes mostly trigonous, triangular in cross section; styles 3; stems less than $6 \mathrm{~mm}$. in diameter at base (24)

24(23). Achenes black, lustrous, smooth; young flower buds white or greentipped; inflorescence erect..................................20.P. punctatum.

24. Achenes black, dull, minutely pitted; young buds pinkish; inflorescence usually nodding. 21. P. Hydropiper.

25(22). Achenes trigonous; styles 3 (26)

25. Achenes lenticular; styles 2 (27)

26(25). Inflorescences usually less than $4 \mathrm{~cm}$. long, mostly rounded at the apex; marginal cilia of ocreae usually less than $3 \mathrm{~mm}$. long; achene ovoid, longer than wide, lenticular or trigonous..............22. P. Persicaria.

26. Inflorescences usually more than $4 \mathrm{~cm}$. long, tapering to the apex; marginal cilia of ocreae usually $3 \mathrm{~mm}$. long or more; achenes trigonous, about as wide as long...............................23. P. hydropiperoides.

27(25). Inflorescences usually less than $4 \mathrm{~cm}$. long, mostly rounded at the apex; marginal cilia of ocreae usually less than $3 \mathrm{~mm}$. long; achene lenticular or trigonous; annual............................22. P. Persicaria.

27. Inflorescences usually more than $4 \mathrm{~cm}$. long, tapering to the apex; marginal cilia of the ocreae usually $3 \mathrm{~mm}$. long or more; perennial (28)

28(27). Peduncles and ocreolae strigose or stipitate-glandular; stamens or styles strongly exserted from the flowers; perianth in fruit $4 \mathrm{~mm}$. long or more, pinkish-red; inflorescence terminal..........15. P. amphibium.

28. Peduncles and ocreolae not strigose nor stipitate-glandular (glands, if present, sessile); stamens and styles mostly included; perianth in fruit less than $3.5 \mathrm{~mm}$. long, white or pinkish-white; inflorescences numerous, terminal and lateral. 19. P. densiflorum.

1. Polygonum virginianum L. JUMP SEED. Fig. 403.

Annual herb; stems erect or reclining, 3-15 dm. tall; ocreae marginally truncate and ciliate; leaf blades ovate to elliptic-ovate or ovate-lanceolate, 3-16 cm. long, acute; flowers in long terminal very loose and interrupted wandlike or spikelike aggregations; pedicels about $3 \mathrm{~mm}$. long; calyx greenish-white, about $4 \mathrm{~mm}$. long, 4-parted to near the middle; achene lenticular, strongly biconvex, $3.5-4 \mathrm{~mm}$. long, ovoid-oblong, topped by the 2 persistent deflexed and hooked (hornlike) rather rigid styles about $4 \mathrm{~mm}$. long. Antenoron virginianum (L.) Roberty \& Vautier, Tovara virginiana (L.) Raf.

In water or in seepage along streams and about lakes, in low rich woodlands, in e., s.e. and n.-cen. Tex. and Okla. (Ottawa, Muskogee, Pittsburg, Kay, Cherokee and Choctaw cos.), June-Oct.; Que., Ont. and most of e. U.S.; also Pue. and Hgo.

\section{Polygonum sagittatum L. Tearthumb, arrow-vine. Fig. 404.}

Basally stoloniferous or subrhizomatous, probably perennial; stems ascending, thin, weak and reclining or scandent, to $2 \mathrm{~m}$. long, 4-angled and finely channeled, armed on the angles with minute recurved prickles; leaf blades lanceolate or broadly so, 1-12 cm. long, sagittate-cordate basally, apically acute; petioles long in lower leaves, short in upper ones; inflorescences terminal and axillary (a very 


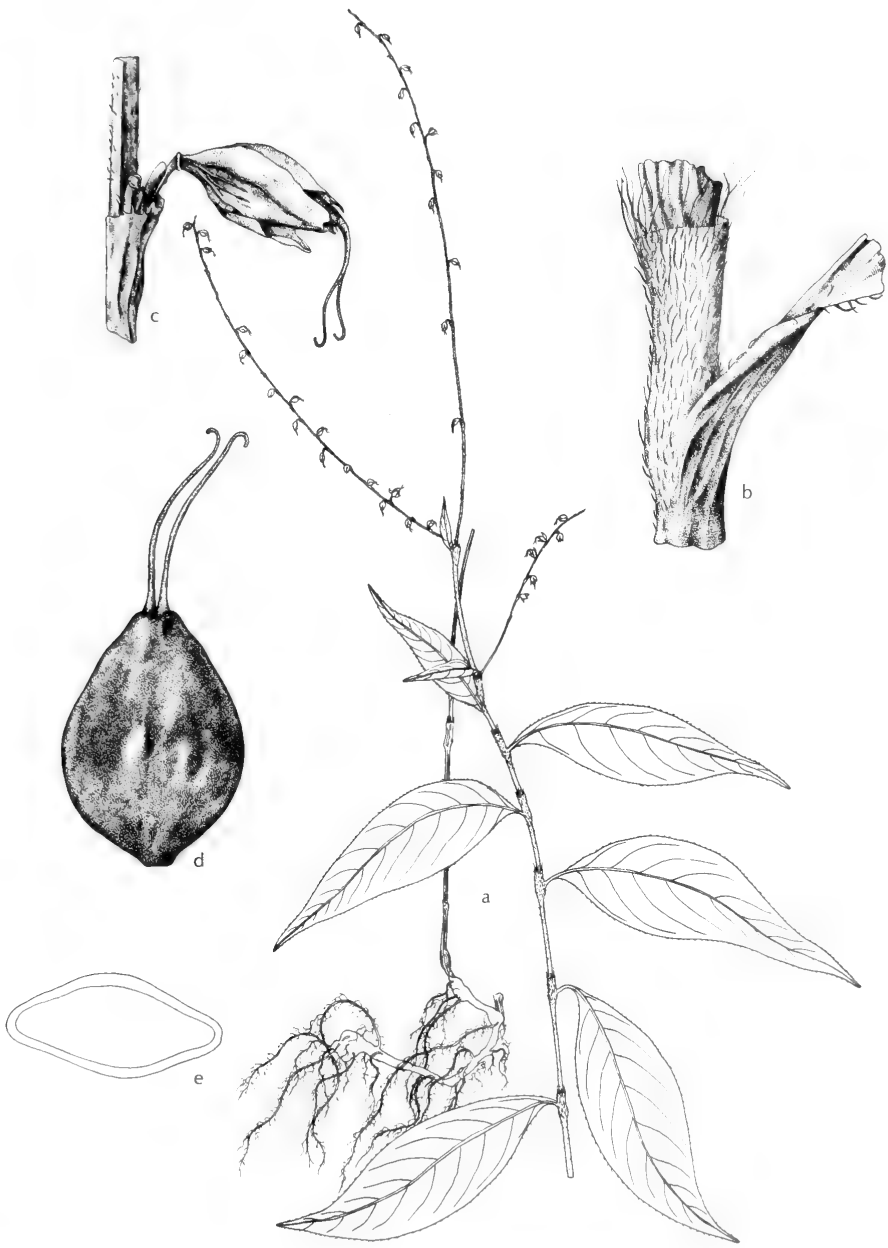

Fig. 403: Polygonum virginianum: a, habit, x 1/3; b, ocrea, x 3; c, ocreola, x 4; d, achene, x 10; e, cross section of achene, x 10. (Courtesy of R. K. Godfrey). 


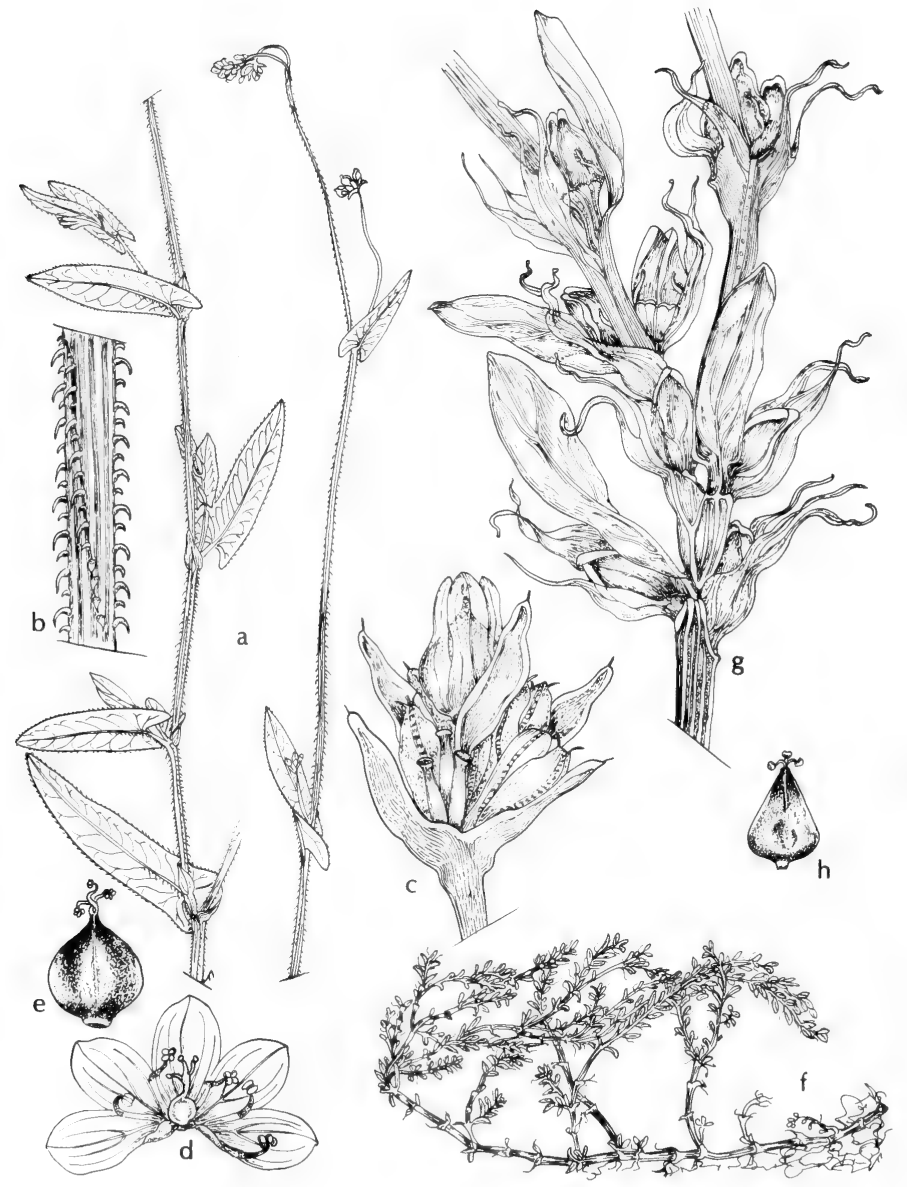

Fig. 404: a-e, Polygonum sagittatum: a, upper part of plant, x 1/2; b, section of stem, x 3; c, flower cluster, x 5; d, flower spread out, x 5; e, mature capsule, x 5. f-h, Polygonum aviculare: $\mathrm{f}$, habit, $\mathrm{x} 1 / 6 ; \mathrm{g}$, section of flowering branch, $\mathrm{x} 5 ; \mathrm{h}$, mature capsule, x 5. (V. F.). 
small tight head of white or pale-pink flowers on a very long peduncle longer than leaves); calyx 5-parted; stamens 8; achene triquetrous, 3-3.5 mm. long, black or brownish, smooth. Tracaulon sagittatum (L.) Small.

Infrequent at margins of lakes, swamps, marshes and bogs in e. Tex., and Okla. (McCurtain and Haskell cos.), June-Oct.; Nfld. to Sask., s. to Fla, and Tex.

\section{Polygonum Convolvulus L. Black BindweEd.}

Annual vine, glabrous but minutely scurfy; stems twining, 1-12 dm. long; leaf blades ovate-deltoid or usually ovate-sagittate, 15-60 mm. long, acuminate; flowers borne usually in pairs or threes at the same nodes or toward the ends of the branches, flowers in racemelike inflorescences; pedicels very slender, $2-3 \mathrm{~mm}$. long, reflexed; calyx after anthesis becoming about $3.5 \mathrm{~mm}$. long, closely investing the achene, the 3 outer sepals minutely keeled; achene $3.5-4 \mathrm{~mm}$. long, triquetrous, black. Bilderdykia Convolvulus (L.) Dum., Tiniaria Convolvulus (L.) Webb \& Moq., Reynoutria Convolvulus (L.) Shinners.

On mud at edge of lakes, streams and ponds, on wet sand-gravel bars along streams and in seepage about springs, commonly in disturbed soil and often in gardens and flowerbeds, nearly throughout Tex., except extreme Trans-Pecos, Okla. (Waterfall), N.M. (widespread), and Ariz. (Apache, Navajo and Coconino, s. to Cochise and Pima cos.), Apr.-Sept.; a Eur. weed now widely adv.

\section{Polygonum cristatum Engelm. \& Gray.}

Short-lived perennial vine (flowering first year); stems annual, twining; leaf blades deltoid to shallowly sagittate-deltoid, 2-9 cm. long, only very slightly (if at all) acuminate; flowers reflexed (pendulous) on very slender pedicels several $\mathrm{mm}$. long, at the middle nodes borne in twos or threes but on some of the distal parts of the stems borne in racemelike masses; calyx after anthesis eventually about $6 \mathrm{~mm}$. long, 3 of the sepals with flat, toothed or crimped wings $0.25-1 \mathrm{~mm}$. broad; achenes lustrous, trigonous, 3-3.5 mm. long. Tiniaria cristata (Engelm \& Gray) Small, Bilderdykia cristata (Engelm. \& Gray) Greene, P. scandens L. var. cristatum (Engelm. \& Gray) Gl., Reynoutria scandens (L.) Shinners var. cristatum (Engelm. \& Gray) Shinners.

Edges of woods, creek bottoms, wet gravel bars along rivers, in e. and n.-cen. Tex. (possibly also canyons in Plains Country), e. Okla. (McCurtain and Cherokee cos.), Aug-Oct.; Tex., Ark., Okla. and La.; sparingly elsewhere where probably adv.

\section{Polygonum texense $M$. C. Johnst.}

Perennial herb to $6 \mathrm{dm}$. tall, each shoot from a short reddish-brown fibrous (from ocreae remnants) caudex 2-3 (-10) $\mathrm{mm}$. thick, usually (perhaps always) with brown rhizomes 2-3 mm. thick and with internodes to $4 \mathrm{~cm}$. long; aerial shoots with solitary ascending stems $1-2 \mathrm{~mm}$. thick from each crown, with some ascending branches at irregular intervals but usually unbranched in their distal halves or thirds; leaf blades of the innovations (emerging in April) lanceolate, 15-24 mm. long, 4-7 mm. broad, green, flat, without conspicuous nervation, blunt at apex, narrowed and with an abscission joint at base, falling by May; petiole about $2 \mathrm{~mm}$. long, inconspicuous and appearing as part of the ocrea; ocreae 6-11 mm. long; lower part of ocrea strongly nerved and clasping the petiole, the upper part hyaline (except for the nerves) and with 3 acute lobes, eventually becoming shredded into fibers and lost; uppermost leaves reduced to bracts with subpersistent blades $2-10 \mathrm{~mm}$. long, those of the upper 2 to $10 \mathrm{~cm}$. of stem usually less than $4 \mathrm{~mm}$. long and quite inconspicuous; flowers solitary or in 2's or 3's at the upper nodes, erect or somewhat nodding; pedicels filiform, about $2 \mathrm{~mm}$. long, almost all included in the lower part of the ocreolae; calyx 
about $2 \mathrm{~mm}$. long, 5-parted to below the middle with the lobes broadly oblong, rounded at apex, white with some medial reddish or greenish markings and at anthesis spreading; achene 2-2.5 mm. long, ovoid in over all outline, in transection almost equilaterally triangular (one side, the one not furnished with an inner sepal, usually slightly smaller and more concave than the others), darkbrown at maturity, rather lustrous.

Infrequent in seasonally moist places on Edwards Plateau and s. part of Plains Country (Andrews, Crockett, Howard, Sutton and Val Verde cos.), Tex., summerfall; endemic.

\section{Polygonum argyrocoleon Kunze. Persian wiregrass. Fig. 405.}

Taprooted glabrous annual, the roots becoming ligneous toward fall and simulating the perennial habit; stems striate, erect with several ascending branches, the whole plant $2-5 \mathrm{dm}$. tall; upper parts of ocreae hyaline and long-lacerate; petioles adnate to and as long as ocreae; blades jointed to petioles, green, membranous, at midstem lance-linear, $1-3 \mathrm{~cm}$. long, narrowed to both ends; upper leaves reduced to minute bracts and the upper internodes shortened so that the flowers are crowded in terminal spikelike clusters $2-5 \mathrm{~cm}$. long or more; calyx about $1.5 \mathrm{~mm}$. long at anthesis, about $2 \mathrm{~mm}$. long in fruit, divided nearly to base; achenes trigonous, reddish-brown, with one face broader than the others, about $2 \mathrm{~mm}$. long, very lustrous.

Infrequent or rare in seasonally moist places such as temporary pools and playa lakes, and in marshy ground, in w. Tex. (Brewster, Hudspeth, Pecos and Upton cos.), N. M. (Lea Co.) and Ariz. (Mohave, Maricopa, Pinal and Yuma cos.), Apr.-Oct.; nat. of Near and Middle East, now adv. in Calif., Ariz., N. M. and Tex.

\section{Polygonum confertiflorum Nutt.}

Glabrous, simple to ascending-branched annual (4-) 6-20 cm. tall, the stems slightly angled; leaves linear, 1-3 (-4) $\mathrm{cm}$. long, 1-2 $\mathrm{mm}$. broad, jointed at base; stipules lacerate, 3-7 mm. long; flowers 2 to 4 per node, subsessile, mostly crowded at the ends of the branches or occasionally a few in the axils of the proximal floral leaves, the lower bracts similar to the leaves, the upper ones shortened and often not exceeding the flowers but usually broadened and more or less white-margined; perianth 1.5-2.5 (usually about 2) $\mathrm{mm}$. long, connate scarcely one third the length, the segments with a greenish midstripe and white to pinkish borders, slightly cucullate-keeled, the 3 outer ones subequal to or considerably longer and broader than the 2 inner ones; stamens usually 8 , the 3 inner ones anther-bearing, the filaments much-expanded at base, the 5 outer ones with abortive (or no) anthers, the filaments linear; styles 3 , connate to midlength, barely $0.3 \mathrm{~mm}$. long; achene $1.5-2 \mathrm{~mm}$. long, yellow-brown to (commonly) brownish-black, usually dull and prominently striate lengthwise but sometimes (even on the same plant) smooth and shining, triquetrous. P. Watsonii Small.

Meadows, seepage about lakes and vernal pools to dry open ground, in N. M. (Rio Arriba and San Juan cos.) and Ariz. (Coconino Co.), May-Sept.; Mont. to Wash., s. to Colo., N.M., Ariz. and Calif.

\section{Polygonum Kelloggii Greene.}

Simple or sparingly branched glabrous annual, the stem angled, mostly $2-7 \mathrm{~cm}$. tall; leaves few, linear, 5-25 mm. long, mostly about $1 \mathrm{~mm}$. broad, basally jointed; stipules lacerate, 2-7 mm. long; flowers subessile (pedicels to $1 \mathrm{~mm}$. long) in crowded terminal clusters of 1 to 4 and usually also axillary to most of the lower foliage leaves, the stems sometimes floriferous almost to the base; floral bracts linear, nearly divergent, only moderately reduced upward, the upper ones usually 


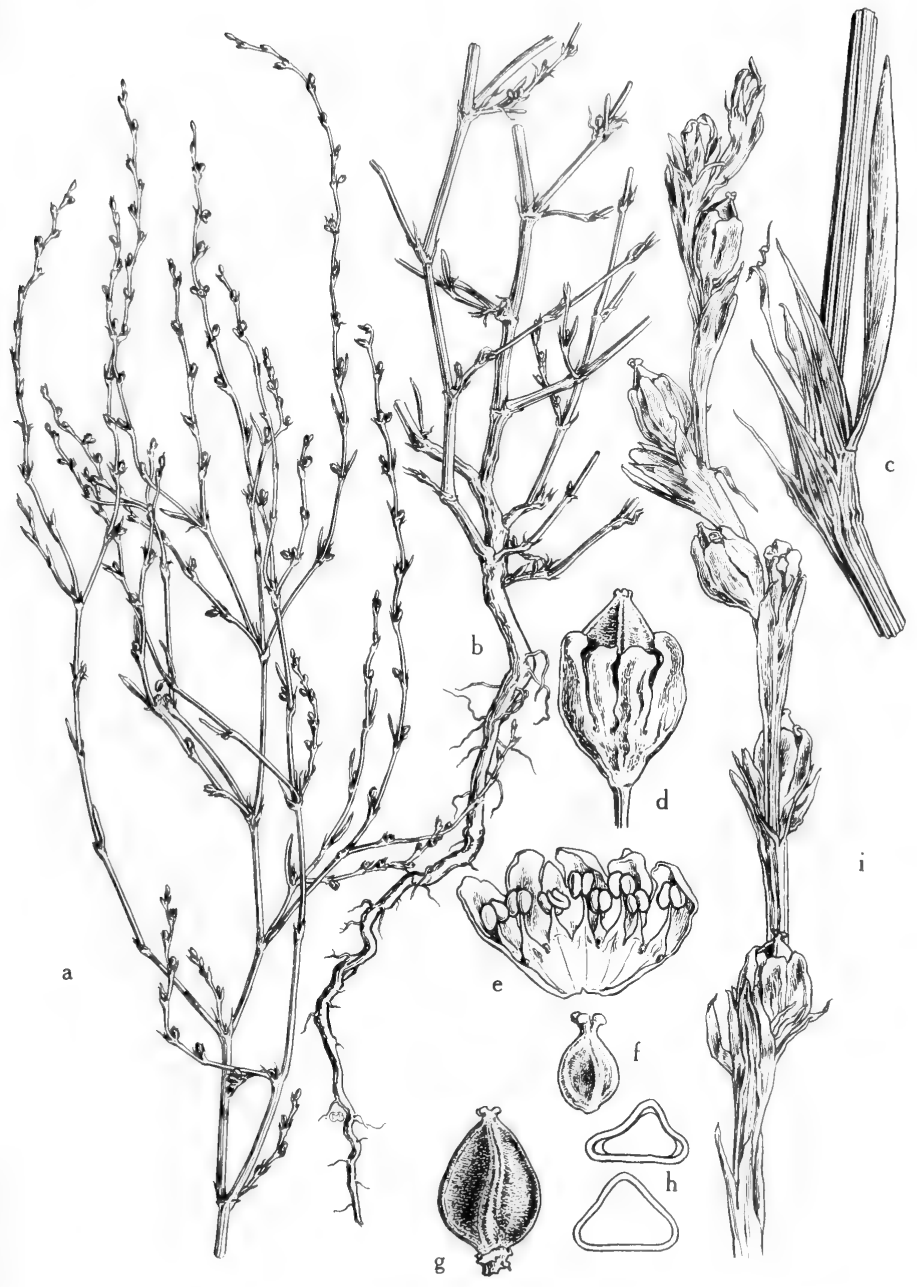

Fig. 405: Polygonum argyrocoleon: a, habit, upper part of plant, x $35 ; \mathrm{b}$, habit, lower part of plant, $\mathrm{x} 2 \% \mathrm{c}$, leaf and sheath, $\mathrm{x} 3 ; \mathrm{d}$, mature achene, partially enveloped by perianth, x 8 ; e, perianth, spread out, showing reduced glands between stamens, x 8; f, pistil, x 8; g, achene, x 6; h, achenes (cross section), x 6; i, tip of inflorescence, X 4. (From Mason, Fig. 196). 
2 to 3 times as long as the flowers but only slightly if at all broadened or whitemargined; perianth (1.5-) 2-2.5 mm. long, connate scarcely one third the length, the 5 lobes subequal or the outer 3 the largest, slightly cucullate-keeled, with a green midstripe and whitish or pinkish borders; stamens 8 , the 5 outer ones with linear filaments and abortive or no anthers, the 3 inner filaments greatly dilated at base and anther-bearing; stigmas 3, subsessile; achene triquetrous, 1.5-2 mm. long, usually light-yellow to greenish-brown, shining and smooth to obscurely striate, sometimes dark-brown, dull and strongly striate lengthwise (both types of achene often on the same plant); style very short, connate about half the length.

Meadows, wet banks of lakes and vernal pools to dry subalpine slopes in Ariz. (Coconino Co.), June-Oct.; Mont. to B.C., s. to Colo., Ariz. and Calif.

\section{Polygonum aviculare L., sens. lat. KnOtWeed, WIREgRass. Fig. 404.}

Taprooted annual or very weak perennial, very diverse in habit, either with an upright mainstem and ascending branches (when growing among dense herbaceous vegetation) or usually prostrate and rooting at the very numerous nodes (when on flat bare ground); leaves few to numerous, sparse to crowded; blades caducous or long-persistent, linear to usually narrowly oblong or narrowly elliptic, (2-) 3-15 (-25) mm. long, green, flat, without conspicuous nervation; flowers solitary or in 2's or 3's at some of the nodes, crowded or not; pedicels filiform, much shorter than the ocreae so that the flower and fruit are always erect; sepals 5 (calyx never opening, perhaps indicating cleistogamy), 3 of them exterior over the angles of the achene and 2 inner ones over 2 of the achene faces.

In marshes and mud on edge of ponds, lakes and streams, wet meadows, floodlands and edge of tidal salt marshes, widespread but local nearly throughout Tex. (except extreme s.), Okla. (Rogers and Osage cos.), N. M. (Lincoln, Grant, Colfax, Otero, San Miguel, Taos and Rio Arriba cos.) and Ariz. (Navajo and Coconino, s. to Cochise and Pima cos.), May-Nov.; very widespread in temp. regions, perhaps originally nat. to Eur.

On the basis of achene and calxy characters 3 species in the $P$. aviculare aggregate may be differentiated as follows: (1) plants having achenes with 2 convex and 1 narrowly concave side are referred to $P$. arenastrum Bor.; achenes mildly striated, reddish-brown, about $2 \mathrm{~mm}$. long; the persistent calyx covering the achene is divided for about half its length; (2) plants designated as $P$. buxiforme Small have reddish-brown striated achenes $2-2.5 \mathrm{~mm}$. long, cordate in shape, with 1 broad flat face and 2 more or less equal concave sides; the persistent perianth is divided for about two thirds its length and is characterized by having lateral papery margins or wings; (3) achenes of $P$. aviculare (sens. str.) are typically coarsely striated, dull, 2.5-3 $\mathrm{mm}$. long and narrower, and less heart-shaped than those of $P$. buxiforme; the persistent perianth completely covers the achene, is divided almost to the base and lacks the lateral papery margins characteristic of $P$. buxiforme.

\section{Polygonum Douglasii Greene.}

Simple to freely branched, erect to strongly ascending annual 1-4 (-5) $\mathrm{dm}$. tall; leaves numerous but not strongly overlapping, linear to narrowly oblong (sometimes more nearly lanceolate or oblanceolate), usually $2-4 \mathrm{~cm}$. long, rarely as much as one fifth as broad, sessile or subsessile, jointed at the base, rather abruptly reduced to the bracts above; stipules short-sheathing, 5-12 $\mathrm{mm}$. long, lacerate; racemes elongate, loose, with (1) 2 to 4 flowers per node; pedicels 1-4 $\mathrm{mm}$. long, reflexed by (or shortly after) anthesis; upper bracts much shorter than the flowers; perianth $2.5-3.5(-4) \mathrm{mm}$. long, distinct nearly to the base, the 5 segments greenish with white or reddish margins; styles 3 , distinct nearly to 
the base, scarcely $0.5 \mathrm{~mm}$. long; achene triquetrous black, smooth and shining, usually included, $3-3.5 \mathrm{~mm}$. long, about half as broad.

In wet meadows, marshes and edge of water in streams and lakes, in $\mathbf{N}$. $\mathbf{M}$. (widespread) and Ariz. (Apache, Coconino and Graham cos.), June-Sept.; throughout most of Can. and U. S.

\section{Polygonum ramosissimum Michx.}

Taprooted annual (in some situations the taproot becoming ligneous and as much as $1 \mathrm{~cm}$. thick late in the season), rather variable in habit but (except in injured specimens) having only one ascending or usually erect mainstem near ground level, the whole plant (2-) 3-12 dm. tall and usually with numerous ascending or erect branches; leaf blades of midstem lanceolate or linear, (4-) 7-22 mm. long, green, flat, without conspicuous nervation, either persistent or falling, uppermost (bracteal) leaves with smaller blades, persistent or falling; flowers solitary or in 2's or 3's at the nodes of the upper $1-2 \mathrm{~cm}$. of the stem and branches, not crowded; pedicels filiform, at least some of them on the plant at fruiting time long enough to bend over (i.e., exserted from ocreae) so that the yellowish-green fruiting calyx (which completely covers the achene) is drooping; sepals nearly always 6 (very rarely 5); achenes mahogany-colored, equilaterally trigonous, sharp-angled, mildly striate to smooth, usually shiny and $2-3 \mathrm{~mm}$. long.

In marshes, edge of streams, ponds and lakes, in seasonally wet areas, widespread in Tex., Okla. (Waterfall), N. M. and Ariz. (Coconino, Apache and Yavapai cos.), summer-fall; most of e. U.S. s. to Del., Pa., O., Ind., IIl., Mo., Okla., Tex., N.M. and Ariz.

\section{Polygonum viviparum $L$.}

Perennial from a short thick erect or ascending rootstock, with 1 to several flowering stems mostly $1.5-3 \mathrm{dm}$. tall; leaves mostly basal, long-petiolate, not jointed to the stem, narrowly oblong to narrowly oblong-lanceolate, $3-8 \mathrm{~cm}$. long; stipules brown, strongly sheathing, $2-5 \mathrm{~cm}$. long, oblique at tip, not lacerate; cauline leaves 2 to 4 , much narrower than basal leaves, reduced upward and becoming sessile; inflorescence a single terminal spikelike raceme usually $4-8 \mathrm{~cm}$. long and $1-1.5 \mathrm{~cm}$. thick; bracts (especially lower ones) somewhat remote and with the flowers replaced by small pinkish to purplish bulblets, the normal flowers of the upper small membranous bracts with pedicels 2-4 $\mathrm{mm}$. long; perianth 3-3.5 $\mathrm{mm}$. long, connate and usually greenish for one fourth to one third of the length, the 5 segments oblong and white to pink; flowers usually functionally imperfect, the stamens 8 when developed and usually exserted, the filaments equalling to twice as long as the perianth; in the pistillate flowers the stamens usually more or less rudimentary and shorter than the perianth; styles 3, distinct nearly to the base, 3-4 mm. long; achenes triquetrous, usually not developing, normally darkbrown, smooth and shining, 2-3 mm. long. Bistorta vivipara (L.) S. F. Gray.

In wet meadows, in mud and seepage about lakes and on stream banks, and shaded woodlands, in N. M. (Colfax, Santa Fe, San Miguel and Taos cos.), and possibly Ariz., May-Sept.; Greenl. to Alas., s. to N. E., Minn., N.M., (?) Ariz. and Wash.

\section{Polygonum bistortoides Pursh. Snakeweed. Fig. 406.}

Perennial from a short thick erect or ascending rhizome, with 1 or more simple erect flowering stems $2-6 \mathrm{dm}$. tall; leaves mostly basal, long-petiolate, not jointed to stem, elliptic to oblong-lanceolate or oblanceolate, to about $1.5 \mathrm{dm}$. long, rounded to cuneate at base; stipules brownish, oblique, not lacerate, 3-6 cm. long; cauline leaves few, noticeably reduced upward, all but the lowest sessile, lanceolate, semicordate at base; racemes terminal, spikelike, many-flowered, mostly 2-4 


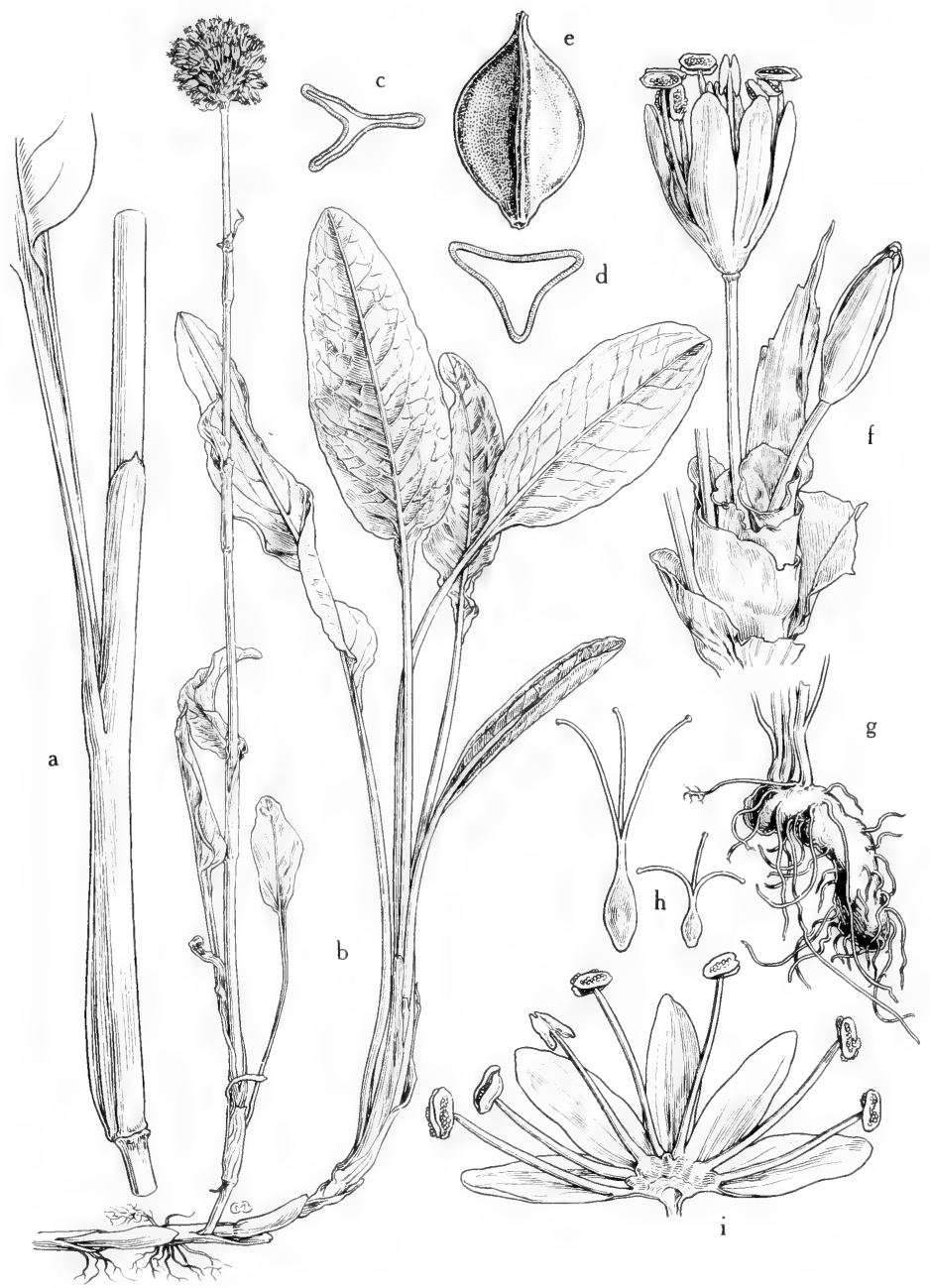

Fig. 406: Polygonum bistortoides: a, stipular leaf sheath, $x 2$; b, habit, showing rhizome, basal leaves, and stem with cauline leaves and solitary spike, $\mathrm{x} 1 / 3$; $\mathrm{c}$ and $\mathrm{d}$, mature achenes (cross section), x 6; e, mature achene, x 6; f, part of flowering spike, showing the long-pediceled flowers exserted from hyaline sheathlike bracts, $\mathrm{x} 4 ; \mathrm{g}$, rootstock, $\mathrm{x} 2 \% ; \mathrm{h}$, pistils, the style 3 -cleft, $\mathrm{x} 4$; $\mathrm{i}$, perianth, spread open, showing the exserted stamens arising from glandular disk just below sinuses or from individual glandular lobes, x 4. (From Mason, Fig. 197). 


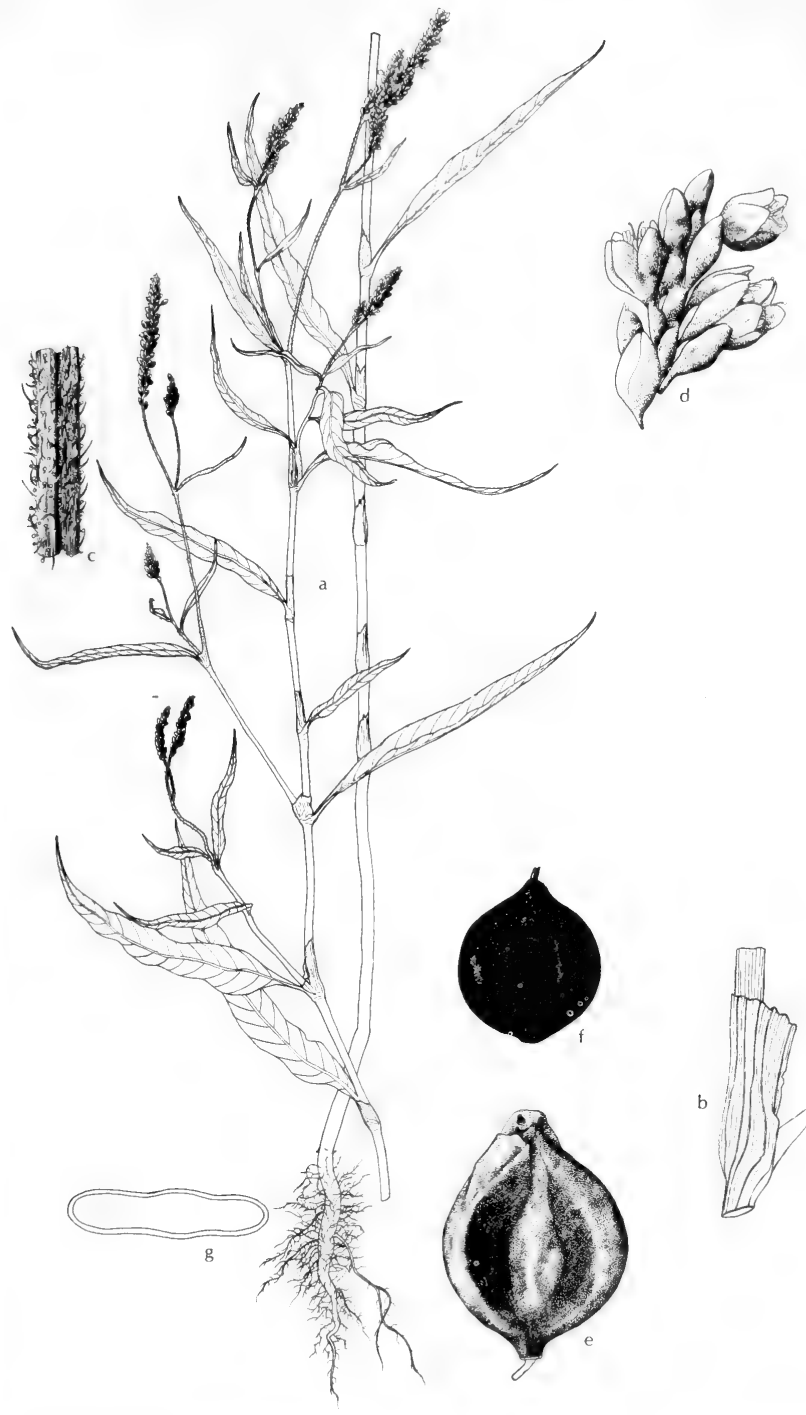

Fig. 407: Polygonum pensylvanicum: a, habit, x $1 / 6$; b, ocrea, x 2 ; c, peduncle enlarged; $d$, part of flowering spike, x 4; e, perianth enclosing mature fruit, $x$ 7; $f$, achene, x 7; g, cross section of achene, x 7. (Courtesy of R. K. Godfrey). 
$\mathrm{cm}$. long and $1.5-2 \mathrm{~cm}$. thick, the small bracts papery and brownish; pedicels 2-7 $\mathrm{mm}$. long; perianth $4-5 \mathrm{~mm}$. long, connate for about one fifth its length, the 5 oblong equal segments white to pinkish; stamens 8, exserted, the filaments to twice as long as the perianth, the inner ones broadly flared at the extreme base; styles 3 , distinct nearly to base, about $3.5 \mathrm{~mm}$. long; achene triquetrous, yellowish-brown, smooth and shining, about $4 \mathrm{~mm}$. long.

Bogs, wet meadows, seepage about lakes, old lake beds and in moist humus of conifer forests, in N. M. (Socorro, Grant, Santa Fe, San Miguel and Taos cos.) and Ariz. (Apache, Coconino, Greenlee and Graham cos.), June-Oct.; Mont. to B.C., s. to N. M., Ariz. and Calif.

\section{Polygonum pensylvanicum L. Pinkweed, smartweed. Fig. 407.}

Stout erect annual from a taproot, branching above; stems 3-20 dm. tall, mostly glabrous below to stipitate-glandular in the inflorescence, greenish or reddish; leaves 4-22 cm. long, 1-5 cm. wide, lanceolate to broadly lanceolate, acuminate, abruptly tapering to short petioles, sparsely punctate above and below, the veins somewhat strigose, the margins strigose-ciliate; stipular sheaths cylindric-funnelform, glabrous, truncate and without bristles, membranous and soon fracturing, 10-15 mm. long; spikes mostly compact, rarely interrupted, $2-4 \mathrm{~cm}$. long, erect, the peduncles densely stipitate-glandular; sheathing bracts funnelform, the tip acute, glabrous to sparsely glandular, the margins with a few minute cilia toward apex, otherwise entire; pedicels exserted, glabrous; perianth rose to white, 3-4 $\mathrm{mm}$. long, 5-parted to below middle; stamens 8 or less, some in the sinuses of perianth, others from between lobes of the glandular disk; disk prominent, 8-lobed; style 2- or 3-cleft to below middle; stigmas capitate; achene lenticular to trigonous, microscopically roughened, dark-brown to black and shiny, 2.5-3.4 mm. long. Persicaria pensylvanica (L.) Small.

In low marshy ground, mud along irrigation ditches, streams and rivers, and about pools, in (mostly) e. Tex., Okla. (Cherokee, Adair, Johnston and Sequoyah cos.), N. M. (Socorro Co.) and Ariz. (Apache, Coconino, Yavapai, Santa Cruz and Pima cos.), May-Nov.; throughout N.A.

\section{Polygonum amphibium L. Floating KnOtweed, Water smartweed. Figs.} 408 and 409.

Dimorphic, amphibious, aquatic or terrestrial perennial, rooting at swollen nodes; terrestrial plants erect or decumbent, to about $15 \mathrm{dm}$. tall; aquatic plants with floating tips and spreading or floating leaves, or at length with erect branched aerial stems; stems at length swollen above the nodes, glabrous to puberulent or finely tomentose; leaves lanceolate-attenuate to oblong-elliptic or ovate, $5-25 \mathrm{~cm}$. long, 1-6 cm. wide, obtuse to acuminate at apex, slightly unequal at the cuneate to truncate or cordate base, finely silky-pubescent, the margins somewhat undulate; petioles $2-4 \mathrm{~cm}$. long, the lower half decurrent and flanked by a stipular sheath extending as a cylinder around the stem for $10-20 \mathrm{~mm}$. above its junction with the petiole; stipular sheath about 12-nerved and truncate across the top, those of floating or submersed stems glabrous and entire, those of emersed stems scabrous and ciliate-margined, with a few hairs of unequal lengths along the nerves or scattered between them; inflorescence of 1 or 2 elongate densely flowered terminal spikes $1-8 \mathrm{~cm}$. long on a stout red densely glandular-pubescent peduncle 1-3 cm. long; flowers fascicled in the axils of hairy stipulate bracts on short glabrous pedicels, 1 flower of each fascicle blooming at a time, the flowers thus blooming in succession over entire spike; perianth 5-merous, petaloid, bright rose-pink, 4-5 $\mathrm{mm}$. long, the ovate lobes free above but united below; stamens 5 , inserted just below the sinuses of the perianth lobes, included or exserted (always of different length than the style); anthers versatile; glandular disk at- 


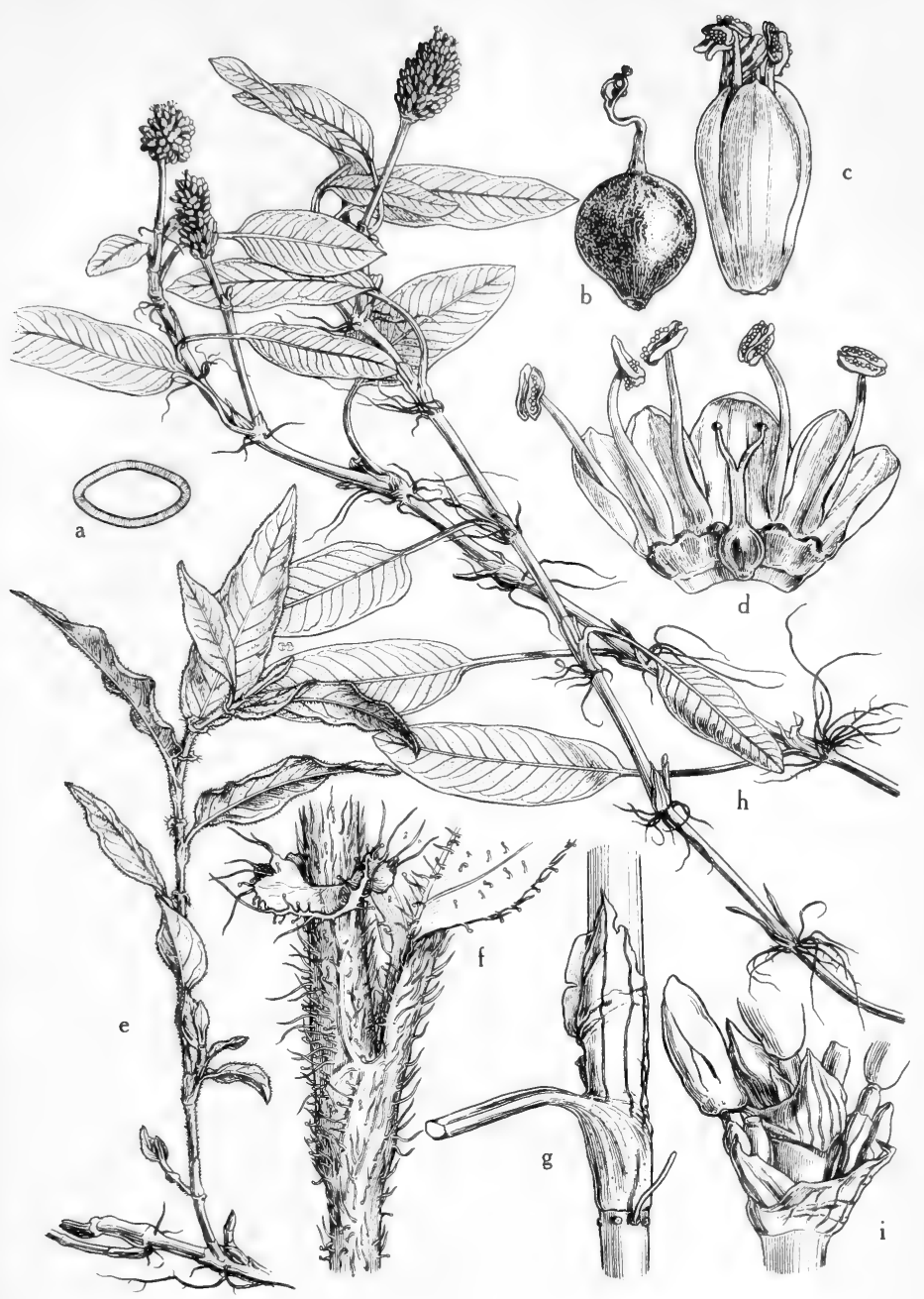

Fig. 408: Polygonum amphibium: a, achene (cross section), x 6; b, mature achene, x 6; c, flower, showing exserted stamens, $x$ 6; d, perianth, spread open, showing the prominent glandular disk and the regularly inserted stout filaments, $\mathrm{x} 6$; e, terrestrial plant, showing habit, scabrous pubescence, $\mathrm{x} 2 \% \mathrm{f}$, stipular sheath of terrestrial plant, scabrous, the broad margin ciliate, x $3, \mathrm{~g}$, stipular sheath of aquatic plant, glabrous and membranous, $\mathrm{x} 2 ; \mathrm{h}$, habit of aquatic plant, showing the rooting nodes, the glabrous floating leaves and the short dense flowering spikes, $x 2 \% ; i$, lower part of spike, showing the bilobed sheathing bracts and the flowers on short glabrous pedicels, x 4. (From Mason, Fig. 199). 


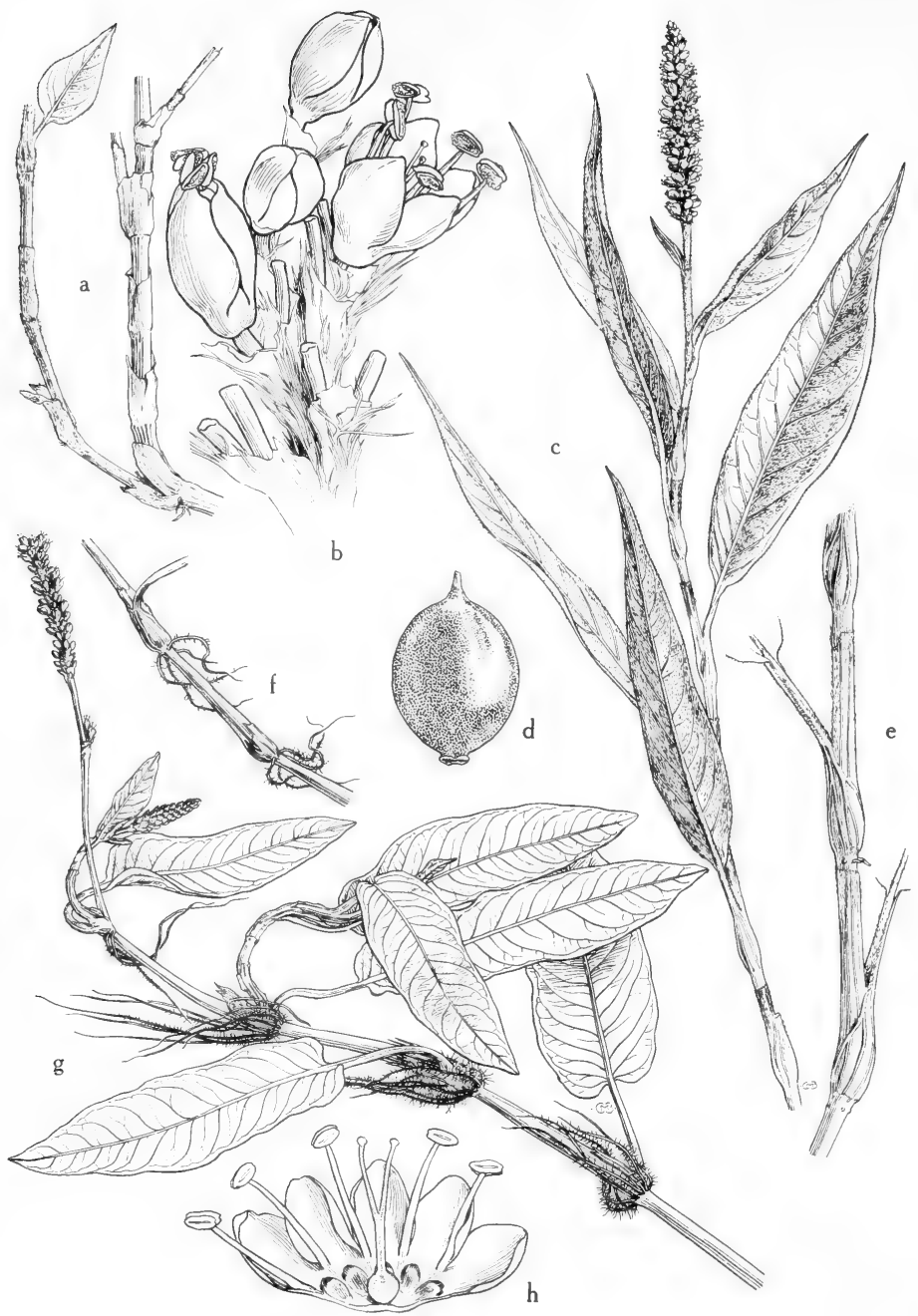

Fig. 409: Polygonum amphibium: a, stem of terrestrial plant, the mature branch glabrous, the young branch puberulent, $x \% ; b$, part of flowering spike, showing the short-pediceled fasciculate flowers in axils of hairy sheathing bracts, $\mathrm{x} 4$; c, habit, terrestrial plant, pubescent, x $2 \%$; d, mature achene, x 6 ; e, stipular leaf sheaths, terrestrial plant, $\mathrm{x} 45 ; \mathrm{f}$, lower part of stem, aquatic form, showing roots at the swollen nodes, $\mathrm{x} 2 \% \mathrm{~g}$, habit aquatic plant, glabrous, $\mathrm{x} 25 ; \mathrm{h}$, flower, spread open to show the conspicuous glandular disk and regular stamen insertion, x 4. (From Mason, Fig. 198). 
tached to the base of the perianth tube, orange-red, 5-lobed, the tips of lobes free; ovary flattened; styles elongate, bifid to about or below the middle, included or exserted; stigmas capitate; achene lenticular, $2.8-4 \mathrm{~mm}$. long, beaked with the persistent style base, blackish to deep reddish-brown, shiny, minutely punctate. $\boldsymbol{P}$. natans Eat., $\boldsymbol{P}$. coccineum Muhl., Persicaria coccinea (Muhl.) Greene, $\boldsymbol{P}$. Muhlenbergii (Meisn.) Small.

In ponds, rivers, streams, lakes, ditches, canals, marshes, swamps and mud in wet meadows, in e. and n.w. Tex., Okla. (LeFlore, Comanche, Kay, Washita, Cimarron and Alfalfa cos.), N. M. (Colfax, Dona Ana, Mora, Sierra, Sandoval, Catron, Taos and Rio Arriba cos,) and Ariz. (Apache, Navajo and Coconino, s. to Santa Clara and Pima cos.), June-Oct.; represented by 2 varieties in N. A. and 1 variety in Eurasia.

Mitchell separates our two varieties as follows:

1. Plants flowering while floating or recently stranded; inflorescence 1-4 or rarely to $6 \mathrm{~cm}$. long; aerial shoots decumbent to spreading, with chlorophyllous flared ocreae in the early season....var. stipulaceum Colem.

1. Plants flowering from aerial shoots on moist soil or strongly emergent from the water; inflorescence $4-11$ or rarely to $15 \mathrm{~cm}$. long at maturity; aerial shoots spreading to erect; ocreae with entire margins, becoming membranous and soon shattering................var. emersum Michx.

\section{Polygonum bicorne Raf. Pink smartweed.}

Annual from taproot; stems erect, much-branched, cherry-red (at least at the nodes), 1-20 dm. high; leaf blades lanceolate, punctate, glabrous except for a few appressed hairs, 5-18 cm. long, 1-4 cm. wide; ocreae eciliate or occasionally with cilia less than $1 \mathrm{~mm}$. long, higher than wide; peduncles stipitate-glandular; racemes erect, numerous, terminal and lateral; calyx pinkish, 5-parted, 2.7-4.6 mm. long; stamens 6 to 8 , included or exserted (always of different length than the styles); styles 2, included or exserted; achene lenticular, ridged or humped on at least one face, dark-brown or black, lustrous, $2.5-3.5 \mathrm{~mm}$. long and nearly as wide. Polygonum longistylum Small, Persicaria bicornis (Raf.) Nieuw.

In and about water of ponds, lakes, sloughs and ditches, marshes, wet meadows and in various disturbed habitats (often a first year invader) throughout Tex., Okla. (McCurtain, LeFlore, Comanche, Logan, Pawnee, Rogers, Ottawa and Nowata cos.), N.M. (San Miguel Co.) and Ariz. (Santa Cruz Co.), May-Jan.; Neb. to Colo. and s. to Tex., N.M., Ariz., Calif. and Mex.

The plants in southern Texas often have slightly fringed ocreolae (fringe absent in north) and more pronounced ridges on the achene than their northern counterparts.

\section{Polygonum lapathifolium L. Willow Smartweed. Fig. 410.}

Stout erect annual to $15 \mathrm{dm}$. tall; stems glabrous, conspicuously swollen above nodes; leaves linear-lanceolate to oblong-lanceolate, $5-30 \mathrm{~cm}$. long, $1-5 \mathrm{~cm}$. wide, acuminate, tapering to short petioles, the upper surface nearly glabrous, with strigose scabrous veins and margins, the undersurface densely glandular-punctate (occasionally densely white-tomentose beneath in aquatic forms); stipular sheaths membranous, cylindric, $1-2 \mathrm{~cm}$. high, glandular on margins, at length splitting and becoming truncately fractured; inflorescence an elongate drooping spikelike raceme, densely flowered, the peduncles glabrous to glandular; sheathing bracts funnelform, obliquely tapered, $2 \mathrm{~mm}$. long, glandular on margins; perianth pink to white, 4- or 5-cleft to below middle, 2-2.9 $\mathrm{mm}$. long, the tube lined with a thin 5-lobed glandular disk, the veins of perianth segments dichotomously forked and recurved at tips, becoming prominent in age; stamens 6 , included, inserted on tube and in sinuses; style 2-parted nearly to base; stigmas capitate; achene 


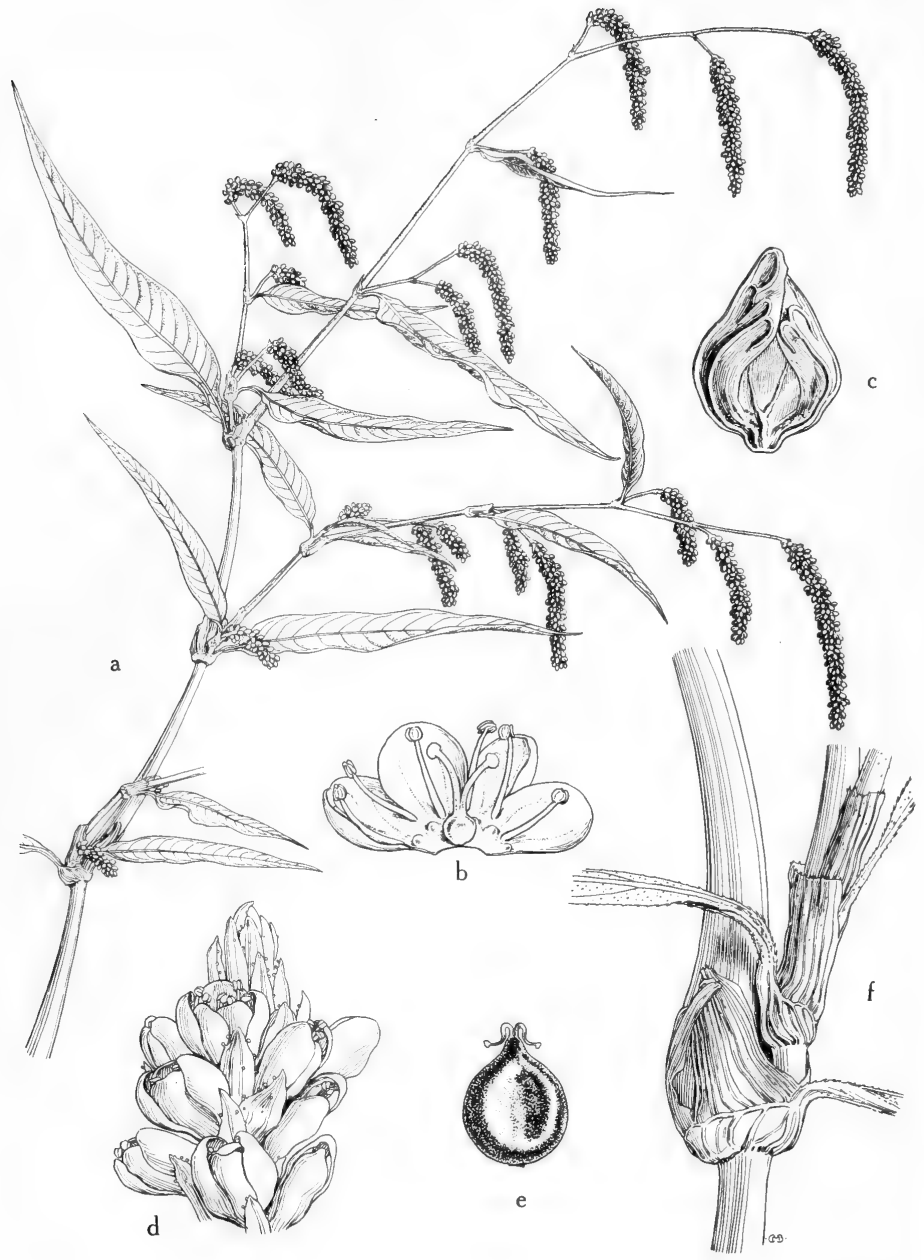

Fig. 410: Polygonum lapathifolium: a, habit, showing the stout stem, swollen above the nodes, and the drooping spikelike racemes, $x$ 1/3; $b$, perianth, spread open, showing glandular disk and the stamen insertion, $\mathrm{x} 8$; c, perianth enclosing mature achene (note the forked recurved veins which have become prominent), x 8; d, tip of spike, the sheathing bracts obliquely tapered, their margins glandular, x 6; e, mature achene, $\mathrm{x}$ 8 ; $\mathrm{f}$, young stipular sheaths, showing glandular or ciliate margins and fractured sheath enclosing the swollen part above the node, x 11/5. (From Mason, Fig. 205). 


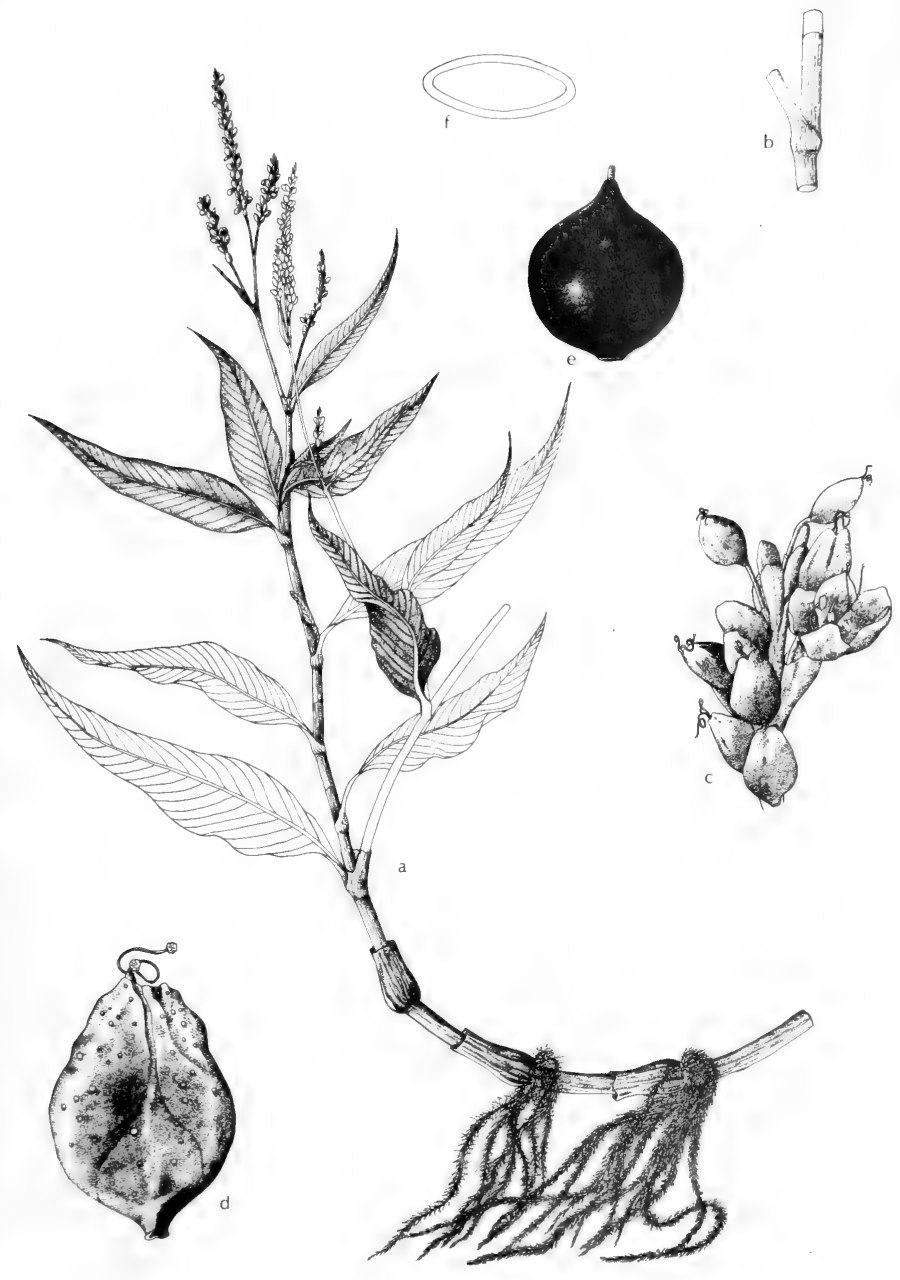

Fig. 411: Polygonum densiflorum: a, habit, x 3; b, ocrea, x 2/3; c, part of flowering spike, $\mathrm{x} 3$; d, perianth enclosing mature fruit, $\mathrm{x} 10$; e, achene, $\mathrm{x} 10$; $\mathrm{f}$, cross section of achene, x 10. (Courtesy of R. K. Godfrey). 
lenticular, minutely roughened, dark shining-brown or blackish, 2-2.5 $\mathrm{mm}$. long. Incl. var. incanum (Roth) K. Koch, Persicaria lapathifolia (L.) Small.

In marshes, wet meadows and in and about water of ponds, lakes and streams, rather frequent throughout Tex., Okla., N.M. and Ariz., Apr.-Dec.; introd. from Eur. and now throughout N.A.

\section{Polygonum orientale L. Princess-FeAther.}

Annual from taproot; stems erect, branched, usually green, strigose, 4-30 dm. high; leaf blades obovate, commonly truncate at base, strigose beneath, $6-22 \mathrm{~cm}$. long, 4-12 cm. wide; ocreae usually ciliate, about as wide as high; peduncles tomentose; racemes numerous, erect; calyx 5-parted, pink to reddish-pink, epunctate, 4-4.5 mm. long in fruit; stamens included; styles 2; achenes lenticular, turgid, oval in cross section, black, lustrous, 3-3.5 mm. long, 1.8-2.6 mm. wide. Persicaria orientalis (L.) Spach.

A nat. of Eur. that is cult. in e. U. S. where it escapes frequently to wet habitats, rare in e. Tex. and Okla. (Waterfall).

\section{Polygonum densiflorum Meisn. Fig. 411.}

Perennial; stems erect, branched, usually $7 \mathrm{~mm}$. or more wide at base, usually glabrous, 6-20 dm. high; leaf blades lanceolate, mostly glabrous, $5-25 \mathrm{~cm}$. long, 2-5 cm. wide; ocreae ciliate or eciliate, brittle, longer than wide; peduncles occasionally glandular or slightly pubescent; racemes numerous, long, often appearing compound, mostly erect; calyx whitish to whitish-pink, 5-parted, 2.3-3.2 $\mathrm{mm}$. long; styles 2; achene lenticular, turgid, oval in cross section, lustrous, darkbrown to black, 1.9-2.5 mm. long. Persicaria densiflora (Meisn.) Moldenke.

Wet areas (often in water) along the Coastal Plain and inland to Okla. (Haskell and Washington cos.), June-Nov.; infrequent but throughout e. U.S. and southw.

\section{Polygonum punctatum Ell. Perennial or Water Smartweed. Fig. 412.}

Aquatic to amphibious perennial, rarely behaving as an annual; stems $3-10 \mathrm{dm}$. tall, erect or decumbent at base, rooting at nodes, simple or much-branched, green above, reddish below, slightly swollen above nodes, glabrous or often glandularpunctate; leaves lanceolate to ovate-lanceolate, acuminate, cuneate at base, 5-15 $\mathrm{cm}$. long, 5-20 mm. wide, glabrous except on veins; petioles short; ocreae cylindric, 9-17 mm. high, membranous, expanding with nodes, at length splitting, scabrous, glandular-dotted, truncate above and bristly-ciliate; flowers in elongate somewhat interrupted spikes, the pedicels glabrous, exserted; sheathing bract narrowly funnelform, truncate, entire or rarely sparsely ciliate, glandular-dotted; perianth green, less than $3 \mathrm{~mm}$. long, 5-parted to below middle, conspicuously glandular-punctate, green to greenish white, jointed to pedicels; stamens 6 to 8 inserted in sinuses or 1 to 3 inserted on lower half of tube, the green glands evident in young fresh material but becoming obsolete in age; style 2- or 3-cleft; stigmas capitate; achene lenticular or trigonous, $1.8-3 \mathrm{~mm}$. long, microscopically roughened, dark-brown or black and shining. Persicaria punctata (Ell.) Small.

In shallow water in marshes, ponds and ditches, in mud of floodplain woods, cienegas and wet fields, in e. Tex., throughout Okla., N.M. (Dona Ana, Grant and Luna cos.) and Ariz. (Navajo and Coconino, s. to Cochise, Santa Cruz and Pima cos.), year around; throughout N.A. to S.A.

Often confused with $P$. Hydropiper which has dull achenes and nodding racemes.

\section{Polygonum Hydropiper L. Water smartweed. Fig. 413.}

Annual or perennial; stems ascending, glabrous or nearly so, green, 1-10 dm. high; leaf blades lanceolate, punctate, 3-16 cm. long, 5-20 mm. wide; ocreae 2 to 4 times as long as wide, ciliate, the bristles usually less than $6 \mathrm{~mm}$. long; 


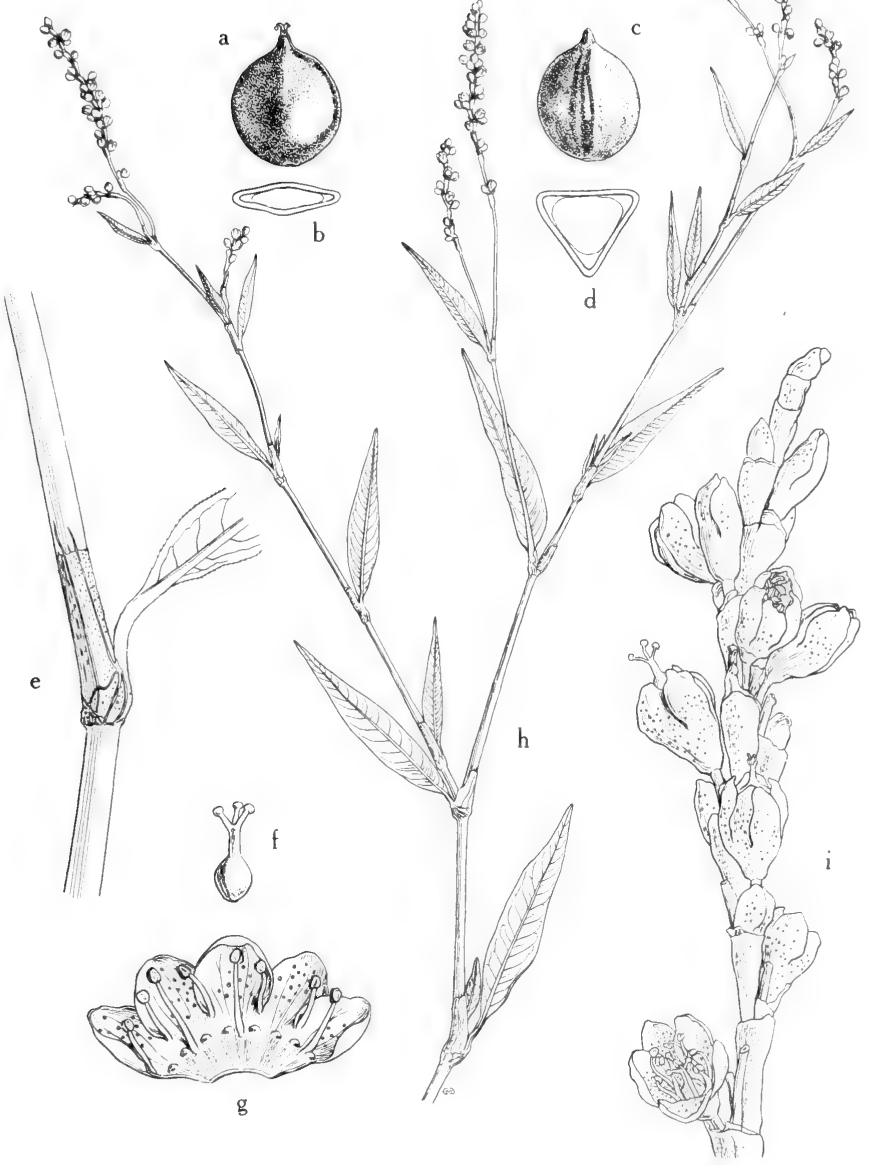

Fig. 412: Polygonum punctatum: a and b, achene, lenticular type (cross section), x 5; c and d, achene, trigonous type (cross section), x 5; e, stipular leaf sheath, glandular-dotted and bristly-ciliate, x 2 ; f, pistil, x 6 ; g, perianth, spread open, showing the small glands of the disk and stamen insertion on two levels, $\times 6$; habit, showing the nearly flat acuminate leaves and the somewhat interrupted spikes, x $2 \%$, ipper part of spike, showing the gland-dotted perianth and the funnelform sheathing bracts, $x$ 4. (From Mason, Fig. 200). 


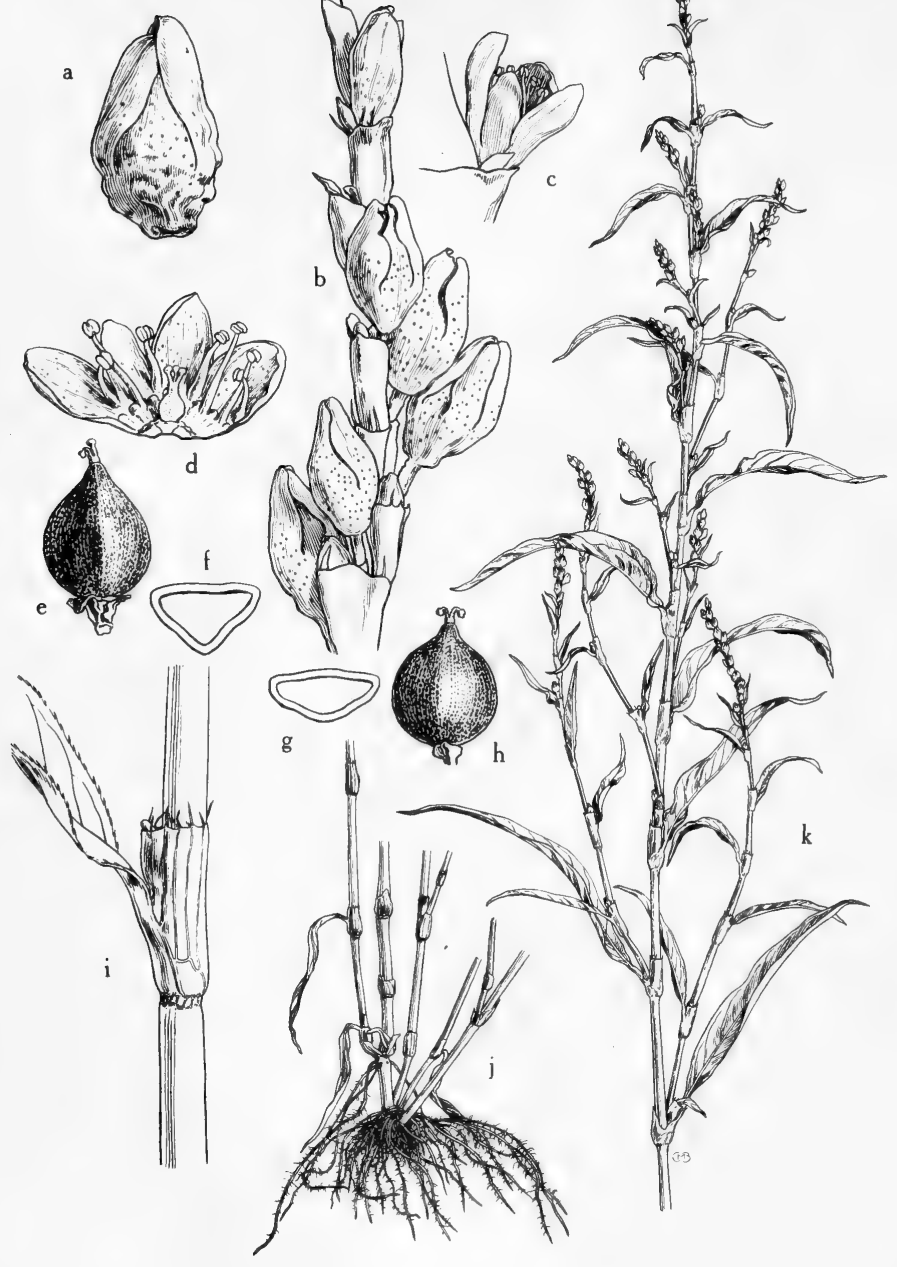

Fig. 413: Polygonum Hydropiper: a, perianth enclosing mature fruit, $x$ 6; b, tip of spike, showing the glandular-punctate flowers and the funnelform ciliate sheathing bracts, $x$ 4; c, young flower, $x$ 6; d, opened perianth, showing the glands of the disk and the longer filaments inserted between them, x 6; e, mature achene, trigonous type, x 6; $f$, mature achene, trigonous type (cross section), x 6; g, mature achene, semilenticular type (cross section), x 6; h, mature achene, semilenticular type, $x \quad 6 ; i$, stipular leaf sheath, showing coarsely ciliate apex, x $2 \frac{1}{2} ; \mathrm{j}$, habit, basal part of plant, showing the roots and the stems swollen above the nodes, $\mathrm{x} \% \varsigma ; \mathrm{k}$, habit, upper part of plant, showing the successively smaller leaves and the variable spikes, $x 2 / 5$. (From Mason, Fig. 201). 


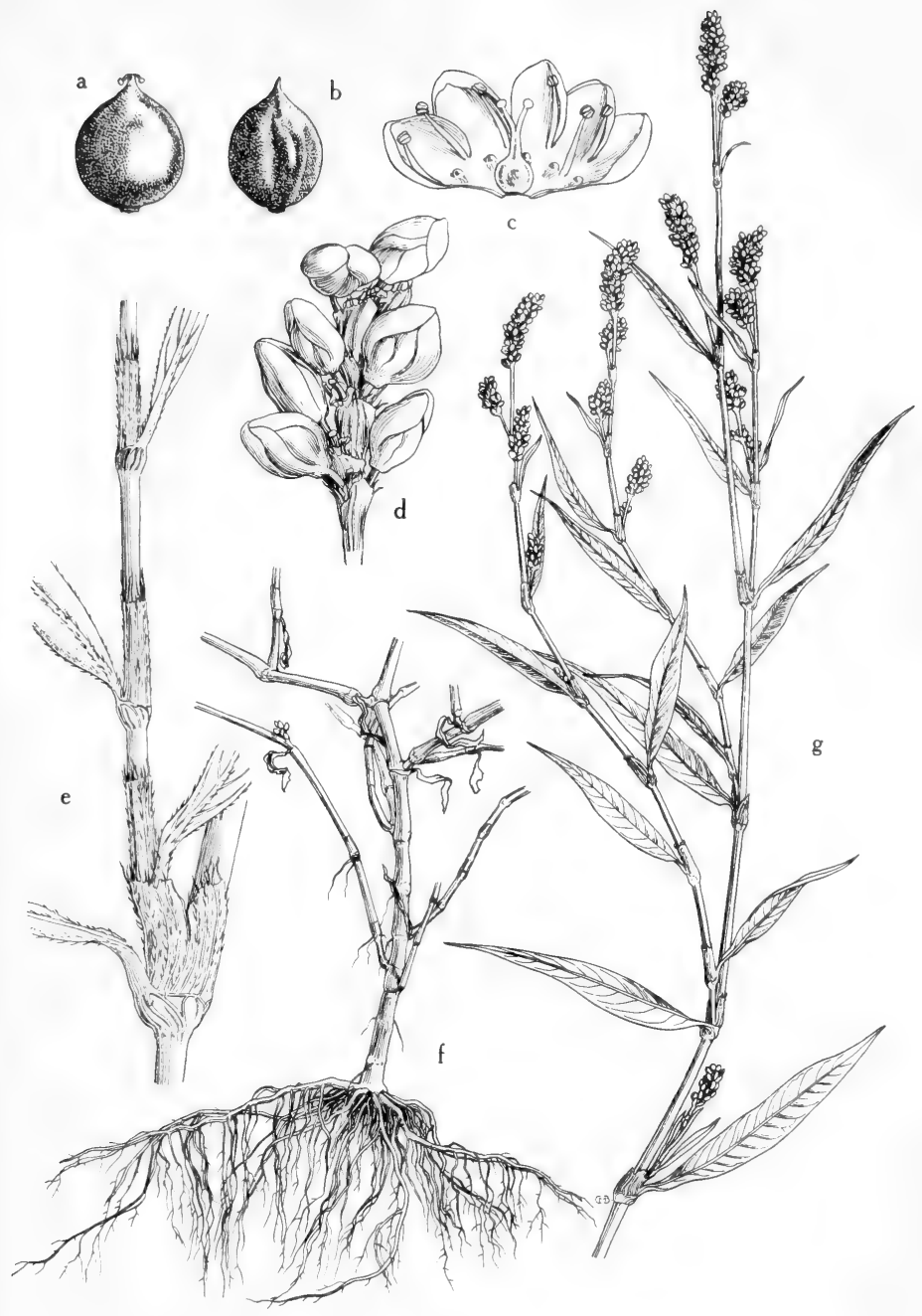

Fig. 414: Polygonum Persicaria: a, mature achene, lenticular, x 6; b, mature achene, trigonous type, $x$ 6; c, perianth, spread open, showing stamens inserted irregularly, $x$ 8; d, tip of spike, showing flowers and ciliate sheathing bracts, $\mathrm{x} 4$; e, stipular leaf sheaths, strigose, apices bristly-ciliate, $\times 1 \frac{1}{2} ; \mathrm{f}$, habit, basal part of plant, showing some roots at nodes, $\mathrm{x} 24 ; \mathrm{g}$, habit, showing the flat, lanceolate leaves and the inflorescence of stout densely flowered spikes, x $2 / 5$. (From Mason, Fig. 203). 
peduncles usually glabrous, glandular; racemes numerous, moniliform, commonly nodding or drooping; calyx yellow-glandular, green or greenish-white (pink at tip on young buds), $2.5-4.1 \mathrm{~mm}$. long in fruit; stamens included; styles usually 3; achenes dark-brown or black, dull, minutely pitted, mostly trigonous, $2-3.3 \mathrm{~mm}$. long. Persicaria Hydropiper (L.) Opiz.

Wet meadows, in water of streams and pasturelands, in Okla. (Delaware Co.) and mostly in e. Tex., June-Dec.; throughout N.A. and also parts of Euras.

Similar to and often confused with $P$. punctatum.

\section{Polygonum Persicaria L. Lady's thumb, moco de guajolote. Fig. 414.}

Erect or decumbent amphibious annual, rooting at nodes, of ten in large clumps; stems $2-9 \mathrm{dm}$. tall, green or marked with red, diffusely branched or occasionally simple and erect, glabrous and at length swollen at nodes; leaves lanceolate to linear-lanceolate, $3-15 \mathrm{~cm}$. long, 5-18 $\mathrm{mm}$. wide, acuminate, tapering to the short petiole, sparsely strigose to nearly glabrous, sometimes glandular-dotted; stipular sheaths extending 1-2 cm. beyond junction of petiole, strigose, the apex truncate and bristly-ciliate; inflorescence of a few short erect stout densely flowered spikes, $8-25 \mathrm{~mm}$. long, these on tips of terminal and lateral branches; sheathing bracts membranous, ciliate; perianth petaloid, $2.2-3.2 \mathrm{~mm}$. long, glandless, deepdull-rose to white, 5-parted to near middle, the base lined with a 5-lobed yellowish green glandular disk; stamens 6, some inserted in the sinuses and 1 to 3 between the glands of the disk; style short, 2- or 3-branched; stigmas capitate; achene lenticular to trigonous, microscopically pitted, dark-brown or black and shining, 2-2.7 mm. long. Persicaria vulgaris Webb. \& Moq.

In marshes, boggy areas, in shallow water and on edge of ponds, lakes and streams, often in disturbed areas, throughout Tex., Okla. (Alfalfa, Murray and Adair cos.), N. M. (widespread) and Ariz. (Navajo, Coconino, Yavapai, Cochise and Mohave cos.), June-Dec.; introd. from Eur. and now throughout N. A.

Similar to and often confused with $P$. hydropiperoides.

\section{Polygonum hydropiperoides Michx. WATERPEPPER.}

Herbaceous annual or perennial, subglabrous to strongly pubescent; stem to $2 \mathrm{~m}$. long, mostly much less, usually somewhat decumbent below and tending to root freely at the nodes; leaves numerous, only slightly reduced upward, shortpetiolate or the upper ones subsessile, narrowly to broadly lanceolate or oblonglanceolate, 5-24 cm. long, to $6 \mathrm{~cm}$. wide, acute to acuminate, glabrous to strongly strigose, acute at base; ocreae 1-2 cm. long, ciliate, strigose and bristly-ciliate; inflorescence of 2 to numerous slender-tapering often interrupted spikelike racemes mostly over $4 \mathrm{~cm}$. long, on a strigose to glabrous peduncle; perianth greenish to white or pinkish, $2.5-3 \mathrm{~mm}$. long, glabrous externally on the exposed area, without glands, 5-lobed for slightly more than half the length with the oblong segments subequal and the inner ones sometimes slightly glandular; stamens 8 , included; style 3 , connate about half their length, about $0.5 \mathrm{~mm}$. long; achene dark-brown to black, smooth and shining, triquetrous (the faces flat), $1.5-3 \mathrm{~mm}$. long.

In marshes, wet meadows, in and on edge of water of streams, ponds and lakes, sometimes forming mats in streams, occurring as one or more variants throughout Tex., Okla., N.M. and Ariz., Apr.-Nov.; Que. to B.C., s. to S.A.

1. Hairs of the ocreae long and spreading, enlarged at base, not adnate; mostly along the Gulf Coast, extending into southeastern Oklahoma.

1. Hairs of the ocreae erect and appressed, adnate at base (2) 


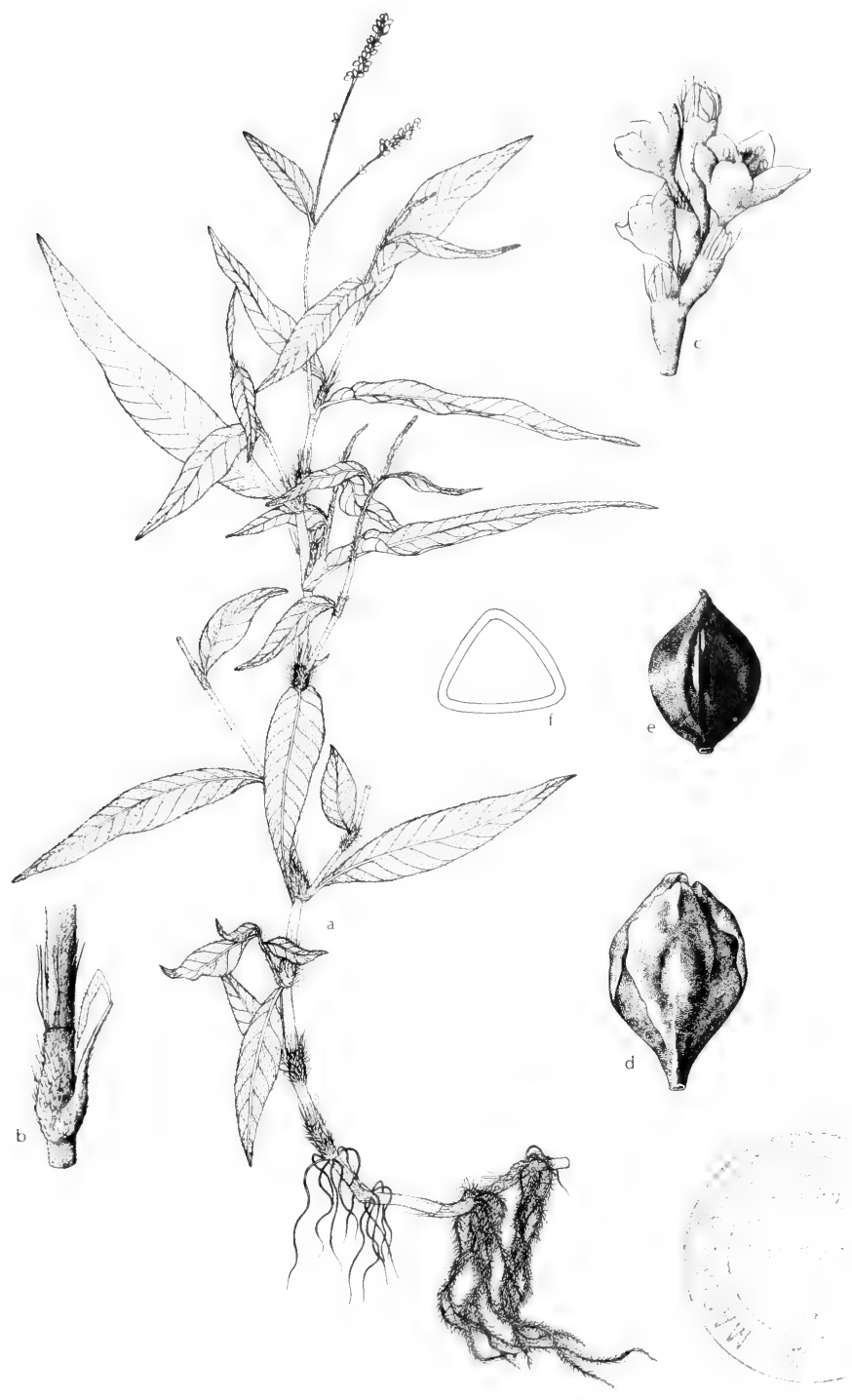

Fig. 415: Polygonum hydropiperoides var. setaceum: a, habit, $x$ 1/4; b, ocrea, x 1; c, part of flowering spike, x 3 ; d, perianth enclosing mature fruit, $\mathrm{x} 8$; e, achene, $\mathrm{x} 8$; f, cross section of achene, $x$ 8. (Courtesy of R. K. Godfrey). 


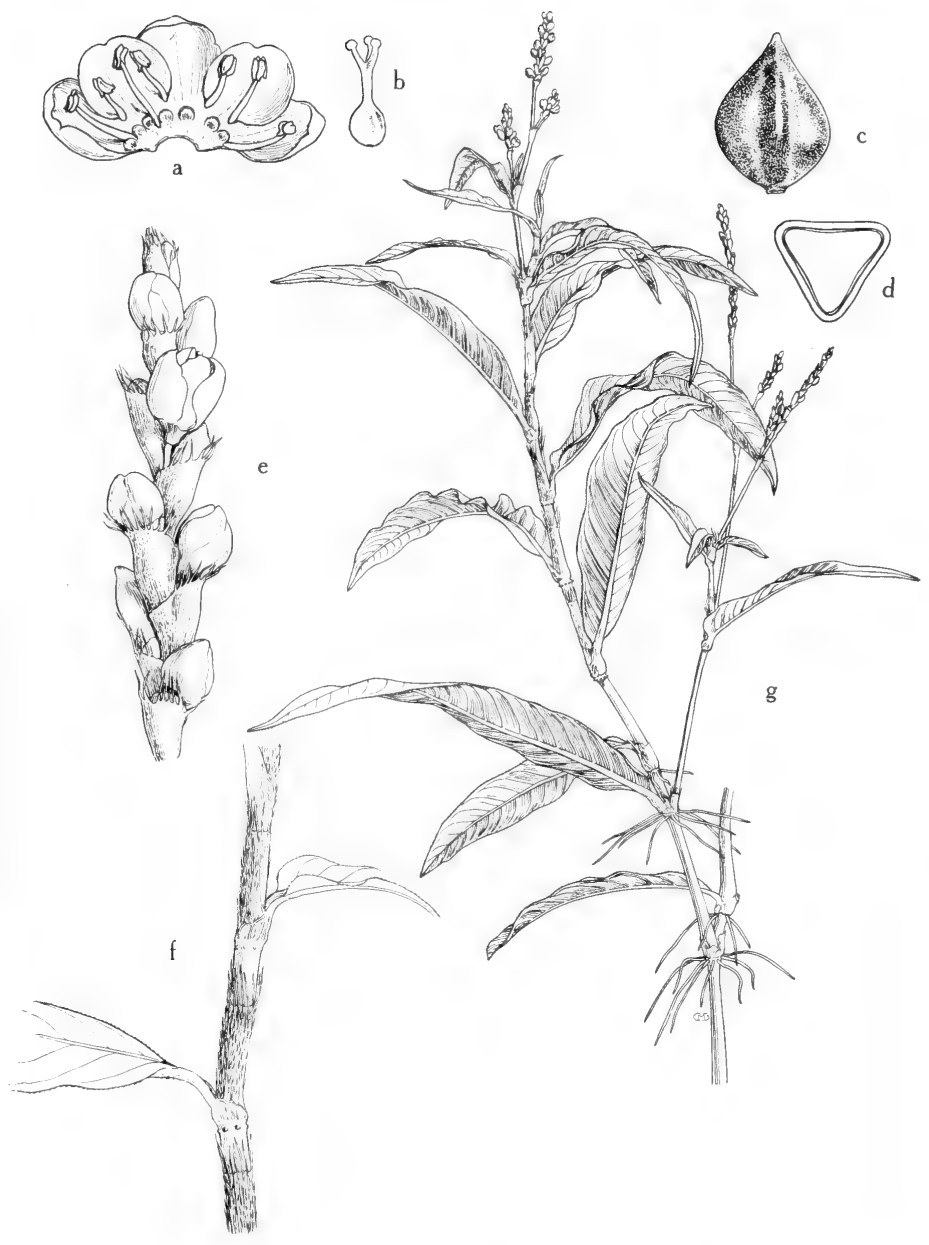

Fig. 416: Polygonum hydropiperoides var. hydropiperoides: a, perianth, spread open, showing irregular stamen insertion, x 6; b, pistil, x 6; c, mature achene, x 8; $\mathrm{d}$, mature achene (cross section), x 8; e, upper part of spike, showing the ciliate sheathing bract subtending the flowers, $x \quad 4$; , stipular leaf sheaths, coarsely strigose, ciliate at apex, x 11/; g, habit, showing roots at lower nodes and slender interrupted spikes, $\mathrm{x} \%$. (From Mason, Fig. 202). 


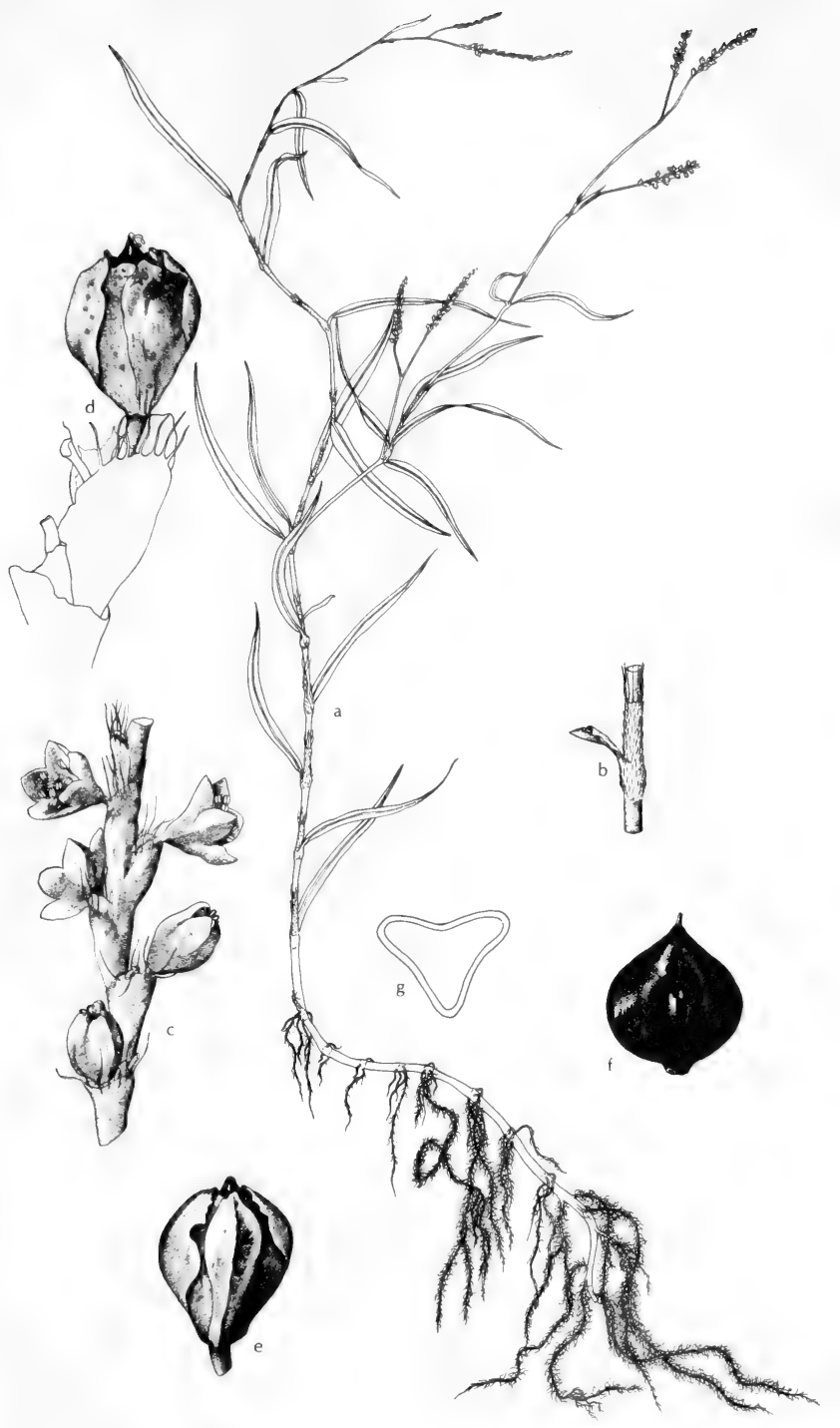

Fig. 417: Polygonum hydropiperoides var. opelousanum: a, habit, $x$ 1/4; b, ocrea, $\mathrm{x} 1$; c, part of flowering spike, $\mathrm{x} 2$; $\mathrm{d}$ and $\mathrm{e}$, two views of perianth enclosing mature fruit, $x 8$; $f$, achene, $x 8 ; g$, cross section of achene, $x 8$. (Courtesy of R. K. Godfrey). 
2(1). Mature achenes included in the perianth; leaves usually much more than $1 \mathrm{~cm}$. wide; distribution widespread. var. hydropiperoides.

2. Mature achenes slightly exserted from perianth; leaves rarely more than $1 \mathrm{~cm}$. wide; distribution mostly on the Gulf Coastal Plain

var. opelousanum

Var. setaceum (Baldw.) Gl. [P. setaceum Baldw., Persicaria setacea (Baldw.) Small]. Fig. 415.

Var. hydropiperoides [Persicaria hydropiperoides (Michx.) Small]. Fig. 416.

Var. opelousanum (Ridd.) Stone [P. opelousanum Ridd., Persicaria hydropiperoides var. opelousana (Ridd.) J. S. Wils.] Fig. 417.

\section{Fam. 52. Chenopodiaceae Vent.}

\section{Goosefoot FAMiLY}

Herbaceous weedy plants, glabrous or pubescent, with inconspicuous flowers; stems more or less succulent, often articulate; leaves opposite or alternate with no stipules nor scarious bracts, sessile or petiolate; blades flat, broad or often succulent and cylindrical or subterete, sometimes reduced to scales, entire, dentate or lobed; flowers perfect, unisexual or polygamous, usually regular, minute, usually green, with the free perianth imbricated in the bud, usually solitary in small cymose glomerules that are spicate, axillary, paniculate or cymose, or flowers axillary and solitary, sometimes arranged in terminal strobiles or sunken in depressions in the stem; stamens as many as lobes of the flower or occasionally fewer and inserted opposite them or on their bases; ovary superior, 1-locular, becoming a 1-seeded thin utricle or rarely an achene; styles or stigmas 2 , rarely 3 to 5; perianth simple, persistent, mostly enclosing the fruit; embryo coiled into a ring around the mealy endosperm (if any is present) or conduplicate or spiraled.

About 100 genera and 1,400 species, world-wide, many weeds.

Similarly to the amaranths, most of our chenopods are found in weedy areas, commonly called "wastelands," the reasons being mainly because they are often poorly drained, subject to flooding and are often saline or alkaline soils. Because of this, it is very possible that we should have included more of these species. However, since we have based our treatment on factual evidence instead of on speculation it must stand as is.

1. Stems jointed; leaves reduced to small alternate or opposite scales; flowers sessile, borne in the depressions of the joints of fleshy spikes or along the stem (2)

1. Stems not joined; leaves not scalelike but sometimes linear (3)

2(1). Branches and leaves opposite; seed pubescent; embryo conduplicate; endosperm lacking..............................................................1. Salicornia

2. Branches and leaves alternate; seed smooth; embryo partially annular, surrounding an abundant endosperm. 2. Allenrolfea

3(1). Bracts and leaves strongly spinulose at the tips; flowers perfect; fruiting perianth segments broadly winged transversely...................3. Salsola

3. Bracts and leaves not spinulose, the spines (if present) cauline in origin; fruiting perianth segments usually not transversely winged, if so the flowers in part imperfect (4)

4(3). Leaves opposite; perianth segments strongly overlapping; plants rhizomatous 4. Nitrophila

4. Leaves all or mainly alternate; perianth segments rarely overlapping; plants very rarely rhizomatous (5) 
5(4). Spinose-branched shrubs with linear semiterete leaves; embryo spirally coiled; endosperm lacking.......................................5. Sarcobatus

5. Herbs or shrubs, if shrubby and at all spinose with flattened leaves and with an annular embryo surrounding the endosperm (6)

6(5). Leaves (present at anthesis) linear to very narrowly lanceolate, entire, densely hairy, grayish to rufous; embryo annular, surrounding the endosperm (7)

6. Leaves at anthesis either broader than very narrowly lanceolate or toothed, or not grayish-hairy; embryo sometimes spiral (8)

7(6). Annual; some or all of the perianth segments in fruit bearing either a dorsal tubercle or a straight hooked spine........................6. Bassia

7. Perennial; perianth segments neither tubercled nor spinose, ultimately horizontally winged.

7. Kochia

8(6). Embryo spirally coiled; endosperm scant or lacking; leaves linear and more or less terete; flowers all axillary, borne singly or in clusters of 2 to 5 along the main stem or in lateral spikes; perianth segments in fruit commonly transversely corrugate or corniculate........8. Suaeda

8. Embryo annular, usually surrounding a copious endosperm; flowers (at least in part) usually in crowded bracteate to ebracteate spikes or panicles; perianth segments usually not as above or sometimes wanting (9)

9(8). Flowers imperfect, the pistillate naked or with a greatly reduced perianth but each subtended and enclosed by 2 accrescent sepaloid bracteoles, the staminate flowers ebracteate and with a 3- to 5-lobed perianth (10)

9. Flowers mostly perfect and with a regular 3- to 5-lobed perianth (11)

10(9). Bractlets of the pistillate flowers laterally compressed, narrowly crenulatewinged dorsally, ovate in outline, strongly bidentate at the tip; annual with orbicular to rhombic-ovate dentate leaves.

9. Suckleya

10. Bractlets of the pistillate flowers dorsiventrally compressed, not dorsally winged; perennials or annuals with multiform leaves.

10. Atriplex

11(9). Annual; perianth segments not winged in fruit but sometimes keeled....... 11. Chenopodium

11. Perennial; perianth segments becoming carinate and horizontally winged in fruit. 7. Kochia

\section{Salicornia L. Glasswort. Saladilla}

Erect to spreading or prostrate annual or perennial herbs or subshrubs, often suffrutescent and succulent; stems much-branched, glabrous, fleshy, with opposite articulate branches, the joints dilated at the apex into a short sheath; leaves scalelike, opposite; flowers perfect or polygamous, sunk in the cavities of the internodes, 3 to 7 together on opposite sides of the joints, partly crowded by the sheathing fleshy bracts, the flowering joints forming cylindric terminal spikes, the flowers usually connate and adnate to the joints; perianth obpyramidal, fleshy, with a 3- or 4-toothed or truncate border, spongiose in fruit; stamens 1 or 2, the anthers exserted and didymous, the filaments filiform or subulate; style lacerate above or ending in 2 to 4 subulate stigmas; ovule subsessile; utricle included in the perianth, ovoid or oblong, the pericarp membranaceous, irregular dehiscent; seed erect, oblong or ellipsoid, compressed, covered with short or long straight or curved hairs; endosperm none; embryo conduplicate; radicle inferior.

About 35 species in temperate and tropical regions of both hemispheres. 
Waterfowl, such as geese and ducks, feed on the fleshy branches and the seedbearing tips of the inflorescences.

1. Stem annual; middle flowers higher than the lateral ones; seed $1.5-2 \mathrm{~mm}$. long.

1. S. Bigelovii.

1. Stem perennial with prolonged subligneous depressed stems and rhizomes; flowers nearly equal in height (2)

2(1). Primary branches of stems prostrate, rooting freely, the erect or ascending flowering branches usually simple and slender; spikes $2.5-3 \mathrm{~mm}$. thick

2. $S$. virginica.

2. Primary branches erect or decumbent, not rooting, usually much-branched, the branches stout; spikes 4-5 $\mathrm{mm}$. thick.

3. S. utahensis.

\section{Salicornia Bigelovii Torr. Fig. 418.}

Annual herb, stout and succulent; stems erect, 1-6 dm. tall, green, with few to many stout spreading or ascending branches, the joints 7-25 $\mathrm{mm}$. long and 2-3 $\mathrm{mm}$. thick; sheaths 2-lobed, the lobes acutely mucronate, 2-4 mm. long, ovate to triangular-ovate, acuminate, at length spreading; spikes obtuse, $2-12 \mathrm{~cm}$. long, 4-6 mm. thick, the joints 2-3.5 mm. long and 4.5-6 mm. thick; flowers 3 in each group; lateral flowers contiguous below the acute lower angle of the central one; middle flower somewhat higher than the lateral ones, reaching very nearly to the edge of the joint; seed nearly black, $1.5-2 \mathrm{~mm}$. long, covered with short curved hairs.

Salt marshes and flats, edge of water on bays, along the Atl. and Gulf coasts of N.A. from N.S. to Fla. and Tex., s. to Yuc., W.I. and Bah. I.; also Calif.; Aug.-Nov.

\section{Salicornia virginica L. Fig. 419.}

Perennial succulent herb, forming extensive mats, from subligneous rhizomes freely forking in sand; stems decumbent or trailing, rooting freely at the nodes, the branches 1-7 dm. long, greenish, turning lead-colored or pale-brown; spikes 1-6 cm. long, 2.5-3 $\mathrm{mm}$. thick, mostly solitary at the tips of the ascending branches or peduncled along some axes, loosening in age, the sheaths rounded or the lobes acutish; joints $2.5-3 \mathrm{~mm}$. long, 3-4 mm. thick; flowers in groups of 3; central flower cuneate-obovate, truncate across the top, scarcely surpassing the obliquely ovate lateral ones; mature scales broader than high, broadly ovate, with prominent horizontally divergent firm margins; seed $0.7-1 \mathrm{~mm}$. long, a little longer than broad, densely covered with slender curved hairs. S. perennis sensu Standl., non Mill.

Coastal salt marshes and flats, wet sandy clay at high tide, sea coasts, s. N.H. to Fla. and Tex.; Alas. to Calif.; widely distributed in the W. I., w. Eur. and N. Afr.; Aug.-Oct., year around southw.

\section{Salicomia utahensis Tidestr. UTAH SAMPHIRE.}

Perennial herb, suffrutescent at the base; stems $1.5-3 \mathrm{dm}$. tall, solitary or clustered, erect or decumbent, not rooting, sparsely- or much-branched, the branches erect or decumbent; joints $7-18 \mathrm{~mm}$. long and $2-5 \mathrm{~mm}$. thick; scalelike leaves connate, broadly triangular, about $3 \mathrm{~mm}$. long, scarious-margined; spikes few, 1-2 cm. long, 4-5 mm. thick, on short lateral branches; flowers 3 in each cluster, subequal, of about the same height, extending nearly to the top of the joint, the bracts broader than long.

Edge of saline lakes and along shores and on islands, Ut., N.M. and Tex.

\section{Allenrolfea O. KTze. Burro WeEd}

Four species that are native to America. 

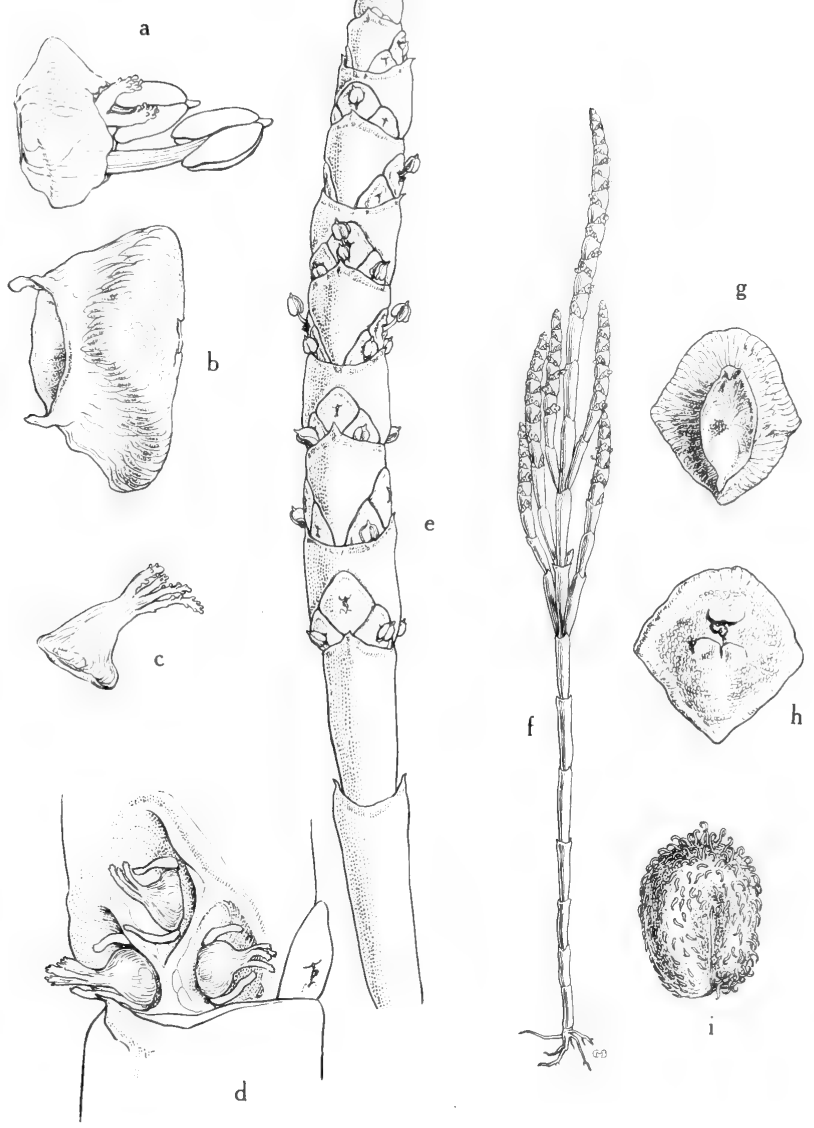

Fig. 418: Salicornia Bigelovii: a, flower, lateral view, the stigmas and stamens exserted from the slitlike orifice of calyx, $x$ 12; b, calyx, lateral view, with the mature seed removed from its cavity, x 12; c, pistil, showing variation in shape of ovary and number of style branches, $\mathrm{x} \mathrm{12;} \mathrm{d}$, triad of flowers in their cavities, the calyces removed, $\mathrm{x} 8$; e, spike, showing the angular triads of flowers and mucronate bracts, $\mathrm{x} 3 ; \mathrm{f}$, habit, the few branches appressed and erect, $x 2 \%$ g, calyx, adaxial view, showing cavity of ovary, $x 8 ; \mathrm{h}$, calyx, abaxial view, the lobes of orifice having closed around the remains of the stigmas, $\times 8$; i, mature seed with retrorse appressed hooked hairs, $x 16$. (From Mason, Fig. 217). 


\section{तs}
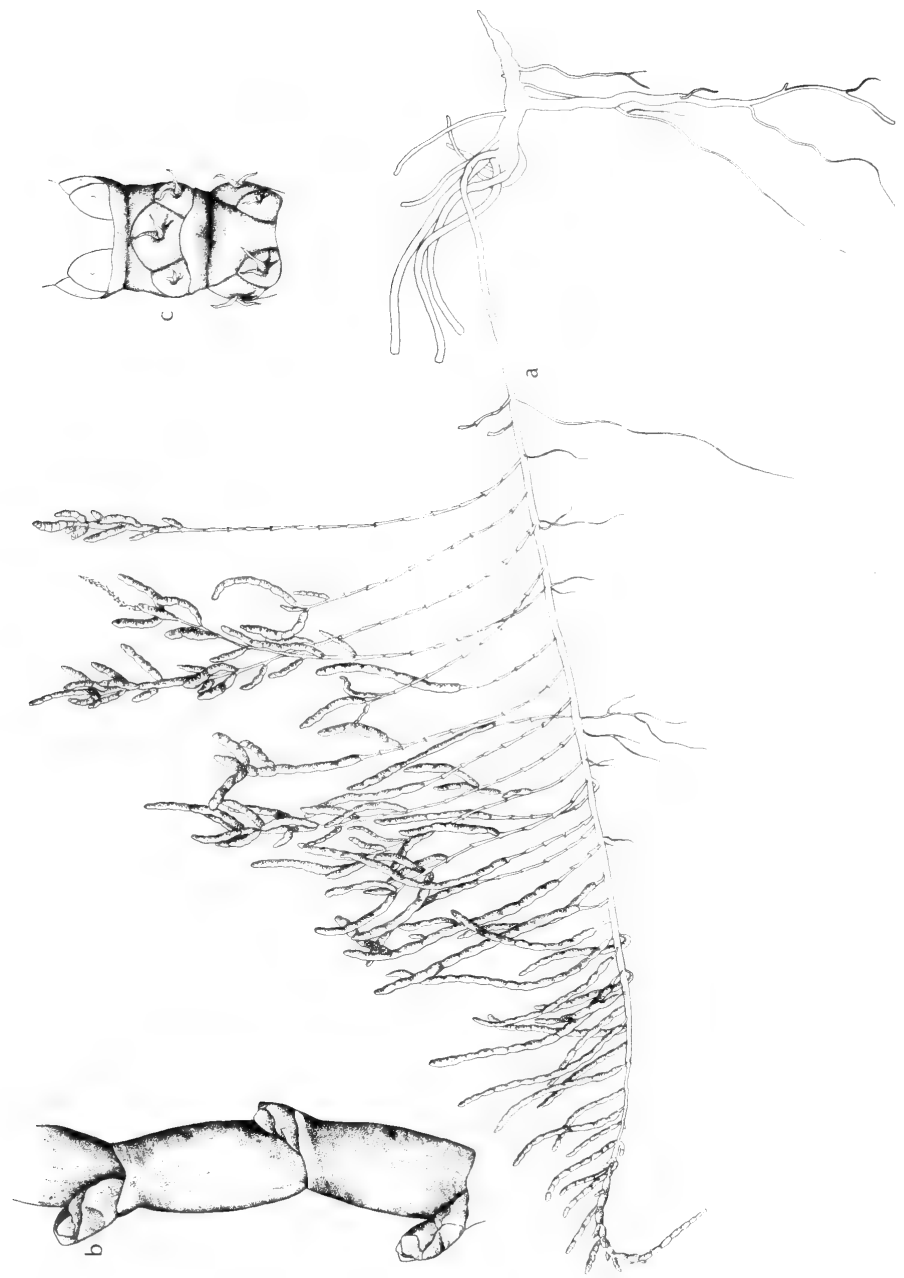

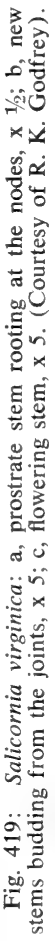


1. Allenrolfea occidentalis (Wats.) O. Ktze. PICKLE-WeEd, IOdine Bush. Fig. 420.

Perennial suffrutescent succulent glabrous shrub 3-15 dm. tall; stems alternate, green or more or less glaucous, much-branched, the articulate brariches ascending or spreading, the younger ones $1-3 \mathrm{~mm}$. in diameter, the joints $2-10$ $\mathrm{mm}$. long; leaves alternate, very short, reduced to scales, triangular, clasping, acute or acutish, soon deciduous or often nearly obsolete; spikes very numerous, 6-25 mm. long, 2.5-4 mm. thick, obtuse; flowers perfect, sessile with fleshy peltate bracts in dense cylindrical spikes; perianth much-reduced, obpyramidal, fleshy, angled, usually 4- or 5-lobed, unchanged in the fruit which it encloses; stamens 1 or 2 , the filaments exserted, the anthers broadly oblong or orbicular; stigmas 2 or 3 , short, usually distinct; utricles ovoid, compressed, enclosed in the spongy fruiting perianth; pericarp membranaceous and free; seed erect, oblong, smooth, brown or reddish-brown, about $0.6 \mathrm{~mm}$. long; embryo partly enclosing the copious endosperm; radicle inferior.

In strongly alkaline places such as floodplains and in marshes among shrubs, in w. Tex., N.M. (rather general) and Ariz. (throughout state), Mar.-Sept.; Ore. to w. Tex., Baja Calif. and Son.

\section{Salsola L.}

About 150 species cosmopolitan in distribution; mostly maritime or in saline soils.

\section{Salsola Kali L. Russian thistle, tumbleweed.}

Annual herb, much-branched from the base, becoming hemispherical; stems 3-8 $\mathrm{dm}$. tall, glabrous to pubescent or short-villous, conspicuously green and purplestriped, often tinged with red, the very stout branches ascending or spreading and glabrous to scabrous or short-villous; leaves usually alternate, linear to filiform, almost terete, sessile or clasping, pungent-tipped, usually $1.2-3 \mathrm{~cm}$. long and thick but occasionally to $7 \mathrm{~cm}$. long and more fleshy or succulent, often bluish-green, scabrous or glabrous, $1.5-2 \mathrm{~mm}$. wide, the upper leaves often shorter and broader, their bases much-thickened and indurate in age and closely enclosing the fruit; bracteal leaves usually 5-8 $\mathrm{mm}$. long; flowers perfect, sessile, small, subtended by two bractlets in addition to the leaf, solitary in the axils or sometimes several together; perianth 5-parted, the segments oblong or lanceolate, concave, becoming strongly transversely carinate and horizontally winged in the fruit, the basal portions free or connate, the apices free and usually inflexed; fruiting perianth $3-10 \mathrm{~mm}$. wide when well-developed, those of the lowest flowers often merely carinate across the back, the segments sharp-pointed; wings of the perianth segments persistent, membranaceous, whitish or pinkish, making the first 3-8 $\mathrm{mm}$. in diameter; stamens 5 or fewer, hypogynous or rarely inserted in a small disk, the filaments subulate or linear, the anthers short or elongate; stigmas 2 or rarely 3 , subulate; ovule subsessile or suspended from a long funicle; utricle flattened, broadly ovoid or orbicular, the apex concave or convex, included in the perianth; pericarp fleshy or membranaceous, free from the seed; seed horizontal, rarely inverted, erect or oblique, orbicular, $1.5-3 \mathrm{~mm}$. broad, black, shining; endosperm none; embryo spiral or cochleate-spiral, usually green. Incl. var. tenuifolia Mey., S. pestifer A. Nels.

Dry plains and valleys, in mud about drying ponds in salt marshes, alkaline floodplains, common along roadsides and in cult. fields, Euras.; perhaps nat. along the e. seacoast and rarely adv. inland; thoroughly naturalized in w. N.A. from Minn. and Sask. to Wash., Calif. and Tex.; July-Oct.

Kearney and Peebles has the following to say about this plant: "In early spring the young plants are readily eaten by livestock, and the dead plants are 


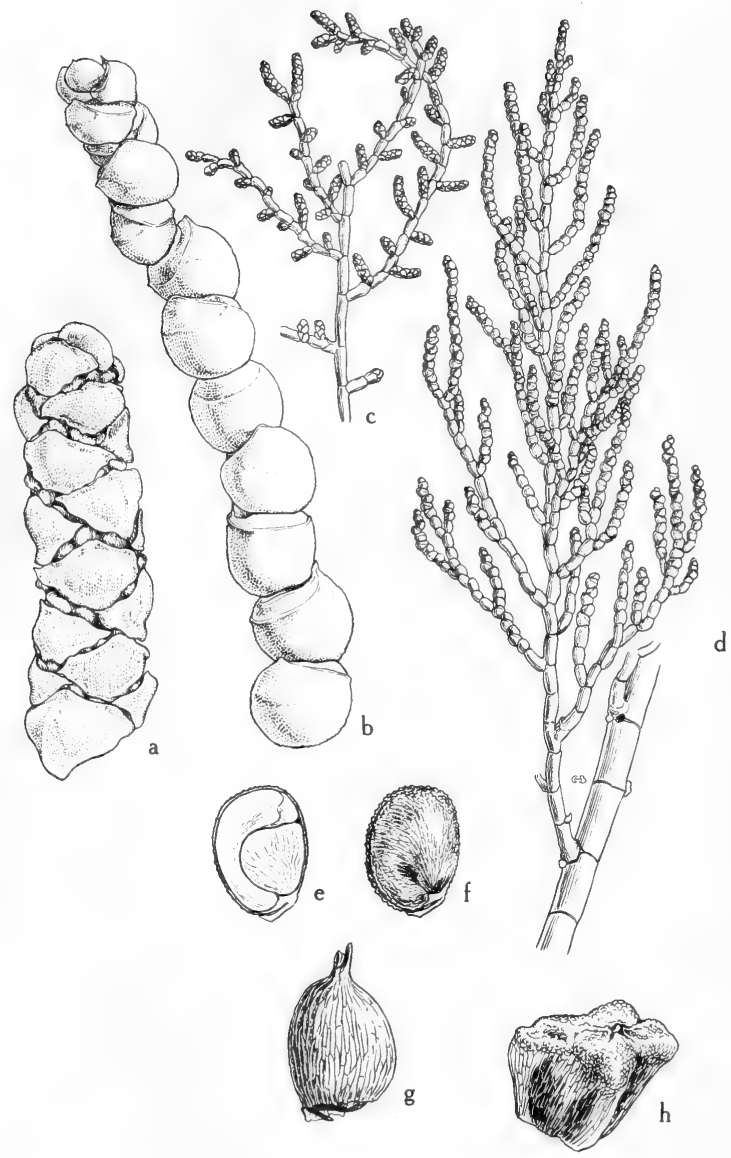

Fig. 420: Allenrolfea occidentalis: a, flowering spike, showing stamens, protruding between scales, $\times 8$; $b$, jointed stem, showing the alternate scalelike leaves, $x$ 6; $c$, inflorescence, $\mathrm{x} 4 / 5 ; \mathrm{d}$, vegetative branch, $\mathrm{x} 4 / 5$; $\mathrm{e}$, seed (longitudinal section) showing the marginal curved embryo, x 20; f, seed, x 20; g, pericarp enclosing the seed, x 20; h, spongy calyx enclosing the fruit, $x$ 16. (From Mason, Fig. 213). 


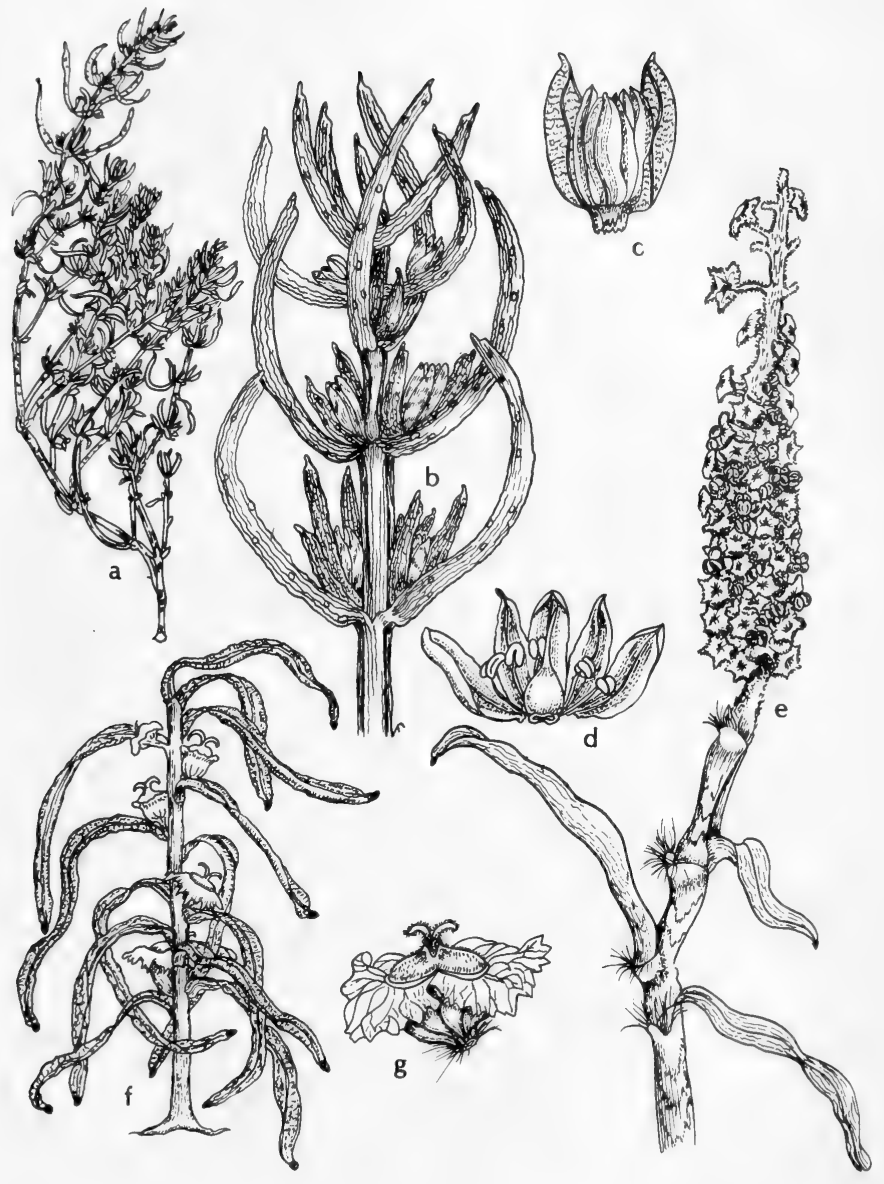

Fig. 421: a-d, Nitrophila occidentalis: a, branch of plant, $x \frac{1}{2} ; \mathrm{b}$, end of branch, x 21/2; c, flower, x 5; d, perianth opened, x 5. e-g, Sarcobatus vermiculatus: e, staminate inflorescence, $x 5$; $f$, pistillate flowers on a branch, $x 2 \frac{1}{2} ; g$, pistillate flower, $x 5$. (V. F.). 
eaten in winter after softening by rains. In case of need, good ensilage can be made from the mature plants, which otherwise are unpalatable. Hay sometimes is made of the young plants. The plant is a typical tumbleweed, breaking off at the surface of the ground when mature and piling up along fences. One of the Hopi Indian names signifies 'white man's plant.'"

Various birds and small mammals eat the seeds while hoofed browsers feed on the young plants.

\section{Nitrophila Wats.}

About 8 species in western United States, Mexico and temperate South America.

\section{Nitrophila occidentalis (Moq.) Wats. Fig. 421.}

Low, perennial, rhizomatous, glabrous herb; stems numerous, tufted, to about $3 \mathrm{dm}$. long; leaves sessile, opposite, fleshy, linear to semiterete, pungent, 1-3 $\mathrm{cm}$. long, reduced upward; flowers axillary, perfect, pink or white; perianth segments 5 to 7 , imbricate, carinate; stamens 5 , united at base into a thin yellowish disk; style longer than the subglobose ovary; stigmas 2 ; achene beaked by the persistent style, included within the connivent perianth segments, the pericarp membranous.

In moist or wettish saline or alkaline soils, in Ariz. (Pinal and Pima cos.), Apr.-May; Ore. to Ariz., Calif. and n.w. Mex.

\section{Sarcobatus NEES}

A North American genus of 1 or 2 species. Known to be toxic to sheep.

1. Sarcobatus vermiculatus (Hook.) Torr. BlACK GREASEwOOD, CHICO. Fig. 421.

Perennial shrub; stems 3-30 dm. tall, erect, much-branched; branches rigidly stout, becoming grayish, the younger ones yellow-white, glabrous or pubescent with short white branched hairs, the ultimate branchlets stout and spinose; leaves linear to linear-filiform, 1-4 cm. long, entire, fleshy, glabrous or sparsely stellatepubescent, obtuse or acute at the apex, narrowed at the base, the lower leaves of the branchlets opposite and often shorter than the others; staminate flowers in terminal catkinlike spikes 7-30 $\mathrm{mm}$. long; perianth lacking but each flower subtended by a peltate stipitate bract, with 3 or less stamens per flower; scales rhombicorbicular, sometimes abruptly acuminate, sometimes tinged with red, glabrous or pubescent; pistillate flowers sessile, solitary or 2 together in the axils of the leaves, with a perianth, this margined by narrow borders which (in fruit) develop into broad membranaceous horizontal wings $6-12 \mathrm{~mm}$. wide, sometimes tinged with red, the axis of the fertile inflorescence often prolonged and bearing 1 to 8 staminate flowers; perianth of the fertile flowers compressed, turbinate, confluent with the ovary; stigmas 2, subulate, recurved; fruit coriaceous, winged at the middle, the broad wing scarious, veined and crenulate, the lower part of the fruit turbinate, the upper part conical, minutely stellate-pubescent (at least when young), the body 4-5 $\mathrm{mm}$. long and 2.5-3.5 $\mathrm{mm}$. broad; seed erect, orbicular; embryo spirally coiled; endosperm none.

Flat ground, barren or alkaline soils, salt marshes, w. Tex., N.M. (generally distributed) and Ariz. (Apache, Navajo and Coconino, s. to Pinal and Maricopa cos.), May-July; w. N.D. to Alta. and Sask., s. to Tex., Colo., N.M., Ariz. and Calif.

\section{Bassia All. Smother-Weed}

About 10 species that are native to the Old World. 

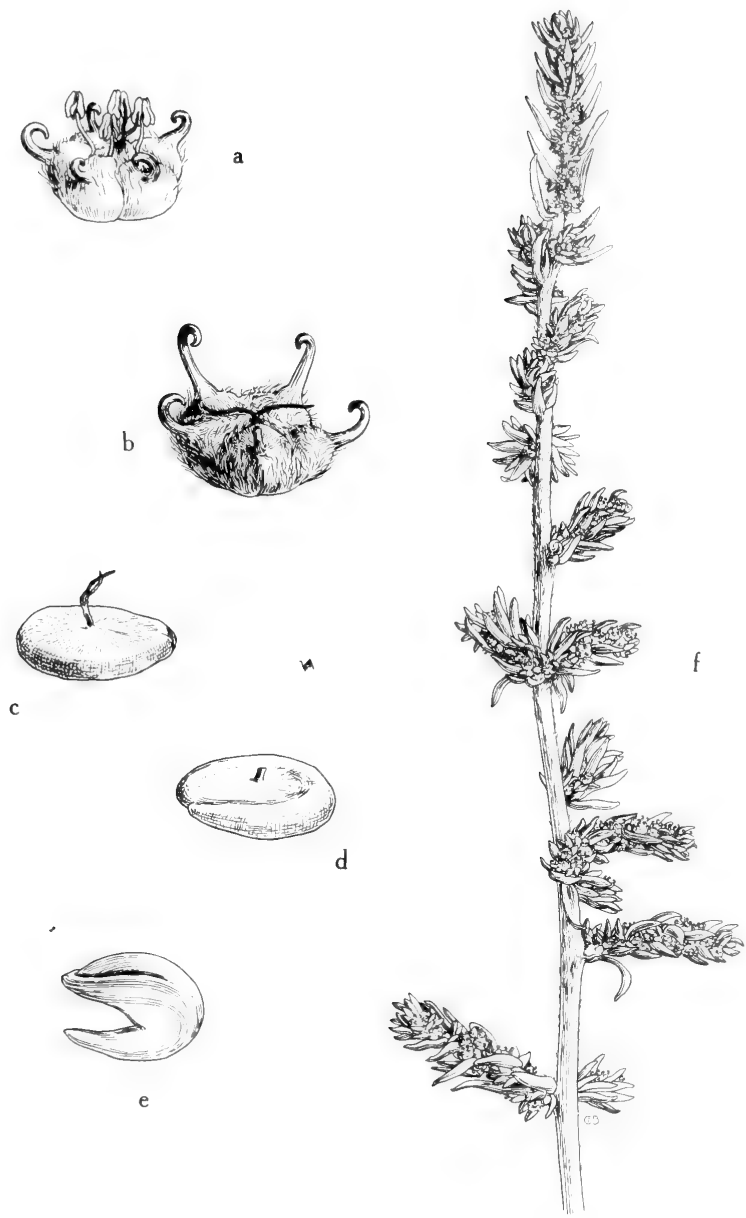

Fig. 422: Bassia hyssopifolia: a, flower, the broadly ovate sepals armed with hooked spines, $x$ 8; b, mature fruit containing a single horizontally placed seed, $x$ 8; $c$ and $d$, mature seeds, x 8; e, curved embryo, x 8; f, stem and inflorescences, x 1. (From Mason, Fig. 216). 


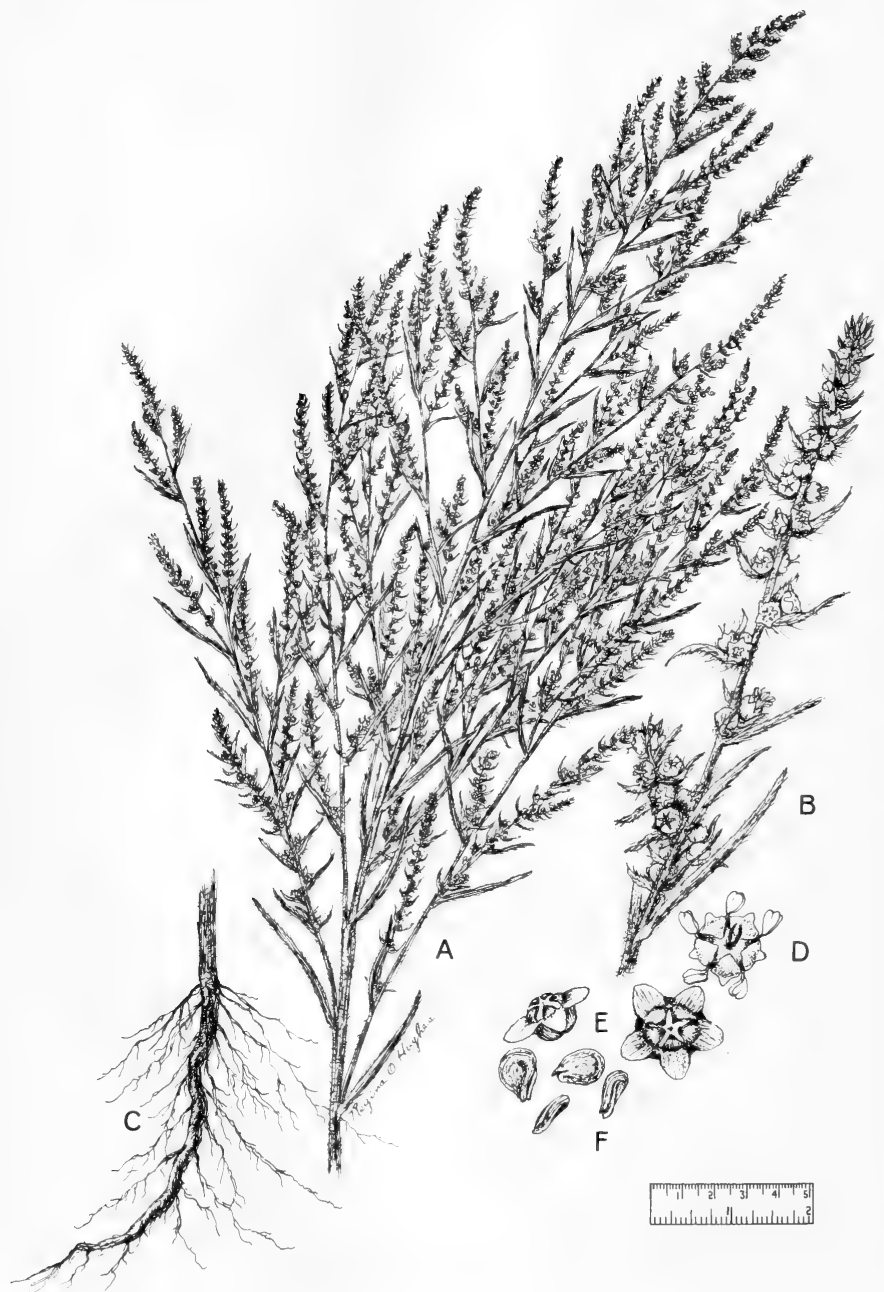

Fig. 422A: Kochia scoparia: A, branch of plant, x 1/2; B, magnified branchlet, showing different flowers at different stages, $x 2 \frac{1}{2} ; \mathrm{C}$, rootstock, $\mathrm{x} 1 \frac{1}{2} ; \mathrm{D}$, flower, $\mathrm{x} 5$; E, fruits, x 5; F, seeds, x 6. (From Reed, Selected Weeds of the United States, Fig. 66). 


\section{Bassia hyssopifolia (Pall.) O. Ktze. Fig. 422.}

Annual herb; stems erect, 2-5 dm. tall, much-branched from the base, tomentose and villous, the branches terete or angulate; leaves alternate, numerous, sessile, linear to oblanceolate or narrowly oblong, obtuse to acute, $1-4 \mathrm{~cm}$. long, often succulent, entire, reduced above, green or grayish-green, silky-villous to appressed-pilose; spikes numerous, about $4 \mathrm{~mm}$. in diameter; flowers perfect, about $1 \mathrm{~mm}$. broad; perianth 5-lobed, densely woolly, the teeth becoming prolonged into red hooked spines in the fruit; stamens 5, exserted, hypogynous; ovary ovoid, attenuate to a short or elongate style, with 2 or 3 capillary stigmas, the ovule subsessile; utricle with a transverse wing, enclosed in the perianth, membranaceous or indurate at the apex, indehiscent, the pericarp free from the seed; seed grayish-brown, dull, horizontal or nearly vertical; embryo annular, enclosing the scanty endosperm; radicle centrifugal. Echinopsilon hyssopifolius (Pall.) Moq.

Waste places, especially in wettish alkaline soils, established in irrigated regions, in w. Tex., N.M. (general) and Ariz. (Maricopa, Navajo, Coconino, Mohave and Yuma cos.), May-Sept.; nat. of Euras., introd. from w. Asia; Mass. to N. Y., w. to Pac. States; Trans-Pecos Tex., s. N.M. and Ariz., to n. Mex.

\section{Kochia Roth SUMmer-CYPRESS}

Annual or perennial herbs or low shrubs, woody at the base; stems erect, much-branched often to form pyramidal or rounded bushes, pubescent or rarely glabrous; leaves alternate or opposite, linear, often terete, entire, fascicled; flowers mostly perfect or some pistillate only, axillary, sessile, solitary or in small glomerules, without bracts; perianth herbaceous, 5-cleft, persistent over the fruit and finally developing horizontal scarious or membranceous wings; stamens 3 to 5 , usually exserted, the filaments compressed; ovary subsessile, depressed, the stigmas 2 or rarely 3 , the styles filiform; utricle depressed-globose, with membranaceous persistent pericarp which is free from the seed; seed horizontal; embryo nearly annular, green; endosperm none

Nearly 100 species, all but one native to the Old World.

1. Annual herb; leaves petiolate, the thin blades lance-linear; calyx wings minute .. K. scoparia.

1. Perennial herb; leaves sessile, the succulent blades terete or nearly so; calyx wings large and conspicuous................................ $K$. americana.

\section{Kochia scoparia (L.) Roth. BelvederE. Fig. 422A.}

Annual herb; stems erect, much-branched, the branches erect or ascending, 3-15 dm. tall, very leafy, glabrous or short-pilose, becoming bright-red with age; leaves alternate, linear to linear-acute, 2-7 cm. long, 3-8 $\mathrm{mm}$. broad, usually prominently 3 - to 5-veined, tapering at the base to a slender petiole, those of the inflorescence smaller and without evident petioles, much-exceeding the small flower clusters, sometimes pilose-sericeous; flowers sessile, clustered in the axils of the leaflike but reduced bracts, forming short dense leafy spikes, pilose or glabrate in age; perianth $1.5-2 \mathrm{~mm}$. broad, strongly winged horizontally, the triangular wings obtuse and $0.6 \mathrm{~mm}$. long or less, not nerved; seed $1.5 \mathrm{~mm}$. in diameter. $K$. alata Bates.

A wasteland weed, in salt flats among Tamarix, rare in Tex., Okla., (Alfalfa Co.) and Ariz. (Coconino Co.), May-Aug.; nat. of Eur.; escaped from cult. in many parts of the U.S.

Var. culta Farw. MeXICAN FIRE-BUSH. This is the most common form in cultivation; grown primarily for its globular dense habit and the foliage which turns purplish-red in autum. Escaped from cult. in many areas of the U.S.

Var. subvillosa Moq., a very hairy form, collected once in Ariz. 


\section{Kochia americana Wats. Perennial summer-CYPRess.}

Perennial herb from a woody base; stems numerous, erect, $1.5-5 \mathrm{dm}$. (to 13 dm.) tall, loosely branched at or just above the base, simple above or occasionally with few erect branches, usually more or less villous-tomentose when young but soon glabrate; leaves numerous, sessile, often fascicled; blades 6-25 mm. long, terete but flattish when dry, fleshy, acutish, erect or spreading, sparsely sericeous or glabrous; flowers solitary or in 2's or 3's, white-tomentose; perianth in fruit $2 \mathrm{~mm}$. broad, the flabellate wings $2 \mathrm{~mm}$. long, distinct, membranaceous, crenulate, finely nerved; utricle glabrate; seed $2 \mathrm{~mm}$. in diameter.

Roadside alkaline plains and marshes, often in saline soils, in w. Tex., N.M. and Ariz. (Apache and Navajo cos.), May-Aug.; Wyo. and Colo. to w. Tex., n.w. N.M., Ariz. and Calif.

Var. vestita Wats., with densely and permanently sericeous-villous herbage, occurs in Ariz.

\section{Suaeda Scop. Sea Blite. Seepweed}

Annual or perennial herbs, sometimes shrubby plants, more or less fleshy; leaves alternate, narrow, usually linear or terete and relatively small; flowers perfect or polygamous, solitary or clustered in the upper axils, bracteate; perianth segments 5, keeled or narrowly winged at maturity; stamens 5 , with short filaments; ovary 1-celled, rounded or flat on the top; styles often 2; utricle compressed, surrounded by the calyx; seed horizontal or vertical; embryo coiled in a flat spiral; endosperm absent or scant.

More than 100 species of cosmopolitan distribution; mostly along sea coasts and in saline soils.

1 Perianth lobes (at least some of them) corniculate-appendaged or winged; leaves broadest at the base, ascending or spreading, those of the inflorescence ovate or ovate-lanceolate; flowers and leaves crowded 1. S. depressa.

1. Perianth lobes not appendaged nor winged, often cucullate or carinate (2)

2(1). Annuals or perhaps sometimes perennial but not suffrutescent at the base; all the perianth lobes equally carinate (3)

2. Perennials, suffrutescent at the base (4)

3(2). Seed 1-1.5 mm. broad

2. S. linearis.

3. Seed $0.8 \mathrm{~mm}$. broad or less. 3. S. mexicana.

4(2). Leaves linear to linear-spatulate, green, usually much more than $10 \mathrm{~mm}$. long....

4. S. Torreyana.

4. Leaves roundish to oblong, often reddish and glaucous, mostly less than 10 $\mathrm{mm}$. long (5)

5(4). Perianth segments deltoid, acutish; plants blackish (when dry) or purplish (when alive) 5. S. nigrescens var. glabra

5. Perianth segments obtuse; plants blue-gray. 6. S. conferta.

\section{Suaeda depressa (Pursh) Wats.}

Annual or perennial herb; stems erect to decumbent, low, simple or freely branching from the base, glabrous and glaucous, 2-10 $\mathrm{dm}$. tall or long; leaves green or glaucous, linear, semiterete, 7-40 $\mathrm{mm}$. long, often crowded, acute, usually broadest at the base, subulate; bracts $2-3 \mathrm{~mm}$. long, ovate-lanceolate, rather crowded on the branchlets; flowers crowded, 3 to 7 in each axil; spikes slender, short or elongate; perianth cleft to the middle, the lobes distinctly unequal, $1.5-2 \mathrm{~mm}$. wide at maturity, the upper 1 or 3 sepals prominently cucullate; stamens 5 ; stigmas 2 to 5 ; seed about $1 \mathrm{~mm}$. broad, slightly reticulate, black, horizontal. 
In saline or alkaline soils, on wet sandbars at edge of bays, w. Minn. and Sask., w. to Mont. and Wash., s. to Okla., Neb., Mo., Tex., Ariz. and Calif.; July-Oct.

Var. erecta Wats. Stems simple or branched at the base, strictly erect, 15-45 $\mathrm{cm}$. tall, glabrous, often glaucous; leaves $2-3 \mathrm{~cm}$. long, acute; flowering branchlets dense, their short leaves ovate-acuminate; calyx lobes somewhat unequal, with a conspicuous horizontal wing on the back.

Alkaline soils, coastal Calif. e. to the Rocky Mts. and Tex.

2. Suaeda linearis (Ell.) Moq. Fig. 423.

Annual herb; stems glabrous, erect or ascending, 2-9 dm. tall, profusely branched; leaves deep-green, not glaucous, narrowly linear, plano-convex, nearly terete, the primary ones to $5 \mathrm{~cm}$. long, those of the branches progressively shorter; spikes often elongate, usually dense; bracts 4-7 $\mathrm{mm}$. long; perianth at maturity about $2 \mathrm{~mm}$. wide, deeply cleft, the lower 4 or 2 perianth segments round on the back, the upper 1 or 3 distinctly cucullate; seed horizontal, 1-1.5 $\mathrm{mm}$. wide, smooth, shining and black.

Salt marshes, sandy coasts, Coastal Plain from Me. to Fla., w. to Tex.; W.I. and Bah. I.; Aug.-Oct.

\section{Suaeda mexicana (Standl.) Standl.}

Annual herb; stems glabrous, pale-green, 3-12 dm. tall, mostly branched at the base, the numerous branches ascending or nearly erect and elongate; leaves numerous but not crowded, linear, the lower ones $12-25 \mathrm{~mm}$. long and $1.2 \mathrm{~mm}$. broad, acuminate or attenuate, those of the inflorescence shorter; inflorescence paniculately branched, the branches erect; flowers crowded in the axils and forming spikes 4-5 mm. thick; perianth deeply cleft, the lobes 'rounded, becoming enlarged, strongly cucullate in age, the fruiting perianth $3 \mathrm{~mm}$. broad; stamens exserted; seed $0.8 \mathrm{~mm}$. in diameter, horizontal, shining, dark brownish-red.

A halophytic gypsophile, often in wet areas, w. Tex. to S.L.P.

\section{Suaeda Torreyana Wats. Quelite salado.}

Perennial shrub; stems erect, mostly glabrous, green, woody at the base, the herbaceous branches usually slender, ascending, sparsely leafy, 6-10 dm. tall; leaves green, subterete or distinctly flattened, linear to linear-spatulate, 1-3 (rarely to 4) $\mathrm{cm}$. long, 1-1.5 mm. wide, acute or slightly acuminate, those of the inflorescence much-reduced to 2-5 mm. long and abruptly mucronate or obtuse; flowers globose, 1 to 5 in each axil, about $1 \mathrm{~mm}$. broad at anthesis, the branches of the inflorescence slender but not flexuous; perianth deeply cleft, the lobes green, obtuse, closely incurved, rounded on the back and obtuse; utricle obovoidlenticular, enclosed by the perianth lobes; seed vertical or horizontal, $1-1.5 \mathrm{~mm}$. broad, dark-brown to black, shining, minutely tuberculate.

Salt marshes and alkaline soils, in mud of drying ponds, in w. Tex., N.M. (rather general) and Ariz. (Apache to Mohave, s. to Cochise, Pima and Yuma cos.), Apr.-Oct.; e. Ore. and Wyo. to Calif., s. through Nev. to Tex. and w. N.M. and Ariz.

\section{Suaeda nigrescens I. M. Johnst. var. glabra I. M. Johnst.}

Perennial shrub; stems 3-6 dm. tall, ascending, erect or decumbent, the branches all glabrous and often glaucous, the young branches rarely very sparsely pilose and pale; leaves succulent, more or less glaucous, glabrous, 3-4 mm. long and roundish; flowers in glomerules at the base of the upper leaves, barely conspicuous, subspicate; fruiting perianth glabrous, turbinate, $1.5-2 \mathrm{~mm}$. in diameter; seed black, shining, obliquely ovoid, erect or horizontal, about $1 \mathrm{~mm}$. long.

Irrigation ditches, saline plains and salt flats, N.M., Tex. and Mex. 


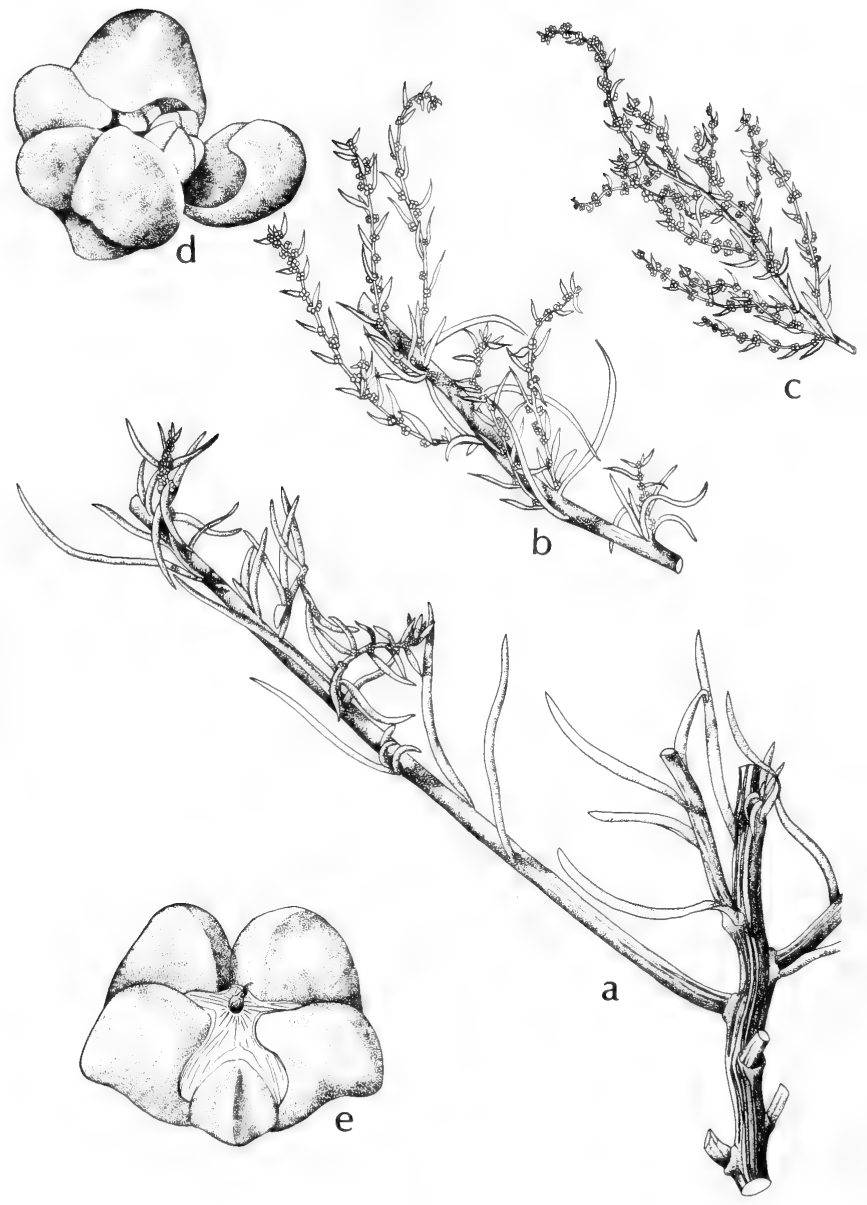

Fig. 423: Suaeda linearis: a, part of stem and branch, $\mathrm{x} 1 / 2 ; \mathrm{b}$ and $\mathrm{c}$, flowering branches, x 1/2; d, young flower, x 20; e, calyx and fruit, x 20. (Courtesy of $\mathbf{R}$. K. Godfrey). 


\section{Suaeda conferta (Small) I. M. Johnst.}

Perennial shrub; stems erect or ascending, 4-10 dm. long, the branches prostrate or spreading, forming dense tufts, very brittle, glabrous; leaves numerous, glabrous, the blades fleshy and blue-gray, mostly less than $1 \mathrm{~cm}$. long and 1-2 mm. broad, oblong; flowers solitary or clustered in the axils of the rather approximate leaves, especially numerous on the branchlets; perianth segments obtuse; seed about $1 \mathrm{~mm}$. broad.

Along the sea coast, in wettish places, Tex. and e. Mex.; W.I.

\section{Suckleya Gray}

\section{A monotypic genus of southwestern United States.}

\section{Suckleya suckleyana (Torr.) Rydb. PoIson SuckleyA.}

Annual succulent herb; stems stout, terete, diffusely branched, 2-4 dm. long, prostrate or ascending, sparingly scurfy-mealy or glabrate; leaves alternate, with petioles equaling or exceeding the blades; blades orbicular to rhombic-ovate, 1-3 $\mathrm{cm}$. long, rounded at the apex, abruptly short-cuneate at the base, repand-dentate with short triangular acute or obtuse teeth, sparsely furfuraceous when young, soon glabrate; male and female flowers on same plant, in dense clusters in the axils of nearly all the leaves; staminate flowers in upper axils, without bracts or bractlets; perianth subglobose, membranaceous, 3- or 4-parted, 2 of the segments larger than the others, spatulate, not appendaged; stamens 3 or 4 , their short filaments broad and flattened; pistillate flowers bibracteate; bracts conduplicate, ovate-rhombic and subhastate, obcompressed, carinate, connate below the middle, in fruit narrowly winged dorsally, the wings crenulate, glabrous or nearly so; with 2 short filiform stigmas; utricle enclosed by the bracts, compressed, the pericarp thinly membranaceous, free; seed ovate, compressed, orbicular, filling the cavity, $3 \mathrm{~mm}$. long, reddish-brown; embryo hippocrepiform or subannular, surrounding the copious endosperm; radicle superior.

Valleys, along streams and about playa lakes and on edge of ponds, Mont. and Colo. to Tex.; July-Aug.

Known to cause cyanide poisoning in livestock.

\section{Atriplex L. Saltbush}

Annual or perennial herbs or shrubs; stems usually furfuraceous; leaves alternate or opposite, sessile or petioled, entire, dentate to serrate or irregularly lobed or cleft; flowers solitary or clustered, axillary or in terminal spikes or panicles; staminate and pistillate flowers on the same or separate plants, either mixed in the inflorescence or the staminate flowers in axillary glomerules superior to or terminal to the pistillate axillary glomerules; staminate flowers ebracteate, with a 3- to 5-parted perianth, the obtuse segments oblong or obovate; stamens 3 to 5 , inserted on the perianth base, the filaments united at the base or distinct, the anthers 2-celled; rudimentary ovary conical or lacking; pistillate flowers each subtended by 2 bracts which enclose the fruit, distinct or united, fleshy, spongy or ligneous, the margins entire or variously indented, the backs smooth or variously appendaged, the perianth none or rarely of 1 to 5 squamellae or a 3- to 5-lobed membranaceous perianth, the stamens absent; ovary ovoid or depressed-globose; stigmas 2, subfiliform but thickened or compressed near the connate base; ovule either oblique or erect and with a short funiculus, or inverted and suspended from the end of an elongated funiculus; utricle with a membranaceous pericarp, this usually free from the seed; seed erect or inverted, rarely horizontal, the coats membranaceous to coriaceous or subcrustaceous; embryo annular around the farinaceous endosperm; radicle inferior, lateral or superior. 
About 200 species, mostly in temperate and subtropical regions; ours mostly in saline or alkaline soils in desertic regions.

The seeds of most species are eaten by various birds and small mammals, and the twigs and foliage are nibbled and browsed by rabbits, deer and antelope. Because of their tolerance to adverse conditions, the plants also provide cover for wildlife in areas often sparsely covered by other types of vegetation.

1. Tall dioecious intricate shrubs, seldom less than $1 \mathrm{~m}$. tall, the entire plant grayish-green and glaucous; leaves short-petiolate, ovate-deltoid to oblong-subquadrate, entire or merely slightly undulate, occasionally subhastate, $1.5-4 \mathrm{~cm}$. long. 1. A. lentiformis.

1. Annual or sometimes perennial monoecious herbs, rarely more than $1 \mathrm{~m}$. tall, the entire plant green to whitish, occasionally tinged (at least in part) with red; leaves various, often sinuate- or repand-dentate (2)

2(1). Perennial, the prostrate whitish stems much-branched; leaves oblong to oblong-obovate, $1-3.5 \mathrm{~cm}$. long; fruiting bracts with nerved sides, becoming red and succulent at maturity.............2. A. semibaccata.

2. Annuals, the stems erect to procumbent; leaves triangular to oblong-lanceolate, often with some hastate; fruiting bracts not nerved nor succulent at maturity (3)

3(2). Fruiting bracts ovate to broadly oval, 7-18 $\mathrm{mm}$. long, united at the base, rounded to acute at apex, entire to merely denticulate, smooth on the sides, sometimes tinged reddish........................... A. hortensis.

3. Fruiting bracts rhombic-oval to obovate or suborbicular, $2-7 \mathrm{~mm}$. long, acute to acutish at apex, dentate to denticulate, usually somewhat tuberculate on the sides, typically without a reddish tinge (4)

4(3). Petioles of lower leaves about one half as long as the blades; fruiting bracts united only at the truncate or rounded base, denticulate; radicle inferior.

4. A patula var. hastata.

4. Petioles of lower leaves much less than one half as long as blades; fruiting bracts united to near the apex, dentate; radicle superior.

5. A. argentea.

1. Atriplex lentiformis (Torr.) Wats. Quail-Brush, Lens-SCale, White-THISTle.

Erect much-branched dioecious shrub 1-3 m. tall; branches spreading, rather slender, not spinose, terete, densely furfuraceous, becoming glabrate and whitish in age; leaves short-petioled, ovate-deltoid to oblong, sometimes subhastate, mostly 15-40 $\mathrm{mm}$. long, rounded or broadly cuneate at base, obtuse to truncate at apex, rather thin, densely furfuraceous on both sides; staminate flowers in paniculate spikes, nearly naked and the branches slender, often drooping; pistillate flowers in dense paniculate spikes; fruiting bracts ovate-orbicular, 3-4 $\mathrm{mm}$. long, strongly compressed, united to above the middle, the margins finely crenulate, thin, furfuraceous.

In saline marshes and in effluent of sewage plants, in Ariz. (Coconino and Mohave, s. to Pima and Yuma cos.), July-Oct.; s. Ut. and Nev. to Ariz., Son. and Calif.

\section{Atriplex semibaccata R. Br. Australian saltbush.}

Perennial herb from a woody elongated taproot; stems prostrate, diffusely spreading from the base, 6-12 dm. long, woody below, much-branched, the slender branches terete and 3-10 dm. long, whitish, sparsely furfuraceous or glabrate; leaves numerous, alternate, short-petioled; blades oblong or obovate-oblong, 1-3.5 $\mathrm{cm}$. long, 2-9 $\mathrm{mm}$. wide, obtuse or acute, cuneate to attenuate at the base, remotely repand-dentate or the upper ones entire, thin, densely and finely whitefurfuraceous beneath, usually glabrate and green on the upper surface; flowers of 
both sexes on same plant, solitary or in small clusters in the axils, the staminate and pistillate flowers usually mixed in the same cluster or the staminate clusters in terminal glomerules; fruiting bracts sessile, red, slightly succulent, rhomboidal, acute, stipelike at the base, united for about one half, toothed at the lateral angles, 3-5 mm. long, smooth on the 3-nerved sides; seed $2 \mathrm{~mm}$. long, dark-brown; radicle lateral.

On alkaline floodplains in w. Tex., N.M. (Dona Ana and Otero cos.) and Ariz. (Graham, Maricopa, Cochise, Pima and Yuma cos.); nat. of Austral.; cult as a forage plant and becoming spontaneous in Calif. and Ariz. to s. N.M. and Tex.

The low-growing plant is a good soil-binder along irrigation ditches, it crowds out undesirable weeds, and provides forage for domestic animals, primarily sheep.

\section{Atriplex hortensis L. French Spinach, garden orache.}

Erect to somewhat decumbent monoecious annual, 6-25 dm. tall, freely branched, somewhat farinose when young but usually glabrate, greenish; leaves slender-petiolate, the lowest few opposite, all the upper ones alternate; blades ovate-triangular to broadly lanceolate, obtuse, abruptly short-cuneate to cordate or slightly hastate, entire to undulate or sinuately dentate, $5-20 \mathrm{~cm}$. long, 3-10 cm. wide; flowers in axillary or terminal panicles of mostly ebracteate spikes, the staminate mixed with the pistillate or above them, with a deeply 5- or sometimes 3-lobed perianth; pistillate flowers dimorphic (some lacking subtending bractlets, the perianth 3- to 5-lobed, the fruit flattened and the seed horizontal), the majority naked but surrounded by 2 ovate to suborbicular strongly accrescent basally connate bracts eventually $6-12 \mathrm{~mm}$. wide with their margins entire to denticulate; fruit short-stipitate, laterally compressed, with an erect seed about $2 \mathrm{~mm}$. broad; radicle inferior.

On moist seepy grassy bank of pond, in N. M. (Taos Co.), July-Sept.; nat. of Asia that is occasionally cult. as a potherb in the U. S. where it rarely escapes.

\section{Atriplex patula L. var. hastata (L.) Gray. Fig. 424.}

Annual herb; stems erect to decumbent or procumbent, 3-9 dm. long, usually much-branched, the branches slender or stout, ascending or spreading, obtusely angled, sparsely or densely furfuraceous when young, often glabrate, green or stramineous; leaves usually opposite below, the others alternate, the petioles of the lower leaves up to half as long as the blades, the upper leaves very shortpetioled; blades of the lower leaves broadly triangular to hastate or oval-hastate, $2.5-7 \mathrm{~cm}$. long and nearly as broad, acute or obtuse at the apex, truncate at the base or with a rounded sinus, the margins entire or more usually sinuate-dentate or shallowly repand-dentate, the basal lobes acute, spreading or reflexed; blades of the upper leaves hastate-oblong to lanceolate and smaller, all the blades thin or succulent, bright-green or densely furfuraceous; flowers of both sexes usually on same plant, in slender or stout dense or interrupted naked simple or broadly paniculate spikes and usually also in axillary fascicles; staminate perianth usually 4-cleft; fruiting bracts sessile, rounded-deltoid or ovate-deltoid, 3-7 mm. long, herbaceous, united only at the truncate or rounded base, often reddish in age, acute, the margins denticulate or rarely entire, the sides usually short-tuberculate, densely furfuraceous or glabrate; seed $1.5-2.5 \mathrm{~mm}$. long, nearly black; radicle inferior.

Saline soils and salt marshes in rich soils, both coastal and inland, in w. Tex. and Ariz. (Navajo and Coconino cos.), May-Nov.; Nfld. to S.C., O., Ind., Ill., Mo., w. to B.C., Ore. and Calif., s. to Tex.; Eur., Asia and N. Afr.

\section{Atriplex argentea Nutt. Silver saltbush.}

Annual herb; stems $15-60 \mathrm{~cm}$. tall, erect, branched from the base, the plants globoid in outline, the branches rather stout, angled, furfuraceous when young; 


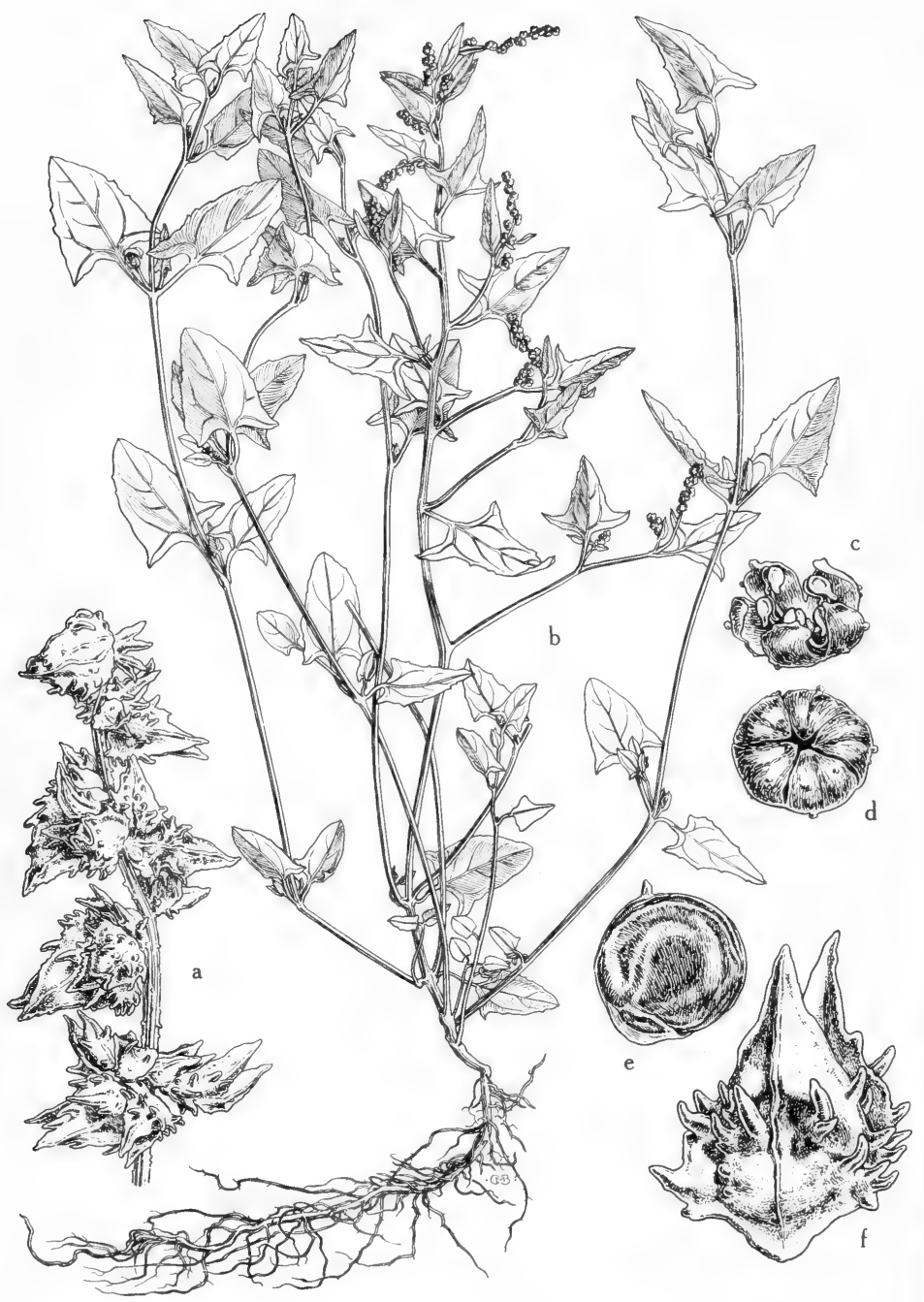

Fig. 424: Atriplex patula var. hastata: a, pistillate inflorescence, x 4; b, habit, showing the spreading branches, the hastate leaves and the spikelike inflorescences, x $2 / 5$; c and $d$, young staminate flowers, x 12; e, seed, showing curved embryo, x 12; f, single pistillate flower, showing tuberculate bracts, x 8. (From Mason, Fig. 215). 
leaves opposite below, subsessile or petioled above, 2-5 cm. long; blades triangular-ovate to rounded-ovate, the margins smooth or sparsely tuberculate or cristate, gray-furfuraceous but sometimes glabrate, the upper surface greener; flowers of both sexes on same plant, the staminate ones in the upper axils or in short dense spikes or the staminate and pistillate flowers mixed in axillary clusters at least at the middle of the plant; fruiting bracts $4-8 \mathrm{~mm}$. long and as wide, united to the middle or above, obovate to cuneate-orbicular, the margins green, subentire to laciniate, the faces smooth or appendaged; seed brown, $1.5 \mathrm{~mm}$. long; radicle superior.

Alkaline grounds, floodplains and valleys, in w. Tex., w. Okla. (Waterfall), N.M. (San Juan and Valencia cos.) and Ariz. (Apache, Coconino and Navajo cos.) ; Sask. to Ore., s. to N.M., Ariz., Tex. and Calif.; introd. in e. U.S.; also in w. Minn. and w. Mo.

Subsp. expansa (Wats.) Hall \& Clem. Annual herb or perennial; stems erect, 3-12 dm. tall, much-branched, forming clumps 3-10 dm. broad, finely mealyscurfy; leaves alternate, with petioles $2-21 \mathrm{~mm}$. long on the lower leaves; blades 3 -nerved at the base, ovate to lanceolate-ovate or deltoid-ovate, irregularly dentate or entire, $25-75 \mathrm{~mm}$. long and often as broad, the upper leaves reduced to sessile and more or less cordate floral bracts as broad as long or broader than long; spikes elongated, slender; flowers in small axillary glomerules or the glomerules in short naked terminal spikes; perianth 5-cleft; fruiting bracts sessile to subsessile, roundish, mostly 3-nerved, 5-7 $\mathrm{mm}$. long, 2-4 $\mathrm{mm}$. broad, the margins sharply dentate, the sides smooth or with a few irregular green projections or crests, or unappendaged; seed brown, $2 \mathrm{~mm}$. long; radicle superior.

Low alkaline valleys and bottomlands, Colo., Ut. and Nev., s. to w. Tex., Calif. and Mex.

\section{Chenopodium L. Goosefoot. Pigweed}

Annual or perennial weedy herbs, rarely suffrutescent, often strongly scented, usually with mealy-coated or glandular foliage but sometimes glabrate; stems sometimes quite rough and nearly woody; leaves alternate, usually petiolate, flat, varying from linear to ovate or hastate to lanceolate, the blade entire, toothed or lobed, quite variable; flowers perfect or narely unisexual, in axillary or terminal spikes or glomerules; perianth usually 5-parted, calyxlike, the persistent segments flat or keeled; stamens 1 to 5 ; ovary superior, usually depressed, 1-celled; styles 2 to 5 ; utricle containing one horizontal or vertical seed; pericarp usually adherent to the seed, sometimes fleshy; embryo curved or annular, surrounding the mealy endosperm; radicle inferior or centrifugal.

A large genus of weedy plants, consisting of nearly 100 species, cosmopolitan but mainly Eurasian.

Some species, such as $C$. album, are used as potherbs while $C$. quinoa Willd. is a valuable cereal plant in South America. Various songbirds, upland game birds and small mammals utilize seeds of most species as a part of their diet. The plants are especially valuable since the seeds persist on most species until late in the year.

1. Plants more or less resinous with sessile or stalked glands, usually strongly aromatic (2)

1. Plants without glands, often glabrous, never strongly aromatic (3)

2(1). Perianth glabrous or only lightly puberulent, only slightly if at all glandular; flowers sessile and more or less glomerate in large panicles or short spikes................................................. C. ambrosioides.

2. Perianth conspicuously glandular, usually also pubescent; flowers in numerous small axillary dichotomously branched cymes.

2. C. Botrys. 
3(1). Seeds usually erect or with some horizontal in the terminal and subterminal glomerules, the fruit laterally flattened; leaves rather fleshy, greenish on both surfaces; flowers in axillary glomerate clusters and in terminal sometimes branched spikes................. C. chenopodioides.

3. Seeds mostly but not always horizontal, sometimes at least some vertical, the fruit flattened on top; leaves not especially fleshy, usually farinose (at least on lower surface); flowers more diffusely borne, not all in axillary glomerules or axillary and terminal spikes (4)

4(3). Plant prostrate or low with spreading-ascending stem and branches; leaves lanceolate to ovate-oblong, green above, grayish-farinose beneath, sinuate-dentate; at least some of the fruits with the seed vertical 4. C. glaucum.

4. Plant typically erect; leaves various; seeds all horizontal (5)

5(4). Leaf blades entire to once or twice hastately lobed at base, the margin mostly not toothed; pericarp not tightly adherent to the seed.

5. C. Fremontii.

5. Leaf blades usually toothed on the margin as well as frequently hastately lobed, the teeth sometimes inconspicuous; pericarp generally very tightly adherent to the seed....................................6. C. album.

\section{Chenopodium ambrosioides L. Mexican tea, wormseed, epazote.}

Annual or perennial herb, glabrous or glandular, ill-scented; stems erect or ascending, 3-10 dm. tall; branches stout, simple or paniculately branched, glabrous or puberulent below, usually glandular-villous or tomentulose about the inflorescence but occasionally glabrous; leaves oblong to ovate or lanceolate, 2-12 $\mathrm{cm}$. long, 15-55 $\mathrm{mm}$. broad, sinuate-dentate or sinuate-pinnatifid, the lobes acute or obtuse, copiously gland-dotted or the glands absent, puberulent to short-villous or glabrous; flowers solitary or usually glomerate in dense or interrupted slender or stout elongate spikes, these naked or leafy (the blades much smaller than the lower ones, lanceolate to oblanceolate or spatulate to linear, obtuse to acute or attenuate); perianth about $1 \mathrm{~mm}$. high, glabrous or short-villous, usually gland-dotted, the lobes rounded-ovate and obtuse, completely enclosing the fruit; stamens exserted; pericarp very thin and deciduous; seed horizontal or vertical, $0.6-0.8 \mathrm{~mm}$. broad, nearly black, the margin obtuse. Incl. var. anthelminticum (L.) Gray.

Waste places, cult. grounds and shores, salt marshes, in floodplains of alkaline and salt regions, and along interior streams, a weedy and medicinal herb, rare in Tex., Okla. (Waterfall) and Ariz. (Cochise, Maricopa, Pinal and Yuma cos.); Ont. and Me., s. to Fla., Tex. and Calif.; summer-fall; Berm.; naturalized in Eur., Asia and Afr.; nat. of trop. Am., W.I. and Mex. and C.A. to S.A.

\section{Chenopodium Botrys L. Jerusalem OAK, FEATHER-Geranium.}

Annual herb, with a strong but not unpleasant aromatic scent; stems erect, 2-6 dm. tall, densely glandular-viscid throughout, much-branched, the branches ascending; leaves oblong or oval, $1-5 \mathrm{~cm}$. long, sinuate-pinnatifid, entire or sinuately lobed, the lobes obtuse or rounded, truncate to cuneate at the base, petioles half as long as or shorter than the blades, the blades of leaves in the inflorescence reduced and often entire; inflorescence of numerous densely manyflowered cymes, the whole finally forming a narrow elongate nearly naked panicle; flowers subsessile, $1 \mathrm{~mm}$. long; perianth cleft nearly to the base, the lobes oval or oblong and acute or acuminate, densely glandular-pubescent, imperfectly enclosing the fruit at maturity; pericarp thin, whitish, firmly attached to the seed; seed subglobose, $0.6 \mathrm{~mm}$. in diameter, dark-brown, dull, vertical or horizontal.

In waste places, ditches, low wettish places, cinder dumps and railroad beds, uncommon in Tex., N.M. (San Juan and Santa Fe cos.) and Ariz. (Maricopa 
and Yavapai cos.); nat. of Eur., Asia and Afr.; adv. and naturalized as a weed throughout U.S. and Can.; also S.A.

\section{Chenopodium chenopodioides (L.) Aellen.}

Annual herb; stems prostrate and low-branching or upright; leaves glabrous or promptly glabrate beneath, rhombic or spatulate, shallowly sinuate or entire; flowers terminal and lateral in glomerules, these either separate or forming contracted spikes in the axils of leaves or bracts, or in small or large panicles, the terminal flowers with horizontal seeds, the lateral flowers with vertical seeds; perianth parts (with vertical seed) 3 or 4 , united nearly to the tips, the free tips minutely but definitely apiculate; stigmas chiefly $0.2-0.3 \mathrm{~mm}$. long, usually ascending as in a V. C. rubrum sensu N. A. auth., C. humile sensu N. A. auth.

Saline habitats and salt marshes, Wash. to Calif., Nev., Wyo., Col. and Tex.; also N. Y.

\section{Chenopodium glaucum $\mathrm{L}$.}

Prostrate to erect eglandular annual with numerous branches 1-4 dm. long; leaves pale-green on upper surface, grayish-farinose on lower surface, very gradually reduced upward; blades lanceolate to ovate-oblong or ovate-deltoid, 1-3 (-5) cm. long, rather coarsely sinuate-dentate, narrowed gradually to stout petioles much shorter than the blades; flowers sessile, glomerate in numerous short bracteate or ebracteate axillary spikes and a terminal simple or somewhat compound spike; perianth cleft nearly to the base into (3 to) 5 (or 7 ) oblongobovate rounded lobes about $1 \mathrm{~mm}$. long; pericarp very thin, greenish, free from the seed; seed varying from commonly horizontal to sometimes vertical in the same cluster of flowers; fruit laterally or dorsally flattened, about $0.8 \mathrm{~mm}$. broad.

In marshes and along streams in saline and alkaline soils, in N. M. (Dona Ana, San Juan and Socorro cos.) and Ariz. (Apache and Navajo cos.), June-Sept.; nat. of Euras., Afr., Austral. and Greenl.; adv. from N.B. to Va., Neb., Tex., N.M. and Ariz.

\section{Chenopodium Fremontii Wats.}

Annual herb; stems erect, 2-10 dm. tall, the branches slender, ascending, often flexuous, sparingly white-mealy to light-green, glabrous; leaves broadly triangular to rhombic, sinuate-dentate, $15-65 \mathrm{~mm}$. long and nearly as broad, rounded and mucronate at the apex, the base with prominent hastate lobes, the lobes oval to rounded-obovate, the slender petiole about half as long as the blade; flowers in clusters, these forming slender spikes or an open panicle; perianth usually sparsely farinose, deeply cleft, strongly carinate, nearly covering the fruit; stigmas short; pericarp free; seed horizontal, smooth or slightly rugulose, black, shining, fully $1 \mathrm{~mm}$. broad, the margin obtuse. C. Watsonii A. Nels.

In marshes and mud about lakes, in seepage about springs and on banks of streams, in n.w. Okla. (Alfalfa Co.), w. Tex., N.M. (widespread) and Ariz. (Apache to Mohave, s. to Cochise, Pima and Santa Cruz cos.), Mar.-Sept.; Sask. and B. C. to N.D., s. to n.w. Okla., w. Tex., N.M., Nev., Ariz. and n. Mex.

Forma farinosum Aellen. Plants more bushy in form and smaller; leaves smaller, thicker, more grayish-farinose, with the habit and seed characteristics of typical $C$. Fremontii. Mainly in $\mathrm{mt}$. areas, Ida. to Tex.

Var. Pringlei (Standl.) Aellen. Very similar to typical C. Fremontii except the leaves are serrate. N.D. to Tex. and Mex.

6. Chenopodium album L. Pigweed, LAMB'S-Quarters, Quelite. Fig. 424A.

Annual herb, pale-green, sometimes turning reddish; stems erect, stout, 6-30 dm. tall, usually simple below the inflorescence, paniculate branched above, 


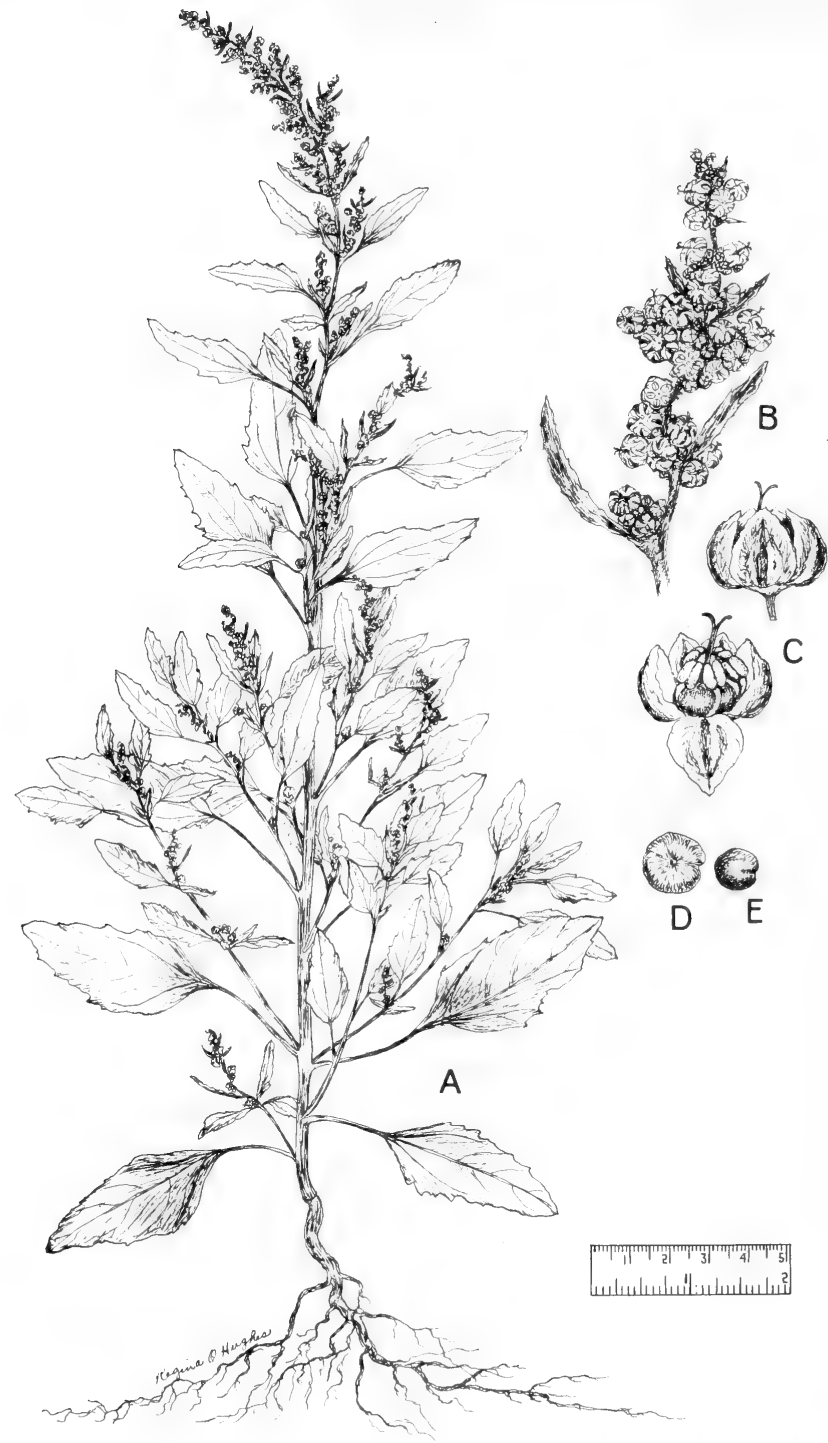

Fig. 424A: Chenopodium album: A. habit, small plant; B, floral spikes, x 21/2; C, flowers, x 71/2; D, utricle, x 4; E, seed, x 4. (From Reed, Selected Weeds of the United States, Fig. 64). 
usually white-mealy throughout to glabrous, obtusely angled, striate; leaves ovalrhombic, rarely ovate or lanceolate, $2.5-8 \mathrm{~cm}$. long, usually conspicuously longer than broad, obtuse or rounded and apiculate at the apex, often shallowly 3-lobed, irregularly sinuate-dentate, rarely subentire, mostly thick, pale-green and glabrate above, very finely and commonly densely farinose beneath, the reduced upper blades ovate to lanceolate, usually entire, acute and mucronate, not hastate; flowers in large glomerules, these in dense axillary.or terminal stout erect or ascending paniculate spikes to $3 \mathrm{dm}$. long, the inflorescence usually narrow and compact, rarely lax, grayish-green, sparsely leafy; perianth copiously and finely farinose, deeply lobed, the lobes green, white-margined, acutely keeled, completely enclosing the fruit; pericarp adherent to the seed; seed horizontal, black, shining, 1.1-1.5 $\mathrm{mm}$. broad, nearly smooth to minutely pitted, the margin obtuse. $C$. viride L.

In mud at edge of lakes, salt flats and on floodlands and in waste places near marshes, uncommon in Tex., Okla. (Alfalfa Co.) and Ariz. (Apache, Coconino, Yavapai and Pinal cos.), Mar.-Sept.; Euras. weed, Nfld. to Fla., w. to Yuk. and B.C., s. to Mex. and S.A.; N. Afr.

This species is commonly grazed by ducks and geese and represents an important item of green food. The leaves and young plants are also eaten by people as cooked greens.

\section{Fam. 53. Amaranthaceae Juss. Amaranth Family}

Weedy herbs and subshrubs, annuals or perennials, with erect to prostrate or scandent stems; leaves alternate or opposite, petioled or sessile, without stipules; flowers perfect to imperfect or polygamous, solitary or glomerulate, racemose, spicate or capitate, each flower or flower cluster subtended by imbricate bracts; perianth of 2 to 5 distinct scarious or chartaceous tepals, rarely 1 or entirely absent in some species of Acnida; corolla absent; stamens 2 to 5, opposite the tepals; ovary superior, 1-celled; styles 1 or 2 and terminal or absent; fruit a membranous utricle, circumscissile, irregularly dehiscent or indehiscent; seeds erect or inverted, lenticular, oblong or reniform-orbicular, smooth or nearly so, lustrous; embryo annular, the cotyledons incumbent, the radicle inferior or superior.

About 850 species in 65 genera, cosmopolitan but mostly tropical.

Most of our amaranths are found in weedy areas, commonly called "wastelands," one reason being because they are often poorly drained or subject to flooding. Because of this, it is very possible that we should have included more of these species. However, since we have based our treatment on factual evidence instead of on speculation it must stand as is.

1. Leaves alternate; anthers 4-celled; filaments distinct or united at the base (2)

1. Leaves opposite; anthers 2-celled; stamens 2 to 5; flowers 5-merous (3)

2(1). Perianth present in all flowers; stamens 5 , rarely 1 to 3 ; bracts not muchenlarged and not cordate in fruit...........................1. Amaranthus

2. Perianth lacking or only occasionally present in pistillate flowers; stamens $5 \ldots$

2. Acnida

3(1). Stem erect; inflorescence paniculate; most of the flowers unisexual.

3. Stem prostrate or decumbent; inflorescence solitary heads or short spikes: few (if any) flowers unisexual (4)

4(3). Style 1 or none; stigma 1 and capitate..............................4. Alternanthera

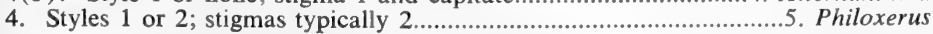




\section{Amaranthus L. Pigweed. Amaranth}

Annual weedy herbs, especially near irrigated or cultivated places, monoecious or dioecious; stems erect or prostrate, branching at the base or above; leaves alternate, petiolate, flat, pinnately veined, entire or undulate; flowers unisexual or a few appearing perfect, with staminate and pistillate flowers on the same or separate plants, in dense terminal or axillary spikes or clusters, each subtended by 3 conspicuous red, green or purple bracts; perianth segments (tepals) 2 to 5 (only 1 evident in $A$. californicus), distinct, glabrous; stamens 5 , sometimes 1 to 3 , separate; anthers 4-celled (appearing 2-celled after dehiscence), opening lengthwise, the filaments distinct; ovary 1-celled, with 2 or 3 stigmas; ovule 1; utricle oneseeded, 2- or 3-beaked at the apex, circumscissile, irregularly splitting or indehiscent; seeds lenticular, erect, compressed, lustrous, smooth; embryo coiled into a ring around the albumen; radicle inferior.

About 60 species, cosmopolitan.

Because of their tremendous production of seeds that may be carried over into the winter, the pigweeds are a vital source of food for songbirds, game birds and other species of wildlife.

1. Flowers all or mostly in small axillary clusters (2)

1. Flowers mostly in elongate terminal spikes or compound panicles, much smaller panicles or clusters may also be present (4)

2(1). Utricle indehiscent; seeds obovate.

2. Utricle circumscissile at the middle (3)

1. A. crassipes.

$3(2)$. Tepals of pistillate flowers 1 to 3 , all except one reduced to minute scales or wanting; stems slender, prostrate, forming mats; seeds orbicular..

3. Tepals of pistillate flowers 3 , equal or nearly so; stems stout, erect or ascending; seeds lenticular...................................................... A. albus.

4(1). Spines present in the axils of the leaves; utricle irregularly or imperfectly dehiscent; plants monoecious, occasional flowers perfect.

4. A. spinosus.

4. Spines lacking; utricle regularly cricumscissile; plants dioecious; flowers all staminate or all pistillate (5)

5(4). Outer tepals (at least the largest) acute to acuminate with the midvein excurrent as a rigid point; bracts and outer tepals conspicuously longer than the inner tepals......................................5. A. Palmeri.

5. Outer tepals obtuse to retuse or sometimes acute, apiculate but the dark vein not excurrent; bracts and outer tepals shorter than or scarcely exceeding the inner tepals.......................................6. A. arenicola.

\section{Amaranthus crassipes Schlecht. Fig. 425.}

Plant from an elongate taproot; stems prostrate or decumbent, 2-6 dm. long, often sparingly branched, rather fleshy, glabrous; leaves alternate, with petioles 4-40 $\mathrm{mm}$. long, obovate to elliptic, $1-4 \mathrm{~cm}$. long, round or notched at the apex, cuneate at the base, deep-green, glabrate; inflorescences axillary, the short axes much-thickened (to $1 \mathrm{~mm}$.) and indurate; male and female flowers on same plant or occasional flowers appearing perfect; bracts minute, keeled; tepals of the pistillate flowers 4 or 5 , spatulate, scarious, $0.2-2.5 \mathrm{~mm}$. long; style bifid or trifid to the base; utricle compressed-obovoid, 1.4-1.8 $\mathrm{mm}$. long, obtuse or emarginate, papillate above the middle, coriaceous, indehiscent; seed broadly obovate, 1-1.4 mm. long, dark-brown or black, lustrous. A. Warnockii I. M. Johnst.

On mud and gravel bars in rivers, along creeks and in playa lakes, in Tex. from the coast through the Rio Grande Plains and Edwards Plateau to the Trans-Pecos, June-Oct.; nat. of trop Am.; naturalized in waste places along the Gulf Coast and 


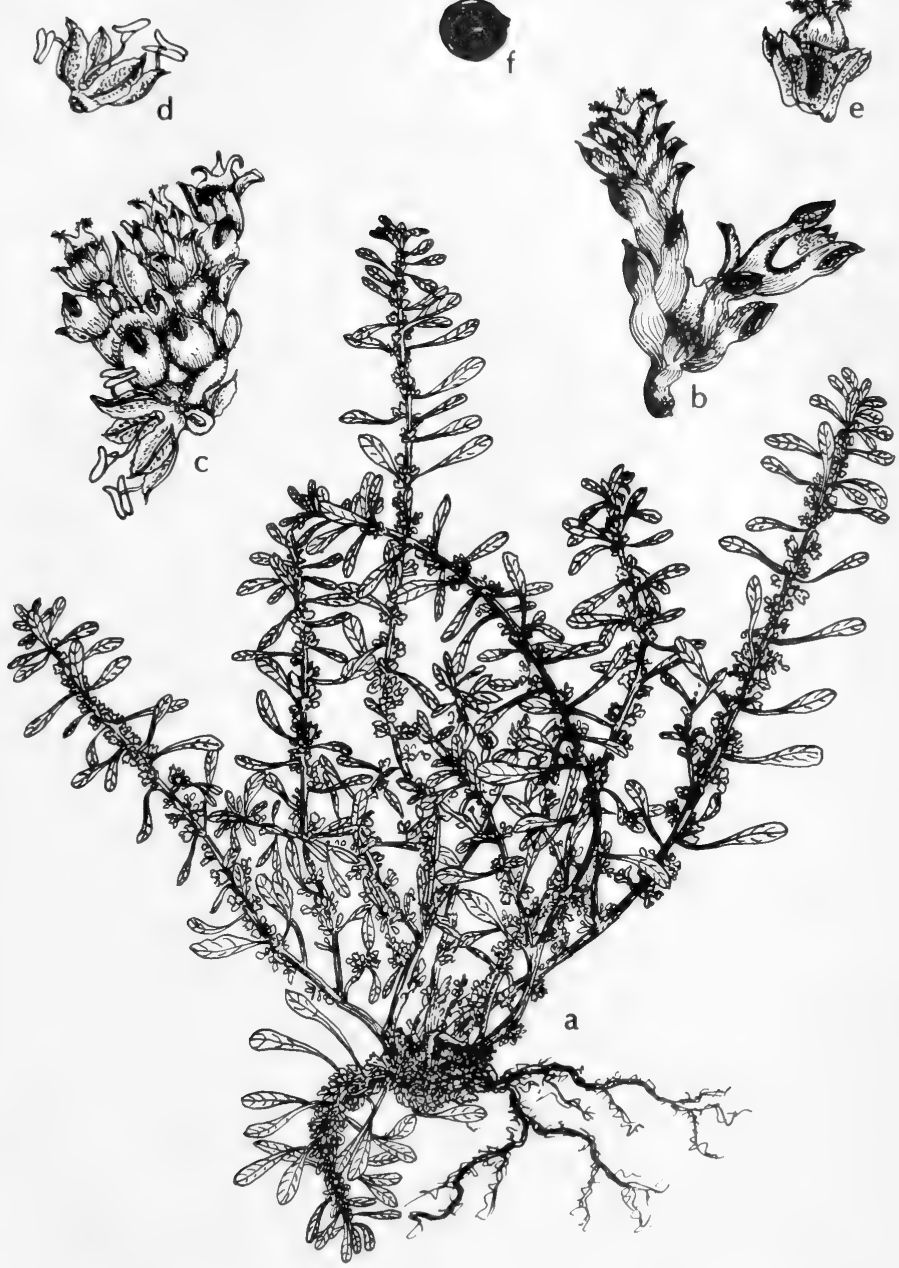

Fig. 425: Amaranthus crassipes: a, habit, x 1/2; $\mathrm{b}$, branch showing sessile buds, $\mathrm{x} 5$; c, branch showing distal pistillate flowers and basal staminate flower, $\mathrm{x} 5$; d, staminate flower, x 5; e, pistillate flower, x 5; f, seed, x 10. (V. F.). 


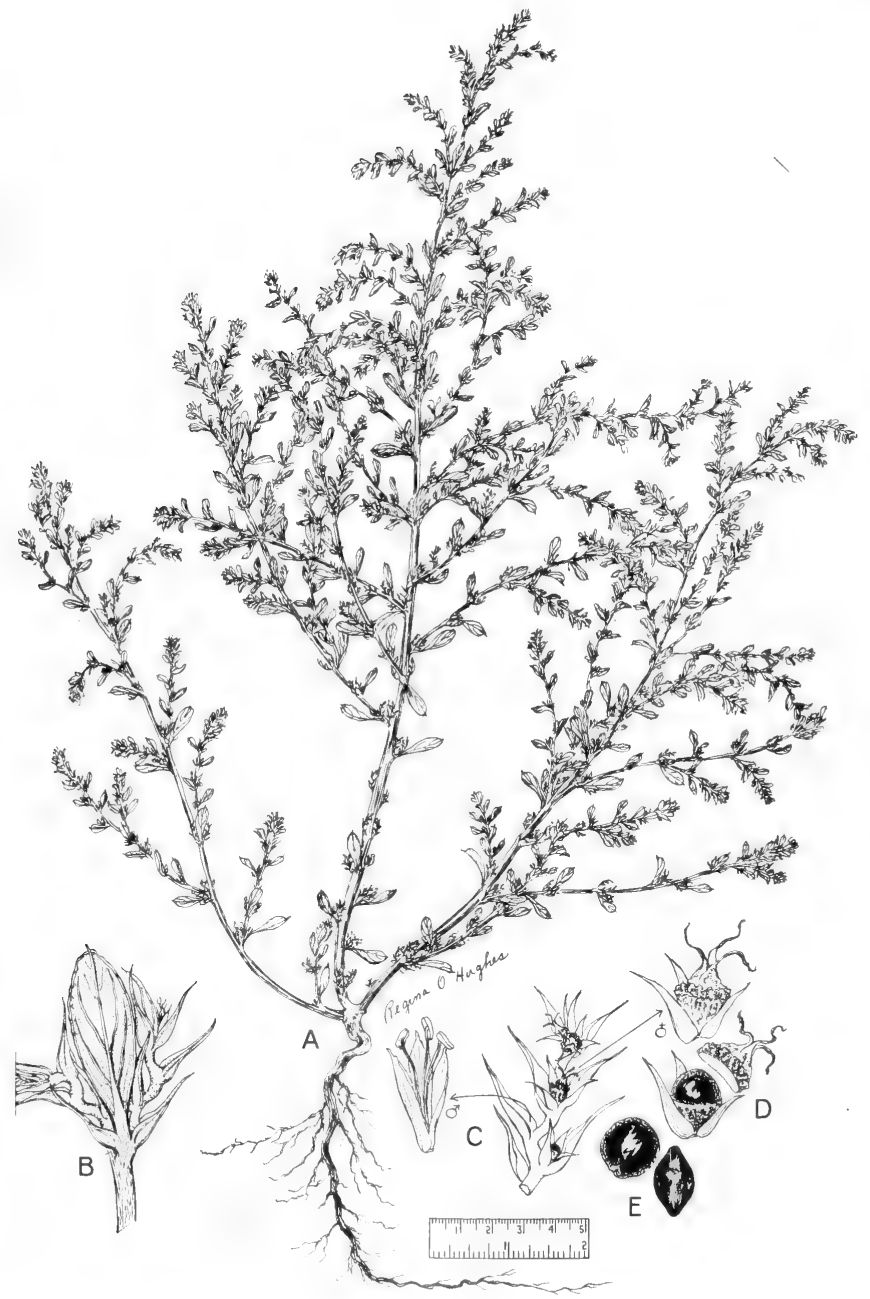

Fig. 425A: Amaranthus albus: A, habit, $\mathrm{x} 1 \frac{1}{2} ; \mathrm{B}$, enlarged node showing flowers and leaf, x 5; C, flower spike, x 5; D, utricles, x 5; E, seeds, x 6. (From Reed, Selected Weeds of the United States, Fig. 69) 
rarely adv, at e. seaports, Fla. and the Keys to Tex.; W.I., Bah. I. and n. S.A.

\section{Amaranthus californicus (Moq.) Wats.}

Stems prostrate from a taproot, stout and rather fleshy, much-branched from the base, $8-50 \mathrm{~cm}$. long, whitish or tinged with red; leaves alternate, numerous, pale-green, with petioles $2-18 \mathrm{~mm}$. long, obovate to oblong, mostly obtuse, prominently mucronate, the veins and margins white, 3-25 $\mathrm{mm}$. long, glabrous, sometimes purplish beneath; male and female flowers on same plant, occasional flowers perfect, in small axillary clusters; bracts lanceolate, acute, subulate-tipped, about equaling the flowers; tepals in staminate flowers 3 (or 2), membranous, ellipticlanceolate to oblong-ovate, mucronate or erosulate; stamens 3 (or 2 or 1); tepals in pistillate flowers mostly 1 ( or 2 or 3 ), inconspicuous, one narrowly lanceolate and acute or acuminate, the others usually reduced and scalelike; utricle subglobose, smooth, often tinged with red or purple, tardily irregularly dehiscent; seed orbicular, dark-reddish-brown, $0.6-0.8 \mathrm{~mm}$. in diameter. A. microphyllus Shinners.

Moist or wettish soils, in beds of dried-up lakes and ponds in the Tex. Plains Country, July-Sept.; s. Wash. and Alta., s. through Ida. and Ore. to Calif., Nev. and Tex.

\section{Amaranthus albus L. Fig. 425A.}

Stems stout, erect, bushy-branched, the branches divaricate or ascending, 2-12 dm. tall, whitish or pale-green, glabrous or sparingly puberulent or villous; leaves alternate, with slender petioles $3-50 \mathrm{~mm}$. long, slender, elliptic to oblong or spatulate to obovate, $1-7 \mathrm{~cm}$. long, cuneate at the base, rounded or mucronatecuspidate at the apex, prominently veined, the veins white beneath; male and female flowers on the same plant, occasional flowers perfect, the staminate ones few, in dense or loose axillary clusters that are usually shorter but sometimes longer than the petioles; bracts green, rigid, 2-4 mm. long, oblong-lanceolate, pungent-pointed and spreading; tepals 3, the staminate ones oblong, cuspidate, scarious; pistillate tepals oblong to linear, acute, 1-nerved, thin, green along the nerve, often tinged with red; stamens 3; style branches 3 ; utricle subglobose, circumscissile, rugose, longer than the perianth, sometimes tinged with red; seed lenticular, $0.6-0.8 \mathrm{~mm}$. in diameter, mahogany-colored, lustrous. A. graecizans of Am. auth.

Waste places and cult. areas, sandy, gravelly or muddy banks and flats along streams, throughout most of Tex. but exceedingly rare, N. M. (widespread) and Ariz. (Apache to Mohave, s. to Cochise and Pima cos.), Aug.-Dec.; widely distributed throughout N.A.; adv. in Eur., Asia, Afr. and S.A.

\section{Amaranthus spinosus L. SPINy PIGWEed, Quelite EsPinoso.}

Plant weedy, from a long (to $4 \mathrm{dm}$.) taproot; stems stout and succulent, erect, branched, $3-12 \mathrm{dm}$. tall, bearing at most nodes a pair of divergent spines $5-10 \mathrm{~mm}$. long; leaves alternate, ovate-lanceolate to ovate, glabrous to sparingly pubescent, $3-10 \mathrm{~cm}$. long, narrowed to an obtuse mucronate tip, broadly cuneate to the long petiole; male and female flowers on same plant, occasional flowers perfect; spikes numerous, 5-15 cm. long, 6-10 $\mathrm{mm}$. thick, the terminal one often wholly or chiefly staminate, the basal part of each and the axillary clusters mostly pistillate; bracts lanceolate or subulate, usually shorter than the tepals; tepals of the staminate flowers lance-oblong, acute or short-acuminate; stamens 5; tepals of the pistillate flowers 5, oblong or acutish, 1-1.5 mm. long; utricle 1.5-2 mm. long, imperfectly dehiscent or bursting irregularly. the terminal portion spongy and roughened; seed black, nearly round, $0.7-1 \mathrm{~mm}$. in diameter, lustrous.

In waste ground, sandy loamy soil, on sand-gravel bars in rivers and in low wet areas, in e. third of Tex., w. to Dallas, Travis and Cameron cos., June-Sept.; 
probably trop. in origin; now abundant in warmer parts of the world, extending to N.Y., Pa., Me. and Man., Ind. and Mo., often adv. farther n.

\section{Amaranthus Palmeri Wats. Careless-Weed, Red-root, Quelite, Bledo.} Fig. 426.

Plant very weedy, with an elongated taproot to $15 \mathrm{~mm}$. in diameter; stems 6-10 $\mathrm{dm}$. tall, branched at the base and much-branched above, glabrous to villouspubescent; leaves alternate, with long slender petioles, rhombic-ovate to rhombiclanceolate, 1-6 cm. long, acute to abruptly acuminate at the apex, cuneate or rounded at the base; staminate and pistillate flowers on separate plants, in slender erect or drooping dense spikes or thyrse $15-30 \mathrm{~cm}$. long, either all terminal on leafy branches or (if leafless) branch thyrses present, these loosely arranged and each subtended by a leaf; bracts 4-6 $\mathrm{mm}$. long, twice as long as the perianth, the midrib moderately heavy in the male, very heavy in the female, excurrent into a spine; male flowers with 5 stamens and 5 tepals; inner tepals $2.5-3 \mathrm{~mm}$. long, obtuse or emarginate; outer tepals 3.5-4 mm. long, acuminate, with conspicuous long-excurrent midvein; female flowers with 5 recurved tepals, each with conspicuous branched midvein; inner tepals usually $2-2.5 \mathrm{~mm}$. long, spatulate, emarginate, slightly denticulate; outer tepals $3-4 \mathrm{~mm}$. long, acute, with a midvein excurrent as a rigid point; style branches usually 2 , rarely 3 ; utricle $1.5-2 \mathrm{~mm}$. long, thin, subglobose, circumscissile, somewhat rugose; seed obovate, lenticular, 1-1.3 $\mathrm{mm}$. in diameter, dark-reddish-brown.

In silt, sandy and gravelly soils, river banks, valleys, arroyos, drainage basins, irrigation ditches, swamps along streams, river bottomlands, about ponds, and in dumps and gardens, in Okla. (Mayes and Ottawa cos.), throughout most of Tex., N.M. (widespread) and Ariz. (Coconino, Yavapai and Greenlee, s. to Santa Cruz, Pima and Yuma cos.), summer-fall; w. Kan. to Calif., s. to Tex. and Mex.; introd. in Mo.; rarely adv. in e. U.S.

\section{Amaranthus arenicola I. M. Johnst. SANDHills amaranth.}

Plant with erect stems to $2 \mathrm{~m}$. tall, whitish, glabrous, striate, simple or branched at the base, branched above; leaves alternate, with slender petioles 5-7 $\mathrm{mm}$. long, oval-oblong to oblong-linear, $1.5-8 \mathrm{~cm}$. long, rounded to acutish at the apex, obtuse to attenuate at the base, yellowish-green, glabrous, the veins conspicuous beneath; male and female flowers on separate plants, in slender dense or interrupted spikes or thyrses to $4 \mathrm{dm}$. long, either all terminal on leafy branches or (if a few leafless) branch thyrses present, these loosely arranged and each subtended by a leaf; bracts usually $1.5-2.5 \mathrm{~mm}$. long, lanceolate, acuminate, the midrib barely excurrent; male flowers with 5 stamens and 5 nearly equal tepals about $5 \mathrm{~mm}$. long, the inner tepals emarginate or obtuse, the outer ones obtuse or acute, all apiculate with dark midveins not excurrent; female flowers with 5 recurved spatulate tepals, each with conspicuous usually branched midvein, the inner tepals $1.5-2 \mathrm{~mm}$. long and emarginate or obtuse, the outer tepals $2-2.5 \mathrm{~mm}$. long and obtuse-apiculate; style branches 2; utricle $1.5 \mathrm{~mm}$. long, thin, subglobose, circumscissile, rather smooth; seed round, lenticular, 1-1.3 mm. in diameter, darkreddish-brown.

Sandhills, swales, dried ponds, lakeshores, river sandbars, marshes, fields, roadsides and along railroads, in Okla. (Nowata, Cimarron and Alfalfa cos.), throughout most of Tex. and e. N.M., July-Nov.; Kan., Okla. and Ia. to Tex., w. to Colo., Nev. and N.M.

\section{Acnida L. WATer-hemp}

Annual herbs; stems erect, glabrous, branched; leaves alternate, petioled, entire; flowers in short panicles that form much more elaborate panicles or spikes; male 


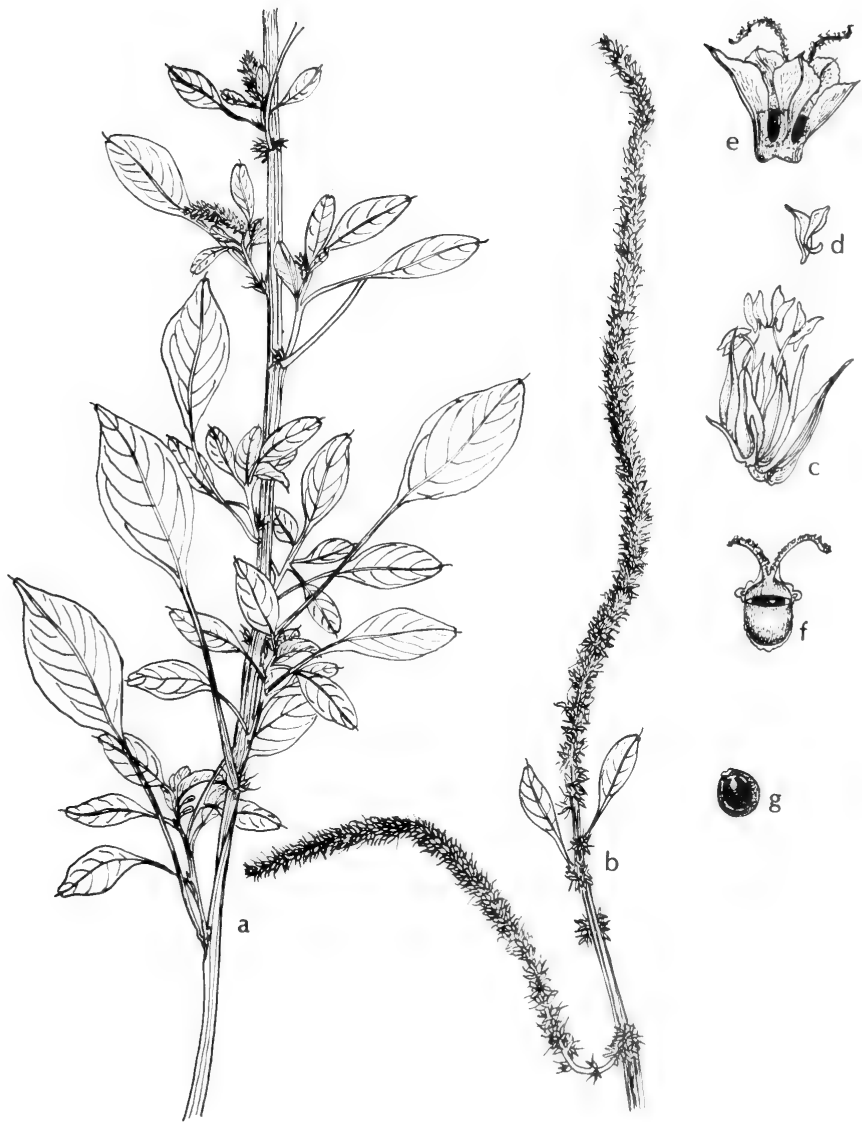

Fig. 426: Amaranthus Palmeri: a, middle section of plant, $\mathrm{x} 1 \frac{1}{2} ; \mathrm{b}$, top of plant, x $1 / 2$; c, staminate flower, x 5; d, single anther, x 6; e, pistillate flower, x 5; f, capsule dehiscing, x 5; g, seed, x 5. (V. F.). 
and female flowers on separate plants; staminate flowers with 5 erect membranous or scarious oblong to lanceolate 1-nerved tepals; stamens 5, the anther locules united only at the middle, the anthers linear-oblong; pistillate flowers naked, without or with 1 or 2 tepals; ovary flattened, obovate or rotund; style very short or absent; style branches 2 to 5, usually elongate, plumose-hispid; ovule 1; utricle thin-walled or fleshy to somewhat coriaceous, indehiscent, irregularly bursting or circumscissile, usually 3- to 5-angled; seed erect, smooth, reddish-brown or nearly black, lustrous; embryo annular, the endosperm copious.

About half a dozen species in Western Hemisphere.

1. Plants pistillate (2)

1. Plants staminate (3)

2(1). Tepals completely lacking or irregularly present and rudimentary, less than $1 \mathrm{~mm}$. long and without visible midveins; utricle indehiscent, with conspicuous longitudinal ridges; leaf blade broadly lanceolate.... 1. A. cuspidata.

2. Tepals regularly present and well-developed, at least $1 \mathrm{~mm}$. long and with distinct midveins, 1 or 2, lanceolate to linear; utricle circumscissile, rugose, with faint ridges; leaf blade usually oblong to lanceolate...

2. A. tamariscina.

3(1). Outer tepals without heavy midveins and not appreciably longer than the inner, with excurrent midveins; bracts mostly with slender midribs not over $2 \mathrm{~mm}$. long, the midrib conspicuously excurrent; leaf blades usually lanceolate, more than $1 \mathrm{~cm}$. wide; inflorescence often with several branch thyrses not subtended by leaves.

1. A. cuspidata.

3. Outer tepals $3 \mathrm{~mm}$. long, with heavy midveins, definitely longer that the inner, the midribs excurrent as rigid spines; bracts with heavy midribs, mostly over $2 \mathrm{~mm}$. long, definitely shorter than the outer tepals; leaf blades usually oblong to linear-oblong......

2. A. tamariscina.

\section{Acnida cuspidata Spreng. Southern WATER-Hemp.}

Glabrous herb; stems stout, 2-3 (-9) m. tall, usually much-thickened at the base, smooth, succulent, much-branched above; leaves few to numerous, with slender petioles $2-20 \mathrm{~cm}$. long, narrowly lanceolate to ovate, $6-30 \mathrm{~cm}$. long, 5-14 mm. wide, acuminate or long-attenuate at the apex, rounded to acute at the base, undulate, yellowish or bright-green, prominently veined beneath; inflorescences (thyrses) flexible or moderately stiff, usually $5-10 \mathrm{~cm}$. long, the terminal thyrse often accompanied by leafless branch thyrses and the uppermost of these not subtended by leaves, the branch thyrses somewhat more numerous and more crowded in the male than in the female plants; bracts $1.5-2 \mathrm{~mm}$. long, the midrib moderately heavy in the male and heavy in the female, not conspicuously excurrent in either; male flowers with 5 stamens; the 5 tepals approximately equal, 1.2-3 mm. long, the inner emarginate, the outer acuminate with excurrent midveins; female flowers without perianth; style branches 3 to 5 , short and stout; utricle obovoid to turbinate, $1.5-2.5 \mathrm{~mm}$. long, fleshy, indehiscent, with 3 to 5 prominent longitudinal ridges, not rugose, stramineous; seed flattened, $1-1.25 \mathrm{~mm}$. in diameter, turgid, round, smooth to minutely granulate, dark-reddish-brown to black, lustrous, Acnida alabamensis Standl., Amaranthus australis (Gray) Sauer.

In salt and marshy places, from coastal Tex., n.w. to the Plains Country, MayAug.; Coastal Plain from Fla. to Tex. and Yuc., W.I., Trin. and Venez.

2. Acnida tamariscina (Nutt.) Wood. Nuttall's water-hemp. Fig. 427.

Herb, glabrous or nearly so; stems stout, erect or ascending, simple or branched, 1-2 m. tall; leaves alternate, with slender petioles to $5 \mathrm{~cm}$. long, rhombic-oblong or lanceolate to ovate-lanceolate, to $1 \mathrm{dm}$. long, attenuate at the base, rounded or 


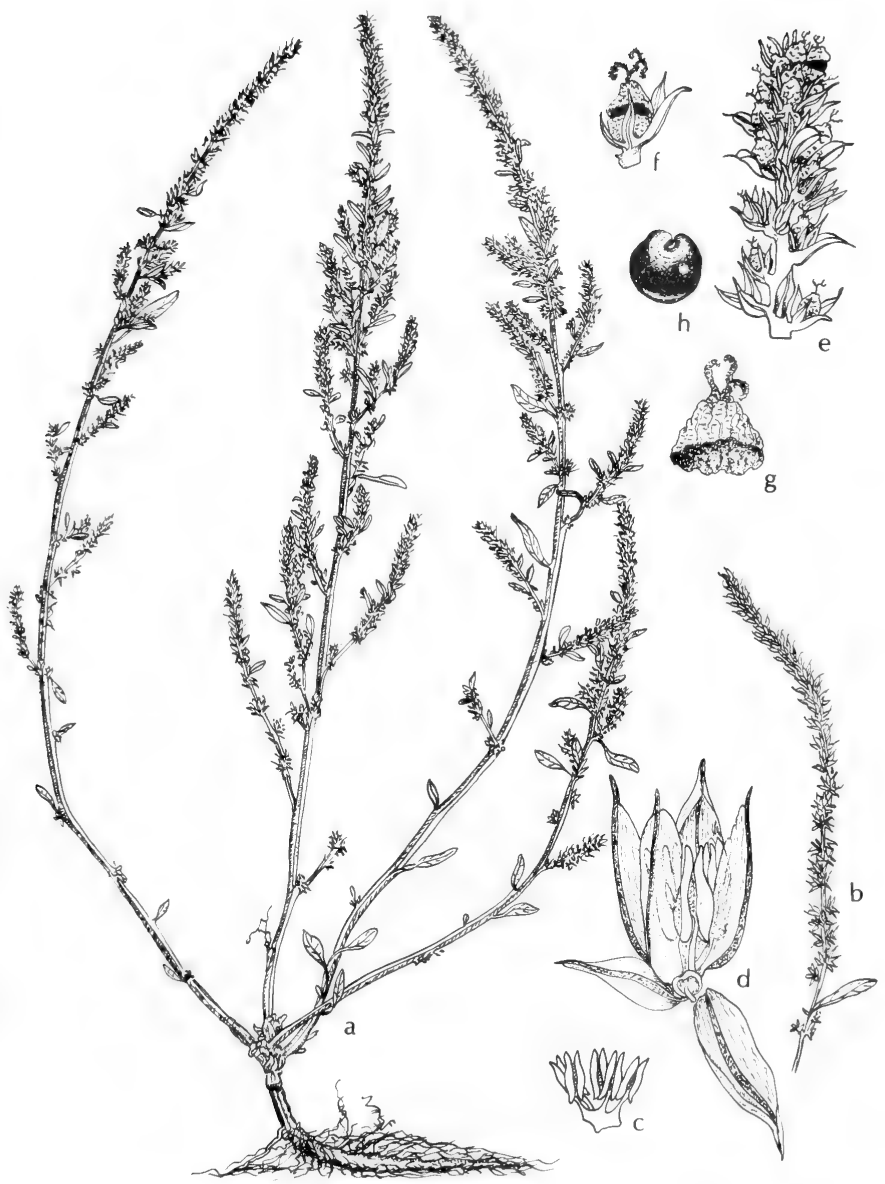

Fig. 427: Acnida tamariscina: a, staminate plant, x $1 / 2 ; b$, staminate branch, $\times 1 \frac{1}{2}$; c, anthers, x 4; d, staminate flower, x 8; e, pistillate branch, x 5; f, fruit, x 10; g, cap of circumscissile capsule, $\times 15 ; \mathrm{h}$, seed, $\mathrm{x} 15$. (V. F.). 
obtuse at the apex, sometimes notched, the much-reduced upper leaves narrowly oblong; inflorescence (thyrses) stiff, usually 1-2 dm. long, either all terminal on leafy branches or (if leafless thyrses present) these loosely arranged and each subtended by a leaf; bracts $1.5-2 \mathrm{~mm}$. long, with moderately heavy excurrent midrib in the male, about $2 \mathrm{~mm}$. long, with heavy excurrent midrib in the female; male flowers with 5 stamens and 5 tepals; inner tepals about $2.5 \mathrm{~mm}$. long, obtuse or emarginate; outer tepals about $3 \mathrm{~mm}$. long, acuminate, with conspicuous excurrent midveins; female flowers with 1 or 2 tepals, the shorter tepal rudimentary, the longer tepal about $2 \mathrm{~mm}$. long, narrowly lanceolate, acuminate, with moderately heavy sometimes branched excurrent midvein; utricle about $1.5 \mathrm{~mm}$. long, circumscissile at the middle, thin, rugose, sometimes with faint ridges corresponding to the 3 or 4 style branches, not angled, often reddish; seed nearly circular, lenticular, about $1 \mathrm{~mm}$. in diameter, dark-reddish-brown. Amaranthus tamariscinus Nutt.

Sandy fields and wastelands, chiefly in moist soils, marshes, in shallow water of ponds and lakes, along streams and sloughs, in swamps, alluvial soils, Okla. (McCurtain, LeFlore, Ottawa, Nowata, Mayes and Alfalfa cos.), throughout most of Tex. except extreme w. part, and N.M., Mar.-Oct.; Ind. to Wisc., S.D. and Colo., s. to N.M., Ark., Tex. and La., occasionally adv. in e. U.S.

\section{Iresine $\mathrm{P} . \mathrm{BR}$. BloodleaF}

About 80 species in both hemispheres.

\section{Iresine rhizomatosa Standl.}

Perennial herb, stoloniferous with slender horizontal rhizomes; stems erect, usually simple up to the inflorescence, 5-15 $\mathrm{dm}$. tall, sparsely pubescent or glabrous, pilose at the slightly swollen nodes, the internodes $5-14 \mathrm{~cm}$. long; leaves opposite, thin, bright-green, ovate to ovate-lanceolate, acute to longacuminate, entire, narrowed at the base, the larger ones 6-15 cm. long and 2-7 $\mathrm{cm}$. broad, with a few short hairs on the upper surface along the veins, sparsely pubescent beneath or glabrous; male and female flowers on separate plants; staminate panicle often laxly branched, the spikelets longer; bracts and bractlets ovate, silvery-white, shorter than the tepals; tepals silvery-white, ovate-lanceolate, 1.2-1.5 mm. long, 1-nerved, those of the pistillate flowers subtended by long hairs as a white wool; pistillate panicles $7-30 \mathrm{~cm}$. long, $2.5-20 \mathrm{~cm}$. broad, muchbranched, the branches erect or ascending, pyramidal, the spikelets opposite or alternate, densely flowered, 5-20 $\mathrm{mm}$. long; utricle round, 2-2.5 mm. long, equaling or longer than the tepals; seed suborbicular, $0.5 \mathrm{~mm}$. in diameter, dark-red, lustrous. I. celosioides Michx., non L.

Sandy alluvial soils, in low wet woods and thickets near streams, and wettish depressions along rivers, in Okla. (Cherokee Co.), scattered in e. half of Tex., w. to Denton and Comal cos., Aug.-Oct.; Md. to s. Ill. and Kan., s. to e. Va., Ala., La. and Tex.

\section{Alternanthera Forsk. CHAFF-FLOWER}

About 200 species, mostly in tropical and subtropical regions.

\section{Alternanthera philoxeroides (Mart.) Griseb. Alligator-WEed. Fig. 428.}

Perennial aquatic to semiterrestrial herb; stems simple or branched, 3-10 dm. long, the branches glabrous, ascending, prostrate or decumbent, stoloniferous, forming mats, stout, the ascending portion 1-6 dm. long, often rooting at the nodes; leaves opposite, thick and fleshy, glabrous, linear to linear-lanceolate or obovate, 2-11 cm. long, 5-20 mm. broad, usually acute or mucronulate at the apex, entire, narrowed to the sessile base; spikes simple, axillary or terminal, 


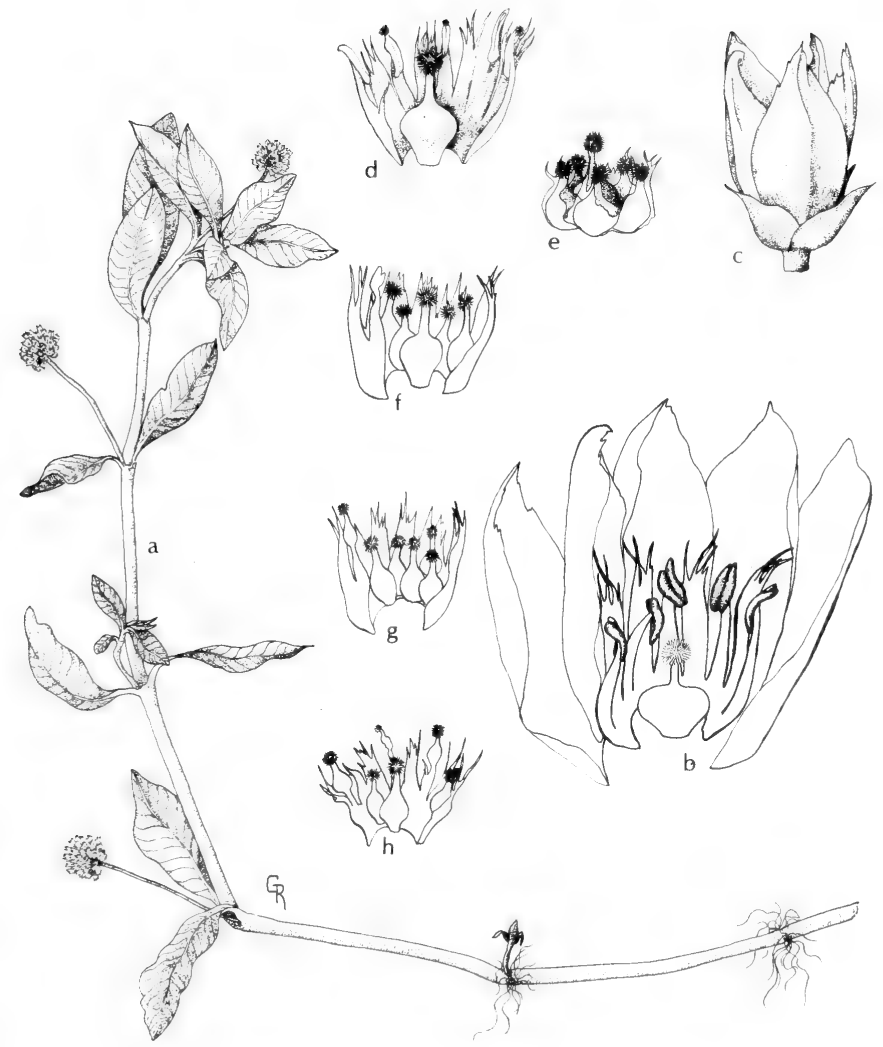

Fig. 428: Alternanthera philoxeroides: a, habit, x 1/2; b, flower opened out, x 15 ; c, flower showing bracts and tepals, x 10; d, flower, tepals removed, staminodia and stamens spread out, x 10; e-h, various flowers sometimes found, $x$ 10. (Courtesy of R. K. Godfrey). 
subglobose or cylindric, on peduncles $2-7 \mathrm{~cm}$. long, glabrous or pubescent in lines; flowers sessile in the bractlets, with a sweet resinous odor; bracts one fourth as long as the tepals, broadly ovate, glabrous; perianth silvery-white; tepals at least 4 , glabrous, 5-6 mm. long, nearly equal, obscurely 4-veined, lanceolate to ovateoblong, acute, firm, serrulate near the apex; filaments linear-subulate; staminodia narrow, usually entire, exceeding the anthers, half as long as the tepals, ligulate, lacerate at the apex; style elongate, the stigma entire. Achyranthes philoxeroides (Mart.) Standl.

In waste places, in ponds, streams, along some rivers, becoming a noxious weed, in s.e. Tex.; Mar.-Aug.; on Coastal Plain, N.C. to Fla., w. to La. and Tex., s. throughout C.A. to S.A., where it is nat. from Col. to Braz. and Arg.

This plant, primarily in conjunction with the highly productive water-hyacinth (Eichhornia crassipes) and several aquatic species of Ludwigia, is rapidly clogging the streams, canals, ponds and other such places in coastal Texas.

\section{Philoxerus R. BR.}

About 10 species, mostly in coastal regions of the tropics.

\section{Philoxerus vermicularis (L.) R. Br. Silverhead.}

Perennial or annual herb, somewhat succulent; stems prostrate, branched, 1-18 $\mathrm{dm}$. long, the branches prostrate or ascending to sometimes $1-5 \mathrm{dm}$. tall; leaves opposite, thick and fleshy, subterete, linear to linear-oblong or oblong to clavate, $15-55 \mathrm{~mm}$. long, 2-12 $\mathrm{mm}$. broad, acutish or blunt at the apex, narrowed to the sessile base, villous in the axils of the leaves, otherwise glabrous; spikes or heads solitary, subglobose to cylindric, densely many-flowered, bright-white, $13 \mathrm{~mm}$. long, 5-11 mm. thick, obtuse, the rachis lanate; flowers perfect, white; bracts broadly ovate, chartaceous, 1-nerved, acute or obtuse; bractlets ovate-oblong, slightly shorter than the tepals, acute, glabrous; perianth compressed, thickened at the base, 5-parted, the segments obtuse; tepals $3.5-4 \mathrm{~mm}$. long, obtuse, the outer ones oblong and glabrous, the inner lanceolate and usually lanate near the base; stamens 5 , the filaments subulate and connate below, the oblong anthers 2-celled; utricle compressed, broadly ovoid, coriaceous, indehiscent; seed orbicular, 0.8-1 mm. broad, dark-brown, lustrous.

Saline soils and dunes along coasts, wet sands at edge of water and on bars, in the Tex. Rio Grande Plains and Gulf Coast, summer-fall; Fla. to Tex., s. through Mex. to Pan.; Col. to Braz.; W.I.; Virg. I.; w. coast of trop. Afr.

\section{Fam. 54. Bataceae Meisn. SAltwort FAmily}

Maritime somewhat woody-succulent dioecious plants; leaves opposite, exstipulate, fleshy, semiterete, linear to clavate, smooth and glabrous, entire, with a small basal loose flange; flowers small, crowded in axillary sessile or short-peduncled conelike spikes; staminate spikes with persistent imbricate scales each subtending a flower; calyx cup-shaped, 2-lobed; corolla absent; stamens 4 or 5, inserted at base of calyx; filaments thick, alternating with staminodia; pistillate inflorescence conelike, 4- to 12-flowered, the scales deciduous, the flowers each consisting of merely a 4-celled ovary with a sessile stigma; ovule 1 in each cell; fruit a fleshy cone.

A monotypic family. Also spelled Batidaceae.

\section{Batis L.}

Characters of the family. Monotypic. A second species of dubious merit has been described recently from the Old World. 


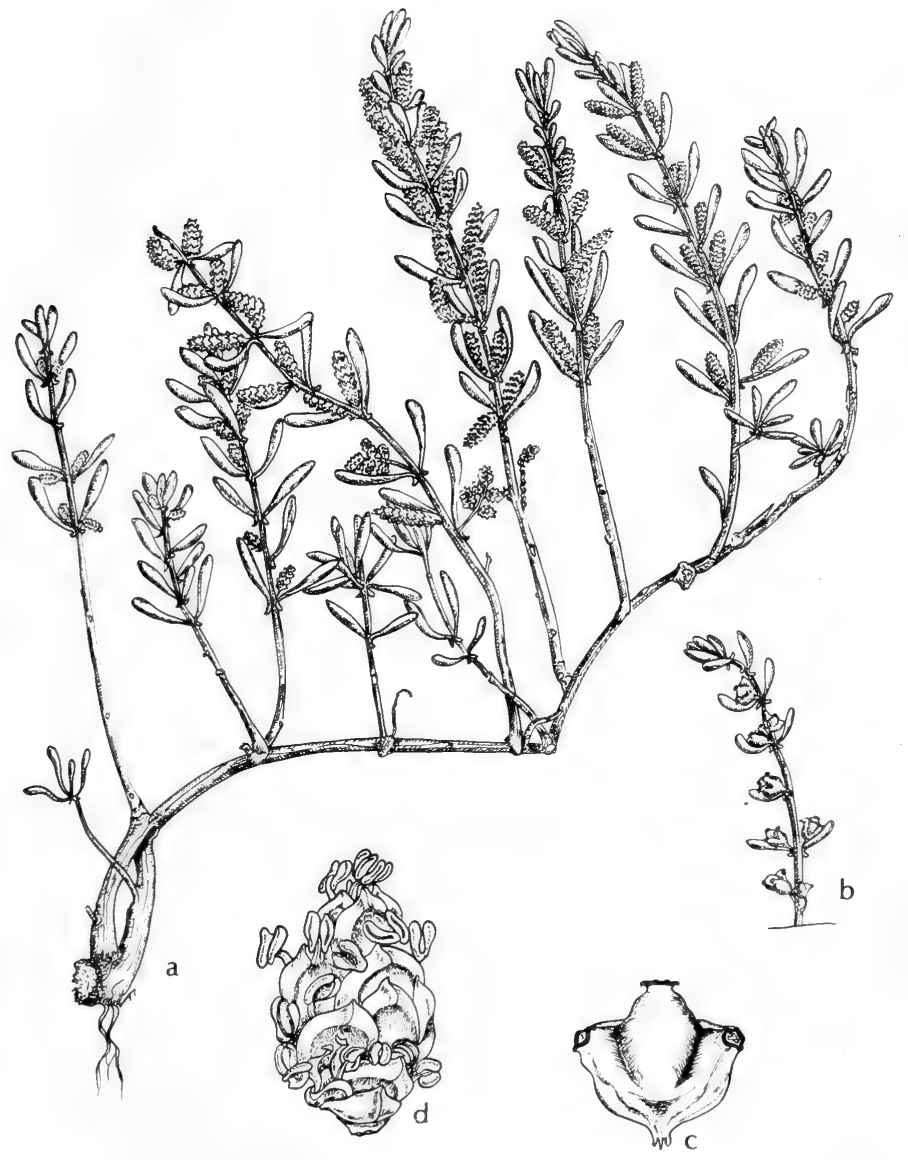

Fig. 429: Batis maritima: a, part of staminate plant, $\mathrm{x} 1 \frac{1}{2} ; \mathrm{b}$, branch of pistillate plant, $\times 1 / 2$ c, fruit, $\times 2 \frac{1}{2}$; d, staminate inflorescence, $\times 5$. (V. F.). 


\section{Batis maritima L. VidRILLos. Fig. 429.}

Plant pale-green, shrublike, strong-scented, with spreading or prostrate often creeping stems to $15 \mathrm{dm}$. long, the stem commonly rooting at tip and forming large colonies; leaves curved, to $25 \mathrm{~mm}$. long; spikes ovoid-cylindric, $5-10 \mathrm{~mm}$. long; bracts reniform to suborbicular, often apiculate; fruit ovoid to oblongellipsoid, 1-2 cm. long, short-stalked, drooping.

In salt flats and along muddy flats of the seashore in s. Tex., June-Aug.; widespread on coastal strands in this hemisphere and in H.I.

\section{Fam. 55. Phytolaccaceae R. Br.}

\section{Pokeweed Family}

Herbs, shrubs, vines or trees, with alternate entire or somewhat undulate mostly exstipulate leaves and perfect or unisexual flowers; calyx 4- or 5-parted, its segments imbricated in bud; petals wanting; stamens as many as the calyx segments and alternate with them, sometimes more numerous, hypognous or epigynous, the filaments distinct or united at base; anthers 2-celled, the sacs longitudinally dehiscent, often nearly separated; ovary several-celled in most of the genera; fruit various.

About 100 species in 12 or more genera, mostly in the tropics.

\section{Phytolacca L.}

About 35 species in tropical and warm-temperate regions.

\section{Phytolacca americana L. Pokeweed, pokeberry, scoke. Fig. 429A.}

Plant glabrous, with an unpleasant odor and a large poisonous perennial rootstock (to $15 \mathrm{~cm}$. in diameter) from which arise stout purplish leafy stalks to $3 \mathrm{~m}$. tall; leaves typically elliptic-lanceolate but sometimes ovate-lanceolate, cuneate or sometimes broadly rounded at base, acuminate at apex, to about $25 \mathrm{~cm}$. long and $1 \mathrm{dm}$. wide; pedicels about $1 \mathrm{~cm}$. long, with 1 or more bracteoles about the middle; sepals 5, white or pinkish, suborbicular, petaloid, $2-3 \mathrm{~mm}$. long; stamens and styles 10 , the ovaries green; berries in long lax racemes, dark-purple, 8-10 $\mathrm{mm}$. in diameter. $P$. decandra L., $P$. rigida Small.

In rich low ground, especially in recent clearings and along roadsides in and about depressions, tanks and ponds, in e. half of Okla., throughout most of Tex., and Ariz. (Cochise and Santa Cruz cos.), July-Oct.; from Fla. to Tex., n. to N.E., s. Que., N.Y. and s. Ont.

The very young sprouts, when properly and safely prepared, are used as a potherb; otherwise, they should not be eaten. Phytolacca rigida is described as having permanently erect, not nodding, fruiting racemes and a berry longer, not shorter, than its stalk.

\section{Fam. 56. Aizoaceae Rudolphi}

\section{CARPET-WEED FAMILY}

Annual or perennial often succulent herbs with stems mostly prostrate or ascending; leaves opposite or whorled, entire, with the base of the petioles sometimes dilated; stipules none or (when present) scarious; flowers solitary or clustered in the axils, regular and perfect; calyx 4- or 5-lobed or -parted, the tube free or adnate to the ovary; petals none (in ours); stamens few to many, inserted on the floral cup or hypogynous, the 2-celled anthers oblong or linear; ovary 1- to 20-celled, superior or only half-superior in Sesuvium; styles as many as the cells of the ovary; fruit a thin-walled capsule, dehiscing loculicidally or septicidally; seeds mostly numerous. 


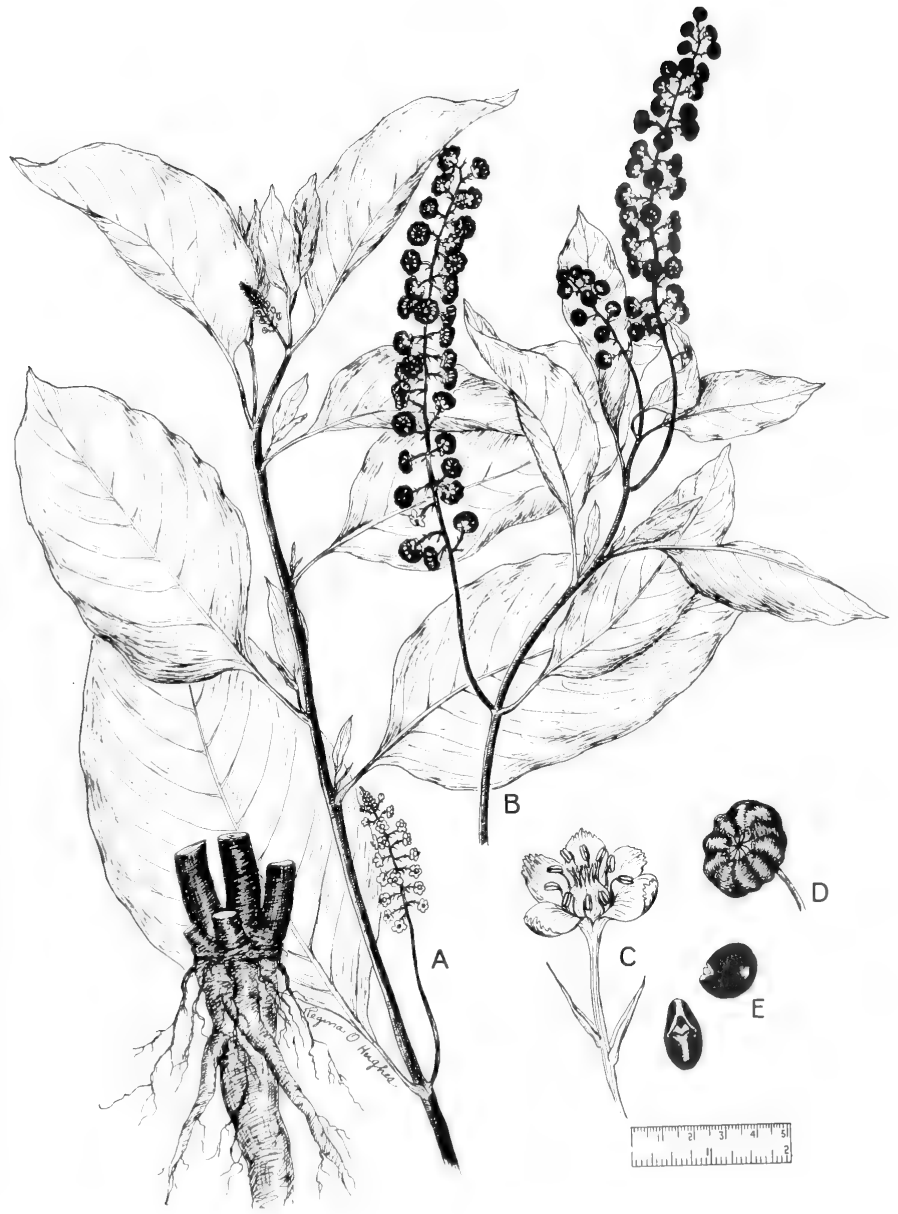

Fig. 429A: Phytolacca americana: A, habit, x 1/2; B, fruiting raceme, $x$ 1/2 C, flower, x 5; D. berry, x 2 ; E, seeds, x $2 \frac{1}{2}$. (From Reed, Selected Weeds of the United States, Fig. 72). 
A family of 130 or more genera and about 1200 species, mainly of the Southern Hemisphere and tropical regions.

1. Leaves whorled; capsule dehiscent by valves (2)

1. Leaves opposite, commonly unequal; capsule circumscissile (3)

2(1). Plants glabrous; flowers with a filiform pedicel; sepals distinct to base; seeds without a strophiole............................................1. Mollugo

2. Plants tomentulose; flowers essentially sessile; calyx cleft only to middle; seeds with a strophiole.

2. Glinus

3(1). Stipules present; ovary 1- or 2-celled; seeds several

3. Trianthema

3. Stipules none; ovary 3 - to 5-celled; seeds numerous.

4. Sesuvium

\section{Mollugo L. CARPET-WeED}

About 20 species, mostly natives of tropical and subtropical regions.

1. Mollugo verticillata L. INDIAN CHICKWEED. Fig. 430.

Annual herb, glabrous throughout; stems dichotomously branched, prostrate or ascending, to $2 \mathrm{dm}$. long; leaves verticillate, 3 to 6 in a whorl, spatulate to narrowly oblanceolate or sometimes linear, obtuse at apex, narrowed to a short petiole, to $3 \mathrm{~cm}$. long and $1 \mathrm{~cm}$. wide; flowers 2 to 5 from each node, with filiform pedicels to $14 \mathrm{~mm}$. long; sepals oblong or elliptic, to $2.5 \mathrm{~mm}$. long and $1 \mathrm{~mm}$. broad; stamens usually 3 ; capsule ovoid to ellipsoid, slightly exceeding the sepals; seeds minute, reniform, dark-reddish-brown, smooth and shining, ridged along the back and sides or rarely without ridges.

In waste places and cult. grounds, open sandy woods and brushlands, lake margins and lowlands, and on dunes throughout Okla., N.M., Ariz. and Tex., year around; throughout temp. and trop. Am.

\section{Glinus L.}

Annuals with the general habit of Mollugo, pubescent or glabrous; leaves verticillate, unequal, entire; flowers in dense glomerules in the leaf axils of upper nodes, on short peduncles; calyx free from the ovary, the 5 sepals distinct; petals none; stamens 3 to 10 or rarely more; ovary superior; fruit a loculicidal 3-valved capsule; seeds numerous, minute, smooth or tuberculate, with a distinct strophiole, the funiculus large, coiled about the seed.

A genus of 12 species, widely distributed in tropical and warm temperate regions.

1. Seeds blackish-brown, tuberculate

1. G. lotoides.

1. Seeds reddish or light-brown, smooth or sometimes pebbly

2. G. radiatus.

1. Glinus lotoides L. Fig. 431.

Plants cinereous-tomentose with branched hairs; stems diffusely branched from the base, prostrate or ascending, to about $35 \mathrm{~cm}$. long; leaves pseudoverticillate, narrowly to broadly obovate, rounded or abruptly acute at the apex, narrowed below to a slender petiole of about equal length, to $25 \mathrm{~mm}$. long and $15 \mathrm{~mm}$. broad; flowers stoutly pedicellate or essentially sessile, in axillary glomerules; sepals lanceolate, stellate-tomentose, to $7 \mathrm{~mm}$. long and $3 \mathrm{~mm}$. broad; stamens 5 to 10 , rarely more; capsule ellipsoid, to $4.5 \mathrm{~mm}$. long; seeds black, tuberculate.

Waste places, locally established on moist flats and along marsh and lake margins, in s.e. Okla. (Waterfall) and e.-cen. Tex.; an Old World species that has become introd. in various parts of N.A.

2. Glinus radiatus (R. \& P.) Rohrb. Fig. 430.

Annual herb with stellate-tomentose foliage; stems to $5 \mathrm{dm}$. long; leaves with slender petioles to $6 \mathrm{~mm}$. long, elliptic to obovate or broadly spatulate, rounded 

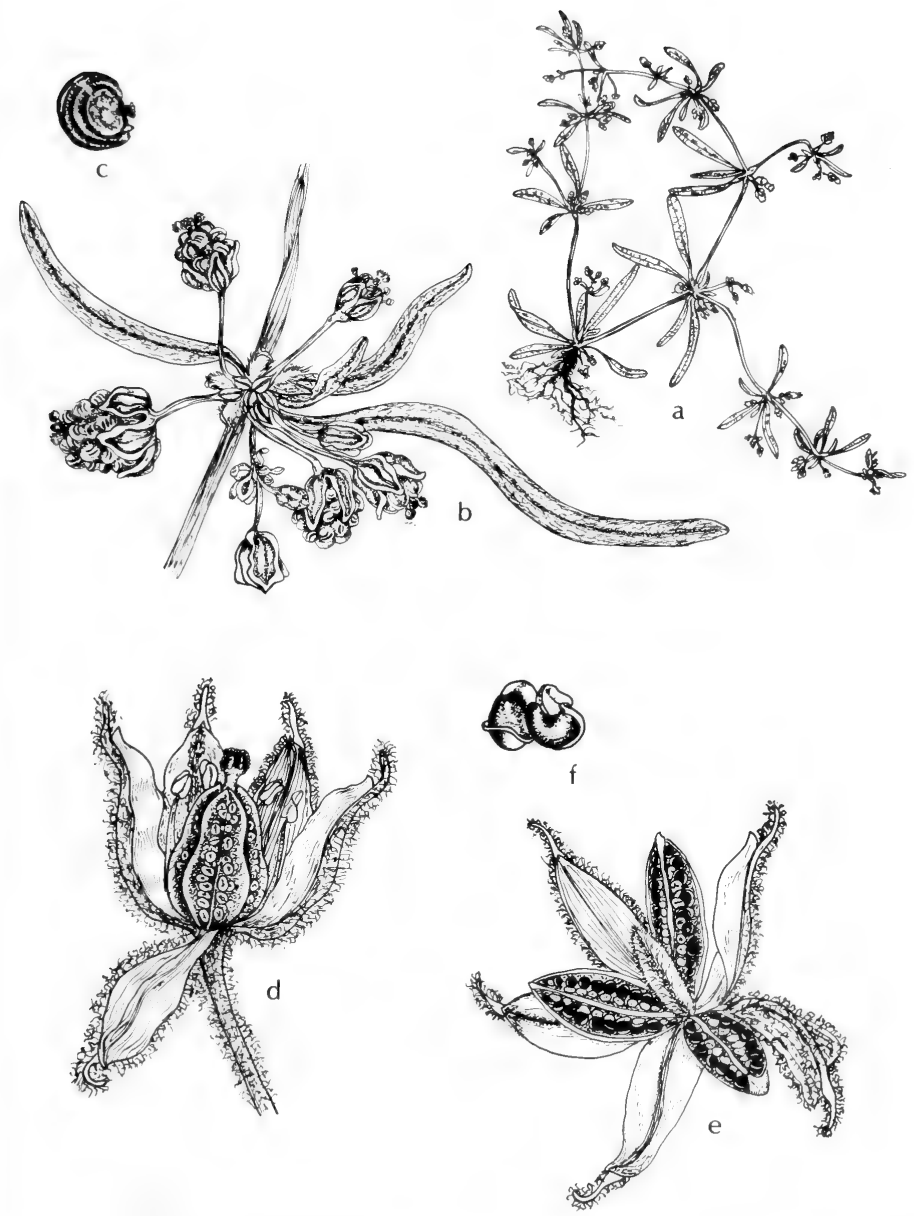

Fig. 430: a-c, Mollugo verticillata: a, habit, x 1/2; b, habit, x 3; c, seed, x 10. d-f, Glinus radiatus: d, flower, $x 6$; e, capsule, open, x 6; f, seed, x 20. (V. F.). 


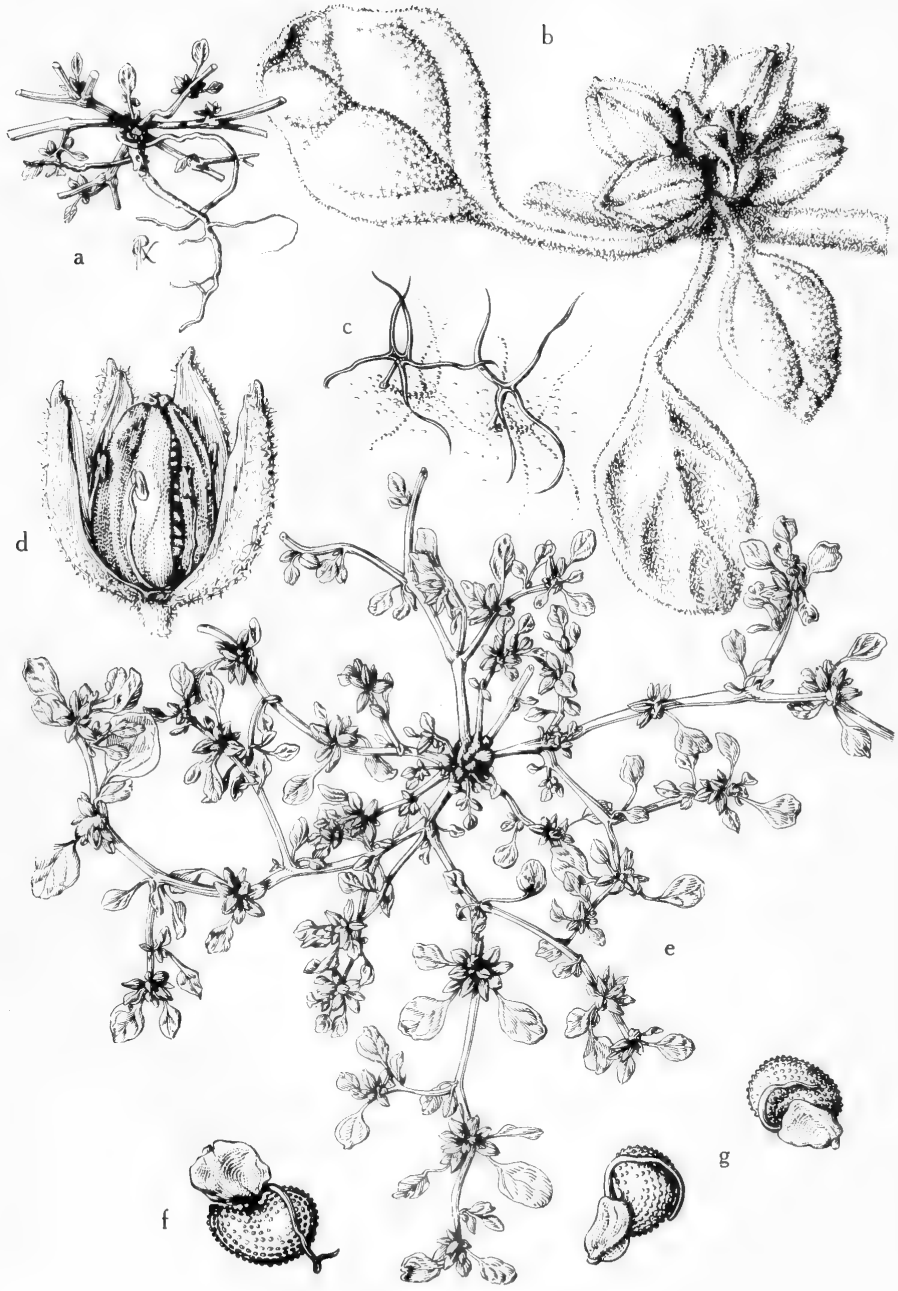

Fig. 431: Glinus lotoides: a, basal part of plant, showing roots, x 2/3; b, leaves and glomerule of flowers, the pubescence of stellate hairs, x 3; c, stalked, stellate hairs, $x$ 40 ; d, flower, 1 sepal removed to show ovary and stamens, x 61/2; e, plant, as seen from above to show prostrate spreading habit, $\mathrm{x} 2 / 3 ; \mathrm{f}$, and $\mathrm{g}$, mature seeds, showing strophiole and funiculus, x 20. (From Mason, Fig. 222). 
to acute or apiculate at apex, to $25 \mathrm{~mm}$. long and $15 \mathrm{~mm}$. wide; flowers in clusters of 10 or more; calyx lobes oblong-elliptic to lanceolate, about $2.7 \mathrm{~mm}$. long, stellate-tomentose: stamens 3 to 5 , shorter than the calyx lobes; filaments filiform, about $1 \mathrm{~mm}$. long: anthers about $0.5 \mathrm{~mm}$. long; capsule ellipsoid, 3-3.5 mm. long: seeds numerous, brown, smooth and shining, sometimes pebbly, about $0.4 \mathrm{~mm}$. long. G. Cambessedesii Fenzl.

In muddy or sandy soils and in mud of lagoons in river bottoms, in s. and e. Tex., Apr.-Oct.; from Tex. through Mex. and the W.I. to S.A.

\section{Trianthema L.}

About 20 species, with all but ours in tropical and temperate regions of the Old World.

\section{Trianthema Portulacastrum L. Horse purslane, verdolaga Blanca. Fig. 432.}

Annual succulent herb, glabrous, branching from the base; branches decumbent, sometimes to $1 \mathrm{~m}$. long; leaves opposite, in unequal pairs, broadly obovate to suborbicular-obovate or the smaller ones narrower, rounded to notched or apiculate at the apex, the blades to $4 \mathrm{~cm}$. long and $3 \mathrm{~cm}$. wide, with smaller ones on the axillary branchlets; petioles about equaling the blade, dilated at the base; stipules scarious, entire; flowers sessile and usually solitary in the leaf axils, partly concealed in the petiolar sheath; calyx lobes 5, ovate-lanceolate to lanceolate, concave, about $2.5 \mathrm{~mm}$. long, pinkish-purple within, with a dorsal mucronation near the apex; petals none; stamens 5 to 10 , perigynous, alternating with the calyx lobes when the same number; ovary superior; capsule about $4 \mathrm{~mm}$. long, cylindrical, somewhat curved, the winged appendages at the apex prominent; seeds reniform, black, rough, about $2 \mathrm{~mm}$. in diameter.

In sandy soils of thickets, on dunes and in waste grounds along streams and irrigation canals, in s. Okla., mostly in s. and w. Tex., through N.M. (Dona Ana and Otero cos.) and generally in Ariz., May-Oct.; from Fla. to Calif., s. through Latin Am.; also Old World trop.

\section{Sesuvium L. Sea Purslane}

Annual or perennial succulent herbs or undershrubs, with prostrate or ascending to suberect stems and branches; leaves opposite, fleshy, without stipules, the petiole often dilated and sometimes connate at the base; flowers solitary in the leaf axils, sessile or with short stout pedicels; calyx tube turbinate, adnate below to the ovary; calyx lobes 5, usually horned on the back near the apex; petals none; stamens 1 to many, perigynous, sometimes slightly united into phalanges, the filaments filiform; ovary half-superior, 2- to 5-celled with as many styles; capsule membranaceous, 2- to 5-celled, ovoid, circumscissile; seeds stalked, usually many in each cell, minute, smooth or rarely rugose.

About 10 species widely distributed but mainly maritime or in saline soils in warm temperate, tropical or subtropical America.

1. Stamens 5 (2)

1. Stamens numerous (3)

2(1). Seeds smooth; in southeast corner of Texas...................... S. maritimum. 2. Seeds conspicuously rugose; in extreme south Texas...........2. S. trianthemoides.

3(1). Flowers all distinctly pedicelled; stems rooting at nodes

3. S. Portulacastrum.

3. Flowers both sessile and with stout inconspicuous pedicels; stems not rooting at nodes (4) 
4(3). Distribution in west and northwest Texas westward; leaves mostly oblanceolate; plants usually drying light-brown

4. S. verrucosum.

4. Distribution primarily on or near the coast in south Texas ( $S$. erectum extending inland along the Rio Grande in Trans-Pecos region); plants drying blackish or dark-gray (5)

5(4). Plants prostrate to decumbent, densely covered with crystalline globules; leaves sessile, mostly all linear-oblong. 5. $S$. sessile.

5. Plants typically erect to erect-spreading, sometimes decumbent, sparsely covered with crystalline globules; leaves mostly oblanceolate

6. S. erectum.

\section{Sesuvium maritimum (Walt.) B.S.P. Fig. 433.}

Plant glabrous and succulent throughout; stems prostrate, procumbent to ascending at tips, freely branched, sometimes forming mats to $2 \mathrm{~m}$. in diameter; leaves spatulate to narrowly oblanceolate or obovate, rounded to obtuse at the apex, tapering at base to a short clasping petiole, to about $25 \mathrm{~mm}$. long; flowers usually solitary in leaf axils, sessile; calyx lobes ovate to ovate-oblong, obtuse, with a subapical dorsal prolonged appendage, pink or purplish within, 2-3 mm. long; stamens 5; capsule ovoid, about $4 \mathrm{~mm}$. long; seeds brownish-black, smooth and somewhat iridescent, $1 \mathrm{~mm}$. long or less.

On sea beaches and low sandy banks near and along the coast in s.e. Tex., flowering the year around; from N.Y. to Fla. and Tex.; also W.I.

\section{Sesuvium trianthemoides Correll. Fig. 432.}

Plant annual, fleshy, brown when dry, branched from the base, the herbage with scattered large crystalline globules; stems to $35 \mathrm{~cm}$. long or more, the internodes 4-5 cm. long; leaves opposite, oblanceolate to spatulate, obtuse at apex, at least $3 \mathrm{~cm}$. long (including the petiole) and $1 \mathrm{~cm}$. wide above the middle, tapered below into a conspicuous petiole; petiole broadly scarious-winged at base and clasping; flowers solitary in the axils of leaves and branches, sessile; calyx lobes triangularovate, subacute at apex, strongly nerved, about $3.5 \mathrm{~mm}$. long, with hyaline margins, the dorsal apical appendage small; stamens 5, with slender filaments about 1 $\mathrm{mm}$. long; ovary ovoid, 2-celled; styles 2, about $0.5 \mathrm{~mm}$. long; capsule ovoidellipsoid, pointed at apex, 4-5 mm. long, circumscissile; seeds about 10 in each capsule, about $1.5 \mathrm{~mm}$. long, conspicuously rugose with brownish granular irregular ridges; with additional light patches extended in irregular lines from the hilum.

In wet depressions in dunes of s. Tex., June-Aug.; endemic.

\section{Sesuvium Portulacastrum L. Cenicilla. Fig. 434.}

Glabrous fleshy perennial herb; stems trailing, much-branched, often rooting at the nodes, sometimes forming patches $2 \mathrm{~m}$. across; leaves narrowly oblong to oblanceolate or elliptic-obovate, to $6 \mathrm{~cm}$. long and $25 \mathrm{~mm}$. broad, obtuse-rounded to abruptly acute at apex, tapered into a clasping base (with these commonly overlapping); flowers pedicelled, solitary in the leaf axils; calyx lobes broadly ovatelanceolate to lanceolate, to $1 \mathrm{~cm}$. long and $6 \mathrm{~mm}$. broad, hooded, pink-purple within, often strongly veined, with a subapical dorsal prolonged appendage; stamens numerous, the filaments about $5 \mathrm{~mm}$. long, the oblong-elliptic anthers about $1 \mathrm{~mm}$. long; ovary ovoid-globose, about $3 \mathrm{~mm}$. long and thick; styles sometimes distinct to base; capsule conic, about $1 \mathrm{~cm}$. long and 5-6 $\mathrm{mm}$. in diameter; seeds black, smooth and lustrous, $1.2-1.5 \mathrm{~mm}$. long.

On beaches, edge of bays and in wet sand or clay dunes along the coast in Tex., subject to salt water flooding, rarely inland, flowering the year around; from Fla. to Tex., s. to S.A.; also the Old World trop. 


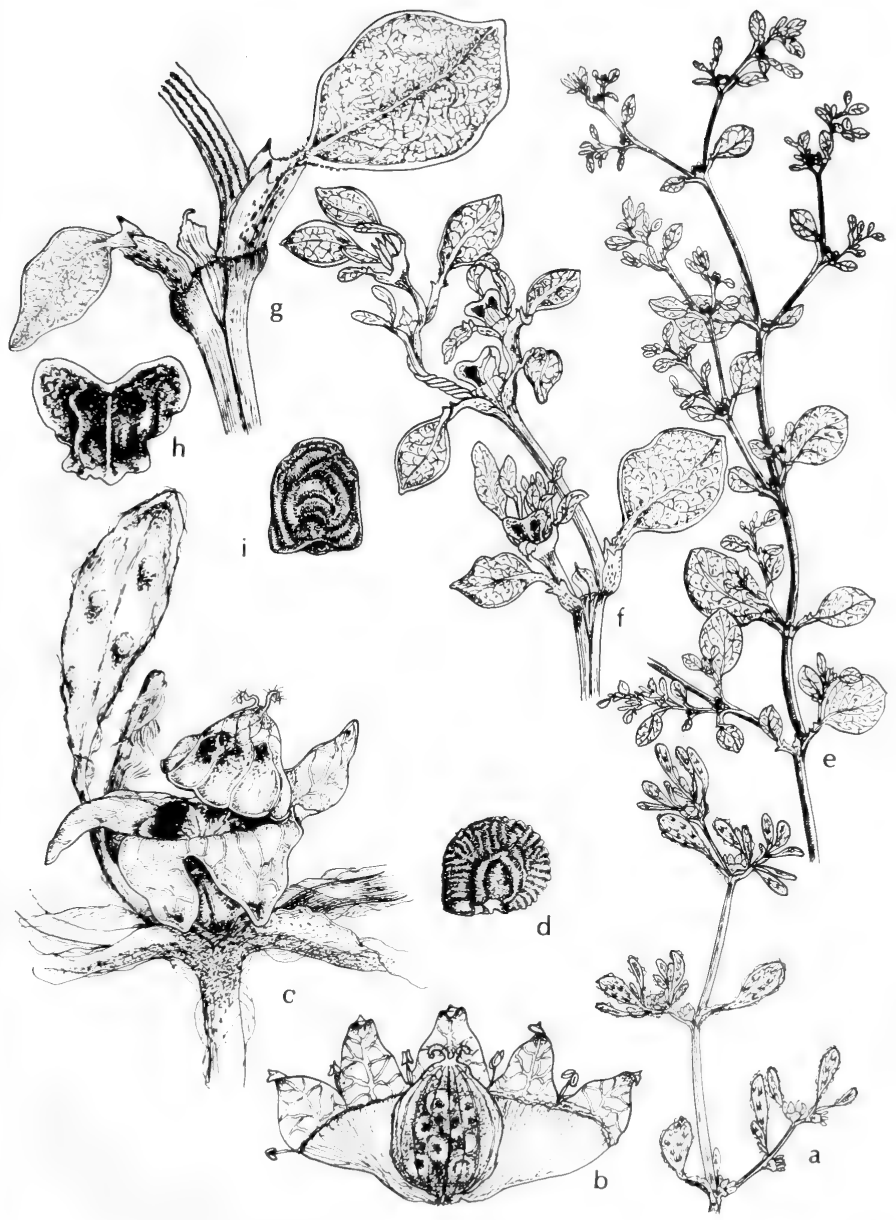

Fig. 432: a-d, Sesuvium trianthemoides: a, habit, x 1\%; b, open calyx, x 5; c, flower, x 5; d, seed, x 10. e-i, Trianthema Portulacastrum: e, habit, x 1/2; f, end of stem, x 11/2; $\mathrm{g}$, node, $\times 2 \frac{1}{2} ; \mathrm{h}$, capsule, $\mathrm{x} 5$; i, seed, x 10 . (V. F.). 


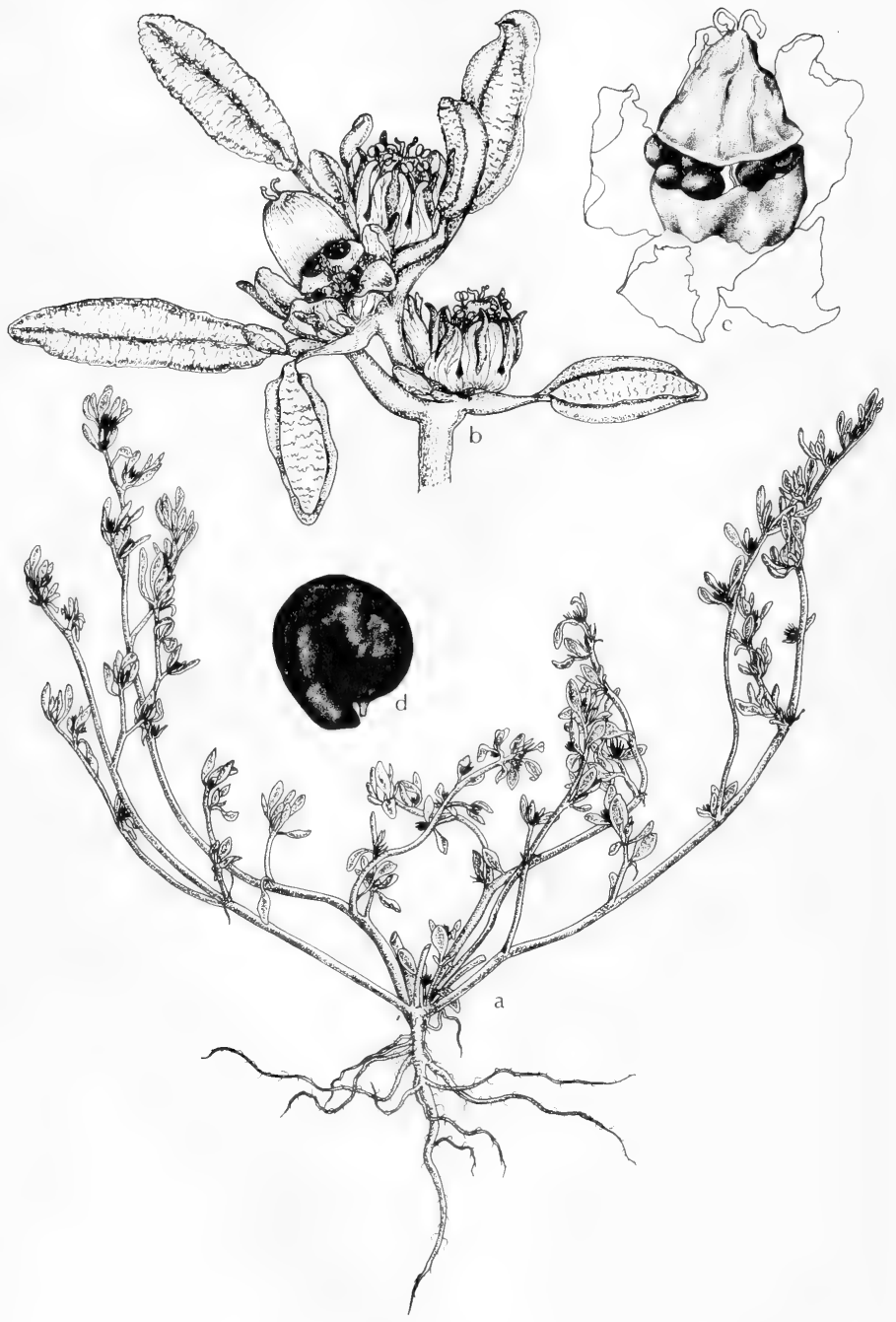

Fig. 433: Sesuvium maritimum: a, habit, $\mathrm{x} 1 / 3$; b, end of branch (note five stamens in flower), x 22/3; c, capsule, x 5; d, seed, x 26. (a, c, d, Courtesy of R. K. Godfrey; b, V. F.). 


\section{Sesuvium verrucosum Raf. Fig. 434.}

Freely branched prostrate perennial herb; stems to $9 \mathrm{dm}$. long, smooth and usually more or less finely verrucose with crystalline globules, when dry brownishtan to light-grayish-tan in color; leaves oblanceolate to oblong-ovate or sometimes with some linear-oblong, rounded to somewhat subacute at apex, tapered into an expanded scarious clasping base, to $3 \mathrm{~cm}$. long and $1 \mathrm{~cm}$. wide above the middle, those of the branchlets mostly shorter than the internodes; flowers subsessile or with a short stout pedicel; calyx lobes broadly ovate-elliptic to ovate-lanceolate, 4.5-7 $\mathrm{mm}$. long, hooded, with a subapical dorsal prolonged appendage; stamens numerous; capsule conic, about $5 \mathrm{~mm}$. long and $3 \mathrm{~mm}$. in diameter; seeds black, smooth and lustrous, about $1 \mathrm{~mm}$. long.

In saline and alkaline soils about lakes, in creek bottoms and on mud flats and clay dunes in w. Okla. (Waterfall), in w. and n.w. Tex., N.M. (Chaves Co.) and Ariz. (Maricopa, Pinal and Yuma cos.), Apr.-Aug.; a plant of the interior from Mo. and Ark. to Tex., N.M., Ariz. and Calif.; also n. Mex.

\section{Sesuvium sessile Pers. Lowland PuRslane.}

Succulent sprawling much-branched perennial that spreads by rhizomes, forming mats to $6 \mathrm{dm}$. or more in diameter, the herbage densely covered and almost completely concealed by crystalline globules, when dry dark-gray to almost blackish; stems prostrate and ascending at tips; leaves essentially sessile, linear to narrowly linear-oblong or some narrowly oblanceolate, obtuse at apex, to $3 \mathrm{~cm}$. long, mostly less than $3 \mathrm{~mm}$. wide, those of the branchlets longer than the internodes; flowers sessile or with short stout pedicels; calyx lobes mostly oblongelliptic, obtuse, 4-7 $\mathrm{mm}$. long, the outer surface densely covered with crystalline globules, pink within, with a subapical dorsal prolonged appendage; stamens numerous, the anthers pink; capsule triangular-ovoid, about $4 \mathrm{~mm}$. long and 3 $\mathrm{mm}$. wide at base; seeds dark-brown, about $1 \mathrm{~mm}$. long.

In moist saline soils about lakes and lagoons, on flats and clay dunes and in open grassy woodlands in extreme s. Tex., very rare inland, flowering the year around; from Tex. to Calif., s. to S.A.

\section{Sesuvium erectum Correll.}

Perennial, typically erect to erect-spreading or sometimes decumbent, more or less adorned throughout with crystalline globules; when dry brownish-black to dark-gray; stems to $5 \mathrm{dm}$. or more long; leaves linear-oblong to oblanceolate or spatulate, obtuse at apex, tapered below to a clasping base, to $4 \mathrm{~cm}$. long and 8 $\mathrm{mm}$. wide; flowers numerous, in the axils of leaves and branches, sessile or with pedicels rarely to $5 \mathrm{~mm}$. long; calyx lobes broadly elliptic to ovate-lanceolate, obtuse to subacute at apex, rose-purple within, 4-8 $\mathrm{mm}$. long, with a subapical dorsal appendage about equal to or greatly exceeding the sepal apex; styles 3 to 5 , conspicuous, typically black when dry; stamens numerous; capsule ovoid, blunt and truncate at apex, about $5 \mathrm{~mm}$. long and $3 \mathrm{~mm}$. in diameter; seeds black, plump, about $1 \mathrm{~mm}$. long.

Along canals, on shell deposits, and about ponds and in depressions in dunes and sand hills on and near the coast in s. Tex. with an extension inland along the Rio Grande to the Trans-Pecos, Apr.-July; undoubtedly also in n.e. Mex.

\section{Fam. 57. Portulacaceae Juss.}

\section{Purslane Family}

Annual or perennial herbs or rarely shrubs, glabrous or rarely pilose at the nodes, more or less succulent; leaves opposite, alternate or in basal rosettes, entire, often fleshy; stipules scarious, lacerate or modified into hairs, or none; flowers solitary, racemose, paniculate or cymose, terminal or axillary, perfect, regular or 


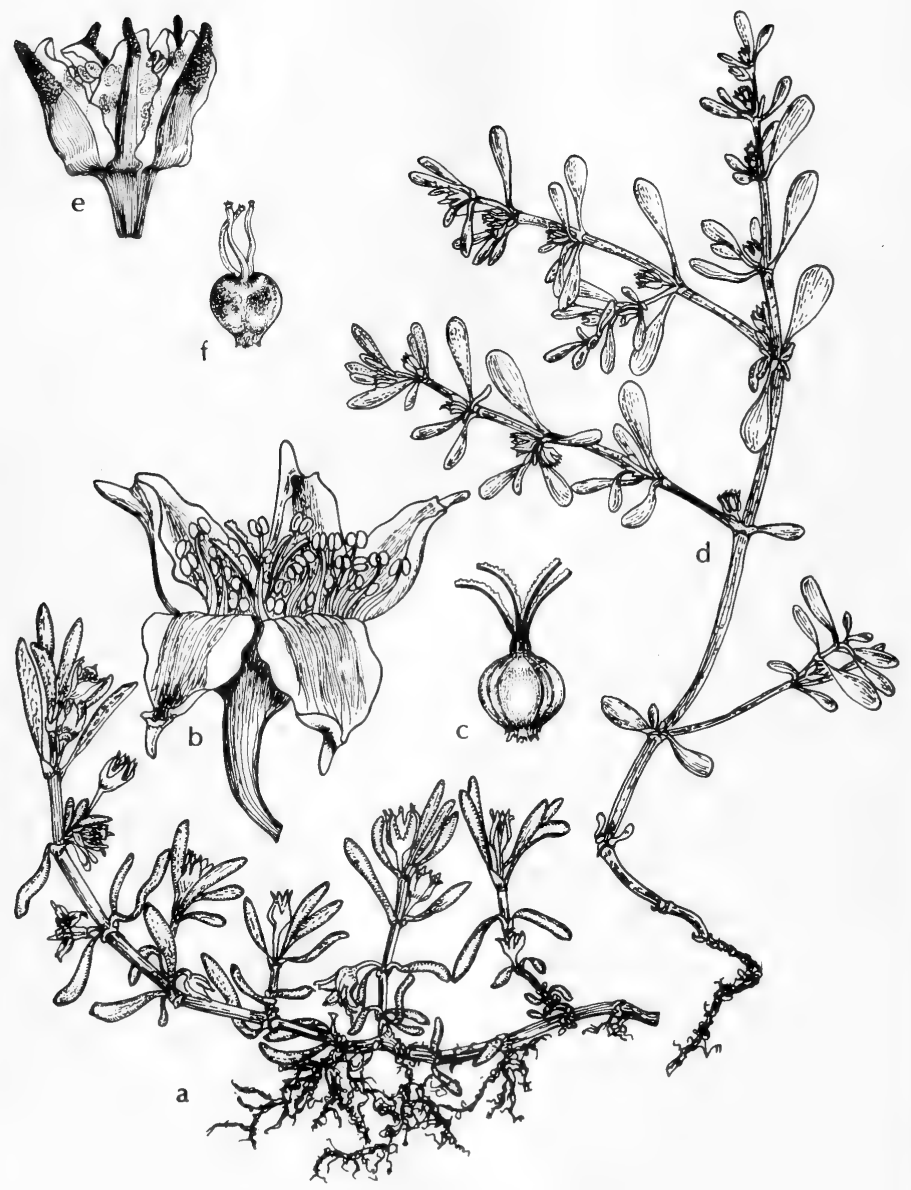

Fig. 434: a-c, Sesuvium Portulacastrum: a, habit, x 1/2; b, flower, x 21/2; c, ovary and style, x 21/2. d-f, Sesuvium verrucosum: d, habit, x 1/2; e, flower, x $2 \frac{1}{2}$; f, ovary, x $2 \frac{1}{2}$. (V. F.). 
nearly so; sepals (sometimes interpreted as bracts) usually 2, persistent or deciduous, scarious or herbaceous; petals (sometimes called sepals) usually 4 or 5 , often fugacious or dehiscent; stamens inserted with the petals, sometimes adnate at the base, of the same number as the petals or usually more; filaments filiform: anthers 2-celled, dehiscent longitudinally; ovary 1-celled, superior or (in Portulaca) partly or wholly inferior; styles 2 to 7 , more or less united; ovules 2 to many, on a central or basal placenta; fruit a loculicidal or circumscissile capsule, the valves as many as the styles; seeds 3 to many or (by abortion) 1 or 2 , mostly round-reniform, compressed, lenticular, the testa often crustaceous and sometimes strophiolate.

A family of a least 19 genera and more than 350 species that are worldwide in distribution.

1. Capsule 2- or 3-valved.

1. Montia

1. Capsule circumscissile.

2. Portulaca

\section{Montia L.}

Herbs annual or perennial by rhizomes or stolons, succulent, glabrous, often glaucous; leaves basal, opposite or alternate; inflorescence paniculate or racemose; pedicels spreading or recurved in fruit; flowers white or pinkish-lavender; sepals 2 , subequal in size, persistent; petals 3 to 5 , often unequal in size; stamens 3 or 5; ovary 1-celled; styles 3; ovules 3; capsule globose or ovoid, 3-valved; seeds 1 to 6 .

About 50 species in North America, South America, temperate Eurasia, mountains of tropical Africa, and Australia.

1. Perennial, with runners ending in a bulblet; stem leaves several, obovate to oblanceolate, tapering to base................................ M. Chamissoi.

1. Annual with fibrous roots; stem leaves 2 , forming a connate-perfoliate disk that subtends the inflorescence..............................2. $M$. perfoliata.

1. Montia Chamissoi (Ledeb.) Durand \& Jackson. Fig. 435A.

Perennial by bulblets produced at the ends of runners; stems prostrate or ascending, 5-30 cm. long, leafy particularly at tip; leaves opposite, petiolate, oblanceolate, 1-5 cm. long; inflorescence axillary or terminal, 3- to 8-flowered, 1 or 2 bracts at base of raceme or bractless; pedicels recurved in fruit; sepals orbicular, about $2 \mathrm{~mm}$. in diameter; petals white or pink, entire or barely retuse; stamens 3 to 5 ; ovules 3 ; capsule $1-1.5 \mathrm{~mm}$. long; seeds black, shining, with low tubercles.

Wet meadows, stream banks and bogs in mts. of N. M. (Rio Arriba, San Miguel and Taos cos.) and Ariz. (Apache to Coconino, Yavapai and Gila cos.), June-Aug.; Ia. to Alas., s. to N. M., Ariz. and Calif.

2. Montia perfoliata (Donn) Howell. Miner's Lettuce. Fig. 435B.

More or less fleshy often reddish annual, erect or spreading, 5-30 cm. high; basal leaves several, petioled, spatulate or lanceolate to rhomboidal, 1-7 cm. long; stem leaves 2, united in an orbicular or angled disk subtending the inflorescence; flowers pink or white, in congested or elongated often verticillate racemes with a bract at the first branch of the inflorescence; sepals rounded, ovate, $2-3 \mathrm{~mm}$. long; petals 5, clawed, notched at the apex, 3-4.5 mm. long; ovules 3; capsule globose; seeds 3, black, shining, 1-2 mm. long, minutely granulate with low tubercles.

Along streams and about springs and in seepage areas in Ariz. (Coconino and Mohave cos. to Santa Cruz and Pima cos.), Feb.-May; S.D. to B.C., s. to Ariz. and Calif.

\section{Portulaca L. Purslane}

Diffuse or ascending annual or perennial succulent herbs; leaves alternate or opposite, flat or terete, often in whorls around the flowers; stipules scarious or none, or reduced to hairy tufts; flowers perfect, solitary or crowded at the top 


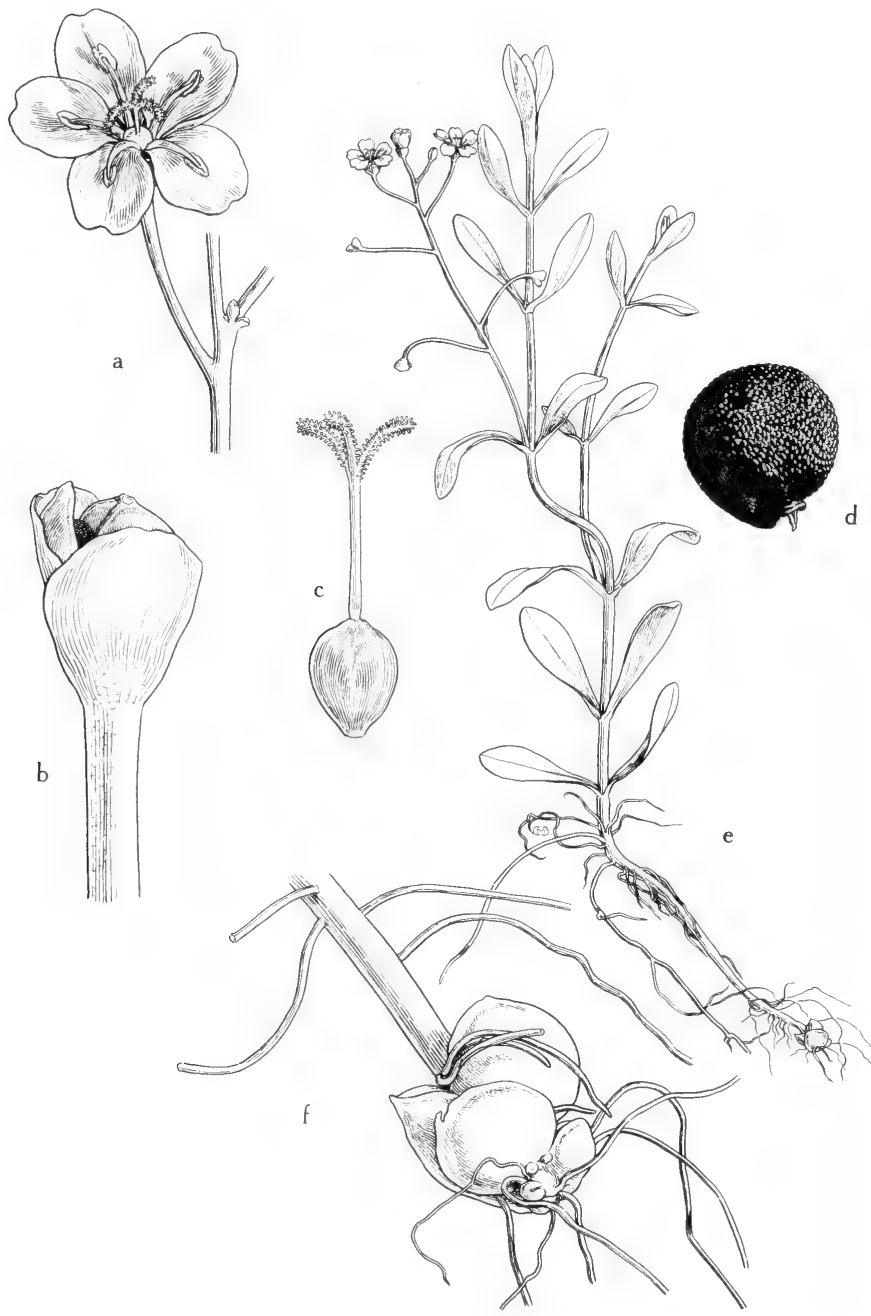

Fig. 435A: Montia Chamissoi: a, flower, x 21/2; b, calyx and capsule at time of dehiscence, $\mathrm{x} 12$; c, pistil, showing the long papillose stigma, $x 8$; $d$, mature seed, the tubercles beadlike, $\mathrm{x} 16$; e, habit. $\mathrm{x} 2 / 3 ; \mathrm{f}$, bulblet at end of runner, $\times 3$. (From Mason, Fig. 224). 

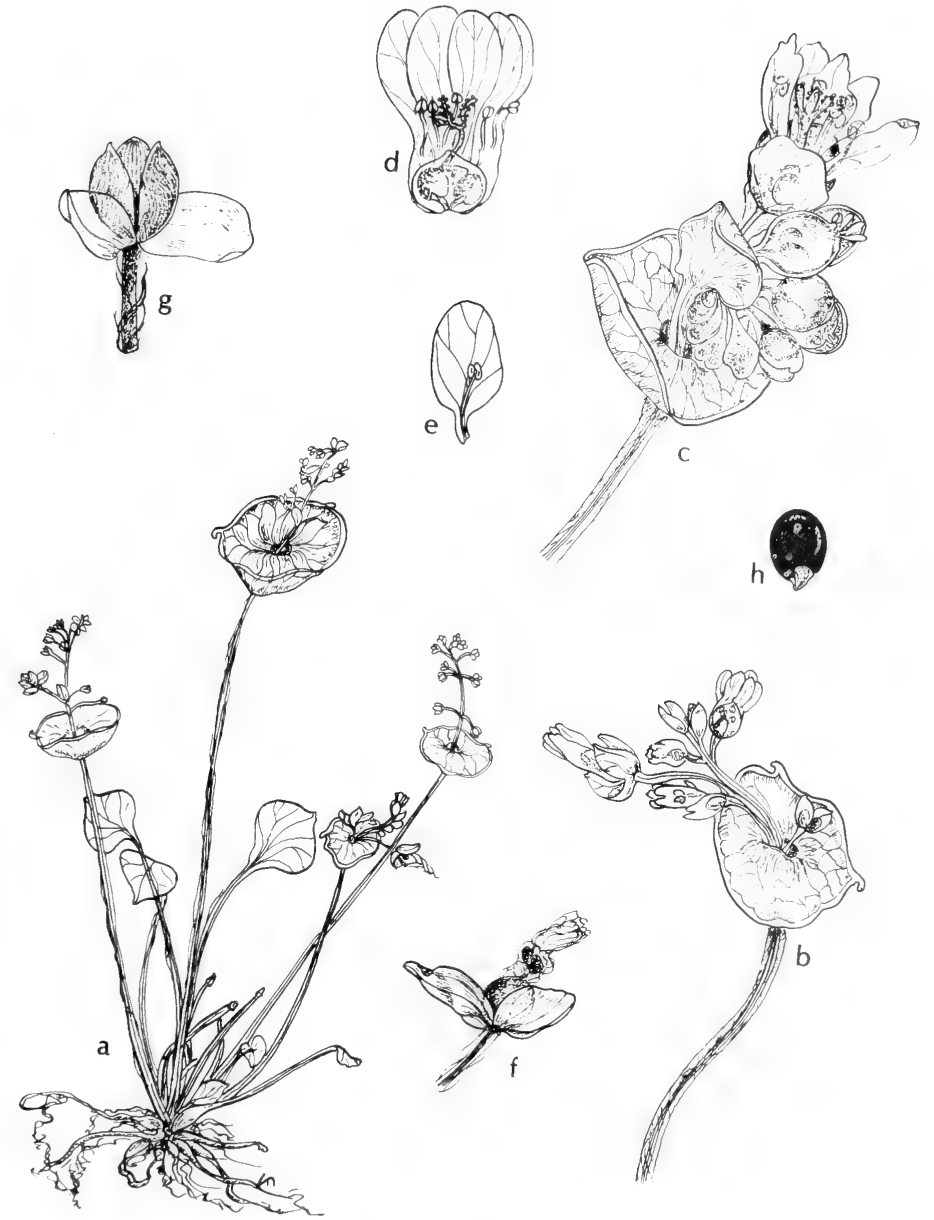

Fig. 435B: Montia perfoliata: a, habit, $\mathrm{x} \frac{1}{12} ; \mathrm{b}$, perfoliate leaf and cluster of flowers, x 2 ; c, perfoliate leaf and cluster of flowers, x 5; d, flower split longitudinally, x 5; e, petal and stamen, x 5; f, calyx and young capsule, x 5; g, valves of capsule, x 5; h, mature seed, x 5. (V. F.). 
of the stem and branches, of various colors; calyx 2-cleft; petals 4 to 6 , usually 5; stamens 8 to many, inserted at the base of the petals; ovary partly or wholly inferior; styles 3 to 9; ovules numerous; capsule 1-celled, membranous, circumscissile, many-seeded; seeds reniform or cochleate, with a smooth or minutely tuberculate or sometimes echinate testa.

About 200 species of world-wide distribution, mostly tropical and subtropical. 1. Lower valve of capsule with an expanded circular membranous wing just below its rim...................................................... P. umbraticola.

1. Capsule rim without a subtending wing. 2. P. oleracea.

\section{Portulaca umbraticola H.B.K.}

A glabrous prostrate to erect or ascending fleshy annual, with angled stems; leaves rather few; blades flat, sessile, the lower spatulate or obovate and obtuse to rounded, the upper oblanceolate to oblong and often acute, 1-3 cm. long, 2-11 $\mathrm{mm}$. broad; flowers clustered at the ends of the branches; sepals ovate, obscurely carinate; corolla yellow or orange and partly red; petals spatulate or obovate, acutish or cuspidate; stamens 7 to 27 ; styles 3 to 6 ; capsule circumscissile at the middle or above, the rim crowned by a narrow wing, the lid flattish; seeds gray, tuberculate. $P$. lanceolata Engelm., $P$. coronata Small.

In sandy soils in prairies, mesquite thickets, saline flats and salt marsh areas in s.w. Okla. (Waterfall) throughout most of Tex. to Ariz. (Greenlee, Graham, Gila, Pinal, Cochise, Santa Cruz and Pima cos.), Mar.-Nov.; from Tex. to Ariz. and Baja Calif.; also Ga., Cuba and Jam.

\section{Portulaca oleracea L. Purslane, verdolaga. Fig. $435 \mathrm{C}$.}

Glabrous fleshy annual, with often stout prostrate or ascending branches, the branches spreading radially and $6-30 \mathrm{~cm}$. or more long; axillary hairs few and inconspicuous; leaves alternate, the flat blades obovate-cuneate or spatulate, 6-30 $\mathrm{mm}$. long, $0.2-13 \mathrm{~mm}$. broad, occasionally larger, rounded or nearly truncate at the apex; buds flattened, acute; flowers clustered or solitary, sessile, the hairs surrounding them inconspicuous or wanting; sepals broadly ovate to orbicular, 2.8-4.5 mm. long, 2.8-3.8 mm. broad, keeled, acutish; corolla yellowish; petals 3-4.6 mm. long, $1.8-3 \mathrm{~mm}$. broad; stamens 6 to 10 ; style lobes 4 to 6 ; capsule 5-9 mm. high, circumscissile at or about the middle; seeds black, $0.7-0.8 \mathrm{~mm}$. (rarely $1 \mathrm{~mm}$.) wide, granulate.

On grassy slopes, moist waste areas, floodlands, dunes and in salt marshes and dry soils of perennial pools throughout most of Okla. and Tex., w. through N. M. to Ariz. (Apache, Navajo, Coconino, Greenlee and Santa Cruz cos.), May-Nov.; in temp. and trop. regions of the world.

\section{Fam. 58. Caryophyllaceae Juss.}

\section{Pink or Chickweed FAMILY}

Annual, biennial or perennial herbs or small woody-based plants, with nodose stems; leaves entire, typically opposite or whorled, often united at base, with or without stipules; flowers regular, perfect or rarely unisexual; sepals 4 or 5 , persistent, distinct or united into a tube; petals as many as sepals, rarely fewer or none, often toothed or lobed; stamens usually as many as and alternating with the petals; filaments sometimes cohering at the base; styles 2 to 5 , distinct or more or less united; ovary free from the calyx, 1-celled or incompletely 2 - to 5-celled at base; capsule few- to many-seeded, opening by 2 to 5 entire or bifid valves; seeds small.

More than 1750 species in about 70 genera, cosmopolitan but most abundant in temperate climates.

1. Stipules present.

1. Stipules none (2) 


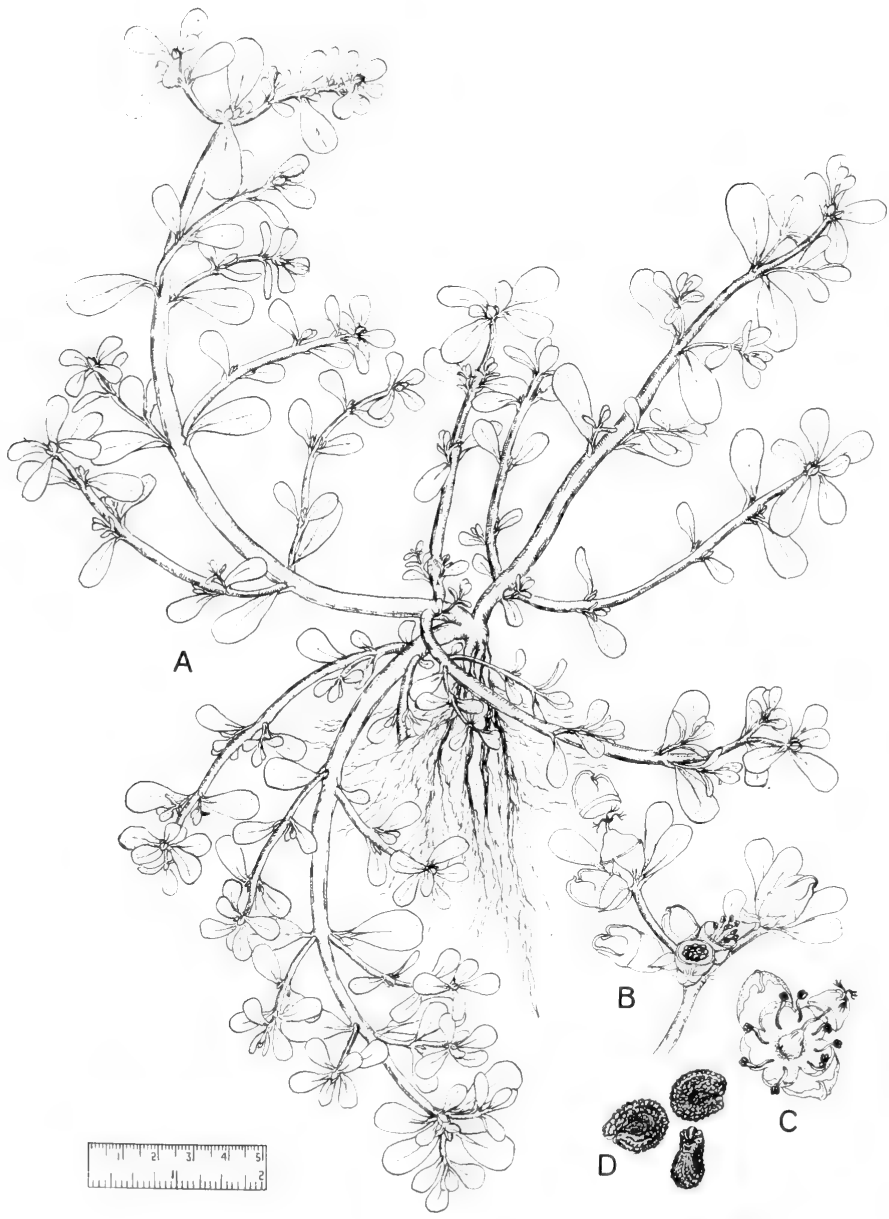

Fig. 435C: Portulaca oleracea: A, habit, x 1/2; B, flowers and capsules, $x$ 11/2; C, flower open, X 4; D, seeds, x 18. (From Reed, Selected Weeds of the United States, Fig. 74). 


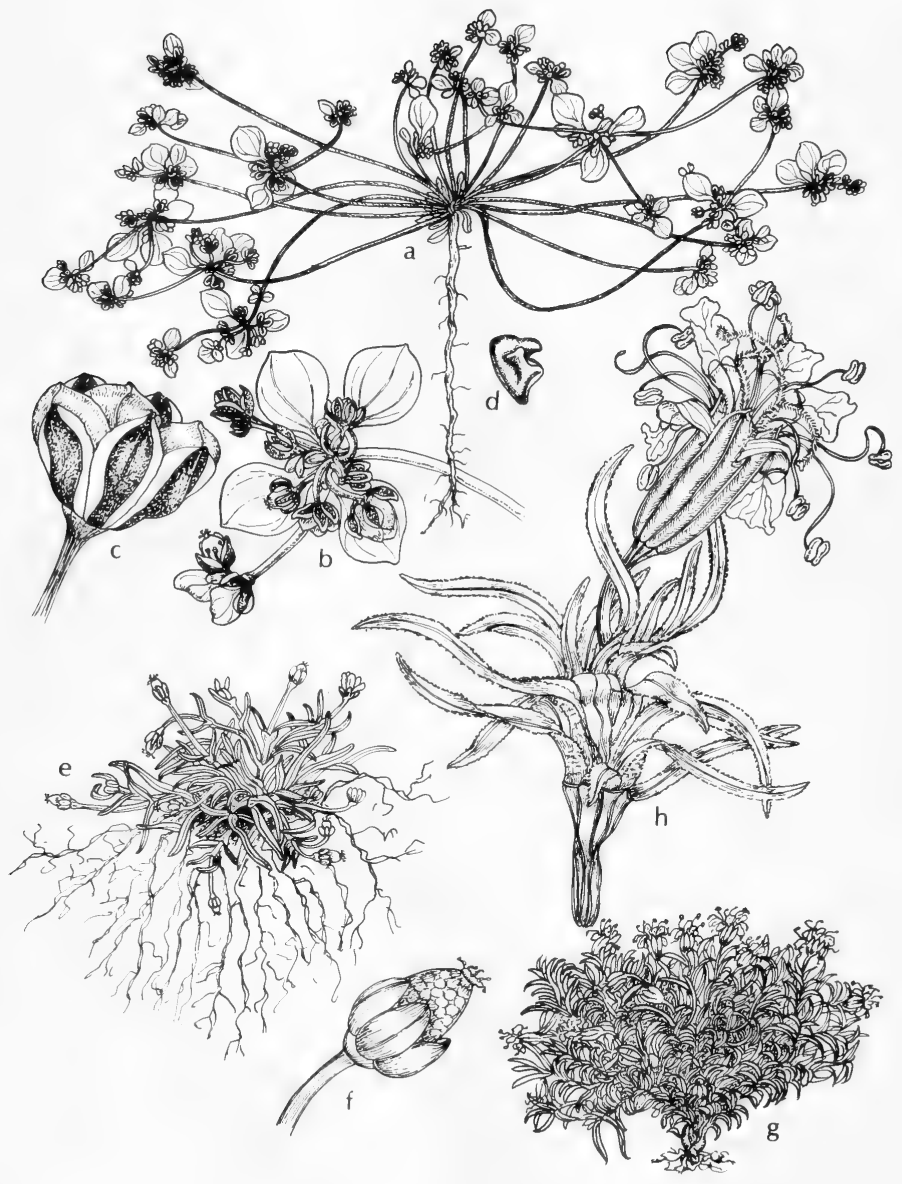

Fig. 436: a-d, Drymaria pachyphylla: a, habit, x 1/2; b, flower cluster, x 1; c, flower, x 5; d, seed, x 5. e and f, Sagina saginoides: e, habit, x 1; f, fruit, x $5 . \mathrm{g}$ and $\mathrm{h}$, Silene acaulis: g, habit, $\mathrm{x} \frac{1 / 2}{2}$ h, flower, $\times 2 \frac{1}{2}$. (V. F.). 
2(1). Sepals united.

2. Sepals free (3)

3(2). Petals present (4)

3. Petals absent (8)

4(3). Petals more or less deeply bifid (5)

4. Petals entire, emarginate or irregularly toothed (7)

5(4). Style 1, 3-cleft; capsule 3-valved.

2. Drymaria

5. Styles 3 or more; capsule opening by twice as many valves or teeth as there are styles (6)

6(5). Styles 5

3. Cerastium

6. Styles 3 (or varying from 3 to 6 )

4. Stellaria

$7(4)$. Fewer styles (2 or 3 ) than sepals.

5. Arenaria

7. As many styles as sepals (4 or 5 )

6. Sagina

8 (3). Leaves linear.

6. Sagina

8. Leaves not linear.

4. Stellaria

\section{Silene L. Catchfly. Campion}

About 500 species of wide geographic distribution, especially the Mediterranean region.

1. Silene acaulis L. var. subacaulescens (Williams) Fern. \& St. John. Moss CAMPION. Fig. 436.

Pulvinate perennial from a woody root and a branched caudex, forming dense mats to $3 \mathrm{dm}$. across; stem mostly $3-6 \mathrm{~cm}$. tall, rarely more; leaves mostly basal, sessile, marcescent for many years, linear to linear-lanceolate, 4-10 (-15) $\mathrm{mm}$. long, 0.8-1.5 (-2) $\mathrm{mm}$. wide, glabrous to scabrous; flowers solitary, from essentially sessile in the rosettes to stalked with peduncles to $4 \mathrm{~cm}$. long, perfect or frequently imperfect and the plants dioecious; calyx tubular-campanulate, (6-) 7-10 (-11) $\mathrm{mm}$. long, 10-nerved, commonly pinkish; corolla pink to lavender or rarely whitish; petals with a claw about twice as long as the blade, oblongoblanceolate, $8-12 \mathrm{~mm}$. long, rounded to slightly emarginate at apex; appendages usually 2 , to about $1 \mathrm{~mm}$. long or reduced to callosities or sometimes lacking; carpophore 1-2 mm. long, sparsely pubescent; styles 3; capsule 3-celled; seeds light brown, weakly papillate, about $1 \mathrm{~mm}$. long.

In wet soil of alpine slopes and meadows, often about rocks and in rock crevices in N.M. (Colfax, Mora and Taos cos.) and Ariz. (Coconino Co.), June-Sept.; the species as a whole circumpolar and alpine in both hemispheres.

\section{Drymaria R. \& S. DRYMARY}

A genus of about 50 species, primarily American.

1. Drymaria pachyphylla Woot. \& Standl. Fig. 436.

Glaucous subsucculent annual, the vegetative branching largely confined to radially diverging branches from a slender yellowish rootstock or to terminal pseudoverticillate branch systems, the elongate spreading internodes muchexceeding the terminally crowded leaves; leaves pseudoverticillate, with clasping petioles to $8 \mathrm{~mm}$. long, glaucous, subsucculent, wrinkling in drying, broadly elliptic to suborbicular, obtuse to acutish at apex, tapering to the petiole, to $14 \mathrm{~mm}$. long and $12 \mathrm{~mm}$. broad; stipules absent; inflorescences of terminal and axillary contracted umbelloid verticils subtended by normal foliage leaves and bracts, the pedicels 1-5 mm. long; bracts ovate, obtuse, scarious and almost nerveless, to $1.5 \mathrm{~mm}$. long; sepals subequal, glabrous, glaucous, ellipsoid, obtuse, to $3.3 \mathrm{~mm}$. long and $2 \mathrm{~mm}$. broad, obscurely 3- to 5-nerved, the central portion green, the margins scarious; petals $5,2.5-3 \mathrm{~mm}$. long, bifid about half their 


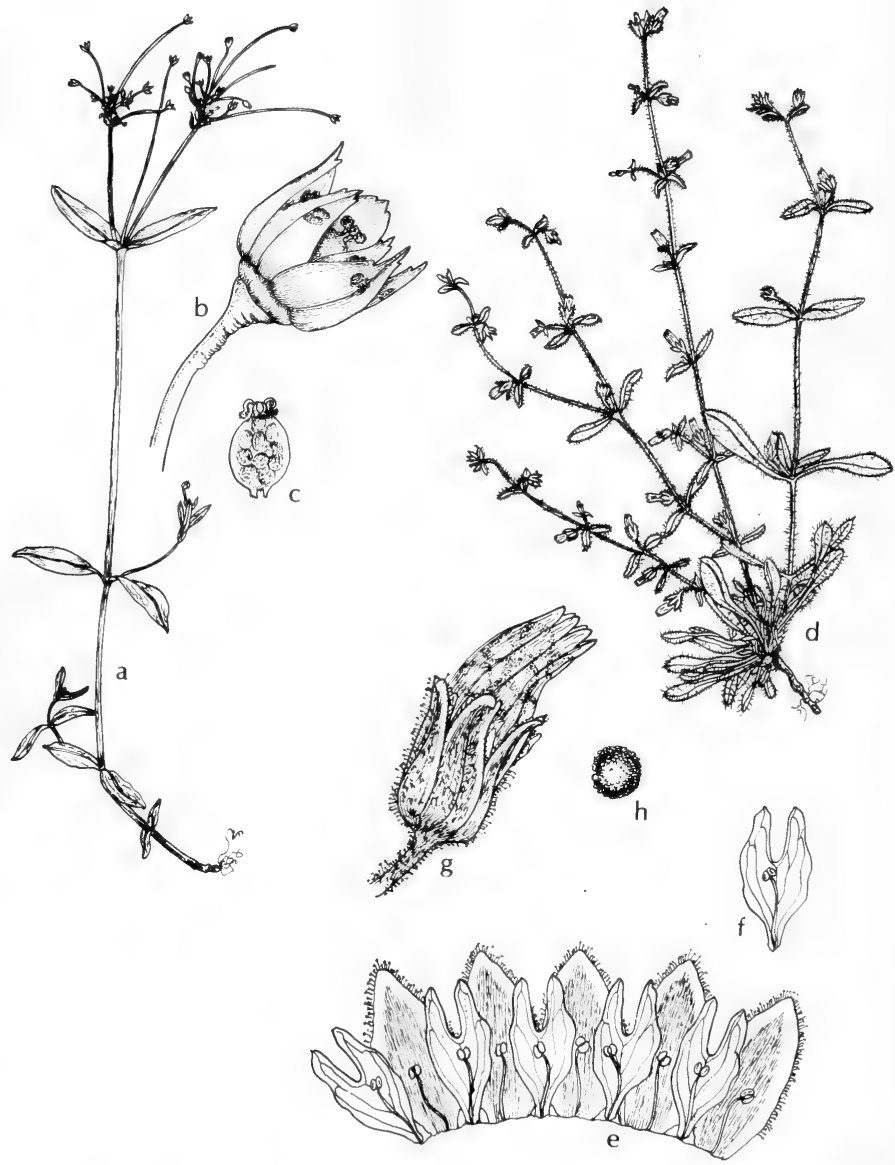

Fig. 437: a-c, Stellaria umbellata: a, habit, x 1/2; b, flower, x 10; c, fruit, x 10. d-h, Cerastium axillare: $\mathrm{d}$, habit, $\mathrm{x} 1 / 2$; e, perianth spread out, $\mathrm{x} 5 ; \mathrm{f}$, petal with stamen, $\mathrm{x}$ $5 ; \mathrm{g}$, calyx and capsule, $\times 5 ; \mathrm{h}$, seed, $\times 6$. (V. F.). 
length, with 2 oblong lobules in the cleft, the serrulate trunk tapered to the base, the claw not clearly delineated; stamens 5 , to $1.5 \mathrm{~mm}$. long, the oblong anthers about $0.5 \mathrm{~mm}$. long; ovary at anthesis subglobose, the short style bifid or trifid more than half its length and slightly exceeding the anthers; capsule subglobose, 3-4 mm. long, mostly exceeding the sepals; seeds as many as 25 , black, vermiculiform, facially gibbous, more or less tessellate, to $1.8 \mathrm{~mm}$. long, about twice as long as broad.

On sand-gravel bars and in wet silty areas along streams and in dry plains in Trans-Pecos Tex., N.M. (Don Ana and Otero cos.) and Ariz. (Cochise Co.), often as a pioneer on bare areas, Jan.-Oct.; in w. U. S. and n. Mex.

This plant is known to be toxic to sheep and cattle.

\section{Cerastium L. Mouse-ear. Chickweed}

Annual or perennial pubescent or hirsute herbs, sometimes viscid; flowers white, few to many, borne in terminal dichotomous cymes, glomerules or singly in leaf axils; sepals 5 or rarely 4; petals of the same number as the sepals or rarely wanting, 2-lobed or -cleft; stamens 10 or rarely fewer; styles equal in number to the sepals and opposite them, rarely fewer; capsule 1-celled, cylindrical, often curved, membranaceous, opening at the summit by twice as many teeth as there are styles, many-seeded; seeds rough.

About 60 species that are widely distributed but mostly in temperature zones.

1. Petals shorter than to about equal to the sepals (2)

1. Petals slightly to decidedly longer than the sepals (3)

2(1). Flowers arising singly in leaf axils along much of stem and branches

2. Flowers concentrated in cymes at apex of stem and branches 1. C. axillare. 2. C. vulgatum.

3(1). Uppermost floral bracts with whitish scarious margins (4)

3. All floral bracts green and herbaceous (5)

4(3). Petals typically twice or more the length of sepals; basal branches and offshoots becoming dry and withered, not hirsute............3. C. arvense.

4. Petals about as long as or very slightly exceeding the sepals; basal branches or offshoots green, hirsute. 2. C. vulgatum.

5 (3). Leaves usually $3 \mathrm{~cm}$. long or less; fruiting pedicels about as long as to shorter or rarely longer than the capsules, straight or at most only gently curved. 4. C. brachypodum.

5. Leaves usually more than $3.5 \mathrm{~cm}$. long; fruiting pedicels typically much longer than the capsules, rather abruptly curved just below the calyx 5. C. nutans.

1. Cerastium axillare Correll. Fig. 437.

Plant apparently annual, to $3 \mathrm{dm}$. high, glutinously glandular-pubescent throughout; stems few or many, suberect or ascending, sparsely branched; leaves typically linear-oblanceolate but occasionally linear-elliptic to elliptic-lanceolate, obtuse to subacute, to $3 \mathrm{~cm}$. long and $8 \mathrm{~mm}$. wide; flowers produced singly in leaf axils along much of main stem and branches; pedicels slender, $1 \mathrm{~cm}$. long or less; sepals elliptic, $4-5 \mathrm{~mm}$. long; obtuse to subacute, densely glandularpubescent (especially on lower half), with scarious margins, noticeably exceeding the petals; petals elliptic-oblanceolate in outline, 3-4 mm. long, divided to near the middle into linear-lanceolate subacute lobules; capsule about twice as long as the calyx; seeds reddish-brown, tuberculate, about $0.5 \mathrm{~mm}$. in diameter.

On open-forested seepage slopes, rocky hills and in grasslands in the mts. of Trans-Pecos Tex., Apr.-Sept.; also Chih. 


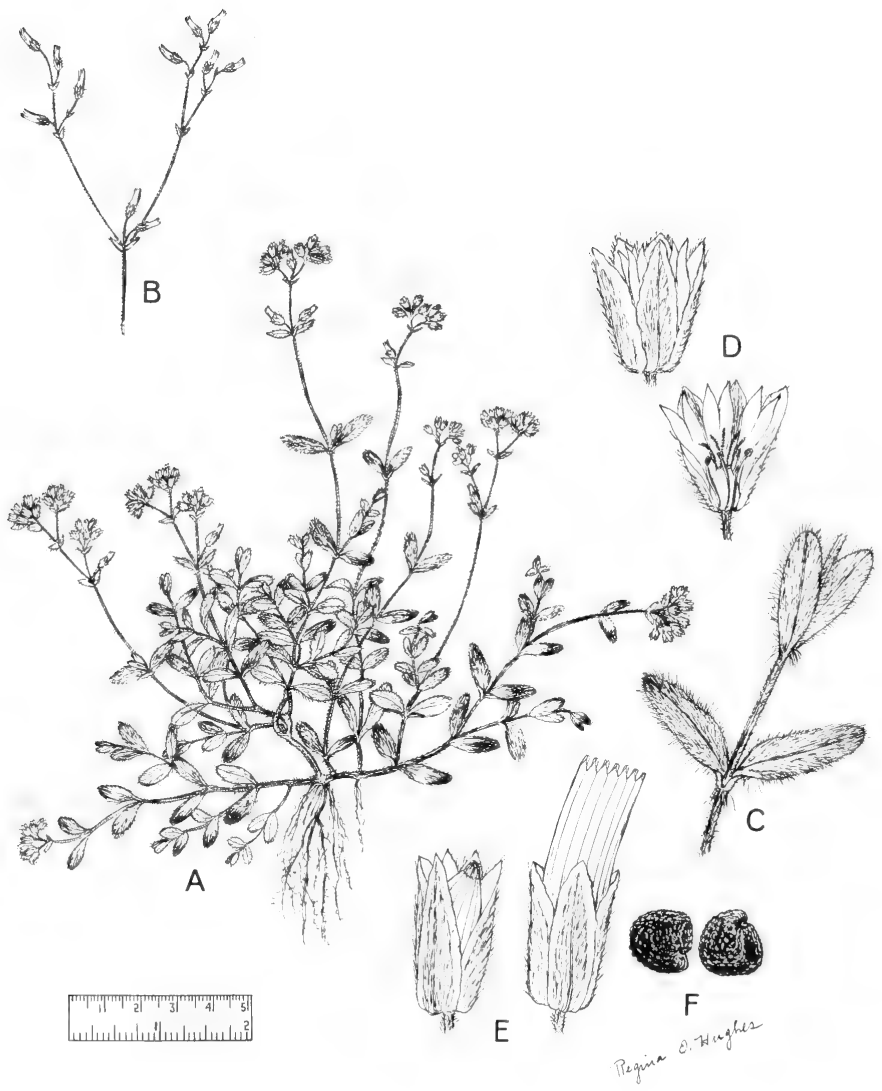

Fig. 437A: Cerastium vulgatum: A, habit, $x$ 1/2; B, mature dichotomous cymes, x $1 / 2$ C, enlarged leaves, $x 1.25 ; D$, flowers, $x 31 \frac{1}{2} ; \mathbf{E}$, capsules, $x 31 \frac{1}{2} ; \mathrm{F}$, seeds, $\mathrm{x} 15$. (From Reed, Selected Weeds of the United States, Fig. 77). 
This species is distinguished from such species as $C$. brachypodum and $C$. vulgatum by having its flowers produced singly in leaf axils along much of the main stem and branches instead of being produced in apical cymes as in those species. The plant is also densely glandular-pubescent, and the small, deeply lobed petals are conspicuously exceeded by the sepals.

\section{Cerastium vulgatum L. COMMON MOUSE-EAR. Fig. 437A.}

Short-lived matted perennial with depressed basal leafy offshoots; flowering stems to $65 \mathrm{~cm}$. high, hirsute to rarely glandular, the median internodes becoming as much as $12 \mathrm{~cm}$. long; leaves of the season in 3 to 7 pairs, oblanceolate to oblong or narrowly oval, conspicuously white-hirsute on both surfaces, the median leaves to $4 \mathrm{~cm}$. long and $15 \mathrm{~mm}$. wide; bracts similar to leaves but smaller, broadly scarious at summit and margin; inflorescences 3- to many-flowered, forming terminal ultimately very dichotomous cymes, at first rather compact, in fruit with the lower pedicels divergent or reflexed and 2 to 4 times the length of the calyx; sepals 5-7 mm. long, ovate-lanceolate to elliptic-lanceolate, obtuse to acute, scarious-margined, hirsute but glabrous at tip; petals $4-5 \mathrm{~mm}$. long, narrow, about equaling or rarely somewhat exceeding the sepals, cleft for about $1 \mathrm{~mm}$. at apex, with ciliate claw; capsule narrowly cylindrical, curved, 9-12 mm. long; seeds to $0.9 \mathrm{~mm}$. in diameter, reddish-brown, bluntly tuberculate. $C$. triviale Link.

A nat. of Euras. that has become naturalized in fields, along roadsides, and about old homesteads, also wet soil of stream banks and wet meadowlands, uncommon in Okla. (Waterfall) and Tex., w. to N. M. (Catron and San Miguel cos.) and Ariz. (Apache, Navajo and Pima cos.), spring-summer; throughout most of temperate N.A.

The var. holosteoides Fries is a glabrescent plant or with minute lines of hairs on the stems; the elliptic to oblong leaves are dark-green, ciliate and round-tipped.

\section{Cerastium arvense L. Fig. 437B.}

Perennial, the stems tufted, erect or ascending, pubescent or nearly glabrous, the flowering stems sparingly branched above, 1-4 dm. high; basal leaves subulatelinear to linear-oblong, 1-4 cm. long, narrowed at the base, rather crowded, those of the flowering stems distant and somewhat reduced; bracts similar to leaves but smaller, scarious-margined; flowers loosely cymose, rather few; pedicels slender, elongated, erect; sepals 4-7 mm. long, lanceolate, glandular-puberulent to glandular-pilose, acute; petals obcordate, much-exceeding the calyx; capsule globose to ovoid, only slightly longer than the sepals.

In wet meadows at high elevations in N. M. and Ariz., June-July; Lab. to Alas., s. to Ga., N. M., n. Ariz. and Calif.; introd. from Eur.

\section{Cerastium brachypodum (Engelm.) Robins.}

Annual, pale-green, finely pubescent or puberulent and sometimes viscid, to about $3 \mathrm{dm}$. high, sparsely branched; leaves linear-oblong to oblanceolate, obtuse to subacute, seldom more than $25 \mathrm{~mm}$. long; flowers in more or less open dichotomous cymes; pedicels about equaling but sometimes shorter than or a little exceeding the capsules, erect or somewhat deflexed, straight or at most gently curved, not hooked below the calyx; calyx about $4 \mathrm{~mm}$. long, the lobes elliptic and acute, very sparsely glandular-puberulent; petals elliptic in outline, about $6 \mathrm{~mm}$. long and $2 \mathrm{~mm}$. wide, exceeding the sepals, notched for about $1 \mathrm{~mm}$. at the apex, the lobules triangular-lanceolate and acute; capsules 2 to 3 times as long as the calyx. Incl. var. compactum Robins. 


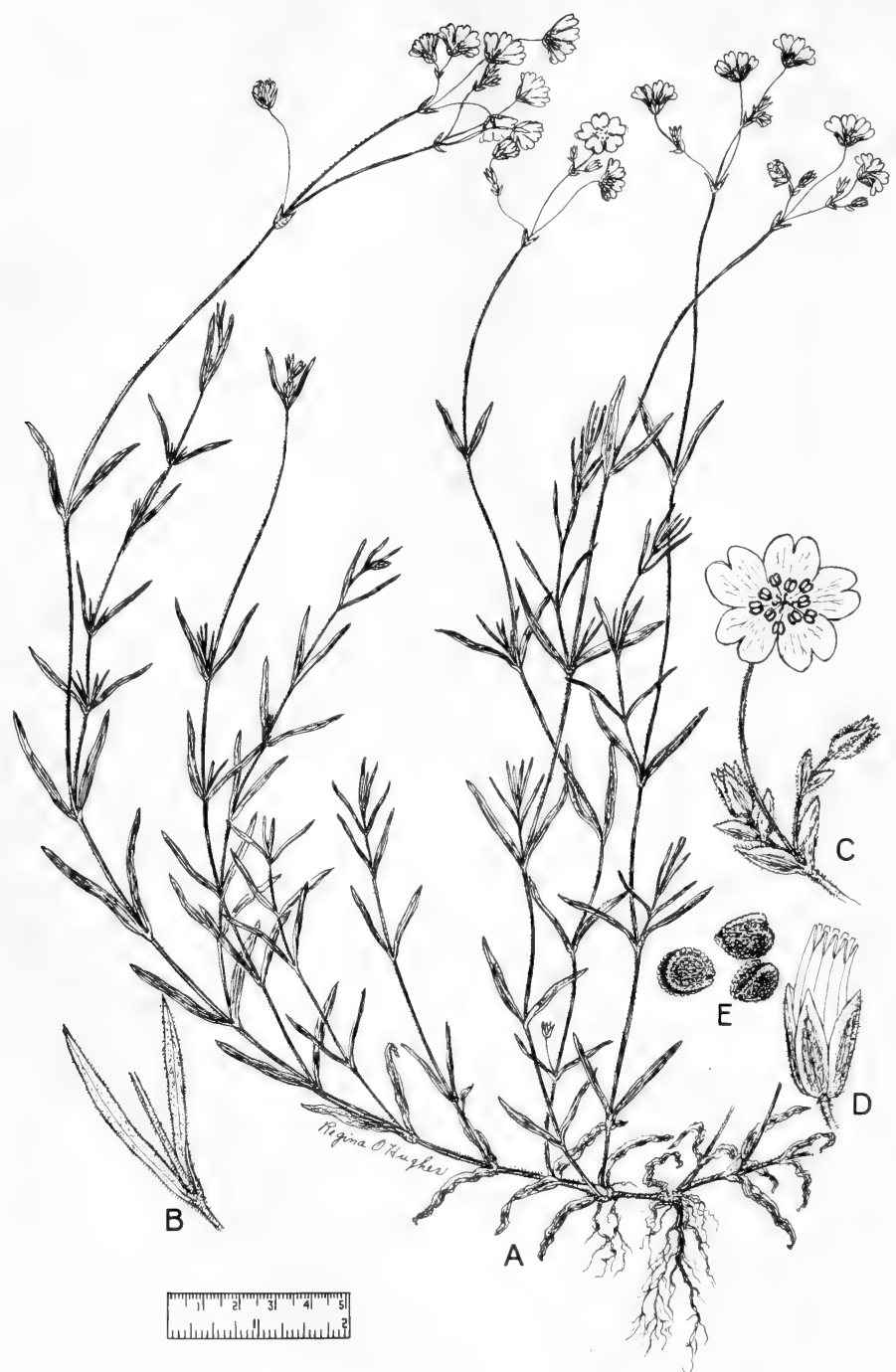

Fig. 437B: Cerastium arvense: A, habit, x $1 / 2 ; \mathrm{B}$, enlarged leaves, $\mathrm{x} 1$; C, flower, X $11 / 2 ; \mathrm{D}$, capsule, $\mathrm{x} 3 ; \mathrm{E}$, seeds, $\mathrm{x} 10$. (From Reed, Selected Weeds of the United States, Fig. 76). 
In open woods, prairies and wet meadows and on slopes in Okla. (Waterfall), mainly in cen. Tex. but extending s. and w., through N. M. (Grant, Lincoln, Otero, San Miguel, Santa Fe, Sierra, Socorro and Taos cos.) to Ariz. (Apache, Cochise, Coconino, Greenlee and Navajo cos.), Feb.-Apr.; from Ga., n. to Va., Tenn., Ill., N. D., Alta. and Wash., w. to Ariz. and Mex.

This species is similar to $C$. nutans but it is a smaller plant and it does not have its pedicels abruptly curved or hooked just below the flowers as in that species.

\section{Cerastium nutans Raf.}

Weak annual, the simple or loosely rather flaccid viscid-pilose stem to $6 \mathrm{dm}$. high, the median internodes to $1 \mathrm{dm}$. long: leaves oblong-lanceolate to narrowly obovate, acute or acutish, thin, the median leaves to $8 \mathrm{~cm}$. long and $15 \mathrm{~mm}$. wide; bracts similar to leaves but smaller, herbaceous; inflorescence loose, simple to dichotomous, 1- to many-flowered; pedicels filiform, ascending or spreadingascending, with hooked tips, in fruit to $55 \mathrm{~mm}$. long; sepals $2-5.5 \mathrm{~mm}$. long, oblong-lanceolate, thin, blunt, pilose; petals narrowly obovate, wanting in cleistogamous flowers, with glabrous claws, cleft nearly to middle, exceeding calyx; capsule curved, to $13 \mathrm{~mm}$. long; seeds about $0.5 \mathrm{~mm}$. in diameter, reddish-brown, bluntly papillate.

In alluvial soils, on wet stream banks and rich wooded slopes, and on calcareous rocks, uncommon in Okla. and Tex., w. through N. M. (Catron, Grant, Lincoln, Otero, Sierra and Socorro cos.) to Ariz. (Apache and Gila cos. to Cochise, Santa Cruz and Pima cos.), Mar.-Oct.; from s. w. Que. and N. E. to B. C., s. to Fla. and w. to Ariz.

The var. obtectum Kearn. \& Peeb. (C. sericeum Wats.) has stems and leaves, at least near the base of the plant, sericeous with long nonglandular hairs.

\section{Stellaria L. CHICKWEED. STARWORT}

Low often diffusely branched annuals or perennials with solitary or cymose flowers; sepals usually 5; petals white, of the same number as the sepals or rarely none, 2-cleft or -parted; stamens 10 or less, hypogynous; ovary 1-celled, manyovuled; styles 3 or rarely 4 or 5 , usually opposite the sepals; capsule ovoid to globose or oblong, 1-celled, dehiscent by twice as many valves as there are styles; seeds several to many, smooth or roughened.

About 120 species that are widely distributed.

1. Petals none or rudimentary; sepals $2-3 \mathrm{~mm}$. long; flowers numerous in terminal umbelliform inflorescences, with filiform pedicels spreading or deflexed.......................................................... S. umbellata.

1. Petals about equaling or exceeding the sepals that are $3-4 \mathrm{~mm}$. long; flowers solitary or in very few-flowered cymes, with slender erect or spreading pedicels (2)

2(1). Leaves ascending, somewhat shiny, broadest near the base, the margins smooth.

2. S. longipes.

2. Leaves spreading, not shiny, broadest near the middle, the margins very finely tuberculate-scaberulous under high magnification....3. S. longifolia.

\section{Stellaria umbellata Turcz. Fig. 437.}

Perennial or (?) annual with very slender rootstocks, glabrous throughout or sometimes the leaves ciliate at base; stems slender, weak, branched, scarcely ridged, 1-2 (-3) dm. tall; leaves oblong to linear-lanceolate, thin, usually $1-2 \mathrm{~cm}$. long, 2-5 $\mathrm{mm}$. wide, the margins smooth but often crisped; flowers numerous in terminal and axillary scarious-bracteate umbelliform cymes, with filiform pedicels to $3 \mathrm{~cm}$. long; sepals lanceolate, acute, scarious-margined, $1.5-3 \mathrm{~mm}$. long; petals rudimentary or lacking; capsule ovoid-oblong, somewhat longer than the calyx; 
seeds brownish, lightly rugose, about $0.6 \mathrm{~mm}$. long. S. gonomischa Boivin, Alsine baicalensis Cov.

In wet meadows and wet or moist forests in N. M. (Lincoln, San Miguel, Santa Fe and Taos cos.) and Ariz. (Coconino Co.), July-Aug.; Ore. and Mont., s, to N. M. and Calif.; Siberia.

\section{Stellaria longipes Goldie.}

Low essentially glabrous perennial with slender rhizomes, often more or less tufted and matted; stems slender, erect or ascending, glabrous or very rarely pubescent near the base, 1-3 dm. tall, 4-angled; leaves sessile, linear to linearlanceolate, 1-3 (-4) cm. long, 1-3 (-5) $\mathrm{mm}$. wide, acute at apex, rigid and stiff, often glaucous, sometimes ciliate at base, the margins smooth; flowers 1 or several in a scarious-bracteate cyme, with slender erect pedicels to $8 \mathrm{~cm}$. long; sepals lanceolate, about $4 \mathrm{~mm}$. long, acute to subobtuse, scarious-margined, glabrous or sometimes ciliolate, 3-nerved; petals 2-cleft, slightly longer to slightly shorter than the sepals; capsule ovoid, usually purplish, somewhat longer than the calyx; seeds lightly reticulate, about $0.8 \mathrm{~mm}$. long.

Wet meadows, bogs, stream banks and seepage areas in $\mathrm{mts}$. of N. M. (Rio Arriba Co.) and Ariz. (Apache and Cochise cos.), May-Aug.; Nfld. to Alas., s. to N. Y., Minn., N. M., Ariz. and Calif.; Euras.

\section{Stellaria longifolia Muhl. ex Willd.}

Spreading perennial; stems decumbent to ascending, to about $6 \mathrm{dm}$. long, 4-angled, glabrous but minutely tuberculate-scaberulous above; leaves sessile, linear-lanceolate to linear, $1.5-3.5(-5) \mathrm{cm}$. long, rarely more than $4 \mathrm{~mm}$. wide, acute at each end, glabrous or with a few basal cilia, the margins very minutely tuberculate-scaberulous; flowers few to many in terminal membranous- to somewhat leafy-bracteate cymes; pedicels divaricate, slender, 5-20 (-30) $\mathrm{mm}$. long; sepals glabrous, narrowly elliptic-lanceolate, 3-4 mm. long, scarious-margined, 3-nerved, acutish; petals usually equalling or slighty exceeding the sepals; capsule greenishyellow, usually considerably longer than the calyx; seeds finely reticulate-warty but appearing smooth.

In marshes, on stream banks and in wet meadows in N. M. (San Miguel and Taos cos.) and Ariz. (Apache and Coconino cos.), May-Aug.; Nfld. to Alas., s. to S. C., N. M., Ariz. and Calif.; Euras.

\section{Arenaria L. SANDWORTS}

Small usually tufted annual or perennial herbs; stems slender or wiry; leaves sessile to subpetiolate, exstipulate; flowers mostly white, in terminal cymose or capitate inflorescences or rarely axillary and solitary; sepals 5 ; petals 5 or sometimes wanting, entire to slightly notched or even bifid; stamens 10 ; styles 2 to 5 , usually 3; ovary 1-celled, usually many-ovuled; capsule ovoid to spherical or ellipsoid, splitting into as many or twice as many valves as there are styles; seeds few to many, globose or reniform, often flattened.

About 150 species of wide geographical distribution, mainly in North Temperate Zone.

1. Plants forming cushions or mats, in subalpine or alpine regions (2)

1. Plants not forming cushions or mats, usually at lower elevations (3)

2(1). Sepals obtuse and usually somewhat cucullate at apex, much shorter than petals; rarely as many as 3 flowers on a stem..........1. A. obtusiloba.

2. Sepals acute to acuminate at apex, about equal to the petals; some stems usually with more than 3 flowers. 2. A. rubella. 
3. Capsules dehiscent by 6 (rarely 4 or 5 ) valves or teeth (4)

4(3). Sepals obscurely 3- to 5-nerved; leaves ovate, 3-5 (-7) $\mathrm{mm}$. long; annual.... 4. A. serpyllifolia.

4. Sepals prominently 1-nerved; leaves lanceolate to narrowly elliptic or linearoblanceolate, typically more than $10 \mathrm{~mm}$. long; perennial.

5. A. lanuginosa.

\section{Arenaria obtusiloba (Rydb.) Fern.}

Cespitose perennial from a woody caudex, forming mats to about $4 \mathrm{dm}$. across, the trailing stems covered with marcescent leaves; basal leaves numerous, linear, imbricate, 5-10 $\mathrm{mm}$. long, mostly less than $0.5 \mathrm{~mm}$. wide, mucronulate, 1-nerved, ciliolate or glandular-pubescent to glabrous; flowering stems erect, to about $6 \mathrm{~cm}$. tall, supporting 1 to rarely 3 erect flowers, with 1 or 2 pairs of reduced bracts, granular-puberulent to pubescent and more or less glandular above; sepals oblong, 4-5 mm. long, 3-nerved, obtuse, the usually purplish tip membranous and typically somewhat erose and slightly cucullate, mostly glandular-pubescent; petals narrowly oblong-oblanceolate, to about twice as long as the sepals; styles 3 or sometimes 4; capsule ovoid-cylindric, 3-valved, to about twice as long as the sepals; seeds essentially smooth, reddish-brown, $0.7-1 \mathrm{~mm}$. long.

In wet seeping subalpine and alpine meadows, on gravel bars and talus slopes in N. M. (Taos Co.) and Ariz. (Coconino Co.), July-Sept.; Greenl. to Alas., s. in $\mathrm{mts}$. to N. M. and Ariz.

\section{Arenaria rubella (Wahlenb.) J. E. Sm.}

Cespitose perennial, typically with a small taproot and a branched crown, forming cushions to about $1 \mathrm{dm}$. across, finely glandular-puberulent or -pubescent throughout or the leaves and calyx glabrous; stems numerous, short, prostrate, with marcescent leaves; leaves mostly basal and somewhat imbricate, linear to linear-subulate, usually to about $1 \mathrm{~cm}$. long, obtuse to slightly acicular, 3-nerved, those of sterile shoots with fascicled secondary leaves in their axils; flowering stems usually to about $8 \mathrm{~cm}$. tall, very slender, simple or dichotomously branched, with 1 to rarely as many as 7 flowers in an open leafy-bracteate cyme; the leaves shorter than the internodes; sepals lanceolate, 2.5-4 mm. long, acute to acuminate, scarious-margined, 3-nerved; petals slightly shorter to slightly longer than sepals; stamens borne on the edge of a perigynous disk surrounding the ovary; styles 3 ; capsule narrowly ovoid, slightly exceeding the calyx, 3-valved; seeds lightbrown, finely tesselate-tuberculate, about $0.5 \mathrm{~mm}$. long.

In wet meadows and slopes in subalpine and alpine regions and on gravelly stream banks in N. M. (reported from but not seen) and Ariz. (Coconino Co.), June-Aug.; Greenl. to Alas., s. in mts. to N. M., Ariz. and Calif.; Euras.

3. Arenaria patula Michx. Fig. 438.

Diffusely branched annual with capillary stems to $3 \mathrm{dm}$. high; leaves slightly fleshy, linear-filiform to linear-lanceolate, to $4 \mathrm{~cm}$. long and $3 \mathrm{~mm}$. wide; pedicels divergent, to $45 \mathrm{~mm}$. long, often glandular; sepals elliptic to lance-attenuate, acute at apex, often somewhat glandular, to $6 \mathrm{~mm}$. long, strongly 3- to 5-ribbed; petals obcordate, to 3 times the length of the sepals; capsule about equaling or exceeding the calyx, its blunt valves entire; seeds $0.5-0.6 \mathrm{~mm}$. long.

In sandy, clayey or gravelly soil in prairies, wet meadows, fields and on rock outcrops, in Okla. (Waterfall) and mostly in e. Tex., Mar.-May; from Ala., Tex. and Ark., n. to e. Kan., O. and Minn.

Var. patula may be distinguished from var, robusta not only by its smaller more compact size, seldom attaining more than $15 \mathrm{~cm}$. in height, but by its 


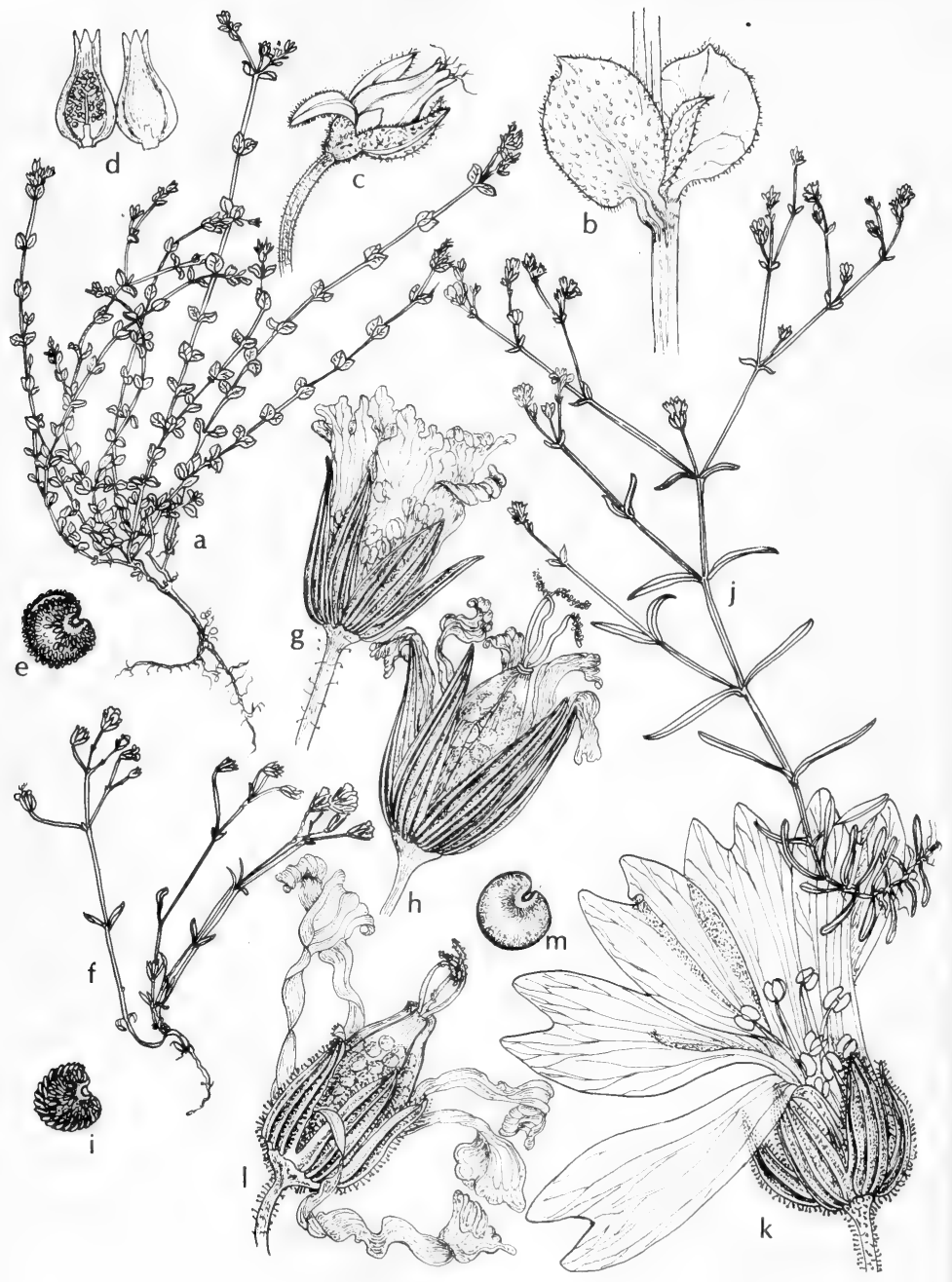

Fig. 438: a-e, Arenaria serpyllifolia: a, habit, x 1/2; b, leaves, x 5; c, flower x 5; d, open capsule, x 5; e, seed, x 10 . f-i, Arenaria patula var. patula: f, habit, x $1 / 2 ; \mathbf{g}$, flower, $x \quad 5 ; \mathrm{h}$, capsule, $\mathrm{x} 5$; $\mathrm{i}$, seed, $\mathrm{x} 10 . \mathrm{j}-\mathrm{m}$, Arenaria patula var. robusta: $\mathrm{j}$, habit, x $1 \frac{1}{2}$; $\mathrm{k}$, flower, x $5 ; 1$, capsule, $x 5 ; \mathrm{m}$, seed, x 10 . (V. F.). 
narrower leaves (1.5 mm. wide or less), prominently 5-ribbed sepals, capsules mostly shorter than the calyx, and its corolla scarcely exceeding the calyx.

Var. robusta (Steyerm.) Maguire is a larger more open plant with wide leaves, 3 -ribbed sepals, capsules commonly exceeding the calyx, and corolla prominently exceeding the calyx.

\section{Arenaria serpyllifolia L. Thyme-Leaved Sandwort. Fig. 438.}

Annual, the stems simple to intricately forking, to $2 \mathrm{dm}$. high; branches cinereous-puberulent; leaves ovate, sessile, acute to acuminate, ciliate, scabrous, to $7 \mathrm{~mm}$. long; inflorescence a leafy nearly regular panicle of dichotomous cymes; pedicels straight, to $1 \mathrm{~cm}$. long; fruiting calyx $3-4 \mathrm{~mm}$. long, 2-3 $\mathrm{mm}$. broad at base, composed of lanceolate to ovate-lanceolate acuminate 3- to 5nerved scabrous sepals; petals oblong, shorter than the sepals; capsule ovoid to flask-shaped, its 2-cleft olive valves hard and resistent; seeds globose-reniform. opaque, strongly rugose, about $0.6 \mathrm{~mm}$. long.

Along river bars, in wet meadows and seepage areas, a weed of fields, lawns and roadsides, in Okla. (Waterfall), e. and cen. Tex., Mar.-July; a Eur. adv. that has become naturalized from Fla, to Calif., n. to Que., Tenn. and Mo.

\section{Arenaria lanuginosa (Michx.) Rohrb.}

Perennial with more or less creeping subterranean stems; flowering stems lax, weak and reclining or sometimes trailing, to about $6 \mathrm{dm}$. long, with lines of minute pubescence; leaves thin, lanceolate to narrowly elliptic or linear-oblanceolate, acute or pungent, narrowed to a somewhat ciliate base, to $3 \mathrm{~cm}$. long and $8 \mathrm{~mm}$. wide, more or less punctate; flowers axillary, subtended by leafy bracts; pedicels slender, puberulent, to $4 \mathrm{~cm}$. long; sepals lanceolate, acute to acuminate, 3-4 mm. long, somewhat dorsally keeled along the solitary midnerve; petals white, about half as long as sepals, sometimes wanting; capsules about $5 \mathrm{~mm}$. long; seeds smooth, shining, black, flattened, about $1 \mathrm{~mm}$. in diameter. $A$. alsinoides Willd., A. confusa Rydb., A. saxosa Gray.

In loam of damp woods, wet meadows, shaded ditches and other such places throughout our region, uncommon, June-Oct.; from Fla. to Calif. and Mex., n. to Va.; also W. I. and S. A.

Var. cinerascens (Robins.) Shinners is a somewhat more rigid plant than is var. lanuginosa, grayish throughout with a fine pubescence, and leaves pungent. Also, their flowers have petals that are about half as long as the sepals.

\section{Sagina L. Pearlwort}

Small often inconspicuous annual or perennial herbs; leaves subulate-filiform to linear, opposite, scarious-connate at base; flowers terminal, usually solitary and long-pediceled; sepals free, 4 or 5 (6) or none; petals usually shorter than sepals, entire, white; stamens 3 to 10 ; styles 4 or 5 (6); capsule ovoid or spheroid; seeds numerous, smooth.

About 25 species that are native to the Northern Hemisphere.

1. Plants forming dense mats, perennial; distribution in mountains of New Mexico and Arizona............................................... S. saginoides.

1. Plants not forming mats, annual; distribution in eastern half of Oklahoma and Texas. 2. S. decumbens.

\section{Sagina saginoides (L.) Karst. Fig. 436.}

Perennial with leafy rosettes clustered at base; stems rarely to $5 \mathrm{~cm}$.long; branches decumbent or ascending, forming mats to $1.5 \mathrm{dm}$. across; leaves filiformsubulate, to about $2 \mathrm{~cm}$. long, somewhat bristle-tipped; flowers terminal, 5 - or rarely 6-merous; pedicels $1-3 \mathrm{~cm}$. long, erect, hooked at summit after anthesis, becoming straight, glabrous; sepals 1-3 mm. long, oval to oblong, glabrous, 


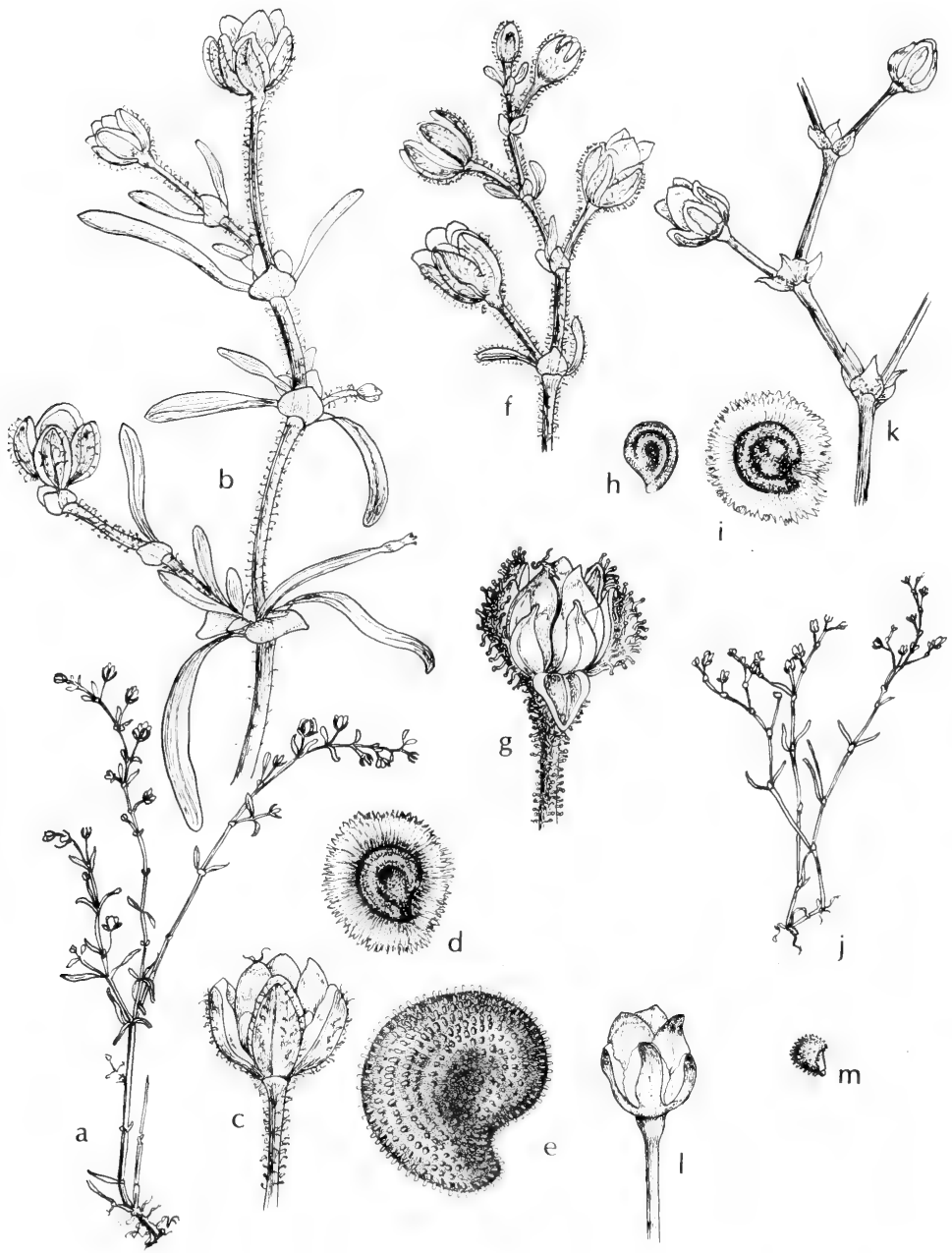

Fig. 439: a-e, Spergularia echinosperma: a, habit, x 1/2; b, branch, x 21/2; c, calyx with dehisced capsule, $x$ 5; d, seed with wing, $x 10$; e, seed without wing, $x 25$. f-i, Spergularia marina: f, branch, $\mathrm{x} 2 \frac{1}{2}$; g, calyx with dehisced capsule, $\mathrm{x} 4$; h, seed without wing, $x 10 ; i$, seed with wing, $x 10$. $j-m$, Spergularia platensis: $j$, habit, $x 1 / 2 ; k$, branch, $x 2 \frac{1}{2} ; 1$, calyx with dehisced capsule, $x$ 5; $\mathrm{m}$, seed $\times 10$. (V. F.). 
appressed-ascending, in fruit spreading and about half as long as the mature capsule; petals about $1 \mathrm{~mm}$. long; stamens 10 or rarely 5; capsule conic-ovoid, 3-5 mm. long, its valves erect after dehiscence.

In wet soil and mud flats about lakes and ponds, and on seepage slopes in N.M. (Rio Arriba, San Miguel and Taos cos.) and Ariz. (Coconino Co.), JuneSept.; Greenl. to Alas., s. to N.M., Ariz. and Calif.; Euras.

Var. hesperia Fern. has sepals not more than $2 \mathrm{~mm}$. long.

2. Sagina decumbens (Ell.) T. \& G.

Annual, usually without a basal rosette; stems capillary, erect, ascending or rarely decumbent, simple or slightly forking, to $17 \mathrm{~cm}$. high; leaves linearsubulate, often spreading-recurved, slenderly mucronate, exstipulate; pedicels filiform, axillary, straight, not hooked after anthesis, glabrous or glandular-pubescent above, to $25 \mathrm{~mm}$. long; sepals 4 or 5 , oblong to elliptic, obtuse, with scarious margins, to $2.5 \mathrm{~mm}$. long, closely appressed-ascending; petals none or 1 to 5 and rudimentary or sometimes equaling or slightly exceeding sepals; stamens 3 to 10 ; styles as many as sepals and alternate with them; capsule slenderly ovoid, 2-3.5 $\mathrm{mm}$. long, 1-2 mm. thick, its valves as many as sepals and opposite them, mostly recurved at apex after dehiscence; seeds reddish-brown, delicately marked with slender ridges, $0.2-0.3 \mathrm{~mm}$. long.

In wet meadows, wet or dryish fields, along paths and in open places in woods in e. half of Okla. (Waterfall) and e., cen. and s. Tex., Feb.-June; from Fla. to Tex., n. to e. Mass., s. Vt., s. N.Y., Ky., Ill., Mo. and e. Kan.

\section{Spergularia J. \& C. PResL SAND-SPURRey}

Low branching annual or perennial herbs; leaves opposite or sometimes fascicled, linear to filiform, fleshy or setaceous; stipules scarious; flowers pink or whitish, in terminal racemose bracted or leafy cymes; sepals 5; petals 5, fewer or sometimes wanting, entire; stamens 2 to 10 ; ovary 1 -celled, many-ovuled; styles 3 ; capsule 3-valved to the base; seeds reniform-globose or compressed, smooth or roughened, often finely sculptured and sometimes echinate or winged.

About 40 species mostly in saline soils, widely distributed.

1. Plant glabrous throughout; cyme much-compounded; sepals to $1.6 \mathrm{~mm}$. long; mature capsules 1.4-2.6 $\mathrm{mm}$. long; seeds $0.4 \mathrm{~mm}$. long or less, never winged ....................................................... S. platensis.

1. Plant more or less glandular-pubescent (at least in the inflorescence); cyme lax; sepals $1.6 \mathrm{~mm}$. long or more; mature capsules $3 \mathrm{~mm}$. long or more; seeds $0.5 \mathrm{~mm}$. long or more, wingless or sometimes winged (2)

2(1). Seeds smooth or (at most) minutely papillose, usually dull in appearance....

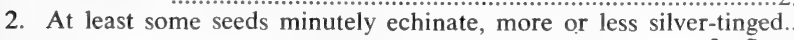

2. S. marina. 3. S. echinosperma.

1. Spergularia platensis (St.-Hil. \& A. Juss.) Fenzl. Fig. 439.

Annual diffusely branched plants, often forming depressed mats $2-3 \mathrm{dm}$. across, glabrous throughout, the ultimate branches filiform; leaves narrowly linear to filiform, mucronate, $1-3 \mathrm{~cm}$. long, scarcely $1 \mathrm{~mm}$. wide; stipules deltoid, acuminate, 1-3 mm. long; flowers numerous, in open cymes; pedicels filiform, $2-8 \mathrm{~mm}$. long; sepals broadly lanceolate, $0.8-1.5 \mathrm{~m}$. long; petals white, minute or rarely none; stamens 5; capsule 1.5-2.5 mm. long; seeds brown, minute, less than 0.5 $\mathrm{mm}$. long, strongly rough-tuberculate, not winged. Spergula platensis (St.-Hil. \& A. Juss.) Shinners.

In low wet saline soils in n.-cen. and s. Tex., Mar.-June; a nat. of S. A., introd. in Calif. and Tex. 
2. Spergularia marina (L.) Griseb. SALT-MARSh SAND-SPURREY. Fig. 439.

Annual erect or more often diffuse fleshy plants with branches to $35 \mathrm{~cm}$. long, usually more or less glandular-pubescent; leaves rarely fascicled, linear, bluntly mucronate, to $4 \mathrm{~cm}$. long and $1.5 \mathrm{~mm}$. wide; stipules triangular, about as long as broad or slightly longer, 2-4 mm. long; cymes usually lax, the lower and sometimes the upper bracts foliaceous and elongate or the upper much-abbreviated; sepals ovate to ovate-lanceolate, blunt, $2.5-5 \mathrm{~mm}$. long, much-exceeding the white or pink petals; stamens 2 to 5 ; capsule ovoid, equaling or exceeding the calyx, 3.5$6.5 \mathrm{~mm}$. long; the lower fruiting pedicels to $1 \mathrm{~cm}$. long; seeds pale-brown or reddish, opaque, not sculptured, smooth or minutely papillose, 0.5-0.9 $\mathrm{mm}$. long, wingless or with a thin friable wing. S. salina J. \& C. Presl.

In saline or brackish soils in depressions in dunes and on flats from e. Tex. along the coast to s. Tex. and apparently isolated along the Rio Grande near El Paso and Ariz. (Coconino, Yavapai, Gila, Maricopa, Pinal, Pima and Yuma cos.), Mar.-June; from Fla., n. to Que., B.C. and Ill., w. to Tex., Calif. and Wash.; also Euras.

\section{Spergularia echinosperma Cĕlak. Fig. 439.}

Annual diffuse plants with stems to $2 \mathrm{dm}$. long, usually more or less glandularpubescent throughout; leaves linear, to $35 \mathrm{~mm}$. long and $1.4 \mathrm{~mm}$. wide, usually not fascicled or with only one leaf in the axil; stipules deltoid, 1.4-2.4 $\mathrm{mm}$. long; cymes laxly flowered; sepals ovate, $2.4-3.6 \mathrm{~mm}$. long; petals pink or rosy at the apex, 1.6-2.8 $\mathrm{mm}$. long; stamens as many as 4 ; styles 3 , separated to the base; mature capsule $3.4-5 \mathrm{~mm}$. long, exceeding the calyx by $0.4-1.8 \mathrm{~mm}$; fruiting pedicels filiform, reflexed or not, $5-11 \mathrm{~mm}$. long; seeds $0.5-0.8 \mathrm{~mm}$. long, deep reddishbrown or nearly black with a silvery tinge, rounded in outline, surface always roughened, echinate, with or without a broad scarious wing. S. salsuginea var. bracteata Robins.

In salt marshes and flats and in dune pockets in e. Tex., along the coast to Corpus Christi (Nueces Co.), apparently isolated near Ft. Stockton (Pecos Co.), Feb.-June; introd. into s. U. S. from the Old World.

\section{Fam. 59. Nymphaeaceae SALISB.}

\section{WATER-LILY FAMILY}

Aquatic perennial herbs with horizontal rhizomes and peltate or cordate leaves floating or emersed, the submerged leaves (when present) usually capillarydissected; vernation involute; flowers axillary, solitary, perfect; sepals usually 3 to 6 , green to petaloid, free or slightly united, hypogynous; petals 3 to many, showy and inserted on the surface of the ovary, sometimes transitional to stamens; stamens 3 to many, extrorse or introrse; pistils 1 to several; fruit a many-seeded berry or nut, or 1- to 3-seeded, small and indehiscent.

About 75 species in several genera of wide geographic distribution. Including Cabombaceae and Nelumbonaceae.

Most of the species are of some value to wildlife. For instance, various wildfowl, such as ducks, marsh, shore and song birds, at various times eat the seeds of all our species. The rootstocks, roots and petioles of Nelumbo, Nymphaea and Nuphar are eaten by beaver, muskrats and porcupines, and the leaves, stems and flowers are frequently browsed by deer. The usually large leaves that harbor insects and algae also provide shade and shelter, but very little food, for fish.

1. Carpels united either along their sides or along the outer margins by adnation to a cuplike "receptacle;" stigmas radiate; ovules numerous in each cell; stamens numerous, introrse; fruit an irregularly dehiscent berry, ripening in the water; leaves with a basal sinus (2) 
1. Carpels free or (in Nelumbo) embeded in the receptacle; ovules solitary or 1 to 3 in each carpel; stamens hypogynous, few to many ( 3 to 36 ) and extrorse or slightly introrse, or very numerous and extrorse; fruits leathery or hard, indehiscent; floating or emersed leaves peltate and lacking a sinus (3)

2(1). Perianth wide-spreading, composed of 4 sepals and 12 to 32 showy white, pink, blue or yellow petals; carpels sunken in a cup-shaped fleshy receptacle or hypanthium on the outer surface of which the petals and stamens are inserted, prolonged upward into slender incurved projections (carpellary styles); seeds arillate...............1. Nymphaea

2. Perianth subglobose, composed of 6 concave yellow (green- or red-tinged) sepals and numerous scalelike or stamenlike "petals" inserted with the numerous stamens on the receptacle beneath the ovary; carpels completely united, the stigmas radiate and sessile on a disk; seeds not arillate.

2. Nuphar

3(1). Perianth of numerous segments, the flowers large and showy; receptacle large, top-shaped, with the many uniovulate carpels sunken separately in cavities on the upper side, only the stigmas protruding; receptacle becoming enlarged greatly in fruit, the carpels maturing into nuts; stamens very numerous, extrorse, hypogynous; all leaves floating or emergent on strong petioles, centrally peltat $\epsilon$, large, glaucous; plants lacking mucilage................................5. Nelumbo

3. Perianth composed of 6 to 8 segments, the flowers small; receptacle small, with 4 to 18 free superior carpels; fruit small, 1 - to 3 -seeded; leaves all floating or submersed; plants more or less coated with mucilage (4)

4(3). Plants with dissected opposite submersed leaves and small peltate floating leaves; perianth petaloid, white or purplish; stamens 3 to 6 .

3. Cabomba

4. Plants with only undivided alternate peltate floating leaves; sepals persistent, the petals dull-purple; stamens 18 to 36 ; plants heavily coated (especially on lower leaf surface) with mucilage.. 4. Brasenia

\section{Nymphaea L. WATER-LILY. WATER-NYMPH}

Plants with floating leaf blades and white, pink, blue or yellow flowers; leaves subpeltate, cleft at the base; sepals 4 , nearly free, spreading; petals few to many, spreading, the inner petals passing into stamens, the outer petals about as large as the sepals, all borne with the stamens on the hypanthium that encloses the ovary; ovary 12 - to 35 -celled, the concave summit tipped by a globular projection at the center around which are the radiate stigmas that project at the margin to extend as linear and incurved sterile appendages; fruit depressed-globose, usually covered with the persistent petal- and stamen-bases, maturing under water; seeds enveloped by a saclike aril.

About 50 species, widely dispersed in the tropics.

1. Corolla yellow; rootstock stoloniferous at the apex. 1. N. mexicana.

1. Corolla white, pinkish, blue or violet; rootstock not stoloniferous (2)

2(1). Flower raised on a peduncle above surface of water; corolla blue or violet; outer stamens with the connective produced into an apical appendage; carpels free at the sides; styles mere blunt protuberances

2. Flowers floating; corolla white or pinkish; outer stamens not appendaged at the apex; carpels united at sides; styles subulate (3)

3(2). Petals oblanceolate to subspatulate, widest above the middle, tapered at base but obtusely rounded at apex; rhizome branches tuberlike...... 3. N. tuberosa. 
3. Petals broadly elliptic to narrowly oblong-elliptic, widest at about the middle, somewhat tapered at both ends; rhizome without tuberlike branches 4. N. odorata.

1. Nymphaea mexicana Zucc. Yellow water-Lily, LAMPazo amarillo. Fig. 440.

Rootstock warty with the persistent petiole bases; leaves oval to suborbicular, to $2 \mathrm{dm}$. wide, glabrous, bright-green above, purple or crimson on the lower surface; flowers 6-10 cm. wide; sepals lanceolate to narrowly elliptic-lanceolate; petals usually about 25 , bright-yellow, more elliptic than the sepals; stamens 50 to 60 , the petaloid stamens mostly $2-2.5 \mathrm{~cm}$. long; anthers of the inner stamens 4-6 mm. long; styles 7 to 9; berry ovoid, 2-2.5 cm. long; seeds $4-5 \mathrm{~mm}$. in diameter. N. flava Leitn.

In lakes, ponds and slow streams in e. and s. Tex. and Ariz. (Pinal Co.), spring-summer; also s. Fla. and Mex.

\section{Nymphaea elegans Hook. Blue Water-lily, LAMPazos. Fig. 441.}

Rootstock stoutish; leaves ovate to oval-orbicular, to $2 \mathrm{dm}$. wide, usually much smaller, undulate-sinuate or nearly entire, usually dark red-purple and somewhat veiny on the lower surface; flowers usually raised on a slender peduncle $1-2.5 \mathrm{dm}$. above the water; sepals mostly lanceolate, $4-5 \mathrm{~cm}$. long; petals 6 to 10 , lanceolate or sometimes ovate-lanceolate, blue or pale-violet; stamens numerous; styles 15 to 25 , mere blunt protuberances; berry depressed-globose, $1.5-3 \mathrm{~cm}$. in diameter; seeds 1-1.5 mm. in diameter. Castalia elegans (Hook.) Greene.

In ponds, pools and ditches in s. Tex., Apr-July; also s. Fla. and Mex.

\section{Nymphaea tuberosa Paine.}

Rather coarse plant; rhizome with readily disarticulating branches strongly constricted at base and tuberlike; petioles green, striped above with brown; leaf blades green beneath or rarely dull purple, flat and floating or somewhat elevated above the water, 1-4 dm. across; flower odorless or scarcely fragrant, 1-2.5 cm. broad, opening for 3 or 4 days from early morning to early afternoon; sepals green on the back; petals oblanceolate to subspatulate, obtusely rounded at summit; filaments broader than their anthers; seeds $2.8-4.4 \mathrm{~mm}$. long.

Pond margins and slow streams in Okla. (Ottawa Co.), June-Sept.; from s.w. Que. to n. Ont., Minn. and Neb., s. to Md., O., Ind., Ill., Ark. and Okla.

\section{Nymphaea odorata Ait. WHITE WATER-LILY, ALLIGATOR-BONNET, NINFA ACUÁticA. Fig. 442.}

Rhizome stout, horizontal, elongate, mostly $2.5-3 \mathrm{~cm}$. thick; leaves arising along the rhizome, suborbicular, to $25 \mathrm{~cm}$. wide, with a narrow sinus, green above, green tinged with red or purplish-red and obscurely veined on the lower surface; flowers very fragrant; sepals often purplish on back, elliptic to ovate or ovatelanceolate, to $8 \mathrm{~cm}$. long and $25 \mathrm{~mm}$. wide; petals usually more than 25 , white, elliptic or slightly broadened upward, thickish; stamens mostly more than 70 , the petaloid stamens 3-4 cm. long; styles mostly about 20; berry depressed-globose, mostly $2.5-3 \mathrm{~cm}$. in diameter; seeds ellipsoid, about $2 \mathrm{~mm}$. long. Incl. var. villosa Casp. and var. gigantea Tricker, N. spiralis Raf., N. lekophylla (Small) Cory, Castalia odorata (Ait.) Woodv. \& Wood, C. lekophylla Small.

In ponds, lakes, slow streams and ditches in Okla. (Comanche and LeFlore cos.), e. Tex. and Ariz. (Yavapai Co.), Mar.-Oct.; from Fla. to Tex., n. to e. Can. and Man.; Ariz. 


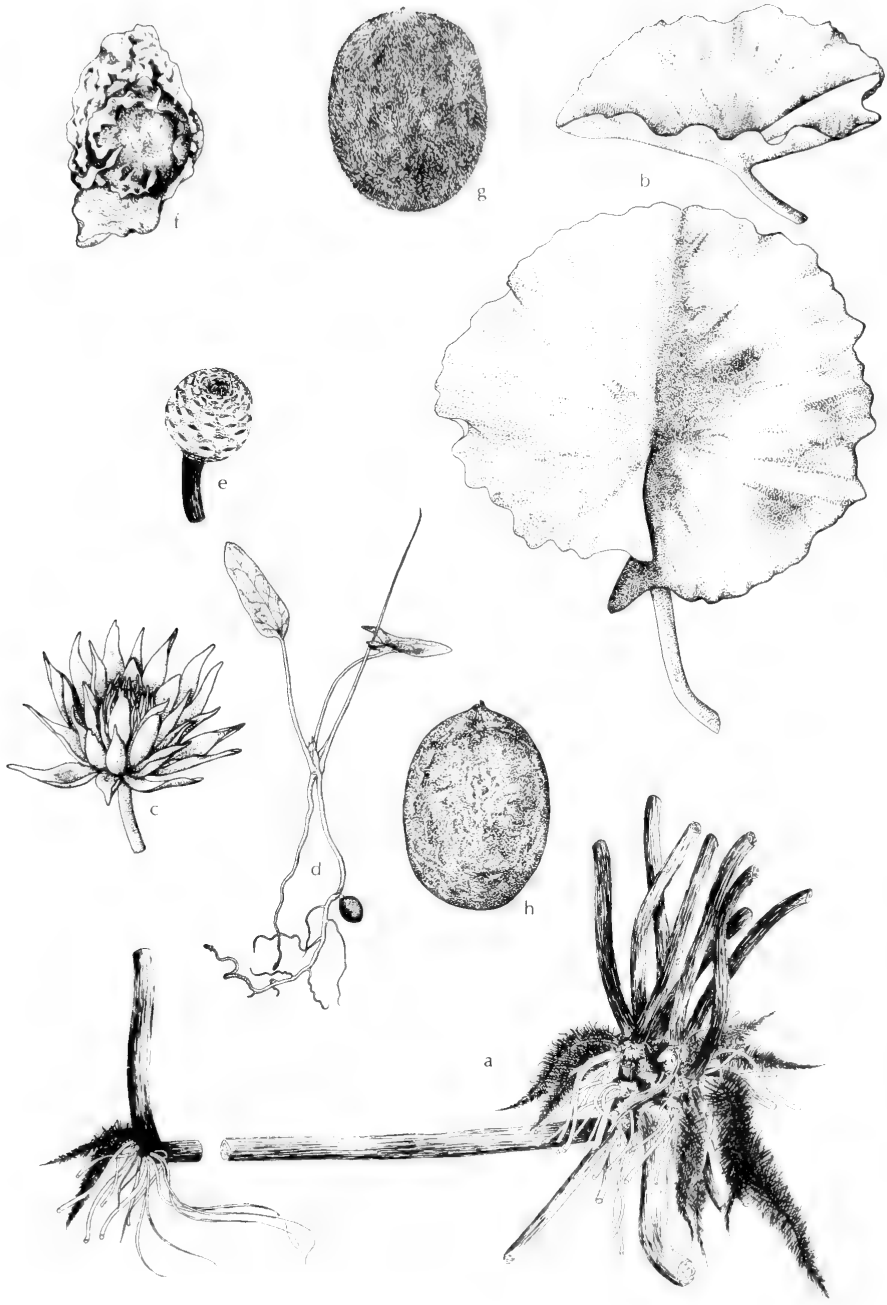

Fig. 440: Nymphaea mexicana: a, rootstock, x 1/3; b, leaves, x 1/3; c, flower, x 1/3; $\mathrm{d}$, seedling, $\mathrm{x} 1 / 3$; e, young fruit, $\mathrm{x} 2 / 3 ; \mathrm{f}$, seed in sac, $\mathrm{x} 4 ; \mathrm{g}$ and $\mathrm{h}$, seeds, $\mathrm{x} 5$. (Courtesy of R. K. Godfrey). 


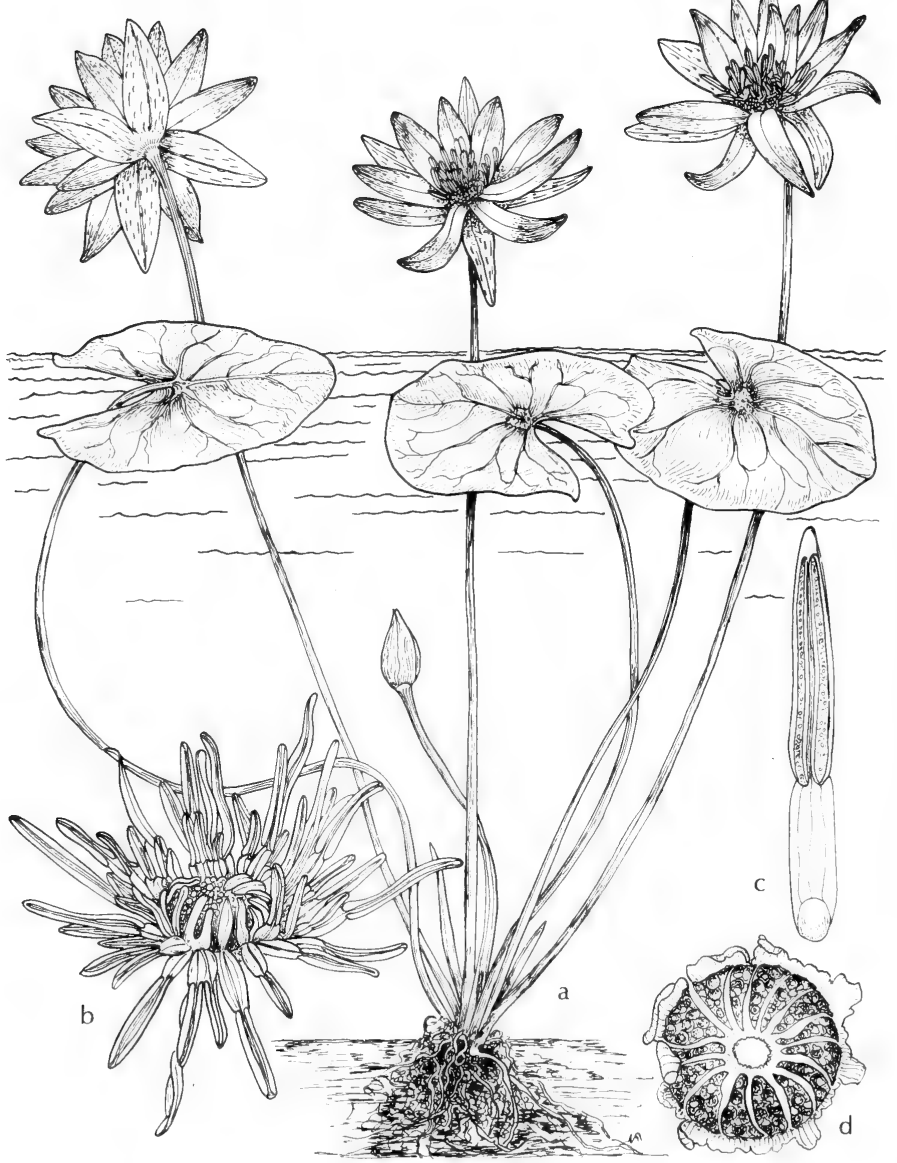

Fig. 441: Nymphaea elegans: a, habit, $x 1 / 2 ; b$, grouping of indefinite stamens, x $1 \frac{1}{2}$; c, stamen, $x 2 \frac{1}{2}$; d, fruit, $x 1$. (V. F.). 

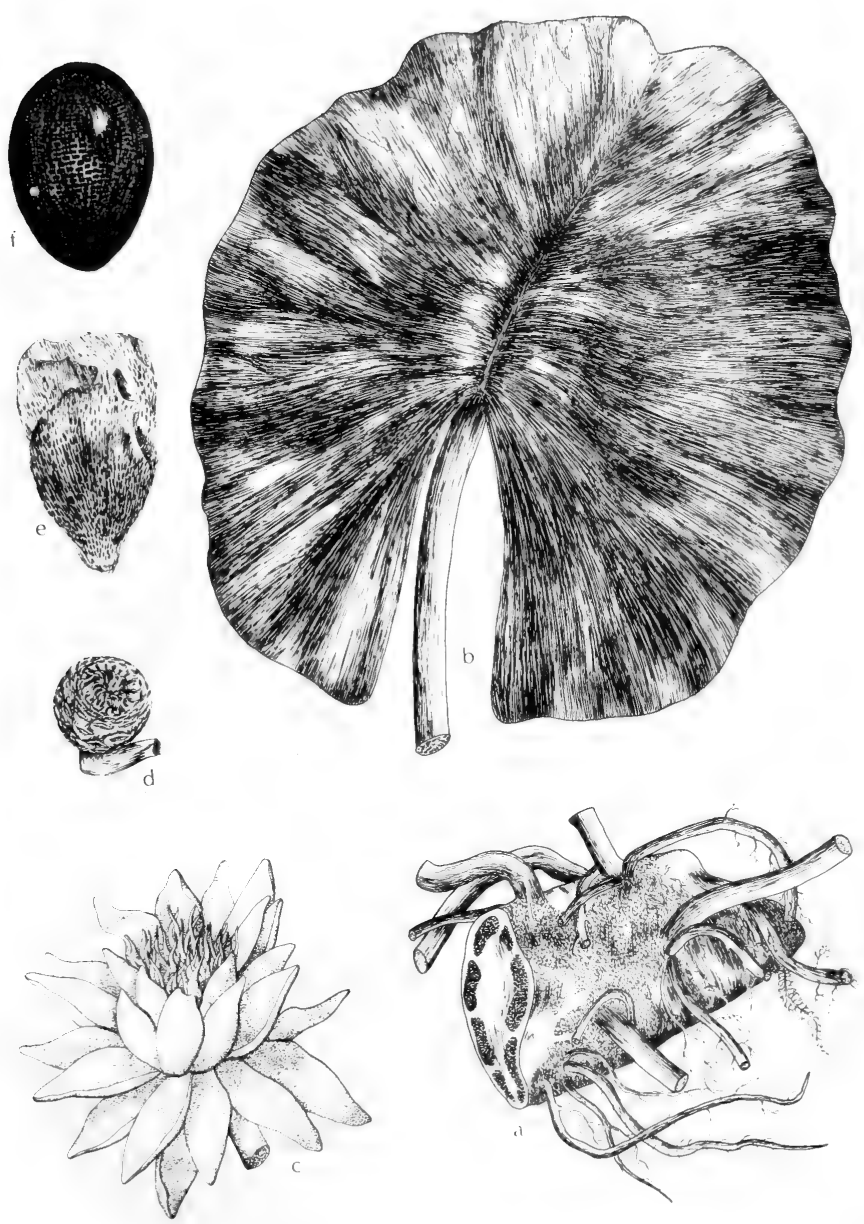

Fig. 442: Nymphaea odorata: a, rhizome, x $1 / 3$; b, leaf, x $1 / 3$; c, flower, x $1 / 3$; $d$, fruit, $x 1 / 3$; e, seed in sac, $x 5$; 1 , seed, $x$. (Courtesy of $R$. K. Godfrey). 


\section{Nuphar SM.}

About a dozen or more species and their variants in the North Temperate Zone.

1. Nuphar luteum subsp. macrophyllum (Small) E. O. Beal. Yellow Cow-LiLy, SPATTERDOCK. Fig. 443.

Perennial aquatics with procumbent branching cylindrical rhizomes: leaves spirally arranged, with a deep sinus at the base; petioles and peduncles with numerous minute air-cavities; exposed leaves floating or emergent and erect, broadly ovate to suborbicular, to $3 \mathrm{dm}$. long or more and $25 \mathrm{~cm}$. wide, with overlapping to divergent basal lobes, glabrous to more or less pubescent on lower surface; submersed leaves (when present) thin and translucent, essentially like the floating ones in size and shape; petioles terete to more or less flattened above, glabrous to pubescent; flowers to $25 \mathrm{~mm}$. across, and $25 \mathrm{~mm}$. high; sepals 6 , roundish, concave, the inner portion green to yellow, rarely red-tinged; petals numerous, small and thickish, stamenlike or scalelike, truncate to emarginate, inserted with the numerous short stamens on the receptacle under the ovary, not surpassing the disklike 5- to 25-rayed sessile stigma, mostly persistent and at length recurved; anthers 3-7 mm. long, yellow, sometimes red-tinged; fruit ovoid, slightly constricted below the entire to crenate stigmatic disk; stigmatic rays 5 to 25 , mostly ending 1-2 mm. from the disk margin; stigmatic disk sometimes red-tinged; seeds numerous, broadly ovoid, 4-6 mm. long, 3.5-5 mm. wide. Nymphaea microcarpa Mill. \& Standl., N. ovata Mill. \& Standl., N. puberula Mill. \& Standl., Nuphar advena of auth., N. advena $\beta$ tomentosa Nutt., N. microcarpum (Mill. \& Standl.) Standl., N. ovatum (Mill. \& Standl.) Standl., N. puberulum (Mill \& Standl.) Standl.

In water or on mud in ponds, shallow lakes, streams and springs, in e. Okla. (Choctaw, McCurtain Ottawa, Pushmataha and Sequoyah cos.) and in Tex. mostly on the Edwards Plateau and in the e., Mar.-Oct.; throughout most of e. N.A.; also n. Mex. and Cuba.

Beal, the latest monographer of Nuphar, placed all Oklahoma and Texas material in subsp. macrophyllum. We have found no reason to differ from his conclusions.

Two other subspecies should eventually be found in our region. These are subsp. polysepalum (Engelm.) E. O. Beal ( $N$. polysepalum Engelm.) (Fig. 444) of extreme southern Colorado, northward and westward, characterized by having 9 to 12 sepals, anthers commonly red-tinged and seeds narrowly ovoid, and subsp. ozarkanum (Mill. \& Standl.) E. O. Beal of extreme western Arkansas and Missouri, characterized by having the inner portion of its 6 sepals and its fruit more or less red-tinged.

\section{Cabomba Aubl.}

About a half dozen species in the warmer parts of the Western Hemisphere.

\section{Cabomba caroliniana Gray. FAnwort. Fig. 445.}

Delicate aquatic herbs rooting in mud; stems slender, branched, to $2 \mathrm{~m}$. long or more, with a thin gelatinous coating; submersed leaves opposite or whorled, with petioles to $3 \mathrm{~cm}$. long, rounded in outline, to $6 \mathrm{~cm}$. wide, palmately dissected into linear-filiform segments; floating leaves few, alternate, peltate, entire, linearelliptic, mostly slightly constricted at the middle, often bifid at one end, usually pubescent beneath, to about $2 \mathrm{~cm}$. long; flowers solitary on long slender axillary peduncles, to $12 \mathrm{~mm}$. long, white or cream-color, with yellow spots at base and sometimes pink-tinged at tips; sepals 3 ; petals 3 , oval, biauriculate above the abbreviated claw; stamens 6 , the short anthers extrorse; carpels 2 to 4 , with small terminal stigmas; fruit 3-seeded, indehiscent. 


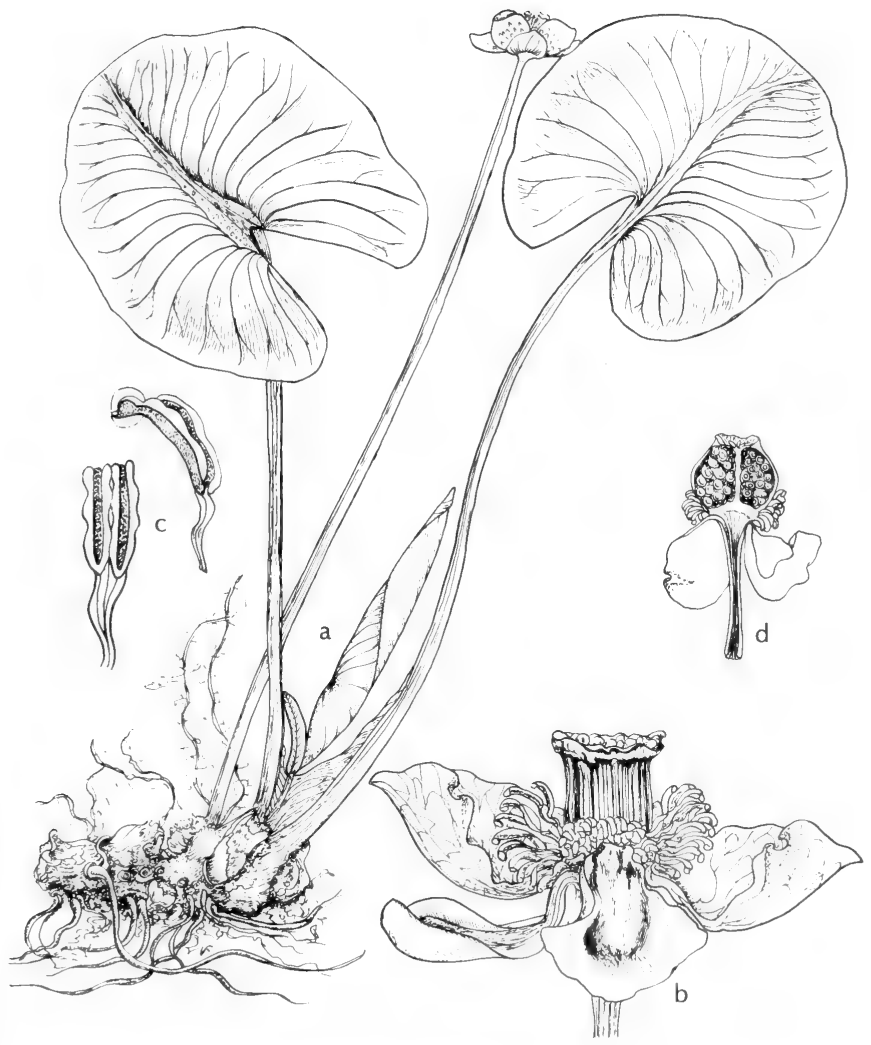

Fig. 443: Nuphar luteum subsp. macrophyllum: a, habit, x 1/3; b, flower, x 1; c, stamens, x 3; d, fruit, $x$ 1. (V. F.). 


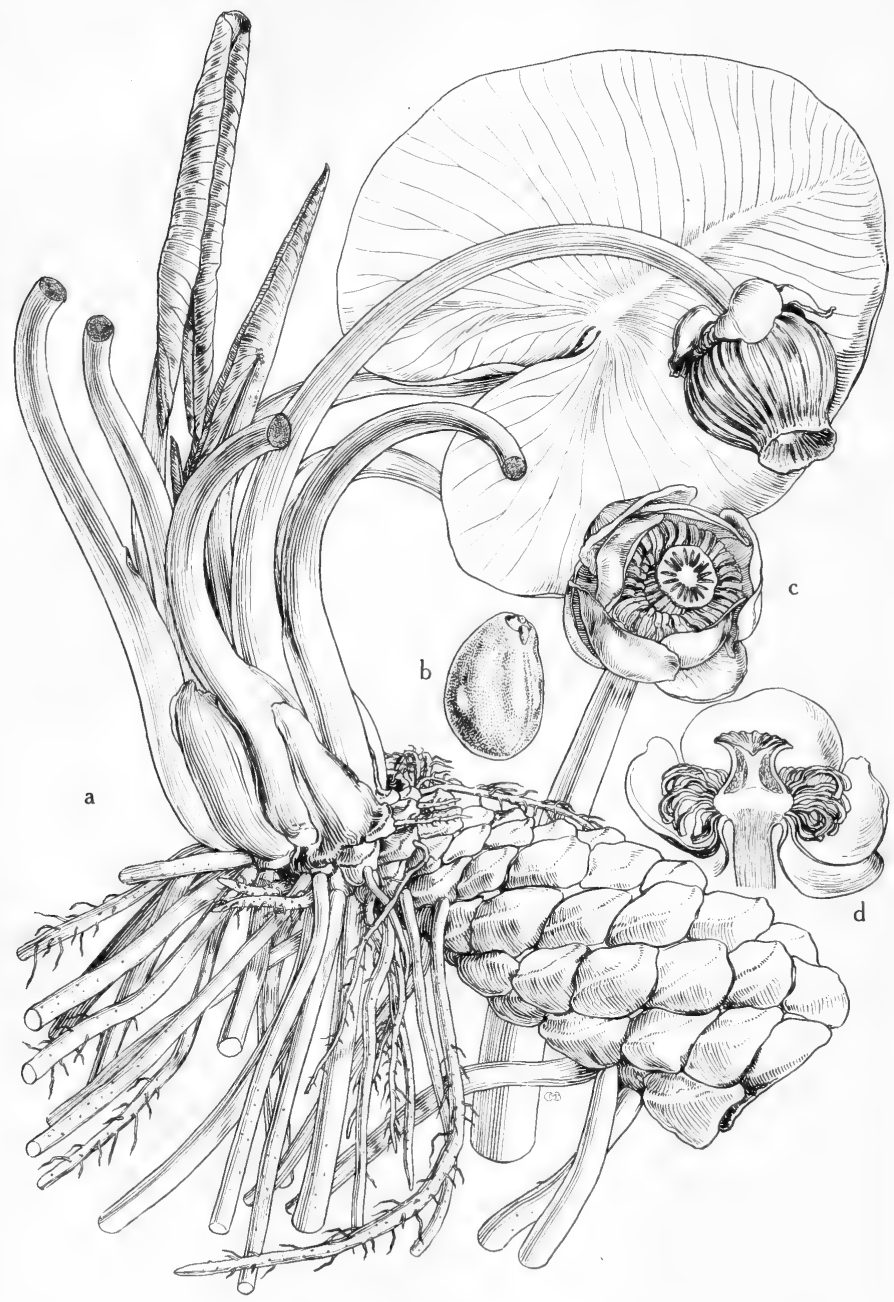

Fig. 444: Nuphar luteum subsp. polysepalum: a, habit, showing rootstock and fruit, $x_{2}^{2} ;$; b, seed, $x 4$; c, flower, showing the conspicuous thick sepals, the numerous arching stamens and the radiate stigma, $\mathrm{x} / 5$; d, flower (longitudinal section), the short petals concealed by the stamens, $x \%$. (From Mason, Fig. 228). 

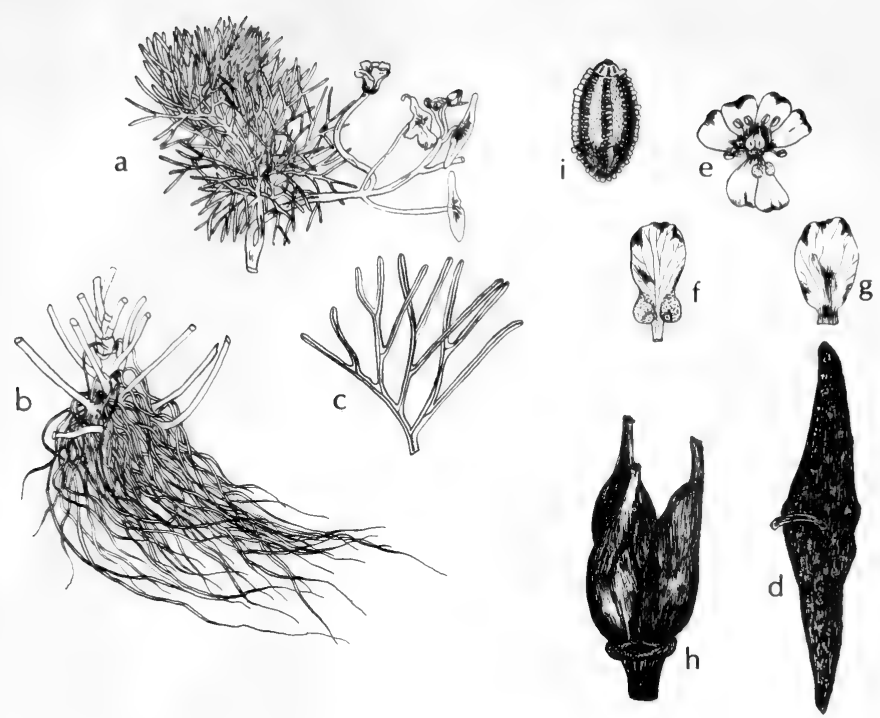

Fig. 445: Cabomba caroliniana: a, submersed leaves, floating leaves and flowers, x $1 / 2$; b, rooting base of stem, x 1/2; c, submersed leaf, x 1; d, floating leaf, x 3; e, flower, X 1 ; f, petal, $x 1 \frac{1}{2} ; \mathrm{g}$, sepal, $\times 1 \frac{1}{2} ;$ h, young carpels, $x 7 ;$, mature seed, $x$ 5. (Courtesy of R. K. Godfrey).

In lakes, ponds and quiet streams mainly in s.e. Okla. (Waterfall) and e. Tex., Apr.-July; from Fla. to Tex., n. to Va., s. Ill. and e. Mo., somewhat naturalized farther $\mathbf{n}$.

\section{Brasenia Schreb.}

A monotypic genus of wide distribution.

1. Brasenia Schreberi J. F. Gmel. PURPLE WEN-DOCK, WATER-SHIEld. Fig. 446.

Rootstock slender, creeping in mud; stems slender; leaves alternate, longpetioled, centrally peltate, floating, broadly oval to suborbicular, rounded at both ends, entire or rarely very shallowly crenate, thickish, smooth on upper surface, gelatinous on lower surface, to $10 \mathrm{~cm}$. long; flowers axillary, small, dull-purple, emergent; sepals and petals 3 or 4 each, linear-oblong, $1-1.5 \mathrm{~cm}$. long; stamens 18 to 36 , the filaments filiform, the anthers slightly introrse; pistils 4 to 18 , separate, the stigmas linear; fruits clavate, coriaceous, indehiscent, $6-8 \mathrm{~mm}$. long. B. purpurea Casp.

In lakes, ponds and slow streams in e. Okla. (Atoka, Pushmataha and Sequoyah cos.) and e. Tex., Apr.-May; from Fla. to Tex., n. to P.E.I., s. Que., s. Ont. and Minn., w. to s. B.C., Ore. and Calif. 


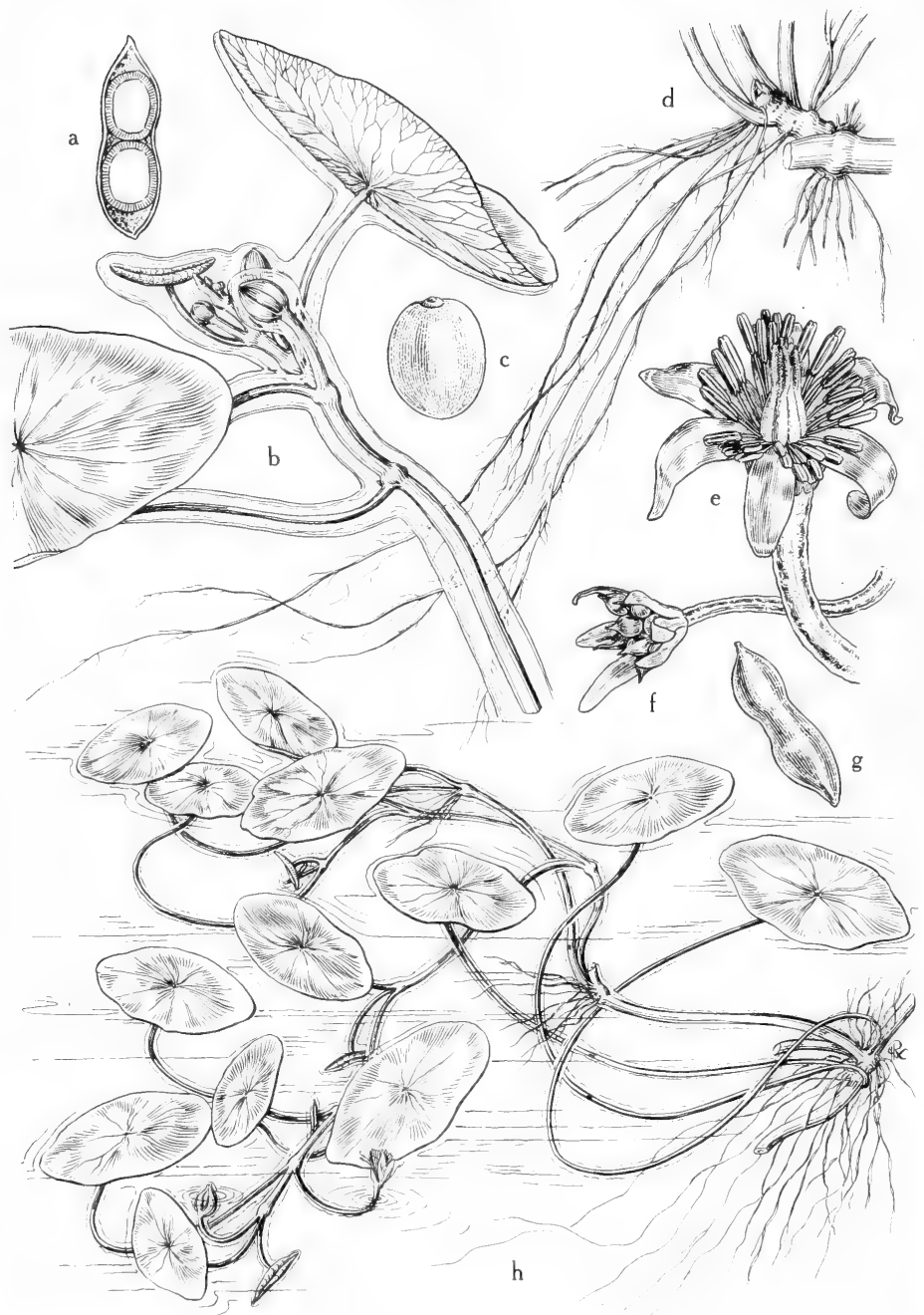

Fig. 446: Brasenia Schreberi: a, fruit (longitudinal section), $x$ 2; b, flowering branch, all the submersed parts clothed with a thick translucent gelatinous coating, $\mathrm{x} 4 / 5$; c, mature seed, $\mathrm{x} 4$; d, roots, $\mathrm{x} 4 / 5$; e, flower, $\mathrm{x} 3$; f, mature fruits, $\mathrm{x} 115 ; \mathrm{g}$, mature fruit, $x$ 2; h, habit, showing peltate leaves, x 1/5. (From Mason, Fig. 229). 


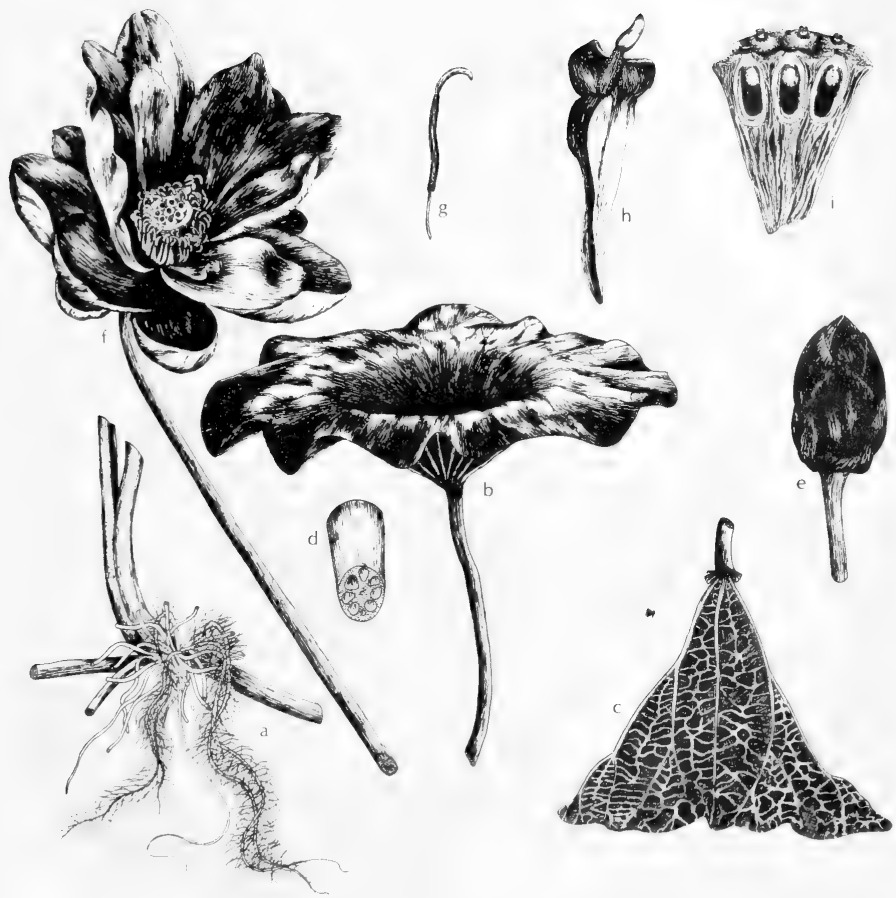

Fig. 447: Nelumbo lutea: a, rhizome, x $1 / 3$; b, leaf, $x 1 / 6$; , under side of leaf, x $1 / 6$; d, section of rhizome, $x 2 / 3$; e, bud, $x 1 / 3 ; f$, flower, $x 1 / 3 ; g$, stamen, $x 3 / \%$, section through young fruit, enlarged; i, fruits in receptacle. (Courtesy of R. K. Godfrey). 
The stems, petioles and lower surface of the leaves are heavily coated with a viscid, gluey jelly.

According to Mason (Fl. Marshes Calif. 491. 1957), Tokura observed in Japan that the flowers of this species open on two successive days. On the first day the flower is elevated above the water about 6 A.M. and opens within an hour, during which time pollination is effected. The flower closes at about 9 A.M. and is then withdrawn beneath the water. On the next day the same flower is again pushed even higher above the water surface. The stamens then dehisce, and after a few hours the flower is again withdrawn, never to emerge again.

\section{Nelumbo Adans. Sacred Bean}

Represented in both hemispheres by one species each.

1. Nelumbo lutea (Willd.) Pers. Yellow Lotus, WATER-ChinQuapin, POND-Nut. Fig. 447.

Aquatic herb with slender rhizomes rooted in mud; leaves orbicular, centrally peltate, floating or mostly raised above the water on long stout petioles, to $7 \mathrm{dm}$. in diameter, with the center depressed or cupped; peduncles stout, rising to about $1 \mathrm{~m}$. above the water surface, the solitary pale-yellow flower to $25 \mathrm{~cm}$. broad; sepals and petals numerous, commonly 20 or more, scarcely differentiated, the outermost (external in the bud) green and sepaloid; stamens numerous, spirally inserted and closely surrounding the pistils; anthers antrorse, tipped with a slender hooked appendage; fruiting receptacle prolonged, obconic, to $1 \mathrm{dm}$. in diameter, the numerous 1 -ovuled ovaries sunk in small pits on its flat truncate summit; fruit nutlike, indehiscent, each separately embedded in the accrescent receptacle, about $1 \mathrm{~cm}$. in diameter.

In quiet water of ponds and sluggish streams in e. Okla. (Atoka, Love and McCurtain cos.) and the e. third of Tex., May-July; from Fla. to Tex., n. locally to s. N.E., N.Y., s. Ont., Minn. and Ia.

The farinaceous storage tubers along the rhizome are edible as well as the seeds.

\section{Fam. 60. Ceratophyllaceae S. F. GRAY}

\section{HORNWORT FAMILY}

Submersed aquatic rootless herbs, with a slender primary stem and scattered lateral branches; leaves whorled, sessile, finely dissected; flowers minute, unisexual, without a perianth, solitary and sessile in leaf axils, subtended by an 8- to 12-cleft involucre in place of a calyx; stamens 12 to 16 , the filaments short, the rather large anthers terminating in 2 or 3 sharp points; pistillate flower consisting of a simple 1-celled ovary with a suspended orthotropous ovule; fruit an achene, beaked by the slender indurated style.

A monotypic family.

\section{Ceratophyllum L.}

\section{HORNWORT. COON-TAIL}

Characters of the family; plants olive-green; leaves usually 1- to 4-dichotomously dissected into filiform to narrowly linear divisions.

About 10 species that are widely dispersed. Our species are highly tolerant of conditions that prove disastrous for many species of hydrophytes, such as fluctuating water levels and turbidity. When pieces break from the mother-plant they function as new plants.

1. Leaves usually forked 1 or 2 times, the division conspicuously serrate on one side; achenes without lateral spines.......................... . C. demersum.

1. Leaves usually forked 2 to 4 times, the divisions entire or only obscurely serrulate; achenes with 3 to 5 lateral spines............2. C. echinatum. 
1. Ceratophyllum demersum L. COMMON hornwort. Fig. 448.

Plants entirely submersed; lowest leaves of seedling simple; stems prolonged, sometimes to $3 \mathrm{~m}$. long, branched and forming large masses, brittle or somewhat cordlike and flexuous; leaves as many as 12 in a verticil, finely dissected into capillary to linear and flattened serrate divisions, very variable as to the length, breadth and toothing of the leaf divisions, usually about $15 \mathrm{~mm}$. long; achene compressed, ellipsoid, wingless, smooth, 4-6 mm. long, with 2 basal spines 2-5 $\mathrm{mm}$. long; style 4-6 mm. long.

In quiet waters of lakes, ponds and slow streams in most of Okla,. throughout Tex. but mostly in the e. part of state, N. M. (Dona Ana, Grant and Rio Arriba cos.) and Ariz. (widespread), summer; from Que. to n. B.C., s. to Mex.; also Old World.

The seeds and occasionally the foliage provide food for wildfowl especially ducks. The usually dense growth, that may crowd out other more desirable species, provides shelter for fish, shrimp and other small animals as well as a haven for insects that are valuable as fish food.

\section{Ceratophyllum echinatum Gray.}

Plants entirely submersed, closely resembling $C$. demersum; lowest leaves of seedling cleft; stems prolonged and branched; leaves usually with entire capillary divisions, $1.5-2 \mathrm{~cm}$. long, the uncleft base somewhat expanded; achene narrowly winged by the confluent bases of the lateral spines, with a somewhat tuberculate surface, 5-7 mm. long; style 5-10 mm. long. C. demersum var. echinatum Gray.

In quiet waters of streams, lakes and pools in n.e. Tex. (Bowie Co.), summer; from Fla. to Tex. and Mex., n. to s.w. N.B., s. Me., N.Y., O., Mich., Ill. and Minn.

\section{Fam. 61. Ranunculaceae Juss. CROWfoot FAmily}

Herbaceous or occasionally woody plants; leaves basal, alternate or in a few genera opposite or whorled; flowers hypogynous, regular or irregular (in Delphinium), with all parts free and distinct or the pistils connate in Nigella; sepals present, usually imbricate, varying from petaloid to small and caducous; petals present or absent; stamens usually numerous; pistils 1 to many, simple; ovules 1 to many; style 1; stigma lateral or terminal, usually minute; fruit an achene, follicle or berry.

Perhaps about 1,000 species in about 50 genera of world-wide distribution but mostly in the forested parts of the North Temperate Zone.

1. Carpels with 2 or more ovules; fruit follicular (2)

1. Carpels with a solitary ovule; fruit an achene (6)

2(1). Cauline leaves (at anthesis) in a dense cluster at the top of the woody stem; wood yellow; flowers small, purplish-brown; staminodia present; rare in southeastern Texas..........................1. Xanthorhiza

2. Leaves, wood and flowers not as above; mostly from central Texas westward

3(2). Flowers irregular, large and showy, commonly blue or bluish (4)

3. Flowers regular, mostly yellowish or whitish, rarely partly bluish (5)

4(3). Upper sepal extended into a conspicuous cylindric spur.

4. Upper sepal expanded into a helmet-shaped hood 


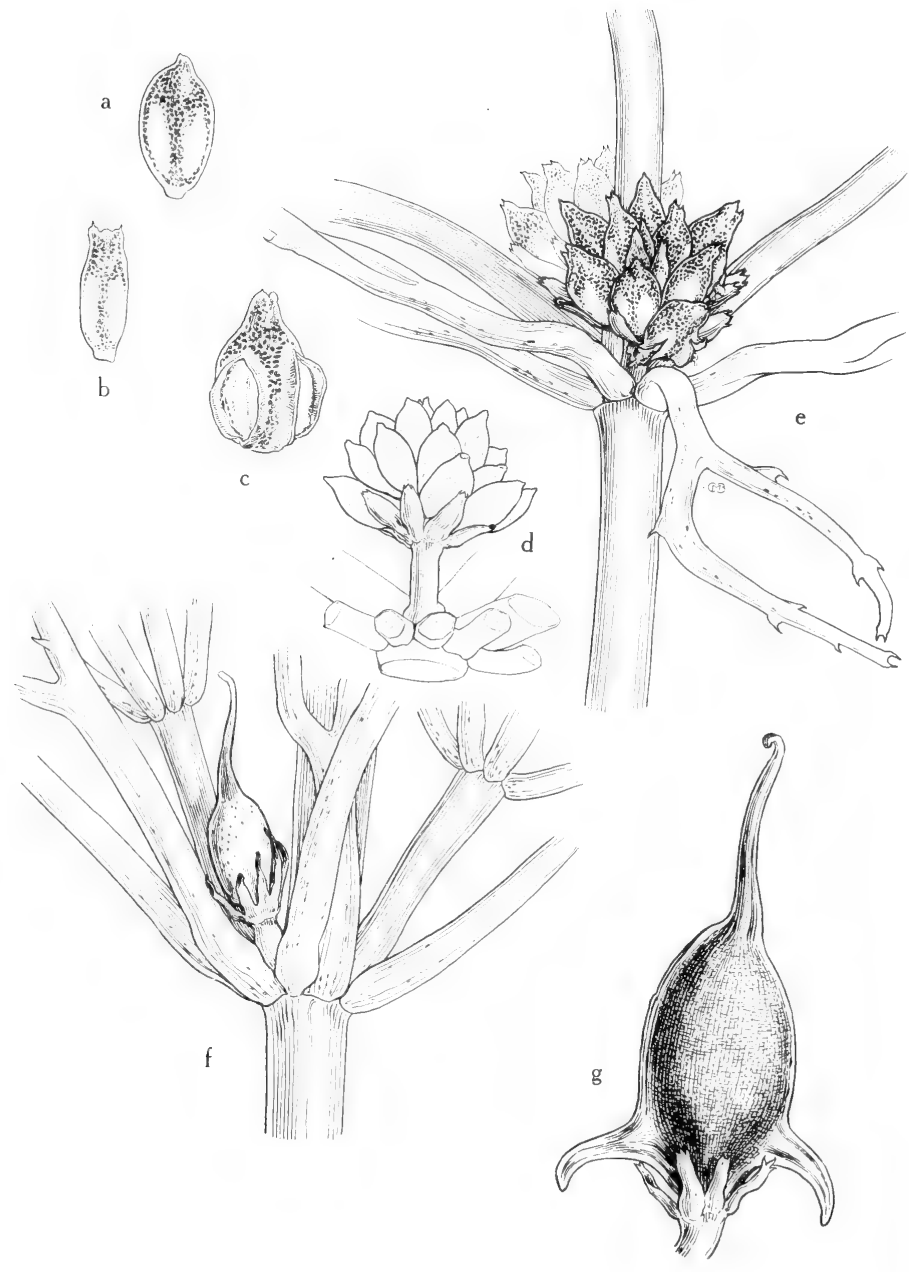

Fig. 448: Ceratophyllum demersum: a-c, stamens at various stages of development, x 8; d, staminate flower, the involucre calyxlike, x 4; e, node with leaves, branches and a pair of staminate flowers arising on opposite sides of stem, x 4 ; $f$, node with leaves, branches and solitary pistillate flower, $x 8 ; g$, mature fruit, the basal spines recurved, x 6. (From Mason, Fig. 230). 
5(3). Petals with a relatively small erect limb, produced below into a long tapering hollow spur that is clavate at the end......

5. Petals none, the sepals petal-like; flower rather simple 2. Caltha

6(1). Petals present (except sometimes in Myosurus); leaves commonly alternate or all basal (7)

6. Petals none or rudimentary (8)

7(6). Sepals spurred at base, the spur usually elongate, scarious; petals very small or none; receptacle becoming greatly elongate with the fruits in a slender cylindric spike; plants scapose

7. Myosurus

7. Sepals not spurred; petals usually present, often showy; receptacle not becoming greatly elongate with the fruits in a conic to ovoid or hemispheric head; stems commonly leafy........................9. Ranunculus

8(6). Sepals large and showy, petal-like, somewhat persistent; achenes globose and with long often plumose tails...............................6. Clematis

8. Sepals small, less conspicuous than the stamens, caducous; achenes without long plumose tails (9)

9(8). Leaves simple, palmately lobed or parted; outer filaments flat, somewhat petaloid; anthers oval or ovate, about $1 \mathrm{~mm}$. long.

8. Trautvetteria

9. Leaves decompound; filaments all filiform; anthers narrowly linear, much more than $1 \mathrm{~mm}$. long..... 10. Thalictrum

\section{Xanthorhiza MARSH.}

A monotypic genus.

\section{Xanthorhiza simplicissima Marsh. Brook-FEATHER, yellowroot.}

Plant low, weak, shrubby, with deep-yellow and bitter bark and long roots, to about $6 \mathrm{dm}$. high; leaves approximate, 1- or 2-pinnate: leaflets mostly 5, ovate to elliptic, 25-75 $\mathrm{mm}$. long, incised-toothed or divided; flowers polygamous, in compound drooping racemes, appearing along with the leaves from large terminal buds in early spring; sepals regular, 5, spreading, deciduous, ovate to ovatelanceolate, brownish-purple; petals 5 , glandlike; stamens 5 or 10 , the filaments stout; pistils 5 to 15 , with 2 pendulous ovules; follicles elliptic 1 -seeded, 3-4 mm. long, the short style becoming dorsal.

In damp woods, thickets and on wooded stream banks, often on the edge of water, rare in s.e. Tex., Mar.-May; from N.Y., s. to Fla. and Tex.

\section{Caltha L. Marsh Marigold}

About 20 species in Arctic and North Temperate regions.

1. Caltha leptosepala DC. ELK's LIP. Fig. 449.

Glabrous perennial; petioles from shorter than to several times longer than the blade; blades ovate-oblong to oblong, obtuse, bright green, to about $7 \mathrm{~cm}$. long and $4 \mathrm{~cm}$. wide, subentire to serrate or dentate, the basal sinus mostly open; scape to about $6 \mathrm{~cm}$. long, usually with a single leaf and a solitary peduncle mostly $3-10$ or rarely to $20 \mathrm{~cm}$. long; flower solitary; sepals 5 to 9 , petal-like, the inner surface white, the outer surface bluish; pistils 5 to 10 , with scarcely any styles; follicles compressed, spreading, somewhat stipitate.

In wet meadows, marshes and wet soils about mt. lakes, below snow-banks and along streams, in N.M. (San Juan, San Miguel and Taos cos.) and Ariz. (Apache, Coconino and Graham cos.), June-Sept.; Mont. to Alas., s. to N.M., Ariz. and Wash. 


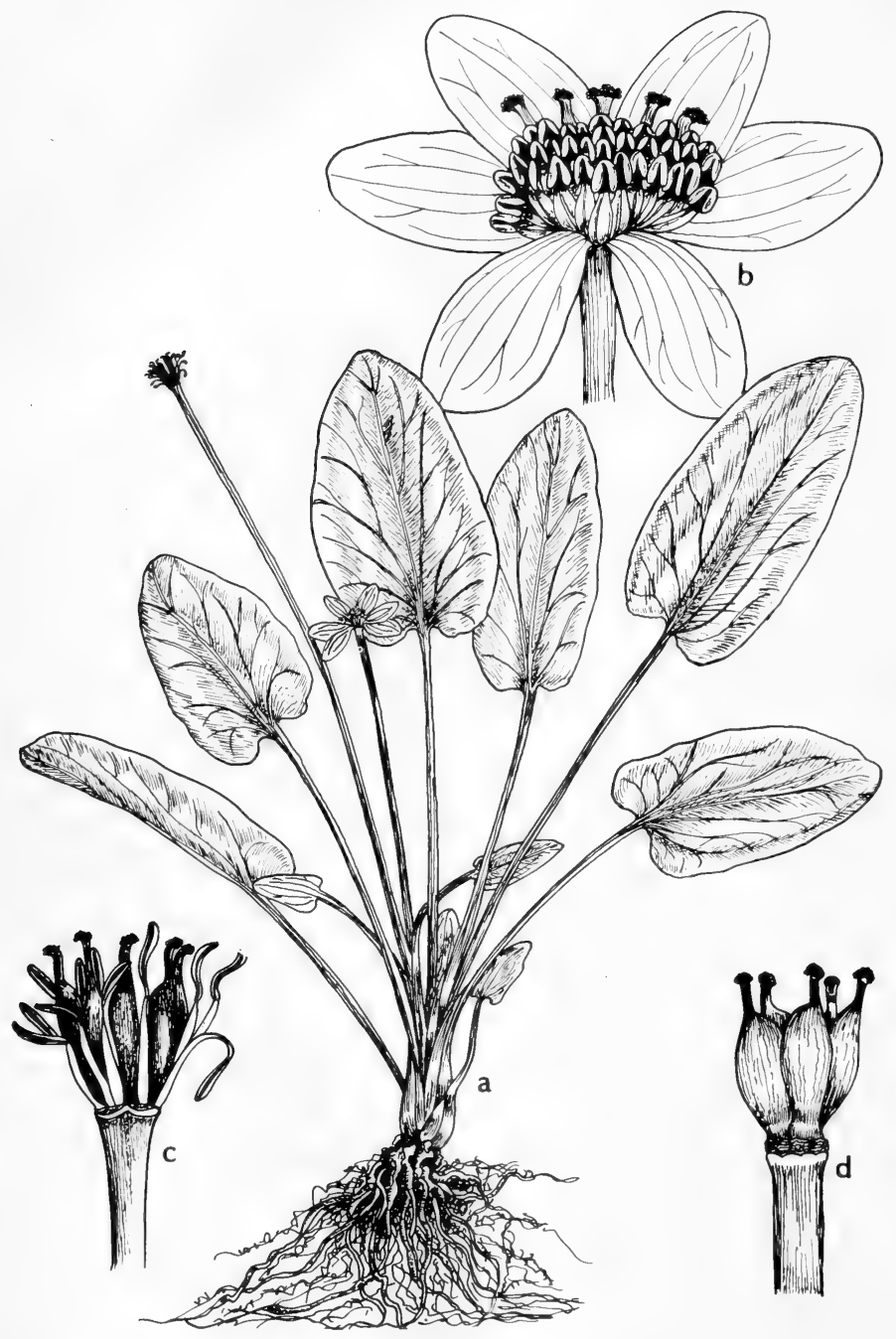

Fig. 449: Caltha leptosepala: a, habit, x 1/2; b, flower, $x 2 \frac{1}{2}$; c, carpels and stamens, × 21/2; d, mature carpels, $\times 2 \frac{1}{2}$. (V. F.). 


\section{Aquilegia L. Columbine}

Perennial herbs from a stout caudexlike rhizome; leaves petiolate, 2 or 3 times ternately compounded; flowers regular, few but conspicuous; sepals 5 , short-clawed at base, petal-like, soon deciduous; petals 5, the terminal portion expanded, prolonged backward from the base below the flower into an elongate hollow spur that secretes nectar from an internal gland at its apex; stamens numerous, separate but often more or less connivent, the innermost staminodal; filaments elongate; anthers oval; pistils usually 5 , erect, each prolonged into a slender style; fruits a severalseeded slender-beaked follicle.

About 100 species in the North Temperate Zone.

1. Flowers basically bluish or purplish.

1. Flowers yellow (2)

2(1). Sepals about $17 \mathrm{~mm}$. wide; petal blade about $2 \mathrm{~cm}$. long and $16 \mathrm{~mm}$. wide; leaves biternate; endemic in Sierra Vieja Mts., Presidio Co., Texas

2. A. Hinckleyana.

2. Sepals $5-10 \mathrm{~mm}$. wide or (if wider) the spur more than $1 \mathrm{dm}$. long; leaves often triternate (3)

3(2). Petal blade 8-16 mm. long; spurs 4-9 cm. long, rarely longer; flowers clear-yellow; petioles to $2 \mathrm{dm}$. long; leaflets about $4 \mathrm{~cm}$. long or less......................................................................... . chrysantha.

3. Petal blade $15-30 \mathrm{~mm}$. long; spurs $10-15 \mathrm{~cm}$. long; flowers pale-yellow; petioles to $3 \mathrm{dm}$. long; leaflets usually more than $4 \mathrm{~cm}$. long...

4. A. longissima.

\section{Aquilegia coerulea James. Rocky Mountain columbine.}

Caudex simple to somewhat branched; leaves mainly basal, somewhat reduced upward on the stem, glaucous, biternate, the segments short-petiolate, cuneateobovate, from shallowly to very deeply 1 to 3 times cleft, usually somewhat pubescent beneath, 1-3 cm. long; stems 2-6 (-8) dm. tall, sparsely pubescent to glabrous below, glandular-pubescent above; flowers usually several or rarely solitary, erect; sepals light- to deep-blue or somewhat purplish, lanceolate to oblong-lanceolate or nearly elliptic, $2-4 \mathrm{~cm}$. long; petals colored similarly to the sepals but the blades usually much lighter to nearly white; spurs slender, nearly straight, mostly $3.5-4.5 \mathrm{~cm}$. long, truncate, the blades about half as long; inner stamens modified into membranous staminodia; follicles mostly 5 or 6 but sometimes as many as 10 , erect, densely glandular-puberulent, $2-3 \mathrm{~cm}$. long.

On seepage banks above lakes and on slopes, in wet soil along $\mathrm{mt}$. streams, in N. M. (Rio Arriba, San Juan, San Miguel and Taos cos.) and Ariz. (Apache and Coconino cos.), June-July; Mont. to N.M. and Ariz.

The beautiful columbine is the state flower of Colorado.

\section{Aquilegia Hinckleyana Munz.}

Stems 5-7 dm. high, glabrous and glaucous below, glandular-pubescent and freely branched in the inflorescence: basal leaves biternate, glabrous and pale-green above, glabrous and more glaucous beneath; petioles glabrous, rather slender, 2.5-3 dm. long, the glaucous primary petiolules subglabrous and $2.5-5 \mathrm{~cm}$. long, the secondary petiolules to $25 \mathrm{~mm}$. long and sparingly pilose; leaflets suborbicular, rather thin in texture, 2-4 cm. long, cleft to about the middle, each segment then with 2 or 3 rounded-oblong teeth or lobes; cauline leaves several, gradually reduced upward; pedicels to about $7 \mathrm{~cm}$. long; flowers suberect, golden-yellow, subglabrous; sepals spreading, ovate, obtuse, about 25 $\mathrm{mm}$. long and $17 \mathrm{~mm}$. wide; petal blades spatulate-obovate, rounded truncate, about $2 \mathrm{~cm}$. long and $16 \mathrm{~mm}$. wide; spurs slender, straight or slightly curved, about $4 \mathrm{~cm}$. long and $5 \mathrm{~mm}$. wide at base, then gradually narrowed to almost 
filiform tube and slightly enlarged tip; stamens exserted 6-7 mm.; staminodia $12-14 \mathrm{~mm}$. long, abruptly narrowed at apex; follicles $2-2.5 \mathrm{~cm}$. long, glandularpuberulent, with slightly flaring tips; styles almost glabrous, filiform, about $2 \mathrm{~cm}$. long; seeds about $1.5 \mathrm{~mm}$. long.

Apparently endemic to the Capote Falls region in Presidio Co., Texas, where it occurs on dripping cliffs about the falls, Mar.-Nov.

\section{Aquilegia chrysantha Gray.}

Stems 4-12 dm. high, glabrous at base and glandular-pubescent above or throughout, usually much-branched above; basal leaves mostly triternate, rather thin, glabrous and light-green above, glaucous and glabrous to pubescent beneath; petioles slender, 5-20 cm. long, glaucous, glabrous or pubescent; primary petiolules $2-5 \mathrm{~cm}$. long, the secondary petiolules about half as long and the tertiary to $25 \mathrm{~mm}$. long; leaflets cuneate-obovate to orbicular-obovate, to $45 \mathrm{~mm}$. long, usually much smaller, cleft to middle or beyond, the main divisions with 2 or 3 round-oblong lobes; cauline leaves well-developed; pedicels to about $1 \mathrm{dm}$. long; flowers erect, clear golden-yellow throughout, somewhat glandular-pubescent; sepals spreading, lanceolate to ovate-lanceolate, usually acuminate, $2-3.5 \mathrm{~cm}$. long, 5-10 mm. wide; petal blades oblong-obovate, usually rounded at apex, spreading, 8-16 mm. long; spurs usually spreading, 4-7 cm. long, 4-6 mm. wide at base, gradually narrowed to an almost filiform tube with slight apical thickening; stamens usually exceeding petal blades by $8-10 \mathrm{~mm}$.; anthers $1.5-2 \mathrm{~mm}$. long; staminodia 9-12 $\mathrm{mm}$. long, very little crinkled, subacuminate; follicles glandularpubescent, 2-3 cm. long, the tips spreading; styles pubescent, 12-18 $\mathrm{mm}$. long: seeds about $2 \mathrm{~mm}$. long.

On wet seepage banks and edge of pools and streams, sometimes on edge of water, in sheltered crevasses, in Tex. rare in the mts. of the Trans-Pecos, N. M. (Dona Ana, Grant, Bernalillo, Catron, Socorro and Otero cos.) and Ariz. (Apache to Mohave, s. to Cochise, Santa Cruz and Pima cos.), Apr.-Aug.; from Ariz., Colo., N.M. and Tex., s. to n. Mex.

\section{Aquilegia longissima Gray. Longspur columbine.}

Stems 5-12 dm. high, often forming large clumps, glabrous below and glandularpubescent above or glandular-pubescent throughout, open-branched above; basal leaves triternate rather thin, light-green and glabrous to slightly pubescent above, glaucous and glabrous to pubescent beneath; petioles slender, 2-3 dm. long, glabrous to pubescent; primary petiolules $3-5 \mathrm{~cm}$. long, the secondary petiolules $1-5 \mathrm{~cm}$. long and the tertiary to $15 \mathrm{~mm}$. long; leaflets much as in $A$. chrysantha, 15-45 mm. long; cauline leaves well-developed; pedicels to $2 \mathrm{dm}$. long; flowers erect, pale-yellow, somewhat glandular-puberulent; sepals spreading, lanceolate, acuminate, 25-35 $\mathrm{mm}$. long, 6-13 $\mathrm{mm}$. wide; petal blades spreading almost horizontally, spatulate to spatulate-obovate, $1.5-3 \mathrm{~cm}$. long, rounded to emarginate; spurs filiform, pendent, mostly $9-15 \mathrm{~cm}$. long, 2-3 $\mathrm{mm}$. wide at base, the tips about $1.5 \mathrm{~mm}$. thick; stamens 5-12 $\mathrm{mm}$. longer than petal blades; anthers $1.5 \mathrm{~mm}$. long; staminodia $12-14 \mathrm{~mm}$. long, rather plane, subacuminate; follicles glandular-pubescent, about $25 \mathrm{~mm}$. long, with spreading tips; styles 16-26 $\mathrm{mm}$. long; seeds almost $2 \mathrm{~mm}$. long.

Along streams and in wet places among boulders, on ledges and in sheltered crevices in canyons of Chisos Mts. in the Tex. Trans-Pecos and Ariz. (Cochise and Pima cos.), June-Nov.; also n.e. Mex.

\section{Delphinium L. LARKSPUR}

Annual or usually perennial herbs, with erect to virgate or ascending stems from a usually tuberiform or rhizomatous rootstock; leaves palmately or rarely 
pinnately cleft or divided; flowers commonly showy, morphologically very similar in our species, in terminal racemes or panicles; sepals 5, irregular, petal-like, the upper one prolonged into a spur at the base; petals 4 or rarely 2 (united into one), irregular, the upper pair continued backward into long spurs that are enclosed in the spur of the calyx, the lower pair with short claws; stamens usually numerous; pistils 3 or fused into 1, forming many-seeded follicles.

This is a complex genus of about 150 species mostly in the North Temperate Zone. Many species and hybrids are valued as ornamentals, and many of the species are known to be poisonous to livestock. The complexity of the genus is emphasized by the existence of multiple hybrids. This fact should be considered when identification of our plants is undertaken.

1. Raceme, sepals and follicles strongly glandular-pubescent or -puberulent.

1. The above organs usually puberulent, without glands (2)

1. D. sapellonis.

2(1). Stem typically 1-2 m. tall; leaves coarsely dissected; racemes open, not conspicuously bracteate; sinus of the lower petals $1 \mathrm{~mm}$. deep: follicles oblong, 10-14 mm. long.......................2. D. andesicola.

2. Stem usually less than $1 \mathrm{~m}$. tall; leaves finely dissected; racemes interruptedspicate, usually conspicuously leafy-bracteate below; sinus of the lower petals 3-4 mm. deep; follicles ovate, $9-11 \mathrm{~mm}$. long.....

..3. D. tenuisectum.

\section{Delphinium sapellonis Cockll.}

Strict slender more or less virgate perennial from a short slender rootstock; stems fistulous, glabrous below, glandular-pubescent in the raceme, $1-2 \mathrm{~m}$. tall; leaves mainly midcauline, numerous, variable even on the same plant; blades mostly longer than the petioles, palmatisect into narrowly cuneate primary divisions that are distally irregularly lobed or simply toothed, the shortly acute ultimate segments glabrous on both surfaces; racemes spicate with the numerous flowers close-set or laxly paniculate with the few flowers scattered; bracts filiform, 1-1.2 cm. long; sepals mostly dull brownish or greenish veined with purple, in bud varying to from pale green to very dark purple, ovate, abruptly acute, streaked, somewhat crisped to entire, $8-9 \mathrm{~mm}$. long, 4.5-5 $\mathrm{mm}$. wide, usually glandular-pubescent dorsally; spur somewhat decurved, 6-9 $\mathrm{mm}$. long; limb of the lower petals narrowly oblong, comose, the sinus $2 \mathrm{~mm}$. deep, the upper petals oblique, shortly acute; follicles oblong, erect, 12-16 mm. long, densely glandularpuberulent, the cusp thin and spreading; seeds rounded or quadrate-angled, brownish, with prominent hyaline wing margins, 2-2.5 $\mathrm{mm}$. long.

Damp or wet soil along streams, edge of meadows and in woodlands, in N. M. (Mora, San Miguel and Sandoval cos.), July-Aug.

\section{Delphinium andesicola Ewan.}

Medium to tall stout erect perennial from a stout woody-fibrous deep-seated rootstock; stems simple or few from the rootcrown, $1-2 \mathrm{~m}$. tall, leafy to the racemes, purplish, with a uniform fine puberulence; leaves predominantly cauline, the basal similar, withering at flowering time, minutely puberulent; principal cauline leaves with petioles $6-9 \mathrm{~cm}$. long, of 3 cuneate-rhomboid or -obovate divisions that are again pinnatifid distally into narrowly oblong few-toothed long ultimate segments, the teeth acute, the proximal half of the division blade entire and gradually narrowed below, the segments $1-1.5 \mathrm{~cm}$. wide at base of lobes; racemes elongate, open, $25-35 \mathrm{~cm}$. long; flowers numerous, with ascending or spreading puberulent pedicels $2-3 \mathrm{~cm}$. long; sepals dull ashy- or dark-blue, ovate, subacute, 9-12 mm. long, cinereous-puberulent; upper petals pale-blue; lower petals ovate-oblong, notched, with sinus $1 \mathrm{~mm}$. deep, blue-purple, moderately 


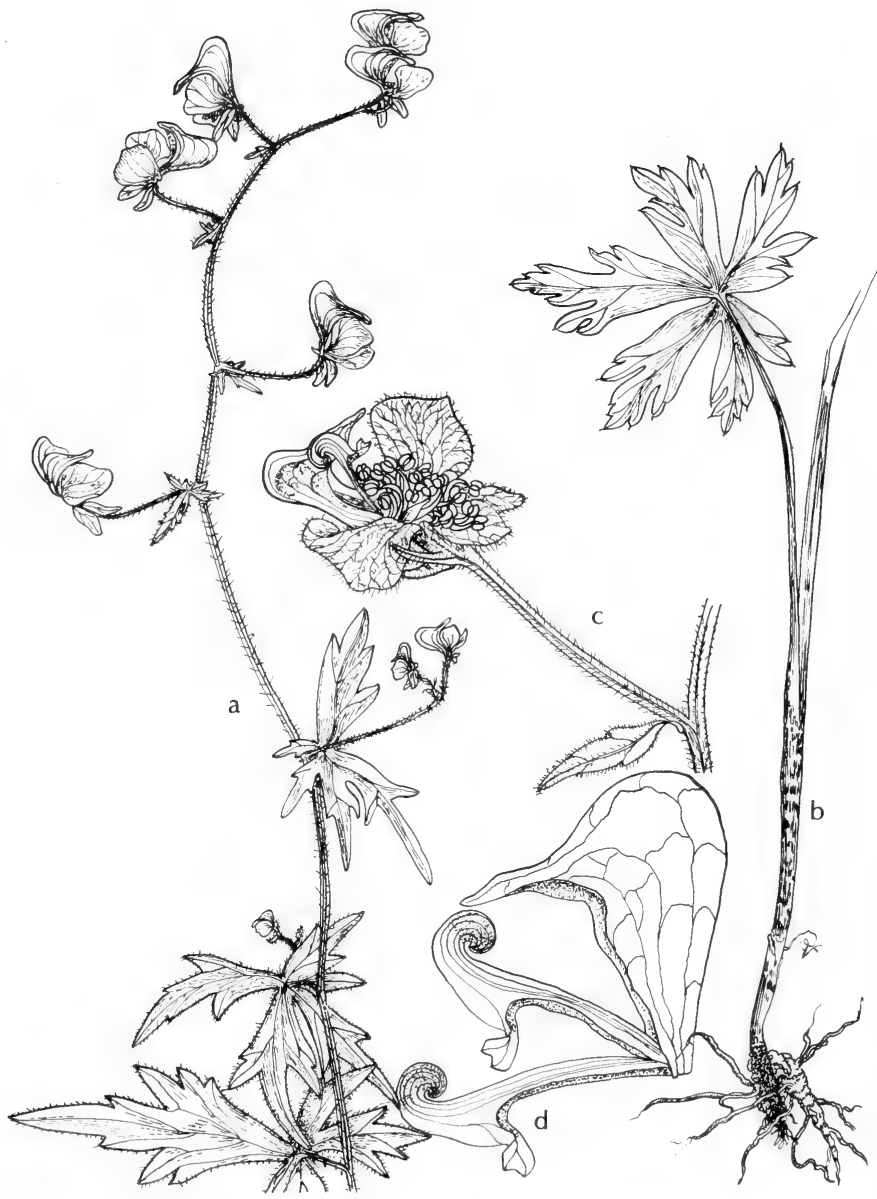

Fig. 450: Aconitum columbianum: a, top of plant, $\mathrm{x} \frac{1}{2} ; \mathrm{b}$, basal part of plant, $\mathrm{x} 1 / 2$; c, flower, $\mathrm{x} 1$; d, hood (upper sepal) and 2 upper petals, $x 2 \frac{1}{2}$. (V. F.). 
white-villous; follicles oblong, obscurely venulose, $1-1.4 \mathrm{~cm}$. long, with short thin pricklelike cusp; seeds $2.5-3 \mathrm{~mm}$. long, the angles narrowly winged.

In wet soil of swales and $\mathrm{mt}$. stream bottoms, in Ariz. (Apache, Greenlee, Graham, Cochise, Santa Cruz and Pima cos.), Aug.-Sept.

Besides typical material, the subsp. amplum Ewan is found in the more northern area of the distribution, characterized by having a less pubescent stem and shorter, broader ultimate divisions of the leaves.

\section{Delphinium tenuisectum Greene.}

Rather tall leafy-stemmed virgate perennial from a stout woody vertical rootcrown; stems strict, stout, simple, finely puberulent throughout (densely so on rachis), 8-12 dm. tall; leaves up to the raceme, spreading, the lower slender petioles $8-10 \mathrm{~cm}$. long; blades finely dissected, 7-9 $\mathrm{cm}$. wide, the primary divisions indistinct by the approximation of the linear-pectinate narrowly acute ultimate segments, sometimes the divisions of the lowermost blades broader (to $3 \mathrm{~mm}$. wide) and more abruptly acute, all finely puberulent on both surfaces; racemes interrupted-spicate; flowers rather large, dark-blue; bracts filiform-attenuate, the lower foliaceous; sepals ovate, abruptly acute or apiculate, finely puberulent dorsally and more or less pale with a median gray band, 11-13 mm. long, 5.5-6.5 mm. wide; spur medium, rather stout, nearly straight, $12-18 \mathrm{~mm}$. long; limb of lower petals ovate-oblong, bifid, the open sinus 3-4 mm. deep; upper petals short, essentially included, short-acute; stamens lightly glandular-hairy; follicles ovate to oblong, 9-11 (-26) $\mathrm{mm}$. long, stramineous, finely puberulent, the cusp firm and spreading; seeds prismatic-quadrate, strongly wing-angled, 2-2.5 mm. long, dark-brown.

In wet meadows and in wet gravel and soil along streams, in N.M. (Colfax, Grant, Otero, Socorro, Taos and Valencia cos.) and Ariz. (Apache Co.), JulyAug.; also n. Mex.

Our plant is referred to subsp. amplibracteatum (Woot.) Ewan, with shorter stems, less finely dissected leaves, and much smaller follicles than in typical D. tenuisectum.

\section{Aconitum L. MonKSHOod}

Possibly several hundred species in North Temperate regions of the world.

\section{Aconitum columbianum Nutt. Fig. 450.}

Herbaceous perennial with several erect stems from a short thickened tuberous crown, mostly 5-20 dm. tall thickened and fistulose, glabrous to slightly crisppuberulent below, spreading-pubescent above and glandular (at least in the inflorescence); leaves mostly cauline, long-petiolate below to subsessile above; blades 5-20 cm. wide, very variable but mostly deeply 3 - or 5-lobed with the segments rhombic-ovate to cuneate-oblanceolate and variously incised to toothed or nearly entire; raceme simple to freely branched; pedicels slender, acutely ascending; bulblets often developed in the leaf axils or in the place of some of the flowers; sepals 5, yellow or greenish-yellow to deep purplish-blue, rarely white, rarely glabrous to hirsute and often somewhat glandular; hood $1.5-3 \mathrm{~cm}$. high, not so broad, the outer edge sharply declined and with scarcely any beak to gradually or abruptly narrowed into a conspicuous descending to porrect beak; lateral sepals obovate to reniform-obovate, to $2 \mathrm{~cm}$. long; lower sepals lanceolate, to about $1.5 \mathrm{~cm}$. long, commonly the 2 unequal in width; only the upper petals usually developed, the spur generally coiled; follicles 3 to 5 , glabrous to glandularpubescent, 1-2 cm. long; seeds about $3.5 \mathrm{~mm}$. long, with a prominent longitudinal wing and a series of delicate ruffled sinuous transverse lamellae. 

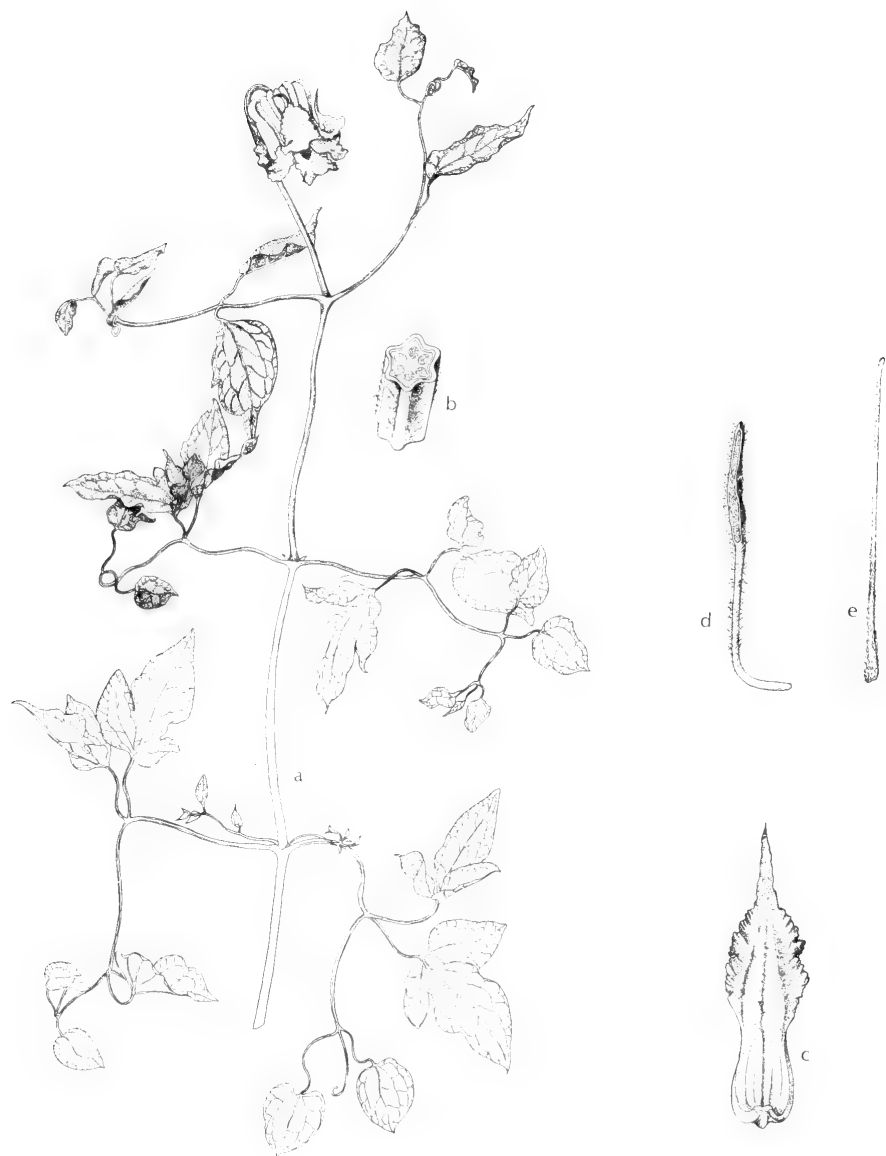

Fig. 451: Clematis crispa: a, part of plant, $\mathrm{x} 1 / 3$; b, section of stem, $\mathrm{x} 3$; c, sepal, about x 1; d, stamen, x 3; e, style, x 3. (Courtesy of R. K. Godfrey). 
In water of marshes, seepage areas, at edge of water along streams, subalpine meadows, and in conifer forests, in N.M. (Taos, Rio Arriba, Santa Fe, San Miguel, Bernalillo and Otero cos.) and Ariz. (Apache, Coconino, Cochise, Santa Cruz and Pima cos.), June-Sept.; Mont. to B.C., s. to N.M., Ariz. and Calif.

\section{Clematis L. Clematis}

Herbaceous perennial vines that climb by twining of the petiolules or erect suffrutescent herbs; leaves opposite, simple or variously compound; flowers solitary or in panicles, terminal or axillary, often nodding; sepals usually 4, rarely 5 or 6 , thin to coriaceous, white to variously colored, valvate in the bud, the margins often induplicate; petals none or small, transitional into stamens; stamens numerous, with adnate anthers; achene bodies compressed, usually more or less rimmed; achene tails plumose to pubescent or nearly naked.

About 250 species widely distributed in temperate and subtropical regions, with several in temperate regions.

1. Flowers small, creamy-white, in cymose panicles; sepals oval to oblong, 6-12 $\mathrm{mm}$. long.......................................................... . virginiana.

1. Flowers large, rose-color to violet-color, solitary and nodding on long peduncles; sepals $25 \mathrm{~mm}$. long or more, with wide undulate or crisped margins..................................................... . C. crispa.

\section{Clematis virginiana L. Virgin's-Bower, DeVIL's DARNING-NEEdLE.}

Plant almost glabrous; leaves simply 3 -foliolate, very rarely pinnately 5 -foliolate; leaflets thin, ovate, often subcordate, $5-7.5 \mathrm{~cm}$. long, incisely few-toothed or somewhat lobed, glabrous or sparingly pilose and glabrate on lower surface; panicles corymbiform, with numerous creamy-white flowers; sepals oval or oblong, 6-12 mm. long, anthers $0.6-1.5 \mathrm{~mm}$. long; achenes brown or rufescent, pilose or villous-hirsute, the styles $1-3 \mathrm{~cm}$. long.

Low grounds, thickets and borders of woods, edge of swamp forests, commonly climbing in trees, in Okla. (Waterfall) and e. Tex. (San Augustine Co.), JulySept.; from e. Can to Man., s. to Ga., Ala., Miss., La., Tex. and e. Kan.

\section{Clematis crispa L. Blue Jasmine. Fig. 451.}

Plant climbing freely, glabrous or nearly so, often flowering when only $3 \mathrm{dm}$. high; leaves compounded with 2 to 5 pairs of leaflets; leaflets from ovate to lanceolate or even linear, cuneate to cordate at base, acute to acuminate at apex, entire to rarely 3-foliolate, membranaceous, little reticulated; peduncle naked, arising between a pair of compound or rarely simple leaves; calyx cylindriccampanulate or urceolate-campanulate, rose-colored varying to violet; sepals $2.5-5 \mathrm{~cm}$. long, recurved or spreading from near the middle, the spreading portion with broad undulate thinnish margins; achenes $6-9 \mathrm{~mm}$. broad; style canescent to somewhat villous in flower, in fruit $2-3 \mathrm{~cm}$. long and either almost glabrate (and the upper part falling away in age) or finely appressed-pubescent. C. cylindrica Sims, Viorna crispa (L.) Small.

Frequently in wet soils, climbing on shrubs, along streams in low woodlands or sometimes on coarse dry sandhills with available water in s.e. Okla. (McCurtain Co.) and e. Tex., w. to Calhoun and Williamson cos., Mar.-Oct.; from Fla. to Tex., n. to s.e. Va., Ill. and Mo.

The plant which typically flowers when low and has narrowly lanceolate to linear leaflets (6-8 $\mathrm{mm}$. wide) and whose sepals are artificially outspread is referred to var. Walteri Gray. 


\section{Myosurus L. Mousetall}

Very small acaulescent annual herbs, with fibrous roots; leaves in a radical tuft, linear to filiform or at first spatulate, entire; scapes simple, one-flowered, the yellowish or whitish flower succeeded by the slender spike or (in depauperate specimens) oblong head of carpels; sepals 5, spurred at the base; petals 5, small and narrow, raised on a slender claw at the summit of which is a nectariferous pit; stamens 5 to 20; achenes numerous, somewhat 3- or 4-sided, apiculate, crowded on a very long and slender spikelike receptacle, the seed suspended.

About 15 species of local occurrence but widely distributed.

1. Achenes when mature roundish, with a dorsal cup or border nearly surrounding the base of the beak, the cup often larger than the body of the achene................................................................. M. cupulatus.

1. Achene when mature more or less quadrangular, without cup or border, keeled dorsally from base to apex, the subulate beak not strongly flattened laterally (2)

2(1). Back of the achene scarcely wider on each side than the very prominent keel, the latter prolonged into a beak at least half as long as the body of the achene. 2. M. aristatus.

2. Back of the achene distinctly wider on each side than the relative low keel, the latter prolonged into a beak much less than half as long as the body of the achene, or the beak sometimes obsolete..3. M. minimus.

\section{Myosurus cupulatus Wats. Fig. 452.}

Tufted annual, often very diminutive, $3-8 \mathrm{~cm}$. tall; leaves linear to linearspatulate, $1-5 \mathrm{~cm}$. long; sepals 5 or 6 , oblong, the variable spur often short or "blunt-tapered" and sometimes as much as one third as long as the blade; petals linear-filiform, with a narrow, elongate claw 4 to 5 times as long as the narrow short-oblong blade; scapes $3-8 \mathrm{~cm}$. long; fruiting spike slender, $2-5 \mathrm{~cm}$. long; achenes with a thickened margin producing a cuplike depression on the back from which protrudes the divergent beak; seed short-oblong, flattened.

Vernally wet spots, seepage areas and in shelter of boulders, in N. M. (Grant and Sierra cos.) and Ariz. (Greenlee to Mohave, s. to Cochise, Santa Cruz and Pima cos.), Feb.-July; N. M. to Calif. and Son.

This species may readily be distinguished by the loose-fitting achenes which at maturity are separated by obvious spaces.

\section{Myosurus aristatus Benth. ex Hook. Fig. 453.}

Tufted annual; leaves linear to linear-spatulate, $1-5 \mathrm{~cm}$. long, with a broad almost membranous base; scapes very slender, $2-5 \mathrm{~cm}$. tall; sepals oblong, erect or spreading, with a slender spur from one half as long to fully as long as the blade; petals present or (at maturity) often none; fruiting spike $5-10 \mathrm{~mm}$. long; achenes somewhat quadrate in outline, the back sharply keeled and extending to the elongate divergent sometimes falcate beak.

In wet and muddy places in N. M. (Bernalillo and San Juan cos.) and Ariz. (Coconino and Pima cos.), Mar.-June; Neb. to B. C., s. to N.M., Ariz. and Calif.; S.A.

As Mason (1957) noted, $M$. aristatus may be readily distinguished by the elongate, divergent beaks of the achene, which are fully as long as the body of the achene, and by the very short spike, which, because of the achene, appears somewhat bristly.

3. Myosurus minimus L. Fig. 454.

Leaves narrowly linear to filiform, blunt, $3-15 \mathrm{~cm}$. long; scape $3-15 \mathrm{~cm}$. long; sepals oblong, 2-3 mm. long; spurs slender, acute, $1-3 \mathrm{~mm}$. long; petals linear to 


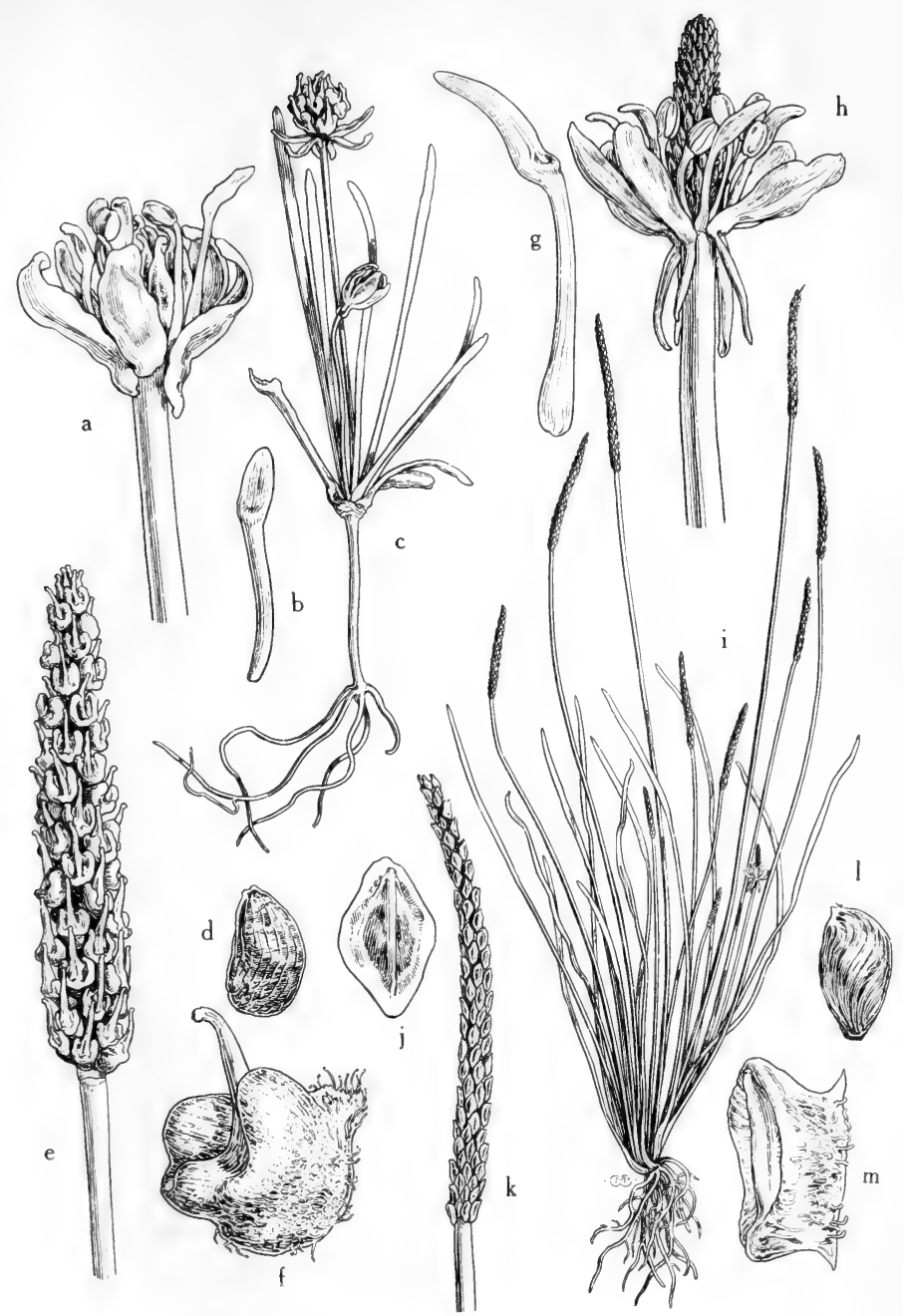

Fig. 452: Myosurus. a-f, $M$. cupulatus: a, flower, the spurs and petals variable in size, $\mathrm{x} 16$; b, petal, showing the short blade and the shallow nectariferous pit, $\mathrm{x} 16$; $\mathrm{c}$, habit, showing leaves and flowering scapes, x 4; d, mature seed, x 20; e, mature fruiting spike, $x$ 4; f, mature achene, showing the divergent beak arising between thickened margins, x 20. g-m, M. minimus var. filiformis: g, petal, showing long claw and rounded nectariferous pit, $x$ 16; h, flower, showing long slender spurs and numerous petals, x 6; $\mathrm{i}$, habit, the leaves, scapes and spikes very slender, $\mathrm{x} 2 / 3 ; \mathrm{j}$, mature achene, abaxial view, $\mathrm{x} 16 ; \mathrm{k}$, mature fruiting spike, $\times 2 ; 1$, mature seed, longitudinally striate, flattened and twisted, x 20; m, mature achene, lateral view, showing short beak, x 20 . (From Mason, Fig. 233). 


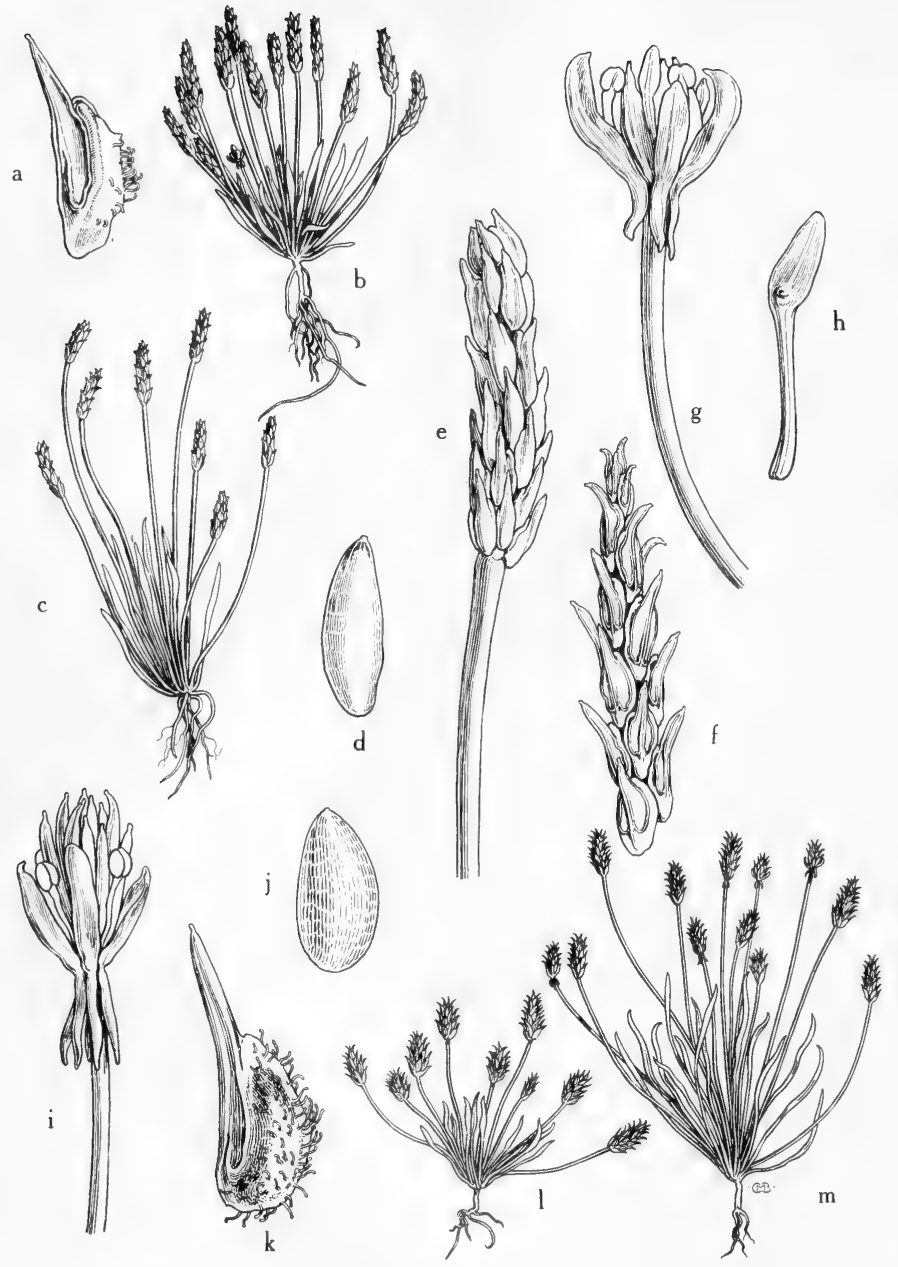

Fig. 453: Myosurus. a-h, $M$. aristatus subsp. montanus: a, mature achene with divergent beak and strongly nerved lateral angles, x 8; b and $c$, habit variations, scapes extending above the leaves, $\mathrm{x} 4 / 5 ; \mathrm{d}$, mature seed, $\mathrm{x} 12$; e, young fruiting spike, $\mathrm{x} 4$; $\mathrm{f}$, part of a mature fruiting spike, $\mathrm{x} \mathrm{4;g}$, flower, stamens few, $\mathrm{x} 12 ; \mathrm{h}$, petal, the nectariferous pit rounded, $\mathrm{x} 16$. $\mathrm{i}-\mathrm{m}, M$. aristatus: $\mathrm{i}$, flower, the calyx spurs long and slender, $x 8 ; j$, mature seed, $x 16 ; \mathrm{k}$, mature achene, the beak long and divergent, $\mathrm{x}$ $12 ; 1$ and $\mathrm{m}$, habit variations, the fruiting spikes bristly, $\mathrm{x} 4 / 5$. (From Mason, Fig. 234). 


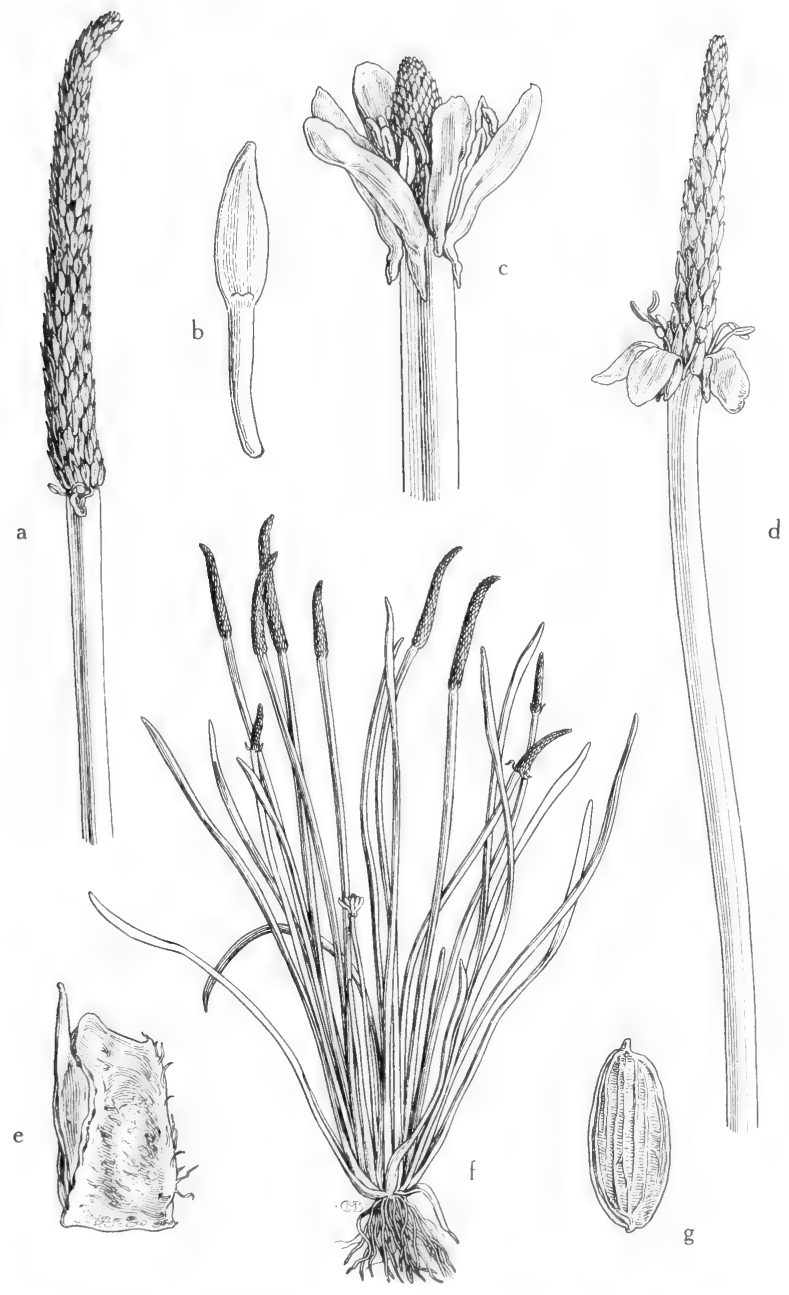

Fig. 454: Myosurus minimus: a, mature fruiting spike, x 2; b, petal and terete claw, showing nectariferous pit, $\times 20$; c, flower, the spurs of sepals short, $x 6$; d, young fruiting spike, x 4; e, mature achene, its beak paralled with back, x 16; $\mathrm{f}$, habit, showing the slender clavate scapes and the linear spatulate leaves, $\mathrm{x} 2 / 3 ; \mathrm{g}$, mature seed, $\mathrm{x} 20$. (From Mason, Fig. 232). 
narrowly spatulate, sometimes wanting, $2-3 \mathrm{~mm}$. long; fruiting spike $2-5 \mathrm{~cm}$. long, 2-3 mm. thick; mature carpels somewhat quadrate, with broader usually rhomboidal and flat back, traversed by very low keel, ending in a short and appressed or often obsolete pointed tip.

In damp argillaceous or calcareous soils, fallow fields, in water of borrow pits, wet meadows, mud of ditches and on edge of ponds and about playa lakes, in Okla. (Waterfall), throughout Tex., but mostly in cen: part, N. M. (Grant, Luna and Rio Arriba cos.) and Ariz. (Navajo, Coconino, Yavapai, Pinal, Cochise, Santa Cruz and Pima cos.), Mar.-July; from Fla. to Tex., N.M. and Ariz., n. to e. Va., s. Ont., Ill., Minn. and Sask., also Euras. and Afr.

\section{Trautvetteria F. \& M.}

\section{Probably 2 or 3 species in North America and Asia}

\section{Trautvetteria grandis $T$. \& $G$.}

Large perennial herb 5-10 dm. high, glabrous or nearly so, with slender underground rootstocks and fascicled roots; stems slender, erect, branching above and forming corymbose cymes; leaves large, palmately lobed; lower leaves longpetioled, 1-2 dm. wide, deeply 5- to 11-lobed with the lobes acute and irregularly and sharply deeply toothed; cauline leaves smaller than lower ones and shortpetioled to sessile; sepals 3 to 5, 3-6 mm. long, strongly concave, greenish-white, early deciduous; epetalous; stamens numerous, conspicuous; filaments white, clavate, 7-10 mm. long; pistils many, forming inflated glabrous achenes $(3-5 \mathrm{~mm}$. long) with short recurved styles.

In swamps about springs, bogs and along streams in N. M. (San Juan, San Miguel, Bernalillo, Grant and Socorro cos.) and Ariz. (Apache Co.), July-Aug.; Ida. to B. C., s. to N. M., Ariz. and Calif.

\section{Ranunculus L. Crowfoot. Buttercup}

Annual or perennial herbs of various aspects; cauline leaves alternate; flowers regular, perfect, solitary or somewhat corymbed; sepals 3 to 5 or rarely more, green or yellowish; petals commonly 5 , more or less in some species, plane or concave, mostly yellow or white, rarely reddish or green, each with a nectariferous pit or scale on inner surface at or near base; stamens mostly numerous, rarely as few as 5; filaments slender; anthers oblong or linear; pistils numerous in a globose to ovoid or cylindric head; ovule 1; style long or short, straight, curved or hooked; fruit an achene.

About 400 species mostly in colder regions or at high altitudes in the tropics. It is reported that all of the species are acrid or even poisonous.

(Adapted from Lyman Benson in Am. Midl. Nat. 40:1-261. 1948.)

1. Achenes roughly transversely ridged; petals not glossy, white, the claws sometime yellow; aquatic plants (2)

1. Achenes or utricles not transversely ridged (except in $R$. sceleratus which has 40 or commonly 100 to 300 minute beakless achenes in an elongate head); petals usually glossy, yellow or rarely red, white or green; plants of wet places or occasionally aquatic (4)

2(1). Style persistent after flowering; achene beak $0.7-1.1 \mathrm{~mm}$. long; dissected leaves once- or sometimes twice-trichotomous, then dichotomous.... 31. $R$. longirostris.

2. Style largely deciduous after flowering; achene beak 0.3 or rarely $0.5 \mathrm{~mm}$. long; body of the achene obovoid, 1-1.5 mm. long, finely transversely wrinkled (3) 
3(2). Pedicels not recurved at fruiting time; submersed dissected leaves (sometimes the only kind) usually petioled, the first divisions arising usually but not always well above the non-dilated stipular leaf bases (the ends of these not free), usually collapsing when withdrawn from the water, not circinate, usually about equaling or a little shorter than the internodes; achenes usually about 10 to 20 or as many as 40 ; dissected leaves usually repeatedly trichotomous

29. $R$. aquatilis.

3. Pedicels recurved at the bases at fruiting time; submersed dissected leaves (the only kind) usually sessile, the first divisions arising within the usually dilated stipular leaf bases (the ends of these often free), usually not collapsing when withdrawn from the water, circinate, much shorter than the internodes; achenes mostly 30 to 45 or 80 ; dissected leaves usually once- or twice- trichotomous.

30. R. subrigidus.

4(1). Pericarp striate, the nerves 3 or more on each face (these sometimes branched), the ovary wall thin and usually fragile at fruiting time (5)

4. Pericarp not striate nor nerved, thick and firm (6)

5(4). Fruiting receptacle enlarged to several times its size in anthesis, cylindroid or long-ovoid; nectary scale overarching the nectary, truncate, the margins free from the blade of the petal; stolons present; leaves simple............................................................27. R. Cymbalaria.

5. Fruiting receptacle but slightly enlarged from its size in anthesis; nectary scale not overhanging the nectary, consisting of a mere transverse ridge below the gland; stolons not present; leaves compound.

28. $R$. ranunculinus.

6(4). Leaves (both cauline and basal) entire, dentate, serrulate or wavy; dorsoventral measurements of the achene not more than twice or thrice the lateral; nectary scale forming a pocket (7)

6. Leaves (either the cauline or the basal) lobed, parted or divided (very rarely all the leaves entire in single plants of $R$. glaberrimus var. ellipticus) (10)

7(6). Perennials; achenes $1.2-3.2 \mathrm{~mm}$. long, the beaks $0.3-1.5 \mathrm{~mm}$. long, rarely less; petals 5 to 10 , usually large and conspicuous, longer than the sepals (8)

7. Annuals; achenes $0.6-1$ or rarely to $1.5 \mathrm{~mm}$. long, the beaks $0.1-0.2 \mathrm{~mm}$. long (9)

8(7). Achene beak $0.2-0.5 \mathrm{~mm}$. or rarely to $0.7 \mathrm{~mm}$. long, the stigmatic surface mostly across the broad apex of the style.

20. R. flammula.

8. Achene beak $0.8-1 \mathrm{~mm}$. long, the stigmatic portion long-attenuate.

21. $R$. hydrocharoides.

9(7). Petals 5 to 9, large and conspicuous, about twice as long as the sepals; styles in anthesis $0.5 \mathrm{~mm}$. long, filiform, deciduous in fruit; head of achenes hemispheroidal or ovoid........................22. $R$. laxicaulis.

9. Petals 1 to 3 , minute and inconspicuous, shorter than or equal to the sepals; styles in anthesis $0.1-0.2 \mathrm{~mm}$. long........................23. R. pusillus.

$10(6)$. Achenes covered with spines, hooks or papillae, or with papillae produced into hooked hairs, rarely smooth in $R$. Sardous; dorsoventral measurement of the achene 3 to 6 times the lateral; receptacle in fruit 1 to 3 times its length in anthesis (11)

10. Achenes smooth, sometimes hairy (13) 
11(10). Petals 1-3 mm. long; mature achenes papillate, the papillae produced into slender hooked spines or hooked hairs; nectary scale free laterally. ...

10. $R$. parviflorus.

11. Petals at least $4 \mathrm{~mm}$. long; mature achene either papillate or with straight or curved but not hooked stout spines, when papillate the papillae not produced into hairs or spines, rarely smooth (12)

12(11). Mature achenes papillate or rarely some or perhaps all of them smooth.... 11. R. Sardous.

12. Mature achenes with stout spines on the margin or faces.....12. $R$. muricatus.

13(10). Style and achene beak practically lacking, if otherwise the achene with a corky thickening on the margin of the body; nectary scale either with the gland in a pocket on its ventral surface or else the scale forked and prolonged anteriorly on the surface of the petal or surrounding the gland (14)

13. Style and achene beak present, the achene neither corky-keeled nor with nectary thickening on the margin of the body; nectary scale ventral to the nectary (covering it), apically truncate or rounded (16)

14(13). Styles and achene beaks practically lacking, the stigmas nearly sessile; achene with some corky thickening of the pericarp..24. $R$. sceleratus.

14. Styles and achene beaks well-developed, the beaks at least half as long as the achene bodies, $0.6-1.5 \mathrm{~mm}$. long; achenes with conspicuous corky thickening of either the keel or the pericarp beside the keel (15)

15(14). Achenes each with corky thickening beside the inconspicuous keel (especially in the basal and ventral regions); leaves once- or twice-parted or -lobed, pentagonal, $1-2 \mathrm{~cm}$. long, $1.5-2.5 \mathrm{~cm}$. wide, rarely dissected but not triternately so; anthers elliptic, $0.5-1 \mathrm{~mm}$. long; petals 4-7 mm. long...........................................25. R. Gmelinii.

15. Achenes each with a conspicuous corky keel; leaves of aquatic specimens finely triternately dissected into ribbonlike segments $1-2 \mathrm{~mm}$. wide, the complete blades $1.5-10 \mathrm{~cm}$. long and $2-12 \mathrm{~cm}$. wide; anthers oblong, 1-1.5 mm. long; petals $7-15 \mathrm{~mm}$. long......26. R. flabellaris.

16(13). Nectary scale free laterally for at least two-thirds its length, not forming a pocket (except in $R$. recurvatus var. recurvatus); dorsoventral measurement of the achene 3 to 15 times the lateral; receptacle in fruit (in most species) 1 to 3 times its length in anthesis; sepals usually not lavender- or purple-tinged but sometimes markedly so (17)

16. Nectary scale attached to the petal laterally and forming a pocket; dorsoventral measurement of the achene 1 to 2.5 times the lateral; receptacle in fruit (in most species) 3 to 15 times its length in anthesis; sepals usually tinged dorsally with purple or lavendar (25)

17(16). Achene beaks regularly recurved or curved, or clearly falcate or hooked at the apices, $2 \mathrm{~mm}$. long or less, usually shorter than the bodies or sometimes equaling them (the beak sometimes straight in $R$. Macounii but then only about half as long as the body) (18)

17. Achene beaks not regularly curved nor recurved, nor markedly hooked, 1.5 or usually 2-4 mm. long, usually always equaling or exceeding the bodies (23)

18(17). Receptacle in fruit at least 3 times its length in anthesis, hispid; head of achenes ovoid to cylindroid (19)

18. Receptacle in fruit not more than 2.5 times its length in anthesis; head of the achenes hemispheroidal or globose (20) 
19(18). Sepals about twice as long as the petals; petals $2-3 \mathrm{~mm}$. long; head of achenes cylindroid, 11-17 mm. long; stems never rooting.

5. $R$. pensylvanicus.

19. Sepals equal to or somewhat shorter than the petals; petals (3-) 5-10 mm. long; head of achenes ovoid, 7-12 mm. long...........6. R. Macounii.

20(18). Petals (when fully expanded) usually $8-18 \mathrm{~mm}$. long, large and conspicuous, 1.5 to 3 times as long as the sepals (21)

20. Petals minute, $2-4$ or rarely $6-7 \mathrm{~mm}$. long, shorter than or slightly exceeding the sepals (22)

21(20). Stems rooting at the nodes, some of them usually stoloniferous; receptacle usually hispid................................................. $1 . R$. repens.

21. Stems never rooting; receptacle glabrous....................................... $R$. acris.

22(20). Receptacle glabrous; nectary scale not forming a pocket, free laterally for its entire length..............................................$R$. uncinatus.

22. Receptacle hispid; nectary scale forming a pocket at least basally, the distal margin sometimes proliferating into a flap with free margins.

4. $R$. recurvatus.

23(17). Achenes mostly 40 to 130 , rarely fewer; sepals usually $8-10 \mathrm{~mm}$. long, rarely less; petals 8 to 18

9. R. macranthus.

23. Achenes 10 to 30 , rarely more; sepals $6-8 \mathrm{~mm}$. long; petals 5 (24)

24(23). Stems rooting at the nodes (especially when plants are in wettish soils); plants usually stoloniferous.................................. . $R$. carolinianus.

24. Stems never rooting; roots both tuberous and filiform......... 8. R. fascicularis.

25(16). Head of 70 to 150 achenes globose, $10-20 \mathrm{~mm}$. in diameter; nectary scale usually distally ciliate; herbage glabrous; roots large and fleshy, 2-3 mm. thick, the cluster conspicuous and dense; stems prostrate or ascending...................................19. $R$. glaberrimus.

25. Head of achenes cylindroid to ovoid or globose, if globose $2.5-7 \mathrm{~mm}$. in diameter, the horizontal diameter in any case never more than 9 mm. (26)

26(25). Sepals covered dorsally with dense conspicuous long reddish-brown hair

26. Sepals not covered dorsally with reddish-brown hair (27)

13. R. Macauleyi.

27(26). Petals 1-3.5 mm. long, shorter than or scarcely equal to the sepals; achenes glabrous................................................18. $R$. abortivus.

27. Petals (when fully expanded) 4-18 mm. long or in plants with canescent achenes $(\boldsymbol{R}$. inamoenus) rarely shorter $(28)$

28(27). Achenes swollen or broadened at the bases and therefore obovoid-oblong 14. R. Eschscholtzii.

28. Achenes obovoid to flattened-obovoid or discoid, not swollen nor flat-stiped at the base (29)

29(28). Petals 2.5-8 mm. long; achenes glabrous; stems mostly 1- to 4-flowered (rarely 6)

15. $R$. inamoenus.

29. Petals (6-) 8-18 mm. long or (in plants with canescent achenes or with

5- to 11-flowered stems) sometimes shorter (very rarely none in R. pedatifidus) (30)

30(29). Achenes glabrous.

17. R. pedatifidus.

30. Achenes canescent (31)

31(30). Nectary scale ciliate, the adjacent surface of the petal sometimes hairy also...... 16. R. cardiophyllus.

31. Nectary scale and the petal glabrous (32) 


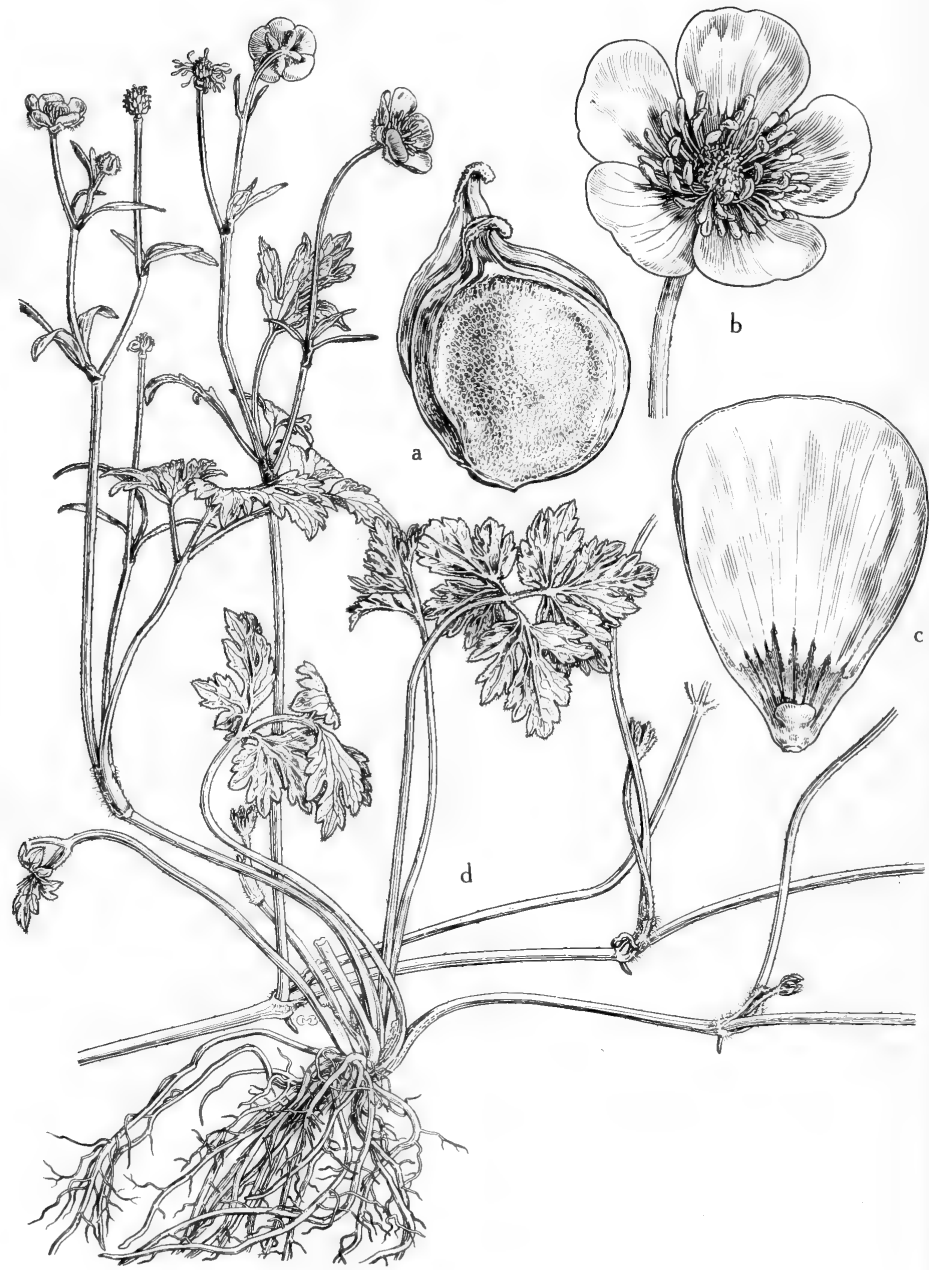

Fig. 455: Ranunculus repens: a, mature achenes, showing variation in the recurved beak, $x 12 ; \mathrm{b}$, flower, $\mathrm{x} 1 \frac{1}{2} ; \mathrm{c}$, single petal, showing the broad scale covering the nectariferous pit, $x 3$; d, habit, showing the trailing stems, the coarsely serrate divided leaves, and the large flowers, $x \%$. (From Mason, Fig. 236). 
32(31). Petals narrow; sepals glabrous or thinly appressed-pubescent, some of the basal leaves proximally attenuate, acute to obtuse, at least some basal leaves on each plant crenate, occasional leaves 3-lobed or -divided..........................................................15. $R$. inamoenus.

32. Petals broadly cuneate-obovate; sepals pilose-tomentose; basal leaves proximally cordate..................................................17. $R$. pedatifidus.

\section{Ranunculus repens L. Creeping buttercup. Fig. 455.}

Hirsute terrestrial or palustrine perennial; stems prostrate to suberect, rooting at least at the lower nodes, commonly but not always with some stoloniferous, to $9 \mathrm{dm}$. long, branching, not fistulous, hirsute to glabrous or nearly so; leaves compound, deltoid-cordate in outline, to $11 \mathrm{~cm}$. long and $13 \mathrm{~cm}$. broad, usually much smaller, pinnate with 3 sessile or petiolulate leaflets that are cuneate to subtruncate or sometimes rounded or subcordate at the base and lobed and toothed (but acute in outline) at apex, sometimes the leaflets tending to be rounded, the middle petiolule to $4 \mathrm{~cm}$. long, the lateral petiolule to $2 \mathrm{~cm}$. long, the petioles $4-25 \mathrm{~cm}$. long, hirsute to subglabrous, the stipular leaf bases $6-20 \mathrm{~mm}$. long; cauline leaves alternate, like the basal; pedicels $2-10 \mathrm{~cm}$. long in flower, $4-15 \mathrm{~cm}$. long in fruit; pubescent; sepals 5, greenish, spreading, 5-7 $\mathrm{mm}$. long, 3-4 $\mathrm{mm}$. broad, pilose, promptly deciduous; petals 5 or rarely the staminodia forming a "double" flower, cuneate-obovate, 7-13 $\mathrm{mm}$. long, 5-10 $\mathrm{mm}$. broad, the glabrous truncate nectary scale free laterally for two thirds of its length and $1-1.3 \mathrm{~mm}$. long; stamens 50 to 80 , the number reduced in "double" flowers, achenes 20 to 25 in a subglobose head 6-7 mm. in diameter, obovoid-discoid, $2.5 \mathrm{~mm}$. long, smooth, glabrous, the margin prominent, the recurved beak stout and $1 \mathrm{~mm}$. long; receptacle subgloboseovoid, 1-2 mm. long in flower, $3 \mathrm{~mm}$. long in fruit, pubescent or rarely glabrous.

This Old World species sometimes occurs as an escape, especially the garden form, var. pleniflorus Fern. It becomes established along stream courses, wet meadows, marshes and in wet springy places.

\section{Ranunculus acris L. Fig. 455A.}

Hirsute terrestrial perennials, the pubescence spreading or rarely appressed; roots stout but not tuberous, $0.5-1 \mathrm{~mm}$. thick; stems several, erect, not rooting, 5-10 dm. long, freely branching above, glabrous or sparsely hirsute; petioles 5-17 $\mathrm{cm}$. long, hirsute, the stipular leaf bases $3-5 \mathrm{~cm}$. long; basal leaf blades simple, pentagonal in outline, $4-8 \mathrm{~cm}$. long, 5-10 cm. wide, deeply 3-parted and again lobed, appearing 5-parted by forking of the lateral primary parts, proximally deeply cordate, distally rounded in outline, densely appressed-hirsute beneath, more sparsely so above; cauline leaves alternate, petioled, the bracts of 3 linear divisions sessile; pedicels $1-5 \mathrm{~cm}$. long in flower, 4-12 cm. long in fruit, densely pubescent; sepals 5, greenish, spreading, ovate, 4-7 mm. long, about $3 \mathrm{~mm}$. wide, densely pubescent dorsally, promptly deciduous; petals 5 , obovate-cuneate, 8-14 $\mathrm{mm}$. long, 6-10 mm. wide; nectary scale glabrous, free laterally for two-thirds of its length, $1.2 \mathrm{~mm}$. long, truncate; stamens 40 to 80 ; achenes 25 to 40 in a globose head about $6 \mathrm{~mm}$. in diameter, obovoid-discoid, 2-2.5 mm. long, $1.8 \mathrm{~mm}$. dorsoventrally, $0.5 \mathrm{~mm}$. laterally, smooth, glabrous, the margin conspicuous, keeled, the recurved beak deltoid at base and $0.3-0.6 \mathrm{~mm}$. long; receptacle pyriform, 1-2 $\mathrm{mm}$. long in flower, $2.5 \mathrm{~mm}$. long in fruit, glabrous.

In water on edge of streams and ponds, in N. M. (Catron Co.) May-July; an Old World species now widespread through much of N.A., especially in the north.

\section{Ranunculus uncinatus D. Don.}

Hirsute or hispid to glabrous terrestrial annual or perennial; roots $0.5-1 \mathrm{~mm}$. thick; stems erect, not rooting, 3-10 dm. long, freely branching above, glabrous 


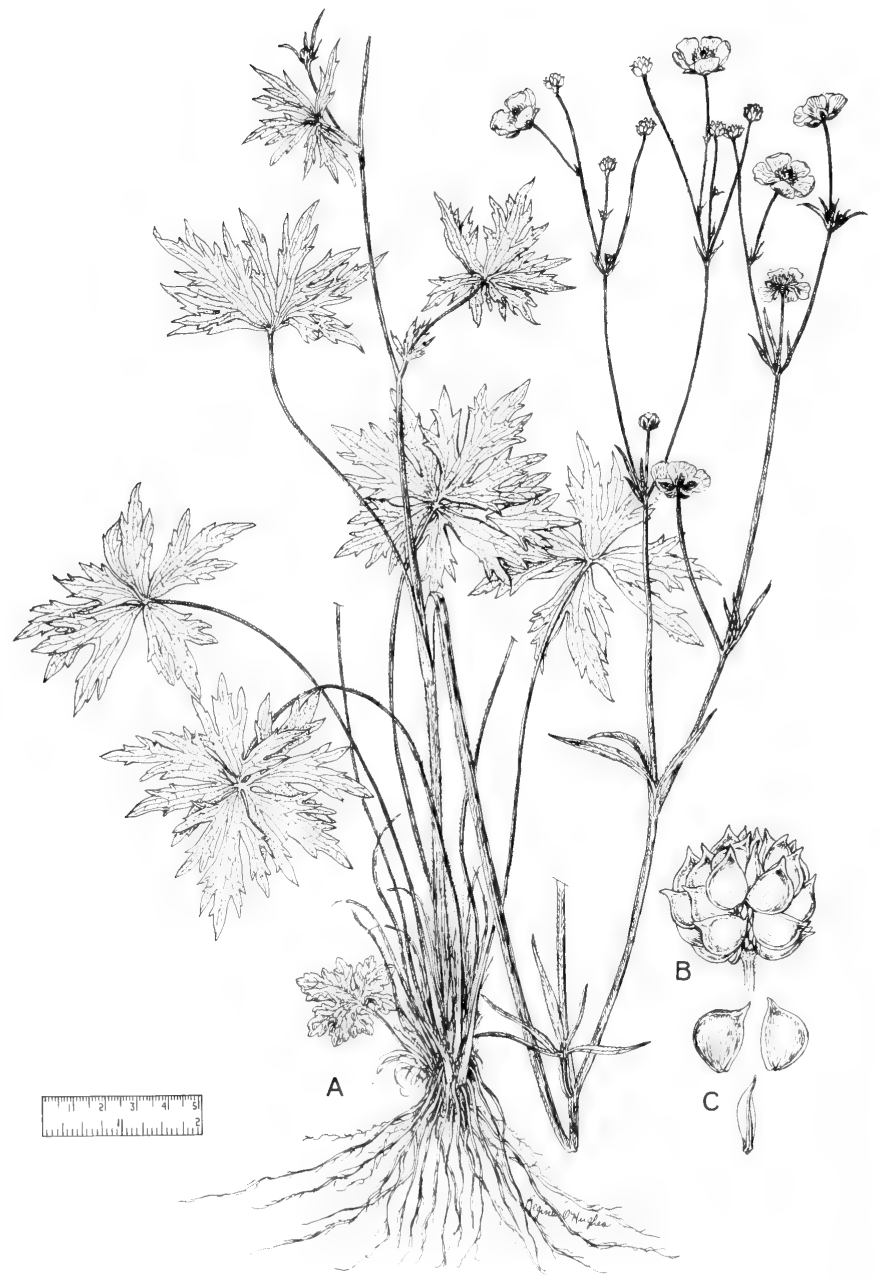

Fig. 455A: Ranunculus acris: A, habit, x 1/2; B, fruiting head, x 3; C, achenes, $\mathrm{x}$ 4. (From Reed, Selected Weeds of the United States, Fig. 91). 
or hispid with reddish-brown or white hairs; petioles $5-17(-25) \mathrm{cm}$. long, glabrous to densely hispid with reddish-brown or white hairs; stipular leaf bases oblong, 2-3 cm. long, 10-12 mm. broad, thin; basal leaf blades simple, cordatereniform, 2-9 $\mathrm{cm}$. long, 2-14 $\mathrm{cm}$. wide, 3-parted with the parts lobed and obtusely or acutely toothed, proximally cordate and distally acute, glabrous or appressed-hispidulous; cauline leaves alternate, petioled; pedicels to $2 \mathrm{~cm}$. long in flower, to $5 \mathrm{~cm}$. long in fruit, appressed-pubescent; sepals 5, yellowish-green, reflexed, narrowly elliptic, $3 \mathrm{~mm}$. long, 1-1.5 mm. wide, appressed-pubescent dorsally, promptly deciduous; petals 5, rarely less, yellow, narrowly elliptic, 2.5-3 (-7) $\mathrm{mm}$. long, 1-1.8 (-3) $\mathrm{mm}$. wide; nectary scale glabrous, free for most of its length, rounded to truncate at apex; stamens 10 to 15 ; achenes usually 8 to 30 , sometimes more or less, in globose-ovoid to hemispheroidal clusters $3-5 \mathrm{~mm}$. long and 4-5 $\mathrm{mm}$. in diameter, discoid to elliptic or obovate, 1.8-2.5 (-3) $\mathrm{mm}$. long, smooth or with a trace of reticulation, glabrous or hispid, the slender beak 1-2 $\mathrm{mm}$. long and recurved or hooked at tip; receptacle subglobose to pyriform or rarely ovoid, $0.5-1 \mathrm{~mm}$. long in flower, $1-1.5$ or rarely $3 \mathrm{~mm}$. long in fruit, glabrous. Incl. var. Earlei (Greene) L. Benson.

In wet soil on edge of and in water about springs and ponds, and along streams, in N. M. (Bernalillo Co.) and Ariz. (Coconino Co.), June-July; B.C. to Alas., s. to N.M., Ariz. and Calif.

\section{Ranunculus recurvatus Poir.}

Hirsute terrestrial perennial; stems erect, commonly forming a nearly spherical bulbous base $5-10 \mathrm{~mm}$. in diameter, not rooting, $1.5-7 \mathrm{dm}$. long, branching mostly above, the lowest internode elongated, fistulous, markedly villous hirsute or rarely glabrous, the hairs rarely appressed; basal leaves with glabrous or hirsute petioles 5-10 $\mathrm{cm}$. long, simple, cordate-reniform in outline, to $75 \mathrm{~mm}$. long and $9 \mathrm{~cm}$. broad, usually much smaller, 3-cleft to deeply 3-parted with the parts either crenately lobed or toothed, cordate at base, the parts rounded or angled at apex, nearly glabrous or hirsutulous or hirsute; stipular leaf bases deltoid, 1-1.8 $\mathrm{cm}$. long, 5-9 mm. broad, thin; cauline leaves similar to the basal but not usually larger, as deeply parted as the deepest of the basal; pedicels $1-8 \mathrm{~mm}$. long in flower, $1-5 \mathrm{~cm}$. long in fruit, sparsely appressed-pubescent; sepals 5, greenish, reflexed almost their whole length, ovate-acute, 4-5 mm. long, 2-2.5 mm. broad, sparsely pilose dorsally, promptly deciduous; petals 5, narrowly elliptic, 2.5-3.5 $\mathrm{mm}$. long, $1.2 \mathrm{~mm}$. broad; nectary scale forming an obdeltoid pocket, the apical margins truncate or sometimes proliferated into a flat scale not forming a pocket; stamens 10 to 25 ; achenes 10 to 25 in a globose head 5-7 mm. in diameter, discoid, 1.5-2 $\mathrm{mm}$. long, minutely reticulate-pitted, glabrous, the margin with a minute keel, the recurved beak slender and 1.2-1.4 $\mathrm{mm}$. long, the tip hooked; receptacle broadly or narrowly pyriform, $1 \mathrm{~mm}$. long in flower, $3 \mathrm{~mm}$. long in fruit, conspicuously hispid, densely so at the apex.

In swamps, woods and bottomland thickets, Okla. (Delaware Co.) and n.e. Tex. (Harrison Co.), Mar.-June; from Ont. and Nfld., s. to Fla. and Tex.

\section{Ranunculus pensylvanicus $\mathrm{L}$.}

Hirsute to hispid terrestrial annual (or perennial?); roots $0.7-1 \mathrm{~mm}$. thick; stems erect, not rooting, 4-10 dm. long, branching above, the lower internodes usually elongate, hirsute to hispid with the hairs $2 \mathrm{~mm}$. long; petioles $3-15 \mathrm{~cm}$. long, hirsute, the stipular leaf bases $1-2.5 \mathrm{~cm}$. long; basal leaves withering early, pinnately compound, 5-7 cm. long, 9-12 cm. wide; leaflets petiolulate, cuneate, middle one 3-parted, the lateral ones 2-parted; cauline leaves alternate, similar to the basal, the bracts similar to cauline leaves but reduced and sessile; pedicels $3-18 \mathrm{~mm}$. long in flower, $1.5-5.5 \mathrm{~cm}$. long in fruit, appressed-pubescent; sepals 5 , 
yellowish, reflexed, narrowly elliptic, 4-5 mm. long, 2-2.5 mm. wide, slightly hairy, promptly deciduous; petals 5, yellow, nearly orbicular, 2-3 mm. long and wide; nectary scale glabrous, free for two-thirds of its length, about the breadth of the adjacent petal surface; stamens 15 to 20 ; achenes 60 to 80 in a cylindroid to cylindroid-ovoid head $10-14 \mathrm{~mm}$. long and 7-9 $\mathrm{mm}$. in diameter, ovate, about $2.5 \mathrm{~mm}$. long, smooth, glabrous, the stout beak $0.6-0.9 \mathrm{~mm}$. long and not recurved; receptacle cylindroid, about $2 \mathrm{~mm}$. long in flower, $8-12 \mathrm{~mm}$. long in fruit, pubescent.

In wet meadows, standing in shallow water on edge of pools and lakes, in N. M. (Grant, Rio Arriba, San Miguel, Socorro and Taos cos.) and Ariz. (Apache, Navajo, Coconino and Yavapai cos.), Apr.-July; Nfld. to Alas., s. to N.J., N.M. and Ariz.; Burma, China.

\section{Ranunculus Macounii Britt. Fig. 456.}

Hirsute or glabrous annual or perennial; roots $1.5-2 \mathrm{~mm}$. thick; stem reclining (at least below) or prostrate to suberect, often rooting at least at the lower nodes, 2.5-9 dm. long, branching, densely hirsute or hispid, or glabrous; petioles 5-20 cm long, densely hirsute to glabrous, the stipular leaf bases $1-3 \mathrm{~cm}$. long; basal leaf blades simple or pinnately compound, deltoid in outline, 3-8 cm. long, 5-13 $\mathrm{cm}$. wide, divided into 3 divisions or pinnate with 3 or 5 leaflets 3 -parted and the parts again lobed, pubescent to glabrous; cauline leaves alternate, all but the uppermost similar to the basal and petioled; pedicels $1-8 \mathrm{~cm}$. long in flower, $3-10 \mathrm{~cm}$. long in fruit, usually appressed-hispidulous; sepals 5, yellowish, often purpletinged, reflexed almost their whole length, ovate-triangular, 4-6 (-7) mm. long, 2.5-4 mm. wide, glabrous to pilose, promptly deciduous; petals 5 , yellow, obovate, 3-5 (-7.5) mm. long, 2.5-3.5 (-6.5) $\mathrm{mm}$. wide; nectary scale glabrous, free for most of its length, truncate; stamens 15 to 35 ; achenes 20 or 30 to 50 in an ovoid-cylindroid head 7-12 $\mathrm{mm}$. long and 5-7 $\mathrm{mm}$. in diameter, obovate with an acute base, 2-3 mm. long, smooth, glabrous, the margin conspicuously bevelled and narrowly keeled, the stout beak nearly deltoid and $1-1.2 \mathrm{~mm}$. long, gradually curving or straight with a right angle bend at the tip; receptacle fusiformcylindroid, 1-2 $\mathrm{mm}$. long in flower, 4-5 $\mathrm{mm}$. long in fruit, hispid.

Creeping in mud about lakes and ponds in marshes and ditches, in N. M. (Colfax, Sandoval, San Miguel and Taos cos.) and Ariz. (Apache and Coconino cos.), June-Sept.; Nfld. and Lab. to Alas., s. to Mich., Neb., N.M., Ariz. and Calif.

\section{Ranunculus carolinianus DC. Fig. 457.}

Tufted perennial with thick fibrous roots, subglabrous to spreading-pubescent (especially on stem), after flowering developing long trailing or repent leafy branches; earliest basal leaves small, ovate, simple or 3-lobed or 3-cleft; later leaves larger, long-petioled, with 3 mostly petiolulate rhombic cuneate 3 -cleft or 3-divided and sharply toothed leaflets; flowering stems slender, flexuous, subglabrous. pilose or spreading-hirsute, elongating to $5 \mathrm{dm}$. long, finally producing trailing branches; flowers 1 to 10 ; sepals $3.5-5 \mathrm{~mm}$. long, promptly reflexed; petals oblong, $8-12 \mathrm{~mm}$. long, $2.5-7 \mathrm{~mm}$. broad; fruiting head subglobose, 7-13 $\mathrm{mm}$. in diameter, with only 10 to 20 achenes; fruiting receptacle $4-5 \mathrm{~mm}$. long; achenes obliquely rounded-ovate, with body $3.5-5 \mathrm{~mm}$. long, the marginal wing $0.5-1 \mathrm{~mm}$. wide and separated from the face by a high acute ridge; beak submarginal, erect, lance-subulate, 1.5-2.5 mm. long, with short deciduous terminal stigma $R$. septentrionalis Poir. var. pterocarpus L. Benson.

Low woods, swamps, marshy ground, edge of water and in mud, thickets and shores in s.e. Okla. (McCurtain and Craig cos.) and e. fourth of Tex , Feb.-May; from Fla. to Tex., n. to Md., W.Va., s. Ind., s. Ill., Mo. and Neb. 


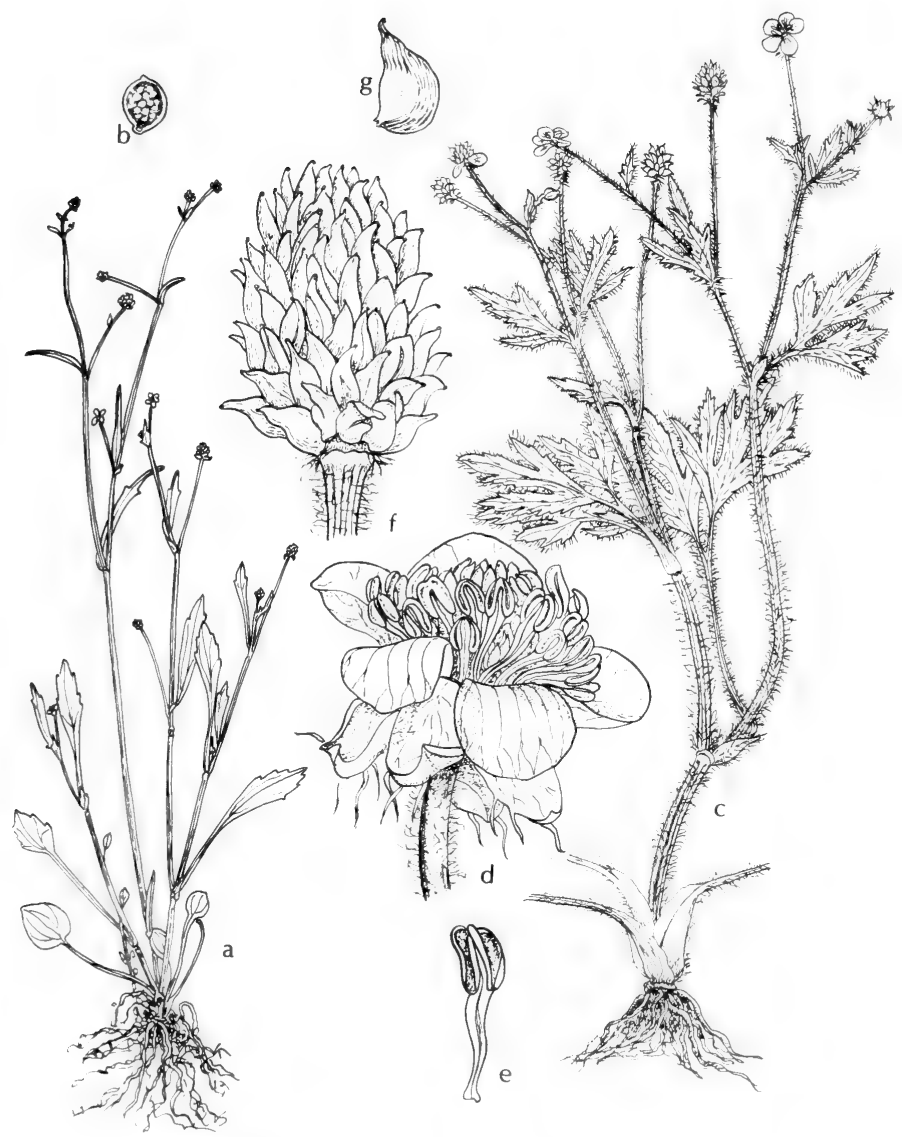

Fig. 456: a and b, Ranunculus pusillus: a, habit, x 1/2; b, achene, x 5. c-g, Ranunculus Macounii: c, habit, x 1/2; d, flower, x 3; e, stamen, x 5; f, fruit, x 3; g, achene, x 5 . (V. F.). 


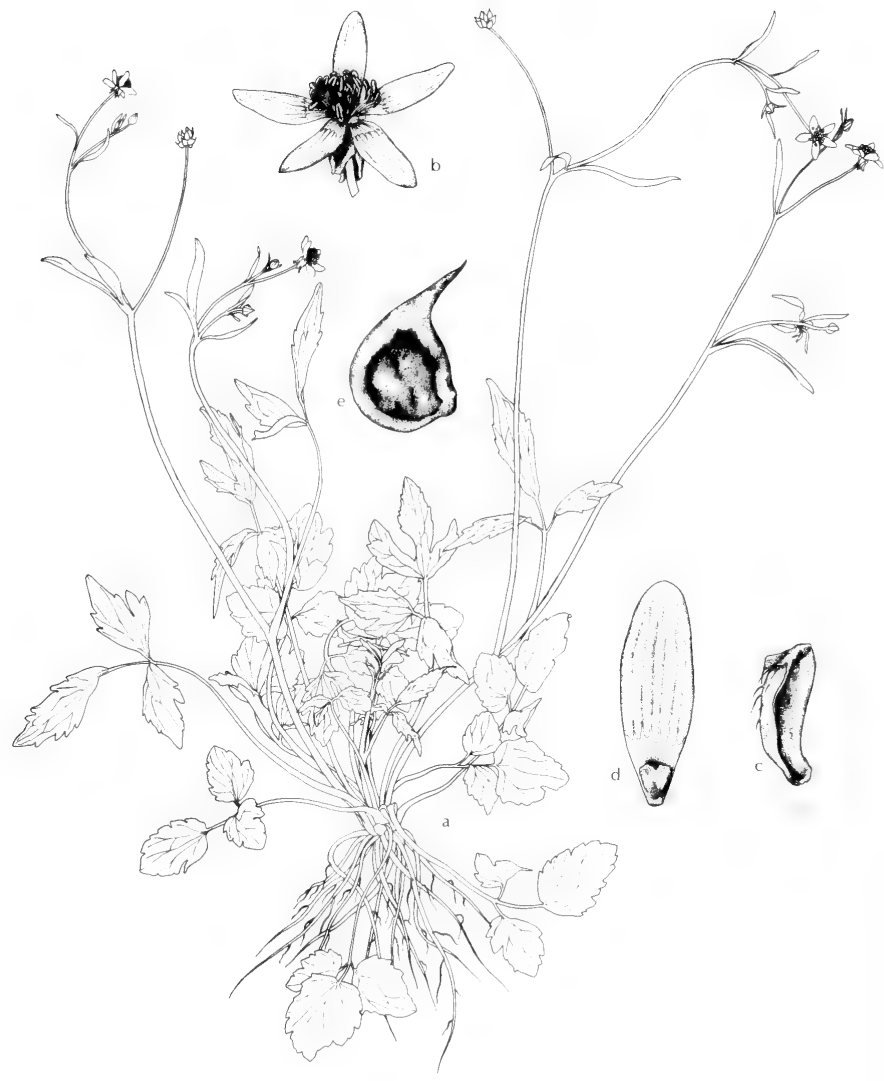

Fig. 457: Ranunculus carolinianus: a, habit, x 1/3; b, flower, $x 2$; c, sepal, $x$ 3; d, petal, x 3; e, achene, x 6 . (Courtesy of R. K. Godfrey). 
Those plants with noticeably spreading-pubescent stems are segregated as var. villicaulis Shinners.

\section{Ranunculus fascicularis Muhl. Prairie Buttercup.}

Appressed-pubescent terrestrial perennial; roots filiform or fusiform-tuberous, to $5 \mathrm{~mm}$. in diameter; stems weak, erect or suberect, often scapose, not rooting, silky-canescent, 1-3 dm. long, not fistulous; basal leaves with petioles about 1 $\mathrm{dm}$. long, compound or at least the early ones 3-parted, ovate-oblong in outline, 25-55 mm. long, 2-4 cm. broad, distinctly longer than broad, sometimes the leaf partly bipinnate, the 3 or 5 leaflets or divisions simple and rounded to deeply 3- to 7-parted and again angularly toothed, the ultimate parts blunt or rounded at the apices; stipular leaf bases $15-35 \mathrm{~mm}$. long; cauline leaves usually 1 or 2 , alternate, much-reduced; pedicels $1.5-6 \mathrm{~cm}$. long in flower, $2.5-9 \mathrm{~cm}$. long in fruit; sepals 5, greenish-yellow, spreading, ovate-attenuate, $6-8 \mathrm{~mm}$. long, 2-3 $\mathrm{mm}$. broad, usually silvery-pubescent, promptly deciduous; petals 5 or sometimes up to 9 , yellow, obovate-oblanceolate, 7-15 $\mathrm{mm}$. long, 3-6 $\mathrm{mm}$. broad, the truncate nectary scale glabrous and free almost its whole length; stamens usually 40 to 50 ; achenes 10 to 30 in a subglobose head $4.5-8 \mathrm{~mm}$. long and $6-10 \mathrm{~mm}$. in diameter, obovate-orbicular but with a short flat stalk, the main body 1.5-3 $\mathrm{mm}$. long, smooth, glabrous, the margin keeled but usually not prominent, the straight beak slender and 2-2.3 mm. long; receptacle fusiform or obovoid, 1.5-2.5 $\mathrm{mm}$. long in flower, 3-7 $\mathrm{mm}$. long in fruit, sparsely hispidulous.

In sandy soil in shallow water, low pinelands, meadows and seepage slopes in Okla. (Waterfall) and e. Tex., Feb.-May; widespread in e. N.A., w. to Tex. and Kan.

The two following varieties are found in our area.

Var. apricus (Greene) Fern. ( $R$. apricus Greene). Stems 1-3 dm. long; leaflets or leaf segments oblanceolate to narrowly elliptic, shallowly few-toothed apically or entire; petals 5 .

Var. cuneiformis (Small) L. Benson. Stems 18-25 cm. long; petals 7 to 9, 13-15 $\mathrm{mm}$. long when fully expanded; achenes $3 \mathrm{~mm}$. long, $2.5 \mathrm{~mm}$. dorsiventrally, the margin $0.5 \mathrm{~mm}$. broad, distinctly marked; endemic in Kerr Co., Tex.

\section{Ranunculus macranthus Scheele. LARge buttercup. Fig. 458.}

Strongly hirsute to subglabrous terrestrial perennial with stout roots; stems reclining to suberect, not rooting, to $1 \mathrm{~m}$. long, usually much smaller, fistulous, densely hirsute; basal leaves with hirsute to glabrous petioles to $3 \mathrm{dm}$. long, compound and dissected or sometimes simple and merely lobed, oblong-ovate in outline, 4-23 cm. long, 3-25 cm. broad, usually of 3 to 7 leaflets that are truncate or obtuse at base and acute or barely obtuse at apex, appressed-hispidulous; pedicels to $11 \mathrm{~cm}$. long in flower and $3 \mathrm{dm}$. long in fruit, appressed-pubescent; sepals 5, yellowish-green, reflexed, ovate-attenuate, 6-10 mm. long, 3-5 mm. broad, appressed-pilose dorsally, promptly deciduous; petals 8 to 18 , yellow, oblanceolate or rarely obovate, sometimes emarginate, $1-2 \mathrm{~cm}$. long, $2.5-10 \mathrm{~mm}$. broad; achenes 35 to 130 in a subglobose or cylindroid head $7-14 \mathrm{~mm}$. long and 7-10 $\mathrm{mm}$. in diameter, elliptic-oblong to obovate, $2.5-4 \mathrm{~mm}$. long smooth, glabrous, the margin keeled, the straight beak slender and 3-5 mm. long; receptacle cylindroid, 2-3 mm. long in flower, 5-12 mm. long in fruit, hairy but the hair often sparse.

In swamps, marshes, wet meadows, wet soil in drainage areas, wet woods along creeks, on mud flats about pools and seepage slopes in cen., s. and w. Tex., w. to Ariz. (Apache, Navajo, Cochise and Santa Cruz cos.), Mar.-Sept.; in s.w. U.S. and Mex. 


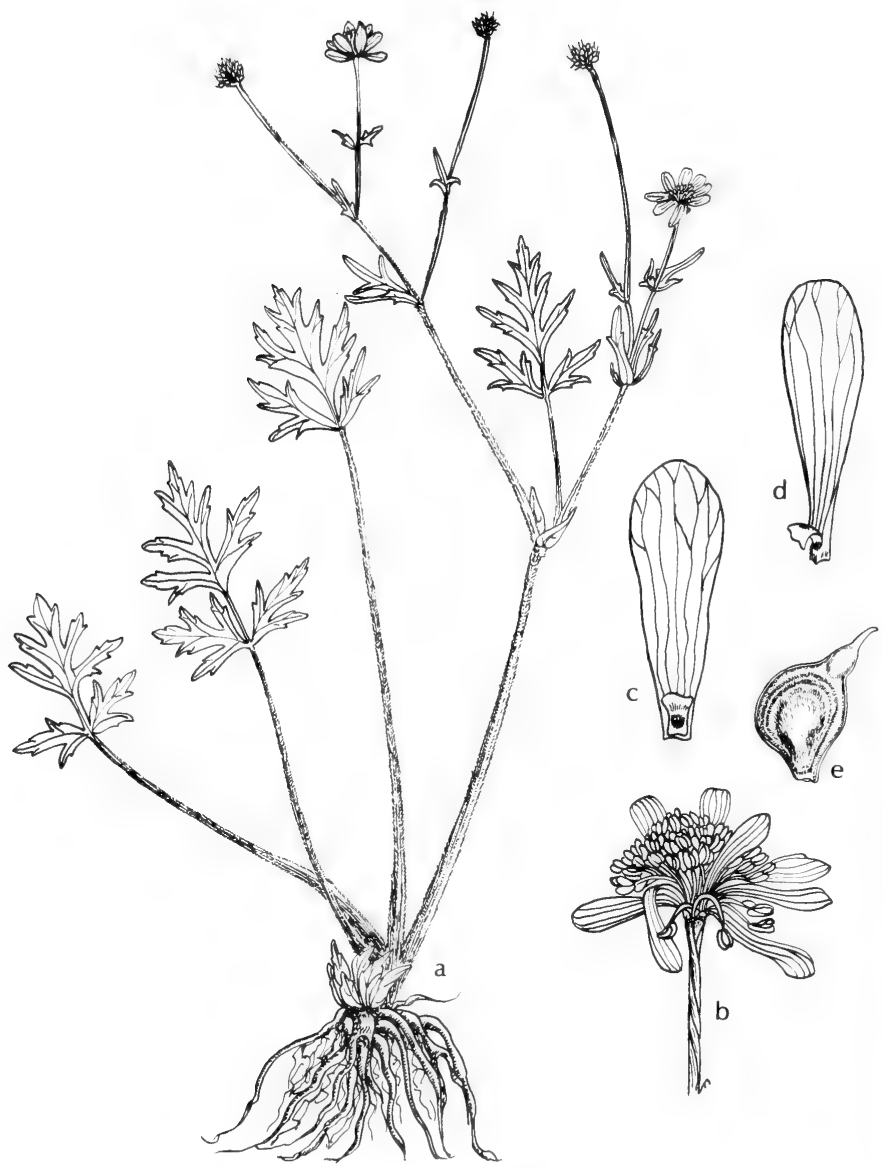

Fig. 458: Ranunculus macranthus: a, habit, x 1/4; b, flower, $\mathrm{x} 1$; c, petal showing nectary scale from the top, $x 2 \frac{1}{1} 2$; d, petal showing attachment of nectary scale, $x 2 \frac{1}{2}$; e, achene, x 5. (V. F.). 


\section{Ranunculus parviflorus $\mathrm{L}$.}

Hirsute terrestrial annual; stems erect, not rooting, 1-3 dm. long, freely branching and diffuse, not fistulous, thinly hirsute; basal leaves with petioles $3-6 \mathrm{~cm}$. long, simple, reniform, $1.5-2 \mathrm{~cm}$. long, 2-2.5 cm. broad, 3-parted or -divided and again lobed, cordate at base, rounded at apex, the ultimate lobes acute, hirsute with fine hairs, pilose, the stipular leaf bases about $1 \mathrm{~cm}$. long; cauline leaves alternate, short-petioled, similar to the basal, the bracts 3-parted; pedicels 1-4 $\mathrm{mm}$. long in flower, 3-18 $\mathrm{mm}$. long in fruit, pubescent; sepals greenish-yellow, spreading, narrowly ovate, about $1 \mathrm{~mm}$. long, less than $1 \mathrm{~mm}$. broad, densely pubescent, promptly deciduous; petals 5, yellow, narrowly elliptic, 1-2 $\mathrm{mm}$. long, less than $1 \mathrm{~mm}$. broad, the truncate nectary scale glabrous and free laterally; stamens about 10 ; achenes 10 to 20 in a globose head and about $4 \mathrm{~mm}$. in diameter, obovate, $1.5 \mathrm{~mm}$. long, with reddish-brown papillae covering both faces of the pericarp which are produced into minute slender hooks, the margin strongly marked, the deltoid beak recurved and $0.5 \mathrm{~mm}$. long; receptacle globose, less than $1 \mathrm{~mm}$. long in flower, $1-1.3 \mathrm{~mm}$. long in fruit, glabrous.

On moist hardwood slopes, in grassy copses and along ditches in Okla. (Waterfall) and in e. fourth of Tex., Mar.-June; a nat. of the Old World that is naturalized in various parts of N.A

\section{Ranunculus Sardous Crantz.}

Hirsute terrestrial perennial with filiform roots; stems suberect, not rooting, 1-5 dm. long, branching freely, not fistulous, hirsute; basal leaves with hirsute petioles 3-16 cm. long, pirinately compound, broadly cordate in outline, 2-3 $\mathrm{cm}$. long, 2-2.5 $\mathrm{cm}$. broad, the leaflets parted and lobed, the ultimate segments deltoid, pubescent, cordate to truncate at base, rounded at apex, appressedpubescent, the stipular leaf bases $1-1.5 \mathrm{~cm}$. long; cauline leaves alternate, the bracts of about 3 linear divisions, sessile; pedicels $3-5 \mathrm{~cm}$. long in flower, 2-6 $\mathrm{cm}$. long in fruit, thinly appressed-hairy; sepals greenish-yellow, reflexed, ovateattenuate, 3-5 mm. long, 1.5-2 $\mathrm{mm}$. broad, pilose, promptly deciduous; petals 5, yellow, 8-9 $\mathrm{mm}$. long, 5-7 $\mathrm{mm}$. broad, the truncate nectary scale glabrous and free laterally; stamens 25 to 50 ; achenes 12 to 25 in a subglobose head 4-6 mm. long and 5-8 $\mathrm{mm}$. in diameter, nearly circular, 2-3 $\mathrm{mm}$. long, usually sparsely papillate or some achenes of the same plant smooth, glabrous, the margin strongly marked, the deltoid beak $0.3 \mathrm{~mm}$. long and curved at the tip; receptacle pyriform, $1 \mathrm{~mm}$. long in flower, $2 \mathrm{~mm}$. long in fruit, covered with long white hairs.

Moist grassy slopes and in wet soil of swales, in e. Tex., Apr.-June; a nat. of the Old World naturalized mostly about seaports in N. A.

\section{Ranunculus muricatus L. SPRING BUTTERCUP. Fig. 459.}

Glabrous terrestrial annual or sometimes perennial; stems reclining or erect, not rooting, 2-5 dm. long, 2-5 mm. in diameter, freely branching, not markedly fistulous; basal leaves with petioles $4-15 \mathrm{~cm}$. long, simple, broadly cordate to reniform or semicircular, 2-5 $\mathrm{cm}$. long, 2-6 cm. broad, deeply 3-parted, the parts again shallowly crenately lobed, cordate to truncate at base, rounded at apex, the stipular leaf bases 1 or $2 \mathrm{~cm}$. long; cauline leaves alternate, similar to the basal; pedicels $5-20 \mathrm{~mm}$. long in flower, 2-6 cm. long in fruit, glabrous; sepals greenish, spreading, ovate, mucronate, 4-7 mm. long, 2-3 mm. broad, with a few bristles, promptly deciduous; petals 5 , yellow, obovate, 5-8 mm. long, 3-4 $\mathrm{mm}$. broad, the truncate nectary scale glabrous and forming a pocket that is much narrower than the adjacent part of the petal; stamens few; achenes 10 to 20 in a globose cluster $1-1.3 \mathrm{~cm}$. in diameter, obovate, about $5.5 \mathrm{~mm}$. long, covered with stout curved spines, glabrous, the margin very prominent, keeled, spineless, produced into the stout falcate beak 2-2.5 $\mathrm{mm}$. long; receptacle subglobose, 


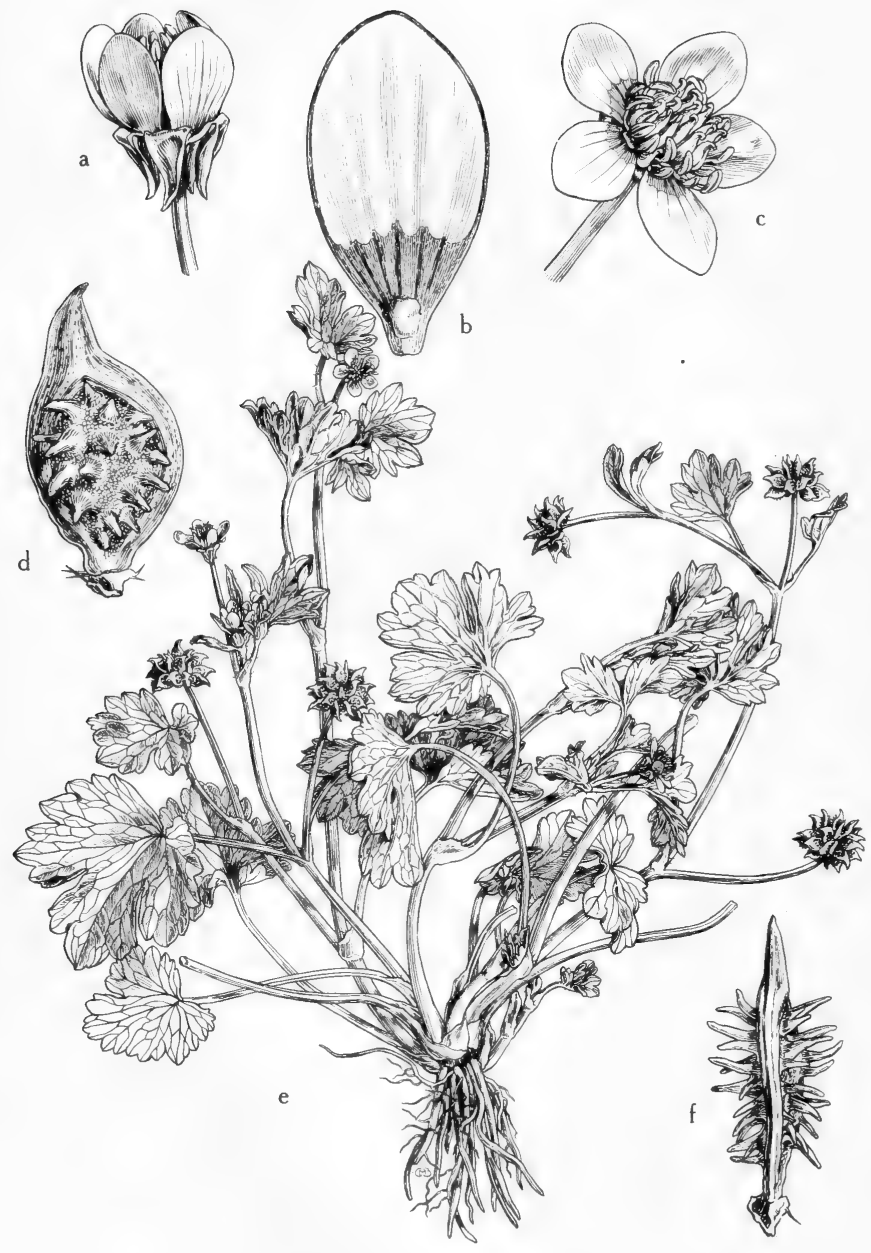

Fig. 459: Ranunculus muricatus: a, young flower, showing reflexed sepals, $x$ 21/2; $\mathrm{b}$, petal, showing scale covering nectariferous pit, $\mathrm{x} 6$; c, flower, $\mathbf{x} 2 \frac{1}{2} ; \mathrm{d}$, mature muricate achene, side view, x 4; e, habit, plant branched from the base, the petioles succulent, x $2 \%$; f, mature achene, marginal view, x 4. (From Mason, Fig. 241). 
about $1 \mathrm{~mm}$. long in flower, $2 \mathrm{~mm}$. long in fruit, hispid.

On grassy banks, along roads, in sandy marshes, and in wet soil about ponds and along streams, often in shallow water, in e. fourth of Tex., Mar-May; a nat. of the Old World that is naturalized in various parts of N.A.

\section{Ranunculus Macauleyi Gray.}

Nearly glabrous terrestrial perennial; stems scapose, erect, not rooting, 8-15 $\mathrm{cm}$. long, glabrous except on the pedicels; petioles $2-6(-10) \mathrm{cm}$. long, glabrous; leaf bases broad and membranous, $3-6 \mathrm{~cm}$. long, persistent several seasons and becoming fibrous; basal leaf blades simple, narrowly elliptic or elongate to sometimes narrowly obovate or ovate, $1.5-4.5 \mathrm{~cm}$. long, $5-20$ or rarely $2-2.8 \mathrm{~cm}$. wide, 3- or 5-toothed at the apices or occasionally serrate on the distal halves or rarely laciniately or sharply crenately toothed, or with 2 of the sinuses to 13 $\mathrm{mm}$. deep (the leaf lobed) and the middle lobe 3-toothed or entire, proximally acute and distally acute to somewhat rounded, glabrous or sometimes ciliate; cauline leaves alternate or practically opposite, almost always ciliate at least near the bases with the hairs to $8 \mathrm{~mm}$. long; bracts entire or toothed, elliptic to obovate, sessile; pedicels $2-6 \mathrm{~cm}$. long in flower, $5-7 \mathrm{~cm}$. long in fruit, glabrous or brown-pilose; sepals spreading, rich-brown, narrowly obovate, 6-10 mm. long, 2.5-5 mm. wide, densely and almost always conspicuously dorsally pilose with dark-brown hairs about $2 \mathrm{~mm}$. long, deciduous after anthesis; petals 5 or as many as 8 , yellow, cuneate to cuneate-obovate, (6-) 10-14 $\mathrm{mm}$. long, (4-) 6-10 $\mathrm{mm}$. wide; nectary scale glabrous, forming a pocket, $1 \mathrm{~mm}$. long, truncate; stamens 30 to 50 ; achenes 20 to 30 in an ovoid or cylindroid head $5-10 \mathrm{~mm}$. long and 4-5.5 mm. in diameter; flattened-obovoid, about $1.7 \mathrm{~mm}$. long, smooth, glabrous, the slender beak $0.5-0.6$ or rarely $1.5-2.2 \mathrm{~mm}$. long, straight or recurved; receptacle elongate-cylindroid, 2-3 mm. long in flower, $4-10 \mathrm{~mm}$. long in fruit, glabrous.

In wet meadows, on the edge of snow banks and in seepage areas, in N. M. (Mora, Rio Arriba and Taos cos.) June-Aug.; also Colo.

\section{Ranunculus Eschscholtzii Schlecht.}

Glabrous perennial; roots slender; caudex 1-6 cm. long; stems scapose, erect, not rooting, 4-15 cm. long, 1- to 3 -flowered; petioles $3-8 \mathrm{~cm}$. long, the stipular leaf bases $1-2.5 \mathrm{~cm}$. long, persistent or soon disintegrating or deciduous; basal leaf blades simple or rarely compound, semicircular to reniform in outline, 1.3-3 $\mathrm{cm}$. long, 2.5-4 $\mathrm{cm}$. broad, 3-cleft or -divided, the middle lobe again 3-lobed or entire, the lateral ones asymmetrically 3- to 7-lobed or -parted or sometimes -divided, the blades proximally truncate or rounded; cauline leaves alternate, the bracts usually 3 -lobed and the lobes entire, sessile; pedicels usually $1-3 \mathrm{~cm}$. long, in flower, 3-13 cm. long in fruit, glabrous; sepals 5, yellow, dorsally tinged with lavender, spreading, obovate, $4-8 \mathrm{~mm}$. long, 3-5 $\mathrm{mm}$. wide, glabrous or with sparse light-colored hair, deciduous after anthesis; petals 5, yellow, cuneateobovate, (5-) 7-12 (-17) $\mathrm{mm}$. long, 5-11 (-19) $\mathrm{mm}$. wide; nectary scale glabrous, forming a pocket usually $0.3-0.4 \mathrm{~mm}$. deep; stamens usually 20 to 40 ; achenes in a cylindroid or ovoid head 7-16 $\mathrm{mm}$. long and 4-7 $\mathrm{mm}$. in diameter, oblong-obovoid, 1.3-1.7 mm. long, smooth, glabrous or sometimes hispidulous, the margin inconspicuous, the slender beak $0.8-1 \mathrm{~mm}$. long and not recurved; receptacle cylindroid, $1-2 \mathrm{~mm}$. long in flower, 6-15 $\mathrm{mm}$. long in fruit, glabrous or sometimes puberulent.

In wet meadows and on wet seepage slopes, in N. M. (San Miguel and Santa Fe cos.) and Ariz. (Coconino Co.), July-Aug.; from Alas. to N.M., Ariz. and Calif. 


\section{Ranunculus inamoenus Greene.}

Hirsute or glabrous perennial; roots slender; stems erect, not rooting, 1-3 dm. long, each with 3 to 7 or rarely 11 flowers, hirsute; petioles $4-10 \mathrm{~cm}$. long, appressed-pubescent or glabrous, the stipular leaf bases $1.5-2.5$ to rarely $4 \mathrm{~cm}$. long; basal leaf blades simple and ovate or orbicular, $1-4 \mathrm{~cm}$. long, $1.3-5 \mathrm{~cm}$. wide, crenate, 3-lobed or -divided, proximally more or less attenuate to rounded or subcordate and distally rounded, glabrous or appressed-pubescent; cauline leaves alternate, the bracts of 3 or 5 nearly linear lobes, sessile; pedicels to about $3 \mathrm{~cm}$. long in flower and 1-5 (-8) $\mathrm{cm}$. long in fruit, appressed-pubescent or glabrous; sepals 5, greenish-yellow, spreading or turned downward, narrowly obovate, 3-5 (-7) $\mathrm{mm}$. long, 2-2.5 (-4.5) $\mathrm{mm}$. wide, pilose, deciduous after anthesis; petals 5, yellow, narrowly elliptic to obovate, $2.5-8 \mathrm{~mm}$. long, 2-4 $\mathrm{mm}$. wide; nectary scale glabrous, forming a pocket, truncate; stamens 30 to 50 ; achenes 50 or 60 to 100 in a cylindroid or barrel-shaped head 6-17 mm. long and $5-8 \mathrm{~mm}$. in diameter, discoid-obovoid, about 1.5 or rarely $2-2.3 \mathrm{~mm}$. long, smooth, densely short-pubescent or glabrous, the margin usually inconspicuous, the slender beak 1-2 $\mathrm{mm}$. long and recurved or straight; receptacle slender, cylindroid, 2-3 mm. long in flower, 6-15 mm. long in fruit, hispidulous or glabrous.

In wet mt. meadows, on seepage slopes and in wet soils below snow banks, and coniferous forests, in N. M. (Otero Co.) and Ariz. (Apache, Coconino, Mohave and Gila cos.), May-Sept.; Ida. and B.C., s. to N.M. and Ariz.

\section{Ranunculus cardiophyllus Hook.}

Pilose terrestrial perennial; roots $1-2 \mathrm{~mm}$. thick; stems erect, not rooting, 2-4 $\mathrm{dm}$. long, branching from near base or scapose, 1- to 5- or 8-flowered, pilose or glabrous, striate; petioles $5-10(-18) \mathrm{cm}$. long, pilose or glabrous, the stipular leaf bases 1-4 cm. long and not markedly fibrous after withering; basal leaf blades simple, cordate, $1-6 \mathrm{~cm}$. long, $1-5 \mathrm{~cm}$. wide, crenate, the apex sometimes lobed or rarely parted, proximally cordate and distally rounded, pilose; cauline leaves alternate, the bracts divided into 3 to 7 linear lobes, sessile; pedicels 5-12 $\mathrm{cm}$. long in flower, $6-17 \mathrm{~cm}$. long in fruit, densely pilose above; sepals 5 , greenishyellow, petaloid at apices, spreading, obovate, deeply concave, 6-10 mm. long, 4-7 mm. wide, densely pilose dorsally, deciduous soon after anthesis; petals 5, yellow, broadly cuneate-obovate to obovate or obovate-oblanceolate, (5-) 8-15 $\mathrm{mm}$. long, (4-) 6-13 mm. wide; nectary scale long-ciliate on apical margin (the surrounding petal surface also often with similar long hairs), forming a pocket, obdeltoid to oblong; stamens 35 to 80 ; achenes 20 to 125 in a cylindroid head 5-15 $\mathrm{mm}$. long and 4-6 or usually 7-9 $\mathrm{mm}$. in diameter, obovate, $2 \mathrm{~mm}$. long, $1.5 \mathrm{~mm}$. dorsoventrally, $0.6-0.8 \mathrm{~mm}$. laterally, smooth, finely canescent, the margin inconspicuous, the slender beak $0.6-1 \mathrm{~mm}$. long and recurved or straight; receptacle ovoid-cylindroid, 1-4 mm. long in flower, 4-14 $\mathrm{mm}$. long in fruit, densely hairy.

In wet meadows, wet gravelly loam and conifer forests, in N. M. (Catron, Lincoln, Rio Arriba and Socorro cos.) and Ariz. (Coconino and Apache cos.), June-Sept.; S.D. and Alta. to B.C., s. to N. M. and Ariz.

Most of our material is usually referred to var. subsagittatus (Gray) L. Benson with often subsagittate leaves.

\section{Ranunculus pedatifidus J. E. Sm.}

Sparingly pilose terrestrial perennial; roots $0.5-1 \mathrm{~mm}$. thick; stems erect, not rooting, 2-4 dm. long, pilose to nearly glabrous, striate; petioles $4-10 \mathrm{~cm}$. long, pilose, the stipular leaf bases $1.5-3 \mathrm{~cm}$. long; basal leaf blades simple, cordate in outline, $1.5-3.5 \mathrm{~cm}$. long, $1.5-4 \mathrm{~cm}$. wide, pedately divided or parted into 5 
or 7 linear divisions some of which are again lobed, the blade proximally cordate, the lobes distally acute or obtuse, thinly pilose to glabrous; cauline leaves alternate, the bracts divided into 3 to 7 linear lobes, sessile; flowers 1 to 5 or sometimes 8 ; pedicels $1.5-7 \mathrm{~cm}$. long in flower, $5-14 \mathrm{~cm}$. long in fruit, pilose; sepals greenish-yellow but ashy with dense pubescence, spreading, obovate, deeply concave, the tips abruptly becoming petaloid, 4-6 $\mathrm{mm}$. long, 3-5 $\mathrm{mm}$. wide, densely pilose dorsally, tardily deciduous after anthesis; petals 5 or rarely none, yellow, broadly cuneate-obovate, $8-10 \mathrm{~mm}$. long, 5-7 $\mathrm{mm}$. wide; nectary scale glabrous, forming a pocket $0.4-1.5 \mathrm{~mm}$. long and $0.4 \mathrm{~mm}$. wide, sometimes deeply parted, truncate; stamens 25 to 60 ; achenes 25 or usually 40 to 70 in a cylindroid head $8-10 \mathrm{~mm}$. long and 5-6 mm. in diameter, flattened-obovoid, about $2 \mathrm{~mm}$. long, smooth, very finely canescent or glabrate, the slender beak 0.6-1 $\mathrm{mm}$. long and recurved; receptacle ovoid to obovoid or cylindroid, 2-3 $\mathrm{mm}$. long in flower, 7-9 mm. long in fruit, canescent. Incl. var. affinis ( $\mathrm{R}$. Br.) L. Benson.

On seepage slopes below snow banks and in wet meadows, in Ariz. (Coconino Co.), June-July; circumpolar, Greenl., Nfid, and Lab. to Alas., s, to Ariz.

\section{Ranunculus abortivus $L$.}

Glabrous terrestrial biennial with filiform roots, sometimes enlarged at the base; stems erect or suberect, not rooting, to about $5 \mathrm{dm}$. long, branching, fistulous, striate; basal leaves with petioles $4-11 \mathrm{~cm}$. long, simple or rarely some trifoliate, reniform to orbicular in outline, to $9 \mathrm{~cm}$. long and $1 \mathrm{dm}$. broad, usually much smaller, crenulate to crenate or crenately lobed; stipular leaf bases scarious, 1-2 cm. long; cauline leaves alternate, sessile, the bracts deeply once- or twiceparted to form 3 or 5 elliptic lobes or rarely cuneate or obovate and apically shallowly lobed or toothed; flowers as many as 50 , with pedicels to $15 \mathrm{~mm}$. long in flower and $9 \mathrm{~cm}$. long in fruit, glabrous; sepals 5, yellowish, spreading, elliptic, 3-5 mm. long, 1-2 mm. broad, glabrous, deciduous after anthesis; petals 5, elliptic, 2.5-3.5 mm. long, $1.3-2 \mathrm{~mm}$. broad, the glabrous nectary scale forming a pocket and emarginate; stamens 15 to 20 ; achenes 10 to 35 in an ovoid head $3-6 \mathrm{~mm}$. long and 2.5-4 mm. in diameter, discoid-obovate, 1.4-1.6 mm. long, smooth, glabrous, the margin inconspicuous, the beak minute; receptacle fusiformcylindroid, about $2 \mathrm{~mm}$. long in flower, 2-4 mm. long in fruit, sparsely villous or sometimes glabrous.

In moist, marshy or swampy ground, in mud on edge of pools and lakes, and in open areas or rich woodland in s.e. Okla. (McCurtain Co.) and e. Tex., Mar.-May; transcontinental from N.S. to Alas., s. to Wash., Colo., Tex. and Fla.

\section{Ranunculus glaberrimus Hook.}

Glabrous perennial; roots large and fleshy, 2-3 mm. thick; stems prostrate or ascending, not rooting, $4-8 \mathrm{~cm}$. long; 1 - to 6 -flowered; petioles $3-9 \mathrm{~cm}$. long, the stipular leaf bases usually 5 or rarely $20 \mathrm{~mm}$. long; basal leaf blades simple and entire or rarely compound and dissected, orbicular or ovate to elliptic or oblanceolate, or the blade dissected but deltoid to reniform in outline, $2-5 \mathrm{~cm}$. long, 1-1.8 cm. broad, entire or 3- (or 5-) lobed at the apices or rarely dissected triternately into narrow divisions, thick, proximally rounded or tapered and distally rounded to acute; cauline leaves and bracts alternate, 3-parted or -divided or rarely dissected, sessile; pedicels $1-4 \mathrm{~cm}$. long in flower, $5-12 \mathrm{~cm}$. long in fruit; sepals dorsally lavender-tinged, spreading, elliptic, 5-8 $\mathrm{mm}$. long, 3-5 $\mathrm{mm}$. wide, slightly pubescent dorsally, promptly deciduous; petals 5, or rarely more, yellow or with age turning white, obovate, 6-15 $\mathrm{mm}$. long, 5-10 mm. wide; nectary scale nearly always ciliate, forming a cuneate-rectangular pocket $1.5-3 \mathrm{~mm}$. deep, truncate or 2-lobed, the apex sometimes free; stamens 40 to 60 ; achenes 75 to 150 in a large globose head $1-2 \mathrm{~cm}$. in diameter, irregularly obovoid, 2 
$\mathrm{mm}$. long, smooth, usually finely pubescent, the margin inconspicuous but winged along the short stalk at the base, the slender or flattened beak a little winged and $0.6 \mathrm{~mm}$. long (not recurved); receptacle globose, $2-3 \mathrm{~mm}$. long in flower, 8-17 mm. long in fruit, glabrous.

In wet mt. meadows, old lake beds, in wettish soils about lakes but also in dry situations in N. M. (Rio Arriba Co.) and Ariz. (Coconino Co.), June-Sept.; S.D. to B.C., s. to N.M., Ariz. and Calif.

Our material is usually referred to var. ellipticus Greene, with basal leaves usually entire and elliptic to oblanceolate and cauline leaves entire to 3-lobed.

\section{Ranunculus fiammula L. Fig. 460.}

Nearly glabrous perennial; roots filiform; stems reclining, often stoloniferous, rooting at the lower nodes, $1-5 \mathrm{dm}$. long, simple or branching above and 2- to 25-flowered, glabrous or with a few stout appressed hairs; leaves alternate, often in fascicles at rooting nodes; petioles $2-7$ or $13 \mathrm{~cm}$. long or the leaves sessile, the stipular leaf bases mostly $1-2.5 \mathrm{~cm}$. long; blades simple, linear-filiform to oblanceolate or lanceolate to obovate, 2-6 $(-8) \mathrm{cm}$. long, to $13 \mathrm{~mm}$. broad, entire or serrulate, acute at both ends or apically truncate and glandular, glabrous or somewhat appressed-hairy; pedicels 2-10 cm. long, appressed-hairy; sepals 5, yellowish-green, 1.8-5 mm. long, about $1.5-2.5 \mathrm{~mm}$. broad, appressed-hairy dorsally or glabrous, promptly deciduous; petals 5 or rarely up to 11 , yellow, obovate to cuneate-obovate, 2-8 $\mathrm{mm}$. long, 1.3-7 mm. broad; nectary scales glabrous, forming a tiny pocket, usually truncate; stamens 25 to 50 ; achenes 5 to 50 in a globose or hemispheroidal head $1.5-5 \mathrm{~mm}$. long and 2-5 $\mathrm{mm}$. in diameter, obovate, $1.3-1.7 \mathrm{~mm}$. long, smooth or finely reticulate, glabrous, the margin clearly marked but not prominent; beak stout or in some varieties slender, $0.1-0.5$ or $0.7 \mathrm{~mm}$. long, straight, usually stigmatic largely across the truncate apex; receptacle obovoid, $1 \mathrm{~mm}$. long in flower, $0.6-3 \mathrm{~mm}$. long in fruit, glabrous. Incl. var. ovalis (Bigel.) L. Benson.

In mud and water at edge of lakes, ponds and streams, in wet meadows, marshes, ditches and swamps, often brackish, in N.M. (San Juan and Socorro cos.) and Ariz. (Apache, Navajo and Coconino cos.), June-Sept.; Nfld. and N.S. to Alas., s. to Pa., N.J., N.M., Ariz. and Calif.

\section{Ranunculus hydrocharoides Gray. Fig. 461.}

Glabrous or slightly appressed-pubescent perennial; roots filiform or slender; stems procumbent or floating or some of the flowering ones suberect, rooting at the lower or all the nodes, 1-2.5 dm. long, 1- to 3-flowered, often fistulous in the aquatic forms; petioles $2-8 \mathrm{~cm}$. long; basal leaf blades simple, cordate, elliptic or ovate to lanceolate, $5-28 \mathrm{~mm}$. wide, entire or dentate to serrate, proximally truncate, subcordate or angled and distally acute or somewhat rounded; cauline leaves alternate, like the basal but tending to be ovate-lanceolate or lanceolate, petioled; pedicels mostly $1-6 \mathrm{~cm}$. long in flower, $3-8 \mathrm{~cm}$. long and curved in fruit, glabrous or sparsely pubescent; sepals 5, greenish-yellow, spreading, ovate, 2-3 mm. long, $1.5-2 \mathrm{~mm}$. wide, early deciduous; petals 5 to 8 or 13 , light-yellow, 2-6 mm. long, 1-3 mm. wide; nectary scale forming a pocket or at least a shallow one, glabrous; stamens 10 to 40 ; achenes 10 to 25 in a hemispheroidal or subglobose head 2-3 $\mathrm{mm}$. in diameter, obovoid, 1-4 mm. long, smooth, glabrous, the margin inconspicuous; beak produced from the ventral side of the apex of the body, slender, $0.8-1 \mathrm{~mm}$. long, straight; stigma long-attenuate; receptacle pyriform-globose, $1 \mathrm{~mm}$. long in flower, $1-2 \mathrm{~mm}$. long in fruit, glabrous, Incl. var. stolonifer (Hemsl.) L. Benson.

In mud and water of springs, ponds, lakes and streams, in wet meadows, swamps and marshes, in N. M. (Catron, Grant and Socorro cos.) and Ariz. 


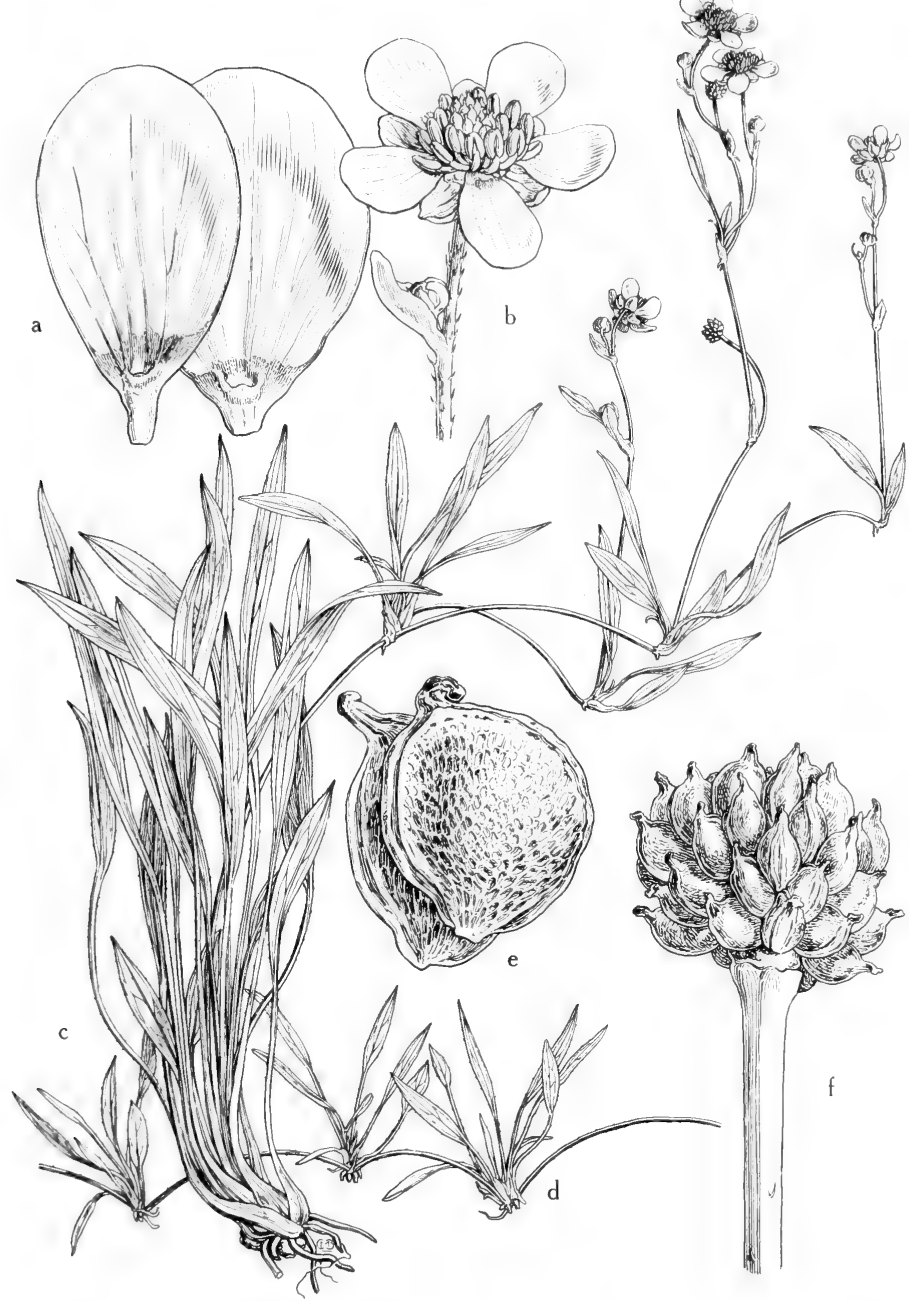

Fig. 460: Ranunculus flammula var, ovalis: a, petals, showing the shallow nectariferous pit, $x 8$; $b$, flower, the petals much longer than the sepals, $x 3$; c, habit, showing the slender arching stolons and the erect leaves, $\mathrm{x} 2 \frac{3}{3}$; $\mathrm{d}$, horizontal stolon, $\mathrm{x} 2 \pi ;$; e, mature achenes, showing variation in size and shape of beak, x 20; $\mathrm{f}$, mature fruiting head, x 6. (From Mason, Fig. 240). 


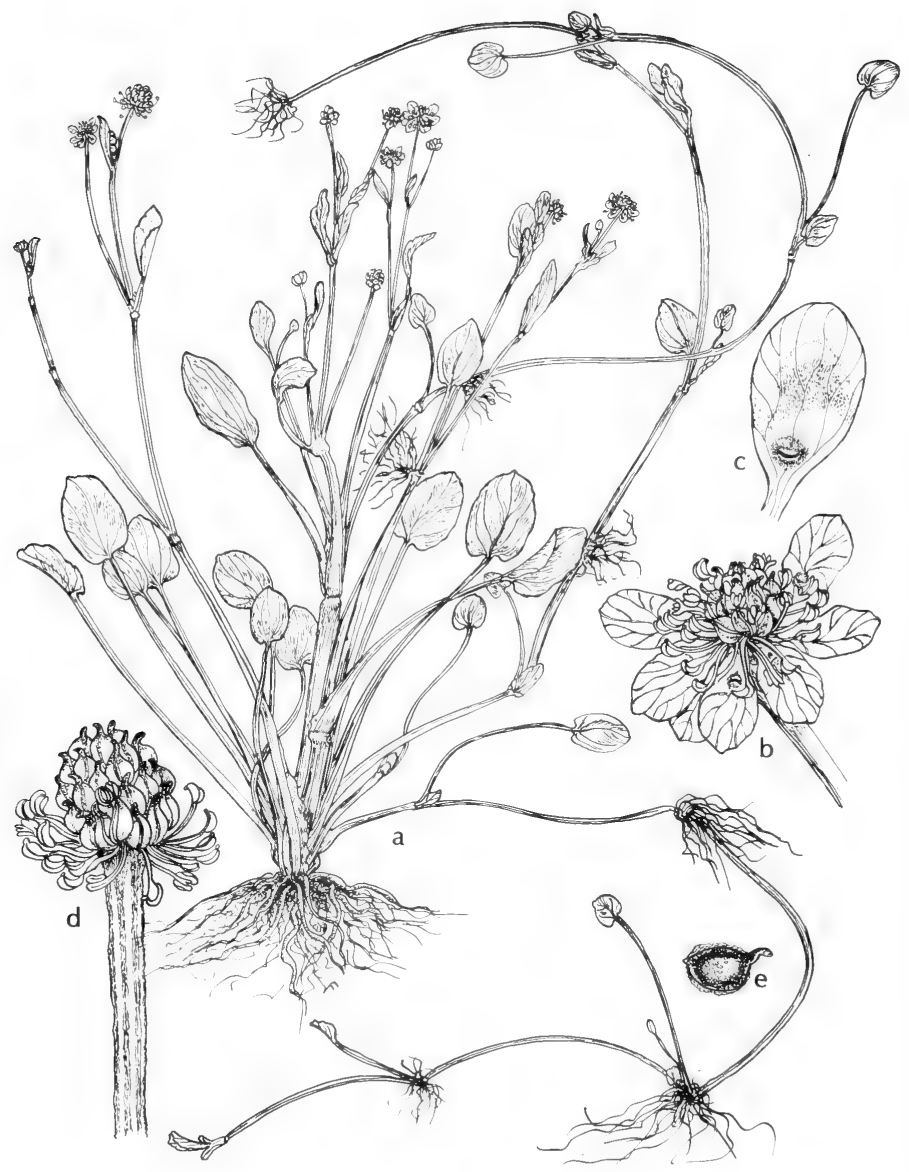

Fig. 461: Ranunculus hydrocharioides: a, habit, x 1/2; b, flower, x 5; c, petal, x 10; d, head of achenes, x 5; e, achene, x 10. (V. F.). 
(Apache, Navajo, Coconino, Greenlee, Cochise and Santa Cruz cos.), Apr.-July; also Calif, and $\mathrm{s}$. into Mex.

\section{Ranunculus laxicaulis (T. \& G.) Darby. Fig. 462.}

Glabrous palustrine annual with filiform roots; stems erect or reclining, rooting adventitiously at only the lowest nodes, 1-5 dm. long, freely branching, fistulous; stem and axis of panicle often proliferating late in season by flabelliform leafy offshoots; basal leaves with petioles $1-7 \mathrm{~cm}$. long or longer when in water, simply ovate to oblong, to $45 \mathrm{~mm}$. long, 6-18 mm. broad, dentate to serrulate or entire, truncate or rounded at base, truncate or obtuse at apex; the stipular leaf bases about $1 \mathrm{~cm}$. long; upper cauline leaves alternate, sessile, linear or lanceolate to oblanceolate or very narrowly elliptic, acute, $15-35 \mathrm{~mm}$. long, 2-6 $\mathrm{mm}$. broad, dentate; pedicels to $2 \mathrm{~cm}$. long in flower and $6 \mathrm{~cm}$. long in fruit; sepals 5 , greenish-yellow, spreading, ovate, $1.5-3 \mathrm{~mm}$. long, about $1.5 \mathrm{~mm}$. broad, glabrous or sparsely hairy, promptly deciduous; petals 5 or rarely as many as 10 , yellow, 3-9 mm. long, $1.5-2.5 \mathrm{~mm}$. broad; nectary scale glabrous, forming a pocket $0.3-0.5 \mathrm{~mm}$. long, truncate or prolonged a little on the margins; stamens 10 to 30 ; achenes 15 to 50 in a hemispheroidal head $2 \mathrm{~mm}$. in radius or an ovoid head $2-4 \mathrm{~mm}$. long and $2-2.5 \mathrm{~mm}$. in diameter, obovate to subglobose, 0.6-0.7 $\mathrm{mm}$. long, smooth and glabrous, the margin inconspicuous, the style about $0.5 \mathrm{~mm}$. long; receptacle pyriform or spheroid, $1.5-2 \mathrm{~mm}$. long in flower, $1.5-3 \mathrm{~mm}$. long in fruit, glabrous. $R$. texensis Engelm., $R$. pusillus of auth., not Poir.

Boggy shores of lakes, in depressions, ditches, cypress ponds and marshes in e. Okla. (Waterfall) and s.e. Tex., Mar.-June; from Fla. to Tex., n. to Conn., Ind., Ill., Mo. and Kan.

\section{Ranunculus pusillus Poir. Fig. 456.}

Glabrous palustrine annual with filiform roots; stems reclining, usually rooting at the lowest nodes, 1-5 dm. long, freely branching, fistulous; basal and lower cauline leaves with petioles $1-6 \mathrm{~cm}$. long, simple, oblong to ovate or rarely cordate, to $5 \mathrm{~cm}$. long, $5-15 \mathrm{~mm}$. broad, entire or a little irregular, truncate or rounded at base, truncate to rounded or acute at apex, the stipular leaf bases to $1 \mathrm{~cm}$. long; upper cauline leaves alternate, sessile, linear or lanceolate to oblanceolate or very narrowly elliptic, 1-5 cm. long, 2-5 $\mathrm{mm}$. broad, entire or sometimes dentate; pedicels to $15 \mathrm{~mm}$. long in flower and $6 \mathrm{~cm}$. long in fruit, glabrous; sepals 5, greenish-yellow, spreading, ovate, $1-2 \mathrm{~mm}$. long, $0.8-1 \mathrm{~mm}$. broad, glabrous or sparsely hairy, promptly deciduous; petals 1 to 3 or rarely 5 , yellow, obovate, $1.5-2.5 \mathrm{~mm}$. long, $1 \mathrm{~mm}$. broad; nectary scale glabrous, forming a pocket $0.2 \mathrm{~mm}$. deep, truncate; stamens 5 to 10 ; achenes as many as 125 in a hemispheroid head about $4 \mathrm{~mm}$. in diameter or an ovoid head 2-4 $\mathrm{mm}$. long and $2-2.5 \mathrm{~mm}$. in diameter or a cylindroid head $5-8 \mathrm{~mm}$. long and $2-3 \mathrm{~mm}$. in diameter, oblong-obovate, about $1 \mathrm{~mm}$. long, smooth (with fine reticulations) or slightly or markedly papillate, glabrous, the margin inconspicuous, the style in anthesis $0.1-0.2 \mathrm{~mm}$. long, the achene beak $0.1-0.2 \mathrm{~mm}$. long; receptacle pyriform or spheroid, 1.5-2 $\mathrm{mm}$. long in flower, 1.5-3 $\mathrm{mm}$. long in fruit, glabrous. Incl. var. angustifolius (Engelm.) L. Benson, R. tener Mohr.

In shallow water and mud of ditches, marshes, bogs, seepage areas and ponds in prairies, open woods and thickets in Okla. (McCurtain, Marshall and Johnston cos.) and the e. fourth of Tex., w. to Burnet Co., Mar.-May; from Calif. to Mo. and N.Y. s. to Tex. and Fla.

24. Ranunculus sceleratus L. CURSED BUtTERCUP. Fig. 463.

Glabrous or rarely hirsute palustrine or rarely aquatic annual or short-lived perennial; stems erect, rarely rooting, to $1 \mathrm{~m}$. long, profusely branching, fistulous, 


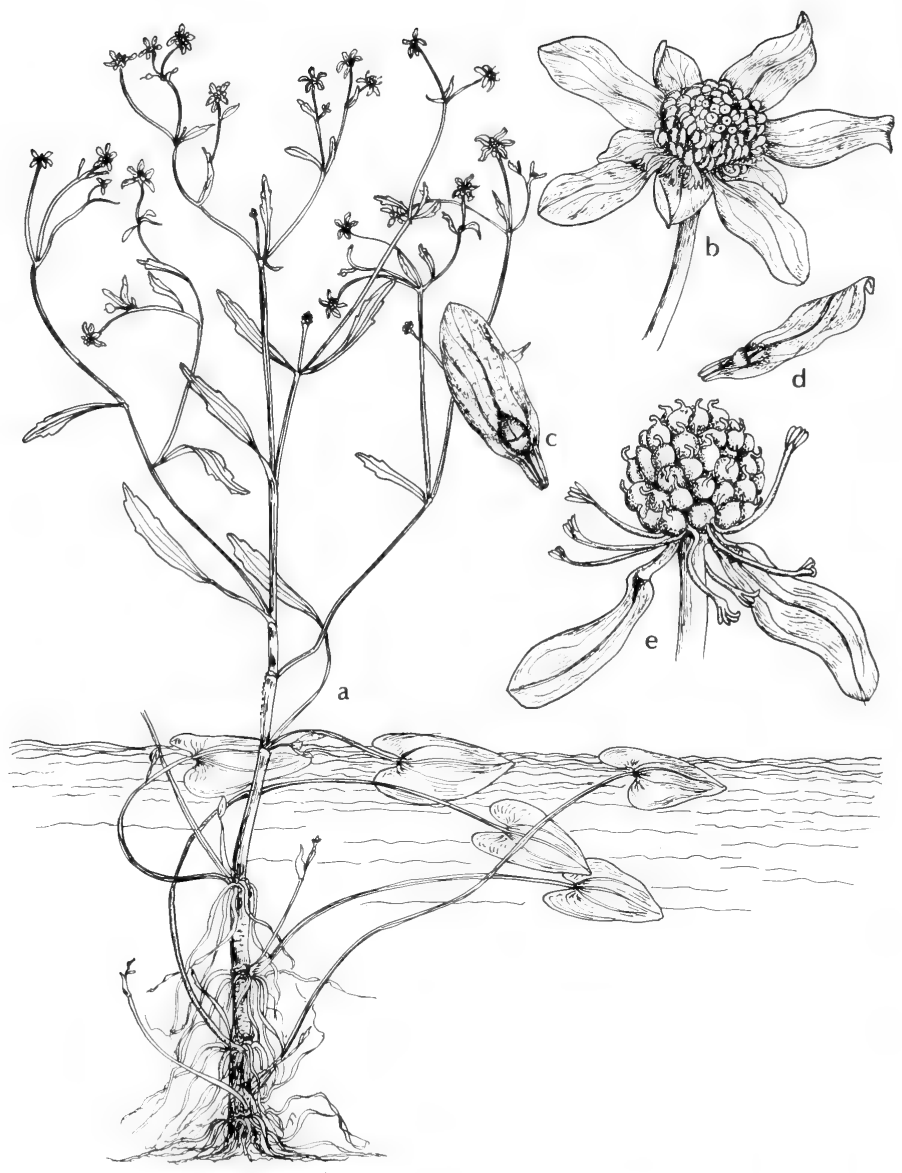

Fig. 462: Ranunculus laxicaulis: a, habit showing lower leaves in water, $\mathrm{x} 1 \frac{1}{4}$; b, flower, $\mathrm{x} 5$; c, petal showing nectary scale from the top, $\mathrm{x} 5$; d, petal showing nectary scale from the side, x 5; e, receptacle covered with achenes, x 5. (V. F.). 

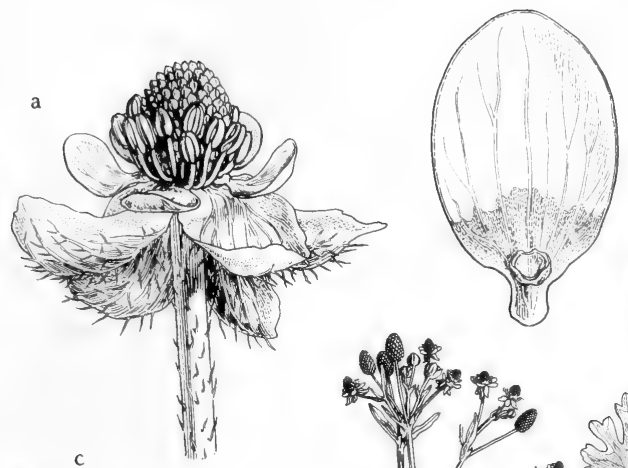

$\mathrm{b}$
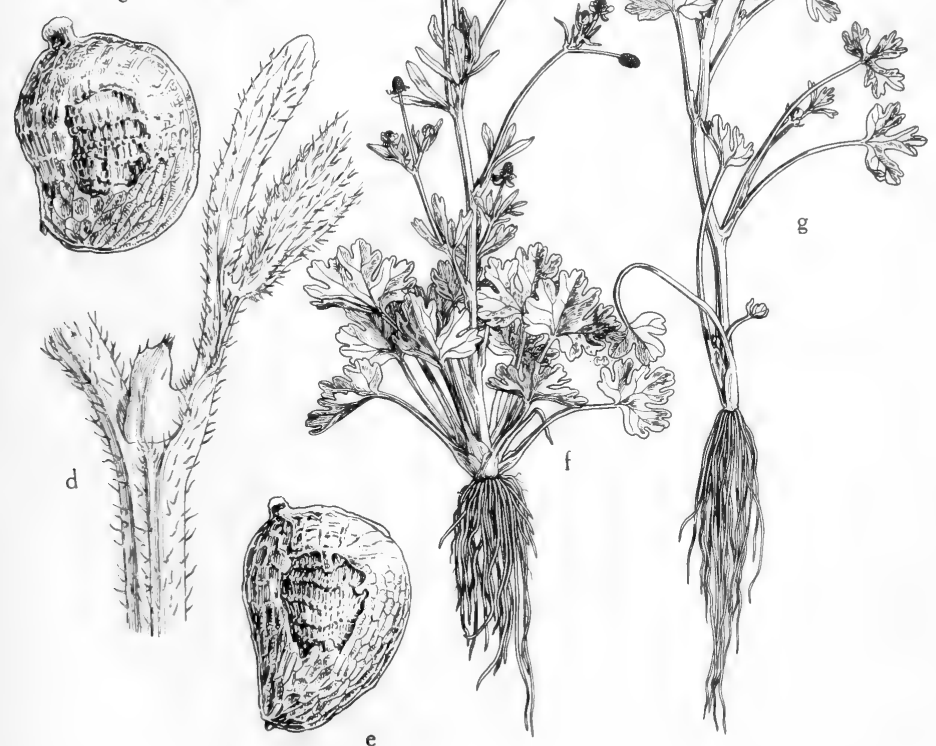

Fig. 463: Ranunculus sceleratus: a, flower, the hairy sepals reflexed, $x$ 4; $b$, petal, showing the open nectariferous pit at the constricted base of the petal, x 20; c, mature achene, x 20; d, young upper leaf and auricle of sheath, x 4; e, variation in achene, x 20; f, habit, showing the cluster of basal leaves and the flowering and fruiting heads, $\mathrm{x} \% 5 ; \mathrm{g}$, habit variation, scarcely any basal leaves present, x \% . (From Mason, Fig. 238). 
inflated; basal leaves with petioles rarely to $25 \mathrm{~cm}$. long, simple, reniform, to 6 $\mathrm{cm}$. long and $1 \mathrm{dm}$. broad, deeply 3-parted or -divided, the primary parts or divisions lobed to parted or divided, the ultimate lobes obtuse or rounded, the sinuses rounded, cordate at base, rounded at apex, the broad stipular leaf bases 5-10 $\mathrm{mm}$. long; cauline leaves alternate, the bracts often oblanceolate and entire, sessile; pedicels to $2 \mathrm{~cm}$. long in flower, $1-3 \mathrm{~cm}$. long in fruit; sepals 5 , greenishyellow, spreading, ovate, 2-3 mm. long, 1.5-2 mm. broad, pilose or glabrous, persisting later than the corolla; petals 5 , light-yellow, obovate, $2-5 \mathrm{~mm}$. long, 1-3 mm. broad; nectary scale glabrous with the margins prolonged along the blade of the petal, sometimes 1 or both with a free flap at the tip or the scale often completely surrounding the nectary; stamens 10 to 25 ; achenes 40 to 300 in a cylindroid head $3-10 \mathrm{~mm}$. long and 2-6 $\mathrm{mm}$. in diameter, obovoid, $0.8-1$ $\mathrm{mm}$. long, often with minute irregular transverse ridges in the central unthickened portion of each face, the periphery of the pericarp at least somewhat corkythickened, the surface often with ridges or a circle of "pin-prick" depressions at the inner margin of the thickened zone, glabrous, the marginal keel obscure, the style and the achene beak almost lacking, not recurved; receptacle obovoid or cylindroid, 1-2 $\mathrm{mm}$. long in flower, $2.5-9 \mathrm{~mm}$. long in fruit, pubescent or sometimes glabrous.

Borders of lakes, streams and marshland, often thriving in brackish or alkaline sites, in Okla. (Garvin, Grady, Johnston, Roger Mills, Comanche, Alfalfa and Cimarron cos.), in s.e. and s. Tex. to the Panhandle (Donley Co.), N. M. (widespread) and Ariz. (Navajo and Pinal cos.), Mar.-Sept.; from Wash. to N.E., s. to Tex., La. and Ga.

The acrid sap of this species is said to raise blisters on human skin.

\section{Ranunculus Gmelinii var. Hookeri (D.Don) L. Benson.}

Glabrous or hirsute perennial; roots slender but fleshy, $1 \mathrm{~mm}$. thick; stems reclining or sometimes floating, prostrate, rooting at nodes, usually $1-5 \mathrm{dm}$. long and a little branched; leaves all cauline and alternate or basal present and longpetioled; petioles 1-4 cm. long, the stipular leaf bases $3-6 \mathrm{~cm}$. long; blades pentagonal in outline, $1-2 \mathrm{~cm}$. long, $1.5-2.5 \mathrm{~cm}$. wide or rarely to 6 or $9 \mathrm{~cm}$. in diameter, deeply 3-parted or -divided with the divisions 2 or 3 times forked or sometimes dissected into ribbonlike divisions, the blade when dissected not triternately dissected as in the dissected leaves of $R$. flabellaris, proximally deeply cordate and distally rounded; often as many as 50 flowers produced; pedicels $1-2.5 \mathrm{~cm}$. long in flower, 2-4 cm. long in fruit, glabrous or appressed-pubescent; sepals 5, yellowish-green, spreading, ovate to nearly orbicular, 2.5-6 $\mathrm{mm}$. long, 1.5-5 mm. wide, glabrous or pubescent, usually thick, deciduous with or before the corolla; petals 5, yellow, orbicular or obovate, 4-7 mm. long, 3-6 mm. wide; nectary scale variable, its margins prolonged into flaps (the tips of which are usually free from the petal and joined, thus the scale usually encircling the gland, or sometimes the margins joined distally, glabrous); stamens 20 to 40 , the ellipsoid anthers $0.5-1 \mathrm{~mm}$. long; achenes 50 to 70 , in an ovoid head 5-7 mm. long and 4-6 mm. in diameter, flattened-obovoid, 1-1.5 mm. long, smooth, glabrous, the keel not corky-thickened but the basal and ventral portions of the pericarp callous-thickened, the broad and thin beak $0.6-0.8 \mathrm{~mm}$. long and recurved; receptacle ovoid to obovoid, 1-2 $\mathrm{mm}$. long in flower, about $4 \mathrm{~mm}$. long in fruit, hairy.

In mud and shallow water of lakes, streams and marshes, often attached and floating, in N. M. (Rio Arriba, Colfax and Taos cos.), June-Sept.; Nfld. and N.S. to Alas., s. to Me., Ia., Mich., Minn., N.D., N.M. and Nev. 


\section{Ranunculus flabellaris Raf. YELLOW WATER CROWFOOT.}

Glabrous or rarely hirsute perennial; roots filiform; stems floating or reclining, rooting at the lower nodes, 3-7 dm. long, branching; petioles $3-8 \mathrm{~mm}$. long, composed wholly of the stipular leaf bases; leaves all cauline, alternate, the blades finely triternately dissected, semicircular to reniform in outline, 1.5-10 $\mathrm{cm}$. long, 2-12 cm. broad, the numerous divisions ribbonlike and $1-2 \mathrm{~mm}$. broad, not dissected in palustrine specimens in which the leaves are merely parted or divided and with the divisions again lobed or parted; pedicels $1-5 \mathrm{~cm}$. long in flower, 2-6 cm. long in fruit, glabrous or hairy; sepals greenish-yellow, spreading, ovate, 5-8 mm. long, 4-6 mm. broad, usually glabrous, early deciduous; petals 5 to 8 , yellow, obovate, 7-15 mm. long, 4-12 $\mathrm{mm}$. broad; nectary scale glabrous, free laterally, the gland in a pocket on the ventral surface of the scale; stamens 50 to 80 , the anthers $1-1.5 \mathrm{~mm}$. long, oblong; achenes 50 to 75 in an ovoid head 7-10 $\mathrm{mm}$. long and 5-8 $\mathrm{mm}$. in diameter, obovate, $2 \mathrm{~mm}$. long, smooth, glabrous, the margin conspicuously thickened into a corky keel, the broad achene beak flat and $1.5 \mathrm{~mm}$. long (straight); receptacle ovoid cylindroid, 2-3 mm. long in flower, $5-7 \mathrm{~mm}$. long in fruit, hairy.

In mud and water of shallow ponds, bayous and mud flats, in marshes and swamps, Okla. (Waterfall), Apr.-Aug.; Me. to B.C., s. to N.C., La., Okla., Ut. and Calif.

\section{Ranunculus Cymbalaria Pursh. Fig. 464.}

Glabrous or sparingly hirsute palustrine perennial; scapes erect, to $3 \mathrm{dm}$. high, branched or unbranched, with filiform stolons several dm. long, not fistulous; basal leaves with petioles $2-5 \mathrm{~cm}$. long, simple, ovate or reniform to trapezoidal or rectangular, to $35 \mathrm{~mm}$. long and $2 \mathrm{~cm}$. broad, crenate to dentate or sometimes merely. 3-toothed or -lobed at the rounded to truncate apices, cordate to rounded or truncate at base, the stipular leaf bases $2-9 \mathrm{~mm}$. long; pedicels $1-3 \mathrm{~cm}$. long in flower and $2-6 \mathrm{~cm}$. long in fruit, usually pubescent; sepals 5, greenish-yellow, spreading, elliptic, 2-5 $\mathrm{mm}$. long, $1.5-3 \mathrm{~mm}$. broad, glabrous, thick, promptly deciduous; petals 5 or up to 12 , bright-yellow, narrowly obovate, 2-8 $\mathrm{mm}$. long, 2-3 $\mathrm{mm}$. broad; nectary scale over-arching the nectary, truncate, the margins free from the blade of the petal; stamens 10 to 30 ; achenes as many as 300 (usually much fewer) in a cylindroid head 3-13 $\mathrm{mm}$. long and 3-6 $\mathrm{mm}$. in diameter, cuneate-oblong, thin-walled, $1.5-2.3 \mathrm{~mm}$. long, each face with about 4 longitudinal striations or branched nerves, glabrous, the margins noticeable, the triangular beak about $0.3 \mathrm{~mm}$. long and not curved; receptacle cylindroid, 2-3 $\mathrm{mm}$. long in flower, 4-7 $\mathrm{mm}$. long in fruit, hairy.

In mud, especially of brackish streams and marshes, wet meadows, marshes, and in shallow water about pools and along streams, in Okla. (Harper, Beaver, Ellis, Texas and Cimarron cos.), N. M. (widespread), and Ariz. (Coconino, Yavapai, Navajo, Apache, Mohave and Yuma cos.), May-Sept.; across Can. to Alas. and Sib., s. to the Andes of S.A.

The following two variants are found in our area.

Var. Cymbalaria. Stems and petioles mostly $0.5 \mathrm{~mm}$. thick; scapes $2.5-11 \mathrm{~cm}$. high, usually branched; basal leaves cordate to ovate or reniform, 5-22 mm. long, 4-20 mm. broad, crenate or sometimes merely 3-lobed at the apices in some of the leaves, thin; sepals and petals $3-5 \mathrm{~mm}$. long; stamens usually 15 to 25 ; achenes 40 to 150 in a cylindroid head $3-8$ or $13 \mathrm{~mm}$. long and $3-4$ or $6 \mathrm{~mm}$. in diameter.

Var. saximontanus Fern. Stems and petioles mostly $1 \mathrm{~mm}$. thick; scapes 5-30 $\mathrm{cm}$. high, usually branched; basal leaves cordate to ovate or rarely reniform, 12-40 mm. long, 10-33 mm. broad, mostly crenate, thick; sepals and petal 4-8 


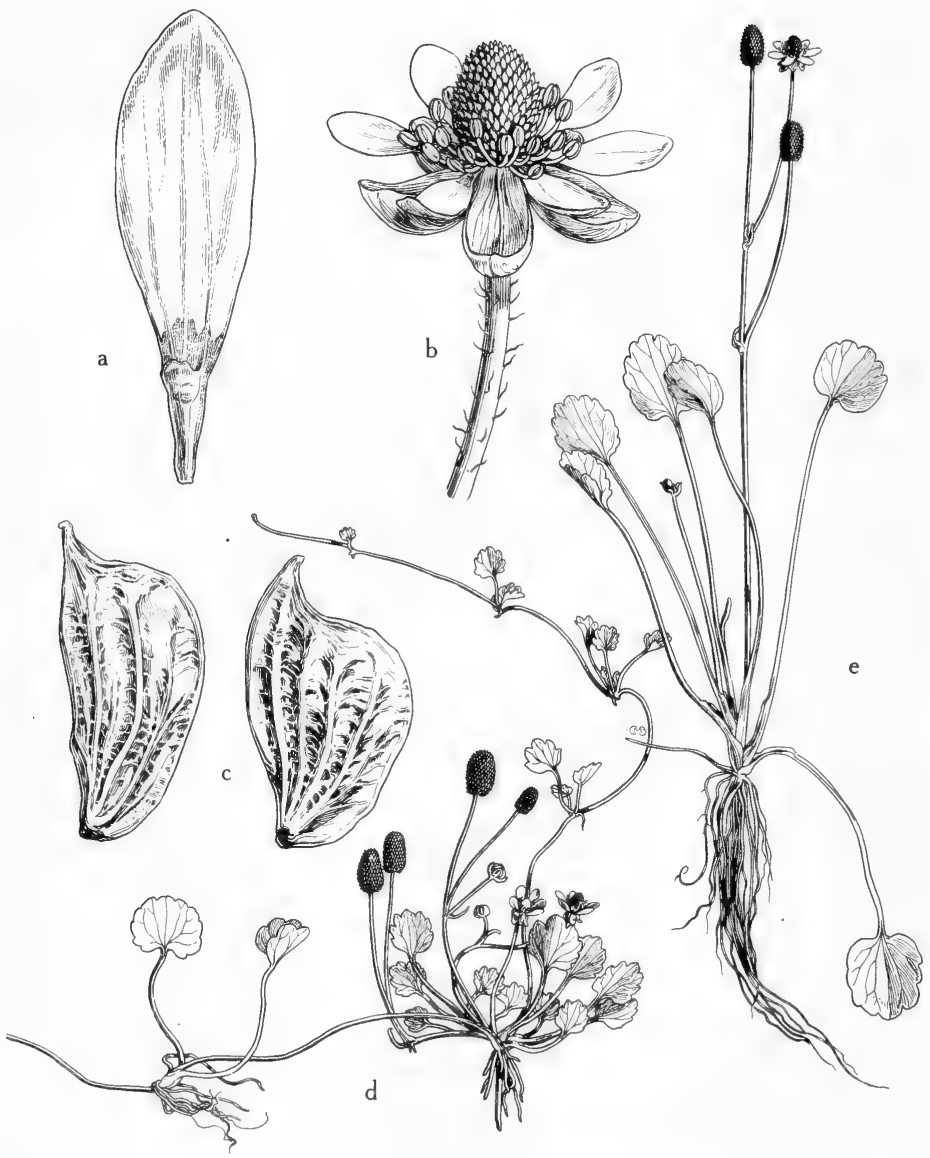

Fig. 464: Ranunculus Cymbalaria var. saximontanus: a, petal, gland covered by scale, $x 12 ; b$, flower, the petals shorter than the sepals, $x 4 ; c$, mature achenes, showing variation in shape, $x$ 20; $d$ and e, variations in habit, $x$ 2/3. (From Mason, Fig. 242). 
$\mathrm{mm}$. long; stamens usually 20 to 35 ; achenes 100 to 300 in a head $5-12 \mathrm{~mm}$. long and $3-5 \mathrm{~mm}$. in diameter.

\section{Ranunculus ranunculinus (Nutt.) Rydb.}

Glabrous terrestrial perennial; roots about $1 \mathrm{~mm}$. thick; stems erect, not rooting, 1-3 dm. long, freely branching above; petioles $5-13 \mathrm{~cm}$. long, the stipular leaf bases 1-2 cm. long; basal leaf blades compound, ternately divided into 3 primary leaflets and these again nearly always ternately divided into secondariy leaflets that are ternately lobed, parted or divided, the ultimate divisions tending to be lanceolate to narrowly elliptic or ovate and 2-3 or rarely $8 \mathrm{~mm}$. wide and more or less coriaceous; cauline leaves alternate, similar to the basal or reduced, the upper sessile; pedicels $1-3 \mathrm{~cm}$. long in flower, usually $2-6 \mathrm{~cm}$. long in fruit, glabrous; sepals yellow tinged with green, spreading, narrowly elliptic, 3-6 mm. long, 1.2-2.2 mm. wide, glabrous, thin, promptly deciduous; petals 5 or rarely none or 1, yellow, narrowly obovate, 5-7 mm. long, 1.5-2.5 mm. wide; nectary scale glabrous, not overhanging the nectary, consisting of a mere transverse callus ridge below the gland; anthers elliptic, achenes 5 to 15 in a capitate cluster, oblong, 2.5-3.5 mm. long, the thin pericarp marked on each face by 3 to 5 or 6 striations or branched nerves, glabrous, the style persistent and flexible in fruit and 1.5-2 mm. long; receptacle pyriform, $1 \mathrm{~mm}$. long in flower, $1-1.5 \mathrm{~mm}$. long in fruit, scaly, not hairy.

In wet soils along streams and in seepage areas, in N. M. (Colfax and Sandoval cos.), May-June; Wyo. and Ut., s. to N.M.

\section{Ranunculus aquatilis L. Fig. 465.}

Glabrous or hispidulous perennial; stems submersed, rooting at the lowest nodes, 2-6 or rarely to $20 \mathrm{dm}$. long, branching, with large air chambers present in the cortex, the vascular system far in the interior, sometimes hispidulous; leaves usually all cauline, alternate, somewhat shorter than the internodes or exceeding them; petioles to $3 \mathrm{~cm}$. long, including the stipular leaf bases which in the submersed leaves are $2-5 \mathrm{~mm}$. long (these sometimes bordering the entire petiole but usually not so); leaf blades often all submersed and finely dissected into filiform divisions, usually repeatedly trichotomous, the leaf as a whole not globular, usually but not necessarily collapsing when withdrawn from the water, $2-4 \mathrm{~cm}$. long, 3-5 cm. wide; the upper leaves (when floating) simple, reniform in outline, $1.5-2.5 \mathrm{~cm}$. broad, 3-lobed and again lobed or parted and lobed, with broad stipular bases; pedicels stout, 1-2 cm. long in flower, $1.5-3 \mathrm{~cm}$. long and not reflexed in fruit, glabrous; sepals 5, light-green, spreading, ovate, $2-3 \mathrm{~mm}$. long or sometimes longer, 1-1.8 $\mathrm{mm}$. wide, glabrous, deciduous before the corolla; petals 5, white or the bases yellow, 4-8 or $14 \mathrm{~mm}$. long, $1.5-2 \mathrm{~mm}$. wide; nectary scale glabrous, forming a shallow pocket or sometimes greatly reduced; stamens 5 or 10 to 25 ; achenes usually 10 to 20 in a globose cluster, obovoid, $1-1.5$ or rarely $2-2.5 \mathrm{~mm}$. long, roughly transversely-ridged, glabrous from the beginning or the pistils hispid and the achenes giabrate or with some hairs persisting on or near the dorsal sutures, the margins rather sharp, the style deciduous, the achene beak about $0.1-0.3 \mathrm{~mm}$. long; receptacle subglobose, 1 $\mathrm{mm}$. long in flower, $1 \mathrm{~mm}$. long in fruit, densely pubescent.

Commonly attached and floating in ponds, streams, pools and springs, often in swift-flowing water, in N. M. (Rather widespread) and Ariz. (Apache, Coconino and Yavapai cos.), Apr.-Aug.; Nfld. and Lab. to Alas., s. to N.C., Ind., N.M., Ariz. and Baja Calif.

Our plants are usually referred to var. capillaceus (Thuill.) DC., with stems $1-2.5 \mathrm{~mm}$. thick and stamens usually 10 or more. 


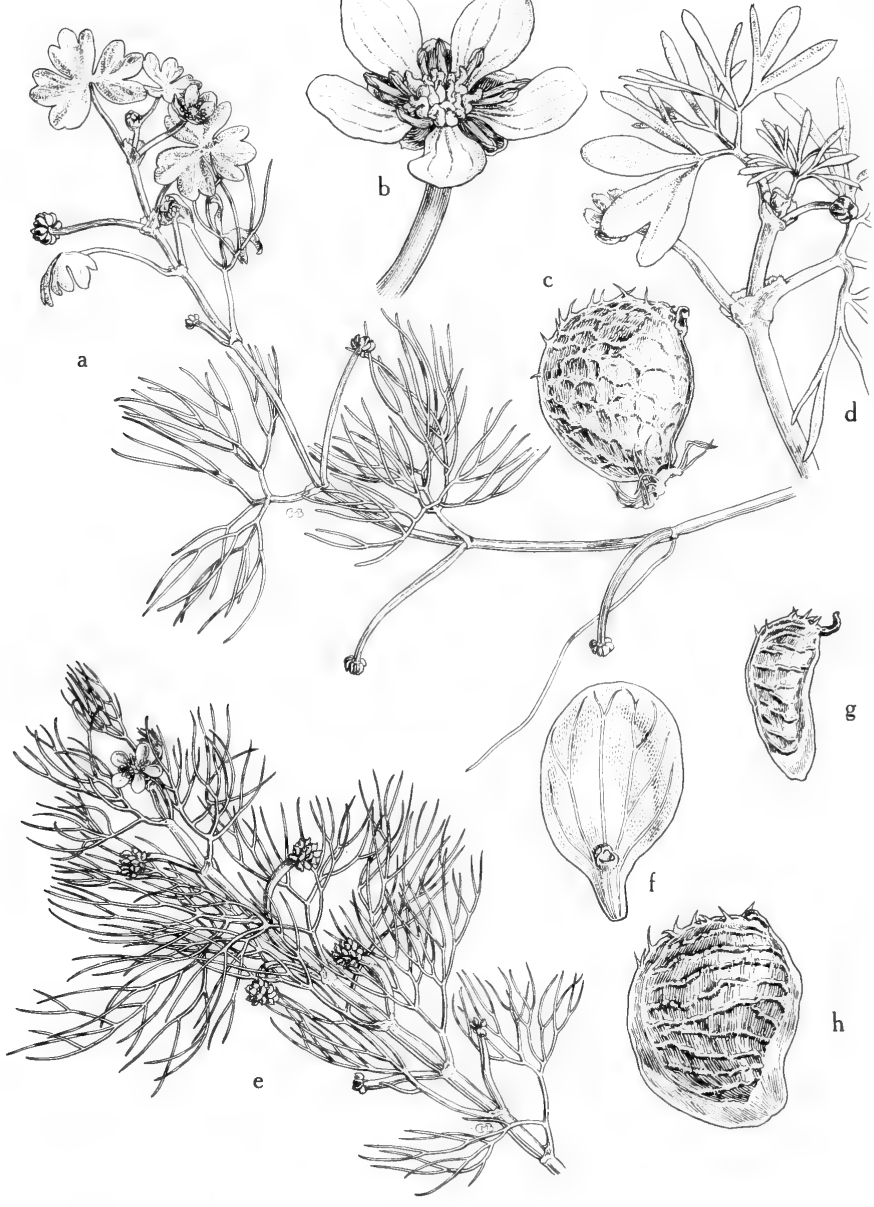

Fig. 465: Ranunculus aquatilis: a-d, R. aquatilis var. hispidulous: a, habit, showing submersed and floating leaves, the flowers and fruiting heads on long slender peduncles,

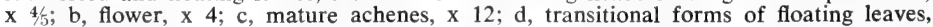
showing toothed summit, x 11/2. e-h, R. aquatilis var. capillaceus: e, habit, submersed leaves only, the peduncle short and stout, $x_{4}^{4} ; \mathrm{f}$, single petal, showing the low scale surrounding the shallow nectariferous pit, $\mathrm{x} 8 ; \mathrm{g}$, achene from head comprised of about 35 achenes, $x$ 12; h, achene from a head comprised of a few achenes, $x$ 12. (From Mason, Fig. 244). 


\section{Ranunculus subrigidus Drew.}

Glabrous or essentially glabrous aquatic perennial with filiform roots; stems submersed, rooting at the lowest nodes, to about $6 \mathrm{dm}$. long, branching, with large air chambers in the cortex; leaves cauline, all submersed and finely dissected into filiform divisions, once- or twice-trichotomous then dichotomous, the leaf as a whole globular, usually not fully collapsing when withdrawn from the water (but sometimes so), usually circinate, $1-2 \mathrm{~cm}$. long, $1.5-3 \mathrm{~cm}$. broad, much shorter than the adjacent internodes; petioles developed only occasionally, the first leaf divisions arising within the stipular leaf base (the leaf base dilated and the ends usually free); pedicels stout, $2-4 \mathrm{~cm}$. long in flower, about $1 \mathrm{~cm}$. longer and markedly recurved at the bases in fruit, glabrous; sepals 5, light-green, spreading, elliptic, 3-5 $\mathrm{mm}$. long, deciduous before the corolla; petals 5 , white or the bases yellow, 5-9 $\mathrm{mm}$. long, 2-4 $\mathrm{mm}$. broad, narrowly obovate, the nectary scale nearly or fully obsolete; stamens 5 to 10 ; achenes 30 to 80 , in a globose-ovoid head 4-6 mm. long and 4-5 mm. in diameter, obovoid, 1-1.5 mm. long, roughly transversely-ridged, glabrous, hispidulous or glabrate, the style largely deciduous, the achene beak $0.2-0.5 \mathrm{~mm}$. long; receptacle subglobose, $1 \mathrm{~mm}$. long in flower, $1-1.5 \mathrm{~mm}$. long in fruit, hispidulous, $R$. circinatus Sibth. var. subrigidus (Drew)

\section{Benson.}

In ponds, lakes or pools, often brackish, frequently attached and floating in streams, in the Tex. Rio Grande Valley, N. M. (Rio Arriba, San Miguel and Grant cos.) and Ariz. (Coconino and Gila cos.), May-Sept.; from Can. s. to cen. Mex.

\section{Ranunculus longirostris Godr. WHITE WATER-CROWFOOT.}

Similar to R. subrigidus; leaves firmer, often stiff, the stipular base larger and from three fourths to entirely adnate to the very short petiole; pedicels appearing to be axillary (actually terminal, the stem sympodial), 1-5 cm. long, apparently not recurved in fruit, glabrous; sepals yellowish-green or purplish, spreading, narrowly elliptic, 3-4 $\mathrm{mm}$. long, 1-1.5 mm. broad, early-deciduous; petals 5, white, obovate, 4-9 $\mathrm{mm}$. long, 2.5-6 $\mathrm{mm}$. broad; the nectary scale reduced to a very shallow pocket or a lunate ridge along the base and sides of the gland or wholly absent, the glandular area only $0.2-0.3 \mathrm{~mm}$. in diameter; stamens 10 to 20 ; achenes 7 to 25 in a subglobose cluster or head $3-5 \mathrm{~mm}$. long and 4-6 mm. in diameter, obovoid, $1.3-1.7 \mathrm{~mm}$. long, roughly transversely-ridged, glabrous or hispidulous, the margin evident, the slender beak $0.7-1.1 \mathrm{~mm}$. long and straight; receptacle globose or pyriform, $1 \mathrm{~mm}$. long in flower, 1-2 $\mathrm{mm}$. long in fruit, densely hispid.

Floating in water of streams and lakes, often forming large mats in Okla. (McCurtain and Beaver cos.) and in Tex. from the Rio Grande Plains to the Panhandle, N. M. (widespread) and Ariz. (Apache and Navajo cos.), Apr.-July; from Can., s. to Ariz., N.M., Tex., Ark., Ala. and Del.

\section{Thalictrum L. MEADOW-RUE}

Plants herbaceous, perennial, often polygamous or dioecious; leaves alternate, rather large, twice or thrice ternate with numerous usually cleft or shallowly lobed leaflets, the basal leaves long-stalked; petioles dilated at base; flowers mostly unisexual, small, greenish or yellowish, usually in terminal panicles; sepals 4 or 5, caducous, petaloid or greenish; petals none; stamens numerous, exserted, the filaments filiform or slender-clavate; stigma unilateral; achenes 4 to 15 , with longitudinal grooves or ribs extending from base to apex, sometimes inflated.

About 150 species, mostly in the Northern Hemisphere. 
1. Leaflets usually rather thick and rigid, mostly longer than wide, entire to usually acutely 3 -lobed with the lobes entire; polygamo-dioecious....

.1. T. dasycarpum.

1. Leaflets usually thin and flaccid, as wide as long or wider, typically 3-lobed with the lobes obtuse to rounded and often notched or crenate; dioecious, rarely polygamous. 2. T. Fendleri.

\section{Thalictrum dasycarpum Fisch. \& All. PurPle MEAdow-RUE.}

Caudex short and thick, erect; stem to $2 \mathrm{~m}$. high, often purple; upper leaves sessile or subsessile, their ovate to suborbicular stipules brown; leaflets firm, obovate in outline, to about $55 \mathrm{~mm}$. long and $4 \mathrm{~cm}$. wide, with veins prominent beneath, provided on lower surface with a fine non-glandular pubescence or glabrous, or sometimes glaucous; inflorescences corymbose-paniculate; sepals lanceolate to narrowly ovate, acuminate, commonly slender-tipped, $3-5 \mathrm{~mm}$. long; filaments filiform, 4-7 mm. long, soon drooping and entangling; anthers oblong-linear, 1.5$3.2 \mathrm{~mm}$. long, with subulate tip only $0.1-0.2 \mathrm{~mm}$. long; stigma $2-5 \mathrm{~mm}$. long, about equaling the ovoid to lanceolate body of carpel.

In meadows, swamps and damp thickets, on rich wooded slopes or along wooded streams in Okla. (Waterfall), the e. third of Tex. and the n. Panhandle, N. M. (San Juan and Sandoval cos.) and Ariz. (Navajo Co.), Mar.-July; from Ont. to Alta., s. to O., Ind., Ill., Mo., Kan., La., Tex., N.M. and Ariz.

The var. hypoglaucum (Rydb.) Boivin ( $T$. hypoglaucum Rydb.) is an entirely glabrous plant with somewhat thinner leaves that are glaucous on the lower surface, often longer stigmas $(2.5-5 \mathrm{~mm}$.), longer filaments $(4-7 \mathrm{~mm}$.) and a more elongate receptacle than in var. dasycarpum.

\section{Thalictrum Fendleri Engelm.}

Plant always more or less pubescent, rarely subglabrous or even glabrous, never waxy nor blue nor glaucous, the stem sometimes purplish, to $15 \mathrm{dm}$. high, more or less stoloniferous; sepals erose, the staminate ovate to elliptic and 3-5 $\mathrm{mm}$. long, the pistillate ovate to rhombic or broadly lanceolate and about $1.5 \mathrm{~mm}$. long; filaments 4-7.5 mm. long, deep-yellow; anthers oblong to linear, pale- or deep-yellow, 2.2-3.4 mm. long, with acumen to $0.8 \mathrm{~mm}$. long; stigma $1.5-4 \mathrm{~mm}$. long; ovary (densely) green, with the ventral surface ovate to lanceolate, often densely pubescent; mature carpel spreading, ovate to lanceolate, green to brown, more or less pubescent to sometimes glabrous, with a stipe to $2 \mathrm{~mm}$. long, the ventral surface to $9 \mathrm{~mm}$. long and $4.5 \mathrm{~mm}$. wide, with lateral nerves rarely branching and sinuate, never minutely sinuate nor anastomosing nor reticulate, with the nerve curved ventrally rather than dorsally.

On moist shaded canyon slopes, muddy seepage banks, edge of streams, and in wet meadows and thickets in mts. of the Tex. Trans-Pecos, N. M. (rather widespread) and Ariz. (Apache to Mohave, s. to Cochise, Santa Cruz and Pima cos.), Apr.-Sept.; from Tex., w. to Ore., Wyo. and Ariz.; also n. Mex.

\section{Fam. 62. Magnoliaceae Juss.}

\section{Magnolia FAmily}

Trees, rarely shrubs or vines with bitter aromatic bark and with the leaf buds covered by membranous stipules; leaves alternate, petiolate, entire, pinnatelyveined; flowers solitary or several clustered, usually large and fragrant, polypetalous, hypogynous, with many stamens; perianth segments ( 3 sepals and 6 to 9 petals) similarly colored, deciduous, imbricated in the bud; stamens numerous, linear, caducous; anthers adnate; carpels numerous, crowded together to cover the prolonged receptacle, cohering with each other and in fruit forming a fleshy or rather woody conelike fruit; mature carpels opening on the back from which the 1 or 2 anatropous arillate seeds hang by an extensile thread. 


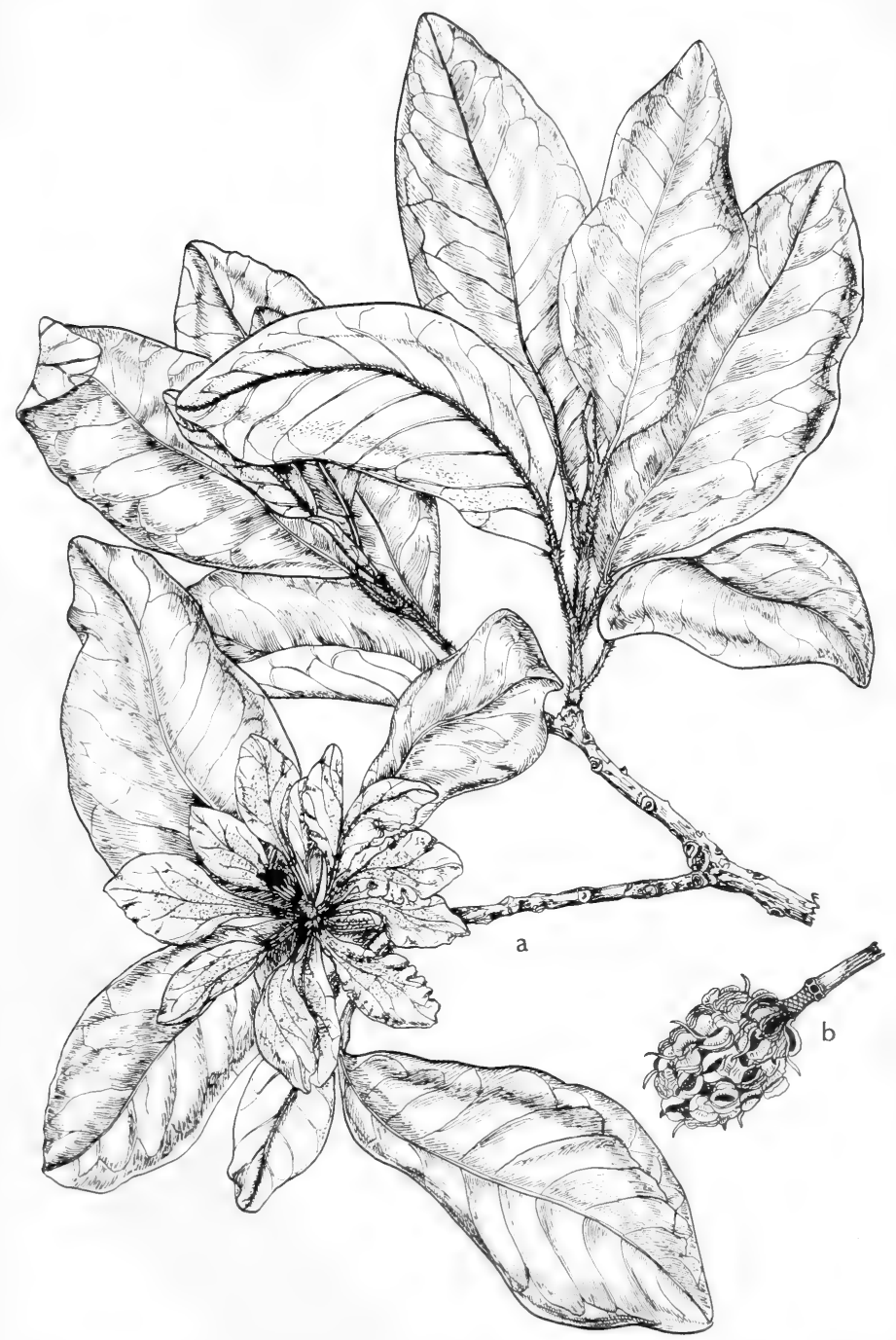

Fig. 466: Magnolia virginiana: a, twig with flower, $x \frac{1}{2} ; b$, fruit, $x \frac{1}{1} 2$. (V. F.). 


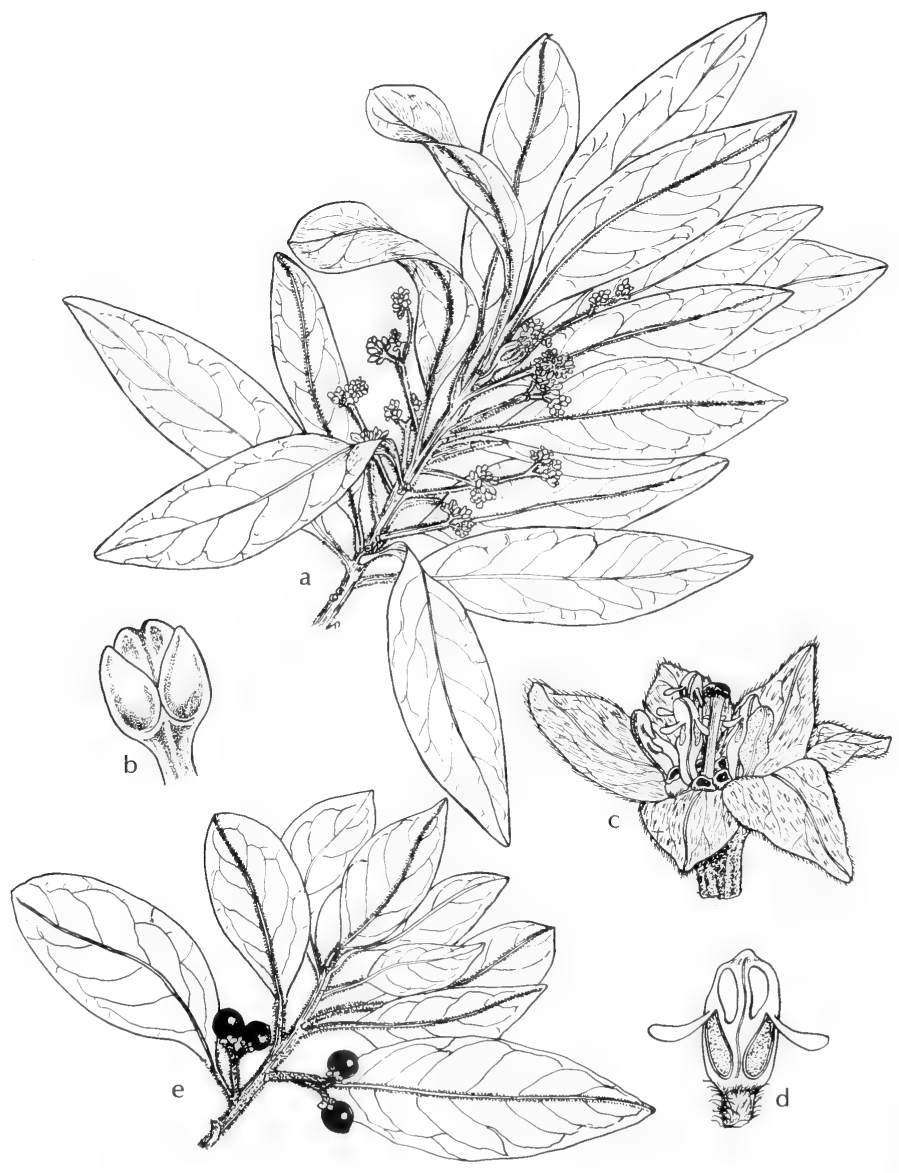

Fig. 467: Persea Borbonia: a, branch with flowers, x $1 \frac{1}{2}$; b, bud, x 5; c, flower, $x$ 5; d, anther, $x$ 10; e, branch with fruit, x $1 / 2$. (V. F.). 
About 230 species in 12 genera, world-wide in distribution.

\section{Magnolia L. MAgnolia}

Characters of the family. About 80 species, mostly Asiatic.

1. Magnolia virginiana L. SWAMP BAY, SWEET BAY. Fig. 466.

A slender semievergreen tree to $20 \mathrm{~m}$. tall, with a trunk to $15 \mathrm{~cm}$. in diameter or rarely shrubby and deciduous; branchlets slender, bright-green and hoarypubescent when they first appear, usually soon glabrous; buds pubescent; leaves elliptic to oblong-lanceolate, $10-15 \mathrm{~cm}$. long, to $6 \mathrm{~cm}$. wide, acute or obtuse at apex, broadly cuneate or sometimes rounded at base, pale or whitish on lower surface and silky-pubescent at first; petioles slender, 1-2 cm. long; silky-pubescent to glabrous; flowers subglobose, $5-7 \mathrm{~cm}$. across, white, fragrant of lemon, on slender peduncles; sepals thinner and shorter than the petals, spreading; petals 9 to 12 , obovate, obtuse to acutish, 3-6 cm. long, concave; fruit ellipsoid, $4-5 \mathrm{~cm}$. long, about $12 \mathrm{~mm}$. thick, dark-red, glabrous; seeds red, obovoid, flattened, about $7 \mathrm{~mm}$. long. $M$. glauca $\mathrm{L}$.

In swamps, low woods, along boggy streams and on seepage slopes in e. Tex., Apr.-June; from Mass., s. to Fla. and Tex.

Those plants in our region that have young branchlets and petioles more or less persistently densely silky pubescent, and tomentose pedicels, are referable to var. australis Sarg.

\section{Fam. 63 Lauraceae Juss. Laurel Family}

Aromatic trees or occasionally shrubs with alternate simple persistent or deciduous leaves, or sometimes twining parasitic vines with greatly reduced scalelike leaves, without stipules; flowers small, clustered, greenish or yellowish, without petals; calyx of 4 to 6 sepals that are imbricate and free from the ovary, mostly fewer than the stamens; stamens basically 12, in 4 series of 3 each, any one or more series reduced to staminodia or altogether lacking; anthers 2- or 4-celled, opening by 2 or 4 uplifted valves; ovary 1 -celled, the ovule solitary and pendulous; style simple; fruit a 1-seeded berry or drupe; seeds anatropous, suspended.

A family of more than 2,000 species in about 32 genera, chiefly tropical and subtropical.

1. Tree to $20 \mathrm{~m}$. tall; leaves broad and coriaceous

1. Persea

1. Parasitic orange to green twining viny herb with leaves reduced to scales

2. Cassytha

\section{Persea Mill.}

About 150 species primarily of tropical America, of which the avocado ( $P$. americana Mill.) is best known.

\section{Persea Borbonia (L.) Spreng. Red Bay. Fig. 467.}

Tree to $20 \mathrm{~m}$. tall or more, with ascending branches and densely rusty-tomentose to thinly puberulent or sometimes glabrous twigs; leaves alternate, entire, coriaceous, lanceolate to elliptic or elliptic-oblanceolate, tapering into the petiole (to $25 \mathrm{~mm}$. long), broadly rounded to abruptly short-acuminate at apex, to $2 \mathrm{dm}$. long and $6 \mathrm{~cm}$. wide, persistent, thinly tomentose on lower surface but commonly glabrescent with age; flowers perfect, in small panicles, peduncle to $7 \mathrm{~cm}$. long, usually less than $3 \mathrm{~cm}$. long; calyx 6-parted, surrounding base of fruit; inner row of sepals elliptic, at least twice as long as the outer row and with the upper twothirds early-deciduous; fertile anthers 9 in 3 rows, the innermost 3 with extrorse 
anthers and biglandular at base, a fourth inner row reduced to staminodes; anthers 4-celled and 4-valved; drupes subglobose, dark-blue or blackish, about $1 \mathrm{~cm}$. long, 1 -seeded. $P$. pubescens (Pursh) Sarg., P. palustris (Raf.) Sarg.

In woods, swamps, along streams and about seashores in s.e. Tex., May-June; from Fla. to Tex., n. to Del.

\section{Cassytha L.}

About 15 species, mainly tropical and subtropical.

\section{Cassytha filiformis $\mathrm{L}$. WoE-VINE, LOVE-VINE.}

Parasitic vine superficially resembling Cuscuta, with yellowish or palegreen wiry entwined stems and branches with a spicy fragrance; leaves wanting or reduced to spirally arranged scales; flowers perfect, subtended by a minute bract and 2 similar bracteoles, 2 to several at irregular intervals in a slender spike; sepals 6 , in 2 unequal series, topping the accrescent fruit; the several inner sepals triangularovate, about $1.5 \mathrm{~mm}$. long, much larger than the outer bractlike sepals; fertile stamens 9 in 3 rows, the innermost 3 with extrorse anthers and basal glands, a fourth inner row reduced to 3 cordate staminodia; anthers 2-celled and 2-valved; drupe globose, blackish, to about $7 \mathrm{~mm}$. in diameter.

Parasitic on various herbaceous and woody plants mostly in marsh areas along coastal Tex., rare, May-July; from Fla. and Tex.; also Latin Am. and Afr.

\section{Fam. 64. Cruciferae Juss. Mustard Family}

Herbs with watery and mostly pungent sap, infrequently suffrutescent and subshrubby; leaves alternate (rarely opposite), entire to lobed or pinnately divided and without stipules; flowers bisexual, usually tetradynamous, mostly regular and ebracteate in terminal racemes, infrequently solitary and pedunculate; sepals 4, deciduous, usually oblong, erect and appressed to the corolla or spreading at anthesis; petals 4 (rarely absent), hypogynous, entire or emarginate, rarely lobed or fimbriate, yellow, white or lavendar; stamens 6 (rarely fewer or more) in two whorls, outer single stamens 2 , inner paired stamens 4 ; ovary with 2 locules (rarely with a single locule); fruit a dry usually dehiscent silique with a wide range of shapes from narrowly linear to depressed-globose; seeds without an endosperm; embryo curved with radicle usually folded retrorsely along cotyledon margins (accumbent), or along the back of one cotyledon (incumbent), or in a somewhat intermediate position; embryo rarely straight as in Leavenworthia.

About 375 genera and over 3,000 species. Nearly cosmopolitan, but mostly in the temperate and cold parts of the world. At high elevations elsewhere. Many species have become widespread weeds.

1. Siliques of a linear or elliptic type, at least 3 times longer than broad (2)

1. Siliques variously shaped from globose to orbicular or triangular, sometimes shortly ellipsoid, didymous or flattened, less than 3 times longer than broad (19)

2(1). Siliques with a transverse partition, indehiscent except by breaking into jointed segments. 10. Cakile

2. Siliques dehiscent by longitudinal linear valves (3)

3(2). Siliques flattened parallel to the septum (4)

3. Siliques terete or (if compressed) flattened contrary to septum (11)

4(3). Stems arising from a basal rosette of leaves or a branched caudex, or with rhizome leaves present (5)

4. Stems with lower leaves separated by internodes, no basal rosette or tuft of leaves present (10) 
5(4). Petals white to lavender; inflorescences racemose, none of the flowers pedunculate; styles less than $3 \mathrm{~mm}$. long (6)

5. Petals yellow; at least some flowers pedunculate or styles over $5 \mathrm{~mm}$. long; pedicels much-elongated (9)

$6(5)$. Valves not extending to silique margin, elastic and rolling up after dehiscence................................................................6. Cardamine

6. Valves extending to edge of the replum margin, not elastic and rolling upon dehiscence (7)

$7(6)$. Siliques linear-elliptical; seeds wingless, in 2 distinct rows in each loculus....

7. Siliques linear; seeds winged, in a single row in the loculus $(8)$

$8(7)$. Leaves entire to dentate; pedicels expanded below receptacle........2. A rabis

8. Leaves pectinate to pinnatifid; pedicels not expanded below receptacle....

3. Sibara

9(5). Leaves pinnately or bipinnately dissected; siliques thick, spongy and margined or the styles over $5 \mathrm{~mm}$. long.............................11. Selenia

9. Leaves lyrately lobed to entire; siliques flattened, not thick and spongy nor margined; styles less that $2 \mathrm{~mm}$. long......................12. Leavenworthia

10(4). Cauline leaves petiolate or cuneate at base, upper ones entire.....2. Arabis 10. Cauline leaves sessile and auriculate, upper ones lobed.

3. Sibara

11(3). Leaves entire or lobed, never divided as far as midrib (12)

11. Leaves (at least some) pinnately lobed to bipinnate, the primary lobes cut to the leaf rachis (15)

12(11). Flowers yellow or yellowish, never white to lavender......

7. Rorippa

12. Flowers white to lavender, never yellow (13)

13(12). Upper cauline leaves auriculate

3. Sibara

13. Upper cauline leaves petiolate or cuneate at base (14)

14(13). Lower cauline leaves auriculate; cotyledons accumbent........1. Iodanthus

14. Lower cauline leaves petiolate or cuneate at base; cotyledons incumbent.

4. Sisymbrium

15(11). Trichomes mostly highly branched; stems and leaves often grayish from a dense pubescence; leaves often bipinnate to tripinnate.....

5. Descurainia

15. Trichomes mostly simple or absent; stems and leaves greenish; leaves at most pinnate plus secondary lobing (16)

16(15). Petals yellow or yellowish (17)

16. Petals white to lavender (18)

17(16). Cauline leaves auriculate or clasping stem at base......

17. Cauline leaves not auriculate or clasping stem

9. Barbarea 4. Sisymbrium

18(16). Plants aquatic or of very wet habitats; valves of siliques nerveless; cauline leaves pinnate to bipinnate.

7. Rorippa

18. Plants terrestrial, ubiquitous in habitats, either dry or wet; valves of siliques nerved; cauline leaves at most lobed...... 4. Sisymbrium

19(1). Weak aquatic perennial with capillary-dissected submerged leaves; petals white

8. Armoracia

19. Terrestrial annuals in wet or dry habitats, if in water the petals yellow (20)

20(19). Siliques strongly flattened at right angles to septum, the replum much narrower than silique width, broader above than below, more or less triangular to heart-shaped in outline.

14. Capsella 
20. Siliques inflated or compressed parallel to septum, the replum equaling the silique width (21)

21(20). Siliques globose to pyriform or ovoid, sometimes slightly longer than broad or broader than long but not compressed laterally (22)

21. Siliques compressed to strongly flattened parallel to septum (23)

22(21). Cauline leaves sagittate-clasping stems; silicle somewhat pyriform, the firm valves 1 -nerved. 15. Camelina

22. Cauline leaves not sagittate; silicle globose to ovoid. .7. Rorippa

23(21). Leaves pinnately to bipinnately dissected; petals yellow. 11. Selenia 23. Leaves entire or merely lobed; petals white to lavender. 13. Draba

\section{Iodanthus STEUD.}

Four species from central United States and Mexico.

\section{Iodanthus pinnatifidus (Michx.) Steud. PurPle Rocket.}

Perennial; stem usually single from base, branched above, leafy, glabrous or rarely sparsely pubescent, with simple trichomes below, 3-8 dm. tall; leaves glabrous, ovate to lanceolate, petiolate or the upper sessile and cuneate, irregularly serrate, lower leaves usually with a winged petiole and auricles clasping the stem; inflorescence narrowly racemose, elongated; sepals oblong, erect, often purplish, 6-8 mm. long; petals white to light-lavender, spatulate to narrowly obovate, 7-14 $\mathrm{mm}$. long; pedicels widely spreading, glabrous, 4-10 $\mathrm{mm}$. long; siliques linear, widely spreading to divaricately ascending, straight, nearly terete, glabrous, 2-4 $\mathrm{cm}$. long, sessile or with a short stipe; seeds oblong, wingless, 1-1.5 mm. long; cotyledons accumbent.

Alluvial soil of river bottoms and in rich woods, n.e. Okla. (Waterfall) and cen. and e. Tex., Apr.-June; Pa. to Ia., Ala. and Tex.

\section{Arabis L. RocK-CRESS}

Annual, biennial or perennial herbs; stems erect, stiff, simple or branched, glabrous to pubescent; basal leaves petiolate; cauline leaves petiolate or sessile; inflorescence racemose, ebracteate; flowers tetradynamous; sepals erect, oblong; petals spatulate to oblong, white, cream or lavender; siliques sessile, straight to curved, erect to pendulous, flattened parallel to partition; styles evident, entire; seeds orbicular to oblong, winged; cotyledons accumbent.

About 150 species in Eurasia, North America and Africa.

1. Seeds definitely in 1 row in each locule..

1. Seeds in 2 rows in each locule (2)

1. A. hirsuta.

2(1). Fruiting pedicels merely ascending or divaricately spreading, finely stellatepubescent or glabrous; stem finely appressed-pubescent at base with forked trichomes.

.2. A. divaricarpa.

2. Fruiting pedicels strictly appressed or subappressed, glabrous; stem hirsute at base or glabrous.

3. A. Drummondii.

1. Arabis hirsuta (L.) Scop. var. pycnocarpa (M. Hopk.) Roll.

Stoutish biennial; stem 2-8 dm. high, slender, hirsute usually to summit with spreading mostly simple hairs; radical leaves oblong to oblanceolate, $2-8 \mathrm{~cm}$. long, villous-hirsute to hirtellous on both surfaces; cauline leaves very numerous, imbricated or nearly so, oblong to lanceolate, 1-4 cm. long, obtuse to subacute, the lower auriculate- to subsagittate-amplexicaul, hirsute, the upper merely sessile and less pubescent or smooth; racemes slender, becoming lax; sepals herbaceous; petals whitish to ochroleucous or rarely pinkish, lanceolate, 4-6 mm. long, 0.7-1 $\mathrm{mm}$. wide; siliques erect or appressed, flat, often moniliform, $1.5-5 \mathrm{~cm}$. long, 
0.7-1 mm. broad; style usually slender, less than $1 \mathrm{~mm}$. long; seeds in 1 row in each cell, $0.6-1.5 \mathrm{~mm}$. long, broadly winged above. A. ovata of Woot. \& Standl.

In wet meadows and water in and about springs, seepage areas, stream beds and damp woods in N. M. (widespread in mts.) and Ariz. (Apache and Coconino cos.), May-Aug.; Anticosti to Yuk., s. to Pa. or occasionally n.w. Ga., Mo., Kan., N.M., Ariz. and Calif.; Euras.

\section{Arabis divaricarpa A. Nels.}

Stem erect, 2-9 dm. tall, simple or branched, sparingly appressed-pubescent at base with forked hairs; rosette leaves narrowly oblanceolate to oblanceolatespatulate, 2-6 cm. long, acute, usually dentate, minutely stellate-pubescent; cauline leaves narrowly oblong to linear-lanceolate, strongly ascending, entire or subentire, auriculate or sagittate at base, mostly glabrous; flowers in loose racemes; pedicels soon divergent, minutely stellate-pubescent or glabrous; petals pink or purplish to rarely white, oblanceolate-spatulate, 5-8 $\mathrm{mm}$. long; siliques glabrous, the lowest and mature ones loosely ascending to divergent, $2.5-9 \mathrm{~cm}$. long, $1.2-3 \mathrm{~mm}$. broad, with style $0.2-0.7 \mathrm{~mm}$. long; seeds in 2 rows in each cell, 1-1.5 $\mathrm{mm}$. in diameter, narrowly winged.

In wet mt. meadows and seepage areas, about rocks and in sandy soils in N.M. (Taos Co.), May-Aug.; Gaspé Pen. to Man. and Yuk., s. to N.Y., O., Mich., Wisc, Ia., Neb., N.M. and Calif.

\section{Arabis Drummondii Gray.}

Stem erect, simple or branched, often glaucous, glabrous throughout or rarely appressed-pubescent at base; radical leaves to $9 \mathrm{~cm}$. long, glabrous or merely with ciliate petioles; flowers erect or strongly ascending; pedicels glabrous; petals 5-10 mm. long; siliques suberect or subappressed, flattish, 4-10 cm. long, 1.5-3.3 $\mathrm{mm}$. broad; seeds in 2 rows, about $1 \mathrm{~mm}$. in diameter. A. oxyphylla Greene.

In moist or wet soil in mt. meadows and along streams in N. M. (Colfax, Rio Arriba, San Miguel and Taos cos.) and Ariz. (Apache and Coconino cos.), May-Sept.; Lab. to Alta. and B.C., s. to Del., O., Ind., Ill., Ia., N.M., Ariz. and Calif.

\section{Sibara Greene}

Eleven species, primarily of southwestern United States and Mexico.

\section{Sibara virginica (L.) Roll.}

Annual herb; stems arising from rosette of basal leaves, erect or decumbent, usually hirsute toward base, 1-3 dm. tall; leaves pinnatifid with narrow lateral segments, terminal lobe somewhat broader; cauline leaves petiolate, not auriculate; flowers small and inconspicuous; petals white to faintly pinkish, oblanceolate to narrowly oblong, 1.5-3 mm. long; pedicels divaricately ascending, short, mostly less than $4 \mathrm{~mm}$. long; siliques narrowly oblong to linear, flattened parallel to septum, obtuse above and below, 15-25 mm. long, $1.5-2 \mathrm{~mm}$. wide, glabrous; seeds nearly orbicular, flattened, narrowly winged.

Old fields, on mud along sloughs and streams, roadsides and open areas, Okla. (Waterfall) s., cen. and e. Tex., Mar.-Apr.; s. Calif. and Okla. to O., Va. and Fla.

\section{Sisymbrium L.}

About 90 species, mainly in Eurasia, the Mediterranean region and temperate Africa, North America and South America.

\section{Sisymbrium altissimum L. Tumble-mustard. Fig. 468.}

Annual; stems loosely branched above, to $1.5 \mathrm{~m}$. tall, hirsute toward base with large spreading simple trichomes; lower leaves petiolate, hirsute, pinnately lobed, 


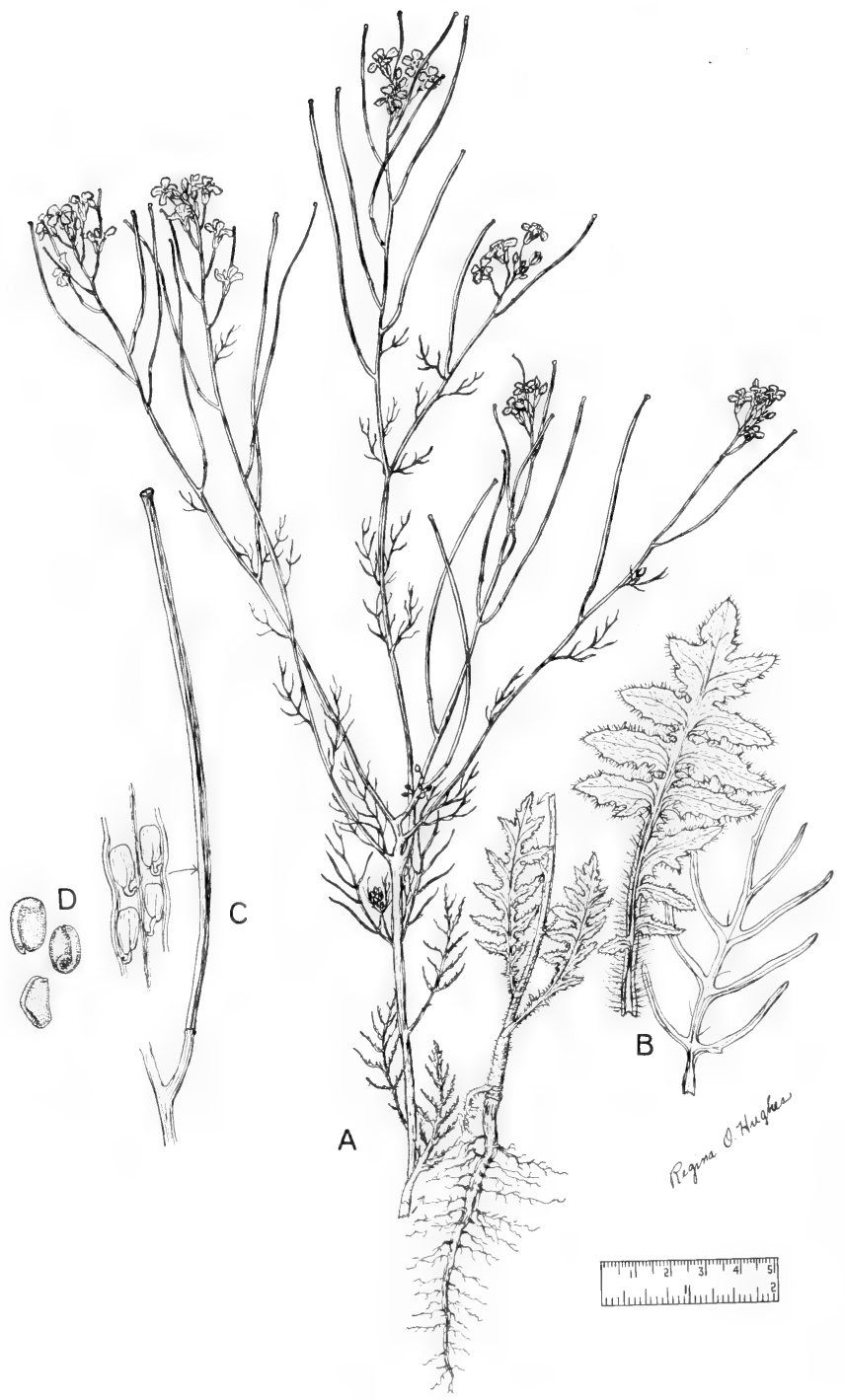

Fig. 468: Sisymbrium altissimum: A, habit, about $\times 1 \frac{2}{2}$; B, leaves, basal and cauline, $\mathrm{x} 3 / 4$; C, silique, about $\times 1 ; \mathrm{D}$, seeds, $\mathrm{x} 7$. (From Reed, Selected Weeds of the United States. Fig. 104). 
the lobes oblong and dentate, gradually changing upward on the plant to leaves with linear-filiform entire segments; flowers loosely racemose; petals pale-yellow, 6-9 mm. long; pedicels straight, widely spreading, similar in diameter to siliques; siliques terete, straight, long-linear, widely spreading and extending same angle as pedicel, 5-10 cm. long, glabrous; styles $1-2 \mathrm{~mm}$. long; seeds wingless, plump, oblong, about $1 \mathrm{~mm}$. long; cotyledons incumbent.

An ubiquitous weed of fields, roadsides and waste places, also wet meadows, edge of ponds and streams, throughout most of our region, May-Aug.; nat. of Eur.

\section{Descurainia WebB \& Berth. TANSY-MUSTARD}

More than 50 species in the cold and temperate regions of America, Eurasia and South Africa.

\section{Descurainia californica (Gray) Schulz.}

Annual or biennial; stems erect, 3-8 dm. tall, branched above, glabrous or very sparsely pubescent below; leaves simply pinnate; pinnae in 2 to 4 pairs, lanceolate, about $5 \mathrm{~cm}$. long, entire to serrulate or somewhat incised, often slightly pubescent; pedicels slender, 3-7 mm. long, erect-ascending to somewhat spreading; petals yellow, $1.5-2 \mathrm{~mm}$. long, barely exceeding the sepals; fruit 3-6 $\mathrm{mm}$. long, to about $1.3 \mathrm{~mm}$. thick, fusiform, the style $0.5 \mathrm{~mm}$. long or more; seeds 2 to 7 , in 1 row in each cell.

In marshes and in wet soil at head of ponds in N.M. (Taos Co.) and Ariz. (Apache and Coconino cos.), June-Sept.; Wyo. to Ore., s. to N.M., Ariz. and Calif.

\section{Cardamine L. Bitter-Cress}

Annual, biennial or perennial herbs, glabrous to sparsely hirsute with simple trichomes; leaves entire to pinnately compound, petiolate, alternate; flowers in racemes or panicles; petals white or purple, obovate to spatulate; siliques linear, straight, slightly compressed parallel to septum; valves opening elastically from silique base; replum margin extending partially over valvular area; seeds uniseriate, marginless, plump, longer than broad; cotyledons accumbent.

Between 150 to 175 species, cosmopolitan, mostly temperate.

1. Perennials with slender or tuberous rootstocks; leaves simple, the cordate-ovate to obovate or reniform blades entire to repand or shallowly dentate (2)

1. Annuals with fibrous roots; leaves pinnately lobed to compound (3)

2(1). Stems from a short hard tuber; distribution in eastern Texas................. 1. C. bulbosa.

2. Stems from a slender creeping rootstock; distribution in New Mexico and Arizona. 2. C. cordifolia.

3(1). Siliques $1.5-2 \mathrm{~mm}$. wide; petals greenish, strap-shaped.

3. Siliques $1 \mathrm{~mm}$. wide or less; petals white, usually spatulate (4)

4(3). Petioles of cauline leaves hirsute-ciliate at base; stems several to many from the base

4. C. hirsuta.

4. Petioles of cauline leaves naked at base; stems one or few from the base (5)

5(4). Stem hispid or hispidulous near the base; terminal leaflet usually much broader than the elliptic to obovate lateral leaflets that are noticeably decurrent on the rachis. 5. C. pensylvanica. 
5. Stem glabrous; terminal leaflet usually about as broad as the linear lateral leaflets that are cuneate or short-petiolulate at base.

..6. C. parviflora var. arenicola.

1. Cardamine bulbosa (Schreb.) B.S.P. SPRING-CRESS. Fig. 469.

Stems erect from a short tuber, 2-6 dm. tall, simple or branched above, with fine pubescence on the lower part; leaves simple; basal leaves long-petioled and obovate to cordate-ovate; lower cauline leaves petioled, the upper sessile, entire to remotely dentate; petals white, $7-15 \mathrm{~mm}$. long; siliques linear-lanceolate to linear, divaricate, $2-3 \mathrm{~cm}$. long, on slender pedicels $2-3 \mathrm{~cm}$. long; styles $2-3 \mathrm{~mm}$. long; seeds variable, suborbicular to elongate-oval.

Wet woods, creek bottoms and marshy meadows, n.e. Okla. (Waterfall) and e. Tex., Feb.-May; Tex. to Fla., Minn. and Que.

\section{Cardamine cordifolia Gray. Fig. 470.}

Erect perennial with extensively developed slender rootstocks $2-2.5 \mathrm{~mm}$. thick; flowering stems simple, 2-6 dm. tall, glabrous to rather densely pubescent near the base with short spreading simple hairs; leaves simple, rather fleshy, glabrous, almost entirely cauline, the basal ones often with a slender petiole 2 to 5 times as long as the blade; blade reniform to cordate-rotund or cordate-deltoid, usually sinuately crenate, $3-10 \mathrm{~cm}$. wide; upper cauline leaves often with petioles proportionately less than half as long as those of the lower leaves, the more nearly cordate-deltoid blades sinuate to lobed-mucronulate and 2-6 cm. long; racemes simple, ebracteate; pedicels spreading-ascending, 1-2 cm. long; sepals 3-4 mm. long, glabrous, the outer ones slightly saccate at the base; petals white, obovatespatulate, long-clawed, 7-12 mm. long; stamens slightly longer than the sepals; siliques straight, ascending to nearly erect, $2-3.5 \mathrm{~cm}$. long, $1.5-4 \mathrm{~mm}$. wide, the valves very indistinctly 1 -nerved near the base; stylar beak usually $0.5-2 \mathrm{~mm}$. long; seeds about $1.5 \mathrm{~mm}$. broad, flattened but not winged, nearly smooth.

Mt. streams, stream banks, marshes, seepage areas and alpine wet meadows in N.M. (Rio Arriba, Santa Fe, San Miguel, Lincoln, Taos and Otero cos.) and Ariz. (Apache and Coconino cos.), June-Sept.; Wyo. and Ida., s. to N.M. and Ariz.

\section{Cardamine macrocarpa Brandeg. var. texana Roll.}

Herbaceous annual; stems several from base, 2-4 dm. long, glabrous, semierect to decumbent, highly branched, slightly angled with a narrow wing; leaves pinnatifid to simply pinnate, nonauriculate, the rachis minutely puberulent; leaflets usually petiolulate, dentate to shallowly lobed, infructescences with a gyrate rachis; petals greenish, strap-shaped, less than $1 \mathrm{~mm}$. wide; pedicels straight, divaricate, minutely puberulent to glabrous, $5-8 \mathrm{~mm}$. long; siliques straight, $2.5-4 \mathrm{~cm}$. long, 1.5-2 mm. wide; styles $1-2 \mathrm{~mm}$. long.

Damp or wet shady places in the mts. of the Tex. Big Bend region, Apr.-July; Tex. to Coah.

\section{Cardamine hirsuta L. Hairy bitter-Cress. Fig. 470.}

Annual; stems erect to slightly decumbent, several to numerous from the base, simple or sparsely branched above, 1-2.5 (-3) dm. tall; leaves pinnately lobed, basal and lower cauline with entire to shallowly dentate suborbicular lobes and simple spreading trichomes on the petioles and leaf bases, upper cauline reduced and usually glabrous with oblong lobes; flowers small; petals white, spatulate, to $3 \mathrm{~mm}$. long; siliques erect, straight, 15-25 $\mathrm{mm}$. long, about $1 \mathrm{~mm}$. wide, the valves elastic; styles $0.5 \mathrm{~mm}$. long or less; seeds broadly oblong; cotyledons accumbent. 


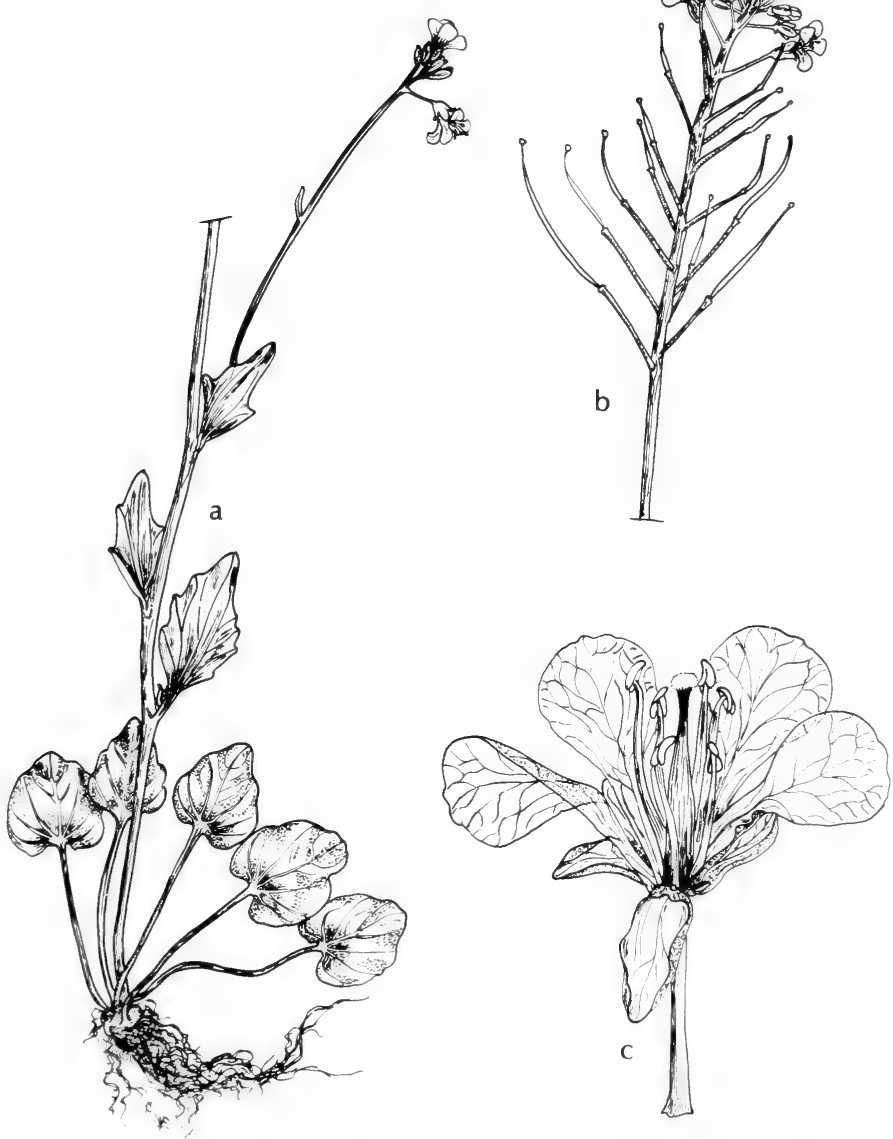

Fig. 469: Cardamine bulbosa: a, lower part of plant, $\mathrm{x} \frac{1}{2} ; \mathrm{b}$, upper part of plant. x $1 / 2$; c, flower, $x 2 \frac{1}{1 / 2}$. (V. F.). 


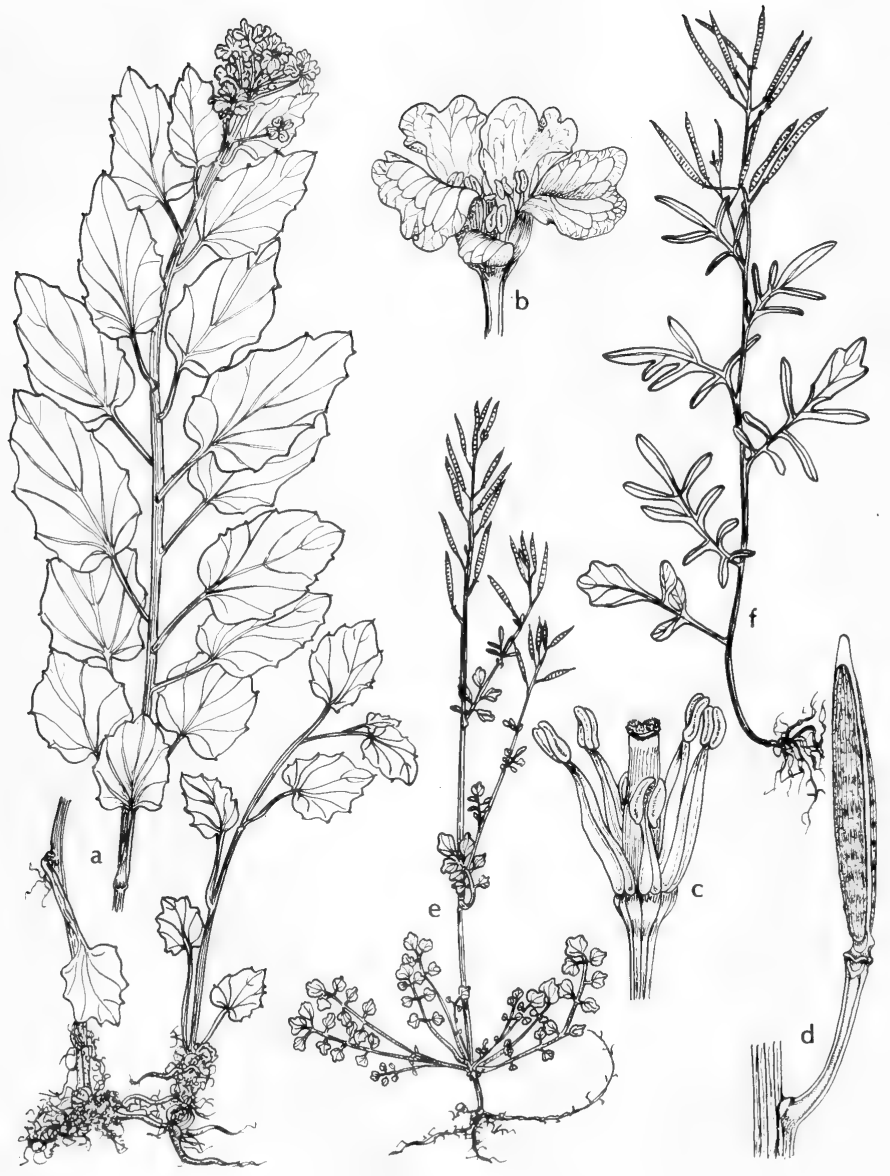

Fig. 470: Cardamine. a-d, C. cordifolia: a, habit, $x$ 1/2; b, flower, $x$ 2; c, ovary and stamens, x 5; d, fruit, x 2. e, C. hirsuta: e, habit, x 1/2. f, $C$. pensylvanica: $\mathrm{f}$, habit, X 1/2. (V. F.). 
Roadsides, open fields and other weedy situations, usually in damp or wet soil, rare in e. Tex. where recently found in Cass Co., spring; introd. from Eur. and found mostly in the s.e. U.S.

\section{Cardamine pensylvanica Muhl. ex Willd. Fig. 470.}

Biennial or short-lived perennial 2-8 dm. tall; stem usually hispid at base, otherwise glabrous, erect or decumbent and trailing when wholly or partially submersed, simple or much-branched; rosette leaves with 1 to 6 pairs of elliptic to obovate or rounded glabrous leaflets with bases decurrent along or confluent with the rachis, dentate to undulate, the terminal leaflet largest; cauline leaves with membranous leaflets linear-oblanceolate to obovate, their bases oblique and confluent with the rachis, the terminal leaflet usually much broader than the laterals; petals white, $1.5-4 \mathrm{~mm}$. long; stamens 6 ; siliques narrowly linear, $1-3 \mathrm{~cm}$. long, with slender pedicels $2-15 \mathrm{~mm}$. long, beaked by a tapering style $0.5-2 \mathrm{~mm}$. long; seeds 1-1.5 mm. long.

In swamps and wet woods, about springs, in seepage areas and along streams in Okla. (Johnston Co.) and Tex. (Fernald), Mar.-Aug.; from Lab. to B.C., s. to Fla., Ala., Ark., (?) Tex. and Oreg.

\section{Cardamine parviflora L. var. arenicola (Britt.) Schulz. Fig. 471.}

Glabrous annual; stems usually erect, simple or branched above, 1-3 dm. tall; leaves pinnatifid to pinnately lobed, petiolate; leaf lobes entire to shallowly dentate, cuneate at base or with a short petiolule; flowers small, crowded; petals white, spatulate, 2.5-3.5 mm. long; pedicels slender, ascending, 5-8 mm. long; siliques erect, 2-3 cm. long; styles less than $1 \mathrm{~mm}$. long; seeds plump, oblong, $0.7-0.9 \mathrm{~mm}$. long; cotyledons accumbent.

Moist seeps, wet sandy soils and open wet places in wooded areas, ditches and stream banks, e. Okla. (Waterfall) and cen. and e. Tex., Feb.-Apr.; Fla. to e. Can., w. to Ore. and Wash.

\section{Rorippa SCOP. Yellow-CRESS}

Annual to perennial herbs, mostly glabrous or sparingly pubescent; stems usually branched; leaves simple to pinnate or compound; flowers in terminal or axillary racemes; sepals spreading in anthesis; petals yellow or white, small or absent; siliques terete, narrowly cylindrical to globose, sessile; valves nerveless; seeds usually numerous, plump, small, marginless; cotyledons accumbent.

About 70 species in temperate and subtropical areas of the world.

Probably all or most of the species, especially the water cress ( $R$. Nasturtiumaquaticum), are of value as food for wildfowl and wildlife, generally. The herbage of the water cress, used as a salad by man, is known to be eaten by various ducks, muskrats and deer, and it also provides a haven for small aquatic life that, in turn, provide food for fish. Under optimum conditions water cress grows rapidly, often at the expense of most other aquatic vegetation.

1. Petals conspicuous, white; leaves pinnately compound.

1. Petals yellow if present, minute or absent; leaves entire to pinnatifid but not compound (2)

2(1). Petals exceeding sepals, broadly oblong to obovate; plants perennial with underground rhizomes.

2. $R$. sinuata.

2. Petals about as long as or shorter than sepals or absent, narrowly oblanceolate when present; plants with a taproot (3)

3(2). Siliques sessile or pedicels less than $2 \mathrm{~mm}$. long; petals absent.

3. Siliques pedicellate; pedicels $2 \mathrm{~mm}$. long or more; petals present (4) 


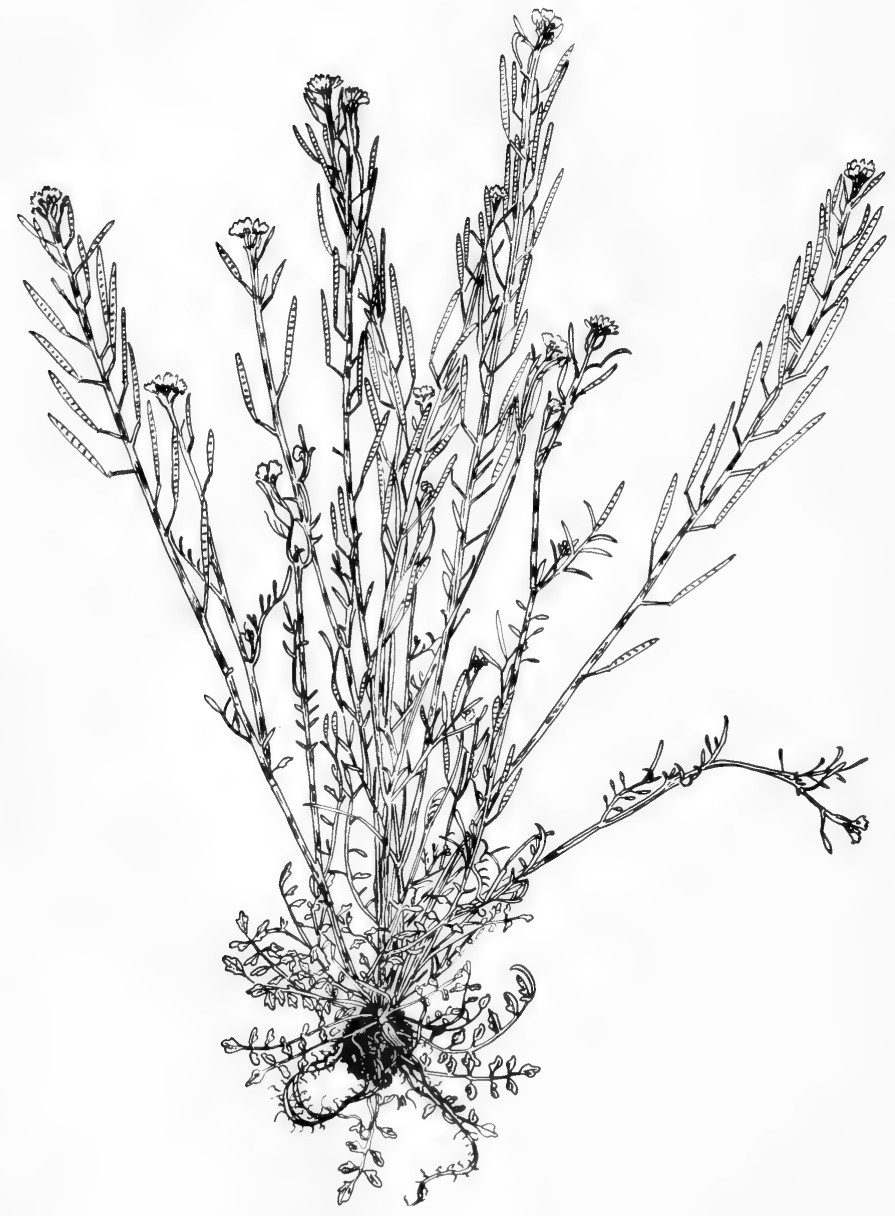

Fig. 471: Cardamine parviflora: habit, $x$ 1/2. (V. F.). 


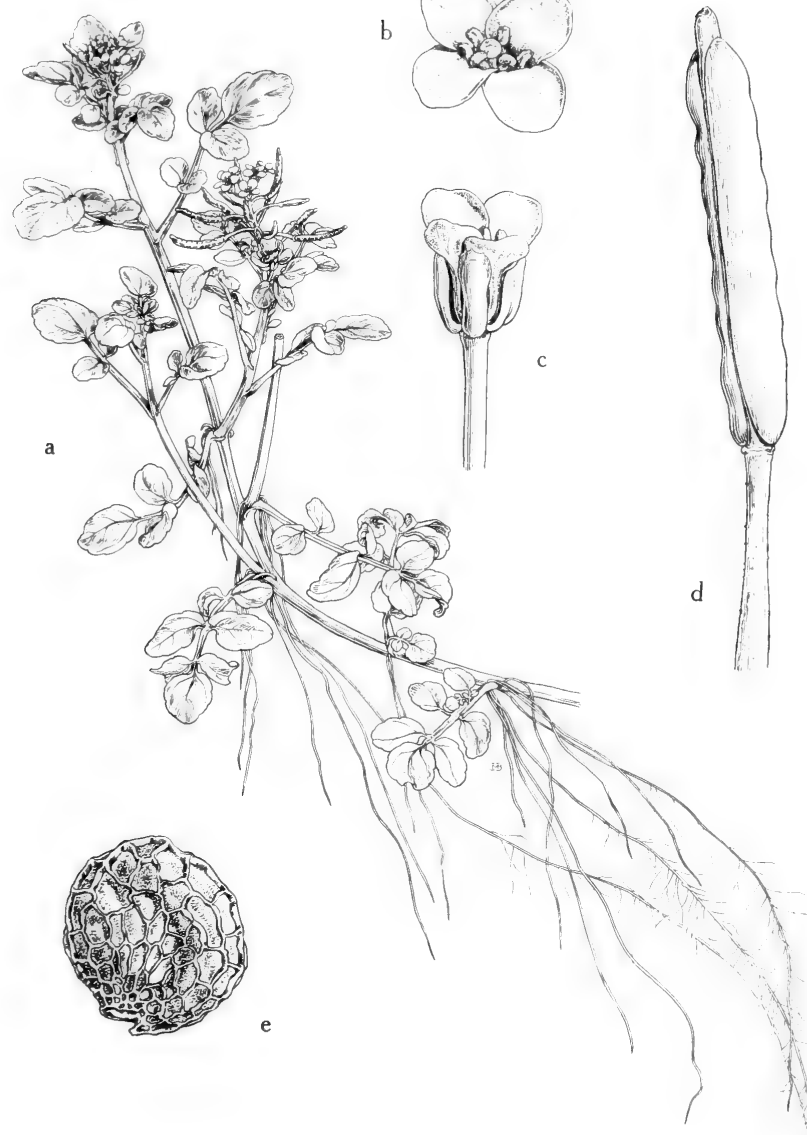

Fig. 472: Rorippa Nasturtium-aquaticum: a, habit, x $\% 3$; b, flower, top view, $\mathrm{x} 4$; c, flower, side view, x 4; d, pod, x 4; e, seed, x 20. (From Mason, Fig. 246). 
4(3). Siliques short and thick, globose or ovoid to broadly oblong and obtuse (5) 4. Siliques elongated, terete (6)

5(4). Siliques globose, about $2 \mathrm{~mm}$. in diameter. 4. R. sphaerocarpa.

5. Siliques ovoid to broadly oblong, obtuse, usually more than $3 \mathrm{~mm}$. long. 5. $R$. islandica.

6(4). Plants glabrous or (if with indument) the trichomes simple and pointed (7) 6. Vesicular trichomes present on stems, foliage or siliques (8)

7(6). Pods usually strongly curved, $8 \mathrm{~cm}$. long or more; leaf segments linear to oblong, mostly acute; style stout, not over $0.5 \mathrm{~mm}$. long.

6. $R$. curvisiliqua.

7. Pods not curved, $4-8 \mathrm{~cm}$. long; leaf segments obovate or rounded; style slender, 1-2 $\mathrm{mm}$. long. 7. R. obtusa.

8(6). Leaf segments deeply dentate; lower leaves pinnatifid; cauline leaves petiolate.................................................................... $8 . R$. teres.

8. Leaf segments entire; lower leaves merely lobed; cauline leaves sessile

.9. $R$. ramosa.

1. Rorippa Nasturtium-aquaticum (L.) Hayek. WATER-CRESS. Fig. 472.

Aquatic to semi-aquatic perennial, glabrous; stemis floating, creeping or ascending, rooting at the nodes; leaves pinnately compound with 3 to 9 segments; leaflets ovate to oval, terminal larger than the lateral, somewhat fleshy; petals 3-4 mm. long; fruiting pedicels divaricate, $8-12 \mathrm{~mm}$. long; fruit $1-2 \mathrm{~cm}$. long, ellipsoid, spreading or curved upward; style about $1 \mathrm{~mm}$. long; seeds about $1 \mathrm{~mm}$. long, plump, nearly orbicular. Nasturtium officinale $\mathrm{R}$. Br.

In clear water of slow-running streams and on stream margins, in and about cold springs, throughout most of our region, Mar.-July; widely dispersed as an introd. from Eur.

This is the common water cress used in salads.

2. Rorippa sinuata (Nutt.) Hitchc. Fig. 473.

Perennial with creeping rhizomes; stems 2-4 dm. tall, glabrous, highly branched, erect to decumbent; leaves oblong to oblanceolate, deeply pinnatifid, the segments entire or nearly so; petals obovate, not differentiated into blade and claw, exceeding sepals; pedicels slender, 6-10 $\mathrm{mm}$. long, spreading; siliques curved upward, 8-14 mm. long, about $2 \mathrm{~mm}$. wide; seeds angular, plump, 0.7-0.8 $\mathrm{mm}$. long.

Moist gravel along streams, seepy stream banks, borders of lakes and marshes, also waste places generally, in Okla. (Waterfall), n. and w. Tex. and N. M. (Mora Co. ), Apr.-July; Ill. and cen. Can. to Wash., Nev. and N. M.

\section{Rorippa sessiliflora (Nutt.) Hitchc.}

Annual or biennial with a taproot; stems erect, branched, 2-5 dm. tall, glabrous; leaves petiolate, oblanceolate, dentate; flowers in terminal and lateral racemes, small; sepals yellowish; petals absent or very rarely a petal may be seen in one or two flowers of a plant; pedicels less than $1 \mathrm{~mm}$. long; siliques sessile or nearly so, terete to slightly compressed parallel to septum, oblong, 6-10 mm. long; styles less than $1 \mathrm{~mm}$. long; seeds numerous, cordiform, plump, $0.4-0.6 \mathrm{~mm}$. long.

Wet land, river floodplains and along sluggish stream margins or around ponds, in n.-cen. Okla. (Alfalfa Co.) and n. and e. Tex., Apr.-Aug.; Tex. and La. to Va., Ind. and Minn. 


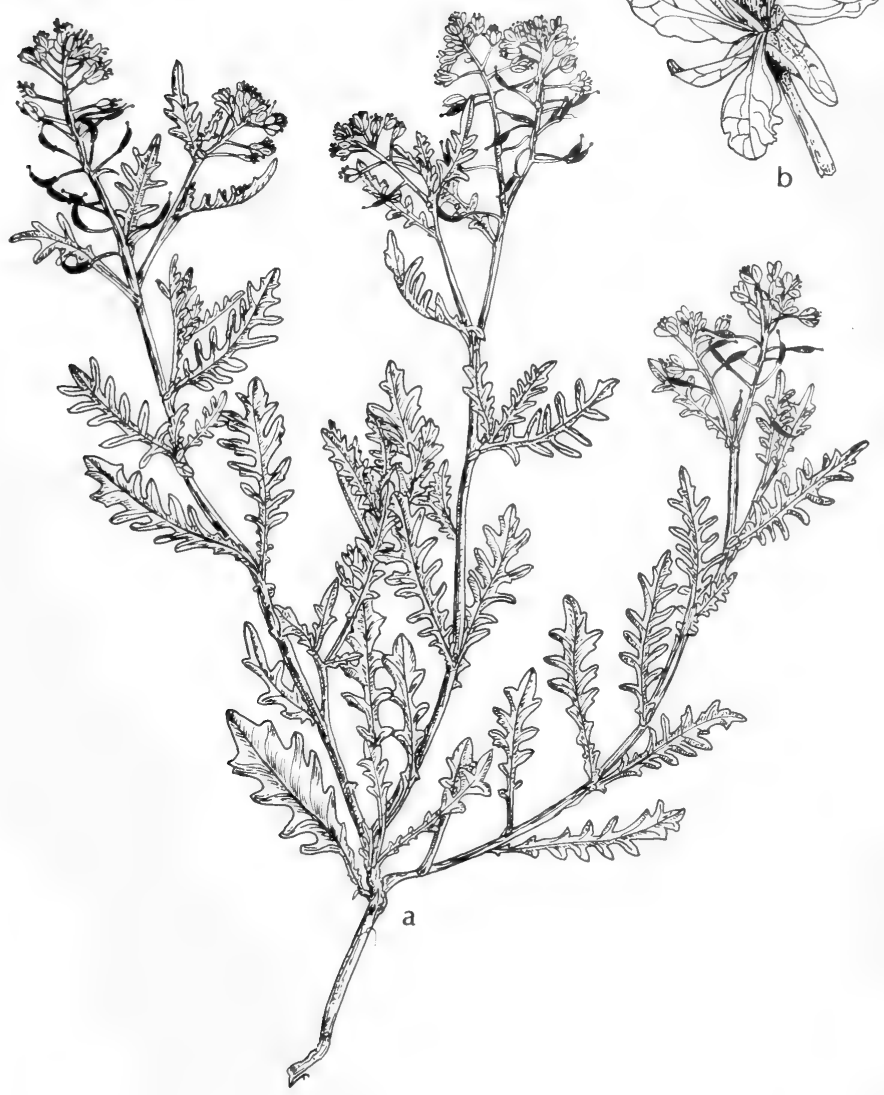

Fig. 473: Rorippa sinuata: a, habit, $x \frac{1}{2} ;$; , flower, $x$ 3. (V. F.). 


\section{Rorippa sphaerocarpa (Gray) Britt.}

Annual or biennial; stems 1-3 dm. tall, erect or decumbent, diffusely branched from the base, glabrous; leaves oblong, the lower ones lyrate-pinnatifid to sinuately lobed, the upper ones nearly entire; pedicels 2-3 $\mathrm{mm}$. long, rarely to 5; petals yellow, about $1.5 \mathrm{~mm}$. long; siliques globose or nearly so, typically 2 (rarely 3 ) $\mathrm{mm}$. in diameter; style about $0.5 \mathrm{~mm}$. long, the stigma not much enlarged.

In water of streams, marshes, seepage areas, wet meadows and mud about lakes and ponds in N. M. (Catron, Colfax, Sandoval, Taos and Union cos.) and Ariz. (Coconino and Navajo cos.), June-Oct.; Ill. to Wyo., s. to N. M., Ariz. and Calif.

This plant is placed by some authors in $R$. obtusa, and perhaps rightly so. However, when plants with strictly orbicular fruits are compared with plants of typical $R$. obtusa with its ovoidish pointed fruits the two look quite different.

\section{Rorippa islandica (Oeder) Borbás. BOG MARSH-CRESS.}

Annual or biennial; stems 2-13 dm. tall, simple or branched above, glabrous to hirsute with simple pointed trichomes; leaves pinnate to pinnatifid or merely toothed; pedicels filiform, 4-12 mm. long, usually about equaling the fruit, spreading; sepals about $2 \mathrm{~mm}$. long; petals yellow, 1.7-2 mm. long; stamens 6; siliques slenderly ellipsoid to ovoid, (2-) 3-10 mm. long, 1-4 mm. thick; style $0.5-1 \mathrm{~mm}$. long; seeds plump, cordiform, 0.4-0.9 mm. long. $R$. palustris (L.) Bess.; $R$. hispida (Desv.) Britt.

In marshes, bogs, muddy soil on edge of ponds, seepage areas, about springs and along streams in Okla. (Alfalfa, Caddo, Craig, Custer, Bryan, Grady, McCurtain and Delaware cos.), n.e. and n.w. Tex., N.M. (Lincoln, Otero, Sandoval, San Juan, San Miguel and Taos cos.) and Ariz. (Apache, Coconino, Greenlee and Pinal cos.), May-Sept.; widely distributed throughout much of N.A. and Euras.

We have several phases of this highly variable species whose separation is adapted from Fernald.

1. Leaves all or nearly all pinnate to deeply pinnatifid, the numerous lanceolate dentate segments decurrent along the rachis; siliques slenderly ellipsoid, often curved, 4-10 $\mathrm{mm}$. long, equaling the pedicels; thinleaved glabrous plant................................................var. islandica.

1. Lower leaves merely pinnatifid to runcinate or uncleft, the middle and upper leaves coarsely toothed to subentire; plants relatively coarse, to 13 $\mathrm{dm}$. tall, the leaves (except when submersed) firm (2)

2(1). Siliques slenderly ellipsoid to subcylindric, 3-9 $\mathrm{mm}$. long, 1-2.5 $\mathrm{mm}$. thick; plant glabrous throughout or the stem hispid below. .var. Fernaldiana Butt. \& Abbe.

2. Siliques short-ellipsoid to ovoid or subglobose, $2-5.5 \mathrm{~mm}$. long, 1.7-4 mm. thick; base of stem or lower leaves frequently hispid. .var. hispida (Desv.) Butt. \& Abbe.

\section{Rorippa curvisiliqua (Hook.) Bessey.}

Annual or biennial, diffusely branched or single-stemmed and branched above, 1-4 dm. tall, the branches ascending, glabrous to sparsely strigillose throughout or only on the stems; leaves variable, $2-7 \mathrm{~cm}$. long, usually somewhat oblonglanceolate, nearly entire to toothed or pinnately parted to pinnatifid, the oblong to ovate obtuse segments entire to dentate; flowers in short racemes; pedicels mostly spreading, usually $2-4 \mathrm{~mm}$. long, occasionally more, about half as long as fruit; sepals 1-2 $\mathrm{mm}$. long, promptly deciduous or remaining until the fruits are well-formed; petals yellow, 1-2 mm. long; siliques 8-15 mm. long, 1-1.5 mm. broad, nearly terete, curved or sometimes straight; style $0.3-1 \mathrm{~mm}$. long, the small stigma entire; seeds finely areolate-papillate. 


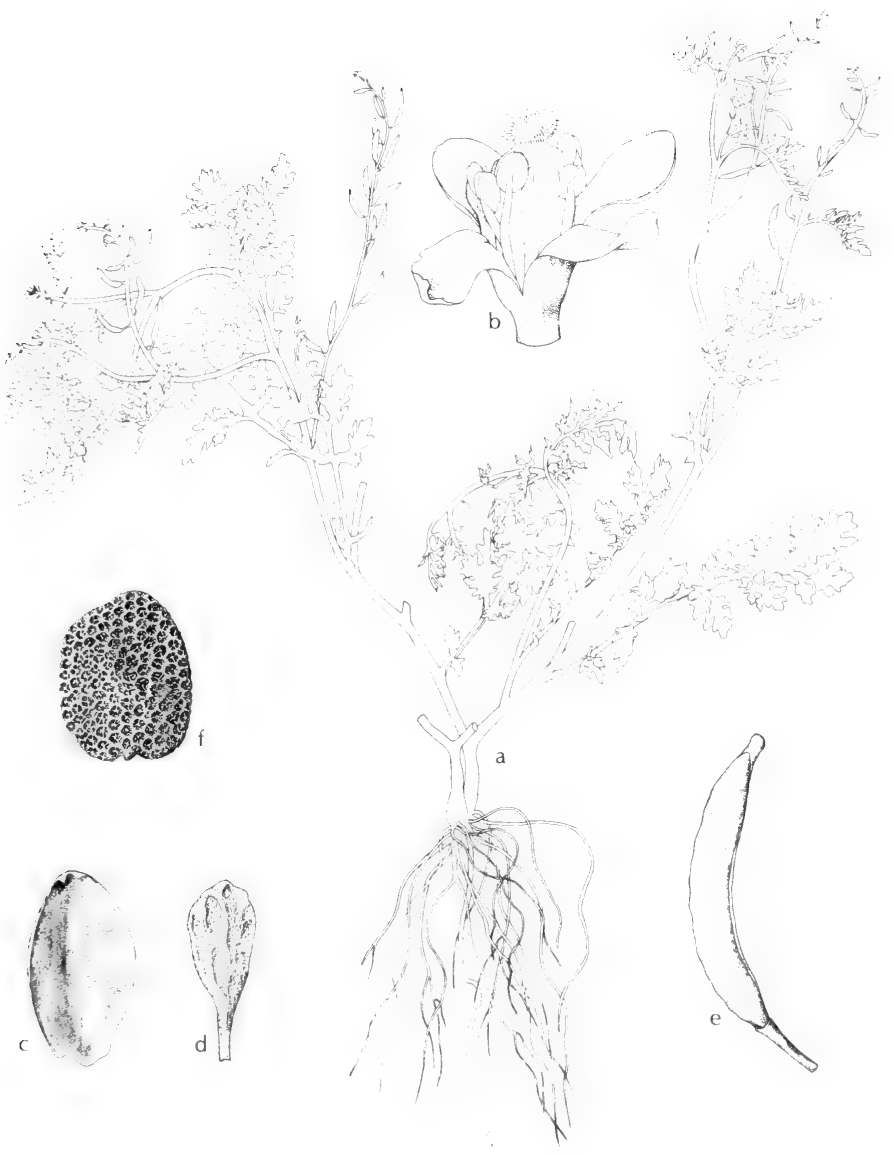

Fig. 474: Rorippa teres: a, habit, x 1/2; b, flower, x 25; c, sepal, x 25; d, petal, x 25 ; e, silique, $x 3$; f, seed, $x$ 100. (Courtesy of R. K. Godfrey). 


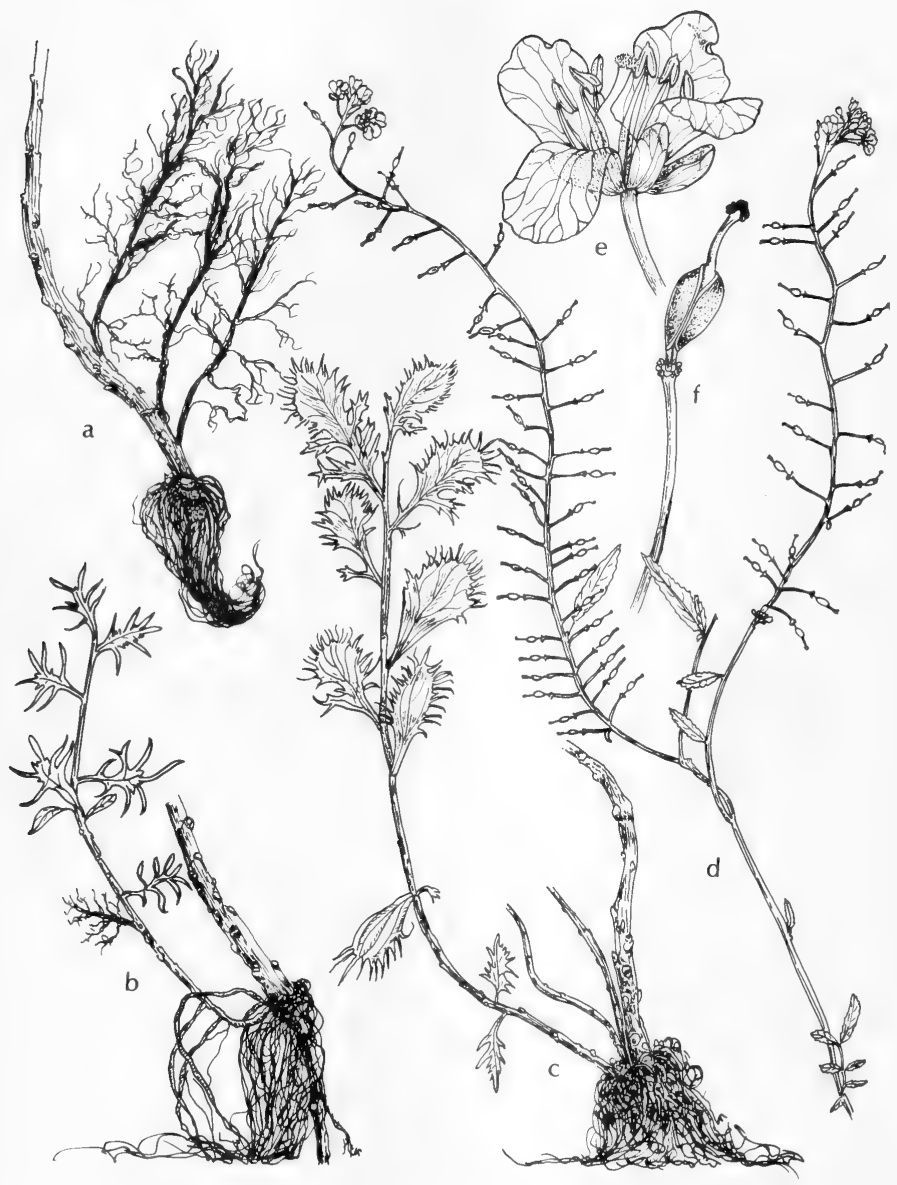

Fig. 475: Armoracia aquatica: a-c, lower parts of stems showing variation in submerged leaves, x 1/2; d, upper part of emersed plant, x 1/2; e, flower, x 3 ; f, fruit, x 3 . (V. F.). 
In mud at edge of lakes and ponds, and other wet places, in Ariz. (Coconino, Navajo, Pinal and Yavapai cos.), June-Sept.; Mont. and Wyo., s. to Ariz. and Calif.

\section{Rorippa obtusa (Nutt.) Britt.}

Diffusely branched glabrous annual with erect to somewhat decumbent stems 1.5-4 dm. long; leaves oblong-lanceolate, 2-6 cm. long, shallowly sinuately lobed to pinnatifid with the obovate rounded segments sinuately lobed to entire; pedicels ascending to spreading, 2-4 (-7) $\mathrm{mm}$. long, usually shorter than the fruit; sepals deciduous shortly after anthesis; petals pale-yellow, spatulate, 1-2 mm. long; siliques ovoid to oblong-lanceolate, $4-8 \mathrm{~mm}$. long, 2-2.5 $\mathrm{mm}$. broad; style $0.5-1$ $\mathrm{mm}$. long, the small stigma entire; seeds about $0.5 \mathrm{~mm}$. long, minutely alveolatepapillate.

Wet soil along streams and ditches, and in wet meadows, rather widespread in mts. of N. M. and Ariz., June-Sept.; Mich. and Mo., w. to B.C., N.M., Ariz. and Calif.

\section{Rorippa teres (Michx.) Stuckey. Fig. 474.}

Annual or biennial; stems 1-3 dm. long, erect to decumbent, branched; sparsely pubescent with vesicular trichomes, rarely glabrous; leaves oblong to oblanceolate, deeply pinnatifid and with the remote segments obtusely toothed, petiolate; racemes terminal and axillary, densely flowered; petals minute, about $1 \mathrm{~mm}$. long, yellow; pedicels spreading, 2-5 mm. long; siliques linear-oblong, $1-1.5 \mathrm{~cm}$. long, straight or slightly curved; styles evident, about $1 \mathrm{~mm}$. long; seeds numerous, plump, slightly longer than broad, about $0.5 \mathrm{~mm}$. long. $R$. Walteri (Ell.) Mohr.

Wet fields, lakes, ponds and stream margins and swamp land, s.-cen. Okla. (Marshall Co.) and e. and s.w. Tex., Dec.-May; S.C. and Fla. to Okla. and C. A.

\section{Rorippa ramosa Roll.}

Perennial; stems numerous, decumbent, highly branched, sparsely pubescent with vesicular trichomes, 3-6 dm. long; leaves numerous, sessile, auriculate, oblong to broadly lanceolate, pinnately lobed, 3-5 cm. long, 5-12 mm. wide; inflorescences short, mostly less than $5 \mathrm{~cm}$. long; petals pale-yellow, 2.5-3 mm. long; pedicels widely spreading to ascending, 3-5 $\mathrm{mm}$. long; siliques divaricately spreading to erect, oblong to lanceolate in outline, plump, 6-10 $\mathrm{mm}$. long; valves densely covered with vesicular trichomes along their margins; styles $1.5-2.5 \mathrm{~mm}$. long; seeds plump, cordiform, about $1.5 \mathrm{~mm}$. in diameter.

Floodplains and intermittent stream beds, Big Bend region near the Rio Grande in w. Tex., Mar.-May; also Coah. to Dgo.

\section{Armoracia Gaertn.}

Three species in Eurasia and one species in North America. The ground thick roots of $A$. rusticana (Lam.) Gaertn., Mey. \& Scherb. is the condiment, horse-radish.

\section{Armoracia aquatica (Eat.) Wieg. LAKE CRESS. Fig. 475.}

Plant weak from a slender rootstock, to about $6 \mathrm{dm}$. tall; stems commonly submersed; submersed leaves repeatedly pinnately dissected into numerous filiform segments; emersed leaves (if present) lancolate to narrowly oblong, 3-7 cm. long, finely to coarsely dentate; petals $6-8 \mathrm{~mm}$. long; mature pedicels divaricate, about $1 \mathrm{~cm}$. long; fruits rarely perfected, ellipsoid or somewhat obovoid, $5-8 \mathrm{~mm}$. long, 1-celled; persistent style slender, $2-4 \mathrm{~mm}$. long.

In quiet water of lakes and streams, and on muddy shores in e. Okla. (Cherokee and McCurtain cos.) and e. Tex. (Tyler Co.), Apr.-July; Que. to Ont. and Minn., s. to Fla. and Tex. 


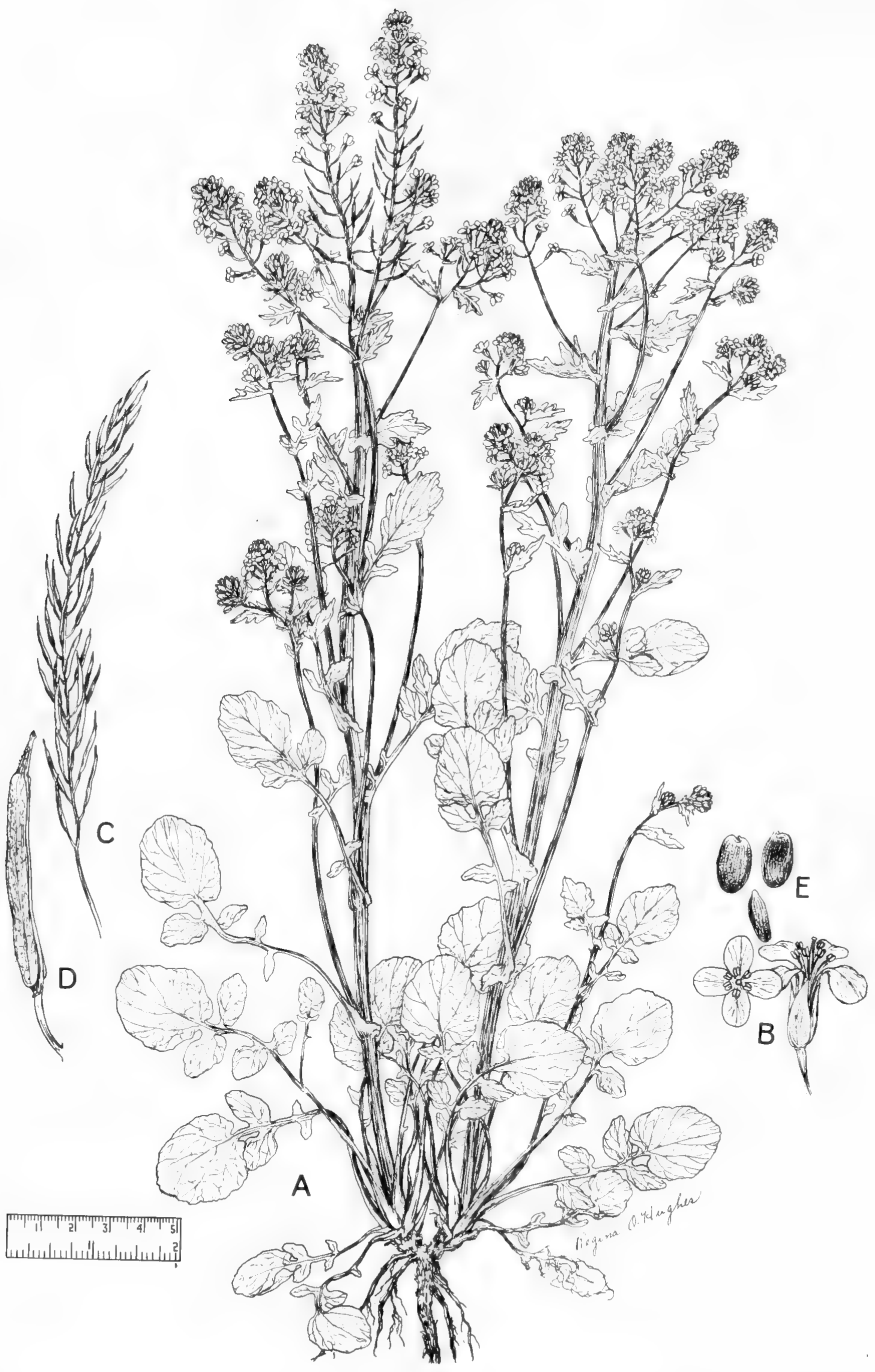

Fig. 476: Barbarea vulgaris: A, habit, about $\mathrm{x} 1 \frac{1}{2} ; \mathrm{B}$, flower, $\mathrm{x} 2$; C, raceme of fruits, about x 1/2; D, silique, x 2; E, seeds, x 5. (From Reed, Selected Weeds of the United States, Fig. 93). 


\section{Barbarea R. BR.}

\section{Winter Cress}

Glabrous to sparsely hirsute biennial or perennial herbs with overwintering rosettes; stem erect, angled, branched above; cauline leaves with clasping bases; flowers yellow, in elongate ebracteate racemes: stamens 6; silique linear, terete or somewhat 4-sided, the valves keeled by a midnerve; style more or less beaklike; seeds in a single row in each locule, marginless; cotyledons accumbent.

About a dozen species in North America and Eurasia.

1. Beak of silique slender, $1.8-3 \mathrm{~mm}$. long; uppermost leaves typically coarsely dentate, angulate or lobed....................................... B. vulgaris.

1. Beak of silique stoutish, 0.3-1 (-2) $\mathrm{mm}$. long; uppermost leaves typically lyrate-pinnatifid.

2. B. orthoceras.

1. Barbarea vulgaris $\mathrm{R}$. Br. var. arcuata (Opiz) Fries. Yellow Rocket, winter CRESS. Fig. 476.

Smooth or sometimes basally hirsute biennial or perennial; lower leaves lyrate or rarely simple, the terminal elliptic-oblong to suborbicular lobe much the largest, the lateral smaller and narrower lobes in 1 to 4 pairs or wanting; upper leaves obovate to rounded, coarsely dentate, angulate or lobed but rarely pinnatifid; flowers somewhat racemose even in anthesis; raceme lax and open; petals narrowly obovate, 5.5-8 $\mathrm{mm}$. long, 2-3 mm. wide, bright yellow; siliques with slender spreading pedicels, arcuate-ascending to horizontally divergent, not imbricated, mostly 2-3 cm. long, with a slender beak (style) $1.5-3 \mathrm{~mm}$. long; seeds shortoblong to quadrate, $1-1.5 \mathrm{~mm}$. long, the lustrous grayish surface rugulose.

Wet meadows, alluvial ground near streams, and ubiquitous in weedy areas, in Okla. (Waterfall), Apr.-June; Que. to Ill., s. to Va., Ky. and Okla.

\section{Barbarea orthoceras Ledeb. AMERICAN WINTER CRESS.}

Glabrous or sparsely hirsute biennial with a taproot and usually a simple caudex, 3-6 dm. tall; stems usually many from base, stiff, erect, angled, usually much-branched; basal leaves long-petiolate, to $12 \mathrm{~cm}$. long; blade oblong-elliptic or subcordate to lyrate-pinnatifid to pinnate, the 2 to 6 linear lateral lobes entire to obtusely toothed, the ovate to orbicular terminal lobe irregularly toothed to entire, the petiole and sometimes the blade often long-ciliate or sparsely hirsute; lower cauline leaves similar to the basal but reduced upward, sometimes becoming simple, sagittate and winged-petiolate; racemes single and terminal, or more generally compound, reduced racemes present in the lower leaf axils; pedicels stout, 2-3 mm. long; sepals pale yellowish-green, about $2 \mathrm{~mm}$. long; petals yellow, spatulate-oblanceolate, 3-5 mm. long; siliques $2-5 \mathrm{~cm}$. long, $1.5-2.5 \mathrm{~mm}$. broad, slightly compressed but somewhat 4-angled due to the prominence of the midnerve of the valves, erect or strongly ascending, straight or somewhat arcuate, acute; style beaklike, $0.5-2 \mathrm{~mm}$. long; stigma very silghtly lobed; seeds uniseriate, finely pitted, about $1.5 \mathrm{~mm}$. long, not mucilaginous. B. americana Rydb.

Meadows, moist slopes, stream banks, springs, bogs and moist woods, in N. M. (Colfax and Taos cos.) and Ariz. (Apache, Cochise, Coconino and Graham cos.), Mar.-Aug.; Lab. and N.E., w. to Alas., s. in mts. to Colo., N.M., Ariz., Calif. and Mex.; Euras.

\section{Cakile Mill. Sea Rocket}

Annual herbs, fleshy, glabrous, caulescent, chiefly maritime; leaves alternate, entire or pinnatifid; flowers racemose, perfect; sepals erect, gibbous at the base; corolla cream to white or light-lavender; ovary sessile, the style wanting and the stigma entire; fruit indehiscent, 2-jointed, the joints 1-chambered with each usually 1 -seeded; seeds wingless; cotyledons accumbent, oblique or incumbent. 


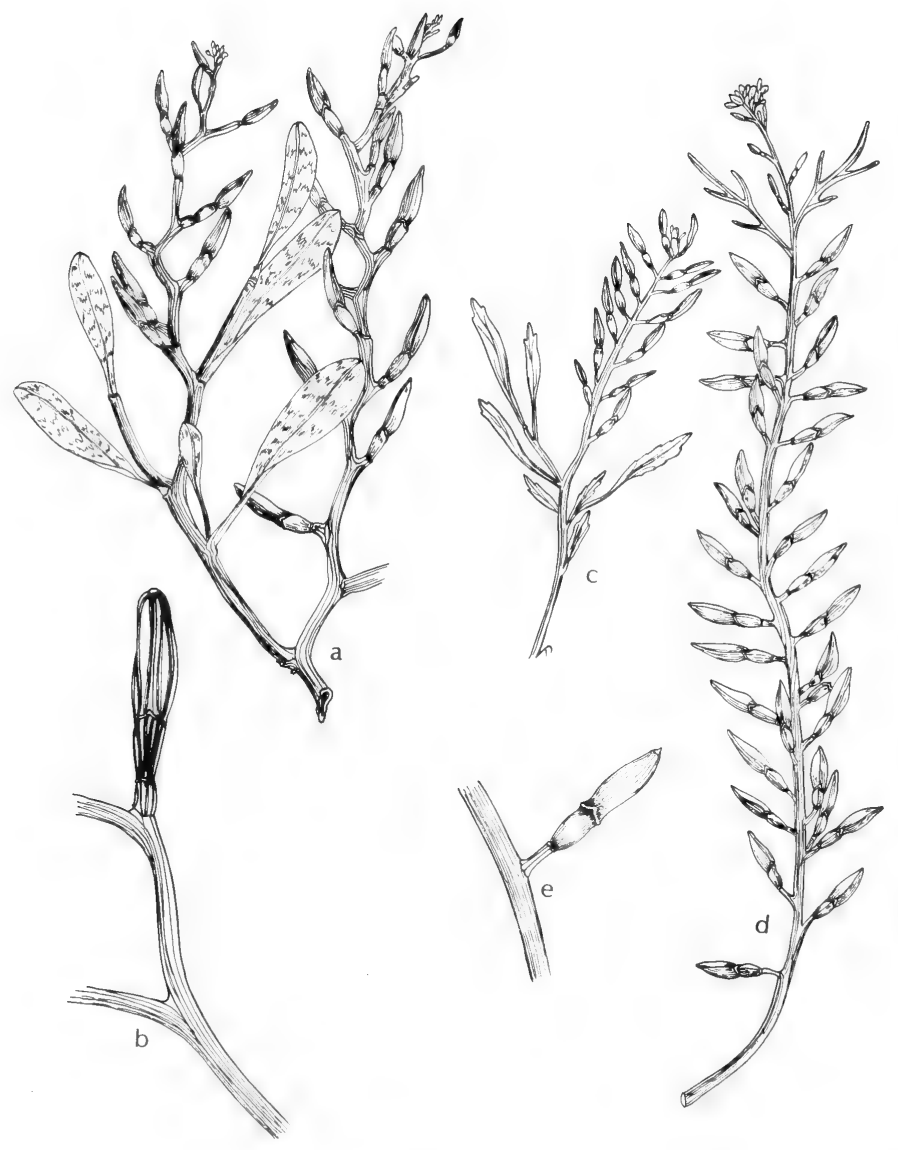

Fig. 477: a and b, Cakile geniculata: a, end of branch, x 1/2; b, fruit, x 1. c-e, Cakile fusiformis: c, tip of branch with fruit and leaves, $\mathrm{x} 1 / 2$; $\mathrm{d}$, tip of branch with mature fruit, $x 1 / 2$; e, fruit, $x 1$. (V. F.). 
About 15 species bordering oceans and large lakes in temperate North America, Eurasia and Australia.

1. Upper joint of pod less than $1 \mathrm{~cm}$. long, delicately 4-ridged; pedicels more slender than rachis; infructescence not geniculate.

1. C. fusiformis.

1. Upper joint of the pod over $1 \mathrm{~cm}$. long or more, coarsely 8-ridged; pedicels nearly same diameter as rachis; infructescence geniculate.

2. C. geniculata.

\section{Cakile fusiformis Greene. Fig. 477.}

Stems erect or spreading, 3-7 dm. long, fleshy; leaves $5-15 \mathrm{~cm}$. long, ovate in outline, laciniate-pinnatifid, obtuse, the segments linear; racemes greatly elongating, reaching 2-4 dm. long, rachis not geniculate; pedicels more slender than rachis, 3-5 $\mathrm{mm}$. long; fruit slender, 15-25 mm. long, the lower joint turbinate, nearly terete, usually 1-seeded, the upper joint subulate or lance-linear (longer than the lower).

Sandy areas near the ocean, mainland and offshore islands, edge of water and in periodical inundated areas, flowers any month; Fla. to Tex.

\section{Cakile geniculata (Robins.) Millsp. Fig. 477.}

Stout glabrous herbs; stem branching and more or less spreading, 1-4 dm. long; leaves 3-7 cm. long, oblanceolate to linear-oblanceolate, entire or with a few coarse rounded teeth; raceme $1-2 \mathrm{dm}$. long, strongly geniculate at maturity; pedicels very stout, 3-5 $\mathrm{mm}$. long, spreading or ascending; fruit nearly terete, 2-3 cm. long, the lower joint with a prominent border at the summit, the upper joint lanceolate or oblong-lanceolate and usually curved, usually 1 -seeded but occasionally 2-seeded (twice as long as the lower joint).

Beaches and sandy places near ocean, mainland and offshore islands, edge of water and in periodically inundated areas, flowers any month; n.w. Fla. to Tex.

\section{Selenia NutT.}

Low glabrous annuals with pinnately dissected leaves, caulescent or acaulescent; flowers odoriferous, in loose leafy-bracted racemes or on peduncles arising from the axils of a rosette of leaves; sepals spreading or erect, thickened with a low crest to markedly appendaged on exterior surface just below apex; petals obovate to spatulate, yellow; siliques subsessile to stipitate, flattened parallel to septum to inflated, broadly oblong to depressed globose; seeds biseriate in the silique, flattened, strongly margined or winged; cotyledons accumbent.

Five species, all from southwestern United States and adjacent Mexico.

1. Silique valves with vesicles present; siliques sessile; sepals persistent to fruit maturity............................................................ S. grandis.

1. Silique valves glabrous; siliques with at least a short stipe; sepals shed shortly after anthesis (persisting somewhat in $S$. dissecta) (2)

2(1). Siliques margined, tapered above and below, flattened parallel to septum; pedicels over $3 \mathrm{~cm}$. long......................................... S. dissecta.

2. Siliques not margined, rounded above and below, inflated and depressedsubglobose; pedicels less than $3 \mathrm{~cm}$. long.................... S. Jonesii.

\section{Selenia grandis Martin.}

Winter annual, branched near base with the lateral decumbent branches equaling or exceeding the central erect stem; main stem or branches to $6 \mathrm{dm}$. long; leaves bipinnate, petiolate, glabrous or with vesicular trichomes along midvein or petiolule, to $2 \mathrm{dm}$. long; inflorescences very leafy with each pedicel subtended by a leaflike bract; sepals with a prominent hornlike appendage, 
persisting while fruits mature; petals yellowish, broadly obovate, notched at apex, barely exceeding the sepals; pedicels slender to stout, widely spreading, to $2 \mathrm{dm}$. long; mature siliques thick and fleshy, broadly oblong, sessile, to $15 \mathrm{~mm}$. long and $1 \mathrm{~cm}$. wide, valve exterior covered with vesicular trichomes; seed somewhat flattened, margined.

Heavy soils and open floodplain areas, periodically flooded, from Dimmit and La Salle cos. southw, in the lower Rio Grande Valley of Tex., Feb.-Mar.; endemic.

\section{Selenia dissecta T. \& G.}

Mostly acaulescent, occasionally developing flowering stems, winter annual, often with a well-developed root; leaves bipinnate with acute lobes, glaucous, petiolate, to $1 \mathrm{dm}$. long; flowers mostly pedunculate as if on stems, then in an indefinite raceme; sepals widely spreading at anthesis, with a definite hornlike appendage; petals yellow, obovate to spatulate, exceeding the sepals; pedicels erect to spreading, to $8 \mathrm{~cm}$. long; siliques at first inflated, becoming thick and fleshy at maturity, flattened parallel to septum, stipitate, to $3 \mathrm{~cm}$. long, $1 \mathrm{~cm}$. wide; style flaring broadly at base, to $5 \mathrm{~mm}$. long; seeds margined, flattened.

Low places and playa lake margins, Big Bend region e. to Ector Co. in Tex., Feb.-June; also N.M. and n.e. Mex.

\section{Selenia Jonesii Cory.}

Winter annual, branching at crown; branches decumbent, to $3 \mathrm{dm}$. long; leaves bipinnate with small obtuse ultimate lobes, petiolate, to $1 \mathrm{dm}$. long; flowers both pedunculate and on stems in leafy-bracted racemes; sepals tawny, oblong, with a short pouchlike appendage to merely a thickened area below sepal apex; petals yellow, spatulate; pedicels widely spreading, to $3 \mathrm{~cm}$. long; siliques inflated, subglobose, short-stipitate, rounded above and below, to $12 \mathrm{~mm}$. in diameter; styles 2-3 mm. long; seeds widely winged; cotyledons accumbent.

Moist or wet swales and buffalo wallows on high prairies and plateaus of w.-cen. Tex., Mar.-Apr.; endemic.

\section{Leavenworthia TORR.}

Seven species in central and southern United States.

\section{Leavenworthia aurea Torr.}

Winter annual; leaves rosette-forming, the early ones with only an orbicular entire and remote terminal blade portion, later leaves with few to several lateral lobes; early and mid-season flowers on scapes $3-9 \mathrm{~cm}$. long, later flowers usually borne in a raceme on lateral decumbent branches; sepals 4-5 mm. long; petals narrowly lingulate, lemon-yellow to orange-yellow, shallowly emarginate, 7-10 $\mathrm{mm}$. long; siliques strongly flattened parallel to septum, thickish, erect, $1.5-3 \mathrm{~cm}$. long, 4-5.5 mm. wide; styles 2-3.5 mm. long; gynophore nearly $1 \mathrm{~mm}$. long; seeds nearly orbicular, $3.5-4.5 \mathrm{~mm}$. in diameter, strongly flattened, narrowly winged; radicle of embryo straight.

In seepage of limestone cedar glades and fossil outcrops, in s.e. Okla. (Waterfall) and local near San Augustine, San Augustine Co., Tex., Mar.-May.

\section{Draba L. Whitlow-Grass}

Annual, biennial or perennial herbs; stems leafy or scapose, usually pubescent with simple or branched trichomes; leaves entire or dentate; racemes short to elongate; petals white or yellow; silicles elliptic to linear, latiseptate, flat or sometimes twisted; seeds numerous, biseriate to irregularly seriate; cotyledons accumbent. 
About 250 species in temperate and cold parts of North America, South America, Europe and Asia.

1. Styles $0.5-1.5 \mathrm{~mm}$. long; pedicels in fruit ascending to erect. 1. D. aurea.

1. Styles $1.5-3.5 \mathrm{~mm}$. long; pedicels in fruit spreading or spreading-ascending...... ..2. D. Helleriana.

\section{Draba aurea Vahl.}

Canescent to greenish short-lived perennial, 1-5 dm. tall, the crown simple to branched; stems 1 to several, erect or somewhat decumbent at base, pilose-hirsute with a mixture of simple, bifid and cruciform hairs; leaves numerous, densely pubescent with a mixture of mostly cruciform but also some bifid or simple hairs; basal leaves rosulate, petiolate, mostly oblanceolate, entire to rarely denticulate, $1-5 \mathrm{~cm}$. long; cauline leaves as many as 30 , sessile or subsessile, ovate to oblanceolate, entire to dentate; racemes elongate, without bracts or the lower flowers bracteate; pedicels $3-20 \mathrm{~mm}$. long, in fruit ascending to erect; sepals $2-3.5 \mathrm{~mm}$. long; petals pale- to deep-yellow, 4.5-6 $\mathrm{mm}$. long; silicles narrowly to broadly lanceolate, 7-20 mm. long, 2-4 mm. broad, plane or contorted, softly pubescent to glabrous; style $0.5-1.5 \mathrm{~mm}$. long; seeds 20 to 50 , about $1 \mathrm{~mm}$. long.

In wet alpine meadows, on seepage slopes along streams, forested slopes and ravines in N. M. (Hitchcock et al) and Ariz. (Apache, Cochise and Coconino cos.), June-Aug.; Alas., s. through the Rocky Mts. to N.M. and Ariz.

Most of our material can be referred to var. leiocarpa (Pays. \& St. John) C. L. Hitchc. with relatively small flowers, short glabrous capsules and short fruiting styles.

\section{Draba Helleriana Greene}

Almost identical in characteristics to those of $D$. aurea except those noted in the key. They may represent two phases of a single species.

In similar habitats to D. aurea in N. M. (Bernalillo, Grant, Sandoval, Santa Fe, San Miguel, Socorro, Sierra and Taos cos.) and Ariz. (Apache, Cochise, Coconino, Graham, Greenlee and Pima cos.), June-Sept.; Colo., N. M., Ariz. and n. Mex.

\section{Capsella Medic.}

About 5 species native to Eurasia.

\section{Capsella Bursa-Pastoris (L.) Medic. Shepherd's Purse, Paniquesillo. Fig.} 477A.

Stem 1-5 dm. tall, branching, pubescent below, glabrous above; basal leaves in a rosette, usually lyrate-pinnatifid; stem leaves auricled, dentate to entire; flowers in long racemes; petals white, $1.5-2 \mathrm{~mm}$. long; pedicels slender, spreading at right angles or nearly so, $8-15 \mathrm{~mm}$. long; siliques obcordate-triangular, 5-8 $\mathrm{mm}$. long, strongly flattened contrary to the partition; styles less than $0.5 \mathrm{~mm}$. long; seeds numerous, oblong, orange-yellow, wingless, about $1 \mathrm{~mm}$. long; cotyledons incumbent.

In mud and seepage areas about springs and along streams, wet meadows, a ubiquitous weed, Feb.-Sept.; widespread weed occurring in most parts of the world; introd.

\section{Camelina Crantz False Flax}

About 10 species of the Mediterranean area, Europe and Asia.

\section{Camelina sativa (L.) Crantz. Gold-of-Pleasure.}

Annual 3-9 dm. tall, erect, usually with ascending branches; stem glabrous or with minute closely appressed stellate hairs; leaves lanceolate, the lowest tapering 


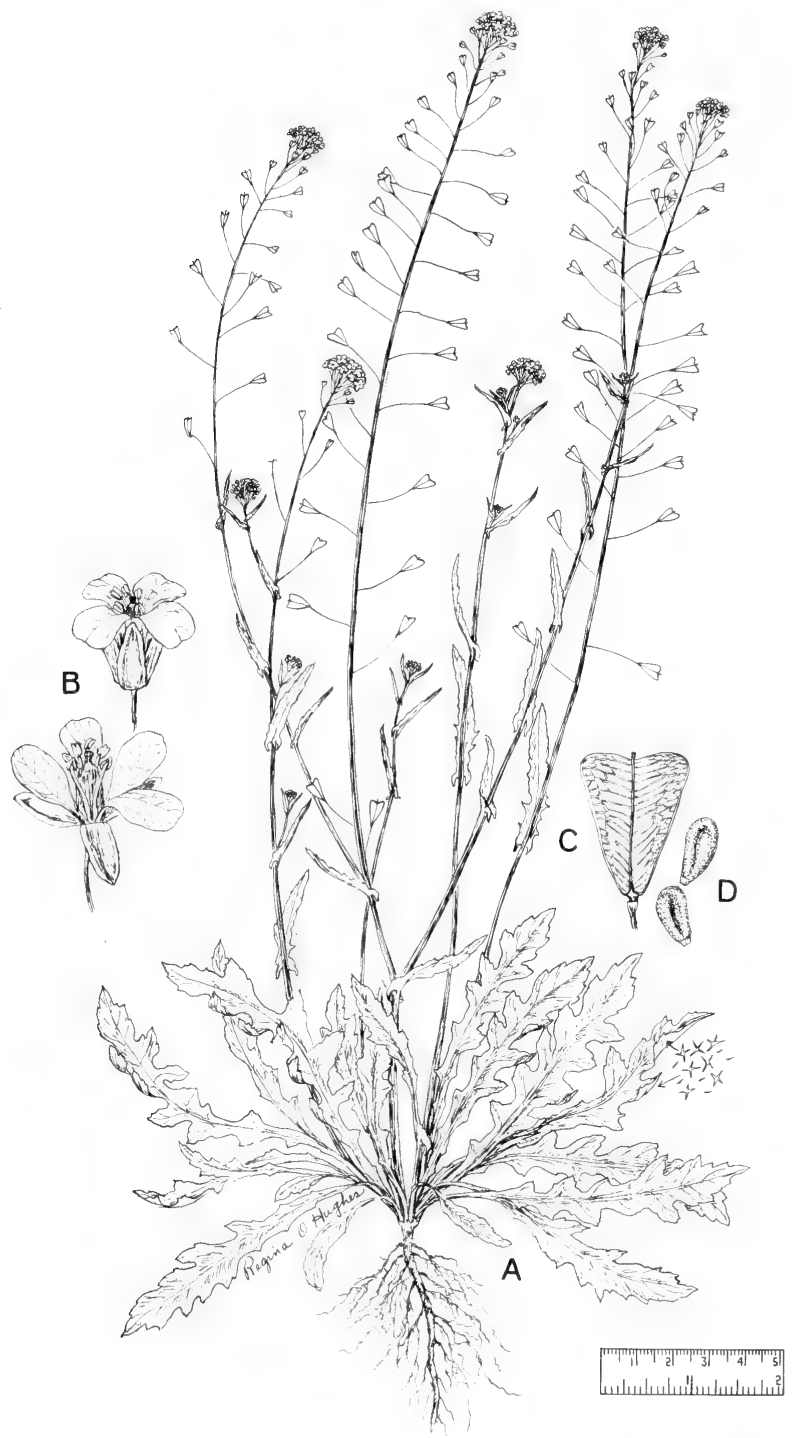

Fig. 477A: Capsella Bursa-Pastoris: A, habit, about x 1/2; B, flower, x 5; C, silicle, X 4; D, seeds, x 10. (From Reed, Selected Weeds of the United States, Fig. 97). 
to petioles, the others with sagittate sessile bases; racemes elongating; silicles mostly 7-9 $\mathrm{mm}$. long, 3 to 4 times as long as style, $6-7 \mathrm{~mm}$. thick, with pedicels $1.2-3$ $\mathrm{cm}$. long, the capsule walls soon hardening; seeds mostly $1-1.5 \mathrm{~mm}$. long, pale yellowish-brown.

In seepage along streams and wet meadows, a ubiquitous weed, in N. M. (Taos Co.), Apr.-Aug.; Que. to B. C., s. to S. C., Ill., Mo., Kan., N.M. and Calif.; adv. from Eur.

The oil-rich seeds were formerly used in making soaps and as an illuminant.

\section{Fam. 65. Capparidaceae Juss. CAPER Family}

Herbs (ours), shrubs or trees often with rank odor; leaves alternate, palmately (1-) 3- to 11-foliolate; stipules minute or lacking; flowers single and axillary or in terminal bracteate or ebracteate many-flowered racemes, somewhat zygomorphic, perfect, 4-merous, polypetalous; sepals 4, free or partially fused; petals 4, free; stamens 6 to 27 or more, as long as or longer than petals; nectariferous disk or gland between corolla and stamens frequent; ovary 1, superior; fruit a 2-valved unilocular capsule, usually borne on a slender gynophore (stipe above receptacle) or sessile, with many free-falling seeds or a 2-valved schizocarp with 1- or 2-seeded closed achenelike mericarps (in Wislizenia); seed reniform, the seed coat deeply invaginated. Also spelled Capparaceae.

About 500 species in about 40 genera, mostly tropical America and Africa, often xerophytic.

This family is included with full knowledge that practically all of its species in our region can be found in xeric habitats. Since, however, some also tolerate periodically inundated or excessively wet places we consider that they fall within the province of our research.

1. Fruits 2-parted schizocarps, with each of the 2 valves (1-2 mm. long) closely and permanently enclosing its single seed and falling with it; racemes ebracteate (bracts minute), very dense; southwest Texas.

\section{Wislizenia}

1. Fruits unilocular capsules with free-falling seeds; racemes bracteate or flowers singly in the axils of cauline leaves (2)

2(1). Capsules elongate, many-seeded, 1-8 cm. long; petals white, yellow, pink or purple.

1. Cleome

2. Capsules rhomboidal, few-seeded, 4-8 mm. long, as wide as or wider than long, the valves laterally expanded cones; petals yellow..........2. Cleomella

\section{Cleome L. Spider Flower. Cleome}

Erect slender to robust annual (ours) or perennial herbs, shrubs or small "trees," glabrous or glandular-pubescent, often spiny; leaves palmately 1 - to 11 -foliolate; leaflets entire or serrulate, flat or conduplicate; stipules none or minute; racemes terminal, greatly elongating in fruit, bracteate or flowers singly in axils of cauline leaves; corolla open or closed in bud; sepals 4, free or fused at base; petals 4, subequal, free, white, yellow, pink or purple, spatulate, entire, acute to rounded; disk conic, the nectary inconspicuous, sometimes adaxially expanded; stamens 6; anthers elongate, longitudinally dehiscent; capsules elongate, pendent, deflexed or erect, sessile or born on a stipe (gynophore); seeds many, the invagination open (if very narrow) or fused by a membrane.

About 150 species, mostly of tropical America and Africa, often of arid habitats.

Doves, pheasants and small mammals are said to eat the seeds of most species.

1. Petals yellow; leaflets of lowermost leaves 5 or 7

1. C. lutea.

1. Petals pink to pink-purplish; leaflets 3 (2) 
2(1). Leaflets narrowly elliptic, 5-15 mm. wide; flowers $8-13 \mathrm{~mm}$. long, racemose in the axils of small 1 -foliolate bracts; siliques $3-9 \mathrm{~mm}$. wide.

2. C. serrulata.

2. Leaflets linear, $2 \mathrm{~mm}$. wide or less; flowers $4-7 \mathrm{~mm}$. long, singly in axils of 3-foliolate cauline leaves; siliques $2-4 \mathrm{~mm}$. wide....3. C. multicaulis.

\section{Cleome lutea Hook. Yellow bee-Plant.}

Glaucous glabrous to sparsely pilose annual with erect to branching stems 5-15 dm. tall; leaves glabrous, usually 3 - to 7-foliolate, slender-petioled or the upper subsessile; leaflets oblong to oblong-oblanceolate, entire, sessile or subsessile, 1.5-5 $\mathrm{cm}$. long; racemes much-elongate in fruit; pedicels slender, 1-2 cm. long; calyx deeply 4-parted; petals yellow, obovate to oblanceolate, 6-8 $\mathrm{mm}$. long; pod linear, nearly terete, $3-7 \mathrm{~cm}$. long; fruiting stipe slender, longer than the pedicel; seeds pustulose.

In wet gravel, mostly along streams and in bottom lands in N. M. and Ariz. (rather widespread), May-Sept.; Neb. to Wash., s. to N. M., Ariz. and Calif.

\section{Cleome serrulata Pursh. Rocky Mountain beE-Plant.}

Erect somewhat shrubby branched annual, 2-15 dm. tall, glabrous, glaucous, unarmed; leaflets 3 , narrowly elliptic, 2-6 cm. long, 5-15 $\mathrm{mm}$. wide, pointed at both ends; flowers in dense elongated many-flowered racemes; bracts narrow, simple; sepals united for one half to two thirds their length, persistent in fruit; petals bright-pink to purplish, rarely white (f. albiflora Cockll.), 8-12 mm. long; disk with nectariferous adaxial scale to $4 \mathrm{~mm}$. long; stamens $13-20 \mathrm{~mm}$. long; capsules variable, linear-cylindric to fusiform, pointed sharply at both ends, $2-8 \mathrm{~cm}$. long, 3-9 mm. wide, deflexed; gynophore 11-23 mm. long; pedicel 14-20 mm. long; seeds several to many, ovoid, sharply pointed, 3-4 $\mathrm{mm}$. long, black-brownishmottled, blistered, the cleft fused. Peritoma serrulatum (Pursh) DC., P. integrifolia Nutt.

In seepage of springs and on edge of streams, in woods and along railroads and roadsides, in s.-cen. Okla. (Johnston Co.) and n.e. corner of Tex. Panhandle, widespread in N. M. and Ariz., May-Sept.; widespread throughout the Rocky Mts., Great Basin and Great Plains, from n.w. Calif. to s.w. Can., Ariz., N.M., n. Tex., s.-cen. Okla., Neb. and Minn.; adv. eastw.

\section{Cleome multicaulis DC.}

Slender erect unbranched or sparingly branched glabrous annual, 2-7 dm. tall; leaflets 3 , linear, strongly folded, 1-3 cm. long, 1-3 mm. wide; flowers in axils of cauline leaves, in very open elongate racemes; petals pinkish-purple, 4-7 mm. long; disk small, bulbous; capsule obovoid to linear, 9-18 $\mathrm{mm}$. long, 2-4 mm. thick, deflexed; gynophore 3-10 $\mathrm{mm}$. long, the pedicel $15-22 \mathrm{~mm}$. long, both delicate; seeds subglobose, light-brown, 1.8-2.5 mm. long, smooth. C. sonorae Gray, Peritoma sonorae (Gray) Rydb.

In alkaline sinks, cienegas and old saline lake beds in Larrea belt in w. Tex. (Presidio Co.) to N. M. and Ariz.; from s. Colo. to s.e. Ariz., s.w. N.M. to s.-cen. Mex. (D.F.), very sporadic and rare; June-Aug.

\section{Cleomella DC.}

Erect slender to robust glabrous (rarely pubescent) annuals (ours) or perennial herbs; leaves alternate, palmately 3-foliolate; leaflets entire, mucronate, less than $4 \mathrm{~cm}$. long; stipules minute, filiform; racemes terminal, bracteate; sepals minute, barely fused at base, tardily deciduous; corolla yellow, closed in bud, the petals subsessile; stamens 6, equal; anthers tightly coiled when dry; capsule an obdeltoid or rhomboidal silicle, often wider than long, the 2 valves deciduous, expanded contrary to the placenta into 2 obtuse to sharply pointed cones; gynophore elongate; style slender, persistent, indurate; seeds 3 to 20 . 
A small endemic North American genus of 10 zerophytic species, differing from Cleome (Sect. Peritoma) and Wislizenia in fruit characters.

1. Seeds 3 to 6 per capsule; fruiting gynophore $6-17 \mathrm{~mm}$. long; style $0.5 \mathrm{~mm}$. long; petals 4-6 $\mathrm{mm}$. long; flowering portion of raceme short, flat or rounded, 1-2 cm. long; leaflets acute; eastern half of Texas.....

1. $C$ angustifolia.

1. Seeds 6 to 16 per capsule; fruiting gynophore $4-7 \mathrm{~mm}$. long; style $1.5-2 \mathrm{~mm}$. long; petals $6-9 \mathrm{~mm}$. long; flowering portion of raceme oblongoidelongate, $2-5 \mathrm{~cm}$. long; leaflets often rounded to emarginate; TransPecos Texas

2. C. longipes.

\section{Cleomella angustifolia Torr.}

Glabrous erect often very bushy annual, 6-26 dm. tall; leaflets 3, linear-elliptic, acute, 25-60 $\mathrm{mm}$. long, 2-8 $\mathrm{mm}$. wide; racemes to $4 \mathrm{dm}$. long, the flowering portion flat to rounded and $1-2 \mathrm{~cm}$. long, bracteate (the lower 3 -foliolate, the upper 1-foliolate); petals yellow, 4-6 mm. long; mature capsules oblongoid to rhomboidal or obdeltoid (cones acute to rounded), 5-10 $\mathrm{mm}$. long, 5-9 $\mathrm{mm}$. wide; style 0.5 $\mathrm{mm}$. long or less; gynophore 4-7 $\mathrm{mm}$. long, the androgynophore prominent and 1-1.5 mm. long; pedicel 7-12 (-17) $\mathrm{mm}$. long; seeds 3 to 6 per capsule, darkbrown-mottled.

Deep sands, gravels in river bottoms, edge of ponds, roadsides, sandy prairies and bare sandstone shale in e. half of Tex. (also Dawson Co.), June-Oct.; Tex. to e. Kan., w. Neb. and n.e. Colo.

\section{Cleomella longipes Hook.}

Glabrous erect branched annual (or rarely perennial?) 3-8 dm. tall; leaflets 3, oblanceolate to oblong-oblanceolate, acute to rounded or emarginate, $15-30 \mathrm{~mm}$. long, 4-10 mm. wide; racemes 1-5 dm. long, the flowering portion oblong-cylindric and 2-6 cm. long; bracts 1-foliolate or upper flowers ebracteate; petals yellow, 6-9 mm. long; mature capsule (silicle) obdeltoid or rhomboidal (the cones often sharply acuminate ), 4-8 $\mathrm{mm}$. long, 6-10 mm. wide; style 1-2 $\mathrm{mm}$. long; gynophore 6-17 mm. long; pedicel 5-18 mm. long; seeds 6 to 16 per capsule, obovoid, when mature dark-brown.

In saline or alkaline soils or sands of semideserts, saline playas and wet soil on alkali flats, in the Tex. Trans-Pecos, N.M. (Grant Co.) and Ariz. (Cochise Co.), May-Sept.; s.e. Ariz., s.w. N.M. and w. Tex. to cen. Mex.

\section{Wislizenia Engelm. JACKass Clover}

About 3 species (or monotypic, with one highly polymorphic species ?) in southwestern United States and northwest Mexico; very similar to Cleomella.

\section{Wislizenia refracta Engelm.}

Robust glabrous annual, 4-7 dm. high (easily confused with Cleomella spp.), sparsely to densely branched; leaflets 3 , oblanceolate to elliptic or ovate-oblong, $1-2(-3) \mathrm{cm}$. long, 3-8 $(-11) \mathrm{mm}$. wide, rounded at apex, attenuate at base into slender petiolules to $4 \mathrm{~mm}$. long; stipules minute tufts of filiform hairs; racemes short, 1-8 cm. long, very dense, ebracteate; sepals minute, tardily deciduous; corolla closed in bud; petals yellow, subsessile, 2-4 mm. long; stamens 6, 6-7 mm. long, the anthers tightly coiled when dry; pistil long-exserted; style 4-6 mm. long in fruit, very slender; gynophore slender, 3-7 $\mathrm{mm}$. long, strongly refracted against the slender pedicel $(4-10 \mathrm{~mm}$. long); fruit a 2-celled twin pod that separates into 2 divaricate or deflexed obovoid nutlets, each with 1 or 2 seeds permanently enclosed by the capsule-valve; nutlets $1.5-2.5 \mathrm{~mm}$. long, smooth to veined, minutely to markedly tuberculate at distal end; seed smooth, yellow. 
In alkaline sandy or loamy soils of semideserts, on edges of playas, in seepage, stream beds and grasslands (Hilaria assoc.), riversides and roadsides, in the Tex. Trans-Pecos, N.M. (Dona Ana Co.) and Ariz. (Graham Co.), Mar-Aug.; Tex. and n. Mex. to Nev. and Baja Calif.

\section{Fam. 66. Sarraceniaceae DuM.}

\section{Pitcher-Plant FAMily}

Perennial rhizomatous and insectivorous plants with clustered tubiform leaves and solitary nodding flowers borne on a long naked erect scape; leaves rigidly erect, trumpet-shaped and partially filled with liquid, with a ridge on the adaxial side and terminated by an expanded hood; flowers regular, bisexual; sepals 5, with 3 appressed persistent bracts; petals 5, pendent, deciduous; stamens numerous; anthers 2-celled, dehiscing longitudinally; style simple below, expanded above into a large persistent 5-lobed umbrellalike structure, with a small stigma under each of the notched lobes; ovary 5-celled; fruit 5-valved; seeds keeled or winged on one side.

A small family of three genera comprising about 15 species.

\section{Sarracenia L. Pitcher-Plant. Trumpet}

Characters of the family. A genus of 8 species, all of which are confined to the United States with the exception of $S$. purpurea $L$. which extends into Canada.

\section{Sarracenia alata Wood. Yellow tRumpets. Frontispiece.}

Leaves yellow-green, trumpet-shaped, dilated upward, to $7 \mathrm{dm}$. long; hood ovate to suborbicular, with inconspicuous reddish veins, $8 \mathrm{~cm}$. long; scape about as long as the leaves; sepals broadly ovate to rhombic-ovate, bluntly obtuse at apex, curved, $4-5 \mathrm{~cm}$. long, to $4 \mathrm{~cm}$. wide; petals greenish-yellow, drooping, panduriform, 5-6 cm. long, to $4 \mathrm{~cm}$. wide near the broadly rounded apex; style to $8 \mathrm{~cm}$. wide, convex; capsule muricate; seeds tuberculate. S. Sledgei Macfarl.

In wet acid bogs on slopes and flats in pinelands in e. and s.e. Tex., Mar.-Apr.; on the Gulf Coastal Plain from s. Ala. to e. Tex.

An insect attractant is exuded near the mouth of the tubular leaf. After entering the tube the retrorse bristly hairs lining its inner surface prevents the insect from leaving the ingenious trap. It soon falls into fluid at the bottom of the funnel and is then digested by the plant.

\section{Fam. 67. Droseraceae SALISB.}

\section{SUNDEW FAMILY}

Perennial or biennial (rarely annual) insectivorous herbs growing in wet or damp soil; leaves circinate in bud, expanding into a rosette or tuft at base of scape or rarely scattered in submersed plants, with or without prominent stipules, red or green, adorned with gland-tipped hairs that exude drops of a clear glittering glutinous fluid; scape with a simple or branched few-flowered secund inflorescence that nods at the undeveloped apex; flowers regular, shortly pedicellate, opening only in sunlight, hypogynous, usually 5-merous, soon withering but persistent; calyx imbricated; petals convolute; stamens 5, opposite the sepals, the anthers fixed by the middle; style 3 or 5, bipartite to base; capsule 3 - to 5-valved, with as many parietal placentas as valves; seeds numerous.

About 4 genera of more than 125 species of world-wide distribution.

\section{Drosera L. Sundew}

Characters same as those of the family. More than 100 species primarily in the Southern Hemisphere. 


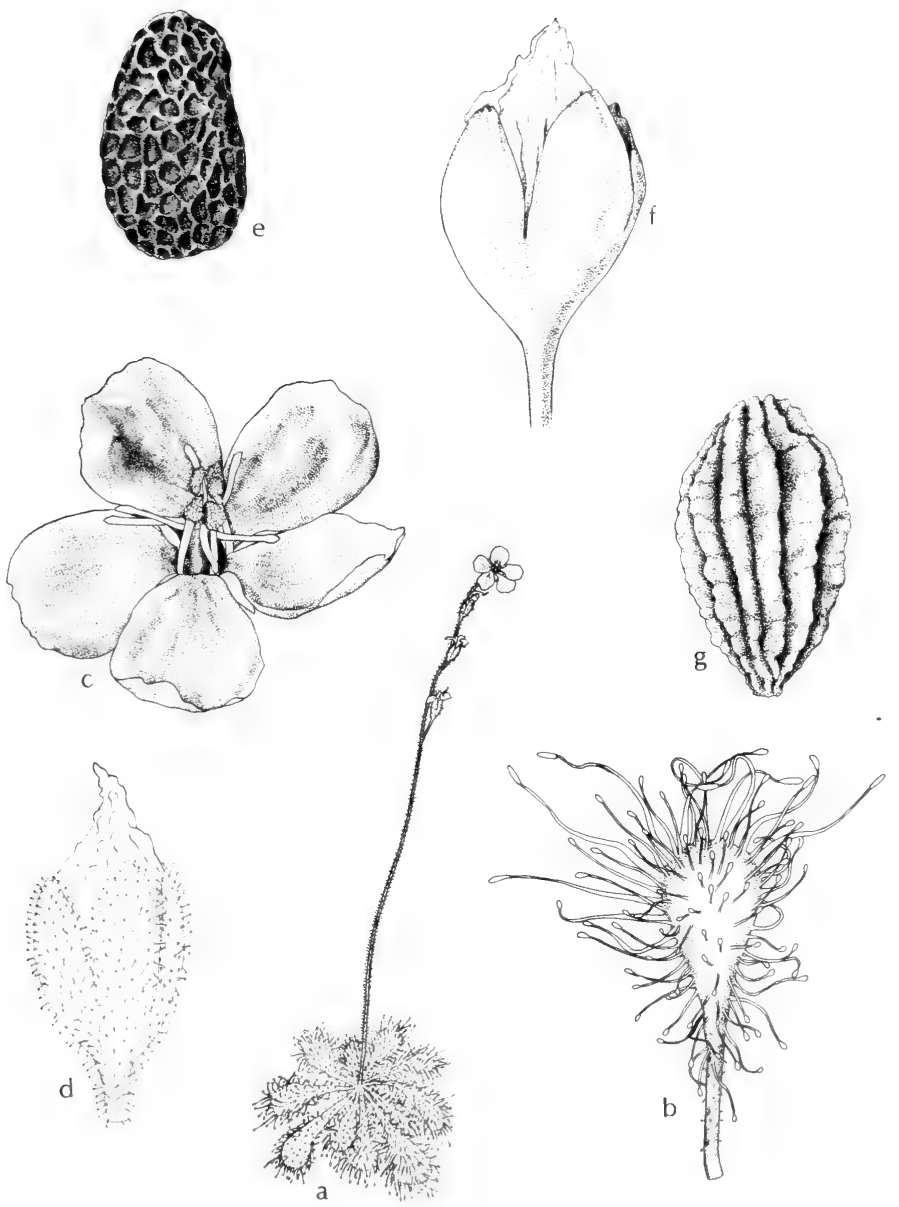

Fig. 478: a-e, Drosera brevifolia: a, habit, x 1/2; b, leaf, x 11/2; c, flower, x 5; d, calyx, x 5; e, seed, x 160. f-g, Drosera capillaris: f, calyx, x 71/2; g, seed, x 66 . (Courtesy of R. K. Godfrey). 


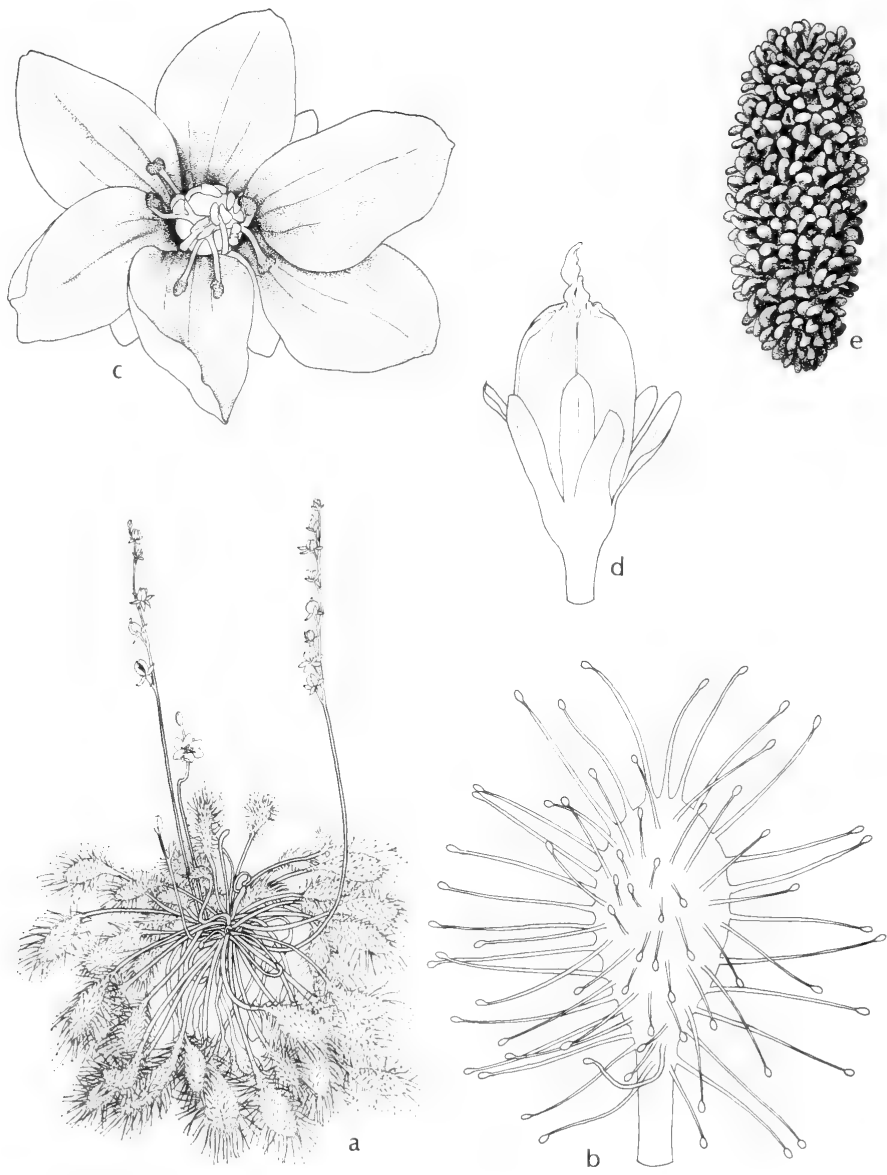

Fig. 479: Drosera intermedia: a, habit, x 1/2; b, leaf, x 11/2; c, flower, x 5; d, calyx and capsule, x 5; e, seed, x 50 . (Courtesy of R. K. Godfrey). 
The glandular hairs and leaf blade, itself, of these species are capable of enmeshing and enfolding a luckless insect, after which it is digested.

1. Scape with gland-tipped hairs except toward base; stipules absent or vestigial; seeds crateriform, $0.3-0.4 \mathrm{~mm}$. long......................... D. D. annua.

1. Scape glabrous or with inconspicuous sessile glands; stipules prominent, free (2)

2(1). Petioles with few to many long lax hairs lacking gland-tip; flowers pink, about $10 \mathrm{~mm}$. in diameter; seeds $0.4-0.5 \mathrm{~mm}$. long, papillosecorrugated with 14 to 16 ridges............................2. D. capillaris.

2. Petioles glabrous or with inconspicuous sessile glands; flowers white, $7-8 \mathrm{~mm}$. in diameter; seeds $0.7-1 \mathrm{~mm}$. long, irregularly and densely covered with long papillae.

3. D. intermedia.

1. Drosera annua E. L. Reed. Fig. 478.

Leaf blades suborbicular to cuneate-flabellate, to $8 \mathrm{~mm}$. long and wide, about one-third as long as the glandular petiolar base; stipules lacking or rudimentary; scape erect, to $12 \mathrm{~cm}$. tall, provided with gland-tipped hairs, supporting as many as 6 flowers; sepals ovate, subacute, to $4 \mathrm{~mm}$. long, united at base; petals pink or roseate, obovate, to $9 \mathrm{~mm}$. long; capsule obovoid, $3.5-4 \mathrm{~mm}$. long; seeds black, obovoid, the pits in 10 to 12 rows.

In wet sand in pinelands or mixed forests and in open bogs in Okla. (Waterfall) and e. and s.e. Tex., Feb.-June; Tenn., s. to Ala., Okla., La. and Tex.

Referred by some authors to $D$. brevifolia Pursh.

2. Drosera capillaris Poir. Fig. 478.

Leaf blades broadly spatulate to obovate, to $1 \mathrm{~cm}$. long and $9 \mathrm{~mm}$. wide, exceeded in length by the more or less pubescent petioles that are $4 \mathrm{~cm}$. long; stipules divided into numerous setaceous segments to $5 \mathrm{~mm}$. long; scape erect, to $25 \mathrm{~cm}$. tall, glabrous or inconspicuously glandular, supporting as many as 20 glabrous flowers in a strictly erect inflorescence; sepals oblong-elliptic, obtuse, to $4 \mathrm{~mm}$. long and $2 \mathrm{~mm}$. wide, united at base; petals pink, to $7 \mathrm{~mm}$. long and $3 \mathrm{~mm}$. wide; capsule ellipsoid-obovoid, to $5 \mathrm{~mm}$. long; seeds ovate-oblong to elliptic, asymmetric, brown, coarsely papillose-corrugated.

In wet sands and on seepage slopes and in bogs in e. Tex., Feb.-June; Va., Tenn. and Ark., s. to Fla. and Tex.; also W.I., Mex., C.A. and n. S. A.

3. Drosera intermedia Hayne. Fig. 479.

Leaves usually basal but sometimes extending up the stem when the plants grow in water or very wet places; leaf blades spatulate to oblong-obovate, to $2 \mathrm{~cm}$. long and $5 \mathrm{~mm}$. wide, with slender glabrous or inconspicuously glandular petioles to $5 \mathrm{~cm}$. long; stipules divided into several setaceous segments to $5 \mathrm{~mm}$. long; scape erect, to $2 \mathrm{dm}$. tall, glabrous or inconspicuously glandular, supporting as many as 20 flowers in an inflorescence that at first curves outward and often downward at the base before becoming erect; sepals oblong, to $4 \mathrm{~mm}$. long and $1.5 \mathrm{~mm}$. wide, united at base; petals white or sometimes pinkish, to $5 \mathrm{~mm}$. long and wide; capsule ellipsoid, to $5 \mathrm{~mm}$. long; seeds oblong, reddish-brown, blunt at the ends, densely and irregularly covered with long papillae.

In wet sands and peaty areas in s.e. Tex., June-Aug.; Nfld. to Ont., w. to O., Ill. and Minn., s. to Fla. and Tex.

\section{Fam. 68. Podostemaceae AgARDH}

RIVER-WEED FAMILY

Aquatic herbs, attached to rocks in swift-flowing water by disklike processes, in habit resembling some species of algae and mosses; leaves alternate, 2-ranked, 
simple to lobed or decompound; flowers naked, solitary, perfect, arising from a spathelike involucre; perianth wanting or composed of 3 to 5 scalelike or membranous sepals; stamens 1 to many; fruit a 2- or 3-celled many-seeded ribbed capsule.

About 130 species in more than 40 genera, mostly tropical.

\section{Podostemon MichX. River-WeEd}

Characters of the family. More than a dozen species of wide distribution.

\section{Podostemon Ceratophyllum Michx. Thread-Foot. Fig. 480.}

Plant olive-green, firm, glabrous; leaves long-petiolate, rigid, divided into linear or filamentous segments or sometimes simple, with dilated base sheathing the stem; stems abbreviated to very elongate, sometimes as much as $6 \mathrm{dm}$. long or more; flowers green, arising along the stems or in clusters at apex of stems, with slender pedicels; perianth obsolete; stamens 2 , the more or less united filaments exceeding the ovary; ovary 2-celled; stigmas 2, subulate; capsule unequally 2-valved, with one 5-ribbed valve persistent, broadly ellipsoid, 2-3 mm. long.

Attached to rocks in streams and rivers in Okla. (McCurtain Co.) and (?) e. Tex., May-July; from Ga., along the Gulf Coast to Okla., n. to Ont. and N. B.

\section{Fam. 69. Crassulaceae DC. ORPINE FAMILY}

Annual or perennial succulent exstipular herbs with perfect symmetrical flowers usually in a cyme; leaves alternate or opposite, simple or sometimes dentate; petals (free or somewhat united) and pistils the same number as the calyx segments and the stamens the same or double their number; fruit a 1-celled follicle that opens down the ventral suture, 1- to many-seeded.

About 1,500 species in 35 genera that are world-wide in distribution.

1. Plants minute, spreading or decumbent; leaves opposite and connate at base, $7 \mathrm{~mm}$. long or less; flowers solitary or in glomerules usually in axil of leaves; stamens as many as calyx segments; follicles $1.5-2 \mathrm{~mm}$. long...............................................................................1. Tillaea

1. Plants ascending or trailing; leaves not opposite, usually more than $10 \mathrm{~mm}$. long; flowers in spreading cymes; stamens twice as many as the calyx segments; follicles $4-6 \mathrm{~mm}$. long.. 2. Sedum

\section{Tillaea L. PIGMY-WEED}

About 20 species of world-wide distribution.

1. Tillaea aquatica L. WATER PIGMY-WEed. Fig. 481.

Tufted or matted diminutive more or less aquatic annual, glabrous throughout; stems filiform, much-branched from base, spreading or decumbent, to $10 \mathrm{~cm}$. long; leaves opposite, connate-perfoliate, linear to linear-oblong, entire, to $7 \mathrm{~mm}$. long; flowers minute, solitary, axillary, 4-merous, essentially sessile or with pedicels longer than the leaves; calyx $1 \mathrm{~mm}$. long, about half as long as the greenish-white petals; follicles ovoid, 1.5-2 mm. long, 8 to 10 -seeded. Crassula aquatica (L.) Schoenl., Tillaeastrum aquaticum (L.) Britt.

On dry mud flats about pools and along shores, sometimes in water, in e. and s.e. Tex., May-Aug.; from Nfid. w. to Wash., Ut., Wyo. and Tex., s to Md. and La.; also Mex.

Plants with some of the pedicels exceeding the leaves have been segregated as var. Drummondii (T. \& G.) Jeps. [Tillaea Drummondii T. \& G., Crassula Drummondii (T. \& G.) Fedde, Tillaeastrum Drummondii (T. \& G.) Britt.] 

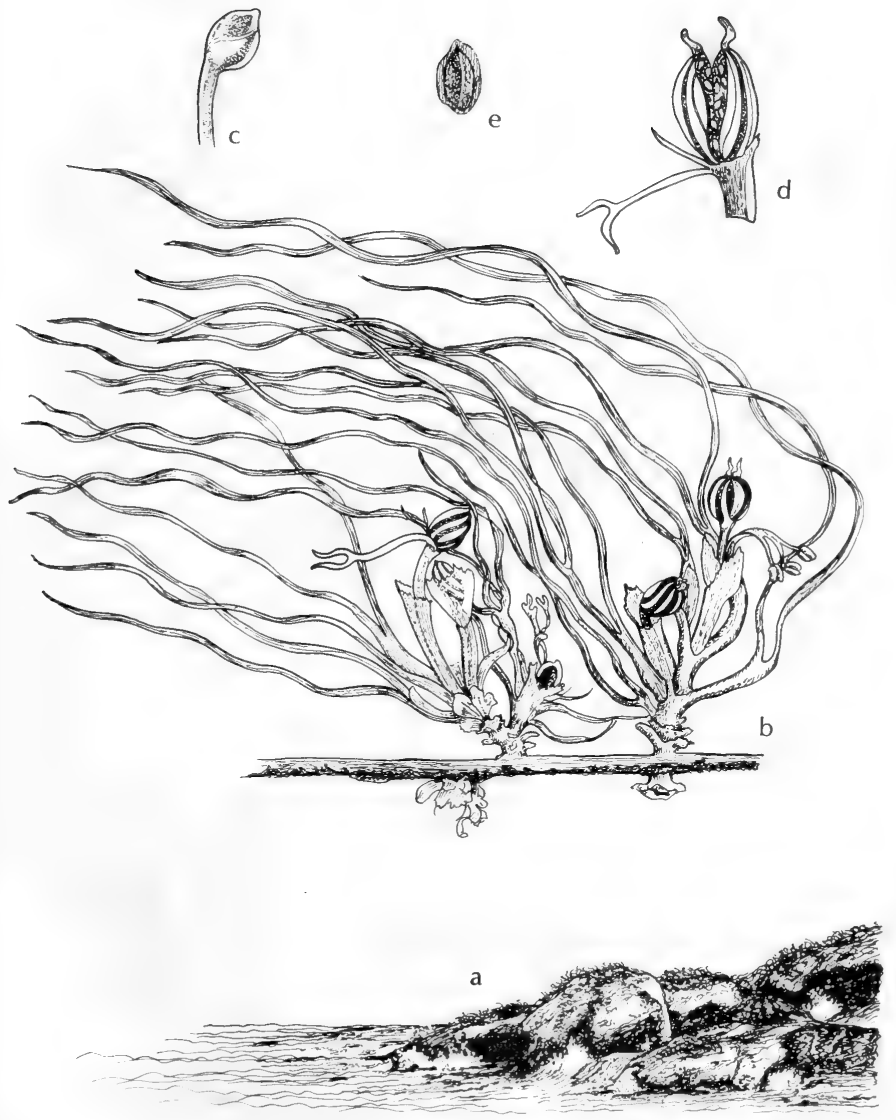

Fig. 480: Podostemon Ceratophyllum: a, habitat, on rocks in river rapids; b, habit, x $2 \frac{1}{2}$; c, bud, $x$ 5; d, fruit, $x$ 5; e, seed, x 12. (V. F.). 


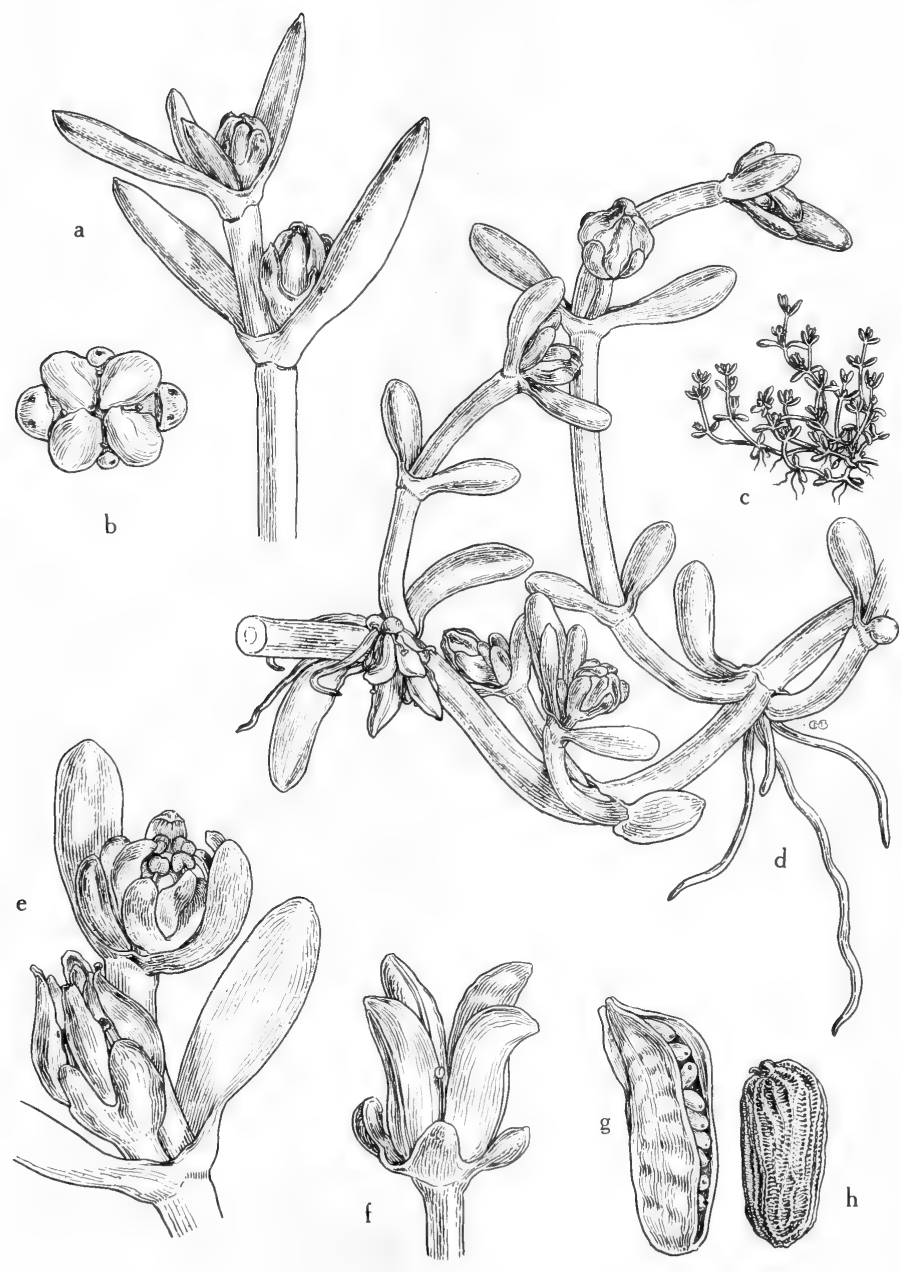

Fig. 481: Tillaea aquatica: a, tip of branch, showing flowers solitary in leaf axils, $\mathrm{x} 6$; b, flower, top view, $\mathrm{x} 12$; c, habit, $\mathrm{x} 2 / 3$; d, part of plant, showing the flowers and the stems rooting at the nodes, x 6; e, flowers, showing different stages in anthesis, $\mathrm{x} 12$; f, fruit, x 12; g, single carpel, after dehiscence, x 16; h, seed, x 60. (From Mason, Fig. 250). 


\section{Sedum L. STONECROP. ORPINE}

Smooth and fleshy-leaved perennials or occasionally annuals with mostly alternate (sometimes opposite or whorled) or imbricated simple leaves and flowers in broad to one-sided terminal or axillary cymes; sepals and petals 4 or 5 , the usually narrow petals free or scarcely united at base; stamens 8 to 10 , mostly perigynous; follicles several- to many-seeded, each subtended by a basal scale.

About 600 species, mainly in temperate and boreal regions of the Northern Hemisphere.

1. Distribution in eastern Oklahoma and Texas. 1. S. pulchellum.

1. Distribution in mountains of New Mexico and Arizona (2)

2(1). Inflorescence a terminal congested essentially naked cyme; petals 3-4 mm. long, obtuse to acute................................................. R. Rosea.

2. Inflorescence a racemose panicle with leafy bracts; petals $7-10 \mathrm{~mm}$. long, acuminate. 3. S. rhodanthum.

\section{Sedum pulchellum Michx.}

Glabrous annual (or biennial ?), ascending or trailing, branched, 1-3 dm. long; leaves crowded, terete, linear, sessile, obtuse, slightly auriculate at the base, 7-25 mm. long, about $2 \mathrm{~mm}$. wide; cyme 4- to 7-forked, its branches spreading or recurved in flower; flowers sessile, close together, $8-12 \mathrm{~mm}$. broad; petals light-pink, linear-lanceolate, acute, about twice the length of the lanceolate obtusish sepals; follicles 4-6 mm. long, tipped with slender styles.

In seepage on and about calcareous and granitic rocks in Okla. (Johnston Co.) and e. Tex. (San Augustine Co.), Mar.-May; from w. Va., w. to s. Ill., Mo. and Kan., s. to Ga., Ala., Ark. and Tex.

\section{Sedum Rosea (L.) Scop. Roseroot. Fig. 482.}

Fleshy perennial from a short scaly suckering rootstock that is fragrant when bruised; stems several, erect or ascending, 1-5 dm. tall; leaves pale, equally distributed up the stems, rather crowded, flat, rather thin, sessile, obovate to oblanceolate, $1.5-4.5 \mathrm{~cm}$. long, to $1 \mathrm{~cm}$. wide, acute, entire to dentate above the middle; inflorescence a terminal more or less congested cyme to $6 \mathrm{~cm}$. across; flowers perfect or unisexual, 4- or 5-merous; calyx lobes lanceolate, 1.5-2 mm. long; petals dark-purple, 3-4 mm. long, oblong, obtuse to acute, somewhat spreading; stamens 10 , equaling or exceeding petals; follicles plump, erect, dark-purple, 3-5 mm. long, tipped with a divergent or recurved beak.

Seepage along streams, bordering lakes and in moist rocky places in N. M. (Taos Co.), May-Aug.; Me. to B. C., s. to mts. of N. C., Tenn., N. M. and Calif.; Euras.

\section{Sedum rhodanthum Gray. Fig. 482.}

Plants glabrous; stems several from a thick rootstock, simple, 1-3.5 dm. tall; leaves sessile, alternate, linear-oblong to oblanceolate, $1.5-3 \mathrm{~cm}$. long, entire or toothed; flowers in dense terminal racemose panicles with leaflike bracts; sepals distinct; petals 7-10 mm. long, light-rose to pink or whitish, linear-lanceolate, acuminate, about twice as long as sepals; stamens 10, these opposite the petals and adnate to them; carpels 5 , erect.

Wet meadows, marshes, about lakes and along streams in N.M. (Taos Co.) and Ariz. (Apache and Coconino cos.), June-Sept.; Mont. to Ut., s. to N.M. and Ariz. 

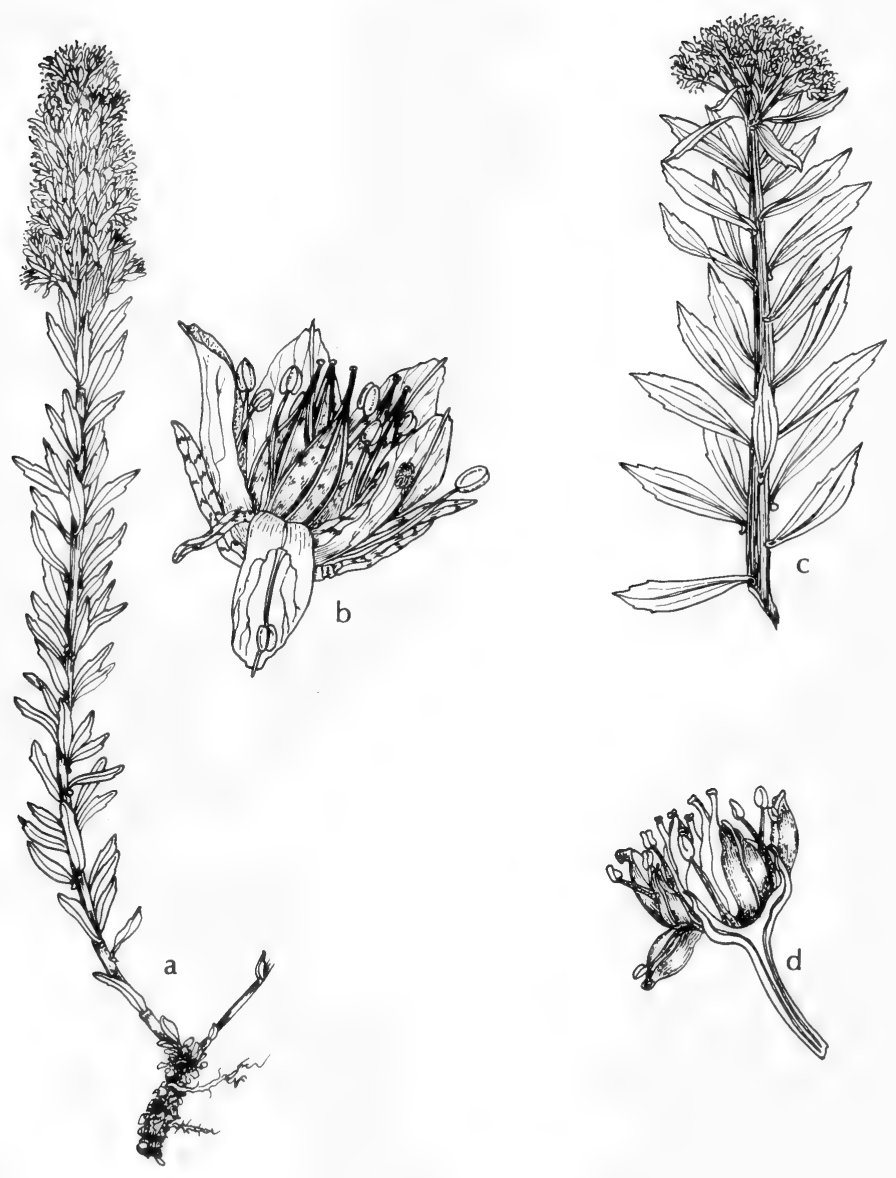

Fig. 482: a and b, Sedum rhodanthum: a, habit, x 1/2; b, flower, x 3. c and d, Sedum rosea: c, top of plant, $\mathrm{x} 1 / 2$; d, flower, $\mathrm{x} 3$. (V. F.). 
Perennial herbs, woody vines, shrubs or rarely small trees with opposite or alternate usually exstipulate leaves; inflorescence variable; stamens mostly definite; carpels commonly fewer than the sepals, either separate or partly so or all combined into one compound pistil; floral cup either free or adherent to ovary, usually persistent or withering away; stamens and petals almost always inserted on rim of floral cup; ovary usually at least partly inferior; fruit a capsule or berry; ovules anatropous; seeds with copious endosperm.

Closely allied to Rosaceae and with some genera without clear relationships; sometimes split into several families. Estimated to be more than 1,000 species in nearly 100 genera in both hemispheres.

1. Herbs (2)

1. Shrubs (5)

2(1). Plants diminutive, forming prostrate mats less than $5 \mathrm{~cm}$. across

2. Plants with erect flowering stems (3)

1. Lepuropetalon

3(2). Leaves scattered along the flowering stem; ovary 5- to 7-celled, mostly superior; follicles circumscissally dehiscent..............2. Penthorum

3. Leaves mostly basal and rosulate; ovary 1- or 2-celled, about half-inferior; fruits not dehiscent as above (4)

4(3). Fertile stamens 10; without staminodia; ovary 2-celled 3. Saxifraga

4. Fertile stamens 5; staminodia present; ovary 1-celled 4. Parnassia

5(1). Leaves opposite

7. Jamesia

5. Leaves alternate $(6)$

6(5). Leaves pinnately veined, unlobed, at most with serrulate margins; ovary superior; fruit a capsule.

5. Itea

6. Leaves noticeably palmately veined and lobed; ovary more or less inferior; fruit a berry. 6. Ribes

\section{Lepuropetalon ELL.}

A monotypic genus. Segregated by some authors as a monotypic family, Lepuropetalaceae.

\section{Lepuropetalon spathulatum (Muhl.) Ell.}

Annual diminutive herbs, growing in small tufts, glabrous, mostly in hemispheric patches 1-1.5 cm. across; stems abbreviated, usually branched from the base, the branches angled; leaves alternate, simple, sessile, spatulate, 2-6 mm. long, obtuse, usually adorned with lines of reddish glands; entire; flowers inconspicuous but large for the plant, solitary near or at the ends of the stems and branches; hypanthium flattish, at maturity longer than the calyx; calyx 1.5-2 mm. wide; sepals 5, ovate, spreading 1-2 mm. long at maturity; corolla white, minute, regular; petals 5, broad, scalelike, shorter than the sepals, reniform to ovatereniform; stamens 5; filaments subulate, very short; ovary partly inferior, the 3 or 4 short carpels united; fruit about $2 \mathrm{~mm}$. long, the folliclelike carpel apices erect, slightly spreading; fruit a capsule loculicidal at apex; seeds pitted.

Sandy soil about sinks and on wet soil in the e. half of Tex., Feb.-Mar.; from S.C. and Ga. to Tex. and Mex.; also Chile.

\section{Penthorum L. Ditch-stonecrop}

About 3 species, with 2 in Asia. Segregated by some authors as a monogeneric family, Penthoraceae. 


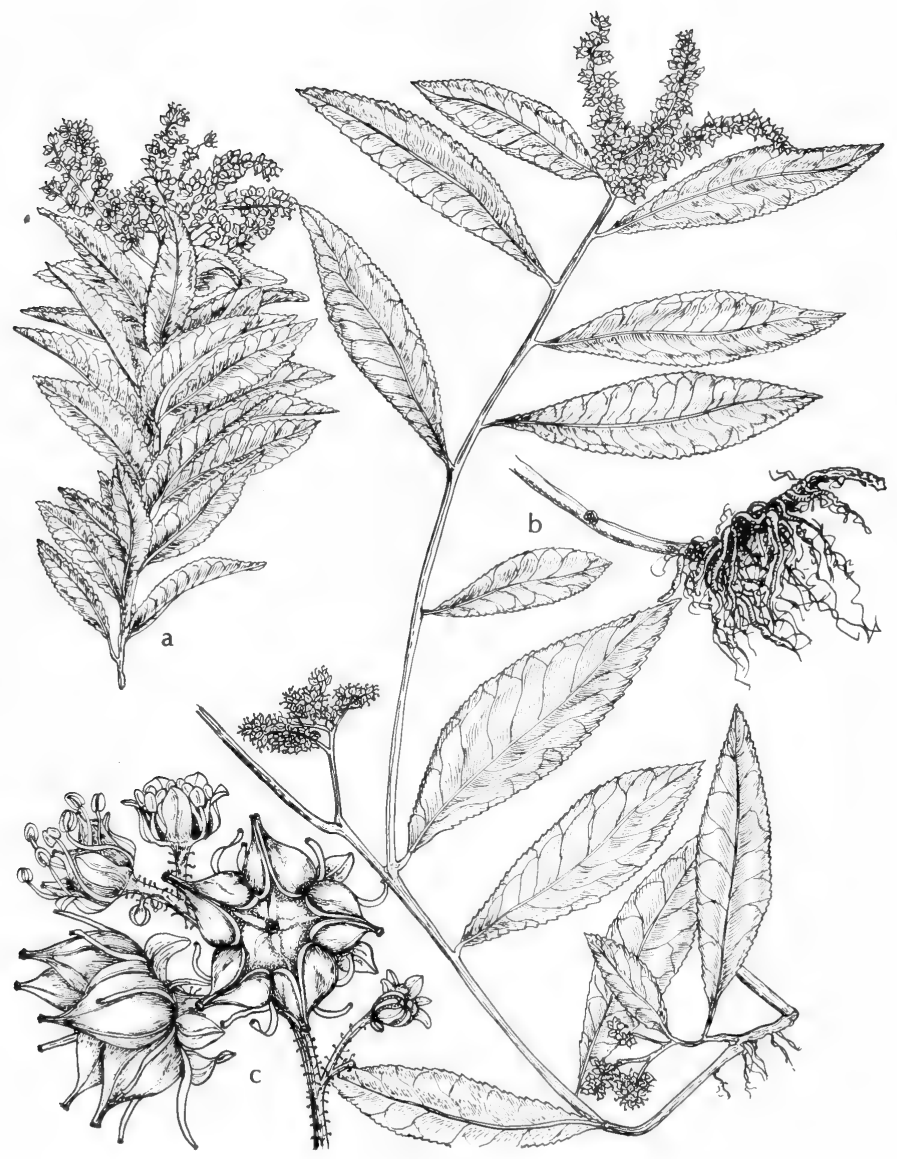

Fig. 483: Penthorum sedoides: a, top of plant, x 1/2; b, part of procumbent stem of plant and roots, $x \frac{1}{2}$; c, cluster of flowers and fruit, $x$ 5. (V. F.). 


\section{Penthorum sedoides L. Figs. 483 and 484.}

Upright or somewhat bushy-sprawling weedlike perennial herb, stoloniferous; stem decumbent at base, simple to widely branched, to about $8 \mathrm{dm}$. tall; leaves alternate, scattered, elliptic to broadly lanceolate, serrate, acute to acuminate at apex, narrowly cuneate at base, to $15 \mathrm{~cm}$. long and $4 \mathrm{~cm}$. wide; flowers yellowish-green, loosely spiked along the upper side of the naked scorpioid branches of the cyme; calyx lobes 5 to 7 ; petals usually absent; stamens 10; pistils 5 or 7 , united below and slightly sunken in the receptacle, forming a 5-angled 5-horned and 5-celled capsule that opens by dehiscence of the caplike beaks, with numerous ellipsoid echinate seeds.

Wet ground, usually along and on edge of water in streams throughout Okla. and in e. and s.e. Tex. and in the Panhandle (Hemphill Co.), June-July; from Fla. to Tex., n. to s. N.B., N.E., s.w. Que., s. Ont., Mich., Wisc., Minn. and Neb.

\section{Saxifraga L. SAXIFRAGE}

Mostly perennial herbs; stems leafy or scapelike, erect to decumbent or prostrate; leaves simple, mostly in a basal cluster; flowers perfect, regular, solitary or in simple or compound cymes; calyx adnate to at least the base of the ovary, the lobes 5; petals 5, perigynous; stamens 10, inserted with petals; carpels 2 , united below or nearly distinct; ovary nearly free or more or less inferior; follicles 2-beaked, divergent, many-seeded.

About 370 species, mostly in the North Temperate Zone.

1. Distribution in eastern Oklahoma and Texas. 1. S. texana.

1. Distribution in mountains of New Mexico and Arizona (2)

2(1). Plants usually less than $1 \mathrm{dm}$. tall, more or less tufted; flower stem leafy, supporting 1 to 3 flowers (3)

2. Plants $1 \mathrm{dm}$. tall or more, not tufted; scape supporting a many-flowered inflorescence (4)

3(2). Basal leaves linear-oblanceolate to spatulate, entire...........2. S. chrysantha. 3. Basal leaves somewhat reniform, 3- to 7-lobed. 3. S. debilis.

4(2). Leaves orbicular to reniform, coarsely and deeply crenate-dentate; flowers in paniculate cymes. 4. S. arguta.

4. Leaves rhombic-ovate to ovate, shallowly crenate-dentate; inflorescence capitate to interrupted-thyrsiform. 5. S. rhomboidea.

\section{Saxifraga texana Buckl.}

Perennial herb from a bulbous base, to $15 \mathrm{~cm}$. tall; leaves simple, in a basal rosette, spreading, broadly ovate to ovate-oblong, obtuse at apex, abruptly narrowed into a petiolate base, to $4 \mathrm{~cm}$. long, usually much smaller, with undulate margins, essentially glabrous; scapes erect, usually solitary, green or rose-colored, coarsely white-pubescent (especially below the middle); cymules aggregated into tight heads; sepals ovate to oblong, obtuse, 1.5-2 $\mathrm{mm}$. long, commonly rose-colored; petals white, broadly elliptic to obovate, $2.5-3 \mathrm{~mm}$. long, narrowed at base; stamens 10; folliclelike carpel tips 3 or 4 , about $3 \mathrm{~mm}$. long, the stout tips ascending or somewhat spreading, S. Reevesii Cory, Micranthes texana (Buckl.) Small.

In seepage on rock outcrops in fields and on edge of woods in e. Okla. and e. Tex., uncommon, Feb.-Mar.; in Mo., Kan., Ark., Okla. and Tex.

\section{Saxifraga chrysantha Gray.}

Perennial with slender rootstocks and few to numerous leafy offsets, glabrous to sparsely glandular-pubescent; leafy flowering stem simple, $2-6 \mathrm{~cm}$. tall; rosulate leaves linear-oblanceolate to spatulate, glabrous, fleshy, 5-10 mm. long; cauline 


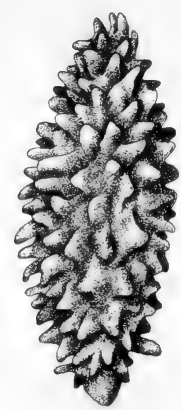

Fig. 484: Penthorum sedoides: seed, x 100. (Courtesy of R. K. Godfrey).

leaves 2 to 5 , linear to narrowly oblong, 3-7 $\mathrm{mm}$. long, glabrous to sparsely glandular-pubescent; flowers solitary or paired; calyx lobes ovate to ovate-oblong, sharply reflexed, $2-3 \mathrm{~mm}$. long, the free hypanthium scarcely $0.5 \mathrm{~mm}$. long; petals yellow, finely cross-rugulose with orange below the middle, deciduous, broadly obovate to ovate, 5-7 mm. long, 5- to 9-nerved, clawed; filaments slender; capsule ovoid, 6-8 mm. long; seeds brown, about $1 \mathrm{~mm}$. long, narrowly oblong-fusiform, lightly wrinkled. Leptasea chrysantha (Gray) Small.

On open rocky-grassy slopes and moraines on higher mts., commonly near snowbanks in seepage, in N. M. (Colfax, Rio Arriba and Mora cos.); Wyo, and Ut., s. to N.M.

3. Saxifraga debilis Engelm. ex Gray. Pigmy SaXifrage.

Tufted perennial forming small patches to $8 \mathrm{~cm}$. across, glabrous to glandularpubescent and often pilose (especially on the bases of lower leaves); flowering stems several, leafy, to $1 \mathrm{dm}$. tall; leaves mostly basal, often bulbiferous, the petioles slender, often brownish-pilose, stipular; blades more or less reniform, 5-15 mm. wide, coarsely and shallowly 3- to 7-lobed; cauline leaves usually 1 to several, similar to basal leaves or entire; flowers 1 to 3 ; calyx turbinate-campanulate, usually purplish, $2.5-3.5 \mathrm{~mm}$. long, the erect lobes ovate to ovate-oblong and rounded; petals deciduous, white and usually somewhat pinkish-veined, narrowly oblong to cuneate-oblong, 2 to 3 times as long as calyx lobes, scarcely clawed at rounded base; stamens equaling calyx lobes, the filaments not clavate; capsule 4-6 mm. long; seeds about $0.5 \mathrm{~mm}$. long, brownish, ellipsoidal.

In wet locations, mostly on cliffs, in rock crevices and on talus below snowbanks on San Francisco Peaks, Coconino Co., Ariz., July-Aug.; Mont. to Colo., Ariz. and Calif.

\section{Saxifraga arguta D. Don. Brook Saxifrage. Fig. 485.}

Acaulescent perennial with a long horizontal rootstock; leaf blades orbicular to reniform, cordate, $2-8 \mathrm{~cm}$. wide, the margins coarsely and deeply crenate-dentate; glabrous or ciliate, the petioles $4-12(-20) \mathrm{cm}$. long; flowering stems $1.5-5 \mathrm{dm}$. tall, terminating in an open paniculately cymose inflorescence; sepals ovate-oblong to oblong-lanceolate, $1.5-2 \mathrm{~mm}$. long, often purple, sharply recurved; petals suborbicular, abruptly and shortly clawed, about twice as long as the sepals; filaments 

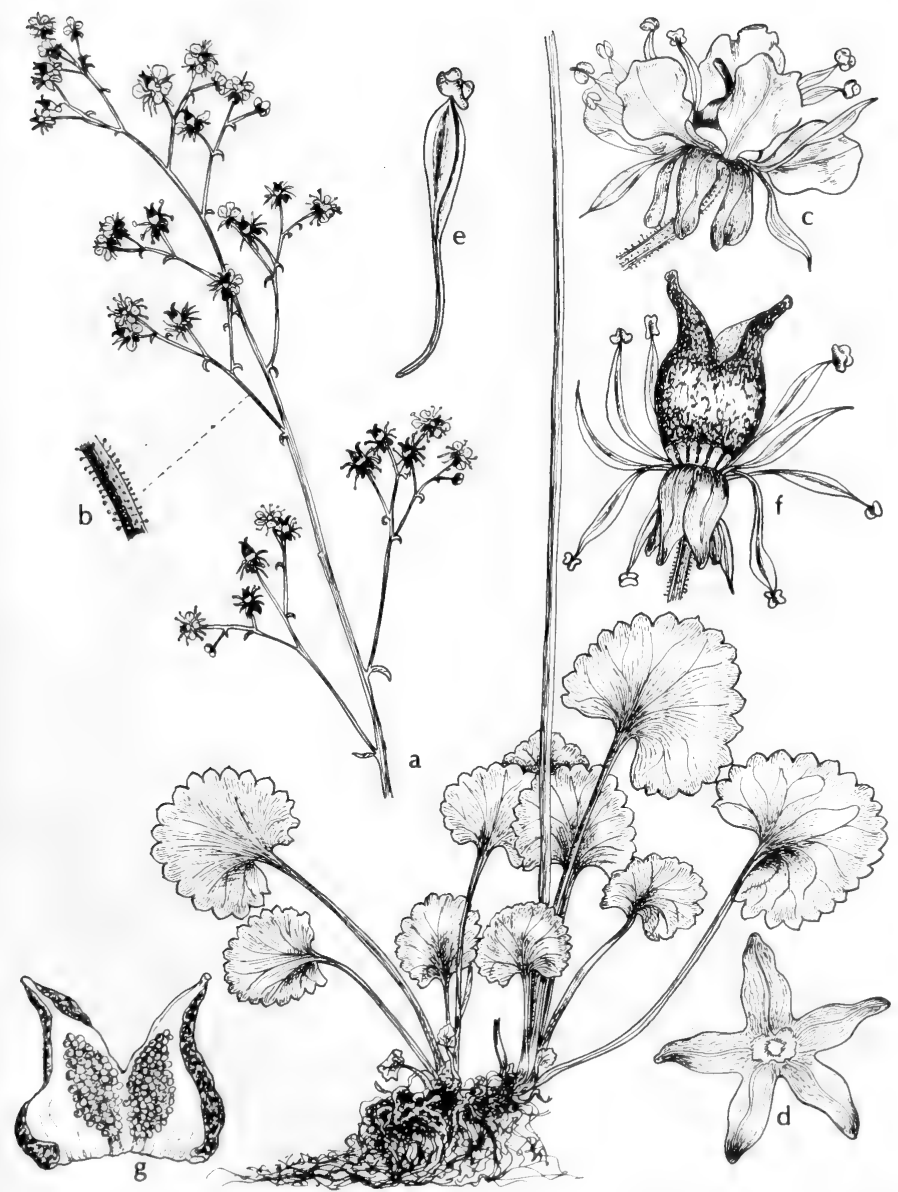

Fig. 485: Saxifraga arguta: a, habit, $x \frac{1}{2}$; b, portion of peduncles, $x 3$; c, flower, x $5 ; \mathrm{d}$, calyx, x 5 ; e, stamen, x $10 ; \mathrm{f}$, capsule, $\mathrm{x} 5 ; \mathrm{g}$, capsule opened to show seed, x 5. (V. F.). 


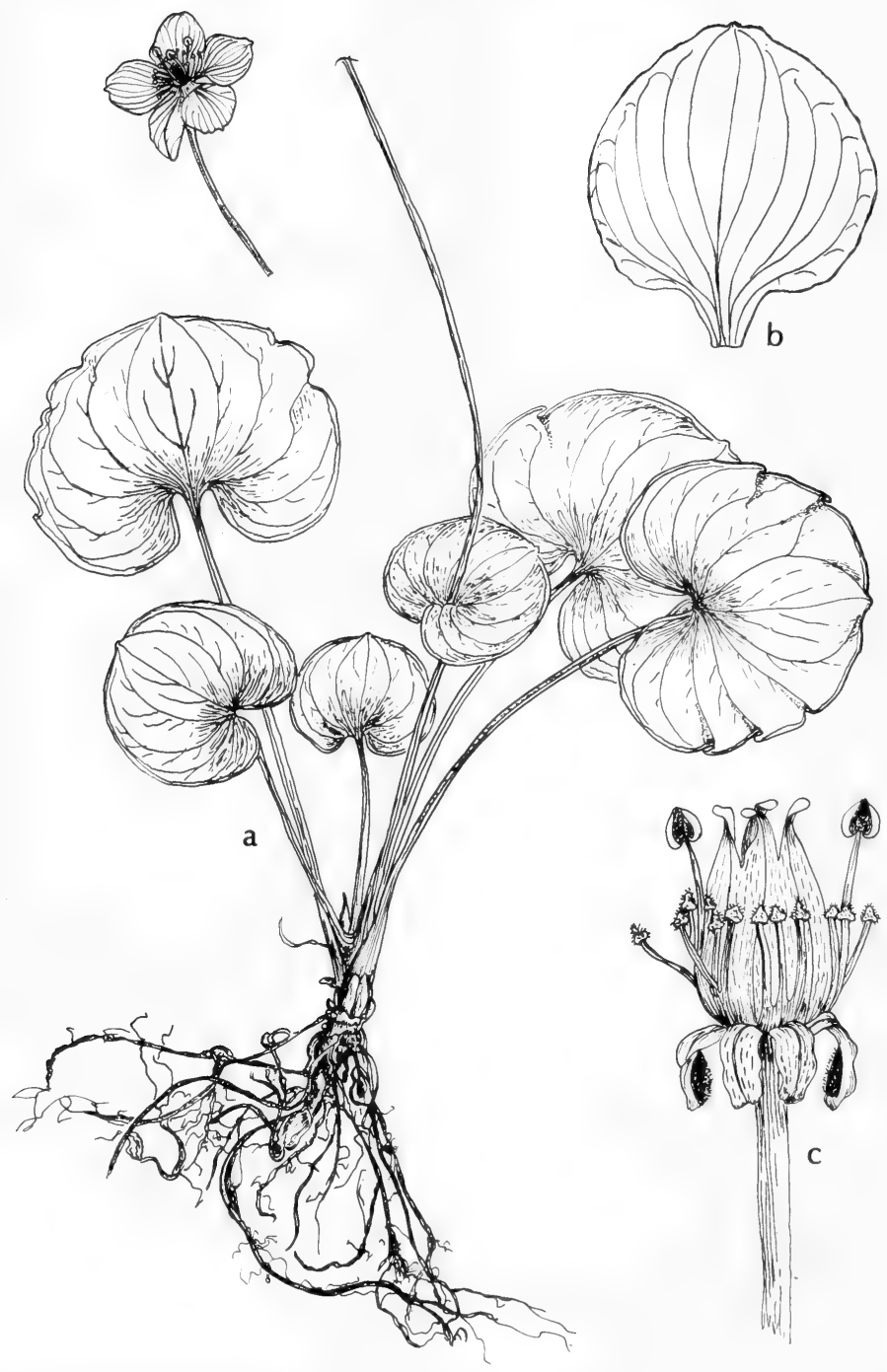

Fig. 486: Parnassia asarifolia: a, habit, x 1/2; b, petal, x 21/2; c, fruit, x 21/2. (V. F.). 
broadened above, petaloid, conspicuous because of the early falling of the petals; mature fruits to $1 \mathrm{~cm}$. long, twice as long as broad. Micranthes arguta (D.Don) Small.

On wet slopes, in wet meadows, about lakes and along streams in mts. of N.M. (Grant, San Miguel, Santa Fe, Socorro and Taos cos.) and Ariz. (Apache Co.), July-Aug.; Mont. to B.C., s. to N.M., Ariz. and Calif.

\section{Saxifraga rhomboidea Greene.}

Acaulescent plants; leaves in a basal rosette, rhombic-ovate to ovate, 2-6 cm. long (including the petiole that is rarely longer than the blade), cuneate at base, obtuse at apex, usually somewhat crenate or dentate, glabrous or with the margins ciliate; scapes 1-3 dm. tall, glandular-pubescent to rarely glabrate; inflorescence at first capitate, eventually interrupted-thyrsiform; sepals ovate to oval, $1.5-3.5 \mathrm{~mm}$. long, erect; petals oblong-obovate, $2.5-4 \mathrm{~mm}$. long, often emarginate at apex and clawed at base; filaments not clavate; capsule 3-4.5 mm. long, often purplish. Micranthes rhomboidea (Greene) Small.

Wet alpine meadows in N. M. (Colfax, San Miguel, Santa Fe and Taos cos.) and Ariz. (Apache to Coconino and Gila cos.), Apr.-July; Mont. s. to N. M. and Ariz.

\section{Parnassia L. Grass-of-Parnassus}

Perennial glabrous herbs with short rootstocks and with a scapelike stem; leaves simple, entire, mostly basal and petioled, the single cauline leaf sessile; scape typically 1-flowered; hypanthium short and usually poorly developed; sepals 5, imbricated in bud; petals 5 , imbricated in bud, white, conspicuously greenish- or yellowish-veined, deciduous; stamens 5 , persistent and alternate with the petals and with 5 clusters of more or less united staminodia that are gland-bearing at the ends; ovary 1-celled, superior to half-inferior; style short or none; stigmas 4, sessile; capsule 1-celled, 4-valved.

About 50 species in the Northern Hemisphere. Segregated by some authors as a monogeneric family, Parnassiaceae.

1. Distribution in eastern Texas (2)

1. Distribution in mountains of New Mexico and Arizona (3)

2(1). Leaves reniform; petals with claw; staminodes 5-9 $\mathrm{mm}$. long, equaling or shorter than the stamens........................................... P. asarifolia.

2. Leaves suborbicular-ovate; petals sessile; staminodes $12-15 \mathrm{~mm}$. long, conspicuously longer than the stamens. 2. P. grandifolia.

3(1). Petals entire.

3. P. parviflora.

3. Petals fimbriate on the sides near the base. 4. P. fimbriata.

1. Parnassia asarifolia Vent. Fig. 486.

Flowering stem 2-5 dm. high; basal leaves with petioles to $15 \mathrm{~cm}$. long, broadly reniform, 3-4 cm. long, wider than long; cauline leaf about or below middle of stem, similar to but smaller than the basal leaves; petals oblong-elliptic, contracted at base into a claw, $12-18 \mathrm{~mm}$. long, with 11 to 15 radiating veins; staminodia 3 -pronged, usually slightly shorter than the stamens, 5-9 $\mathrm{mm}$. long, united for one fifth to two fifths their length.

In sphagnum moss of evergreen shrub bogs in e. Tex., rare, Sept.-Nov.; from Va. and W.Va., s. to Ga. and Tex.

2. Parnassia grandifolia DC. Fig. 487.

Flowering stems to $4 \mathrm{dm}$. tall; basal leaves with petioles to $15 \mathrm{~cm}$. long, thick and firm, ovate to suborbicular, usually subcordate at base, to $1 \mathrm{dm}$. long and 8 $\mathrm{cm}$. wide; cauline leaf ovate to suborbicular-ovate, usually borne below the middle 


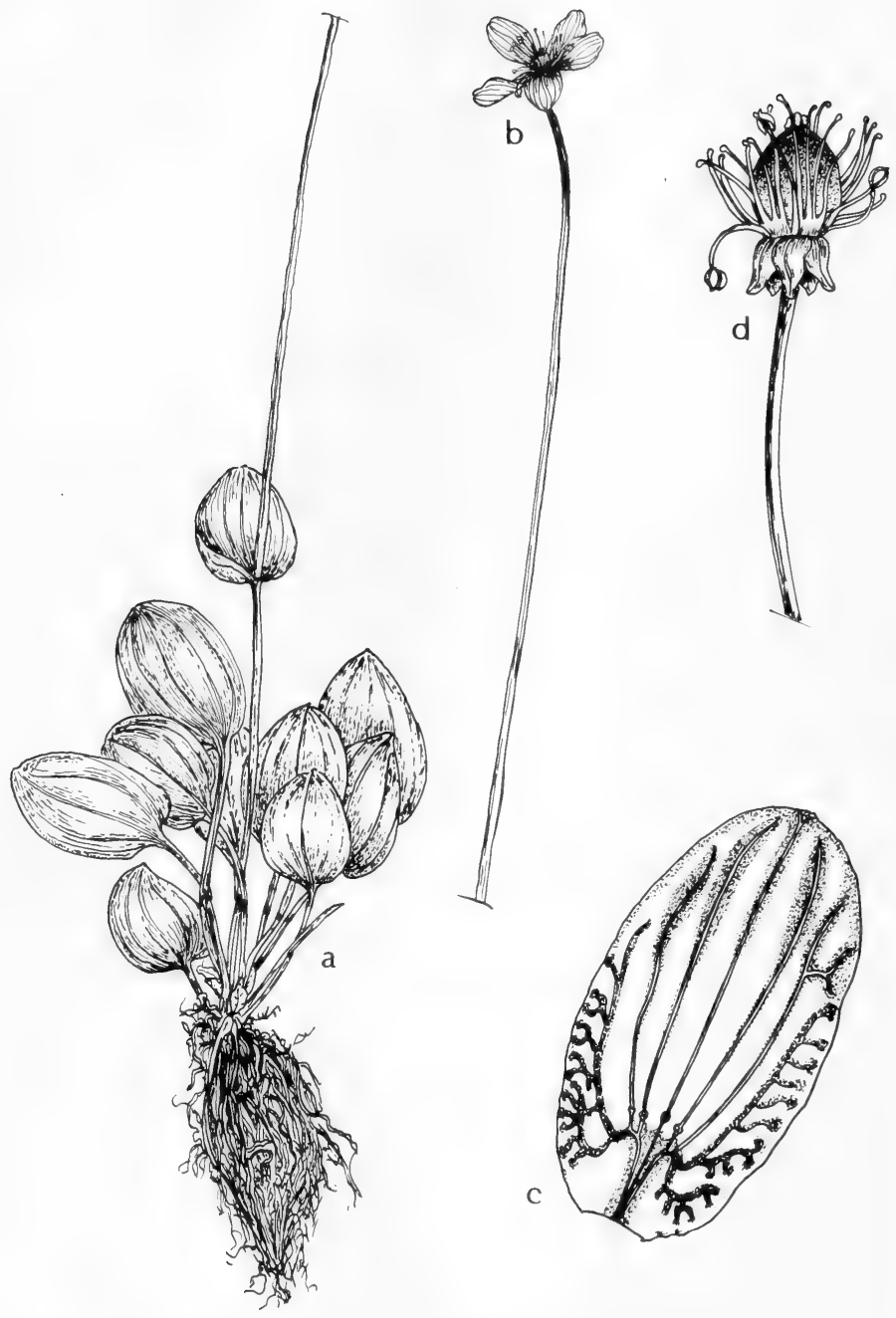

Fig. 487: Parnassia grandifolia: a, lower part of plant, $\mathrm{x} \frac{1}{2} ; \mathrm{b}$, top of plant, $\mathrm{x} \frac{1}{12}$; c, petal, x 3; d, fruit, x 1/1/2. (V. F.). 


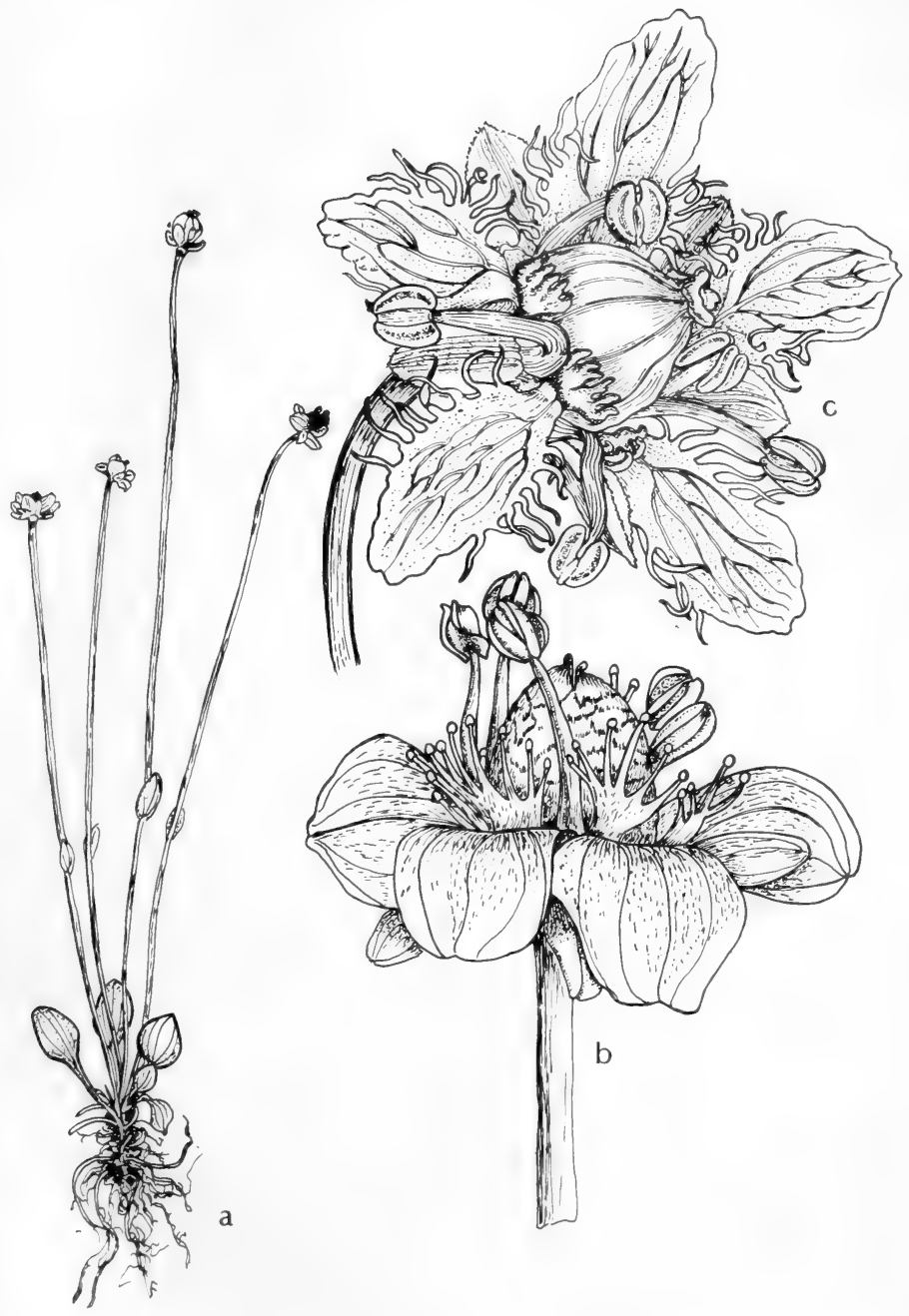

Fig. 488: a and b, Parnassia parviflora: a, habit, x 1/2; b, flower x 5. c, Parnassia fimbriata: c, flower, $\times 2^{1 / 1} 2$. (V. F.). 
of the scape; sepals elliptic, 4-5 mm. long, 3- to 7-veined; petals elliptic, 15-20 $\mathrm{mm}$. long, with about 7 strong veins; filaments $7-8 \mathrm{~mm}$. long, subulate; anthers ovate, acute, about $3 \mathrm{~mm}$. long; staminodia nearly filiform, $12-15 \mathrm{~mm}$. long, 3 to 5 in each set, united only at the base; capsule ovoid, about $15 \mathrm{~mm}$. long.

In wet meadows and wet marly situations in e. Tex., rare, Aug.; from Fla. to Tex., n. to W.Va., Tenn. and Mo.

\section{Parnassia parviflora DC. Fig. 488.}

Rootstock short; basal leaves oval to ovate, cuneate at base, 1-2.5 cm. long, with petioles $1-5 \mathrm{~cm}$. long; scape $1-3 \mathrm{dm}$. tall; bract below middle of scape, ovate to lanceolate, sessile; sepals 5-8 mm. long, oblong; petals cuneate-obovate or elliptic to oval, entire, clawless, $6-10 \mathrm{~mm}$. long; staminodial scales with 5 to 7 filiform filaments capitate at apex to resemble small stamens; capsule ovoid, 7-11 mm. long.

Bogs, wet meadows and seepage areas, sometimes saline, in N.M. (Lincoln, Otero and Taos cos.) and Ariz. (Apache and Coconino cos.), June-Sept.; Lab. and Que. to B.C., s. to N.M. and Ariz.

\section{Parnassia fimbriata Koenig. Fringed grass-of-Parnassus. Fig. 488.}

Rootstock short; basal leaves reniform to reniform-cordate, $2-4 \mathrm{~cm}$. wide, with petioles $5-15 \mathrm{~cm}$. long; scape $2-3 \mathrm{dm}$. high; bract near the middle of the scape, cordate-clasping, 5-15 mm. long; sepals elliptic to oval, 5-6 mm. long, often with short cilialike teeth; petals obovate, with a more or less distinct claw, 1-1.2 cm. long, fimbriate on the lower lateral margins; filaments filiform, 4-5 mm. long; staminodial scales rather fleshy, with 5 to 9 short lobes; capsule $8-10 \mathrm{~mm}$. long.

Springs, bogs and edge of water along streams in N.M. (Rio Arriba and Taos cos. ), July-Sept.; Alas., s. to N.M. and Calif.

\section{Itea L. SWEET-SPIRE}

About 15 species, mostly in southeast Asia. This genus, along with Choristylis Harv., is treated as a segregate family, Iteaceae, by some authors.

\section{Itea virginica L. TASSEL-whITE. Fig. 489.}

Shrubs to $25 \mathrm{dm}$. tall; leaves simple, alternate, petioled, deciduous, broadly elliptic to oblong or obovate, acute to abruptly acuminate at apex, minutely serrate, at time of flowering to $8 \mathrm{~cm}$. or more long; racemes simple, terminating the branchlets, to $2 \mathrm{dm}$. long and $2 \mathrm{~cm}$. in diameter, loose and open, the rachis and pedicels evident; calyx 5-cleft, free from the ovary or nearly so; petals 5, white, lanceolate, much longer than the calyx and longer than the 5 stamens; capsule 7-10 mm. long, ovoid to ellipsoid, 2-grooved, 2-celled, tipped by the 2 united styles, 2-parted when mature, several-seeded.

Swamps, about lakes and along wooded streams in Okla. (LeFlore and McCurtain cos.) and e. Tex., Apr.-May; from Fla. to Tex., n. to N.J., e. Pa., Ky., s. Ill., Mo. and Okla.

\section{Ribes L. Currant. Gooseberry}

Shrubs with arching or straggly branches, unarmed or sometimes spiny; leaves alternate or appearing to be fascicled, broadly rounded, mostly palmately lobed, with the lobes toothed or crenate; flowers solitary or in fascicles or abbreviated racemes; calyx 5-lobed, often colored, the tube adherent to the ovary; petals 5, small, inserted in the calyx tube; stamens 5 , inserted on calyx tube alternately with the petals; ovary 1-celled; berry crowned by the shriveled remains of the flower.

About 150 species in cold or temperate regions in both hemispheres. A number of species are of economic importance because they are alternate hosts for the white pine blister rust, the fruits are eaten by birds, animals and man, and many 


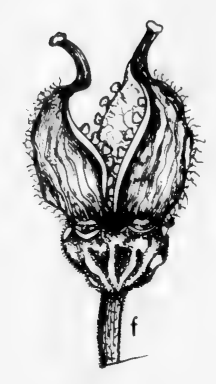


are favorite browse plants of both domestic animals and deer. This genus, along with Grossularia Mill., is treated by some authors as a segregate family, Grossulariaceae.

1. Plants with spines or prickles at nodes; pedicel not jointed below the ovary; flowers 5 or less per raceme..................................... $R$. inerme.

1. Plants without spines and prickles; pedicels usually jointed below the ovary; flowers more than 5 in each raceme (2)

2(1). Flowers bright-yellow, becoming reddish with age; hypanthium tubularfunnelform, 6-10 mm. long, glabrous......................2. $R$. aureum.

2. Flowers whitish to greenish-white or yellowish-white; hypanthium saucershaped or tubular-campanulate, less than $5 \mathrm{~mm}$. long (3)

3(2). Plant more or less adorned with yellowish sessile crystalline glands; hypanthium $3.5-4.5 \mathrm{~mm}$. long, glabrous. 3. $R$. americanum.

3. Plant without crystalline glands; hypanthium $1-1.5 \mathrm{~mm}$. long, crisp-puberulent

4. R. mogollonicum.

\section{Ribes inerme Rydb.}

Erect to sprawling shrubs usually 1-2 m. tall; young branches glabrous or somewhat retrorse-bristly, commonly with 1 to 3 nodal spines to about $1 \mathrm{~cm}$. long; leaves with petioles about as long as blade, mostly broadly ovate and $2-5 \mathrm{~cm}$. wide, rounded to cordate at base, rather deeply 3-lobed with the lobes deeply crenate-serrate, the lateral lobes sometimes again lobed; racemes with 2 to 4 drooping flowers, glabrous, shorter than the leaves; pedicels slender, 3-7 $\mathrm{mm}$. long, not jointed; bracts ovate, 1-2 mm. long, ciliolate; hypanthium tubularcampanulate, mostly $2.5-3 \mathrm{~mm}$. long, greenish to purplish- or reddish-tinged, glabrous or sparsely hirsute; calyx lobes oblong-lanceolate, spreading or somewhat reflexed; petals white or pinkish, cuneate-oblong to oblong, 1-1.5 mm. long; stamens subequal to calyx lobes, the filaments glabrous; berry smooth, reddishpurple, 7-9 mm. long, palatable. Grossularia inermis (Rydb.) Cov. \& Britt.

Wet stream banks, flats and thickets at edge of wet meadows to open mt. ridges, in N. M. (Grant, Rio Arriba, San Miguel, Santa Fe and Socorro cos.), May-July; Mont. and Wyo. w. to B. C., s. to N. M. and Calif.

\section{Ribes aureum Pursh. Golden currant.}

Shrub to $2 \mathrm{~m}$. tall; young branchlets light-tan-color, glabrous or puberulous; leaves orbicular-reniform to obovate, cuneate to subcordate at base, to $5 \mathrm{~cm}$. wide, 3-lobed, the coarsely crenate-dentate lobes often with only 2 or 3 teeth, glabrous or sometimes puberulous on lower surface; petioles about as long as blade; flowers yellow, fragrant or slightly so, 5 to 15 in a raceme; bracts oblong to obovate; pedicels to $8 \mathrm{~mm}$. long, jointed under the ovary; hypanthium slender, yellow, 6-10 $\mathrm{mm}$. long, $1.5 \mathrm{~mm}$. wide; sepals more than half as long as the tube, spreading, upright and close in the faded flowers; petals changing to red; fruit globose, black or purplish-brown, 6-8 $\mathrm{mm}$. in diameter.

Wet stream banks, flood plains, grasslands and conifer forests, in mts. of Trans-Pecos Tex., N. M. (Grant, Guadalupe, Lincoln, Luna, San Juan, San Miguel and Valencia cos.) and Ariz. (Navajo and Yavapai to Greenlee, Cochise, Santa Cruz and Pima cos.), Mar.-June; from S. D. to Assiniboia and Wash., s. to w. Tex., N.M., Ariz. and Calif.

\section{Ribes americanum Mill. BLACK CURRANT.}

Erect to somewhat spreading unarmed shrubs to about $1 \mathrm{~m}$. tall; young branches crisp-puberulent and somewhat dotted with sessile yellowish crystalline glands, eventually black with age; leaves with petioles equal to or shorter than blade; shallowly cordate, $3-8 \mathrm{~cm}$. wide, almost as long, deeply 3 -lobed with the 
triangular-ovate lobes coarsely doubly crenate-serrate, the lateral lobes sometimes again lobed, somewhat glandular-pubescent at least on lower surface; raceme pubescent, with as many as 15 drooping flowers; bracts lanceolate, to about $1 \mathrm{~cm}$. long; hypanthium broadly tubular-campanulate, $3.5-4.5 \mathrm{~mm}$. long, yellowishgreen to greenish-white; calyx with reflexed oblong-spatulate to oblong lobes usually slightly shorter than hypanthium; petals whitish or greenish-white, oblong to oblong-obovate, $2.5-3 \mathrm{~mm}$. long; stamens subequal to petals, the glabrous filaments broad below; berry ovoid, about $1 \mathrm{~cm}$. long, smooth, unpalatable.

Swamps, wet soil on stream banks, and moist ravines and canyons, in N. M. (San Miguel Co.), May-June; N.S. s. to Va., w. to Alta. and N. M.

\section{Ribes mogollonicum Greene.}

Glandular unarmed shrub to $3 \mathrm{~m}$. tall, erect to low-spreading; young branches puberulent but soon glabrous; leaves with petioles subequal to the blade, broadly orbicular in outline and 3- or 5-lobed, deeply cordate at base, the broadly ovate lobes finely doubly serrate-dentate, bright green and glabrous on upper surface, paler and somewhat glandular-puberulent on lower surface; racemes $2-5 \mathrm{~cm}$. long, spreading to erect, in part glandular-puberulent; bracts oblong-spatulate $4-5 \mathrm{~mm}$. long, equal to or about twice as long as pedicels; hypanthium broadly saucershaped, 1-1.5 mm. long, crisp-puberulent; calyx lobes oblong, 2.5-3.5 mm. long, spreading, several-veined; petals whitish-green to yellowish-green, flabelliform, less than half as long as calyx lobes; stamens about equal to the petals, scarcely exserted; berry ovoid, black, glandular, about $1 \mathrm{~cm}$. long. $R$. Wolfii of auth.

About lakes and in seepage areas, moist woods, in N. M. (widespread in higher mts.) and Ariz. (Apache, Coconino and Graham cos.), May-Aug.; Colo. and Ut. to N. M. and Ariz.

\section{Jamesia T. \& G.}

\section{A monotypic genus of western North America.}

\section{Jamesia americana $T$. \& $G$.}

Erect much-branched shrub to $2 \mathrm{~m}$. tall, the grayish- to reddish-brown bark shreddy, the young twigs strigose or short-villous; leaves opposite, ovate, $1.5-2.5$ $\mathrm{cm}$. long, thinnish, prominently crenate-serrate with the teeth mucronulate, the lower surface strigose-canescent, the upper surface sparsely strigose and brightgreen, the prominent lateral veins impressed on the upper surface; flowers numerous in dense cymes; pedicels and hypanthium strigose; sepals triangular-ovate, about $2.5 \mathrm{~mm}$. long; petals 5, white or pink, narrowly oblong-ovate, 6-7 $\mathrm{mm}$. long; stamens 10, the filaments broad and flat; styles 3 to 5 , elongating after anthesis, becoming twice the length of the calyx; capsule about half inferior, conic, beaked by the persistent style.

On rock ledges and canyon walls, commonly along mt. streams and often with its roots in running water, widespread in mts. of N. M. and Ariz. (Cochise, Graham and Pima cos.), June-Aug.; Wyo. to N.M., Ariz. and Calif.

An ornamental shrub that is occasionally cultivated.

\section{Fam. 71. Hamamelidaceae R. BR.}

\section{WiTCH-HAZEL FAMILY}

Shrubs or trees with alternate simple leaves and deciduous stipules; flowers in heads or clusters, often polygamous or perfect; calyx (when present) adherent to the base of the ovary; petals (when present) inserted on the calyx, narrow, valvate or imbricate in the bud; stamens numerous or twice as many as the petals and with half of them (those opposite the petals) sterile and changed into scales; ovary of 2 pistils united below and forming a 2-beaked 2-celled woody 
capsule that opens at the summit, usually with 1 or 2 anatropous seeds in each cell.

About 80 species in 22 genera in both hemispheres, chiefly tropical.

\section{Liquidambar L.}

Considered to be 3 species, one in America and 2 in Asia. Segregated by some authors into a separate family, Altingiaceae. The foliage is highly ornamental in the fall.

\section{Liquidambar Styraciflua L. SweET-GUM, BILSTED. Fig. 490.}

Tree to $40 \mathrm{~m}$. tall or more, with grayish-brown furrowed bark and commonly with corky ridges on the branchlets, often exuding a gum said to be pleasant to chew (with which we differ); leaves deciduous, with slender petioles to $12 \mathrm{~cm}$. long, rounded in outline, to $18 \mathrm{~cm}$. long and $12 \mathrm{~cm}$. wide, deeply 5 - or 7-lobed to resemble a star, smooth and shining, fragrant when bruised, turning crimson in autumn, truncate to somewhat cordate at base, the triangular lobes acuminate and glandular-serrate; flowers unisexual, apetalous; staminate flowers intermixed with small scales in globose heads that are disposed in terminal racemes; pistillate flowers in slender-peduncled globose heads, consisting of more or less coherent 2-celled 2-beaked ovaries subtended by minute scales; styles 2, stigmatic along the inner surface; fruit globose, woody, to $3 \mathrm{~cm}$. in diameter, on peduncles to 5 $\mathrm{cm}$. long, the individual capsules opening between the persistent subulate rigid styles and producing 1 or 2 winged seeds, the capsules filled mostly with abortive seeds that resemble sawdust.

In wet situations and in swampy woods in s.e. Okla. (McCurtain Co.) and e. and s.-cen. (w. to Lee Co.) Tex., Mar.-May; from Fla. to Tex., Mex. and C.A., n. to s. Conn., s.e. N.Y., W.Va., s. O., s. Ind., s. Ill. and Okla.

\section{Fam. 72. Platanaceae DuM.}

\section{Plane-tree Family}

Trees usually large, monoecious, with wide-spreading branches and mostly exfoliating bark; leaves deciduous, alternate, palmately lobed; petiole dilated and hollow at the base to envelop the axillary bud; stipules membranous, caducous, encircling the twig; flowers densely arranged in long-stemmed unisexual globose heads; calyx and corolla insignificant or sometimes wanting; staminate flowers with numerous subsessile linear 2-celled anthers that are subtended by minute scales, the connective peltate at apex; pistillate flowers with numerous subsessile carpels intermixed with scattered linear bracts; ovary tapered above, 1-celled, with a unilateral stigma extending for most of the length of the inner face of the linear-subulate style; fruit indehiscent, surrounded at the base by a tuft of long bristly tawny hairs that are directed upward parallel with and almost encompassing the fruit; seed orthotropous, one in each carpel, linearfusiform.

Only one genus of uncertain relationship.

\section{Platanus L. Sycamore. Plane-tree. Buttonwood}

Characters of the family. About 10 species in the North Temperate Zone.

1. Head of fruit usually solitary; leaves broadly ovate, truncate to rarely cuneate at base, shallowly 3- or 5-lobed; lobes broad, sparsely toothed or entire............................................................ $P$. occidentalis.

1. Heads of fruit racemose; leaves deeply 5- or 7-lobed, deeply cordate to cuneate or truncate at base; lobes elongate, entire to rarely dentate 


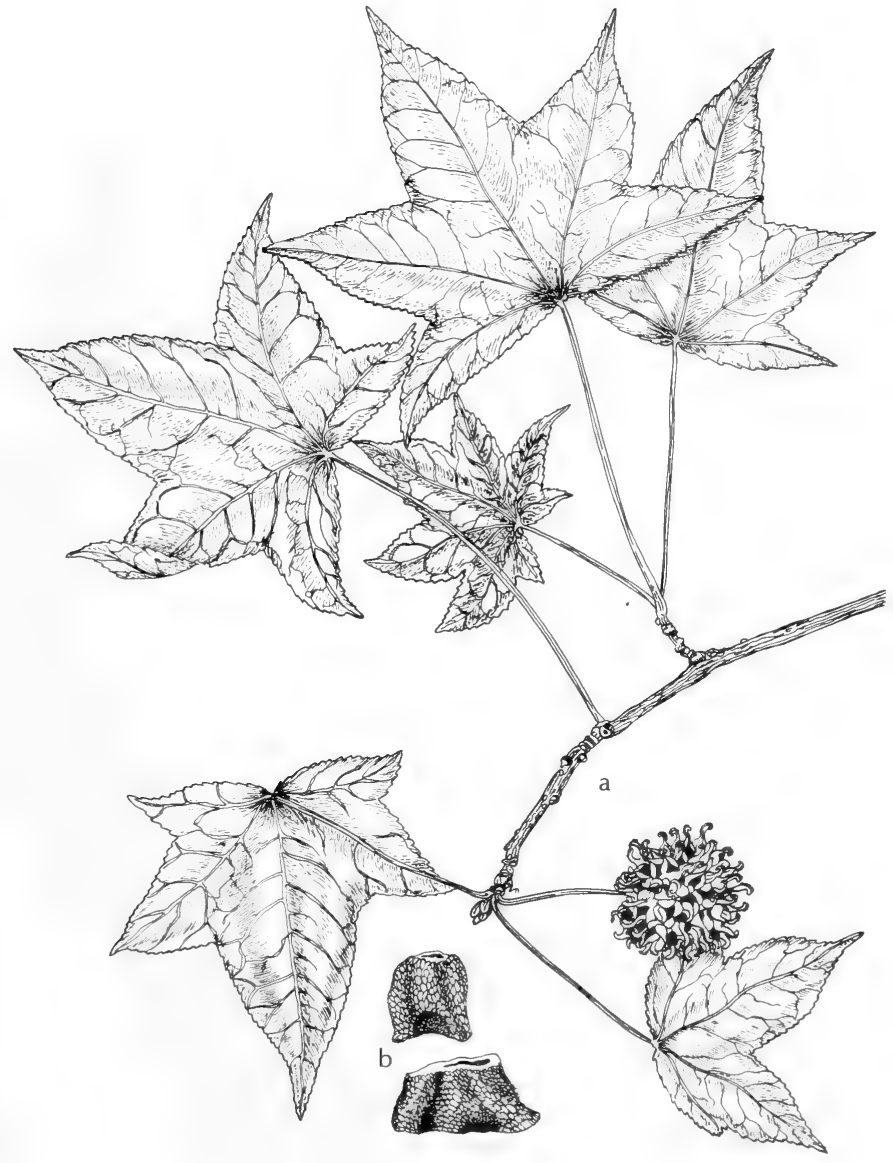

Fig. 490: Liquidambar styraciflua: a, twig with fruit, X 1/2; b, seeds, about X 10 . (V. F.). 


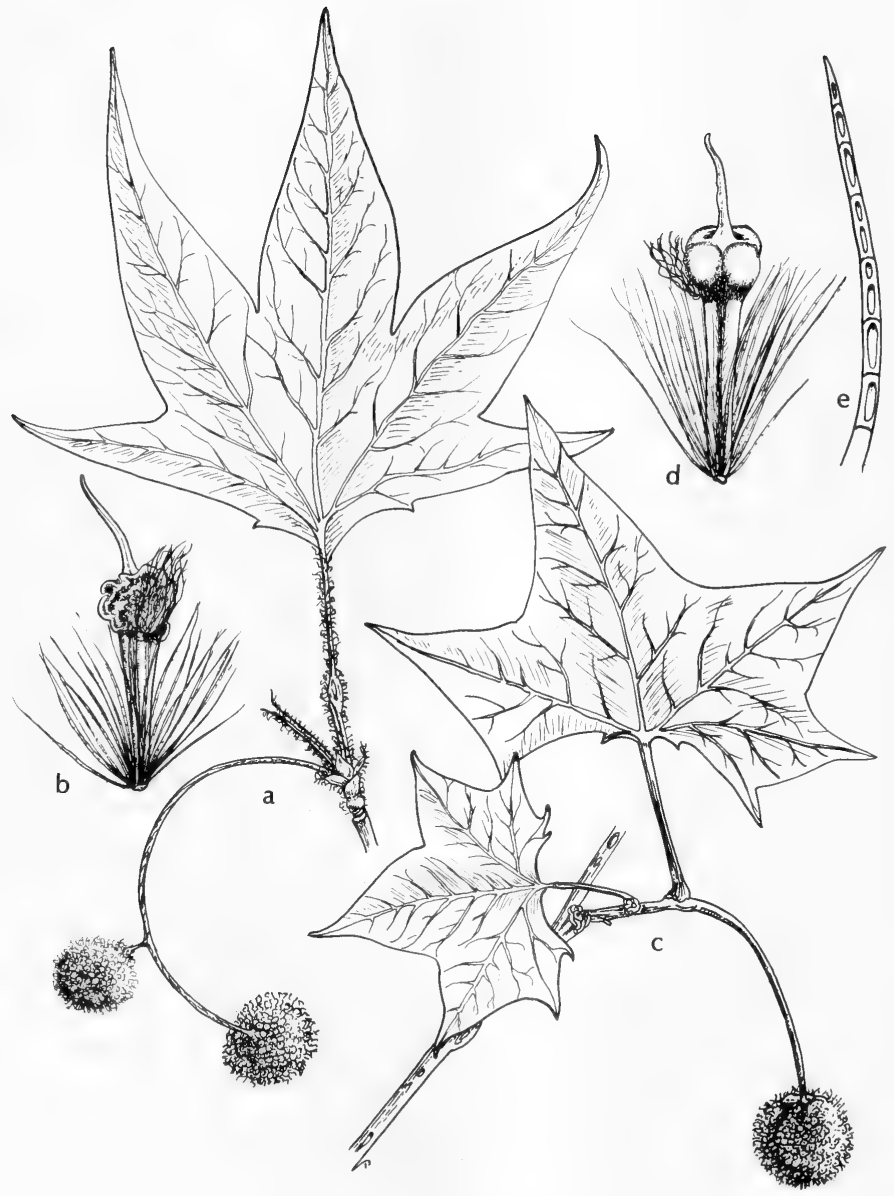

Fig. 491: a and b, Platanus Wrightii: a, twig with fruit, $\mathrm{x} 1 / 2 ; \mathrm{b}$, achene, $\mathrm{x} 5$. c-e, Platanus occidentalis: $c$, twig with fruit, $\mathrm{x} 1 / 2 ; \mathrm{d}$, achene, $\mathrm{x} 5$; e, hair, enlarged, $\mathrm{x} 25$. (V. F.). 


\section{Platanus occidentalis L. Fig. 491.}

Large tree to $50 \mathrm{~m}$. tall and with a trunk to $4 \mathrm{~m}$. in diameter; bark mottled brown and white or buff due to exfoliation; leaves broadly ovate to suborbicular or broadly reniform in outline, to about $2 \mathrm{dm}$. in diameter, truncate to cordate at base, essentially glabrous or with stellate pubescence on lower surface, 3- or 5-lobed, usually with broadly rounded shallow sinuses; leaf lobes mostly broadly triangular and acuminate, entire or with few long remote pointed teeth; fruiting heads $25 \mathrm{~mm}$. or more in diameter, usually persistent on the tree during at least part of winter; fruit narrowly clavate, about $8 \mathrm{~mm}$. long; seed brownish, about 6 $\mathrm{mm}$. long. Incl. var. glabrata (Fern.) Sarg. and f, attenuata Sarg.

Mostly along streams and in bottomlands in s.e. Okla. and throughout most of Tex. e. of Val Verde Co., Mar.-May; from Me., w. to Ont. and Neb., s. to n. Fla. and Tex.

\section{Platanus Wrightii Wats. Arizona sycamore. Fig. 491.}

Large tree to $24 \mathrm{~m}$. high, with arched white-barked branches spreading to form a broad crown; trunk and branches with the outer bark flaking off to expose the smooth whitish inner bark; buds enclosed in the dilated bases of the petioles; leaves large, to about $3 \mathrm{dm}$. in diameter, alternate, palmately lobed; flowers numerous in dense globose heads; sepals and petals minute; pistils 3 or 4 , distinct; fruit a 4-sided achene, with a basal tuft of long hairs. $P$. racemosa Nutt. var. Wrightii (Wats.) L.Benson.

Along streams and in low wettish areas, rather widespread in southw. N.M. and the s. half of Ariz., Apr.-May; also n. Mex.

\section{Fam. 73. Rosaceae Juss. Rose Family}

Trees, shrubs or herbs; leaves alternate, simple or compound; stipules present, sometimes caducous to obsolete or wanting; flowers mostly perfect, regular or nearly so, having a floral cup ("hypanthium") formed by the fusion of the bases of sepals, petals and stamens (this appearing in some taxa with inferior ovaries to be merely the outer layer of the ovary wall); sepals usually 5 , sometimes 3 to 8 , rarely united at base, often appearing double by a row of outer bractlets; petals as many as the sepals, rarely wanting or numerous by "doubling," mostly imbricated in the bud and usually inserted with the stamens on the edge of the floral cup; stamens usually numerous, inserted near the edge of the floral cup; pistils one to many, distinct or united and sometimes adnate to the floral cup or hypanthium; ovules 1 to several in each carpel; endosperm scanty or absent; fruit a follicle, achene, pome or more or less aggregate drupelets or an achenelet.

This diverse family of plants perhaps comprise more than 2,000 species in about 100 genera. They are represented in most areas of the world but are most abundant in eastern Asia, North America and Europe. Its production of miscellaneous fruits edible to man is not surpassed by any other family of plants; among these are the apple, peach, pear, cherry, apricot, plum, almond, strawberry, raspberry and blackberry. Its contribution to ornamentals, epitomized by the rose, is of the highest importance. Many species provide food and forage for domestic and wildlife.

1. Annual or perennial herbs above ground, unarmed, the caudex often somewhat woody (2)

1. Hardy or perennial shrubs or trees, if somewhat herbaceous then provided with prickles (6) 
2(1). Ovaries several to many, borne on a broad to elongate receptacle, not enclosed by the calyx (3)

2. Ovaries one to many, becoming achenes that are covered by the calyx (5)

3(2). Styles persistent and elongating after anthesis, plumose or jointed..6. Geum

3. Styles not elongate after anthesis, mostly deciduous (4)

4(3). Receptacle dry, not greatly enlarged in fruit. 5. Potentilla

4. Receptacle pulpy and greatly enlarged in fruit. 4. Duchesnea

5(2). Calyx beset with hooked bristles, the 5-cleft limb closed after flowering and persistent; petals yellow...............................................8. Agrimonia

5. Calyx not bristly, the 4 petaloid lobes greenish or rose-tinged; petals none.... 9. Sanguisorba

6(1). Ovary inferior, enclosed by and adnate to the calyx tube (hypanthium) which becomes more or less fleshy; fruit a pome (applelike or berrylike); calyx lobes more or less persistent at apex of fruit; petals white (7)

6. Ovary superior but sometimes concealed by the hypanthium; calyx tube not fleshy and enclosing the pistils or (if so) not adnate to them (8)

7(6). Plants typically armed with strong woody spines; mature carpels hard and bony, 1 to 5 , free or coherent in the pulpy fruit..............3. Crataegus 7. Plants unarmed; mature carpels papery or soft-cartilaginous...................2. Pyrus

8(6). Calyx tube enclosing the numerous carpels, becoming fleshy; fruit (hip) simulating a pome, crowned by the persistent calyx...........10. Rosa

8. Calyx tube not enclosing the carpels or not becoming fleshy (9)

$9(8)$. Fruit becoming juicy and more or less edible; stems usually armed with prickles. 7. Rubus

9. Fruits much-inflated, not becoming juicy; stems without prickles

1. Physocarpus

\section{Physocarpus Maxim.}

About a dozen species, one in Manchuria, the others in North America.

1. Physocarpus monogynus (Torr.) Coult. Mountain Ninebark.

Shrub usually less than $1 \mathrm{~m}$. high, with usually decumbent stems and exfoliating bark; branches brownish, glabrous to sparingly stellate-pubescent; leaves alternate, with petioles $15 \mathrm{~mm}$. long or less, suborbicular-ovate to reniform, usually deeply palmately 3 - or 5-lobed, incised, $1-4 \mathrm{~cm}$. long, glabrous or nearly so and green on both sides; terminal corymbs few- to many-flowered; bracts lanceolate, caducous; pedicels $1-1.5 \mathrm{~cm}$. long, usually sparingly stellate pubescent; hypanthium hemispheric, about $3 \mathrm{~mm}$. wide, stellate-pubescent; sepals 5, persistent, ovate-lanceolate to elliptic, usually obtuse, densely stellate-pubescent on both sides; petals 5 , white, orbicular, spreading, about $3 \mathrm{~mm}$. long; stamens 20 to 40 , on a disk clothing the mouth of the hypanthium; filaments long, slender, filiform; anthers didymous; pistils 2 or 3 , more or less united at the base; styles filiform, terminal; stigmas capitate follicles 2 or 3 , united to above the middle, densely stellate-pubescent, 3-5 mm. long, with ascending-spreading beaks, opening along both sutures; seeds over $1.5 \mathrm{~mm}$. long, usually 2 , obliquely pyriform, shining, with a bony coat. Opulaster monogynus (Torr.) O. Ktze.

Rare on seepage ledges in canyons and on open or forested slopes in w. Okla. (Cimarron Co.), the Tex. Trans-Pecos, N. M. (widespread) and Ariz. (Apache, Cochise and Graham cos.), Apr.-June; from Tex. to S. D., Wyo., N. M. and Ariz. 


\section{Pyrus L. Pear}

About 50 species mainly in the North Temperate Zone.

\section{Pyrus arbutifolia (L.) L.f. Red ChOKeberRy. Fig. 492.}

Colonial shrub or small slender tree (spreading by subterranean offsets) to $7 \mathrm{~m}$. high, usually much smaller; branches slender, loosely ascending, the new branchlets gray- or white-tomentose; leaves alternate, broadly oblanceolate to narrowly obovate or elliptic, tapering to the base, acute to short-acuminate or apiculate, darkgreen and glabrous (except for glandular midrib) above, densely pannosetomentose and pale beneath to rarely glabrous, crenate-serrate, in maturity to 9 $\mathrm{cm}$. long and $4 \mathrm{~cm}$. wide; flower clusters terminal on the stem and short axillary branches, $1.5-6 \mathrm{~cm}$. broad, as many as 25-flowered, the rachis and pedicels tomentulose; flowers about $1 \mathrm{~cm}$. broad; hypanthium tomentose; sepals bearing stipitate glands; petals white or pink-tinged; fruit obovoid to subglobose, bright- or dull-red, 5-7 mm. in diameter. Aronia arbutifolia (L.) Ell. and f. macrophylla (Hook.) Rehd.

Low woods, thickets, swamps, wet pine barrens and bogs in e. Tex., Mar.-May; from Fla. to Tex., n. to. N. S., N. Y., Ont., Mich. and Mo.

\section{Crataegus L. Hawthorn. Red Haw. Thorn}

Small trees or shrubs with usually crooked thorny branches and simple serrate or variously lobed deciduous leaves; leaves at the ends of vegetative shoots differently shaped, large and usually more deeply cut than those on the flowering branchlets; flowers solitary or comrnunly in corymbs; calyx tube campanulate or obconic, its limb 5-parted; petals normally 5, deciduous; stamens usually 5 to 20 , in 1 to 3 series; filaments filiform; anthers oblong, white, yellow or some shade of red; styles 1 to 5 , distinct; fruit a pome with 1 to 5 bony usually 1 -seeded nutlets.

There are close to 1,000 specific proposals that have been made in this primarily North American genus. There is no way to estimate the number of valid species that might occur. Species comprising some Series, such as Molles and Virides, seem to intergrade imperceptibly into each other. Although we are inclined to combine even more of these than have been combined thus far, the conclusions of E. J. Palmer have been followed as closely as possible since our treatment is derived and adapted from his various published contributions regarding this genus. Palmer considered the primary taxonomic characters, in descending order of importance, to be color of anthers, number of stamens, the pubescent or non-pubescent condition of the corymb at time of flowering, and, lastly, general shape of the leaves. He was of the opinion that if these characteristics were used in combination species determinations could be made.

One of the characteristic habitats of many species of hawthorns is open, poorly drained flatwoods that become momentarily flooded after heavy rains. An attempt was made to discriminate between such habitats and those that are somewhat similar in appearance but which fit more nearly into our wet land habitat concept. If, perchance, a specimen is collected in these temporarily wet habitats and is not to be found in our work its identity should be sought in a local or regional Flora.

The fruit of many species are edible and make fine jellies and preserves, and most have ornamental qualities. The usually dense, thorny growth of most species provide favorite nesting sites for many birds. Their fruits are eaten to some extent by most birdlife and various small animals, and deer browse on the foliage and twigs. 


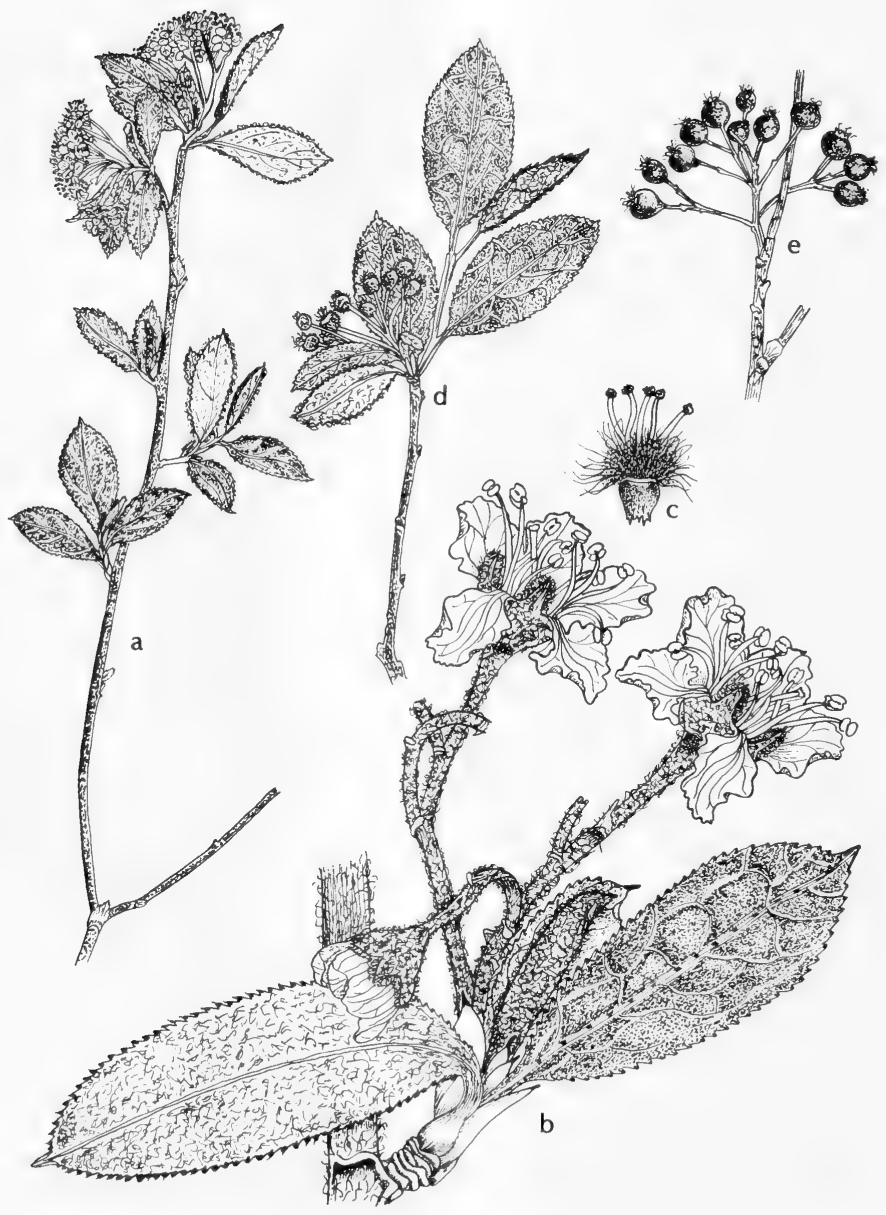

Fig. 492: Pyrus arbutifolia: a, branch with flowers, $x \frac{1}{2}$; b, flower cluster, $x$ 21/2; c, pistil, $x 2 \frac{1}{2}$; d, branch with fruit, $x \frac{1}{2}$; e, mature fruit, $x 1 / 2$. (V. F.). 
1. Primary veins of the larger leaves running to the sinuses as well as to the points of the lobes. 1. C. spathulata.

1. Primary veins of the leaves running only to the points of the lobes, very rarely with some running to the sinuses (2)

2(1). Thorns short and stout, rarely slender or more than $2 \mathrm{~cm}$. long; fruits blue or black at maturity (3)

2. Thorns usually slender, typically more than $4 \mathrm{~cm}$. long, rarely absent; fruits red, yellow or remaining green at maturity (4)

3(2). Leaves mostly abruptly pointed or rounded at the apex, lustrous above; fruit blue and glaucous at maturity; in eastern Texas.

2. C. brachyacantha.

3. Leaves mostly acute to acuminate at the apex, dull-green above; fruit grading from purple to black, lustrous but not glaucous; in northwestern Texas and New Mexico. 3. C. rivularis.

4(2). Flowers 2 to 5 in simple clusters; stamens 20 to 25 4. C. opaca. 4. Flowers usually more numerous, as many as 20 in simple or compound cymes or corymbs; stamens 5 to 20 (5)

5(4). Leaves of flowering branchlets usually rhombic to somewhat obovate or sometimes ovatish, typically narrowed at base, relatively thin, dullgreen above; fruit becoming soft or mellow with age; nutlets 3 to 5

7. C. viridis.

5. Leaves of flowering branchlets mostly narrowly obovate or oblong-obovate, seldom over $2-3 \mathrm{~cm}$. wide, mostly thick or firm, glossy above; fruit remaining hard and often green at maturity; nutlets commonly 1 to $3(6)$

6(5). Foliage and inflorescence glabrous or essentially so......5. C. pyracanthoides. 6. Foliage and inflorescence more or less pubescent or somewhat scabrous. 6. C. berberifolia.

\section{Crataegus spathulata Michx. Pasture haw.}

Shrub or tree 5-7 m. high, with stoutish usually thorny horizontal branchlets and thin scaly or smooth gray bark; leaves of flowering branchlets narrowly obovate, mostly $1-2 \mathrm{~cm}$. long and to $1 \mathrm{~cm}$. wide, with several coarse rounded teeth or small lobes above the middle or near the apex, gradually narrowed to the entire base, firm, glabrous at maturity, glossy above, with strongly ascending or nearly parallel obscure veins; petioles one fourth to half as long as the blades; flowers 6-8 mm. across, numerous in compact glabrous corymbs; stamens about 20; anthers pale-yellow; calyx lobes deltoid, entire, persistent on fruit; fruit subglobose, 4-7 mm. thick, red, with thin mellow flesh and 3 or 4 nutlets. C. microcarpa Lindl.

Sandy or sandy clay woods, palmetto marsh area where occasionally flooded, fencerows and pastures in e. Okla. and e. Tex., fruiting Oct.-Nov.; from Fla. to Tex. and Okla., n. to Va. and s. Mo.

\section{Crataegus brachyacantha Sarg. \& Engelm. BLUBERRY HAWTHORN.}

Tree to $15 \mathrm{~m}$. high; branchlets light-green and slightly pubescent early in the season, soon becoming glabrous and ultimately ashy-gray in color, armed with numerous short stout somewhat curved spines that are rarely to $2 \mathrm{~cm}$. long; leaves oblong-oblanceolate to somewhat rhombic, abruptly pointed or rounded at the apex, gradually narrowed to the cuneate base, crenulate-serrate above with minute incurved glandular teeth, somewhat pubescent at first; mature leaves subcoriaceous, glabrous, lustrous, dark-green, to $5 \mathrm{~cm}$. long and $25 \mathrm{~mm}$. wide; flowers numerous in crowded glabrous corymbs, on slender pedicels, about $8 \mathrm{~mm}$. wide; sepals short, triangular, narrowed to a gland-tipped apex; stamens 15 to 20 ; anthers yellow; 
fruit subglobose to obovoid, on erect pedicels, $8-13 \mathrm{~mm}$. thick, bright-blue, covered with a glaucous bloom; nutlets 3 to 5 .

Borders of streams in rich soil in e. Tex., fruiting Aug.-Sept.; in Ark., La. and Tex.

\section{Crataegus rivularis Nutt.}

Tree occasionally to $6 \mathrm{~m}$. high; branchlets slender, reddish-brown, lustrous, unarmed or armed with straight slender spines usually about $25 \mathrm{~mm}$. long; leaves lanceolate to oblong-obovate or elliptic, acute to acuminate at apex, gradually narrowed to a concave-cuneate base, very finely crenately serrate above with glandular teeth, about $5 \mathrm{~cm}$. long and $18 \mathrm{~mm}$. wide; petioles slender, slightly winged at apex, about $12 \mathrm{~mm}$. long; flowers about $12 \mathrm{~mm}$. wide, on long slender pedicels, in rather compact glabrous corymbs; sepals linear, entire or glandular, glabrous on outer surface, sparingly villous on inner surface; stamens 10 to 20; anthers pale rose-color; fruit short-oblong, full and rounded at the ends, darkcrimson becoming black and lustrous at maturity, $8-13 \mathrm{~mm}$. long; flesh thin, yellow, dry and mealy; nutlets 3 to 5 .

On banks of streams in extreme n.w. Tex. and N. M. (Socorro Co.), fruiting Sept.-Oct.; from s.e. Ida. to s.w. Colo., n. N. M. and Tex.

\section{Crataegus opaca H. \& A. Western mayhaw, apple haw.}

Tree to $9 \mathrm{~m}$. high; branchlets slender, villous-pubescent when they appear but soon glabrous, armless or armed with straight chestnut-brown spines; leaves elliptic to oblong-elliptic or oblong-cuneiform, acutish at apex, cuneate at base, the margins essentially entire or with minute glandular teeth, densely pubescent when young, at maturity dull-green above and pubescent with rusty-brown hairs beneath, to $65 \mathrm{~mm}$. long and $25 \mathrm{~mm}$. wide; petioles slender, villous-pubescent, about $7 \mathrm{~mm}$. long; flowers 2 to 5 in glabrous corymbs, about $25 \mathrm{~mm}$. wide; sepals triangular and acute at gland-tipped apex, essentially entire; stamens 20; anthers large, deep-rose-color; fruit depressed-globose, scarlet, lustrous, 12-15 mm. in diameter; nutlets 3 to 5 .

Commonly in depressions that are filled with water part of the year, along streams and on border of swamps in e. Tex., fruiting May-July; from Ala. to Tex.

\section{Crataegus pyracanthoides Beadle.}

Tree 8-10 m. high, with slender thorny or sometimes unarmed branchlets and dark-gray scaly bark; leaves obovate to oblanceolate, pointed or rarely rounded at the apex, shallowly serrate except near the base, glabrous, firm, dark-green and lustrous above; flowers $1-1.3 \mathrm{~cm}$. wide, mostly 5 to 8 in lax glabrous corymbs; stamens 10 or 20 ; anthers white to pale-yellow or purplish; fruit subglobose or short-oblong, 6-10 mm. thick, red, with thin mellow flesh and 2 or 3 nutlets. Incl. var. uniqua (Sarg.) E. J. Palm. and var. arborea (Beadle) E. J. Palm., C. uniqua Sarg., C. arborea Beadle.

In low rich woods and wet ground along streams in e. Tex., fruiting Oct.; from Ind. to Mo., s. to Fla. and Tex.

\section{Crataegus berberifolia T. \& G. BIGTREe HAWTHORN.}

Tree to $12 \mathrm{~m}$. high, with a trunk about $3 \mathrm{dm}$. in diameter and branchless for about $6 \mathrm{~m}$. above ground, the dark bark scaly and fissured; branchlets slender, dull-red-brown and slightly villous, armed with stout straight spines; leaves oblongobovate to oval, acute to acuminate at the gradually narrowed apex, cuneate at base, coarsely and often doubly serrate above with glandular teeth, coriaceouslustrous and slightly roughened on the upper surface, pale-green and scabrate on the lower surface, $3.5-5 \mathrm{~cm}$. long, to $25 \mathrm{~mm}$. wide; flowers $1-2 \mathrm{~cm}$. across, in slightly villous 4 - or 5-flowered slender-branched compact narrow corymbs; calyx 
tube glabrous or slightly villous below; calyx lobes linear-lanceolate, entire, obscurely glandular-serrate, reflexed after anthesis; stamens about 20; anthers yellow to rose-color; fruit short-oblong, slightly pruinose, dull-green tinged with red, $8-15 \mathrm{~mm}$. long.

In low wet woods and on dryish hills in e. Tex., fruiting Sept.-Oct.; endemic.

Our plant has been referred to var. edita (Sarg.) E. J. Palm. (C. edita Sarg.) whose anthers are rose-color instead of being yellow as in var. berberifolia.

\section{Crataegus viridis L. GREen HAWTHORN.}

Tree sometimes to $12 \mathrm{~m}$. high, with slender unarmed or sometimes thorny branchlets and thin scaly pale-gray bark over orange-brown inner bark; leaves variable and often asymmetrical, thin, glabrous at maturity except for tufts of tomentum in the axils of the veins beneath, on flowering branchlets mostly rhombic or oblong-elliptic, $2.5-5 \mathrm{~cm}$. long, 13-25 mm. wide, finely serrate above the middle or nearly to the base, on vegetative shoots often ovate and sharply serrate and sharply lobed or deeply cut toward the base; petioles slender, 1.2-5 $\mathrm{cm}$. long; flowers $12-15 \mathrm{~mm}$. wide, numerous in glabrous or rarely pubescent corymbs; stamens about 20 ; anthers small, pale-yellow or rarely red; fruit subglobose, 5-8 mm. thick, red or orange-red, with thin juicy fleshy and usually 5 nutlets. C. Davisii Sarg.

In low wet or alluvial woods, and fields in sandy soils and clays in e. Okla. and e. and s.-cen. Tex., fruiting Sept.-Nov.; from Va. and Fla., w. to Ill., Mo., Okla. and Tex.

Those plants with somewhat villous-pubescent corymbs and branchlets are segregated as var, velutina (Sarg.) E. J. Palm. (C. velutina Sarg.). Those plants with leaves shorter than typical have been segregated as f. abbreviata (Sarg.) E. J. Palm. (C. abbreviata Sarg.), a possible hybrid of this species with $C$. mollis.

\section{Duchesnea SM. Indian StrawberRy}

About 6 species native to Asia.

\section{Duchesnea indica (Andrz.) Focke.}

Perennial herb from a short rhizome, with leafy stolons and 3-foliolate leaves similar to those of the true strawberries; leaflets ovate to elliptic, $2-4 \mathrm{~cm}$. long, crenately toothed, sparsely strigose on lower surface; peduncles $3-10 \mathrm{~cm}$. long; flowers solitary, 15-18 mm. wide; calyx 5-parted, the lobes alternating with much larger foliaceous spreading 3-toothed appendages; petals 5, yellow; receptacle in fruit spongy but not very juicy; fruit bright-red, resembling a strawberry, insipid, about $1 \mathrm{~cm}$. in diameter.

Edge of low woods and thickets, seepage areas and marshes, along roadsides and in old fields in s.e. Okla. (Waterfall) and e. Tex., Mar.-Aug.; nat. of Asia that is established in many parts of the world.

\section{Potentilla L. Cinquefoil. Five-Finger}

Herbs or rarely shrubs with compound leaves and solitary or cymose flowers whose parts are rarely in fours; calyx flat, deeply 5-cleft, with as many bractlets at the sinuses so as to appear 10-cleft; petals 5, usually roundish; stamens few to many; achenes numerous, collected in a head on the dry mostly pubescent or hairy receptacle, often partly enclosed by the persistent accrescent calyx; styles slender, lateral or terminal, deciduous.

About 500 species chiefly throughout the North Temperate Zone.

1. Petals dark-reddish-purple.

1. Petals yellow to whitish (2)

1. P. Thurberi. 
2(1). Plant shrubby; ovaries and achenes strongly hirsute 2. P. fruticosa.

2. Plant herbaceous: ovaries and achenes glabrous (3)

3(2). Leaves palmately (or digitately) lobed or divided (4)

3. Leaves pinnately lobed or divided (8)

4(3). Perennials with usually well-developed rootstocks; leaves often whitetomentose on the lower surface; stamens 20 to 40 (5)

4. Annuals, biennials or sometimes short-lived perennials but without definite rootstocks; leaves never white-tomentose on lower surface; stamens 5 to $20(6)$

5(4). Plant 1.5-4.5 dm. tall, alpine or subalpine; leaflets only occasionally more than $3.5 \mathrm{~cm}$. long, typically greenish or about equally grayishsericeous on both surfaces; anthers $0.4-0.6 \mathrm{~mm}$. long.....

8. $P$. diversifolia.

5. Plants to $8 \mathrm{dm}$. tall, in lowlands to medium elevations in mountains; leaflets mostly much more than $3.5 \mathrm{~cm}$. long, the lower surface usually tomentose and much paler than upper surface; anthers $0.8-1.3 \mathrm{~mm}$. long.

9. P. gracilis.

6(4). Lower leaves 5-foliolate or ternate with the lateral leaflets 2-cleft to near the base; stamens 5 .

6. Leaves 3-foliolate (7)

4. P. pentandra.

7(6). Petals about half as long as sepals; hypanthium in fruit $5 \mathrm{~mm}$. wide or

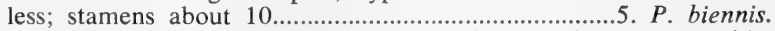

7. Petals equaling the sepals or nearly so; hypanthium in fruit about $7 \mathrm{~mm}$. wide;

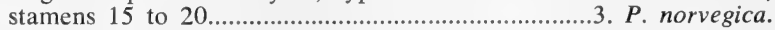

8(3). Annuals, biennials or sometimes short-lived perennials but without definite rootstocks; leaves never white-tomentose on lower surface; stamens 5 to $20(9)$

8. Perennials with usually well-developed rootstocks; leaves often white-tomentose on the lower surface; stamens 20 to 40 (10)

9(8). Principal leaves below inflorescence typically 3-foliolate; achenes smooth and without ventral protuberances.............................6. P. rivalis.

9. Principal leaves below inflorescence with 5 to several leaflets; achenes longitudinally ribbed and with a corky protuberance on ventral surface 7. $P$. paradoxa.

10(8). Basal leaves bipinnately lobed.

12. P. plattensis.

10. Basal leaves simply pinnate (11)

11(10). Flowers single on naked peduncles.

13. P. Anserina.

11. Flowers usually several on more or less leafy flowering stems (12)

12(11). Style slenderly fusiform, attached below middle of ovary; stamens 25 or more (13)

12. Style usually tapered from base or filiform, or attached near top of ovary; stamens 20 (14)

13(12). Cymes narrow and strict, the lateral branches almost erect; sepals 5-9 $\mathrm{mm}$. long at anthesis; herbage conspicuously villous....11. P. arguta.

13. Cymes usually open to diffuse, the lateral branches not tightly appressed; sepals 4-6 mm. long at anthesis; herbage not conspicuously villous

10. P. glandulosa.

14(12). Leaves silky-strigose to glabrate on lower surface, the two surfaces essentially concolorous; anthers mostly $0.4-0.6 \mathrm{~mm}$. long.

8. $P$. diversifolia.

14. Leaves white-tomentose on lower surface, the upper surface dark green; anthers mostly $0.8-1.3 \mathrm{~mm}$. long. 9. $P$. gracilis. 


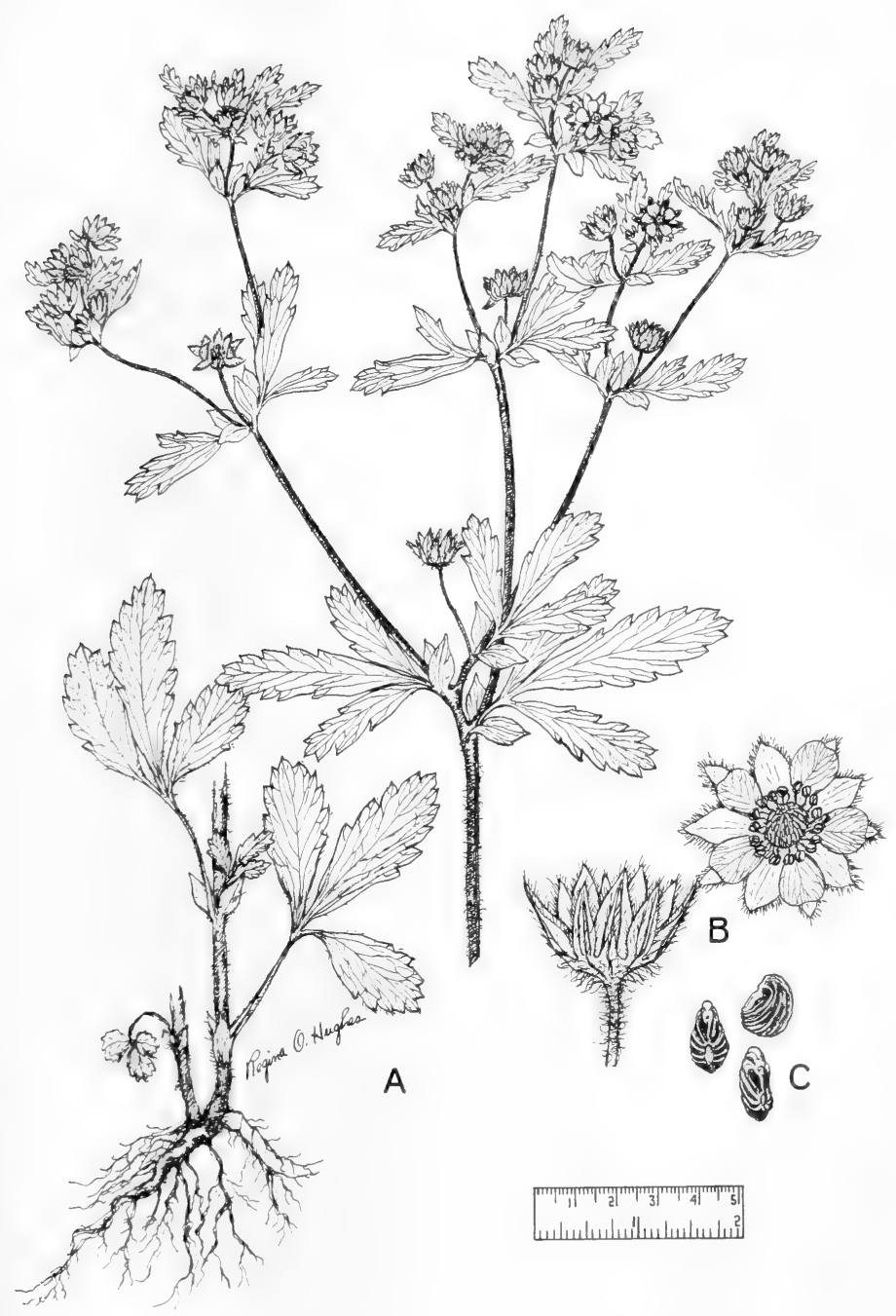

Fig. 492A: Potentilla norvegica: A, habit, x 1/2; B, flower and calyx, x 21/2; C, achenes, x 10. (From Reed, Selected Weeds of the United States, Fig. 107). 


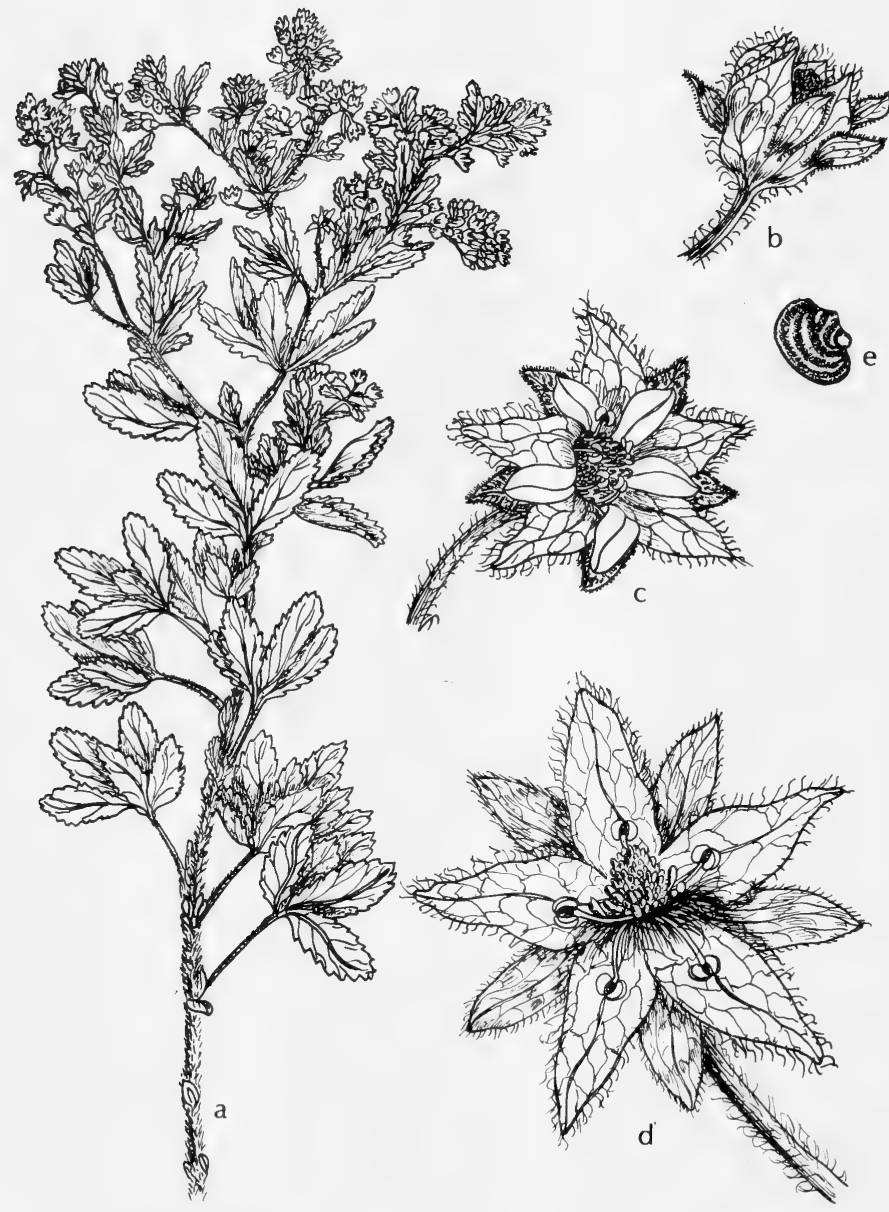

Fig. 493: Potentilla pentandra: a, top of plant, x $1 / 2 ; \mathrm{b}$, bud, $\mathrm{x} 5$; c, flower open, x 5; d, flower spread open, without corolla, showing 5 stamens, $x$ 5. (V. F.). 


\section{Potentilla Thurberi Gray.}

Perennial with a woody taproot and short caudex; stem ascending, 3-7 dm. tall, finely pubescent and sparingly villous; basal and lower stem leaves long-petioled, digitately 5- or 7-foliolate, glabrate to slightly sericeous (var. Thurberi) to densely silvery-sericeous [var. atrorubens (Rydb.) Kearn. \& Peeb. ( $P$. atrorubens Rydb.)] beneath; leaflets obovate, $3-5 \mathrm{~cm}$. long, coarsely toothed with broad teeth or almost crenate; upper stem leaves sessile, 3- or 5-foliolate, with oblong leaflets; stipules 1-2 cm. long, broadly ovate, coarsely toothed; cyme open and branched; flowers about $1.5 \mathrm{~cm}$. across; hypanthium puberulent, in fruit about $1 \mathrm{~cm}$. in diameter; bractlets lanceolate, 5-6 $\mathrm{mm}$. long, about equal to the triangular acute sepals; petals almost orbicular, emarginate, exceeding the sepals, dark-reddishpurple, $7-10 \mathrm{~mm}$. long; stamens 20 to 30 , the inner 5 with thicker filaments, borne on a ringlike thickening of the disk; pistils numerous.

In wet meadows, seepage along streams and about water bodies, and wooded slopes, in N. M. (Grant, Lincoln, Otero, Sierra and Socorro cos.) and Ariz. (Apache to Coconino and s. to Cochise and Pima cos.), June-Sept.; also n. Mex

\section{Potentilla fruticosa L. Shrubby or BUSH CINQUefoIl.}

Much-branched shrub, with very leafy erect or ascending stems, 2-12 dm. high, the reddish-brown bark shreddy; leaflets 3 to 7 , linear to oblong, entire, acute at each end, 5-20 $\mathrm{mm}$. long, silky-pubescent, the margins revolute; flowers in small loose cymes or solitary; bractlets linear-oblong, usually a little longer than the ovate acuminate sepals; petals yellow, orbicular, 5-15 $\mathrm{mm}$. long.

Wet (sometimes saline) meadows, creek bottoms, along streams and on moist rocky slopes, in N. M. (Rio Arriba, Bernalillo, Otero and Sandoval cos.) and Ariz. (Apache and Coconino cos.), June-Sept.; widely distributed in cooler parts of the N. Hemis.

This handsome-flowered shrub does well under cultivation, and various forms have been selected for horticultural use. In nature, plants are heavily browsed by deer and domestic stock.

\section{Potentilla norvegica L. Fig. 492A.}

Stout leafy annual or short-lived perennial, to $9 \mathrm{dm}$. high; stem erect or ascending, much-branched, hirsute with stiff mostly spreading hairs, often with shorter pubescence intermixed; lower leaves long-petioled, 3-foliolate; leaflets obovate to oblanceolate, to $8 \mathrm{~cm}$. long, coarsely serrate, usually more or less hirsute, otherwise green; upper leaves sessile, often with narrow leaflets; inflorescence a leafy cyme; calyx in fruit enlarging to $17 \mathrm{~mm}$. high, its bracteoles acutish; petals yellow, obovate, mostly shorter than calyx lobes; stamens 15 to 20; style slenderly conical at base, subterminal, about equaling the mature carpel; achenes longitudinally ribbed, to $1.3 \mathrm{~mm}$. long. Incl. var. hirsuta (Michx.) Lehm., $P$. monspeliensis $\mathrm{L}$.

In wet meadows and in marshes about lakes and ponds, along irrigation ditches and in thickets, in n.e. Okla. (Delaware Co.), Trans-Pecos Tex., N. M. (Rio Arriba, San Juan, San Miguel, Taos and Union cos.) and Ariz. (Apache, Coconino and Greenlee cos.), May-Sept.; widespread in N.A.; Euras.

\section{Potentilla pentandra Engelm. Fig. 493.}

Slender annual or biennial, ascending to about $1 \mathrm{~m}$. tall; stems rather stout, leafy, hirsute, chiefly branching and flowering above the middle; lower leaves pedately 5 -foliolate or 3-foliolate with the lateral leaflets 2-cleft, with hirsute petioles 3-8 cm. long; uppermost leaves 3-foliolate and very short-petioled; leaflets 2-10 cm. long, oblong to oblanceolate or cuneate, deeply serrate, pubescent on 


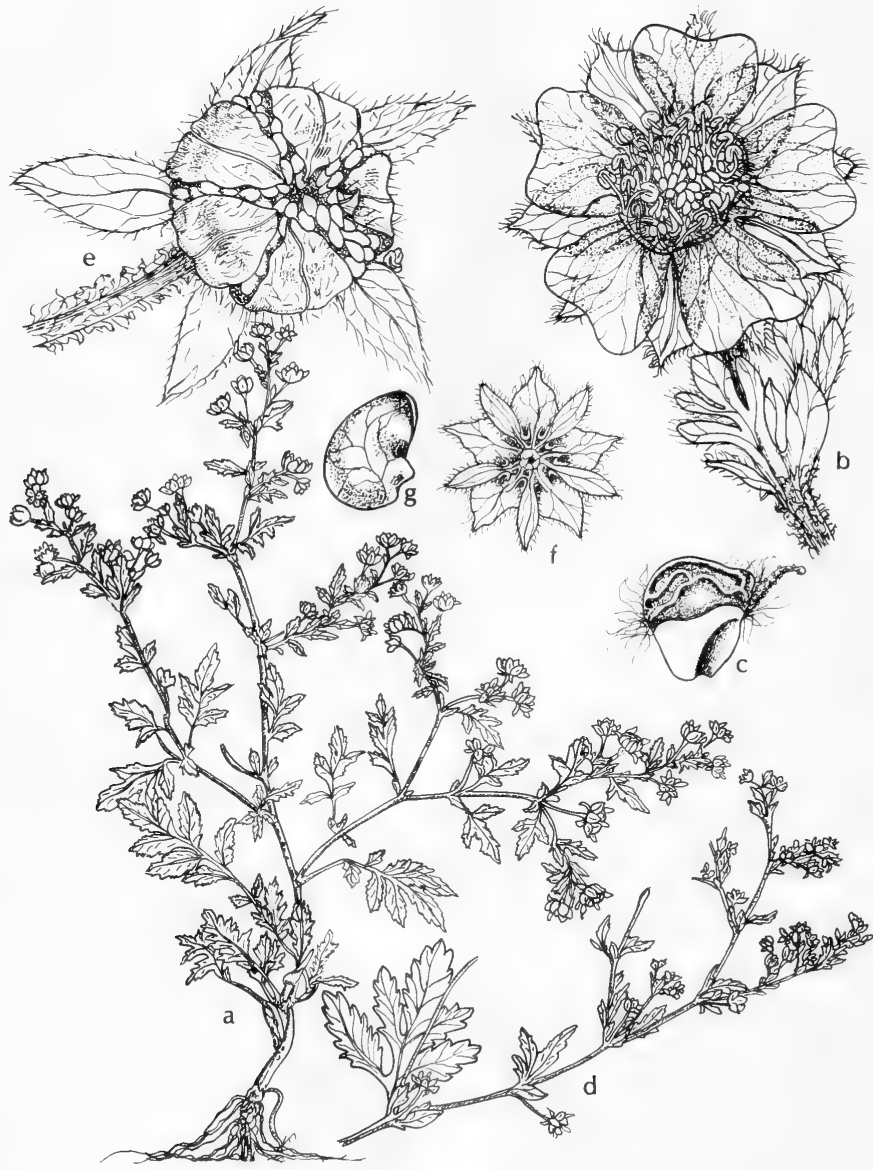

Fig. 494: a-c, Potentilla paradoxa: a, habit, x 1/2; b, flower, x 5; c, seed, x 15 . d-g, Potentilla rivalis: d, branch, x 1/2; e, fruit, x 5; f, calyx, x 21/2; g, seed, x 15 . (V. F.). 
both sides; stipules broadly ovate and acuminate, 1-2 cm. long, deeply toothed; cyme very dense and leafy, usually soon flat-topped; flowers with short hirsute pedicels, less than $5 \mathrm{~mm}$. in diameter; hypanthium sparingly hirsute and finely pubescent, in age about $5 \mathrm{~mm}$. in diameter; bractlets oblong, acute, about $3 \mathrm{~mm}$. long or nearly as long as the ovate acute sepals but much narrower; petals paleyellow, obovate, scarcely half as long as sepals; stamens seldom more than 5; pistils numerous; styles terminal, short-fusiform, glandular below; achenes smooth, brownish.

In wet soil on edge of lakes and ponds, sandy bottomlands and moist prairies in n.-cen. Okla. (Kay Co.), May-Aug.; Minn. and Alta. s. to Ark. and Okla.

\section{Potentilla biennis Greene.}

Annual or biennial with a slender taproot and usually a simple branched caudex, pubescent with a mixture of fine slender spreading to somewhat appressed or tomentose hairs and thicker multicellular glandular hairs; stems mostly single, ascending to erect, 1-6 dm. tall, the usually numerous branches strongly ascending and terminating in leafy-bracteate many flowered rather open cymes; leaves mostly cauline, reduced upward, with well-developed oblong-lanceolate usually entire stipules and 3 to 5 rotund-obovate to oblanceolate coarsely crenate-serrate leaflets 1-4 cm. long; calyx glandular-puberulent and often appressed-hirsute, shallowly cupshaped, 5-8 mm. broad at anthesis, considerably accrescent in fruit; sepals erect, ovate-triangular, much longer than the hypanthium; petals yellow, cuneateobovate, about half as long as the sepals; stamens usually either 10 or 15 ; pistils numerous, the style basally thickened and terminal; achenes yellow, about $0.8 \mathrm{~mm}$. long, smooth.

Waste places, along roadsides, and especially in sandy soil along streams, ponds, lakes and in wet meadows, in Ariz. (Coconino Co.), May-Aug.; Sask. to B. C., s. to. n. Ariz. and Baja Calif.

\section{Potentilla rivalis Nutt. BrooK CINQUefoIL. Fig. 494.}

Annual or biennial, rather slender, freely branched, ascending to erect, to $5 \mathrm{dm}$. high, softly villous, with paniculate-cymose very leafy flowering summit and branches; lower leaves pinnate, with 2 or 3 closely approximate pairs of leaflets or a single pair with the terminal leaflet 3-parted; cauline leaves with 3 or 5 leaflets; leaflets cuneate-obovate to -oblong, $2-5 \mathrm{~cm}$. long, usually blunt, strongly toothed; flowers $4-8 \mathrm{~mm}$. broad; mature calyx $5-8 \mathrm{~mm}$. high, pilose; petals tiny, cuneate; stamens 5 to 20 ; achenes smooth.

In wet situations about lakes and ponds, along streams, in swamps and ditches in the Tex. Panhandle, N. M. (Colfax, Grant, San Miguel and Santa Fe cos.) and Ariz. (Coconino, Yavapai and Pinal cos.), May-July; from Man. to B. C., s. to Mo., Kan., Tex., Mex. and Calif.

\section{Potentilla paradoxa Nutt. Fig. 494.}

Annual, biennial or shortlived perennial, superficially resembling $P$. rivalis, somewhat villous, to about $4 \mathrm{dm}$. high; stems diffusely branched, decumbent or ascending, slender or stout, leafy; leaves all pinnate, oblong to oblong-obovate; leaflets in 2 to 5 distinct pairs, oblong to cuneate-obovate, sparsely crenate-dentate, to about $3 \mathrm{~cm}$. long, usually much smaller; cyme open-paniculate, leafy; flowers yellow, on erect stalks, 5-7 mm. wide, the segments and bractlets subequal; stamens about 20; achenes longitudinally ribbed, with a prominent corky protuberance along the ventral suture.

Moist or wet soil on river banks and lake margins in the Tex. Panhandle and N. M. (Dona Ana, Mora, Santa Fe and Taos cos.), May-July; from Ont. to B. C., s. to La., Tex. and N. M. 


\section{Potentilla diversifolia Lehm.}

Perennial with a branching caudex and short thick rootstocks, from sparsely hirsute-strigose and greenish to rather grayish-sericeous (at least on the lower surface of the leaflets); stems usually several, spreading to erect, $1.5-4.5 \mathrm{dm}$. tall; leaves mainly basal, the blades with 5 or 7 main leaflets, mostly digitate but sometimes semipinnate or truly pinnate, often with 1 or 2 (to 4 ) much-reduced sometimes entire leaflets more or less distant from the main ones; leaflets oblong or oblanceolate to broadly obovate, mostly $1-3 \mathrm{~cm}$. long, from shallowly triangulartoothed to dissected almost to the midvein into narrowly oblong to linear segments; cauline leaves mostly 1 or 2 below the inflorescence; stipules ovate-lanceolate, 1-2 $\mathrm{cm}$. long, usually entire; cymes open, many-flowered; calyx saucer-shaped, villoussericeous, to $1.5 \mathrm{~cm}$. broad in fruit, the triangular-lanceolate lobes $4-6 \mathrm{~mm}$. long; petals yellow, obcordate, 6-9 mm. long; stamens usually 20; pistils numerous; style slender, equaling or exceeding the fruit and subapically attached to it; achenes 1.3-1.6 mm. long, ultimately weakly reticulate.

In wet meadows and along stream banks in high mts., in N. M. (Colfax, Rio Arriba and Santa Fe cos.) and Ariz. (Apache, Coconino and Pima cos.), JulyAug.; w. Can., s. to N. M., Ariz. and Baja Calif.

\section{Potentilla gracilis Dougl. ex Hook.}

Perennial with a heavy branched erect or ascending caudex, exceedingly variable as to pubescence; stems usually several, ascending to more commonly erect, 3-8 dm. tall, sparsely to thickly spreading-hirsute to puberulent, somewhat lanate or perhaps mostly commonly chiefly strigose or strigillose; basal leaves numerous, variable, the petioles to $3 \mathrm{dm}$. long, the blades commonly digitate but sometimes semipinnate; leaflets 5 to 11 , usually 7 , cuneate-oblanceolate to broadly oblanceolate or oblong-elliptic, (2-) 3-8 $(-12) \mathrm{cm}$. long, plane to occasionally folded, nearly glabrous or almost equally strigose to puberulent or hirsute, more or less glandular, generally concolorous to much more heavily strigose or tomentose and much lighter on the lower surface, from evenly crenate-dentate with 5 or 6 teeth per $\mathrm{cm}$. to very deeply dissected almost to the midvein into segments that vary from lanceolate and as much as $1 \mathrm{~cm}$. broad at base to narrowly linear and less than $2 \mathrm{~mm}$. broad at base, the margins plane to slightly revolute; stipules lanceolate, to $2.5 \mathrm{~cm}$. long, entire to toothed or lacerate; cauline leaves 1 to 3 ; cymes mostly large and many-flowered, open, conspicuously bracteate, usually more or less flat-topped; calyx cupuliform, 6-10 $\mathrm{mm}$. broad, in fruit accrescent and to $12 \mathrm{~mm}$. broad and nearly as high, from sparsely pubescent and glandular or more commonly eglandular to hirsute, sericeous or strigose, the bracteoles narrowly lanceolate, slightly to considerably shorter than the lanceolate to ovate-lanceolate and usually acuminate 4-10 $\mathrm{mm}$. long lobes; petals yellow, obovate-obcordate, slightly to considerably longer than the sepals; stamens usually 20; pistils numerous; style subapically attached, slender but very slightly enlarged and somewhat glandular-verrucose near the base, $1.5-2 \mathrm{~mm}$. long, usually about equaling the mature nearly or quite usually greenish achene. Incl. var. pulcherrima (Lehm.) Fern.; P. pulcherrima Lehm.

In marshes and in mud about ponds and lakes, wet alpine meadows, in N. M. (Lincoln, Rio Arriba, Taos and Union cos.) and Ariz. (Apache, Navajo and Coconino cos.), June-Sept.; Alas. e. to Sask. and Neb., s. to N. M., Ariz. and Baja Calif.

We have two variants.

Var. brunnescens (Rydb.) C. L. Hitchc. ( $P$. filipes Rydb.) with calyx sparsely hirsute but finely glandular-pubescent and leaves greenish and finely glandularpubescent as well as hirsute on both surfaces. 
Var. glabrata (Lehm.) C. L. Hitchc, with calyx usually abundantly strigose to hirsute and non-glandular, and leaves seldom glandular.

\section{Potentilla glandulosa Lindl.}

Stems strict, slender, 3-6 dm. high, viscid and glandular-hirsute, branching above; basal leaves pinnate, with 5 to 9 leaflets, nearly glabrous above, sparingly glandular-hirsute beneath; leaflets obovate, simply or doubly serrate, $1-3 \mathrm{~cm}$. long; stem leaves reduced; flowers in an open many-flowered cyme; hypanthium glandular-hirsute; sepals ovate-lanceolate, acute to acuminate, 6-7 mm. long, becoming $10 \mathrm{~mm}$. long in fruit; bractlets linear-lanceolate, 4-5 mm. long; petals obovate, yellow to cream-colored, about equaling the sepals; stamens 25 to 40 ; style fusiform, somewhat roughened below. Drymocallis glandulosa (Lindl.) Rydb.

In wet places in N. M. (Colfax, Rio Arriba and San Miguel cos.) and Ariz. (Coconino and Gila cos.), June-Sept.; Alas. e. to Sask. and Neb., s. to N. M., Ariz. and Baja Calif.

Our plants are usually referred to subsp. arizonica (Rydb.) Keck (P. Macdougalii Tidestr., Drymocallis arizonica Rydb.), characterised by having paleyellow or cream-color petals.

\section{Potentilla arguta Pursh. var. convallaria (Rydb.) Th. Wolf.}

Perennial from a simple or branched caudex and usually rather short rootstocks; stems mostly 4-8 dm. tall, commonly athocyanous, conspicuously pilose or villous with multicellular, moniliform, glandular often brownish hairs; basal leaves several, somewhat rosulate, pinnate; leaflets usually 5 to 9 , ovate to obovate or oblong to elliptic, mostly $1.5-4 \mathrm{~cm}$. long, deeply serrate-dentate to doubly serrate or shallowly incised, usually copiously short-hirsute and glandularpuberulent or sometimes sparsely hairy or glabrate; flowers in a narrow tight cyme, the lateral branches mostly numerous and almost strictly erect to form a flat-topped inflorescence; calyx glandular, its oblong-lanceolate lobes mostly 6-8 $\mathrm{mm}$. long and flared at anthesis but to about $12 \mathrm{~mm}$. long and erect in fruit; hypanthium saucer-shaped; petals pale-yellow to whitish, oblong-obovate to obovate, somewhat shorter to longer than the sepals; stamens about 25; styles slenderly fusiform, inserted below mid-length of ovary; achenes $1-1.3 \mathrm{~mm}$. long, slightly beaked. Incl. subsp. convallaria (Rydb.) Keck.

Wet meadows, valleys and prairies, in Okla. (Waterfall), N. M. (Kearney \& Peebles) and Ariz. (Apache and Navajo cos.), May-July; Que. to Alas., s. to D.C., Ind., Ill., Mo., Okla., N. M. and Ariz.

\section{Potentilla plattensis $T$. \& $G$.}

Low perennial; stems $1-2(-3) \mathrm{dm}$. high, usually several, erect to ascending or prostrate, glabrate to villous; leaves mostly basal, pinnately compound; leaflets 7 to 17 , obovate-oblong, incised to near the midrib into linear or narrowly oblong lobes, 6-8 mm. long, glabrous to appressed-strigose; stem leaves reduced, the uppermost only 3-cleft; stipules large for size of plant, about $1 \mathrm{~cm}$. long, broadly ovate, subentire and often obtuse; cymes few- to several-flowered; calyx strigose, the sepals 4-5 mm. long; bractlets narrower and definitely shorter than sepals; petals 5-7 mm. long, yellow with an orange spot often present near base; stamens about 20; anthers about $0.8 \mathrm{~mm}$. long; styles long and filiform; achenes glabrous.

In wet grassy meadows in N. M. (Taos Co.) and Ariz. (Apache and Coconino cos.), July-Aug.; Sask. and Alta., s. to N. M., Ariz. and Nev. 


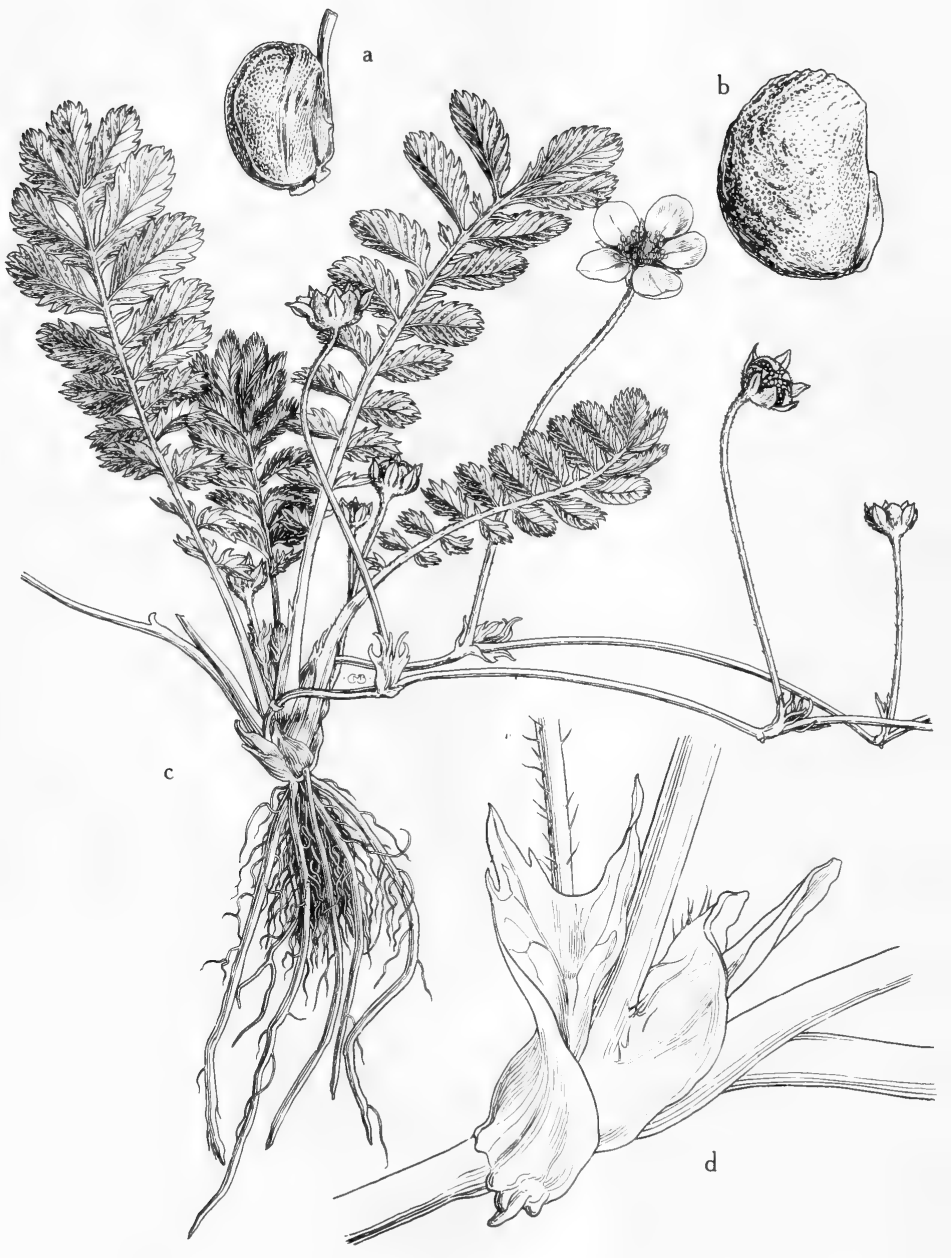

Fig. 495: Potentilla Anserina: a, young achene, showing basal part of style, x 12; $b$, mature achene, $x$ 12; c, habit, x 2/3; d, stipules, x 4. (From Mason, Fig. 252). 
13. Potentilla Anserina L. Silverweed. Fig. 495.

Leaves and peduncles in a basal tuft from a cluster of roots (main stem almost none) producing numerous runners 3-6 dm. long; leaves 1-2 dm. long, pinnate with 9 to 31 larger leaflets and smaller ones interposed, spreading or flat on the ground; main leaflets obovate to oblong, rounded, sharply and coarsely serrate, usually $1-3.5 \mathrm{~cm}$. long, silky and green above, white-silky and tomentose beneath; flowers 1-2 cm. in diameter, with pedicels $3-10 \mathrm{~cm}$. long; bractlets simple and lanceolate or often broader and ovate-lanceolate, toothed or divided, generally a little longer than the broadly ovate sepals; petals yellow, oval, 7-10 $\mathrm{mm}$. long; stamens 20 to 25; achenes numerous, corky, grooved at upper end. Incl. var. concolor Ser.; Argentina Anserina (L.) Rydb.; A. argentea Rydb.

Marshy or springy places, wet meadows, pond and lake margins, mud flats and stream banks, in N. M. (widespread in mts.) and Ariz. (Apache, Coconino and Greenlee cos.), May-Aug.; widely distributed in cooler parts of N. Hemis.

The sweetish roots are said to be edible either raw or cooked.

\section{Geum L. Avens}

Perennial rhizomatous herbs with pinnate or lyrate leaves; flowers few, solitary (in ours); calyx campanulate or deeply 5-cleft, usually with 5 small bractlets at the sinuses; petals 5; stamens numerous; achenes numerous, crowded on a conical or cylindrical dry receptacle, the long-persistent styles forming hairy or naked and straight or jointed tails; seed erect.

About 40 species, mostly in the North Temperate Zone.

1. Sepals reflexed at anthesis; hypanthium saucer-shaped, usually lined with a glandular disk at least on the lower half; styles strongly geniculate and jointed, the persistent lower portion hooked at the tip (2)

1. Sepals ascending to erect at anthesis; hypanthium turbinate to bowl-shaped, the lower half usually not disk-lined; styles often neither geniculate nor jointed and hooked on the persistent portion (4)

2(1). Petals white or sometimes very pale-yellow; distribution in eastern Oklahoma and eastern Texas......................................... G. canadense.

2. Petals golden-yellow; distribution in mountains of New Mexico and Arizona (3)

3(2). Lower persistent portion of the style without glands, glabrous or slightly hirsute near the base; terminal segment of the basal leaves somewhat larger than the main lateral lobes but similarly cuneate-based

2. G. aleppicum.

3. Lower persistent portion of the style somewhat glandular-pubescent; terminal segment of the basal leaves many times larger than the main lateral lobes and usually rounded to subcordate at base.

3. G. macrophyllum.

4(1). Petals erect to convergent, the flower somewhat vase-shaped; cauline leaves 2 or rarely 4 , opposite, their bases more or less sheathing......

4. G. triflorum.

4. Petals spreading or at least not erect or convergent, the flower more nearly rotate; cauline leaves 1 to several, alternate (5)

5(4). Style strongly geniculate and jointed, the terminal portion eventually deciduous, the persistent lower portion hooked at the tip; hypanthium bowl-shaped; basal leaves lyrate-pinnatifid, the segments 7 to 15 ; plants mostly $4-6 \mathrm{dm}$. tall...............................5. G. rivale.

5. Styles straight or only slightly bent, not jointed, persistent on the achene; hypanthium shallowly funnelform; basal leaves interruptedly pinnatifid, with 9 to 31 segments; plants rarely over $3 \mathrm{dm}$. tall........ 


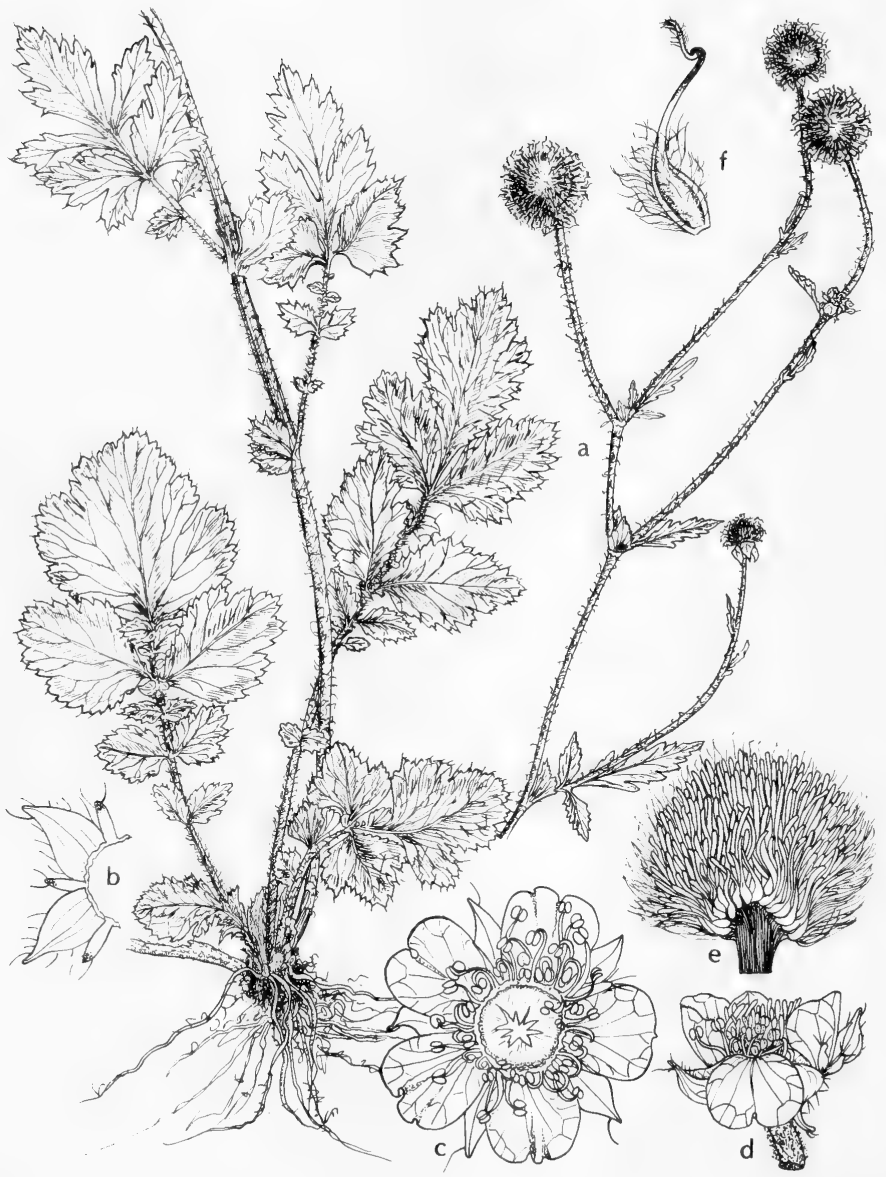

Fig. 496: Geum macrophyllum: a, habit, x 1/2; b, portion of calyx, 21/2; c, top view of corolla and stamens, $x 21 \frac{1}{2}$; d, flower, $x 21 \frac{1}{2}$; e, fruit, $x 2 \frac{1}{2}$; f, achene, $x$. (V. F.). 


\section{Geum canadense Jacq. White aVENS.}

Stem rather slender, to $12 \mathrm{dm}$. high, glabrous to sparingly hirsute, often minutely pubescent or glandular-puberulent at summit; leaves of basal tufts long-petioled, the petioles smooth or sparsely hairy, simple and undivided or with 3 to 5 (rarely 7) rhombic serrate leaflets; lower stem leaves similar to the basal leaves but shortpetioled to sessile, mostly with 3 leaflets; upper stem leaves ternately cleft or simple, sharply serrate and acute; stipules ovate-oblong, 1-2 cm. long, subentire or cleft; peduncles filiform, minutely pilose to glandular-puberulent; pedicels velvety-puberulent; calyx lobes lanceolate to ovate-lanceolate, acuminate, 4-10 $\mathrm{mm}$. long; petals white, oblong to obovate, 5-9 $\mathrm{mm}$. long, 2-4.5 $\mathrm{mm}$. broad, about equaling to longer than calyx lobes; fruiting head spherical, with numerous achenes, $1.2-2 \mathrm{~cm}$. in diameter; the upper segment of the style ascending or spreading, only tardily reflexed; denuded receptacle densely white-villous.

In swamps, mud at edge of lakes and streams and in moist rich woods in Okla. (Murray, McCurtain, Woodward and Bryan cos.) and in the e. third of Tex., w. to Real Co., Apr.-July; from N. S. to S. D., s. to Ga. and Tex.

We have two variants of this species that may be segregated as follows:

1. Terminal segment of median cauline leaves usually acute; carpels $3-4 \mathrm{~mm}$. long, broadly ovate ( $G$. camporum Rydb.)

..var. camporum (Rydb.) Fern.

1. Terminal segment of median cauline leaves usually obtuse; carpels $2-3 \mathrm{~mm}$. long, narrowly obovate to cuneate.......................var. texanum Fern.

\section{Geum aleppicum Jacq.}

Perennial with short rootstock and 1 to several simple stems to $1 \mathrm{~m}$. tall, puberulent below and spreading-hirsute above; basal leaves several, somewhat rosulate, oblong-obovate in outline, to $2 \mathrm{dm}$. tall, interruptedly lyrate-pinnatifid; primary segments 5 to 9 , cuneate-obovate, strongly cleft and usually doubly dentate, the terminal segment lobed for more than half its length; cauline leaves several, the lower ones pinnatifid and with large leafletlike stipules, the upper ones becoming trilobed; flowers several in a leafy-bracteate unsymmetrical cyme; hypanthium saucer-shaped, 3-4 mm. long; sepals 5-8 mm. long, reflexed; petals yellow, spreading, about equal to or slightly longer than the sepals; stamens 60 or more; achenes flattened, elliptic in outline, 3-4 mm. long; style strongly geniculate above mid-length, of 2 distinct segments, the lower brownish persistent and hooked segment glabrous or slightly hirsute near the base and about $4.5 \mathrm{~mm}$. long, the hirsute upper segment about $1.5 \mathrm{~mm}$. long and deciduous. G. strictum Ait., nom. illegit.

Along streams, in marshes, swamps, wet meadows and wet woods in N. M. (wide spread in mts.) and Ariz. (Apache, Navajo, Coconino and Yavapai cos.), June-Aug.; Nfld. and Que. to B. C., s. to Pa., W. Va., O., Ind., Ill., Ia., Neb., Ariz., N.M. and Mex.; also Euras.

Arizona specimens are usually referred to var. decurrens (Rydb.) Kearn. \& Peeb., with leaf segments more or less decurrent on the rachis.

\section{Geum macrophyllum Willd. var. perincisum (Rydb.) Raup. Big LEAF AVENS.}

Fig. 496.

Perennial herb with stout stems, erect, bristly pubescent, 3-10 dm. tall; stipules broad, foliaceous; basal leaves petioled; leaflets incised and serrate, the terminal leaflets very large and lobed to one third or one half the length, round-cordate, 6-10 cm. broad, the lateral leaflets oval or obovate, with smaller ones interspersed; cauline leaves reduced, their leaflets usually shallowly cleft to deeply toothed; flowers in open cyme; bractlets linear, minute; penduncles and pedicels strongly glandular; sepals 3-5 $\mathrm{mm}$. long; petals yellow, 4-8 $\mathrm{mm}$. long; fruiting heads 
globose or slightly elongate, 5-12 mm. long; achenes small, sparsely puberulent to glabrous on faces, with a hooked beak. G. oregonense (Scheutz) Rydb.

Wet meadows in mts., seepage along streams and wet soil about lakes and ponds in N. M. (San Juan, Santa Fe, San Miguel and Taos cos.) and Ariz. (Apache, Coconino and Graham cos.), May-Sept.; Mich. to B. C., s. to N. M., Ariz. and Calif.

\section{Geum triflorum Pursh. Oldman-Whiskers, Grandfathers-Beard.}

Perennial with thick scaly rootstocks, forming clumps to $3 \mathrm{dm}$. across or more; flowering stems to about $3.5 \mathrm{dm}$. tall, with a pair of opposite much-reduced leaves with leafletlike stipules about midway its length; leaves mostly basal, oblong to obovate, $5-15 \mathrm{~cm}$. long, unequally and interruptedly pinnate to pinnatifid or lyrate above; leaf segments as many as 29 , unequal, the primary ones from deeply cleft into linear or oblong ultimate divisions to cleft much less than half their length and again 2- or 3-toothed, puberulent to hirsute or pilose, somewhat grayish; flowers as many as 9 , mostly cymose; calyx narrowly to broadly turbinate or campanulate to cup-shaped, reddish-purple to pink or nearly yellow and only reddish-veined; sepals erect to convergent, valvate, 8-12 $\mathrm{mm}$. long; hypanthium almost hemispheric, 4-5 $\mathrm{mm}$. long; bracteoles linear to narrowly elliptic, somewhat spreading, simple to 2- or 3-cleft, shorter to longer than the sepals; petals valvate, erect to convergent, light-yellow to strongly pinkish- or reddish-purple-tinged, elliptic to elliptic-obovate, longer or shorter than calyx bracteoles; achenes pyriform, about $3 \mathrm{~mm}$. long; lower part of purplish straight or tortuous style strongly pubescent and $2.5-5 \mathrm{~cm}$. long, the terminal glabrous segment 3-6 $\mathrm{mm}$. long and often slightly geniculate at the point of juncture with the lower segment and usually tardily deciduous from it.

In wet mt. meadows, pine forests and open hillsides in N. M. (Taos Co.) and Ariz. (Apache, Navajo, Coconino and Gila cos.), May-Aug.; Nfld. to B. C., s. to N. Y., Ill., Neb., N. M., Ariz. and Nev.

\section{Geum rivale $\mathrm{L}$.}

Perennial with short to elongate scaly rootstocks; flowering stems mostly 4-7 $\mathrm{dm}$. tall, hirsute below, puberulent above; basal leaves several, somewhat rosulate, to about $3 \mathrm{dm}$. long, lyrate-pinnatifid; leaflets 7 to 15 , once or twice crenate-serrate, 1 to 3 of them larger than the others, the terminal one cuneate-obovate and to $1 \mathrm{dm}$. long; cauline leaves 2 to 5 , alternate, with leafletlike stipules, the blades pinnatifid below to deeply trilobed above; infiorescence open, mostly 3 - to 7 flowered, cymose but alternately branched, the flowers nodding in bud but soon erect; calyx reddish-purple, the erect lanceolate lobes acute to acuminate and about $1 \mathrm{~cm}$. long; hypanthium broadly cup-shaped, shorter than the sepals; petals yellow to pinkish, 2-3 mm. long; stamens 100 or more; achene elliptic in outline, 3-4 $\mathrm{mm}$. long, strongly hirsute; styles strongly geniculate, the lower persistent segment 6-8 $\mathrm{mm}$. long, hirsute below, glabrous above and hooked at the tip, the upper sparsely hirsute and soon deciduous segment $3-4 \mathrm{~mm}$. long.

In swamps, wet meadows, bogs, and in seepage along streams in N. M. (Santa Fe, San Miguel and Taos cos.), May-July; Nfld. and Que. to Alta., s. to Pa., Ind., Mich., Mo. and N. M.

\section{Geum Rossii (R.Br.) Ser. in DC. var. turbinatum (Rydb.) C. L. Hitchc.}

Perrenial with thick scaly rootstocks, forming dense clumps to $3 \mathrm{dm}$. across; flowering stems simple, mostly $8-20 \mathrm{~cm}$. tall, sparsely pubescent to villous; basal leaves many, noticeably marcescent, oblong in outline, mostly $4-10 \mathrm{~cm}$. long, interruptedly pinnate or pinnatifid into usually 15 to 25 main segments; leaf segments varying from entire and linear to elliptic or broadly cuneiform and 3to 7-toothed or -cleft, from nearly glabrous and greenish to silvery-sericeous or 
-villous and sparingly glandular-pubescent; cauline leaves several, alternate, muchreduced; flowers 1 to 4 ; calyx usually strongly purple-tinged, subglabrous to pubescent, the sepals 6-10 $\mathrm{mm}$. long; hypanthium shallowly funnelform, 3-5 mm. long, less than twice as long as broad, equaled or exceeded by the bracteoles; petals spreading, yellow, obovate, $6-12 \mathrm{~mm}$. long, occasionally retuse; stamens 50 to 70 , inserted just below the petals near tip of hypanthium; achenes fusiformlanceolate, 2.5-4 $\mathrm{mm}$. long, hairy, the straight glabrous style persistent and about as long as the achene. G. turbinatum Rydb.; Sieversia turbinata (Rydb.) Greene.

In wet meadows, talus slopes and cirques in high mts. in N. M. (Otero, San Miguel and Santa Fe cos.) and Ariz. (Coconino Co.), May-July; Mont. and Ore. s. to N. M. and Ariz.

\section{Rubus L. Bramble. Dewberry. Blackberry}

Perennial shrubs or less often herbs, very often prickly, with simple or more commonly compound serrate or lobed leaves and small to large perfect or unisexual white to pink or reddish flowers; hypanthium small, flat to hemispheric; sepals usually 5, valvate, spreading to reflexed, commonly ending in a short caudate appendage; bractlets none; petals as many as the sepals, erect or spreading, spatulate to obovate or elliptic; stamens numerous; pistils numerous, inserted on a convex to conic receptacle that often elongates in fruit; style filiform or clavate; fruit a cluster of drupelets that fall together or sometimes separately, the receptacle falling with the drupelets or remaining attached to the pedicel, usually edible.

In the shrubby species, the plant sends up from a perennial base a series of biennial stems, during their first year these are termed "primocanes" that normally do not branch nor flower, during their second year they are known as "floricanes" at which time they emit a number of short lateral branches with a few leaves and usually with a terminal flower or inflorescence; leaves of the primocanes compound; leaves of the floricanes often partly simple, regularly smaller and often of a different shape than those of primocanes.

The taxonomy of Rubus is complicated by hybridization, polyploidy and apomixis. More than 1,000 entities have been proposed in this genus. At present, there exists no infallible method for properly categorizing these proposals.

Species of Rubus have a tendency to become entangled with shrubby vegetation in or in proximity to wet lands. It is quite possible that we should have included additional entities, but for the present, considering the taxonomic plight of this genus, we feel that to have done so would not have served any real purpose.

Practically all wildlife eat either the fruit or vegetation of most of these species. The thorny brambles often make thickets where birds and small animals find protection and nesting sites.

1. Stems prostrate, only the flowering branches erect; distribution in Arizona.... 1. $R$. arizonensis.

1. Stems erect or high-arching; distribution in central Oklahoma and central Texas eastward (2)

2(1). Main leaflets of mature primocane leaves long and narrow, attenuate at apex, the length usually twice or more the width, narrowed to the tip mostly in concave or sunken curves; floricane leaflets usually also narrow. 2. $R$. louisianus.

2. Main leaflets of mature primocane leaves typically ovate to elliptic, the width distinctly more than one-half the length, the sides often convex toward the apex; floricane leaflets similarly to but smaller than the primocane leaflets. 3. R. oklahomus. 


\section{Rubus arizonensis Focke. ARIZONA DEWBERRY.}

Stem biennial, trailing, terete, glabrous, 1-6 m. long, armed with short recurved flattened prickles, yellowish-green; leaves of the primocanes 5-foliolate; stipules subulate, adnate at the base, about $5 \mathrm{~mm}$. long; petioles, petiolules, and midveins sparingly pubescent, armed with strongly flattened recurved short prickles; terminal leaflet ovate, irregularly dentate-serrate, acute at the apex, rounded at the base, 4-5 cm. long, thin, sparingly pilose above, more or less softly pubescent beneath, its petiolule about $2 \mathrm{~cm}$. long; lateral leaflets ovate, short-petioluled, the outermost lanceolate to oblanceolate, sessile, 2-3 cm. long; floral branches 5-10 cm. long; leaves 1- to 5-foliolate, 1-4 cm. long, more pubescent and more sharply serrate than those of the primocanes; inflorescence 1- to 5-flowered, corymbiform, leafy-bracted, villous and armed with recurved prickles; sepals ovate, mucronate, 5-6 mm. long, villous-tomentose on both sides; petals white, broadly obovate or oval, 8-9 mm. long; fruit globose, 10-12 mm. broad; drupelets 12 to 25 , large and juicy; putamen strongly reticulate, $3 \mathrm{~mm}$. long. $R$. oligospermus Thornb.

In wet soil along streams, often in partial shade, Ariz. (widespread), Mar.-May; also Son., S.L.P., Jal. and Dgo.

Because of its trailing habit this plant is considered to be a good ground cover that protects the soil against erosion.

\section{Rubus louisianus Berger.}

Erect high-arching and stiffish glandless bramble to $5 \mathrm{~m}$. high; canes sharply angled and deeply furrowed, downy when young, eventually glabrous, green or greenish-brown, adorned along the angles with scattered straight or curved prickles; stipules subulate, ciliate; primocane leaflets 5, narrowly lanceolate to oblanceolate, rather long-pointed at apex and somewhat narrowed toward the base, bright-dull-green above, paler and sparsely soft-pubescent beneath, rather regularly and sharply simply or doubly serrate; petiole rather stout, like the petiolules pubescent or villous and with scattered curved prickles that extend to the midveins; floricane leaves in threes or with the upper one simple and ovatedeltoid, similar to but smaller than those of the primocanes, the terminal leaflet 2 to 3 times as long as wide; fruiting racemes pubescent, with 4 to 15 erect pedicels that are pubescent and provided with a few curved prickles; flowers rather large; calyx pubescent, the ovate-deltoid lobes tomentose inside; petals white, oblong-elliptic to obtusely oblanceolate or obovate, $6-15 \mathrm{~mm}$. long, 3.5-10 mm. wide; fruit oblong-oval, with numerous small drupelets, whitish, sweet. $R$. texanus Bailey, $R$. ramifer Bailey, $R$. arvensis Bailey, $R$. abundiflorus Bailey, $R$. argutus of auth.

In damp and sandy thickets, pastures and wet lowland areas, and along fencerows in s.e. Okla. and e. Tex., Apr.; from Okla. and Tex. to S. C., n. to Md. and $\mathrm{Va}$.

\section{Rubus oklahomus Bailey.}

Upright but arching very prickly glandless bramble to $2 \mathrm{~m}$. high, with long weak horizontal or depressed branches some of which tip-root; canes terete but sometimes angular; prickles straight or curved, 3-6 $\mathrm{mm}$. long, broad-based; primocane leaflets 3 or 5 , broadly oval or the lower lateral pair rhombic, essentially obtuse at apex, rounded or expanded at base, about $7 \mathrm{~cm}$. long and $4 \mathrm{~cm}$. wide or more, thinly pubescent above, somewhat grayish and densely to sparsely soft-pubescent beneath, the margins dentate with obtuse-apiculate teeth; floricane leaflets much smaller but otherwise similar to those of the primocanes, the upper ones in the flower cluster sometimes simple; flowers 3 to 5 , large, showy, projecting on short laterals that are leafy at base, the ascending pedicels pubescent and armed; calyx lobes very broad, apiculate or sometimes with foliaceous tips, 
becoming reflexed; corolla about $3 \mathrm{~cm}$. across, the petals very broad and rounded. $R$. largus Bailey, $R$. putus Bailey, $R$. valentulus Bailey.

In thickets, edge of woods, on slopes, in stream bottoms and along fencerows in n.-cen. Okla. (Logan Co.) and n.-cen. Tex., Apr.; also Ark.

\section{Agrimonia L. Agrimony. Cocklebur. Harvest-lice}

Perennial herbs from stout rhizomes; leaves pinnate with crenate-serrate leaflets, interspersed with smaller leaflets; stipules foliaceous; flowers yellow, small, spicateracemose; floral bracts 3-cleft; calyx tube (hypanthium) turbinate or hemispherical, the throat beset with hooked bristles, indurated in fruit and enclosing 2 achenes, the 5-cleft limb closed after flowering; petals 5; stamens 5 to 15 ; styles terminal; fruit an achene.

About 15 species mostly in the North Temperate Zone.

1. Axis of inflorescence conspicuously glandular and pubescent; main leaflets 11 or more per leaf, lanceolate; mature fruits $5 \mathrm{~mm}$. long or less ..1. A. parviflora.

1. Axis of inflorescence without glands, finely and densely short-pubescent; main leaflets 7 or fewer per leaf, ovatish; mature fruits $6-8 \mathrm{~mm}$. long

2. A. striata.

\section{Agrimonia parviflora Ait.}

Plant stout and tall, to $2 \mathrm{~m}$. high, from long fibrous roots; stem densely and divergently long-hirsute or villous; larger leaflets of middle and upper leaves 11 to 15 , lanceolate-acuminate, sharply serrate, firm, veiny, copiously glandulardotted beneath; smaller interspersed leafiets very unequal, often 3 to 5 pairs on the intervals of the hirsute rachis; axis of inflorescence glandular and finely pubescent; fruits 4-5 $\mathrm{mm}$. long, the hooked bristles borne on a horizontal flange and spreading to ascending, the outer bristles strongly spreading; hypanthium turbinate, with deep rounded grooves.

In damp thickets and meadows and in marshy areas in Okla., the $\mathbf{n}$. Panhandle and n.e. Tex., July-Oct.; from Fla. to Tex., n. to Conn., N. Y., Ont., O., Ind., Ill. and Neb.

\section{Agrimonia striata Michx.}

Fibrous-rooted rhizomatous perennial 5-10 dm. tall, papillate-hirsute below, both hirsute and puberulent and occasionally somewhat glandular above; leaves with 5 to 13 unequal primary leaflets; leaflets strongly serrate, somewhat strigose on the upper dark-green surface, glandular-pubescent on the paler lower surface, the upper leaflets to about $6 \mathrm{~cm}$. long; stipules to $2 \mathrm{~cm}$. long; racemes $5-20 \mathrm{~cm}$. long; hypanthium about $3 \mathrm{~mm}$. long at anthesis, subequal to the ovate-lanceolate calyx lobes, accrescent in fruit to become about $5 \mathrm{~mm}$. long, crowned with 3 or 4 rows of subterminal ascending hooked bristles nearly as long as the sepals, the sides distinctly 10-furrowed and lightly strigose.

In wet soil along creeks, in wet meadows often among willows and loamy soils in conifer forests, in Okla. (Waterfall), N. M. (widespread) and Ariz. (Apache to Coconino cos., s. to Cochise and Pima cos.), June-Sept.; Que. and N. S. to B.C., s. to N. Y., Ia., Okla., N. M. and Ariz.

\section{Sanguisorba L.}

Several species in the Northern Hemisphere.

\section{Sanguisorba minor Scop.}

Perennial from a usually branched caudex, often somewhat rhizomatous; flowering stems generally with several scarcely reduced leaves, simple or branched above, 2-6 dm. tall, mostly sparsely pilose with multicellular more or less moniliform 
hairs; leaves somewhat unequally pinnate; basal leaves several and somewhat rosulate, with adnate stipules; cauline leaves several, reduced upwards but the stipules becoming free and leafletlike above; leaflets mostly 9 to 17 , oval to ovateoblong, 1-2 cm. long, coarsely serrate; spikes globose to ovoid, 8-20 mm. long, about $10 \mathrm{~mm}$. thick; bractlets ovate, ciliate; flowers mostly imperfect, the lower ones staminate, the upper ones pistillate, a few often perfect; calyx greenish to rose-tinged; in fruit the hypanthium urceolate, 4-5 $\mathrm{mm}$. long, woody, very prominently papillate-warty between as well as along the rather prominent ridges; stamens about 12, the filaments filiform; pistils and achenes 2 .

In wet meadows about lakes and in waste places, in N. M. (Otero Co.), JuneAug.; nat. of Eur. that is introd. in various parts of N. A.

\section{Rosa L. Rose}

Woody perennials, upright or trailing, usually with prickly stems; leaves alternate, compound or rarely simple, typically with adnate stipules or these rarely absent; leaflets 3 to 15 , serrate or biserrate, often pubescent and glandular; flowers perfect, solitary, corymbose or paniculate; sepals 5 , rarely 4 ; petals 5 , rarely 4 or (by transformation of the stamens) numerous, obovate to obcordate; stamens numerous, inserted on a disk at the margin of the hypanthium; ovaries numerous within the hypanthium; styles connate or free, included or exserted; stigmas thickened; hypanthium urceolate or globose, contracted at the mouth, becoming fleshy at maturity (the hip); fruit an achene.

Probably a little more than 200 valid cosmopolitan species that are native mainly in the Northern Hemisphere.

Rose hips provide food throughout the year for most wildlife, and browsers nibble the vegetation. Also, a tasty jelly said to be high in Vitamin $\mathrm{C}$ can be prepared from the hips. Excellent nesting sites and protective cover are provided by thickets of wild roses for game birds and songbirds.

1. Prickles of the stem straight or nearly so, typically very slender; rachis and petiole densely glandular-puberulent; sepals sparingly glandular dorsally.............................................................. R. Fendleri.

1. Prickles of the stem mostly recurved, typically rather stout; rachis and petiole finely puberulent; sepals dorsally glabrate, tomentose on the margins 2. $R$. arizonica.

\section{Rosa Fendleri Crép.}

Stem low, $1 \mathrm{~m}$. high or less, reddish, terete, armed with a few prickles that are slender, straight and $5 \mathrm{~mm}$. long or less; stipules glandular-pruinose on the back, more or less glandular-dentate; rachis and petiole densely glandular-puberulent and often somewhat glandular-hispid or with weak prickles; leaflets 5 or 7 , elliptic to oval or obovate, $1-3 \mathrm{~cm}$. long, rather thin, green and glabrous above, slightly paler, puberulent and glandular-pruinose beneath, often doubly-serrate; hypanthium globose, glabrous, in fruit $8-10 \mathrm{~mm}$. broad; sepals sparingly glandular on the back; petals rose-colored, obcordate, about $1.5 \mathrm{~cm}$. long. $R$. Woodsii Lindl. var. Fendleri. (Crép.) Rydb.

On wet seepage banks along streams and on sandstone rocks in w. Okla. (Panhandle), N. M. (widespread) and Ariz. (Apache, Coconino, Yavapai and Cochise cos.), June-Aug.; Minn. to B. C., s. to n. Mex.

\section{Rosa arizonica Rydb.}

Stem low, much-branched, to $1 \mathrm{~m}$. high or less, armed with small recurved prickles 3-5 mm. long; bark in age becoming almost white and exfoliating; floral branches $1 \mathrm{dm}$. long or less, often unarmed; stipules adnate, less than $1 \mathrm{~cm}$. long, the upper dilated, finely puberulent; rachis and petioles finely puberulent; leaflets 
usually 5 or rarely 7 , broadly oval, coarsely toothed, to about $2 \mathrm{~cm}$. long, cuneate at base, light-green, glabrous above, finely puberulent and more or less granuliferous beneath; flowers mostly 2 or more, sometimes solitary; pedicels glabrous, about $1 \mathrm{~cm}$. long; hypanthium globose, glabrous, in fruit $7-8 \mathrm{~mm}$. broad; sepals broadly lanceolate, caudate-attenuate, $1-1.5 \mathrm{~cm}$. long, tomentose on the margins, glabrate dorsally; petals obovate, dark-rose-colored, to $2 \mathrm{~cm}$. long; styles distinct, persistent, not exserted.

Wet meadows and seepage banks along streams in N. M. (Valencia Co.) and Ariz. (Apache, Navajo and Coconino cos., s. to Cochise and Pima cos.), MayJuly.

\section{Fam. 74. Leguminosae Juss.}

\section{LEGUME FAMILY}

Trees, shrubs, vines or herbs; leaves and branches alternate; stipules usually well-developed and persistent; leaves usually compound (when simple then so through reduction or fusion), the leaflets often with stipels; flowers rarely solitary, usually in terminal or axillary panicles, racemes, spikes, heads or glomerules, usually perfect and complete, perigynous (but the floral cup sometimes evanescently short and the flowers essentially hypogynous), bilaterally symmetrical (in the Mimosoideae, appearing radially symmetrical except for the gynoecium) and often markedly zygomorphic (especially in the Papilionoideae); calyx valvate at a very early stage of development or variously imbricate; sepals 5 , these in most genera fused at least partly and in some genera only 4 in number through fusion; corolla basically of 5 petals attached at the rim of the floral cup, rarely fewer through reduction (and in the Papilionoideae, often appearing to be only 4 because of fusion of the lower 2), in some genera of the Mimosa group the petals neotenically connate; aestivation valvate or variously imbricate; stamens 1 to numerous, separate or variously coalescent in groups or in some flowers of some genera modified into staminodia; gynoecium of a single superior simple pistil with a ventral placentary suture oriented upward in most flowers, the ovules 1 to numerous and attached in 2 alternating rows to the coalescent margins of the placentary suture; style simple; fruit a "pod" or follicle-like usually dry structure, either indehiscent or breaking up into 1-seeded sealed units or most commonly splitting lengthwise both along the ventral suture and the dorsal "midrib" (when thus dehiscent the fruit is said to be a "legume"); seeds 1 to numerous, with 2 thin integuments, essentially none or very little endosperm and large well-developed embryos. Fabaceae; Papilionaceae; Mimosaceae.

The Leguminosae comprise over 500 genera and well over 10,000 species and are distributed in all parts of the world inhabitable by seed plants. They include some of the extremely important economic plants such as beans, peas, alfalfa and clovers.

This family posed one of the most difficult problems in regard to what plants should or should not be included. For instance, perhaps more of the clovers should have been included, but time limitation prevented us from pursuing this further. Several woody species, namely, our huisache (Acacia Smallii Isely) and retama (Parkinsonia aculeata L.) occasionally cover low, poorly drained or even flooded areas, and sometimes they completely fill up tanks and ponds to the point of causing complete desiccation of these habitats. Perhaps these should have been included.

1. Leaves simple, linear to linear-oblanceolate. 16. Alhagi

1. Leaves compound, with 2 or more leaflets (2)

2. Leaves pinnately once-compound or pinnate (6) 
3 (2). Flowers in open terminal racemes, usually deep-orange-yellow and brownish; petals $4 \mathrm{~mm}$. wide or more.

3. Flowers in dense globose heads or in axillary spikes; petals $2 \mathrm{~mm}$. wide or less (4)

4(3). Large spiny tree; flowers in spikes usually more than $4 \mathrm{~cm}$. long. 3. Gleditsia

4. Prostrate or clambering viny plants; flowers in globose or ellipsoid heads (5)

5(4). Flower heads yellowish; roots orange-color; fruits abruptly narrowed at the base to form a distinct stipe; plants unarmed..........2. Neptunia

5. Flower heads white or pinkish; roots not orange-color; plants either armed and clambering or unarmed and prostrate. 1. Mimosa

6(2). Leaves (most of them) with 4 or more leaflets (7)

6. Leaves with 2 or 3 leaflets (23)

7(6). Perennial or annual herbs or herbaceous vines, the aerial stems dying back each winter, any new stems arising from the previous year's root or underground stem (8)

7. Shrubs, trees or woody vines, the stems of most of them persisting to produce new growth each year (21)

8(7). Leaves palmate. 5. Lupinus

8. Leaves (most of them) pinnate, the leaflets arranged alternately or opposite on the rachis (9)

9(8). Leaves gland-dotted; fruit a prickly pod $1-2 \mathrm{~cm}$. long.

9. Leaves not gland-dotted; fruit smooth, not prickly (10)

15. Glycyrrhiza

10(9). Leaves with an even number of leaflets or bearing tendrils toward the end of the leaves; leaf rachis not terminated by a leaflet (11)

10. Leaves not bearing tendrils and having an odd number of leaflets; leaf rachis terminated by a leaflet (13)

11(10). Stems stiffly erect, 4-20 dm. tall; leaves without tendrils; leaflets 20 to numerous; flowers yellow, red or orange-color..........12. Sesbania

11. Stems weak, ascending or climbing by tendrils; leaflets less than 20 ; flowers blue, violet or purplish (12)

12(11). Style with a dense ring of hairs just below the stigma 19. Vicia

12. Style flattened, with a line of hairs down the inner surface. 20. Lathyrus

13(10). Rachis of leaf 2-15 (-20) $\mathrm{mm}$. long; flowers 1 to 3 (or 4), terminal on slender peduncles, never racemose along a central axis; leaflets 3 to 9 (14)

13. Rachis of leaf $15-150 \mathrm{~mm}$. long or (if shorter) then the flowers in severalflowered racemes; leaflets 5 to numerous (15)

14(13). Stems and leaves appressed-pubescent or glabrate. 9. Lotus

14. Stems and leaves densely pubescent with wide-spreading glandular hairs 17. Aeschynomene

15(13). Fruit a loment, indehiscent, breaking into 1-seeded segments at maturity; stems stiffly erect, to $25 \mathrm{dm}$. tall; flowers 1 to 4 in axillary fasciculate clusters, short racemes or solitary.................17. Aeschynomene

15. Fruits dehiscent or indehiscent but not breaking up into 1-seeded segments at maturity; stems mostly $4 \mathrm{dm}$. long or shorter, but if longer and stiffly erect then the flowers numerous in each raceme (16)

16(15). Plants perennial; stems erect or high-twining, 3-20 dm. long; legume 6 to 20 times as long as broad, not inflated (17) 
16. Plants annual or perennial; stems prostrate to weakly ascending (often acaulescent), if stiffly erect and more than $3 \mathrm{dm}$. tall then the legume inflated and less than 6 times as long as broad (18)

17(16). Grayish-pubescent erect subshrubs, not climbing. 10. Indigofera

17. Not grayish-pubescent, high-climbing vine. 21. Apios

18(16). Peduncle of mature flowering racemes $8-30 \mathrm{~cm}$. long.

18. Peduncle of flowering racemes $1-8(-9) \mathrm{cm}$. long (19)

19(18). Flowers when fresh brick-red or reddish (often fading to lavender when in dried specimens); perennials.

10. Indigofera

19. Flowers of various colors but not brick-red or reddish; annuals or perennials (20)

20(19). Keel petals acute, blunt or rounded apically

13. Astragalus

20. Keel petals with the apex extending into a sharp erect point; plants acaulescent; flowers purple or pinkish-purple

14. Oxytropis

21(7). Leaves gland-dotted

11. Amorpha

21. Leaves not gland-dotted (22)

22(21). Rachis of leaf 1-8 cm. long; legume 15-35 mm. long; flowers 5-10 mm. long....................................................................10. Indigofera

22. Rachis of leaf $8 \mathrm{~cm}$. long or more; legume $30 \mathrm{~mm}$. long or more; flowers $10 \mathrm{~mm}$. long or more

12. Sesbania

23(6). Leaves with tendrils

20. Lathyrus

23. Leaves without tendrils (24)

24(23). Twining vines (often trailing when support is lacking)

22. Vigna

24. Herbs or shrubs with erect or trailing stems, never twining (25)

25(24). Leaflets dentate or denticulate at least near the apex (sometimes minutely so) (26)

25. Leaflets entire, not at all toothed (28)

26(25). Flowers in slender elongate racemes at least 4 to 8 times as long as thick

7. Melilotus

26. Flowers in short thick racemes or umbels 3 times as long as thick or shorter (27)

27(26). Fruit coiled or curved, longer than the calyx; leaves trifoliolate, not palmate.

6. Medicago

27. Fruit not coiled nor curved, shorter than the calyx; leaves usually palmate

8. Trifolium

28(25). Leaves (or at least some of them) with petioles $15 \mathrm{~mm}$. long or more

28. Leaves with petioles less than $14 \mathrm{~mm}$. long (29)

18. Lespedeza

29(28). Stipules minute, reduced to glands; fruit several-seeded.

29. Stipules not reduced to glands; fruit 1 -seeded.

9. Lotus 18. Lespedeza

\section{Mimosa L. Mimosa. Catclaw}

Shrubs or lianes or (in 1 species) prostrate perennial herbs, in most species the herbage and even the legumes armed with scattered recurved prickles; leaves pinnately twice-compound with 1 to 14 pairs of pinnae; leaflets few to numerous; stipules usually small and subulate, never spinescent; flowers small and aggregated into white, pink to reddish globes or rarely short spikes; stamens 8 to 10 (usually exactly twice as many as petals), usually colored, free above the floral cup; fruit a flattened (sometimes contorted) pod usually a few $\mathrm{cm}$. long, with 
a unique mode of dehiscence, the margins remaining more or less intact and more or less persistent while the valves separate from them and often break up into 1-seeded sections somewhat like loments. Mimosopsis Britt. \& Rose.

A large genus of about 400 species in tropical and subtropical regions, principally in North America and South America.

1. Plants with herbaceous prostrate unarmed stems. 1. M. strigillosa.

1. Plants with clambering prickly frutescent stems, never prostrate

2. M. malacophylla.

\section{Mimosa strigillosa T. \& G. Powderpuff, vergonzosa.}

Perennial herb with sprawling annual stems 1-2 (-4) m. long, usually copiously furnished with stiff spreading bristlelike emergences, but these not noxious; pinnae 4 to 6 pairs, more or less; leaflets usually 10 to 15 pairs per pinna, linear, usually 3-6 mm. long, $0.5-1 \mathrm{~mm}$. broad; flowers in pink or purple globes; pod oblong, 15-20 mm. long, 10-12 mm. broad, setulose, with 1 to few joints.

In marshes, wet grasslands and openings in forests on sandy loam, in s.e. Okla. (Waterfall), e. and s.e. Tex. and coastal parts of Rio Grande Plains, May-Oct.; s.e. U.S. w. to Okla. and Tex.; Tam.; Parag. and Arg.

\section{Mimosa malacophylla Gray. Raspilla.}

Liane climbing in trees or forming a tangle, usually 3-4 m. high, less commonly a weak-stemmed shrub, the stems armed with recurved prickles; petioles and rachises with prickles also; pinnae 3 to 5 pairs; leaflets 3 to 6 pairs per pinna, pubescent or glabrous, ovate to oblong or obovate, the larger ones on any plant $10 \mathrm{~mm}$. long or longer; flowers whitish, in heads $1-2 \mathrm{~cm}$. thick; legume broadly linear to oblong, 40-75 mm. long, 8-10 mm. broad, stipitate, several-jointed. Incl. var. glabrata Benth., M. Wootonii Standl.

Rare in wetlands, depressions, about ponds and in woodlands along streams, Rio Grande Plains of Tex., June-July; also Tam. and N. L.

\section{Neptunia Lour.}

Perennial unarmed herbs with somewhat thickened woody orangish-colored taproots and few to several sprawling prostrate or decumbent annual stems (rarely floating); leaves pinnately twice-compound; pinnae 2 to 11 pairs, with or without a gland between the lowest pair of pinnae; leaflets 8 to 43 pairs per pinna, usually linear to oblong or somewhat tapered toward the apex; stipules well-developed, lanceolate or lance-acuminate; peduncles axillary, several $\mathrm{cm}$. long, often conspicuously bracteolate; flowers small, densely crowded in round or slightly elongated heads, yellow or yellow-green, often the lower flowers of the head lacking functional genitalia or at least functional gynoecia, the upper flowers perfect; sepals and petals 5 each, free above the floral cup; stamens 10 (at least in the upper flowers of the head), free above the floral cup, the anthers with a small gland apically between the 2 cells; fruit a thin legume, definitely stipitate, $1-5 \mathrm{~cm}$. long, 6-17 mm. broad, flat, promptly dehiscent; seeds few to several, elongate, oriented transversely in the pod.

A genus of 11 species, scattered in warm-temperature parts of the Americas, Africa, Asia and Australia.

1. Petiole glandular; flowering peduncles bearing 2 large cordate bracts 4-8 $\mathrm{mm}$. long and 3-5 $\mathrm{mm}$. wide; leaflets without raised reticulate veins; plants semiaquatic or terrestrial....................................... plena.

1. Petiole eglandular; flowering peduncles bearing 1 or 2 subulate bracts $1-3$ $\mathrm{mm}$. long and 1-2 $\mathrm{mm}$. wide, or bracts absent; leaflets with raised reticulate veins; plants terrestrial but sometimes in wetlands (2) 
2(1). Flowers in head with stamens all alike, anther-bearing; flower heads (when in bud) with 30 to 60 flowers, subcylindric; stipe of pod 4-15 mm. long; leaflets 8 to 18 pairs; calyx $1-2 \mathrm{~mm}$. long (including lobes) 1. N. lutea.

2. Flowers in upper part of head with anther-bearing stamens, those in lower part smaller and with yellow (drying orange) petaloid staminodes; flower heads (in bud) with 20 to 30 flowers, ovoid; stipe of pod $0-4 \mathrm{~mm}$. long (rarely $5 \mathrm{~mm}$.); leaflets 14 to 43 pairs; calyx $2-2.7$ $\mathrm{mm}$. long (including lobes)..... 2. N. pubescens.

\section{Neptunia lutea (Leavenw.) Benth. Yellow-PUfF.}

Pinnae 2 to 11 pairs; petioles and rachises glandless; leaflets 8 to 18 pairs per pinna, with raised reticulate venation beneath; floral cup (plus sepals) $1-2 \mathrm{~mm}$. long; flowering peduncles with 1 or 2 subulate bracts $1-3 \mathrm{~mm}$. long and 1-2 mm. broad, or these absent; flower heads with 30 to 60 flowers, slightly elongate; stipe of pod (4-) 5-15 mm. long. Incl. var multipinnatifida B. L. Turner.

Scattered or locally frequent in fields, meadows and wetlands in the e. half of Okla. and over the e. half of Tex. s. to Aransas and Goliad cos., w. to n.-cen. Tex. (one record for Runnels Co.), Apr.-Oct.; Ala., Miss., Ark., La., Okla. and Tex.

\section{Neptunia pubescens Benth.}

Pinnae 2 to 5 (or 6) pairs; petioles and rachises glandless; leaflets 14 to 43 pairs per pinna, with raised reticulate venation beneath; flower cup (plus sepals) 2-2.7 $\mathrm{mm}$. long; flowering peduncles with 1 or 2 subulate bracts $1-3 \mathrm{~mm}$. long and 1-2 mm. broad, or these absent; flower heads with 20 to 30 flowers, essentially round or ovoid; stipe of pod $0-4 \mathrm{~mm}$. long (rarely to $5 \mathrm{~mm}$.).

Frequent in marshes, grasslands and dry sandy places near the coast and inland to Val Verde Co., Tex. Represented with us by 2 varieties as follows:

Var. pubescens. Stipe of legume longer than the persistent calyx; legume usually tapering to the stipe; leaves with 3 to 6 pairs of pinnae. $N$. floridana Small, $N$. Lindheimeri Robins. Coastal Plain of Tex. inland to Anderson, Leon and Gonzales cos., May-Oct.; Gulf Coastal States; W.I., Mex., C.A., Col., Peru, Parag. and Arg.

Var. microcarpa (Rose) Windler. Stipe of legume usually shorter than the persistent calyx (shorter than $2 \mathrm{~mm}$.) ; legume usually rounded to the stipe; leaves usually with 2 to 3 pairs of pinnae. N. Palmeri Britt. \& Rose. N. part of Rio Grande Plains from McMullen and Atascosa cos.w. to Val Verde Co. in Tex., May-July; Tex., Coah., N.L. and Jal.

\section{Neptunia plena (L.) Benth.}

Terrestrial to semiaquatic; stems when in watery environment producing a thick spongy indument; pinnae 2 to 5 pairs; petioles with a gland just below the lowest pair of pinnae; leaflets 9 to 38 pairs per pinna, without raised reticulate veins; flowering peduncles bearing 2 large cordațe bracts about 4-8 $\mathrm{mm}$. long and 3-8 $\mathrm{mm}$. broad; flower head ovoid; stipe of pod 3-9 $\mathrm{mm}$. long, longer than the persistent calyx.

Known from a single collection from a temporary lake just s. of Armstrong, Kenedy Co. in s. Texas, Oct. 17, 1938, probably not a persistent member of our flora; Braz. and Peru, n. to W.I. and Mex.; adv. in India.

\section{Gleditsia L. Honey Locust}

A genus of 11 species in North America, South America, Asia and Africa. The name is sometimes spelled "Gleditschia." 


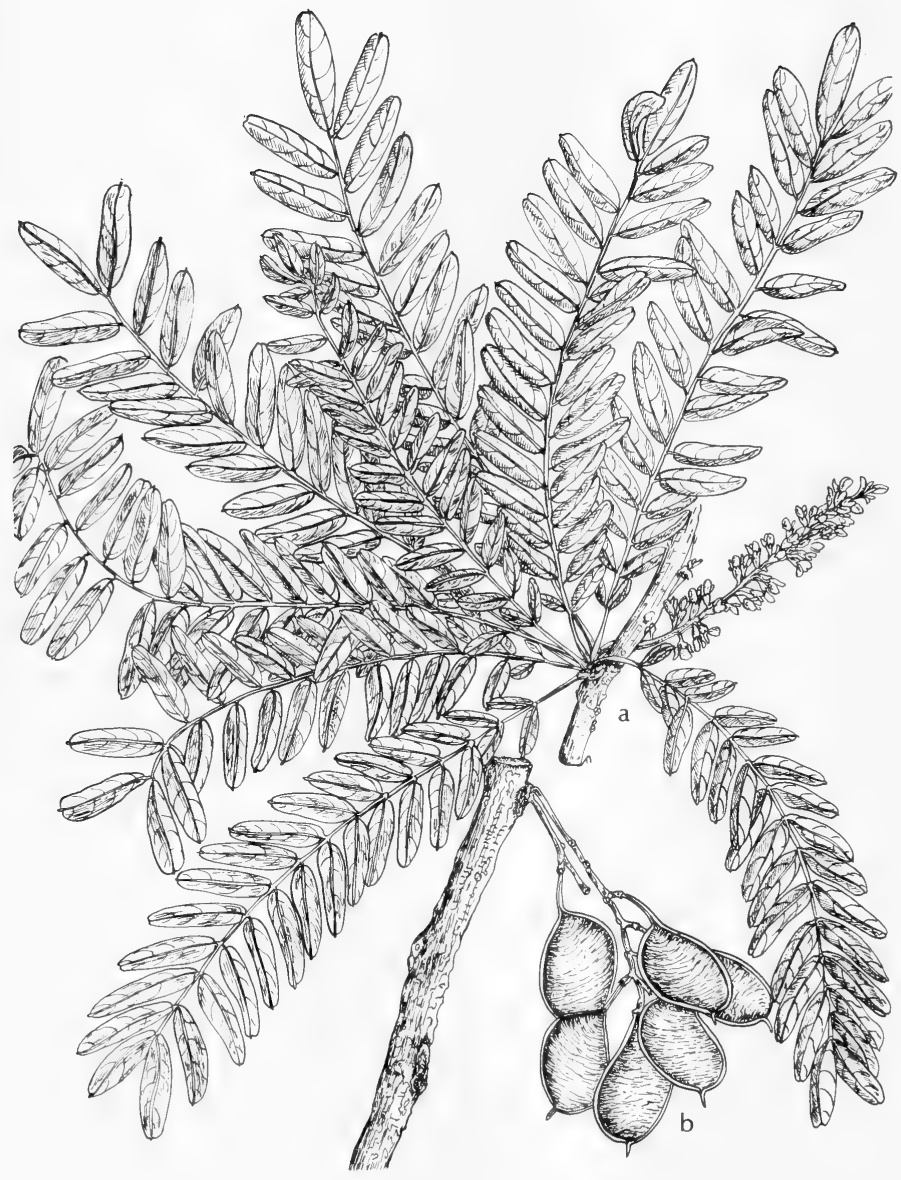

Fig. 497: Gleditsia aquatica: a, section of branch with flowers, $\mathbf{x} 1 / 2 ; \mathbf{b}$, fruit, $\mathbf{x} 1 / 2$. (V. F.). 


\section{Gleditsia aquatica Marsh. WATER or SWAMP LOCUST. Fig. 497.}

Tree to $20 \mathrm{~m}$. tall or rarely shrubby, spiny; leaves pinnate to bipinnate; leaflets 12 to 18 , ovate-oblong, $2-3 \mathrm{~cm}$. long, usually rounded to emarginate at apex, slightly crenulate and often entire below the middle, glabrous except for a few hairs on the petiolules; bipinnate leaves with 6 or 8 pinnae; petioles pubescent on the edges of the grooves; flowers in axillary racemes $7-10 \mathrm{~cm}$. long; pedicels short; floral cup campanulate; sepals equal or subequal, free; petals 3 to 5 , subequal, 4-5 mm. long, very narrow, yellowish or greenish-yellow, the uppermost internal in bud; stamens 3 to 10 , the filaments free; ovary glabrous; pod ovate to elliptic, $2.5-5 \mathrm{~cm}$. long, flattened, long-stipitate; seeds 1 or 2 , not embedded in packing tissue.

Scattered in swamps, along rivers and in low bottomland forests, e. and s.e. Tex., May-June; cen. U.S. to Fla. and Tex.

\section{Hoffmanseggia CAV. RUSH-PEA}

About 40 species in America and South Africa. The genus is sometimes included in Caesalpinia.

\section{Hoffmanseggia glauca (Ort.) Eifert. Hog-POTATO, CAMOTE-DE-RATON.}

Stem 1-3 dm. high, glabrous or puberulent; stipules ovate; petiole and rachis glandular; pinnae 5 to 11 ; leaflets 5 to 11 pairs, oblong to obovate, glabrous or puberulent, 3-8 mm. long; inflorescence terminal, glandular, pubescent, 1-2 dm. long, 5- to 15-flowered; bracts ovate, caducous; pedicels $2-5 \mathrm{~mm}$. long; calyx pubescent and glandular, its oblong lobes 6-7 mm. long; petals 10-12 mm. long, with long glandular claws; stamens shorter than the petals, glandular and pubescent; pod falcate, 2-4 cm. long, $4-8 \mathrm{~mm}$. broad, glandular, glabrous or puberulent, reticulate-veined; seeds 4 to 8 . Hoffmanseggia falcaria Cav., $H$. densiflora Gray, Larrea densiflora (Gray) Britt.

Along roadsides and in hard alkaline soils, especially where periodically flooded, in w. Okla., w. Tex., N. M. (widespread) and Ariz. (Navajo to Mohave, s. to Graham, Cochise, Pima and Yuma cos.), Mar.-Sept.; cen. and s.w. U. S. to Mex. and w. S.A. A highly variable species.

According to Kearney and Peebles, "The tuberous enlargements of the roots make valuable hog feed, and after roasting were used for food by the Indians." Although the plant is a good soil binder, it can become a troublesome weed in pastures and cultivated fields because of its habit of forming large colonies by an underground root system.

\section{Lupinus L. Bluebonnet}

A genus of perhaps 200 species in the temperate regions of both hemispheres; not in Africa nor Australia.

\section{Lupinus Kingsii Wats.}

Annual or possible biennial; stems 5-20 cm. tall, branched near base, erect to widely spreading, silky-villous with spreading often tawny hairs; leaflets 1-3 $\mathrm{cm}$. long, oblanceolate to oblong-lanceolate, silky-villous; raceme dense and subcapitate, seldom over $2 \mathrm{~cm}$. long; peduncles variable but flower cluster shorter to somewhat longer than the leaves; calyx ciliate, the lips subequal, 4-7 $\mathrm{mm}$. long; corolla 7-10 $\mathrm{mm}$. long, purplish or blue; fruit ovate to rhombic-ovate, about $1 \mathrm{~cm}$. long, not noticeably constricted between the 2 seeds, villous.

In mud and wet soil at edge of lakes, ponds and in meadows, also in dryish soils, in N. M. (Grant, McKinley and Socorro cos.) and Ariz. (widespread), June-Sept.; also Colo. and Ut. 


\section{Medicago L. Bur-Clover. Medick}

A genus of about 120 species of temperate regions of the Old World, some of the species widely cultivated and introduced in America.

Alfalfa or lucerne ( $M$. sativa L.), though frequently cultivated under heavy irrigation, occurs as an escape mainly in dryish, well-drained soils. This European perennial is readily distinguished by its dense racemes of violet-colored flowers.

\section{Medicago lupulina L. BLACK MEDICK.}

Annual; stems and branches usually decumbent, 1-4 (-6) dm. long, usually pubescent; leaflets broadly obovate or nearly orbicular to almost elliptical, pubescent, 1-2 cm. long, 3-10 mm. broad; stipules lanceolate to ovate-lanceolate, 5-10 $\mathrm{mm}$. long, adnate to the petiole for about $2-3 \mathrm{~mm}$.; peduncles $5-40 \mathrm{~mm}$. long, axillary, slender; racemes very compact, 10 - to 50 -flowered, 7-10 mm. long; petals $1.5-2 \mathrm{~mm}$. long, yellow; pod dark-brown or nearly black at maturity, making one partial revolution, vaguely reniform, prickleless, $2-3 \mathrm{~mm}$. in diameter; seed solitary.

Scattered and weedy along roadsides, in lawns and occasional along irrigation ditches and in wet marshy fields, in Okla., the e. half of Tex., N. M. (Grant, San Miguel, Santa $\mathrm{Fe}$ and Taos cos.) and Ariz. (Navajo, Coconino, Yavapai, Graham, Gila and Pima cos.) spring; nat. of Euras., now widely introd.

\section{Melilotus Mill. Sweet Clover}

Biennial or annual herbs, taprooted, 3-30 dm. tall, the stems erect and usually nearly glabrous; leaves alternate, pinnately trifoliolate; leaflets usually oblanceolate to obovate, serrulate on the distal margin, the terminal leaflet petiolulate; stipules partially fused to the base of the petiole, obliquely ovate; peduncles axillary, usually several $\mathrm{cm}$. long; flowers usually only a few $\mathrm{mm}$. long, papilionaceous, white or yellow, in lax to crowded usually many-flowered spikelike racemes; calyx campanulate, minute, with nearly equal subulate to lanceolate acute to acuminate lobes; petals white or yellow, only a few $\mathrm{mm}$. long, deciduous after anthesis; stamens 10, diadelphous, 9 of the filaments coalescent, the tenth (upper) one free; fruit ovoid to globose, straight or nearly so, usually 1 -seeded and minute, commonly reticulate, indehiscent or essentially so.

A genus of about 20 species native to the Old World, widely introduced in the New World, valuable as forage crops. The genus is only very weakly distinguished from Medicago, and probably should be merged with it.

These ubiquitous plants are tolerant of habitats ranging from semidesert to bog or marsh.

1. Flowers white; pod reticulate-veined, dark-brown to black at maturity. 1. $M$. albus.

1. Flowers yellow; pod appearing cross-ribbed or smooth, gray or light-brown to tan at maturity (2)

2(1). Flowers 1-3 mm. long; pod globose; stipules widened below with scarious margins; annual. 2. $M$. indicus.

2. Flowers 3-5 mm. long; pod ovoid (longer than broad); stipules not widened below with scarious margins; biennial.......................... M. officinalis.

\section{Melilotus albus Lam. White SWeEt CLOVer, hubaM.}

Annual or biennial 3-15 $(-30) \mathrm{dm}$. tall; racemes with 30 to 80 flowers; petals white; banner $3-5 \mathrm{~mm}$. long, somewhat exceeding the wing and keel in length; pod $2-3.5 \mathrm{~mm}$. long, $2-2.5 \mathrm{~mm}$. broad, about $1.5-2 \mathrm{~mm}$. thick, glabrous, very short-stalked, usually dark-brown to blackish at maturity, reticulate-veined.

Scattered as a weed over Okla. and Tex. (seemingly rare on Edwards Plateau and in far e. Tex.), N. M. (widespread) and Ariz. (widespread), spring-summer; nat. of Euras., now widely introd. 


\section{Melilotus indicus (L.) All. Sour Clover, Alfalfilla.}

Annual 1-5 dm. tall; stipules lanceolate, those of the lower leaves widened below the middle, scarious and partially encircling the stem and with a small free basal lobe; racemes with 10 to 60 flowers; flowers $1-3 \mathrm{~mm}$. long; petals yellow; banner about $3 \mathrm{~mm}$. long; pod flattened, nearly orbicular, $1.5-2.5 \mathrm{~mm}$. long, yellowish or reddish at maturity, very short-stalked, not reticulate-veined.

More often in dry situations but occasionally in wet ditches and boggy places, scattered over Tex. (rare in Rio Grande Plains and higher parts of Plains Country, infrequent in Trans-Pecos and Edwards Plateau), in N. M. (widespread) and Ariz. (widespread), spring-summer; nat. of Medit. area, now widely introd.

\section{Melilotus officinalis (L.) Lam. YELLOW SWEET CLOVER.}

Biennial or rarely annual, 4-10 (-20) dm. tall; stipules lanceolate, acute, mostly 5-8 mm. long, entire, not widened below nor with scarious margins; racemes with 30 to 70 flowers; flowers $3-5 \mathrm{~mm}$. long; petals yellow; banner about $5 \mathrm{~mm}$. long; pod ovoid, 2.5-4 mm. long, 2-2.5 mm. broad, about $1.5 \mathrm{~mm}$. thick, distinctly short-stalked, glabrous, usually light-brown to tan at maturity, the transverse ridges more prominent than the longitudinal ones.

Frequent in Okla., n.-cen. Tex. and scattered elsewhere, N. M. (Dona Ana and San Juan cos.) and Ariz. (Navajo, Coconino, Yavapai and Gila cos.), JuneOct.; nat. of Euras., now widely introd.

\section{Trifolium L. Clover}

Annual, biennial or perennial herbs; stems usually weak and with some of them at least partially decumbent; leaves alternate, trifoliolate (either palmately so or the terminal leaflet longer-stalked), typically obovate to nearly orbicular, serrulate on the distal margin, rarely more than $3 \mathrm{~cm}$. long; petioles well-developed; stipules conspicuous, persistent and usually at least partially adnate to the base of the petiole; inflorescence axillary and/or terminal, sessile or peduncled capitate or spikelike racemes or umbel-like aggregations; flowers sessile or pedicellate; calyx persistent, the tube campanulate or cylindrical and with 5 to 10 (to 20) nerves, the lobes linear to deltoid and equal or unequal; corolla papilionaceous, never blue nor purple; petals united below with the filament tube in some species; stamens 10 , diadelphous, 9 filaments coalescent into a tube, the tenth (uppermost) one free; pod often enclosed within the calyx tube and typically enveloped by the persisting petals, obovoid to oblong-linear, usually membranous, indehiscent or opening by a suture, or more rarely circumscissile; seeds 1 to 4 .

A large genus of 300 species of temperate regions of the world.

Many of the clovers, especially those introduced from Europe, Asia and Africa, are cultivated for hay and forage. The foliage of nearly all species, both indigenous and introduced, is grazed by domestic stock and wild animals. The hard, small seeds, as well as the foliage, are important food for game birds, shorebirds and marsh birds.

1. Heads involucrate (2)

1. Heads naked, without involucres (10)

2(1). Involucre a monophyllous irregularly lobulate or laciniate disk at base of head (3)

2. Involucre not as above, with distinct lobes when they are present (8)

3 (2). Lobes of involucre 7 to 10 , ovate to triangular-ovate, acute to subacuminate, with broad scarious margins.....................1. T. microcephalum.

3. Lobes of involucre more or less laciniate to linear-lanceolate and attenuate 
4(3). Calyx silky-hairy, becoming much-inflated in fruit to increase the size of the head 2 or 3 times.

2. $T$. fragiferum.

4. Calyx not as above (5)

5(4). Flowers of head enclosed within 1 or 2 involucres; pod 1 - or 2-seeded 3. $T$. pinetorum.

5. Flowers of each floral circle of the heads enclosed within a separate involucre; 3 to 6 involucres to the head; pod 2- to 6-seeded (6)

$6(5)$. Involucre coarsely toothed or 10 - to 12-lobed with their lobes 3 - to 6toothed.

4. T. Wormskjoldii.

6. Involucre with lobes not deeply cleft but 3- or 5-toothed (7)

7(6). Heads $2-4 \mathrm{~cm}$. wide; corolla $12 \mathrm{~mm}$. or longer; standard emarginate at apex.....................................................................5. T. Fendleri.

7. Heads $1-2 \mathrm{~cm}$. wide; corolla less than $12 \mathrm{~mm}$. long; standard obtuse and entire at apex

6. T. lacerum.

8(2). Heads loose, few-flowered; involucre minute, rudimentary 7. $T$. nanum.

8. Heads compact, turbinate, globose or hemispheric; involucre evident (9)

$9(8)$. Involucre glabrous, of 5 to 8 broadly obovate bracts at base of head and an inner bract at the base of each flower.................... 8. T . Parryi.

9. Involucre densely pubescent, the several lobes triangular-linear and attenuate 9. T. dasyphyllum.

10(1). Perennial (doubtful cases should be keyed under both alternatives), with densely plumose linear-attenuate calyx lobes (11)

10. Annual or biennial (13)

11(10). Heads mostly less than $2 \mathrm{~cm}$. high; rare in extreme southeast Arizona

11. Heads rarely less than $2 \mathrm{~cm}$. high; in eastern Arizona and/ or New Mexico (12)

12(11). Stipules narrowly lanceolate, long-acuminate, glabrous; standard ovatelanceolate; pods glabrous, with 2 or 3 seeds.........11. T. Rydbergii.

12. Stipules ovate, abruptly short-acuminate, somewhat pubescent; standard elliptic; pods somewhat pubescent, with 2 seeds

12. T. neurophyllum.

13(10). Flowers sessile or subsessile in the heads; calyx more or less pubescent; stipules oblong, conspicuously veined, the free portion triangular with a setaceous point........................................13. T. pratense.

13. Flowers conspicuously pedicellate in the long-peduncled heads; calyx glabrous (14)

14(13). Stem creeping, often rooting at nodes; leaflets obovate, usually with a whitish crescent toward base, notched at apex............14. T. repens.

14. Stem erect or ascending; leaflets oval or ovate, without a white spot, rounded at apex 15. T. hybridum.

\section{Trifolium microcephalum Pursh}

Sparsely to densely villous annual with prostrate to erect stems 1-7 dm. long; stipules ovate to ovate-lanceolate, denticulate-serrulate, about one-half as long as the leaflets; leaflets 3 , obovate-oblanceolate, $1.5-2.5 \mathrm{~cm}$. long; heads involucrate, 5-10 mm. long, 10- to 60-flowered; involucres villous, sometimes exceeding the lower flowers, shallowly crateriform, with about 10 (6 to 12) nearly entire acute cuspidate shallow lobes; flowers 4-5 (-7) $\mathrm{mm}$. long; calyx usually either hirsute or villous (rarely glabrous), the simple teeth setaceous and longer than the tube; corolla white to pinkish; legume 2-3 mm. long, 1- or 2-seeded, usually rupturing the calyx by maturity. 
Wet meadows, wet sandy stream and river banks, and hillsides, Ariz. (Gila and Pinal cos.), Apr.-May; Mont. to B. C., s. to Ariz. and Baja Calif.

\section{Trifolium fragiferum L. STRAWBerRy CLOVER.}

Perennial; stems branching, creeping and rooting at nodes, glabrous or nearly so; petioles long; leaflets 6-30 $\mathrm{mm}$. long, obovate, finely serrulate to subentire, glabrous or sparingly long-hairy at base; peduncles $8-15 \mathrm{~cm}$. long, exceeding the leaves; head 1-1.4 cm. wide in anthesis, globose, with an involucre; calyx 3-4 $\mathrm{mm}$. long, silky-hairy, the slender teeth about as long as the tube, becoming much-inflated in fruit to increase the size of the head 2 or 3 times, becoming reticulate-veined and often reddish-tinged; corolla 5-7 $\mathrm{mm}$. long, pink to rosecolor; fruit 1 -seeded.

In wet meadows and marshes, in N. M. (San Juan and San Miguel cos.), June-Aug.; introd. from Euras. and N.Afr., now widely spread.

\section{Trifolium pinetorum Greene.}

Perennial; stems slender, reclining, glabrous, much-branched, to about $6 \mathrm{dm}$. long; petioles slender, several times as long as the leaflets; stipules narrow, attenuate, entire or nearly so; leaflets obovate to elliptic-oblong, rounded or obtuse at apex, cuneate at base, bright-green, glabrous, prominently veined with the veins slightly prolonged beyond the low teeth; peduncles slender, 4-6 cm. long, nearly glabrous but with a few long crinkled hairs, often tomentulose just below the often few-flowered head; involucre short but distinct, one-third to one-half as long as the flowers, composed of linear-lanceolate subulate bracts free almost to their bases; calyx one-half to two-thirds as long as the cornlla, the linearsubulate teeth almost twice as long as the tube; corolla pale-purplish, to about $11 \mathrm{~mm}$. long, the banner emarginate. T. longicaule W. \& S.

In wet meadows, muddy seepage, edge of pools and along streams in N. M. (Lincoln and Otero cos.) and Ariz. (widespread in mts.), June-Oct.

\section{Trifolium Wormskjoldii Lehm.}

Glabrous taprooted perennial with decumbent-based and often rhizomatous stems 1-8 dm. long; stipules $1-4 \mathrm{~cm}$. long, lacerate-margined and usually acuminate; leaflets 3 , linear-elliptic to oblong-obovate, $1-3 \mathrm{~cm}$. long, finely serrulate; heads involucrate, axillary, 2- to 60 -flowered, 2-3 cm. broad; involucres flared, from as much as $2 \mathrm{~cm}$. broad and lacerately 8- to 12-lobed to shallowly lobed or toothed with the lobes entire; peduncles $3-11 \mathrm{~cm}$. long; heads nearly globose, 15-25 mm. thick; flowers $10-18 \mathrm{~mm}$. long, erect or spreading, reddish to purple, often white-tipped; pedicels $0.5-2 \mathrm{~mm}$. long; calyx glabrous, two thirds to three fourths as long as the corolla, the tube 10 -veined, about equaled by the 5 subequal narrowly lanceolate-acicular (occasionally bifid) teeth; legume 1- to 4seeded. T. Willdenovii Spreng.

Wet meadows, stream beds and banks, in mts. of w. Tex. (Jeff Davis Co.), N. M. (Hitchcock, et al.) and possibly Ariz., May-Sept.; Ida. to B. C., s. to N. M., Calif. and Mex.

\section{Trifolium Fendleri Greene. Fig. 498.}

Perennial from slender roots; stems not fistulose, mostly erect, to $5 \mathrm{dm}$. tall, glabrous, longitudinally striate; leaves long-petioled, glabrous, bright-green; leaflets mainly elliptic to oblanceolate or (in the lower leaves) obovate, usually less than $3 \mathrm{~cm}$. long, sharply denticulate to serrulate; stipules broad, oblong-lanceolate to ovate, deeply and sharply toothed to laciniate; peduncles normally glabrous; heads $2-4 \mathrm{~cm}$. wide, more than 10-flowered, globular, borne above the leaves, involucrate; involucral bracts not foliaceous, relatively broad and deeply cleft with setaceous teeth, in a whorl and more or less united about a third their length 


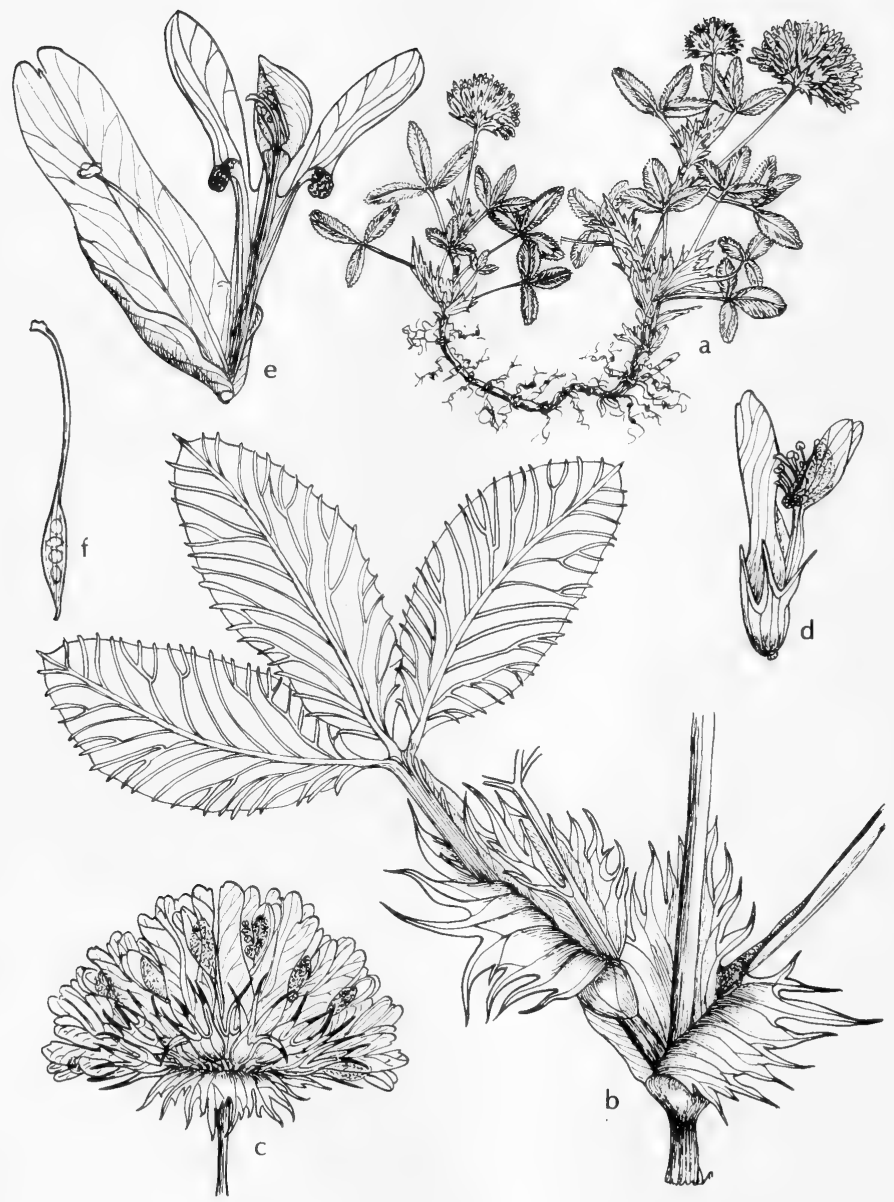

Fig. 498: Trifolium Fendleri: a, habit, x 1/2; b, leaf with stipules, x 5; c, flower head, $x 1 \frac{1}{2}$; d, young flower, $x 2 \frac{1}{2}$; e, mature flower, $x 4$; f, pistil, $x 4$. (V. F.) 
to form a cup-shaped basal portion; pedicels slender, about $1 \mathrm{~mm}$. long; calyx 5-8 $\mathrm{mm}$. long, thin, glabrous, the teeth longer than the tube; corolla 8-14 $\mathrm{mm}$. long, white to pink or rose-color; fruit 2- to 4-seeded.

In wet meadows, mud, boggy areas, edge of water along streams and about ponds, and on slopes, in N. M. (widespread in mts.) and Ariz. (Apache to Coconino, s. to Greenlee and Gila cos.), June-Sept.; also Colo. and Ut.

\section{Trifolium lacerum Greene.}

Stem much-elongated, reclining; leaflets narrowly linear to lanceolate or oblanceolate, often conspicuously cuspidate and spinulose-serrate; stipules broad, oblong-lanceolate to ovate, deeply and sharply toothed to laciniate; peduncles normally glabrous; heads $1-2 \mathrm{~cm}$. wide and more than 10 -flowered, with a manifest involucre; involucral bracts not foliaceous, relatively broad and deeply cut, with setaceous teeth, united for about a third their length to form a cupshaped basal portion; corolla less than $12 \mathrm{~mm}$. long.

Low wet meadows and wet places in N. M. (Grant, McKinley, Socorro and Taos cos.) and Ariz. (Coconino to Cochise and Pima cos.), Mar.-Aug.

\section{Trifolium nanum Torr.}

Cespitose perennial, 2-6 $\mathrm{cm}$. tall, erect or spreading from woody branched crowns of roots, acaulescent, glabrous; petioles slender, longer than the leaflets; leaflets 6-15 mm. long, narrowly obovate to linear-oblanceolate or oblong, glabrous, slightly serrate to almost or quite entire; heads of 2 or 3 flowers, peduncled, often borne somewhat above the leaves, essentially non-involucrate or with 2 or 3 small inconspicuous whitish cupulate involucres that are usually not over 1.5 $\mathrm{mm}$. long; flowers ascending on slender pedicels 1-2 $\mathrm{mm}$. long; calyx glabrous, the campanulate tube $3-4 \mathrm{~mm}$. long, with lanceolate to deltoid teeth about 2 $\mathrm{mm}$. long; corolla $1.6-2 \mathrm{~cm}$. long, reddish-purple or rose-purple, rarely whitish; fruit 5 - to 10 -seeded.

Wet meadows in high mts., in N. M. (Mora Co.), summer; Mont., s. to N. M. and Ut.

\section{Trifolium Parryi Gray.}

Glabrous to brownish-pubescent tufted perennial from a thick taproot; stems numerous, $1-5 \mathrm{~cm}$. long, covered with stipules that are thin, scarious, marcescent, entire to toothed and rounded to acutely pointed; leaflets 3 , broadly elliptic to obovate, entire to serrulate or denticulate, rounded to acute at apex, $1-4 \mathrm{~cm}$. long; petioles 1-6 cm. long; head involucrate, subglobose, 10-35 mm. thick, 4- to 30-flowered; peduncles usually exceeding the leaves; involucral bracts 6 to 12, distinct, thin and scarious, entire-margined, purplish-brown, rounded to acute or bifid at apex, usually about equaling the calyces; flowers 11-22 mm. long, spreading to erect, the pedicels $0.5-2 \mathrm{~mm}$. long; calyx glabrous, scarious, about one half the length of the corolla, the tube from one half as long to as long as the subulate to triangular subequal teeth; corolla dark reddish-purple, aging brown; legume 1- to 4-seeded.

In wet alpine to subalpine meadows and on wet stream banks in N. M. (Mora Co. ), June-Sept.; Mont. and Ida., s. to mts. of N. M. and e. Ut.

\section{Trifolium dasyphyllum T. \& G.}

Cespitose acaulescent perennial, $5-15 \mathrm{~cm}$. tall or more, from a woody branched caudex; petioles elongate; leaflets linear-lanceolate to lanceolate, 1-3 cm. long, cuneate at base, acuminate at apex, sparsely to densely strigose especially below, entire; heads borne on peduncles above the leaves, globose, $1.5-2.5 \mathrm{~cm}$. wide, with 10 to 30 flowers, without an involucre or this obsolescent; pedicels short and pubescent, about $1 \mathrm{~mm}$. long; flowers reflexed or not in age; calyx 6-10 $\mathrm{mm}$. long 
or more, silky, strigose, the subulate lobes subequal and about twice as long as tube; corolla $1-1.5 \mathrm{~cm}$. long, purple to pink, usually bicolored, with wings and keel darker; fruit 3- to 5-seeded. T. stenolobum Rydb.

In alpine wet meadows in N. M. (Bernalillo, Sandoval, San Miguel and Santa Fe cos.), summer; also Colo.

\section{Trifolium amabile H.B.K.}

Plants caulescent, with large thick roots; stems prostrate, to about $2 \mathrm{dm}$. tall or long, decumbent; leaflets cuneate-obovate, glabrous or glabrate; heads $1-1.6 \mathrm{~cm}$. in diameter and height, on villous peduncles; involucre vestigial, seldom more than $1 \mathrm{~mm}$. long; flowers strongly reflexed on villous petioles; calyx villous, the lobes toothed; corolla equal to or a little longer than calyx; fruit 2-seeded.

In wet sandy soil about springs and along brooks, rare in Ariz. (Cochise Co.), Aug.-Oct.; also s. to C.A.

\section{Trifolium Rydbergii Greene.}

Stems usually erect and single, 2-4 dm. tall, glabrous below, somewhat strigose above; leaflets linear-lanceolate to oval, $2-5 \mathrm{~cm}$. long or those of the basal leaves shorter and broader, usually acute, sharply denticulate, glabrous or somewhat pubescent on lower surface; peduncles 4-10 cm. long; heads 2-4 cm. long, noninvolucrate; calyx pubescent, the tube about $2 \mathrm{~mm}$. long, with subulate-setaceous teeth 4-5 $\mathrm{mm}$. long or more; corolla white to pinkish, about $1.5 \mathrm{~cm}$. long.

Wet meadows and edge of pools in N.M. (Rio Arriba Co.) and Ariz. (Coconino Co. ), July-Sept.; N. M. and Ariz., n. to Mont. and Ida.

\section{Trifolium neurophyllum Greene.}

Perennial; stems scattered from horizontal rootstocks, 1.3-2.5 dm. tall, erect or decumbent, canescently villous, usually with a solitary peduncled head; leaflets of lowest leaves obovate to oblong, 1-2 cm. long, these passing above to such as are $4 \mathrm{~cm}$. long, linear to narrowly lanceolate and spinescently acute, loosely villous especially on the midvein, all very prominently transverse-venulose and doubly spinulose-denticulate with the teeth incurved; head without an involucre, at first flowering broader than high, eventually $2.5 \mathrm{~cm}$. long and the flowers deflexed; calyx villous with long appressed hairs, with 5 equally slenderly subulate lobes of at least twice the length of the turbinate tube; corolla deep-red-purple, twice the length of the calyx

Wet soils and wet edge nools and streams, N. M. (Grant and Socorro cos.) and Ariz. (Coconino, Apache and Greenlee cos.), July-Sept.

\section{Trifolium pratense $L$. RED CLOVER.}

Sparsely soft-hairy, short-lived, taprooted perennial; stems several, 3-10 dm. tall; stipules ovate-lanceolate, $1-3 \mathrm{~cm}$. long, conspicuously greenish veined; leaflets 3 , lanceolate to oblong-obovate, $2-6 \mathrm{~cm}$. long, very inconspicuously serrulate; heads terminal, sessile or with peduncles shorter than the 2 subtending leaves, 50 - to 200-flowered, globose-conic, $2.5-3.5 \mathrm{~cm}$. broad and about as long, noninvolucrate but the stipules of the upper leaves often somewhat involucral; flowers sessile, spreading to erect, deep-red, 13-20 $\mathrm{mm}$. long; calyx one half to two thirds as long as the corolla, short villous-hirsute, the teeth acicular, pubescent with straight somewhat pustulose hairs, the 2 upper ones about equal to the tube, the lower 3 nearly twice as long; legume 2-seeded.

Wet meadows and marshes, occasional in Okla., N.M. and Ariz., May-Aug.; introd. from Eur., widely cult. and sometimes found as an escape.

\section{Trifolium repens $\mathrm{L}$. White CLOVER.}

Glabrous or very sparsely pubescent perennial; stems creeping and stolonous to erect, 1-6 dm. long; stipules 3-10 mm. long, connate most of their length, 
the free portion shortly acuminate; petioles from only slightly to many times longer than the leaflets; leaflets 3 , obovate but usually somewhat retuse to obcordate, 1-2 cm. long, finely serrulate; heads axillary, often long-pedunculate, $1.5-2 \mathrm{~cm}$. broad, nearly as long, noninvolucrate; flowers $5-9 \mathrm{~mm}$. long, white or cream to pinkish-tinged, pendulous at anthesis on pedicels $2-5 \mathrm{~mm}$. long; calyx glabrous, about half the length of the corolla, the teeth lanceolate-subulate, about equal to the tube; banner much more erect than in the native clovers; legume 1- to 3seeded.

Wet meadows, marshes and in wet soil about ponds and along streams, in Okla. (Waterfall), N. M. (Otero, Rio Arriba, San Juan, San Miguel, Santa Fe and Taos cos.) and Ariz. (Navajo, Coconino, Mohave, Yavapai and Cochise cos.), MaySept.; introd. from Eur. and now widely established in w. N. A.

\section{Trifolium hybridum L. Alsike or Alsatian clover.}

Perennial, glabrous or very nearly so; stems erect or ascending, 3-6 dm. tall, branching, often stout and succulent; stipules ovate-lanceolate, 12-25 mm. long, acuminate-attenuate, membranous; leaflets $12-25 \mathrm{~mm}$. long, petiolulate, elliptic to obovate, rounded and occasionally emarginate at apex, cuneate at base, serrulate with sharp-pointed teeth; heads globose, long-peduncled, not involucrate; flowers white and pink, turning brown after anthesis, $6-8 \mathrm{~mm}$. long, reflexed; pedicels slender, 5-10 mm. long; calyx glabrous, the linear-subulate teeth about equaling the tube, $1.7-2.5 \mathrm{~mm}$. long; corolla much-exceeding the calyx teeth.

In wet meadows, along irrigation ditches, streams and in marshes, in Okla. (Waterfall), N. M. (Rio Arriba and San Miguel cos.) and Ariz. (Coconino Co.), July-Sept.; introd. from Eur. and now widespread.

\section{Lotus L. DeEr Vetch. Trefoil}

Annual or perennial leafy herbs, usually 1-5 dm. tall; leaves alternate, oncepinnately 3- to 5 -foliolate or by reduction palmately trifoliolate; petioles short, often shorter than the rachis or not much longer; stipules in one species welldeveloped and in the others nearly obsolescent and glandlike; leaflets small, rarely more than $1 \mathrm{~cm}$. long, linear to nearly orbicular, usually with appressed pubescence, usually entire; stipules absent; peduncles usually several $\mathrm{cm}$. long, emerging from the upper axils and longer than the leaves; flowers about $1 \mathrm{~cm}$. long, solitary or paired or in umbel-like groups at the end of the peduncle; calyx cylindric to campanulate with more or less equal lobes at the end of the tube; corolla papilionaceous, the petals usually basically yellowish or whitish but with red, rose or purple areas; banner external to the rest in bud, ovate to obovate; wings obovate or oblong and adhering to the incurved keel of usually fused petals; stamens 10, diadelphous, 9 with filaments coalescent and the tenth (uppermost) free, the filaments (all or part of them) expanded just below the anthers; ovary sessile; legume linear, usually 1-3 (-4) cm. long, nearly straight, dark-brown, thin-walled, promptly dehiscent, acute; seeds numerous. World.

A genus with about 120 species in temperate areas of the Old World and New

As in the case of clovers, both the seeds and foliage of these species are relished by wildlife.

1. Stems stout, erect or nearly so; leaflets 7 to 11 , narrowly lanceolate to elliptic or obovate, 1-3 cm. long; corolla 10-14 mm. long, purple-veined; pods about $2 \mathrm{~mm}$. wide.................................. L. oblongifolius.

1. Stems slender, procumbent; leaflets 3 to 5 , broadly obovate, less than $1 \mathrm{~cm}$. long; corolla usually 4-7 mm. long; pods $1-1.5 \mathrm{~mm}$. wide. 


\section{Lotus oblongifolius (Benth.) Greene.}

Herbaceous perennial; stems several, stout, erect or ascending from slender, branched rootstocks, $1.5-4 \mathrm{dm}$. long; herbage appressed-pubescent to nearly glabrous; leaves with 7 to 11 leaflets, these linear-lanceolate to elliptic, acute, 7-20 $\mathrm{mm}$. long, equally distributed on opposite sides of rachis, the stipules membranous; peduncles exceeding the leaves in height; umbels 1- to 5-flowered, closely subtended by a 1 - to 3 -foliate bract; calyx tube 2-3 $\mathrm{mm}$. long, the teeth narrowly subulate, about as long as the tube; petals $10-12 \mathrm{~mm}$. long, the claws short and little exserted from calyx, the banner yellow or orange, ovate, erect, the keel and wings whitish to yellow, sometimes tinged with red; pods straight, dehiscent, not beaked, remaining erect, $2.5-4 \mathrm{~cm}$. long.

Wet places at elevations of 1,000-6,000 feet, Ariz. (Cochise Co.), May-Oct.; also s. Calif. and n. Mex.

\section{Lotus alamosanus (Rose) Gentry.}

Stems procumbent, slender, rooting at the nodes, glabrous or the younger parts with appressed hairs; stipules 4-8 $\mathrm{mm}$. long, foliaceous, ovate, acute; leaves 3- to 5-pinnate; leaflets obovate, obtuse, 4-10 mm. long; peduncles slender, 5-10 cm. long, 1- to 4-flowered (mostly 2); bracts 1, setaceous; flowers 4-6 mm. long; calyx tube less than $2 \mathrm{~mm}$. long, its lobes almost as long as tube and very narrow; corolla yellow; pods $2-3 \mathrm{~cm}$. long, terete, erect, 12 - to 15 -seeded; seeds turgid, oblong, lucid.

Wet sandy soil along creeks, in seepage spring waters of canyons and in wet meadows in Ariz. (Santa Cruz Co.), Apr.-May; also Son. and Dgo.

\section{Indigofera L. INDIGO}

Perennial herbs, usually gray-pubescent all over, the pubescence appressed with the hairs often medifixed (with 2 ends free); leaves alternate, once-imparipinnately-compound; petioles short; stipules herbaceous, subulate to setaceous; leaflets 5 to 15 , usually oblanceolate to obovate or elliptic, rarely linear, either or not opposite on the rachis; flowers in axillary sometimes spikelike racemes: calyx teeth 5; corolla papilionaceous, brick-red (less often pinkish or purplish); banner orbicular or obovate, short-clawed; wings oblanceolate to oblong or linear, short-clawed, slightly adherent to the keel, the blade forming a basal auricle; keel petals united distally, the claws separate, the blades spurred or pouched; stamens 10, diadelphous, 9 with coalescent filaments, the tenth (uppermost) free, the anther connective glanduliferous; pod not much if at all compressed, promptly dehiscent, several-seeded, straight or falcate, linear or curvilinear; seeds usually separated in the pod by partitions, not stipitate.

A genus of about 400 species of warm regions.

1. Mature pods with a small swollen reddish glabrous knob at the base; leaves densely strigose on both surfaces.................... I. Lindheimeriana.

1. Mature pod acute at base, without a swollen reddish knob; leaves sparsely strigose, the upper surface less densely so to glabrous.

2. I. suffruticosa.

\section{Indigofera Lindheimeriana Scheele.}

Erect stems 5-10 dm. tall; leaflets 7 to 15 , opposite or nearly so on the rachis, densely strigose on both surfaces; racemes in flower somewhat shorter than the leaves but in fruit slightly longer; calyx less than half as long as the corolla, the teeth lanceolate or deltoid and not or only slightly exceeding the calyx tube; pod 20-25 mm. long, basally with a small swollen reddish glabrous knob.

Local in often wet alluvial soil of creeks in limestone hill areas, s. margin of Edwards Plateau in Tex. from Crockett and Terrell cos. to Comal Co., May-Aug.; also N. L. and Coah. 


\section{Indigofera suffruticosa Mill. INDIGO.}

Erect stems 5-20 dm. tall; leaflets 9 to 15 , opposite or nearly so on the rachis, sparsely strigose; racemes shorter than the leaves; calyx less than half as long as the corolla, the teeth lanceolate or deltoid and not or only slightly exceeding the calyx tube; pods (when mature) 15-20 $\mathrm{mm}$. long, acute basally.

Local in silty often wet alluvial soils in the Tex. Coastal Plains from Hardin Co. to Cameron Co. and inland to Brazos, Gonzales and Wilson cos., July-Nov.; nat. to trop. Am., now widely introd.

This species and 1 . tinctoria $\mathrm{L}$. are the sources of the substances which are the chemical precursors of the blue dye indigo, formerly important in commerce.

\section{Amorpha L.}

Unarmed erect shrubs, often rhizomatous, the herbage and calyx often glanddotted; leaves alternate, deciduous, usually $8 \mathrm{~cm}$. or more long, once-imparipinnate with 7 or more leaflets; leaflets (4-) 5-30 $\mathrm{mm}$. broad; stipules setaceous, caducous; stipels present; flowers in dense spikelike racemes; calyx obconoid, 5-toothed, persistent; corolla very irregular, reduced to 1 petal (the uppermost one, banner), the rest absent, this banner purplish, bluish or whitish; stamens 10 , exserted; filaments all united briefly at the base, free for most of their length; fruit 4-8 $\mathrm{mm}$. long, gland-dotted, not much if at all compressed, slightly exserted from the calyx, 1- or 2-seeded, very tardily dehiscent or seemingly indehiscent.

A genus of about 20 species in the temperate regions of North America.

1. Branchlets and leaf rachis with pricklelike glands; calyx lobes triangularlanceolate, nearly equaling the tube......................1. A. californica.

1. Branchlets and leaf rachis without pricklelike glands; calyx lobes mostly short-triangular, much shorter than the tube (2)

2(1). Branchlets and the conspicuously veiny lower leaf surface tomentose; flower spike usually 2-4 dm. long; fruit densely pubescent.

2. A. paniculata.

2. Branchlets and the inconspicuously veiny lower leaf surface glabrous to somewhat pubescent; flower spike usually much less than $2 \mathrm{dm}$. long; fruit usually glabrous (3)

3(2). Petiolules 3-5 mm. long, usually pubescent and conspicuously glandular; calyx tube pubescent

3. A. texana.

3. Petiolules about $2 \mathrm{~mm}$. long, not glandular-warty; calyx tube mostly glabrous or glabrescent. 4. A. fruticosa.

\section{Amorpha californica Nutt. Stinking-willow, Mock locust.}

Shrub 1-3 $\mathrm{m}$. high, the branches pubescent and beset with scattered pricklelike glands; leaves 1-2 dm. long, ascending; petioles (about $1 \mathrm{~cm}$. long) and leaf rachis pilose and with scattered pricklelike glands; leaflets 11 to 25 , broadly oval to elliptic, rounded at both ends or retuse and mucronate at apex, $1-3 \mathrm{~cm}$. long, pilose throughout; racemes $5-20 \mathrm{~cm}$. long, the rachis pilose; calyx 5-6 $\mathrm{mm}$. long, densely pilose, 10-grooved, the lanceolate lobes nearly equaling the tube; standard reddish-purple, obovate-cuneate, $5 \mathrm{~mm}$. long; pod curved on the back, $8 \mathrm{~mm}$. long, $3 \mathrm{~mm}$. wide, puberulent and conspicuously glandular-dotted.

Mostly along streams and in river valleys, in N. M. (widespread) and Ariz. (Yavapai, Graham, Cochise and Pima cos.), June; also Calif. and Baja Calif.

\section{Amorpha paniculata T. \& G.}

Stout shrub 2-3 m. tall; branchlets sulcate, tomentose; leaves $20-35 \mathrm{~cm}$. long; petioles $4-5 \mathrm{~cm}$. long; leaflets 15 to 19 , ovate or oblong, 3-8 cm. long, (15-) 20-30 $\mathrm{mm}$. broad, rounded at both ends or rarely emarginate apically, when 
young finely short-pilose above and densely tomentose beneath, at maturity glabrous and glossy above and still tomentose on lower surface, with prominent venation beneath; spikes of inflorescence (15-) 20-40 cm. long; calyx oblique, narrowly companulate, pubescent, the lobes lanceolate and about half as long as the tube; banner purple; pod $6-8 \mathrm{~mm}$. long, more or less curved dorsally, pubescent and with large resinous gland-dots.

Deep acid woodlands and bogs, e. Tex., May-June; Ark., La. and Tex.

\section{Amorpha texana Buckl.}

Shrub 1-3 m. tall, with spreading branches; branches, foliage and inflorescence more or less pubescent to glabrous; leaves 10-15 cm. long; petioles $1-2 \mathrm{~cm}$. long; leaflets 7 to 15 , broad-oblong or ovate, $15-40 \mathrm{~mm}$. long, 15-30 $\mathrm{mm}$. broad, rounded at both ends or emarginate apically, firm, dark-green and glossy above, paler and pubescent beneath at least along the inconspicuous veins; petiolules 3-5 $\mathrm{mm}$. long, usually pubescent and conspicuously glandular; spikes of inflorescence solitary or few, (5-) 10-15 $(-20) \mathrm{cm}$. long, rather loosely flowered at least near the base; rachis puberulent; calyx narrow-campanulate, 4-5 $\mathrm{mm}$. long, uniformly pubescent or glabrous, gland-dotted; calyx lobes all much shorter than the tube, the 2 upper ones blunt or round, the 3 lower short-lanceolate and acute; banner blue or violet; pod 6-7 mm. long, nearly straight dorsally, conspicuously glanddotted. Incl. var. glabrescens E. J. Palm.

Scarce along Edwards Plateau creeks and rivers in Bandera, Blanco, Comal, Gillespie, Kendall and Kerr cos. in Tex., spring; endemic.

\section{Amorpha fruticosa L. Bastard indigo. Fig. 499.}

Shrub 2-3 m. tall; branches and foliage more or less pubescent with shortappressed hairs; leaves 1-2 dm. long; petioles (1-) 2-3 cm. long; leaflets 11 to 27 (to 35), oblong or elliptic, rounded or narrowed at base, rounded or rarely abruptly pointed apically, 15-30 mm. long, 7-15 (-20) $\mathrm{mm}$. broad, firm but thin at maturity, dark-green and slightly reticulate-veined above, paler and sparingly gland-dotted and more or less pubescent at least along veins beneath, not crowded on rachis; petiolules short, not glandular-warty; spikes solitary or several, $8-15(-20) \mathrm{cm}$. long, peduncled; calyx $3-4 \mathrm{~mm}$. long, nearly glabrous or pubescent; calyx lobes all much shorter than the tube, the upper 2 broad and obtuse, the lower 3 triangular and acute, villous or ciliate along the margins; banner dark-blue; pod 6-7 mm. long, slightly curved dorsally, glabrous and conspicuously gland-dotted.

Widespread, on the edge of water of lakes and streams, depressions, boggy places and floodplain woods, Apr.-Aug.; represented with us by 4 subtaxa:

Var. fruticosa. Leaflets broad, elliptic. Rare in e. Tex.; e. U.S.

Var. angustifolia Pursh. Leaflets narrower. Widespread in Tex. except absent in Rio Grande Plains and rare in e. and far w. Tex.; widely scattered in U. S.

Var. croceolanata (P. W. Wats.) Mouillef. With densely pubescent leaves and calyxes. Rare in s.e. Tex.; s.e. U. S.

Var. occidentalis (Abrams) Kearn. \& Peeb. With oval or oblong glabrate leaflets and mostly solitary spikes. Scattered in w. half of Tex. to Wyo., Calif., N. M., Ariz., Son., etc.

\section{Sesbania SCOP.}

Annual or perennial herbs or subshrubs or weak deciduous shrubs, unarmed, with long green glabrous rarely branched branches and stems; leaves alternate, remote, once even-pinnately compound, often 2-3 dm. long; petioles short; stipules herbaceous, caducous; leaflets numerous, usually linear or narrowly ob- 


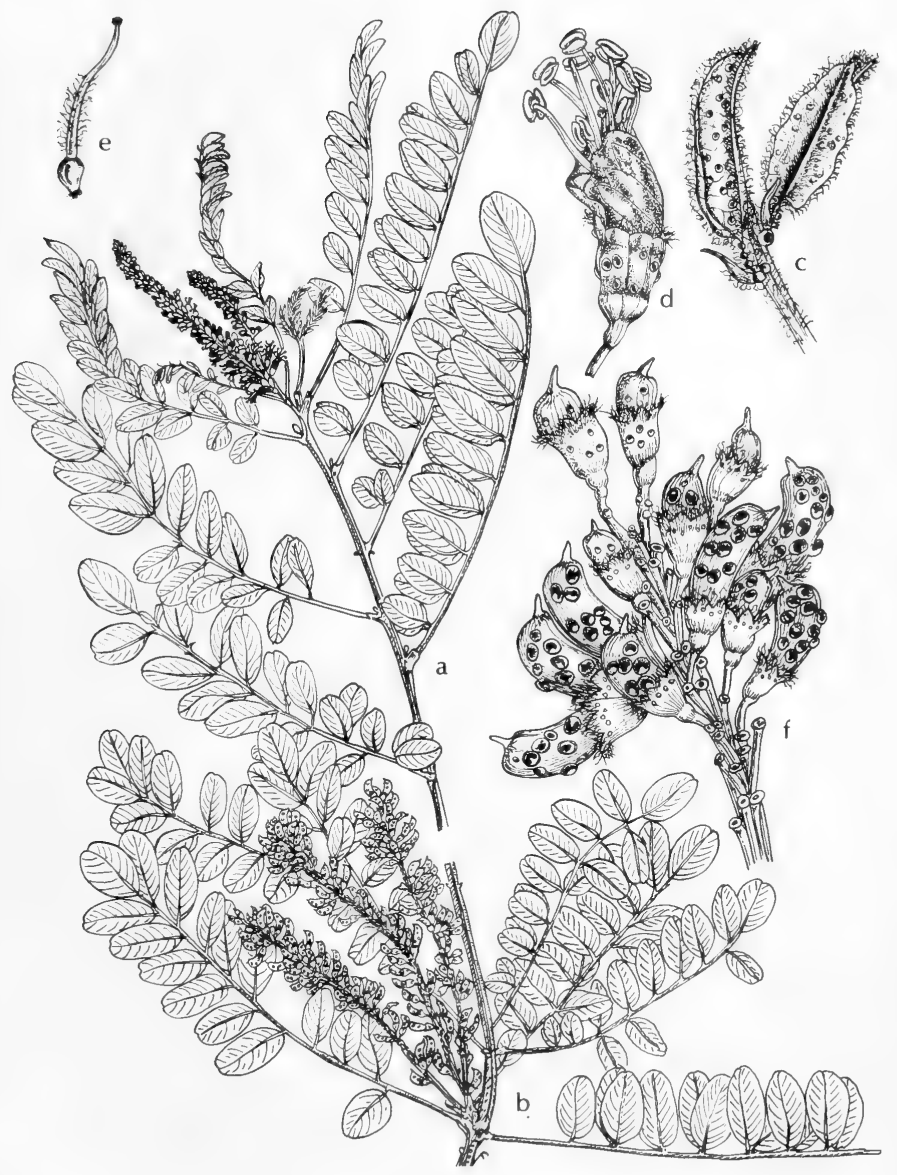

Fig. 499: Amorpha fruticosa: a, upper part of plant with flowers, x 1/2; b, part of plant with fruits, $x 1 \frac{1}{2}$; c, young leaflets, $x 2 \frac{1}{2}$; d, flower, x 5; e, pistil, x 5; f, cluster of fruit, $x 2 \frac{1}{2}$. (V. F.). 


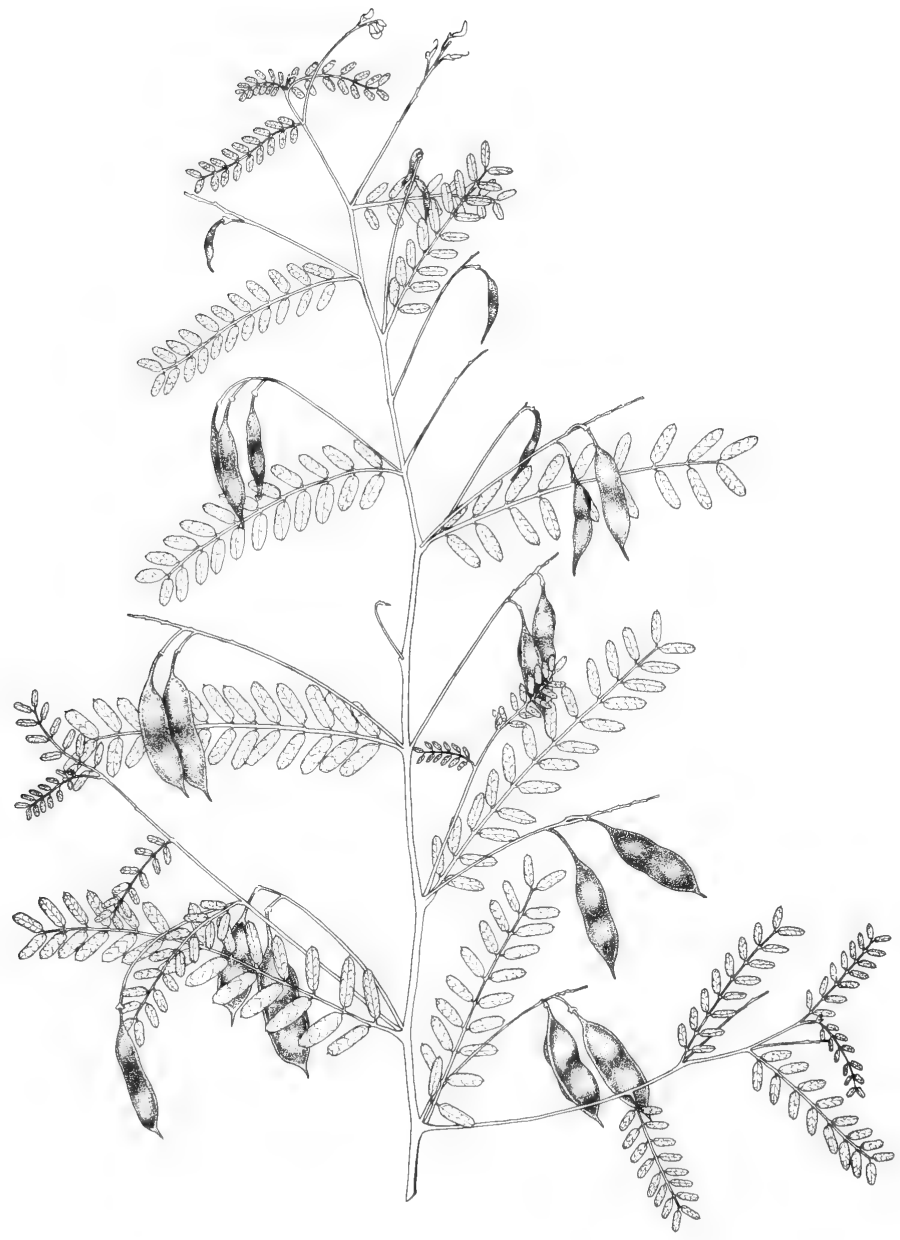

Fig. 500: Sesbania vesicaria: top of plant, x 1/2. (Courtesy of R. K. Godfrey.) 
long, often 2-3 cm. long, glabrous, green; stipels absent; flowers in axillary racemes usually shorter than the foliage; peduncle 1-12 cm. long; each flower subtended by a caducous bract; calyx closely subtended by a pair of caducous bractlets, the broadly campanulate tube usually broader than high and regular or nearly so; calyx lobes much shorter than the tube, nearly equal, deltoid, acute; corolla papilionaceous, yellowish, red to orange, 6-20 mm. long; banner reflexed, longer that the other petals, the blade suborbicular, the claw short; wing blades oblanceolate to oblong, the claws a fourth to a third as long as the blade; keel petals auriculate, strongly arching, with elongate claws about as long as the blades; stamens diadelphous, 9 of the filaments coalescent basally, the tenth (uppermost) one free; fruit a dry elongate linear 2-valved or 4-sided or 4-winged dehiscent or indehiscent pod. Daubentonia DC.; Glottidium Desv.

A genus with about 40 species in the tropical and subtropical regions of both hemispheres, usually growing in seasonally wet places, in river bottoms and overflow lands. They are troublesome weeds in the Texas Gulf Coastal Plain rice fields.

1. Peduncle 5-12 cm. long; flowers 6-9 mm. long; pods with 2 seeds.

........................................................................... S. vesicaria.

1. Peduncle 1-5 cm. long; flowers $10-20 \mathrm{~mm}$. long; pods with several to many seeds (rarely 2 by abortion) (2)

2(1). Racemes of 2 to 6 flowers; pods elongate, linear; not winged.

2. Raceme of 10 to 30 flowers; pods short, thickened, 4-winged

2. S. macrocarpa.

3. S. Drummondii.

1. Sesbania vesicaria (Jacq.) Ell. BAG-POD, BLADDER POD. Fig. 500.

Annual herb; leaves $10-15 \mathrm{~cm}$. long; leaflets 20 to 40 (to 52 ), 1-4 cm. long, 3-6 mm. broad; peduncle 5-12 cm. long; flowers 6-9 $\mathrm{mm}$. long; corolla yellowish or tinged with pink or red; stipe of legume 1-2 cm. long, 1-1.5 mm. thick; legume body oblong to ellipsoid, 25-80 $\mathrm{mm}$. long, 15-20 $\mathrm{mm}$. thick, the valves separating at maturity into 2 layers (the outer thicker, the inner thin and paperymembranous); legume beak about 5-7 mm. long. Glottidium vesicarium (Jacq.) Harper.

Frequent, in s.e. Okla. (Waterfall) and e. third of Tex. w. to Palo Pinto, Erath, Bastrop, Gonzales, Karnes and San Patricio cos., Aug.-Sept.; Coastal States, N.C. to Tex.; also W.I. Perhaps adv. on the continent from the W.I.

2. Sesbania macrocarpa Muhl. Bequilla, Colorado River hemp. Fig. 501.

Robust annual 7-40 dm. tall, rather gracefully ascending with few or no branches or occasionally with some wide-spreading branches; leaves $1-3 \mathrm{dm}$. long; leaflets up to 70 , mostly $1-3 \mathrm{~cm}$. long and 2-6 mm. broad; peduncle $2-4$ $\mathrm{cm}$. long; flowers 11-16 mm. long, yellow; legume linear, glabrous, 1-2 dm. long, 3-4 mm. broad, $1 \mathrm{~mm}$. thick, with much-thickened sutures and a beak 5-10 mm. long; seeds 30 to 40. Sesbania exaltata (Raf.) A. W. Hill.

Infrequent or locally abundant, in e. and s.e. Okla. (Waterfall) and e. third of Tex., w. to Denton, Tarrant, Travis, Hays, Comal, San Patricio and Cameron cos., Aug.-Oct.; Fla. to Tex. and n. to Mo.; locally waifed in n.e. U.S.

\section{Sesbania Drummondii (Rydb.) Cory. Rattlebush, POISON bean, Coffee bean.}

Shrub (in the north extremity of distribution the branches often die back during the winter, only the lowest part of the plant remaining alive and becoming woody) 4-30 dm. tall; leaves mostly 1-2 dm. long; leaflets 20 to 50 , mostly 15-35 $\mathrm{mm}$. long and 4-7 $\mathrm{mm}$. broad; peduncle 1-5 cm. long; flowers 13-16 $\mathrm{mm}$. long, yellow (often with red lines); pod often $5-6 \mathrm{~cm}$. long, about $1 \mathrm{~cm}$. broad, short- 


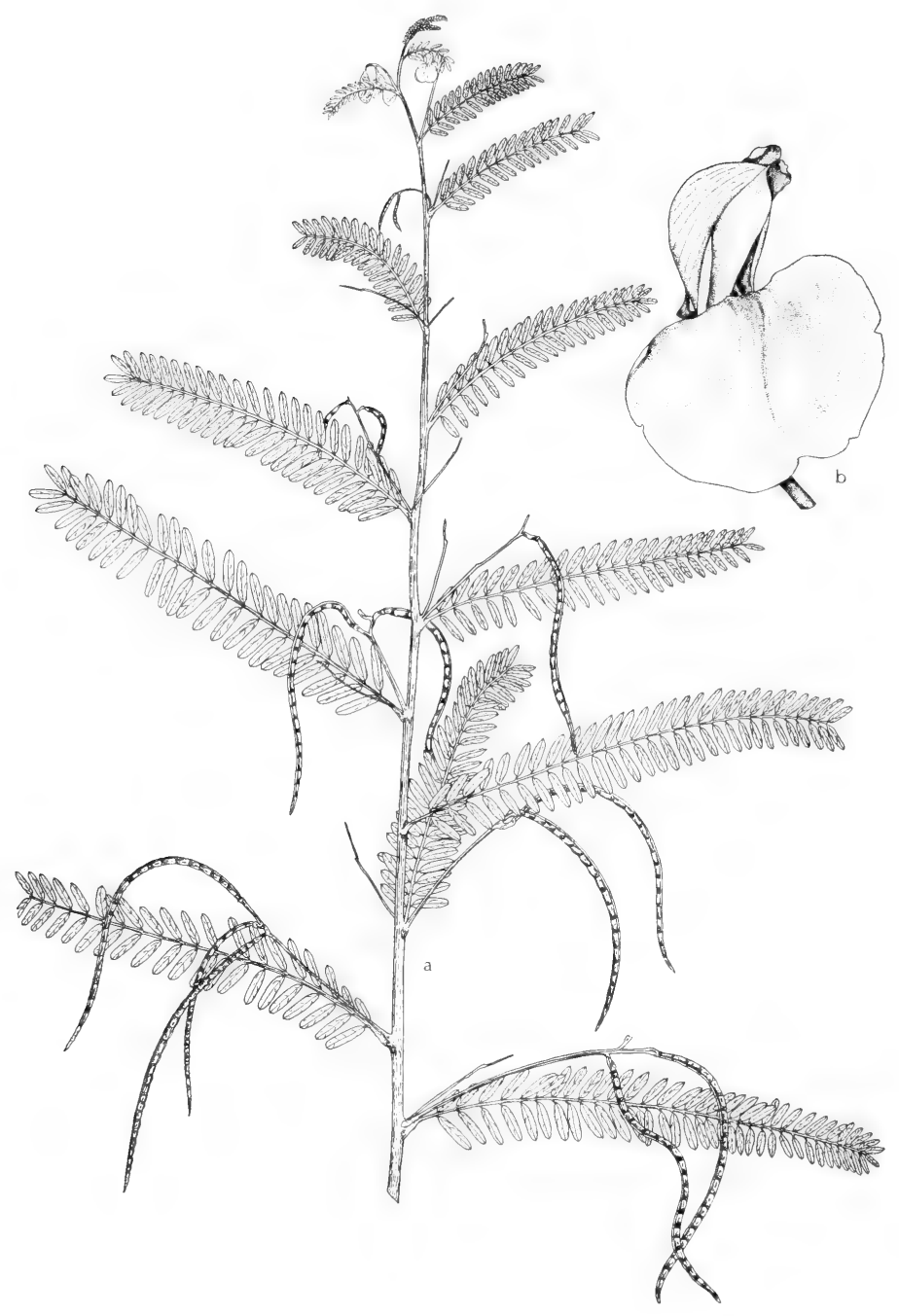

Fig. 501: Sesbania macrocarpa: a, top of plant, x 1/3; b, flower, x 4. (Courtesy of R. K. Godfrey). 
stiped and short-beaked, the body 4-winged the full length, the wings about $3 \mathrm{~mm}$. broad. Daubentonia Drummondii Rydb.

Coastal Plain in Tex., inland to Denton, Williamson, Travis, Comal, Wilson, McMullen and Starr cos., locally very abundant, June-Sept.; Coastal States, Fla. to Ver. and inland to S.L.P.

The seeds are loose in the mature pods which rattle when the bush is in motion, hence the common name. The seeds, if eaten, are known to be poisonous to sheep and goats.

\section{Astragalus L. MilK-Vetch. Loco WeED}

Unarmed perennial or annual herbs, caulescent or not, leaves once-imparipinnately compound, petioled; stipules present, often well-developed and forming sheaths or other structures but never spinescent in our species, leaflets several to many; stipels absent; flowers in axillary racemes (rarely single), often these nearly spikelike; calyx with a campanuloid to cylindric tube and 5 equal to unequal deltoid to setaceous lobes; corolla papilionaceous, white, yellow to purplish or lavender, never red; banner reflexed, the blade oblanceolate to broadly cuneate, claw present; wings clawed, the blade auricled at the base on the upper side and with a depression; keel petals coalescent distally, the blades auricled basally and with a low prominence which fits into the wing's socket; keel petals obtuse to acute; stamens diadelphous, 9 of the filaments coalescent, the tenth (uppermost) one free; fruit a linear to globose dry to fleshy (often very tardily) dehiscent legume exserted from the calyx; dehiscence sometimes occurs after the fruit has fallen to the ground; seeds 1 to several.

A very large, difficult genus with about 1,500 species occurring throughout the subtropical and temperate parts of the world except Australia. Many plants of this genus accumulate selenium ions in toxic concentrations, and when ingested in sufficient quantity by stock cause the symptoms known as "loco disease;" other species which do not accumulate selenium are useful forage. The hard seeds of many species are eaten by various game birds.

1. Flowers 7-12 $\mathrm{mm}$. long, spreading or drooping in an elongate lax raceme, shortly pedicelled; stipules deltoid.................................. A. alpinus.

1. Flowers about $17(13-19) \mathrm{mm}$. long, subsessile in closely crowded ovoid heads; stipules linear to ovate.............................2. A. dasygloitis.

\section{Astragalus alpinus $L$.}

Sparsely to densely strigillose to silky (but usually greenish) perennial with widespread rootstocks; stems slender, ascending to erect, 5-20 cm. long; leaves 5-15 cm. long; stipules 1-3 mm. long, deltoid, all except the uppermost connate; leaflets 13 to 23 , ovate to oblong-elliptic, often retuse, $5-15 \mathrm{~mm}$. long, rarely as much as $10 \mathrm{~mm}$. broad; peduncles equaling or exceeding the leaves; racemes closely 10- to 30-flowered, elongate, lax, often secund in fruit; pedicels about $1 \mathrm{~mm}$. long; flowers 7-12 mm. long, pale-lilac to purplish, the keel usually darkest in color (about equaling the erect banner, both longer than the wings); calyx black-hairy, 3-4.5 $\mathrm{mm}$. long, the teeth about half the length of the tube; pod usually pendulous (spreading), with a slender stipe about equal to the calyx teeth, the body black-hairy, membranous, narrowly ellipsoid, 8-12 mm. long, cordate-triangular in cross section, the lower suture deeply sulcate and intruded to form a nearly complete partition.

In wet meadows, on open grassy slopes and in open woodlands, in N.M. (Rio Arriba, San Miguel and Taos cos.), May-Aug.; Mont. to Wash., s. to N.M. and Nev.; circumpolar. 


\section{Astragalus dasyglottis Fisch. ex DC.}

Low appressed-pubescent perennial with long rootstocks from a buried crown; stems numerous, slender, decumbent to erect, 1-3 dm. tall; stipules linear to ovate, usually basally connate; leaves $4-10 \mathrm{~cm}$. long; leaflets 11 to 19 , linear-lanceolate to oblong-lanceolate, mostly retuse, 1-2 cm. long; racemes headlike, axillary, 7to 20 -flowered, $1.5-2.5 \mathrm{~cm}$. broad and not much longer (even in fruit); peduncles shorter to longer than the leaves; flowers erect, about 17 (13-19) $\mathrm{mm}$. long; pedicels thick, scarcely $0.5 \mathrm{~mm}$. long; calyx tubular-campanulate, about half the length of the corolla, grayish- to blackish-strigose, the linear teeth somewhat shorter than the tube; corolla usually purplish or the wings whitish, rarely more nearly uniformly whitish and merely purplish-tinged; banner narrow, longer than the slender wings which are about $4 \mathrm{~mm}$. longer than the slightly acutish keel; pod sessile, erect, about $1 \mathrm{~cm}$. long, grayish- to blackish-hirsute, ovoid, cordate in cross section, deeply sulcate, 2-celled by the complete intrusion of the lower suture. A. goniatus Nutt.

In wet meadows, grassy alpine slopes and river valleys and plains, in N. M. (Rio Arriba, San Miguel and Union cos.), May-Aug.; Minn. to Yuk., s. to Ia., Kan., N.M. and Calif.; e. Asia.

\section{Oxytropis DC. Crazy-weed. Purple loco}

Perennial herbs, from a stout woody taproot and usually with a muchbranched crown; leaves basal or nearly so, odd-pinnate; flowers racemose, spicate or somewhat congested, terminating a scapelike peduncle; calyx campanulate, with subequal teeth; petals clawed; standard erect, ovate to oblong; wings oblong; keel produced into a porrect beak; stamens 10, diadelphous; pods sessile or stipitate, coriaceous or leathery, usually completely or incompletely 2-celled by the intrusion of the upper suture.

A genus of about 150 to 300 species of north-temperate regions.

1. Leaves with verticillate leaflets................................................... $O$. splendens.

1. Leaves strictly pinnate, the leaflets paired or scattered but never verticillate (2)

2(1). Racemes 10- or more-flowered, usually elongating in fruit. 2. O. Lambertii.

2. Racemes 1- to 5-flowered, subcapitate in anthesis and not becoming muchelongated in fruit (3)

$3(2)$. Leaflets 5 to 11 ; pods about $1 \mathrm{~cm}$. long, inflated, ovoid, densely whitevillous................................................................. $O$. oreophila.

3. Leaflets 13 to 21 ; pod $1.5-2.3 \mathrm{~cm}$. long, not inflated but coriaceous, cylindric to oblong, black-hairy. 4. O. Parryi.

1. Oxytropis splendens Dougl. ex Hook.

A nearly or quite acaulescent densely silky perennial with a branched caudex; leaves $10-25 \mathrm{~cm}$. long; stipules membranous, $10-15 \mathrm{~mm}$. long, adnate to the petiole for $2 / 3$ of their length and tubular-connate; leafiets mostly in verticils of 3 to 6 , lanceolate to elliptic, $5-20 \mathrm{~mm}$. long; peduncles usually slightly exceeding the leaves; racemes spikelike, densely 20 - to 80 -flowered, usually $5-10 \mathrm{~cm}$. long but sometimes more elongate (especially in fruit); flowers reddish-purple, 12-15 $\mathrm{mm}$. long; calyx one half to two thirds as long as the corolla, the obtuse linearlanceolate lobes one third to one fourth the length of the tube; beak of the keel straight to slightly curved, slender, to $1 \mathrm{~mm}$. long; pod 10-15 mm. long, 3-4 mm. long, 3-4 $\mathrm{mm}$. broad, cordate in cross section because of the intrusion of the upper suture, narrowed to a distinct beak about $3 \mathrm{~mm}$. long.

Gravel bars and wet meadows, N. M. (Hitchcock et al.), June-Aug.; Ont. to Alas., s. to Minn. and N. M. 


\section{Oxytropis Lambertii Pursh. Loco-WEed. Fig. 501A.}

Perennial herb, often forming colonies by short rhizomes; stems several from the crown, very short; herbage all pubescent with hairs attached in the middle and with 2 free ends; petioles short; stipules broad, persistent, 7-24 mm. long; leaves basal, alternate, once-imparipinnately-compound, lower leaves shorter than the upper ones, 4-21 cm. long; leaflets ( 7 or) 9 to 19 , narrowly linear to linearoblong, 10-35 mm. long, 1-3.5 (-5.5) $\mathrm{mm}$. broad, thick, firm, basally asymmetric; racemes $2-4 \mathrm{~cm}$. thick at full anthesis, terminal on nearly leafless scapes $5-25 \mathrm{~cm}$. long and commonly surpassing the foliage; flowers usually 10 to 25 per raceme, 15-26 $\mathrm{mm}$. long; calyx with a tube and 5 lobes, silky-pilose, the tube $6-8 \mathrm{~mm}$. long, the deltoid-subulate teeth 1.2-3 (rarely to 4) $\mathrm{mm}$. long; corolla papilionaceous, purple or pink-purple to almost white or various shades of rose or lavender; banner 18-25 mm. long; wings 15-26 mm. long, commonly much-dilated upward; keel 14-19 mm. long, the keel petals apically extending into a sharp erect point; stamens 10, diadelphous, 9 filaments coalescent, the tenth (uppermost) free; pod sessile, stiffly woody, the body ovoid to cylindric or oblong-ovoid, commonly 7-25 mm. long and exserted, beaked; seeds several. Incl. var. articulata (Greene) Barneby; var. Bigelovii Gray; Astragalus Lambertii (Pursh) Spreng. var. abbreviatus (Greene) Shinners.

More or less ubiquitous, in wet meadows, calcareous muds, dry open slopes and prairies, represented in our area by one or more described variants, widespread in Okla., scattered mainly in cen. and n.w. Tex., through N.M. to Ariz., Apr.-July; also n. to Sask. and Man.

This species is one of the most dangerous of all the loco-weeds since it is readily eaten by horses, cattle and sheep, especially when grass is scarce, often with fatal effect.

\section{Oxytropis oreophila Gray. RocK-LOVING OXYTROPE.}

Perennial with a much-branched cespitose woody caudex, densely silvery-silky pubescent throughout; leaves crowded at the apex of the caudex branches, 1.5-3 $\mathrm{cm}$. long; leaflets 5 to 11 , lance-elliptic, 4-6 mm. long; scape slender, 2-7 cm. long; racemes short, 1- to 8-flowered; calyx silky-villous, the tube $5 \mathrm{~mm}$. long, the teeth $1.5 \mathrm{~mm}$. long; corolla violet-purple, 10-12 mm. long; pod inflated, ovoid, about $1 \mathrm{~cm}$. long, densely white-villous.

Rocky alpine ridges and wet slopes and meadows, Ariz. (Coconino Co.), JuneJuly; also Ut., Nev. and Calif.

\section{Oxytropis Parryi Gray.}

Plants 1-10 $(-15) \mathrm{cm}$. tall, acaulescent or nearly so; stipules adnate to the petioles; leaves $3-5 \mathrm{~cm}$. long; leaflets (9 to) 13 to 21 , oblong-lanceolate, $3-10$ $\mathrm{mm}$. long, grayish-silky-strigose; racemes 1- to 5-flowered, short and not elongating in fruit; calyx cinereous-pubescent, some of the hairs black, the tube $3-5 \mathrm{~mm}$. long with teeth $2-3 \mathrm{~mm}$. long; corolla about $1.5 \mathrm{~cm}$. long, purple; fruit erect or spreading, cylindric to oblong, not inflated but coriaceous, black-hairy, 1.5-2.3 $\mathrm{cm}$. long, the suture well-intruded.

Alpine regions in wet meadows, N. M. (Mora Co.), summer; Wyo. and Ida., s. to N. M. and Calif.

\section{Glycyrrhiza L.}

A genus of about 15 species in the temperate and subtropical parts of the world. Licorice of commerce is obtained from the roots of the European G. glabra L. 


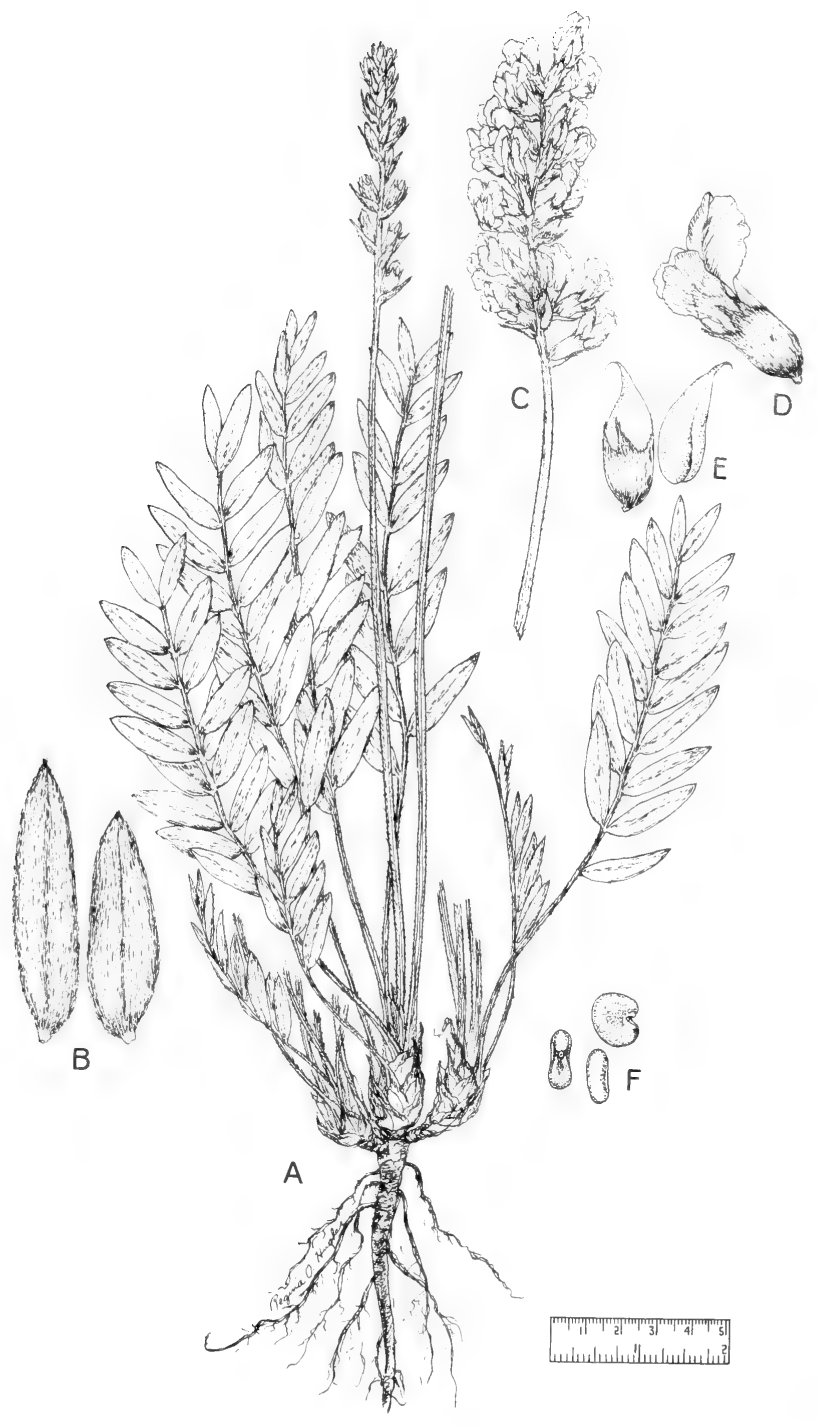

Fig. 501A: Oxytropis Lambertii: A, habit, x 1/2; B, leaves, x 1; C, flower spike, x 1/2; D, flower, x 1; E, legumes, x 1; F, seeds, x 4. (From Reed, Selected Weeds of the United States, Fig. 114). 


\section{Glycyrrhiza lepidota Pursh. LICORICE.}

Perennial herb with tall $(6-9 \mathrm{dm}$.) erect stems arising from stout sweet roots, the herbage all glandular-viscid; leaves alternate, once-imparipinnately-compound; stipules minute, slender; petioles short; leaflets 15 to 19 , oblong-lanceolate, mucronate-pointed, sprinkled with little scales when young and with corresponding dots when old; flowers in spiciform axillary racemes; calyx somewhat 2-lipped, the upper lip nearly entire (that is, the 2 upper lobes nearly completely coalescent), the 3 lower lobes not coalescent so high; corolla whitish, very much as in Astragalus; stamens diadelphous, 9 filaments coalescent, the tenth (uppermost) free, the anthers alternating large and small (shorter ones smaller); fruit dry and indehiscent or scarcely dehiscent, laterally compressed, few-seeded, oblong, beset with hooked prickles suggesting the projections of cockleburs.

Infrequent in alluvial and sandy soils, often in seepage and wet soils, stream beds or roadside and irrigation ditches, in Okla. (Waterfall), in Tex. in the Trans-Pecos and higher parts of the Plains Country, e. locally to Wichita Co. along the Red River and N.M. (widespread), Apr.-June; widespread in U. S. except the s.e. portion.

A good soil-binder but potentially a noxious weed.

\section{Alhagi GagnebIN}

A genus with perhaps 3 species of the deserts of central and western Asia, of which 1 has been introduced in the deserts of North America.

\section{Alhagi camelorum Fisch. CAMEL-THORN.}

Much-branched thorny glabrous shrubs, spreading by rhizomes, to about $1 \mathrm{~m}$. high; leaves alternate, small, unifoliolate, with a distinct petiolule $1-3 \mathrm{~mm}$. long; blade linear or linear-oblanceolate to obovate, leathery, to about $3 \mathrm{~cm}$. long and 7 $\mathrm{mm}$. wide; flowers numerous in short racemes; calyx with a campanuloid tube nearly truncate or with 5 apical teeth or lobes; corolla papilionaceous, purplishpink; fruit a slender brownish moniliform pod $2-3 \mathrm{~cm}$. long and with 1 to several suborbicular joints that do not separate from each other at maturity, indehiscent.

Established along drainage ditches and streams, often in gypseous soils, in Culberson and El Paso cos. in the Tex. Trans-Pecos and in Ariz. (Navajo, Coconino and Maricopa cos.), June-July; introd. into Tex., Ariz., etc. from Asia.

A potentially pernicious weed. According to Kearney and Peebles this plant is of great value as a browse in the desert regions of Asia, but it is a dangerous introduction since it is extremely difficult to eradicate from cultivated fields, having deep and extensive rootstocks. In Persia and Afghanistan an exudate, similar to the drug manna that is obtained from Fraxinus Ornus, is collected from the camel-thorn.

\section{Aeschynomene L. Joint Vetch}

A genus of about 100 species of the warmer parts of the world.

\section{Aeschynomene indica L. Figs. 502 and 503.}

Perennial herb; stems erect, 5-25 dm. tall, much-branched, glabrous to hispidulous; stipules peltate, appendiculate below the point of attachment; leaves alternate, 5-10 cm. long; leaflets 19 to 63 ; flowers pinkish or salmon-color, papilionaceous, 8-10 mm. long; stamens 10 , monadelphous; fruit a loment, with 5 to 14 joints.

Local in wet coastal areas, Kleberg Co. to Jefferson Co. in Tex., Aug.-Sept.; N.C. to Tex., s. to Braz. and Arg. 


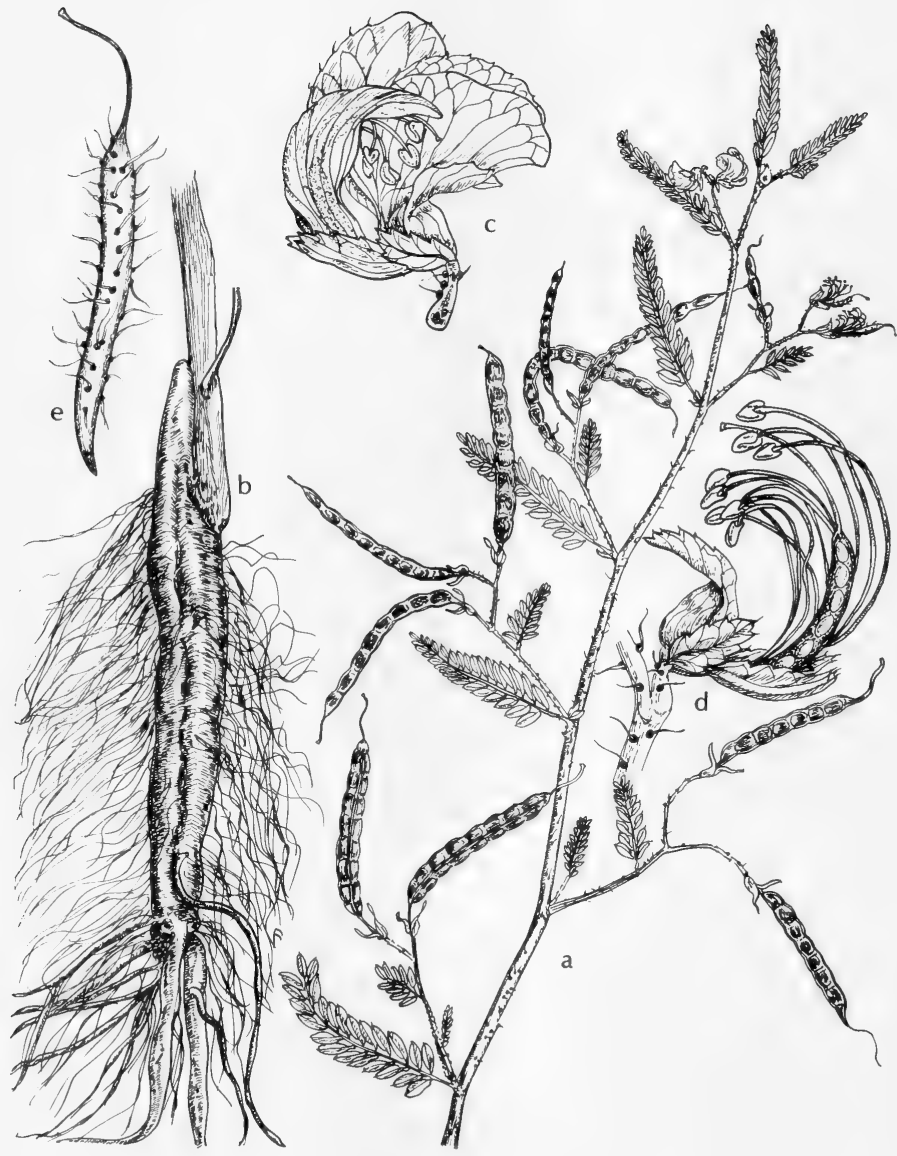

Fig. 502: Aeschynomene indica: a, upper part of plant, x 1/2; b, root system, x 1/2; c, flower, x $2 \frac{1}{2}$; d, young fruit, x $2 \frac{1}{2}$; e, mature fruit, x $2 \frac{1}{2}$. (V. F.). 

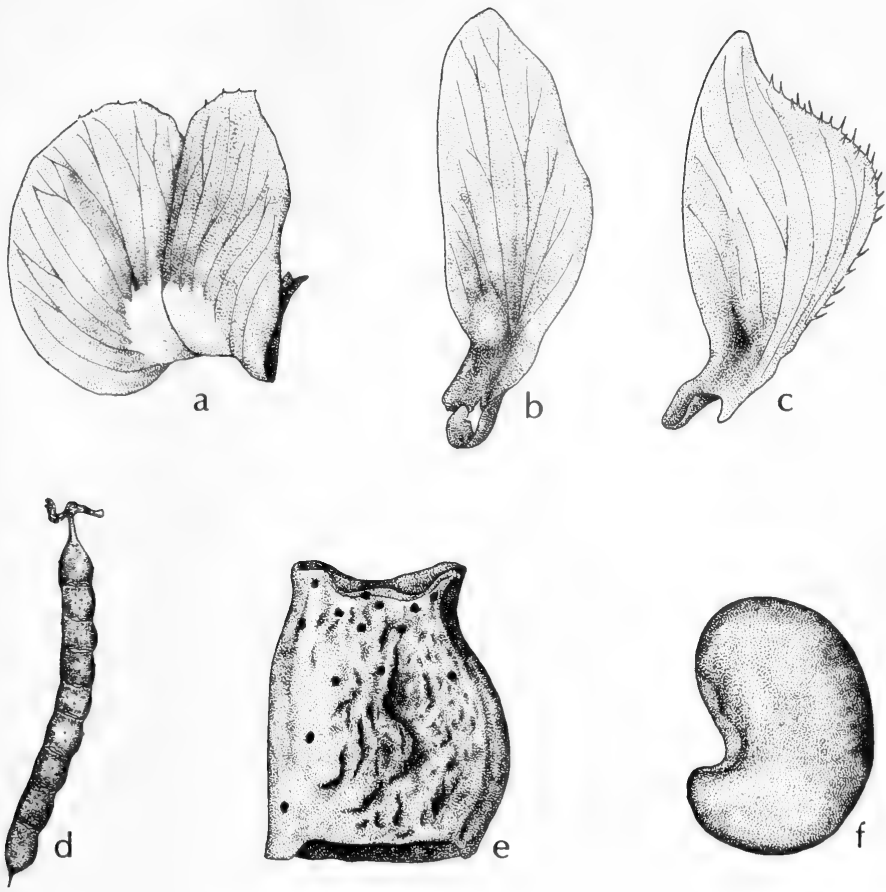

Fig. 503: Aeschynomene indica: a, standard, x 4; b, wing, x 4; c, keel, x 4; d, loment, $x$ 1/2; e, article of loment, x 4; f, mature seed, x 4. (Courtesy of R. K. Godfrey).

Our plants have fruits only $2.5-3.5 \mathrm{~mm}$. broad, which would place them technically in the taxon $A$, evenia Wright, which replaces $A$. indica in much of tropical America but seems not to be specifically separable from it.

\section{Lespedeza MichX. Bush Clover}

Unarmed annual or perennial herbs; leaves alternate, trifoliolate; stipules persistent; leaflets entire; stipels absent; flowers borne in pairs on loose or contracted racemes, often cleistogamous; calyx tube shorter than or equaling the lobes, the 5 subequal lobes persistent in fruit, often the calyx of cleistogamous flowers shorter than those of chasmogamous flowers; corolla papilionaceous (white to purple with purple throats) or absent (actually vestigial) in cleistogamous flowers; banner oblong to obovate or suborbicular, clawed, free or slightly adherent to the incurved obovate keel petals; stamens 10, diadelphous, the uppermost filament free; fruit a solitary flattened 1-seeded ovate or rounded indehiscent pod, often reticulated; style persistent (though easily broken in dried material), elongate on chasmogamous pods or very short and tightly recurved on cleistogamous pods. 
A genus of about 90 species of Asia, Australia and North America. Several Asian species have been introduced for erosion control, forage and for use in wild-life management, especially for quail and other game birds. A few hybrids often occur wherever two or more perennial species exist in moderate numbers, making identification somewhat difficult.

1. Stems upwardly appressed-pubescent; leaflets of the younger or upper leaves conspicuously ciliate marginally; petioles of the principal leaves mostly 4-10 mm. long......................................... 1. L. stipulacea.

1. Stems downwardly appressed-pubescent; leaflets not conspicuously ciliate; petioles of the principal leaves usually less than $3 \mathrm{~mm}$. long

2. L. striata.

\section{Lespedeza stipulacea Maxim. KOREAN BUSH CLOVER.}

Bushy-branched tap-rooted annual with stems under $4 \mathrm{dm}$. long, antrorsely appressed-pubescent; stipules ovate to ovate-lanceolate, mostly 5-8 $\mathrm{mm}$. long on the mainstem; stalk of terminal leaflet not much longer than the petiolules of the laterals (thus leaf subpalmate); petioles of the principal leaves mostly 4-10 $\mathrm{mm}$. long; leaflets spatulate to obovate, mostly $1-2 \mathrm{~cm}$. long, the upper or younger (i.e., bracteal) leaves conspicuously ciliate on the margins; flowers and fruits in short leafý racemes; corolla pink; pods about $3 \mathrm{~mm}$. long.

Scattered on sandy and gravelly bars along rivers and streams, wet meadows and roadsides in Okla. and e. Tex., June-Sept.; nat. of e. Asia, now widely introd. in N. A.

\section{Lespedeza striata (Thunb.) H. \& A. JAPANESE BUSH ClOVER.}

Bushy-branched taprooted annual with stems mostly under $4 \mathrm{dm}$. long, retrorsely appressed-pubescent; stipules ovate to ovate-lanceolate, 3-5 mm. long; stalk of the terminal leaflet not much longer than the petiolules of the laterals (thus subpalmate); petioles usually less than $3 \mathrm{~mm}$. long; leaflets obovate to narrowly oblong, not conspicuously ciliate on the margin; flowers and fruits in short leafy racemes; corolla pink; pod $3-4 \mathrm{~mm}$. long.

Abundant in sandy open areas, seepage slopes, in mud along streams, in Okla. and e. Tex., infrequent w. to n.-cen. Tex., June-Sept.; nat. of e. Asia, now widely introd. in N. A.

\section{Vicia L. VETCH}

A genus of perhaps 150 species in temperate regions of the earth. Some species are important silage, pasture and green-manure legumes, and several have been introduced for these purposes.

\section{Vicia angustifolia L. NARROW-LEAVED VETCH.}

Glabrous or glabrate annual; stems decumbent, ascending, 1-6 dm. long, usually branched only at base; leaves with usually 4 to 10 (or 12) leaflets, those of the lower leaves oblong and truncate, of the upper linear to narrowly elliptic or lance-attenuate [in var. segetalis (Thuill.) Koch leaflets of the upper leaves oblong to oblong-obovate, 2-9 $\mathrm{mm}$. broad, the apexes truncate or emarginate and mucronate], 15-30 $\mathrm{mm}$. long, 1-4 mm. broad; stipules semisagittate, serrate or the upper entire, often lacking a nectary; flowers commonly paired in the upper axils, $10-18 \mathrm{~mm}$. long, blue or violet varying to white; calyx $7-11 \mathrm{~mm}$. long, the campanulate tube 4-6 mm. long, the linear-lanceolate teeth about equal and 3-6 $\mathrm{mm}$. long, the 3 lower teeth bearing a usually inconspicuous pale-stramineous nectary on the outer face; pod very dark-brown to almost black at maturity, terete.

Occasionally escaped in fields and wet meadows, in Okla. (Waterfall), e. Tex. and N. M. (Rio Arriba Co.), May-June; Eur., now widely introd. 
About 120 species in the temperate regions of the world (except Australia).

\section{Lathyrus arizonicus Britt.}

Stems slender, ascending; stipules linear-lanceolate, with an acute descending auricle; leaves with 2 to 8 leaflets; leaflets elliptic to linear-elliptic, 2-4 cm. long, less than 10 times as long as wide, occasionally more, glabrous to sparsely hairy; tendrils slender, bristlelike, unbranched, not at all prehensile; flowers 2 to 4 on a slender peduncle $2-3 \mathrm{~cm}$. long; pedicels slender, about $3 \mathrm{~mm}$. long; calyx 5-7 $\mathrm{mm}$. long, the triangular-acute lobes shorter than the tube; corolla 11-14 mm. long, white with thin pink lines, aging to tan or yellowish.

In boggy or seepy areas and on slopes along forested streams in N. M. (Taos Co.) and Ariz. (Apache and Coconino, s. to Cochise and Pima cos.), May-Oct.; Colo. and Ut., s. to n.-cen. Mex.

\section{Apios Boehm. Potato Bean. Groundnut}

A genus of about 8 species of temperate eastern Asia and North America.

\section{Apios americana Medic. American potato bean.}

Perennial from tuberous rhizomes; stems annual, 1-3 m. long, twining and high-climbing; leaves alternate, once-pinnately 5- or 7-foliolate; petioles $15-70 \mathrm{~mm}$. long; stipules setaceous, soon deciduous, 4-6 mm. long; rachis stalk of terminal leaflet and rachis internodes $1-3 \mathrm{~cm}$. long; leaflets mostly ovate or lance-ovate, acuminate, rounded at base, (15-) 20-70 (-100) mm. long, pubescent usually; stipels 1-2 $\mathrm{mm}$. long, deciduous; flowers in rather dense axillary racemes usually shorter than the foliage; peduncles (2-) $3-5 \mathrm{~cm}$. long; pedicels only 2-6 $\mathrm{mm}$. long, each with 2 minute promptly deciduous bractlets; calyx 5-11 mm. high, nearly truncate or the 5 sepals distinguishable only as slight undulations at the rim of the tube; corolla papilionaceous, about $1 \mathrm{~cm}$. long; banner whitish dorsally, brownred ventrally; keel sickle-shaped, very slender, brownish-red; wings down-curved, brown-purple; stamens 10, diadelphous, 9 filaments coalescent, the tenth (uppermost) free; fruit a linear slightly flattened legume 5-10 (-12) cm. long, 4-6 $(-7) \mathrm{mm}$. broad, with coriaceous valves. Incl. var. turrigera Fern.

In swamps, on seepage slopes and thickets in e. Okla. (w. to Woodward Co.), infrequent in e., s.e. and n.-cen. Tex., rare in Edwards Plateau (Tom Green Co.), usually in woods near streams, reported from Hemphill Co. in the Panhandle, May-Sept.; s.e. Can. and e. U.S.

\section{Vigna SAVI}

A genus of about 60 species in the tropical and subtropical parts of the world. One species, $V$. unguiculata (L.) Walp., is of great economic value; when the peas are gathered very young they are called "cream-peas," when mature they are called "black-eyed peas" because of the increased pigmentation near the micropyle.

\section{Vigna luteola (Jacq.) Benth. Fig. 504.}

Perennial; leaflets ovate to lanceolate or linear-lanceolate, obtuse to broadly cuneate at base, acute, $2-8 \mathrm{~cm}$. long; peduncles usually several times longer than the foliage; flowers closely clustered at anthesis (internodes elongating, separating the fruits), 15-18 mm. long; calyx with tube $2-2.5 \mathrm{~mm}$. long, the lobes $1.5-$ $2.5 \mathrm{~mm}$. long; corolla yellow; pods $3-7 \mathrm{~cm}$. long. V. repens (L.) O. Ktze., not of Baker.

Local in wet places, in Tex. in the coastal tier of counties and inland to $\mathrm{Hi}$ dalgo Co., Mar.-Nov.; trop. Am. n. to Gulf States, rarely to N.C. 


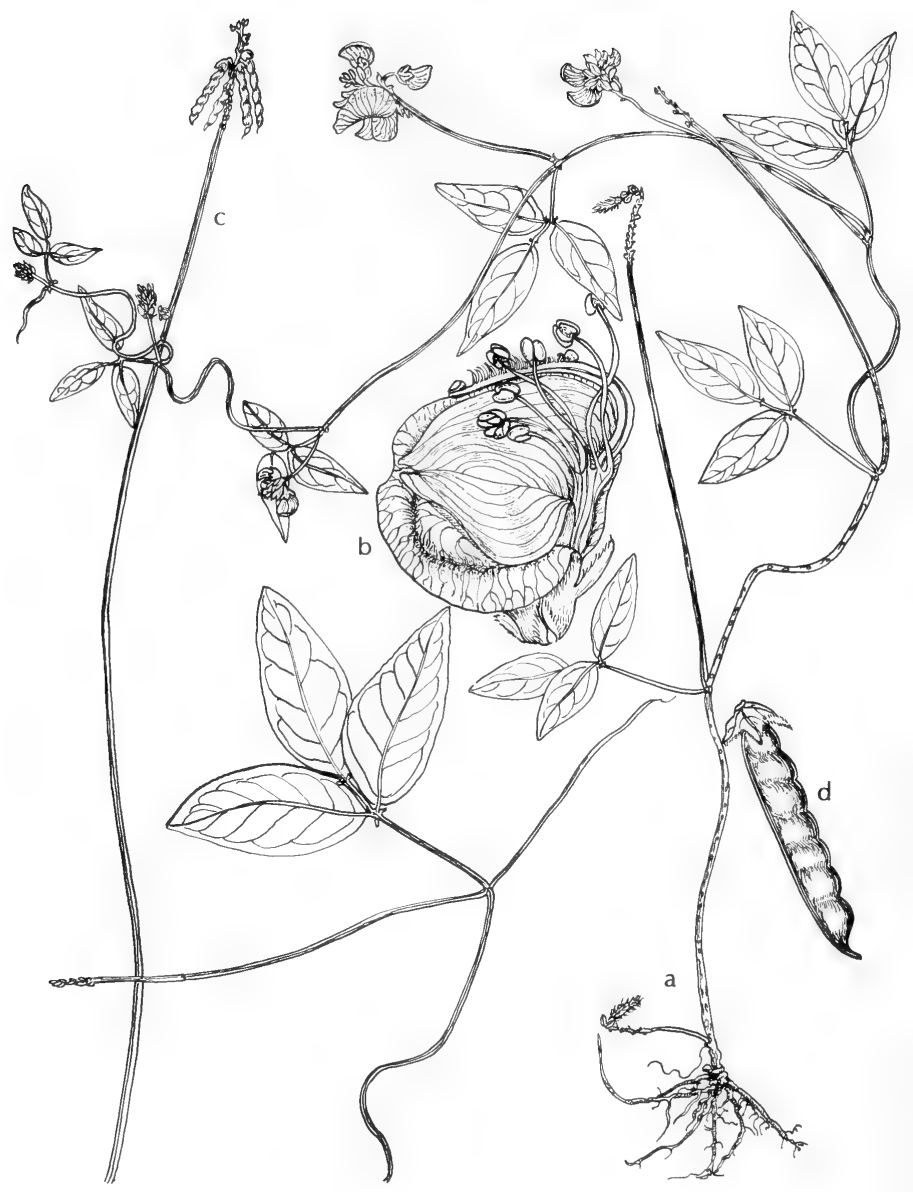

Fig. 504: Vigna luteola: a, habit, $\mathrm{x} \mathrm{1/2;} \mathrm{b,} \mathrm{flower,} \mathrm{x} \mathrm{3}$; c, young fruit on elongate peduncle, $x \frac{1}{2} ; \mathrm{d}$, mature fruit, $x 1$. (V. F.). 
Winter annual, biennial or perennial herbs; leaves alternate or basal, lobed or divided, stipulate; inflorescence cymose or a solitary flower; flowers perfect, regular or nearly so, 5-merous, hypogynous; sepals imbricated in the bud, persistent; glands of the disk 5, alternate with the petals; stamens (counting the sterile filaments) as many as or commonly twice as many as the sepals, when as many then opposite the sepals; ovary at base with 5 equal lateral lobes; carpels 2-ovuled, 1-seeded, when mature separating elastically with their long styles from the elongated axis.

A family of about 5 genera and some 750 species of temperate and subtropical regions.

\section{Geranium L. Cranesbill}

Annual or perennial herbs with much-branched stems and pinnate or palmately lobed petiolate leaves; flowers usually in pairs on a slender peduncle and slender pedicels that are subtended by narrow bracts; stamens 10 or rarely 5, all with perfect anthers, the 5 longer ones with glands at their base and alternate with the petals; stylar portions usually remaining attached by their apex to the summit of the torus.

Consisting of about 500 species mainly in temperate regions; many are used as ornamentals.

The seeds of geraniums are eaten by birds and rodents such as squirrels and chipmunks while browsers eat the plant.

1. Stylodia 3-5 mm. long; petals whitish or purple-tinged; leaves sharply incised, the lobes and teeth acute to acuminate; filaments reddish-purple........

1. G. Richardsonii.

1. Stylodia $6-7 \mathrm{~mm}$. long; petals purplish-pink to lavender; leaves usually not sharply incised, the lobes and teeth obtuse to acute; filaments pinkish-buff. 2. G. eremophilum.

\section{Geranium Richardsonii Fisch. \& Trautv. Fig. 505.}

Perennial; stems erect or ascending, 2.5-7 dm. high, usually simple, glabrous or sparingly glandular-pubescent; leaves thin, 3-15 cm. broad, 3- to 7-parted; leaf divisions incised to toothed or lobed, sparsely strigose on the upper surface and on the veins beneath; pedicels slender, 1-2 cm. long, glandular-pubescent, the glands usually purple; sepals awn-tipped, $8-12 \mathrm{~mm}$. long, the outer ones more or less glandular-pubescent at least below; petals white with pink or purple veins, rarely flushed with pink, $1-1.8 \mathrm{~cm}$. long, pilose within for about half their length; filaments 6-9 mm. long, reddish-purple, short-pilose about three fourths their length; mature stylar column 2-2.5 cm. long, pubescent and with interspersed glandular-villous hairs; stylodia yellowish, 3-5 mm. long; carpel bodies sparingly pubescent, glandular-hispid on the keels; seeds $2.5-3.5 \mathrm{~mm}$. long, coarsely reticulate.

Moist soils in coniferous forests, wet meadows, seepage areas about lakes and along streams, marshes at head of lakes and crevices of boulders, in N. M. (widespread in mts.) and Ariz. (Apache to Coconino, s. to Cochise and Pima cos.), Apr.-Oct.; S.D. to B.C., s. to N.M., Ariz. and s. Calif.

\section{Geranium eremophilum Woot. \& Standl.}

Perennial with a slender branched caudex; stems tufted, slender, weak, divaricately branching, suberect to decumbent, 4-7 dm. long, finely retrorsely pubescent; basal leaves with retrorsely pubescent petioles $4-6 \mathrm{~cm}$. long, pentagonal in outline, $2.5-4 \mathrm{~cm}$. wide, finely appressed-pubescent, obtuse to truncate at base, 3- or 5-lobed with the rhombic-cuneate lobes 3-toothed and obtuse to acute; cauline leaves 


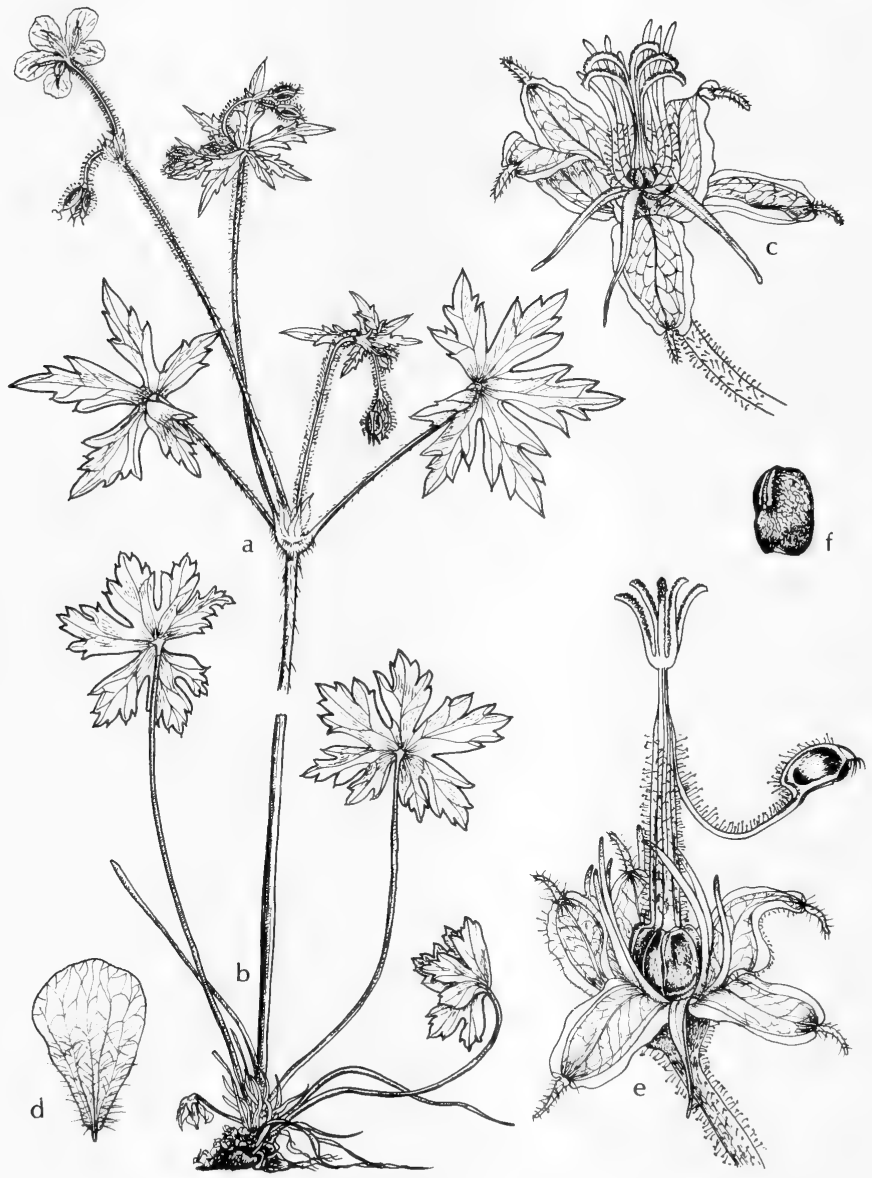

Fig. 505: Geranium Richardsonii: a, upper part of plant, $\mathrm{x} 1 / 2$; b, basal leaves and lower part of stem, x 1/2; c, flower with petals removed, $x 2 \frac{1}{2}$; d, petal, $x 1 \frac{1}{2}$; e, calyx and carpels, x 21/2; f, seed, x 5. (V. F.). 
smaller, thin, 3-lobed, more or less halberd-shaped, sparingly appressed-pubescent above, the lower surface similar except for some retrorse pubescence on the veins; stipules attenuate-lanceolate, to about $1 \mathrm{~cm}$. long, puberulent, ciliate; peduncles axillary, slender, $3-15 \mathrm{~cm}$. long; pedicels paired, finely retrorsely pubescent and often somewhat glandular, $1.5-3 \mathrm{~cm}$. long; sepals $8-10 \mathrm{~mm}$. long, oval-lanceolate, appressed-pubescent, the mucro 1-2 $\mathrm{mm}$. long; petals purplish-pink or sometimes paler, $1-1.5 \mathrm{~cm}$. long, obovate, retuse, pilose about half their length; filaments pinkish-buff, to about $1 \mathrm{~cm}$. long; mature stylar column $2.5-3 \mathrm{~cm}$. long, appressedpubescent or glandular-pubescent; stylodia 6-7 mm. long; carpel bodies 4-5 $\mathrm{mm}$. long, sparingly short-strigose; seeds about $3 \mathrm{~mm}$. long, reticulate.

Muddy seepage banks about springs and along streams, wet meadows and wooded slopes in mts., in N.M. (Grant, Socorro and Dona Ana cos.) and Ariz. (Apache to Mohave, s. to Cochise and Pima cos.), June-Oct.

A closely related species, G. caespitosum James, that usually grows in dryer habitats may occasionally be found in somewhat wettish places. It is an entirely non-glandular plant.

\section{Fam. 76. Linaceae S. F. Gray Flax Family}

Herbs or shrubs; leaves simple, alternate, opposite or whorled; stipular glands present or none; flowers bisexual, regular, cymose; calyx 4- or 5-merous, imbricate; corolla 4- or 5-merous, convolute, the petals distinct or rarely united basally, fugacious; stamens commonly as many as and alternate with the petals, united at the base, sometimes with diminutive intervening staminodia; pistil 1, ovary superior; carpels 2 to 5 , the locules often twice as many by the intrusion of false septa; ovules 2 per carpel; styles as many as carpels, separate or united; stigma capitate or slender; fruit a capsule or rarely fleshy; seeds flat, oily.

About 200 species in ten genera, widespread in tropical and temperate regions. Represented in our area by a single genus.

\section{Linum L. FLAX}

Annual or perennial herbs, mostly with scorpioid cymes; flowers 5-merous throughout; fruit a more or less completely 10-celled capsule, dehiscing into 10 or (along the false septa) into 5 parts; otherwise with the characters of the family.

About 150 species, widely distributed in subtropical and temperate regions.

1. Margins of inner sepals with conspicuous stalked glands; mature fruit in dried specimens usually adhering to the plant; leaves narrowly lanceolate to oblanceolate....................................... L. medium var. texanum.

1. Margins of inner sepals glandless or with very inconspicuous glands; mature fruit in dried specimens usually soon shattering; leaves elliptic to oblanceolate or obovate............................................2. L. striatum.

1. Linum medium (Planch.) Britt. var. texanum (Planch.) Fern. Sucker flaX.

Erect glabrous perennial, 2-8 dm. tall; leaves narrowly lanceolate, $1-2.5 \mathrm{~cm}$. long, the lower few opposite, otherwise alternate; stipular glands none; inflorescence paniculate; sepals $2-3.5 \mathrm{~mm}$. long, the outer entire, the inner glandular-toothed; petals yellow, 5-8 mm. long; staminodia none; styles separate, 1-3 mm. long; fruit depressed-globose or subspherical, about $2 \mathrm{~mm}$. high, tardily separating into 10 segments; false septa nearly complete, eciliate; seeds about $1.5 \mathrm{~mm}$. long.

Open fields, meadows, beaches and swales, e. Tex. and e. Okla. (Waterfall), May-Aug.; Tex. to Fla. and Bah. I., n. to Ia. and Me.

\section{Linum striatum Walt.}

Glabrous perennial; stems usually several from the base, 3-10 dm. tall; leaves elliptic to oblanceolate or obovate, $15-35 \mathrm{~mm}$. long, the lower opposite, the upper 
alternate; stipular glands none; inflorescence paniculate with spreading branches; sepals $1.5-3 \mathrm{~mm}$. long, entire or the inner with a few diminutive marginal glands; petals yellow, 2.5-4.5 mm. long; staminodia none; styles separate, 1.2-2 mm. long; fruit depressed-globose or subspherical, about $1.75 \mathrm{~mm}$. high, splitting freely upon drying into 10 segments; false septa nearly complete, eciliate; seeds about $1.2 \mathrm{~mm}$. long.

Open or semishaded marshes, wet meadows, swamps, bogs and margins of streams and roadside ditches, e. Tex. and s.e. Okla. (Waterfall), May-Aug.; Tex. to n. Fla., n. to Mich. and Mass.

\section{Fam. 77. Polygalaceae R. BR.}

\section{MILKWORT FAMILY}

Represented in our region only by the genus Polygala that differs from other genera in the family primarily by its 2-celled dehiscent capsular fruit that very rarely has one of the cells aborted.

About 800 species in 12 genera of world-wide distribution.

\section{Polygala L. Polygala. Milkwort}

In our region herbaceous annuals or suffruticulose perennials with simple entire leaves; leaves alternate, opposite or whorled, sessile to shortly petiolate; flowers in terminal or axillary racemes, subsessile to distinctly pedicellate; sepals 5 , the 3 outer herbaceous or the 2 lower very rarely petaloid, free or the 2 lower connate, persistent or deciduous; the 2 inner sepals (wings) usually petaloid, much larger than the others, deciduous, persistent; petals typically 3, united at base, the lower (keel) cymbiform, clawed, occasionally 3-lobed, unappendaged or usually with an apical beak or crest; the 2 upper petals ligulate to ovate, sometimes galeate, united to staminal tube or keel (or both) at least at base; 2 lateral petals rarely present, always minute; stamens 8 or rarely 6 , the filaments united nearly to apex into a sheath split on the upper side, adnate to keel and upper petals at base; anthers usually confluently 1-celled, opening by an apical or introrse-apical pore; ovary 2-celled; ovules solitary, pendulous from the apex of the central placenta; style usually slender and often elongate, bent, more or less excavated at apex; stigma 2-lobed, often tufted; capsule equally or unequally 2-celled, winged to margined or marginless, compressed contrary to the partition, usually membranousherbaceous, the cells usually dehiscent; seeds globose to fusiform or conic, usually pubescent and almost always arillate.

About 550 species of world-wide distribution.

1. Sepals not decurrent on the pedicels; pedicels not winged; flowers never truly yellow, the racemes never compounded into a cymose panicle (2)

1. Sepals decurrent on the winged pedicels; flowers yellow or orange, often turning green in drying, sometimes compounded in a cymose panicle (10)

2(1). Cleistogamous flowers present, borne on short leafless basal branches; flowers bright rosy-purple, in loose racemes............1. P. polygama.

2. Cleistogamous flowers absent, flowers white to purple (3)

$3(2)$. Wings less than half as long as keel; stem glaucous; aril cellular, equitant, not obviously lobed. 2. $P$. incarnata.

3. Wings equal to or exceeding keel, rarely slightly shorter; stems not glaucous; aril 2-lobed, rarely obsolete (4)

4(3). Racemes cylindric or conic-cylindric or at least distinctly tapering above (5)

4. Racemes capitate to ovoid or cylindric, obtuse or merely apiculate (7)

5(4). Wings 3-3.3 $\mathrm{mm}$. long.

3. P. Hookeri.

5. Wings $1.2-3 \mathrm{~mm}$. long (6) 
6. Leaves alternate throughout or whorled only at base of stem..5. P. leptocaulis.

7(4). Wings broadly elliptic or oval, (2.8-) 4.5-6.3 $\mathrm{mm}$. long, about twice as long as keel; aril more than half as long as seed........6. P. sanguinea.

7. Wings equal to or but little longer than keel; aril usually less than half as long as seed (8)

8(7). Leaves all alternate. 7. P. mariana.

8. Leaves whorled at least below (9)

$9(8)$. Wings ovate to ovate-oblong, merely acute and short-mucronate; racemes 6-12 mm. thick................................................... . P. Hookeri.

9. Wings acuminate and strongly cuspidate from a deltoid base; racemes 10-17 $\mathrm{mm}$. thick.

8. P. cruciata.

10(1). Racemes solitary at tips of stems and branches, capitate or thick-cylindric, 9-20 $\mathrm{mm}$. thick; bracts mostly deciduous.

9. P. nana.

10. Racemes several or many, cymosely arranged at apex of stem and branches, 6-13 $\mathrm{mm}$. thick; bracts persistent. 10. P. ramosa.

\section{Polygala polygama $L$.}

Stems solitary to many from a biennial rootstock, erect or ascending, simple or sparsely branched, $1.5-3 \mathrm{dm}$. tall, glabrous, bearing loose racemes of cleistogamous flowers from the base or (in late season) from the axils of the leaves; leaves all alternate or the very lowest sometimes opposite, the lower or sometimes all spatulate to obovate and obtuse to rounded and mucronulate, slightly fleshy, the longer upper leaves usually linear to spatulate-linear and acutish, 12-31 mm. long, 2-8 mm. wide; peduncles $1-2 \mathrm{~cm}$. long; racemes cylindric, obtuse, loose, 9-14 mm. thick, the axis $13.5 \mathrm{~cm}$. long or less; bracts ovate to oblong-ovate, glabrous, deciduous, $1-1.3 \mathrm{~mm}$. long; pedicels $1-4 \mathrm{~mm}$. long; flowers pink to pink-purple, rarely pale-lilac or nearly white; sepals oval to oval-ovate, rounded to acutish, glabrous, $1.3-2.2 \mathrm{~mm}$. long; wings oval to oval-obovate, $3.2-6 \mathrm{~mm}$. long, 2-3.8 mm. wide, obtuse or rounded at apex, cuneate or clawed at base, about 3-nerved, glabrous; keel 3-5 mm. long, the crest on each side of a lamella and 2 or 3 divided lobes; capsule oval, margined, sometimes erose, plump, 2.5-4 $\mathrm{mm}$. long, 2-3 $\mathrm{mm}$. wide; seed ellipsoid, short-pointed at base, plump, pilose, $1.8-2.8 \mathrm{~mm}$. long; aril $0.8-2 \mathrm{~mm}$. long, the pilose corneous umbo terminating the beak of the seed, the 2 linear-elliptic to oval cellular-scarious lobes appressed. Incl. var. obtusata Chod.

In bogs, low sandy soil in open woodlands and along streams in open woods in Okla. (LeFlore Co.) and e. Tex., Apr.-June; from Fla. to e. Tex., n. to N.S., s.w. Que., s. Ont., Mich., Wisc. and Minn.

\section{Polygala incarnata L. Fig. 506.}

Simple or sparsely branched annual, about $35 \mathrm{~cm}$. tall, the glaucous stem sulcate and sparsely leaved; leaves scattered (the very lowest often opposite or even whorled), linear, 4-6 mm. long, 0.3-0.6 mm. wide, acuminate, cuspidate, glaucous; peduncles 2-3.5 cm. long; racemes dense, 6-38 mm. long, $1-1.3 \mathrm{~cm}$. thick in flower, 5.6-6 mm. thick in fruit; pedicels $0.5 \mathrm{~mm}$. long; flowers rose-purplish; sepals oblong-ovate to lanceolate, rounded to subacuminate, serrulate, $2-2.5 \mathrm{~mm}$. long; wings linear-oblong, about $3 \mathrm{~mm}$. long and $0.6 \mathrm{~mm}$. wide, somewhat undulate-convolute, obtuse to submucronulate, not clawed; upper petals $6.7 \mathrm{~mm}$. long; keel $7 \mathrm{~mm}$. long, united with the staminal tube and upper petals into a trough $5 \mathrm{~mm}$. long; crest on each side of about 3 lobes, these variously lobed or cleft; capsule suborbicular-ovate, cordate at base, $2.4 \mathrm{~mm}$. long, $2 \mathrm{~mm}$. wide; seed 
plump, pilose, $2.2 \mathrm{~mm}$. long; aril $1.1 \mathrm{~mm}$. high, membranaceous-cellular, equitant, erect, scarcely lobed.

In open grassy areas, savannahs and bogs, and open flat woodlands in Okla. (Waterfall) and the e. third of Tex., May-Sept.; from Fla. to Tex. and Mex., n. to L.I., N.J., Pa., s. Ont., s. Mich., s. Wisc., Ia. and Neb.

\section{Polygala Hookeri T. \& G.}

Slender erect or procumbent annual, papillose-puberulent above, 1-2.5 dm. tall; leaves in remote whorls of 3 or 4 or the uppermost scattered, linear, 4-10 $\mathrm{mm}$. long, 0.5-1 $\mathrm{mm}$. wide, acutish, barely mucronulate, strongly revolute, glanduliform-puberulous; peduncles mostly 3-7 cm. long; racemes coniccylindric, acuminate or at least apiculate, loose, 6-9 mm. thick, the axis 7-40 $\mathrm{mm}$. long; bracts triangular-ovate, ciliolate, spreading, persistent, $1 \mathrm{~mm}$. long; pedicels 1.5-2 mm. long; flowers pink; sepals broadly ovate, short-mucronate, ciliolate, 1.1-1.4 mm. long; wings oblong-ovate, about $3 \mathrm{~mm}$. long, 1.3-1.5 mm. wide, inflexed and very short-mucronate at apex, rounded at the oblique sessile base, stipitate-glandular-ciliolate on the upper margin, 7-nerved; keel $2.8 \mathrm{~mm}$. long, the crest on each side of a triangular lamella and 2 entire lobes; capsule orbicular, plump, strongly winged beneath on the stipelike base, 1.4-2.2 $\mathrm{mm}$. long and wide; seed plump, ellipsoid, somewhat shining, short-pubescent, $1.2 \mathrm{~mm}$. long; aril equaling the seed, the 2 linear lobes appressed.

In low pinelands and wet savannahs, in e. Tex., Apr.-Aug.; along the coast from N. C. and Fla. to Tex.

\section{Polygala verticillata $L$.}

Erect single-stemmed glabrous annual, 5-40 cm. tall, usually freely branched; leaves in whorls of 4 or 5 up to middle of stem or throughout, rarely with only 1 or 2 whorls below with the rest alternate, those of the branches scattered, linear to narrowly elliptic, 5-30 $\mathrm{mm}$. long, $0.7-5.5 \mathrm{~mm}$. wide, acute to acuminate at each end and cuspidate; peduncles to $9 \mathrm{~cm}$. long; racemes conic to cylindricconic, acute to acuminate, dense or loose, 2.2-4.5 mm. thick, the axis $35 \mathrm{~mm}$. long or less; bracts subulate, glandular-denticulate, deciduous; pedicels $0.2-1 \mathrm{~mm}$. long, rarely to $2 \mathrm{~mm}$. long; flowers whitish and greenish, rarely purplish-tinged; sepals ovate, ciliolate, $0.9-1.1 \mathrm{~mm}$. long; wings obovate-oval, 1.6-2 mm. long, 1.1-2 mm. wide, broadly rounded at apex, short-clawed, about 3-nerved; keel 1.2-1.5 mm. long, the crest on each side of a lamella and 1 or 2 lobes; capsule oval, 1.8-2.1 mm. long; seed pilosulous, $1.5-1.8 \mathrm{~mm}$. long; aril $0.7-1 \mathrm{~mm}$. long, the 2 lobes linear-oblong or obovate. Incl. var. isocycla Fern. and var. sphenostachya Penn. and var. dolichoptera Fern.

In prairies, marshes, wooded streams, sandy post-oak and pine woodlands in the e. third of Tex. and Okla. (McCurtain Co.), May-July; from Fla. to Tex., Okla., Colo. and Ut., n. to Mass. and s. Man.

Plants found in our area with most of the leaves alternate or with only 1 or 2 whorls below have been segregated as var. ambigua (Nutt.) Wood.

\section{Polygala leptocaulis T. \& G. Fig. 506.}

Slender annual, to $5 \mathrm{dm}$. high, glabrous, branched above; leaves all scattered, linear to subfiliform, $8-25 \mathrm{~mm}$. long, $1 \mathrm{~mm}$. or less wide, acuminate, slightly revolute; racemes cylindric, loose or rather dense, $5-5.5 \mathrm{~mm}$. thick, the axis to about $10 \mathrm{~cm}$. long; pedicels $0.8-1 \mathrm{~mm}$. long; flowers rosy, rarely white; sepals ovate, obtuse, $1 \mathrm{~mm}$. long; wings obovate, about $2 \mathrm{~mm}$. long and $0.9 \mathrm{~mm}$. wide, rounded at apex, cuneate at base, 3-nerved; keel $2 \mathrm{~mm}$. long, the crest of 2 or 3 lobes on each side; capsule oblong, often very slightly narrowed toward apex, with a row of glands on each side of septum, 1.6-1.8 mm. long; seed subcylindric, 


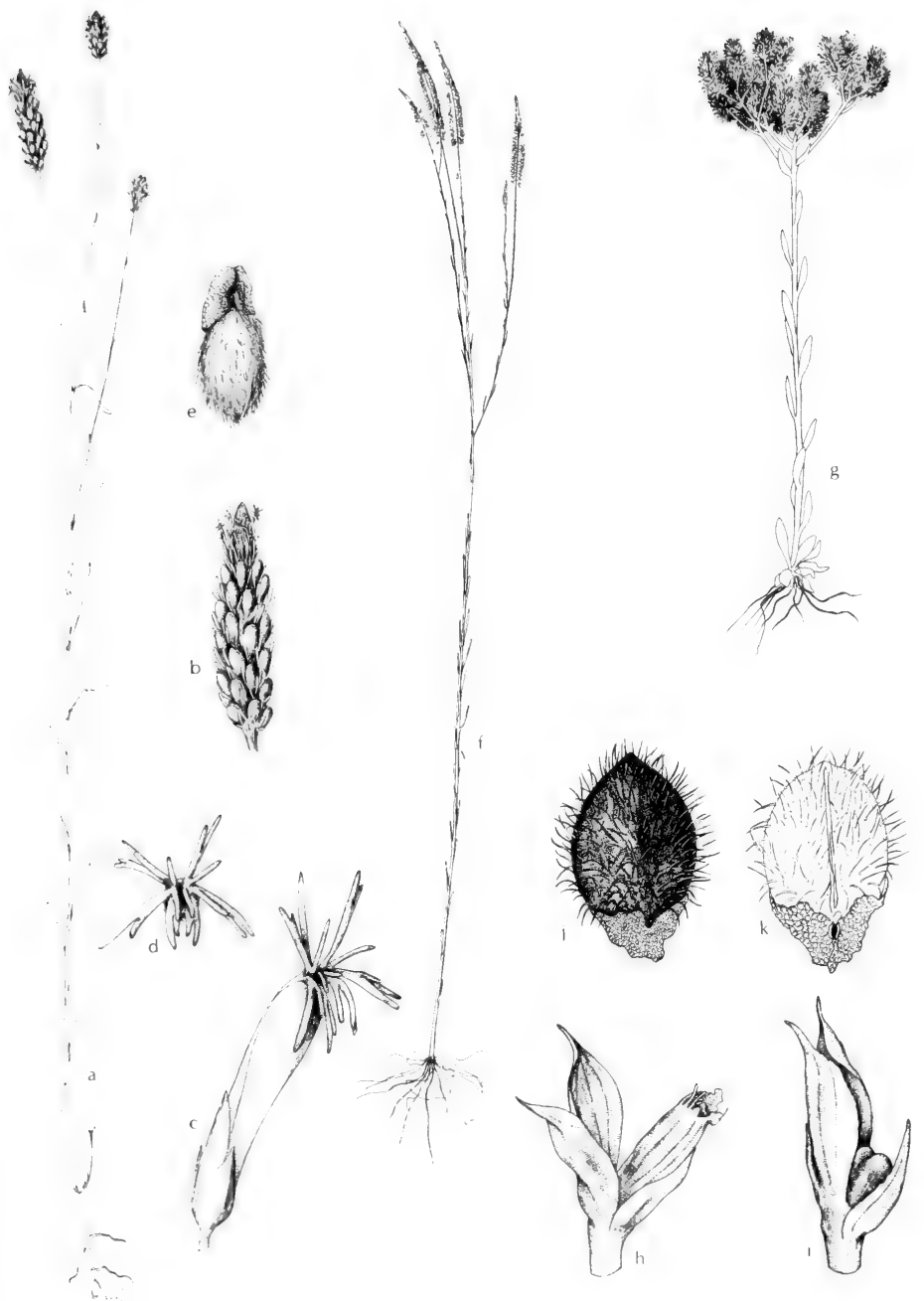

Fig. 506: a-e, Polygala incarnata: a, habit, x 1/3; b, inflorescence, x 1; c, flower, x 5; d, lobed crest, x 5; e, seed, x 8. f, Polygala leptocaulis: $\mathrm{f}$, habit, about x 1/5. g-k, Polygala ramosa: $\mathrm{g}$, habit, $\mathrm{x} 1 / 3 ; \mathrm{h}$, flower, $\mathrm{x} 10 ; \mathrm{i}$, capsule, $\mathrm{x} 10 ; \mathrm{j}$ and $\mathrm{k}$, two views of seed, x 30. (Courtesy of R. K. Godfrey). 


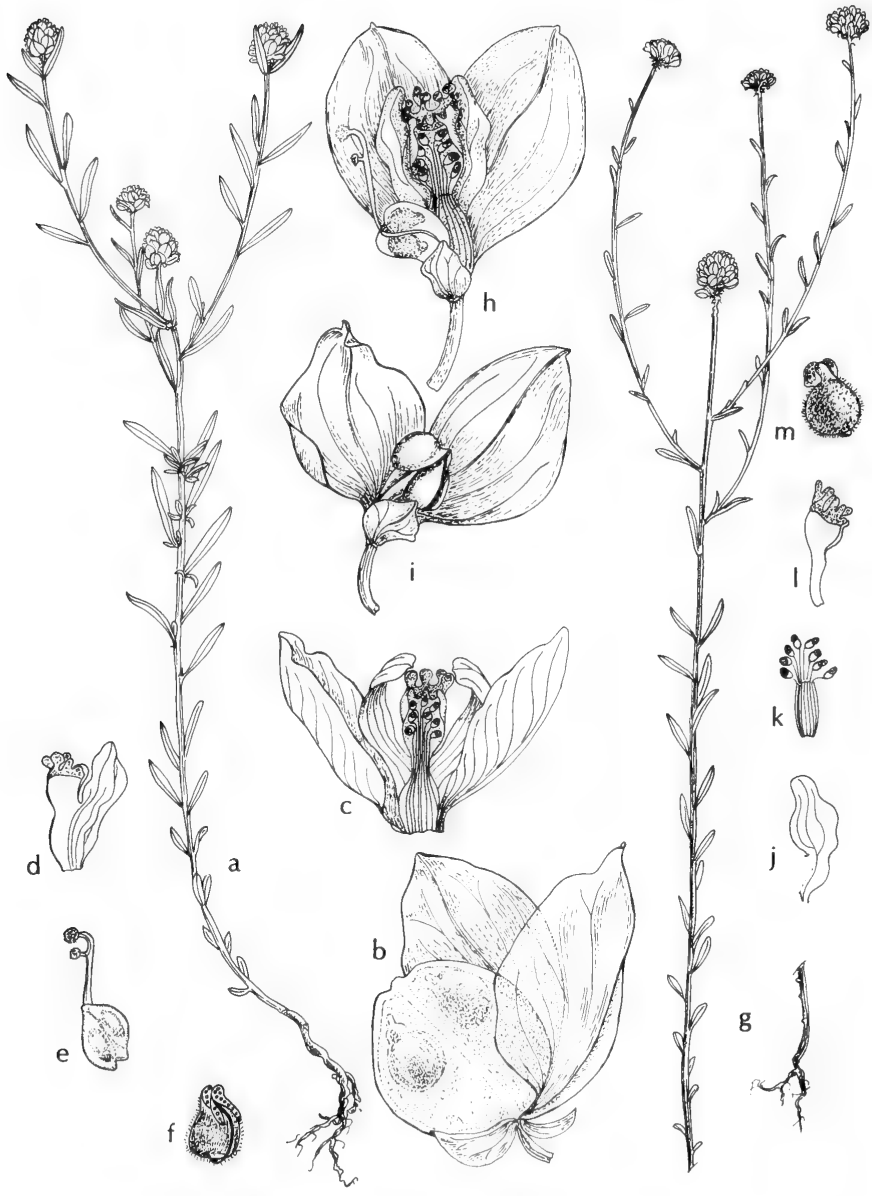

Fig. 507: a-f, Polygala sanguinea: a, habit, $\mathrm{x} 1 / 2 ; \mathrm{b}$, capsule with wings, $\mathrm{x} 6$; $\mathrm{c}$, flower, x 6; d, keel, x 5; e, pistil, x 7; f, seed, x 7, g-m, Polygala mariana: g, habit, x 1/2; $h$, flower, $x 6$; $i$, capsule with wings, $x 6$; $j$, one petal, showing attachement to stamens, x 5 ; k, stamens, x 5; 1, keel, x 5; m, mature seed, x 8. (V. F.). 
appressed-pubescent, $1.2 \mathrm{~mm}$. long; aril minute, 2-lobed, about one tenth as long as seed.

In wet savannahs and low open pinelands in e. Tex., May-June; along Coastal Plains from Miss. to Tex, also Mex., C.A., Cuba and S.A.

\section{Polygala sanguinea L. Fig. 507}

Slender erect annual, $4 \mathrm{dm}$. tall or less, simple or branched; leaves all alternate, numerous, linear to elliptic-linear, 7-39 mm. long, 1-4.5 $\mathrm{mm}$. wide, acute to acuminate and mucronulate, erect or ascending, papillose-serrulate on margin with subglandular teeth; peduncles $3-30 \mathrm{~mm}$. long; racemes capitate to thickcylindric, very obtuse and dense, 6-14 $\mathrm{mm}$. thick, the axis 7-40 $\mathrm{mm}$. long; bracts subulate, 1-1.5 mm. long, at length deciduous; pedicels 1.1-1.5 mm. long; flowers greenish and rosy or purplish, rarely white; sepals oval to elliptic-ovate, acute to subacute, glabrous, $1.3-1.8 \mathrm{~mm}$. long; wings ovate-oval, 4.8-6.3 mm. long, 2.5-3.5 mm. wide, rounded at apex, short-clawed, 9-nerved; keel 2.5-2.7 $\mathrm{mm}$. long, the crest on each side of a lamella and a cuneate lobe, or these connate; capsule cuneate-suborbicular, with short flattened sterile base, 2.5-3 mm. long, 2-2.5 mm. wide; seed subglobose-pyriform, pointed at base, rounded at apex, short-pilose, $1.5-1.7 \mathrm{~mm}$. long; aril $1-1.3 \mathrm{~mm}$. long, the 2 lobes linear or linearoblong, scarious, appressed. $P$. viridescens $\mathrm{L}$.

In bogs and moist open flatwoods, wet meadows, edge of ponds and roadside ditches, in n.e. Tex. and Okla. (Waterfall), May-July; from N.S. to s. Ont. and Minn., s. to Tenn., Okla., La. and n.e. Tex.

At anthesis the pedicels are $1.5 \mathrm{~mm}$. long or less and the wing is more than $4.5 \mathrm{~mm}$. long. These characteristics readily separate this species from $P$. mariana.

\section{Polygala mariana Mill. Fig. 507.}

Slender erect annual, 1.5-4 dm. tall, sparsely papillose-puberulent above; leaves all alternate, linear or the lower spatulate, 6-24 mm. long, 0.5-2.5 mm. wide, cuspidate, usually ascending; racemes capitate to short-cylindric, obtuse to apiculate, 6-11 mm. thick, the axis 5-35 mm. long; bracts subulate-ovate, erose, often ciliolate, deciduous; pedicels $1.8-2 \mathrm{~mm}$. long or more; flowers pink or purple; sepals elliptic to ovate-lanceolate, obtuse to subacuminate, sometimes ciliolate, $0.8-1.8 \mathrm{~mm}$. long; wings broadly elliptic to elliptic-obovate, $3-5 \mathrm{~mm}$. long, 1.3-3 mm. wide, slightly apiculate at apex, cuneate at base, commonly 6-nerved; keel papillose below, 2.3-3.2 $\mathrm{mm}$. long, the crest on each side of a lamella and a single lobe; capsule suborbicular to rhombic-suborbicular, with a broad stipelike sterile base, about $2.2 \mathrm{~mm}$. long, 1-2 mm. wide; seed subglobosepyriform, rostrate at base, rounded or apiculate at apex, short-pilose, $1.1 \mathrm{~mm}$. long; aril $0.4 \mathrm{~mm}$. long, the 2 oblong cellular lobes fastened to the point of seed, loosely descending and standing forward. P. Harperi Small.

In low moist open pinelands and savannahs, pitcher plant bogs, savannah-evergreen shrub bogs and on seepage slopes in s.e. Tex., Apr.-Sept.; from Fla. to Tex., n. to N.J., Del., Md. and Ky.

At anthesis the pedicels are about $2 \mathrm{~mm}$. long or occasionally longer and the wings are rarely more than $4.5 \mathrm{~mm}$. long. These characteristics readily separate $P$. mariana from $P$. sanguinea.

\section{Polygala cruciata L. Fig. 508.}

Slender erect annual, 6-40 cm. tall, simple or usually cymosely branched; leaves in whorls of 3 or 4 throughout or the uppermost scattered, linear to linear-elliptic, the upper largest, $8-35 \mathrm{~mm}$. long, 1-5 mm. wide, usually apiculate at the obtuse to rounded apex, narrowed at base; peduncles to $5 \mathrm{~cm}$. long; racemes thickcylindric to ovoid-cylindric, obtuse to apiculate, $1-1.7 \mathrm{~cm}$. thick, the axis $6 \mathrm{~cm}$. 

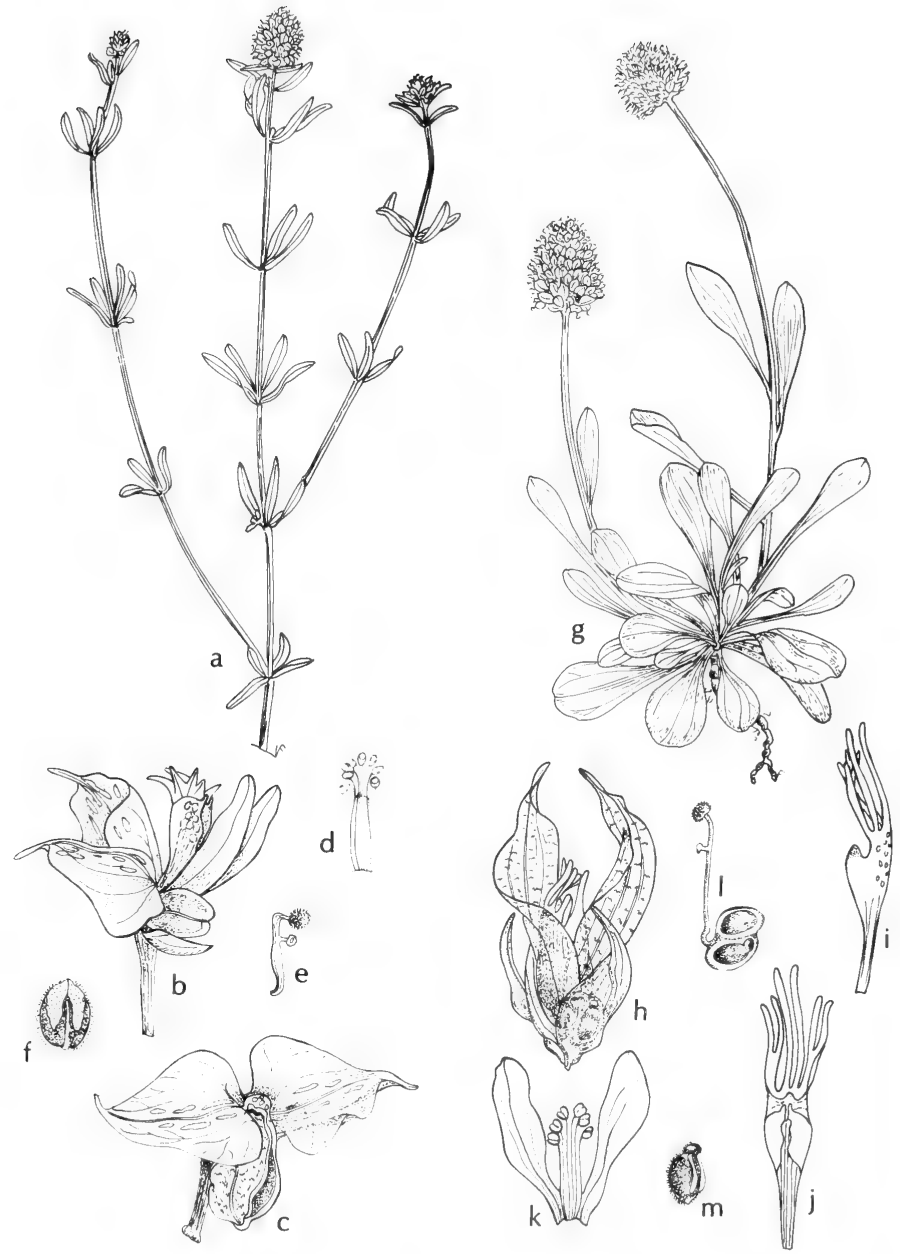

Fig. 508: a-f, Polygala cruciata: a, top of plant, x 1/2; b, flower, $x$ 5; c, wings and fruit, x 5; d, monadelphous filaments, x 5; e, pistil, x 5; f, mature seed, $x$. g-k, Polygala nana: g, habit, $\mathrm{x} 1 / 2 ; \mathrm{h}$, flower, $\mathrm{x} 5$; $\mathrm{i}$ and $\mathrm{j}$, two views of keel, $\mathrm{x} 8 ; \mathrm{k}$, filaments connected to petals, $x 8 ; 1$, pistil, $x 8 ; \mathrm{m}$, mature seed, $x$ 8. (V. F.). 
long or less; bracts subulate-attenuate from an ovate base, ciliolate, spreading, persistent, $1.5-2.5 \mathrm{~mm}$. long; pedicels $2-2.4 \mathrm{~mm}$. long; flowers rosy-purple to greenish or rarely white; sepals ovate, obtuse to acutish, ciliolate, $0.8-1.4 \mathrm{~mm}$. long: wings broadly deltoid-ovate, $3.5-5.6 \mathrm{~mm}$. long, $2.7-3.6 \mathrm{~mm}$. wide near base, subsessile or very shortly clawed at the truncate or slightly oblique base, acuminate and strongly cuspidate at apex, about 9-nerved; keel $2.8-3.5 \mathrm{~mm}$. long, the crest on each side of a lamella and 2 or 3 entire or bifid lobes; capsule suborbicular, very plump, strongly oblique and winged below on the stipelike base, 2-2.2 $\mathrm{mm}$. long, 1.8-2.1 mm. wide; seed ellipsoid, plump, short-pubescent, 1.1-1.3 mm. long; aril $0.9-1.1 \mathrm{~mm}$. long, the 2 linear lobes appressed.

In and on edge of bogs, on seepage slopes and in savannahs in e. Tex., MaySept.; from Fla. to e. Tex., n. along the coast to Va. and inland to Ky.

\section{Polygala nana (Michx.) DC. Fig. 508.}

Stems several from an annual or biennial rootstock, simple, erect to ascending, 7-17.5 cm. tall; basal leaves tufted, spatulate to obovate or elliptic-obovate, 15-43 mm. long, 3-17.5 mm. wide, rounded and sometimes mucronulate at apex, narrowed at base, thickish, 3- to 5-nerved; stem leaves few, alternate, linearspatulate to oblanceolate or obovate, $1.3-4 \mathrm{~cm}$. long, $1.5-8 \mathrm{~mm}$. wide, rounded to acuminate and mucronulate at apex; peduncles solitary, 23-75 $\mathrm{mm}$. long; racemes conic-capitate, becoming ovoid-ellipsoid or thick-cylindric, acute to very obtuse, 1-1.7 cm. thick, 1-3.7 cm. long; bracts linear-subulate, ciliolate, at length deciduous or sometimes persistent, 5.5-6.5 $\mathrm{mm}$. long; flowers subsessile, yellow turning deep- or bright-green in drying; sepals elliptic-lanceolate to linear-subulate, 3-5.3 mm. long, cuspidate-acuminate, ciliate; wings elliptic, $6.5-7.5 \mathrm{~mm}$. long, $1.8-2.8 \mathrm{~mm}$. wide, acuminate and somewhat involute at apex into a cusp to $1 \mathrm{~mm}$. long, scarcely narrowed at base, sparsely ciliolate, 3- to 5-nerved; keel 4.5-5.8 $\mathrm{mm}$. long, the crest on each side of 3 linear entire to 3-parted lobes; anthers 6; capsule oval to suborbicular-oval, 1.6-2 mm. long, 1.2-1.6 mm. wide; seed ellipsoid to subpyriform, pilose, with a prominent thick blunt rostrum at base, $0.8-1.8 \mathrm{~mm}$. long; aril $0.7-1.1 \mathrm{~mm}$. long, the 2 linear scarious lobes appressed, one third to nearly as long as seed. Pilostaxis nana (Michx.) Raf.

On seepage slopes, in wet savannahs and low open pinelands in s.e. Tex., Apr.-June; from Fla. to S.C. and Tex.

Plants of this species are sometimes confused with the more eastern $P$. lutea $\mathrm{L}$. The cusp of the largest sepals of that species, however, is less than $1 \mathrm{~mm}$. long and the sepals are orange-color instead of yellow.

\section{Polygala ramosa Ell. Fig. 506.}

Erect glabrous annual, 1.5-4 dm. tall, fibrous-rooted; stems solitary, simple or branched; basal leaves in a small tuft, elliptic to obovate, 7-20 mm. long, 2-6 $\mathrm{mm}$. wide, rounded at apex, usually narrowed into a petiolelike base; stem leaves linear to spatulate or elliptic, 7-24 $\mathrm{mm}$. long, $1.5-8 \mathrm{~mm}$. wide, acute to obtuse at each end; branch leaves linear, reduced; racemes numerous, terminal and on axillary branches forming a flattish cymose panicle to $14 \mathrm{~cm}$. broad, the separate racemes loosely flowered and $7-11 \mathrm{~mm}$. thick and $18 \mathrm{~mm}$. long or less; bracts lance-ovate, ciliolate, spreading, persistent, $1.5 \mathrm{~mm}$. long; pedicels narrowly winged, 1.3-2.3 $\mathrm{mm}$. long; flowers yellow, turning very dark-green in drying; sepals ovate, ciliolate, acuminate, 1.1-2 mm. long; wings obovate to ellipticobovate, strongly cuspidate at the somewhat involute apex, 2.9-3.5 mm. long, 1.1-1.3 mm. wide, 3-nerved; keel $2.1 \mathrm{~mm}$. long, the crest on each side of a lobed lamella and a 2- or 3-parted lobe; capsule suborbicular, plump, $0.8 \mathrm{~mm}$. long and wide; seed ellipsoid, very plump, short-hairy, 0.6-0.7 mm. long; aril $0.2 \mathrm{~mm}$. long, the 2 lobes oval, appressed. Pilostaxis ramosa (Ell.) Small. 
In seepage areas of savannahs, open slopes, pitcher plant bogs, in mud about lakes and in boggy open pinelands in s.e. Tex., May-Sept.; from Fla. to Tex., n. to N. J.

\section{Fam. 78. Euphorbiaceae Juss.}

\section{SPURGE FAMILY}

Herbs, shrubs or trees; leaves opposite or alternate or whorled, usually stipulate (but stipules commonly very small or caducous); highly variable as to inflorescence and flower form but the flowers are always unisexual; petals can be present or absent; a lobate "disk" is commonly present at least in the pistillate flowers; the ovary is nearly always 3-celled and each locule has a separate style which in some species is deeply dissected; the placentation is axile and the ovules pendulous, anatropous, with a ventral raphe; seeds 1 or 2 per cell, when 2 then collateral; the micropyle in many species is covered by a caruncle; the fruit is usually a capsule, when ripe the dorsal walls of the locules usually separate septicidally from the central placental axis called the columella; seeds liberated through the ventral (axile) openings of the locules which are in many species eventually loculicidal.

A vast and diverse family of over 200 genera and several thousand species. It is said by some authors that most Euphorbiaceae are poisonous. A number of our species are known to be toxic to livestock. The starchy, tuberous roots of Manihot species replace grains as staple starchy crops in much of the hot, forested lowlands of South America; these roots have to be specially treated, steeped, dried and heated, before the edible materials (mandioca, cassava, tapioca) can be prepared from them. The Brazilian rubber trees (genus Hevea) are widely planted in Malaysia and Africa. The castor-bean (Ricinus) formerly was valuable for its oil. Croton oil is prepared from species of Croton. Some species of the family are valued as ornamentals (Breynia, Acalypha, Ricinus, Codiaeum, etc.)

1. Stems and branches glabrous or slightly scabridulous; leaves oblong to elliptic or obovate, entire, $3 \mathrm{~cm}$. long or less; ovules 2 in each of the 3 cells of the ovary, collateral; capsules glabrous.................1. Phyllanthus

1. Stems and branches with whitish more or less glandular-tipped spreading hairs; leaves lanceolate, serrate, rarely less than $3 \mathrm{~cm}$. long; ovules 1 in each cell; capsules glandular-setulose.

2. Caperonia

\section{Phyllanthus L. Leaf-Flower}

Trees, shrubs or herbs; branches persistent or deciduous (in the latter instance, leaves on main stem then reduced to scales); leaves entire; petioles short; stipules deciduous or persistent; male and female flowers borne on same plant in ours; flowers usually axillary, solitary or in cymules, apetalous, gamosepalous; disk usually present; staminate flowers with mostly 3 to 6 stamens, the filaments free or connate; disk usually dissected; pistillode absent; pollen grains colporate (in local taxa); pistillate flowers pedicellate or subsessile; calyx lobes usually 5 or 6 , entire; disk continuous or segmented (rarely absent); carpels 3 (in ours); ovules 2 in each locule, hemitropous; styles free or united, bifid or variously divided or dilated; fruits capsular and ballistically dehiscent (indehiscent in some exotic taxa); seeds usually 2 in each locule, collateral; seed coat dry and crustaceous; endosperm copious; embryo straight or slightly curved.

A polymorphic genus of some 700 species, best developed in the Old World tropics.

1. Filaments free; stems terete, not winged; capsule $1.7-2 \mathrm{~mm}$. in diameter; seeds 0.8-1 mm. long................................................. P. caroliniensis.

1. Filaments connate; stems compressed-winged; capsule $2.9-3.2 \mathrm{~mm}$. in diameter; seeds $1.2-1.5 \mathrm{~mm}$. long. 2. P. pudens. 


\section{Phyllanthus caroliniensis Walt.}

Glabrous erect annual monoecious herb $1.3 \mathrm{dm}$. high; branches terete to somewhat compressed but not winged; leaves distichous, elliptic to obovate, obtuse or rounded and sometimes apiculate at the tip, acute at the base, 5-20 (-30) $\mathrm{mm}$. long, 4-10 (-13) $\mathrm{mm}$. broad; stipules lanceolate, acuminate, basally denticulate, (0.5-) $0.8-1.3 \mathrm{~mm}$. long; most axils in all axes floriferous; cymules bisexual, with 1 or 2 male and 1 or 2 female flowers; male flowers with pedicels $0.5-1 \mathrm{~mm}$. long; calyx lobes 6 (rarely 5 ), oblong to ovate or suborbicular, $0.5-0.8 \mathrm{~mm}$. long; disk segments 6 (5), more or less cuneate; stamens 3; filaments free, $0.2-0.3 \mathrm{~mm}$. long; anthers dehiscing transversely, about $0.3 \mathrm{~mm}$. broad; female flowers with pedicels becoming geniculate-reflexed and $0.5-1(-1.5) \mathrm{mm}$. long; calyx lobes 6 (rarely 5), linear-lanceolate to narrowly spatulate, greenish or reddish, with unbranched midrib, 0.7-1.2 (-1.4) mm. long; disk patelliform, entire or nearly so; ovary smooth; styles nearly free, spreading, bifid, $0.3 \mathrm{~mm}$. long or less, style branches obtuse or subcapitate; capsules oblate, 1.7-1.9 mm. in diameter; seeds fuscous-brown, verruculose (with verrucae in wavy lines), $0.8-1 \mathrm{~mm}$. long.

In moist or wet alluvial soils and gravel bars along streams, wet thickets, marshes, wet depressions and river floodplains in e. and n.e. Tex. (from Tarrant and Harris cos. eastw.), June-Nov.; Ill. and Pa., s. to Arg. and Urug.

\section{Phyllanthus pudens Wheeler.}

Erect annual monoecious herb 2-5 dm. high; stems compressed and distinctly but narrowly winged; scabridulous; leaves distichous, oblong or elliptic, acute or obtuse and apiculate at the tip, obtuse to rounded at the base, $1-2 \mathrm{~cm}$. long, 3-10 $\mathrm{mm}$. broad; stipules ovate-lanceolate, acuminate, basally more or less denticulate, 1.2-2 mm. long; most axils on all axes floriferous; cymules bisexual, with 1 to 3 male and 1 or 2 (rarely 3 ) female flowers; male flowers with pedicels about 0.5 $\mathrm{mm}$. long; calyx lobes 5 or 6 , ovate, $0.5-0.7 \mathrm{~mm}$. long; disk segments 5 or 6 , suborbicular or cuneate; stamens 3 ; filaments completely united into a column $0.2-0.3$ $\mathrm{mm}$. high; anthers dehiscing horizontally, about $0.25 \mathrm{~mm}$. broad; female flowers with pedicels becoming geniculate-reflexed and (1-) 1.4-2.2 $\mathrm{mm}$. long; calyx lobes 6 (rarely 5), oblong to ovate, often reddish at base, herbaceous with unbranched midrib, 0.7-1.2 mm. long; disk patelliform, 6-angled, entire; ovary smooth; styles horizontal, bifid, basally fused into a triangular platform $0.5-0.6 \mathrm{~mm}$. across, style branch tips subcapitate; capsules oblate, sometimes reddish-tinged, 2.9-3.2 mm. in diameter; seeds yellowish- to fuscous-brown, verruculose (with verrucae in irregular wavy lines), 1.2-1.5 mm. long.

Coastal prairies, mainly in wet depressions of river bottomlands and marshy areas, from Matagorda Co. to Chambers Co. and eastw. in Tex., May-Nov.; also s. La.

\section{Caperonia ST.-HIL.}

A tropical genus of about 40 species, of which we have one.

\section{Caperonia palustris (L.) St.-Hil. Fig. 509.}

Annual herb, (2-) 3-10 dm. tall, stout, mostly simple in the lower half, with few ascending branches above, the upper stem and branches with spreading whitish occasionally gland-tipped hairs; leaves alternate; blades broadly lanceolate or elliptic-lanceolate, (3-) 5-15 cm. long, serrate, with numerous closely parallel secondary nerves ending at the marginal teeth, the tertiaries percurrent; petioles 3-25 $\mathrm{mm}$. long, pubescent like the adjacent stem; stipules triangular to subulate, 3-5 $\mathrm{mm}$. long; flowers in lax secund androgynous spikes in the upper axils, the peduncles about half as long as the leaves; each flower subtended by a minute 


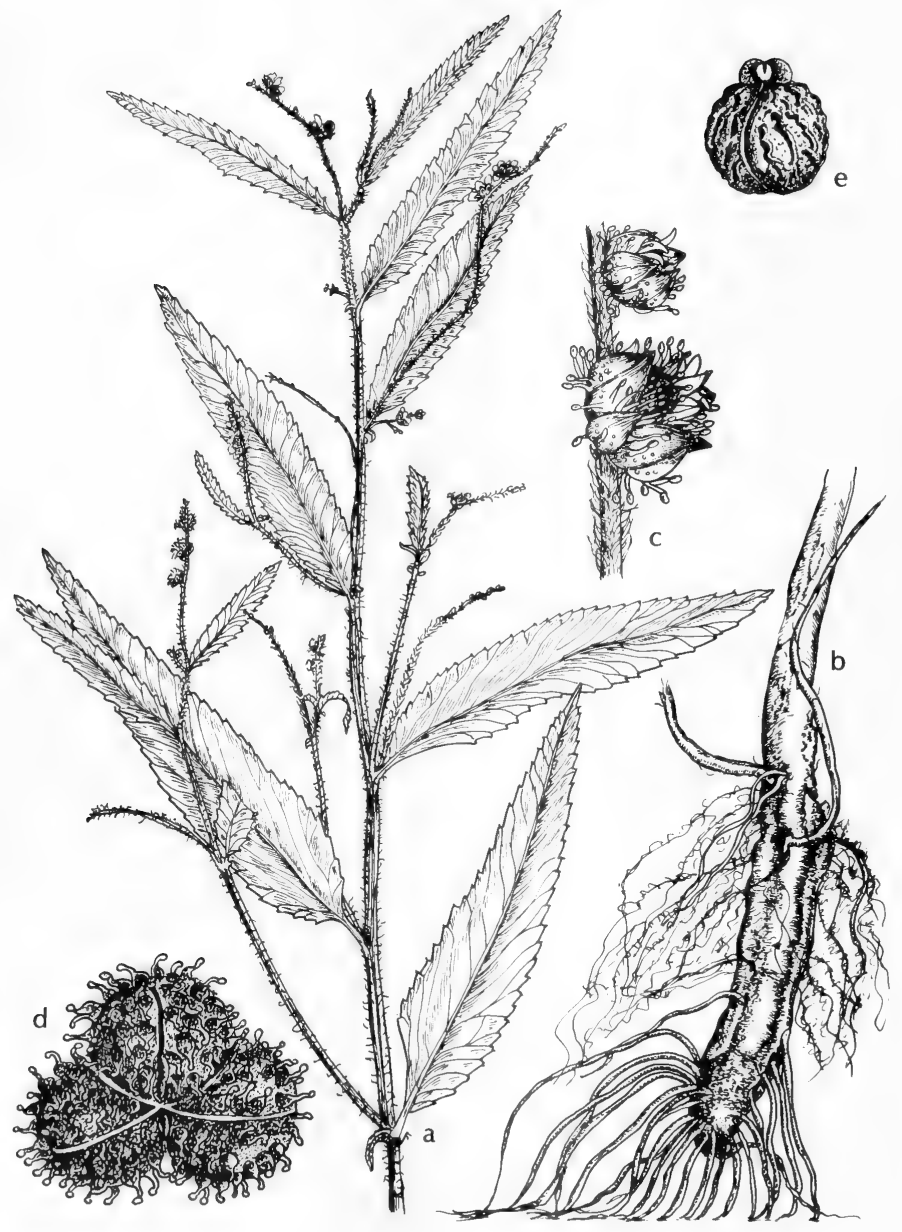

Fig. 509: Caperonia palustris: a, top part of stem, x 1/2; b, lower part of stem and roots, x 1/2; c, flower, x 5; d, capsule, x 5; e, seed, x 5. (V. F.). 
bract; staminate flowers 6 to 20 per spike, sessile; calyx 5-lobed, the lobes about $1 \mathrm{~mm}$. long; petals spatulate-lanceolate, obtuse, slightly exceeding the calyx; androphore columnar, bearing two whorls of short stamens and prolonged above the upper whorl; stamens short, about 5 in each whorl; pistillate flowers 1 to 6 per spike, essentially sessile; calyx deeply and unequally 6-parted, with 3 longer (2-3 $\mathrm{mm}$. long) lobes opposite the carpels and 3 shorter ones opposite the petals, all the lobes acute, the whole calyx glandular-setulose on the exterior; petals 5 or 6 , shorter than the longer calyx lobes, whitish, clawed, caducous soon after anthesis; disk absent; ovary tricoccous, densely glandular-setulose; styles 3, laminar, each about 4- or 5-lobed about half the length; capsule deeply tricoccous, about $4 \mathrm{~mm}$. high and $6 \mathrm{~mm}$. broad, loculicidal and septicidal; columella short; seeds about $3 \mathrm{~mm}$. long, nearly spherical, foveolate.

Frequent in rice fields, ditches and other marshy areas, s.e. Tex. (Harris, Jefferson and Matagorda cos.), July-Oct.; widespread in warmer parts of Am., s. to Parag. and n. to Tex., La. and Fla. The species arrived in Tex. about 1920.

\section{Fam. 79. Callitrichaceae LINK}

\section{WATER-STARWORT FAMILY}

Aquatic or terrestrial annual or perennial herbs with delicate stems, monoecious or rarely dioecious; leaves opposite, entire, without stipules; flowers unisexual, the perianth lacking, each flower subtended by a pair of falciform or obliquely oval bracteoles (or these wanting); staminate flowers 1 to 3 in the axil of a foliage leaf, consisting of a single anther on a slender filament; pistillate flowers 1 or rarely more, similarly placed, composed of a single pistil of 2 carpels; styles 2, slender, often much longer than the ovary; carpels splitting at maturity and usually forming a fruit of 4 achenelike mericarps; mericarps flattened, winged, margined or smooth, each bearing 1 seed.

A monotypic family.

\section{Callitriche L. WATER-STARWORT. WATER-CHICKWEed}

Characters of the family. A group of highly polymorphic species due to apomixis in many of the species and to variations and different outward appearances resulting from the same species inhabiting diverse habitats, either amphibious or terrestrial.

About 40 species distributed throughout the world.

The broad, floating leaves of most species, that arise from slender, rooted stems provided with linear submersed leaves, form mats on the surface of water and provide cover for fish and for some of their food population. Ducks have been observed to eat the seeds and herbage. The often winged, suberous covered mericarps are ideally suited for dispersal by water.

1. Leaves dark-bright-green, linear-lanceolate, narrowed to a clasping base, the base not connected by a wing, all submersed; faces of mericarps obscurely and irregularly pitted...................... C. hermaphroditica.

1. Leaves bright green, of various shapes; nodes with a narrow membranous wing connecting the leaf-bases; faces of mericarps usually reticulate; plants submersed or on mud (2)

2(1). Fruit as high as wide or a little higher, rarely slightly wider than high; stigmas to $6 \mathrm{~mm}$. long; stamens elongating to $1.5-3 \mathrm{~mm}$. as the fruit matures; anthers to $1.5 \mathrm{~mm}$. wide; flowers with 2 whitish inflated bracteoles at base; leaves of various types on different or the same plant; plant amphibious, growing entirely submersed or with a terminal rosette of floating leaves, or as a mat on mud (3) 


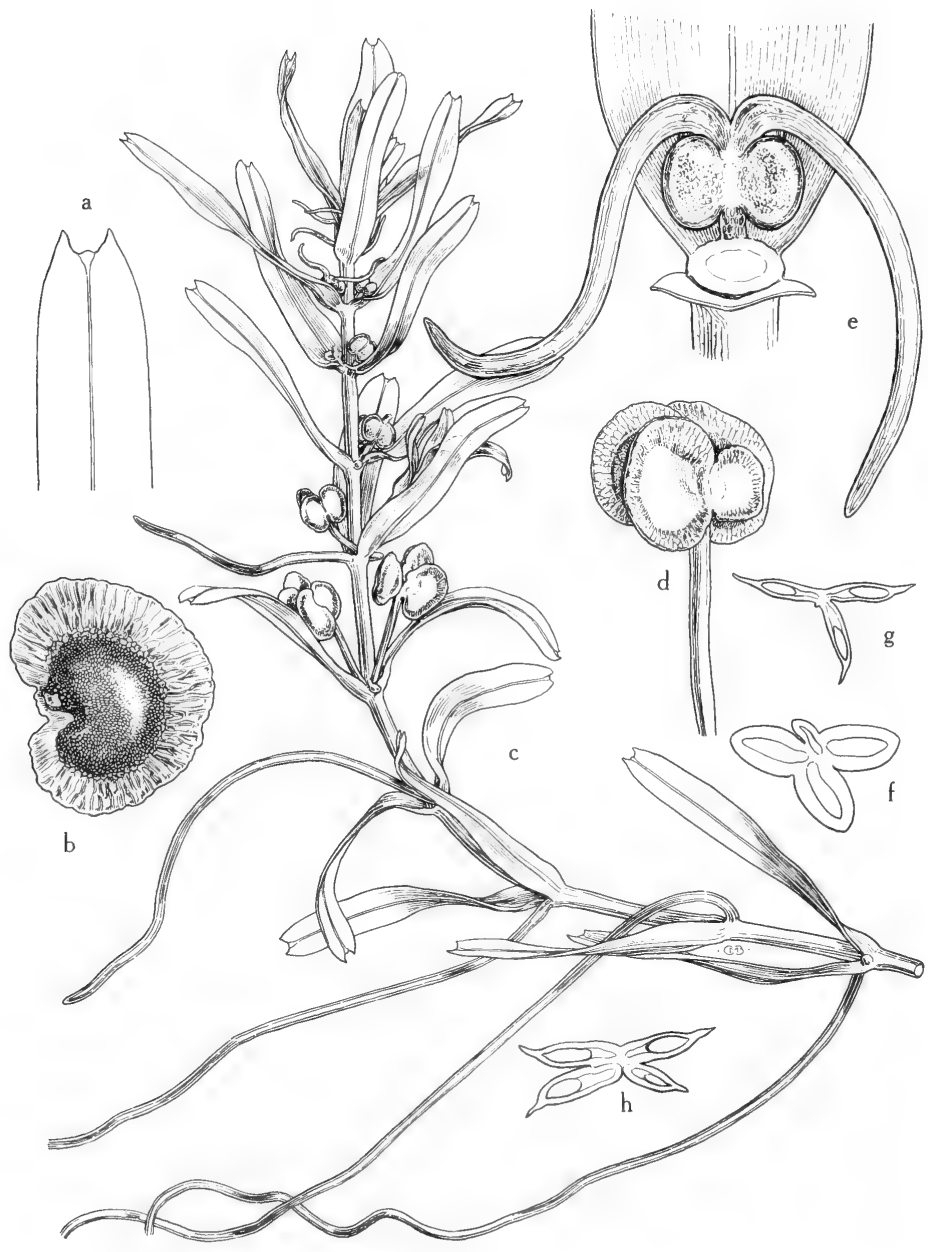

Fig. 510: Callitriche hermaphroditica: a, leaf tip, $\times 12 ; \mathrm{b}$, mature carpel, showing broad wing, x 20; c, habit, wholly submersed plant, showing the linear-lanceolate notched leaves, the flowers and the short-peduncled fruits, $x 4 ; \mathrm{d}$, mature fruit, $\mathrm{x} 8$; $\mathrm{e}$, young flower, showing the long deflexed styles, $\mathrm{x} 40$; $\mathrm{f}$, young fruit (cross section), $\mathrm{x} 12 ; \mathrm{g}$ and $\mathrm{h}$, mature fruit (cross section), $\mathrm{x}$ 8. (From Mason, Fig. 256). 


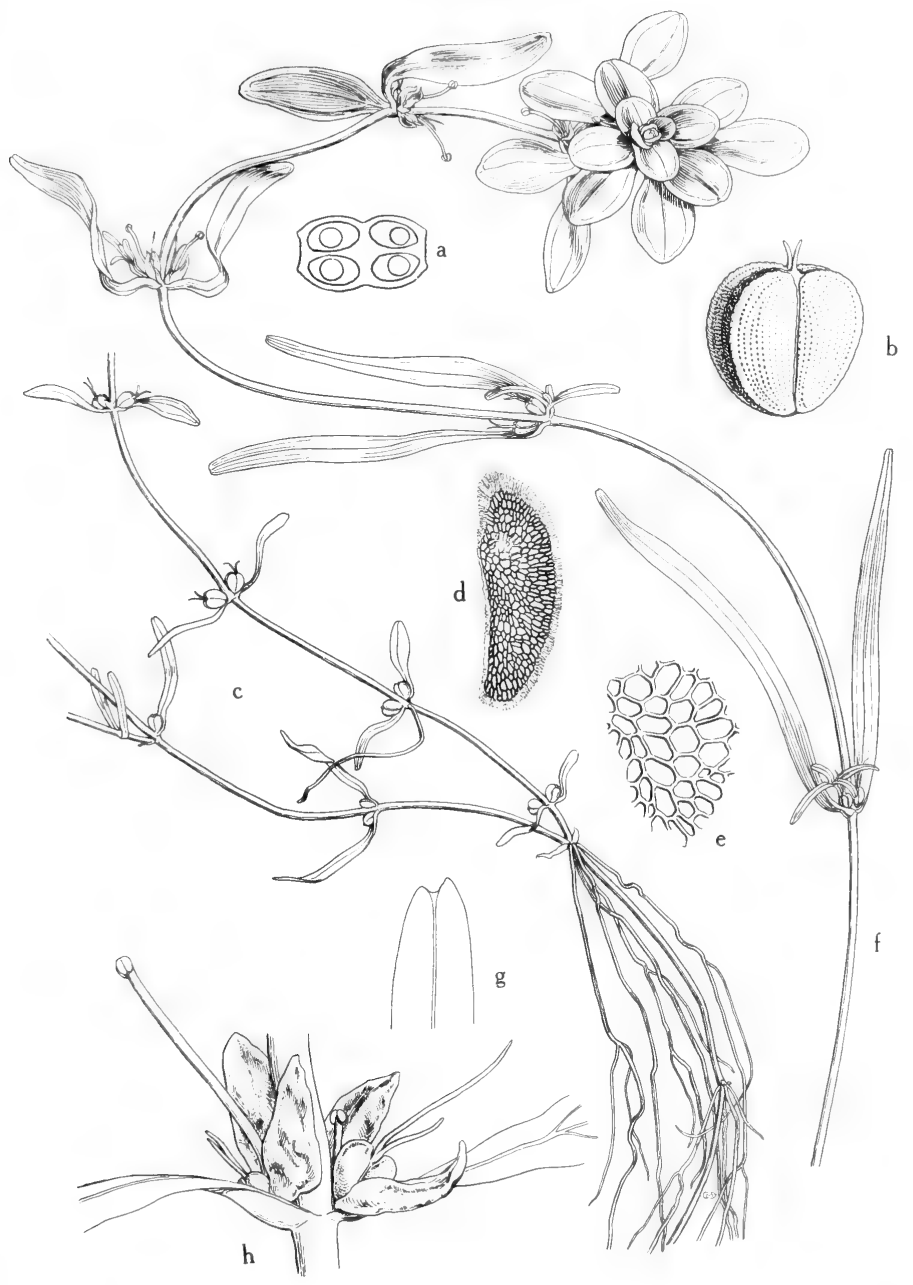

Fig. 511: Callitriche verna: a, fruit (cross section), x 12; b, mature fruit, $\mathrm{x}$ 12; c, habit, lower submersed part of plant, showing the short leaves and the sessile fruits, $\mathrm{x} 11 \% \mathrm{n}$, mature carpel, showing the longitudinal wing, $\mathrm{x} 20$; e, reticulation of carpel surface, $x$ 40; f, habit, showing upper part of stem terminating in a rosette of spatulate floating leaves, the submersed leaves linear, $x$ 11:; $g$, apex of young leaf, slightly notched, $x$ 10; h, flowers, showing the winglike bracteoles, x 8. (From Mason, Fig. 255). 
2. Fruit broader than high; stigmas to $1 \mathrm{~mm}$. long; stamens to $1.2 \mathrm{~mm}$. long and not elongating as the fruit develops; anthers $0.1-0.2 \mathrm{~mm}$. wide; flowers without bracteoles; leaves essentially uniform; plants mostly terrestrial or on mud (4)

$3(2)$. Height of fruit exceeding the width by $0.2 \mathrm{~mm}$; l lower end of mericarps curved outward so that the fruit is thickest at base.......... 2 . C. verna.

3. Height of fruit equaling width or not varying by more than $0.1 \mathrm{~mm}$.; lower end of mericarps straight so that fruit is thickest a little below the middle; commisural grooves very narrow.

3. C. heterophylla.

4(2). Fruit 0.3-0.8 mm. wide, more or less gibbous at base.........4. C. peploides. 4. Fruit $0.5-1.2 \mathrm{~mm}$. wide, not gibbous at base (5)

5(4). Fruit pedicelled; wing and thin margin of carpel turned outward at right angles to the surface of the fruit or revolute and appearing like a thickened margin.

5. C. Nuttallii.

5. Fruit almost sessile; margin of carpel appearing as if not winged but under high magnification showing a minute wing; styles usually deflexed.

6. C. terrestris.

\section{Callitriche hermaphroditica L. Fig. 510.}

Fruit 1-2.5 mm. wide, about as high as wide; surface of carpels obscurely and irregularly pitted; margins of carpels with a narrow wing but the outer part of the carpel itself strongly compressed and winglike; style sharply reflexed from between the mericarps, usually breaking and leaving the persistent base; floral bracts absent; leaves lance-linear, uniform, dark-bright-green, with bases clasping the stem.

Submersed aquatic in N.M. (Taos Co.) and Ariz. (Coconino Co.), June-Oct.; Greenl., across Can. to Alas., n. U. S., s. in the w. to Ariz. and N.M.

\section{Callitriche verna L. emend. Kütz. Fig. 511.}

Fruits sessile, suborbicular, 0.6-1.4 mm. wide, the height always exceeding the width, the width greatest above the middle, the thickness at base greater than at summit; face of mericarps sharply reticulate, the reticulations appearing more or less clearly in vertical rows; margins of carpels widely spreading with a definite scarious wing that is always widest at summit and runs a greater or lesser distance down the sides; pale green submersed aquatic or sometimes terrestrial on the margins of ponds or streams; stems to about $5 \mathrm{dm}$. long; leaves very variable, the lower submersed ones often linear, 0.3-1 mm. wide, 1-nerved, shallowly bidentate at apex, the upper ones often dilated and the terminal leaves petioled and narrowly obovate to spatulate and commonly in a floating rosette, various intermediate leaves are present on many plants. $C$. palustris $\mathrm{L}$.

In quiet shallow water or stranded on mud in e. and cen. Tex. through N.M. (Catron, Taos and Sandoval cos.) to Ariz. (Apache, Coconino and Pima cos.), Mar.-June; from Greenl. to Alas., s. to Tex., N.M., Ariz. and Calif.; also Mex., Eur. and Asia.

Young fruits of $C$. verna, when pressed, sometimes widen as they flatten to simulate in outline those of $C$. heterophylla.

\section{Callitriche heterophylla Pursh emend. Darby. Fig. 512.}

Fruit $0.6-1.2 \mathrm{~mm}$. wide, the height equaling the width or not more than $0.1 \mathrm{~mm}$. greater or $0.1 \mathrm{~mm}$. less than the width; carpels more broadly rounded at summit than at base so that the outline of the fruit is slightly heart-shaped, convex on the face and thickest just above the base; margins of fruits wingless or rarely with a narrow wing at the summit; styles 1-6 mm. long, erect or spreading, persistent or caducous; plants rather dark green; leaves of many types, often linear and one- 

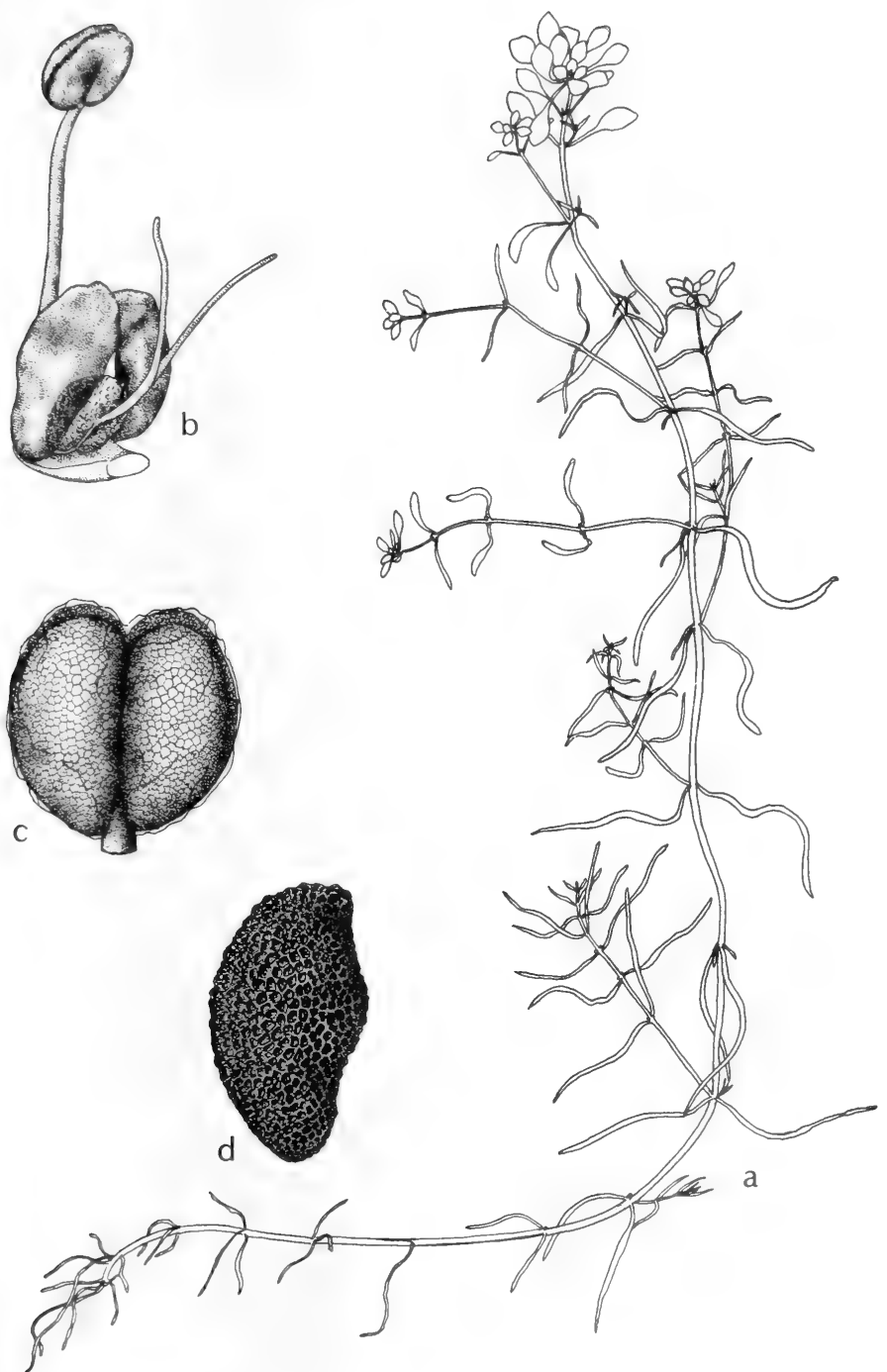

Fig. 512: Callitriche heterophylla: a, habit, x 1/2; b, flower, x 40; c, fruit, x 40; d, mature carpel, x 50. (Courtesy of R. K. Godfrey). 


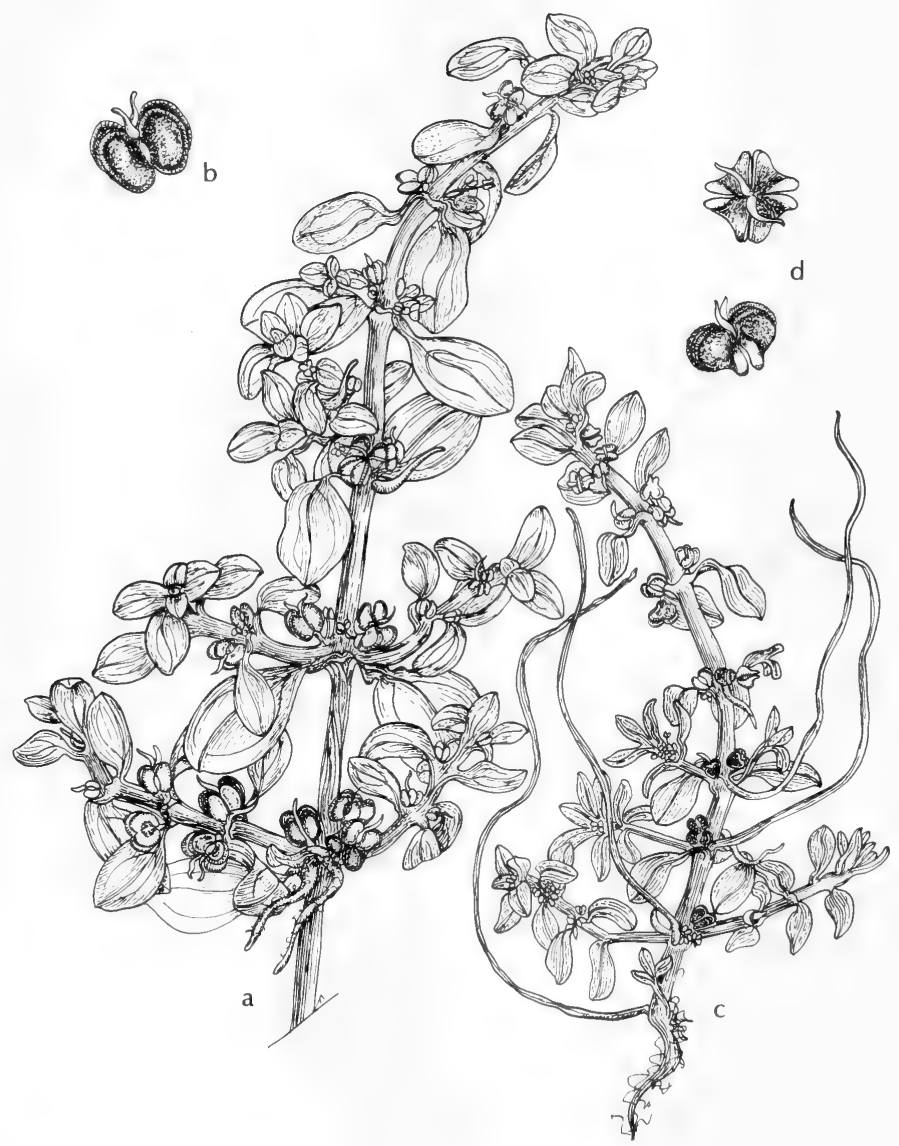

Fig. 513: a and b, Callitriche terrestris: a, habit, x 5; b, mature fruit, x 15. c and d, Callitriche peploides: c, habit, x 5; d, mature fruit, x 15. (V. F.). 
nerved at the lower nodes with a rosette of floating obovate leaves, or (on plants stranded on the mud) all linear or all obovate or oblong; linear one-nerved leaves shallowly bidentate at tip with an enlarged but scarcely excurrent nerve ending.

In quiet waters and on mud throughout Tex. and Okla., N.M. (Catron and Taos cos.) and Ariz. (Coconino, Gila, Pima and Santa Cruz cos.), Feb.-Sept.; from e. Can. throughout the U.S., s. through Mex. to Guat.

\section{Callitriche peploides Nutt. Fig. 513.}

Fruit black when ripe, $0.5-0.8 \mathrm{~mm}$. wide, not quite so high; mericarps narrowed and elongate at base, pushing against each other so that each is bent at an angle with the face and the fruit appears greatly thickened at base; stigmas about $0.2 \mathrm{~mm}$. long, often persistent and loosely reflexed; filaments about $0.2 \mathrm{~mm}$. long; anther about $0.1 \mathrm{~mm}$. wide; stems rooting below and apparently creeping, the erect branches $1-5 \mathrm{~cm}$. high; leaves only slightly crowded at the tips of the branches, 2-5 mm. long, cuneate to spatulate-obovate, 1 - to 3-nerved but often so faintly so as to appear nerveless.

On mud and in wet sands throughout the e. half of Tex., Feb.-May; from S.C. to Fla., s.e. Ark. and w. to Tex.; also e. Mex. to C.R.

\section{Callitriche Nuttallii Torr. Fig. 514.}

Fruit with pedicels of various lengths, buried in the mud at maturity, $1 \mathrm{~mm}$. wide, $0.6-0.8 \mathrm{~mm}$. high, $0.3-0.5 \mathrm{~mm}$. thick; mericarps with flat faces, the margins with a thin wing that is curled toward the face to give the appearance of thickened margins; stigmas about $0.8 \mathrm{~mm}$. long, sometimes persistent and loosely ascending or somewhat reflexed; filaments $0.2-0.5 \mathrm{~mm}$. long; anthers $0.2-0.3 \mathrm{~mm}$. wide; plant a minute annual; leaves 3-4 $\mathrm{mm}$. long, 0.5-1.5 mm. wide, oblanceolate-obovate, very obscurely 3 -veined.

In damp soil in fallow fields and flats in e. Tex., Mar.-May; along Gulf Coast from Ala. to Tex., inland to cen. Ala. and Ark.

\section{Callitriche terrestris Raf. emend. Torr. Fig. 513.}

Fruit $0.6-0.9 \mathrm{~mm}$. wide, $0.4-0.7 \mathrm{~mm}$. high, with pedicels mostly $0.2 \mathrm{~mm}$. long or rarely reaching $0.6 \mathrm{~mm}$. long; mericarps usually equally rounded at each end but rarely broadly rounded above so that the fruit becomes slightly heart-shaped; faces of mericarps flat; outer edges of mericarps appearing scarcely winged but under high magnification showing a very narrow wing with radii but little anastomosing of radii; stigmas $0.2-0.4 \mathrm{~mm}$. long, usually persistent and deflexed; anthers $0.1-0.2 \mathrm{~mm}$. wide, on filaments $0.1-0.2 \mathrm{~mm}$. long; a minute annual with simple to much-branched slender stems to about $3.5 \mathrm{~cm}$. long; leaves rather uniform, obovate-oblanceolate to spatulate, $2-3.5 \mathrm{~mm}$. long, 0.6-1 mm. wide, very obscurely 3-nerved. C. Austinii Engelm., C. deflexa A. Br. var. A ustinii (Engelm.) Hegelm.

On damp soil, moist pathways, wet open spots in lawns and other such places in e. Tex. and e. Okla., Mar.-June; from N.E., s. to s.e. Va., w. Ala., La., Tex., Okla., Mo. and IIl.

\section{Fam. 80. Anacardiaceae LindL.}

\section{SumaC FAMILY}

Trees, shrubs or vines with resin-ducts in the bark and sometimes in the herbage, with a resinous or milky and usually acrid juice; leaves alternate or rarely opposite, simple to 3-foliolate or pinnate, deciduous or persistent, usually essentially exstipulate; flowers numerous, small, in terminal thyrses or axillary panicles, or rarely in clusters of spikes, perfect or unisexual through abortion, mostly regular with 5-parted (less often 3- or 4-parted) whorls; receptacle various, flat, concave or convex, sometimes forming a cushionlike gynophore, developing into a ring- or 


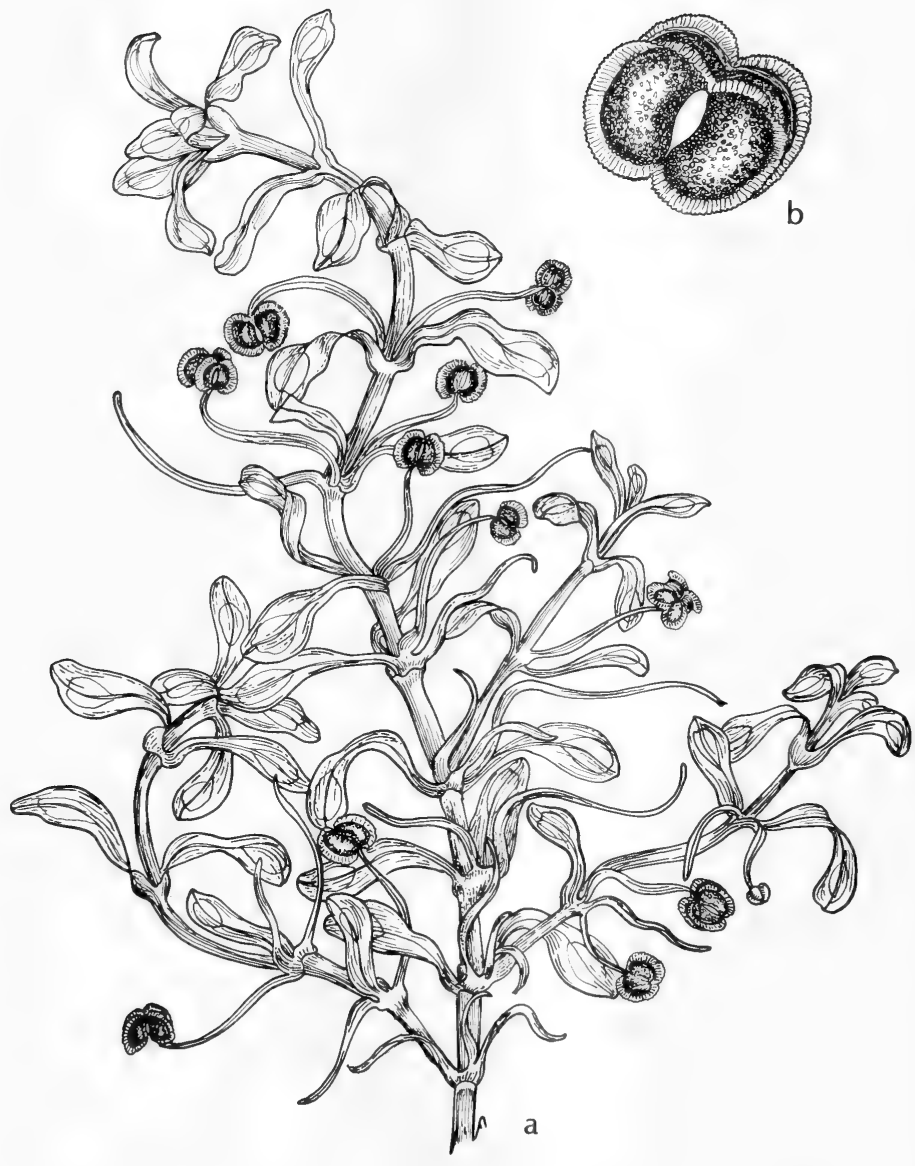

Fig. 514: Callitriche Nuttallii: a, habit, x 5; b, mature fruit, x 25. (V. F.). 
cup-shaped disk; calyx inferior, rarely lacking; corolla seldom lacking; stamens as many as and alternate with the petals, sometimes twice as many or partially aborting; carpels 1 or 2 to 5 united; styles separate or more usually coalesced; fruit various, dry or drupaceous, with resinous or ceriferous mesocarp and crustaceous or bony endocarp (stone); seed with little or no endosperm.

About 60 genera and nearly 600 species, mostly in the tropics.

\section{Rhus L. SumaC}

Shrubs or small trees, rarely vines; leaves alternate, simple or compound (in ours): flowers polygamous, in axillary or terminal panicles; calyx lobes 4 to 6 , usually 5, persistent; petals imbricated in the bud, spreading in anthesis; disk annular; stamens 5; ovary 1-celled, 1-ovuled; styles 3, terminal; drupe small, subglobose or compressed, pubescent or glabrous, the exocarp persistent or deciduous; seed solitary, inverted on a stalk that rises from the base of the ovary.

About 250 species of temperate and tropical regions, most abundant in South Africa. The venacular name is commonly pronounced "shumac."

1. Leaflets 5 to 17 ; large shrubs or trees, always in wet habitats........1. R. Vernix.

1. Leaflets typically 3 ; small shrubs or vines of usually (but not always) dryish habitats (2)

2(1). Terminal leaflet oblong-elliptic, with broad blunt apex; leaflets entire or with shallow rounded lobes or broad blunt teeth; low creeping shrub..............................2. R. Toxicodendron var. Toxicodendron.

2. Terminal leaflet ovate or rhombic, with narrowed apex; usually with some leaflets deeply lobed or sharply toothed (3)

3(2). Petioles and lower surface of leaflets pubescent; low or high-climbing vine, sometimes creeping and with erect branches to $18 \mathrm{dm}$. tall......

.2. R. Toxicodendron var. vulgaris.

3. Petioles and leaflets glabrous; low shrub usually less than $10 \mathrm{dm}$. tall, forming beds from creeping rootstocks........2. R. Toxicodendron var. eximia.

1. Rhus Vernix L. Poison sumac, Poison elder, Poison dogWood. Fig. 515.

Shrub or small tree to $7 \mathrm{~m}$. high; branchlets glabrous, glaucous at first, gray at maturity; leaves odd-pinnate, with glabrous petioles; leaflets 5 to 13 , shortstalked, elliptic to elliptic-oblong, $4-10 \mathrm{~cm}$. long, acuminate at apex, cuneate at base, entire, slightly pubescent at first, becoming quite glabrous, with 8 to 12 pairs of veins; flowers greenish, in slender axillary panicles to $2 \mathrm{dm}$. long; fruit subglobose, compressed, 5-6 mm. across, whitish or light yellowish-gray.

In swamps, bogs, on seepage slopes and in wet thickets in e. Tex., Apr.-June; from Fla. to Tex., n. to N.E. and s.e. Minn.

The plant, at all seasons, is virulently poisonous to the touch. The leaves turn to orange or scarlet in the fall and are most attractive but dangerous!

\section{Rhus Toxicodendron L. Poison IVy, Poison oAK, Hiedra. Fig. 515A.}

Small shrub or vine with slender glabrate to densely pubescent or puberulent stems and branches, sometimes with aerial root and/or subterranean stolons; leaflets 3 , very rarely with some 5 , variable, at first more or less pubescent, later glabrate (especially above) or somewhat pubescent beneath, ovate to elliptic or rhombic to obovate, entire or irregularly serrate or dentate to regularly lobate-dentate with 3 to 7 rounded blunt or rarely subacute lobes, rounded to acute or acuminate at apex, rounded to cuneate at the base; terminal leaflet 3-20 $\mathrm{cm}$. long, 1.5-13 cm. wide, with a petiolule $1-4.5 \mathrm{~cm}$. long; lateral leaflets somewhat smaller than terminal one, inequilateral, often subentire on the upper margin and 3- to 7-lobed on the lower margin, with petiolules 1-5 $\mathrm{mm}$. long; inflorescence 


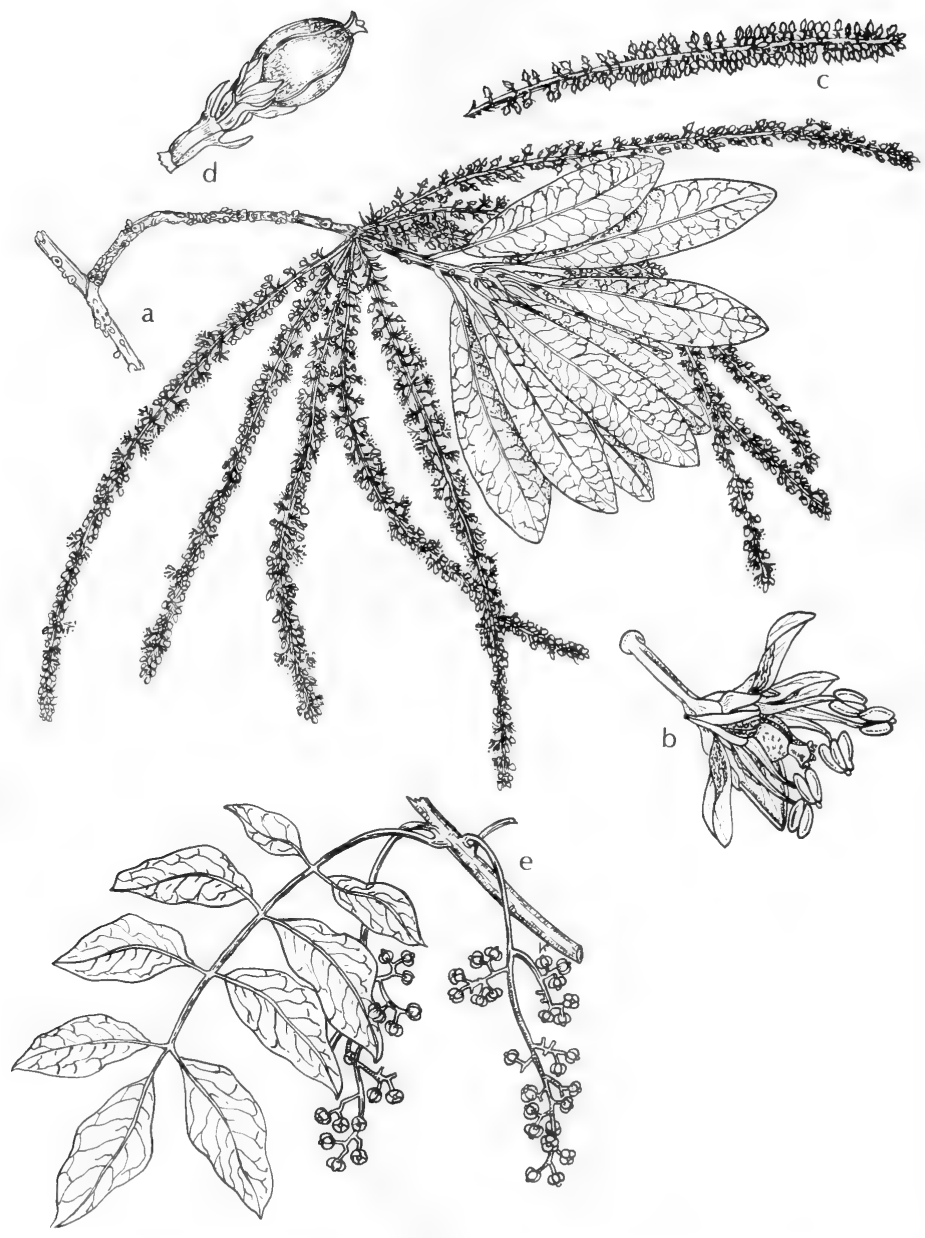

Fig. 515: a-d, Cyrilla racemiflora: a, branchlet with flowers, $\mathrm{x} 1 \frac{1}{2}$; b, flower, $\mathrm{x} 5$; $\mathrm{c}$, one raceme in fruit, $\mathrm{x} 1 / 2$; $\mathrm{d}$, fruit, $\mathrm{x} 5$. e, Rhus vernix: e, branch with fruit, $\mathrm{x} 1 / 2$ (adapted from Sargent, Manual of the Trees of North America, fig. 599). (V. F.). 
composed of lateral panicles; fruit mostly whitish or cream-colored, subglobose, 5-7 mm. in diameter, glabrous or somewhat pubescent; seeds about $4 \mathrm{~mm}$. broad.

An extremely perplexing and ubiquitous assemblage of variants make up this "species." One or more variants are found throughout much of our region where they occur from dry barrens to swampy or boggy habitats, spring-summer; N.S. to B.C., s. to Fla., Ariz. and Oax.

The plants are commonly showy in autumn with the brilliant scarlet or orange tint of their leaves that are very poisonous to the touch. The fumes from burning plants can also be very poisonous.

The following varieties, whose difference are given in the key, are in our region. It is entirely possible that additional variants can be found in our area.

Var. eximia (Greene) McNair [Rhus verrucosa Scheele, $R$. radicans var. verrucosa (Scheele) Fern. and var. Rydbergii (Small) Rehd., Toxicondendron eximium Greene, T. radicans var. eximium (Greene) Barkl. and var, verrucosum (Scheele) Barkl.] In uplands and on limestone outcrops.

Var. Toxicodendron [Rhus Toxicodendron var. quercifolia Michx., Toxicodendron quercifolium (Michx.) Greene]. In sandy woods and open area.

Var. vulgaris Michx. [Rhus Toxicodendron var. microcarpa Michx. and var. radicans (L.) Torr., $R$. radicans L. and var. vulgaris (Michx.) DC., Toxicodendron radicans (L.) O. Ktze.]. Stream bottoms, swampy lowlands or hillside woods or thickets, fencerows and disturbed soils.

\section{Fam. 81. Cyrillaceae Endl. Cyrilla Family}

Shrubs or trees; leaves alternate, simple, without stipules, usually borne at the ends of the branchlets, chartaceous to coriaceous, entire, persistent, petiolate; flowers small, regular, perfect, borne in narrow lateral or terminal racemes or panicles; calyx usually 5- (rarely 4- to 8-) parted; sepals equal or unequal, imbricate, persistent; petals hypogynous, the same number as the sepals, sessile or short-clawed, free (in ours), slightly convolute, deciduous; stamens hypogynous, 5 or 10 , when 5 alternate with the petals, when 10 those opposite petals shorter; filaments subulate or flattened, distinct, sometimes appendaged; anthers basifixed or dorsifixed, 2-celled, longitudinally dehiscent; disk annular, subcupular or cylindric, confluent with the base of the ovary; ovary superior, 2 - to 5-celled, terete or angled; ovules anatropous, 1 or 2 pendulous from the apex of the cell or 3 (rarely 2 or 4 ) attached to a short placenta pendulous from the apex of the cell; style elongate or wanting; stigma entire or 2- to 5-lobed; fruit small, crustaceous or spongy, indehiscent, sometimes winged; seed usually solitary in each cavity, elongated, with fleshy endosperm; embryo central, elongated; radicle superior.

A small American family of 3 genera and about 13 species.

\section{Cyrilla L.}

A variable but apparently monotypic American genus.

\section{Cyrilla racemiflora L. LeATHERWOOD, BLACK TITI. Fig. 515.}

Usually small trees, to $10 \mathrm{~m}$. tall, with a trunk to $3 \mathrm{dm}$. in diameter; leaves alternate, petiolate, oblanceolate, chartaceous to coriaceous, usually widest above the middle, entire, usually turning a rusty-red or -yellow in the fall; racemes slender, lateral, clustered, arising at the base of twigs of current year, $6-18 \mathrm{~cm}$. long, spreading; flowers numerous, fragrant; pedicels $1.5-3 \mathrm{~mm}$. long, basally jointed, with 1 conspicuous persistent bract at base and 2 persistent bractlets below the calyx; calyx small; sepals 5, equal, acute, coriaceous; petals 5, white, 


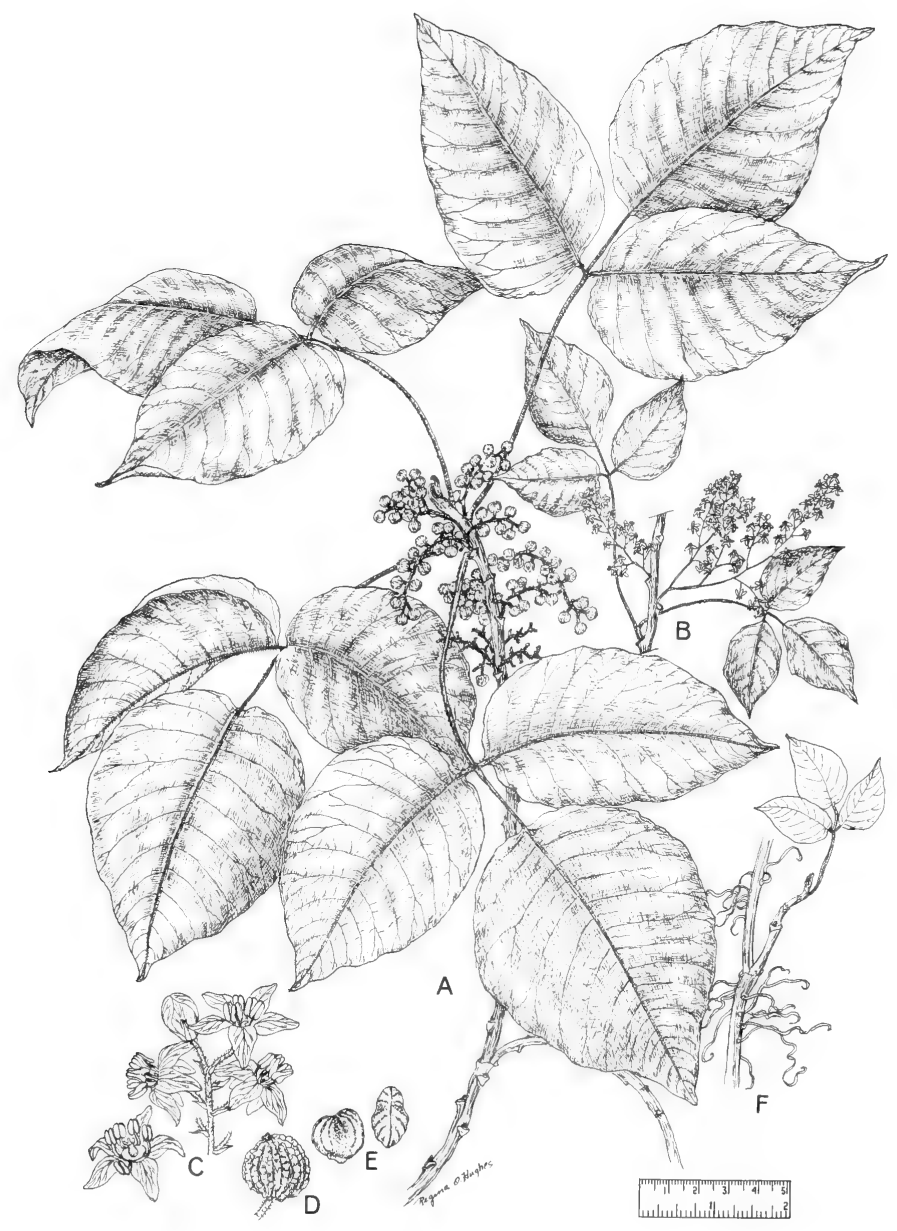

Fig. 515A: Rhus Toxicodendron: A, habit, x 1/2; B, flower panicle, $\mathrm{x} 1 / 2$; C. flowers,

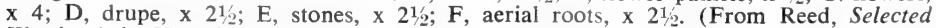
Weeds of the United States, Fig. 126). 
lanceolate to oblong-lanceolate, $2.5-3.2 \mathrm{~mm}$. long; stamens 5 , equal, inserted at the base of the corolla; filaments subulate; disk cylindric; ovary oblong, 2-celled; style short, stigma 2-lobed; ovules 3 (rarely 2 or 4 ) attached to a short placenta pendulous from the apex of the cell; fruit small, indehiscent, ovoid, subterete, 2-3 mm. long, 2-celled, pericarp spongy, cells 1-seeded.

In bottomlands, swamps, boggy areas and along streams in s.e. Tex., $\mathrm{n}$. to Trinity Co., May-July; from s. Va., s. to Fla., w. along the coast to Tex.

We have two noticeably distinct flowering forms; plants with racemes mostly less than $10 \mathrm{~cm}$. long and suborbicular-ovoid apically blunted fruits and plants with racemes more than $10 \mathrm{~cm}$. long and narrowly ovoid pointed fruits.

\section{Fam. 82. Aquifoliaceae BArTL.}

\section{Holly Family}

Shrubs or trees, usually evergreen, mostly polygamo-dioecious; leaves alternate, simple, usually stipulate, petiolate, margin entire to toothed or sometimes spiny; inflorescence normally cymose, pedunculate or sessile, axillary, solitary or fasciculate, 1- to many-flowered; flowers regular, small, usually 4- to 6-parted, sometimes more; calyx small, free from the ovary and drupe, persistent, the lobes imbricate; corolla white or greenish, deciduous; petals imbricate, rarely valvate, alternate with the sepals, free or united at the base; stamens usually 4 to 6 , inserted at the base of the corolla, alternate with the petals, all fertile; filaments subulate, erect, shorter than the petals; anthers introrse, 2-celled, longitudinally dehiscent; staminodia in pistillate flowers similar to stamens, smaller in size, sterile; ovary free, superior, angled or lobed, sessile, usually 2- to 6- (rarely many-)celled; stigma capitate or discoid, usually sessile, with as many lobes as cells in the ovary; ovules 1 (rarely 2) in each cell, suspended, anatropous; ovary in staminate flowers abortive; fruit drupaceous, globose to ellipsoid or rarely lobed, usually containing 4 to 8 (rarely to 18 ) horny or crustaceous stones; stones smooth, ribbed or striate, usually 1-seeded; seed suspended, the testa membranaceous, the fleshy endosperm copious.

A family of three genera containing about 500 species.

\section{Ilex L. Holly}

Shrubs or trees; leaves alternate, petiolate, persistent or deciduous, entire to dentate or spinescent; stipules minute, deciduous; staminate and pistillate flowers on separate plants or occasional flowers appearing perfect, small, axillary, cymose, fasciculate or solitary, usually pedicellate; calyx minute, 4- to 9-parted, persistent; corolla rotate; petals 4 to 9 , hypogynous, elliptic or oblong, obtuse, free or united at the base, white or greenish, deciduous; stamens inserted on the base of the corolla, as many as and alternate with the petals; filaments subulate; anthers attached on the back, oblong, usually rudimentary in the fertile flower; ovary free, sessile, subcylindrical, usually 2- to 8-celled, rudimentary in the sterile flower; style usually wanting; stigmas as many as the cells of the ovary, distinct or confluent; ovules $\mathbf{i}$ or 2 in each cell, suspended from near the apex, collateral, anatropous; fruit drupaceous, subglobose, crowned by the persistent stigma, usually containing 4 to 8 bony or crustaceous stones; stones 1 -seeded, smooth, ribbed or striate.

A genus of about 400 species, widely distributed over the temperate and tropical regions of the world, most abundant in China.

Many species are grown as ornamentals. Their usually brightly colored fruits and mostly evergreen foliage are not only attractive to man, but many species of birds and small mammals eat their fruits and seek their year around shelter. 
1. Fruit red or black, sometimes yellow, with smooth stones; pistillate flowers with usually 6 to 9 petals and calyx lobes (2)

1. Fruit red or purple, sometimes yellow, with ribbed or striate stones; pistillate and polygamous flowers with usually 4 or 5 (rarely 7 ) petals and calyx lobes (4)

2(1). Sepals ciliate; leaves thin, deciduous. 1. I. verticillata.

2. Sepals not ciliate but sometimes obscurely ciliolate or erose-denticulate; leaves coriaceous, persistent (3)

3(2). Young twigs velutinous-puberulent; leaves crenate or crenate-serrate above the middle, the 1 to 3 marginal teeth closely appressed to sinus, the apex not noticeably spine-tipped................... I. I. glabra.

3. Young twigs glabrous or viscid-puberulent; leaves mostly spinescent-serrate above the middle, the several teeth erect or spreading, the apex spine-tipped.

3. I. coriacea.

4(1). Leaves relatively thin, deciduous; inflorescence sessile, all the flowers solitary or fasciculate; pedicels without bractlets at base (5)

4. Leaves coriaceous, persistent; inflorescence peduncled, the flowers in cymes or solitary; pedicels with bractlets at base (7)

5(4). Pedicels 4-6 mm. long; leaf blades mostly spatulate to obovate, attenuate at base, commonly emarginate at apex.

4. I. decidua.

5. Pedicels $6-30 \mathrm{~mm}$. long; leaf blades typically obovate-elliptic, cuneate at base, acute to acuminate at apex (6)

6(5). Leaf blades short-hirtellous or puberulent along midvein beneath

6. Leaf blades hirsute along midvein beneath

5. I. longipes var. longipes.

5. I. longipes var. hirsuta.

7(4). Leaf blades essentially entire or rarely with several obsolescent teeth above middle.

8. I. Cassine.

7. Leaf blades coarsely toothed (rarely with some entire in I. opaca) (8)

$8(7)$. Leaf blades only occasionally with some more than $4 \mathrm{~cm}$. long

6. 1. vomitoria.

8. Leaf blades usually much more than $4 \mathrm{~cm}$. long.

7. I. opaca.

1. Ilex verticillata (L.) Gray. Black Alder, Winter-Berry.

Shrub or small slender tree to $5 \mathrm{~m}$. high; leaves with a petiole $1-1.5 \mathrm{~cm}$. long. round-obovate to elliptic or elliptic-lanceolate, cuneate at base, more or less abruptly acuminate at apex, serrate, appressed-pilose or downy to glabrous beneath, dull above, thin-textured, deciduous, to $8 \mathrm{~cm}$. long and $35 \mathrm{~mm}$. wide; staminate flowers clustered, 2 to 10 , all short-stalked, 4- to 6-merous; pistillate flowers shortstalked, 5- to 8-merous; calyx segments obtuse, ciliate; drupes bright-red varying to yellow, 5-7 mm. in diameter; stones smooth on the back.

In or about swamps, pond-margins, river banks and damp thickets in s.e. Tex., Apr.-June; from Nfld. to Minn., s. to Ga. and e. Tex.

\section{Ilex glabra (L.) Gray. InK-BERRy, GallberRy.}

Shrub to $4 \mathrm{~m}$. high, usually much smaller; twigs slender, angled, finely puberulent; leaves persistent, rather crowded on the short twigs, with finely puberulent petioles usually 2-5 $\mathrm{mm}$. long, coriaceous, lustrous above, paler on undersurface, oblanceolate to obovate or elliptic, to $5 \mathrm{~cm}$. long and $3 \mathrm{~cm}$. wide, obtuse and mucronulate at apex, acute to subcuneate at base, the margin distantly serrate above the middle with 1 to 3 teeth on each side or rarely entire, punctate, puberulent above along the elevated midvein; inflorescence axillary, peduncled, the staminate with 3 or more flowers, the pistillate 1- to 3-flowered; peduncles slender, puberulent, to $1 \mathrm{~cm}$. long in staminate inflorescence, shorter in pistillate; pedicels 
puberulent, those of staminate flowers 1-5 mm. long; flowers 5- to 8-parted; calyx glabrous, subcupuliform, 2-3 mm. in diameter, the ovate-triangular lobes often obscurely ciliolate; corolla in staminate flowers to $7 \mathrm{~mm}$. wide; petals united at base, broadly elliptic to suborbicular, to $3 \mathrm{~mm}$. long, the margin subentire; stamens and staminodia shorter that the petals; ovary in pistillate flowers suburceolate, about $2 \mathrm{~mm}$. long, 5- to 8-celled, the stigma discoid; drupe globose, black, 5-8 $\mathrm{mm}$. in diameter, 5- to 8 -sulcate, crowned by the persistent stigma; stones up to 8 in number, not ribbed, about $4 \mathrm{~mm}$. long.

In low sandy soil, usually in pine lands, pine barrens and swamps in n.e. Tex., rare, Feb.-July; from N.S. and e. Mass., s. to Fla. and Tex.

\section{Ilex coriacea (Pursh) Chapm. BAy-Gall Bush. Fig. 516.}

Shrub, usually arborescent, evergreen, to $5 \mathrm{~m}$. high and a trunk $5 \mathrm{~cm}$. in diameter; twigs rather slender, subterete or inconspicuously angled, minutely puberulent; leaves with rather stout puberulent petioles $3-10 \mathrm{~mm}$. long, coriaceous, often rigid, dark-green and lustrous above, paler beneath, elliptic to oblong-elliptic or obovate-elliptic to oblanceolate, to $9 \mathrm{~cm}$ long and $35 \mathrm{~mm}$. wide, the margin entire or with several small spinescent teeth above the middle, not crenulate, the spinescent apex acute to obtuse or rarely subacuminate, acute or sometimes rounded at base, the midvein puberulent above at first and beneath at base, punctate and sometimes glaucous on the undersurface, the costa conspicuous on both surfaces; flowers solitary or fasciculate, usually in the leaf axils, sometimes appearing racemose on short leafy twigs; pedicels without bractlets at base, those of staminate flowers glabrous and 3-6 (rarely 10) $\mathrm{mm}$. long, those of pistillate flowers puberulent and 5-9 (rarely 15) $\mathrm{mm}$. long; flowers 5- to 9-parted; calyx glabrous, the triangular lobes acute and erose-denticulate, equaling or surpassing the tube; corolla white; petals united at base, elliptic to oblong-elliptic, erose, in staminate flowers to $3.5 \mathrm{~mm}$. long, in pistillate flowers smaller; stamens fully three fourths as long as the petals; staminodia about one half as long as the petals; ovary in pistillate flowers depressed-globose, about $2 \mathrm{~mm}$. long including the short thick style; 4 - to 9-celled, the stigma discoid; drupe globose, black, to $8 \mathrm{~mm}$. in diameter, crowned by the persistent stigma; stones as many as 9 , laterally compressed, smooth, to $4 \mathrm{~mm}$. long.

In swamps, low hammocks and along streams in s.e. Tex., Mar.-Apr.; from Va., s. to Fla. and Tex.

This species is commonly confused with the usually smaller I. glabra.

\section{Ilex decidua Walt. Possum-HaW, Deciduous holly, Winter-BerRy.}

Shrub or small tree to $10 \mathrm{~m}$. high, the trunk to $25 \mathrm{~cm}$. in diameter; twigs terete, pale-silvery-gray, glabrous or rarely puberulent, the lateral ones usually spurlike and short, the vigorous shoots slender and elongate; leaves deciduous, usually fascicled on the ends of the short spurlike lateral branches; petioles canaliculate, densely puberulent above with incurved hairs, glabrous beneath, slender, 2-11 $\mathrm{mm}$. long; blades at first membranaceous, firmer with age, pale on undersurface, oblanceolate to oblong-spatulate or obovate to broadly obovate-elliptic, to $8 \mathrm{~cm}$. long and $45 \mathrm{~mm}$. wide, obtuse to rounded or obtusely subacuminate at apex, usually emarginate, cuneate or narrowed and acute at base, the margin remotely crenulateserrulate, the small incurved teeth tipped with glands; flowers solitary or fasciculate, usually aggregated at the ends of the lateral spurlike branches of the previous season, rarely solitary on the shoots of the year, appearing with the leaves; pedicels without bractlets at base, glabrous, those of staminate flowers slender and to 12 $\mathrm{mm}$. long, those of pistillate flowers to $6 \mathrm{~mm}$. long; flowers 4- or 5-parted; calyx lobes triangular, acute, entire or denticulate in staminate flowers, sometimes obscurely ciliolate in pistillate flowers, equaling or surpassing the tube; corolla 


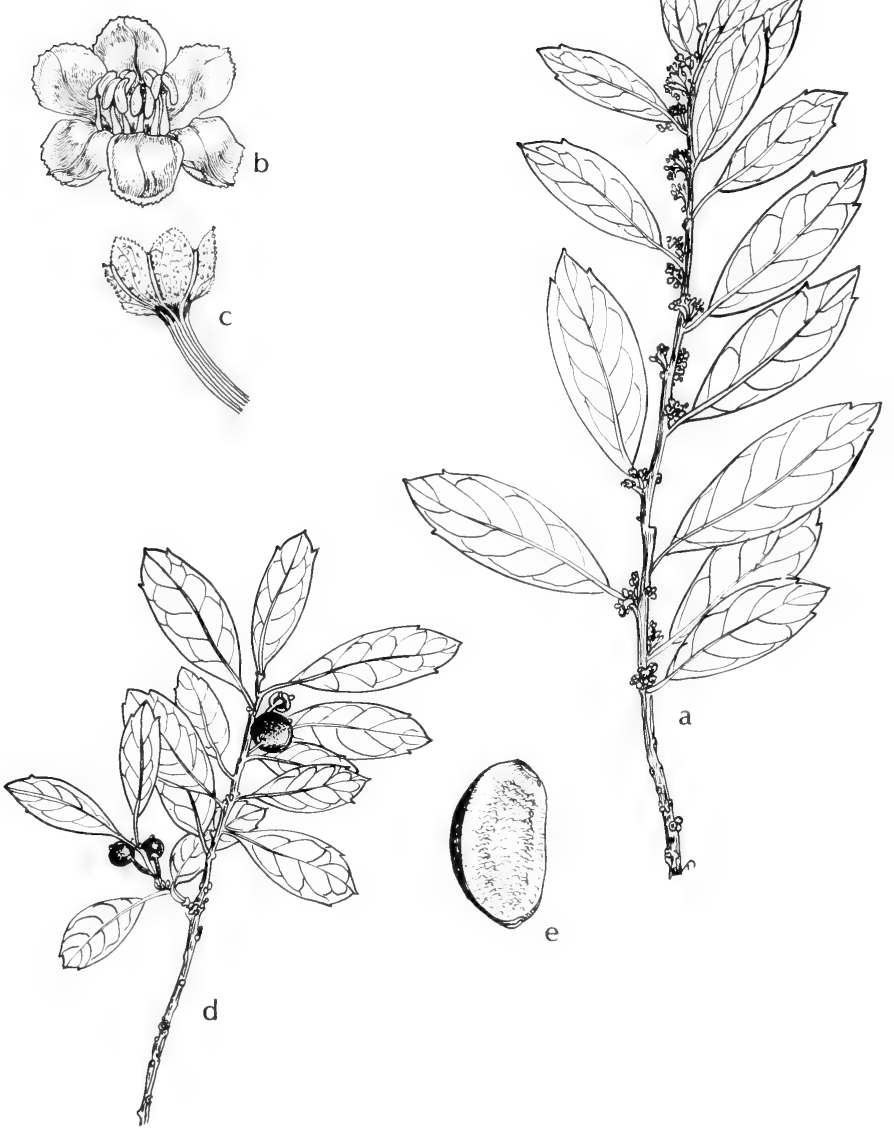

Fig. 516: Ilex coriacea: a, flowering branch, $\mathrm{x} 1 \frac{1}{2} ; \mathrm{b}$, flower from the top, $\mathrm{x} 5$; $\mathrm{c}$, calyx, x 5; d, fruiting branch, x 1/2; e, seed, $x$ 5. (V. F.). 
white; petals united at base, elliptic to oblong-elliptic, $3-3.8 \mathrm{~mm}$. long; stamens in staminate flowers slightly shorter than the petals; staminodia in pistillate flowers about three fourths as long as the petals; ovary in pistillate flowers ovoid, about $1.5 \mathrm{~mm}$. long, usually 4-celled; stigma large, sessile, capitate; drupe globose or depressed-globose, bright-red or orange, to $7.5 \mathrm{~mm}$. in diameter, crowned by the persistent stigma, often persisting on the branches until the leaves appear the following spring: stones usually 4 , strongly ribbed, to $5 \mathrm{~mm}$. long.

In woods, often bordering streams, swamps or ravines in e. and cen. Tex. and e. Okla. (Waterfall), Mar.-May; from Va., w. to Ill., s. to Fla., Tex. and Kan.

\section{Ilex longipes Chapm. Georgia holly, Chapman's holly.}

Shrub or small tree, rarely to $7 \mathrm{~m}$. high; twigs slender, subterete, glabrous; leaves deciduous; petioles slender, canaliculate, puberulent above with minute incurved hairs, 3-10 mm. long; leaf blades membranaceous or chartaceous with age, darkgreen above, paler beneath, elliptic to obovate or oblanceolate-elliptic, to $6 \mathrm{~cm}$. long and $3 \mathrm{~cm}$. wide, short-acuminate to acute or obtusish at apex, minutely mucronulate, subcuneate and acute at base, the margin subcrenulate-serrulate, the teeth subappressed-mucronulate, sparsely short-hirtellous above along the midvein, irregularly ciliolate, short-hirtellous or puberulent beneath along the midvein and primary veins; inflorescence axillary, not peduncled, the staminate flowers fasciculate, the pistillate flowers usually solitary; pedicels slender, glabrous, usually 1-2 $\mathrm{cm}$. long, sometimes to $3 \mathrm{~cm}$. long; flowers 4-parted, small; calyx glabrous; staminate calyx subcupuliform, about $2 \mathrm{~mm}$. in diameter, the triangular lobes acute and denticulate; calyx of pistillate flowers slightly larger; corolla rotate; petals united at base, elliptic, to $3.3 \mathrm{~mm}$. long, not ciliolate: stamens subequaling petals, the staminodia a third shorter than petals; ovary in pistillate flowers ovoid, to $2.5 \mathrm{~mm}$. long, 4-celled, the stigma capitate; drupe globose, 5.5-8 $\mathrm{mm}$. in diameter; stones 4 , inconspicuously striate-sulcate, to $5.5 \mathrm{~mm}$. long.

In swamps, upland forests and often on sandy banks of streams in s.e. Tex., Mar.-May; from N.C. and Tenn., s. to Fla. and Tex.

The var. longipes is usually a larger plant than var. hirsuta Lundell. Characters used in the key are the main ones for separating these two entities.

\section{Ilex vomitoria Ait. Yaupon.}

Shrub or tree, evergreen, to $8 \mathrm{~m}$. high; twigs usually short, rather stout, rigid, obtusely angled, densely puberulent; petioles puberulent, usually $1-3 \mathrm{~mm}$. long. sometimes to $6 \mathrm{~mm}$. long; leaf blades coriaceous, dark-green and lustrous above, paler beneath, elliptic to oblong or oblong-elliptic to ovate-elliptic, sometimes obovate-elliptic, to $55 \mathrm{~mm}$. long and $28 \mathrm{~mm}$. wide, usually much smaller, crenulate to crenate or crenulate-serrulate, the teeth mucronulate, obtuse and usually minutely emarginate and mucronulate at apex, obtuse to rounded or rarely acuti is at base, at first puberulent above along the midvein and at base, glabrous otherwise; inflorescences fasciculate in the leaf axils, the staminate usually 3 -flowered, the pistillate 1-flowered; peduncle of staminate inflorescence short, usually puberulent; pedicels 1.3-3.8 mm. long, those of staminate flowers glabrous, those of pistillate flowers puberulent; flowers 4-parted; calyx glabrous, the broadly ovate or rounded lobes about $0.5 \mathrm{~mm}$. long; corolla white; petals united at base, elliptic to oblong-elliptic, 2-3 $\mathrm{mm}$. long, to $2 \mathrm{~mm}$. wide; stamens subequaling the petals; staminodia shorter than the petals; ovary in pistillate flowers conic-ovoid, $1.5-2 \mathrm{~mm}$. long, 4-celled, the stigma capitate; drupe globose, lucid, bright-red, to $6.5 \mathrm{~mm}$. in diameter, crowned by the persistent stigma; stones 4 , striate, to $4 \mathrm{~mm}$. long.

In low woods, hammocks and sandy pine lands, occasionally in swamps and fioodplain woods, in s.e. and s.-cen. Tex. and s.e. Okla. (Waterfall), Apr.-May; from Va., s, to Fla., Ark. and Tex. 
This is the most abundant of our hollies. The leaves, which contain a caffeine, were used by aborigines to decoct a ceremonial drink.

\section{Ilex opaca Ait. American holly.}

Tree, evergreen, usually small, sometimes to $16 \mathrm{~m}$. high; twigs rather stout, densely puberulent, subterete or striate-sulcate; petioles puberulent, usually 5-12 $\mathrm{mm}$. long, sometimes to $18 \mathrm{~mm}$. long, canaliculate; leaf blades variable, coriaceous, sometimes rigid, dark-green above, paler beneath, elliptic to obovate, to $12 \mathrm{~cm}$. long and $6 \mathrm{~cm}$. wide, acute to subacuminate and spine-tipped at apex, obtuse to rounded or sometimes acutish or subcuneate at base, spinose-dentate or sometimes nearly or quite entire, puberulent above at first along the midvein and at base, often sparsely short-hirtellous beneath along the midvein; inflorescences scattered or fasciculate in the leaf axils, the puberulent staminate cymes 3- to 10-flowered and to $25 \mathrm{~mm}$. long, the pistillate usually 1 -flowered; peduncle of staminate inflorescence to $1 \mathrm{~cm}$. long; pedicels puberulent, those of staminate flowers to $7 \mathrm{~mm}$. long and without bractlets, those of pistillate flowers $2-10 \mathrm{~mm}$. long and bearing 2 bractlets near middle; flowers 4-parted; calyx sparsely puberulent or glabrous, ciliate, the ovate-triangular lobes $1-1.5 \mathrm{~mm}$. long and acute or acuminate; corolla white or yellowish; petals united at base, usually elliptic, to $4 \mathrm{~mm}$. long and $3 \mathrm{~mm}$. wide, sometimes sparsely ciliolate; stamens equaling or exceeding the petals; staminodia shorter than the petals; ovary in pistillate flowers conic-ovoid, about $2.5 \mathrm{~mm}$. long, 4-celled, the stigma capitate; drupe globose or ellipsoid, red, rarely yellow, to $12 \mathrm{~mm}$. in diameter; stones 4 , ribbed, to $8 \mathrm{~mm}$. long.

In moist woods, hammocks, along banks of streams and in swamps in e. and s.-cen. Tex., most abundant near the coast, Apr.-June; from Mass., w. to Wisc., s. to Fla. and Tex.

The small branches of this species, loaded with red "berries," are everywhere gathered for decorative use at Christmas time. Although usually found in welldrained woodlands, the American holly is known to be tolerant of wet, swampy woodlands.

\section{Ilex Cassine L. Dahoon, dahoon holly.}

Small tree, evergreen, to $10 \mathrm{~m}$. high; twigs rather slender, glabrous or pubescent; petioles glabrous or pubescent, canaliculate, stout, to $12 \mathrm{~mm}$. long; leaf blades coriaceous, dark-green and lustrous above, paler beneath, obovate-oblong to oblanceolate or oblong, to $14 \mathrm{~cm}$. long and $45 \mathrm{~mm}$. wide, acute to mucronate or rarely rounded at apex, acute at base, the margin revolute, entire or sometimes serrate above the middle with sharp mucronate teeth, puberulent above, at first densely pubescent beneath but glabrous at maturity except for occasional hairs on the lower surface of the broad midrib; inflorescence peduncled, to $25 \mathrm{~mm}$. long, produced from the young shoots or occasionally from branches of the previous year, the staminate 3- to 9-flowered, the pistillate usually 3-flowered; peduncles and pedicels pubescent, the peduncles to $15 \mathrm{~mm}$. long but usualiy much shorter, the pedicels to $6 \mathrm{~mm}$. long; flowers usually 4-parted; calyx glabrous, $1.5-2 \mathrm{~mm}$. in diameter, the ovate-triangular lobes acute to acuminate and ciliate; corolla in staminate flowers to $5 \mathrm{~mm}$. wide; petals united at base, oblong-elliptic, to $2.5 \mathrm{~mm}$. long; stamens subequaling petals; staminodia in pistillate flowers shorter than petals, the small anthers abortive; ovary in pistillate flowers conical, about $2 \mathrm{~mm}$. long, 4-celled, the stigma capitate; drupe globose, red, 5-6 $\mathrm{mm}$. in diameter; stones 4 , ribbed, about $4 \mathrm{~mm}$. long.

In swamps, hammocks and along streams in s.e. Tex., May-June; from Va., s. to Fla, and Tex.

Texas material is commonly referred to var. latifolia Ait. 
Shrubs, woody vines or small trees; leaves simple, opposite or alternate; stipules lacking or minute, fugacious; flowers with jointed pedicels, regular, perfect or unisexual, 4- or 5-merous, the perianth parts imbricated in the bud; stamens 4 to 10 , commonly as many as the petals and alternate with them, inserted on a broad flat usually lobed disk that fills the bottom of the calyx and sometimes covers the ovary; ovules anatropous; styles completely united; fruit 1- to 5-celled, free from the calyx; seeds mostly arillate.

About 850 species in more than 50 genera, world-wide in distribution.

\section{Euonymus L. SPinde-TreE}

Shrubs or small trees with 4-sided green-barked branchlets; leaves opposite, serrulate; flowers small, perfect, 4- or 5-merous, solitary or in loose pedunculate cymes in the leaf axils; sepals united at the base to form a short flat calyx; petals rounded, spreading; stamens short, inserted on the margin of a broad and flat 4- or 5-angled disk that coheres with the calyx to conceal the ovary and more or less adhere to it; style short or none; capsule 3- to 5-lobed and-valved, loculicidal; seeds 1 to 4 in each cell, enclosed in a red aril.

About 175 species, primarily in North America, Eurasia and Australia.

1. Leaves often essentially sessile, with petioles less than $5 \mathrm{~mm}$. long; flowers 5-merous; fruits tuberculate.

1. E. americanus.

1. Leaves with prominent petiole more than $5 \mathrm{~mm}$. long; flowers 4-merous; fruit smooth (2)

2(1). Leaves ovate-elliptic to elliptic, acute or abruptly short-acuminate, persistently pubescent beneath...2. E. atropurpureus var. atropurpureus.

2. Leaves lanceolate, attenuate at apex into a long acumen, entirely glabrous .2. E. atropurpureus var. Cheatumii.

\section{Euonymus americanus L. Strawberry-BUSh, bursting-heart.}

Low erect or straggling shrub to about $2 \mathrm{~m}$. high; leaves sessile or essentially so, firm, bright-green above, pale beneath, ovate to elliptic or oblonglanceolate, acute to acuminate, crenulate-serrulate, essentially glabrous, to about $1 \mathrm{dm}$. long and $35 \mathrm{~mm}$. wide; flowers solitary or in few-flowered cymes, 5-merous, 1-1.2 cm. wide, greenish-purple; petals distinctly clawed; capsules rough-warty, 3- to 5-lobed, depressed, about $15 \mathrm{~mm}$. thick, crimson when ripe, the aril and dissepiments scarlet.

In mud along streams, swamps, river bottomlands and on forested stream banks in e. Tex. and s.e. Okla. (Waterfall), May-June; from Fla. to Tex., n. to N.Y., Pa., W.Va., Ind., Ill., Mo. and Okla.

\section{Euonymus atropurpureus Jacq. BURNING-BUSH, WAHOO.}

Erect shrub or small tree to $8 \mathrm{~m}$. high; leaves with petioles $1-2 \mathrm{~cm}$. long, oblong-oval to lanceolate, acute to acuminate or long-attenuate, pubescent beneath or entirely glabrous, 7-13 cm. long, serrulate; peduncles 7 - to 15-flowered; flowers dark-red or purple, 4-merous, mostly 6-8 mm. wide; ovules ascending, 2 in each cell; fruits red or purple, depressed-obovoid, about $15 \mathrm{~mm}$. broad, deeply 4-lobed, smooth; seeds brown, with a scarlet aril.

Rich moist woods, bottomlands, swamps, thickets and ravines, mainly in n.-cen. Tex. and e. half of Okla. (Waterfall), Apr.-July; from Ont. to Mont., s. to N.C., Tenn., Ala., Ark., Okla. and Tex.

We have two variants as noted in the key-var. atropurpureus and var. Cheatumii Lundell. 
Trees and shrubs with watery saccharine sap, polygamo-dioecious; leaves opposite, simple and palmately lobed or pinnately divided; flowers small, regular, with or without petals; ovary 2-celled, 2-lobed; ovules 2 in each cell.

Three genera comprising about 200 species in the North Temperate Zone and tropical mountains.

\section{Acer L. MAPLE}

Deciduous trees or rarely shrubs; flowers mostly 5-merous, in racemes, panicles or corymbs; calyx colored, 5 (rarely 4 to 12) -lobed or -parted; petals either none or as many as the lobes of the calyx, equal, usually with short claws, inserted on the margin of a perigynous or hypogynous disk; stamens 3 to 12; ovary 2-celled, with a pair of ovules in each cell; styles 2, long and slender, united only below, stigmatic down the inner side; back of each carpel bearing a wing, converting the fruit into two 1-seeded eventually separable samaras or "keys."

Nearly 200 species in the Northern Hemisphere.

Most of our species are used as street and shade trees, the ubiquitous $A$. Negundo being extensively used in arid regions. Their buds, flowers and fruits are eaten by many kinds of wildlife.

1. Leaves compound, with 3 to 9 pinnately veined leaflets............1. A. Negundo. 1. Leaves simple, palmately veined and mostly palmately lobed (2)

2(1). Leaf margins smooth, not closely serrate; terminal and upper lateral lobes of leaf with straight or concave sides, the lobes somewhat quadrate or squarish; base of sinus between lobes forming a rounded or obtuse angle; the yellowish flowers and fruits produced along with the leaves or after they develop; calyx bearded; fruit more or less pubescent.............................................................2. A. barbatum.

2. Leaf margins more or less closely serrate; terminal and/or at least the upper lateral lobes of the leaf with gradually rounded or tapering sides, the lobes triangular; base of sinus between lobes forming an acute angle; the reddish flowers and fruits produced before leaves develop; calyx and fruit glabrous

3. A. rubrum.

1. Acer Negundo L. Boxelder, ash-leaved maple, arce, fresno de Guajuco.

Small tree with green pubescent to glabrous twigs and branchlets; leaves pinnate, with 3 to 9 petiolulate very veiny and more or less pubescent leaflets, when mature pubescent to glabrate beneath; leaftets $5-10 \mathrm{~cm}$. long and $5-7.5 \mathrm{~cm}$. wide; terminal leaflet elliptic to obovate; lateral leaflets narrower and coarsely few-toothed or entire; leaves of vigorous tips and sprouts with more numerous often lobed leaflets; flowers greenish, unisexual, produced just before the leaves, the staminate flowers fascicled and pendulous on filiform pedicels, the pistillate flowers racemose; petals and disk absent; samaras $25-35 \mathrm{~mm}$. long, yellowish, strongly ascending, the seed prolonged. Rulac Negundo (L.) Hitchc.

River banks, edge of springs, along streams, floodplain woods, waste places, fencerows mainly in the e. half of Tex., Okla. (Bryan and Caddo cos.), N.M. (widespread) and Ariz. (Apache to Mohave, s. to Cochise and Pima cos.), Feb.-Apr.; from Fla. to Tex., n. to w. N.E., N.Y., s. Ont., and s.e. Minn.; much cult. and naturalized e. to Maritime Provinces and e. Que.

Those trees with the branchlets more or less permanently puberulent are usually segregated as var. texanum Pax. 
2. Acer barbatum Michx. Florida maple, southern sugar maple.

Tree to $20 \mathrm{~m}$. high, with thin whitish-gray smooth bark that becomes furrowed in age, the trunk to $7 \mathrm{dm}$. in diameter; branchlets grayish and purple-tinged, glabrous to short-pilose; leaves with glabrous to pilose petioles to $75 \mathrm{~mm}$. long, 3- to 5-lobed, minutely pilose to glabrescent and somewhat glaucescent beneath, to $9 \mathrm{~cm}$. long and $11 \mathrm{~cm}$. broad, truncate to subcordate at base, with entire or slightly lobulate obtuse to acute lobes; flowers yellowish-green, with pedicels elongating to $5 \mathrm{~cm}$., in many-flowered nearly sessile corymbs; calyx to $2.5 \mathrm{~mm}$. long, with a conspicuous long white beard projecting from throat; corolla absent; ovary long-setose; samaras $1.5-3 \mathrm{~cm}$. long, fruit body to $1 \mathrm{~cm}$. long, sparingly villous while young, the wings to $9 \mathrm{~mm}$. wide. A. floridanum (Chapm.) Pax, A. saccharum var. floridanum (Chapm.) Small \& Heller.

Along streams and in wettish flat woodlands in s.e. Tex., Mar.-Apr.; from Fla. to s.e. Tex., n. to e. Va, and s.e. Mo.

\section{Acer rubrum L. Red Maple, SCARlet maple.}

Tree to about $35 \mathrm{~m}$. high, with spreading to ascending smoothish branches to form a globular crown, the trunk to about $1 \mathrm{~m}$. in diameter; branchlets red; leaves with mostly reddish petioles to $1 \mathrm{dm}$. long, 3- to 5-lobed, to $1 \mathrm{dm}$. long and wide, the margins coarsely serrate, broadly cuneate to rounded or subcordate at base, the lobes triangular-ovate and short-acuminate, herbaceous to somewhat coriaceous, dark-green and lustrous above, glaucous and subglabrous to densely whitish- or tawny-pubescent beneath, mostly always pubescent on veins beneath; flowers appearing before the leaves, usually reddish, on slender stalks; petals linear-oblong, about $2 \mathrm{~mm}$. long; samaras $15-25 \mathrm{~mm}$. long, on pendulous stalks to $1 \mathrm{dm}$. long, glabrous, the fruit body about $8 \mathrm{~mm}$. long, the wings to about 12 mm. wide.

Usually in swamps, along streams or in alluvial woods in e. Tex. and Okla. (Waterfall), Feb.-Apr.; from Fla. to Tex., n. to Man. and e. Can.

The var. rubrum has, at most, hairs along the nerves on the lower surface of the leaves, whereas the var. Drummondii (H. \& A.) Sarg. and var. trilobum $\mathrm{K}$. Koch have the lower surface of their leaves densely and usually permanently hairy. In addition, the leaves of var. trilobum have only three well-developed lobes, with the smaller lateral basal lobes being suppressed.

\section{Fam. 85. Balsaminaceae A. Rich.}

\section{TOUCH-ME-NOT FAMILY}

Herbs or undershrubs with bland watery juice; leaves alternate, opposite or rarely whorled, simple, exstipulate; flowers irregular, perfect, hypogynous; calyx petaloid, imbricated, spurred; stamens 5, with short flat filaments and introrse more or less connivent obconic anthers; ovary 5-celled; fruit a capsule or berry; seeds without albumen.

About 500 species in 4 genera, mostly in the tropics of Asia and Africa.

\section{Impatiens L. Touch-Me-not. Jewel-weed. Balsam}

Annual or perennial herbs; stems fistulose, succulent; leaves simple, alternate or whorled; flowers zygomorphic, in pedunculate clusters or 1 to 3 in leaf axils; sepals (in ours) 3, the two upper ones (as the flower hangs on its pedicel) small, the lower saccate one open in front and spurred at bottom of sac; petals 5, appearing to be 3 , the upper one often broader than long, each of the two lateral ones lobed and regarded as 2 petals united; fruit dehiscing elastically into 2 valves.

About 400 species, nearly all of which are in the Old World. 


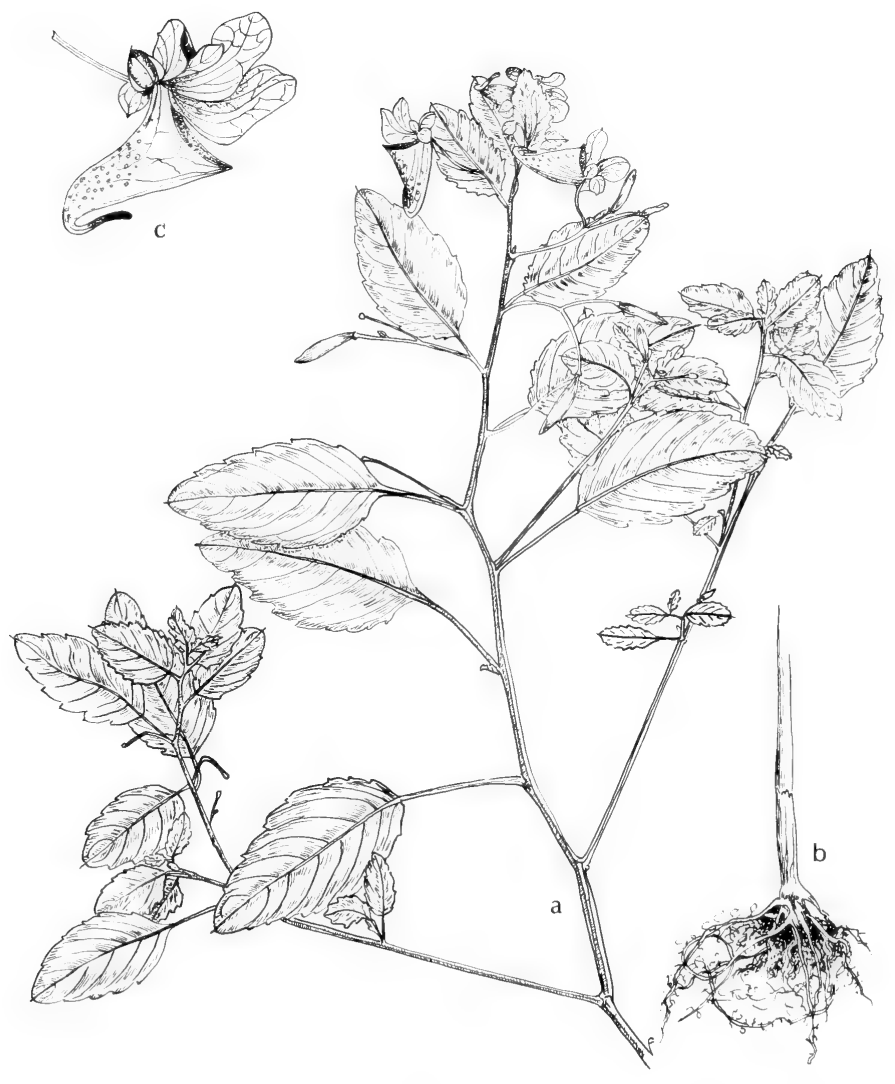

Fig. 517: Impatiens capensis: a, habit, $\mathrm{x} \frac{1}{12} ; \mathrm{b}$, basal part of plant, showing roots, $x \frac{1}{2}$; c, flower, $x 1$. (V. F.). 


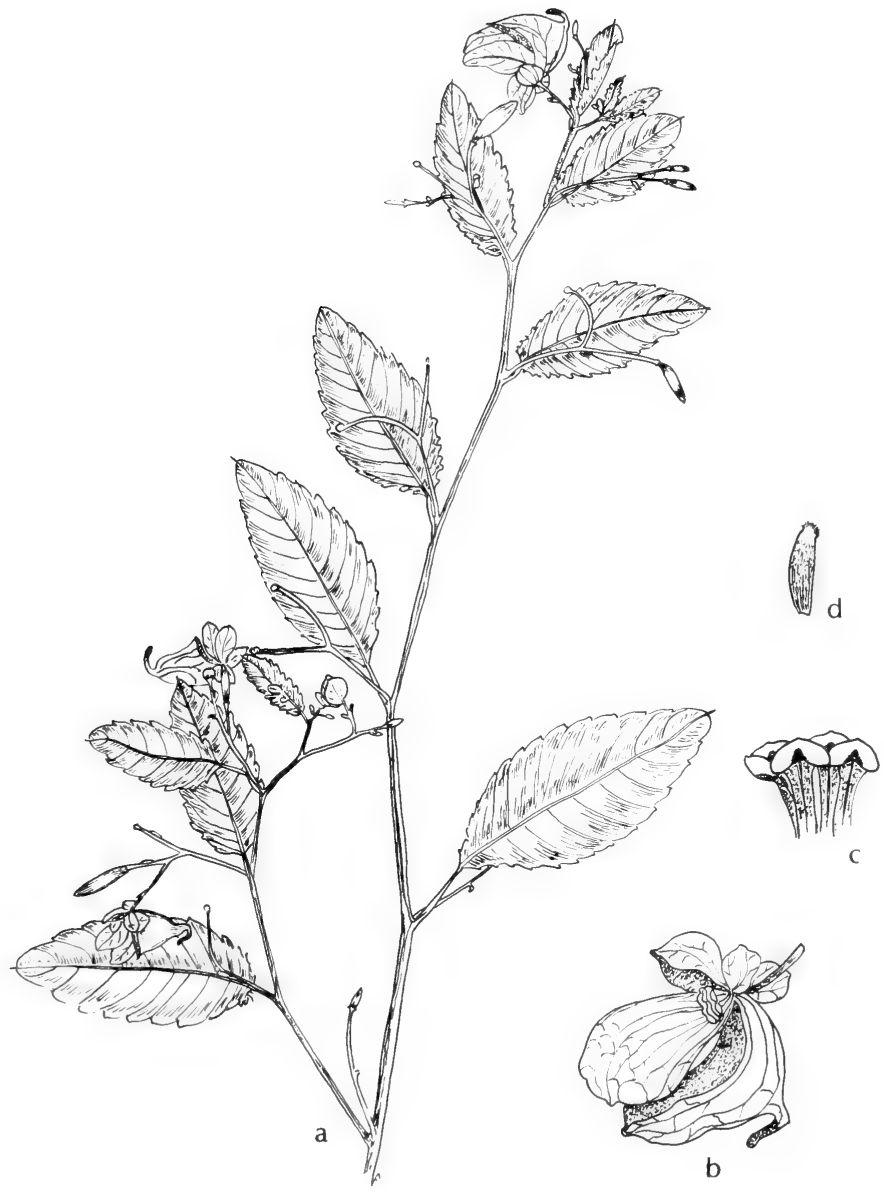

Fig. 518: Impatiens pallida: a, habit, $x \frac{1}{2} ; \mathrm{b}$, flower, $\mathrm{x} 1$; c, stamens, $\mathrm{x} 3$; d, ovary, x 3. (V. F.). 
The rapid spread of these species when once they are introduced to a marshy area is due to the explosive nature of the fruit upon dehiscence. This action propels the seeds for some distance from the mother plant.

1. Flower orange to reddish; spur gradually bent parallel with the sac and one third to one half its length, the sac longer than broad.

1. I. capensis.

1. Flower pale-yellow; spur bent at right angles to the sac and one fifth to one fourth its length, the sac broader than long................... I. pallida.

\section{Impatiens capensis Meerb. Spotted touch-Me-Not. Fig. 517.}

Succulent annual, glabrous, bright-green, to $15 \mathrm{dm}$. high, the stems simple or freely branched; leaves with petioles to $1 \mathrm{dm}$. long, broadly ovate to ovateelliptic, obtuse-mucronate at apex, broadly cuneate to rounded at base, pale or glaucous beneath, to $12 \mathrm{~cm}$. long and $8 \mathrm{~cm}$. wide, coarsely crenate-mucronate; flowers axillary or panicled, often both normal and cleistogamous flowers produced; bracts of inflorescence linear-subulate; flowers $2-3 \mathrm{~cm}$. long, pendulous on filamentous pedicels to about $2 \mathrm{~cm}$. long, usually orange-color with crimson spots; sepals apparently 4, the anterior sepal notched at the apex, the large posterior saccate sepal longer than broad and its spur one third to half its length and bent back parallel with it; filaments appendaged with a scale on the inner side, the 5 scales connivent over the stigma; capsules about $2 \mathrm{~cm}$. long, the 5 valves coiling elastically and dehiscing explosively when touched or shaken. I. biflora Walt.

In moist woods, along streams and in springy places in open or shade in e. Tex. and Okla., May-Sept.; from Nfld. and Que. to Alas., s. to Fla. and Tex.

\section{Impatiens pallida Nutt. Fig. 518.}

Freely branched glabrous annual, to about $2 \mathrm{~m}$. tall; leaves elliptic to ovateelliptic, to $13 \mathrm{~cm}$. long and $8 \mathrm{~cm}$. wide, rounded at base, crenate, the petiole to $6 \mathrm{~cm}$. long; axillary panicles small; flowers $2.5-4 \mathrm{~cm}$. long, typically pale-yellow and more or less dotted with red; saccate sepal obtuse, nearly or quite as wide as long, the short (about $5 \mathrm{~mm}$. long) spur abruptly deflexed; capsules $2-2.5 \mathrm{~cm}$. long, 3-4 mm. in diameter; seeds dark-brown, ellipsoidal, 4-6 $\mathrm{mm}$. long, the inner seed coat blue.

Wet woods and meadows in e.-cen. Okla. (Cherokee Co.), May-Aug.; Que. and N.S., w. to Sask., s. to N.C., Tenn., Mo. and Okla.

\section{Fam. 86. Vitaceae Juss. Grape Family}

Shrubs or woody vines with watery acid juice, usually climbing by tendrils opposite the leaves or on the peduncles; leaves alternate, essentially entire to palmately 3- or 5-lobed or compound; stipules deciduous; inflorescences opposite the leaves; flowers often unisexual and perfect on the same plant, small, regular, greenish, 4- or 5-merous, with a minute or truncated calyx (its limb mostly obsolete) and stamens as many as the valvate petals and opposite them; filaments slender; anthers introrse; style short or none; stigma slightly 2-lobed; grape 2-celled, 1-to 4-seeded; seeds bony, with a minute embryo at the base of the hard albumen.

More than 600 species in about 20 genera widespread in tropical and temperate regions.

1. Bark loosening and freely exfoliating in shreds and without lenticels; pith brownish; leaves simple; inflorescence a compound thyrse; petals separating only at base, falling without expanding; seeds mostly pyriform. 
1. Bark tight, covered with lenticels; pith white; leaves rarely simple; inflorescence a dichotomous or umbelliform cyme; petals expanding, free from one another, dropping singly; seeds trigonous (2)

2(1). Cyme dichotomous; flowers 5-merous; disk with entire or crenulate margins 2. Cyme umbelliform; flowers 4-merous; disk deeply 4-lobed

2. Ampelopsis

\section{Vitis L. GRAPE}

Deciduous rarely evergreen polygamo-dioecious viny shrubs, climbing by tendrils; pith brown, interrupted at the nodes by a diaphragm; leaves simple, dentate, mostly rounded and cordate, usually lobed, rarely palmately compound; flowers fragrant, 5-merous, in a compound thyrse opposite a leaf; sepals minute or obsolete; petals cohering at the apex and falling as a whole at anthesis; disk hypogynous, consisting of 5 nectariferous glands alternate with the stamens; ovary 2-celled; cells 2-ovuled; style conical, short; fruit a pulpy 2- to 4-seeded berry; seeds usually pyriform, with a contracted beaklike base, with 2 grooves on the ventral side.

About 60 species in the Northern Hemisphere, mainly in temperate regions.

Most wild grapes provide food, protection and nesting sites for birds, and food and cover for wild animals. Both fresh and dried fruits are eaten. The shreddy bark of most species is also used in nest building.

1. Lower surface of fully grown leaves more or less covered with a permanent indument or (if somewhat naked) either whitened to silvery-bluishgreen, covered with both short and long cobwebby hairs continuous or in patches (floccose) lying parallel to the surface; younger shoots, petioles and peduncles thinly to densely woolly or pubescent (2)

1. Lower surface of fully grown leaves (except usually the veins) green and glabrous or rarely with short straight hairs erect-spreading from surface; younger shoots, petioles and peduncles glabrous or thinly woolly or with short erect-spreading hairs (3)

2(1). Leaves of flowering shoots unlobed or shallowly lobed with the lobes toothed to the base; lower surface of leaves dull-green with a more or less uniform continuous (though often thin) covering of grayish cobwebby hairs..................................................... 1. . cinerea.

2. Leaves of flowering shoots shallowly or deeply lobed, the deeply lobed ones with entire sinuses; lower surface of leaves usually with grayish or reddish-brown cobwebby hairs, sometimes blue-glaucous and thinly hairy..... 2. V. aestivalis.

3(1). Leaves (at least some) deeply lobed (4)

3. Leaves entire or (at most) shallowly lobed (5)

4(3). Axis of inflorescence sparsely and loosely long-pubescent or glabrous; fruit gray-bluish and glaucous; margins of leaves often ciliolate.

3. V. riparia.

4. Axis of inflorescence densely short-pubescent; fruit black, not glaucous; margins of leaves scarcely or not at all ciliolate

4. V. palmata.

5(3). Distribution in mountains of Trans-Pecos Texas and westward

5. Distribution in eastern third of Texas.

5. V. arizonica.

1. Vitis cinerea Engelm. Graybark grape, sweet grape, parra silvestre.

Lax high-climbing vine; growing tips and branchlets angled, permanently closepubescent with ashy-white or gray hairs; diaphragm 3-5 mm. thick; stipules 2-4 $\mathrm{mm}$. long; leaves of fertile branches suborbicular to broadly ovate, with a prolonged 
and tapering triangular apex, 1-2 dm. long above petiole, slightly less wide, the basal sinus either narrow or broad, with irregular usually smallish and shallow apiculate or short-mucronate teeth, either unlobed or with short shoulders or (more rarely) with 2 or 4 prolonged lobes, the upper surface floccose but becoming glabrate, the pale-green or somewhat glaucous lower surface canescent-pilose or grayish-floccose with cobwebby hairs, the looser hairs somewhat deciduous; petiole shorter than the blade, canescent or floccose; thyrse slender, 6-15 cm. long, canescent or gray-floccose, rather open; grapes 4-9 $\mathrm{mm}$. in diameter, blackish or purplish, with a slight bloom, finally sweet; seeds $4-5 \mathrm{~mm}$. long.

River and creek banks, in marshes, about lakes, bottomlands and pond margins in Okla. (Waterfall) and n.-cen. to s.e. Tex., fruiting Sept.-Nov.; from Fla. to Tex., n. to Va., O., Ind., Ill., Ia. and Neb.

Those plants with suborbicular-cordate very shallowly toothed leaves that lack the triangular or 3-lobed aspect of var. cinerea and whose lower surface is prominently soft-pubescent or densely canescent instead of being cobwebby and/or floccose are referred to var. canescens Bailey.

\section{Vitis aestivalis Michx. SUMMer GRAPE, PIGEOn GRAPE.}

High-climbing vine; young branchlets and petioles with rusty or reddish persistent to flocculent-deciduous tomentum or velutinous pilosity; diaphragm 3-4 mm. thick; leaves of fertile branches suborbicular-ovate, cordate, $7-20 \mathrm{~cm}$. long from top of petiole, about as broad as long, the basal sinus mostly deep and prominent, the margins irregularly and not deeply sinuate-toothed and the teeth often sharp, unlobed or merely shouldered to deeply 3- or 5-lobed, upper surface dull-green and essentially glabrous, lower surface with subpersistent but loose and flocculent tomentum of cobwebby hairs, the prominent ribs and veins tomentose to velutinoushispid; thyrse $5-18 \mathrm{~cm}$. long, the axis with cobwebby hairs; grapes 5-12 $\mathrm{mm}$. in diameter, dark-purple or blackish, with a thin bloom, persistent, variable in quality and taste, sometimes sweet and pleasant-tasting; seeds 5-7 $\mathrm{mm}$. long, 4-5 $\mathrm{mm}$. broad.

In sandy soils mostly along rivers and streams in the e. third of Tex. and Okla. (Waterfall), fruiting Sept.-Oct.; from Ga. to Tex., n. to Mass., N.Y., O., Mich. and Wisc.

\section{Vitis riparia Michx. Riverbank GRAPE, Frost GRAPE.}

Vigorous high-climbing vine; new branchlets green or dull-red, glabrous or pubescent and glabrate; diaphragm $0.8-2 \mathrm{~mm}$. thick; leaves of fertile branches with glabrous petioles, $8-18 \mathrm{~cm}$. long from a petiole, about as broad as long, cordateovate, with a prolonged acuminate apex, with a broad open basal sinus, the margins with coarse acuminate teeth and usually conspicuously ciliate, glabrous or glabrate, with 2 or more erect and prolonged lobes $1-4 \mathrm{~cm}$. long; leaves of vegetative sprouts similar or more deeply palmate-lobed; thyrse $4-15 \mathrm{~cm}$. long, its axis and branches sparsely and loosely long-pubescent to glabrous or essentially so; grapes crowded, 8-12 mm. in diameter, purple-black, with heavy bloom, acid; seeds about $5 \mathrm{~mm}$. long. $V$. vulpina of auth.

On trees and cliffs in open woodlands, in alluvial soils along streams and in canyons in the Trans-Pecos, e. to n.-cen. Tex., Okla. (Waterfall) and (?) N.M., fruiting Aug.-Oct.; from Que. to Man. and Mont., s. to Tenn., Mo., Tex. and N.M.

\section{Vitis palmata Vahl. Missouri GRAPE, RED GRAPE, CATBIRD GRAPE.}

Slender high-climbing vine; shoots and flowering branchlets herbaceous, angled, bright-red when fresh; diaphragm 4-5 mm. thick; stipules 3-4 mm. long; tendrils red when young; leaves of fertile branches thin, ovate, long-acuminate, $7-12 \mathrm{~cm}$. long above petiole, about as broad as long, with a broad open sinus to almost trun- 
cate at base of leaf, with little or no cilia on the margins, unevenly large-toothed with sharp or mucronate points, with 2 prolonged acuminate erect lateral lobes; leaves of vegetative shoots larger and with 3 or 5 long-acuminate lobes with broad rounded sinuses; upper leaf surfaces shining dark-green and glabrous except on veins, the lower surface pale and usually retaining pubescence on veins with tufts in the axils; petioles red; thyrse $5-15 \mathrm{~cm}$. long, long-stalked, rather open, its rachis and branches copiously hirtellous; grapes $5-10 \mathrm{~mm}$. in diameter, black or bluish-black, without bloom, the skin thick, finally sweet; seeds $4.5-6 \mathrm{~mm}$. long.

On margins of ponds or sloughs, or in low woods in e. Tex. and s.e. Okla. (Waterfall), fruiting Sept.-Oct.; from La. and Tex., n. to Ind., Ill. and Ia.

\section{Vitis arizonica Engelm. CANYON GRAPE, GULCH GRAPE, PARRA DEL MONTE.}

Grayish more or less shrubby vine, mostly small and weak, much-branched, usually not high-climbing; young parts ashy-gray from a tomentum to essentially glabrous; diaphragm 2-4 mm. thick; stipules $2-3 \mathrm{~mm}$. long; tendrils soon deciduous if not attached; leaves broadly cordate-ovate to nearly reniform, with a triangular apex, 5-12 cm. long above the petiole and mostly slightly broader than long, the basal sinus from narrowly inverted U-shaped to broad and open, the margins with rather small or rarely large sharp and mucronate uneven teeth, commonly obscurely lobed or shouldered, rarely deeply 3 -lobed, at first both sides cottony, with age the upper surface becoming indifferently floccose and the lower surface more or less permanently covered with grayish-white short erect hairs, the lower surface also commonly becoming glabrous and somewhat glossy except for a usual tuft of erect hairs in the vein axils; petioles often pink-tinged and either slightly floccose or glabrous; thyrse $5-10 \mathrm{~cm}$. long, slender-stalked, the short peduncle and rachis more or less floccose to subglabrous; grapes $6-10 \mathrm{~mm}$. thick, black and sometimes with a thin bloom, the skin thin, the pulp juicy and sweet; seeds 4-6 mm. long, 3-4 mm. broad, short-beaked.

Climbing on trees, shrubs and over boulders along streams and in canyons of mts. in the Tex. Trans-Pecos, N.M. (widespread) and Ariz. (Navajo, Coconino and Mohave, s. to Greenlee, Cochise, Santa Cruz and Pima cos.), fruiting Aug.Oct.; from Tex. to Ariz. and n. Mex.

The leaves of var, arizonica are usually smaller and their lower surface is more or less permanently covered with short straight whitish hairs, whereas the var. glabra Munson ( $V$. Treleasei Munson) has leaves to $12 \mathrm{~cm}$. long and their lower surface is essentially glabrous or the vein axils are provided with small tufts of short straight hairs.

Kearney and Peebles has the following to say about this species. "The berries are of good quality for jelly and grape juice and are much eaten by birds. They are also eaten, both fresh and dried, by the Indians. The vines are useful in checking erosion along creeks. The leaves when chewed allay thirst."

\section{Vitis vulpina L. FoX GRAPE, WINTER GRAPE, FROST GRAPE, CHICKEN GRAPE.}

Vigorous high-climbing vine with stout trunk; young growth glabrous or soon glabrate, the branchlets terete; diaphragm 2-6 mm. thick; stipules 5-8 mm. long; leaves of fertile branches thick-herbaceous, broadly cordate-ovate, usually with a long sharp apex, $8-18 \mathrm{~cm}$. long from petiole, longer than wide, the basal sinus prevailingly broadly inverted U-shaped, coarsely and sharply irregularly toothed, unlobed or merely with angled shoulders, upper surface bright-green and lustrous, lower surface lighter-green and usually glabrous except for short straight hairs on veins and as tufts in the axils of veins; petiole shorter than blade, usually with short straight erect or spreading hairs; thyrse loose and open, to $2 \mathrm{dm}$. long; fruiting pedicels about $5 \mathrm{~mm}$. long; peduncles sometimes with an early-deciduous tendril; grapes black and shining, of ten glaucous, $5-10 \mathrm{~mm}$. in diameter, persistent, edible after frost; seeds 5-6 $\mathrm{mm}$. long, 4-5 mm. thick. 
Edge of woods and in woods, fields, along roadsides and on trees along rivers and streams in e. third of Tex. and Okla. (Waterfall), fruiting Oct.-Nov.; from Fla. to Tex., n. to N.J., Wisc. and Neb.

\section{Ampelopsis MichX.}

Climbing or erect shrubs with tight bark and lenticels, the pith white, with or without tendrils opposite the leaves; leaves thin, deciduous; inflorescence a dichotomous cyme; flowers small, greenish, mostly 5-merous and perfect; calyx scarious, saucer-shaped; petals free, spreading; disk cup-shaped, free from ovary except at base, the margins entire or scarcely crenate; berry dry or pulpy; seeds 1 to several, trigonous-obovoid.

About 25 species in North America and Asia.

1. Leaves simple or rarely only shallowly lobed, cordate to truncate at base.

1. Leaves twice-pinnate or ternate, the leaflets small.

1. A cordata.

1. Ampelopsis cordata Michx.

2. A. arborea.

Plant nearly glabrous, high-climbing; leaves petiolate, broadly ovate to suborbicular-ovate, cordate to truncate at base, acuminate at apex, to about $15 \mathrm{~cm}$. long and wide, typically smaller, coarsely and sharply toothed, unlobed or very rarely with some shallowly 3-lobed, dark-green above, pale-green beneath; paniculate cymes lax; style slender; berries oblate, less than $1 \mathrm{~cm}$. in diameter, bluishpurple or greenish. Cissus Ampelopsis Pers.

In rich woodlands and bottomlands along rivers and streams in the e. half and the Panhandle of Tex. and in Okla. (Waterfall), Apr.-June; from Fla. to Tex. and Mex., n. to Va., O., Ind., Ill. and Neb.

\section{Ampelopsis arborea (L.) Koehne. PePPER-VIne.}

Plant nearly glabrous, bushy or high-climbing; leaves petiolate, triangular-ovate in outline, twice-pinnate or ternate, $15 \mathrm{~cm}$. long or more; leaflets ovate to rhombicovate, acute to acuminate at apex, rounded to cuneate at base, the larger ones 3-7 $\mathrm{cm}$. long, coarsely cut-toothed, dark-green above, pale-green beneath; cymes rather short, mostly less than $8 \mathrm{~cm}$. long; disk very thick, adherent to the ovary; berries black, pulpy, subglobose to obovoid, 1-1.5 cm. in diameter. Cissus arborea (L.) Des Moul.

Along streams, in and on edge of swamp forests, in fencerows and waste places, mostly in s. and e. Tex. and Okla. (Waterfall), June-Aug.; from Fla. to Tex. and n.e. Mex., n. to Md., Ill., Mo. and Okla.

\section{Cissus L. Possum-Grape}

A mostly pantropical genus with several hundred species.

1. Cissus incisa (Nutt.) Des Moul. Marine-IVy, ivy treebine, cow-ITCh, hierba DEL BUEY.

A stout heavy vine with warty tight-barked stems to at least $10 \mathrm{~m}$. long from tuberous roots; pith white; leaves petiolate, fleshy-thickened and succulent, to $8 \mathrm{~cm}$. long and about as wide, deciduous or semievergreen, extremely variable, from simple and broadly ovate or ovate-reniform to more or less trilobed or trifoliolate, the margins coarsely and irregularly toothed; leaflets ovate to obovate, cuneate; peduncle at first risually exceeding the subtending leaf, supporting an umbelliform cyme; flowers 4-merous, perfect or unisexual; petals free, spreading; disk a deeply 4-lobed cup that is free from the ovary except at its base; berry obovoid, black, 6-8 $\mathrm{mm}$. long, dry, beaked by the persistent style, on recurved pedicels, 1 - to 4-seeded; seeds trigonous-obovoid. 
Sprawling or climbing over rocks, trees and shrubs in chaparral, salt marshes and open woodlands, in Okla. (Waterfall), throughout most of Tex. but rare or absent in the extreme e. part and in the Panhandle, May-Sept.; from Fla. to Tex. and adj. Mex., n. to Mo. and Kan.

Plants with simple undivided leaves are frequent in the Rio Grande Plains and Valley. There seems to be no other difference, however, that would separate these plants from the typical plants with trilobed or trifoliolate leaves.

\section{Fam. 87. Malvaceae Juss. MaLlow FAMILY}

Plants herbaceous or shrubby, rarely arborescent, with more or less mucilaginous sap, usually pubescent with simple, stellate or forked hairs; leaves simple, alternate, petioled, stipulate; flowers regular, perfect; calyx often subtended by a calyxlike involucel; petals 5, hypogynous, convolute in the bud, asymmetric, more or less united at base to the stamen column; stamens numerous, monadelphous; anthers 1-celled, reniform; pollen grains large, spiny; carpels 3 or more, 1-celled; style usually several-branched; fruit a loculicidal capsule or (in most of the genera) the mature carpels separating from one another and from the receptacle; seeds often pubescent.

About 1,000 species in about 75 genera in tropical and temperate regions throughout the world.

A family of highly ornamental plants, with numerous species of Hibiscus, Malva, Abutilon and Althaea under cultivation. It includes the cotton plants (Gossypium spp.), the vegetable okra (Hibiscus esculentus L.) and the marshmallow (Althaea officinalis L.), of Europe, whose mucilaginous root is used in making the popular confection.

Game birds, such as ducks and quail, are known to eat the seeds of some species, especially in the genus Hibiscus.

1. Fruit capsular, loculicidally dehiscent or indehiscent, the cells 5 or fewer, the carpels remaining attached to one another and to the axis; stamen tube usually not filamentiferous at the apex, usually dentate or lobed; involucel usually present but sometimes much-reduced (2)

1. Fruit a schizocarp, the carpels separating finally from one another and from the axis; stamen tube commonly filamentiferous at and often also below the apex (3)

2(1). Ovules solitary in each cell, ascending; capsule depressed, saliently 5-angled 3. Kosteletzkya

2. Ovules 2 or more in each cell; capsule not depressed or (if lightly so) not saliently angled.

4. Hibiscus

3(1). Involucel of 3 bractlets (4)

3. Involucel none (5)

4(3). Ovules and seeds normally 3 in each carpel; stems erect and tall

1. Iliamna

4. Ovule and seed normally solitary in each carpel; stems prostrate and spreading on ground.

5. Modiola

5(3). Style branches filiform, longitudinally and introrsely stigmatic; carpels reniform to subreniform. 2. Sidalcea

5. Style branches terminating in a capitate or truncate stigma (6) 
6(5). Lateral walls of the carpels firm, persistent; seeds without an aril-like envelope; flowers axillary and solitary or more or less aggregated in racemes, spikes or heads; calyx usually angulate, sometimes much-accrescent, the lobes commonly erect or connivent over the fruit; carpels muticous or acute to birostrate or biaristate, often rugose or muricate, indehiscent or slightly dehiscent at apex.

6. Sida

6. Lateral walls of the carpels fragile, soon disappearing or becoming lacerate; seeds usually more or less enveloped by an arilliform often reticulate endocarp, this sometimes closely adherent to the seed coat; fruit discoid to nearly hemispheric, depressed, the carpels incurved and with a dorsal hispid spur. 7. Anoda

\section{Iliamna Greene Wild Hollyhock}

About 7 species mainly in western United States.

\section{Iliamna grandiflora (Rydb.) Wiggins.}

Erect herbaceous perennial 1-2 m. tall, somewhat suffrutescent at the base; stems glabrate at base, sparsely stellate-pubescent above; leaves $6-10 \mathrm{~cm}$. wide, deeply 5- or 7-lobed, sparsely stellate-pubescent, the hairs more scattered on the upper surface than beneath; leaf lobes lanceolate to triangular, the midlobe from slightly longer to twice as long as the lateral lobes, coarsely toothed with rounded-triangular abruptly apiculate teeth; petioles to $15 \mathrm{~cm}$. long; stipules lance-linear, deciduous; flowers in small clusters in axils of upper leaves and in an interrupted congested spicate or corymbose terminal inflorescence; pedicels stout, 2-15 $\mathrm{mm}$. long, densely pubescent with stellate hairs; involucellate bracts lanceolate, $8-12 \mathrm{~mm}$. long, 2-3 $\mathrm{mm}$. wide, less densely stellate-pubescent than the calyx; calyx densely villous-hirsute with long-rayed stellate hairs, $1-1.5 \mathrm{~cm}$. broad at anthesis, the lobes broadly triangular-ovate and abruptly acute to shortacuminate; petals broadly obovate, rounded, about $3 \mathrm{~cm}$. long, pink, densely villous on the margins of the claws; stamineal column stout, about $1.5 \mathrm{~cm}$. long, hirsute at the base with stiff long-rayed stellate hairs; fruit subglobose, 12-15 mm. broad, about $10 \mathrm{~mm}$. high, deeply retuse at apex; carpels membranous, oblong, half as wide as high, smooth on the sides, pubescent on the back with coarse erect simple hairs about $3 \mathrm{~mm}$. long, dehiscent to the base or nearly so; seeds reniform, 2.5-3 mm. long, brown, muricate with scattered short simple hairs, usually 3 in each carpel, the surface of the seed coat distinctly tesselated by the outlines of the cell walls.

In damp or wet places in mts. of n. N. M. and Ariz., May-Aug.; also Colo. and Ut.

\section{Sidalcea Gray Checker-mallow. Prairie-mallow}

Erect perennial herbs; leaves long-petioled, with orbicular crenately incised to parted or divided blades; flowers in bracteate spikelike racemes, all perfect or with perfect and pistillate flowers or unisexual; calyx without bracteoles; petals purple to rose or white; stamens usually in an upper and a lower series on the stamen column; fruit of 5 to 91 -seeded indehiscent carpels.

About 25 species in western North America. Some of the species, namely $S$. neomexicana, are reported to be used as greens by the Indians.

1. Petals white to cream-colored; inflorescence and calyx densely long stellatepubescent.

1. Petals rose-purple to mauve-colored; inflorescence and calyx sparsely hirsute to glabrescent. .2. S. neomexicana. 


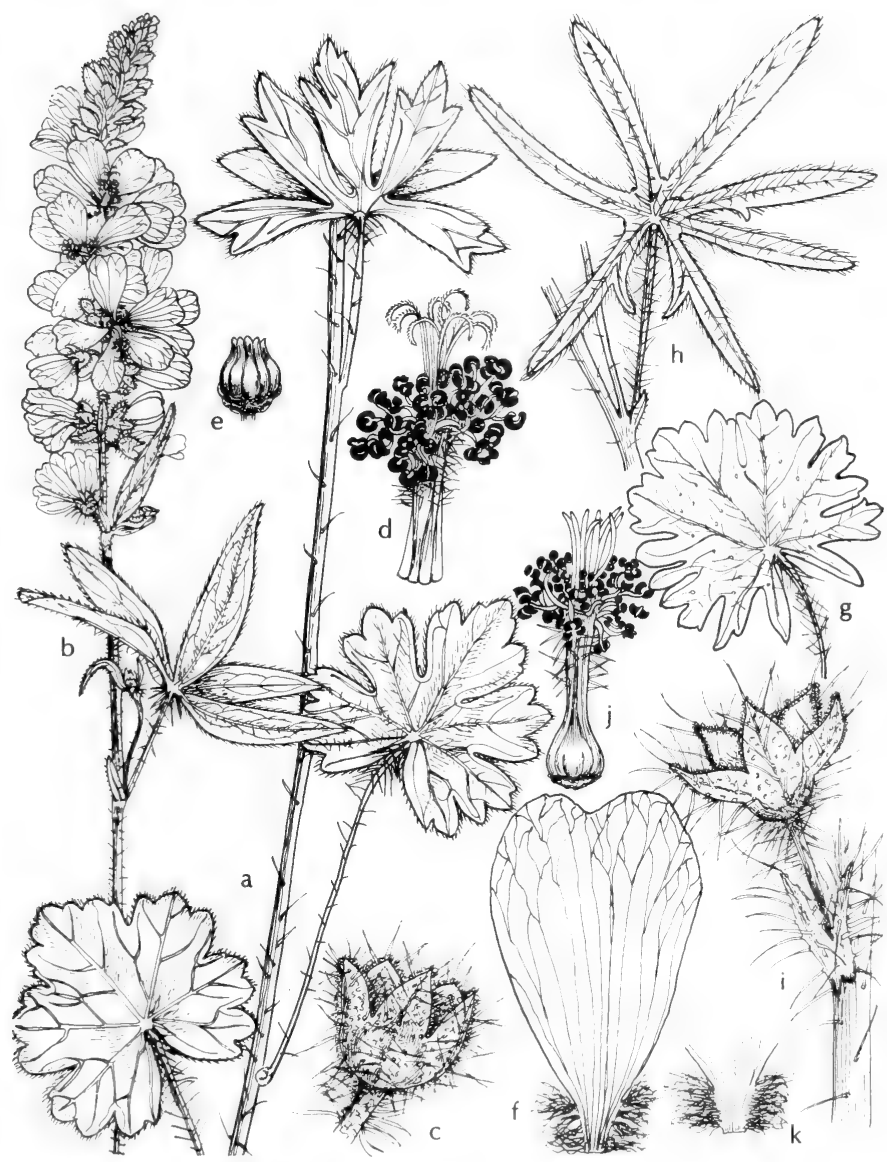

Fig. 519: a-f, Sidalcea candida: a, lower part of stem, x 1/2; b, upper part of plant,

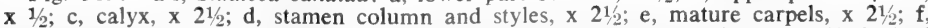
petal, x $2 \frac{1}{2}$, g-k, Sidalcea neomexicana: g, leaf from lower part of stem, x $1 / 2$; h, leaf from upper part of stem, x $1 \frac{1}{2} ; \mathrm{i}$, calyx and bract, $\times 2 \frac{1}{2} ; \mathrm{j}$, stamen column and styles, x 21/2; , base of petal, x 21/2. (V. F.). 


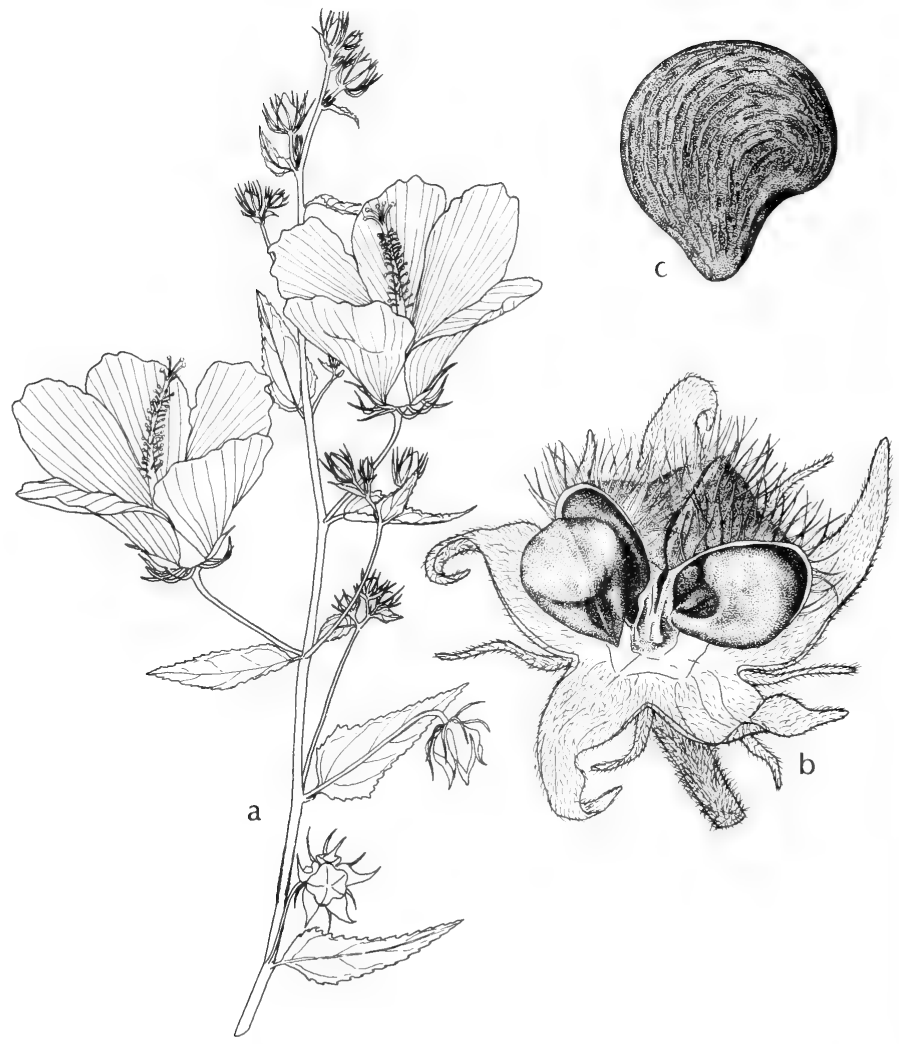

Fig. 520: Kosteletskya virginiana: $\mathrm{a}$, top of plant, about $\mathrm{x} 1 / 2 ; \mathrm{b}$, capsule broken open, x 5; c, seed, x 10. (Courtesy of R. K. Godfrey). 


\section{Sidalcea candida Gray. Fig. 519.}

Stems 4-10 dm. high, simple, erect, usually glabrous to the inflorescence; leaves 4-15 cm. wide, glabrous on upper surface, with a few stiff hairs on lower surface; basal leaves orbicular, typically 7-lobed, coarsely rounded-dentate; cauline leaves cut more than half way to base into 1 to 7 linear-lanceolate mostly entire segments; inflorescence racemose, the rachis and pedicels stellate-pubescent; bracts $8-10 \mathrm{~mm}$. long, bifid; calyx 4-6 mm. long in anthesis, densely stellate-pubescent, the lobes triangular-ovate; petals $10-15 \mathrm{~mm}$. long, white or yellowish.

Wet meadows, edge of ponds and along streams in n. N.M., June-Sept.; Wyo. to Nev., s. to N.M. and Ut.

\section{Sidalcea neomexicana Gray. Fig. 519.}

Stems 1-8 dm. high, hirsute to glabrescent throughout, occasionally a few geminate or stellate hairs on leaves and calyces; leaves orbicular, 1-6 cm. broad, crenate to shallowly 5- to 9-lobed, the lobes crenate; upper leaves 3- or 5-divided, the segments entire or 2- to 5-lobed and ciliate; inflorescence racemose, many-flowered; rachis glabrous to sparsely hirsute or stellate-pubescent; bracts 5-10 mm. long, bifid; pedicels densely hirsute to glabrous; calyx 4-6 $\mathrm{mm}$. long, more or less hirsute and with a few intermingled stellate hairs in some specimens, the lobes triangularovate, acuminate; petals $10-15 \mathrm{~mm}$. long, mauve-colored to rose-purple; carpels 2.5-3 mm. high, nearly as wide, reticulate on the angles, the back usually smooth; beak stout, obtuse, somewhat reflexed, hispid-tipped.

Mountain wet meadows, along streams, in seepage and about pools in N.M. and Ariz., June-Sept.; Wyo. and Ida., s. to Calif. and Mex.

\section{Kosteletzkya Presl Salt Marsh-mallow}

About 30 species, mostly in tropical America and Africa.

\section{Kosteletzkya virginica (L.) Gray. Fig. 520.}

Branched perennial herb closely resembling Hibiscus, to about $15 \mathrm{dm}$. high, rather roughly stellate-hirsute or -tomentose throughout, greenish or somewhat cinereous; leaves gray-green, densely pubescent, the lower ones cordate-suborbicular to -ovate and angulate or coarsely toothed, the upper and bracteal leaves mostly lanceolate and without or with hastately divergent basal lobes; pedicels capillary to coarse and short, frequently equaling or exceeding the bracteal leaves; flowering calyx minutely puberulent to densely pubescent, 5-lobed, $8-13 \mathrm{~mm}$. long, its linear-subulate bracteoles $6-10 \mathrm{~mm}$. long; petals 5 , roseate, $3-4.5 \mathrm{~cm}$. long, 2-3 $\mathrm{cm}$. wide; column (including styles) $15-25 \mathrm{~mm}$. long; fruit prominently 5-angled, depressed; carpels copiously villous-hirsute with hairs $1.5-2 \mathrm{~mm}$. long; seeds smooth, one in each carpel.

In brackish or nearly fresh marshes and along shores of lakes and ponds, and in swamps, along coastal e. Tex., June-Oct.; from Fla. to Tex., n. to Va. and Del.; also Cuba.

Our plant is usually referred to var. althaefolia Chapm. [K. althaefolia (Chapm.) Gray], characterized by having its stems and calyces densely pubescent.

\section{Hibiscus L. Rose-mallow}

Plants perennial or rarely annual, often shrubby; leaves merely crenate or dentate, or pedately cleft; flowers axillary, solitary, the petals $2 \mathrm{~cm}$. long or more; involucel usually present; fruit a loculicidal capsule, the carpels 5; seeds several in each cell, essentially glabrous to long-hairy.

A bout 300 species mainly in tropical and subtropical regions. 
1. Leaves and stems glabrous (2)

1. Leaves and stems more or less variously pubescent (3)

2(1). Bracteoles and calyx densely hirsute 1. H. dasycalyx.

2. Bracteoles and calyx glabrous or very sparsely hirsute. 2. H. militaris.

3(1). Stems usually with prickles; calyx lobes long-attenuate at apex; capsules densely covered with long spreading simple tawny hairs.

3. $H$ cubensis

3. Stems not prickly; calyx lobes mostly acute-apiculate at apex; capsules short stellate-pubescent to glabrous (4)

4(3). Leaves commonly elliptic-lanceolate and broadly cuneate to rounded at base, with age usually becoming glabrous above, gray-pannose beneath; capsules glabrous...................................4. H. Moscheutos.

4. Leaves ovate to ovate-lanceolate, rounded to cordate at base, permanently pubescent on both surfaces; capsules more or less pubescent (5)

5(4). Upper surface of leaves bearing many simple or subsimple hairs; bractlets of involucel ciliate with long simple hairs in addition to being shortly stellate-tomentose; capsules usually densely villous-hirsute.

5. H. lasiocarpos.

5. Both surfaces of leaves with a very fine and dense stellate pubescence; bractlets without long simple hairs; capsules eventually glabrescent.

6. H. leucophyllus.

1. Hibiscus dasycalyx Blake \& Schiller. Fig. 521.

Herbaceous perennial to $15 \mathrm{dm}$. high; stem greenish, terete, glabrous, about 3 $\mathrm{mm}$. thick above; upper nodes mostly $3-5 \mathrm{~cm}$. long; leaves with slender petioles 3-5 cm. long, 3-lobed and hastate at base, 5-9 cm. long, 3-10 cm. wide at base across the lobes, glabrous, the lobes linear-attenuate (3-6 $\mathrm{mm}$. wide) and usually irregularly incised or serrate; flowers 6 or 7, solitary in uppermost axils; peduncles about $15 \mathrm{~mm}$. long, articulate near middle, with spreading hairs above; bracteoles about 12, narrowly linear-attenuate, the inner surface and margins densely hirsute, hirsute to subglabrous on outside, about $15 \mathrm{~mm}$. long, $1-1.5 \mathrm{~mm}$. wide; calyx about $25 \mathrm{~mm}$. long, campanulate, densely spreading-white-hirsute on outside, densely yellowish-pilose with subappressed hairs on inner surface, the lobes deltoid-apiculate and about $7 \mathrm{~mm}$. long; corolla white with a purple spot, when dry about $6 \mathrm{~cm}$. long, the apex spreading; ovary densely and subappressed yellowish-pilose; styles free above and there pilose; fruit unknown.

Rare in marshes and along canals in Trinity Co. in e. Tex., May-July; endemic.

\section{Hibiscus militaris Cav. Scarlet rose-Mallow, halberd-Leaved rose-mallow.} Fig. 522.

Herbaceous perennial, often tinged with red; stems to $25 \mathrm{dm}$. high, essentially glabrous; leaves with slender petioles to $1 \mathrm{dm}$. long or more, triangular-hastate in general outline, glabrous, the basal lobes (if developed) widely divergent, the middle lobe long-acuminate and 2 to 6 times as long as the body of the leaf; bractlets linear-setaceous, tapering to a filiform point, to $3 \mathrm{~cm}$. long; calyx glabrous or very nearly so; petals obovate, pink or whitish with a purplish base, $6-8 \mathrm{~cm}$. long; capsule glabrous or nearly so; seeds pubescent with short reddish-brown hairs.

In marshes and shallow water of lakes, ponds and streams in e. and n.-cen. Tex. and e. and n.-cen. Okla., reported from the Tex. Panhandle, May-Nov.; from Fla. to Okla. and Tex., n. in the interior to O. and Minn.

\section{Hibiscus cubensis A. Rich. Fig. 523.}

Herbaceous perennial, to $3 \mathrm{~m}$. high, densely gray-velutinous throughout (except on corolla) with short stellate hairs; stem (sometimes also the petioles and peduncles) remotely or rather densely aculeate with straight spreading (at length) corky- 


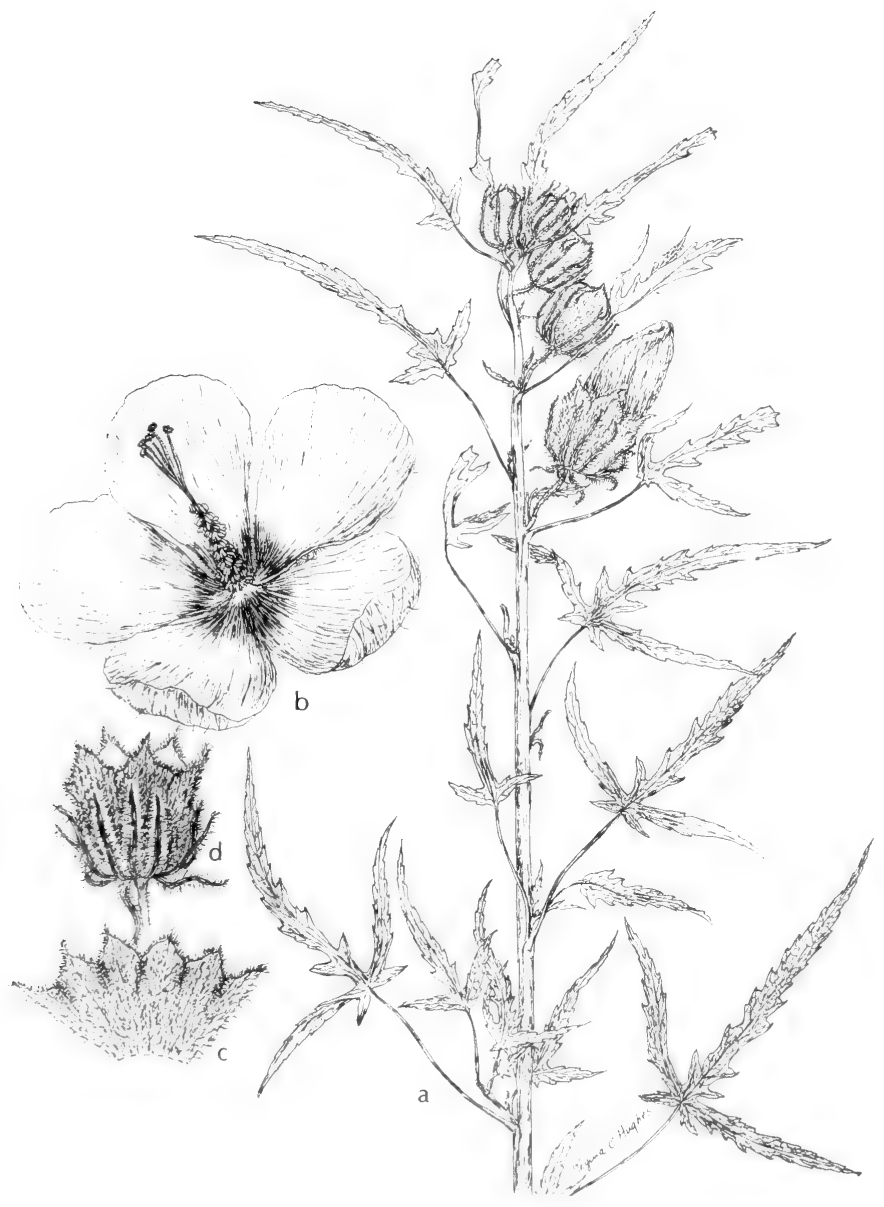

Fig. 521: Hibiscus dasycalyx: a, top of plant, x $1 \frac{2}{2}$; b, corolla, x $1 \frac{1}{2}$; c, calyx spread out, inner view, $\mathrm{x} 1 / 2 ; \mathrm{d}$, calyx, $\mathrm{x} 1 / 2$. (From Blake \& Schiller in Jour. Wash. Acad. Sci. 48: 278, 1958), 


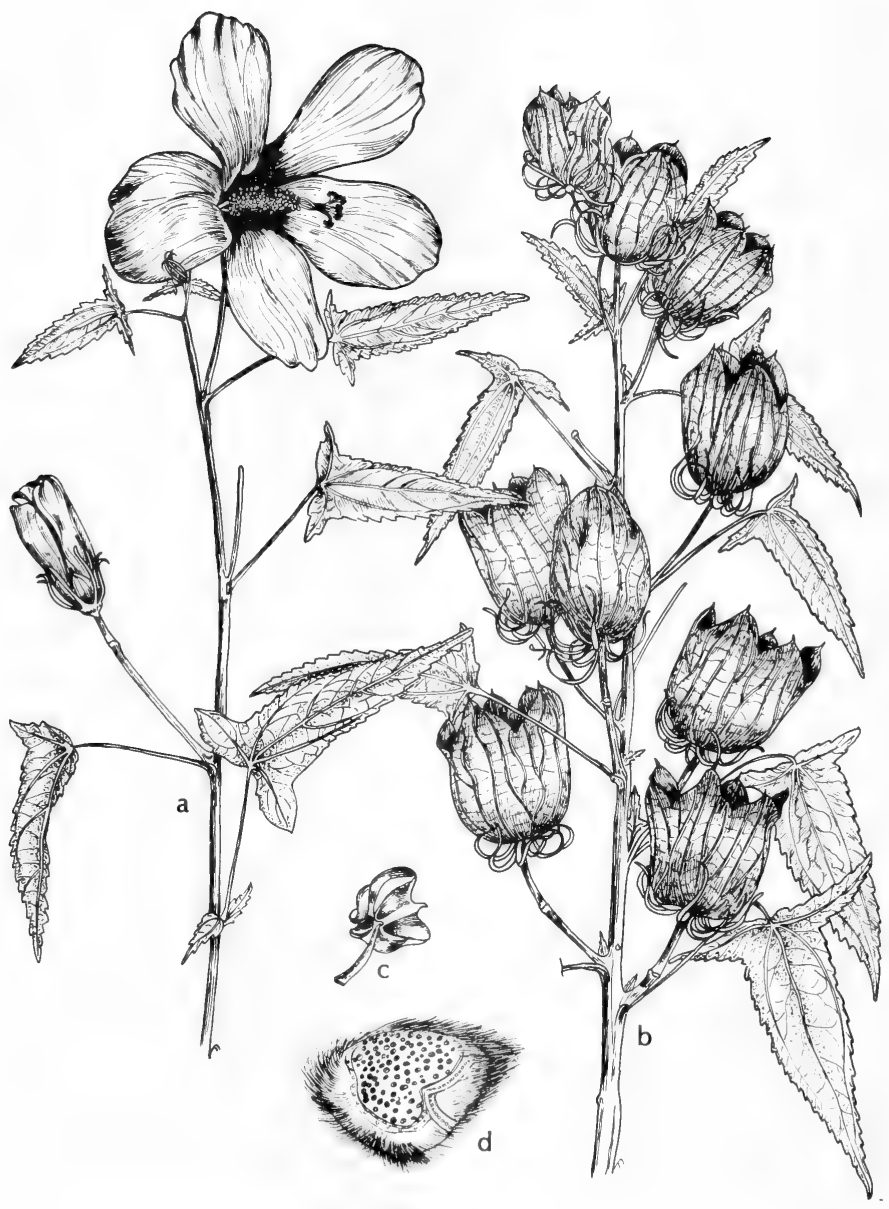

Fig. 522: Hibiscus militaris: a, branch with flower, $\mathrm{x} 1 / 2 ; \mathrm{b}$, branch with fruit, $\mathrm{x}$ $1 / 2$; c, anther, x 5; d, seed, x 5. (V. F.). 
based prickles $3 \mathrm{~mm}$. long or less, the prickles apparently sometimes lacking; leaves with petiole $2-6 \mathrm{~cm}$. long, triangular-lanceolate to oblong-lanceolate or ovate-oblong, $8-11 \mathrm{~cm}$. long, $3.5-5 \mathrm{~cm}$. wide, acute to acuminate, subtruncate to shallowly cordate at base, the margin crenate-serrate throughout, not at all or only obscurely greener above than below; peduncles solitary in the upper axils, to $35 \mathrm{~mm}$. long, jointed almost to the base; bractlets about 12, narrowly linear or (in age) somewhat involute-margined and linear-filiform, 12-15 mm. long, to $1.5 \mathrm{~mm}$. wide, sometimes sparsely hispid as well as densely velutinous, in age reflexed; calyx (in flower) about $28 \mathrm{~mm}$. and at maturity about $32 \mathrm{~mm}$. high, sometimes more or less hispid outside (especially on the nerves), the broadly triangular acuminate teeth about equaling the tube; corolla 8-9 cm. long, purplish-pink with dark-reddish basal blotch, the petals with spreading tips; capsule subglobose, abruptly apiculate, densely spreading-hispid outside with ochroleucous hairs and between them minutely hispidulous, glabrous inside; seeds densely and shortly rufescent-velvety, $2.5 \mathrm{~mm}$. long; styles united to apex; stigmas oblong.

In marshes and along canals in s.e. Tex., May-Oct.; also in temp and trop. Am.

\section{Hibiscus Moscheutos L. Swamp rose-mallow, mallow-Rose.}

Plants erect, to about $25 \mathrm{dm}$. high, the stems minutely stellate-pubescent to glabrescent; leaves with slender petioles to about $5 \mathrm{~cm}$. long, ovate to ellipticlanceolate or lanceolate, canescent-pannose beneath with minute and close down, less so to glabrate and green above, broadly cuneate to rounded or subcordate at base, acuminate at apex, to about $22 \mathrm{~cm}$. long and $9 \mathrm{~cm}$. wide, the margins coarsely incised-dentate, unlobed or with the middle and lower leaves tricuspidate; with one to several peduncles usually fused for as much as three fourths their length to the subtending petiole; bractlets and calyx canescent but not hairy; petals $5-10 \mathrm{~cm}$. long, light creamy-yellow or white with a crimson-purple base; style branches glabrous or remotely hispid; capsule conic-ovoid, tapering to an erect beak, glabrous, $2.5-3 \mathrm{~cm}$. long. H. incanus Wendl.

In marshes and low wet areas on edge of woods, in swamps and wet meadows in e. Okla. and e. Tex., June-Oct.; from Fla. to Tex., n. to Md., Va., W.Va., O and Ind.

\section{Hibiscus lasiocarpos Cav. Woolly rose-mallow. Fig. 524.}

Plants erect, to about $2 \mathrm{~m}$. high, the stems pubescent; leaves with petioles to 1 $\mathrm{dm}$. long, broadly to narrowly ovate, cordate to subcordate at base, acute to acuminate at apex, the margins crenately dentate, occasionally some leaves angulate or somewhat 3-lobed, 1-2 dm. long, more or less velvety-tomentose on both sides with the upper surface bearing many simple or subsimple hairs, the uppermost leaves often ovate-lanceolate; bractlets more or less ciliate with villous or hirsute cover; calyx lobes at maturity prominently 5- or 7-nerved; corolla white to cream-color or pale rose-color with a crimson or deep-purplish-red blotch at base, the petals $7.5-10 \mathrm{~cm}$. long; capsule short-cylindric, subtruncate, usually densely villoushirsute.

In marshes, wet meadows, floodplains, ditches, on edge of lakes and along streams and rivers in e. Okla. and from e. to n.w. Tex. and s.e. N.M., June-Sept.; from Ga. to Tex., $\mathbf{n}$. in the Miss. basin to Ky., Ind., Ill. and Mo.

\section{Hibiscus leucophyllus Shiller.}

Roots perennial, succulent; stems to $8 \mathrm{dm}$. high, somewhat branched upwardly, densely puberulous with minute many-branched sessile stellate hairs; leaves numerous, with petioles to $4 \mathrm{~cm}$. long, densely puberulous like the stems, narrowly ovate, to $14 \mathrm{~cm}$. long and $6 \mathrm{~cm}$. wide, rounded or the larger leaves subcordate at base, sharply long-acuminate at apex, coarsely and bluntly serrate except at very base and at apex, 7-nerved at base, the nerves raised beneath and impressed above, light olive-green above, paler and ashy beneath, densely stellate-pubescent on both sides, 


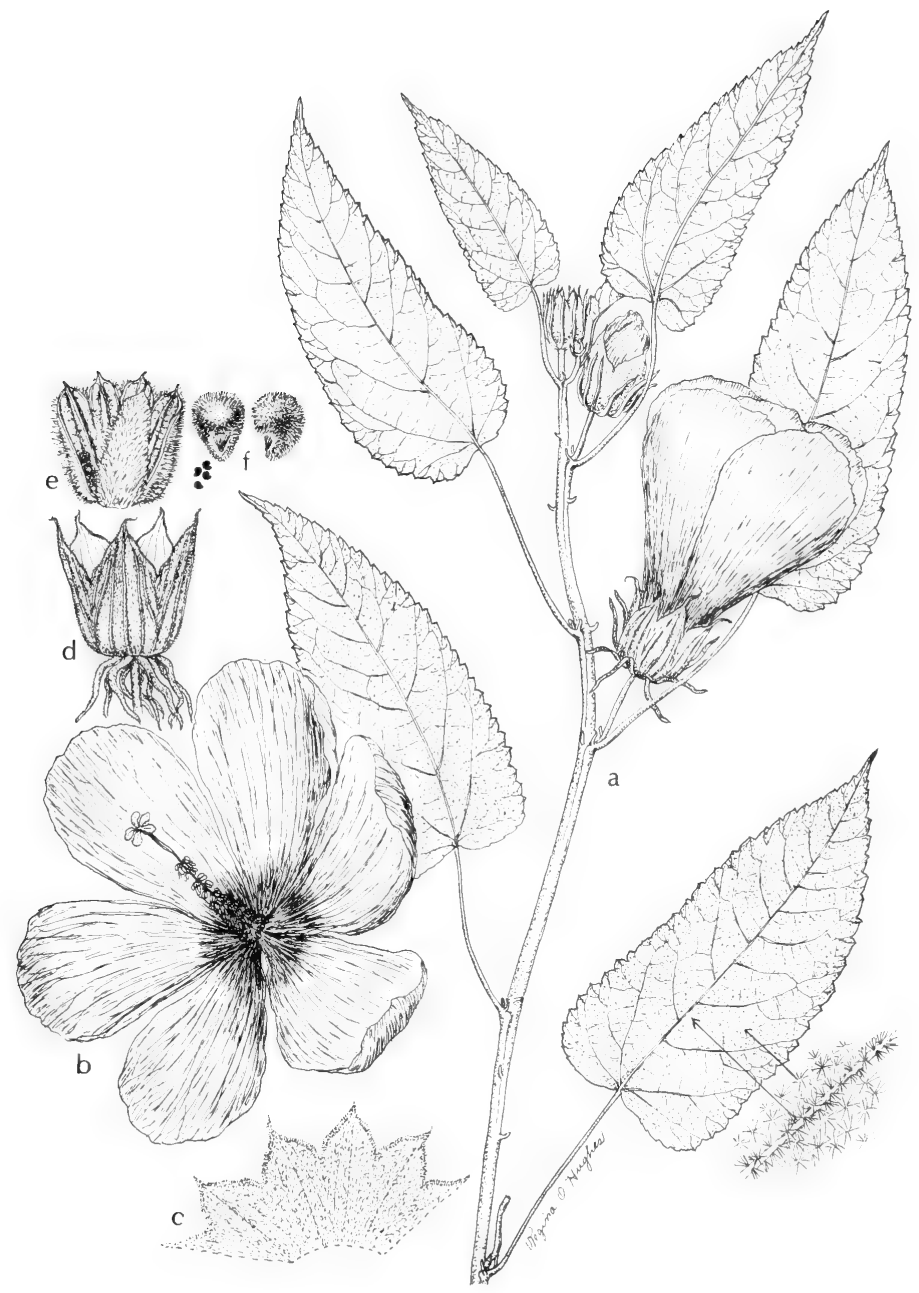

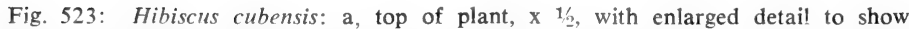
character of hairs; $b$, corolla, $x 1 / 2 ; c$, calyx spread out, inner view, $x 1 \frac{1}{2} ; d$, calyx with fruit removed, $x 1 \frac{1}{2} ; \mathrm{e}$, fruit, $\mathrm{x} 1 / 2 ; \mathrm{f}$, seeds, $\mathrm{x} 1 / 2$, and enlarged to show detail, $\mathrm{x} 4$. (From Blake \& Schiller in Jour. Wash. Acad. Sci. 48: 279, 1958). 


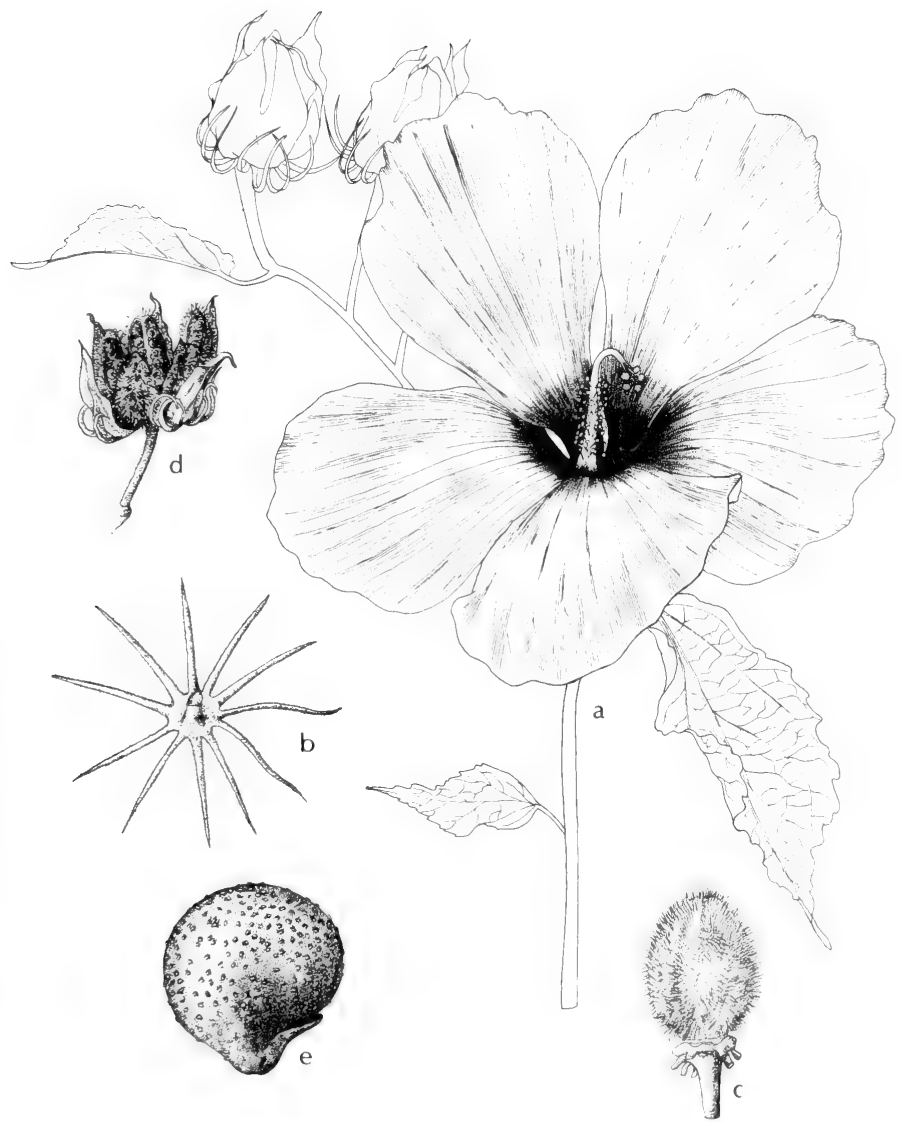

Fig. 524: Hibiscus lasiocarpus: a, top of plant, $\mathrm{x} 1 \frac{1}{2} ; \mathrm{b}$, involucel of bractlets from the base, $x 1$; c, capsule, $x 3 \frac{1}{4}$; d, mature open capsule, $x 1 \frac{1}{2}$; e, seed, $x 9$. (Courtesy of R. K. Godfrey). 
the hairs beneath conspicuously whitish; peduncles axillary, one-flowered, shorter than the pedicels; involucre of numerous linear free bractlets that are much shorter than the calyces, densely tomentulose, lacking long simple bristly hairs on the margins; calyx $2-2.5 \mathrm{~cm}$. long, the ovate lobes longer than the tube, densely stellatetomentulose externally; petals $7-8 \mathrm{~cm}$. long, white with a purple blotch at the base; capsule short-beaked, $2-2.3 \mathrm{~cm}$. long, densely and minutely stellate-tomentose when young, finally glabrescent although with some persistent hairs along the margins of the valves; seeds glabrous.

In sandy wet soils in s.e. Tex., May-July; also La. and Miss.

\section{Modiola MoENCH}

A monotypic genus.

\section{Modiola caroliniana (L.) G. Don.}

Low creeping diffuse chiefly perennial herb, hirsute with simple or geminate hairs, to $6 \mathrm{dm}$. long or more; leaves with petioles to $3 \mathrm{~cm}$. long, rounded, palmately 3 - or 5-lobed and incised, to $6 \mathrm{~cm}$. long and $4 \mathrm{~cm}$. wide; peduncles commonly filiform and equaling or surpassing the petiole; flowers small, solitary on axillary peduncles, subtended by a persistent involucel of 3 foliaceous bractlets; petals small, salmon-color to purpish-red, obovate, 4-6 $\mathrm{mm}$. long, little-surpassing the calyx; stamens 10 to 20; stigmas capitate; fruit depressed, composed of 15 to 30 thin-coriaceous carpels; carpels reniform, much-compressed, more or less hirsute, with a dorsal bipartite cusp and hispid at summit, eventually falling free from the axis and tardily bivalved at the top, eventually becoming somewhat glabrate.

In water and mud on edge of lakes and in salt marshes, lawns and similar places, s.e. Okla. and mostly in s. Tex., Mar.-June; from Fla. to Tex., n. to Va. and s. to Arg.

\section{Sida L.}

Plants mostly perennial, herbaceous or suffrutescent, more or less pubescent with forked stellate or scalelike hairs; flowers axillary, solitary or in small cymules, these sometimes assembled in terminal leafy panicles; involucel usually none; carpels indehiscent or dehiscent only part way from the apex, more or less rugose and often reticulate on the sides.

More than 200 species, mostly in warmer regions of the world, especially in Latin America.

1. Involucel of 1 to 3 subulate bractlets; leaves suborbicular to flabelliform, wider than long, densely stellate-canescent................ $1 . S$. hederacea.

1. Involucel none; leaves oblong to oblanceolate, longer than wide, at most puberulent

2. S. rhombifolia.

\section{Sida hederacea (Dougl. ex. Hook.) Gray. Dollar Weed, alKali mallow.}

Plant with decumbent stems and branches to about $3 \mathrm{dm}$. long, scurfy-canescent with stellate hairs; leaves with petioles about one half as long as blades, obliquely subreniform or triangular-ovate, more or less cordate at base, broadly rounded to bluntly obtuse at apex, to about $4 \mathrm{~cm}$. long and $5 \mathrm{~cm}$. wide, the margins variably and irregularly crenate to acute-serrate; flowers axillary, with pedicels usually slightly longer than the petioles; calyx 4-8 $\mathrm{mm}$. long, the lobes ovate to triangularlanceolate and short-acuminate; petals whitish to cream-color or pale-brownishyellow, rose-color in drying, to about $15 \mathrm{~mm}$. long; carpels 6 to 10 , acutish, tomentulose to glabrate, splitting into 2 valves. S. leprosa var. hederacea (Dougl. ex Hook.) K. Schum. 
In rocky or silty soils, on alkaline floodlands, along irrigation canals and in depressions in s.w. Okla., w. and n.w. Tex., through N.M. and Ariz., Mar.-Oct.; from Wash. and Ida., s. to Mex. and e. to Kan., s.w. Okla. and Tex.

\section{Sida rhombifolia L. Axocatzin.}

Plant herbaceous or shrubby, to about $2 \mathrm{~m}$. high, the stems minutely stellatepubescent; leaves short-petiolate, varying from rhombic-oblong to ovate-cuneate or oblanceolate, obtuse to rounded or subacute at apex, cuneate to rounded at base and usually minutely cordate at the very base, to $8 \mathrm{~cm}$. long and $4 \mathrm{~cm}$. wide, pale and cinerous-puberulent beneath, green and subglabrous above, serrate or serrulate; stipules setaceous, caducous; pedicels more or less elongated; calyx 5-7 mm. long, minutely cinereous-puberulent, the base (at maturity) with 5 to 10 callous-thickened nerves, the lobes broadly ovate and acuminate; petals pale-yellow to orange-yellow, about $6 \mathrm{~mm}$. long, sometimes red at base; carpels 10 , smoothish, subulate 2 -awned or merely acute. $S$. alba Cav.

In sandy-clayey soils in meadows, brushlands, low open woods and alluvial soils in s.e. Okla. and e. third of Tex., apparently isolated in s. Ariz., throughout the year; from N.C. to Fla. and Tex.; widespread, mostly in the trop.

\section{Anoda CAv.}

About 10 species that are confined to the Western Hemisphere.

\section{Anoda cristata (L.) Schlecht.}

Plant branched from near base, erect, to about $8 \mathrm{dm}$. high, sparsely hirsute with mostly simple hairs; leaves petiolate, deltoid to triangular-ovate or -lanceolate, truncate to broadly cuneate at base, acute to acuminate at apex, occasionally hastate or subtrilobate at the base, the margins either irregularly dentate or entire; flowers solitary on long peduncles in the axils; calyx with triangular-lanceolate acuminate spreading lobes to $15 \mathrm{~mm}$. long, often purplish-red; petals purple, commonly cuneiform and retuse, 1-2.5 cm. long; fruit depressed, hemispheric or disklike: carpels 15 to 20, rather conspicuously beaked, hispid, the dorso-basal portion wholly thinscarious and veinless and with slender midnerve, the sides or partitions wholly obliterated in the breaking up of the fruit; seeds naked, puberulent. A. lavaterioides Medic., A. hastata of auth.

In moist meadows and along streams, on gravelly banks and in open woods from w. Tex. to s. Ariz., July-Nov.; also s. to S.A.

The leaves of this species are exceedingly variable, even upon the same individual. Our plant usually has the upper leaves elongated and conspicuously hastate.

\section{Fam. 88. Sterculiaceae BARTL.}

\section{Cacao Family}

Trees, shrubs or herbs, sometimes scandent, the pubescence chiefly of stellate hairs; leaves alternate, simple or rarely compound, usually stipulate; flowers large or small, mostly in axillary cymes, perfect or unisexual, regular or sometimes irregular; calyx persistent, gamosepalous, usually 5-parted; petals 5 or none. hypogynous, free or united with the stamen tube; stamens 5 , connate at least at the base, the tube commonly with 5 staminodia, the 2-or 3-celled anthers borne in the sinuses; fruit dry or rarely baccate, usually 5-celled, variously dehiscent.

About 700 species in 60 genera, mainly tropical and Old World. The seeds of the important tropical American tree, Theobroma cacao L., are the source of cocoa and chocolate. The Chinese parasol-tree, Firmiana simplex W. Wight, is cultivated in central and south Texas, but it apparently does not occur as an escape. 


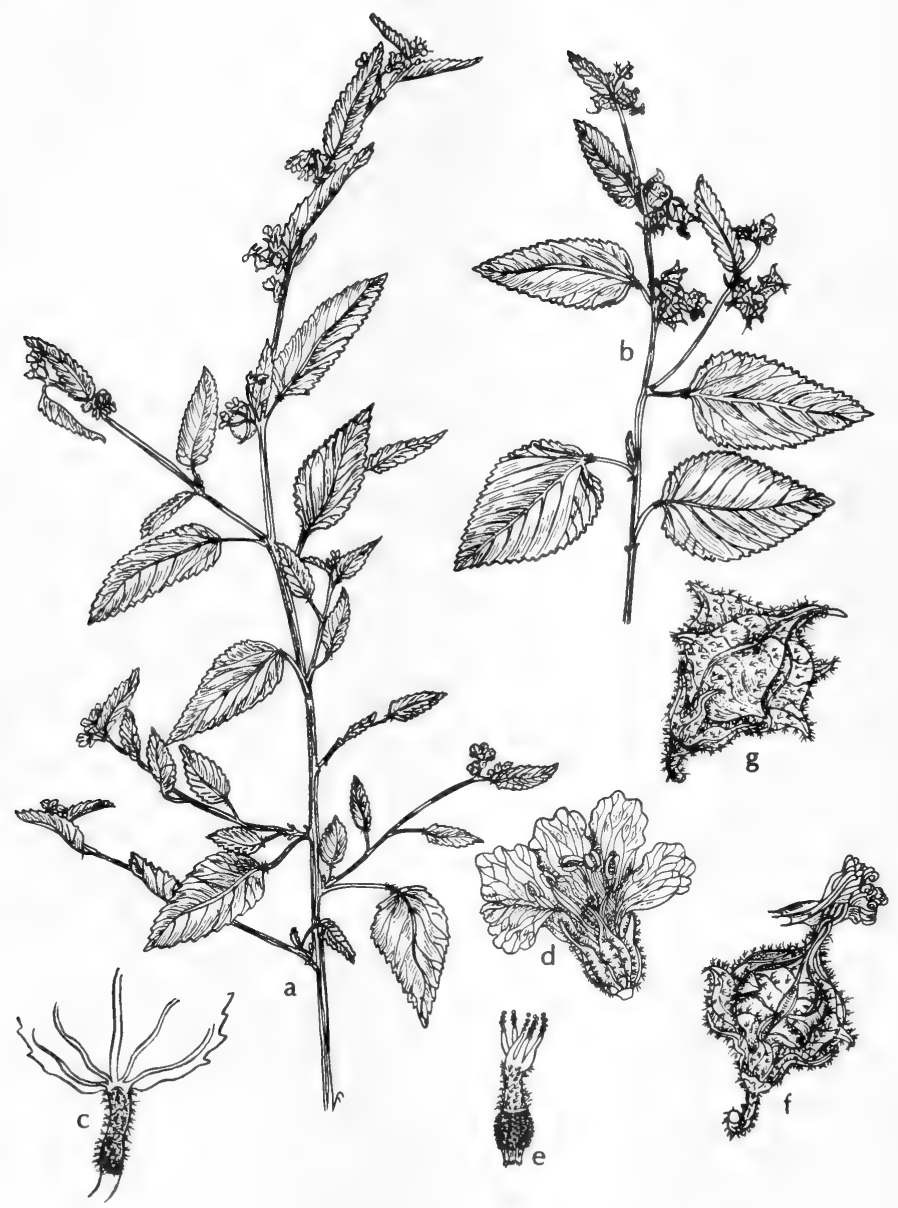

Fig. 524A: Melochia pyramidata: a, upper part of flowering plant, x $1 / 2$; b, upper part of fruiting plant, $\times 1 / 2$; c, petiole just below blade, $x 1 \frac{11}{2}$; d, flower, partly spread open, $x 2 \frac{1}{2}$; e, style, x $2 \frac{1}{2}$; f, young fruit, $\times 2 \frac{1}{2} ; \mathrm{g}$, mature fruit, $x 2 \frac{1}{2}$. (V. F.). 


\section{Melochia L. Broom-wood}

Shrubs or herbs, with pubescence of simple or stellate hairs; leaves dentate; flowers mostly small, in cymes or dense axillary glomerules; involucel present or wanting; calyx 5-lobate; petals 5, spatulate, marcescent; stamens 5, the filaments connate at the base or higher; capsule 5-celled, loculicidally 5-valvate, the cells 1-seeded; carpels easily separating, sometimes indehiscent.

About 75 species in warm regions of both hemispheres.

1. Involucel of 3 or more bractlets; capsule subglobose, scarcely beaked, $5 \mathrm{~mm}$. or less wide................................................... $M$. corchorifolia.

1. Involucel wanting; capsule angular or pyramidal, long-beaked, much more than $5 \mathrm{~mm}$. wide.................................................... . pyramidata.

\section{Melochia corchorifolia L.}

Stem to $15 \mathrm{dm}$. high, glabrous or sparingly pubescent, virgately branched; leaves with petioles to about $2 \mathrm{~cm}$. long, ovate to ovate-lanceolate, to $6 \mathrm{~cm}$. long and $3 \mathrm{~cm}$. wide, irregularly serrate and sometimes lobate, usually entirely glabrous; flower cluster dense; calyx lobes acute; petals purple or with the claw yellowish, 4-7 mm. long; capsule subglobose, strigose with simple hairs, 4-4.5 $\mathrm{mm}$. in diameter.

Old fields, in water of borrow pits and rice fields, cult. grounds and waste places in s.e. Tex., Aug.-Oct.; from Fla. to Tex. and S.C., s. to Braz.; also Old World tropics, where native.

\section{Melochia pyramidata L. Fig. 524A.}

Slender shrub to $2 \mathrm{~m}$. high, often herbaceous, lightly pubescent to glabrate throughout; leaves with slender petioles to $12 \mathrm{~mm}$. long, rounded-ovate to lanceolate, obtuse to short-acuminate at apex, rounded to broadly cuneate at base, to 35 $\mathrm{mm}$. long and $2 \mathrm{~cm}$. wide, serrate, thin, green, glabrous or frequently sparsely pubescent; flowers solitary or in axillary cymes, mostly pedicellate; calyx lobes longacuminate; petals pink or violet, about $7 \mathrm{~mm}$. long; capsule broadly triangular in outline, glabrate or sparsely puberulent, 5-6 $\mathrm{mm}$. long and somewhat broader, the lobes truncate or broadly rounded at base, acute and spreading, seeds dull-brown to black.

In wet sandy or rocky soil in mesquite thickets, palm groves, stream beds, about ponds, ditches and waste places in the Edwards Plateau and Trans-Pecos, s. to the coast in Tex., Apr.-Nov.; widely distributed in the warmer regions of both hemispheres.

We have only var. pyramidata.

\section{Fam. 89. Hypericaceae Juss.}

\section{ST. JOHN'S-WORT FAMILY}

Annual or perennial herbs or shrubs; leaves with or without a basal articulation, opposite, entire, glandular-dotted as seen under a lens with transmitted light, mostly sessile, exstipulate; flowers perfect, usually regular and hypogynous; sepals 4 or 5 , imbricated in the bud, herbaceous, with or without a basal articulation, persistent; petals 4 or 5 , mostly deciduous, oblique and mostly convolute in the bud; stamens many or few, sometimes grouped in 3 or more clusters or bundles; capsule 1-celled, with 2 to 5 parietal placentae and as many usually persistent styles, sometimes 3- to 7-celled by the union of the placentae in the center, mostly septicidally dehiscent; seeds numerous, usually areolate or reticulate.

Approximately 1,000 species in about 50 genera, primarily tropical in distribution. 
1. Sepals 4, in 2 very unequal pairs; petals 4 ; stamens many, distinct

1. Ascyrum

1. Sepals 5; petals 5; stamens many to few, often in 3 to 5 clusters

2. Hypericum

\section{Ascyrum L.}

\section{St. Peter's-wort}

Low smooth pale essentially evergreen shrubs; stems simple or sparsely branched, when young 2-edged or winged; leaves usually numerous, small; flowers solitary or in small cymules, pedicellate, each subtended by a pair of bractlets; sepals 4 , herbaceous, the 2 outer ones broad and leaflike, compressed and persistent, the 2 inner ones usually much smaller; petals 4, pale-yellow, oblique, fugacious, cruciate, spreading, convolute in the bud; stamens numerous, the filaments distinct and not noticeably in clusters, marcescent; capsule 1-celled, ovoid, 2- to 4-valved, enclosed by the sepals; seeds numerous, black, reticulate.

Five species, mainly in southeastern United States; merged with Hypericum by some authors.

1. Styles 3 or 4 ; inner sepals only slightly smaller than the outer ones that are to $2 \mathrm{~cm}$. long and $15 \mathrm{~mm}$. wide; leaves oblong-elliptic, the upper ones somewhat cordate and clasping............................. A. Atans.

1. Styles 2; inner sepals minute or obsolete; leaves mostly linear- to oblongoblanceolate, narrowed at base.. 2. A. hypericoides.

\section{Ascyrum stans Michx. St. Peter's-wort.}

Plant with stems erect or suberect, mostly 3-8 dm. high; leaves oblong-elliptic, rounded to somewhat acute at apex, the upper ones somewhat cordate and clasping, coriaceous, to about $3 \mathrm{~cm}$. long and $15 \mathrm{~mm}$. wide; pedicels to $1 \mathrm{~cm}$. long, with lanceolate bractlets $3-5 \mathrm{~mm}$. below the calyx; outer 2 sepals broadly ovate to suborbicular, cordate at base, acute at apex, $1-1.5 \mathrm{~cm}$. long, about as wide; inner 2 sepals lanceolate, $7-14 \mathrm{~mm}$. long, to $4 \mathrm{~mm}$. wide; petals showy, obliquely obovate, commonly exceeding the sepals, to $15 \mathrm{~mm}$. wide; styles 3 or 4 ; capsule exserted at maturity. Hypericum stans (Michx.) Adams \& Robson.

In sandy bogs, swampy woods and moist grasslands in e. Tex., June- Sept.; from Fla. to Tex., n. to N.Y., N.J., e. Pa., Ky., Tenn., Ark. and Okla.

\section{Ascyrum hypericoides L. ST. Andrew's-Cross.}

Plant with reddish-brown stems that are erect-ascending to decumbent and somewhat diffuse, simple or more or less branched from the base or above the base, to $1 \mathrm{~m}$. or more high or long, the bark exfoliating in shreds; leaves linear to oblanceolate, more or less narrowed at the sessile base, rounded to obtuse at apex, to about $3 \mathrm{~cm}$. long and $8 \mathrm{~mm}$. wide, the margin somewhat revolute; pedicels $3-6 \mathrm{~mm}$. long, the bractlets borne near apex; outer 2 sepals ovate to elliptic, rounded-cuneate to subcordate at base, obtuse to acute at apex, to $12 \mathrm{~mm}$. long and about as wide; inner 2 sepals minute or obsolete; petals narrowly oblong-elliptic, about equaling the outer sepals, to $4 \mathrm{~mm}$. wide; styles 2 ; capsule included or exserted at maturity. Hypericum hypericoides (L.) Crantz.

Mostly in light sandy soils in open pine-hardwood and hardwood forests, thickets, grasslands and in bogs in s.e. Okla. (McCurtain Co.) and the e. third of Tex., May-Nov.; from Fla. to Tex. and e. Mex., s. to Hond. and the W.I., n. to N.E., Ky., Mo. and Okla.

This species is highly variable in the size and shape of its leaves and outer calyx lobes, and some of our coastal material might eventually be segregated as a small narrow-leaved variant. Not only decumbent plants with several basal stems and oblanceolate leaves, segregated as var. multicaule (Michx.) Fern. [Hypericum hypericoides var. multicaule (Michx.) Fosb.], are to be found in Oklahoma and 
Texas but also the erect plant, segregated as var. oblongifolium (Spach) Fern., with rather broadly oblanceolate leaves and prominent basally cordate outer calyx lobes that are up to $15 \mathrm{~mm}$. long and $1 \mathrm{~cm}$. wide. Var. hypericoides, our most common plant, is erect and freely branched above the ground level and has linear to linear-elliptic leaves.

\section{Hypericum L. ST. JOHN's-WORT}

Herbs or shrubs; leaves opposite, sometimes verticillate; flowers solitary or in cymes; sepals 5, usually subequal, persistent; petals 5, oblique, usually convolute in the bud, yellow, flesh-colored or sometimes reddish or purplish; stamens usually numerous, mostly united or clustered in 3 to 5 fascicles, the filaments elongate; styles abbreviated or elongate, separate or (at first) connate for most or part of their lengths, more or less united below the middle, mostly persistent on the capsules, the stigmas minute or capitate; capsules mostly 1-celled or sometimes 3 - to 5-celled; seeds short-cylindric, mostly reticulate.

About 300 species that are cosmopolitan in their distribution.

Deer are known to browse tender shoots of some species while ducks and game birds will eat the seeds.

1. Distribution in New Mexico and/or Arizona (2)

1. Distribution in Oklahoma and/or Texas (3)

2(1). Stems numerous, weak, slender, procumbent to ascending, rooting at lower nodes, usually less than $2 \mathrm{dm}$. long; leaves not dotted; petals salmon-colored, 2-4 mm. long........................... H. anagalloides.

2. Stems one or several, erect from a creeping rootstock, usually more than 2 $\mathrm{dm}$. tall; leaves black-dotted on the margins; petals yellow, 7-14 $\mathrm{mm}$. long.

2. H. formosum.

3(1). Stems woody throughout or at least on lower part; styles typically closely appressed their entire length at maturity, the stigmas minute; translucent or pellucid-punctate glands present (4)

3. Stems herbaceous or rarely slightly woody at very base; styles either appressed or separate (11)

4(3). Mature leaves and sepals linear-subulate or needlelike, the leaf margins essentially parallel.

7. H. fasciculatum.

4. Mature leaves and sepals with expanded non-needlelike blades, the leaves somewhat wider above the middle (5)

5(4). Leaves and sepals without a basal articulation or groove; inflorescence appearing naked due to the much-reduced bracts (6)

5. Leaves and sepals with a basal articulation or groove; inflorescence appearing leafy due to the foliaceous bracts (8)

6(5). Leaves linear-oblong to linear-lanceolate, less than $1 \mathrm{~cm}$. wide, midnerve beneath prominently keeled and running into a stem wing...........

6. Leaves ovate-lanceolate to elliptic, usually well over $1 \mathrm{~cm}$. wide (7)

7(6). Inflorescence usually a many-flowered (rarely 3 ) dichasium; mature capsules $3.5-7 \mathrm{~mm}$. long, 3-4.5 $\mathrm{mm}$. wide; raphe of seed welldeveloped, forming a conspicuous keel................. 8. H. nudiflorum.

7. Inflorescence a 3-flowered dichasium, sometimes 6- or 1-flowered; mature capsules 6-14 $\mathrm{mm}$. long, 4.5-7 $\mathrm{mm}$. wide; raphe of seeds only slightly developed, forming a low ridge but not a conspicuous keel 9. H. apocynifolium.

8(5). Largest leaves $1.5-3 \mathrm{~cm}$. long; seeds $0.7-0.8 \mathrm{~mm}$. long.

8. Largest leaves $3-7.5 \mathrm{~cm}$. long; seeds $0.9-1.6 \mathrm{~mm}$. long (9)

6. H. galioides. 
9(8). Mature capsules exceeding $7 \mathrm{~mm}$. in length and $3.5 \mathrm{~mm}$. in width, lanceovoid; flowers in 1- to 7-flowered terminal and subterminal dichasia, the inflorescence usually narrow and compactly thyrsoid; stamens 5-8 mm. long; seeds dark-brown or black, 1-1.7 mm. long 5. H. prolificum.

9. Mature capsules $6 \mathrm{~mm}$. or less long and $3 \mathrm{~mm}$. wide, slender-conic; flowers in 7- to many-flowered terminal and subterminal compound dichasia, the inflorescence presenting an obpyramidal aspect; stamens 3-4 mm. long; seeds reddish-brown, 0.8-1.3 mm. long (10)

10(9). All flowers with only 3 styles present....4. H. densiflorum var. densiflorum. 10. Some flowers with 4 or 5 styles present.....4. H. densiflorum var. lobocarpum.

11(3). Petals yellow or orange-color, convolute in bud; stamens numerous or few, distinct or united at base into 3 to 5 clusters without intervening glands; flowers terminal or in terminal cymes (12)

11. Petals flesh-color to mauve-purple, imbricated in bud; stamens mostly 9, strongly triadelphous, with 3 large orange glands alternating with 3 bundles of stamens; flowers clustered in the axils and at summit of stem (16)

12(11). Stamens numerous, usually 20 or more; roots perennial (13)

12. Stamens usually less than 20 ; annuals or rarely perennials (14)

13(12). Stems and leaves copiously pilose; sepais ciliate; petals clear yellow.... 11. H. setosum.

13. Stems and leaves glabrous; sepals glabrous; petals streaked with dark lines 3. H. punctatum

14(12). Leaves subulate or subulate-linear, appressed or strongly ascending; stem fastigiate-branching; root annual. 14. H. Drummondii.

14. Leaves flat, varying from suborbicular-ovate to linear-lanceolate, spreading; stem simple or loosely branched, from a slightly woody base (15)

15(14). Diffusely branched; leaves ovate-oblong to shortly elliptic, rounded at apex; capsule short-ellipsoid.

12. H. mutilum

15. Simple or nearly so, virgate, the cymes with ascending branches; middle and upper leaves ovate-deltoid, tapering to apex; capsule slender-conical 13. H. gymnanthum.

16(11). Leaves tapering below middle to a distinctly slender petiole

16. Leaves sessile at the rounded to cordate-clasping base (17)

16. H. Walteri

17(16). Leaves with translucent glands and dark-punctate on lower surface; styles $2-3 \mathrm{~mm}$. long........................................15. H. virginicum.

17. Leaves without translucent glands or superficial dots on lower surface; styles $1 \mathrm{~mm}$. long.

17. H. tubulosum.

\section{Hypericum anagalloides Cham. \& Schlecht. Tinker's PEnny. Fig. 525.}

Weak annual with few to many erect or procumbent stems or forming dense mats with ascending stems; leaves lanceolate to ovate, obtuse, 4-12 mm. long; flowers small, terminal and solitary or in leafy cymose cluters or panicles; sepals ovate, unequal in length, longer than capsule; petals orange-yellow (coppery); stamens 10 to 20 ; capsule 1 -celled.

About fresh-water streams and springs or in wet meadows or bogs in Ariz. (Coconino Co.), May-Aug.; Mont. to B.C., s. to n. Ariz. and s. Calif.

2. Hypericum formosum H.B.K. Fig. 526.

Perennial herb with horizontal rootstocks; stems 2-6 dm. high, simple at base, sometimes branched above, erect; leaves oval to elliptic or sometimes oblong-ovate, 


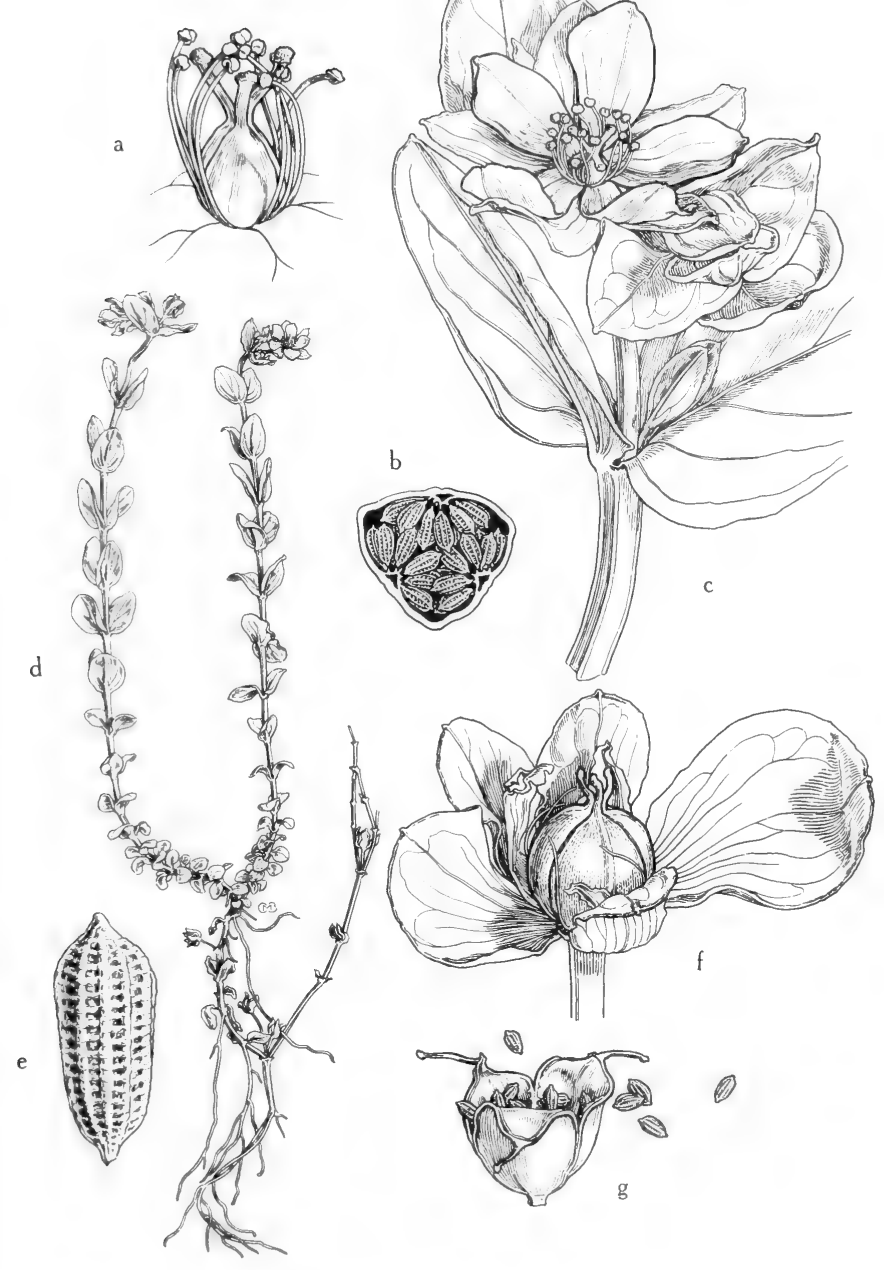

Fig. 525: Hypericum anagalloides: a, stamens, ovary and styles, $\mathrm{x} 8$; b, mature capsule (cross section), x $8 ; \mathrm{c}$, inflorescence, $\mathrm{x} 3 ; \mathrm{d}$, habit, the leaves sessile, ovate, $\mathrm{x} 2 \%$; e, mature seed, $\mathrm{x} 40 ; \mathrm{f}$, mature capsule in calyx, the sepals unequal in length, x 6; g, capsule, showing septicidal dehiscence, x 6. (From Mason, Fig. 263). 


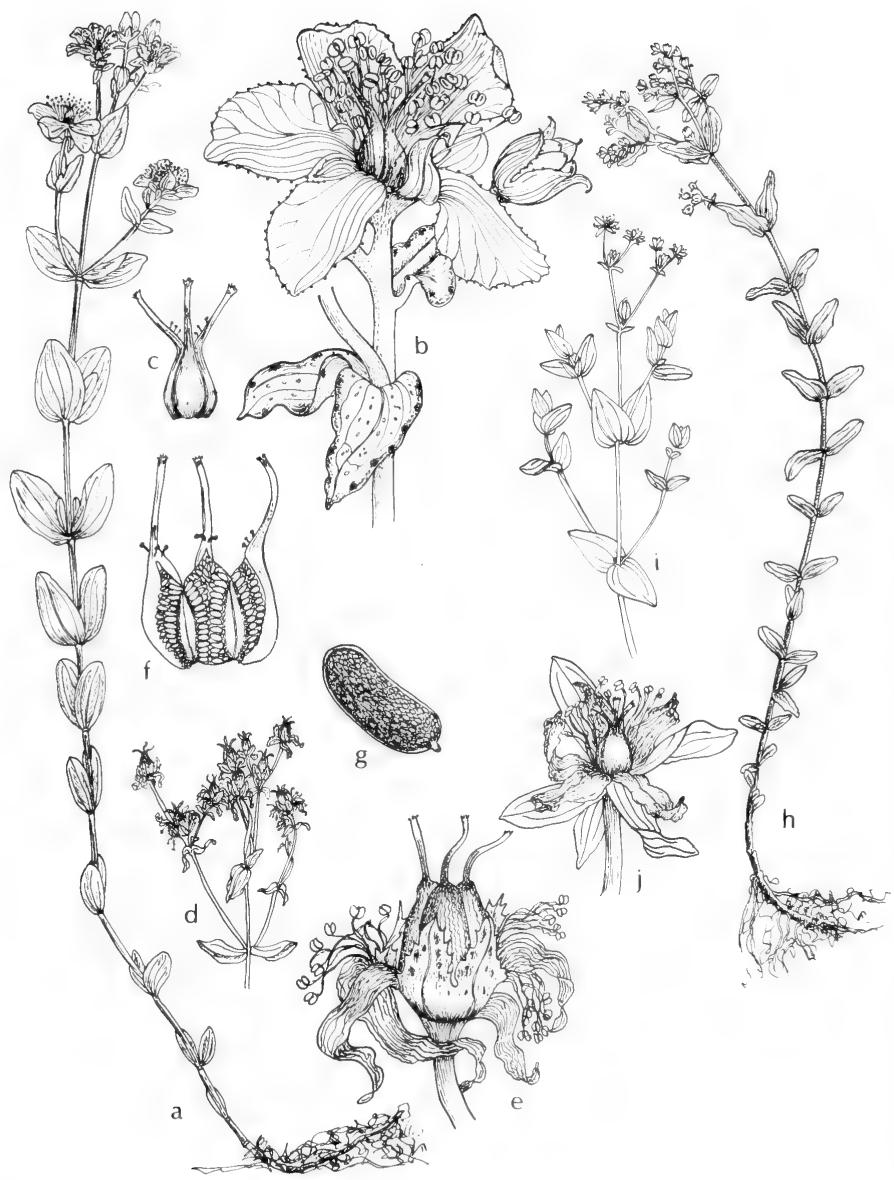

Fig. 526: a-g, Hypericum formosum: a, habit, x 1/2; b, flower, x 3; c, ovary, x 3; d top of plant with fruit, $x 1 \frac{1}{2}$; e, capsule, $x$ 3; f, capsule split open, $x 3$; g, seed, x 20 . $\mathrm{h}-\mathrm{j}$, Hypericum mutilum: $\mathrm{h}$, habit, $\mathrm{x} \frac{1}{2} ; \mathrm{i}$, top of plant showing branching, $\mathrm{x} \frac{1}{2} ; \mathrm{j}$, flower, x 3. (V. F.). 
1-3 cm. long, obtuse, black-dotted beneath at least along the margins; flowers in cymes; sepals 2-5 mm. long, ovate, black-dotted at least on margins, obtuse to acuminate; petals 7-14 mm. long, with black dots or glands on margins; stamens separate or nearly so, numerous (over 20); capsule about $8 \mathrm{~mm}$. long.

Along streams, in seepage or in wet meadows in N.M. (Catron, Colfax, Lincoln, Otero, San Miguel, Sandoval and Taos cos.) and Ariz. (Apache, Coconino, Navajo and Pima cos.), June-Sept.; Wyo. to N.M., Ariz., s. Calif. and Mex.

\section{Hypericum punctatum Lam.}

Plant erect, to about $1 \mathrm{~m}$. high, conspicuously marked with black and pellucid dots, the main stems mostly simple and with few to no branches below the inflorescence; leaves sessile or somewhat clasping at the base, typically oblong to oblongelliptic but sometimes narrowly ovate-oblong, to $7 \mathrm{~cm}$. long and $2 \mathrm{~cm}$. wide, rounded to obtuse or even retuse at apex; flowers crowded in small clusters that terminate short branches at summit of plant; sepals heavily dotted and lined with black, ovate-oblong to triangular-lanceolate, obtuse to subacute at apex, $2.5-4 \mathrm{~mm}$. long; petals pale-yellow, copiously black-dotted, 4-7.5 $\mathrm{mm}$. long; styles 2-4 $\mathrm{mm}$. long, mostly persistent; capsules ovoid, 4-6 mm. long, conspicuously beset with amber-colored glands; seeds less than $1 \mathrm{~mm}$. long.

On open-wooded hills and on edge of woods and fields and low wet areas, in e. Okla. (Haskell, LeFlore, McCurtain and Ottawa cos.) and n.-cen. and n.e. Tex., June-July; from Fla. to Tex., n. to Que. and Minn.

\section{Hypericum densiflorum Pursh. Fig. 527.}

Shrub to $2 \mathrm{~m}$. high, much-branched above, the upright branches slender; leaves linear to linear-elliptic or oblanceolate, obtuse-apiculate to acute at apex, tapering at base to a short petiole, to $75 \mathrm{~mm}$. long and $15 \mathrm{~mm}$. wide, with smaller leaves in axillary fascicles; flowers numerous in crowded compound cymes; sepals firm, linear-lanceolate to elliptic, 2-5 mm. long; styles 3 to 5 , persistent, somewhat connate at base, either completely separate from the beginning or tardily separating, 2-3 mm. long; capsules lance-ovoid to slender-conic, more or less deeply lobed or sulcate, the body to $6 \mathrm{~mm}$. long and $3 \mathrm{~mm}$. thick, composed of 3 to 5 distinct carpels; seeds reddish-brown, $0.8-1.3 \mathrm{~mm}$. long.

On pinewood slopes and in and on the edge of swamps, bogs and marshes, and along wooded streams, in s.e. Okla. (McCurtain and Pushmataha cos.) and in s.e. Tex., May-Aug.; from Fla. to Tex., n. to N.Y., N.J., W.Va., s. Ind. and s. Mo.

The usually 4 or 5 styles and the deeply lobed capsules of the more southern var. lobocarpum (Gatt.) Svens. (H. lobocarpum Gatt.) set it apart from var. densiflorum and $H$. prolificum. The leaves are also usually larger than those of var. densiflorum whose leaves are usually less than $5 \mathrm{~cm}$. long and $8 \mathrm{~mm}$. wide. In our material, where there is a preponderance of flowers with 4 or 5 styles these are early separated in flower. However, in var. densiflorum and in those plants having only a few flowers with 4 or 5 styles, the styles often remain tightly coherent or even twisted together until the fruit is well-developed.

\section{Hypericum prolificum L. ShrubBy ST. JohN's-worT.}

Rather coarse diffusely branched shrub to $2 \mathrm{~m}$. high, with sharply 2-edged twigs; leaves typically narrowly oblong, $3-7.5 \mathrm{~cm}$. long and to $15 \mathrm{~mm}$. wide, narrowed at base to a short petiole, obtuse at apex; cymes both terminal and in the upper axils, contracted, the inflorescence thus interruptedly cylindric; sepals elliptic, 5-7 mm. long; petals obovate, 7-10 mm. long; styles 3 (rarely 4); capsules lance-ovoid to subcylindric-conic, 3-carpellate, 8-15 mm. long, 3-5 mm. thick. H. spathulatum (Spach) Steud. 
In meadows, dry or damp or rocky thickets, on seepage slopes, along wooded streams and on slopes in s.e. Okla. (McCurtain Co.) and e. Tex., June-Aug.; from Ga. to Tex. and Ark., n. to s.e. N.Y., Ont. and Minn.

\section{Hypericum galioides Lam. Fig. 528.}

Shrub 3-18 dm. high; leaves narrowly linear to linear-oblanceolate, narrowed to the base, obtuse to acute at apex, to $3 \mathrm{~cm}$. long and $5 \mathrm{~mm}$. wide, usually noticeably verticillate and marginally revolute in drying; flowers numerous, terminal or axillary; sepals linear to linear-spatulate, 3-4 $\mathrm{mm}$. long; petals bright-yellow, narrowly cuneate, obliquely or almost laterally pointed, 4-7 $\mathrm{mm}$. long; capsules triangularconic, subtruncate-rounded at base, tapering to the acute apex, deeply sulcate, 5-6 $\mathrm{mm}$. long, the persistent 3 styles about $2 \mathrm{~mm}$. long.

In wet pinelands, swamps and depressions, about ponds and lakes, and along ditches in s.e. Tex., May-Aug.; from Fla. to Tex., n. to Tenn. and N.C.

\section{Hypericum fasciculatum Lam. SAND-WEED. Fig. 528.}

Shrub to about $1 \mathrm{~m}$. high; bark dark-brown, spongy-thickened, exfoliating in tissue-thin sheets; leaves verticillate, numerous, crowded, typically linear-filiform or very narrowly linear, coriaceous, revolute, $1-2 \mathrm{~cm}$. long, mostly about $1 \mathrm{~mm}$. wide, with a cluster of smaller leaves in the axils of the larger ones; flowers several terminating the upper branches; sepals linear, 3-4 mm. long, about $1 \mathrm{~mm}$. wide; petals bright-yellow, obliquely apiculate, $7-8 \mathrm{~mm}$. long; capsules ovoid to ovoidconic, 4-5 mm. long, 3-lobed. $H$. galioides var. fasciculatum (Lam.) Svens.

In wet places about ponds and lakes, in low pinelands and along forested streams, in s.e., Tex., June-Aug.; from Fla. to Tex., n. to N.C.

This species is closely allied to $H$. galioides. The juvenile leaves found on seedlings and sometimes on adult plants are very similar to the leaves found on that species.

\section{Hypericum nudiflorum Michx.}

Shrub to $2 \mathrm{~m}$. high, usually much smaller, the stems ligneous below, sending up long subherbaceous brown-barked 4-angled flowering branches; leaves ovatelanceolate to linear-oblong, obtuse, thin, to about $7 \mathrm{~cm}$. long, pale-green, minutely punctate beneath, revolute in drying, usually without axillary fascicles; flowers numerous, in open terminal dichotomous cymes; bracts lance-subulate, 2-3 mm. long; sepals firm, linear to oblong, 2-5 mm. long; petals to $1 \mathrm{~cm}$. long; styles 3 ; capsules ovoid, to $7 \mathrm{~mm}$. long, with 3 inwardly projecting placentae.

In moist sandy woods, thickets or swamps in e. Tex., June-Aug.; from Fla. to Tex., n. to Va. and Tenn.

\section{Hypericum apocynifolium Small.}

Shrub 4-7 dm. high, the stems with red somewhat shreddy bark and the branchlets narrowly 4-winged; leaves essentially sessile, oblong to oblong-elliptic, more or less cuneate at the base, rounded to emarginate at apex, 2-4 cm. long, thin, bright-green, pale beneath, minutely punctate, rarely revolute; flowers 3 to 5 in terminal cymes; sepals spatulate to elliptic or oval, obtuse, persistent, 3-5 $\mathrm{mm}$. long, at least one half as long as the petals; petals yellow, oblong, 8-9 mm. long; capsules oblong-conic, thick-walled, to $14 \mathrm{~mm}$. long, acute.

In swamps and marshes in n.e. Tex., June-Aug.; from Ga. and Fla. to Tex. and Ark.

\section{Hypericum cistifolium Lam.}

Slender subherbaceous perennial; stem somewhat woody, reddish-brown, prominently 2-winged and simple or very sparingly branched, to $9 \mathrm{dm}$. high; leaves firm, linear-oblong to linear-lanceolate, to $3 \mathrm{~cm}$. long and $6 \mathrm{~mm}$. wide, obtuse to sub- 


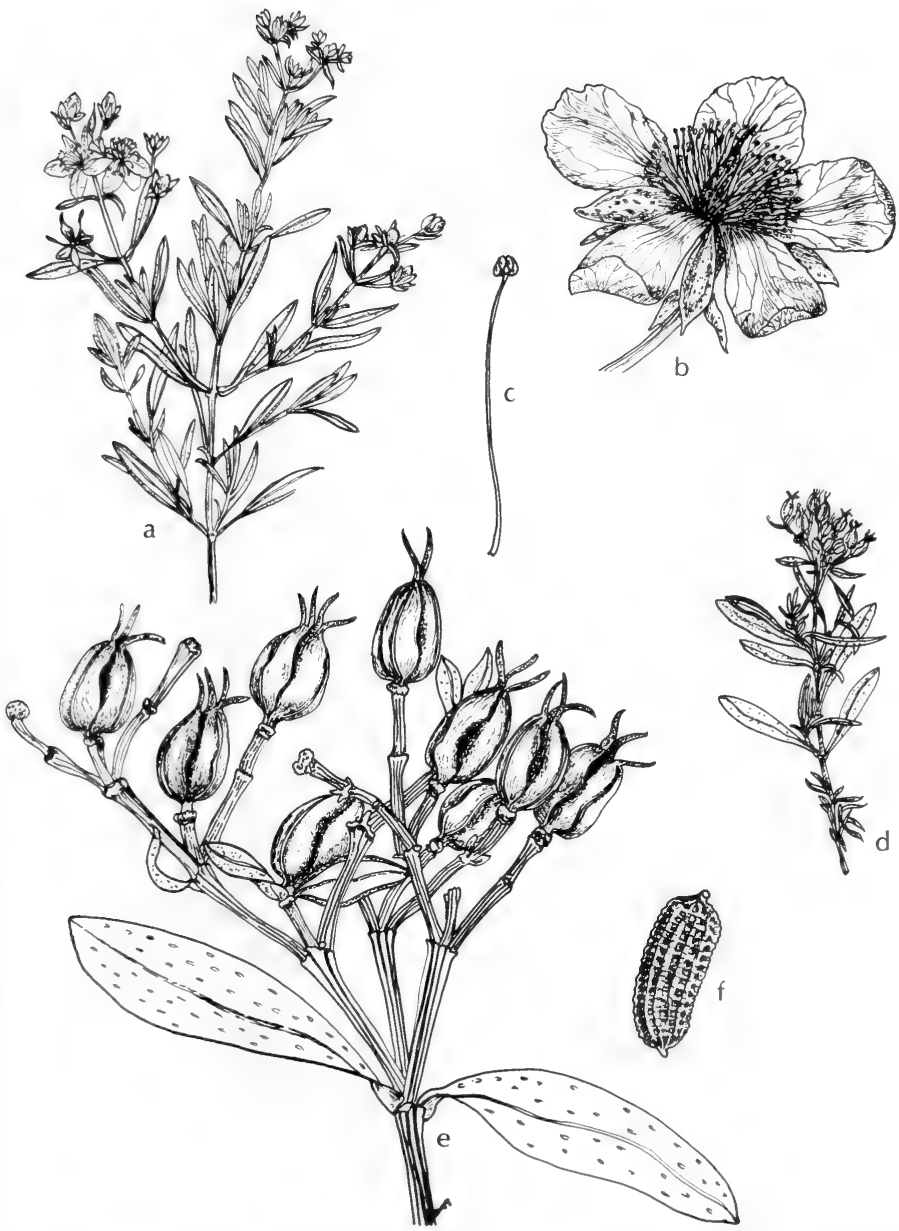

Fig. 527: Hypericum densiflorum var. lobocarpum: a, top of plant, x 1/2; b, flower, $\mathrm{x} 2 \frac{1}{2} ; \mathrm{c}$, anther, $\mathrm{x} 5$; $\mathrm{d}$, top of plant in fruit, $\mathrm{x} 1 \frac{1}{2} ; \mathrm{e}$, fruit, $\mathrm{x} 2 \frac{1}{2} ; \mathrm{f}$, seed, $\mathrm{x} 20$. (V. F.). 


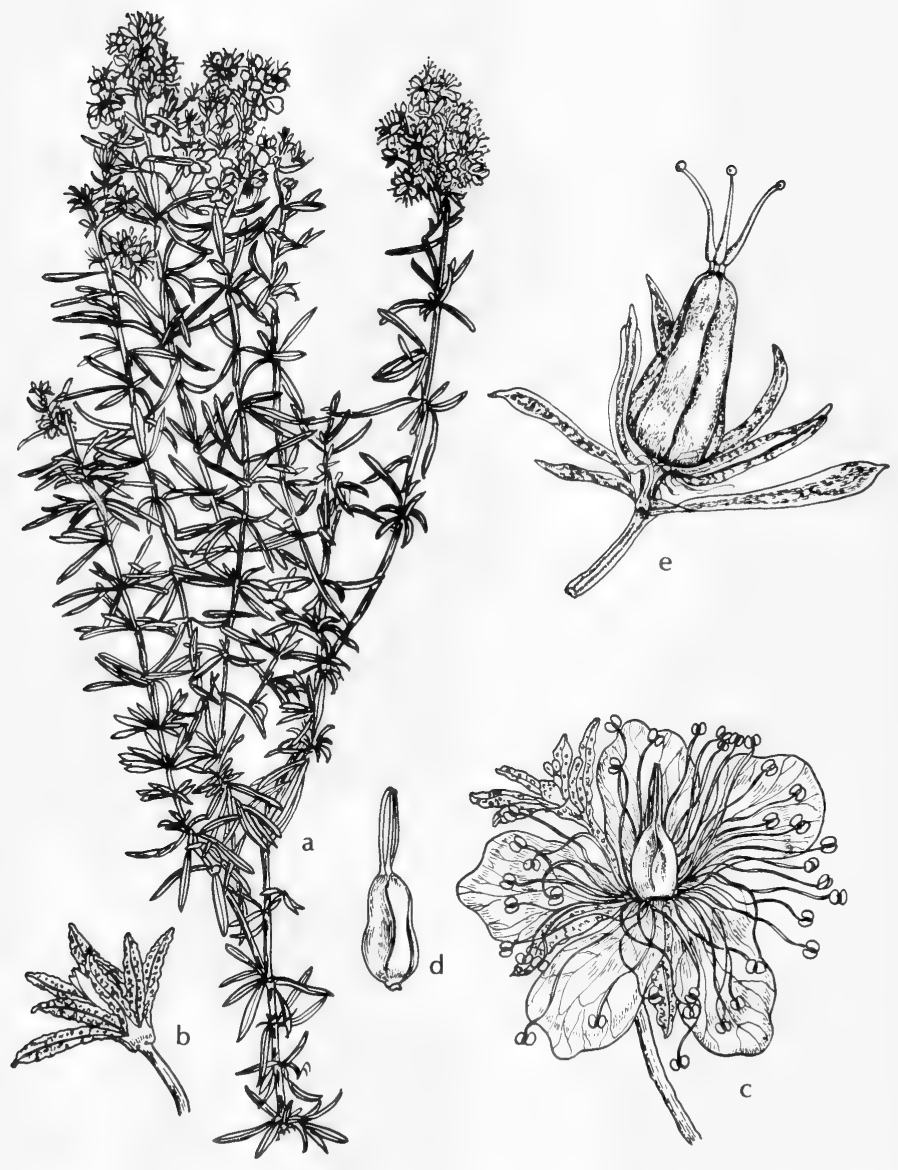

Fig. 528: a-d, Hypericum fasciculatum: a, upper part of plant, x 1/2; b, bud, x 4; c, flower, x 4; d, capsule, x 5. e, Hypericum galioides: e, capsule, x 5. (V. F.). 
acute at apex, the margins strongly revolute, sessile, subauriculate and clasping at the base, the solitary midnerve beneath keeled and continuous into the wing on the stem, with fascicles of smaller leaves in their axils; flowers numerous in terminal or axillary dichotomous cymes, the bracts subulate and about $3 \mathrm{~mm}$. long; sepals ovate to elliptic or oval, to $3 \mathrm{~mm}$. long and $1.5 \mathrm{~mm}$. wide; petals yellow, convolute in bud, obliquely cuneate to obovate, 5-10 mm. long; filaments elongate; styles 3 , coherent, somewhat persistent, the stigmas minute; capsule globose to globoseovoid, to $7 \mathrm{~mm}$. long, 3-lobed, 1-celled; seeds wrinkled.

In sandy soils in savannahs, evergreen shrub bogs and ditches, rare in extreme s.e. Tex., June-Aug.; from Fla. to Tex., n. to N.C.

The peculiar thin-tissued, somewhat auriculate-clasping base of the leaves, and the keeled midnerve that continues into a stem-wing, distinguish this species.

\section{Hypericum setosum $L$.}

Plant herbaceous, scabrous-tomentose to -pilose throughout, the stem simple or sometimes virgately branched, to $75 \mathrm{~cm}$. high; leaves sessile, numerous, erectappressed, ovate to linear-oblong or lanceolate, acute at apex, the margins somewhat revolute, to $15 \mathrm{~mm}$. long and $4 \mathrm{~mm}$. wide, gradually reduced up the stem; flowers few in cymes; sepals ovate to ovate-lanceolate or elliptic, acute to acuminate, to $4 \mathrm{~mm}$. long, conspicuously ciliate; petals yellow, 5-6 $\mathrm{mm}$. long, obliquely oblongelliptic, obtuse; styles 3, subpersistent; capsule ovoid-oval, 4-5 mm. long.

In bogs and wet pinelands in s.e. Tex., June-Sept.; from Fla. to Tex., n. to Va.

\section{Hypericum mutilum L. Fig. 526.}

Plant annual or perennial, 3-9 dm. high, with weak slender erect to ascending stems, widely branching above, sometimes forming extensive colonies, often with leafy-bracted decumbent bases; leaves ovate to lanceolate or narrowly oblong, sessile and partly clasping at base, rounded to broadly obtuse at apex, mostly 5 -nerved, to $35 \mathrm{~mm}$. long and $15 \mathrm{~mm}$. wide; cyme in well-developed plants diffuse and somewhat leafy-bracted, the ultimate bracts setaceous; flowers light-yellow, about $4 \mathrm{~mm}$. across; sepals variable in length and size, linear to linear-lanceolate or elliptic-oblanceolate, equal to or much-exceeding the capsules; stamens 6 to 12; capsules subglobose to short-ellipsoid, the rounded summit capped by the short persistent styles that are about $1 \mathrm{~mm}$. long.

On the edge of and in water of streams, ponds, swamps, marshes and other wet situations in e. Okla. (Adair, Delaware, LeFlore, Mayes, McCurtain, Pushmataha and Sequoyah cos.) and cen. and e. Tex., May-Oct.; from Fla. to Tex., n. to s. N.E., cen. N.Y., O., Ill., Mo. and Kan.; introd. in Calif. (fide Mason).

Those plants with sepals broadly lanceolate to oblong and foliaceous have been segregated as var. latisepalum Fern.

\section{Hypericum gymnanthum Engelm. \& Gray.}

Plant herbaceous, almost simple, with strict stem and branches, to $9 \mathrm{dm}$. high, usually much smaller; leaves firm, clasping, 5- to 7-nerved, deltoid-cordate, acute to obtuse at apex, about $15 \mathrm{~mm}$. long and $1 \mathrm{~cm}$. wide below middle; cymes naked, elongated, the floral leaves reduced to small subulate bracts 3-4 $\mathrm{mm}$. long; sepals thickish, erect, lanceolate, acuminate, 3-5 mm. long; petals 3-6 mm. long; stamens 10 to 12 ; styles 3 , persistent, about $0.75 \mathrm{~mm}$. long, the stigmas only slightly dilated; capsule ellipsoid-conical, pointed, about $4 \mathrm{~mm}$. long.

In sandy soils in bogs, savannahs, barrens or low ground in s.-cen. and s.e. Tex., June-July; from Fla. to Tex., n. locally to N.Y., N.J., Pa., W.Va., O., Ill., Mo. and e. Kan. 


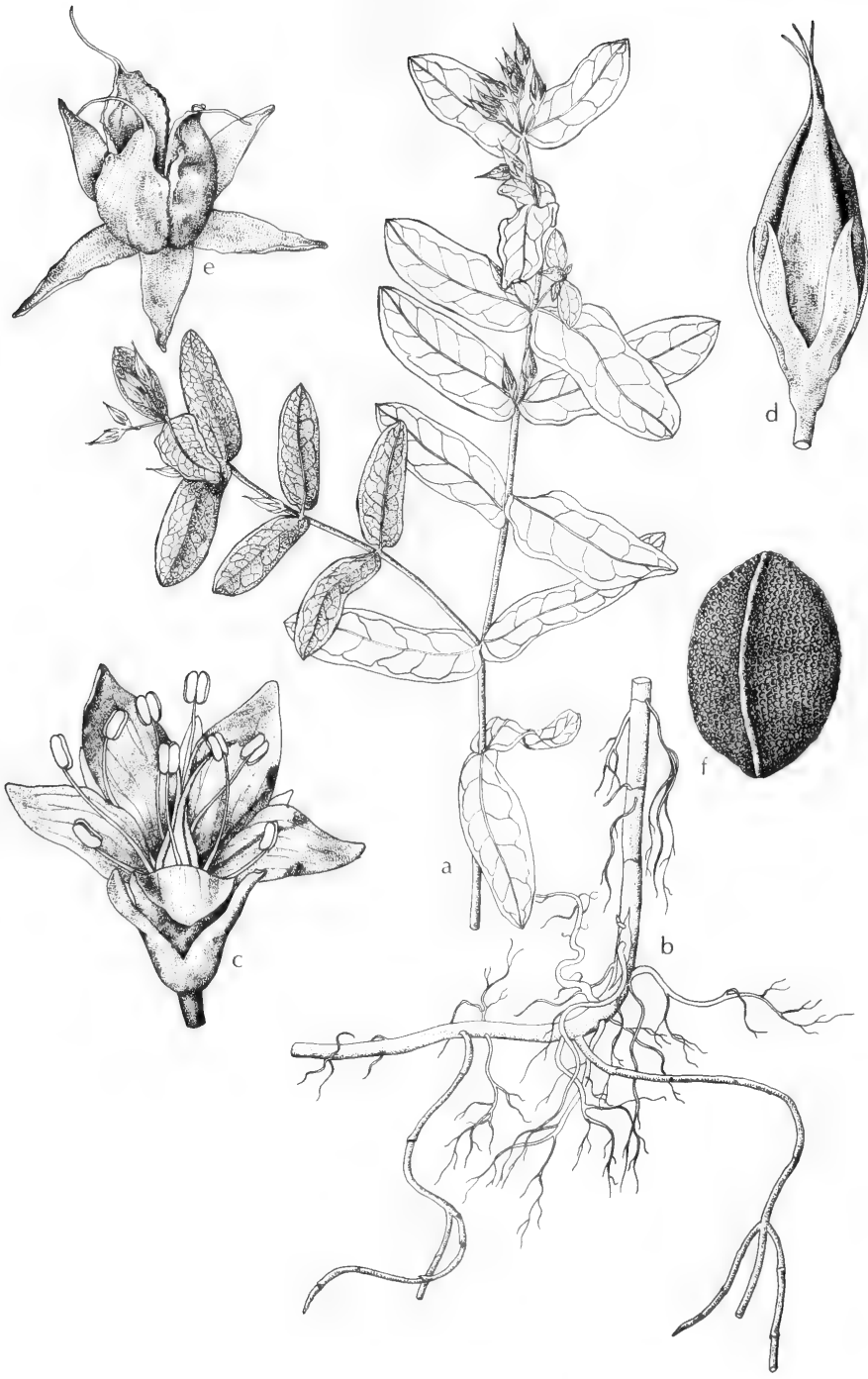

Fig. 529: Hypericum virginianum: a, top of plant, x $1 / 3 ; \mathrm{b}$, base of plant, $\mathrm{x} 1 / 3$; c, flower, x 31/3; d, ripe capsule, x 31/3; e, capsule ruptured, x 31/3; f, seed, x 22. (Courtesy of R. K. Godfrey). 


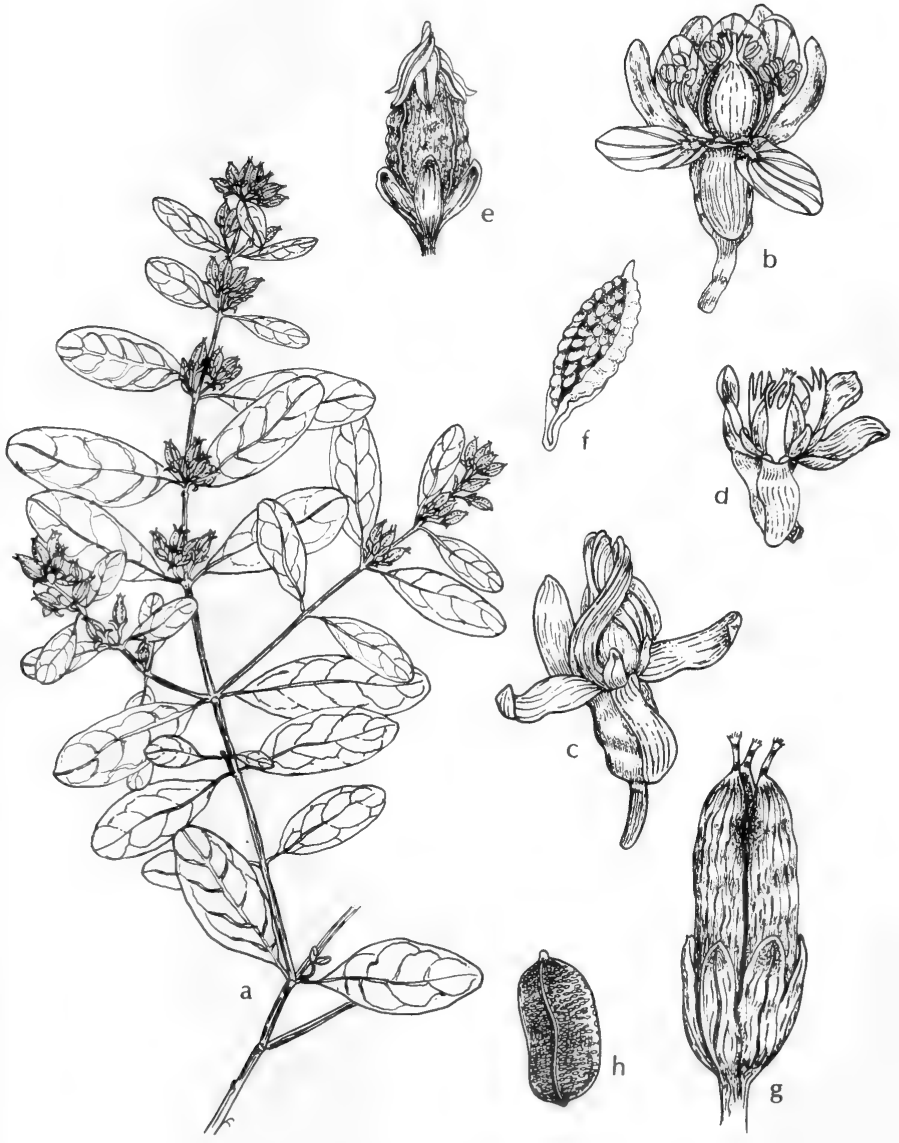

Fig. 530: Hypericum Walteri: a, top of plant, x 1/2; b, flower, x 5; c, flower begining to shed corolla, $\mathrm{x} 5$; $\mathrm{d}$, flower with corolla and anthers removed, showing united filaments, $\times 2 \frac{1}{2}$; e, capsule with corolla still adhering to tip, $\times 21 \frac{1}{2}$; f, section of capsule with young seed, $x 2 \frac{1}{2}$; g, mature fruit, $x 5$; h, seed, $x 20$. (V. F.). 


\section{Hypericum Drummondii (Grev. \& Hook.) T. \& G. Nits-AND-LICE.}

Plant annual, to $8 \mathrm{dm}$. high, the stem and the alternate bushy branches rigidly erect, mostly densely punctate throughout; leaves numerous, linear to linearsubulate, ascending to nearly erect, not appressed, 1-nerved, 6-20 $\mathrm{mm}$. long; flowers short-pedicelled, mostly solitary in the axils along the upper part of the leafy branches; sepals narrowly lanceolate, acute, 3-5 $\mathrm{mm}$. long; petals orange-yellow, withering before noon; stamens 10 to 20; capsules ovoid, 4-5 mm. long, reddishbrown, barely as long as or but slightly exceeding the sepals; seeds oval, darkbrown, strongly ribbed and rugose, about $1 \mathrm{~mm}$. long. Sarothra Drummondii Grev. \& Hook.

In dry sandy or gravelly soils in fallow fields, about lakes and marshes, in open scrub oak and cedar-oak flatwoods in Okla. (fide Waterfall) and cen. and e. Tex., July-Sept.; from Fla. to Tex., n. to Md., W.Va., O., Ind., s. Ill., Ia. and s.e. Kan.

\section{Hypericum virginicum L. MARSH St. John's-wORT. Fig. 529.}

Plants stoloniferous, the stem simple or bushy-branched (especially above), to $7 \mathrm{dm}$. high; leaves sessile and cordate or clasping at base, oblong-elliptic to ovateoblong, rounded at the retuse to apiculate apex, the principal leaves to $7 \mathrm{~cm}$. long and $3 \mathrm{~cm}$. wide, dark-punctate beneath, dotted with translucent glands, often purplish; flowers in small clusters in the upper axils and terminal; sepals linearelliptic to lanceolate, obtuse to acute, 4-7 $\mathrm{mm}$. long; petals flesh-color or mauve, 7-10 $\mathrm{mm}$. long; filaments free except near the base, the 3 fascicles alternating with 3 large orange-colored glands; capsule ellipsoid, tapering to the apex, about $1 \mathrm{~cm}$. long, the mature styles 2-3 mm. long; seeds tan-color, oblong, pitted, about $1 \mathrm{~mm}$. long. Triadenum virginicum (L.) Raf.

In or on the edge of water along streams, in bogs and swamps, and about lakes and ponds in e. Tex., Aug.-Oct.; from Fla. to Tex., n. to N.S., s. N.E., N.Y., O., Ind. and Ill.

\section{Hypericum Walteri Gmel. Figs. 530 and 531.}

Similar in habit to $H$. virginicum but usually larger and more branched; leaves oblong to oblong-oblanceolate, obtuse to rounded at the apex, tapering into the slender petiole, to $15 \mathrm{~cm}$. long and $35 \mathrm{~mm}$. wide, yellowish-green above, paleglaucous and translucent-dotted beneath, often reddish-tinged; flowers in small axillary and terminal clusters; sepals linear-elliptic, obtuse, 3-4 $\mathrm{mm}$. long; petals reddish, 5-7 mm. long; filaments united to about or above the middle; capsules ellipsoid-cylindric, rounded to tapered at apex, 7-11 $\mathrm{mm}$. long, the styles about $1 \mathrm{~mm}$. long; seeds oblong, dark-brown at maturity, about $0.75 \mathrm{~mm}$. long. $H$. petiolatum Walt., H. tubulosum Walt. var. Walteri (Gmel.) Lott, Triadenum petiolatum (Walt.) Britt., T. Walteri (Gmel.) Gl.

In or on the edge of water along streams, in bogs and swamps, and about ponds and lakes, sometimes on cypress knees and trunks, logs and occasionally on moist sandy wooded slopes, in e. Okla. ( fide Waterfall) and e. Tex., Aug.-Oct.; from Fla. to Tex., n. to Md., W.Va., s. Ind. and s.e. Mo.

\section{Hypericum tubulosum Walt.}

Erect rhizomatous plant with stem simple or branched above, 3-8 dm. tall, glabrous throughout; leaves sessile, ample, lacking translucent glands or superficial dots on lower surface, oblong to elliptic-oblong or elliptic-oblanceolate, 5-15 $\mathrm{cm}$. long, 2-5 cm. wide, scarcely tapered to a broadly rounded to truncate or somewhat cordate base, obtuse to broadly rounded at apex; cymes axillary, fewflowered, on peduncles to $3 \mathrm{~cm}$. long; sepals oblong-lanceolate, acute, 4-6 $\mathrm{mm}$. long; petals pink, 5-8 mm. long; fruit 9-11 mm. long; styles 3 , about $1 \mathrm{~mm}$. long. Triadenum tubulosum (Walt.) Gl. 


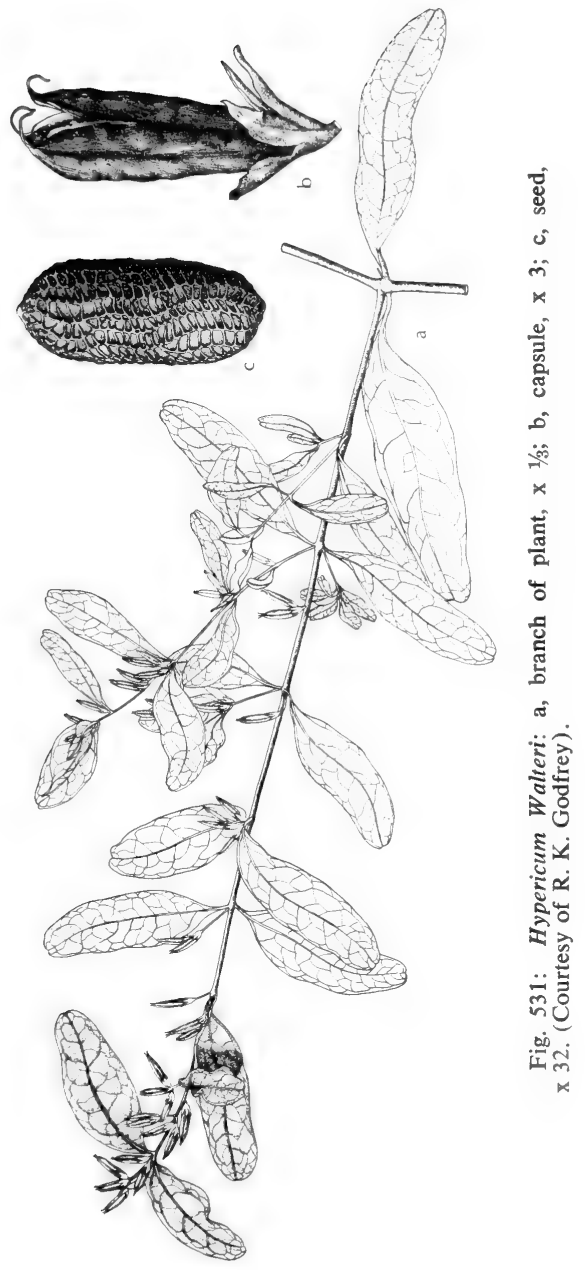


In wet soil of wooded swamps, open floodplain woods and on lake shores in s.e. Tex. where recently found in Newton Co., Sept.-Oct.; mainly on Coastal Plain from s.e. Va. to s.e. Tex., n.w. in the interior to s. Mo. and s. O.

\section{Fam. 90. Elatinaceae DuM.}

\section{WATERWORT FAMILY}

Low annual or perennial herbs with opposite simple leaves with membranous paired stipules between them and small regular axillary flowers; the persistent or marcescent sepals and petals imbricated in the bud; stamens as many as the petals and alternate with them or twice as many; ovary 2- to 5-celled, the placentae axile; valves of capsule alternate with dissepiments; seeds several to many, oblongcylindric, straight or curved, usually with a reticulate surface pattern.

A family of the following two genera and about 40 species of cosmopolitan distribution.

1. Plants less than $1 \mathrm{dm}$. tall or long, creeping, glabrous; flowers 2- to 4-merous; sepals obtuse, not scarious-margined.............................1. Elatine

1. Plants $1 \mathrm{dm}$. or more tall, erect-ascending, glandular-puberulent; flowers 5merous; sepals cuspidate, scarious-margined...................... . Bergia

\section{Elatine L. WATERWORT}

Aquatic, amphibious or terrestrial dwarf annuals from the bottoms of pools or slow streams or on wet sandy or muddy shores; stems erect or prostrate, flaccidsucculent, to about $10 \mathrm{~cm}$. long; herbage glabrous; leaves (in ours) opposite, sessile or petioled, with hyaline entire or toothed stipules, the blade linear-spatulate to oblong or orbicular-obovate, the margin obscurely and remotely crenate; flowers 1 or 2 to a node, sessile or pediceled, 2-, 3-, or 4-merous; sepals 3 or 4 , or reduced to 2 , equal or unequal in size, in some species withering-persistent; petals membranous, hypogynous, usually orbicular in outline, in terrestrial plants often campanulately spreading, in aquatic plants often closely investing the ovary or in some not evident; stamens as many as the petals or twice as many or (in some aquatic forms) reduced to 1 or sometimes none; styles or capitate stigmas 2 to 4 ; capsule membranous, 2- to 4-celled, several- to many-seeded, 2- to 4-valved, septicidally dehiscent, the partitions left attached to the axis or evanescent.

A genus of about 20 species in fresh-water habitats in temperate and warm regions.

The nomenclature of some of the species is in a state of flux, usually with no two authors in agreement. The genus is in need of a thorough revision. These plants form part of the diet of various ducks.

As Fassett (p. 250) points out, "The differentiation of species is based almost entirely on mature seeds, which must be examined with a compound microscope. Superficially all species look alike; in fact, members of the same species growing on mud or in water will differ more in appearance than will species growing in the same habitat. In other words, the general form of the plant is greatly influenced by submergence or emergence, only the seeds remaining diagnostic."

1. Capsule 4-celled; pedicels elongating in fruit; seeds J- or U-shaped; stamens 8....................................................................... . E. californica.

1. Capsule 2- or 3-celled, sessile; seeds slightly curved to almost straight; stamens 3 or varying from 1 to 6 (2)

2(1). Seeds with 9 to 15 pits in each longitudinal row, the pits nearly as long as broad; leaves not emarginate at tip...............2. E. brachysperma.

2. Seeds with 16 to 35 pits in each longitudinal row, the pits much broader than long; leaves commonly emarginate at tip (3) 


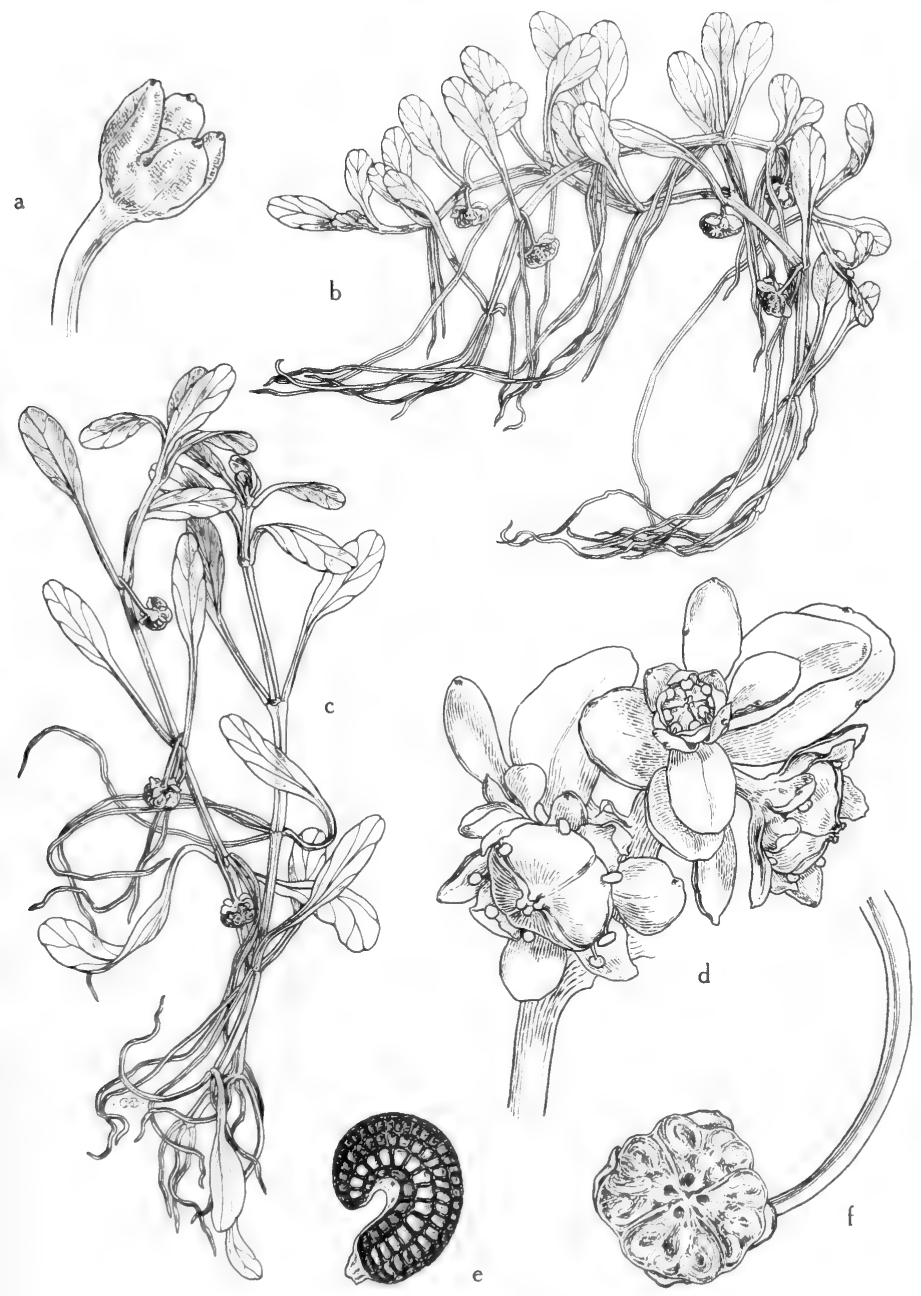

Fig. 532: Elatine californica: a, bud, showing calyx, x 12; b and c, habit, x 2; d, terrestrial form, showing apex of branch in flower and fruit, $x$ 8; e, mature seed, $x$ 40; f, mature capsule, showing 4 carpels, top view, x 12. (From Mason, Fig. 265). 


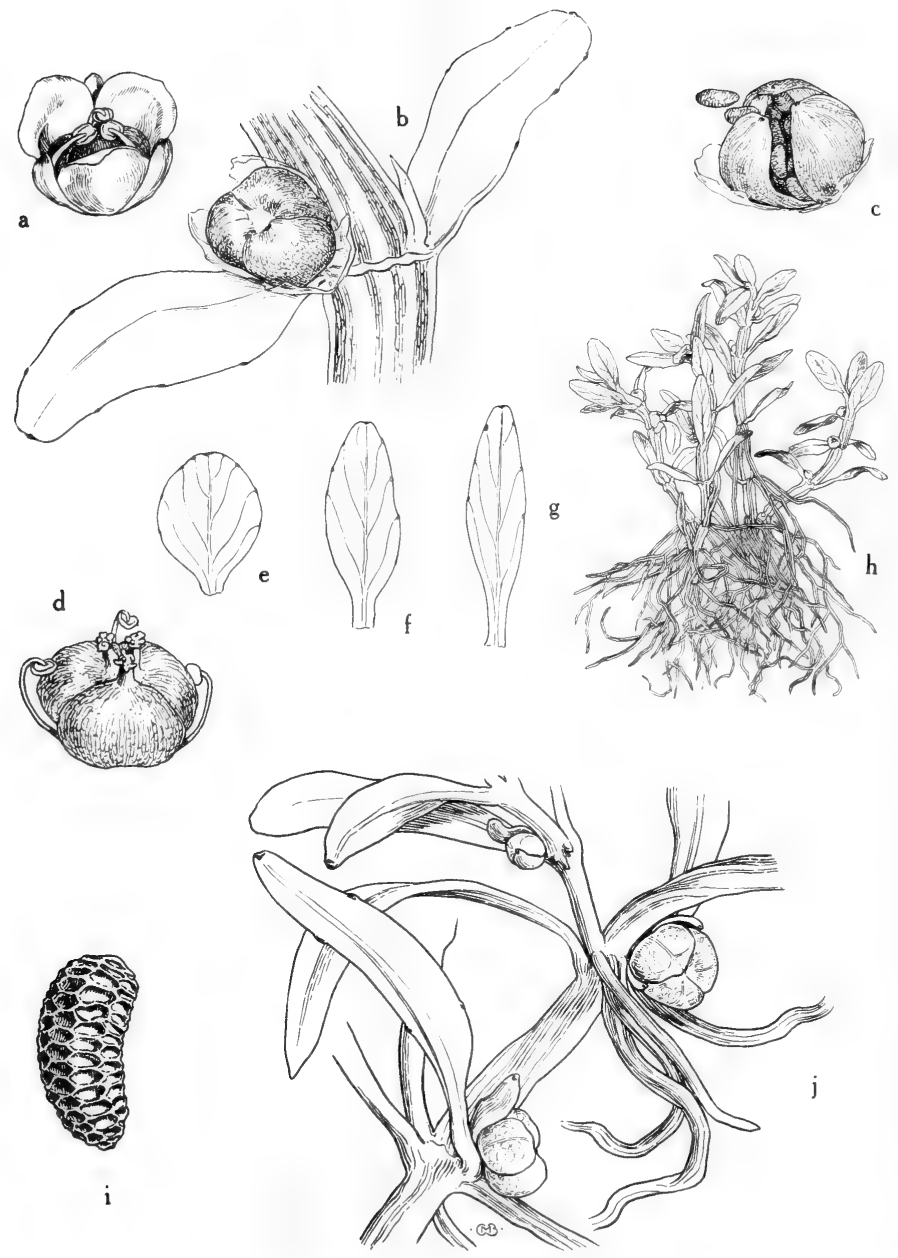

Fig. 533: Elatine brachysperma: a, flower, x 10; b, capsule in leaf axil, x 10; c, mature capsule at dehiscence, $x$ 12; $d$, young capsule, the stamens alternating with the carpels, x 16; e-g, leaf variation, x 4; $h$, habit, aquatic form, x 1; i, mature seed, x 60 ; j, terrestrial form, part of stem, showing roots, capsules and slender type of leaf, $x 6$. (From Mason, Fig. 269). 
1. Elatine californica Gray. Fig. 532.

Matted prostrate plant of muddy shores or erect aquatic; leaves short-petioled to subsessile, obovate to oblanceolate, 4-12 mm. long; flowers on short pedicels, the pedicel elongating in fruit to become 1 to 2 times as long as the fruit; sepals 4 , equal or subequal to one another in size, oblong, united at base and growing with the fruit; petals 4, obovate; stamens 8 ; capsule with 4 carpels; seeds J- or U-shaped, rounded at one end and truncate at the other with a subapiculate base.

In ponds, vernal pools, in wet mud on margins of lakes, streams and ditches, in Ariz. (Coconino Co.). July-Sept.; Mont. to Wash., s. to n. Ariz. and Calif.

\section{Elatine brachysperma Gray. Fig. 533.}

Plant forming tiny low spreading mats to $5 \mathrm{~cm}$. across, the branches somewhat ascending; leaves to $6 \mathrm{~mm}$. long and $2 \mathrm{~mm}$. wide; flowers sessile, 3-merous; sepals 2 or with a third greatly reduced; petals 3, pinkish; capsule depressed, 3-celled; seeds shortly oblong-ellipsoid, with 9 to 15 pits in each triangular row, the pits separated by acute cross-ribs. E. triandra var. brachysperma (Gray) Fassett.

Rare on mud about vernal pools, ponds and in ditches, or in shallow water in cen. Tex., Okla. (Comanche Co.) and Ariz. (Apache, Coconino and Gila cos.), Mar.-Oct.; O. and Ill. w. to Ore., s. to Okla., Tex., Ariz. and Calif.

\section{Elatine chilensis Gay. Fig. 534.}

Plants to about $10 \mathrm{~cm}$. long, aquatic or when on wet mud creeping and rooting at nodes; leaves obovate to broadly spatulate, rounded at summit, 3-4 mm. long, 1-3 $\mathrm{mm}$. wide, narrowed at base to a petiole, with entire triangular attenuate hyaline stipules; flowers solitary in leaf axils, sessile; sepals 2, oblong, sometimes with a third much reduced one present; petals white to pink, orbicular; stamens 3, alternate with the carpels; seeds 20 or more in each cell, borne at the base of the placental axis, erect, cylindric, slightly curved, with 25 to 35 short broad pits in each row, with the transverse ridges more conspicuous than the longitudinal ones (the seed therefore appearing as though transversely rugose).

In mud on shores of lakes and ponds, Ariz. (Coconino Co.), May-Aug.; also Calif. and S.A.

\section{Elatine triandra Schkuhr.}

Matted creeping plant; leaves mostly truncate or emarginate, to $7 \mathrm{~mm}$. or more long and $3 \mathrm{~mm}$. wide; flowers sessile, 3-merous; seeds 15 or less in each cell, borne along entire length of thickened central axis, horizontally divergent, slendercylindric and curved, with meandering obscure longitudinal ridges and somewhat angular pits in each row, the larger seeds with 15 to 25 pits in each row. (?) $E$. americana (Pursh) Arn.

In mud and shallow water in cen. Tex., Okla. (Comanche Co.), N. M. (Sandoval Co.) and Ariz. (Apache and Coconino cos.), Mar.-Oct.; from Wisc. to Alta. and Wash., s. to Tex. and n. Mex.; also Euras.

\section{Bergia L.}

A small essentially tropical or subtropical genus of about 20 species.

1. Bergia texana (Hook.) Walp. Fig. 535.

Diffuse or ascending plant that is branched from the base, to $4 \mathrm{dm}$. tall, more or less glandular-puberulent throughout; flowers shortly pedicelled, 1 to 3 in the axils of the leaves; leaves elliptic-oblong to oblong-oblanceolate, tapering at base, serrulate, to $3 \mathrm{~cm}$. long; stipules lanceolate, deeply serrate; sepals 5 , to $3.5 \mathrm{~mm}$. long, 


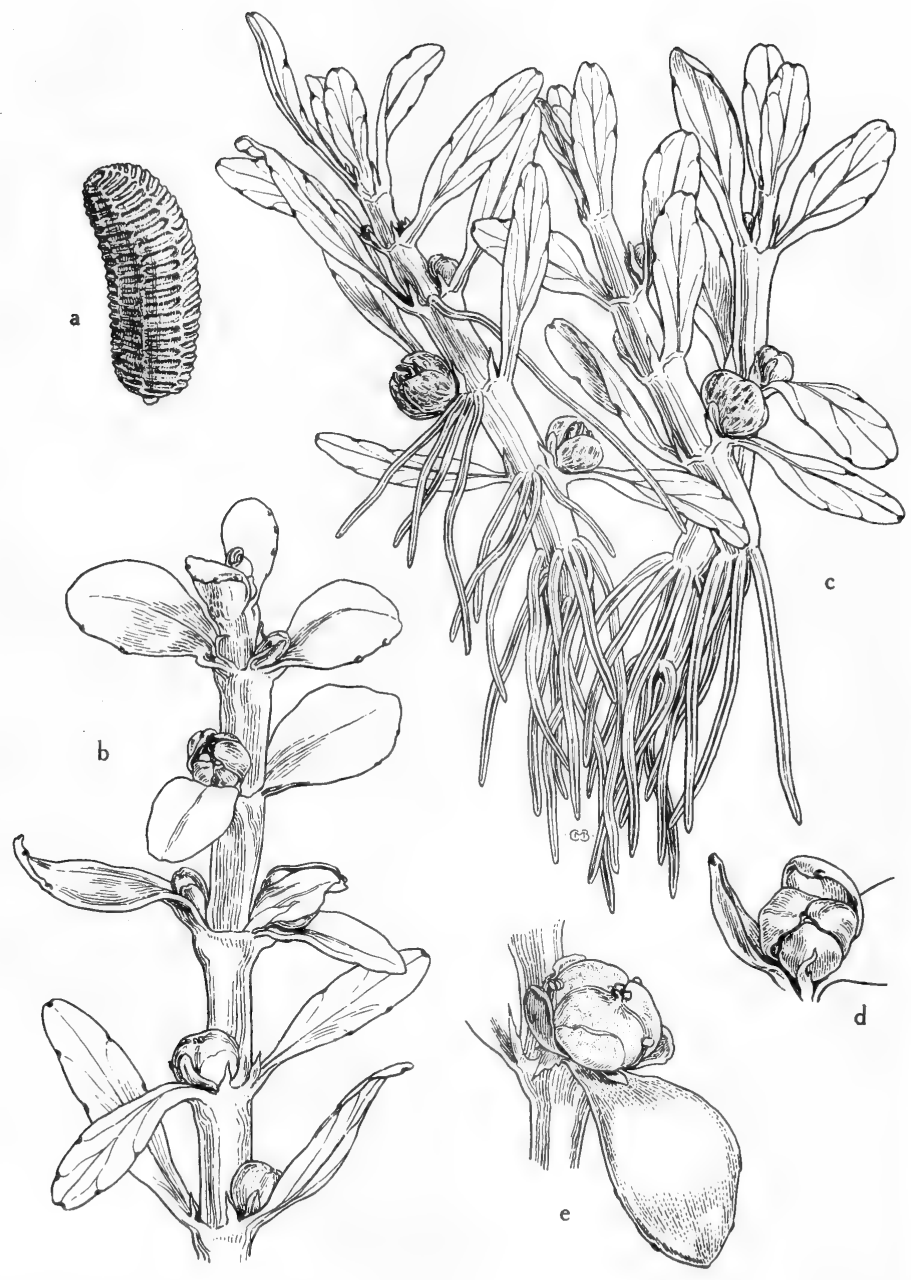

Fig. 534: Elatine chilensis: a, mature seed with conspicuous transverse ridges, $\mathrm{x}$ $60 ; \mathrm{b}$, branch, terrestrial form, $\times 6$; $\mathrm{c}$, habit, aquatic form, $\mathrm{x} \mathrm{4}$; d, young flower, showing the pair of large sepals, x 12; e, mature capsule, showing the third reduced sepal, the petals and the stamens alternating with the carpels, x 6. (From Mason, Fig. 268). 


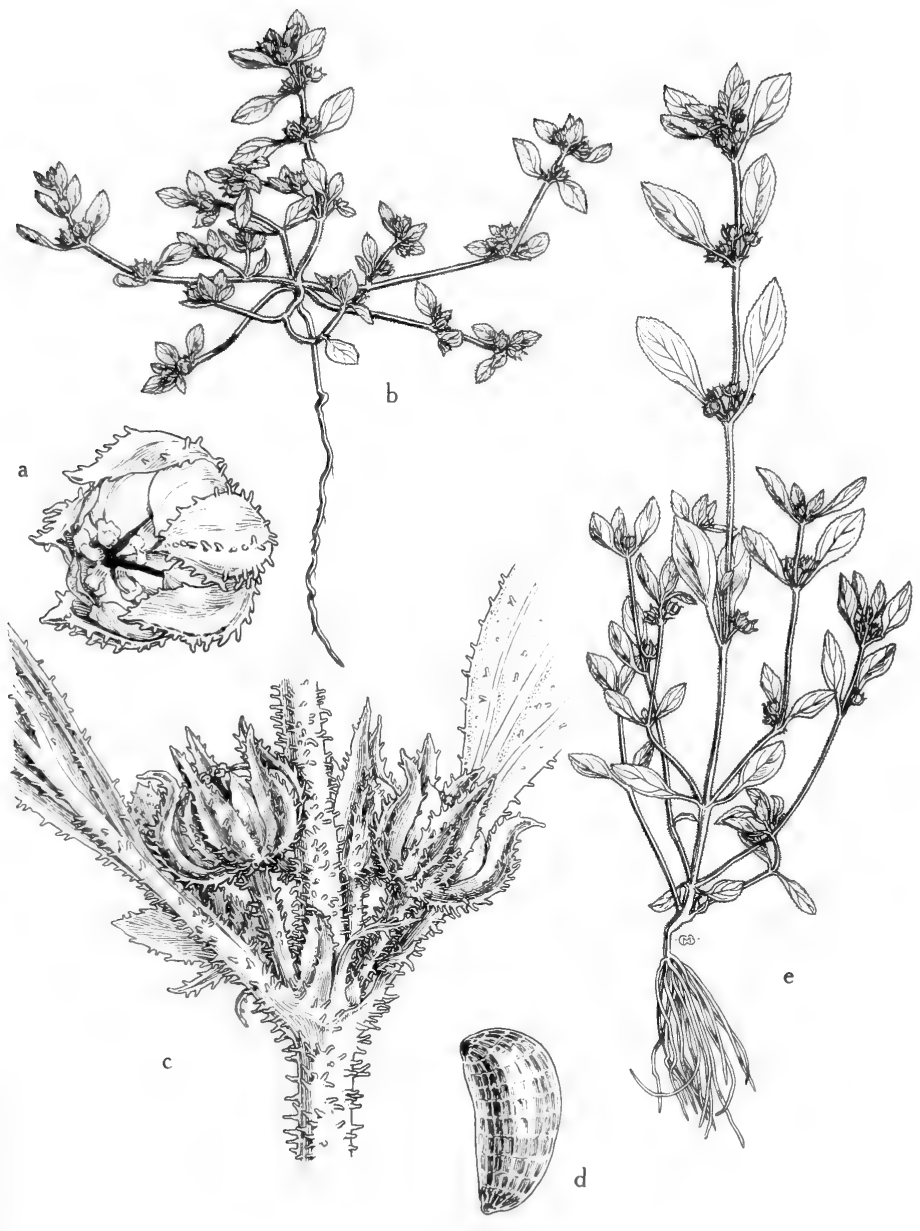

Fig. 535: Bergia texana: a, mature capsule at dehiscence, showing the denticulate sepals, $x$ 6; b, habit, prostrate form, $x \frac{2}{3}$; c, leaf axil with flowers, $x 4$; d, mature seed, shiny brown, obscurely quadrate-reticulate, x 60 ; e, habit, erect form, x $2 / 3$. (From Mason, Fig. 264). 
acuminate, with thickened greenish midnerve and wide scarious margins, roughened on the keeled midnerve; petals 5, white, oblong, shorter than the sepals; stamens 5 or 10 ; fruit subglobose, $2-3 \mathrm{~mm}$. in diameter, firm-textured, 5-carpellate; seeds glossy, light-brown, elliptic-oblong, curved, obscurely reticulate.

In ditches, swamps, marshes and on mud about ponds and on wet banks in Okla. (Waterfall) and s. Tex., June-Oct.; from Ark. to Tex. and s. Calif., n. to s. Ill., Mo., S.D. and Wash.

\section{Fam. 91. Tamaricaceae LINK.}

\section{TAMARISK FAMILY}

Shrubs or small trees; leaves alternate, exstipulate, sessile, small and scalelike, entire, commonly imbricated; flowers mainly perfect, regular, in spicate racemes that are usually collected to form a panicle; sepals 4 or 5 , imbricated; petals 4 or 5 , distinct, somewhat imbricated; disk 5- or 10 -lobed or obsolete; stamens $4,5,8$ or 10 , the distinct filaments free, the anthers opening lengthwise; ovary 1-celled, superior, with 3 to 5 basal placentae; stigmas 2 to 5 , distinct; ovules 2 to many on each placenta; fruit a capsule; seeds erect, terminating in a sessile tuft of hairs.

More than 60 species in four genera, all natives of the Old World.

\section{Tamarix L. TAMARISK. SAlt Cedar}

Deciduous shrubs or small trees with irregularly and widely spreading slender terete stems; the ultimate small branchlets deciduous with the leaves; leaves clasping or sheathing; flowers small, short-pediceled or sessile; petals pink or white, inserted under the disk; capsule dehiscent into 3 to 5 valves; seeds numerous.

About 50 species in the Old World, many of which are cultivated for their feathery foliage and profuse pink or white flowers. Occasionally planted for windbreaks and for sand binding. Most have become naturalized in such places as along rivers, streams and irrigation ditches (especially if saline), about lakes, in and about salt flats and in waste places generally. They flower periodically throughout the year.

These attractive and ornamental flowering trees and shrubs provides abundant shade and are excellent honey plants. In some regions they are considered to be beneficial in preventing too rapid run-off after heavy rains. Because of their tolerance to alkaline and saline conditions, they are valuable as shade and ornamental plants in such areas. In many regions, such as along the Pecos River, they have become a rather serious problem because of having formed extensive stands along its banks with consequent great loss of water from this important water course.

Adapted from Bernard R. Baum in Baileya 15(1):19-25. 1967.

1. Flowers 4-merous, occasionally with more than 4 stamens........5. T. parviflora.

1. Flowers 5-merous, occasionally with more than 5 stamens (2)

2(1). Staminal filaments arising from the alternating disk-lobes (3)

2. Staminal filaments not as above (4)

3(2). Racemes mostly on last year's branches, $6-9 \mathrm{~mm}$. broad (in dried material); petals ovate to broadly trulliform-ovate, more than $2 \mathrm{~mm}$. long 1. T. africana.

3. Racemes mostly on green branches, $4-5 \mathrm{~mm}$. broad; petals elliptic to somewhat ovate-elliptic, less than $2 \mathrm{~mm}$. long......................4. T. gallica.

4(2). Staminal filaments inserted between the more or less retuse lobes of the disk; petals caducous (sometimes 1 or 2 persisting)....2. T. aphylla.

4. Staminal filaments as above but with at least 3 of them inserted under the disk near the margin; petals persistent after maturity (5) 
5(4). Sepals more or less entire; petals ovate to elliptic; flowers of those racemes that occur on green branches with 1 or 2 of the filaments inserted between lobes of disk.

3. T. chinensis.

5. Sepals denticulate; petals obovate; all filaments of all flowers inserted below disk near margins.............................................6.T. ramosissima.

\section{Tamarix africana Poir.}

Bark black to dark-purple; leaves sessile; racemes $3-7 \mathrm{~cm}$. long, 6-9 mm. broad (in dry material), those occurring on green branches of the current year somewhat smaller; bracts longer than pedicels; flowers pentamerous; sepals subentire, the outer 2 slightly keeled and longer than the inner more obtuse ones; petals ovate to broadly trulliform-ovate, about $2.5-3 \mathrm{~mm}$. long in vernal flowers, $3 \mathrm{~mm}$. long or more in aestival; staminal filaments inserted on gradually tapering lobes of disk.

Nat. of Eur. and the Medit. region; introd. in Cailf., Ariz., Tex. and S.C.

\section{Tamarix aphylla (L.) Karst.}

Bark reddish-brown to gray; leaves vaginate; racemes 3-6 cm. long, 4-5 $\mathrm{mm}$. broad; bracts longer than pedicels; flowers pentamerous; sepals entire, the inner somewhat larger; petals elliptic-oblong to ovate-elliptic, 2-2.25 $\mathrm{mm}$. long, caducous, sometimes 1 or 2 persisting after maturity; staminal filaments inserted between the more or less retuse disk-lobes.

Nat. of Afr. and the Middle East; introd. in Tex., Ariz. and Calif.

\section{Tamarix chinensis Lour. Fig. 536.}

Bark brown to black-purple; leaves sessile; vernal inflorescences of many dense racemes, aestival ones loose and of slender racemes; racemes 2-6 cm. long, 5-7 $\mathrm{mm}$. broad; bracts equaling to slightly longer than pedicels; flowers pentamerous; sepals subentire, acute; petals elliptic to ovate, persistent after maturity, about 1.5-2.25 mm. long; filaments inserted between lobes of disk but from its lower part near the margin; in aestival flowers 1 or 2 filaments are inserted in the sinuses between the lobes and the other 3 or 4 under the disk near the margin.

Nat. of the Far East; introd. and widespread in Can. and the U.S.

In regard to the insertion of the filaments either direct from the disk surface or from the lower surface near its margin, the separation of this species and the poorly known (not included here) $T$. aralensis Bunge is most tenuous.

\section{Tamarix gallica L. TAMARISCo, ROMPEVIEntos.}

Bark blackish-brown to deep-purple; leaves sessile; racemes $2-5 \mathrm{~cm}$. long, 4-5 $\mathrm{mm}$. broad; bracts longer than pedicels, not exceeding the calyx; flowers pentamerous; sepals acute, entire or subentire; petals caducous, elliptic to slightly ovateelliptic, $1.5-1.75 \mathrm{~mm}$. long; staminal filaments inserted on apices of the gradually attenuating lobes of disk.

Nat. of s. Eur.; introd. and rare in s. U.S.

Tamarix canariensis Willd, a species allied to $T$. gallica, is known to have been introduced recently into Arizona. It has densely incised-denticulate sepals and the rachis of the raceme is papillose.

\section{Tamarix parviflora DC.}

Bark brown to deep-purple; leaves sessile; racemes more often on last year's branches, 1.5-4 cm. long, 3-5 mm. broad; bracts diaphanous, longer than pedicels; flowers tetramerous; sepals eroded-denticulate, the outer 2 trulliform-ovate, acute and keeled, the inner 2 ovate and obtuse; petals parabolic or ovate, $2 \mathrm{~mm}$. long; staminal filaments emerging gradually from the disk-lobes.

Nat. of the Medit. region; introd. and widespread in Can. and the U.S. 


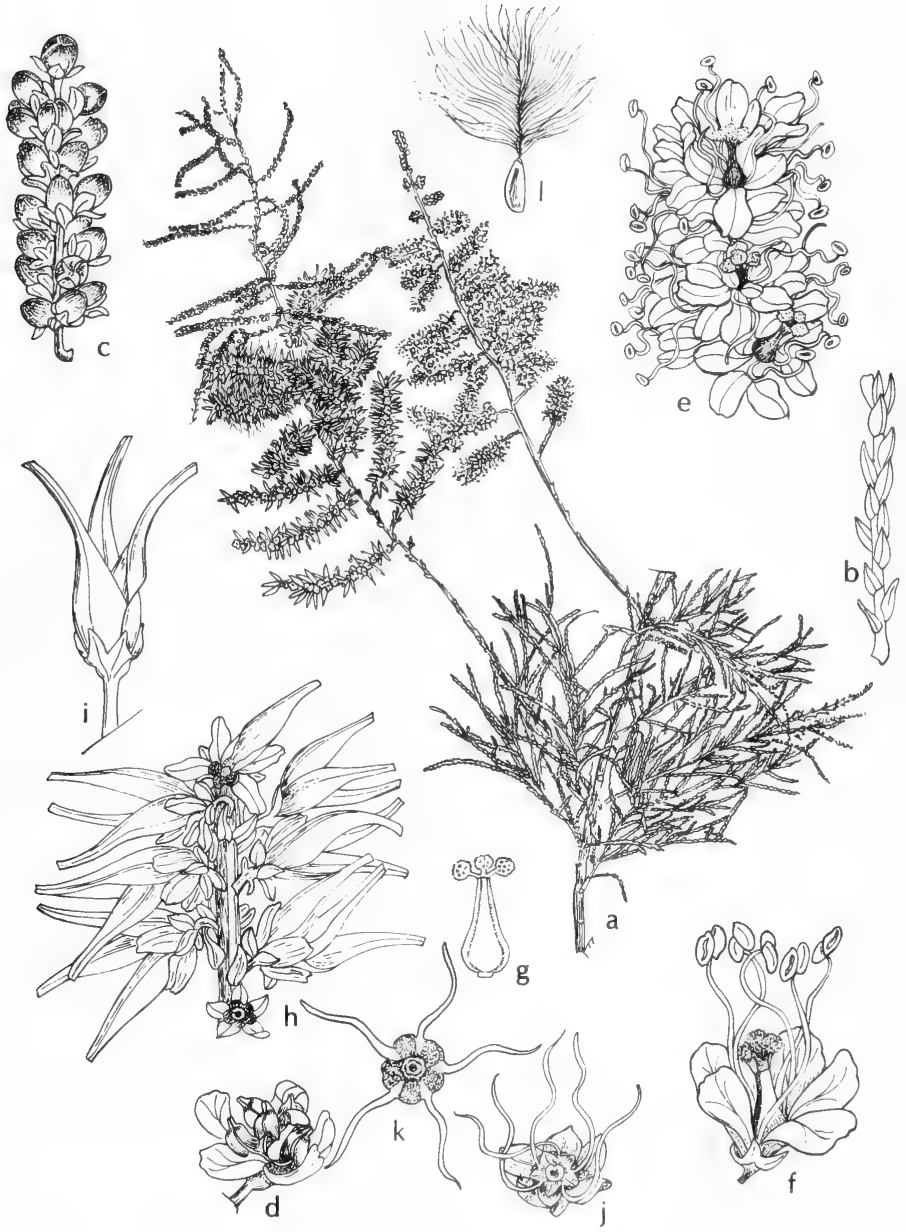

Fig. 536: Tamarix chinensis: a, flowering branch, $\mathrm{x} 1 / 2 ; \mathrm{b}$, twig with leaves, $\mathrm{x} 5$; c, portion of inflorescence in bud, x 5; d, young flower, $x 7$; e, portion of inflorescence in flower, $\mathrm{x} 7 ; \mathrm{f}$, mature flower, $\mathrm{x} 7 ; \mathrm{g}$, ovary with stigmas, $\mathrm{x} 7 ; \mathrm{h}$, portion of inflorescence in fruit, $x 5 ; \mathrm{i}$, capsule split open, $\times 7 ; \mathrm{j}$, disk, filaments and calyx, $\mathrm{x} 7 ; \mathrm{k}$, disk and filaments, $x 10 ; 1$, seed, $\times 7$. (V. F.). 


\section{Tamarix ramosissima Ledeb.}

Bark reddish-brown; leaves sessile; racemes $1.5-7 \mathrm{~cm}$. long, 3-4 $\mathrm{mm}$. broad; bracts longer than pedicels; flowers pentamerous; sepals more or less acute, eroded to irregularly denticulate, the inner 3 broader than the outer; petals $1-1.75 \mathrm{~mm}$. long, obovate to broadly elliptic-obovate; filaments inserted under the disk near the margin between the usually emarginate lobes.

Nat. of Euras.; introd. and widespread mainly in s. U.S.

\section{Fam. 92. Violaceae BATSCH}

\section{VIOLET FAMiLY}

Herbs, vines, shrubs or small trees with lobed or unlobed stipulate leaves; flowers irregular, perfect, 5-merous, polypetalous, axillary; calyx with separate sepals, often the two lowermost spurred; corolla bilaterally symmetrical, the lowermost petal spurred or gibbous; stamens hypogynous, with adnate introrse anthers, the filaments continued beyond the anther locules; ovary 1-celled, 3-carpellate, with parietal placentation, free from calyx; fruit a 3-valved capsule. Reduced cleistogamous flowers produced in most species during summer; with 5 sepals, 2 rudimentary petals that are not exposed and 2 stamens; pollen tubes grow directly from anthers into ovary.

About 800 species in 15 genera; cosmopolitan.

\section{Viola L. VIOLET}

Herbs (in our area) with large stipules; petals unequal, the lowermost spurred; 5 stamens closely surrounding ovary but not fused, two lower ones bearing spurs that are housed in spur of basal petal; cleistogamous flowers produced by all species.

About 450 species, cosmopolitan, but chiefly in temperate North America and northern South America.

The seeds of violets are eaten by upland game birds, such as doves and quail, and wild turkeys not only eat the seeds but they relish the succulent rootstocks.

1. Plants with leafy aerial stems. ..1. V. pubescens var. eriocarpa.

1. Plants without leafy aerial stems (2)

\section{2(1). Petals white; stoloniferous (3)}

2. Petals blue to violet; not stoloniferous (5)

3(2). Leaf blades ovate, 1.5 to 2 times as long as broad............2. V. primulifolia. 3. Leaf blades linear to lanceolate, 3.5 to 15 times as long as broad (4)

4(3). Leaf blades lanceolate, 3.5 to 5 times as long as broad.

3. V. lanceolata subsp. lanceolata.

4. Leaf blades linear, 6 to 15 times as long as broad.

3. V. lanceolata subsp. vittata.

5(2). Leaf blades divided (6)

5. Leaf blades entire (7)

6(5). Leaves pedately cut, with narrow lobes.

6. Leaves palmately cut, with broad lobes.

4. V. septemloba. 5. $V$. esculenta.

7(5). Leaves moderately to densely pubescent on both surfaces.......6. V. sororia. 7. Leaves glabrous on both surfaces or with fine hairs on upper surface only (8)

8(7). Leaves glabrous on lower surface, bearing short stiff hairs on upper surface of basal lobes.

8. Leaves glabrous on both surfaces (9) 7. V. nephrophylla. 
9(8). Leaf blades (at least some) broader than long, rather uniformly toothed to the acute apex.

8. V. papilionacea.

9. Leaf blades mostly as long as broad or longer, with somewhat attenuate apices that bear fewer more widely spaced teeth than rest of margin (10)

10(9). Upper third of leaf blades with 10 to 14 teeth, narrowly triangular; peduncles exceeding the petioles........................... . V. Langloisii.

10. Upper third of leaf blades with 0 to 6 teeth, broadly triangular; peduncles not exceeding the petioles. 10. V. missouriensis.

1. Viola pubescens Ait. var. eriocarpa (Schwein.) Russell. SMooth Yellow violet.

Tall sparingly branched perennial, $1-4.5 \mathrm{dm}$. high, typically with 4 to 8 basal leaves and 3 to 5 leafy aerial stems; leaves cordate, uncut, smooth to sparingly hairy on all surfaces; stipules small and entire; flowers yellow; capsule glabrous to soft-tomentose; seeds 2-2.5 mm. long. $V$. eriocarpa Schwein.

Rich moist or wet forest and floodplain woods or wet meadows, often by streams, n.e. Tex. and Okla. (Waterfall), Mar.-May; n.e. Tex. to N.C., n. to Que. and Ont.

\section{Viola primulifolia L.}

Acaulescent perennial with cordlike rhizomes, producing runners throughout growing season (these take root at the nodes and form new crowns); leaves ovatelanceolate to broadly ovate, variously pubescent, the blade tapering to a petiole as long as or longer than blade; flowers white with light-blue veins (especially on lower petal), small; capsules green, borne on erect peduncles; seeds $1.5-1.7 \mathrm{~mm}$. long. Incl. var. villosa Eat.

Roadside ditches and open marshy fields, wet meadows, moderately abundant in Okla. (Waterfall) and e. Tex., Mar.-May; Tex. to Fla., n. to N.S., n. Ind. and Okla.

\section{Viola lanceolata L. subsp. lanceolata. LANCE-LEAVED VIOLET.}

Acaulescent perennial with cordlike rhizomes, producing runners through growing season (these root at the nodes and form new crowns); leaves lanceolate, glabrous, about 3.5 to 5 times as long as broad; flowers white with bluish veins; capsules green, on erect peduncles; seeds light brown, 1.4-1.5 mm. long.

Roadside ditches and wet open fields, rare in n.e. Tex., Mar.-Apr.; Tex. to Ga., n. to Que. and Minn.

Subsp. vittata (Greene) Russell. Fig. 537.

Acaulescent perennial, similar to subsp. lanceolata in most respects, differing in having vittate leaves often 3-5 dm. long and 5 to 14 times as long as broad. Drainage ditches, marshes, bogs, savannahs and other wet open habitats, moderately frequent in s.e. Okla. (McCurtain Co.) and e. Tex., Mar.-Apr.; Tex. to Fla., n. to s. Va. and s.e. Okla.

\section{Viola septemloba LeConte.}

Acaulescent perennial, reproducing vegetatively by fragmentation of the horizontal rhizome; leaves spreading, with 3 to 6 narrow somewhat oblanceolate lateral lobes, thin, sometimes purple-tinged in spring, overall leaf shape orbicular to ovate; flowers blue-violet, on peduncles exceeding the leaves; lateral petals villous at base; fruits green, on erect peduncles; seed with inconspicuous caruncle.

Wet lowland forests, often by streams, swamps and sandy pinelands, rare in extreme e. Tex., Mar.-Apr.; e. Tex. to s. Fla., n. to Va. and Tenn.

\section{Viola esculenta Ell.}

Acaulescent perennial, reproducing vegetatively by fragmentation of the fleshy horizontal rhizome; leaves spreading, somewhat fleshy, with 4 to 6 broad palmately 


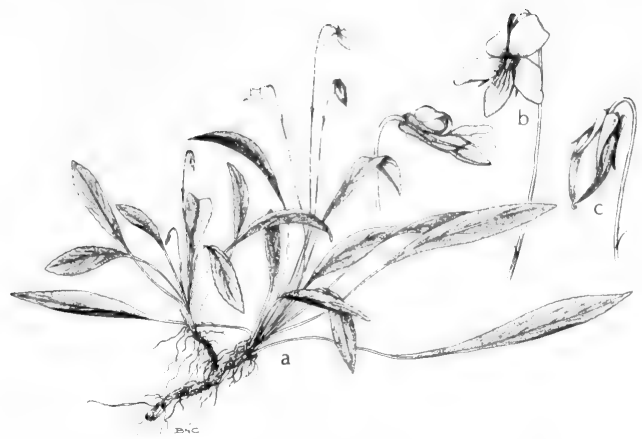

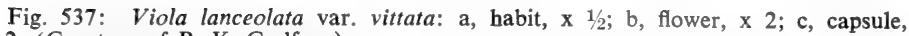
x 2. (Courtesy of R. K. Godfrey).

cut basal lobes; leaf lobes with parallel margins, not oblanceolate nor obovate as in $V$. septemloba; flowers pale-violet; sepals with emarginate auricles; spurred petal slightly hairy; capsules cylindrical, green, borne on spreading peduncles.

Wet open land or swampy woods and thickets, in s.e. corner of Tex., Mar.-Apr.; Tex. to s. Fla., n. to s. Va. and n. Miss.

6. Viola sororia Willd. Wooley BLUE VIOLET.

Acaulescent perennial, reproducing vegetatively by fragmentation of the thick horizontal rhizome; leaves spreading, broadly ovate to reniform, entire, pubescent on both surfaces with long hairs, sometimes villous; flowers varying in color from light-lilac to reddish-purple or dark-violet-purple; sepals with short broad ciliate auricles; peduncles of open flowers equaling or shorter than petioles; capsules large, ovoid, purple or purple-spotted, prostrate or buried in leaves; seeds buff to brown, ovoid, 1.75-2.5 mm. long.

In sandy alluvial soils along streams, wet meadows, rich woods, thickets or dryish woodlands, sometimes a weed in cities, Okla. (Waterfall) and e. half of Tex., Mar.Apr.; Tex. to n. Fla., n. to Que. and N.D.

\section{Viola nephrophylla Greene.}

Acaulescent perennial, spreading from horizontal somewhat fleshy rootstocks; leaves erect or ascending, orbicular to slightly reniform, entire, glabrous except for a scattering of tiny hairs on the upper surfaces of the lobes; petioles about $2 \mathrm{~cm}$. long in summer; laminas of young leaves often purple on lower surface; flowers light-blue; sepals with short blunt glabrous auricles; spurred petal villous; capsules green, slightly ovoid, borne on erect peduncles above the leaves; seeds with pronounced caruncles.

Open wet fields, bogs, wet meadows, springy places, depressions in woods, willow thickets and wet grasslands, rare in n.e. Tex., (?) Okla., N. M. (Rio Arriba, San Juan, San Miguel, Santa Fe, Taos and Socorro cos.) and Ariz. (Apache and Coconino, s. to Cochise and Pima cos.), Mar.-May; n.e. Tex. to Que. and Ont. w. to N.D. and throughout Rocky Mts.

Represented in Arizona chiefly by var. arizonica (Greene) Kearn. \& Peeb., characterized by sparsely pubescent or at least ciliate leaves; these glabrous in var. nephrophylla. 


\section{Viola papilionacea Pursh. Meadow violet, common blue violet.}

Plant glabrous; rhizome horizontal, stout, branching; petioles usually smooth and glabrous, sometimes sparingly pubescent; leaf blades reniform to ovate in outline above the cordate base, becoming as much as $13 \mathrm{~cm}$. wide, acute or abruptly pointed at apex, crenate with the teeth $2-7 \mathrm{~mm}$. long and $0.5-2 \mathrm{~mm}$. wide; flowers shorter than or sometimes overtopping the leaves, usually rich-violet and whitecentered; corolla 2-3 cm. across, the spurred petal cymbiform; cleistogamous flowers on horizontal peduncles, their capsules $(1-1.5 \mathrm{~cm}$. long) ellipsoid to cylindric and usually purplish; seeds dark-brown.

In low alluvial soil bordering streams, ponds, wet ditches, fields and meadows, thickets and low wet woods, in Okla. (Waterfall), Mar.-May; Me. and Que. to N.D. and Wyo., s. to Ga. and Okla.

\section{Viola Langloisii Greene.}

Acaulescent perennial, reproducing vegetatively by fragmentation of the horizontal rhizome; leaves small, short, spreading, ovate, with cordate bases and slightly attenuate apices, with 10 to 14 teeth in upper third of each margin, completely glabrous; flowers blue-violet, borne on erect peduncles above the leaves; sepals narrow, slightly sagittate.

River forests, wet or damp slopes and edge of streams, in Okla. (Waterfall) and e. Tex., especially in the s.e., Mar.-Apr.; cen. Tex., and Okla., e. to cen. Fla., n. to n. Miss.

\section{Viola missouriensis Greene}

Acaulescent perennial, reproducing vegetatively by fragmentation of the thick horizontal rhizome; leaves large and numerous, often 20 to 30 produced from one crown, ovate to orbicular, with cordate bases, triangular at apex, with 0 to 6 widely spaced crenations, glabrous; flowers light-blue, borne on erect peduncles about same length as petioles; sepals broad, the auricles not pronounced; grading into $V$. Langloisii.

In low rich alluvial woods, bogs, river forests, along streams and ledges, in Okla. (Waterfall), cen. and n.e. Tex. and N.M. (San Miguel Co., fide Wooton \& Standley), Mar.-May; s. Tex. e. to Ark., n. to Minn. and Neb., w. to N.M.

\section{Fam. 93. Lythraceae St.-HiL. Loosestrife FAMILY}

Herbs, shrubs or trees; leaves opposite, whorled or alternate, simple, entire; stipules minute or wanting; flowers perfect, regular or sometimes irregular, solitary or clustered, 4- to 7-parted, the peduncles usually bibracteolate; calyx tubular to campanulate, persistent, 4- to 6-toothed and often with accessary teeth in the sinuses, the toothlike lobes valvate; petals inserted in the throat of the hypanthium between the lobes or rarely absent; stamens 4 to many, inserted on the hypanthium, when as many as the petals then opposite the sepals; style simple or wanting, the stigma capitate; fruit capsular, dry, 1- to several-celled.

About 550 species in 25 genera, mostly in the tropics.

Ducks are known to eat the seeds of some species, notably those of Decodon and Lythrum, and it is quite possible that other wildfowl eat seeds of these plants. Small mammals also eat the seeds as well as parts of the herbage of most species.

1. Erect or viny shrubs (2)

1. Herbs or only partially suffrutescent (3)

2(1). Flowers in cymes in leaf axils; aquatic shrub. 1. Decodon

2. Flower solitary in leaf axils; not strictly aquatic. 


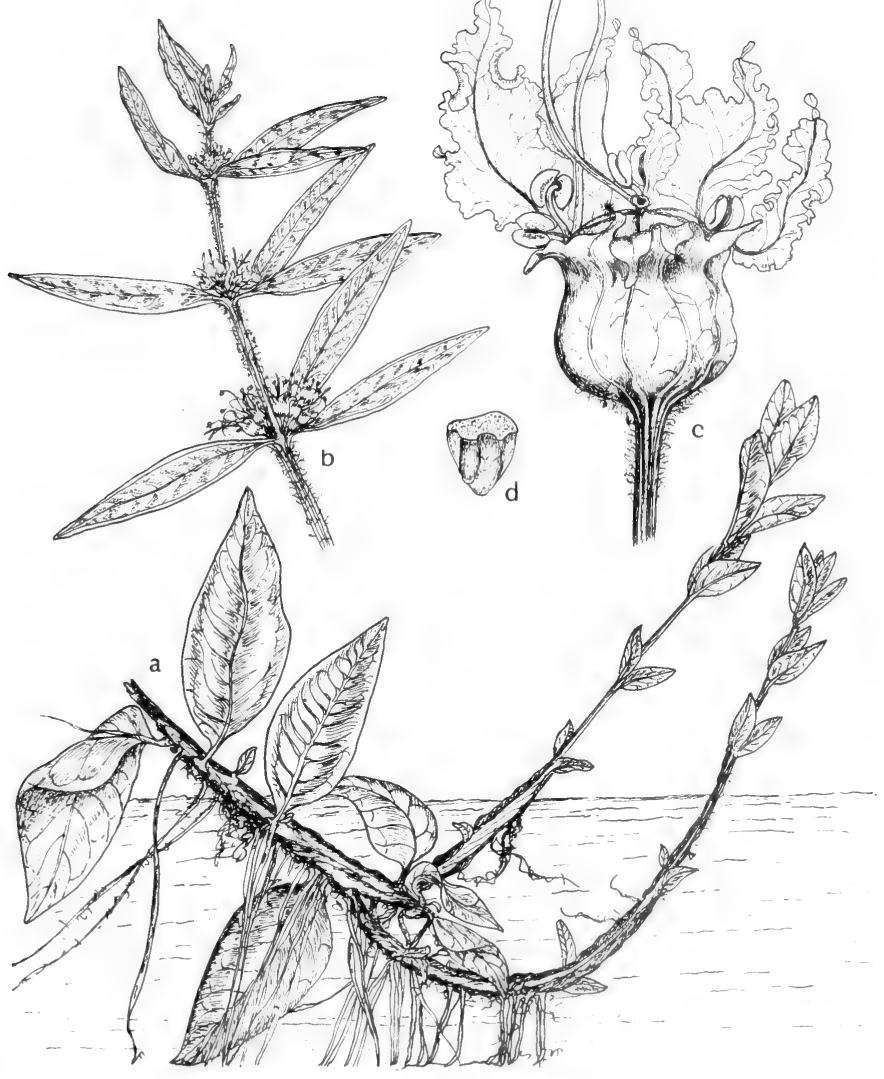

Fig. 538: Decodon verticillatus: a, part of submersed stem showing adventitious roots and sprouting shoots, $\mathrm{x} 1 / 2 ; \mathrm{b}$, upper part of plant, $\mathrm{x} 1 / 2 ; \mathrm{c}$, flower, $\mathrm{x} 5$; $\mathrm{d}$, seed, X 5. (V. F.). 


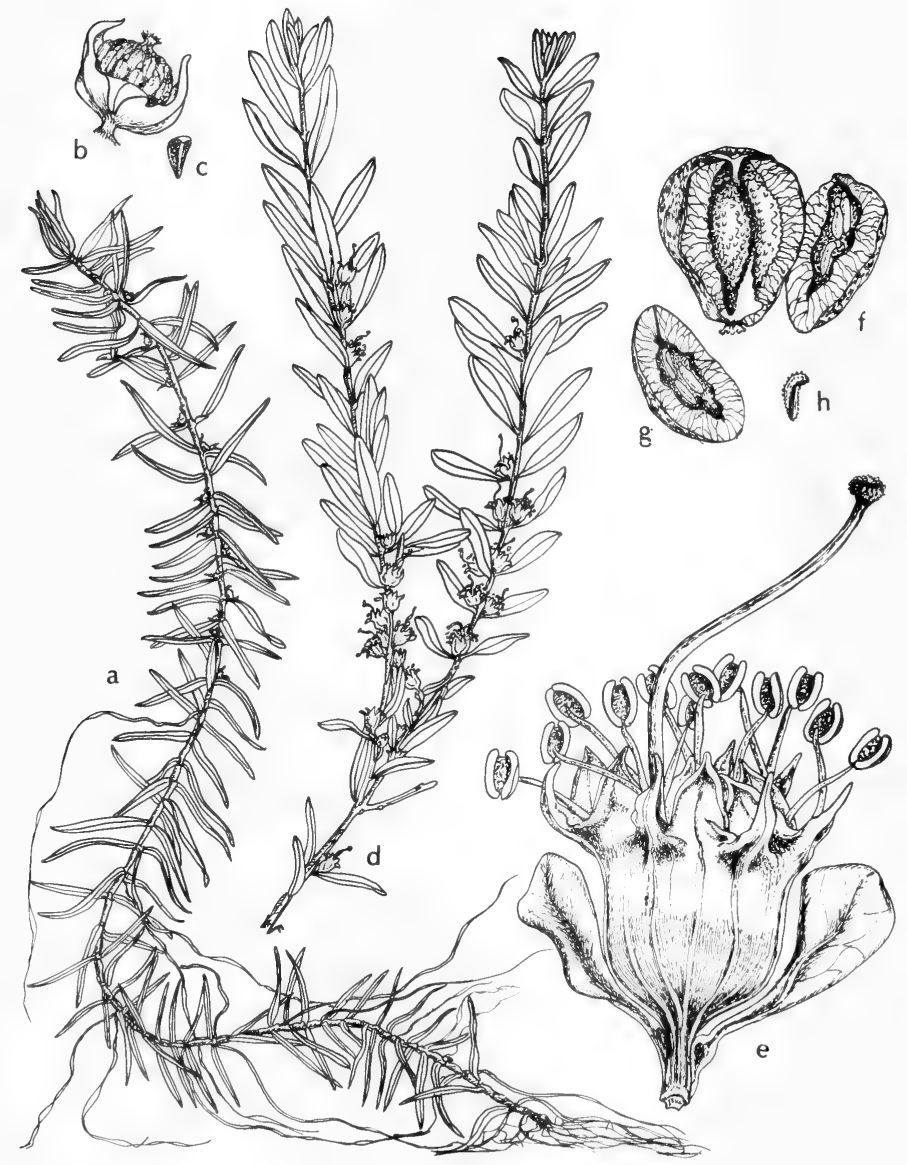

Fig. 539: a-c, Peplis diandra: a, habit, $x$ 1/2; b, fruit, $x$ 5; c, seed, $x$ 5. d-h, Heimia salicifolia: d, branch of plant, $\mathrm{x} 1 / 2$; e, flower, $\mathrm{x} 5$; $\mathrm{f}$, capsule broken open, $\mathrm{x} 5 ; \mathrm{g}$, one section of capsule, x 5; h, seed, x 5. (V. F.). 
3(1). Flowers irregular; calyx gibbous or spurred at base; petals unequal.....

3. Flowers regular or nearly so, symmetrical (4)

4(3). Hypanthium elongated, cylindrical or tubular. 3. Lythrum 4. Hypanthium campanulate or turbinate, becoming hemispheric or globose (5)

5(4). Flowers two or more in leaf axils; capsules bursting irregularly..... 4. Ammannia

5. Flowers solitary in leaf axils; capsules indehiscent or regularly dehiscent (6)

6(5). Petals wanting; capsules indehiscent; submersed aquatic plants......5. Peplis 6. Petals present; capsules dehiscent; terrestrial or marsh plants (7)

$7(6)$. Flowers sessile; capsules septicidally dehiscent. 6. Rotala

7. Flowers pedunculate; capsules variously dehiscent.

2. Heimia

\section{Decodon J. F. GMEL.}

A monotypic genus.

1. Decodon verticillatus (L.) Ell. WATER-Willow, sWAMP-LOOSESTRIFe. Fig. 538.

Perennial herb or suffrutescent, smooth or downy; stems 4- to 6-sided, to $25 \mathrm{dm}$. long, recurved-arching and rooting at tips, the bark of submersed parts spongythickened; leaves shortly petioled, opposite or whorled, elliptic-lanceolate to lanceolate, acute to subacuminate, to about $1 \mathrm{dm}$. long and $4 \mathrm{~cm}$. wide, the upper ones with clustered pedicelled flowers in their axils; flowers trimorphous; calyx with 5 to 7 erect teeth and as many longer and spreading terete hornlike processes at the sinuses; petals 5, cuneate-lanceolate, magenta, crinkly, about $12 \mathrm{~mm}$. long; stamens 10, of 2 lengths, exserted; style filiform, about $14 \mathrm{~mm}$. long; capsule globose, 3- to 5-celled, loculicidal, black, 3-5 $\mathrm{mm}$. in diameter.

In swamps, shallow pools, in and on margin of ponds and lakes in e. Tex. (Wood, Hardin, Madison and Cass cos.), July-Oct.; from Fla. to Tex., n. to N.E., N.Y., s. Ont. and s. Ill.

The characteristic of the stems rooting at their tips enables the plant to spread rapidly. They are thus capable of forming mats over water over which other plant species may take root.

\section{Heimia LINK \& OTTO}

Slender deciduous herbs or shrubs; leaves opposite or with some alternate, exstipulate; flowers pedunculate, solitary in the axils of the leaves; calyx campanulate, with hornlike spreading processes between the lobes; petals 5 to 7 ; stamens 10 to 18 ; style slender, the stigma capitate; capsule 4-celled.

Three species from Texas south to Argentina.

1. Leaves tapering to a sessile or short-petioled base; peduncle stout, about 2 $\mathrm{mm}$. long, the bracts elliptic-oblanceolate and about $4 \mathrm{~mm}$. long and $2 \mathrm{~mm}$. wide; petals yellow............................ H. salicifolia.

1. Leaves auricled at base; peduncle filiform, more than $1 \mathrm{~cm}$. long, the bracts ovate and about $2 \mathrm{~mm}$. long and $1 \mathrm{~mm}$. wide; petals pink to purple.

2. H. longipes.

1. Heimia salicifolia (H.B.K.) Link \& Otto. HaChinal. Fig. 539.

Shrub to $3 \mathrm{~m}$. high, forming clumps, usually much smaller, glabrous throughout: leaves mostly opposite, sessile to short-petioled, linear-oblanceolate to linearlanceolate or lanceolate, to about $5 \mathrm{~cm}$. long and $1 \mathrm{~cm}$. wide, obtuse to acute at apex; flowers solitary and short-pedunculate in the axils, inodorous; calyx campanulate, 5-9 $\mathrm{mm}$. long, with triangular acuminate lobes that become closely connivent over the capsule; petals 5 to 7 , orange-yellow, oval, 12-17 $\mathrm{mm}$. long, fugacious; 
capsule about $4 \mathrm{~mm}$. in diameter, loculicidal. Nesaea salicifolia H.B.K.

Along resacas, streams or in wet soil in brushlands in the Rio Grande Plains and Valley of s. Tex., Mar.-June; from Tex., s. through Mex. to C.A. and S.A.; also Jam.

\section{Heimia longipes (Gray) Cory. Fig. 540.}

Subshrubby to somewhat herbaceous plants with sprawling and trailing muchbranched slender stems to $9 \mathrm{dm}$. or more long, glabrous throughout; leaves subsessile, linear, acute at apex, auriculate at base, with prominently revolute margins, to $5 \mathrm{~cm}$. long and $4 \mathrm{~mm}$. wide; peduncles filiform, elongated, often about as long as the leaves, bibracteolate below the flowers; calyx 5-7 $\mathrm{mm}$. long, with short 2-grooved triangular lobes; petals pink to purple, obovate, 6-7 mm. long; style filiform, much-exserted; capsule about $4 \mathrm{~mm}$. in diameter, opening by a little lid and then splitting septifragally. Nesaea longipes Gray.

On seepage rocks and about springs in the Edwards Plateau and the Trans-Pecos of Tex., May-July; apparently endemic.

\section{Lythrum L. LOOSESTRIFE}

Herbs or shrubs with 4-angled stems; leaves opposite, alternate or sometimes whorled, entire; flowers usually solitary in the axils, often dimorphous, with a short bibracteolate peduncle; calyx tube cylindric, 8- to 12-ribbed, 4- to 7-toothed, with an equal number of appendages in the sinuses; petals 4 to 6 , attached to the rim of the calyx tube, rarely wanting; stamens 4 to 12 , inserted rather low on the calyx tube; style filiform; capsules cylindrical, included in the calyx tube, membranous, 2-celled, usually bursting irregularly; seeds numerous.

About 35 species of wide geographical distribution.

Lythrum lineare L., a plant with mostly opposite linear-oblong leaves which is found in and about brackish and saline marshes east to Florida and New Jersey has been reported from Texas. We have seen no material of it from our region.

1. Stem leaves mostly widest at or above the middle, tapering or abruptly contracted into a subpetiolar base (2)

1. Stem leaves mostly widest below the middle, somewhat rounded to subauriculate at the usually sessile to clasping base (3)

2(1). Stem leaves broadly elliptic to elliptic-obovate, rounded to subobtuse at apex; endemic in Texas Edwards Plateau.............1. L. ovalifolium.

2. Stem leaves typically narrowly elliptic, acute to acuminate at apex; widespread in eastern third of Texas and Oklahoma....2. L. lanceolatum.

3(1). Leaves of inflorescence typically linear-lanceolate; appendages of calyx tube subulate and erect, much longer than the teeth; distribution Panhandle and north-central Texas and Oklahoma.....

3. L. dacotanum.

3. Leaves of inflorescence typically linear; appendages of calyx tube fleshymammillate and curved outward, about as long as the teeth; distribution south-central and west Texas westward..

4. L. californicum.

\section{Lythrum ovalifolium Koehne. Fig. 541.}

Perennial herb to $35 \mathrm{~cm}$. high, the stem much-branched from near base; stem leaves broadly elliptic to elliptic-obovate, rounded to obtuse at apex, to $25 \mathrm{~mm}$. long and $8 \mathrm{~mm}$. wide, abruptly contracted at base, membranous; leaves of inflorescence similar to stem leaves but much smaller; calyx tube 5-6 $\mathrm{mm}$. long; petals obovate, lavender, 3-4.5 mm. long, 1.5-2 mm. wide.

Rare along and in water of rivers and streams in the e. Edwards Plateau of cen. Tex., Apr.-June; endemic. 


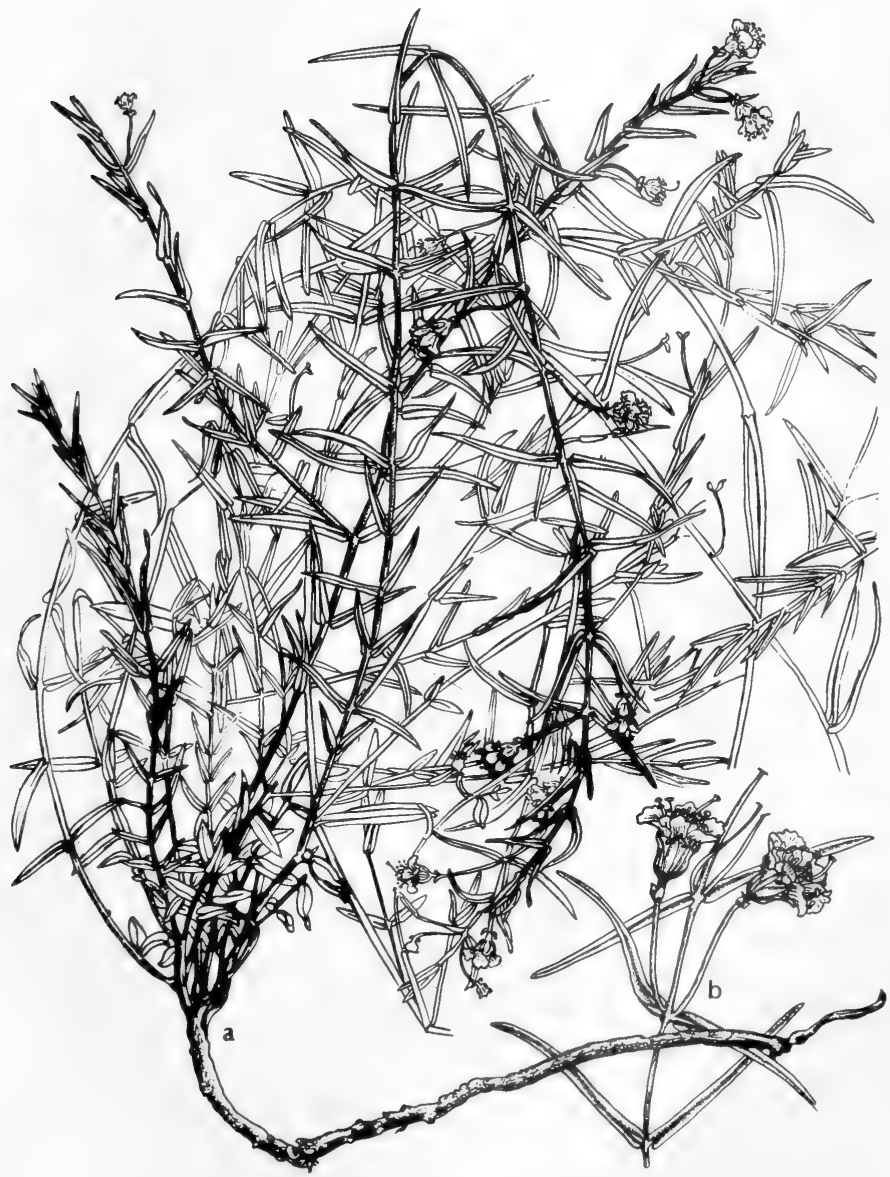

Fig. 540: Heimia longipes: a, habit, $x$ 1/2; b, branch with flowers, $x$ 1. (V. F.). 


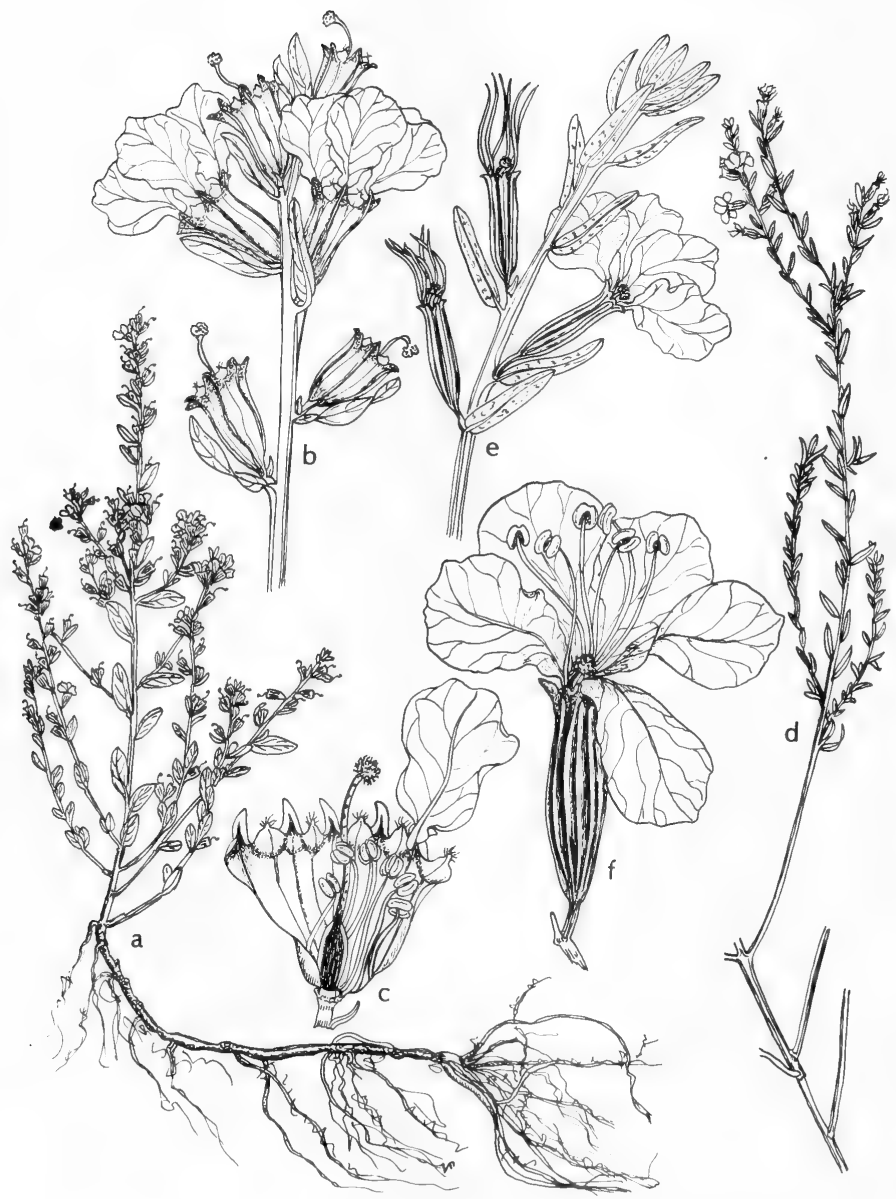

Fig. 541: a-c, Lythrum ovalifolium: a, habit, x 1/2; b, branch of inflorescence, $\mathbf{x} 3$; c, flower split longitudinally, x 5. d-f, Lythrum californicum: d, branch, x 1/2; e, branch of inflorescence, $x 3$; f flower, $x$. $(\mathrm{V} . \mathrm{F}$.). 


\section{Lythrum lanceolatum Ell.}

Plant to $1 \mathrm{~m}$. or more high, the stem usually much-branched (especially above), often in large clumps; stem leaves elliptic to elliptic-lanceolate, to $55 \mathrm{~mm}$. long and $1 \mathrm{~cm}$. wide, acute to acuminate at apex, tapering to a cuneate base with straight margins; leaves of inflorescence similar to stem leaves but much smaller; calyx tube about $5 \mathrm{~mm}$. long, the slenderly subulate appendages much longer than the teeth; petals obovate, purple or cerise-red to lavender-blue, 3-6 $\mathrm{mm}$. long; ovary with a thick ring at base. L. alatum Pursh var. lanceolatum (Ell.) T. \& G.

Rather frequent in meadows, prairies, marshes, about lakes and ponds, ditches and depressions in the e. third of Tex., rare elsewhere in Tex. and Okla. (Johnston, McCurtain, Haskell, Choctaw, Grady, LeFlore and Love cos.), Apr.-Oct.; from Tex. and Okla., e. to Fla., Va. and Tenn.

\section{Lythrum dacotanum Nieuw.}

Perennial from a woody rootstock, to about $1 \mathrm{~m}$. high, the stems mostly muchbranched, rarely simple; stem leaves elliptic to elliptic-lanceolate or linearlanceolate, rounded to subauriculate at base, obtuse to acute at apex, to $35 \mathrm{~mm}$. long and $7 \mathrm{~mm}$. wide; leaves of inflorescence similar to the stem leaves but much smaller; calyx tube 5-6 mm. long; petals purple, obovate, $5-7 \mathrm{~mm}$. long. L. alatum of Okla. and Tex. reports (probably).

Mostly in prairies and meadows, seepage areas and about ponds and lakes, of Panhandle and n.-cen. Tex. and Okla. (Jefferson and Mayes cos.), May-July; from Tex. and Ark., e. to Ga., Tenn. and Va., w. to Colo. and Wyo., n. to Ont.

\section{Lythrum californicum T. \& G. Hierba del CÁNCER. Fig. 541.}

Perennial with creeping woody rootstock, to $15 \mathrm{dm}$. high, usually much smaller, pale-green and glabrous; stems mostly erect, paniculately and divaricately branched above; stem leaves alternate, firm, narrowly linear to linear-oblong or the lower leaves sometimes lanceolate, acute at apex, more or less rounded to somewhat auriculate at the sessile base, to about $3 \mathrm{~cm}$. long and $5 \mathrm{~mm}$. wide; leaves of inflorescence linear, obtuse to acute, much smaller than the stem leaves; calyx tube cylindric, 5-7 mm. long, the subulate teeth sharply acute; petals obovate, brightpurple, 4-6 $\mathrm{mm}$. long, 2-4.5 $\mathrm{mm}$. wide; capsule oblong-clavate, the linearlanceolate seeds about $1 \mathrm{~mm}$. long. L. alatum Pursh var. beviflorum (Gray) Wats., L. linearifolium (Gray) Small, L. parvulum Nieuw.

In moist ground or water along streams, marshes, about ponds and springs, in depressions, and salt flats mainly in s.-cen. and w. Tex., Okla. (probably), N. M. (Grant, Sierra, Don Ana, Socorro, Otero and Chaves cos.) and Ariz. (widespread), Mar.-Nov.; from Tex., n. to Kan. and w. to Calif. and n. Mex.

\section{Ammannia L.}

Mostly low and inconspicuous glabrous annual herbs, the stems mostly 4-angled: leaves opposite, sessile, entire, narrow and often etongated; flowers small, usually in 3- to many-flowered axillary cymes, usually 4-merous; calyx globose or campanulate, 4-angled, 4-toothed, usually with a little horn-shaped appendage in each sinus; petals 4 , small, deciduous, sometimes wanting; stamens 4 to 8 , inserted on the calyx tube; style somewhat persistent; capsule 2- to 4-celled, bursting irregularly; seeds numerous, angled and minutely pitted.

About 30 species widespread in tropical and warm temperate regions.

1. Cymes decidedly pedunculate; mature capsule surpassing the calyx.

1. Cymes sessile or essentially so; mature capsule equal to or shorter than the calyx (2) 
2(1). Style 1.5-3 mm. long; leaves linear to narrowly oblong, clasping stem at the auriculate base................................................2. A. coccinea.

2. Style about $0.5 \mathrm{~mm}$. long; leaves linear-oblong to oblanceolate, the lower ones cuneate at base, the upper ones truncate to cordate-auriculate at base.

3. A teres.

1. Ammannia auriculata Willd. Fig. 542.

Plant erect or with a few short ascending branches, to about $8 \mathrm{dm}$. high, usually much smaller; leaves linear-lanceolate to linear, long-attenuate, to $5 \mathrm{~cm}$. long and $7 \mathrm{~mm}$. wide, all but the very lowest auriculate-cordate at base; cymes loosely 3- or more-flowered on peduncles to $5 \mathrm{~mm}$. or more long or with solitary flowers on pedicels to about $3 \mathrm{~mm}$. long; calyx $1.5-2 \mathrm{~mm}$. long, with prominent triangular teeth, 8-nerved, in fruit becoming subglobose and 2-4 $\mathrm{mm}$. in diameter; petals minute, purple to white, soon dropping; style filiform, 1.5-3 mm. long; capsule surpassing the calyx; seeds reddish-brown. Incl. var. arenaria (H.B.K.) Koehne.

In swamps, ditches and about pond margins throughout much of cen. Tex., rare in the Panhandle (Lipscomb Co.), Okla. (Carter, Ottawa, Comanche, LeFlore and Craig cos.) and possibly Ariz., May-Sept.; from Mo. and Miss. to N.M., (?) Ariz. and Mex., n. to Ind. and S.D.

\section{Ammannia coccinea Rottb. Tooth-CuP. Fig. 542.}

Plants rather stout, ascending or depressed-spreading, to about $5 \mathrm{dm}$. high, the stem branched below and spongy when growing in water; leaves linear-oblong to linear-lanceolate, to $1 \mathrm{dm}$. long and $15 \mathrm{~mm}$. wide, mostly much smaller, cordateauriculate and clasping stem at base, acute to acuminate at apex; cymes closely 2 - to 5-flowered, essentially sessile; calyx $2.5-5 \mathrm{~mm}$. long, in fruit $3-5 \mathrm{~mm}$. in diameter; petals pink to purple, 1-2 mm. long, fugacious; style persistent, 1.5-3 $\mathrm{mm}$. long; capsule about $4 \mathrm{~mm}$. long.

In mud of ditches, ponds, marshes, lakes and streams in e., cen. and extreme s. Tex., Okla. (Creek, Pittsburg, McIntosh, Stephens, Jefferson, Johnston, LeFlore. Craig and Nowata cos.) and Ariz. (Maricopa, Cochise, Pima and Yuma cos.), Apr.-Nov.; from Fla. to Tex. and Mex., n. to O., Ill., Minn., Neb., Mont. and Wash.

Readily distinguished from $A$. auriculata by the compact, sessile whorls of flowers and fruits.

\section{Ammannia teres Raf. Fig. 543.}

Plant erect, the stout stems simple or with few erect branches near the base, to about $6 \mathrm{dm}$. high, usually much smaller, fleshy; leaves oblong to oblanceolate, obtuse to subacute at apex, tapering at base or rarely subauriculate, the longer leaves to $6 \mathrm{~cm}$. long; flowers several in the axils, sessile; calyx teeth very short and broad; petals pink, about $1 \mathrm{~mm}$. long, fugacious; style thick, about $0.5 \mathrm{~mm}$. long; fruiting calyx about $5 \mathrm{~mm}$. in diameter; seeds whitish-brown.

Swamps and tidal marshes in s.e. Tex., summer; from Fla. to Tex., n. to N.J.

\section{Peplis L.}

A monotypic genus.

1. Peplis diandra Nutt. Water-purslane. Fig. 539.

Aquatic or sometimes terrestrial herb, rooting in mud, glabrous, with slender simple stems to about $4 \mathrm{dm}$. long; leaves opposite, those of submersed plants elongated, linear, minutely retuse at the obtusish apex, thin and flaccid, closely sessile by a broad base, to about $3 \mathrm{~cm}$. long and $3 \mathrm{~mm}$. wide, when emersed shorter and contracted at base; flowers small, greenish, solitary and sessile in axils of leaves; calyx without appendages, 2-3 $\mathrm{mm}$. long, with 4 broad triangular pinkish lobes; 


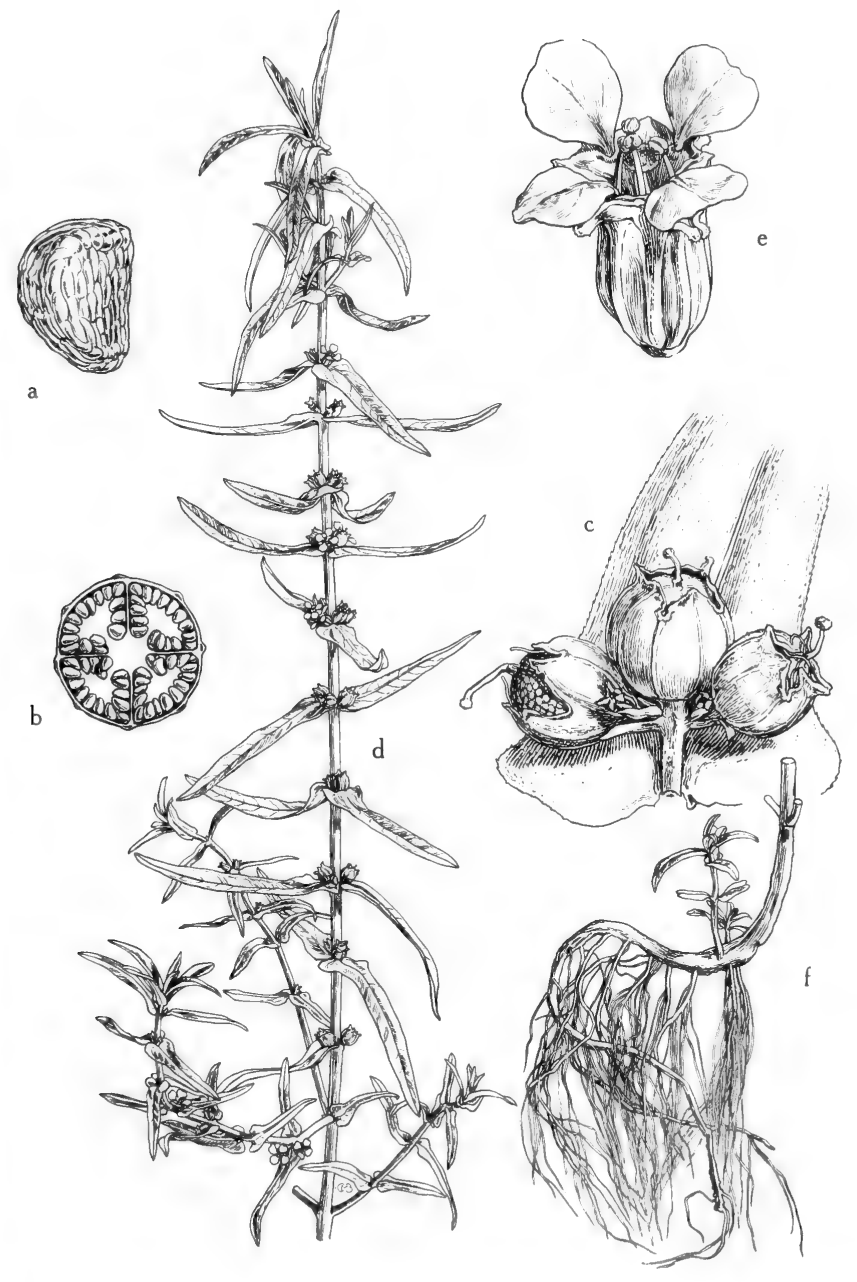

Fig. 542: Ammannia. a-c, $A$. auriculata: a, mature seed, x 40; b, mature capsule (cross section), the placentation axile, $\mathrm{x} 4$; c, peduncled inflorescence, the subtending leaf auricled at base, x 3. d-f, A . coccinea: d, habit, the flowers sessile in leaf axils, x 25 ; e, flower, x 4; f, habit, basal part of plant, showing roots; x $2 / 5$. (From Mason, Fig. 273). 

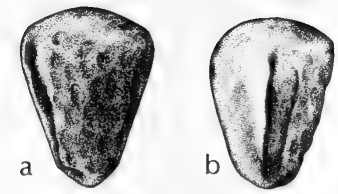

Fig. 543: Ammannia teres: a, seed, front view, much enlarged; b, seed, side view, x 75. (Courtesy of R. K. Godfrey).

petals none; stamens 4; style abbreviated; capsule globose, 2-celled, indehiscent, about $2 \mathrm{~mm}$. in diameter. Didiplis diandra (Nutt.) Wood.

In shallow water and on margin of water of ponds, streams and lakes in e. Tex. and Okla. (McCurtain Co.), Mar.-June; from Fla. to Tex., n. to Va., O., Ind. and Wisc.

\section{Rotala L.}

Small annual herbs, glabrous or nearly so; leaves opposite, narrow; flowers regular or nearly so, axillary, mostly solitary, small, bibracteolate; calyx with appendages shorter to longer than the regular teeth; petals 4 or wanting; ovary ellipsoid; valves of the capsule minutely transverse-striate.

About 50 species, widespread mostly in tropical or subtropical regions.

1. Bractlets usually shorter than the calyx; appendages half as long as to about equal to the calyx teeth; ovary subovoid-globose........1. $R$. ramosior.

1. Bractlets often twice as long as the calyx; appendages often 3 times as long as the calyx teeth; ovary ellipsoid............................ $R$. dentifera.

\section{Rotala ramosior (L.) Koehne. Tоотн-CUP. Fig. 544.}

Small annual herb, low and sprawling to erect and spreading, with simple or diffusely branched 4-angled stems, glabrous, to $45 \mathrm{~cm}$. high, usually much smaller; leaves opposite, subsessile to somewhat petioled, linear-oblong to elliptic or oblanceolate, obtuse, to about $45 \mathrm{~mm}$. long and $1 \mathrm{~cm}$. wide; flowers regular or nearly so, small, solitary in leaf axils, 4-merous, bibracteolate; calyx with appendages shorter to longer than the teeth, the tube campanulate to globose; petals 4 , attached to rim of calyx tube, white or pink; stamens 4, attached low on calyx tube; capsule globose, 4-celled, enclosed in the membranous calyx, the valves minutely transversestriate, to $5 \mathrm{~mm}$. long and $4.5 \mathrm{~mm}$. broad, the somewhat persistent style about 0.5 $\mathrm{mm}$. long; bractlets linear-lanceolate to subulate, to $4 \mathrm{~mm}$. long.

In sandy or muddy soil in water or on the edge of ponds, lakes, tanks and in depressions in the e. half of Tex., Okla. (LeFlore, Comanche, Johnston, McCurtain, Ottawa and Carter cos.) and Ariz. (Cochise Co.), May-Oct.; from Fla. to Tex. and Ariz., n. to N.E., N.Y. and the Lake States; also Wash. and Ore.

Most of our material is referable to var. interior Fern. \& Grisc. This is a more robust and upright plant than var. ramosior. The larger leaves are usually subsessile and are $5-10 \mathrm{~mm}$. wide, the capsules are $3.5-5 \mathrm{~mm}$. long and $3.2-4.5 \mathrm{~mm}$. broad, and the linear-lanceolate bractlets are $1.6-4 \mathrm{~mm}$. long. These organs in var. ramosior have smaller measurements.

2. Rotala dentifera (Gray) Koehne. Fig. 545.

Stems erect or ascending, 3-50 cm. long; herbage glabrous; leaves lanceolateelliptic to oblanceolate, narrowed to a very short petiole or subsessile, $2-4 \mathrm{~cm}$. long; flowers sessile and solitary in the leaf axils; bracts linear to linear-lanceolate, accres- 


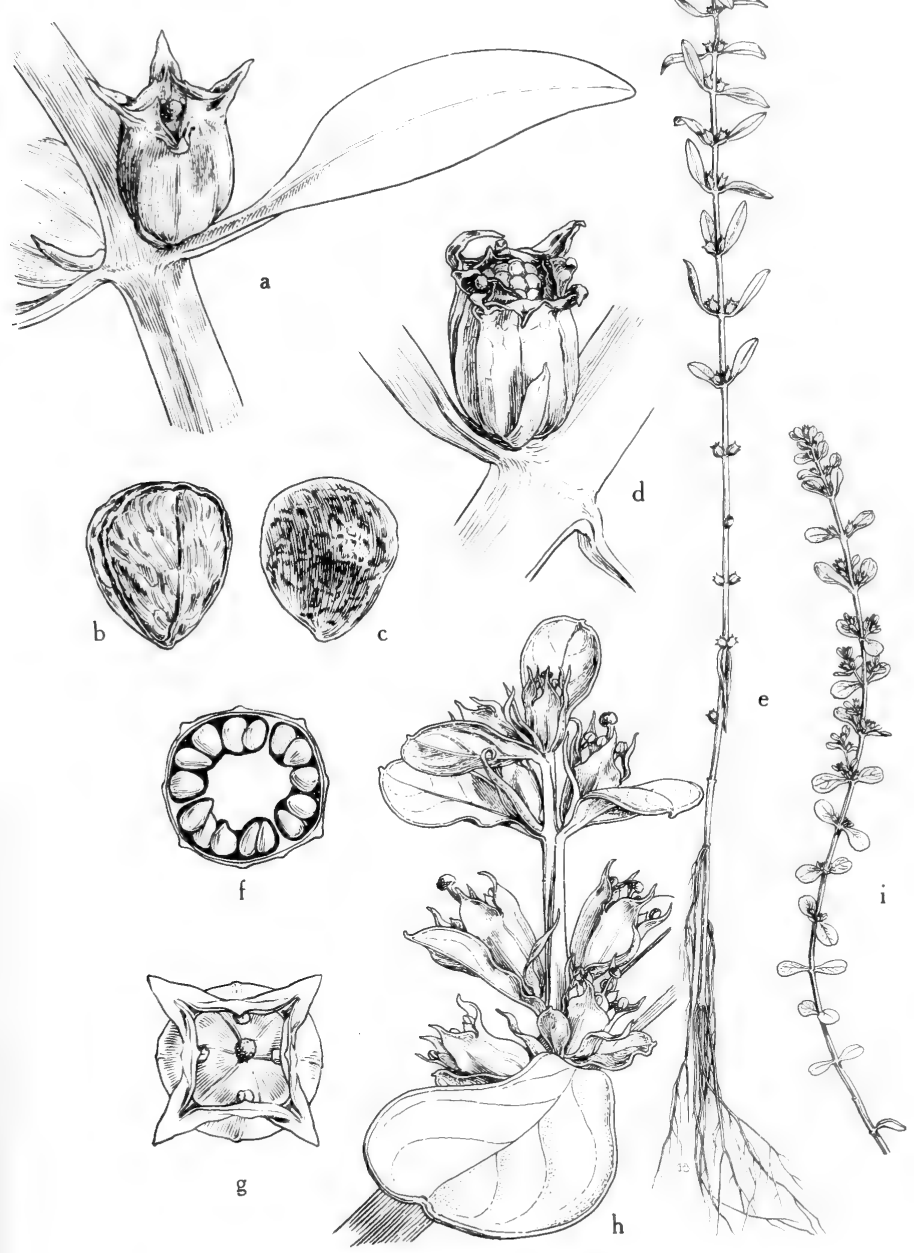

Fig. 544: Rotala. a-g, R. ramosior: a, fruit in leaf axil, showing the short bracts, x 6; b and c, mature seeds, adaxial and abaxial views, x 40; d, mature capsule, x 6; $\mathrm{e}$, habit, $\mathrm{x} 2 / 3 ; \mathrm{f}$, capsule (cross section), $\mathrm{x} 8 ; \mathrm{g}$, maturing capsule, top view, $\mathrm{x} 8 . \mathrm{h}$ and $\mathrm{i}, \boldsymbol{R}$. indica: h, spikelike branch, the flowers solitary in the leaf axils, the bracts slender, x 6; i, habit, x 2/3. (From Mason, Fig. 276). 


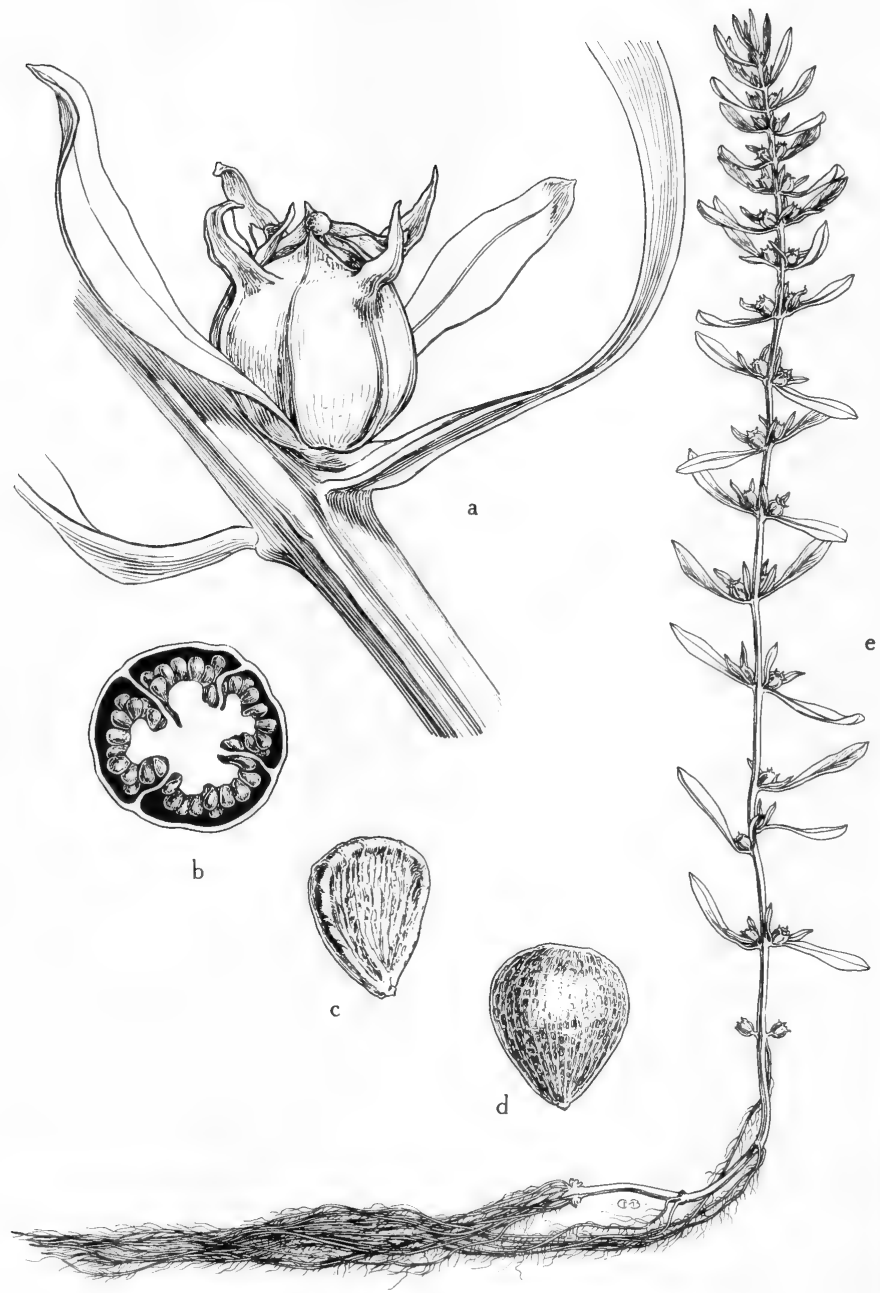

Fig. 545: Rotala dentifera: a, fruit in leaf axil, showing the long bracts, $\mathrm{x}$ 6; $\mathrm{b}$, mature capsule (cross section), showing axile placentation, $\mathrm{x} 6$; $\mathrm{c}$ and $\mathrm{d}$, mature seeds, adaxial and abaxial views, $x$ 40; e, habit, showing the flowers solitary in leaf axils, x 25 . (From Mason, Fig. 275). 
cent, longer than the flowers, 1 to 2 times as long as the fruit; appendages of calyx 2 to 5 times as long as the sepals, sometimes becoming reflexed; sepals longtriangular, sometimes cuspidate; petals small, pink to white, elliptic, $1 \mathrm{~mm}$. long; style short or obsolete; ovary 4-celled (sometimes 3-celled).

In shallow water or at the margins of ponds or streams, probably in s. Ariz.; also n. Son.

\section{Cuphea P. BR.}

Herbs or woody plants, mostly clammy-pubescent; leaves entire; flowers solitary in axils or in terminal spikes or racemes; calyx tubular, 12-ribbed, gibbous or spurred at base on upper side, the 6 lobes with small teeth in the sinuses; petals 6 , unequal; ovary with a curved gland at the base next to the calyx spur, 1- or 2-celled; style slender, the stigma 2-lobed; stamens 6 to 14 , adnate to near the top of the hypanthium; embryo with orbicular cotyledons; capsule ovoid or ellipsoid, few-seeded, soon ruptured on one side.

About 250 species, primarily in the American tropics.

1. Perennial; stems thin and wiry, spreading-assurgent; stem leaves sessile or essentially so, about $1.5 \mathrm{~cm}$. long............................ C. glutinosa.

1. Annuals; stems stoutish and erect; stem leaves distinctly petiolate, usually $2 \mathrm{~cm}$. long or more (2)

2(1). Mature calyx 5-7 $\mathrm{mm}$. long, the limb subequally 5-lobed.

2. Mature calyx 8-12 mm. long, the limb noticeably bilabiate.

2. C. carthagensis.

3. C. viscosissima.

\section{Cuphea glutinosa Cham. \& Schlecht.}

Perennial with slender rootstocks, the roots fibrous, the herbage more or less glandular-viscid throughout; stems thin and wiry, spreading-assurgent, 1-3 dm. long, simple or usually sparingly branched; leaves sessile or nearly so, ovate to oblong-lanceolate, acute, about $1.5 \mathrm{~cm}$. long or less; pedicel about $1.5 \mathrm{~mm}$. long; hypanthium 7-8 mm. long, curved, gibbous; calyx limb with 5 minute equal deltoid lobes; petals deep violet-color, elliptic-oblong, obtuse, 5-6.5 $\mathrm{mm}$. long; seeds discoid, about $2 \mathrm{~mm}$. long.

Wet meadow about small woodland lake in s.e. Tex. (Tyler Co.), Sept.-Nov.; also La.; nat. of S.A.

\section{Cuphea carthagensis (Jacq.) Macbr. Fig. 546.}

Plant annual, 2-9 dm. high, the stem and branches with scattered bristly hairs; leaves short-petiolate, elliptic to oval or sometimes obovate, $2-6 \mathrm{~cm}$. long, rugose (especially with age); hypanthium and calyx 5-7 $\mathrm{mm}$. long, usually with few bristles; calyx lobes minute, broadly deltoid; petals pink or bluish, elliptic or nearly so, 1.5-2 mm. long; capsule 4-5 mm. long.

On edge of low wet woods and swamps, rare in s.e. Tex. (Hardin Co.), JulySept.; from S.A., n. through C.A. and Mex. to Tex. and N.C.

\section{Cuphea viscosissima Jacq. Blue Waxweed. Fig. 546.}

Plant annual, viscid-hairy, 1-7 dm. high; leaves with petioles to about $15 \mathrm{~mm}$. long; blade lanceolate to ovate-lanceolate, $1-3.5 \mathrm{~cm}$. long; hypanthium and calyx 8-12 mm. long; calyx limb prominently bilabiate, the upper lip much broader than long; petals ovate, short-clawed, rose-purple, the upper ones $4.5-5.5 \mathrm{~mm}$. long; capsule 6-8 mm. long; seeds flat. C. petiolata (L.) Koehne.

Fields, roadsides, wet gravel bars of rivers, edge of streams and lakes, one Tex. record without definite locality and in e. third of Okla. (Cherokee and McCurtain cos.), July-Oct.; from Ga. to La., Tex. and Okla., n. to Kan., Ia. and N.E. 

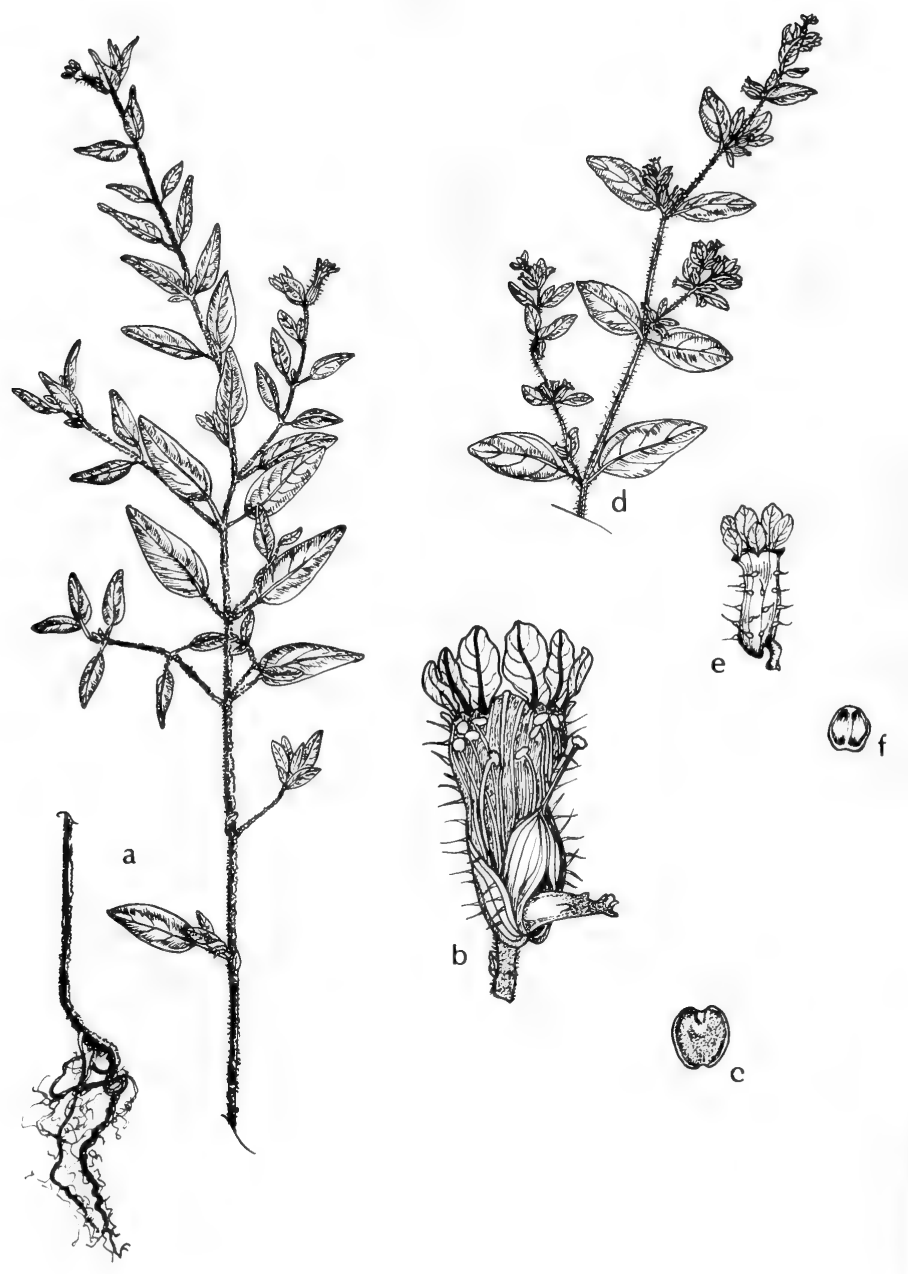

Fig. 546: a-c, Cuphea viscosissima: a, habit, $\mathrm{x} 1 / 2$; $\mathrm{b}$, flower split longitudinally, $\mathrm{x}$ $2 \frac{1}{2}$; c, seed, x 21/2. d-f, Cuphea carthagensis; d, branch of plant, x 1/2; e, flower, x 21/2; f, seed, $x 2 \frac{1}{2}$. (V.F.). 
Trees, shrubs, herbs or rarely vines with simple opposite 3- to 7- or rarely 1 -nerved leaves and commonly showy cymose flowers; flowers perfect, regular, mostly 4- or 5-merous; hypanthium variously shaped; sepals valvate and petals convolute in bud; stamens twice as many as petals, often dimorphic; anthers opening by pores at the apex, commonly with an appendage; ovary superior; fruit a capsule; seeds usually numerous, variously shaped and adorned.

A large tropical family of about 240 genera and 3,000 species.

\section{Rhexia L. Meadow Beauty. Deer-grass}

Erect herbaceous or suffrutescent perennials, with one to several simple or branched stems arising from the bases of previous shoots, from a woody crown, from horizontal-spreading roots or from tuberous roots, essentially glabrous to densely glandular-pubescent throughout; stems becoming woody or spongy below (when growing in water), subterete about the middle with 4 well-defined faces (sides) whose edges are inconspicuously to prominently winged; faces of stem flat to convex and essentially equal or with one pair of opposing faces flat to concave and much narrower than the other pair of convex or rounded faces; leaves opposite, sessile to petiolate, suborbicular-ovate to linear-lanceolate or narrowly ellipticlinear, with one to several palmate veins and with the margins ciliate to serrulate or serrate; flowers usually showy, solitary or borne in cymes; petals 4, distinct, oblique, cuneate to suborbicular, fugacious, mostly rose-color to purple, sometimes white or yellow; hypanthium more or less urceolate, glabrous to variously glandularpubescent, the lower portion somewhat ventricose and enclosing all or most of the capsule, constricted or narrowed above to usually form a neck, sometimes expanded above the neck; calyx lobes 4 , erect to spreading or strongly recurved, deltoid to lanceolate, obtuse to acuminate or rarely aristate; stamens 8 , isomorphic; anthers 1-celled at anthesis, basifixed, commonly with an appendage at base, yellow, smooth to papillose, more or less lanceolate in outline, straight or curved to sigmoid, dehiscing by a pore; ovary 4-celled; fruit a capsule; seeds strongly curved to cochleate, variously adorned. States.

A small genus of about a dozen species that are centered in southeastern United

1. Anthers straight, $1-3 \mathrm{~mm}$. long, the pore nearly equaling the diameter of the anther tip; neck of the hypanthium conspicuously constricted at the base, abruptly expanded above (2)

1. Anthers curved, $4 \mathrm{~mm}$. long or more, the pore only about one third the diameter of the anther tip; neck of the hypanthium not constricted at the base, gradually (if at all) expanded above (3)

2(1). Petals rose-color; stem glabrous; leaves ovate to oval or elliptic, less than 3 times as long as wide............................................ I. R. petiolata.

2. Petals yellow; stem hirsute; leaves typically linear-elliptic, more than 3 times as long as wide.

2. R. lutea.

3(1). Stems glabrous throughout; hypanthium typically densely short glandularhairy; seeds wedge-shaped. 5. $R$. alifanus.

3. Stems always more or less hairy especially at nodes; hypanthium not as above; seeds cochleate (4)

4(3). One pair of opposing faces of the stem flat to concave and much narrower than the other pair of convex or rounded faces; stem neither conspicuously winged nor spongy-thickened below; leaves usually petiolate; petals or mature hypanthium (or both) glabrous; flowers white, rose or purple.............................$R$. mariana var, mariana. 


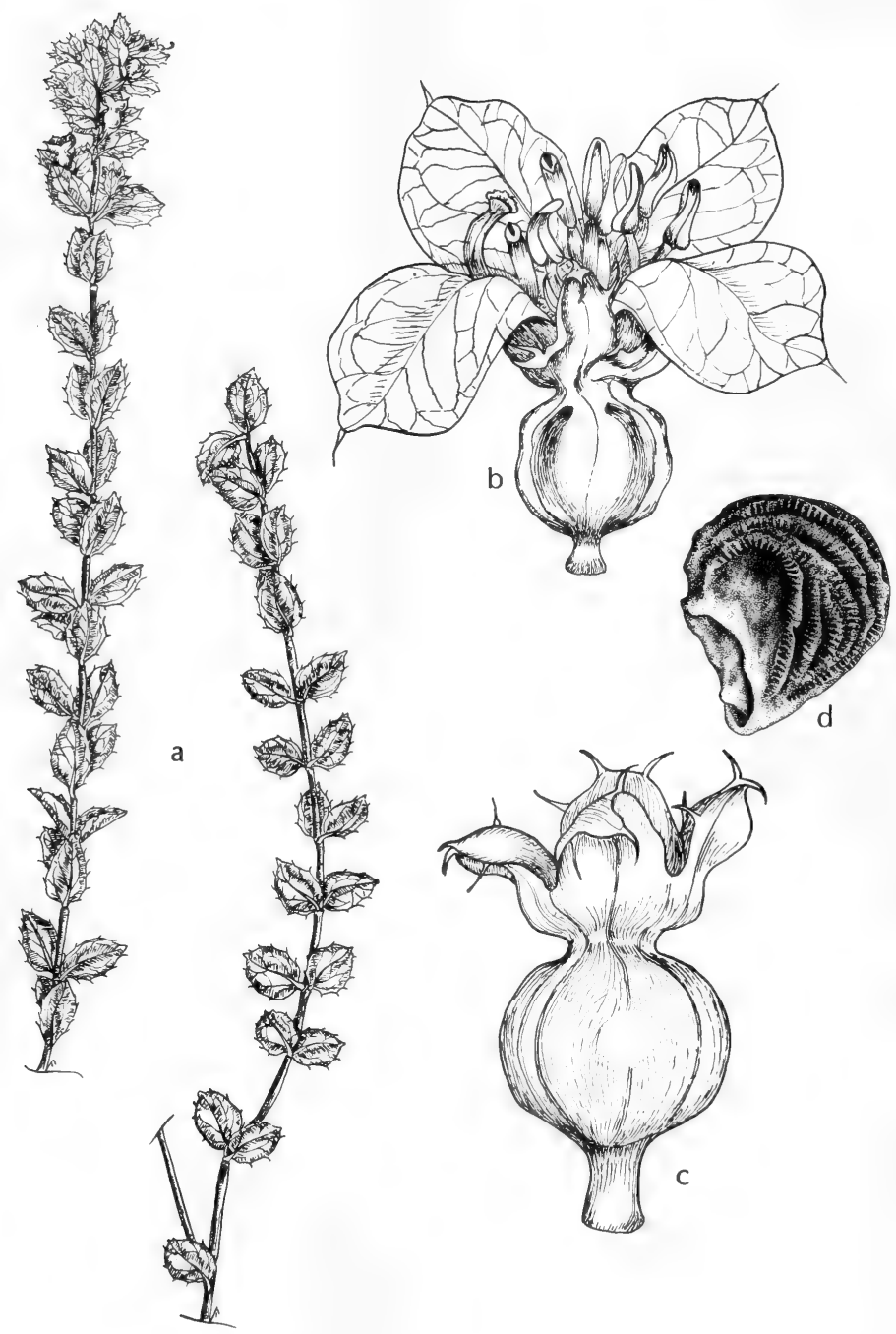

Fig. 547: Rhexia petiolata: a, branches of plant, x 1/2; b, flower, x 5; c, fruit, x 5; d, seed, about x 40. (V. F.). 


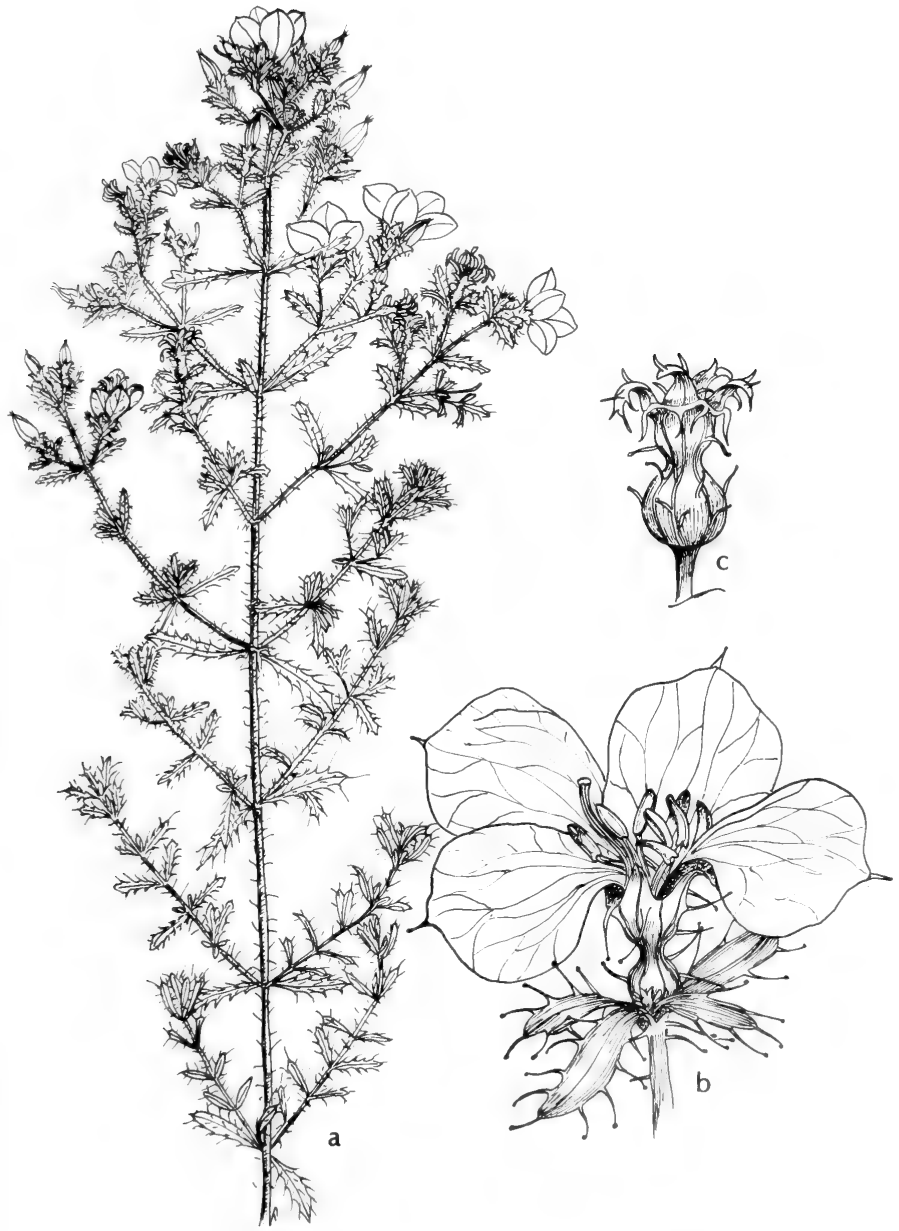

Fig. 548: Rhexia lutea: a, upper part of plant, x 1/2; b, flower, x 2; c, fruit, x 2 . (V. F.). 
4. Faces of the stem flat to convex and essentially equal; stem with conspicuous wings (to about $2 \mathrm{~mm}$. wide) and spongy-thickened below or (if neither) then with hairs on the abaxial surface of the petals and on the mature hypanthium; leaves sessile or nearly so; flowers rose to purple (5)

5(4). Roots tuberous; stem with conspicuous wings and often spongy-thickened below; leaves frequently broadest near the base; hypanthial neck rarely longer than the body of hypanthium...............4. $R$. virginica.

5. Rootstock rhizomatous, nontuberous; stem lacking conspicuous wings and rarely spongy-thickened below; leaves frequently broadest near the middle; hypanthial neck usually longer than body of hypanthium 3. R. mariana var. interior.

\section{Rhexia petiolata Walt. Fig. 547.}

Plant to $6 \mathrm{dm}$. tall; leaves to $25 \mathrm{~mm}$. long and $15 \mathrm{~mm}$. wide, 3-nerved, somewhat petiolate; hypanthium glabrous at maturity, 5-9 $\mathrm{mm}$. long; calyx lobes to $4 \mathrm{~mm}$. long and $3 \mathrm{~mm}$. wide, with serrate to ciliate margins; petals rose-color, elliptic, to $2 \mathrm{~cm}$. long. $R$. ciliosa Michx.

In peaty or sandy soils of wet pinelands and evergreen shrub or pitcher plant bogs, in s.e. Tex., July-Sept.; along coast from s.e. Va. to cen. Fla., w. to Tex.

The typically oval leaves and sessile flowers are characteristics of this species.

\section{Rhexia lutea Walt. Fig. 548.}

Plant to $5 \mathrm{dm}$. tall, the stems usually much-branched; leaves to $25 \mathrm{~mm}$. long and $8 \mathrm{~mm}$. wide, 3-nerved, essentially sessile; hypanthium at maturity glabrous or with few scattered glandular hairs, 5-8 $\mathrm{mm}$. long; calyx lobes to $3 \mathrm{~mm}$. long and wide, with glandular hairs on margins; petals yellow, elliptic, to $13 \mathrm{~mm}$. long.

In wet savannahs and open pinelands, hillside seepage and bogs of s.e. Tex., May-June; along coast from e. N.C. to n. Fla., w. to Tex.

The yellow petals are distinctive.

\section{Rhexia mariana L. var. mariana. Fig. 549.}

Plant to $7 \mathrm{dm}$. tall, the stem with axillary branches; leaves petiolate, elliptic to lanceolate, to $6 \mathrm{~cm}$. long, the margins serrate, ciliate; calyx lobes triangular to lanceolate, to $3 \mathrm{~mm}$. long; petals obovate, to about $18 \mathrm{~mm}$. long. Incl. var. exalbida Michx.

In marshes, ditches, wet meadows, seepage bogs, savannahs, edge of thickets and similar places that are wet or moist, throughout e. Tex. and e. Okla. (McCurtain, Haskell, LeFlore and Pushmataha cos.), May-Sept.; from Mass. s. to Ga., w. to Tex. and Okla., n.w. to Mo., Ill. and Ind.

The leaves narrowed to petioles readily distinguish this species from $R$. virginica.

Var. interior (Penn.) Kral \& Bostick.

This is not an altogether clear taxon, especially since it has some characteristics usually attributed to $R$. virginica. It may well represent a hybrid but for the present we follow the most recent revisionists of this genus, $R$. interior Penn.

In water of ponds, marshes and lowlands; centered in the interior prairies of Mo. and Kan., extending e. to Ind., Ky. and Tenn. and s. to La., Tex. and e. Okla. (LeFlore, Adair, Sequoyah and McCurtain cos.).

\section{Rhexia virginica L. Common meadow beauty. Fig. 550.}

Plant to $1 \mathrm{~m}$. tall; leaves ovate to ovate-lanceolate or elliptic, to $1 \mathrm{dm}$. long and $35 \mathrm{~mm}$. wide, the margins serrate-ciliate, sessile or with petioles to $5 \mathrm{~mm}$. long; hypanthium to $1 \mathrm{~cm}$. long, glandular-hispid at maturity; calyx lobes triangular to lanceolate, to $2.5 \mathrm{~mm}$. long; petals dark-rose-color to purple, obovate, to $17 \mathrm{~mm}$. long. 


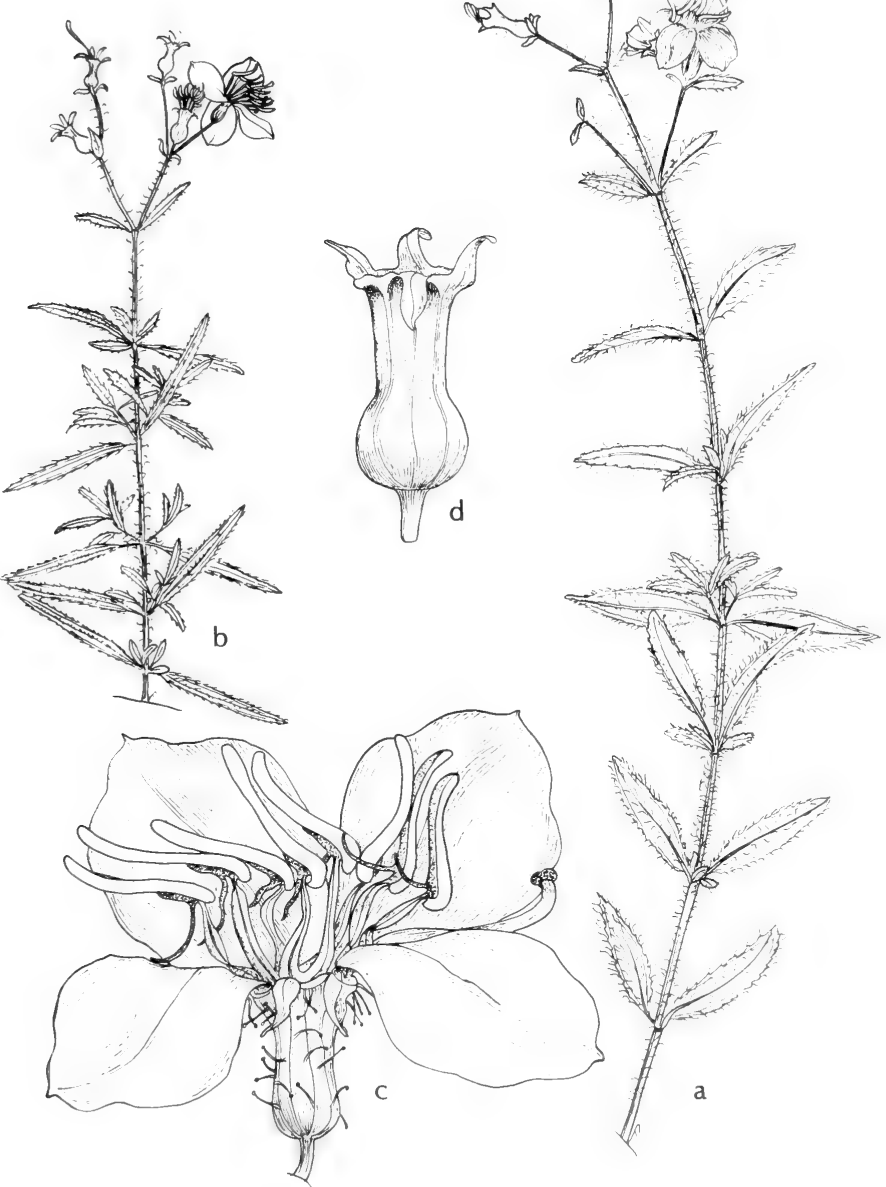

Fig. 549: Rhexia mariana: a and b, tops of two plants showing variation of leaf appearance, $x 1 \frac{1}{2}$; c, flower, $x 2$; d, fruit, $x 2$. (V. F.). 


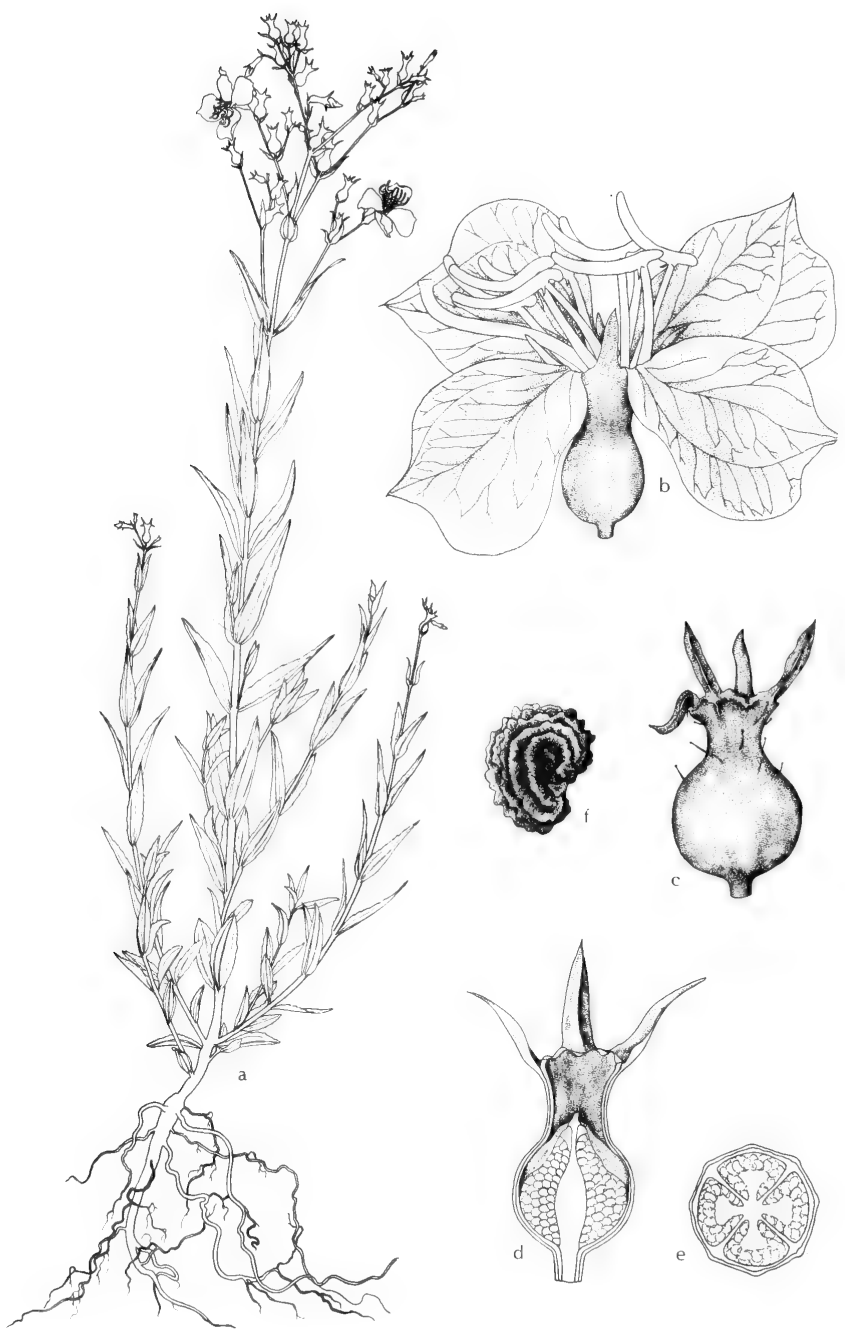

Fig. 550: Rhexia virginica: a, habit, x 1/3; b, flower, $x 2$; c, capsule, $x 2$; d, capsule split open to show seeds, $\times 2$; e, cross section of capsule, $\times 2 ; \mathrm{f}$, seed, about $\times 27$. (Courtesy of R. K. Godfrey). 
On open seepage slopes, ditches and in bogs of e.-cen. Tex., June-Oct.; throughout e. U.S., excluding Fla., n. to N.S. and Ont., w. to Kan. and Tex.

\section{Rhexia alifanus Walt.}

Erect glabrous perennial with simple or basally branched wandlike stems to about $1 \mathrm{~m}$. high, from an enlarged spongy rootstock; leaves ovate-lanceolate or narrowly elliptic, glabrous, 3-nerved, entire, to $7.5 \mathrm{~cm}$. long and $1 \mathrm{~cm}$. wide, acute to acuminate at apex, cuneate to the sessile base; flowers few in a paniculate cyme; sepals deltoid, 1-1.5 mm. long; petals rose-color or purplish, somewhat glandularpubescent on outer surface, 2-2.5 cm. long; anthers yellow, linear-lanceolate, curved, 7-8 $\mathrm{mm}$. long, short-appendaged, with filaments $6-8 \mathrm{~mm}$. long; mature hypanthium 7-10 $\mathrm{mm}$. long, glandular-setose, with a short neck; seeds lustrous, brown, angled, 1-2 mm. long.

A plant of savannahs, bogs and peaty pinelands, in s.e. Tex. (Hardin Co.), Apr.Aug.; from e. N.C., s. to Fla. and w. to Tex.

This is one of the most distinctive of all species in this genus. It is an erect, smooth plant with large, rose-color flowers.

\section{Fam. 95. Onagraceae Juss. Evening Primrose Family}

Herbs, sometimes woody near the base; leaves alternate or opposite, simple. entire, toothed or pinnatifid; stipules minute or lacking; flowers actinomorphic or slightly zygomorphic, perfect, 2-, 4- or 5- (rarely 6-) merous, borne in the axils of usually reduced foliage leaves; hypanthium prolonged beyond the ovary or not; sepals free; corolla white to rose-purple or yellow, the petals free; stamens as many as the sepals and opposite them or twice as many; ovary 4- or 5-locular; fruit a loculicidally dehiscent poricidal capsule or nutlike indehiscent structure.

About 650 species in 19 genera, world-wide but largely extratropical; best developed in subarid western North America.

1. Calyx persistent, divided down to the ovary

1. Calyx deciduous after flowering (2)

2(1). Flowers 2-merous; fruit indehiscent, obovoid, usually with hooked hairs 4. Circaea.

2. Flowers 4-merous; fruits various (3)

$3(2)$. Seeds with tufts of hairs (coma) at one end 2. Epilobium.

3. Seeds without a coma

3. Oenothera

\section{Ludwigia L.}

Seedbox. Water-Primrose

Herbs of wet places with alternate or opposite entire or minutely toothed leaves; stems spongy when in water; stipules present, minute; flowers actinomorphic, 4- or 5- (rarely 6-) merous, borne in the axils of upper leaves; hypanthium not prolonged beyond the apex of the ovary; sepals persistent in fruit; petals yellow or absent; stamens as many or twice as many as the sepals; stigma capitate or globose, undivided; fruit a loculicidally or poricidally dehiscent capsule; seeds lacking a coma. Jussiaea L.

About 70 species, mostly of the tropics and subtropics and best represented in tropical South America.

The seeds of the various species are eaten by wildfowl, especially ducks, and the base of the stem of $L$. palustris is said to be eaten sparingly by muskrats.

1. Leaves opposite (2)

1. Leaves alternate (3) 


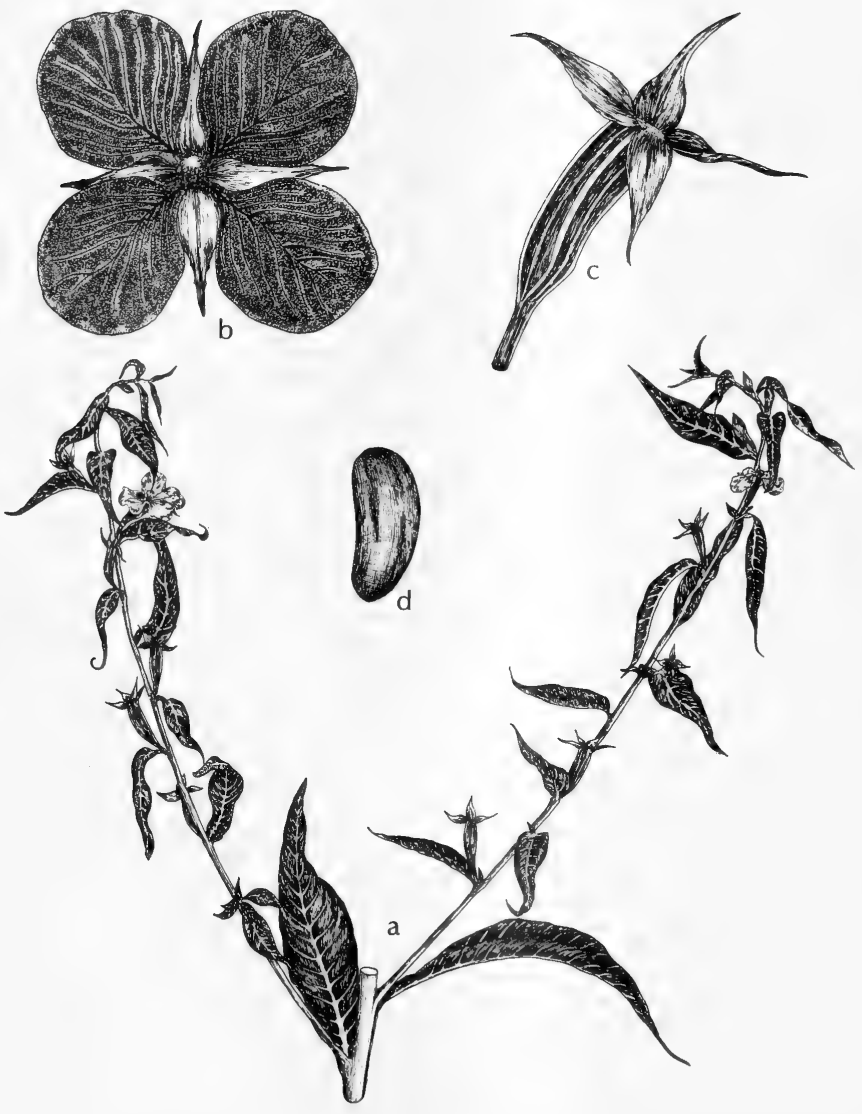

Fig. 551: Ludwigia decurrens: a, part of plant, x 1/3; b, flower, x 2; c, capsule, x 21/2; d, seed, x 36. (Courtesy of R. K. Godfrey). 


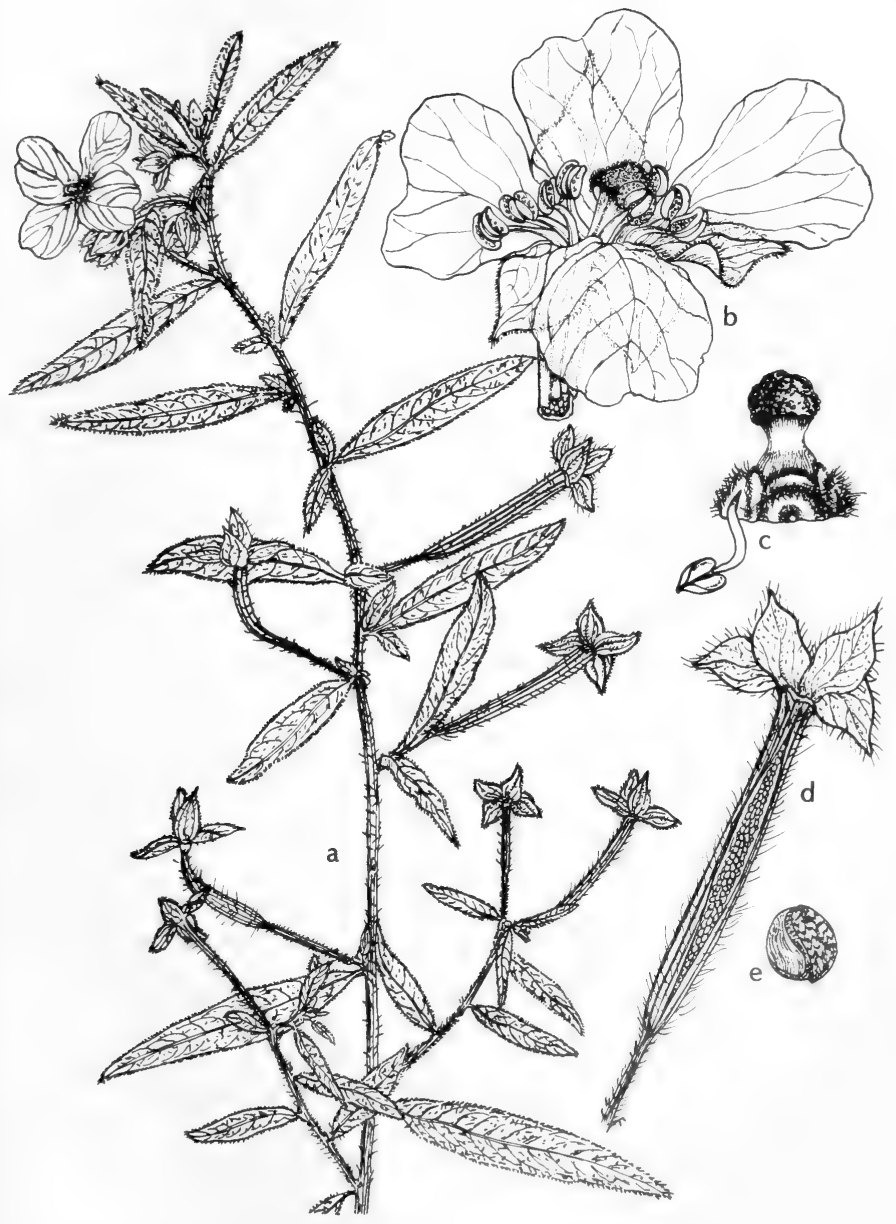

Fig. 552: Ludwigia octovalvis: a, top of plant, $\mathrm{x} 1 \frac{1}{2}$; b, flower, $\mathrm{x} 1 \frac{1}{2}$; c, style and one stamen, $\mathrm{x} 1 \frac{1}{1} 2$; $\mathrm{d}$, capsule, showing young seeds, $\mathrm{x} 1$; e, mature seed, $\mathrm{x} 10$. (V.F.). 
2(1). Petals absent; capsule with a broad green band at each corner.

12. L. palustris.

2. Petals present; capsule lacking green bands

13. L. repens.

$3(1)$. Stamens twice as many as the sepals, in 2 series (4)

3. Stamens as many as the sepals, in 1 series (8)

4(3). Stems conspicuously 4-winged.

1. L. decurrens.

4. Stems not conspicuously 4-winged (5)

5(4). Sepals 4; seeds in several series in each locule of the capsule, free.

........................................................................ L. octovalvis.

5. Sepals 5 (rarely 6); seeds in 1 series in each locule of the capsule, surrounded by woody endocarp at maturity (6)

6(5). Seeds each surrounded by a horseshoe-shaped (hippocrepiform) piece of endocarp, readily falling free.

3. L. leptocarpa.

6. Seeds fused in large masses of endocarp, the entire capsule tough and woody (7)

7(6). Flowering stems erect; plants covered with long spreading pubescence; petals $12-33 \mathrm{~mm}$. long................................5. L. uruguayensis.

7. Flowering stems usually decumbent; plants subglabrous; petals 7-14 (-24) $\mathrm{mm}$. long...........................................................4. L. peploides.

8(3). Capsule nearly globose, opening by a terminal pore; roots fascicled; stolons lacking (9)

8. Capsules variable in shape, irregularly dehiscent; roots not fascicled or if so the capsule not globose; plants with creeping stolons (10)

9(8). Plants hirsute; leaves sessile.

6. L. hirtella.

9. Plants glabrous to puberulent; leaves petiolate. 7. L. alternifolia.

10(8). Petals present.

8. L. linearis.

10. Petals absent (11)

11(10). Plants glabrous to pubescent or strigulose; bracteoles less than $2 \mathrm{~mm}$. long or wanting (12)

11. Plants conspicuously pilose; bracteoles inserted above the base of the capsule, 2.5-4.2 $\mathrm{mm}$. long. 9. L. pilosa.

12(11). Capsule globose to subglobose, $2.5-5.6 \mathrm{~mm}$. long.....10. L. sphaerocarpa. 12. Capsule subcylindric, 2-8 $\mathrm{mm}$. long, 1.5-2 mm. thick........11. L. glandulosa.

1. Ludwigia decurrens Walt. Primrose-willow. Fig. 551.

Subglabrous erect herb to $2 \mathrm{~m}$. tall, freely branched, the stems 4-winged; leaves lanceolate to elliptical, 2-12 $(-16) \mathrm{cm}$. long, 2-35 $\mathrm{mm}$. wide, subsessile; sepals 4 , 7-10 $\mathrm{mm}$. long; petals 8-12 mm. long; stamens 8; disk not elevated, with a sunken white-hairy nectary surrounding the base of each epipetalous stamen; capsule 1-2 $\mathrm{cm}$. long, 3-4.5 mm. thick, sharply 4-angled, irregularly and readily loculicidal, the pedicel $0-1 \mathrm{~cm}$. long; seeds in several series in each locule, free, 0.3-0.4 mm. long, the raphe about one fifth the diameter of the body. Jussiaea decurrens (Walt.) DC.

Swamps and wet places, in water of ditches and streams, about ponds and often forming a vegetative mat in lakes, in Okla. (McCurtain, McIntosh, LeFlore, Johnston, Adair, Sequoyah and Choctaw cos.) and e. Tex., June-Oct.; s.e. U.S. to e. Tex. and scattered to n. Arg.

\section{Ludwigia octovalvis (Jacq.) Raven subsp. octovalvis. Fig. 552.}

Subglabrous to strigulose usually well-branched weedy herb to $1 \mathrm{~m}$. tall or more; leaves lanceolate or narrowly lanceolate to narrowly ovate, 3-14.5 cm. long, 4-40 


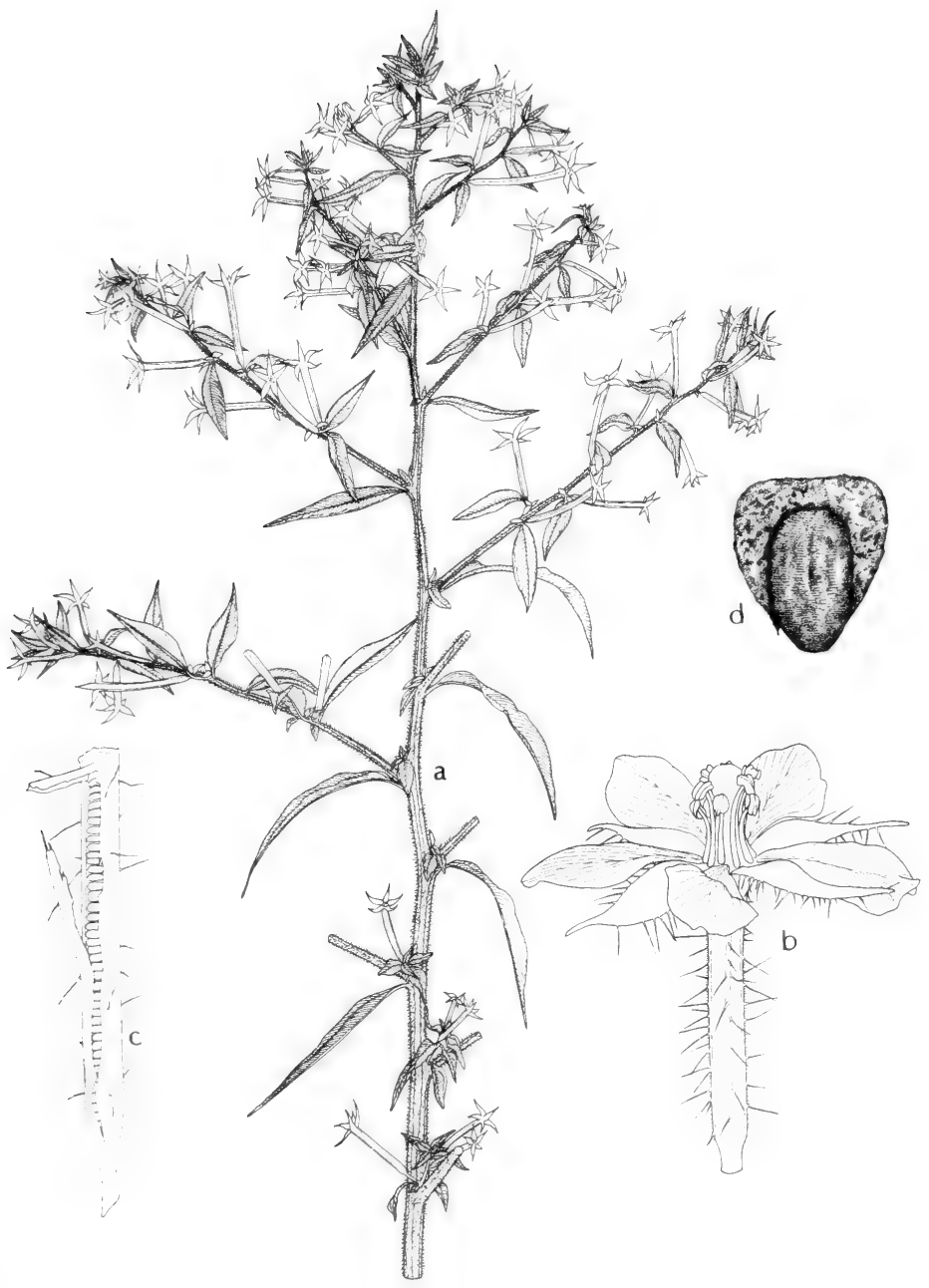

Fig. 553: Ludwigia leptocarpa: a, top of plant, x 1/3; b, flower, x 2; c, capsule, x 2; d, seed, x 20. (Courtesy of R. K. Godfrey). 


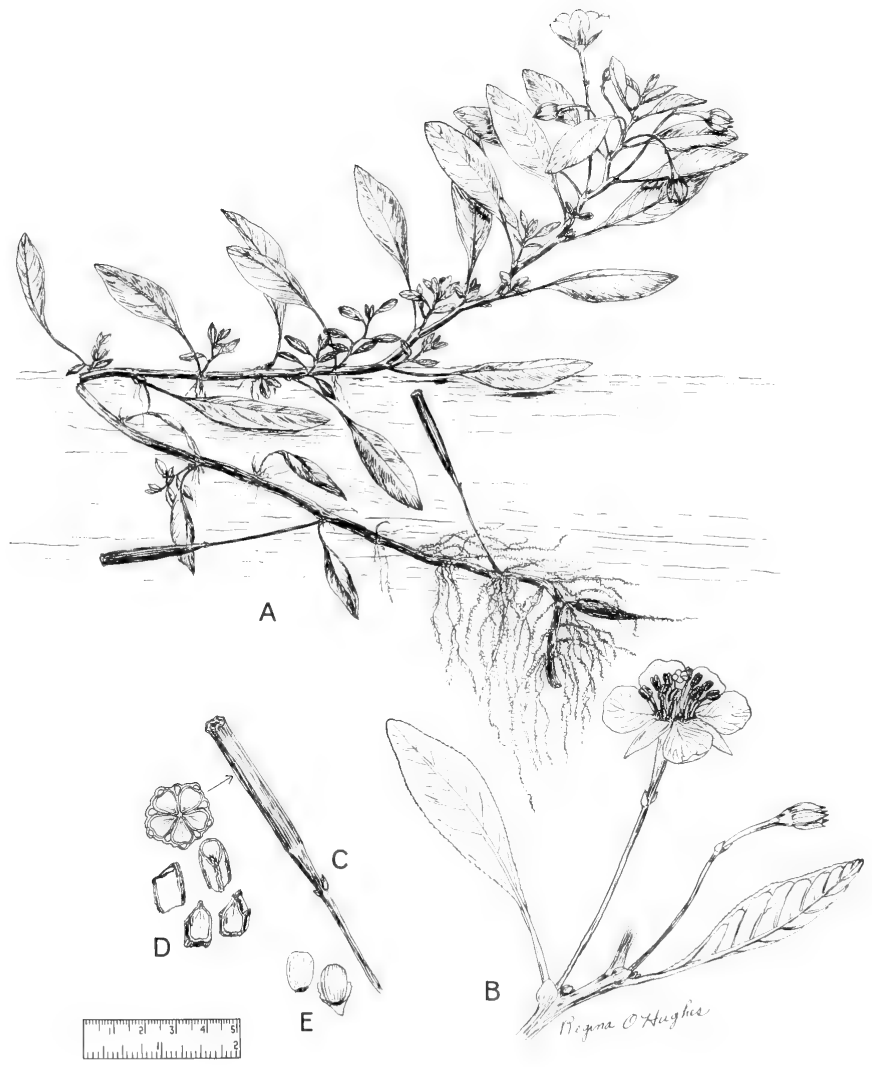

Fig. 554: Ludwigia peploides subsp. peploides: A, habit, showing bladder on root, $\mathrm{x} 1 / 2$; B, flower, about $\mathrm{x} 1$; C, capsule, about $\mathrm{x} 1$; D, seeds with endocarp, $\mathrm{x} 6$; E, seeds about x 6. (From Reed, Selected Weeds of the United States, Fig. 133). 
$\mathrm{mm}$. wide, the petiole $0-1 \mathrm{~cm}$. long; sepals 4 , (6-) $8-13 \mathrm{~mm}$. long; petals 5-16 mm. long; stamens 8 ; disk slightly elevated, with a white-hairy sunken nectary surrounding the base of each epipetalous stamen; capsule thin-walled, 17-45 $\mathrm{mm}$. long, 2-8 $\mathrm{mm}$. thick, readily and irregularly loculicidal, the pedicel $0-1 \mathrm{~cm}$. long; seeds in several indistinct rows in each locule, $0.6-0.75 \mathrm{~mm}$. long, free, each with an inflated raphe equal in size to the body of the seed. Jussiaea suffruticosa L. [incl. var. octofila (DC.) Munz. and var. ligustrifolia (H.B.K.) Griseb.]

In swamps, marshes and other wet places, widespread through s. half of Tex., July-Oct.; warmer regions of the world.

The presence in Texas of the closely related $L$. bonariensis (Mich.) Hara requires confirmation. The ovary of this species at anthesis about equals the sepals instead of exceeding them, the capsule is usually shorter than the pedicel instead of longer and the petals are $20-35 \mathrm{~mm}$. long.

\section{Ludwigia leptocarpa (Nutt.) Hara. Fig. 553.}

Usually robust hairy plants to $15 \mathrm{dm}$. tall, freely branched; leaves broadly lanceolate, $3.5-18 \mathrm{~cm}$. long, 1-4 cm. wide, the petiole 2-35 $\mathrm{mm}$. long; sepals 5 (rarely 4 , 6 or 7 ), 5.5-11 mm. long; petals 5-11 mm. long; stamens twice as many as the sepals; disk slightly elevated, with a depressed hairy nectary surrounding the base of each epipetalous stamen; capsule $1.5-5 \mathrm{~cm}$. long, 2.5-4 mm. thick, slowly and irregularly loculicidal, the pedicel $2-20 \mathrm{~mm}$. long; seeds in 1 series in each locule, horizontal, 1-1.2 mm. long, each loosely embedded in an easily detached horseshoeshaped (hippocrepiform) segment of firm endocarp 1-1.5 $\mathrm{mm}$. thick and about $1 \mathrm{~mm}$. high. Jussiaea leptocarpa Nutt.

Wet places, as along ditches and in water about ponds and lakes, in Okla. (McCurtain Co.) and e. Tex., Aug.-Oct.; e. to Mo., Ga., n. Fla., s. to W.I., Peru and Arg.; trop Afr.

\section{Ludwigia peploides (H.B.K.) Raven subsp. peploides. Verdolaga DE AGUA.} Fig. 554.

Subglabrous sprawling or floating herb with somewhat ascending flowering branches to $6 \mathrm{dm}$. long; leaves oblong to oblong-spatulate, 1-9 cm. long, 5-40 mm. wide, the petiole 2-40 $\mathrm{mm}$. long; sepals 5, 4-12 $\mathrm{mm}$. long; petals 7-14 (-24) mm. long; stamens 10; disk slightly elevated, with a depressed white-hairy nectary surrounding the base of each epipetalous stamen; capsule $1-4 \mathrm{~cm}$. long, 3-4 mm. thick, very tardily and irregularly dehiscent, the pedicel $1-6(-8) \mathrm{cm}$. long; seeds in 1 series in each locule, more or less vertical, $1.1-1.3 \mathrm{~mm}$. long, each firmly embedded in a coherent cube of woody endocarp $1.2-1.5 \mathrm{~mm}$. high, $1-1.2 \mathrm{~mm}$. thick, the endocarp firmly fused to the capsule wall. Jussiaea repens L. var. glabrescens O. Ktze. and var. peploides (H.B.K.) Griseb.

Ponds and streams, attached and floating as mats on water, in Okla. (widespread), e.-cen. and e. Tex., locally w. to the Trans-Pecos, N.M. (Union Co.) and Ariz. (Coconino, Yavapai and Maricopa cos.), Apr.-Oct.; throughout warmer portions of New World; the species as a whole also in n.e. Asia and temp. Austral. and introd. elsewhere.

\section{Ludwigia uruguayensis (Camb.) Hara. Fig. 555.}

Long hairy perennial herb with decumbent rooting and more or less erect ascending branches to $1 \mathrm{~m}$. tall, the floating branches subglabrous; leaves spatulate to oblanceolate, 3-10 cm. long, 3-10 $\mathrm{mm}$. wide, the petiole 1-5 (-25) $\mathrm{mm}$. long; sepals 5 (rarely 6), 6-14 mm. long; petals 12-23 $\mathrm{mm}$. long; stamens twice as many as the sepals; disk slightly elevated, with a depressed white-hairy nectary surrounding the base of each epipetalous stamen; capsule 13-25 mm. long, 3-4 mm. thick, very tardily and irregularly dehiscent, the pedicel $5-50 \mathrm{~mm}$. long; seeds in 1 series 


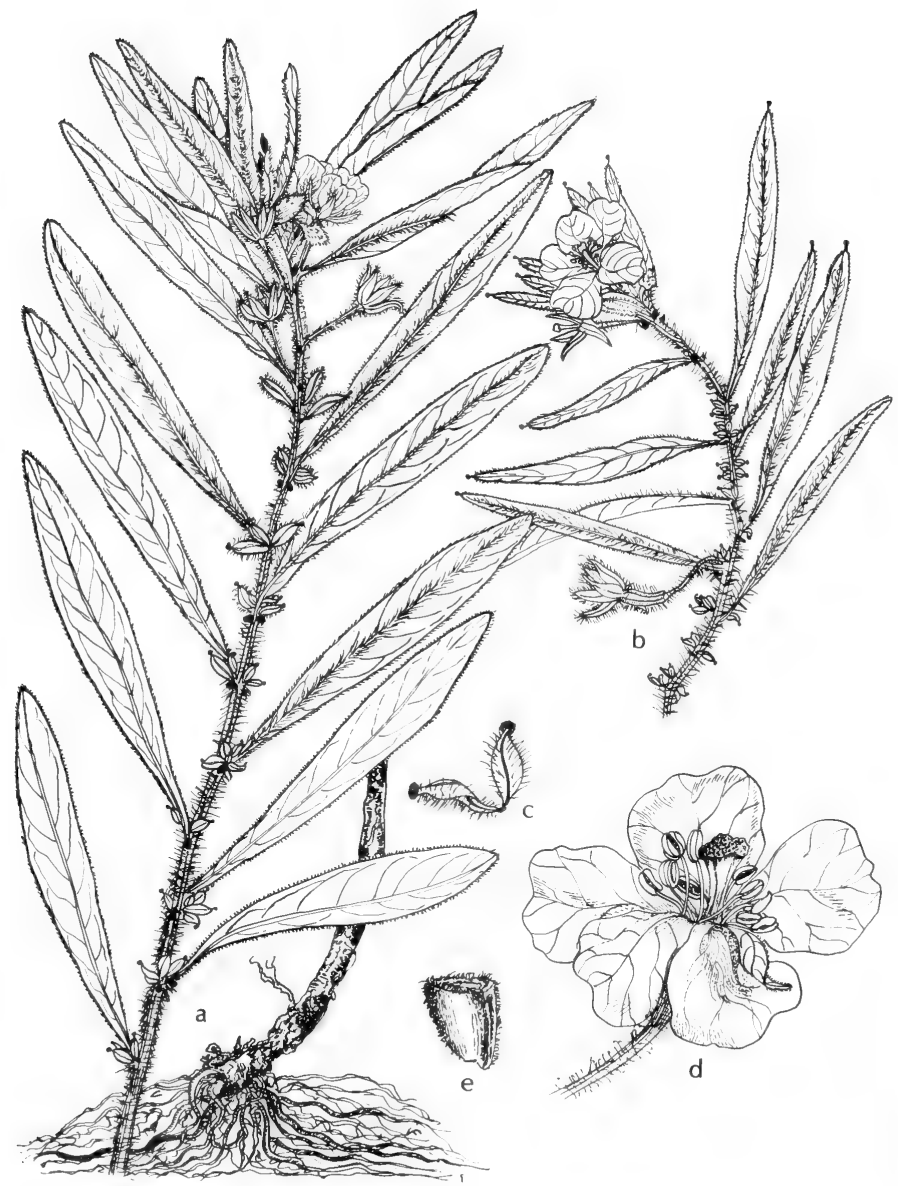

Fig. 555: Ludwigia uruguayensis: a, habit, $\mathrm{x} 1 / 2 ; \mathrm{b}$, twig showing variety in leaf shape and a maturing capsule, $\mathrm{x} 1 / 2$; c, stipules, $\mathrm{x} 1$; d, flower, $\mathrm{x} 1$; e, seed, $x$ 5. (V. F.). 

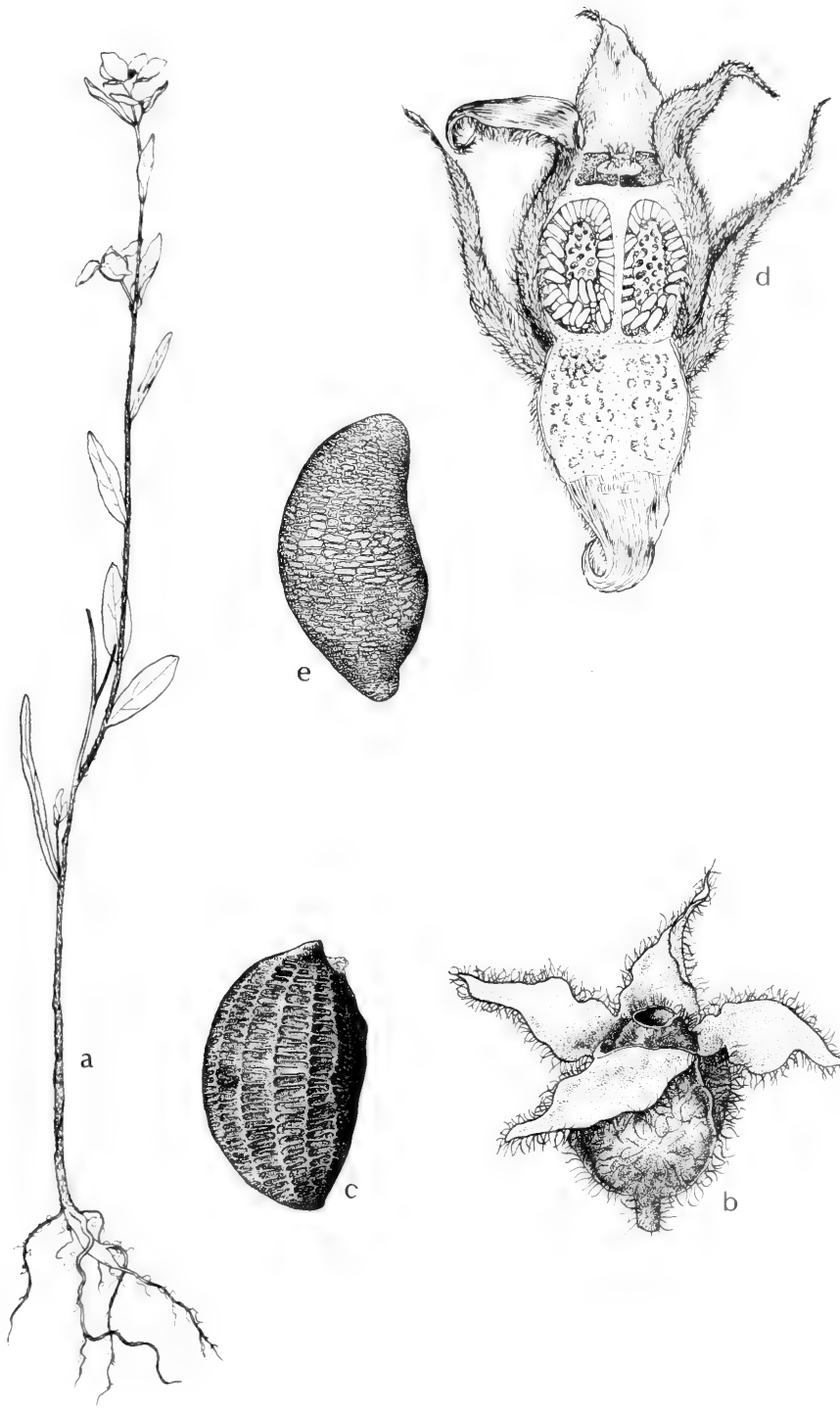

Fig. 556: a-c, Ludwigia hirtella: a, habit, x $1 \frac{1}{2}$; b, capsule, x 5; c, seed, x 50 . d and e, Ludwigia pilosa: d, capsule, opened to show seed, x 5; e, seed, x 50. (Courtesy of R. K. Godfrey). 
in each locule, more or less vertical, 1-1.3 $\mathrm{mm}$. long, each firmly embedded in a coherent cube of woody endocarp 1.2-1.5 mm. high, 1-1.2 $\mathrm{mm}$. thick, the endocarp firmly fused to the capsule wall. Jussiaea uruguayensis Camb., J. Michauxiana Fern.

Wet places, as along ponds and ditches, in irrigation canals and in water in lakes and ponds, in Okla. (Waterfall) and scattered in s.e. Tex., June-Oct.; s.e. U.S. and scattered s. to n. Arg. and introd. elsewhere.

\section{Ludwigia hirtella Raf. SPINDLE-ROOT. Fig. 556.}

Erect hirsute herb with fascicled ovoid to spindle-shaped roots, to $1 \mathrm{~m}$. tall; leaves narrowly lanceolate, $1.5-6 \mathrm{~cm}$. long, 3-18 mm. wide, essentially sessile; sepals 4, 7-10 mm. long; petals 10-15 mm. long; stamens 4; disk strongly elevated, a depressed white-ciliate nectary surrounding the base of each epipetalous stamen; capsule subglobose-cubical, 4-6 mm. long and thick, dehiscent by a terminal pore, the pedicel $4-8 \mathrm{~mm}$. long; seeds in several indistinct rows in each locule, about $0.6 \mathrm{~mm}$. long, free.

Rare along wet places in pine woods, on seepage slopes, in bogs and wettish savannahs, in Okla. (McCurtain Co.) and e. Tex., June-Sept.; e. along Coastal Plain to Fla. and N.J.

\section{Ludwigia alternifolia L. Seed-Box, Rattle-Box. Fig. 557.}

Erect subglabrous or puberulent herb with fascicled spindle-shaped roots, to $12 \mathrm{dm}$. tall; leaves lanceolate, 4-8 (-12) $\mathrm{cm}$. long, 8-15 (-24) $\mathrm{mm}$. wide, the petiole 3-7 (-10) $\mathrm{mm}$. long; sepals 4, 7-10 $\mathrm{mm}$. long; petals $8-10 \mathrm{~mm}$. long; stamens 4; disk strongly elevated, a depressed white-ciliate nectary surrounding the base of each epipetalous stamen; capsule subglobose-cubical, 5-6 mm. long and thick, dehiscent by a terminal pore, the pedicel 3-5 $\mathrm{mm}$. long; seeds in several indistinct rows in each locule, $0.6-0.7 \mathrm{~mm}$. long, free. Incl. var. pubescens Palm. \& Steyerm.

Occasional along ditches and in wet places, in marsh-meadows, seepage areas, in sluggish streams and on the edge of pools and lakes, in Okla. (McCurtain, Adair, LeFlore, Haskell and Sequoyah cos.) and e. Tex., June-Aug.; Mass and Ont. to n. Fla., e. Tex. and Ia.

\section{Ludwigia linearis Walt. Fig. 558.}

Glabrous to puberulent erect usually well-branched herb to $1 \mathrm{~m}$. tall; leaves linear to narrowly elliptical, $2.5-6 \mathrm{~cm}$. long, $1.5-5 \mathrm{~mm}$. wide, subsessile; sepals 4 . 2.5-4 mm. long; petals 3.5-5 mm. long; stamens 4; disk elevated, glabrous, prominently 4-lobed, the lobes opposite the petals; capsule elongate-obpyramidal, 6-8 mm. long, irregularly loculicidal, sessile; seeds in several indistinct rows in each locule, about $0.6 \mathrm{~mm}$. long, free. Incl. var. puberula Engelm. \& Gray.

Occasional in wet places, especially in pine woods, on seepage slopes, in ditches and wet savannahs, in ponds and bogs, in s.e. Tex., June-Sept.; e. to n. Fla., Tenn. and N.J.

\section{Ludwigia pilosa Walt. Fig. 556.}

Pilose erect usually well-branched herb to $12 \mathrm{dm}$. tall; leaves linear to elliptical, 2-10 $\mathrm{cm}$. long, 3-15 mm. wide, the petiole 1-5 (-15) $\mathrm{mm}$. long; sepals 4, 4-5 mm. long; petals absent; stamens 4 ; disk elevated, glabrous, prominently 4-lobed, the lobes opposite the sepals; capsule cubic-globose, 3-4 mm. long and thick, irregularly loculicidal, sessile; bracteole $2.5-4.2 \mathrm{~mm}$. long; seeds in several indistinct rows in each locule, about $0.5 \mathrm{~mm}$. long.

Occasional in wet places, especially in pine woods, in bogs, seepage areas, marshes, wet savannahs and wet soil about ponds and lakes, in s.e. Tex., July-Oct.; e. along the Coastal Plain to n. Fla. and s. Va. 

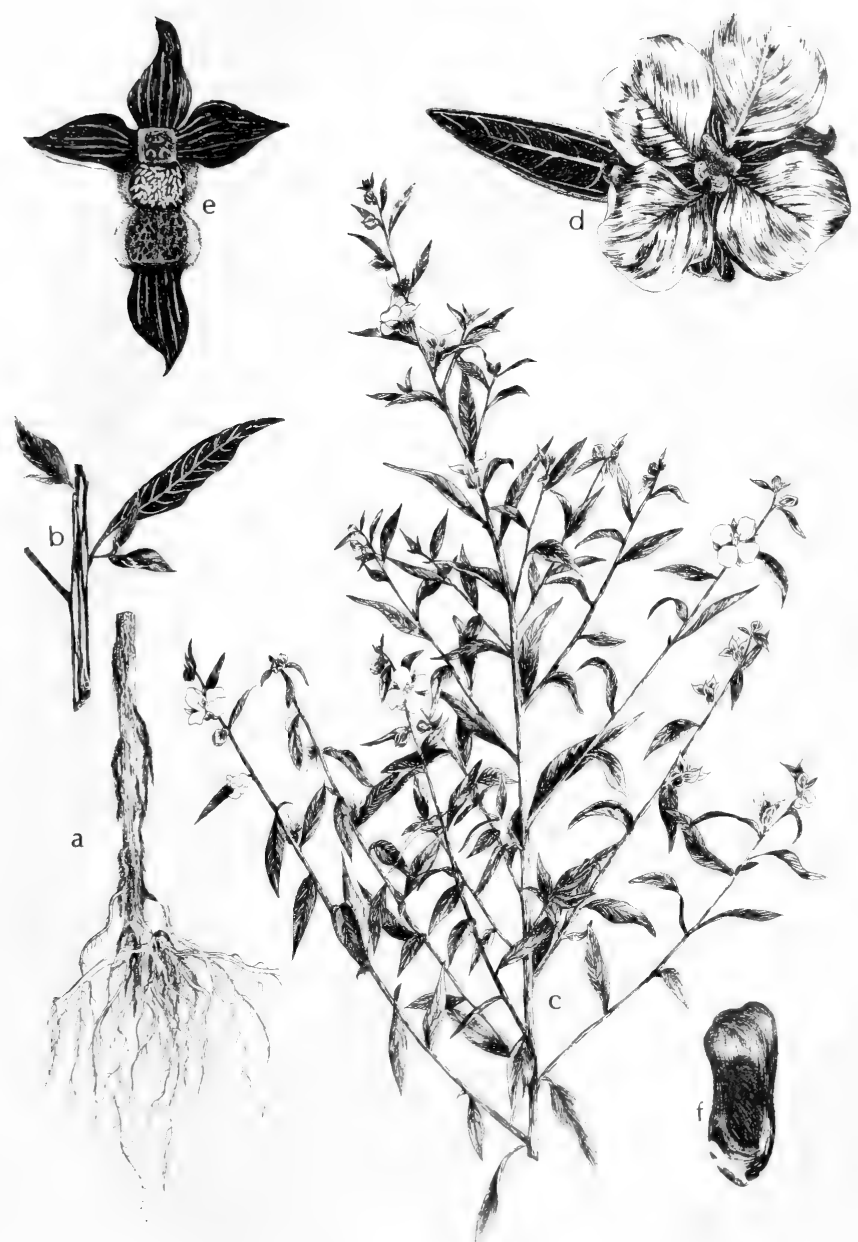

Fig. 557: Ludwigia alternifolia: a, basal part of plant, $\mathrm{x} \frac{1}{3} ; \mathrm{b}$, center section of stem, $x 1 / 3$; c, top of plant, $x 1 / 3$; d, flower, $x 4$; e, capsule, split open, $x 4$; , seed, x 40. (Courtesy of R. K. Godfrey). 


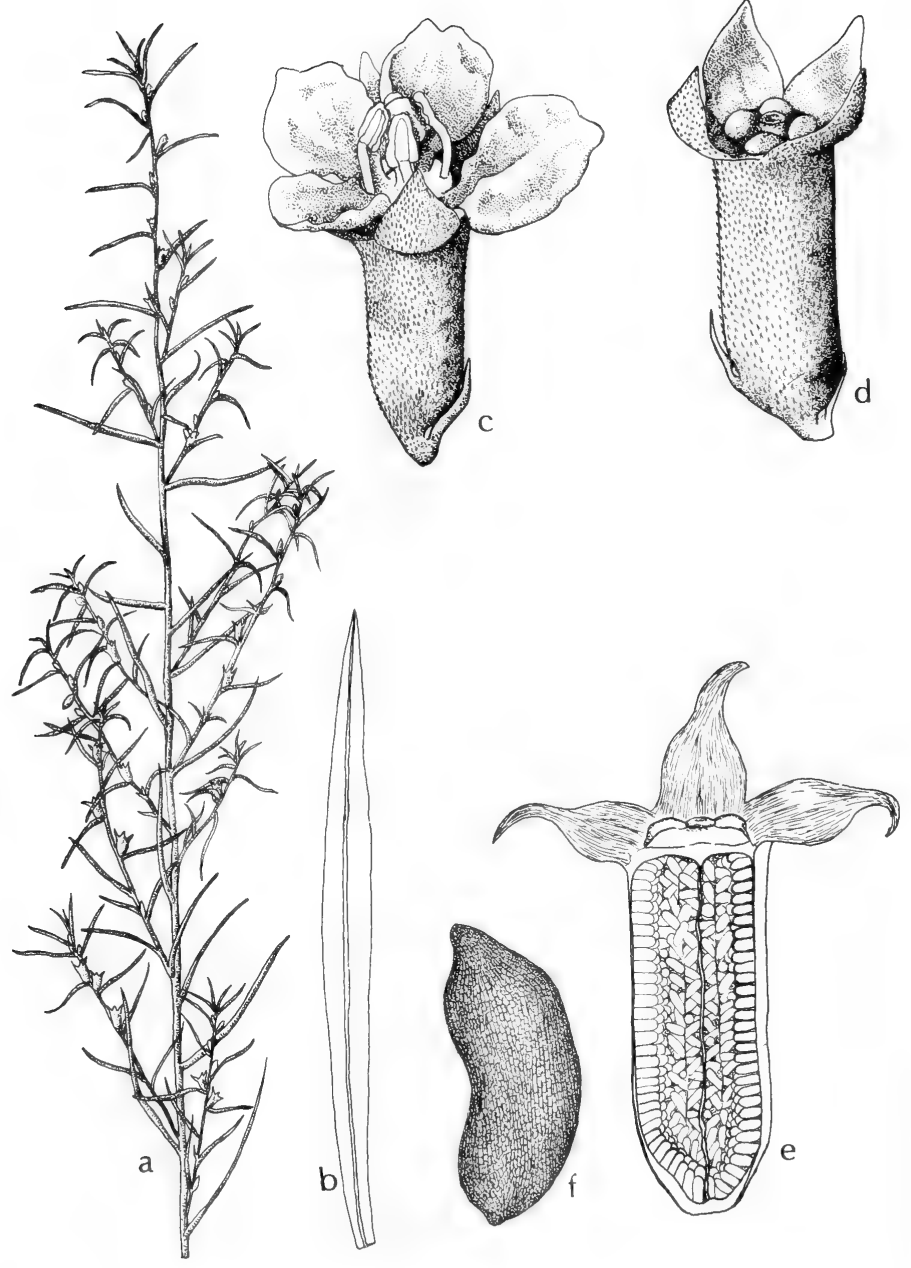

Fig. 558: Ludwigia linearis: a, top of plant, x 1/2; b, leaf, x 2; c, flower, x 5; d, fruit, $x$ 5; e, mature fruit, split open to show seeds, $x$ 5; f, seed, $x$ 70. (Courtesy of R. K. Godfrey). 
10. Ludwigia sphaerocarpa Ell. Fig. 559.

Stems thickly spongy when in water, commonly much-branched above, to $1 \mathrm{~m}$. tall, glabrous or finely pubescent; leaves lanceolate to linear to narrowly oblong, the larger commonly $5-10 \mathrm{~cm}$. long, glabrous or pubescent, tapering to the base, those subtending the flowers similar in shape but much smaller; flowers subsessile, separated by distant internodes; petals none; capsules subglobose, finely pubescent, 2.5-4 mm. long, not angled; calyx-lobes deltoid; bracteoles attached near the base of the hypanthium or below it, less than $2 \mathrm{~mm}$. long, very rarely more than half as long as the capsule.

Swamps and wet soil in savannahs and low pinelands, in Tex. (Angelina, Hardin and Wood cos.), June-Sept.; Mass. to Fla. and Tex.; also Ind. and Mich.

\section{Ludwigia glandulosa Walt. Cylindric-Fruited Ludwigia. Fig. 560.}

Glabrous or minutely strigulose erect well-branched herb to $1 \mathrm{~m}$. tall; leaves lanceolate or elliptical, $1.5-10 \mathrm{~cm}$. long, 4-20 mm. wide, the petiole 2-10 $\mathrm{mm}$. long; sepals 4, 1-2 mm. long; petals absent; stamens 4; disk elevated, glabrous, prominently 4-lobed, the lobes opposite the petals; capsule subcylindric, $2-8 \mathrm{~mm}$. long, 1.5-2 mm. thick, irregularly loculicidal, sessile; seeds in several indistinct rows in each locule, about $0.6-0.7 \mathrm{~mm}$. long, free. Incl. var. Torreyi Munz.

Wet places, as along ditches and in swamps, in marsh-meadows, shallow water and in mud on edge of ponds, streams and lakes, in Okla. (McCurtain, Love and LeFlore cos.) and in e. Tex., June-Oct.; n. and e. to s. Ill., Va. and n. Fla.

\section{Ludwigia palustris (L.) Ell. Marsh Purslane. Fig. 561.}

Glabrous herb, creeping and rooting at the nodes, the stems to $5 \mathrm{dm}$. long; leaves broadly elliptical or subovate, 7-45 $\mathrm{mm}$. long, 4-23 mm. wide, the petiole 3-12 mm. long; sepals 4, 1.4-2 mm. long; petals absent; stamens 4; disk elevated, glabrous, prominently 4-lobed, the lobes opposite the petals; capsule elongate-globose, (2-) $2.5-5 \mathrm{~mm}$. long, 2-3 mm. thick, fairly readily and irregularly loculicidal, sessile; seeds in several indistinct rows in each locule, $0.6-0.9 \mathrm{~mm}$. long, free. Incl. var. americana (DC.) Fern. \& Grisc. and var. nana Fern. \& Grisc.

Wet places, as along ditches and in swamps, in marsh-meadows, shallow water wet gravel bars, in Okla. (LeFlore, Ottawa, Sequoyah, Craig, Haskell, Comanche, Mayes and Murray cos.) and e. and s.-cen. Tex. to the Llano area and in the Davis Mts., and Ariz. (Pima and Santa Cruz cos.), June-Sept.; temp. N.A. except Rocky Mt. area to Col.; also in w. Euras., N. and S. Afr. and introd. elsewhere.

13. Ludwigia repens Forst. FloAting or CREEPING PRIMROSE-WILlow, WATER PRIMROSE. Fig. 562.

Glabrous to puberulent herb, creeping and rooting at the nodes, the stems to $5 \mathrm{dm}$. long; leaves very narrowly elliptic to subrotund, 9-40 $\mathrm{mm}$. long, 2-20 $\mathrm{mm}$. wide, the petiole 3-25 mm. long; sepals 4, 2.4-4.2 mm. long; petals 4-5 mm. long, fugacious; stamens 4; disk elevated, glabrous, prominently 4-lobed, the lobes opposite the petals; capsule short-cylindrical, 3.3-7.5 mm. long, $1.9-4.5 \mathrm{~mm}$. thick. tardily and irregularly dehiscent, the pedicel $0.3-1.5 \mathrm{~mm}$. long; seeds in several indistinct rows in each locule, about $0.7 \mathrm{~mm}$. long, free. L. natans Ell. and var. rotundata (Griseb.) Fern. \& Grisc.

Scattered in wet places as along streams and about ponds, in shallow water floating on surface, wet mud on edge of water bodies, in Okla. (Alfalfa, Murray and Johnston cos.) and in Tex., $\mathrm{n}$. of the Rio Grande Plains but very rare in $\mathrm{n}$. Tex. and the Panhandle, and N.M. (Eddy and Guadalupe cos.), July-Sept.; N.C. to Fla., Tex. and Okla., s. to cen. Mex. and W.I.; widely grown as an aquarium plant. 


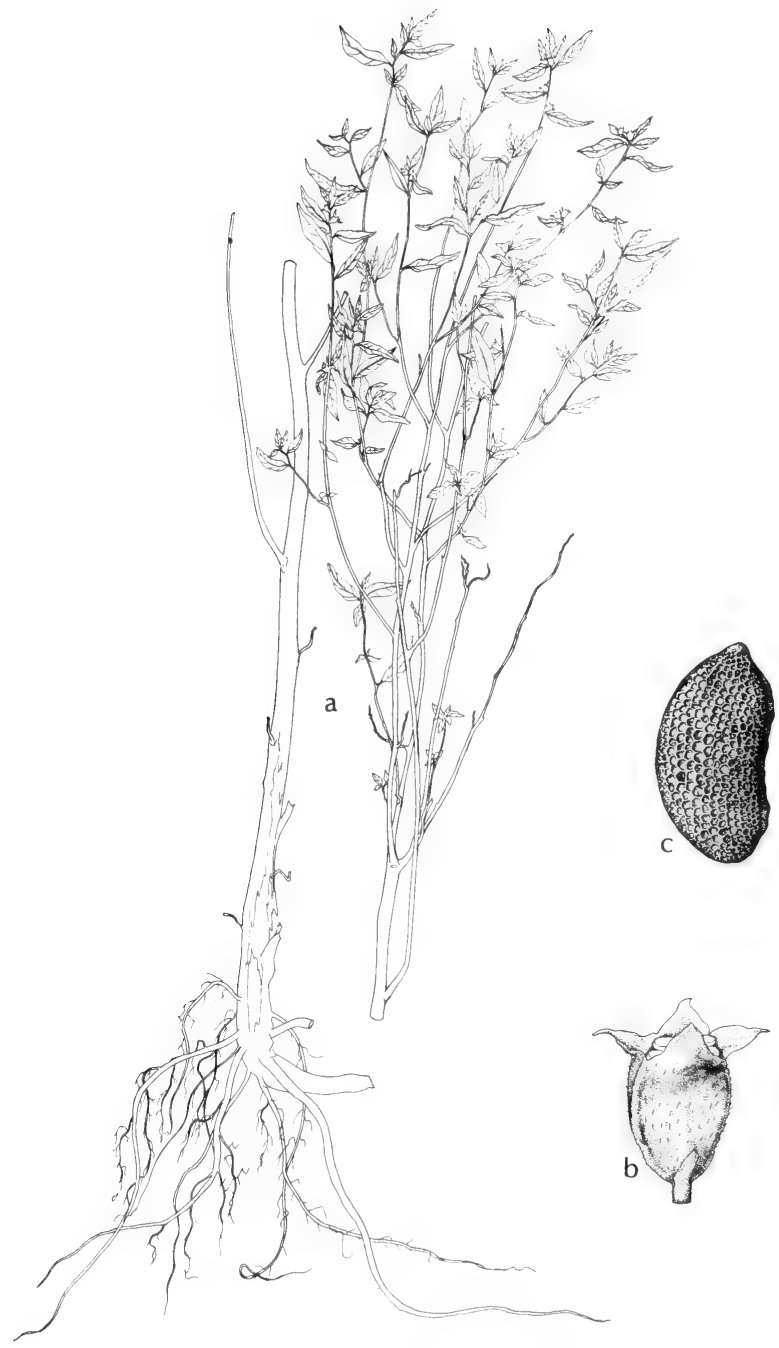

Fig. 559: Ludwigia sphaerocarpa: a, habit, x 1/3; b, flower, x 6; c, seed, x 46 . (Courtesy of R. K. Godfrey). 


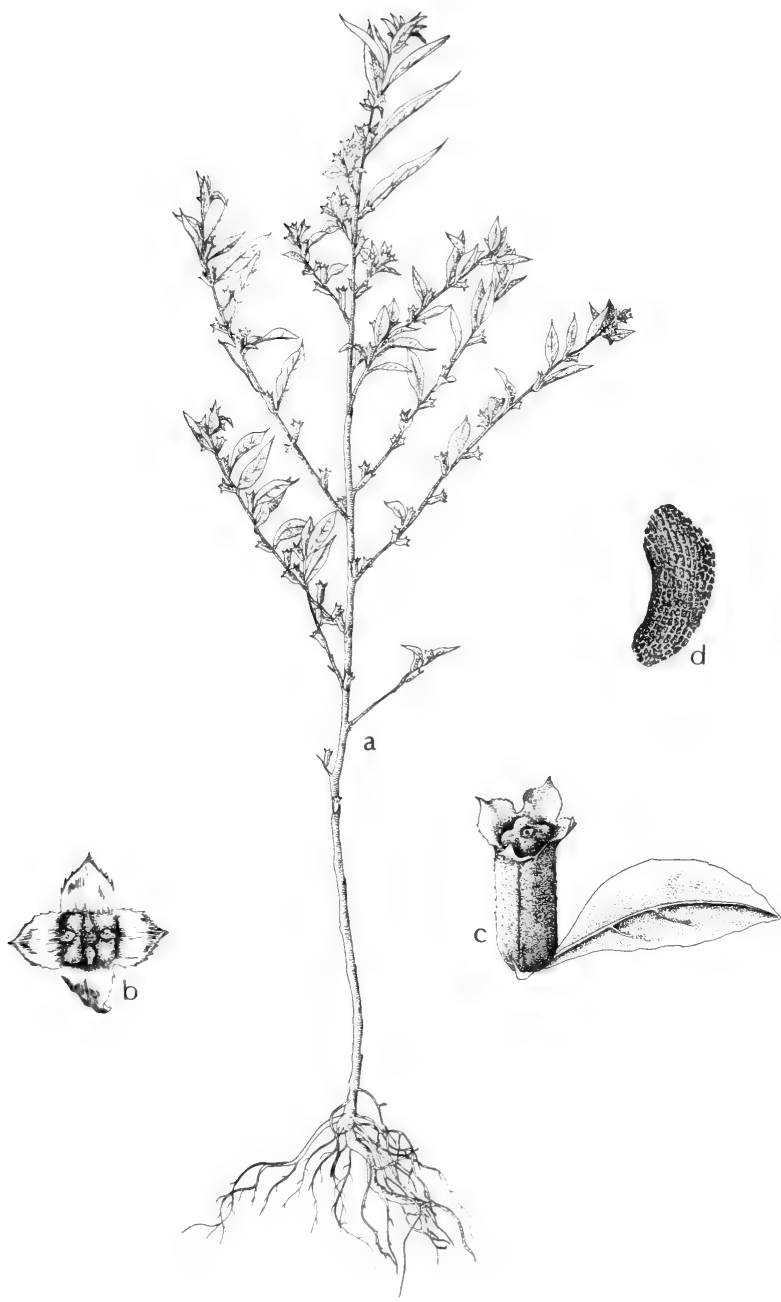

Fig. 560: Luduigia glandulosa: a, habit, $x \frac{1}{3}$; b, flower, from above, $x 4$; c, capsule, x 4; d, seed, x 30. (Courtesy of R. K. Godfrey). 


\section{Epilobium L.}

WILLOW-HERB

Perennial herbs of wet places, often flowering the first year; leaves opposite below, alternate above, denticulate or serrate; stipules absent; flowers actinomorphic, 4-merous, borne in the axils of reduced upper leaves; hypanthium well-developed; sepals not persistent in fruit; petals white to pink; stamens 8; stigma subclavate, undivided; fruit an elongate loculicidally dehiscent capsule; seeds numerous, with a coma, strongly papillose or smooth.

About 215 species of temperate and cold regions, extending into the tropics in the mountains and world-wide.

We have adapted the ultra-conservative treatment used by C. Leo Hitchcock et al. (1961) wherein several macrospecies accommodate the infinite individual variations found in this genus. For our purpose, their treatment would seem to be most practical.

1. Stigma 4-cleft; petals usually more than $1 \mathrm{~cm}$. long.............1. E. angustifolium.

1. Stigma usually entire; petals rarely to $1 \mathrm{~cm}$. long (2)

2(1). Plant with bulblike offsets (turions) present; seeds commonly papillate....

2. Plants without turions; seeds various (3)

3(2). Stems seldom over $3 \mathrm{dm}$. tall, simple or with a few basal branches; rhizomes usually well-developed and the plants matted; leaves seldom over $4 \mathrm{~cm}$. long, mostly entire; seeds smooth or the papillae very small and not in distinct rows; coma usually dingy....3. E. alpinum.

3. Stems usually well over $3 \mathrm{dm}$. tall and commonly freely branched above the middle; rhizomes short or lacking; leaves usually over $4 \mathrm{~cm}$. long, typically denticulate to serrate; seeds often conspicuously crestedpapillate in numerous parallel longitudinal lines; coma white or brownish (4)

4(3). Coma cinnamon-colored; seeds abruptly rounded distally; mature flower buds tipped with 4 projecting or divergent points (sepal tips)

4. E. coloratum.

4. Coma white or nearly so; seeds narrowed distally to a short beak; flower buds usually obtuse or rounded at the summit, rarely somewhat pointed 5. E. Watsonii.

1. Epilobium angustifolium L. Fireweed, blooming-Sally. Fig. 563.

Perennial from widespread rhizomelike roots that form adventitious buds freely; stems usually simple, to about $3 \mathrm{~m}$. tall, usually much smaller, glabrous except for fine puberulence in the inflorescence and especially on the ovaries; leaves alternate, subsessile, narrowly lanceolate, mostly $8-15 \mathrm{~cm}$. long, subentire; racemes terminal, many-flowered, small bracted, greatly elongate; flowers reflexed in bud, then ascending; hypanthium essentially lacking; sepals $8-12 \mathrm{~mm}$. long, short-clawed; petals 1-2 cm. long, entire, spreading, rose-color to purple or rarely white; style longer than the stamens, pilose on the lower portion; stigma 4-cleft; capsule 5-8 $\mathrm{cm}$. long; coma dingy.

Bogs, edge of water in streams, wettish meadows, margin of woods, in N.M. (Sandoval and Taos cos.) and Ariz. (Apache to Coconino, Greenlee and Graham cos.), May-Sept.; widespread from Alas. to Calif., Ariz. and N. M., eastw. to Atl. Coast; Euras.

\section{Epilobium glandulosum Lehm.}

Perennial from slender to filiform rhizomes ending in globose turions, the scales of previous offsets usually persistent through the season; stems simple to branched at the base or above, erect, to about $9 \mathrm{dm}$. tall, glabrous to pilose, often crisppuberulent in lines, frequently glandular-puberulent in the inflorescence; leaves opposite, from sessile and often somewhat clasping to petiolate with slender to 

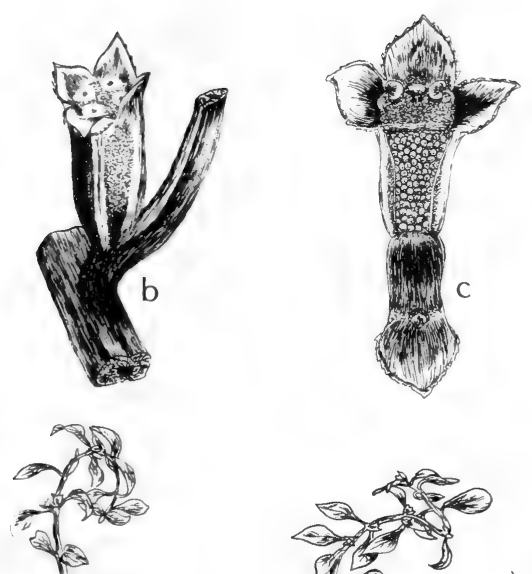

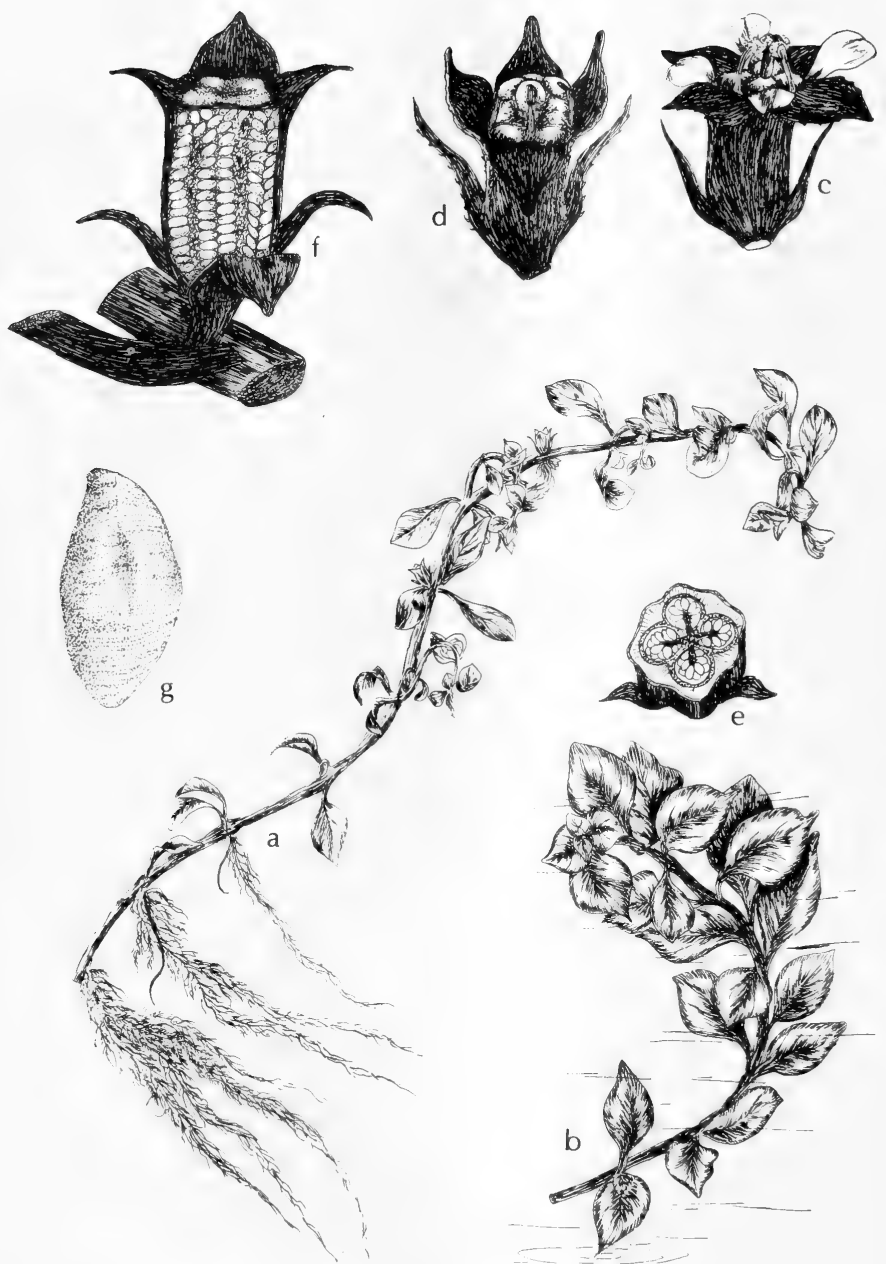

Fig. 562: Ludwigia repens: a, part of plant, $\mathrm{x} \frac{1}{2}$; b, end of branch, about $\mathrm{x} 1$; $\mathrm{c}$, flower, $x 5$; d, young fruit, $x 5$; e, cross section of fruit, $x 5 ; \mathrm{f}$, mature fruit, $\mathrm{x} 5 ; \mathrm{g}$, seed, x 60. (Courtesy of R. K. Godfrey). 
broad petioles to about $6 \mathrm{~mm}$. long, linear-lanceolate to ovate-lanceolate, to about $12 \mathrm{~cm}$. long, entire to prominently denticulate, from crowded and overlapping to remotely spaced, gradually reduced upward to the floral bracts; racemes fewflowered; pedicels 5-30 mm. long; hypanthium $1.5-3 \mathrm{~mm}$. long; sepals 2-5 $\mathrm{mm}$. long; petals pale- to dark-pink or purplish, notched, 3-10 $\mathrm{mm}$. long; stigma entire; capsules slender, 2-7 cm. long, from nearly glabrous to strigillose, glandularpuberulent to glandular-pilose; seeds $0.5-2 \mathrm{~mm}$. long, from nearly smooth to lightly alveolate (with the borders of the alveolae appearing in silhouette as papillae) to papillate-echinulate; coma white to tawny. E. Halleanum Hausskn., E. saximontanum Hausskn.

Wet seepage banks along streams, wet or boggy places at high elev., N.M. (Taos Co.) and Ariz. (A pache, Coconino, Graham and Greenlee cos.), June-Sept.; Alas., s. to Calif., Ariz. and N.M., e. to Atl. Coast; Asia.

\section{Epilobium alpinum L.}

Low usually matted perennial, spreading by rhizomes and stolons but not producing turions; stems decumbent-based to erect, usually simple but sometimes with a few basal branches, usually $5-30 \mathrm{~cm}$. tall, entirely glabrous or mostly glabrous below and with crisp-puberulent lines above or glandular-puberulent only in the inflorescence; leaves sessile to short-petiolate, usually opposite but sometimes alternate above, mostly about equally spaced, ovate to linear, mostly $1-5 \mathrm{~cm}$. long, entire to serrulate; flowers few, nodding to erect; pedicels $5-50 \mathrm{~mm}$. long; hypanthium 1-2 mm. long; sepals 1.5-6 mm. long; petals white to deep-pink or lilac-rose. notched, 3-13 mm. long; stigma entire; capsule 2-7 cm. long, linear to subclavate; seeds about $1 \mathrm{~mm}$. long, smooth to obscurely papillate, the coma dingy or sometimes white. E. oregonense Hausskn., E. Hornemannii Reichenb.

Wet meadows, bogs, seepage slopes and wettish open woods, in N. M. (Grant. San Miguel and Socorro cos.) and Ariz. (Apache and Coconino cos.), June-Sept.; throughout mts. of w. N.A., s. to Calif., Ariz. and N.M., e. to Atl. coast; Euras.

\section{Epilobium coloratum Biehler.}

Perennial herb with sessile basal rosettes, 5-10 dm. tall, usually well-branched above, minutely strigulose above (especially along elevated lines decurrent from the margins of the petioles); hypanthium about $0.5 \mathrm{~mm}$. long; sepals $1.5-3 \mathrm{~mm}$. long; petals pink, 3-5 mm. long; capsule $3-4.5 \mathrm{~cm}$. long; seeds about $1.5 \mathrm{~mm}$. long, the coma cinnamon-colored.

Rare in wet places, in Okla. (Waterfall) and Tex. High Plains (Hemphill and Wheeler cos.), July-Oct.; Que. to S.D., s. to Ga., Okla. and Tex.; Hisp.

\section{Epilobium Watsonii Barbey. Fig. 564.}

Perennial but often blooming the first season, eventually spreading by short rootstocks that produce rosettes of leaves but no turions; stems $3-10 \mathrm{dm}$. tall, usually simple below but branched above, often glandular above (especially in the inflorescence), weakly to densely pubescent with the hairs either in decurrent lines or more general; leaves opposite, short-petiolate to subsessile, narrowly lanceolate to ovate-lanceolate, 3-7 cm. long, more or less serrulate; inflorescence mostly compound; sepals 2-5 mm. long, often purplish; petals $3-10 \mathrm{~mm}$. long, notched, white or cream-color to deep purplish-red; stigma entire or if lobed the lobes mostly coalescent; capsule linear, $4-8 \mathrm{~cm}$. long, strigillose to glandular-puberulent; seeds $0.5-1.2 \mathrm{~mm}$. long, distinctly crested-papillate in numerous parallel longitudinal lines; coma white. E. adenocaulon Hausskn. and its var. perplexans Trel., E. californicum Hausskn., (?) E. ciliatum Raf.

In wet meadows, marshes, seepage areas, in water of springs, ditches and ponds and on edge of streams in mud or boggy areas, in N.M. (widespread) and Ariz. (Navajo and Coconino cos.), July-Oct.; rather generally spread over much of the U.S., Can. and Alas. 
We have two recognized variants.

Var. occidentale (Trel.) C. L. Hitchc. is glandular-pubescent in the inflorescence.

Var. Parishii (Trel.) C. L. Hitchc. has nonglandular somewhat appressed hairs.

\section{Oenothera L. Evening Primrose}

Herbs, sometimes woody near the base, with alternate entire to pinnatifid leaves; stipules absent; flowers actinomorphic, 4-merous, borne in the axils of upper leaves or in a more or less distinct inflorescence, opening either near sunset or near sunrise; hypanthium well-developed; sepals not persistent in fruit; petals yellow or white to rose-purple; stamens 8; stigma deeply 4-lobed; fruit a loculicidally dehiscent or nutlike indehiscent capsule; seeds lacking a coma.

About 80 species of the temperate regions of North America and South America, widely introduced elsewhere.

Oenothera sessilis (Penn.) Munz, distinguished by its yellow flowers and linearclavate subsessile to shortly stipitate capsules, was last collected in marshy place near Galveston, Texas, more than 100 years ago. It is also found in Louisiana.

1. Capsule clavate, the lower part narrowed and stipelike; seeds clustered, not in definite rows (2)

1. Capsule ovoid to cylindric; seeds usually in definite rows (5)

2(1). Petals rose-color; flowers opening near sunrise (3)

2. Petals white, fading pinkish; flowers opening near sunset (4)

3(2). Stigma usually elevated above the anthers; hypanthium 10-30 mm. long; petals $20-35 \mathrm{~mm}$. long....................................... O. tetraptera.

3. Stigma surrounded by the anthers; hypanthium (5-) $20 \mathrm{~mm}$. long; petals 10-20 mm. long.....

2. O. Kunthiana.

4(2). Hypanthium 15-21 mm. long; petals 12-21 mm. long.

4. Hypanthium 4-8 $\mathrm{mm}$. long; petals $4.5-12 \mathrm{~mm}$. long.

3. O. texensis. 4. O. rosea.

5(1). Capsule ovoid-pyramidal or oblong-ovoid, commonly indehiscent; low rhizomatous or acaulescent herbs (6)

5. Capsule subcylindrical, readily dehiscent at maturity (at least at the apex) (7)

6(5). Acaulescent herb; leaves rosulate, more than $2 \mathrm{~cm}$. long; hypanthium much more than $20 \mathrm{~mm}$. long............................................. O. flava.

6. Low bushy plant; leaves cauline, less than $1.5 \mathrm{~cm}$. long; hypanthium 5-15 $\mathrm{mm}$. long...

6. O. canescens.

7(5). Seeds ascending, not sharply angled; capsule oblong-fusiform to subclavate ..7. O. rhombipetala.

7. Seeds horizontal, sharply angled; capsule gradually tapered upward (8)

$8(7)$. Petals 1-2 cm. long; styles mostly $0.3-1.7 \mathrm{~mm}$. long.

8. Petals $2-5 \mathrm{~cm}$. long; styles $20-60 \mathrm{~mm}$. long (9)

8. O. biennis.

9(8). Hypanthium 25-45 mm. long.....

9. Hypanthium 60-120 mm. long (10)

10(9). Distribution in Oklahoma and Texas.

10. O. Jamesii.

10. Distribution in Arizona. 11. O. longissima.

\section{Oenothera tetraptera Cav.}

Well-branched strigulose to hirsute annual to $4 \mathrm{dm}$. tall; leaves sinuate to sinuatepinnatifid, the upper ones subentire, lanceolate to oblanceolate or occasionally narrowly elliptic, 1-9 $\mathrm{cm}$. long, (2-) 10-25 mm. wide, the petiole 2-20 $\mathrm{mm}$. long; flowers opening near sunset; mature buds erect; hypanthium 1-3 cm. long; sepals 2-4 cm. long, with free tips to $3 \mathrm{~mm}$. long; petals white, fading pink, $2-3.5 \mathrm{~cm}$. 


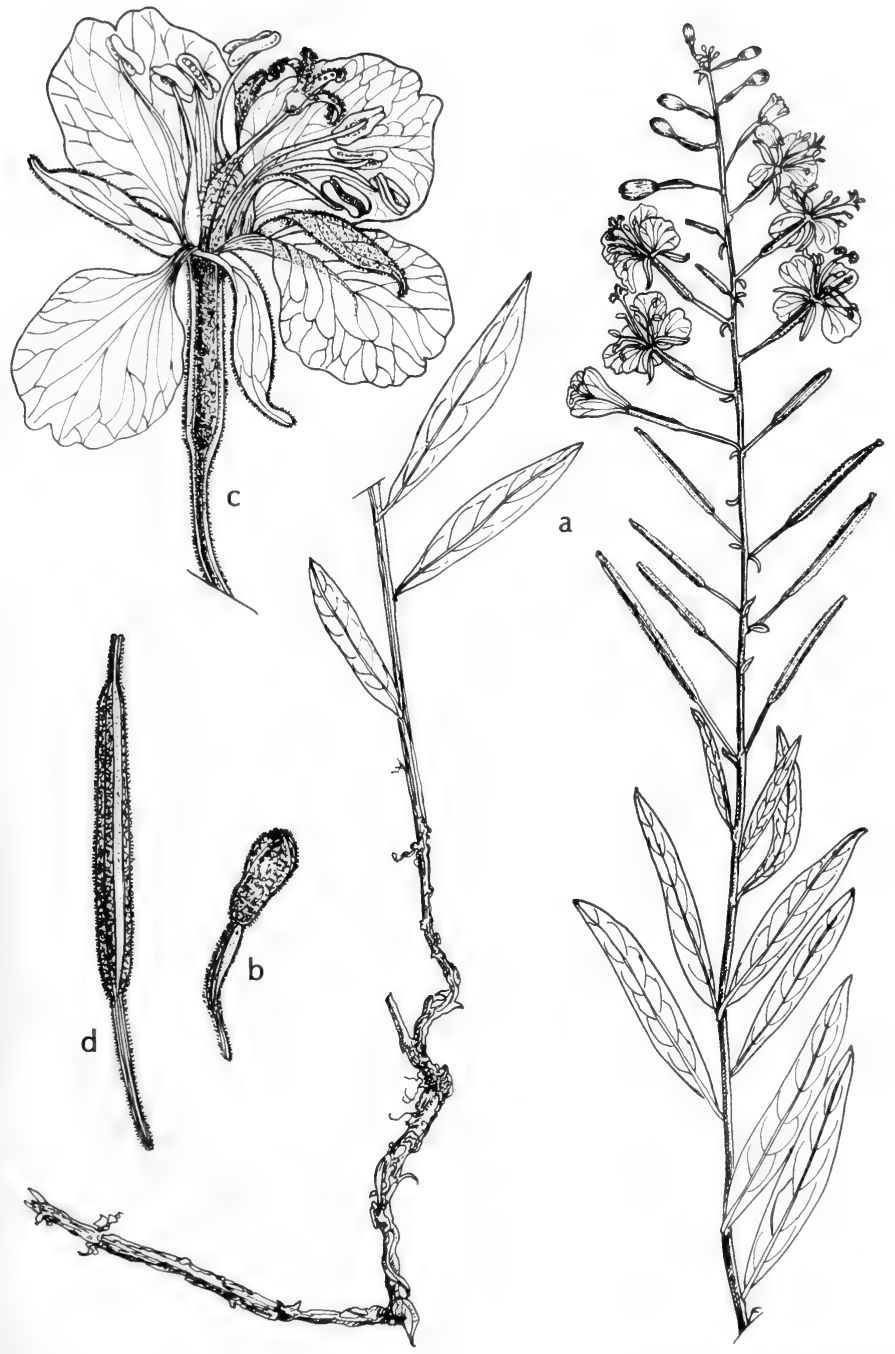

Fig. 563: Epilobium angustifolium: a, habit, x 1/2; b, bud, x 11/2; c, flower, x 11/2; d, capsule, x $1 \frac{1}{1 / 2}$. (V. F.). 


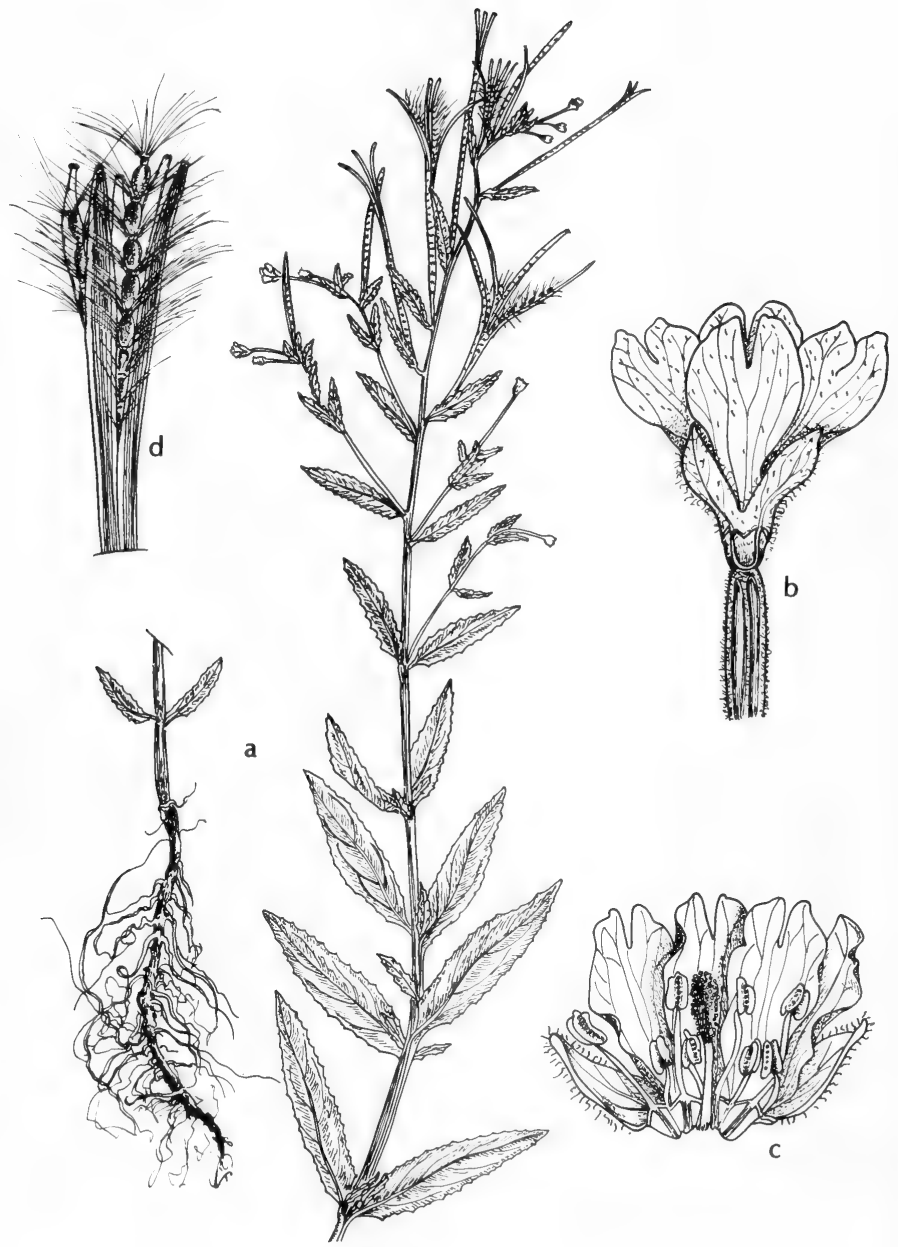

Fig. 564: Epilobium Watsonii: a, habit, x $1 \frac{2}{2}$; b, perianth and top of ovary, $\mathrm{x} 5$; c, perianth split longitudinally, showing 2 rows of stamens, x 5 ; d, end of splitting capsules, showing coma of seeds, x 5. (V. F.). 
long; pollen fertile; capsule obovoid, 1-2 cm. long, on a pedicel (4-) 10-45 mm. long; seeds in several indistinct rows in each locule, $1.2-1.5 \mathrm{~mm}$. long.

Gravel bars, wet alluvial flats and open places, rare and scattered, s. and w. Tex., Mar.-May; to Col. and w. Venez.; cult. and naturalized elsewhere.

\section{Oenothera Kunthiana (Spach) Munz.}

Similar in general to $O$. tetraptera; plants subglabrous to strigulose; hypanthium (0.5-) 1-2 cm. long; sepals 5-20 mm. long, with tips coherent at anthesis; petals 1-2 cm. long; pollen approximately $50 \%$ sterile.

Gravel bars and wettish flat sandy often weedy places in the Trans-Pecos, Edwards Plateau and s. Tex., Feb.-May; s. to C. R.

\section{Oenothera texensis Raven \& Parnell.}

Well-branched strigulose or rarely hirsute perennial herb, flowering the first year, to $5 \mathrm{dm}$. tall; leaves serrulate to sinuate-pinnatifid, elliptic to ovate, $2.5-4 \mathrm{~cm}$. long, 8-18 $\mathrm{mm}$. wide, the petiole 4-21 $\mathrm{mm}$. long, flowers opening near sunrise; mature buds erect; hypanthium 15-21 mm. long; sepals $15-18 \mathrm{~mm}$. long, lacking free tips; petals rose, 12-21 mm. long; pollen fertile; capsule obovoid, 8-14 mm. long, on a pedicel 7-12 mm. long; seeds in several indistinct rows in each locule, $0.8-1 \mathrm{~mm}$. long.

Gravel bars and along streams in canyons, Jeff Davis Co., in the Trans-Pecos, Tex., May-Aug.; s. to Sin., Coah. and Tam.

\section{Oenothera rosea Ait. RoSE SUndRops.}

Well-branched strigulose or rarely hirsute perennial herb, flowering the first year, to $4 \mathrm{dm}$. tall; leaves subentire or sinuate-pinnatifid, elliptic or rarely narrowly ovate, $2-5 \mathrm{~cm}$. long, 1-2.5 cm. wide, the petiole $2-25 \mathrm{~mm}$. long; flowers opening near sunrise; mature buds erect; hypanthium 4-8 mm. long; sepals 7-12 mm. long, lacking free tips; petals rose, $4-12 \mathrm{~mm}$. long; polien approximately $50 \%$ sterile; capsule obovoid, 5-10 $\mathrm{mm}$. long, on a pedicel $4-8 \mathrm{~mm}$. long; seeds in several indistinct rows in each locule, $0.7-0.9 \mathrm{~mm}$. long.

Along creeks and river bottoms in low weedy places, and in permanent marshy cienagas, in the Tex. Trans-Pecos, Edwards Plateau and s. Tex., N.M. (Union Co.) and Ariz. (Pinal, Cochise, Santa Cruz and Pima cos.), Apr.-Aug.; s. to Arg., a pan-trop. weed.

\section{Oenothera flava (A.Nels.) Garrett.}

Cespitose acaulescent rather sparsely strigillose to subglabrous perennial, with a thick taproot; leaves in tufts or rosettes, oblanceolate, $5-20 \mathrm{~cm}$. long, to about 15 $\mathrm{mm}$. wide, deeply runcinate to runcinate-pinnatifid in the lower third, the terminal lobe entire to undulate-dentate; flowers sessile among the leaves, vespertine; calyx usually purplish, the free hypanthium slender, $2-12 \mathrm{~cm}$. long; calyx lobes free or slightly connate and turned to one side; petals yellow, aging to purplish, $1-2 \mathrm{~cm}$. long; anthers linear, 4-8 mm. long; stigma lobes linear, about $3 \mathrm{~mm}$. long; capsule woody, ovoid, 1-2 cm. long, conspicuously 4-winged; seeds numerous, dark-brown, about $2 \mathrm{~mm}$. long, minutely granular, cuneate-obovoid.

In wet meadows, wettish flats, in swales or in wettish soil around vernal pools in N. M. (Colfax, Rio Arriba, San Juan, San Miguel, Socorro and Taos cos.) and Ariz. (Navajo, Coconino, Mohave, Yavapai and Gila cos.), Apr.-Sept.; Can. to N.M., Ariz., Calif. and Mex.

\section{Oenothera canescens Torr. \& Frem. SPotTED Primrose.}

Low bushy densely strigulose to canescent rhizomatous perennial with stems to $2 \mathrm{dm}$. long; leaves denticulate, lanceolate, 5-15 $\mathrm{mm}$. long, 2-7 mm. wide, subsessile; flowers opening near sunset; mature buds erect; hypanthium 5-15 mm. long; 
sepals $8-14 \mathrm{~mm}$. long, lacking free tips; petals pinkish or more rarely white on first opening, 8-12 mm. long, red-spotted all over; capsule ovoid-pyramidal, sharply 4-angled, beaked, 7-8 mm. long; seeds in several rows in each locule, about $1 \mathrm{~mm}$. long.

Dried up ponds and lakes in clay soil, and on muddy banks of ponds, in Okla. Panhandle (Waterfall), in the Tex. Edwards Plateau n. through the Panhandle and N. M. (Union Co.), local, May-Aug.; n. on the Plains to Neb. and Wyo.

\section{Oenothera rhombipetala T. \& G.}

Erect strigulose winter annual or biennial from a fleshy taproot, the stems to $1 \mathrm{~m}$. tall; leaves narrowly oblanceolate to narrowly ovate (broader above), 2-8 cm. long, 3-15 mm. wide, sinuate-pinnatifid to subentire; petioles short or absent; flowers opening near sunset; mature buds erect; hypanthium $2.5-3 \mathrm{~cm}$. long; sepals 1-1.8 $\mathrm{cm}$. long, with free tips $0-1.5 \mathrm{~mm}$. long; petals yellow, $1.3-2 \mathrm{~cm}$. long; capsule cylindric, 12-16 $\mathrm{mm}$. long; seeds in 2 rows in each locule, about $1 \mathrm{~mm}$. long.

In marshes, sometimes alkaline and in sandy and waste places, in Okla. (Alfalfa Co.) and in e. half of Tex., June-Sept.; Ind. to Wisc. and Minn. s. to Tex. and scattered (possibly introd.) e. to the Atl. Coast.

\section{Oenothera biennis L. Common evening PRIMrose.}

Weedy variously pubescent biennial to $2 \mathrm{~m}$. tall; leaves lanceolate; rosette leaves sinuate-pinnatifid to denticulate, $8-30 \mathrm{~cm}$. long and 1-6 $\mathrm{cm}$. wide, their petioles long; cauline leaves denticulate, 5-16 cm. long, 15-35 mm. wide, subsessile; flowers opening near sunset; mature buds erect; hypanthium $2-5 \mathrm{~cm}$. long; sepals $1-2 \mathrm{~cm}$. long, the free tips 1-4 mm. long; petals yellow, 1-2 cm. long; capsule thick, cylindric, 14-25 mm. long; seeds in 2 rows in each locule, $1.2-1.8 \mathrm{~mm}$. long. O. pratincola Bartlett.

Weedy places and woods, in wet meadows, and wet soil about ponds, lakes and along streams, scattered, in Okla. (Adair and Johnston cos.) and n.e. Tex., Aug.Oct.; Alta. to Wisc. and Mich., s. to Tex. and La. and e. to Atl. Coast; the species as a whole ranges to Nfld., Que. and Ont.

Represented by several varieties.

Var. biennis. Hairs scattered on flowers and fruits.

Var. canescens T. \& G. Hairs on flowers short and appressed.

Var. hirsutissima Gray. Some of the hairs on floral parts long and spreading.

\section{Oneothera Hookeri T. \& G.}

Robust erect biennial or perennial to $2 \mathrm{~m}$. tall; leaves oblanceolate to elliptic, densely strigose and sometimes also pilose, entire to sinuate-serrulate, the rosette leaves narrower near the base, 1-3 dm. long, $2-5 \mathrm{~cm}$. wide, their petioles $5-18 \mathrm{~cm}$. long, the cauline leaves $5-15 \mathrm{~cm}$. long and $8-25 \mathrm{~mm}$. wide, short-petioled to subsessile; flowers opening near sunset; mature buds erect; hypanthium $25-45 \mathrm{~mm}$. long; sepals $2.5-4 \mathrm{~cm}$. long, with free tips $2-6 \mathrm{~mm}$. long; petals yellow, fading reddish, $2-4.5 \mathrm{~cm}$. long; capsule thick, cylindric, $2-4 \mathrm{~cm}$. long; seeds in 2 rows in each locule, 1-1.6 mm. long.

S.e. Wash. and s. Ida. to Baja Calif., Kan., Tex. and Chih.

In our area represented by 2 subsp. as follows:

Subsp. hirsutissima (Gray) Munz. Pubescence largely loose with some spreading hairs; free sepal tips 2-4 (-5) $\mathrm{mm}$. long; seeds $1.2-1.6 \mathrm{~mm}$. long. Rare in wet places in the Tex. Trans-Pecos and in N. M. (widespread) and Ariz. (Apache and Coconino, s. to Cochise and Pima cos.), July-Oct.; Ut. and s. Colo. to w. Kan., Chih. and Son.

Subsp. Hewettii Cockll. Pubescence appressed; free sepal tips 3-6 mm. long; seeds about $1 \mathrm{~mm}$. long. Incl. var. irrigua (Woot. \& Standl.) Gates, O. Simsiana sensu Munz, Fl. Tex. 226. 1944. Rare in wet places in the Tex. Trans-Pecos and in 
N.M. (Dona Ana, San Juan, Colfax and Bernalillo cos.) and Ariz. (Navajo, Coconino, Graham and Gila cos.), July-Oct.; Nev. and s. Ut. to Tex. and Chih.

\section{Oenothera Jamesii T. \& G.}

Robust erect densely appressed-pubescent biennial to $2 \mathrm{~m}$. tall; leaves elliptic to broadly lanceolate, appressed-pubescent; rosette leaves narrower near the base, sinuate-pinnatifid to denticulate, $6-20 \mathrm{~cm}$. long and $2-4 \mathrm{~cm}$. wide, their petioles $2-6 \mathrm{~cm}$. long; cauline leaves denticulate, $5-12 \mathrm{~cm}$. long and $2-3.5 \mathrm{~cm}$. wide, shortpetioled below to subsessile above; flowers opening near sunset; mature buds erect; hypanthium 6-11 cm. long; sepals 4-6 cm. long, with free tips 3-6 mm. long; petals yellow, fading reddish, $3.5-5 \mathrm{~cm}$. long; capsule thick, cylindric, $2-5 \mathrm{~cm}$. long; seeds in 2 rows in each locule, $1.5-2 \mathrm{~mm}$. long.

On stream banks in wet places, scattered, in Okla. (Waterfall) and in the Tex. Edwards Plateau and Llano area w. to the Trans-Pecos, July-Oct.; Okla. and w. Tex. to Coah.

\section{Oenothera longissima Rydb.}

Biennial to short-lived perennial, simple to branched, erect, 1-3 m. tall, more or less hirsute (especially above), somewhat muricate on the stems, the hair mostly appressed, upper parts also glandular-pubescent; leaves of rosette oblanceolate; blades 1-2 dm. long, $1.5-3 \mathrm{~cm}$. wide, with winged petioles $5-10 \mathrm{~cm}$. long; cauline leaves linear-lanceolate, plane, stiffly spreading-ascending, gradually reduced upward to sessile lanceolate bracts soon exceeded by buds; flower tube $8-12 \mathrm{~cm}$. long, more or less reddish; sepals $3.5-4.5 \mathrm{~cm}$. long, the tips $3-5 \mathrm{~mm}$. long; petals obovate, about $4 \mathrm{~cm}$. long; anthers 14-18 $\mathrm{mm}$. long; capsules subquadrangular, $3.5-4.5 \mathrm{~cm}$. long, about $5 \mathrm{~mm}$. thick; seeds $1-1.5 \mathrm{~mm}$. long.

In wet springy places, in Ariz. (Navajo, Coconino and Mohave cos.), July-Sept.; also Ut., Nev. and Calif.

The typical plant has pubescence ashy-strigose, stems not muricate and inflorescence not glandular-pubescent.

Subsp. Clutei (A. Nels.) Munz has pubescence more or less hirsute (especially above), stems somewhat muricate and inflorescence glandular-pubescent.

\section{Circaea L. Enchanter's Nightshade}

About 7 species in North America and Eurasia.

\section{Circaea alpina $L$.}

Perennial from slender rootstocks, 1-5 dm. tall, simple to freely branched, clear green; stems usually glabrous on the lower half, often sparsely strigose to shortpilose above and in the inflorescence; leaves opposite, thin, with petioles somewhat shorter than blade, cordate-ovate to ovate, usually acuminate, 2-6 cm. long, subentire to saliently dentate, sparsely to rather thickly strigillose (especially on lower surface); racemes often with 1 or 2 linear bracts at the base, the small individual flowers (1-1.5 mm. long) with a minute sometimes glandlike bractlet; pedicels spreading to erect in flower, becoming reflexed and equaling or slightly exceeding the fruit; hypanthium short, deciduous and with a ringlike disk within; sepals 2, reflexed; and petals 2 , white, notched; stamens 2 , alternate with petals; fruits turbinate, nutlike, 1- or 2-seeded, obovoid, indehiscent, usually with hooked hairs, about $2 \mathrm{~mm}$. long. C. pacifica Asch. \& Magn.

Moist or wet woods and mossy bogs, in mts. of N. M. (Socorro Co.), and Ariz. (Apache, Coconino and Graham cos.); Nfid. to Alas., s. to N.Y., Tenn., N.C., Ind. and S.D. to N.M., Ariz. and Calif. 


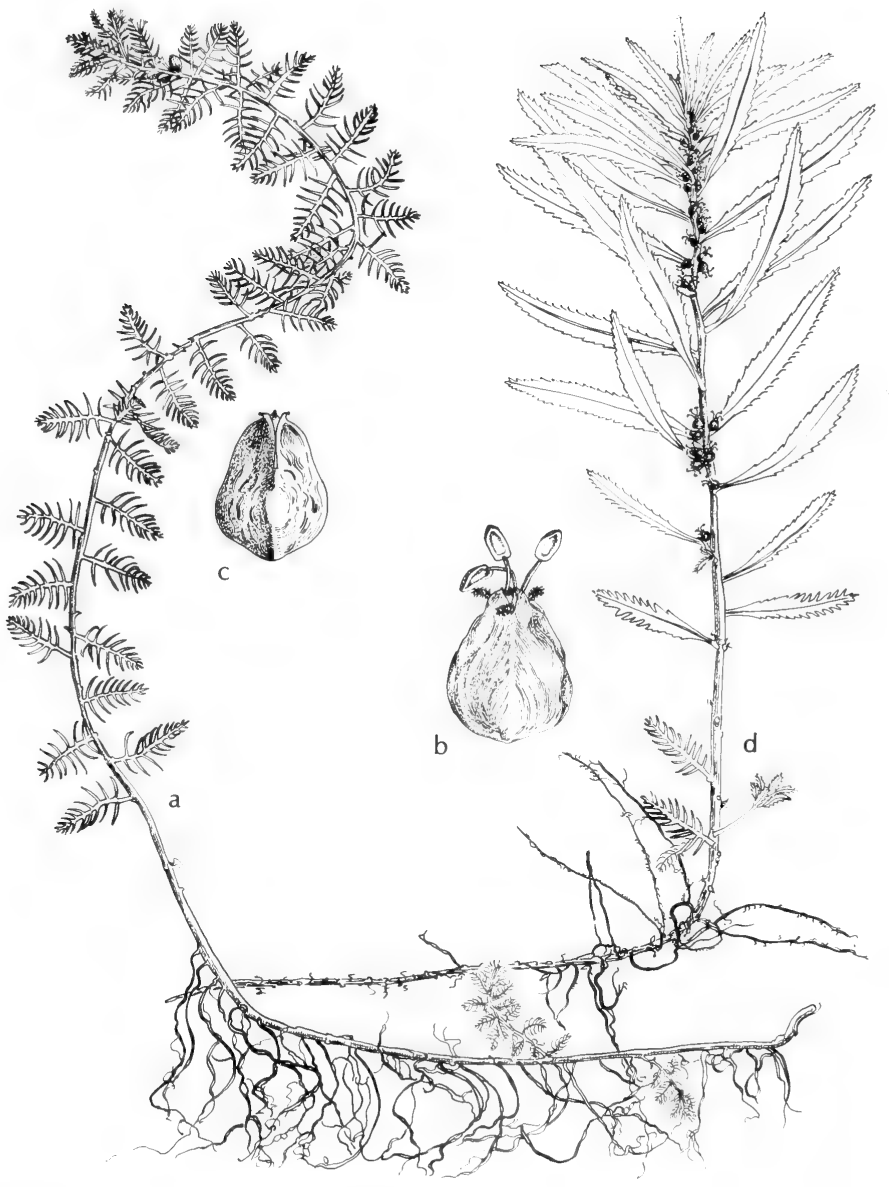

Fig. 565: a-c, Proserpinaca pectinata: a, habit, x 1/2; b, young fruit, x 5; c, mature fruit, x 5. d, Proserpinaca palustris: d, habit, x 1/2. (V. F.). 
Aquatic or paludal plants with the inconspicuous symmetrical perfect or unisexual flowers sessile in the axils of leaves or bracts; calyx tube (hypanthium) adherent to the ovary that consists of 3 (or 4) united carpels; styles or sessile stigmas distinct: limb of the calyx obsolete or very short in perfect or pistillate flowers; petals small or none; stamens 1 to 8 ; fruit indehiscent, 3 - or 4-celled, with a single anatropous seed suspended from the summit of each cell.

About 120 species in 6 genera, cosmopolitan. The name is sometimes misspelled "Haloragidaceae."

1. Flower parts in threes; leaves alternate, the emersed ones amply foliaceous 1. Proserpinaca

1. Flower parts in fours; leaves whorled or rarely partly opposite or alternate, the emersed ones much-reduced and mostly bractlike (sometimes enlarged in $M$. heterophyllum)..... 2. Myriophyllum

\section{Proserpinaca L. Mermaid-Weed}

Low herbaceous perennials with simple or sparsely branched stems that are creeping and rooting at the rhizomatous base; leaves alternate, pinnately dissected or the upper ones lanceolate and serrate, those on the same plant uniform or of both extreme types and intermediate forms; flowers sessile and solitary in the leaf axils, perfect; calyx 3-parted; corolla wanting; stamens 3; pistil 3-angled, with 3 stigmas; fruit nutlike, 3-angled, 3-celled, 3-seeded.

Several species in North America.

The fruits of these plants are eaten by waterfowl, especially ducks, and sparingly so by muskrats.

1. Upper leaves lanceolate, serrate.

1. P. palustris.

1. Upper leaves like the lower ones, pinnately divided.

2. P. pectinata.

\section{Proserpinaca palustris L. Fig. 565.}

Plant repent and rooting along the stems at base; stems ascending or suberect, occasionally trailing up into shrubs, to $1 \mathrm{~m}$. or more long, the base submersed, the summit becoming emersed; submersed leaves rufescent, sessile, finely pinnatified, to $6 \mathrm{~cm}$. long, with 8 to 14 linear-filiform divisions on each side, the divisions to $3 \mathrm{~cm}$. long, commonly bearing minute black axillary spicules, the median portion linear and about $1 \mathrm{~mm}$. wide; amphibious leaves petioled, pinnatisect, to $7 \mathrm{~cm}$. long, lanceolate, with the lanceolate middle portion to $1 \mathrm{~cm}$. broad; emersed leaves lanceolate to oblanceolate, to $85 \mathrm{~mm}$. long and $15 \mathrm{~mm}$. wide, serrate; flowers in leaf axils of only the serrate leaves, solitary or in clusters of 2 to 5 , subtended by minute lanceolate serrate bracts; calyx tube 3-angled, its ovate to deltoid lobes obtuse to acute; petals rudimentary; fruit trigonous-urceolate or pyramidal, $2.5-6 \mathrm{~mm}$. broad.

In shallow water, about springs, in ditches and along shores of streams and lakes in s.e. Okla. (Pushmataha Co.) and e. Tex., spring-summer; from e. Can., s. to Ga. and Tex.

Our plant belongs to var. amblyogona Fern., characterized by having the angles of the fruits rounded or nearly obsolete, or to var. creba Fern. \& Grisc., with angles of the fruit subacute.

\section{Proserpinaca pectinata Lam. Fig. 565.}

Stem very slender, repent, with an ascending rufescent summit to $3 \mathrm{dm}$. high; leaves all deeply pinnatifid, ovate-elliptic in outline, to $25 \mathrm{~mm}$. long, with a linear median portion about $1 \mathrm{~mm}$. wide and 4 to 9 slender rather firm divisions (to 7.5 $\mathrm{mm}$. long) on each side, sometimes bearing minute black spicules; flowers solitary or rarely in twos or threes in the middle and upper leaf axils; calyx lobes acuminate; 
fruit urceolate, with rounded or obtuse angles, 3-4 mm. long, 2-3 mm. broad.

In peaty soils of swamps and savannahs and in shallow water, rare in s.e. Tex., spring-summer; mostly in the Coastal Plain from N.S. and s.w. Me., s. to Tenn., Fla. and Tex.

\section{Myriophyllum L. WATER-MILFOIL}

Perennial aquatics; stems mostly elongated; leaves usually whorled (in ours), the submersed ones pinnately parted into capillary divisions; flowers unisexual and perfect on the same plant, small, sessile, chiefly in the axils of the upper leaves or bracts, usually above water in summer, the uppermost ones staminate; calyx of the staminate flowers 4-parted, of the pistillate flowers 4-toothed; petals 4 or none; stamens 4 or 8 ; stigmas 4 , recurved; fruit nutlike, 4-celled, deeply 4-lobed.

About 45 species, cosmopolitan.

Wildfowl, especially ducks, are known to eat the fruits of these species, and they, as well as muskrats, occasionally eat the herbage. Several species, especially $M$. heterophyllum, $M$. brasiliense and $M$. exalbescens, frequently become a weedy nuisance. All of the plants form shelter and provide a breeding place for fish and insects; the latter, in turn, provide food for fish and water birds. The lower stems and roots are said to provide a nesting place for black bass.

1. Leaf whorls on middle and lower parts of stem mostly $1 \mathrm{~cm}$. or more apart (2)

1. Leaf whorls on middle and lower parts of stem usually much less than $1 \mathrm{~cm}$. apart (4)

2(1). Leaf divisions stoutish, mostly less than $6 \mathrm{~mm}$. long; flowers borne in clusters in the axils of leaves............................... M. brasiliense.

2. Leaf divisions filiform, typically $6 \mathrm{~mm}$. or more long; flowers borne in whorls on a slender terminal spike, mostly longer than the subtending bract (3)

3(2). Lowermost bracteal leaves commonly exceeding the flowers and fruits, pectinate to serrate; leaves of middle whorls usually less than 2.5 $\mathrm{cm}$. long, with 12 or more segments on each side of rachis, the segments rarely to $1.5 \mathrm{~cm}$. long; stems reddish-brown to pinkishtawny in drying................................................2. M. spicatum.

3. Lowermost bracteal leaves not exceeding the flowers and fruits, serrulate to entire; leaves of middle whorls usually $3 \mathrm{~cm}$. long or more, with 11 or fewer segments on each side of rachis, the segments commonly more than $1.5 \mathrm{~cm}$. long; stems whitish in drying......

3. M. exalbescens.

4(1). Floral bracts pinnately dissected or lobed.

4. Floral bracts entire or only toothed (5)

5(4). Leaves mostly all in definite whorls; submersed leaves with 5 to 10 capillary divisions on each side; bracteoles ovate to lanceolate, acuminate; carpels with 2 smoothish dorsal ridges...........5. M. heterophyllum.

5. Leaves whorled, subverticillate, opposite or alternate on the same plant; submerged leaves with about 5 capillary divisions on each side; bracteoles obtusely triangular; carpels with 2 prominently tuberculate dorsal ridges. 6. M. pinnatum.

1. Myriophyllum brasiliense Camb. Parrot's-Feather, Water-Feather. Fig. 566.

Plants pallid or light-green, with the upper part emersed or trailing on mud or seepage and erect-ascending; stems simple or sparsely branched; leaves all whorled, oblong in outline, stiffish, 2-5 cm. long, puberulent when young, glabrous with age. dissected into 10 or more pectinately arranged linear-filiform divisions on each side, the upper divisions 3-6 $\mathrm{mm}$. long, the lower divisions much-reduced; bracteoles 


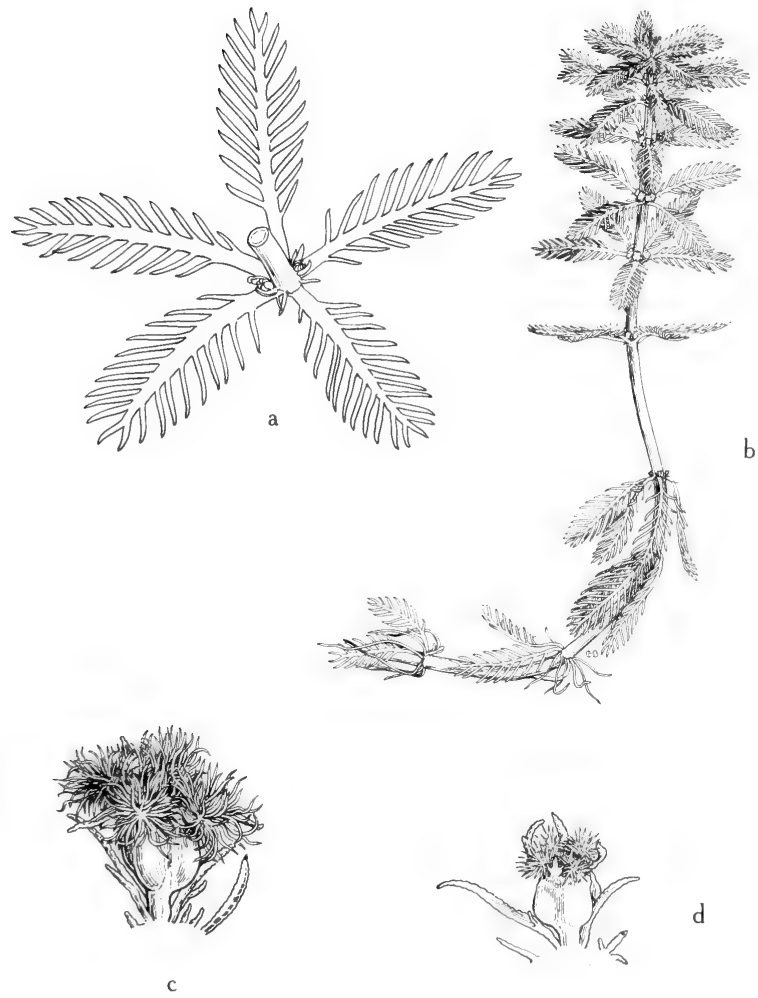

Fig. 566: Myriophyllum brasiliense: a, section of stem, showing whorl of leaves with flowers in the axils, $x 2$; b, habit, the emersed part of plant erect, with flowers in the leaf axils, and the submersed part of plant with roots arising at the nodes, $x 4 / 5$; c, pistillate flower, showing bracteoles, $x$ 8; d, young pistillate flower of upper part of plant, showing calyx lobes and bracteoles, x 8. (From Mason, Fig. 280). 


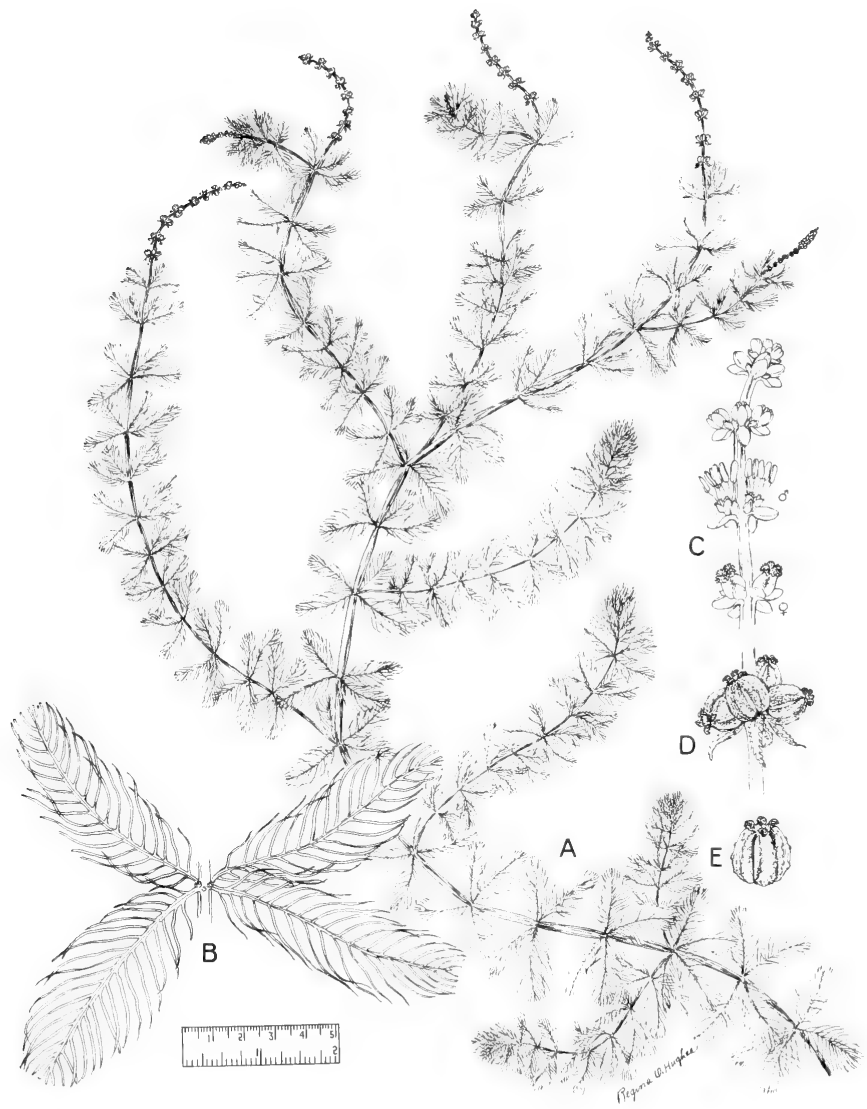

Fig. 567: Myriophyllum spicatum: A, habit, x 1/2; B, whorl of leaves, x 2; C, part of flower spike, with pistillate flowers below and staminate flowers above, $\mathrm{x} 4$; D, immature fruits, $\times 4$; E, mature fruit, $\mathrm{x} 4$. (From Reed, Selected Weeds of the United States, Fig. 136). 
filiform, 2- or 3-cleft; flowers unisexual, in the axils of the leaves; pistillate flowers about $1.5 \mathrm{~mm}$. long, conspicuous as a tuft of white or pinkish plumose stigma lobes; staminate flowers not seen; fruit $1.5-2 \mathrm{~mm}$. long, minutely glandular. $M$. proserpinacoides Gill.

Widely scattered in ponds, ditches, streams and on scepage slopes, introd. in Okla. (ficle Waterfall), mainly on the Edwards Plateau and in e. Tex., rare in Ariz. (Pinal Co.), Mar.-May; nat. to S.A., tending to escape from cult, and persistent in s. U. S.

\section{Myriophyllum spicatum L. Fig. 567.}

Plant rhizomatous with branching leafy shoots to $2.5 \mathrm{~m}$. long; stems reddishbrown to pinkish-tawny in drying; leaves in whorls of 3 to 5 mostly $1 \mathrm{~cm}$. apart or more on stem, those of the middle whorls usually less than $2.5 \mathrm{~cm}$. long, simply pinnate with 12 or more segments on each side of rachis; leaf segments rarely to $1.5 \mathrm{~cm}$. long, regularly placed $1-2.5 \mathrm{~mm}$. apart on rachis; spike to about $15 \mathrm{~cm}$. long, emergent, erect; flowers usually in whorls of 4 in the axils of bracts; all but the lowest bracts essentially entire and shorter than the flowers and fruits, the lowest pectinate to serrate and commonly exceeding the flowers; flowers progressing from 4 basal whorls of pistillate flowers through 1 perfect flower to the upper whorls of staminate flowers with reddish caducous petals about $3 \mathrm{~mm}$. long; stamens 8; fruit subglobular, 4-lobed.

In lakes, ponds and slow-flowing streams in s. and w. Okla. (Cimarron and Comanche cos.), on the e. Edwards Plateau and in s.-cen. Tex. (Burnet, Hays, Colorado and Fayette cos.), n. N.M. (Rio Arriba Co.) and Ariz. (Apache, Coconino, Gila, Navajo, Pima and Yavapai cos.), Apr.-Sept.; from s.e. Lab. to Alas., s. to W. Va., Tex., N.M., Ariz. and s. Calif.; nat. of Euras, and N. Afr.

\section{Myriophyllum exalbescens Fern. American milfoil. Fig. 568.}

Stems simple or forked, purple, becoming white when dry; leaves in whorls of 3 or 4 mostly $1 \mathrm{~cm}$. apart or more on stem, those of the middle whorls usually $3 \mathrm{~cm}$. long or more, simply pinnate with 11 or fewer segments on each side of rachis; leaf segments commonly more than $1.5 \mathrm{~cm}$. long, rather widely and irregularly spaced 2-4 mm. apart on rachis; spike almost naked, emergent, erect, to about $15 \mathrm{~cm}$. long; flowers in verticils, the lowermost pistillate, the upper ones staminate, the bracteal leaves shorter than the flowers and fruits; petals oblongobovate, concave, about $2.5 \mathrm{~mm}$. long; anthers 8 ; fruits subglobose, very narrowly 4-sulcate, 2-3 mm. long, the mericarps rounded on the back, smooth or rugulose. M. spicatum var. exalbescens (Fern.) Jeps.

In ponds, lakes, irrigation ditches and quiet streams, often somewhat calcareous or brackish, in w. Okla. (Beaver Co.), through cen. Tex. to the Panhandle, N. M. (Grant, Rio Arriba, San Miguel and Sandoval cos.) to Ariz. (Apache and Coconino cos.), Apr.-Sept.; from s.e. Lab. to Alas., s. to W. Va., Tex., N. M., Ariz. and s. Calif.

\section{Myriophyllum verticillatum L. Fig. 569.}

Stems simple or with few elongate branches to $25 \mathrm{dm}$. long, in autumn producing crowded winter-buds 1-2 cm. long; leaves in fours and fives; submersed leaves to $45 \mathrm{~mm}$. long, with 9 to 13 opposite or alternate pairs of capillary flaccid divisions to $28 \mathrm{~mm}$. long; emersed leaves and bracts smaller and with coarser divisions or merely pectinate-pinnate; flowers in whorls of 4 to 6 , perfect or the lower ones pistillate and the upper staminate; bracteoles palmately 7-lobed, about $0.5 \mathrm{~mm}$. long; petals (merely rudiments in pistillate flowers) spoon-shaped, obtuse, about $2.5 \mathrm{~mm}$. long; anthers 8 or 4 , about $2 \mathrm{~mm}$. long; fruit subglobose, 2-2.5 mm. long, deeply 4-furrowed, the brown smooth or somewhat tuberculate (in ours) carpels rounded on back. 

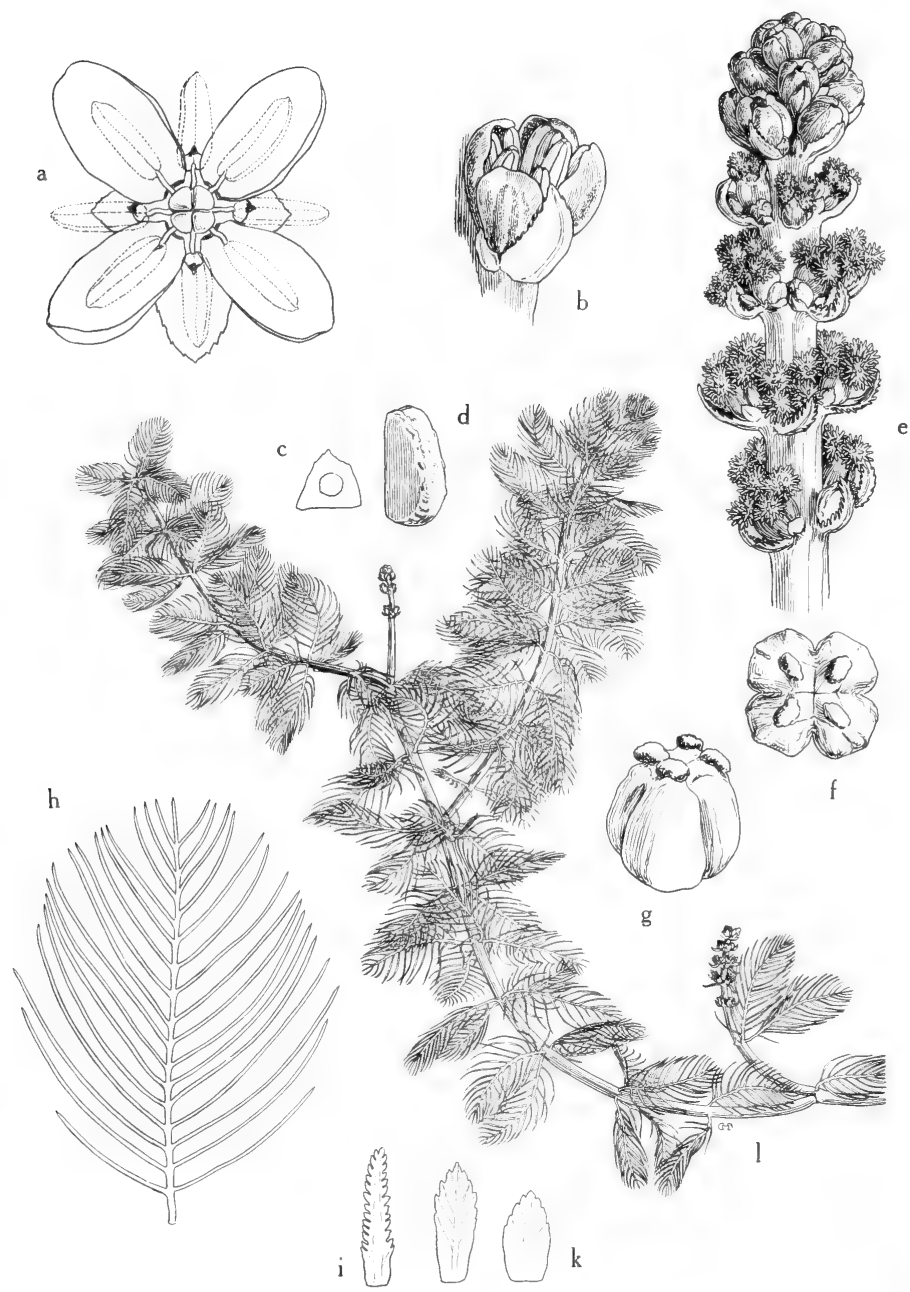

Fig. 568: Myriophyllum exalbescens: a, diagram of staminate flower, showing perianth segments in 4 's, stamens 8 , and 3 subtending bracts, with 2 of them shorter than the third, $\mathrm{x} \mathrm{10}$; b, young staminate flower, $\mathrm{x} 8$; c, nutlet (cross section), $\mathrm{x} 8$; d, mature nutlet, rugose on back, $x$ 8; e, spike, the staminate flowers at the apex, the pistillate flowers below, x 4; f, mature fruit, top view, x $8 ; \mathrm{g}$, mature fruit, side view, x 8; h, submersed leaf, x 2; i-k, bracts of inflorescence, x 6; 1 , habit of plant entirely submersed except for the spike, showing whorls of leaves, $x 2 / 3$. (From Mason, Fig. $281)$. 
In lakes in n.e. Tex., Apr.-June; a highly variable circumpolar species that occurs in N.A. from Nfld. to B.C., s. to Ut. and n.e. Tex.

Plants referred here are typical in regard to leaves and floral bracts, but their fruits are atypical in that they closely resemble those of $M$. heterophyllum. These plants may eventually be found to represent a completely new entity. The closely spaced whorls of leaves readily separate this species from $M$. spicatum, to which it is referred by some authors.

\section{Myriophyllum heterophyllum Michx. Fig. 570 .}

Stems rather stout; leaves whorled, in fours to sixes, the submersed pinnate leaves $2-5 \mathrm{~cm}$. long and with 7 to 10 flaccid capillary divisions on each side, the divisions to about $2 \mathrm{~cm}$. long, the amphibious leaves pinnatisect; emersed leaves and bracts firm, lanceolate or spatulate-lanceolate to elliptic, entire or serrate, to $3 \mathrm{~cm}$. long and $1 \mathrm{~cm}$. wide; spikes emersed, to $4 \mathrm{dm}$. long, usually much shorter; flowers in whorls of 4 to 6 , perfect or with the lower pistillate and the upper staminate; bracteoles ovate, acuminate, serrate, $1-1.3 \mathrm{~mm}$. long, $0.5-0.7 \mathrm{~mm}$. wide; petals (of staminate flowers) acutish, 1.5-3 mm. long; anthers 4 , to $2.5 \mathrm{~mm}$. long; fruit subglobose, 1-1.5 mm. long and wide, minutely papillose, with the carpels 2-ridged on the back but rounded on the sides and prominently beaked.

In ponds, lakes and streams, in s. Okla. (Murray and Pushmataha cos.) and mainly on the Edwards Plateau and in s.e. Tex., Apr.-Aug.; from Fla. to Tex. and N.M., n. to N.D.., Ont. and s.w. Que.

A large-bracted form of this species occurs in southeast Texas.

6. Myriophyllum pinnatum (Walt.) B.S.P. GreEN PARRoT'S-FEATHER. Fig. 571.

Plant variable, either submersed or essentially terrestrial; stems rooting in mud freely branched or becoming much-elongated when growing in water; leaves in whorls of 3 to 5 or subverticillate or commonly scattered, to about $3 \mathrm{~cm}$. long, the submersed leaves with about 5 or more short or somewhat elongate remote capillary divisions on each side; emersed leaves linear to oblanceolate, pectinate or sharply serrate, to $2 \mathrm{~cm}$. long; flowers in the axils of the emersed leaves, perfect or unisexual; bracteoles bluntly triangular, about $1 \mathrm{~mm}$. long; petals purplish, 1.5-2 $\mathrm{mm}$. long, rounded above, with a short claw; anthers 4, about $1 \mathrm{~mm}$. long; fruit pale, ovoid, 1.3-1.8 mm. long, the carpels with flat sides and 2 tuberculate dorsal ridges. $M$. scabratum Michx.

In swamp forests, on muddy shores or in shallow waters in e. Okla. (McCurtain, Ottawa and Sequoyah cos.) and on the Edwards Plateau and in e. and s.e. Tex., Mar.-June; from Fla. to Tex., n. to s. N. E., W. Va., Ky., Ill. and Ia.

\section{Fam. 97. Hippuridaceae LINK}

\section{MARE'S-TAIL FAMILY}

Aquatic or amphibious plant with simple, sessile, whorled, entire leaves and minute flowers in the upper axils to form a long terminal spike; flowers pistillate or perfect, epigynous; hypanthium completely enclosing the ovary and bearing at its summit in the perfect flowers a single stamen with short filament and large 2 -celled anther; sepals and petals none; ovary 1 -celled and 1-ovuled, terminated by a filiform style; fruit hard, indehiscent, nutlike, 1-seeded.

A monogeneric family.

\section{Hippuris L. MARE's-TAIL}

Characters of the family. A monotypic genus or sometimes as many as 3 species are recognized. 

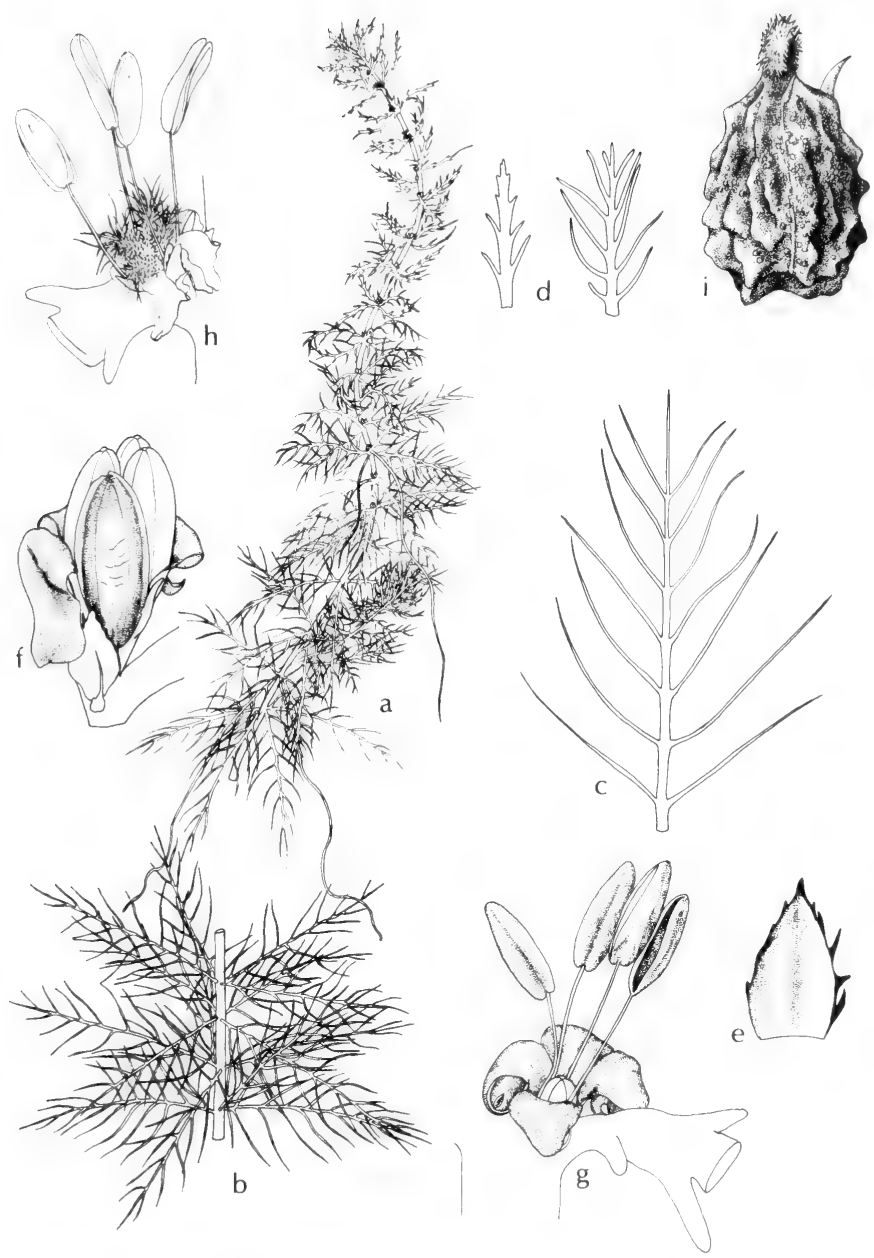

Fig. 570: Myriophyllum heterophyllum: a, end of branch, x 1; b, section of branch under water, $\mathrm{x} 1$; c, leaf, $\mathrm{x} 2$; d, underwater leaf, $\mathrm{x} 1 \frac{113}{3}$, e and $\mathrm{f}$, bracts, $\mathrm{x} 11 \frac{1}{3} ; \mathrm{g}$, staminate flower, $x 8$; $h$, stamen, $x 16$; , pistillate flower, $x 12 ; j$, fruits, $x 3$. (Courtesy of R. K. Godfrey). 

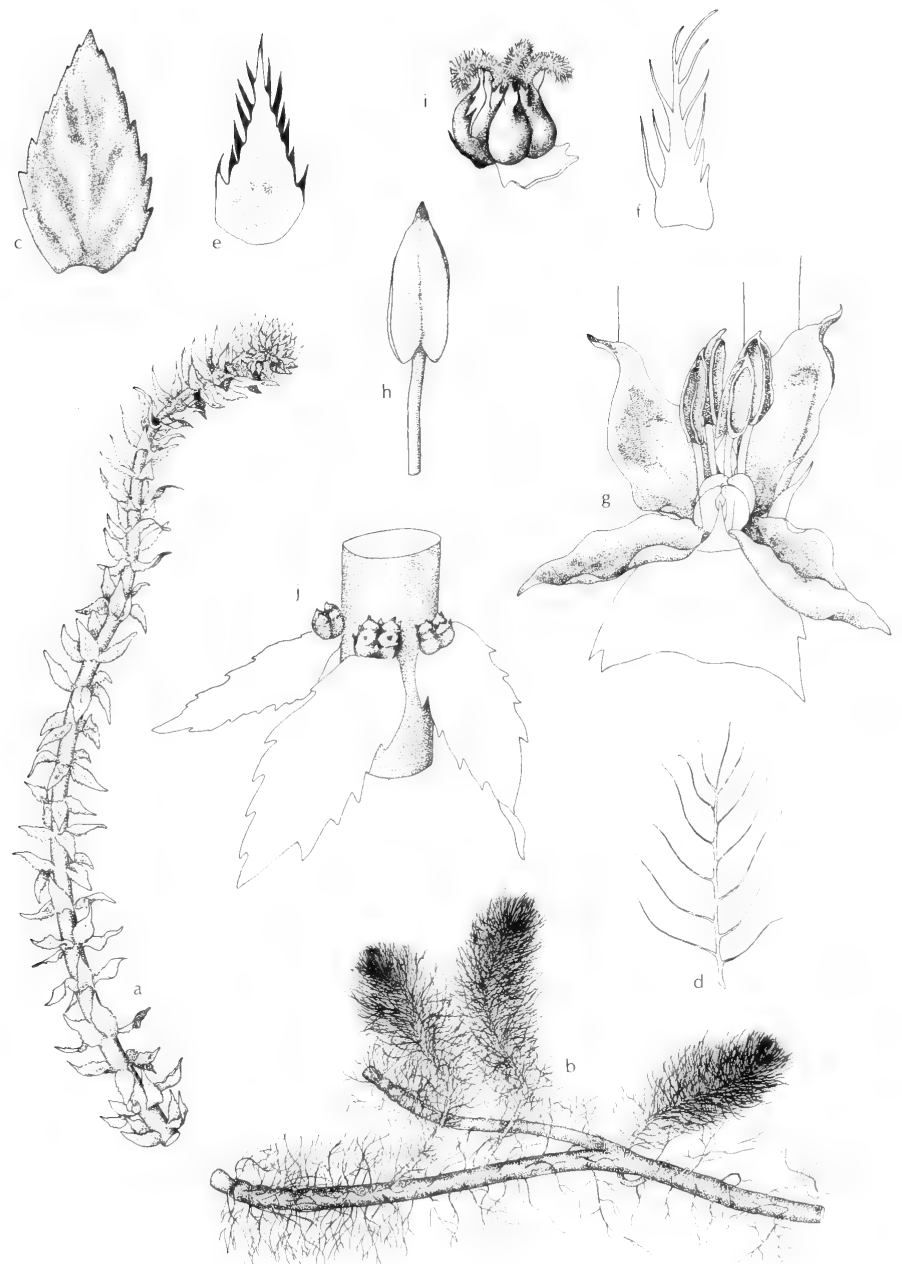

Fig. 571: Myriophyllum pinnatum: a, distal end of branch, x 1/2; b, central section of branch, $\mathrm{x} 1 / 2$; c, leaf, $\mathrm{x} 1$; d, variation in leaves, $\mathrm{x} \mathrm{1}$; e, bracteole, $\mathrm{x} 10$; $\mathrm{f}$, bud, $\mathrm{x} 25$; g, male flower, x 13; h, perfect flower, x 13; i, face view of single mericarp, x 25 . (Courtesy of R. K. Godfrey). 


\section{Hippuris vulgaris L. Fig. 572.}

Stems submersed or partly emersed, erect, simple, 3-6 dm. tall, hollow, arising from a creeping horizontal rhizome; herbage glabrous, usually pallid; leaves simple, 6 to 12 in a whorl, linear-attenuate, $5--35 \mathrm{~mm}$. long, thick: flowers sessile in middle and upper axils, usually perfect; petals none; stamen 1, inserted on anterior edge of calyx; ovary inferior, crowned with the rimlike entire calyx; fruit $2-3 \mathrm{~mm}$. long, 1 -celled and 1 -seeded.

Rooted in mud of shallow water in ponds and streams, marshes and wet meadows, in N. M. (Rio Arriba, Taos, Santa Fe and San Juan cos.) and Ariz. (Apache Co.), June-Aug.; widely distributed in the cooler parts of the Northern Hemisphere.

The seeds and occasionally the foliage are eaten by wildfowl. The usually dense colony of plants also provide shelter for small animal life.

\section{Fam. 98. Umbelliferae Juss.}

\section{PARSLEY FAMily}

Primarily herbaceous plants, acaulescent or caulescent, annual, biennial or perennial, with commonly hollow stems; leaves alternate or rarely opposite or basal, compound or sometimes simple, usually much-incised or -divided, with usually sheathing petioles; flowers small, regular, in simple or compound umbels, or the umbels sometimes proliferous or capitate; rays sometimes subtended by bracts forming an involucre; umbellets usually subtended by bractlets forming an involucel; calyx tube wholly adnate to the ovary; calyx teeth usually obsolete or small; petals 5, usually with an inflexed tip; stamens 5, inserted on an epigynous disk; ovary inferior, bilocular; styles 2 , sometimes swollen at the base, forming a stylopodium; fruit consisting of two mericarps united by their faces (commissure), compressed or flattened dorsally (parallel to the commissure), laterally (at right angles to the commissure) or terete, each mericarp with 5 primary ribs, one down the back (dorsal rib), two on the edges near the commissure (lateral ribs) and two between the dorsal and lateral ribs (intermediate ribs) and rarely with secondary ribs, the ribs filiform to broadly winged and thin or corky; oil tubes obsolete or present in the intervals (spaces between the ribs) and on the commissural surface, rarely also in the pericarp; mericarps 1-seeded, splitting apart at maturity, usually suspended from the summit of a slender prolongation of the axis (carpophore).

A cosmopolitan family of world-wide distribution consisting of at least 200 genera and perhaps 3,000 species.

(Adapted mainly from various works published by Mildred E. Mathias and Lincoln Constance.)

1. Flowers and fruits borne in compound umbels or bracteate heads (2)

1. Flowers and fruits borne in simple noncapitate umbels; leaves small and relatively simple $(28)$

2(1). Flowers and fruits (or some of them) pedicellate; fruits more or less evidently ribbed; calyx minute or obsolete (3)

2. Flowers and fruits sessile or subsessile in dense bracteate heads or headlike umbellets; fruits with obsolete ribs, crowned by the prominent and persistent calyx and densely beset with scales or tubercles.

.27. Eryngium

3(2). Fruits terete to somewhat compressed laterally, the ribs not prominently winged (4)

3. Fruits strongly flattened dorsally, some or all of the ribs broadly winged (24)

4(3). Fruits merely bristly-pubescent to glabrous (5)

4. Fruits armed with uncinate bristles or prickles, or tuberculate, papillate or callous-toothed (22) 


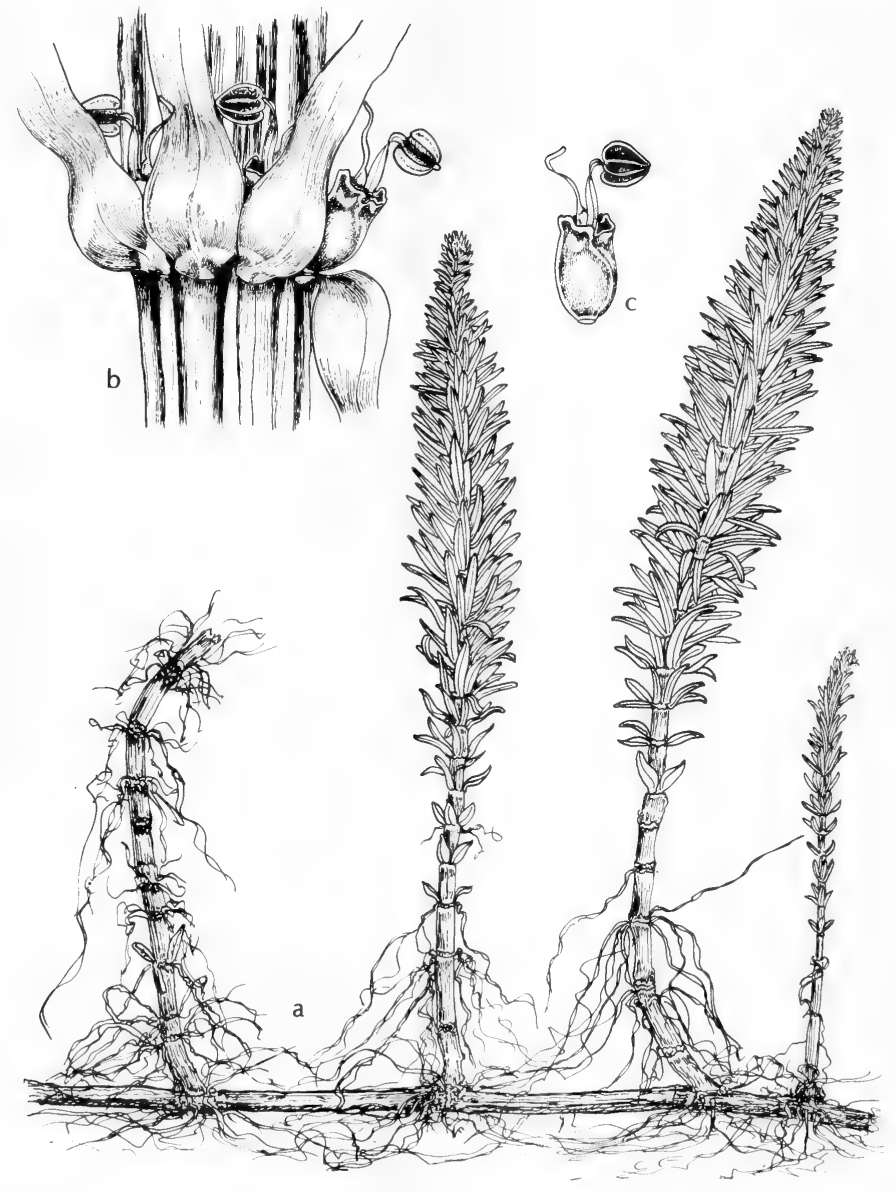

Fig. 572: Hippuris vulgaris: a, habit, x 1/2; b, node, x 5; c, single flower, x 5. (V. F.). 
5. Fruits linear to oblong, more than twice as long as broad (19)

6(5). Pericarp not corky-thickened; fruit ribs filiform to prominent, never corky (7)

6. Pericarp of some or all of the fruit ribs corky-thickened (14)

7(6). Perennials; leaflets not pinnately dissected; stylopodium lacking (8)

7. Annuals or biennials; leaflets usually pinnately dissected; stylopodium depressed-conic to conic (9)

8(7). Plants acaulescent; calyx teeth minute; seed face deeply sulcate.

4. Tauschia

8. Plants caulescent, branching; calyx teeth prominent; seed face slightly concave.

12. Zizia

9(7). Involucre present; fruit ribs undulate, crenate; oil tubes very small, numerous, irregular; stems variously spotted.

14. Conium

9. Involucre lacking (sometimes a few bracts in Perideridia) (10)

10(9). Involucel lacking (11)

10. Involucel present; low diffuse annuals (13)

11(10). Flowers yellow; plants with aniselike odor.

11. Foeniculum

11. Flowers white or pinkish; plants without aniselike odor (12)

12(11). Plants from slender elongate roots; umbels axillary or terminal; calyx lobes inconspicuous.

13. Apium

12. Plants from fascicled tuberous or fusiform roots; umbels terminal; calyx lobes conspicuous. 15. Perideridia

13(10). Fruit ribs filiform, rounded, subequally spaced; plants glabrous.

13. Fruit ribs acute, the lateral of the two mericarps contiguous and appearing to form a single rib; plants roughened. 5. Ammoselinum

14(6). Perennials; pericarp or at least some of the dorsal as well as the lateral fruit ribs corky-thickened (15)

14. Annuals; only the lateral fruit ribs corky-thickened (17)

15(14). Fruit ribs obscure in the corky-thickened pericarp; plants stoloniferous

15. Fruit ribs prominent, corky-thickened; plants not stoloniferous (16)

16(15). Involucre prominent; rays few; fruit ribs subequal in cross section.

16. Involucre inconspicuous or lacking; rays usually numerous; fruit ribs unequal in cross section.

18. Cicuta

17(14). Leaves decompound with filiform divisions

20. Ptilimnium

17. Leaves entire, palmately parted or pinnate, with narrow elongate divisions (18)

18(17). Fruit prominently beaked; cauline leaves palmately parted; petals with a narrower inflexed apex....................................21. Cynosciadium

18. Fruit rounded at apex; leaves entire or pinnate; petal apex not inflexed.

22. Limnosciadium

19(5). Fruits without secondary ribs (20)

19. Fruits with prominent corky or bristly secondary ribs, the primary ribs obscure.

9. Trepocarpus 
20(19). Involucel lacking or inconspicuous; carpophore divided to the base; seed face plane..

6. Cryptotaenia

20. Involucel conspicuous; bractlets entire; carpophore bifid or 2-cleft above the middle; seed face sulcate (21)

21(20). Annuals; fruits 4-8 mm. long, obtuse at base.

10. Chaerophyllum

21. Perennials; fruits $10-20 \mathrm{~mm}$. long, acute or caudate at base.......7. Osmorhiza

22(4). Fruit with uncinate prickles along the ribs.

8. Caucalis

22. Fruits glabrous or finely tuberculate, papillate or callous-toothed; petals without an inflexed apex (23)

23(22). Fruit ribs filiform, rounded, subequally spaced; plants glabrous.

23. Fruit ribs acute, the lateral of the two mericarps contiguous and appearing to form a single broad rib; plants roughened....

5. Ammoselinum

24(3). Lateral fruit ribs broadly winged, the dorsal very narrowly winged to obsolete (25)

24. Lateral ribs and one or more of the dorsal broadly winged or the oil tubes prominent but short (26)

25(24). Plants annual; lateral fruit wings thick and corky; leaves entire or palmately divided...............................................21. Cynosciadium

25. Plants perennial from fascicled tubers; lateral fruit wings thin, nerved dorsally at the inner margins, the fruit thus appearing 5-ribbed; leaves oncepinnate or reduced to bladeless phyllodes......................25. Oxypolis

26(24). Leaves more or less dissected, without well-defined leaflets or with the leaflets more or less cleft; ovaries glabrous...........23. Conioselinum

26. Leaves with more or less definite, entire or toothed leaflets or a few with irregular lobes; ovaries sparsely hispidulous or puberulent (Heracleum lanatum sometimes has glabrate ovaries) (27)

27(26). Oil tubes extending only part way from the apex toward the base of the fruit; herbage tomentose......................................26. Heracleum

27. Oil tubes extending to the base of the fruit; herbage glabrous to pubescent...... 24. Angelica

28(1). Leaves reduced to hollow cylindric jointed petioles.

19. Lilaeopsis

28. Leaves with a definite blade, orbicular to round-reniform or ovate-cordate to oblong (29)

29(28). Involucre of 2 conspicuous bracts; fruit with 3 primary and 2 reticulated secondary dorsal ribs; petioles sheathing..........................2. Centella

29. Involucre multibracteate, inconspicuous; fruit without secondary ribs; petioles not sheathing.....................................................1. Hydrocotyle

\section{Hydrocotyle L. WATER-PENNYWORT}

Plants low, glabrous or pubescent, herbaceous, perennial with slender creeping stems or rootstocks, rooting at the nodes; leaves peltate or nonpeltate, entire or parted to the base; inflorescence usually a simple umbel, sometimes proliferous or an interrupted spike, the axillary peduncles obsolete to much longer than the leaves; involucre inconspicuous, of numerous bracts; rays spreading to reflexed, sometimes obsolete; flowers white, greenish or yellow, the calyx teeth minute or obsolete, the stylopodium conspicuously conic to depressed; fruit ovoid to ellipsoid (broader than long), strongly flattened laterally, the dorsal surface rounded or acute, the dorsal ribs acute or obsolete, the slender lateral ribs conspicuous and acute or rarely obsolete; oil-bearing cells conspicuous to obsolete, strengthening cells usually surrounding the seed cavity, the seed face plane to concave.

A genus of about 100 species, chiefly of the tropics and the Southern Temperate Zone.

The seeds and occasionally the foliage are eaten by wildfowl; $H$. umbellata is considered to be especially desirable as duck food. 


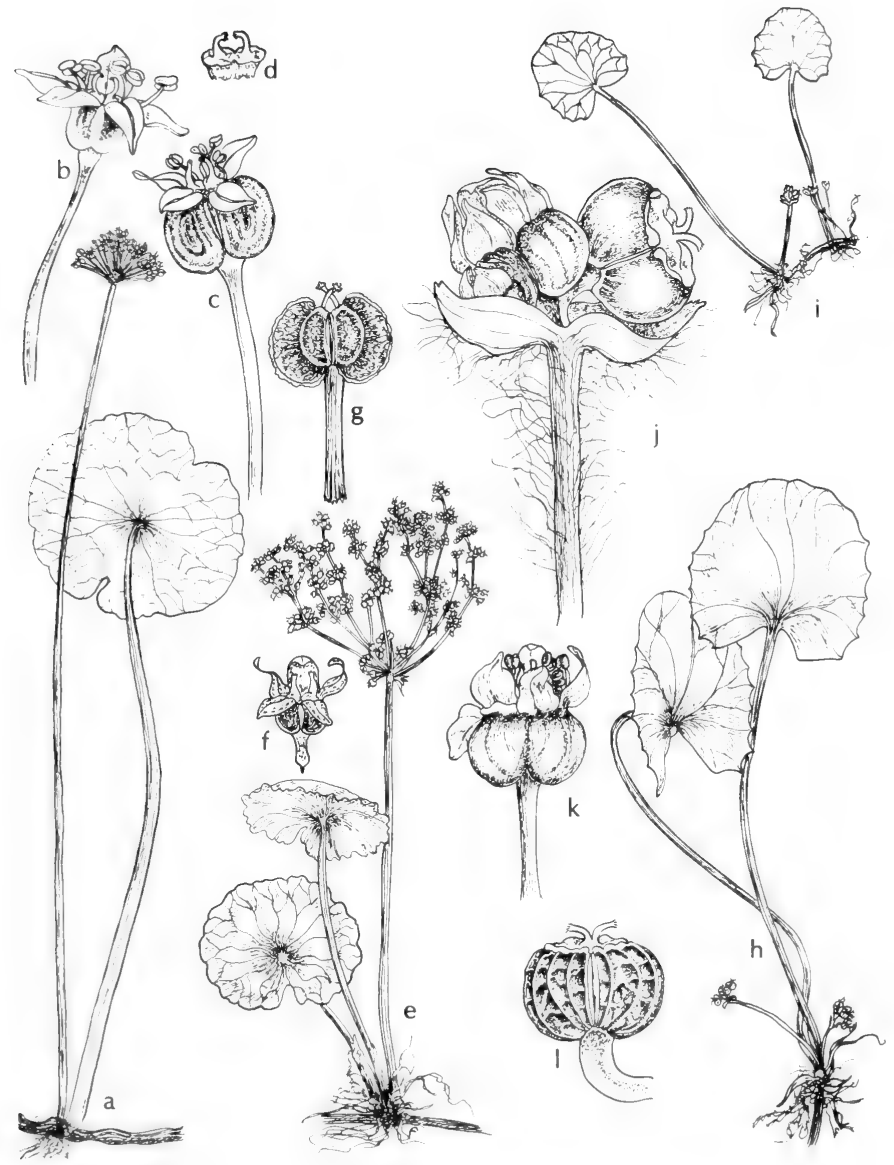

Fig. 573: a-d, Hydrocotyle umbellata: a, habit, x 1/2; b, flower, x 5; c, fruit, x 5; d, stylopodia, x 5. e-g, Hydrocotyle bonariensis: e. habit, x 1/2; f, young fruit, x 5; g. mature fruit, x 5. h-l, Centella asiatica: $\mathrm{h}$ and $\mathrm{i}$, two different plants showing variation in size, $x_{1 / 2}^{1 / j}$, inflorescence, $x 5$; $k$, flower, $x 5 ; 1$, fruit, $x 5$. (V. F.). 

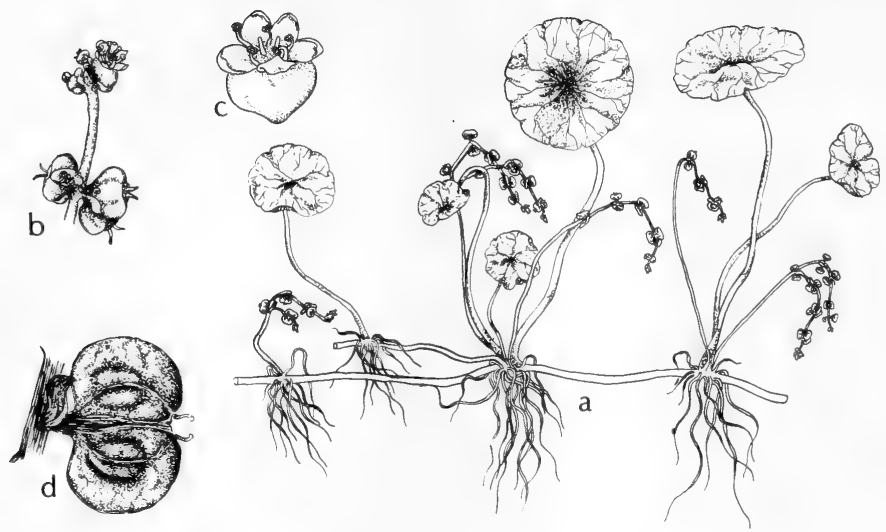

Fig. 574A: Hydrocotyle verticillata var. verticillata: a, habit, $\mathrm{x} 1 / 2 ; \mathrm{b}$, part of inflorescence, x 6; c, flower, x 10; d, fruit, x 12. (Courtesy of R. K. Godfrey).

1. Leaves reniform, not peltate, the petioles attached in a sinus at one edge of the blade. 5. $H$. ranunculoides.

1. Leaves peltate, the petioles attached to the middle of the blade (2)

2(1). Flowers and fruits in a simple (not proliferous) umbel

1. H. umbellata.

2. Flowers and fruits in a proliferous umbel or an interrupted spike (3)

3 (2). Inflorescence profusely branched.

4. H. bonariensis.

3. Inflorescence usually unbranched or only bifurcate (4)

4(3). Inflorescence often bifurcate; fruits sessile or subsessile.

2. $H$. verticillata var. verticillata.

4. Inflorescence rarely bifurcate; fruits pedicellate

3. H. verticillata var. triradiata.

1. Hydrocotyle umbellata L. Ombligo de Venus. Fig. 573.

Plants glabrous; stems slender to somewhat thickened, floating or creeping; leaves orbicular-peltate, to $75 \mathrm{~mm}$. in diameter, crenate or crenately lobed; petioles mostly slender, to $40.5 \mathrm{~cm}$. long, usually much shorter; peduncles usually exceeding the leaves, to $35 \mathrm{~cm}$. long; umbels simple, many flowered; rays to $2.5 \mathrm{~mm}$. long, spreading and reflexed; stylopodium depressed; fruit orbicular to ellipsoid, 1-2 $\mathrm{mm}$. long, 2-3 $\mathrm{mm}$. broad, the dorsal surface acute, the dorsal and lateral ribs evident and obtuse; strengthening cells lacking.

In swampy areas in shallow water, bogs, edge of ponds, ditches, marshy ground in Okla. (Waterfall) and in the e. half of Tex., Apr.-Oct.; from N.S., s. to Fla., w. to Minn. and Tex.; also Ore., Calif., W.I. and from Mex., s. to S.A

2. Hydrocotyle verticillata Thunb. var. verticillata. Fig. 574A.

Plants glabrous; stems filiform, creeping; leaves orbicular-peltate, to $6 \mathrm{~cm}$. in diameter, 7- to 14-veined, shallowly 8- to 13-lobed, the lobes crenate; petioles slender, to $26 \mathrm{~cm}$. long, usually much shorter; inflorescence an axillary simple interrupted once- or twice-bifurcate (rarely tri- or quadrifurcate) spike, to $17 \mathrm{~cm}$. long, with 2 to $7 \mathrm{few}$-flowered verticils, the interverticillar distance to $6 \mathrm{~cm}$., the flowers sessile or subsessile; involucre of a few inconspicuous lanceolate bracts; 


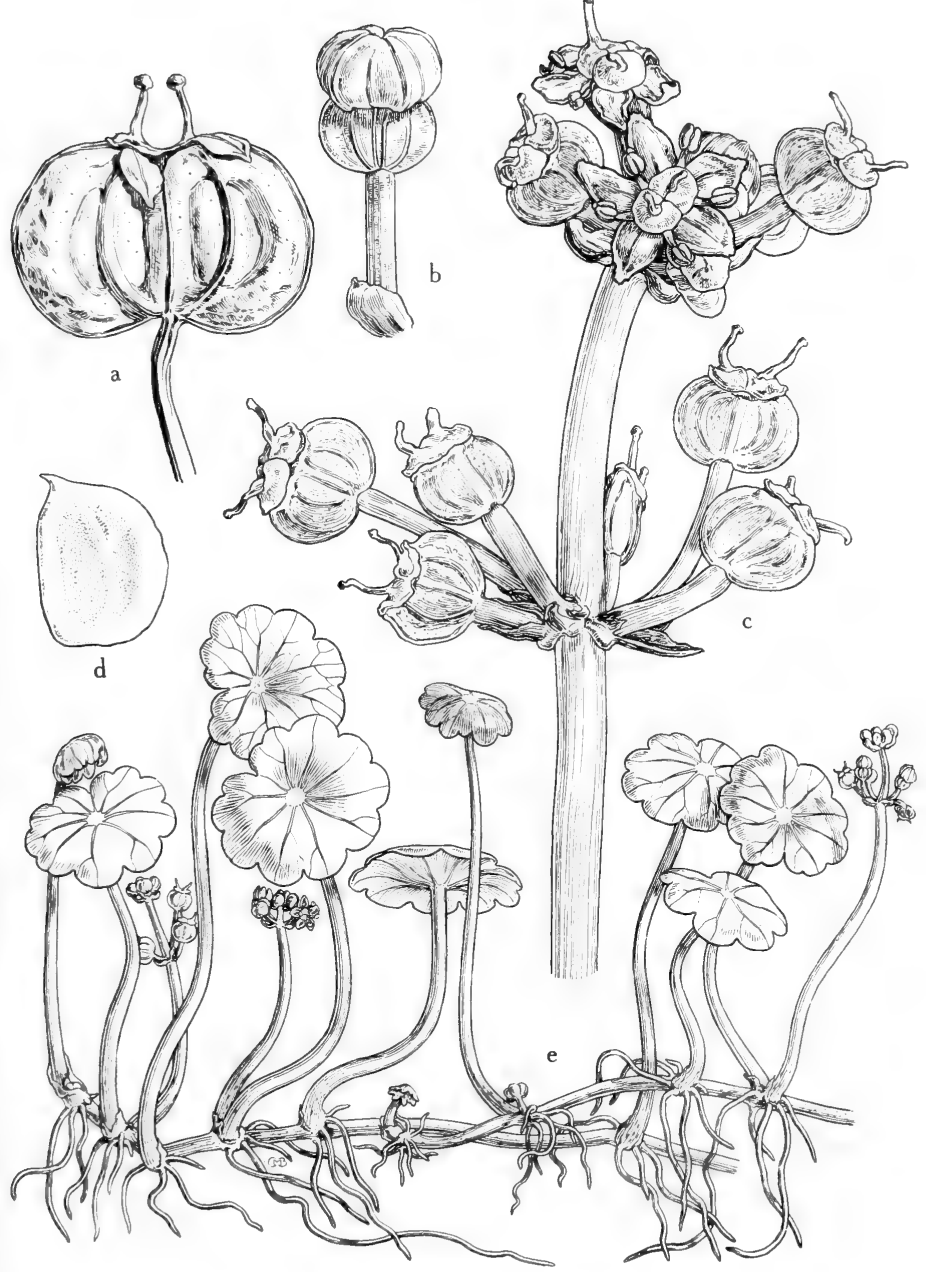

Fig. 574B: Hydrocotyle verticillata var. triradiata: a, fruit, strongly flattened laterally, $x 12 ; b$, bud, $x 12 ; c$, inflorescence, the stylopodia conspicuous at the summit of each fruit, x 8; d, carpel, x 12; e, habit, x 11/2. (From Mason, Fig. 285). 


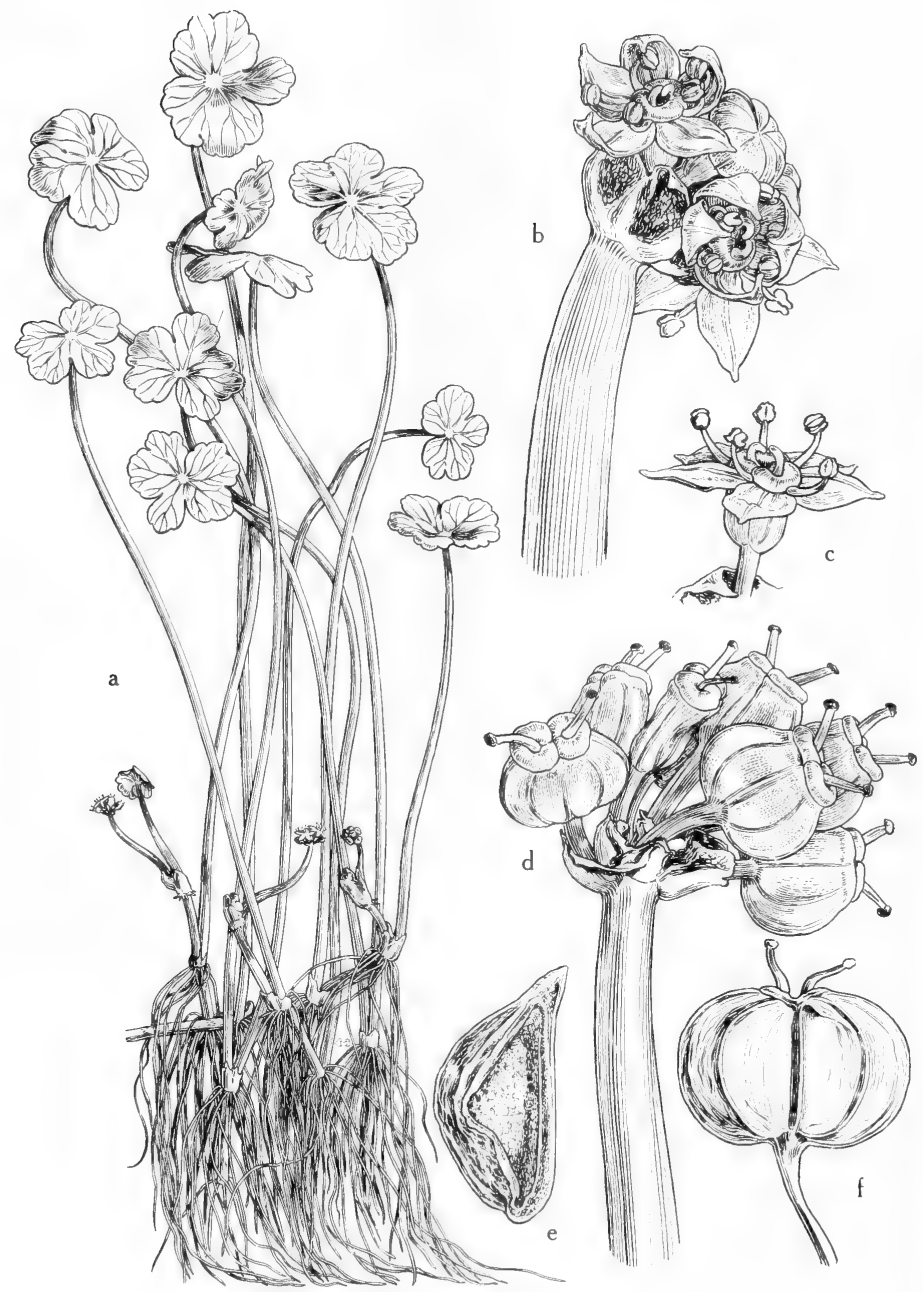

Fig. 575: Hydrocotyle ranunculoides: a, habit, $\mathrm{x} 2 \frac{3}{3} ; \mathrm{b}$, umbel of flowers, $\mathrm{x} 8$; $\mathrm{c}$, flower, x 8; d, umbel in fruit, x 8; e, carpel, x 32; f, fruit, x 12. (From Mason, Fig. 286). 
fruit ellipsoid, 1-3 $\mathrm{mm}$. long, 2-4 $\mathrm{mm}$. broad, the dorsal surface acute, narrowly rounded to cuneate at the base, oblong in cross section, the acute dorsal and lateral ribs distinct, the commissural surface constricted; oil-bearing cells conspicuous; seed oblong-ovate in cross section.

Along streams and low muddy ground or in shallow water in Okla. (Waterfall), in Tex. in the Timber Belt, Coastal and Blackland Prairies and the Edwards Plateau, N.M. (Eddy Co.) and Ariz. (Widespread), June-Aug.; from Mass., s. to Fla., w. to Mo., Tex., s. Ut., N.M., Ariz., Calif., Mex. and W.I.; also in H.I. and S. Afr.

\section{Hydrocotyle verticillata var. triradiata (A. Rich.) Fern. Fig. 574B.}

Similar in habit to var. verticillata; leaves to $6 \mathrm{~cm}$. in diameter, 8- to 14-nerved, shallowly 8 - to 14-lobed; petioles slender, to $35 \mathrm{~cm}$. long; inflorescence an axillary interrupted simple or rarely branched spike to $22 \mathrm{~cm}$. long, with few 4- to 15 flowered verticils, the interverticillar distance to $4 \mathrm{~cm}$., the flowers radiate, the rays to $1 \mathrm{~cm}$. long. $H$. Canbyi Coult. \& Rose, $H$. australis Coult. \& Rose.

In open marshes and wet areas in Okla. (Cherokee Co.), in Tex. chiefly in the Timber Belt, Coastal and Blackland prairies, Rio Grande Plains and Edwards Plateau, w. to Ariz. (Santa Cruz, Pima, Yavapai and Mohave cos.), May-Aug.; from Mass., s. to Fla., w. to Nev. and Calif., also Mex., C.A., W.I. and S.A..

\section{Hydrocotyle bonariensis Lam. Sombrerillo. Fig. 573.}

Plants glabrous; stems slender, creeping; leaves orbicular to ovate-peltate, to $12 \mathrm{~cm}$. in diameter, shallowly 12 - to 19 -lobed, the lobes crenate; petioles slender, to $37 \mathrm{~cm}$. long; peduncles exceeding the leaves; umbels proliferous, many-flowered; rays to $2 \mathrm{~cm}$. long, spreading and reflexed; involucral bracts lanceolate, acute; flowers white to yellow; stylopodium depressed; fruit ellipsoid, 1-2 mm. long, 2-4 $\mathrm{mm}$. broad, the dorsal surface acute, the acute dorsal and lateral ribs evident, the commissural surface constricted.

In sandbar ditches, wet depressions, along stream banks and in streams, in the Tex. Coastal and Blackland prairies, and on the Gulf side of the Rio Grande Plains, May-Nov.; from N.C., s. to s. S.A.; S. Afr.

\section{Hydrocotyle ranunculoides L.f. Fig. 575.}

Plants glabrous; stems slender to somewhat thickened, floating or creeping; leaves roundish-reniform with a sinus at the base, not peltate, to $8 \mathrm{~cm}$. long and wide, 5- or 6-lobed about to the middle, the lobes crenate or lobulate; petioles mostly slender, to $34.5 \mathrm{~cm}$. long; peduncles shorter than the leaves, axillary; umbels simple, 5- to 10-flowered; rays 1-3 mm. long, spreading and ascending; stylopodium depressed; fruit suborbicular, 1-3 $\mathrm{mm}$. long, 2-3 $\mathrm{mm}$. broad, the dorsal surface rounded, the ribs obsolete; strengthening cells absent.

In shallow pools and muddy shores in Okla. (Waterfall), Tex. in the Timber Belt and Blackland Prairies and Ariz. (Cochise, Pima and Santa Cruz cos.), Apr.-July; from Pa. and Del., s. to Fla., w. to Ark. and Ariz.; also from Wash., s. along the coast to Pan., Cuba and S.A.

\section{Centella L.}

A genus of perhaps 20 species, chiefly of the Southern Hemisphere.

\section{Centella asiatica (L.) Urban. Fig. 573.}

Plant perennial from slender creeping rootstocks, with stems 1 to several $\mathrm{dm}$. long, rooting at nodes; leaves ovate-cordate to oblong, obtuse, to $10 \mathrm{~cm}$. long and $9 \mathrm{~cm}$. wide, entire or repand-toothed; petioles glabrous to fulvous-pubescent, usually with a tuft of hairs at the apex, to $35 \mathrm{~mm}$. long, usually much shorter; inflorescence of simple lax to subcapitate umbels; peduncles axillary, shorter than 
to exceeding the leaves, to $11.5 \mathrm{~cm}$. long; involucre of 2 conspicuous ovate to suborbicular scarious bracts; rays 2 to 5 , to $4 \mathrm{~mm}$. long; flowers white or rose-tinged, the calyx teeth obsolete, the stylopodium obsolete; carpophore entire; fruit ellipsoid, 3-4 mm. long, 3-5 mm. broad (broader than long), constricted at the commissure and flattened laterally, glabrous, the filiform primary ribs prominent, the secondary ribs and reticulations evident, the seed face plane; an oil-bearing layer beneath the epidermis, occasionally containing small oil tubes and a thick layer of strengthening cells surrounding the seed cavity. C. erecta (L. f.) Fern.

Edges of streams and other wet places in e. half of Tex., May-Sept.; from Del., s. to Fla. and w. to Tex.; also W.I. and Mex. to C.A., S.A. and e. Asia.

\section{Spermolepis Raf. Scale-SEED}

A genus of 5 species, three in the southeastern and central United States and adjacent Mexico, one in southern South America, and the fifth in the Hawaiian Islands.

\section{Spermolepis divaricata (Walt.) Raf. Fig. 576.}

Slender annual from taproot, erect, 1-7 dm. high; leaves oblong to oblong-ovate, to $5 \mathrm{~cm}$. long and $35 \mathrm{~mm}$. wide, ternately or ternate-pinnately decompound; ultimate divisions of leaves linear, acute; inflorescence of compound umbels, the terminal and axillary peduncles exceeding the leaves; peduncles $1-5 \mathrm{~cm}$. long; involucre lacking; involucel of a few linear acute bractlets with the margins scarious and usually callous-toothed; rays 3 to 7 , divaricate, subequal, 5-35 $\mathrm{mm}$. long; pedicels 1 to 6 , to $3 \mathrm{~cm}$. long or the central flower of each umbellet sessile; flowers white, the calyx teeth obsolete; the stylopodium low-conic; carpophore 2-cleft at the apex; fruit ovoid, compressed laterally, $1.5-2 \mathrm{~mm}$. long, about $1.5 \mathrm{~mm}$. broad, tuberculate, the filiform ribs rounded; oil tubes 1 to 3 in the intervals and 2 on the commissure, the seed face sulcate.

In swamps and moist woodlands in the Timber Belt and Blackland Prairies of Tex., Apr.-June; from Va., s. to Fla., w. to Kan. and Tex.

\section{Tauschia Schlecht}

A genus of about 20 species of the highlands of Mexico and northern South America and western United States.

\section{Tauschia texana Gray. Fig. 577.}

Acaulescent perennial from a taproot, 1-4 dm. high, glabrous throughout; leaves oblong, to $15 \mathrm{~cm}$. long and $4 \mathrm{~cm}$. wide, pinnate; leaflets sessile to petiolulate, ovate, distinct, the larger ones pinnately parted or lobed, the divisions cuneate; inflorescence of compound umbels; peduncles 1-4 dm. long; involucre lacking or of a single foliaceous bract; involucel of several linear to lanceolate connate bractlets, shorter than the flowers; fertile rays 5 to 8 , unequal, $5-25 \mathrm{~mm}$. long; flowers yellow, with pedicels 1-2 mm. long; calyx teeth minute; fruit oval, 3-4 mm. long, 2-3 $\mathrm{mm}$. broad, slightly compressed laterally, glabrous, the ribs filiform; oil tubes 3 or 4 in the intervals and 4 on the commissure; seed face deeply sulcate. Museniopsis texana (Gray) Coult. \& Rose.

In alluvial thickets and wet woods in s. part of Blackland Prairies and in coastal region in Tex., Feb.-June; endemic.

\section{Ammoselinum T. \& G. SAnd-PARsLey}

A genus of 4 species of the south-central and southwestern United States and adjacent Mexico; one species in southern South America. 


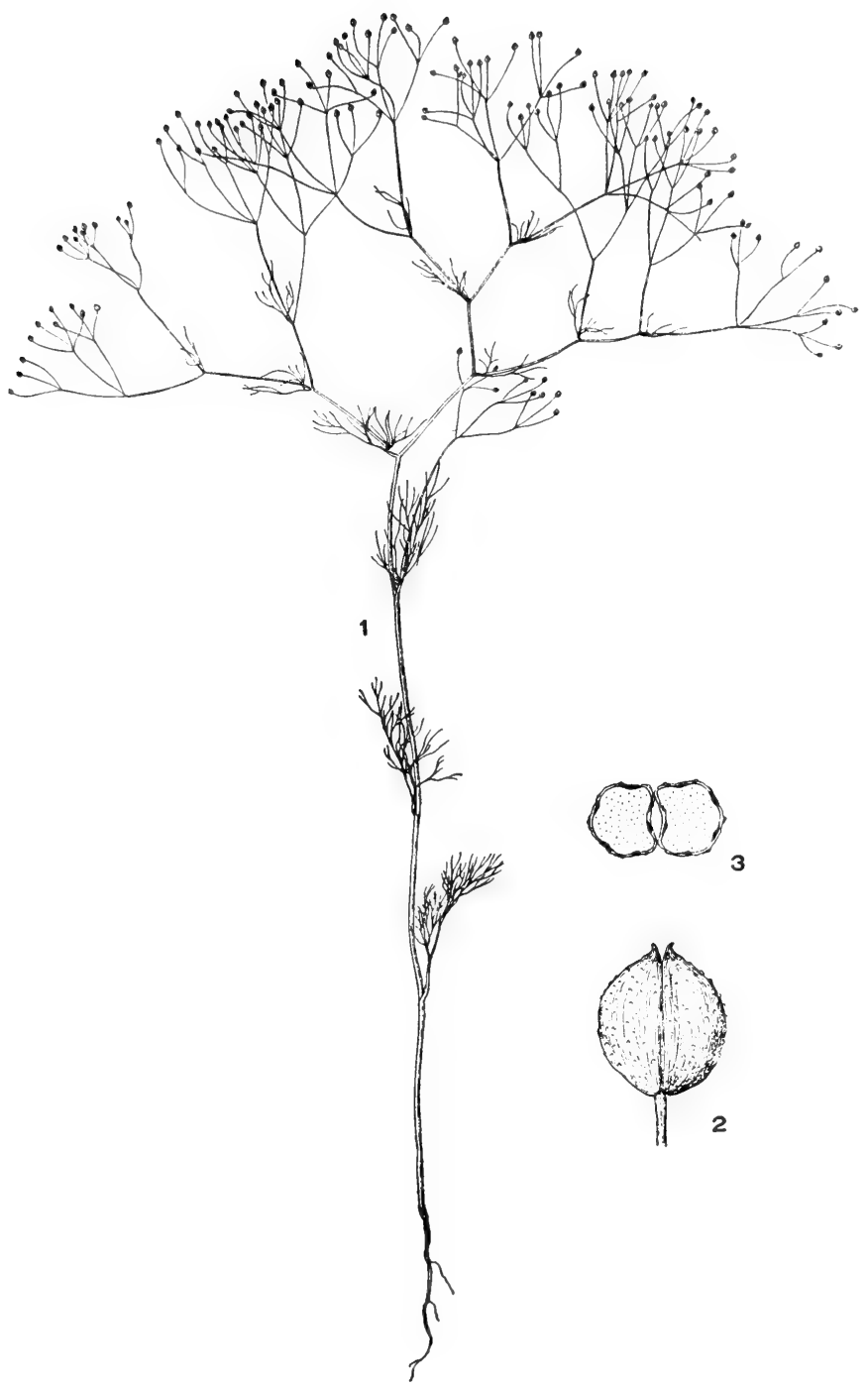

Fig. 576: Spermolepis divaricata: 1, plant, x $1 \frac{1}{2} ; 2$, fruit, side view, x $10 ; 3$ fruit, transverse section, x 10. (From Mathias \& Constance in Lundell's Flora of Texas, Vol. 3, Pl. 46). 


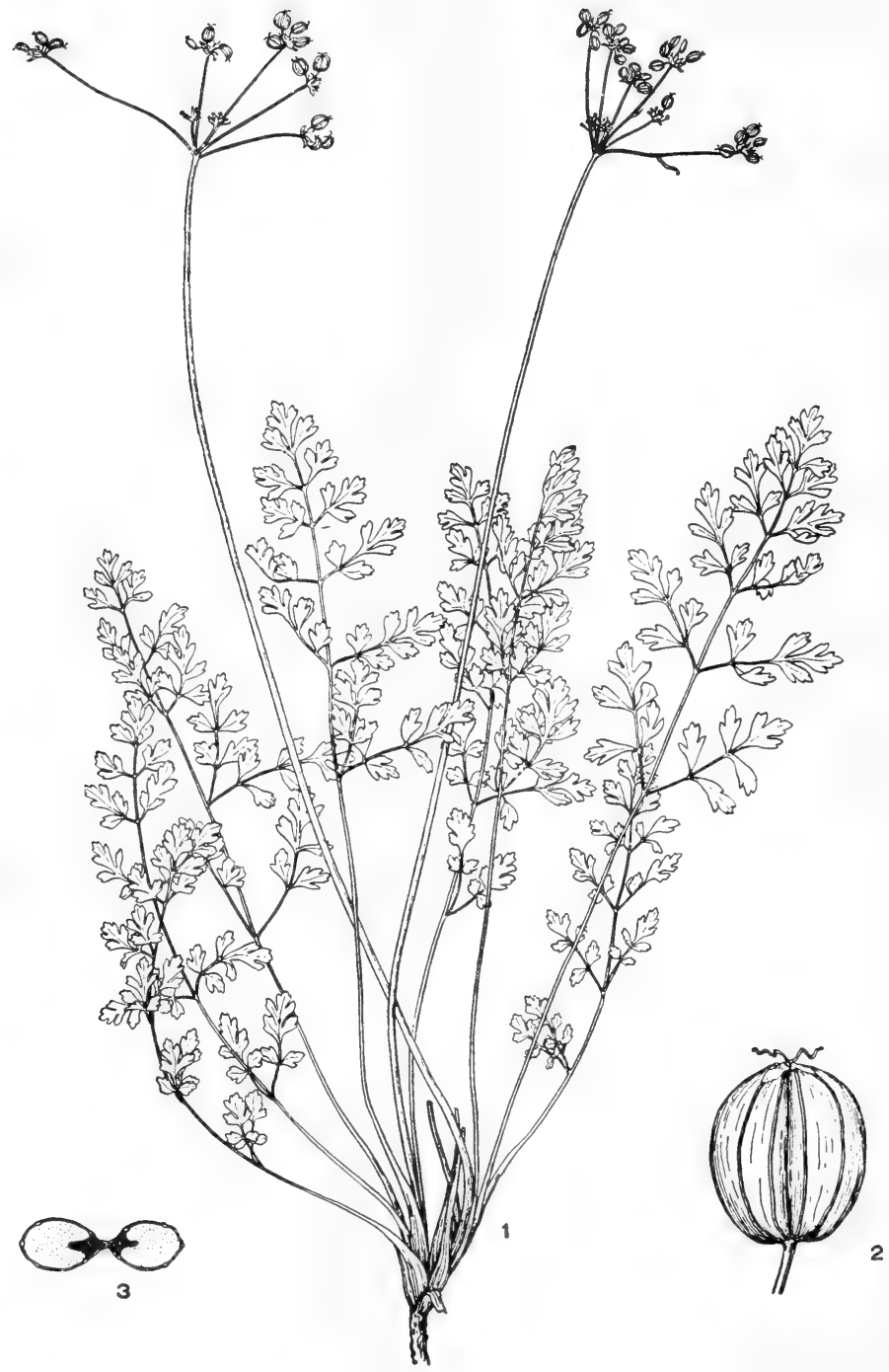

Fig. 577: Tauschia texana: 1 , plant, $\mathrm{x} 1 / 2 ; 2$, fruit, side view, $\mathrm{x} 6 ; 3$, fruit, transverse section, x 6. (From Mathias \& Constance in Lundell's Flora of Texas, Vol. 3, Pl. 35). 


\section{Ammoselinum Butleri (Wats.) Coult. \& Rose. Fig. 578.}

Annual from slender taproot, plant branching from the base, 4-5 $(-12) \mathrm{cm}$. high; leaves oblong, to $25 \mathrm{~mm}$. long and $15 \mathrm{~mm}$. wide, biternate or ternate-pinnate, ultimate divisions of leaves linear, obtuse, mucronulate, glabrous; inflorescence of compound umbels, umbels sessile in the axils; involucre lacking; involucel of a few foliaceous bractlets, shorter than the pedicels; rays 2 to 6 , unequal, to $2 \mathrm{~cm}$. long to obsolete; pedicels 1 to 10 , unequal, $1-6 \mathrm{~mm}$. long; flowers white, the calyx teeth obsolete, the stylopodium low conic; carpophore 2-cleft at the apex; fruit ovoid, compressed laterally, $2.5-3 \mathrm{~mm}$. long, $1-1.5 \mathrm{~mm}$. broad, glabrous to sparsely roughened with callous teeth, the subacute ribs prominent, the lateral ribs of the two mericarps closely contiguous and appearing to form a single broad rib; oil tubes solitary in the intervals and 2 on the commissure, the seed face plane or nearly so.

Principally in bottomlands and moist or wet woodlands along rivers in s.e. Okla. (Waterfall) and in Tex. in the Timber Belt and the Blackland and Coastal prairies, Mar.-Apr.; also Ark.

\section{Cryptotaenia DC. Honewort. Wild Chervil}

A chiefly circumboreal genus of about 6 species.

\section{Cryptotaenia canadensis (L.) DC.}

Plant slender, erect, caulescent, branching, glabrous, herbaceous, perennial from slender fascicled roots, 3-9 dm. high; leaves ternate, oblong-ovate, to $13 \mathrm{~cm}$. long and $15 \mathrm{~cm}$. wide; leaflets oblong-lanceolate to obovate, to $13 \mathrm{~cm}$. long and $8 \mathrm{~cm}$. wide, short-acuminate at the apex, cuneate at the base, closely and doubly serrate or occasionally deeply 2- or 3-lobed; upper cauline leaves reduced to lanceolate dentate bracts; inflorescence of compound umbels, the peduncles terminal and lateral, usually paniculate; involucre and involucel lacking or of few inconspicuous bracts or bractlets; rays 2 to 7 , unequal, ascending, $1-6 \mathrm{~cm}$. long, the 2 to 10 unequal pedicels ascending and to $35 \mathrm{~mm}$. long; flowers white, the calyx teeth obsolete or minute, the styles erect or reflexed, the stylopodium slender-conic; carpophore divided to the base; fruit linear-oblong, compressed laterally, $3.5-8 \mathrm{~mm}$. long, $1.5-3 \mathrm{~mm}$. broad, glabrous, the filiform obtuse ribs subequal and conspicuous; oil tubes 1 to 4 in the intervals and 2 on the commissure, the seed face plane. Deringia canadensis (L.) O. Ktze.

In moist woodland and in wet mud at edge of stream in woods in Okla. (Murray and Adair cos.) and in Tex. in the Timber Belt., May; from e. Can., s. to Ga., w. to Man., Neb. and Tex.; also Japan and s. China.

\section{Osmorhiza Raf. Sweet Cicely}

A genus of 11 species of East Asia and eastern North America, and of western North America to South America.

\section{Osmorhiza longistylis (Torr.) DC. ANISE-ROot. Fig. 579.}

Plant rather stout, 6-10 dm. high, villous or hirsutulous; leaves orbicular, 8-25 $\mathrm{cm}$. long, biternate or ternate-pinnate; leaflets ovate to oblong-lanceolate, acute, coarsely serrate, incised or pinnately lobed toward the base, hirsutulous especially on the veins and margins; peduncles $5-13 \mathrm{~cm}$. long; involucre of 1 to several linear or lanceolate foliaceous, ciliate, sharply reflexed bracts to $15 \mathrm{~mm}$. long; rays 3 to 6 , spreading-ascending, $1.5-5 \mathrm{~cm}$. long; pedicels spreading-ascending, 5-8 $\mathrm{mm}$. long, flowers white, the stylopodium high-conic; carpophore cleft about one third of its length; fruit oblong-fusiform, 15-20 mm. long, acute at the apex, caudate at the base, the appendages $4-6 \mathrm{~mm}$. long, sparingly bristly on the ribs. 


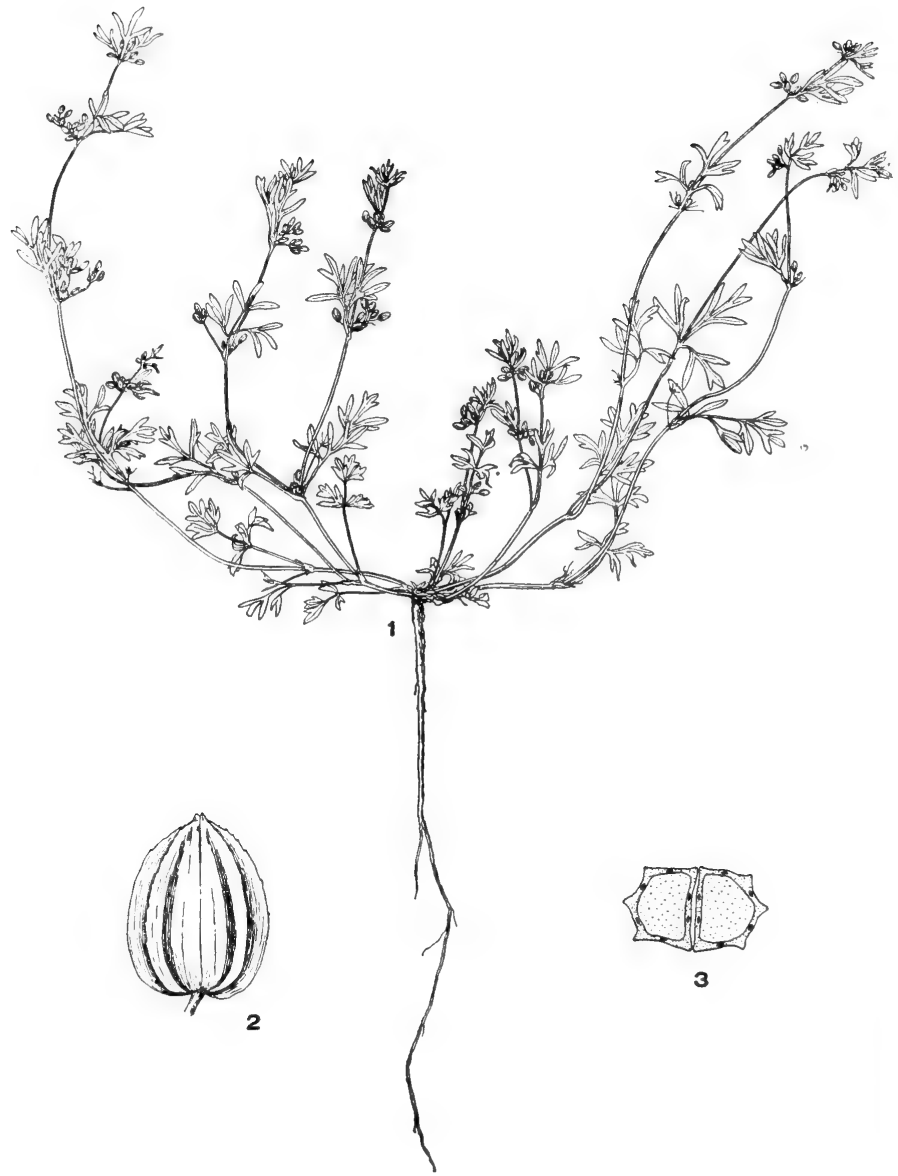

Fig. 578: Ammoselinum Butleri: 1, plant, x 3/4; 2, fruit, side view, x $12 ; 3$, fruit, transverse section, x 12. (From Mathias \& Constance in Lundell's Flora of Texas, Vol. 3, Pl. 44). 


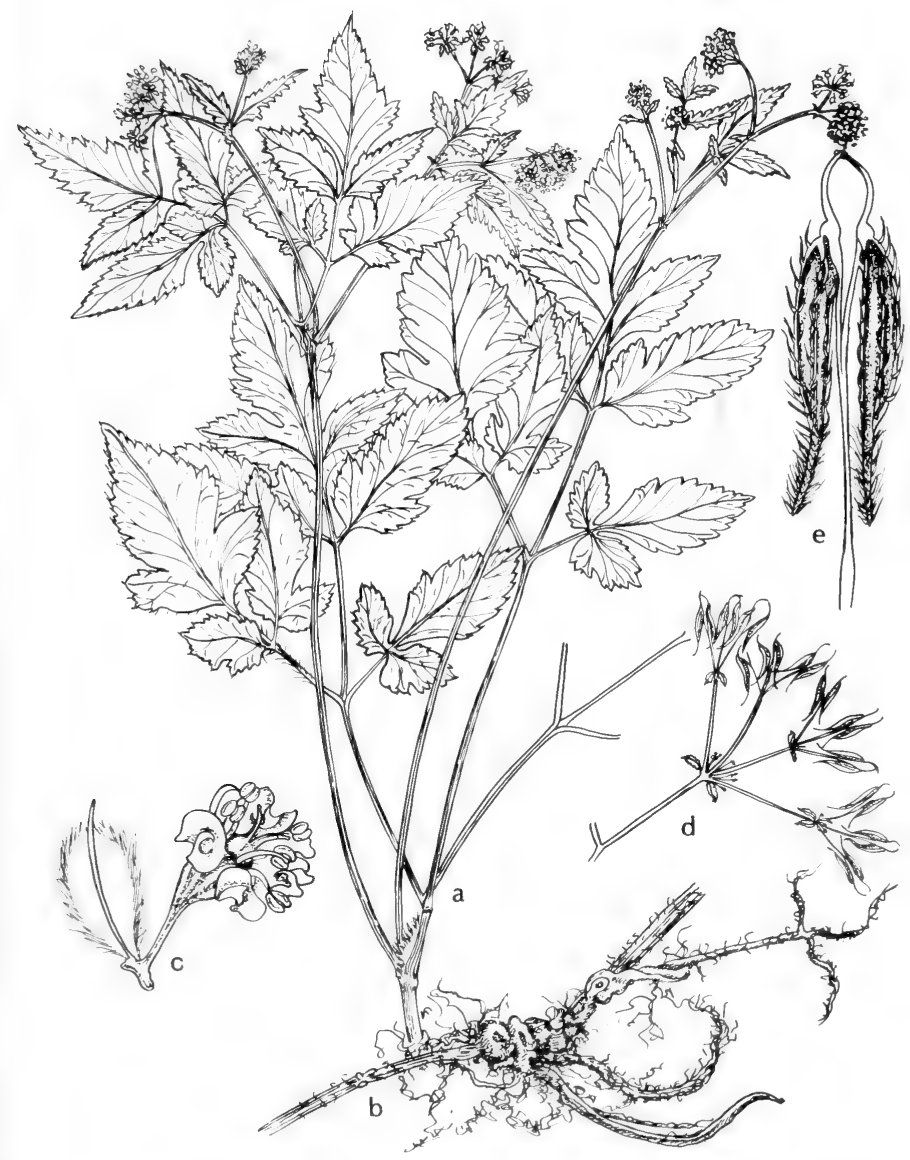

Fig. 579: Osmorhiza longistylis: a, top of plant, $\mathrm{x}{ }^{1} / 2 ; \mathrm{b}$, basal part of plant, $\mathrm{x} 1 \frac{1}{2}$; c, flower with one bractlet, $\mathrm{x} 5$; d, young fruit, $\mathrm{x} 2 \frac{1}{2}$; e, mature fruit showing the 2 mericarps, x $2^{1}$. (V. F.). 
Along streams and wet meadows in Okla. (the var. villicaulis) and Tex. in the Blackland Prairies and perhaps in the Timber Belt, N. M. (Colfax Co.), rare; from e. Can., s. to Ala. and Tex., w. to Alta., Colo. and N. M.

\section{Caucalis L.}

A genus of about 5 species, native to Asia, the Mediterranean region and North America and Central America.

\section{Caucalis microcarpa $H$. \& A.}

Slender annual 1-4 dm. tall, simple or branched especially above, more or less spreading-hirsute throughout; leaves chiefly cauline, the blade mostly $2-6 \mathrm{~cm}$. long and $2-5 \mathrm{~cm}$. wide, pinnately dissected into small, narrow ultimate segments; inflorescence of compound umbels; involucre of several fairly well-developed, scarcely modified leaves; rays of the umbel 1 to 9 , ascending, 1-8 cm. long; involucel of several pinnatifid to entire bractlets; pedicels markedly unequal; flowers white; calyx teeth evident; petals cuneate or obovate, with a slender inflexed tip; styles short, the stylopodium thick and conic; fruit oblong, 3-7 $\mathrm{mm}$. long, beset with uncinate prickles along the ribs, those of alternate ribs larger and tending to be confluent at the base.

Along streams and on open vernally wet slopes in Ariz. (Coconino, Mohave, Gila, Pima and Santa Cruz cos.) Apr.-June; Ida. to B.C. s. to Ariz. and Baja Calif.

\section{Trepocarpus DC.}

A monotypic genus of the southern United States.

\section{Trepocarpus Aethusae Nutt. Fig. 580.}

Plant slender, erect, 3-5.5 dm. high, caulescent, simple or branching, glabrous, herbaceous, annual from slender taproots; leaves pinnately decompound, $8-10 \mathrm{~cm}$. long, the short divisions linear and acute; cauline leaves little reduced upward; infiorescence of compound umbels; peduncles to $95 \mathrm{~mm}$. long, lateral and opposite the leaves; involucre of 1 to several foliaceous entire or divided bracts to $15 \mathrm{~mm}$. long; involucel of bractlets (3-8 $\mathrm{mm}$. long) like the bracts; rays 2 to 4 , spreading, to $15 \mathrm{~mm}$. long, the 2 to 8 pedicels very short; flowers white, the calyx teeth linear and unequal, the stylopodium conic; carpophore divided to the base; fruit oblonglinear, $8-10 \mathrm{~mm}$. long, slightly compressed laterally, glabrous, the primary ribs obsolete but 4 secondary ribs and the face of the commissure prominently corky; oil tubes small, solitary under the secondary ribs and 2 on the commissure, more or less imbedded in the seed and adhering to it, the seed face plane or slightly concave.

Chiefly on river bottoms and terraces in wet ditches and ponds, and marshmeadows, in Okla. (McCurtain and Le Flore cos.) and in Tex. in the Timber Belt and Blackland and Coastal prairies, Apr.-June; from Tex., n. to Ark. and e. to S.C.

\section{Chaerophyllum L. Chervil}

Plants erect or spreading, caulescent, branching, glabrous or pubescent, herbaceous, annual or biennial from taproots or tubers; leaves ternate-pinnately decompound, the ultimate divisions or lobes small; inflorescence of compound umbels, the peduncles terminal and axillary or frequently obsolete; involucre usually lacking; involucel of numerous conspicuous bractlets that are longer or shorter than the pedicels and reflexed or spreading in fruit; rays few, spreading-ascending, the pedicels spreading; flowers white (rarely red or yellow), the calyx teeth obsolete, the stylopodium conic; carpophore 2-cleft part-way to the base; fruit linear to 


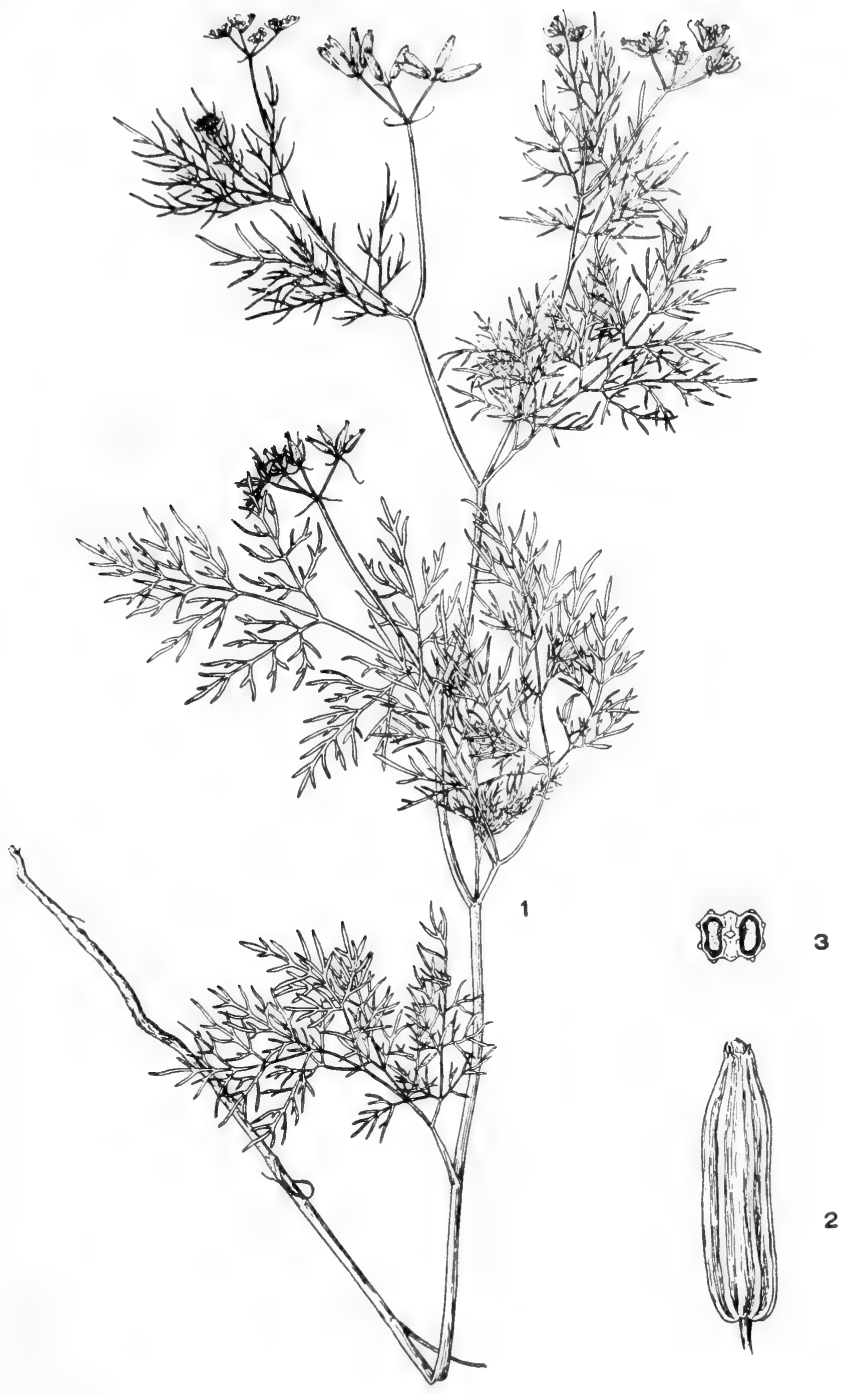

Fig. 580: Trepocarpus Aethusae: 1, plant, x 1/2; 2, fruit, side view, x 4; 3, fruit, transverse section, x 4. (From Mathias \& Constance in Lundell's Flora of Texas, Vol. 3, PI. 43). 


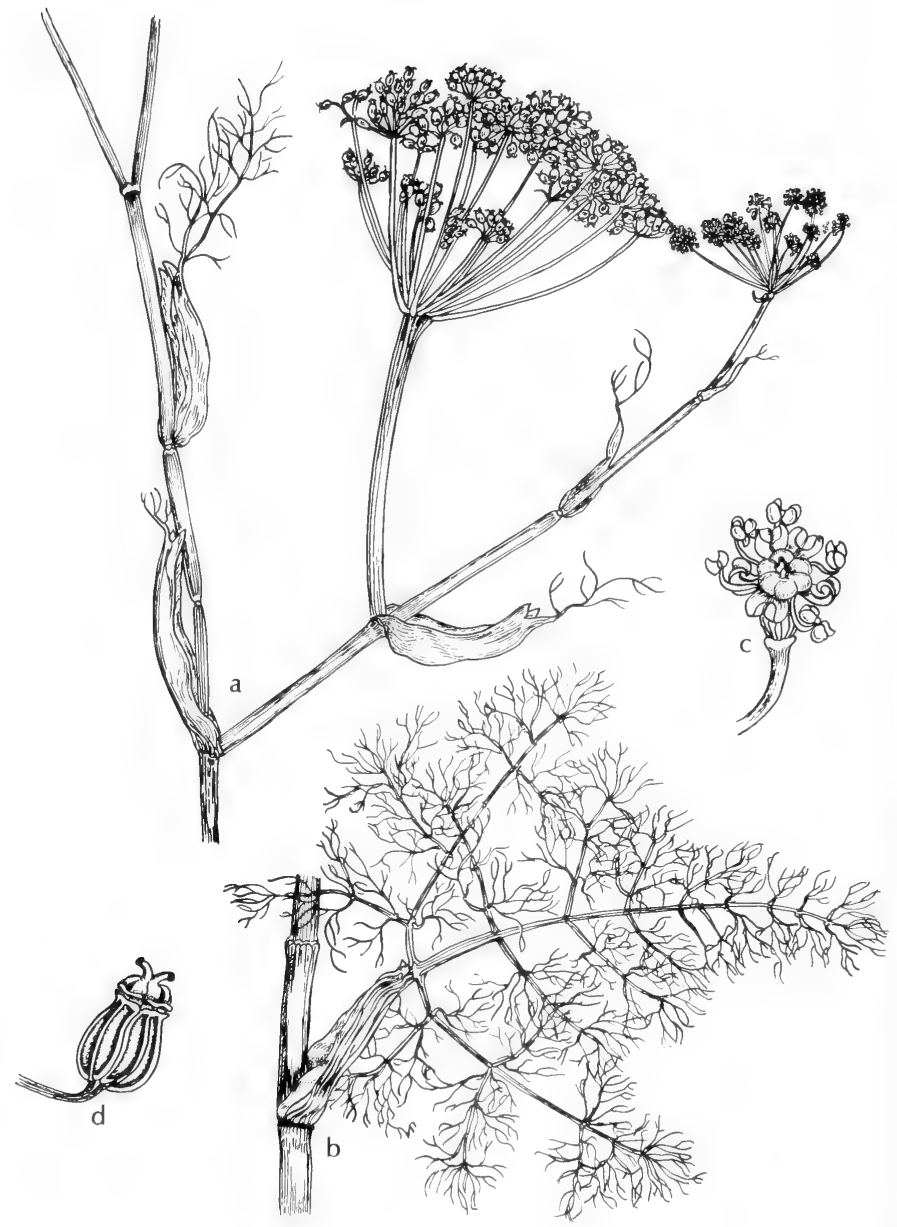

Fig. 581: Foeniculum vulgare: a, part of top of plant, $\mathrm{x} \frac{1}{2}$; $\mathrm{b}$, leaf from central part of stem, $x \frac{1}{2} ;$ c, flower, $x 5$; d, fruit, $x 5$. (V. F.). 
narrowly oblong, beaked or beakless, often narrowed toward the apex, rounded or narrowed toward the base, compressed laterally, the prominent ribs unwinged and narrower or broader than the intervals; oil tubes small, usually solitary in the intervals and 2 on the commissure, the seed face sulcate; each rib with a large group of strengthening cells.

A circumboreal genus of about 40 species, chiefly Eurasian.

1. Fruit elliptic to oblong, broadest at or near the middle; ribs narrower than the intervals

1. C. procumbens.

1. Fruit lanceolate, broadest distinctly below the middle; ribs as wide as the intervals or contiguous (2)

2(1). Ovaries and fruits glabrous.

2. C. Tainturieri var. Tainturieri.

2. Ovaries and fruits conspicuously pubescent......2. C. Tainturieri var. dasycarpum.

\section{Chaerophyllum procumbens (L.) Crantz.}

Stems spreading, often weak, usually branched from the base, 2-6 dm. long, glabrous or sparsely pubescent; leaf segments oblong to ovate, glabrous beneath or with a few widely scattered hairs; primary rays 1 to 3 ; pedicels 2 to 6 , at anthesis very short, at maturity to $1 \mathrm{~cm}$. long, filiform; fruit elliptic or oblong, broadest at or near the middle, 5.5-10 mm. long, a fourth to a third as wide, convexly narrowed to the summit; ribs slender, narrower than the intervals.

Moist or wet woods, alluvial soil along streams and in valleys, glades and thickets, Okla. (Waterfall) ; N.Y. to s. Mich., Ia., and Kan., s. to Ga., Ark. and Okla.

\section{Chaerophyllum Tainturieri Hook var. Tainturieri.}

Plant erect, 1.5-9 dm. high, annual, the stems solitary and usually branching near the base, sparsely hispid or hispidulous above and densely retrorsely hispid beneath to glabrate; leaves oblong to ovate-oblong, to $12 \mathrm{~cm}$. long and $10 \mathrm{~cm}$. wide, ternate-pinnately dissected, the ultimate divisions distinct or more or less confluent, linear to ovate, obtuse to acute, glabrous to more or less hispid; peduncles usually obsolete; involucel of several conspicuous ovate rounded to acute ciliate-margined bractlets usually longer than the pedicels and spreading or reflexed in fruit; rays 1 to 5 (usually about 3 ), to $75 \mathrm{~mm}$. long; pedicels 3 to 20 , to $1 \mathrm{~cm}$. long; fruit narrowly oblong, beaked or narrowed toward the apex, rounded to narrowed toward the base, 4-8 $\mathrm{mm}$. long, $1.5-2 \mathrm{~mm}$. broad, the ribs narrower to much broader than the intervals. C. texanum Coult. \& Rose.

In prairies, wet woodlands and alluvial thickets, widespread in Okla. (Waterfall) and in the e. half of Tex., Mar.-May; from Va., s. to Fla., w. to Kan., Mo., Tex. and Ariz.

Var. dasycarpum Wats. Similar to var. Tainturieri in vegetative characters but the ovaries and fruits are conspicuously pubescent. With the typical phase chiefly in Okla. (Waterfall) and the e. half of Tex., Mar.-May; from Tex. e. to Ala. and n. to Mo.

\section{Foeniculum Adans. Fennel}

A genus of about 5 species, chiefly of the Mediterranean region.

\section{Foeniculum vulgare Mill. CoMmon FEnNEL. Fig. 581.}

Plant rather stout, erect, branching, glabrous and glaucous, with a strong anise odor, perennial or biennial from taproots, 9-21 dm. high; leaves ovate to ovatetriangular, $3 \mathrm{dm}$. long, $4 \mathrm{dm}$. wide, pinnately decompound, dark-green, the ultimate divisions filiform; inflorescence of compound umbels; peduncles terminal and axillary, 15-65 mm. long; involucre and involucel lacking; rays 15 to 40 , spreadingascending in flower, ascending to suberect in fruit, somewhat unequal, $1-6.5 \mathrm{~cm}$. long; pedicels several, spreading, 2-10 mm. long, subequal; flowers yellow, the 
calyx teeth obsolete, the stylopodium conic; carpophore divided to the base; fruit 3.5-4 mm. long, 1.5-2 mm. broad, oblong, slightly compressed laterally, glabrous, the prominent ribs acute or obtuse; oil tubes solitary in the intervals and 2 on the commissure, the seed face plane or slightly concave.

Introd. in marshes and low areas in coastal and s. Tex., Mar.-May; a Medit. species that is adv. throughout the W. Hemis.

\section{Zixia $\mathrm{KoCH}$}

A genus of about 4 species, primarily of eastern United States and adjacent Canada, but extending to the Pacific Northwest.

\section{Zizia aurea (L.) Koch. Golden Alexanders.}

Erect caulescent usually branching perennial from fascicled roots, 4-8 dm. high; basal leaves petiolate, ovate to orbicular, to $1 \mathrm{dm}$. long and $12 \mathrm{~cm}$. wide, biternate or the middle leaflet pinnatifid; leaflets ovate to lanceolate, distinct, sharply serrate; cauline leaves like the basal, becoming narrowly lanceolate and confluent upwards; inflorescences of compound umbels; peduncles $5-15 \mathrm{~cm}$. long; involucre lacking; involucel of a few inconspicuous linear acute bractlets $1-3 \mathrm{~mm}$. long, shorter than or equaling the pedicels; rays 10 to 15 , spreading-ascending, unequal, $1-3.5 \mathrm{~cm}$. long; pedicels 2-3 mm. long; the central flower of each umbellet sessile or subsessile; flowers yellow; calyx teeth prominent; stylopodium lacking; fruit oblongovoid, 2-4 mm. long, 1.5-2 mm. broad, compressed laterally, the ribs filiform; oil tubes solitary in the intervals and 2 on the commissure; seed face slightly concave.

In wet sandy woodlands and sandy-clay floodplains in Okla. (Waterfall) and the e. third of Tex., Apr.-Aug.; from e. Can., s. to Fla., w. to Sask., Mont. and Tex.

Zizia aptera (Gray) Fern., with leaflets of stem leaves not more than 3, occurs in Oklahoma, but it is usually in less moist areas than the habitat of $Z$. aurea.

\section{Apium L. Celery}

Plants slender or stout, erect, ascending or prostrate, caulescent (usually), branching, herbaceous, glabrous, annual, biennial or a somewhat woody-based perennial from taproots or creeping rootstocks rooting at the nodes; leaves simply pinnate to ternate-pinnately decompound; inflorescence of compound (rarely simple) umbels, the peduncles lateral and terminal or some umbels sessile; involucre and involucel lacking to conspicuous; rays usually few, spreading-ascending, the pedicels spreading to ascending; flowers white or greenish, the calyx teeth minute or obsolete, the stylopodium short-conic to depressed; carpophore entire, shortly bifid or more or less deeply 2-cleft; fruit oblong-oval to orbicular or ellipsoid, compressed laterally and somewhat constricted at the commissure, glabrous or rarely somewhat setulose, the prominent filiform ribs subequal and obtuse; oil tubes solitary in the intervals and 2 on the commissure, the seed face plane.

A cosmopolitan genus of about 30 species.

1. Plant annual; leaves pinnately or ternate-pinnately decompound, the leaflets filiform to linear .............................................. 1. A. leptophyllum.

1. Plant perennial or biennial; leaves pinnate, the leaflets orbicular to ovate

2. A. graveolens.

\section{Apium leptophyllum (Pers.) F. v. Muell. Fig. 582.}

Plant annual, alternately branched above, 5-60 cm. high; leaves oblong-ovate, to $10 \mathrm{~cm}$. long and $8 \mathrm{~cm}$. wide, 3- or 4-pinnately decompound, the leaflets linear to filiform; umbels simple or compound, sessile or pedunculate, the peduncles to 2 $\mathrm{cm}$. long; involucre and involucel lacking; rays 3 to $5,1-2.2 \mathrm{~cm}$. long; pedicels 2-8 mm. long; calyx teeth inconspicuous; carpophore shortly 2-cleft; fruit ovoid, 1.2-3 mm. long, 1.5-2 mm. broad, glabrous. A pium ammi (Jacq.) Urban. 


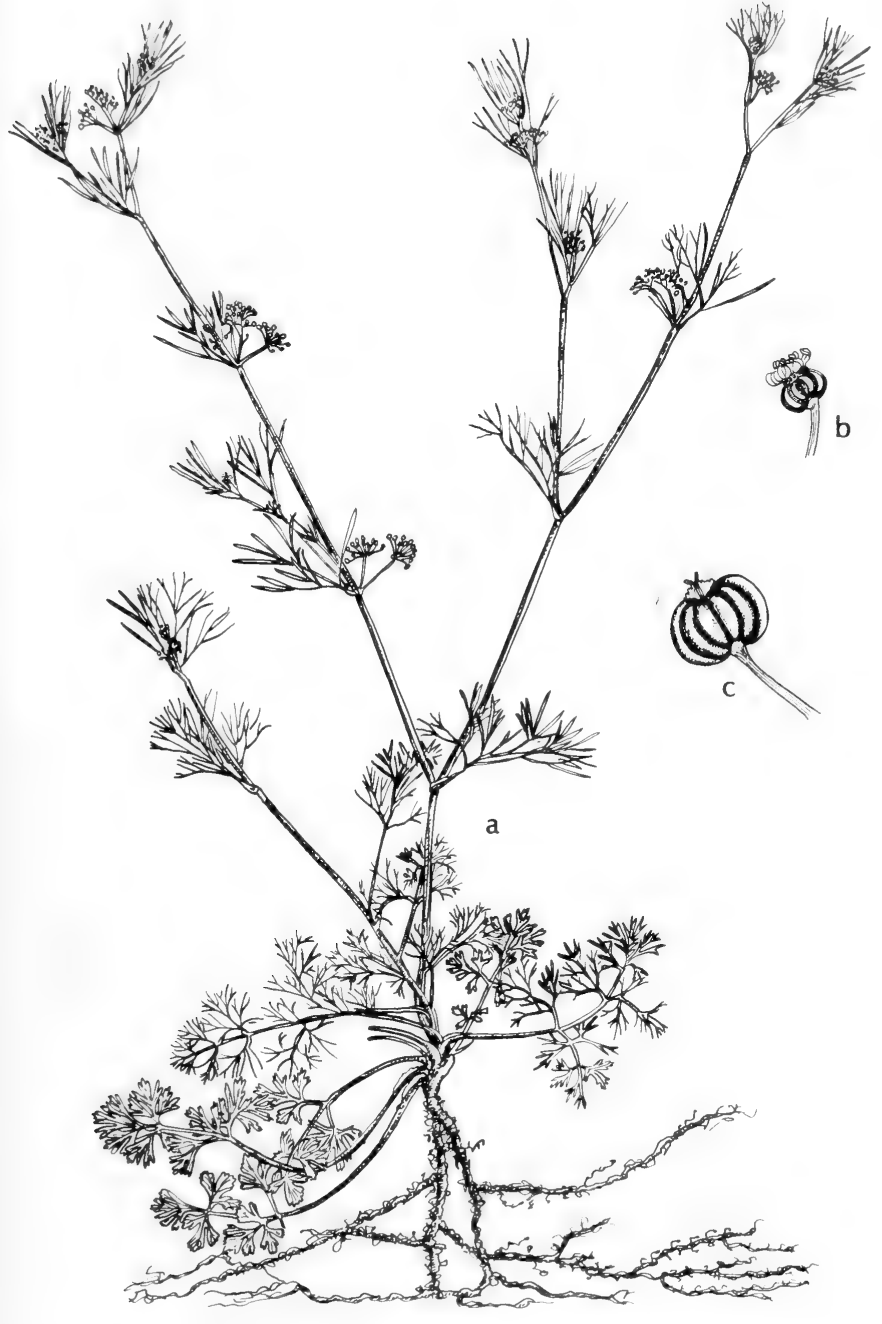

Fig. 582: Apium leptophyllum: a, habit, x $1 \frac{1}{2}$; b, flower, x 5; c, fruit, x 5. (V. F.). 


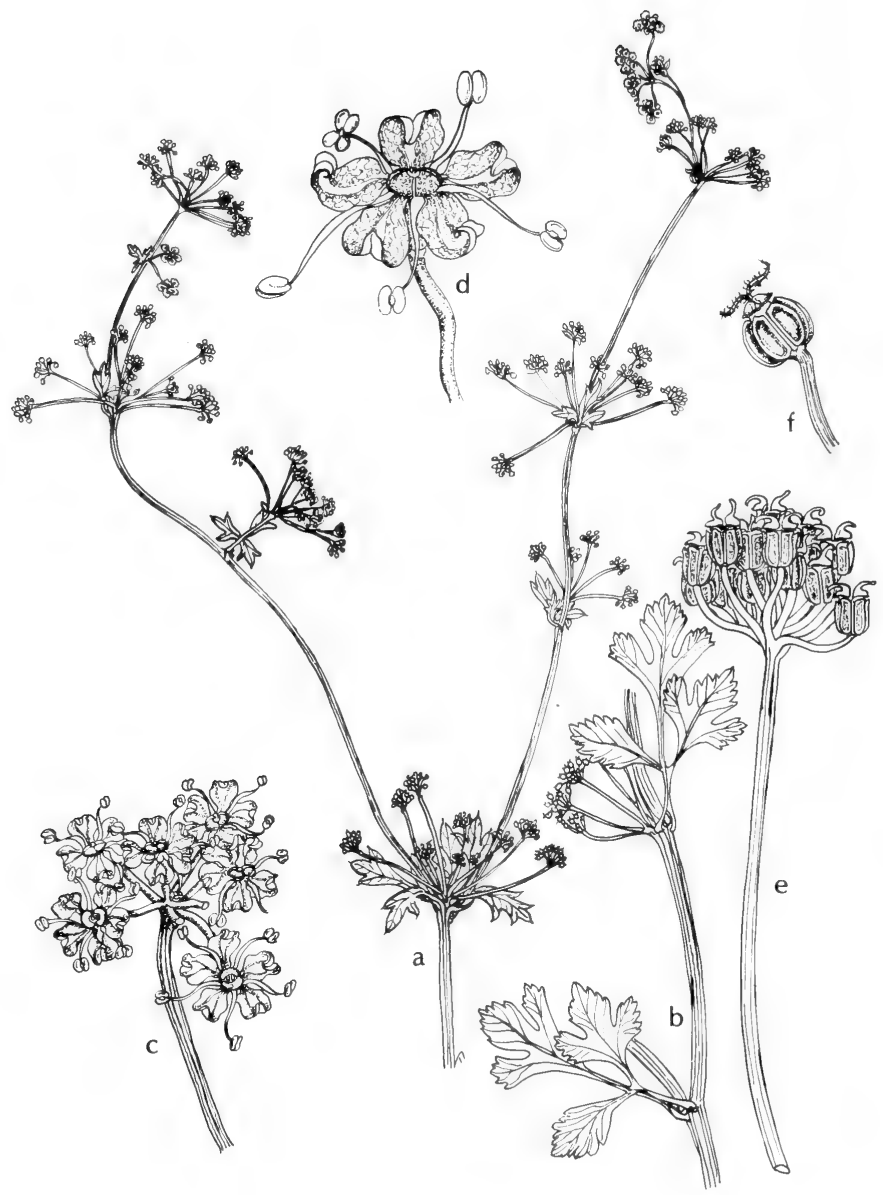

Fig. 583: Apium graveolens: a, top of plant, $\mathrm{x} 1 \frac{1}{2} ; \mathrm{b}$, central part of stem, $\mathrm{x} 1 / 2$; c, umbellet in flower, $\times 5$; , flower, $x 10$; e, umbellet in fruit, $x 5 ; \mathrm{f}$, mature fruit, $x 5$. (V. F.). 
Widely distributed in moist or wet soil in Okla. (McCurtain Co.), Tex. in the Coastal and Blackland prairies and the Rio Grande Plains, and Ariz. (Cochise, Pima and Maricopa cos.), Mar.-June from s. U.S. and W.I., s. to S.A.; a pantrop. weed.

\section{Apium graveolens L. Wild celery. Fig. 583.}

Plant perennial, erect or ascending from a taproot, not rooting at the nodes, $5-15 \mathrm{dm}$. high; leaves oblong to obovate, to $18 \mathrm{~cm}$. long and $8 \mathrm{~cm}$. wide, pinnate with few pairs of ovate to suborbicular leaflets that are usually 3 -lobed to near the middle: cauline leaves frequently cuneate, sometimes laciniate; umbels sessile or short-pedunculate, the peduncles to $12 \mathrm{~mm}$. long; involucre and involucel lacking; rays 7 to 16 , to $25 \mathrm{~mm}$. long; pedicels $1-6 \mathrm{~mm}$. long; calyx teeth minute but evident; carpophore shortly bifid; fruit suborbicular to ellipsoid, about $1.5 \mathrm{~mm}$. long, 1.5-2 mm. broad. Celeri graveolens (L.) Britt.

A garden plant escaped from cultivation found in marshes and along streams and other wet places in Ariz. (Coconino to Cochise, Pinal and Yavapai cos.) and in Trans-Pecos Tex., June-July; a Euras. species widely adv. in the W. Hemis.

\section{Conium L.}

A genus of 2 species, one circumboreal in damp places, the other African.

\section{Conium maculatum L. Poison Hemlock. Fig. 584.}

Plant slender, erect, glabrous, 5-30 dm. high, biennial from stout taproots, the branching stems usually spotted; leaves broadly ovate, $1.5-3 \mathrm{dm}$. long, 5-30 cm. broad, pinnately decompound, the ultimate divisions pinnately incised; inflorescence a compound dichasium of compound umbels, the peduncles terminal and axillary; involucre of short ovate-acuminate bracts; involucel of numerous bractlets like the bracts, with a conspicuous midrib, shorter than the pedicels; rays numerous, subequal, 15-25 mm. long, spreading-ascending; pedicels spreading, 4-6 mm. long; flowers white, the calyx teeth obsolete, the stylopodium depressed-conic; carpophore entire; fruit broadly ovoid, 2-2.5 mm. long, about $2 \mathrm{~mm}$. broad, compressed laterally, glabrous, the prominent obtuse ribs undulate and crenate; oil tubes very small and numerous, irregular, the seed face deeply and narrowly sulcate.

Sporadically introd. in wet places in Okla. (Waterfall), in the s. half of Tex., N.M. (Lincoln and Otero cos.) and Ariz. (Yavapai, Greenlee and Graham cos.), May-Aug.; a Euras. species widely introd. throughout temp. regions in the world.

Fatally poisonous if eaten.

\section{Perideridia ReICHB.}

Slender or stout caulescent branching glabrous perennial herbs from tuberous or fusiform fascicled roots; leaves ternately, pinnately or ternate-pinnately compound, with linear divisions; umbels compound; involucre absent or of few to numerous entire bracts; involucel of usually scarious or colored bractlets; flowers white to pinkish; sepals evident; stylopodium conical or low-conical; fruit compressed laterally; ribs filiform; oil tubes 1 to 5 in the intervals, 2 to 8 on the commissure.

An American genus of nine species, two in our area.

1. Fruits orbicular to suborbicular, $2-3 \mathrm{~mm}$. long, the oil tubes solitary in the intervals; bractlets usually setaceous........................ P. Gairdneri.

1. Fruits oblong to ovoid, $2.5-3.5 \mathrm{~mm}$. long, the oil tubes 2 to 4 in the intervals; bractlets scarious or scarious-margined, often conspicuous 


\section{Perideridia Gairdneri (Hook. \& Arn.) Mathias.}

Plants slender, to $12 \mathrm{dm}$. high, from a solitary fusiform tuber or a small fascicle of tubers; leaf divisions to $15 \mathrm{~cm}$. long, entire or toothed; involucre absent or of one to several setaceous bracts; rays 8 to 20 , to $6 \mathrm{~cm}$. long; fruit $2-3 \mathrm{~mm}$. long.

Wet heavy soil, in Ariz. (Apache, Coconino and Navajo cos.) and N. M. (Socorro Co.); B. C., Wash., to s. Calif., e. to Alta. and N. M.; June-Aug.

\section{Perideridia Parishii (Coult. \& Rose) Nels. \& Macbr.}

Plants slender, to $8 \mathrm{dm}$. tall, from a solitary tuber or a fascicle of fusiform or ovoid tubers; leaves ternate, or sometimes simple or biternate, the leaflets to $10 \mathrm{~cm}$. long, the terminal often elongate; involucre usually absent; rays 8 to 15 , unequal, to $4 \mathrm{~cm}$. long; bractlets conspicuous, scarious or colored; fruit $2.5-3.5 \mathrm{~mm}$. long.

Usually in moist or wet meadows or moist soil in pine woods, in Ariz. (Coconino Co.); Calif., Nev. and n. Ariz.

\section{Berula HoFFM. WATER-PARSNIP}

A genus of two species, one circumboreal, the other African.

\section{Berula erecta (Huds.) Cov. Fig. 585.}

Plants slender, erect, stoloniferous, perennial from fascicled fibrous roots, 2-8 $\mathrm{dm}$. high; leaves narrowly oblong, to $3 \mathrm{dm}$. long and $1 \mathrm{dm}$. wide, pinnate; leaflets oblong, distinct, subentire to serrate or lobed, those of the submerged leaves decompound; cauline leaves reduced, the leaflets often linear; inflorescence of compound umbels; peduncles terminal and axillary, 2-8 cm. long; involucre of 6 to 8 linear to lanceolate unequal foliaceous scarious-margined entire to incisely toothed bracts, 5-15 mm. long; involucel of 4 to 8 linear to lanceolate acute entire bractlets, 1-5 $\mathrm{mm}$. long; rays 6 to 15 , subequal, spreading-ascending, 1-2 cm. long; pedicels 2-5 $\mathrm{mm}$. long; flowers white, the minute calyx teeth subulate, the stylopodium conic; carpophore divided to the base, the halves wholly adnate to the mericarps; fruit oval to orbicular, $1.5-2 \mathrm{~mm}$. long, compressed laterally, the filiform ribs obscure in the thick corky pericarp; oil tubes numerous about the seed, the seed face plane; strengthening cells lacking. B. pusilla (Nutt.) Fern.

In marshes, streams, seeping banks, edge of ponds and wet places in Okla. (Alfalfa, Woods and Major cos.), Tex. in the Blackland Prairies, Plains Country and Trans-Pecos, N. M. (widespread), Ariz. (Apache to Coconino and Yavapai, s. to Santa Cruz and Cochise cos.), May-Nov.; throughout the U.S. and adj. Can., s. to Guat,; also Eur. and the Medit region.

\section{Sium L. WATER-PARSNIP}

A chiefly circumboreal genus, containing perhaps a dozen species.

\section{Sium suave Walt. Fig. 586.}

Plant stout, perennial, 6-12 dm. high, the corrugated branching stems arising from fusiform fascicled roots; leaves oblong to ovate, to $25 \mathrm{~cm}$. long and $18 \mathrm{~cm}$. wide, pinnate or rarely simple and serrate and incised, the submerged leaves usually decompound; leaflets lanceolate to linear, 1-4 cm. long, 3-15 mm. wide, distinct, remote, the lower frequentiy obsolete, finely to coarsely serrate or incised; peduncles stout, 4-10 cm. long; involucre of 6 to 10 lanceolate or linear bracts 3-15 mm. long that are acute, entire or incised, unequal and reflexed; involucel of 4 to 8 linear-lanceolate bractlets $1-3 \mathrm{~mm}$. long, acute, entire; rays 10 to 20 , slender, subequal, 1.5-3 cm. long; pedicels 3-5 mm. long; flowers white; calyx teeth minute, the stylopodium usually depressed; the halves of the carpophore adnate to the mericarps; fruit oval to orbicular, 2-3 mm. long, 2-2.5 $\mathrm{mm}$. broad, slightly compressed laterally and constricted at the commissure, the ribs prominent, subequal, 


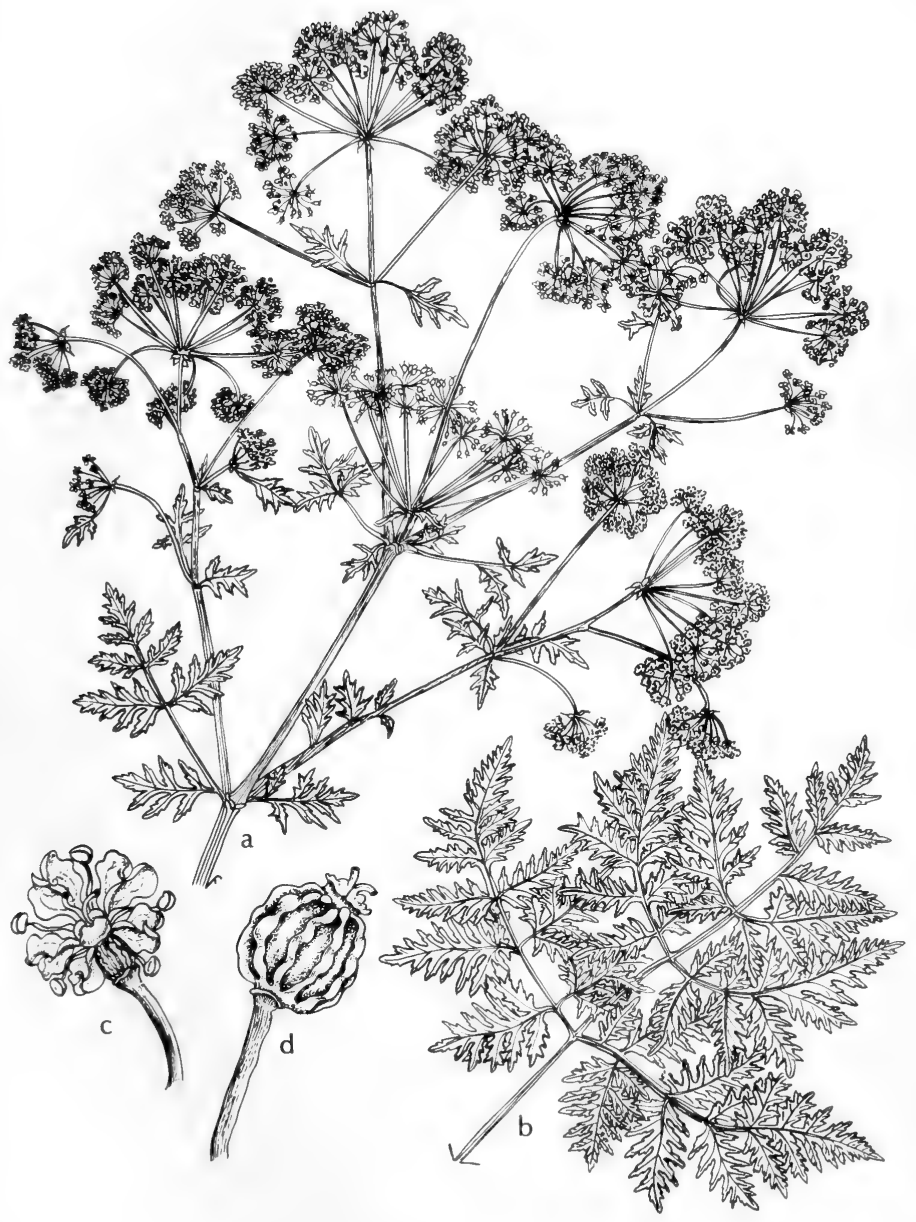

Fig. 584: Conium maculatum: a, upper part of plant, x $1 \frac{1}{2}$; b, leaf, x $1 \frac{1}{2}$; c, flower. x 5; d, fruit, x 5. (V. F.). 


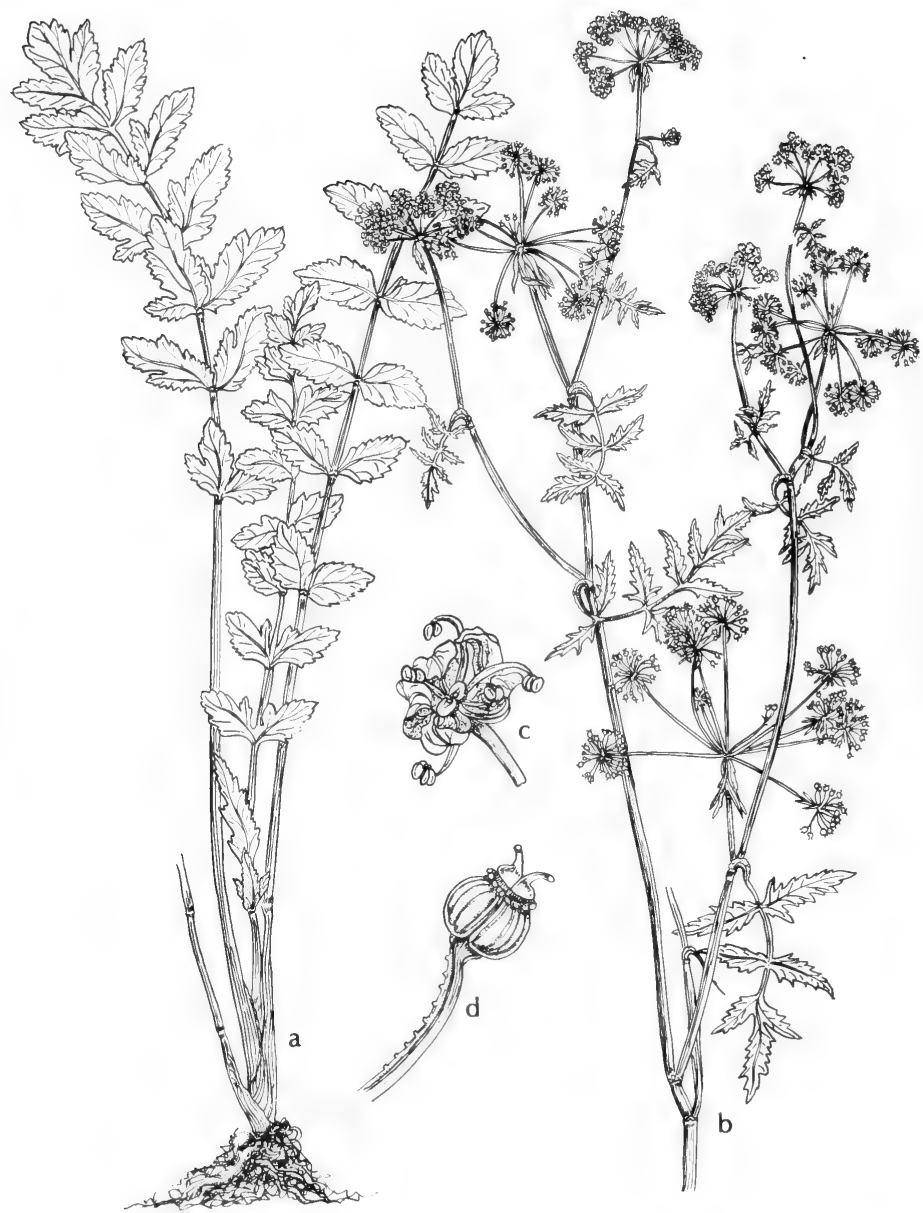

Fig. 585: Berula erecta: a, basal leaves, $\mathrm{x} 1 / 2$; b, top of plant, $\mathrm{x} 1 \frac{1}{2}$; $\mathrm{c}$, flower, $\mathrm{x} 5$; d, fruit, x 5. (V. F.). 
corky; oil tubes 1 to 3 in the intervals and 2 to 6 on the commissure, the seed face plane: prominent group of strengthening cells in the apex of each rib. Sium cicutaefolium Schrank.

In swamps and marshes and other wet places in Okla. (Comanche Co.), s.-cen. Tex. and Ariz. (Coconino Co.), May-Sept.; from Nfld,, s. to. S.C., w. to B.C. and Calif.

This species, which superficially resembles the deadly poisonous Cicuta maculata, may be distinguished from that species by its simply pinnate leaves and corrugated stems. The primary lateral veins also are directed to the teeth instead of the sinuses.

\section{Cicuta L. Water-Hemlock}

Plants stout or slender, erect, caulescent, branching, herbaceous, perennial from a tuberous base bearing fibrous to fleshy-tuberous roots; leaves 1- to 3-pinnate or ternate-pinnate, the leaflets serrate to incised; primary lateral veins of leaflets usually directed toward sinuses rather than teeth of the leaflets; inflorescence of compound umbels, the peduncles terminal and lateral, exceeding the leaves; involucre usually lacking; involucel of several narrow bractlets or rarely lacking; rays numerous, slender, spreading-ascending, the slender pedicels spreading; flowers white or greenish, the calyx teeth evident, the stylopodium depressed or low-conic; carpophore divided to the base, deciduous; fruit oval or ovoid to orbicular or ellipsoid, compressed laterally and constricted at the commissure or not constricted, the usually prominent ribs obtuse and corky; oil tubes solitary in the intervals and 2 on the commissure, the seed face plane to slightly concave.

A circumboreal genus of about 8 species, one Eurasian, the others American. These plants, abundant in wet places, are notable for being virulently poisonous to both man and animals. Although all parts of the plant of these species are poisonous, the roots and rootstocks are especially so, and the spotted cowbane ( $C$. maculata) is considered to be the most violently poisonous of any of the species in this genus. If a strong emetic followed by a purgative medicine is given to anyone known to have eaten any of the plant, recovery is very possible. The seeds of these plants are eaten by wildfowl without any apparent harmful effects.

1. Fruit not constricted at the commissure; lateral ribs much broader than the dorsals in surface display........................................ . C. maculata.

1. Fruit constricted at the commissure; lateral ribs about equaling the dorsals in surface display (2)

2(1). Oil tubes large; seed oily, evidently channeled under the oil tubes

2. C. mexicana.

2. Oil tubes small; seed less oily, terete or only slightly sulcate under the oil tubes

3. C. Douglasii.

1. Cicuta maculata L. Spotted cowbane, beaver-poison. Fig. 587.

Plant stout, from a usually erect tuberous base bearing fleshy or fleshy-tuberous roots as well as often some fibrous roots above (all of which are deadly poisonous to man and animals), $6-18 \mathrm{dm}$. high; leaves ovate, to $3 \mathrm{dm}$. long and $26 \mathrm{~cm}$. wide, 2 - to 3-pinnate; leaflets lanceolate, acute to acuminate, $2-12 \mathrm{~cm}$. long, 5-30 mm. wide, sharply and coarsely serrate or incised; peduncles $2-10 \mathrm{~cm}$. long; involucre of a few narrow bracts or lacking; involucel of several linear to lanceolate acute to acuminate scarious-margined bractlets, 2-5 mm. long, entire or denticulate, shorter than the flowers; rays unequal to subequal, 1.5-6 cm. long; pedicels $3-10 \mathrm{~mm}$. long; fruit oval to orbicular, 2-4 $\mathrm{mm}$. long, 2-3 mm. broad, not constricted at the commissure, the ribs low and corky, about as broad as the usually reddish-brown intervals, the lateral ribs of the two carpels closely contiguous and forming a broad flat 


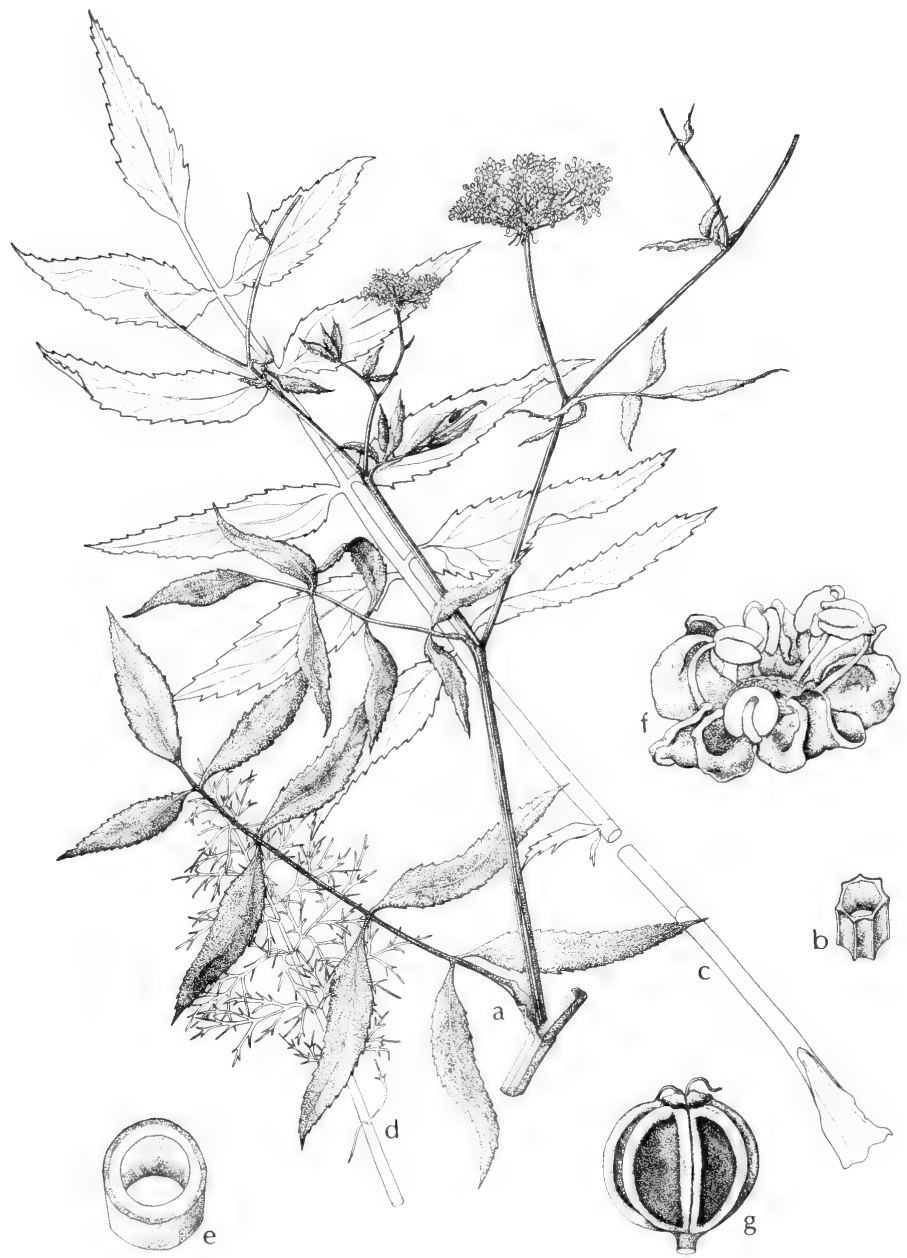

Fig. 586: Sium suave: a, top of plant, $x$ 1/3; b, section of stem, x 1; c, lower stem leaf, $x 1 / 3$; d, submersed leaf, x 1/3; e, section of petiole, x 2 ; f, flower, $x 15 ; \mathrm{g}$, fruit, $x 7$. (Courtesy of R. K. Godfrey). 


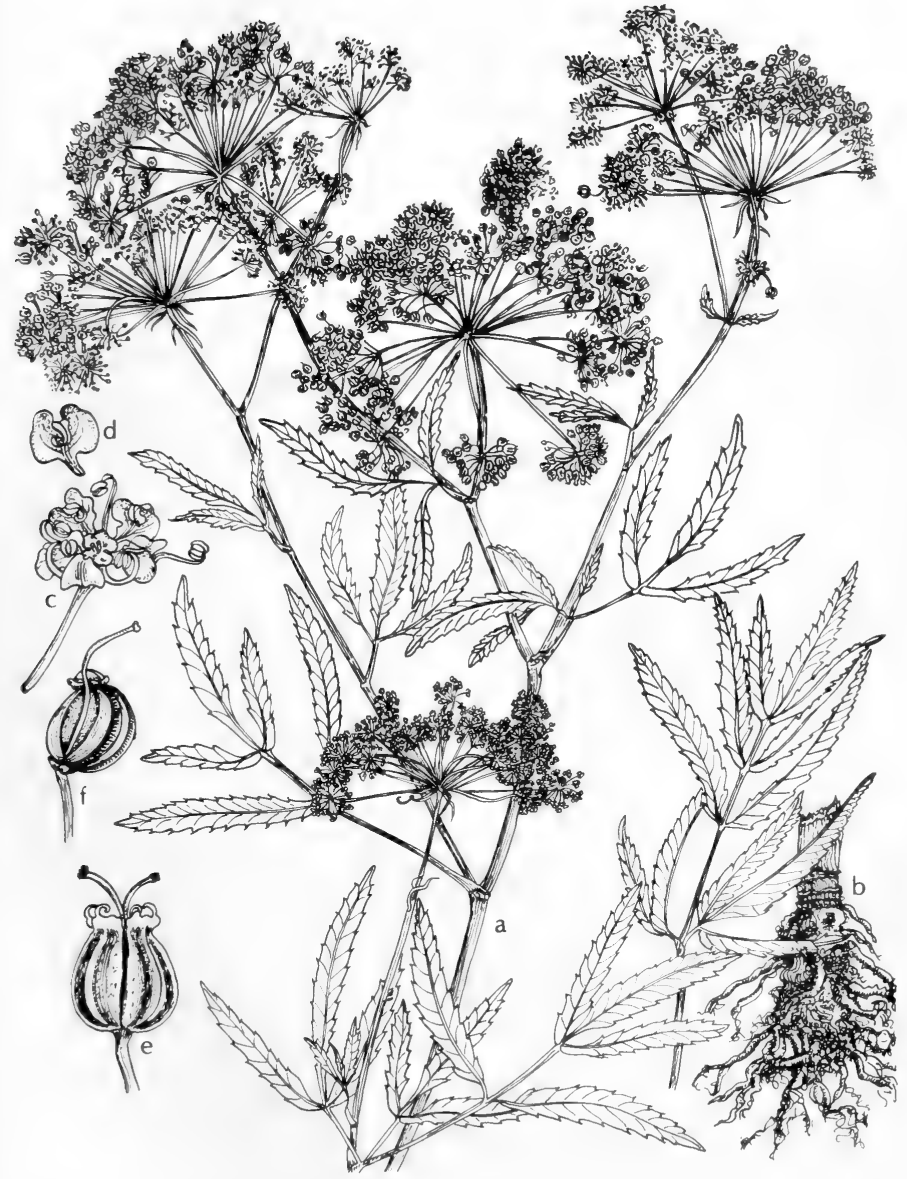

Fig. 587: Cicuta maculata: a, upper part of plant, $\mathrm{x} 1 \frac{1}{2} ; \mathrm{b}$, basal part of plant and basal leaf, $x 1 \frac{1}{2}$; c, flower, $x$ 5; d, petal, x 10 ; e, fruit, $x$ 5; f, one mericarp, x 5 . (V. F.). 
band and with much greater surface display than the dorsal ribs; oil tubes moderately large; seed not very oily, not sulcate or only very shallowly so under the tubes, the face plane to concave.

Along streams, in marshes and other wet places in Okla. (McCurtain, Adair, Murray and Washington cos.) and e., cen. and n. Tex., May-Sept.; throughout e. U.S. and Can., s. to Ga. and La., w. to the Dakotas and Tex.

\section{Cicuta mexicana Coult. \& Rose. Fig. 588.}

Plant stout, from a usually erect tuberous base bearing fleshy-tuberous roots, 9-24 dm. high; leaves ovate-deltoid, to $35 \mathrm{~cm}$. long, ternate-pinnate or 2-pinnate; leaflets oblong-lanceolate, $4-10 \mathrm{~cm}$. long, $1.5-4 \mathrm{~cm}$. wide, finely to coarsely serrate, thick and strongly reticulate; peduncles $5-9 \mathrm{~cm}$. long; involucre of 1 to several narrow bracts or lacking; involucel of several lanceolate to linear acute scariousmargined bractlets $2-5 \mathrm{~mm}$. long, shorter than or equalling the flowers; rays very unequal, 2-8 cm. long; pedicels $3-15 \mathrm{~mm}$. long; fruit orbicular or nearly so, 2-3 $\mathrm{mm}$. long, constricted at the commissure, the low ribs broad and corky, subequal in surface display, broader than the intervals, the lateral ribs of the two carpels separated by an interval; oil tubes large; seed very oily, deeply sulcate under the tubes, the face plane or concave. Cicuta Curtissii Coult. \& Rose.

In swamps and other wet places in e. third of Tex. and along the coast, MayOct.; from Middle Atl. U.S., s. to the Isthmus of Tehuantepec, Mex.

\section{Cicuta Douglasii (DC.) Coult. \& Rose.}

Stems stout, from a vertical or horizontal short or elongate tuberous base that bears fibrous or fleshy-fibrous roots, 6-20 dm. tall; leaves oblong to ovate in general outline; petioles 1-8 cm. long; blade $12-38 \mathrm{~cm}$. long, 7-22 cm. broad, 1 - to 3-pinnate; leaflets linear-lanceolate to ovate-lanceolate, $3-10 \mathrm{~cm}$. long, 6-35 mm. wide, remotely to coarsely serrate or incised; peduncles $5-15 \mathrm{~cm}$. long; involucre of 1 to several narrow bracts, or wanting; involucel of several ovate-lanceolate to linear acute to acuminate scarious-margined bractlets that are $2-15 \mathrm{~mm}$. long; rays 2-6 cm. long; pedicels 3-8 mm. long; fruit ovoid to orbicular, 2-4 mm. long, 2-3 $\mathrm{mm}$. broad, constricted at the commissure; ribs low, broad and corky, subequal in surface display, broader than the reddish-brown or homochromous intervals, the lateral ribs of the 2 carpels separated by intervals; oil tubes small; seeds not very oily, not sulcate under the tubes, the face plane. C. occidentalis Greene.

In ditches, fresh-water marshes, swamps, shallow standing water or flowing streams, in N.M. (rather widespread) and Ariz. (Apache, Navajo, Coconino and Greenlee cos.), June-Aug.; Mont. and Alas. to N.M., Ariz., Calif. and Chih.

\section{Lilaeopsis GREENE}

About a half dozen species of world-wide distribution.

\section{Lilaeopsis recurvata A.W.Hill. Fig. 589.}

Glabrous inconspicuous perennial; stems creeping and rooting in mud; leaves reduced to fistulose cylindric petioles that are transversely septate, elongate when growing in water; peduncles shorter than leaves; umbels simple; involucre of a few small bracts; calyx teeth minute; corolla white; stylopodium depressed; fruit subglobose or slightly compressed laterally, 2-2.5 mm. long, the lateral ribs very thick and corky, the dorsal ribs filiform, the oil tubes solitary in the intervals ( 2 on the commissure), the seed face somewhat convex.

On mud in or about streams, ponds and lakes in s. Ariz. (Cochise, Santa Cruz, Pima and Pinal cos.), July-Aug.; known only from s. Ariz. 


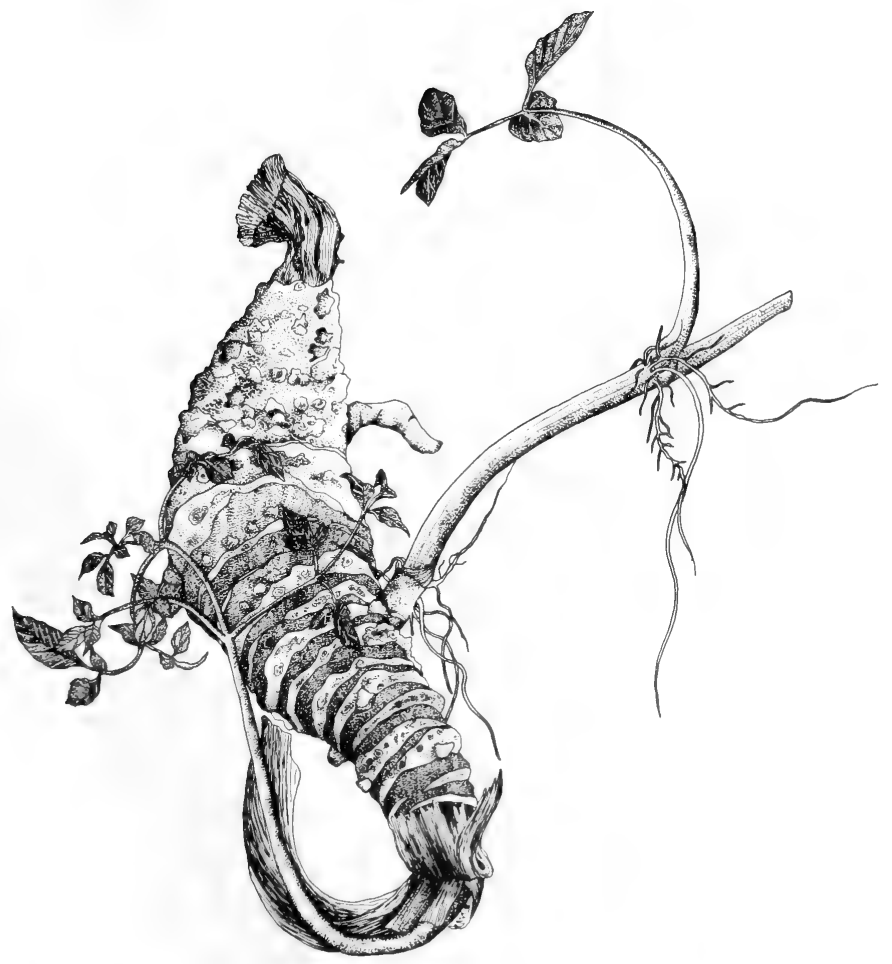

Fig. 588: Cicuta mexicana: rhizome, x 1/2. (Courtesy of R. K. Godfrey). 


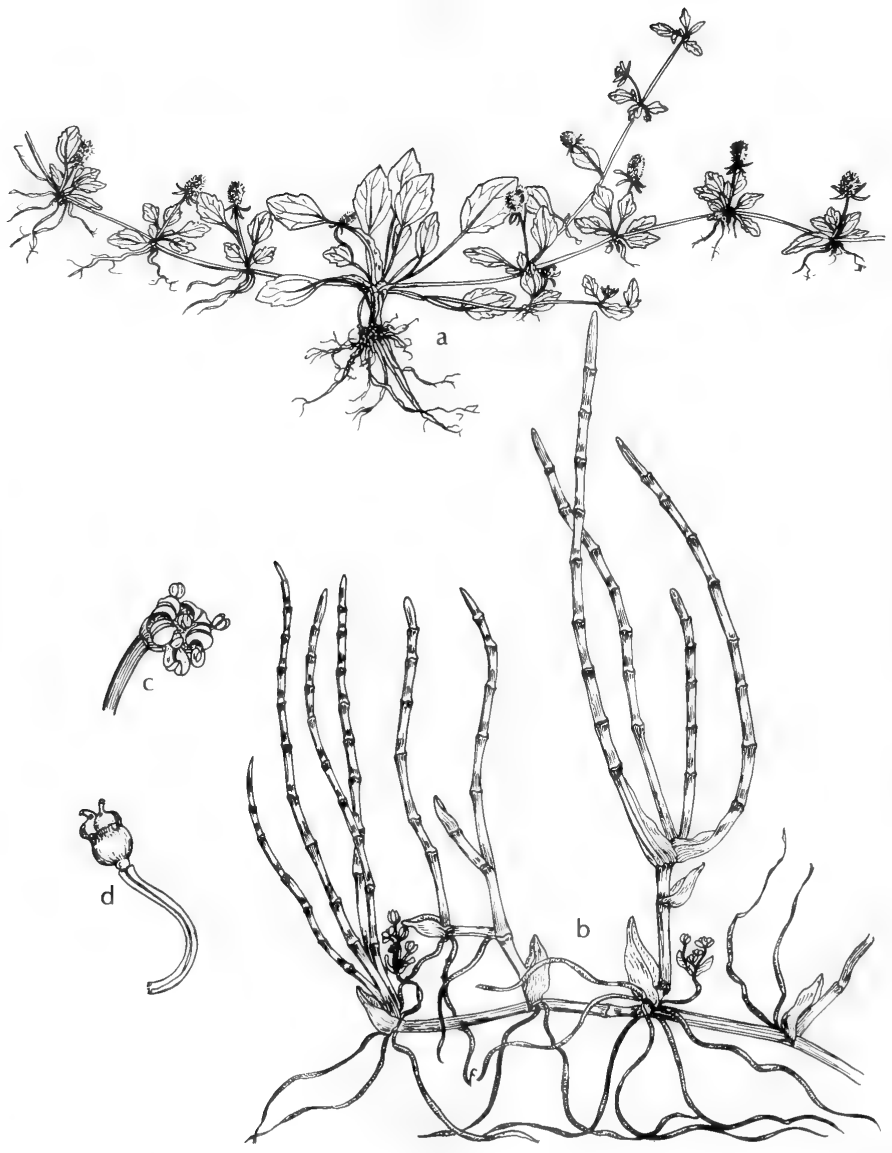

Fig. 589: a, Eryngium prostratum: a, habit, x 1/2. b-d, Lilaeopsis recurva: b, habit, x $1 / 2$; c, flower, x 5; d, fruit, x 5. (V. F.). 


\section{Ptilimnium RaF.}

\section{Mock BISHOP's-WEed}

Plants slender, erect, caulescent, branching, herbaceous, annual, from a fascicle of fibrous roots; leaves pinnately decompound with filiform ultimate divisions or the leaves reduced to fistulose sheathing petioles; inilorescence of compound umbels, the peduncles terminal and axillary; involucre of entire or pinnatifid bracts; involucel of entire bractlets; rays few to numerous, spreading-ascending to spreading, the pedicels spreading; flowers white, rarely pink, the calyx teeth small to prominent, the stylopodium conic; carpophore bifid at the apex or cleft to the middle: fruit ovoid to suborbicular, compressed laterally, the dorsal ribs filiform, rounded or acute, the lateral ribs small to corky-winged, forming a band around the fruit: oil tubes solitary in the intervals and 2 on the commissure, the seed face plane.

A genus of five species of southeastern and south-central United States.

1. Leaf segments crowded, appearing verticillate; styles $1.5-3 \mathrm{~mm}$. long; plant robust, $8-15 \mathrm{dm}$. high.

2. P. costatum.

1. Leaf segments not crowded; styles $0.2-1.5 \mathrm{~mm}$. long; plants $2-8 \mathrm{dm}$. high (2)

2(1). Leaf segments usually 3 at a node on the rachis; bracts usually 3 -cleft; styles $0.2-0.5 \mathrm{~mm}$. long, not strongly recurved............... 1. P. capillaceum. 2. Leaf segments usually 2 at a node on the rachis; bracts usually entire; styles $0.5-1.5 \mathrm{~mm}$. long, strongly recurved. 3. P. Nuttallii.

\section{Ptilimnium capillaceum (Michx.) Raf. Fig. 590.}

Plant 1-8.5 dm. high; leaves verticillate at the nodes, polymorphic in submerged forms, broadly oblong, to $13 \mathrm{~cm}$. long and $4 \mathrm{~cm}$. wide, pinnately decompound, the segments usually filiform, 3 at a node on the rachis; peduncles $2.5-10.5 \mathrm{~cm}$. long, exceeding the leaves; involucre of several pinnately cleft or rarely entire bracts about one half as long as the rays; involucel of filiform bractlets shorter than the pedicels; rays 4 to 20 , spreading, subequal, $1-3.5 \mathrm{~cm}$. long; pedicels 5 to $20,3-12$ (usually 4-6) $\mathrm{mm}$. long: calyx teeth small, persistent; styles $0.2-0.5 \mathrm{~mm}$. long, not strongly recurved; fruit broadly ovoid, $1.5-3 \mathrm{~mm}$. long, $1.5-2 \mathrm{~mm}$. broad, the lateral ribs conspicuous.

In wet places in Okla. (Pushmataha and McCurtain cos.) and the e. half of Tex., May-Aug.; from Mass., s. to Fla., w. to Mo., Kan. and Tex.

\section{Ptilimnium costatum (Ell.) Raf. Fig. 591.}

Plant 8-15 dm. high: leaves oblong, to $14 \mathrm{~cm}$. long and $7 \mathrm{~cm}$. wide, pinnately decompound, the ultimate divisions filiform, crowded, appearing verticillate; peduncles 7-14 cm. long, exceeding the leaves; involucre of very short usually entire bracts; involucel of usually entire bractlets shorter than the pedicels; rays about 20 . spreading, subequal, $1.5-4 \mathrm{~cm}$. long; pedicels 15 to 20 , spreading, $4-5 \mathrm{~mm}$. long; calyx teeth conspicuous, deltoid, acute to subacuminate, persistent; styles 1.5-3 $\mathrm{mm}$. long; fruit ovoid, 2-4 mm. long, 2-3 mm. broad.

In swamps, boggy areas, savannahs and edge of moist woods in the e. half of Tex., June-Oct.; from N.C. to Ga., w. to Mo. and Tex.

Plants described as $P$. texense Coult. \& Rose, formerly referred to $P$. costatum by Mathias and Constance are considered by Easterly (Brittonia 9:144. 1957) to be of possible hybrid origin, combining the fruit characteristics of $P$. Nuttallii with the vegetative characteristics of $P$. capillaceum. The center of distribution apparently is in Robertson County and the taxon is found through a large area of eastern Texas in acid bogs and marsh land, flowering July to August.

\section{Ptilimnium Nuttallii (DC.) Britt.}

Plant 3-6 dm. high; leaves oblong, to $9 \mathrm{~cm}$. long and $4 \mathrm{~cm}$. wide, pinnately decompound, the ultimate divisions filiform, usually 2 at a node on the rachis; 


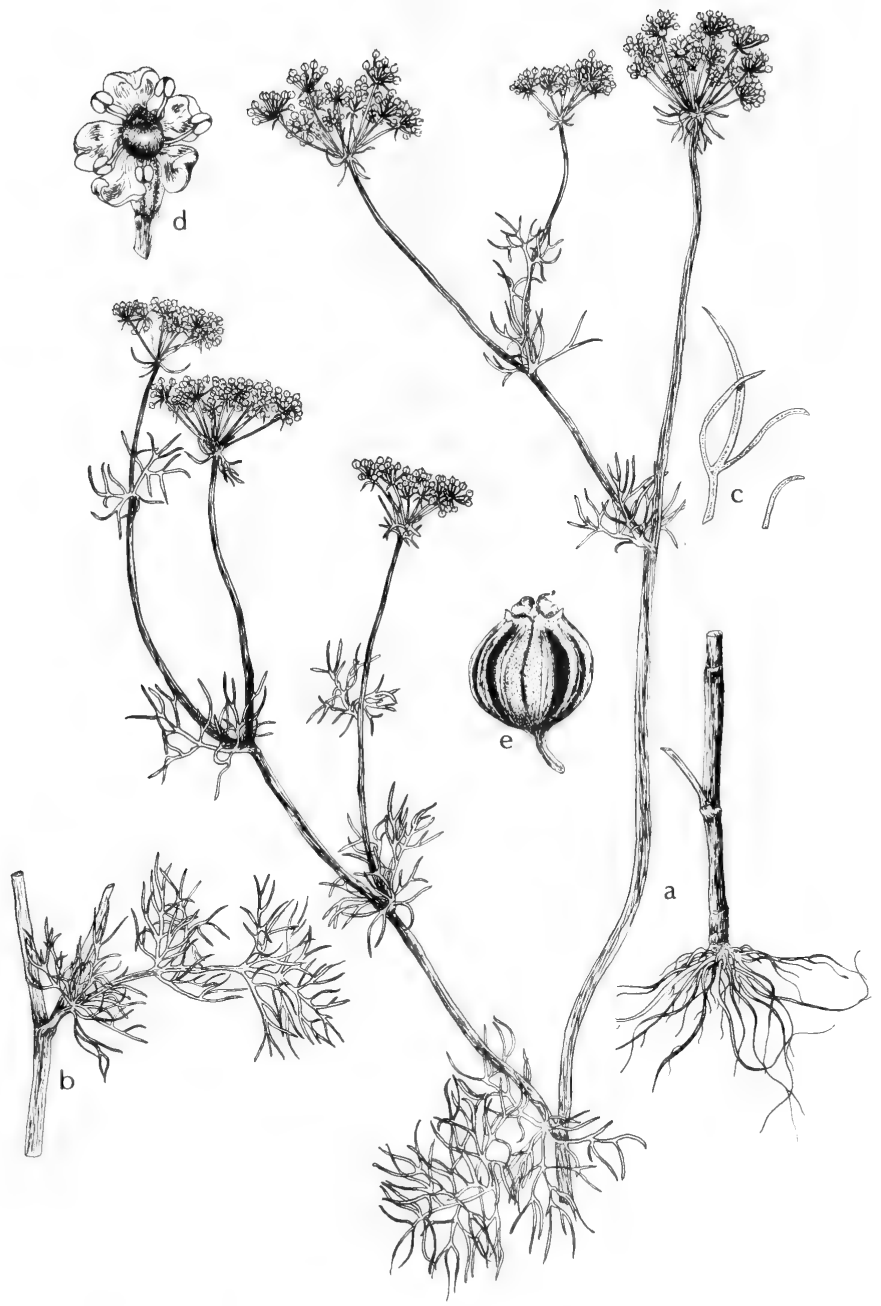

Fig. 590: Ptilimnium capillaceum: a, top and basal part of plant, x 1/2; b, leaf from central part of stem, x $1 / 2$; c, enlarged upper leaf; d, flower, x 20; e, fruit, x 16 . (Courtesy of R. K. Godfrey). 


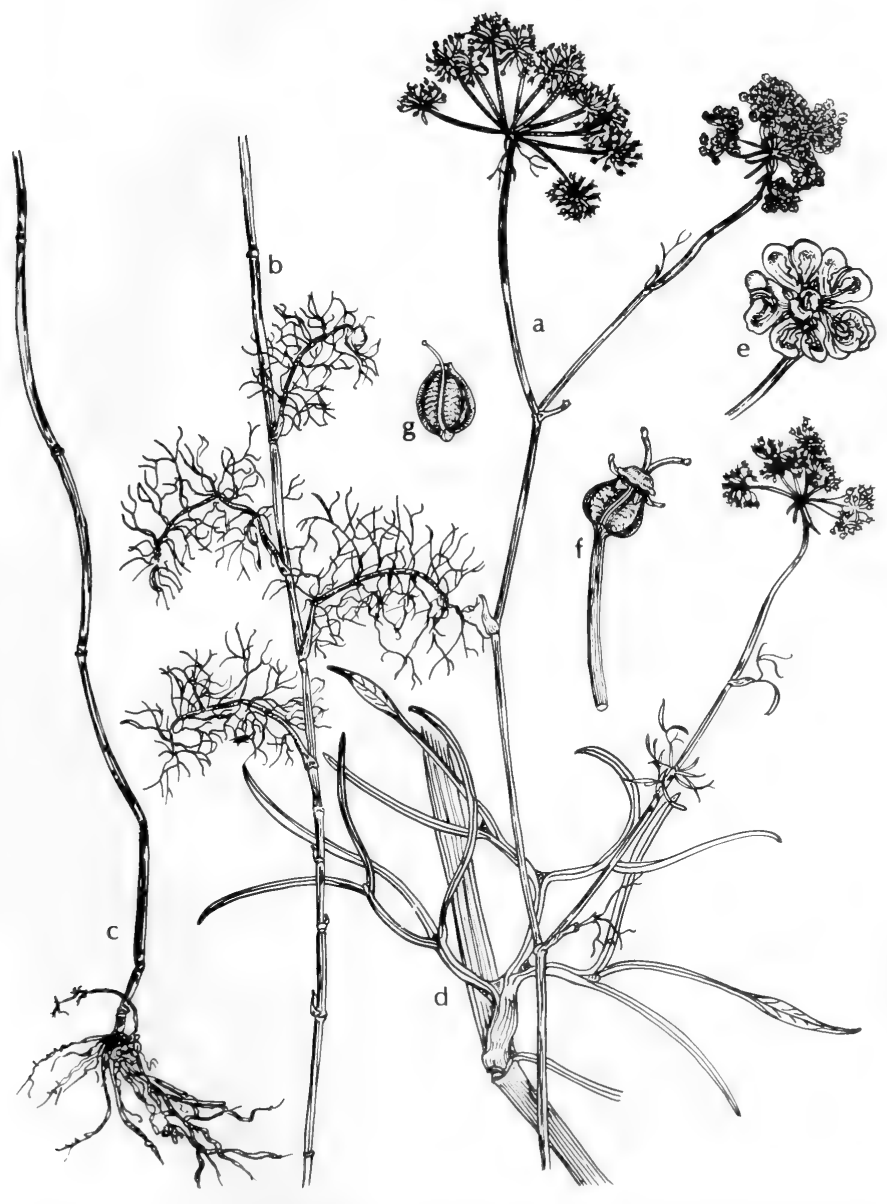

Fig. 591: Ptilimnium costatum: a, top of plant, x 1/2; b, central part of stem, $\mathrm{x}$

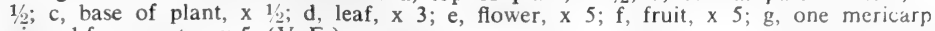
viewed from center, $x$ 5. (V. F.). 
peduncles $4-12 \mathrm{~cm}$. long; involucre of filiform mostly entire bracts much shorter than the rays; involucel of filiform entire bractlets shorter than the pedicels; rays 25 to 30 , spreading, subequal, $15-35 \mathrm{~mm}$. long; pedicels 25 to 30 , spreading, 3-8 mm. long; calyx teeth conspicuous, linear-lanceolate, persistent; styles $0.5-1.5$ $\mathrm{mm}$. long, strongly recurved; fruit ovoid, $1-1.5 \mathrm{~mm}$ long, $1 \mathrm{~mm}$. broad, the lateral ribs inconspicuous, only slightly corky-thickened.

In moist sandy soil, in wet prairies and other moist places in Okla. (widespread) and in the e. half of Tex., Apr.-July; from Ill., s. to La. and w. to Kan. and Tex.

\section{Cynosciadium DC.}

A monotypic genus.

\section{Cynosciadium digitatum DC. Fig. 592.}

Plant slender, erect, caulescent, herbaceous, annual, $15 \mathrm{~cm}$. high, dichotomously branching in the inflorescence, from a fascicle of fibrous roots; basal leaves linearlanceolate, tapering at base, acute at apex, entire and septate, to $12 \mathrm{~cm}$. long and $5 \mathrm{~mm}$. wide; cauline leaves 3 to 5 , palmately parted with narrow elongate divisions; inflorescence of compound umbels, the peduncles $(1.5-8 \mathrm{~cm}$. long) axillary and terminal; involucre and involucel usually lacking or the latter of a few linear bractlets shorter than the pedicels; rays 2 to 10 , unequal, slender, spreadingascending, 1-4 cm. long or some umbellets frequently sessile or proliferating; pedicels 2 to $11,5-20 \mathrm{~mm}$. long, spreading-ascending; flowers white, the prominent calyx teeth ovate, the stylopodium conic; carpophore bifid at the apex; fruit ovoid, 2-3 mm. long, 1.5-2.5 mm. broad, glabrous, prominently beaked at the apex, rounded at the base, slightly compressed laterally or nearly terete, the narrow dorsal ribs prominent, the lateral ribs broadly corky-winged; oil tubes solitary in the intervals and 2 on the commissure, the seed face plane.

In wet places in Okla. (LeFlore Co.) and the Coastal and Blackland prairies of Tex., May-July; from Tex. n. to s. Mo. and e. to La.

\section{Limnosciadium MATH. \& CONST.}

Plants low and diffuse to erect, slender, caulescent, branching, herbaceous, annual, from a fascicle of fibrous roots; leaves entire and septate or pinnate with narrow elongate divisions; inflorescence dichotomously branching, of compound umbels, the peduncles axillary and terminal or some umbels sessile; involucre lacking or of a few narrow entire bracts; involucel of several narrow entire bractlets shorter than the pedicels; rays few, unequal, spreading-ascending; flowers white, the prominent calyx teeth ovate-lanceolate, the stylopodium conic; carpophore shortly bifid at the apex; fruit oblong-oval to orbicular, rounded at apex and base, slightly compressed dorsally, glabrous, the dorsal ribs filiform, the lateral broadly corky-winged; oil tubes solitary in the intervals and 2 on the commissure, the seed face plane.

A genus of 2 species, inhabiting wet places in the south-central United States.

1. Plant erect or assurgent; calyx teeth $0.5 \mathrm{~mm}$. or less long, attached well below and shorter than the stylopodium; fruit oblong-oval, $2-4 \mathrm{~mm}$. long, 1-2 mm. broad....................................................... L. pinnatum.

1. Plant low and diffuse; calyx teeth to $1.5 \mathrm{~mm}$. long, attached shortly below and equaling the stylopodium; fruit oval to orbicular, 2-3 $\mathrm{mm}$. long, 2 $\mathrm{mm}$. broad. 2. L. pumilum

1. Limnosciadium pinnatum (DC.) Math. \& Const. Fig. 593.

Plant erect or assurgent, 1-8 dm. high; basal leaves linear-lanceolate, acute at the apex, tapering at the base, to $20 \mathrm{~cm}$. long and $25 \mathrm{~mm}$. wide, entire and septate or pinnate, the terminal division elongate; cauline leaves pinnate or the lowest and uppermost entire, with 2 to 9 linear to linear-lanceolate divisions, acute at both 


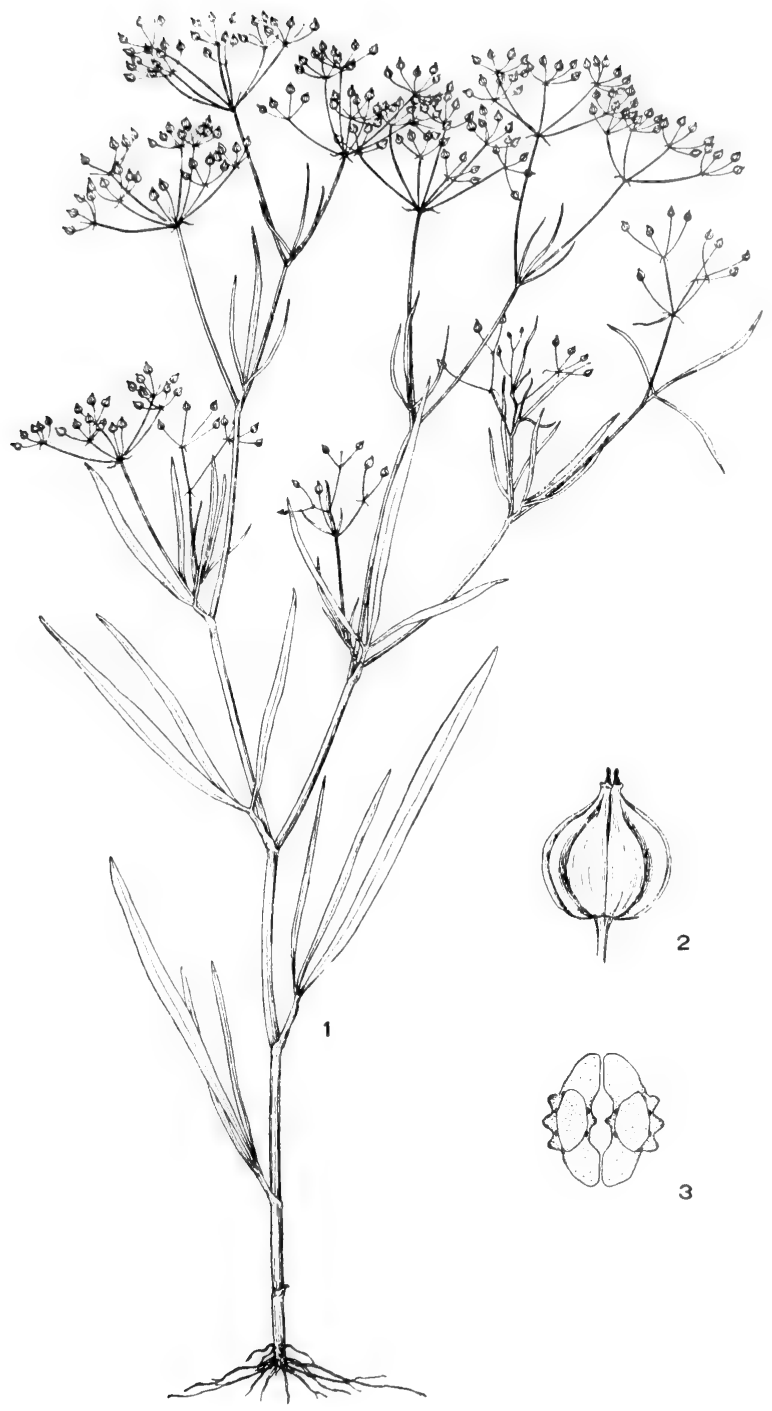

Fig. 592: Cynosciadium digitatum: 1, plant, $x$ 1/2; 2, fruit, side view, $x 8 ; 3$, fruit, transverse section, x 8. (From Mathias \& Constance in Lundell's Flora of Texas, Vol. 3, Pl. 39). 


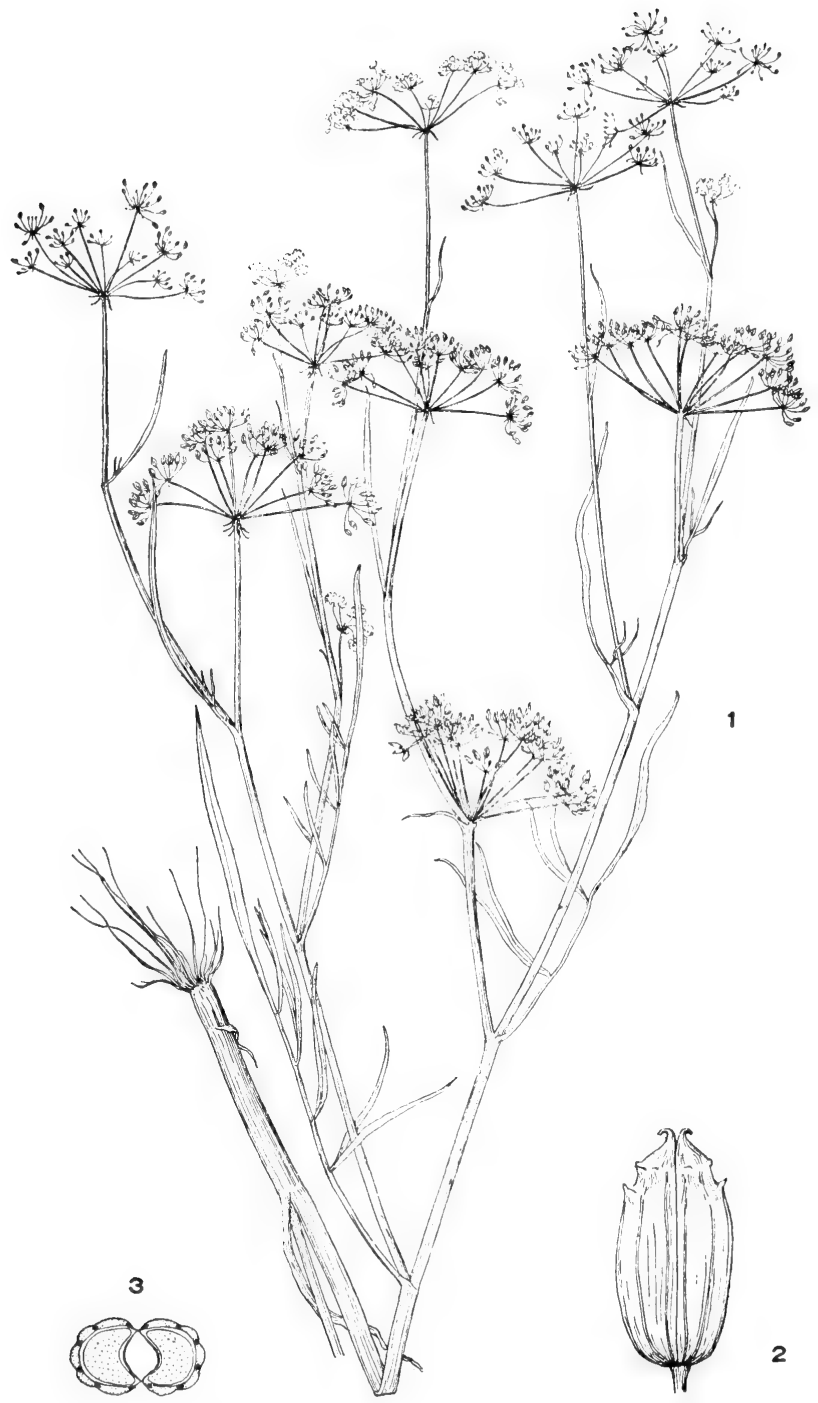

Fig. 593: Limnosciadium pinnatum: 1, plant, x 1/2; 2, fruit, side view, x 12; 3, fruit, transverse section, x 12. (From Mathias \& Constance in Lundell's Flora of Texas, Vol. 3, Pl. 40). 
ends; peduncles $1-8 \mathrm{~cm}$. long or some umbels sessile; involucre of several linear or linear-lanceolate reflexed bracts 2-6 mm. long; involucel of several linear bractlets $1-5 \mathrm{~mm}$. long; rays 3 to 12 , slender, $5-35 \mathrm{~mm}$. long; pedicels 4 to $20,2-8 \mathrm{~mm}$. long; calyx teeth $0.5 \mathrm{~mm}$. long or less, attached well below and shorter than the stylopodium; fruit oblong-oval, 2-4 mm. long, 1-2 mm. broad, the dorsal ribs low. the lateral corky wings slightly broader. Cynosciadium pinnatum DC.

In wet places, banks of ponds and lakes in Okla. (Comanche and LeFlore cos.) and in the e. half of Tex., s. to the Rio Grande Plains, May-June; from Tex. and La., n. to Ill. and Kan.

\section{Limnosciadium pumilum (Engelm. \& Gray) Math. \& Const. Fig. 594.}

Plant low and diffuse, 5-40 cm. high or long; basal leaves lanceolate to linearlanceolate, acute at the apex, tapering at the base, to $8 \mathrm{~cm}$. long and $8 \mathrm{~mm}$. wide, entire and septate or pinnate, the terminal division elongate; cauline leaves pinnate or entire, with 3 to 7 filiform to lanceolate divisions, acute at the apex, tapering at the base; peduncles $5-75 \mathrm{~mm}$. long or frequently some umbels sessile; involucre lacking or of a few minute bracts; involucel of several linear to linear-lanceolate bractlets 2-4 mm. long; rays 3 to 8 , slender, 1-5 cm. long; pedicels several, 2-4 $\mathrm{mm}$. long; calyx teeth to $1.5 \mathrm{~mm}$. long, attached shortly below and about equaling the stylopodium; fruit oval to orbicular, 2-3 mm. long, $2 \mathrm{~mm}$. broad, the dorsal ribs filiform, the lateral wings broad and corky. Cynosciadium pumilum (Engelm. \& Gray) Coult. \& Rose.

In seeping meadows, bogs and other wet places in cen. and s. Tex., Mar.-June; endemic.

\section{Conioselinum HoF FM.}

A genus of about 10 species of North America and Eurasia, mostly in boreal or mountainous regions.

\section{Conioselinum scopulorum (Gray) Coult. \& Rose}

Plants perennial from a cluster of fleshy roots, caulescent, nearly simple, 6-9 $\mathrm{dm}$. high, more or less leafy, with puberulent inflorescence; lower leaves often very large, twice- to thrice-ternate then once- or twice-pinnate; leaflets (sometimes small) laciniately pinnatifid; upper leaves often ternate-pinnate or simply pinnately compound; umbel of numerous rays, with involucels of several narrowly linear elongated bractlets; rays (fruiting) $5-7.5 \mathrm{~cm}$. long; pedicels $12 \mathrm{~mm}$. long; flowers white; calyx teeth obsolete; stylopodium conic; fruit about $6 \mathrm{~mm}$. long; oil tubes usually 1 in the dorsal intervals and 2 in the lateral, 2 to 4 on the commissural side.

In streams or on riverbanks in N. M. (Taos, Otero, San Juan, Bernalillo, Socorro and Grant cos.), Ariz. (Navajo, Graham, Cochise and Pima cos.), Aug.Sept.; N.M., Ariz., Colo. and Ut. to e. Ore.

\section{Angelica L.}

A circumboreal genus of about 50 species.

\section{Angelica pinnata Wats.}

Perennial, glabrous or the leaves and inflorescences sometimes scabrous; stems 2.5-9 dm. high, rather slender; leaves once-pinnate or incompletely bipinnate; leaflets lanceolate to ovate-lanceolate, 3-9 cm. long, sessile or nearly so, serrate to rarely entire, some of the lower often lobed or nearly divided; cauline leaves with rather conspicuously dilated petioles; peduncles exceeding the leaves; umbels compound; involucre wanting or of sheathlike bracts; involucel wanting; rays 6 to 25 , ascending or spreading-ascending, unequal, the whole umbel somewhat flattened above; pedicels $3-8 \mathrm{~mm}$. long, spreading and ascending; flowers white or pinkish; 


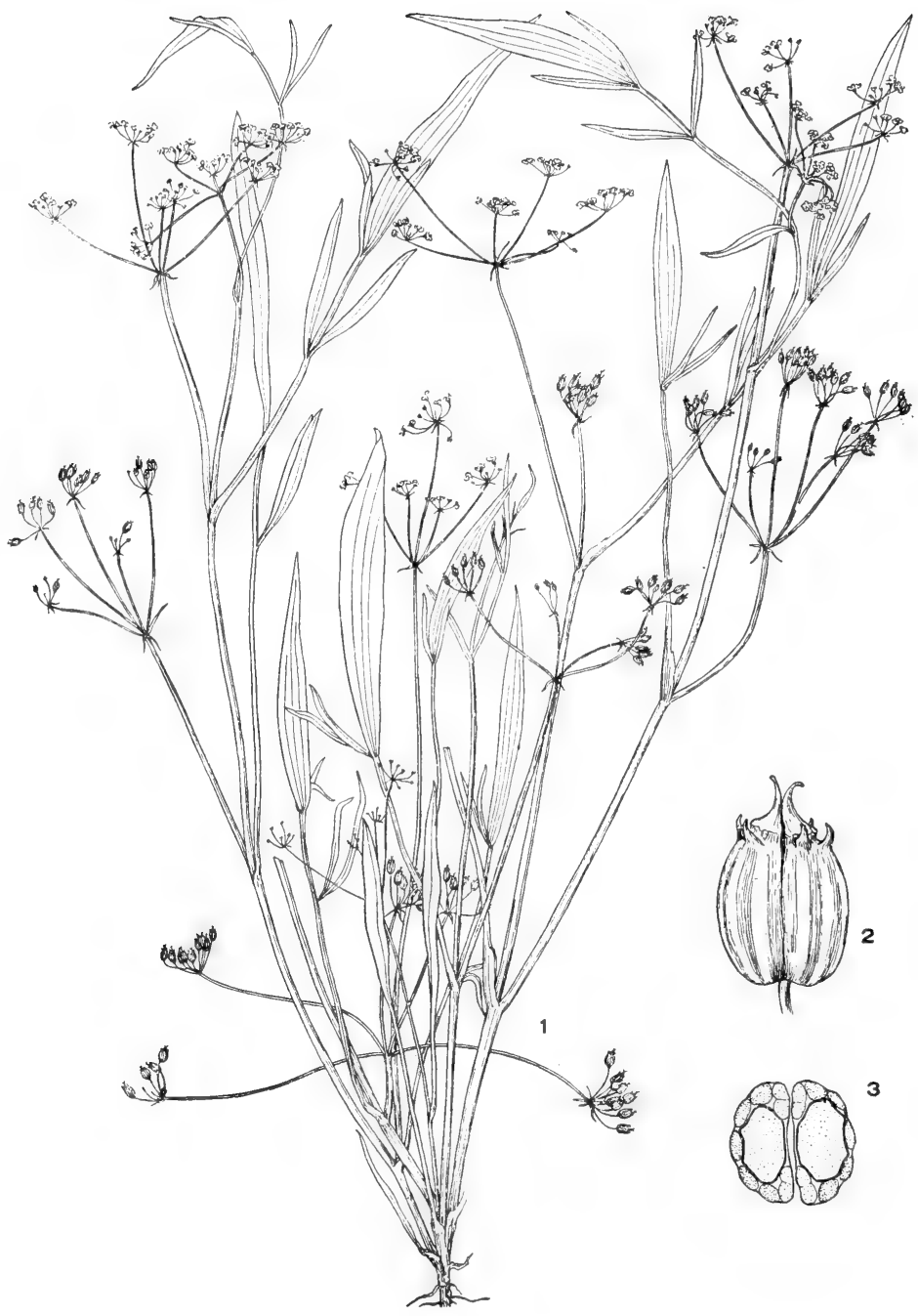

Fig. 594: Limnosciadium pumilum: 1, plant, x 1; 2, fruit, side view, x 10;3, fruit, transverse section, x 10. (From Mathias \& Constance in Lundell's Flora of Texas, Vol. 3, Pl. 41). 
stylopodium conic; fruit 3-6 mm. long, nearly orbicular, glabrate but hispidulous when young, dorsal ribs narrowly winged, lateral ribs more broadly winged, these nearly as wide as the body; oil tubes solitary in the intervals, sometimes in pairs, 2 to 4 on the commissure; seed face slightly concave, the seed remaining attached to the pericarp.

In wet meadows, bogs and in wet mud in partial shade along streams in N. M. (Taos, Rio Arriba and San Juan cos.) and Ariz. (Apache and Coconino cos.), July-Aug.; n.w. Wyo., s. Mont., Ida., s. to n. N.M. and n. Ariz.

\section{Oxypolis RaF. Hog-FenNeL}

Plants slender, erect, caulescent, glabrous, herbaceous, perennial from fascicled tubers; leaves simply pinnate to ternate or reduced to hollow acute septate phyllodes; leaflets (when present) broad or narrow, serrate to incised, mostly distinct and sessile; inflorescence of compound umbels, the peduncles terminal and axillary; involucre of a few slender bracts or lacking; involucel similar to the involucre or lacking; rays few to numerous, usually spreading-ascending, the slender pedicels ascending to spreading; flowers white or purple, the calyx teeth prominent or minute, the stylopodium conic; carpophore divided to the base; fruit oblong to obovoid, strongly flattened dorsally, glabrous, the dorsal ribs filiform, the lateral broadly thin-winged and nerved dorsally at the inner margin to give the appearance of 5 filiform dorsal ribs; oil tubes large, solitary in the intervals, 2 to 6 on the commissure, the seed face plane; strengthening cells beneath the dorsal ribs and the nerves of the lateral wings.

A genus of about half a dozen species, chiefly of the eastern and southeastern United States.

1. Leaves reduced to cylindrical or flattened entire septate phyllodes.

1. Leaves pinnate; leaflets mostly toothed (2)

2(1). Leaflets entire or sharply-toothed; lateral wings broad; rays 15 to 45 .

2. $O$. rigidior.

2. Leaflets serrate to crenate-toothed; lateral wings narrow; rays 5 to 12 .

3. O. Fendleri.

1. Oxypolis filiformis (Walt.) Britt. Fig. 595.

Plant to $14 \mathrm{dm}$. high; leaves reduced to hollow septate phyllodes 2-6 dm. long; peduncles $2-9 \mathrm{~cm}$. long; involucre of several linear to lanceolate bracts $5-15 \mathrm{~mm}$. long; involucel of linear to lanceolate bractlets $2-4 \mathrm{~mm}$. long; rays 8 to 14 , spreading, slightly unequal, $2-4.5 \mathrm{~cm}$. long; pedicels spreading, 5-10 mm. long; calyx teeth conspicuous; fruit oval or obovoid, 5-8 mm. long, 3-5 $\mathrm{mm}$. broad, the lateral wings thinner than the body.

Wet places in the Timber Belt and the Blackland and Coastal prairies, July-Sept.; from Va. s. to Fla. and w. to Tex.; also Bah. I. and Cuba.

\section{Oxypolis rigidior (L.) Raf. Cowbane, WATER-Dropwort. Fig. 596.}

Plant 6-15 dm. high; leaves oval to triangular or lanceolate, to $30 \mathrm{~cm}$. long and $25 \mathrm{~cm}$. wide, pinnate; leaflets 5 to 9 , lanceolate or linear, lemotely salient-dentate or entire; peduncles $6-30 \mathrm{~cm}$. long; involucre of a few linear bracts $1-2 \mathrm{~cm}$. long; involucel of a few linear bractlets $3-5 \mathrm{~mm}$. long; rays 15 to 45 , spreading, subequal, 3-12 cm. long; pedicels spreading, 5-15 mm. long; calyx teeth conspicuous; fruit oval or oblong, 4-7 mm. long, 2.5-4 mm. broad.

Along streams and in other wet places in Okla. (Waterfall) and in Tex. in the Timber Belt and the Blackland and Coastal prairies, Aug.-Oct.; from N.Y., s. to S.C., w. to Minn. and Tex. 


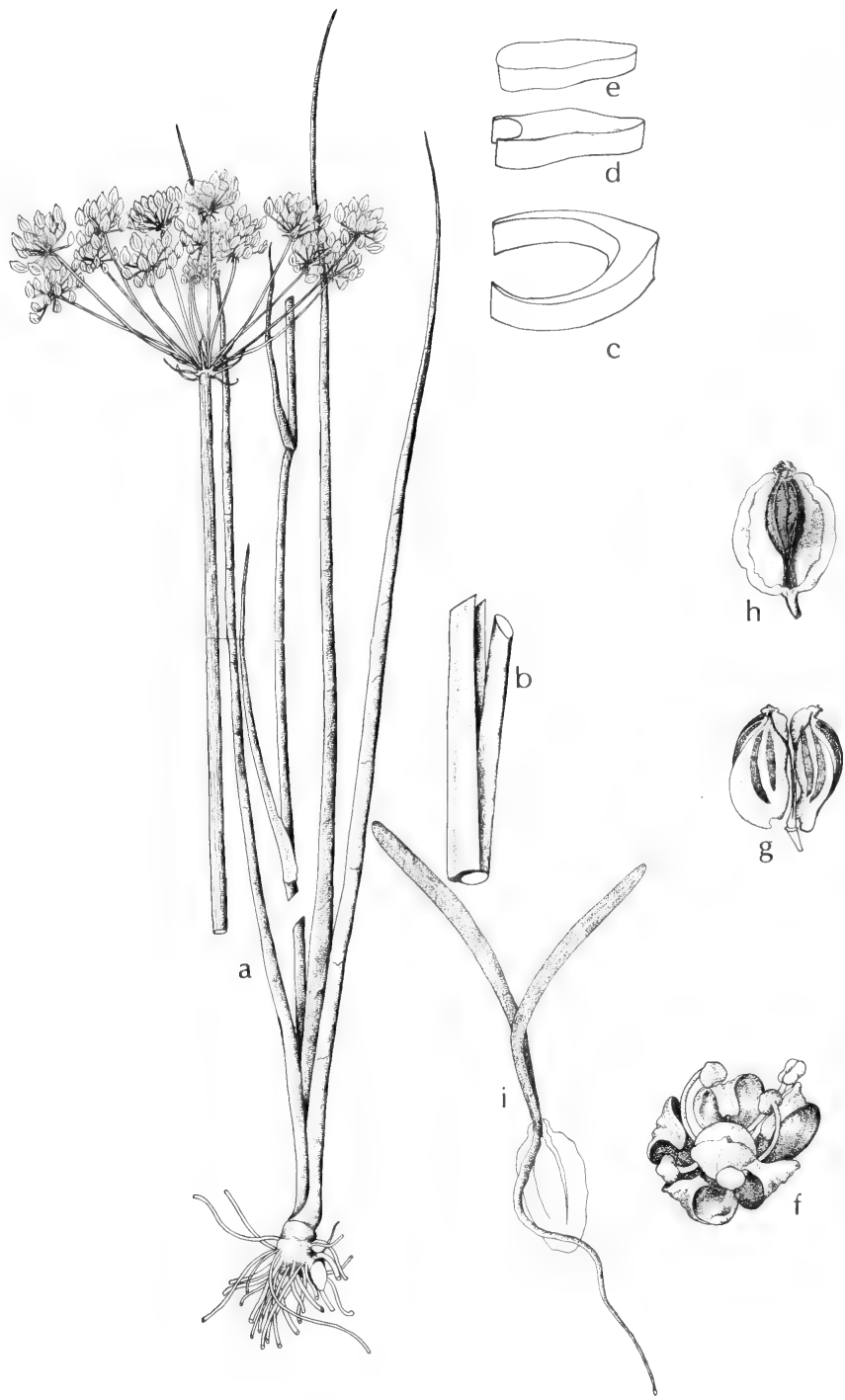

Fig. 595: Oxypolis filiformis: a, habit, about $\times 1 / 3 ; b$, section of phyllode sheath and stem, about x 1; c, enlarged section near base of sheath; d, enlarged section at apex of sheath; e, enlarged section of phyllode; f, flower, enlarged; $g$, fruit showing mericarps attached to carpophore, $\mathrm{x} 3$; $\mathrm{h}$, fruit from dorsal side showing filiform ribs, $\mathrm{x} 3$. (Courtesy of R. K. Godfrey). 


\section{Oxypolis Fendleri (Gray) Heller. Fig. 597.}

Glabrous caulescent perennial, 3-6 dm. high, from fascicled tubers; leaves with dilated sheaths, oblong in outline, simply pinnate, 5- to 9-foliate; leaflets broadly ovate to narrowly lanceolate, obtuse, crenate-dentate or incisely serrate, rarely incised, 2.5-5 cm. long; peduncles $8-20 \mathrm{~cm}$. long; inflorescence of loose compound umbels; rays unequal, 5 to $12,1-3.5 \mathrm{~cm}$. long; involucre and involucels wanting; calyx teeth conspicuous; corolla white or purple; stylopodium conic; fruit oblong or oval, about $4 \mathrm{~mm}$. long, glabrous, strongly compressed dorsally, the dorsal ribs filiform, the lateral ones broadly thin-winged, the oil tubes large and solitary in the intervals ( 2 to 4 on the commissure), the seed face plane.

In water of small streams, bogs or streamsides in partial shade in Ariz. (Apache Co. ) and N. M. (Taos, Rio Arriba, San Miguel, Santa Fe and Socorro cos.), JuneAug.; Wyo. to N.M., s.e. Ut. and Ariz.

\section{Heracleum L. Cow-PARSNIP}

A circumboreal genus of about 60 species, only one native to North America.

1. Heracleum lanatum Michx. Masterwort. Fig. 598.

Coarse rank-smelling pilose to lanate perennial, 1-2.5 m. high, with fistulose ribbed stems; leaves pinnately or ternately divided (especially above); leaf segments palmately cleft or parted, ovate, those of the upper leaves 1-2 dm. long, serrate; petiole sheaths conspicuously expanded, $2-5 \mathrm{~cm}$. wide when spread out; umbels compound, axillary and terminal; peduncles tomentose to villous, $5-25 \mathrm{~cm}$. long; involucral bracts linear, $1-2 \mathrm{~cm}$. long, deciduous; rays usually 20 to 30 , spreading to ascending, $3-10 \mathrm{~cm}$. long; involucel similar to involucre; pedicels 7-18 $\mathrm{mm}$. long; petals white, unequal, those of the perfect flowers ligulate to obovate, lobed or bifid, 3-9 $\mathrm{mm}$. long, those of the staminate flowers smaller, more regular; fruit puberulent or glabrate, obovate, $8-12 \mathrm{~mm}$. long; mericarps strongly flattened dorsally, the 4 brown oil tubes clearly visible on the dorsal surface. $H$. maximum Bartr.

Meadows, stream banks and other wet areas in Ariz. (Graham, Pima, Apache and Navajo cos.) and N. M. (Colfax, Taos, Rio Arriba, San Miguel and Santa Fe cos.), June-Aug.; widely distributed in U.S. and Can.

\section{Eryngium L. ERYNGO}

Plants creeping to erect, caulescent or acaulescent, usually glabrous, herbaceous, annual, biennial or perennial from stout taproots or rootstocks bearing fibrous roots; leaves coriaceous or membranaceous, entire to pinnately or palmately lobed to divided, often ciliate to spinose, the venation parallel or reticulate, the petioles sheathing and sometimes septate; inflorescence capitate, the heads solitary or in cymes or racemes; involucre of one or more series of entire or lobed bracts subtending the head; involucel of entire or lobed bractlets subtending the flowers; flowers white to purple, sessile; sepals ovate to lanceolate, obtuse to acute, entire or rarely spinescent, persistent; stylopodium lacking; carpophore lacking; fruit globose to obovoid, scarcely compressed laterally, variously covered with scales or tubercles, the ribs obsolete, the commissure broad; oil tubes mostly 5, inconspicuous; seed face plane or slightly concave.

A genus of more than 200 species, in the temperate and warmer parts of the world, with important centers of development in Brazil-Paraguay, Mexico, western Asia, the Mediterranean region, and southeastern and western United States.

1. Leaves parallel-veined; plants with a monocotyledonous habit (2)

1. Leaves reticulate-veined; plants not monocotyledonoid (4) 
2(1). Leaves with numerous marginal setae (3)

2. Leaves with no (or very few) marginal setae

3(2). Leaves $10-30 \mathrm{~mm}$. broad, the marginal setae usually solitary; bracts ovatelanceolate.................................2. E. yuccifolium var. yuccifolium.

3. Leaves $5-10 \mathrm{~mm}$. broad, the marginal setae usually in groups of 2 to 4 ; bracts linear-lanceolate............................ E. yuccifolium var. synchaetum.

4(1). Cauline leaves conspicuously spinulose-pungent; bracts mostly broad, variously spinose-toothed, rarely entire, pungent (5)

4. Cauline leaves entire to pinnatifid, not spinulose-pungent; bracts very narrow, sometimes pungent-tipped, entire or occasionally with 3 to 5 spiny teeth (7)

5(4). Inflorescence a single head (rarely more); basal leaves on long petioles

5. Inflorescence cymosely or paniculately branched (6)

4. E. phyteumae.

6(5). Bracts bicolored, green or bluish beneath, yellow-white above

5. E. heterophyllum.

6. Bracts greenish above and below, not bicolored .6. E. Hookeri.

7(4). Plant erect; lower bractlets tricuspidate; basal leaves usually cordate 7. E. integrifolium.

7. Plants prostrate to ascending; bractlets entire; basal leaves not cordate (8)

8(7). Heads in a terminal branched inflorescence, subsessile, many-flowered; bractlets exceeding the fruit.............................. E. E. nasturtiifolium.

8. Heads solitary, on filiform peduncles, few-flowered; bractlets shorter than the fruit. 9. E. prostratum.

\section{Eryngium sparganophyllum Hemsl.}

Slender caulescent glabrous perennials, 4-12 dm. high; stems solitary to several, erect; basal leaves numerous, linear to linear-lanceolate, 1-9 dm. long, 5-15 mm. wide, broadest at base, attenuate at apex, entire or obsoletely spinulose-dentate with teeth $2 \mathrm{~mm}$. long or less, axillary spines absent, venation parallel; cauline leaves few and reduced; inflorescence branching; heads ovoid or ovoid-oblong, 15-25 mm. long, 10-15 mm. broad; bracts 8 to 12 , much shorter than heads; bractlets $5 \mathrm{~mm}$. long, slightly exceeding fruit; coma wanting; fruit ovoid, 3-4 mm. long.

Wet seeps and marshy ground, Ariz. (Pima Co.), e. into N.M. (Grant Co.), s. into Mex.

\section{Eryngium yuccifolium Michx. var. yuccifolium. RATTLESNAKE-MASTER, BUTTON} SNAKE-ROOT.

Plants stout, glabrous, 3-18 dm. high, perennial from a fascicle of tuberous woody roots; stems slender, solitary, branching above; basal leaves rigid, broadly linear, to $10 \mathrm{dm}$. long, 1-3 cm. wide, acute, remotely bristly with solitary (or occasionally 2 or more) bristles, the venation parallel; sheaths short; cauline leaves like the basal, reduced above; inflorescence cymosely branched, the pedunculate heads large, the flowers numerous; heads globose-ovoid, $1-2.5 \mathrm{~cm}$. in diameter; bracts 6 to 10 , spreading-ascending, ovate-lanceolate, to $15 \mathrm{~mm}$. long, cuspidate, mostly entire, shorter than the heads; bractlets like the bracts, entire or minutely serrulate, exceeding the fruit; coma wanting; sepals ovate, obtuse, mucronulate; styles exceeding the sepals; fruit oblong, 4-8 $\mathrm{mm}$. long, the flattened scales of the angles lanceolate, $1.5-3 \mathrm{~mm}$. long, those of the dorsal surfaces reduced or obsolete. 


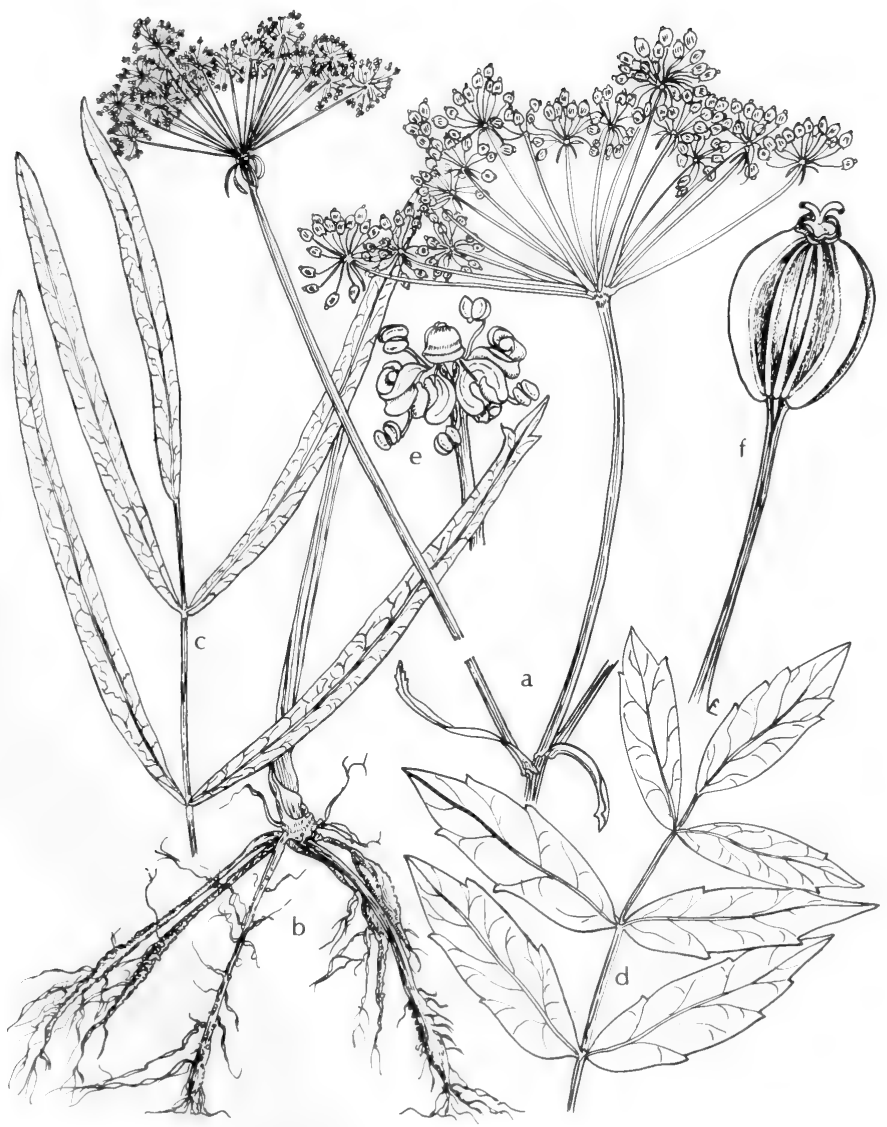

Fig. 596: Oxypolis rigidior: a, top of plant, $\mathrm{x} 1 \frac{1}{2} ; \mathrm{b}$, basal part of plant, $\mathrm{x} \frac{1}{2} ; \mathrm{c}$ and $\mathrm{d}$, showing variation in shape of leaflets, $\mathrm{x} 1 / 2 ; \mathrm{e}$, flower, $\mathrm{x} 5 ; \mathrm{f}$, fruit, $\mathrm{x} 5$. (V. F.). 


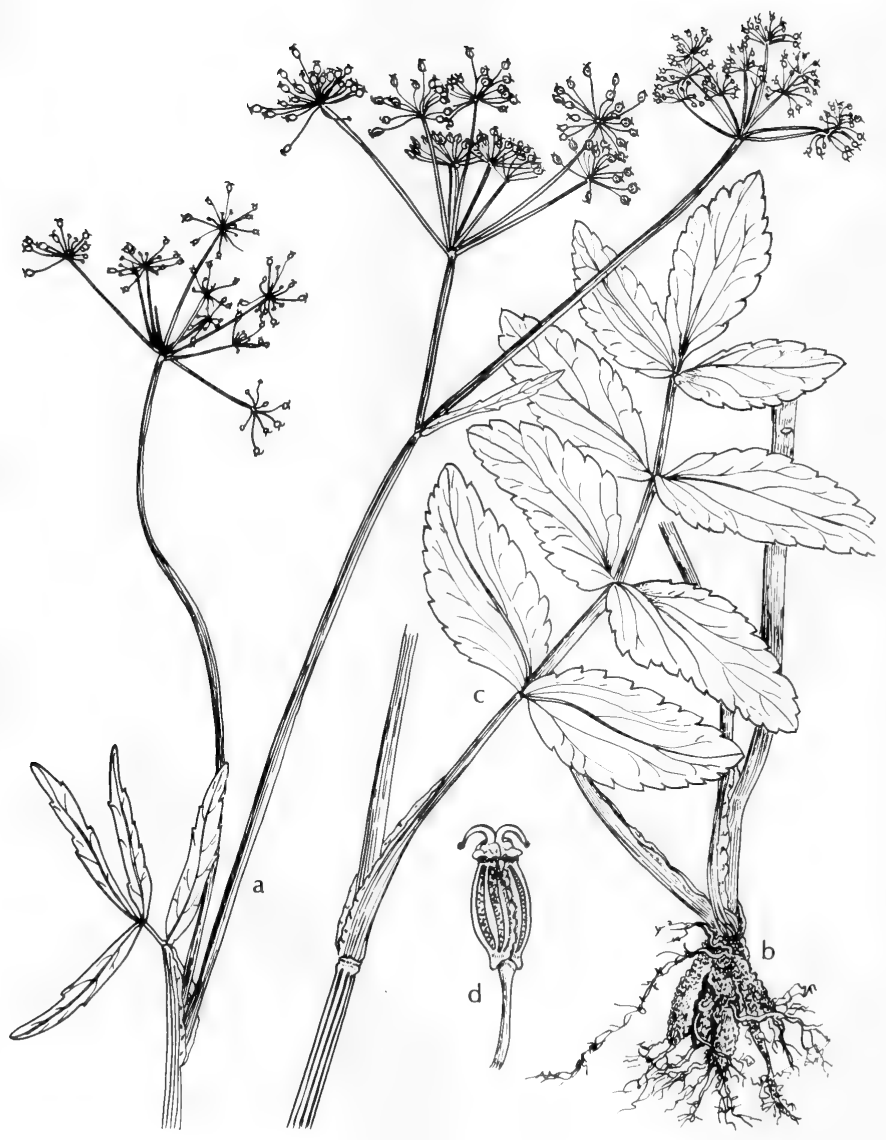

Fig. 597: Oxypolis Fendleri: a, top of plant, x 1/2; b, basal part of plant, x 1/2; c. leaf, $x \frac{1}{2}$; d, fruit, $x$ 5. (V. F.). 
In water of ditches, swales and ponds and in open prairies in Okla. (Ottawa and Pushmataha cos.). Tex, in the Timber Belt and the Coastal and Blackland prairies, May-Aug.; from Conn., s. to Fla., w. to Minn., Kan. and Tex.

\section{Eryngium yuccifolium var. synchaetum Coult. \& Rose.}

Plants slender: basal leaves to $35 \mathrm{~cm}$. long and $1 \mathrm{~cm}$. wide, remotely spinulosesetose, with the weak setae in groups of 2 to 4 and to $1 \mathrm{~cm}$. long; heads subglobose, $1-1.5 \mathrm{~cm}$. in diameter; bracts 6 to 9 , spreading or reflexed, linear-lanceolate, to 1 $\mathrm{cm}$. long, entire or few-toothed; bractlets like the bracts but broader, about $5 \mathrm{~mm}$. long, entire, exceeding the fruit; sepals acute; petals oblong, $1.5 \mathrm{~mm}$. long. E. synchaetum (Coult. \& Rose) Coult. \& Rose.

In water of depression, wet savannahs in pine woodlands, in Okla. (Waterfall). Tex. in the Timber Belt and in the Blackland and Coastal prairies, July-Aug.; from Ga. and Fla., w. to Tex. and Okla.

Var. synchaetum is distinguishable from var. yuccifolium, if at all, with difficulty: it may be an ecological variant, but it requires further study.

\section{Eryngium phyteumae Delar.}

Stem erect, slender, 3-6 dm. high, bearing a single head (rarely more); basal leaves on very long petioles, oblong to narrowly oblanceolate, thin, slightly crenate; stem leaves few, sessile, linear-lanceolate, acutely or spinosely toothed; head ovate-oblong, about $12 \mathrm{~mm}$. long, with involucre of numerous linear-lanceolate spinose-tipped bracts (white within and green without) longer than the heads and entire or sparingly spinose-toothed, and a conspicuous terminal tuft of exserted bractlets resembling the bracts; ordinary bractlets narrow, with a long spinose acumination; fruit with ovate abruptly cuspidate-tipped calyx lobes and long slender styles.

In water, in low places and cienagas, s. Ariz. (Cochise Co.), southw. into Mex., Sept.

\section{Eryngium heterophyllum Engelm. MEXICAN-THISTLE}

Plants rather stout, caulescent, glabrous, 2-6 dm. high, perennial from a stout taproot, the stems erect and branching; basal leaves rosulate, narrowly oblanceolate to oblong-oval, to $12 \mathrm{~cm}$. long and $3 \mathrm{~cm}$. wide, cuneate, acute or obtuse, those of the sterile rosettes setose-dentate, the fertile leaves spinose-serrate to pinnatifid or bipinnatisect, the teeth or lobes acute, pungent, callous-margined, the venation pinnately reticulate; petioles narrowly winged, sheathing at the base, shorter than the blades; cauline leaves numerous, like the basal, the lower pinnatifid or bipinnatisect, the upper leaves opposite, sessile and palmately parted; inflorescence paniculately branched, the numerous pedunculate heads rather small, the flowers numerous; heads ovoid, blue to white, 7-15 mm. long, 5-10 mm. broad; bracts 8 to 14 , rigid, spreading-ascending, linear-lanceolate to lanceolate, to $25 \mathrm{~mm}$. long and $5 \mathrm{~mm}$. wide, pungent or acuminate, with 1 or 2 pairs of spinose teeth or entire, green or bluish beneath and yellowish-white above, exceeding or occasionally shorter than the heads; bractlets subulate, 3-5 mm. long, entire, curved, exceeding the fruit; coma of 1 to 4 entire bractlets 5-15 $\mathrm{mm}$. long or occasionally obsolete; sepals ovate, about $1 \mathrm{~mm}$. long, obtuse or truncate and apiculate; styles slender, exceeding the sepals; fruit globose, $1.5-2.5 \mathrm{~mm}$. in diameter, with flat scales below the sepals and on the upper angles, the faces papillate.

In sandy soil along creek and rivers, Ariz. (Cochise, Santa Cruz and e. Pima cos.), N. M. (Grant Co.) and in Tex. in mts. of Trans-Pecos, Aug.-Oct.; from w. Tex, w. to Ariz. s. to Oax. 


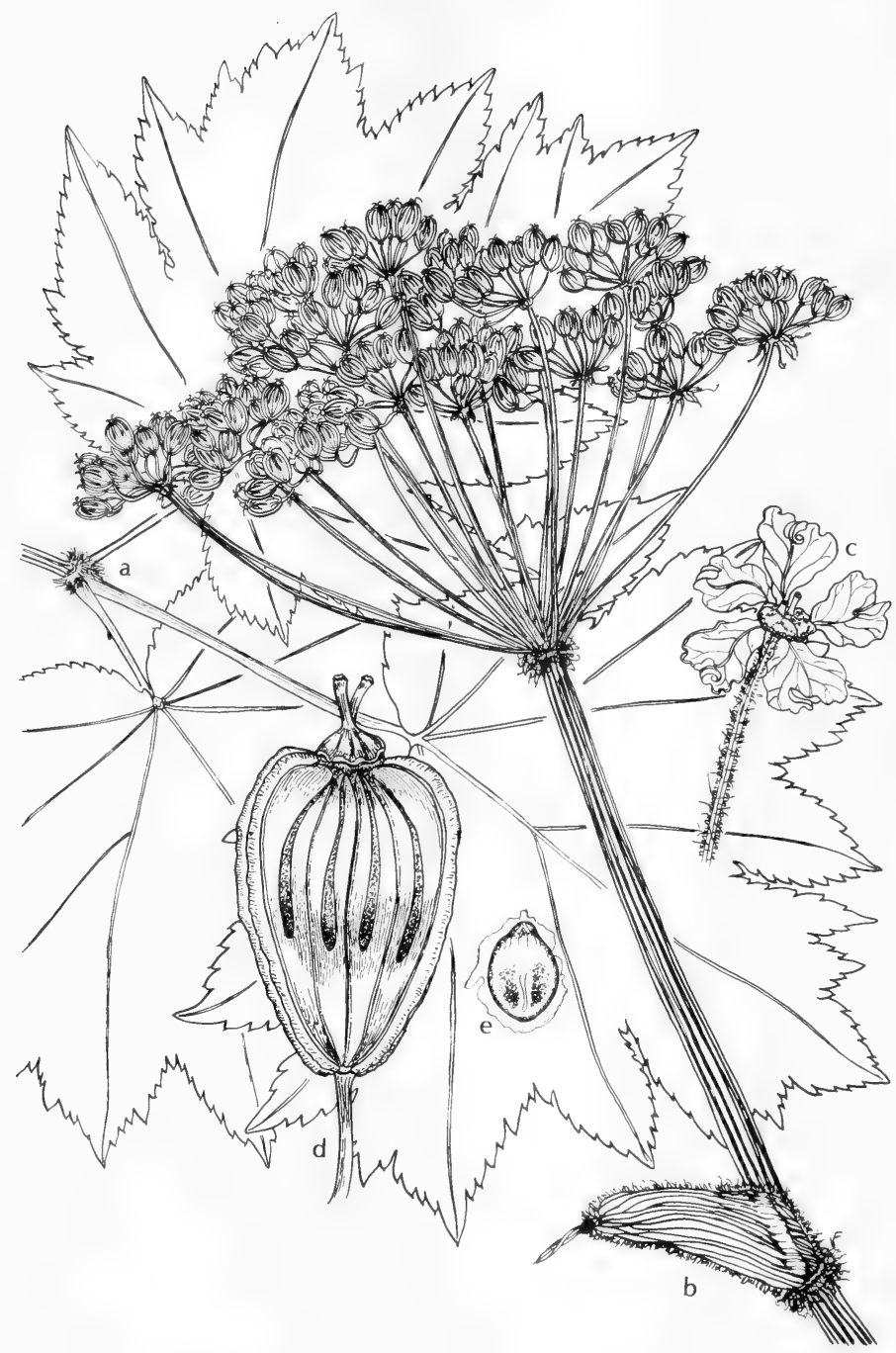

Fig. 598: Heracleum lanatum: a, leaf, x 1/2; b, top of plant, x 1/2; c, flower, x 5; d. fruit, x 5, e, seed, x 5. (V. F.). 


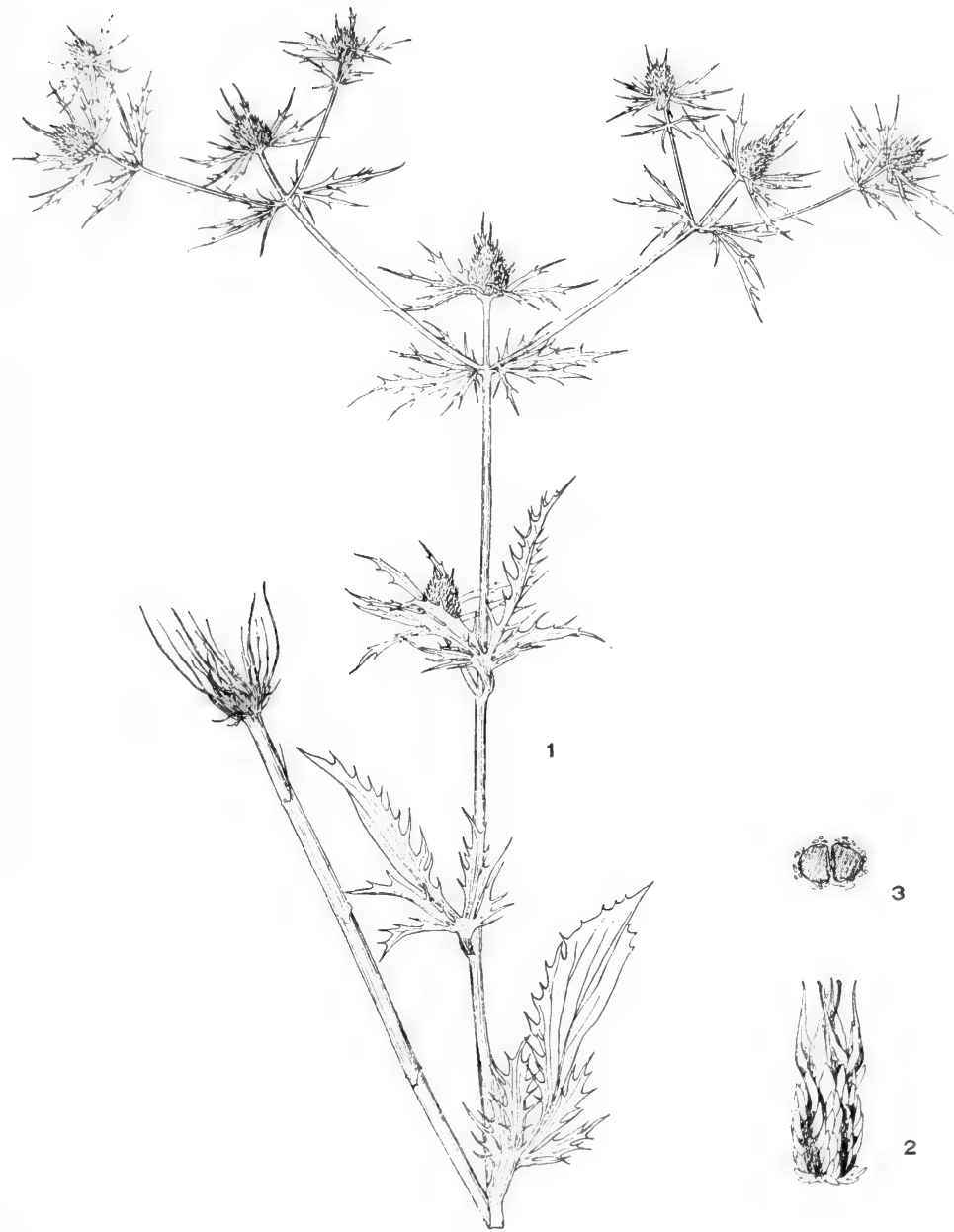

Fig. 599: Eryngium Hookeri: 1, plant, x 1/2; 2, fruit and calyx, side view, x 6; 3 fruit, transverse section, x 6. (From Mathias \& Constance in Lundell's Flora of Texas Vol. 3, Pl. 54). 
Plants slender, caulescent, glabrous, 3-6 dm. high, annuals from fascicled fibrous roots, the erect stems solitary and branched above; basal leaves obovate to oblong-lanceolate, $6-9 \mathrm{~cm}$. long, $2-3 \mathrm{~cm}$. wide, acute, somewhat serrate or dentate, the venation reticulate; petioles slender, sheathing at the base; lower cauline leaves nearly sessile, lanceolate, laciniately toothed and spinulose with a pair of small laciniate segments at the base; upper cauline leaves ovate, palmately divided with 5 to 7 oblong laciniate or pinnatifid spinulose lobes $2-3 \mathrm{~cm}$. long; inflorescence cymosely branched, the pedunculate heads rather large, the flowers numerous; heads amethystine, ovoid to cylindric-ovoid, 8-15 $\mathrm{mm}$. in diameter; bracts numerous, rigid, linear-lanceolate, 1-2 cm. long, spinulose-serrate, broadly winged at the base, exceeding the heads; bractlets lanceolate, 4-6 mm. long, pungent, entire, exceeding the fruit; coma of a few elongate bractlets or wanting; sepals ovate-lanceolate, $2 \mathrm{~mm}$. long, pungent-acuminate; styles shorter than the sepals; fruit 1-2 mm. long, densely covered with flat tawny scales to $0.5 \mathrm{~mm}$. long.

In moist or wet limy soil in the Coastal and Blackland prairies of Tex., JulySept.; also La.

\section{Eryngium integrifolium Walt. Fig. 600.}

Plants slender, caulescent, glabrous, 3-8 dm. high, perennial from a fascicle of tuberous or fleshy-fibrous roots, the erect stems solitary and branching above; basal leaves oblong-lanceolate to oblong-ovate, to $6 \mathrm{~cm}$. long and $2.5 \mathrm{~cm}$. wide, usually cordate at the base, obtuse, entire to shallowly crenate, the venation reticulate; petioles sheathing at the base, lower cauline leaves like the basal but short-petiolate to sessile, the uppermost leaves linear to oblanceolate or ovate, acute, usually spinulose-serrate or rarely laciniate or subentire; inflorescence branched, the pedunculate heads rather small, the flowers numerous; heads amethystine, ovoid to globose, $5-15 \mathrm{~mm}$. in diameter; bracts 6 to 10 , rigid, linear, 1-2 cm. long, entire or usually with 3 to 5 spiny teeth, exceeding the heads; bractlets tricuspidate, $3 \mathrm{~mm}$. long, exceeding the fruit; coma lacking; sepals lanceolate, 1-1.5 $\mathrm{mm}$. long, mucronate; styles slender, exceeding the sepals; fruit about $2 \mathrm{~mm}$. long, the angles densely covered with rows of lanceolate white scales $0.5-1 \mathrm{~mm}$. long, the surfaces usually scaleless.

In moist woods and bogs in Okla. (Waterfall) and in the Timber Belt and the Coastal and Blackland prairies of Tex., Aug.-Oct.; from N.C., s. to Fla. and w. to Tex. and Okla.

\section{Eryngium nasturtiifolium Juss. HIERBA DEL SAPO.}

Plants prostrate, ascending or rarely erect, 1-3 dm. high or long, glabrous, biennial or perennial from a fascicle of fibrous roots or a slender taproot, the leafy stems several and branched from the base; basal leaves spatulate to oblanceolate, to $10 \mathrm{~cm}$. long, $1-3 \mathrm{~cm}$. wide, cuneate, coarsely dentate to runcinatepinnatifid, the teeth or lobes mucronulate or spinose, the venation reticulate; petioles broad, winged; cauline leaves like the basal, spinose-dentate or spinose pinnatifid; inflorescence divaricately trifurcate or cymose, the lateral branches often elongated and continuous to form a monochasium, the small heads numerous and nearly sessile, the flowers numerous; heads ovoid to ovoid-cylindric, to 15 $\mathrm{mm}$. long and $8 \mathrm{~mm}$. broad; bracts 5 to 9 , rigid, spreading, subulate to linearlanceolate, $8-20 \mathrm{~mm}$. long, entire, pungent, about equaling the heads; bractlets lanceolate to obovate, 4-9 $\mathrm{mm}$. long, broadly scarious-margined at the base, entire, exceeding the fruit; coma of several short bractlets 3-7 $\mathrm{mm}$. long, resembling the bracts; sepals ovate, 1-1.5 mm. long, obtuse or acute, mucronulate, serru- 


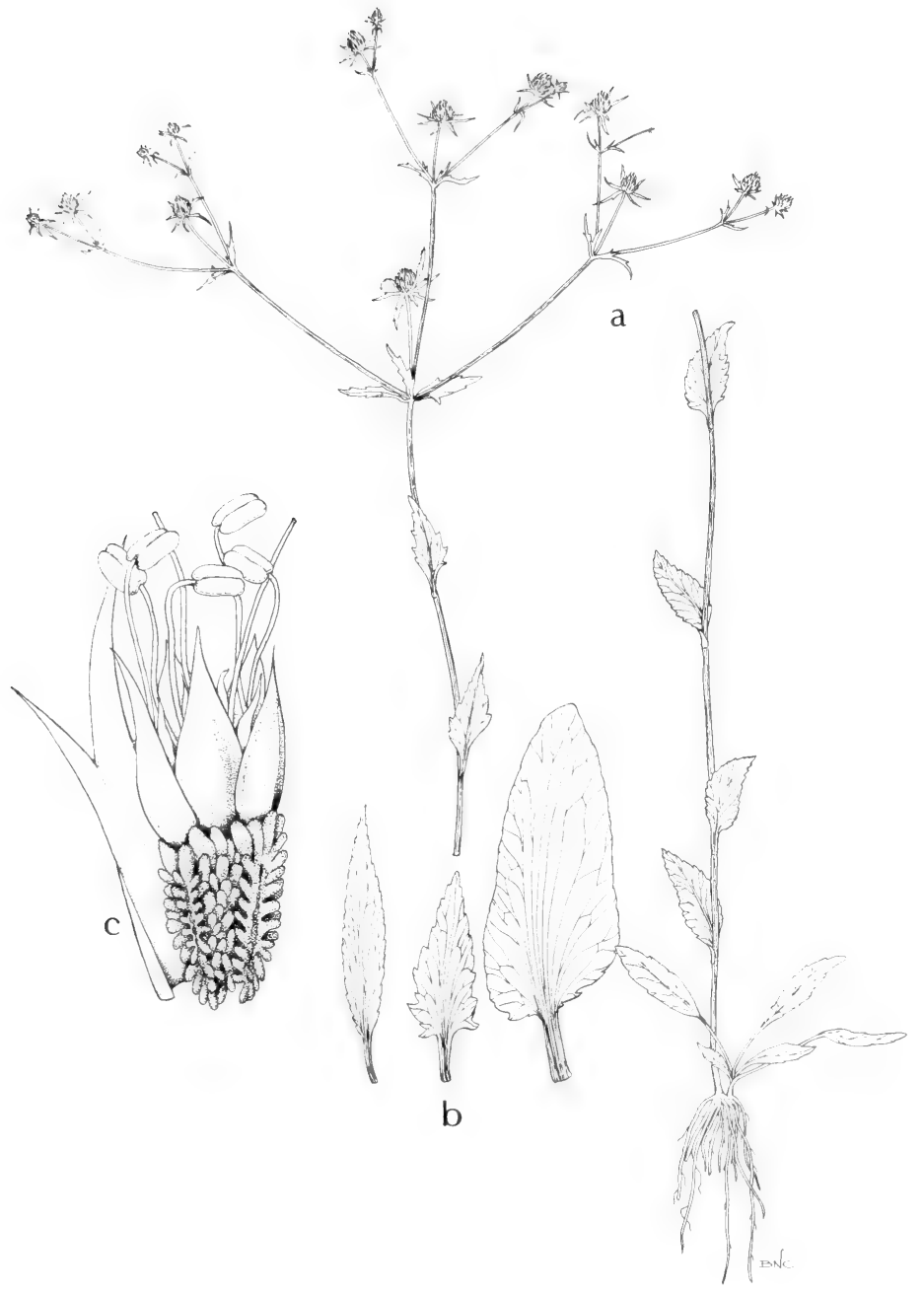

Fig. 600: Eryngium integrifolium: a, habit, $\mathrm{x} \frac{1}{2}$; b, leaves to show variation; c, flower with bractlet, x 25. (Courtesy of R. K. Godfrey). 
late toward the apex; styles shorter than to exceeding the sepals; fruit ovoidglobose, 2-3 mm. long, densely covered with elliptic to linear white or flavescent scales to $2 \mathrm{~mm}$. long.

In moist heavy, usually wet soil in the Tex. Rio Grande Plains, Mar.-July; Tex., Mex. and Cuba.

\section{Eryngium prostratum DC. Fig. 589.}

Plants low, prostrate or ascending, glabrous, 1.5-7 dm. high, perennial from a fascicle of fibrous roots, the stems very slender and simple or somewhat branched above; basal leaves ovate to lanceolate, to $55 \mathrm{~mm}$. long and $25 \mathrm{~mm}$. wide, simple or palmately lobed, the margins entire or irregularly and remotely dentate, the venation reticulate; petioles slender; cauline leaves like the basal, reduced, clustered at the nodes, sessile above; inflorescence of elongated monochasia bearing small numerous heads on filiform axillary peduncles, the flowers few; heads often blue, ovoid to ovoid-cylindric, to $9 \mathrm{~mm}$. long and $4 \mathrm{~mm}$. broad; bracts 5 to 10 , foliaceous, reflexed, lanceolate, to $12 \mathrm{~mm}$. long, acute, equaling the heads; bractlets narrowly subulate, about $1 \mathrm{~mm}$. long, acute, shorter than the fruit; coma lacking; sepals ovate to semiorbicular, about $0.8 \mathrm{~mm}$. long, obtuse, mucronulate; styles exceeding the sepals; fruit subglobose, $2 \mathrm{~mm}$. in diameter, sparsely covered with low white tubercles.

In wet ditches, swales or moist soil in Okla. (McCurtain, LeFlore and Pushmataha cos.), and in Tex. in the Timber Belt and the Coastal and Blackland prairies, May-Sept.; from S.C., s. to Fla. and w. to Ky., Mo., Okla. and Tex.

\section{Fam. 99. Cornaceae Dum. Dogwood FAmily}

Shrubs to large trees; leaves alternate or opposite, simple, entire or nearly so, without stipules; flowers regular, small, perfect or unisexual, 4- or 5-merous; calyx small or obsolete; petals (when present) 4 or 5 ; stamens 4 or as many as 12 in two series; filaments elongate; anthers introrse; pistil 1 ; styles 1 or 2 ; ovary inferior, 1- or 2-celled; fruit a drupe.

About 120 species in 14 genera, chiefly in the North Temperate Zone but also in the tropics of both hemispheres.

1. Large trees, mostly above $10 \mathrm{~m}$. in height, leaves alternate; stamens 5 or more.... 1. Nyssa

1. Shrubs or small trees, mostly less than $5 \mathrm{~m}$. in height; leaves opposite; stamens 4 ....... 2. Cornus

\section{Nyssa L. Tupelo. Sour-gum}

Trees with simple alternate deciduous leaves and greenish or greenish-white flowers borne at the summit of axillary peduncles; leaves entire or rarely slightly toothed, often crowded near tip of branchlets; flowers perfect or unisexual; staminate flowers numerous, the calyx small and 5-parted, the small fleshy petals soon deciduous or entirely lacking; stamens 5 to 12 , inserted on the outer edge of a convex disk; pistillate flowers solitary or as many as 8 , sessile in a bracted cluster, much larger than the staminate flowers; style simple, elongate; ovary 1-celled; fruit an ovoid to ellipsoid 1 -seeded drupe.

A small genus of about 10 species in North America and Asia. Placed by some authors in the segregate family Nyssaceae.

1. Leaves usually much more than $1 \mathrm{dm}$. long, mucronate; staminate flowers sessile in a capitule; pistillate flowers solitary; fruits $20 \mathrm{~mm}$. or more long; endocarp wing-ridged. 1. N. aquatica. 


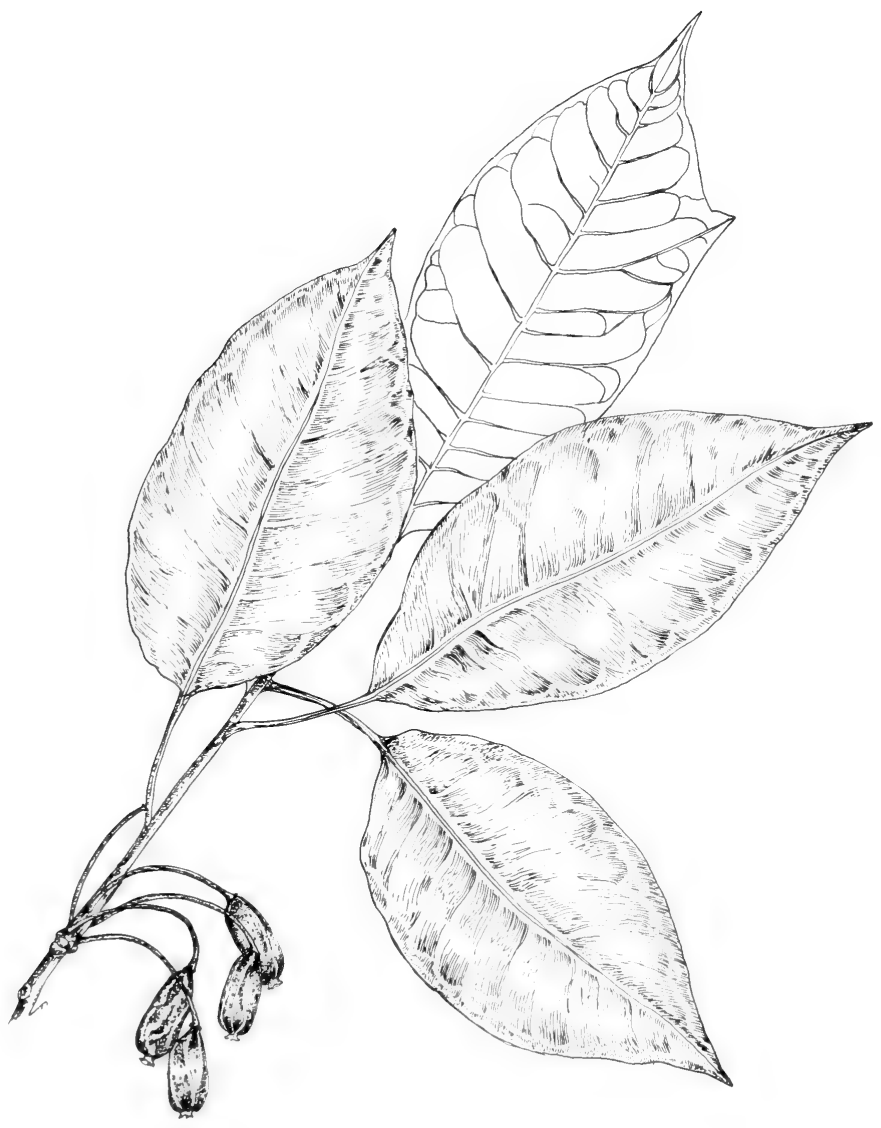

Fig. 601: Nyssa aquatica: branchlet with fruit, $\mathrm{x}$ 1/2. (V. F.). 


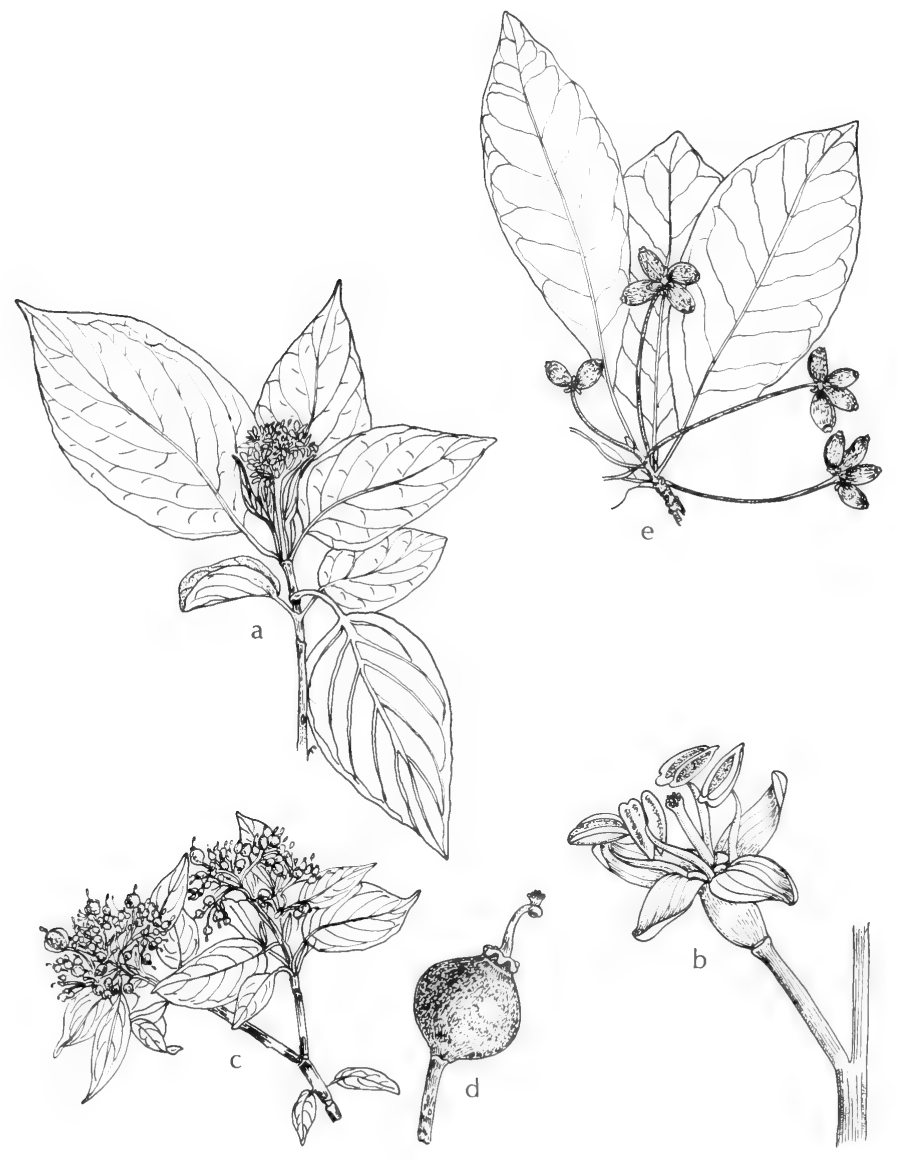

Fig. 602: a-d, Cornus stolonifera: a, end of branch in flower, $\mathrm{x} 1 / 2 ; \mathrm{b}$, flower, $\mathrm{x} 5$ : $\mathrm{c}$, end of branch with fruit, $\mathrm{x} 1 / 2$; d, fruit, $\mathrm{x} \mathrm{21/2}$. e, Nyssa sylvatica: e, end of branch with fruit, $x \frac{1}{1 / 2}$. (V. F.). 
1. Leaves usually less than $1 \mathrm{dm}$. long, not mucronate; staminate flowers pedicellate in an umbel or congested raceme; pistillate flowers 2 or more on a peduncle; fruits less than $15 \mathrm{~mm}$. long; endocarp smooth or obtusely ridged (2)

2(1). Leaves obovate to broadly elliptic, typically about 2 times as long as broad, usually thin-textured, when young with a densely long-pilose petiole .2. N. sylvatica var. sylvatica.

2. Leaves mostly linear to oblanceolate, typical 3 times as long as broad, usually leathery, the petiole subglabrous or only sparsely short-pilose............

2. N. sylvatica var. biflora.

1. Nyssa aquatica L. Tupelo, cotton-Gum. Fig. 601.

Large tree to $30 \mathrm{~m}$. or more tall, with the trunk somewhat swollen at base; leaves with petioles to $6 \mathrm{~cm}$. long, ovate to broadly oblong-elliptic, cuneate or sometimes slightly cordate at base, rather abruptly acute to acuminate and mucronate at apex, to $3 \mathrm{dm}$. long and $1 \mathrm{dm}$. broad, pale and usually downy-pubescent on lower surface; fruit ellipsoid, bluish. N. uniflora Wang.

In inundated swamps and along sluggish streams in e. Tex., Mar.-Apr.; from Va., s. Ind., s. Ill. and Mo., s. to Fla. and Tex.

The source of an excellent honey.

2. Nyssa sylvatica Marsh. var. sylvatica. BLACK-GUM, SOUR-GUM, PEPPERIDGE. Fig. 602 .

Rather large trees to $30 \mathrm{~m}$. tall, with horizontally spreading branches; leaves with petioles to $2 \mathrm{~cm}$. long, broadly rounded to abruptly acuminate at apex, lustrous on upper surface, smooth and glabrate or eventually glabrous on lower surface, to $14 \mathrm{~cm}$. long and $7 \mathrm{~cm}$. broad; fruiting peduncle usually more than $3 \mathrm{~cm}$. long; fruits somewhat acid. Incl. var. dilatata Fern. and var. caroliniana (Poir.) Fern.

In swamps, low woods and sandy open woodlands in e. Tex. and e. Okla. (Waterfall), Apr.-May; from Me., s. to Okla., Mo., Fla. and Tex.; also Mex.

Var. biflora (Walt.) Sarg. BLACK-GUM.

Large trees to $35 \mathrm{~m}$. tall, with the base of the trunk swollen when submersed; leaves rounded to acute at apex, glabrous or nearly so, to $12 \mathrm{~cm}$. long or more and rarely to $4 \mathrm{~cm}$. broad; fruiting peduncle usually less than $3 \mathrm{~cm}$. long; fruits bitterish. N. biflora Walt.

In periodically inundated swamps, low wet woods and along streams in e. Tex., Mar.-Apr.; from Del. and Md., s. to Fla. and Tex.

The fruits are eaten by many different songbirds, ducks and game birds as well as by most mammals, and deer and beaver eat the vegetative parts.

\section{Cornus L. Dogwood. Cornel}

Shrubs or small trees with opposite (in ours) deciduous leaves and small flowers in open cymes or close heads; flowers perfect; calyx minutely 4-toothed; petals 4, oblong-elliptic, obtuse, spreading; stamens 4, the filaments slender; style slender; stigma flat or capitate; fruit a small drupe, with a 2-celled and usually 2-seeded stone.

About 40 species in the North Temperate Zone.

The fruits of these species are eaten by various birdlife, wildfowl and game birds as well as by small mammals, while the vegetative parts are eaten by deer, beaver and various other small mammals.

1. Distribution in New Mexico and Arizona.

1. C. stolonifera.

1. Distribution in Oklahoma and Texas eastward (2)

2(1). Cymes elongate, laxly paniculate; pedicels usually bright-red; branches grayish; fruit white or creamy-white at maturity.... 2. C. racemosa.

2. Cymes broad, compact, flat or only slightly rounded across the top (3) 
3(2). Leaves more or less scabrous on upper surface, pilose-woolly on lower surface; pith usually brown; fruits white at maturity...3. C. Drummondii.

3. Leaves glabrous or nearly so; pith white; fruits bluish at maturity.

4. C. foemina.

1. Cornus stolonifera Michx. Red-OSIER Dogwood. Fig. 602.

Shrub 2-5 m. tall, erect, with reddish or purplish branches; pith white; leaves deciduous, ovate to ovate-lanceolate, shortly acute, 3-10 cm. long, the upper surface dark-green and glabrate, the lower lighter green surface with prominent veins and microscopically puberulent with appressed straight 2-branched hairs; cymes 2-5 cm. across, their peduncles and branches sparsely to densely pubescent; flowers whitish, appearing after leaves; style glabrous; mature drupe subglobose, white to bluish, the stone 4-5 mm. wide and smooth or furrowed.

Wet soil about springs, along streams and on wet seepy slopes, often with willows and alders, in N.M. (widespread in mts.) and Ariz. (Apache and Coconino, s. to Cochise and Pima cos.), May-July; Can. and Alas., s. to D.C., N.M., Ariz. and Calif.

\section{Cornus racemosa Lam.}

Shrub or small tree to $5 \mathrm{~m}$. high often forming thickets, the slender twigs reddish, soon becoming grayish, the pith usually pale-brown; leaves narrowly ovate or lanceolate to elliptic, mostly $4-8 \mathrm{~cm}$. long, to about $4 \mathrm{~cm}$. wide, abruptly longacuminate, cuneate at base, papillose and somewhat whitened beneath, minutely appressed-strigillose on both sides; lateral veins 3 or 4 on each side; inflorescences often numerous, usually paniculiform, to $6 \mathrm{~cm}$. long; pedicels and branchlets reddish; fruit at first lead-color, becoming white with maturity, 5-7 mm. high, the stone obliquely subglobose. C. candidissima Marsh., non Mill.

In moist or wet soil on seepage slopes, in swamps, thickets and on stream banks in open woodlands in e. Tex. and s.e. Okla. (McCurtain Co.), Apr.-June; from Me. to Man., s. to Fla. and Tex.

\section{Cornus Drummondii C. A. Mey. Rough-leaf dogwood.}

Shrubs or small trees to $5 \mathrm{~m}$. tall; branchlets gray or sometimes dark-brown or reddish, the pith brownish; leaves with petioles to $15 \mathrm{~mm}$. long, ovate to ellipticlanceolate, usually abruptly acuminate-attenuate at apex, to $10 \mathrm{~cm}$. long and $6 \mathrm{~cm}$. wide, more or less scabrous on upper surface, pilose-woolly on lower surface with the hairs mostly spreading; cymes (or corymbs) round-topped, pubescent, to about $75 \mathrm{~mm}$. across; flowers white or creamy-white, somewhat malodorous; corolla cylindric in bud; petals $3.5-5.5 \mathrm{~mm}$. long; fruits white, 5-6 $\mathrm{mm}$. in diameter, the stone globose. C. asperifolia of auth.

In damp woodlands and thickets, swamp at head of lakes and seepage areas, occasionally on dry hills, in e. half of Tex. and Okla. (Jefferson and Woodward cos.), Apr.-June; from e. Va., s. Ind. and s.e. Mo. and Okla., s. to Fla. and Tex.

\section{Cornus foemina Mill. English Dogwood.}

Shrub or small tree to $4 \mathrm{~m}$. tall; branchlets reddish or brown, smooth, the pith usually. white; leaves with petioles $1 \mathrm{~cm}$. or less long, broadly lanceolate to narrowly ovate-elliptic, tapering to a narrow elongate tip, to about $10 \mathrm{~cm}$. long and $4 \mathrm{~cm}$. wide, glabrous or nearly so, dark-green on upper surface, paler on lower surface; cymes round-topped, open; flowers creamy-white; corollas subcylindric in bud; anthers bluish; fruits bluish, about $5 \mathrm{~mm}$. in diameter, the stone longer than broad and slightly furrowed. C. stricta Lam., Svida stricta (Lam.) Small.

Swamps, seepage bogs and low wet woodlands in e. Tex., May-June; from Ind. and Va., s. to Fla., La. and Tex. 
Shrubs with alternate serrate deciduous leaves, simple or stellate hairs and very fragrant flowers in crowded terminal simple or paniculate racemes; fiowers regular, hypogynous, polypetalous, 5-merous; disk none; sepals separate, imbricate in bud; stamens 10, the filaments elongate; anthers sagittate, extrorse in bud, their sacs opening by pores at base and inverted at anthesis; ovary superior, 3-celled; syle 3-cleft near summit; capsule globose, 3-valved, the valves 2-cleft at maturity, many-seeded, enclosed in the persistent calyx.

Only one genus.

\section{Clethra L. Sweet Pepper-bush. White Alder}

Characters those of the family. Consisting of about 120 species that are found mainly in Asia and tropical America; also in temperate America and Madeira.

\section{Clethra alnifolia L. Fig. 603.}

Shrub to $3 \mathrm{~m}$. tall; leaves 5-12 cm. long, obovate-elliptic to cuneate-obovate or occasionally elliptic-lanceolate, obtuse to shortly acuminate at apex, tapering to a petiole to $2 \mathrm{~cm}$. long, sharply serrate above the middle, nearly entire below the middle, straight-veined; racemes erect, to $2 \mathrm{dm}$. long, densely short-pubescent; the deciduous bracts shorter than the flowers; flowers on short-pubescent pedicels 2-5 mm. long; calyx lobes triangular-ovate, acute, short-pubescent; petals white, oblongobovate, about $8 \mathrm{~mm}$. long; filaments glabrous; style slender; capsule pubescent, about $3 \mathrm{~mm}$. in diameter, erect or ascending.

In swamps, about lakes and in wet woods and thickets in s.e. Tex., July-Sept.; from Me. s. to Fla. and Tex.

In some regions this species is known as "poor man's soap"-the flowers when crushed in water form a lather.

\section{Fam. 101. Ericaceae Juss. Heath Family}

Shrubs, trees or rarely herbs or vines, evergreen or deciduous; leaves simple, alternate, or rarely opposite or whorled, exstipulate, leathery to thin-herbaceous, entire or serrate; flowers perfect, regular or irregular, usually in racemes or panicles, rarely solitary; calyx of 4 to 7 distinct or partially united sepals, usually persistent; corolla of 4 to 7 distinct or united petals, commonly funnelform, campanulate or urceolate; stamens hypogynous, twice as many as the corolla lobes; anthers bilocular, often appendaged, dehiscing by "apical" slits, clefts or pores; style single, the stigma minute and discoid; fruit a loculicidal or septicidal capsule, drupe or berry.

Perhaps 2,000 species in about 75 genera nearly world-wide in distribution. A great many ornamental species occur in this family primary of which are the rhododendrons.

1. Ovary inferior; fruit a juicy berry crowned by the persistent calyx teeth....

1. Ovary superior; fruit a dry capsule (2)

2(1). Corolla funnelform, elongate, the tube more or less glandular-stipitate; capsule ellipsoid-conic, septicidal.........................2. Rhododendron

2. Corolla urceolate, ovoid or cylindric, short, nonglandular; capsule subglobose to ovoid, loculicidal (3) 

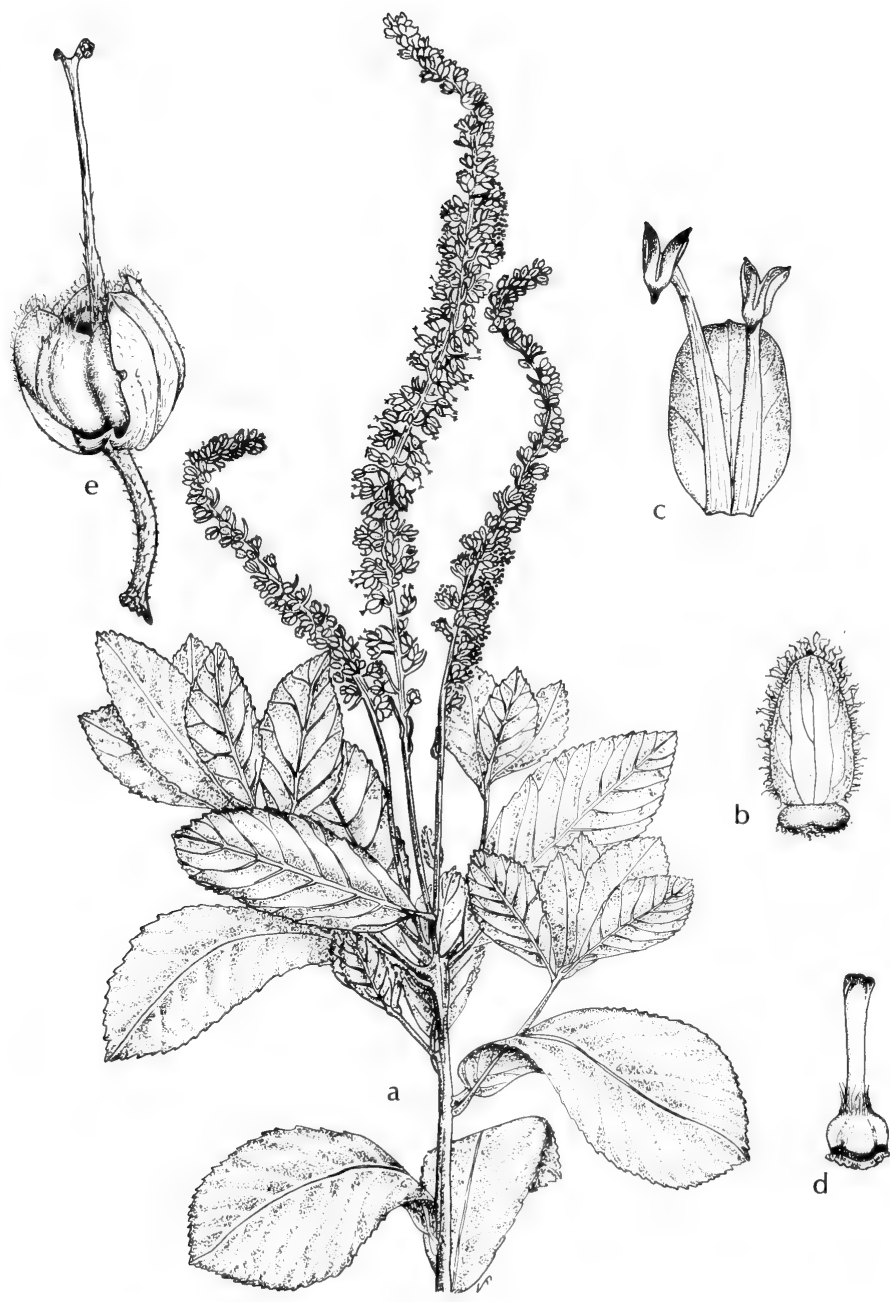

Fig. 603: Clethra alnifolia: a, habit, x 1/2; b, inner surface of sepal, x 5; c, inner surface of petal with stamens, x 5; d, young style and stigmas, x 5; e, capsule with part of calyx removed, x 5. (V. F.). 
3(2). Inflorescence clearly elongate, racemose; sepals imbricate (at least in bud); capsule ovoid, truncate, the margins not differentiated..3. Leucothö̈

3. Inflorescence of corymbose clusters in axils of leaves or bracts of the same or preceding season; sepals valvate or separated even in bud; capsule subglobose-compressed, the carpel midrib not differentiated.

4. Lyonia

\section{Vaccinium L. Blueberry}

Shrubs or small trees; leaves alternate, entire to serrate; flowers usually solitary, in clusters or racemes; corolla variously shaped, the limb 4- or 5-cleft; stamens 8 or 10; anthers awned on back or awnless, the cells opening by a terminal pore; berry 4- or 5-celled, many-seeded, sometimes 8 - or 10-celled by false partitions extending from the back of each cell to the placenta, edible in most species.

A large genus of polymorphic species that are represented throughout the world. The edible fruits of several species provide the "blueberry" of the market place.

The fruit of these plants, a much-appreciated item in the human diet, is one of the most important foods for songbirds, some game birds and animal life. The plants are also browsed by deer, rabbits and domestic stock. The species are worthy of cultivation, not only to attract and feed wildlife but because of their ornamental attractiveness.

1. Flowers on specialized lateral branches, subtended by foliaceous bracts (2)

1. Flowers not on specialized branches, usually at the first nodes of a normal leafy branch (3)

2(1). Bracts of inflorescence conspicuously smaller than the foliage leaves, rarely more than $1 \mathrm{~cm}$. wide; mature leaves rarely less than $5 \mathrm{~cm}$. long...... 1. $V$ stamineum.

2. Bracts of inflorescence one half to nearly as large as the foliage leaves, $1-2 \mathrm{~cm}$. wide; mature leaves to $5 \mathrm{~cm}$. long.

2. V. caesium.

3(1). Lower surface of leaves bearing small glandular hairs (4)

3. Lower surface of leaves nonglandular (5)

4(3). Plants mostly less than $10 \mathrm{dm}$. high; leaves 3-4.5 (rarely 5) cm. long; corolla $6-9 \mathrm{~mm}$. long............................................ V. virgatum.

4. Plants $15 \mathrm{dm}$. or more high; leaves 4-5 (rarely 6.5 ) $\mathrm{cm}$. long; corolla 9-12 mm. long.

4. V. amoenum.

5(3). Leaves serrate, rarely more than $3 \mathrm{~cm}$. long

5. Leaves entire, rarely less than $5 \mathrm{~cm}$. long..

5. V. Elliottii.

\section{Vaccinium stamineum L. DeERrERry, SQUAW-HUCKLEBERry.}

Diffusely branched shrub to $3 \mathrm{~m}$. high, commonly stoloniferous, the young branchlets and leaves more or less pubescent to essentially glabrous; leaves subsessile or with a petiole to $3 \mathrm{~mm}$. long, ovate or oblong-elliptic to elliptic-lanceolate or elliptic-oblanceolate, subcordate to rounded or cuneate at base, obtuse to acute and apiculate at apex, to $9 \mathrm{~cm}$. long and $4 \mathrm{~cm}$. wide, pale, often glaucous or whitened beneath; flowers $6-10 \mathrm{~mm}$. long, in loose bracted racemes, pendulous on filiform pedicels about $1 \mathrm{~cm}$. long; floral bracts similar to but usually much smaller than the foliage leaves, obtuse to acute, usually much less than $1 \mathrm{~cm}$. wide; calyx glabrous or the lobes marginally ciliate; corolla white to greenish-white or purplish, open-campanulate, with 5 spreading lobes; anthers much-exserted, their awns much shorter than the tubular tips; berry juicy, tough-skinned, greenish to amber-color, sometimes purple or blue, with or without bloom, about $1 \mathrm{~cm}$. in diameter, dropping promply: seeds soft. Polycodium stamineum (L.) Greene.

In sandy or clayey soils in pinelands, mixed forests, wet savannahs and bottomlands in Okla. (Waterfall) and s.e. Tex., rarely on wooded bluffs in n.e. Tex. 
(Bowie Co.), Mar.-May; from Tex. to Fla., n. to Mass., N.Y., s. Ont., O., Ind. and Mo.

This is a highly variable species and, east of Texas, a number of segregates have been proposed based on the presence or lack of pubescence and glaucousness of the leaves, stems, hypanthium and calyx. Most of these unstable variants can probably be found in our flora but they are scarcely worth recognizing.

\section{Vaccinium caesium Greene.}

Small shrubs mostly less than $5 \mathrm{dm}$. high, pubescent to glabrate; leaves green or somewhat whitened beneath, typically oblong-elliptic, rounded to subcordate at base, usually bluntly obtuse-apiculate at apex, to $5 \mathrm{~cm}$. long; bracts of inflorescence similar in shape to foliage leaves and one half to nearly as long as them, $1-2 \mathrm{~cm}$. wide, noticeably exceeding the pedicels.

In wettish savannahs and open pine-hardwood forests in e. Tex., rare, Mar.Apr.; from Fla. to Tex., n. to W.Va. and Pa.

This dubious species is distinguished from $V$. stamineum solely in having small, bluntly rounded foliage leaves, and bracts of the racemes $1-2 \mathrm{~cm}$. wide and one half to nearly as large as the foliage leaves.

\section{Vaccinium virgatum Ait.}

Shrubs in rather extensive colonies, rarely more than $1 \mathrm{~m}$. high; leaves deciduous, green, the lower surface conspicuously glandular, pubescent along the midrib or sometimes glabrous, spatulate to oblanceolate or narrowly elliptic, narrowly cuneate at base, acute to acuminate at apex, usually 3-4.5 (sometimes 5 ) $\mathrm{cm}$. long and $1-1.5$ (sometimes 2 ) $\mathrm{cm}$. wide, the margin sharply serrate; corolla cylindricurceolate, 6-9 mm. long, pink-tinged, often conspicuously so; fruit usually shinyblack, 6-10 $\mathrm{mm}$. in diameter, generally of poor flavor and texture.

Mostly along streams in open forests, in boggy areas and flatwoods in e. Tex. and Okla. (Waterfall), Mar.-Apr.; from n. Fla., Ga. and Ala., w. to Tex. and Okla.

This species and $V$. amoenum are separated entirely upon size-differences of certain organs as given in the key. Although such a basis for separating species is usually eschewed, this particular characteristic for these two entities is remarkably constant.

\section{Vaccinium amoenum Ait.}

Plants suckering to form dense clumps that are occasionally a meter or more in diameter at the base, sometimes crown-forming, 15-25 dm. high; leaves deciduous, dark-green or rarely slightly glaucescent, the lower surface bearing conspicuous glands, pubescent along the veins or rarely glabrescent, obovate to oblanceolate or elliptic, cuneate at base, acuminate at apex, 4-5 (rarely to 6.5 ) $\mathrm{cm}$. long and $15-25$ (rarely to 30 ) $\mathrm{mm}$. wide, the margin sharply serrate; corolla narrowly to broadly cylindric-urceolate, 9-12 mm. long, often deep-pink; fruit black or darkblue, $8-10 \mathrm{~mm}$. in diameter, usually thick-skinned and of unpleasant flavor.

Usually along streams in woodlands and on edge of woods and in wettish savannahs in e. Tex., Mar.-May; from S. C. to n. Fla., w. to Tex. and Ark.

\section{Vaccinium Elliottii Chapm. Elliott's blueberRy.}

Plants crown-forming or sometimes in much-restricted colonies, $2-4 \mathrm{~m}$. high; leaves deciduous, usually thin-textured, green and shining, the lower surface nonglandular, glabrous to puberulent or even pubescent, usually broadly elliptic, to $3 \mathrm{~cm}$. long and $15 \mathrm{~mm}$. wide, the margins serrate or rarely subentire; corolla narrowly urceolate, 6-7 mm. long, usually some shade of pink; fruit usually dark, sometimes black and shining but often dull and occasionally glaucous, $5-8 \mathrm{~mm}$. in diameter or larger in some forms, the flavor fair to poor. 
In open flatwoods and ravines, rarely in swampy areas and occasionally in cleared river bottoms that are subject to periodic flooding, in e. Tex., Feb.-Apr.; from s.e. Va., s. to Fla., w. to Tex. and Ark.

\section{Vaccinium arkansanum Ashe.}

Large shrub, often with several stems, crown-forming or (if disturbed) suckering from a rather small base, 2-4 m. high; leaves deep-green, the lower surface rather pale and nonglandular, pubescent, broadly elliptic, rounded to cuneate at base. acute and apiculate at apex, to $8 \mathrm{~cm}$. long and $4 \mathrm{~cm}$. wide, the margin entire; corolla cylindric-urceolate, 6-8 mm. long, greenish-white, often with pink or red stripes or the whole surface suffused with pink; fruit dull-black or with a bloom. $7-10 \mathrm{~mm}$. in diameter, of fine flavor. $V$. atrococcum and $V$. corymbosum of Texas reports.

Sandy lake or stream margins or in swamps or marshes, occasionally in bogs or open flatwoods, in e. and s.e. Tex., Feb.-Apr.; from n. Fla., w. to Tex. and Ark.

This species has excellent possibilities of being improved and commercially grown for its tasty fruit on sour evergreen-shrub bog soils in southeast Texas. Where found, it produces abundant deep blue fruits with a fine blueberry flavor.

\section{Rhododendron L. Rhododendron. Azalea}

Shrubs or small trees, evergreen or deciduous; buds with several to many imbricate scales; leaves alternate, entire or rarely serrulate; flowers pedicellate, usually in umbellate clusters or corymbs; calyx small, 5-parted, persistent; corolla variously colored from white to purple or red, sometimes yellow, funnelform to tubular or rotate to campanulate, usually with a 5-lobed limb, deciduous; stamens mostly twice as many as the corolla lobes and greatly exceeding them, usually declined; anther cells opening by a small apical pore; style elongated and mostly surpassing the stamens, the stigma capitate; capsule septicidal, usually ellipsoidconic, the seeds numerous.

About 600 species in temperate and cold regions of the Northern Hemisphere.

Our plants fall into the deciduous-leaved "Azalea" section of Rhododendron. The genus, as a whole, is of great ornamental value. Species in the various sections of the genus are easily hybridized, and numerous garden hybrids exist.

1. Outer surface of corolla lobes with stipitate glands extending up to or near the apex; flowers appearing (or expanding) after the leaves have unfolded; pedicels, calyx and capsules copiously stipitate-glandular: filaments usually only slightly exceeding the corolla (2)

1. Outer surface of corolla lobes without stipitate glands to near the apex, glabrous or at most puberulent or pubescent; flowers appearing before or with the leaves as they unfold; filaments usually conspicuously longer than the corolla (3)

2(1). Shrubs 4-10 dm. high, rhizomatous to form colonies............... R. Coryi. 2. Shrubs rarely less than $10 \mathrm{dm}$. high, not noiceably rhizomatous or colonial 2. R. oblongifolium.

3(1). Pedicels, young twigs, petioles, calyx and capsules all canescent-strigose, rarely with a few short scattered inconspicuous glands

3. R. canescens.

3. Pedicels, young twigs, petioles, calyx and (to a lesser extent) the capsules all copiously and conspicuously glandular-stipitate.....

4. R. prinophyllum.

\section{Rhododendron Coryi Shinners.}

Shrub 4-10 dm. high, with a woody rhizome, the branches more or less strigose: leaves oblong-obovate to obovate-elliptic or oblanceolate, to $45 \mathrm{~mm}$. long and 
$2 \mathrm{~cm}$. wide, mostly marginally strigose; flowers produced after the leaves have unfolded; pedicels pubescent and glandular-stipitate; sepals much-abbreviated, pubescent and glandular-stipitate; corolla probably white, about $4 \mathrm{~cm}$. long, the lobes dorsally glandular-stipitate up to or near the apex.

In bogs, savannahs and low woodlands along streams in s.e. Tex., Mar.-June; apparently endemic.

In Texas, this species replaces the similarly rhizomatous $R$. atlanticum (Ashe) Rehd. of eastern United States. It differs markedly, however, from that species. The pedicels, calyx and corolla of $R$. Coryi are not only adorned with stipitate glands but are also more or less densely pilose while those of $R$. atlanticum are essentially glabrous and only glandular-stipitate. The style of $R$. Coryi also is only puberulent or minutely pubescent near its base whereas the style of $R$. atlanticum is conspicuously long-pubescent in most or all of its lower half.

As in $R$. oblongifolium, the flowers in this species develop after the leaves have unfolded, whereas the flowers of $R$. atlanticum appear before or with the young leaves. There is little besides its rhizomatous habit and small stature to separate $R$. Coryi from $R$. oblongifolium. A more realistic treatment might be to consider it as only varietally different from $R$. oblongifolium.

\section{Rhododendron oblongifolium (Small) Millais.}

Shrub to $25 \mathrm{dm}$. high; branchlets finely villous to glabrous and more or less reddish-strigose; buds grayish-pubescent; leaves short-petioled, obovate to elliptic or oblanceolate, to $1 \mathrm{dm}$. long, cuneate or only slightly rounded at base, rounded to acute and mucronate at apex, pubescent beneath to nearly glabrous and sometimes glaucescent; pedicels to $15 \mathrm{~mm}$. long, hirsute to subglabrous and glandularstipitate; flowers white, produced after the leaves are developed; sepals ovate to lanceolate, 1-3 mm. long, glandular; corolla tube usually stoutish, 2-3 cm. long, rather abruptly dilated at the apex, villous and copiously glandular-stipitate on the outside; corolla lobes dorsally glandular-stipitate up to or near the apex; styles white or pink; capsule ellipsoid-conic, 1.5-2 cm. long, blackish and sometimes shiny, profusely adorned with large stipitate glands. Azalea oblongifolia Small.

In sandy or light soils in boggy or seepage areas, savannah-evergreen shrub bogs, along wooded streams and ravines, and in open low pine and pine-hardwood forests in s.e. Okla. (Waterfall) and e. Tex. and La., Apr.-July or even as late as Sept.

In our region this species takes the place of the more eastern $R$. viscosum (L.) Torr. (Azalea viscosa L.) which it closely resembles and under which name our plant has been placed in the past. It is our most widespread and frequent rhododendron, and it also begins flowering a little later than the other species found in our area. The flowers are manifestly viscid or glutinous to the touch.

\section{Rhododendron canescens (Michx.) Sweet. Hoary azalea. Fig. 604.}

Shrub to about $3 \mathrm{~m}$. high, sparingly branched; branchlets canescent-pilose and more or less strigose and sometimes with scattered small glands; leaves mostly oblanceolate to narrowly obovate or oblong, subglabrous to grayish-pubescent or tomentose beneath, to $11 \mathrm{~cm}$. long, cuneate at base, rounded to subacute and mucronate at apex; flowers produced before or with the leaves, slightly fragrant; pedicels canescent-strigose, rarely sparsely glandular; calyx lobes glandless, canescent; corolla tube slender, 15-23 mm. long, usually pink, abruptly expanded at the apex, about twice as long as the whitish glandless lobes; filaments mostly about 3 times the length of the corolla tubes; style $4-6 \mathrm{~cm}$. long; capsule darkbrown, ellipsoid, about $15 \mathrm{~mm}$. long, villous-setose, nonglandular. Azalea canescens Michx. 


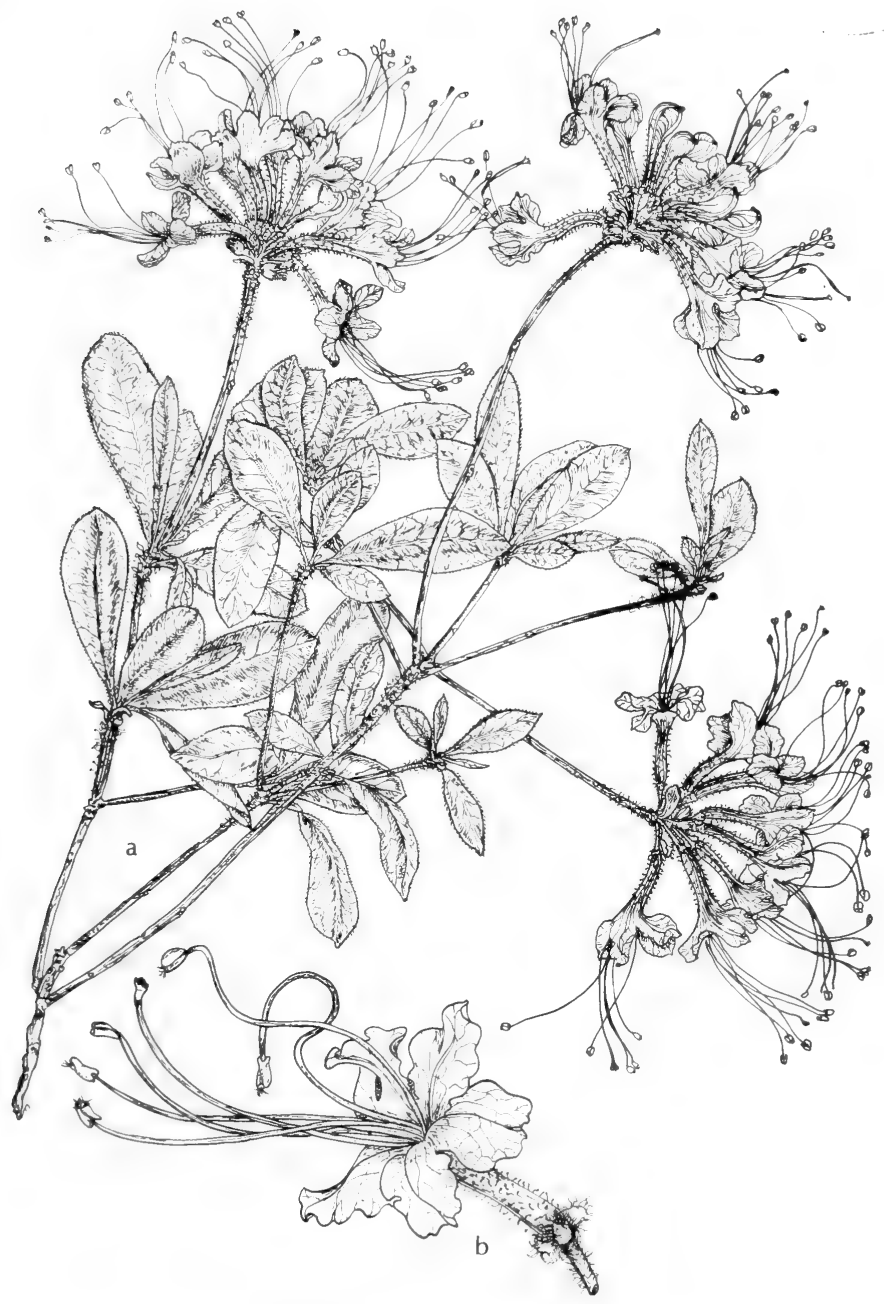

Fig. 604: Rhododendron canescens: a, branch, $\mathrm{x} 1 \frac{1}{2}$; b, flower, x 1. (V. F.). 
In sandy or light soils in and on the edge of bogs, in seepage areas, along wooded streams and in pine-hardwood flats in e. Okla. (Waterfall) and e. Tex., Mar.-May; from Fla. to Tex., n. to Del., Md. and O.

This species includes those plants from our area that have previously been placed in $R$. nudiflorum (L.) Torr. (Azalea nudiflora L.). The name, var. subglabrum Rehd., has been assigned to those plants with glabrous or glabrescent leaves.

\section{Rhododendron prinophyllum (Small) Millais. Honeysuckle, Early-AZalea.}

Shrub to about $3 \mathrm{~m}$. high; branchlets finely pubescent and more or less strigose and glandular-stipitate; buds grayish-pubescent; leaves usually narrowly oblanceolate to elliptic, sometimes obovate, more or less dull-bluish-green in color, to $9 \mathrm{~cm}$. long, obtuse to acute or short-acuminate, grayish-pubescent or short-pilose beneath, more or less pilose above; flowers produced with the leaves, very fragrant; pedicels with stipitate glands among the villosity; calyx lobes ovate, rarely $1 \mathrm{~mm}$. long, glandular-ciliate; corolla glandular-stipitate and villous, bright-pink varying to whitish or with the tube rose-color; corolla tube $1.5-2 \mathrm{~cm}$. long, gradually dilated upward, more or less glandular-stipitate on outside, pubescent inside, about equaling the glandless lobes; filaments mostly about twice the length of the corolla tube; style $4-5 \mathrm{~cm}$. long, commonly purplish above base; capsule dark-brown, oblong-ellipsoid, $1.5-2 \mathrm{~cm}$. long, slightly puberulous and somewhat glandular.

In sandy or light soils usually in moist or wet situations in swamps, along wooded streams and in bog areas in s.e. Tex., late Feb.-May; from Me. to Que., s. and s.w. to Tenn., Mo. and Tex.

\section{Leucothoë D. Don FetTer-Bush. Leucothö̈}

About 50 species mostly in the New World with several in eastern Asia.

\section{Leucothoë racemosa (L.) Gray. Fig. 605.}

Deciduous shrub to $4 \mathrm{~m}$. high, with ascending branches; leaves alternate, short-petioled, oblong to oblanceolate or obovate, acute to short-acuminate, finely serrulate, to $8 \mathrm{~cm}$. long, somewhat pubescent when young; racemes mostly solitary, somewhat secund, ascending or divergent, mostly terminating leafless branches of the previous year, to $7 \mathrm{~cm}$. long; pedicels 2-3 $\mathrm{mm}$. long; flowers white, 5-merous, scaly-bracted; sepals ovate-lanceolate, ciliate, about $3 \mathrm{~mm}$. long, persistent, imbricated in bud; corolla $7-9 \mathrm{~mm}$. long, tubular, constricted at throat, the short lobes spreading; stamens 10; anther-cells each 2-awned; capsules depressed-globose, not lobed, 2.5-3 mm. long, 3-4 $\mathrm{mm}$. thick, the style longpersistent, the sutures not thickened; seeds angled and wingless. L. elongata Small.

Moist thickets, seepage areas, swamp forests and sunny lake shores, rare in s.e. Tex. (Tyler Co.), spring-fall; from Tex. to Fla., n. to Mass., s.e. N.Y. and e. $\mathrm{Pa}$.

\section{Lyonia NuTT.}

Shrubs or rarely arborescent, deciduous or evergreen; leaves alternate, herbaceous to coriaceous, entire or serrulate; flowers white to rose-color, 5-merous, long-pedicellate, in fascicles, racemes or panicles; calyx lobes valvate: corolla cylindric-ovoid to globose-urceolate, with short lobes; stamens 10; filaments basally dilated, hairy and often toothed or appendaged; anthers ovate to oblong, awnless, opening by 2 terminal pores; capsule globose to ovoid, scarcely 5-angled, the dorsal sutures with a thickened ridge that usually divides at dehiscence of the capsule.

About 30 species in Asia and the New World. 


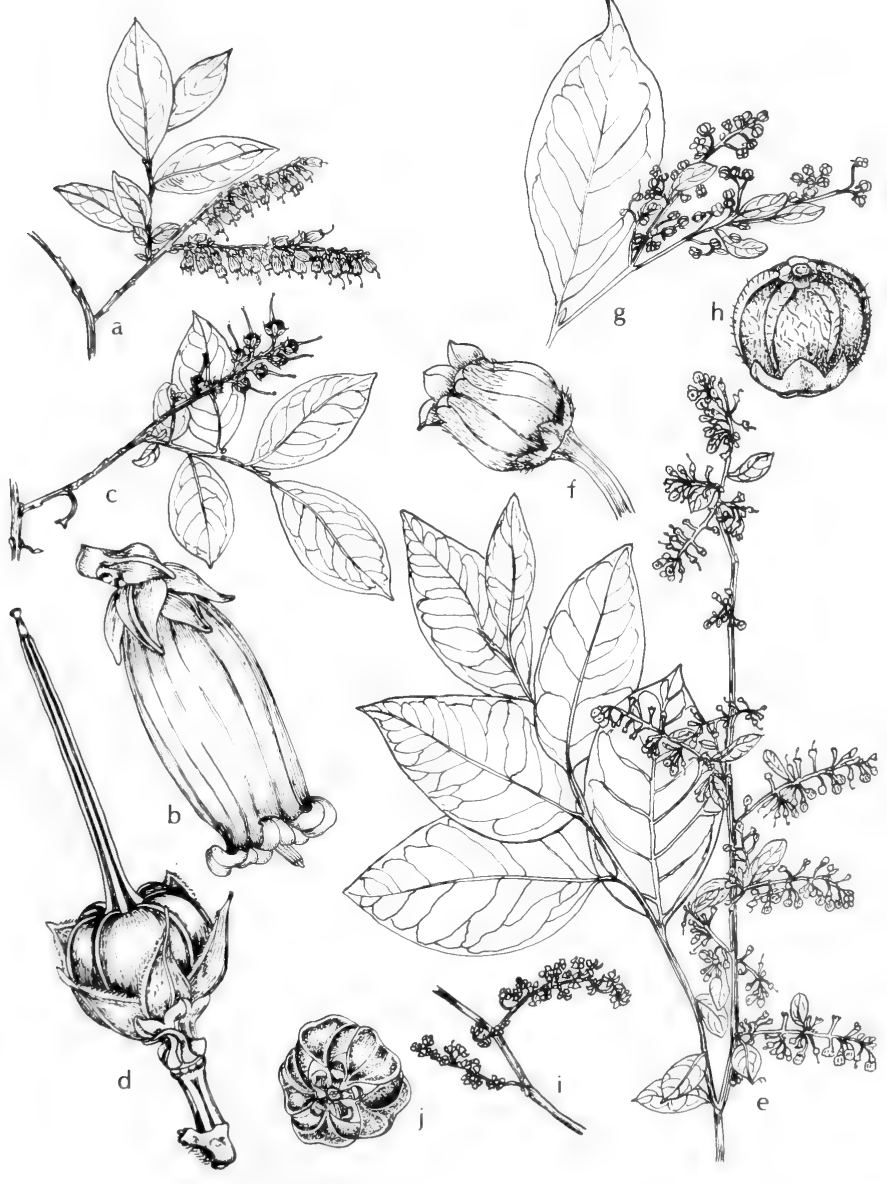

Fig. 605: a-d, Leucothoë racemosa: a, branchlet in flower, x 1/2; b, flower, x 5; c, branchlet in fruit, $\mathrm{x} 1 / 2 ; \mathrm{d}$, fruit, $\mathrm{x} 5$. e-j, Lyonia ligustrina: e, branchlet in flower, $\mathrm{x} 1 / 2$; $\mathrm{f}$, flower, $\mathrm{x} 5 ; \mathrm{g}$, branchlet in fruit $\mathrm{x} 1 \frac{1}{2} ; \mathrm{h}$, new fruit, $\mathrm{x} 5 ; \mathrm{i}$, branchlet with fruit of previous season, $x \frac{1}{2} ; \mathrm{j}$, remains of old fruit, $x$ 5. (V. F.). 
1. Leaves serrulate; inflorescence paniculate; sepals triangular, 1-1.5 mm. long; corolla globose- to ovoid-urceolate, white, about $3 \mathrm{~mm}$. long..........

.1. L. ligustrina.

1. Leaves entire; inflorescences umbellate-racemose; sepals oblong, 3-10 mm. long; corolla nodding, cylindric-ovoid, white to pink, 8-13 $\mathrm{mm}$. long..

.2. L. mariana.

1. Lyonia ligustrina (L.) DC. He-HuCKLeberry, maleberRy. Fig. 605.

Shrub to $4 \mathrm{~m}$. high, sometimes arborescent, deciduous, the bark scaly; leaves short-petiolate, thin, elliptic or elliptic-lanceolate to obovate or oblanceolate, acute to abruptly acuminate, to $95 \mathrm{~mm}$. long and $45 \mathrm{~mm}$. wide, serrulate to rarely subentire; racemes borne in panicles terminating the branches or from the upper axils, the bracts (in ours) foliaceous; sepals $1-1.5 \mathrm{~mm}$. long, broadly triangular; corolla whitish, globose- to ovoid-urceolate, to $3 \mathrm{~mm}$. long; filaments flat, not appendaged; capsule globose to subglobose, to $3 \mathrm{~mm}$. long, about $4 \mathrm{~mm}$. thick. Incl. var. capreaefolia (Wats.) DC. and var. salicifolia (Wats.) DC.

In bog and seepage areas, and along wooded streams and in thickets on edge of lakes, in s.e. Okla. (Waterfall) and e. Tex., Apr.-June; from Fla. to Tex., n. to N.E., N.Y., W.Va., Ky., Ark. and Okla.

\section{Lyonia mariana (L.) D.Don. StAgger BUSH.}

Slender upright shrub, usually with stems naked below and with strongly ascending branches above, usually more or less pilose throughout, to about $2 \mathrm{~m}$. high, usually less than $1 \mathrm{~m}$. high; leaves shortly petiolate, borne on new shoots, deciduous, elliptic-oblong to elliptic-lanceolate or narrowly obovate, obtuse to acute, to $11 \mathrm{~cm}$. long and $5 \mathrm{~cm}$. wide, entire; inflorescences umbellate-racemose, fascicled along leafless old branches; pedicels 1-2 cm. long, bracteolate at the very base; flowers nodding; sepals narrowly oblong, to $1 \mathrm{~cm}$. long, tardily deciduous; corolla cylindric to cylindric-ovoid, $8-13 \mathrm{~mm}$. long, white or pinkish; filaments usually bidentate near apex; capsule ovoid-pyramidal, truncate at the contracted apex, about $7 \mathrm{~mm}$. long, surrounded by the finally appressed sepals.

Peaty or sandy pinelands and edge of evergreen shrub bogs, edge of water about lakes and ponds, usually in moist soils, in e. and s.-cen. Tex. and s.e. Okla. (McCurtain Co.), Mar.-June; from Fla. to Tex., n. to s. N.E., s.e. N.Y., e. Pa., w. Tenn., s. Mo., Ark. and Okla.

The foliage is considered to be poisonous to young grazing animals.

\section{Fam. 102. Primulaceae Vent. Primrose Family}

Annual or perennial herbs with simple or rarely dissected leaves and regular perfect usually 5-merous flowers; calyx free from or partially adherent to the ovary, merely toothed or divided nearly to base; corolla gamopetalous, shallowly lobed to deeply divided; stamens as many as the lobes of the corolla and inserted opposite to them on the tube or at base of lobes; ovary 1-celled, with a central free placenta rising from the base and bearing several to many seeds; style and stigma one, the stigma truncate to capitate; fruit a 2- to 6-valved dehiscent capsule.

About 1,000 species in about 20 genera that are widely distributed in the Northern Hemisphere.

1. Aquatic plants with pectinately dissected leaves; flowers in whorls on the conspicuously inflated floating peduncles........................ Hottonia

1. Marsh or terrestrial plants in wet habitats, with entire or merely toothed leaves; flowers solitary, umbellate or racemose (2)

2(1). Ovary partially inferior, adnate to the calyx tube; inflorescence an elongate naked raceme, the pedicels bracteate or ebracteate. 2. Samolus 
2. Ovary wholly free from calyx; inflorescence axillary flowers, umbels or leafy racemes (3)

3(2). Plant scapose; leaves in basal rosettes; flowers in involucrate umbels (4)

3. Plant caulescent; leaves scattered along stems; flowers solitary in leaf axils or in racemes (6)

4(3). Lobes of the corolla several times as long as the tube, sharply reflexed; stamens protruding their full length........................3. Dodecatheon

4. Lobes of the corolla less than twice as long as the tube, not sharply reflexed; stamens usually included (5)

5(4). Flowers numerous in open inflorescence, usually less than $5 \mathrm{~mm}$. long..... 4. Androsace

5. Flowers few in a rather close inflorescence, well over $5 \mathrm{~mm}$. long

5. Primula

6(3). Flowers sessile in the leaf axils (7)

6. Flowers pedicellate in the leaf axils or terminal (8)

7(6). Corolla absent; sepals petaloid; ascending perennial with mostly opposite leaves; capsules valvate

6. Glaux

7. Corolla present; minute prostrate annual with mostly alternate leaves; capsules circumscissile.

7. Centunculus

$8(6)$. Leaves somewhat clasping, less than $2 \mathrm{~cm}$. long; prostrate to ascending annual; capsules circumscissile..................................8. Anagallis

8. Leaves not noticeably clasping, well over $2 \mathrm{~cm}$. long; erect or arching perennial; capsules valvate.............................................. . Lysimachia

\section{Hottonia L. Featherfoil. Water-Violet}

Two species, the Eurasian $H$. palustris $\mathrm{L}$. and the present one in the United States.

\section{Hottonia inflata Ell. American featherfoil. Fig. 606.}

Aquatic herb with the erect or ascending hollow leafless flower stems to $3 \mathrm{dm}$. long, the internodes inflated; submersed stems to $5 \mathrm{dm}$. long; leaves oblong in outline, to about $7 \mathrm{~cm}$. long, dissected into filiform divisions, clustered at base of flower stems and scattered along the rooting and floating vegetative stems; flowers white, pedicellate, subtended by sepaloid bracts, several in whorls at the nodes or joints to form an interrupted raceme; calyx and corolla subequal, 4-5 $\mathrm{mm}$. long; calyx 5-parted, the divisions linear; corolla with a short tube, the limb 5-parted; stamens 5, included, the filaments short; capsule subglobose or obpyriform, many-seeded, the 5 valves cohering at base and summit; seeds anatropous.

In lakes, pools and ditches in e. Tex. (Liberty, Harrison and Red River cos.) and s.e. Okla. (LeFlore and McCurtain cos.), Apr.-June; from Fla. to Tex., n. to N.E., N.Y., O., Ind., s. Ill., Mo. and Okla.

This species has the potential nuisance value of the water hyacinth (Eichhornia crassipes).

\section{Samolus L. WATER-PIMPERnEL. BrooKWEed}

Perennial somewhat succulent caulescent herbs; leaves in basal rosettes and then usually alternate on stem, entire; flowers on wiry pedicels in simple or panicled bracted or naked racemes; calyx herbaceous, campanulate, 5-lobed, persistent; corolla perigynous, white or pink, the tube short, the 5 rounded lobes imbricated; stamens 5, included, adnate to the corolla tube, sometimes alternating with 5 narrow staminodia that are in the sinuses between the corolla lobes; anthers cordate, erect; ovary half-inferior, 1-celled, the stigma obtuse or capitate; ovules 


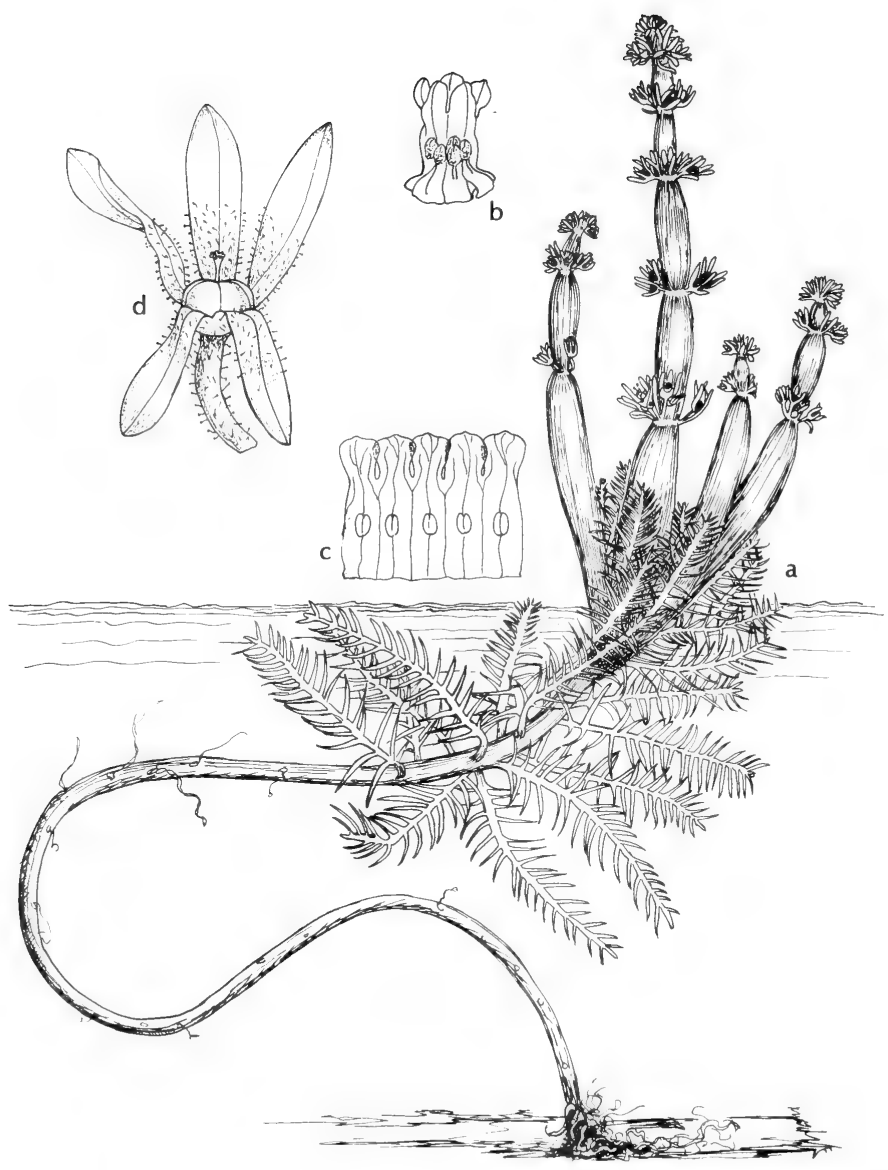

Fig. 606: Hottonia inflata: a, habit, x 1/2; b, corolla, x 5; c, corolla spread out, x 5; e, calyx and capsule, x 5. (V. F.). 
numerous, half-anatropous, in a subglobose placenta; capsule subglobose, 5-valved at the thickened apex; seeds numerous.

About 10 species that are widely distributed, especially in the Southern Hemisphere.

1. Racemes long-peduncled; pedicels bractless; corolla lobes usually much shorter than tube, the staminodia wanting (2)

1. Racemes sessile or nearly so; pedicels with small bract; corolla lobes longer than tube, with staminodia in the sinuses between the lobes (3)

2(1). Peduncles and racemes glabrous; corolla 6-9 $\mathrm{mm}$. broad, the lobes typically suborbicular........................................ $1 . S$. ebracteatus.

2. Peduncles and racemes glandular-pilose; corolla 4-6 $\mathrm{mm}$. broad, the lobes typically cuneate-obovate. 2. S. cuneatus.

3(1). Stems erect or ascending, bearing several or numerous leaves; basal leaves usually oval to elliptic; inflorescences several- to many-flowered; bract borne near the middle of the pedicel; calyx lobes mostly shorter than the tube............................................. $S$. parviflorus.

3. Stems mostly procumbent, stolonlike, bearing few leaves; basal leaves obovate to spatulate; inflorescence few-flowered; bract borne near the base of the pedicel; calyx lobes equal to or longer than the tube.

4. S. vagans.

\section{Samolus ebracteatus H.B.K. Figs. 607 and 608.}

Plant glabrous, bright-green or glaucous, to $55 \mathrm{~cm}$. tall, the usually sparingly branched stems solitary or tufted and erect or ascending; leaves spatulate to obovate, sessile or with winged petioles, decurrent, rounded to obtuse and sometimes apiculate at apex, to $1 \mathrm{dm}$. long and $35 \mathrm{~mm}$. wide, usually much smaller; racemes with stoutish erect straight peduncles that usually exceed the stems, to $2 \mathrm{dm}$. long; pedicels ascending, to $5 \mathrm{~cm}$. long, usually much shorter; calyx lobes triangularovate to triangular-lanceolate, acute, equal to or up to about twice as long as the tube; corolla pink or whitish, 6-9 mm. broad; corolla lobes suborbicular, rounded and often noticeably erose or retuse at apex, with a glandular tuft at base, shorter than the tube; stigma subentire to notched; capsules $3-4 \mathrm{~mm}$. in diameter.

In salt marshes and flats, in saline and brackish soil, and on dunes and in sandy soil on the coast of Tex. and in w. Okla. (Waterfall) and Nev. (Clarke Co.), possibly in N. M. and Ariz., Apr.-Oct.; from Fla. to Tex., Nev. and Mex.; also W.I.

\section{Samolus cuneatus Small.}

Plant deep-green, to $6 \mathrm{dm}$. tall, usually much smaller, the usually branched stems more or less tufted and ascending or reclining; leaves obovate to oblanceolate or broadly spatulate, the bases decurrent as broad wings, rounded and usually minutely mucronate at apex, to $15 \mathrm{~cm}$. long and $6 \mathrm{~cm}$. wide; racemes with stoutish straight peduncles longer than the stems, both more or less glandular-pilose; pedicels slender, spreading or ascending, to $3 \mathrm{~cm}$. long; calyx lobes triangular, acute, somewhat roughened in appearance and often purple-tinged, longer than or about as long as the tube; corolla white, 4-6 mm. broad; corolla lobes broadly cuneate to cuneate-obovate, somewhat coarsely toothed at the rounded to subtruncate apex; capsules 3-4 mm. in diameter. S. ebracteatus subsp. cuneatus (Small) Knuth.

On wet limestone and in marsh and seepage areas or in moist soil along streams and rivers from cen. to Trans-Pecos Tex., s. to the Tex. Rio Grande Plains, n. to n. Okla. (Alfalfa Co.), the Tex. Panhandle (Collingsworth Co.) and w. to N. M. (Chaves, Dona Ana and Eddy cos.), Mar.-Oct.; also n. Mex.

The characteristics used to separate this plant from $S$. ebracteatus are not too strong. When revisionary work is undertaken it is quite possible that they will be considered to be conspecific. 


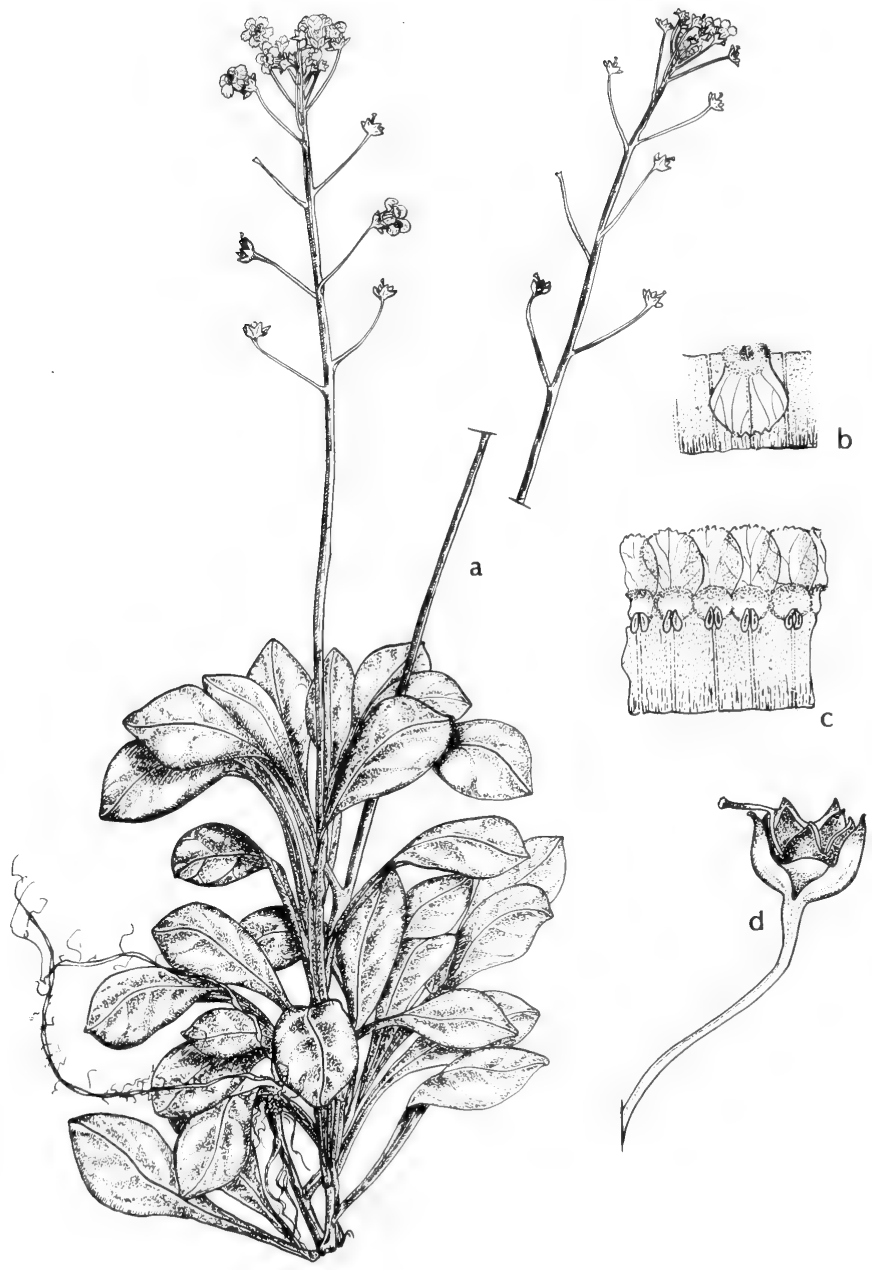

Fig. 607: Samolus ebracteatus: a, habit, $x$ 1/2; b, outer surface of flower to show reflexed petal, x $2 \frac{1}{2} ; c$, corolla spread out, inner surface, x $2 \frac{1}{2} ; \mathrm{d}$, mature fruit with pistil attached to one segment, x $2 \frac{1}{2}$. (V.F.). 

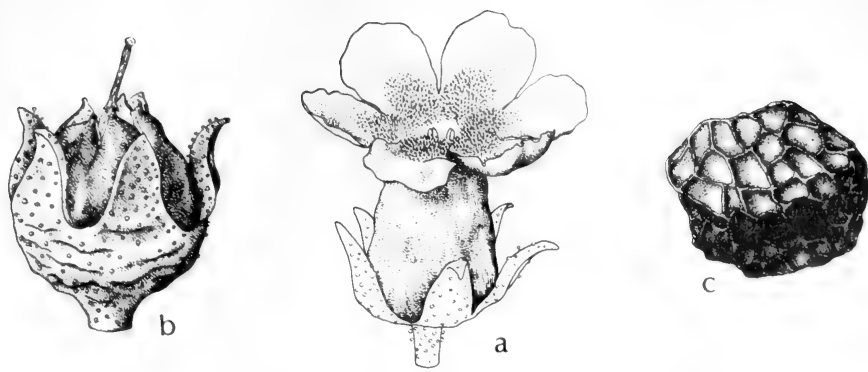

Fig. 608: Samolus ebracteatus: a, flower, x 8; b, capsule, x 8; c, seed, x 40. (Courtesy of R. K. Godfrey).

\section{Samolus parviflorus Raf. Fig. 609.}

Plant light-green, glabrous, to $6 \mathrm{dm}$. tall, the stems simple or diffusely branched; leaves obovate to spatulate or oblanceolate, sessile or narrowed into a winged petiole, rounded to obtuse at apex, to $15 \mathrm{~cm}$. long and $4 \mathrm{~cm}$. wide; racemes sessile or nearly so, the slender rachis straight or flexuous; pedicels filiform, spreading or ascending, to $2 \mathrm{~cm}$. long; calyx lobes ovate to triangular-ovate, acute, about as long as or shorter than the tube; corolla white, $2-3 \mathrm{~mm}$. broad; corolla lobes oblong, rounded or emarginate at apex and longer than the tube; staminodia 5; capsule 2-3 $\mathrm{mm}$. in diameter. S. floribundus H.B.K.

In wet soils and about various types of wet rocks, along streams, in marshes, about lakes and seepage areas throughout Okla. and Tex., w. to N. M. (Chaves and Grant cos.) and Ariz. (Navajo, Coconino, Yavapai, Greenlee, Santa Cruz, Pinal and Pima cos.), Mar.-Sept.; from Fla. to Calif. and Mex., n. to e. Can., Mich., Ill. and B.C.; also trop Am.

\section{Samolus vagans Greene.}

Stems mostly procumbent, stolonlike; basal leaves obovate to spatulate; cauline leaves scattered along stem, oval to elliptic to somewhat obovate; inflorescence few-flowered; pedicels spreading, lax, bearing a small bract near its base; calyx lobes equal to or longer than the tube; corolla less than $3 \mathrm{~mm}$. long.

In wet sand in s.e. Ariz. (Cochise, Santa Cruz and Pima cos.), May-Oct.

\section{Dodecatheon L. Shooting-STAR. AMERICAN Cowslip}

Scapose herbaceous perennial from slender to thick rhizomes or very short caudices, often with small bulblets among the roots, glabrous to conspicuously glandular-pubescent; leaves petioled, entire to dentate; flowers showy, 4- or 5 -merous, borne in terminal involucrate umbels or sometimes single, on recurved slender pedicels; calyx short-tubular, the lobes lanceolate; corolla showy, shorttubular, the white to purple lobes long and strongly reflexed, the tube very short; stamens connivent around the style; filaments short, free or connected by a membrane; anthers long and slender, basally attached, dehiscent on the inner surface. the connective prominent, highly colored, smooth to transversely rugose; style slightly exceeding the stamens; stigma capitate, sometimes rather conspicuously enlarged; fruit a 1-celled capsule, valvate to the tip or the tip operculate with the style and the walls valvate below; seeds numerous. 


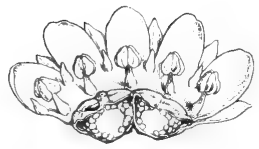

a
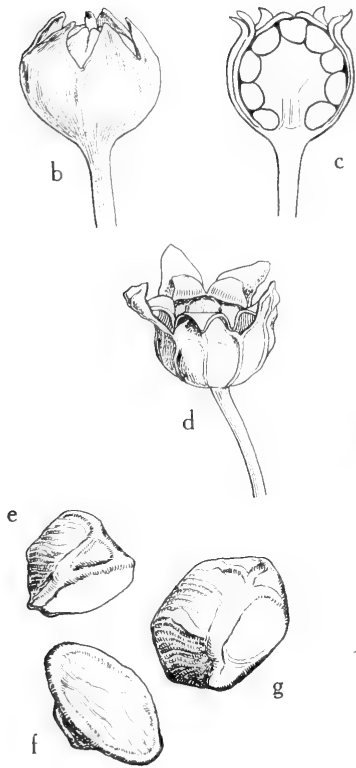

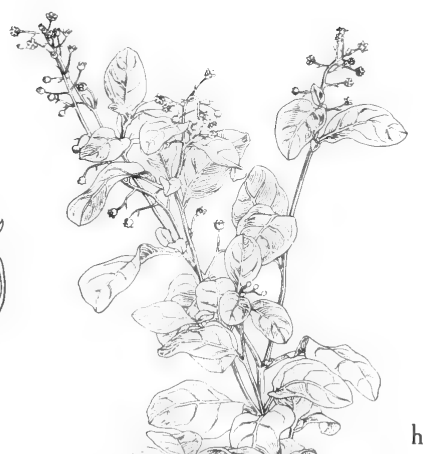

h

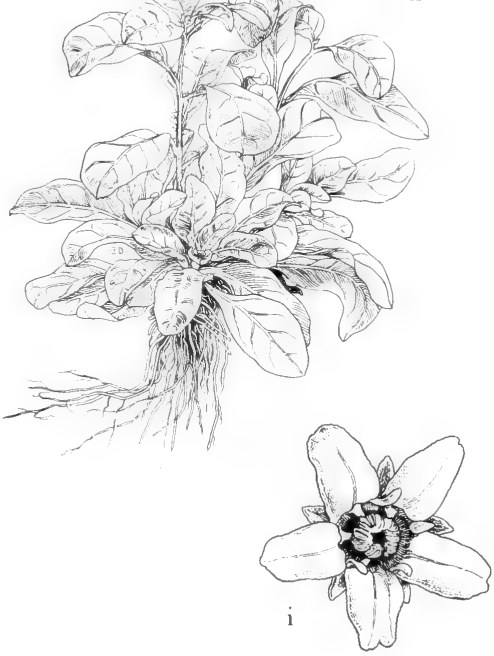

Fig. 609: Samolus parviflorus: a, flower, spread open, x 8; b, fruit, enclosed by calyx, x 8; c, fruit (longitudinal section), x 8; d, capsule after dehiscence, x 8; e-g, seeds, x 40; h, habit, x 2\%; i, flower, x 8. (From Mason, Fig. 292). 
About 50 species in North America and Asia, of which about 14 are in North America. All are worthy of cultivation and are easily grown, especially in rich moist or even wet partially shaded situations. They readily seed themselves.

1. Flowers 4-merous; stigma enlarged, at least twice the diameter of the style; connective rugose; filaments short, $0.5 \mathrm{~mm}$. long, free.

1. D. alpinum.

1. Flowers 5-merous; stigma not enlarged; connective smooth (sometimes roughened in drying); filaments $0.5-3.5 \mathrm{~mm}$. long, free or somewhat united into a tube (2)

2(1). Capsule wall thick, ligneous, not flexible; distribution in Oklahoma and Texas......................................................................... D. Meadia.

2. Capsule wall thin, usually flexible under the slightest pressure; distribution in New Mexico and Arizona (3)

3(2). Leaf blades gradually tapered into the petiole, with a cuneate base; anthers lanceolate; corolla lobes usually magenta to lavender.

3. D. pulchellum.

3. Leaf blades abruptly narrowed into the petiole, with a subcordate base; anthers subulate; corolla lobes always white.

..4. D. dentatum.

\section{Dodecatheon alpinum (Gray) Greene subsp. majus H. J. Thomps.}

Plants usually glabrous, the upper part of the scape and inflorescence sometimes glandular-pubescent; roots white, without bulblets; leaves including petiole 6-16 $\mathrm{cm}$. long, 9-16 mm. wide, linear to linear-oblanceolate, acute to obtuse, the blade gradually tapered into petiole and entire; scape $14-30 \mathrm{~cm}$. tall; umbels $4-$ to 10 -flowered; bracts to $1 \mathrm{~cm}$. long, lanceolate, acute to acuminate; pedicels $1-3 \mathrm{~cm}$. long in flower, longer in fruit; flowers 4-merous; calyx tube 2-3 mm. long; calyx lobes 4-6 mm. long, lanceolate, acute; corolla tube maroon, yellow above; corolla lobes $9-16 \mathrm{~mm}$. long, magenta or lavender, never white; filaments $0.5 \mathrm{~mm}$. long, free or united by a thin membrane, black; anthers 5-7 mm. long, linear, the straight sides gradually tapered to the obtuse to blunt apex, the pollen sacs dark, the rugose connective dark maroon to black; stigma enlarged, at least twice the diameter of the style; capsule 6-8 mm. long, 3-4 $\mathrm{mm}$. wide, ovoid, the wall thin, valvate.

In wet $\mathrm{mt}$. meadows and along streams in Ariz. (Apache, Navajo, Coconino and Greenlee cos.), June-Sept.; also Ore., Calif., Nev. and Ut.

\section{Dodecatheon Meadia L.}

Perennial glabrous herb with fibrous roots and a cluster of basal leaves from which arise a simple naked scape to $55 \mathrm{~cm}$. high that supports at the summit an involucre of small bracts that subtend an umbel of showy flowers; leaves narrowly elliptic-oblong to oblanceolate, blunt or rounded at apex, tapering from the reddishtinged base into the petiole, usually with entire margins, to $2 \mathrm{dm}$. long and $4 \mathrm{~cm}$. wide above middle; flowers few to many; pedicels slender, erect when young, recurving in anthesis, ascending in fruit; calyx lobes 5 , lanceolate, usually about $5 \mathrm{~mm}$. long in anthesis, slightly longer and persistent in fruit; corolla lilac to palepink, with a very short tube and thickened throat, the 5 oblong-elliptic lobes to $25 \mathrm{~mm}$. long and $1 \mathrm{~cm}$. wide, strongly reflexed; tube of filaments $1-2 \mathrm{~mm}$. long; anthers linear, about $8 \mathrm{~mm}$. long, connivent to form a slender cone; capsule ovoid, dark-reddish-brown, to $18 \mathrm{~mm}$. long, with firm ligneous wall, opening by 5 short terminal valves.

On open slopes, swampy flatwoods, about lakes, base of bluffs, in cedar brakes and in open moist woods in e. third of Tex. w. rarely to Travis Co, and e. and Arbucklean Okla. (Waterfall), Mar.-May; from D.C., w. to Wisc., s. to Ga. and Tex. 


\section{Dodecatheon pulchellum (Raf.) Merrill. Fig. 610.}

Roots white, without bulblets; leaves including petiole $4-25 \mathrm{~cm}$. long, 1-6 cm. wide, oblanceolate to ovate or spatulate, acute to obtuse or rounded; blade gradually tapered into petiole, usually entire, occasionally sinuate or crenate; scape 6-50 $\mathrm{cm}$. high; umbel 3- to 25 -flowered; bracts to $1.5^{\circ} \mathrm{cm}$. long, deltoid to lanceolate or spatulate, acute to obtuse; pedicels $1-5 \mathrm{~cm}$. long in flower, longer in fruit; flowers 5-merous; calyx tube 2-3.5 mm. long; calyx lobes $2.5-6 \mathrm{~mm}$. long, lanceolate to subulate, acute to acuminate; corolla tube maroon, yellow above, the magenta to lavender lobes 9-20 mm. long; filaments $0.5-3.5 \mathrm{~mm}$. long, united into a tube or nearly free, yellow, smooth or rugulose; anthers $3-8 \mathrm{~mm}$. long, lanceolate, obtuse or acute, the pollen sacs yellow or sometimes red or maroon; connective dark maroon to black, rarely yellow, smooth (often longitudinally wrinkled upon drying); stigma not enlarged; capsule 7-17 mm. long, 4-7 mm. wide, cylindric to ovoid, the wall thin, valvate. $D$. radicatum Greene.

In seepage and wet meadows, wet stream banks, in N.M. (Rio Arriba, Lincoln, Otero, Santa Fe, San Miguel and Taos cos.) and Ariz. (Graham Co.), June-Aug.; from Alas. to Wisc. and e. U. S., s. to Dgo.

\section{Dodecatheon dentatum Hook. subsp. Ellisiae (Standl.) H. J. Thomps.}

Plants glabrous; roots white, without bulblets; leaves including petiole $6-20 \mathrm{~cm}$. long, $1.5-4.5 \mathrm{~cm}$. wide, ovate to oval, acute to obtuse; blade abruptly narrowed into petiole, cordate to subcordate at base, dentate to entire; scape $1-3.5 \mathrm{dm}$. tall; umbel 1 - to 6 -flowered; bracts to $8 \mathrm{~mm}$. long, lanceolate to oblanceolate, acute to obtuse; pedicels $1.5-3 \mathrm{~cm}$. long in flower, longer in fruit; flowers 5-merous; calyx tube 2-3 mm. long; calyx lobes $2.5-4 \mathrm{~mm}$. long, triangular to lanceolate, acute to acuminate; corolla tube maroon, yellow above, the white lobes $8-15 \mathrm{~mm}$. long; filaments less than $1 \mathrm{~mm}$. long, free or slightly united; anthers $6.5-8 \mathrm{~mm}$. long, lanceolate to subulate, acute to acuminate, the pollen sacs yellow or reddishspotted; connective dark maroon to black above, yellow below, smooth (often longitudinally wrinkled upon drying); stigma not enlarged; capsule 9-12 mm. long, 4-5 $\mathrm{mm}$. thick, cylindric, the thin wall valvate. D. Ellisiae Standl.

Wet stream banks and wet meadowlands, rich moist soils in coniferous forests, in N. M. (Bernalillo and Sandoval cos.) and Ariz. (Apache, Graham, Greenlee and Pima cos.), June-Aug.

\section{Androsace L. RocK-JASMine}

Small annual herbs with clustered radical leaves and very small flowers in an umbel terminating a scape; calyx 5-cleft, the obconic tube short; corolla salverform or funnelform, the somewhat inflated tube shorter than the calyx, constricted at the throat, the limb 5-parted; capsule longitudinally 5-valved, enclosed in the persistent calyx.

About 100 species in cooler parts of the North Temperate Zone.

1. Calyx lobes linear-elliptic to triangular-lanceolate, equal to or longer than the tube; involucral bracts broadly elliptic-obovate to oblanceolate.

1. A. occidentalis

1. Calyx lobes deltoid to acerose, much shorter than the tube; involucral bracts narrowly lanceolate to subulate.... 2. A. septentrionalis.

\section{Androsace occidentalis Pursh.}

Dwarf plants to $7 \mathrm{~cm}$. tall, usually much smaller; rosette leaves typically ellipticoblanceolate, to $2 \mathrm{~cm}$. long and $6 \mathrm{~mm}$. wide, entire or somewhat coarsely dentate above middle, white-pubescent above with mostly simple hairs; scapes one to many, erect or recurved-ascending, more or less equal in length, scabrous with stellate hairs; involucral bracts elliptic-obovate to oblanceolate, to $6 \mathrm{~mm}$. long; pedicels 

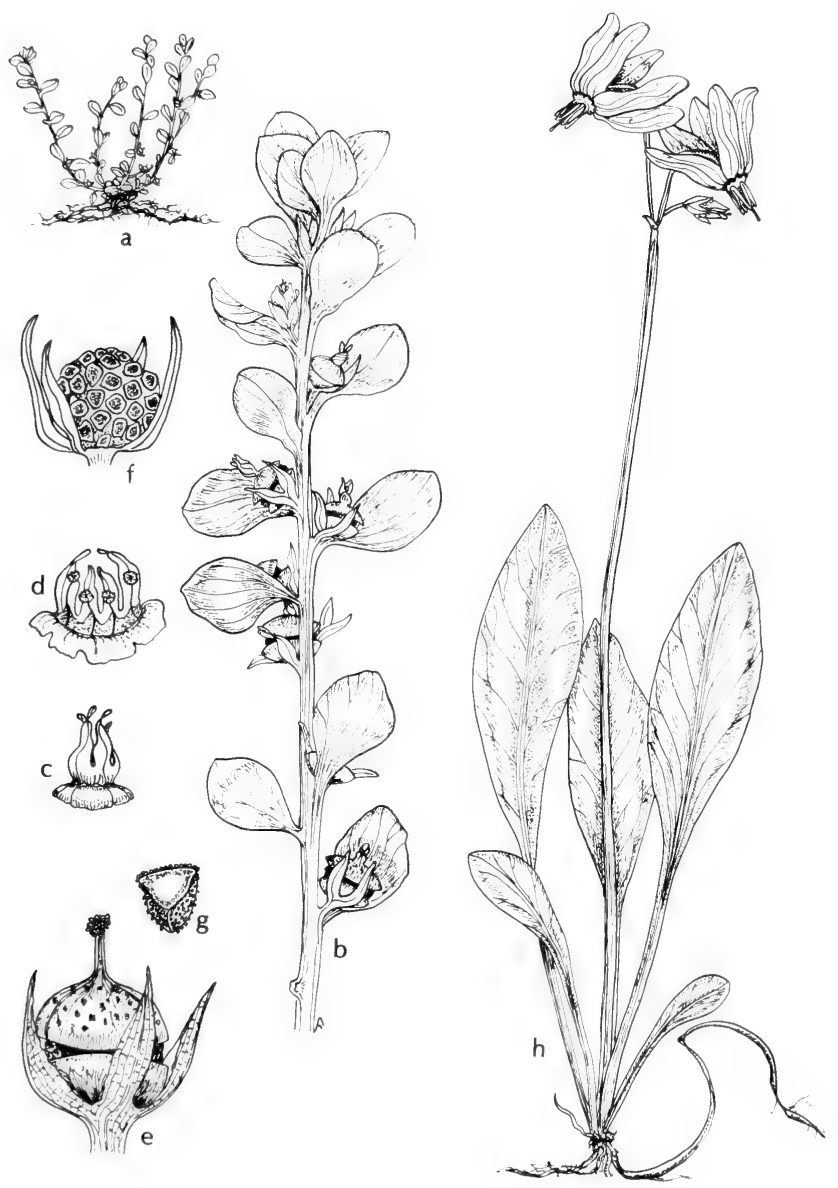

Fig. 610: a-g, Centunculus minimus: a, habit, $x$ 1/2; b, stem, x 21/2; c, flower, x 8; d, corolla split open, x 8 ; e, capsule split, x 8; f, placenta with seeds, x $8 ; \mathrm{g}$, seed, $\mathrm{x}$ 25. h, Dodecatheon pulchellum: h, habit, $x$ 1/2. (V. F.). 


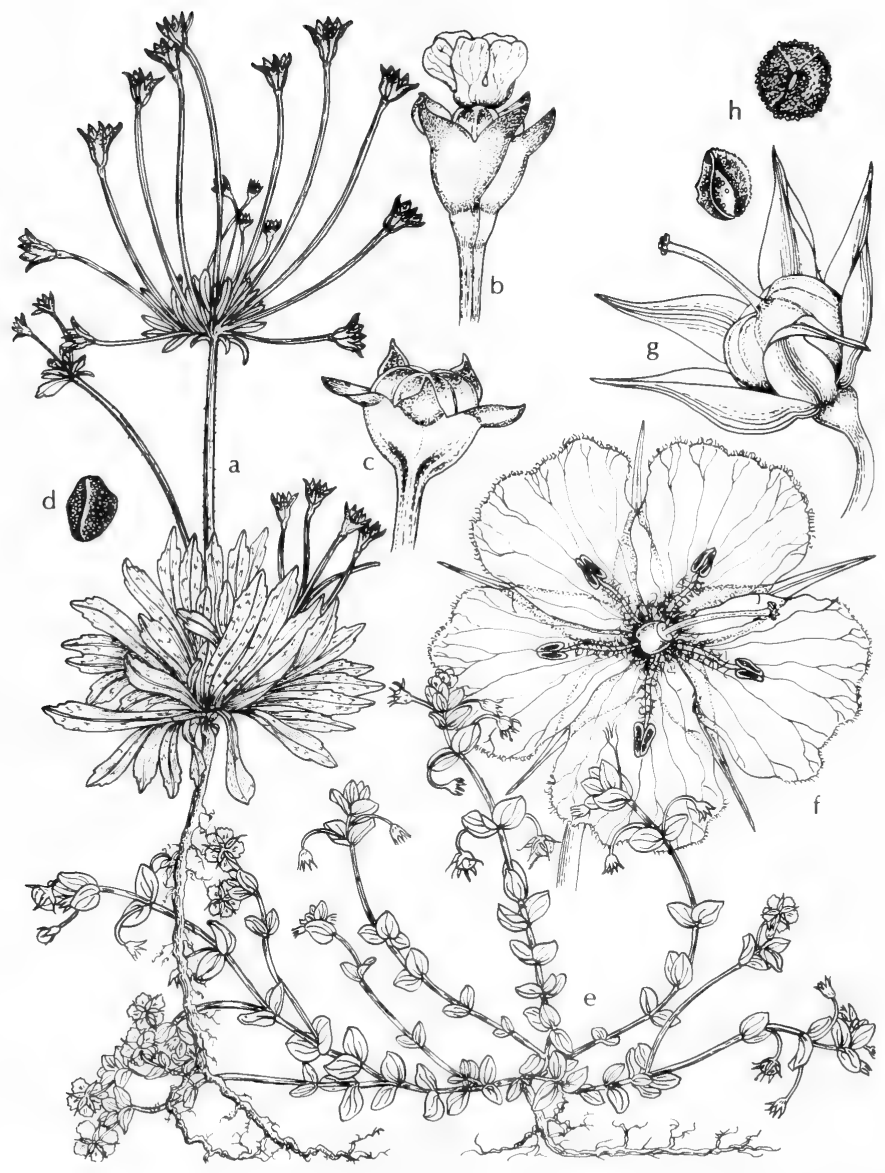

Fig. 611: a-d, Androsace septentrionalis var. puberulenta: a, habit, x 1; b, flower x 5; c, fruit, x 5; d, seed, x 5, e-h, Anagallis arvensis: e, habit, x 1/2; f, flower, x 5; g, fruit, $\times 5 ;$ h, seed, $\times 5$. (V. F.). 
erect or ascending, mostly less than $25 \mathrm{~mm}$. long, stellate-pubescent; calyx tube pale, campanulate, the bright-green pubescent lobes linear-elliptic to narrowly triangular-lanceolate.

Dry soils in open country or in open rocky woods, sometimes in muddy soils along streams and on edge of water bodies, in cen. and w. Tex., Okla. (Waterfall), N.M. (Rio Arriba and Socorro cos.) and Ariz. (widespread); Feb.-Apr.; from Ont. to B.C., s. to Tex., N.M. and Ariz.

A plant in southern Arizona, designated as var. arizonica (Gray) St. John, has larger, green and foliaceous calyx lobes that are more spreading-recurved than in var. occidentalis, with which it intergrades.

\section{Androsace septentrionalis L. Fig. 611.}

Plant to $3 \mathrm{dm}$. tall, glabrous to more or less puberulent with reddish glandular or non-glandular hairs; rosette leaves linear-spatulate to oblanceolate, to about $35 \mathrm{~mm}$. long and $6 \mathrm{~mm}$. wide above middle, often with stellate pubescence, entire or jagged-toothed; scapes usually several, erect, only the central one well-developed with the others much shorter or wanting; umbels compact; involucral bracts mostly linear-subulate, to $3 \mathrm{~mm}$. long; pedicels strictly ascending or erect, to at least 55 $\mathrm{mm}$. long, soon glabrate; calyx turbinate-campanulate, stramineous to green, with short acerose to narrowly triangular or deltoid lobes. A. glandulosa Woot. \& Standl. A. pinetorum Greene.

In open rocky areas on $\mathrm{mt}$. summits, in mud at edge of lakes and ponds, springy places, on gravel bars and in seepage, in the Tex. Trans-Pecos, N.M. (Rio Arriba. Bernalillo, Lincoln, Sandoval, Sante Fe, Socorro and Taos cos.) and Ariz. (Apache and Coconino, s. to Cochise and Pima cos.), Apr.-Sept.; in high mts. of s.w. U.S.

This species is represented in our region by several named varieties; namely, var. glandulosa (Woot. \& Standl.) St. John, the herbage puberulent with numerous reddish glandular hairs; var. subulifera Gray ( $A$. diffusa Small), with glabrous herbage and calyx lobes slender-subulate to acerose; var, puberulenta (Rydb.) Knuth, with puberulent herbage and calyx lobes narrowly triangular.

\section{Primula L. Primrose}

Plants scapose usually herbaceous perennials, often tufted; flowers showy, in involucrate umbels, 5-merous; calyx persistent, the tube elongated, angled; corolla salverform, surpassing the calyx at anthesis, often with obcordate lobes, the limb pink or reddish-purple, the open throat greenish or yellowish, fornices absent or inconspicuous; stamens attached in the upper third of the corolla tube, included, the filaments very short; ovary superior; style usually included; capsule opening apically by valves or teeth.

Probably 200 species mainly in boreal or alpine regions in the North Temperate Zone, especially abundant in south-central Asia.

1. Scapes with 1 or occasionally 2 flowers; plants $7 \mathrm{~cm}$. tall or less.....

1. Scapes with 3 or more flowers; plants $10 \mathrm{~cm}$. tall or more $(2)$

2(1). Plants $25-40 \mathrm{~cm}$. tall, stout; leaves $3-5 \mathrm{~cm}$. wide, usually entire

2. P. Parryi.

2. Plants less than $25 \mathrm{~cm}$. tall, slender; leaves less than $2 \mathrm{~cm}$. wide, noticeably denticulate (3)

3(2). Scapes about equaling the leaves; calyx $7 \mathrm{~mm}$. high

3. Scapes twice as long as the leaves; calyx $4-5 \mathrm{~mm}$. high.

3. P. Ellisiae

\section{Primula angustifolia Torr.}

Plants to about $7 \mathrm{~cm}$. tall; leaves lanceolate-spatulate to linear-lanceolate, 1.5-5 $\mathrm{cm}$. long, 2-7 mm. wide, obtuse, entire, not farinose but slightly short glandular- 
hairy on some, rather thick; involucral bracts lanceolate, 1-7 $\mathrm{mm}$. long; scape 1- to ocassionally 2-flowered; calyx 5-8 $\mathrm{mm}$. wide, the acute to acuminate lobes 2-3 $\mathrm{mm}$. long; corolla tube 5-8 mm. long, the limb 5-6 mm. long and 1-2 mm. wide, purple or sometimes white; capsule ovoid.

In wet mt. meadows and in seepage along streams in N.M. (Santa Fe and San Miguel cos.), summer; also Colo.

2. Primula Parryi Gray. Fig. 612 .

Scapose perennial; leaves oblong-spatulate to narrowly oblanceolate, obtuse to acute, 6-30 cm. long, rather fleshy, often denticulate, often somewhat puberulent, not farinose; scape $8-40 \mathrm{~cm}$. high, erect; involucre bracts $3-12 \mathrm{~mm}$. long, lanceolate; flowers malodorous, 5 to 12 ; calyx 7-15 mm. long, ovoid-campanulate, glandular, its lanceolate acuminate lobes 5-8 mm. long; corolla 1.2-2 cm. long, deepred or purplish in drying, the tube about as long as or a little longer than the limb; limb $1.5-3 \mathrm{~cm}$. broad, the lobes notched; capsule ovoid, 7-11 $\mathrm{mm}$. long.

In wet soil near snow banks, bogs, wet meadows and along stream banks, and among rocks, N.M. (Santa Fe and San Miguel cos.) and Ariz. (Coconino and Apache cos.), June-Aug.; Mont. and Ida., s. to N.M., Ut. and Ariz.

\section{Primula Ellisiae Pollard \& Cockll.}

Plants about $1 \mathrm{dm}$. tall, from a stout vertical caudex; leaves oblong-spatulate, tapering to a scarious-margined petiole, obtuse to subacute at apex, minutely scabrous, the upper half irregularly and sharply serrulate with salient teeth; scape scarcely surpassing the leaves, bearing a dense umbel of rather large flowers; calyx densely farinose but tending to become glabrate with age, the lanceolate lobes exceeding the tube; corolla lobe twice the length of the calyx, the limb about $7 \mathrm{~mm}$. in diameter, lavender-purple with a yellow eye, the lobes truncate and retuse.

Rare in high wet mt. meadows in N.M. (Bernalillo, Sandoval, Lincoln and Otero cos.), summer.

\section{Primula Rusbyi Greene.}

Scape slender, not more than $25 \mathrm{~cm}$. long; leaves oblong-spatulate, $5-13 \mathrm{~cm}$. long, (including the margined petiole), more or less puberulent but not white-mealy on lower surface, dentate with the teeth conspicuously glandular; involucral bracts 3 or more, lanceolate to ovate-lanceolate, thin; flowers 6 to 10 ; pedicels not glandular-puberulent but more or less white-mealy; calyx tube white and as if farinose at base, campanulate, longer than the ovate-triangular lobes; corolla limb more than $1 \mathrm{~cm}$. wide, the lobes obcordate, the tube surpassing the calyx.

Usually on seepy slopes and damp mossy ledges in N. M. (Socorro, Grant and Sierra cos.) and Ariz. (Graham, Cochise, Santa Cruz and Pima cos.), May-Sept.

\section{Glaux L. Sea Milkwort}

\section{A monotypic genus.}

\section{Glaux maritima L. Fig. 613.}

Glabrous and glaucous perennial herb; rootstocks horizontal, slender; stems slender, branched, ascending, 5-20 cm. long; leaves sessile, oval to linear-oblong, 4-10 mm. long, fleshy, obtuse to acute at apex, the lower ones opposite, the upper ones usually alternate; flowers sessile or subsessile in leaf axils about midway along stem; calyx petaloid, campanulate, 3-4 mm. long, 5-cleft, whitish; corolla absent; stamens 5, inserted at base of calyx tube and alternate with its lobes, the filaments as long as the calyx lobes, the anthers hairy; ovary superior, ovoid; style filiform; stigma capitate; capsule about $2.5 \mathrm{~mm}$. long, beaked by persistent style.

Saline or brackish shores, marshes and sandy soils, in N. M. (fide Fernald). June-July; Que. to Va., B. C. s. to Ore., Calif. and N. M. 


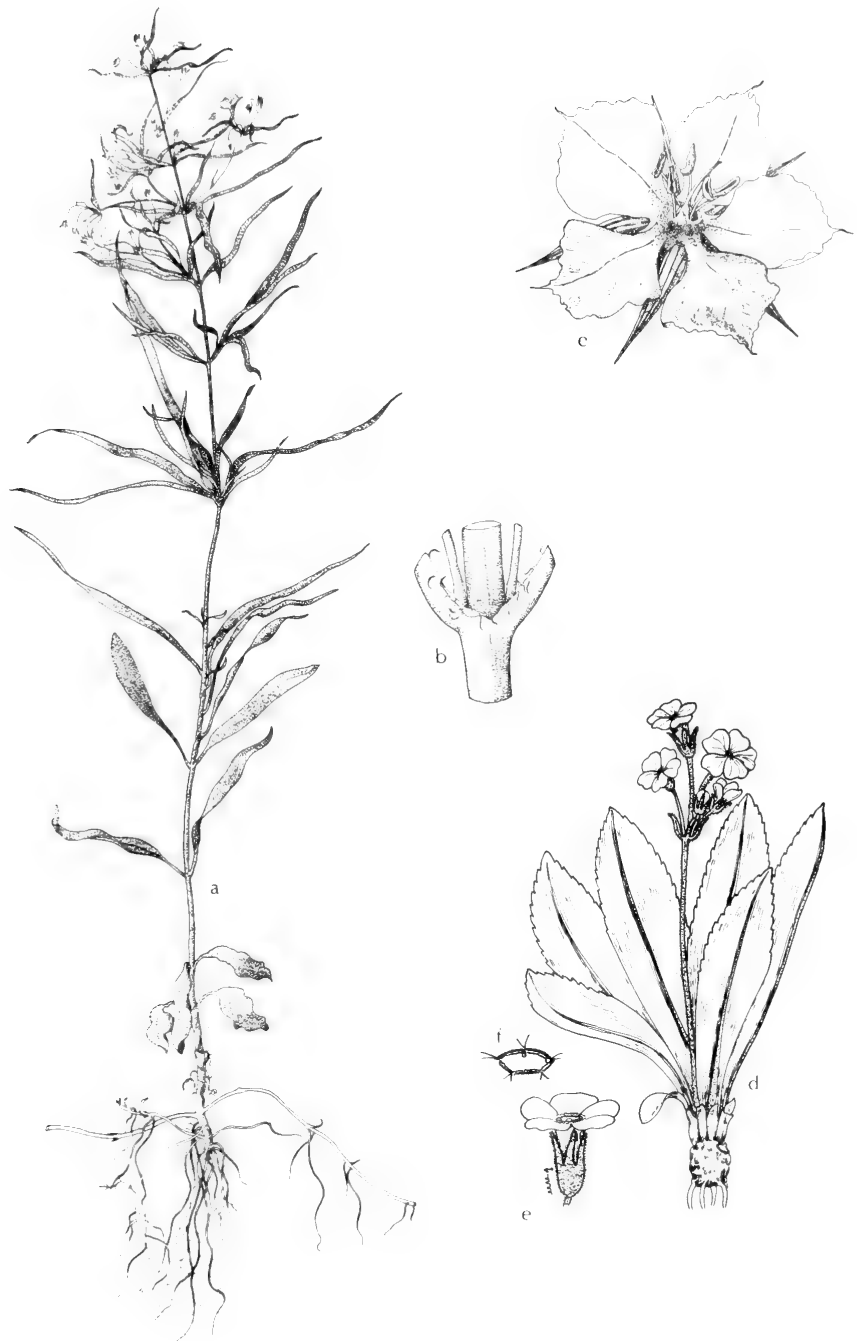

Fig. 612: a-c, Lysimachia lanceolata: a, habit, x 1/3; b, node enlarged; c, flower, $x$ 2. d-f, Primula Parryi: d, habit, $x \frac{1 / 3}{3}$; e, flower, $x_{2}^{2}$; f, top of tube of corolla, $\mathrm{x}$ 123. (a-c. Courtesy of R. K. Godfrey; d-f, redrawn from Hitchcock, et al., Vascular Plants of the Pacific Northwest, Pt. 4, p. 56). 

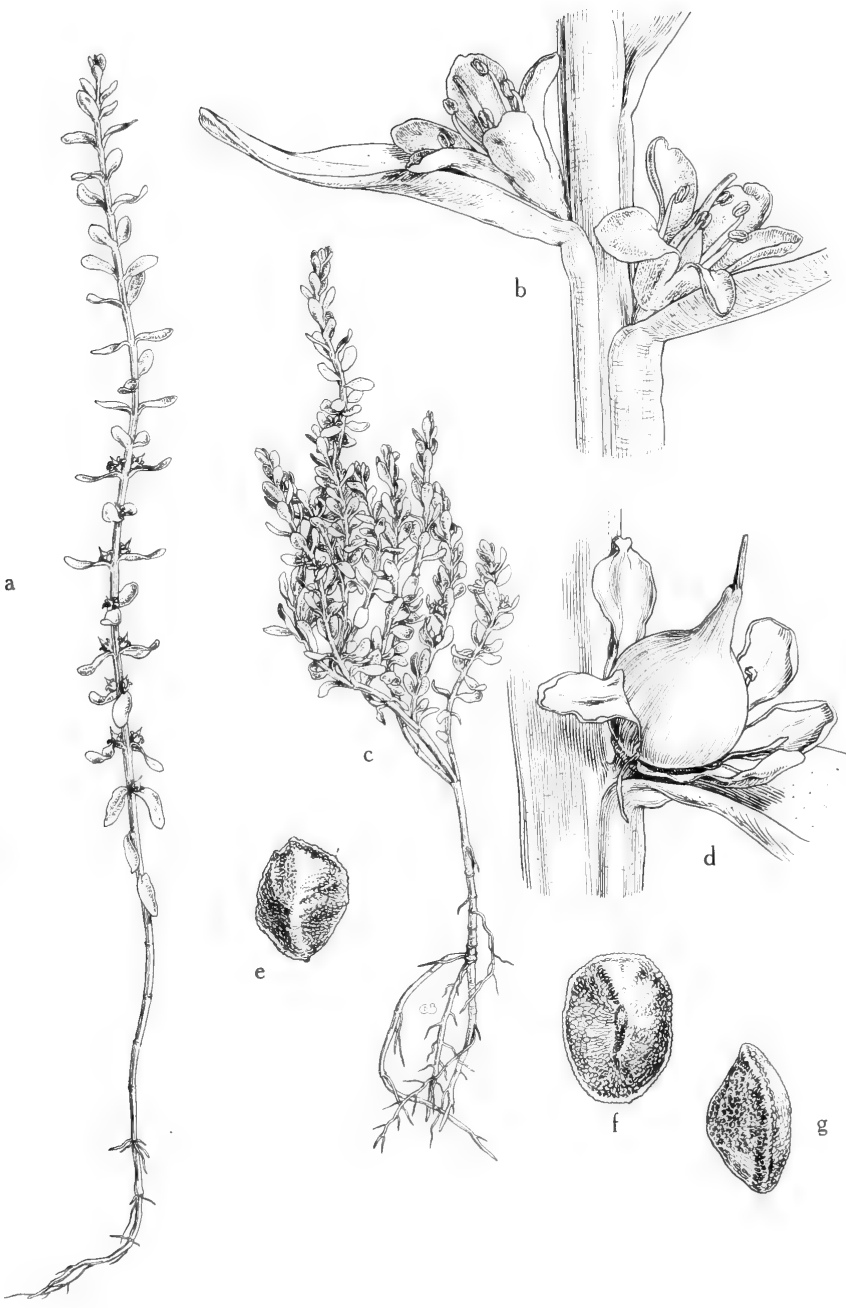

e

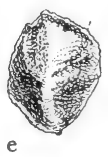

C
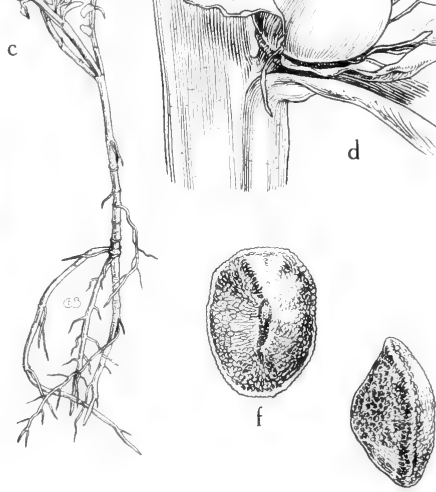

Fig. 613: Glaux maritima: a, habit, unbranched plant, $\mathrm{x} 2 \%$; $\mathrm{b}$, flowers at anthesis, $\mathrm{x} \mathrm{4}$; c, habit, branched plant, $\mathrm{x} 2 \%$; d, young fruit, x 6; e-g, seeds, x 16. (From Mason, Fig. 289). 


\section{Centunculus L.}

\section{Chaffweed}

A monotypic genus that is sometimes included in Anagallis.

\section{Centunculus minimus L. Fig. 610 .}

Annual, often forming mats or small clumps, the stems erect or ascending, to $12 \mathrm{~cm}$. long; leaves subsessile, alternate, entire, obovate to oblanceolate or oblongspatulate, to $8 \mathrm{~mm}$. long and $5 \mathrm{~mm}$. wide; flowers sessile in leaf axils, ephemeral, 4- or occasionally 5-merous; sepals linear-lanceolate, about $2 \mathrm{~mm}$. long; corolla rotate, pinkish, about $1 \mathrm{~mm}$. wide, with an urceolate short tube and ovate-lanceolate lobes about half as long as the tube, withering on the apex of the capsule; stamens 4 or 5 , inserted near corolla throat, included, the filaments beardless; capsule subglobose, circumscissile, to $2 \mathrm{~mm}$. in diameter.

In damp sand and mud in depressions, bogs, along streams, grasslands and open woods mainly in e. and s. Tex., Okla. (Johnston and McCurtain cos.), N.M. (probably) and Ariz. (Coconino, Graham, Cochise, Santa Cruz and Pima cos.), Feb.-May; from Fla. to Tex., Calif. and Mex., n. to N.S., O., Ill., Minn., and Sask., nearly cosmopolitan.

\section{Anagallis L. Pimpernel}

About 28 species that are cosmopolitan in distribution.

1. Anagallis arvensis L. Scarlet pimpernel, hierba del páJaro, poorman'sWEATHER-GLASS. Fig. 611.

Low spreading or procumbent annual herb with opposite leaves and solitary flowers on axillary pedicels, forming loose prostrate mats, the diffuse 4-angled stems much-branched and to $3 \mathrm{dm}$. long; leaves sessile or somewhat clasping the stem, suborbicular to ovate or elliptic, to $2 \mathrm{~cm}$. long and $1 \mathrm{~cm}$. wide; pedicels slender, exceeding the leaves; flowers variable in size and color, from scarlet to salmon-color and sometimes almost white or blue [in f. caerulea (Schreb.) Baumg.] with the petals more or less without cilia; calyx lobes lanceolate, 3-4 mm. long; corolla rotate; petals 5, about equal to the calyx lobes, obovate to cuneate-obovate; somewhat fringed with minute teeth and stalked glands at the obtuse to rounded apex; stamens 5, inserted near base of corolla tube, the filaments bearded; capsules about $4 \mathrm{~mm}$. in diameter, globose, membranous, circumscissile, many-seeded.

Usually in moist places, wet depressions and wet sands in prairies and flatlands mostly in e. and s. Tex., Okla. (Delaware Co.), N.M. (Sierra Co.) and Ariz. (Maricopa, Cochise, Pinal and Pima cos.), Mar.-Sept.; nat. from Eur.

\section{Lysimachia L. LoOSESTRIFE}

Leafy-stemmed perennials with entire opposite or whorled leaves and longpedicelled yellow to orange-color and sometimes purple-dotted corollas; calyx 5- or 6-parted, imbricate or valvate in bud; corolla 5- or 6-parted, rotate, convolute in bud or with each division convolute about its stamen; stamens 5, the filaments distinct or nearly so on a ring at base of corolla or monadelphous at base, the anthers ovoid to slender; capsule subglobose to ovoid, few to many-seeded, the style persistent on one valve.

About 200 species of wide distribution, especially eastern Asia and North America.

1. Stems of flowering branches arched-reclining or creeping, often rooting at nodes; divisions of corolla $3-5 \mathrm{~mm}$. long. 1. $L$. radicans.

1. Stems erect, slender, arising from slender cordlike rhizomes and stolons; divisions of corolla $7-13 \mathrm{~mm}$. long (2) 
2(1). Principal leaves ovate or ovate-lanceolate, with rounded or cordate base with a distinct petiole. 2. L. ciliata.

2. Principal leaves linear to linear-lanceolate, gradually tapering at base.... 3. L. lanceolata.

\section{Lysimachia radicans Hook. Fig. 614.}

Stem slender, soon reclined, to $1 \mathrm{~m}$. long, laxly and diffusely branched, the elongated branches often rooting at the nodes; leaves membranous, with a slender narrowly winged bristly-ciliate petiole to $3 \mathrm{~cm}$. long; blade ovate-lanceolate to lanceolate, to $9 \mathrm{~cm}$. long and $25 \mathrm{~mm}$. wide, rounded at base, acuminate at apex; pedicels filiform, to $3 \mathrm{~cm}$. long; flowers nodding, to $12 \mathrm{~mm}$. wide; calyx segments ovate-lanceolate, acuminate, 3-5 mm. long; corolla segments obovate-cuneate, erose-dentate and cuspidate; capsule exceeding the calyx. Steironema radicans (Hook.) Gray.

In swamp forests, along streams and in moist pinelands in s.e. Tex., May-July; from Miss, to Tex., n. to Mo., Tenn. and locally to e. Va.

\section{Lysimachia ciliata L.}

Stem erect, simple or branched, $12 \mathrm{dm}$. high from a slender rhizome; leaves ovate to ovate-lanceolate, acuminate, broadly rounded to subcordate at the base, the blades to $15 \mathrm{~cm}$. long with long ciliate-fringed petioles; flowers on thin axillary peduncles, mostly whorled, to $28 \mathrm{~mm}$. wide; calyx segments firm, subulate-tipped, to $1 \mathrm{~cm}$. long; corolla yellow, not spotted, its broad segments cuspidate and erosedentate; capsule exceeding or shorter than the mature calyx. Steironema pumilum Greene, $S$. ciliatum (L.) Raf.

Swamps, seepage, marshes, low ground, thickets, rich woods and shores in n.e. Tex., Ozarkian Okla. (Waterfall), N.M. (San Miguel, Socorro and Grant cos.) and Ariz. (Apache, Navajo, Coconino and Gila cos.), June-Sept.; from s. Can. to Fla., Tex., Ariz. and Colo.

The plant with relatively narrow obscurely ciliolate leaves is usually segregated as var. validula (Greene) Kearn. \& Peeb. (Steironema validulum Greene).

\section{Lysimachia lanceolata Walt. Fig. 612.}

Stems slender and firm, from elongate slender cordlike rhizomes and stolons, to $7 \mathrm{dm}$. tall, simple or with ascending branches; basal leaves often rosulate and longpetiolate, elliptic to oblong-elliptic, usually persistent; middle and upper leaves linear or linear-lanceolate, to $13 \mathrm{~cm}$. long and $15 \mathrm{~mm}$. wide, attenuate to the usually short-petiolate bristly-ciliate base, acuminate at apex, paler beneath; pedicels filiform, to $4 \mathrm{~cm}$. or more long at anthesis, from upper axils; flowers to $2 \mathrm{~cm}$. wide; calyx segments firm, linear-lanceolate, acuminate, to $7 \mathrm{~mm}$. long; corolla segments suborbicular to broadly obovate, erose, cuspidate; filaments equaling or longer than anthers; capsule shorter than the calyx. Steironema lanceolatum (Walt.) Gray.

Dry or moist open woods, in thickets, sometimes in or about water of lakes, seepage and streams, swamps and wetlands generally, in Okla. (Waterfall) and e. Tex., May-July; from Fla. to Tex., n. to Pa., O., w. to Mich. and Wisc.

A plant segregated as L. hybrida Michx. [L. lanceolata subsp. hybrida (Michx.) Ray] has been reported from our region. It is considered to be closely allied to L. lanceolata from which it differs in having a thicker, more robust stem with longer internodes, basal offshoots and nonpersistent essentially sessile basal leaves, no cordlike rhizomes, and a more open-paniculate inflorescence. The leaves are also green on both surfaces instead of being pale-green or somewhat glaucous beneath as in $L$. lanceolata. 


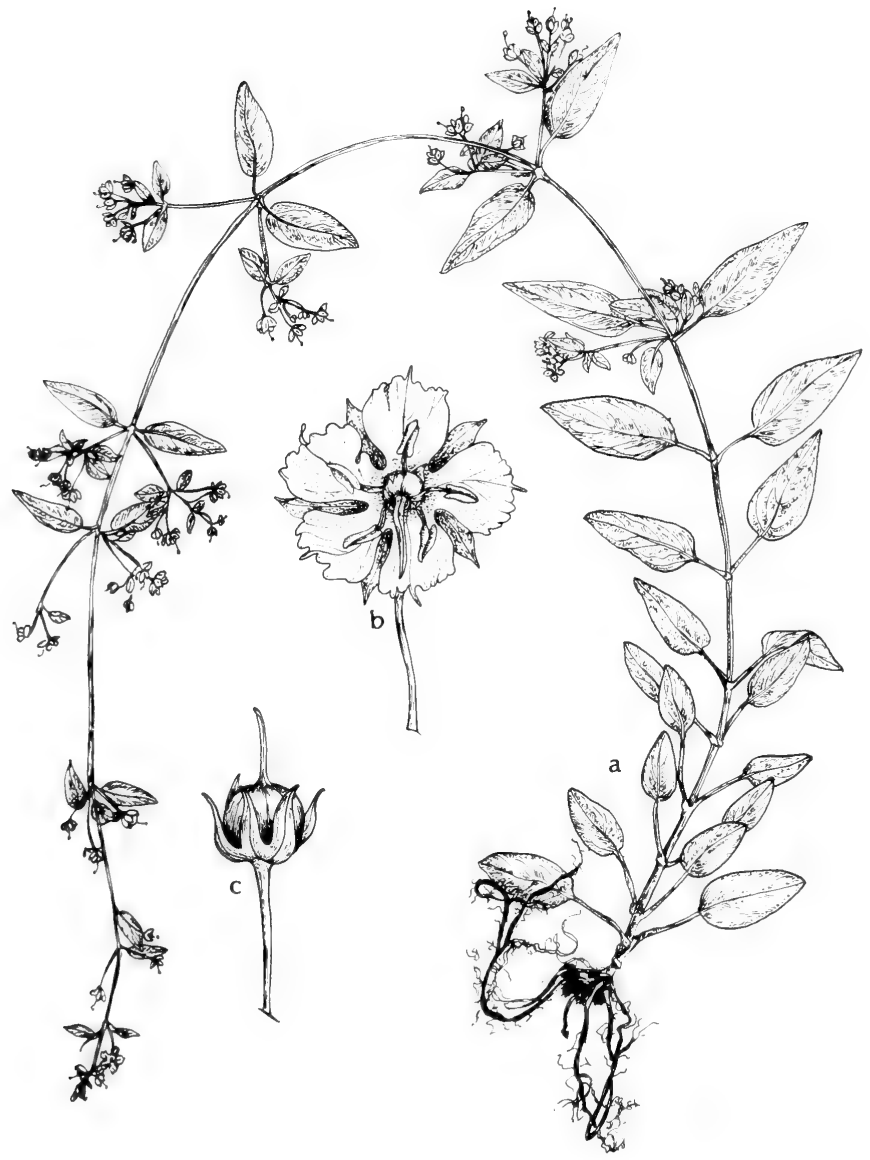

Fig. 614: Lysimachia radicans: a, habit, x 1/2; b, flower, x 3; c, capsule, x 3. (V. F.). 


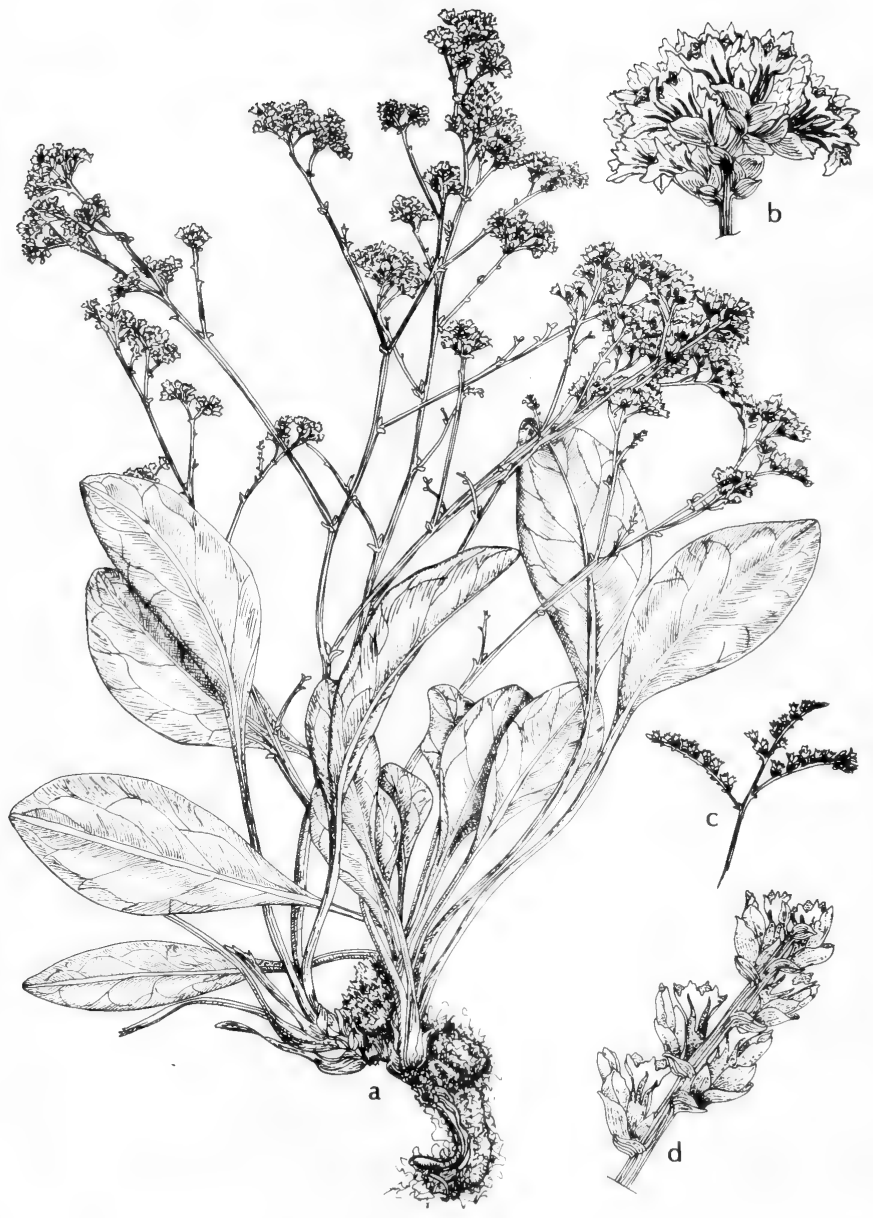

Fig. 615: a and b, Limonium limbatum var. limbatum: a, habit, x 1/2; b, flower cluster, x 2. c and d, Limonium limbatum var. glabrescens: c, branch, x 1/2; d, end of branch, $x$ 2. (V, F.). 


\section{Fam. 103. Plumbaginaceae Juss.}

\section{Plumbago Family}

Perennial herbs or shrubs, with basal or alternate entire leaves and perfect and regular flowers; calyx inferior, 4- or 5-toothed, sometimes plaited at the sinuses, the tube 5- to 15-ribbed; corolla of 4 or 5 hypogynous clawed segments connate at the base or united into a tube; stamens 4 or 5 , opposite the corolla segments, hypogynous; anthers 2-celled, dorsally attached to the filaments, the sacs longitudinal dehiscent; disk none; ovary superior, 1-celled; ovule solitary, anatropous, pendulous; styles 5; fruit a utricle, achene or capsule, enclosed by the calyx; seed solitary.

About 10 genera and 500 species of wide distribution, many in saline or semiarid situations.

\section{Limonium Mill. Sea-Lavender. Marsh-Rosemary}

Perennials with woody roots and petioled radical thick leaves, the nearly naked erect flowering stems or scapes branched into panicles; flowers solitary or 2 or 3 together in several-bracted spikelets that are approximate or scattered on 1-sided branches; calyx funnelform, dry and membranous, persistent; corolla of 5 nearly or quite distinct petals, with long claws, the 5 stamens attached to their bases; styles 5 or rarely 3, separate; fruit membranous and indehiscent, scarcely exserted from the calyx.

About 300 species that are widely distributed. This genus, in North America, is sorely in need of a modern revision.

1. Calyx $4 \mathrm{~mm}$. long or less, the short broadly triangular-ovate lobes spreading at maturity; plants of alkaline flats in Trans-Pecos Texas, westward 1. L. limbatum.

1. Calyx $5 \mathrm{~mm}$. long or more, the narrowly ovate-lanceolate lobes erect at maturity; plants of beach and dune areas along the Gulf Coast (2)

2(1). Spikelets 1 - to 3 -flowered, mostly $3 \mathrm{~mm}$. or less apart; calyx usually prominently pubescent on ribs below middle, rarely glabrous..........

2. L. Nashii var. Nashii.

2. Spikelets nearly all 1 -flowered, mostly $4 \mathrm{~mm}$. or more apart at maturity; calyx glabrous or sparsely short-pubescent near base

2. L. Nashii var. angustatum.

1. Limonium limbatum Small. Fig. 615.

Plant to $6 \mathrm{dm}$. high, bluish-green or glaucescent; leaves with petioles to $15 \mathrm{~cm}$. long, obovate to elliptic, rounded or retuse at the barely mucronulate apex, narrowed into the petiole, thick, leathery, venose, to $16 \mathrm{~cm}$. long and $65 \mathrm{~mm}$. wide; scape stout, much-branched from below the middle; panicle large, to $3 \mathrm{dm}$. wide or more, the branches divergent-ascending, the 2-flowered spikelets densely and distichously aggregated into $1-1.4 \mathrm{~cm}$. long spikes on the ultimate branchlets or somewhat elongated in var. glabrescens; outermost bractlet ovate-orbicular to orbicular, acute to acutish, mucronate or apiculate, hyaline-margined, $1-1.4 \mathrm{~mm}$. long; middle bractlet oblong-oval, retuse at apex, hyaline with green midrib, $3 \mathrm{~mm}$. long; innermost bractlet very firm, elliptic, rounded to retuse at apex, hyalinemargined, 3-3.5 mm. long; calyx trumpet-shaped, with wide-spreading limb, about $4 \mathrm{~mm}$. long, with 2 or 3 of the ribs pubescent to the middle and the other ribs generally pubescent only at the extreme base or not at all, the ribs glabrous or nearly so in var. glabrescens; calyx lobes deltoid-ovate, obtuse to acute, about $0.7 \mathrm{~mm}$. long; intermediate teeth depressed-deltoid, about $0.2 \mathrm{~mm}$. long or obsolescent; corolla bright-blue.

In wet meadows, saline flats and in depressions in the Texas Trans-Pecos, reported from the Panhandle, N.M. (Guadalupe and Valencia cos.) and Ariz. (Graham Co.), June-Aug. 
The ultimate branchlets of the inflorescence in var. glabrescens Correll are somewhat elongated and more laxly flowered than in var. limbatum. The calyx ribs are also glabrous or are provided with only a few scattered hairs instead of being densely pubescent as in var. limbatum.

\section{Limonium Nashii Small. Fig. 616.}

Plant 3-8.5 dm. high, the scape solid; leaves with a petiole to $16.5 \mathrm{~cm}$. long, linear-elliptic to narrowly spatulate or obovate, obtuse to rounded at the barely mucronulate apex, narrowed into the petiole, to $17 \mathrm{~cm}$. long and $45 \mathrm{~mm}$. wide; scape paniculately much-branched from near the middle; panicle $2-3 \mathrm{dm}$. across, the somewhat fractiflex lax branches spreading-ascending or arcuate, the ultimate branchlets compactly or loosely flowered; spikelets 1- to 3-flowered; outermost bractlet ovate, acute to acuminate, mucronate, hyaline-margined, $1.8-2.5 \mathrm{~mm}$. long; middle bractlet ovate to oblong, somewhat erose at the obtuse to mucronate apex, hyaline with a distinct midrib, 2.5-4 mm. long; innermost bractlet elliptic, rounded to retuse or subacute at apex, hyaline-margined, 3.8-4.5 $\mathrm{mm}$. long; calyx obconic, glabrous to sparsely or rather densely pilose at extreme base and often on one or two ribs for about half their length, 5-7 $\mathrm{mm}$. long, the whitish 5-lobed limb erect; calyx lobes ovate-lanceolate, acuminate, 1-1.5 mm. long; teeth very short and bifid or obsolescent; corolla violet to lavender; capsule 5-7 $\mathrm{mm}$. long.

On beaches, salt flats and marsh borders, in grasslands and in loose sand among dunes along the Gulf Coast, June-Nov.; mostly from S.C., s. to Fla. and w. to Tex. and n.e. Mex., rare n. of S. C.

The inflorescence of this species is more laxly and openly branched than in that of the eastern $L$. carolinianum (Walt.) Britt. Plants ascribed to $L$. carolinianum var. compactum Shinners belong to var. Nashii.

In our region var. angustatum (Gray) Ahles seems to be more southern in its distribution than var. Nashii, being rather frequent on south Padre Island, Texas. Its leaf blades are typically smaller than those of var. Nashii, being up to about $10 \mathrm{~cm}$. long and $2.5 \mathrm{~cm}$. wide. L. angustatum (Gray) Small, L. carolinianum var. angustatum (Gray) Blake.

\section{Fam. 104. Styracaceae Dum. Storax FAmily}

Shrubs or trees commonly with stellate pubescence; leaves alternate, simple, exstipulate; flowers regular, perfect; calyx adherent to the ovary or at least to its base, entire or with 4 to 8 valvate teeth or lobes; corolla with 4 or 5 (rarely more) petals that are (in ours) united at base or rarely more; stamens as many as or several times as many as the corolla lobes, free or adnate to corolla tube; anthers elongate; ovary inferior or partly inferior in Styrax; style one; fruit a drupe or capsule.

A small family of about 180 species in 12 genera in warm temperate regions. 1. Calyx adherent to whole surface of ovary; corolla 4-lobed; fruit ellipsoid to ellipsoid-obovoid, 2- to 4-winged...................................1. Halesia.

1. Calyx adherent only to base of ovary; corolla 5-lobed; fruit globular, wingless

2. Styrax.

\section{Halesia ELLIS}

Shrubs or small trees, with large veiny deciduous leaves and snowy-white flowers drooping on slender pedicels in clusters or short racemes, the pubescence partly stellate; calyx inversely conical, 4-toothed, the tube ribbed; corolla openly campanulate; petals 4 , white, united at base or sometimes to above the middle; stamens 8 to 16 ; filaments united into a ring at base and usually a little adherent 


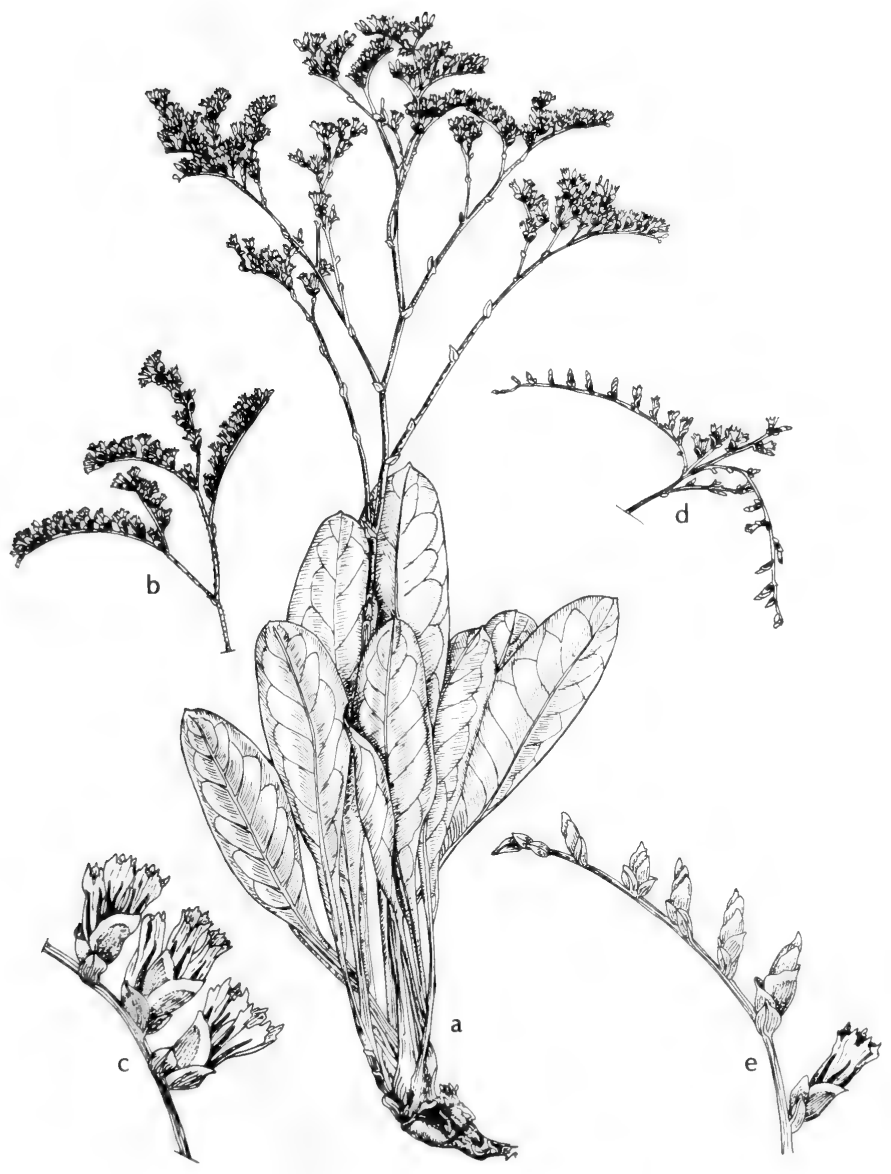

Fig. 616: a-c, Limonium Nashii var. Nashii: a, habit, x 1/2; b, branch, x 1/2; c, three flowers, x 2. d and e, Limonium Nashii var. angustatum: $\vec{d}$, branch, x 1/2; e, end of branch, $x$ 2. (V. F.). 


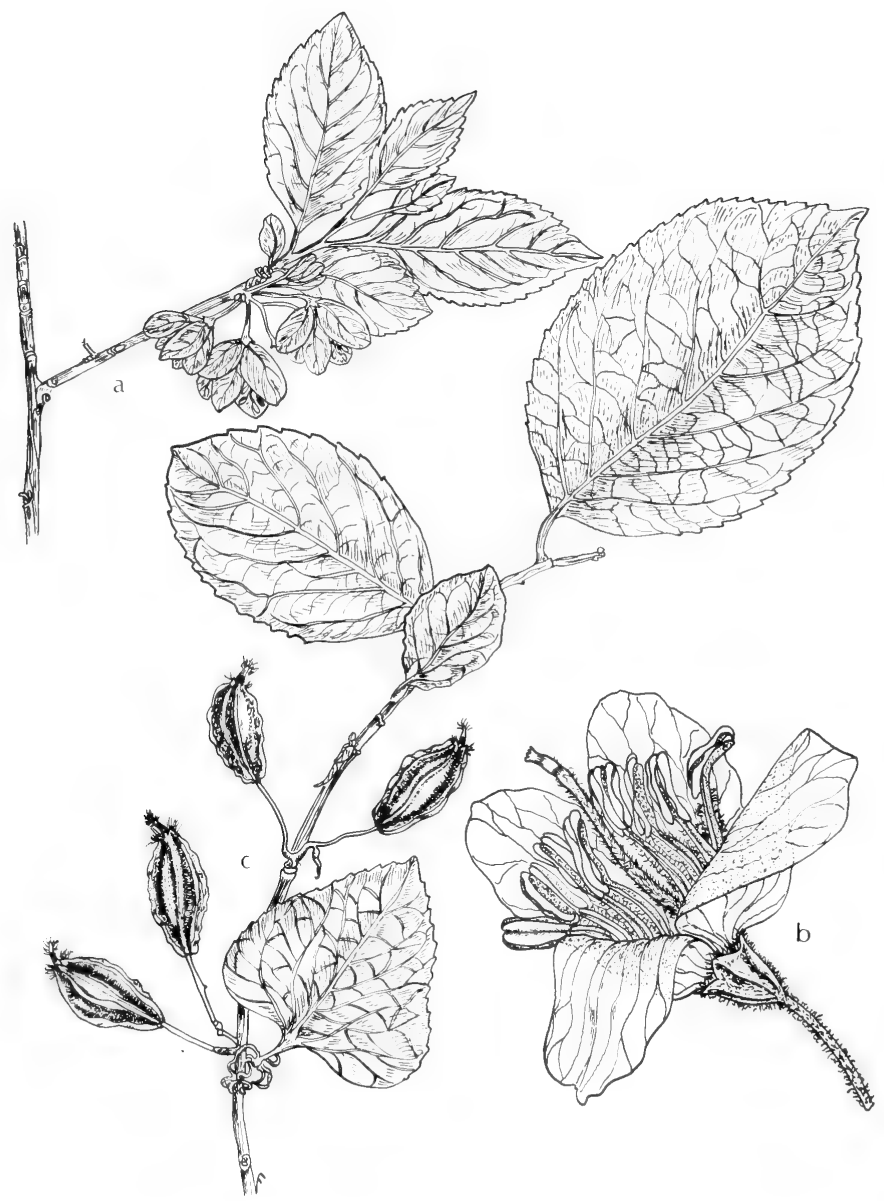

Fig. 617: Halesia diptera: a, flowering twig, x 1/2; b, flower, $x$ 2; c, fruiting twig, $\mathrm{x}$ 1/2. (V. F.). 
to the base of the corolla; anthers linear-oblong; ovules 4 in each cell; fruit large and dry, bony within; seeds single, cylindrical.

A few species found in North America and China.

1. Corolla lobes shorter than the tube; fruit 4-winged.

1. Corolla lobes longer than the tube; fruit 2-winged.

1. H. carolina.

2. $H$. diptera.

1. Halesia carolina L. Carolina SIlver-bells, o'possum-wood.

Large shrubs or small tree to about $12 \mathrm{~m}$. tall; leaves broadly ovate to elliptic or obovate, to $15 \mathrm{~cm}$. long and $8 \mathrm{~cm}$. wide, acute to acuminate, serrulate; flowers in clusters of 2 to 5 , with slender pedicels to $15 \mathrm{~mm}$. long; calyx 5-6 mm. long; corolla to $2 \mathrm{~cm}$. long; filaments and styles glabrous; fruit $2.5-4 \mathrm{~cm}$. long, ellipsoid to ellipsoid-obovoid, short-beaked.

In rich woods and along stream banks in e. Tex. and s.e. Okla. (Waterfall), Apr.-May; from Fla. to Tex. (fide Small), n. to Va., W.Va., s. O., s. Ind., s. Ill., s.e. Mo. and Okla.

\section{Halesia diptera Ellis. SNOWdrop-TREe. Fig. 617.}

Small tree or shrub to $8 \mathrm{~m}$. tall; leaves elliptic to obovate or sometimes ovate, rounded to cuneate at base, abruptly acute to acuminate at apex, when mature essentially glabrous, to $15 \mathrm{~cm}$. long and $9 \mathrm{~cm}$. wide, rather coarsely toothed; flowers with pedicels about $1 \mathrm{~cm}$. long; calyx 3-4 mm. long, pubescent; corolla 1.5-2 $\mathrm{cm}$. long, copiously pubescent; petals broadly elliptic, obtuse; filaments and style pubescent; fruit $3.5-5 \mathrm{~cm}$. long, narrowly ellipsoid, prominently beaked.

Woods and along streams or edge of swamps, in e. Tex. and (?) s.e. Okla. (Waterfall), Mar.-Apr.; from n. Fla. n. to S.C., w. to Tex. and Ark.

\section{Styrax L. Storax. Silver Bells}

Shrubs or small trees with deciduous leaves and axillary or leafy-racemed white and showy flowers on drooping peduncles; calyx somewhat 5- to 7-toothed and sometimes glandular at truncate apex; petals soft-downy; stamens twice as many as the corolla lobes; filaments flat, united at the base into a short tube; anthers linear; fruit dry. often 3-valved; seeds globular, erect, with a hard coat.

Over 130 species found in warm regions of North America and Eurasia.

1. Leaves characteristically broadly elliptic to obovate; distribution in east Texas

1. Leaves characteristically suborbicular to broadly ovate; distribution in central Texas. ..2. S. platanifolia.

1. Styrax americana Lam. Mock-ORAnge. Fig. 618.

Shrub or small tree to $6 \mathrm{~m}$. tall; leaves elliptic to obovate, tapering to base, more or less abruptly acute to short-acuminate at apex, to $13 \mathrm{~cm}$. long and $8 \mathrm{~cm}$. wide, subglabrous to pulverulent or somewhat scurfy on lower surface, the margins (especially above the middle) irregularly serrulate to serrate-sublobulate; flowers axillary or in several-flowered racemes to $7 \mathrm{~cm}$. long, the racemes subglabrous to scurfy-canescent, the pedicels usually about $5 \mathrm{~mm}$. long; calyx puberulent; corolla lobes valvate to somewhat convolute in bud, elliptic to elliptic-oblanceolate, obtuse to acute at apex, to $15 \mathrm{~mm}$. long and $5 \mathrm{~mm}$. wide; capsule subglobose, about $1 \mathrm{~cm}$. long, apiculate. Incl. f. pulverulenta (Michx.) Perkins, S. pulverulenta Michx.

In moist woods, swampy areas and along streams in e. Tex. and s.e. Okla. (McCurtain Co.), Apr.-May; from Fla., w. to Tex., n. to s.e. Va., s. Ind., s.e. Mo., Ark. and Okla.

\section{Styrax platanifolia Engelm.}

Shrub or small tree to $4 \mathrm{~m}$. tall, much-branched; leaves more or less pubescent with stellate hairs, rarely subglabrous, strongly reticulate-veined, broadly ovate to suborbicular, with the margins undulate to angulate or occasionally sinuately 


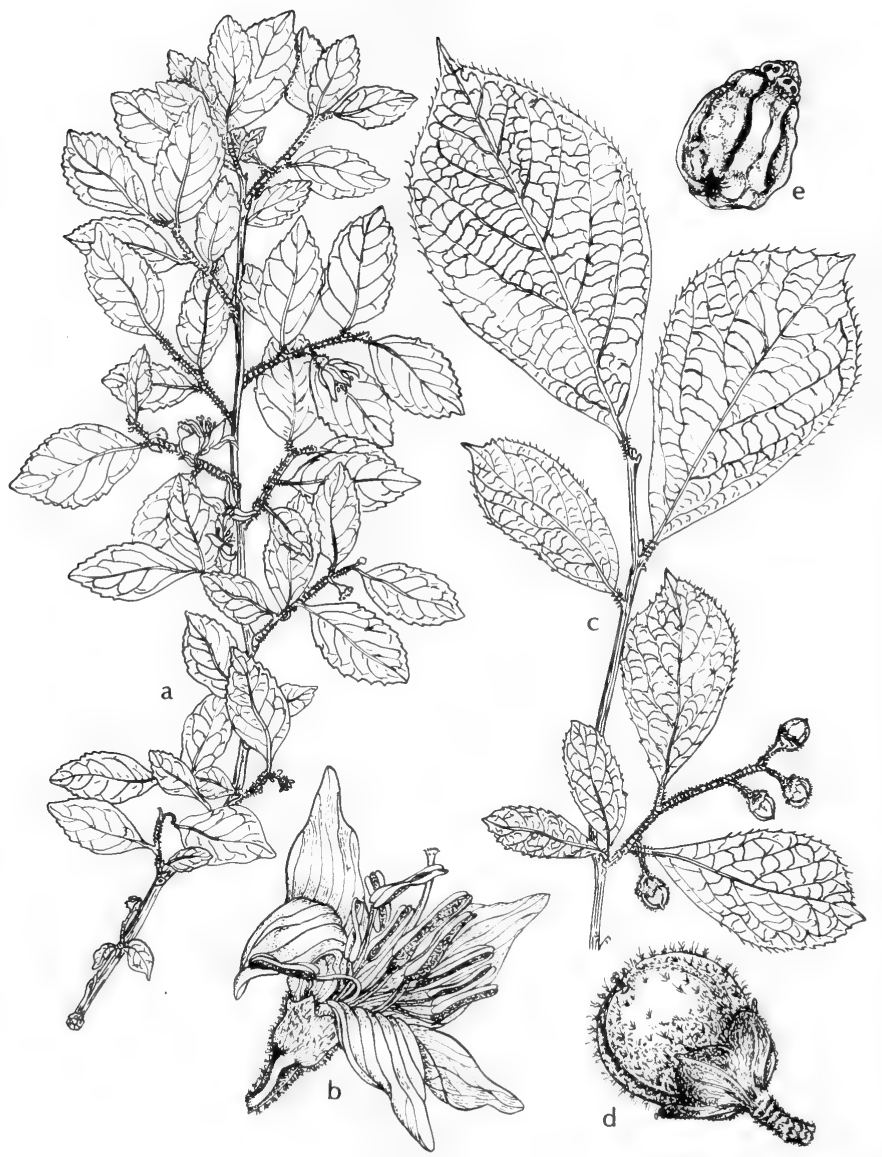

Fig. 618: Styrax americana: a, flowering branch, x 1/2; b, flower, x 31/2; c, fruiting branch, $x$ 1/2; d, fruit, x $2 \frac{1}{2}$; e, fruit (dried), x $2 \frac{1}{2}$. (V. F.). 
lobulate, truncate to subcordate at base, obtuse to somewhat abruptly acute at apex, to $1 \mathrm{dm}$. long and wide; flowers several in corymbose racemes, with puberulent pedicels; calyx puberulent; petals elliptic to elliptic-lanceolate, acute, about $15 \mathrm{~mm}$. long; capsule about $1 \mathrm{~cm}$. in diameter, puberulent, apiculate. Incl. var. stellata Cory.

Along streams and on seepage ledges in limestone canyons of Tex. Edwards Plateau, Apr.-May; endemic.

\section{Fam. 105. Symplocaceae DESF.}

\section{SWEeT-LeAf FAMILY}

Tree or sometimes shrubs; leaves alternate, simple, without stipules; flowers perfect, regular; calyx campanulate, adherent to the ovary, its lobes valvate or imbricate; corolla with as many as 11 petals ( 5 in ours) that are united at base; stamens in clusters at the base of each petal, in several series, free or variously united at base; anthers minute, subglobose; ovary partly inferior, 2- to 5-celled; ovules 2 to 4 , pendulous; style 1; fruit baccate or drupaceous, crowned by the calyx lobes, 1- to 5-celled, with a solitary anatropous seed in each cell.

Two genera of about 500 species, mostly tropical and subtropical.

\section{Symplocos JACQ. SWeET-LEAF}

Characters of the family. About 350 species, mostly in tropical regions of both hemispheres.

\section{Symplocos tinctoria (L.) L'Her. Horse-sugar, yellow-wood. Fig. 619.}

Large shrubs or small trees to $6 \mathrm{~m}$. tall; leaves elliptic to elliptic-obovate or oblanceolate, tapering to the short petiole, acute to shortly acuminate at apex, subentire to obscurely toothed, usually subcoriaceous and evergreen or latedeciduous, glossy on upper surface, pale and minutely pubescent on lower surface, to $15 \mathrm{~cm}$. long and $6 \mathrm{~cm}$. wide; flowers 6 to 14 in close and bracted clusters on the old wood, yellow, fragrant, the clusters axillary and sessile, opening before or with the leaves; petals 5 , obovate, $6-8 \mathrm{~mm}$. long; drupes cylindric-ellipsoid, about $1 \mathrm{~cm}$. long.

In woods, Palmetto marsh areas where occasionally flooded, swamps and bottomlands in e. Tex. and s.e. Okla. (McCurtain Co.), Feb.-Apr.; from Fla. to Tex. and Okla., n. to Del.

The sweetish leaves are much relished by browsing animals.

\section{Fam. 106. Oleaceae Hof FMSG. \& LINK}

\section{Olive Family}

Trees, shrubs or rarely subherbaceous; leaves opposite or rarely alternate, simple to pinnatifid or pinnate, exstipulate; flowers perfect or unisexual, regular, variously disposed; calyx 4-lobed or -parted, rarely 5- to 16-lobed or wanting; corolla gamopetalous, 4-lobed or rarely 6- to 12 -lobed, sometimes of distinct petals or wanting; stamens 2 or rarely 3 to 5 , adnate to the corolla and alternate with the lobes; ovary free, 2-celled, with usually 2 ovules in each cell; style 1 or wanting, with a simple or 2-lobed stigma; fruit a drupe, capsule or samara; seeds anatropous, with large straight embryo, with or without albumen.

About 30 genera with over 600 species in temperate and tropical regions. Many ornamental species; a few are of economic importance and some are valuable timber trees. Species of the Old World jasmine (Jasminum spp.) are commonly cultivated in our area, and Olea europaea provides the olive of commerce. 


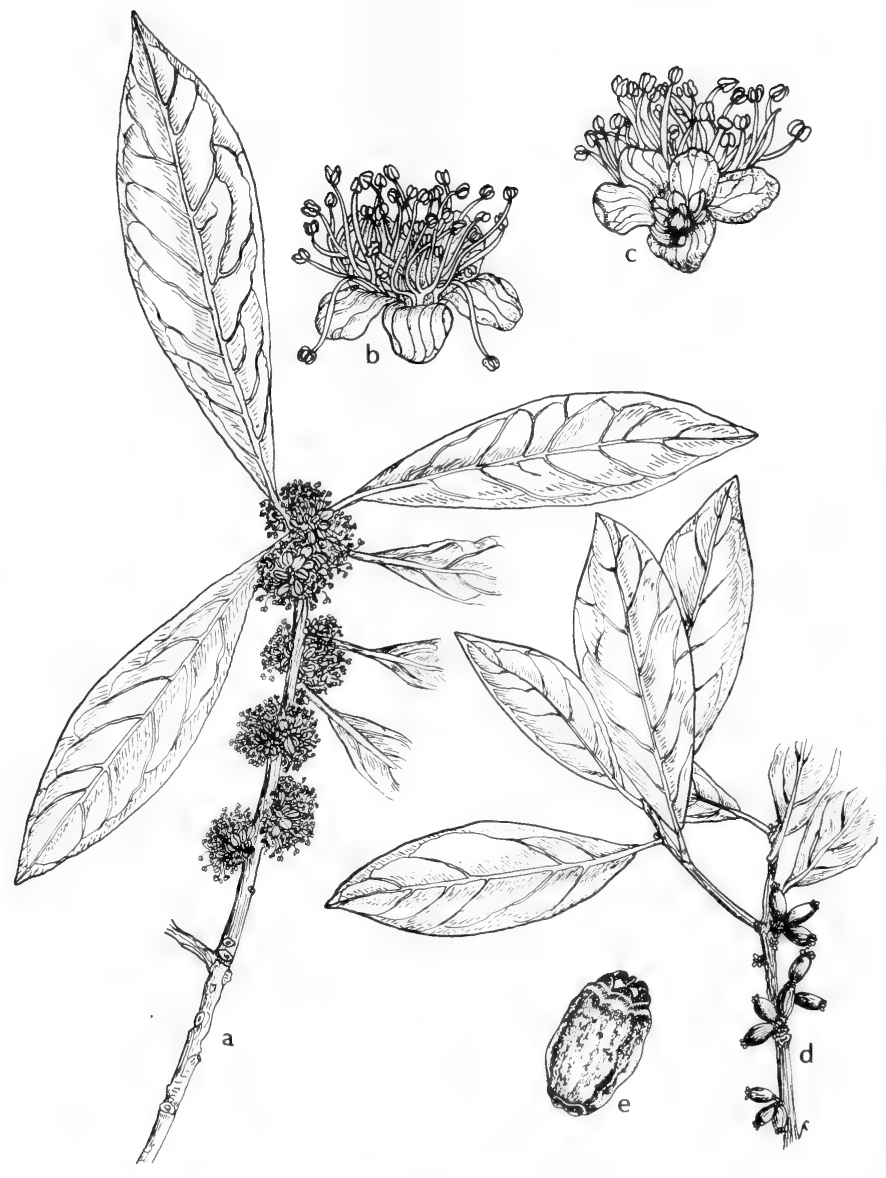

Fig. 619: Symplocos tinctoria: a, flowering branch, $\mathrm{x}$ 1/2; b, flower showing branched filaments, $x 2$; c, flower showing calyx and bud scales, $x 2$; d, fruiting branch, $x 1 / 2$; e, drupe, $x$ 21/2. (V. F.). 
1. Fruit a samara; leaves pinnately compound

1. Fruit a drupe; leaves entire (2)

2(1). Corolla lobes linear, many times longer than the tube, valvate; flowers in pendulous panicles.

2. Corolla wanting; flowers in small axillary clusters 2. Chionanthus 3. Forestiern

\section{Fraxinus L. AsH}

Deciduous trees or very rarely shrubs; winter buds often superposed, with 1 or 2 pairs of outer scales, usually brown or black and scurfy, the outer pair sometimes foliar (that is, obscurely pinnate at apex); leaves opposite, petioled, odd-pinnate, rarely reduced to 1 leaflet; male and female flowers on separate plants or occasional flowers may appear perfect; flowers small, in crowded panicles or racemes; calyx small, 4-parted or -lobed or wanting: corolla of 2 to 6 (usually 4) distinct petals, rarely connate at base or wanting; stamens usually 2; ovary 2-celled; stigmas 2; fruit a samara or 1-seeded nutlet with a usually elongated wing at the apex; seed oblong, albuminous.

About 70 species in the Northern Hemisphere. Ornamental trees with handsome foliage, some with conspicuous flowers; several species are important timber trees.

1. Plants in Oklahoma and the eastern two thirds of Texas from the eastern Panhandle through the central Edwards Plateau south to the upper Gulf Coast (2)

1. Plants in the western third of Texas, mainly in the Trans-Pecos, western Edwards Plateau and Rio Grande Valley, westward (4)

2(1). Body of fruit compressed, its broad wing extending to the base; confined to southeast Texas. 1. F. caroliniana.

2. Body of fruit terete or nearly so (3)

3 (2). Wing of fruit decurrent to about or below the middle of the fruit body; leaves lighter green but not noticeably pale on the lower surface......

..2. F. pensylvanica.

3. Wing of fruit terminal or only slightly decurrent on the fruit body; leaves usually pale-glaucous on lower surface, somewhat papillose on upper surface.

3. F. americana.

4(1). Leaves and branchlets glabrous; wing of the fruit decurrent to or near the base of the somewhat compressed fruit body; in the Texas Edwards Plateau and Rio Grande Plains and Valley........4. F. Berlandieriana.

4. Leaves and branchlets pubescent or glabrous; wing of the fruit (at most) decurrent to above the middle of terete fruit body; in the Texas TransPecos region westward.............................................5. F. velutina.

1. Fraxinus caroliniana Mill. Carolina ASh, POP ASH, WATER ASH. Fig. 620.

Shrubby tree rarely more than $10 \mathrm{~m}$. high and trunks to $3 \mathrm{dm}$. in diameter, the winter buds chestnut-brown; branchlets terete, glabrous or pubescent; leaves with terete petioles; leaflets 5 or 7 , with slender petiolules to $2 \mathrm{~cm}$. long, ovate-lanceolate to elliptic or oblong, to $12 \mathrm{~cm}$. long, broadly cuneate or sometimes rounded at the base, acuminate at apex, serrate or rarely entire, pale-green and glabrous or sparingly pilose on the veins or rarely pubescent beneath; anthers linear, apiculate, on slender filaments; samaras rhombic to elliptic or obovate-oblanceolate, $3-5 \mathrm{~cm}$. long, acute to emarginate, the fruit body compressed and surrounded by the wing, sometimes 3-winged.

Usually in swamps and along rivers in s.e. Tex., Mar.-May; from Va. to Fla., w. to Ark. and Tex. 


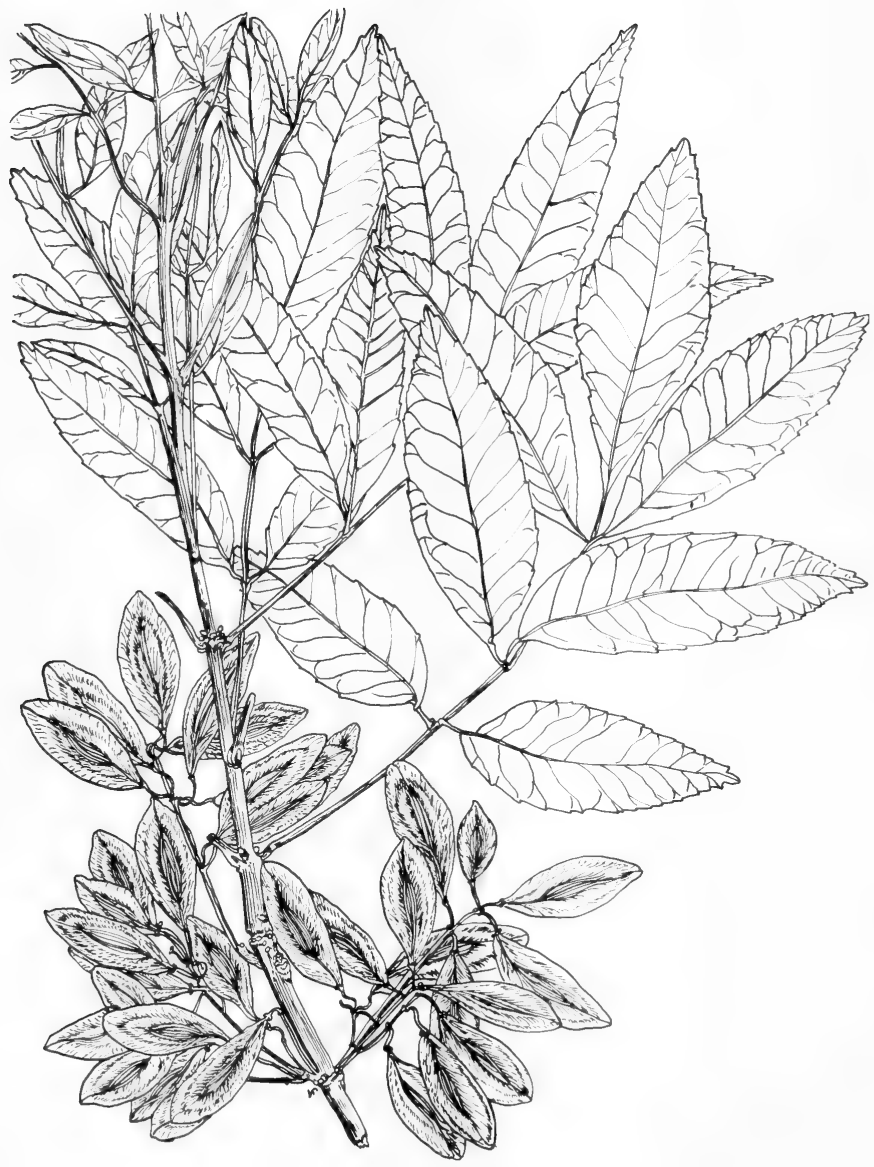

Fig. 620: Fraxinus caroliniana: in fruit, $x \frac{1}{2}$. (V. F.). 


\section{Fraxinus pensylvanica Marsh. RED ASH.}

Tree to $20 \mathrm{~m}$. high, with a trunk rarely to $5 \mathrm{dm}$. in diameter; branchlets and petioles densely pubescent to glabrous; leaflets 5 to 9 , with petiolules to about 1 $\mathrm{cm}$. long, ovate to elliptic-oblong or lanceolate, to $15 \mathrm{~cm}$. long, broadly cuneate to somewhat rounded at base, acute to acuminate at apex, the margins entire to serrate, bright-green above, pubescent to glabrous or pubescent only along midrib beneath: panicle rather compact, tomentose to glabrous: anthers linear-oblong, on short filaments: samaras $3-7.5 \mathrm{~cm}$. long, brownish; fruit body slender, terete, to $3 \mathrm{~cm}$. long; wing lanceolate to oblong-obovate, rounded to acuminate or rarely emarginate at apex, decurrent to about or below the middle or very rarely nearly to the base.

Along rivers and streams, in alluvial woods and swamps, and in depressions in savannahs, in Tex. mainly e. of a line drawn from Victoria Co. on the coast to Hemphill Co. on the Rolling Plains in the Panhandle, and Okla. (Craig and Alfalfa cos. ), Feb.-Apr.; from N.S. to Man., s, to Ga., Ala. and Tex.

Our plant is usually referred to var. subintegerrima (Vahl) Fern. [var. lanceolata (Buckl.) Sarg.] which is essentially glabrous throughout.

\section{Fraxinus americana L. WHITE ASH, FRESNO.}

Tall tree to $40 \mathrm{~m}$. high; young branchlets dark-green or brownish, glabrous and lustrous: leaflets 5 to 9 , usually 7 , with slender petiolules to $15 \mathrm{~mm}$. long, ovate to ovate-lanceolate or elliptic-lanceolate, to $15 \mathrm{~cm}$. long, cuneate to rounded at the base, mostly acuminate but sometimes blunt at apex, usually entire or only slightly undulate or dentate toward the apex, dark-green above, glaucous beneath and usually glabrous; anthers linear to oblong, apiculate; samaras $3-5 \mathrm{~cm}$. long, the terete fruit body to $15 \mathrm{~mm}$. long; wing narrowly oblong to spatulate, not decurrent, 4-7 $\mathrm{mm}$. broad, emarginate or obtuse at apex.

Along streams and in damp or wet forests in the e. third of Tex. and in Okla. (Waterfall), Feb.-Mar.; from N.S. to Minn., s. to Fla. and Tex.

\section{Fraxinus Berlandieriana A.DC. MEXICAN ASH, FRESNO.}

Small tree to about $10 \mathrm{~m}$. high; leaves petiolate, grayish-green to bright-green; leaflets 3 to 5 , with petiolules to $12 \mathrm{~mm}$. long, lanceolate to elliptic or obovate, typically narrow, to $12 \mathrm{~cm}$. long, narrowly to broadly cuneate at base, subobtuse to acuminate at apex, nearly entire to coarsely serrate, pale and glabrous or hairy in the axils of the veins beneath; samaras $25-35 \mathrm{~mm}$. long, oblong-obovate to spatulate; wing decurrent to or near the base of fruit body, occasionally 3-winged.

Mostly along wooded streams and in canyons in Tex. in the Edwards Plateau and on the Rio Grande Plains and Valley, s. to Cameron Co., Mar.-Aug.; also in adj. Mex.

\section{Fraxinus velutina Torr. Velvet ash, Arizona ash, desert ash, fresno.}

Small to medium-sized tree to $12 \mathrm{~m}$. high and $3 \mathrm{dm}$. in trunk diameter, with spreading branches to form a rounded crown; bark deeply furrowed into ridges, gray, the light-brown wood soft and heavy; branchlets velvety-tomentose to glabrescent; twigs brown, glabrous to pubescent; leaves petioled, pinnately compound. $7.5-15 \mathrm{~cm}$. long; leaflets 3 to 9 , usually 5 , short-petiolulate to subsessile, varying greatly in appearance, elliptic to lanceolate or ovate, obtuse to long-pointed at apex, 25-75 $\mathrm{mm}$. long, essentially entire to somewhat dentate on upper margins, varying from thin to thick and leathery and from glabrous to densely shortpubescent beneath; flowers small, yellow (staminate) and green (pistillate), appearing before the leaves, many in clusters; samaras numerous in dense clusters, 2-3.5 $\mathrm{cm}$. long; wing oblong-obovate to elliptic or spatulate, shorter than the terete fruit body and decurrent scarcely to the middle, 3-4 mm. wide. Incl. f. Toumeyi Britt. and var. Toumeyi (Britt.) Rehd., F. Standleyi Rehd. 


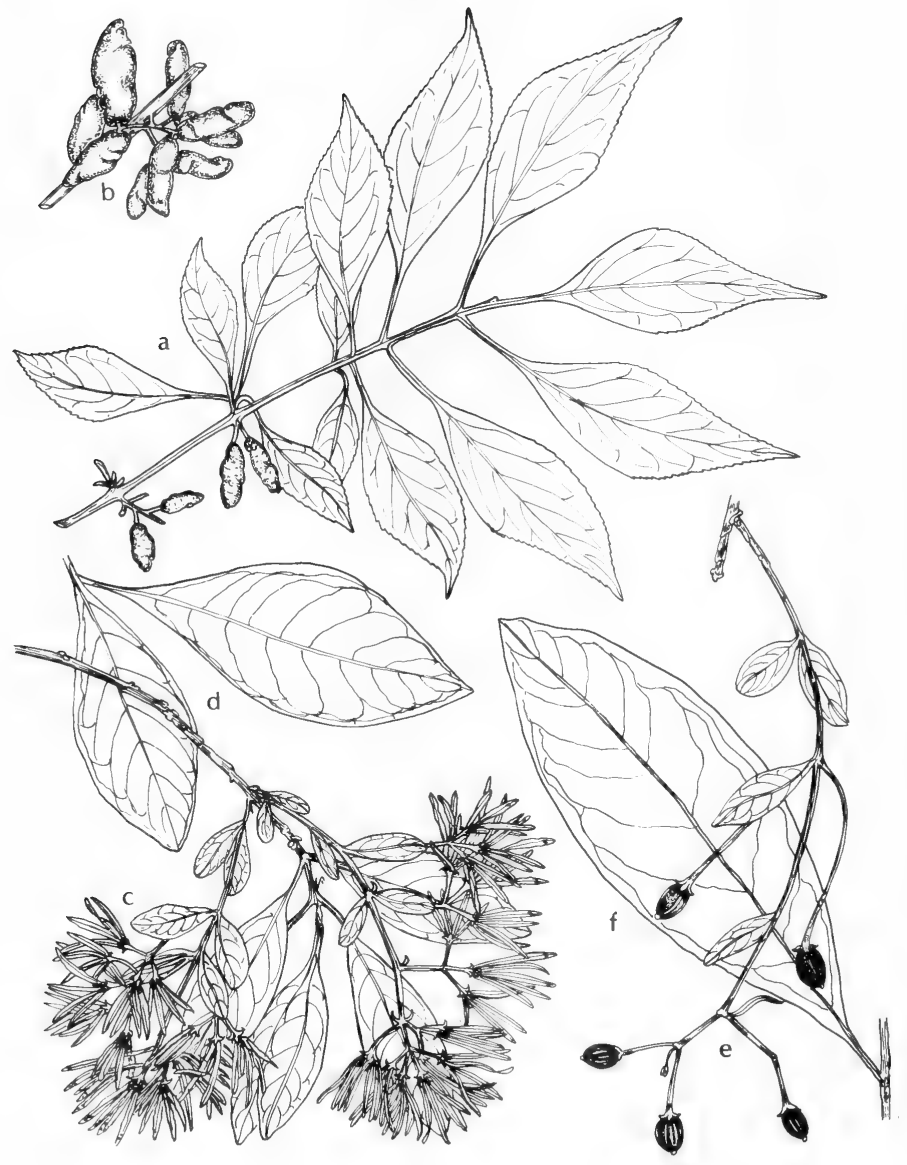

Fig. 621: a and b, Forestiera acuminata: a, branch with fruit, $\mathrm{x} 1 / 2 \mathrm{~g} ; \mathrm{b}$, fruit, $\mathrm{x}$ 11/2. c-f, Chionanthus virginicus: c, flowering branch, $x 1 / 2 ; d$, leaves showing size at flowering time, $x 1 / 2 ; \mathrm{e}$, fruiting branch, $x_{1 / 2}^{1 / 2} ; \mathrm{f}$, leaves showing relative size at fruiting time, $x$ 1/2. ( $a$ and $b$, Redrawn from Godfrey, Trees of Northern Florida, Fig. 174; c-f, V.F.). 
In canyons and borders of streams, lakes and springs in the Tex. Trans-Pecos, N.M. (Grant, Luna, Dona Ana, Lincoln and Otero cos.) and Ariz. (Apache to Coconino, s. to Cochise, Santa Cruz and Pima cos.), spring; from w. Tex. to Ut., Nev., Calif. and n. Mex.

Similarly to most of our ashes, $F$. velutina is an extremely variable species that has been given a number of names based on its variations. The plant with glabrous branchlets and leaves has been designated as var. glabra (Thornb.) Rehd.

\section{Chionanthus L. Fringe-TreE}

Two species, ours and another in eastern Asia.

\section{Chionanthus virginica L. Old-MAn's BeARD. Fig. 621.}

Low deciduous tree to about $10 \mathrm{~m}$. high; branchlets stout, pubescent when young; leaves with petioles to $25 \mathrm{~mm}$. long, opposite to alternate, entire, oval to oblong or oblanceolate, cuneate at base, acute to acuminate at apex, to $2 \mathrm{dm}$. long and $6 \mathrm{~cm}$. wide, usually much smaller, dark-green and lustrous above, paler and sometimes pubescent beneath; panicles densely flowered, to $2 \mathrm{dm}$. long, usually leafy-bracted at base; flowers delicate, white or greenish-white, on slender pedicels, opening with or before the leaves, in loose and drooping graceful panicles from lateral buds in the uppermost leaf axils, functionally unisexual; calyx 4-parted, very small, persistent; calyx lobes triangular; petals $1.5-3 \mathrm{~cm}$. long, about $2 \mathrm{~mm}$. wide, narrowly linear, acute, varying to 5 or 6 in number: stamens 2 , subsessile on the base of the corolla; style very short, the stigma notched; drupe purple, with a bloom, ovoid to ellipsoid, fleshy, to $18 \mathrm{~mm}$. long.

In damp woods, low wet depressions in flatwoods, in thickets or on bluffs in s.e. Okla. (Waterfall) and e. Tex., Mar.-Apr.; from Fla. to Tex., n. to N.J., e. Pa., W.Va., s. O., s. Mo. and Okla.; spreading from cult. northw.

Those plants with pubescent panicles and pubescent lower surface of leaves are usually referred to var. maritima Pursh.

\section{Forestiera PoIR.}

Shrubs or small trees; leaves opposite or subopposite, the phyllotaxis in some species obscured by the foreshortening of the internodes of the twigs ("spurs" or "short shoots"); leaf blades entire, simple, usually porulose (with darkish minute craters scattered in the epidermis); stipules absent; male and female flowers borne on separate bushes or an occasional flower appearing perfect; flowers inconspicuous, borne in small axillary glomerules, unisexual; sepals minute; corolla absent; staminate flowers comprising merely 4 (or 5 ) minute sepals and 4 (or 5 ) stamens: pistillate flowers comprising usually 4 (or 5) minute sepals, 4 (or 5) staminodia and a central stipitate ovary; ovary one-celled, uniovulate; fruit a slow-maturing drupe, longitudinally ribbed prior to ripening, the mesocarp becoming juicy only very shortly before maturity, the exocarp passing through shades of purple to nearly black and with a whitish bloom, the stone thin-walled and made of a series of longitudinal ribs; endosperm copious.

A genus of North America and Central America and the West Indies, of about 12 inclusive species or up to 20 finely divided ones.

Some species are among the most sought-after browse, and tend to disappear in over-browsed areas. The ripe drupes are eaten by game birds and some waterfowl.

1. Leaf blades mostly more than $3.5 \mathrm{~cm}$. long, acuminate; petioles $5 \mathrm{~mm}$. long or more.

1. F. acuminata.

1. Leaf blades rarely more than $3.5 \mathrm{~cm}$. long, obtuse to acute; petioles $1-3 \mathrm{~mm}$. long................................................................... F. pubescens.

1. Forestiera acuminata (Michx.) Poir. Swamp Priver. Fig. 621.

Shrubs to about $3 \mathrm{~m}$. tall or small trees to $10 \mathrm{~m}$. tall, glabrous; leaves deciduous, 
with a petiole $5-15 \mathrm{~mm}$. long, ovate-oblong to ovate-lanceolate, $3-10 \mathrm{~cm}$. long, cuneate at base, acuminate at apex, light-green, slightly serrate, rarely somewhat pubescent; flowers greenish, minute, the staminate in dense bracted clusters, the pistillate in short panicles; fruit narrowly oblong, dark-purple, 12-15 $\mathrm{mm}$. long. Incl. f. vestita (E.J.Palm.) M.C.Johnst.

In swamp forests, edge of water of streams and ponds and lowland woods, in s.e. Okla. (McCurtain Co.), n.-cen., e. and s.-cen. Tex., spring; s.e. U. S., n. to S.C., Tenn., Ind. and Ill., w. to Okla. and Tex.

The fruits of this species have been likened to soft, miniature, wrinkled sausages.

2. Forestiera pubescens Nutt. Elbow-BUSh, SPRING HERALD, STRETCH-BERry, DESERT OLIVE.

Rounded shrubs with arcuate branches, to about $3 \mathrm{~m}$. tall, with spiny glabrous to soft-pilose branchlets; leaves simple, opposite or fascicled, with petioles $1-3 \mathrm{~mm}$. long, deciduous, ovate to obovate or oblong-oblanceolate, $1.5-4 \mathrm{~cm}$. long, 6-11 $\mathrm{mm}$. wide, cuneate at base, acute to obtuse at apex, the somewhat revolute margins shallowly crenulate or serrulate, distinctly punctate-dotted beneath, either totally glabrous (var. glabrifolia Shinners, $F$. sphaerocarpa Torr.) or pubescent on both surfaces ( $F$. neomexicana Gray and var. arizonica Gray); flowers polygamodioecious, in clusters, the staminate sessile, the pistillate pedicellate; scales of flower buds obovate to suborbicular, $1.5-2.5 \mathrm{~mm}$. long, yellowish, ciliolate near base; stamens 2 to 4 ; anthers yellow, $0.5 \mathrm{~mm}$. long, subglobose, the filaments about $2 \mathrm{~mm}$. long; drupes ovoid to broadly ellipsoid, blue-black, somewhat glaucous, 4-8 mm. long; style slender, 1-1.5 mm. long, deciduous.

On river and valley flats, canyon slopes, along streams, in open pastures and brushy prairies where not too heavily browsed, Okla. (Arbuckle and Wichita mts., and Caddo Co.), cen. and w. Tex., N.M. (widespread) and Ariz. (Apache to Mohave, s. to Graham, Gila and Yavapai cos.), Mar.-June; Okla. and Tex., w. and s.w. to Calif. and mts. of Chih.

The plants of Oklahoma and most of Texas, including the mountains of the Trans-Pecos, Coahuila and Chihuahua, have blades only about twice as long as broad and are the more typical $F$. pubescens. Those of the western states and from the margin of Salt Flat in Culberson and Hudspeth counties, Texas, and of canyons on the High Plains country have blades about three times as long as broad and are referable to $F$. neomexicana. But there is complete intergradation in western Texas. Alleged differences in pedicel length are unreliable and differences in pubescence are found even in one population. There is no very meaningful way to recognize two species in this complex.

Children are known to chew the fruits of this species with ordinary chewinggum to produce a sort of "bubble-gum."

\section{Fam. 107. Loganiaceae MART.}

\section{LOGANIA FAMILY}

Herbs, vines, shrubs or trees (tropical) with opposite unlobed leaves and stipules or a stipular line or membrane between them; flowers regular, perfect, 4- or 5-merous, gamopetalous, variously arranged; calyx deeply lobed or with separate sepals; corolla salverform to tubular or campanulate; stamens perigynous, as many as the corolla lobes and alternate with them; ovary 2-celled, free from calyx; fruit a capsule or pod.

Traditionally, about 800 species in 30 or more genera in tropical and warmtemperate regions of both hemispheres. 

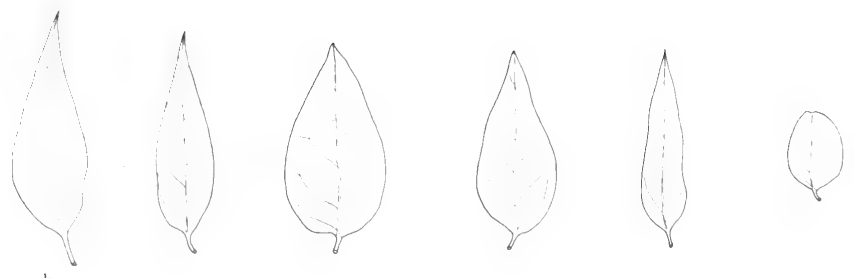

b
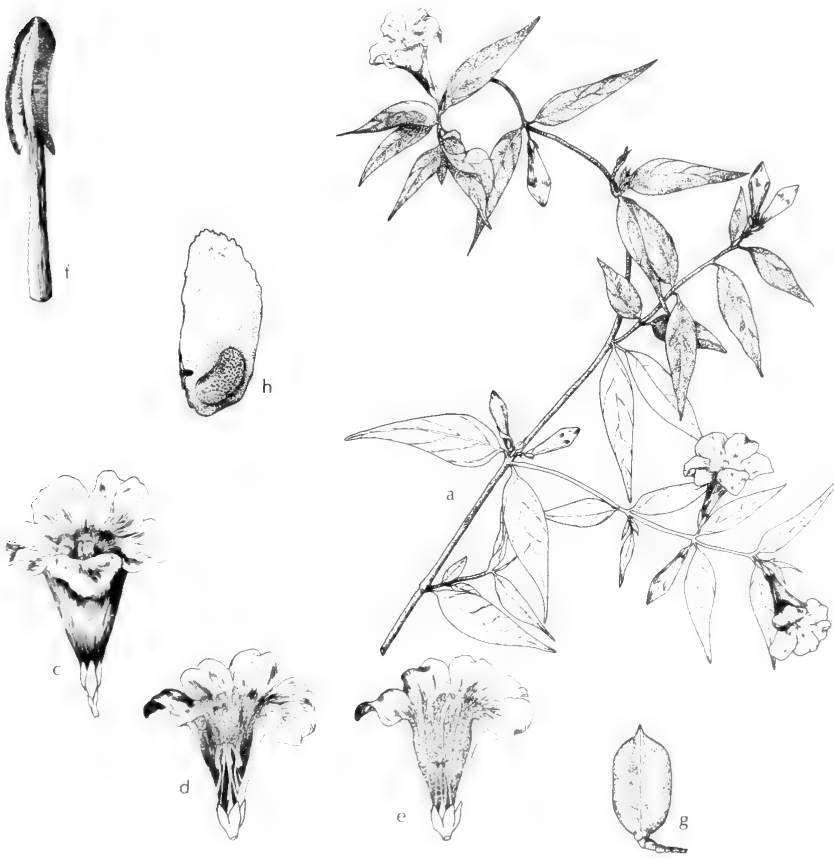

Fig. 622: Gelsemium sempervirens: a, upper part of plant, $x 1_{1}^{\prime} ; \mathrm{b}$, leaves to show variation, $x \frac{1}{3}$; c, flower, $x \frac{2}{3}$; d and e, dimorphic flowers opened, $x 2 \frac{3}{3}$, anther, enlarged; g, capsule, x $\frac{2}{3}$; h, seed on septum, x 2. (Courtesy of R. K. Godfrey). 

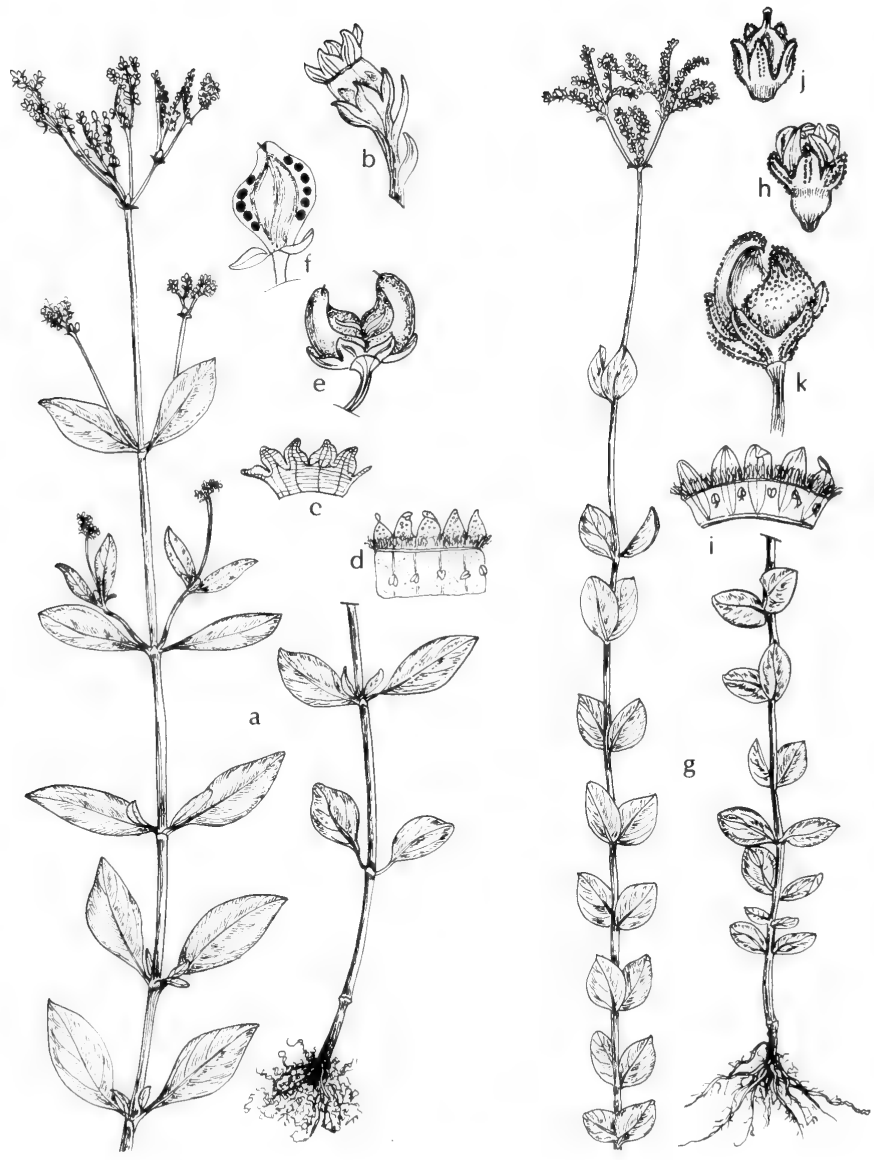

Fig. 623: a-f, Cynoctonum Mitreola: a, habit, x 1/2; b, flower, x 10; c, calyx spread out, x 10; d, corolla spread out, x 10; e, two-lobed capsule, x 10; f, dehiscent capsule, $\mathrm{x} 10 . \mathrm{g}-\mathrm{k}$, Cynoctonum sessilifolium: $\mathrm{g}$, habit, $\mathrm{x}$ 1/2; $\mathrm{h}$, flower, $\mathrm{x} 5$; $\mathrm{i}$, corolla spread out, x $5 ; \mathrm{j}$, young capsule, $x$ 5; $\mathrm{k}$, two-lobed capsule, $x$ 5. (V. F.). 
1. Twining woody climbers with semievergreen leaves; flowers yellow, axillary, more than $20 \mathrm{~mm}$. long...... 1. Gelsemium

1. Erect herbs; flowers white or pinkish, along one side of the branches of a terminal peduncled cyme, less than $8 \mathrm{~mm}$. long.......2. Cynoctonum

\section{Gelsemium Juss. Yellow-Jessamine}

Three species known; two in North America, another in eastern Asia.

1. Gelsemium sempervirens (L.) Jaume St. Hil. Carolina-Jessamine, poor MAN'S ROPE. Fig. 622.

Smooth and twining shrubby perennial; stems high-climbing, wiry, brownishred; leaves with petioles about $5 \mathrm{~mm}$. long, ovate to elliptic or lanceolate, semievergreen, to $75 \mathrm{~mm}$. long and $3 \mathrm{~cm}$. wide; stipules minute, deciduous; pedicels scaly-bracted; flowers 5-merous, fragrant, in axillary clusters of as many as 6, sometimes solitary; corolla yellow, funnelform, 25-35 $\mathrm{mm}$. long; anthers oblong, sagitıate; style long, slender; pod elliptic, 2-celled and 2-valved, to $15 \mathrm{~mm}$. long, flattened contrary to the narrow partitions; seeds numerous, winged.

Usually in sandy loam on edge of or in open woodlands but sometimes in swamps, evergreen shrub bogs and floodplain woods, in e. Tex., Feb.-Apr.; from Fla. to Tex., n. to s.e. Va. and Ark.

\section{Cynoctonum J. F. Gmel. Miterwort. Hornpod}

Annual smooth herbs with small stipules between the leaves and small whitish or pink-tinged flowers spiked along one side of the branches of a terminal peduncled cyme; flowers 5-merous; sepais ovate to elliptic, united at base; corolla longer than the calyx, somewhat globose-funnelform with small elliptic severalveined lobes; stamens included; ovary slightly adnate to the bottom of the calyx, 2-celled; capsule exserted, strongly bicornute or mitriform, opening down the inner side of each horn, many-seeded.

About 6 species of warm-temperate regions.

1. Capsule $3-4 \mathrm{~mm}$. high, its outer surface essentially smooth; leaves tapering to a petiolate base, typically narrowly elliptic, thin, at least some $3 \mathrm{~cm}$. long or more........................................................ . Mitreola.

1. Capsule 2-3 mm. high, its outer surface densely cellular-papillose; leaves sessile, typically broadly oval, firm, rarely more than $2 \mathrm{~cm}$. long 2. C. sessilifolium.

\section{Cynoctonum Mitreola (L.) Britt. Fig. 623.}

Stem simple or laxly slender-branched, to $75 \mathrm{~cm}$. tall; leaves thin, petiolate, ovate-elliptic to elliptic or elliptic-lanceolate, obtuse to acuminate at apex, 2-8 $\mathrm{cm}$. long: cymes on long slender peduncles, their branches loosening in fruit; corolla about twice as long as the calyx; fruiting calyces slightly distant; capsules 3-4 $\mathrm{mm}$. high, the outer surface smooth or rarely with few scattered papillae. Mitreola petiolata (Walt.) T. \& G.

In moist soil in seepage, along ditches and streams, in mud of marshes and swamps, and about ponds and lakes in e. and cen. Tex., w. to Val Verde Co. and s.w. to Victoria Co., and s.e. Okla. (McCurtain Co.), May-Oct.; from Fla. to T'ex., n. to s.e. Va., Tenn., Ark. and Okla.

\section{Cynoctonum sessilifolium (Walt.) J. F. Gmel. Fig. 623.}

Stem stiffly erect, simple or with few erect branches, to about $5 \mathrm{dm}$. tall; leaves firm, sessile, oval to elliptic or suborbicular-ovate, bluntly obtuse to abruptly tipped, the margin usually noticeable papillose, rarely more than $2 \mathrm{~cm}$. long and wide; cymes more compact than in $C$. Mitreola; corolla only slightly longer than the usually prominently keeled calyx lobes; fruiting calyces approximate; capsules 
2-3 mm. high, the outer surface conspicuously and densely cellular-papillose.

On seepage slopes and in bogs and wet savannahs, in water of borrow-pits, and along wooded streams, in e. Tex., June-Oct.; from Fla. to Tex., n. to s.e. Va.

\section{Fam. 108. Gentianaceae Juss. Gentian FAmily}

Annual or perennial herbs, glabrous or essentially so, with simple exstipulate entire opposite, whorled or rarely alternate sessile to occasionally long-petioled leaves; flowers solitary or borne in clusters or in simple or compound cymes, 4- to 12-merous, regular, perfect, hypogynous, sympetalous; calyx persistent; corolla tubular, salverform, campanulate or rotate; stamens on the corolla tube, alternate and as many as the lobes; ovary 1-celled or essentially 2-celled by intrusion of 2 parietal placentae; style elongate to obsolete, the stigma entire to prominently 2-cleft; capsule usually 2-valved and septicidal, many-seeded.

A large world-wide family of about 80 genera and 900 species, mostly in temperate regions. By many authors segregated into 2 families, in which case the genus Nymphoides, because of its alternate leaves and valvate aestivation, is placed in the Menyanthaceae.

1. Leaves alternate, the petiole usually much longer than the floating blade; corolla lobes valvate in bud; plant aquatic............... 9. Nymphoides

1. Leaves opposite or whorled, rarely alternate, sessile or with petiole much shorter than the blade; corolla lobes never valvate in bud; plants in wet habitats but not aquatic (2)

2(1). Corolla lobes imbricate in bud, without appendages or glands; leaves reduced to opposite or alternate scales.......................... 8. Bartonia

2. Corolla lobes convolute in bud, with or without appendages or glands; leaves ample, opposite or sometimes whorled (3)

3(2). Style filiform, usually deciduous from capsule; anthers either twisted or prominently curved in age (4)

3. Style usually stout and persistent, rarely obsolete; anthers remaining straight or only slightly curved (6)

4(3). Stigmas linear or nearly so, about as long as the style; corolla rotate, the tube conspicuously shorter than the lobes; anthers merely recurved or revolute...

4. Stigmas roundish, much shorter than the style (5)

1. Sabatia.

5(4). Corolla salverform, the tube surpassing the calyx and exceeding or equal in length to the lobes; anthers more or less spirally twisted.

2. Centaurium

5. Corolla deeply campanulate, the tube much shorter than the calyx and the lobes; anthers straight or only slightly recurved.

3. Eustoma

6(3). Corolla rotate, the small tube much shorter than the lobes or the calyx lobes (7)

6. Corolla tubular to funnelform or campanulate, the usually well-developed tube as long as or longer than the lobes and calyx lobes (8)

7(6). Style well-developed

7. Swertia

7. Style none, the stigmas decurrent along the sides of the ovary

5. Lomatogonium

$8(6)$. Corolla not spurred at base

4. Gentiana

8. Corolla of well-developed flowers 4-spurred at base.

6. Halenia 


\section{Sabatia Adans.}

Erect glabrous annual or perennial herbs, with slender leafy stems and mostly cymose panicled flowers; leaves mostly cauline but also basal in some species; flowers perfect, regular, long-pedicelled or subsessile; calyx gamosepalous, 5- to 12-parted, the lobes slender; corolla 5- to 12-parted, rotate; stamens 5 to 12; filaments slender, inserted on upper edge of corolla tube and alternate with the lobes; anthers basally attached, soon recurved; style slender; stigmatic branches 2; capsule ovoid to cylindric, with numerous seeds.

A genus of 17 species native to continental North America and the West Indies. The name has often been misspelled "Sabbatia."

1. Flowers 7- to 12-merous (2)

1. Flowers 5 - or rarely 6 -merous (3)

2(1). Flowers several approximate, sessile or nearly so, subtended by foliaceous bracts; annual..................................................... S. gentianoides.

2. Flowers solitary on long peduncles, without bracts; perennial..2. S. dodecandra.

3 (1). Calyx tube very prominently 5-nerved and thinly membranous-winged; lateral nerves of the calyx lobes much more strongly developed than the midnerve; flowers 5-merous; annual (4)

3. Calyx tube smooth or finely nerved and lacking membranous wings; midnerve of the calyx lobes almost equaling or even more strongly developed than the lateral nerves; flowers either 5- or rarely 6-merous; annual or perennial (5)

4(3). Leaves and calycine lobes thin and membranous, neither succulent nor heavily cutinized; leaves broadest near the base, usually strongly clasping the stem, the midvein at least prominently elevated beneath; calyx lobes usually 2 to 6 times longer than the calyx tube, generally 4 to 8 times longer than broad; corolla lobes typically equaling or exceeding the calyx lobes, usually longer than $1 \mathrm{~cm}$. and wider than $7 \mathrm{~mm}$.; stigmatic lobes over $5 \mathrm{~mm}$. long; anthers longer than $2 \mathrm{~mm}$... 4. S. campestris.

4. Leaves and calycine lobes thick and succulent, heavily cutinized; leaves broadest above the base, tapering somewhat to the sessile non-clasping base, the venation obscure and flush with the surface; calyx lobes usually less than twice the length of the calyx tube, generally less than 4 times as long as broad; corolla lobes usually equaled or exceeded by the calyx lobes, the corolla lobes usually less than $1 \mathrm{~cm}$. long and narrower than $7 \mathrm{~mm}$; stigmatic lobes less than $5 \mathrm{~mm}$. long; anthers shorter than $2 \mathrm{~mm}$.....................................5. S. arenicola.

5(3). Perennial with elongate rhizomes, sometimes stoloniferous; leaves oblong to narrowly obovate; calyx lobes broadened above the middle.

6. S. calycina.

5. Annual without rhizomes or stolons; leaves suborbicular to cordate-ovate; calyx lobes narrowed above the middle. 3. S. angularis.

1. Sabatia gentianoides Ell. Fig. 624.

Erect strict annual to $5 \mathrm{dm}$. tall; stem usually unbranched or only slightly branched above the middle; leaves dimorphic, thick, the venation obscure, those of the basal rosette wide-spreading and oblong to orbicular-spatulate, to $3 \mathrm{~cm}$. long and $12 \mathrm{~mm}$. wide; cauline leaves linear, strongly ascending or sometimes appressed to the stem, to $1 \mathrm{dm}$. long and less than $3 \mathrm{~mm}$. wide; flowers subsessile, 7- to 12-merous, borne singly or in clusters of several at apex of main stem or in axils of uppermost leaves, subtended by 2 conspicuously long linear bracts; calyx tube broadly campanulate, smooth and nerveless, to $8 \mathrm{~mm}$. long, the subulate recurved 


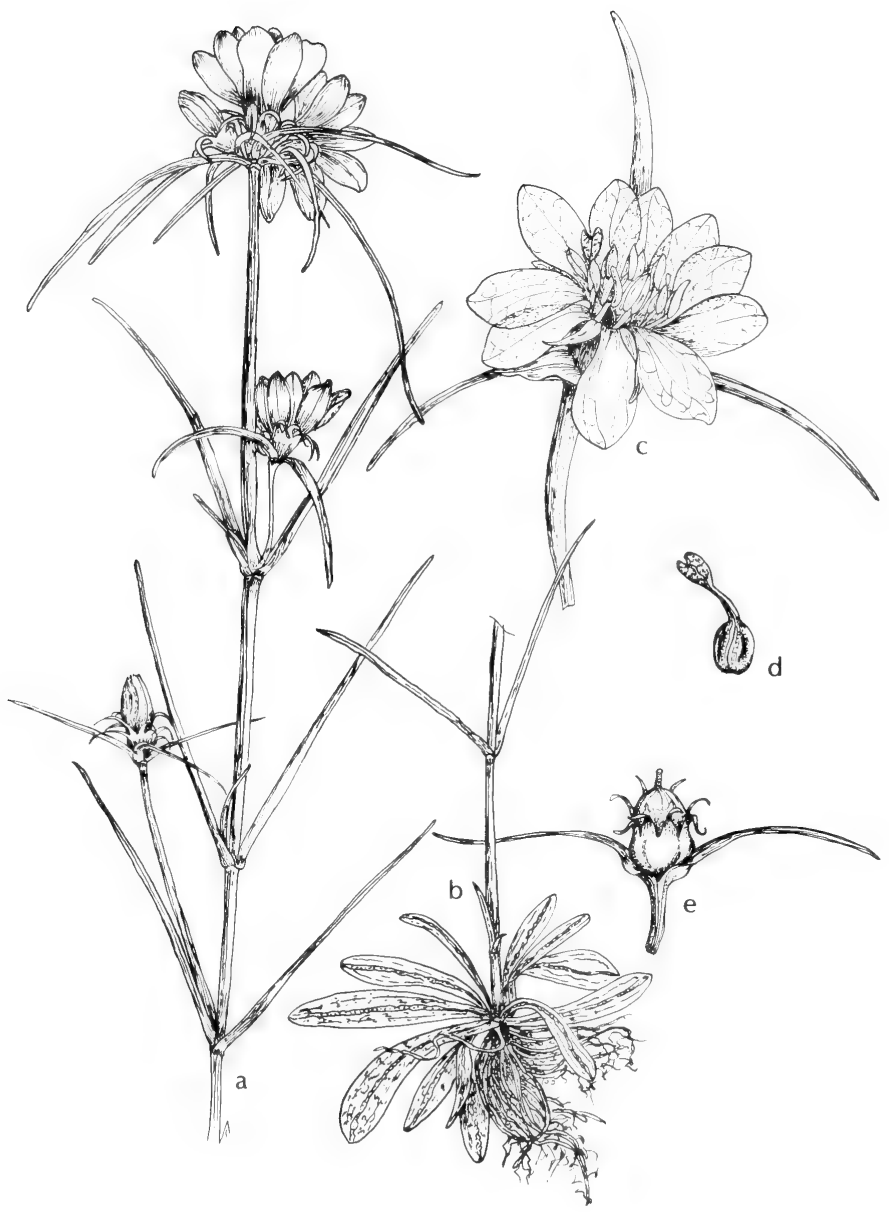

Fig. 624: Sabatia gentianoides: a, upper part of plant, $x \frac{1}{12} ; \mathrm{b}$, basal rosette and lower part of stem, x 1/2; c, flower, x 1; d, ovary, x 1; e, fruit, x 1. (V. F.). 
lobes to $15 \mathrm{~mm}$. long: corolla pink to deep-rose-color; corolla lobes elliptic to oblanceolate or spatulate, obtuse to acute, to $3 \mathrm{~cm}$. long and $1 \mathrm{~cm}$. wide; stigmatic lobes 4-7 $\mathrm{mm}$. long: capsule ovoid, to $10 \mathrm{~mm}$. long and $6 \mathrm{~mm}$. in diameter.

In boggy or wet pinelands, pitcher plant bogs and savannahs in s.e. Tex., MayAug.; from N.C., s. to Fla. and Tex.

\section{Sabatia dodecandra (L.) B.S.P. LARGE MARSH-PINK. Fig. 625.}

Perennial to about $7 \mathrm{dm}$. high, rhizomatous and stoloniferous, with alternate branches or dichotomous above the middle; leaves narrowly elliptic to lanceolate, 2-5 cm. long, obtuse to acute or subacuminate; flowers 8- to 12-merous; calyx lobes lanceolate, 1-3 mm. wide, conspicuously 3- or 5-nerved; corolla lobes pink or whitish, yellow at the base, narrowly oblanceolate to somewhat spatulate, 15-22 $\mathrm{mm}$. long, 4-9 cm. wide.

In s.e. Tex., June-Aug.; from S.C. to Tex.

Our plants are referable to var. foliosa (Fern.) Wilbur, characterized by having internodes that are equal to or shorter than the subtending leaves, stolons present, and growing in depressions in open woods, marshy areas, about ponds and on stream margins and in ditches. Var. dodecandra is typically coastal where it occurs in brackish habitats on the Atl. Coast.

\section{Sabatia angularis (L.) Pursh. Rose-Pink, Bitter-bloom.}

Erect annual to $7 \mathrm{dm}$. tall, with simple strongly 4-angled slightly winged stems or bushy-branched; cauline leaves membranous, the lower suborbicular, the middle and upper cordate-ovate, clasping, 3- to 7-nerved, to $3 \mathrm{~cm}$. long and $25 \mathrm{~mm}$. wide; calyx tube about $1.5 \mathrm{~mm}$. long, the thin lobes narrowed above middle and about $1 \mathrm{~cm}$. long; corolla pink or roseate, delicately fragrant; corolla lobes oblong to obovate or elliptic, obtuse, to about $2 \mathrm{~cm}$. long; stigmatic lobes slender, 3-6 $\mathrm{mm}$. long; capsule to $8 \mathrm{~mm}$. long and $5 \mathrm{~mm}$. wide.

In open pine-hardwood flats, marshlands and edge of woods in e. Tex. and Okla. (Waterfall), May-July; N.Y., w. to Ill. and s. to Fla. and Tex.

\section{Sabatia campestris Nutt.}

Erect annual to $5 \mathrm{dm}$. tall, usually much smaller; stem with few or no branches on lower half but with several simple or forking mostly alternate branches above; leaves membranous, oblong-elliptic to broadly ovate-elliptic, obtuse to acute, broadly clasping stem, to $45 \mathrm{~mm}$. long and $2 \mathrm{~cm}$. wide; calyx tube to $8 \mathrm{~mm}$. long, strongly pentagonal with 5 short wing-angles extending up to the sinuses, its 3nerved lobes linear-lanceolate and to $25 \mathrm{~mm}$. long; corolla roseate to pale-pink or rarely white; corolla lobes broadly obovate to elliptic, obtuse to acute, to $23 \mathrm{~mm}$. long and $15 \mathrm{~mm}$. wide, their yellow basal spots 3 - to 6-lobed with 1 or 2 middle lobes longest; stigmatic lobes greenish, becoming yellow with age, 5-8 mm. long; capsule to $9 \mathrm{~mm}$. long.

In moist or dry soil in fields, prairies, cedar-oak flats and along streams, on mud flats and in wet soil about ponds and lakes, and in roadside ditches, in Okla. (Grady, Pushmataha, Jefferson, Stephen and Ottawa cos.) and in e. half of Tex. and s.w. along the coast, Apr.-July; Ill. and Kan., s. to Tex. and Miss.

\section{Sabatia arenicola Greenm.}

Erect or erect-spreading annual, to $3 \mathrm{dm}$. tall; stems simple or branching from the base upward to form a globose intricate mass; leaves thick-succulent, widely spreading, the venation obscured, varying from elliptic-obovate at base to oblong or ovate-lanceolate above, obtuse, to $25 \mathrm{~mm}$. long and $13 \mathrm{~mm}$. wide, usually much smaller; calyx tube to $8 \mathrm{~mm}$. long, strongly pentagonal due to the thick costae or ribs, the thick lobes triangular-lanceolate and to $15 \mathrm{~mm}$. long; corolla roseate 


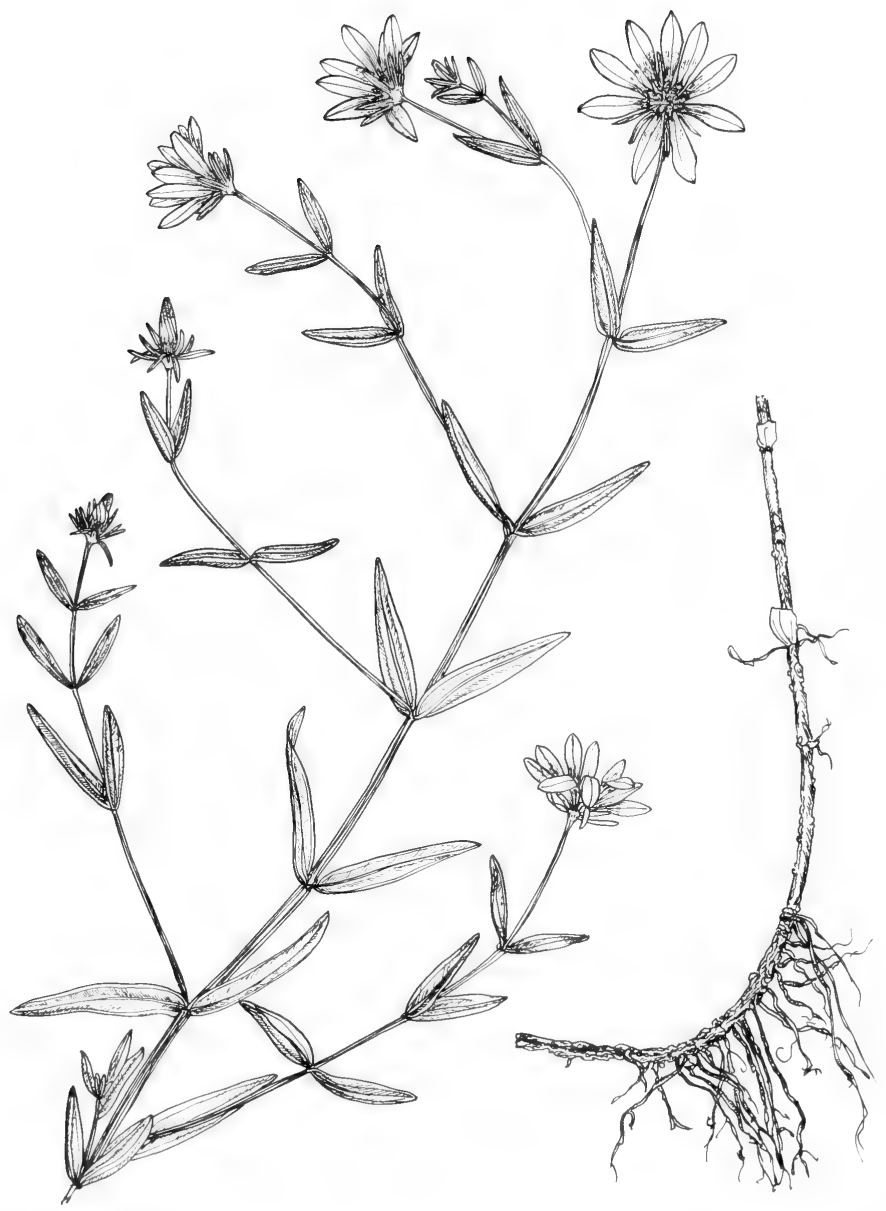

Fig. 625: Sabatia dodecandra: habit, X 1/2. (V. F.). 
to sometimes white; corolla lobes about as long as or shorter than the calyx lobes, obovate to oblong, obtuse; stigmatic lobes greenish, $2.5-4 \mathrm{~mm}$. long; capsule to $9 \mathrm{~mm}$. long. S. carnosa Small.

On beaches, depressions in dunes, salt flats, fields and wet savannahs in s. Tex., Apr.-July; in La., Tex. and n.e. Mex.

\section{Sabatia calycina (Lam.) Heller.}

Rigidly erect perennial with a slender or thick rhizome, to $4 \mathrm{dm}$. tall; stems weak, simple or with either opposite or alternate divergent or somewhat ascending branches; leaves membranous, oblong to narrowly obovate, obtuse to acute, to $1 \mathrm{dm}$. long and $2 \mathrm{~cm}$. wide; flowers usually borne singly, 5- or 6-merous; calyx tube thin, smooth or with the veins only slightly elevated, to $5 \mathrm{~mm}$. long, its thin foliaceous lobes oblanceolate to spatulate and to $3 \mathrm{~cm}$. long; corolla white or pale-rose to pink; corolla lobes oblanceolate to spatulate or elliptic, obtuse or acute, to $15 \mathrm{~mm}$. long and $6 \mathrm{~mm}$. wide; stigmatic lobes 4-6 mm. long; capsule to $1 \mathrm{~cm}$. long and $8 \mathrm{~mm}$. in diameter.

Ditches and shaded river swamps and bottoms in s.e. Tex., June-July; from s.e. Va., s. to Fla. and Tex.; also Cuba and Hisp.

\section{Centaurium Hill Centaury}

Mostly low and small branching annuals but sometimes tall and showy; leaves opposite; flowers light-pink to rose-purple or reddish; calyx 4- or 5-parted, the lobes slender and appressed to the corolla tube; corolla funnelform or salverform, with slender tube and 4- or 5-parted limb; anthers exserted, erect, spirally twisting; style slender, single; stigma capitate or bifid.

A genus of about 45 species in temperate regions of the world.

1. Corolla lobes $7 \mathrm{~mm}$. or more long, about as long as the corolla tube (2)

1. Corolla lobes rarely more than $6 \mathrm{~mm}$. long, shorter than the corolla tube (4)

2(1). Some of the leaves oblong or oblong-elliptic; corolla tube and calyx lobes about equal in length. 1. C. calycosum var, calycosum.

2. All leaves typically linear; corolla tube conspicuously exceeding the calyx lobes (3)

3(2). Plant without minute glands. 2. C. Beyrichii var. Beyrichii.

3. Plant (especially the leaves) densely covered with minute glands.

..2. C. Beyrichii var. glanduliferum.

4(1). Distribution in central and southern Texas.

4. Distribution in New Mexico and/or Arizona (5)

1. C. calycosum var. breviflorum.

5(4). Basal leaves several approximate to form a basal rosette, obovatish, much wider than the cauline leaves; corolla lobes 4-6 $\mathrm{mm}$. long...

3. C. nudicaule.

5. Basal leaves well-spaced, not forming a basal rosette, similar in shape and size to the cauline leaves; corolla lobes $3-4 \mathrm{~mm}$. long

4. C. exaltatum

\section{Centaurium calycosum (Buckl.) Fern. var. calycosum. RositA. Fig. 626.}

Plant erect, simple or corymbosely branched, to $6 \mathrm{dm}$. tall, usually much smaller; cauline leaves oblong to oblong-elliptic or sometimes narrowly lanceolate, to $6 \mathrm{~cm}$. long and $13 \mathrm{~mm}$. wide; pedicels equaling or sometimes exceeding the calyx; flowers pink to rose-color, rarely white; corolla tube about equaled in length by the oblong to obovate or oval lobes (7-13 $\mathrm{mm}$. long) and the calyx lobes; seeds light-brown. Erythraea calycosa Buckl. 
Usually in moist soil along streams, in marshes with willows and in seepage areas, prairies and meadows, and on hillsides in cen. and w. Tex., N.M. (De Baca, Grant, San Juan and Dona Ana cos.) and Ariz. (throughout state), Mar.Nov.; from Tex. to Mo., w. to Ut., Nev., N.M., Ariz. and n. Mex.

The var. breviflorum Shinners of central and south Texas is distinguished from var. calycosum by its smaller corolla lobes $(5-7 \mathrm{~mm}$. long) and the calyx lobes (6-10 $\mathrm{mm}$. long) being shorter than the corolla tube. It occurs in similar habitats but is also found in salt marshes along the coast.

\section{Centaurium Beyrichii (T. \& G.) Robins. var. Beyrichii. MountaIn PINK.}

Plant slender, to $3 \mathrm{dm}$. tall, at length fastigiately branched; cauline leaves linear to very narrowly linear-oblanceolate, to $3 \mathrm{~cm}$. long and $3 \mathrm{~mm}$. wide, the uppermost nearly filiform; pedicels about equal to or shorter than the calyx; flowers numerous, pink; corolla tube equal to or somewhat exceeding in length the elliptic to linear-oblong lobes (7-12 $\mathrm{mm}$. long), about half again the length of the calyx lobes; seeds dark-brown. Erythraea Beyrichii T. \& G.

On rocky open limestone slopes and in seepage on granite boulders from n.-cen. to w. Tex., where it is rare, and Okla. (Waterfall), May-Aug.; also Ark.

The var. glanduliferum Correll, of west Texas, is a small much-branched plant about $15 \mathrm{~cm}$. tall. It is distinguished from var. Beyrichii by the occurrence of numerous minute glands, especially on the leaves. It also has blackish or very dark-brown seeds.

\section{Centaurium nudicaule (Engelm.) Robins.}

Rather lax glabrous biennial; stems usually with less than 6 pairs of leaves, to about $3 \mathrm{dm}$. tall; the branches, pedicels and often the leaves ascending-spreading; basal leaves forming a rosette, obovatish, $8-16 \mathrm{~mm}$. long, noticeably wider than the cauline leaves that are linear to linear-lanceolate; flowers few on long pedicels; corolla lobes pinkish, 4 or 5 , oblong, obtuse, at most $6 \mathrm{~mm}$. long, nearly as long as the tube; anthers linear-oblong, slightly twisted.

Along streams, marsh areas and wet sand-gravel bars in stream beds, in Ariz. (Pima and Mohave cos.), Apr.-Aug.; also Baja Calif.

\section{Centaurium exaltatum (Griseb.) Wight ex Piper.}

Plant glabrous; stems simple or usually branched, to about $3 \mathrm{dm}$. tall; leaves ascending, oblong-elliptic to elliptic-lanceolate or oblanceolate, $1-3 \mathrm{~cm}$. long, obtuse to acute; flowers usually few, rarely solitary or many; pedicels strictly erect, $1-5 \mathrm{~cm}$. long, much-exceeding the subtending bract; calyx lobes $8-10$ $\mathrm{mm}$. long, subulate; corolla tube exceeding the calyx; corolla lobes pale-pink to white, oblong, obtuse, 3-4 mm. long, usually about one-third as long as tube; anthers oblong, about $1 \mathrm{~mm}$. long, slightly twisted; stigma lobes flabellate; capsule nearly twice the length of the calyx; seeds suborbicular, about $0.25 \mathrm{~mm}$. long.

In marshes with willows and tamarix, and wet places generally, often alkaline, in N.M. (San Juan Co.), June-Aug.; Neb. to Wash., s. to N.M. and Calif.

\section{Eustoma Salisb. Catchfly-gentian}

Annual or short-lived perennial, more or less glaucous, with erect or ascending leafy stems from a taproot and usually a rosette; leaves opposite, sessile and clasping the stem, entire; flowers long-pedicelled, showy, solitary or paniculate; calyx deeply cleft, the lobes long-attenuate, keeled; corolla deeply campanulate; corolla lobes erect, convolute in bud, the apex entire or somewhat erose and sometimes apiculate; stamens 5 or 6 , inserted on the corolla throat; anthers oblong, versatile, straight or recurved; style slender, subpersistent, with a prominently two-lipped stigma; capsule ellipsoid, 2-valved, many-seeded.

An American genus of several species, mostly in Mexico. 


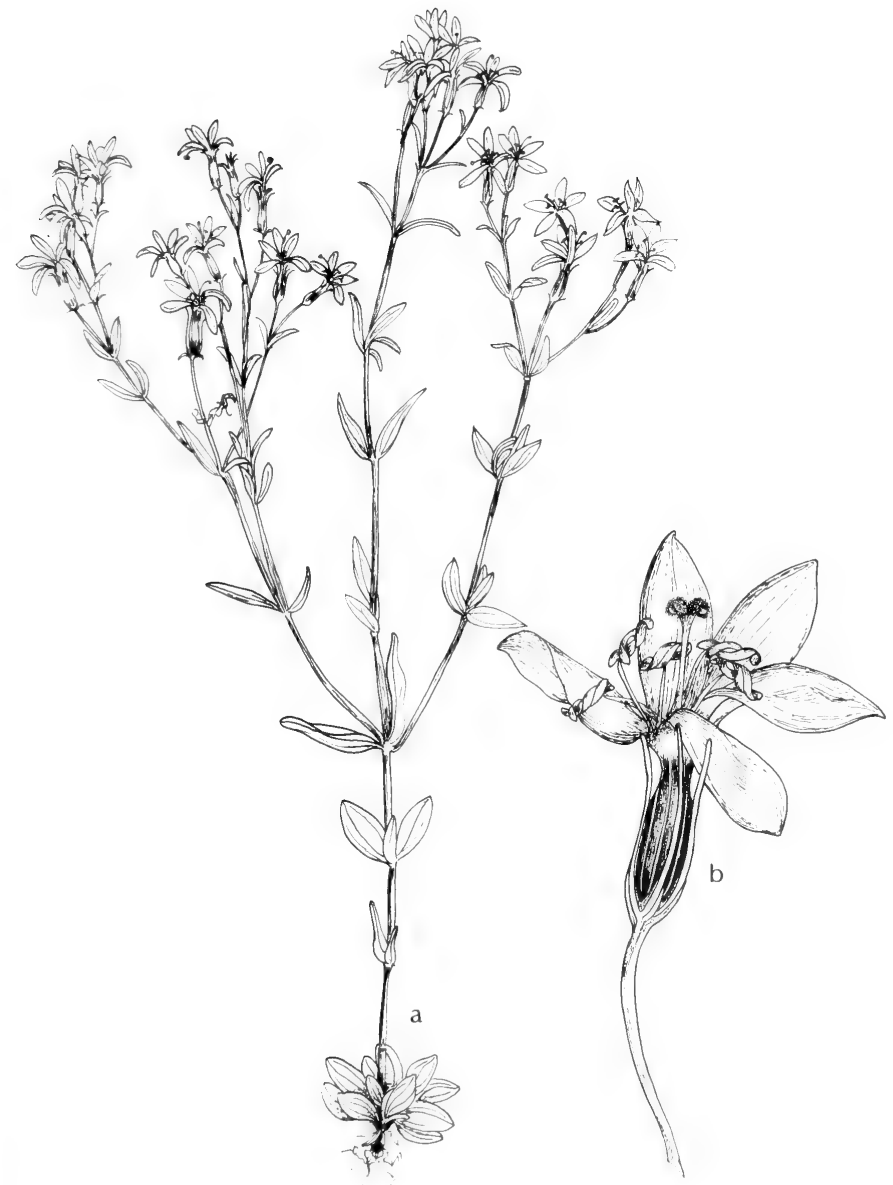

Fig. 626: Centaurium calycosum: a, habit, $x \frac{1}{1} 2$; b, flower, $x 2 \frac{1}{2}$. (V. F.). 


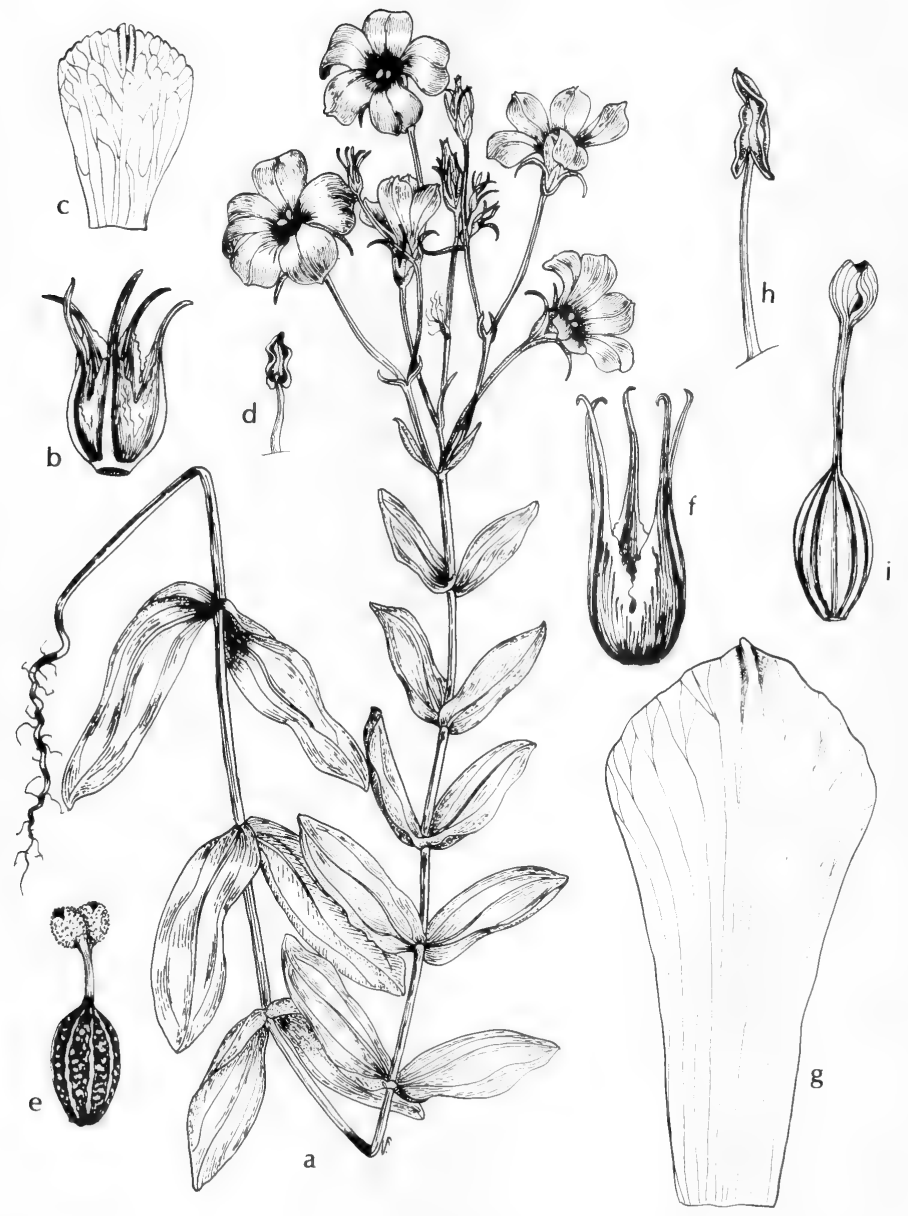

Fig. 627: a-e, Eustoma exaltatum: a, habit, x 11; b, calyx, 11\%; c, petal, x 11/2; d, stamen, x 11/2; e, ovary, x 11/2, f-i, Eustoma grandiflorum: f, calyx, x 11/2; g, petal, x $1 \frac{1}{2} ;$, h, stamen, $x 1 \frac{1}{2} ;$ i, ovary, x $1 \frac{1}{12}$. (V. F.) 
1. Eustoma exaltatum (L.) G. Don. Fig. 627.

Plants to $7 \mathrm{dm}$. tall, with one or several stems branched above; basal leaves obovate, the cauline leaves oblong to oblong-elliptic and obtuse to subacute, to $9 \mathrm{~cm}$. long and $3 \mathrm{~cm}$. wide; pedicels to $1 \mathrm{dm}$. long; calyx lobes to $18 \mathrm{~mm}$. long; corolla blue to deep-lavender or white, the tube about $1 \mathrm{~cm}$. long; corolla lobes oblong-obovate, about twice as long as the tube or rarely to $25 \mathrm{~mm}$. long; style slender, about $5 \mathrm{~mm}$. long; stigma lobes about $2 \mathrm{~mm}$. long; capsule to $2 \mathrm{~cm}$. long. E. silenifolium Salisb.

In damp places in prairies and fields, along streams or in wet meadows, often in alkaline or saline soils in s. and w. Tex., N. M., (Guadalupe, Socorro, Dona Ana, Otero and Chaves cos.) and Ariz. (Mohave, Yavapai, Graham, Gila, Maricopa and Pima cos.), June-Oct.; in s. U.S., Mex., Br. Hond. and W.I.

The white-flowered plant has been designated f. albiflorum Benke.

2. Eustoma grandiflorum (Raf.) Shinners. LiRA DE SAN PEdRo, Bluebells. Fig. 627.

Plants very similar to $E$. exaltatum, to $7 \mathrm{dm}$. tall; leaves ovate to elliptic-oblong or elliptic-lanceolate, noticeably 3 -veined, to $8 \mathrm{~cm}$. long and $3 \mathrm{~cm}$. wide; pedicels to $6 \mathrm{~cm}$. long; calyx to $3 \mathrm{~cm}$. long, the lobes subulate; corolla variously colored blue-purple, pinkish, white or white and purple-tinged or yellowish; corolla lobes 3-4 cm. long, elliptic-obovate, at least 3 times as long as the tube; capsule to $2 \mathrm{~cm}$. long. E. Russellianum (Hook.) Sweet.

In moist places in prairies and fields and about tanks in most of Tex. and Okla. (Waterfall), June-Sept.; Okla. and Tex., w. to Neb. and Colo., s. to Mex.

Several forms have been segregated based on the following flower-colors; white, f. Fisheri (Standl.) Shinners; white with purple-tinged lobes, f. bicolor (Standl.) Shinners; pink, f. roseum (Standl.) Shinners; yellow, f. flaviflorum (Cockll.) Shinners.

\section{Gentiana L. Gentian}

Annual, biennial or perennial herbs from fleshy roots or slender rhizomes, mostly glabrous; leaves opposite, petiolate to sessile and sometimes clasping; flowers solitary to numerous in flat-topped to much-elongated cymose clusters, 4- to 5- or rarely 6-merous (except the pistil), white or yellowish to bluish or purplish, often with much green mottling; calyx tubular by fusion of lobes or divided to near the base, sometimes lined with an inner membrane that projects above the base of the often unequal lobes; corolla narrowly funnelform to sa!verform but usually closing quickly, persistent, lobed for one-fifth to one-third its length, often either plicate in the sinuses (with the plaits notched, rounded to acute or lobed or toothed) or with setaceous scales at the base of the lobes on the inner surface; stamens adnate to the corolla tube for one-third to three-fifths of its length, the adnate portion often with free winglike margins, the free filaments often conspicuously flattened; anthers versatile, erect to recurved; ovary stipitate to sessile; style usually short and rather stout, ending in 2 stigmatose lobes or with enlarged crenate-margined stigmas; capsules 1-celled, 2-valved, many-seeded.

Probably as many as 300 or more species, cosmopolitan except in Africa, mainly in alpine areas. Many have beautiful, ornamental flowers.

1. Corolla without plaits or lobes in the sinuses; calyx without an intercalycine membrane inside the tube, its lobes imbricate; nectariferous pits borne well down on the corolla tube (2) 
1. Corolla plicate in the sinuses, the plaits more or less extended into membranous lobes or teeth, or rarely essentially entire; calyx with an intercalycine membrane inside the tube, its lobes valvate; ovary bearing nectariferous pits on its base (5)

2(1). Fiowers 4-merous, usually over $3 \mathrm{~cm}$. long; inner sepals broader, membranous-margined; corolla lobes fringed or toothed; corolla tube without fringes on the throat (3)

2. Flowers 5 (4)-merous, less than $2 \mathrm{~cm}$. long; outer sepals broader; corolla lobes never fringed, rarely toothed; corolla tube with a fringe on the throat (4)

3(2). Flowers closely invested by a bractlike pair of upper leaves; stems not over $15 \mathrm{~cm}$. tall; perennial..................................... G. barbellata.

3. Flowers on naked peduncle and not invested by bractlike leaves; stems usually over $15 \mathrm{~cm}$. tall; annual............................... G. detonsa.

4(2). Flowers clustered; plants $3 \mathrm{dm}$. tall or more.

4. Flowers solitary; plants rarely more than $1 \mathrm{dm}$. tall.....

3. G. Amarella. ..4. G. tenella.

5 (1). Dwarf annual or biennial; leaves broadly scarious-margined; flowers solitary, terminal; anthers cordate, versatile; capsule long-stipitate and exserted beyond corolla.

5. G. Fremontii.

5. Perennials; leaves not scarious-margined; flowers short-pedunculate (at least some of them axillary); anthers linear or oblong, extrorse; capsules not long-stipitate nor exserted (6)

6(5). Cauline leaves linear to linear-lanceolate; floral bracts linear; plait between corolla lobes plane or somewhat lacerate (7)

6. Cauline leaves ovate to elliptic or elliptic-lanceolate; floral bracts ovate to elliptic; plaits between corolla lobes somewhat erose or lacerate (8)

7(6). Corolla $3.5-5 \mathrm{~cm}$. long, white with blue markings; bracts shorter than the flowers; plant rarely more than $15 \mathrm{~cm}$. tall.................6. G. algida.

7. Corolla less than $3 \mathrm{~cm}$. long, dark blue to purplish; bracts usually longer than the flowers; plant usually more than $20 \mathrm{~cm}$. tall........7. G. Bigelovii.

$8(6)$. Corolla light blue to whitish; margins of leaves and calyx lobes conspicuously ciliolate; plaits about as long as corolla lobes, cut into coarse broad segments.

8. G. Saponaria.

8. Corolla deep-blue; margin of leaves and calyx lobes scaberulous; plaits conspicuously shorter than corolla lobes, cut into narrow fine segments 9. G. affinis.

\section{Gentiana barbellata Engelm.}

Perennial; stems single or in pairs from a slender fusiform root or caudex, 5-13 $\mathrm{cm}$. tall; leaves rather thick and fleshy, obtuse, with rather rough callous margins; basal leaves spatulate, $2-5 \mathrm{~cm}$. long, slender-petioled; cauline leaves in 2 or 3 pairs, linear-spatulate or the uppermost linear and connate at base; flowers 1 to 3 , sessile or nearly so between the involucrate foliaceous bracts; calyx lobes subulatetriangular; corolla bright-blue, $2.5-3.8 \mathrm{~cm}$. long, about twice the length of the calyx, deeply 4-cleft; corolla lobes oblong, erose-denticulate above, conspicuously fimbriate along the middle; capsule short and not stipitate; seeds squamuloseroughened. Anthopogon barbellatus (Engelm.) Rydb.

In wet meadows, on alpine and subalpine seepage slopes, and open coniferous forests, in N. M. (Colfax, Taos and Rio Arriba cos.) and Ariz. (Coconino Co.), Aug.-Sept.; Wyo. to N.M. and Ariz.

\section{Gentiana detonsa Rottb.}

Glabrous annual 1-4 dm. tall; stems usually several from the base, simple or branched; leaves numerous in basal tuft, oblanceolate to spatulate, $1.5-4 \mathrm{~cm}$. long; 
cauline leaves in 2 to 4 pairs, narrowly lanceolate to oblong or oblanceolate, $1.5-5$ $\mathrm{cm}$. long; flowers 4- or rarely 3-merous, terminal on long naked peduncles and usually also axillary on elongate peduncles with a pair of scarcely reduced foliaceous bracts at or below midlength; calyx 15-25 mm. long; calyx lobes acuminate, subequal, alternately narrower and broader at the base, about equaling the tube; corolla 3.5-6 cm. long, deep-blue to purplish, glandular at the base between the bases of the filaments; corolla lobes subequal to the tube, oblong-obovate, eroselacerate at the rounded apex, more deeply lacerate on the sides, the sinuses neither plaited nor appendaged; stamens slightly shorter than and inserted about midlength of the corolla tube, the adnate portion broadly wing-margined, the free portion thin and flat; anthers oblong, 3-4 mm. long; ovary stipitate; style relatively slender, 4-6 mm. long; stigma lobed, broad and flattened, pectinately fringe-margined; seeds prismatic, terete, about $0.5 \mathrm{~mm}$. long, dark-brown, finely alveolate. $G$. thermalis O. Ktze., G. elegans A. Nels., G. grandis (Gray) Holm, G. superba Greene, Anthopogon elegans (A.Nels.) Rydb.

In marshes, wet meadows, bogs, seepage banks along streams and coniferous forest slopes, in N.M. (Colfax, Mora, Santa Fe, Taos and Sandoval cos.) and Ariz. (Cochise and Santa Cruz cos.), July-Nov.; circumboreal, in N.A. from Nfld. to Alas., s. to N.Y., Ind., S.D., N.M., Ariz., Calif. and Mex.

\section{Gentiana Amarella L.}

Annual or biennial $5-40 \mathrm{~cm}$. tall, entirely glabrous or sometimes with scaberulous-ciliolate leaves and calyx lobes; stems simple to freely branched, lightly angled; basal leaves usually several, mostly oblanceolate, 5-40 $\mathrm{mm}$. long; cauline leaves mostly in 5 to 8 pairs, from ovate-lanceolate and clasping-based to lanceolate, oblong or oblong-oblanceolate, as much as $6 \mathrm{~cm}$. long and $3 \mathrm{~cm}$. broad, not connate at the base; flowers immediately subtended by bractlets or with pedicels 3-20 $\mathrm{mm}$. long, 4- or 5-merous (even on the same plant), varying greatly in size according to their position and the time of blossoming but mostly $1-2 \mathrm{~cm}$. long, sometimes few or even solitary but usually numerous, the plants often floriferous from near the base, the axillary cymes sometimes very elongate; calyx one third to one half the length of the corolla, lobed two thirds to four fifths of its length, often more deeply cleft on one side, the unequal lobes linear to lanceolate; corolla salverform but usually closed and apparently tubular, violet, dark purplish-blue, pale bluishpurple, lavender or clear blue to pale yellowish and lightly bluish-tinged; corolla lobes about one half the length of the tube, oblong to lanceolate, rounded to obtuse, appendaged at the base with slender fimbriae one half to three fourths as long, sinuses not plaited; stamens well-included in and attached to the lower third of the corolla tube, the adnate portion not wing-margined; ovary sessile; style essentially lacking; stigmatic lobes oblong, rounded; capsule slightly exceeding the persistent corolla; seeds ovoid to spherical, yellow, nearly smooth. G. strictiflora (Rydb.) A. Nels., Amarella strictiflora (Rydb.) Greene.

In wet meadows, marshes, seepage along streams, old lake beds and open coniferous forests, in N.M. (Catron, Colfax, Grant, Otero, Rio Arriba, Sandoval, Santa Fe, San Juan and Taos cos.) and Ariz. (Apache, Coconino, Graham, Yavapai and Yuma cos.), June-Sept.; over much of N.A. from Alas. to Mex.; Euras.

Included here is an assortment of plants that vary from those that have numerous, crowded, whitish or yellowish mostly short-pedicelled flowers to those that have few, lax, blue to purplish or lavender distinctly pedicelled flowers. All types of intergradation can be found between these two extremes.

\section{Gentiana tenella Rottb.}

Glabrous annual 4-15 cm. tall; stems simple to freely branched near the base, very slender, 4-angled; basal leaves usually several, oblanceolate, 3-10 mm. long; 

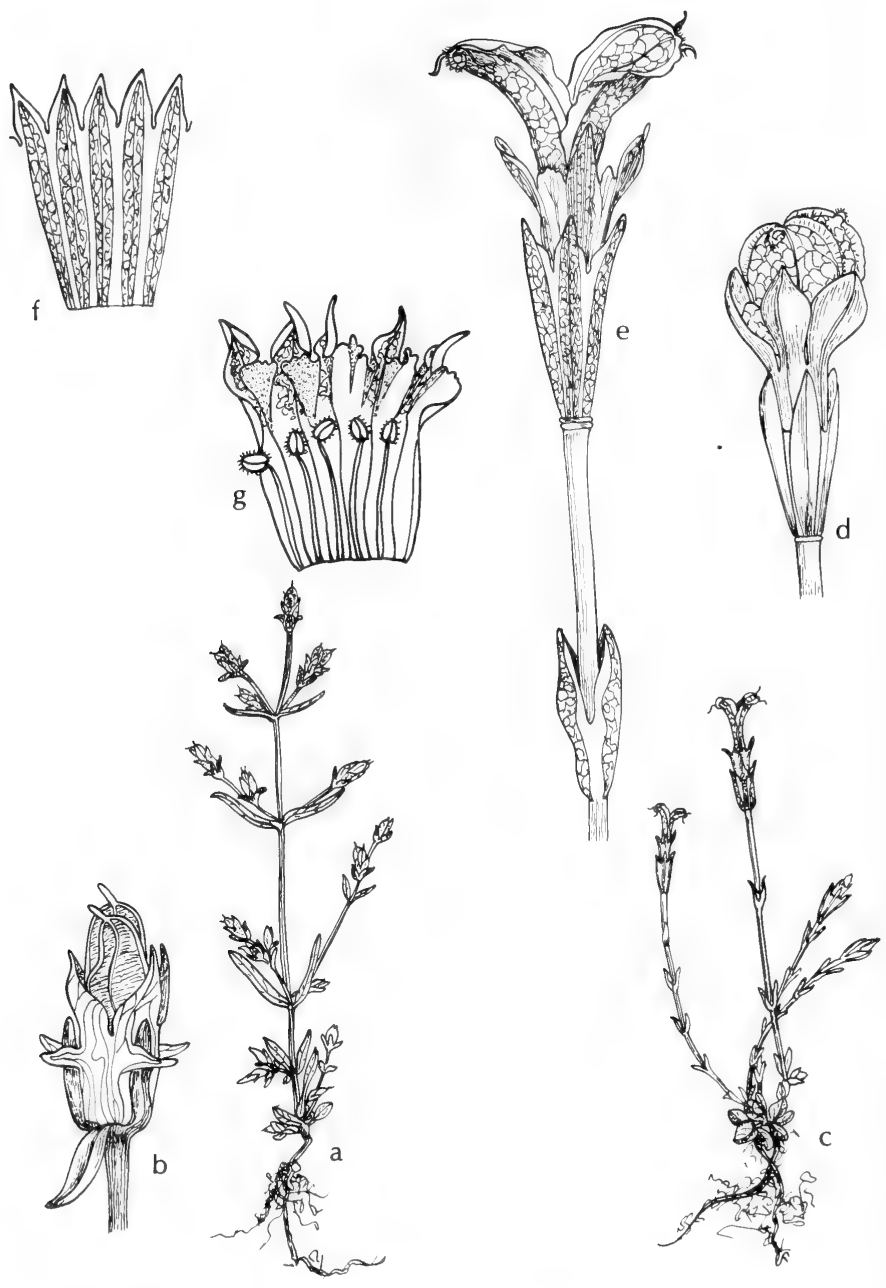

Fig. 628: a and b, Halenia recurva: a, habit, x 1/2; b, flower, x 21/2. c-g, Gentiana Fremontii: c, habit, X 1/2; d, flower with capsule, x 21/2; e, dehiscent capsule, x 21/2; f, corolla (outer surface), x 21/2; g, corolla (inner surface), x 21/2. (V. F.). 
cauline leaves few, oblanceolate, 5-15 mm. long: flowers 8-15 mm. long, 5 (4) -merous, single and terminal on long naked peduncles, or few to many from the lower leaves on elongate pedicels as much as $10 \mathrm{~cm}$. long: calyx half the length of the corolla or longer: calyx lobes nearly distinct, slightly gibbous-based, the outer 2 broader and shorter than the inner, usually more rugose and with membranous margins; corolla white to bluish-purple, tubular, not plicate in the sinuses; corolla lobes about one third the length of the tube, oblong-lanceolate, obtuse to acute, each fringed within by 2 basal erect lacerate scales about one third as long; stamens shorter than and freed about midlength of the corolla tube, the rather broad filaments not wing-margined below the point of insertion; anthers sagittate-cordate; ovary sessile; style very short, the stigmatic lobes oblong; capsule slightly exceeding the corolla; seeds yellow, ovoid, nearly smooth.

In wet meadows, seepage about lakes and rocky places at timberline, in N. M. (Santa Fe and Taos cos.) and Ariz. (Coconino Co.), July-Sept.; circumpolar; Greenl. to Alas., s. to N. M., Ariz. and Calif.; Euras.

\section{Gentiana Fremontii Torr. Moss gentian. Fig. 628.}

Annual or biennial; stems simple or branched at or near base, $3-10 \mathrm{~cm}$. tall; leaves all broadly scarious-margined, mucronate; basal leaves orbicular to obovate, 5-6 mm. long; cauline leaves erect, oblong to linear, 4-6 mm. long; flowers terminal, solitary; calyx narrowly funnelform, about $7 \mathrm{~mm}$. long, the acute lobes scarious-margined; corolla tubular, greenish-white, 5-7 $\mathrm{mm}$. long, the tube shorter than the calyx, the lobes with minutely toothed plaits in the sinuses; capsule at maturity about $1 \mathrm{~cm}$. long, exserted on an elongate stipe (to $2 \mathrm{~cm}$. long), 2-valved, dehiscent at the summit with the valves spreading to appear trumpet-shaped or so as to suggest a large bilobed stigma; seeds $1 \mathrm{~mm}$. long, ellipsoid, apiculate. Chondrophylla Fremontii (Torr.) A. Nels.

Boggy meadows and seepage about springs and along streams, in N.M. (Taos and San Miguel cos.) and Ariz. (Apache Co.), May-Aug.; Alta. to N.M., Ariz. and Calif.

\section{Gentiana algida Pall.}

Cespitose perennial with 1 to several stems 5-20 cm. tall; basal leaves linearoblanceolate, 4-12 cm. long; cauline leaves in 3 to 5 pairs, linear-oblong to oblonglanceolate, 3-5 cm. long, mostly about $5(10) \mathrm{mm}$. broad, their bases connate for 5-8 mm., the subtending leaves of the usually 5-merous closely crowded subsessile flowers often considerably broader, sometimes ovate-lanceolate; calyx narrowly funnelform, mostly about $2 \mathrm{~cm}$. long, usually purplish-blotched, the tube truncate between the lobes; calyx lobes subequal, linear to lanceolate, from about half as long as to subequal to the tube and somewhat carinate and more or less transrugose; corolla usually about twice the length of the calyx, $3.5-5 \mathrm{~cm}$. long, white or pale-yellowish, purple-blotched and purplish-streaked from the back of the lobes nearly to the calyx, strongly plicate between the acuminate short lobes; filaments freed slightly below midlength of the corolla, the adnate portion broadly wingmargined, free filaments about twice the length of the 3-4 $\mathrm{mm}$. anthers: ovary long-stipitate; style deeply 2-cleft, the stigmatic portion elliptic-oblong. G. Romanzovii Ledeb. ex Bunge, Dasystephana Romanzovii (Ledeb. ex Bunge) Rydb.

Alpine bogs and wet meadows, and on seepage banks along streams and about lakes, in N. M. (Santa Fe, San Miguel and Taos cos.), July-Sept.; N.M. to Alas. and e. Sib.

\section{Gentiana Bigelovii Gray.}

Perennial, glandular-ciliolate throughout (especially on the nerves, calyx and leaf margins), to $3 \mathrm{dm}$. tall, the slender erect stem leafy; leaves thickish, oblong to oblong-lanceolate, obtuse, to $35 \mathrm{~mm}$. long and $1 \mathrm{~cm}$. wide; flowers 5 -merous, short- 
pedicelled to sessile in upper axils to form a several- to many-flowered leafy-bracted raceme; calyx nearly regular, the tube to $7 \mathrm{~mm}$. long and the slightly irregular linear-subulate lobes about as long; corolla violet-color, cylindrical-funnelform, nearly closed in anthesis, $2-2.5 \mathrm{~cm}$. long, the short lobes acutish; lobes of the plaits triangular, 2-cleft, acute, about half as long as the corolla lobes. Dasystephana Bigelovii (Gray) Rydb.

Rocky wet meadows and seepage slopes of high mts. in w. Tex., N. M. (Bernalillo, San Miguel, Lincoln and Torrance cos.) and Ariz. (Graham, Cochise and Pima cos. ), Aug.-Oct.; from Colo. to w. Tex., N.M. and Ariz.

\section{Gentiana Saponaria L. BotTle-gentian, soapwort-Gentian.}

Perennial with a stout caudex and coarse roots, to $8 \mathrm{dm}$. tall, the stem glabrous or sometimes slightly puberulent in lines; leaves narrowly elliptic to lanceolate, obtuse to acute or occasionally shortly acuminate, abruptly narrowed at base, ciliate, to $1 \mathrm{dm}$. long; involucre of 2 to 4 leaves, the outer to $6 \mathrm{~cm}$. long and $2 \mathrm{~cm}$. wide; calyx lobes firm, oblong to oblanceolate or sometimes lanceolate, ascending, to $12 \mathrm{~mm}$. long; corolla blue or whitish, cylindric-oblanceolate, $3-5 \mathrm{~cm}$. long, $1-1.5 \mathrm{~cm}$. in diameter at the slightly open summit, the rounded to subacute lobes erect and only slightly longer than the appendages.

In moist woods, thickets and sandy swamps in s.e. Tex. (Newton Co.) and s.e. Okla. (LeFlore Co.), Sept.-Nov.; from Ga. to e. Tex., n. to N.Y., W. Va., Ind., Wisc. and Minn.

\section{Gentiana affinis Griseb. ex Hook.}

Cespitose perennial from rather thick fleshy roots, without rhizomes; stems 1 to several, erect to decumbent at the base, $1.5-8 \mathrm{dm}$. tall, minutely puberulent in lines below the slightly decurrent leaf bases; leaves in 8 to 15 pairs, the lowermost usually reduced to bladeless connate sheathing bases; middle cauline blades narrowly lanceolate to oblong or oblong-oblanceolate to broadly lanceolate or ellipticovate, 2-5 cm. long, 5-20 (-25) $\mathrm{mm}$. broad, usually very finely glandular-ciliolate (at least near their bases); floral leaves similar to the cauline ones or shorter and broader; flowers 5-merous, few, closely crowded, often arising from the top 2 or 3 nodes only or the upper 3 to 5 nodes all floriferous; peduncles $3-25 \mathrm{~mm}$. long, bracteate at the summit; bracteoles foliaceous to somewhat scarious, linear to ovate; calyx tube 3-9 mm. long, tubular-funnelform, greenish- to bluish- or purplish-tinged, with an inner membranous lining projecting above the bases of the lobes and toothed inside them; calyx lobes usually unequal, from ovate to linear and from longer than the tube to reduced to mere teeth or lacking entirely, the tube then nearly entire to erose and from nearly truncate to oblique or deeply parted once or twice; corolla tubular-funnelform, (2-) $2.5-4(-4.5) \mathrm{cm}$. long, deepblue but usually variously mottled or streaked with green; corolla lobes (3-)4-6(-7) $\mathrm{mm}$. long, oblong-ovate to ovate, rounded to acute or abruptly pointed, the plaits of the sinuses one half to three fourths the length of the lobes and usually laciniately deeply cleft into 2 to 5 narrow segments (entire); stamens slightly shorter than the corolla tube; filaments adnate to near midlength of the corolla, the adnate portion broadly wing-margined; anthers $2.5-4 \mathrm{~mm}$. long; ovary long-stipitate; style short, cleft above, the stigmatic surfaces oblong-oval; seeds flattened and wing-margined, very finely reticulate. G. Parryi Engelm., Dasystephana Parryi (Engelm.) Rydb., D. interrupta (Greene) Rydb.

In alpine and subalpine wet meadows, old lake beds, seepage slopes along streams and about lakes, and wooded slopes, in N.M. (widespread in mts.) and Ariz. (Apache, Navajo, Coconino, Gila and Greenlee cos.), July-Oct.; Sask. to B.C., s. to N.M., Ariz. and Calif. 
One species in North America; about 15 species in temperate Eurasia.

\section{Lomatogonium rotatum (L.) Fries ex Nyman. Fig. 629.}

Slender annual glabrous plant with mostly simple stem to about $3 \mathrm{dm}$. tall; leaves opposite, the basal ones oblong-oblanceolate to linear above, 2-3 cm. long: flowers whitish or bluish-tinged, mostly axillary on long slender pedicels; calyx 7-12 mm. long, deeply parted to near base with usually 4 or 5 linear lobes; corolla rotate, deeply parted, the acute lobes elliptic-oblong to ovate-lanceolate and 7-12 $\mathrm{mm}$. long, with a pair of scalelike appendages at the base; stamens on short corolla tube; anthers versatile but sagittate at one end; style none; stigmas consisting of decurrent lines on the sutures of the ovary; capsules narrowly ellipsoid to ovoid-oblong, not stipitate; seeds numerous. Pleurogyna rotata (L.) Griseb.

In mt. bogs and wet meadows, sometimes saline, in N. M. (Taos Co., fide Wooton), summer-fall; Greenl. to Alas., s. to Colo. and (?) N. M.

\section{Halenia Börckh. Spurred Gentian}

About 100 species mostly in America with several in Asia.

\section{Halenia recurva $(\mathrm{Sm}$.$) Allen. Fig. 628$.}

Annual 2.5-5 dm. tall; stem simple, often branched above; basal leaves elliptic-lanceolate to spatulate, less than $3.5 \mathrm{~cm}$. long, about $6 \mathrm{~mm}$. wide; cauline leaves remote, lance-linear, $1.5-4 \mathrm{~cm}$. long, about $3.5 \mathrm{~mm}$. wide, obscurely 3 -nerved, the midrib prominent below; inflorescence a loosely flowered subumbellate cyme; flowers on slender pedicels, 5-30 mm. long, often in sevens; calyx lobes lanceolate, acute-attenuate, to $6 \mathrm{~mm}$. long, 1-nerved, papillate; corolla brightyellow, 10-12 mm. long, the tube less than one half the length of the entire corolla; corolla lobes ovate, subacuminate, delicately veined, papillate; spurs curved, horizontal or ascending, to $16 \mathrm{~mm}$. long from tip to tip; anthers broadly oblong, mucronate, papillate; filaments slightly obovate; capsule ovate-lanceolate; seeds yellow-brown, subglobose-ovoid, granular. H. Rothrockii Gray.

In wet mt. meadows, swampy ground, about spring-fed ponds and in moist soil of coniferous forests, in N. M. (Socorro Co.) and Ariz. (Apache, Graham and Cochise cos.), Aug.-Sept.; also n. Mex.

\section{Swertia L.}

More than 50 species; cosmopolitan but mainly in eastern Asia.

\section{Swertia perennis L. FELWORT. Fig. 629.}

Glabrous perennial with a short rootstock and a single erect simple stem 1-3 $\mathrm{dm}$. high; leaves mostly basal, obovate to elliptic or oblanceolate, the lower 4-12 $\mathrm{cm}$. long with blades about equal to the broad petioles; cauline leaves few, smaller than basal leaves, alternate or the upper ones opposite and sessile; panicle or raceme narrow, terminal, elongate, the lowest pedicels mostly $1-4 \mathrm{~cm}$. long; flowers 5(4)-merous; calyx lobes lanceolate, 4-5 $\mathrm{mm}$. long; corolla lobes oblong-ovate, mostly deep slate-blue, sometimes white-veined dorsally, obtuse, $8-10 \mathrm{~mm}$. long; glands 2 on each corolla lobe, round-elliptic, fringed all around; capsules ellipsoid, flattened, about $1 \mathrm{~cm}$. long; seeds compressed, roundish, brown, winged about three fourths way around, about $1 \mathrm{~mm}$. wide. S. palustris A. Nels.

In wet meadows, bogs, edge of lakes and streams, grassy slopes, in N. M. (San Miguel, Santa Fe and Taos cos.) and Ariz. (Apache Co.), July-Sept.; Alas. s. to N. M., Ariz. and Calif.; Euras. 


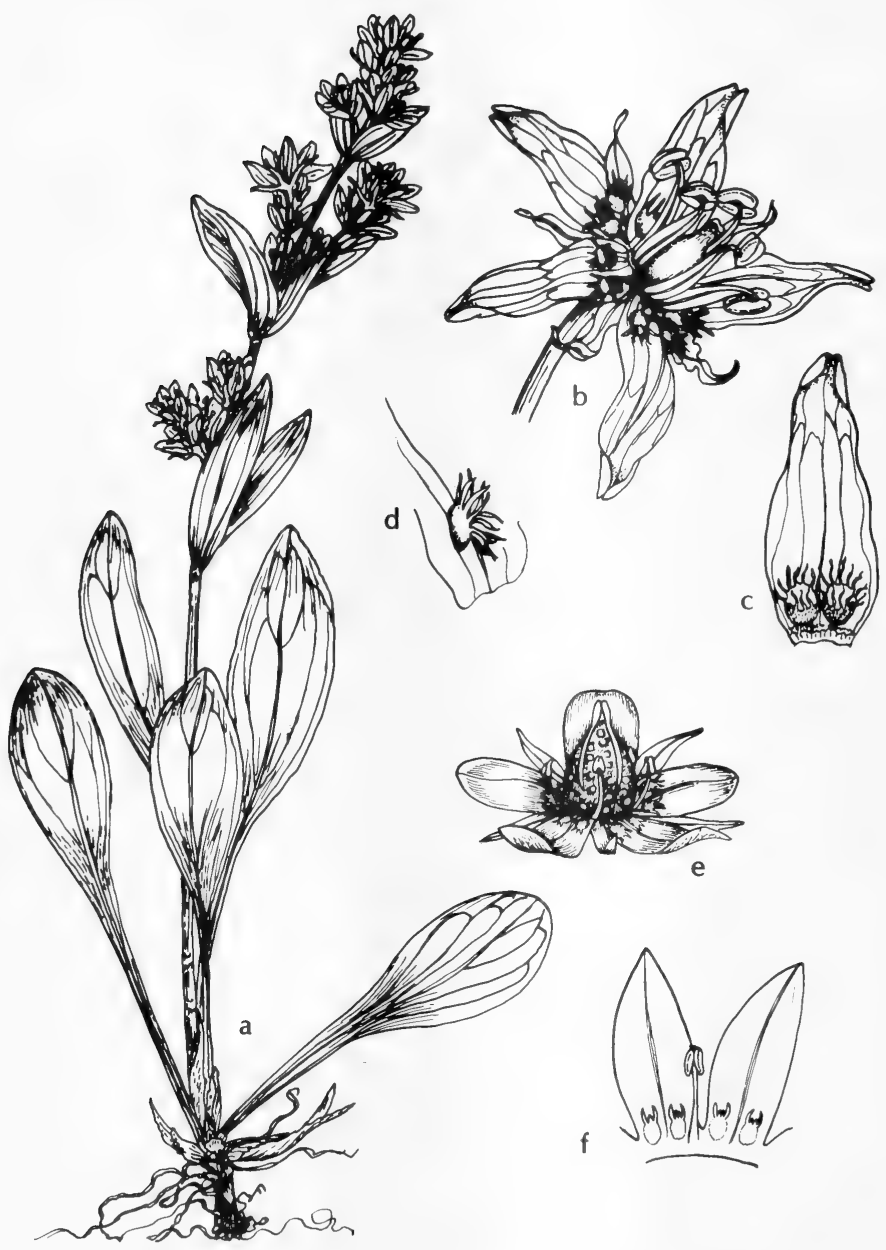

Fig. 629: a-d, Swertia perennis: a, habit, x 1/2; b, flower, x 2; c, petal, x 3; d, gland, $\mathrm{x}$ 3. e and $\mathrm{f}$, Lomatogonium rotatum: e, flower, about $\times 2$; $\mathrm{f}$, enlargement of 2 petals and stamen. (e and $\mathrm{f}$ adapted from Hitchcock, et al., Vascular Plants of the Pacific Northwest; V. F.). 


\section{Bartonia MuHL.}

Plants annual or biennial, herbaceous; stem filiform, often somewhat spiraled or twining, mostly green or yellowish; leaves reduced to subulate scales; inflorescence a terminal panicle or raceme of small white to yellowish or purplish 4-merous flowers; calyx cleft to or near the base; corolla campanulate, the lobes about equaling the tube, imbricate in bud; stamens short, inserted at the sinuses of the corolla; anthers oval; style very short and stout; capsule thick-cylindric, flattened, 2-valved; seeds numerous.

Four species confined to the eastern half of North America.

1. Flowering in early spring (February and March); corolla 5-10 mm. long....... 1. $B$. verna.

1. Flowering in late summer and fall (August to October); corolla $5 \mathrm{~mm}$. long or less (2)

2(1). Calyx about $3 \mathrm{~mm}$. long; corolla about $5 \mathrm{~mm}$. long, the lobes lanceolate and tapering to an acute to acuminate apex; capsule shorter than the corolla, the style about $1.5 \mathrm{~mm}$. long................ 2 . Baniculata.

2. Calyx 1.5-2 mm. long; corolla about $2.5 \mathrm{~mm}$. long, the lobes elliptic and obtuse to obtuse-apiculate; capsule usually exceeding the corolla, the style about $0.5 \mathrm{~mm}$. long.

3. B. texana.

\section{Bartonia verna (Michx.) Muhl.}

Stems erect, purplish to rarely yellowish, 5-20 $\mathrm{cm}$. high; leaves opposite or subopposite, reduced to scales 1-3 mm. long; flowers solitary, racemose or sometimes paniculate on robust plants; pedicels 5-20 $\mathrm{mm}$. long, rarely more; sepals triangular-acute, 2-3 mm. long; corolla white, rotate; petals oblanceolate to obovate, obtuse, entire, 5-10 mm. long, 1.5-4 mm. wide; stamens about half as long as corolla, ascending; pistil two thirds as long as corolla; capsule 3-7 mm. long.

In pitcher plant bogs and low savannahs in s.e. Tex. (Tyler Co.), Feb.-Mar.; from N.C. s. to Fla. and w. to Tex.

\section{Bartonia paniculata (Michx.) Muhl. SCREW-STEM. Fig. 630.}

Plant glabrous, to about $4 \mathrm{dm}$. high, with an erect or somewhat twining or flexuous stem; leaves scalelike, alternate or sometimes opposite below; inflorescence usually a short-branched panicle, elongate; pedicels slender, ascending or divergent, about $1 \mathrm{~cm}$. long; flowers to about $5 \mathrm{~mm}$. long; sepals lanceolate, subacuminate, 2-3 mm. long; petals lanceolate, creamy-white, long-acuminate; capsule ellipsoid, usually much shorter than the corolla, the persistent style about $1.5 \mathrm{~mm}$. long.

In sandy bogs and meadows in e. Tex., reported (but not seen) from LeFlore Co., Okla., Aug.-Sept.; mostly along the coast from N.S. and N. J., s. to Fla., Okla. and Tex.

\section{Bartonia texana Correll. Fig. 630.}

Plant inconspicuous, glabrous, to $3 \mathrm{dm}$. high; stem slender, usually rigidly erect; leaves scalelike, alternate or rarely subopposite, about $1 \mathrm{~mm}$. long; flowers in a slender lax raceme or panicle; pedicels slender, ascending, to $15 \mathrm{~mm}$. long; calyx 1.5-2 mm. long, the lobes triangular-lanceolate and acute; corolla whitish, about $2.5 \mathrm{~mm}$. long, the lobes elliptic and obtuse to obtuse-apiculate; stamens in sinus of petals; capsule ellipsoidal-subquadrate, usually exceeding the corolla, dehiscent at apex by separation of the style, the persistent style about $0.5 \mathrm{~mm}$. long.

On sphagnum moss along wooded stream in Tyler Co., s.e. Tex., Sept.-Oct.; endemic. 


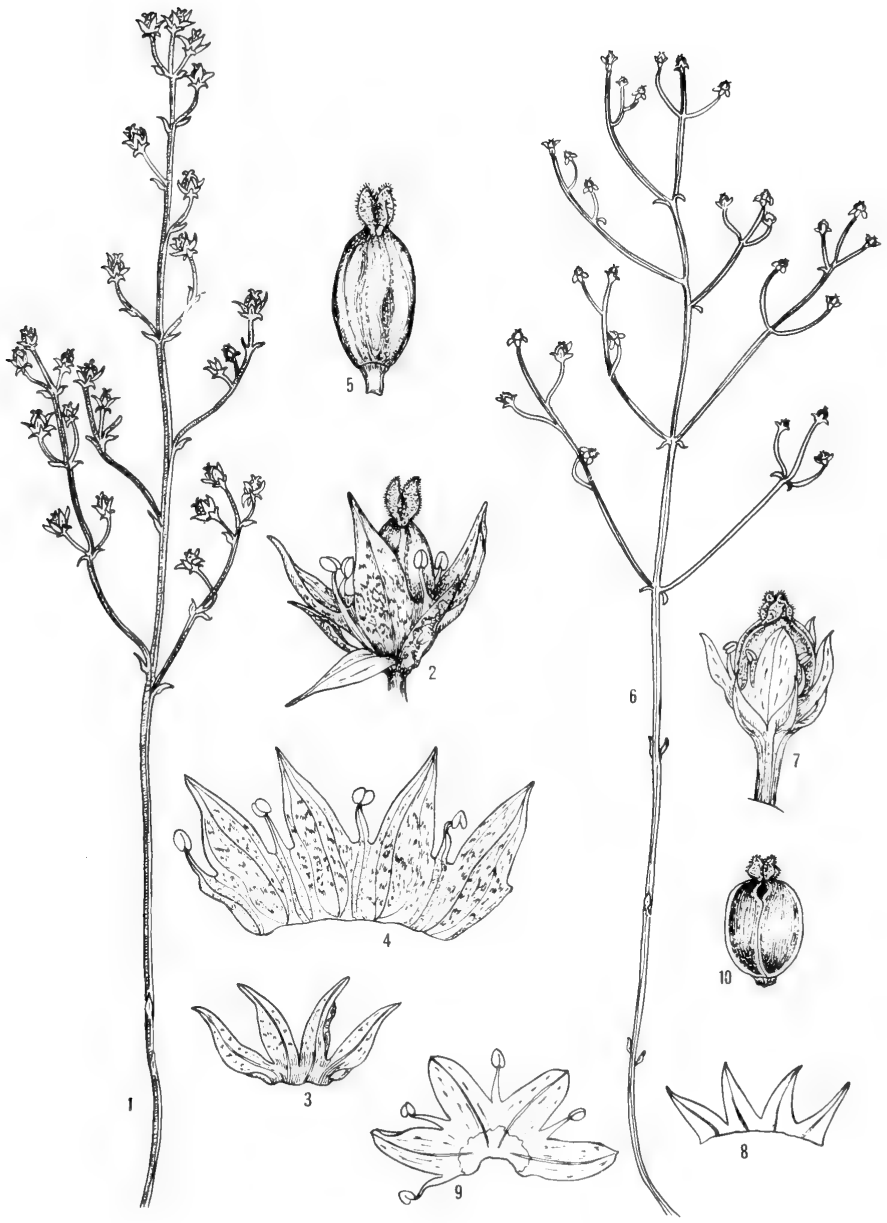

Fig. 630: 1-5, Bartonia paniculata: 1, habit, x 1; 2, flower with one sepal spread out, $x 5 ; 3$, calyx, spread out, x $5 ; 4$, corolla, spread out, x $5 ; 5$, capsule, x 5. 6-10, Bartonia texana: 6 , habit, x $1 ; 7$, flower, x 5;8, calyx, x 5;9, corolla, x 5; 10 , capsule, x 5. (V. F.). 
Perennial submersed aquatic plants with floating alternate leaves on long petioles that bear near their summit an umbel of flowers and often a cluster of short spurlike roots; calyx 5-parted; corolla almost rotate, 5-parted, the lobes bearing a glandular appendage near the base; style short or none, the persistent stigma 2-lobed; capsule few- to many-seeded, at length bursting irregularly; seeds papillate, the coat hard.

A genus of about 20 species; in America, Eurasia and Africa; often placed in the segregate family Menyanthaceae.

1. Petioles slender, sometimes with clusters of roots just below the leaf blade; leaves mostly basal; flowers white, in clusters on the petioles............

..................................................................... N. aquatica.

1. Petioles rather stout, without clusters of roots; leaves mostly from branching stems; flowers yellow, axillary. ..2. N. peltata.

\section{Nymphoides aquatica (Gmel.) O. Ktze. Figs. 1 and 631.}

Plant coarse: leaves mostly basal, suborbicular to reniform, with a deep basal sinus, heavy in texture, smooth and yellowish green on upper surface, darkpunctate or pitted on lower surface, to $15 \mathrm{~cm}$. wide; petiole slender, arising from a cluster of fleshy roots, purple-glandular, to $25 \mathrm{~cm}$. or more long; pedicels to 8 $\mathrm{cm}$. long; calyx to $5 \mathrm{~mm}$. long; corolla white, about $15 \mathrm{~mm}$. broad; capsule elongate, to $15 \mathrm{~mm}$. long; seeds glandular-roughened. Limnanthemum trachyspermum Gray.

In ponds and sluggish streams in e. Tex., May-July; from Fla. and Tex., n. locally to s. N.J. and Del.

\section{Nymphoides peltata (Gmel.) O. Ktze. Yellow floAting-Heart.}

Plant coarse; stem stout, extensively creeping and branching: leaves subtending the umbel, suborbicular, coarsely undulate-dentate, to about $15 \mathrm{~cm}$. long and wide; pedicel often $6 \mathrm{~cm}$. long or more, stout; calyx lobes elliptic-lanceolate, subobtuse, $1 \mathrm{~cm}$. long or more; corolla bright-yellow, $2-3 \mathrm{~cm}$. broad, its segments somewhat fringed: anthers 4-5 $\mathrm{mm}$. long; capsule strongly beaked, to $25 \mathrm{~mm}$. long; seeds flat, narrowly winged, with fringelike margins.

In quiet waters of rivers, lakes and streams, and on wet sandy shores of lakes in s.e. Okla. (McCurtain and Bryan cos.), n.-cen. Tex. and Ariz. (Santa Cruz Co.), June-Sept.; introd. from Eur. for cult. but escapes and has become established from N.Y.s. to Tex. and Ariz.

\section{Fam. 109. A pocynaceae Juss.}

DOGBANE FAMILY

Trees, shrubs, vines or herbs, often with milky juice; leaves opposite or alternate or occasionally verticillate, entire; flowers regular, perfect: calyx gamosepalous, the 5 usually imbricate lobes mostly parted nearly to the receptacle, frequently bearing various glandular appendages within; corolla gamopetalous, varying from salverform or infundibuliform to urceolate or campanulate, the tube sometimes bearing somewhat conspicuous faucal appendages within, the limb 5-parted, the lobes sinistrorsely or dextrorsely contorted in aestivation; stamens 5, alternate with the corolla lobes in the tube, the introrse anthers 4-celled; ovary bicarpellary, the single style surmounted by a massive stigma of diversified structure; fruit follicular (in ours); seeds naked or comose.

About 180 genera and 1,500 species of cosmopolitan distribution. The family contains many ornamental as well as poisonous plants.

1. Leaves alternate. 1. Amsonia

1. Leaves opposite or whorled (2) 


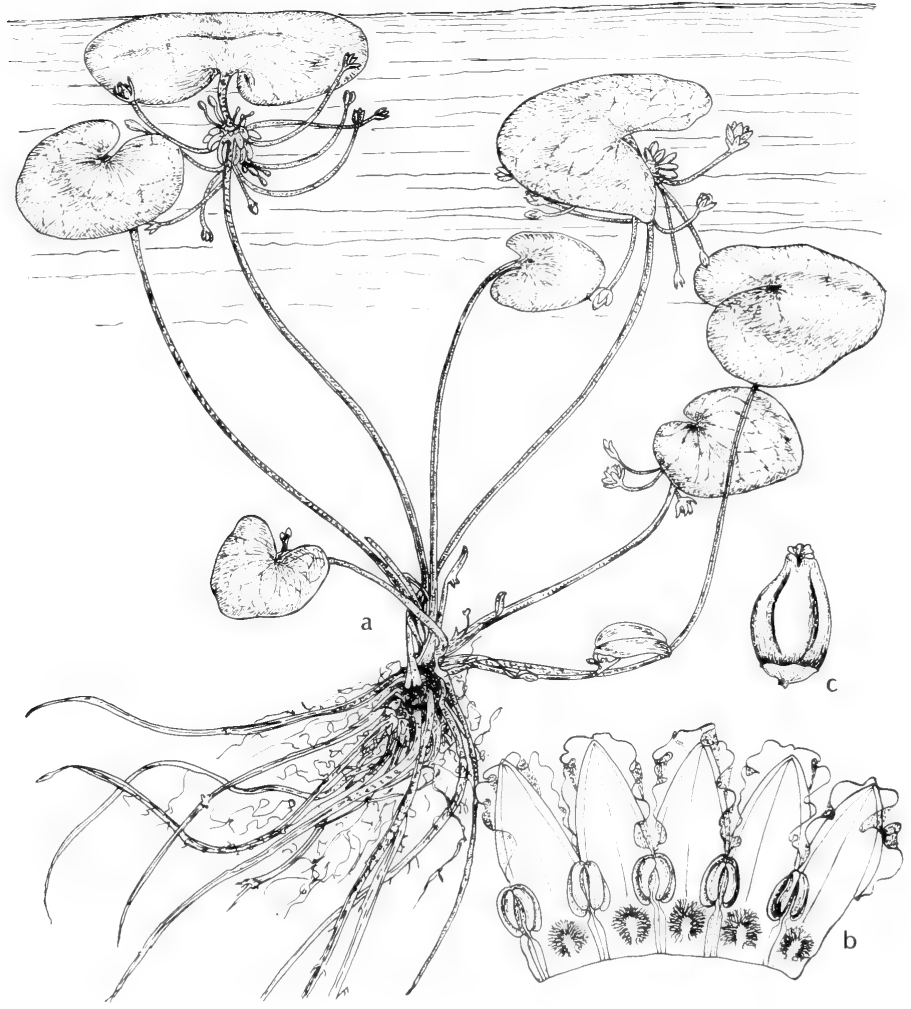

Fig. 631: Nymphoides aquatica: a, habit, x 1/2; b, corolla spread open, x 5; c, capsule, x 5. (V. F.). 


\section{Amsonia Walt. Blue-star}

Caulescent herbaceous perennials; leaves alternate or subverticillate, not glandular; inflorescence thyrsiform, terminal or occasionally lateral, bearing several to many flowers; calyx 5-parted, the lobes essentially equal, scarcely imbricate, without squamellae; corolla salverform, the limb regularly 5-parted, the lobes sinistrorsely contorted; anthers not connivent, without an enlarged connective, wholly included; ovary apocarpous, without a nectary, containing numerous ovules; follicles terete, continuous or more or less moniliform; seeds numerous, naked, rather corky.

A genus of about 25 species in North America and one in Japan.

1. Corolla glabrous externally.

1. A. glaberrima.

1. Corolla pubescent externally (2)

2(1). Calyx glabrous; leaves thinly membranaceous, opaque above

2. A. tabernaemontana.

2. Calyx more or less pilose; leaves firmly membranaceous or subcoriaceous, lustrous above. 3. A. illustris.

\section{Amsonia glaberrima Woods.}

Stems to $8 \mathrm{dm}$. tall, wholly glabrous; leaves alternate, firmly membranaceous, oblong-elliptic to narrowly lanceolate, to $8 \mathrm{~cm}$. long and $2 \mathrm{~cm}$. wide, acuminate, narrowed at the base, wholly glabrous, opaque on both sides, the petioles $2-4 \mathrm{~mm}$. long: inflorescence rather diffuse, scarcely surpassing the foliage, bearing several to numerous medium-sized azure flowers; pedicels 3-4 $\mathrm{mm}$. long, glabrous; calyx lobes ovate-triangular, acute, about $1.5 \mathrm{~mm}$. long, glabrous; corolla wholly glabrous externally, the tube $6.5-7 \mathrm{~mm}$. long, about $1 \mathrm{~mm}$. in diameter at the base, somewhat dilated above the insertion of the stamens, not constricted at the orifice, the lobes $6-7 \mathrm{~mm}$. long, glabrous, somewhat spreading; follicles relatively slender, continuous, $8-10 \mathrm{~cm}$. long, glabrous.

In dense wet lowland woods, about pools, in wet savannahs and low pinelands in extreme s.e. Tex., Mar.-Nov.; also La.

\section{Amsonia tabernaemontana Walt.}

Stems 3-10 dm. tall; leaves alternate, rather thinly membranaceous, ovate to oblong-elliptic or lanceolate, 6-15 $\mathrm{cm}$. long, to $5 \mathrm{~cm}$. broad, acute to acuminate at apex. obtuse to broadly acute at the base, wholly glabrous to finely puberulent beneath, opaque on both sides, the petioles 3-6 $\mathrm{mm}$. long; inflorescence barely surpassing the foliage, bearing several to numerous azure flowers; pedicels 3-6 $\mathrm{mm}$. long; calyx lobes ovate to ovate-lanceolate, 1-2 mm. long, glabrous; corolla more or less pilose externally, the tube $6-8 \mathrm{~mm}$. long, about $1 \mathrm{~mm}$. in diameter at the base, somewhat dilated above the insertion of the stamens, not constricted at the orifice, the lobes 4-7 mm. long, spreading; follicles relatively slender, continuous, $8-12 \mathrm{~cm}$. long, glabrous.

In sandy soil about lakes and along streams in n.e. Tex. and Okla. (Waterfall), Mar.-May; from Pa., s. to Ga. and s.w. to Tex.

Those plants with lanceolate to narrowly oblong-elliptic leaves $6-15 \mathrm{~cm}$. long and $1-2.5 \mathrm{~cm}$. wide have been placed in var. salicifolia (Pursh) Woods. (var. Gattingeri Woods.)

This species, along with $A$. glaberrima and $A$. illustris, form an extremely close alliance, and it is questionable as to whether or not they should be maintained as separate species rather than variants of one complex unit. The degree of 
pubescence or lack of pubescence on the corolla and calyx, that mainly separates these entitites, is not an entirely reliable characteristic.

\section{Amsonia illustris Woods. Fig. 632.}

Stems erect, rather stout, from a woody rootstock, to $12 \mathrm{dm}$. tall; leaves alternate, subcoriaceous to firmly membranaceous, rather narrowly lanceolate to elliptic-lanceolate, to $1 \mathrm{dm}$. long and $3 \mathrm{~cm}$. broad, acute to acuminate, cuneate at the base, glabrous, the upper surface lustrous, the petioles $1-4 \mathrm{~mm}$. long; inflorescence barely surpassing the foliage, bearing numerous pale-blue flowers; pedicels 2-8 mm. long; calyx lobes narrowly lanceolate, acuminate, 1.5-3 mm. long, more or less pilosulous; corolla more or less pilose externally, the tube $6-8 \mathrm{~mm}$. long, about $1 \mathrm{~mm}$. in diameter at the base, slightly dilated at the insertion of the stamens, not constricted at the orifice, the lanceolate lobes 5-10 mm. long, spreading; follicles somewhat articulate to essentially continuous, slender, papyraceous, 8-14 cm. long, glabrous.

In wet soil of swamps, coastal prairies, meadows, low woodlands, in mud about lakes and in streams and ditches in the e. third of Tex. and s.e. Okla. (McCurtain Co.), Mar.-June; from s. Mo. and e. Kan. to Tex.

\section{Trachelospermum Lem. Climbing Dogbane}

About 30 species, all but the following in the Eastern Hemisphere.

\section{Trachelospermum difforme (Walt.) Gray. Fig. 633.}

Herbaceous twining plant, glabrous to variously puberulent; leaves opposite, with petioles to $12 \mathrm{~mm}$. long, extremely variable and not infrequently heterophyllous on a single plant, thinly membranaceous, elliptic to obovate-elliptic, occasionally linear-elliptic or suborbicular, to $12 \mathrm{~cm}$. long and $75 \mathrm{~mm}$. broad, acuminate at apex (occasionally very shortly and abruptly so), cuneate to rounded at the base; flowers numerous, small, in alternate-axillary thyrsiform inflorescences; pedicels 4-7 $\mathrm{mm}$. long; calyx 5-parted nearly to the receptacle; calyx lobes ovate-lanceolate, acuminate, 3-4 mm. long, minutely and rather sparsely barbellate at the tips, bearing within alternate pairs of squamellae; corolla paleyellow, salverform or subinfundibuliform, the tube $5.5-6.5 \mathrm{~mm}$. long, about $1 \mathrm{~mm}$. in diameter at the base, somewhat inflated at the orifice, the 5 lobes obliquely obovate, 3-4 mm. long, dextrorsely contorted, spreading; anthers connivent and agglutinated to the stigma, with an enlarged narrowly 2 -lobed connective; ovary apocarpous, containing numerous ovules, surrounded at the base by 5 separate or more or less concrescent nectaries; stigma fusiform, borne upon an elongate style; follicles 2 , slender, terete, obscurely undulate-articulate to essentially continuous, $15-23 \mathrm{~cm}$. long, glabrous; seeds many, truncate, comose.

Climbing on trees and shrubs along streams, in swamps and low ground, about ponds, and on the edge of forests and in weedy areas in e. Tex. and s.e. Okla. (Waterfall), Apr.-June; from Del. s. to Fla. and Tex., w. to Ill., Ind., Mo. and Okla.

\section{Apocynum L. Dogbane. Indian Hemp}

Herbaceous perennials, reproducing freely by horizontal gemmiferous roots, with branching stems; leaves opposite or rarely verticillate, not glandular, often mucronate-pointed; flowers small and pale, on short pedicels in terminal and axillary cymes; calyx 5-parted nearly to the receptacle, without internal squamellae, the lobes equal, scarcely imbricate; corolla campanulate to urceolate or cylindric, the tube short, the limb regularly 5-parted, with small sagittate appendages at the base opposite the lobes, dextrorsely contorted; stamens on the very base of corolla; anthers connivent and agglutinated to the stigma, with an enlarged 


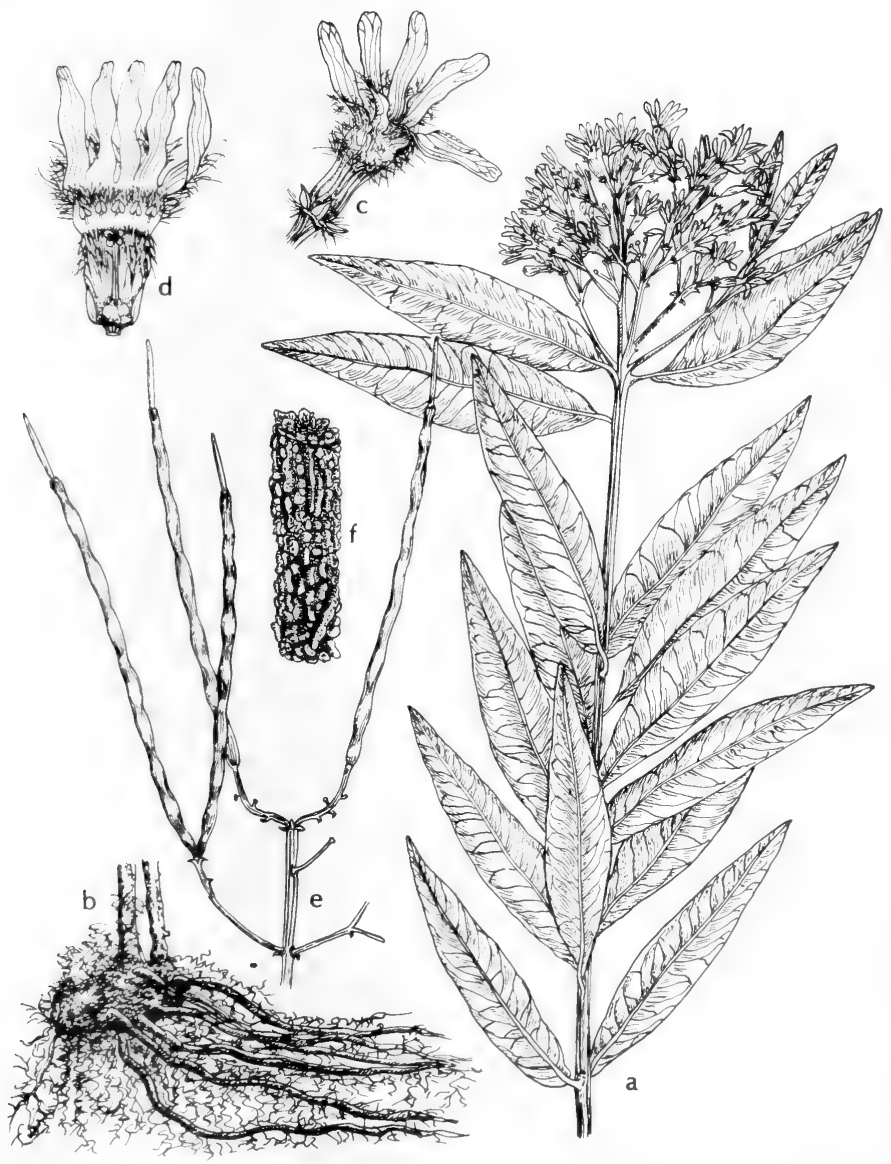

Fig. 632: Amsonia illustris: a, top of plant, x 1/6; b, basal part of plant, $\mathrm{x} 1 / 2 ; \mathrm{c}$, flower, $x 2$; , corolla opened out, x 2 ; e, fruit, $\times 1 / 2 ;$ f, one mature seed, X 3 . (V. F.). 


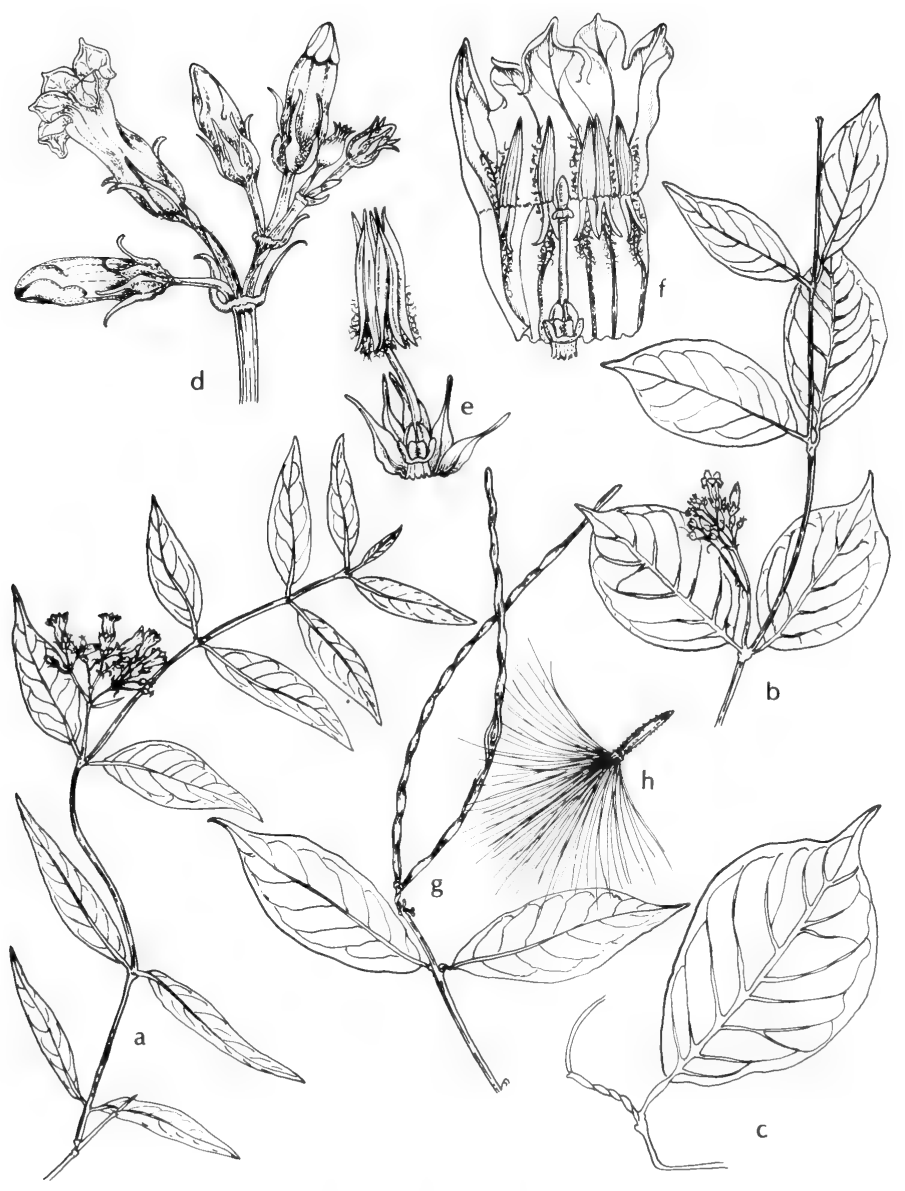

Fig. 633: Trachelospermum difforme: $\mathrm{a}$ and $\mathrm{b}$, habits showing different leaf shapes, $\mathrm{x} 1 / 2$; c, leaf, $\mathrm{x} 1 \frac{1}{2}$; $\mathrm{d}$, inflorescence, $\mathrm{x} 21 \frac{1}{2}$; e, calyx split to show ovary and nectaries, and anthers connivent with the stigma, x 5; f, open corolla, x 5; g, follicles, x 1/2; e, seed, x 1. (V. F.). 
narrowly 2-lobed connective; ovary apocarpous, containing numerous ovules, surrounded at the base by 5 distinct ovoid nectaries; stigma usually virtually sessile, variable in shape but essentially ovoid-fusiform; follicles usually 2, separate or somewhat agglutinated at the tips, slender, terete; seeds numerous, truncate, comose.

About 7 species in North America and 70 elsewhere in temperate and tropical regions. The separation of species in this extremely complex genus is not too satisfactory.

1. Leaves noticeably petiolate or only the very lowest sessile, narrowed to broadly rounded at the base, pubescent to glabrous; bracts of inflorescence scarious and aristate.......................................... A. cannabinum.

1. Leaves sessile or nearly so, the lowest cordate at base and usually clasping the stem, always glabrous; bracts of inflorescence more or less foliaceous and laminate.

2. A. sibiricum.

1. Apocynum cannabinum L. INDIAN HeMP. Fig. 633A.

Plant glabrous to variously pubescent; stems erect or ascending to $1 \mathrm{~m}$. tall, glabrous, with ascending branches; leaves petiolate or the lowermost sometimes subsessile, ascending or only slightly spreading, ovate to oblong-elliptic or lanceolate, rounded to acute and usually apiculate at apex, narrowly cuneate to somewhat rounded at base, to $14 \mathrm{~cm}$. long and $7 \mathrm{~cm}$. broad, glabrous above, glabrous to more or less densely pilosulous or tomentulose beneath; calyx lobes lanceolate to ovate-lanceolate, 3-4 mm. long, glabrous; corolla cylindric to urceolate, 3-6 $\mathrm{mm}$. long, white to greenish, the lobes erect or only slightly spreading; follicles $12-20 \mathrm{~cm}$. long, glabrous, pendulous at maturity.

Usually in wet or moist sandy or clayey soil in ditches and along streams and rivers, in marshy areas, about ponds, occasionally in fields and open woodlands in e., cen. and n.-cen. Tex. and Okla. (Osage, Ottawa and LeFlore cos.), Apr.Aug.; throughout the U.S. and s. Can.

Those plants that are entirely glabrous throughout are segregated as var. glaberrimum A. DC., while those plants that are more or less tomentulose throughout are segregated as var. pubescens (R.Br.) A.DC.

\section{Apocynum sibiricum Jacq. Prairie dogbane.}

Stems erect or somewhat ascending to $7 \mathrm{dm}$. tall, glabrous throughout, with ascending branches; leaves sessile or subsessile (especially on the main stem) and often with a cordate-clasping base, those on the upper branches frequently shortly petiolate, ascending or slightly spreading, oblong or oblong-lanceolate to oval or rarely linear to linear-lanceolate, to $14 \mathrm{~cm}$. long and $45 \mathrm{~mm}$. wide, obtuse to rounded or cordate at the base; inflorescence usually dense, the bracts usually conspicuous and more or less herbaceous; calyx lobes lanceolate, 2-4 mm. long; corolla urceolate to shortly cylindric, about as long as broad, $3-5 \mathrm{~mm}$. long, white to yellow or greenish, glabrous externally, the lobes erect or slightly spreading; follicles $4-10 \mathrm{~cm}$. long, glabrous, pendulous at maturity. A. hypericifolium Ait., A. Suksdorfii Greene.

Usually in sandy soil along creeks and on dunes, in marshes about lakes, seepage along streams and about springs and in arroyos and gullies of badlands in n.-cen. Tex., the Edwards Plateau, Plains Country and Trans-Pecos, Okla. (Alfalfa Co.) and N. M. (Eddy, Dona Ana and Guadalupe cos.), Apr.-Sept.; throughout most of N.A.

Those plants with the main stem leaves ovate to oval-oblong and deeply cordate and clasping at the base are segregated as var. cordigerum (Greene) Fern., while those plants with very narrow leaves and corolla longer than broad are segregated as var. salignum (Greene) Fern. [A. angustifolium Woot., A. Suksdorfii var. angustifolium (Woot.) Woods.] 


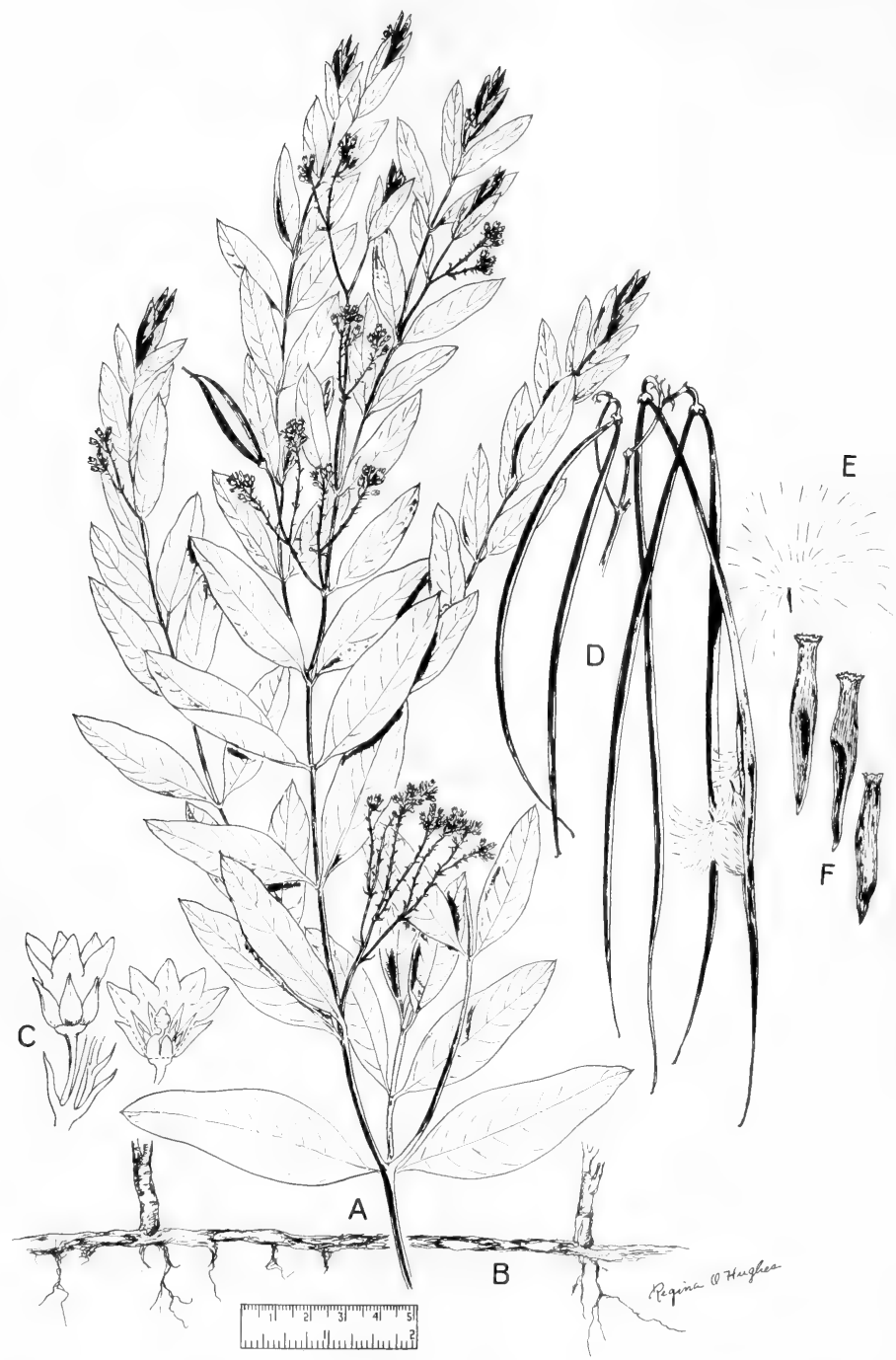

Fig. 633A: Apocynum cannabinum: A, habit, x 1/2; B, rootstock, x 1/2; C, flowers, $\mathrm{x} 5 ; \mathrm{D}$, follicles, $\mathrm{x} 1 / 2$; E, seed with coma, $\mathrm{x} 1 ; \mathrm{F}$, seeds, $\mathrm{x} 5$. (From Reed, Selected Weeds of the United States, Fig. 140). 
Perennial herbs, vines or shrubs with milky juice; leaves opposite, whorled or sometimes alternate, without stipules; flowers perfect, regular, usually umbellate, commonly 5-merous; calyx deeply lobed, the lobes mostly imbricate; corolla 5-lobed or -cleft, the lobes commonly valvate in bud; a 5-lobed crown is usually present between the corolla and stamens and is adnate to either or both; stamens 5 , inserted on the corolla tube usually near its base, the filaments monadelphous or sometimes distinct; anthers united and tipped with a scarious membrane inflexed on the summit of the stylar disk; pollen grains united into waxlike or granular pollinia; carpels 2, with distinct superior ovaries and styles but united above by the peltate discoid stigma; fruit of 2 follicles (or 1 by abortion); seeds many, compressed, usually with long coma.

About 130 genera and 2,000 species widely distributed but most frequent in warm regions.

1. Stamen column or its base with 1 row of flat thin appendages...2. Cynanchum

1. Stamen column or its base surrounded by 5 separate fleshy-inflated or fleshythickened erect or spreading appendages (hoods) (2)

2(1). Stems prostrate to erect, not twining; base of corolla without a fleshy disk under the separate appendages..............................1. Asclepias

2. Stems twining, at least toward tips; corolla with a fleshy disk at base under the appendages

3. Sarcostemma

\section{Asclepias L. Milkweed. Silkweed}

Herbs, rarely fruticose or suffruticose, perennial or rarely annual, usually laticiferous; leaves usually decussate, infrequently whorled or irregularly approximate; inflorescence terminal or interpetiolar, umbelliformly cymose, very rarely reduced to a solitary flower; calyx lobes 5 , equal, divided nearly to the receptacle, bearing few to many minute glandular squamellae within at the base; corolla rotate, the lobes 5, valvate, equal, reflexed, spreading or rarely erect; gynostegium definitely stipitate to sessile; corona of 5 hoods attached to the column and subtending the connivent anthers; hoods cucullate to clavate with various modifications, more or less stipitate to sessile and deeply saccate at the basal attachment to the column, usually bearing an internal horn or crest; anthers 2-celled, with more or less prominent corneous marginal wings enclosing the 5 stigmatic chambers and with membranaceous apical appendages; pollinia paired and pendulous from the translator arms, flat and uniformly fertile, enclosing granular pollen with thin hyaline intine; anther head peltate, more or less pentagonal; fruit follicular, containing many compressed comose or rarely naked seeds.

About 120 species that are native mostiy to the Americas.

1. The complete hoods or only their apical portion widespread from the anther head. 1. A. speciosa.

1. The hoods erect to suberect, more or less parallel to and contiguous with the anther head (2)

2(1). Leaves typically broad, suborbicular to ovate-elliptic or elliptic to cblonglanceolate (3)

2. Leaves typically narrow, lanceolate to narrowly triangular-lanceolate or linearlanceolate to filiform, sometimes ovate (5)

3(2). Hoods shorter than to only slightly longer than the anther head; corolla white. 10. A. texana.

3. In natural position the hoods extending at least a third longer than the anther head (4) 
4(3). Hoods noticeably dilated above the middle, repand to emarginate at the broad apex; corolla greenish-white or yellow......2. A. oenotheroides.

4. Hoods not dilated above the middle, rounded and sometimes slightly notched at the apex; corolla deep-rose. 3. A. purpurascens.

5(2). In natural position the hoods extending at least a third longer than the anther head (6)

5. Hoods shorter than to only slightly longer than the anther head (7)

6(5). Hoods acute to obtuse at apex; leaves ovate to lanceolate. 4. A. rubra.

6. Hoods broadly rounded at apex; leaves linear-lanceolate. 5. A. lanceolata.

7(5). Leaves more or less heterophyllous at the nodes, linear, all of them $4 \mathrm{~mm}$. wide or less. 6. A. subverticillata.

7. Leaves not heterophyllous, mostly lanceolate to linear-lanceolate, typically most of them more than $5 \mathrm{~mm}$. wide (8)

8(7). Hoods obovate, without horns. 7. A. longifolia.

8. Hoods oblong to quadrate, with conspicuous acicular horns that more or less arch over the anther head (9)

9(8). Corolla usually bright-crimson or scarlet, the lobes $5-10 \mathrm{~mm}$. long. ..8. A. curassavica.

9. Corolla white to bright-pink, the lobes $3-5 \mathrm{~mm}$. long (10)

10(9). Inflorescences usually paired at the upper nodes, solitary below; flowers typically bright-pink. 9. A. incarnata.

10. Inflorescences solitary at the upper nodes; flowers white, the corolla occasionally tinged with purple on outer surface (11)

11(10). Follicles erect on erect pedicels; seeds comose; distribution central and west Texas. 10. A. texana.

11. Follicles pendulous; seeds naked; distribution southeast Texas. 11. A. perennis.

\section{Asclepias speciosa Torr. Showy-milkweed.}

Herbaceous perennial; stems usually very stout, simple, 6-10 dm. tall, densely white-tomentose generally; leaves opposite, shortly petiolate, broadly ovate or oval to rather narrowly oblong or ovate-lanceolate, usually very broadly obtuse to rounded at apex, rather rarely acute, very broadly obtuse to rounded and sometimes broadly and shallowly cordate at base, $6-20 \mathrm{~cm}$. long, 3-14 cm. broad, firmly membranaceous, very densely white-tomentose beneath, more or less glabrate above; petioles to $15 \mathrm{~mm}$. long; inflorescences lateral and solitary at few to several of the upper nodes, several- to many-flowered, densely whitetomentose throughout; peduncles rather stout, to $1 \mathrm{dm}$. long; pedicels $2-3 \mathrm{~cm}$. long; flowers very large and showy; calyx lobes lanceolate, 5-6 mm. long, very densely white-tomentose; corolla purplish-rose, the lobes $1-1.5 \mathrm{~cm}$. long; gynostegium pale-rose or pinkish-cream, subsessile; column very broadly obconic, about $1 \mathrm{~mm}$. long and $3 \mathrm{~mm}$. broad; hoods very narrowly ovate-lanceolate, gradually attenuate at apex, widely spreading, 1-1.4 cm. long; horn adnate toward the base, falciform-acicular, sharply incurved, very much shorter than the hoods; anther head broadly truncate-conic, about $3 \mathrm{~mm}$. long and $4.5 \mathrm{~mm}$. broad; follicles erect on deflexed pedicels, broadly or rather narrowly fusiform, abruptly or gradually attenuate, 9-12 cm. long, 2-3 cm. broad, densely spiny to smooth, very densely white-tomentose; seed oval, 6-9 $\mathrm{mm}$. long, the white coma 3-4 cm. broad.

Widely tolerant to habitat and becoming weedy in cult. fields, also in wet meadows and wet alkali soils, along roadsides and railways on the High Plains in 
Tex., Okla.. (Waterfall) and N. M. (Guadalupe and Sandoval cos.); May-Sept.; from s. Man. to B.C., Minn. and Tex., w. to the Pac. Coast.

This species has the most massive flowers of any milkweed.

\section{Asclepias oenotheroides Cham. \& Schlecht. Hierba de Zizotes.}

Low herbaceous perennial; stems clustered from the thick rootstalk, ascending or decumbent, moderately stout, more or less branched from the base or simple, to $45 \mathrm{~cm}$. long, minutely puberulent; leaves opposite, rather long-petiolate, rhombicovate to oblong-lanceolate, obtuse to acute at apex, acute to broadly obtuse at base and abruptly cuneate to the petiole, $4-12 \mathrm{~cm}$. long, 1-6 cm. broad, firmly membranaceous, pale-green, minutely puberulent particularly beneath; petioles 1-2 $\mathrm{cm}$. long; inflorescences lateral and solitary from few to several of the upper nodes, very shortly pedunculate or subsessile, several-flowered; peduncles $1-2 \mathrm{~cm}$. long or nearly obsolete, minutely puberulent; pedicels rather slender, $15-25 \mathrm{~mm}$. long, minutely puberulent; flowers mediocre; calyx lobes ovate-lanceolate, 3-4 mm. long, minutely puberulent; corolla reflexed-rotate, greenish-white or yellow, the lobes 8-14 mm. long; gynostegium very shortly stipitate, pale-greenish-cream; column broadly obconic, about $1.5 \mathrm{~mm}$. long and $2.5 \mathrm{~mm}$. broad; hoods narrowly obovate-flabellate, 7-10 $\mathrm{mm}$. long, conspicuously narrowed to a narrowly laminate stipe from somewhat above the middle, the tip broadly laminate and minutely erose or repand; horn adnate to near the tip of the hood, the free portion falciform and incurved, usually accompanied by a smaller posterior appendage; anther head truncate-conic, about $3 \mathrm{~mm}$. long and 4-5 mm. broad; follicles erect on deflexed pedicels, broadly fusiform or ovoid, shortly apiculate, $7-9 \mathrm{~cm}$. long, $1.5-2 \mathrm{~cm}$. broad, smooth, minutely pilosulose to glabrate; seeds oval, $6-8 \mathrm{~mm}$. long, the pale-tawny coma $2-2.5 \mathrm{~cm}$. long. A. longicornu Benth., A. Lindheimeri Engelm. \& Gray.

Rocky, chiefly clay soil in llanos, mesas and hills, in dunes, salt marshes, fields and thickets, long roadsides in much of w. half of Tex. and Okla. (Waterfall), flowering throughout the year; also N.M., s. to C.A.

\section{Asclepias purpurascens L. Purple-Milkweed.}

Herbaceous perennial; stem rather stout, simple, 4-10 dm. tall, minutely pilosulose when young, becoming glabrate; leaves opposite, petiolate, broadly ovate or oval to ovate- or oblong-lanceolate, obtuse to acute at apex, obtuse to broadly rounded at base and very shortly and abruptly cuneate into the petiole, $6-18 \mathrm{~cm}$. long, 3-10 cm. broad, firmly membranaceous, dark-green and glabrate above, paler and densely and generally puberulent below; petioles to $25 \mathrm{~mm}$. long; inflorescences terminal and solitary or paired, several- to rather many-flowered; peduncles rather slender, $1.5-9 \mathrm{~cm}$. long, minutely puberulent; pedicels slender, 2-3.5 cm. long, minutely puberulent; flowers rather large and very showy; calyx lobes ovate-lanceolate, 3-4 $\mathrm{mm}$. long, minutely puberulent; corolla deep-rose. reflexed-rotate, the lobes $7-10 \mathrm{~mm}$. long; gynostegium deep-rose, very shortly stipitate: column obconic, 1.5-2 $\mathrm{mm}$. long, 2.5-3 $\mathrm{mm}$. broad; hoods oblong-elliptic, acute to acuminate, 6-7 $\mathrm{mm}$. long; horn about half-adnate, falciform and sharply incurved, much shorter than the hoods; anther head truncately conic, about $2 \mathrm{~mm}$. long and $3 \mathrm{~mm}$. broad; follicles erect on deflexed pedicels, narrowly fusiform, graduadly attenuate, 10-16 cm. long, 1-2 cm. thick, smooth, minutely puberulent to glabrate; seeds oval, 5-6 mm. long, the white coma $35-45 \mathrm{~mm}$. long.

Thickets, swamps, alluvial woodlands and open woods, prairies and fields, spreading to roadsides and railways, in n.e. Tex., Apr.-July; from s. Ont. and N.E. s. to Va. and Tex. 


\section{Asclepias rubra L. Fig. 634.}

Herbaceous perennial; stems rather slender, 4-10 dm. tall, simple, glabrous or very inconspicuously pilosulose in decurrent lines from the nodes; leaves opposite, sessile or subsessile, broadly ovate to narrowly lanceolate, acute to acuminate at apex, rounded to somewhat cordate at base, 5-16 cm. long, to 65 $\mathrm{mm}$. broad, firmly membranaceous, glabrous, dark-green above, glaucous beneath; inflorescences terminal and lateral from the uppermost nodes, commonly paired when terminal, several- to many-flowered; peduncles $3-10 \mathrm{~cm}$. long; pedicels 1-1.5 cm. long; flowers moderately large; calyx lobes lance-trigonal, about $3 \mathrm{~mm}$. long, glabrous; corolla reflexed-rotate, dull-red to purplish or lavender, the lobes 8-9 mm. long; gynostegium stipitate, usually pinkish-cream or purplish; column cylindrical, about $2 \mathrm{~mm}$. long and broad; hoods lanceolate, acute, 6-7 mm. long; horn basal, narrowly acicular, somewhat shorter than the hoods, gradually arching over the anther head; anther head narrowly conic, about $3 \mathrm{~mm}$. long and broad, with entire or very inconspicuously notched wings; follicles erect on deflexed pedicels, rather narrowly fusiform, $8-12 \mathrm{~cm}$. long and $15 \mathrm{~mm}$. thick, smooth, glabrous; seeds broadly oval, about $7 \mathrm{~mm}$. long, the white coma about $4 \mathrm{~cm}$. long.

Bogs, marshes, wet meadows and low pine barrens in e. Tex, May-Aug.; from N.J., s. to Ga., Ala., La. and Tex.

\section{Asclepias lanceolata Walt. Fig. 635.}

Herbaceous perennial from rather tuberous rootstalks; stems relatively slender, simple, 5-12 dm. tall, glabrous or essentially so; leaves opposite, linear-lanceolate, narrowly acuminate at apex, acute to obtuse at the base, $7-25 \mathrm{~cm}$. long, to $17 \mathrm{~mm}$. broad, firmly membranaceous, glabrous, somewhat glaucous beneath; inflorescences terminal, solitary or paired, few-flowered; peduncles $15-75 \mathrm{~mm}$. long; pedicels 1-2 cm. long; flowers moderately large; calyx lobes lance-trigonal, 2.5-4 $\mathrm{mm}$. long; corolla reflexed-rotate, dull-red, the lobes 9-10 $\mathrm{mm}$. long; gynostegium stipitate, yellow, orange or reddish; column cylindrical, about $2 \mathrm{~mm}$. long and $1.5 \mathrm{~mm}$. broad; hoods broadly oblong, rounded at the tip, 5-6 $\mathrm{mm}$. long; horn basal, narrowly acicular, somewhat shorter than the hood, arching over the anther head; anther head narrowly conic, about $3 \mathrm{~mm}$. long and $2.5 \mathrm{~mm}$. broad, the wings conspicuously spurred at the base; follicles erect on deflexed pedicels, narrowly fusiform, $8-10 \mathrm{~cm}$. long, about $1 \mathrm{~cm}$. thick, smooth, glabrous; seeds broadly oval, about $1 \mathrm{~cm}$. long, the coma about $35 \mathrm{~mm}$. long. Incl. var. paupercula (Michx.) Fern.

Brackish to fresh marshes, wet pine barrens and low glades in s.e. Tex., MayAug.; from s. N.J., s. to Fla. and w. to Tex.

\section{Asclepias subverticillata (Gray) Vail.}

Herbaceous perennial from rather stout woody rootstalks; stems to $12 \mathrm{dm}$. tall, almost invariably with sterile dwarf microphyllous branches, occasionally simple, more or less puberulent in decurrent lines from the nodes, occasionally quite glabrous; leaves predominantly 3 to 5 in whorls but occasionally opposite above on the flowering stems, shortly petiolate, linear, 2-13 cm. long, 1-4 mm. broad, membranaceous, glabrous to inconspicuously pilosulose, those of the sterile dwarf branches opposite and much-reduced and giving the plant a heterophyllous aspect; petioles 1-2 $\mathrm{mm}$. long; inflorescences usually solitary at the upper nodes, rarely paired, several- to many-flowered; peduncle slender, $1.5-3 \mathrm{~cm}$. long; pedicels slender, 5-8 mm. long; flowers relatively small; calyx lobes narrowly trigonal, 1.5-2 $\mathrm{mm}$. long, inconspicuously pilosulose to glabrate; corolla reflexed-rotate, white, rarely slightly suffused with greenish-purple, the lobes $3-5 \mathrm{~mm}$. long; gynostegium narrowly stipitate, white; column cylindrical, about $1 \mathrm{~mm}$. long and slightly narrower; hoods cucullate, oval, about $1.5 \mathrm{~mm}$. long; horn basal, narrowly 


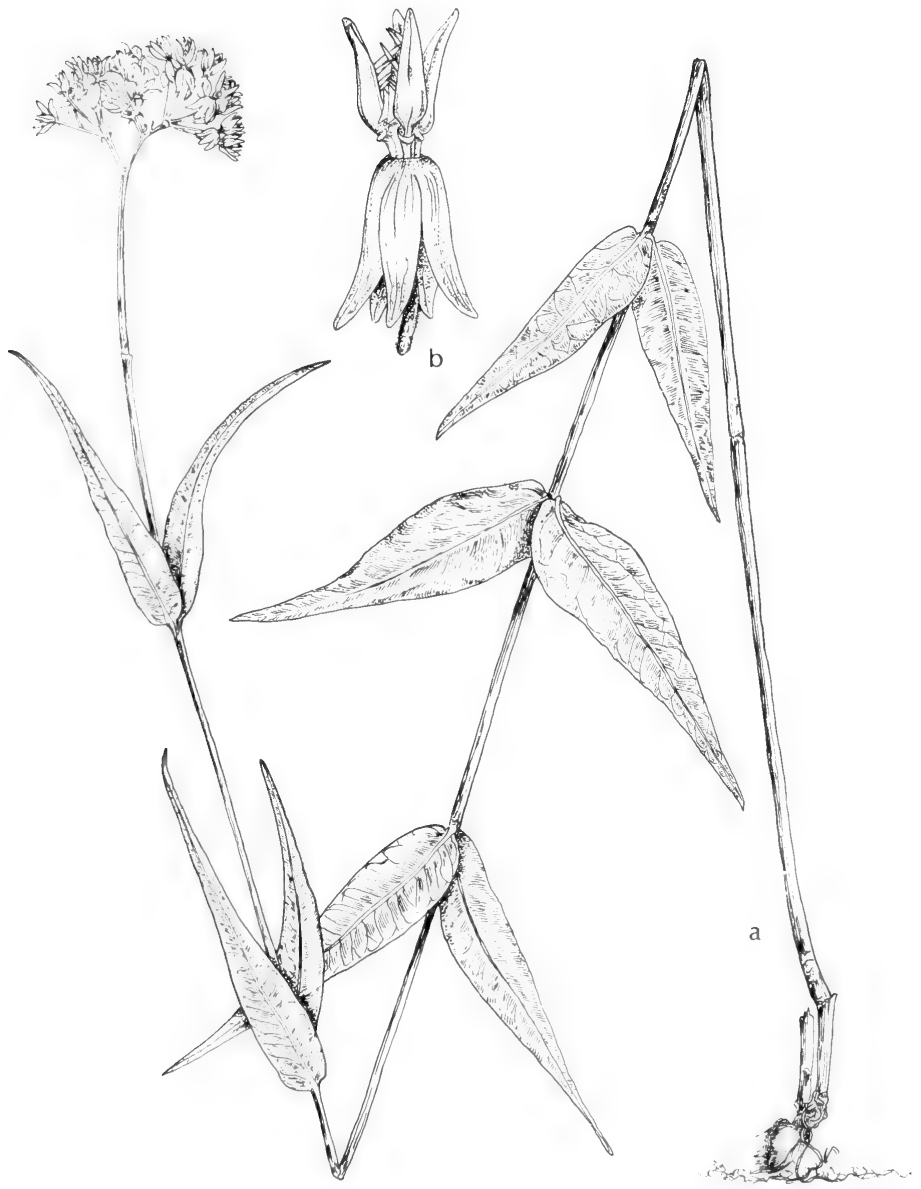

Fig. 634: Asclepias rubra: a, habit, x 1/2; b, flower, x 3. (V. F.). 


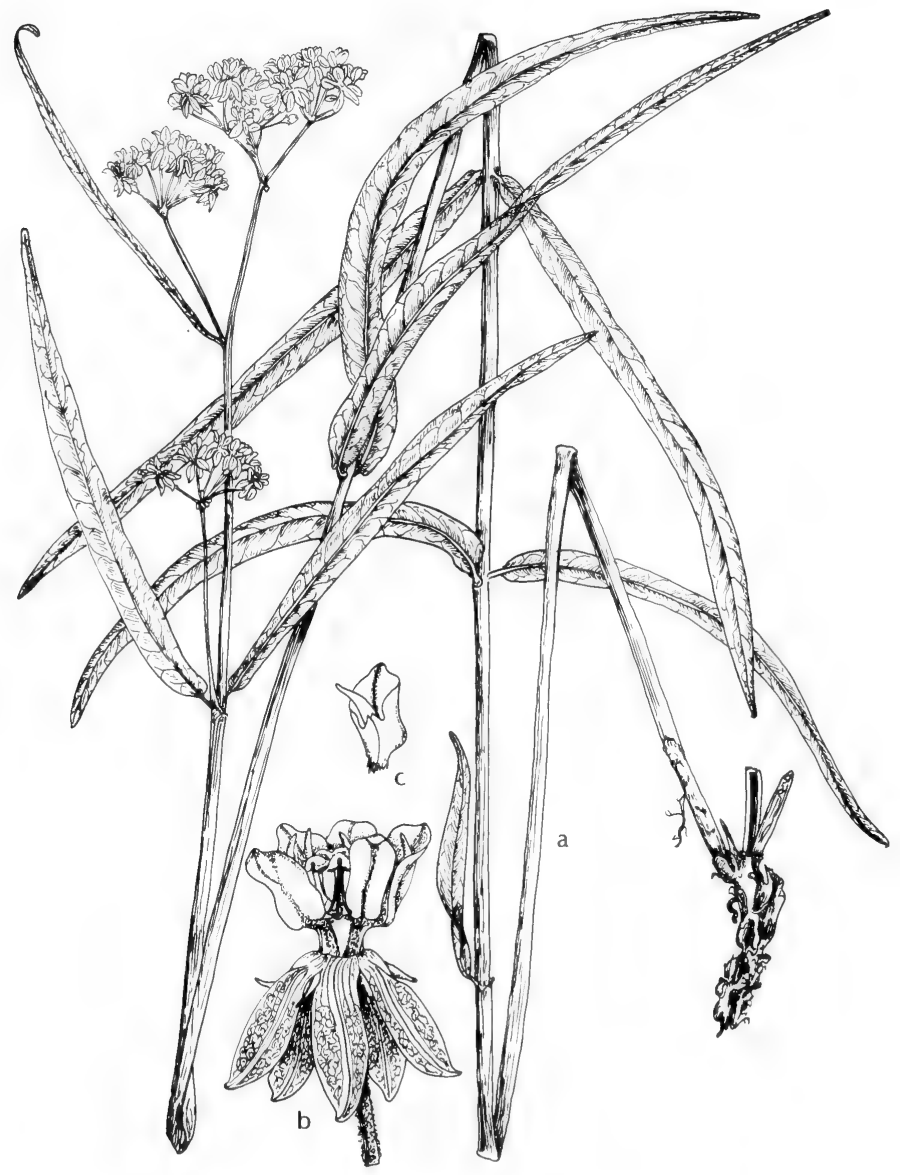

Fig. 635: Asclepias lanceolata: a, habit, x 1/2; b, flower, x 21/2; c, incurved horn, x $2 \frac{1}{2}$. (V. F.). 
acicular, somewhat longer than the hoods, gradually arching over the anther head; anther head cylindric, about $1.5 \mathrm{~mm}$. long and broad; follicles erect on erect pedicels, narrowly fusiform, $5-9 \mathrm{~cm}$. long and $6-8 \mathrm{~mm}$. thick, smooth, glabrous or inconspicuously pilosulose; seeds broadly oval, $7-8 \mathrm{~mm}$. long, the white coma about $2 \mathrm{~cm}$. long. A. galioides of Am. auth.

Sandy and rocky plains and flats, marshes, seepage along streams and about springs, and along irrigation ditches, in the w. half of Tex., especially in the Trans-Pecos, Okla. (Alfalfa Co.), N.M. (DeBaca, Dona Ana, Colfax and Taos cos.) and Ariz. (Cochise Co.), May-Sept.; from Tex., w. to Ut., Colo., Ariz. and n. Mex.

This plant is known to be very poisonous to livestock.

\section{Asclepias longifolia Michx.}

Herbaceous perennial from a stout rather tuberous rootstalk; stems rather slender, simple, 2-7 dm. tall, minutely pilosulose; leaves irregularly approximate, sessile or subsessile, linear-lanceolate, gradually acuminate at apex, attenuate at base, 6-18 cm. long, 2-10 $\mathrm{mm}$. broad, minutely pilosulose to glabrate; inflorescences terminal and solitary and lateral from few of the uppermost nodes, several- to many-flowered, rather lax and hemispherical, pedunculate; peduncles slender, $2-6 \mathrm{~cm}$. long, rarely obsolete, minutely pilosulose; pedicels very slender, $1.5-2 \mathrm{~cm}$. long, minutely pilosulose; corolla reflexed-rotate, pale-greenish-white, liberally tinted with purple (particularly without), the lobes about $5 \mathrm{~mm}$. long; gynostegium shortly but definitely stipitate, greenish-white tinted with purple below; column about $1.5 \mathrm{~mm}$. long and $1 \mathrm{~mm}$. broad; hoods deeply saccate, obovoid, about $2 \mathrm{~mm}$. long, without a horn, much lower than the anther head; anther head about $1.5 \mathrm{~mm}$. long and broad; follicles erect on deflexed pedicels, narrowly fusiform, long-attenuate, minutely pilosulose, $8-12 \mathrm{~cm}$. long, about $1 \mathrm{~cm}$. thick; seeds rather broadly oval, about $1 \mathrm{~cm}$. long, the white coma about $35 \mathrm{~mm}$. long.

Flatwoods, swamps, wet savannahs, wet depressions and low pinelands in e. Tex. and s.e. Okla. (LeFlore Co.), Apr.-Oct.; from Del. to Fla. and w. to Tex.

\section{Asclepias curassavica L. Veintiunilla.}

Herbaceous annual; stems $3-12 \mathrm{dm}$. tall, frequently rather woody toward the base, simple or branched, minutely arachnoid-tomentulose when young, soon glabrate; leaves opposite, petiolate, elliptic-lanceolate, acute to acuminate at apex, acute to obtuse at base, $5-12 \mathrm{~cm}$. long, $1-3 \mathrm{~cm}$. broad, minutely pilosulose when very young, soon glabrate, thinly membranaceous; petioles to $1 \mathrm{~cm}$. long; inflorescences solitary at the upper nodes, several- to many-flowered; peduncles $3-6 \mathrm{~cm}$. long; pedicels $1-2 \mathrm{~cm}$. long; flowers rather large and showy; calyx lobes narrowly lanceolate, 2-3 mm. long; corolla reflexed-rotate, bright-crimson, rarely yellow or white, the lobes 5-10 mm. long; gynostegium long-stipitate, deep-yellow; column cylindric or conic, $2-3 \mathrm{~mm}$. long and $1 \mathrm{~mm}$. broad at the base; hoods cucullate, distinctly stipitate, broadly oblong, rounded at the tip. $3-5 \mathrm{~mm}$. long; horn basal, narrowly acicular, $4-5 \mathrm{~mm}$. long, slightly incurved over the anther head; anther head cylindrical, $2-3 \mathrm{~mm}$. long, $1.5-2.5 \mathrm{~mm}$. broad; follicles erect on erect pedicels, narrowly fusiform, $6-10 \mathrm{~cm}$. long, smooth, glabrous; seeds broadly oval, $5-7 \mathrm{~mm}$. long, the white coma $2-3 \mathrm{~cm}$. long.

In moist or wet soil in s. Tex., Apr.-Aug.; an almost ubiquitous waif of the trop. and subtrop. of Am., also widely introd. in the trop. of the Old World.

\section{Asclepias incarnata L. Swamp-milkweed. Fig. 636.}

Herbaceous perennial from rather short and superficial rootstalks; stems usually fairly stout, 4-15 dm. tall, simple to copiously branched; leaves opposite or very rarely certain nodes condensed to form a false whorl, petiolate, ovate- 


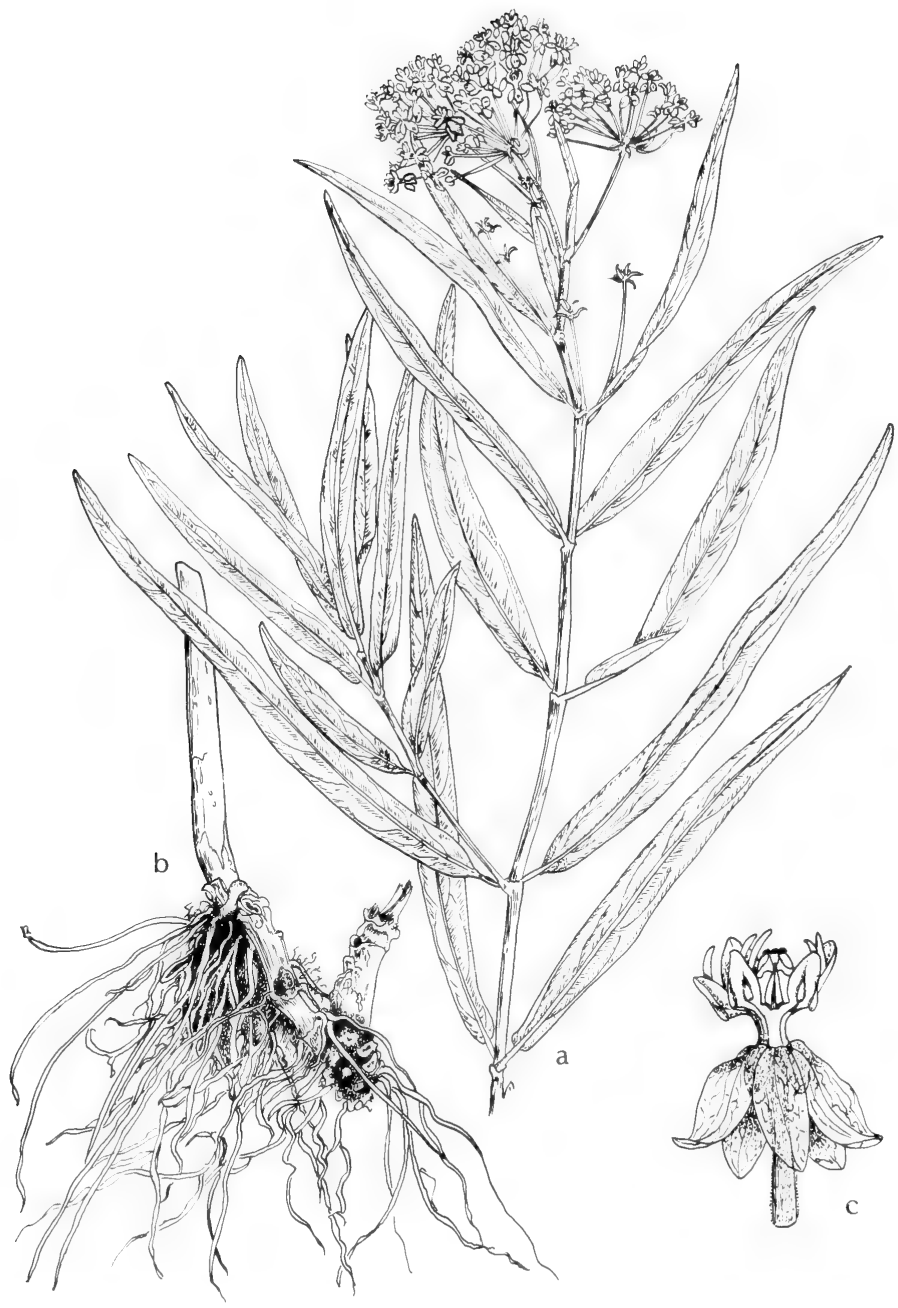

Fig. 636: Asclepias incarnata: a, habit, x 1/2; b, basal part of plant showing roots, x $1 \frac{1}{2} ;$ c, flower, $x 2 \frac{1}{2}$. (V. F.). 
elliptic to linear-lanceolate, acute to acuminate at apex, obtuse to somewhat cordate at base, $5-15 \mathrm{~cm}$. long, to $4 \mathrm{~cm}$. broad, membranaceous; petioles to $1 \mathrm{~cm}$. long; inflorescences usually paired at the upper nodes, solitary below, several- to many-flowered; peduncles $1.5-7 \mathrm{~cm}$. long; pedicels $1-1.5 \mathrm{~cm}$. long; flowers rather small; calyx lobes linear-oblong, 1-1.5 mm. long, pilosulose; corolla bright-pink or rarely white, reflexed-rotate, the lobes 3-4 mm. long; gynostegium paler pink or rarely white; column cylindric, 1-1.5 mm. long, about $1 \mathrm{~mm}$. wide; hoods cucullate, rounded at the tip, about $1.5 \mathrm{~mm}$. long; internal horn narrowly acicular, slightly incurved over the stigma head, somewhat longer than the hood; anther head about $1.5 \mathrm{~mm}$. long; follicles erect on erect pedicels, fusiform, long-attenuate, 7-9 $\mathrm{cm}$. long, to $12 \mathrm{~mm}$. thick, smooth, glabrous to generally pilosulose; seeds broadly oval, 7-10 $\mathrm{mm}$. long, the white coma about $2 \mathrm{~cm}$. long.

In moist or wet soil about water-bodies and in marshes, water of lakes and along and in sluggish or clear-flowing streams from the Plains Country to s.-cen. Tex., Okla. (widespread) and N. M. (Chaves, Colfax, Lincoln and Otero cos.), June-Oct.; from e. Can., s. to Fla. and w. to Ut. and N. M.

The following two phases of this species are found sympatrically. Muskrats are known to eat the rootstocks.

1. Plant scatteringly and inconspicuously pubescent to essentially glabrous; stems usually repeatedly branching; leaves usually rather narrowly oblongto linear-lanceolate, the apex gradually acuminate, the base obtuse to truncate, rather long-petiolate.

.var. incarnata (var. longifolia Gray).

1. Plant generally and conspicuously pubescent; stems simple or branching infrequently; leaves ovate- to broadly oblong-elliptic, the apex acute to abruptly acuminate, the base rounded to somewhat cordate, infrequently broadly obtuse, rather short-petiolate. ..var. pulchra (Ehrh.) Fern.

\section{Asclepias texana Heller.}

Herbaceous perennial, becoming somewhat shrubby at the base after several years; stems slender, to $5 \mathrm{dm}$. tall, usually branching, inconspicuously pilosulose in decurrent lines from the nodes; leaves opposite, petiolate, broadly oval to narrowly oblong-elliptic, obtuse to acuminate at apex, obtuse or rarely attenuate at the base, 2-7 cm. long, to $35 \mathrm{~mm}$. broad, thinly membranaceous, finely puberulent upon the midrib and veins beneath; petioles to $1 \mathrm{~cm}$. long, minutely pilosulose; inflorescences solitary at the uppermost nodes, several- to many-flowered; peduncles slender, 1-2 cm. long; pedicels $1-1.3 \mathrm{~cm}$. long, finely puberulent; flowers small; calyx lobes narrowly lanceolate, 1.5-2 mm. long, minutely puberulent; corolla reflexed-rotate, white, the lobes about $3 \mathrm{~mm}$. long and widely spreading; gynostegium long-stipitate, white; column cylindric, about $1.5 \mathrm{~mm}$. long and 1.7 $\mathrm{mm}$. wide at the base; hoods cucullate, about $2 \mathrm{~mm}$. long, rounded at the tip; horn basal, narrowly acicular, nearly twice as long as the hood, slightly incurved over the anther head; anther head about $2.5 \mathrm{~mm}$. long; follicles erect on erect pedicels, narrowly fusiform, 9-12 cm. long, smooth, glabrous; seeds broadly oval, about $8 \mathrm{~mm}$. long, the white coma about $2 \mathrm{~cm}$. long.

Canyons, arroyos, rocky hills and edge of water along streams in the Edwards Plateau and Trans-Pecos of Tex., May-Aug.; also n. Mex.

\section{Asclepias perennis Walt. Fig. 637.}

Herbaceous perennial from rather short and superficial rootstalks; stems slender, 3-5 dm. tall, usually branching only from the base, very inconspicuously pilosulose in decurrent lines from the nodes or essentially glabrous; leaves opposite, elliptic-lanceolate to narrowly oblong or broadly oval to ovate-elliptic, acuminate at apex, attenuate at the base, $5-14 \mathrm{~cm}$. long, to $15 \mathrm{~mm}$. broad, thinly mem- 


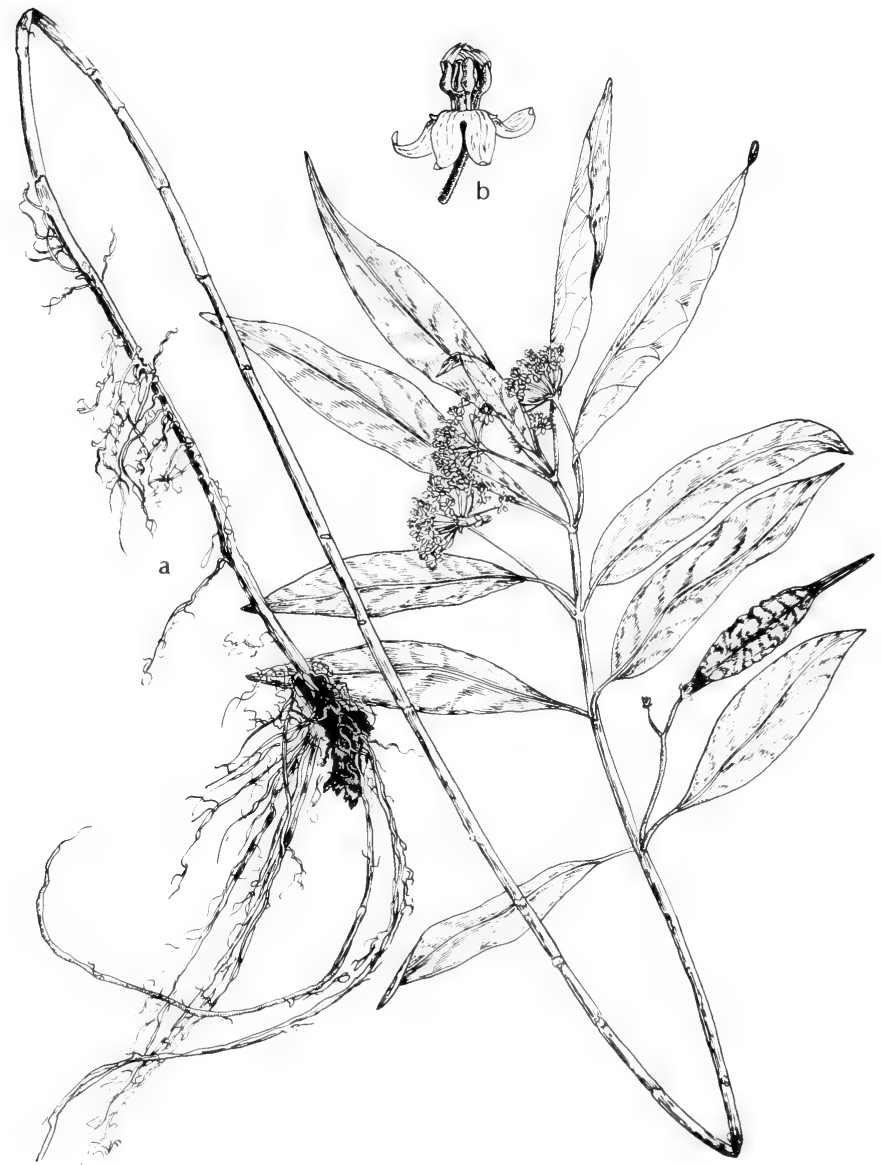

Fig. 637: Asclepias perennis: a, habit, X 1/2; b, flower, X 3. (V. F.). 
branaceous, glabrous; petioles to $15 \mathrm{~mm}$. long; inflorescences solitary at the uppermost nodes, several- to many-flowered; peduncles slender, $1-4 \mathrm{~cm}$. long; pedicels $1-1.3 \mathrm{~cm}$. long, usually somewhat suffused with purple; flowers small; calyx lobes oblong-elliptic, about $1 \mathrm{~mm}$. long, sparsely and minutely pilosulose; corolla reflexed-rotate, white and usually suffused with pale-pink, the lobes 3-4 $\mathrm{mm}$. long; gynostegium stipitate, white; column cylindric, about $1 \mathrm{~mm}$. long and wide; hoods cucullate, rounded at the tip, about $2 \mathrm{~mm}$. long, slightly longer than the anther head; horn basal, narrow-acicular, somewhat longer than the hoods, slightly arching over the anther head; follicles pendulous on deflexed peduncles, rather broadly ovoid-fusiform with a rather long apical beak, 4-7 cm. long, $1-2.5 \mathrm{~cm}$. broad, smooth, glabrous; seeds broadly oval, about $15 \mathrm{~mm}$. long, without a coma.

Low swampy ground, frequently with bald cypress, alluvial woods, sloughs and ditches mostly in s.e. Tex., Apr.-Aug.; from S.C., s. to Fla. and w. to Tex., s. Mo., Ill. and s.w. Ind.

\section{Cynanchum L.}

About 150 species mostly in the warmer regions of both hemispheres.

\section{Cynanchum angustifolium Pers.}

Vine slender, glabrous, somewhat succulent, twining, to $1 \mathrm{~m}$. or more long; leaves short-petioled, narrowly linear, acute, to $8 \mathrm{~cm}$. long and $5 \mathrm{~mm}$. wide; peduncles slender, mostly shorter than the leaves; cymes several-flowered; calyx $2-2.5 \mathrm{~mm}$. long, the lobes ovate-lanceolate to lanceolate and acute; corolla purplish or greenishwhite, $6-8 \mathrm{~mm}$. broad, the lobes ovate and acuminate; crown lobes $1.5-2 \mathrm{~mm}$. long, retuse: follicles slender, to $7 \mathrm{~cm}$. long and $5 \mathrm{~mm}$. thick. Lyonia palustris (Pursh) Small, Seutera palustris (Pursh) Vail, Cynanchum palustre (Pursh) Heller.

Climbing over shrubs and herbs in and on the edge of salt marshes and in moist sandy soils, local along the Tex. Gulf Coast, May-Aug.; from N.C. to Fla. and Tex.; also Bah. I. and W.I.

\section{Sarcostemma R. BR.}

A world-wide genus of about 10 species.

\section{Sarcostemma cynanchoides Dcne.}

Stems twining or trailing to $1 \mathrm{~m}$. or more long, much-branched, glabrous to sparsely puberulent; leaves with petioles to $2 \mathrm{~cm}$. long, broadly to narrowly ovatelanceolate to triangular-lanceolate or linear to linear-lanceolate, acute to acuminate at apex, cordate to hastate or rounded-cuneate at base, to $6 \mathrm{~cm}$. long and $35 \mathrm{~mm}$. wide, thin-membranaceous, sparsely puberulent on both surfaces, with one or more glands on the midrib at the base; inflorescences umbelliform, as many as 20-flowered; peduncle slender, to $55 \mathrm{~mm}$. long; bracts linear, minute; pedicels slender, to $17 \mathrm{~mm}$. long; calyx lobes 5, ovate to ovate-linear, 2-3 mm. long, pilosulose without, glabrous within; squamellae absent to solitary or paired; corolla rotate-subcampanulate, greenish-white to purple or pinkish, the tube $1-2 \mathrm{~mm}$. long; corolla lobes 5 , ovate, acute to acuminate, 5-7 $\mathrm{mm}$. long, glabrous within, fimbriate-ciliate; ring of the crown thin, revolute, not adnate to the base of the crown-vesicles that are $1.5 \mathrm{~mm}$. long; follicles fusiform, to $7 \mathrm{~cm}$. long, lanceolate in outline, attenuate above, puberulent.

In sandy or rocky soils, usually climbing on shrubs, and in marshes and banks of irrigation ditches, in the w. half of Tex., Okla. (Waterfall), N. M. (Sierra Co.) and Ariz. (Yavapai Co.), Apr.-Sept.; from Okla. and Tex., w. to Calif., s. to cen. Mex. 
Var. cynanchoides [Funastrum cynanchoides (Dcne.) Schltr., Philibertella cynanchoides (Dcne.) Vail] is widespread in the western half of Texas and it typically has broadly triangular-lanceolate leaves, whereas var. Hartwegii (Vail) Shinner ( $S$. heterophyllum of auth.), with linear to linear-lanceolate leaves, occurs only in the Trans-Pecos. Few specimens have been seen that are intermediate between these two varieties. The flowers of var. cynanchoides are also usually greenish-white while those of var. Hartwegii are usually purplish or pinkish.

\section{Fam. 111. Convolvulaceae Juss. MORning Glory FAMILY}

Annual or perennial herbs, vines or shrubs (trees south of our area); leaves alternate, simple or compound, entire, toothed or lobed (wanting in Cuscuta), without stipules; flowers axillary or terminal, solitary or cymose, perfect, 5-merous; sepals 5, equal or unequal (often overlapping laterally), separate or united in basal portion; corolla gamopetalous, regular (rarely with curved tube or slightly irregular limb), 5-angled to deeply 5-lobed; stamens epipetalous; ovary 2- (occasionally 1- or 3- to 5-) celled, free from the calyx; fruit a 1 - to several-seeded capsule (indehiscent in some species).

About 1,600 species in about 30 to 50 genera, in tropical (chiefly) and temperate regions of both hemispheres.

1. Leafless parasitic annual twiners, not ground-rooting by flowering time

6. Cuscuta

1. Leafy or leafy-bracted ground-rooting annual or perennial twiners, trailers, erect herbs or shrubs (2)

2(1). Stigmas linear or oblong, more than twice as long as broad......4. Calystegia

2. Stigmas globose to reniform or flat-topped, as broad as long or broader (minute and scarcely larger than style in some species) (3)

3(2). Corolla shorter than or up to twice as long as calyx, with prominent lobes one third to three fourths its total length, the lobes as long as wide or longer (4)

3. Corolla more than twice as long as the calyx, shallowly lobed (lobes broader than long) or merely angled (5)

4(3). Leaf blades orbicular-ovate to orbicular-reniform, cordate, becoming longpetioled. ..1. Dichondra

4. Leaf blades elliptic to oblong-lanceolate or reduced to small bracts, very shortpetioled or sessile.

2. Cressa

5(3). Style usually 2-branched (rarely with 1 branch suppressed); stigmas minute, little larger than diameter of style....................... S. Stylisma

5. Style unbranched; stigma globose and undivided or with 2 or 3 subglobose lobes.

5. Ipomoea

1. Dichondra Forst. \& Forst. PONY-FOOT

Creeping or trailing perennials; leaves long-petioled; blades orbicular-ovate to orbicular-reniform, entire; flowers very small, axillary, solitary or paired, longpedicelled; sepals 5, united at base; corolla shallowly funnelform, deeply 5-lobed, light-green or white; fruit indehiscent or dehiscent, 2- or 4-seeded.

About 15 species, in tropical and warm-temperate regions of both hemispheres.

1. Pedicel straight; calyx lobes 2 or 3 times as long as wide...... 1. D. carolinensis.

1. Pedicel abruptly recurved near summit; calyx lobes 1.5 to 2 times as long as wide (2) 
2(1). Calyx 1.5-2 mm. long in flower (to $2.5 \mathrm{~mm}$. in fruit); creeping stems mostly less than $1 \mathrm{~mm}$. thick.............................2. D. micrantha.

2. Calyx $2.5-3.2 \mathrm{~mm}$. long in flower (to $3.8 \mathrm{~mm}$. in fruit); creeping stems $1-2$ $\mathrm{mm}$. thick.

3. D. recurvata.

\section{Dichondra carolinensis Michx.}

Rooting at the nodes, mat-forming, 1-12 cm. high, sparsely pubescent; pedicels one third to two thirds as long as petioles in flower; corolla nearly as long as calyx, light-green. D. repens var. carolinensis (Michx.) Choisy.

Damp open ground, in mud on edge of lakes and ponds, edge of swamps and marshes, roadsides and lawns, s.e. Okla. (McCurtain Co.) and cen. and e. Tex., Mar.-June: e. and n. to Fla. and Va.

\section{Dichondra micrantha Urban.}

Rooting at the nodes, mat-forming, 1-6 cm. high, sparsely pubescent; pedicels subsessile to one fourth or one half as long as petioles; corolla as long as calyx or slightly longer, white.

Damp ground and lawns, bogs and wet meadows, s. Tex., Apr.-May; adj. Mex., W.I., Pac. Is., e. Asia.

\section{Dichondra recurvata Tharp \& M. C. Johnst.}

Rooting at the nodes, mat-forming, $2-17 \mathrm{~cm}$. high, rather sparsely pubescent; pedicels one tenth to one half as long as petioles; corolla nearly one third longer than calyx.

Gravelly or sandy open oak woods, wet meadows and wet sandy gravel along creeks, cen. Tex., Mar.-May; endemic.

\section{Cressa L.}

Low densely appressed-pubescent perennials with deep vertical or oblique branching rhizomes, forming colonies, aboveground stems erect or partly decumbent, freely branched; leaves sessile, small, entire; flowers axillary, solitary, shortpedicelled; calyx bracteolate; sepals 5 , united at base, laterally overlapping, elliptic; corolla white, funnelform to subsalverform, 5-lobed, exceeding calyx; stamens exserted; styles 2; stigma capitate; capsule 1- to 4-seeded.

About 6 species in warm-temperate to tropical regions of both hemispheres.

1. Leaf blades well-developed, broadly elliptic to lanceolate, the larger 5-12 mm. long and 1.5-6 mm. wide, those on main stems crowded and overlapping................................................................ C. depressa. 1. Leaf blades very reduced, at flowering time the plant usually with only small bracts $1-4 \mathrm{~mm}$. long and $0.6-2.8 \mathrm{~mm}$. wide, those on main stems widely spaced. 2. C. nudicaulis.

1. Cressa depressa Goodd. Alkali weed. Fig. 638.

Plant densely leafy, gray-pubescent, $8-25 \mathrm{~cm}$. tall. C. truxillensis H.B.K. var. vallicola (Heller) Munz.

In depressions or damp or wet strongly alkaline soil and in wet heavy soils of river valleys and canal banks, in s.w. Okla. (Waterfall), the Tex Trans-Pecos, N. M. (Dona Ana Co.) and Ariz. (Coconino, Mohave, Maricopa, Pinal and Yuma cos.), Apr.-July: w. to Calif.; Mex.

2. Cressa nudicaulis Griseb. Leafless cressa. Fig. 638.

Plant at first with a few very small leaves, appearing leafless or nearly so at flowering time, with bracts only, 7-20 cm. tall. C. aphylla Heller.

On brackish clay banks and flats just above water and periodically wetted, in coastal cos. of Tex. from San Patricio Co. s., Apr.-May or Sept.; also Arg. 


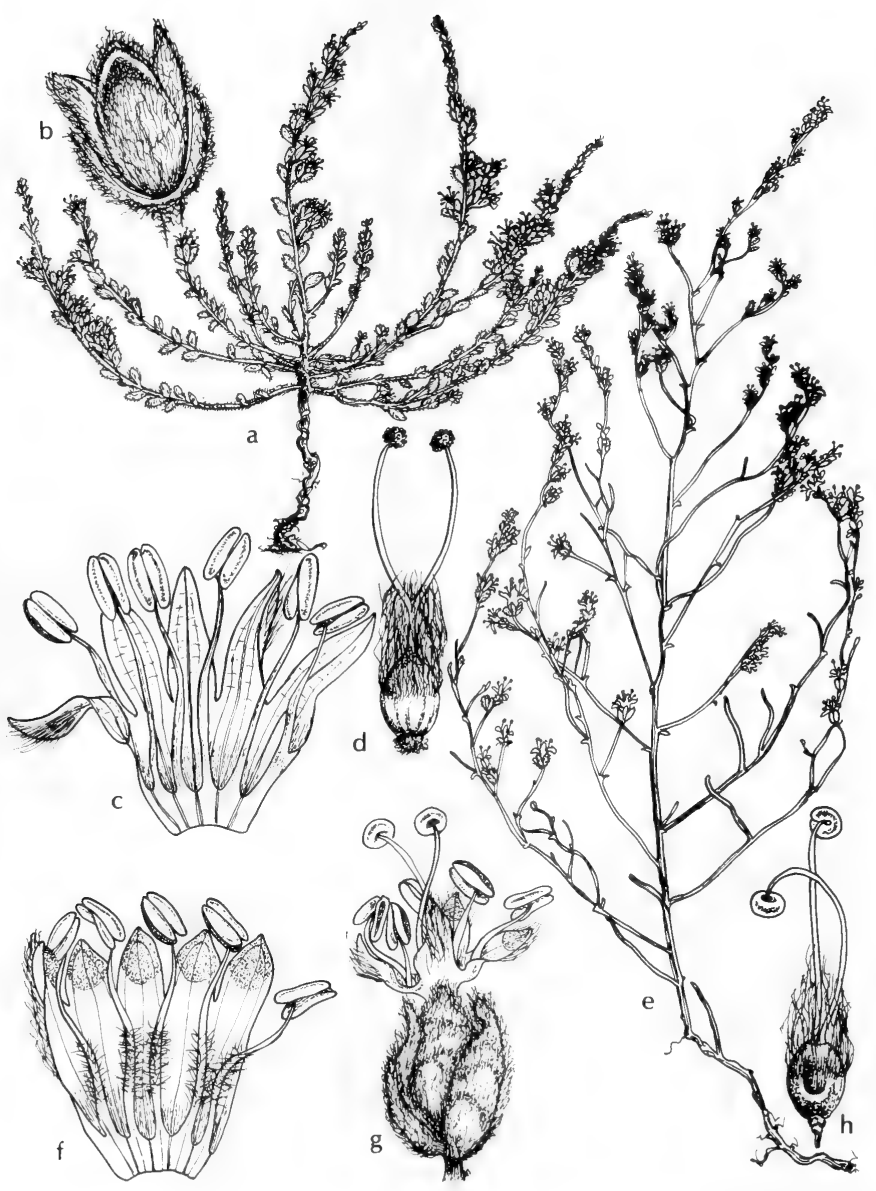

Fig. 638: a-d, Cressa truxillensis: a, habit, x 1/2; b, calyx, x 5; c, open corolla and stamens, x 5; d, ovary, styles and stigmas, x 5. e-h, Cressa aphylla: e, habit, x 1/2; f, open corolla and stamens, x $5 ; \mathrm{g}$, flowers, $\mathrm{x} 5$; h, ovary, styles and stigmas, x 5 . (V. F.). 


\section{Stylisma RAF.}

Six species, confined to southeastern United States.

\section{Stylisma aquatica (Walt.) Raf.}

Stems prostrate or twining, short-pubescent, to $15 \mathrm{dm}$. long; leaves short-petioled; blades oblong-elliptic or oblong-lanceolate, truncate or slightly cordate at base, densely short-pubescent on both surfaces, $1-3 \mathrm{~cm}$. long, $3-10 \mathrm{~mm}$. wide; peduncles exceeding leaves; pedicels shorter than calyxes; corolla lavender, 10-15 mm. long. Breweria aquatica (Walt.) Gray, B. Michauxii Fern. \& Shub., Bonamia aquatica (Walt.) Gray, B. Michauxii (Fern. \& Schub.) K. A. Wils.

Sandy open ground, in shallow water of ponds, depressions and lowlands, rare in s.e. Tex., May-June; Tex. to Ark., Fla. and N.C.

\section{Calystegia R. Br. Hedge-Bindweed}

About 30 species, chiefly in temperate regions of both hemispheres.

\section{Calystegia sepium (L.) $\mathrm{R}$. $\mathrm{Br}$.}

Perennial from creeping rhizomes; stems trailing and twining, to $2 \mathrm{~m}$. long; leaves long-petioled; blades abruptly contracted to deeply cordate at base, acuminate at apex: flowers axillary, solitary or paired; peduncle at first much shorter (later becoming longer) than leaves, 1-flowered; floral bracts 2, elliptic-ovate, laterally overlapping, $12-25 \mathrm{~mm}$. long, about twice as long as calyx and concealing it; corolla funnelform, 5-angled, 4-8 cm. long, white; ovary commonly 1-celled; style simple: stigmas oblong to linear, scarcely or not flattened, obtuse; capsule mostly 2- to 4-seeded. Convolvulus sepium L.

In marshes and wet soil of stream branks and gravel beds, May-Oct.; throughout temp. N. A. and Euras.

Var. fraterniflora (Mack. \& Bush) Shinners. Leaf blades deltoid-ovate to oblongovate, glabrous to rather densely pubescent on both surfaces, mostly $4-8 \mathrm{~cm}$. long. $2.5-5 \mathrm{~cm}$. wide, the basal lobes rather widely spreading with the broad sinus open. C. fraterniflora (Mack. \& Bush) Brummitt, Convolvulus fraterniflorus Mack. \& Bush, C. sepium var. fraterniflorus Mack. \& Bush.

Rare in Okla. (Ottawa Co.) and in far n. and n.e. Tex. (known only from Ochiltree, Cooke and Anderson cos.), N. M. (Dona Ana, San Juan and Rio Arriba cos.) and Ariz. (Navajo and Coconino cos.), May-Oct.; cen. U. S.

Var. repens (L.) Gray. Leaf blades narrowly deltoid-ovate to deltoid-lanceolate. usually densely soft-pubescent on both surfaces (rarely glabrate), mostly 4-9 cm. long, $2.5-5 \mathrm{~cm}$. wide at base, rather abruptly contracted above base to an oblonglanceolate main portion $1-2 \mathrm{~cm}$. wide, the basal lobes directed backward (parallel with petiole) or somewhat spreading with the sinus narrow to moderately broad. Convolvulus sepium var. repens (L.) Gray.

Rare on Gulf Coast and lower Rio Grande of Tex., July; Gulf and Atl. coasts, rarely inland.

\section{Ipomoea L. Morning Glory}

Annual or perennial herbs or woody vines, shrubs or trees; stems erect to trailing, creeping or twining and climbing; leaves sessile to long-petioled, simple or palmately compound (in one species pinnately cut almost to midrib, appearing compound), entire or toothed or shallowly to deeply lobed: flowers axillary or terminal, solitary to numerous; peduncles and pedicels various: sepals 5, commonly laterally overlapping; corolla 5-angled or shallowly 5-lobed, salverform to funnelform or campanulate, usually large, variously colored, usually open for less than 24 hours (morning, daytime or night); stamens included or exserted; ovary 1 - to 3-celled; 
style simple; stigma globose or with 2 or 3 globose lobes; capsule 1 - to severalseeded, variously dehiscent or (a few species) indehiscent.

Over 600 species (often referred to 6 to 10 unsatisfactorily distinguishable genera), warm-temperate and tropical regions of both hemispheres. (Incl. Batatas, Calonyction, Exogonium, Merremia, Mina, Operculina, Pharbitis, Quamoclit, Turbina.)

Most of the species in this genus are weedy in character, and many are essentially ubiquitous. It is quite possible that additional species in our region should be included here. The seeds of some species are eaten by game birds. The genus includes the sweet potato (I. Batatas) as well as ornamentals and medicinal plants.

1. Corolla more or less strongly salverform, the long narrow tube only slightly widened to near or above the middle, rather abruptly flaring near summit, at mid-level 3-7 $\mathrm{mm}$. in diameter, the maximum breadth at summit (corolla rim) 5 to 20 times as great as mid-level diameter (2)

1. Corolla funnelform to campanulate, with short to rather long tube gradually expanding from below middle (but often more sharply flaring near summit), at mid-level 4-20 $\mathrm{mm}$. in diameter, the maximum breadth at summit (corolla rim) 2 to 5 times as great as mid-level diameter (3)

2(1). Calyx (5-) 6-8 mm. long.

1. I. coccinea.

2. Calyx 4-4.5 mm. long..... 2. I. hederifolia.

3(1). Pedicels and peduncles with reflexed hairs (sometimes also some spreading ones) (4)

3. Pedicels and peduncles glabrous or with widely spreading to ascending hairs or soft spreading to slightly down-curved prickles (5)

4(3). Sepals soft-pilose or pubescent on back with slender hairs.

3. I. acuminata.

4. Sepals hispid-pilose on back, the hairs (at least those toward pedicel) with swollen bases

4. I. hederacea.

5(3). Anthers large and strongly spirally twisted when flowers have opened...... 13. I. sinuata.

5. Anthers large or small, straight or merely slightly curved (6)

6(5). Leaf blades divided to base, the lobes or leaflets narrow....... I. Wrightii.

6. Leaf blades entire or with broad or irregular lobes, not divided to base (7)

$7(6)$. Stems rooting at nodes, long-creeping (8)

7. Stems not rooting at nodes, trailing to twining and climbing (9)

8(7). Leaf blades mostly irregularly lobed; sepals oblong-lanceolate, much longer than wide.

6. I. stolonifera.

8. Leaf blades entire except for notched apex; sepals suborbicular, nearly as wide as long or wider. .7. I. Pes-caprae.

9(7). Sepals about equal in length (10)

9. Sepals markedly unequal in length, the outer three fourths to five sixths as long as the inner (13)

10(9). Sepals suborbicular, obtuse to broadly rounded at apex (sometimes very inconspicuously notched or mucronate).

10. I. amnicola.

10. Sepals elliptic to oblong-lanceolate, strongly mucronate or acute to acuminate at apex (11)

11(10). Sepals 15-22 mm. long in flower; corolla 5.5-9 cm. long.

11. Sepals $6-13 \mathrm{~mm}$. long in flower; corolla $1.8-5.5 \mathrm{~cm}$. long (12)

I. acuminata. 
13(9). Corolla white with purple-red center; leaf blade cordate-ovate.

13. Corolla all lavender-pink to red-purple; leaf blade sagittate........... 9. I. sagittata.

1. Ipomoea coccinea L. Scarlet creeper, Star-glory.

Low-climbing annual essentially glabrous vine; leaf blades ovate, shallowly to deeply cordate, entire or angled-toothed, acuminate, those on flowering branches 3-7 cm. long, 3-7 cm. broad; peduncles 1- to several-flowered; sepals with soft spinelike tips; corolla salverform, $2-4 \mathrm{~cm}$. long, to $3 \mathrm{~cm}$. broad, orange-red or red with yellow tube. Quamoclit coccinea (L.) Moench.

Commonly cult., seeding itself and tending to escape to alluvial low ground and muddy banks and wet gravel bars of streams, low thickets, fields and waste places, hillsides and canyons, in Tex., Okla. (Waterfall), N. M. (Santa Fe, San Miguel, Sierra and Grant cos.) and Ariz. (Navajo and Coconino, s. to Greenlee, Cochise. Santa Cruz and Pima cos.), July-Nov.; nat. of s.e. U.S.

\section{Ipomoea hederifolia $\mathrm{L}$.}

Similar to $I$. coccinea; leaf blades variable, commonly quadrate-ovate to quadratereniform in outline, 3-lobed. I. coccinea var. hederifolia (L.) Gray, Quamoclit hederifolia (L.) G. Don.

Damp or wet thickets near the Tex. coast, Orange Co. to Matagorda Co., N. M. (San Miguel, Grant, Sierra, Dona Ana, Lincoln and Otero cos.) and Ariz. (distribution similar to that for 1 . coccinea), also cult. and escaped farther inland, JulyNov.; Fla. to Tex. and w. to Ariz.; W.I. and Mex.

\section{Ipomoea acuminata (Vahl) R. \& S.}

Low- to high-climbing perennial vine, glabrous or pubescent; leaf blades cordateovate, acuminate, entire to deeply 3-lobed, glabrous to densely soft-pubescent beneath, those on flowering shoots $4-16 \mathrm{~cm}$. long, 3-12 cm. wide; peduncles long, with reflexed hairs, several- to many-flowered; sepals narrowly ovate-lanceolate, acuminate; corolla funnelform, red-purple, $6-9 \mathrm{~cm}$. long. I. cathartica Poir., I. congesta R. Br., I. Leari Paxt., I. mutabilis Lindl., Pharbitis cathartica (Poir.) Choisy.

Damp thickets, wet depressions and waste ground, s. Tex.; also cult., Mar.-Nov.; Fla. to Tex.; W.I., Mex., S.A. and Old World.

All of our collections are of the form with pilose stems and densely softpubescent leaves and sepals.

\section{Ipomoea hederacea Jacq. Fig. 638A.}

Annual low- to high-climbing vine; stems moderately to densely pilose; leaf blades cordate-ovate, entire or usually 3-lobed; peduncles 1- to few-flowered, it (and pedicels) with reflexed hairs; corolla funnelform, lavender to blue with white center in wild plants, varying to purple or red in cult. forms, $3-5 \mathrm{~cm}$. long (slightly larger in cult.) Incl. var. integriuscula Gray, I. barbigera Sims.

Gravel bars, wet stream banks, fields and lowland disturbed ground in Okla. (Waterfall) and e. Tex. w. to West Cross Timbers, s. to Rio Grande, locally up river to Big Bend, also commonly cult. and locally escaped, July-Nov.; s.e. U. S. to W.I. and Mex.

\section{Ipomoea Wrightii Gray.}

Glabrous annual or perennial low-climbing vine with palmately compound leaves; leaflets 3 to 5 , narrowly lanceolate, $2-5 \mathrm{~cm}$. long, obtuse to acute and mucronate at apex; peduncles slender, 1 - to few-flowered, short at first and on younger 


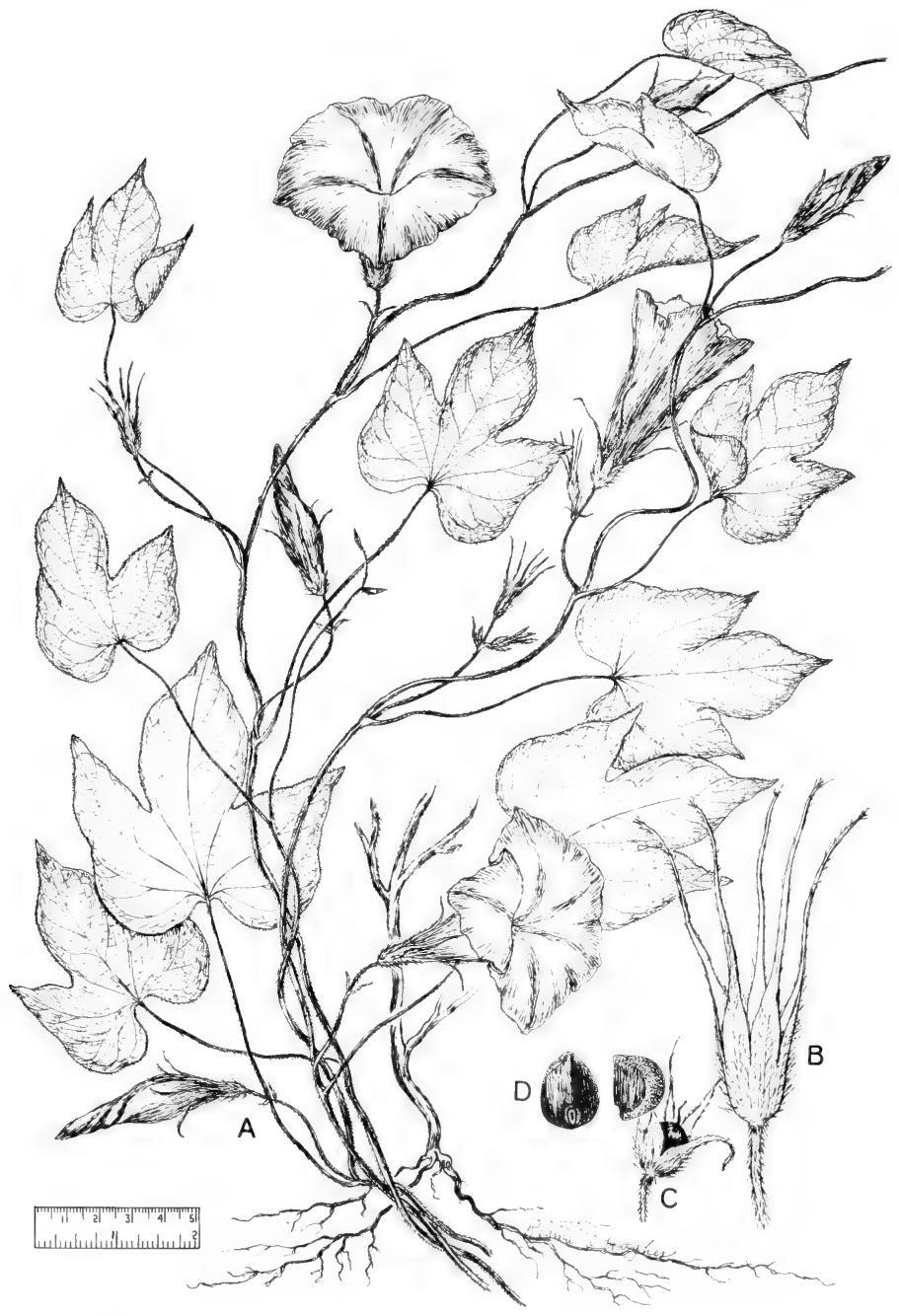

Fig. 638A. Ipomoea hederacea: A, habit, x 1/2; B, sepals, x 11/2; C, capsule, x 2; D, seeds, x 5. (From Reed, Selected Weeds of the United States, Fig. 148). 
branches, becoming very elongate and spirally twisted or coiled; sepals broadly ovate- to oblong-elliptic, about $5 \mathrm{~mm}$. long, broadly rounded at apex; corolla narrowly funnelform, lavender-pink, about $1.5 \mathrm{~cm}$. long; capsule ovoid, smooth, about $1 \mathrm{~cm}$. long. I. heptaphylla (Roxb.) Voigt, illegit. name, I. spiralis House, I. pulchella of auth.. not Roth.

Alluvial or damp silty or clayey soil, in mud at edge of water of lakes and ponds, locally abundant in cen. and s. Tex. and s.e. Okla. (McCurtain Co.), June-Oct.; nat. probably of India, now widespread in warm countries around the world.

\section{Ipomoea stolonifera (Cyr.) Gmel. BEACH MORNING GLORY.}

Glabrous perennial; stems prostrate and rooting at nodes, not twining; leaf blades rather fleshy or leathery, varying from oblong-ovate or broadly short-oblong and entire with obtuse to truncate or emarginate apex to deeply and unequally 3 - to 7-lobed, 2-4 cm. long, 1-4 cm. wide; peduncles 1-flowered; sepals elliptic-oblong; corolla white with yellow center, $4.5-7 \mathrm{~cm}$. long. I. littoralis (L.) Boiss., not B1.

Beaches, wettish depressions and flats, and dunes along the Tex. Gulf Coast, Apr.-Nov.; warm regions around the world.

7. Ipomoea Pes-caprae (L.) Sweet var. emarginata Hallier f. RaIlroad vine, goatFOOT MORNING GLORY.

Glabrous perennial; stems prostrate and rooting at nodes, not twining; leaf blades rather fleshy or leathery, suborbicular, entire but more or less deeply notched at apex, 4-10 cm. long and wide; peduncles 1 - or usually several-flowered; sepals elliptic-orbicular; corolla rosy or purple, 5-7 cm. long. Incl. subsp. brasiliensis (L.) v. Ooststr.

Beaches, wettish depressions and flats, and dunes along the Tex. Gulf Coast, June-Nov.; warm regions around the world.

\section{Ipomoea pandurata (L.) Mey. Wild potato.}

Glabrous or pubescent, trailing or twining and low-climbing from woody tuberous root; petioles 1-8 cm. long; leaf blades cordate or cordate-ovate, often with indented sides and almost 3 -lobed, 3-10 cm. long, 2-9 cm. wide, glabrous to densely soft-pubescent beneath; peduncles 1 - to several-flowered; sepals markedly unequal, oblong-elliptic; corolla white with purple-red center, $5-8 \mathrm{~cm}$. long.

Thickets, alluvial low wettish ground, along streams and edge of lakes and ponds, fallow fields and roadsides, e. Tex. w. to Bexar, Blanco and Johnson cos. and Okla. (Waterfall), June-Sept.; s.e. U.S.

\section{Ipomoea sagittata Poir. Fig. 639.}

Glabrous perennial, tightly twining, low-climbing, from creeping root; leaf blades deeply sagittate, deltoid-lanceolate to narrowly ovate-lanceolate in outline, entire, 4-10 cm. long, 1-5 cm. wide (across base); peduncles 1-flowered; sepals markedly unequal, oblong-elliptic, apex broadly rounded with an abrupt small point; corolla red-purple, funnelform-campanulate, $6-9 \mathrm{~cm}$. long.

Beaches and dunes, edge of marshes, in wet savannahs, in and about lakes and ponds, and along drainage and irrigation canals, along the Tex. Gulf Coast, rarely inland up the Rio Grande to Val Verde Co., Apr.-Oct.; Tex. to Fla. and W.I.; also w. Medit., where probably an early introd.

\section{Ipomoea amnicola Morong.}

Glabrous, twining, low-climbing, from creeping root; leaf blades cordate-ovate, entire, 2-6 cm. long, 2-7 cm. wide; peduncles several- to many-flowered, rather short; sepals oblong-orbicular; corolla white with purple-red center, funnelform, $2-4 \mathrm{~cm}$. long. 


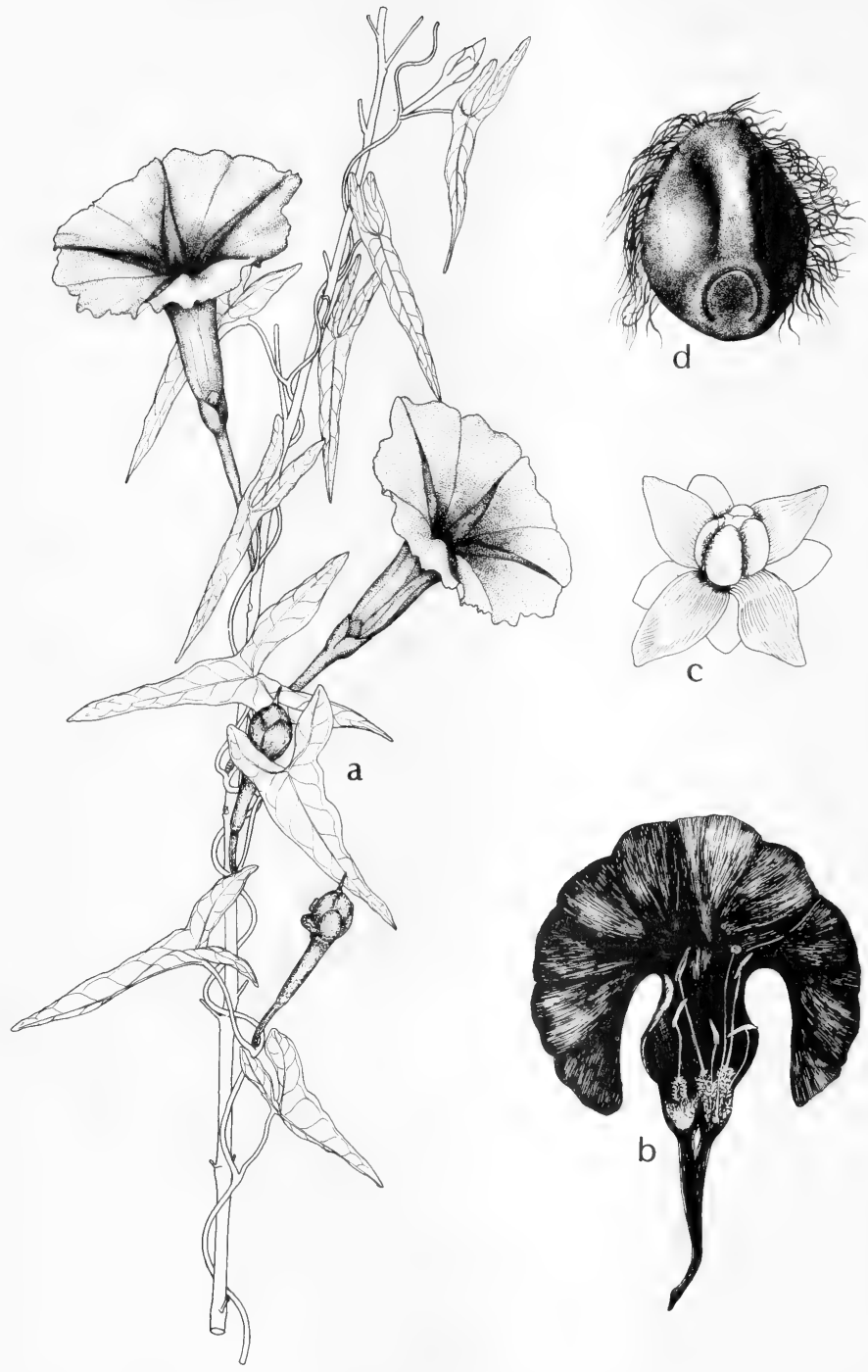

Fig. 639: Ipomoea sagittata: a, vine on stem of another plant, $\mathrm{x} 1 / 2 ; \mathrm{b}$, flower opened, $\mathrm{x} 3 / 4 ; \mathrm{c}$, capsule in calyx, $\mathrm{x} 3 / 4$; $\mathrm{d}$, one valve of capsule, $\mathrm{x} 3$. (Courtesy of R. K. Godfrey). 
Fields, wet depressions, ditch banks and roadsides, in Tex. common in lower Rio Grande Valley, locally n. to Bexar Co., Apr.-July; nat. of Parag., introd. in s. Tex., adj. Mex. and n. S.A.

\section{Ipomoea trichocarpa Ell.}

Perennial but flowering first year, from branched root, twining and low-climbing; leaf blades very variable, cordate-ovate in outline, entire to deeply 3- or 5-lobed, 2-8 cm. long, $1.5-7 \mathrm{~cm}$. wide: peduncles 1 - to several-flowered; sepals noticeably unequal, oblong-elliptic, acuminate; corolla rosy-lavender to purple-rose with dark center (rarely white), $2.8-5.5 \mathrm{~cm}$. long. I. commutata R. \& S., I. carolina (L.) Pursh, not L.: has been incorrectly referred to the related tropical species 1 . triloba L. and 1 . trifida H.B.K.

Thickets, fields, wet depressions and flats, roadsides and disturbed ground, June-Oct.

Var. trichocarpa. Sepals hispid-pilose, at least on margins; stem and leaves glabrous to moderately densely hispid-pilose. Common in e. third of Tex. (but absent from cos. near Red River), local w. to Medina and Menard cos.; s.e. U.S.

Var. Torreyana (Gray) Shinners. Sepals glabrous; stem and leaves glabrous. Common in cen. Tex., from Dallas, Throckmorton, Sutton and Val Verde cos. to lower Rio Grande Valley, rare in e. Tex. (Cass and Nacogdoches cos., perhaps introd.); also Mex.

\section{Ipomoea lacunosa $L$.}

Annual from slender taproot, sparsely to rather densely hispid-pubescent, twining and low-climbing; leaf blades variable, cordate-ovate to deltoid-ovate in outline, entire or angled-toothed or 3-lobed, 2-10 cm. long, 1.5-9 cm. wide; peduncles 1- or 2-flowered; sepals markedly unequal, oblong-elliptic, acuminate; corolla white (rarely rosy), $1.8-2.3 \mathrm{~cm}$. long.

Damp thickets, stream banks and ditches, swamps, wet meadows and wet alluvial soils in prairies, common in e. Tex., w. and s. to Tarrant, Travis and Matagorda cos., and Okla. (LeFlore and Cherokee cos.), Sept. -Oct.; s.e. U.S.

\section{Ipomoea sinuata Ort. Alamo vine, correhuela de las doce.}

Trailing to low-climbing perennial; stem and petioles glabrous or spreadingpilose; leaf blades ovate-orbicular in outline, $4-15 \mathrm{~cm}$. long and wide, palmately deeply 5- or 7-lobed, the lobes dentate to pinnatifid, obtuse; peduncles 1- or 2-flowered; sepals oblong-elliptic, mucronate; corolla white with purple-red center, 3.5-5 cm. long. I. dissecta (Jacq.) Pursh, not L., Merremia dissecta (Jacq.) Hallier f., Operculina dissecta (Jacq.) House.

Stream banks, wet thickets and in wettish depressions, open ground and disturbed places, s.-cen. Tex. (Travis to Galveston and Val Verde cos. and s.), also cult., May-Nov.; Tex. and Fla. to W.I., Mex. and S.A.

\section{Cuscuta L. Dodder. Love-Vine}

Plants leafless and rootless, herbaceous, parasitic; stems yellowish or orangecolor, filiform, fleshy-herbaceous, glabrous, twining; flowers small (mostly 2-6 mm. long), sessile or short-pedicellate, in few- to many-flowered cymose clusters, commonly 5-merous but sometimes 3 - or 4-merous; perianth parts mostly united; corolla campanulate to cylindric, shallowly or deeply lobed; stamens inserted in the throat of the corolla, alternating with the usually longer lobes; scalelike toothed, fringed or fimbriate appendages commonly present at base of the corolla tube opposite the stamens; ovary 2-celled; stigmas linear to capitate; fruit a capsule, indehiscent or sometimes opening with a regular or irregular line of circumscission near the base; embryo acotyledonous, filiform or more or less enlarged at one end.

About 170 species, mostly in the Americas. 
Some species may exhibit a host preference, but most will grow upon a wide range of herbaceous or woody plants including pteridophytes and grasses. A few species show a predilection for cultivated crop plants, especially legumes and flax, and sometimes cause considerable damage. In enumerating the host plants here only those that grow in water or wetlands are cited. While commonly considered to be wholly parasitic, many species show evidences of chlorophyll in the stems, flowers or maturing fruits and are, therefore, at least partly autophytic. Additional vernacular names to those above are "angel's hair," "tangle gut," "witches' shoelaces," "devil's gut," "strangle vine."

1. Capsules circumscissile (that is, easily separating near the base in a more or less regular line of cleavage). 1. C. umbellata.

1. Capsules not circumscissile (that is, not separating in a regular line of cleavage), when forcibly separated either coming away entirely or breaking very irregularly (2)

2(1). Calyx gamosepalous; inflorescence not markedly bracteate or congested (3) 2. Calyx deeply divided to form distinct or nearly distinct sepals; inflorescence with numerous bracts, loose or mostly compact (18)

3(2). Calyx lobes with fleshy hornlike projections; corolla lobes strongly inflexed to essentially cover the capsule; flowers conspicuously papillate......

3. Flowers without all of the above characteristics (4)

4(3). Styles short and subulate; interstylar aperture comparatively large; calyx lobes commonly unequal (5)

4. Styles longer and only slightly (if at all) subulate (6)

5(4). Flowers mostly 5-parted. 3. C. obtusiflora var. glandulosa.

5. Flowers mostly 3-or 4-parted. 4. C. Polygonorum.

6(4). Flowers 3- or 4-parted; withered corolla capping the capsule.....

6. Flowers 5-parted; withered corolla rarely capping the capsule (7)

5. C. Cephalanthi.

7(6). Calyx conspicuously 5-angled by the projecting lobes where they overlap at the sinuses.

6. C. pentagona.

7. Calyx not obviously 5-angled (8)

8(7). Capsules depressed-globose or globose, not at all ovoid or evidently thickened about the style bases, commonly about as wide as long (9)

8. Capsules globose-ovoid, apically narrowed, mostly more or less thickened about the style bases (11)

9(8). Calyx lobes overlapping at the base; withered corolla about the lower part of the smooth capsule.

7. C. campestris.

9. Calyx lobes scarcely overlapping; withered corolla surrounding the capsule which is typically papillate about the top (10)

10(9). Calyx and pedicels not papillate.

10. Calyx and pedicels papillate.

8. C. glabrior var. glabrior.

11(8). Corolla lobes acute, with inflexed or erect tips (12)

11. Corolla lobes obtuse or rounded at apex (15)

12(11). Flowers commonly smooth, 5-parted; scales shorter than corolla tube; capsules usually 1 -seeded.

9. C. salina.

12. Flowers typically fleshy, papillate; capsules mostly 2 - to 4 -seeded (13)

13(12). Flowers mostly 4-parted; scales represented by wings that are shorter than the corolla tube.

13. Flowers 5-parted; scales well-formed, reaching the filaments (14) 
15(11). Withered corolla about the top of the capsule (16)

15. Withered corolla not at the top of the capsule (17)

16(15). Calyx lobes denticulate, overlapping to enclose the corolla tube; scales merely denticulate; corolla lobes erect..............12. C. denticulata.

16. Calyx lobes not enclosing the corolla tube; scales deeply fringed; corolla lobes widely spreading....................13. C. Gronovii var. calyptrata.

17(15). Calyx lobes mostly about half as long as the corolla tube.....

17. Calyx lobes mostly about as long as the corolla tube

13. C. Gronovii var. Gronovii. 13. C. Gronovii var. latiflora.

18(2). Flowers pedicellate, loosely paniculate; sepals and bracts oval-orbiculateovate. 14. C. cuspidata.

18. Flowers sessile, in dense compact clusters (19)

19(18). Sepals and bracts acute.... 15. C. squamata.

19. Sepals and bracts obtuse.

16. C. compacta.

\section{Cuscuta umbellata H.B.K. Fig. 640.}

Flower stramineous, smooth or infrequently slightly papillate, commonly with some pellucid glandlike cells, mostly $2-2.5 \mathrm{~mm}$. long from base to corolla sinuses, rarely much longer, with pedicels varying in length from shorter than to much longer than the flowers, in dense or loose compound cymose clusters, the ultimate umbellate divisions of 3 to 7 flowers; calyx lobes scarcely overlapping, triangularovate to sublanceolate, acute to acuminate, smooth or slightly papillate, the margins even or sometimes irregular; scales reaching the filaments, oblongsubspatulate, fringed with medium-length processes; styles slender and longer than the ovary; capsule depressed-globose, with a thickened collar about the interstylar apertures, commonly easily circumscissile but some specimens tardily so, surrounded by the withered corolla. Incl. var. reflexa (Coult.) Yunck.

Mainly in the Tex. Trans-Pecos and Rio Grande Plains, Okla. (Cimarron Co.), N.M. (Santa Fe, Sandoval, Union, Socorro, Sierra, Dona Ana, Valencia and Grant cos.) and Ariz. (Pinal, Cochise, Pima and Yuma cos.); s. U. S., the W.I., Mex. and n. S.A.; parasitic on a wide range of mostly low herbaceous hosts including species of Polygonum, Atriplex, Suaeda, Amaranthus, Alternanthera, Sesuvium, Trianthema and Portulaca.

\section{Cuscuta Warneri Yunck.}

Stems filiform; flowers white, fleshy, 5-parted, about $2 \mathrm{~mm}$. long when mature, in few-flowered glomerules, on pedicels scarcely $1 \mathrm{~mm}$. long; calyx strongly papillate-hispidulous, reaching to above the middle of the corolla tube, divided to about the middle into triangular-ovate lobes; calyx lobes thickened apically to form a large prominent divergent acute cone-shaped or hornlike projection $0.5-0.75 \mathrm{~mm}$. long, also with a small rounded corresponding projection at the base; corolla papillate-hispidulous (especially downward); corolla lobes triangularovate, acute, the margins slightly irregularly denticulate, suberect to strongly inflexed-connivent, slightly projecting and angular at the base of the sinuses, about half as long as the campanulate-suburceolate tube at maturity; stamens shorter than the corolla lobes, incurved, the anthers ovoid and about as long as the slightly subulate filaments; infrastamineal scales thin, oblong, sparingly toothed at the truncate apex, bridged low, scarcely reaching the stamens; capsule globose, indehiscent, rather thin and finely longitudinally striate when mature, with a 
prominent thickened shallowly 4-lobed cuplike or collarlike apex, enveloped by the corolla when mature; styles slender, scarcely exceeding the corolla, the stigma globose.

Growing on Phyla cuneifolia about wet bank of shallow pond in Ariz. (Coconino Co.), June-Aug.; also Ut.

\section{Cuscuta obtusiflora H.B.K. var. glandulosa Engelm. Fig. 640.}

Flowers 1.5-2 mm. long from base to corolla sinuses, 5-merous, commonly with numerous enlarged pellucid glandlike cells, subsessile in scattered moderately open glomerate-cymose clusters; calyx lobes nearly enclosing the corolla tube, commonly unequal (one smaller than the others), ovate, obtuse, scarcely overlapping at base; corolla lobes somewhat shorter than the tube, ovate to ovateoblong, obtuse to acutish, upright to spreading; scales about reaching the filaments, oblong, fringed about the top, sometimes bifid or truncated; styles stoutish and subulate, shorter than or about equaling the ovary; capsule depressed-globose, interstylar aperture large, the withered corolla remaining at the base. C. glandulosa (Engelm.) Small.

Occasional throughout Tex. but most frequent in the s.e. section, and Okla. (Haskell and Muskogee cos.); also the Gulf States, W.I., Mex. and S.A.; most frequently on species of Polygonum but also on other plants as Justicia americana.

\section{Cuscuta Polygonorum Engelm. Smartweed dodder. Fig. 640.}

Flowers 1-1.5 mm. long from base to corolla sinuses, mostly 3- or 4-merous, subsessile in compact glomerulate clusters; calyx lobes triangular-ovate, often unequal, not overlapping at base, as long as or longer than the corolla tube; corolla lobes triangular, acute, upright, as long as or longer than the tube; scales oblong, about reaching the filaments or commonly shorter, mostly bifid, the processes mostly few and near the top; styles shorter than the ovary, becoming subulate and divergent; capsule globose or obpyriform, commonly depressed, appearing cubical about the maturing seeds, interstylar aperture large and rhombic.

From N.E. and Ont., w. and s.w. to Neb., Okla. (Waterfall) and Tex. (fide Small); mostly on species of Polygonum but also on species of Penthorum, Impatiens, Lycopus and others.

\section{Cuscuta Cephalanthi Engelm. Button-Bush dodder. Fig. 640.}

Flowers about $2 \mathrm{~mm}$. long from base to corolla sinuses, 3- or 4-merous, rarely 5 -merous, with numerous pellucid glandlike cells, sessile or subsessile in spicate or paniculately cymose clusters, frequently originating endogenously in the regions of the haustoria, the clusters at first open but soon becoming compact as the capsules mature; calyx shorter than the corolla tube, deeply divided, the ovate-oblong lobes obtuse and slightly overlapping at the base, the margins often minutely irregular; corolla lobes much shorter than the tube, ovate, obtuse, erect to spreading; scales narrowly oblong, about reaching the filaments, fringed with scattered processes; styles slender, about equal to or slightly longer than the ovary; capsule depressed-globose or globose, commonly only 1 or 2 seeds maturing, more or less lopsided when but one seed matures, the walls thin, capped by the withered corolla that is easily removed.

Rare in n.-cen. Tex., (?) Okla. and Arız. (? Cochise Co.); from Me. and Va., w. to Wash., and Calif., less frequently s. to Mex.; parasitic on a wide variety of woody and herbaceous hosts including species of Salix, Boehmeria, Justicia, Teucrium, Physostegia, Cephalanthus, Vernonia, Solidago and Aster.

\section{Cuscuta pentagona Engelm. Fig. 640 .}

Flowers 1-1.5 mm. long from base to corolla sinuses, the protruding capsules soon causing the flowers to appear larger, commonly with pellucid glandlike cells, 

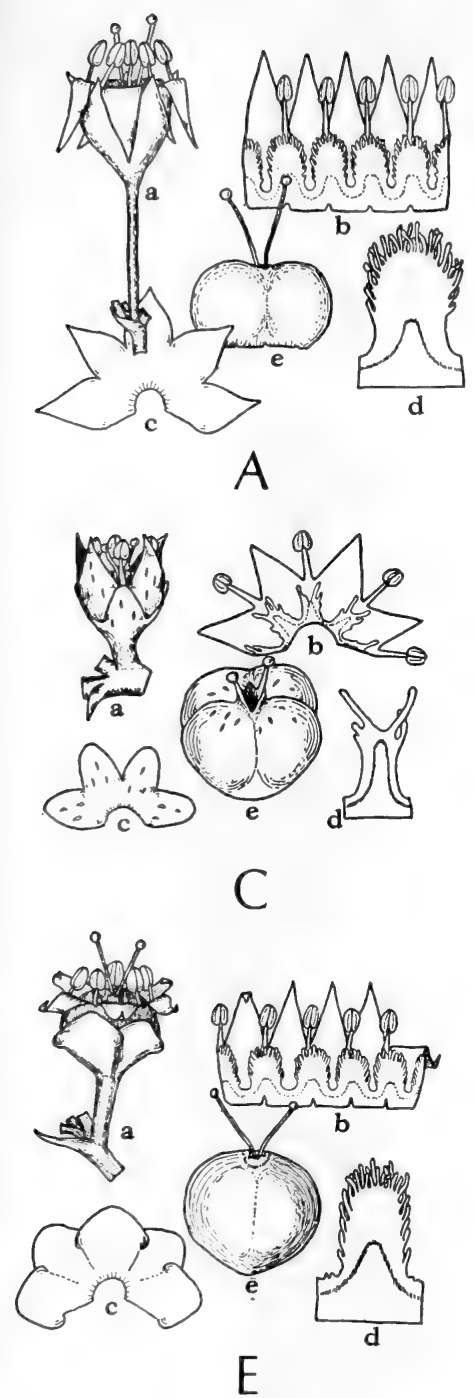
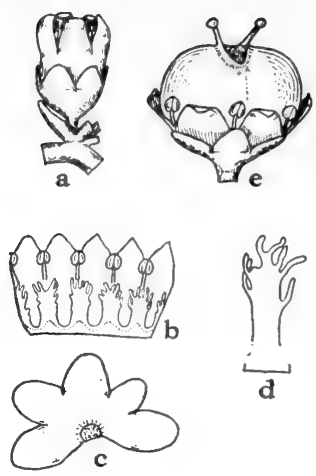

B

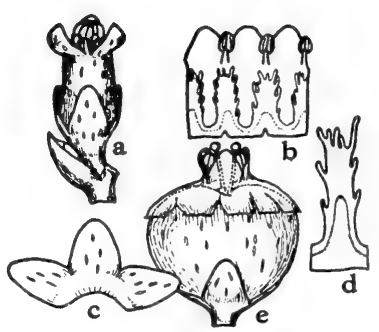

D

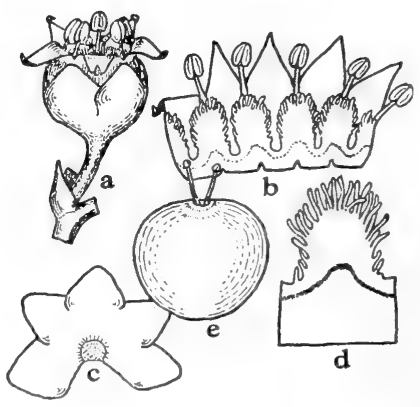

$\mathrm{F}$

Fig. 640: A, Cuscuta umbellata; B, Cuscuta obtusiflora var. glandulosa; C, Cuscuta Polygonorum; D, Cuscuta Cephalanthi; E, Cuscuta pentagona; f, Cuscuta campestris. In each figure: $a$, flower, $x 5 ; b$, opened corolla, $x 5 ; c$, opened calyx, $\times 5$; $d$ infrastamineal scale, x 10; e,matured capsule, x 5. (From Yuncker in Lundell's Flora of Texas, Vol. 3, Pt. 2). 


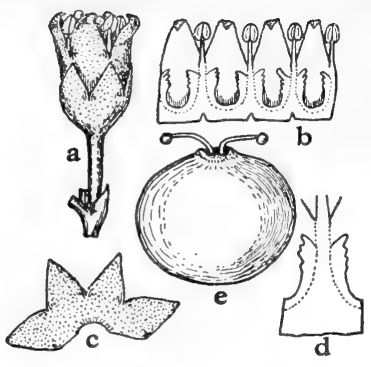

A
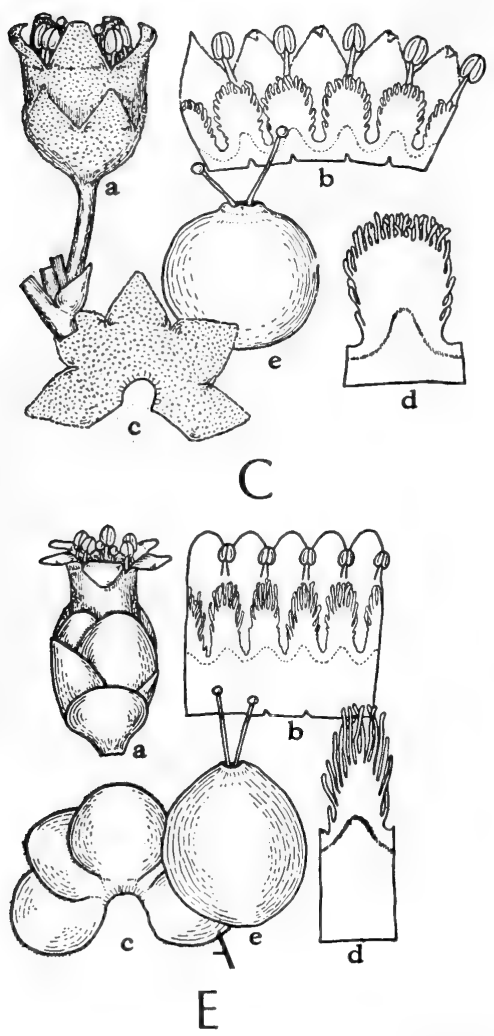

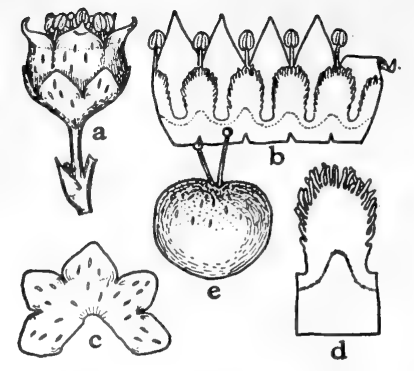

B

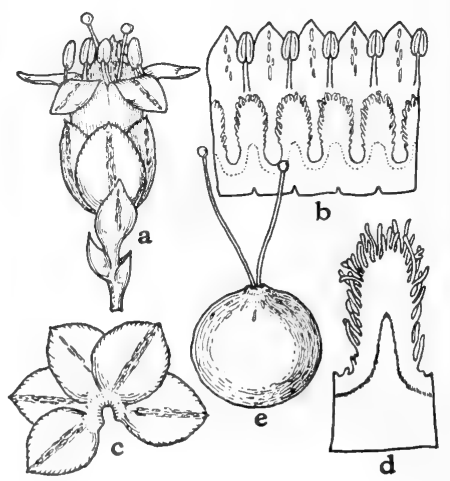

D

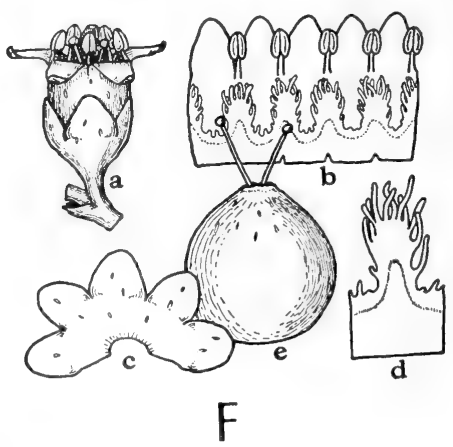

Fig. 641: A, Cuscuta Corylii; B, Cuscuta glabrior; C, Cuscuta indecora; D, Cuscuta cuspidata; E, Cuscuta compacta; F, Cuscuta Gronovii. In each figure: a, flower, x 5; $\mathrm{b}$, opened calyx, x 5; d, infrastamineal scale, x 10; e, matured capsule, x 5. (From Yuncker in Lurdell's Flora of Texas, Vol. 3, Pt. 2). 
with pedicels about as long as the flowers or commonly somewhat shorter, in loose cymose clusters; calyx mostly about as long as and loose about the corolla tube; calyx lobes broadly ovate, obtuse, commonly as hroad as or broader than long, often unequal, widely overlapping at the sinuses to form 5 conspicuous angles; corolla lobes lanceolate, about as long as or slightly longer than the tube, spreading or reflexed, the acute tips inflexed; scales ovate-oblong, reaching the filaments, prominently fringed; styles slender, about equal to or slightly shorter than the ovary; capsule mostly more or less depressed-globose to somewhat ovoid, frequently longer than wide, the withered corolla remaining about the lower part.

Frequent in the e. part of the U.S., w. to Okla., Tex., Colo., Mont. and Calif.; parasitic on species of Justicia, Hibiscus, Solidago, Aster, Ambrosia, Artemisia and many others.

\section{Cuscuta campestris Yunck. Field dodder. Fig. 640.}

Flowers to about $2.5 \mathrm{~mm}$. long from base to corolla sinuses, appearing much larger when in fruit, smooth or with scattered pellucid glandlike cells, with pedicels mostly shorter than the flowers, in glomerate-cymose clusters; calyx lobes about as long as the corolla tube, overlapping at the base but not markedly angled at the sinuses, ovate to oval-ovate, commonly as long as wide, obtuse; corolla lobes triangular to sublanceolate, about as long as the tube, spreading to reflexed, often granulate, the acute tips inflexed; scales reaching the filaments, ovateoblong, abundantly fringed; style slender to slightly subulate, as long as or longer than the ovary; capsule depressed-globose, the withered corolla remaining about the lower half. C. arvensis Engelm.

Throughout Tex., Okla. (Craig Co.) and Ariz. (Coconino, Yavapai and Pima $\cos$.), distributed over the range of the genus; parasitic on a great variety of mostly herbaceous hosts including species of Justicia, Xanthium, Penthorum, Ludwigia and Trifolium.

8. Cuscuta glabrior (Engelm.) Yunck. var. glabrior. Fig. 641.

Flowers about $2 \mathrm{~mm}$. long from base to corolla sinuses, white or often reddish, commonly with numerous pellucid glandlike cells, subsessile or mostly with pedicels no longer than the flowers or rarely longer, in compact or loose globularcymose clusters; calyx lobes as long as or somewhat shorter than the corolla tube, ovate to oval-ovate, commonly not overlapping at base, the sinuses often obtusish; corolla lobes triangular to sublanceolate, smooth or commonly more or less papillate, about as long as the tube, spreading to reflexed, the acute to acuminate tips inflexed; scales reaching the filaments, oblong-spatulate, abundantly fringed; styles as long as or somewhat longer than the ovary that is more or less scabrouspapillate; capsule depressed-globose, the interstylar aperture large, often with numerous pellucid glandlike cells, scabrous-papillate at least above the middle, rarely smooth, sometimes easily breaking loose from the calyx and thus may be mistaken as circumscissile, surrounded by the withered corolla.

Frequent in Tex., ranging from N. M. (Chaves Co.) to Okla. (Waterfall) and La., s. into n.e. Mex.; parasitic on a variety of mostly herbaceous hosts including species of Amaranthus, Oenothera, Gaura, Verbena, Plantago, Aster, Ambrosia, Bifora, Liatris, Phyllanthus, Asclepias and Justicia.

Var. pubescens (Engelm.) Yunck. All parts of the flower (including ovary and capsule) and pedicel more or less densely papillate; otherwise similar to var. glabrior.

\section{Cuscuta salina Engelm. Fig. 642.}

Flowers 2-4 mm. long, 5-parted, on pedicels mostly shorter than the flowers, in umbellate-cymose clusters; calyx lobes ovate-lanceolate, acute to acuminate, about as long as the corolla tube; corolla lobes about as long as the campanulate 

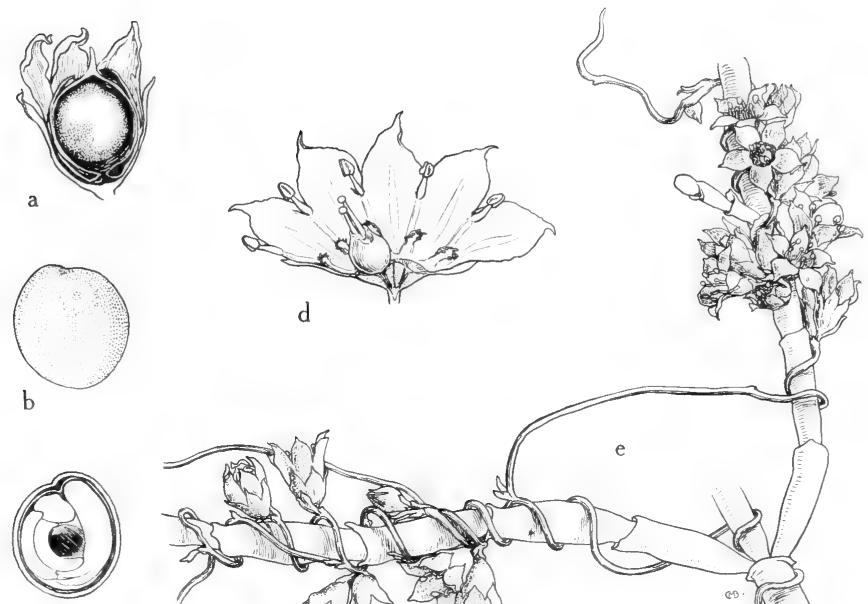

C

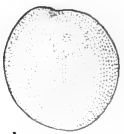

d

b

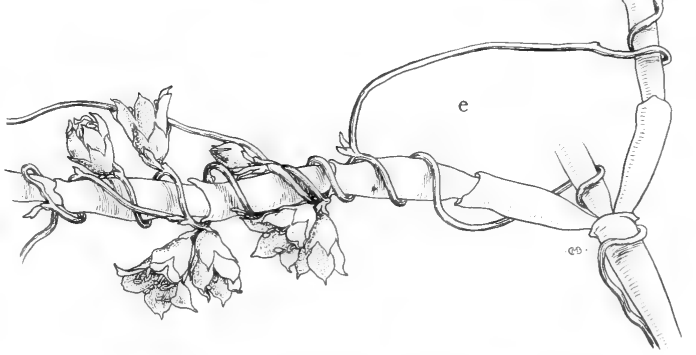

Fig. 642: Cuscuta salina: a, fruit (longitudinal section), x 6; b, seed, x 8; c, seed (longitudinal section), x 8; $\mathrm{d}$, flower, spread open, $\mathrm{x} 4$; e, habit, plant growing on Salicornia, x 2. (From Mason, Fig. 294).

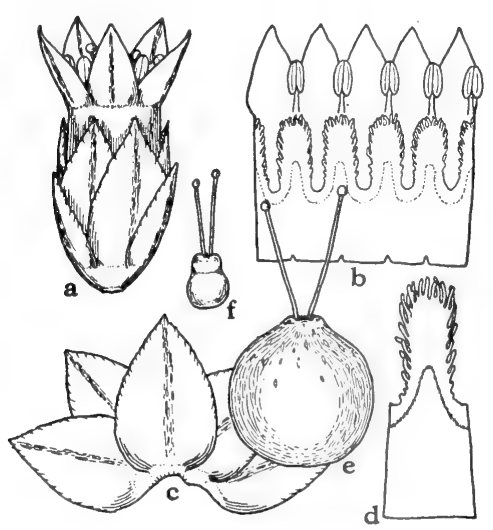

Fig. 643: Cuscuta squamata: a, flower, x 5; b, opened corolla, x 5; c, opened calyx, x 5; d, infrastamineal scale, x 10; e, matured capsule, x 5; f, ovary, x 5. (From Yuncker in Lundell's Flora of Texas, Vol. 3, Pt. 2). 
or somewhat cylindrical tube, ovate-lanceolate, sometimes granulate, acute to acuminate, upright or sometimes spreading, the edges frequently uneven, more or less overlapping; scales narrow, oblong, shorter than the tube, fringed with short processes, closely attached to the tube for nearly their entire length, bridged below the middle; filaments subulate and about equal to or shorter than the oval anthers; styles slender or slightly subulate, shorter than or about equaling the globose pointed ovary; capsule globose, pointed, usually 1-seeded, surrounded or capped by the withered corolla.

Ariz. (Pinal and Pima cos.); B.C. to Calif., Ut., Ariz. and (?) Mex. On Atriplex, Allenrolfea, Cressa, Suaeda, Salicornia, Salsola and Nitrophila.

\section{Cuscuta Coryli Engelm. Hazel dodder. Fig. 641.}

Flowers fleshy, papillate, $1.5-2 \mathrm{~mm}$. long from base to corolla sinuses, mostly 4-merous, with pedicels shorter or longer than the flowers, in cymose-paniculate clusters, sometimes the flowers originate endogenously in the region of the haustoria and form dense glomerate clusters about the stem of the host; calyx lobes about as long as the corolla tube, triangular-ovate, scarcely overlapping at base; corolla lobes about as long as the tube, triangular-ovate to lanceolate, upright, the acute tips inflexed; scales mostly reduced to toothed wings on either side of the filament attachment, rarely free and bifid or toothed; styles slightly subulate, mostly about as long as the ovary, becoming divergent in fruit; capsule globose, enveloped by the withered corolla, the interstylar aperture rather large and thickened.

From Mont. and Ariz. (Coconino Co.), eastw.; parasitic on a large variety of herbaceous and woody hosts including species of Salix, Carya, Rhus, Callicarpa, Stachys, Symphoricarpos, Solidago, Aster and Helianthus.

\section{Cuscuta indecora Choisy var. indecora. PRetTy dodder. Fig. 641.}

Flowers variable in size, to $3 \mathrm{~mm}$. long from base to corolla sinuses, white, fleshy, smooth or mostly granulate to papillate-hispid, with pedicels commonly about as long as or shorter than the flowers or infrequently longer, in loose or rather dense paniculately cymose clusters; calyx lobes mostly shorter than the tube, triangular-ovate, slightly overlapping at base, acute to obtuish; corolla lobes shorter than the tube, upright to spreading, triangular-ovate, inflexed at the acute tip; scales reaching the filaments, oblong to subspatulate, abundantly fringed; styles slender or slightly subulate, about as long as the ovary, capsule depressedglobose, thickened about the interstylar aperture, surrounded by the withered corolla which is eventually split by the enlarging capsule.

Throughout Tex., Okla. (Comanche Co.) and Ariz. (Coconino, Yavapai, Graham, Gila, Maricopa, Pinal and Pima cos.); abundant in the s. states from Fla. to Calif., n. through the cen. states to Minn., Mich. and S.D., also in n. Mex., the W.I. and S.A.; parasitic on a wide range of herbaceous and woody hosts including species of Polygonum, Clematis, Sesbania, Cissus, Cephalanthus, Vernonia, Aster, Baccharis, Iva, Pluchea, Borrichia, Helianthus, Helenium, Campanula and Eryngium.

The size of the flowers, length of the pedicels and the proportionate size of the calyx vary greatly, sometimes even on the same specimen. Most of the flowers are more or less granulate because of the lenticular outer surface of the cells and occasional specimens are papillate-hispid.

Var. longisepala Yunck. This variety has the characteristics of the var. indecora with the exception of the calyx lobes that are lanceolate and mostly longer than the corolla tube. 


\section{Cuscuta denticulata Engelm.}

Flowers about $2 \mathrm{~mm}$. long, subsessile, in shortened more or less bracteate inflorescences of few flowers; bracts often 1 to 3 , ovate-lanceolate, acute; calyx deeply divided; calyx lobes orbicular, obtuse to rounded at apex, denticulate, overlapping to enclose the corolla tube; corolla campanulate, becoming urceolate in fruit; corolla lobes ovate to oval, somewhat overlapping, spreading, about equaling the tube; scales denticulate, about reaching the anthers, oblong-ovate, bridged at about the middle or below; anthers oval, shorter than the corolla lobes, about equal to the filaments; styles shorter than the small conic ovary; stigmas small; globose; capsule conic, bearing the withered corolla about the top, mostly 1 -seeded.

Ariz. (Mohave and Yuma cos.); s. Ut. to Calif. and w. Ariz. Parasitic on Tamarix, Nicotiana and Hymenoclea.

\section{Cuscuta Gronovii R. \& S. var. Gronovii. Fig. 641.}

Flowers mostly 2-3 mm. long from base to corolla sinuses, rarely smaller or larger, commonly with few to many pellucid glandlike cells, with pedicels varying in length but mostly shorter than the flowers, rarely longer, in loose or dense paniculately cymose clusters, occasionally endogenously formed; calyx lobes commonly reaching to about the middle of the corolla tube, mostly oval-ovate, sometimes suborbicular or oblong, obtuse, overlapping at base, margins more or less uneven; corolla lobes shorter than the tube, mostly oval-ovate, obtuse, spreading; scales shorter than the corolla tube or reaching the filaments, oblong, deeply fringed about the upper part, more shallowly so toward the base and on the bridge; styles stoutish and sometimes somewhat subulate, mostly shorter than or about equal to the ovary, occasionally longer; capsule mostly globose-conic to obpyriform, surrounded by the withered corolla.

The most common species of Cuscuta found throughout the cen. and n.e. states and the W.I., w. to the Rocky Mts. (Coconino Co., Ariz.), commonly in low wet areas where it grows on a great variety of hosts including species of Boehmeria, Helianthus, Myrica, Solidago, Salix, Hypericum, Mimulus and Lycopus; occasionally reported as damaging ornamentals or other nonweedy hosts.

Var. latiflora Engelm. The flowers are commonly smaller than in var. Gronovii, the calyx lobes are more oblong-oval and less overlapping at the base and reach the corolla sinuses, the corolla tube is broadly campanulate with the throat wider than the tube which tapers toward the base and ordinarily is borne at the base of the maturing and thus protruding naked capsule.

Var. calyptrata Engelm. In this variety the corolla tube is commonly somewhat longer than in var. Gronovii and with the lobes less than half as long as the tube, when mature the capsule carries the withered corolla about the top; otherwise similar to the var. Gronovii.

\section{Cuscuta cuspidata Engelm. Fig. 641.}

Flowers membranous in texture, about $3 \mathrm{~mm}$. long from base to corolla sinuses, subsessile or commonly pedicellate in loose paniculate clusters, the whole inflorescence more or less bracteate; calyx shorter than the corolla tube, of distinct or very slightly united segments, subtended by one or more ovate-orbicular obtuse to acutish sometimes cuspidate bracts, or these rarely lacking; calyx segments ovateorbicular, obtuse to acutish and cuspidate, the margins commonly thin and serrulate, sometimes globular-thickened along the median line, broadly overlapping; corolla lobes oval-oblong to subovate, shorter than the funnelform tube, commonly more or less acute and somewhat cuspidate, occasional lobes serrate near apex, sometimes obtuse, commonly with a line of pellucid glandlike cells along the middle, spreading; scales shorter than the corolla tube, oblong, fringed with 
medium-length processes; styles slender, much longer than the ovary; capsule subglobose, with a thickened ridge or collar about the interstylar aperture, commonly with glandlike cells, enveloped at the top by the withered corolla.

Through the cen. states from Ut. and Colo., e. to s.w. Ind., Okla. (Ottawa Co.) and Tex., parasitic on a number of different species of herbaceous hosts but seems to prefer members of the Compositae including species of Ambrosia, Baccharis, Helianthus, Iva and Liatris.

\section{Cuscuta squamata Engelm. Fig. 643.}

Flowers about $3 \mathrm{~mm}$. long from base to corolla sinuses, sessile, in scattered few- to several-flowered glomerules, or these densely clustered about the host, subtended by 2 to several ovate acute often cuspidate serrulate closely appressed bracts that are mostly shorter than the calyx; calyx lobes distinct or nearly so, ovate, acute, often cuspidate, closely appressed and widely overlapping at base, commonly serrulate, with pellucid glandlike cells along the middle; corolla lobes ovate-lanceolate or slightly oblong, acute, sometimes cuspidate, shorter than the tube, spreading to reflexed, more or less glandular along the middle; scales about reaching the filaments, oblong, fringed with medium-length processes; styles slender, longer than the ovary; capsule globose to subconic, more or less umbonate, carrying the withered corolla about the top.

Rare in Tex. in the Trans-Pecos, Plains Country and Hardin Co. in s.e. Tex.; also s. N.M. (Dona Ana and Chaves cos.) and n. Mex.; parasitic usually on various weedy species of Compositae, such as Helianthus ciliaris.

\section{Cuscuta compacta Juss. Fig. 641.}

Flowers often greenish, to $4.5 \mathrm{~mm}$. long from base to corolla sinuses, sessile or rarely short-pedicellate, in few- to several-flowered scattered glomerules, or these commonly closely clustered about the host, frequently originating endogenously and forming a dense ropelike cluster about the stem of the host, subtended by 2 to several ovate-orbicular fleshy tightly appressed bracts; calyx deeply divided; calyx segments distinct or nearly so, broadly overlapping, fleshy, cupped, rounded, obtuse, tightly appressed about corolla, the margins fringed with short slender filamentous processes; corolla lobes spreading to reflexed, much shorter than the tube, oval-oblong, rounded, obtuse, sometimes fringed with short filamentous processes; scales reaching the filaments, fringed with long processes, small secondary scales often present on the bridge between the larger ones; styles mostly longer than the ovary; capsule globose-conic, upper part with glandlike cells and capped by the withered corolla, thickened at the top about the interstylar aperture.

Extending from N.E. to Fla. and w. to Mo., s.e. Okla. (McCurtain and Leflore cos.) and Tex.; parasitic on a wide range of herbaceous and woody hosts including species of Carya, Alnus, Magnolia, Rubus, Rosa, Rhus, Ilex, Acer, Vitis, Cissus, Clethra, Vaccinium, Tecoma, Cyrilla, Cephalanthus, Lycopus, Myrica and Boehmeria.

\section{Fam. 112. Polemoniaceae Juss.}

\section{Phlox FAMILY}

Perennials, biennials, annuals or rarely subshrubs; leaves either all alternate or opposite, or opposite below and becoming alternate up the stem, undivided to pinnately compound or rarely palmately dissected or lobed, the margin entire to toothed; inflorescence of sparse cymes or glomerules in corymbose or paniculate disposition, sometimes a solitary flower; flowers regular or sometimes irregular; sepals 5, partly united into a herbaceous or scarious calyx; petals 5 , convolute in bud, partly united into a rotate, campanulate, funnelform or salverform corolla; 
stamens 5, partly adnate to the corolla tube; carpels 3 , superior, united up to the linear stigmas; fruit usually a trilocular capsule, dehiscent loculicidally; seeds one to many in each cell, rounded, angulate or rarely winged, in some species becoming viscid when wet.

About 300 species in 15 genera, mostly in North America.

1. Leaves pinnatifid or variously lobed (2)

1. Leaves entire (4)

2(1). Leaves palmatifid into linear elongate segments.

1. Linanthastrum

2. Leaves not as above (3)

3(2). Calyx tube of essentially uniform texture throughout, somewhat accrescent, not ruptured by the developing capsule.

2. Polemonium

3. Calyx tube with green costae separated by hyaline intervals. 3. Gilia

4(1). Calyx tube of essentially uniform texture throughout, somewhat accrescent, not ruptured by the developing capsule.

4. Collomia

4. Calyx tube with green costae separated by hyaline intervals......... . Microsteris

\section{Linanthastrum EWAN}

One or possibly two species of western United States and northern Mexico.

\section{Linanthastrum Nuttallii (Gray) Ewan.}

Taprooted fragrantly aromatic perennial woody-based herb to about $3 \mathrm{dm}$. tall; stems numerous, slender, simple or branched, puberulent at least above; leaves sessile, opposite, paimatifid into 5 to 9 linear elongate spinulose-tipped segments to $2 \mathrm{~cm}$. long, each usually with a fascicle of smaller leaves; flowers subsessile in compact leafy-bracteate clusters at the ends of the stems; calyx 6-9 mm. long, scarcely accrescent; corolla salverform, white or cream-color, the wholly-puberulent tube about equaling the calyx, the limb about $1 \mathrm{~cm}$. wide; stamens about equal and inserted at the base of the short throat, the anthers just reaching the orifice of the corolla; capsule 1 -seeded in each locule, the valves persistent after dehiscence.

Mostly in open pine forests but also in seepage below dams and along streams, in Ariz. (Apache, Navajo, Coconino, Yavapai, Greenlee, Gila and Pima cos.), July-Nov.; Ida. and Wash., s. to Chih., Ariz. and Baja Calif.

\section{Polemonium L. Jacob's LAdDer}

Erect, spreading, decumbent or rhizomatous annuals or perennials; stems simple or branched; leaves pinnately divided; leaflets entire to palmately 3- or 5-parted, narrowly linear to rotund; flowers in terminal or axillary cymes, solitary to capitately congested, or in a sympodial raceme: calyx herbaceous throughout, accrescent, campanulate, the lobes deltoid to acuminate; corolla rotate-campanulate to narrowly funnelform, with no sharp distinction between tube and throat; lobes spatulate to rotund, white, yellow, pink, purple or blue; stamens equally inserted on the tube, the level of insertion varying according to species; filaments of equal length, included or exserted; pistil included or exserted; capsule ovoid, each locule from 1- to 10-seeded; seeds sometimes becoming mucilaginous when moistened; embryo orthotropic.

About 40 species, mostly in the Northern Hemisphere.

It is very possible that additional species should have been included here.

1. Corolla almost salverform, the lobes only about a third as long as the tube and throat............................................................1. P. pauciflorum.

1. Corolla funnelform-campanulate to rotate-campanulate, the lobes longer than the tube and throat (2) 
2. Distribution New Mexico and Arizona (3)

$3(2)$. Stem usually pubescent nearly or quite to the base, copiously so above; leaflets elliptic to ovate-oblong, acutish; corolla lobes obtuse or mucronulate 3. P. foliosissimum.

3. Stem glabrous or nearly so toward the base, sparsely pubescent above; leaflets usually narrowly lanceolate, acute to acuminate; corolla lobes acutish. 4. P. filicinum.

\section{Polemonium pauciflorum Wats.}

Perennial to $5 \mathrm{dm}$. tall, musky-glandular above, the stem sparsely to copiously branched; leaves alternate, to $15 \mathrm{~cm}$. long, with basally expanded petiole and oblong pinnately compound blade; leaflets 11 to 21 , the terminal confluent, to 25 $\mathrm{mm}$. long and $6 \mathrm{~mm}$. wide; flowers paired or solitary, projecting horizontally, the peduncle to $45 \mathrm{~mm}$. long; sepals at anthesis about $15 \mathrm{~mm}$. long, enlarging in fruit, united one third their length, tapering to a callous tip; corolla yellowish or greenish, often suffused with purple, funnelform, the tube to $3 \mathrm{~cm}$. long and the limbs to $1 \mathrm{~cm}$. long; stamens zygomorphic, about equaling the corolla tube, pilose at the short-adnate base; stigmas exceeding the anthers; seeds usually fusiform and angulate, several in each cell of capsule. P. Hinckleyi Standl.

In wet soil along streams and in springy places, in wooded canyons of Davis Mts. in the Tex. Trans-Pecos, July-Aug.; also n. Chih.

The Texas plant has been segregated as subsp. Hinckleyi (Standl.) Wherry primarily on the basis of its thinner stem-pubescence and longer sepals than in subsp. pauciflorum.

\section{Polemonium reptans $L$.}

Perennial from a woody caudex; stems slender, erect, 2-4 dm. long, ascending or eventually diffuse, branched above, pubescent or glabrous; basal leaves longpetioled; cauline leaves short-petioled or the upper sessile; leaflets lanceolate to oblong or elliptic, usually 2-4 (or occasionally 7) $\mathrm{cm}$. long, those of the principal leaves 7 to 17 , of the upper 3 or 5 ; panicles few-flowered, loose and open; pedicels at anthesis almost as long as or longer than the calyx; calyx mostly 5-6 mm. long, the broadly triangular lobes nearly as long as the tube; corolla $1-1.5 \mathrm{~cm}$. long, lobed to about the middle with entire lobes; stamens subequal to or shorter than the corolla.

In springy places, in wet alluvial soils along streams, wet meadows and grassy slopes and rich moist woods in e. Okla. (Mayes and McCurtain cos.), Apr.-June; N. Y. to Minn., s. to Va., Ala., Ark. and Okla.

3. Polemonium foliosissimum Gray. Fig. 644.

Stems 3-9 dm. high, erect, simple or terminally branched, villous to glabrous, often glandular above; leaves little reduced upwards; leaflets $12-25 \mathrm{~mm}$. long, commonly confluent near tip, ovate-oblong or lanceolate to oblong-lanceolate, acutish; inflorescence a broadly open corymbose cyme; calyx 6-10 mm. long, the lobes as long as or longer than the tube, often glandular; corolla $8-20 \mathrm{~mm}$. long, funnelform-campanulate to rotate-campanulate, the obtuse or mucronulate lobes about twice as long as the tube, purplish to white; stamens included. Incl. subsp. albiflorum (Eastw.) Brand, P. grande Greene.

In wet soil along streams and about seepage slopes, wet meadows and woods, in N.M. (Santa Fe, San Miguel and Otero cos.) and Ariz. (Apache and Coconino cos.), June-Aug.; also Colo. and Ut.

The Arizona plants are commonly referred to subsp. robustum (Rydb.) Brand, with violet corolla $12-15 \mathrm{~mm}$. long, included styles and copious pubescence. 

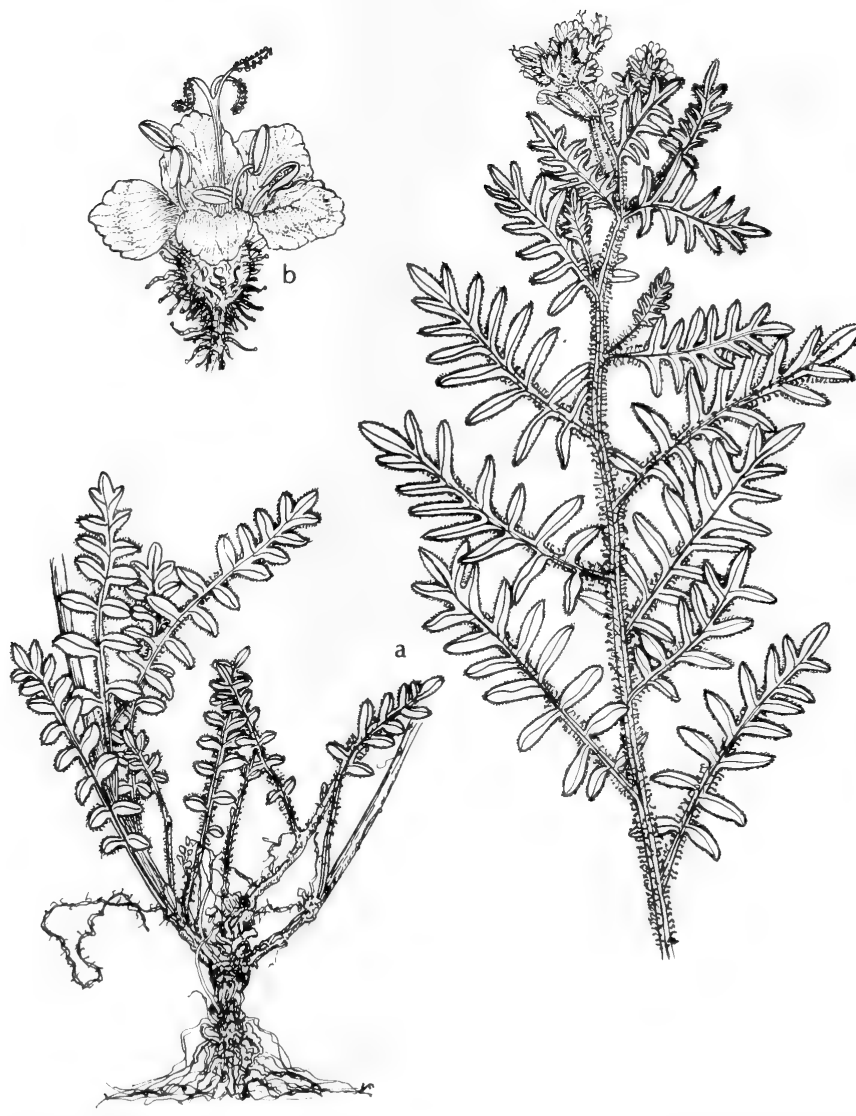

Fig. 644: Polemonium foliosissimum: a, habit, x 1/2; b, flower, x 2. (V. F.). 


\section{Polemonium filicinum Greene.}

Stems solitary or few, stout, to $4 \mathrm{dm}$. long or more, with numerous leaves, glabrous or nearly so toward base, sparsely pubescent above; leaflets lanceolate (usually narrowly so), acute to acuminate, to $2.5 \mathrm{~cm}$. long, thin, the uppermost ones decurrent and confluent, not appearing verticillate; inflorescence several- to manyflowered, narrowly thyrsiform, somewhat viscid; corolla funnelform-campanulate to rotate-campanulate, $1.2-2 \mathrm{~cm}$. long, the acutish lobes violet and longer than the tube and throat.

In wet soils along streams and in springy places, in N.M. (Lincoln, Otero and Sierra cos.) and Ariz. (Apache, Greenlee and Cochise cos.), July-Sept.

\section{Gilia R. \& P.}

Perennials, biennials or annuals; leaves alternate, borne mainly below midstem, pinnately toothed or dissected, the segments herbaceous or rarely subacerose; flowers in bracted glomerules, unevenly paired or solitary, terminating paniculately disposed branches; sepals partly united, separated and bordered by scarious membranes; petals violet-blue to lavender, often with yellow throat, partly united to a regular rotate to funnel-salverform corolla; stamens even to moderately uneven; seeds viscid when wet.

About 60 species in western North America and South America.

1. Leaves linear in outline, pinnatifid with numerous linear or narrowly oblong segments 3-8 mm. long; inflorescence an open panicle; stems strict .. G. calcarea.

1. Leaves with several narrowly lanceolate lobes; inflorescence 2 - to 6-flowered glomerules; stems often decumbent.

2. G. gilioides.

\section{Gilia calcarea M. E. Jones. Fig. 645.}

Biennial or perennial; stems 1-5 dm. tall, usually single from a taproot, simple or branching above the base, erect, glandular-puberulent and often viscid; leaves mainly in a basal rosette, pinnatifid into linear or narrowly oblong segments 3-8 $\mathrm{mm}$. long, glandular; inflorescence open-paniculate, often compound from branches bearing flowers; calyx 2-3 mm. long, glandular, united for two thirds or more of its length, scarious below the sinuses, the lobes with a green midrib; corolla 6-9 $\mathrm{mm}$. long, blue to purplish or sometimes whitish, salverform, the often yellowish tube about twice as long as the calyx; stamens conspicuously exserted. G. pinnatifida Nutt., not Moç. \& Sessé, G. viscida Woot. \& Standl.

In wet meadows and on gravel bars along streams in N. M. (Taos, Santa Fe, and Bernalillo cos.), July-Sept.; Neb. and Wyo., s. to N.M.

\section{Gilia gilioides (Benth.) Greene. Straggling Gilia.}

Erect or decumbent annual, of ten very much loosely branched, sometimes simple, villous to glandular-viscid; lower leaves $2-7 \mathrm{~cm}$. long, sometimes in a basal tuft, 3- to 9-lobed, the lobes narrowly lanceolate and entire or irregularly toothed; cauline leaves 3 - or 5-lobed, the terminal elongate, the lanceolate lobes entire or irregularly toothed; inflorescence composed of glomerules of 2 to 6 flowers, either terminal or on short lateral branchlets; pedicels $2-5 \mathrm{~mm}$. long, often elongating with the growing capsule: calyx $3-4 \mathrm{~mm}$. long, the linear lobes acuminate, the membranous pseudotube about one half the calyx length; corolla $5-10 \mathrm{~mm}$. long, about 2 times the calyx length, the tube and throat continuous and $6 \mathrm{~mm}$. long, the lobes 2-2.5 mm. long; capsules 3-4 mm. long, the locules usually 1-seeded or rarely 2 -seeded.

In moist or wet soil along streams in Ariz. (Gila and Yavapai to Pima cos.), Mar.-May; Ore. to Nev., Ariz. and Calif. 


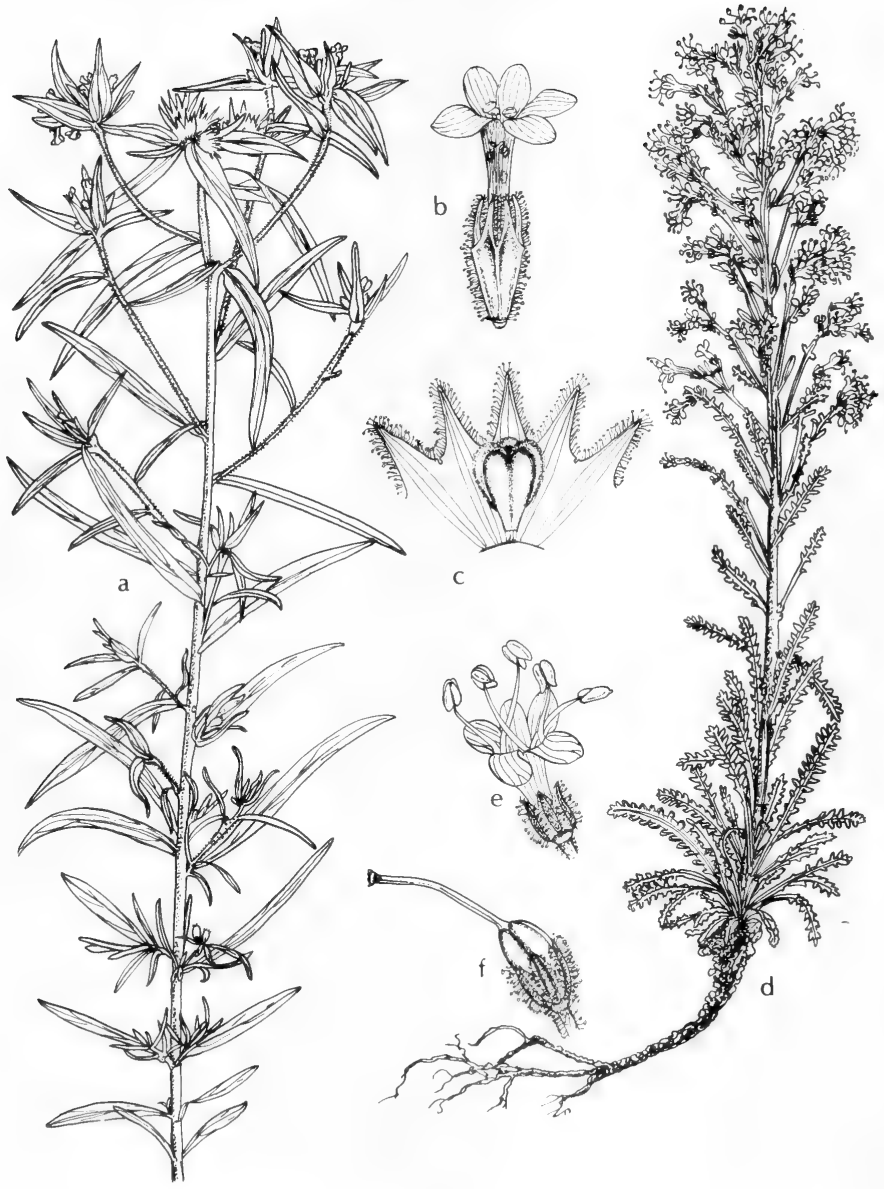

Fig. 645: a-c, Collomia linearis: a, habit, x 1/2; b, flower, x 2; c, calyx opened out. d-f, Gilia calcarea: d, habit, x 1/2; e, flower, x 2; f, fruit, x 2. (V. F.). 


\section{Collomia Nutr.}

About 13 species native to temperate North America and South America.

\section{Collomia linearis Nutt. Fig. 645.}

Annual, to $6 \mathrm{dm}$. tall, usually much less, finely puberulent or in part subglabrous below, the pubescence becoming longer and glandular or viscid above; stems simple and unbranched or with several or many short or elongate axillary branches, the main stem and each of the branches terminating in a dense leafy-bracteate cluster of essentially sessile flowers; leaves numerous, sessile or nearly so, nearly all alternate, lanceolate to linear, entire, $1-7 \mathrm{~cm}$. long, to about $1 \mathrm{~cm}$. wide, those subtending the flower clusters often relatively broader than the others; calyx lobes narrowly triangular, acute, herbaceous, $1.5-3 \mathrm{~mm}$. long at anthesis, commonly $3-4 \mathrm{~mm}$. long in fruit; corolla pink or bluish to white, $8-15 \mathrm{~mm}$. long, with slender tube and short lobes $1.5-3 \mathrm{~mm}$. long; filaments unequally inserted, about $1 \mathrm{~mm}$. long or less: ovules 1 in each cell of ovary.

In wet meadows and wet soil on edge of ponds and lakes, in N.M. (Rio Arriba, San Juan, San Miguel, Santa Fe and Taos cos.) and Ariz. (Apache and Coconino cos. ), June-Sept.; N.B. to B.C., s. to N.M., Ariz. and Calif.

\section{Microsteris GREENE}

A monotypic genus.

\section{Microsteris gracilis (Hook.) Greene}

Annual herb to about $8 \mathrm{~cm}$. tall, much-branched at maturity, commonly as broad as high or broader, puberulent or glandular-puberulent at least above; leaves mostly opposite, linear to linear-lanceolate or elliptic, sometimes the lower ones obovate, to about $5 \mathrm{~cm}$. long and $8 \mathrm{~mm}$. wide; flowers mostly in pairs at the ends of the stem and branches, one subsessile, the other evidently pedicellate, or sometimes borne singly; corolla salverform, 5-10 $\mathrm{mm}$. long, the lobes 1-2.5 $\mathrm{mm}$. long, with white or yellowish tube and pink to lavender limb; stamens inserted at different levels; ovules usually solitary in each cell of ovary. M. micrantha (Kell.) Greene.

Moist or wet soil about springs and along streams, in wet meadows and on open grassy slopes, in N. M. (Bernalillo and Rio Arriba cos.) and Ariz. (Apache to Mohave, s. to Santa Cruz and Pima cos.), Feb.-June; Mont. to Alas., s. to N.M., Ariz. and Baja Calif.; S.A.

\section{Fam. 113. Hydrophyllaceae R. BR.}

\section{Waterleaf FAmily}

Herbs, less commonly shrubs, with alternate or opposite entire to variously divided or compound exstipulate leaves; flowers regular, perfect, 5-merous, gamopetalous, cymose to solitary; calyx deeply lobed; corolla tubular to rotate but usually campanulate; stamens epipetalous, as many as the corolla lobes and alternate with them, usually with a pair of scales at the base of each filament; ovary 1- or 2-celled, usually free from calyx; fruit a few- to many-seeded capsule.

About 300 species in 18 genera, chiefly in the warm-temperate regions of North America and South America.

1. Leaves (at least some) variously toothed, lobed or divided (2)

1. Leaves always entire (4)

2(1). Delicate annual herb; flowers solitary or several in a terminal non-scorpioid cyme. 1. Ellisia

2. Rather coarse perennials or biennials; flowers numerous in scorpioid open or congested cymes (3) 


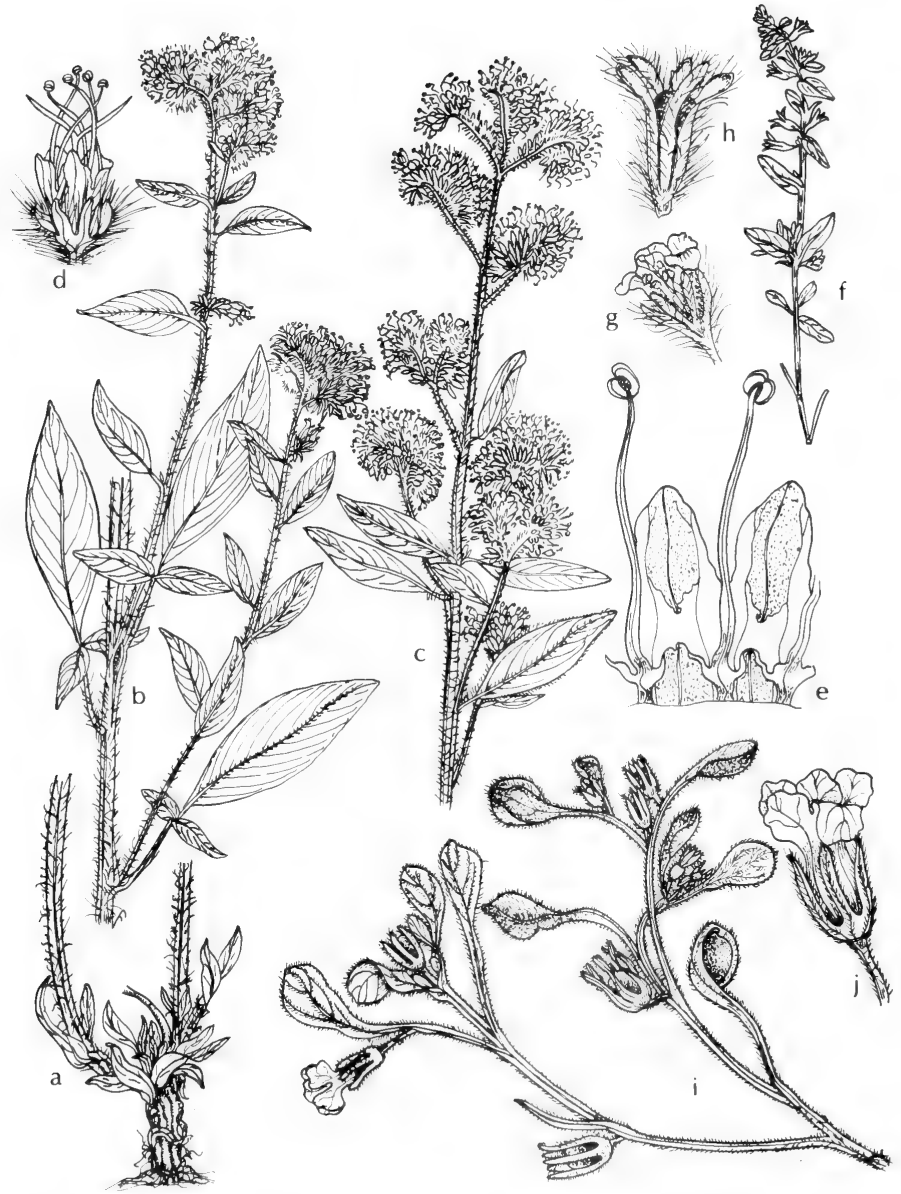

Fig. 646: a-e, Phacelia heterophylla: a, base of plant, $\mathrm{x} 12 ; \mathrm{b}$ and $\mathrm{c}$, upper branches of plant, $x$ 1\%; d, flower, $x 2$; e, part of open corolla, x 5. f-h, Nama stenocarpum: f, top of plant, $\mathrm{x} 1 \% \mathrm{~g}$, flower, $\mathrm{x} 2 ; \mathrm{h}$, fruit in calyx, $\mathrm{x} 2$. $\mathrm{i}$ and $\mathrm{j}$, Nama torynophyllum: $i$, end of branch, $x 2 ; j$, flower, x 5. (V.F.). 
3. Leaf blade pinnatifid or pinnately lobed, the segments toothed or lobulate.

3. Hydrophyllum

4(1). Terrestrial herbs sometimes in wet soils; capsule unilocular, often somewhat divided by intrusion of placentae; style solitary but usually shallowly lobed to bipartite.

4. Nama

4. Aquatic spiny herbs; capsules bilocular; styles 2, quite distinct. 5. Hydrolea

\section{Ellisia L. AUnT LUCY}

Monotypic in temperate North America.

\section{Ellisia Nyctelea L.}

Delicate annual herb; stems very slender, retrorsely hispid; leaves mostly alternate, oblong to ovate, $3-8 \mathrm{~cm}$. long and $1-3 \mathrm{~cm}$. wide, pinnately divided into 7 to 13 oblong divisions; flowers small, white or bluish, solitary or several in a terminal cyme; calyx normally unappendaged, accrescent in fruit; corolla narrowly campanulate, shorter than to about equaling the calyx; stamens included, a pair of minute scales at the base of each filament; styles cleft less than one third; capsule globose, usually 4-seeded, 5-6 mm. in diameter, exceeded by the strongly accrescent subrotate calyx; seeds globose, regularly reticulate, without an appendage.

Damp soil, low pastureland, in wet alluvial woodlands, stream banks, weedy along roadsides and in cult. land, reportedly introd. in Tex. (Denton Co.), Okla. (Waterfall) and N.M. (Union Co.); from N. Y. and Pa. s. to Va., w. to Mich. and Okla. and as a weed as far w. as Sask., Wyo., and N.M.

\section{Phacelia Juss.}

A polymorphic American genus of perhaps 200 species, mostly of the western United States and adjacent Mexico.

\section{Phacelia heterophylla Pursh. Fig. 646.}

Biennial or short-lived perennial from a taproot, with one main stem and sometimes several secondary erect or ascending stems to about $1 \mathrm{~m}$. tall, usually much shorter; herbage green or grayish with pubescence, the stems usually covered with short loose or spreading often glandular hairs as well as spreading bristles; leaves prominently veined, the lower petiolate, the uppermost ones essentially sessile; blades elliptic to lanceolate and subobtuse to acute, to about $9 \mathrm{~cm}$. long, the upper cauline ones simple, the basal and lower cauline ones typically with one or rarely two pairs of smaller lobes at base; inflorescence densely bristly and short-hairy, usually elongate and narrow, somewhat virgate or sometimes openly branched or short and compact; corolla dull whitish to purplish, 3-7 mm. long and broad; filaments conspicuously exserted, hairy near the middle; ovules 4, often with only 1 or 2 reaching maturity. $P$. magellanica of auth.

Usually on dryish slopes but also in marshes and wet meadows along streams, in N.M. (San Juan, Rio Arriba, Union, San Miguel, Santa Fe, Socorro, Otero and Lincoln cos.) and Ariz. (Apache to Coconino, s. to Cochise and Pima cos.), Apr.Oct.; Alta. and B.C., s. to N.M., Ariz. and Calif.; S.A.

\section{Hydrophyl!um L. WATERLEAF}

Erect pubescent to glabrate perennial herbs from horizontal rootstocks, bearing fleshy-fibrous or tuberous roots; leaves basal and alternate, pinnately divided to pinnatifid, the cauline leaves lobed or divided, petiolate; flowers several to many in terminal open to capitate cymes, pedicellate; calyx divided nearly to the base, 


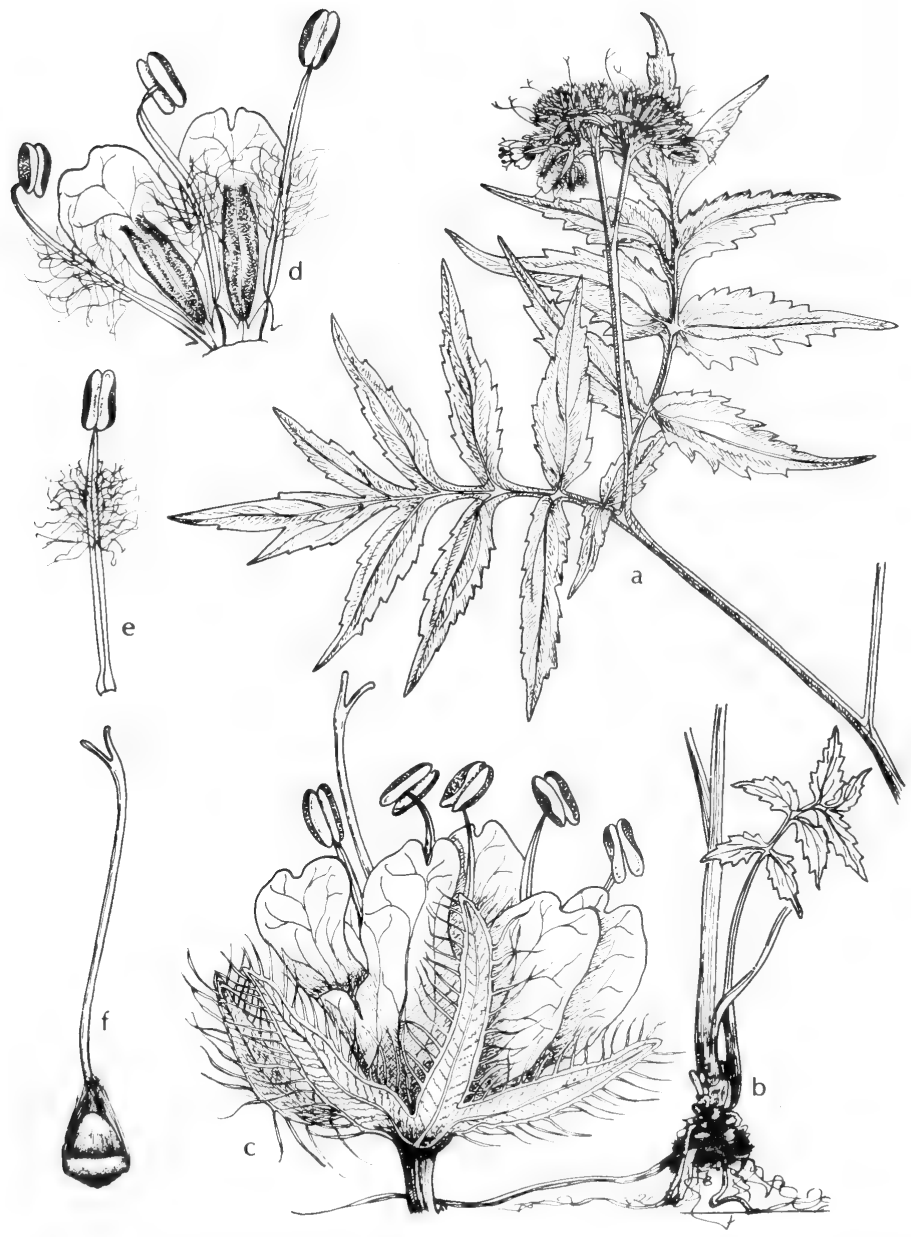

Fig. 647: Hydrophyllum Fendleri: a, top of plant, x 1/2; b, base of stem, x 1/2; c, flower, x 3; d, part of corolla spread out, x 3; e, stamen, x 3; f, overy with style, x 3. (V.F.). 
the lobes subequal, the sinuses naked in ours; corolla greenish or whitish to purple or violet, or white and marked with violet, deciduous, campanulate to subpelviform, divided to the middle or below, longer than the calyx; stamens exserted, equal and equally inserted on the corolla; appendages linear, a pair bordering each filament, one edge free, ciliate; style exserted, shallowly bifid; mature capsules membranaceous, unilocular, loculicidally dehiscent; ovules a pair on the front of each of the 2 large parietal placentae; seeds 1 to 3 , subglobose, brown, reticulate.

About 8 species in the United States and Canada.

1. Distribution eastern Oklahoma eastward. 1. H. virginianum.

1. Distribution New Mexico and/or Arizona westward (2)

2(1). Leaflets acuminate, the teeth usually 8 to 12 and acuminate; cymes lax in fruit.

2. H. Fendleri.

2. Leaflets obtuse to abruptly acute, the teeth usually 3 to 6 and obtuse to acute; cymes compact in fruit. 3. H. occidentale.

\section{Hydrophyllum virginianum $L$.}

Perennial to about $8 \mathrm{dm}$. tall, the upper portion of stem, cymes, pedicels and back of sepals sparsely to densely strigose with appressed to ascending hairs to about $0.5 \mathrm{~mm}$. long; cauline leaves broadly ovate to broadly triangular in outline, 1-2 dm. long and a little wider, pinnately lobed almost to the midrib; leaf segments 5 to rarely 9 , the terminal one and the basal pair often 2 - or 3-lobed, all with acute to acuminate apices and strongly ascending teeth; cymes very dense at anthesis; sepals sparsely hirsute-ciliate; corolla white to pale-pink-purple, 7-10 $\mathrm{mm}$. long; stamens long-exserted.

Wet meadows, moist or wet woodlands and open wet places generally, in Ozarkian Okla. (Waterfall), Apr.-June; Que. to N.D., s. to Va., Ky., Okla. and Kan.

\section{Hydrophyllum Fendleri (Gray) Heller. Fig. 647.}

Perennial to about $8 \mathrm{dm}$. tall, the stems retrorse-hispid, the rhizome bearing fleshy-fibrous roots; leaves petiolate, oblong to oval, $6-30 \mathrm{~cm}$. long, 6-20 cm. broad, pinnatifid, the principal divisions usually 9 to 13 , ovate to lanceolate, acuminate, $2-12 \mathrm{~cm}$. long, the lower pairs usually distinct, the upper confluent, all coarsely serrate to incised with ovate-lanceolate lobes, strigose on both surfaces; cymes one to several, open; pedicels 2-6 mm. long; calyx lobes linearlanceolate, 4-6 mm. long, 1-2 mm. wide, sparsely strigose and often hispid on the back, ciliate with flattened hyaline hairs, nearly equaling the corolla; corolla white or violet, or white and marked with violet, $6-8 \mathrm{~mm}$. long, the lobes 3-4 $\mathrm{mm}$. long; style exserted 5-7 mm.; capsules about $4 \mathrm{~mm}$. in diameter; seeds 1 to 3 , light brown, 2.5-3 $\mathrm{mm}$. in diameter.

Moist shaded soil, in water of marshes and in seepage along wooded streams, in N. M. (Taos, Rio Arriba, Santa Fe, San Miguel, Otero and Socorro cos.), MaySept.; Wyo., Ida., Wash. and Ore., s. to Calif., Ut. and N. M.

\section{Hydrophyllum occidentale (Wats.) Gray.}

Perennial to about $6 \mathrm{dm}$. tall, the stems densely short-pubescent to somewhat retrorse-hispid, the rhizome bearing fleshy-fibrous roots; leaves oblong, 3-30 cm. long, 3-15 cm. broad, pinnatifid; principal leaf divisions 7 to 15 , broadly oblong to ovate, $1.5-7 \mathrm{~cm}$. long, all incised or lobed (rarely entire) with ovate lobes, strigulose on upper surface, paler on lower surface with dense fine subappressed hairs; cymes one to several, globose; pedicels $2-5 \mathrm{~mm}$. long; calyx lobes narrowly lanceolate, 3-4 mm. long, 1-2 $\mathrm{mm}$. broad, strigulose on the back, hispid-ciliate; corolla violet to white, $7-10 \mathrm{~mm}$. long, the lobes $4-6 \mathrm{~mm}$. long, oblong; style 
exserted 5-8 mm.; capsules about $4 \mathrm{~mm}$. in diameter; seeds 1 or 2 , brown, about $3 \mathrm{~mm}$. in diameter.

Along streams in shade, in wet thickets and in seepage areas, in Ariz. (Coconino and Gila cos.), Apr.-Aug.; Ore. and Calif., e. to Ut. and Ariz.

\section{Nama L.}

Low, pubescent annual or occasionally perennial herbs with mostly alternate, essentially entire leaves and conspicuous or inconspicuous white to purplish-violet flowers in non-scorpioid terminal cymes or solitary; calyx usually divided nearly to base, unappendaged, little-accrescent; corolla tubular to broadly funnelform or campanulate, usually exceeding calyx; stamens included, usually unequal and unequally inserted, filament base usually appendaged or dilated; style shallowly bifid to bipartite; capsule ovoid to globose, often partially divided by intrusion of placentae, many seeded; seeds minute, usually reticulate and sometimes shallowly pitted.

A genus of 40 to 50 species principally of the southwestern United States and northern Mexico, a few in South America, and one in Hawaii.

1. Calyx divided one half to three fourths distance to base, the tubular portion adnate to the ovary which is thus inferior...........1. N. stenocarpum.

1. Calyx divided to base or nearly so, not grown to the superior ovary (2)

2(1). Leaves broad, plane; petiole conspicuously decurrent on the winged stem; hardened calyx lobes adherent to capsule. 2. N. jamaicense.

2. Leaves narrow, revolute and spoon-shaped; petiole not decurrent; calyx neither hardened nor adherent to capsule. 3. N. torynophyllum.

\section{Nama stenocarpum Gray. Fig. 646.}

Prostrate to ascending or erect sparsely hirsute annual, branching from base, the leafy branches 1-3 dm. long; leaves alternate, oblong to spatulate, $1-4 \mathrm{~cm}$. long, 2-10 mm. wide, often undulate, sometimes clasping; flowers lavender, solitary or paired at nodes; calyx lobes linear-spatulate, 4-7 $\mathrm{mm}$. long, calyx tube adnate to the inferior ovary; corolla tubular-campanulate, 5-7 $\mathrm{mm}$. long, little longer than calyx; stamen bases dilated into free-margined scales about equaling the free filament; seeds yellowish, finely alveolate.

Mud of poorly drained clay soil, often alkaline, and along resacas, in s. and s.e. Tex., Mar.-May; w. to Ariz. and Calif., s. to adj. Mex.

\section{Nama jamaicense $L$.}

Prostrate or ascending, strigose-hirsute, leafy annual, branching from base, the branches 1-5 dm. long; leaves alternate, spatulate to obovate, 15-80 $\mathrm{mm}$. long, 5-35 mm. wide, plane, conspicuously decurrent at base to form a winged stem; flowers white, usually solitary in upper leaf axils; calyx lobes linear or linearspatulate, enlarging and adherent to ovary in fruit; corolla nearly tubular, 6-7 $\mathrm{mm}$. long; stamen bases dilated into free-margined scales shorter than the free filament; seeds brown, finely alveolate.

Moist places under shrubs, in wet clay along streams and about ponds, and on brushy hills in s. and s.e. Tex., Apr.-July; e. to Fla. and s. to W.I. and C. A.

\section{Nama torynophyllum Greenm. Fig. 646.}

Prostrate, matted, leafy, densely villous annual, with very short branches; leaves alternate, spatulate, revolute and spoon-shaped, $1 \mathrm{~cm}$. long, $1.5-4 \mathrm{~mm}$. wide; flowers white or pinkish, numerous, arranged singly along the branches; calyx lobes linear-spatulate, 3-3.5 mm. long; corolla tubular, 3-4 mm. long; stamen bases not dilated, the adnate portion much shorter than the free filament; seeds brown, shallowly pitted. 


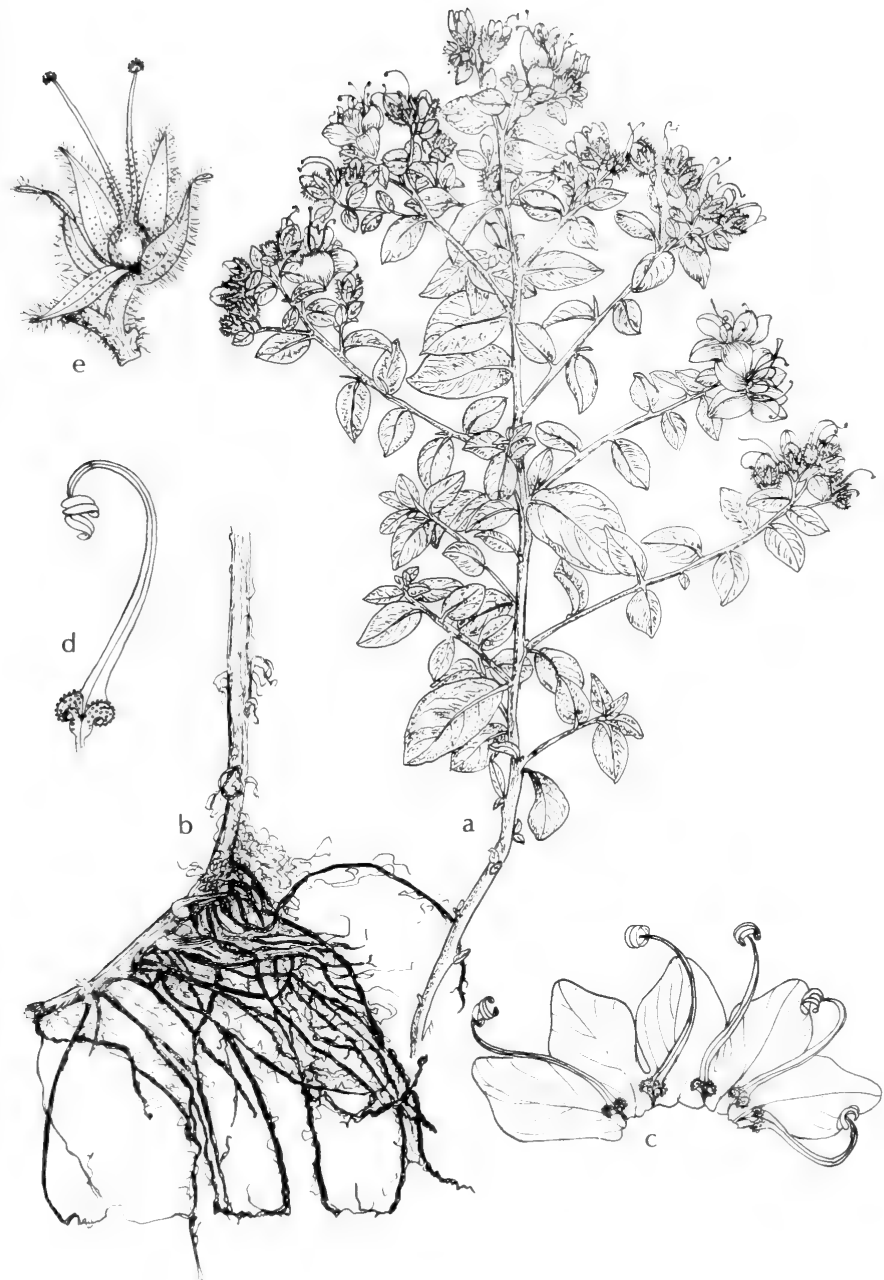

Fig. 648: Hydrolea ovata: a, top part of plant, $x \frac{1}{2}$; b, basal part of stem with adventitious roots, $x_{12} ; \mathrm{c}$, corolla, $\mathrm{x} 1 \frac{1}{2} ; \mathrm{d}$, stamen, $\mathrm{x} 3$; e, ovary with calyx, $\mathrm{x} 11 \frac{112}{2}$. (V. F.). 


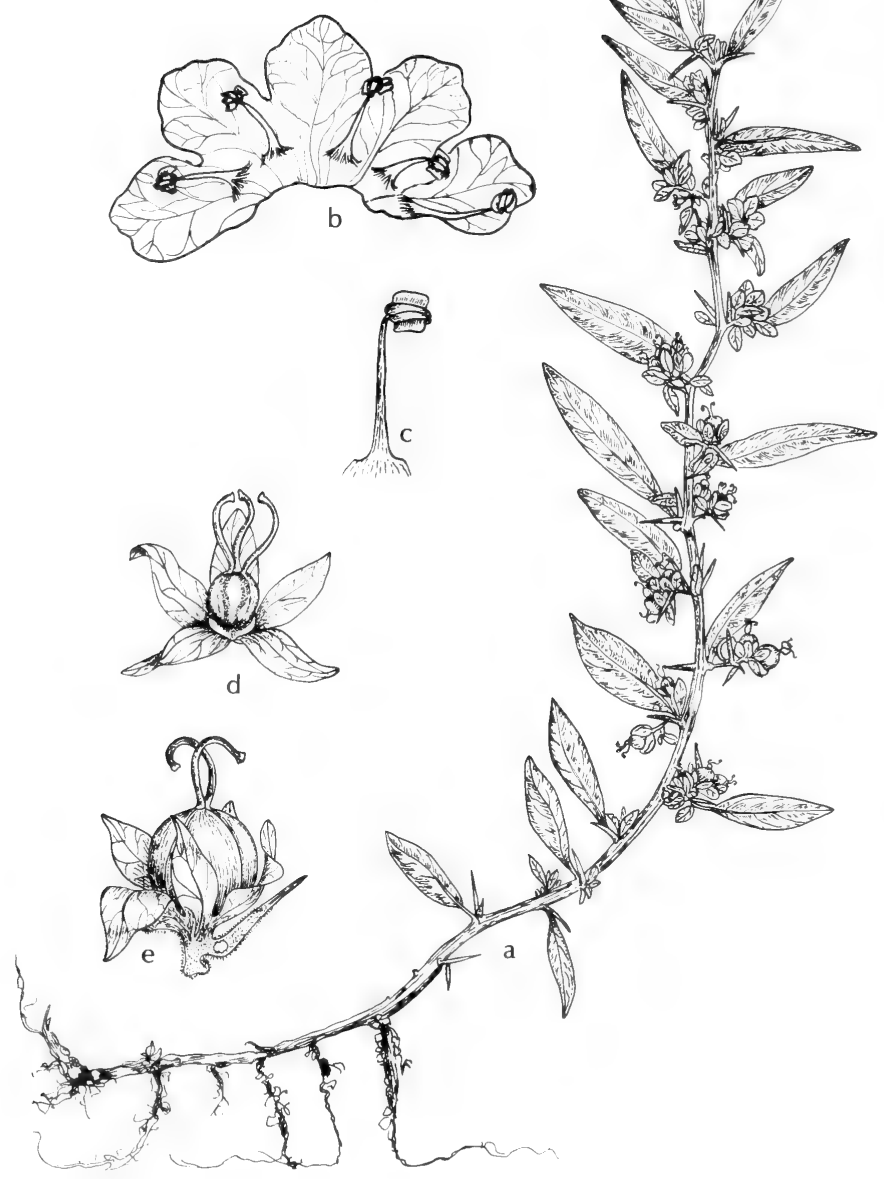

Fig. 649: Hydrolea uniflora: a, habit, x 1/2; b, corolla spread out, x 21/2; c, stamen, x 5 ; d, ovary with less usual 3 styles, $x 2 \frac{1}{2}$; e, capsule with usual 2 styles, $x 2 \frac{1}{2}$. (V. F.). 
On wet gravel-sand bars along the Rio Grande and tributaries in Brewster Co., Tex., Feb.-Apr.; also Coah.

\section{Hydrolea L.}

Annual or perennial, usually spiny, aquatic or marsh herbs with alternate entire leaves and corymbose or cymose blue flowers; calyx unappendaged, not conspicuously accrescent; corolla rotate-campanulate, exeeding or equaling the calyx; stamens included or exserted; corolla scales 0 ; styles distinct; capsule ovoid or globose, many seeded, often dehiscing irregularly; seeds minute, striate or rugose.

Approximately 20 species, pantropical, but predominantly subtropical America.

1. Plants essentially glabrous; leaves lanceolate; flowers in small axillary clusters, the calyx essentially glabrous................................... H. uniflora.

1. Plants conspicuously pubescent; leaves oblong to ovate; flowers in terminal clusters, the calyx hirsute (2)

2(1). Foliage and inflorescence finely hirtellous; anthers slightly exserted.

1. H. ovata.

2. Foliage and inflorescence hirsute and usually glandular; anthers included......

2. H. spinosa.

\section{Hydrolea ovata Choisy. Fig. 648.}

Stout erect spiny hirtellous perennial, from rhizomes that form colonies; leaves 3-6 cm. long, 15-25 $\mathrm{mm}$. wide; flowers bright blue or occasionally white, showy, 15-25 mm. broad; sepals shorter than corolla.

Edges of and in water of ponds, ditches and streams in Okla. (Atoka, Pushmataha, McCurtain, Pittsburg, Sequoyah and Le Flore cos.) and e. and s.e. Tex., Sept.-Oct.; La. to Tex., n. to Okla. and Ark.

\section{Hydrolea spinosa $L$.}

Stout erect usually very spiny perennial, hirsute and usually glandular; leaves 3-12 cm. long, 5-30 mm. wide; flowers showy, $1-1.5 \mathrm{~cm}$. broad; sepals shorter than corolla.

In water, Cameron Co., Tex., June; s. to Mex., W.I., C.A. and S.A.

\section{Hydrolea uniflora Raf. Fig. 649.}

Slender weakly erect spiny glabrous perennial; leaves $5-8 \mathrm{~cm}$. long, $1.5-2 \mathrm{~cm}$. wide; flowers rather inconspicouous, $1-1.5 \mathrm{~cm}$. broad; sepals equaling corolla. H. affinis Gray.

Edges of and in shallow water of ponds and streams in s.e. Okla. (Waterfall) and e. and s.e. Tex., Sept.-Oct.; n. Ark., Mo. and s. Ill.

A colony of plants found in Red River County, Texas represents what is undoubtedly the product of crossing between $H$. uniflora and $H$. ovata. The plants are strikingly intermediate between these two species in pubescence and corolla.

\section{Fam. 114. Boraginaceae Juss. Borage FAmily}

Plants herbaceous, shrubby or arborescent, usually bristly; leaves simple, alternate; flowers perfect, regular, solitary or cymose; cymes giomerate-racemose or spicate, frequently unilateral and coiled (scorpioid), usually with bracts between, to one side of, or opposite the flowers; calyx usually deeply lobed, somewhat irregular; corolla 5-lobed, commonly with folds or saccate-intruded appendages in the throat; stamens 5 , borne on the corolla tube alternate with the lobes; ovary superior, bicarpellate, usually 4-ovulate, entire or lobed, becoming tough or bony at maturity; fruit commonly breaking up into 4 single-seeded lobes (achenelike mericarps) or remaining intact but the mesocarp becoming fleshy and the fruit thus drupaceous; 
style lobed or entire, seated in the pericarp at the apex of the fruit or borne between the fruit lobes (nutlets) on the receptacle, or on an upward prolongation thereof (gynobase); endosperm absent or scarce.

The classification of this large family is based primarily upon the structure of the fruit. In many cases it is very difficult to recognize the genus and almost impossible to obtain a precise identification of the species if the specimens lack mature fruiting structures. Numerous species are cultivated as ornamentals, notably in the genera Heliotropium (heliotrope), Anchusa, Echium and Myosotis (forget-me-not).

1. Ovary entire or shallowly lobed, the style terminal. 1. Heliotropium

1. Ovary deeply 4-lobed, the style borne on the gynobase and arising between the lobes of the ovary (2)

2(1). Mericarps conspicuously armed with glochidiate prickles.

2. Hackelia

2. Mericarps smooth and shining or rugose, lacking glochidiate prickles (3)

$3(2)$. Leaves typically narrowly oblanceolate to spatulate; mericarps basally attached to a flat gynobase, smooth and shining; corolla lobes convolute in bud................................................................. Myosotis

3. Leaves typically ovate to lanceolate; mericarps obliquely attached to a convex gynobase, rugose and not shining; corolla lobes imbricate in bud 4. Mertensia

\section{Heliotropium L.}

\section{Turnsole. Heliotrope}

Annual or perennial, herbaceous or more or less shrubby plants; leaves small to large, sessile or petiolate; cymes unilateral and generally distinctly scorpioid, with or without bracts; corolla white, yellow or purple, variable in form, throat frequently pubescent inside; anthers included, filaments extremely short; style present or absent; stigma usually frustrumlike or conic, mostly sterile, receptive only in a band around the base; fruit dry, at maturity breaking up into 41 -seeded or 2 2-seeded mericarps; seeds usually with a thin endosperm.

About 250 species widely represented in the warmer parts of the world. The species are particularly numerous in arid regions.

1. Mature fruit breaking up to form 2 2-seeded mericarps; leaves evidently veined; cymes bractless (2)

1. Mature fruit breaking up into 41 -seeded mericarps; leaves may or may not be evidently veined; cymes with or without bracts (3)

2(1). Plant with simple hairs; leaf blades ovate to broadly lanceolate or somewhat cordate, 3-6 cm. long, 1-4 cm. wide; veins numerous, evident, branched; fruit with a corky mesocarp; each mericarp with a single sterile cell. 1. H. molle.

2. Plant with malpighiaceous hairs on stems and leaves; leaf blades lanceolate, 2-4.5 cm. long, rarely' more than $1 \mathrm{~cm}$. wide; veins few or none, obscure, always simple; fruit lacking a corky mesocarp; each mericarp with 3 sterile cells of which the 2 larger are partially filled with corky tissue. 2. H. glabriusculum.

3(1). Plant very succulent, glabrous, usually somewhat glaucous (4)

3. Plant not noticeably succulent, hairy, never glaucous (6)

4(3). Corolla white, the limb $1.5-3 \mathrm{~mm}$. in diameter; leaves $8 \mathrm{~mm}$. wide or less 3. $H$. curassavicum var. curassavicum.

4. Corolla white and often purple-tinged at throat, the limb more than $3 \mathrm{~mm}$. in diameter; leaves to $2 \mathrm{~cm}$. wide (5)

5(4). Corolla limb $3-5 \mathrm{~mm}$. in diameter. 3. H. curassavicum var. oculatum. 5. Corolla limb $5-10 \mathrm{~mm}$. in diameter.............3. H. curassavicum var, obovatum. 
6. Annual with typically erect stems (7)

7(6). Throat of corolla pubescent just below the limb; corolla lobes narrow and acute; mericarps coarsely strigose.. 5. H. procumbens.

7. Throat of corolla glabrous; the shallow corolla lobes broad and rounded; mericarps glabrous or at most puberulent. .6. H. indicum.

\section{Heliotropium molle (Torr.) I. M. Johnst.}

Low perennial, occurring in colonies; stems decumbent, loosely branched, 1-3 $\mathrm{dm}$. long, developing anew each year from the root or from a small weakly developed caudex, gray or tan, appressed hispid-villose; leaves numerous, with a petiole 1-3.5 cm. long, densely hispid-villose with appressed hairs, the margins moderately to coarsely crenate and visually crisped, apex acute to obtusish, base usually broadly asymmetric; inflorescence terminal on the leafy stems or opposite leaves, consisting of 2 or 3 densely flowered scorpioid cymes borne at the apex of a naked peduncle 2-4 cm. long; calyx subsessile, at anthesis $2-3.5 \mathrm{~mm}$. long, the lobes at maturity 3-5 mm. long, linear-lanceolate, hairy, embracing the fruit; corolla white or slightly stained with purplish, in throat yellow, total length 6-10 $\mathrm{mm}$. long, funnelform, the lobes rounded and separated by well-developed plaited inflexed sinuses; fruit dry, ovoid-globose, 3.5-4 mm. high, dorsiventrally $4.5-5 \mathrm{~mm}$. long.

Growing in valley soils, on flats, usually in places where water collects and stands for a short time after rain storms, and most commonly in places in the vic. of Upper Cretaceous outcrops, in Tex., only from Brewster Co. and from along the Rio Grande in w. Presidio Co., Apr.-Sept.; also Coah. and Chih.

It is worthy of note that another Texan species of this genus, which also grows on clay flats in places where there is a shallow pooling of water after rains, likewise has what appears to be buoyant corky tissue developed in the mericarp. This corky tissue in the mericarps of $H$. molle and $H$. glabriusculum may be useful in the dissemination of the fruit by water and may be adaptations for the specialized habitat these plants affect.

\section{Heliotropium glabriusculum (Torr.) Gray. Cola DE ALACRAN.}

Perennial, forming colonies; stems usually several, springing from the root crown or from a small caudex, renewed annually, grayish strigose with the hairs all malpighiaceous, loosely decumbent and branched, 1-3 dm. long; leaves numerous, green, minutely and abundantly dotted, firm, usually glabrous except on the petiole and along the prominent midrib on the lower surface, the margin weakly revolute and usually more or less evidently crisped, apex acute, base narrowed into a petiole 1-6 mm. long; inflorescence terminal on the leafy stems and branches, consisting of 2 or sometimes 3 densely flowered scorpioid cymes borne clustered on a naked peduncle 1-3 cm. long; flowers fragrant; calyx sessile, 2-3 $\mathrm{mm}$. long, the lobes lanceolate, attenuate, moderately unequal, with a few malpighiaceous hairs down the middle line and sparingly ciliate with simple hairs on the margin; corolla white with a greenish-yellow throat when fresh, becoming cream-colored with a purplish throat when dry, 4-5.5 mm. long, the sinus between the short corolla lobes simple, closed with neither plaits nor lobules; fruit grayish from a dense pubescence of minute simple hairs. Heliophytum glabriusculum Torr.

Growing on valley soils, usually on clay in limestone areas, and particularly in places subjected to temporary flooding after rain storms, in Tex. it has been collected most frequently in s. Brewster and s. Pecos cos., but it is also known from Val Verde, Maverick, Webb and McMullen cos., May-Aug.; from Tex. s. to e. Dgo. and n. Zac.

The malpighiaceous hairs readily distinguish $H$. glabriusculum. 
3. Heliotropium curassavicum L. var, curassavicum. SEASIDE heliotrope, cola DE MICO. Fig. 650.

Perennial, usually with a deep rhizome; stems prostrate or laxly decumbent, rubbery, to $4 \mathrm{dm}$. long and $5 \mathrm{~mm}$. thick, ascendingly branched; leaves oblanceolate, often narrowly so, thick and juicy, strongly compressed, to $4 \mathrm{~cm}$. long and $8 \mathrm{~mm}$. wide, the apex obtuse or rounded; inflorescence terminal or extra-axillary and lateral along the leafy stems, single or paired or rarely ternate, densely flowered, entirely bractless, scorpioid cymes, in fruit elongating, becoming as much as $1 \mathrm{dm}$. long and the rachis usually more or less broadened and flattened; calyx sessile or nearly so, lobed almost to the base, the lobes lanceolate or oblong, equal or nearly so, fleshy, at anthesis 1-1.4 mm. long, moderately accrescent in fruit; corolla white, small, $1.2-3.5 \mathrm{~mm}$. long, entirely glabrous, the lobes rounded, the tube shortly surpassed by the calyx lobes; fruit 4-lobed, $2-2.5 \mathrm{~mm}$. high, 2-3 mm. thick, obscurely compressed laterally, embraced by the somewhat accrescent calyx lobes, smooth and glabrous; mericarps bearing a thick layer of firm vesicular exocarp which apparently functions as a float-organ in water dissemination.

In sandy soil along beaches, about ponds, saline flats and similar areas throughout Tex., Okla., N.M. and Ariz. most of the year; from Fla., n. to Del., w. to Okla., Tex., N.M. and Ariz., s. in the W.I., Mex. and C.A. to Surinam and Col. and thence s. along the Pac. Coast of S.A. to Chile and Arg.; introd. in s. Eur.

Var. oculatum (Heller) I.M. Johnst. Corolla limb 3-5 $\mathrm{mm}$. in diameter; fruit 1.5-2 mm. wide. H. oculatum Heller. Rather widespread in w. half of Ariz., throughout year; also Ut. to Baja Calif.

Var. obovatum DC. The corolla limb of var. obovatum is $5-10 \mathrm{~mm}$. wide, at most only purplish-tinged at the throat, and the fruit is $2.5 \mathrm{~mm}$. wide. The oblanceolate to spatulate leaves are also to $2 \mathrm{~cm}$. wide $H$. spathulatum Rydb. Rare, Dallam and Bailey cos. in the Tex. Plains Country in old buffalo wallows (playa lakes) and N.M., June-July; w. U.S.

\section{Heliotropium Greggii Torr.}

Plant from a deep rhizome, strigose, pale-green; stems usually numerous, prostrate or loosely decumbent, ascendingly branched, leafy, to $15 \mathrm{~cm}$. long; leaves numerous, thickish, lanceolate to linear, sessile or with petioles to $3 \mathrm{~mm}$. long, midrib prominent but veins absent, the margin revolute; inflorescence at first glomerate and then elongating into a loose racemose cyme to $5 \mathrm{~cm}$. long, commonly 5- to 10-flowered; calyx lobes about equal, 2-3 mm. long, lanceolate; corolla white with a yellow throat, fragrant, the limb $7-12 \mathrm{~mm}$. broad, shallowly lobed with 5 broad rounded principal lobes and (alternating with these) 5 smaller somewhat triangular incurved lobes, the throat with hairy inflexed plaits, the tube inside bearing an inconspicuous nectariferous ring about $0.5 \mathrm{~mm}$. above the base; fruit very hairy, about $3 \mathrm{~mm}$. thick and $1.5 \mathrm{~mm}$. high.

Usually forming colonies in places where water collects temporarily, frequent along roadside shoulders and ditches, in sand, gravel or on clay flats, lacking in volcanic areas, frequent and widely distributed in Trans-Pecos Tex. and also e. in Loving, Ward, Crane and Upton cos., with outlying stations in Knox and Medina cos., and s.e. N.M. (Chaves, Dona Ana, Eddy and Otero cos.), Apr.-Sept.; N.M., Tex., Coah., Chih., Dgo. and Zac.

\section{Heliotropium procumbens Mill. Fig. 651.}

Plant erect to loosely decumbent, $1-5 \mathrm{dm}$. tall, moderately to abundantly strigose or appressed hispid-villose, pale-green or somewhat cinereous or even canescent; stems one to several, when single usually loosely and ascendingly branched above the base; leaves numerous, with petioles to $1 \mathrm{~cm}$. long, narrowly oblanceolate to 


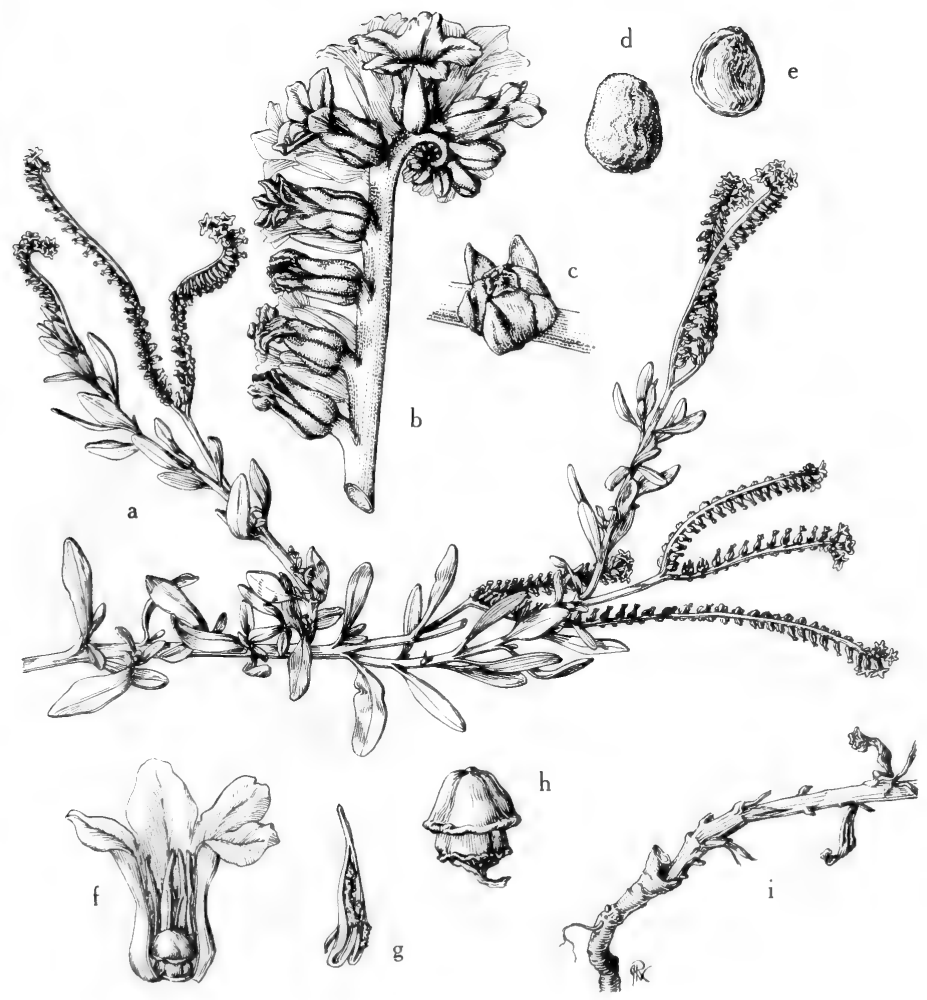

Fig. 650: Heliotropium curassavicum: a, branch, showing semiprostrate habit, x $2 / 3$; b, apex of inflorescence, x 3 ; c, ovary, x 3 ; d, nutlet, abaxial view, x 12; e, nutlet, adaxial view, $x$ 12; f, flower, with 1 lobe and 1 anther removed, x 61/2; g, anther, x 12; h, pistil, $\mathrm{x} 12$; $\mathrm{i}$, basal part of stem and stout root, $\mathrm{x} 2 / 3$. (From Mason, Fig. 297). 


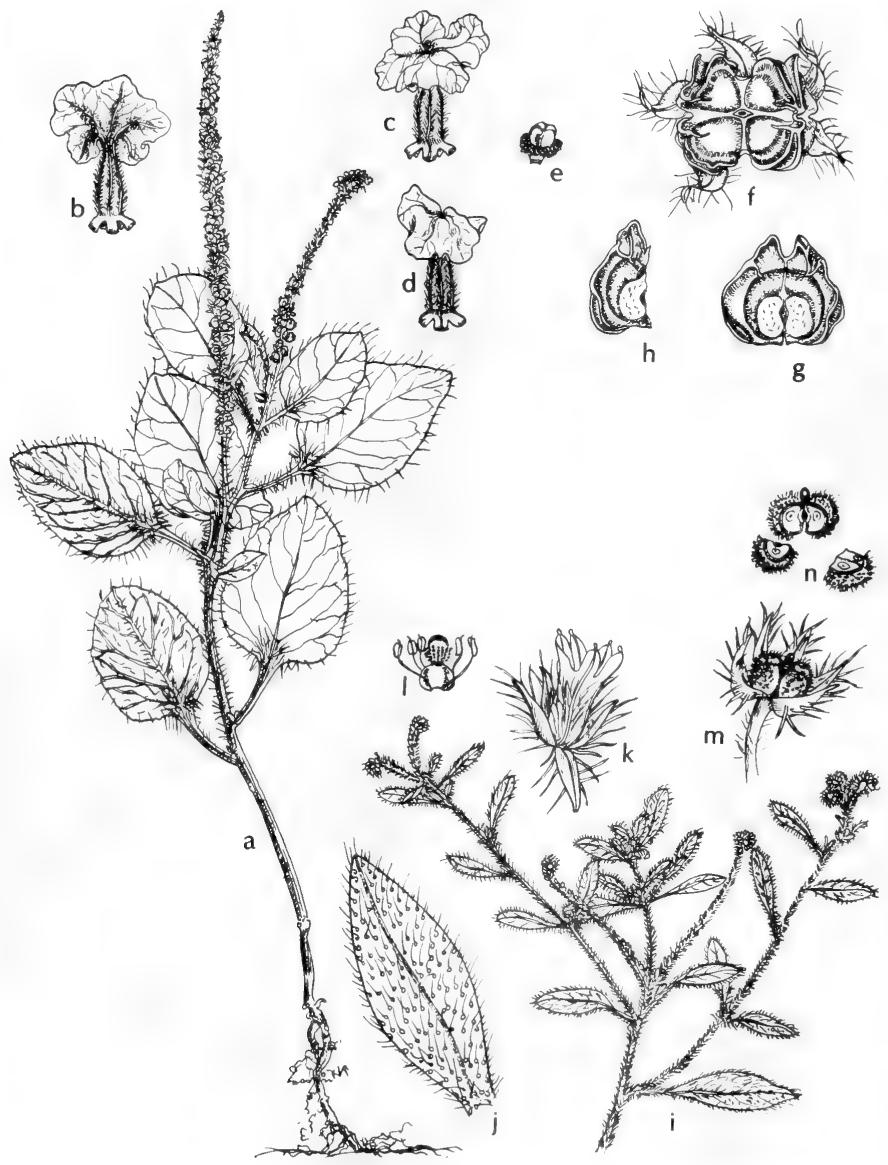

Fig. 651: a-h, Heliotropium indicum: a, habit, x 1/z; b, flower from beneath, $\mathrm{x} 5$; c and d, flowers, x 5; e, young ovary, x 5; fruit from top, x 5;g, one half of fruit from center, x 5; h, one mericarp from side, x 5. i-n, Heliotropium procumbens: $\mathrm{i}$, top of plant, $x 1 / 2 ; \mathrm{j}$, leaf, $\times 2 \frac{1}{2}, \mathrm{k}$, flower, $\mathrm{x} 5 ; 1$, ovary, $\mathrm{x} 5 ; \mathrm{m}$, strigose fruit, $\mathrm{x} 5 ; \mathrm{n}$, fruit breaking into 4 mericarps. (V. F.). 
elliptic, plane or more or less evidently revolute, to $4 \mathrm{~cm}$. long and $2 \mathrm{~cm}$. wide, apex usually acute, base cuneate, upper and lower surfaces consimilar in coloration and indument: inflorescence consisting of usually numerous scorpioid cymes; cymes solitary or geminate. densely flowered, borne terminal or extra-axillary along the leafy stems, 3-10 cm. long, on naked peduncles $1-3 \mathrm{~cm}$. long; calyx at anthesis 1-1.2 mm. long, the lobes unequal (especially in width), linear to broadly lanceolate, as long as or slightly longer than the corolla tube, at maturity nearly doubling in size and becoming more unequal; corolla white, $1.5-3 \mathrm{~mm}$. long, the tube sparsely strigose outside, the limb 2-3 mm. broad; fruit 1-2 mm. thick, 1-2 mm. high.

A weedy species, usually growing in marshes or damp situations or on land subject to flooding, in Tex., n. to Jefferson, Hays, Bexar and Brewster cos., and s.e. Okla. (McCurtain Co.), Apr.-Nov.; in Fla.. La. and Tex. and Okla., mostly on the Coastal Plain, widely distributed in the W.I., C.A. and trop. S.A.

\section{Heliotropium indicum L. Turnsole, alacrancillo. Fig. 651.}

Coarse, annual herb, villous to hispid or hispidulous, to $1 \mathrm{~m}$. tall; stems loosely branched, leafy, frequently fistulose; leaves with a petiole $4-10 \mathrm{~cm}$. long, ovate to elliptic, drying thin, to $15 \mathrm{~cm}$. long and $1 \mathrm{dm}$. wide, the margin repand or undulate, apex acute, base obliquely acute to obtuse or subcordate; inflorescence a simple very elongating scorpioid cyme to $3 \mathrm{dm}$. long, bearing two ranks of crowded flowers and fruits; calyx broadly sessile, $1.5-2 \mathrm{~mm}$. long, the lobes linear or linearlanceolate, unequal; corolla blue or violet (or rarely white), puberulent or strigose outside, the limb to $4.5 \mathrm{~mm}$. in diameter, the tube elongate, evidently surpassing the calyx, usually about $3 \mathrm{~mm}$. long, constricted at the throat; fruit miter-shaped, glabrous or puberulent.

Along river banks and bottoms, ditches, lake shores, swamps and along creeks, e. half of Tex. w. to Dallas, Bexar and Hidalgo cos. and e. Okla. (LeFlore, Hughes, McCurtain cos.), June-Oct.; widely distributed in the warmer parts of Am. from n. Arg. to s. U.S.; also in the trop. of the Old World; probably a nat. of Am.

\section{Hackelia OpIz STICKSEED}

Coarse biennial or perennial or rarely annual herbs; leaves alternate, broad and veiny; flowers in naked or inconspicuously bracted racemes paniculately disposed; pedicels slender, recurving in fruit; calyx cut to the base into spreading ovate to oblong or lanceolate lobes; corolla white or blue, with a short or elongate tube; lobes rounded, imbricate, throat with trapeziform intruded appendages; stamens included, affixed at middle of tube; filaments slender, short; anthers oblong to elliptic; style slender, scarcely if at all surpassing the mericarps; stigma capitate; ovules 4; mericarps 4, erect, ovoid, affixed ventrally to the pyramidal gynobase by a broad medial or submedial areola, margin with subulate glochidiate appendages that are frequently confluent at the base, back smooth or with glochidiate appendages.

A genus centering in western North America with outlying species in South America and Eurasia.

1. Mericarps subequally prickly over the whole back or face........ $1 . H$. virginiana.

1. Mericarps only marginally prickly.

2. H. floribunda.

\section{Hackelia virginiana (L.) I.M. Johnst.}

Plant to about $1 \mathrm{~m}$. tall, hirsute throughout, the stem freely branched above; radical leaves broadly ovate to cordate, narrowed to a slender petiole, to $2 \mathrm{dm}$. long; cauline leaves ovate-oblong to oblong-lanceolate, acuminate at apex, tapering to the sessile base, to $15 \mathrm{~cm}$. long, progressively reduced above and passing into the bracts; the numerous loosely paniculate racemes divaricate, with small bracts; pedicels and flower each about $2 \mathrm{~mm}$. long, frequently supra-axillary; 


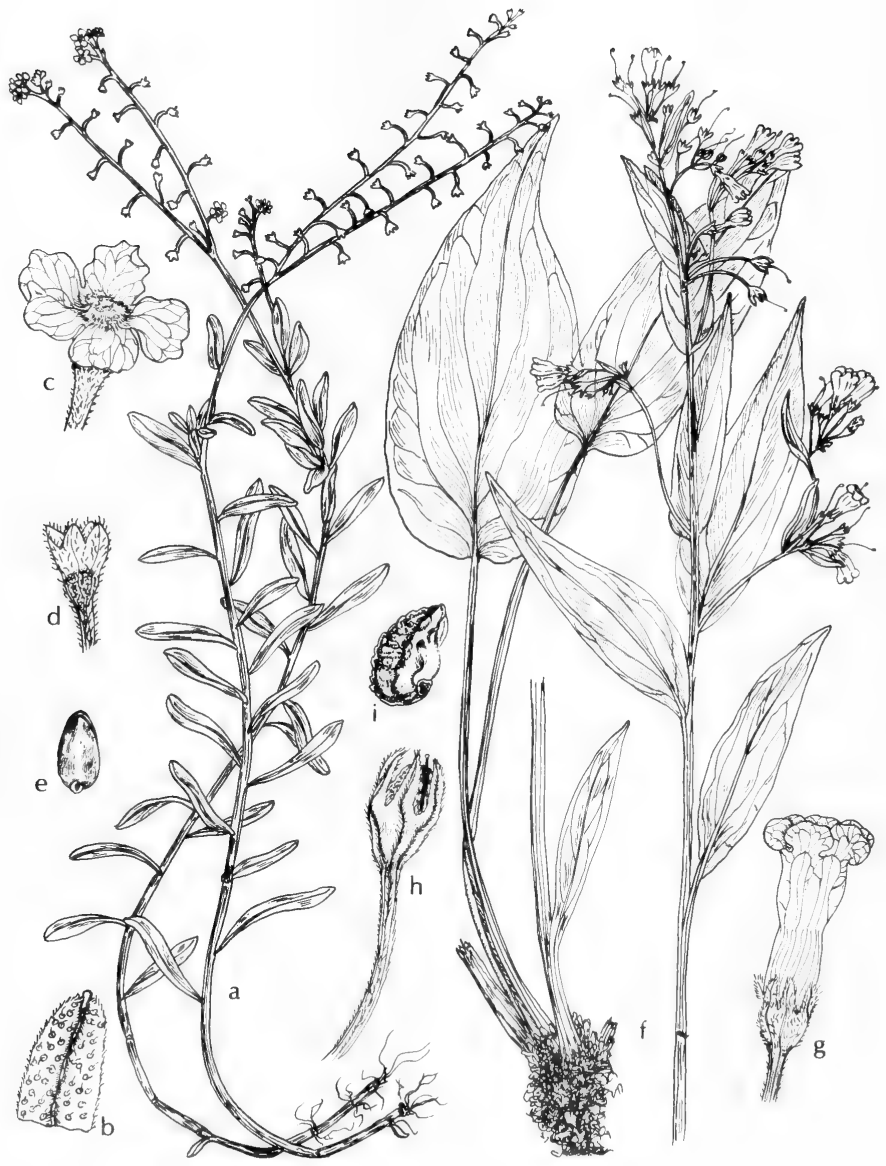

Fig. 652: a-e, Myosotis scorpioides: a, habit, x 1/2; b, end of leaf, x 21/2; c, flower, x $2 \frac{1}{2}$; d, calyx, x 21/2; e, seed, x 5. f-i, Mertensia franciscana: f, habit, x 1/2; g, flower, x $2 \frac{1}{1} ; \mathrm{h}$, calyx and young capsule, $x 2 \frac{1}{2} ; \mathrm{i}$, seed, $x$. (V.F.). 
corolla whitish, about $2 \mathrm{~mm}$. wide; mericarps of the globose fruit equally shortglochidiate over the whole back, 3-4 mm. long.

In rich woods, swampy areas and along wooded streams and open thickets in e. Okla., n.e. Tex. and the Tex. Panhandle, July-Sept.; from Que. and Me., w. to S.D., s. to Ga., Ala., La. and Tex.

\section{Hackelia floribunda (Lehm.) I. M. Johnst.}

Plants erect, stout, from a short-lived perennial root, 5-12 dm. tall, the rough pubescence deflexed, mixed with some spreading hairs; leaves oblanceolate to linear or oblong, hirsutulous-appressed, the basal leaves petiolate, with spreading hairs, the stem leaves sessile above; racemes many, rather strict, densely flowered; pedicels 5-7 mm. long in fruit; corolla blue, 4-7 mm. broad; appendages small, obscurely papillate, not closing the throat; mericarps $3-5 \mathrm{~mm}$. long, face of mericarp with a median ridge, muriculate, hirsutulous, without short glochidiate prickles, the marginal spines much-flattened at base, distinct or somewhat confluent, 4 to 6 on each side, mostly exceeding in width the face of the mericarp.

Brushy slopes and edge of woods in Tex. Trans-Pecos and in wet meadows and on seepage slopes in N.M., July-Aug.; mostly w. U.S. and Can., e. to Ont. and Minn.

\section{Myosotis L. FORGET-ME-NOT}

About 50 species in Eurasia, Africa, Australia and New Zealand.

\section{Myosotis scorpioides L. Fig. 652.}

Perennial with slender rootstock or stolons; herbage thinly strigulose with straight, pointed hairs; stems $1.5-4 \mathrm{dm}$. long, decumbent or ascending, rooting at lower nodes; leaves oblanceolate to spatulate, $2.5-8 \mathrm{~cm}$. long, the upper stem leaves sessile, the lower ones narrowed to a winged petiole; racemes slender, loosely flowered, in fruit to $2 \mathrm{dm}$. long, bractless; fruiting pedicels as long as or longer than the calyx; calyx with straight, appressed hairs, its lobes equal in size, shorter than the tube, more or less spreading in fruit; corolla blue with a yellow eye, the tube longer than the calyx, 6-9 mm. broad; style longer than the nutlets.

In water of small spring and pond in Ariz. (Coconino Co.), Aug.; nat. of Euras. that escapes from cult.

\section{Mertensia Roth}

\section{BLUEBELLS}

Glabrous to strigose or hirsute perennial herbs, the hairs not pungent; leaves usually ample; flowers in modified bractless mostly small cymes that terminate the stem and branches; calyx usually cleft to just above or well below the middle, often to the base; corolla blue or sometimes white or pink, mostly tubular below and abruptly expanded at the throat into a shallowly 5-lobed limb, the fornices usually evident; filaments attached at or below the level of the fornices, often conspicuously expanded; nutlets attached to the gynobase at or below the middle, usually rugose.

About 35 to 40 species, native to extratropical Eurasia and North America.

1. Leaves strigillose on upper surface; pedicels strigose............. . . franciscana.

1. Leaves glabrous or somewhat papillose on upper surface; pedicels papillose or rarely with a few strigose hairs................................ . ciliata.

\section{Mertensia franciscana Heller. Fig. 652.}

Stems erect or ascending, to about $10 \mathrm{dm}$. tall, usually several from each rootstock; leaves strigillose on upper surface, glabrous to densely pubescent with spreading hairs on lower surface; basal leaves oblong-elliptic to elliptic, to $15 \mathrm{~cm}$. long and $9 \mathrm{~cm}$. wide, subcordate to cuneate at base, obtuse to acuminate at apex; 
petioles longer or shorter than the blade; cauline leaves elliptic to narrowly ovate, to $14 \mathrm{~cm}$. long and $5 \mathrm{~cm}$. wide, obtuse to acuminate, the lowermost petiolate, becoming sessile toward the inflorescence; flowers paniculately disposed in an ebracteate modified scorpioid cyme, the branches elongating in age; pedicels strigose, to $2 \mathrm{~cm}$. long; calyx $2.5-5 \mathrm{~mm}$. long, divided almost to the base; calyx lobes linear to lanceolate, 1-2 mm. wide, acute to obtuse, glabrous or pubescent on the back, strongly ciliate; corolla tube 5-9 (mostly about 6) $\mathrm{mm}$. long, glabrous or pubescent within; corolla limb 4-9 (mostly about 6) $\mathrm{mm}$. long, moderately expanded; anthers $2.5-3 \mathrm{~mm}$. long; filaments $2-2.5 \mathrm{~mm}$. long, glabrous or with spreading hairs; fornices prominent, usually pubescent; style 9-20 $\mathrm{mm}$. long, usually shorter than the corolla; nutlets rugose and papilliferous.

In the pine-aspen belt in seepage along streams and wet soil about lakes and ponds, wet meadows and thickets and wet cliffs, widespread in the mts. of N.M. and Ariz., June-Sept.; also Colo., Ut. and Nev.

\section{Mertensia ciliata (James) G. Don.}

Stems erect or ascending, to $12 \mathrm{dm}$. tall, usually with many stems from each rootstock; leaves glabrous or somewhat papillose on upper surface and ciliate on the margins; basal leaves variable, oblong- to lanceolate-subcordate, to $15 \mathrm{~cm}$. long and $10 \mathrm{~cm}$. wide; petioles about as long as blade; cauline leaves lanceolate to ovate, obtuse to acuminate at apex, narrowly cuneate to subcordate at base, the lowermost short-petiolate, the uppermost sessile, of ten glaucous, thin; inflorescence from axils of leaves, the peduncles elongated with age, in young plants the flowers aggregated at the top of the plant with each peduncle terminated by a modified ebracteate scorpioid cyme or sometimes umbellate; pedicels to about $1 \mathrm{~cm}$. long, glabrous to papillose or rarely with a few short strigose hairs; calyx lobes $1.3-3 \mathrm{~mm}$. long, glabrous on the back, ciliate to papillate on the margins, more or less strigose within, obtuse to acute; corolla tube 6-8 (mostly about 7) $\mathrm{mm}$. long, glabrous or with crisped hairs within; corolla limb 4-10 (mostly about 6) $\mathrm{mm}$. long, moderately expanded; anthers $1-2.5 \mathrm{~mm}$. long, about as long as filaments; fornices prominent, glabrous to papillate or pubescent; style about as long as or exceeding the corolla; nutlets rugose or mammillate.

On wooded slopes, in wet soil about springs and seepage along streams, bogs and wet meadows, in N.M. (Sandoval and Taos cos.), June-Sept.; Mont. to Ore., s. to N.M.

\section{Fam. 115. Avicenniaceae ENDL.}

BLACK-MANGROVE FAMILY

Shrubs or trees of maritime regions; branches and twigs usually terete, nodose, articulate; leaves opposite, thick, persistent, petiolate, extipulate, entire; inflorescence axillary or terminal, spicate or subcapitate, the axillary ones mostly paired; flowers sessile, perfect, hypogynous, small; sepals 5, nearly separate, ovate, imbricate, subtended by a false involucre of a scalelike bract and 2 alternate scalelike prophylla slightly shorter than the calyx and imbricate with each other and the sepals; corolla regular, gamopetalous at the base, campanulate-rotate, 4-parted; stamens 4 , inserted in the corolla tube, equal or subdidynamous; carpels 2; ovary superior, compound but with a free central often more or less 4-winged placenta; ovules 4 , pendent, orthotropous, hanging from the tip of a central columella; fruit a compressed oblique capsule, the exocarp juicy, somewhat fleshy, usually tomentulose, dehiscent by 2 valves, usually only 1 -seeded; seeds without a testa; embryo viviparous.

A single genus. 


\section{Avicennia L.}

Characters of the family. Composed of 11 living species, 5 varieties, and 4 fossil species; one of the chief constituents of coastal mangrove belts throughout the tropics and subtropics of the world.

\section{Avicennia germinans (L.) L. Black-Mangrove, mangle blanco. Fig. 653.}

Shrub rarely over $1 \mathrm{~m}$. tall in our area (to $16 \mathrm{~m}$. in tropics); petioles 2-27 mm. long, often farinaceous; leaf blades oblong or lanceolate to elliptic or obovate, to $15 \mathrm{~cm}$. long and $44 \mathrm{~mm}$. wide, obtuse or acute at the apex, entire, acute to cuneate at the base, usually grayish-mealy beneath, sometimes glabrous and punctate; spikes to $65 \mathrm{~mm}$. long and $15 \mathrm{~mm}$. wide during anthesis, the axillary ones usually only a single pair at the base of the terminal one and shorter than it or a second pair in the next lower leaf axils; calyx lobes $3-5 \mathrm{~mm}$. long, 2-3 mm. wide, densely appressed-pubescent outside, glabrous within; corolla white, 1.2-2 $\mathrm{cm}$. long, parted to about the middle, the tube equaling or shorter than the calyx, practically glabrous, the lobes spreading, densely gray-pubescent outside and velvety within; fruit obpyriform or ovate, asymmetric, to $2 \mathrm{~cm}$. long and $12 \mathrm{~mm}$. wide, densely gray-hairy, $A$. nitida Jacq.

In mangrove lagoons and along tidal shores, s. e. and s. Tex.; very variable, ranging from Fla. and Tex., Berm., Bah. I. and both coasts of Mex., through W.I. and C.A. to the coasts of Braz. and Peru.

The fruits of the red mangrove, Rhizophora Mangle L. (Rhizophoraceae), of southern Florida and tropical America, are commonly washed ashore (especially near the mouth of the Rio Grande), where they have been known to sprout, but no living plant has apparently thus far become established in Texas. This species grows in habitats similar to those of the black mangrove but it is readily distinguished from that species by its aerial roots that arise from its trunk and branches, its regular corolla, and the development of a conspicuous radicle to several decimeters in length.

\section{Fam. 116. Verbenaceae ST.-HIL.}

\section{VeRVAin FAMily}

Herbs, shrubs, woody vines or trees; branchlets and twigs mostly tetragonal, not prominently nodose nor articulate; leaves mostly opposite, deciduous, extipulate, mostly simple, sometimes compound or 1-foliolate, the blades entire or variously dentate, incised or cleft; inflorescence axillary or terminal, determinate or indeterminate, as cymes, racemes, spikes, panicles, thyrsi, heads or false umbels, sometimes involucrate, the axillary ones mostly solitary; flowers sessile or pedicellate, perfect or imperfect, hypogynous, sometimes heterostylous or polygamous, large or small, mostly irregular, the individual ones not involucrate; calyx gamosepalous, campanulate to tubular or salverform, persistent, usually accrescent, mostly 4- (more rarely 2-, 5- or 7-) lobed or toothed or sometimes the rim subentire; corolla regular or irregular, gamopetalous, mostly funnelform or salverform, usually with a well-developed tube with its limb 4- or 5- (rarely 7- or many-) parted, often somewhat 2-lipped; stamens mostly 4 and didynamous or reduced to 2 , sometimes 4 or 5 and equal, inserted in the corolla tube; staminodes often present; carpels mostly 2 (rarely 4 or 5), united, one sometimes aborted; ovary superior, mostly compound, sessile, mostly somewhat 4-lobed, at first 2- to 5-celled but almost invariably soon becoming 4- to 10-celled through formation of false partitions, never with a free central placenta or columella; the axile placentaelobes each bearing 1 ovule, the unpartitioned cells 2-ovulate, partitioned cells 1-ovulate; ovules anatropous and basal or hemianatropous and lateral; fruit usually a dry schizocarp separating into "cocci" at maturity or less commonly a drupe 


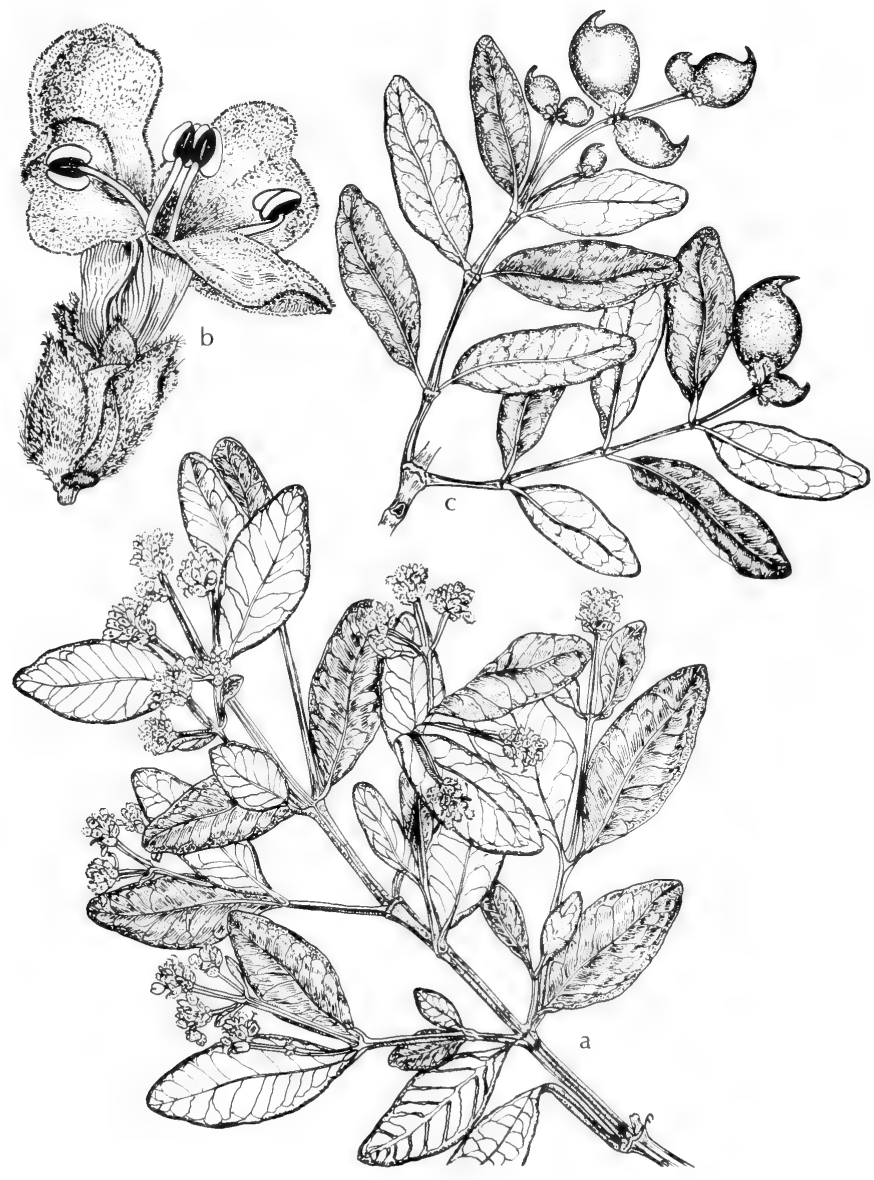

Fig. 653: Avicennia germinans: a, end of flowering branch, $\mathrm{x} 1 / 2$; b, flower, $\mathrm{x} 5$; $\mathrm{c}$, part of fruiting branch, $x \frac{1 / 2}{2}$ (V.F.). 
or fleshy schizocarp, with a thin and dry or fleshy exocarp and more or less hard endocarp, 2- to 4-celled and indehiscent when ripe or dehiscent into 2 (or rarely 4 to 10 ) 1- or 2-celled pyrenes; seeds plainly testate; embryo not viviparous.

About 3,375 species and subspecific taxa in 76 genera, very widely distributed almost throughout the world except in the Arctic and Antarctic.

1. Inflorescence determinate and centrifugal, cymose.

1. Callicarpa

1. Inflorescence indeterminate and centripetal, racemose (2)

2(1). Fruit composed of four 1-seeded pyrenes, schizocarpous.

2. Verbena

2. Fruit not composed of four 1-seeded pyrenes (3)

3(2). Fruit usually with a fleshy exocarp (rarely dry); calyx truncate or obscurely toothed or lobed.

3. Lantana

3. Fruit with a thin dry exocarp; calyx deeply 2- to 5-toothed or -lobed (4)

4(3). Erect shrub; spikes not usually elongating in fruit; bractlets ovate, often more or less 4-ranked.

4. Lippia

4. Herbs mostly with trailing or ascending stems, sometimes somewhat woody; spikes elongating in fruit; bractlets cuneate-obovate to flabelliform, not 4-ranked.

5. Phyla

\section{Callicarpa L. Beautyberry}

A complex genus of 147 species, 54 named forms and varieties, and 1 known hybrid, widely distributed in subtropical and tropical America, Asia and Oceanica, a few species extending into temperate portions of Asia and the southeastern United States; 1 in Madagascar; several are widely cultivated and tend to escape.

1. Fruit blue or pink to lilac, violet or purple. 1. C. americana.

1. Fruit white 1. C. americana var. lactea.

1. Callicarpa americana L. American beautyberry, French-Mulberry, BerMUDA-MULBERRY, SOUR-BUSH, BUNCHBERRY, FILIGRANA, FILIGRANA DE MAZORCA, FILIGRANA DE PINAR, FOXBERRY, PURPLE BEAUTYBERRY, SPANISH-MULBERRY, TURKEYBERRY.

Bush or shrub to $3 \mathrm{~m}$. tall, usually much-branched; branches densely stellatescurfy; leaves opposite or ternate; petioles to $38 \mathrm{~mm}$. long, stellate-scurfy; leaf blades very thin, ovate to elliptic, $8-23 \mathrm{~cm}$. long, $3.5-13 \mathrm{~cm}$. wide, acute or acuminate, coarsely serrate or crenate-dentate except at base and apex, cuneately narrowed into the petiole, stellate-scurfy with whitish tomentum (especially beneath and when immature); cymes $1-3.5 \mathrm{~cm}$. long and wide, many-flowered, usually shorter than the petiole, many times dichotomous; peduncles $3-10 \mathrm{~mm}$. long, stellate-scurfy or glabrate; pedicels $0.4-1.2 \mathrm{~mm}$. long, scurfy or glabrate; bractlets subulate or setaceous; calyx obconic or campanulate, $1.6-1.8 \mathrm{~mm}$. long, 1-1.5 mm. wide, slightly puberulent-granulose, rim subtruncate, very shortly apiculate; corolla small, bluish, pinkish, reddish or white, funnelform, the tube 2.6-2.9 mm. long, lobes about $1.5 \mathrm{~mm}$. long and $1 \mathrm{~mm}$. wide; fruit showy, rosepink or lilac to violet or red-purple, globose, $3-6 \mathrm{~mm}$. long and wide.

Woods, moist thickets, wet slopes, low rich bottomlands, fencerows and the edges of swamps, in e. and s.e. Okla. (Waterfall) and e. third of Tex., JuneDec.; also Md. to Fla. and La., Berm., Cuba and Coah.; also widely cult.

Var. lactea F. J. Mull. differs in having the mature fruit white; sandy open woods, e. Tex.; also N.C. to Fla. and Ark.; sometimes cult.

This is an ornamental shrub worthy of cultivation, not only for its beauty but also because it is an attractant to desirable bird life. Its clusters of bright reddish or purplish fruits are much relished by such birds as the robin, mockingbird, catbird and brown thrasher. 


\section{Verbena L. VERVAIN}

Herbs; stems and branches procumbent, ascending or erect, glabrous or variously pubescent; leaves mostly opposite, dentate (very rarely entire) or variously lobed, incised or pinnatifid; inflorescence spicate, terminal, usually densely manyflowered, often flat-topped and pseudo-umbellate, sometimes greatly elongate with scattered flowers, very rarely also axillary; flowers small or medium-sized, each solitary in the axil of a usually narrow bractlet; calyx usually tubular, 5angled, 5-ribbed, unequally 5-toothed, not at all or but slightly changed in fruit; corolla salver- or funnelform, its tube straight or curved, often slightly ampliate at the apex, the limb flat, weakly 2 -lipped, lobes 5, usually rather elongate, obtuse or rounded to emarginate at apex; stamens 4 , didynamous, inserted in the upper half of the corolla tube, mostly included; anthers ovate, with parallel or slightly divergent thecae, the connective unappendaged or glandular-appendaged; style single, usually short, shortly 2 -lobed, the posterior lobe smooth, the anterior lobe broader, papillose and stigmatic; ovary 2-carpellary, 4-lobed, completely 4celled, 4-ovulate; fruit mostly enclosed by the mature calyx, schizocarpous, readily separating at maturity into four 1 -seeded linear cocci.

A complex genus of about 206 species, 122 named varieties and forms, and 49 named hybrids, mostly of temperate and tropical America; 2 or 3 species native to the Mediterranean region and introduced elsewhere in the Old World; many are widely cultivated and tend to escape.

1. Heads or spikes crowded and short (at least during anthesis), not at any time greatly elongate or open, generally disposed in compound cymes (2)

1. Spikes slender and open or compact at anthesis, greatiy elongate in fruit, solitary or in simple cymes or panicles (3)

2(1). Leaves semiamplexicaul and subcordate at the base 1. V. bonariensis.

2. Leaves tapering into a cuneate--attenuate subsessile or petiolar base.

.2. V. brasiliensis.

3(1). Spikes panicled at the apices of the stem and branches, subtended chiefly by inconspicuous bracts; floral bractlets not prominent (4)

3. Spikes solitary or in 3's at the apices of stem and branches or panicled and subtended by leafy bracts at the base; floral bractlets often conspicuous (9)

4(3). Spikes very slender, elongate and graceful, usually with remote fruits (5) 4. Spikes thicker and densely flowered, usually with contiguous fruits (8)

5(4). Leaves very scabrous above; fruiting calyx spreading; calyx lobes connivent; stigmatic surface subtended by 2 sterile style lobes (6)

5. Leaves not pronouncedly scabrous above; fruiting calyx ascending; calyx lobes not connivent; stigmatic surface subtended by 1 sterile style lobe (7)

6(5). Leaf blades ovate, to $5 \mathrm{~cm}$. wide. 3. V. scabra.

6. Leaf blades narrowly elliptic to elliptic-lanceolate, to $2 \mathrm{~cm}$. wide... 3. V. scabra f. angustifolia.

7(5). Lower leaf surface glabrous or scattered long-pilose 4. V. urticifolia.

7. Lower leaf surface uniformly and densely short-pubescent. 4. V. urticifolia var. leiocarpa.

8(4). Leaf blades membranous, not conspicuously scabrous above, mostly glabrous or inconspicuously strigillose beneath.. 5. V. hastata.

8. Leaf blades rigid, harshly scabrous above, often conspicuously pubescent beneath. .5. V. hastata var. scabra. 
9. Leaves deeply incised-dentate to pinnatifid or 3-cleft (10)

10(9). Spikes conspicuously bracteose with somewhat foliaceous bractlets (at least at the base of the spike)............................ . V. bracteata.

10. Spikes not conspicuously bracteose; bractlets not foliaceous (11)

11(10). Corolla mostly blue.

8. V. Runyonii.

11. Corolla mostly rose-color. 8. V. Runyonii f. rosiflora.

\section{Verbena bonariensis L. South American vervain.}

Stiffly erect, $1 \mathrm{~m}$. or more tall, somewhat scabrous-pubescent; leaves sessile, subcordate and semiamplexicaul at base, lanceolate or oblong, sharply serrate, rugose and hirtellous above, spreading-pubescent beneath; spikes compact, mostly short, usually sessile and crowded in dense fasciculate cymes, not elongating; bractlets lanceolate-acuminate, barely equaling or slightly surpassing the calyx, pubescent; calyx $3 \mathrm{~mm}$. long, pubescent, the acute lobes with short subulate tips; corolla blue to violet or purple, the tube scarcely twice as long as the calyx, pubescent outside, limb inconspicuous.

Sandy loam, ditch banks, wet or moist flatlands and along rice field fences, in Okla. (McCurtain Co.) and in e. Tex. from Red River to Jefferson cos., Apr.June; nat. of Braz., Parag., Urug. and Arg.; introd. in W.I., S. U.S. and elsewhere.

\section{Verbena brasiliensis Vell. Brazilian Vervain.}

Stems stout, to $25 \mathrm{dm}$. tall, acutely tetragonal, practically glabrous below, somewhat scabrous-pubescent above, slightly contracted at nodes; leaves elliptic or lanceolate, tapering into a cuneate subsessile or petiolar base, sharply serrate or incised (at least above the middle), strigillose and somewhat pustulate above with impressed venation, sparsely pubescent beneath; spike compact, mostly short, not much elongating, usually sessile in open cymes, numerous but not crowded; bractlets scarcely as long as the calyx, lanceolate-subulate, ciliate; calyx 2.5-3.5 mm. long or more, somewhat appressed-pubescent, the acute lobes with short subulate tips; corolla purple or lilac, the tube a little longer than the calyx, pubescent outside, the limb $2.5 \mathrm{~mm}$. wide, inconspicuous.

Waste places, dry sandy soil, coastal prairies, in swamps and marshes about lakes and on seepy banks of ponds, in Okla. (Woodward Co.) and mainly in s.e. Tex., May-Oct., introd.; nat. to most of S.A.; naturalized from Va. to Fla. and Gulf Coast, Ore., Calif., Jam., S. Afr. and elsewhere.

\section{Verbena scabra Vahl. Sandpaper vervain. Fig. 654.}

Stems to $1 \mathrm{~m}$. tall, erect, solitary, simple or branched, hispidulous; leaves ovate, 3-13 cm. long, to $5 \mathrm{~cm}$. wide, petiolate, acute or obtusish, serrate-dentate, very rough and usually strigillose above, less scabrous and paler beneath, hispidulous on the venation; spikes paniculate, slender, pedunculate, closely many-flowered; bractlets ovate-acuminate, half as long as the calyx, hispidulous; calyx $2.5-3 \mathrm{~mm}$. long, ovoid, hispidulous, diverging from the rachis by $45^{\circ}$ or more, the unequal lobes acutely connivent; corolla blue, the tube about equaling the calyx, limb 2 $\mathrm{mm}$. wide, lobes obtuse; stigmatic surface midway between 2 almost equal obtusish sterile style lobes.

Mostly rich soil of low ground, marshes, swamps and edges of lakes and streams, Okla. (Cherokee Co.) and throughout most of Tex. except Plains Country, N. M. (Eddy Co.) and Ariz. (Gila, Pinal, Santa Cruz and Pima cos.), Mar.Dec.; N.C. to Fla. and W.I., w. to Ariz., Calif. and n. Mex.

Forma angustifolia Moldenke differs in having elliptic-lanceolate leaves only to $2 \mathrm{~cm}$. wide; known only from Burnet Co., Tex. 


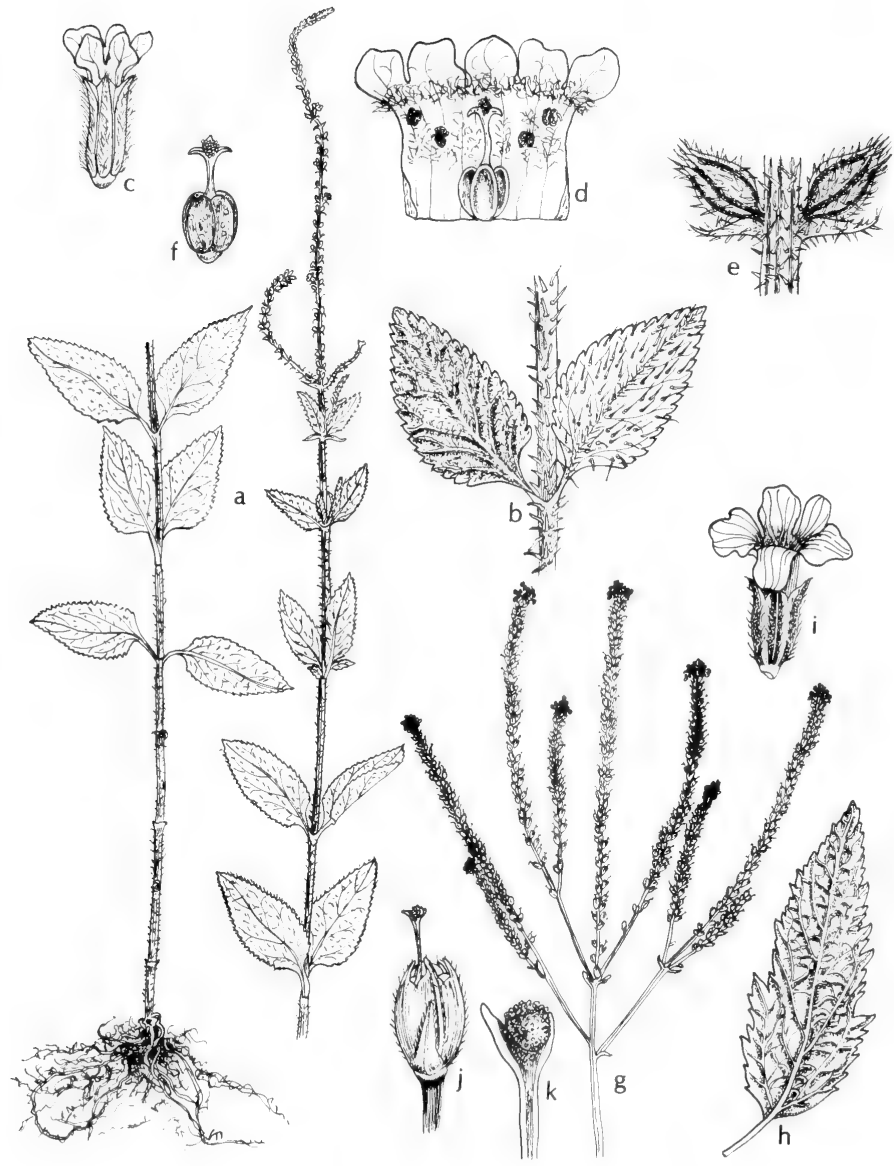

Fig. 654: a-f, Verbena scabra: a, habit, x 1/2; b, leaves, x 1; c, flower, $x$ 71/2; d, open corolla, x 71/2; e, fruit, x 5; f, nutlet with style and stigma, x 71/2. g-k, Verbena hastata: $\mathrm{g}$, inflorescence, $\mathrm{x} 1 / 2$; $\mathrm{h}$, leaf, $\mathrm{x} \mathrm{1/2}$; $\mathrm{i}$, flower, $\mathrm{x} \mathrm{5} ; \mathrm{j}$, fruit, $\mathrm{x} 5$; $\mathrm{k}$, style and stigma, x 10. (V. F.). 


\section{Verbena urticifolia L. White vervain.}

Stems solitary, to $25 \mathrm{dm}$. tall, coarse, simple or branching from near the base, hispid or hirtellous to almost glabrous; leaves petiolate, broadly lanceolate to oblong-ovate, $8-20 \mathrm{~cm}$. long, acute or shortly acuminate, coarsely crentate-serrate, rounded at base and decurrent into the petiole, glabrous on both surfaces or scattered-pilose with rather long irregular hairs beneath; spikes paniculate, slender, pedunculate, rather sparsely flowered, often very elongate; bractlets ovate-acuminate, very short, ciliate; calyx $2 \mathrm{~mm}$. long, pubescent (especially on the veins), the obtuse lobes not connivent, the short and subequal teeth subulate; corolla white, very small, the tube scarcely surpassing the calyx, limb $2 \mathrm{~mm}$. wide, lobes obtuse.

Low rich or open woods, wet meadows, thickets, river floodplains and bottomlands, waste places, fencerows, pastures and streamsides, Okla. (Murray Co.) and in Tex. from Bowie and Wilbarger to Newton, Brazoria and Gonzales cos., also in Wheeler Co. in the Panhandle, June-Oct.; Que. and Ont. to Neb., s. to Fla. and w. to Tex. and Okla.

Var. leiocarpa Perry \& Fern. differs in having the lower leaf surface uniformly and densely short-pubescent; known from Cass Co., Tex.; it occurs sporadically almost throughout the extra-limital range of the species.

\section{Verbena hastata L. Blue vervain. Fig. 654.}

Stems to $23 \mathrm{dm}$. tall, mostly simple, stiffly erect, often branched above, mostly rough-pubescent with short antrorse hairs; leaves lanceolate or oblong-lanceolate, occasionally ovate-lanceolate, petiolate, 5-18 cm. long, gradually acuminate, coarsely serrate or incised, sometimes hastately 3-lobed at base, glabrous or slightly pubescent, not scabrous; spikes usually numerous, paniculate, stiffly erect, pedunculate, compact, densely many-flowered; bractlets lanceolate-subulate, usually a little shorter than the calyx; calyx 2.5-3 mm. long, pubescent, the acute lobes with short subulate tips and more or less connivent; corolla purplish-blue, the tube somewhat longer than the calyx, pubescent outside, the limb 3-4.5 $\mathrm{mm}$. wide.

Moist fields, wet meadows, prairies, swamps, woods and streamsides, edge of ponds, lakes and sloughs, often forming large conspicuous colonies in wetlands, in Okla. (Ottawa Co.), the Tex. Plains Country, N.M. (Grant Co.) and Ariz. (Coconino and Yavapai cos.), July-Oct.; N.S. to B.C., s. to Fla., Neb. and Ariz.

In dry fields and pastures a field-form is developed with the leaves more canescent-puberulous beneath and slightly rough above, the stem many-branched, and the terminal inflorescences in many groups, all more or less equally dense.

Var. scabra Moldenke differs in its more rigid leaves that are conspicuously scabrous above and often more or less conspicuously pubescent beneath; known from Hemphill Co., Tex.; a western form of the species, B.C., Ida., Mont. and N.D. to Calif., N.M. and Tex., e. to Wisc. and Kan.

\section{Verbena Macdougalii Heller. New Mexican vervain.}

Stems to $1 \mathrm{~m}$. tall, stout, obtusely tetragonal, simple or occasionally branched, ashy-green, hirsute-pubescent; leaves oblong-elliptic or elongate-ovate, $6-10 \mathrm{~cm}$. long, short-petiolate or narrowed into a subpetiolar base, coarsely and irregularly serrate-dentate, hirtellous, rugose and minutely pustulate above, densely pilosepubescent and prominently veined beneath; spikes solitary or sometimes several, thick, comparatively dense both in anthesis and in fruit; bractlets lanceolatesubulate, usually longer than the calyx, pubescent, ciliate; calyx 4-5 mm. long, rather densely pubescent, the very obtuse lobes ending in short subulate teeth; corolla deep-purple, the tube scarcely surpassing the calyx, the limb $6 \mathrm{~mm}$. wide.

On flats at high elev., in wet mt. meadows and valleys, w. Tex. (Culberson Co.), N.M. (widespread in mts.) and Ariz. (Apache, Navajo, Coconino, Greenlee, 
Yavapai and Pima cos.), June-Oct., also s. Wyo. and cen. Ut.

\section{Verbena bracteata Lag. \& Rodr. Prostrate Vervain.}

Stems usually several from a common base, diffusely branched, prostrate or decumbent, rarely erect, coarsely hirsute; leaves $1-6 \mathrm{~cm}$. long, pinnately incised or 3-lobed (lateral lobes narrow and divaricate, middle lobe large, cuneate-obovate, incised-dentate or cleft), narrowed into a short margined petiole, hirsute on both surfaces, larger venation slightly prominent beneath; spikes terminal, sessile, ascending, rather thick, conspicuously bracteose; bractlets much longer than the calyx, spreading-ascending, recurved in age, coarsely hirsute, foliaceous, the lowermost often incised, the upper linear-lanceolate, acute to acuminate and entire; calyx 3-4 mm. long, hirsute especially on the veins, the very short lobes connivent; corolla bluish to lavender or purple, the tube slightly surpassing the calyx, very finely pubescent outside, the limb $2.5-3 \mathrm{~mm}$. wide. V. bracteosa Michx.

Low and newly cleared ground, in mud about lakes, ponds and along sloughs, river bottoms, grassy places, waste ground and roadsides, in Tex. from the TransPecos and Plains Country through the Edwards Plateau e. to Newton Co., Okla. (Waterfall), N. M. (widespread) and Ariz. (throughout state), Apr.-Oct.; almost throughout the w. U. S. and s. Can., introd. and local eastw.

\section{Verbena Runyonii Moldenke. Rio Grande vervain.}

Stems erect, coarse, to $14 \mathrm{dm}$. tall, green, rather stout, sharply tetragonal, sparsely hirsutulous with short whitish divergent hairs especially on the angles and the nodes, glabrescent in age but more or less scabrellous on the angles; leaves sessile, clasping, 2-6 cm. long, 8-30 mm. wide, more or less 3-parted with each division pinnatifid-incised with broad acute teeth, abundantly hirsutulous on both surfaces with rather short whitish hairs that are bulbous-based, the upper surface scabrous on older leaves; spikes compound, the branches slender, erect, 14-25 cm. long, rather closely many-flowered, often with 1 to 3 pairs of much reduced leaves near the base; flowers with a faint odor, very densely imbricate before and during anthesis, rather uniformly separated in fruit; peduncles and rachis slender, sharply tetragonal, spreading-pilose and glandular, the hairs very short; bractlets linear-lanceolate, $3 \mathrm{~mm}$. long, equaling the calyx, sharply attenuate, rather sparsely puberulent and glandular, sparsely and irregularly ciliolate toward the base; calyx $3 \mathrm{~mm}$. long, glandular-pilose with short spreading hairs; corolla blue, $6 \mathrm{~mm}$. long, tube puberulent at apex outside, limb $4 \mathrm{~mm}$. wide.

Mostly in moist or wet ground, open fields, banks, resaca bottoms, ditches and roadsides in Tex. from Hidalgo and Cameron cos. along the coast to Nueces Co., Feb.-June; also N. L.; introduced in Ore.

F. rosiflora L. I. Davis differs in having rose-colored corollas; known only from Cameron Co., Tex.

\section{Lantana L. LANTANA}

A genus of about 160 species and 75 named varieties and forms, mostly natives of tropical and subtropical America; a few also in tropical Asia and Africa.

\section{Lantana horrida H.B.K. Texas lantana, hierba de cristo, calico bush}

Shrub to $2 \mathrm{~m}$. tall, much-branched; stems and branches unarmed or with many stout recurved prickles, glabrous to sparsely hirsute, the younger ones often more hirtellous; petioles 2-12 mm. long, pilose-hirsute; leaf blades ovate or subrotundovate, usually $3-5 \mathrm{~cm}$. long and $2-4 \mathrm{~cm}$. wide, acute or obtuse, usually truncate or subtruncate at base, often very shortly cuneate-attenuate into the petiole, very coarsely serrate from apex almost to base with large rather irregular widely spread- 
ing acute or obtuse teeth, short-strigose and very scabrous above, subglabrate to puberulent or hirtellous on the venation beneath, often sub-bullate above; peduncles 3-9 cm. long, usually slightly surpassing the leaves, subglabrate to hispidulous; bractlets narrow-lanceolate or oblong, 4-9 mm. long, 1-2 mm. wide, acute, strigillose, the innermost usually one half the length of the corolla, the outermost often larger and forming an involucre subequaling the corolla tube; heads hemispheric, $2-3 \mathrm{~cm}$. wide, densely many-flowered, not elongating; corolla very showy, yellow to orange or red, the tube 7-10 $\mathrm{mm}$. long, densely pubescent outside, limb 5-9 mm. wide; fruit black or dark-blue, edible.

Fields, thickets, swamps, rich sandy woods, scrub, gravelly hills, flats, bank of streams, chaparral and roadsides, often in large patches, almost throughout Tex., except the n.w., N.M. (Moldenke) and Ariz. (Pima Co.); also cult. and in Calif., n. Mex., and introd. in N.C. and Miss.

\section{Lippia Houst. LIPPIA}

A genus of about 206 species and 44 named forms and varieties, widely distributed in subtropical and tropical America; a few also in tropical portions of the Old World.

1. Lippia alba (Mill.) N. E. Br. Bushy Lippia, alfombrilla, Cidrilla, hierba BUENA, ORÉGano dE BURRo, SALVA DO BRASIL, SALVA COLORADo, TÉ DE CASTILla, TORONJIL DE ESPAÑA, HIERBA NEgRA, HIERBA DEL NEGRO.

Aromatic shrub to $2 \mathrm{~m}$. tall, usually much-branched, with long rooting suckers at base; branches elongate, slender, ascending, pubescent; leaves often ternate; petioles 3-8 mm. long, gray-pubescent; leaf blades ovate or oblong, 2-7 cm. long, 12-23 mm. wide, acute or obtuse, serrate or serrulate except at base, cuneately narrowed into petiole at base, puberulent or strigose-hirtellous and rugose (when mature) above, densely short-pubescent or tomentose beneath; inflorescence axillary, capitate, mostly much shorter than the leaves or only subequaling the petiole, solitary or rarely paired in all the upper leaf axils; heads subglobose or shortoblong, 8-12 mm. long; bractlets ovate, 3-5 mm. long, the lowermost 3-3.5 mm. wide, nearly as long as the corollas; corolla purple to violet, pink or white, the tube 4-5 mm. long. L. geminata H.B.K.

Woods, low wettish bottomlands, river banks and resacas, Hidalgo and Cameron cos. n.e. to Wharton Co. in Tex., Mar.-Oct.; widespread in W.I., Mex., C.A. and S.A., introd. elsewhere, widely cult.

\section{Phyla Lour. Frog-Fruit}

Perennial procumbent or creeping herbs, with trailing or ascending stems, sometimes somewhat woody at base or even shrubby, subglabrate or appressedstrigose with more or less cinereous malpighiaceous hairs; leaves opposite, variously dentate except at the base, flat or pinnately plicatulate above; inflorescence spicate, axillary; spikes cylindric, very densely many-flowered, usually greatly elongate in fruit, solitary or paired or ternate in the leaf axils, never aggregated into corymbs or panicles; flowers small, sessile, borne singly in the axils of small cuneate-obovate or flabelliform bractlets, not at all 4-ranked; otherwise with characters of Lippia.

A genus of about 10 species and 10 named forms and varieties, widely distributed in subtropical and tropical America; a few introduced in the warmer parts of the Old World.

1. Leaf blades mostly widest at or below the middle, toothed from below the middle to the apex (2)

1. Leaf blade mostly widest toward the apex and toothed only near the apex (4) 


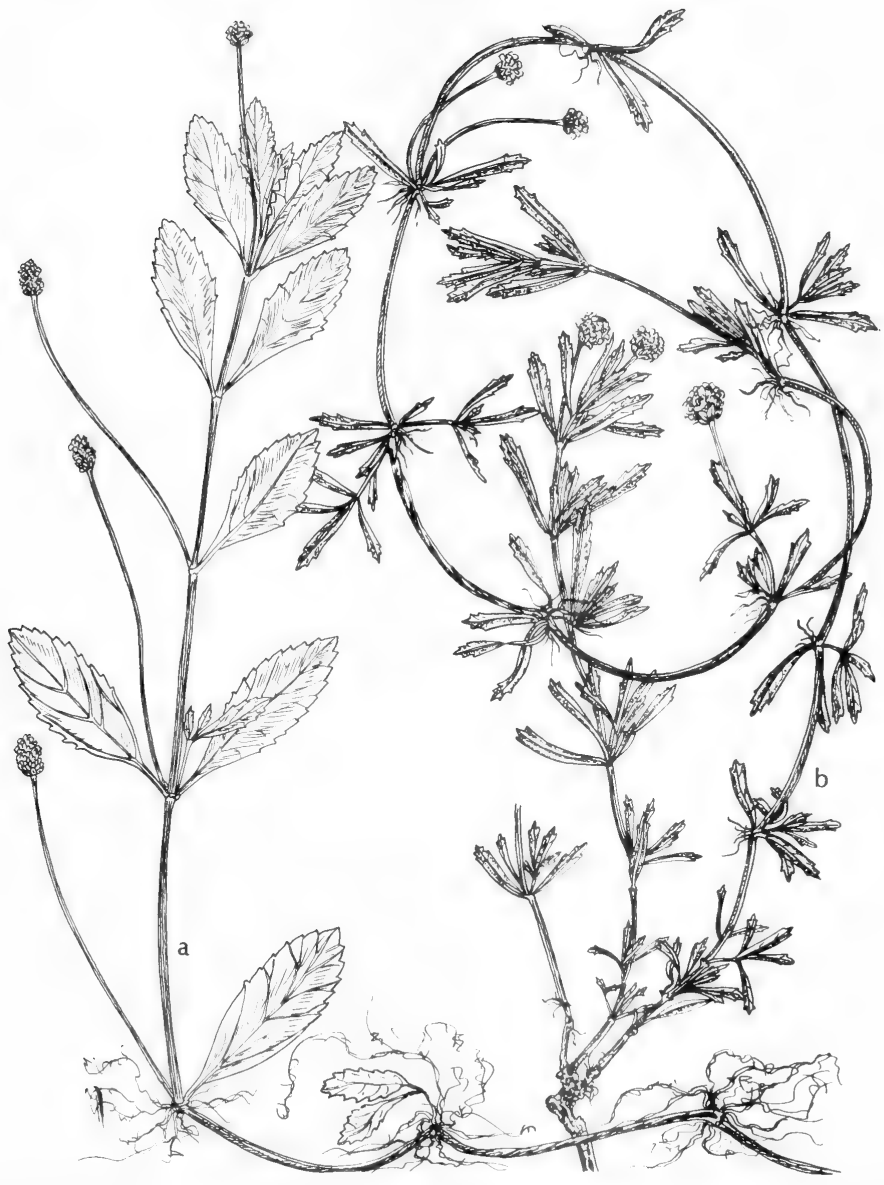

Fig. 655: Phyla lanceolata: a, habit, $x$ 1/2. Phyla cuncifolia: b, habit, x 1/2. (V. F.). 
2(1). Leaf blades mostly oblong-lanceolate or oblong-ovate, mostly widest at or near the middle, not plicatulate, the teeth antrorsely appressed, extending below the widest part of the leaf.............. $P$. lanceolata.

2. Leaf blades mostly ovate or triangular-ovate to rhomboid, often plicatulate, widest below the middle, the teeth coarse and divergent, not extending below the widest part of the leaf (3)

3(2). Mature leaves mostly to $75 \mathrm{~mm}$. long and $20 \mathrm{~mm}$. wide

2. P. strigulosa.

3. Mature leaves mostly less than $15 \mathrm{~mm}$. long and $10 \mathrm{~mm}$. wide

2. P. strigulosa var. sericea.

4(1). Leaf blades with 1 to 4 pairs of remote salient teeth (5)

4. Leaf blades with numerous pairs of small mostly antrorse teeth (6)

5(4). Bractlets 2-3 mm. long, closely imbricate, acute, not conspicuously reflexed; peduncles 1.5 to 4 times as long as the subtending leaf during anthesis; heads $5-10 \mathrm{~mm}$. thick, becoming elongate-cylindric or oblong in fruit; fruit obovoid.................................... P. P. incisa.

5. Bractlets $5 \mathrm{~mm}$. long, wide-spreading, the apex long-acuminate and finally reflexed; peduncles 0.7 to 1.5 times as long as the subtending leaf during anthesis; heads $7-12 \mathrm{~mm}$. wide, usually not elongating in fruit; fruit oval................................................. 4 . P. cuneifolia.

6(4). Leaves uniformly elongate, to $5.5 \mathrm{~cm}$. long, 4-10 $\mathrm{mm}$. wide.

5. $P$. nodiflora var. longifolia.

6. Leaves mostly shorter, cuneate-spatulate to rhomboid, 1-3 cm. long (7)

7(6). Midrib and secondaries usually prominent beneath, often very conspicuous, often impressed above; blades often large and elliptic or rhomboid, coarsely toothed.................................... P. nodiflora var. reptans.

7. Midrib and secondaries usually obscure or indiscernible on both surfaces; blades usually small and spatulate or cuneiform (8)

8(7). Plants usually densely matted, more or less densely strigose-canescent throughout; leaves mostly very small and cuneiform, usually thintextured and few-toothed, sometimes entire or subentire

5. $P$. nodiflora var. rosea.

8. Plants usually creeping and wide-spreading, open in growth, often with ascending branches, usually green and only finely strigillose; leaves mostly larger, cuneate-spatulate or spatulate to obovate, thicktextured, usually more abundantly toothed (9)

9(8). Teeth on leaf blades mostly rather large, coarse and salient-spreading........ 3. $P$. incisa.

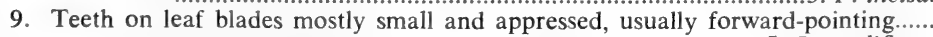
5. P. nodiflora.

1. Phyla lanceolata (Michx.) Greene. Northern frog-fruit. Fig. 655.

Stems procumbent or ascending, to $6 \mathrm{dm}$. long, simple or somewhat branched, often rooting at the nodes, glabrous or obscurely white-strigillose with closely appressed hairs; petioles $5-10 \mathrm{~mm}$. long or obsolete, obscurely appressed-strigillose; leaf blades bright-green on both surfaces, oblong to oblong-lanceolate or ovate, 18-75 mm. long, 5-30 mm. wide, acute or subacute, sharply serrate to below the middle, widest at or below the middle, narrowed to the cuneate base, rather obscurely appressed-strigillose on both surfaces, venation flat but conspicuous above, rather prominent and very conspicuous beneath; inflorescence equaling or surpassing the leaves; peduncles $4-9 \mathrm{~cm}$. long, rather sparsely and obscurely whitestrigillose; heads at first globose, later cylindric and elongating to $35 \mathrm{~mm}$. and 5-7 $\mathrm{mm}$. wide; bractlets obovate, closely imbricate, $3 \mathrm{~mm}$. long, acute, appressedstrigillose; corolla pale-blue, purplish or white. Lippia lanceolata Michx. 
Moist soil of river bottoms, lake shores and coastal marshes, in swamps and in and about water of sloughs, ditches and ponds, and savannahs, in Okla. (McCurtain, Mayes, Cherokee, Woodward, Ottawa, Grady and Alfalfa cos.), in most of Tex. except in the extreme w., N. M. (Chaves Co.) and Ariz. (Pima and Mohave cos.), May-Oct.; also Ont, to Minn., N.J., Ill., Kan., Fla., Calif. and n. Mex.

\section{Phyla strigulosa (Mart. \& Gal.) Moldenke. Diamond-Leaf Frog-Fruit, turRe HEMBRA, HIERBA BUENA MONTES.}

Procumbent, freely branched from the base; branches rooting at the nodes, to $2 \mathrm{~m}$. long, often sulcate, often reddish to purplish toward the base, graystrigillose with closely appressed antrorse hairs, the tips ascending or erect; petioles 1-5 mm. long, mostly winged, rather obscurely canescent-strigillose or glabrescent; leaf blades mostly broadly ovate or triangular-ovate to rhomboid or ovate-elliptic, mostly conspicuously widest below the middle, to $75 \mathrm{~mm}$. long and $2 \mathrm{~cm}$. wide, rounded or acute (in outline) and at apex, abruptly acuminate at base and prolonged into the petiole, conspicuously and regularly coarse-dentate from apex to the widest part with sharply acute or apiculate broadly triangular rather divergent teeth (their margins often thick and involute), both surfaces rather densely but microscopically canescent-strigillose, often plicatulate, the larger venation white and very prominent beneath; peduncles $25-55 \mathrm{~mm}$. long, deeply sulcate, densely canescent-strigillose or glabrescent; heads 4-8 cm. long, later elongating; bractlets ovate to obovate, $3 \mathrm{~mm}$. long, $1.5 \mathrm{~mm}$. wide, sharply acute or acuminate, densely canescent-strigose, strongly costate; corolla about $3 \mathrm{~mm}$. long, white, sometimes lavender- or purple-tinged in age, limb $1.5 \mathrm{~mm}$. wide. Lippia strigulosa Mart. \& Gal., $P$. yucatana Moldenke.

Fields, woods, open ground, swamps, sandy stream banks and muddy hollows, in Tex. in the Rio Grande Plains and Valley, Feb.-May; widespread from Mex. and Gr. Ant. through Virg. I., C.A. and S.A.

Var. sericea (O. Ktze.) Moldenke differs in having the mature leaves to $15 \mathrm{~mm}$. long and $1 \mathrm{~cm}$. wide. Incl. var. parviflora (Moldenke) Moldenke. In Tex. in the Rio Grande Plains and Valley, Feb.-May; also Mex., Bah. I., W. I., Trin. and Venez.

\section{Phyla incisa Small. Texas frog-Fruit.}

Stems mostly prostrate, often swollen and rooting at the nodes, simple or branched, often purplish, appressed-strigillose; branches decumbent to ascending or erect, abundantly appressed white-strigose; petioles usually obsolete or 1-3 $\mathrm{mm}$. and winged; leaf blades often thick-textured, narrow-oblong or cuneiform to broadly obovate, very variable, $1-5 \mathrm{~cm}$. long, 2-15 $\mathrm{mm}$. wide, acute to obtuse or rounded (in outline) at apex, usually with only 1 to 4 pairs of coarse and saliently spreading teeth near the apex, cuneate from the middle or above the middle to the base, appressed-strigillose on both surfaces with small inconspicuous white hairs, secondary venation mostly obscure on both surfaces; inflorescence usually much-surpassing the subtending leaves; peduncles $2-9 \mathrm{~cm}$. long, appressed-strigillose; heads at first globose, later cylindric and elongating to $3 \mathrm{~cm}$., 5-10 mm. wide; bractlets obovate, $2-3 \mathrm{~mm}$. long, closely imbricate, acute, abundantly whitestrigillose; corolla white with yellow center, the tube $2-2.5 \mathrm{~mm}$. long, limb $2 \mathrm{~mm}$. wide. Lippia incisa (Sriall) Tidestr.

Open ground, fields, pastures, wet clay or sandy flats, dry river banks and bottoms, floodplains, damp or wet shady woods and seashores, in Okla. (Pittsburg, Kiowa and Jefferson cos.), practically throughout Tex., N.M. (Dona Ana, Otero, Luna and Socorro cos.) and Ariz. (Apache, Yuma and Pima cos.), Mar.-Nov.; Colo., Okla. and Mo. to N.M., Ariz., s. Calif. and n. Mex. 
4. Phyla cuneifolia (Torr.) Greene. Wedge-leaf frog-fruit. Fig. 655.

Stems branching from a woody base, procumbent, often rooting at the nodes to $1 \mathrm{~m}$. long. sparsely appressed-strigillose with very short white hairs, fractiflex, often with short erect branchlets at the nodes; leaves sessile, rigid, thicktextured, often with a fascicle of smaller ones in the axils, linear-oblanceolate or cuneiform, often canescent when young, $1-5.2 \mathrm{~cm}$. long 2-8 $\mathrm{mm}$. wide, acute or subacute, with 2 to 8 very sharp and often salient teeth above the middle or rarely entire, gradually attenuate to the cuneate base, appressed-strigillose on both surfaces, secondary venation indiscernible on both surfaces; inflorescence shorter than or slightly surpassing the leaves; peduncles $8-50 \mathrm{~mm}$. long, obscurely appressed-strigillose; heads at first globose, later cylindric and elongating to $2 \mathrm{~cm}$., 8-12 mm. wide; bractlets conspicuous, obovate, $5 \mathrm{~mm}$. long and $3 \mathrm{~mm}$. wide, abruptly long-acuminate, at least the tip soon wide-spreading and finally reflexed scarious on the upper margins, densely appressed-strigillose; corolla whitish or purplish, the tube 4-5 $\mathrm{mm}$. long, limb 2-4.5 $\mathrm{mm}$. wide. Lippia cuneifolia (Torr.) Steud.

Plains and low prairies, wet banks of irrigation ponds and ditches, playa lakes and stream beds, in Okla. (Cimarron Co.), mostly in cen. and w. Tex., N.M. (Union, McKinley, Roosevelt, Quay and San Miguel cos.) and Ariz. (Apache to Coconino, Yavapai and Cochise cos.) May-Sept.; also S.D., Neb. and N.M. to Ariz., s. Calif. and n. Mex.

5. Phyla nodiflora (L.) Greene. Common frog-Fruit, Cape-Weed, turkeyTANGLe, MAT-GRASS, hierba dE LA vírgen MARía. Fig. 656.

Stems prostrate, to $9 \mathrm{dm}$. long, mostly rooting at the nodes; branches procumbent or ascending, glabrate or puberulent to appressed-strigillose; petioles obsolete or 2-8 $\mathrm{mm}$. long and cuneate-winged; leaf blades thick-textured, spatulate to oblanceolate or obovate, sometimes elliptic or cuneiform, 1-7.2 cm. long, 6-25 mm. wide, rounded or obtuse to subacute at apex, cuneate into the petiole, rather regularly sharply serrate above the middle with numerous appressed antrorse acute or acuminate teeth, glabrous or strigillose-puberulent on both surfaces, secondary venation practically indiscernible on both surfaces; peduncles usually much lorger than the leaves, to $11.5 \mathrm{~cm}$. long, appressed-puberulent or strigose with antrorse canescent hairs or glabrous; heads at first globose, cylindric in age and elongate to $25 \mathrm{~mm}$., 6-9 mm. thick; bractlets closely imbricate, obovate or subrhomboidcuneate, subequaling the corolla tube, often rather broadly membranous-margined toward the apex, mucronate-acuminate or muticous, glabrous or finely ciliate; corolla rose-purple or white, $2-2.5 \mathrm{~mm}$. long, slightly surpassing the bractlets, slightly strigillose outside, limb exiguous. Lippia nodiflora (L.) Michx.

Wet or moist soil, fields, clearings, hillsides, ditches, thickets and beaches, along the Tex. coast from Chambers to Cameron cos., inland to Kendall, Tom Green and Childress cos., May-Oct.; almost cosmopolitan in subtrop. and trop, regions of the Old World and New World; Pa. to Fla., Ky., Ark., La., Okla. and Calif.

Var. longifolia Moldenke differs in having much more uniformly elongate leaves, the blades being oblanceolate-cuneate, to $55 \mathrm{~mm}$. long and $4-10 \mathrm{~mm}$. wide, and sharply spreading-dentate toward the apex; open sandy wettish flats near the seacoast, Cameron Co., Tex.; also along the coasts of Mex., C.A. and w. S.A.

Var. reptans (H.B.K.) Moldenke differs in usually being more densely strigose throughout and having the leaves thinner in texture, often rhomboid-elliptic, with the teeth usually more spreading and the larger venation firmer and more or less prominent beneath; low moist ground, shaded places, clearings, ditches, lawns and roadsides, in Tex. from Presidio to Cameron and Chambers cos., n. to Dallas and Wichita cos., Feb.-Sept.; occurring sporadically almost throughout the range of the species. 


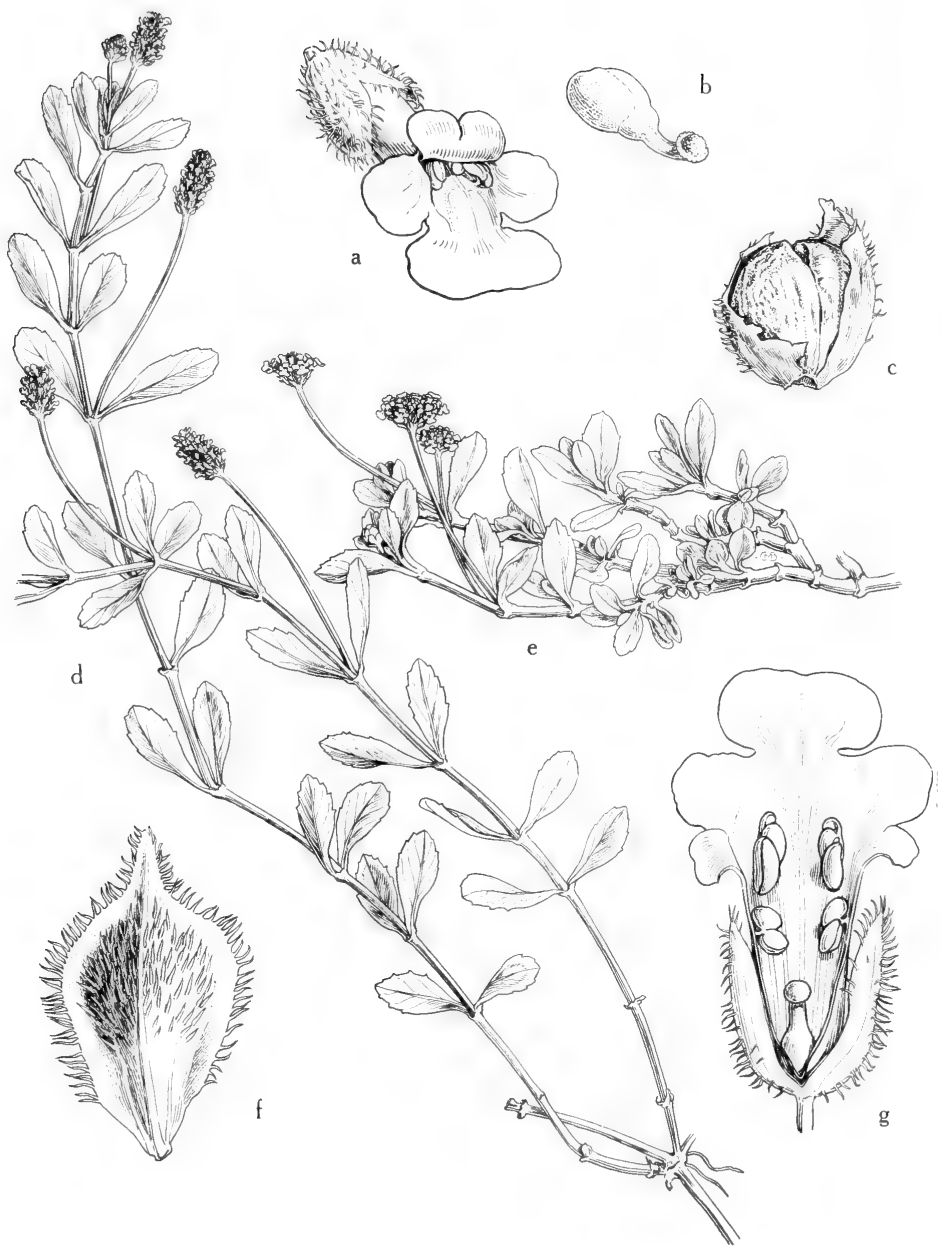

Fig. 656: Phyla nodiflora: a, flower, x 12; b, pistil, x 12; c, nutlets, x 12; d, habit, decumbent plant, the spikes in fruit $\mathrm{x} 2 \% 3$; e, habit, prostrate plant, the spikes in flower, $\mathrm{x} 2 / 3, \mathrm{f}$, bract of the inflorescence, $\mathrm{x} 12 ; \mathrm{g}$, flower, split longitudinally on adaxial side, x 12. (From Mason, Fig. 298). 
Plants herbaceous annuals or perennials with spreading rhizomes, occasionally woody shrubs; stems typically square; leaves opposite; flowers variously arranged; calyx usually more or less 2-lipped, the upper 3 teeth more or less joined, the lower pair of teeth usually free, occasionally all teeth subequal, the tube mostly enlarged in fruit; corolla obscurely to distinctly 2 -lipped, the upper 2 petals usually joined to form an erect sometimes galeate lip that includes the stamens or sometimes very short and deeply notched, occasionally with the 5 lobes subequal, the lower lip usually spreading with its midlobe sometimes dipperlike; stamens 2 or 4 , mostly in 2 unequal pairs, the connective sometimes strongly developed at the expense of the filament; anthers parallel or divergent, with one cell sometimes completely or partly aborted; style bifid at apex, arising between the quite distinct lobes of the 4-lobed ovary or from near the apex of the ovary when the lobes (and the cocci) are partly united below.

A large family of about 3,500 species in 180 genera of world-wide distribution.

The typically aromatic plants provide many herbs used as condiments. The family contains numerous important honey plants.

1. Ovary 4-lobed; style not basal; cocci almost completely united, laterally or obliquely attached.

1. Teucrium

1. Ovary of 4 distinct or nearly distinct lobes; style basal; cocci essentialiy free, basally attached (2)

2(1). Calyx 2-lipped, the lips entire

2. Scutellaria

2. Calyx regularly 5- (rarely 10 -) toothed or 2-lipped with 3 teeth on the upper lip and 2 teeth on the lower lip (3)

3(2). Stamens declined toward or resting on the lower lip of the corolla, 2 long and 2 short; corolla declined, the upper lip with 4 entire lobes, the lower lip saccate and abruptly deflexed at the contracted and callous base.

3. Hyptis

3. Stamens not declined and resting on the lower lip of the corolla (4)

4(3). Fertile stamens 4, all with 2-celled anthers; upper lip of corolla usually but not always galeate or concave (5)

4. Fertile stamens 2 or (if 4) the upper pair shorter than the lower pair and the upper corolla lip neither galeate nor concave (10)

5(4). Upper pair of filaments longer than the lower pair (6)

5. Upper pair of filaments shorter than the lower pair (8)

6(5). Anther sacs parallel or nearly so; stamens evidently exserted, readily visible......

4. Agastache

6. Anther sacs widely divergent; stamens ascending under the more or less galeately rounded upper lip of the corolla, scarcely or not at all exserted (7)

$7(6)$. Calyx regular or nearly so, with subequal teeth

5. Nepeta

7. Calyx strongly irregular, with the upper teeth much broader than the other 4 6. Dracocephalum

8(5). Calyx strongly 2-lipped

7. Prunella

8. Calyx not 2-lipped, the Iobes essentially similar (9)

9(8). Tube of the calyx faintly nerved, inflated at maturity. 8. Physostegia

9. Tube of the calyx prominently 5- or 10-nerved, not inflated at maturity. 
10(4). Functional stamens 2, ascending and parallel, the upper pair wanting or rudimentary; anthers mostly appearing to be 1-celled; corolla strongly 2-lipped (11)

10. Functional stamens 2 or (if 4 ) with the upper pair shorter than the lower pair; anthers always 2-celled; corolla scarcely 2-lipped, the upper lip neither galeate nor curved (12)

11(10). Connective of the anther elongated, usually but not always bearing a perfect sac at one end and a rudimentary sac at the other end, very rarely 2 -celled. 10. Salvia

11. Connective of the anther short; anther sacs confluent. 11. Monarda

12(10). Flowers in loose terminal racemes or panicles, slender-pedicelled. 12. Perilla

12. Flowers in axillary whorls or clusters that sometimes form terminal spikelike racemes or panicles (13)

13(12). Corolla regular or essentially so, with 4 or 5 equal lobes (14)

13. Corolla more or less 2-lipped; upper corolla lip erect, entire or emarginate (15)

14(13). Fertile stamens 2; flowers white, clustered in the axils of reduced upper leaves; foliage scarcely aromatic... 13. Lycopus

14. Fertile stamens 4; flowers purplish to bluish or white, spicate or clustered in upper axils; foliage strongly aromatic........................14. Mentha

15(13). Stamens distant and straight, often spreading-divergent, never connivent nor curved.....................................................15. Pycnanthemum

15. Stamens ascending or arched, commonly converging or ascending parallel under upper lip of corolla (16)

16(15). Calyx with 5 subequal lobes, scarcely 2-lipped; leaves more or less orbicular......

16. Micromeria

16. Calyx distinctly 2-lipped, the lobes unequal; leaves of a linear type.

17. Satureja

\section{Teucrium L. Germander}

Perennial herbs to $15 \mathrm{dm}$. high, with simple serrate leaves and the flowers in terminal slender spikes or smaller annual or perennial plants with at least some of the leaves pinnatifid and with the flowers in the axils of the reduced upper leaves; calyx saccate, toothed or deeply 5-lobed; corolla pinkish to bluish or pallid, the upper lip very short and deeply notched, the lower lip conspicuous and spreading, with small lateral lobes; stamens 4 , paired, exserted from the deep cleft between the 2 upper lobes of the corolla; cocci roughened.

About 300 species in temperate and tropical regions of both hemispheres.

1. Leaf blades toothed, pubescent on lower surface; flowers in a terminal bracteate spike; corolla lavender with dark spots...........1. T. canadense.

1. Leaf blades noticeably lobed (especially the lower ones), glabrous; flowers in the axils of the reduced upper leaves; corolla white with pink to purple markings toward the base. 2. T. cubense.

\section{Teucrium canadense L. American germander, wood Sage. Fig. 657.}

Perennial herb as much as $1 \mathrm{~m}$. tall, with creeping rootstocks and erect stems that branch chiefly in the inflorescence, the latter usually silvery with closely appressed minute hairs, sometimes pubescent with fine appressed hairs, curled hairs or hirsute with elongate spreading or deflexed glandular or eglandular hairs, rarely glabrate; leaves prevailingly $6-10 \mathrm{~cm}$. long and $2-4 \mathrm{~cm}$. broad, narrowly elliptic to oval or ovate, acute to acuminate or rarely obtuse at apex, generally narrowed below the middle but sometimes rounded at the base or even subtruncate, 


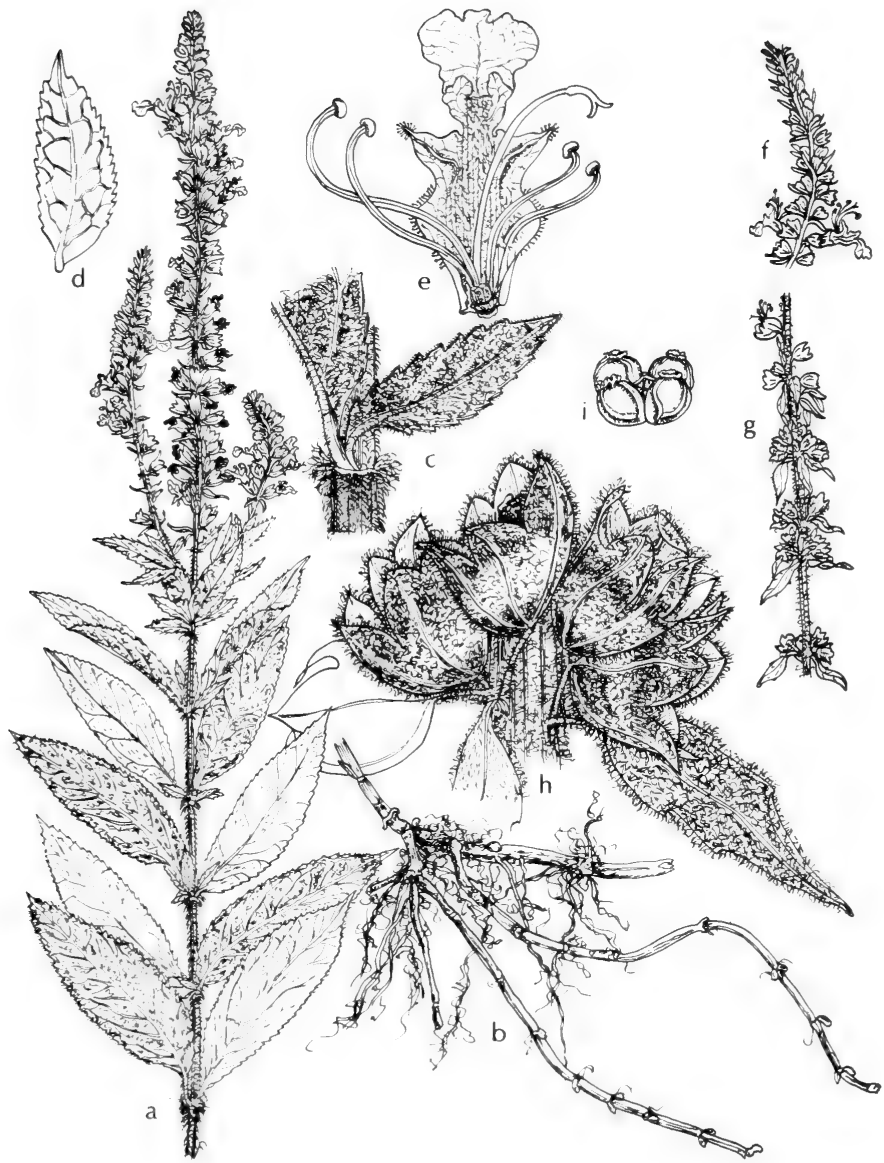

Fig. 657: a-e, Teucrium canadense var. canadense: a, upper part of plant, $\mathrm{x} 1 / 2$; $b$, lower part of plant, $x{ }_{12}^{1}$; c, part of leaf and stem, $x 31 \frac{1}{2}$; d, veins of leaf, $x 1$; e, flower split open, x $2^{1}$. f-i, Teucrium canadense var. occidentale: $\mathrm{f}$ and $\mathrm{g}$, parts of inflorescence, $x 1_{2} ; h$, fruit in the leaf axils, $x 3 \frac{1}{2} ; \mathrm{i}$, nutlets, $x 3 \frac{1}{2}$. (V. F.). 


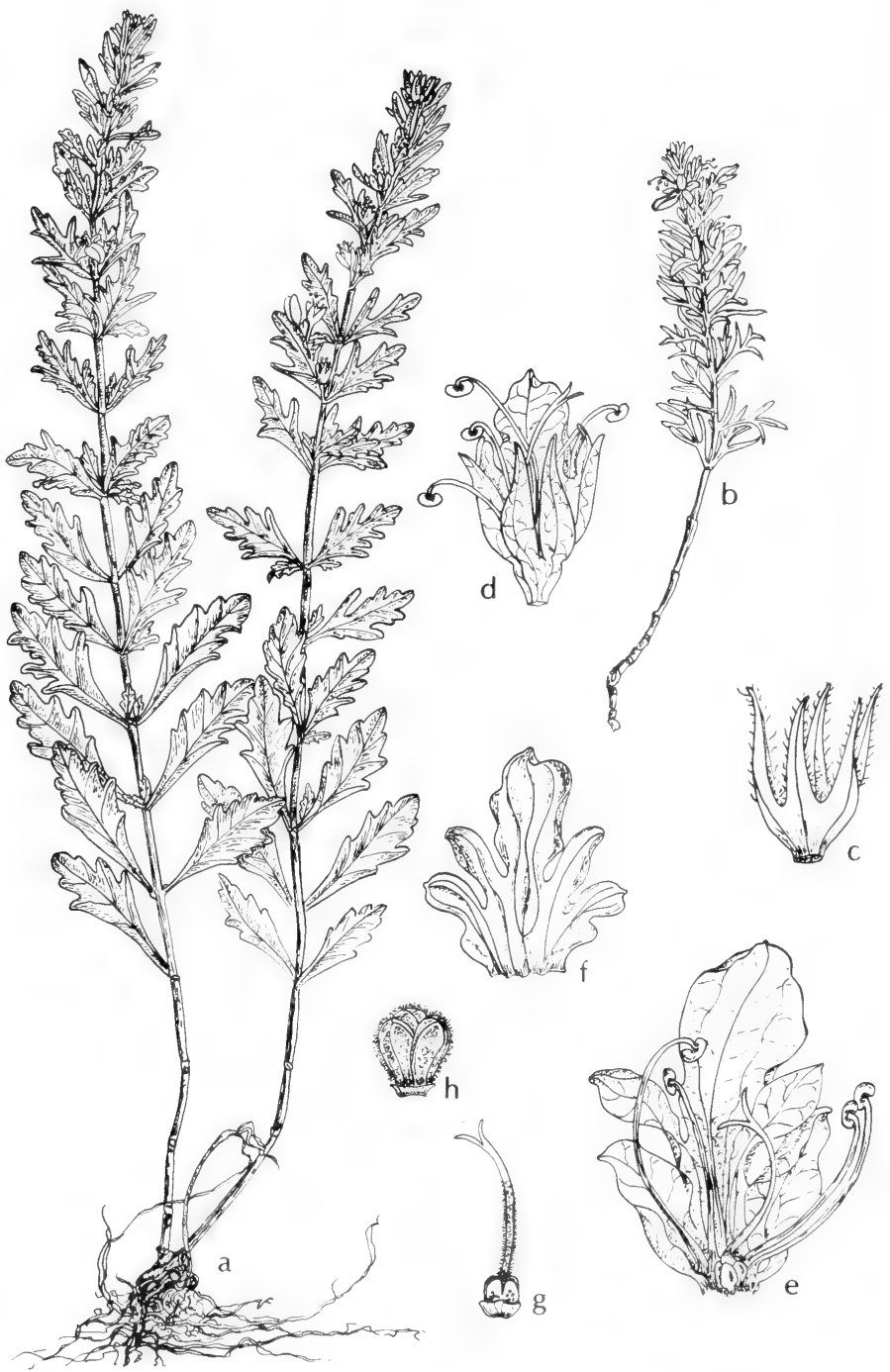

Fig. 658: Teucrium cubense: a, habit, $\mathrm{x} 1 / 2 ; \mathrm{b}$, top of plant showing variation in

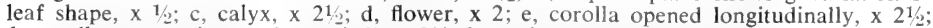
f, corolla, outer view, $x 2 ;$ g, pistil, $x 2 \frac{1}{2} ;$ h, nutlets, $x 2 \frac{1}{2}$. (V. F.). 
obscurely or strongly toothed, the upper surfaces glabrous or variably pubescent with curled or straight hairs or variably hirsute with elongate stiffish glandular or eglandular hairs, the lower surfaces silvery with minute closely appressed hairs or pubescent with small curled hairs or even tomentose with longer curled hairs or hirsute with glandular spreading hairs, rarely glabrous; median petioles to 15 $\mathrm{mm}$. long: flowers subsessile, disposed in usually dense conspicuously bracteate spikes 2-3 dm. long, the bracts usually exceeding the calyces; flowering calyces 5-7 mm. long, silvery with minute appressed hairs or pubescent with curled and spreading glandular hairs or hirsute with elongate mostly glandular hairs, these variably combined in some forms, the tube enlarged and cuplike at maturity but scarcely saclike or inflated, the orifice oblique; calyx teeth deltoid, the three upper more or less joined and tending to be obtuse or blunt, the two lower more or less acute or acuminate and generally about $2 \mathrm{~mm}$. long; corolla $11-18 \mathrm{~mm}$. long, the tube 4-7 mm. long; cocci glabrous, wrinkled. Inc. var. virginicum (L.) Eat., T. virginicum $\mathrm{L}$.

In water and mud along streams and canals, about lakes, in marshes and wet grassy swales throughout Tex., Okla. (Alfalfa, Caddo, Haskell, Choctaw, McCurtain, Logan, Jefferson, Johnston and Murray cos.), N. M. (Colfax, Valencia, San Juan, McKinley, Socorro, Dona Ana and Chaves cos.) and Ariz. (Navajo, Yavapai, Graham and Pima cos.), May-Sept.; a variable species that occurs from Que. to B.C., s. to Cuba and Mex.

The following varieties are found in our area.

1. Pubescence very fine and appressed var. angustatum Gray.

1. Pubescence not as above (2)

2(1). Hairs of the stem and lower leaf surface elongate, spreading, dense, more or less glandular; calyx tomentose with short as well as long glandular hairs ( $T$. occidentale Gray)

.var. occidentale (Gray) McCl. \& Epl.

2. Hairs of stem and lower leaf surface minute, curling and eglandular; calyx mostly thinly pubescent with nonglandular hairs........var. canadense.

\section{Teucrium cubense Jacq. Fig. 658.}

Annual or perennial weedy herb; stems usually several from a taproot, branching at the base and often above, more or less bushy, as much as $7 \mathrm{dm}$. high, usually much smaller, glabrous or cinereous with minute spreading or downwardly curled hairs, sometimes pubescent in the inflorescence with longer somewhat curled hairs; basal leaves oblong to obovate, shallowly lobed to crenate or entire, attenuate to petioles that are usually shorter than the blades, soon withering, these passing into the cauline leaves that are variably lobed, these (in turn) passing gradually into the leaves of the inflorescence that are sometimes subentire, sometimes lobed to the middle or sometimes lobed nearly to the base with the lobes linear; flowers with slender pedicels $4-12 \mathrm{~mm}$. long, usually in the upper half of the stem, sometimes nearly to the base; flowering calyces campanulate, glabrous or hirtellous with minute spreading hairs and glandular or sometimes pubescent with longer somewhat curled hairs, 5-10 mm. long, the tubes $2-3 \mathrm{~mm}$. long; calyx teeth 3-6 mm. long, deltoid-lanceolate, closed over the cocci at maturity or spreading; corolla white, often with purple lines in throat, pubescent, tending to be bearded in the throat, 7-15 $\mathrm{mm}$. long, the tube 1-2 $\mathrm{mm}$. long, the lower lip 4-8 $\mathrm{mm}$. long; stamens glabrous, the longer pair 6-8 $\mathrm{mm}$. long; cocci pitted or grooved lengthwise (the grooving may be a function of the degree of maturity), glabrous or pubescent at the tip. Melosma cubense (Jacq.) Small.

In clay or hard sandy loams, along streams and draws, in wet soil along streams, sand-gravel bars subject to flooding, in palm groves and low grassy soils, 
in Tex. along the coast and Rio Grande Plains, w. to the Trans-Pecos, w to Ariz. (Maricopa, Pinal, Santa Cruz, Pima and Yuma cos.), throughout the year; from s.w. U.S., through W. I. to s. S.A.

The following varieties are found in our area:

1. Plant annual, pubescent along the stem and in the inflorescence with scattered long coarse somewhat curled hairs; flowers disposed often nearly to the base of the stems; cocci conspicuously pubescent at the apex with a tuft of hairs; in the Tex. Trans-Pecos westward [T. depressum (Small) $\mathrm{McCl}$. \& Epl.].................................var. densum Jeps.

1. Plant annual or perennial, glabrous or sparingly puberulent along the stem and in the inflorescence; flowers chiefly in upper part of stem; cocci with globular glands or rarely minutely pubescent (2)

2(1). Median leaves irregularly lobed about halfway to the midrib or only deeply crenate; floral leaves 3-lobed to the middle or entire [subsp. chamaedrifolium (Mill.) Epl.].......................................var. cubense.

2. Median leaves mostly 3- or 5-lobed nearly to the midrib, the lobes linear; floral leaves 3-parted nearly to the base [T. laevigatum Vahl, Melosma laevigatum (Vahl) Small]..... subsp. laevigatum (Vahl) $\mathrm{McCl}$. \& Epl.

\section{Scutellaria L. SKULlCAP}

Bitter perennial or annual herbs or subshrubs, commonly rhizomatous or tuberous, not aromatic; flowers 1 to 3 together on short peduncles or pedicels in the axils or often in 1-sided bracted axillary racemes or terminal spikes or racemes; calyx campanulate in flower, splitting to the base at maturity, strongly bilabiate, the lips entire, the upper longer lip usually falling away, in fruit with an appendage or scale; corolla with an elongated curved ascending tube exserted from the calyx, dilated at the throat, the upper lip entire or barely notched, the lateral lobes mostly connected with the upper rather than the lower lip, the lower spreading lobe or lip convex and notched at the apex; stamens 4 , ascending under the upper lip; anthers approximate in pairs, ciliate or bearded, those of the lower stamens 1-celled, those of the upper stamens 2-celled and cordate; cocci variously marked.

About 300 species of wide geographic distribution.

Seeds of some species are eaten by birdlife.

1. Median cauline leaves oblong to linear-lanceolate, entire, tapered at base to a short petiole.

1. S. integrifolia.

1. Median cauline leaves deltoid-ovate to ovate-oblong, more or less dentate or serrate, rounded to somewhat cordate at base (2)

2(1). Median leaves ovate-oblong; petiole mostly $3 \mathrm{~mm}$. long or less; distribution in Texas Panhandle westward......................... S. galericulata.

2. Median leaves broadly ovate to ovate-lanceolate; petiole usually much more than $5 \mathrm{~mm}$. long (3)

3(2). Stems strict and stiffish; calyx and triangular-ovate leaflike bracts subtending the flowers coarsely ciliate on margins; galea and corolla tube 13-22 $\mathrm{mm}$. long; distribution in eastern Texas.

3. S. cardiophylla.

3. Stems mostly weak and spreading; calyx and elliptic-lanceolate bracts subtending the flowers essentially glabrous or minutely puberulent; galea and corolla tube 5-7 $\mathrm{mm}$. long; distribution in northeastern Texas and Oklahoma westward........................................4. S. lateriflora.

1. Scutellaria integrifolia L. Rough SKULlCAP. Fig. 659.

Perennial herb 3-7 dm. high; stems rather slender, 1 or several from a subligneous base, simple or with arched-ascending branches above, often with abbre- 


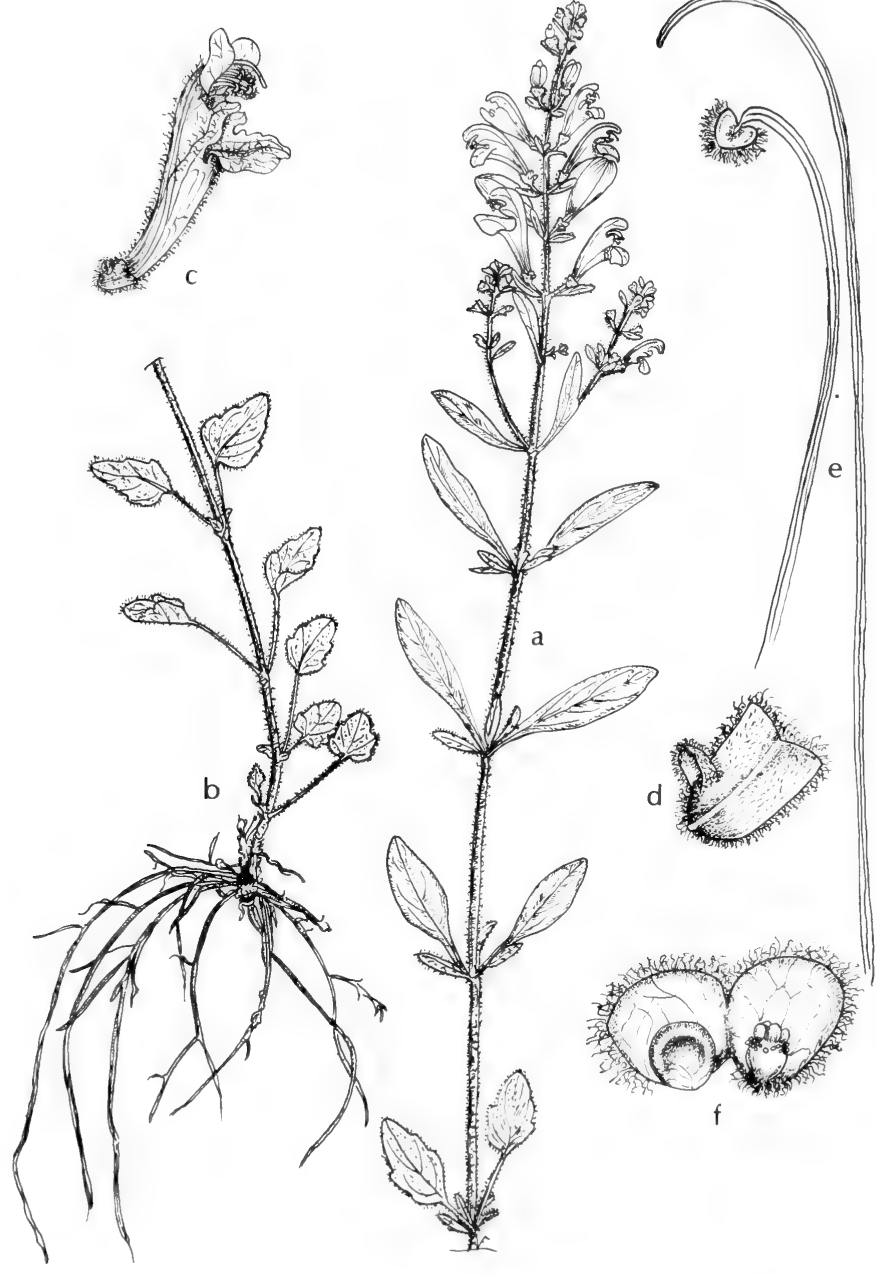

Fig. 659: Scutellaria integrifolia: a and b, habit, x 1/2; c, flower, x 1; d, calyx, x 5; e, stamen and style, $\mathrm{x} \mathrm{5}$; f, calyx opened to show nutlets on gynophore, $\mathrm{x} 5$. (V. F.). 


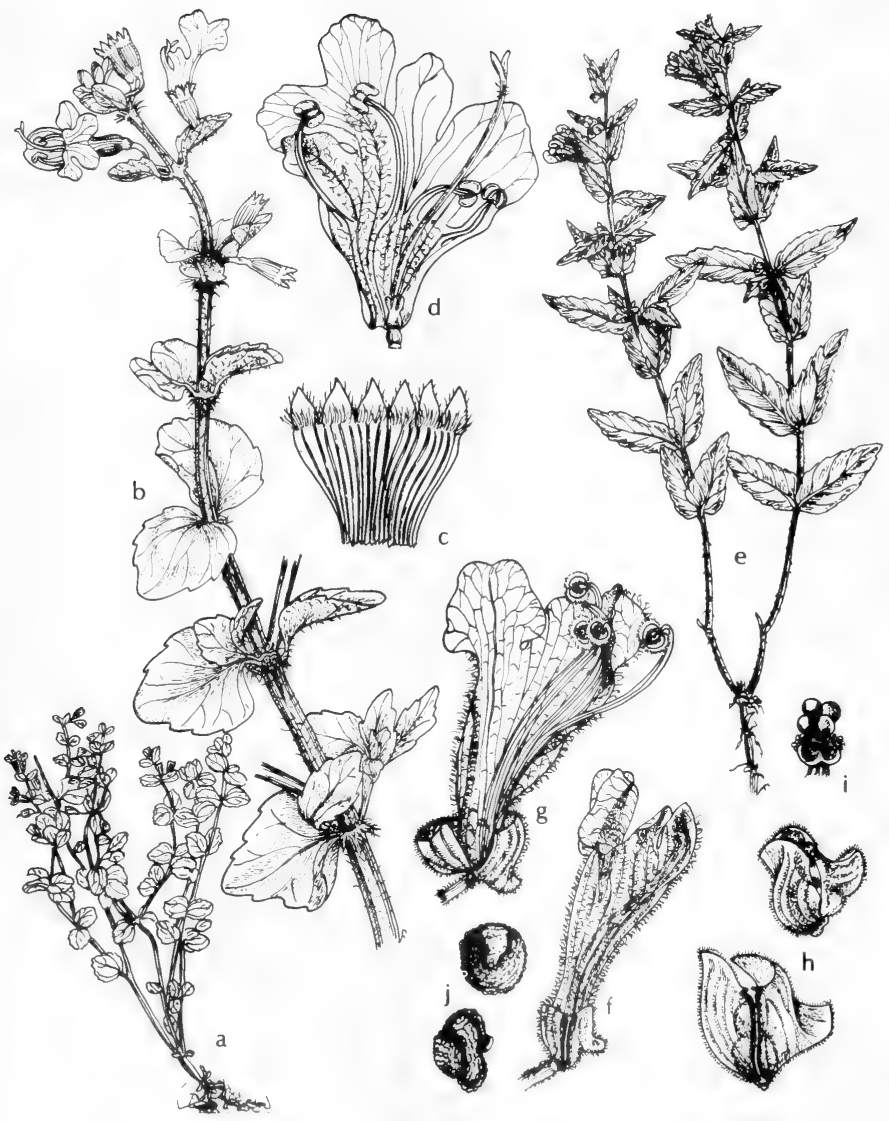

Fig. 660: a-d, Micromeria Browneii: a, habit, x 1/2; b, end of branch, x 21/2; c, calyx opened out, x 5; d, corolla opened out, x 5. e-j, Scutellaria galericulata: e, habit, $\mathrm{x} 1 \frac{1}{2}$; f, flower, $\mathrm{x} 2 \frac{1}{2} ; \mathrm{g}$, corolla and calyx split open, $\mathrm{x} 21 \% \mathrm{~h}$, two calyces with mature nutlets, $x 2^{1} \frac{1}{2}$; i, immature nutlets on gynophore, $x 2^{1} \frac{1}{2} ;$ j, nutlets, $x$ 5. (V. F.). 
viated axillary branches densely incurved-pilose above, sometimes with divergent hairs, with or without some glands; leaves 3 to 8 pairs below inflorescence; lowest leaves ovate, slender-petioled, crenate; the successively narrower middle and upper leaves mostly oblong to linear-lanceolate and entire, narrowed to petioles to $1 \mathrm{~cm}$. long, punctate, minutely hoary, 2-6 cm. long, to $1.6 \mathrm{~cm}$. broad; lowest internodes $1-2.5 \mathrm{~cm}$. long; inflorescence a terminal raceme or leafy elongate panicle of 6- to 40 -flowered racemes, all but lowest flowers in axils of much reduced foliaceous linear-lanceolate bracts; pedicels short; calyx $2.5-3.5 \mathrm{~mm}$. long in anthesis, becoming 5-7 mm. long in fruit, puberulent; corolla $2-2.5 \mathrm{~cm}$. long, purple-blue and whitish or rarely rose-pink, the large lips subequal; the lower stamens inserted about $8.5 \mathrm{~mm}$. above base of tube; cocci subglobose, blackish, $1.2-1.6 \mathrm{~mm}$. in diameter, covered with rosulate flattish subimbricated papillae.

Borders of woods, thickets and clearings, bogs, along streams, on seepage slopes and about ponds in e. Tex., Apr.-June; from Fla. to Tex., n. to N.E., O., Ky. and Mo.

The var. hispida Benth. has stems with numerous straighter and more divergent hairs, and the transition from lower to median leaves more gradual than in var. integrifolia. Plants with rose-pink flowers are designated as f. rhodantha Fern.

\section{Scutellaria galericulata L. Marsh SKullCAP. Fig. 660.}

Perennial with slender creeping rhizome and mostly subterranean slightly thickened stolons; stems ascending, simple or forking, to $1 \mathrm{~m}$. high, minutely pilose on angles above with recurved hairs; leaves sessile or shortly petioled, oblong-lanceolate to ovate-oblong, crenate, rounded to cordate at base, to $8 \mathrm{~cm}$. long and $3 \mathrm{~cm}$. broad, often somewhat rugose, veiny, minutely pubescent (often canescent) beneath with recurving hairs; flowers solitary in the axils of reduced upper leaflike bracts to form 1-sided interrupted racemes, very short-pedicelled; calyx 3.5-4.5 (in fruit 5-6.5) $\mathrm{mm}$. long, minutely pilose; corolla blue-violet with whitish throat and tube, pilose, $15-25 \mathrm{~mm}$. long, stamens inserted $8-10 \mathrm{~mm}$. above base of tube; cocci pale-olive, $1.5-2 \mathrm{~mm}$. long, with broad low pebbling. S. epilobiifolia A. Hamilt.

Gravelly, sandy or rocky shores, in mud on edge of ponds and creeks, in sloughs, wet meadows, marshes, swampy thickets in $\mathrm{n}$. Panhandle of Tex., N.M. (Colfax, Mora, Sandoval, San Juan and Taos cos.) and Ariz. (Apache, Navajo and Coconino cos.), June-Aug.; from Nfld. and Lab. n.w. to Alas., s. to Del., Pa., W.Va., O., Ind., Ill., Mo., Kan., Tex., N.M., Ariz. and Calif.

\section{Scutellaria cardiophylla Engelm. \& Gray.}

Annual, 4-6 dm. high, rather strict and stiffish, branching freely above the middle, the branches ascendent and strict, clothed with recurved appressed hairs (particularly along the angles), sometimes with spreading glandular hairs in the lowermost parts as well; basal leaves soon deciduous; median leaves deltoid, lightly cordate, $2-5 \mathrm{~cm}$. long, crenate-dentate, the lower ones borne on petioles as long as the blades, the uppermost subsessile and subentire, gradually diminished upward, the upper surfaces of all glabrous, the lower surface hispidulous with spreading hairs, their margins usually ciliate with longer hairs; flowers produced in the upper parts of the plant in the axils of gradually diminished leaves, the pedicels clothed as are the stems; flowering calyces retrorse-pubescent and ciliate on the margins, the lower lip 4-4.5 $\mathrm{mm}$. long at anthesis but 5-6 $\mathrm{mm}$. long at maturity, the scale about $3.5 \mathrm{~mm}$. tall and concave; galea and tube $13-22 \mathrm{~mm}$. long, the tube pilose within, the lip giabrous; lower filaments seated 7-13 $\mathrm{mm}$. above the base of the tube; cocci black, shallowly papillate. 
Usually in sandy or rocky soils on the edge of woods and in grassy areas in open woods, on banks, in seepage areas and old fields in e. fourth of Tex., w. to Kaufman, Freestone and Madison cos., Apr.-Oct.; also Ark. and possibly w. La.

\section{Scutellaria lateriflora L. MAD-Dog SkullcAP. Fig. 661.}

Perennial with filiform rhizomes and stolons; stem to $1 \mathrm{~m}$. high, simple or freely branched, smooth or minutely pilose on the angles with incurved-ascending hairs; leaves with slender pilose petioles to $3 \mathrm{~cm}$. long, ovate to deltoid-ovate, acuminate, coarsely serrate or serrate-dentate, rounded to subcordate at base, thin, glabrous or at most minutely pilose on veins beneath and on margin, to $12 \mathrm{~cm}$. long and $6 \mathrm{~cm}$. broad; racemes 1 -sided, axillary and terminal (occasionally reduced to 1 flower), usually with 2 to 44 flowers in the axils of progressively smaller leafy bracts, internodes of lateral racemes mostly 2-7 (rarely -10 ) $\mathrm{mm}$. long; calyx 2-2.7 (becoming in fruit 3-4) $\mathrm{mm}$. long, puberulent; corolla slender, blueviolet, 5-9 $\mathrm{mm}$. long, pilose; upper stamens inserted about middle of tube; cocci pale, $1.4-1.7 \mathrm{~mm}$. high, obtusely pebbled.

In alluvial thickets, meadows, marshes, swampy woods and on seepage slopes, edge of water in lake, along streams and sloughs, in n.e. Tex. and n. Panhandle, Okla. (Adair and Mayes cos.) and Ariz. (Yavapai and Coconino cos.), JulySept.; from Ga. to s. Calif., n. to Nfld., Que., Ont., Man., Sask., Alta. and B. C.

\section{Hyptis JACQ.}

About 400 species, mostly in tropical America.

1. Hyptis alata (Raf.) Shinners. Cluster bushmint, desert-lavender. Fig. 662.

Herbaceous perennial from a woody rootstock; stem stout and elongate, to about $2 \mathrm{~m}$. high, finely pubescent, simple or rarely branched; leaves ovate to rhombiclanceolate or linear-lanceolate, to about $15 \mathrm{~cm}$. long and $5 \mathrm{~cm}$. wide, coarsely and irregularly serrate, cuneately narrowed into a petiolar base; flowers in dense axillary glomerules about $2 \mathrm{~cm}$. thick that are supported by peduncles to $5 \mathrm{~cm}$. long; calyx 6-8 $\mathrm{mm}$ long, the tube strongly cross-ribbed at maturity, the lobes subulate-lanceolate and short-hairy; corolla declined, 2-lipped, white with lavender dots, 8-10 $\mathrm{mm}$. long, the upper lip with 4 entire lobes, the lower lip saccate, abruptly deflexed at the contracted and callous base; stamens 4 , declined or resting on the lower lip, didynamous; disk entire or with a gland on the anterior side; cocci oval, nearly $1.5 \mathrm{~mm}$. long. Hyptis radiata Willd.

In low pinelands, seepage areas, coastal meadows, swamps and marshes in s.e. Tex., May-Nov.; from Fla. to Tex., n. to N.C.

\section{Agastache Clayt.}

\section{A North American genus of about 30 species.}

\section{Agastache nepetoides (L.) O. Ktze. Fig. 662.}

Stems erect, 1-1.5 m. tall, branched above; leaves thin, green, ovate to ovatelanceolate, to $15 \mathrm{~cm}$. long but much-reduced in size toward summit of stem, acute to short-acuminate, coarsely serrate, rounded to subcordate at base, finely pubescent on lower surface, the hairs evident with magnification; petioles of larger leaves to $6 \mathrm{~cm}$. long, those of the upper leaves progressively reduced to $5 \mathrm{~mm}$.; spikes nearly cylindrical, to $2 \mathrm{dm}$. long, $1-1.5 \mathrm{~cm}$. in diameter, commonly continuous, occasionally somewhat interrupted at base; bracteal leaves inconspicuous, broadly ovate, acuminate; calyx at anthesis glabrous, about $6 \mathrm{~mm}$. long; calyx lobes ovate-lanceolate, 1-1.5 mm. long, obtuse to subacute; corolla greenishyellow; cocci ovoid, commonly smooth.

Along and on edge of slow-moving streams in forests in Okla. (Washington Co.), June-Sept.; Que. to Ont. and S.D., s. to Ga., Ky., to Mo. and Okla. 


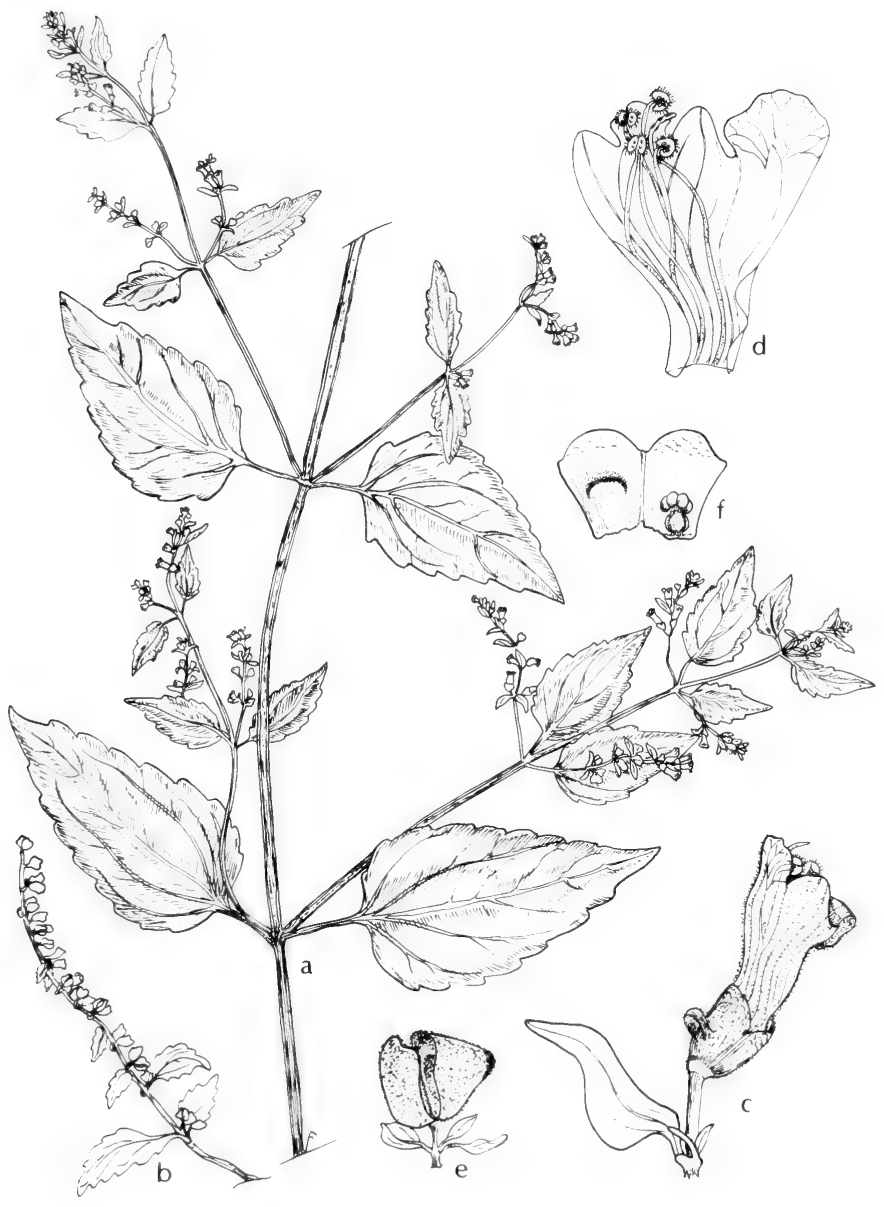

Fig. 661: Scutellaria lateriflora: a, part of plant, x 1/2; b, branchlet, x 1; c, flower, $\mathrm{x} 5 ; \mathrm{d}$, corolla spread out, $\mathrm{x} 5$; e, calyx, x $5 ; \mathrm{f}$, calyx opened showing nutlets on gynophore, x 5. (V. F.). 


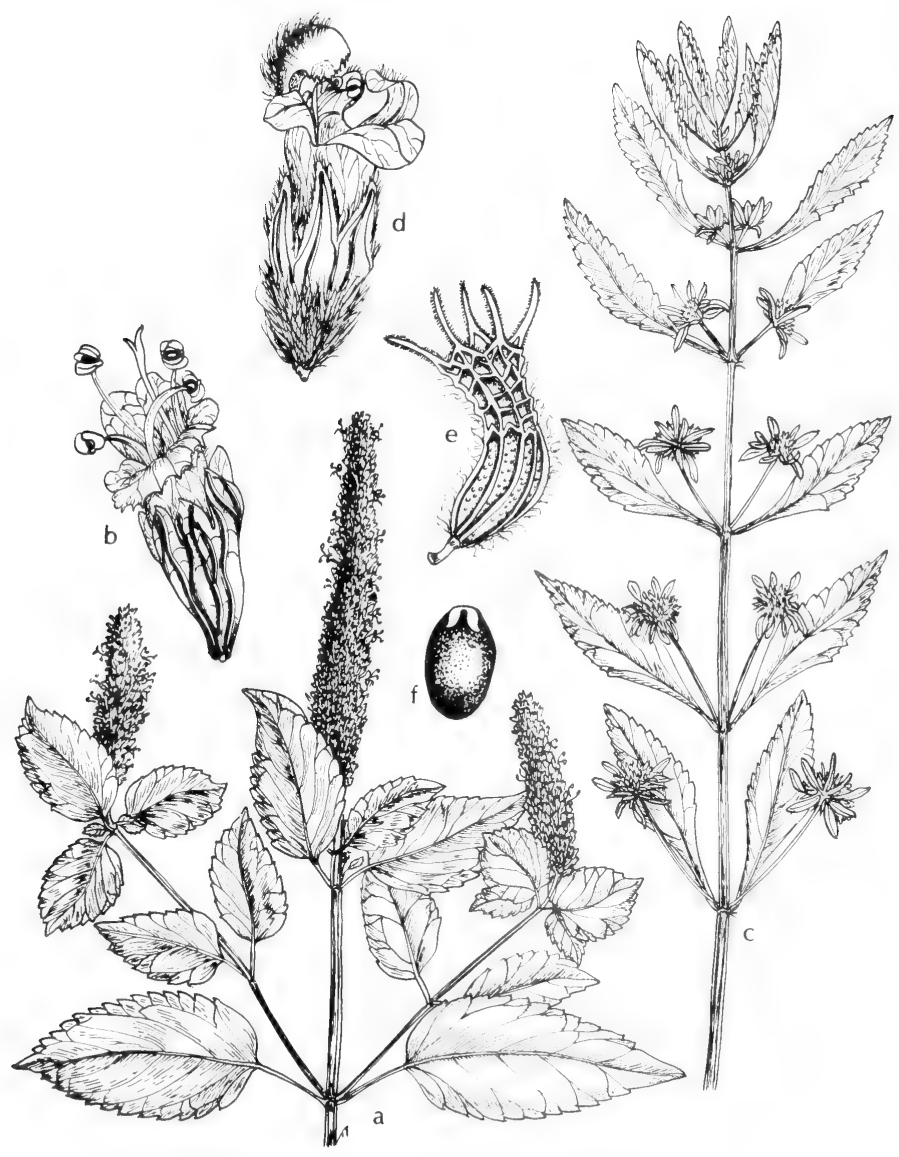

Fig. 662: a and b, Agastache nepetoides: a, top of plant, x 1/2; b, flower, x 5. c-f, Hyptis alata: c, top of plant, $\mathrm{x} 1 / 2$; d, flower, $\mathrm{x} 5$; e, calyx with fruit, $\mathrm{x} 5$; $\mathrm{f}$, nutlet, $\mathrm{x}$ 10. (V. F.). 


\section{Nepeta L. CATMint}

A genus of about 250 species, all of which are natives of Eurasia and Africa.

\section{Nepeta Cataria L. CATnIP.}

Perennial erect herb with pale-green and densely canescent herbage; stems to about $1 \mathrm{~m}$. high, with ascending branches: leaves petioled, ovate to triangularovate or oblong, to about $8 \mathrm{~cm}$. long and $5 \mathrm{~cm}$. wide, acute at apex, usually cordate at base, coarsely dentate or crenate-serrate; flower verticils in the axis of small foliaceous bracts to form dense or interrupted terminal spikes; bractlets subulate: calyx urceolate, slightly oblique at apex, about $6 \mathrm{~mm}$. long, very pubescent, the 5 subulate teeth about half as long as the tube, short-pubescent on the prominent 15 nerves; corolla white to pale-purple, dotted with dark-purple, strongly 2-lipped, $1-1.2 \mathrm{~cm}$. long, puberulent on the outer surface, the upper lip erect and somewhat 2-lobed, the broad middle lobe of the 3-lobed lower lip crenulate; stamens 4, all fertile, didynamous, ascending under the upper lip; anther sacs 2, divergent; ovary deeply 4-parted; style 2-cleft at summit; cocci ovoid, compressed, smooth.

In waste places, along streams and in water of spring branches, in e. and cen. Tex., n.e. Okla. and Wichita Mts. (Waterfall), N. M. (widely established as a weed) and Ariz. (Navajo, Coconino, Yavapai and Cochise cos.), May-Sept.; a nat, of Eur. that is naturalized in various parts of N.A.

\section{Dracocephalum L. DRAGON-HEAD}

\section{About 45 species, all but ours are Eurasian.}

\section{Dracocephalum parviflorum Nutt. Fig. 663.}

Annual, biennial or short-lived perennial herb from a taproot; the solitary or more often clustered stems $1.5-8 \mathrm{dm}$. tall, simple or branched, inconspicuously strigose or hirtellous with retrorse hairs; leaves obscurely short-hairy, petiolate, the lower small ones relatively broad and often soon deciduous, the other ones with elliptic-lanceolate to oblong-lanceolate or broadly triangular-lanceolate blades $2.5-8 \mathrm{~cm}$. long and $1-2.5 \mathrm{~cm}$. wide, coarsely serrate or somewhat incised with the teeth often spine-tipped; inflorescence dense and spikelike, $1.5-3.5 \mathrm{~cm}$. thick, often interrupted below, the terminal segment $2-10 \mathrm{~cm}$. long; bracts subfoliaceous, mostly 1-3 cm. long, nearly or quite sessile, aristately few-toothed; flowers shortpedicellate, rather numerous in each verticil; calyx loosely hirsute or subglabrous, about $1 \mathrm{~cm}$. long, the tube equaling the aristate-tipped lobes; upper calyx lobe broadly ovate-oblong, conspicuously wider but not much longer than the narrowly triangular-lanceolate lateral and lower lobes; corolla purplish, scarcely surpassing the calyx, villous on outer surface, with short lips; anthers nearly equaling the upper corolla lip. Moldavica parviflora (Nutt.) Britt.

Wet meadows, along streams and on edge of marshy areas, open-wooded slopes, N. M. (widespread in mts.) and Ariz. (Apache, Coconino, Mohave, Yavapai, Gila, Maricopa and Pinal cos.), May-Aug.; Can. to N. M. and Ariz.

According to Kearney and Peebles, the Havasupai Indians are reported to make flour from the seeds of this plant.

\section{Prunella L.}

About 7 species of world-wide distribution.

1. Prunella vulgaris L. Common self-heal, heal-all, Carpenter-Weed. Fig. 663A.

Perennial herb with simple or several stems and slender rootstocks, tufted or loosely ascending from leafy-tufted bases, to about $6 \mathrm{dm}$. high, usually much 


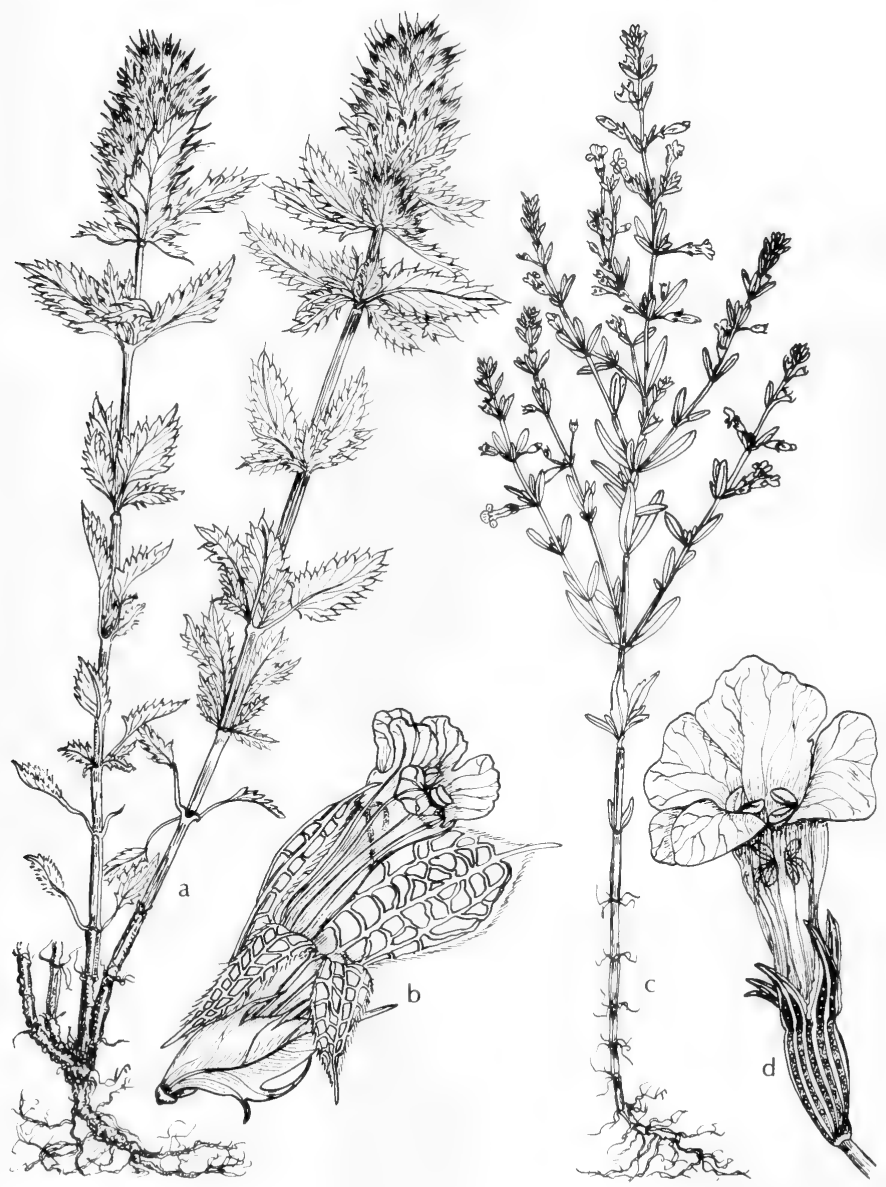

Fig. 663: a and b, Dracocephalum parviflorum: a, habit, x 1/2; b, flower, x 5. c and d, Satureja arkansana: c, habit, x 1/2; d, flower, x 5. (V. F.). 


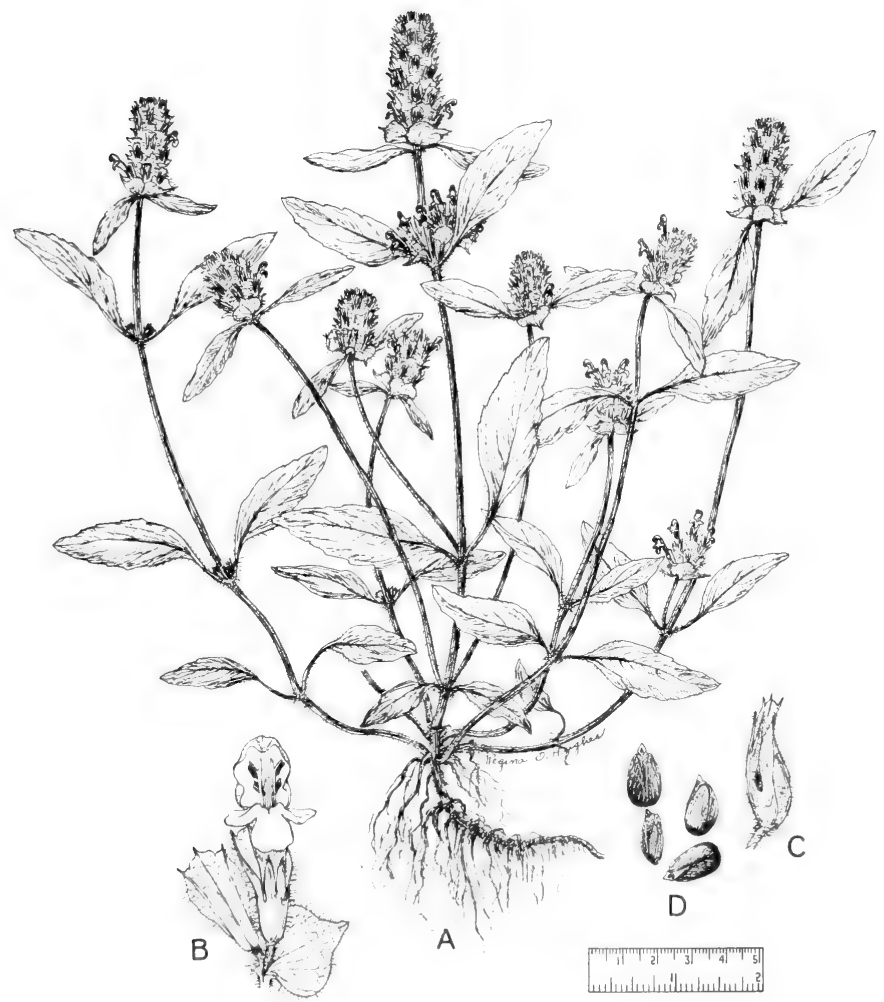

Fig. 663A: Prunella vulgaris: A, habit, x 1/2; B, flower, $\mathrm{x} 2$; C, persistent calyx, about $x 2$; D, nutlets, $\times 4$. (From Reed, Selected Weeds of the United States, Fig. 156). 
smaller, glabrous or commonly pilose (especially above); leaves ovate to ovatelanceolate or oblong-lanceolate, 3-7 cm. long and about a third as wide, acute to acutish or sometimes rounded at apex, narrowed to a short or elongate petiole, entire or irregularly and remotely toothed; flowers in clusters of 3 , sessile in the axils of round and bractlike membranaceous floral leaves, imbricated in a close spike $2-5 \mathrm{~cm}$. long; bracts orbicular to broadly ovate, cuspidate, more or less bristly-ciliate, green or often tinged with purple; calyx tubular-campanulate, about half as long as the corolla, usually 10-nerved, naked in the throat, closed in fruit, deeply 2-lipped, the upper lip truncate or with 3 short often ciliate teeth, the lower lip cleft into 2 lanceolate often ciliate teeth; corolla $1-2 \mathrm{~cm}$. long, violet or rarely white, ascending, strongly 2 -lipped, the upper lip arched, the lower lip spreading and 3-lobed; stamens 4, didynamous, ascending under the upper lip, the lower pair longer; filaments 2-toothed at apex with one of the teeth bearing the anther, the other sterile; anther cells 2, divergent; ovary deeply 4-parted; cocci ovoid, smooth.

In low meadows, open woodlands, on seepy banks and gravel bars of streams, ponds and ditches, along roadsides and pasturelands in the e. fourth of Tex., Okla. (Craig, Osage, Mayes and Pittsburg cos.), N.M. (widespread) and Ariz. (Apache, Navajo and Coconino, s. to Graham and Pima cos.), Apr.-June; widespread throughout the N. Hemis.

This species is represented in Texas by var. hispida Benth. with densely pubescent stems and lower surface of leaves, and var. lanceolata (Bart.) Fern. with narrow leaves.

\section{Physostegia Benth. False Dragon-head. Obedient-Plant}

Smooth perennial herbs with upright simple or sparingly branched stems; leaves sessile or the lower ones sometimes petiolate, linear to lanceolate or oblong, mostly crenate or dentate; flowers usually large and showy, opposite, scattered or crowded in simple or panicled terminal leafless spikes; calyx regular, obscurely 10-nerved, short-tubular to campanulate, more or less enlarged and slightly inflated in fruit; corolla funnelform, the tube exceeding the calyx, with a muchinflated throat, varying from white to rose-color and commonly spotted or variegated with purple, 2-lipped; upper corolla lip erect, nearly entire; lower corolla lip 3-parted, spreading, small, its larger middle lobe broad and rounded, notched; stamens 4, ascending beneath the upper corolla lip; cocci ovoid, smooth.

About a dozen species that extend from Canada to northern Mexico.

The vernacular name, "obedient-plant," is derived from the fact that when the flowers are moved laterally in the inflorescence they remain where placed. All of these species have value as ornamentals.

1. Corolla rarely to $2 \mathrm{~cm}$. long (2)

1. Corolla more than $2 \mathrm{~cm}$. long (3)

2(1). Corolla less than $1 \mathrm{~cm}$. long; calyx 3-4 mm. long.............. 1 . P. micrantha.

2. Corolla more than $1 \mathrm{~cm}$. long; calyx $5 \mathrm{~mm}$. long or more.......2. P. intermedia.

3(1). Plant mostly slender and to about $1 \mathrm{~m}$. high; leaves on lower half of stem linear to linear-lanceolate, rarely more than $15 \mathrm{~mm}$. wide (4)

3. Plant large, coarse, commonly above $1 \mathrm{~m}$. high; leaves on lower half of stem elliptic to oblong-elliptic or oblong-lanceolate, $20 \mathrm{~mm}$. wide or more (5)

4(3). Flowering from April to July

4. Flowering from August to November.

3. $P$, angustifolia. 4. P. praemorsa.

5(3). Distribution in Val Verde County, Texas, commonly in flowing water; rhizome large and elongate.....................................5. P. Correllii. 


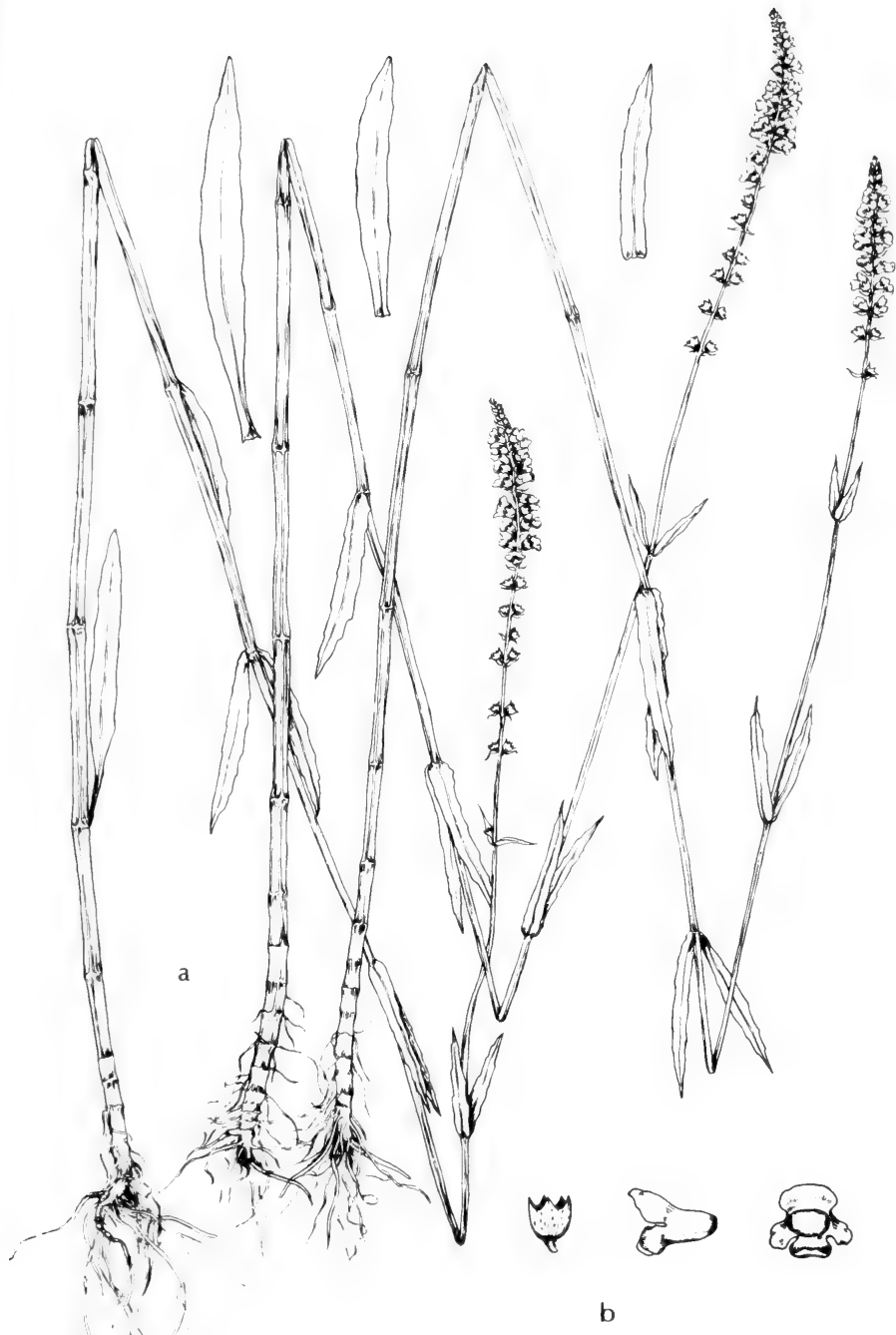

Fig. 664: Physostegia micrantha: a, habit, x 1/2; b, calyx and corolla, x 2. (From Lundell's Flora of Texas, Vol. 2, pl. 17). 


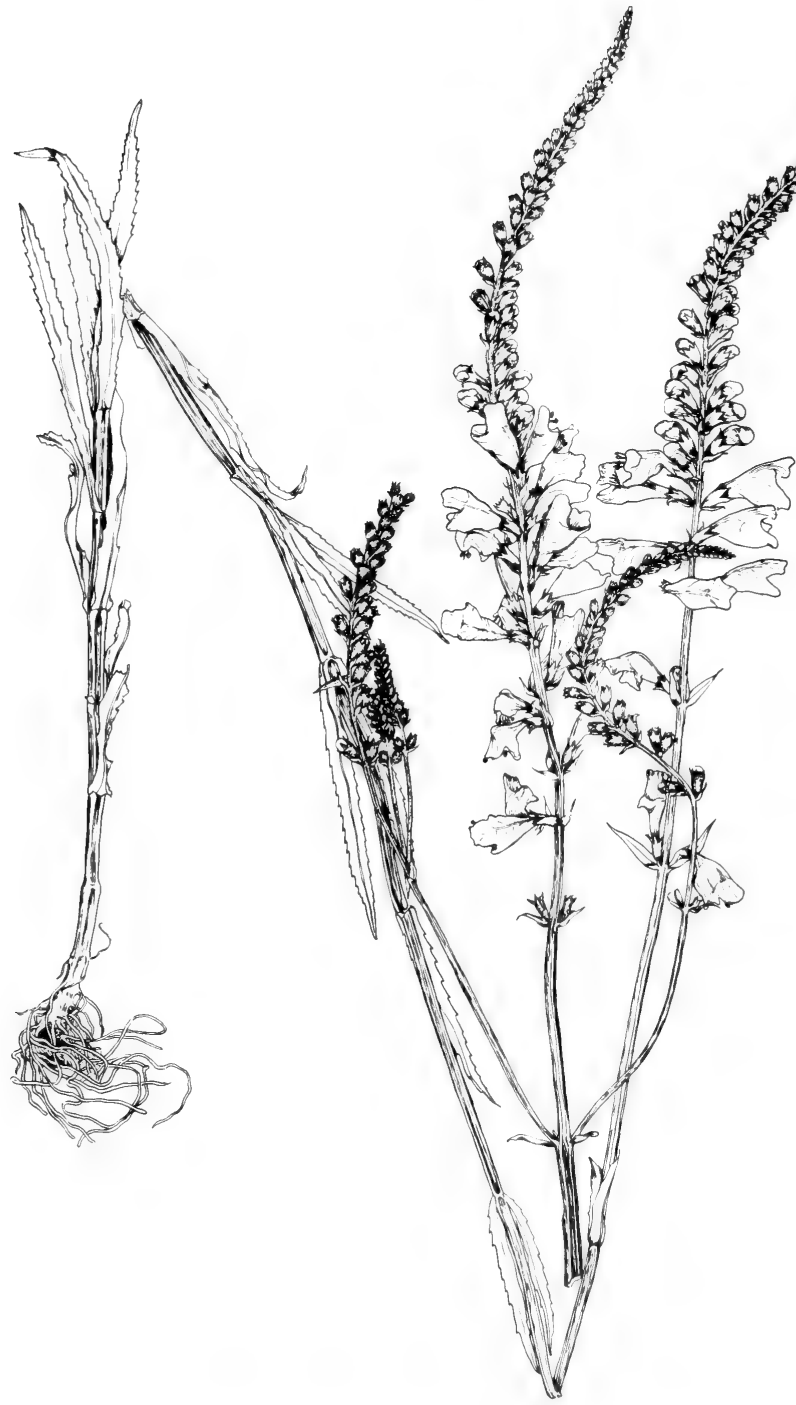

Fig. 665: Physostegia angustifolia: habit, $x$ 1/2. (From Lundell's Flora of Texas, Vol. 2, pl. 18). 
5. Distribution in eastern half of Texas, in dry or wet soil; rhizome short and thick (6)

6(5). Corolla very pale lavender-pink or whitish; mostly in sandy or gravelly soils

6. P. Digitalis.

6. Corolla reddish-purple or deep lavender-pink, the lobes purplish; mostly in wet clayey soils.

7. P. pulchella.

\section{Physostegia micrantha Lundell. Fig. 664.}

Erect rhizomatous herb to $9 \mathrm{dm}$. high, slender, the internodes progressively longer from base to apex, the upper nodes puberulent, otherwise glabrous below the inflorescence; leaves small, glabrous, chartaceous, linear-lanceolate or oblonglanceolate, acute to acuminate, to $12 \mathrm{~cm}$. long and $11 \mathrm{~mm}$. wide, the basal leaves petiolate, the medial leaves largest, sessile, clasping at base, the apical leaves bractlike below the inflorescence; leaf margin repand to sinuate, rather remotely and inconspicuously denticulate; inflorescence to $2 \mathrm{dm}$. long, slender, usually simple, sometimes with 2 lateral branches at the basal node, densely puberulent; bracts shorter than the calyx, puberulent; flowers subsessile, the puberulent pedicels about $1 \mathrm{~mm}$. long; calyx pellucid-punctate, puberulent, 3-4 mm. long, the acute teeth slightly shorter than tube; corolla white, tinged lavender or pink, puberulent, 5-7 $\mathrm{mm}$. long, the campanulate tube shorter than the calyx; filament glabrous.

Wet bottomland along creek in mud and water and about ponds in river floodplains, in Tex. (Grimes and Titus cos.) and Okla. (McCurtain Co.), May-June.

\section{Physostegia intermedia (Nutt.) Englem. \& Gray.}

Slender, rhizomatous, 3-15 dm. high; leaves dark-green, linear-lanceolate to linear, thickish, the larger $3-12 \mathrm{~mm}$. broad, the margin repand-sinuate and entire or rarely obscurely dentate, all but the lowest attenuate, the uppermost greatly reduced; spike very slender, much-interrupted, the lateral ones (if developed) strictly erect, the rachis $5-35 \mathrm{~cm}$. long; corolla lavender, purple-spotted in throat, $1-1.5 \mathrm{~cm}$. long, rarely more.

Usually found in wet periodically flooded areas or even growing as an aquatic along ditches, in swamps, marshes and bottomlands in Okla. (Waterfall) and in e. and most of s. half of Tex., Apr.-June; from Ky. to Kan., s. to Ala., La. and Tex.

\section{Physostegia angustifolia Fern. Fig. 665.}

Stem stiffly erect, with rhizomes to $3 \mathrm{dm}$. long, to about $2 \mathrm{~m}$. high; leaves rigid, sessile or the lower ones with slender petioles to $2 \mathrm{~cm}$. long, grayish or pale, linear to narrowly lanceolate or oblong-lanceolate, the lower leaves obtuse to subacute; median leaves attenuate and appressed-acerose-serrate, to $13 \mathrm{~cm}$. long and $12 \mathrm{~mm}$. wide, rarely larger, the uppermost leaves passing rather abruptly into the small leafy bracts of the inflorescence; spikes slender, virgate, solitary or with few erect laterals, to $35 \mathrm{~cm}$. long, remotely flowered; branches of inflorescence, bracts and calyces finely and densely pubescent with nonglandular hairs; calyx 6-10 mm. long; corolla pale- to deep-purple or whitish, purple-spotted, 2.5-3 $\mathrm{cm}$. long; cocci dark-brown, $3 \mathrm{~mm}$. long or more. P. edwardsiana Shinners.

In marshy areas, on gravel bars, along streams, roadsides and fields and meadows in e. and cen. Tex., Apr.-July; from Ill. to Tenn., s. to Miss., La. and Tex.

\section{Physostegia praemorsa Shinners.}

Perennial with rhizomes; stem glabrous, to about $12.5 \mathrm{dm}$. high; lower leaves shortly petiolate, narrowly oblong to lanceolate or oblong-lanceolate, acute, 3-7 $\mathrm{cm}$. long, 5-13 $\mathrm{mm}$. wide, the margins sharply serrate except near base, gradually reduced above to sessile linear-lanceolate bracteal leaves; inflorescence simple 
or virgately branched, with the bracts and calyx densely and minutely pubescent with glandular and nonglandular hairs; calyx 6-10 mm. long, the teeth narrowly deltoid-lanceolate; corolla showy, light-lavender-violet to whitish, with rosepurple spots, 22-32 $\mathrm{mm}$. long, the tube 7-14 $\mathrm{mm}$. long, often exserted from calyx; cocci dark-brown, about $4 \mathrm{~mm}$. long, sharply 3-angled. P. serotina Shinners.

Along streams and ditches, in moist grasslands in e. and n.-cen. Tex., with a disjunct area in the Guadalupe Mts., Aug.-Oct.; also La. and N.M., probably also Okla.

\section{Physostegia Correllii (Lundell) Shinners. Fig. 666.}

Plants erect, robust, somewhat succulent, to $22 \mathrm{dm}$. high, with thick creeping rhizomes; stems simple or sparingly branched, to $25 \mathrm{~mm}$. thick, glabrous, as many as 20 nodes per stem; leaves decussately opposite, sessile, leathery and firm, elliptic or oblong-elliptic, $5-13 \mathrm{~cm}$. long, 2-6.5 cm. wide, short-acuminate at apex, slightly narrowed at base and inconspicuously clasping, the margin conspicuously and sharply serrate-dentate to base, primary veins usually 2 or 3 on each side, the upper leaves only slightly reduced; racemes spikelike, simple or compound, short, leafy at base, finely pubescent, comparatively few-flowered; bracts leafy, ovate, those at base of raceme equal to or longer than calyx, reduced above, acuminate; pedicels very short, about $1 \mathrm{~mm}$. long in fruit; calyx finely pubescent, gland-tipped hairs abundant, subcylindric, $8-9.5 \mathrm{~mm}$. long, the acuminate lobes slender and subequaling tube, inflated at maturity; corolla lavender-pink, spotted or streaked with purple, about $3 \mathrm{~cm}$. long, sparsely pubescent; cocci about $2.3 \mathrm{~mm}$. long, sharply angled. Dracocephalum Correllii Lundell.

In water along streams and in irrigation ditches in Val Verde Co., Tex., JuneJuly; also N. L. and Son.

\section{Physostegia Digitalis Small. Fig. 667.}

Stems erect, to $2 \mathrm{~m}$. high, stout, sharply angled; leaves several, sessile and partly clasping at base, somewhat leathery-thickened, oblong to elliptic-oblong, to $22 \mathrm{~cm}$. long and $75 \mathrm{~mm}$. wide, acute to subacute, the margins undulate or repand-serrate above the middle; raceme simple or compound, finely pubescent; bracts ovate-lanceolate to lanceolate, 4-6 $\mathrm{mm}$. long; pedicels very short; calyx 8-10 $\mathrm{mm}$. long, the tube turbinate or cylindric-turbinate, the lanceolate lobes acuminate and about one half as long as the tube; corolla pale-lavender to whitish, commonly with reddish-purple dots, $2-2.5 \mathrm{~cm}$. long, barely puberulent dorsally, the upper lip slightly undulate, the lower lip spreading with the lobes oblong (the middle lobe emarginate and about twice as long as the others). P. obovata of auth.

In sandy open pinelands, edge of forests, prairies, grasslands and swampy areas in e. Tex., June-Aug.; from e. Tex. to La., Ark. and probably Okla.

\section{Physostegia pulchella Lundell. Fig. 668.}

Erect rhizomatous herb to $14 \mathrm{dm}$. high, slender or robust; stem to $15 \mathrm{~mm}$. in diameter near base; basal leaves chartaceous, usually with slender petioles to $8 \mathrm{~cm}$. long, expanded and clasping at base, narrowed above, entire to subentire or remotely dentate; leaves above base oblong-lanceolate or oblong-elliptic, to $12 \mathrm{~cm}$. long and $25 \mathrm{~mm}$. wide, tapering into a winged petiole, obtuse at apex, the margin subentire to denticulate; leaves of middle stem rather firm, chartaceous, pallid, oblong to oblanceolate-oblong or oblong-elliptic, $7.5-15 \mathrm{~cm}$. long, 1-2 cm. wide, sessile and clasping at base or with a broadly winged petiole below, the apex acute or obtuse, the margin usually serrate to base or sometimes subentire below; apical leaves bractlike below the inflorescence; inflorescence densely pubescent throughout, simple or with two or more lateral branches from the basal bracts, usually less than $3 \mathrm{dm}$. long, sometimes to $6 \mathrm{dm}$. long; flowers rather remote, 


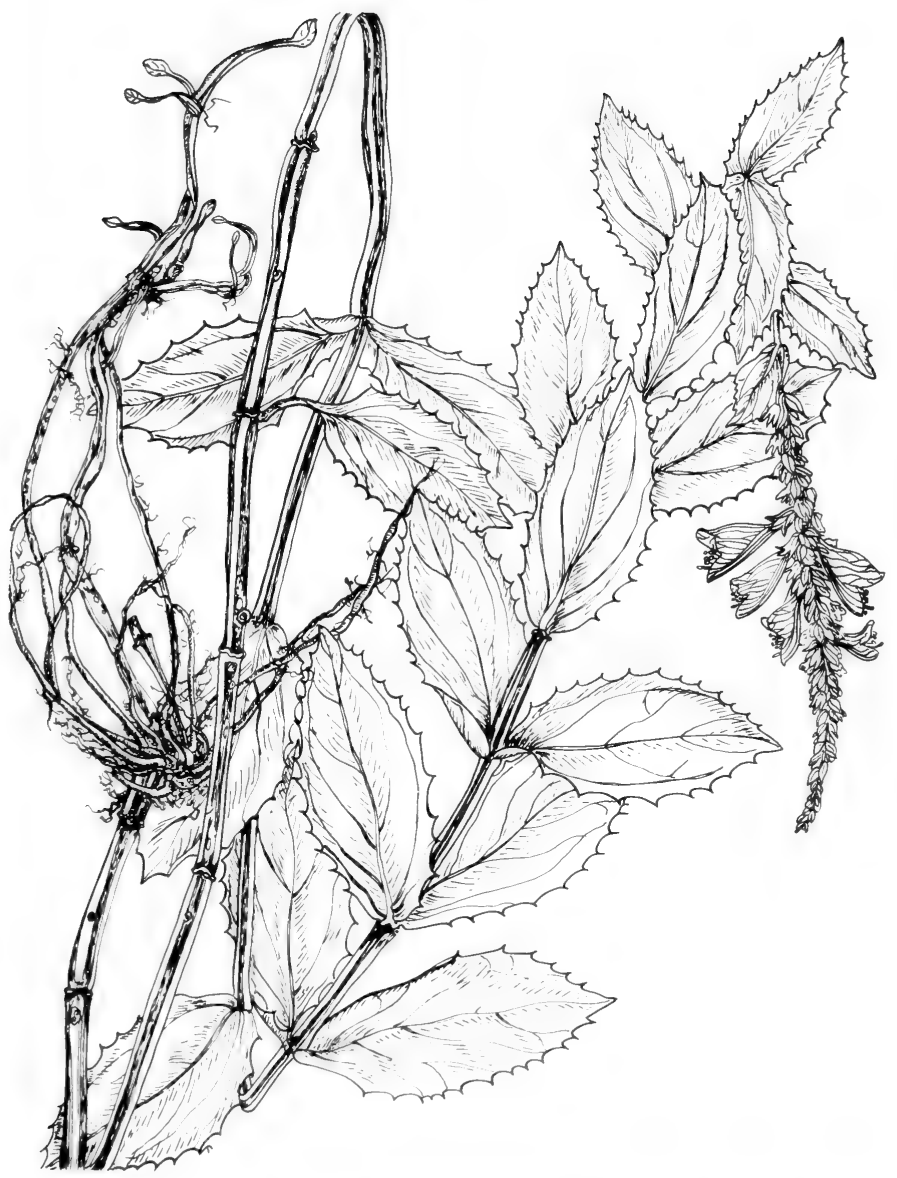

Fig. 666: Physostegia Correllii: flowering plant, x 1/2. (From Lundell's Flora of Texas, Vol. 2, pl. 23). 


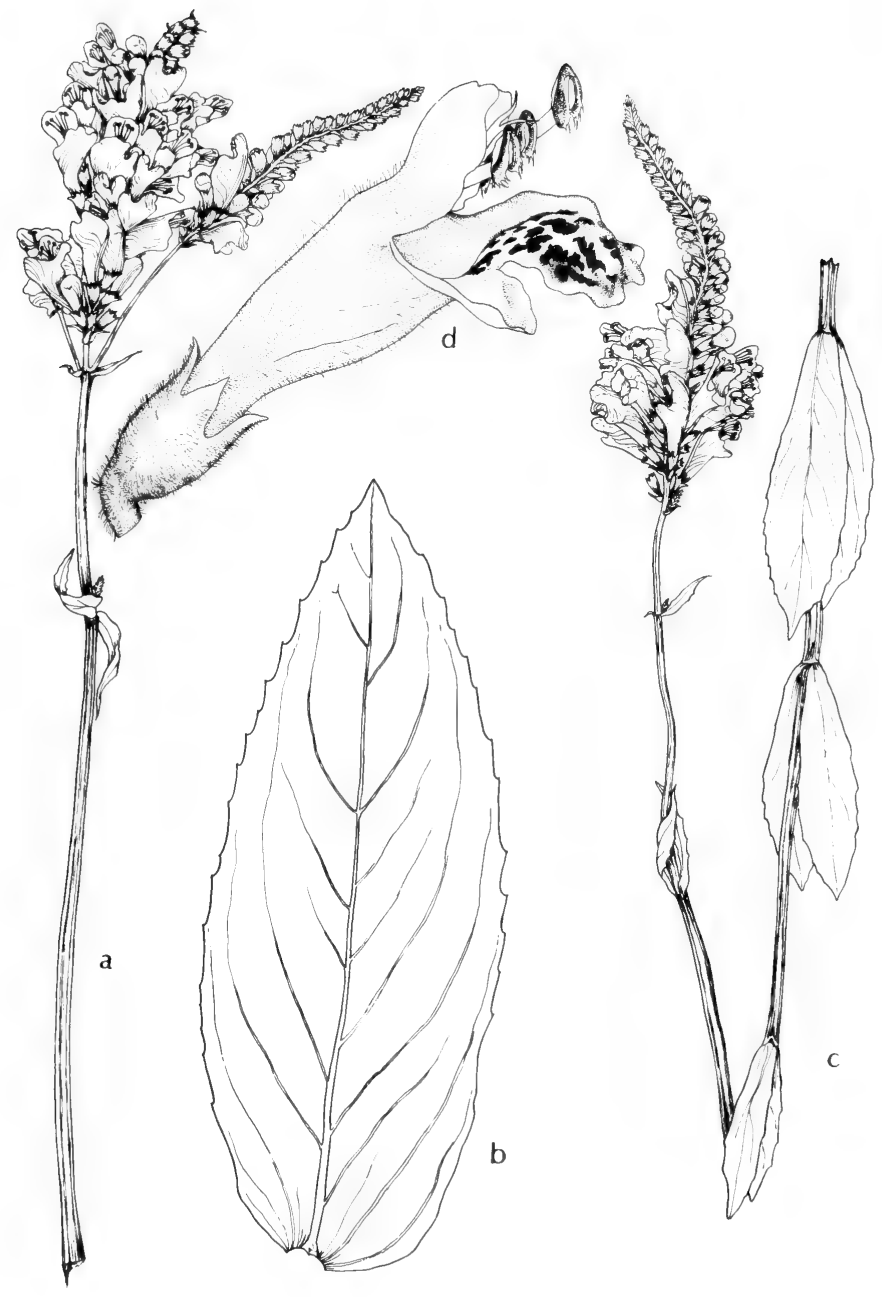

Fig. 667: Physostegia Digitalis: a, inflorescence and upper stem, x 1/2; b, leaf, x $1 / 2 ; \mathrm{c}$, inflorescence and upper 5 nodes of stem, $\mathrm{x} 1 / 2 ; \mathrm{d}$, flower, $\mathrm{x} 7$. (a-c, from Lundell's Flora of Texas, Vol. 2, pl. 25; d, Courtesy of R. K. Godfrey). 
not crowded, subsessile, subtended by small ovate acuminate bracts $2-3 \mathrm{~mm}$. long; pedicels in fruit not over $1.5 \mathrm{~mm}$. long; calyx tubular-campanulate, 6-7 mm. long at anthesis, the pellucid-punctate acute teeth ovate-deltoid or ovate and 1.5-2 mm. long; corolla pink-lavender to deep reddish-purple, the lobes purplish, the throat red-purple striped or maculate, finely pubescent, $2-3 \mathrm{~cm}$. long, the tube subequaling the calyx, the upper lobe entire, the lower lobes inconspicuously emarginate and subentire; filaments villous below; anthers glabrous or sparsely short-villous; fruiting calyx turbinate, 6-7 $\mathrm{mm}$. long, about $5 \mathrm{~mm}$. in diameter at base, the rigid teeth slightly incurved; cocci brown, 3-angled, about $3 \mathrm{~mm}$. long, the ridges hyaline.

In wet soil of bottomlands along streams mostly in e. Tex., May-June; endemic.

\section{Stachys L. Hedge-nettle}

Annual, biennial or perennial herbs, mostly pubescent or hispid; flowers in verticils to form dense or interrupted terminal racemes or spikes, sometimes in the upper leaf axils; calyx usually campanulate, 5- to 10-nerved, 5-toothed with the teeth nearly equal and erect or spreading; corolla mostly reddish or purplish, the narrow tube not dilated at the throat and strongly 2-lipped; upper corolla lip erect, often arched, concave, entire or emarginate; lower corolla lip spreading, 3-lobed, the middle lobe broader than the often deflexed lateral ones and sometimes 2-lobed; stamens 4, didynamous, ascending under the upper corolla lip, the anterior pair the longer; anthers contiguous in pairs, the sacs divergent; ovary deeply 4-lobed; style 2-cleft, the lobes subulate; cocci ovoid or oblong, obtuse.

Nearly 300 species mostly in the North Temperate Zone, with several in South America and South Africa.

1. Leaves sessile to subsessile, the petiole usually much less than $1 \mathrm{~cm}$. long (2)

1. Leaves distinctly petiolate, the petiole typically much more than $1 \mathrm{~cm}$. long (3)

2(1). Calyx lobes three fourths to fully as long as the tube

1. S. palustris.

2. Calyx lobes about half as long as the tube

2. S. Nuttallii.

3(1). Annual or biennial with decumbent or weakly erect stems; leaves crenate; mostly in central and south Texas.................................. S. S crenata.

3. Perennials with erect stems; leaves dentate or serrate; in eastern Texas and/or eastern Oklahoma (4)

4(3). Plant glabrous or nearly so; inflorescence essentially glabrous; petioles less than one fourth as long as the blades................4. S. tenuifolia.

4. Plant more or less hirsute; inflorescence puberulent or glandular-puberulent; petioles one third to one half as long as the blades.

5. S. floridana.

\section{Stachys palustris L.}

Rhizomatous perennial, simple or branched, 2-7 dm. tall, apparently hairy throughout and often also glandular; stem typically with long coarse spreading or somewhat retrorse hairs along the angles and shorter more slender frequently viscid or gland-tipped hairs along the sides or all around; leaves sessile or some near middle of stem short-petiolate (to $1 \mathrm{~cm}$. long); lowermost leaves short and deciduous, the others triangular-lanceolate or ovate-lanceolate to elliptic, acute to acuminate, broadly rounded to truncate-subcordate at base, $3.5-9 \mathrm{~cm}$. long and to $4 \mathrm{~cm}$. wide, crenate; inflorescence a series of verticils, the lower often axillary to foliage leaves, the others to progressively reduced bracts; calyx 6-9 $\mathrm{mm}$. long, pubescent with slender gland-tipped hairs and long stout glandless ones, the narrow lobes three fourths to fully as long as the tube and tapering to a slender firm point; corolla purplish, white-maculate, $1-1.6 \mathrm{~cm}$. long, the tube only slightly if at all surpassing the calyx, abruptly expanded on the lower side of the level 


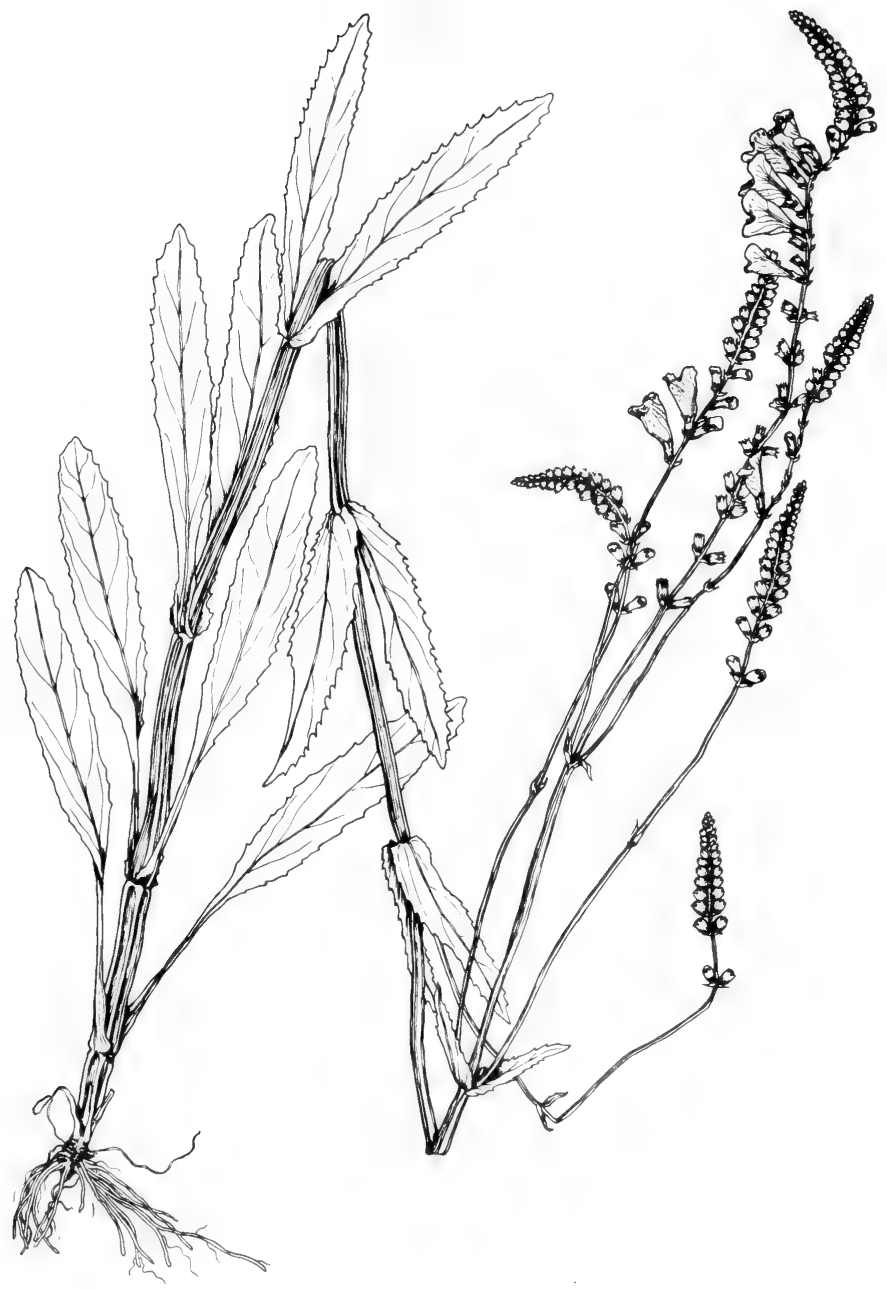

Fig. 668: Physostegia pulchella: habit, x 1/2. (From Lundell's Flora of Texas, Vol. 2, pl. 20). 
of the base of the oblique internal ring of hairs and often with a small saccate gibbosity; anthers explanate. Incl. var. pilosa (Nutt.) Fern. and var. nipigonensis Jennings.

In water of ditches, wet meadows, swampy open ground along streams and sloughs, and on edge of lakes and ponds, in Okla. (Waterfall), N. M. (Rio Arriba and Taos cos.) and Ariz. (Apache, Coconino and Greenlee cos.), JulyOct.; Que. to Alas., s. to N.E., N.Y., O., Mich., Ill., Ia., Mo., Okla., N.M. and Ariz.

\section{Stachys Nuttallii Shuttlew.}

Plant coarse, with long rhizomes; stems erect, simple, 7-12 dm. tall, the angles hispid, the sides glandular-puberulent; leaves sessile to subsessile, narrowly ovate to oblong-elliptic or elliptic-lanceolate, $8-13 \mathrm{~cm}$. long, 2-4.5 cm. wide, cordate at base, acuminate at apex, nearly or quite glabrous on lower surface except for hispid nerves, crenate to crenate-serrate; verticils usually many-flowered; calyx glandular and short-pilose, with tube $3.5-5.5 \mathrm{~mm}$. long and deltoid acuminate teeth about half as long as the tube; mericarps 1.9-2 $\mathrm{mm}$. long.

In meadows and bogs, in Okla. (Gleason, Waterfall), June-July; w. Va. and N. C. to Ark. and Okla.

This plant is closely allied to $S$. palustris, to which it may eventually be referred.

\section{Stachys crenata Raf. Shade betony.}

Annual or biennial, hirsute; stems usually branched at the base, the branches erect or decumbent, to $3 \mathrm{dm}$. long; leaves ovate to oblong, to $4 \mathrm{~cm}$. long, obtuse at apex, crenate, truncate to cordate at base, the lower ones with petioles as long as or longer than blade, the uppermost sessile; clusters few-flowered; pedicels 1-2 mm. long; bracts oval to suborbicular, subulate-tipped; calyx 3-5 mm. long; calyx lobes ovate-lanceolate to lanceolate, with subulate tips, mostly shorter than the tube, glabrous beyond the middle; corolla 5-6 mm. long, pink-lavender, pink to blue or rarely white, glabrous except the bearded upper lip, the lobes of the lower lip rounded or the middle one barely emarginate; cocci about $1 \mathrm{~mm}$. long, granular. S. agraria Cham. \& Schlecht.

In shaded rocky or gravelly soils in woods, ravines in prairies, in mud on edge of ponds and lakes and along streams, on banks and in open grounds in e., cen. and s. Tex., Feb.-May; also n.e. Mex.

The plant with white corolla and green calyx teeth is segregated as $\mathrm{f}$. albiflora Benke.

\section{Stachys tenuifolia Willd. Fig. 669 .}

Perennial, extensively creeping, glabrous or nearly so; the erect simple or branching stems glabrous or at most sparsely hirtellous on the sides, smooth to roughened or hirsute on the angles, to $13 \mathrm{dm}$. high; leaves with petiole $1-2 \mathrm{~cm}$. long, linear or linear-lanceolate to narrowly ovate, the principal ones $6 \mathrm{~cm}$. broad, glabrous or hirsute on one or both faces, with rounded to subtruncate or tapering base, taper-pointed, sharply dentate to serrate, the middle and lower blades 4 to 11 times as long as their petioles; spike few-flowered, interrupted; calyx 5-6 mm. long, glabrous or bristly along the angles, the lance-attenuate teeth soon outwardly curving; corolla about $1 \mathrm{~cm}$. long, the tube surpassing the calyx, the lower lip drooping and slightly shorter than the tube, the upper lip concave and glandular-pubescent on the back; filaments villous at the base; cocci $2 \mathrm{~mm}$. long, somewhat lustrous.

Rich bottomlands, lake shores, muddy bayous, swamps, marshes, low woods and wet meadows in e. fourth of Tex. and Okla. (Cherokee Co.), Aug.-Nov.; from N. Y. to Minn., s. to S. C., Tenn., La., Okla. and Tex. 


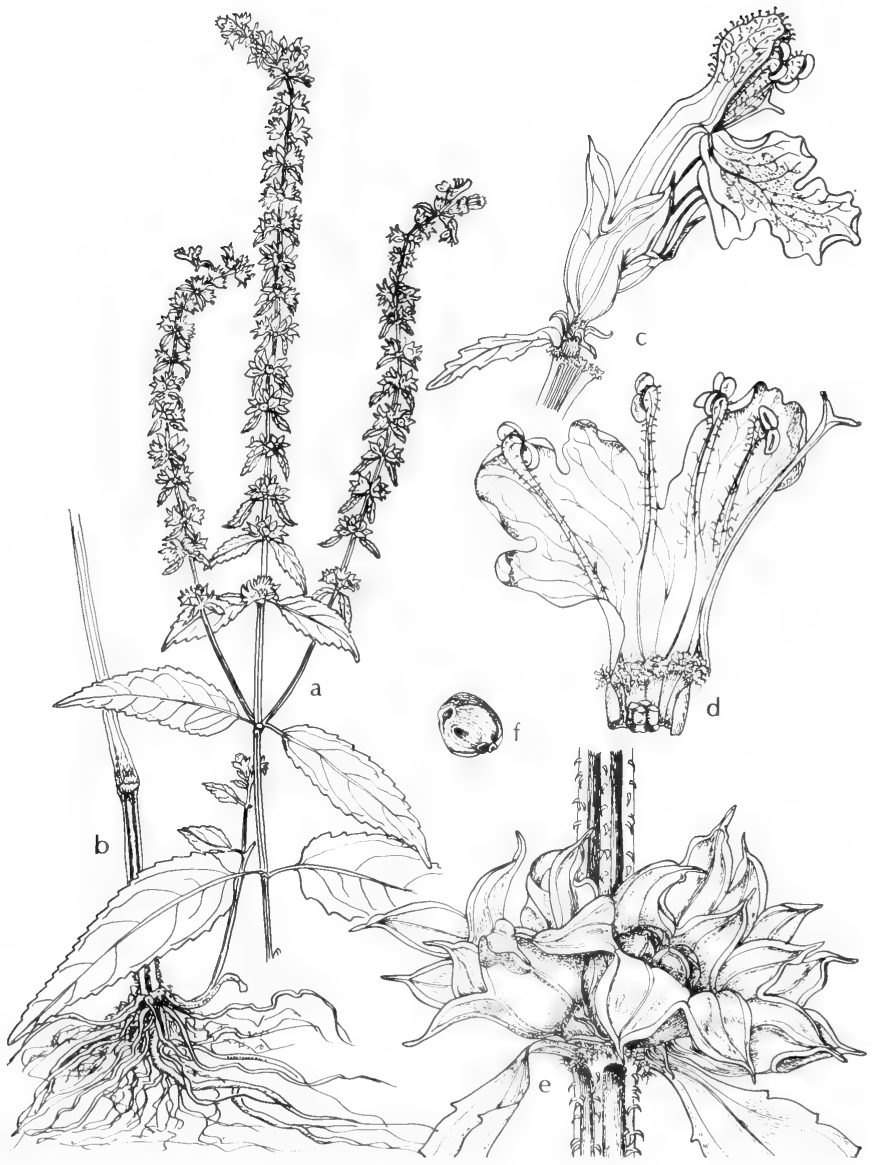

Fig. 669: Stachys tenuifolia: a, top portion of plant, $\mathrm{x} \frac{1}{1} / 2 ; \mathrm{b}$, basal part of plant, $\mathrm{x} 1 / 2 ; \mathrm{c}$, flower, $\mathrm{x} 4$; d, flower opened longitudinally, $\mathrm{x} 4$; e, fruit in the leaf axils, x 4; f, nutlet, x 5. (V. F.). 


\section{Stachys floridana Shuttlew.}

Plant spreading by means of elongate sometimes branching tubers; stem to about $4 \mathrm{dm}$. high, hirsute; leaves elliptic to ovate, serrate or dentate, $1-4 \mathrm{~cm}$. long, the middle and lower blades shorter to slightly longer than their petioles; calyx 5-7 mm. long, puberulent, the lobes lanceolate; corolla $1-1.3 \mathrm{~cm}$. long, the lower lip as long as the tube; cocci $1.5 \mathrm{~mm}$. long or rarely smaller.

In wet sandy soils and in marshes, in s.e. Tex. (Tyler Co.), Mar.-June; from Fla. to Tex., n. to N.C.

\section{Salvia L. SAGE}

Shrubs or herbs of varied habits, often aromatic; flowers commonly large and showy, in interrupted spikes or terminal heads; calyx bilabiate, usually somewhat laterally compressed, the upper lip commonly entire but sometimes 3-toothed or 3-mucronate, the lower lip usually 2-toothed; corolla mostly blue, red or white, tubular, strongly bilabiate, the upper lip either plane and emarginate or galeate and entire; stamens 2, exserted from the corolla tube beyond the limb or contained within the galea, the connective strongly developed, often more prominent than the filament, bearing a single terminal anther sac, either straight or projected back into the corolla tube, sometimes geniculate; style usually exserted from the galea or beyond the upper lip; cocci smooth.

About 700 species distributed throughout the world but mostly in temperate and tropical regions, centered in South America.

1. Corolla violet-color or light-blue, $2-3 \mathrm{~cm}$. long; leaves subentire to lyratepinnatifid; widespread in eastern Texas and less so in eastern Oklahoma...................................................................... S. lyrata.

1. Corolla crimson, about $4 \mathrm{~cm}$. long; leaves entire or obscurely denticulate; endemic to Edwards Plateau in central Texas.

2. S. penstemonoides.

\section{Salvia lyrata L. CANCER-WEED, LYRE-LEAF SAGE.}

Rosulate perennial from a somewhat tuberous root, more or less pilose throughout, the scapiform stem to $8 \mathrm{dm}$. high or more; basal obovate to oblanceolate leaves petioled, membranaceous, the vernal ones sinuate to repand or lyratepinnatifid and to $3 \mathrm{dm}$. long, those of summer and autumn (holding over winter) mostly subentire, usually sparsely strigose-hirsute, often purple-tinged; scape naked or with 1 or 2 pairs of small leaves, simple or with virgate branches; whorls of flowers 3 to 10 , becoming distant; floral bracts oblong-linear, mostly shorter than the calyx; calyx campanulate, membranaceous, to $12 \mathrm{~mm}$. long at maturity, the broad upper lip truncate and with 3 widely separated teeth, the lower lip with 2 longer lanceolate cuspidate-pointed teeth; corolla violet or light-blue with darker blue markings, $2-3 \mathrm{~cm}$. long, ampliate-funnelform, exserted, its straight upper lip much shorter than the broad lower one; both forks of connective bearing fertile anthers; cocci fuscous, obovoid, about $2 \mathrm{~mm}$. long.

Sandy open woods, wet meadows and clearings, wet grassy swampy ground, gravelly alluvial soils along streams, in Okla. (Waterfall) and e. fourth of Tex., Dec.-May; from Fla. to Tex., n. to Conn., N.Y., N.J., Pa., W.Va., O., Ind., Ill., Mo. and Okla.

\section{Salvia penstemonoides Kunth \& Bouché. BIG RED SAGE.}

Perennial, nearly glabrous or below sparsely hirsute; stems to $15 \mathrm{dm}$. high, leafy to the summit; leaves thickish, linear-lanceolate to oblong-lanceolate, acute to acuminate and mucronate, entire or obscurely denticulate and with ciliolatescabrous margins, the midnerve prominent beneath; lower leaves $7.5-13 \mathrm{~cm}$. long, with long margined petioles; upper leaves gradually much smaller and be- 
coming essentially sessile; floral leaves and the similar persistent bracts and bractlets of the elongated racemiform or narrowly thyrsoidal inflorescence ovate-lanceolate to linear-lanceolate, cuspidate; cymules subsessile, 3- to 5-flowered; calyx equaled by the hirsute pedicels, campanulate, strongly bilabiate, about $13 \mathrm{~mm}$. long, glandular-puberulent, the upper broad lip truncate and with 3 short and broad cuspidate-mucronate teeth, lower lip 2-parted with its teeth lanceolate and cuspidate; corolla crimson, about $4 \mathrm{~cm}$. long, slightly pubescent, its tube villousannulate towards the base inside, its large and nearly straight upper lip half the length of the gradually enlarged exserted tube, the middle lobe of the small lower lip concave and entire; style glabrous.

In seepage on limestone ledges and wet banks along streams in cen. Edwards Plateau of Texas., June-Oct.; endemic.

\section{Monarda L. Monarda. Horsemint}

About 20 species extending from Canada to Mexico.

Several other species, among which are $M$. austromontana Epl., $M$. punctata L., $M$. clinopodioides Gray and $M$. citriodora Cerv., are occasionally found in floodplains along streams but, since they are more likely to be found in dry or moist loamy soils, they are omitted here.

1. Monarda fistulosa L. Wild Bergamont, Long-Flowered horsemint. Fig. 670.

Perennial herb to $15 \mathrm{dm}$. high; stems simple or usually branched, pubescent in the upper parts with downwardly curled hairs, glabrous below, sometimes with longer spreading hairs, rarely glabrous; leaves gray-green, firm (except in deep shade), narrowly triangular-ovate to -lanceolate, or sometimes cuneate at base, the straightish serrate-dentate sides tapering to tip, definitely petioled, spreadinghirsute or -villous with long hairs along the nerves beneath, the larger blades to $4 \mathrm{~cm}$. broad and with petioles to $15 \mathrm{~mm}$. long; uppermost leaves and foliaceous reflexed bracts often pink-tinged; glomerules mostly terminal, to $3 \mathrm{~cm}$. broad (excluding the corollas); calyx $7-12 \mathrm{~mm}$. long, puberulent with short spreading hairs, the acuminate teeth usually $1-2 \mathrm{~mm}$. long, the orifice hirsute with stiff erect hairs within, sometimes bristling with similar spreading hairs at the base of the teeth; corolla lavender, $2-3 \mathrm{~cm}$. long, pubescent with short soft curling hairs, the upper lip comose, the tube $15-24 \mathrm{~mm}$. long and gradually expanded upward; stamens seated about $1 \mathrm{~mm}$. within the tube.

In dry open woods, old fields, wet meadows and ditches, alluvial thickets, edge of woods and marshes in e. fourth of Tex. and Okla. (Waterfall), May-July; from Que. and N.E., w. to Minn., s. to Ga., Ala., La, and Tex.

\section{Perilla L.}

About a half dozen species natives of Asia.

\section{Perilla frutescens (L.) Britt. Beefsteak Plant.}

Coarse aromatic annual, often purple or suffused with purple; stem erect, branching, to about $1 \mathrm{~m}$. high; leaves ovate-oblong to broadly ovate, to $15 \mathrm{~cm}$. long, short-acuminate at apex, coarsely serrate or incised, obtuse to rounded at base but cuneately tapered into the long petiole; flowers small, purple or white, borne singly in the axils of small bracteal leaves to form a loose elongate spikelike 1 -sided raceme to $15 \mathrm{~cm}$. long; bracteal leaves oval, folded, rarely greatly enlarged; pedicels 1-3 mm. long; calyx campanulate, 10-nerved, bilabiate, the lips lobed, at anthesis about $3 \mathrm{~mm}$. long, in fruit distended on the lower side and 9-12 mm. long, hairy within; corolla white, tubular, about as long as calyx or slightly longer; corolla lips about equal in length, the 5 lobes broadly rounded; stamens 4 , nearly equal, straight, not connivent, about as long as the corolla; cocci globose, reticulated. 


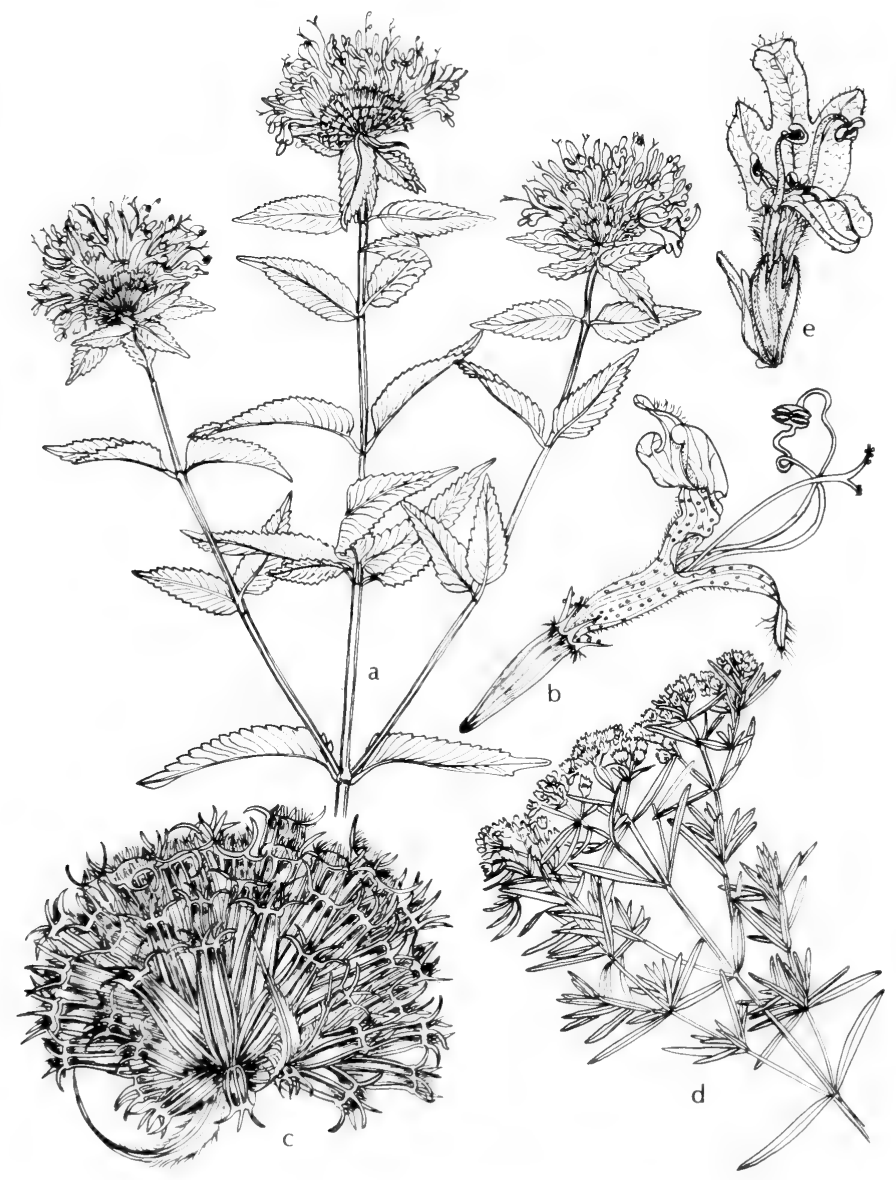

Fig. 670: a-c, Monarda fistulosa: a, top of plant, $x \frac{1}{2} ; \mathrm{b}$, flower, $\mathrm{x} 2$; c, headlike cluster of calyces with fruit, $\mathrm{x} 2$. d and e, Pycnanthemum tenuifolium: d, top of plant, x 1/2; e, flower, x 5. (V. F.). 


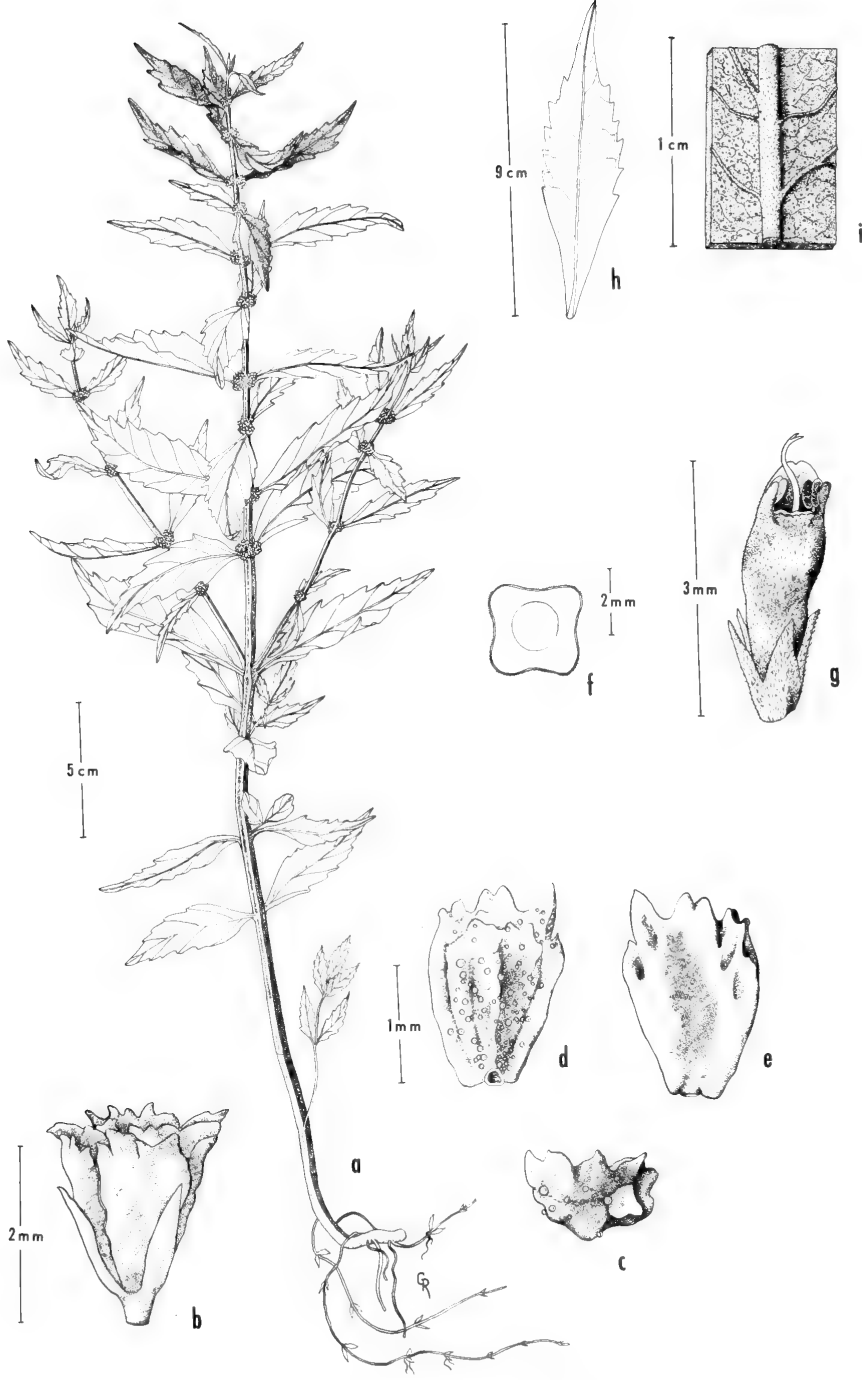

Fig. 671: Lycopus virginicus: a, habit; b, four nutlets within the calyx; c, upper surface of nutlet; d, inner surface of nutlet; e, outer surface of nutlet; $f$, diagrammatic cross section of stem; $g$, nower showing included stamens, erect lobes of the corolla, notched adaxial lobe and the position of the exserted style; $h$, middle cauline leaf; $i$, portion of lower leaf surface showing pubescence. (Courtesy of R. K. Godfrey). 
In damp woods, edge of water in streams, wet gravel bars in river beds, along open-wooded streams and seepage areas in e. Tex. and Okla. (McCurtain and Cherokee cos.), July-Nov.; from Fla. to Tex., n. to N.E., N.Y., O., Ind., Mo. and Kan.; a nat. of India that locally often becomes a troublesome weed.

The seeds produce an edible oil that is used in commerce.

\section{Lycopus L. WATER-HOREHOUND. Bugle-WEED}

Perennial mostly stoloniferous or tuber-bearing herbs resembling Mentha but not fragrant; stem erect, simple or branched; leaves mostly toothed or pinnatifid; floral bracts similar to leaves and much longer than the dense axillary whorls of small mostly white flowers; calyx campanulate to ovoid, 4- or 5-toothed, naked in the throat; corolla more or less campanulate; stamens 2, distant, the upper pair either sterile rudiments or wanting; cocci with thickened margins.

More than a dozen species in the North Temperate regions.

1. Mature cocci exceeding the lanceolate to triangular calyx lobes and mostly concealing them (2)

1. Mature cocci noticeably exceeded by the subulate or cuspidate calyx lobes (3)

2(1). Stem usually puberulent, rising from a slender base, with elongate mostly non-tuberous stolons; calyx ovoid-cylindric; corolla tubular with erect lobes; stamens and style included.................... L. virginicus.

2. Stem glabrate, from a tuberous base, the stolons bearing whitish tubers; calyx campanulate; corolla with flaring lobes; stamens and style mostly exserted..

2. L. uniflorus.

3(1). Lower and median leaf blades sessile; plant tuberiferous.

3. L. asper.

3. Lower and median leaf blades tapering to petioles or to subpetiolar bases; tubers rarely developed (4)

4(3). Ridge of cocci entire, relatively soft and corky; lower and median primary leaves typically incised or pinnatifid at least at base.

4. L. americanus.

4. Ridge of cocci verrucose to tuberculate; lower and median leaves merely serrate..............................................................5. L. rubellus.

\section{Lycopus virginicus L. Virginia BUGLE-WEed. Fig. 671 .}

Stem obtusely angled, usually puberulent with curved hairs, to about $8 \mathrm{dm}$. high, rising from a slender (not conspicuously tuberous-thickened) base; stolons filiform, mostly not tuberiferous; leaves dark-green or purple-tinged, ovate to ovate-oblong or elliptic, firm, rather abruptly acuminate at both ends, coarsely toothed, to $15 \mathrm{~cm}$. long and $5 \mathrm{~cm}$. broad; glomerules dense, often seemingly compound, in maturity $8-15 \mathrm{~mm}$. broad, the mature cocci usually concealing the calyces; calyx ovoid-cylindric; corolla tubular, with erect lobes; stamens mostly included; cocci asymmetrical, their summits deeply muricate.

Rare in marshy soils and along woodland streams, in alluvial thickets along streams, sloughs and lakes or river floodplains, wet meadows and along ditches, in s. e. Tex. and Okla. (Waterfall), Aug.-Dec.; from Ga. to Tex., n. to N.E., N.Y., O., Ind., Wisc., Minn. and Neb.

\section{Lycopus uniflorus Michx. Fig. 672.}

Plant from thick, often tuberlike rootstock and often stoloniferous from lower nodes; stems erect, slender, simple or branched, 1-8 dm. tall; herbage green or purplish; leaves sessile or subsessile, $2-7 \mathrm{~cm}$. long, to $2.5 \mathrm{~cm}$. wide, lanceolate to ovate, acute, cuneate at base, unequally serrate to dentate-serrate, pubescent on veins beneath; calyx lobes oblong-ovate to triangular, 1.3-1.5 mm. long, obtuse; corolla 2-3 mm. long; stamens 2, rudimentary stamens absent or much-reduced; 


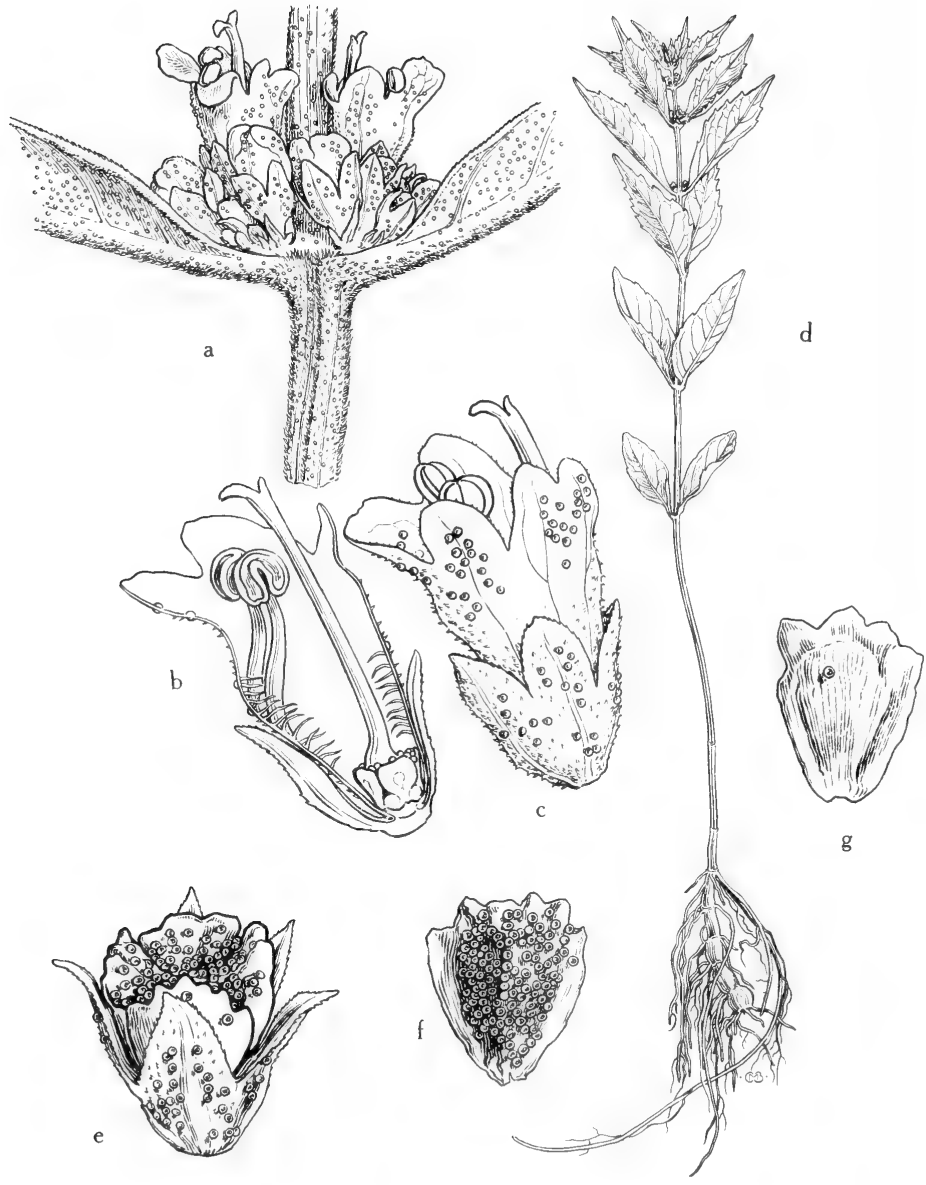

Fig. 672: Lycopus uniflorus: a, flower clusters in leaf axils, $\mathrm{x}$ 8; b, flower (longitudinal section), $\mathrm{x} 11 \frac{1}{5} ; \mathrm{c}$, flower, the calyx and corolla gland-dotted, $\mathrm{x} 12$; $\mathrm{d}$, habit, the rootstock tuberlike, x $2 / 5$; e, calyx containing mature nutlets, $x$ 16; $\mathrm{f}$, nutlet, gland-dotted, adaxial view, x 20; g, nutlet, abaxial view, x 20. (From Mason, Fig. 299). 


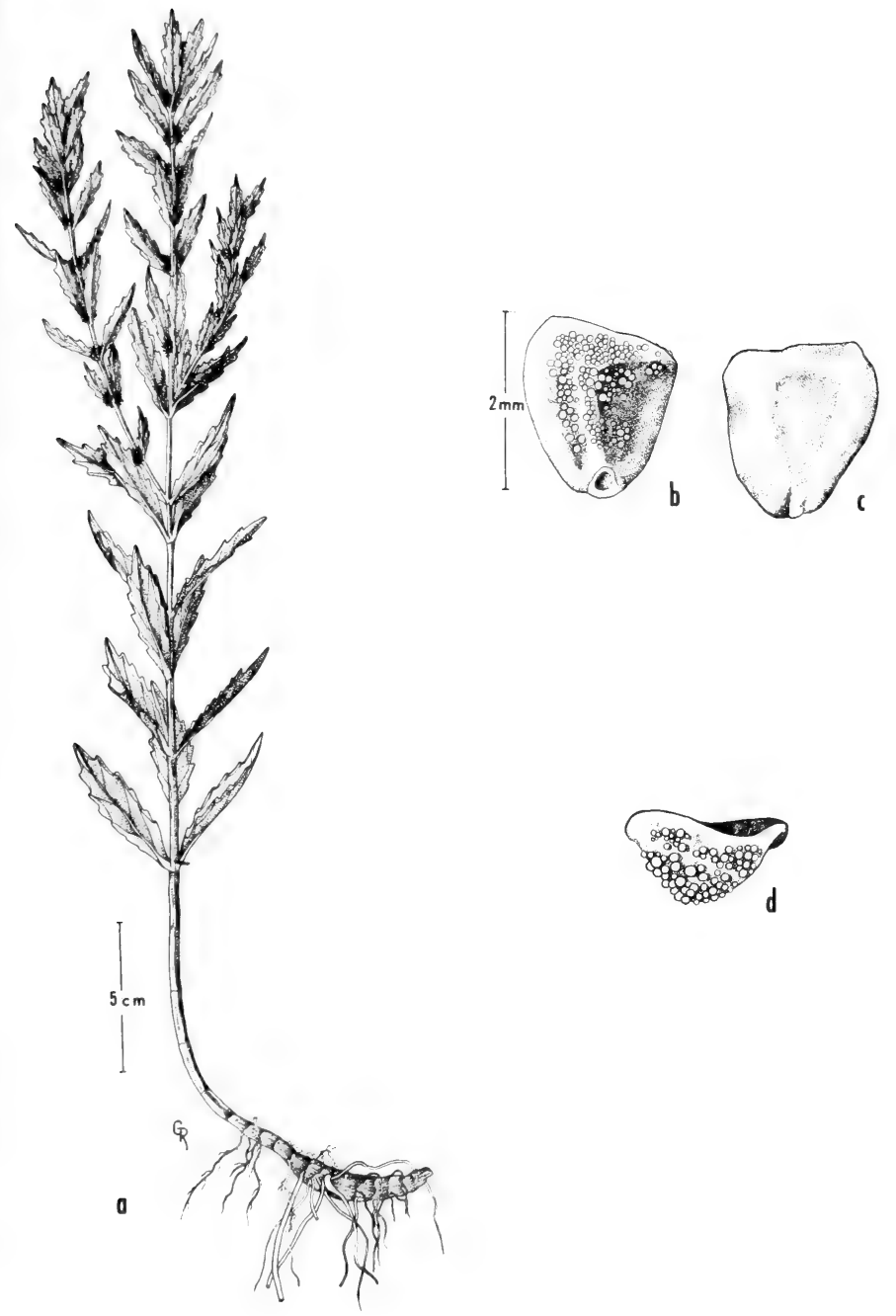

Fig. 673: Lycopus asper: a, habit; b, inner surface of the nutlet; c, outer surface of the nutlet; d, upper surface of nutlet. (Courtesy of R. K. Godfrey). 
filaments exceeding the corolla throat; nutlets slightly shorter than the sepals to longer, somewhat irregular across the truncate tip.

Bogs, wet woodlands and swampy places in Okla. (Waterfall), June-Sept.; Nfld. to B.C., s. to N.C., O., Ind., Ill., Ia., Okla., Mont. and Ore.

\section{Lycopus asper Greene. Fig. 673.}

Stem strict, rather stout, simple or slightly forking, to about $5 \mathrm{dm}$. high, from elongate tubers, the internodes spreading-pubescent with long multicellular hairs; leaves sessile, lanceolate to oblong-lanceolate, acute at apex, dark-green, mostly longer than the internodes, appressed to spreading-ascending, scabrous, the larger ones $5-8 \mathrm{~cm}$. long with 6 to 12 sharp teeth on each side; bracts lanceolate, nearly equaling the glomerules, dilated; calyx teeth triangular to ovate, acuminate, 2-3 mm. long, minutely ciliolate; corolla tube scarcely exceeding the calyx; cocci about $2 \mathrm{~mm}$. long and $1.7 \mathrm{~mm}$. broad, with entire angles and oblique nontuberculate summit. L. lucidus of auth.

In wet meadows, marshes and wet shores, in mud of seepage, alluvial soils of floodplains, in the Tex. Panhandle, N.M. (San Juan and Valencia cos.) and (?) Ariz., June-Sept.; from Alas. to Calif., e. to Mich., Ill., Mo., Tex. and N. M.

\section{Lycopus americanus Muhl. Fig. 674.}

Stem erect, slender, to about $9 \mathrm{dm}$. high, glabrous or very sparingly appressedpubescent with dark hairs, freely stoloniferous, without tubers; leaves petioled, to about $1 \mathrm{dm}$. long and $3 \mathrm{~cm}$. wide; lower primary leaves incised or pinnatifid (especially at base), glabrous or minutely pubescent on veins beneath, glabrous to scabrous-puncticulate above, lanceolate to narrowly ovate or oval; upper leaves lance-attenuate, sinuate to sharply toothed; bracts short; calyx teeth with long subulate tips; corolla white, the tubes scarcely or barely longer than the calyx teeth, the filaments exserted; cocci $1-1.5 \mathrm{~mm}$. long, $0.6-1 \mathrm{~mm}$. broad, with entire or barely undulate angles, the dorsal angular face relatively soft and dark, the summit entire. L. sinuatus $\mathbf{L}$.

Low grounds, soggy meadows, marshes, in water of and on edge of ponds, streams and ditches, wet soils about lakes and in canyons in n.-cen. Tex. and the Panhandle, Okla. (widespread), N. M. (Colfax, San Juan, San Miguel, Taos, Valencia, Bernalillo, and Grant cos.) and Ariz. (Navajo Co.) July-Nov.; from Nfld. to B.C., s. to Fla., Ala., Miss., Tex., N.M., Ariz. and Calif.

Those plants whose leaves are scabrous-puncticulate on the upper surface are segregated as var. scabrifolius Fern.

\section{Lycopus rubellus Moench. WATER-HOREhOund. Fig. 675.}

Stem arising from slender stolons and rhizomes to about $12 \mathrm{dm}$. high; leaves elliptic to elliptic-ovate or -lanceolate, petioled, at most sharply serrate or serratedentate, acuminate, to about $15 \mathrm{~cm}$. long and $5 \mathrm{~cm}$. wide; bracts minute; calyx teeth acuminate and sharp-pointed, scarcely subulate-tipped; corolla white, often with purple spots, 3.5-4 $\mathrm{mm}$. long, twice as long as calyx; sterile filaments mostly included; nutlets $1-1.6 \mathrm{~mm}$. long, about $1 \mathrm{~mm}$. broad, firm throughout, the low dorsal angle rounded and the lateral ones often undulate, the summit definitely so.

In marshes, swamps, bogs, meadows, ditches, seepage areas and shallow water in Okla. (Washington, Creek, Pushmataha and McCurtain cos.) and e. Tex. (Marion, Tyler, Newton, Jasper and Hardin cos.), Aug.-Dec.; from Fla. to Tex., n. to N.E., N.Y., O., Mich., Ill., Mo. and Okla.

We have two variants in this species that are separated as follows: 

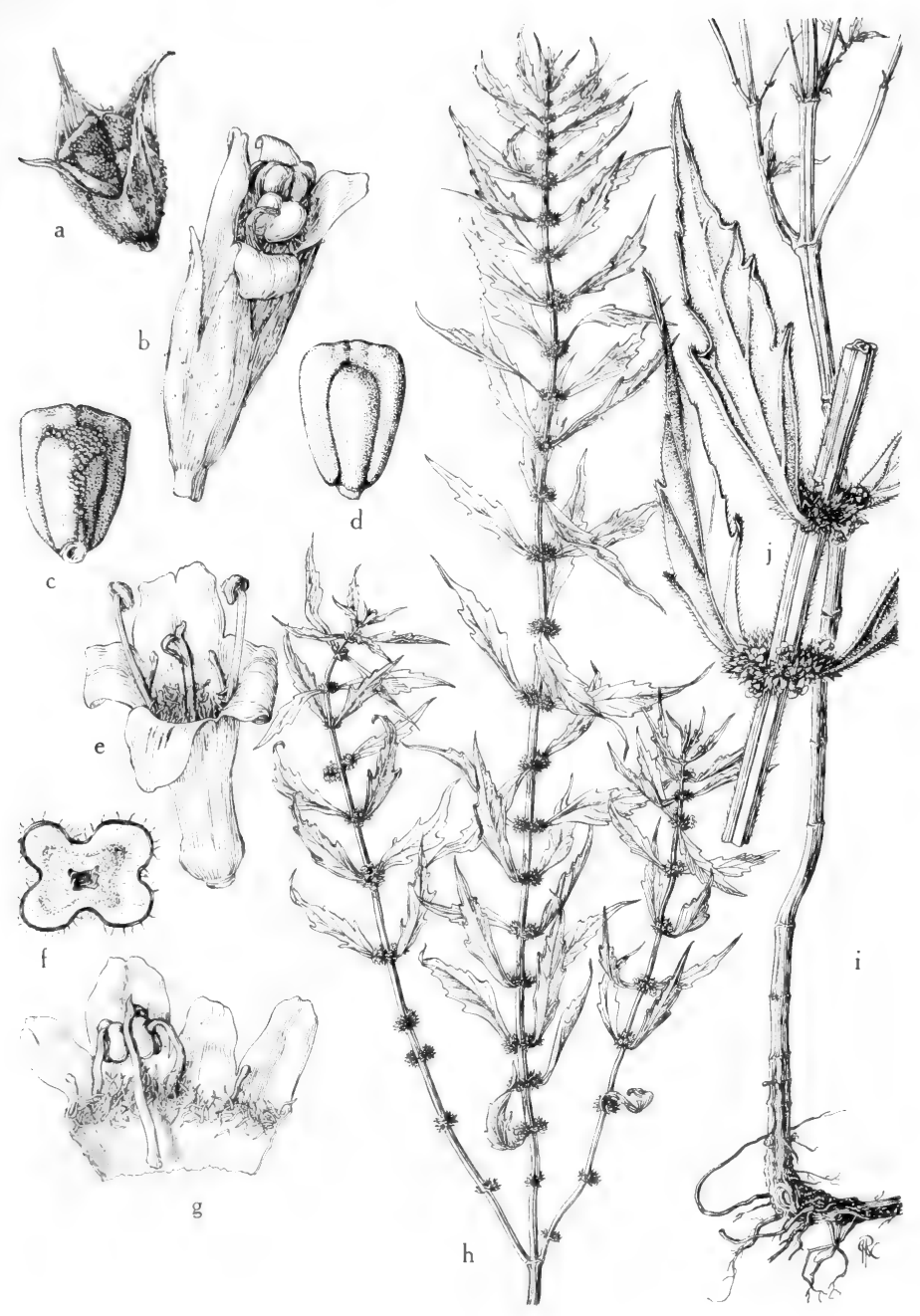

Fig. 674: Lycopus americanus: a, calyx containing mature nutlets, x 12; b, flower, x 12; c, nutlet, adaxial view, x 20; d, nutlet, abaxial view, x 20; e, corolla, showing rudimentary and fertile stamens and the pubescent tube, $\mathrm{x} 12$; $\mathrm{f}$, stem (cross section), $\mathrm{x} 12 ; \mathrm{g}$, corolla, spread open to show rudimentary stamens and the pubescence in the tube, $\mathrm{x} 12 ; \mathrm{h}$, habit, tip of the flowering plant, $\mathrm{x} \% \mathrm{i} ; \mathrm{i}$, habit, base of plant, showing stout rhizome, $x=2 / j$, flower clusters in the leaf axils, $x$ 11/2. (From Mason, Fig. 300). 

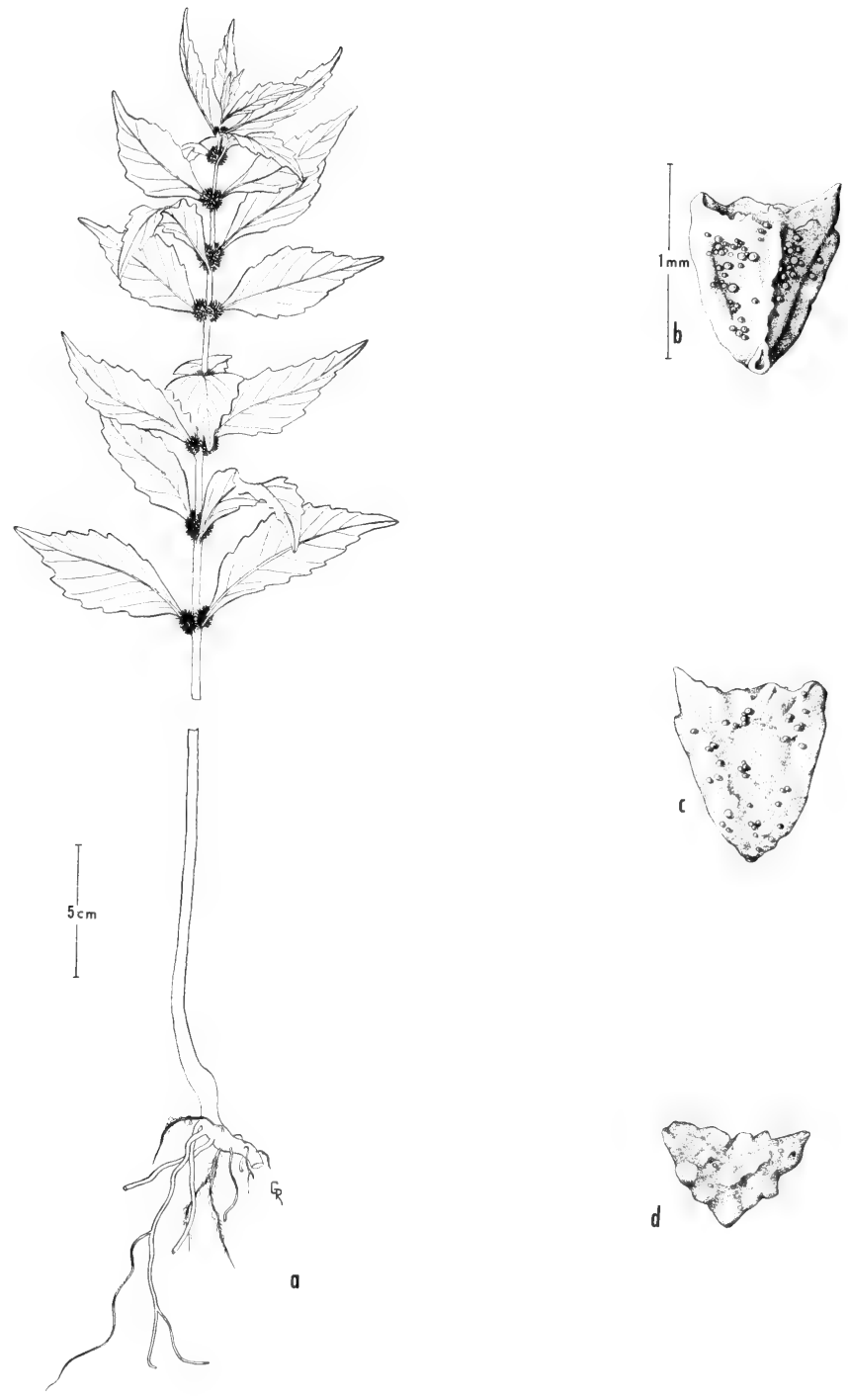

Fig. 675: Lycopus rubellus: a, habit; b, inner surface of nutlet; c, outer view of nutlet; d, top surface of the nutlet. (Courtesy of R. K. Godfrey). 
1. Primary leaves sharply serrate to serrate-dentate; stem glabrous or essentially so; calyx teeth and tube subequal, glabrous, the teeth straight........ var. rubellus.

1. Primary leaves with low and depressed teeth; younger internodes and lower surfaces of leaves pubescent; calyx teeth of ten with recurving tips ..var. arkansanus (Fresen.) Benner.

\section{Mentha L. MinT}

Odorous perennial rhizomatous herbs with erect or diffuse stems; leaves sessile or petioled, usually punctate; flowers small, in whorls that are axillary or in terminal congested or interrupted spikes, of two sorts as to the fertility of the stamens in most species; calyx campanulate to cylindric, 10-nerved, regular or slightly bilabiate, 5-toothed; corolla pale-purple or whitish, bilabiate, the tube shorter than the calyx, the upper lip entire or emarginate, the lower lip 3-lobed; stamens 4, equal, erect, included or exserted; filaments glabrous; anther sacs parallel; ovary 4-parted; style 2-cleft at the summit; cocci ovoid, smooth.

About 25 species in the North Temperate regions.

The seeds are eaten by waterfowl and game birds, and the succulent rhizomes are known to be eaten by muskrats.

1. Flower whorls all distant and in leaf axils; leaves exceeding the whorls 1. M. arvensis.

1. Flower whorls forming terminal spikes or some of the lower in the leaf axils and somewhat distant (2)

2(1). Plants tomentose or villous-tomentose; leaves sessile.......2. $M$. rotundifolia.

2. Plants glabrous or nearly so; leaves more or less petiolate (3)

3(2). Leaves short-petioled to nearly sessile; spike slender, more or less interrupted.

3. M. spicata.

3. Leaves all distinctly petioled; spikes thick and mostly dense.......... 4 . piperita.

1. Mentha arvensis L. FiELD MINT. Fig. 676.

Plant aromatic; stems stoloniferous, freely branching below or nearly simple, to about $8 \mathrm{dm}$. high, more or less retrorse-pubescent (especially on the angles); leaves oblong to ovate or lanceolate, rounded at base to a distinct petiole, usually rather closely serrate, minutely pubescent or short-villous, the larger leaves to about $5 \mathrm{~cm}$. long, the upper leaves not much smaller than the lower ones; flower whorls all axillary; calyx pubescent, about $3 \mathrm{~mm}$. long, the triangular-subulate teeth about equaling the tube; corolla pink to violet or white, about twice as long as the calyx, nearly or quite glabrous. Incl. var. villosa (Benth.) S. R. Stewart and var. glabrata (Benth.) Fern., M. Penardii (Briq.) Rydb., M. canadensis L.

In moist rich soils, cat-tail swamps, seeping wet meadows, marshes, about lakes, springs and along ditches and streams, in w and n.w. Tex., N. M. (Colfax, Otero, Rio Arriba, San Juan, Sandoval, Union, Taos, San Miguel and Catron cos.) and Ariz., (Apache, Navajo, Coconino, Yavapai, Greenlee, Santa Cruz and Cochise cos.), May-Oct.; circumboreal.

\section{Mentha rotundifolia (L.) Huds. Applemint, roundleaf Mint. Fig. 677.}

Perennial with leafy stolons, the herbage more or less tomentose and viscid; stems mostly erect, to about $15 \mathrm{dm}$. high, simple or branched; leaves sessile or short-petioled, elliptic to ovate- oblong, subcordate to rounded at base, obtuse at apex, the larger leaves to $5 \mathrm{~cm}$. long, crenate-serrate, more or less rugosereticulate beneath; flower whorls approximate or the lower especially somewhat distant, forming rather slender spikes to $1 \mathrm{dm}$. long in fruit; bracts ovate-lanceolate to lanceolate, acuminate, usually shorter than the flowers; calyx campanulate, greenish, velvety, barely $2 \mathrm{~mm}$. long, the subulate teeth about as long as the tube and connivent in fruit; corolla white or pink, about $4 \mathrm{~mm}$. long, puberulent. 


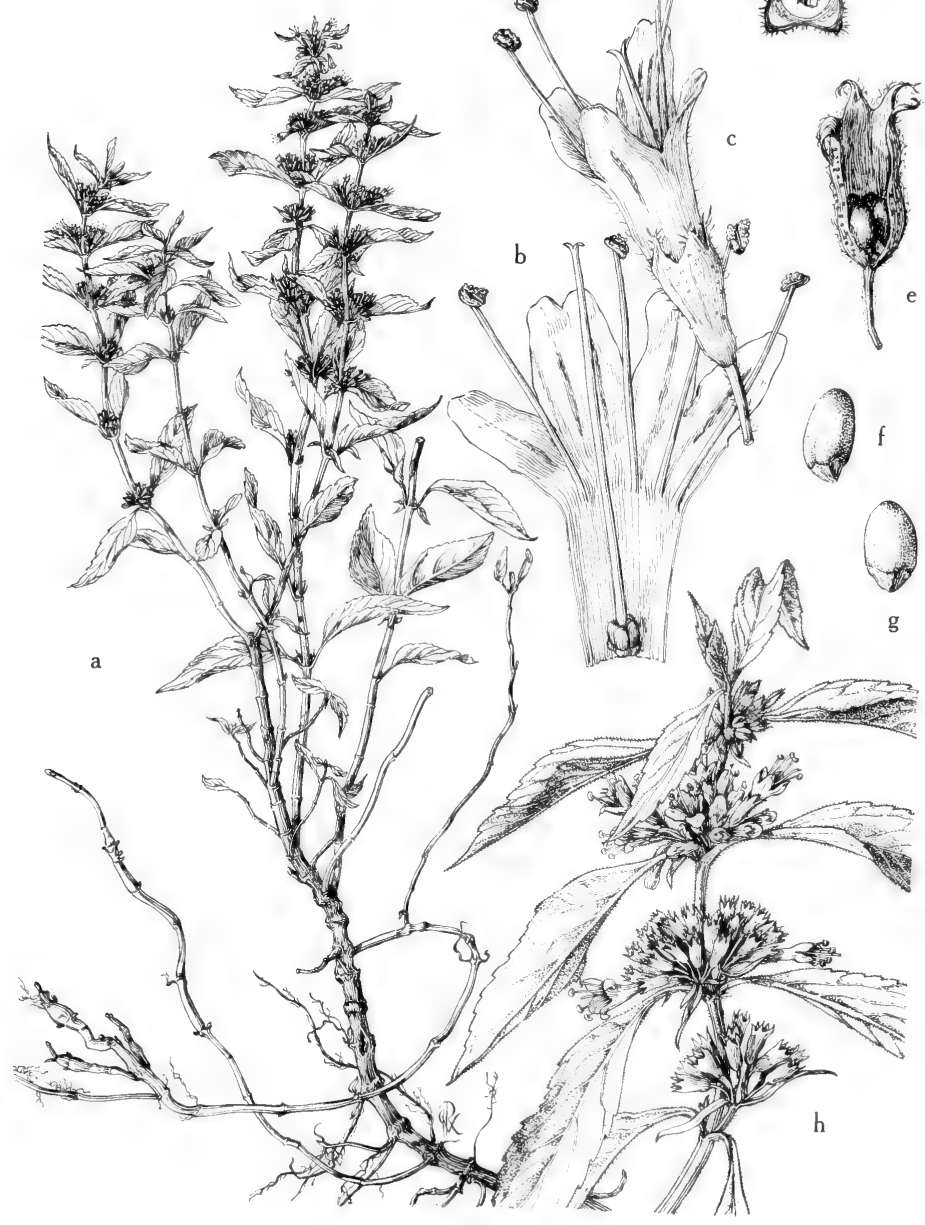

Fig. 676: Mentha arvensis: a, habit, X $\%$; b, corolla, spread open, x 8; c, flower, $\mathrm{x} 8$; $\mathrm{d}$, stem (cross section), $\mathrm{x} 3$; e, calyx, spread open to show the 4 nutlets, $\mathrm{x} 8$; $\mathrm{f}$ nutlet, adaxial side, $x 12 ; \mathrm{g}$, nutlet, abaxial side, $\mathrm{x} 12 ; \mathrm{h}$, inflorescence, $\times 1 \frac{1}{2}$. (From Mason, Fig. 305). 

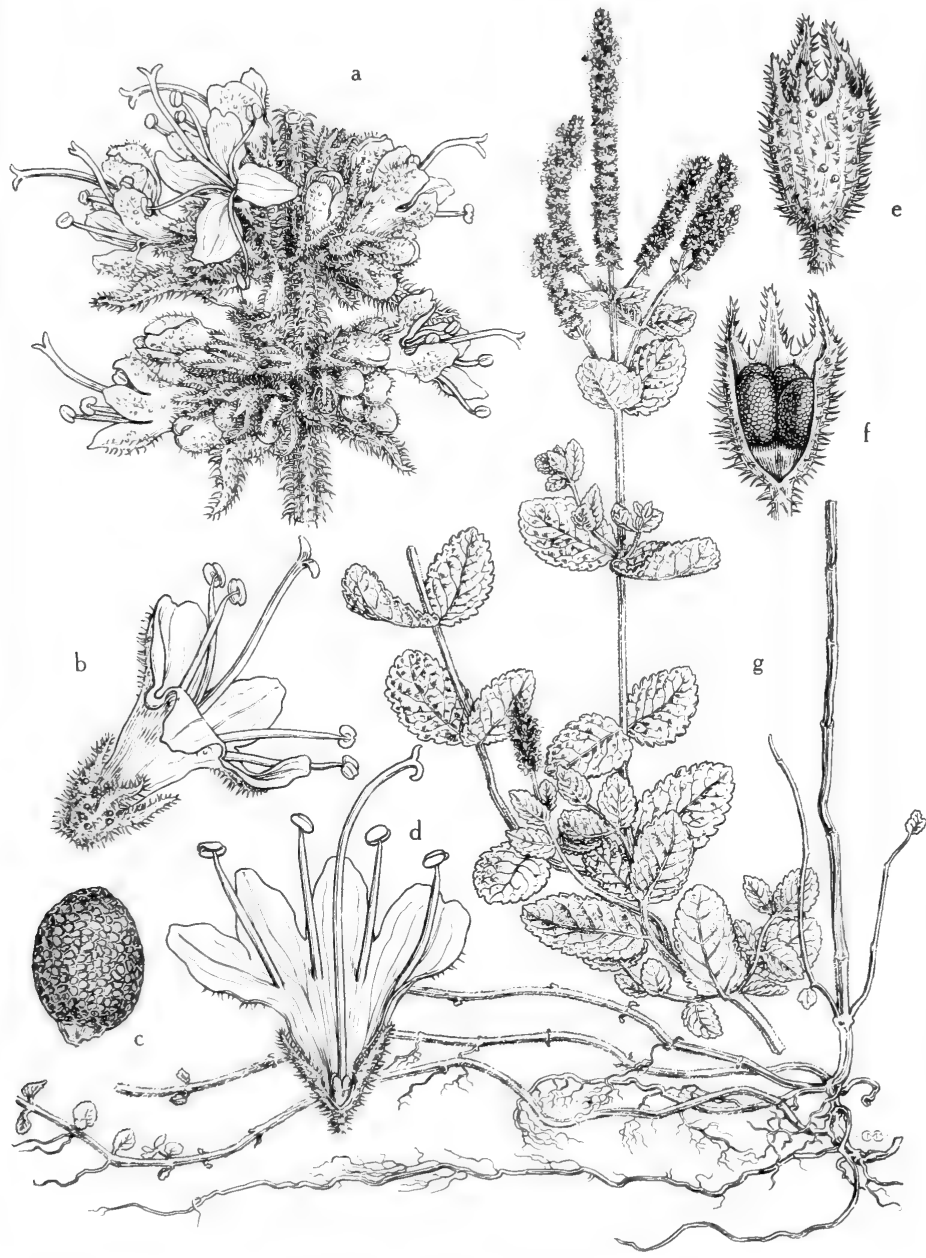

Fig. 677: Mentha rotundifolia: a, flower clusters at nodes, x 4; b, flower, x 8; c, nutlet, x 28; d, flower, spread open, x 8; e, calyx, x 12; f, calyx spread open to show the 4 mature nutlets, $x$ 12; g, habit, $x \% 5$. (From Mason, Fig. 303). 
Along roadsides, in old fields, wet seepage areas, thickets and waste places in cen. and w. Tex., N. M. (Dona Ana and Otero cos.) and Ariz. (Cochise Co.), May-Sept.; a nat. of Eur. that has become naturalized in various parts of N.A.

\section{Mentha spicata L. Spearmint. Fig. 678.}

Perennial with stolons, glabrous or sparingly pubescent at the nodes; stems usually branched, to $12 \mathrm{dm}$. high, often purplish; leaves sessile or short-petioled, oblong-lanceolate to ovate-lanceolate, acute to acuminate at apex, obtuse to somewhat rounded to subcordate at base, unequally sharply serrate, the larger leaves 3-6 cm. long; flower whorls in slender terminal leafless spikes often $6-8 \mathrm{~cm}$. long in fruit; bracts subulate-lanceolate, equaling or surpassing the calyx, green, glabrous or ciliate; calyx teeth subulate, about equaling the tube, ciliate on the margins, the inflorescence otherwise glabrous; corolla pale-lavender.

In moist fields and wet meadows, seepage bank of streams and about springs, open marshes and about ponds and along ditches, mostly near settlements, in cen. and w. Tex., Okla. (Murray Co.), N.M. (Dona Ana, Guadalupe and Santa Fe cos.) and Ariz. (Mohave, Yavapai, Santa Cruz. Pima and Gila cos.), June-Oct.; a nat. of Eur. that has become naturalized in much of N.A.

\section{Mentha piperita L. PePpermint. Fig. 678.}

Perennial with underground sometimes leafy-bracted stolons; stems erect or somewhat decumbent, branched, to about $8 \mathrm{dm}$. high, often purplish; leaves petioled, lanceolate to ovate-lanceolate, acute, sharply serrate, dark-green and firm, glabrous or sparsely pubescent on the veins beneath; whorls of flowers in terminal dense or interrupted spikes, to $12 \mathrm{~cm}$. long in fruit; bracts narrowly lanceolate, acuminate, not surpassing the flowers; pedicels elongate; calyx tube glabrous, the teeth about equaling or shorter than the tube and hirsute (sometimes sparingly so), ciliate; corolla glabrous, rose-purple to white.

In wet places about ponds, lakes and along streams, sloughs and ditches, wet meadows and spring branches, mostly in w.-cen. Tex. and Okla. (Adair and Cherokee cos.), June-Oct.; a nat. of Eur. that has become naturalized in much of N.A.

\section{Pycnanthemum Michx. Mountain-Mint. Basil}

Perennial erect herbs with a pungent mintlike flavor, corymbosely branched above, the floral leaves often whitened; the many-flowered whorls dense, crowded with bracts and usually forming terminal heads or close cymes; calyx about 13nerved, naked in the throat; corolla short, whitish or purplish, more or less 2-lipped, the lips mostly dotted with purple, the upper lip straight, nearly flat, entire or slightly notched, the lower lip 3-cleft with its lobes all ovate to oblong and obtuse; stamens exserted or included in different flowers; lower pair of stamens rather longer than the upper; anther cells parallel.

About 21 species, mostly in eastern United States.

1. Leaves linear, entire, rarely more than $4 \mathrm{~mm}$. wide............... $1 . P$. tenuifolium.

1. Leaves ovate to linear-lanceolate, subentire to remotely toothed, usually more than $5 \mathrm{~mm}$. wide (2)

2(1). Leaves typically linear-lanceolate, subsessile or with petioles less than 3 $\mathrm{mm}$. long; flowers in tight globose heads.............2. P. virginianum.

2. Leaves typically ovate-lanceolate, with petioles $4-12 \mathrm{~mm}$. long; flowers in irregular corymbs to form glomerules........................ P. albescens.

1. Pycnanthemum tenuifolium Schrad. Fig. 670.

Plant to about $1 \mathrm{~m}$. high, glabrous, forming dense colonies by horizontal roots, usually bearing abundant sterile simple or forking axillary branches; leaves sessile, linear, to about $6 \mathrm{~cm}$. long and $5.5 \mathrm{~mm}$. wide, tapering to apex, firm and some- 

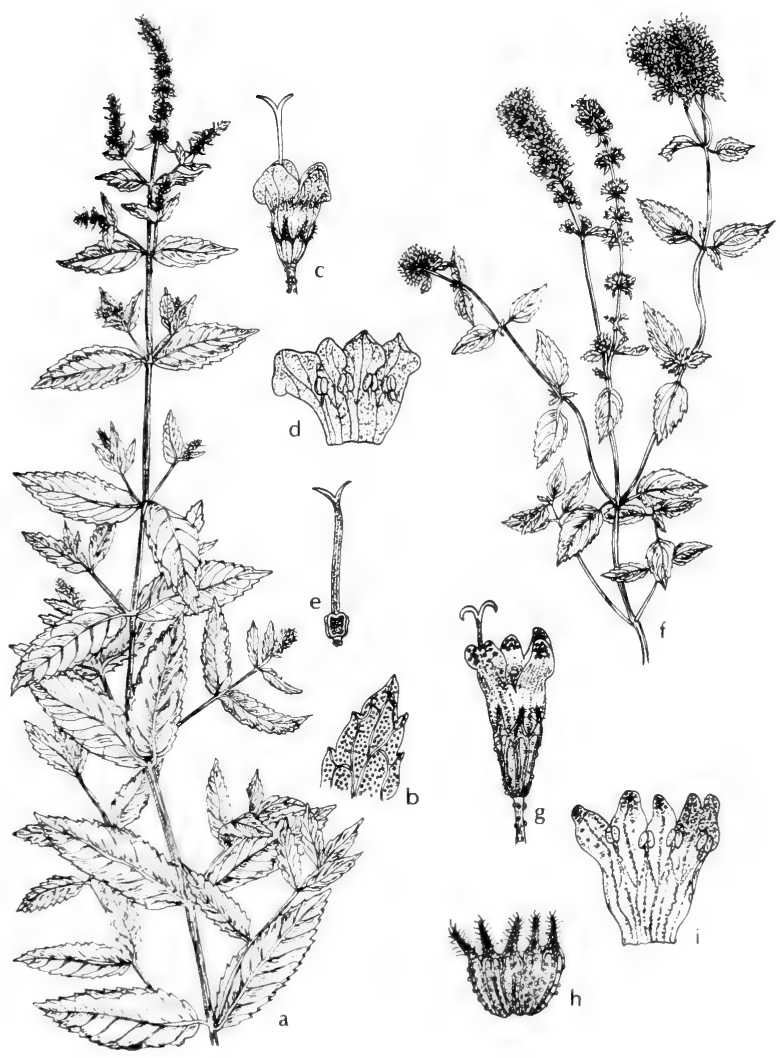

Fig. 678: a-e, Mentha spicata: a, upper part of plant, $\mathrm{X} 1 / 2$; b, tip of leaf, $\mathrm{x} 1$; c, flower, x 5; d, corolla spread out, x 5; e, ovary and style, x 5. f-i, Mentha piperita: f, upper part of plant, $x_{1 / 2}^{1} ; \mathrm{g}$, flower, $x 5 ; \mathrm{h}$, calyx spread out, x 5 ; i, corolla spread out, x 5. (V.F.). 
times with revolute margins, glabrous or sparsely puberulent, entire; glomerules solitary and terminal, disposed in rather crowded or open corymbs that are simple or made up of several to many secondary corymbs; appressed lance-attenuate bracts and glabrescent lance-subulate calyx teeth 1-2 mm. long, with firm sharp tips; corolla white to pale-lavender, usually purple-spotted; corolla tube $3-4.5 \mathrm{~mm}$. long, pubescent within the throat, the upper lip 2-2.5 $\mathrm{mm}$. tall..P. flexuosum of auth.

In grassy moist open woods, bogs, savannahs, old fields, meadows and marshes in the e. fourth of Tex. and s.e. Okla. (LeFlore Co.), May-Oct.; from Ga. to Tex., n. to N. E., N.Y., Ont., O., Mich., Wisc., and Minn.

\section{Pycnanthemum virginianum (L.) Dur. \& Jacks.}

Stems to $1 \mathrm{~m}$. tall, freely branched, above the middle, finely pubescent or hirsutulous on the angles, glabrous or nearly so on the sides; leaves numerous or crowded, linear-lanceolate, glabrous above, often puberulent on the midvein beneath, minutely scabrous on the margin, the principal ones usually $3-6 \mathrm{~cm}$. long and $3-10 \mathrm{~mm}$. wide, the bracteal leaves similar in shape but much smaller than the cauline leaves; lateral veins 3 or 4 on each side of the midvein, the uppermost arising near the middle of the leaf; inner bracts thin, acute to short-acuminate, densely canescent to tomentulose; calyx densely canescent toward the apex, the deltoid lobes about $0.7 \mathrm{~mm}$. long.

Wet meadows, swamps, wet ledges, moist ground along streams and spring branches in Okla. (Waterfall), July-Sept.; Me. to N.D., s. to Ga. and Okla.

\section{Pycnanthemum albescens T. \& G.}

Plant to $15 \mathrm{dm}$. high, branching in the upper parts, the branches ascendent or divaricate-ascendent; median internodes about equal to the subtending leaves, the upper internodes pubescent with short curled hairs and bearing a few longer spreading hairs or pubescent with short curled hairs only; leaves with petioles 4-12 mm. long, ovate to ovate-lanceolate or elliptic, all but the lower strongly whitened, paler and minutely pubescent beneath, serrate, $2.5-7 \mathrm{~cm}$. long, 1-2.5 $\mathrm{cm}$. broad; glomerules terminal and solitary or occasionally 2 , loose, disposed in irregular corymbs, the branches apparent, canescent; bracts of the involucre foliar and strongly whitened, canescent, rarely with a few longer hairs; calyx canescent throughout with minute appressed hairs, without bristles at the tip, $3.5-5 \mathrm{~mm}$. long, the lower pair of ovate or oblong teeth obtuse and $1-1.3 \mathrm{~mm}$. long, the upper deltoid teeth connate to the middle or more and obtuse; corolla white or lavender, usually spotted; corolla tube gradually enlarged upward, 3-4.5 mm. long, the upper lip 2-4 mm. tall.

In low open woods, often along streams, in wettish savannahs and in thicket areas in Okla. (Waterfall) and e. Tex., July-Nov.; from Fla. to Tex., n. to Mo. and e. Okla.

\section{Micromeria BENTH.}

About 100 species widely distributed.

\section{Micromeria Brownei (Sw.) Benth. var. pilosiuscula Gray. Fig. 660.}

Weak plants with slender sprawling or diffusely spreading sparsely pilosepubescent stems, to about $4 \mathrm{dm}$. high or long; leaves petioled, suborbicular to broadly ovate, obscurely crenate, the larger ones to $25 \mathrm{~mm}$. long and $2 \mathrm{~cm}$. wide, thin, glabrous to sparingly pubescent; pedicels filiform, to $15 \mathrm{~mm}$. long; flowers 1 to 3 in axillary one-flowered cymes; calyx sparingly pilose to glabrate, $4-5 \mathrm{~mm}$. long, somewhat villous in the throat; calyx lobes 5, subequal, ovate-deltoid, 1-1.5 $\mathrm{mm}$. long, those of the upper lip abruptly acute or even acuminate; corolla 
2-lipped, 7-8 mm. long, pink to lavender-pink or whitish, the tube much-dilated, the midlobe of the lower lip about as wide as long and notched; stamens 4, more or less exserted. M. pilosiuscula (Gray) Small, Satureja Brownei (Sw.) Briq.

In swamps, marshes, on stream banks, wet meadows, in woods and along ditches in coastal and s. Tex., throughout year; from Fla. to Tex.

\section{Satureja L.}

More than 100 species mostly in warmer regions of the world.

\section{Satureja arkansana (Nutt.) Briq. Fig. 663.}

Perennial with odor of pennyroyal, freely stoloniferous, the repent stolons usually with short ovate to elliptic leaves; stems slender, mostly erect, 1-4 dm. high, simple or branching, glabrous or scarcely bearded at the nodes; cauline leaves linear to linear-oblanceolate, nearly or quite entire, the larger ones to $25 \mathrm{~mm}$. long and $5 \mathrm{~mm}$. wide; cymes few- to many-flowered, their bractlets 3-5 $\mathrm{mm}$. long; calyx tubular, about $3 \mathrm{~mm}$. long, strongly ribbed, sharply toothed; corolla about $1 \mathrm{~cm}$. long, bluish; corolla with straight tube and an inflated throat, distinctly 2-lipped, the upper erect lip flattish and entire or notched, the lower spreading lip 3-parted with the middle lobes usually largest; stamens 4, somewhat ascending; filaments very slender, 4 to 5 times as long as anther; style branches both elongate, strongly curling. Satureja glabra (Nutt.) Fern., S. glabella (Michx.) Briq. var. angustifolia (Torr.) Svens., Clinopodium glabrum (Nutt.) O.Ktze., Calamintha arkansana (Nutt.) Shinners.

On calcareous rocks in ravines, on banks and in barrens, in wet meadows along spring branches and in seepage of bluffs and about springs, gravel bars of rivers, in Okla. (McCurtain and Murray cos.) and e. and cen. Tex., Apr.-Aug.; from Ont. to Minn., s, to Ark., Okla. and Tex.

\section{Fam. 118. Solanaceae JuSS.}

\section{Potato or Nightshade FAmily}

Herbs, shrubs or trees; leaves alternate or fascicled, sometimes with some opposite, entire to odd-pinnate; flowers in umbels, cymes or panicles, or solitary and lateral, perfect, regular or nearly so, 4- to 6-merous; calyx usually 5-toothed or 5-cleft (rarely 4-toothed), rotate, campanulate or tubular, usually persistent; corolla tubular, campanulate, infundibuliform or rotate, usually more or less 5-lobed, with the lobes valvate or imbricate and usually plicate in bud; stamens usually 5 , distinct or slightly united by the anthers; filaments distinct, inserted on the corolla tube alternate with the lobes; anthers opening by slits or pores; styles 1; stigma entire or 2-lobed; ovary superior, usually 2-celled; fruit a berry or capsule.

A family of about 2,100 species in about 90 genera, widely distributed but mostly in the Western Hemisphere.

This family contains a number of important economic species, among which are the potato (Solanum tuberosum), egg-plant (S. Melongena), tomato (Lycopersicon esculentum), red-pepper (Capsicum spp.) and tobacco (Nicotiana Tabacum). As its somber vernacular name, "Nightshade," implies it also contains a number of very poisonous species, among which are henbane (Hyoscyamus niger) and belladonna (Atropa Belladonna), which are sources of the powerful drugs hyoscymine and atropine, respectively. A number of genera have ornamental species that are widely grown horticulturally, among which are Petunia, Solanum and Nicotiana.

1. Corolla rotate to broadly campanulate. 1. Solanum

1. Corolla funnelform to tubular-campanulate (2) 
2(1). Corolla $12 \mathrm{~mm}$. long or more; plants ample, the strong stems and branches erect or ascending.....................................................2. Nicotiana

2. Corolla about $6 \mathrm{~mm}$. long; plant small, the weak stems and branches prostrate.

3. Petunia

\section{Solanum L. Nightshade}

Herbs, shrubs or trees of various habit; larger leaves often accompanied by a smaller lateral (rameal) one; peduncles mostly lateral (or becoming lateral) and extra-axillary; calyx and corolla more or less 5-parted or 5-cleft (rarely 4- to 10-parted); corolla plaited in the bud, valvate or induplicate; stamens exserted; filaments usually very short; anthers converging around the style, opening at the tip by two pores or chinks; berry usually 2 -celled.

A polymorphous and largely tropical genus of perhaps as many as 1,750 species.

1. Flowers large; corolla $6-11 \mathrm{~mm}$. long from base to apex; anthers $2.6-4 \mathrm{~mm}$. long; style exserted about $2 \mathrm{~mm}$. beyond the anthers; stigma very slightly expanded; bushy perennial............................. S. Douglasii.

1. Flowers smaller; corolla about $3 \mathrm{~mm}$. long; anthers $1.2-2.6 \mathrm{~mm}$. long; style barely exserted beyond the anthers: stigma usually enlarged and capitate. 2. $S$. nodiflorum.

\section{Solanum Douglasii Dun.}

Bushy perennial, often suffrutescent, sometimes to $3 \mathrm{~m}$. high, usually much smaller, sparsely to densely cinereous-puberulent or short-pilose, the hairs mostly appressed or subappressed; leaves ovate, $2-10 \mathrm{~cm}$. long, entire to variously angulate-toothed; flowers commonly in umbelliform cymes or sometimes solitary, these borne on peduncles nearly as long as or longer than the pedicels; corolla white or purple-tinged, $1-1.8 \mathrm{~cm}$. in diameter; fruiting calyx erect; berries black at maturity, many-seeded, persistent.

In igneous soil or on sandy banks, streamsides and in swales in mts. of TransPecos Tex., N.M. (Grant Co.) and Ariz. (Coconino, s. to Cochise, Santa Cruz, Pima and Yuma cos.), Mar.-Oct.; w. to Calif. and adj. Mex.

Plants here previously referred to the $S$. nigrum $\mathrm{L}$. complex.

\section{Solanum nodiflorum Jacq. Fig. 679.}

Plant slender, annual or perennial, often tall, sparsely puberulent to strigose or glabrate; leaves firm, entire to sparsely sinuate-dentate, acuminate; flowers commonly in umbelliform cymes or sometimes solitary, these borne on peduncles nearly as long as to longer than pedicels; calyx firm, the lobes all distinct and reflexed in fruit; corolla white or sometimes tinged with purple, not more than $8 \mathrm{~mm}$. wide; berries black at maturity, concretions of stone cells absent or few (rarely more than 3 ).

A weed in marshes and on ditch banks on drying floodplains and wet gravel of creek beds, in Ariz. (Mohave, Yavapai, Maricopa and Pinal cos.), May-Aug.; Wash. to Calif., Ariz. and (?) Tex.

Plants here previously referred to the $S$. nigrum L. complex.

\section{Nicotiana L. Tовассо}

Annual or perennial herbs or rarely small trees or shrubs, narcotic-poisonous and heavy-scented, usually viscid-pubescent; leaves entire or sometimes repand or panduriform, petiolate or sessile; flowers few to many in racemes or panicles; calyx tubular-campanulate, 5-cleft; corolla funnelform or salverform, usually with a long tube, the plaited 5-lobed limb usually spreading; stamens 5, variously inserted on the corolla; stigma capitate; capsule ovoid to narrowly ellipsoid, acute or blunt, 2-celled, 2- or 4-valved from the apex; seeds numerous, minute.

About 60 species in North America, South America, Australia and South Pacific.

Kearney and Peebles makes the following comments about these plants: "The leaves of many species besides $N$. Tabacum contain nicotine and were smoked 


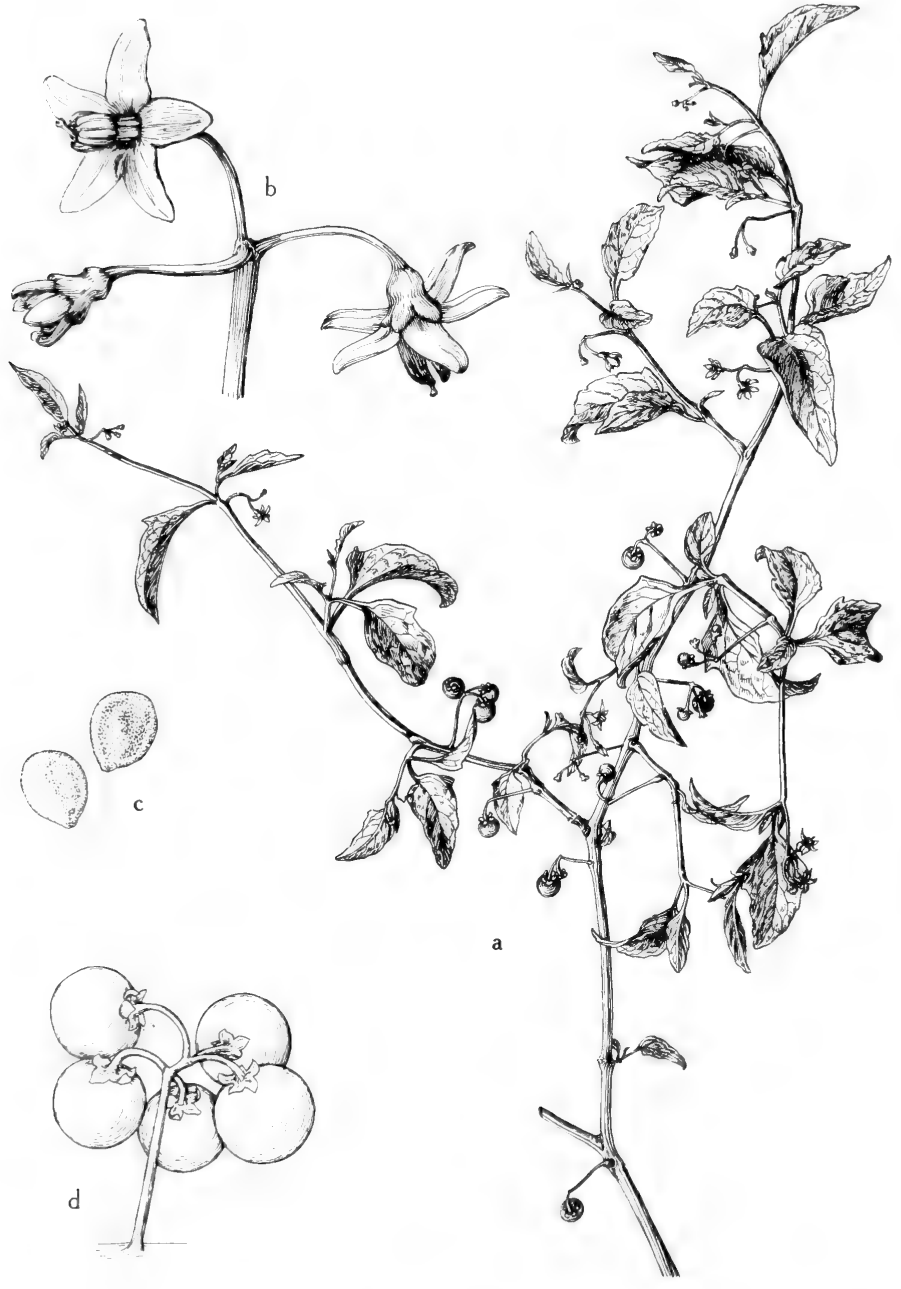

Fig. 679: Solanum nodiflorum: a, habit, x $2 / 5$; b, inflorescence, x 4; c, seeds, $x$ 61/2; d, fruit, x 11/2. (From Mason, Fig. 307). 

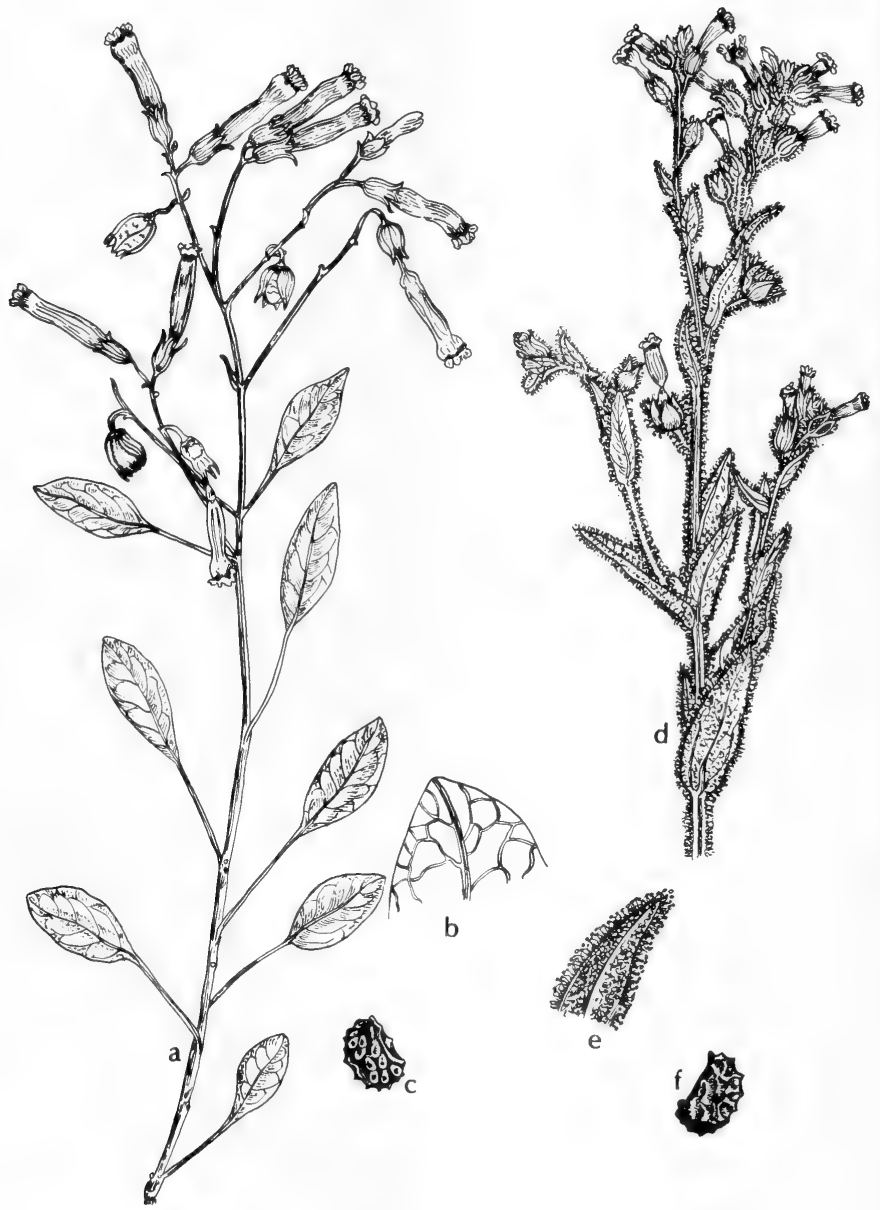

Fig. 680: a-c, Nicotiana glauca: a, end of branch, x 1/2; b, leaf tip, x 11/2; c, seed, $\mathrm{x}$ 10. d-f, Nicotiana trigonophylla: d, end of branch, $\mathrm{x} 1 / 2$; e, leaf tip, $\mathrm{x} 1 \frac{1}{2} ; \mathrm{f}$, seed, x 10. (V.F.). 
by the Indians. $N$. trigonophylla is still used for this purpose, chiefly on ceremonial occasions. Animals usually avoid these plants, but cases of poisoning in cattle, horses, and sheep have been reported. Tree tobacco ( $N$. glauca) contains an alkaloid, anabasine, reported to be more efficacious than nicotine in killing certain species of aphid,"

1. Trees or large shrubs; leaves glaucous, glabrous; flowers yellow.

1. N. glauca.

1. Plants herbaceous; leaves green, more or less viscid-pubescent; flowers mostly white, often variously tinged with green, violet or red (2)

2(1). Leaves commonly repand or panduriform........................... N. repanda.

2. Leaves entire or the margins more or less undulate or crisped (3)

3(2). Corolla 12-23 mm. long, greenish; capsule $11 \mathrm{~mm}$. long or less; native to western half of Texas westward...................... $N$. trigonophylla.

3. Corolla $25 \mathrm{~mm}$. long or more, not noticeably greenish; capsule more than $11 \mathrm{~mm}$. long; introduced in south Texas..........4. N. plumbaginifolia.

1. Nicotiana glauca Grah. Tree tobacco, mustard tree, Rapé, gigante, buena MOZA. Fig. 680.

Glabrous shrub or small tree to $8 \mathrm{dm}$. high; leaves long-petiolate, glaucous, somewhat leathery, ovate to oblong-lanceolate, $5-18 \mathrm{~cm}$. Iong, cuneate to subcordate at the base, obtuse to acute at the apex, entire to slightly repald; flowers in lax terminal panicles; calyx tubular-campanulate, 8-12 $\mathrm{mm}$. long, 5-toothed, the teeth much shorter than the tube; corolla tubular, greenish-yellow, 35-45 mm. long, minutely villosulose, the limb narrow; filaments inserted below middle of the tubular portion of corolla; capsule ovoid, acute, $1-1.2 \mathrm{~cm}$. long, 4-valved at the summit; seeds reddish-brown, slightly shining, finely favose-reticulate.

In sandy or clayey soils along stream banks, wet river banks, edge of lakes and canals, washes, roadsides, on talus slopes and ledges along the coast and in extreme s. Tex., w. to the Trans-Pecos, N. M. (Sierra Co.) and Ariz. (Greenlee, Gila, Maricopa, Pinal, Cochise, Pima and Yuma cos.), flowering throughout the year; a nat. of S. A. that has become naturalized northw. to Tex. and Calif.

2. Nicotiana repanda Willd. Fiddle-leaf tobacco, Wild tobacco, tabaco CIMARRón.

Annual, minutely pubescent or above glabrate, to about $9 \mathrm{dm}$. high, with loose slender branches extending into open racemose or somewhat paniculate naked inflorescences; leaves thin, ovate or the lower ones obovate and sometimes panduriform, commonly repand, to $2 \mathrm{dm}$. long and $1 \mathrm{dm}$. wide, rarely larger, the lowest leaves contracted into a winged petiole, the upper ones deeply cordateclasping; bracts minute or often wanting; flowers vespertine; calyx lobes slender, fully as long as the short-campanulate acutely 10-ribbed tube; corolla with the tube frequently $5-6 \mathrm{~cm}$. long, somewhat clavate or funnelform at the open throat; corolla limb spreading, white or sometimes tinged with rose, or dorsally brownstriped, to $4 \mathrm{~cm}$. in diameter, its lobes short and obtuse or acute; capsule ovoid, about $1 \mathrm{~cm}$. long, 4-valved; seeds brown, pitted-reticulate, shiny or dull. $N$. Roemeriana Scheele.

In sandy or clayey soils along streams, on flats and in wet depressions, shelter of boulders, thickets and moist wooded ravines on the Edwards Plateau and in s. Tex., Feb.-July; also adj. Mex.

\section{Nicotiana trigonophylla Dun. Desert toBAcco, TABAQuillo. Fig. 680.}

Biennial or perennial, viscid-pubescent, to about $9 \mathrm{dm}$. high, with a simple or virgately branched stem; leaves all sessile or only the lower ones tapering into a winged petiole and obovate-oblong, the upper ones elliptic-lanceolate 

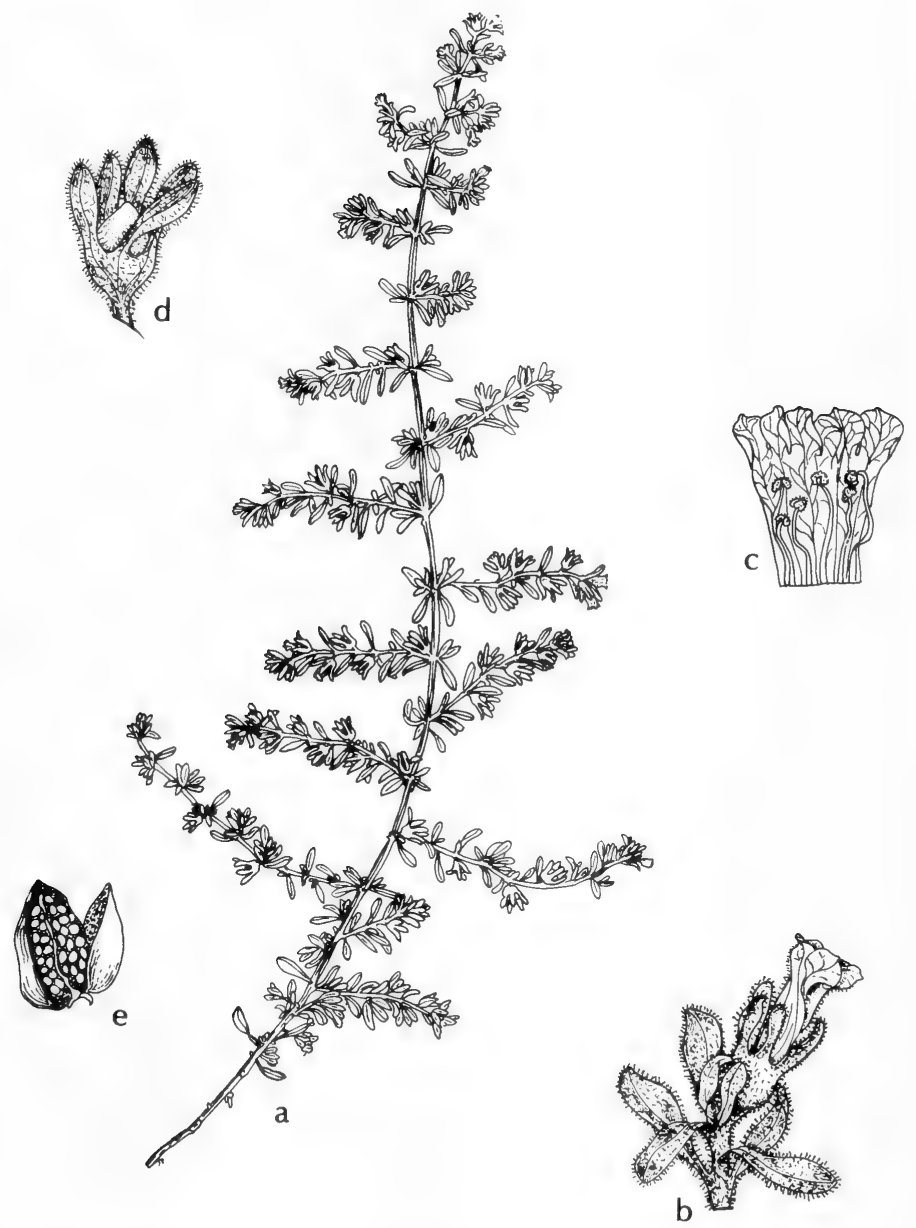

Fig. 681: Petunia parviflora: a, branch of plant, x 1/2; b, flower and leaves, x 21/2; c, corolla spread open, x $2 \frac{1}{2}$; d, calyx with capsule, x $2 \frac{1}{2}$; e, capsule open showing seeds, x $2 \frac{1}{2}$. (V. F.). 
to oblong-elliptic with a broader cordate half-clasping base, some spatulatelanceolate with a dilated auriculate-clasping base, the largest leaves to about $22 \mathrm{~cm}$. long and $6 \mathrm{~cm}$. wide, rounded to acuminate at apex; inflorescence at length loosely paniculate-racemose, with the later bracts very small or wanting and somewhat unilateral pedicels about the length of the calyx; flowers open throughout the day; calyx lobes subulate-lanceolate but rather obtuse, shorter than or equaling the campanulate tube, attaining the middle of the corolla tube, about equaling the 4-valved capsule, somewhat callous-margined; corolla tubularcampanulate, greenish-white or yellowish, 12-23 $\mathrm{mm}$. long, somewhat pubescent, a little constricted at the orifice, the tube slightly enlarging upward, the sinuately 5-lobed limb about $8 \mathrm{~mm}$. in diameter; capsule ovoid, 8-11 mm. long; seeds brown, shining, pitted-reticulate.

On breaks of arroyos and canyons, in wet or dry sandy-clay soils of river beds and washes, in gravelly-sandy soils on slopes, at base of boulders and on ledges of mesas and mts. in the Tex. Rio Grande Plains, South Plains and TransPecos, Okla. (Jackson Co.), N. M. (widespread) and Ariz. (almost throughout state), Mar.-Nov.; from Tex., w. to Calif. and n. Mex.

\section{Nicotiana plumbaginifolia Viv.}

Annual to about $1 \mathrm{~m}$. high, the erect stem slender and tuberculate-hispid, with long basal branches; basal rosulate leaves few, spatulate to obovate-spatulate or oblanceolate, hispid, to about $25 \mathrm{~cm}$. long; cauline leaves progressively smaller and becoming lanceolate or linear-lanceolate to the widely branched inflorescence, sessile or clasping and auriculate at base, abruptly acuminate and somewhat twisted at apex, usually strongly undulate-plicate; flowers few, vespertine; calyx tubular, 8-13 mm. long, the long narrow segments subulate-filiform and about equal to the tube; corolla puberulent on outer surface, the slender tube 25-35 $\mathrm{mm}$. long, greenish-white and lavender or purplish-tinged, the limb about $1 \mathrm{~cm}$. wide and with ovate acute lobes; capsule narrowly ovoid, $8-11 \mathrm{~mm}$. long; seeds light-brown with wavy-reticulate surface.

In resacas on edge of water in the Brownsville region in s. Tex., Jan.-Apr.; from Tex, through Mex., W.I. and C. A. to S. A.

\section{Petunia Juss.}

About 40 species, mostly in South America.

\section{Petunia parviflora Juss. Wild petunia, seaside petunia. Fig. 681.}

Annual; stems leafy, prostrate and rooting at the nodes, diffusely branched to form mats to $3 \mathrm{dm}$. wide or more, glandular-puberulent; leaves linear-oblong to spatulate, fleshy, about $1 \mathrm{~cm}$. long; flowers solitary, lateral, on very short peduncles; calyx 5-parted to below middle; sepals in fruit to $11 \mathrm{~mm}$. long and $1.5 \mathrm{~mm}$. wide, linear-oblanceolate to linear-spatulate, obtuse; corolla funnelform, purple or reddish-violet, with yellow or whitish tube and 5 minute unequal retuse lobules that are plicate in bud, the tube about $6 \mathrm{~mm}$. long; stamens inserted low in corolla; filaments 3 short and 2 longer; capsules $3-4 \mathrm{~mm}$. long, ovoidellipsoid, acute, 1-celled, bivalved, the valves leathery-chartaceous; seeds numerous, angular and more or less raised-reticulate:

In moist or wet soil in beds of streams, about lakes, in water and shallow streams, along beaches and on muddy flats in most of Tex., N. M. (Sierra, Bernalillo and Dona Ana cos.) and Ariz. (Navajo to Mohave, s. to Graham, Pima and Yuma cos.), Apr.-Sept.; from s. Fla. to Calif., n. to Va., s. to trop. Am.

Our plant is a "poor" relative of the showy cultivated petunias that are derived from $P$. axillaris (Lam.) B.S.P. and P. violacea Lindl. of South America. 
Mainly herbs, occasionally shrubs or rarely trees; leaves various; flowers perfect, in racemes or panicles, never terminal (in ours); sepals 4 or 5 , free or united; corolla bilabiate or more or less irregular, rarely almost regular, the 4 or 5 lobes imbricated in bud; stamens didynamous, sometimes only 2 (rarely 5 ), inserted on the corolla tube; style single, the stigma entire or bilobed; capsule 2-celled and usually many-seeded, with the placentae in the axis; seeds anatropous or amphitropous.

More than 3,000 species in about 220 genera of cosmopolitan distribution.

1. Corolla with the upper lobes external and overlapping in the bud (2)

1. Corolla with the lower lobes external and overlapping in the bud (13)

2(1). Stigmas wholly united, punctiform or capitate; seeds not simply reticulate, either smooth, tuberculate, ridged or winged; stamens 4, didynamous (3)

2. Stigmas distinct, usually flattened (except in Bacopa Monnieri); seeds reticulate, wingless; capsule walls membranous; inflorescence simply racemorse, the bracts foliaceous and the flowers axillary; stamens 4 , didynamous or reduced to 2 ; leaves opposite or whorled (4)

3(2). Capsule septicidal or 4-valved, its walls firm or woody; corolla not spurred at base; erect or ascending perennial herbs or shrubs.

11. Penstemon

3. Capsule loculicidal; corolla spurred at base, strongly zygomorphic, yellow; repent annual herb.

13. Kickxia

4(2). Cells of anther parallel; corolla with throat anteriorly rounded or flattened, obscurely or not ridged within; sepals distinct; pedicels often bibracteolate (5)

4. Cells of anther divergent; corolla with throat 2-ridged within anteriorly; sepals often united; pedicels never bracteolate (11)

5(4). Anthers 1-celled by confluence; plants tufted or stoloniferous; stigma capitate; leaves entire, long-petioled; flowers borne on scapelike axillary pedicels; corolla whitish, nearly regular, rotate-campanulate

2. Limosella

5. Anthers distinctly 2-celled; plants caulescent; stigma flattened; leaves entire or not (6)

6(5). Corolla campanulate, nearly regular, the lobes equaling or only slightly shorter than the tube, the posterior lobes united a little farther than the others; sepals unequal; stems creeping or floating, usually ascending at apex.................................................................. Bacopa

6. Corolla narrower than above, decidedly zygomorphic, the lobes distinctly shorter than the tube, the posterior lobes united for over half their length or throughout (7)

7(6). Leaf blades (at least some) pinnatisect, often bipinnatifid; pedicels not bracteolate; seeds commonly pale-greenish-yellow, nearly colorless; corolla pink or lavender (8)

7. Leaf blades entire or merely toothed; pedicels bibracteolate or (rarely in Gratiola) with bractlet single or lacking; seeds yellow to brown or blackish (9)

8(7). Plant terrestrial in wet soils, the short bushy-branched stem erect; flowers numerous with slender pedicels $5 \mathrm{~mm}$. long or more.

6. Leucospora

8. Plant aquatic, the elongate sparsely branched stem floating; flowers few, sessile. 7. Limnophila 
9(7). Anther cells separated on short arms of the connective; corolla violet-blue; sepals uniform.

9. Anther cells proximate; corolla yellow or white; sepals usually somewhat unequal either in width or length (10)

10(9). Pedicels bibracteolate at the base; outer sepals much wider than the inner; fertile stamens 4; leaf blades pinnately veined.

3. Mecardonia

10. Pedicels bibracteolate at the apex; sepals nearly equal in width; fertile stamens 2; leaf blades palmately veined.........................4. Gratiola

11(4). Filaments attached to the base of the corolla, always simple and both pairs antheriferous; capsule loculicidal; seeds more or less reticulate; sepals united; corolla $1-4 \mathrm{~cm}$. long.......................8. Mimulus

11. Filaments attached to corolla for most of their length, the anterior each with a projecting knoblike process; capsule not loculicidal; seeds marked with fine transverse lines or smooth; sepals distinct or united (12)

12(11). Corolla violet-blue, 5-12 $\mathrm{mm}$. long; the postero-lateral filaments present and antheriferous; capsule 1-6 $\mathrm{mm}$. long, ellipsoid to ovoid, 2celled, septicidal, the platelike septum persisting; sepals 5.

9. Lindernia

12. Corolla white, 1-2 mm. long; the postero-lateral filaments lacking; capsule 0.5-1 mm. long, globose, 1-celled (by lack of septum distally), rupturing irregularly; sepals $4 \ldots \ldots \ldots \ldots \ldots \ldots \ldots \ldots \ldots . . . . . .10$. Micranthemum

13(1). Upper lobes of corolla flattened or widely arched, often spreading; anthers all distinct (14)

13. Upper lobes of corolla narrowly arched to form a definite galea that encloses the anthers; stigmas wholly united; anthers frequently cohering, the pollen being shed in a mass; stamens 4, didynamous; capsules loculicidal; commonly root-parasites (18)

14(13). Stamens 2, the postero-lateral pair alone developed; corolla 2-5 mm. long, the posterior lobes wholly united; plants not parasitic (15)

14. Stamens 4, didynamous; corolla $7 \mathrm{~mm}$. long or more, the lobes all evident; root-parasites (16)

15(14). Stems scapelike, the larger leaves in a basal rosette, the cauline leaves reduced and bractlike; flowers in dense cylindric spikelike racemes; corolla bilabiate, cleft nearly to the base.....................12. Besseya

15. Stems leafy, the leaves opposite (at least below the inflorescence); flowers axillary or in loose racemes; corolla nearly regular, rotate or nearly so.

14. Veronica

16(14). Stamens with only one anther cell developed, the other wholly abortive; corolla salverform, blue to violet-purple or white, the throat very narrow and filled with short stiff hairs; filaments and style less than half the length of the corolla tube; capsule nearly or quite included in the calyx tube; pedicel bibracteolate.

17. Buchnera

16. Stamens with both anther cells equally developed; corolla neither salverform nor blue, its throat wide; filaments and style nearly as long as or longer than the corolla tube; capsule partly or nearly wholly exserted from the calyx; pedicel not bracteolate (17)

17(16). Anther cells glabrous or rarely with a few bristlelike hairs at apex; corolla semirotate, 7-16 mm. long; stigma punctiform or capitate 15. Dasistoma

17. Anther cells villous; corolla semicampanulate, $10-60 \mathrm{~mm}$. long; stigma somewhat elongate. 16. Agalinis 
18(13). Cells of anther equal in size and position; seed coat close, not obviously reticulate (19)

18. Cells of anther unequally placed, the upper one attached by its middle; seed coat loose, evidently reticulate (20)

19(18). Capsule symmetrical, both cells dehiscing equally; anther cells mucronate-tipped; stem leaves sessile and clasping............18. Parentucellia

19. Capsule asymmetrical, usually decurved, opening on the distal side; anther cells not mucronate-tipped; stem leaves prominently petiolate.

19. Pedicularis

20(18). Upper corolla lip (galea) much longer than the small 3-toothed or 3keeled lower lip; calyx tubular; plants perennial or rarely annual....

20. Castilleja

20. Upper corolla lip not (or not greatly) surpassing the inflated saccate lower lip; calyx tubular-campanulate; plants annual.........21. Orthocarpus

\section{Bacopa Aubl. Water-HyssoP}

Low succulent perennial herbs; flowers axillary; calyx 5-parted, the uppermost divisions broadest, the innermost often very narrow; upper lip of corolla entire to notched or 2-cleft and the lower lip 3-lobed or the limb almost equally 5-lobed; style dilated or bilobed at apex; seeds numerous.

About 100 species, primarily in warm regions.

1. Leaves cuneate to narrow bases, 1-nerved; pedicels much-exceeding the subtending leaves, conspicuously 2-branched below the calyx.

1. B. Monnieri.

1. Leaves rounded to broad or more or less clasping bases, 3- or more-nerved; pedicels mostly shorter than the subtending leaves (2)

2(1). Leaves ovate, pellucid-punctate; flower usually closely subtended by a pair of minute bractlets; ovary surrounded by a slenderly $10-$ to 12 toothed disk; upper lip of corolla obcordate.........2. B. caroliniana.

2. Leaves suborbicular to broadly obovate, not obviously punctate; flowers not subtended by bractlets; disk at base of ovary none or without slender teeth; upper lip of corolla merely emarginate.

3. B. rotundifolia.

\section{Bacopa Monnieri (L.) Wettst. Fig. 682.}

Plant with prostrate to decumbent or loosely ascending stems, forming mats, fleshy, glabrous; leaves spatulate to cuneate-obovate, obtuse to rounded at apex, entire or nearly so, to about $2 \mathrm{~cm}$. long; flowers single in nodes, with 2 linear bracts at base of calyx; pedicels to $25 \mathrm{~mm}$. long, soon exceeding the subtending leaves; larger sepals lanceolate to ovate, to $5 \mathrm{~mm}$. wide; corolla campanulate, only obscurely bilabiate, white to lilac or pale-blue, $8-10 \mathrm{~mm}$. long, glabrous within; capsule slenderly conic to ovoid, 5-7 mm. long, shorter than the calyx. Incl. var. cuneifolia Fern., Bramia Monnieri (L.) Penn.

In mud and sand in depressions among dunes, about ponds, along streams and ditches, in wet mud on edge of water, forming mats in water, in e., cen. and s. Tex., Apr.-Sept.; from Fla. to Tex., n. to Va.

\section{Bacopa caroliniana (Walt.) Robins. Blue Hyssop. Fig. 682.}

Stems from creeping rhizome, floating or ascending, to about $4 \mathrm{dm}$. high, lanate at summit; plant (when bruised) lemon-scented; leaves in subapproximate pairs, ovate to ovate-elliptic, obtuse, clasping, to $25 \mathrm{~mm}$. long, entire, pellucidpunctate, fragrant, the nerves pedately radiating from base; flowers single, scarcely exserted beyond leaves, with short pedicels; calyx often with 2 minute subulate basal bracts, the outer sepals cordate; corolla blue, about $1 \mathrm{~cm}$. long, pubescent 


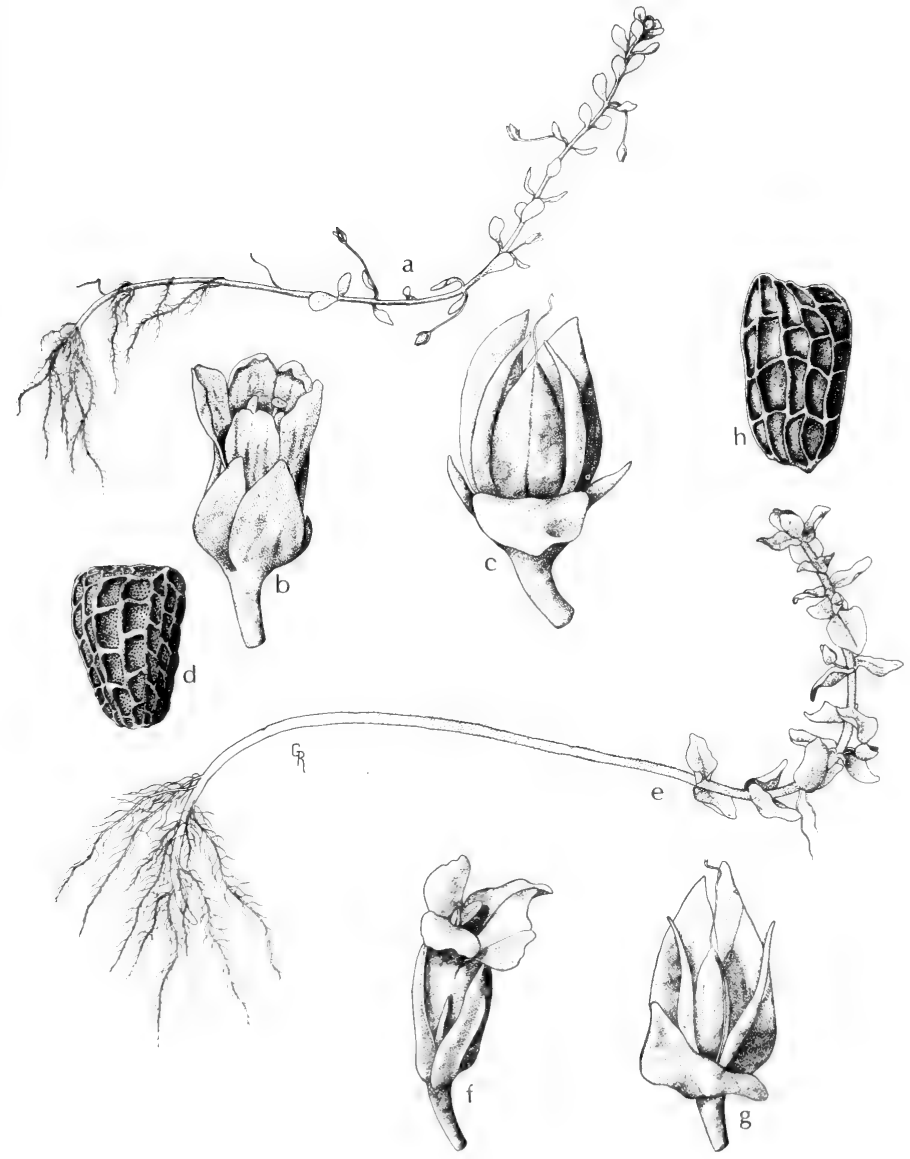

Fig. 682: a-d, Bacopa Monnieri: a, habit, x 1/3; b, flower, x 21/3; c, capsule, x 3; d, seed, x 45. e-h, Bacopa caroliniana: e, habit, x 1/3; f, flower, x 21/3; g, capsule, x 3; d, seed, x 45. (Courtesy of R. K. Godfrey). 

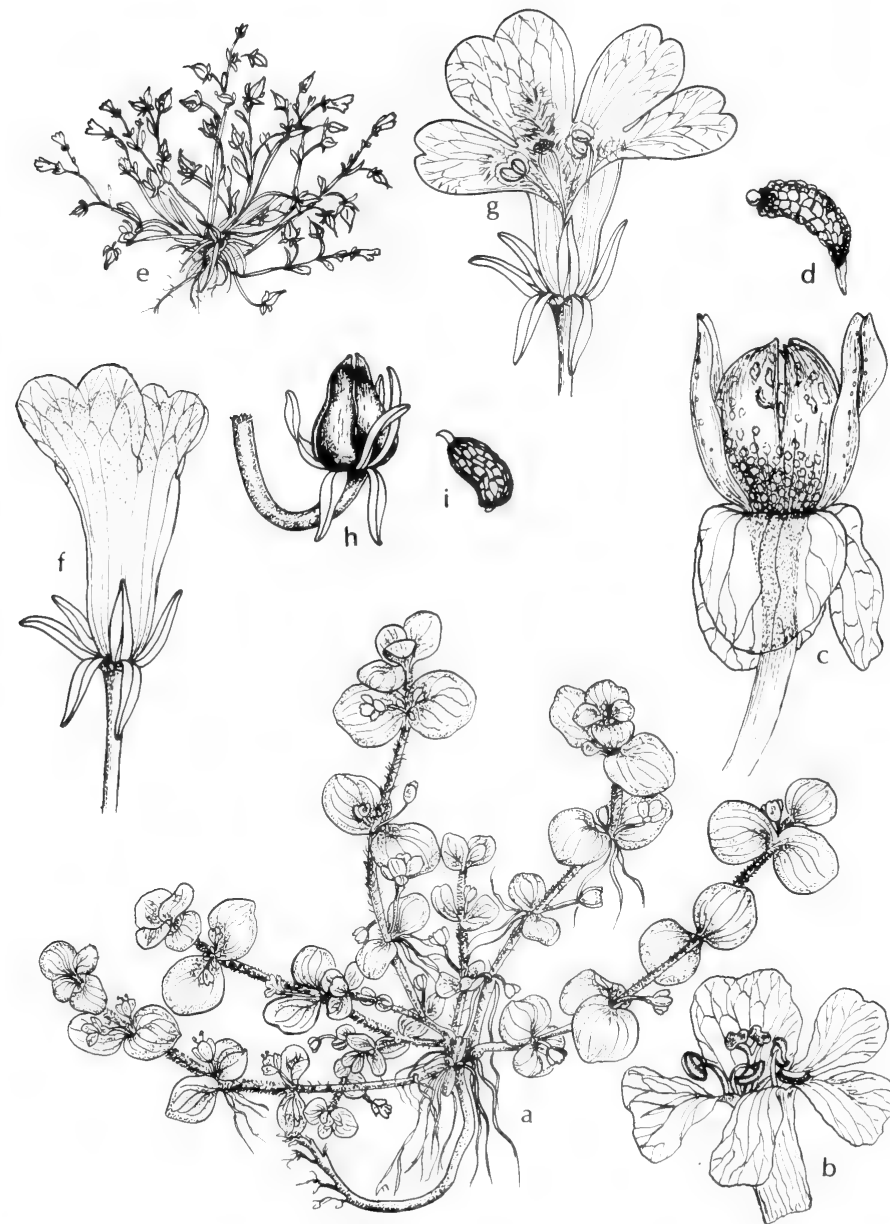

Fig. 683: a-d, Bacopa rotundifolia: a, habit, x 1/2; b, flower, x 5; c, capsule, x 5; d, seed, x 20. e-i, Gratiola flava: e, habit, x 1/2; f, flower, x 5; g, flower spread open, x 5; h, capsule, x 3 ; i, seed, x 20. (V. F.). 
within, its upper lip obcordate; ovary surrounded by a slenderly 10 - to 12-toothed disk; capsule ovoid, acute, about $5 \mathrm{~mm}$. long. Hydrotrida caroliniana (Walt.) Small.

On margins of ponds and streams, in swamps, forming mats in water, and in bogs in pinelands in e. Tex., May-Oct.; from Fla. to Tex., n. to Va.

\section{Bacopa rotundifolia (Michx.) Wettst. DisC WATER-HYSSOP. Fig. 683.}

Plant creeping, with elongate and lax terminally pubescent branches to $6 \mathrm{dm}$. long, forming mats on mud or attached and floating; leaves thin, suborbicular to broadly obovate, with subcuneately narrowed but clasping bases, clearly palmately many-nerved, the larger ones to $35 \mathrm{~mm}$. long and $25 \mathrm{~mm}$. wide; flowers usually 2 to 4 from upper nodes; pedicels 2 or 3 times as long as calyx, slender, pubescent, to $2 \mathrm{~cm}$. long; outer sepals ovate, $6-8 \mathrm{~mm}$. long; corolla exserted, campanulate, 6-10 $\mathrm{mm}$. long, the wide-spreading limb about as broad, white, with yellow throat; capsule globose to subglobose, about as long as sepals. Macuillamia rotundifolia (Michx.) Raf.

In mud and water in and about lakes, pools, ditches and ponds in Okla. (McCurtain, Johnston, Washington and Comanche cos.), throughout Tex. and Ariz. (Maricopa Co.), May-Nov.; from Miss. to Tex. and Ariz., n. to Ind., Ill., Minn., N.D. and Mont.

\section{Limosella L. MUdWORT}

Small rosulate plants of aquatic or wet habitats, usually acaulescent; leaves basal, erect, rarely cauline; flowers solitary on naked 1-flowered scapes, white to pink or pale-blue; calyx campanulate; corolla campanulate, nearly regular, the upper surface of petals minutely to sparsely papillate; stamens 4; style terminal or subterminal; capsule globose to ellipsoid, 2-celled by a very thin partition, many-seeded.

About 15 cosmopolitan species.

An Arizona species, L. publiflora Penn., known only from the type collection (Cochise Co.) has oblanceolate leaves attenuate at base, obtuse puberulent corolla lobes, globose-ovoid capsules, and seeds a little longer than wide.

1. Leaves linear to linear-spatulate, $2 \mathrm{~mm}$. wide or less; corolla lobes rounded; style $0.5-1 \mathrm{~mm}$. long, straight or arcuately curved........ 1 . L. acaulis.

1. Leaves with an elliptic-oblong blade and long petiole, $2-8 \mathrm{~mm}$. wide; corolla lobes acute; style $0.2-0.4 \mathrm{~mm}$. long, usually sharply decurved at base. 2. L. aquatica.

\section{Limosella acaulis Ses. \& Moç. Fig. 684.}

Cespitose, stoloniferous plants, often forming mats; leaves flat, linear to linear-spatulate, 1-6 cm. long, the stipules somewhat auriculate; flowers solitary on erect scapes; calyx campanulate; corolla nearly regular, white; petals oblong, rounded, sparsely papillate on inner face; stamens 4 ; style $0.2-0.7 \mathrm{~mm}$. long, equal to or shorter than ovary; capsule ovoid, about $3 \mathrm{~mm}$. long, 2-celled by a thin partition; seeds many, ridged and reticulate.

Margins of ponds, lakes and streams, often in shallow water, in N. M. (Catron, Mora and Sandoval cos.) and Ariz. (Apache, Coconino and Santa Cruz cos.), June-Oct.; N.M., Ariz., Calif. and Mex.

\section{Limosella aquatica L. Fig. 685.}

Tufted annual 5-12 cm. tall, from threadlike rhizomes or stolons, rooting at nodes; leaves on long slender petioles, $3-10 \mathrm{~cm}$. long, the blades from linearspatulate to broadly oblong-elliptic, 1-3 cm. long, 3-12 $\mathrm{mm}$. wide, with broad sheathing base and conspicuous hyaline stipules; peduncles shorter than leaves, 


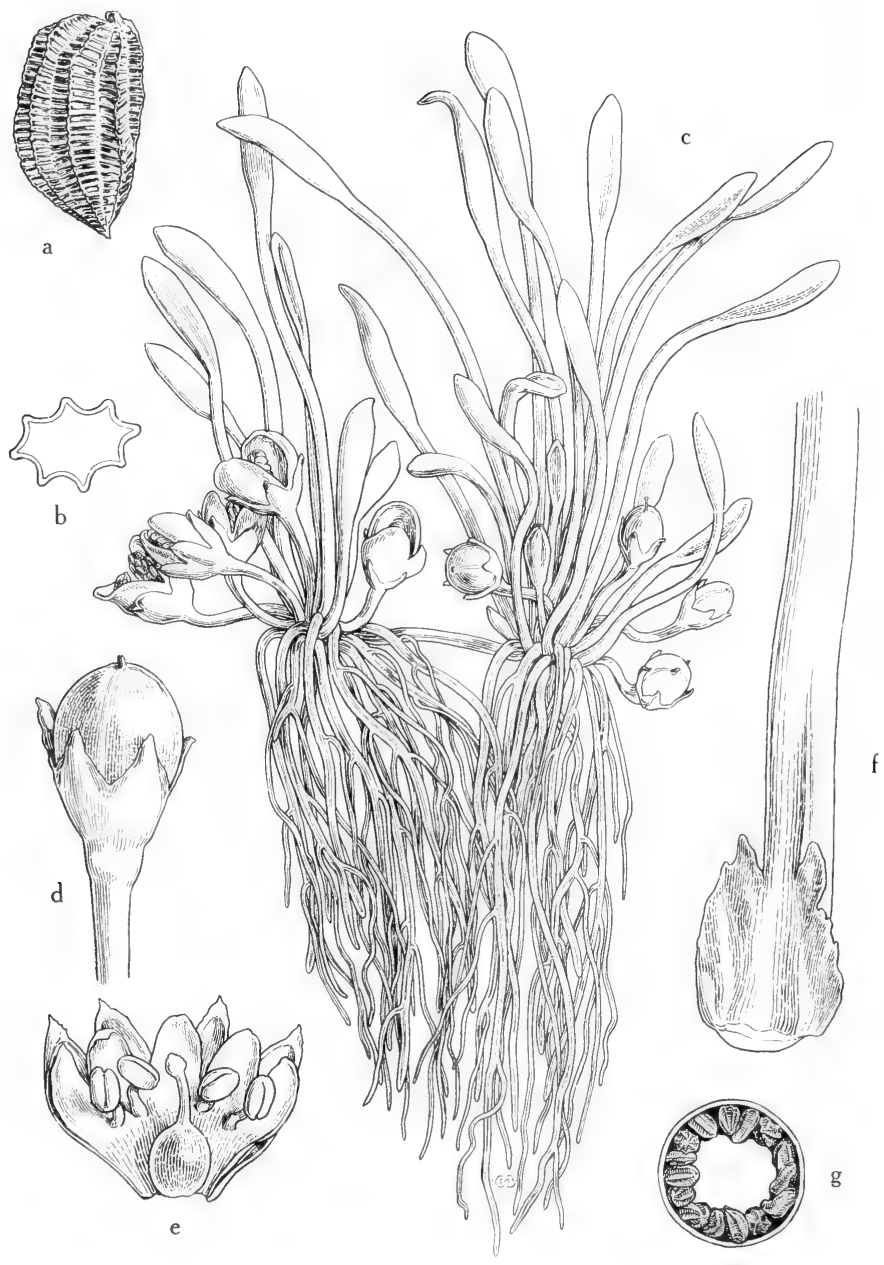

Fig. 684: Limosella acaulis: a, mature seed, x 40; b, seed (cross section), x 40; c, habit, showing stolon, leaves and capsules, x 2; d, mature capsule, x 6; e, corolla, spread open, $\mathrm{x} 12$; $\mathrm{f}$, base of petiole, showing auriculate stipules, $\mathrm{x} 8$; $\mathrm{g}$, capsule (cross section), x 8. (From Mason, Fig. 317). 


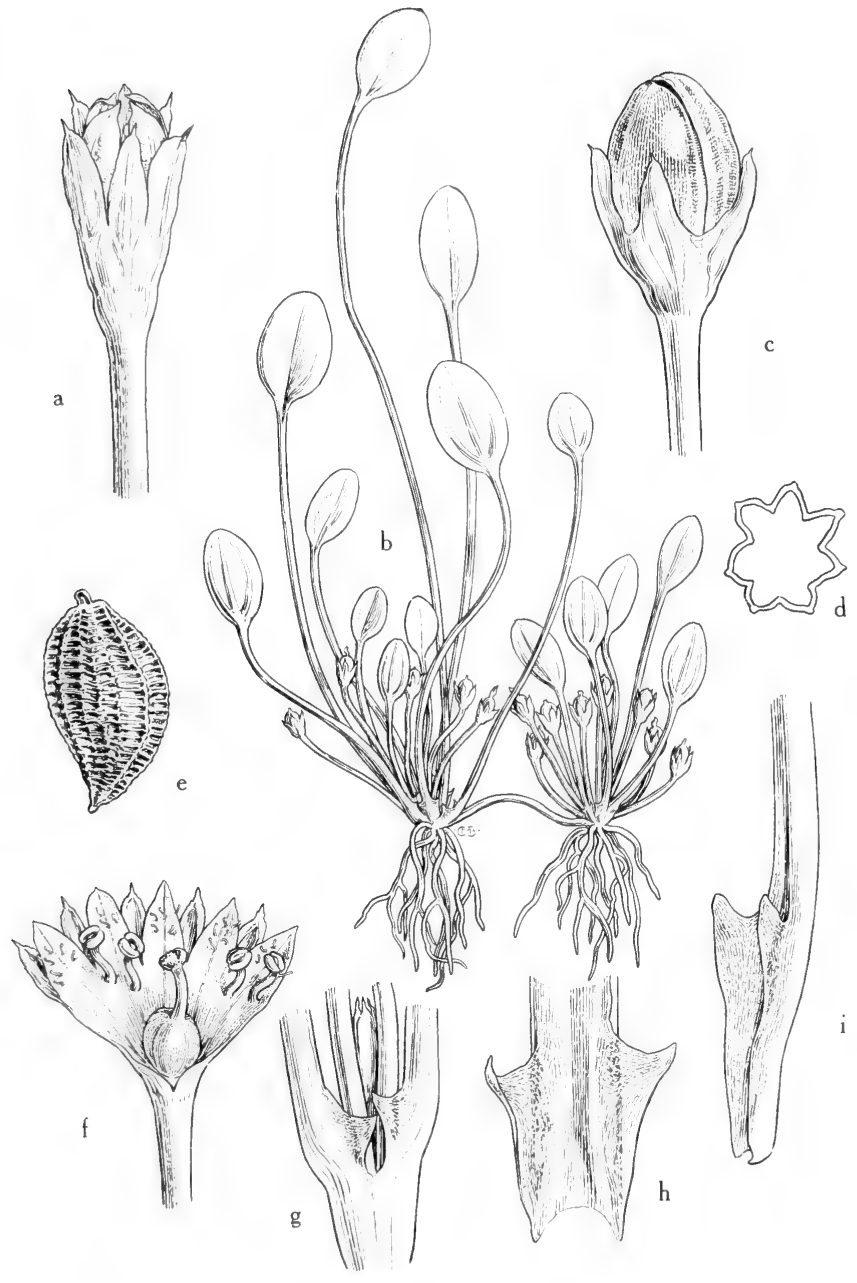

Fig. 685: Limosella aquatica: a, young flower, x 10; b, habit, showing the slender rhizome, the long petioles and broad leaf blades, and the short peduncles, $\mathrm{x} 4 / 5 ; \mathrm{c}$, mature capsule, x 6; d, seed (cross section), x 40; e, mature seed, x 40; f, corolla, spread open, the lobes sparsely papillate, $x$ 10; $\mathrm{g}$-i, bases of petioles, showing hyaline stipules, x 8. (From Mason, Fig. 318). 
1-flowered; calyx campanulate, regular; corolla scarcely longer than calyx; petals oblong, acute, sparsely papillate within, white or pink, nearly regular; stamens 4; style short, 0.2-0.4 mm. long; stigma obscurely 2-lobed; capsule ovoid, about $3 \mathrm{~mm}$. long, 2-celled, many-seeded, ridged, reticulate; seeds much longer than wide.

Along margins of pools, on stream banks, in irrigation ditches, in mud and shallow water of ponds and lakes, in N.M. (widespread) and Ariz. (Coconino and Pinal cos.), June-Sept.; almost throughout N.A. except s.e. U. S.; Euras.

\section{Mecardonia R. \& P.}

Erect or diffuse much-branched glabrous herbs from a perennial root, often becoming black upon drying; stems 4-angled; leaves opposite, narrowed to a sessile base, toothed, glandular-punctate; flowers axillary in leaflike bracts; bractlets 2 , at the base of the slender pedicel and much shorter than the bracts; sepals 5 , unequal, the outer ones much wider than the inner ones; corolla bilabiate with the lobes shorter than the tube, the posterior lip more or less united and pubescent within at base; stigmas liplike; capsule cylindric to ovoid, acute, glabrous, septicidal, the valves only slightly loculicidal at apex; seeds numerous, cylindric, reticulate, wingless.

About a dozen species in warmer parts of America.

1. Corolla yellow, its upper bearded lobes essentially united or forming only a slightly notched lamina; 3 outer sepals broadly ovate to ovateelliptic, more than 3 times as wide as the 2 inner sepals; leaves typically ovate or oval, abruptly cuneate at base, less than $25 \mathrm{~mm}$. long; plant procumbent or ascending.................. M. vandellioides.

1. Corolla white, often with purplish stripes, its upper bearded lobes typically separated at least one third their length; 3 outer sepals lanceolate, rarely more than 2 times as wide as the 2 inner sepals; leaves typically oblanceolate, tapering to the narrow base, more than 3 $\mathrm{cm}$. long; plant erect or diffusely branched...........2. M. acuminata.

\section{Mecardonia vandellioides (H.B.K.) Penn. Fig. 686.}

Plant very variable, glabrous throughout; stems procumbent to erect-ascending, often branched and widely spreading from the base, to about $4 \mathrm{dm}$. long; leaves opposite, sessile, ovate to oval or obovate to obovate-oblong, obtuse to subacute, more or less serrate or serrulate above the middle, $1-2.5 \mathrm{~cm}$. long; pedicels axillary, solitary, usually noticeably exceeding the subtending leaf and the 2 small basal bracteoles; calyx 5-parted, the 2 interior lobes linear, the 3 outer lobes broadly ovate to ovate-elliptic, acutish, sometimes serrulate above the middle; corolla 6-12 mm. long, always longer than the calyx, bilabiate, yellow with longitudinal dark veins on the essentially united upper pair of lobes; capsule ellipsoid, about as long as or shorter than the calyx. M. procumbens (Mill.) Small, $M$. peduncularis (Benth.) Small, $M$. viridis Small, M. montevidensis (Spreng.) Penn., Pagesia peduncularis (Benth.) Penn., P. vandellioides (H.B.K.) Penn.

In mud and water of ditches, lagoons, ponds and streams, and in moist soils of depressions, mostly in cen., s., and w. Tex., and Ariz. (Cochise, Santa Cruz and Pima cos.), Mar.-Nov.; from Fla. to Tex., Ariz. and Mex., s. to s. S.A.

\section{Mecardonia acuminata (Walt.) Small. Fig. 686.}

Stems from a subligneous crown, erect or ascending, glabrous, simple to branched, to about $7 \mathrm{dm}$. high; leaves oblanceolate to oblong-lanceolate, mostly narrowly obtuse, tapering below to a narrowly cuneate base, firm, serrate above the middle, mostly $2-4 \mathrm{~cm}$. long; pedicels filiform, equaling or surpassing the subtending leaves and 2 small basal bractlets; outer 3 sepals oblong-lanceolate, broader than the lanceolate inner 2 sepals; corolla white, often tinged or lined with purple, $7-10 \mathrm{~mm}$. long, bearded within at the base of the upper obviously 


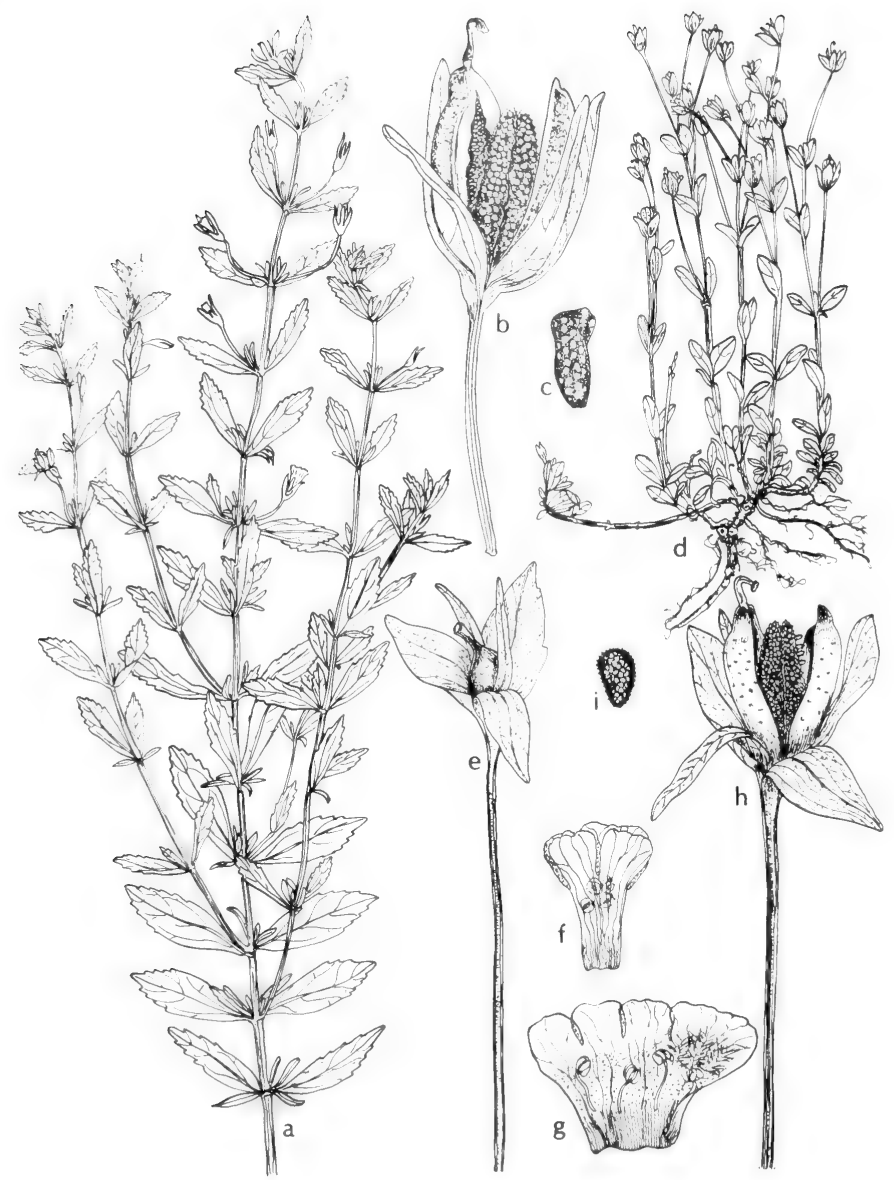

Fig. 686: a-c, Mecardonia acuminata: a, upper part of plant, x 1/2; b, capsule split open, x $3 ;$ c, seed, x 15 , d-i, Mecardonia vandellioides: d, habit, $x 1 / 2$; e, flower with corolla removed, $x 3 ; \mathrm{f}$, corolla, $\mathrm{x} 3 ; \mathrm{g}$, corolla spread out, $\mathrm{x} 3 ; \mathrm{h}$, capsule split open, $x 3$; i, seed, $x$ 15. (V. F.). 


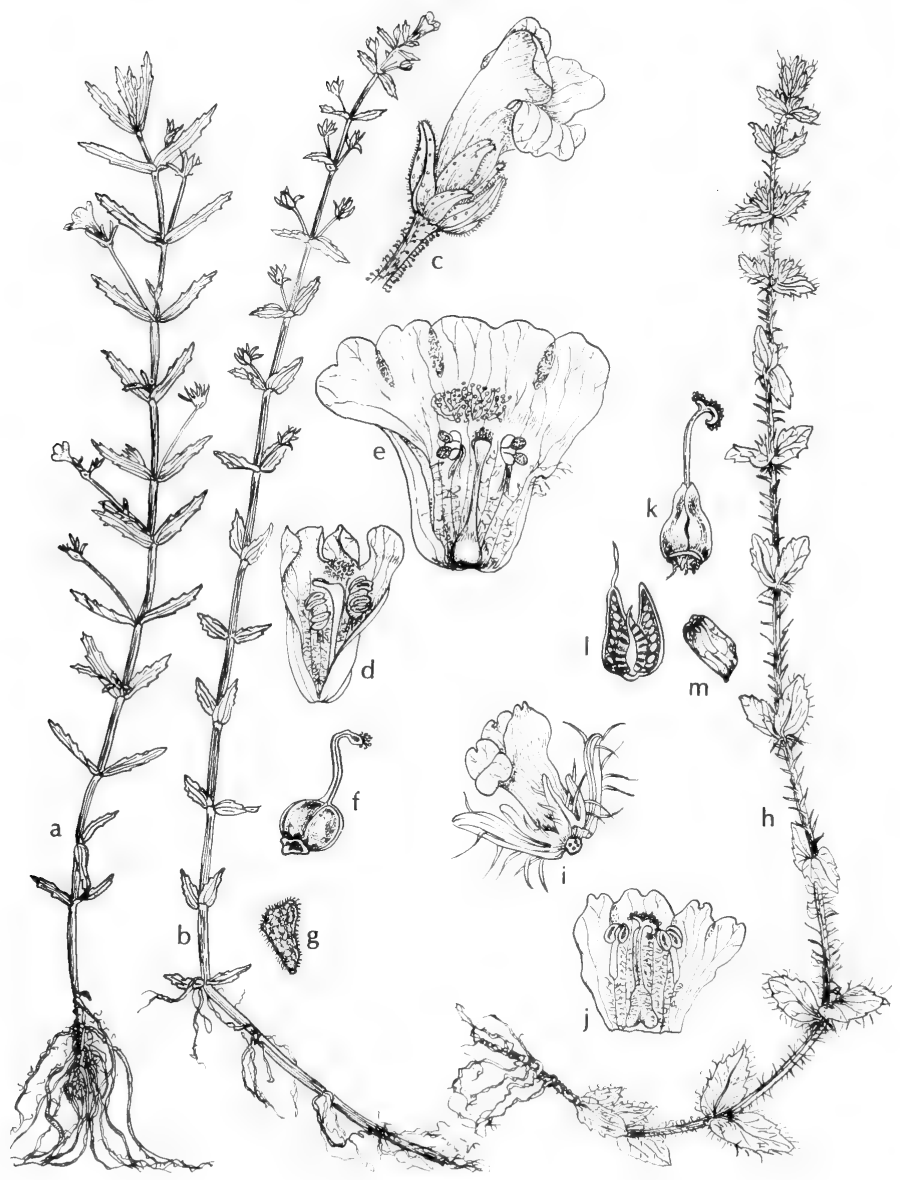

Fig. 687: a-g, Gratiola brevifolia: a and b, two plants showing variation in habit, $\mathrm{x} 1 / 2 ; \mathrm{c}$, flower, $\mathrm{x} 21 \frac{1}{2} ; \mathrm{d}$ and e, two corollas in different stages of growth, split open, x $21 / 2 ; \mathrm{f}$, pistil, $x 21,2$ g, seed, $x 10$. h-m, Gratiola pilosa: h, habit, x $1 / 2 ;$ i, flower,

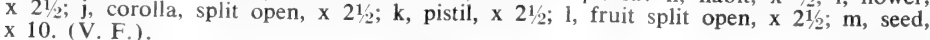


Penn.

In ditches, bogs, wet depressions in ficlds and prairies, swamps and flat pinelands in Okla. (Pittsburg, McCurtain and Le Flore cos.) and in e. Tex., Aug.Oct.; from Del. and Md., s. to Fla., Tex., Okla. and Mo.

\section{Gratiola L. Hedge-HysSOP}

Low mostly perennial or some biennial or annual herbs; leaves sessile; two (rarely 1) bractlets usually at base of calyx; the 5 narrow divisions of calyx more or less subequal; corolla tubular or narrowly campanulate, bilabiate; upper lip of corolla entire or 2-cleft, the lower lip 3-cleft; style dilated or bilabiate at apex; capsule 4-valved, many-seeded.

About 20 species that are widely distributed.

1. Plant villous-hirsute; anthers with contiguous vertical cells; flowers subsessile; calyx lobes very unequal; corolla only slightly exceeding the calyx 1. G. pilosa.

1. Plant glabrous or at most puberulent; anthers with a broad connective, the cells transverse; flowers mostly distinctly pedicellate; calyx lobes equal or nearly so; corolla much-exceeding the calyx (2)

2(1). Capsule 1-3 mm. long, much-exceeded by the calyx lobes; cauline leaves clasping by a wide base, usually at least the upper with resinous dots; rhizomes perennial, slender, stoloniferous........2. G. brevifolia.

2. Capsule $3-6 \mathrm{~mm}$. long, equal to or only slightly exceeded by the calyx lobes; cauline leaves narrowed to a sessile or scarcely clasping base, obscurely glandular-punctate; roots annual, the main root thick and producing many fibers (3)

3(2). Corolla golden-yellow (especially the limb); capsule ovoid-pyramidal, nearly twice as long as calyx lobes; stem less than $1 \mathrm{dm}$. high, thin, not fleshy; in central and south Texas................................... G. G. flava.

3. Corolla white (at least as to the limb); capsule globose to globose-ovoid, nearly or quite equaled by the calyx lobes; stems usually more than $1 \mathrm{dm}$. high, relatively thick and fleshy, mostly in east Texas (4)

4(3). Pedicels slender, over $1 \mathrm{~cm}$. long; hairs on upper side of corolla throat clavate; capsule $4-5 \mathrm{~mm}$. long, globose-ovoid, about equal to the calyx lobes........................................................4. G. neglecta.

4. Pedicels stout, mostly much less than $1 \mathrm{~cm}$. long; hairs on upper side of corolla throat filiform; capsule globose, usually slightly exceeding the calyx lobes.

5. G. virginiana.

1. Gratiola pilosa Michx. Hairy HedGe-Hyssop. Fig. 687.

Perennial, the firm tufted stems from a subligneous crown, villous-hirsute, to $75 \mathrm{~cm}$. high; leaves sessile by broad rounded clasping bases, to about $2 \mathrm{~cm}$. long, ovate to ovate-lanceolate, crenate-serrate; flowers subsessile or very shortstalked in the axils; calyx segments very unequal; corolla white or purple-tinged, 5-9 $\mathrm{mm}$. long, little-exceeding the calyx; anthers with contiguous vertical cells; capsule 4-5 mm. long, slenderly conical. Sophronanthe pilosa (Michx.) Small, Tragiola pilosa (Michx.) Small \& Penn.

In bogs, swamps and moist sandy woods, in wet meadows at head of lakes and forming colonies in water, in Okla. (LeFlore Co.) and in e. third of Tex., JuneAug.; from Fla. to Tex., n. to N.J., Md., N.C., Ky., Ark. and Okla.

2. Gratiola brevifolia Raf. Sticky hedGe-Hyssop. Fig. 687.

Annual or short-lived perennial, puberulent and somewhat viscid, to about $35 \mathrm{~cm}$. high; leaves lanceolate to linear-lanceolate, acute to acuminate, sparsely 
and acutely serrate, to $35 \mathrm{~mm}$. long and $1 \mathrm{~cm}$. wide, equal to or shorter than the pedicels; sepals and bractlets linear-subulate, much longer than the capsule; corolla whitish, 1-1.2 cm. long; sterile filaments short. G. ramosa [var.] Drummondii (Benth.) Penn., G. Drummondii Benth., Ilysanthes inaequalis (Walt.) Penn.

In bogs, marshes, wet meadows and in and on the edge of water in ponds and lakes, in wet savannahs, in Okla. (Pushmataha Co.) and in e. Tex., Apr.-Sept.; from Ga. to Tex., Okla. and Ark.

\section{Gratiola flava Leavenw. Golden HedGe-Hyssop. Fig. 683.}

Annual, glabrous throughout, less than $1 \mathrm{dm}$. high, the slender stems clustered at base and erect-ascending; leaves few, opposite, linear-oblanceolate, entire or with few obscure serrations, to $15 \mathrm{~mm}$. long and $5 \mathrm{~mm}$. wide, clasping at the sessile base, obtuse at apex; bracteole 1, linear-spatulate, about as long as the sepals; calyx lobes 3-5 mm. long, linear to linear-lanceolate, obtuse; corolla with orange-yellow tube and golden-yellow limb, about $12 \mathrm{~mm}$. long; capsule brown, ovoid-pyramidal, noticeably exceeding the sepals; seeds brown, with coarse reticulation. G. pusilla Torr.

In sandy wet soil in prairies and fields in cen. and s. Tex., Feb.-Apr.; also La.

\section{Gratiola neglecta Torr. Fig. 688.}

Annual with simple or loosely branched soft stem to $4 \mathrm{dm}$. high, the upper internodes, pedicels and expanding leaves more or less clammy-puberulent; leaves thin, rhombic-lanceolate to lanceolate, tapering to base and apex, undulatedentate or entire, to $55 \mathrm{~mm}$. long; pedicels filiform, elongating to $25 \mathrm{~mm}$. long; bractlets foliaceous, equal to or exceeding the calyx; corollas honey-color to creamy-white, with yellowish tube, the earlier ones $8-12 \mathrm{~mm}$. long, the inside of the throat with clavate bearding; sterile stamens minute or none; capsule $3-5 \mathrm{~mm}$. long, globose-ovoid; seeds thick-cylindric, about $0.5 \mathrm{~mm}$. long. G. gracilis Benth., G. Torreyi Small.

In wet or muddy places about ponds, in water of swamps, marshes, and in woods in e. Okla. (Waterfall) and e. third of Tex., N. M. (Rio Arriba Co.) and Ariz. (Coconino Co.), Mar.-Aug.; from Que. and Me. to B.C., s. through most of the U. S.

\section{Gratiola virginiana L. Figs. 688 and 689.}

Rather coarse plant, the fleshy base often biennial; stems simple or with few ascending branches, to $45 \mathrm{~cm}$. high, usually glabrous; leaves lanceolate to elliptic or oblong-obovate, shallowly undulate to sharply serrate, to $7 \mathrm{~cm}$. long; pedicels stoutish, usually less than $5 \mathrm{~mm}$. long; calyx 4-8 $\mathrm{mm}$. long; corolla milk-white or pink-tinged to honey-colored, the earlier ones to $15 \mathrm{~mm}$. long, with filiform hairs inside at throat; capsule globose, slightly exceeding to shorter than the calyx, 4-7 mm. long; seeds slender-cylindric, about $0.8 \mathrm{~mm}$. long.

In water of streams, lakes, ponds and ditches, often forming colonies in water, in boggy areas and in open flats in forests in Okla. (LeFlore and Comanche cos.) and e. third of Tex., Mar.-May.; from Fla. to Tex., n. to N.J., Md., W.Va., O., Ind., IIl., Ia. and Kan.

\section{Stemodia L.}

About 30 species, mostly in tropical regions.

1. Stemodia durantifolia (L.) Sw. Fig. 690.

Annual, glandular-pubescent, rather rigidly erect, often much-branched, the branches slender, to about $9 \mathrm{dm}$. high; leaves sessile and amplexicaul, opposite or several at the nodes, oblong-elliptic to linear-oblong or linear-lanceolate to 


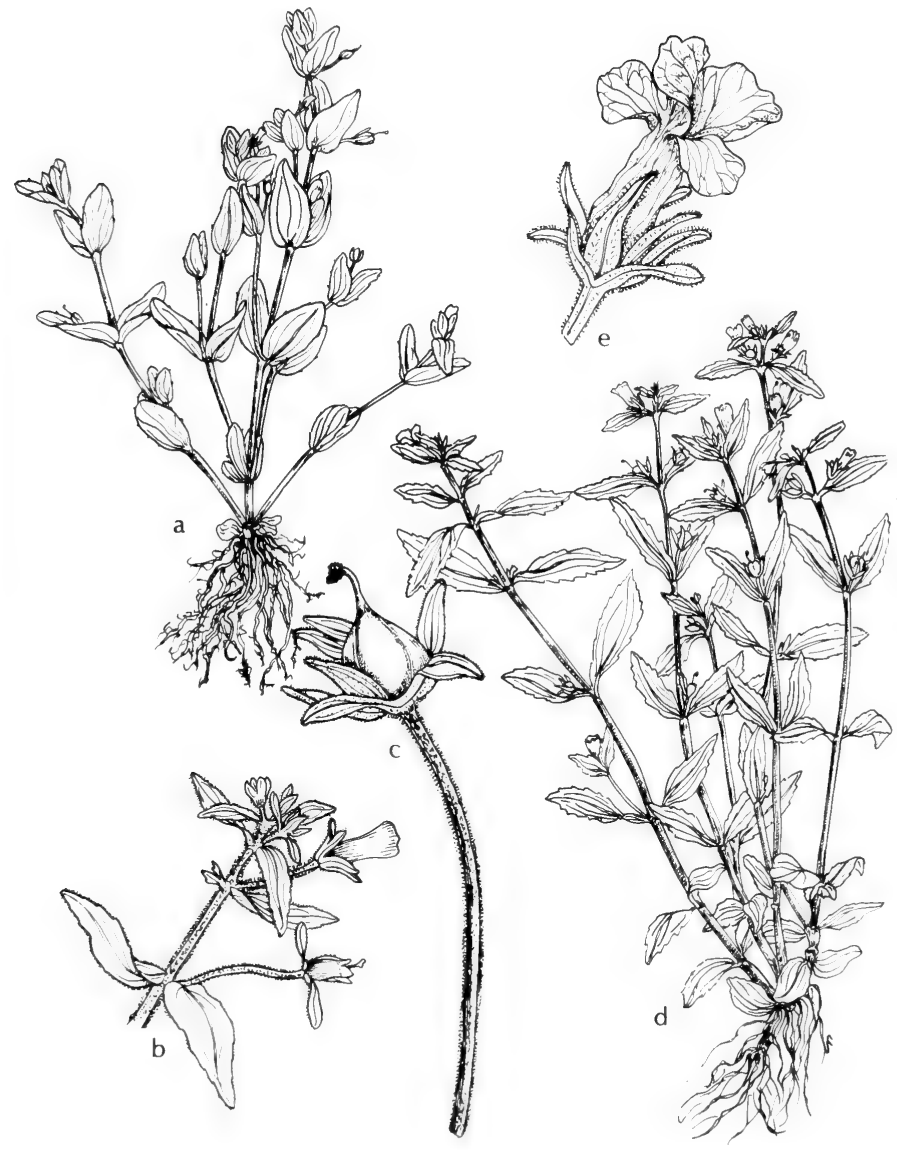

Fig. 688: a, Lindernia dubia: a, habit, x 1/2. b and c, Gratiola neglecta: $\mathrm{b}$, end of branch, $\mathrm{x} 1$; c, capsule, x 5. d and e, Gratiola virginiana: d, habit, x 1/2; e, flower, x 5 . (V. F.). 


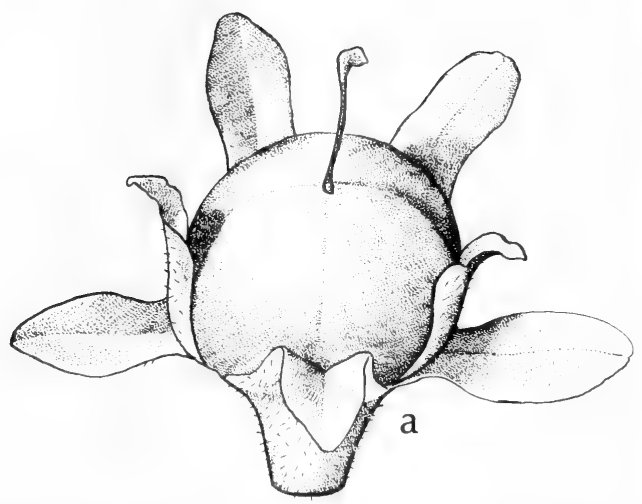

Fig. 689: Gratiola virginiana: a, capsule, x 4; b, seed, $x$ 5. (Courtesy of $\mathrm{R}$. K. Godfrey).

oblanceolate, the upper ones linear, acute to acuminate or obtuse at apex, serrate or serrulate, those of the stem to $9 \mathrm{~cm}$. long, with narrowed bases; flowers nearly sessile, solitary in the axils or in spiciform leafy-bracted racemes; bractlets 2, linear, shorter than the calyx; sepals about $5 \mathrm{~mm}$. long, lanceolate, acuminate; corolla blue or purple, glandular-pubescent, longer than the calyx.

In wet soil along streams and about springs, and on edge of water, in s. Tex. and Ariz. (Gila, Maricopa, Pinal and Pima cos.), Feb.-Oct.; from Calif. to Tex., southw. in Latin Am.

\section{Leucospora NUTT.}

A monotypic genus.

\section{Leucospora multifida (Michx.) Nutt. Fig. 691.}

Low much-branched annual herb, diffusely spreading, to about $2 \mathrm{dm}$. high and about as wide, puberulent throughout; leaves opposite, petioled, triangular-ovate in outline, $2-3 \mathrm{~cm}$. long, pinnately parted, the divisions oblong to linear-cuneate; pedicels naked, solitary in axils, 5-10 mm. long; calyx 5-parted, the sepals linear; corolla tubular, bilabiate, pale-lavender, about $4 \mathrm{~mm}$. long, scarcely exceeding the calyx, upper lip bilobed, the lower lip 3-parted; anthers approximate; stigma bilobed, the lobes cuneiform; capsule ovoid, septicidal, many-seeded. Conobea multifida (Michx.) Benth. 

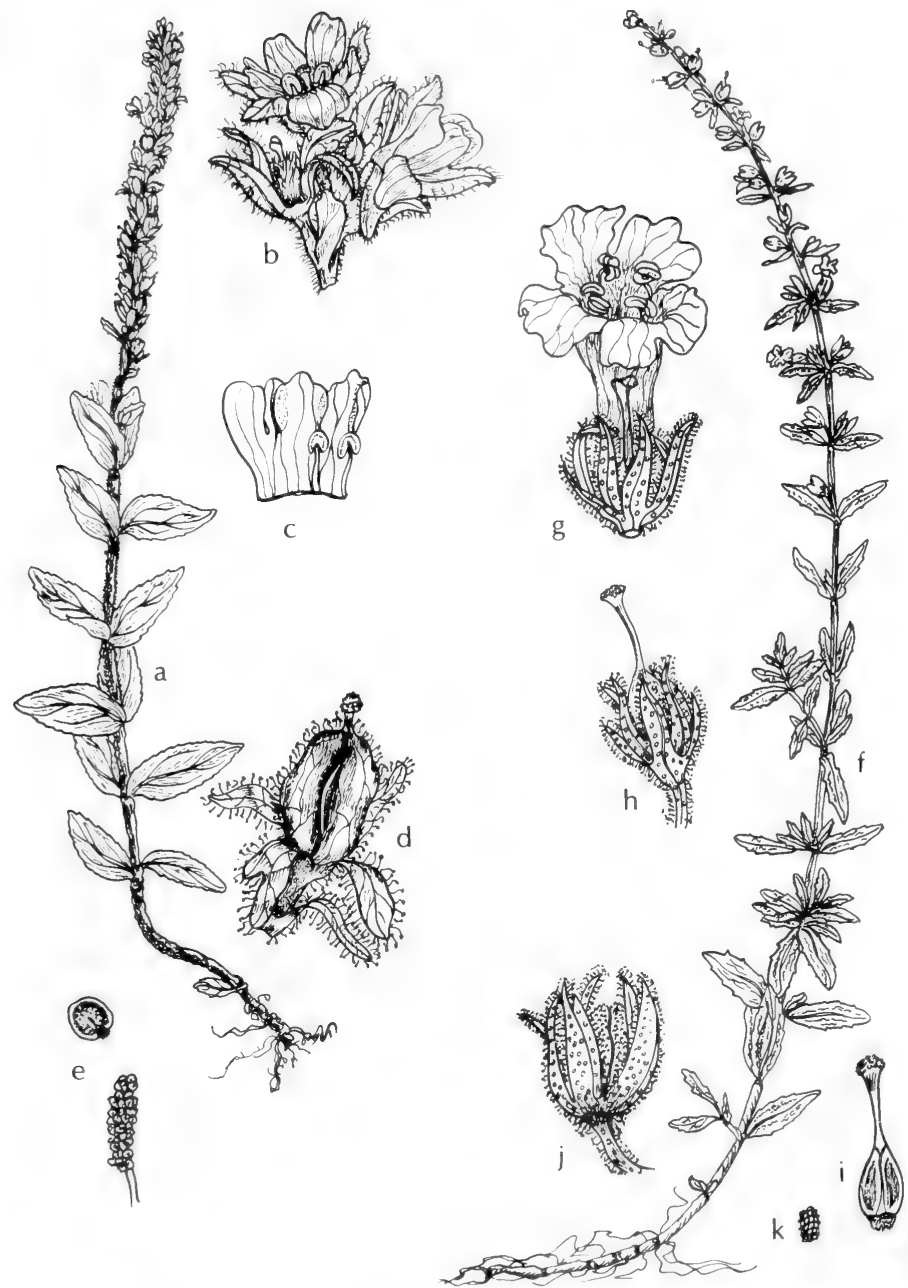


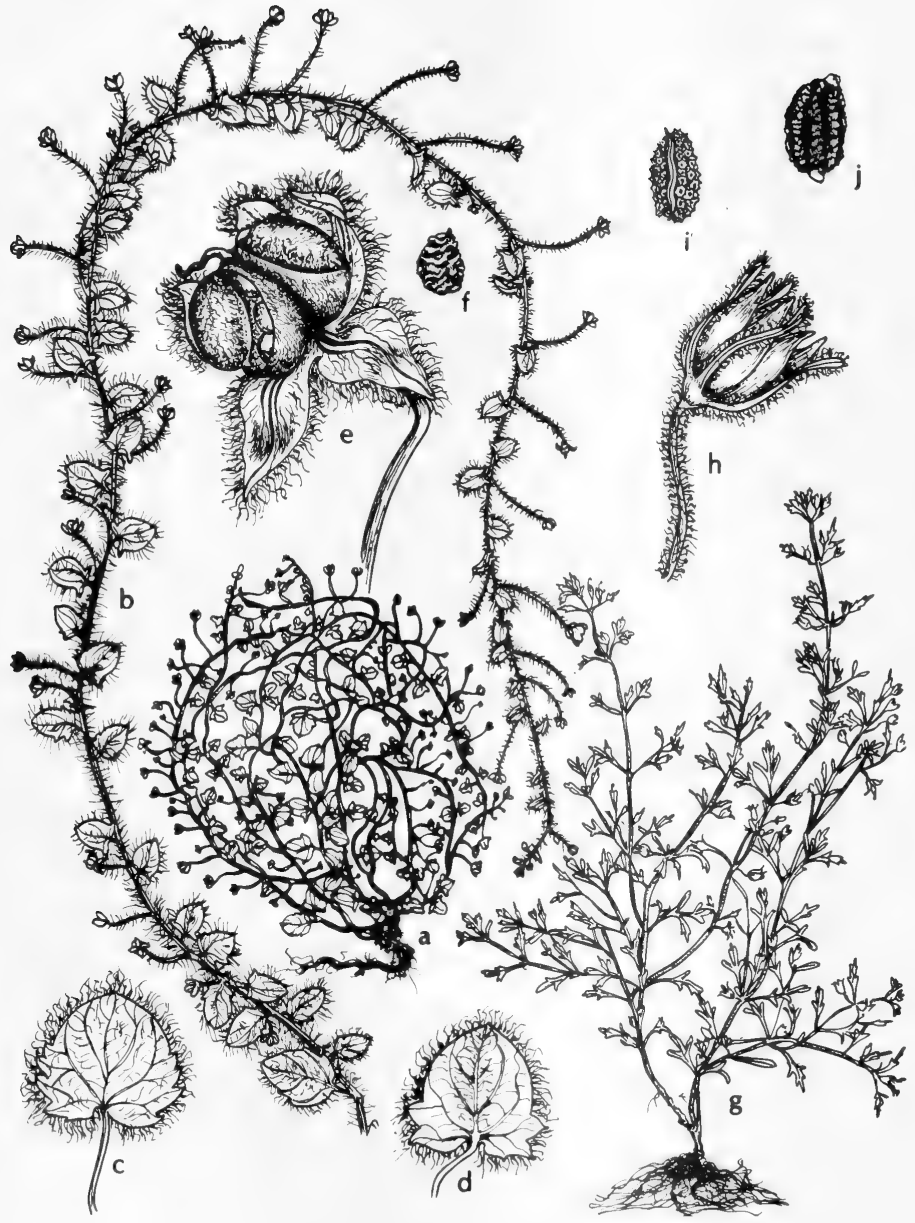

Fig. 691: a-f, Kickxia Elatine: a, habit x 1/6; b, branch, x 1/2; c and d, two leaves showing characteristic shapes, $\mathrm{x} 1$; e, two-celled capsule, each cell circumscissile, $\mathrm{x}$ 5; f, mature seed, x 6. g-k, Leucospora multifida: g, habit, x 1/2; h, flower, x 5; i, seeds removed from capsule, x 5 ; j, seed, x 25 . (V. F.). 
In mud and sand-gravel along streams and on shores, in wet seepage areas and in stream beds, in Okla. (McCurtain, Stephens and Johnston cos.) and mostly in cen. and e. Tex., June-Oct.; from Ont. to Ia. and Kan., s. to Ga., Ala., La. and Tex.

\section{Limnophila R. BR.}

About 30 species that are native mainly in Africa and Australia.

\section{Limnophila sessiliflora BI. Fig. 692.}

Aquatic glabrous herbs with mostly branched leafy stems that are to $5 \mathrm{dm}$. long or more; leaves 3 to 6 in a whorl, all pinnatisect or the uppermost opposite, linear-spatulate and toothed, gland-dotted, usually $2-2.5 \mathrm{~cm}$. long; flowers axillary, solitary, sessile or very shortly pedicelled; calyx about $8 \mathrm{~mm}$. long, with 5 ovate acuminate lobes, the tube hemispheric in fruit; corolla about $12 \mathrm{~mm}$. long, pink or lavender-pink, bilabiate, the upper lip entire or bifid, the lower lip nearly equally 3-lobed and spreading, the tube cylindric; capsule orbicular, swollen, about $5 \mathrm{~mm}$. thick.

Attached to bottom of lake and in current of river at San Marcos (Hays Co.), Tex. where it has been introd. and has become well-established, July-Nov.; a nat. of Asia.

\section{Mimulus L. MONKey-Flower}

Herbs (in ours) with perennial rhizomes or stolons; flowers axillary; calyx tubular, angled or prismatic, regular or irregular, the lobes shorter than the tube; corolla irregular, bilabiate; lobes of upper corolla lip erect to reflexed; lobes of lower corolla lip spreading or deflexed, arched in the throat or with 2 elevated ridges partially or completely closing the orifice; stamens 4 , didynamous, inserted near middle of corolla tube, the anthers approximate in pairs with their sacs divergent; style elongate, the stigmas 2 and platelike; capsule cylindric, loculicidal, many-seeded.

More than 100 species that are world-wide in distribution, mostly in western United States.

1. Calyx teeth equal or nearly so (2)

1. Calyx teeth unequal, the posterior tooth larger than the others (8)

2(1). Corolla lobes distinctly unequal (3)

2. Corolla lobes equal or nearly so (6)

$3(2)$. Corolla throat nearly closed by the prominent palate (4)

3. Corolla throat broad and more or less open (5)

4(3). Leaves mostly sessile; pedicels more than one half as long as the leaves....

4. Leaves distinctly petioled; pedicels mostly less than one half as long as the leaves.

2. M. alatus.

5(3). Corolla scarlet or carmine; calyx teeth 4-6 mm. long.......3. M. Cardinalis. 5. Corolla yellow; calyx teeth less than $3 \mathrm{~mm}$. long.................4. M. floribundus.

6(2). Annual; corolla yellow throughout or the lobes purple-red.

6. Perennials ( 7 )

5. M. rubellus.

7(6). Flowers solitary, scapose; corolla yellow; plant small, rarely to $1 \mathrm{dm}$. tall 6. M. primuloides.

7. Flowers several, racemose; corolla scarlet or carmine; plant rather stout 7. M. Eastwoodiae. 
8(1). Corolla throat open; flowers axillary or several in a lax terminal raceme (9)

8. Corolla throat partly or nearly closed by the prominent palate; flowers mostly numerous in a definite raceme (11)

9(8). Annual; stems usually erect; leaves oblong-lanceolate; calyx deeply cleft, the upper tooth about equaling the tube; herbage viscid-villous with long white hairs. 8. M. pilosus.

9. Perennials; stems low, creeping or procumbent; leaves ovate to suborbicular; calyx shallowly cleft, the teeth all much shorter than the tube (10)

10(9). Leaves less than $1 \mathrm{~cm}$. long, more or less covered with short stiff white hairs; corolla laciniately lobed or erose.................. 9. M. dentilobus.

10. Leaves $3 \mathrm{~cm}$. long or more, essentially glabrous; corolla lobes entire. 10. M. glabratus.

11(8). Upper calyx tooth rarely more than twice the length of the others, the lower teeth at maturity usually folding over and only partly closing the orifice............................................................11. M. guttatus.

11. Upper calyx tooth about 3 times the length of the others, the lower teeth in maturity folding over and nearly closing the orifice.

12. M. nasutus.

\section{Mimulus ringens $L$.}

Perennial by stoloniferous rootstocks, glabrous; stems simple or branched, 4angled, to $13 \mathrm{dm}$. high; leaves thin, oblong to oblong-lanceolate, to $1 \mathrm{dm}$. long and $3 \mathrm{~cm}$. wide, acute to obtuse at apex, tapering to a broad often auriculateclasping sessile base, serrate to rarely entire; pedicels stout, to $35 \mathrm{~mm}$. long, mostly shorter than the subtending leaves; calyx tubular, 14-17 mm. long, strongly angled, with slender subulate or aristate teeth about one fourth as long as tube, with broad ciliate sinuses; corolla $25-35 \mathrm{~mm}$. long, blue, rarely pink or white, the exserted tube slightly funnelform, the throat nearly closed, upper lip erect and strongly reflexed, lower lip longer and the stigma broadly bilamellate; capsule included, broadly oblong; seeds oblong, papillate, spreading with the margins erose; upper pair of stamens slightly exserted; style exserted, the stigma broadly bilamellate; capsule included, broadly oblong; seeds oblong, papillate.

In wet places such as wet mud along streams, in marshes, swamps and sloughs, in Okla. (Cleveland and Oklahoma cos.) and possibly in n.e. Tex., June-Sept.; from Can. to Fla., w. to N.D. and s. to Okla. and (?) Tex.

\section{Mimulus alatus Ait. Fig. 693.}

Stems stoloniferous, glabrous, simple or branched, to $7 \mathrm{dm}$. high, 4-angled, the angles more or less winged; leaves broadly ovate to ovate-lanceolate, acute, to $15 \mathrm{~cm}$. long and $6 \mathrm{~cm}$. wide, serrate, tapering to a narrow-margined petiole to $25 \mathrm{~mm}$. long; pedicels stout, mostly shorter than the calyx; calyx oblong, 14-17 $\mathrm{mm}$. long, with sharp angles, the broad mucronate teeth about $1.5 \mathrm{~mm}$. long; corolla blue or violet, sometimes tinged with pink or rarely white, $2-2.5 \mathrm{~cm}$. long, the tube slightly exserted, the throat nearly closed, lobes of the upper lip erect and strongly reflexed, the lower lip longer and spreading; stamens and style included; capsule ovoid, obtuse; seeds oval, papillate.

In wet areas (especially along wooded streams), about lakes and in marshes, in wet mud of ponds, in Okla. (McCurtain, Johnston, Pittsburg, Osage, Mayes, Cherokee, Washington and Ottawa cos.) and in e. Tex., w. to Blackland Prairies, June-Nov.; from Mass., s. to S. C. and w. to Tex. and Okla.

\section{Mimulus Cardinalis Dougl. Crimson monkey-Flower. Fig. 694.}

Coarse perennial from a thick rhizome; stems erect or ascending, 3-10 dm. tall, 

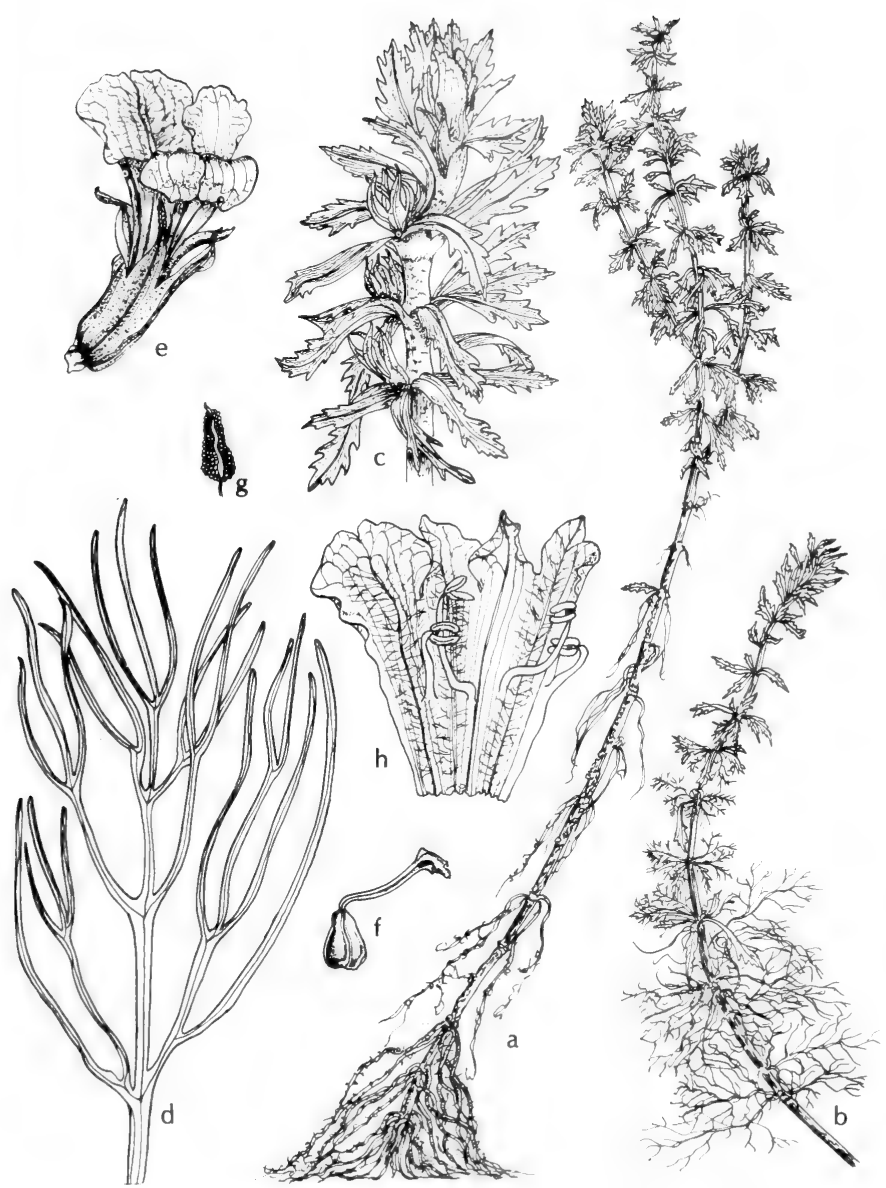

Fig. 692: Limnophila sessiliflora: a and b, habit, showing emergent and submerged leaves, $x_{1 / 2} ; \mathrm{c}$, flowering shoot, $\mathrm{x} 11 \frac{1}{2} ; \mathrm{d}$, submerged leaf, $\mathrm{x} 11 \frac{1}{2} ; \mathrm{e}$, flower, $\mathrm{x} 5$; f, pistil, x 5; g, seeds removed from capsule, x 5; h, corolla spread out, x 5. (V. F.). 


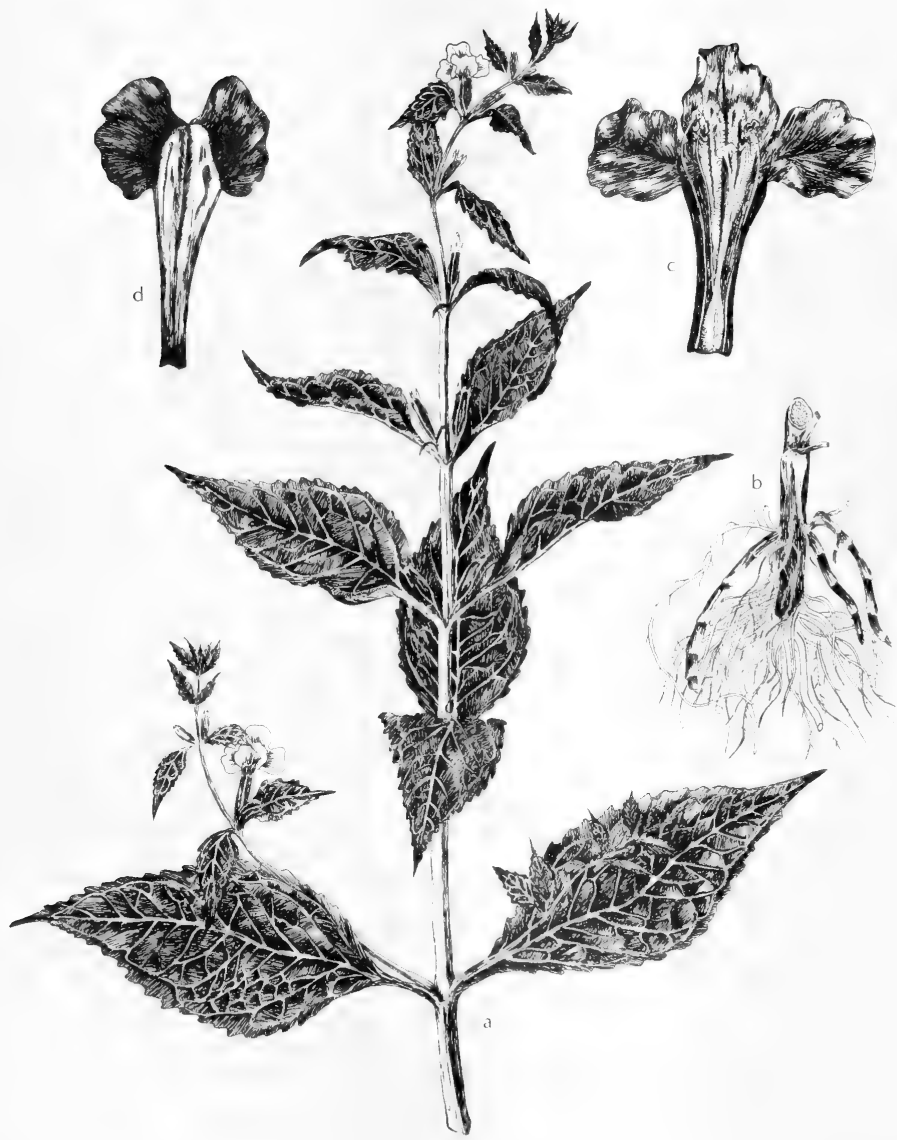

Fig. 693: Mimulus alatus: a, top of plant, x 1/3; b, base of plant, $x 1 / 3$; , flower opened, $x$ 11/3; d, end of style, x 15 . (Courtesy of R. K. Godfrey). 
rooting where they touch the ground, sometimes much-branched; herbage viscidpubescent; leaves broadly lanceolate to linear-lanceolate, dentate to entire; flowers on slender pedicels in the leaf axils, the pedicels $2-8 \mathrm{~cm}$. long; calyx tubular, campanulate, the lobes nearly equal; corolla $3-5 \mathrm{~cm}$. long, bright-scarlet, the upper lip erect and 2-lobed, the lower lip with 3 reflexed lobes, the throat closed; anthers 4 , clothed with scalelike hairs; capsule ovate, acuminate.

Along streams and in bogs, rooted in water about springs and on canals, in N. M. (Grant Co.) and Ariz. (Coconino, Mohave, Yavapai, Apache, Graham and Pima cos.) May-Oct.; N. M. and Ariz. to Ore. and Calif.

Var, verbenaceus (Greene) Kearn. \& Peeb., of Arizona, has corolla tube nearly twice as long as the calyx.

\section{Mimulus floribundus Dougl. Fig. 695.}

A viscid-villous more or less slimy annual; stems $8-50 \mathrm{~cm}$. long, diffusely branched from the base, somewhat weak, often climbing over moist rocks; leaves scattered, thin, ovate to ovate-lanceolate, $1.5-5 \mathrm{~cm}$. long, $1-3 \mathrm{~cm}$. wide, acute, dentate with short salient teeth, ciliate, the base broad, mostly truncate or subcordate, 3- or 5-nerved, usually shorter than the internodes; petioles longer or shorter than the blade, sometimes slightly winged or occasionally essentially lacking; pedicels filiform, frequently shorter than the leaves and more or less spreading at maturity; calyx plicate-carinate, slightly campanulate, 4-7 mm. long, broadly ovate in fruit and 6-10 $\mathrm{mm}$. long, often spotted or tinged with red; calyx teeth triangular, lanceolate, 1-1.5 mm. long, ciliate, equal; corolla cylindrical to funnelform, 7-14 mm. long, yellow, tube slightly exserted, throat short, ampliate, dotted or streaked with red, lobes unequal, mostly erect, short, rounded, the lower lip sometimes slightly spreading; style and stamens glabrous, included, stigma lips equal and rounded; capsule chartaceous, shorter than the calyx, oblong, placentae completely adherent; seeds oval, longitudinally wrinkled.

In wet sand, growing in streams and in marshes, in N.M. (Rio Arriba Co.) and Ariz. (Apache and Coconino, s. to Yavapai, Graham, Santa Cruz and Pima cos.), Apr.-Sept.; Wyo. to B.C., s. to n. Mex. and Calif.

\section{Mimulus rubellus Gray. Fig. 696.}

Annual, glandular-puberulent to almost glabrate, the erect stems often muchbranched, to $2 \mathrm{dm}$. high; leaves sessile or with the lowest smaller and petioled, elliptic-oblong to elliptic-lanceolate, entire or only slightly toothed, 3-veined, to about $2 \mathrm{~cm}$. long; pedicels to $22 \mathrm{~mm}$. long; calyx 5-9 $\mathrm{mm}$. long, often reddish, ridge- to wing-angled, its ciliate lobes low-triangular or its mucronate tips less than $0.5 \mathrm{~mm}$. long; corolla yellow throughout or the lobes purple-red, 7-9 $\mathrm{mm}$. long, the throat narrow, ventrally 2-ridged and puberulent, the orifice open and the slightly spreading lobes notched; anthers glabrous; capsule $4 \mathrm{~mm}$. long, not dehiscing through septum apex.

In moist or wet places, seepage about springs, creek beds and in mud along streams, in extreme w. Tex., N. M. (Sierra and Dona Ana cos.) and Ariz. (Coconino and Mohave, s. to Greenlee, Cochise, Santa Cruz and Pima cos.), Apr.-June; from w. Tex., N.M., Ariz., Wyo. and s. Colo. to Calif.

\section{Mimulus primuloides Benth. Fig. 695.}

A variable perennial, stoloniferous or reproducing by surface runners or by bulbils attached to the underground stems, subacaulescent with radical leaves or the stems $3-10 \mathrm{~cm}$. high, bearing several pairs of leaves, internodes close together or almost as long as the leaves, glabrous or viscid-pilose with long soft hairs; leaves broadly obovate, oblong or sometimes cuneate, tapering to a narrow some- 


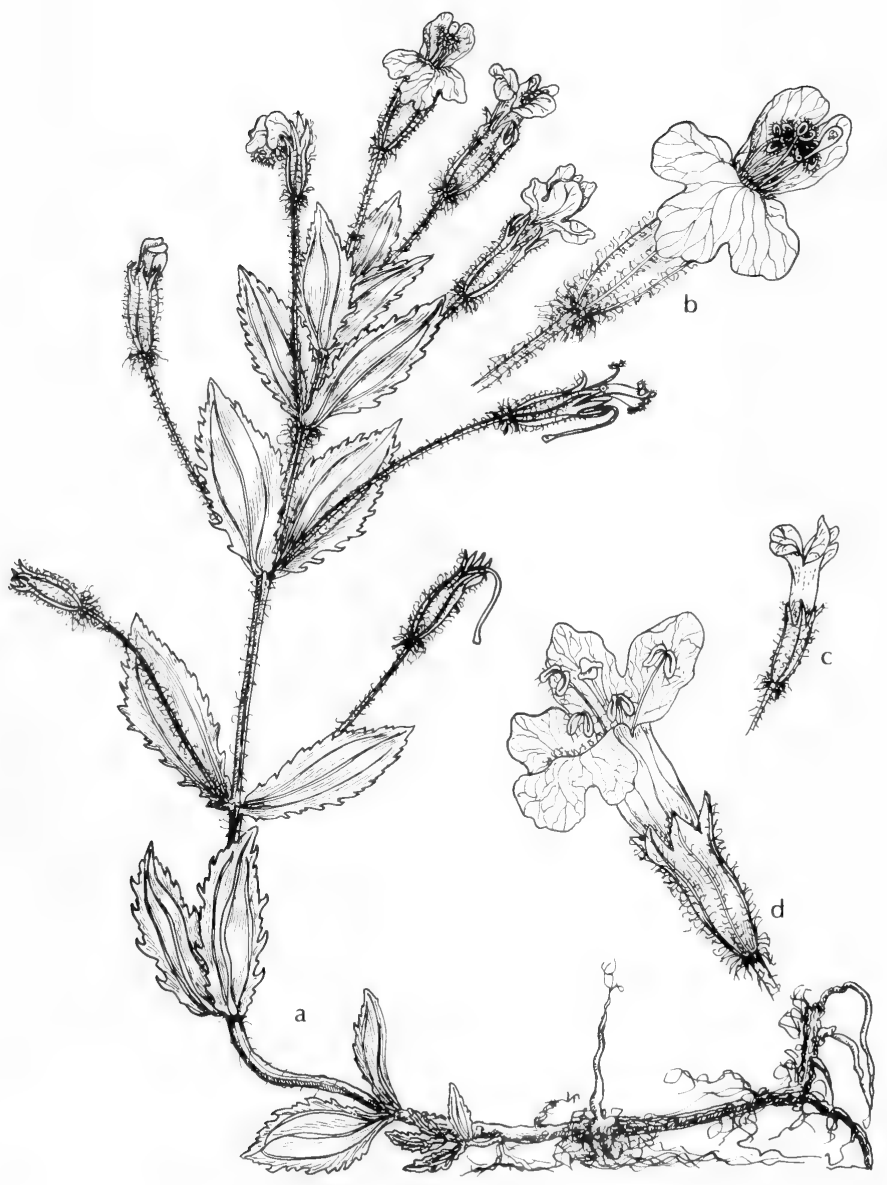

Fig. 694: a and b, Mimulus cardinalis: a, habit, x 1/2; b, flower, $x$ 1. c and d, Mimulus cardinalis var. verbenaceus: c, flower showing longer corolla tube than that of var. cardinalis, x $1 / 2$; d, flower, $x 1$. (V.F.). 


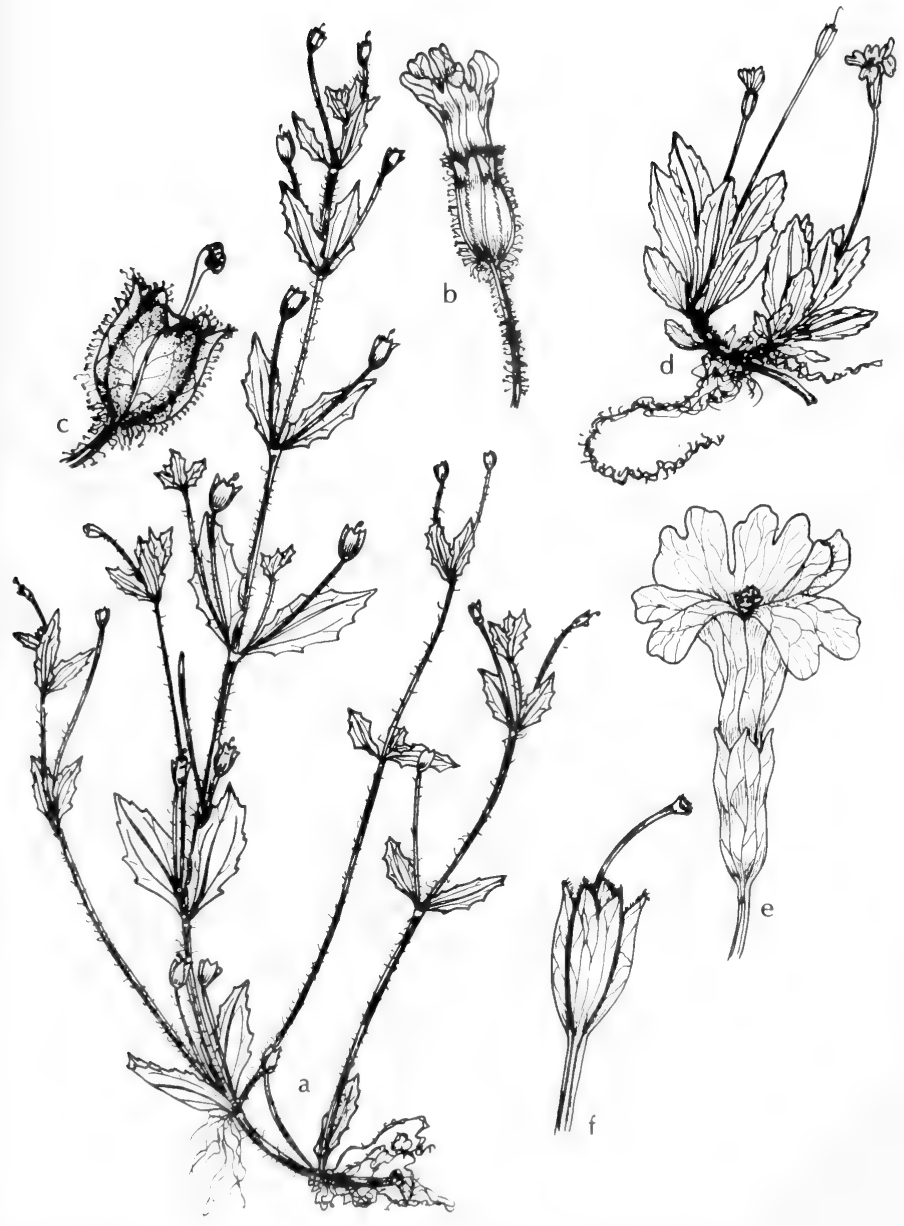

Fig. 695: a-c, Mimulus floribundus: a, habit, x 1/2; b, flower, x 21/2; c, capsule, $x$ 21. d-f, Mimulus primuloides: d, habit, x 1/2; e, flower, $x$ 3; f, calyx with capsules, x 3. (V. F.). 
what connate sessile base, 1-2.5 $\mathrm{cm}$. long, 5-7 $\mathrm{mm}$. broad, light-green to graygreen, thin, entire or dentate, occasionally with an undulate margin, 3- or 5-nerved, glabrous or with long white jointed hairs scattered on the upper surface; flowers few, mostly solitary, scapose; pedicels $4-10 \mathrm{~cm}$. long, glabrous, slender, elongated; calyx tubular, 4-8 mm. long, weakly angled, glabrous, often tinged with red; calyx teeth broadly triangular-acute, frequently mucronate, equal, mostly ciliate; corolla funnelform, 1-2 cm. long, yellow, sometimes with reddish-brown spots on the lobes and down the throat below the lower lip, tube exserted and less than twice as long as the calyx, throat ampliate, lobes spreading, emarginate or obcordate, the lower lip slightly longer than the upper; upper pair of stamens exserted, anthers hispid or rarely glabrous, filaments glabrous; style exserted, glabrous, stigma lips oblong and unequal; capsule included, placentae separating at the apex; seeds oval, reticulate.

In wet meadows, bogs and marshes, in Ariz. (Apache, Coconino and Cochise cos.), July-Aug.; Ida. to Ariz. and s. Calif.

\section{Mimulus Eastwoodiae Rydb.}

Plants usually densely woolly-canescent; stems terete, short, more or less procumbent, from a creeping rootstock or from short stolons; leaves broadly obovate or oblong, $2-5 \mathrm{~cm}$. long, to $2 \mathrm{~cm}$. wide, acute, coarsely and saliently dentate along the upper half, tapering to a broad sessile base, the lower leaves sometimes spatulate or cuneate, frequently reddish on the lcwer surface; flowers few, mostly solitary; pedicels slender, usually longer than the leaves; calyx somewhat funnelform, 2.2-2.7 cm. long; calyx teeth triangular, acute or subulate, ciliate, slightly unequal, 4-6 mm. long; corolla $3.5-4 \mathrm{~cm}$. long, crimson, tube broadly funnelform, exserted less than twice its length, more or less tinged with yellow, throat ampliate, upper lip erect, lower erect or somewhat spreading, lobes nearly equal, emarginate; stamens much-exserted, anthers yellow and densely bearded; style and stigma nearly as long as the corolla, stigma narrowly oblong to spatulate; capsule unknown.

In wet shaded places such as seepage about springs, in Ariz. (Apache, Navajo, Coconino and Mohave cos.), Apr.-July; also Ut. and Nev.

\section{Mimulus pilosus (Benth.) Wats.}

Plant to about $3 \mathrm{dm}$. tall, eventually much-branched, leafy, soft-villous and slightly viscid, rarely glabrate, flowering from near the base; leaves sessile, lanceolate to narrowly oblong, entire, obscurely 3-nerved at base, the lower leaves surpassing (the upper scarcely equaling) the pedicels; calyx oblique at orifice, the tube somewhat 5 -sulcate below the sinuses, the posterior tooth equaling the tube; corolla 6-8 $\mathrm{mm}$. long, rather obscurely bilabiate, the lobes nearly equal, bright-yellow and usually with a pair of brown-purple spots on the lower lip; capsule long-ovoid, acute.

Wet sandy soils along streams and about pools, in Ariz. (Yavapai, Graham, Gila, Pinal, Maricopa and Pima cos.), Apr.-Aug.; Nev. and Ore., s. to Ariz. and s. Calif.

\section{Mimulus dentilobus Robins. \& Fern. Fig. 696.}

Low creeping plants, rooting from the nodes and forming dense mats, the terete stems nearly glabrous or sparsely pubescent, to $5 \mathrm{~cm}$. high; leaves broadly ovate to suborbicular, $2-7 \mathrm{~mm}$. long, 2-5 mm. wide, dentate to crenate or nearly entire, mostly with winged petioles shorter than the blade, more or less covered with stiff white hairs; flowers few, axillary or terminal; pedicels slender, almost filiform, pubescent, much-exceeding the leaves; mature calyx turbinate, 5-7 mm. long, sparsely pubescent or rarely glabrous, with triangular acute teeth; corolla 

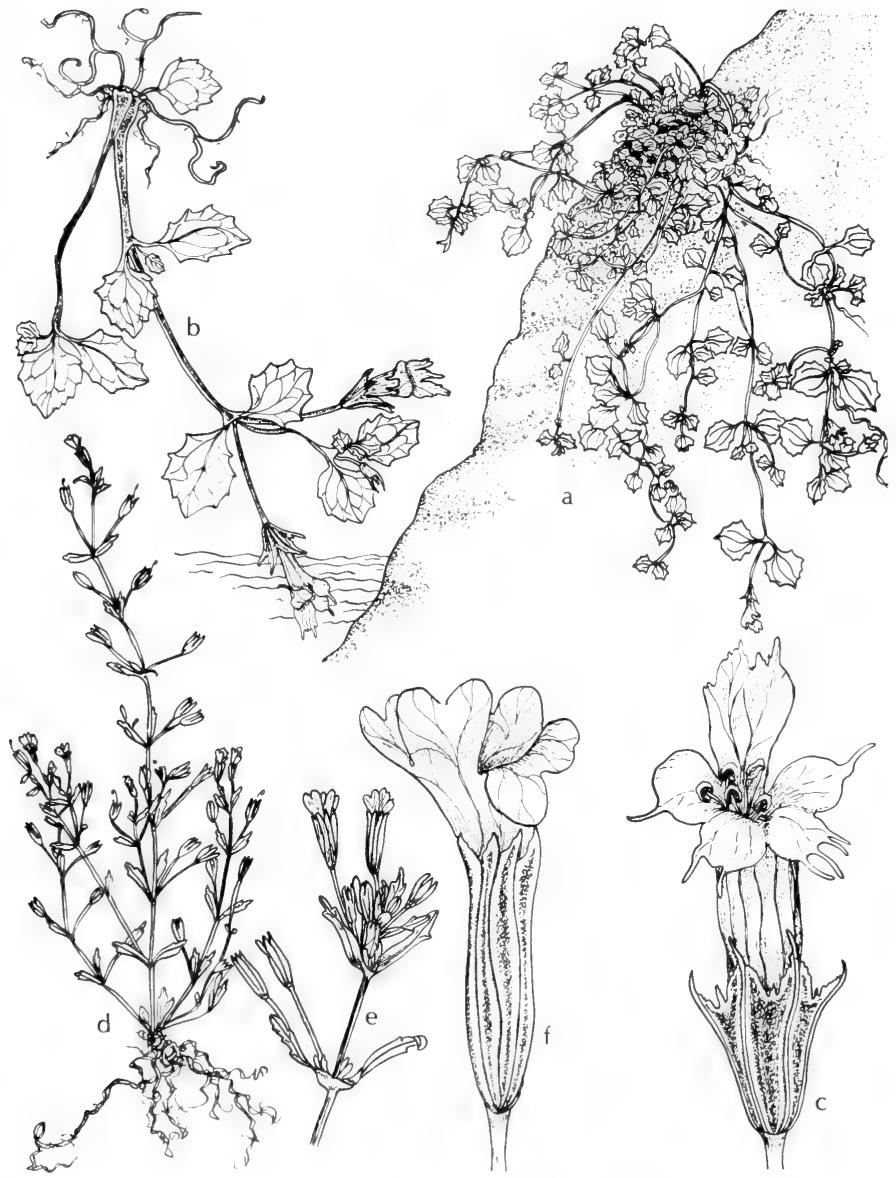

Fig. 696: a-c, Mimulus dentilobus: a, plant showing position on seeping rock cliff, x $1 / 2 ; b$, habit, x 1; c, flower, x 5. d-f, Mimulus rubellus: d, habit, x 1/2; e, flower cluster, x 1; f, flower, x 5. (V. F.). 


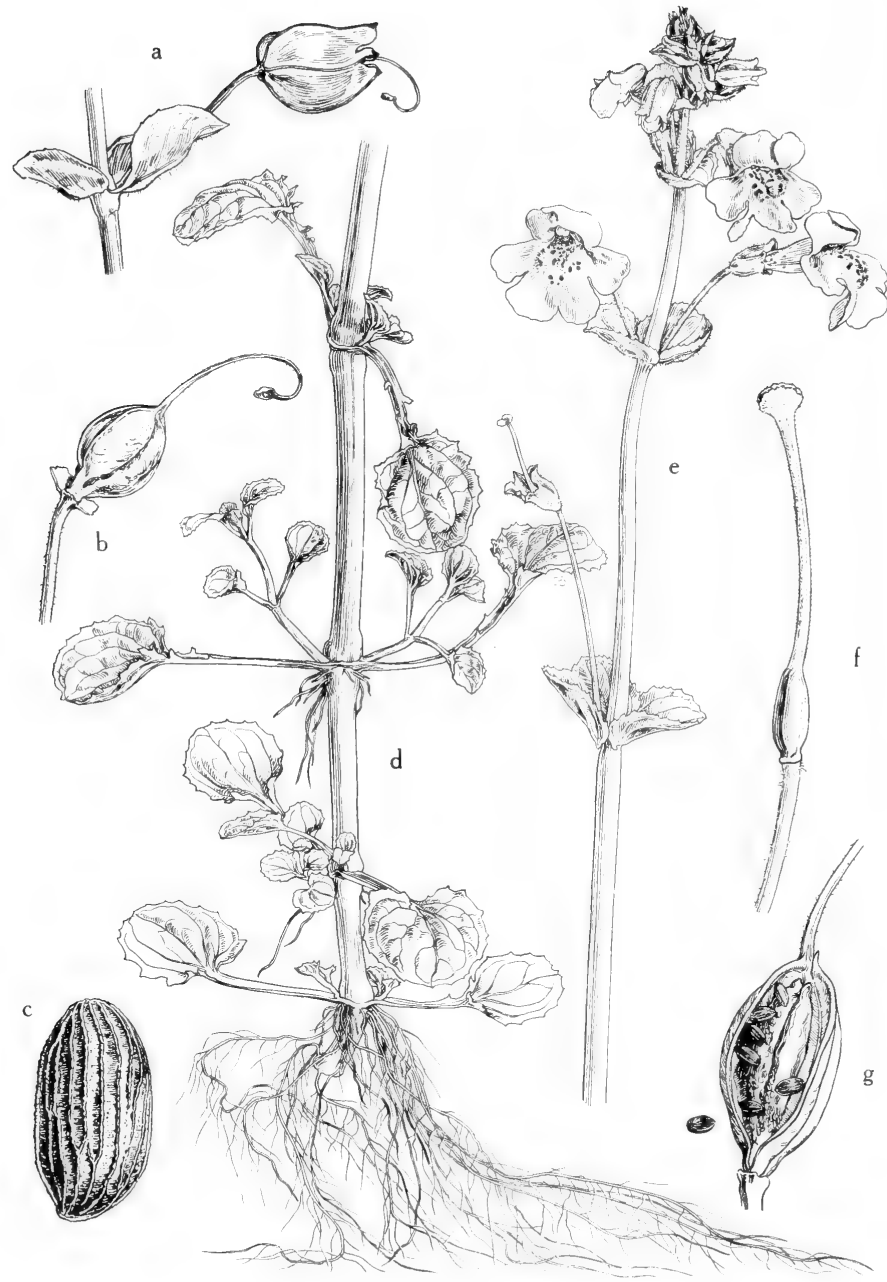

Fig. 697: Mimulus guttatus: a, calyx enclosing mature fruit, x $11 \%$; b, capsule, dehiscent by lateral sutures, x 2; c, seed, x 40; d, habit, basal part of plant, x 75 ; e, habit, inflorescence, $\mathrm{x} 2 / 3 ; \mathrm{f}$, pistil, showing the fimbriolate stigma lobes, x 2; g, capsule, showing dehiscence, x 4. (From Mason, Fig. 320). 
9-13 mm. long, the throat spotted with red below the lower lip, the lobes erose or somewhat laciniate; style puberulent or glabrous; capsule oblong, less than half as long as calyx, compressed; seeds brownish, oval, sometimes 3-sided, longitudinally striate and often bearing stiff scattered hairs.

In permanently wet places such as seepage cliffs and ledges in mts. of the Tex. Trans-Pecos (Presidio Co.), N. M. (Catron and Grant cos.) and Ariz. (Pima co.), May-Aug.; from w. Tex. and Ariz. to n. Mex.

\section{Mimulus glabratus H.B.K.}

Low perennial, glabrous or nearly so, stoloniferous or with creeping stems that root freely at the lower nodes; stems usually numerous, hollow, weak, to $75 \mathrm{~cm}$. long; leaves broadly ovate to suborbicular, to $7 \mathrm{~cm}$. long and $6 \mathrm{~cm}$. wide, irregularly dentate, sometimes shallowly lobed at the base, 3- or 5-nerved, the basal leaves cuneate to subcordate or with margined petioles at base, upper leaves subcordate at the sessile base; flowers axillary, mainly on upper part of stem; pedicels slender, glabrous or pubescent, longer or shorter than leaves; calyx campanulate, often spotted or tinged with red, to $1 \mathrm{~cm}$. long, glabrous or pubescent, larger in fruit, the broad short unequal teeth spreading; corolla tubular, to $15 \mathrm{~mm}$. long, the tube slender, lower lip heavily bearded, middle lobe much longer than the lateral ones; style glabrous; capsule oblong, rounded, constricted at the base but not stipitate, shorter than the calyx tube; seeds oval, longitudinally striate. Incl. var. Fremontii (Benth.) Grant.

In shallow water of streams or muddy places with the stems often floating or creeping and more or less procumbent, in Okla. (Alfalfa and Love cos.), in Tex. on the Edwards Plateau and in the Trans-Pecos, N. M. (Otero, Mora, Lincoln and Colfax cos.) and Ariz. (Apache and Coconino, s. to Cochise, Santa Cruz and Pima cos.), throughout the year; from Ont. and Man., s. to Tex., Nev. and Mex.

\section{Mimulus guttatus DC. Fig. 697.}

Annual or perennial herb; stems simple or branched, erect or declined, 1-6 $\mathrm{dm}$. long; herbage glabrous or somewhat pubescent; leaves elliptical, irregularly serrate to dentate or the blades lobed at base, the lower leaves short-petioled, the upper ones sessile; flowers in terminal bracteate racemes on slender pedicels; calyx campanulate, folded on the angles, the teeth connivent in age; corolla yellow, with reddish-brown spots, sometimes conspicuously spotted, 2-4 cm. long, the upper lip of 2 erect lobes, the lower lip of 3 reflexed lobes, with a conspicuous palate closing the throat; capsule ovate, flattened, 2-celled, incompletely partitioned. Incl. var. puberulus (Greene) Grant.

The most common and most variable species of Mimulus in our area, occurring almost everywhere where water stands on rich soil, principally in bogs, swamps, marshes, and stream banks, widespread in N. M. and Ariz., June-Sept.; Mont., s. to Mex. and n. to Alas.

\section{Mimulus nasutus Fisch.}

Puberulent to nearly glabrous annuals, rarely pubescent; stem usually branched from the base, erect or ascending, 1-6 dm. high, quadrangular, frequently winged, fistulous when growing under very favorable conditions; leaves 3- or 5-nerved, round-ovate or oblong, to $11 \mathrm{~cm}$. long, nearly as broad, irregularly and coarsely dentate or lobed, often with additional small lobes at the base of the blade, more or less tinged with red on the lower surface, lower leaves with long broad clasping petioles, the upper leaves sessile; inflorescence racemose; pedicels nearly glabrous, 2 to 3 times as long as the mature calyx, erect, becoming strongly recurved in 
fruit; calyx appressed-puberulent, with short white hairs at the sinuses, frequently tinged with red, much-inflated when mature, 6-18 mm. long, 3-11 mm. wide, teeth acute, the upper about 3 times as long as the others, the latter folding over and appearing as though truncate with a long index-finger pointing outward; corolla varying greatly in size, from 7 to $23 \mathrm{~mm}$. long; lower corolla lip densely bearded, spreading and much longer than the upper lip, usually with a reddishbrown blotch below the middle lobe and numerous smaller dots down the throat; style puberulent, the stigma lips unequal; capsule short-stipitate, oblong; seeds reticulate.

In moist or wet places generally, in wet meadows, on edge of streams, wet rocks and springy places, in N. M. (Dona Ana Co.) and Ariz. (Graham, Gila, Pinal, Cochise and Pima cos.), Mar.-Sept.; Ida. to B.C., s. to Chih., N.M., Ariz. and Baja Calif.

\section{Lindernia All. False Pimpernel}

Diffuse annual herbs; leaves opposite, denticulate to nearly entire; bracteoles none; flowers in axils of most leaves; sepals 5, distinct; corolla blue-violet, bilabiate, the upper lip with 2 short erect acutish lobes, the lower lip much larger and spreading, with 2 hairy yellow ridges within the throat; filaments 4 , didynamous, the upper short and antheriferous, the lower forming the hairy ventral ridges of the corolla and projecting from apex as sterile knobs; stigmas distinct, lamelliform; capsule septicidal, ovoid to ellipsoid, the septum persisting as a thin plate; seeds smooth or finely lined transversely.

About 80 species, mainly in warm regions of Asia and Africa.

1. Lower pedicels shorter than their subtending leaves; main leaves obovate to elliptic or ovate, rounded or narrowed to base; capsule often equaled or exceeded by the calyx lobes........................ L. dubia.

1. Lower and upper pedicels exceeding their subtending leaves; main leaves ovate to elliptic, broadest at the rounded to cordate base; capsule mostly exceeding the calyx lobes.

2. L. anagallidea.

\section{Lindernia dubia (L.) Penn. Fig. 688.}

Plant glabrous, the simple or much-branched stems erect-ascending, to $35 \mathrm{~cm}$. high; leaves narrowly elliptic to oblong or obovate, to $3 \mathrm{~cm}$. long, the lower ones narrowed but the upper ones rounded and clasping at base, entire to remotely dentate; pedicels 5-12 mm. long, stoutish; calyx lobes linear; corolla 7-10 mm. long, those of the later flowers mostly falling unopened; style $2.5-3.5 \mathrm{~mm}$. long; capsule obliquely ellipsoid, about $4 \mathrm{~mm}$. long. Incl. subsp. major Penn., Ilysanthes gratioloides (L.) DC., I. dubia (L.) Barnh.

In mud of swamps and stream margins, in mud at edge of ponds and lakes, and in pools along water courses, in Okla., (Alfalfa, Adair and Pushmataha cos.) and in e. Tex. and (?) Ariz., June-Aug.; from throughout most of U.S., s. to S.A.

\section{Lindernia anagallidea (Michx.) Penn. Fig. 698.}

Plant glabrous, the slender stems diffusely branched, to about $2 \mathrm{dm}$. high; leaves ovate to ovate-elliptic, to $2 \mathrm{~cm}$. long, broadest at the rounded or clasping base, the lowermost leaves often slightly narrowed at base, essentially entire; pedicels filiform, to about $25 \mathrm{~mm}$. long; calyx lobes linear; corolla 7-9 $\mathrm{mm}$. long, apparently all opening; capsules $4-5 \mathrm{~mm}$. long.

Sandy margins of streams and ponds, and in marshes, throughout most of Okla. and Tex. except the Trans-Pecos, Apr.-Oct.; from throughout most of the U.S., s. to S.A. 


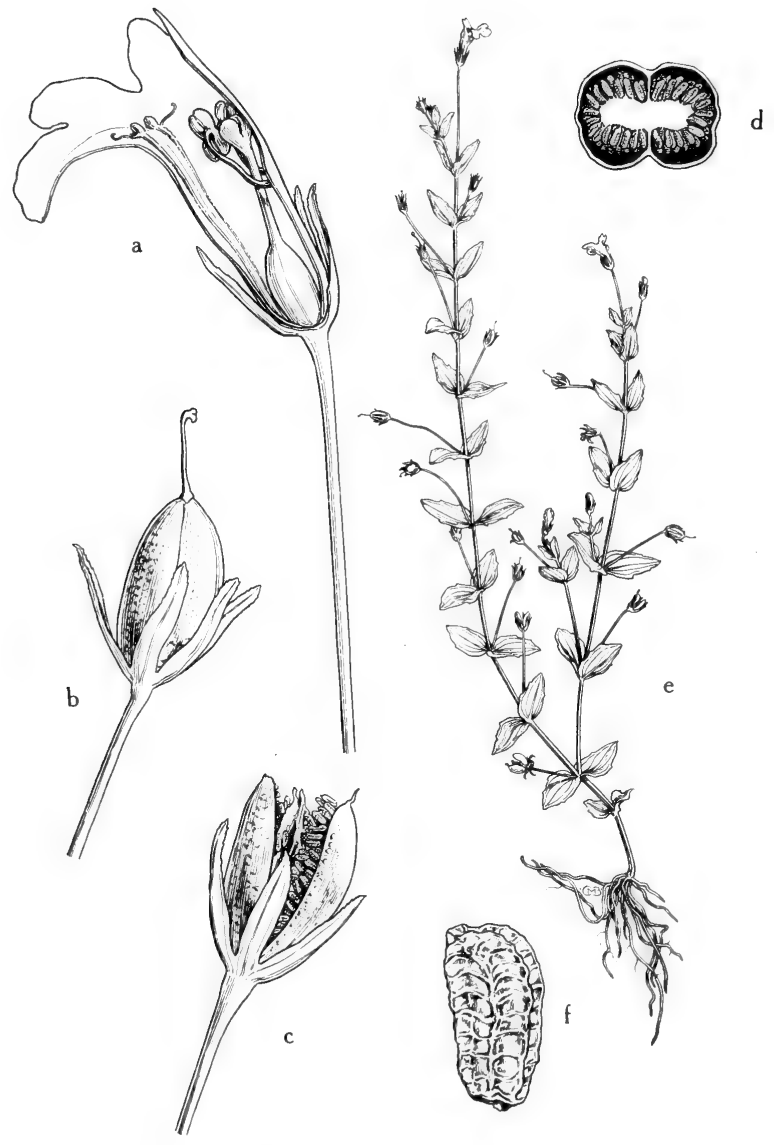

Fig. 698: Lindernia anagallidea: a, flower (longitudinal section), x 6; b, capsule, x 6; c, capsule after dehiscence, x 6; d, capsule (cross section), x 8; e, habit, x $2 / 3$; f, seed, x 60. (From Mason, Fig. 319). 


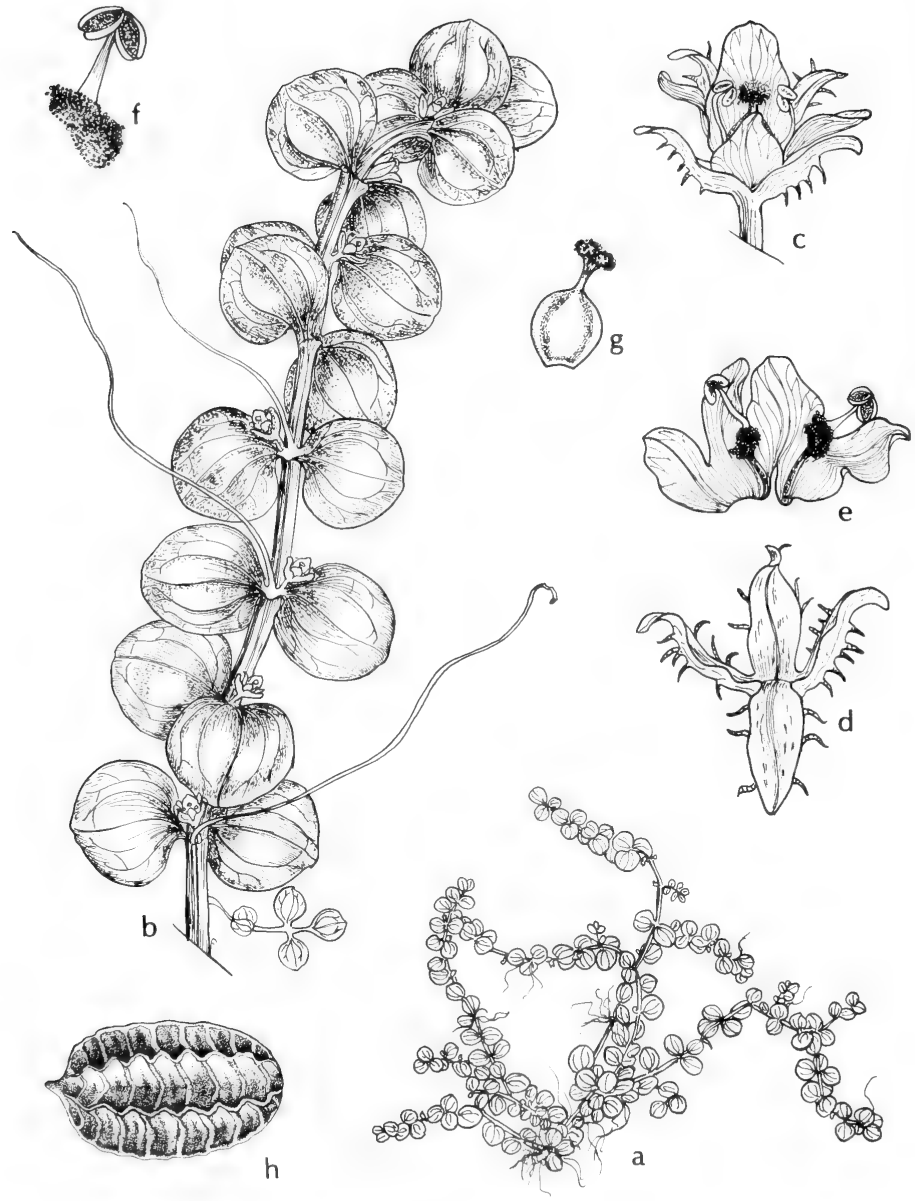

Fig. 699: Micranthemum umbrosum: a, habit, x 1/2; b, portion of plant, x 21/2; c, flower $\times 10$; d, calyx, x 10; e, corolla, spread out, x 10; f, stamen, x 20; g, pistil, x 10 ; h, seed, about x 100 . (V. F.). 


\section{Micranthemum MichX.}

Two species in the Western Hemisphere.

1. Micranthemum umbrosum (Walt.) Blake. Shade Mud-Flower. Fig. 699.

Stems repent, freely branched, to $3 \mathrm{dm}$. Iong or more; leaves sessile, opposite, succulent, rotund, 4-9 mm. wide; flowers small, white or purplish, solitary in the axils of some of the middle leaves; pedicels to $1 \mathrm{~mm}$. long; calyx $1.5-2 \mathrm{~mm}$. long, equally 4-cleft into oblanceolate lobes; corolla obliquely salverform, barely equaling the calyx, the 4-lobed limb longer than the tube with upper lip developed; appendage of the 2 stamens a mere tooth, the filaments with an appendage; stigmas short; capsule about $1 \mathrm{~mm}$. in diameter, globose, thin, with an evanescent partition, several- to many-seeded. Globifera umbrosa (Walt.) J. F. Gmel.

On mud or wet sand in low woods and along streams, in water of sluggish streams, wet mud in swamps, often forming mats on edge of lakes, in e. Tex., Apr.-Sept.; from Fla. to Tex., n. to Va.; also trop. Am.

\section{Penstemon Mitch. Beard-tongue}

Herbs or shrubs; leaves opposite, decussate, the lower often petiolate, the upper sessile; pubescence (if present) glandular in the inflorescence, simple below; inflorescence usually a narrow terminal panicle; sepals 5; corolla tubular, the upper lip 2-lobed, the lower lip 3-cleft, the lower inner surface (floor) of the throat and tube often with colored lines; stamens 4; staminode 1, filamentlike, often bearded apically; anthers 2-chambered, these confluent if dehiscent across the connective; capsules septicidal or else 4-valved; seeds many, usually multiangular, with a rough coat. Flowering from spring to fall.

About 300 species; indigenous to America from Alaska to Guatemala.

1. Distribution in eastern Oklahoma and/or eastern Texas (2)

1. Distribution in New Mexico and Arizona (4)

2(1). Floor of corolla strongly pleated; staminode densely bearded with golden hairs for most of its length, exserted....................... 1. P. laxiflorus.

2. Floor of corolla rounded; staminode more lightly bearded with yeliow hairs, included (3)

3(2). Corolla pink, $15-17 \mathrm{~mm}$. long; leaves regularly sharply but shallowly toothed................................................................... . tenuis.

3. Corolla white, $16-30 \mathrm{~mm}$. long; leaves subentire or unevenly toothed. 3. P. Digitalis.

4(1). Leaves (at least a few of them) toothed; corolla glandular externally.

4. Leaves always entire; corolla not glandular externally (5)

4. P. Whippleanus.

5(4). Throat of the corolla more or less distinctly 2-ridged within ventrally, the ridges densely hairy about the orifice; leaves oblanceolate to elliptic...............................................................5. P. Rydbergii.

5. Throat of the corolla rounded ventrally, lightly if at all hairy at the orifice; leaves mostly linear.....................................................6. P. virgatus.

\section{Penstemon laxiflorus Penn.}

Plants 3-7 dm. tall, the stem and leaves glabrous to puberulent; leaves welltoothed, those of the midstem $3.2-10.5 \mathrm{~cm}$. long, 4-17 $\mathrm{mm}$. wide, narrowly lanceolate; inflorescence lightly glandular-pubescent; sepals $2-5 \mathrm{~mm}$. long; corolla white to pink, 22-30 $\mathrm{mm}$. long, narrow, little-expanded, the floor prominently pleated, lined within; staminode densely bearded with golden hairs for most of its length, exserted; anther sacs cymbiform; seeds $1-1.5 \mathrm{~mm}$. long. 
Acid soils of the Gulf Coastal Plain, edge of marshes, in seepage areas, bogs, about ponds and lakes and grassy flatwoods, throughout e. Tex., Mar.-June; Ga. to Okla. and Tex.

\section{Penstemon tenuis Small.}

Plants 4-9 dm. tall, the stem very lightly puberulent; leaves sharply but shallowly toothed, those of the midstem 7-10 cm. long, $1.5-3 \mathrm{~cm}$. wide, oblonglanceolate; inflorescence glabrous; sepals 3-5 mm. long; corolla pink, 15-17 mm. long, abruptly inflated, the floor rounded, with violet lines; staminode with yellow hairs on apical half.

Uncommon in low poorly drained loamy soils, in water of shallow depressions, and in low prairies and marshes, in the Gulf Prairies and Marshes in Tex. and (?) Okla. (McCurtain Co.), Apr.-May; also La. and Ark.

\section{Penstemon Digitalis Nutt.}

Plants mostly 5-9 dm. tall, the stem and leaves glabrous; leaves subentire or obviously toothed, those of the midstem mostly 9-12 cm. long, 15-25 mm. wide, lanceolate; inflorescence glabrous or a little glandular; sepals 5-6 mm. long, glabrous or a little glandular; corolla white, 16-30 mm. long, moderately ventricose, the lobes extending, the floor rounded and commonly unlined; staminode lightly bearded with yellow hairs; anther sacs cymbiform, spiny or hairy on the backs; seeds less than $1 \mathrm{~mm}$. long.

An Ozarkian species which has become widely spread as a weed in poorly drained soils, in water of streams, in wet meadows, alluvial woodlands, in wet soil on edge of ponds and lakes, occasional in Okla. (McCurtain and Atoka cos.) and n.e. and e. Tex., Apr.-July; Me. and Que. to S.D., s. to Ala., La., Tex. and Okla.

\section{Penstemon Whippleanus Gray.}

Plants tufted from surficial branched caudex, 2-6 dm. tall, essentially glabrous below, becoming strongly glandular-hairy in the inflorescence; leaves (at least a few of them) toothed, the basal with elliptic to ovate blade to $6 \mathrm{~cm}$. long and 3.5 $\mathrm{cm}$. wide, longer or shorter than the petioles; cauline leaves mostly sessile, oblong to lanceolate, to about $6 \mathrm{~cm}$. long and $1.5 \mathrm{~cm}$. wide; inflorescence of 2 to 7 verticillasters that are not very dense; calyx elongate, 7-11 $\mathrm{mm}$. long, the lanceolate segments essentially entirely herbaceous; corolla glandular-pubescent externally, blue or violet to dull-purple or lavender to cream-color, sometimes varicolored, 18-28 mm. long, strongly inflated distally, mostly $7-11 \mathrm{~mm}$. wide at the mouth, strongly bilabiate, the lower lip much the longer; palate bearded; pollen sacs broadly ovate, glabrous, 1-1.4 mm. long, wholly dehiscent, becoming opposite and eventually explanate; staminode noticeably exserted from the orifice of the corolla, usually bearded toward the scarcely expanded tip; ovary and capsule usually glandular-puberulent near the tip; capsule $6-9 \mathrm{~mm}$. long. P. stenosepalus (Gray) Howell.

On seepage banks about small lakes, wet meadows and on conifer forest slopes, in N. M. (Bernalillo, Sandoval and Taos cos.) and Ariz. (Coconino and Mohave cos.), July-Sept.; Mont. to N.M. and Ariz.

\section{Penstemon Rydbergii A. Nels.}

Plant more or less tufted from a loose or compact surficial woody rhizomecaudex, 2-7 (-12) dm. tall, rather slender-stemmed, glabrous throughout or sometimes puberulent in the inflorescence and along the stem; leaves entire, the basal ones petiolate, oblanceolate to narrowly elliptic, often forming distinct rosettes, to $15 \mathrm{~cm}$. long and $2 \mathrm{~cm}$. wide; cauline leaves few and mostly welldeveloped, usually sessile or nearly so, rarely to $10 \mathrm{~cm}$. long and $2 \mathrm{~cm}$. wide; 
inflorescence of one to several rather dense verticillasters, the flowers spreading at right angles to the stem; calyx usually 3-7 (-9) $\mathrm{mm}$. long, the segments obscurely to evidently scarious-margined and sometimes erose, tapering or abruptly narrowed to the apex: corolla blue-purple, mostly $11-15 \mathrm{~mm}$. long and 3-5 mm. wide at mouth; palate bearded; staminode usually bearded at least at the expanded tip, rarely glabrous; pollen sacs glabrous, ovate, mostly $0.6-1 \mathrm{~mm}$. long, dehiscent throughout and becoming opposite but seldom explanate; capsule 5-6 $\mathrm{mm}$. long.

Wet mt. meadows and wet open forest slopes, in N. M. (Rio Arriba and San Juan cos.) and Ariz. (Coconino Co.), June-Aug.; Wyo. and Ida., s. to N.M. and Ariz.

\section{Penstemon virgatus Gray.}

Plants minutely glandular-pruinose to glabrous; stem strict and elongate, 3-6 $\mathrm{dm}$. tall; leaves linear to linear-lanceolate, $4-10 \mathrm{~cm}$. long; peduncles short, 1 - to 3 -flowered; thyrse virgate; sepals ovate; corolla lilac with purple veins, about 2 $\mathrm{cm}$. long, abruptly dilated into a broadly campanulate-funnelform throat about as wide as long, distinctly bilabiate, the lower lip usually bearded, the broad lips widely spreading; stamens nearly equaling the lips of the corolla; anther sacs glabrous or finely scabrid on the sides, opening throughout, opposite, straight; staminodes glabrous.

In wet meadows and in seepage areas, in N. M. (widespread) and Ariz. (Apache to Mohave, s. to Cochise, Gila and Yavapai cos.), summer.

\section{Besseya Rydb. Kitten-TAils}

Perennial subscapose herbaceous plants; leaves alternate and mostly basal; stem leaves sessile, bractlike and smaller than basal ones: basal blades cordateovate to oblong, toothed, short-petioled; flowers in terminal spikes or spikelike racemes, conspicuously bracted; sepals usually 4 and almost distinct but sometimes 1 to 3 and variously united; corolla wanting or when present irregular and 2-lipped, violet-purple, yellow or white, upper lip entire and concave, lower lip shorter and more or less 3-lobed; stamens 2, exserted, the anther sacs parallel or nearly so, adnate to corolla or when latter is lacking inserted on a hypogynous disk; seeds several, flat.

\section{About a dozen species, all in North America.}

1. Corolla $5 \mathrm{~mm}$. long or more, strongly exserted; capsules emarginate at apex, 5-6 $\mathrm{mm}$. long; leaves typically subcuneate at base, to $20 \mathrm{~cm}$. long 1. B. plantaginea.

1. Corolla not more than $5 \mathrm{~mm}$. long, moderately exserted; capsules rounded to somewhat acute at apex, not more than $5 \mathrm{~mm}$. long; leaves rounded to subcordate at base, not more than $8 \mathrm{~cm}$. long.

2. B. arizonica.

\section{Besseya plantaginea (James) Rydb.}

Plants more or less tomentose (especially at first); basal leaves $5-20 \mathrm{~cm}$. long, ovate to ovate-oblong, sometimes lanceolate-oblong, broadly to narrowly cuneate at base, crenate; scapes usually 2-4 dm. high, sometimes shorter, with several to many bractlike leaves below the inflorescence: sepals with lateral lobes united at base for less than one third their length: corolla $5-8 \mathrm{~mm}$. long, conspicuously exserted, the lower lip with lobes over one third the length of the lip, white to purplish-tinged; filaments not especially conspicuously colored; capsules emarginate at apex, 5-6 $\mathrm{mm}$. long.

On moist slopes and in wet meadows in N. M. (Santa Fe, San Miguel and Otero cos.), and Ariz. (Apache and Greenlee cos.), June-Aug.; also n. to Wyo. 


\section{Besseya arizonica Penn.}

Plant probably solitary, the flower stem 2-4 dm. tall and white-hirsute throughout, with 10 to 16 narrowly ovate acute bractlike leaves; petioles $2-9 \mathrm{~cm}$. long, appressed-hirsute; leaf blades ovate to oval, rounded to subcordate at base, 5-8 $\mathrm{cm}$. long, 4-7.5 $\mathrm{cm}$. wide, undulate-crenate to crenate, tardily glabrate above and pilose beneath, permanently pubescent on the principal veins; floral bracts lanceolate to ovate, acute, white-ciliate, in anthesis $3-5 \mathrm{~mm}$. long; pedicels usually to $1 \mathrm{~mm}$. long in anthesis, the lower ones sometimes to $5 \mathrm{~mm}$. long; calyx 3-4 $\mathrm{mm}$. long, the 4 lobes uneven in width and oblong-lanceolate to -elliptic, long-ciliate, those lobes of each side united near base; corolla about $4 \mathrm{~mm}$. long, probably white, the tube short, the lips parted nearly or quite to the base, the anterior lobes one third to one fourth the length of the basal portion of the lip; filaments exserted; style 3-4 mm. long, deflexed from corolla; capsule 4-5 $\mathrm{mm}$. long, equally wide, nearly circular, acutish or rounded at apex, to about 4 $\mathrm{mm}$. long, minutely ridge-veined, glabrous.

In moist or wet meadows, marshy areas along streams and on coniferous forest slopes, in N. M. (McKinley Co.) and Ariz. (Apache and Coconino cos.), MayAug.

\section{Kickxia Dum. CANCERWORT}

About 25 species from the Mediterranean region to India.

\section{Kickxia Elatine (L.) Dum. Fig. 691.}

Annual; stems prostrate, widely spreading, freely branched, villous, to $5 \mathrm{dm}$. long; petioles 1-5 mm. long; leaves broadly ovate to triangular-ovate, $1-3 \mathrm{~cm}$. long, truncate at base, more or less hastate by the development of 1 to 3 low teeth at the lateral angles; pedicels very slender, 1-3 cm. long, glabrous throughout or villosulous near the base and summit only; calyx lobes ovate-lanceolate, acute, 3-5 $\mathrm{mm}$. long; corolla 6-8 $\mathrm{mm}$. long, yellow, the upper lip purple within; spur decurved, about $5 \mathrm{~mm}$. long; capsule loculicidal, orbicular, about $4 \mathrm{~mm}$. high.

In moist sandy soil and cobbly areas along river sandbars and in river and stream beds in Okla. (Cherokee, Ottawa, Delaware and Sequoyah cos.), MaySept.; N.Y. to Ind., Mo. and Okla., s. to Fla. and La.

\section{Veronica L. SPEEDWELL}

Erect or repent perennial, biennial or annual herbs; leaves mostly opposite; bracteoles none; flowers in axillary or terminal racemes or solitary in axils of leaves; sepals 4 or 5, distinct; corolla with very short tube, nearly rotate, 4-lobed due to fusion of upper pair; stamens 2; stigmas united and slightly capitate; capsule flattened, loculicidal; seeds flattened, smooth or rarely roughened.

About 300 species, mostly in the North Temperate Zone.

1. Main stem terminating in an inflorescence, its flowers either densely crowded or more remote and axillary, the upper bract leaves usually alternate (2)

1. Main stem never terminated by an inflorescence, the leaves opposite throughout and the flowers all in axillary racemes (4)

2(1). Annual, fibrous-rooted; stem usually rather strictly erect; leaves typically linear-oblong. 1. V. peregrina.

2. Perennials; stems often from a creeping or procumbent rooting base; leaves elliptic to lanceolate or ovate (3) 
3(2). Capsules higher than wide; stem usually somewhat decumbent at base, sparsely to densely villous-hirsute with laxly spreading hairs; leaves glabrous or villous-hirsute like the stem; filaments $1-1.5 \mathrm{~mm}$. long 2. V. Wormskjoldii.

3. Capsules wider than high; stem tending to creep at base and to produce lower branches, finely and closely puberulent; leaves glabrous or nearly so; filaments mostly $2-4 \mathrm{~mm}$. long...................... V. serpyllifolia.

4(1). Leaves all short-petiolate

4. V. americana.

4. Leaves sessile (at least the middle and upper ones)

(5)

5(4). Leaves 1.5 to 3 times as long as wide; fruiting pedicels mostly strongly ascending or upcurved; capsules about as high as wide or a little higher; flowers blue or violet..................... V. Anagallis-aquatica.

5. Leaves mostly 3 to 5 times as long as wide; fruiting pedicels divaricately spreading; capsules mostly a little wider than high; flowers white to pink or pale-bluish.

..6. $V$. catenata.

\section{Veronica peregrina L. Purslane speedwell, necklace weed. Fig. 700.}

Annual, erect, simple or with spreading branches, to $3 \mathrm{dm}$. high, glabrous throughout or pubescent with gland-tipped hairs; leaves sessile or with the lower somewhat petioled, usually linear-oblong, obtuse, dentate to entire; flowers in spiciform leafy-bracted terminal racemes; pedicels 1-2 $\mathrm{mm}$. long; sepals 4 , linearoblong to oblanceolate, obtuse, about $3 \mathrm{~mm}$. long; corolla white, 2-2.5 mm. wide; filaments very short; style about $0.3 \mathrm{~mm}$. long; capsule $3-3.5 \mathrm{~mm}$. long.

In water of tanks and streams, open flatwoods, swamps, marshes, wet meadows, about lakes and ponds, prairies and dune areas in Okla. (Waterfall), throughout most of Tex., N.M. (Otero, San Miguel, Taos, Catron, Lincoln, Sandoval, Rio Arriba and Grant cos.) and Ariz. (Coconino, Yavapai, Pima, Apache and Santa Cruz cos.), Feb.-June; throughout most of N.A., introd. in many parts of the world.

Represented in our area by two variants.

1. Plant glabrous. ..var. peregrina.

1. Plant pubescent with short gland-tipped hairs that are usually present even on the capsules. var. xalapensis (H.B.K.) Penn.

\section{Veronica Wormskjoldii R. \& S. Fig. 690.}

Perennial from a loose or compact system of shallow rhizomes; stems simple, erect or curved-ascending at base, 1-3 dm. tall, sparsely to densely villous-hirsute with loosely spreading hairs, the inflorescence more densely so and somewhat viscid or glandular; leaves all cauline, sessile, opposite or the uppermost ones alternate, elliptic to lanceolate or ovate, $1-4 \mathrm{~cm}$. long and to $2 \mathrm{~cm}$. wide, rounded to acute at apex, villous-hirsute like the stem or sometimes glabrous, slightly toothed to entire; flowers with pedicels $2-4 \mathrm{~mm}$. long, in well-defined terminal racemes that are at first compact but later often elongate; at least the upper bracts usually alternate; calyx lobes ovate-lanceolate to oblong, villous; corolla deep blue-violet, 6-10 mm. wide when expanded; filaments $1-1.5 \mathrm{~mm}$. long; style 1-3 mm. long; capsules glandular-pubescent, broadly notched, 4-7 mm. high and a little less wide; seeds numerous, about $1 \mathrm{~mm}$. long.

In wet mossy areas, seepage bank of lake, bogs, wet meadows, upland marshes and edge of stream, in N. M. (Taos, Santa Fe and San Miguel cos.) and Ariz. (Apache and Coconino cos.), June-Aug.; Greenl. to Alas., s. to N. H., N.M., Ariz. and Calif.

\section{Veronica serpyllifolia $L$.}

Perennial from a loose or compact branching system of creeping rhizomes; stems 1-3 dm. long, finely and closely puberulent, tending to creep at the base 


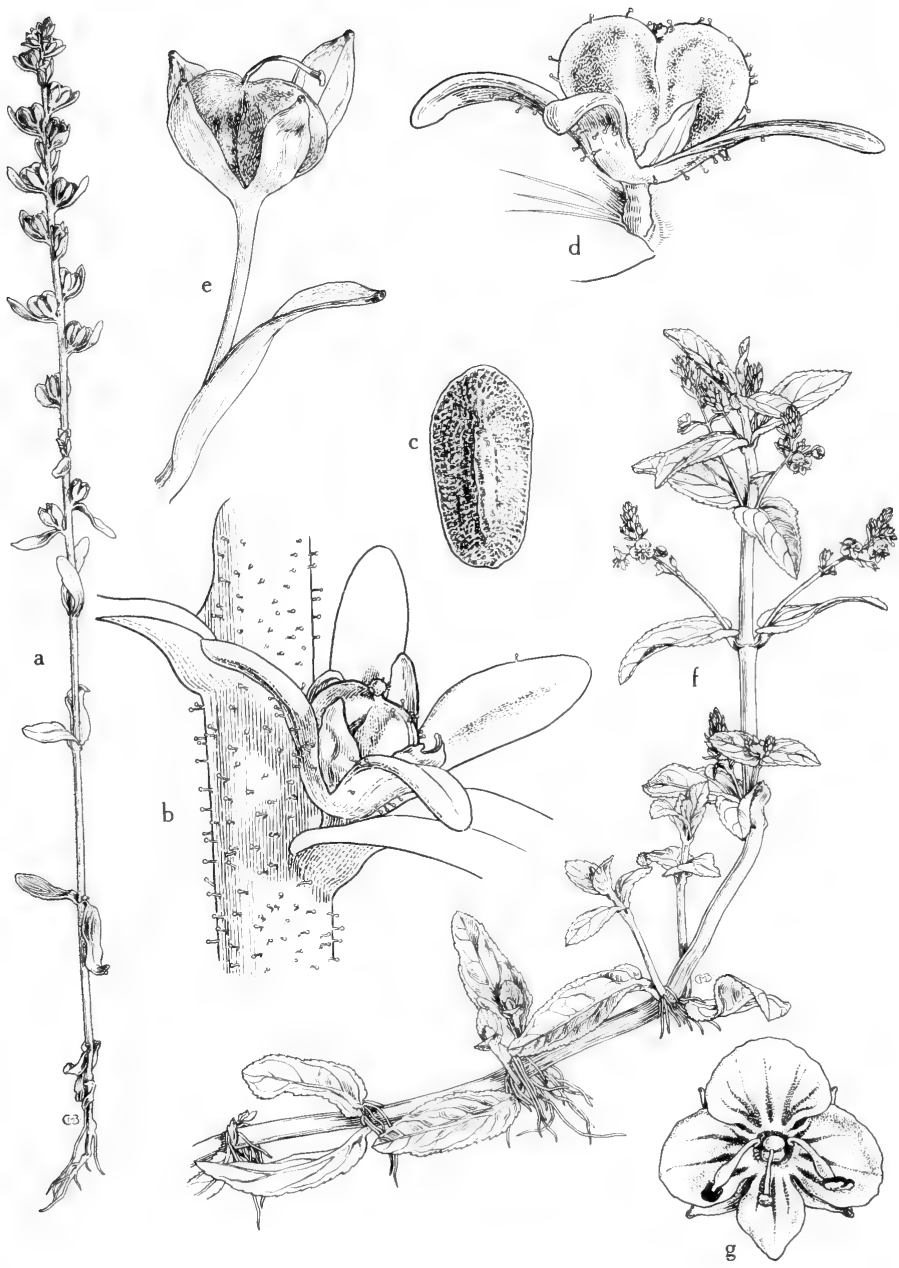

Fig. 700: Veronica. a-d, $V$. peregrina: a, habit, $\mathrm{x} 4 \%$; b, flower in leaf axil, $\mathrm{x} 6$; c, seed, x 32; d, capsule, x 6. e-g, V. americana: e, capsule, x 4; f, habit, x 2\%; g, corolla, x 4. (From Mason, Fig. 321). 
or to produce prostrate lower branches; leaves opposite or the reduced upper ones alternate, elliptic to broadly ovate, $1-2.5 \mathrm{~cm}$. long and to $1.5 \mathrm{~cm}$. wide, rounded to somewhat acute at apex, glabrous or nearly so, entire to slightly toothed, the lowermost leaves sometimes short-petiolate; flowers pedicellate in definite terminal racemes that become lax and clongate, at least the upper bracts usually alternate; corolla 4-8 $\mathrm{mm}$. wide when expanded; styles 2-3.5 $\mathrm{mm}$. long; capsules finely and sometimes sparsely glandular-pubescent, notched, 3-4 mm. high and somewhat broader; seeds numerous.

In wet meadows and seepage about lakes and ponds, in N. M. (Taos, Santa Fe, San Miguel, Rio Arriba and San Juan cos.) and Ariz. (Apache, Coconino, Greenlee, Graham and Cochise cos.), June-Aug.; throughout most of N.A.; Euras.

\section{Veronica americana (Raf.) Schwein. American brooklime. 700.}

Fleshy and more or less succulent glabrous perennial with creeping to decumbent bases; stems to about $1 \mathrm{dm}$. long; principal leaves of middle and upper part of flowering stems distinctly petioled, narrowly ovate to lanceolate, somewhat acute, to about $9 \mathrm{~cm}$. long, the margins serrate to dentate; racemes lax, with arching rachises, axillary below the prolonged tip, 6- to 30-flowered; pedicels to about $11 \mathrm{~mm}$. long, the lower mature ones filiform and divergent; corolla light bluish-violet; capsule turgid, suborbicular.

In shallow water or wet sandy soil of gravelly streams, in marshes and about springs in Okla. (Grady Co.), in the Tex. Edwards Plateau (Kendall Co.), N. M. (rather widespread) and Ariz. (Apache, Navajo and Coconino, s. to Gila and Pinal cos.), June-Aug.; from Nfld. w. to Alas., s. to N.C., Tex., Mex. and Calif.; also n.e. Asia.

\section{Veronica Anagallis-aquatica L. Water speedwell, Brook-Pimpernel. Fig.} 701.

Usually perennial, glabrous throughout or obscurely glandular-puberulent in the inflorescence; stems shortly creeping and rooting at base, then ascending to erect, to $1 \mathrm{~m}$. high; leaves sessile, rounded to clasping bases, oblong-lanceolate, acute, serrate to merely denticulate, those of autumnal shoots smaller and rounded; flowers many in small-bracted axillary racemes; pedicels $6-8 \mathrm{~mm}$. long; sepals 4, lanceolate, acute, 4-4.5 $\mathrm{mm}$. long; corolla 5-6 $\mathrm{mm}$. wide, pale-lavender, the lobes with violet lines; style $1.8-2.5 \mathrm{~mm}$. long; capsule $4 \mathrm{~mm}$. long, more or less orbicular, obtuse at the narrowed obscurely notched apex; seeds about 0.5 $\mathrm{mm}$. long.

Usually in water of streams and in gravelly-sandy soils, swamps and irrigation ditches, in Okla. (Grady, Alfalfa, Caddo and Cimarron cos.), in cen. and n.-cen. (Fannin Co.) Tex., N. M. (widespread) and Ariz. (Apache to Mohave, s. to Graham, Gila and Pinal cos.), Mar.-Oct.; throughout N.A., naturalized from Euras.

\section{Veronica catenata Penn.}

Plant glabrous, very similar to $V$. Anagallis-aquatica; stems submersed or distally emersed; leaves sessile, clasping, oblong-lanceolate, usually 3 to 5 times as long as wide, essentially entire; racemes axillary, few-flowered; sepals broad and obtusish; corolla white to pink or pale-bluish; fruiting pedicels divaricately spreading; capsules obcordate, prominently apically notched, mostly a little wider than high. $V$. connata Raf. subsp. glaberrima Penn.

Scattered in marshes and bogs, and in water of slow-moving streams and ditches, in Ariz. (Yavapai Co.), June-Aug.; Mass. and Ont. to Sask. and Wash., s. to $\mathrm{Pa}$., Tenn., Ariz. and Calif.; also Eur. 


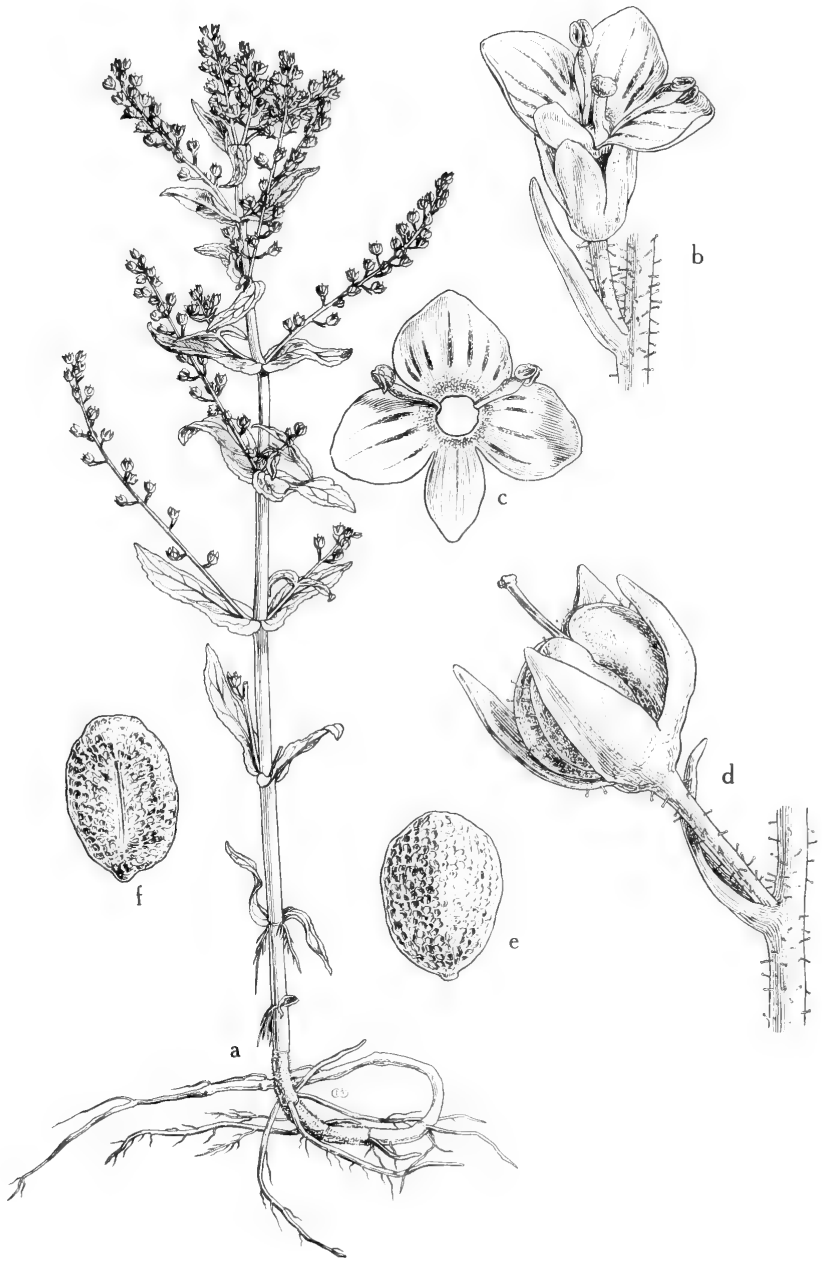

Fig. 701: Veronica Anagallis-aquatica: a, habit, x $2 \%$; b, flower, x 6; c, corolla, showing stamen insertion, $x$ 6; d, capsule, x 6; e and f, seeds, x 32. (From Mason, Fig. 


\section{Dasistoma Raf. Mullein Foxglove}

A monotypic genus. Sometimes misspelled Dasystoma in some works.

\section{Dasistoma macrophylla (Nutt.) Raf.}

Annual, rather pubescent, to about $2 \mathrm{~m}$. high, branched, said to be parasitic on Aesculus; leaves opposite, ovate to lanceolate in outline, the margins subentire to crenate-serrate, to about $3 \mathrm{dm}$. long and $1 \mathrm{dm}$. wide, the lower ones pinnately divided and with the broad lanceolate divisions pinnatifid and incised, progressively smaller up the stem with the uppermost ones narrowly lanceolate; flowers in an elongate leafy spike; calyx slightly zygomorphic, about $1 \mathrm{~cm}$. long, the tube cup-shaped, the 4 lower oblong lobes obtuse and about equaling the tube, the upper median lobe shorter and narrower; corolla tube narrowly campanulate, incurved, about $1 \mathrm{~cm}$. long, woolly within, the spreading limb about $15 \mathrm{~mm}$. wide; stamens 4 , strongly didynamous; filaments villous, inserted near middle of corolla tube and barely exserted; anthers oblong, completely dehiscent; style somewhat dilated and notched at apex; capsule globose-ovoid, about $1 \mathrm{~cm}$. long, loculicidal, each valve terminated by a short flat triangular beak; seeds angular, 2-3 $\mathrm{mm}$. long, the papery coat reticulate. Seymeria macrophylla Nutt.

In rich woods and on banks and edges of streams in Okla. (Murray Co.) and n.-cen. Tex. (Dallas Co.), June-Sept.; from W. Va. to Wisc., Ia. and Neb., s. to Ga., Ala., Miss., La. and Tex.

\section{Agalinis RAF.}

Annual (in ours) or perennial herbs with usually thin stems and branches; leaves linear, mostly entire, opposite, tending to become alternate on the branches; flowers often large for the plant, arising from the axils of the somewhat reduced upper leaves to form a raceme or (by reduction) appearing to be terminal, frequently only one flower of pair developed; calyx regular, gamosepalous, the tube campanulate to hemispheric, usually much longer than the lobes; corolla zygomorphic, membranous, pink to purple, sometimes white, commonly with yellow lines and reddish-purple spots in throat; corolla tube campanulate, often somewhat distended on the lower side; corolla lobes all equally distinct, commonly marginally ciliate, the lower 3 spreading, the upper 2 arched and spreading or somewhat recurved; stamens 4, didynamous, the lower pair the longer; filaments pubescent (at least toward base); anther sacs obtuse to cuspidate at base; capsule typically globose or subglobose, loculicidal.

About 60 species in temperate America.

1. Pedicels mostly $1 \mathrm{~cm}$. long or more, typically filiform and always much longer than the calyx at anthesis (2)

1. Pedicels mostly less than $1 \mathrm{~cm}$. long, stoutish or slender and about as long as or shorter than the calyx at anthesis, rarely with some slightly longer than the calyx (3)

2(1). Plant fleshy and succulent, bushy-branched below and with elongate subscapose racemes above; leaves and calyx lobes obtuse or essentially so; in saline habitats............................................. A. maritima.

2. Plant not fleshy, more uniformly branched; leaves and calyx lobes acute to acuminate; in nonsaline soils................................. A. tenuifolia.

3(1). Plant fleshy and succulent, bushy-branched below and with elongate subscapose racemes above; leaves and calyx lobes obtuse; in saline habitats............................................................. A. maritima.

3. Plant not fleshy, more uniformly branched; leaves and calyx lobes acute to acuminate; in nonsaline soils (4) 

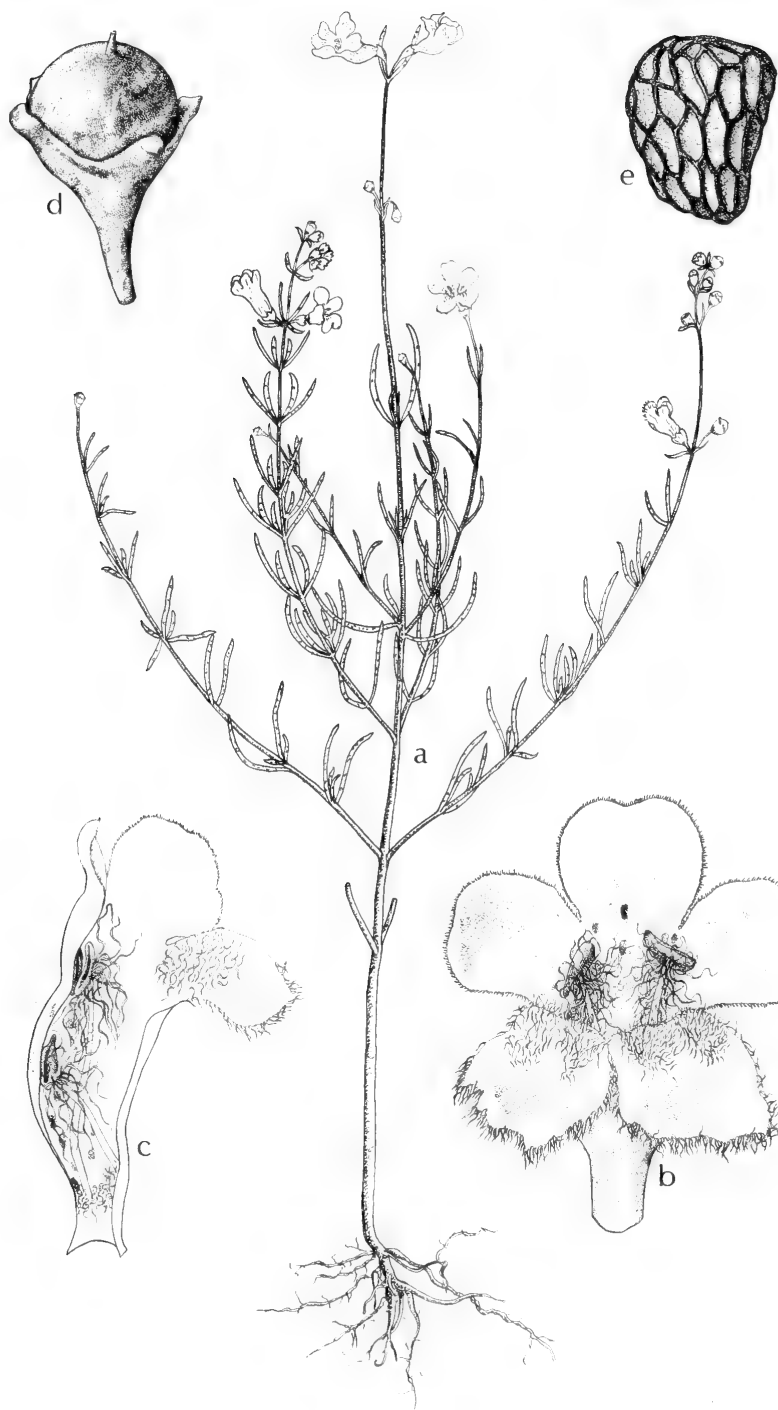

Fig. 702: Agalinis maritima: a, habit, $\mathrm{x} 1 / 3$; b, flower, $\mathrm{x} \cdot 3$; c, flower, cut section, x 3; d, capsule, x 3; e, seed, x 20. (Courtesy of R. K. Godfrey). 
4(3). Calyx lobes nearly as long as to longer than the tube, the sinuses narrow; leaf blades linear-lanceolate to lanceolate or sometimes linear, to $6 \mathrm{~mm}$. wide, the lower occasionally 3-cleft at base.

3. A. heterophylla.

4. Calyx lobes typically much-abbreviated, much shorter than the tube, the sinuses broad and open; leaf blades linear to filiform or subulate, always entire (5)

5(4). Primary leaves to $4 \mathrm{~cm}$. long, spreading or widely arcuate-ascending; stem smooth to more or less scabridulous, commonly angled; stigma 2-3 mm. long.................................................... A. purpurea.

5. Primary leaves mostly less than $2.5 \mathrm{~cm}$. long, erect-ascending or closely arcuate-ascending, often somewhat appressed to stem, typically with well-developed axillary fascicles; stem scabrous-puberulent, subterete; stigma 3-4 mm. long................................5. A. fasciculata.

1. Agalinis maritima (Raf.) Raf. Seaside gerardia, Salt marsh gerardia. Fig. 702 .

Plant to about $6 \mathrm{dm}$. high, usually much smaller, with short leafy branches below, smooth; leaves fleshy, broadly linear, obtuse, to about $3 \mathrm{~cm}$. long and $3 \mathrm{~mm}$. wide; flowers few, in a more or less naked simple raceme; pedicels 2-10 $\mathrm{mm}$. long, shorter to longer than the floral bracts; calyx tube broadly campanulate, 2-3 mm. long in anthesis, slightly longer in fruit; calyx lobes broad, short and thick, $0.5-1 \mathrm{~mm}$. long, very obtuse to acutish; corolla rose-pink, glabrous, 1.2-2 $\mathrm{cm}$. long; anther cells mucronulate at base, $1.3-2.3 \mathrm{~mm}$. long, villous to glabrous; capsule globular to ovoid, 4-6 mm. long. A. spiciflora (Engelm.) Penn., Gerardia maritima Raf.

In salt marshes and beach dunes along the Tex. coast, May-July; from N.S. to Fla. and Tex., also Mex, and W. I.

Our material is usually referred to var. grandiflora (Benth.) Shinners, characterized by having anther cells $1.8-2.3 \mathrm{~mm}$. long and usually villous with long white hairs; pedicels mostly equaling or longer than the bracts; calyx lobes typically obtuse; corolla $1.5-2 \mathrm{~cm}$. long.

\section{Agalinis tenuifolia (Vahl) Raf.}

Plant usually smooth, to about $5 \mathrm{dm}$. high, usually much smaller, paniculately much-branched; leaves mostly narrowly linear and plane, spreading, to $6 \mathrm{~mm}$. wide, about equaling the lower but mostly shorter than the uppermost pedicels; inflorescence racemose; pedicels filiform, widely divergent, commonly $1-2 \mathrm{~cm}$. long at anthesis; calyx tube $2-4 \mathrm{~mm}$. long; calyx lobes broadly triangular to subulate, usually less than $1 \mathrm{~mm}$. long, rarely to $2 \mathrm{~mm}$.; corolla pink to mallowpurple or paler, $1-2.3 \mathrm{~cm}$. long, glabrous except for the ciliate margins of the nearly equal lobes, its upper lip arching over the stamens; anther cells cuspidatemucronate at base, densely to sparingly villous; capsules $3-7 \mathrm{~mm}$. long. Gerardia tenuifolia Vahl. and var. leucanthera (Raf.) Shinners.

In moist areas along streams, about ponds, in wet meadows, fields and low flatwoods, in Okla. (Pittsburg Co.) and n.e. Tex., Sept.-Nov.; from Me. to Man. and N.D., s. to Fla. and Tex.

Our material is usually referred to subsp. leucanthera (Raf.) Penn. characterized by having a corolla $15-23 \mathrm{~mm}$. long and calyx lobes less than $1 \mathrm{~mm}$. long.

\section{Agalinis heterophylla (Nutt.) Small. Prairie Agalinis.}

Plant to about $6 \mathrm{dm}$. high, the stem smoothish, paniculately branched or the branches virgate; leaves rather erect, thickish or rigid, the lowest or primary ones broadly linear (to $45 \mathrm{~mm}$. long and $8 \mathrm{~mm}$. wide) and 3-cleft or laciniate, the others narrowly linear and mucronate-acute, those of the branchlets short and 
somewhat subulate, scabrous above and on the margins; pedicels to $2 \mathrm{~mm}$. long; calyx tube $3.5-5 \mathrm{~mm}$. long, the midvein keeled into the lobes; calyx lobes triangular-lanceolate or subulately attenuate from a broad base, very acute, in age spreading, 3.5-6.5 mm. long, almost always as long as or longer than the tube; corolla deep-pink to white and lavender-tinged, 2.5-3 cm. long; capsule subglobose, about $8 \mathrm{~mm}$. long. Gerardia heterophylla Nutt.

In prairies and plains, grasslands and fallow fields, in wet soil of waterfilled pits, wet gravelly soil on edge of lakes and ponds, sometimes on rocky soils or in open woodlands, usually somewhat moist, in Tex. in a line from Grayson Co. to Cameron Co. and eastw., and in Okla (Love, LeFlore and Ottawa cos.), June-Oct.; from Mo. and Okla. to La. and Tex.

\section{Agalinis purpurea (L.) Penn.}

Plant to $12 \mathrm{dm}$. high, usually much smaller, smooth to scabridulous, commonly angled, with virgate rather wide-spreading branches; leaves usually spreading or widely arcuate-ascending, narrowly linear, to about $4 \mathrm{~cm}$. long and $4 \mathrm{~mm}$. wide, either somewhat scabrous or smooth with merely scabrous margins; axillary fascicles sometimes slightly developed; flowers few to many; pedicels 1-4 mm. long, shorter than the calyx; calyx tube $2-4 \mathrm{~mm}$. long; calyx lobes triangular, acute to acuminate, $1 \mathrm{~mm}$. long or more; corolla rose-pink to pink, $2.5-3 \mathrm{~cm}$. long; capsule globular, 4-6 mm. long. Gerardia purpurea L.

Moist sandy soil in bogs, seepage areas, moist prairies, open pinelands, barrens and along shores in e. Tex., Aug.-Nov.; from N.S. to Minn., s. to Fla. and Tex.; also Mex. and the W. I.

\section{Agalinis fasciculata (Ell.) Raf.}

Plant to about $7 \mathrm{dm}$. high, the stem scabrous-puberulent, nearly terete at base, the branches angled; leaves erect-ascending to closely arcuate-ascending, scabrous, commonly 1-2 mm. wide, the axillary fascicles usually well-developed; bracteal leaves reduced, much shorter than the flowers; racemes elongate, 12to 30-flowered; pedicels 2-4 mm. long at anthesis; calyx tube $3-4 \mathrm{~mm}$. long, with subquadrate sinuses, the acuminate lobes to $2 \mathrm{~mm}$. long; corolla $2-3.5 \mathrm{~cm}$. long, rose-pink, with rounded to truncate spreading lobes $7-10 \mathrm{~mm}$. long; anther cells 2.5-3.5 mm. long, with acute to cuspidate bases; capsule globose-ovoid, 5-6 mm. long; seeds to $0.8 \mathrm{~mm}$. long. Gerardia fasciculata Ell.

In dry or moist soils in savannahs, open weedy areas, on edge of ponds and lakes, open flatwoods and in dune hollows and tidal marshes, in e. Okla. (Ottawa Co.), in s.e., e. and n.-cen. Tex., Sept.-Oct.; from Fla. to Tex., n. to Md., Mo., Okla. and Ark.

\section{Buchnera L. BlueheARTS}

Perennial rough-hairy herbs that turn black in drying, apparently root-parasitic; leaves sessile, opposite or the uppermost alternate; flowers opposite in a terminal spike, bracted and with 2 bractlets; calyx tubular, obscurely nerved; corolla with a straight or curved tube and an almost equally 5-cleft limb, the lobes oblong to cuneate-obovate, flat; stamens included, the anthers 1-celled; style clavate and entire; capsule bivalved and many-seeded.

About 100 species, mostly in the Old World tropics and subtropics.

1. Leaf blades clearly 3-veined, ovate-lanceolate, sinuate-dentate to somewhat lacerate; corolla lobes 5-8 $\mathrm{mm}$. long; capsule usually 6-7 $\mathrm{mm}$. long; stem usually hirsute-pubescent............................. B. americana.

1. Leaf blades obscurely or not 3-veined, elliptic-lanceolate, repand-dentate to entire; corolla lobes $2-5 \mathrm{~mm}$. long; capsule about $5 \mathrm{~mm}$. long; stem pilose to glabrate.. 2. B. floridana. 


\section{Buchnera americana $L$.}

Plant rough-hairy, the virgate stem to about $8 \mathrm{dm}$. high; lower leaves lanceolate to obovate-oblong, to $1 \mathrm{dm}$. long, the others ovate-oblong to linear-lanceolate, sparingly and coarsely toothed, scabrous, veiny; spike interrupted; calyx pubescent, 6-7 mm. long, exceeding the bracts; corolla deep-purple, the tube about $1 \mathrm{~cm}$. long, the lobes 5-8 mm. long; capsule ovoid-oblong, about $7 \mathrm{~mm}$. long.

In moist sandy soil of open woods, prairies, meadows and marshy areas in e. Okla. (Waterfall) and e. Tex., June-Dec.; from Fla. to Tex., n. to N.J., N.Y., Ont., Mich., Ill., Mo. and Kan.

\section{Buchnera floridana Gand.}

Stem to about $6 \mathrm{dm}$. high, slightly pilose to glabrate above, commonly from thickened roots; leaves rough-pubescent, the larger one elliptic-oblanceolate and to $1 \mathrm{dm}$. long and $18 \mathrm{~mm}$. wide; bracts $2-3 \mathrm{~mm}$. long, spreading; calyx lobes triangular, acute, to $1 \mathrm{~mm}$. long, the anterior sinus the deeper; corolla violet to purplish or rarely white, the tube $7-8 \mathrm{~mm}$. long, the triangular-obovate lobes 3-5 $\mathrm{mm}$. long; capsule about $5 \mathrm{~mm}$. long. B. breviflora Penn.

In sandy or gravelly soils, bogs and coastal savannahs, throughout most of the s. half of Tex., Apr.-Nov.; from Fla. to Tex., n. to N. C.

\section{Parentucellia VIV.}

Four species native to Eurasia.

\section{Parentucellia viscosa (L.) Caruel. Fig. 703.}

Erect glandular-pubescent annual, to about $5 \mathrm{dm}$. tall; stem simple or branched above the middle; leaves opposite to subopposite or spirally arranged, $3-5 \mathrm{~cm}$. long, ovate-lanceolate to triangular-lanceolate, acute, sessile and clasping at the rounded base, saliently toothed, pubescent except between ribs on lower leaf surface; flowers essentially sessile in spicate racemes terminating the main stem and branches; bracteoles none; calyx with 4 lanceolate lobes; corolla goldenyellow, 15-17 mm. long, 2-lipped with the upper lip galeate; capsule about $8 \mathrm{~mm}$. long, distally brown-hirsute; seeds $0.3 \mathrm{~mm}$. long.

In moist to wet sandy soil and grassy-seepy areas along streams, in s.e. Tex. (Jasper Co.), Apr.-June; an Old World species introd. in n. Calif., Ore. and Tex.

\section{Pedicularis L. LOUSEWORT. WOOD-BETONY}

Erect perennial herbs with (in ours) alternate leaves and a usually spikelike raceme of yellow, purple, red or white flowers; bracteoles none; calyx with 5, 4, or seemingly 2 lobes; corolla bilabiate, its upper lip galeate and often extended into a beaklike process, its lower lip shorter and with the oblique lobes spreading or appressed; stamens 4, didynamous; anthers glabrous, their cells equivalent, obtuse to subulate-tipped; capsule flattened, glabrous, loculicidal; seeds several, turgid, often slightly winged.

About 500 species in the Northern Hemisphere.

1. Distribution in eastern Oklahoma and eastern Texas................ . P. canadensis.

1. Distribution New Mexico and Arizona (2)

2(1). Corolla bright-pink to red-purple; galea prolonged into a filiform beak that is curved outward and upward and is as long as the remainder of the corolla...................................................... 2. P. groenlandica.

2. Corolla yellow-white or sordid-yellow; galea not prolonged into a slender beak, much shorter than the rest of the corolla (3)

3(2). Corolla 1-2 cm. long, yellowish-white; galea falcate, the short stout beak conic and straight or slightly incurved. 3. P. Parryi. 


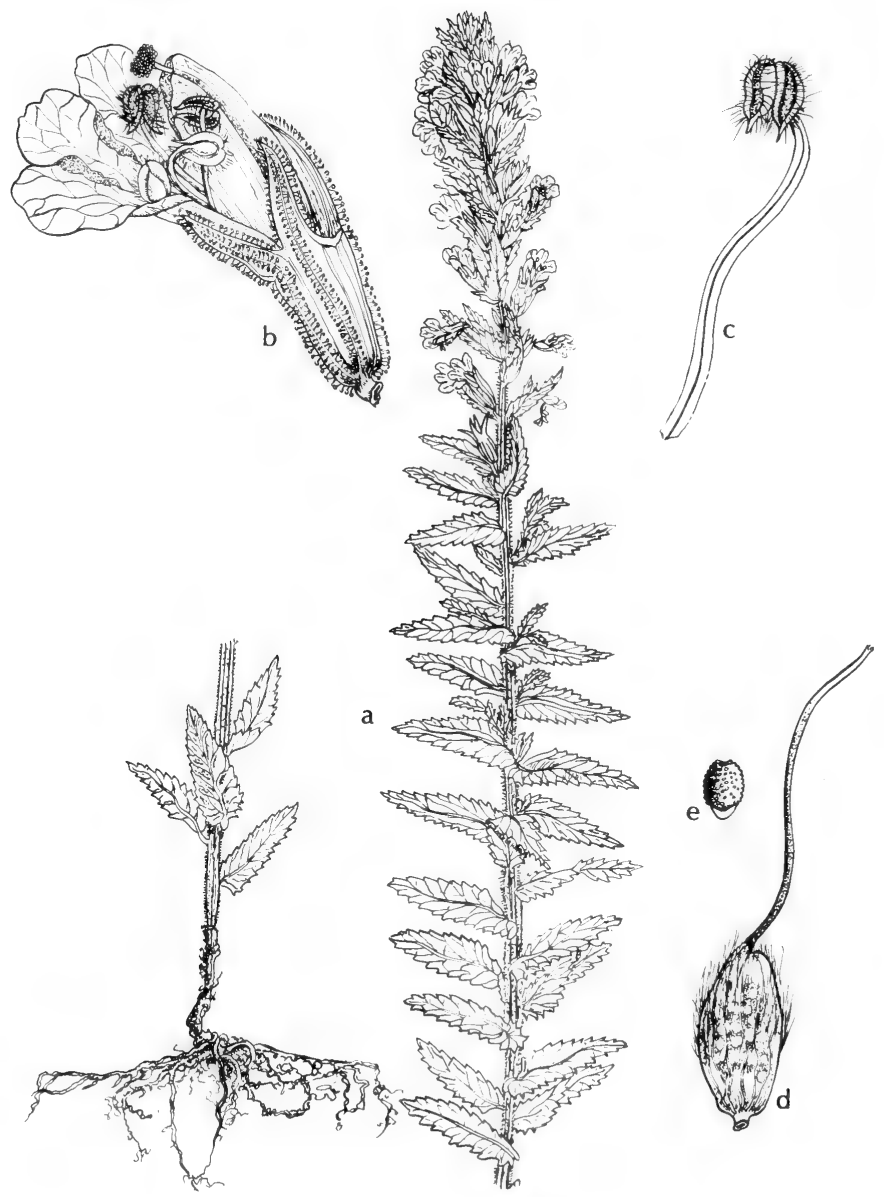

Fig. 703: Parentucellia viscosa: a, habit, x 1/2; b, flower, x 21/2; c, stamen, $\mathrm{x} 5$; d, fruit, x 21/2; e, seed, x 10. (V. F.). 
3. Corolla $2.5-3 \mathrm{~cm}$. long, sordid-yellow, sometimes streaked with red; galea strongly cucullate at apex, not beaked but with 2 lateral teeth just below apex.

4. P. Grayi.

\section{Pedicularis canadensis L. COMMON lousewort. Fig. 704.}

Perennial, hairy; stems simple, closely clustered, to about $4 \mathrm{dm}$. high; leaves scattered, the lowest pinnately parted, the others pinnatifid, all or nearly all petioled, the blade to about $15 \mathrm{~cm}$. long and $5 \mathrm{~cm}$. wide; large-bracted raceme dense and short $(3-5 \mathrm{~cm}$.) in flower, elongated to $2 \mathrm{dm}$. in fruit; calyx 7-9 mm. long, split in front, otherwise almost entire, oblique; corolla yellow or yellowish, to $23 \mathrm{~mm}$. long, strongly bilabiate, the incurved upper lip hooded and 2-toothed under the apex; lower corolla lip erect at base, 2-crested above, 3-lobed; lobes commonly spreading, the lateral ones rounded and larger; anthers transverse, the cells pointless; capsule lance-oblong-flattened, several-seeded, twice as long as calyx.

In open forests, on the edge of forests, on open seepage slopes and marshy soils, also in clearings and prairies, in Okla. (Waterfall) and e. Tex., Mar.-May; from Me. and Que. to Man., s. to Fla., Miss., La., Tex. and n. Mex.

\section{Pedicularis groenlandica Retz. Elephant's head. Fig. 705.}

Plant glabrous throughout; stems $3-7 \mathrm{dm}$. tall, exceeding the leaves that are basal and on lower part of stem; leaves $10-15 \mathrm{~cm}$. long and $2 \mathrm{~cm}$. wide, with 12 to 15 pairs of pinnules (all cut to the narrowly margined midribs), each linear-lanceolate and somewhat saliently and callosely serrate-dentate, the basal on petioles usually shorter than the blades, the cauline short-petioled or sessile, the upper much smaller; bracts of inflorescence shorter than the flowers, linearlanceolate, with a few pairs of slender lobes; pedicels $1-1.5 \mathrm{~mm}$. long; calyx 4-5 $\mathrm{mm}$. long, with 5 subulate entire lobes of which the uppermost is scarcely shorter than the others, the calyx tube scarcely cleft ventrally; corolla $8-10 \mathrm{~mm}$. long, glabrous, bright-pink to red-purple, its tube straight. its upper lip arched and decurved, dark-purple, terminating in a slender and side-curving dark-purple beak 4-8 mm. long, its lower lip deflexed-spreading, light mallow-purple, the middle lobe somewhat the narrowest; anther cells acute; capsule $6-8 \mathrm{~mm}$. long, dorsally rounded and dehiscing throughout, ventrally less rounded and dehiscing distally; seeds $3 \mathrm{~mm}$. long.

In wet mt. meadows, seepage banks about lakes and ponds, in swamps and marshy areas, in N. M. (Taos Co.) and Ariz. (Apache Co.), June-Sept.; Greenl. to Alas., s. in mts. to N.M., Ariz. and Calif.

\section{Pedicularis Parryi Gray. Fig. 704.}

Plant glabrous or the inflorescence slightly pubescent; stem strict, to about $4 \mathrm{dm}$. tall, very leafy at base but slightly so above; leaves linear-lanceolate in outline, the lower ones 4-10 cm. long, deeply pinnately parted into numerous linear-lanceolate acute pinnatifid divisions 4-6 mm. long and closely callousserrate; uppermost leaves reduced to narrow linear bracts; spike dense, elongatespiciform, 4-20 cm. long; calyx 5-toothed, the teeth entire; corolla 1-2 cm. long, ochroleucous or more yellow: galea strongly falcate, with decurved subulateconical beak of about the length of the width of the galea.

In wet mt. meadows, in and along boggy streams, N. M. (Rio Arriba, Colfax and Mora cos.) and Ariz. (Apache, Greenlee and Coconino cos.), June-Oct.; Wyo. to Mont., s. to N.M. and Ariz. 


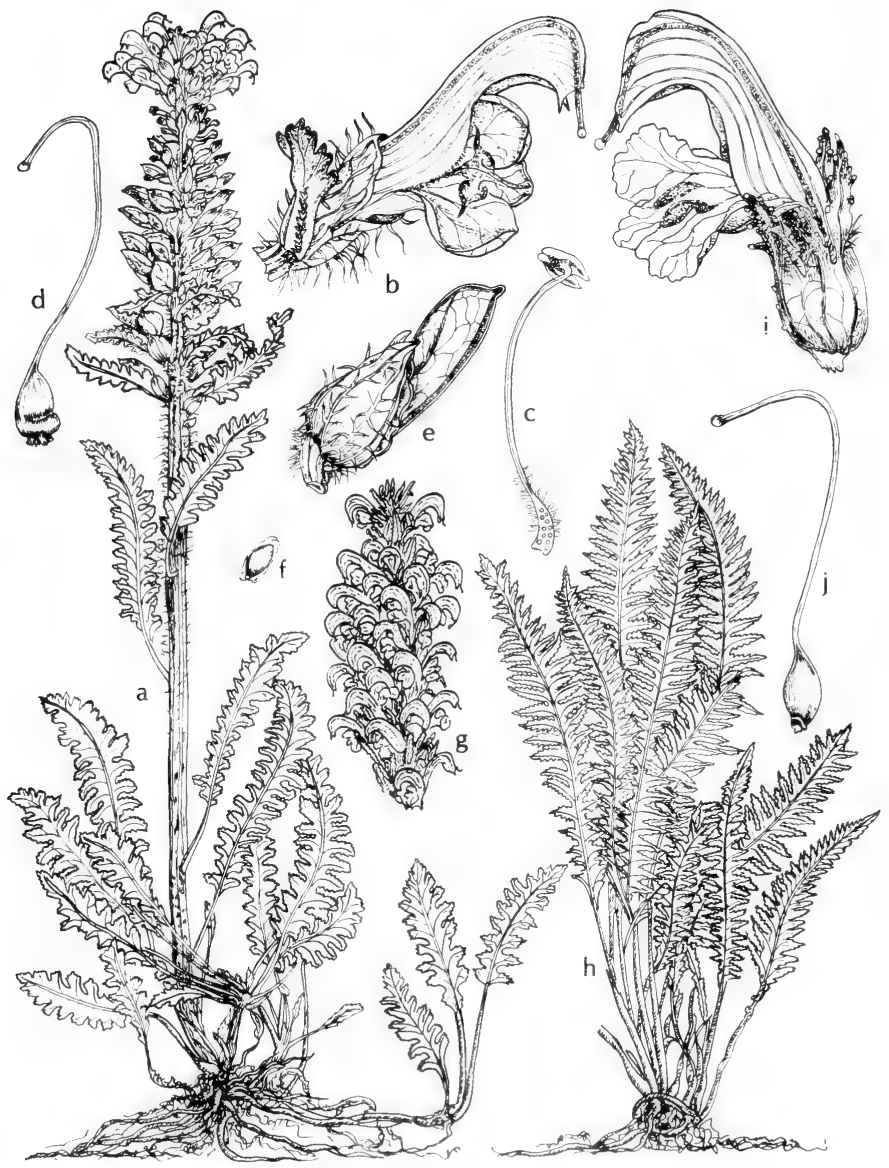

Fig. 704: a-f, Pedicularis canadensis: a, habit, $x 1 / 2 ; b$, flower, $x 2$; c, stamen, $x$ 2; d, pistil, x 2; e, fruit, x 2; f, seed, x 5. g-j, Pedicularis Parryi: g, inflorescence, $x$ $1 / 2$; h, basal leaves, $x 1 / 2$; i, flower, $x 2$; j, pistil, $\times 2$. (V. F.). 


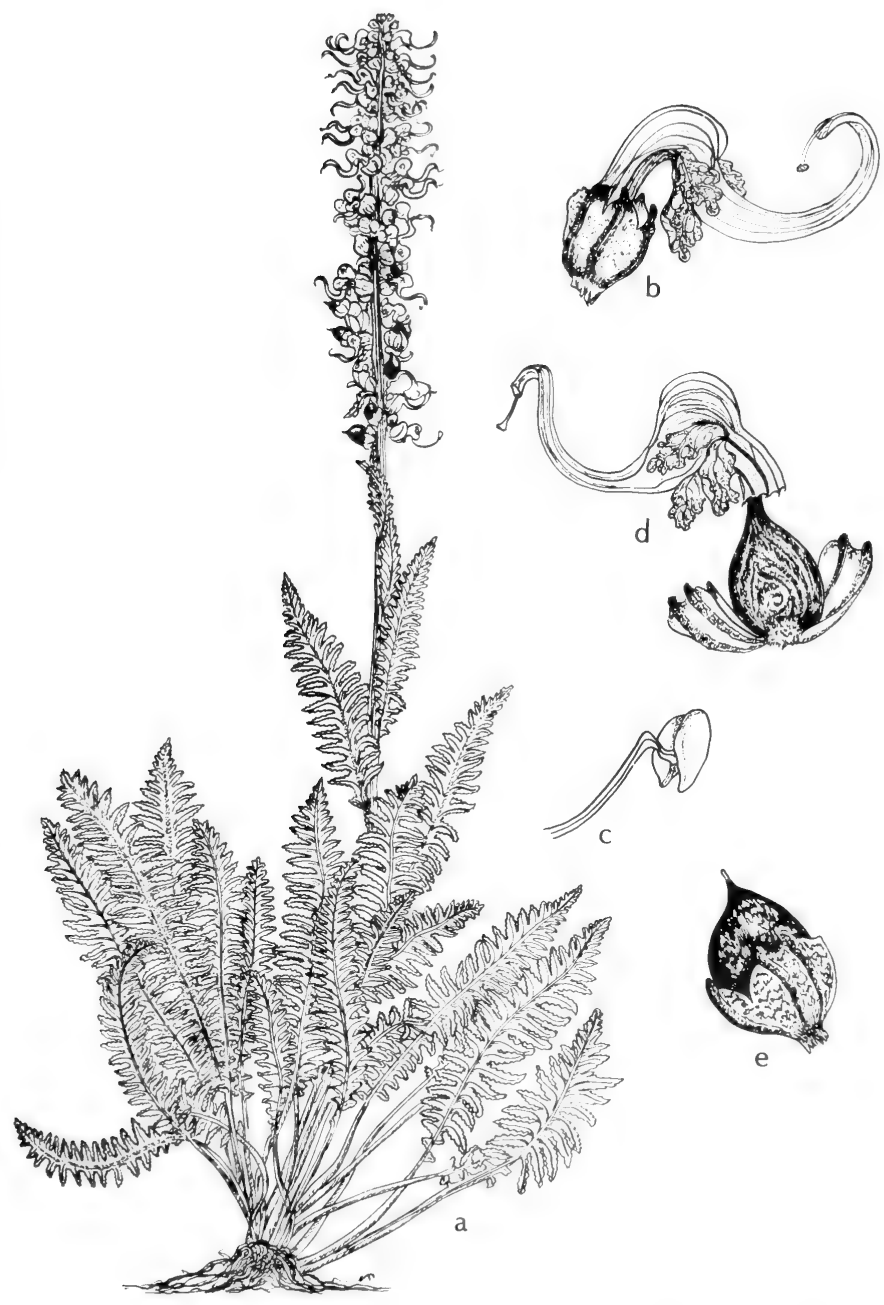

Fig. 705: Pedicularis groenlandica: a, habit, x 1/2; b, flower, $\mathrm{x} 2$; c, anther, $\mathrm{x} 5$; $\mathrm{d}$, fruit with corolla sloughing off, $\times 2$; e, fruit, $\times 2$. (V.F.). 


\section{Pedicularis Grayi A. Nels.}

Stems 4-10 dm. tall, fistulose, glabrous or pubescent above and in the inflorescence; leaves 2-6 dm. long, basal and cauline, glabrous or somewhat pubescent when young, pinnately divided to the midrib with the segments pinnatifid into serrate or incised lobes; inflorescence $15-40 \mathrm{~cm}$. long, spicate, many-flowered; bracts linear from an ovate-lanceolate base, the lower ones pinnatifid and often longer than the flowers; calyx $1-1.5 \mathrm{~cm}$. long, with 5 linear-lanceolate lobes; corolla $2.5-3 \mathrm{~cm}$. long, sordid-yellow or sometimes streaked with red; galea 9-15 $\mathrm{mm}$. long, curving downward and cucullate, not at all beaked but with 2 lateral teeth just below apex.

In damp woods, marshes and wet meadows along streams, in N.M. (widespread in mts.) and Ariz. (Apache, Greenlee, Graham and Cochise cos.), June-Sept.; also Wyo.

\section{Castilleja L.f. Indian Paintbrush. Painted-CuP}

Perennial or annual herbs, sometimes woody at the base; leaves alternate, entire or pinnately lobed; flowers in bracteate spikes; bracts prominent, usually more conspicuously colored than the flowers; calyx tubular, terminating in 4 or (if wholly united laterally) 2 lobes; corolla extremely zygomorphic, with a long narrow galeate (hooded) upper lip and a shorter often vestigial lower lip, the tube long and narrow; stamens 4, didynamous, each pair of anther sacs unequally placed; capsule ovoid, bilocular, loculicidal; seeds numerous, the testa loose and alveolately reticulate.

More than 150 species, concentrated in western North America, Mexico and Central America; 1 species in the West Indies, about 5 species in South America and about 10 species in Eurasia. The common name "Indian blanket" is sometimes loosely applied to this genus but that name should be reserved for Gaillardia of the Compositae.

1. Distribution in eastern Oklahoma.

1. Distribution New Mexico and/or Arizona (2)

2(1). Root annual, fibrous; stems solitary, simple or often branched from near base; leaves and bracts linear to narrowly lanceolate, entire, usually tipped with red or scarlet (3)

2. Root perennial, mostly woody; stems several clustered, sometimes decumbent and rooting at the base; leaves entire or frequently the uppermost with 1 or 2 pairs of small lateral lobes; bracts typically ovateoblong, entire or more often with 1 or more pairs of small lateral lobes (4)

3(2). Stems typically slender, sparsely villous to glabrate (at least below); leaves linear to linear-lanceolate; corolla with galea exserted from calyx, the lower lip bright red and differently colored from rest of corolla

.2. C. minor.

3. Stems typically stout, copiously villous nearly to the base; leaves lanceolate; corolla with galea mostly included in calyx, the lower lip not differently colored from rest of corolla............................

4(2). Bracts bright- to dull-yellow, rarely streaked or somewhat tinged with red or purple (5)

4. Bracts typically bright-red, crimson or scarlet, yellow only in rare individuals (7)

5(4). Stems and leaves more or less densely tomentose; seed coat dark and often pubescent. 4. C. lineata.

5. Stems and leaves glabrous to variously hairy but not at all tomentose; seed coat light colored, never pubescent (6) 
6(5). Plants 1-2 dm. tall, unbranched, strongly viscid-villous (at least in the inflorescence); bracts sometimes streaked or tinged with red or purple; typically in alpine situations....................5. C. occidentalis.

6. Plants mostly $2-5 \mathrm{dm}$. tall, often branched, glabrous to slightly viscid-villous; bracts pale-yellow; mostly below alpine zones.........6. C. sulphurea.

7(4). Inflorescence commonly branched; primary lobes of calyx each with 2 linear-attenuate sharp segments.

7. C. miniata.

7. Inflorescence simple; primary lobes of calyx each with 2 short blunt segments 8. C. rhexifolia.

\section{Castilleja coccinea (L.) Spreng. Painted cup, indian Paint-Brush.}

Annual, more or less pubescent; stem usually simple, 2-6 dm. tall; principal cauline leaves very diverse, varying from rarely entire to commonly 3- or 5-cleft, the segments linear to narrowly oblong, the lateral ones almost always shorter or narrower than the terminal one; spike at first dense and 4-6 cm. long, elongating to as much as $2 \mathrm{dm}$. in fruit; bracteal leaves wholly or mostly scarlet, rarely pale, commonly 3-lobed or occasionally 5-lobed; calyx $2-3 \mathrm{~cm}$. long, thin and membranous, often more or less scarlet, deeply divided into 2 lateral halves; each calyx half gradually widened distally and at the summit broadly rounded to truncate or barely emarginate; corolla greenish-yellow, little surpassing the calyx, the minute lip less than a third as long as the galea.

In wet meadows, bogs, moist prairies and wet sandy soils in Okla. (Delaware, Haskell, Mayes and Muskogee cos.), May-Aug.; Mass. to Ont. and Man., s. to S.C., Miss., La. and Okla.

\section{Castilleja minor Gray. Fig. 706.}

Slender annual; stems erect, simple or branched from near base, 2-10 dm. tall; herbage variously pubescent but with some gland-tipped hairs, occasionally glabrate below, usually somewhat viscid or "clammy"; leaves linear to lanceolateattenuate, entire, 4-10 cm. long, minutely but densely pilose, interspersed with gland-tipped hairs; bracts entire, linear to lanceolate-attenuate, the lower bracts green, the upper ones red-tipped; flowers in spikelike raceme, pediceled, the lower flowers remote; calyx cleft medianly into 2 ovate-attenuate lobes, these cleft or notched at apex; corolla short, but the galea well-exserted, the reddish lower lip included in calyx or barely exserted, the galea about $1 / 2$ to nearly as long as corolla tube; capsule included in growing calyx, 10-12 mm. long.

Subsaline to alkaline marshes and bogs, around springs and along streams, in N. M. (Grant, Sierra and San Juan cos.) and Ariz. (Navajo, Coconino and Mohave, s. to Greenlee, Cochise, Santa Cruz and Pima cos.), Apr.-Aug.; also n. Mex.

\section{Castilleja exilis A. Nels. Fig. 706.}

Slender to coarse annual; stems simple or with few branches from base, 3-10 dm. tall; pubescence various, often of coarsely hispid-pilose hairs intermixed with fine hairs or sometimes with gland-tipped hairs; leaves lanceolate-attenuate to linear, entire; bracts foliaceous, lanceolate, entire, erect and scarlet-tipped when young, soon becoming green, entire; flowers in a stout spikelike raceme, the flowers becoming more remote after anthesis; calyx green, 15-18 mm. long, cleft medianly for about two thirds of its length into ovate-attenuate lobes, these entire, toothed or emarginate at apex, rarely cleft; corolla 14-20 mm. long, included within or barely exserted from the calyx, the galea about one half as long as tube; capsule $8-12 \mathrm{~mm}$. long.

Saline or alkaline hogs or marshes, cat-tail swamps, wet meadows and wet soil near springs, in N. M. (San Juan Co.) and Ariz. (Coconino Co.), Apr.-Sept.; Mont. to Wash., s. to N.M., Ariz. and Nev. 


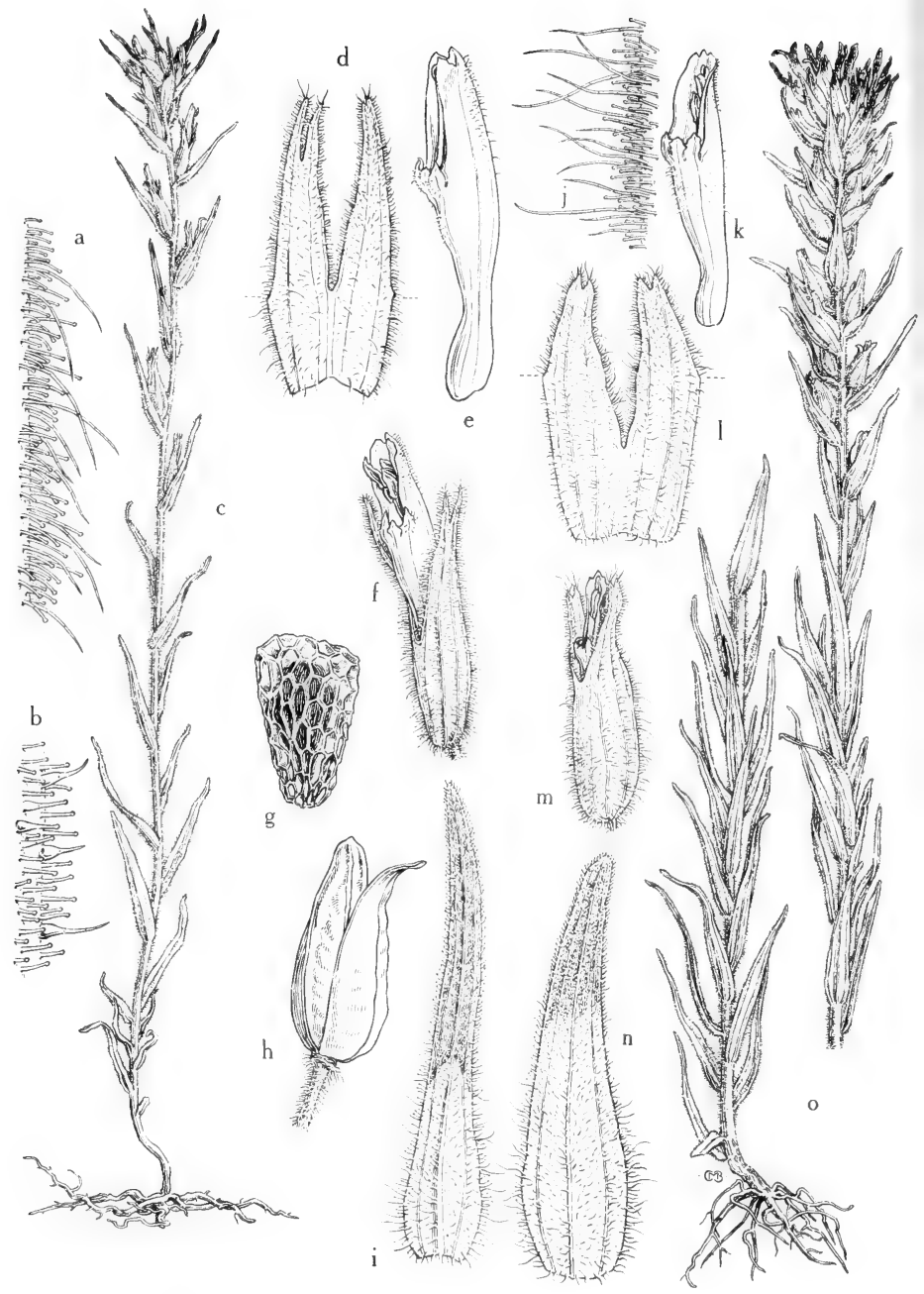

Fig. 706: Castilleja. a-i, C. minor: a, stem hairs, x 6; b, calyx and bract hairs, $\mathrm{x}$ 8 ; c, habit, $\mathrm{x} 25 \%$; , calyx, spread out, the cut tube extending from the base to the dotted lines, x 2 ; e, corolla, side view, x 2 ; f, flower, $x 11 \%$; g, seed, $x 12$; h, capsule, $\mathrm{x} 2$; $\mathrm{i}$, bract, $\mathrm{x} 2$. j-o, C. exilis: $\mathrm{j}$, stem hairs, x $4 ; \mathrm{k}$, corolla, x $2 ; 1$, calyx, spread open, the cut tube extending from the base to the dotted lines, $\mathrm{x} 2 ; \mathrm{m}$, flower, $\mathrm{x} 11 \frac{1}{2}$; n, bract, x 2; o, habit, x \%. (From Mason, Fig. 312). 


\section{Castilleja lineata Greene.}

Perennial; stems several, erect or ascending from a woody caudex, 1-4 dm. tall, grayish-tomentose; leaves linear, $2-4 \mathrm{~cm}$. long, usually with 1 or 2 pairs of lateral lobes, tomentose; inflorescence narrow and elongating in fruit; bracts broader than the leaves, 3- or more-cleft or pinnatified with narrow lobes, the middle lobe broadest, dull-yellow; calyx 18-20 mm. long, yellowish or greenish, subequally cleft to middle above and below and deeply cleft laterally; corolla about $2 \mathrm{~cm}$. long, greenish; galea 4-7 $\mathrm{mm}$. long, shorter than the corolla tube; lower corolla lip not much over $1 \mathrm{~mm}$. long.

In marshy meadows and in wet soil along streams, in N. M. (Colfax and Rio Arriba cos.) and Ariz. (Apache Co.), July-Sept.; also Colo.

\section{Castilleja occidentalis Torr.}

Perennial; stems clustered, erect or ascending from a woody base, 1-2 $\mathrm{dm}$. tall, unbranched, mostly purplish, more or less viscid-villous; leaves linear-lanceolate, typically entire but sometimes the upper ones with a pair of lateral lobes, viscid-villous to -puberulent; inflorescence short and compact, predominantly yellow but varying to streaked or tinged with red and purple; bracts ovate-oblong, entire and rounded at apex or with 1 or 2 pairs of lateral lobes, viscid-villous; calyx 15-20 mm. long, deeply and subequally cleft above and below, its primary lobes again divided into 2 mostly blunt segments $1-4 \mathrm{~mm}$. long; corolla $18-25 \mathrm{~mm}$. long, its minutely puberulent galea much shorter than the tube and only 3 to 4 times the length of the prominent but scarcely saccate lower lip.

Wet mt. meadows and wet alpine slopes, in N.M. (Mora and Rio Arriba cos.) June-Aug.; N. M. and Ut., northw.

\section{Castilleja sulphurea Rydb.}

Perennial; stems clustered, erect or ascending from a woody base, $2-5 \mathrm{dm}$. tall, often branched above, usually glabrous or glabrate below, commonly viscidvillous above, occasionally puberulent throughout; leaves linear to ovate-lanceolate, acute to acuminate, mostly all entire but the upper ones sometimes lobed, glabrous to puberulent or finely villous; inflorescence conspicuous, pale-yellow, at first short and broad but often elongating in fruit; bracts ovate-oblong, pale yellow, mostly entire and rounded but sometimes acute or with 1 or 2 pairs of very short lateral lobes, puberulent and villous; calyx $15-25 \mathrm{~mm}$. long, deeply and subequally cleft above and below, its primary lobes again notched or cleft into 2 blunt or acute segments 1-3 mm. long; corolla $18-30 \mathrm{~mm}$. long, its minutely puberulent galea shorter than the tube and 3 to 4 times the length of the dark-green thickened lower lip. $C$. septentrionalis of auth., C. luteovirens Rydb.

Wet or moist meadows and slopes, on edge of lakes, ponds and streams, in N. M., (Rio Arriba, Sandoval, San Miguel, Santa Fe, Rio Arriba and Union cos.), July-Sept.; Mont. to Alta., s. to N. M.

\section{Castilleja miniata Hook.}

Perennial; stems few, erect or ascending from a woody base, rarely creeping and rooting at the base or decumbent, 2-8 dm. tall, often branched, glabrous to short-pubescent or somewhat viscid-villous (especially above); leaves linear to lanceolate, sometimes broader, usually all entire but sometimes a few lobed, glabrous to puberulent or finely villous with simple hairs; inflorescence conspicuous, bright-red or scarlet, occasionally crimson or rarely yellow, at first broad and short but often elongating in fruit; bracts ovate-oblong, more or less toothed or cleft with acute segments, rarely entire, puberulent and villous, often viscid; calyx 15-30 mm. long, deeply and subequally cleft above and below, its 
primary lobes again divided into 2 usually linear segments $3-9 \mathrm{~mm}$. long; corolla $2-4 \mathrm{~cm}$. long, its puberulent to pubescent galea three fourths to about as long as the tube and 5 or more times the length of the dark-green thickened lower lip. C. confusa Greene, C. trinervis Rydb.

Wet meadows, marshes and slopes in N. M. (Bernalillo, Colfax, Rio Arriba, Sandoval, San Miguel and Santa Fe cos.) and Ariz. (Apache to Coconino cos.); also Colo., June-Oct.

\section{Castilleja rhexifolia Rydb.}

Perennial; stems clustered, erect or ascending from a woody base, mostly 1-3 dm. tall, usually unbranched, glabrate to villous and sometimes viscid-villous; leaves narrowly lanceolate, typically entire but sometimes with the upper ones lobed, glabrous to puberulent or villous (-viscid); inflorescence mostly crimson and drying purplish but varying to scarlet or infrequently somewhat yellow, at first short and broad but elongate in fruit; bracts oblong-elliptic to ovate-oblong, entire and rounded to sometimes acutish at apex, sometimes with 1 or 2 pairs of short lateral lobes, villous-puberulent; calyx 15-25 $\mathrm{mm}$. long, subequally cleft above and below, its primary lobes again divided into 2 usually blunt segments 3-6 mm. long; corolla 20-35 mm. long, its puberulent galea usually much shorter than the tube and 4 to 5 times as long as the dark green thickened lower lip. C. lauta A. Nels.

In marshes, wet mt. meadows, seepage about ponds and lakes, and along streams, in N. M. (Rio Arriba and Taos cos.), July-Sept.; Alta. and B.C., s. to N.M. and Ut.

\section{Orthocarpus Nutt. OWl Clover}

About 30 species, in western North America; one in the Andes.

\section{Orthocarpus luteus Nutt. Fig. 707.}

Stems 1-3 dm. tall, erect, usually simple or branching near the top, more or less pubescent; leaves linear to linear-lanceolate, 1-4 cm. long, usually entire or rarely 3-cleft; inflorescence many-flowered, to $10 \mathrm{~cm}$. long or more; bracts leaflike, 10-15 mm. long, 3- or 5-cleft; calyx 5-8 mm. long, the lobes 1-2 mm. long; corolla 10-15 mm. long, golden-yellow, galea apex obtuse, not inflexed, lower lip about as long as and not much wider than the galea; seeds $1-1.25 \mathrm{~mm}$. long.

In marshes and wet meadows, in N. M. (Rio Arriba and San Miguel cos.) and Ariz. (Apache and Coconino cos.), June-Oct.; Man. to B. C., s. to N. M., Ariz. and Calif.

\section{Fam. 120. Martyniaceae STAPF}

\section{UNICORN-PLANT FAMILY}

Coarse stout annual or perennial herbs with branching stems, viscid to glandular-pubescent and usually strongly scented; leaves exstipulate, simple, longpetioled, opposite to alternate; flowers usually large and showy in loose terminal racemes; calyx bibracteate, composed of 5 irregular sepals or spathaceous and 5-lobed; corolla sympetalous, 5-lobed and somewhat bilabiate; fertile stamens 4 , didynamous (the rudiment of the 5th usually obvious), or 2 , the second pair forming staminodes; filaments attached to the corolla; anthers gland-tipped and with 2 divergent cells; carpels 2, united to form a 1-celled ovary with 2 parietal intruded placentae expanded into 2 broad lamellae, the ovary apparently inserted on an annular glandular disk; ovules anatropous; style 1, slender; stigma with 2 flat sensitive lobes; fruit a drupaceous capsule, bivalved and loculicidally dehiscent or indehiscent, imperfectly 5-celled, frequently crested and always terminated by 


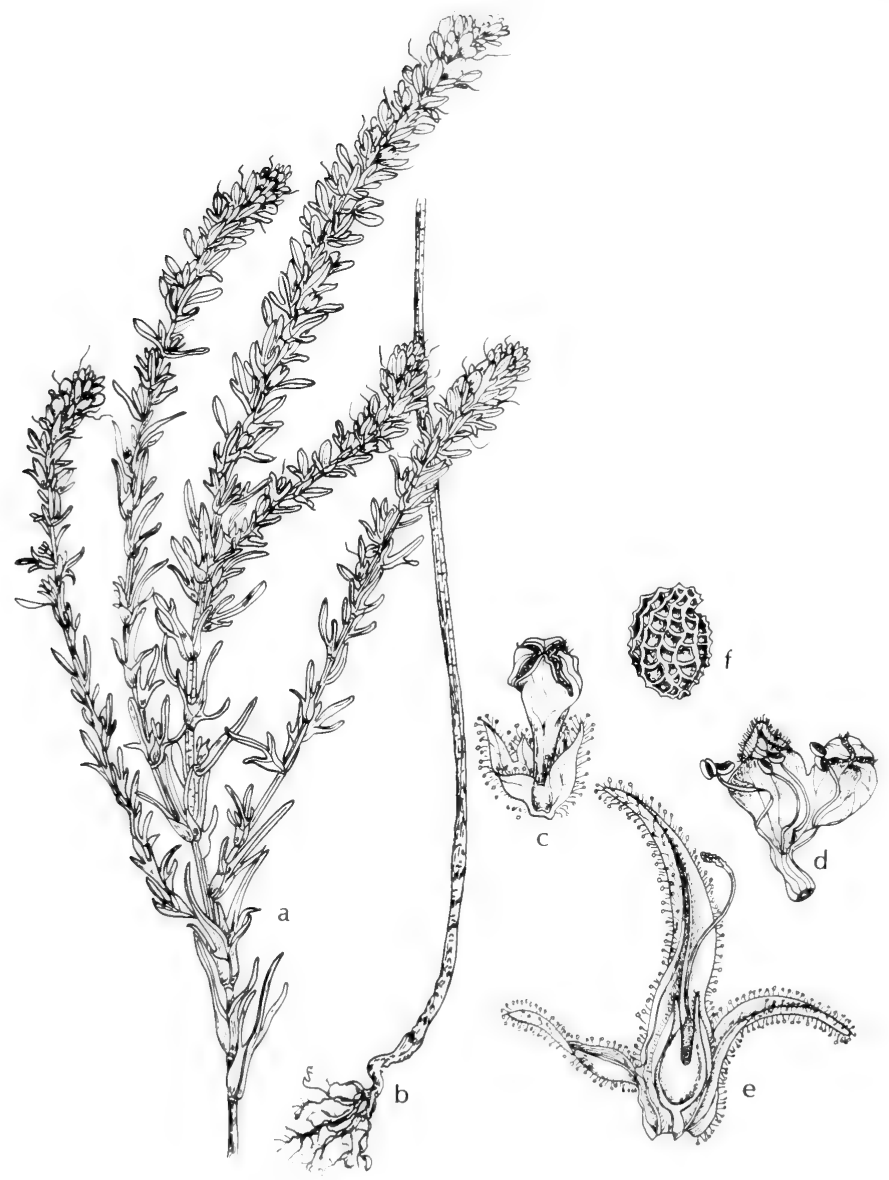

Fig. 707: Orthocarpus luteus: a, top of plant, x $1 \frac{1}{2} ; \mathrm{b}$, basal part of plant, $\times 1 / 2$ c, flower, $\mathrm{x} 2$; $\mathrm{d}$, corolla spread out, $\mathrm{x} 2$; e, capsule in bract with part of calyx removed, $x 2$; , seed, $\times 10$. (V. F.). 
a prominent incurved 2-horned beak; exocarp fleshy, separating in age from the woody reticulate-sculptured or spinose endocarp; seeds 4 or many, the testa corky-tuberculate or membranous-reticulate; endosperm none; embryo straight; cotyledons large and fleshy.

About 20 species in 5 genera, native to the Western Hemisphere.

\section{Proboscidea Schmid. Unicorn-Plant. Devil's Claw. Cinco LLAGAS}

About 12 species, most of which are confined to North America.

1. Proboscidea louisianica (Mill.) Thell. Unicorn-Plant, COMMON DEVIL's Claw, RAM'S HORN.

Coarse viscid-pubescent annual with prostrate or ascending opposite branches to $1 \mathrm{~m}$. long; leaves opposite or the upper ones subalternate, with densely shortpubescent petioles to $2 \mathrm{dm}$. long and $5 \mathrm{~mm}$. thick, orbicular-reniform to broadly ovate, cordate at base, with entire or sinuate margins, to $3 \mathrm{dm}$. wide and slightly shorter; flowers 8 to 20 in an open raceme; pedicels $2-3 \mathrm{~cm}$. long in anthesis, $45 \mathrm{~mm}$. in fruit; pedicel bracts linear, 5-10 mm. long; calyx bracts oblong-falcate to ovate, $1 \mathrm{~cm}$. long or less; calyx to $2 \mathrm{~cm}$. long, the 5 lobes acutish to obtuse, one half the length of the calyx, thick and green or somewhat membranous and yellowish; corolla to $55 \mathrm{~mm}$. long and nearly as wide, dull-white or somewhat purplish or pinkish throughout, mottled or blotched with reddish-purple and yellow or occasionally nearly clear reddish-violet, conspicuous reddish-purple spots extend internally the entire tube length, the cylindrical portion of the tube short $(5$ $\mathrm{mm}$. or less), the remainder broadly campanulate, $15-25 \mathrm{~mm}$. long, $15-17.5 \mathrm{~mm}$. wide at orifice, ventricose, the lobes $1.5-2 \mathrm{~cm}$. long and $1.5-3 \mathrm{~cm}$. wide; filaments glabrous or sparsely villous or tomentose below their point of attachment, glandular on the arcuately curved portion; fruit body stout, to $1 \mathrm{dm}$. long, $3 \mathrm{~cm}$. thick, the horns one and one half to three times longer than the body. P. Jussieui Schmid., Martynia louisianica Mill.

In wet or dryish meadows, playa lakes, waste places and on stream banks, mostly in cen. and n.e. Tex., Okla. (Waterfall) and N.M. (Chaves, Guadalupe and Union cos.), June-Sept.; nat. to s. U.S. but spontaneous northw.; sometimes cult. for its young pods which are made into pickles.

\section{Fam. 121. Lentibulariaceae Rich.}

\section{BLADDERWORT FAMILY}

Aquatic, amphibious or terrestrial annual or perennial plants, commonly possessing traps and insectivorous or carnivorous; leaves alternate, cauline or in a basal rosette, simple or dissected; flowers 1 to several on an erect scape; calyx bilabiate, 2- or 5-lobed; corolla deeply bilabiate, the lower lip often 3-lobed, spurred at base in front and with a conspicuous palate; stamens 2; ovary free, 1-celled, the placentation free-central; capsule ovoid to globose, 2- or 4-valved, often bursting irregularly; seeds minute.

About 170 species in 4 genera that are worldwide in distribution.

1. Plants mostly aquatic, rarely amphibious or terrestrial; leaves filiform-dissected and usually bladder-bearing; flowers yellow or purplish in $U$. purpurea; calyx 2-lobed.

1. Utricularia

1. Plants terrestrial in moist soil; leaves entire, in basal rosette, not bladderbearing; flowers whitish or pale-violet; calyx 5-lobed.

2. Pinguicula 

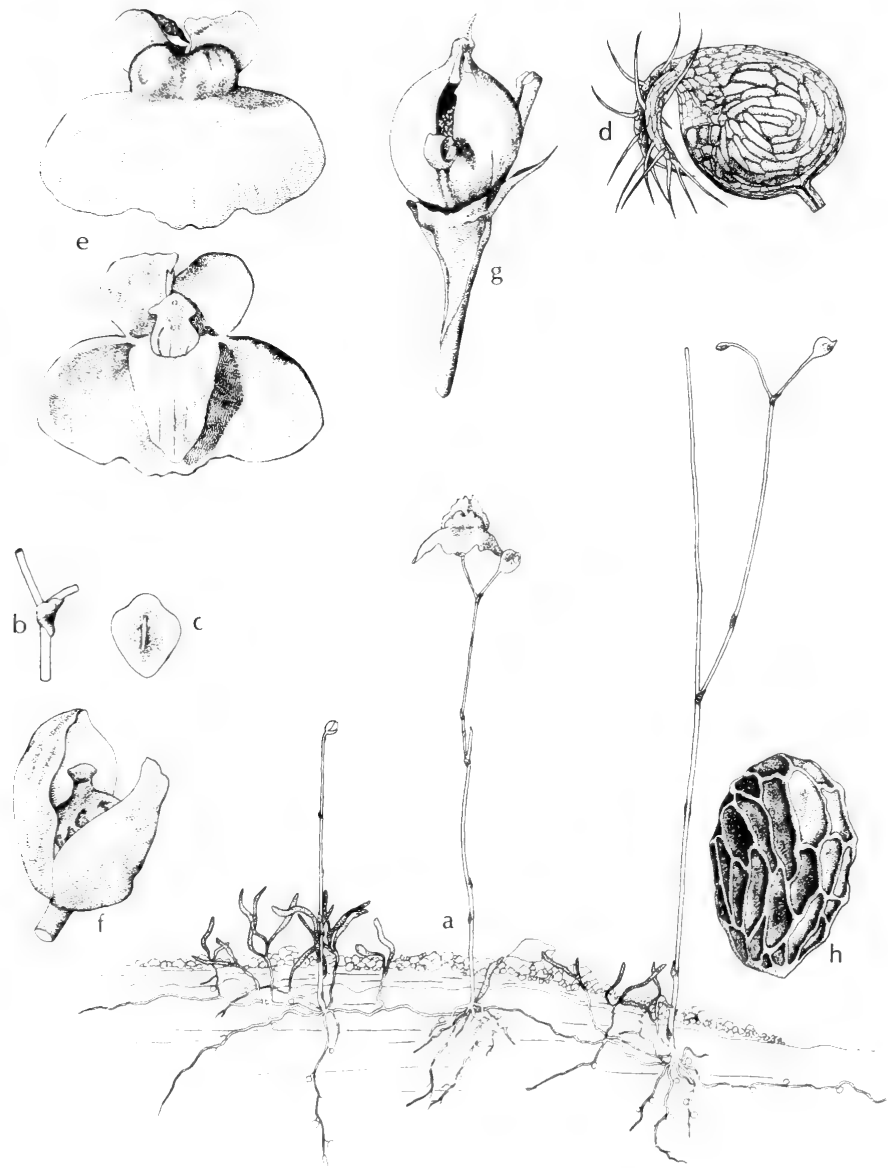

Fig. 708: Utricularia subulata: a, habit, $\mathrm{x} \mathrm{1;} \mathrm{b,} \mathrm{bract,} \mathrm{x} \mathrm{5;} \mathrm{c,} \mathrm{bract,} \mathrm{dorsal} \mathrm{view}$ showing attachment scar, x 10; d, trap, x 25; e, two views of corolla, x 5; f, capsule, x 13; g, capsule, split open, x 13; h, seed, x 25. (Courtesy of R. K. Godfrey). 


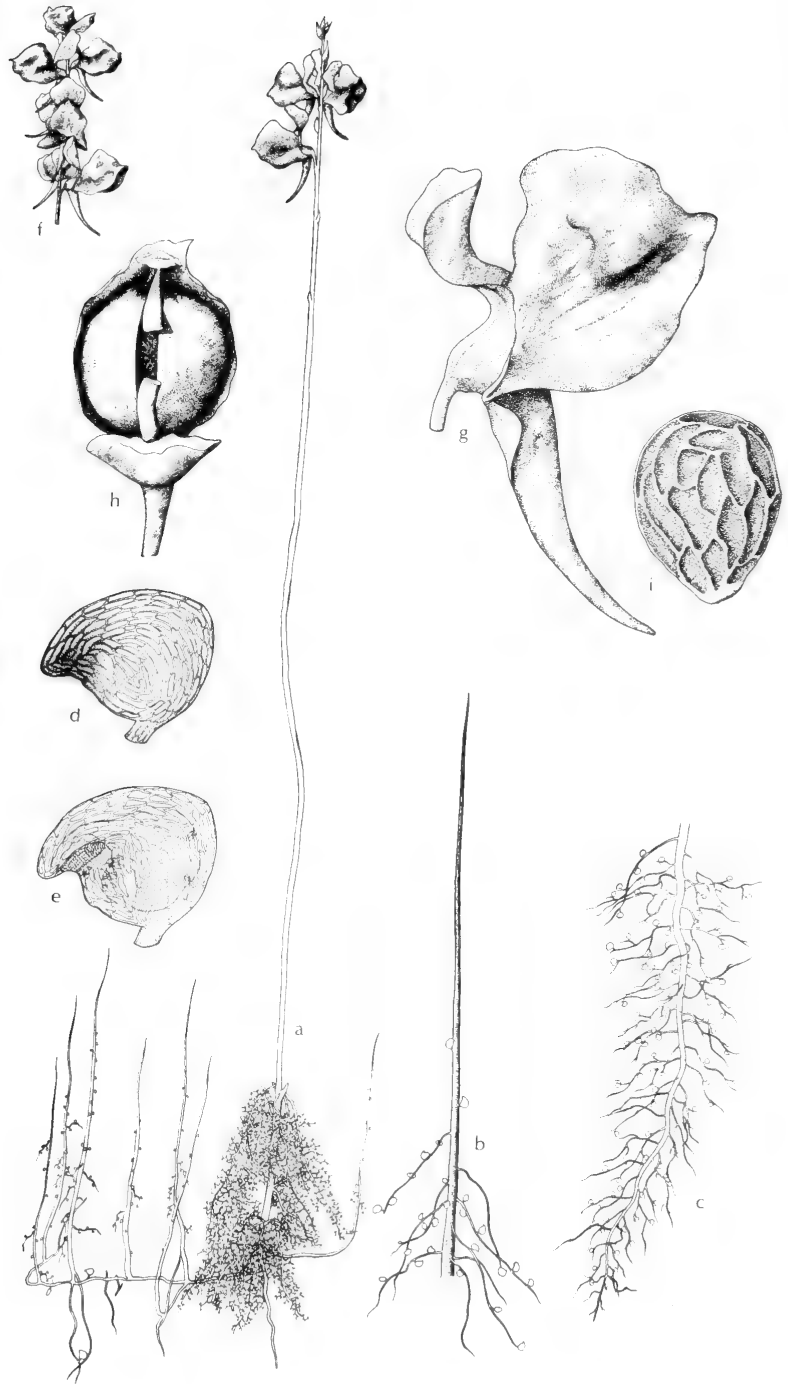

Fig. 709: Utricularia cornuta: a, habit, about $\times 1$; b, erect branch, $\mathrm{x}$ 4; c, prop branch, x 4; d, leaf blades, x 35; e, basal bladder, x 70; f, inflorescence, x 1; g, flower, x 3 ; h, capsule, x 5; i, seed, x 115 . (Courtesy of R. K. Godfrey). 


\section{Utricularia L. BLADDERWORT}

Perennial herbs, strictly aquatic, amphibious or in wet soil; stems slender; leaves capillary-dissected and usually bearing bladderlike traps with a few flagellae at their orifice and a valvelike action for trapping micro-organisms; flowers 1 to several on slender scapes; calyx bilobed; corolla bilabiate, the lower lip usually 3 -lobed and with a conspicuous projecting usually bearded palate that often closes the throat, the erect upper lip usually entire, spurred at the base in front; stamens 2, the anthers convergent; capsule 2-valved.

About 120 species that are cosmopolitan in distribution.

Species of Utricularia are not only known to provide food but they also provide shelter for fish and a habitat for minute animal life upon which fish feed. These plants are incidentally eaten by wildfowl and muskrats. Some species can become so concentrated in water bodies that, along with Myriophyllum spp., Ceratophyllum demersum and Cabomba caroliniana, they become a nuisance and hindrance to small boat navigation. With the lowering of water levels some of these plants may die and foul the water with their decayed vegetation, contributing to eutrophication.

1. Leaves minute and linear or none, always inconspicuous; vegetative branches subterranean or horizontal and submersed, only the erect filiform flowering scape aerial; bladders minute or none (2)

1. Leaves once to several times finely dichotomously branched, usually conspicuous on the submersed stems, the flowers arising above the surface of the water (4)

2(1). Bracts at base of pedicels peltate, not accompanied by bractlets; pedicels filiform, several times longer than the bracts............. U. subulata.

2. Bracts at base of pedicels basally attached, accompanied each by a pair of minute bractlets; pedicels stout, at most scarcely exceeding the bracts (3)

3(2). Flowers approximate, the expanding lower ones overtopping the unexpanded buds above; pedicels mostly exserted beyond the basal bracts; corolla (from tip of spur to tip of upper lobe) $15 \mathrm{~mm}$. high or more...................................................................$U$. cornuta.

3. Flowers not crowded, the expanding lower ones not reaching unexpanded buds above; pedicels exceeded by the basal bracts; corolla $15 \mathrm{~mm}$. high or less.................................................................... 3. . juncea.

4(1). Leaves (at least the upper ones) in whorls of 4 to 9 , the petioles often inflated (5)

4. Leaves all alternate, the petioles never inflated (7)

5(4). Flowers rose-purple; petioles not inflated

4. U. purpurea.

5. Flowers yellow; scape provided about or below the middle with a whorl of inflated petioles that act as floats (6)

6(5). Flowers usually 9 to 14 ; pedicels recurved in fruit; corolla spur notched at tip; raceme bracts longer than broad, never lobed; each lateral foliar unit with its primary basal division comprised of 2 unequal forks; base of floats tapering gradually from the expanded central portion toward the scape axis, terete in cross section, the tips muchcurved ventrally and submersed.

5. U. inflata.

6. Flowers usually 3 or 4 ; pedicels rarely recurved in fruit, mostly stiffly erectascending; corolla spur never notched at tip, rounded or with a small terminal papilla; raceme bracts as broad as long or broader, variable with respect to lobing; each lateral foliar unit with primary basal division comprised of 2 equal forks; bases of floats uniform in breadth, tapering abruptly only at the scape axis, flattened in cross section, their tips scarcely curved ventrally, usually straight 

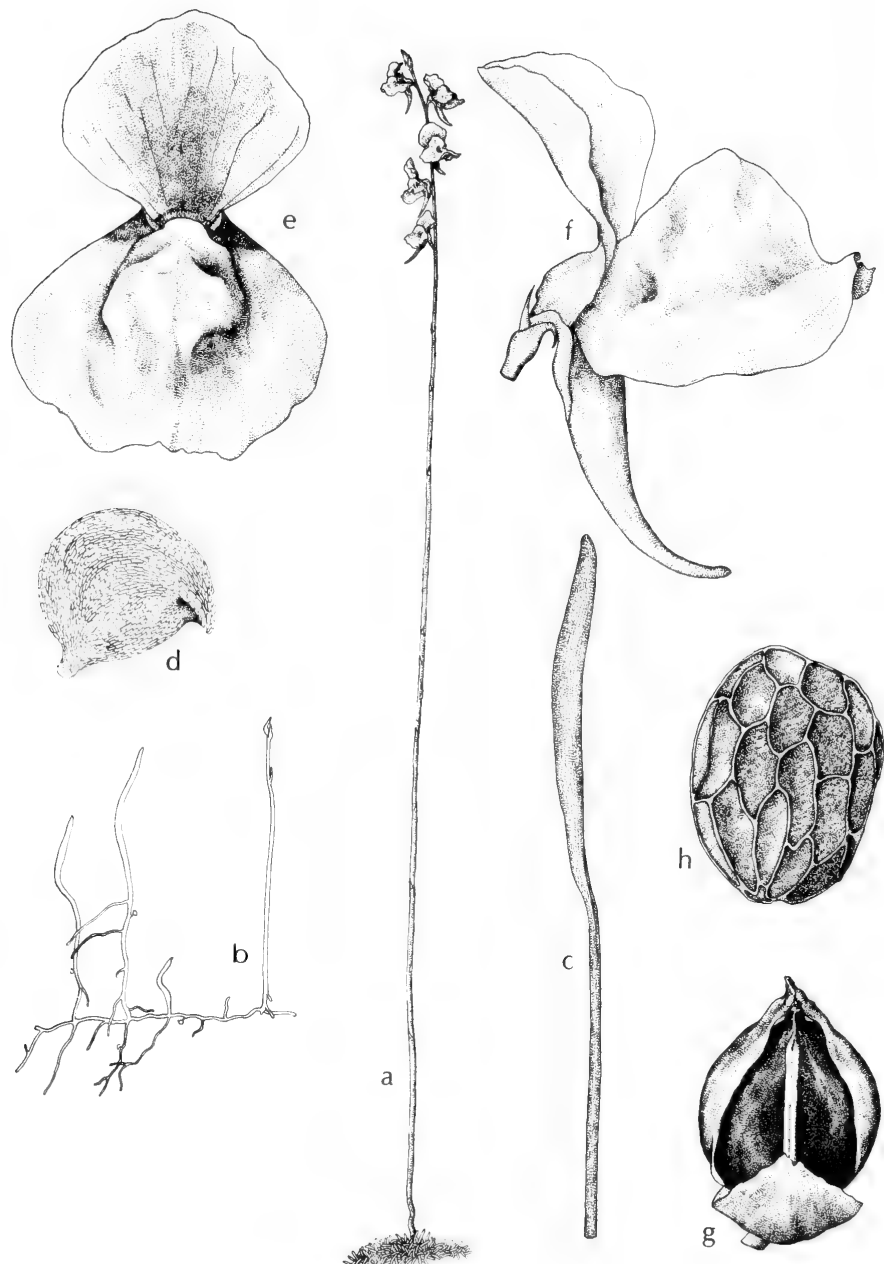

Fig. 710: Utricularia juncea: a, habit, $\mathrm{x} 1 \frac{1}{2}$; b, roots, shoots, leaves, traps, etc., x 1/2; c, leaf, x 30; d, trap, x 30; e and f, two views of corolla, x 6; g, capsule, about x 8 ; h, seed, x 125. (Courtesy of R. K. Godfrey). 


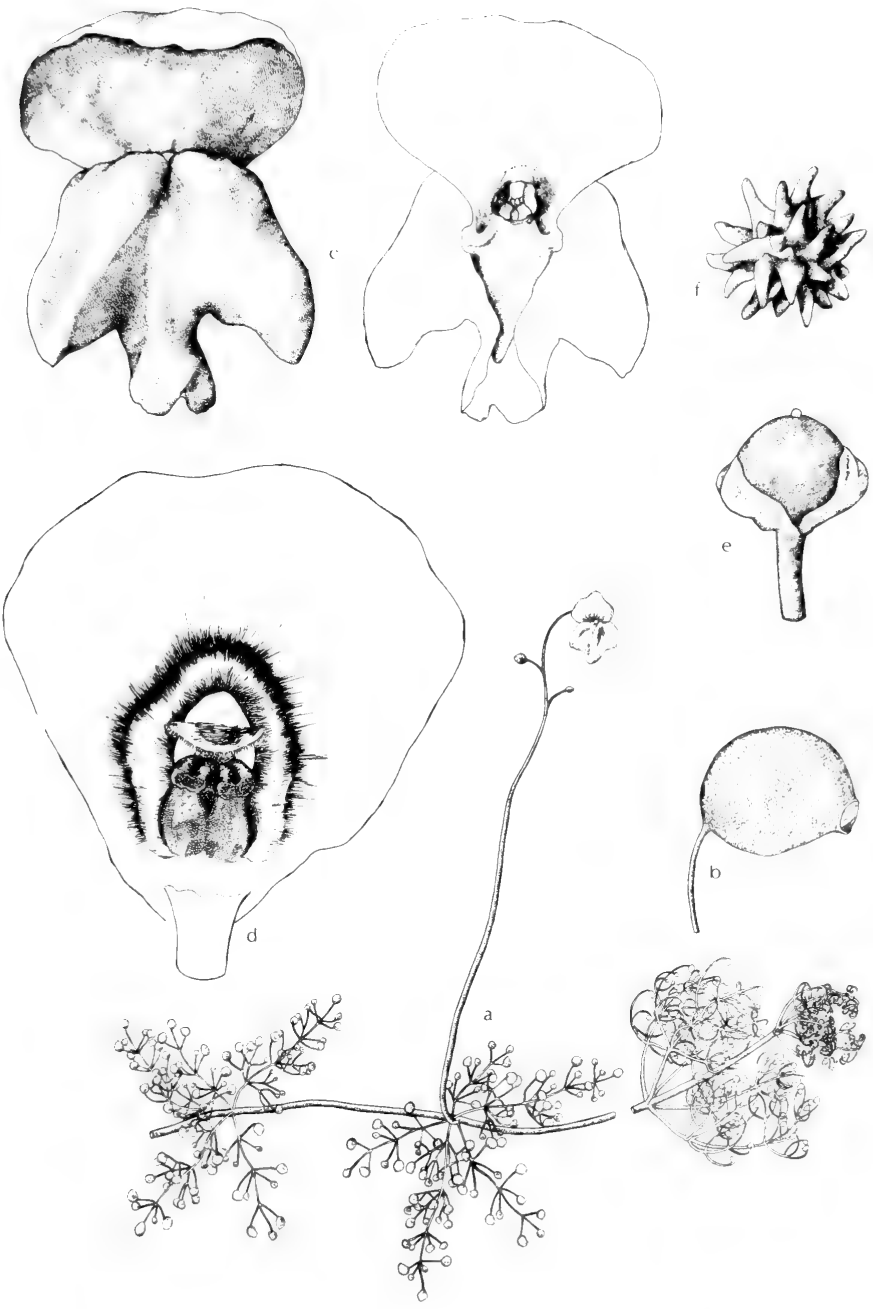

Fig. 711: Utricularia purpurea: a, habit, about $\times 1 / 2 ; b$, bladder, $x 7$; $c$, two views of flower, $x 31 \frac{3}{2}$, view looking into the flower showing stamens and anther sacs, X 10; e, capsule, x 5; f, seed, x 75. (Courtesy of R. K. Godfrey). 
7(4). Floral bracts 3-6 mm. long; scape stout, usually bearing more than 8 flowers; leafy stems floating beneath surface of water.

7. U. vulgaris.

7. Floral bracts $3 \mathrm{~mm}$. or less long; scape slender-filiform, bearing fewer than 8 flowers; leafy stems creeping at the bottom of shallow water, or more of them radiating from the base of a flowering scape (8)

$8(7)$. Lower corolla lip 5-7 mm. long, distinctly exceeding the thick very blunt spur; body of seed smooth......................................... . U. gibba.

8. Lower corolla lip $8-10 \mathrm{~mm}$. long, about equaling or slightly shorter than the conic spur (9)

$9(8)$. Leafy branches from the base of the flower stalk dimorphic, some bearing twice-dichotomous leaves and numerous bladders, others with thricedichotomous leaves that lack bladders; body of seed rough-tuberculate...................................................................... U. fibrosa.

9. Leafy branches all alike, bearing small dichotomous leaves with numerous bladders 10. U. biflora.

1. Utricularia subulata L. Fig. 708.

Plants terrestrial, with filiform subterraneal branches and slender undissected leaves, the minute traps borne on separate underground branchlets; scapes filiform, to $2 \mathrm{dm}$. tall, bearing as many as 12 flowers; floral axis usually flexuous when several flowers are developed; flowers with elongate filiform pedicels to about 15 $\mathrm{mm}$. long; bracts at base of pedicels attached at or slightly below their middle, tapering to base and apex, 1-2 $\mathrm{mm}$. long; sepals elliptic to suborbicular, blunt, about $2 \mathrm{~mm}$. long; corolla yellow, 3.5-12 $\mathrm{mm}$. long, the rounded-ovate upper lip smaller than the 3-lobed lower lip, the prominent palate 2-lobed, the compressed spur appressed to and about as long as the lower lip.

In wet peat, sands and on seepage slopes and pond shores in e. Tex., also Winkler Co. in w. Tex., Mar.-June; from Fla. to Tex. and Ark., n. to L.I., s.e. Mass. and w. N.S.

Sometimes plants with cleistogamous flowers are found. These are known as f. cleistogama (Gray) Fern.

\section{Utricularia cornuta Michx. Horned BladDerwort. Fig. 709.}

Plants terrestrial or on floating mats; stem delicate, usually creeping underground and bearing linear-filiform simple leaves (seen only by collecting sods and gently washing away the soil); traps minute, borne along the leaf margins; scapes erect, wiry, slender, to $35 \mathrm{~cm}$. tall, 1- to several- or rarely as many as 9-flowered; flowers subtended by an acute sessile bract to $2 \mathrm{~mm}$. long and 2 smaller included bractlets, very fragrant, at first approximate, the freshly expanding lower ones over-topping the unexpanded buds above; pedicels mostly exserted somewhat beyond the bracts; longer sepal yellowish, acuminate; corolla yellow, 15-25 mm. high (from tip of long spur to tip of upturned upper lip), nearly as broad; the larger lower lip helmet-shaped, with a projecting convex center and recurved sides; spur subulate, turned downward and outward, 7-12 mm. long; capsule covered by the beaked calyx.

In wet peaty, sandy or muddy shores or bogs, sometimes on edge of water, in the e. half of Tex., May-Sept.; from Nfld. to n. Ont. and Minn., s. to Fla. and Tex.

\section{Utricularia juncea Vahl. Fig. 710.}

Very similar to $U$. cornuta but smaller in all its parts, the more slender scapes to $4 \mathrm{dm}$. tall and bearing as many as 12 flowers; flowers not crowded, the expanding ones not reaching the unexpanded buds above; pedicels mostly over- 


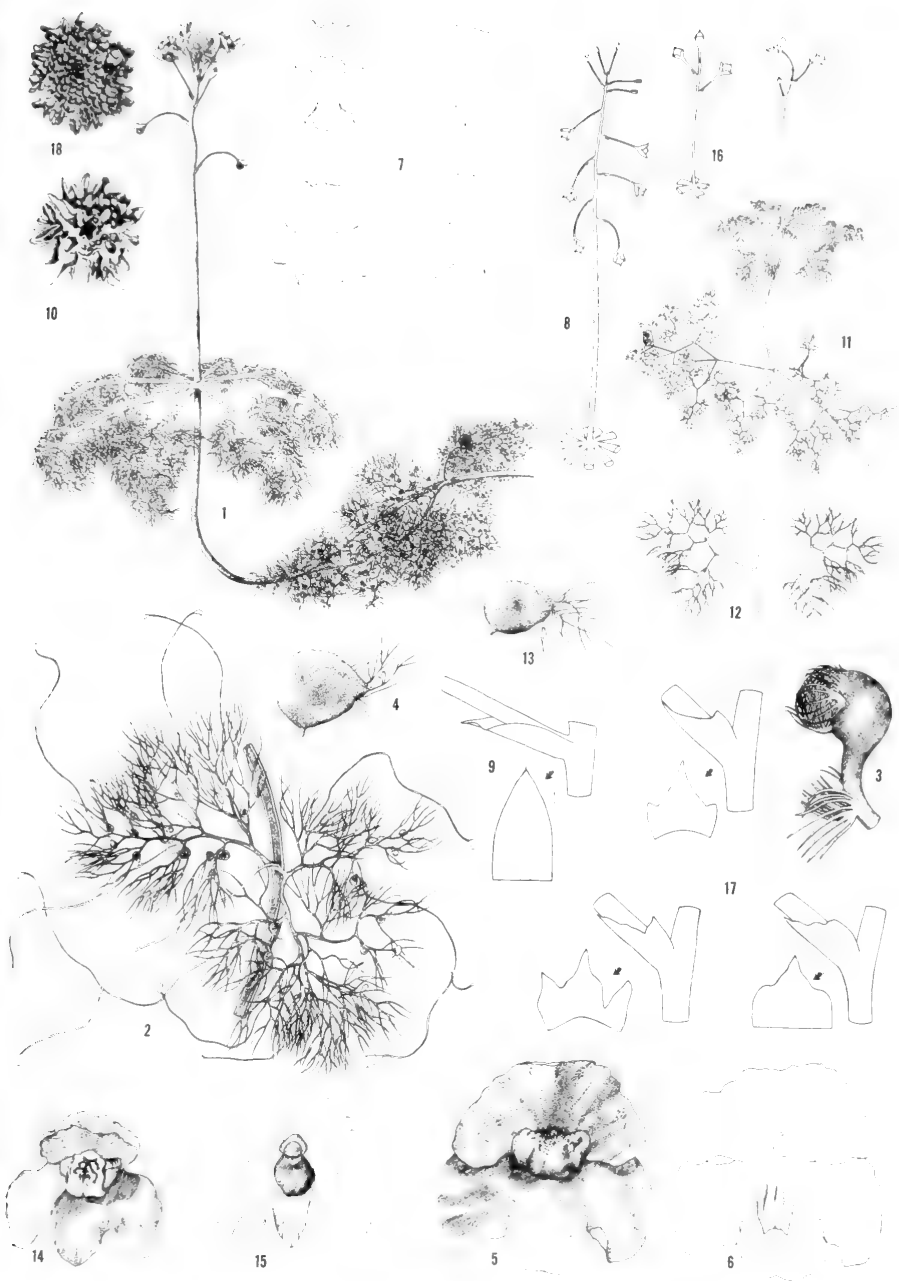

Fig. 712: 1-10, Utricularia inflata: 1, habit, small portion of plant; 2, lateral foliar unit with tuher-bearing branches; 3 , germinating tuber; 4 , bladder; 5 , corolla, abaxial view; 6 , corolla, adaxial view showing spur; 7 , sketches showing variation in lower lip of corolla: 8 , fruiting raceme: 9 , node of raceme with substending bract and outline of bract: 10, seed. 11-18, Utricularia radiata: 11, habit, small portion of plant; 12, lateral foliar unit; 13, bladder; 14, corolla, abaxial view; 15, corolla, adaxial view showing spur: 16, fruiting raceme; 17 , three nodes of raceme with subtending bracts and outline of bracts to show variation; 18, seed. (Courtesy of R. K. Godfrey; Amer. Jour. Bot. 49(3): 214. 1962), 


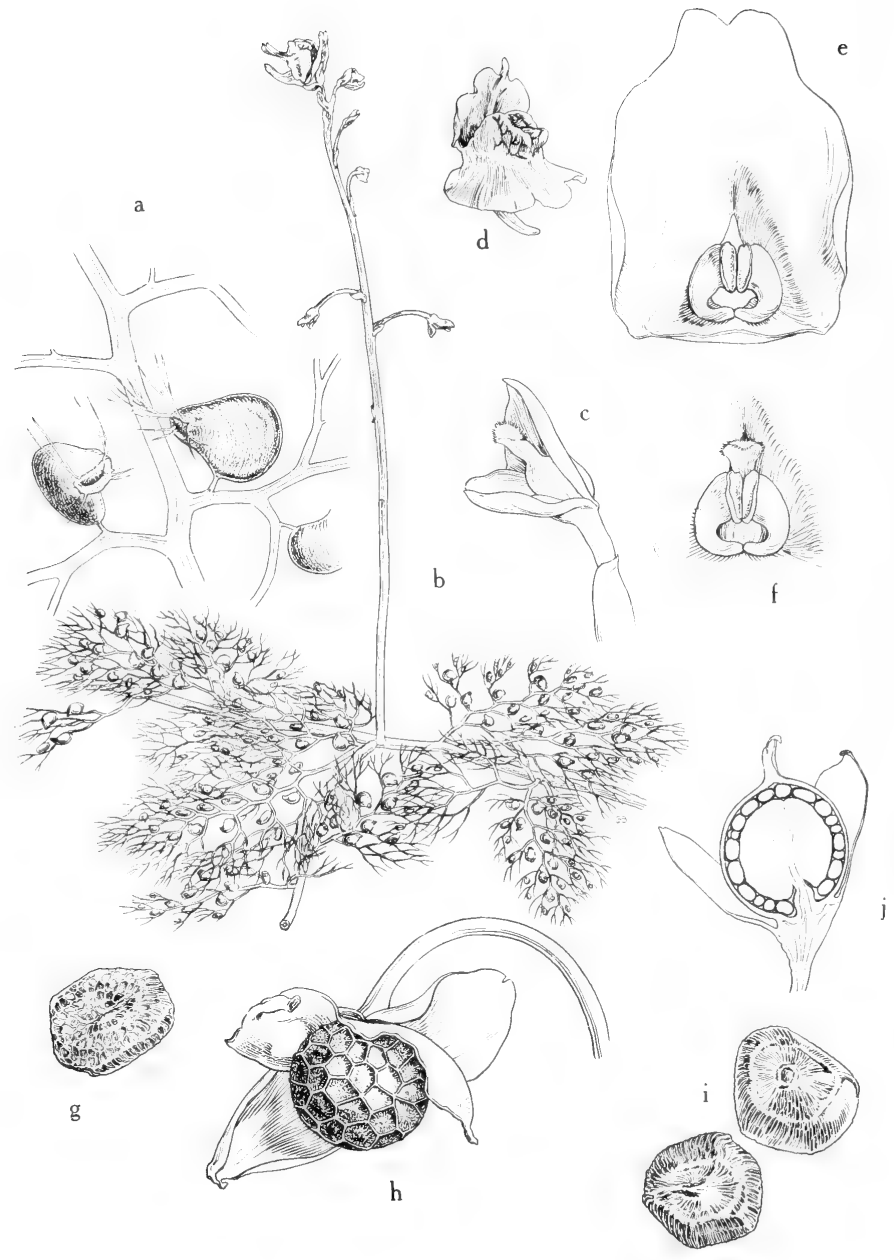

Fig. 713: Utricularia vulgaris: a, capillary leaf segments with bladders, $\mathrm{x}$ 4; b, habit, showing the erect flowering scape and the floating stems, leaves and bladders, $\mathrm{x} \%$; c calyx and pistil, $\mathrm{x} 4$; d, corolla, $\mathrm{x} 11 \%$, e, upper lip of corolla, showing stamens in front of throat, $x 4 ; \mathrm{f}$, throat of corolla, showing position of stamens, style and stigma, x $4 ; \mathrm{g}$, mature seed, $\mathrm{x} 20 ; \mathrm{h}$, mature capsule at dehiscence, the seeds in a tight mass, x 6; i, mature seeds, x 20; j, capsule (longitudinal section), x 4. (From Mason, Fig. 324). 
topped by the bracts; corolla $1-1.5 \mathrm{~cm}$. high, to $1 \mathrm{~cm}$. broad; the lower lip obovate, consisting mostly of the high-arched palate, without broad recurving margin; spur 5-7 mm. long; fruiting calyx 5-7 mm. long.

In wet sand and on margin of ponds and streams in s.e. Tex., May-Sept.; from Fla. to e. Tex., n. to L.I.; also W.I. and S.A.

\section{Utricularia purpurea Walt. PURPle bladderwort. Fig. 711.}

Stems submersed, to about $1 \mathrm{~m}$. long: leaves numerous, in whorls of 5 to 7 separated by internodes to $5 \mathrm{~cm}$. long, verticillately branched into filiform segments that often bear a terminal bladder; scape to $15 \mathrm{~cm}$. long, 1 - to 4-flowered; corolla about $1 \mathrm{~cm}$. long, rose-purple to violet, the upper lip flat or concave, the lower lip adorned with a yellow spot at base, 3-lobed with the lateral lobes strongly and separately elevated at base into a palate; spur shorter than lower lip and appressed to it. Vesiculina purpurea (Walt.) Raf.

In pools and lakes of quiet water, s.e. Tex. (Hardin Co.), May-Sept.; from Que. and N.S. to Minn. and n. Ind., s. along the Coastal Plain to Fla., La. and Tex.; also W.I.

\section{Utricularia inflata Walt. FloAting BladderWort. Fig. 712.}

Plants free-floating, the elongated submersed stems with alternate leaves that are 4 to 6 times dichotomous into delicate capillary segments and bearing small ovoid bladders; scape supporting a whorl of 4 to 10 leaves that have inflated petioles which serve as floats, from the whorl of floats to the lowest pedicel 7-25 $\mathrm{cm}$. long, supporting as many as 14 (usually about 8) flowers; floats $4-9 \mathrm{~cm}$. long, the petiole $4-8 \mathrm{~mm}$. thick, the basal divisions of their pinnately dissected blades $0.5 \mathrm{~mm}$. or more in diameter; floral bracts $3-4 \mathrm{~mm}$. long; calyx lobes 4-7 $\mathrm{mm}$. long; corolla yellow, about $2 \mathrm{~cm}$. broad, to $25 \mathrm{~mm}$. high, the lower lip 3-lobed and twice as long as the appressed spur; fruiting pedicels to $35 \mathrm{~mm}$. long, spreading or recurved.

In ditches, swamps, slow streams, lakes and ponds in e. Tex., Mar.-July; from Fla. to Tex., n. to Del. and N.J.

\section{Utricularia radiata Small. Fig. 712.}

Very similar in habit to $U$. inflata; floats several, $2-5.5 \mathrm{~cm}$. long, with inflated petioles 2-4 mm. thick; peduncle $1.5-5 \mathrm{~cm}$. long, supporting usually 3 or 4 flowers; calyx lobes $3-4 \mathrm{~mm}$. long; corolla about $15 \mathrm{~mm}$. broad; fruiting pedicels 1-2 cm. long. U. inflata var. minor Chapm.

In lakes, ditches, slow streams and ponds in e. Tex., Mar.-June; Fla. to Tex., n. to N.S., Tenn. and Ind.

\section{Utricularia vulgaris L. COMMON BLADDERWORT. Fig. 713.}

Plants rather coarse, with elongated stems to $2 \mathrm{~m}$. long and $0.5 \mathrm{~mm}$. or more thick that are free-floating just beneath the surface of the water, the plumose branches of foliage to $12 \mathrm{~cm}$. in diameter; leaves elliptic to ovate-elliptic, to $4 \mathrm{~cm}$. long, much-dissected, the coarser capillary segments slightly less than $1 \mathrm{~mm}$. thick, the numerous bladders large; scape erect, stoutish, to about $8 \mathrm{dm}$. high, supporting as many as 20 flowers, naked at the base or producing slender smallleaved stolonlike divergent offshoots; bracts 3-6 $\mathrm{mm}$. long; corolla yellow, with brown or orange vertical stripes on the large conspicuous palate, $15-25 \mathrm{~mm}$. high, the broad lower lip somewhat 3-lobed and slightly shorter than the curved obtuse or acutish conical spur; fruiting raceme elongate, the arched-recurved pedicels to about $2 \mathrm{~cm}$. long; winter buds ellipsoid, $1-2 \mathrm{~cm}$. long, their crowded leaves hairy; seeds brown, lustrous, striate-reticulate. Incl. var. americana Gray, $U$. macrorhiza Le Conte. 


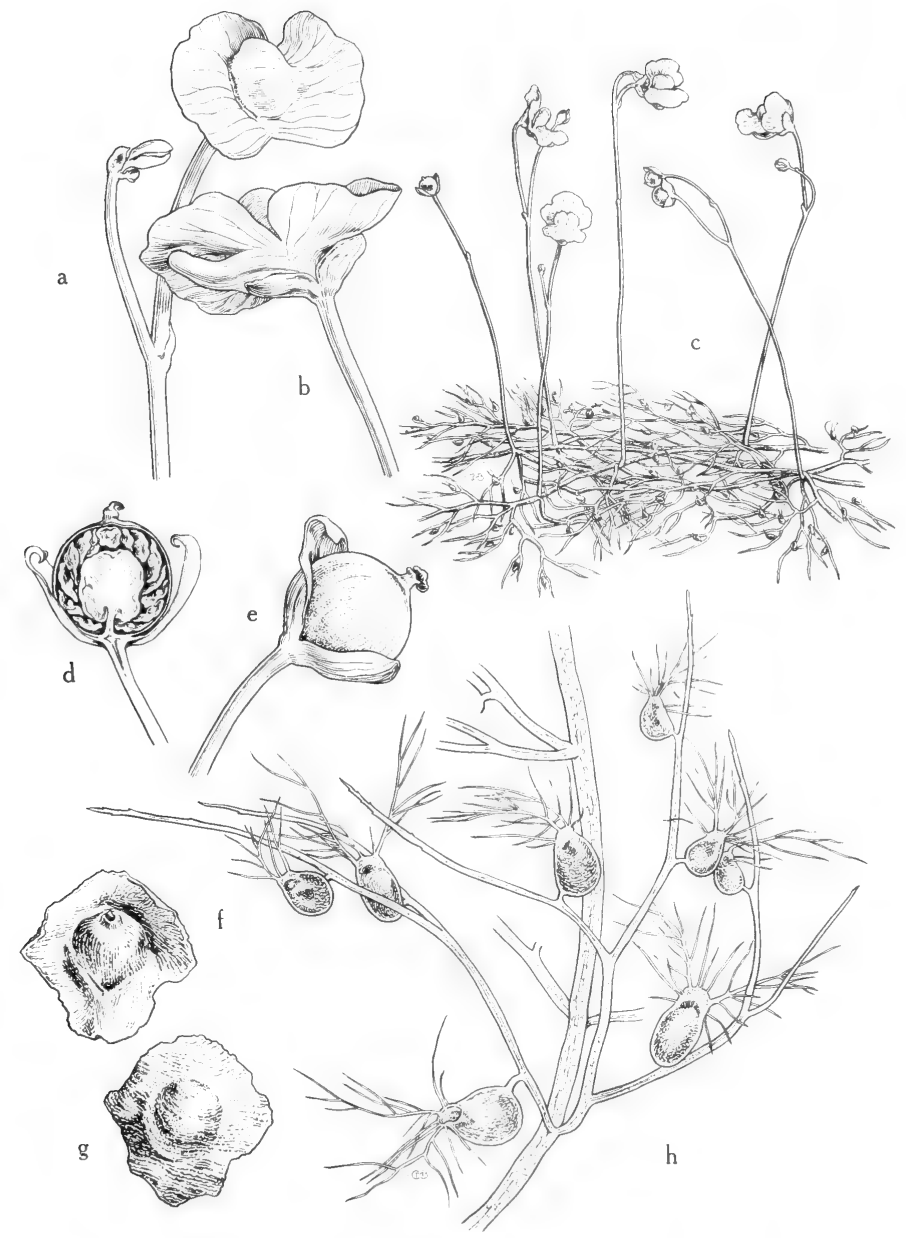

Fig. 714: Utricularia gibba: a and b, flowers showing lips more or less equal in size, rounded palate, and short spur, $x$ 3; c, habit, showing the erect flowering and fruiting scapes and the floating leaves and bladders, $x \quad 4 \% \mathrm{~d}$, capsule (longitudinal section), $\mathrm{x} 4$; e, mature capsule, $\mathrm{x} 4$; $\mathrm{f}$ and $\mathrm{g}$, mature seeds, the wings broad, $\mathrm{x} 24 ; \mathrm{h}$, part of stem, showing bladders borne on the leaf segments, x 6. (From Mason, Fig. $327)$. 


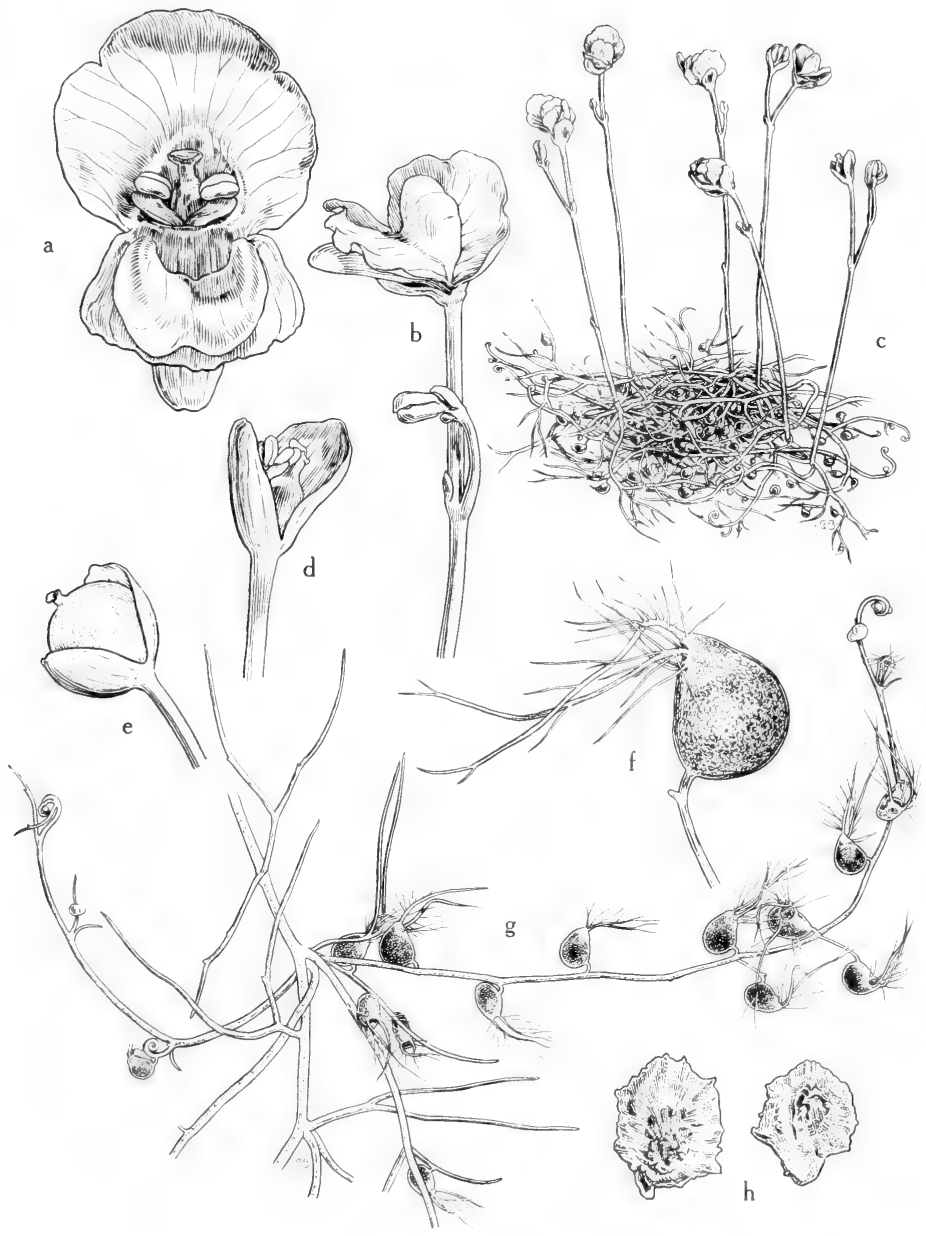

Fig. 715: Utricularia fibrosa: a, flower, the palate bent down to show stamens and pistil, $\times 6$; b, flowering scape, showing young bud and flower, the lips subequal in size and the palate conspicuous, $\mathrm{x} 4$; c, habit, showing dense mass of stems, leaves and bladders, and the erect scapes, $x$ 11/ $d$, calyx, $x 6$; e, capsule, $x 4$; , bladder, x $12 \mathrm{~g}$, bladders on stems and leaves, x 3; h, mature seeds, x 12. (From Mason, Fig. $328)$. 
In deep or shallow quiet water, rare in s.e. Okla. (McCurtain Co.) and s.e. Tex. (also reported from the Panhandle), westw. through N.M. (Catron, San Juan and Sandoval cos.) to Ariz. (Apache and Coconino cos.), Apr.-Aug.; from s. Lab. to Alas., s. to Va., O., Ind., Mo., Tex. and Mex.

\section{Utricularia gibba L. CONE-SPUR Bladderwort. Fig. 714.}

Plant with delicate filiform creeping or floating stems and branches, the sparsely leafy often intricately entangled plumes of foliage to $2 \mathrm{~cm}$. in diameter and $3 \mathrm{dm}$. long; leaves usually with 2 filiform segments and with few scattered bladders; scapes to $1 \mathrm{dm}$. high, 1- to 3-flowered; larger sepal suborbicular, 2-3 $\mathrm{mm}$. long; corolla yellow, 6-12 $\mathrm{mm}$. high, 6-8 $\mathrm{mm}$. broad, the nearly equal lips projecting forward, the oblong-conic obtuse spur much shorter than the lower lip; fruiting pedicels ascending, to $1 \mathrm{~cm}$. long; capsule $2-3 \mathrm{~mm}$. thick, about as long as the sepals; seeds broadly winged, the body smooth.

In mud of marshes, bogs and seepage areas and forming mats and on floating debris in shallow water in e. half of Okla. and mostly in the e. half of Tex., s. to Cameron Co. and w. to Val Verde Co., June-Oct.; from Fla. to Tex. and Mex., n. to e. Can., Mich., Wisc., Minn. and Okla., w. to Calif.

\section{Utricularia fibrosa Walt. Fig. 715.}

Plant closely resembling $U$. gibba; stems creeping on the bottom in shallow water, radiating from the base of the scape, dimorphic, some without bladders that have rather crowded thrice-forked leaves to about $15 \mathrm{~mm}$. long, the other with smaller twice-forked leaves bearing numerous bladders; peduncles to about $15 \mathrm{~cm}$. high, with 2 to 6 long-pediceled flowers; corolla yellow, the lower lip 8-10 $\mathrm{mm}$. long and with a prominent palate; spur equaling or slightly exceeding the lower lip; capsule globose; seeds broadly winged, the body rough-tuberculate.

Floating on mats of debris and rooted in shallow water of slow streams, ponds and lakes in e. Okla. (Waterfall) and e. Tex., June-July; from Mass. to Fla., w. to Tex., Ark. and Okla.

This is our only Utricularia with dimorphic stems and leaves. The bladders are borne mostly on stems and only occasionally on the leaves.

\section{Utricularia biflora Lam. Fig. 716.}

Plant closely resembling both $U$. gibba and $U$. fibrosa; stems all alike, with bladders throughout, floating on mats of debris or creeping on the bottom in shallow water; leaves very delicate, rarely more than $5 \mathrm{~mm}$. long, usually with 3 or more segments; scapes erect, to about $15 \mathrm{~cm}$. long, usually much shorter, with 1 to 4 flowers; pedicels filiform, about $15 \mathrm{~mm}$. long; sepals 2.5-4 mm. long; corolla yellow, very similar to those of $U$. fibrosa, to $17 \mathrm{~mm}$. high; lower lip $8-10$ $\mathrm{mm}$. long, with a prominent palate; spur about as long as or much shorter than the lower lip; fruiting pedicels to $25 \mathrm{~mm}$. long; capsule $3.5-4 \mathrm{~mm}$. thick, slightly exserted. $U$. pumila Walt.

In shallow water e. Okla. (Waterfall) and s.e. Tex., June-July; from e. Mass. to Fla., Tex. and Okla.

\section{Pinguicula L.}

About 35 species, widely distributed.

\section{Pinguicula pumila Michx. Small butterwort. Fig. 717.}

Perennial terrestrial scapose herb with fibrous roots; leaves in a basal rosette, soft-fleshy, greasy to the touch, elliptic to elliptic-obovate, obtuse to rounded at apex, narrowed at base, 1-3 cm. long; scapes one or usually several, 1-flowered, naked, very slender, erect, glandular-puberulent, to $2 \mathrm{dm}$. tall, usually much smaller; calyx 5-lobed, more or less united and bilabiate; calyx lobes oblong, 


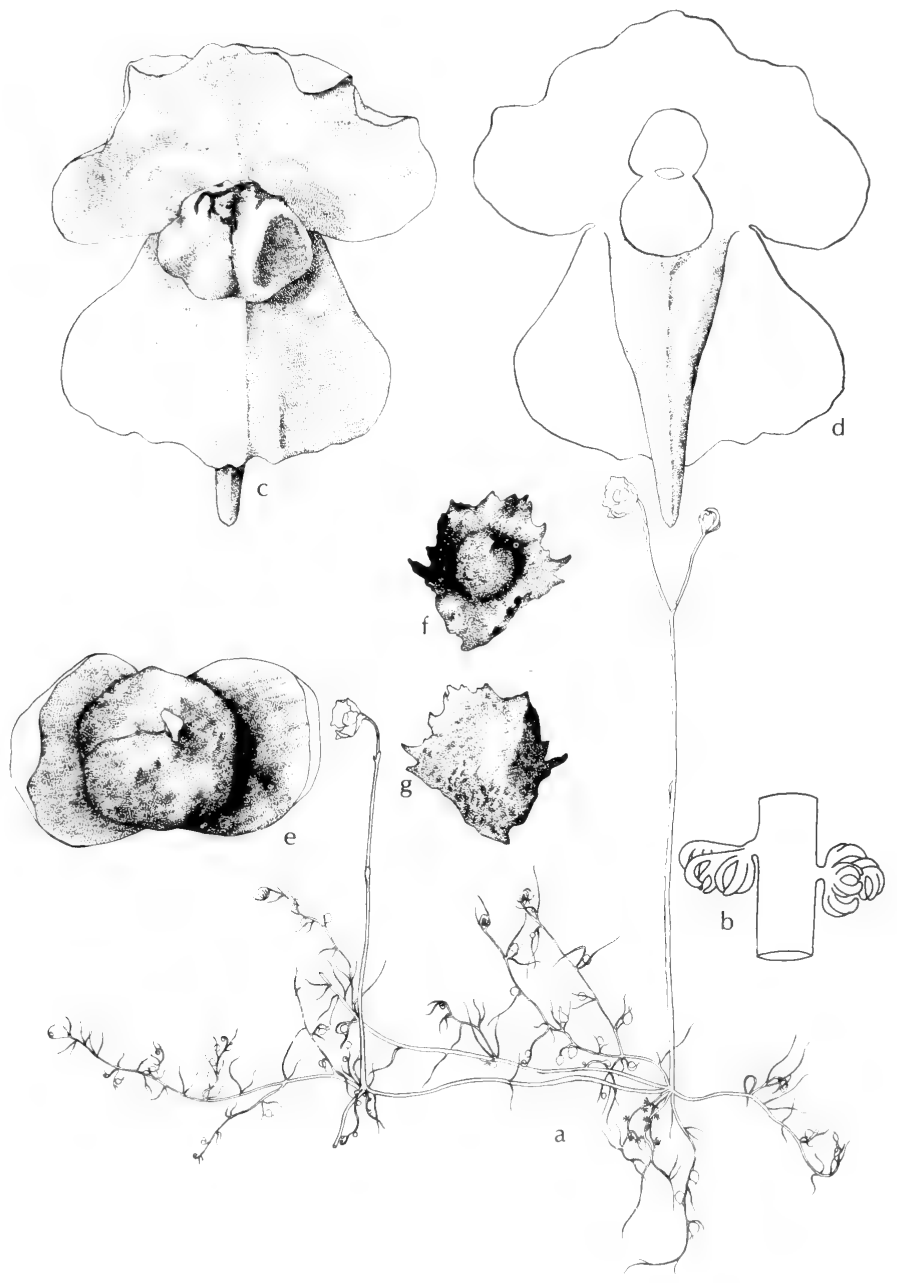

Fig. 716: Utricularia biflora: a, habit, $\mathrm{x} 1$; $\mathrm{b}$, vegetative reproduction bud, $\mathrm{x} 12$; c, flower, $\mathrm{x} 5$; d, flower showing spur, $\mathrm{x} 5$; e, capsule, $\mathrm{x} 12 ; \mathrm{f}$ and $\mathrm{g}$, two views of seed, x 20. (Courtesy of R. K. Godfrey). 

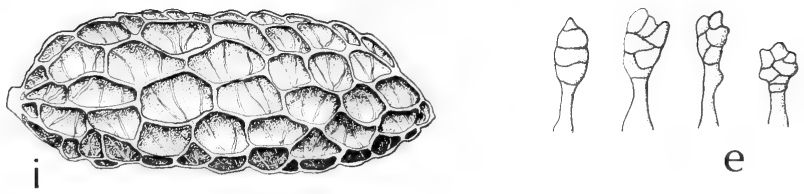

e
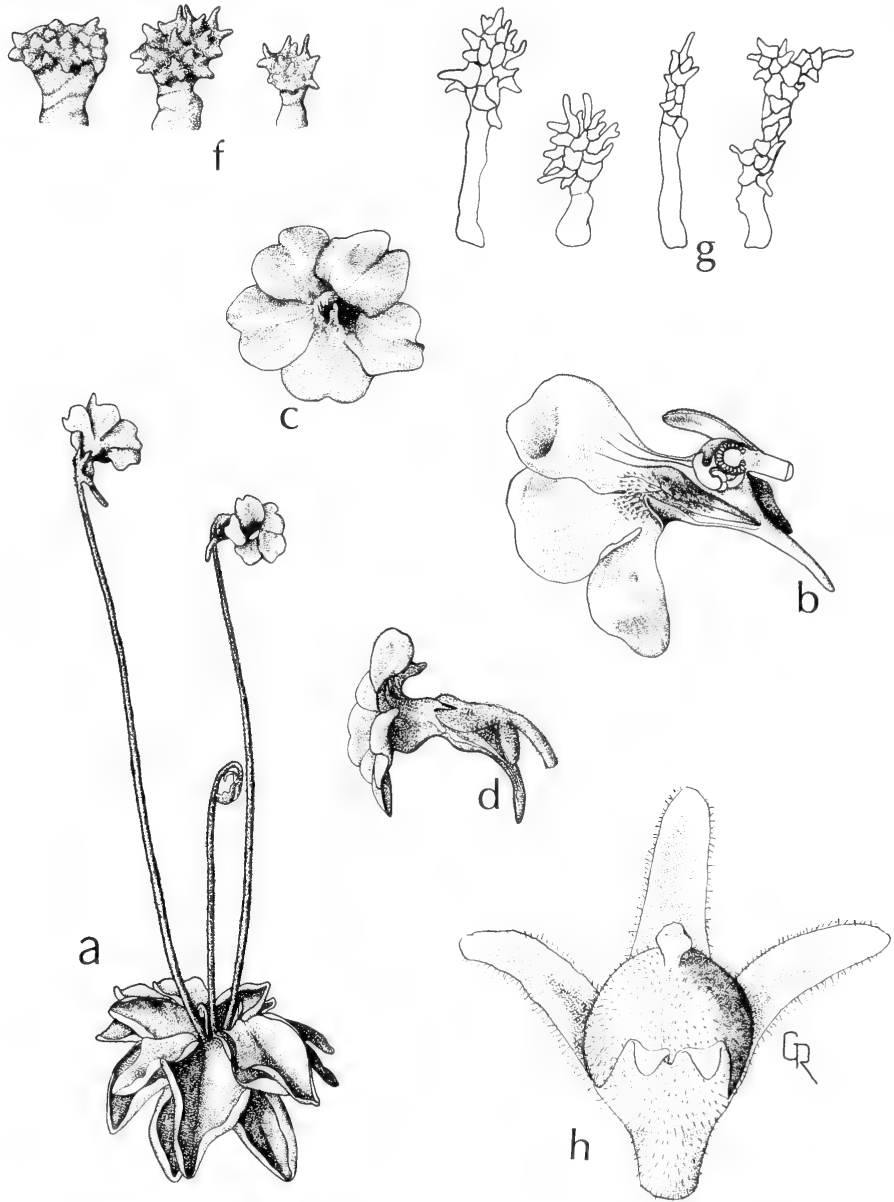

Fig. 717: Pinguicula pumila: a, habit, about $\times 1 / 2$; b, flower, longitudinal section, about $\mathrm{x} 2$; c and $\mathrm{d}$, flower, face and lateral view, $\mathrm{x} 11 \frac{1}{2}$; e, trichomes from palate, greatly enlarged; $\mathrm{f}$, trichomes from ridge on corolla behind the palate, greatly enlarged; $\mathrm{g}$, trichomes from inner walls of the corolla tube, greatly enlarged; $h$, capsule, $x \quad 8 ; i$, seed, about x 60. (Courtesy of R. K. Godfrey). 
obtuse, 2-4 mm. long; corolla whitish or pale-violet, sometimes marked with purple and yellow, somewhat bilabiate with the 5 lobes subequal, $1-2 \mathrm{~cm}$. broad; corolla spur subulate, about $3 \mathrm{~mm}$. long, usually shorter than the saclike base of the corolla, the palate (in ours) subulate or clavate, included in the tube; capsule 2- to 4-valved.

In seepage and wet soils of savannahs and low pinelands on the Coastal Plain in s.e. Tex., Mar.-June; from Fla. to Tex. and S.C.; also Bah. I.

\section{Fam. 122. Acanthaceae Juss.}

\section{ACANTHUS FAMILY}

Herbs or small shrubs, usually with cystoliths appearing as minute short lines on the vegetative parts; leaves simple, usually entire, opposite or sometimes alternate or subopposite; flowers irregular to nearly regular, perfect; calyx persistent, inferior, the segments 5 or occasionally fewer; corolla gamopetalous, the limb 5-lobed or 2-lipped (rarely 1-lipped); stamens 4, didynamous or 2 only; staminodes often present in the 2-stamened flowers; anther sacs 2 or 1, longitudinally dehiscent; ovary 2-celled, the ovules 2 to 10 in each cavity; style filiform, simple; stigmas 1 or 2 ; fruit a capsule, 2 celled, 2-valved; seeds usually flat, borne on funicles which are papilliform in a few genera but usually hook-shaped, the testa smocth or roughened, often mucilaginous when moistened.
A large pantropical family of about 2,500 species in 250 genera.

1. Corolla lobes contorted (convolute) at aestivation; stamens 4 (2)

1. Corolla lobes imbricate (3)

2(1). Corolla deeply bilabiate; flowers in axillary fascicles; capsule terete and 2-celled to the very base.......................................1. Hygrophila

2. Corolla scarcely or not at all bilabiate, the 5 broad lobes rounded and spreading. 2. Ruellia

3(1). Placenta separating from the capsule wall at maturity; corolla with narrow cylindric tube; anther cells usually rounded at base.

3. Placenta not separating; corolla with short non-cylindric tube (4)

3. Dicliptera

4(3). Corolla subequally 4-lobed; anther cells muticous or rarely mucronate at base. 4. Yeatesia

4. Corolla deeply bilabiate; lower anther cell mucronate or calloused at base ..5. Justicia

\section{Hygrophila $R$. BR.}

The genus is cosmopolitan. Of the numerous species described, only about 80 are now considered as valid.

\section{Hygrophila lacustris (Schlecht. \& Cham.) Nees. Fig. 718.}

Herb to $8 \mathrm{dm}$. high, sparingly hirtellous to glabrate; stems obtusely quadrangular, branching; leaves lanceolate, $5-12 \mathrm{~cm}$. long, 5-25 $\mathrm{mm}$. wide, acute at apex, entire; flowers sessile, clustered in the axils; bracts linear: calyx segments 5 , lanceolate, about $5 \mathrm{~mm}$. long, white-margined, pilose; corolla yellow, puberulent, the cylindric tube $5 \mathrm{~mm}$. long, the bidentate upper lip $2.5 \mathrm{~mm}$. long, the lower lip 3-lobed; stamens 4, didynamous or 2 perfect stamens and 2 staminodes, the filaments of each pair united at base by a membrane; anthers 2-celled, muticous or mucronulate: posterior stigma lobe abortive; capsules narrowly oblong, 8-12 $\mathrm{mm}$. long, glabrous, 16- to 18 -seeded.

In marshy regions along streams, swamps or on shores of ponds in s.e. Tex. where its rhizomes form colonies, June-Sept.; from Fla. to Tex. 


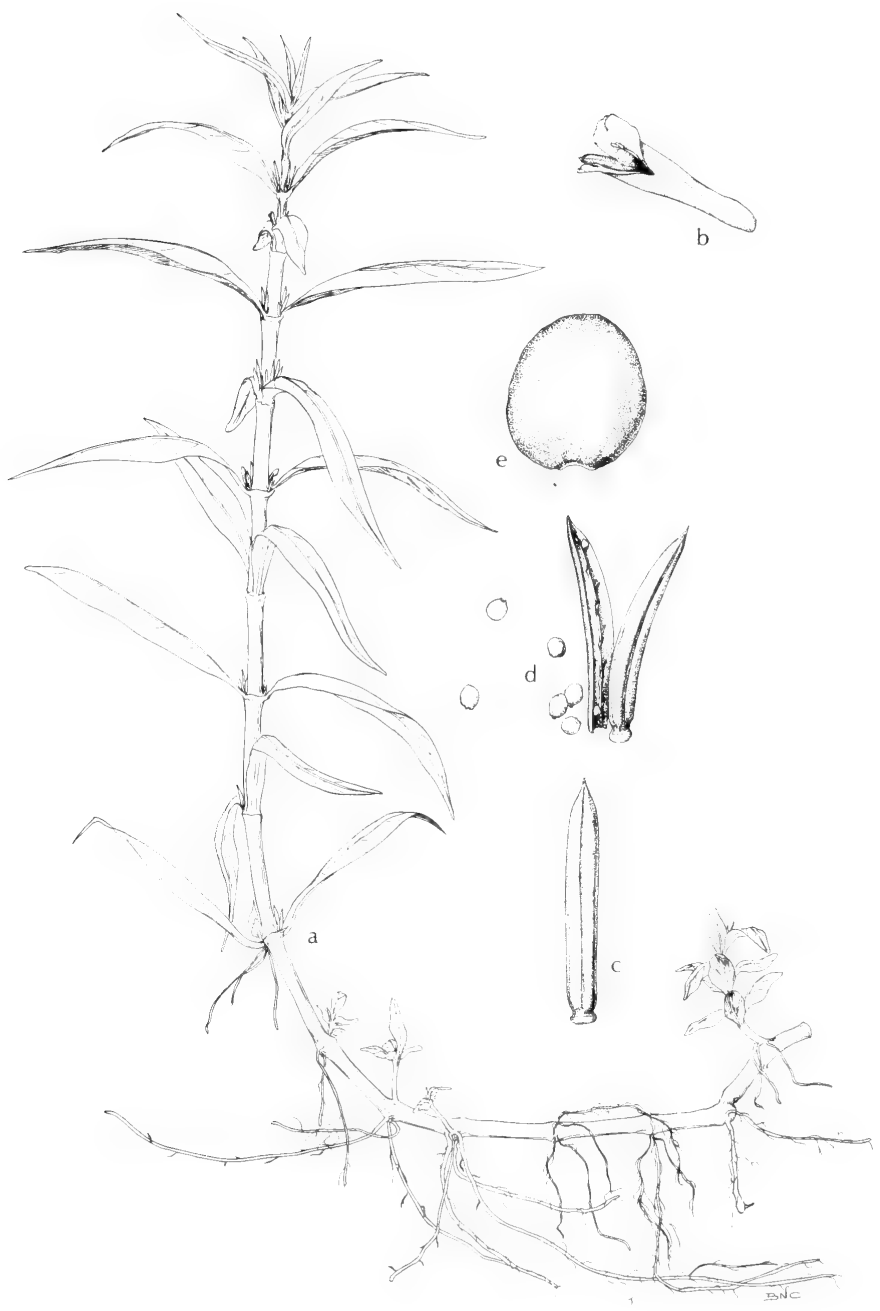

Fig. 718: Hygrophila lacustris: a, habit, x 1/3; b, flower, $x$ 3; c, capsule, $\times 21 \frac{1}{3}$; d, capsule split open, x 21/3; e, seed, x 17. (Courtesy of R. K. Godfrey). 


\section{Ruellia L.}

Perennial herbs or shrubs; leaves petioled, entire to undulate or rarely dentate; flowers usually large and showy, solitary or clustered in the axils or borne in terminal cymose panicles; calyx usually 5-parted, the segments often narrow; corolla red, yellow, white or purple (usually mauve), funnelform or salverform, sometimes saccate, the tube usually narrow below, the upper portion more or less campanulate, the limb of 5 obtuse spreading lobes; stamens 4 , didynamous, the flat to tip ( $2-4 \mathrm{~mm}$. wide, villous-ciliate, villous to glabrate on back; corolla

A large genus containing upward of 200 species, a majority of which are tropical or subtropical. The geographic center of distribution in the Western Hemisphere is somewhere in southern Mexico or Central America.

1. Calyx lobes linear-lanceolate, flat to the tip, $2-4 \mathrm{~mm}$. wide........ $R$. strepens.

1. Calyx lobes narrowly linear, the prolonged tips very slender to almost bristleform. 2. $R$. humilis.

\section{Ruellia strepens $L$.}

Stem to about $1 \mathrm{~m}$. high, simple or with few ascending branches, minutely pilose to glabrous; principal leaves membranaceous, ovate, rounded or tapering to slender petioles at base, acuminate at apex, entire to barely undulate, to $18 \mathrm{~cm}$. long and $9 \mathrm{~cm}$. wide, short-strigillose to glabrous; peduncles borne from 1 to 3 median nodes, to $9 \mathrm{~cm}$. long, terminated by 2 dilated leafy bracts that subtend 1 to 3 showy flowers; calyx segments lanceolate to linear-lanceolate, flat to tip, 2-4 mm. wide, villous-ciliate, villous to glabrate on back; corolla pale-blue-violet, broadly expanding, 3-6 cm. long, with broadly funnelform throat; capsule glabrous, 1-2 cm. long, usually overtopped by calyx segments.

In rich woods, talus slopes and low woodlands, seepage areas, gravel bars and floodplains, commonly in calcareous areas, in e. and n.-cen. Tex. and Okla. (Cherokee and Osage cos.), Apr.-May; from Tex. to S.C., n. to N.J., Pa., O., Ind., Ill., Mo. and Kan.

The var. cleistantha Gray has smaller cleistogamous flowers usually in cymose clusters and from several of the axils, and a peduncle lacking or shorter than that of var. strepens.

\section{Ruellia humilis Nutt.}

Stem coarse to slender, usually erect or rarely decumbent at base, to $8 \mathrm{dm}$. high, in clusters from knotty shortened rhizomes, often strongly 4-angled, villoushirsute with whitish hairs or glabrescent, usually with slender elongate archedascending to horizontally divergent or reclining branches; leaves of the main axis as many as 36 , coriaceous, to $8 \mathrm{~cm}$. long and $45 \mathrm{~mm}$. wide; main leaves with petioles to $3 \mathrm{~mm}$. long, ovate to lanceolate or broadly elliptic, subacute to acute or mostly obtuse or rounded at apex, truncate to broadly cuneate and decurrent at base, entire or slightly undulate, hirsute to villous or sometimes pilose-ciliate on margins; bracts lanceolate to linear-lanceolate or oblanceolate to elliptic; flowers usually few in the axils of the median and upper leaves, on very short peduncles; calyx lobes linear-attenuate, 15-25 $\mathrm{mm}$. long, villous-hirsute and conspicuously ciliolate; corolla lavender to light-blue, $3-7 \mathrm{~cm}$. long, the tube to $45 \mathrm{~mm}$. long, the limb mostly 2 to rarely $4 \mathrm{~cm}$. broad, in cleistogamous flowers the reduced corolla is tubular and closed; capsule brownish, to $15 \mathrm{~mm}$. long and $5 \mathrm{~mm}$. broad, glabrous, constricted at base; seeds few, ovate to suborbicular, $3 \mathrm{~mm}$. in diameter. $R$. ciliosa of auth.

In open forests, savannahs and old fields, edge of streams and in mud about lakes and ponds, primarily in e. fourth of Tex., rare on Edwards Plateau and in the Panhandle, and Okla. (Atoka, Kay and McCurtain cos.), Apr-Oct.; from Pa. and W. Va. to Mich., Ia. and Neb., s, to Fla. and Tex. 
Those variations in this species that are considered to be distinctive and that have been named are segregated here.

Var. depauperata Tharp \& Barkl. is characterized by its weak filiform stems that are glabrescent to sparsely pilose, and its more or less oblanceolate sparsely pubescent to sparsely pilose leaves.

Var. frondosa Fern. has internodes strongly villous-hirsute, the large usually obtuse leaves of the primary axis ovate to oval-oblong or widely elliptic and $3.5-8 \mathrm{~cm}$. long and $2-4 \mathrm{~cm}$. wide, the corolla $3-5 \mathrm{~cm}$. long and the tube $1.2-3$ $\mathrm{cm}$. long.

Var. Iongiflora (Gray) Fern. with stems villous-hirsute; leaves copiously villoushirsute on veins and margins; larger leaves of the main axis elliptic-oblong to oblong-lanceolate, $3-6 \mathrm{~cm}$. long, $1-2.5 \mathrm{~cm}$. wide, obtuse to subacute at the apex; corolla $5-8 \mathrm{~cm}$. long, its tube $3-5 \mathrm{~cm}$. long.

Var. expansa Fern. with stems to $85 \mathrm{~cm}$. high, the internodes strongly villoushirsute; larger leaves of the principal axis ovate to oval-oblong or broadly elliptic, obtuse at apex, $3-7.5 \mathrm{~cm}$. long, $2.5-4 \mathrm{~cm}$. wide, ciliate-hirsute; corolla $5-8 \mathrm{~cm}$. long, the tube $3-5 \mathrm{~cm}$. long.

\section{Dicliptera JUSS.}

About 150 species in tropical and temperate regions of the world. The species are easily recognized by their hexagonal stems and flattened bracted reduced cymes.

\section{Dicliptera brachiata (Pursh) Spreng. Fig. 719.}

Herb to $7 \mathrm{dm}$. high; stems more or less hexagonal in cross section, erect or ascending, rather slender, with numerous spreading branches, from almost glabrous to pilose-pubescent, rarely spreading-villous or hirsute; leaves oblong-ovate to ovate-lanceolate, to $1 \mathrm{dm}$. long and $5 \mathrm{~cm}$. wide, membranaceous, mostly acuminate at apex, narrowed at base and decurrent on a slender petiole to $3 \mathrm{~cm}$. long, glabrous to pilose-pubescent; flowers clustered in the axils and more or less paniculate, short-peduncled to subsessile; branches of the panicle subtended by leaves similar to but smaller than those of the main stem; floral bracts varying from broadly obovate to spatulate-oblong, to $7 \mathrm{~mm}$. long and $4 \mathrm{~mm}$. wide near the middle, rounded at summit, narrowed at base; calyx subhyaline, 3-3.5 mm. long, campanulate, papular-puberulous or glabrous toward base; corolla purple or flesh-colored, finely pubescent, $1.5-2 \mathrm{~cm}$. long; stamens partly enclosed by the upper lip of the corolla and reaching to its apex, the filaments glabrous to minutely pilose toward base; capsule ovoid, 5-6 $\mathrm{mm}$. long, the solid stipitate basal portion $1 \mathrm{~mm}$. long, the tip of the capsule emarginate and apiculate, the surface of capsule ciliate toward apex, the placentae separating elastically from their walls and rupturing on dehiscence, sparsely pilose elsewhere; seeds 2 or 4 , brown, oval, flattened, about $2 \mathrm{~mm}$. long and broad, essentially glabrous. Incl. var. glandulosa (Scheele) Fern. and var. Ruthii Fern., Diapedium brachiatum (Pursh) O. Ktze.

In shady and moist places, in water at edge of streams and about ponds, mostly in cen. and s. Tex. and Okla. (Choctaw, McCurtain and Ottowa cos.), July-Oct.; from Fla. to Tex., n. to Va., Ind., Mo. and Okla.

\section{Yeatesia Small}

A monotypic genus.

\section{Yeatesia viridiflora (Nees) Small.}

Perennial to $6 \mathrm{dm}$. high, puberulent to almost glabrous; stem erect, simple or branched, slightly glaucous, when dry with a contracted ring above each node as 


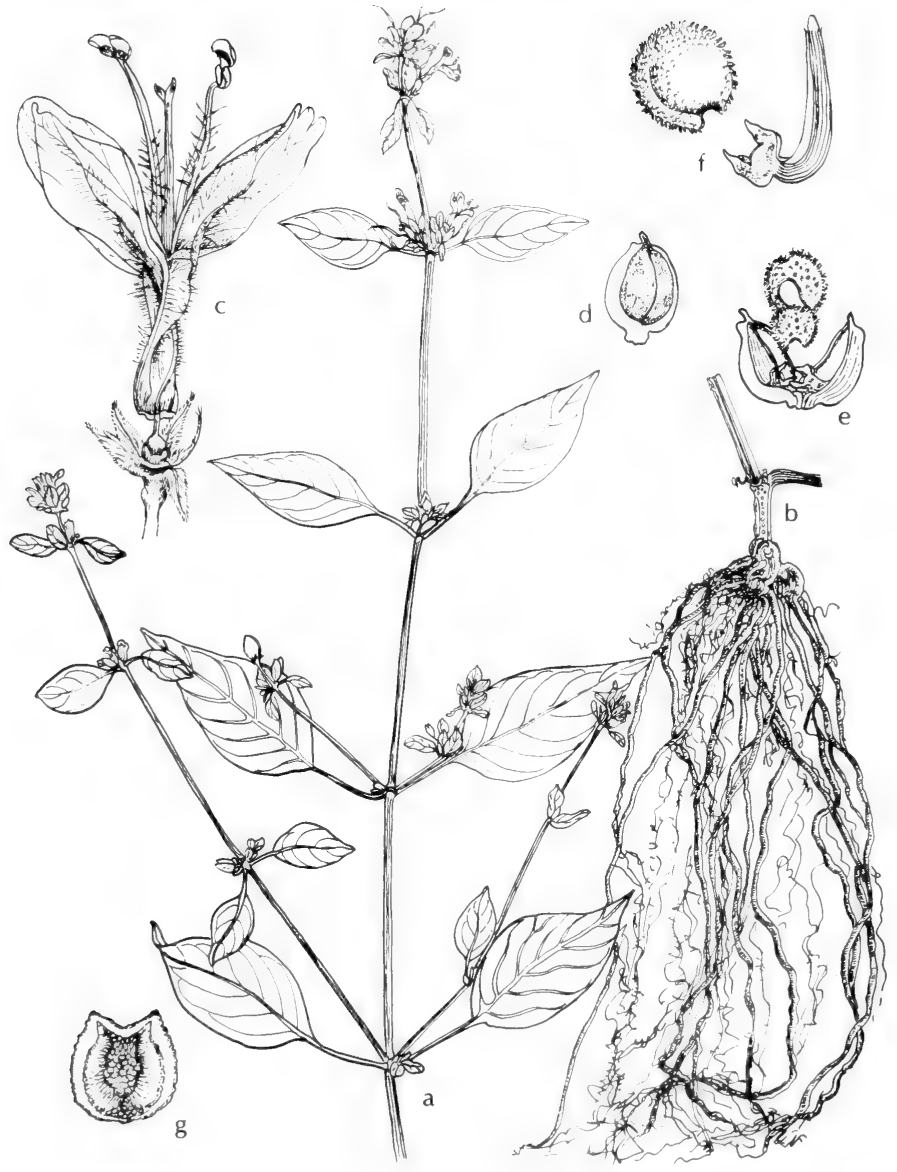

Fig. 719: Dicliptera brachiata: a, habit, upper part of plant, x 1/2; b, habit, basal part of plant, showing roots, $x 1 \frac{1}{2}$; c, flower. $x 2^{1}$; , capsule, $x 2 \frac{1}{2}$; e, open capsule with seed, x $21 \frac{1}{2} ;$, seed and ovary, x $5 ; \mathrm{g}$, stem (cross section), x 5, V. F.). 


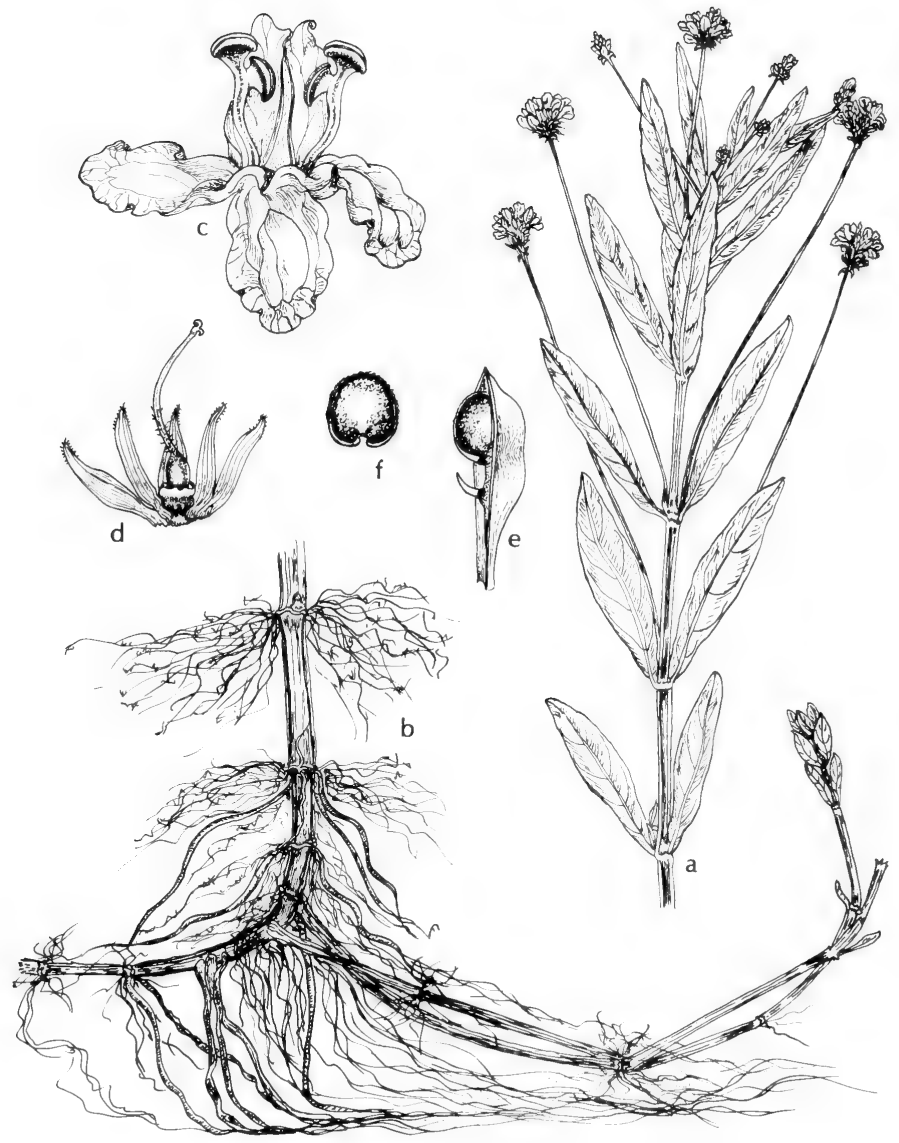

Fig. 720: Justicia americana: a, habit, upper part of stem, x 1/2; b, habit, basal part of plant, showing roots, $\mathrm{x} 1 / 2 ; \mathrm{c}$, flower, $\mathrm{x} 21 / 2 ; \mathrm{d}$, open calyx with ovary and style, $x 2 \frac{1}{2}$; e, open capsule, $x 2 \frac{1}{2} ;$ f, seed, $x 2 \frac{1}{2}$. (V. F.). 
if articulated; leaves large, to $12.5 \mathrm{~cm}$. long and $5 \mathrm{~cm}$. wide, bright-green, membranaceous, ovate-lanceolate to oval, acuminate at apex, gradually tapering into a short petiole, glabrous on lower surface, slightly hairy above; flowers numerous, axillary and terminal, in oblong and somewhat strobilaceous usually shortpeduncled cylindrical compact spikes; bracts oval to obovate, with a narrowed base, about $15 \mathrm{~mm}$. long, mucronate, hirsute-ciliate; bractlets similar to bracts but smaller, about half the length of the capsule; calyx sessile, somewhat glumaceous, deeply 5-parted; calyx lobes setaceous-subulate, sparingly hirsute-ciliate, the innermost smaller; corolla white to flesh-colored, 3- or 4-toothed, almost salverform, about $15 \mathrm{~mm}$. long, the spreading lobes about $5 \mathrm{~mm}$. long; stamens 2, with oblong contiguous and similar anther cells that are muticous, with rarely one or both mucronate at base; filaments slender, inserted and included within the tube of the corolla; capsule clavate-oblong, firm-coriaceous, 4-seeded, the body longer than the stipelike base; seeds glabrous, minutely rugulose. Gatesia laetevirens (Buckl.) Gray.

In pinewoods, gulf prairies, marshes and swamps of e. Tex., July-Oct.; from Fla. to Tex., n. to Ga. and Tenn.

\section{Justicia L.}

Herbs or shrubs; leaves opposite, petiolate, entire; flowers solitary or in spikes or panicles; bracts various, small, linear to subulate, distant, conspicuous and imbricate; calyx segments 5 or (in some species) 4, usually narrow and nearly equal; corollas usually white, pink or purple, sometimes with purple or white markings in throat, the tube usually rather narrow, the limb 2-lipped, the upper lip 2-lobed, the lower lip 3-lobed; stamens 2, often slightly exserted but usually not exceeding the corolla lips; anther cells 2, more or less superposed, one or both cells apiculate or tailed, the connective narrow to broad, the lobes parallel or obliquely affixed; capsules clavate, 4-seeded.

About 300 species, mostly tropical.

1. Flowers capitate, the heads dense, at length oblong......... J. americana.

1. Flowers in spikes, lax on one side................ lanceolata.

1. Justicia americana (L.) Vahl. American water-willow. Fig. 720.

Perennial glabrous plant, colonial by rhizomes, to $1 \mathrm{~m}$. high; stem erect, sulcateangled, slender, usually simple, often rooting below; leaves linear to lanceolate or narrowly oblong, gradually acuminate, narrowed at base into short petioles or sessile, to $16 \mathrm{~cm}$. long and $25 \mathrm{~mm}$. wide; flowers borne in capitate spikes to $3 \mathrm{~cm}$. long at ends of slender axillary stiffly ascending peduncles that are to 15 $\mathrm{cm}$. long; calyx 5-parted, longer than the internodes above it; calyx lobes linearsubulate, about $7 \mathrm{~mm}$. long; corolla violet or nearly white, $1-1.2 \mathrm{~cm}$. long, its tube shorter than the lips, the base of the lower lip rough and palatelike, marked with purple dots; stamens 2 , the glabrous filaments attached at tip of corolla tube and $6 \mathrm{~mm}$. long; anther cells separating and somewhat unequal, the terminal anther sac transverse; capsule about $12 \mathrm{~mm}$. long, exceeding the calyx, its stipe about the length of the slightly compressed body; seeds 4 , densely verrucose, 3 $\mathrm{mm}$. long, $2 \mathrm{~mm}$. wide, Dianthera americana L. and var. subcoriacea (Fern.) Shinners.

In shallow water and mud in e. and s.e. Tex., also on the Edwards Plateau and in n.-cen. Tex. and Okla. (Adair, Cherokee, Comanche, Craig, Johnston, McCurtain, Murray and Pushmataha cos.), Apr.-Sept.; from Ga. to Tex., n. to Que., Vt., N.Y., Ont., Wisc., Mo. and Kan.

2. Justicia lanceolata (Chapm.) Small. LANCE-Leaved Water-Willow. Fig. 721. Perennial herb to $3 \mathrm{dm}$. high; stems erect or spreading, more or less branched; 


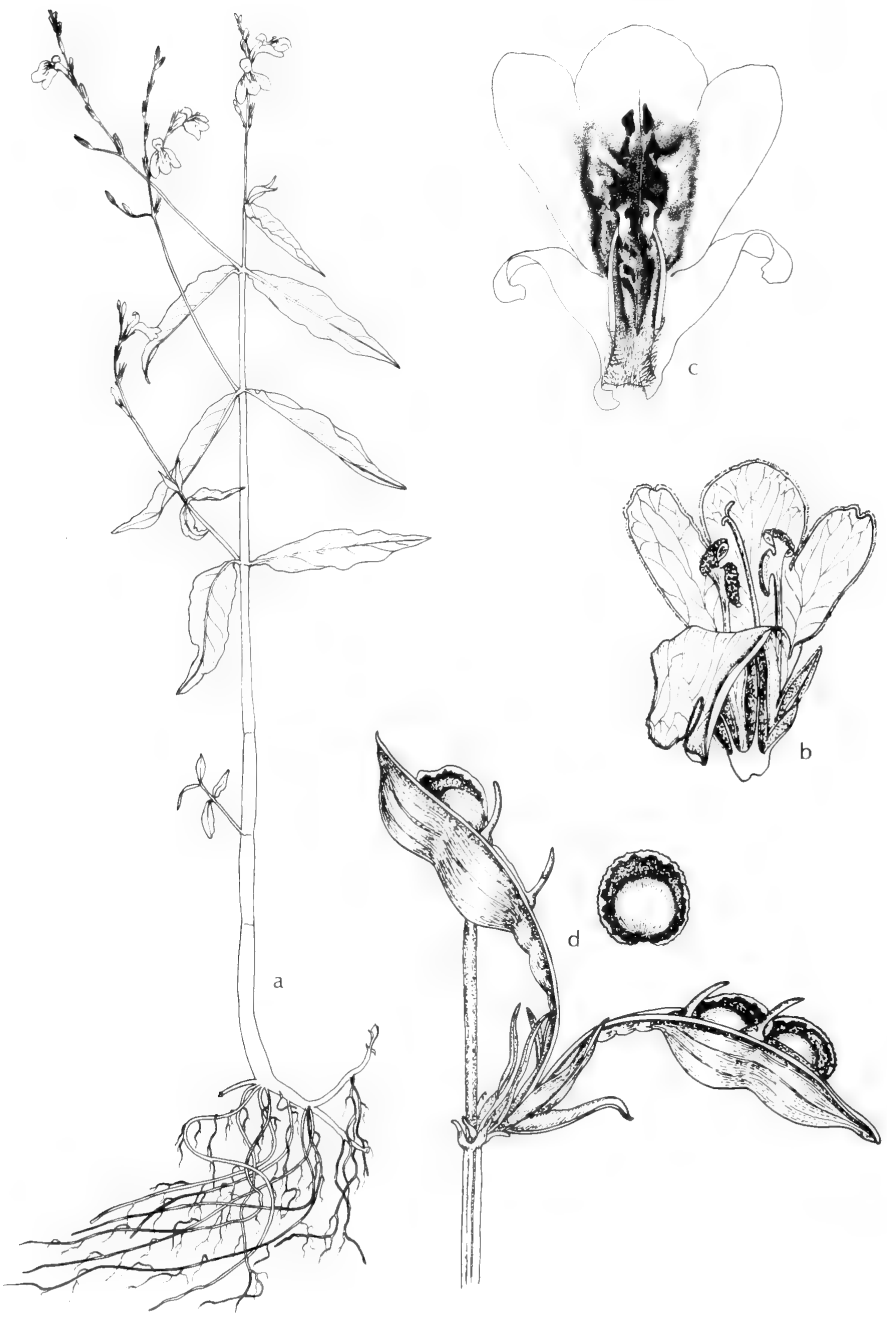

Fig. 721: Justicia lanceolata: a, habit, $x 1 / 3$; b, flower, $x 31 / 3 ; \mathrm{c}$, flower, partly dissected to show attachment of stamens, about $\times 3$; , capsule with one seed removed, x 31/3. (a and c, Courtesy of R. K. Godfrey; b and d, V. F.). 
leaves sessile or nearly so, linear to linear-elliptic or elliptic-lanceolate, somewhat acuminate, minutely puberulent, to $1 \mathrm{dm}$. long and $3 \mathrm{~cm}$. wide: peduncles often branching, longer than the leaves; spikes slender, $3-10 \mathrm{~cm}$. long, the numerous flowers scattered singly and quite evenly along one side: calyx segments narrowly linear, 5-7 mm. long and less than $1 \mathrm{~mm}$. wide; corolla about $1 \mathrm{~cm}$. long, lips nearly as long as the tube which is saccate near the base. the upper lip truncate or retuse, the lower lip 3 -lobed with middle lobe truncate or retuse and the lateral lobe obtuse: stamens slightly exserted, the glabrous filaments attached about midway in the tube and $3-4 \mathrm{~mm}$. long; anther cells unequal, the upper lobe $0.8 \mathrm{~mm}$. long, the lower lobe $1 \mathrm{~mm}$. long and apiculate, the connective broad; ovary $1.5 \mathrm{~mm}$. long, 2-celled, glabrous, ovules 2 in each cell; style $1 \mathrm{~cm}$. long, puberulent at base, the small stigma 2-cleft; capsule $1-1.5 \mathrm{~cm}$. long, the body as long as the stipelike base or shorter; seeds 4 , disklike, $2 \mathrm{~cm}$. in diameter, with thickened margins and smooth surface. J. ovata (Walt.) Lindau var. lanceolata (Chapm.) Gl., Dianthera lanceolata (Chapm.) Small.

In wet and swampy grounds and edge of water along streams, in e. Tex. and s.e. Okla. (McCurtain Co.), Mar.-June; from Fla. to Tex. and Okla., n. to Va.

\section{Fam. 123. Plantaginaceae Juss.}

\section{Plantain Family}

Annual or perennial scapose herbs without or with an abbreviated stem; leaves all basal or nearly so; flowers small, perfect or unisexual, hypogynous, regular or slightly irregular in the calyx, in long-peduncled bracted terminal spikes; calyx and corolla 4-divided or -lobed, persistent, usually scarious or scarious-margined; stamens 4 or 2 , distinct, inserted on the corolla tube; style filiform, stigmatic for most of its length; ovary superior, 2- to 4-celled; fruit a capsule, 1 to few seeds per cell.

A family of 3 genera and about 270 species, cosmopolitan in distribution.

\section{Plantago L. Plantain}

Flowers in spikes or heads, each sessile or subsessile in the axil of a bract; sepals 4 , the 2 next to the bract often somewhat different from the 2 next to the axis; corolla salverform, long-persistent after anthesis, its tube covering the summit of the capsule, its lobes reflexed and spreading or erect and connivent; capsule circumscissile at or below the middle.

More than 250 species, widely distributed.

Species of Plantago are not usually considered to be aquatic or even wetland plants. However, the species we are including, many of which are weedy, are found in springy places, seepage areas, some in salt marshes and in ditches and streams in water or in wet situations, although most of the species may also be found in dry areas.

1. Bracts scarious except at base and in center, ovate and abruptly narrowed into a long scarious tip................................................ P. lanceolata.

1. Bracts scarious-margined or wholly herbaceous, without slender scarious tips (2)

2(1). Sepals and bracts glabrous; spikes 2-4 mm. thick in flower (3)

2. Sepals and bracts pubescent or villous; spikes $3.5-12 \mathrm{~mm}$. thick in flower (6)

3(2). Leaf blades elliptic to ovate, more than $1.5 \mathrm{~cm}$. wide; stamens 4 (4)

3. Leaf blades linear to narrowly oblanceolate, less than $1.5 \mathrm{~cm}$. wide; stamens 2 (9)

4(3). Corolla lobes definitely more than $1 \mathrm{~mm}$. long; bracts and sepals without keels; capsules ovoid.

.2. P. eriopoda. 
4. Corolla lobes less than $1 \mathrm{~mm}$. long; bracts and sepals with definite keels; capsules ellipsoid (5)

5(4). Capsules slenderly ellipsoid, about $4 \mathrm{~mm}$. long, circumscissile far below the middle; bracts triangular-lanceolate.. 3. P. Rugelii.

5. Capsules ellipsoid, usually less than $4 \mathrm{~mm}$. long, circumscissile near the middle; bracts broadly ovate. 4. P. major.

6(2). Bracts at base of spike not keeled nor clasping; corolla lobes spreading or reflexed after flowering and bracts rigid, scarious with green or purple midrib...................................................5. P. insularis.

6. Bracts at base of spike keeled and/or clasping (7)

7(6). Plant perennial, flowering in late summer; capsule usually 3-seeded

7. Plant annual, flowering in spring; capsule usually 2-seeded (8)

$8(7)$. Bracts $1-2.5 \mathrm{~mm}$. long; corolla lobes $0.8-2.3 \mathrm{~mm}$. long; mature seeds oblong, 1.25-1.75 mm. long, 0.7-0.8 mm. wide, yellow-brown to black, deeply grooved ventrally, not transparent-margined

7. $P$. virginica.

8. Bracts $3-4.5 \mathrm{~mm}$. long; corolla lobes $2-3 \mathrm{~mm}$. long; mature seeds oval or oblong-oval, $2.4-2.8 \mathrm{~mm}$. long, $1.3-1.8 \mathrm{~mm}$. wide, bright-red to reddish-black, shallowly concave ventrally, with pronounced transparent margin..................................................8. P. rhodosperma.

9(3). Corolla lobes erect in age; capsule about twice as long as the calyx; seeds 10 to 30 , somewhat asymmetrical.

9. P. hybrida.

9. Corolla lobes becoming reflexed in age; capsule slightly surpassing the calyx; seeds (2 to) 4 (to 8 ), symmetrical......... 10. P. elongata.

\section{Plantago lanceolata L. English Plantain, RibWort. Fig. 721 A.}

Glabrous or more or less pubescent perennial or biennial; leaves narrowly lanceolate to oblanceolate, acute at apex, long-tapering at the petiolar base, strongly several-ribbed, to about $5 \mathrm{dm}$. long and $35 \mathrm{~mm}$. wide, entire or remotely toothed, essentially glabrous or pubescent beneath; scapes exceeding the leaves, channeled, commonly strigose above; spikes very dense, ovoid when young to long-cylindric and to $1 \mathrm{dm}$. long and $8 \mathrm{~mm}$. thick when mature; bracts broadly ovate, scarious, with a narrow herbaceous center and abruptly long-acuminate hyaline tip, conspicuously surpassing the calyx; outer 2 sepals united into a broadly obovate truncate lamina with 2 midveins, the inner sepals ovate; corolla lobes ovate, acute, with a prominent brown midrib, 2-3 $\mathrm{mm}$. long, usually spreading; capsule ellipsoid, obtuse, 3-4 mm. long, circumscissile near the base; seeds 2, black, semiellipsoid, 2-3 mm. long, cymbiform.

A common weed of lawns, roadsides, fields and waste places, also in wet soils on edge of lakes, ponds and along streams, and in seepage about springs, throughout much of the U.S. and Can.; introd. from the Old World.

\section{Plantago eriopoda Torr.}

Perennial; rootstock stout, sometimes elongate, the crown more or less longvillous with rust-colored hairs among the old leaf bases; leaves oblong-lanceolate to elliptic or oblanceolate, acute, 6-25 cm. long, 3- to 9-nerved, narrowed to a winged petiole about one half the length of the blade, glabrous and somewhat leathery; spikes sparsely pubescent with septate hairs, loosely flowered, $8-18 \mathrm{~cm}$. long; bracts broadly ovate to rounded, the narrow scarious margins sometimes ciliolate or erose, not keeled; sepals oval, scarious-margined, 2-2.5 mm. long; corolla lobes ovate, 1-2 mm. long, often unsymmetrical; style much-exserted, as long as or longer than the stamens; capsule broadly conical or ovoid, about 3 


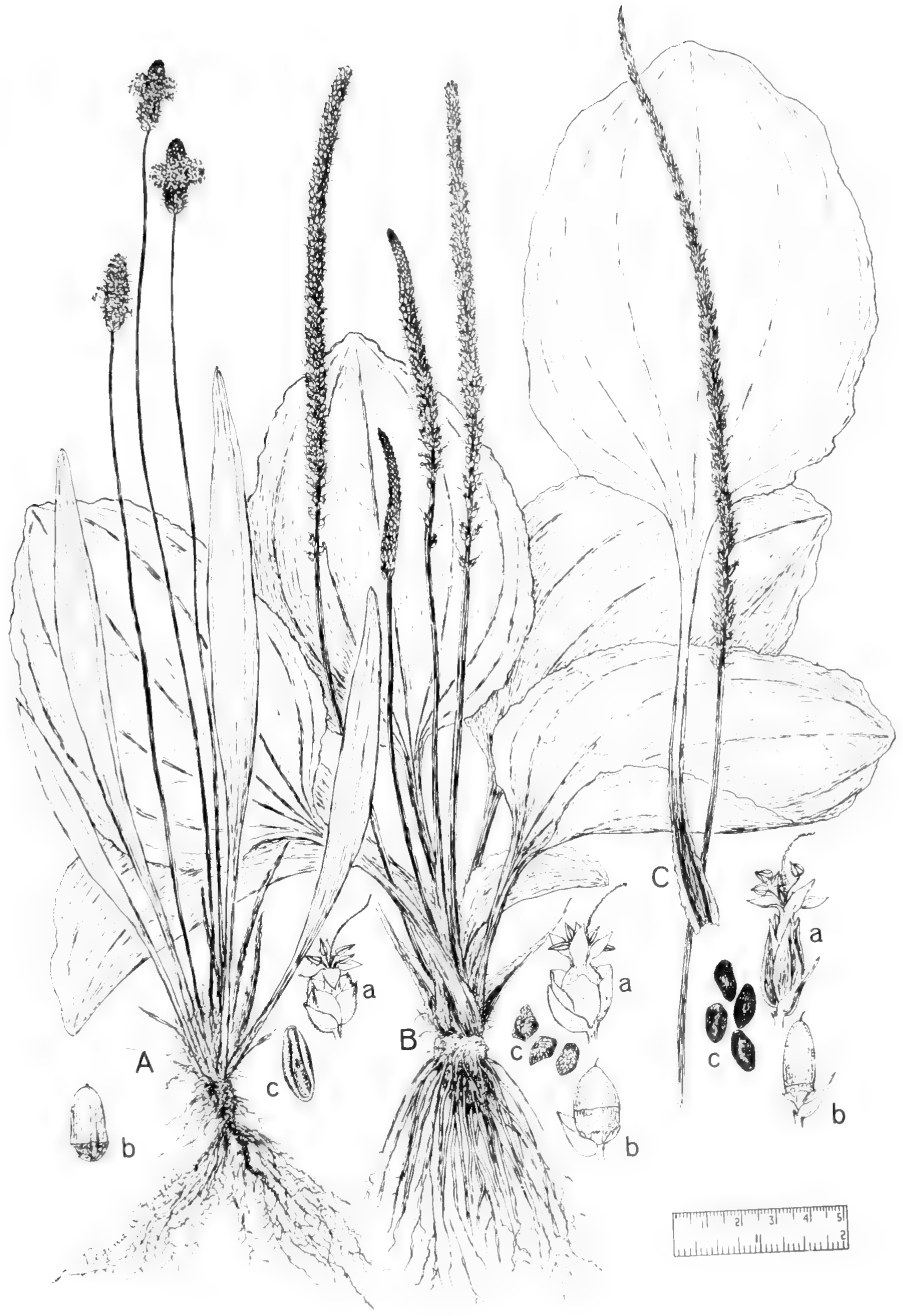

Fig. 721A: habit for all, x 1/2. A, Plantago lanceolata: a, flower, x 21/2; b, capsule, x 3; c, seed, x 5. B, Plantago major: a, flower, x 21/2; b, capsule, x 3; c, seeds, x 5 .

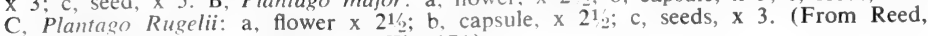
Selected Weeds of the United States, Fig. 171). 
mm. long or more, often tipped by persistent base of style; seeds 3 or $4,2-2.5$ $\mathrm{mm}$. long.

In moist or wet meadows and saline marshes, in mud on edge of lakes in N.M. (McKinley Co.) and Ariz. (Coconino Co.), July-Aug.; Can. to N.M., Ariz. and Calif.

\section{Plantago Rugelii Decne. Fig. 721A.}

Annual or perennial; leaves erect or spreading, with thinnish pale smooth or slightly hirtellous blades with red petioles, broadly elliptic to oval, to about 2 $\mathrm{dm}$. long and half to two thirds as wide; spikes slender, dense to alternate-flowered, attenuate to apex, up to $3 \mathrm{dm}$. long, about $5 \mathrm{~mm}$. wide; bracts narrowly triangularlanceolate, keeled, shorter than the calyx; calyx lobes oblong to lance-triangular, acutely keeled; capsules slenderly ellipsoid, 3-6 mm. long, circumscissile nearly at base, 4- to 9-seeded; seeds black, oval, about $2 \mathrm{~mm}$. long, not reticulated.

Damp shores, roadsides and waste places, along clear spring-fed streams, gravel bars in streams, creek beds, edge of sloughs, in small ponds, in Okla. (Pittsburg, Washington, Cherokee, Mayes and Ottawa cos.), May-Aug.; from Que. to N.D., s. to Okla.

\section{Plantago major L. Common plantain, lanten. Fig. 721 A.}

Glabrous or more or less sparsely pubescent stout perennial; leaves thickish, strongly ribbed, spreading, ovate to broadly elliptic, rounded at apex, broadly cuneate to subcordate at base, to $3 \mathrm{dm}$. long (including the broad channeled petiole), undulate to sinuate-dentate or angular-toothed; scapes curved-ascending or sometimes decumbent, commonly shorter than the leaves; spike dense, to about $2(-3) \mathrm{dm}$. long and $8 \mathrm{~mm}$. thick; bracts ovate, acute, shorter than to rarely longer than calyx, brownish with a slender green keel; calyx lobes broadly ovate to elliptic, 1.5-2 $\mathrm{mm}$. long; corolla lobes $1-1.5 \mathrm{~mm}$. long, reflexed; capsules ovoid, broadly conic to rounded at summit, brown or purplish, about $3 \mathrm{~mm}$. long, circumscissile below tips of sepals; seeds 6 to 16 , angulate, reticulated, $1-1.5 \mathrm{~mm}$. long.

In marshes, wet meadows, in water on edge of streams, ponds and lakes, wet gravel bars along streams, and in seepage areas, introd. from Eur. to become a weed in many places in the U.S. and Can. as well as elsewhere.

\section{Plantago insularis Eastw.}

Low annual with short erect stem and abbreviated ascending branches, villous and tomentose throughout; leaves linear-lanceolate, acute, entire or with minute callous teeth, to about $1 \mathrm{dm}$. long and $8 \mathrm{~mm}$. wide, villous to lanate; scapes numerous, axillary, erect or ascending, to $18 \mathrm{~cm}$. high, more or less pilose to tomentose; spikes many-flowered, erect, short-cylindric, to $2 \mathrm{~cm}$. long and 8 $\mathrm{mm}$. thick, villous to heavily tomentose; bracts oblong to ovate, scarious with green or brown rigid glabrous to villous midrib, as long as the calyces or slightly shorter; calyx lobes ovate to obovate, the midribs green or brown; corolla lobes ovate, apiculate, concave, about $2 \mathrm{~mm}$. long and $1.5 \mathrm{~mm}$. wide, reflexed-spreading, with a brown spot at base of each; capsule twice as long as the calyx, oval, rounded at apex, about $4 \mathrm{~mm}$. long and $2 \mathrm{~mm}$. thick; seeds 2 , brown, narrowly oblong, very finely pitted, about $2.8 \mathrm{~mm}$. long and $1.3 \mathrm{~mm}$. wide, rim of face thickened. Incl. var. fastigiata (Morris) Jeps.

On wet gravel bars in stream beds and on cobbly slopes of canyons in s. TransPecos Tex., and Ariz. (Coconino, Mohave, Maricopa, Pinal, Pima and Yuma cos.), Feb.-May; from s. Calif., Ut. and Nev. to w. Tex. and n. Mex.

\section{Plantago hirtella var. Galeottiana (Decne.) Pilger.}

Perennials with a short thick caudex covered with persistent leaf-bases and long villous hairs; stems erect, $1.5-4 \mathrm{dm}$. tall with septate white hairs near the 
apex; leaves thin, elliptic to broadly obovate, 5-22 cm. long, $1.5-8 \mathrm{~cm}$. wide, narrowed below to a winged petiole less than one half the length of the leaf blades, the 5 to 7 veins of the blade continuing into the petiole, margin entire or somewhat denticulate, pilose at least on the upper surface; spikes polygamous, 5-35 cm. long, 5-12 mm. wide, densely flowered except at the base; bracts ovate to lance-ovate, a little shorter than the calyx, 2-2.5 $\mathrm{mm}$. long, keeled, pubescent, the margins scarious and ciliate; calyx lobes obtuse, scarious-margined; corolla lobes of perfect or staminate flowers spreading, about $2 \mathrm{~mm}$. long, narrowly obovate; corolla lobes of pistillate flowers erect in anthesis; stamens 4 with anthers white; capsule oblong, 3-3.5 mm. long; seeds green-brown, minutely tuberculate, usually 3, with one side flattened, about $2 \mathrm{~mm}$. long. Incl. var, mollior Pilger.

Moist or wet ground along ditches and wet fields, in boggy and springy places along streams in Ariz. (Cochise and Pima cos.), along the Pac. Coast from Wash. to Calif. e. to Ariz., N. M. and cen. Mex.

\section{Plantago virginica L. PAle-Seeded Plantain.}

Annual with a slender taproot, glabrate or usually villous with septate hairs; leaves spreading or ascending, oblanceolate to obovate, obtuse to subacute, entire to coarsely but remotely repand-dentate, hirsutulous, to $2 \mathrm{dm}$. long and $4 \mathrm{~cm}$. wide, usually much smaller; scape to $3 \mathrm{dm}$ long, usually noticeably exceeding the leaves, short-hirsute; spikes dense or interrupted, to $2 \mathrm{dm}$. long and $8 \mathrm{~mm}$. thick; bracts lanceolate to linear-lanceolate, about $2 \mathrm{~mm}$. long, mostly shorter than the calyx, hirsutulous, essentially without a scarious margin; calyx lobes oblongobovate, 2-2.5 $\mathrm{mm}$. long, rounded at apex, the brownish keel hirsutulous, the whitish scarious margin broad and glabrous; pistillate corolla lobes sharply acute, erect and connivent after anthesis; capsules ovoid, about as long as the calyx lobes; seeds 2 , dull pale-brown to nearly black, to $2 \mathrm{~mm}$. long, less than half as wide, with no differentiated margin, cymbiform, the hilum nearly as long as the seed. Incl. var, viridescens Fern.

In thin soil over rocks, along roadsides, in open thickets and flat woods, in wet soil and gravel on edge of lakes and ponds, in salt marshes and dunes along the coast and dry open slopes, rarely on caliche outcrops in e. third of Tex., Okla. (Murray Co.) and Ariz. (Coconino, Cochise and Pima cos.), Mar.-June; from Mass. and N.Y., w. to Wisc., Ia. and Kan., s. to Fla. and Tex.; introd. farther w.

\section{Plantago rhodosperma Dcne. ReD-SEEded Plantain.}

Annual with slender taproot; leaves oblanceolate, long-cuneate at base, obtuse to acute at apex, to $35 \mathrm{~cm}$. long and $5 \mathrm{~cm}$. wide, usually much smaller, grayishgreen, pubescent, entire to coarsely pectinate- or salient-dentaie; scapes one to several, hirsute, shorter than to much-exceeding the leaves; spikes to $2 \mathrm{dm}$. long and $1 \mathrm{~cm}$. thick; bracts and floral segments similar to $P$. virginica but the acute to acuminate keels of calyx lobes extended beyond the scarious margin; seeds 2, bright-red to reddish-black, $2-3 \mathrm{~mm}$. long, more than half as wide, nearly flat on both sides, with a thin pale margin, the central hilum less than a third as long as the seed.

Usually in rocky soils in brushlands and on slopes, occasionally in sandy soils and on gravel bars of washes and streams, in Tex. almost entirely w. of the Blackland Prairies, Okla. (Waterfall) and Ariz. (Yavapai. Gila, Maricopa, Pinal, Cochise and Pima cos.), Mar.-May; from Mo, and Tenn., w. to Kan., Tex. and Ariz.; adv. farther w.

\section{Plantago hybrida Bart.}

Annual with numerous lateral fibrous roots as well as a taproot; leaves linear to linear-subulate, narrowly obtuse to acute at the rigid callous tip, entire, to 15 
$\mathrm{cm}$. long and less than $5 \mathrm{~mm}$. wide, not woolly at base; scape slender, slightly pubescent, shorter than to conspicuously longer than the leaves; spikes slender and elongate, cylindrical, to $13 \mathrm{~cm}$. long and $5 \mathrm{~mm}$. thick, rather loose to expose the axis, the lower spikelets remote; bracts acute, equal to or about twice as long as calyx; calyx lobes ovate, with narrow green midribs; corolla lobes triangularovate, erect and somewhat connivent with age, less than $0.5 \mathrm{~mm}$. long; stamens only 2; capsule about twice as long as the calyx; seeds 10 to 30 , blackish, asymmetrically angular, less than $1 \mathrm{~mm}$. long. (?) P. heterophylla Nutt.

In wet sands and shallow soils in rocky areas, fallow fields and flat woods, occasionally in salt marshes and edge of wet meadows, in Okla. (Johnston Co.) and the e. third of Tex., Apr.-May; rather widespread, especially in s. U.S.

\section{Plantago elongata Pursh.}

Annual with prominent taproot; leaves narrowly linear, 3-10 cm. long; scapes several to many, commonly surpassing the leaves; spikes mostly $2-10 \mathrm{~cm}$. long, loosely flowered so as to expose the axis; bracts ovate to triangular-ovate, mostly shorter than the calyx but sometimes equal to or barely surpassing it, glabrous to slightly hispid, the central herbaceous portion about as wide as the scarious margins, becoming saccate at base; anterior sepals inequilateral and with narrow midvein and wide scarious margins, the posterior sepals similar but conduplicate and sharply keeled; corolla lobes $0.5-1 \mathrm{~mm}$. long, reflexed with age; stamens only 2 ; capsules ovoid, rounded to the summit, $1.5-3.5 \mathrm{~mm}$. long; seeds normally 4 or more, from $1.5 \mathrm{~mm}$. in length (if many seeds) to $2.5 \mathrm{~mm}$. long (if only 4 seeds). $P$. pusilla Nutt.

In moist or dry sandy soil, commonly shallowly covering flat rocks, and in muddy soil about lakes and ponds, in Okla. (Waterfall), rare in e., s. and n.-cen. Tex., spring; from N.E. to the Lake States, s. to Fla. and Tex.

\section{Fam. 124. Rubiaceae JUSS. MADDER FAMILY}

Trees, shrubs or herbs, rarely climbing; leaves opposite or whorled, simple, entire; stipules often united to form a sheath, rarely leaflike; flowers perfect or unisexual, regular, usually in panicles or cymes, sometimes solitary or aggregated into heads; calyx tube more or less united with the inferior ovary, the segments 4 to 8 , crowning the ovary and commonly persistent in the fruit; corolla funnelform, salverform or rotate, the 3 to 5 segments with valvate, imbricate or contorted aestivation; stamens 3 to 5 , inserted on the corolla throat or at the throat, the filaments free, the anthers introrse; ovary crowned by a more or less developed disk, inferior or rarely half-inferior, 1- to several-celled; style filiform, often divided above; fruit a capsule, berry, drupe or schizocarp (in Galium).

Probably more than 6,000 species in about 500 genera, world-wide in distribution. An important family that includes coffee (Coffea spp.) and quinine (Cinchona spp.)

1. Leaves verticillate, with foliaceous stipules. 1. Galium

1. Leaves opposite or (if verticillate) large shrubs, with distinctive stipules (2)

2(1). Ovules few to many in each cell of the ovary (3)

2. Ovule solitary in each cell of the ovary (4)

3(2). Flowers 4-merous; top of capsule nearly always extending beyond the hypanthium.....................................................................2. Hedyotis

3. Flowers 5-merous; top of capsule included in the hypanthium.........3. Pentodon

4(2). Shrubs; flowers in naked dense globular heads about $15 \mathrm{~mm}$. in diameter

4. Herbs; flowers not as above (5)

4. Cephalanthus 
5(4). Trailing glabrous evergreen herbs of dense woodlands; fruit a soft berrylike scarlet drupe. 5. Mitchella

5. Erect to ascending or rarely prostrate nonevergreen herbs mostly in weedy or waste areas; fruit capsular, with 2 or more carpels (6)

6(5). Capsule splitting when ripe into 2 carpels with one carpel open on the inner face, the other one closed..................................6. Spermacoce

6. Capsule splitting when ripe into 2 or 3 carpels, if tardily splitting then conspicuously 6-ribbed.

7. Diodia

\section{Galium L. Bedstraw. Cleavers}

Slender annual or perennial herbs with 4-angled slender stems and whorled sessile or short-petioled leaves, the roots often containing a red coloring matter; stipules foliaceous; flowers perfect or in some species unisexual, mostly in axillary or terminal cymes or panicles, occasionally solitary or few on simple branchlets, the pedicels usually jointed with the calyx; calyx tube ovoid or globose, the teeth obsolete; corolla rotate, 3- or 4-lobed, valvate in the bud; stamens 4, rarely 3 , short; styles 2; fruit dry or fleshy, globular or ellipsoid, twin, separating when ripe into the 2 seedlike indehiscent 1 -seeded carpels.

About 400 species of wide geographic distribution.

1. Fruit smooth or (at most) granulose (2)

1. Fruit ornamented with hairs or occasionally verrucose, tuberculate or muricate (6)

2(1). Plant glabrous throughout; pedicels short and stoutish; leaves in whorls of 4 (3)

2. Plant more or less scabrous (on angles of stems and/or on leaves); pedicels elongate and slender; leaves in whorls of 4 to 6 or 8 (4)

3(2). Leaves firm, with callous margins, mucronate at apex; flowers sessile in a whorl of bracteal leaves; ovary and young fruits scabro-puberulous or at length granulose....................................... G. microphyllum.

3. Leaves fleshy-thickened, without callous margins, obtuse at apex; flowers on short pedicels, the bracts fugacious; ovary and fruit smooth.

2. G. Brandegei.

4(2). Corollas white, $2-3 \mathrm{~mm}$. broad, typically with 4 acute to acutish lobes; stems smooth, stiffish, erect or suberect, without matted basal autumnal offshoots................................................ G. obtusum.

4. Corollas greenish-white, $1.5 \mathrm{~mm}$. broad or less, typically with 3 (sometimes 4 ) obtuse lobes; stems scabrous, diffuse or weakly reclining, developing prostrate matted basal offshoots (5)

5(4). Leaves linear to linear-oblanceolate, typically in whorls of 4 ; the filiform simple peduncles or the 2 or 3 filiform arcuate pedicels scabrous, 5-30 mm. long; distribution New Mexico and Arizona.

4. G. trifidum.

5. Leaves broadly oblanceolate to oblong-spatulate, those of the main axis in whorls of 4,5 or 6 ; the stiffer and straighter peduncles mostly shorter than above, the 2 to 4 pedicels glabrous: distribution Oklahoma and Texas...........................................5. G. tinctorium.

6(1). Fruits tuberculate or with slender or bristly strongly hooked hairs (7)

6. Fruits with slender or bristly straight or only slightly curved hairs (8)

7(6). Plant densely pilose to hirsute throughout; leaves in whorls of 4.

6. G. uncinulatum.

7. Plant not pilose nor hirsute, at most somewhat scabrous or hispidulousciliolate; leaves in whorls of 5 to 8 , usually 6

.7. G. mexicanum var. asperulum. 
8(6). Plant erect, to $9 \mathrm{dm}$. tall, typically smooth and glabrous; leaves in whorls of 4 ; flowers bright-white.

8. G. boreale.

8. Plant weak and reclining; leaves in whorls of 6 to 8 , more or less scabrid or hispid; flowers dull-white or greenish-white (9)

9(8). Leaves mostly oblanceolate, the margins retrorsely bristly; stems retrorsely bristly on the angles, usually pubescent above the nodes; annual

..9. G. A parine.

9. Leaves mostly elliptic-lanceolate, the margins with ascending cilia; stems smooth; perennial, stoloniferous. 10. G. triflorum.

\section{Galium microphyllum Gray.}

Diffusely spreading or ascending perennial, smooth and glabrous but not shining; branches to $3 \mathrm{dm}$. long; leaves firm, shorter than the internodes and narrowly linear, usually mucronate, with narrow midrib prominent beneath and callous naked margins, to $12 \mathrm{~mm}$. long, usually smaller; flowers solitary on a very short or on a longer and pedunclelike axillary branchlet and sessile in its whorl of involucriform leaves, or this proliferous and bearing a second whorl and flower; ovary and young fruit scabro-puberulous or at length granulose, at maturity fleshybaccate. Relbunium microphyllum (Gray) Hemsl.

In canyons and rocky ravines and on ledges and talus slopes, mostly along streams, edge of wet meadows, moist woods, cracks in boulders, in mts. of the Tex. Trans-Pecos, N. M. (rather widespread) and Ariz. (Greenlee to Coconino and Mohave, s. to Cochise, Santa Cruz and Pima cos.), May-Oct.; from Tex. to Ariz. and adj. Mex.

\section{Galium Brandegei Gray.}

Plant glabrous throughout, low and simple to matted and freely forking, the weakly ascending stems $5-15 \mathrm{~cm}$. tall; leaves of primary axes in whorls of 4 , oblanceolate to oblong-spatulate, fleshy-thickened, obtuse at apex, 4-10 mm. long; flowers solitary or sometimes 2 or 3 , on simple or forking peduncles, these and the straight to arching pedicels $3-10 \mathrm{~mm}$. long; pedicels becoming stout in fruit; fruits smooth, 1.5-2 mm. in diameter. G. trifidum var. pusillum Gray.

At edge of water of small ponds, along streams and in low wettish grounds, in N.M. (Taos and San Miguel cos.) and Ariz. (Coconino Co.), May-Aug.; Greenl. and Lab. to Alas., s. to N. M., Ariz. and Calif.

\section{Galium obtusum Bigel. Bluntleaf Bedstraw.}

Stems erect, from capillary rhizomes, simply (not intricately) branched, to about $8 \mathrm{dm}$. high, smooth, stiffish; leaves mostly in fours, rarely in fives or sixes, elliptic-oblong to lanceolate or broadly linear, obtuse, those of the primary axis to $3 \mathrm{~cm}$. long and $6 \mathrm{~mm}$. broad, loosely spreading, slightly scabrous on the margins; cymes terminating stems and branches, their several flowers grouped in twos or threes; the straight peduncles and pedicels ascending in anthesis, often divergent in fruit; corolla white, $2-3 \mathrm{~mm}$. broad, commonly with 4 acute lobes; fruits globose, smooth, $2.5-3.5 \mathrm{~mm}$. in diameter. G. trifidum var. latifolium Torr.

In low woods, bogs at edge of ponds, swamps and wet shores in Okla. (Waterfall) and e. Tex., Mar.-July; from Fla. to (?) Ariz., n. to s.w. N.S., s. and w. N.E., s. Ont., Mich., Wisc., Minn. and Neb.

\section{Galium trifidum L. Fig. 722.}

Weakly erect perennial from a slender rootstock, often freely branching to form dense mats, to about $3 \mathrm{dm}$. high, smooth and glabrous except for the retrorsely scabrous angles of the stems and usually more hispidulous and sparse roughness of the midrib beneath and margins of the thin leaves; leaves mostly in 


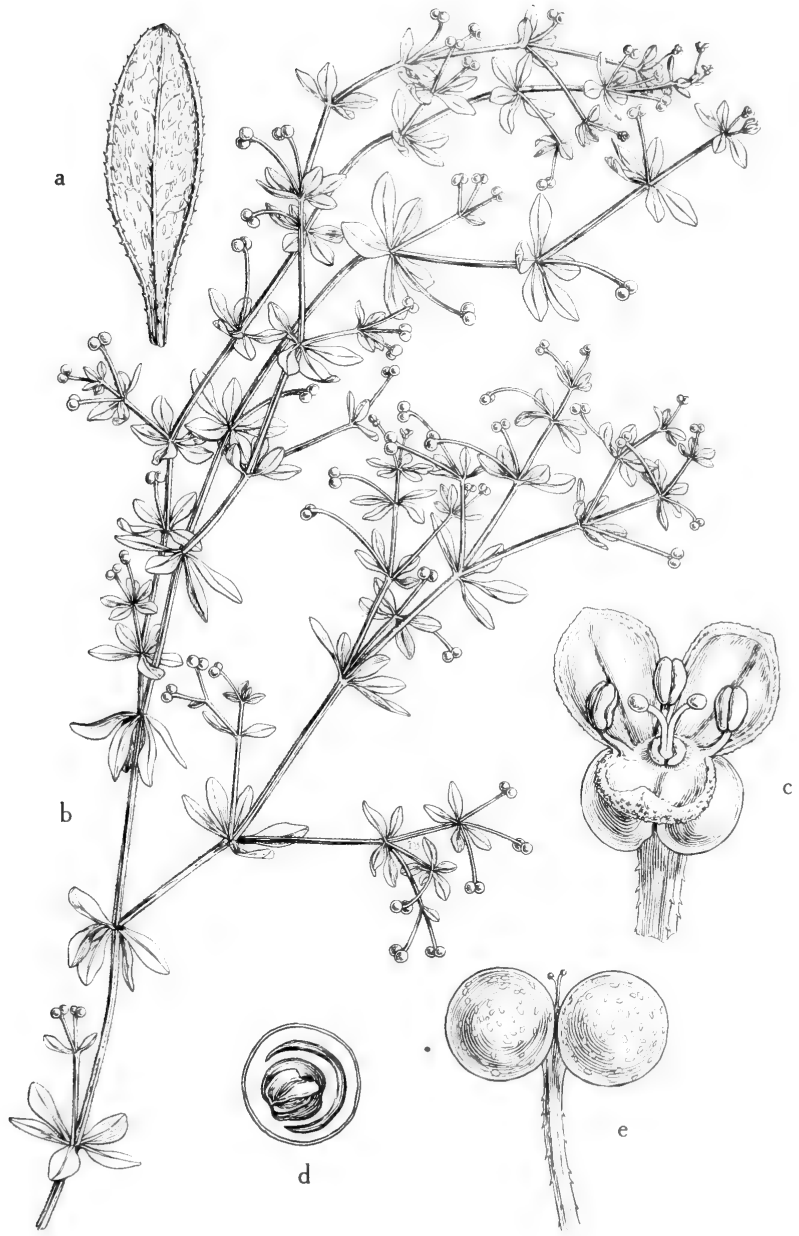

Fig. 722: Galium trifidum: a, leaf, x 4; b, habit, x 4\%; c, flower, x 20; d, fruit (longitudinal section), x 8; e, fruit, x 8. (From Mason, Fig. 329). 
fours, occasionally in fives or sixes, linear to oblanceolate or oblong-lanceolate, obtuse, to $2 \mathrm{~cm}$. long; peduncles slender, scattered; flowers solitary or (when terminal) in threes on capillary scabrous peduncles or pedicels to $3 \mathrm{~cm}$. long; corolla whitish-green, about $0.5 \mathrm{~mm}$. long, its 3 or 4 lobes obtuse; fruit smooth, annular in cross section.

In wet ground, mud, edge of pools, wet depressions in woods, marshes and wet meadows, in mts. of the (?) Tex. Trans-Pecos, N. M. (Taos Co.) and Ariz. (Coconino Co.), summer; from Nfld. and Lab. to Aleutian Is., s. to (?) Tex., N.M., Ariz. and Calif.; also Euras.

\section{Galium tinctorium L. Dye bedstraw, stiff Marsh bedstraw.}

Perennial with stiff ascending or reclining stems, the younger internodss retrorsescabrous on angles; leaves of main axis mostly in fives or sixes, sometimes in fours, broadly oblanceolate to oblong-spatulate, firm, to $2 \mathrm{~cm}$. long; peduncles stiff, straight or straightish, the longest ones $1-1.7 \mathrm{~cm}$. long with 3 (sometimes more) nearly uniform smooth short (to $8 \mathrm{~mm}$. long) straight divergent pedicels; corolla greenish-white, usually 3-lobed, less than $2 \mathrm{~mm}$. broad; mature pairs of fruit smooth, 2-3 mm. across.

In swamps and damp places, in bogs, and mud about lakes and ponds, in the e. fourth of Tex. and Okla. (Waterfall), reported from Ariz. (Kearney \& Peebles), Mar.-Aug.; from Nfld. to Ont. and Neb., s. to S.C., Ky., Mo. and Tex.

Var. subbiflorum (Wieg.) Fern. Many flowers on 1, 2 or 3 separate axillary peduncles or a few peduncles 2- or 3-forked. Lab. and Nfld. to Alas., s. to N.E., N.Y., Mich., Minn., N.M., Ariz. and Calif.

Some recent authors have considered $G$. tinctorium and $G$. trifidum to be conspecific. We are, however, not entirely convinced that this is so.

\section{Galium uncinulatum Gray.}

Perennial herb to $3 \mathrm{dm}$. high, with spreading branches that form a dense procumbent mass, rather densely pilose to hirsute throughout; leaves in fours, narrowly to broadly elliptic to obovate-elliptic, mostly rounded and somewhat mucronate at apex, averaging $1 \mathrm{~cm}$. long or more; pedicels short, stout, rigid, rarely more than $8 \mathrm{~mm}$. long, more or less puberulent; corolla yellow or yellowishwhite, 2-3 $\mathrm{mm}$. broad, the ovate lobes pilose; bristles of the fruit hooked. Incl. var. obstipum (Schlecht.) Wats.

In wet gravelly soil along streams, on steep hillsides, ledges and canyons in Brewster Co., e. to the upper Rio Grande Plains and w. Edwards Plateau in Tex.; also in Mex.

\section{Galium mexicanum H.B.K. var. asperulum (Gray) Dempst.}

Stems erect or diffusely ascending but weak, 3-6 dm. high, from a slender perennial rootstock, minutely retrorse-hispidulous to scabrous or nearly glabrous on the angles; leaves 5 to 8 , usually 6 , lanceolate to oblanceolate, rounded-apiculate to acute at apex, $1-2.5 \mathrm{~cm}$. long, vernicose on upper surface, the margins and midrib beneath antrorsely or retrorsely hispidulous-ciliolate or more or less naked; cymes twice- or thrice-dichotomous, with filiform peduncles and pedicels; corolla white or turning purplish, to $4 \mathrm{~mm}$. broad; fruit less than $2 \mathrm{~mm}$. in diameter, tuberculate, sometimes minutely hispidulous with slender hooked hairs. $G$. asperrimum Gray.

In shaded moist areas, wet depressions and wet soils along streams and irrigation ditches, rich conifer forests, in mts. of the Tex. Trans-Pecos, N. M. (Santa Fe, San Miguel, Bernalillo, Grant, Otero, Lincoln and Taos cos.) and Ariz. (Apache and Navajo, s. to Cochise, Santa Cruz and Pima cos.), May-Oct.; from w. Tex. to Calif., Wash., Mont. and Ida. 


\section{Galium boreale L.}

Plant erect, to $9 \mathrm{dm}$. high, perennial, mostly smooth and glabrous, very leafy; leaves in fours, linear to broadly lanceolate, blunt at apex, rather rigid, distinctly 3-nerved, often with fascicles of smaller leaves in the axils, the uppermost leaves reduced to pairs of small oblong or oval bracts; flowers in numerous close cymules that are collected in a terminal and ample thyrsiform panicle: corolla bright-white, 3-4 mm. wide; fruits small, typically vilious-hirsute with long straight or slightly curved hairs.

In shaded areas in moist wooded ravines, edge of wet meadows, possibly in mts. of the Tex. Trans-Pecos, N. M. (Sandoval and Taos cos.) and Ariz. (Apache and Navajo cos.), May-Aug.; from Can., s. to Pa., (?) Tex., N.M., Ariz. and Calif.; also Euras.

9. Galium Aparine L. Catchweed bedstraw, goose-grass, cleavers. Fig. 722A.

Weak or reclining annual with a slender taproot; stem retrorsely hispid on the angles, hairy above the joints, to $1 \mathrm{~m}$. long: leaves mostly 6 to 8 in a whorl, linearlanceolate, tapering at the base, chiefly $2-7 \mathrm{~cm}$. long, bristle-tipped, the margins and lower midrib retrorsely hispid; peduncles 1- to 3-flowered; corollas white; fruit bristly, 2-4 mm. in diameter. Incl. var. Vaillantii Koch.

In rich woods, thickets, prairies, seashores and waste ground, in seepage along streams and about springs, in e., cen. and s. Tex., Okla. (Grady Co.), N. M. (Dona Ana, Lincoln and Union cos.) and Ariz. (Navajo to Mohave, s. to Greenlee, Graham and Pima cos.), Mar.-May; from Nfld. to Alas., s. to Fla., Tex.. N.M., Ariz. and Calif., both nat. and introd.; also Euras.

\section{Galium triflorum Michx. Fragrant bedstraw.}

Weak perennial from slender creeping rootstocks; stems simple or remotely forking, to $1 \mathrm{~m}$. long or more, smooth; leaves mostly in sixes, thin, elliptic-lanceolate to narrowly oblong, cuspidate, the primary ones $2.8-5 \mathrm{~cm}$. long, the upper ones only slightly reduced, with minute ascending cilia on or near the margin; peduncles axillary, rather short, terminally 3 -flowered, the flowers all pedicelled; corolla whitish or greenish-white, 4-lobed, 2-4 $\mathrm{mm}$. in diameter; fruit densely bristly.

Woods and thickets, seepage area along creeks and about springs, wet depressions in shaded areas, in e. and n.-cen. Tex., Okla. (Waterfall), N. M. (Grant, Socorro, Rio Arriba, Sandoval, San Juan and Taos cos.) and Ariz. (Apache to Coconino, s. to Yavapai, Graham and Pima cos.), May-Sept.; from Nfld. to Alas., s. through e. Can. and the n. states and more sparingly to Va., Tenn., La., Tex.. N.M., Ariz., Calif. and Mex.

The herbage is usually sweet-scented in drying.

\section{Hedyotis L. Bluets}

Erect or prostrate herbs or rarely low shrubs; leaves opposite to infrequently fasciculate, either sessile or petiolate, often linear; flowers large and colored or small and white, 4-merous, heterostylous, homostylous or short-stylous only; corolla salverform, funnelform or infrequently rotate; style slender, 1 ; stigmas 2; ovary 2-celled; capsule didymous or less commonly globular or turbinate, opening loculicidally across the summit. Houstonia $\mathrm{L}$.

A diverse, largely pantropic genus of about 300 species best developed in the Old World; occasional in temperate regions of the Western Hemisphere and Asia.

1. Corolla 4-7 mm. long, whitish to pale-purple; capsule about one-fourth inferior; seeds crateriform, less than 20.................. H. pygmaea.

1. Corolla to $2 \mathrm{~mm}$. long, white; capsule usually wholly inferior; seed angulate, very numerous and small (2) 


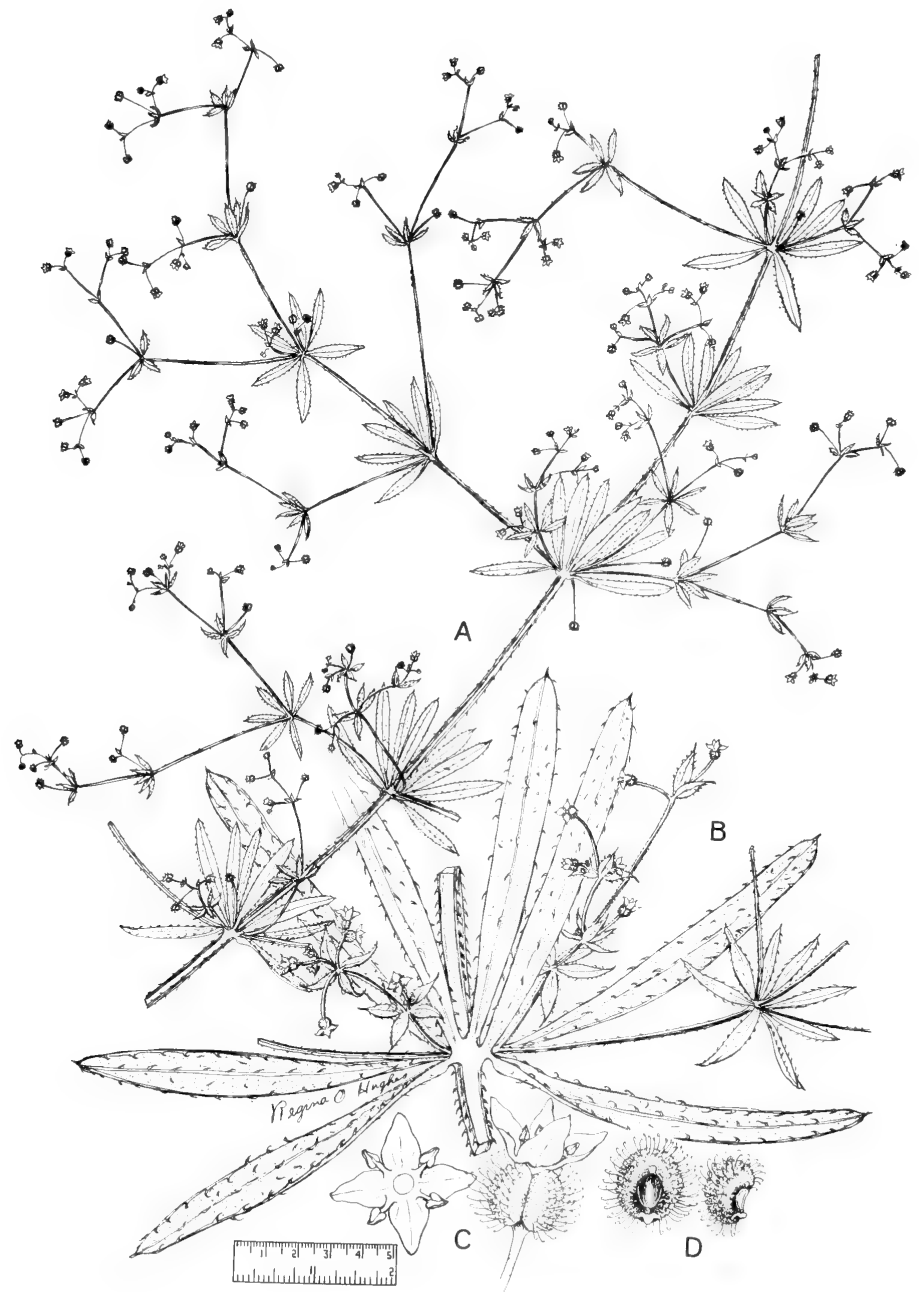

Fig. 722A: Galium Aparine: A, habit, x 1⁄2; B, enlarged leaf whorl, x 2; C, flowers, $\mathrm{x} 12 ; \mathrm{D}$, fruits, $\mathrm{x}$ 10. (From Reed, Selected Weeds of the United States, Fig. 173). 
2(1). Annual; stems usually hirsute; leaves ovate to ovate-elliptic....2. H. uniflora. 2. Perennials or annuals; stems usually glabrous; leaves linear to lanceolate (3)

3(2). Perennial; flowers solitary or in small clusters, subsessile; capsules shortciliate or glabrous; frequent in east Texas.

3. H. Boscii.

3. Annual; flowers in 3-flowered cymes, occasionally solitary, the peduncles and pedicels (when present) each to $15 \mathrm{~mm}$. long; very rare.....

4. H. corymbosa.

\section{Hedyotis pygmaea $R$. \& $S$.}

Cespitose perennial, 5-10 cm. high; numerous stems erect or spreading, scaberulous or papillose; leaves linear, the lowest often spatulate, 5-25 mm. long, 0.5-3 $\mathrm{mm}$. wide, usually scaberulous; flowers axillary or usually in terminal cymes, the short peduncles recurved after anthesis; calyx lobes $1.5-2 \mathrm{~mm}$. long; corolla salverform, white to pale-purple, 4-7 mm. long, the lobes equal to or commonly shorter than the tube, papillose within; capsule to $3.5 \mathrm{~mm}$. in diameter, subdidymous, broader than long, minutely papillose, about one-fourth inferior, the seeds crateriform. Houstonia Wrightii Gray, Hedyotis Wrightii (Gray) Fosb.

Open hillsides, rocky canyon slopes and sandy mt. streams, wet meadows, in muddy seepage about springs, and chaparral, infrequent in cen. Tex. Trans-Pecos and Ariz. (Pima Co.), June-July; from Tex. to cen. Ariz.; also Mex. (to Pue. and Ver.)

\section{Hedyotis uniflora (L.) Lam. Fig. 723.}

Erect to usually spreading summer annual; stems often branched, 1-6 dm. long, white-hirsutulous along the angles to less frequently glabrate; leaves ovate to ovate-elliptic, 1-2.5 cm. long, the midveins and margins commonly whitehirsutulous, the petioles $1-2.5 \mathrm{~mm}$. long or rarely absent; flowers very small, homostylous, axillary in small or large clusters or rarely solitary, subsessile; corolla rotate, white, about $1 \mathrm{~mm}$. long, shorter than the calyx lobes; capsule to $2 \mathrm{~mm}$. broad, usually densely white-hirsutulous, more or less wholly inferior, the angular seeds very numerous. Oldenlandia uniflora $\mathrm{L}$.

On wet sandy-loam banks, in shallow water of ponds and bogs, on floating mats of vegetation in lakes, in e. Tex. and Okla. (McCurtain Co.), June-Sept.; from Fla. to Tex., n. to s. N.Y., Okla. and s.e. Mo.

Var. fasciculata (Bert.) W. H. Lewis. Stems, leaves and usually capsules glabrous; leaves sessile. Infrequent on Gulf Coast, Fla. to Tex.

\section{Hedyotis Boscii DC. Fig. 723.}

Prostrate or spreading perennial; stems branched and often cespitose, 1-3 dm. long, glabrous to infrequently hirtellous; leaves mostly linear, 10-25 mm. long, 1-3 mm. wide, glabrous, sessile or subsessile; flowers very small, homostylous, axillary in small clusters or solitary, subsessile; corolla rotate, white (lobes often tipped pink), about $1 \mathrm{~mm}$. long, shorter than the calyx lobes; capsule to 2.5 $\mathrm{mm}$. broad, glabrous or short-ciliate, more or less wholly inferior, the seeds angular and very numerous. Oldenlandia Boscii (DC.) Chapm.

Edges of ponds and rivers in lowlands and savannahs of e. Tex., rare in s.-cen. Tex. and Okla. (McCurtain and LeFlore cos.), May-Aug.; from Fla. to Tex., n. to s.e. Va., Tenn., s.e. Mo. and Okla.

\section{Hedyotis corymbosa (L.) Lam. Fig. 724.}

Erect or spreading summer annual; stems branched, glabrous; leaves linear to lanceolate, $1-3.5 \mathrm{~cm}$. long, 1-5 $\mathrm{mm}$. wide, the margins scaberulous; flowers small, homostylous, axillary, usually in 3-flowered cymes or solitary, the peduncles to $15 \mathrm{~mm}$. long, the pedicels often as long; corolla more or less salverform, white, 

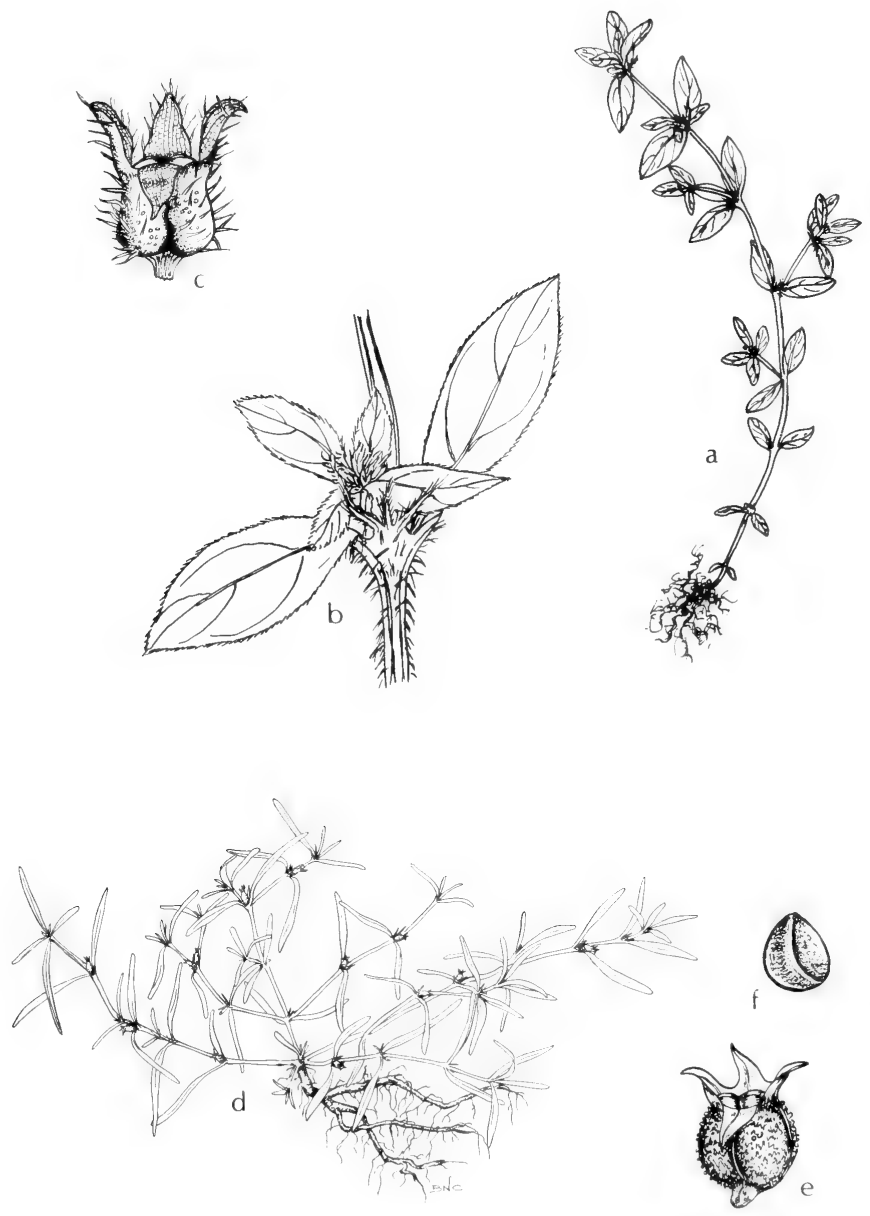

Fig. 723: a-c, Hedyotis uniflora: a, habit, x 1/2: b, node, x 2; c, fruit, $x$ 5. d-f, Hedyotis Boscii: d, habit, X 1; e, fruit, x 5; f, seed, x 50 . (d, Courtesy of R. K. Godfrey; all others V. F.). 


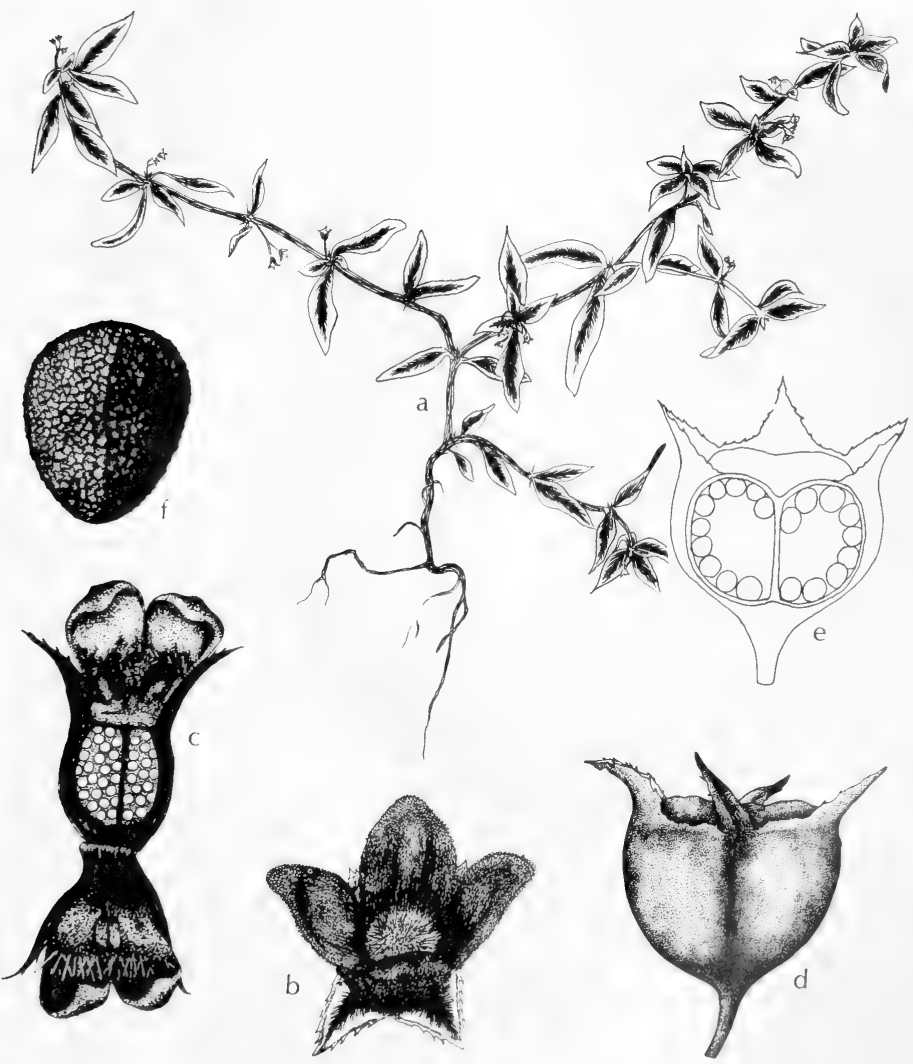

Fig. 724: Hedyotis corymbosa: a, habit, x $1 / 2$; b, flower from top, x 65; c, flower opened up, x 65; d, mature capsule, x 60; e, diagram of section through capsule, $\mathrm{x}$ $60 ;$ f, seed, x 135. (Courtesy of R. K. Godfrey). 
about $2 \mathrm{~mm}$. long, equaling or exceeding somewhat the calyx lobes; capsule to 2 $\mathrm{mm}$. broad, glabrous, more or less wholly inferior, the seeds angular and very numerous. Oldenlandia corymbosa $\mathbf{L}$.

Introd, in lawns and in wettish soils in waste places, rarely in e. Tex. (also Gulf Coast?), July-Sept.; occasional from Fla. to Tex., a widespread pantropic weed.

\section{Pentodon Hochst.}

Two species; represented in both hemispheres.

\section{Pentodon pentandrus (Schum. \& Thonn.) Vatke. Fig. 725.}

Annual glabrous herb, the 4-angled stems often diffusely branched and partly creeping; leaves petioled, ovate to elliptic or elliptic-lanceolate, obtuse to acute, $2-5 \mathrm{~cm}$. long, entire; flowers in axillary or terminal cymes; hypanthium clavate; sepals 5 , triangular-lanceolate to lanceolate, about $1 \mathrm{~mm}$. long; pedicels thick, 3-4 mm. long; corolla white, funnelform, the tube $2-3 \mathrm{~mm}$. long, the abbreviated lobes ovate to lanceolate; stamens 5 , the filaments adnate to above the middle of the corolla tube; style columnar; capsule included in the hypanthium, 2-lobed, 2-4 mm. long. P. Halei (T. \& G.) Gray.

In swampy ground in s.e. Tex., Aug.-Sept.; from Tex. to Fla.

\section{Cephalanthus L.}

\section{BUTTONBUSH}

Shrubs or small trees; leaves opposite or with some verticillate, petiolate; flowers white or yellowish, densely aggregated into spherical peduncled heads; calyx tube obpyramidal, the limb 4- or 5-toothed; corolla tubular-funnelform, the 4 or 5 teeth imbricated in the bud; stamens 4 , inserted on the corolla throat; anthers bicuspidate at base; ovary 2-celled, with one ovule in each cell; style filiform, much-exserted; stigma capitate; fruit small, at length splitting from the base upward into 2 to 4 closed 1 -seeded segments.

About 17 species that are natives of America and Asia; sometimes placed in the segregate family Naucleaceae.

Seeds of these plants are a source of food for various waterfowl and marsh birds; beaver and muskrat nibble the wood while browsers occasionally eat their twigs and foliage.

1. Calyx glabrous outside or the tube with a few long white hairs at the base 1. C. occidentalis.

1. Calyx densely pubescent outside with short appressed hairs.......2. C. salicifolius.

\section{Cephalanthus occidentalis L. Common buttonbush, honey-balls, globe-} FLOWERS. Fig. 726.

Shrub or small tree, sometimes to $15 \mathrm{~m}$. high, with a trunk rarely $3 \mathrm{dm}$. in diameter, the branchlets slender, brown or grayish, glabrous or short-pilose; stipules 2-4 mm. long, deltoid, acute to acuminate, usually with glands along the margins; leaves opposite or ternate, sometimes 4-nate (but this varies on a single plant), the stout or slender petioles to $3 \mathrm{~cm}$. long, glabrous or pilose, ovate to ovate-oblong or narrowly lanceolate, to $19 \mathrm{~cm}$. long and $85 \mathrm{~mm}$. wide, subcordate to cuneate at the base, abruptly or subabruptly long- or short-acuminate at the apex, bright-green above, glabrous or pilose beneath, with prominent lateral veins; peduncles terminal and axillary, simple or branched, stout, to $1 \mathrm{dm}$. long, glabrous; heads about $15 \mathrm{~mm}$. in diameter; bractlets filiform-clavate, pilose above; hypanthium and calyx together $2-3 \mathrm{~mm}$. long, glabrous or sparsely long-pilose at the base; calyx about $1 \mathrm{~mm}$. long, shallowly 4 - or 5 -dentate, densely pubescent within, the lobes rounded, usually glandular; corolla $5-9 \mathrm{~mm}$. long, glabrous outside, the 4 or 5 lobes ovate or oval, sparsely pubescent within, with a small black gland in each sinus; capsule 4-8 $\mathrm{mm}$. long; seed solitary, brown, with a large white aril. 


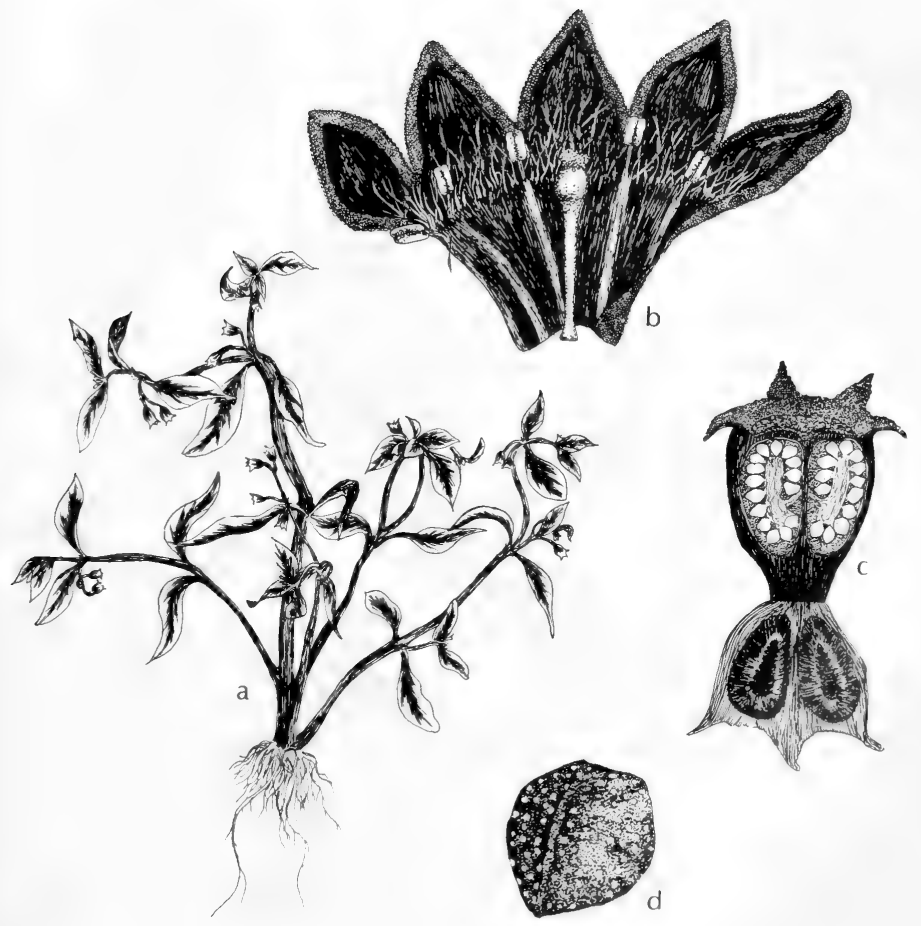

Fig. 725: Pentodon pentandrus: a, habit, $\mathrm{x}$ 1/2; b, flower, spread open, x 5; c, capsule, cut open, x 5; d, seed, x 80. (Courtesy of R. K. Godfrey). 


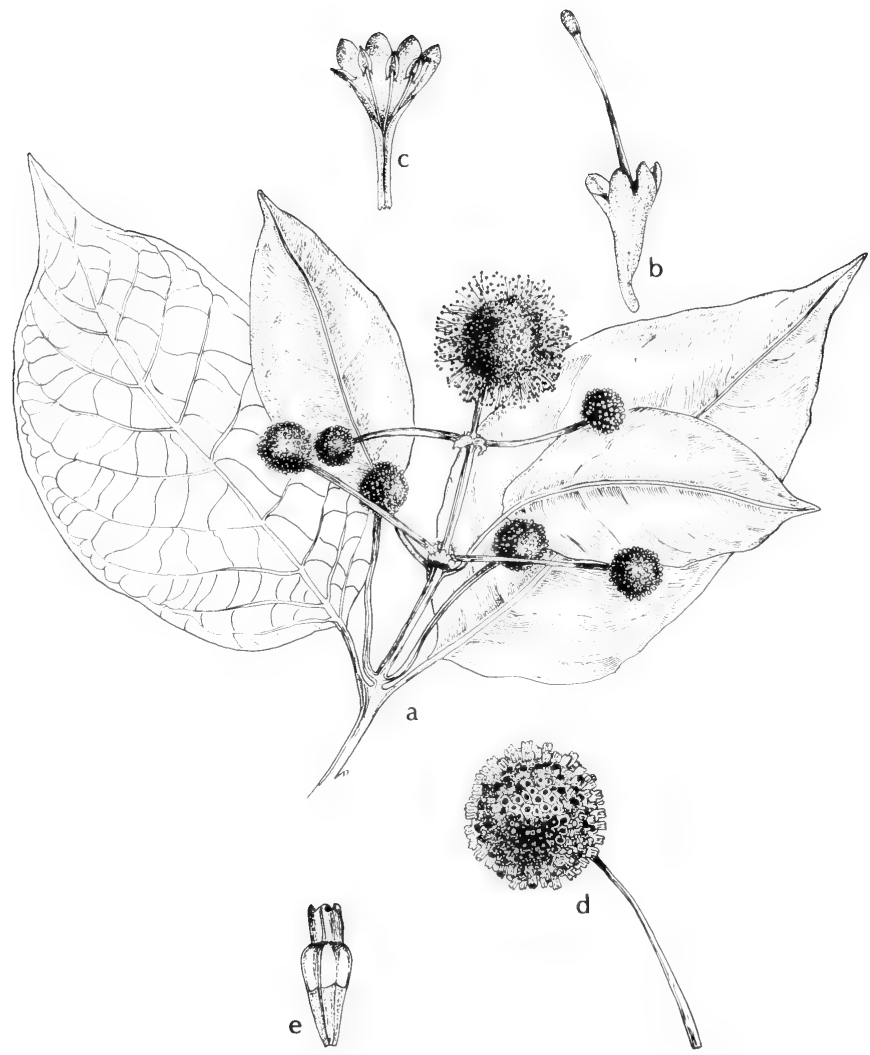

Fig. 726: Cephalanthus occidentalis: a, branch, $x \frac{1}{2} ; \mathrm{b}$, single flower, $\mathrm{x} 2 \frac{1}{2} ; \mathrm{c}$, corolla split open, $x 2 \frac{1}{2}$; d, head of fruit, $x 1$; e, achene, $x 2 \frac{1}{2}$. (V. F.). 
In swamps, marshes, about ponds and margins of streams throughout Tex. and Okla. to Ariz. (Apache. Gila, Maricopa, Pinal and Pima cos.), June-Sept.; from Fla. to Mex., n. to e. Can., N.Y. and w. to Calif.

Those plants with branchlets and at least the lower leaf surfaces soft-pubescent are segregated as var. pubescens Raf., while those with short-petioled narrower leaves arranged in whorls of three are segregated as var. californicus Benth.

\section{Cephalanthus salicifolius H. \& B.}

Shrub or small tree, the branches reddish-brown, glabrous; stipules $2-3 \mathrm{~mm}$. long, deltoid, acute or acuminate, often with marginal glands, glabrous; leaves opposite and ternate, the stout petioles to $4 \mathrm{~mm}$. long, glabrous, narrowly oblong to elliptic-oblong or lanceolate, to $12 \mathrm{~cm}$. long and $23 \mathrm{~mm}$. wide, acute to subcordate at the base, rounded and apiculate to long-attenuate at the apex, glabrous or sparsely pilose beneath along the veins, bright-green above, lustrous; peduncles mostly simple, 2-4 cm. long, glabrous, the heads $6-8 \mathrm{~mm}$. in diameter, the receptacle very densely setose: calyx and hypanthium $2-2.5 \mathrm{~mm}$. long, densely white-sericeous with short hairs; calyx $1 \mathrm{~mm}$. long or shorter, shallowly 4- or 5-dentate, densely pilose within, the lobes minute, rounded, often glanduliferous; corolla 6-7 mm. long, glabrous outside, the lobes oblong or ovate, sparsely pilose within, often with black glands in the sinuses; capsule $4-5 \mathrm{~mm}$. long, densely and minutely sericeous; seeds brown, with a large white aril.

Wet soil in and about ponds, springs and along resacas, in Hidalgo Co., extreme s. Tex., Mar.-July; from s. Tex. to s.-cen. Mex., also Hond.

\section{Mitchella L. PARTRIDGE-BERRY}

Two species, the other Japanese.

\section{Mitchella repens L. TWO-EYEd BERRY, RUNNING BOX.}

Small glabrous trailing evergreen herbs forming appressed mats of indefinite size: leaves petioled, opposite or ovate to orbicular, rounded to cordate at base, obtuse at apex, shining, pinnately veined and sometimes variegated with whitish lines, 15-25 mm. long; stipules triangular-subulate; peduncle short, terminal, bearing 2 flowers at its summit; flowers fragrant, white, often tinged with purple, in pairs with their ovaries united, occasionally 3- to 6-merous, always dimorphous, all flowers of some individuals have exserted stamens and included stigmas, all flowers of other individuals with included stamens and exserted style; calyx 4toothed; corolla tube about $13 \mathrm{~mm}$. long, densely bearded inside, surpassing the oblong spreading lobes: style 1; stigmas 4, linear; drupes edible, 4-6 mm. in diameter, bright-red or rarely white (f. leucocarpa Bissell), overwintering, crowned with the calyx teeth of the 2 flowers, with 4 small seedlike bony nutlets to each flower.

On dry or moist knolls in woods, sandy banks of streams, among sphagnum moss, sandy bogs, low moist woodlands, in e. Tex. and s.e. Okla., May-July; from Fla. to Tex., n. to e. Can., Ont. and Minn.

\section{Spermacoce L. ButtonWeEd}

Low spreading annual or perennial herbs; leaves opposite, their bases or petioles connected by a bristle-bearing stipular membrane; flowers small, whitish to purplish-blue, crowded into sessile axillary and terminal whorled clusters or heads; calyx tube short, obovoid, the limb parted into 4 teethlike lobes; corolla funnelform or salverform, 4-lobed, valvate in the bud; stamens 4 , inserted on the corolla tube; ovary 2-celled; ovules one in each cavity: style slender, the stigma 2-cleft; fruit a dry capsule, sessile, coriaceous or somewhat crustaceous, sometimes didymous, splitting when ripe into 2 carpels, one of the carpels usually carrying 
with it the septum and therefore closed, the other carpel open on the inner face. About 100 species in the warmer parts of America.

1. Flowers numerous in a dense conspicuous head; corolla $2-3 \mathrm{~mm}$. long, densely white-bearded in the throat; fruit 2-4 mm. long, smooth, capped by sepals $1.5-2 \mathrm{~mm}$. long........................................ S. glabra.

1. Flowers few in inconspicuous heads; corolla less than $2 \mathrm{~mm}$. long, somewhat pubescent at and above the throat; fruit $2-2.5 \mathrm{~mm}$. long, mostly puberulent, capped by sepals $1 \mathrm{~mm}$. long or less..........2. S. tenuior.

\section{Spermacoce glabra Michx. Sмоотн вutronweEd. Fig. 727.}

Glabrous perennial herb; stems simple or unbranched, spreading, $6 \mathrm{dm}$. long or more; leaves elliptic to oblong-lanceolate or oblanceolate, acute to acuminate at apex, to $8 \mathrm{~cm}$. long; stipular sheaths with several filiform segments $2-3 \mathrm{~mm}$. long; axillary heads many-flowered; corolla $2-3 \mathrm{~mm}$. long, slightly exceeding the calyx, conspicuously white-bearded in the throat, bearing the anthers at its base; filaments and styles short; fruit somewhat turbinate, smooth, 2-4 mm. long, crowned by the conspicuous triangular-lanceolate spreading calyx teeth.

Damp shores, swamps, edge of lakes, ponds, sloughs and flooded areas, low woodlands and in openings, in the e. third of Tex. and Okla. (LeFlore and Ottawa cos.), May-Oct.; from Fla. to Tex., n. to O., Ind., Ill., Mo. and Kan.

\section{Spermacoce tenuior L. SLender butTonweed.}

Annual, glabrous or nearly so; stems simple and erect or more or less diffusely branched from the base, to about $4 \mathrm{dm}$. long; leaves linear to oblong or oblonglanceolate, narrowed into short petioles, acute to acuminate at apex, more or less scabrous, 2-5 cm. long; axillary heads with few flowers; calyx teeth subulate to subulate-lanceolate; corolla white, about $1.5 \mathrm{~mm}$. long, funnelform, somewhat pubescent at and above the throat; fruit didymous-obovoid, mostly puberulent or short-pubescent, 2-2.5 $\mathrm{mm}$. long, somewhat crustaceous and crowned with the 4 calyx teeth.

In wettish clay soils along creeks in s. Tex., Sept.-Jan.; also Fla. and La., the W.I. and cont, trop. Am.

\section{Diodia L. Buttonweed}

Spreading, decumbent, prostrate or ascending annual or perennial herbs; leaves opposite, entire, mostly sessile; stipules sheathing, long-setiferous; flowers mostly solitary or several and sessile in leaf axils, rarely aggregated at summit of branches; calyx teeth 2 to 5 , often unequal; corolla funnelform or salverform, the lobes 3 or 4 ; stamens and style usually exserted, the stamens usually 4 and inserted on the corolla tube, the style filiform and simple or cleft; fruit composed of 2 or 3 crustaceous or leathery indehiscent carpels that usually separate.

About 50 species, mostly American and African tropics and subtropics.

1. Fruits leathery, strongly 6-ribbed, glabrous or villous, crowned by 2 prominent calyx teeth, the 2 carpels rarely separated; corolla salverform, the tube 7-10 $\mathrm{mm}$. long.. 1. D. virginiana.

1. Fruits crustaceous, not ribbed, commonly hispid or hispidulous, crowned by usually 4 calyx teeth, the carpels readily separated; corolla funnelform, 4-6 $\mathrm{mm}$. long. 2. D. teres.

\section{Diodia virginiana L. Fig. 728.}

Plant diffusely spreading or procumbent from a perennial root, the forking branches to about $6 \mathrm{dm}$. long, nearly glabrous to villous-hirsute; leaves sessile or essentially so, elliptic-oblong to elliptic-oblanceolate or linear-lanceolate, usually tapering to base, obtuse to acute or acuminate at apex, the margins slightly serrulate, mostly bright-green, to $9 \mathrm{~cm}$. long and $2 \mathrm{~cm}$. wide, usually much 


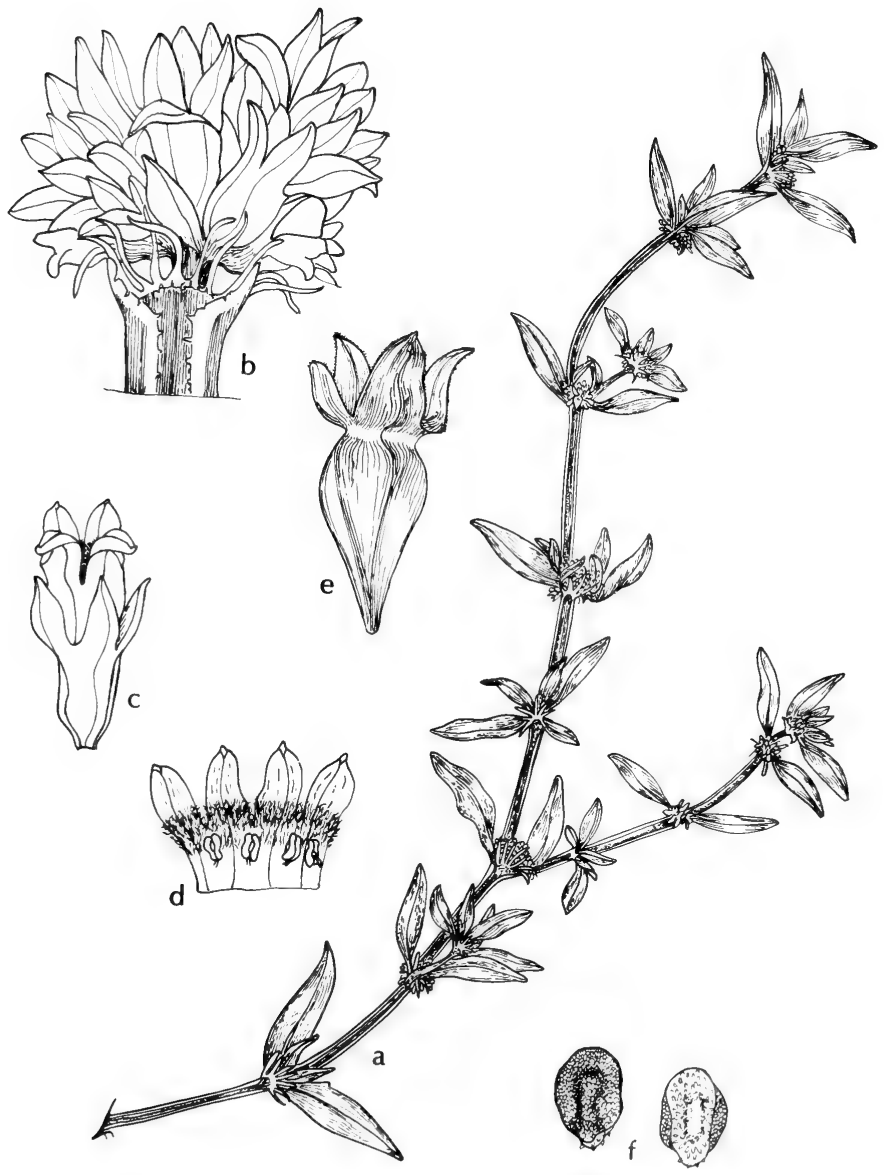

Fig. 727: Spermacoce glabra: a, branch of plant, $x 1 \frac{1}{2} ; \mathrm{b}$, cluster of flowers, $\mathbf{x} 5$; c, flower, x 5; d, coralla spread open, x 5; e, fruit, $x$ 5; $\mathrm{f}$, two views of mature seeds, x 5. (V. F.). 


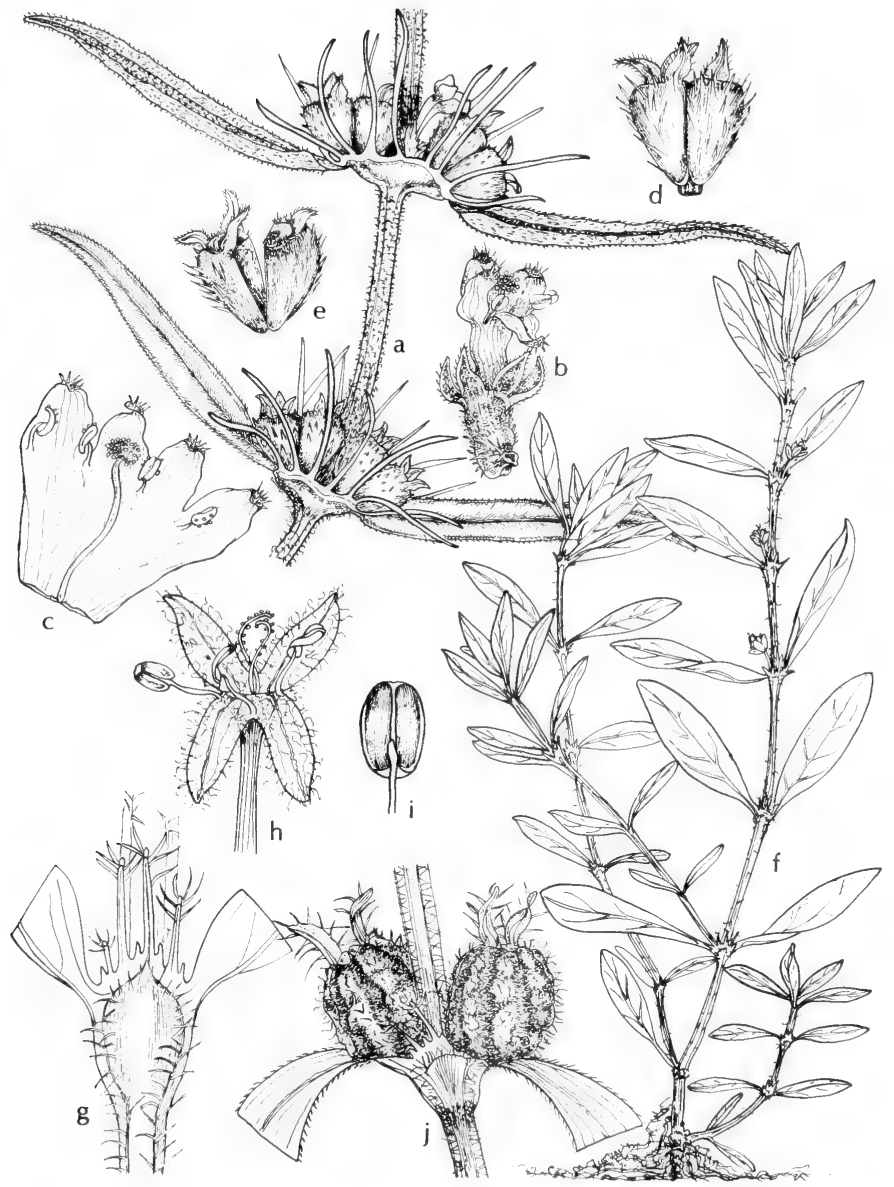

Fig. 728: a-e, Diodia teres: a, portion of plant, x 3; b, flower, x 5; c, open corolla, $\mathrm{x} 5$; $\mathrm{d}$, fruit, $\mathrm{x} 5$; e, two carpels, one with 3 calyx lobes, the other with only one, $\mathrm{x} 5$. $\mathrm{f}-\mathrm{j}$, Diodia virginiana: $\mathrm{f}$, habit, $\mathrm{x} 1 \frac{1}{2} ; \mathrm{g}$, leaf base showing stipules, $\mathrm{x} 10 ; \mathrm{h}$, flower, x 3; i, anther, x 6; j, fruit, x 3. (V.F.). 
smaller; stipular bristles few, strong and flat, sometimes sparingly hirsute; corolla white, 7-10 $\mathrm{mm}$. long, the slender tube abruptly expanded into the large limb; style 2-parted; fruit ellipsoid, bicarpellate, 5-8 $\mathrm{mm}$. long, to $5 \mathrm{~mm}$. in diameter, glabrous to villous, crowned with 2 or sometimes 3 lanceolate more or less pubescent calyx teeth; carpels suberose-crustaceous, 3-ribbed on the back, held together by a thin epicarp that rarely ruptures.

In swamps, wet meadows, marshes, coastal prairies and in mud along streams and about ponds, in e. third of Tex. and Okla. (McCurtain, Latimer, Sequoyah, LeFlore and Choctaw cos.), May-Oct.; from Fla. to Tex., n. to N.J., Ill., Mo. and Okla.

2. Diodia teres Walt. Poor Joe, rough buttonweed. Fig. 728.

Plant diffusely spreading or ascending from an annual but sometimes lignescent root, rigid, puberulent to hirsute; stems and branches to about $8 \mathrm{dm}$. long, terete, rather quadrangular above; leaves linear to lanceolate, rounded to somewhat clasping at the sessile base, acute to acuminate at the apex, rather rigid and often with revolute margins, more or less scabrous, to $5 \mathrm{~cm}$. long and $1 \mathrm{~cm}$. wide, usually much smaller; stipular bristles numerous, filiform, often reddish-brown, usually equaling the flowers and surpassing the fruit; corolla funnelform, whitish to pinkish-purple, 4-6 mm. long; style undivided; fruit obovate-turbinate, not ribbed, commonly hispid or hispidulous, about $4 \mathrm{~mm}$. long, bicarpellate, crowned with usually 4 somewhat unequal ovatish ciliate calyx lobes, when carpels separate often 3 lobes on one carpel and 1 on the other. Incl. var. angustata Gray.

In sandy soils in woodlands and open areas in mud along streams, in ditches, swamps, bogs, in the e. two thirds of Tex., rare on the Edwards Plateau, and Okla. (McCurtain and Ottawa cos.) to Ariz. (Greenlee, Gila, Cochise, Santa Cruz and Pima cos.), May-Nov.; from Fla. to Tex. and Ariz., n. to N.E., O., Ill., Mo. and Okla.

Those plants with a slender apical seta on each young leaf are segregated as var. setifera Fern. \& Grisc.

\section{Fam. 125. Caprifoliaceae Juss. Honeysuckle Family}

Shrubs, vines or rarely herbs with opposite usually exstipulate entire leaves; flowers perfect, gamopetalous, regular or irregular; corolla tubular to funnelform or rotate; calyx tube adherent to the 2- to 5-celled ovary; stamens as many as the corolla lobes and inserted on corolla tube; fruit a berry, drupe or capsule, 1 - to several-seeded; seeds anatropous.

About 12 genera and 450 species mostly in North Temperate regions and tropical mountains.

1. Corolla rotate to open-campanulate, regular, deeply 5-lobed; style abbreviated, the 1 to 5 stigmas sessile or nearly so; inflorescences terminal and cymose (2)

1. Corolla elongate, funnelform to campanulate, often more or less irregular; style 1, elongate, with a usually capitate stigma; inflorescences lateral or terminal (3)

2(1). Leaves simple; fruit a 1-seeded drupe

1. Viburnum

2. Leaves pinnately compound; fruit a 3 -seeded berry.

2. Sambucus

3(1). Corolla funnelform to tubular; ovary 2- or 3-celled; fruit a berry, manyseeded.

3. Lonicera

3. Corolla short-campanulate to salverform; ovary 4-celled; fruit a berrylike drupe, with only 2 stones maturing......

4. Symphoricarpos 


\section{Viburnum L. Viburnum. Arrow-wood}

Shrubs or small trees with simple leaves and numerous white or rarely pink flowers in compound cymes; petioles sometimes bearing appendages that are apparently stipules; leaf buds naked or with pairs of scales; calyx 5-toothed; corolla spreading, rotate to broadly campanulate, deeply 5-lobed; stamens 5, exserted, the anthers oblong and introrse; style none, the 1 to 3 stigmas sessile on summit of ovary; fruit a 1-celled 1-seeded soft-pulpy drupe with a thin-crustaceous tumid or flattened stone.

About 200 species in the North Temperate Zone.

The fruits of most species of Viburnum are eaten by many kinds of wildlife, and man even enjoys the sweet pulpy fruits of the non-wetland southern black-haw (V. rufidulum Raf.)

1. Leaves somewhat lustrous above, the veins raised below and strongly curved, gradually tapering or rounded to the apex, the margin revolute, sometimes somewhat denticulate; twigs, petioles and lower surface of leaves rusty-scurfy; anthers elevated 4-5 mm. above corolla; pulp of drupe bitter; stone globose-obovate, smooth in cross section 1. V. nudum.

1. Leaves dull-dark-green above, the veins not noticeably raised below, usually long-acuminate at apex, the margin only slightly revolute; twigs smooth and glabrous; lower surface of leaves rusty-scurfy when young, becoming light-green with scurfy dots in age; anthers elevated 1-3.5 mm. above corolla; pulp of drupe sweet; stone oblongellipsoid, ridged and grooved in cross section.

2. V. nitidum.

\section{Viburnum nudum L. Possum-Haw. Fig. 729.}

Shrub spreading or somewhat erect and arborescent, to $5 \mathrm{~m}$. tall; buds brown or fuscous; leaves with a petiole to $1 \mathrm{~cm}$. long, lustrous above, usually dotted beneath, coriaceous, elliptic to obovate or oblanceolate, rarely ovate, rounded to abruptly acute at apex, the more or less crenate margin revolute, to about $15 \mathrm{~cm}$. long and $75 \mathrm{~mm}$. wide; cyme to $1 \mathrm{dm}$. wide, on a peduncle $15 \mathrm{~mm}$. or more long; corolla about $5 \mathrm{~mm}$. wide; stamens long-exserted, the filaments 4-5 $\mathrm{mm}$. long; drupe subglobose, bluish-black, glaucous, the flesh usually bitter; stone typically globose-obovoid.

Along streams in swamp forests, bogs and in wet pinelands in e. Tex., Mar.June; from Fla. to Tex., n. to N.E., Ky. and Ark.

\section{Viburnum nitidum Ait. Withe-RoD.}

Shrub or small tree very similar to $V$. nudum, from which it differs primarily in the narrower, long-acuminate, less coriaceous leaves without conspicuously raised veins on their lower surface. V. nudum var. angustifolium T. \& G., V. cassinoides var. nitidum (Ait.) McAtee.

In swamps and wet woods in e. Tex. (Jasper Co.), Apr,-June; from Nfld. to Man., s. to Fla. and Tex.

\section{Sambucus L. Elder-Berry}

Shrubby to arborescent or rarely herbaceous plants with a rank smell when bruised; bark with lenticels clearly evident; leaves pinnate or rarely with some bipinnate, the leaflets serrate and acuminate; flowers small, numerous in terminal compound cymes; calyx lobes minute or obsolete; corolla rotate, with a broadly spreading 5-cleft limb; stamens 5, inserted at base of corolla, the filaments slender; stigmas 3 ; fruit a berrylike juicy drupe that contains 3 small seedlike stones, usually edible.

About 40 species mainly in temperate and subtropical regions. 


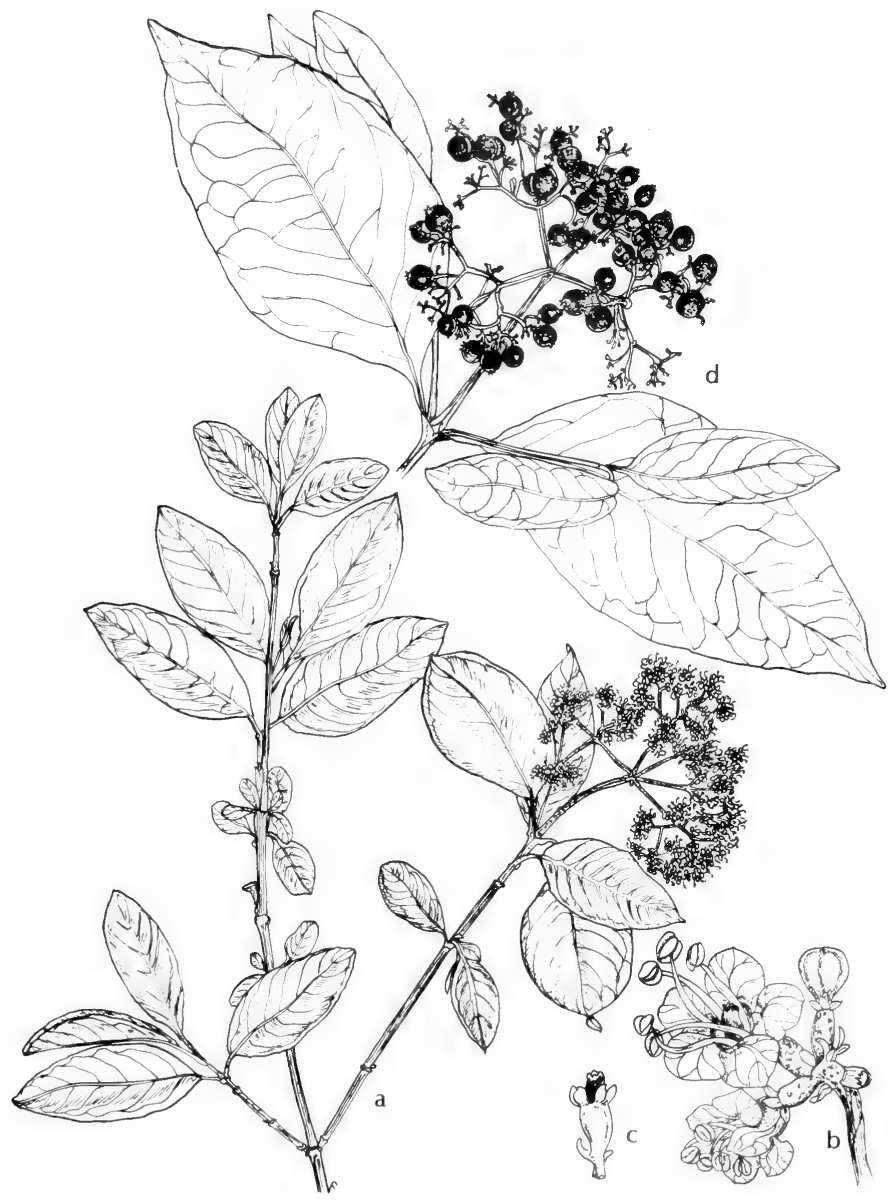

Fig. 729: Viburnum nudum: a, twig with flowers, $x$ 1, b, flowers, x 5; c, calyx and ovary, $x 5$; d, twig with fruit, showing enlargement of leaves by fruiting time, $x 1 / 2$. (V. F.). 


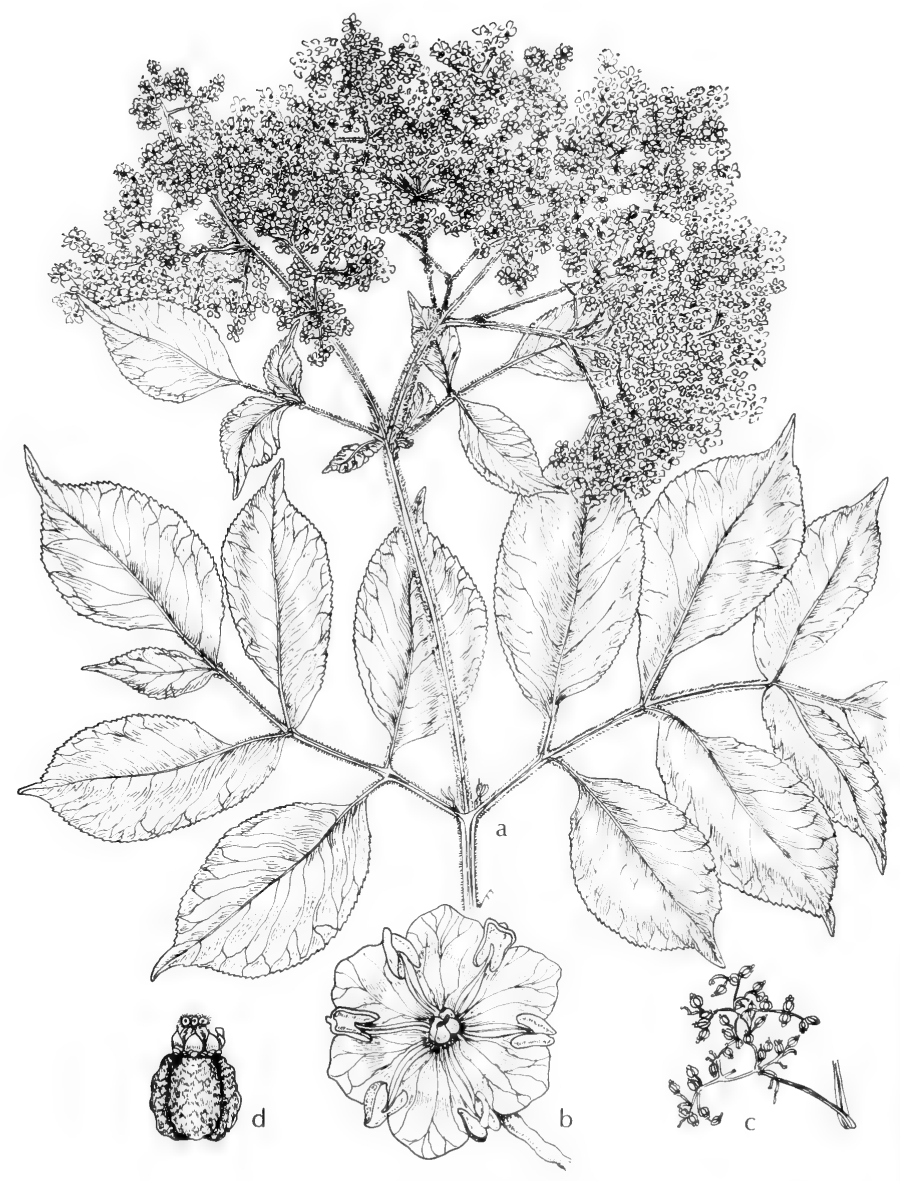

Fig. 730: Sambucus mexicana: a, flowering branch, $\mathrm{x} 1 / 2$; b, flower, $\mathrm{x} 5$; c, cluster of fruit, $x \frac{1}{2} ;$ d, immature fruit, $x$ 5. (V. F.). 
The fruits of some of these plants, especially those of $S$. canadensis, are a favorite food of many species of songbirds and game birds. Not only the fruits but also the twigs, foliage and bark are consumed by various small mammals and browsers.

1. Inflorescence broadly short-pyramidal, with the axis extended beyond the lowest branches; berries bright red, not glaucous....1. S. microbotrys.

1. Inflorescence flat-topped, with elongate compound rays, the axis not extended beyond the lowest branches; berries dark-blue or blackish, commonly glaucous (2)

2(1). Distribution in eastern Oklahoma and throughout most of Texas (except mountains in the Trans-Pecos)

2. S. canadensis.

2. Distribution in New Mexico, Arizona and mountains in Trans-Pecos Texas (3)

3(2). Leaflets narrowly lanceolate and gradually long-acuminate, usually thin, the larger ones seldom less than $8 \mathrm{~cm}$. long; inflorescence rather lax and open.......................................................... S. glauca.

3. Leaflets obovate to oblong-lanceolate or ovate, abrupt acute to acuminate, thickish, usually less than $8 \mathrm{~cm}$. long; inflorescence typically rather compact. 4. S. mexicana.

\section{Sambucus microbotrys Rydb. RED ELDERBERRY.}

Low shrub, rarely more than $1 \mathrm{~m}$. tall, with strong-scented herbage, often thickly branched and spreading; leaves thin and glabrous; leaflets commonly 7 , ascending on the rachis, ovate to ovate-lanceolate or lanceolate, to $10 \mathrm{~cm}$. long, the margin serrate, the acute to acuminate apex entire; flowers white, in a conical or pyramidal paniculate cyme to about $3 \mathrm{~cm}$. across; berries bright red, 4-5 mm. in diameter, reputedly poisonous; seeds ovoid, finely rugose. S. racemosa of auth.

Wet stream banks and about springs and lakes, usually at high elevations, also on moist wooded slopes, in N.M. (San Juan, Rio Arriba, Lincoln, Otero, Grant, San Miguel, Santa Fe and Taos cos.) and Ariz. (Apache, Greenlee and Coconino cos.), June-Aug.; also Colo. and Ut.

\section{Sambucus canadensis L. COMMON ELDER-BERRY.}

Stems scarcely woody, to $4 \mathrm{~m}$. tall, with large white pith; leaflets 5 to 11 , ovate-elliptic to lanceolate, acuminate, to $18 \mathrm{~cm}$. long and $7 \mathrm{~cm}$. wide, sharply serrate, glabrous to hirtellous or rarely canescent beneath (especially along the veins); cymes flat, to $35 \mathrm{~cm}$. broad, the branches and pedicels glabrous or rarely hispidulous; flowers white, about $5 \mathrm{~mm}$. broad, fragrant; fruit purple-black, 4-5 $\mathrm{mm}$. in diameter.

In wet soil in low places, especially along streams and on edge of swamps, mainly in e. and cen. Tex., rare in Panhandle, and Okla. (Woodward Co.), MayJuly; from N.S. and Que., w. to Man. and S.D., s. to Fla. and Tex.

The edible fruits are used in the making of jellies, pies and wine.

Those plants with leaflets densely canescent beneath have been segregated as var. submollis Rehd.

\section{Sambucus glauca Nutt. BLUE ELDER-BERRY.}

Shrub of clustered erect stems to $7 \mathrm{~m}$. tall, rarely taller, sprouting freely from the base, the main stems usually less than $15 \mathrm{~cm}$. in diameter, the young stems and branches brown and sometimes glaucous; leaflets 5 to 9 , often longpetiolulate, oblong-lanceolate to narrowly lanceolate, tapering at the acuminate apex, rounded at the strongly asymmetrical base, to $16 \mathrm{~cm}$. long and $35 \mathrm{~mm}$. wide, pale beneath, rather thick, serrate, glabrous or sparingly to densely tomentose; cymes flat-topped, to $3 \mathrm{dm}$. broad; flowers pale-yellow or creamy-white, 5-6 $\mathrm{mm}$. wide; fruit 5-6 $\mathrm{mm}$. in diameter, dark-blue or blackish, when fully ripe covered with a dense white bloom. S. caerulea Raf., S. neomexicana Woot. 
Wet places in mts., mostly along streams and on talus slopes, in Trans-Pecos Tex. (Brewster and Jeff Davis cos.), N. M. (Lincoln and Otero cos.) and Ariz. (Coconino to Graham, Cochise and Pima cos.), Apr.-Aug.; in mts. from w. Tex. to Alta., Mont., Calif. and n. Mex.

4. Sambucus mexicana Presl. Mexican elder, tapiro, sauco. Fig. 730.

Trees or shrubs to $10 \mathrm{~m}$. tall, usually much smaller, with the main trunks furrowed and to $3 \mathrm{dm}$. in diameter, the smaller branches glabrous or whitetomentulose; leaflets 3 or 5 or sometimes 7 , subsessile to petiolulate, ovate to ovate-lanceolate or oval, abruptly acuminate or sometimes cuspidate at apex, rounded to cuneate at base, to $12 \mathrm{~cm}$. long, coarsely or finely serrate except at base and apex, firm, green on both surfaces, glabrous to densely tomentulose; cyme essentially flat, to $15 \mathrm{~cm}$. broad; flowers pale-yellow or creamy-white, 5-8 $\mathrm{mm}$. broad; fruits $5-7 \mathrm{~mm}$. in diameter, dark-blue or blackish, when fully ripe covered with a dense white bloom. S. caerulea var. arizonica Sarg. and var. mexicana (Presl) L. Benson, S. Rehderana Schwerin.

Along streams and river banks in wet soils, and on slopes in the Tex. TransPecos, N. M. (Dona Ana and Grant cos.) and Ariz. (widespread), Mar.-July; from Tex. to Calif. and Mex.

\section{Lonicera L. HONEYSUCKLE}

About 200 species in the Northern Hemisphere, mainly in eastern Asia. The introduced, weedy Japanese honeysuckle ( $L$. japonica Thunb.), with all leaves distinct, is often found in floodplain woods.

1. Lonicera involucrata (Richards.) Banks. BEAR-BERRY, HONEYSUCKLE, INKBERRY, PIGEON-BUSH, TWIN-BERRY. Fig. 731.

Low shrub to $1 \mathrm{~m}$. tall, freely suckering to form thickets; leaves $5-10 \mathrm{~cm}$. long, short-petioled, the blade ovate, more or less abruptly attenuate, pilose beneath; peduncles $2-3 \mathrm{~cm}$. long, borne in leaf axils and bearing at the summit a conspicuous pair of connate (often purple) bracts which subtend the pair of sessile flowers; corolla orange-yellow, 1-2 cm. long, tubular, the limb spreading, its lobes subequal, the tube gibbous below; ovary of each flower in the pair distinct; fruit fleshy, black; seeds several, flattened, irregularly ovate, bitter, finely pitted, reputed to be poisonous.

High montane stream banks and marshy meadows, seepage slopes and thickets, in N.M. (San Juan, Taos, Rio Arriba, Socorro, Santa Fe, San Miguel and Sandoval cos.) and Ariz. (Apache, Coconino, Greenlee, Graham and Cochise cos.), JuneAug.; Que. to Alas., s. to Mich., Mex. and Calif.

\section{Symphoricarpos BOEHM. SNOW-BERRY}

About 20 species, all except one (in China) found in North America.

\section{Symphoricarpos orbiculatus Moench. Coral-BERry. Indian-CURRANT.}

Shrub erect, to about $2 \mathrm{~m}$. tall; branches leafy, erect or ascending, slender, light-brown to purplish, bark on the older branches gray and shreddy; young twigs densely villosulous-tomentulose to puberulent; leaves opposite, with petioles 2-4 $\mathrm{mm}$. long, oval to ovate or suborbicular, rounded to slightly cuneate at the base, obtuse to acute at the apex, rarely to $6 \mathrm{~cm}$. long, dull-green and glabrous to sparsely pilosulous on the upper surface, somewhat glaucescent and softpubescent on lower surface; flowers in short many-flowered densely crowded axillary spikes on the branches of the season; corolla broadly campanulate, villous within, pinkish, 3-4 $\mathrm{mm}$. long, turned obliquely upward, slightly ventricose on the lower side, the lobes about as long as the tube; anthers $1 \mathrm{~mm}$. long, shorter than the filaments; calyx teeth 5, triangular, ciliate, persistent on the fruit; style $2 \mathrm{~mm}$. long, pilose; fruit a delicate coral-red varying to pink or sometimes purple- 


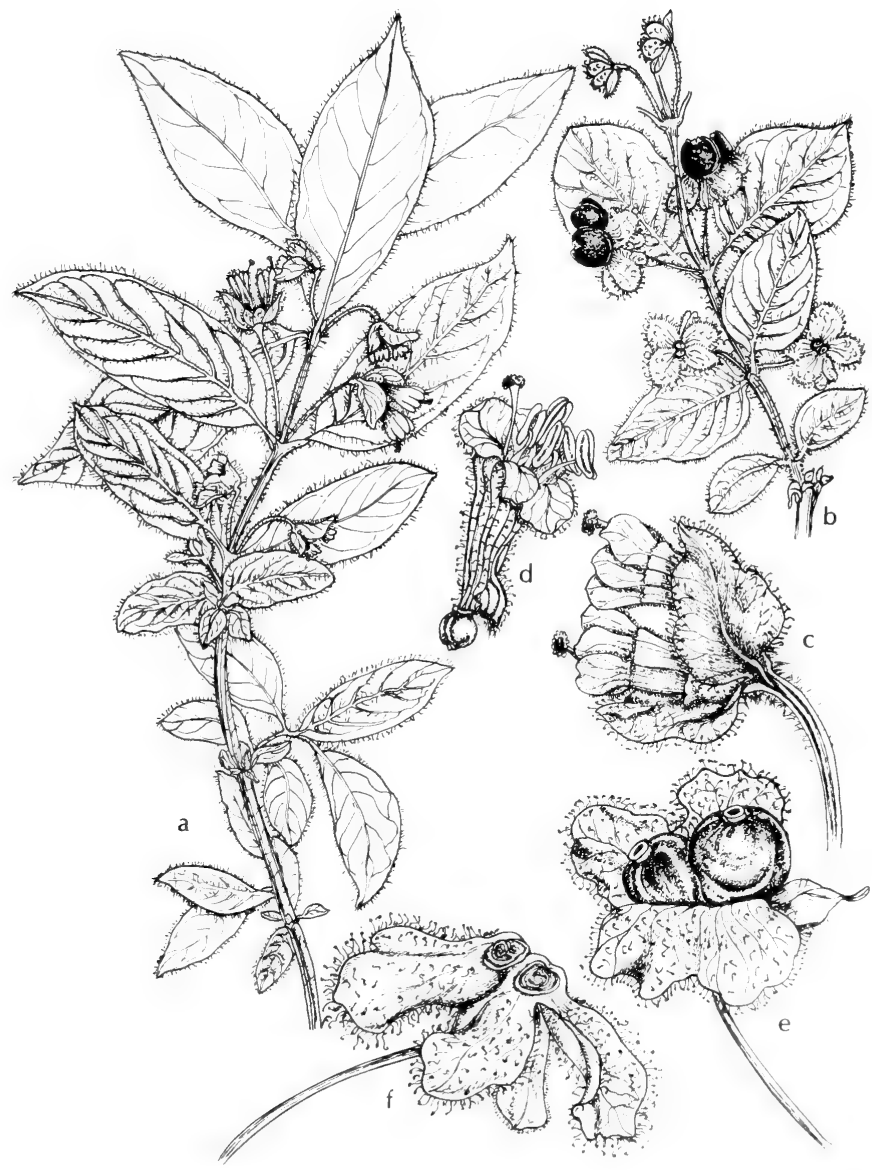

Fig. 731: Lonicera involucrata: a, twig with flowers, $\mathrm{X} 1 / 2 ; \mathrm{b}$, twig with fruit, $\mathrm{x} 1 / 2$; $\mathrm{c}$, twin flowers, $\mathrm{x} 1$; d, individual flower, $\mathrm{x} 1$; e, twin fruits, $\mathrm{x} 1$; $\mathrm{f}$, connate bracts with fruits removed, $x$ 1. (V. F.). 
tinged, glaucous, ellipsoid, 5-7 mm. long, 4-5 mm. thick, the beak about $1 \mathrm{~mm}$. long; stones oval, flattened, 2.5-3.5 mm. long, about $2 \mathrm{~mm}$. wide, obtuse at each end. S. vulgaris Michx., S. spicatus Engelm.

In woods and thickets, especially along streams, occasionally in marshes and wet meadows, in e. third of Tex. and e. half of Okla., Apr.-July; from N.Y., s. to Fla. and w. to Tex., n. Mex., Colo. and e. S.D.

\section{Fam. 126. Valerianaceae BATSCH}

\section{VALERIAN FAMILY}

Herbaceous annuals or perennials with opposite exstipulate leaves; flowers small, in cymes or capitate, perfect or unisexual; calyx annular or variously toothed, often inrolled in flower and forming a feathery pappus in fruit; corolla funnelform to rotate or almost salverform, 4- or 5-lobed, the base often saccate or spurred on one side; stamens 1 to 4 , inserted near the base of the corolla tube; ovary inferior, mostly 3 -celled, with 1 cell fertile and the other 2 cells sterile or essentially wanting; ovule 1 , pendulous; fruit dry, indehiscent.

About 13 genera and 400 species mostly in the Northern Hemisphere.

1. Plants perennial; distribution in mountains of the Texas Trans-Pecos, westward...................................................................... Valeriana

1. Plants annual; distribution east of the mountains of the Texas Trans-Pecos and Oklahoma, eastward 2. Valerianella

\section{Valeriana L. VALERIAN. TOBACCO-ROOT}

Perennial herbs with thickened strong-scented roots or rhizomes and with leafy or scapose stems; leaves entire to pinnate; inflorescence determinate, the cymes clustered or paniculate; calyx at first involute, later spreading, the limb sessile, hyaline, membranaceous, becoming setose distally, the setae plumose or the limb short-cupuliform and more or less toothed or lobed; corolla rotate to funnelform, the tube straight or gibbous, the throat more or less hairy, the 5 lobes subequal; stamens usually 3; anthers sessile or on filaments, 2- to 4-lobed; ovary 3-celled, maturing 1 fertile adaxial carpel with 1 pendulous ovule, the other 2 abaxial carpels vestigial; style 1, the stigma 3-lobed; fruit an achene.

About 200 species in temperate and cold regions of the Northern Hemisphere. Dried plants of the species in this genus are persistently malodorous.

1. Plants from rhizomes; leaves mostly pinnate or pinnatifid, sometimes undivided, petiolate, the blade of undivided leaves more or less abruptly expanding; corolla infundibuliform or rotate; achene smooth, more or less plane adaxially; flowers hermaphroditic or gynodioecious (2)

1. Plants from a stout caudex and conical taproot; leaves mostly lingulatespatulate, gradually decurrent to the subpetiolar and clasping base; cauline leaves frequently pinnate to pinnatifid and more or less decurrent; corolla essentially rotate; achene transversely rugose or smooth, adaxial ribs relatively prominent; flowers polygamo-dioecious (3)

2(1). Corolla infundibuliform, 4-8 $\mathrm{mm}$. long; leaves more often oblanceolate to obovate-spatulate.................................................. . capitata.

2. Corolla rotate to subrotate, $3-3.5 \mathrm{~mm}$. long; leaves predominantly oblong 2. V. occidentalis.

3(1). Leaves undivided, elliptic to obovate-spatulate, glabrous; calyx limb 6- to 8-fid. 3. V. texana.

3. Leaves divided and undivided, somewhat repand to undulate-lamellate or entire, uniformly spreading-ciliate; calyx limb 9- to 13-fid. 4. V. edulis. 


\section{Valeriana capitata Link.}

Perennial 1.5-6 dm. tall; rhizome relatively stoui, 2-4 $\mathrm{mm}$. thick; stem glabrous or glabrescent; leaves predominantly basal, more often numerous and forming a rather loosely tufted rosette, undivided or rarely divided, predominantly oblong- to oblanceolate- or obovate-spatulate, $3.5-36 \mathrm{~cm}$. long. $1.2-2.3 \mathrm{~cm}$. wide, short-acuminate or acute to more or less apiculate, glabrous or sometimes spreading-ciliate toward the subpetiolar base; cauline leaves essentially sessile, pinnate to pinnatifid, the lowermost sometimes undivided, $1.5-12 \mathrm{~cm}$. long, usually smaller, the lateral lobes in 2 to 5 pairs, linear to oblong-linear, grading smaller, becoming more or less filiform, 1-3 mm. wide; petioles obscure; inflorescence $1.5-3.5 \mathrm{~cm}$. wide in anthesis; bracts glabrous; calyx limb 10- to 14-fid; corolla 4-8 $\mathrm{mm}$. long, glabrous or sometimes pilosulous toward the base of the tube without; achenes ovate to oblong-lanceolate, $2.5-5 \mathrm{~mm}$. long, 1.5-2 $\mathrm{mm}$. wide, glabrous, frequently purple-maculate.

Wet meadows, along stream sides, open woods and grassy slopes in N.M. (Catron, Mora, San Miguel and Santa Fe cos.) and Ariz. (Apache, Coconino, Graham, Cochise, Santa Cruz and Pima cos.), May-Aug.; also Wyo. and Colo. Our plant is referred to subsp. acutiloba (Rydb.) F. G. Mey.

\section{Valeriana occidentalis Heller.}

Perennial, mostly 4-9 dm. tall, relatively robust, from stoutish rhizomes 3-6 $\mathrm{mm}$. thick; stem 3-6 mm. in diameter, glabrous or glabrescent, the nodes consistently white tufted-pilosulous; leaves at the base forming a loosely tufted rosette with the several adventitious shoots, petiolate, undivided or pinnate to pinnatifid; undivided leaves oblong to narrowly ovate or more or less spatulate, rarely suborbicular, $12-30 \mathrm{~cm}$. long, entire or essentially so, glabrous; blades and terminal lobe of the divided leaves $2-10 \mathrm{~cm}$. long, $1.3-6 \mathrm{~cm}$. wide, shortacuminate or obtuse, the lateral lobes in 1 or 2 pairs, grading smaller; petiole 1 to 1.5 times the blade length, spreading-ciliate toward the base, sometimes spreading to the blade and lateral lobes; cauline leaves in 2 to 4 pairs, the lowermost short-petiolate, pinnate to pinnatifid or sometimes undivided, $4.5-14.5 \mathrm{~cm}$. long, the uppermost much-reduced and sessile, the terminal lobe oblong-linear to ovate or obovate, $1.9-6.8 \mathrm{~cm}$. long, $9-40 \mathrm{~mm}$. wide, acute or obtuse, the lateral lobes in 1 to 6 pairs, grading smaller; inflorescence $3.5-5 \mathrm{~cm}$. wide in anthesis, later diffuse $(8-60 \mathrm{~cm}$. long, $4.5-15 \mathrm{~cm}$. wide), the nodes pilosulous, the internodies glabrous or sometimes scattered-pilosulous; bracts 5-6 mm. long, glabrous; flowers gynodioecious; corolla rotate to subrotate, $3-3.5 \mathrm{~mm}$. long, white, glabrous without, the throat scattered-pilosulous within; stamens and style exserted; achenes linear- to ovate-oblong, 3-5 $\mathrm{mm}$. long, 1-2 $\mathrm{mm}$. wide, sparsely to densely pilosulous or glabrous, tawny, the abaxial ribs often rather prominent; calyx limb 11- to 16-fid.

Wet meadows or grassy wet places among willows, aspen glens and yellow pine woods, in rich loam or on open rocky hillsides, in Ariz. (Coconino Co.) MaySept.; S.D. and Mont. to Ore., s. to Colo., Ariz. and Calif.

\section{Valeriana texana Steyerm. Fig. 732.}

Plant to $3 \mathrm{dm}$. high, with a stout multicipital caudex and forked rugose conical taproots to $2 \mathrm{~cm}$. thick and much contorted in age; stems several, subscapose, glabrous or sometimes sparsely pilosulous at nodes; leaves predominantly basal, undivided, elliptic to obovate-spatulate, narrowly obtuse to acute, to $16 \mathrm{~cm}$. long and $3 \mathrm{~cm}$. wide, tapering to the subpetiolar base, firmly membranaceous, glabrous, usually somewhat marginate, the stem leaves similar to but smaller than the basal leaves; inflorescence $2-6 \mathrm{~cm}$. long in anthesis, later diffuse and to $12 \mathrm{~cm}$. long 


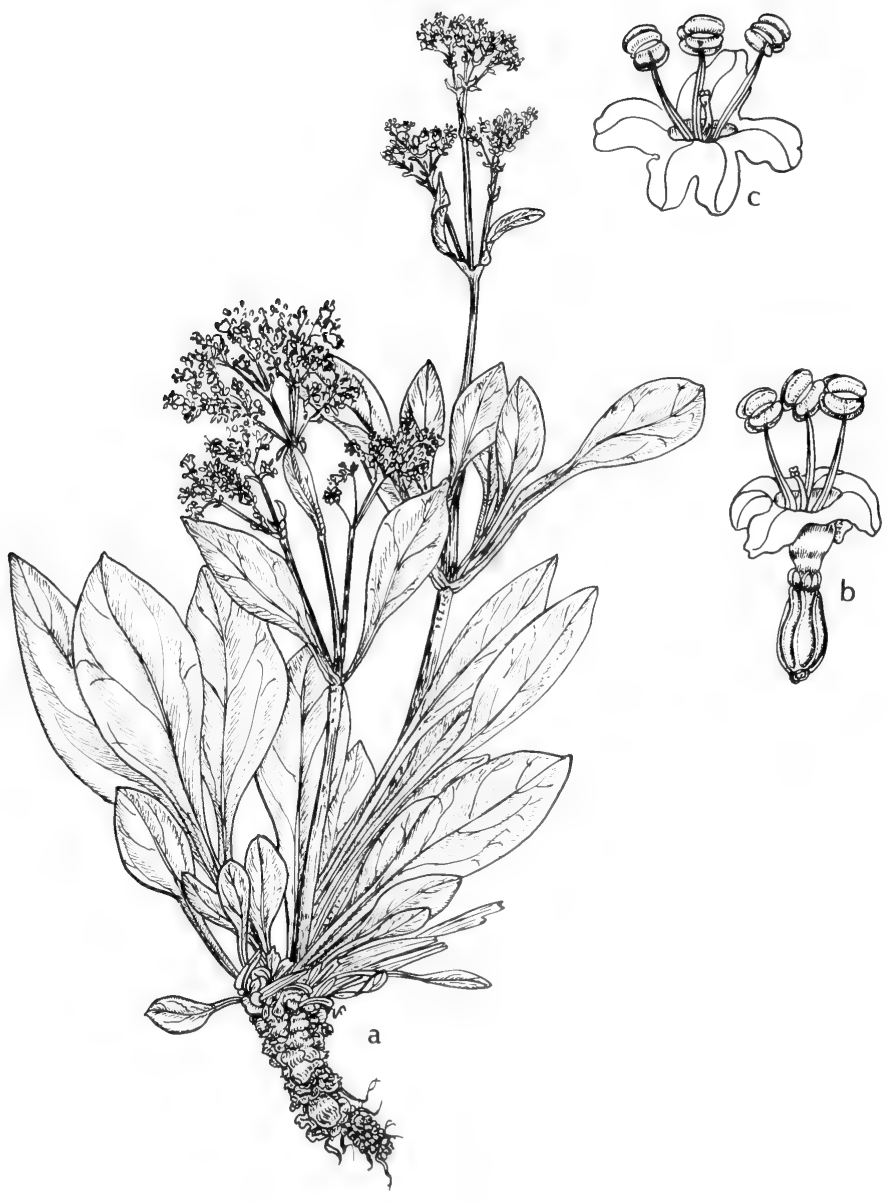

Fig. 732: Valeriana texana: a, habit, x 1/2; b, flower, x 5; c, corolla spread out, x 5 . (V. F.). 
and $7 \mathrm{~cm}$. wide, the internodes glabrous or sometimes thinly pilosulous; bracts 3-4 mm. long, reduced above, glabrous to spreading-ciliate; calyx limb 6- to 8-fid; corolla rotate, $2.5-3 \mathrm{~mm}$. long, whitish, thinly pilosulous at the base on outside, the ovate lobes equal to or shorter than the tube; stamens and style exserted; achenes oblong to linear-oblong, 2-2.5 mm. long and less than $1 \mathrm{~mm}$. wide, smooth, brownish, more or less keeled abaxially, the adaxial ribs evident.

On boulders in creek and on wet rocks, and on moist shaded limestone cliffs in canyons of Guadalupe Mts. in the Trans-Pecos, Tex. and N. M. (Eddy Co.), Apr.-July.

\section{Valeriana edulis Nutt. ex T. \& G.}

Perennial to $12 \mathrm{dm}$. tall, robust; stem subscapose, from a large vertical caudex and conical often forked taproot; leaves thickish, usually numerous and glabrous, predominantly basal, oblong- to obovate-spatulate, entire or pinnately parted, the lateral lobes of the divided leaves mostly distinct and sometimes narrowly decurrent, the terminal lobe $4.5-9 \mathrm{~cm}$. long and 7-20 mm. wide; cauline leaves 2 or 3 well-developed pairs, essentially sessile, usually pinnately parted with few elongate linear to spatulate divisions; inflorescence an elongate open panicle to $75 \mathrm{~cm}$. long and $14 \mathrm{~cm}$. wide at anthesis; calyx limb 9- to 13-fid; corolla yellowish or greenish, that of the perfect and staminate flowers 3-3.5 mm. long, of the minute pistillate flowers $0.5 \mathrm{~mm}$. long, the throat scattered-pilosulous within; achenes $2.5-4.5 \mathrm{~mm}$. long, glabrous to densely hirsutulous.

In wet meadows, marshes, old lake beds, wettish pastures, creek bottoms, yellow pine and aspen woods and $\mathrm{mt}$. slopes, in N. M. (widespread) and Ariz. (Apache to Coconino, Yavapai, Graham and Cochise cos.), May-Oct.; Mont. and Ida. to N. M. and Ariz.

The roots of this species are said to have been boiled and eaten by the Indians.

\section{VALERIANELLA Mill. Corn Salad}

Annual or sometimes biennial often disgustingly malodorous (when dry) herbs with erect dichotomously branched stems; leaves more or less succulent, the basal leaves tufted and entire, the stem leaves sessile and often dentate; flowers small, cymose-clustered, bracted; calyx limb obsolete or short-toothed; corolla funnelform or salverform, white or pale-blue, equally or unequally 5-lobed; stamens 3 or rarely 2 ; fruit 2 -celled or 3 -celled with 2 of the cells empty and sometimes confluent and the other 1 -seeded.

About 80 species in the Northern Hemisphere. In northern Europe, V. locusta (L.) Betcke is commonly used as a potherb in fall and spring.

1. Fertile cell of fruit about one third less than (often to one half) the combined width of the sterile cells, when viewed dorsally it does not completely conceal the 2 sterile cells that extend outward.

1. V. Woodsiana.

1. Fertile cell of fruit usually about equaling or wider than the combined width of the sterile cells, when viewed dorsally it usually completely conceals the 2 sterile cells (2)

2(1). Plants glabrous or sometimes with tufts of hairs on each side of the leaf base near the nodes; fruit always pubescent (3)

2. Plants pubescent, sometimes only on the leaves and the lower part of the stem, in addition to tufts on each side of leaf bases near the nodes; fruit glabrous or sometimes puberulent or pubescent (4)

3(2). Fruit white-hirsute, $1.5-2 \mathrm{~mm}$. long, the hairs uncinate; corymb compact, the glomerate cymules many..................................2. V. amarella.

3. Fruit only sparsely short-pubescent, $1.7 \mathrm{~mm}$. long; corymb open, with few glomerules............................................................... . . florifera. 
4. Fruit dorsiventrally compressed, never strongly carinate, more than $1 \mathrm{~mm}$. long (5)

5(4). Fruits ellipsoid; fertile cell rounded on the dorsal side (6)

5. Fruits ovoid; fertile cell flattened on the dorsal side (7)

6(5). Corolla 2-3 $\mathrm{mm}$. long, conspicuous above the bracts.

.....................................................5. V. stenocarpa var..................

6. Corolla $1.5 \mathrm{~mm}$. long, not conspicuous above the bracts.

5. V. stenocarpa var. parviflora.

7(5). Sterile cells of fruit more or less divergent with a prominent groove between them, their combined width slightly less than or wider than the fertile.................................................6. V. radiata var. radiata.

7. Sterile cells more approximate with only a slight groove between them, their combined width about half the width of the fertile

6. $V$, radiata var. Fernaldii.

1. Valerianella Woodsiana (T. \& G.) Walp. Fig. 733.

Stem 1.5-5 dm. tall, rather stout, pubescent along the angles; leaves hairy on the margin and on the midrib on the lower surface; the lower leaves spatulate, entire, slightly connate; the upper leaves oblong-ovate with several coarse teeth near the base, not connate; bracts elliptic-lanceolate, acute to acuminate, glabrous, usually weakly glandularly fimbriate-serrulate toward the tip; inflorescence lax to somewhat compact, corymbosely cymose; corolla white, $1.5 \mathrm{~mm}$. long, funnelform; tube much shorter than the limb, a saccate gibbosity at base of throat on the ventral side; stamens and style exserted; stigma lobes short; fruit yellowish, subglobose, about $2 \mathrm{~mm}$. long, glabrous or finely pubescent; fertile cell often short-beaked, narrowly oblong to oblong-lanceolate, weakly one-nerved and flattened on the dorsal side, much narrower than the inflated widely divergent sterile cells which have a wide groove between them.

In moist low sandy or clayey soils in woods and on prairies and wet soil on edge of ponds, lakes and along streams in e. Tex. and e. Okla. (Waterfall), Mar.-May.

\section{Valerianella amarella Krok. Fig. 733.}

Stem 1.5-3 dm. tall, glabrous; leaves glabrous except for tufts of hairs on each side of the base near the nodes, the lower obovate-spatulate and entire, the upper oblong-obovate and sessile; bracts glabrous, ovate-lanceolate to ellipticlanceolate, rounded to acute at the apex, usually hyaline-margined; inflorescence compact, corymbosely cymose; corolla white, funnelform, $1.5-3 \mathrm{~mm}$. long; limb usually as long as the throat and tube combined, a saccate gibbosity at the base of the throat on the ventral side; stamens and style usually long-exserted, sometimes either stamens or style short and abortive; stigma lobes short; fruit 1.5-2 mm. long, subglobose, ovoid, brownish, hirsute with rather long uncinate white hairs; sterile cells much smaller than the large fertile cell, contiguous, groove between them narrow and very shallow or inconspicuous.

On rocky calcareous open or wooded hills and in prairies, low wet grounds and barrens, mostly in cen. Tex. and Okla. (Arbuckle Mts. and Caddo Co.), Mar.-May; also e. Kan.

\section{Valerianella florifera Shinners. Fig. 733.}

Stem 9-18 cm. tall, glabrous; leaves entire, glabrous or the lower slightly scabrous-ciliate especially toward apex; lower leaves oblong to oblong-spatulate, sessile; upper leaves oblong to oblong-lanceolate or narrowly deltoid-oblong, 


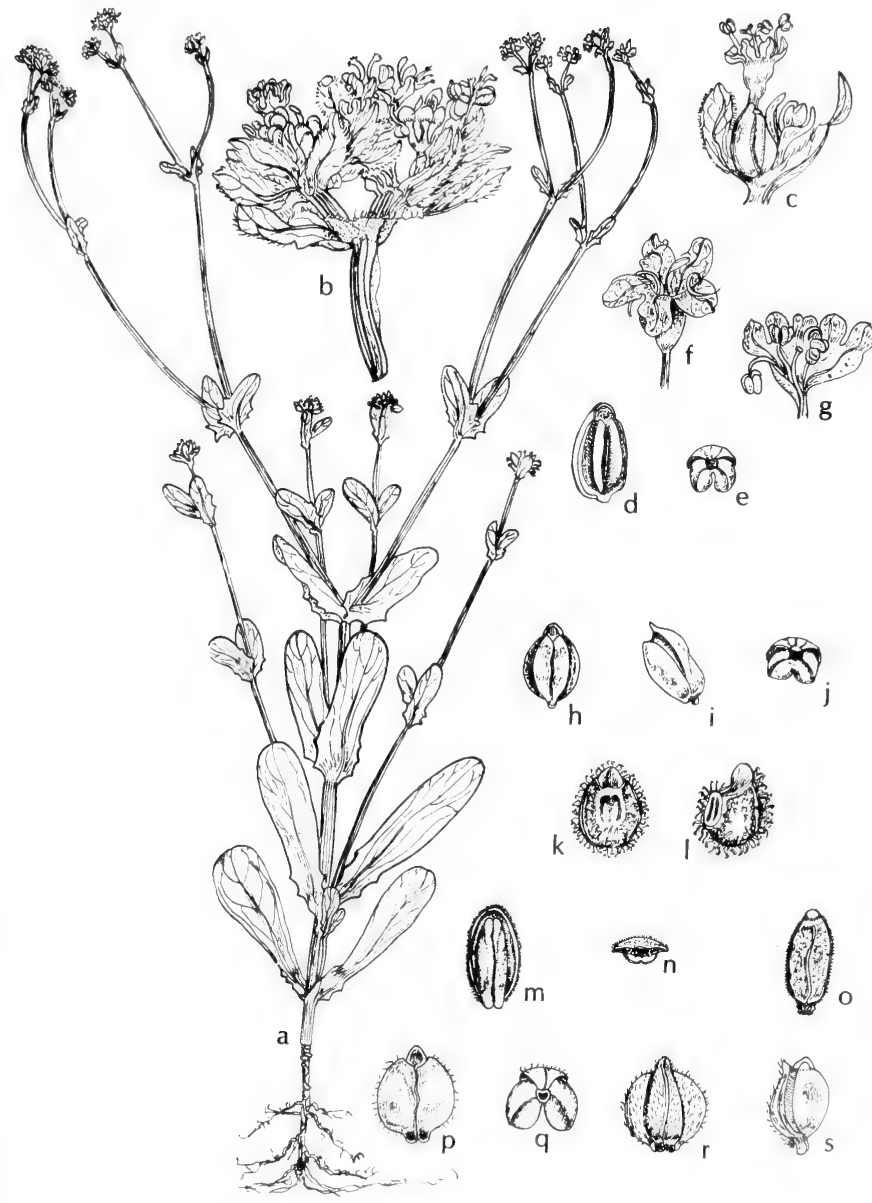

Fig. 733: a-e, Valerianella stenocarpa var. parviflora: a, habit, x 16; b, inflorescence, $\mathrm{X} 3$; c, flower and fruit, $\mathrm{x} \mathrm{3}$; d, fruit, front view, $\mathrm{x} \mathrm{5}$; e, fruit, top view, $\mathrm{x} 5$. $\mathrm{f}$ and $\mathrm{g}$, Valerianella stenocarpa var. stenocarpa: f, flower, $\mathrm{x} 3 ; \mathrm{g}$, corolla opened to show anthers, $\mathrm{x} 3 . \mathrm{h}-\mathrm{j}$, Valerianella radiata: $\mathrm{h}$, fruit, front view, $\mathrm{x} 5 ; \mathrm{i}$, fruit, side view, x 5 ; $\mathrm{j}$, fruit, top view, $\mathrm{x} 5 . \mathrm{k}$ and $\mathrm{l}$, Valerianclla amarella: $\mathrm{k}$, fruit, front view, $\mathrm{x}$ 5; 1, fruit, side view, x 5. m-o, Valerianella florifera: $\mathrm{m}$, fruit, front view, x 5 ; n, fruit, top view, x 5; o, fruit, back view, x 5. p-s, Valerianella Woodsiana: p, fruit, front view, x 5 ; q, fruit, top view, x 5; r, fruit, side view, x 5. (V. F.). 
sessile; bracts lanceolate or elliptic-lanceolate, acute, glandular-denticulate or even lacerate, glabrous; inflorescence rather open, the glomerules few but manyflowered; corolla white, funnelform, the lobes 1.8-2 mm. long, throat 1.3-1.5 mm. long, with basal gibbosity, the tube (below gibbosity) $1.4-1.5 \mathrm{~mm}$. long; stamens and style exserted; fruit narrowly ellipsoid, $1.7 \mathrm{~mm}$. long, $0.6 \mathrm{~mm}$. wide, rather sparsely pubescent with straight erect hairs; fertile cell somewhat flattened dorsally, with noticeable median line toward apex; sterile cells not diverging, their combined width barely equaling that of the fertile cell.

In sandy moist soil in post oak woods and in wet depressions in s.-cen. Tex., Mar.-May; endemic.

\section{Valerianella texana Dyal.}

Stem 1-3 dm. tall, rather frail, pubescent on the angles; leaves hairy on the margin and upper surface, the lower spatulate, the upper oblong-ovate, sessile; bracts lanceolate, ciliate; inflorescence loosely and corymbosely cymose; corolla white, funnelform, 2-2.5 mm. long; tube slender, about as long as the limb; throat rather wide without a conspicuous gibbosity at its base; stamens and style exserted; stigma lobes short; fruit yellowish, laterally compressed, less than $1 \mathrm{~mm}$. long, with four lines of short capitate hairs ( 2 down the dorsal side of the fertile cell and one down the ventral side of each sterile cell); fertile cell narrowly oblong, produced at apex into a prominent tooth, much narrower than the combined width of the sterile cells which have a narrow deep groove between them with a prominent nerve down the middle of the groove.

Wet stream banks in the vicinity of Kini Creek, Gillespie Co., Tex., spring, endemic.

\section{Valerianella stenocarpa (Engelm.) Krok var. stenocarpa. Fig. 733.}

Stem 1-5 dm. tall, pubescent on the angles; leaves ciliate, the lower spatulate with their bases connate, entire, the upper usually ovate with a few teeth on each side near the base; bracts lanceolate, glabrous or rarely weakly glandularly fimbriate-serrulate toward the tip; inflorescence loose, corymbose-cymose; corolla white, 2-3 mm. long, funnelform; tube short, less than one half the length of the limb, a saccate gibbosity at the base of the throat on the ventral side; stamens and style exserted; stigma lobes short; fruit yellowish, narrowly ellipsoid, 1.5-2.3 $\mathrm{mm}$. long, more than twice as long as wide, glabrous or pubescent; fertile cell wider than the combined width of the sterile cells, rounded on the dorsal side, sometimes with a weak nerve down the middle; groove between the slender sterile cells narrow, rarely with a rather prominent nerve down the middle.

Rocky ledges and low moist grounds, wet seepage banks, often along rivers, in cen. and e. Tex., Mar.-May, (?) endemic.

Var. parviflora Dyal. Corolla white, funnelform, $1.5 \mathrm{~mm}$. long; fruit slightly smaller than in var. stenocarpa. Light soils, barrens, and prairies, sometimes in periodically inundated places, in e. and s.e. Tex., west to Calhoun, Bexar and Dallas cos. and Okla. (Waterfall), Mar.-May; also Mo.

\section{Valerianella radiata (L.) Dufr. var. radiata. Fig. 733.}

Stem 1.5-6 dm. tall, rather stout and pubescent along the angles; leaves hairy on the margins and on the midrib on the lower surface, the lower oblong-spatulate, connate, entire, the upper oblong-ovate, often coarsely toothed at the base, not connate; bracts lanceolate, the outer ones slightly ciliate, the inner glabrous; inflorescence loose, corymbosely cymose; corolla white, funnelform, $1.5-2 \mathrm{~mm}$. long; tube shorter than the limb, a saccate gibbosity at the base of the throat on the ventral side; stamens and style exserted; stigma lobes short; fruit yellowish, ovoid, about $2 \mathrm{~mm}$. long, glabrous or pubescent; fertile cell as broad as or broader 
than the combined width of the sterile cells; groove between the sterile cells narrow to rather wide and often rather deep, with a slight groove on each side between the fertile and sterile cells.

Low moist or wet grounds in cen. and e. Tex. and Okla. (Waterfall), spring; from $\mathrm{Pa}$. to Kan., s. to Fla. and Tex.

Var. Fernaldii Dyal. Corolla slightly larger than in var. radiata; fruit more elongate, usually pubescent; fertile cell rounded on the dorsal side, much wider than the combined width of the slender sterile cells; groove between sterile cells slight or wanting. Low moist places in e. Tex.; from Conn. and Pa., s. to N.C., w. to Mo. and Tex.

\section{Fam. 127. Cucurbitaceae Juss. Gourd Family}

Plants herbaceous, annual or perennial; stems with tendrils, trailing or climbing; leaves alternate, petiolate, simple or compound; flowers mostly unisexual, with male and female flowers on the same or separate plants, regular or nearly so, solitary to fasciculate or in racemose or corymbose inflorescences; calyx tube wholly adnate to the ovary; corolla adnate at base to the calyx, usually 5-merous, sympetalous or the petals nearly distinct; stamens 3 or 5 , in the latter case usually appearing to be 3 , four of the anthers being united in pairs; style 1 , the stigmas usually 3 ; ovary 1 - to 4 -celled; fruits various.

About 650 species in about 110 genera throughout the world.

A family of great economic importance that produces the world's melons, squashes, pumpkins, cucumbers and gourds. Most of our cucurbits can be found at times in moist or even wettish situations. The ones given here, however, are considered by us to be more tolerant of such habitats.

1. Seeds numerous in each fruit (2)

1. Seeds less than 10 in each fruit or (if more than 10) the fruit with spines or prickles (3)

2(1). Corolla campanulate, 5-lobed to about the middle; fruit obovoid, hardshelled, to about $9 \mathrm{~cm}$. long.....................................1. Cucurbita

2. Corolla rotate to campanulate, deeply 5-parted to near the base; fruit ovoid to ellipsoid, soft, $1-2 \mathrm{~cm}$. long...................................1. Melothria

3(1). Ovary 3-celled, usually with a solitary ovule ascending to erect from the

3. Ovary 1- or 2-celled; fruit with spines or prickles or (if smooth) with only

3. Ovary 1- or 2-celled; fruit with spines or prickles or (if smooth) with only 1 seed (4)

4(3). Fruit filled with a solitary seed, indehiscent.

4. Fruit with several seeds, variously dehiscent (5)

5(4). Fruit dry, dehiscing by pores, the spines glandular-hirsute; seeds corrugated

4. Echinopepon

5. Fruit baccate, the apex irregularly lacerate, the spines not hirsute; seeds smooth.

5. Echinocystis

\section{Cucurbita L.}

About 15 species confined to America.

\section{Cucurbita texana Gray. TeXAs gourd.}

Plant annual, producing slender long-running and climbing leafy stems with abundant tendrils; leaves broadly ovate to subreniform in outline, angled to distinctly lobed, pubescent, the margins sharp-serrate, to about $15 \mathrm{~cm}$. long, nearly as wide as long; calyx lobes short and slender; corolla yellow, usually 
with prominent somewhat greenish veins, to about $7 \mathrm{~cm}$. long, flaring above, the lobes acute and cuspidate; fruit obovoid, hard-shelled, green and usually with light-green stripes, to $9 \mathrm{~cm}$. long and $6 \mathrm{~cm}$. broad, the flesh bitter and inedible. C. Pepo of auth.

In debris and piles of driftwood, often climbing into trees, along several rivers, especially in floodplains of the Guadalupe that drains the Edward Plateau in cen. Tex., rare but abundant where found, July-Oct.; endemic.

\section{Melothria L. Melonette}

About 10 species in the warmer regions of the New World.

\section{Melothria pendula L. Meloncito.}

Slender climbing vine from a perennial root; leaves more or less orbicular in outline, with a cordate base, subentire to 5-angled or -lobed, more or less scabrous; tendrils simple; male and female flowers on the same vine; flowers small, yellow or somewhat greenish, the staminate flowers racemose or corymbose, the pistillate flowers solitary or clustered; corolla rotate to campanulate, deeply 5-parted; filaments free or barely coherent; ovary contracted beneath the corolla, with 3 placentae and many horizontal ovules, the style short and with 3 stigmas; fruit ovoid to subglobose or eilipsoid, green or yellowish, becoming blackish, $1-2 \mathrm{~cm}$. long; seeds numerous. Incl. var. chlorocarpa (Engelm.) Cong., M. chlorocarpa Engelm.

In sandy and moist rich soils, wettish thickets, banks of canals and streams, climbing on shrubs and small trees, near the coast and in s. Tex. and e. two thirds of Okla. (Waterfall), Mar.-Oct.; from Fla., w. to Tex. and Mex., n. to Va., s. Ind., s. Mo. and Okla.

The seeds are reputed to be purgative.

\section{Cayaponia S. MANSO}

About 50 species mainly in tropical and subtropical America.

\section{Cayaponia quinqueloba (Raf.) Shinners.}

Climbing herbaceous vine from a perennial rhizome; stem slender, finely pubescent; leaves long-petiolate, thickish, cordate at base, $5-10 \mathrm{~cm}$. long, less than $1 \mathrm{dm}$. wide, 3-angled or -lobed, sparingly pubescent beneath, the petioles bristlyvillous; tendrils simple or branched; male and female flowers on same vine; flowers rather large, in racemes or panicles; calyx campanulate, 5-cleft; corolla rotate or subcampanulate, greenish-white, 5-parted; staminate flowers 5-6 mm. across, with 3 distinct stamens, the anther sacs flexuous, the rudimentary ovary 3-lobed; pistillate flowers often with 3 rudimentary stamens; ovary 3-celled, with 1 or 2 ascending ovules in each cell; style 3-cleft, the stigmas dilated; fruit reddish, ovoid to ellipsoid, somewhat fleshy, 12-14 mm. long; seeds 6-8 $\mathrm{mm}$. long and $2 \mathrm{~mm}$. thick. C. Boykinii (T. \& G.) Cogn.

In river bottomlands and wettish soils along streams in e.-cen. Tex., June-Aug.; from Ga. to Tex.

\section{Echinopepon Naud. Wild Balsam-APPLE}

A small American genus.

\section{Echinopepon Wrightii (Gray) Wats.}

Climbing annual with forked tendrils, more or less pubescent throughout; leaves reniform, broadly cordate at base, shallowly lobed or angular, scarcely denticulate, to about $15 \mathrm{~cm}$. wide; male and female flowers on same vine; flowers 5-merous, the staminate flowers in long racemes or panicles, the pistillate flowers solitary; 
calyx absent on staminate flowers; corolla rotate, 6-8 $\mathrm{mm}$. wide, the lobes triangular-ovate and glandular; fruit obovoid, rostrate, to $35 \mathrm{~mm}$. long, less than $15 \mathrm{~mm}$. in diameter, opening by apical pores, spiny with the prickles to $15 \mathrm{~mm}$. long and hirsute, 3-celled. Echinocystis Wrightii (Gray) Cogn.

Climbing on shrubs along streams and in thickets in extreme w. Trans-Pecos Tex., N.M. (Grant Co.) and Ariz. (Santa Cruz and Pima cos.), June-Oct.; from w. Tex., s. N.M., Ariz. and n. Mex.

\section{Echinocystis T. \& G. WILd MOcK-CUCUMBER}

A monotypic genus in North America, as interpreted here.

1. Echinocystis lobata (Michx.) T. \& G.

High-climbing annual, essentially glabrous throughout; tendrils forked; leaves suborbicular-ovate in outline, to $12 \mathrm{~cm}$. long and wide, usually with 5 sharply triangular serrulate cuspidate lobes; flowers 5- or 6-merous, greenish or white, the staminate flowers in long racemes or panicles, the short-peduncled pistillate flowers solitary or in small clusters and from the same axils as the staminate flowers; corolla rotate, about $1 \mathrm{~cm}$. wide, the lobes narrowly lanceolate and acuminate; stamens 3 , united by their filaments into a column, the nearly straight anthers connivent; ovary 2 -celled, with 2 erect ovules in each cell; style with a broad-lobed stigma; fruit ovoid, $3-5 \mathrm{~cm}$. long, to $25 \mathrm{~mm}$. in diameter, bladderyinflated, somewhat beaked at summit and with weak glabrous prickles to about $6 \mathrm{~mm}$. long, bursting somewhat irregularly at the summit; seeds flat, dark.

In moist or wet alluvial soils in thickets of the Tex. Trans-Pecos, n. Okla. and Cimarron Co. (Waterfall) and Ariz. (Coconino Co.), Aug.-Sept.; N.B. to Sask., s. to Fla. and w. to Tex. and Ariz.; escaped from cult. and sporadic in w. U.S.

\section{Sicyos L. One-seeded Bur-Cucumber}

About 15 species in the American and Australasian tropics and temperate regions.

\section{Sicyos angulatus $L$.}

Plant clammy-hairy, with slender climbing stems; hairs weak and distinctly articulated; leaves with petioles to $8 \mathrm{~cm}$. long, suborbicular in outline, cordate at base, to $2 \mathrm{dm}$. long and wide, shallowly 5 -angled or -lobed with the lobes pointed; calyx tube subrotate, 4-5 $\mathrm{mm}$. wide; corolla lobes 3-4 mm. long; fruit yellowish, ovoid, pointed, $1-1.4 \mathrm{~cm}$. long, to $8 \mathrm{~mm}$. thick, sparingly long-setose and villous-tomentose.

In wooded areas along streams and rivers in damp or wet soils, in e. half of Tex. and e. Okla. (Waterfall), May-Sept.; from s. Me. and w. Que. to Minn., s. to Fla., La., Tex. and Okla.

\section{Fam. 128. Campanulaceae Juss. Bluebell Family}

Perennial, biennial or annual herbs, mostly terrestrial but occasionally aquatic or epiphytic; leaves exstipulate, simple or very rarely dissected, alternate and usually spirally arranged; flowers usually perfect and 5-merous except the gynoecium that consists of 2 to 5 united carpels possessing a common style with usually distinct stigmatic tips; ovary inferior, 2- to 5-celled or rarely unicellular; placentation axile or parietal in species with unicellular ovaries; calyx usually 5-parted to the summit of the ovary or its tubular portion forming a rim above the ovary, the lobes alternate with the corolla lobes and opposite the stamens; corolla gamopetalous at least at base, usually 5-parted or -lobed, only exception- 
ally with apparently free segments; corolla and stamens inserted around the periphery of the calyx tube at the summit of the rim; stamens as many as the corolla lobes and alternate with them, epipetalous; seeds mostly small and numerous, with fleshy endosperm.

About 2,000 species in 65 genera of world-wide distribution.

1. Flowers minute, sessile in dense leafless terminal spikes less than $1 \mathrm{~cm}$. in diameter; corolla white, about $2.5 \mathrm{~mm}$. long; stamens inserted about the middle of the corolla tube, distinct; capsule circumscissile.....................................................................1. Sphenoclea

1. Flowers rather large, pedicellate or (if sessile or essentially so) in spikes with foliaceous bracts; corolla typically more than $5 \mathrm{~mm}$. long, red or of various shades of blue and purple to dull-white (or clear-white in albino forms); stamens inserted at the base of the corolla and free from it, distinct or united; capsule loculicidally dehiscent (2)

2(1). Flowers radially symmetrical; corolla regular, campanulate; anthers distinct; capsule opening on the sides by outwardly curled elastic valves or by longitudinal slits.

2. Campanula

2. Flowers bilaterally symmetrical; corolla strongly irregular, two-lipped; anthers united into a tube; capsule opening by apical valves (3)

3(2). Corolla tube slit down one side nearly to the base.

3. Corolla tube entire, not slit down one side.

3. Lobelia 4. Porterella

\section{Sphenoclea Gaertn.}

A monotypic genus of the Old World tropics; segregated by some authors as a distinct family, Sphenocleaceae.

1. Sphenoclea zeylanica Gaertn. Chicken sPIKe. Fig. 734.

Coarse glabrous branched annual herb to $10 \mathrm{dm}$. high or more, with fistulose stems; leaves entire, with a petiole to $2 \mathrm{~cm}$. long, elliptic, somewhat pale on lower surface, to $12 \mathrm{~cm}$. long and $5 \mathrm{~cm}$. wide; spikes erect, dense, cylindric, naked, tapering at tip, to $8 \mathrm{~cm}$. long and $9 \mathrm{~mm}$. in diameter, on peduncles to $1 \mathrm{dm}$. long; floral bracts spatulate, 2-3 mm. long, about $1 \mathrm{~mm}$. wide; flowers small, sessile, 5-merous; calyx lobes imbricate in bud, triangular to suborbicular, erose at the rounded scarious apex, to $2 \mathrm{~mm}$. wide at base, deciduous with capsule; corolla white, about $2.5 \mathrm{~mm}$. long, the lobes triangular and obtuse, deciduous with stamens after anthesis; stamens alternating with the corolla lobes, inserted below middle of tube; anthers roundish, appearing peltate; ovary wholly inferior; capsule bilocular, circumscissile; seeds ellipsoid, about $0.5 \mathrm{~mm}$. long.

In wet places of lowlands and flats, especially rice fields, in e. and s. Tex., Aug.-Nov.; an Old World species that has been introd. in warm regions of the W. Hemis.

\section{Campanula L. Bellf lower}

Perennial or sometimes biennial or annual herbs of various habit; radical leaves often larger and more obtusely pointed with longer petioles than the cauline ones; calyx 5-fid, the sinuses often with reflexed appendages; corolla usually blue or purplish-blue, varying to white in the same species, 5-lobed at apex or 5-parted but usually not parted below the middle, typically campanulate but varying to rotate; stamens 5, distinct; filaments expanded and membranaceous at base; anthers linear; ovary 3- to 5-celled, opening by as many valves as there are cells, the valves varying in position from very base to near apex of capsule.

About 300 species widely distributed in the Northern Hemisphere. 


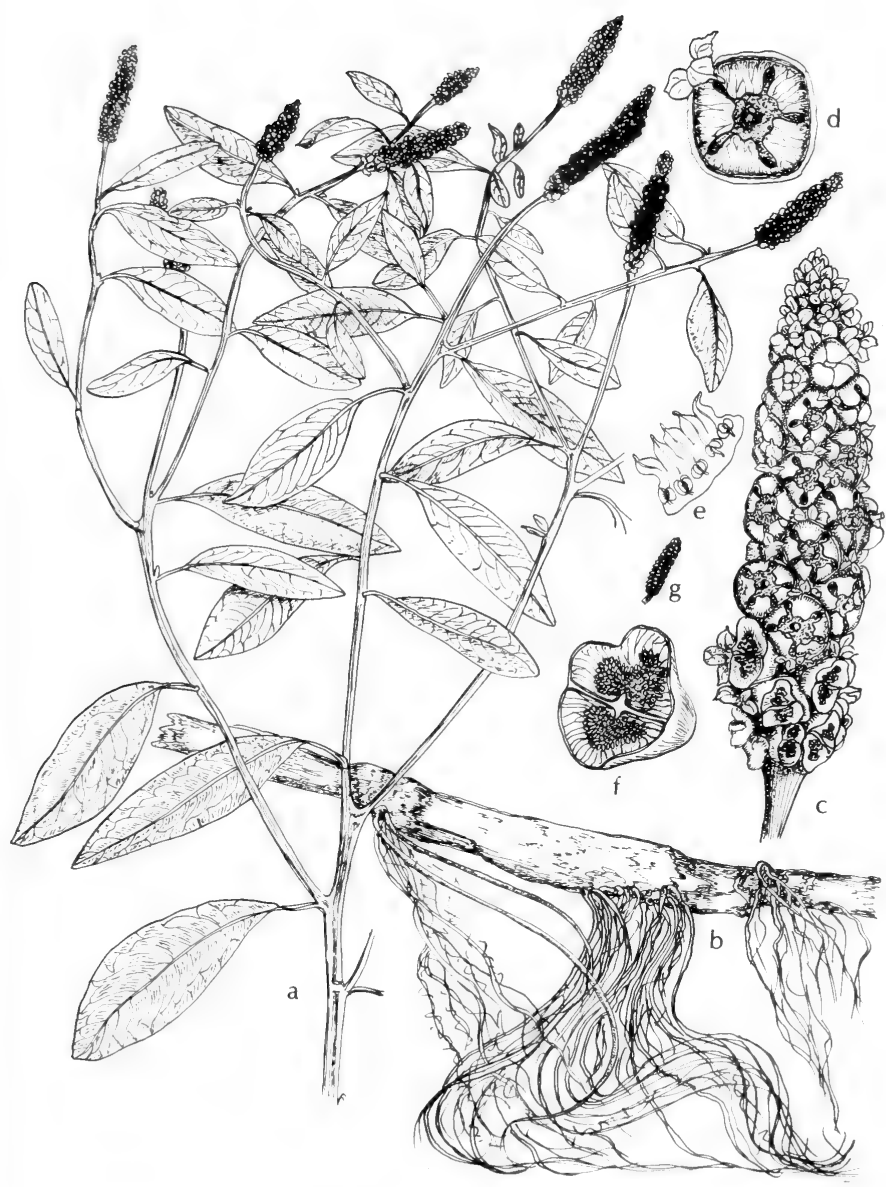

Fig. 734: Sphenoclea zeylanica: a, habit, $x \frac{1}{1} ;$; $b$, basal part of plant showing rooting stem, $\mathrm{x} 1 / 2 ; \mathrm{c}$, spike, $\mathrm{x} 2$; d, calyx and bracts, x 5; e, corolla opened, $\mathrm{x} 5$; $\mathrm{f}$, lower half of circumscissile capsule, $\times 5 ; \mathrm{g}$, seed, $\times 25$. (V. F.). 
1. Calyx lobes entire; mature capsule nodding, the valves at the very base; basal leaves orbicular or nearly so, more or less cordate at base; cauline leaves linear and acuminate-attenuate.................... . rotundifolia.

1. Calyx lobes typically with 1 or more callose teeth on each side; mature capsule erect, the valves distinctly above the middle; basal leaves mostly oblanceolate to obovate, tapering at base; cauline leaves narrowly elliptic and obtuse to long-acute.

2. C. Parryi.

\section{Campanula rotundifolia L. Bluebell, harebell.}

Perennial to about $1 \mathrm{~m}$. high, usually much smaller, the rootstocks slender and elongate; stems erect or decumbent, scabrous, simple to freely branched; leaves often in rosettelike clusters at or near base, long-petioled, round-cordate to elliptic or oblanceolate, to $5 \mathrm{~cm}$. long and wide, mostly toothed, early-withering; cauline leaves numerous, linear to narrowly lanceolate, smooth, to $1 \mathrm{dm}$. long and $3 \mathrm{~mm}$. wide; flowers as many as 15 in a lax raceme; calyx lobes narrowly triangular to linear-subulate, usually entire, with sharp slender tips, erect to spreading or reflexed in fruit, to $1 \mathrm{~cm}$. long and $2 \mathrm{~mm}$. wide; corolla violet-blue, mostly 12-25 mm. long, the tube 7-15 mm. long; corolla lobes ovate-oblong, abruptly pointed at tips, 5-8 $\mathrm{mm}$. wide; filaments $2.5-4.5 \mathrm{~mm}$. long, abruptly dilated and ciliate on the basal portion; anthers 4-6 mm. long; capsule pendent, obovoid to ellipsoid or subglobose, prominently ribbed, 4-8 $\mathrm{mm}$. long, 2-4 mm. in diameter. C. petiolata sensu Woot. \& Standl.

In wet meadows, edge of streams and rocky wooded areas in canyons of mts. in the Tex. Trans-Pecos (Culberson Co.), N.M. (widespread in the mts.) and Ariz. (Apache, Coconino, Greenlee and Graham cos.), June-Oct.; across the n.cen. portion of N.A., s. in the mts. to Tex., and n. Mex.

Throughout its wide area of distribution this species is highly variable.

\section{Campanula Parryi Gray.}

Plant slender, to about $7 \mathrm{dm}$. high; basal leaves mostly oblanceolate to obovate, to about $4 \mathrm{~cm}$. long and $7 \mathrm{~mm}$. wide, tapered at base; cauline leaves linearelliptic to linear-oblanceolate, to about $5 \mathrm{~cm}$. long and $6 \mathrm{~mm}$. wide, obtuse to long-acute at apex; flowers rarely more than 3 , usually solitary; calyx lobes lancesubulate, to about $1.5 \mathrm{~cm}$. long in anthesis, typically with 1 or more callose teeth on each side; corolla bluish-purple, about $2 \mathrm{~cm}$. long, divided to about the middle into broadly ovate apiculate lobes; filaments broad and pubescent, about $2 \mathrm{~mm}$. long; anthers about $6 \mathrm{~mm}$. long; style $1 \mathrm{~cm}$. long; mature capsule erect, the valves distinctly above the middle, usually two thirds to three fourths of the distance from base to apex.

In wet mt. meadows in N.M. (rather widespread) and Ariz. (Apache and Coconino cos.), July-Sept.; also Wyo. and Ut.

\section{Lobelia L. Lobelia}

Perennial, biennial or annual herbs; leaves mostly of a lanceolate type; flowers axillary or chiefly in bracted racemes, usually inverted before anthesis, the pedicel twisted; calyx 5-cleft, regular, parted to the summit of the ovary or the calyx tube extending a little above the ovary; corolla variously colored, with relatively narrow tube and spreading lobes, the tube usually cleft nearly to base between the 2 lobes of the upper lip, the 3 lobes of the lower lip often somewhat united, broad and conspicuous; stamens 5, usually free from the corolla; filaments free at base, united distally into a tube; anthers united into a tube, the orifice of the tube usually partly closed by the incurved tips of the 3 longer anthers, the shorter anthers usually stiff-bearded at apex; corolla, stamens and style withering-persistent on the fruit; capsule 2-celled, many-seeded, cpening by apical loculicidal valves, splitting at apex and the 2 halves recurved laterally. 
A genus of perhaps 300 species, represented in the floras of all the continents and on many oceanic islands; about 80 species in North America.

1. Flowers bright-red; corolla $35-40 \mathrm{~mm}$. long or more; filaments $20 \mathrm{~mm}$. long or more; pedicels with a pair of green or yellowish glandular bracteoles near base; seeds very rough (2)

1. Flowers blue, lavender, purple or white; corolla mostly not over $25 \mathrm{~mm}$. long; filaments $15 \mathrm{~mm}$. long or less; pedicels and seeds various (5)

2(1). Filament tube 24-33 (usually 28-30) $\mathrm{mm}$. long; anther tube 4-5.5 mm. long; leaves usually coarsely and irregularly toothed, the blades 3 to 5 times as long as wide; eastern Texas and Oklahoma.

10. L. Cardinalis var. Cardinalis.

2. Filament tube 19-25 (rarely 30) mm. long; anther tube mostly 3.4-4.5 mm. long; leaves entire to coarsely toothed, the blades often 6 to 12 times as long as wide; western Texas (3)

3(2). Inflorescence appearing pedunculate, usually short, of 20 flowers or fewer, not leafy-bracted; cauline leaves mostly 8 to 12 times as long as wide, linear to linear-lanceolate; plants nearly glabrous; in the Trans-Pecos..........................10. L. Cardinalis var. pseudosplendens.

3. Plants leafy up to the inflorescence, the latter not appearing pedunculate, usually many-flowered, often leafy-bracted; cauline leaves mostly 6 to 8 times as long as wide, lanceolate to oblong or ovate (4)

4(3). Plants densely short-pubescent throughout; leaves subentire to somewhat toothed; in the Trans-Pecos............10. L. Cardinalis var. multiflora.

4. Plants glabrous or sparsely pubescent; leaves usually prominently toothed; chiefly west of the 100 th meridian and east of the Pecos River.... 10. L. Cardinalis var. phyllostachya.

5(1). Filaments 12-15 mm. long; pedicels with a pair of gland-tipped bracteoles at or above the middle; calyx lobes often 5-6 $\mathrm{mm}$. wide, with leafy auricles $2-5 \mathrm{~mm}$. long at base; seeds very rough; northeastern Texas and eastern Oklahoma.................................... 9. L. siphilitica.

5. Filaments 9 (rarely to 11 ) $\mathrm{mm}$. long or less; pedicels, calyx and seeds various (6)

6(5). Filaments more than $5 \mathrm{~mm}$. long; corolla tube 7 (rarely 6.5) $\mathrm{mm}$. long or more; seeds rough (7)

6. Filaments less than $5 \mathrm{~mm}$. long; corolla tube $6 \mathrm{~mm}$. long or less; seeds rough or smooth (10)

7(6). Corolla short-pilose within at base of lower lip, the tube not (or very rarely) fenestrate laterally; plants totally glabrous or puberulent in the inflorescence (8)

7. Corolla glabrous within at base of lower lip, the tube fenestrate laterally near base; plants rather densely and uniformly pubescent or (in exceptional forms) nearly glabrous in the inflorescence (9)

8(7). Leaves all basal or with a few small ones above the base; pedicels with minute inconspicuous bracteoles at base..................5. L. floridana.

8. Leaves mostly cauline, well-distributed along the stem; pedicels bibracteolate well above base (usually about the middle or a little below), the bracteoles often $1 \mathrm{~mm}$. long or more, often green and denticulate 6. L. flaccidifolia.

9(7). Filaments mostly 6-7 $\mathrm{mm}$. long; plants puberulent to glabrate or shorthirsute; flowers numerous, usually about $1 \mathrm{~cm}$. apart; calyx lobes narrowly triangular-lanceolate, not densely pilose at base.

..8. L. puberula. 
9. Filaments $8-11 \mathrm{~mm}$. long; plants long-hirsute (especially the hypanthium); flowers few and distant; calyx lobes broadly ovate-cordate at base and abruptly tapered above, with a dense tuft of hair at the base....

7. L. Reverchonii.

10(6). Corolla tube evidently fenestrate laterally; seeds smooth, polished; annual or biennial with a stout taproot and coarsely serrate leaves; in the Texas Trans-Pecos................................................4. L. fenestralis.

10. Corolla tube not fenestrate laterally; seeds rough or smooth; annuals or perennials with the leaves entire to irregularly dentate (11)

11(10). Plant with a perennial rootstock; cauline leaves linear to linear-lanceolate, acuminate; distribution New Mexico and Arizona.

2. L. anatina

11. Plant annual; cauline leaves ovate to lanceolate, obtuse to acute; distribution east of New Mexico and Arizona (12)

12(11). Seeds rough, cellular-reticulate; calyx lobes usually with at least some vestige of triangular or foliaceous auricles at base; eastern Texas and Oklahoma.................................................. L. appendiculata.

12. Seeds smooth, polished; calyx lobes without any auricles at base; southern and southwestern Texas (13)

13(12). Calyx lobes ciliate; leaves mostly cauline; pedicels nearly upright, 4-10 $\mathrm{mm}$. long in fruit. 1. L. Berlandieri var. brachypoda.

13. Calyx lobes glabrous; leaves mostly in basal rosette; pedicels often incurved, 1. L. Berlandieri var. Berlandieri.

\section{Lobelia Berlandieri A.DC.}

Annual to about $6 \mathrm{dm}$. high; stems erect to decumbent, simple or with as many as 20 ascending branches, glabrous to sparsely pubescent near base; leaves without or with a marginal petiole to $25 \mathrm{~mm}$. long, often near the base or in a basal rosette but also cauline, thin, broadly ovate to elliptic or lanceolate, to $5 \mathrm{~cm}$. long and $35 \mathrm{~mm}$. wide, rounded to cuneate at base, rounded to obtuse at apex, glabrous to ciliate near base, the margins subentire to coarsely and irregularly toothed; inflorescence to about $25 \mathrm{~cm}$. long; pedicels to $2 \mathrm{~cm}$. long in fruit, glabrous or slightly bristly, nearly upright or usually incurved above the middle, with a pair of tiny bracteoles at base; bracts linear to linear-subulate, $3-9 \mathrm{~mm}$. long, glabrous or ciliate; flowers $1-1.3 \mathrm{~cm}$. long; calyx lobes linear-subulate, entire, glabrous to sparsely ciliate, $1.5-3.5 \mathrm{~mm}$. long; corolla pale- or brightpurplish-blue with a white eye, glabrous or hairy within at the summit of the tube; filament tube 2.5-3.5 mm. long; anther tube 1-1.5 mm. long, light-bluishgray; capsules ellipsoid, 3-6 $\mathrm{mm}$. long.

In sandy, rocky or clay soils in fields, moist areas and along streams, springsummer.

The var. Berlandieri occurs in the Rio Grande Plains of south Texas and south into Mexico. The var. brachypoda (Gray) McVaugh, with leaves mostly cauline, occurs in Texas in the Edwards Plateau and Trans-Pecos.

\section{Lobelia anatina Wimmer.}

Plants with a perennial rootstock, to about $6 \mathrm{dm}$. tall, glabrous; basal leaves oblanceolate, to about $7 \mathrm{~cm}$. long and $1.5 \mathrm{~cm}$. wide; cauline leaves linear to linear-lanceolate, acuminate, to about $8 \mathrm{~cm}$. long, less than $1 \mathrm{~cm}$. wide, narrowed at base, never clasping, shallowly dentate to subentire; calyx about $7 \mathrm{~mm}$. long, irregularly linear-subulate lobed to below the middle; corolla blue, about $2 \mathrm{~cm}$. long, divided to about the middle into elliptic-obovate lobes, the tube entire except for the dorsal slit; filament tube $3.5-5 \mathrm{~mm}$. long, the 2 smaller anthers white-tufted, the 3 larger ones smooth or nearly so. 

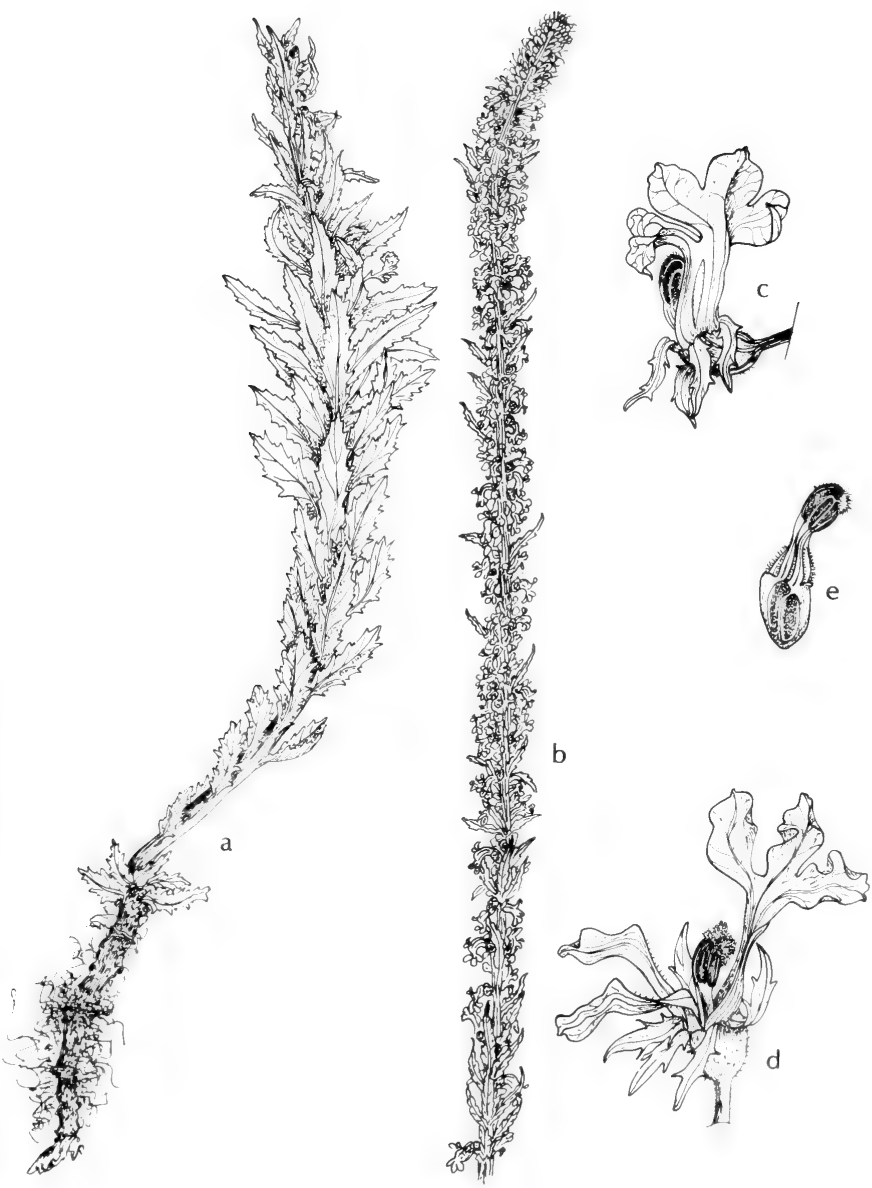

Fig. 735: Lobelia fenestralis: a, basal part of plant, $\times 1 \frac{1}{2}: \mathrm{b}$, spike, $\mathrm{x} \frac{1}{2} ;$; c, flower, x $2 \frac{1}{2}$; d, corolla split, showing anthers, $\times 2 \frac{1}{2}$; e, stamen column, $\times 2 \frac{1}{2} 2$. (V. F.). 


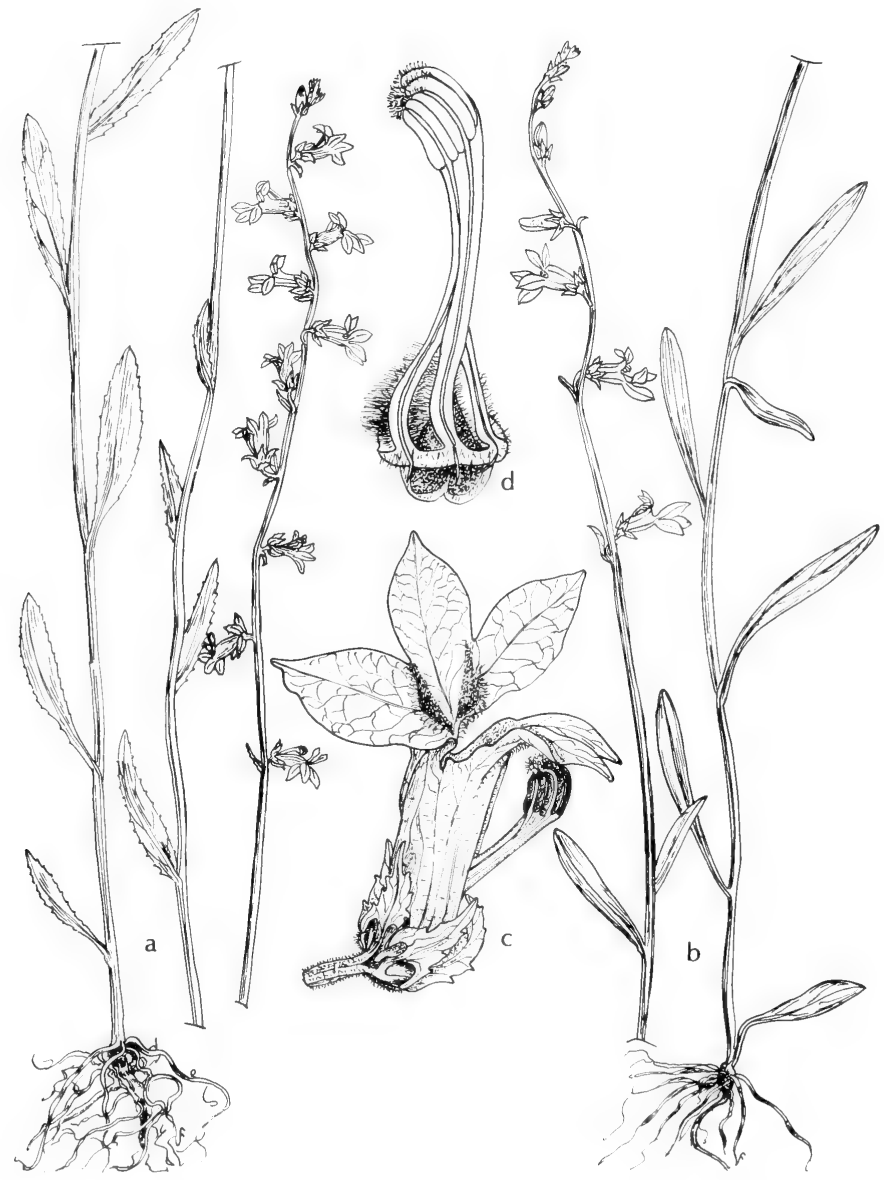

Fig. 736: Lobelia flaccidifolia: a, habit, x 1/2; b, habit showing entire leaves and fewer and larger flowers than in "a", $x 1 / 2 ; c$, flower, $x 5$; , stamen column, $x$ $71 / 2$. (V. F.). 
Meadows, marshy places, seepage areas and stream banks in s. N.M. (Socorro and Grant cos.) and Ariz. (Apache, Coconino, Navajo and Pima cos.), s. to Dgo., July-Oct.

\section{Lobelia appendiculata A.DC.}

Annual or biennial; stem erect, to $9 \mathrm{dm}$. high, simple or with few upright axillary branches, glabrous except for sparse chaffy basal hairs; cauline leaves very thin, sessile or with broad to clasping bases, oblong to ovate, obtuse to acute at apex, essentially glabrous, to $8 \mathrm{~cm}$. long and $3 \mathrm{~cm}$. wide; raceme 1 -sided, to $3 \mathrm{dm}$. long; pedicels $4-8 \mathrm{~mm}$. long, puberulent, with a pair of bracteoles near base; bracts linear to narrowly lanceolate, callous-denticulate, exceeding the pedicels; flowers $1-1.5 \mathrm{~cm}$. long; calyx long-campanulate in fruit, subinflated, its linear-lanceolate lobes bristly-ciliate, its conspicuous flat lanceolate auricles 1-3 $\mathrm{mm}$. long, the auricles drying blue or purplish; corolla lilac or violet, pubescent at base of lip inside, the tube $4-5 \mathrm{~mm}$. long; filament tube $2-4 \mathrm{~mm}$. long; anther tube 2-2.5 mm. long, bluish-gray; capsule partially exserted, horizontal or nodding.

In sandy open ground, often in moist places, in prairies, pinelands and old fields in e. Tex. and e. Okla., Apr.-June; from Ala. to Tex., Ark., Okla., Mo. and Ill.

\section{Lobelia fenestralis Cav. LeAFy Lobelia. Fig. 735.}

Annual or biennial from a taproot, to $14 \mathrm{dm}$. high; stems erect, leafy, simple or with several ascending branches, glabrous or sparsely pubescent on the angles; leaves sessile or somewhat clasping at base, lanceolate to oblong or oblanceolate, acute at apex, coarsely and sharply serrate, glabrous or somewhat pubescent, to $7 \mathrm{~cm}$. long and $12 \mathrm{~mm}$. wide; inflorescence spicate, about $25 \mathrm{~cm}$. long; pedicels to about $5 \mathrm{~mm}$. long, mostly concealed by the lanceolate bracts; flowers 12-14 $\mathrm{mm}$. long; calyx lobes lanceolate to linear-subulate, of ten toothed, ciliate or smooth, 2.5-6.5 mm. long; corolla blue with a white eye, the tube 5-6 $\mathrm{mm}$. long and long-fenestrate; filament tube $1.5-2.3 \mathrm{~mm}$. long; anther tube $1.5-2 \mathrm{~mm}$. long, dark-bluish-gray or blackish; capsules $3-8 \mathrm{~mm}$. long.

Meadows and swales in w. Tex. to Ariz. (Coconino, Cochise and Santa Cruz cos.), southw. to Oax., Aug.-Nov.

\section{Lobelia floridana Chapm.}

Stem erect, to $15 \mathrm{dm}$. high, simple or with several stout upright or spreading branches, glabrous; basal leaves oblanceolate to lanceolate, acute to obtuse at apex, tapered into a margined petiole, to $4 \mathrm{dm}$. long and $25 \mathrm{~mm}$. wide, usually much smaller, entire to crenate or dentate with callose teeth; cauline leaves much smaller and narrower; raceme to $5 \mathrm{dm}$. long, loosely or densely flowered; pedicels stout, 3-6 $\mathrm{mm}$. long in fruit, rough, with a pair of minute bracteoles at base; bracts linear, glabrous, shorter than the pedicels; flowers $1.3-2 \mathrm{~cm}$. long; calyx lobes broadly lanceolate to deltoid, 2-6 mm. long, acute, glabrous, the triangular auricles very small; corolla pale-purplish to nearly white, pubescent without, the lower lip densely hirsute at base within, the tube $8-9 \mathrm{~mm}$. long; filament tube 6-11 mm. long, strongly deflexed; anther tube about $3 \mathrm{~mm}$. long, light-bluishgray; capsule 5-7 $\mathrm{mm}$. long.

In wettish savannahs in s.e. Tex., Apr.-Aug.; from N.C. to Fla., w. to Tex.

\section{Lobelia flaccidifolia Small. Fig. 736 .}

Annual to about $1 \mathrm{~m}$. high; stems erect, simple or with few ascending branches; leaves essentially sessile or the lower ones short-petiolate, thin, lanceolate to oblong or oblanceolate, to $11 \mathrm{~cm}$. long and $15 \mathrm{~mm}$. wide, often rather abruptly narrowed at base, rounded to acute at apex, the margins subentire to incon- 
spicuously crenate or serrate; inflorescence racemose, to $3 \mathrm{dm}$. long; pedicels rough, slender, curved, 4-11 $\mathrm{mm}$. long in fruit, with a pair of bracteoles near or below the middle; bracts linear, denticulate, glabrous or puberulent, about equaling the pedicels; flowers $14-22 \mathrm{~mm}$. long; calyx lobes narrowly sagittate, 3-7 $\mathrm{mm}$. long, acute or attenuate at apex, glabrous or puberulent, often glandular-toothed, the reflexed auricles rounded and about $1.5 \mathrm{~mm}$. long or less; corolla lavender or bluish-lavender to nearly white, with a white eye, pubescent or glabrous, the tube 6.5-8.5 mm. long; filament tube lavender, 5-8 $\mathrm{mm}$. long; anther tube 2-3 $\mathrm{mm}$. long, bluish-gray; capsule 4-6 $\mathrm{mm}$. in diameter.

In low moist pinelands, savannahs and prairies, wet places along streams and in river swamps in s.e. Tex., Apr.-Aug.; from Fla. and Ga. in the Coastal Plain to Tex.

\section{Lobelia Reverchonii B. L. Turner.}

Stems to $1 \mathrm{~m}$. high, conspicuously pilose with white spreading hairs to $1.5 \mathrm{~mm}$. long; leaf blade typically linear to linear-oblanceolate, prominently toothed, to $14 \mathrm{~cm}$. long and $15 \mathrm{~mm}$. wide, mostly 7 to 10 times as long as wide; flowers $2-2.7$ $\mathrm{cm}$. long, usually 10 or fewer, rarely as many as 15 , the lower ones $2.5-5 \mathrm{~cm}$. apart; calyx lobes ovate to ovate-lanceolate, deeply cordate with rounded basal lobes, 3-5 mm. wide, with a tuft of hairs at base; hypanthium and pedicels densely pilose with long white or brownish hairs; corolla tube 9-15 mm. long; lower corolla lobes recurved, with 2 white lenslike markings following the venation between the lobes; filament tube $8-11 \mathrm{~mm}$. long; anther tube 3-4 mm. long, grayish-blue. L. puberula var. pauciflora Bush.

In bogs in e. Tex., autumn; e. to Ala.

\section{Lobelia puberula Michx. Downy lobelia, purple dewdrop. Fig. 737.}

Plant densely short-hirsute or puberulent throughout, rarely glabrate, mostly to 16 (rarely to 27 ) $\mathrm{dm}$. high; stem usually simple; leaves oblong to lanceolate or narrowly obovate, sessile or tapering to base, obtuse to acute at apex, with callous-tipped teeth or subentire, to $12 \mathrm{~cm}$. long and $4 \mathrm{~cm}$. wide, the upper ones passing gradually into the floral bracts; raceme dense or somewhat interrupted below, to $5 \mathrm{dm}$. long, commonly 1 -sided, with as many as 75 flowers, the distance between the lower flowers at most $25 \mathrm{~mm}$; pedicels stout, 3-5 mm. long in fruit, the bracteoles basal or nearly so; bracts usually lanceolate, to $25 \mathrm{~mm}$. long and $8 \mathrm{~mm}$. wide; flower 15-24 mm. long; pedicels and base of calyx lobes glabrous to thinly pubescent; calyx lobes lanceolate to narrowly deltoid-acuminate, with revolute margins, to $15 \mathrm{~mm}$. long and $4 \mathrm{~mm}$. wide, the auricles small; corolla blue to purple or rarely whitish, pubescent, the tube $5-8 \mathrm{~mm}$. long, the lower lobes not recurved, with a white eye extending across the venation; filament tube 6-7 $\mathrm{mm}$. long; anther tube 3-3.5 mm. long, light-bluish-gray; capsule 4-7 mm. long.

In swamps, wet woods, bogs, prairies and open fields, usually in wet places, often in strongly acid soils in partial shade, in e. Okla. and e. Tex., Aug.-Dec.; in s.e. U.S., w. to Okla. and Tex.

9. Lobelia siphilitica L. Big blue lobelia, great lobelia, Blue cardinal FLOWER, LOUISIANA LOBELIA.

Perennial by basal offshoots, to $13 \mathrm{dm}$. high; stem simple, coarse, smooth or sparsely hirsute on the angles; leaves thin, ovate to oblong or broadly lanceolate, irregularly serrate, acute at both ends, strigose above, to $18 \mathrm{~cm}$. long and $6 \mathrm{~cm}$. wide, the upper merging into the floral bracts; raceme dense, to $5 \mathrm{dm}$. long, scarcely secund; pedicels $5-10 \mathrm{~mm}$. long, with median bracteoles; bracts lanceolate, 1-2 cm. long; flowers $23-33 \mathrm{~mm}$. long; calyx hirsute, with broad foliaceous lobes to $14 \mathrm{~mm}$. long and broad auricles $2-5 \mathrm{~mm}$. long; corolla blue, white- 


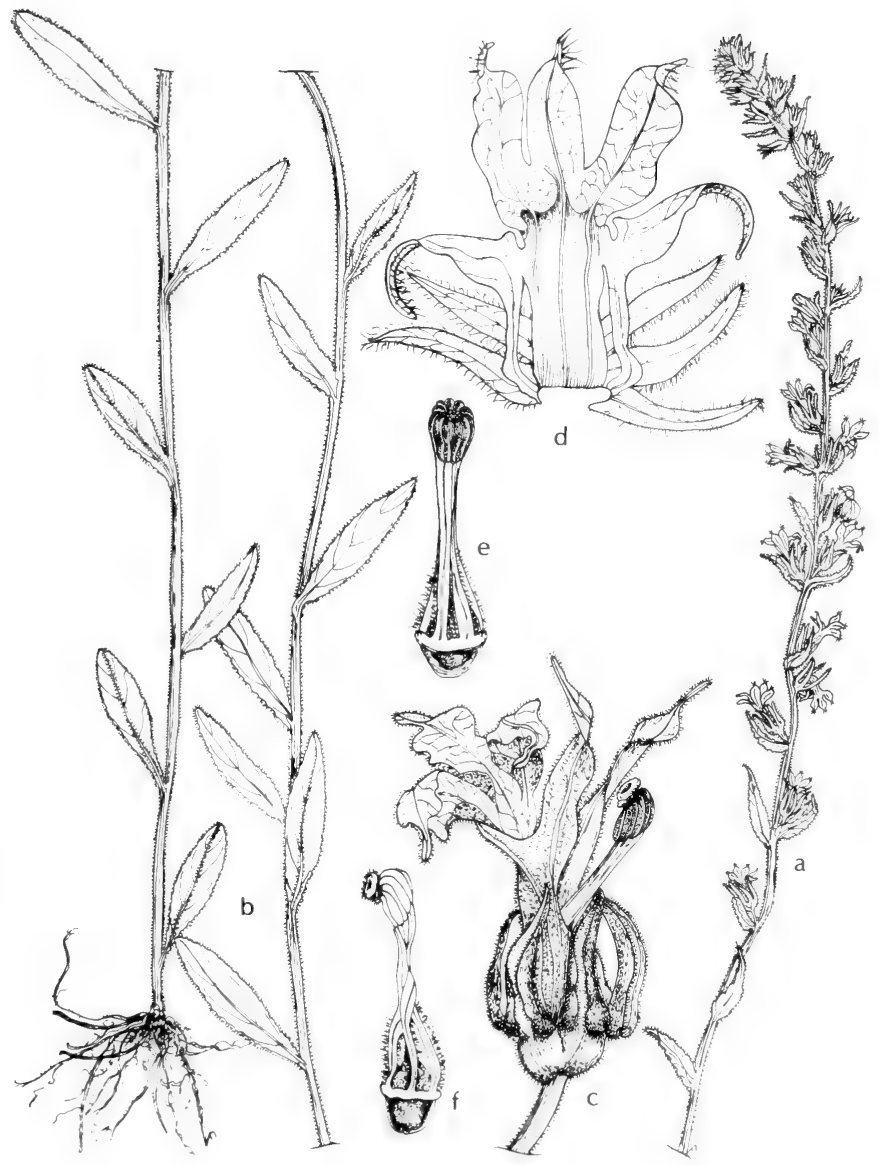

Fig. 737: Lobelia puberula: a, spike, x 1/2; b. basal and central part of stem, x 1/2; c, flower, $x 2 \frac{1}{2} \mathrm{~d}$, corolla open, $\mathrm{x} 2 \frac{1}{2}$; e, stamen column, front view, x $2 \frac{1}{2} ; \mathrm{f}$, stamen column, side view, $\times 2^{1} \frac{1}{2}$. (V.F.). 

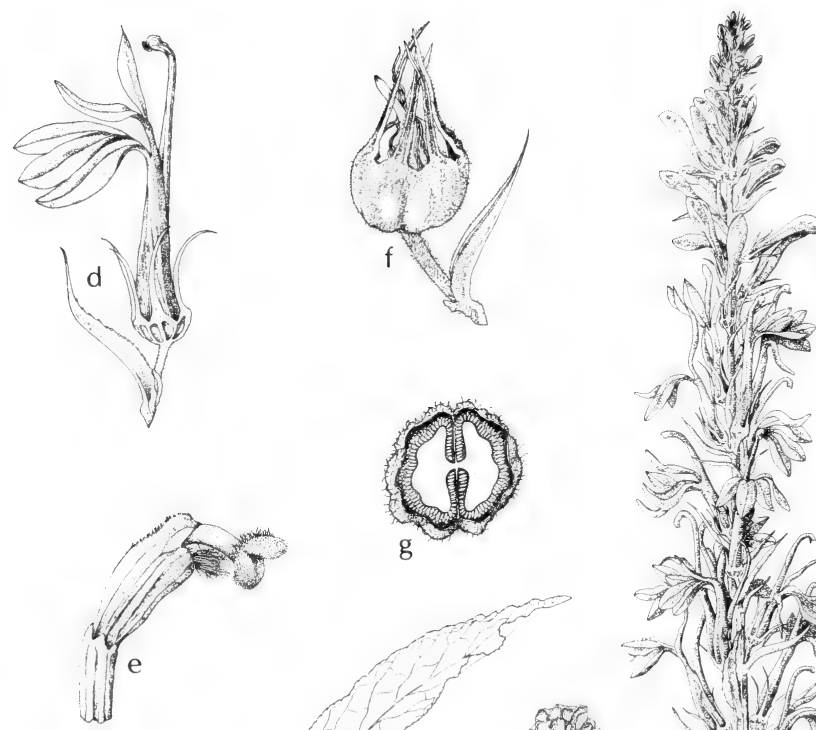

g
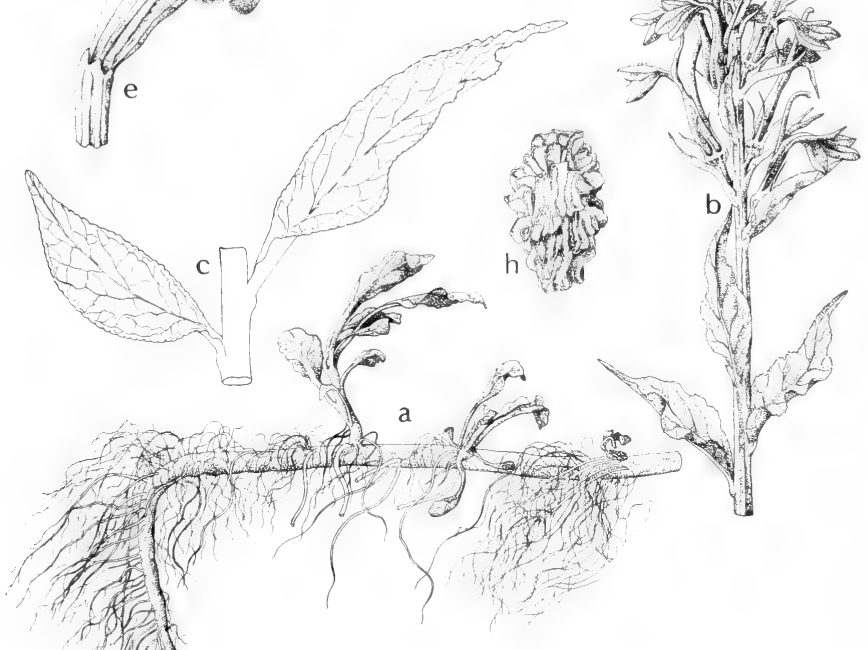

Fig. 738: Lobelia cardinalis subsp. cardinalis: a, basal decumbent part of plant, $\mathrm{x} 1 / 3$; b, top of plant, $\mathrm{x} 1 / 3$; c, section of stem with leaves, $\mathrm{x} 1 / 3$; d, flower, $\mathrm{x} 1$; e, anther tube and style, $\mathrm{x} 4$; $\mathrm{f}$, calyx and capsule, about $\mathrm{x} 2 ; \mathrm{g}$, cross section through calyx and capsule, x 2; h, seed, x 25. (Courtesy of R. K. Godfrey). 
striped in throat, the tube 11-15 mm. long, fenestrate, base of lower lip white and with 2 tubercles; filament tube $12-15 \mathrm{~mm}$. long; anther tube 4-5.5 mm. long, bluish-gray; capsule $8-10 \mathrm{~mm}$. long, partly exserted.

In moist woods and swampy places, low places in prairies, sandy or gravelly margins of ponds and streams, and wet meadows in n.e. Tex. and e. Okla., late summer; from Me. to Minn., Man. and Colo., s. to Tex.

Our plants are referred to the var. ludoviciana A.DC. They are characterized by being glabrous or nearly so, the leaves are mostly $15 \mathrm{~mm}$. wide or less, and the flowers are often fewer than 20.

\section{Lobelia Cardinalis L. Cardinal flower. Figs. 738 and 739.}

Perennial by short basal offshoots, smoothish, to $2 \mathrm{~m}$. high; stem simple, erect, coarse, glabrous or pubescent; leaves numerous, thin, glabrous or hirtellous, ovate to lanceolate, irregularly serrate; raceme terminal, simple, to $5 \mathrm{dm}$. long, somewhat 1-sided; pedicels bristly-puberulent, much shorter than the leafy bracts, bibracteolate near base; bracts linear or broader; pedicels seldom more than 1.5 $\mathrm{cm}$. long in fruit; flowers $3-5 \mathrm{~cm}$. long; calyx lobes foliaceous, ovate to broadly lanceolate, to $14 \mathrm{~mm}$. long and $6 \mathrm{~mm}$. wide, undulate or crisped, ciliate and serrate; corolla vermilion or deep-red, the fenestrate tube $1.5-2 \mathrm{~cm}$. long; filament tube 24-33 mm. long, long-exserted; anther tube 3-5.5 mm. long, bluish-gray; capsule $8-10 \mathrm{~mm}$. long.

In wet or moist soil, open places along streams, in meadows and along roadsides, about springs and ponds, in swamps where shade is not too dense, throughout Tex., except the s. tip, throughout Okla., w. through N.M. to Ariz., MayDec.; from Fla., n. to n.e. N.B., s. Que., S. Ont., Mich., Wisc. and Minn., w. to Nev., Calif. and Mex.

The subsp. graminea (Lam.) McVaugh (L. splendens Willd.) is represented in our region by three varieties of which two, var. multiflora (Paxt.) McVaugh and var. pseudosplendens McVaugh, occur in the Texas Trans-Pecos region only. The remaining one, var. phyllostachya (Engelm.) McVaugh, is the prevailing cardinal flower across the central part of Texas. Although the distinguishing characteristics of each are given in the key, many intermediate forms occur, and it is often not possible to assign individual plants definitely to any one variety; often only the extreme forms are recognizable.

\section{Porterella TORR.}

\section{A monotypic genus.}

\section{Porterella carnosula (Hook. \& Arn.) Torr. Fig. 740.}

Erect, somewhat succulent, annual herb; stems branched, slender to stout, 6-30 $\mathrm{cm}$. tall; herbage glabrous; leaves linear to lanceolate, sessile, 1-3 cm. long, the tip acute or acuminate; flowers solitary in the leaf axils on slender spreading or ascending pedicels; sepals linear-lanceolate, 3-10 $\mathrm{mm}$. long; corolla blue to white, bilabiate, the tube short-cylindrical to somewhat enlarged above, 4-6 mm. long, the lower lip 3-lobed, rotately spreading, the lobes broadly obovate to nearly orbicular, with a broad white area and a central greenish-yellow spot conforming to 2 low ridges near the base of the lip, the upper lobes oblong-lanceolate, united at base, somewhat divergent; stamen column united throughout, the filament tube included, 3-7 $\mathrm{mm}$. long, the anther tube $1.5-3 \mathrm{~mm}$. long, the orifice subapical, the anthers all tufted at tip, the 2 short ones each with a scalelike bristle; ovary inferior, obconic to turbinate, 5-angled, bilocular, 8-14 mm. long.

Vernal pools, wet meadows and margins of streams in Ariz. (Coconino Co.), June-July; Wyo. to Ore., s. to n. Ariz. and n. Calif. 


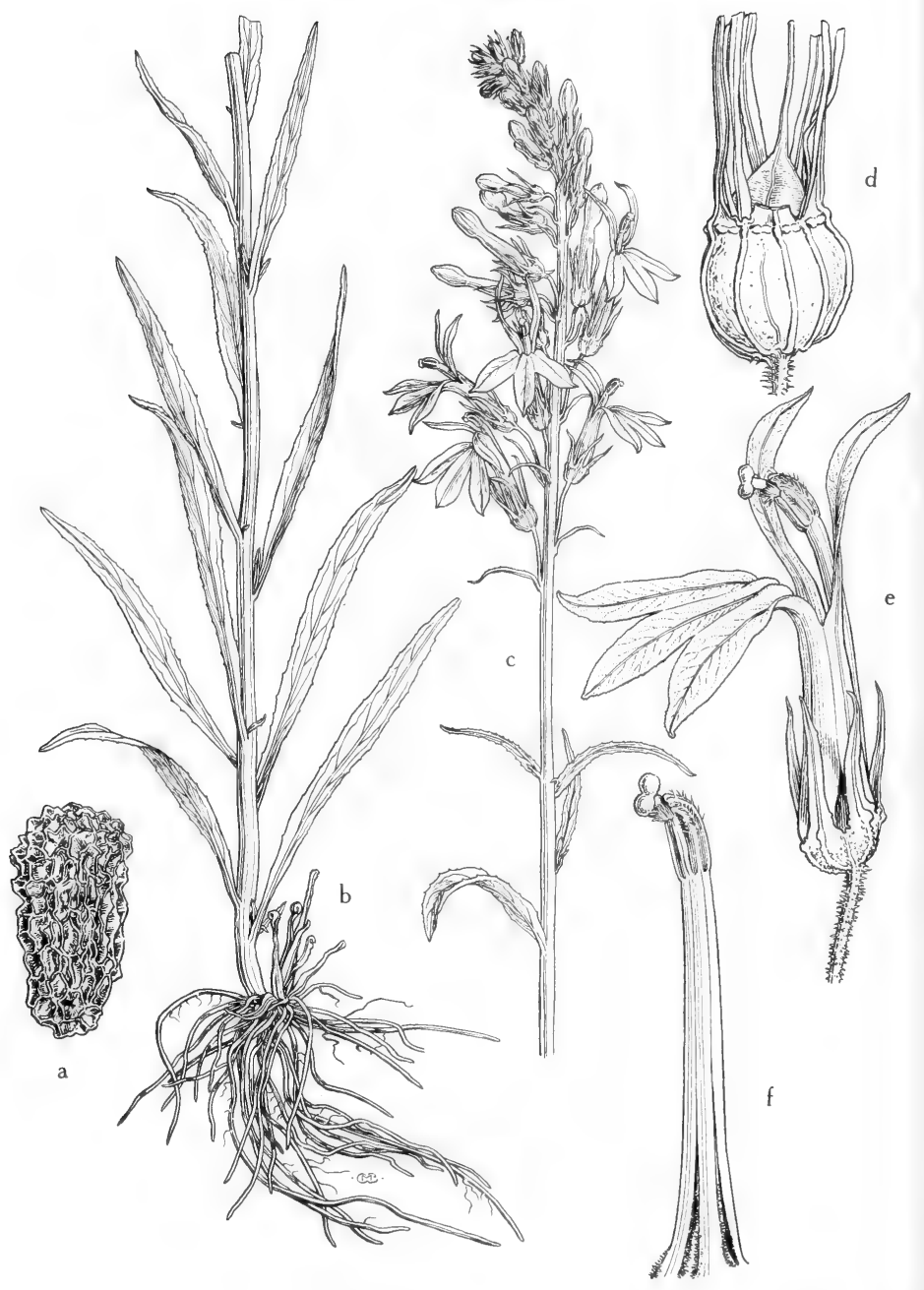

Fig. 739: Lobelia cardinalis subsp. graminea: a, seed, $\mathrm{x} 30$; b and c, habit, x 2/5; d, capsule, x 3; e, flower, x 11/2; f, stamen column, x 21/2. (From Mason, Fig. 342). 


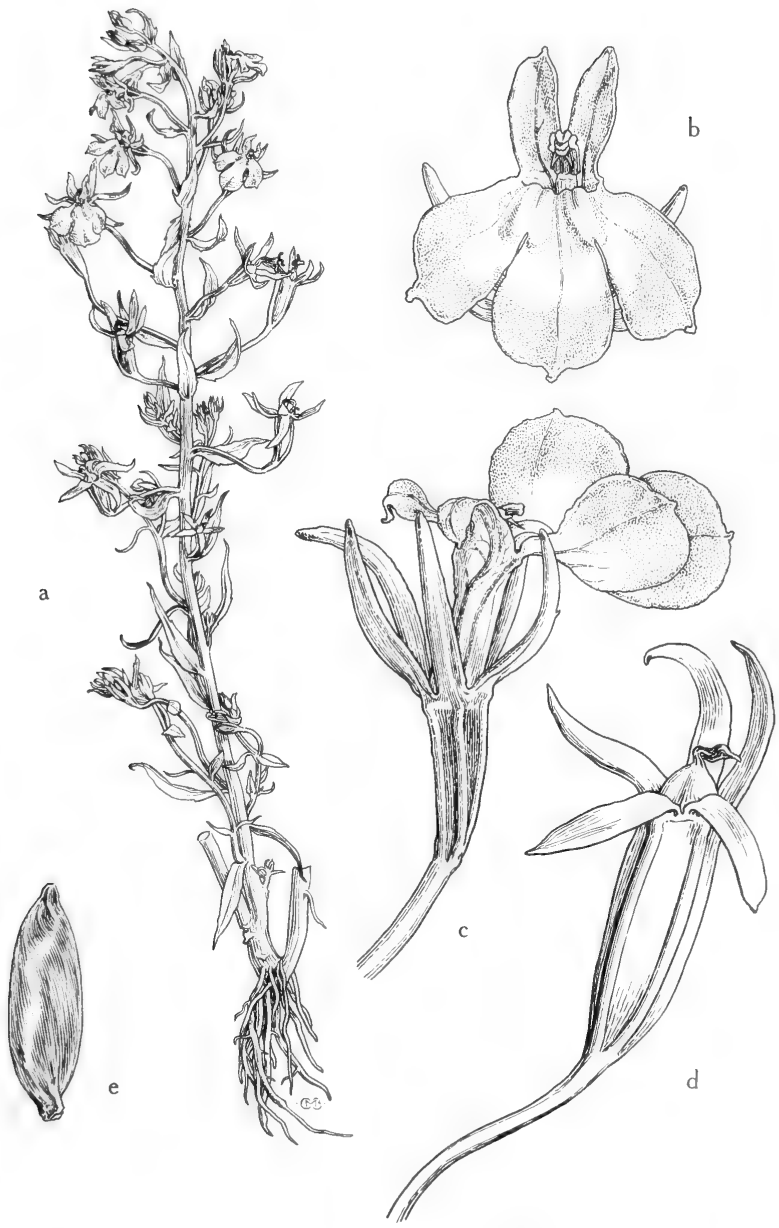

Fig. 740: Porterella carnulosa: a, habit, $\mathrm{x} 4 / \mathrm{s} ; \mathrm{b}$, flower, front view, $\mathrm{x} 4$; c, flower, side view, x 4; d, capsule, x 3; e, seed, x 30. (From Mason, Fig. 344). 
Herbs, vines or shrubs; leaves alternate or opposite, exstipulate; flowers borne in dense involucrate heads (the number of flowers in the head occasionally as few as 1 or 2); axis and/or receptacle of the head usually thicker than its stem (peduncle), globose, cylindrical, conical, convex, flat or concave, near its base usually invested with 1 or more series of persistent or deciduous bracts ("phyllaries") which partly enclose the head as it develops (when 2 or more series of phyllaries are present, only the innermost subtend flowers; any similar bracteal structures subtending the inner flowers of the head are called pales), the receptacle either smooth or usually rough or pitted and in many genera chaffy, i.e., with persistent or deciduous pales subtending some or all of the flowers (note that bracteal structures subtending the most peripheral flowers are called phyllaries); flowers small, epigynous, protandrous, uni- or bisexual, fertile (producing a viable fruit) or infertile; calyx absent or represented by a pappus (a series of scales and/or bristles) at the tip of the achene near the base of the corolla if a corolla is present; corolla sympetalous (composed of 4 or 5 coalescent petals), rarely absent, quite diverse but usually taking one of the following forms or types: (a) more or less radially symmetrical with a basal tube and a more or less well-differentiated thicker (4- or) 5-toothed or -lobed limb; flowers with such corollas are usually bisexual and are called disk flowers because they form the central part ("disk") of the heads of the vast majority of the Compositae; (b) bilaterally symmetrical, with a short basal tube and a flat beltlike or straplike usually 3-toothed or -lobed ray-portion ("ray" is often used to mean the entire corolla); flowers with this kind of corolla are pistillate, lack stamens and are called ray flowers because when present they are peripheral in the head, the rays projecting outward as extensions of the radiuses of the head, similar to spokes of a wheel; (c) bilaterally symmetrical and more or less 2-lipped, with 2 teeth and lobes on the ventral lip (the lip toward the center of the head) and 3 lobes or teeth on the dorsal; such flowers are usually bisexual and are found exclusively in the tribe Mutisieae (not in our area), which displays no other sort; (d) bilaterally symmetrical, with a basal tube or funnel and a flat beltlike or straplike 5-toothed ray-portion ("ray" is often used to mean the entire corolla); flowers of this kind are usually bisexual and are found exclusively in the tribe Cichorieae (genera 49-52), to the exclusion of other sorts of flowers; androecium of (4 or) 5 stamens, alternate with the corolla lobes or teeth; filaments separate, adnate to the lower part of the corolla limb and tube but free for part of the length above (lightly coalescent to each other in Ambrosia, Xanthium and Iva); anthers flat, elongate, 2-celled, coalescent to form a short tube around the style (loosely coherent or nearly free in Ambrosia, Xanthium and Iva); pistil solitary, composed of 2 carpels ( 1 being abortive), the ovary inferior, uniloculate; style columnar and usually exserted late in anthesis, usually 2-branched, the branches often arcuate-diverging, usually each slightly dorsiventrally flattened and often with linear stigmatic areas (stigmatic lines) along proximal parts of the 2 thinner edges, and near the stigmatic lines often with a variously rough or hairy portion and occasionally distally from this an appendage (meaning that portion of the style branch, if any, distal to the stigmatic line); fruit an achene, either columnar or prismatic or conical or often flattened or compressed (the flattening or compression said to be "lateral" when the plane of the achene is radial and includes the axis of the head; "dorsiventral" when the plane of the achene is perpendicular to a plane passing through the axis of the head, and in a dorsiventrally compressed achene the side toward the center of the head is said to be "ventral", that toward the periphery of the head "dorsal"); ovule solitary, basally attached, anatropous; integument solitary. 


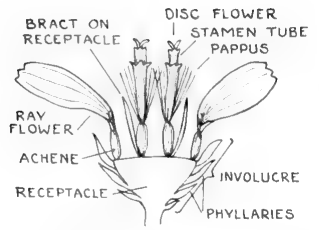

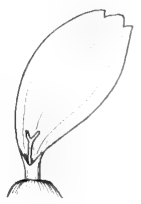

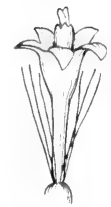

RAY

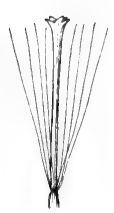

DISC FILIFORM

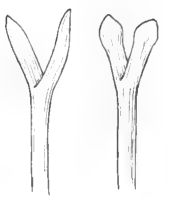

ACUTE OBTUSE STYLE TIPS

\section{DIAGRAM OF
COMPOSITE HEAD}

COROLLA TYPES

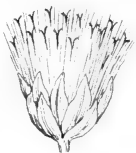

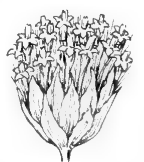

STAMINATE
RADIATE

HEADS

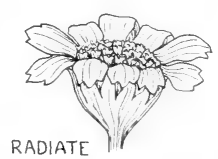

DISCOID
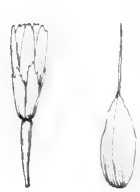

LIGULATE

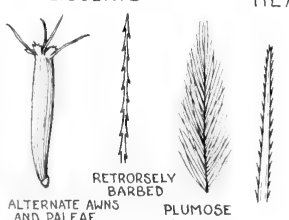
ALTERNATE AWNS
AND PALEAE
PAPPUS
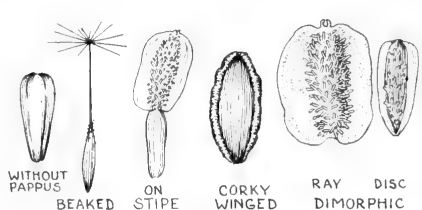
STIPE WINGED DIMORPHIC ACHENES
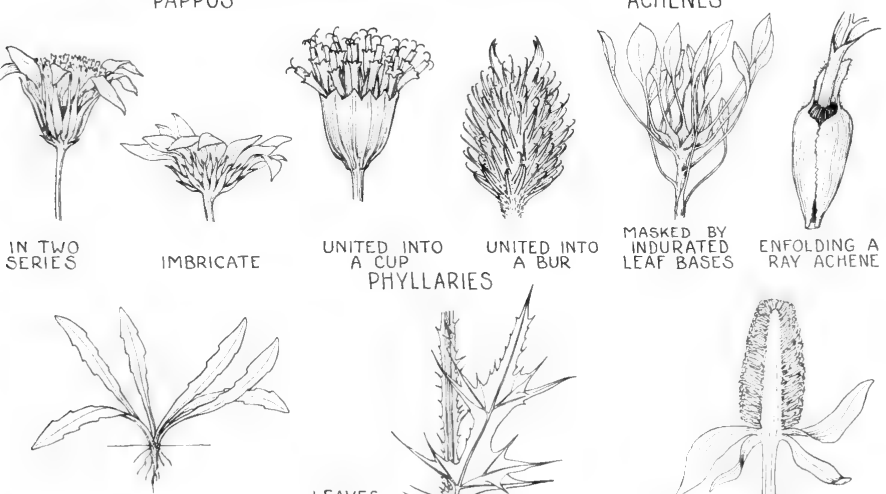

LEAVES BASAL
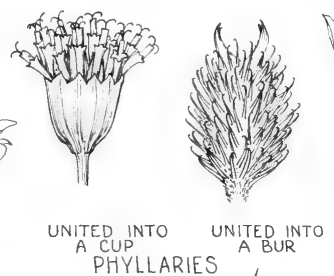

MASKED BY
INDURATED ENFOLDING A INDURATED ENFOLDING A
LEAF BASES RAY ACHENE
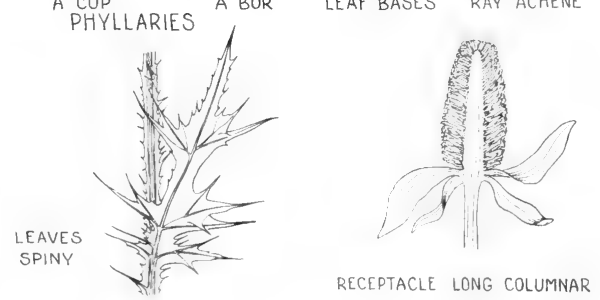

Fig. 741: Characteristic structures in the Compositae. (From Mason, Fig. 345). 
This is one of the largest families of flowering plants whose members are distributed over much of the earth. They consist of about 900 genera and 13,000 species, or about $10 \%$ of the total of flowering plants.

\section{Key to Tribes of the Compositae}

1. Corollas all of type "d" described above.

1. Corollas not of type "d" (2)

X. Cichorieae, p. 1592

2(1). Anthers with elongate cartilaginous mostly connate appendages at the tip and caudate-appendaged basally; receptacle hairy-bristly or naked

IX. Cynareae, p. 1592

2. Plants not with combination of characters given above, occasionaliy with caudate anthers or with hairy receptacle but not both (3)

3(2). Anthers caudate-appendaged basally (i.e., with slender tail-like appendages hanging from the thecae between the filaments); ray flowers (type "b" corollas) absent ........................................IV. Inuleae, p. 1590

3. Anthers not caudate-appendaged basally (in some genera such as in Tribe Vernonieae the anthers narrowly sagittate basally and simulating caudation ); rays often present (4)

4(3). Corollas all of type "a" described above, usually white, red or purple or blue, never yellow (see also Marshallia); stigmatic lines obscure, present (if at all) only below the middle of the style branch (5)

4. Corollas either of type "a" or some of type "b", often yellow; stigmatic lines otherwise than above (6)

5(4). Style branches long, slender, terete, threadlike, minutely hairy all over; leaves alternate, scattered or basal................ Vernonieae, p. 1588

5. Style branches thickened upward or clavate, obtuse, very minutely and uniformly pubescent or nearly glabrous; leaves opposite, whorled or alternate ...................................................II. Eupatorieae, p. 1589

$6(5)$. Style branches of the perfect flowers flattened and smooth, extended into lanceolate or elongate-deltoid hairy appendages; those flowers with type "a" corollas mostly yellow; receptacle essentially naked (except in Xanthisma) (.........................................III. Astereae, p. 1589

6. Style branches of the flowers with type "a" corolla not appendaged or with a very short or slender appendage, or else the type "a" corolla not yellow (7)

7(6). Pappus of soft very fine (capillary) bristles; involucre herbaceous, little or not at all imbricated (i.e., phyllaries equal in length); receptacle naked; stem leaves when present mostly alternate.

VIII. Senecioneae, p. 1592

7. Pappus absent or of scales and/or awns and/or bristles (but when of bristles these not extremely fine and soft); involucre diverse; receptacle naked or not; lowermost stem leaves often opposite (8)

8(7). Phyllaries mostly scarious or papery; pappus absent; style branch tips truncate; leaves alternate.........................VII. Anthemideae, p. 1591

8. Phyllaries or at least some of them mostly herbaceous or membranous (occasionally with hyaline marginal zones) (9)

9(8). Receptacle chaffy (merely with awns or bristles in Eclipta)

.. Heliantheae, p. 1590

9. Receptable naked or merely with persistent awns VI. Helenieae, p. 1591

\section{Key to Genera of Vernonieae}

Pappus of numerous coarse bristles

1. Vernonia, p. 1592 


\section{I. Key to Genera of Eupatorieae}

1. Achenes with 10 to 20 (rarely 6 to 9) ribs; phyllaries indefinite in number...... 2. Liatris, p. 1595

1. Achenes normally with 5 (rarely 4 or 6 ) ribs or angles, prismatic or subprismatic, rarely compressed; phyllaries definite or indefinite in number (2)

2(1). Pappus a low irregular crown of connate scales $0.3 \mathrm{~mm}$. long or less, or essentially absent...................................... Trichocoronis, p. 1599

2. Pappus much longer than $0.3 \mathrm{~mm}$., usually of awns or bristles (3)

3(2). Phyllaries uniformly 4 per head.

4. Mikania, p. 1599

3. Phyllaries more than 4 per head

5. Eupatorium, p. 1601

\section{Key to Genera of Astereae}

1. Heads unisexual; male and female heads on separate plants

1. Flowers (at least disk flowers) perfect (2)

6. Baccharis, p. 1606

2(1). Rays white, pink, violet or purplish, never yellow (3)

2. Rays yellow, sometimes pale-yellow, or absent (16)

3(2). Pappus of disk flowers absent or reduced to a mere vestige or paleaceous crown less than $0.5 \mathrm{~mm}$. long (4)

3. Disk flowers with a manifest nonvestigial pappus (5)

4(3). Phyllaries $0.8-1.6 \mathrm{~mm}$. broad; upper herbage densely viscid-pubescent with glandular-capitate hairs.

16. Egletes, p. 1631

4. Phyllaries 0.4-1.1 mm. broad; upper herbage pubescence not viscid nor glandular. 13. Erigeron, p. 1626

5(3). Receptacle conical or hemispherical to beehive-shaped (6)

5. Receptacle flat to slightly convex (7)

6(5). Achenes with true ribs extending from base to summit, not winged....

6. Achenes lacking true ribs but winged 13. Erigeron, p. 1626 15. Boltonia, p. 1630

7(5). Pappus of disk flowers at least partly of scalelike members, if bristlelike then these not capillary but relatively coarse and basally dorsiventrally flattened.

13. Erigeron, p. 1626

7. Pappus of disk flowers of numerous capillary bristles (8)

8(7). Pappus bristles manifestly in 2 series (9)

8. Pappus bristles in a single series or nearly so (10)

9(8). Achenes with 2 definite ribs

13. Erigeron, p. 1626

9. Achenes either unribbed or with several very weak ribs.

12. Doellingeria, p. 1626

10(8). Phyllaries in 1 or 2 series (11)

10. Phyllaries in 3 to many series (12)

11(10). Tubular portion of ray corolla shorter than the remainder.

13. Erigeron, p. 1626

11. Tubular portion of ray corolla longer than the remainder...

14. Conyza, p. 1630

12(10). Pappus of ray flowers absent.

12. Pappus present in ray flowers (13)

9. Machaeranthera, p. 1609

13(12). Base of plant distinctly woody.

9. Machaeranthera, p. 1609

13. Base of plant not woody (14) 
14(13). Rhizomatous or stoloniferous perennials 11. Aster, p. 1615

14. Taprooted annuals (15)

15(14). Leaves deeply serrate or pinnatifid .9. Machaeranthera, p. 1609

15. Leaves or most of them entire. 11. Aster, p. 1615

16(2). Pappus solely of short or elongate scales, with no bristlelike members either in ray or disk.

7. Xanthocephalum, p. 1608

16. Pappus with at least some bristlelike members (17)

17(16). Leaf blades bristly-serrate, pinnatifid or pinnately parted.

17. Leaf blades entire or merely toothed (18)

18(17). Stems strictly erect, topped by flat or roughly corymbiform aggregations of stems and heads; heads 4-6 mm. high including the flowers.

8. Euthamia, p. 1609

18. Plants not corymbiform or if somewhat corymbiform the heads larger.

10. Solidago, p. 1610

\section{Key to Genera of Inuleae}

1. Phyllaries mostly scarious.

9. Machaeranthera, p. 1609

1. Phyllaries not mostly scarious (2)

2(1). Pappus members of the staminate (central) flowers of the head flattened, whitish, bristlelike, near the tip discolored brownish and about twice as broad as in the lower part...................19. Tessaria, p. 1637

2. Pappus members not broadened upward. 18. Pluchea, p. 1633

\section{$V$. Key to Genera of Heliantheae}

1. Ray flowers fertile but with corollas reduced to a vestige or a minute tube with oblique orifice, or fertile heads burlike and lacking staminate flowers (2)

1. Ray flowers when present with better developed corollas or else infertile (5)

2(1). Heads with both fertile ray flowers and staminate disk flowers, never burlike (3)

2. Heads unisexual (4)

3(2). Receptacle chaffy throughout; involucral bracts in one or more series, usually not enclosing the achenes...........................20. Iva, p. 1637

3. Receptacle chaffy only near the margin; involucral bracts uniseriate, equal, strongly carinate, each enfolding a ray achene; heavy-scented annuals. 21. Madia, p. 1642

4(2). Phyllaries of staminate heads free from each other; pistillate heads burlike

..............................................................23. Xanthium, p. 1646

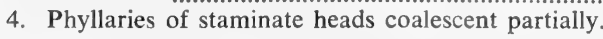

22. Ambrosia, p. 1642

5(1). Ray flowers absent; disk corolla white, cream or pale-lavender or palepurplish, deeply parted into 5 long linear obtuse lobes.

5. Plants not having the same combination of characters $(6)$

36. Marshallia, p. 1675

6(5). Achenes markedly dorsiventrally flattened (7)

6. Achenes (at least those of the disk) flattened laterally or not flattened at all (10)

7(6). Involucre uniseriate, green; depressed or sprawling yellow-headed perennial herbs.

32. Calyptocarpus, p. 1660

7. Involucre at least seemingly double; usually erect herbs (8) 
8(7). Pappus of 2 barbless teeth, a mere crown or absent.

33. Coreopsis, p. 1660

8. Pappus mostly of retrorsely or antrorsely barbed or hispid awns or teeth (essentially absent in Bidens aristosa and B. polylepis) (9)

9(8). Achenes beaked

35. Cosmos, p. 1672

9. Achenes not beaked

34. Bidens, p. 1663

10(6). Chaff of the receptacle merely awns or bristles, or pappus awn solitary (11)

10. Chaff of concavo-convex or folded pales; pappus usually more than 1 awn (12)

11(10). Rays very numerous, usually less than $3 \mathrm{~mm}$. long; disk achenes markedly corky-margined; ray achenes often abortive.

11. Rays 5 to $10,7-12 \mathrm{~mm}$. long; disk achenes not corky-margined...................

12(10). Receptacle conic, subulate or columnar (13)

12. Receptacle flat or convex (16)

13(12). Ray flowers fertile and styliferous; style branches truncate or penicillate; leaves opposite..........................................26. Spilanthes, p. 1649

13. Ray flowers infertile and styleless; style branches of disk flowers with acute or obtuse appendages; leaves mostly alternate (14)

14(13). Receptacle conical

27. Rudbeckia p. 1651

14. Receptacle columnar, cylindric or conic-cylindric at maturity (15)

15(14). Receptacle cylindric or conic-cylindric; phyllaries 2- or 3-seriate, subequal.

27. Rudbeckia, p. 1651

15. Receptacle columnar; phyllaries 2 -seriate, the inner ones half or less than half as long as the outer.

28. Dracopis, p. 1652

16(12). Disk achenes thin-edged, knife-edged or winged.

16. Disk achenes often somewhat flattened but the two thin edges not sharp nor winged (17)

17(16). Ray flowers fertile; maritime rhizomatous subshrubs of saline habitats

17. Ray flowers sterile

29. Borrichia, p. 1655 30. Helianthus, p. 1655

\section{Key to Genera of Helenieae}

1. Phyllaries in 3 to 5 series, imbricated, the outer ones shorter than the inner; receptacle bristly around the sockets................38. Clappia, p. 1681

1. Phyllaries in 1 or 2 series, nearly equal in length, rarely with 1 to 3 small outer calyculate ones (2)

2(1). Achenes columnar, 10-ribbed, rarely slightly flattened....39. Flaveria, p. 1683

2. Achenes distinctly 3-to 5-angled or if less distinctly so then obconic.

37. Helenium, p. 1677

\section{Key to Genera of Anthemideae}

1. Receptacle chaffy at least near the center (2)

1. Receptacle naked or hairy around the sockets (3)

2(1). Receptacle high-conic; disk corolla greenish-yellow; heads solitary.

40. Anthemis, p. 1686

2. Receptacle not high-conic; disk corolla whitish; heads in corymbiform aggregations

41. Achillea, p. 1686 
3(1). Heads solitary; mature achenes stipitate.

42. Cotula, p. 1686

3. Heads in spikes, racemes or panicles; achenes not noticeably stipitate.

43. Artemisia, p. 1689

\section{Key to Genera of Senecioneae}

1. Leaves opposite.

44. Arnica, p. 1689

1. Leaves alternate (2)

2(1). Rays present.

45. Senecio, p. 1689

2. Rays in the usual sense absent (3)

3(2). Marginal pistillate flowers present, their corollas filiform with slight funnelform throat and 3- to 5-lobed summit; annuals

47. Erechtites, p. 1693

3. Marginal pistillate flowers absent; perennials.

46. Cacalia, p. 1693

\section{Key to Genera of Cynareae}

Pappus bristles plumose, at least in the lower part

48. Cirsium, p. 1694

\section{$X$. Key to Genera of Cichorieae}

1. Achenes more or less strongly flattened; large coarse plants usually more than $4 \mathrm{dm}$. tall. 49. Lactuca, p. 1698

1. Achenes terete or prismatic, scarcely flattened; relatively small delicate plants rarely to $3 \mathrm{dm}$. tall (2)

2(1). Achenes spinulose or with some short processes near the summit of the body, tipped by a slender beak.

51. Taraxacum, p. 1703

2. Achenes smooth or nearly so, not evidently spinulose or muricate (3)

3(2). Plants with at least a few cauline leaves, these sometimes much-reduced: heads several or numerous to rarely solitary........50. Crepis, p. 1703

3. Plants strictly scapose, with solitary heads.....................52. Agoseris, p. 1704

\section{Vernonia Schreb. Ironweed}

Perennial herbs; leaves alternate, pinnately veined, mostly narrow and willowlike; heads in terminal corymbiform aggregation, usually 5-14 mm. broad; receptacle flat or convex, essentially naked; involucre usually campanulate-cylindric; phyllaries in several series, strongly imbricated; ray flowers absent; disk flowers numerous, perfect, fertile, the corolla mauve or purple or rose-colored, rarely white but never yellow: anthers not caudate; style branches elongate, filiformsubulate (not thickened upward), hispidulous throughout, with stigmatic lines only near the base; achenes 6- to 10-ribbed, commonly resin-dotted between the ribs; pappus fuscous-white or rusty-white, persistent, double, of numerous coarse bristles.

About 1,000 species in America, Africa, Asia and Australia. Our species show considerable evidence of genetic intercontamination; the determination of some specimens is thus difficult if not impossible.

1. Phyllaries long-acuminate or prolonged into long filiform tips.

1. Phyllaries obtuse, acute or acuminate (2)

1. V. crinita.

2(1). Principal cauline leaves ovate to lanceolate, mostly hairy or tomentose beneath (5)

2. Principal cauline leaves linear-lanceolate to narrowly linear, mostly glabrous and pitted beneath (3) 
3(2). Principal cauline leaves usually $10-30 \mathrm{~mm}$. broad.. ..2. V. fasciculata.

3. Principal cauline leaves usually $1-6(-8) \mathrm{mm}$. broad (4)

4(3). Leaves usually 2-6 mm. broad, scabrous; achenes 4-5 mm. long.

4. Leaves usually $1-1.5 \mathrm{~mm}$. broad, smooth; achenes $3-4 \mathrm{~mm}$. long.

3. marginata

4. V. Lettermannii.

5(2). Lower surface of the leaves tomentose, at least along the veins; flowers 34 to 55 per head.

5. V. missurica.

5. Lower surface of the leaves with straight or slightly curly hairs; flowers 13 to 29 per head.

6. V. altissima.

\section{Vernonia crinita Raf. Fig. 742}

Stems 1-3 m. tall, leafy, commonly glabrous and somewhat glaucous, occasionally minutely puberulent; leaves linear or linear-lanceolate, 10-18 cm. long, 5-20 $\mathrm{mm}$. broad, acuminate, commonly denticulate or sometimes nearly entire, typically glabrous, rarely thinly pubescent, impressed-punctate beneath; inflorescence very irregular, the peduncles 1-5 cm. long, thickened at the summit; heads 55- to 90-flowered; involucre 10-12 mm. high; phyllaries glabrous or pubescent, linear or narrowly lanceolate at the appressed base, tapering to a loosely flexuous filiform tip; achenes strongly ribbed, glabrous or nearly so, 5-6 mm. long; pappus dull purple.

On gravel and sand bars along streams, borders of sloughs, wet meadows, prairies and moist open woods, in Okla. (Mayes, Craig, Ottawa and Cherokee cos.), July-Oct.; cen. Mo. to e. Kan., Ark. and Okla.

\section{Vernonia fasciculata Michx.}

Stems to $2 \mathrm{~m}$. tall, glabrous, often red or purple; leaves linear to linearlanceolate, denticulate to sharply serrate, glabrous on both sides, conspicuously pitted beneath, the larger $1-2(-3) \mathrm{cm}$. broad; inflorescence usually flat and densely flowered, $4-20 \mathrm{~cm}$. wide; heads 20 - to 30 -flowered; involucre 6-9 $\mathrm{mm}$. high, to $2 \mathrm{~mm}$. wide; principal phyllaries rounded to subacute, entirely or sparsely ciliate, commonly glabrous on the back; achenes glabrous or puberulent on the ribs, resinous in the furrows, about $3 \mathrm{~mm}$. long; pappus purple.

In wet prairies and marshes, wet river bottom meadows, along streams, and in upland fields and rich moist soil, n. Okla. (Osage Co.), reported from Tex., July-Sept.; O. to Minn. and Sask., s. to Mo., Okla. and (?) Tex.

\section{Vernonia marginata (Torr.) Raf. Plains IRONWEed.}

Stems erect, simple or rarely branched below the head-bearing region, 4-10 $\mathrm{dm}$. tall, glabrous or minutely puberulent; leaf blades firm-membranous, linear to linear-lanceolate, 5-10 $\mathrm{cm}$. long, 2-6 $(-8) \mathrm{mm}$. broad, acute or acuminate, entire or remotely denticulate, essentially glabrous, pitted underneath; involucre broadly campanulate to thick-cylindric, about $8 \mathrm{~mm}$. broad, 7-10 $\mathrm{mm}$. high; phyllaries appressed, closely and regularly imbricate, mostly acute, glabrous or nearly so except in some specimens on the margins; flowers about 18 to 21 per head; achenes 4-5 mm. long, glabrous, with resin-globules in the furrows. $V$. tenuifolia Small.

In low open meadows near ponds, along streams, about pools in washes, dunes and shallow swales, s.w. Okla. (Waterfall), the Trans-Pecos and Plains Country of Tex., and e. N.M. (Guadalupe, Chaves and Quay cos.), summer; Kan., Okla., Tex. and N. M.

\section{Vernonia Lettermannii Engelm.}

Stem erect, simple except in the uppermost parts, 5-7 dm. tall; cauline leaves 


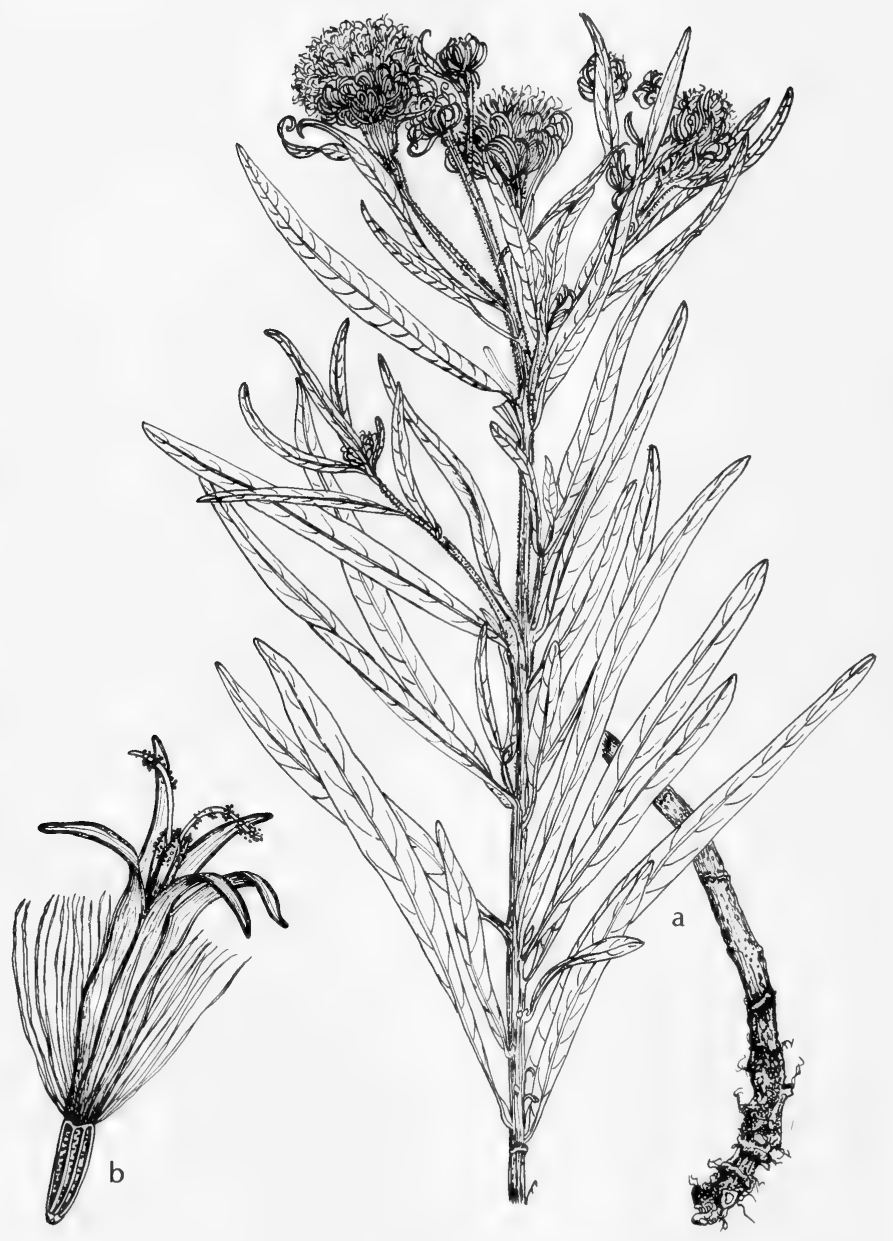

Fig. 742: Vernonia crinita: a, habit, x 1/2; b, flower, x 5. (V. F.). 
linear, to $10 \mathrm{~cm}$. long, 1-1.5 mm. broad, entire, glabrous, minutely pitted; inflorescence paniculate-cymose; heads about $12 \mathrm{~mm}$. high, 4-6 mm. wide, 10- to 14-flowered; phyllaries appressed and imbricated, acute or acuminate, glabrous or with short-ciliate margins, the inner ones purple; achenes 3-4 $\mathrm{mm}$. long, very slightly scabrous along the ribs.

In wet gravel along edge of rivers and at edge of lakes, in Okla. (Pushmataha and McCurtain cos.) and Ark., July-Sept.

\section{Vernonia missurica Raf.}

Erect, 10-15 dm. tall, branched in the upper parts, pubescent; leaves numerous; blades spreading, firm-membranous, sessile to short-petioled, lanceolate to ovatelanceolate, $6-15 \mathrm{~cm}$. long, $1.5-5 \mathrm{~cm}$. broad, long-acuminate, sharply and coarsely serrate to nearly entire, acute or rounded at base, dark-green and scabrellate above, tomentose beneath at least along the veins; involucre broadly campanulate, short-cylindric or hemispheric, 6-8 $\mathrm{mm}$. high; phyllaries appressed, closely and regularly imbricate, purplish or greenish, broadly rounded-keeled (the midnerve not narrowly prominent) or flat, glabrous or pubescent (in genetically contaminated plants with some resin-globules), arachnoid-ciliate at the margins, rounded, obtuse usually; flowers about 35 to 55 per head; achenes about $4 \mathrm{~mm}$. long, resinous in the furrows. $V$. Drummondii Shuttlew.

In standing water and wet ditches and ponds, along streams, low woods, wooded swamps, low meadows, prairies and fields, in Okla. (McCurtain Co.), local or locally abundant in s.e. Tex., infrequent to rare in e. Tex., and in N. M. (Lincoln Co.), July-Sept.; Ont. and O. to Ia. and Neb., s. to Ala., Miss., Ark., Okla., Tex. and N.M.

\section{Vernonia altissima Nutt. Fig. 743.}

Stems erect, 1-3 m. tall, branched above, glabrous or nearly so; leaf blades thin, narrowly elliptic to lanceolate or lance-ovate, $15-25 \mathrm{~cm}$. long, 3-7 cm. broad, long-acuminate, gradually attenuate basally, sharply and irregularly serrate to nearly entire, essentially glabrous above, beneath with short straight conic projections or (in genetically contaminated plants) with some curly hairs along the veins; involucre campanulate, $4-5 \mathrm{~mm}$. high or rarely larger; phyllaries appressed, regularly imbricate, ovate to oblong-ovate, glabrous or puberulent, sparsely ciliate or entire, obtuse or rounded to acute or short-cuspidate; flowers (13 to) 21 to 29 per head; achenes usually with hispidulous ribs, often lacking resin-globules, 3-4 $\mathrm{mm}$. long.

In gravel bars along rivers and streams, low thickets, low woods, wet meadows and prairies in s.e. Okla. (LeFlore Co.) and reported in e. Tex., Aug.-Oct.; N.Y. to O. and Mo., s. to S.C., Ga., La., Okla., and (?) Tex.

\section{Liatris Schreb.}

\section{Gay-Feather. Button-Snakeroot.}

\section{BLAZING-STAR}

Perennial herbs from underground corms; leaves elongate, linear to ovatelanceolate, sessile, more or less conspicuously punctate with impressed and resinous dots or not so punctate, the radical leaves usually much longer than the stem leaves that diminish in length upwards; heads disposed in various ways, usually in spiciform or racemiform arrangements, each head with few to many flowers; ray flowers absent; disk flowers usually numerous, rarely as few as 4; receptacle naked, essentially flat; involucre of several series of imbricated phyllaries; phyllaries variously shaped, usually firm throughout, often marginally ciliate or erose; corolla typically purple, rarely white, never yellow, radially symmetrical, the cylindrical tube usually exceeding the pappus or twice as long 


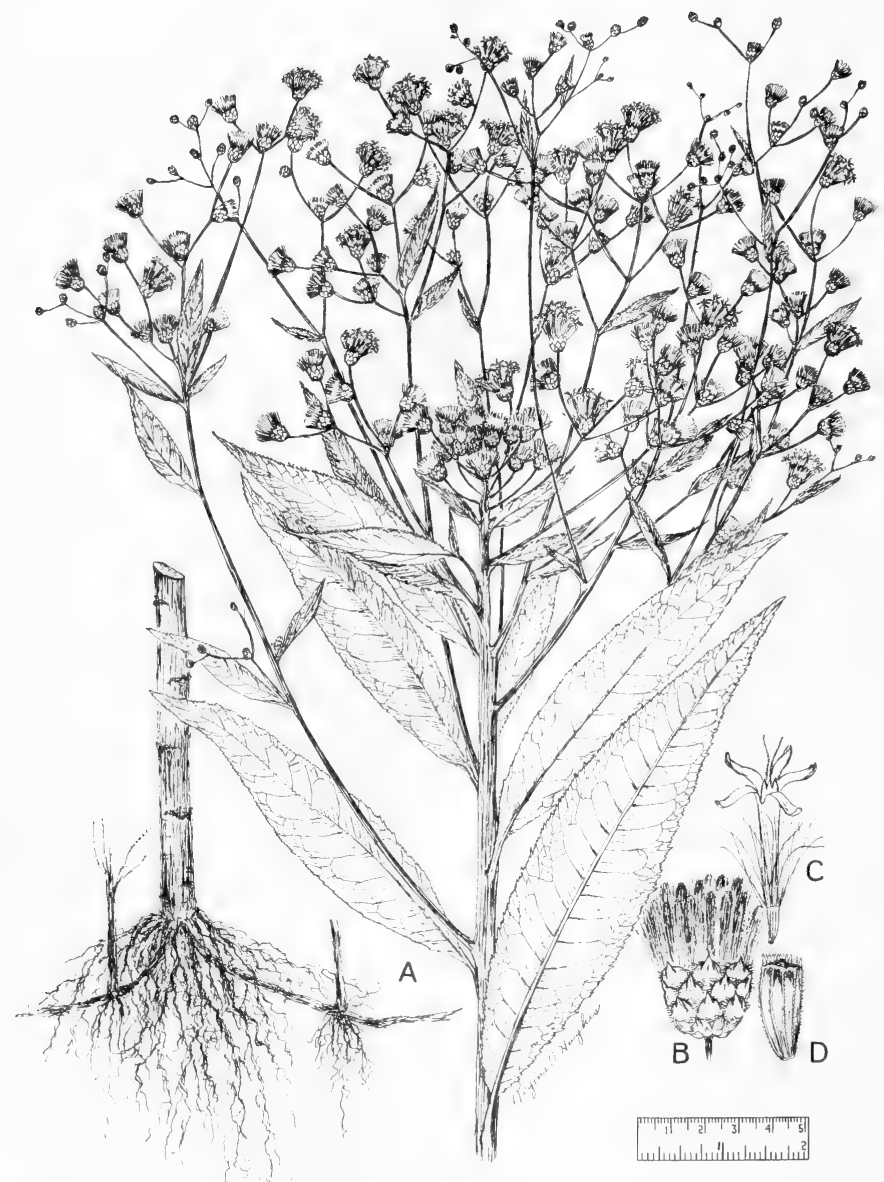

Fig. 743: Vernonia altissima: A, habit, $x$ 1/2; B, flower head, showing the involucre, x 3; C, flower, x 3; D, achene, x 5. (From Reed, Selected Weeds of the United States, Fig. 217). 
as the pappus, the throat scarcely or slightly perceptible as opposed to the tube; corolla lobes 5, equal, ovate, acute, erect or more or less spreading; stamens 5; filaments uniform, equally inserted in the middle of the corolla tube, glabrous or with tiny outgrowths; anthers short, oblong, about half as long as the filaments; style stiff, bifid, exserted late in anthesis, the style branches club-shaped; achenes somewhat cylindrical but pointed basally, about 10-ribbed, pubescent on the ribs and more finely between the ribs; pappus of 12 to 40 bristles, sessile, in one or more series, plumose or barbellate.

About 40 species confined to North America.

1. Phyllaries acuminate and recurved at the tips, at least in some stage of development, often ciliate on the margins..................1. L. pycnostachya.

1. Phyllaries obtuse to acuminate, appressed and never recurved, glabrous (2)

2(1). Each head with about 12 flowers; outer phyllaries punctate except at the edge, deltoid-ovate, purple.

2. L. lancifolia.

2. Each head with 3 to 5 flowers; outer phyllaries few, appressed, not punctate, acute, green or only purple-tinged......

3. L. acidota.

\section{Liatris pycnostachya Michx. Fig. 744.}

Corm globose or more elongate and resembling a rhizome, often $1 \mathrm{dm}$. thick in mature plants; stems 1 to many, 6-15 dm. tall, stiff, striate, generally hirsute, sometimes glabrous; leaves numerous, linear, punctate, the lower ones $1 \mathrm{dm}$. long and 4-5 mm. wide, hirsute or glabrous, gradually decreasing in length upward and passing into bracts subtending the heads; heads with 5 to 12 flowers, cylindrical, about $1 \mathrm{~cm}$. long, sessile, crowded in a very dense spiciform arrangement that is $15-30 \mathrm{~cm}$. long and $2-3 \mathrm{~cm}$. thick with a generally hirsute axis; phyllaries herbaceous or purplish, lanceolate-acuminate or oblong, with more or less acute tips markedly squarrose and scarcely reflexed or merely lax and spreading, the margin mostly ciliate when herbaceous but frequently merely crisped and sometimes petaloid; corolla phlox-purple, occasionally white, 7-9 $\mathrm{mm}$. long, the tube nonpilose or with very few hairs within; achenes $4-7 \mathrm{~mm}$. long; pappus 6-7 $\mathrm{mm}$. long, barbellate.

Frequent in open sandy areas, moist depressions, often in or around moist bogs, in Okla. (Pushmataha Co.) and e. and s.e. Tex., June-Oct.; Ind. to S.D., s. to La. and Tex.

A local race in the east Texas piney woods with extremely hairy leaves and flowering, on the average, later than the var. pycnostachya is called var. lasiophylla Shinners.

\section{Liatris lancifolia (Greene) Kittell. GAY-FEATHER.}

Glabrous perennial to $6 \mathrm{dm}$. tall or more; leaves numerous, broadly linear, the basal ones $2-3 \mathrm{dm}$. long, $10-15 \mathrm{~mm}$. broad near the center (tapering to base and to apex), upper ones shorter and bluntly lanceolate; heads in dense or loose spiciform arrangement $15-30 \mathrm{~cm}$. long, 2-3 cm. thick, each head with about 12 flowers; phyllaries erect, glabrous, punctate, the outer deltoid-ovate, the inner oblong and acute, mostly herbaceous, with narrow purplish ciliolate margins; corolla purple, $6 \mathrm{~mm}$. long, glabrous within; achene $3 \mathrm{~mm}$. long or more; pappus barbellate, about $5 \mathrm{~mm}$. long.

In wet grassland, on banks of spring-fed creeks and open slopes, infrequent in the Tex. Panhandle (Hemphill and Oldham cos.) and N. M. (s. Lincoln, n. Otero and Chaves cos.), June-Aug.; S.D., Neb., Kan., Wyo., N.M. and Tex.

3. Liatris acidota Engelm. \& Gray.

Corm globose, slightly elongate, usually not more than $3 \mathrm{~cm}$. thick, bearing the remnants of previous basal leaves; stems slender, stiffly erect, 5-8 dm. tall, 


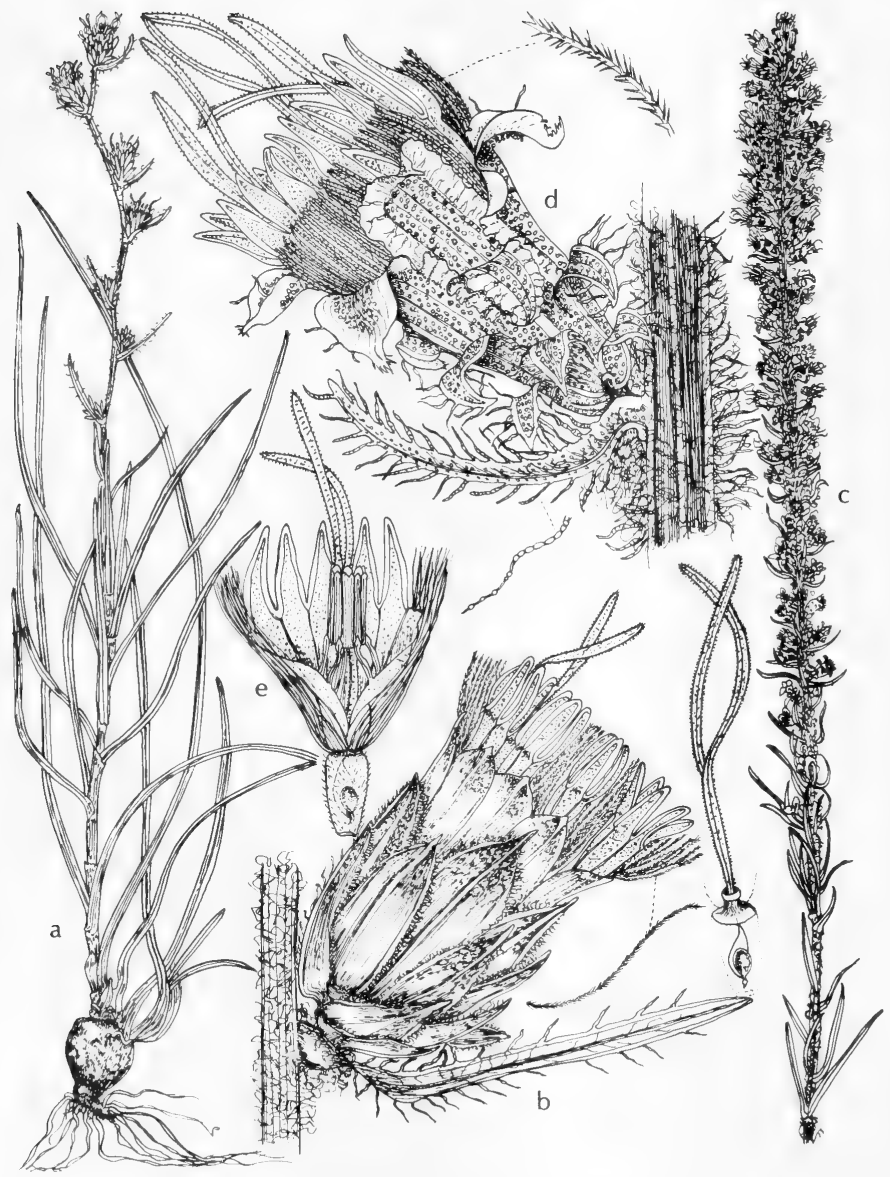

Fig. 744. a and b, Liatris tenuis: a, habit, x 1/2; b, flower head, x 5. c-e, Liatris pycnostachya: c, habit, $\mathrm{x} \frac{1 / 2}{2}$, d, flower head, $\mathrm{x} 5$, with bristle and hair, $\mathrm{x} 10$; e, flower split, x 5. (V. F.). 
glabrous or puberulent, solitary or in 3's or 4's; basal leaves very long, glabrous, linear-lanceolate, 2-4 dm. long, 3-5 mm. broad; leaves of the slender spikes narrowly linear, becoming abruptly shortened, erect and bractlike; heads numerous, loosely covering 1-2 dm. of the erect spikelike head-bearing region, with 3 to 5 flowers, cylindrical but narrowed acutely to the tip when in bud, about $1 \mathrm{~cm}$. long; phyllaries few, glabrous, appressed, the outer ovate, the inner oblonglanceolate, sometimes becoming purplish; corolla $8-10 \mathrm{~mm}$. long, purple, lacking any pilosity within the tube; achene $4-5 \mathrm{~mm}$. long; pappus about $7 \mathrm{~mm}$. long, barbellate.

Frequent in often wet areas, e. and s.e. Tex., w. to Austin Co. and s. to Calhoun Co., July-Dec.; also La.

\section{Trichocoronis GRaY}

Annual or perennial glabrous herbs $5-30 \mathrm{~cm}$. tall, freely branching from the base and rooting at the lower nodes; most of the leaves opposite, only a few upper ones becoming alternate, sessile, 1-3 (-6) $\mathrm{cm}$. long, often shallowly to deeply incised into 3 lobes nearly to the tip but otherwise entire and oblong to cuneate; heads singly terminating the branches; involucres hemispheric, 2-6 mm. high; phyllaries linear or oblong, in roughly 2 subequal series, weak and thin and each obscurely 3-nerved; receptacle slightly convex, naked; ray flowers absent; disk flowers perfect, fertile, numerous, the corollas whitish or purplish-white, sharply divided into a minute glandular-pubescent tube and an abruptly flaring 5-toothed limb; achenes 1-2 mm. long, slightly flattened, 5-ribbed at maturity, glabrous, linear, dark; pappus essentially absent or of a few very minute fimbrillate scales.

A genus of 2 species, both occurring in Texas.

1. Achenes about $1 \mathrm{~mm}$. long and involucre about $2 \mathrm{~mm}$. high

1. Achenes about $2 \mathrm{~mm}$. long and involucre about $5 \mathrm{~mm}$.............

\section{Trichocoronis Wrightii Gray. Fig. 745.}

Depressed annuals (?) with fibrous roots, usually spreading so that the diameter of the clump is greater than the height of the plant; leaves usually oblong, only obscurely toothed near the apex; involucre about $2 \mathrm{~mm}$. high; corolla about $1 \mathrm{~mm}$. long; achenes about $1 \mathrm{~mm}$. long.

Local in moist swales, calcareous clay soil, Rio Grande Plains and s. part of s.e. Tex. (also Gonzales Co.), spring; also Tam.; adv. in Calif.

2. Trichocoronis rivularis Gray. Fig. 745 .

Much-branched and rooting at the nodes, spreading or sprawling; leaves often flaring and slightly lobed apically; involucre usually 5-6 mm. long; corolla 2-3 $\mathrm{mm}$. long; achenes about $2 \mathrm{~mm}$. long. Shinnersia rivularis (Gray) King \& Rob.

Very rare and local in moist spring-fed swales and rooted and submersed in streams in n.e. part of Rio Grande Plains and s. part of Edwards Plateau in Tex., spring; also Coah.

\section{Mikania WiLlD.}

An American genus of about 175 species.

1. Mikania scandens (L.) Willd. Climbing heMP-WEed. Fig. 746.

Perennial twining vine; leaves opposite; blades elongate-deltoid, acute, (2-) 3-10 cm. long, marginally undulate or shallowly lobed, basally often slightly cordate; petioles about half as long as blades; heads in corymbiform aggregations at the ends of the branches; phyllaries 4, lanceolate, a few $\mathrm{mm}$. long, equal, often 


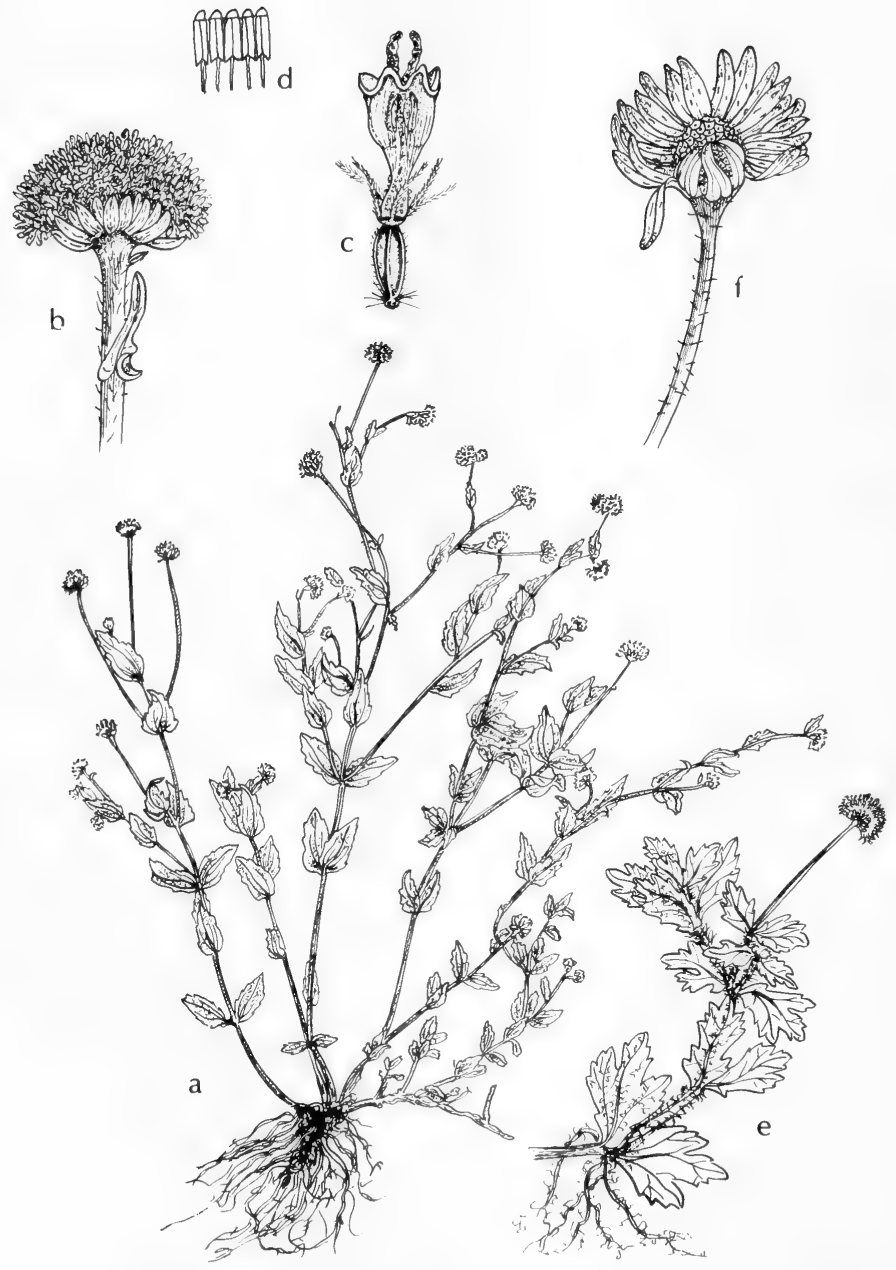

Fig. 745: a-d, Trichocoronis Wrightii: a, habit, $\mathrm{x} 1 \frac{1}{2} ; \mathrm{b}$, flower head, $\mathrm{x} 21 \frac{1}{2} ; \mathrm{c}$, flower, x 10; d, stamens, x 10. e and $\mathrm{f}$, Trichocoronis rivularis: e, part of plant, $\mathrm{x} 1 / 2$; f, phyllaries and receptacle, x 5. (V. F.). 
with a fifth one attached in an outer "series;" receptacle less than $1 \mathrm{~mm}$. broad, essentially flat, naked; ray flowers absent; disk flowers uniformly 4 per head, perfect, fertile, the corolla whitish and 5-toothed terminally; achenes shortcolumnar or slightly obconical, 5-ribbed; pappus persistent, of about 30 rather stiff bristles. Incl. var. pubescens T. \& G.

Frequent in river bottoms and other moist woods, swampy backwaters, in Okla. (Choctaw Co.) and e. and s.e. Tex., rare in Rio Grande Plains and n.cen. Tex., late summer-fall; warmer parts of Am., n. to Sin., and to N.E. and s. Ont.

\section{Eupatorium L. Boneset. Thoroughwort}

Usually perennial herbs, also fairly commonly scandent elongate perennial herbs, or a few species of shrubs; leaves opposite; heads often in roughly corymbiform aggregations either at the top of the plant or terminal on the branches; involucre hemispheric or campanulate to essentially cylindrical; phyllaries more than 4 , in 2 to 6 series, either subequal (when few-seriate) or strongly imbricated, usually with 1 or more vertical nerves, usually herbaceous (rarely papery) in texture, occasionally somewhat indurate basally; receptacle flat to conic, naked; ray flowers absent; disk flowers few to numerous, perfect, fertile, the corolla equally 5-toothed terminally, whitish, bluish, purplish or roseate; style branches long and clavate; achenes usually blackish, subcolumnar or gently narrowed to the base, 5-ribbed (occasionally fainter intermediate stripes visible); pappus of slender bristles, persistent. Conoclinium (L.) DC.

Primarily an American genus of about 1,000 species, a few in Europe, Asia and Africa.

1. Leaves connate-perfoliate. 1. E. perfoliatum.

1. Leaves not connate-perfoliate (2)

2(1). Most of the leaves whorled (3)

2. Most of the leaves only opposite, not whorled (4)

3(2). Stem deep-purple or purple-spotted, not glaucous; inflorescence or its divisions flat-topped.

2. E. maculatum.

3. Stems glaucous, solid, green with purple only at the nodes; inflorescence with a rounded or convex summit.

3. E. purpureum.

4(2). Most of the leaves deeply palmately 3- to 5-lobed and the lobes again pinnately dissected.

8. E. Greggrii.

4. Most of the leaves unlobed (5)

5(4). Receptacle conical; corollas blue (rarely white) (6)

5. Receptacle flat or essentially so; corollas white, pink or purple (7)

6(5). Blades deltoid; stems scandent-climbing to $2 \mathrm{~m}$. tall.......4. E. coelestinum. 6. Blades oblong, usually 2 to 3 times as long as broad, the lower corners often prolonged parallel to the petioles; stem not more than $1 \mathrm{~m}$. tall, much of it reclining and node-rooting..... 5. E. betonicifolium

7(5). Weedy subshrub of southern Arizona; involucres broadly campanulate, about $4 \mathrm{~mm}$. high; head about 25-flowered.....7. E. pycnocephalum.

7. Perennial herb of eastern Texas; involucre inverted-conical, about $7 \mathrm{~mm}$. high; head about 5 -flowered. 6. E. leucolepis.

\section{Eupatorium perfoliatum L. THOROUGHWORT.}

Rhizomatous perennial forming colonies; aerial stems (3-) 5-15 dm. tall, simple below, branched in the upper part; leaves opposite, lanceolate, sessile, perfoliate, (3-) 5-15 cm. long, serrate, softly pubescent especially on the underside; heads numerous and crowded, 10- to 20-flowered; involucre obconic, 3-5 mm. high. 


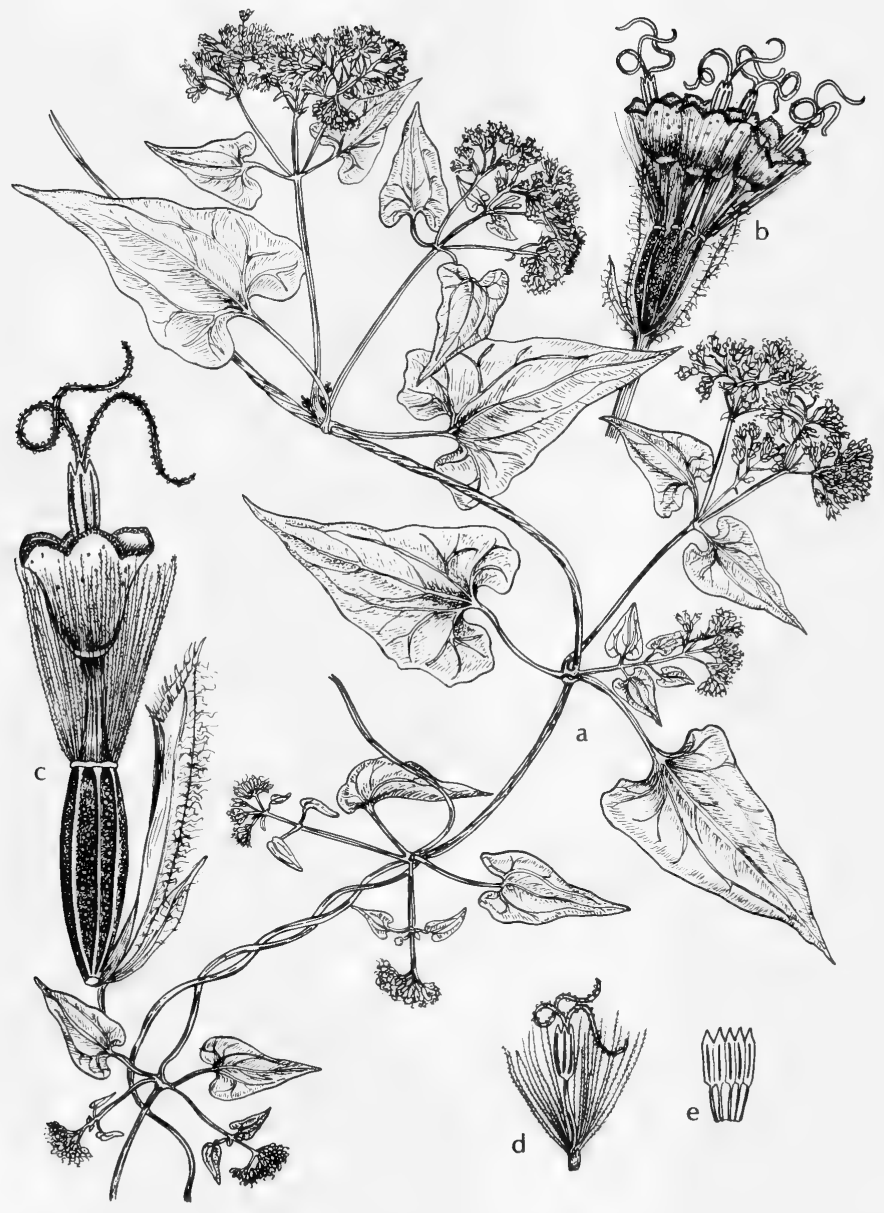

Fig. 746: Mikania scandens: a, section of vining plant, $x \frac{1}{2} ; \mathrm{b}$, head of 4 flowers, $\mathrm{x} 5$; c, single flower, $\mathrm{x} 10$; d, flower with corolla removed showing anthers united into a tube, $x$ 5; e, anthers spread out, $x$ 5. (V. F.). 
softly grayish-pubescent; phyllaries in 2 or 3 size-classes, the outer much shorter than the inner, oblong-linear, blunt (outer) to acutish (inner), the margins and tips thin and whitish; flowers whitish.

Infrequent in moist sand, along streams in woods, ponds and swamps in Okla. (Adair and Woodward cos.) and in e. Tex., late summer-fall; most of e. U.S.

\section{Eupatorium maculatum L. JOE-PYE WEED.}

Fibrous-rooted perennial, 6-20 dm. tall, the stem speckled or sometimes more evenly purplish, viscid-puberulent above; leaves mostly in 4's or 5's, lanceelliptic to lanceolate or ovate-lanceolate, tapering to apex and to base, with a short petiole or subsessile, mostly $6-21 \mathrm{~cm}$. long and $2-9 \mathrm{~cm}$. wide, pinnately veined, sharply and rather coarsely serrate; inflorescence or its divisions flattopped or nearly so; involucre $6.5-9 \mathrm{~mm}$. high, often purplish, its imbricate obtuse phyllaries few-striate, or at least with prominent midvein; flowers purple, 9 to 22 (rarely only 8 ) in each head; corollas about $5 \mathrm{~mm}$. long; achenes atomiferous-glandular, 3.4-4.2 mm. long.

Damp thickets, meadows, edges of marshes, especially in rich or calcareous soils along streams, in N.M. (scattered) and Ariz. (Apache, Navajo and Coconino cos.), July-Sept.; Nfld. to B.C., s. to Md., O., Ill., N.M. and Ariz.

Var. Bruneri (Gray) Breitung is found in New Mexico and some of the plants from Arizona may well be this variety with seldom very large leaves but usually firm in texture and covered with short spreading hairs underneath.

\section{Eupatorium purpureum L. JOE-PYE WEED.}

Fibrous-rooted perennial mostly 6-20 dm. tall, glaucous when fresh, green, purple at the nodes, solid; leaves mostly in 3's or 4's, lanceolate or ovate to elliptic, mostly $8-30 \mathrm{~cm}$. long and $2.5-15 \mathrm{~cm}$. wide, gradually tapering to abruptly cuneate at the base, pinnately veined, usually sharply and coarsely toothed, loosely soft-pubescent to subglabrous beneath, usually minutely atomiferous-glandular; inflorescence a paniculate corymb rounded at the summit; involucre imbricate, 6.5-9 mm. high; heads 3- to 8-flowered; corollas 4.5-7.5 mm. long, creamy-white, pale pink or purplish; achenes 3-5 mm. long.

On wooded slopes, low moist ground, swampy meadows and thickets, borders of sloughs and streams, in Okla. (Waterfall), July-Sept.; N.H. to Minn. and Neb., s. to Fla., Tenn., Ark. and Okla.

When this plant is fresh and is bruised it has a sweet vanilla scent.

\section{Eupatorium coelestinum L. Mist-FLower. Fig. 747.}

Rhizomatous perennial; stems weak, scandent, to $2 \mathrm{~m}$. tall; leaves opposite; blades pubescent, minutely resin-dotted, deltoid, 2-7 cm. long, serrate; petioles 3-20 mm. long; heads in roughly corymbiform aggregations at the ends of the branches; involucres hemispheric, $3-5 \mathrm{~mm}$. high; phyllaries in roughly 3 series (the 2 inner series about equal, the outer a little shorter), linear-subulate, pubescent, obscurely 3-nerved; receptacle conical, naked; flowers numerous, the corollas blue or purplish-blue. Conoclinium coelestinum (L.) DC.

Frequently in moist sandy wooded areas, edges of ponds, along streams and in seepage, in Okla. (Ottawa, McCurtain, Adair, Mayes, Osage and Pushmataha cos.), e. and s.e. Tex. (s. to Kleberg Co.), less frequent w. to n.-cen. Tex., summer-fall; N.J. to Kan., s. to Gulf States.

\section{Eupatorium betonicifolium Mill.}

Rather similar to $E$. coelestinum but plants usually not scandent, not more than $1 \mathrm{~m}$. tall, much of the stem reclining (and node-rooting), only the last 2-3 $\mathrm{dm}$. of the flowering branch ascending and it having very few scattered nodes; 


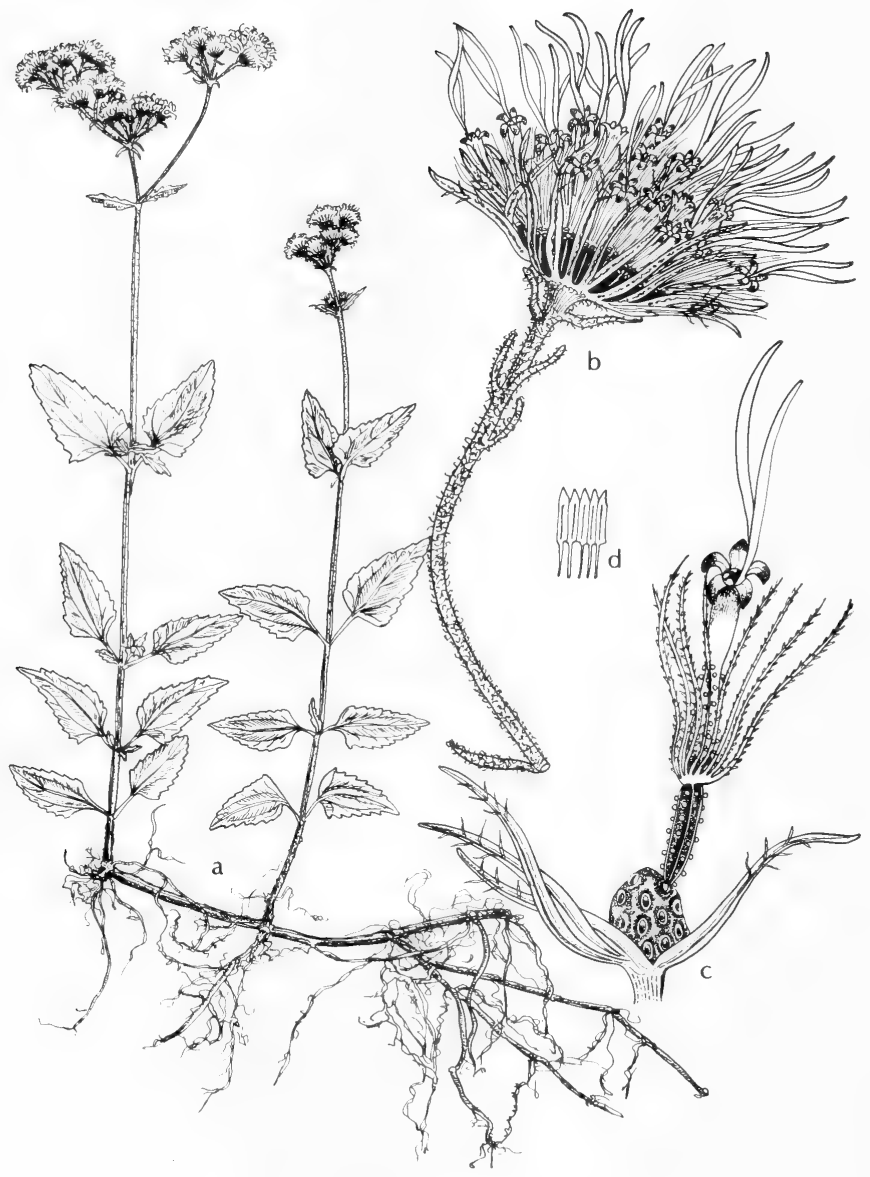

Fig. 747: Eupatorium coelestinum: a, habit, x $1 / 2 ;$ b, flowering head, x 5 ; c, receptacle with one flower, $x 10$; d, anther, x 5. (V. F.). 
blades slightly fleshy, not deltoid but oblong, usually 2 or 3 times as long as broad and rather blunt, the lower corners often prolonged parallel to the petiole. Conoclinium betonicum DC. and var. integrifolium Gray, C. betonicifolium (Mill.) King \& Rob.

Subsaline marshes and poorly drained areas, s.e. Tex. (n. to Refugio Co.) and Rio Grande Plains, n.w. to Val Verde Co.

The plants farther inland (Val Verde Co., etc.) have less distinctly serrate leaves, and perhaps deserve varietal recognition.

\section{Eupatorium leucolepis (DC.) T.\&G. JUSTICE-WEED.}

Perennial herb from a short knotty fibrous-rooted stock; stems erect, 8-12 dm. tall, minutely gray-puberulent; leaves opposite, firm and fairly thick, nearly sessile, those of midstream $3-8 \mathrm{~cm}$. long and 5-9 mm. broad, broadly linear or narrowly oblong, dull-gray, bluntish, on each side in the upper two thirds to five sixths the length with 7 to 12 appressed teeth; heads about 5-flowered, dirty-white, in a roughly corymiform arrangement at the tip; involucre inverted-conical, about $7 \mathrm{~mm}$. high; phyllaries in 2 or 3 series, sharply differentiated with a minute outer series and the longer inner series, the longer ones subulate, acute, mostly herbaceous, with a narrow white margin and white tip-portion (often as much as a third the total length); corollas 3-4 $\mathrm{mm}$. long.

Rare in e. and s.e. Tex. (Hardin, Jasper, Orange and Tyler cos.) in sandy or boggy woods, Oct.; near the coast, N.Y. to Tex.

\section{Eupatorium pycnocephalum Less.}

A subshrubby weedy plant 3-8 dm. tall, with slender striate-puberulent mostly herbaceous stems and sparsely puberulent opposite leaves; petioles slender, 1-3 $\mathrm{cm}$. long; leaf blades deltoid-ovate, broadly cuneate to subtruncate at base, acute to acuminate at apex, mostly $1-2 \mathrm{~cm}$. wide, $1.5-5 \mathrm{~cm}$. long, irregularly crenate-serrate; heads 4-6 mm. long, nearly as wide, about 25-flowered, aggregated in dense rounded corymbs disposed in leafy-bracted panicles; involucres broadly campanulate to nearly hemispheric, about $4 \mathrm{~mm}$. high; outer phyllaries ovate and acute to acuminate, puberulent, $0.5-1.2 \mathrm{~mm}$. long, middle and inner phyllaries elliptic to oblong, rounded or obtuse at tip and nearly or quite glabrous and striate-nerved; corollas pale-purple or rarely white, about $2 \mathrm{~mm}$. long; achenes 1-1.4 mm. long, faintly angled and sparsely puberulent on angles; pappus bristles whitish, slightly longer than achenes.

Rich soil along streams, mountain sides and canyons in Ariz. (Cochise, Santa Cruz, Pima and Pinal cos.), May-Oct.; s. Ariz., s. to S.A.

\section{Eupatorium Greggii Gray.}

Perennial herb, the bases fibrous-rooted and occasionally subrhizomatous; aerial stems weak, 3-8 (-12) dm. tall, often tortuous, sometimes semiscandent, the uppermost 1-2 dm. of the branches few-noded; leaves opposite, nearly sessile, ovate or deltoid in over-all outline but deeply palmately 3 -lobed with the 3 main lobes again pinnately dissected, pubescent and minutely resin-dotted; heads in tight subcorymbiform clusters terminating the branches; involucre hemispheric, 4-6 mm. high; phyllaries in about 3 subequal series, linear-subulate, pubescent, obscurely 3-nerved; receptacle conical, naked; flowers numerous, the corollas blue or purplish-blue; achenes black, columnar, 5-ribbed; pappus persistent, of a number of stiffish bristles. Conoclinium Greggii (Gray) Small.

Frequent along stream beds and in overflow areas in the Tex. Trans-Pecos, infrequent e. to Edwards Plateau and Rio Grande Plains, N.M. (Dona Ana and Socorro cos.) and Ariz. (Cochise Co.), spring-fall; Tex., N.M., Ariz. and n. Mex. 


\section{Baccharis L. GroundSEL-TREe}

Unisexual shrubs or subshrubs, glabrous or hispid; branchlets usually striateangled or slightly striate and terete, smooth to glandular-scabrous; leaves subulate to obovate, alternate, crowded to sparse, entire to serrate or dentate, 1- to 3nerved, sessile or petioled, usually reduced within the inflorescence (sometimes to bractlike leaves); male and female heads on separate plants; heads in somewhat paniclelike, corymbiform or racemose aggregations; pistillate involucre hemispheric to narrowly cylindric with outer phyllaries ovate to lanceolate; inner phyllaries lanceolate to narrowly linear and obtuse to acuminate, usually scariousmargined, the midrib evident or obscure; receptacle pitted to nearly smooth, naked or fimbrillate, flat; ray flowers absent; corolla filiform with 5 minute distinct lobes or teeth, yellowish-white to brown in color; style bifurcate, style branches usually glabrous; achene 5- to 10-ribbed, yellow to reddish, glabrous or hispid, smooth or glandular; pappus of 1 to several series of numerous bristles, flaccid or rigid, equaling or greatly exceeding the style; staminate involucre hemispheric to cylindric with outer phyllaries ovate to lanceolate; inner phyllaries lanceolate to linear and obtuse to acuminate, usually scarious-margined, the midrib dilated and smooth or absent; receptacle pitted to nearly smooth, naked or fimbrillate and flat; ray flowers absent; corolla filiform basally and either abruptly or gradually enlarged and funnelform, white to yellowish-brown, its 5 lobes lanceolate; style clavellate or bifurcate, its branches hispid; pappus not exceeding style, usually one series of numerous bristles, rigid, more or less plumose-tipped, the bristles more or less barbed, usually crisped; ovary abortive.

Plants of this large genus (about 400 species, all American) unfortunately often superficially resemble plants of other asterean genera, and their determination is enigmatic until the unisexuality of the plants and flowers is discovered.

1. Achenes 8- to 10-ribbed; leaves mostly less than $5 \mathrm{~cm}$. long (2)

1. Achenes 5-ribbed; leaves 5-12 cm. long (4)

2(1). Leaves linear, entire, $25 \mathrm{~mm}$. long or less; plants broomlike in appearance 1. B. sarothroides.

2. Leaves oblong to obovate, mostly toothed, usually more than $30 \mathrm{~mm}$. long; plants not broomlike (3)

3(2). Fertile heads hemispheric, $5-10 \mathrm{~mm}$. broad

3. B. salicina.

3. Fertile heads cylindric or long-campanulate, $3-5 \mathrm{~mm}$. broad

2. B. Emoryi.

4(1). Heads in a terminal large corymbiform aggregation; leaves $3-8(-11) \mathrm{cm}$. long, $10(-20) \mathrm{mm}$. broad, not crowded..................4. B. glutinosa.

4. Heads in several smaller corymbiform aggregations terminating lateral branches; leaves $3-5 \mathrm{~cm}$. long, $5 \mathrm{~mm}$. broad, usually crowded.

5. B. viminea.

\section{Baccharis sarothroides Gray.}

Glutinous shrub 1-4.5 m. tall; branchlets conspicuously striate-angled, densely fastigiately branched, often crowded into broomlike masses; leaves on young rapidly growing branches linear to lance-linear, 1-2.5 cm. long, $1.5-3.5 \mathrm{~mm}$. wide, acute at both ends, somewhat leathery, entire, early deciduous, those of the branchlets reduced to minute bracts $1-2.5 \mathrm{~mm}$. long; heads numerous, solitary or in few-headed glomerules at tips of branchlets; pistillate heads about $1 \mathrm{~cm}$. long at anthesis; phyllaries in several series, narrowly ovate to oblong, or oblonglanceolate, slightly granular-glutinous on exposed portions, margins scarious, slightly erose toward the tips; receptacle essentially flat, alveolate but naked; pistillate corollas nearly filiform, about $3 \mathrm{~mm}$. long; achenes about $2 \mathrm{~mm}$. long, 
cylindric, prominently 8 - to 10 -ribbed, glabrous; pappus of pistillate flowers elongate in fruit to more than $10 \mathrm{~mm}$., much-surpassing the styles, rusty to brownish; staminate heads $3.5-7 \mathrm{~mm}$. long; staminate corollas $3.5-4 \mathrm{~mm}$. long, about equaling the narrowly clavate pappus bristles, the clavate portion slightly scaberulous, lower part glabrous, often twisted.

Along streams, bottomlands and in saline periodically wet soils, in s.w. N.M. and Ariz. (widespread), flowering throughout most of the year; s.w. N.M., to s. Calif.; n. Mex. and Baja Calif.

\section{Baccharis Emoryi Gray.}

Glabrous glutinous shrub to $5 \mathrm{~m}$. tall; branchlets striate-angled, sometimes fastigiate and broomlike but often more open; leaves linear-oblong or oblongelliptic to broadly oblanceolate, $1.5-6 \mathrm{~cm}$. long, $2.5-10(-25) \mathrm{mm}$. wide, usually coarsely few-toothed, the uppermost narrower and often entire, acute to obtuse at apex, cuneate at base, 3-nerved from base; heads solitary or in small glomerules at tips of branchlets, campanulate; pistillate heads 10-14 mm. long, narrower than the staminate heads; phyllaries ovate to linear, imbricated in several series, central area thickened, margins scarious, erose-ciliate toward tips, especially on longer innermost phyllaries; pistillate corollas capillary-cylindric, about $5 \mathrm{~mm}$. long, the lobes minute; achenes about $1.5 \mathrm{~mm}$. long, stramineous, finely but distinctly ribbed; pappus of pistillate flowers $10-12 \mathrm{~mm}$. long, silky, white or faintly tawny; staminate heads 6-7.5 $\mathrm{mm}$. long at anthesis; phyllaries ovate to lance-ovate; staminate corollas $3.5-4 \mathrm{~mm}$. long, the lobes slender and recurved or coiled; anthers exserted nearly their full length; pappus bristles of staminate flowers barely equaling corollas, subplumose and somewhat paleaceous toward the tips.

Along streams, arroyos, and other wet or moist areas in N.M. (Dona Ana and Chaves cos.) and Ariz. (Coconino, Mohave to Cochise, Pima and Yuma cos.), Sept.-Nov.; N.M., Ariz., s. Ut. and s. Calif.; n. Mex.

\section{Baccharis salicina T. \& G.}

Shrub 1-3 m. tall; branchlets striate-angled, glabrous; leaves nearly sessile, oblanceolate-oblong, obtuse to acute, $3-4(-6) \mathrm{cm}$. long, 4-8 (-15) $\mathrm{mm}$. wide, serrate with salient teeth about $5 \mathrm{~mm}$. apart, the broader leaves distinctly 3-nerved; pistillate heads with 25 to 30 flowers; involucre campanulate, $6(-8) \mathrm{mm}$. long; phyllaries ovate-lanceolate, obtuse to acute, reddish-brown-tipped, marginally scarious, erose, spreading at maturity; receptacle flat, naked and slightly pitted; corolla filiform, 3-4 mm. long, its 5 minute linear lobes to $0.3 \mathrm{~mm}$. long; pappus biseriate, flaccid, to $12 \mathrm{~mm}$. long, basally united into a ring; achenes $1.2-2 \mathrm{~mm}$. long, glabrous, 8- to 10-ribbed; staminate involucre hemispheric, $3.5-4.5 \mathrm{~mm}$. long; phyllaries ovate-lanceolate, obtuse to acute, marginally scarious and erose; receptacle flat, naked, pitted; filiform corolla gradually funnelform, 3.3-4.3 mm. long, its linear lobes about $1 \mathrm{~mm}$. long; pappus equal to corolla, plumose-tipped, 3-4.5 mm. long, crisped; ovary abortive.

Abundant in the higher parts of the Tex. Plains Country, less so in the lower parts, and in the Trans-Pecos of Tex., Okla. (Waterfall) and N.M. (Bernalillo, Rio Arriba, San Juan and Valencia cos.), usually in disturbed places, often in sandy wettish or dry subsaline soil, summer-fall; Okla., Tex. and N.M.

\section{Baccharis glutinosa (R. \& P.) Pers. JARA, SEepwillow, Water-Wally, Water-} MOTIE.

Shrub 10-35 dm. tall; branchlets striate-angled, glabrous, glutinous; leaves punctate, sessile to indistinctly petioled, lanceolate to narrowly elliptic, tapering from middle to apex and to base, nearly entire to prominently serrate (teeth of larger leaves usually 3-5 mm. apart), 3-8 (-10) $\mathrm{cm}$. long, $1(-2) \mathrm{cm}$. wide, 
distinctly 3-nerved; heads in a terminal corymbiform aggregation, often on several branches; pistillate heads with about 50 flowers or more; involucre hemispheric, about $4(-4.5) \mathrm{mm}$. high; phyllaries ovate or lanceolate, obtuse (inner may be acute), stramineous, brown-purplish-tipped, the midrib distinct with its margins wrious and erose; receptacle flat, nearly smooth, naked; corolla filiform, 2-2.3 fim. long, with 5 narrow linear lobes $0.2 \mathrm{~mm}$. Or less in length; style exserted, bifurcate; pappus uniseriate, flaccid, 4-5 mm. long; achenes about $1 \mathrm{~mm}$. long, glibrous, 5-ribbed; staminate heads 10- to 20-fiowered; involucre campanulate, about $4 \mathrm{~mm}$. high; phyllaries ovate-lanceolate, obtuse to acute, marginally scarious and ercse; receptacle flat, slightly pitted, naked; corolla $3-4 \mathrm{~mm}$. long, filiform, upper half funnelform, its 5 lobes lanceolate and about $1.2 \mathrm{~mm}$. long: pappus 3-4 znm. long, plumose-tipped, crisped, not exceeding corolla; ovary abortive.

Along sandy watercourses in dry areas, often forming thickets along the Rio Crande, in the Trans-Pecos, Edwards Plateau and Rio Grande Plains, Tex., in M. M. (widespread, in river valleys), and Ariz. (common along watercourses), Mar.-Dec.; widespread in Am., n. to Calif, Colo. and Tex.

\section{Baccharis viminea DC, MULE-FAT.}

Shrub; branchlets glabrous or glandular; leaves crowded, punctate, narrowly elliptic, entire to minutely serrate, tapering acutely at both ends, $3-5 \mathrm{~cm}$. long, $5(-10) \mathrm{mm}$. wide, 1-nerved with 2 indistinct lateral nerves narrowiy paralieling the margin; heads in small corymbiform aggregations terminating numerous lateral branches; pistillate heads with 50 or more flowers; involucres campanulate to semi-hemispheric, about $4 \mathrm{~mm}$. high; phyllaries ovate to lanceolate, obtuse to acute, stramineous to brown-purplish-tipped, scarious-margined and erose; receptacle flat, smooth, naked; corolla filiform, with 5 small lobes; pappus uniseriate; achene glabrous; staminate heads with about 20 flowers; involucres broadly homispheric, about $3 \mathrm{~mm}$. high, to $5 \mathrm{~mm}$. thick; phyllaries ovate to lanceolate, obtuse to acute, marginally scarious and erose; receptacle flat, naked; corolla tube filitorm, the limb funnelform, with 5 lanceolate lobes; pappus $3 \mathrm{~mm}$. long, plumose-tipped, crisped; ovary abortive.

Along washes and floodplains of streams, rare and local near El Paso, Tex., through N.M. to Ariz. (Yavapai and Yuma cos.), spring-summer; Baja Calif., Calif., Wash., Ariz., N.M. and Tex.

\section{Xanthocephalum Willd. Broomweed. SNakeweed}

An American genus of perhaps 30 species.

Some of the species are extremely common weeds that increase enormously under the prevalent regime of abusive overstocking. The herbage of several species is known to be toxic to livestock. The annual species are called "broomweed" and the shrubby species "snakeweed."

\section{Xam thocephalinm gymnospermoides (Gray) Rothr.}

Stout annual to $2 \mathrm{~m}$. tall; branchlets often with stipitate glands; leaves alternate, innceolate, 3-15 cm. long, 5-30 mm. broad, glabrous, with entire or serrate margins, acute, above shiny and somewhat glutinous; heads solitary at the ends of the branchlets but clustered in subcymose aggregations; involucre campanulate, glutinous, 3-7 mm. thick, 3-6 mm. high; phyllaries numerous in 2 loose series, glabrous, appressed, usually with green midrib and tips, apically spreading; receptacle flat or slightly convex, alveolate; ray flowers pistillate, 50 to 70 , the yellow rays $2-4 \mathrm{~mm}$. long and $1-1.5 \mathrm{~mm}$. broad, about the same length as the rube; disk flowers 150 to 200,2 to 3 times as many as the ray flowers; corolla about $4 \mathrm{~mm}$. long, with a narrow tube and expanded throat; style with pointed collecting hairs and these restricted to the short deltoid tips; pappus in some plants 
a low crown, in others a few irregular awns up to half as long as the disk corollas; achenes terete, glabrous or slightly pubescent, 1-2 $\mathrm{mm}$. long.

Infrequent along arroyos and about saline swales in Tex. Davis Mts., Ariz. (Pinal, Cochise, Santa Cruz and Pima cos.), Aug.-Oct.; also Son., Chih. and Dgo.

\section{Euthamia NutT.}

This genus is often considered as a section of Solidago, but its relationship is apparently not that close. The genus, entirely American. is considered to consist of about 6 species.

\section{Euthamia camporum Greene.}

Essentially glabrous often slightly glutinous rhizomatous perennial; stems erect, 3-5 dm. tall, freely branching in the upper half with the branches rather stiffly ascending to form a somewhat corymbiform top to the plant, densely leafy; leaves usually ascending, linear, entire, 3 -ribbed, $3-8 \mathrm{~cm}$. long; heads essentially sessile, borne in fascicles; involucre $3-5 \mathrm{~mm}$. high, somewhat campanulate, the outer phyllaries acute to obtuse and wider than the inner ones; receptacle about $2 \mathrm{~mm}$. thick; phyllaries in 3 to 5 series, oblong; ray flowers few, pistillate and fertile, the rays yellow and not exceeding the disk corollas; disk flowers perfect, fertile, 10 to 15 per head, with 5-toothed yellow corollas, only slightly exceeding the involucre; pappus alike in ray and disk, of a single series of more or less equal whitish capillary bristles.

In sandy floodplains of creeks and rivers, in Okla. (Waterfall) and in the Tex. Plains Country (Lipscomb, Wheeler and Wichita cos.), Aug.-Sept.; Kan., Okla., Tex. and Colo.

\section{Machaeranthera NEES}

Herbs; leaves alternate, essentially sessile (especially the basal ones), often pinnately or bipinnately lobed but in some species merely toothed or essentially entire; heads about $1-2 \mathrm{~cm}$. in diameter, usually borne more or less solitary at the ends of branches though occasionally the whole plant subcorymbose or rarely the heads nearly sessile in the upper axils; involucre mostly hemispheric; phyllaries usually linear to lanceolate or subulate, basally and laterally stramineous, the midrib in the upper half herbaceous-green (or at least darker than the stramineous base) and expended into a somewhat rhombic patch that in some species occupies essentially the entire tip-region, the tip either erect or in some species spreading or even squarrose and apically acute to very shortly acute or even hlunt; receptacle 3-10 mm. wide, rough, flat or very slightly convex; ray flowers pistillate, fertile; rays yellowish or white and often tinged with blue, violet and/or red; disk flowers numerous, perfect, fertile; corollas yellowish, with a cylindrical tube that is not distinctly delimited from the greatly ampliate limb (which is composed of a throat and 5 usually short teeth); style appendages various; achenes narrowly turbinate to broadly linear or clavate, rather densely antrorsely pubescent; pappus persistent, in some species absent from the ray flowers but present in the disk flowers, in other species present and alike in both disk and ray, composed of numerous somewhat unequal usually sordid-white slender bristles, the larger ones often slightly dorsiventrally flattened at the base. Haplopappus Sect. Blepharodon DC.: Psilactis Gray, Eriocarpum Nutt.; Xylorhiza Greene.

An American genus of perhaps 50 or 60 species.

1. Ray flowers with evident pappus

3. M. phyllocephala.

1. Ray flowers with pappus none or vestigial (2) 
2(1). Plants $5 \mathrm{dm}$. tall or more, erect, branched only above; stem below glabrous or hirsute; leaves mostly entire or merely toothed.

1. M. Boltoniae.

2. Plants usually about $3 \mathrm{dm}$. tall or less, diffusely branched from the base; stem glandular-hispidulous throughout, usually also somewhat pilose; leaves mostly laciniate-pinnatifid with spinescent-tipped lobes, sometimes merely toothed.

2. M. Coulteri.

\section{Machaeranthera Boltoniae (Greene) Turner \& Horne.}

Annual taprooted herb, erect and nearly simple below, to $1 \mathrm{~m}$. tall or more, with glandular-pubescence above or glabrate; leaves essentially entire, oblanceolate to linear, reduced above, with appressed hairs or glabrate; heads solitary, not crowded; involucre hemispheric, 5-10 mm. across, 3-5 mm. high; phyllaries 0.75-1 mm. broad; flowers 75 to 100 per head (fewer in late-flowering heads); disk yellow and pappus present; rays light-blue or violet-blue to white, never yellow, (4-) 5-7 mm. long; pappus of ray flowers absent; achenes 2-2.4 mm. long. Psilactis asteroides Gray, P. lepta Shinners.

Infrequent in alluvial sandy soil, in marshes, river bottoms and along roadsides, in the Tex. Trans-Pecos (El Paso, Hudspeth and Presidio cos.), through N.M. (widespread) to Ariz. (Navajo and Coconino, s. to Cochise and Pinal cos.), JuneNov.; Ariz., N.M., Tex., s.e. to Michoac. and Pue.

\section{Machaeranthera Coulteri (Gray) Turner \& Horne.}

Divaricately branching throughout, $5-30 \mathrm{~cm}$. tall, stipitate-glandular throughout and usually hispidulous or pilose; leaves oblong to oblanceolate, mostly laciniate-pinnatifid with the teeth spinescent-tipped; lower petiolate leaves $2-3 \mathrm{~cm}$. long; upper leaves closely sessile and appressed, becoming much-reduced, sometimes entire; involucre about $4 \mathrm{~mm}$. high; phyllaries oblong-lanceolate, acute, granular-glanduliferous except on the whitish chartaceous basal portion; rays 20 to 35 , white to lavender, about $5 \mathrm{~mm}$. long; achenes pubescent. Psilactis Coulteri Gray.

In wet or dry saline soils and about playa lakes, in Ariz. (Maricopa, Pinal, Pima and Yuma cos.), Mar.-June; also Nev., Calif. and Son.

\section{Machaeranthera phyllocephala (DC.) Shinners. CAMPHOR DAISY.}

Aromatic often glutinous annual herb, sometimes living over one winter, either erect or near the coast usually prostrate, freely branched especially near the base; leaves usually oblanceolate to narrowly obovate, firm or even fleshy, 15-50 $\mathrm{mm}$. long, on each side with 5 to 8 prominent salient teeth or short lobes, only slightly reduced toward the head, crowded even up to the base of the head; heads solitary; involucre 9-11 mm. high, hemispherical; phyllaries in about 3 series, not much-graduated, the largest ones in any mature head $1.3-1.7 \mathrm{~mm}$. broad, the tip-region often of a different texture from the base being more herbaceous and sometimes spreading; disk and rays yellow; style branch appendages subclavate, shorter and thicker than the stigmatic portion; pappus of ray and disk similar; achene columnar, thick, about $2 \mathrm{~mm}$. long, slightly compressed to plump and subcylindric, fuzzy with whitish ascending pubescence. Haplopappus phyllocephalus DC., $\boldsymbol{H}$. rubiginosus T. \& G., Eriocarpum megacephalum Nash.

Abundant in subsaline wet areas near the Tex. coast, s.e. Tex. and Rio Grande Plains, spring-fall; coastal areas, La. to Tam.

Represented by another variety in the highlands of Mexico.

\section{Solidago L. GOLdENROD}

Rhizomatous perennials; rhizomes sometimes short and forming merely a crown or sometimes extensively creeping; aerial stems usually long and slender, ascending 
gracefully, branched in the upper head-bearing portion, the branches in turn bearing very many short-bearing branchlets which are often ascending; leaves alternate, sessile, not lobed, the lower portions occasionally narrowed to a subpetiolar base; heads rarely more than $1 \mathrm{~cm}$. long; receptacle flat or slightly convex, not chaffy; involucres usually narrowly campanulate; phyllaries in a few series, graduated, usually linear-lanceolate or linear, mostly stramineous and chaffy in texture with a slightly darker more herbaceous median strip which is slightly dilated near the tip; ray flowers pistillate and fertile, several in number (in one species only 2 per head), with yellow rays; disk flowers perfect and fertile, with yellow corollas: pappus simple, of numerous essentially equal capillary bristles; achenes manyribbed, nearly terete.

Solidago is a large North American genus (with one species also in Europe). It is one of our more difficult genera probably because of rampant hybridization.

1. Head-bearing branchlets few, borne on short branches about as long as to shorter than the remote upper serrate leaves from whose axils they arise

1. S. caesia.

1. Head-bearing branchlets usually borne on branches longer than the leaves from whose axils they arise (2)

2(1). Plants perfectly smooth and glabrous, leaves fleshy or thinner, entire and with inconspicuous venation or merely with finely reticulate pattern, rarely with easily visible secondary nerves; basal leaves ascending, often long and grasslike; head bearing portion of the plant often elongate and slender but definitely one-sided and its branches nearly always curly at the tip........................................ S. S sempervirens.

2. Plants usually pubescent, if nearly glabrous then the leaves usually with 2 fairly conspicuous lower secondary nerves and/or not entire margin and/or not at all grasslike (3)

3(2). Upper half of the stem roundly quadrangular, the ridges usually narrowly winged.

2. S. salicina.

3. Upper half of stem not quadrangular nor 4-winged (4)

4(3). Leaves of midstem ovate, 1.3 to 2.5 times as long as broad, the lower surfaces with conspicuous and prominent pale network of nerves, each side with 10 to 20 rather evenly spaced conspicuous marginal serrations.....................................................................4. S. rugosa.

4. Leaves of midstem mostly proportionally longer and narrower or if only 2.5 times as long as broad then broadest in the upper half and/or the lower surfaces with less prominent nervation, the margins usually with fewer teeth or the teeth concentrated toward the tip (5)

5(4). Most of the foliage and stems closely pubescent with microscopic hairs, making parts of the plant cinereous or sordid green; stems 6-20 dm. tall.......................................................................5. S. altissima.

5. Most of the foliage and stems glabrous and yellowish or pale-green with the exceptions of the margins of the leaves and often scattered pubescence in narrow lines on the upper part of the stem or upper part scabro-hirtellous (in S. spathulata) (6)

6(5). Plants with mostly short and stout rhizome or caudex; plants $5-20 \mathrm{~cm}$. tall........................................................................ . S. spathulata.

6. Plants with well developed creeping rhizomes; plants $5-25 \mathrm{dm}$. tall (7)

7(6). Leaves punctate; inflorescence ample in small glomerules, copiously leafybracteate......................................................... 7. S. occidentalis.

7. Leaves not punctate; inflorescence corymbiform; stem glaucous, becoming definitely puberulent in the inflorescence..................6. S. gigantea. 


\section{Solidago caesia L. Blue-STEM GoldenRod.}

Glabrous perennial; stems slender and often slightly fractiflex, the internodes even in the head-bearing portion of the plant $1-3 \mathrm{~cm}$. long; branches about as long as to usually shorter than the upper leaves in the axils of which they are borne and in turn bearing a few head-bearing branchlets; upper leaves remote, spreading, mostly broadly lanceolate, very thin, serrate most of the length.

Rare, in rich wettish woods along creeks in e. Okla. (Delaware Co.) and in e. Tex., Sept.-Oct.; e. U.S. and s.e. Can., w. to Wisc. and Tex.

\section{Solidago salicina Ell.}

Plant coarse, glabrous, about $1 \mathrm{~m}$. tall; upper half of stem roundly (obscurely) quadrangular, often with narrow wings on the ridges; leaves of midstem membranous, broadly lanceolate, to $14 \mathrm{~cm}$. broad, about 3.5 times as long as broad, in the basal third of the length narrowed to subpetiolar (but broadly winged) base, marginally closely serrate on the upper two thirds of the length; terminal headbearing portion diffuse, somewhat one-sided with long whiplike branches, the glomerules of head-bearing branchlets (or occasionally tertiary branches) definitely secund on the outer half to two thirds of these whiplike branches.

Rare in moist loam or in swamps and bogs, in e. Tex. (Nacogdoches Co.), Oct.; Coastal States, Va. to Tex.

\section{Solidago sempervirens L. var. mexicana (L.) Fern. SEAside goldenrod.}

Rhizomes often extensive; plants altogether glabrous and smooth; aerial stems usually 1-2 m. tall; leaves often somewhat fleshy, perfectly entire, the inconspicuous venation forming merely a fine reticulate pattern rarely with readily discernible secondary nerves; basal leaves ascending, often long, grasslike, terminally rounded and narrowed to the subpetiolar base for most of the length; stem leaves much smaller, grasslike to narrow elliptic, often ascending or appressed and apically acute or rarely blunt; leaves of the head-bearing portion usually reduced; head-bearing portion often elongate but definitely one-sided and its branches nearly always curly at the tips. S. stricta Ait., S. angustifolia Ell.

Frequent in marshy often slightly brackish swales and ditches, s.e. Tex. infrequent inland in e. Tex. to Austin and Gonzales cos.), fall; Coastal Plain from Mass. to Ver. (the var. sempervirens from Nfld. to Va.)

This is somewhat variable in habit and size of head; plants with highly reduced upper leaves, relatively narrow head-bearing region and small heads have been segregated as $S$. stricta; every conceivable intergradation occurs.

\section{Solidago rugosa Ait. var. celtidifolia (Small) Fern.}

Rhizomes creeping; aerial stems $8-15 \mathrm{dm}$. tall, shortly hispid; basal leaves divided into an expanded bladelike portion and a linear subpetiolar base; leaves of midstem dark-green or sordid, ovate or narrowly ovate, 4-7 $(-10) \mathrm{cm}$. long, 1.3 to 2.5 times as long as broad, apically acute, somewhat wrinkled, essentially penninerved, marginally with 10 to 20 conspicuous serrations on each side spaced out rather evenly from the apex nearly to the base, often stiffly pubescent on the nerves beneath and with very slight scabrosity on the upper surface which has the nerves impressed and the internerve areoles slightly raised, on the lower surface the nerves prominent and the areoles depressed; head-bearing region one-sided, usually very diffuse with several long whiplike branches the outer portions of which bear the markedly secund head-bearing branchlets. S. aspera Ait. Referred here are some Texas plants which have been called $S$. ulmifolia.

Frequent in sandy soil and seepage in s.e. Okla. (Waterfall) and e. and s.e. Tex., Sept.-Nov.; Que., Ont. and e. U.S. w. to Mich., Ind., Mo., Okla. and Tex. 
Many, many goldenrods show combinations of characteristics of this species and others, especially $S$. altissima. While genetic mixing is not at all unusual in goldenrods, still the abundance of the plants of hybrid origin is remarkable in this instance. In fact, what has been called $S$. rugosa var, aspera (Ait.) Fern. in Oklahoma and Texas is probably merely a group of such plants that are primarily $S$. rugosa but contaminated to varying degrees by $S$. altissima genes.

\section{Solidago altissima $\mathrm{L}$.}

Rhizomatous perennial, usually with numerous stems (6-) 10-20 dm. tall, the stems and foliage totally more or less densely covered with a fine or microscopic pubescence (thus cinereous or sordid-green) and roughish; leaves of midstem broadest at or below the middle, lanceolate to lance-elliptic, ( 3 to) 4 to 5 (to 10 ) times as long as broad, (5-) 10-16 mm. broad, usually triplinerved (i.e., with 2 of the lower secondary nerves nearly as prominent as the midvein beneath and ascending nearly the full length of the blade), marginally usually with a few close teeth ( 5 to 10 ) on each side in the upper half to two thirds of the length; head-bearing portion of stem usually dense, somewhat one-sided, with a number of crowded arcuate branches each for nearly its total length crowded with definitely secund head-bearing branchlets, the total number of heads usually 150 to 500 ; heads small, the involucres usually only $3-4 \mathrm{~mm}$. high. S. arizonica (Gray) Woot. \& Standl.

Open low areas nearly throughout Tex. but most frequent in e., s.e. and n.-cen. Tex., N.M. (San Miguel, Chaves, Eddy, Socorro, Sierra, Grant and McKinley cos.) and Ariz. (Coconino, Navajo, Gila, Cochise, Pima, Santa Cruz and Yavapai cos.), (summer-) fall; Que., Ont. and e. U.S., w. to Wisc., Neb., and Ariz.

The plants of stream margins on the Texas Edwards Plateau (east to Kendall and Uvalde cos.) and of the Trans-Pecos (Brewster, Presidio and Reeves cos.), even rarely the Plains Country (Oldham Co.), have proportionately narrower leaves and smoother, canescent-pubescence, only obsolete marginal teeth and usually looser head-bearing portions. These are the var. canescens (Gray) M. C. Johnst. Plants of Cameron Co. (Brownsville region), Texas have dark-sordid, small, narrow, crowded leaves and extremely crowded heads, up to 1500 heads on some stems; these are the var. pluricephala M. C. Johnst.

\section{Solidago gigantea Ait.}

Rhizomes extensive; aerial stems 5-25 dm. long, 3-8 mm. thick basally, glabrous or with scattered pubescence in vertical lines on the upper part of the stem; leaf transition from midstem to upper stem very gradual and involving mainly diminution in size; leaves of midstem smooth, thin-membranous, glabrous or with only very slight pubescence on the nervation of the undersurface, brightgreen, triplinerved, elliptic or lance-elliptic, 5 to 10 (to 15) times as long as broad, 6-15 cm. long, (8-) 10-19 mm. broad, on each side with 10 to 20 salient teeth which are spaced out evenly from apex nearly to base; upper leaves just beneath the head-bearing region 4 to 8 times as long as broad, smaller and less prominently toothed than the midstem leaves; head-bearing region one-sided, usually fairly dense and compact in relation to the size of the plant, with a number of spreading arcuate branches which nearly to their bases are densely beset with the decidedly secund head-bearing branchlets; involucres about $4 \mathrm{~mm}$. high. Incl. var. leiophylla Fern.

Frequent in tight moist or wet calcareous soil, along streams and in damp thickets in Okla. (Waterfall), in Tex. in Plains Country and n.-cen. Tex. and Edwards Plateau, less frequent s.e. to e. and s.e. Tex. (s. to San Patricio and Karnes cos.) and N.M. (Lincoln and Otero cos.), (Aug.-) Sept.-Oct.; s. Can. and most of U.S., s. to Ut., Colo., Tex. and Gulf States. 

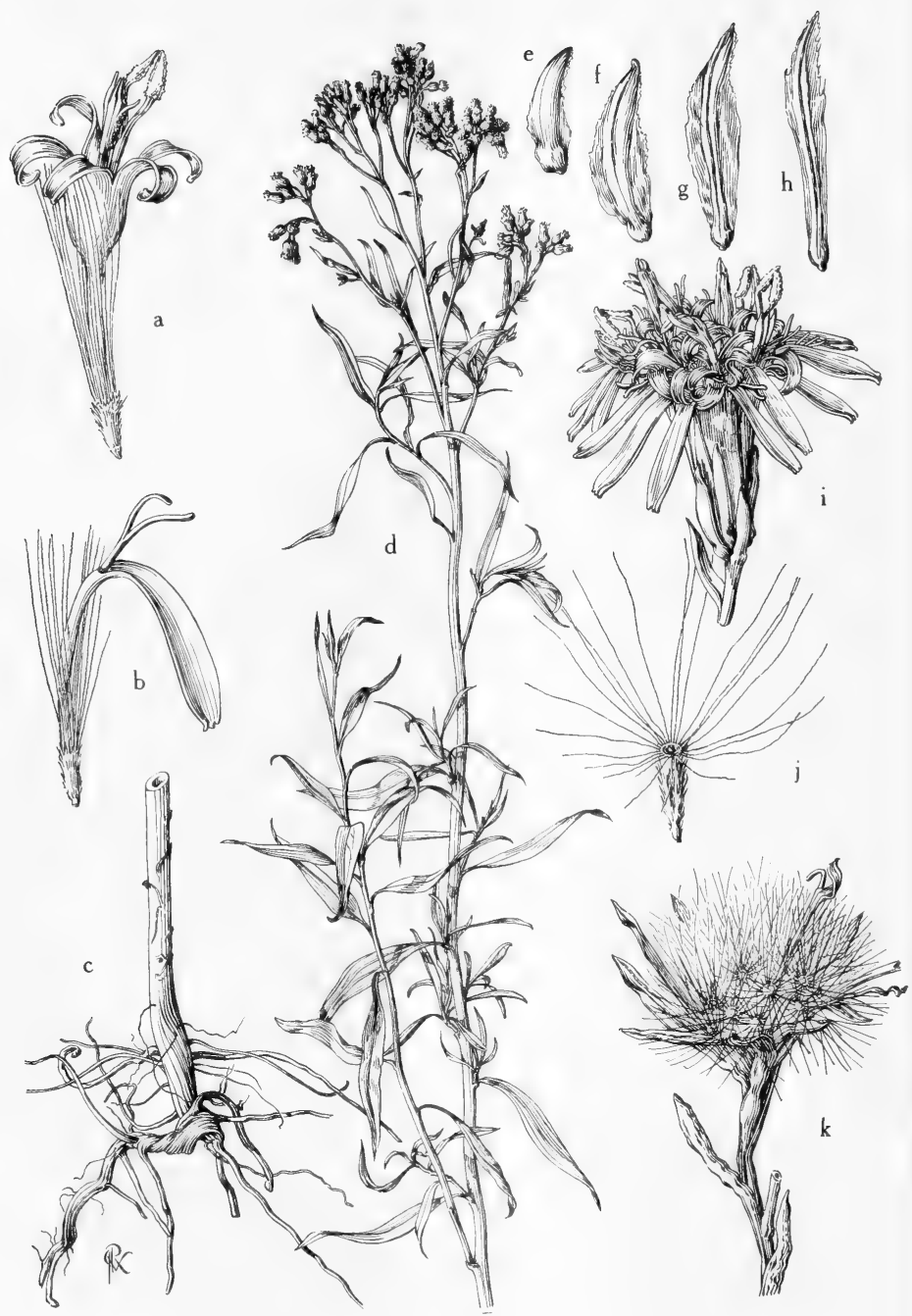

Fig. 748: Solidago occidentalis: a, disk flower, x 8; b, ray flower, $\mathrm{x} 8$; c, rhizome and base of stem, $\mathrm{x} 2 \%$; , habit, upper part of plant, $\mathrm{x} 25 ; \mathrm{e}-\mathrm{h}$, phyllaries, $\mathrm{x} \mathrm{8}$; i, flower head, showing involucre, and ray and disk flowers, $x 5 ; \mathrm{j}$, achene and pappus of scabrous capillary bristles, $x$ 8; $k$, flowering head with mature achenes ready for dispersal, x 5. (From Mason, Fig. 362). 
7. Solidago occidentalis (Nutt.) T. \& G. Fig. 748.

Rhizomatous perennial; stems simple, erect, 10-20 dm. tall, paniculately branched in inflorescence; herbage glabrous; leaves numerous, linear, entire, sessile, dark-punctate, $2-5 \mathrm{~cm}$. long; inflorescence leafy-bracteate; heads small, numerous, corymbosely disposed throughout inflorescence; involucre about $4 \mathrm{~mm}$. high, light-green or yellow; phyllaries linear-lanceolate, chartaceous; ray flowers 15 to $30,1.5-2.5 \mathrm{~mm}$. long, the disk flowers fewer; achenes turbinate.

Very common in marshes and along irrigation ditches in N. M. (Dona Ana Co.) and Ariz. (Navajo, Coconino and Cochise cos.), July-Sept.; Alta. to B.C., s. to N.M., Ariz. and Calif.

\section{Solidago spathulata DC. var. nana (Gray) Cronq.}

Perennial from a caudex or short rhizome, 5-20 cm. tall, glabrous to scabrohirtellous in the inflorescence, usually more or less glutinous (at least the peduncles and involucre); basal leaves spatulate or obovate, toothed or subentire, blunt or rounded, to $15 \mathrm{~cm}$. long (including the rather well-marked petiole) and $3 \mathrm{~cm}$. wide, mostly persistent, the cauline ones progressively reduced and generally few; inflorescence mostly short and compact, not secund, the heads often longpedunculate; involucre 4-6 $\mathrm{mm}$. high; phyllaries evidently imbricate, commonly blunt; rays 5 to 10 , mostly 8 ; disk flowers about 13. S. decumbens Green.

In a variety of habitats but in the mountains often found along streams or on seepage slopes or in wet meadows, in N. M. (Taos, Rio Arriba, San Miguel, Santa Fe and Sandoval cos.) and Ariz. (Greenlee and Coconino cos.), JuneSept.; the species from Yuk. to Que., s. to Calif., Ariz., N.M. and Va.

\section{Aster L. Aster}

Annual or usually perennial herbs, when perennial often with caudexes or horizontal rhizomes; leaves when present alternate, not dissected, usually sessile; perennial species usually with basal leaves dissimilar to cauline leaves and the latter usually passing into the much-reduced leaves of the head-bearing branchlets which are usually leafy to the summit; disk flowers present and perfect, their corollas yellowish or less commonly tinged with blue, rose or violet; ray flowers present, fertile, their corollas white or bluish-white or violet or even rosy at least on the underside but never yellow; heads usually numerous and borne at the ends of the usually leafy branches; head-bearing branchlets usually aggregated into paniclelike inflorescences; receptacle of head flat or slightly convex; disk corolla consisting of a basal cylindrical tube plus an expanded usually funnelform limb, the limb consists of a throat plus 5 lobes; phyllaries in several series, imbricate, the outer ones usually green at least near the tip and often on part of the midrib; pappus of numerous capillary bristles in essentially a single series, similar in disk and ray; achenes more or less flattened, with one or more ribs on the faces; style branches usually subulate.

Aster has several hundred species, mostly in temperate regions. It is one of our more difficult genera, both as to its over-all circumscription and the limitation of the species contained. Only complete specimens, with rhizomes and mature flowers (with anthers exserted), can be determined with any degree of confidence.

1. Distribution in New Mexico and Arizona, primarily montane (2)

1. Distribution in Oklahoma and Texas (13)

2(1). Upper leaves tiny, scalelike, entire; stems suffrutescent; plants tall, essentially glabrous (3)

2. Upper leaves not tiny and scalelike; stems strictly herbaceous (4)

3(2). Heads discoid; stems intricately branched; achenes silky.....4. A. intricatus. 3. Heads radiate; stems often spiny; achenes glabrous.................... A. spinosus. 
4(2). Phyllaries glabrous on the back, sometimes ciliate on the margin (5)

4. Phyllaries more or less densely glandular or pubescent on the back (10)

5(4). Plants annual (doubtful cases should be keyed under both alternatives)

5. Plants perennial (7)

6(5). Rays exceeding the not very copious pappus; phyllaries all linear or lancelinear, acuminate, with a scarious margin; heads loosely panicled 3. A. subulatus.

6. Rays shorter than the very copious and soft mature pappus; outer phyllaries narrowly oblong or linear-spatulate, obtuse or merely acutish, herbaceous; heads usually numerous and crowded....5. A. frondosus.

7(5). Rays white, very rarely lavender.

6. A. falcatus.

7. Rays violet or purple, rarely (in a form of $A$. foliaceus) white (8)

8(7). Plants normally ta:l, $5 \mathrm{dm}$. tall or more.

7. A. hesperius.

8. Plants normally low (not more than $3 \mathrm{dm}$. tall) and simple or little-branched; outer phyllaries narrowly spatulate to oblong-obovate (9)

9(8). Outer phyllaries narrowly spatulate, about $1 \mathrm{~mm}$. wide; leaves normally narrow (less than $1 \mathrm{~cm}$. wide), not or scarcely clasping.

8. A. chilensis.

9. Outer phyllaries broadly oblong-spatulate or oblong-obovate, $2.5-5 \mathrm{~mm}$. wide; leaves usually more than $1 \mathrm{~cm}$. wide and definitely clasping.

9. A. foliaceus.

10(4). Rays white; heads usually numerous and small, not more than $1.5 \mathrm{~cm}$. wide (including the rays); phyllaries never glandular, several seriate, with a whitish coriaceous base and an abrupt usually rhombic green tip, normally cuspidate or mucronate...............6. A. falcatus.

10. Rays lavender or purple; heads usually larger; phyllaries usually glandular (11)

11(10. Leaves grasslike, entire; phyllaries subherbaceous throughout or the inner ones narrowly scarious-margined; leaves elongate-linear or the lower ones narrowly spatulate; involucre densely stipitate-glandular, without other pubescence. 10. A. pauciflorus.

11. Leaves not grasslike, usually toothed; phyllaries not subherbaceous throughout (12)

12(11). Perennial; involucre not conspicuously many-ranked; leaf margins usually hispidulous-ciliate or serrulate..................... 8. A chilensis.

12. Biennial; involucre conspicuously many-ranked; phyllaries with a whitish chartaceous base and an abrupt often squarrose herbaceous tip.

11. A. tephrodes.

13(1). Distribution in Oklahoma (14)

13. Distribution in Texas (22)

14(13). Involucre and parts of herbage glandular.

14. Plants not glandular (15)

15(14). Phyllaries with the midrib greenish but this greenish area not expanded toward the apex or at the broadest part not more than twice as wide as at the narrowest part, usually appearing linear, the marginal areas pale and chaffy in texture; leaves when present usually subulate, tapered all the way from base to apex, rarely with a few serrations, mostly entire and glabrous; head-bearing branchlets nearly naked (16)

15. Phyllaries usually with a green splotch toward the apex formed by the lateral expansion of the greenish area near the midrib; leaves variously ovate to lanceolate or linear but usually serrate, rarely subulate; head-bearing branchlets usually leafy (17) 
16(15). Leaves small or nearly absent, often on some branchlets transformed into green thorns; plants forming colonies from extensively creeping rhizomes. 1. A. spinosus.

16. Leaves well-developed at least in the lower part of the plants; rhizomes (if present) not extensively creeping. 3. A. subulatus.

17(15). Lobes of the disk corollas comprising 45 to 75 per cent of the limb; leaves usually pubescent beneath (at least along the midrib) (18)

17. Lobes of the disk corollas comprising 17 to 45 per cent of the limb; leaves typically glabrous beneath (19)

18(17). Plants with well-developed creeping rhizomes; leaves usually pubescent over the lower surface........................................13.A. ontarionis.

18. Plants without well-developed creeping rhizomes; leaves glabrous beneath except usually along the midrib. 14. A. lateriflorus.

19(17). Heads very small, with involucre $2.5-3.5(-4) \mathrm{mm}$. high and rays 3-6 $\mathrm{mm}$. long, numerous, often unilaterally racemiform (20)

19. Heads larger than above or few, seldom unilaterally racemiform (21)

20(19). Rameal leaves much-reduced, seldom with any of them as much as 1.5 $\mathrm{cm}$. long.

15. A. vimineus.

20. Rameal leaves much larger than above, usually with many of them $1.5 \mathrm{~cm}$. long or more. 16. A. simplex.

21(19). Veinlets of the leaf forming a conspicuous reticulum, the areolae mostly nearly isodiametric; lobes of the disk corollas comprising 17 to 25 per cent of the limb; creeping rhizomes well-developed.

17. A. praealtus.

21. Veinlets of the leaf forming an obscure reticulm or (if the reticulum is evident) the areolae then clearly longer than broad.

18. A. dumosus.

22(13). Phyllaries with the midrib greenish but this greenish area not expanded toward the apex or at the broadest part not more than twice as wide as at the narrowest part, usually appearing linear, the marginal areas pale and chaffy in texture; leaves (when present) usually subulate, tapered all the way from base to apex, rarely with a few serrations, mostly entire and glabrous; head-bearing branchlets nearly naked (23)

22. Phyllaries usually with a green splotch toward the apex formed by the lateral expansion of the greenish area near the midrib; leaves variously ovate to lanceolate or linear but usually serrate, rarely subulate; head-bearing branchlets usually leafy (25)

23(22). Leaves small or nearly wanting, often on some branchlets transformed into green thorns; plants forming colonies from extensively creeping rhizomes. 1. A. spinosus.

23. Leaves well-developed at least in the lower part of the plant; rhizomes (if present) not extensively creeping (24)

24(23). Salt marsh and brackish mud perennial 3-6 dm. tall; heads numbering only 3 to 30 per plant or per shoot, broadly turbinate; involucres 11-17 mm. broad at top...................................... A. tenuifolius.

24. Annual forming colonies in poorly drained areas, (2-) 4-20 dm. tall; heads numbering up to several hundred per plant, turbinate; involucres $7-11 \mathrm{~mm}$. broad at top 3. A. subulatus.

25(22). Leaves of midstem linear, 10-25 (-34) $\mathrm{mm}$. long, 1-2 mm. wide; leaves of the head-bearing branchlets numerous, linear-subulate, ascending 18. A. dumosus.

25. Leaves of midstem usually averaging longer than $20 \mathrm{~mm}$. and always broader than $2 \mathrm{~mm}$. (26) 
26(25). Leaves of midstem with slight basal auricles which make it appear as if the leaves clasp the stem more than half the circumference though the scar involves only about half.......

19. A. scabricaulis.

26. Leaf scar commonly involving as much as half the circumference of the stem but leaf auricles absent (27)

27(26). Mature disk corolla (that is, corolla from a floret with anthers exserted or beginning to be exserted) $3-3.5(-3.9) \mathrm{mm}$. long, consisting of a tube $1-1.5 \mathrm{~mm}$. long plus a throat $0.8-1.2(-1.4) \mathrm{mm}$. long, plus lobes $0.7-1(-1.2) \mathrm{mm}$. long......................14. A. lateriflorus.

27. Mature disk corolla 4-6 mm. long, consisting of a tube $1.3-2.5 \mathrm{~mm}$. long plus a throat $1.5-3 \mathrm{~mm}$. long, plus lobes $0.5-1.1 \mathrm{~mm}$. long (28)

28(27). Phyllaries relatively weakly graduated, the shortest outer ones about half as long as the longest inner ones.....................17. A. praealtus.

28. Phyllaries relatively strongly graduated, the shortest outer ones about a third as long as the longest inner ones (29)

29(28). Mature disk corolla 5-5.6 mm. long, with lobes $0.7-1 \mathrm{~mm}$. long plus throat 2.4-2.7 mm. long, plus tube $2.2-2.5 \mathrm{~mm}$. long; in TransPecos Texas...................................................... $A$. . hesperius.

29. Mature disk corolla (4.1-) 4.5-5 mm. long, with lobes $0.5-0.9 \mathrm{~mm}$. long plus throat $1.5-2.5 \mathrm{~mm}$. long, plus tube $1.3-2.2 \mathrm{~mm}$. long; in eastern half of Texas. 20. A. Eulae.

\section{Aster spinosus Benth. Mexican devil-weed.}

Colonial by rhizomes, essentially leafless or producing a few small leaves when injured near the ground, with minute subulate leaves scattered in some stems; axillary branches often transformed into thorns; heads as in $\boldsymbol{A}$. subulatus (rays short as in var. euroauster) but the phyllaries more strongly graduated and the pale narrow margins narrower than the median dark stripe. Leucosyris spinosa (Benth.) Greene.

Locally very abundant on roadsides and other weedy slopes and banks, about streams and irrigation canals, in river beds, seepage areas and edge of water in marsh, in Okla. (Payne Co., southw.) and s. and w. half of Tex., uncommon n.e. to Brazos, Robertson and McLennan cos., N. M. (Dona Ana Co.) and Ariz. (Coconino and Mohave, s. to Cochise, Pima and Yuma cos.), summer-fall; C.R. n. and w. to Calif., Ut., Ariz., N.M., Okla. and Tex.

\section{Aster tenuifolius L. Fig. 749.}

Relatively low turgid-succulent perennial; rhizomes apparently creeping in mud; leaves only about $2 \mathrm{~mm}$. broad, to $1 \mathrm{dm}$. long; heads larger (but fewer) than in A. subulatus and $A$. spinosus (see below) but with most of the same characters; each plant or shoot from the rhizome with usually only about 10 to 20 remote heads.

Infrequent, salt marshes or brackish mud, s.e. Tex. (Aransas, Brazoria, Calhoun and Galveston cos.), June-Nov.; coastal areas n.e. as far as L.I. and N.H.

\section{Aster subulatus Michx. Hierba del marrano. Fig. 750.}

Robust much-branched glabrous annual; leaves linear-subulate, rarely serrate, mostly 1-10 $(-20) \mathrm{cm}$. long, 2-4 (-7) $\mathrm{mm}$. broad, much-reduced toward the top of the plant; involucres turbinate, of a few series of linear phyllaries, each phyllary pale but with a darker linear midrib (if laterally expanded then the widest portion no more than twice as wide as the narrowest).

In shallow water of ditches and pools, wet mud flats, marshes and floodplains and in coastal saline marshes, in Okla. (Love and Stephens cos.), throughout Tex., N.M. and Ariz. 

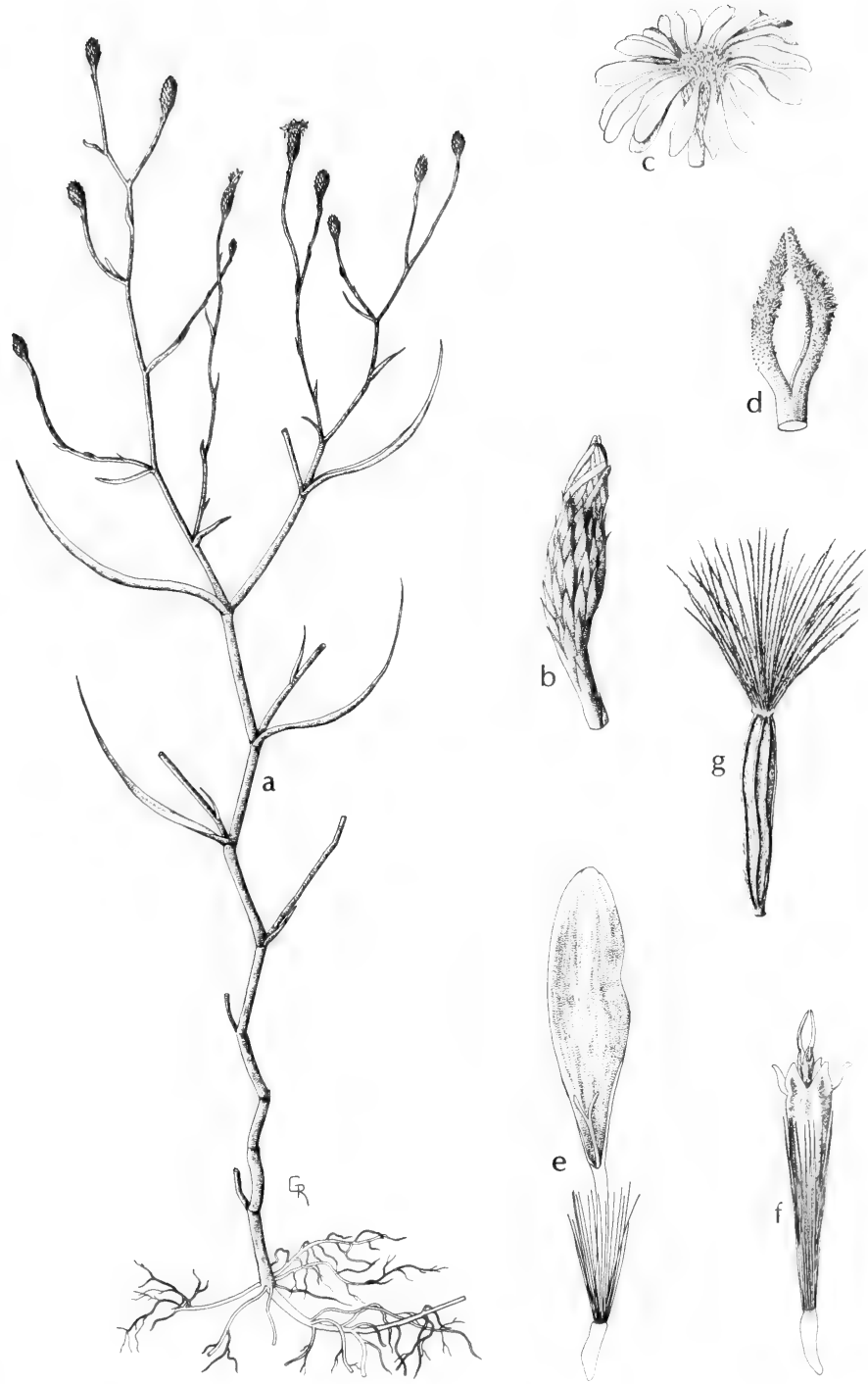

Fig. 749: Aster tenuifolius: a, habit, x $1 \frac{13}{3}$ b, bud, x 2; c, head, x 7; d, style branches, $\mathrm{x} 15$; e, ray flower, $\mathrm{x} 4$; $\mathrm{f}$, disk flower, $\mathrm{x} 4$; $\mathrm{g}$, achene, $\mathrm{x} 15$. (Courtesy of R. K. Godfrey). 


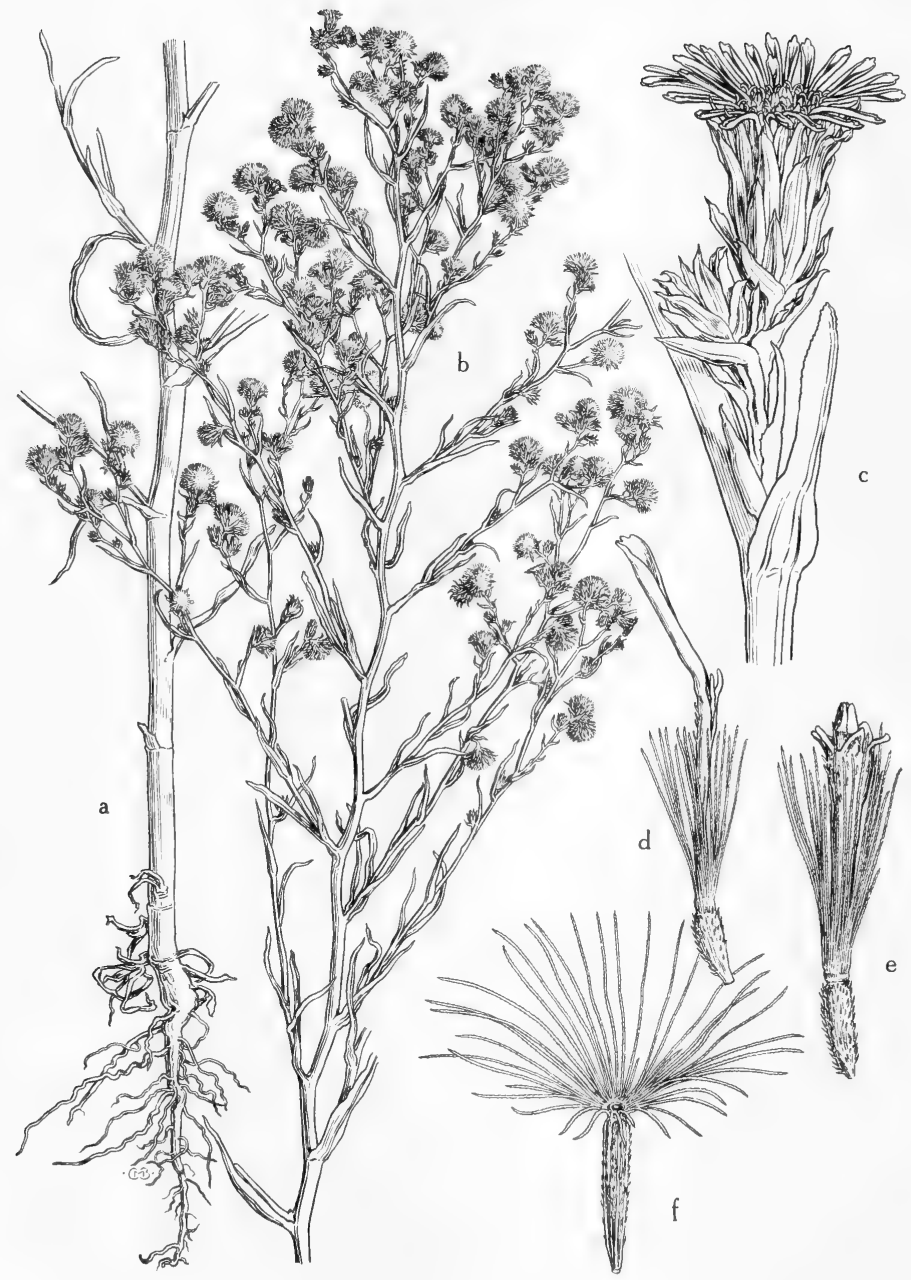

Fig. 750: Aster subulatus: a and b, habit, $\mathrm{x} 2 / 5 ; \mathrm{c}$, part of inflorescence, showing the phyllaries imbricate in several series, $\mathrm{x} 4$; d, ray flower, $\mathrm{x} 8$; e, disk flower, $\mathrm{x} 8$; $\mathrm{f}$, mature achene with pappus, $x$ 8. (From Mason, Fig. 347). 
Most of our plants belong to the var. ligulatus Shinners in which the ligules are several $\mathrm{mm}$. long, surpassing the disk corollas and the pappus; these plants have long passed under the dubious name $A$. exilis Ell. It is an abundant weed in ditches, swales, margins of ponds, lakes and streams and poorly drained places in general, throughout our area, probably our most abundant Aster, summer-fall; widespread in the warmer parts of Am., n. to S.C., Mo., Kan., N.M., Ariz. and Calif. The var. euroauster Fern. \& Grisc., characterized by its much-reduced to essentially nonexistent ligules, is extremely rare in s.e. Tex. (Orange Co.) where it grows about and in ponds, Aug.-Sept. It occurs from Conn. to Fla., w. to Tex. One old Galveston collection is referable to the var. australis Shinners, in which the ligules are about equal to the disk corollas and to the pappus in length. It is widespread in C.A. and S.A. The var. subulatus is very near the coast from Me. to La.

It has been suggested that $A$. spinosus, A. subulatus and A. tenuifolius should be segregated as a genus. They do form a coherent natural group somewhat different from our other Asters.

\section{Aster intricatus (Gray) Blake. Shrubby alkali aster.}

Shrubby perennial; stems $0.6-0.8 \mathrm{~m}$. tall, rigidly and intricately branched, glaucescent and essentially glabrous throughout; leaves linear, 1-2 cm. long, 1-2 mm. wide, entire, mucronulate, fleshy, those of inflorescence reduced, mostly appressed, scalelike, 1-4 mm. long; heads solitary at tips of branches, discoid, 5-8 $\mathrm{mm}$. wide, 8-10 $\mathrm{mm}$. high; involucre turbinate-campanulate, 6-7 $\mathrm{mm}$. high, about 5-seriate; phyllaries strongly graduated, appressed, linear or lanceolatelinear, acute or acuminate, the outer phyllaries cuspidulate, glabrous or obscurely ciliolate, chartaceous, whitish, with green midline; corollas usually yellowish; achenes terete, many-ribbed, appressed-pilose; style appendages lanceolate-subulate, longer than the stigmatic region.

Alkaline meadows, in moist or wet soils, in Ariz. (Mohave, Maricopa, Pinal, Cochise and Pima cos.), May-Oct.; also Nev. and Calif.

\section{Aster frondosus (Nutt.) T. \& G.}

Annual; stems 2-5 dm. tall, leafy, glabrous or nearly so; leaves linear to linear-lanceolate, $3-10 \mathrm{~cm}$. long, entire, acute to obtuse, glabrous but somewhat ciliate; heads numerous, paniculate on the branches; involucre 5-8 $\mathrm{mm}$. high, campanulate; phyllaries in 2 or 3 series, almost equal in length, oblanceolate to oblong-oblanceolate, obtuse to abruptly acute and often cuspidate, with a distinct midrib, glabrous to somewhat ciliate; rays lacking or minute and shorter than the pappus; achenes appressed-pubescent; pappus copious, white.

In wet to moist or dry usually saline soils, in Ariz. (Apache, Navajo and Coconino cos.), Aug.-Sept.; Wyo. to Ore., s. to Ariz. and Calif.

\section{Aster falcatus Lindl.}

Perennial plants from rather long rootstocks; stems about $20-40 \mathrm{~cm}$. tall, branching from the base or above, the branches not especially recurved, glabrate or sparingly strigose; leaves $2-5 \mathrm{~cm}$. long, linear, entire, ending in a callus point, crowded, glabrate to sparingly strigose; heads 1 to few on the branches, not secund; involucres 4-6 mm. high, hemispheric to turbinate; phyllaries oblanceolate, acute to a callus point but tips little if any reflexed, rather thin, glabrate to sparingly strigose; rays $3-5 \mathrm{~mm}$. long, white to pinkish; achenes appressedhairy; pappus bristles many, whitish or tawny.

In water of cataracts below springs and in seepage area, in N.M. (rather widespread in mts.) and Ariz. (Coconino Co.), Aug.-Sept.; Mack. s. to Kan., N.M., Ariz. and Calif. 


\section{Aster hesperius Gray. Marsh ASTER.}

Erect rhizomatous perennial; stem leaves linear to lance-linear with relatively obscure venation pattern, to $16 \mathrm{~cm}$. long and to $15 \mathrm{~mm}$. broad; leaves of the fairly numerous erect (not secund) head-bearing branchlets much smaller, oblong to subulate; heads hemispheric; involucres 6-7 $\mathrm{mm}$. high, with several rows of strongly graduated phyllaries; rays several $\mathrm{mm}$. long, bluish; mature disk corolla with tube $2.2-2.5 \mathrm{~mm}$. long, throat $2.4-2.7 \mathrm{~mm}$. long and lobes $0.7-1 \mathrm{~mm}$. long. A coerulescens of many auth., not DC.

In marshy meadows and swampy soils, in seepage along streams and irrigation ditches, rare in Tex. in the Trans-Pecos (at Muzquiz Swamp, Jeff Davis Co., and Guadalupe Mts., Culberson Co.), N.M. (widespread in mts.) and Ariz. (Apache, Navajo and Coconino, s. to Cochise and Pima cos.), Sept.-Oct.; Alta., N.D. and Wisc. s. to Calif., Ariz., Chih. and Tex.

This is exceedingly close to the $A$, praealtus complex (especially to $A$. coerulescens) and the merit of recognizing it as specifically distinct is doubtful.

\section{Aster chilensis Nees.}

Herbaceous perennial; stems slender, 3-6 dm. tall, usually erect, pubescent all around below or only in lines above; lower leaves narrowly oblanceolate, tapering to petiolelike base, the middle and upper leaves lanceolate to linear, usually entire, somewhat clasping, rough-margined, glabrous to more or less pubescent; heads few to many, in a nearly naked closed or open cyme or cymose panicle about $2.5 \mathrm{~cm}$. wide; involucre 4-7 $\mathrm{mm}$. high; phyllaries usually strongly graduate, erect, linear or linear-oblong, the outermost phyllaries usually spatulate and obtuse to acute, the inner ones acuminate, ciliolate, glabrous or pubescent on back; rays 22 to 35 , violet or purple, about $8 \mathrm{~mm}$. long. A. adscendens Lindl., A. vallicola Greene.

In wet mt. meadows, along streams and in seepy soils, openings in forests, in Ariz. (Navajo and Coconino cos.), Aug.-Sept.; Sask. to Wash., s. to Colo. and n. Ariz.

\section{Aster foliaceous Lindl.}

Herbaceous perennial from a creeping rootstock, 2-5 dm. tall; stems commonly reddish, glabrous below; lower leaves oblanceolate to obovate, 5-20 cm. long, $1.5-4 \mathrm{~cm}$. wide, narrowed to a conspicuously clasping petiolar base, the margins entire, ciliate-appressed, the upper stem leaves sessile; inflorescence mostly 1-headed to corymbose or subcymose with 4 to 6 heads; $9-12 \mathrm{~mm}$. high, to $3.5 \mathrm{~cm}$. wide, usually pubescent below the involucre; phyllaries green, subequal in size, with additional large foliaceous bracts sometimes present, glabrous on the back, ciliate-margined, oblong, obtuse to broadly acute at apex; rays 15 to 60 , purple, $1-1.5 \mathrm{~cm}$. long; achenes glabrous to sparsely pubescent; pappus white or tawny to occasionally reddish.

In seepage areas, along streams, in wet $\mathrm{mt}$. meadows and on moist wooded slopes, in N.M. (Rio Arriba and San Miguel cos.) and Ariz. (Navajo, Coconino, Apache and Greenlee cos.), Aug.-Sept.; Alas., s. to N.M., Ariz. and Calif.

Represented in our region by several weak varieties.

\section{Aster pauciflorus Nutt. Marsh al.kali aster.}

Perennial herb from creeping rootstocks; stems erect, simple or branched from the base, 2-9 dm. tall, glabrous except for glandular inflorescence; leaves somewhat fleshy, with midvein not prominent, linear or lanceolate-linear, entire, sessile, acuminate at apex, 6-12 cm. long, 3-6 mm. wide, reduced and bractlike on the branches of the corymbiform inflorescence; heads 6-12 $\mathrm{mm}$. wide, 6-8 $\mathrm{mm}$. long; involucre densely glandular-puberulent, the phyllaries linear-lanceolate, 
herbaceous except for a narrow hyaline margin, rather loose, of 2 or 3 different lengths but scarcely graduate; ligules pale-purple or whitish, 6-10 mm. long; achenes appressed-pubescent. A. hydrophilus W. \& S.

In alkaline soil about springs and streams, in seepage along streams and about lakes and ponds in N.M. (Bernalillo, Sandoval, San Juan, Sierra, Taos and Valencia cos.) and Ariz. (Cochise and Pima cos.), May-Sept.; Sask. to N.M., Ariz. and Mex.

\section{Aster tephrodes (Gray) Blake.}

Erect biennial; stems simple below, often paniculately branched above, 2-8 dm. tall, stipitate-glandular and cinereous-puberulent or cinereous-pilosulous with mostly incurved hairs; larger leaves oblanceolate or lanceolate, $3-10 \mathrm{~cm}$. long, 4-13 $\mathrm{mm}$. wide, acute, the lower leaves tapering to a petiolelike base, others sessile and often slightly clasping, shallowly toothed with spinescent-mucronate teeth, pubescent chiefly along margin and often stipitate-glandular, more or less distinctly triplinerved, the upper leaves gradually reduced to small entire bracts; heads solitary at tips of cymosely or paniculately arranged branches, $2.5-4 \mathrm{~cm}$. wide; involucre hemispheric, $8-10 \mathrm{~mm}$. high; phyllaries 6- or 7-seriate, graduated, narrowly linear-lanceolate, with whitish chartaceous base, the tip herbaceous, subulate-attenuate, mucronate, spreading or reflexed, cinereous-pilosulous; rays 23 to 40 , violet or purple, $1-1.2 \mathrm{~cm}$. long; achenes striate, finely pubescent; pappus stiffish, scarcely graduate.

River bottomlands, alluvial soils and seepage areas in N.M. (Blake) and Ariz. (Apache, Navajo and Coconino, s. to Graham, Cochise, Pima and Yuma cos.), Mar.-Oct.; also Nev. and Calif.

\section{Aster novae-angliae $L$.}

Perennial from a stout caudex or short thickened rhizome, with numerous fibrous roots, occasionally with creeping rhizomes as well; stems clustered, 3-20 dm. tall, commonly conspicuously spreading-hirsute at least above and becoming glandular upwards as well; leaves lanceolate, entire, mostly $3-12 \mathrm{~cm}$. long and 6-20 mm. wide, sessile and conspicuously auriculate-clasping, scabrous or stiffly appressed-hairy above, more softly hairy beneath or the upper becoming glandular, the lower similar to those above but soon deciduous; heads several or numerous in a leafy usually short inflorescence, the involucre and peduncles densely glandular but scarcely or not at all otherwise hairy; involucre 6-10 mm. high, its numerous slender phyllaries about equal, often purplish, with chartaceous base and loose or spreading attenuate tip, the outer ones sometimes a little broader, more foliaceous and less attenuate than the others; rays commonly 45 to 100 , bright reddish-purple or rosy, rarely blue or white, mostly $1-2 \mathrm{~cm}$. long; achenes densely sericeous or appressed-hirsute, their nerves obscure.

Moist, wet, open or wooded places, wet meadows, prairie swales, wet thickets and along streams, in Okla. (Cherokee Co.), June-Oct.; N.E., s. to Ala., w. to Okla., (?) N.M. and Wyo.

\section{Aster ontarionis Wieg.}

Somewhat resembling $\boldsymbol{A}$. lateriflorus but more colonial and spreading by more elongate rhizomes and numerous stolons; stems coarser, usually 5-20 dm. tall, with abundant spreading to subascending usually forked branches and racemosepaniculate to diffuse inflorescences; leaves closely pilose beneath and sometimes above; flowering branchlets or pedicels elongate, somewhat to not at all secund; involucres 3-4.5 mm. high; phyllaries narrowly linear to linear-oblanceolate, acute, usually puberulent on back, the green midrib slender; rays 15 to 26 , white, 5-7 mm. long and to $1 \mathrm{~mm}$. wide; disk corollas cream-color to purplish, 3-4 $\mathrm{mm}$. long, their 
spreading or ascending lobes about $1 \mathrm{~mm}$. long or about one half the length of the funnelform throat. $A$. pantotrichus Blake.

In alluvial soils in thickets, wet meadows, river bottomlands and in seepage along streams, in Okla. (Waterfall), Aug-Oct.; Que. to Minn. and S.D., s. to Tenn., Miss., Ark. and Okla.

\section{Aster lateriflorus (L.) Britt.}

Perennial from subrhizomatous bases or slender short rhizomes; stems ascending or usually long-arching, semireclining, usually with several whiplike arching secondary branches, the latter bearing in turn a number of very short secund head-bearing branchlets; leaves of midstem usually membranous, elliptic or lanceelliptic, serrate, to several $\mathrm{cm}$. long and $15 \mathrm{~mm}$. broad but usually smaller, sessile, those of the distal head-bearing region still smaller and those few of the very short head-bearing branchlets minute and subulate; heads not very crowded; involucres turbinate to hemispheric, $4-5.5 \mathrm{~mm}$. high; phyllaries in 3 or 4 rows, strongly graduated, the shorter row only about a fourth as long as the longest, mostly pale-stramineous, the dilated portion of the midrib rather smaller (so nearly the whole involucre appears stramineous); rays few and only about $3 \mathrm{~mm}$. long, usually white; mature disk corolla $3-3.5(-3.9) \mathrm{mm}$. long, with a tube 1-1.5 $\mathrm{mm}$. long, plus a throat $0.8-1.2(-1.4) \mathrm{mm}$. long, plus lobes $0.7-1(-1.2) \mathrm{mm}$. long. Incl. var. flagellaris Shinners and var. indutus Shinners, and Tex. plants which have been through error determined as $A$. ontarionis Wieg.

In swamps, wet depressions in prairies, borders of streams, ponds and sloughs, and in sandy usually moist or boggy areas in Okla. (McCurtain Co.) and in e. Tex. (s.w. to Gonzales Co.), rare to s.e. Tex. (Harris Co.), Oct.-Nov.; other varieties occur in s.e. Can. s. to Ga., Tenn. and Ark.

\section{Aster vimineus Lam.}

Perennial from long creeping or sometimes apparently short and stouter rhizomes, the stem 4-15 dm. tall, glabrous or more or less puberulent in lines; leaves glabrous on both sides or slightly scabrous above, linear or narrowly lanceolate, acute, tapering to the sessile base, entire or slightly toothed, to $11 \mathrm{~cm}$. long and $10 \mathrm{~mm}$. wide, those of the branches becoming much reduced; heads numerous in an open ample inflorescence with long divaricate divergently bracteate often recurved branches which tend to be secund, the minutely bracteate peduncles short or sometimes as much as $1.5 \mathrm{~cm}$. long; involucre $2.5-3.5$ or rarely $4 \mathrm{~mm}$. high, glabrous; phyllaries imbricate in several series, their green tips mostly elongate; rays 15 to 30 , white or rarely purplish, 3-6 $\mathrm{mm}$. long; lobes of the disk corollas comprising about $40 \%$ of the limb; achenes few-nerved, sparsely hairy.

Mostly in moist open places and along river bottoms, wet meadows, swamps and alluvial soil about ponds and along streams, in Okla. (McCurtain Co.), Aug.Oct.; Me. to Fla., w. to O. and Okla.

\section{Aster simplex Willd.}

Perennial from long often stout creeping rhizome, becoming densely colonial; stem stout, commonly 6-15 dm. tall, glabrous below, pubescent in lines above, sometimes very scantily so; leaves lanceolate or linear, serrate or occasionally entire, glabrous on both sides or somewhat scabrous above, sessile or tapering to a petiolelike base, sometimes a little clasping but scarcely auriculate, the principal ones mostly $8-15 \mathrm{~cm}$. long and 3-35 $\mathrm{mm}$. wide, mostly not strongly reticulate, the areolae (if visible) generally irregular and longer than wide; heads usually more or less numerous in an elongate leafy inflorescence, the involucre 3-5.5 mm. high; phyllaries narrow, sharply acute to acutish, glabrous except 
for the sometimes ciliolate margins, more or less strongly imbricate, with elongate usually appressed green tips; rays 20 to 40 , white or occasionally lavender or blue, 4.5-12 mm. long; lobes of the disk corollas comprising 30 to 45 per cent of the limb; achenes strigose, few-nerved.

Moist low places, wet meadows, prairie swales, ditches, edge of streams and sloughs, alluvial soil in thickets in Okla. (Waterfall), July-Sept.; N.S. to Va., w. to N.D. and Okla.

\section{Aster praealtus Poir.}

Rhizomatous perennial with ascending stems and branches; stem leaves sessile, generally lance-linear or very narrowly elliptic, the lower ones 4-10 $(-15) \mathrm{cm}$. long and about $1 \mathrm{~cm}$. broad, those higher up gradually smaller and smaller; leaves of the numerous short rarely somewhat secund head-bearing branchlets very small and subulate or linear-subulate; involucres usually hemispheric, about $6 \mathrm{~mm}$. high, with a few rows of weakly graduated phyllaries, the outer shorter of which are about half as long as the inner longest ones; rays several $\mathrm{mm}$. long, usually bluish white or less commonly pure-white; mature disk corollas $4.5-6 \mathrm{~mm}$. long, with a tube $1.5-2.5 \mathrm{~mm}$. long, a throat $1.5-3 \mathrm{~mm}$. long and lobes $0.5-1.3 \mathrm{~mm}$. long.

In marshes, seepage in wet meadows, prairie swales, and on usually moist banks and in ditches, loamy soil, in Okla. (Waterfall), n.-cen. Tex. and lower Plains Country, less frequent or rarely to e. and s.e. Tex., n. part of Rio Grande Plains and e. part of Edwards Plateau, (Sept.-) Oct.-Nov., less commonly other seasons; Que. and Ont. s. to Md., W.Va., and Ky., s.w. to Ia., Mo., Okla., Tex. and Chih. (?).

\section{Aster dumosus $\mathrm{L}$.}

Perennial from slender rhizomes; branches (at least the upper ones) usually ascending and much-branched; leaves firm-membranous, those of midstem linear, 10-25 (-34) $\mathrm{mm}$. long and 1-2 $\mathrm{mm}$. broad, usually falling before the end of Sept. and leaving in Oct. only the numerous nearly uniform minute subulate appressed leaves of the upper branches and of the head-bearing branchlets; headbearing branchlets not markedly secund; involucres $5-7 \mathrm{~mm}$. high; rays a few $\mathrm{mm}$. long, usually bluish-white but variable; mature disk corolla with a tube $1.4-2.3 \mathrm{~mm}$. long plus a narrowly funnel-form throat $1.4-2.3 \mathrm{~mm}$. long, plus usually erect lobes $0.4-1 \mathrm{~mm}$. long, the proportions quite variable. Incl. var. subulaefolius T. \& G. and var. coridifolius (Michx.) T. \& G.

In wet meadows and swampy open ground, and in loamy prairies, in Okla. (McCurtain Co.) and s.e. Tex., rare inland in e. Tex., late Sept.-Nov.; s.e. U.S. n. to Me.; other varieties inland as far as Ont., Mich and Ill.

Some few specimens combine characters of this species and of A. lateriflorus.

\section{Aster scabricaulis Shinners.}

Perennial with rhizomes; stems ascending, weak, 14-18 dm. long, with branches at middle or below to $35 \mathrm{~cm}$. long, scabrous-pubescent throughout, with about 25 to 35 nodes, the middle and upper internodes $1.5-4.5 \mathrm{~cm}$. long; stem leaves withering early, oblong-lanceolate, acute, entire or very shallowly toothed, sessile and clasping (i.e., basally slightly auriculate), scabrous-pubescent on both surfaces or nearly glabrous beneath, about $7 \mathrm{~cm}$. long and $2 \mathrm{~cm}$. broad; leaves of branches similar but much smaller, rather numerous and uniform; heads rather numerous and crowded, the ultimate head-bearing branchlets $3-12 \mathrm{~mm}$. long; involucres $7-8 \mathrm{~mm}$. high; phyllaries in about 5 to 7 rows, subequal, loosely spreading or squarrose.

Rare in boggy ground, e. Tex. (Tyler and Van Zandt cos.), Oct.; endemic. 


\section{Aster Eulae Shinners.}

Rhizomatous perennial; stem erect and with many ascending or spreading branches; head-bearing branchlets mostly $1-3 \mathrm{~cm}$. long, usually somewhat secund; leaves membranous; midstem leaves several $\mathrm{cm}$. long (quite variable in size), usually elliptic to oblanceolate but in their basal third broadly cuneate, usually obscurely serrate; leaves in the upper branches similar in shape but smaller, usually 15-30 mm. long, 3-6 mm. broad; leaves of the head-bearing branchlets linear or linear-lanceolate, not crowded, 3-10 $\mathrm{mm}$. long, about 1-2 $\mathrm{mm}$. broad; involucres hemispheric, 4-5 mm. high, of a few series of well-graduated phyllaries, the shortest of which are about a third or even only a fourth as long as the longest; rays 20 to 30 , about $4 \mathrm{~mm}$. long, usually white but less commonly bluishwhite; mature disk corollas (4.1-) 4.5-5 mm. long, with a tube 1.3-2.2 $\mathrm{mm}$. long, plus a throat $1.3-2.5 \mathrm{~mm}$. long, plus lobes $0.5-0.9(-1.1) \mathrm{mm}$. long.

Frequent in usually heavy clay or clay-loam soil, ditches, banks and openings in river bottom woods, n.-cen. Tex., infrequent to the s. part of e. and s.e. Tex., perhaps as far s. as Nueces Co., Oct.-Nov.; endemic.

\section{Doellingeria NeES}

A monotypic North American genus.

\section{Doellingeria umbellata (Mill.) Nees var. Iatifolia (Gray) House.}

Rhizomatous perennial; aerial stems simple for most of their length, rising at intervals from the rhizome, to $1 \mathrm{~m}$. high; leaves alternate, the lowest leaves (near ground level) actually smaller than those of the midstem, there being an increase in size of the leaves proceeding up the lowest part of the stem; leaves in general ascending or appressed, narrowly ovate-elliptic or broadly lanceolate, several $\mathrm{cm}$. long or reduced in the head-bearing region; upper $3-20 \mathrm{dm}$. of the plant branched, the branches erect and forming a dense corymbiform grouping of heads, each head on a short erect peduncle $3-10 \mathrm{~mm}$. long; involucres about 4 $\mathrm{mm}$. high, of perhaps 3 series of strongly graduated mostly stramineous phyllaries with unexpanded or only very slightly expanded green midribs; rays 2-3 mm. long, whitish; disk yellow; pappus slightly double, of very unequal capillary bristles, alike in disk and ray. Aster umbellatus Mill. var. latifolius Gray.

Rare in wet usually boggy ground, in Okla. (McCurtain Co.) and in e. Tex. (Bowie, Freestone and Nacogdoches cos.), Sept.-Oct.; the species as a whole occurs in s.e. Can. and e. U.S. s. to N.C., Ga., Tenn. and w. to Minn., Ia., Ark. and Tex.

\section{Erigeron L. Fleabane}

Herbs, usually pubescent; leaves alternate, essentially sessile (the blades often narrowed to subpetiolar bases); heads solitary, terminating ascending branches which are often somewhat pedunculiform; involucres usually hemispheric, usually 3-8 mm. tall; receptacle flat or often convex, essentially smooth; phyllaries in only about 2 or 3 series, not or only weakly graduated, usually lance-subulate, acute, mostly herbaceous with very narrow scarious margins; ray flowers present, usually in about 2 series, pistillate, fertile; rays linear, white or pale shades of bluish or rose, never yellow; disk flowers perfect and fertile (except sometimes a few central ones abortive); corollas yellow, with a very short basal tube and a slightly broader subcylindric 5-toothed limb; achene laterally flattened, strongly 2-ribbed (or the extreme peripheral ones often 3-ribbed), nearly glabrous; pappus various, either essentially absent or a paleaceous crown or of fragile capillary bristles and short scales or usually of unequal capillary bristles, these often in 2 size-classes (the pappus then said to be "double"). 
With about 200 species, nearly cosmopolitan, Erigeron is a difficult group of daisy like plants.

1. Plants of east and southeast Texas and eastern Oklahoma (2)

1. Plants of central Texas and central Oklahoma westward (4)

2(1). Trailing plants of sandy soil or salt marshes near the coast; stems often subrhizomatous.

1. E. myrionactis.

2. Erect plants of various habitats (3)

3(2). Plants with superficial rhizomes; disk corollas $4.5-6 \mathrm{~mm}$. long; rays $1 \mathrm{~mm}$. broad or broader.

2. E. pulchellus.

3. Rhizomes absent; disk corollas $2.5-3.2 \mathrm{~mm}$. long; rays $0.6 \mathrm{~mm}$. broad or narrower. 3. E. philadelphicus.

4(1). Pistillate corollas very numerous, filiform, with very narrow short erect rays; rayless pistillate flowers wanting; inflorescence racemiform, the peduncles erect, or the head solitary.............. E. E. lonchophyllus.

4. Pistillate corollas few to numerous, the rays well-developed and spreading (5)

5(4). Cauline leaves usually much-reduced, mostly linear or oblanceolate; plants relatively low and often spreading or trailing............ E. E. flagellaris.

5. Cauline leaves ample, usually lanceolate or broader; plants when welldeveloped tall and erect (6)

6(5). Hairs of the involucre with black crosswalls near the base; rays white; leaves hairy; pappus simple or nearly so..................6. E. Coulteri.

6. Hairs of involucre without black crosswalls; rays, leaves and pappus various (7)

7(6). Rays mostly 2-4 mm. wide; basal leaves tapering to the petiole.

7. Rays mostly $1 \mathrm{~mm}$. wide or less (8)

7. E. peregrinus.

$8(7)$. Rays very numerous (over 150 ) and narrow, about $0.2-0.6 \mathrm{~mm}$. wide; disk corollas mostly $2.5-3.2 \mathrm{~mm}$. long. 3. E. philadelphicus.

8. Rays not excessively numerous, about $1 \mathrm{~mm}$. wide; disk corollas $3.5-4.4 \mathrm{~mm}$. long; stem and involucre glandular or viscid......8. E. formosissimus.

\section{Erigeron myrionactis Small.}

Perennial with stems stoloniferous or subrhizomatous in coastal sands, rooting at the nodes, prostrate; stems often to $1 \mathrm{~m}$. long; herbage with spreading hairs; leaves obovate to spatulate or cuneate, $2-8 \mathrm{~cm}$. long, 5-25 mm. broad, coarsely few-toothed near the end; heads solitary, borne about $1 \mathrm{dm}$. above ground; rays very numerous, white, $5-7 \mathrm{~mm}$. long, about $0.3 \mathrm{~mm}$. broad; disk corollas $3.5-4.5$ $\mathrm{mm}$. long; pappus of ray and disk essentially similar, simple, of about 20 to 25 fragile capillary bristles.

Frequent in coastal sand and salt marshes in s.e. Tex. and the Rio Grande Plains, spring-fall; La., Tex. and Tam.

\section{Erigeron pulchellus Michx. RoBin's-PLANTAIN.}

Hirsute short-lived erect perennial, $15-60 \mathrm{~cm}$. tall, with fibrous root system and superficial rhizomes; basal leaves oblanceolate to suborbicular, tapering to short subpetiolar bases, 2-13 cm. long, 6-50 mm. broad, shallowly toothed above the middle or subentire; stem leaves lanceolate or oblong to more commonly ovate, obtuse or rounded to slightly acute at apex, entire or nearly so, the middle and lower leaves 2-7 cm. long and 6-20 mm. broad; heads few in a flat-topped arrangement; disk corollas $4.5-6 \mathrm{~mm}$. long or usually longer; rays $1(-2) \mathrm{mm}$. broad, 6-10 mm. long; pappus simple, of capillary bristles, alike in ray and disk.

Rare in open places and in woods on stream banks, deep sandy soil, e. Okla. (Waterfall) and e. and s.e. Tex., Apr.-May; most of e. U.S. 


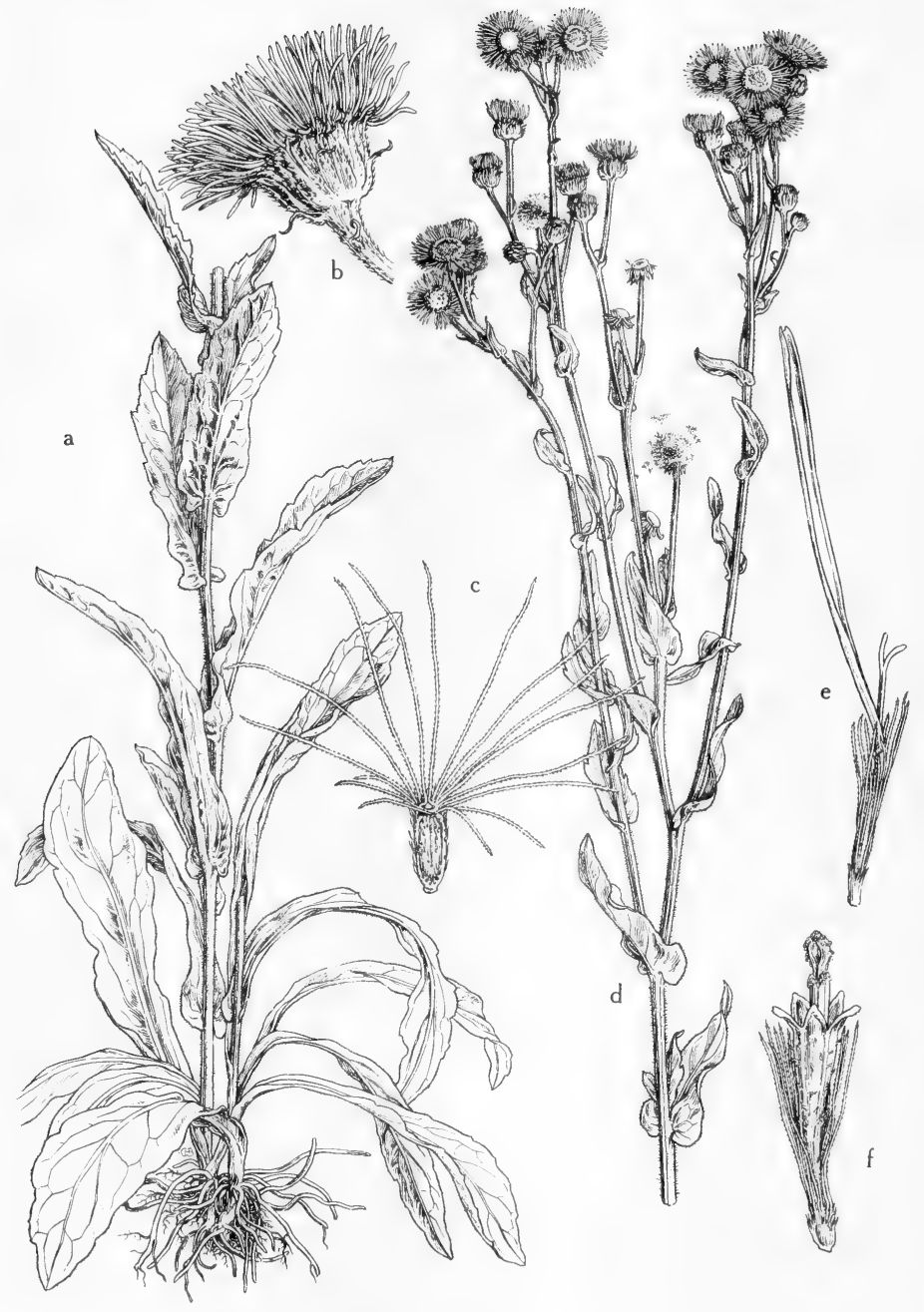

Fig. 751: Erigeron philadelphicus: a, habit, basal part of plant, $\mathrm{x} 1 / 3 ; \mathrm{b}$, flower head, showing the little-imbricate phyllaries and the numerous linear-filiform rays, $\mathbf{x}$ 2 ; $c$, achene and pappus, the bristles of one series short and those of the other series long, x 12; d, habit, upper part of plant, x $2 \%$; e, ray flower, the corolla linear-filiform, the stigma lobes linear and obtuse, $\mathrm{x} \mathrm{8;} \mathrm{f}$, disk flower, the corolla tubular, the stigma lobes broad and triangular-tipped, x 8. (From Mason, Fig. 355). 


\section{Erigeron philadelphicus L. Philadel phia fleabane. Fig. 751.}

Short-lived erect perennial 2-7 dm. tall, with fibrous root system; rhizomes absent; stems and leaves usually with spreading hairs; basal leaves narrowly to broadly oblanceolate or even obovate, coarsely crenate-toothed or lobed, rounded at the apex, tapering to the short subpetiolar base, mostly not more than $15 \mathrm{~cm}$. long and $3 \mathrm{~cm}$. broad; stem leaves clasping basally, crenate to dentate or subentire; head region not crowded; involucre 4-6 mm. high; disk corollas $2.5-3.2$ $\mathrm{mm}$. long; rays 5-10 $\mathrm{mm}$. long, 0.2-0.5 (-0.6) $\mathrm{mm}$. broad, never bluish; pappus alike in ray and disk, simple, of capillary bristles (often shorter than the corolla in the disk).

In many habitats but is occasionally found in bogs and marshes, widespread in Okla., Tex. and N.M., spring; most of U.S. and s. Can.

\section{Erigeron lonchophyllus Hook.}

Weak-rooted biennial or short-lived perennial, erect, 2-60 cm. tall, the herbage spreading-hirsute or the leaves glabrate; basal leaves mostly oblanceolate, to 15 $\mathrm{cm}$. long and $12 \mathrm{~mm}$. wide, the cauline mostly linear, often elongate; peduncles erect or suberect, the lower generally surpassed by their subtending leaves or the head solitary; involucre 4-9 mm. high, hairy, not glandular; phyllaries imbricate, acute or acuminate, commonly purple-tipped; pistillate flowers numerous, with erect inconspicuous mostly white rays $2-3 \mathrm{~mm}$. long and $0.25-0.5 \mathrm{~mm}$. wide; disk corollas $3.5-5 \mathrm{~mm}$. long, shorter than the 20 to 30 pappus bristles. E. minor Rydb.

Meadows and wet ground, mostly in the mts. in N.M. (Taos Co.), July-Aug.; s. Calif., s. Ut. and N.M. n. to B.C. and northw. and eastw.

\section{Erigeron flagellaris Gray. RuNNING FLEABANE.}

Short-lived perennial with few roots, the taproot pronounced and usually ligneous and often a few other roots present; some branches long-trailing; essentially all the hairs of the stem appressed or ascending; pappus of ray and disk essentially similar, double, of about 10 to 15 capillary bristles and some much shorter microscopic bristles.

Infrequent, low moist places in mts. of Trans-Pecos Tex., Okla. (Cimarron Co.), N.M., (widespread) and Ariz. (widespread); S.D., Wyo. and Nev. s. to Tex., N.M. and Ariz.

\section{Erigeron Coulteri Porter.}

Fibrous-rooted perennial from a slender rhizome or branching caudex; stems 1-6 dm. tall, usually amply leafy, spreading-hirsute at least above; leaves hairy, at least the lower generally toothed, the middle cauline ones mostly broadly lanceolate to oblong or ovate, to about $9 \mathrm{~cm}$. long and $3 \mathrm{~cm}$. wide; heads 1 to 4 , mostly naked-pedunculate, the involucre $7-10 \mathrm{~mm}$. high, its thin green phyllaries equal, villous-hirsute, the hairs with black crosswalls toward the base; rays 5 to 100 , white, 9-24 mm. long, 1.2-1.7 $\mathrm{mm}$. wide; disk corollas 3-4.4 $\mathrm{mm}$. long; inner pappus of 20 to 25 bristles, the outer obscure or wanting; achenes 2-nerved.

Meadows and streambanks, in the mts. in N.M. (Rio Arriba, San Miguel and Santa Fe cos.), July-Aug.; n. Ida. and n.e. Ore. to Calif. and N.M.

\section{Erigeron peregrinus (Pursh) Greene.}

Fibrous-rooted perennial from a short rhizome or short stout caudex, to $7 \mathrm{dm}$. tall, amply leafy or in small forms subscapose; heads solitary or few, the disk 10-25 mm. wide; involucre 7-11 $\mathrm{mm}$. high; phyllaries linear, attenuate, loose, mostly rather herbaceous and about equal, about $1 \mathrm{~mm}$. wide; rays 30 to 80 , 8-25 mm. long, 2-4 mm. wide; disk corollas mostly 4-6 mm. long; pappus of 20 
to 30 bristles, occasionally with a few short and inconspicuous outer setae; achenes asymmetrically 4- to 7-nerved, most commonly 5-nerved.

Moist meadows, streamsides or bogs in the mts. of N.M. (Rio Arriba Co.), July-Aug.; mts. of Calif., Ut. and n. N. M.

\section{Erigeron formosissimus Greene.}

Fibrous-rooted perennial with a simple or branched caudex; stem 1-4 dm. high, usually curved at the base, glandular at least above, often spreading-hirsute as well; lowermost leaves oblanceolate or spatulate to oval, petiolate or subpetiolate, to $15 \mathrm{~cm}$. long (including the petiole) and $15 \mathrm{~mm}$. wide, persistent; cauline leaves progressively reduced upwards and becoming sessile but usually fairly ample, mostly lanceolate or oblong to ovate; heads 1 to 6 , the disk $1-2 \mathrm{~cm}$. wide; involucre 5-8 mm. high, glandular and often hirsute, the phyllaries about equal, the outer mostly $0.7-1 \mathrm{~mm}$. wide; rays usually 75 to $150,8-15 \mathrm{~mm}$. long and $1 \mathrm{~mm}$. wide or a little wider, blue, pink or rarely white; disk corollas $3.5-4.4 \mathrm{~mm}$. long; outer pappus setulose and sometimes very scanty; achenes 2-nerved.

Moist meadows and wet seepage banks in the mts. of N.M. (Taos, Socorro, Sierra, Grant, Lincoln and Otero cos.) and Ariz. (Coconino, Apache, Navajo, Greenlee, Graham and Gila cos.), July-Sept.; w. S.D., Wyo. and Ut. to N.M. and Ariz.

\section{Conyza L.}

More than 50 species, chiefly tropical and subtropical in both hemispheres.

\section{Conyza Coulteri Gray.}

Annual herb 2-10 dm. tall, rather rigidly erect, sparingly with ascending branches; leaves narrowly obovate or oblong, with a few salient teeth or shallow lobes, apically rounded, basally rounded or usually with auricles and somewhat clasping; heads numerous and crowded in the upper 1-3 dm. in a subpaniculiform arrangement; heads about $4 \mathrm{~mm}$. high; ray flowers in 2 or 3 peripheral rows; achenes less than $1 \mathrm{~mm}$. long, hispidulous, compressed; pappus a single series of copious dull white capillary bristles about $3 \mathrm{~mm}$. long. Eschenbachia Coulteri (Gray) Rydb.

Frequent in wettish often alkaline soils, river bottoms, in the Tex. Trans-Pecos, less common in Edwards Plateau and rare in Rio Grande Plains, N. M. (widespread) and Ariz. (Coconino to Greenlee, Cochise and Pima cos.), June-Sept.; s.w. U.S. and Mex.

This plant is known to be toxic to livestock.

\section{Boltonia L'Hér.}

Perennial herbs 2-10 dm. tall, essentially glabrous, with taproot plus fibrous root systems and very slender creeping rhizomes (these easily broken off); stems slender, branched, wiry, striate-angled, uppermost parts of the branches pedunculiform; leaves linear, those of midstem 1-3 (-12) $\mathrm{cm}$. long, green, alternate, entire, essentially sessile, grading upward into leaves as small as 1-3 mm. long; heads small, solitary at the ends of the branches, $5-10 \mathrm{~mm}$. across (excluding rays); receptacle conic or hemispheric, naked; involucres hemispheric, 2-4 $\mathrm{mm}$. high, of about 3 series of slightly imbricated lanceolate appressed phyllaries with pale scarious margins and darker midribs which are slightly expanded toward the apex; ray flowers present, pistillate, fertile; rays white (or pink when dry) or lilac, never yellow; disk flowers numerous, perfect, fertile; corollas yellow, the tube not sharply demarcated from the gradually ampliate shallowly 5-lobed limb; achenes laterally compressed, brown, with 2 wings (or in the ray achenes 3- 
winged); pappus of a number of small pointed scales or broad bristles plus 2 (in ray flowers 3 ) longer awns over the wings of the achene.

About 7 species occur in North America; one in eastern Asia.

1. Phyllaries $0.5-1 \mathrm{~mm}$. broad; rays $8-15 \mathrm{~mm}$. long, lilac............ B. asteroides.

1. Phyllaries $0.2-0.5 \mathrm{~mm}$. broad; rays $5-8 \mathrm{~mm}$. long, usually pure-white when fresh. 2. B. diffusa.

1. Boltonia asteroides (L.) L'Hér.

Characters as in the key. B. latisquama Gray. Rare in low meadows, wet prairies, edge of ditches and streams, in Okla. (Ottawa Co.) and in e. and s.e. Tex., summer-fall; most of e. U.S.

\section{Boltonia diffusa Ell.}

Characters as in the key. Infrequent in low moist ground, swampy thickets, wet woods, in Okla. (Waterfall) and e. and s.e. Tex., summer-fall; Ga. and Gulf States, n. to Ky., Ill. and Mo.

\section{Egletes CASs.}

A tropical American genus of about 10 species.

\section{Egletes viscosa (L.) Less.}

Taprooted herb, probably annual; stems subsimple on small plants or bushy branched on larger ones, erect or ascending, 12-60 cm. tall, terete, striate, hispid with widely spreading flat-jointed hairs $1-3 \mathrm{~mm}$. long and pubescent with short widely spreading glandular-capitate hairs $0.1-0.5 \mathrm{~mm}$. long, very densely so in the upper part and on the branches; leaves alternate, simple, the stem leaves usually withering before flowering is over, oblong to obovate, 4-11 cm. long, 2-6 $\mathrm{cm}$. broad, shallowly to deeply pinnatisect or bipinnatisect, the divisions coarsely toothed, the lower ones with narrow clasping subpetiolar bases a third the total length; leaves of upper branches smaller, relatively narrower, less deeply divided, the basal third often entire; upper branchlets or peduncles short, to $2 \mathrm{dm}$. long, shorter than the small leaves in whose axils they arise; heads rather numerous and crowded toward the tips of the branches; involucre urn-shaped; phyllaries equal or slightly unequal, in 2 or 3 series, $0.8-1.6 \mathrm{~mm}$. broad, lanceolate to ovatelanceolate, acute, hispid, glandular-pubescent; receptacle conical, naked; ray flowers in one series, 18 to 28 , usually shorter or only slightly longer than the phyllaries; rays white, oblong-elliptic, erect, $1.6-2 \mathrm{~mm}$. long, $0.6-0.8 \mathrm{~mm}$. broad; disk flowers perfect; corolla yellow, tubular-funnelform, the limb 4- or 5-lobed; achenes similar in disk and ray, more or less compressed, 2-ribbed, basally constricted, 1.3-1.4 mm. long, glandular-pubescent, with a narrow uneven cartilaginous ring around the summit representing the pappus.

Rare in loamy soils at the edges of resacas and lakes on the Rio Grande Delta in Cameron and Hidalgo cos. of extreme s. Tex., summer-fall; Tex., s.e. to C.R.; Cuba.

We have the f. bipinnatifida Shinners, characterized by its bipinnatifid leaves having acute dentate lobes. The species is also represented by another variety in Sinaloa.

\section{Gnaphalium L. Cudweed. Everlasting}

Usually floccose-woolly taprooted annual herbs or rarely weak perennials; leaves alternate, sessile, often decurrent; heads cymosely clustered or in dense glomerules at the top; receptacle naked, essentially flat; phyllaries in several series, subequal or more strongly graduated, nearly totally scarious but usually with a green semirigid midnerve; ray flowers absent; disk flowers numerous, all fertile but 
those toward the center of the head lacking the androecium; corolla linear with 5 minute teeth apically, with two basal tails (one on each theca); style branch appendages absent; achenes terete or flattish, essentially nerveless; pappus of numerous scabrous capillary bristles in one series, minute.

A cosmopolitan genus of perhaps 200 species.

1. Pappus bristles united at base and deciduous in a ring; heads spicate; phyllary tips usually brownish or deep-purple.

1. G. purpureum.

1. Pappus bristles not united at base, falling separately or in groups (2)

2(1). Heads very small, clustered and imbedded in wool, the clusters leafybracted; involucre $2-4 \mathrm{~mm}$. high, scarcely graduated, the scarious tips of phyllaries relatively inconspicuous; low annuals seldom more than $25 \mathrm{~cm}$. high (3)

2. Heads medium size, not leafy-bracted; involucre $4-6 \mathrm{~cm}$. high, strongly graduated, the scarious tips of the phyllaries yellow or strawcolored; plants usually more than $30 \mathrm{~cm}$. high..........2. G. chilense.

3(2). Plants thinly but closely woolly; leaves linear-spatulate to linear, 1-3 mm. wide. 3. G. Grayi.

3. Plants loosely floccose-woolly; leaves spatulate to oblong or obovate, 3-8 mm. wide; heads at the tips of stem and branches, not spicately arranged 4. G. palustre.

\section{Gnaphalium purpureum L. PURPLE CUDWEED.}

Annual, usually 1-3 dm. tall, often with several ascending stems from the base; leaves oblanceolate, lower surfaces closely white-pannose with the subappressed hairs tightly enmeshed, upper surfaces much less densely pubescent, usually green and sparsely pubescent; the few-headed glomerules of heads nearly sessile in the axils of the upper $\mathrm{dm}$. of the stems, thus in a spikelike arrangement; involucre $4-6 \mathrm{~mm}$. high, densely woolly only at the base; pappus bristles united in a ring basally, deciduous as a unit.

On dry, open ground or in vernally wet areas in Okla. (Waterfall), in e. half of Tex., most common in e. Tex. in sandy soils but as far w. as the Llano Region of the Edwards Plateau, and Ariz. (Cochise and Pima cos.), spring; widely distributed in warmer parts of Am., n. to N.E., N.Y., O., Ind., Ill., Mo., Kan. and Ariz.; also Ore.

\section{Gnaphalium chilense Spreng. Cotton-Batting.}

Annual, usually $25 \mathrm{~cm}$. tall or more, often with several simple stems erect or ascending from the base; leaves mostly strongly decurrent, gray-tomentose above as well as beneath; heads in glomerules, 4-6 mm. high, campanulatesubglobose; phyllaries graduated strongly, very obtuse, scarious nearly throughout; tips of phyllaries scarious, yellowish or stramineous; corollas yellowish; achenes smooth; pappus bristles not united basally, attached separately. G. sulphurescens Rydb.

Open, often moist ground in valleys and low hills, along streams, frequently in waste places, in Okla. (Comanche Co.) and in Tex. in Davis Mts. in the Trans-Pecos, recently reported from Garza and Wheeler cos. in the Plains Country (not seen), N. M. (widespread) and Ariz. (widespread), May-Oct.; Mont. to Wash. s. to Tex., N.M., Ariz. and Calif.

\section{Gnaphalium Grayi Nels. \& Macbr.}

Annual; stems $8-25 \mathrm{~cm}$. tall, erect and simple or branching from the base with the branches erect-ascending or spreading, appressed-tomentose; leaves 1-4 $\mathrm{cm}$. long, 1-3 mm. wide, linear-spatulate or linear, thinly but closely woolly; heads very small, clustered and imbedded in wool, with the clusters subtended by 
leaflike bracts; involucre scarcely graduated, about $3 \mathrm{~mm}$. long, the scarious tips of the phyllaries relatively inconspicuous. G. strictum Gray.

Moist or wet places, mountain meadows and at edge of ponds in N. M. (Union and Rio Arriba cos.) and Ariz. (Coconino Co.), Aug.-Sept.; Wyo. to N.M. and Ariz.

\section{Gnaphalium palustre Nutt. Low LAND CUDWEED.}

Annual; stems 5-20 cm. tall, many and branching from often decumbent base, erect or ascending; herbage loosely floccose-woolly, the wool long and eventually more or less deciduous; leaves spatulate, acute, 1-3 cm. long, tapering to a sessile or subsessile base, the upper leaves oblong or lanceolate and little reduced; inflorescences scattered, the densely aggregated heads in globose terminal and axillary clusters, the latter at the tips of short or reduced branches, all clusters leafy-bracted, the encircling leaves longer than the heads; phyllaries loosely woolly, linear, the tips whitish, scarious; achenes smooth or scabrous; pappus bristles falling separately, not hairy at base.

Stream beds, vernal pools, or low moist areas in N. M. (San Juan Co.) and Ariz. (Coconino, Yavapai, Gila, Maricopa, Pinal and Yuma cos.), Apr.-Oct.; Alta. and B.C. to N.M., Ariz., Calif. and Baja Calif.

\section{Pluchea Cass. Marsh-Fleabane. Stinkweed}

Aromatic annual or perennial herbs; leaves alternate; blades simple, unlobed, usually crenate or serrate, ovate to linear-lanceolate, glabrous to glandularpubescent to floccose; petioles present or absent; heads usually crowded in corymbiform terminal aggregations; involucre campanulate to hemispheric; phyllaries, strongly imbricated, herbaceous to chartaceous; receptacle flat, naked; ray flowers absent; disk flowers very numerous, a few central ones perfect but infertile, the much more numerous outer ones pistillate and fertile; corolla rose to rose-purple or creamy-white, tubular, the corolla of the staminate central flowers 5-lobed, that of the fertile flowers 3-lobed; achenes less than $1 \mathrm{~mm}$. long, cylindrical, dark-brown or reddish-brown, 4- to 6-angled or with prominent ridges, setose to hirtellous or glabrous and with a minute white enlargement basally; pappus a single series of fine barbellate bristles.

A genus of about 9 species of the Americas.

1. Leaves broadly elliptical to lanceolate or ovate to ovate-lanceolate, petiolate or sessile, if sessile the bases of the blades narrowed to the midribs, neither auriculate-clasping nor truncate (2)

1. Leaves oblong to oblong-ovate or oblong-elliptical to oblong-lanceolate, sessile, the bases of the blades auriculate-clasping to truncate, not narrowed to the midribs (3)

2(1). Leaves petiolate; phyllaries with resin-globules, only the outermost puberulent and ciliate; the aggregation of heads characteristically elongate and paniculiform, not flat-topped, each branch terminating in a convex aggregation............................................ . camphorata.

2. Leaves sessile or petiolate; phyllaries glandular or not, the outermost and median ones copiously puberulent and ciliate, the inner ones sparsely puberulent on their summits; the overall aggregation of heads cymiform, the younger branches elongating and exceeding the more central ones, thus producing a flat-topped or layered inflorescence....................................................... P. purpurascens.

3(1). Corollas creamy-white; heads $8-10 \mathrm{~mm}$. high; outer phyllaries obtuse or obtuse-apiculate. 3. P. foetida.

3. Corollas rose-purplish; heads $4-6 \mathrm{~mm}$. high; outer phyllaries acuminate. 


\section{Pluchea camphorata (L.) DC. CAMPHOR-WEed.}

Annual or perennial herb to about $15 \mathrm{dm}$. tall; stems glabrate below, puberulent on the upper portions and the head-bearing branchlets, leafy to the summit; blades elliptical to oblong-elliptical, $6-15 \mathrm{~cm}$. long, 3-7 cm. broad, marginally dentateserrate to repand-serrate or essentially entire, upper and lower surfaces with sparsely distributed resin-globules, the lower surfaces puberulent; overall aggregations of heads characteristically elongate-paniculiform, the branches numerous and terminating in smaller convex panicled cymose clusters, the central uppermost "cymes" maturing first but the lateral ones not equaling them in height, occasionally only one terminal "cyme" of heads developing on the entire plant; phyllaries with resin-globules, the outermost sparingly pubescent and ciliate, the median and inner not pubescent.

Frequent in moist places, sometimes salt marshes and alkaline soil in Okla. (LeFlore, McCurtain, Pittsburg and Stephens cos.), e., s.e. and n.-cen. Tex., N.M. (Chaves Co.) and Ariz. (Coconino, Mohave, Maricopa, Pinal and Yuma cos.); summer-fall; Me. to Tex., Nev. and Calif., s. to Mex.

\section{Pluchea purpurascens (Sw.) DC. Canela. Fig. 752.}

Annual herb to about $15 \mathrm{dm}$. tall; stems glabrate below, copiously puberulent on the upper portions and on the cyme-bearing branches, the latter sometimes cinereous or sordid, leafy to the summit; leaves sessile or petiolate, generally short-ovate to ovate-lanceolate, sometimes lanceolate or elliptical, the apexes generally obtuse varying in the more lanceolate or elliptical blades to long-acute, the margins from evenly to unevenly serrate or serrate-dentate or entire; surfaces of the blades varying from essentially glabrous or very sparsely puberulent to copiously puberulent or essentially tomentose; overall placement of heads basically cymiform, the central axis maturing first, the lateral branches equaling or exceeding it in length, thus giving a flat-topped or layered structure; outer and median phyllaries copiously puberulent and ciliate, the inner sparsely puberulent on the summits.

In wet and muddy places in Okla. (Osage, Alfalfa, Logan, Murray, Carter, Stephens, Comanche and Kiowa cos.) and throughout Tex., summer-fall; s. half of U.S. s. to n. S.A.; W.I.

\section{Pluchea foetida (L.) DC. Stinking Fleabane.}

Perennial herb 5-8 dm. tall; stems glabrate below, sparingly pubescent in the median portions, densely pubescent and approximately lanate on the head-bearing branchlets; leaves 3-10 (-13) cm. long, 1-3 cm. broad, sessile; lower cauline leaves lanceolate or oblanceolate with cuneate or truncate bases; median and upper leaves oblong to oblong-elliptical or occasionally ovate-oblong, rarely lance-elliptic, typically shallowly auriculate-clasping but occasionally the median and upper leaves as well as the lower with cuneate bases; leaf margins shallowly and unevenly apiculate-serrate; leaf surfaces glandular above, pubescent below; overall arrangement of heads usually loose panicle-cymelike tending to be flat-topped; heads about $8 \mathrm{~mm}$. high; corollas creamy-white.

Infrequent in mud, in ditches, marshes and savannahs, in e. and s.e. Tex., s. to Aransas Co., summer-fall; s.e. U.S.; W.I.

\section{Pluchea rosea Godfrey.}

Perennial herb 30-55 cm. tall, gray-green; stems glabrate below; surfaces of the stems, leaves and involucres with sessile hemispherical glands and resinglobules, upper stems pubescent, the upper head-bearing branches and involucres tomentose or sometimes rufescent; leaves sessile, the lower oblanceolate with 


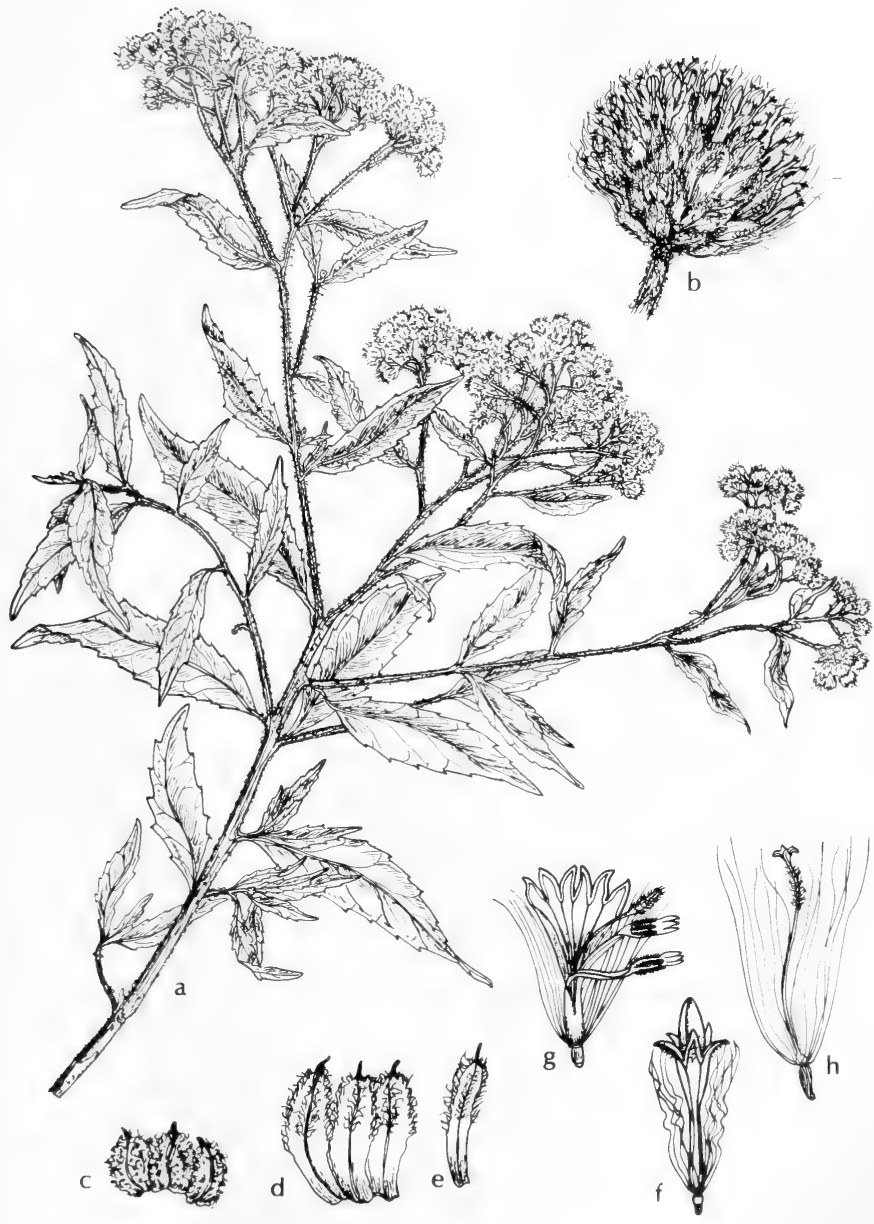

Fig. 752: Pluchea purpurascens: a, upper part of plant, $x 1 / 2$; b, flower head, $x$ $21 \frac{1}{2}$; c, outer phyllaries, $\mathrm{x} 5$; d and $\mathrm{e}$, inner phyllaries, $\mathrm{x} 5$; f, central flower, $\mathbf{x} 5 ; \mathrm{g}$, central flower slit, $x 5 ; \mathrm{h}$, outer pistillate flower, $x 5$. (V. F.). 


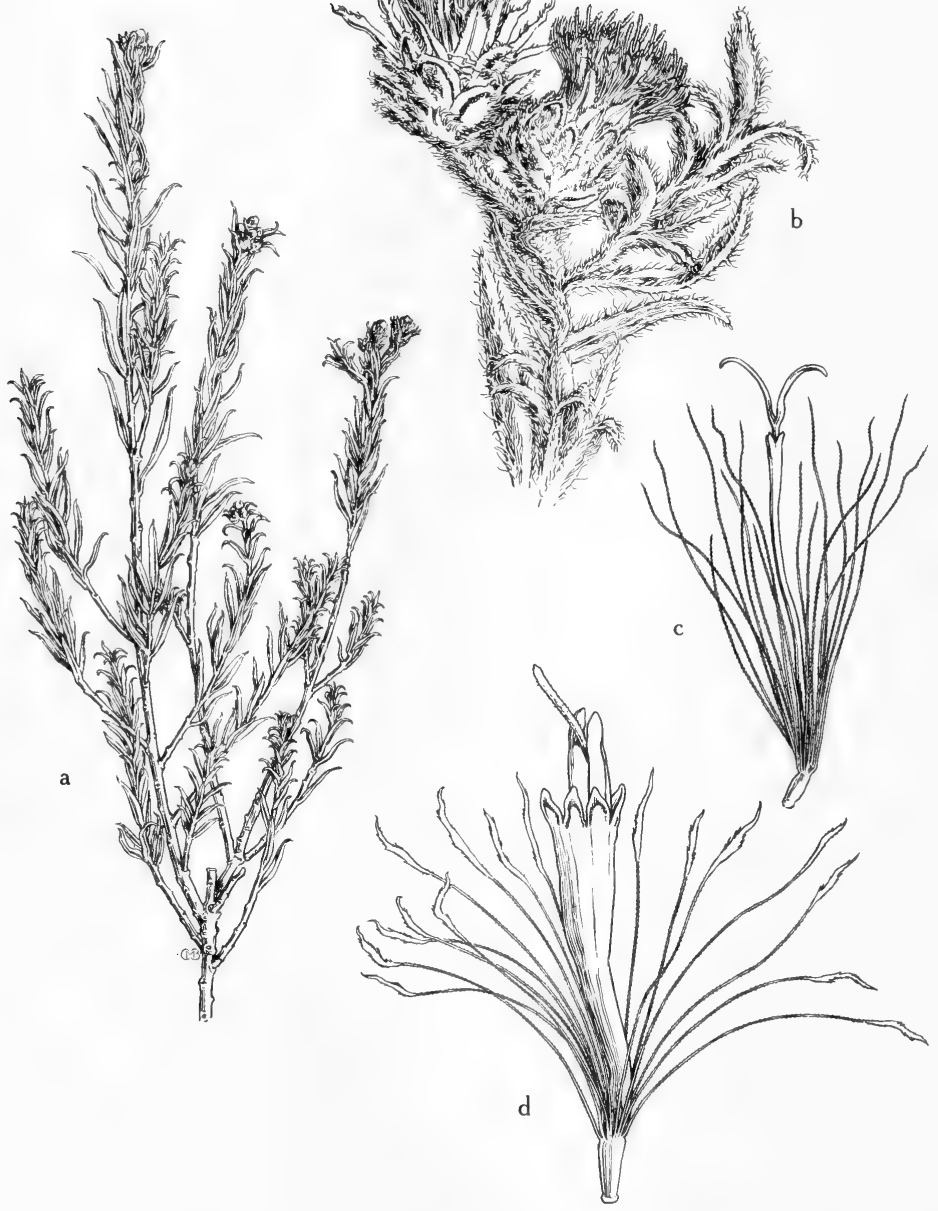

Fig. 753: Tessaria sericea: a, habit, upper branch, x $2 \%$; b, flower heads, $\mathrm{x} 2$; c, outer pistillate flower, x 8; d, inner perfect flower, x 8. (From Mason, Fig. 360). 
truncate to cuneate-truncate bases, midstem leaves larger and wider, oblong to ovate-oblong or elliptical-oblong with cordate subclasping bases or lanceolate to oblanceolate with cuneate-truncate bases, 2-7 cm. long, 5-30 mm. broad; upper leaves smaller but similar; margins of the leaves apiculate-serrate; involucres 4-6 $\mathrm{mm}$. high; corollas rose-purple.

Infrequent in savannahs, ditches and low woods in s.e. Tex. (Hardin and Harris cos.), summer; coastal areas, N.C. to Tex., S.L.P. and Q.Roo; W.I.

\section{Tessaria R. \& P. ARROW-WEED}

American genus of 3 or 4 species, of which we have one.

\section{Tessaria sericea (Nutt.) Shinners. Fig. 753.}

Shrubs $1 \mathrm{~m}$. tall or more with numerous erect branches, willowlike, graygreen, with a "rank" odor; leaves alternate, simply sericeous, linear-lanceolate, entire, essentially sessile, 1-6 cm. long, (2-) 3-5 (-6) $\mathrm{mm}$. broad; heads crowded into convex subcorymbiform aggregation $2-5 \mathrm{~cm}$. across at the ends of the branches; involucre campanulate, 4-5 mm. high; outer phyllaries ovate, obtuse and tomentose; inner phyllaries linear, deciduous with the flowers; receptacle slightly concave, naked; ray flowers absent; disk flowers very numerous, a few central ones perfect but infertile (their corollas flared, purplish, 5-lobed), the much more numerous outer ones pistillate and fertile (the corollas filiform, 4-lobed terminally); achenes of fertile flowers about $0.5 \mathrm{~mm}$. long, brownish, about 5-ribbed, nearly columnar or slightly flattened; pappus of infertile (staminate, central) flowers persistent, of flattened whitish bristlelike members which near the tips are discolored brownish and about twice as broad as the lower part; pappus of fertile flowers white, bristlelike, persistent, not thickened nor discolored. T. borealis T. \& G., Pluchea borealis (T. \& G.) Gray, P. sericea (Nutt.) Cav., Polypappus sericeus Nutt., Bertholetia sericea (Nutt.) Rydb.

Locally abundant in river bottoms, forming dense thickets near streams in the Tex. Trans-Pecos, N.M. (from Socorro Co. northw.) and Ariz. (widespread), summer; Tex., N.M., Chih., Son., Ariz. and Calif.

Reported to be a good honey plant.

\section{Iva L. SUMP-WEED. MARSH-ELDER}

Annual or perennial herbs, glabrous or pubescent; leaves alternate or opposite, entire, serrate, lobed or pinnately divided; heads in a spiciform, spiciform-racemiform or paniculate arrangement, $2-8 \mathrm{~mm}$. broad, containing both pistillate and staminate flowers, the pistillate flowers peripheral, the staminate flowers representing the disk flowers in the center of the head; receptacle essentially flat, paleaceous throughout; involucre hemispheric or turbinate; phyllaries 3 to 9 , sometimes imbricate, free or united; staminate (disk) flowers 3 to 20 , their corolla funnelform, 5-lobed, to $6 \mathrm{~mm}$. long; peripheral pistillate flowers 1 to 9 , the corolla tubular, truncate, to $6 \mathrm{~mm}$. long or in some species rudimentary; achenes 1-13 mm. long, cuneate to obovate, somewhat compressed, glabrous, resin-dotted, tuberculate or pubescent at maturity.

\section{A North American genus of 19 species.}

1. Plant annual; leaves ovate or subcordate, coarsely serrate and sometimes lobed. 3. I. xanthifolia.

1. Plant perennial; leaves elliptic to obovate or lanceolate, never lobed (2)

2(1). Phyllaries united to form a cup.

2. Phyllaries free; maritime plant.

2. I. axillaris. 1. I. frutescens. 


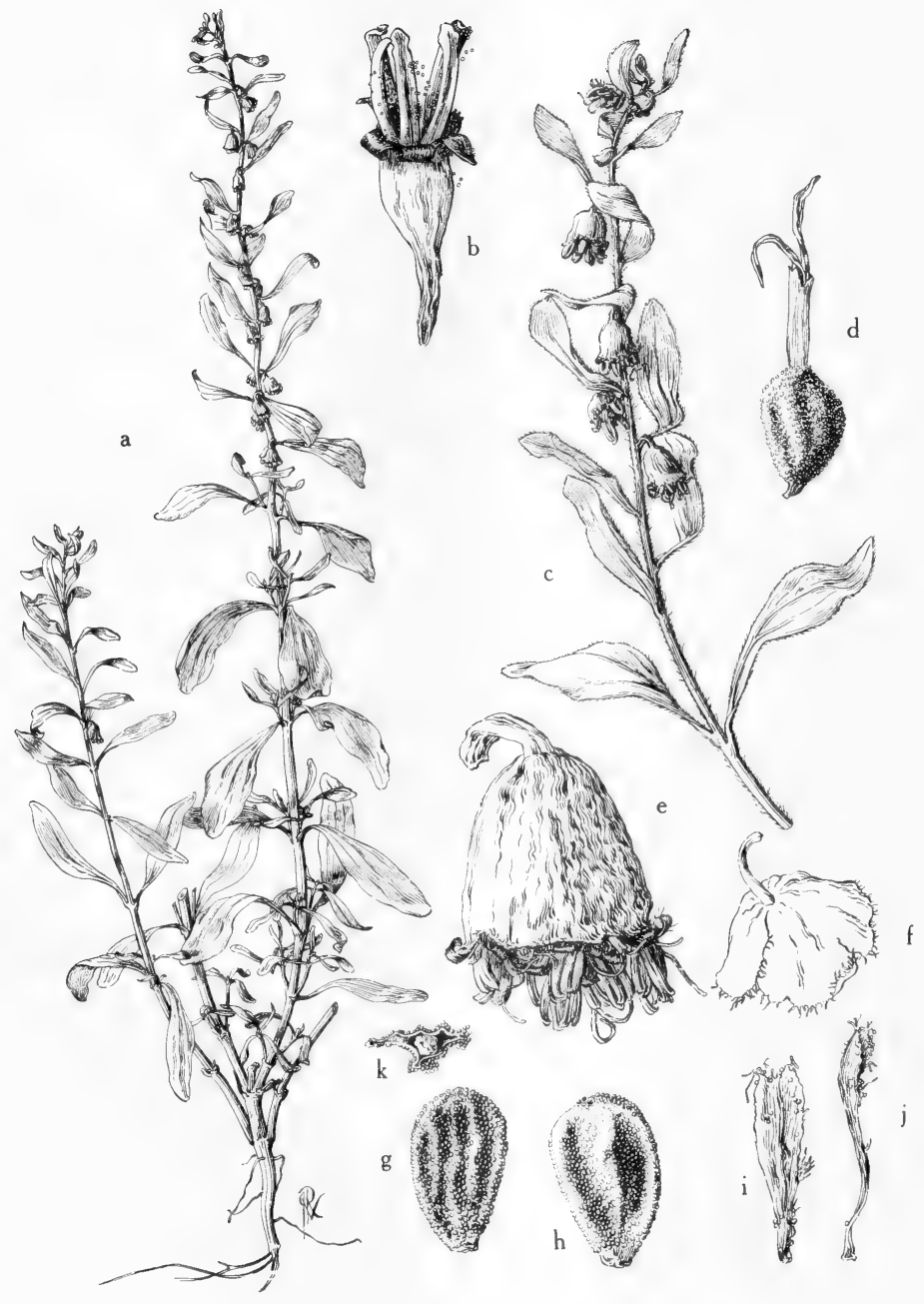

Fig. 754: Iva axillaris: a, habit, $\mathrm{x} 2 \%$; b, central sterile flower, $\mathrm{x} 10$; c, inflorescence, x 11/2; d, marginal pistillate flower, x 10; e, flower head, the toothed involucral cup enclosing flowers, x 6; $\mathrm{f}$, involucral cup with distinct lobes, $\mathrm{x} 4 ; \mathrm{g}$ and $\mathrm{h}$, achenes, the outer and inner sides with surface resin-dotted, $x \quad 10 ; i$ and $j$, chafflike receptacle bracts, x 10; k, achene (cross section), x 10. (From Mason, Fig. 357). 


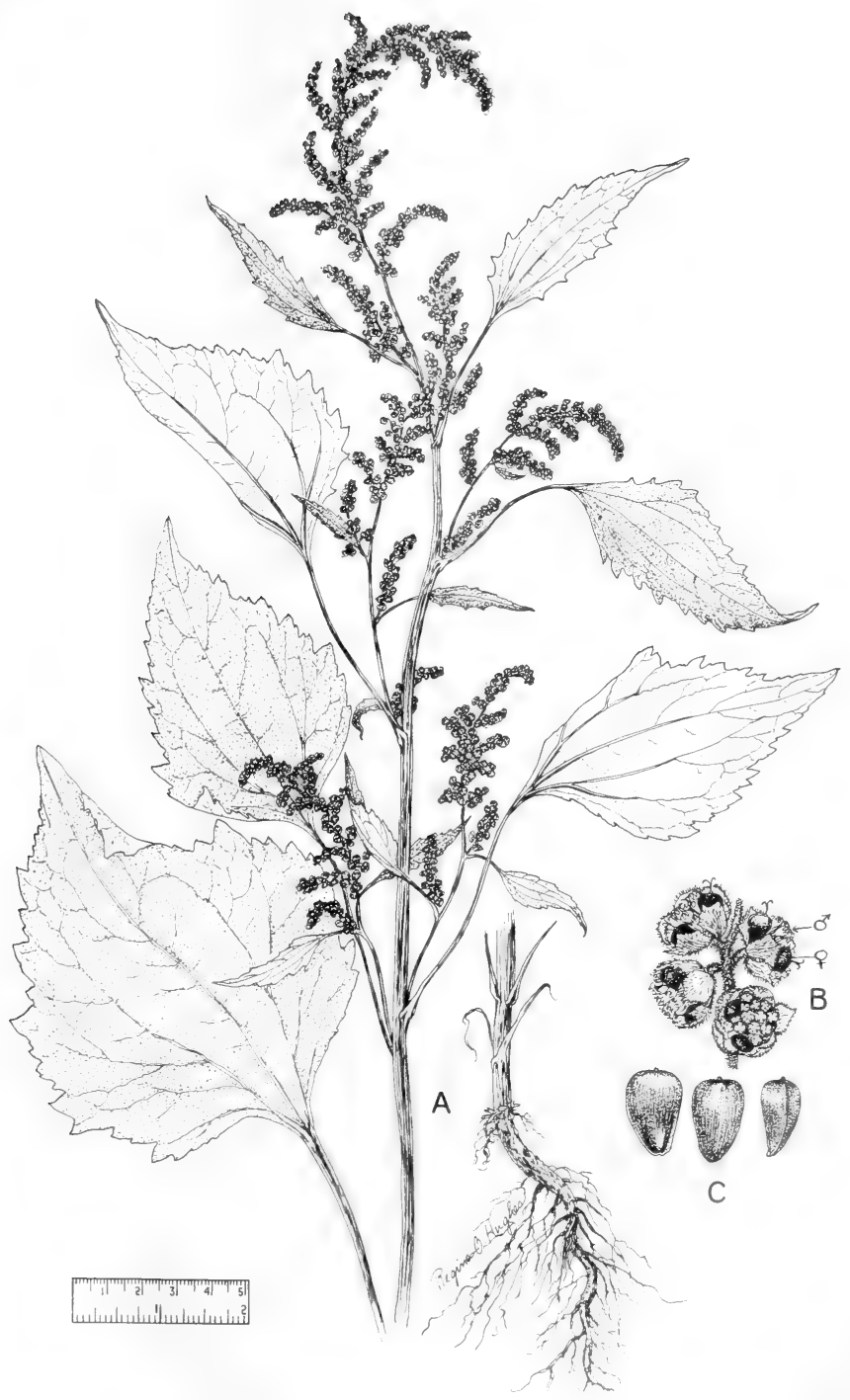

Fig. 755: Iva xanthifolia: A, habit, $\mathrm{x} 1 / 2 ; \mathrm{B}$, inflorescence, showing staminate and pistillate flowers in same head, x 2; C, achenes, x 5. (From Reed, Selected Weeds of the United States, Fig. 208). 


\section{Iva frutescens $L$.}

Bushy perennial; stems 5-35 dm. tall, strigose above, glabrous below; leaves 4-12 cm. long, opposite below, becoming alternate in the head-bearing region, ciliolate with usually 5 to 17 teeth on each side, narrowly lanceolate to lanceolate or elliptic to obovate, often petioled, 3-nerved, strigose above and below, 2.5 to 8 times as long as broad; bracteal leaves of the head-bearing region linear, mostly entire; heads numerous in leafy panicles; involucre hemispheric, 4-6 mm. broad, 2-4.5 mm. high; phyllaries 4 to 6 , free, obovate or ovate, sparingly strigulose on the back; pales subtending the staminate flowers linear to narrowly spatulate to oblanceolate; pales subtending the pistillate flowers broadly oblanceolate to oblong or broadly spatulate to elliptic; staminate flowers 6 to 19 , with corollas about $2 \mathrm{~mm}$. long; pistillate flowers 4 to 6 , corolla about $1 \mathrm{~mm}$. long; mature achenes brown, resin-dotted, 1-3.9 $\mathrm{mm}$. long.

Infrequent in mud flats and shallow water in coastal areas, s.e. Tex., s.w. as far as San Patricio Co., June-Oct.; the species as a whole occurs from N.S. to Tex. along the coast.

Essentially all our plants are referable to the var. frutescens with their leaves mostly 5 to 8 times as long as broad, the measurements of the flower and head parts approaching the lower limits of those given in the general description and the entire plant usually over $1 \mathrm{~m}$. high. Another variety, the var. oraria (Bartlett) Fern. \& Grisc., has been collected rarely at Galveston, the specimens perhaps representing casual introductions. It differs from var. frutescens mainly in being a smaller plant with typically larger elliptic to broadly lanceolate leaves.

\section{Iva axillaris Pursh. Fig. 754.}

Perennial herb from creeping rootstocks; stems herbaceous or ligneous at base, 3-6 dm. tall, strigose to villous; leaves opposite or becoming alternate above, subsessile, unlobed, at margins entire, ovate to elliptic or sometimes spatulate, obtuse, indistinctly 3-nerved; leaves of the capitulescence smaller but similar; heads short-peduncled, solitary in the upper bract axils; involucre hemispheric, 4-5 mm. broad, about $2.5-3 \mathrm{~mm}$. high; phyllaries 4 or 5 , united to the middle or above to form a cup (rarely 1 phyllary free), the tips rounded; pales of staminate flowers oblanceolate to spatulate, those of the pistillate flowers oblanceolate or absent; staminate flowers 8 to 20 ; corolla $2-2.5 \mathrm{~mm}$. long; mature achenes brownish, 2.5-3 $\mathrm{mm}$. long.

In and about playa lakes, edges of salt marshes and cultivated fields in Okla. (?), the Tex. Panhandle (Bailey and Oldham cos.), N.M. (San Juan, Rio Arriba and Quay cos.) and Ariz. (Coconino and Navajo cos.), Apr.-July; Man., Alta. and Wash. s. to Tex., N.M., Ariz. and Calif.

\section{Iva xanthifolia Nutt. Fig. 755 .}

Robust annual; stem 4-20 dm. tall, usually glabrous but sometimes pubescent; leaves of midstem opposite, 7-30 cm. long, 3-nerved, usually scabrous above, strigose or tomentose below, ovate or subcordate, coarsely serrate and sometimes 3 - to 5-lobed; heads numerous in axillary spikes or panicles and naked terminal panicles, sessile or pedunculate; involucre turbinate, 4-5 $\mathrm{mm}$. broad; phyllaries 5 , obovate, acuminate, hispid on the backs; pales subtending the staminate flowers subulate or filiform but sometimes absent in the center of the receptacle, those subtending the pistillate flowers obovate, concave, ciliate; staminate flowers 8 to 20 , corolla about $2.5 \mathrm{~mm}$. long; pistillate flowers usually 5 , corolla $0.5 \mathrm{~mm}$. long or represented only by a small flange at the base of the style; mature achenes obovate, finely muricate, usually dark-brown, about $3 \mathrm{~mm}$. long.

Infrequent in sandy stream beds and sandy stream margins, n.w. Okla. (Waterfall) and Tex. in the higher parts of the Plains Country, N.M. (San Juan, 


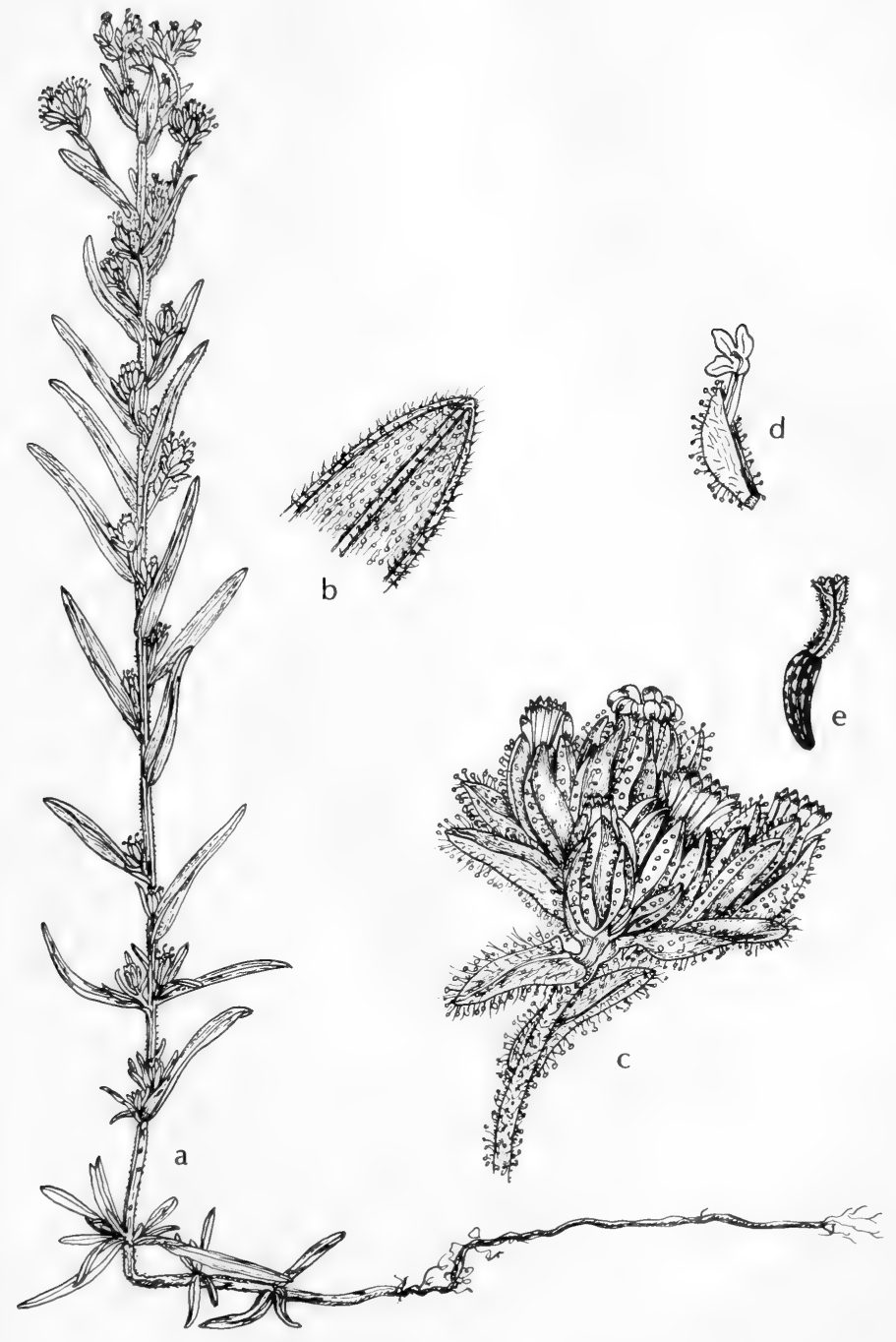

Fig. 756: Madia glomerata: a, habit, x $1 / 2 ; \mathrm{b}$, tip of leaf, $\mathrm{x} 5$; c, glomerule, x 5; d, carinate phyllary closely enveloping ray flower, $x$; e, achene, x 5. (V. F.). 
Rio Arriba, San Miguel, Bernalillo, Torrance, Taos, Colfax and Valencia cos.) and Ariz. (Apache and Navajo cos.), late summer to fall; Que. to Alta, and s. to D.C., O., Mo., Tex., N.M. and Ariz.

\section{Madia Mol. TARWEED}

About 17 species, native to western North America and in Chile.

\section{Madia glomerata Hook. Fig. 756.}

Glandular and hairy odoriferous annual, to about $8 \mathrm{dm}$. tall, usually much smaller; stems simple or with ascending branches; leaves linear to linear-lanceolate, usually 2-7 cm. long and 1-5 mm. wide; heads glomerate in 1 to many very small clusters; involucre fusiform, 6-9 $\mathrm{mm}$. high, about $3-5 \mathrm{~mm}$. wide; rays inconspicuous, yellow, about $2 \mathrm{~mm}$. long, mostly 1 to 3 or wanting from some heads; disk flowers usually several, fertile, their subtending bracts becoming like those of the rays in few-rayed or rayless heads.

In wet meadows and marshes about lakes and ponds, in N.M. (Rio Arriba Co.) and Ariz. (Coconino Co.), June-Sept.; Sask. and B.C., s. to n. N.M., n. Ariz. and Calif.

\section{Ambrosia L. Ragweed}

Annual or perennial herbs (when perennial usually proliferating from runnerlike roots), 2-30 dm. tall, leafy, resinous and aromatic with glandular trichomes; leaves alternate or opposite at the lower nodes (in some species opposite nearly throughout), entire or palmately lobed or (usually) pinnately lobed or dissected, usually petiolate; ray flowers absent; heads unisexual, both staminate and pistillate borne on the same plant; staminate usually in narrow elongate racemelike or spikelike aggregations; pistillate clustered in axils of leaves and bracts below; staminate heads nodding, usually hemispheric; phyllaries few, uniseriate, more or less united; involucre frequently oblique by elongation of the portion away from the stem; receptacle flattish, chaffy throughout (the pales narrow); flowers several to many with rudimentary pistil (pistillodium) and wholly aborted ovaries; anthers usually more or less separated at anthesis; pappus absent; pistillate heads with one or few flowers; phyllaries fused about flowers to form a hard indehiscent nutlike receptacle, the phyllary tips more or less evident as spiny processes that project from the surface of the involucral body at maturity; flowers lacking pappus, corolla and androecium. Franseria Cav.

A predominantly American genus with approximately 43 species, many of these being desert shrubs. They are wind-pollinated, the pollen of all species being highly allergenic.

1. Tubercles or spines of the pistillate head scattered in several series over the body of the fruiting involucre........................................ A. Grayi.

1. Tubercles or spines of the pistillate head in a single series (or absent) near the apex of the fruiting involucre (2)

2(1). Plant annual; cauline leaves distinctly petiolate, lobed; staminate head with 3 striations on distal lobes................................... A. A trifida.

2. Plant perennial; cauline leaves subsessile, pinnatifid; staminate head without striations on distal lobes.

1. Ambrosia Grayi (A.Nels.) Shinners.

Upright perennial herb, proliferating by adventitious shoots from runnerlike underground roots, forming large colonies; leaves alternate; blades narrowed to petiolar bases to $5 \mathrm{~cm}$. long, with several small lobes below the main expanded blade portion; main bladelike portion obovate-deltoid to lanceolate, to $1 \mathrm{dm}$. long and $8 \mathrm{~cm}$. broad, irregularly pinnately lobed, major basal lobes and terminal 


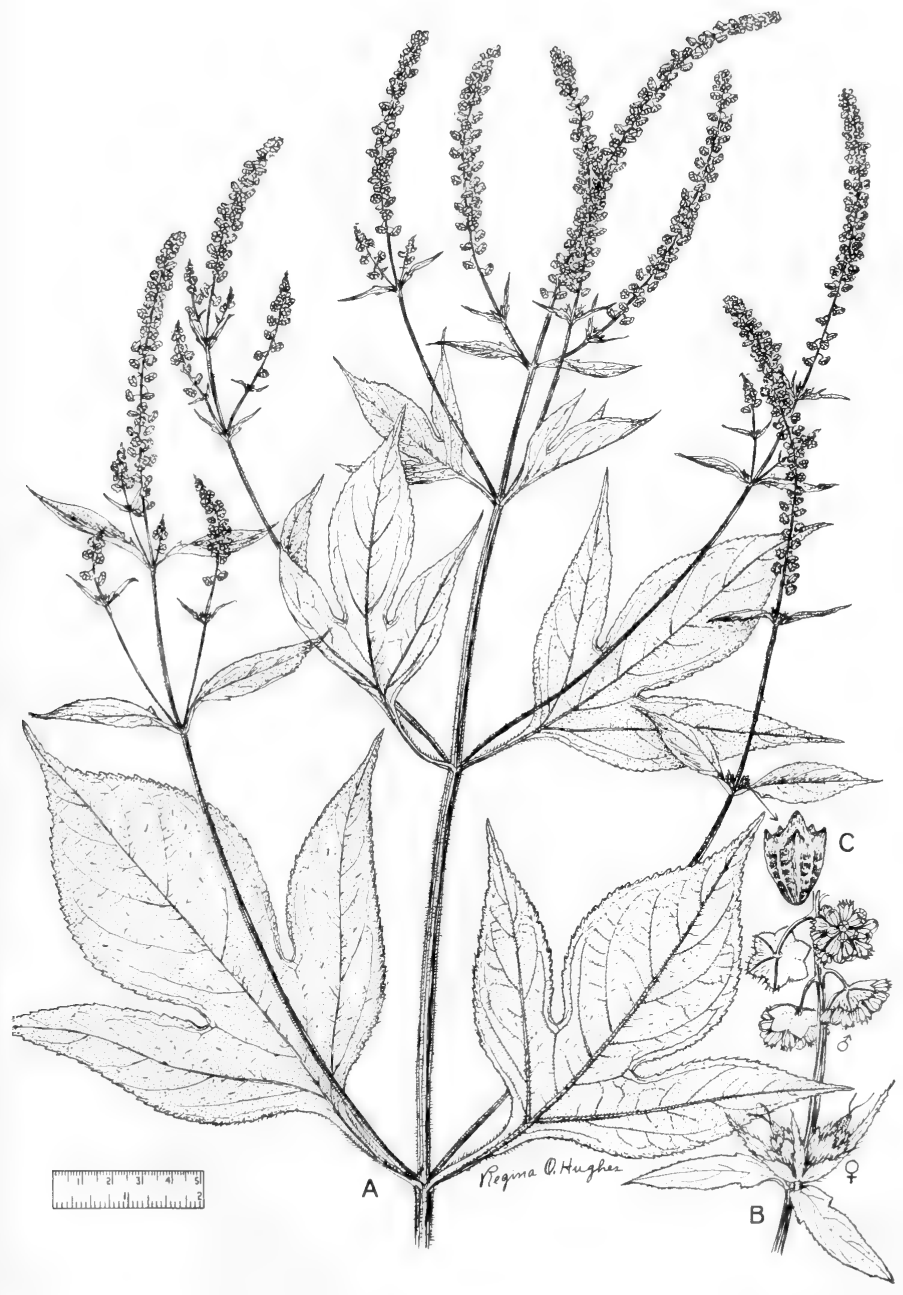

Fig. 757: Ambrosia trifida: A, habit, upper portion, $x$ 1/2; B, portion of flowering raceme, x 21/2; C, achene, x 2. (From Reed, Selected Weeds of the United States, Fig. $181)$. 


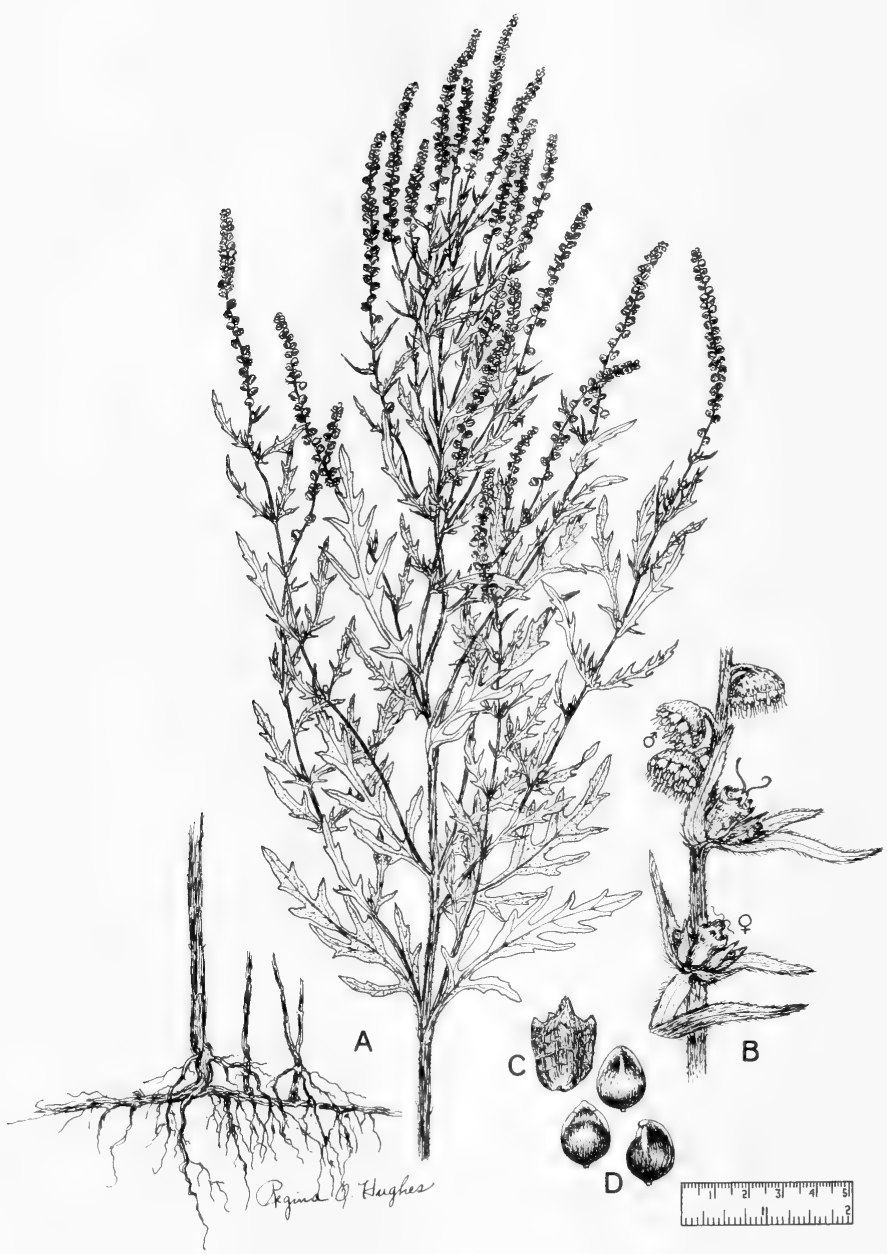

Fig. 758: Ambrosia psilostachya: A, habit, $\mathrm{x} 1 / 2 ; \mathrm{B}$, raceme of male heads and female involucres, x 21/2; C, achene, x 3; D, seeds, x 3. (From Reed, Selected Weeds of the United States, Fig. 180). 
lobe much the largest, large lobes lanceolate-elliptical, serrate, both surfaces (and entire herbage) silvery gray-canescent; staminate heads in racemiform arrangements; pistillate heads in small clusters ( 2 to 5 ) or singly in axils of lower leaves and bracts; staminate involucres stalked, to $5 \mathrm{~mm}$. broad, 5- to 9-lobed, the lobes often somewhat irregular, shallow, the upper surface with fine dark striations along the midveins obscured by pubescence; fruiting involucres to $7 \mathrm{~mm}$. long and $4 \mathrm{~mm}$. broad, each 2-flowered; spines up to 15 , scattered, narrowed to slender uncinate tips. Franseria tomentosa Gray.

Locally abundant in wet or seasonally moist swales and buffalo wallows, and in moist clay soils under cult, higher parts of the Plains Country of Tex. and Okla. (?), summer -early fall; Kan., Neb., Okla., Colo. and Tex.

\section{Ambrosia trifida L. Giant Ragweed. Fig. 757.}

Tall erect annual taprooted herb, 1-3 (-5) $\mathrm{m}$. tall; stem angled, striate and scabrous; leaves opposite nearly throughout, scabrous on both sides, with petioles $5-15 \mathrm{~cm}$. long, wingless or very narrowly winged; blades of lower leaves orbicular in outline, 1-2 dm. long, usually deeply 5-cleft, the major divisions often 2- to 3 -lobed, the upper commonly 3-cleft or simple, becoming rhombic or ovatelanceolate in outline, blades sometimes simple throughout, margin serrate; staminate heads in racemiform arrangements, these often much-branched and paniculate; pistillate heads in small to large clusters in axils of bracteal leaves below the "racemes," subtended by (usually) lobed bracts; staminate involucres saucer-shaped, $3 \mathrm{~mm}$. broad, with 6 to 8 rounded lobes, the 3 outer lobes with dark striations on the upper surface, hispidulous between the ribs, pales of the receptacle rudimentary; fruiting involucres obovoid, about $4 \mathrm{~mm}$. long, reticulate and with 4 to 8 obtuse ridges and as many small or obsolete tuberculate spines, the conic beak $1 \mathrm{~mm}$. long or more.

Abundant in seasonally moist stream bottoms and overflow areas throughout our area, late summer-fall; throughout the midwest. and cen. U.S. to the Rocky Mts. and from s. Can. to n. Mex., adv. in N.E., Fla. and the far West.

Our plants are mostly of the form known as var. texana Scheele (A. aptera DC.), characterized by relatively small fruiting involucres and exceptionally scabrous indument. In the central and southern United States much of the fall hayfever is correctly attributed to this species.

\section{Ambrosia psilostachya DC. Western RagWeed. Fig. 758.}

Erect perennial herb forming extensive colonies from runnerlike roots; stem 3-6 ( -10 or more) $\mathrm{dm}$. tall, often branched above, striate, hirsutulous with short ascending hairs; leaves subsessile, lanceolate to ovate-lanceolate, pinnatifid with the divisions linear-lanceolate, acute or acuminate, entire or the lower few-toothed or weakly lobed, scabrous-hirsutulous and glandular-granuliferous, the hairs with pustulate bases; inflorescence often much-branched; staminate heads in racemiform aggregations; pistillate heads in few- to several-headed clusters below; staminate involucre oblique, broadly obconic, about $2.5 \mathrm{~mm}$. broad, crenate at the margins, often with 2 larger teeth at the distal side, hispidulous, the short hairs with conspicuous pustulate bases; body of fruiting involucre about $2.5 \mathrm{~mm}$. long, obovoid, rugose, hirsutulous; beak nearly $1 \mathrm{~mm}$. long, stout; tubercles 4 to 6 , short, acute or blunt. A. Lindheimeriana Scheele.

Along streams, roadsides, uncultivated lands and marshy flats, very abundant on the Coastal Plain and much of the cen. part of Tex., rare westw., late summerfall; through most of the U.S. and s. Can. except the Rocky Mts. and e.-cen. states, s. to cen. Mex. 


\section{Xanthium L. Cocklebur}

Taprooted annuals, 2-20 dm. tall; leaves alternate (those at the very lowest nodes opposite), petiolate, often irregularly toothed or even lobed, several $\mathrm{cm}$. long; heads axillary, nearly sessile, unisexual; pistillate heads in the middle axils, burlike, the involucre nearly obovoid and completely enclosing the 2 pistillate flowers, forming a conspicuous 2-chambered bur, prickly on the outside; flowers without any corolla or pappus, the achenes solitary in the chambers of the bur; staminate heads in the upper axils much smaller; involucre cup-shaped; phyllaries in 1 to 3 series, separate, foliaceous in texture; the receptacle high-conic, chaffy throughout; ray flowers absent; disk flowers several, with minute tubular corolla and 5 free anthers and vestigial style and ovary.

An American genus (now widely distributed) of two dozen species or possibly as few as 2 species depending on the criteria used. The fruits are known to cause mechanical damage to animals while the young herbage, when eaten, is known to be poisonous to pigs.

1. Most nodes with a trifid yellow lateral spine attached near the base of the leaf. 1. X. spinosum.

1. Herbage not armed, only the heads armed. 2. X. strumarium.

\section{Xanthium spinosum L. SPINy Cocklebur.}

Stems erect or ascending, branching, 2-10 dm. tall, puberulent; leaves lanceolate, 4-8 cm. long, with a pair of long narrow lobes on lower half of blade, sometimes with a few small lobes above middle, green above, densely whitepubescent on lower surface, shortly petioled, each with a pair of long yellow 3- or 4-parted stipular spines at base; fruiting bur weakly spiny, tomentose, about $1 \mathrm{~cm}$. long, the beaks inconspicuous.

Abundant in waste fields, sometimes along dikes and edges of marshy areas, in our area, summer-fall; occasional throughout the U.S.

\section{Xanthium strumarium L. AвroJo. Fig. 759.}

Stems erect, usually branched, 2-9 dm. tall; leaves thick, harsh, deltoid-ovate, cordate at base or subtruncate, irregularly serrate to somewhat 3-lobed, green on both sides, on petioles as long as blades; fruiting bur 1-2 cm. long, cylindric, densely set with hooked yellowish prickles $3-7 \mathrm{~mm}$. long, these often glandular and sparsely pubescent at base, the 2 beaks strongly developed, hooked at tip. $X$. orientale L., $X$. chinense Mill., $X$. italicum Moretti, $X$. pensylvanicum Wallr., $X$. saccharatum Wallr., $X$. speciosum Kearn., $X$. cenchroides Millsp. \& Sherff.

Very abundant in low marshy lands and mud flats about lakes; a weed throughout the U.S., nat. to Atl. Coast.

It seems useless at this point to try to recognize more than one entity in this complex, for all the proposed segregates intergrade completely.

\section{Eclipta L.}

A genus of a few, perhaps only one, species, widespread in the warmer parts of the world.

\section{Eclipta alba (L.) Hassk. Yerba de TAGo. Fig. 760.}

Annual with taproots and occasionally also rooting at the nodes, to $1 \mathrm{dm}$. tall but mostly decumbent stems to $1 \mathrm{~m}$. long, throughout with antrorse-appressed stiff hairs about $0.3-0.5 \mathrm{~mm}$. long; leaves opposite, short-petiolate; blades membranous, $2-10 \mathrm{~cm}$. long, linear-oblong to narrowly elliptic, usually remotely and obscurely toothed; heads solitary at the ends of short axillary peduncles, about $1 \mathrm{~cm}$. high; involucre broadly campanulate; phyllaries in roughly 2 series, outer 


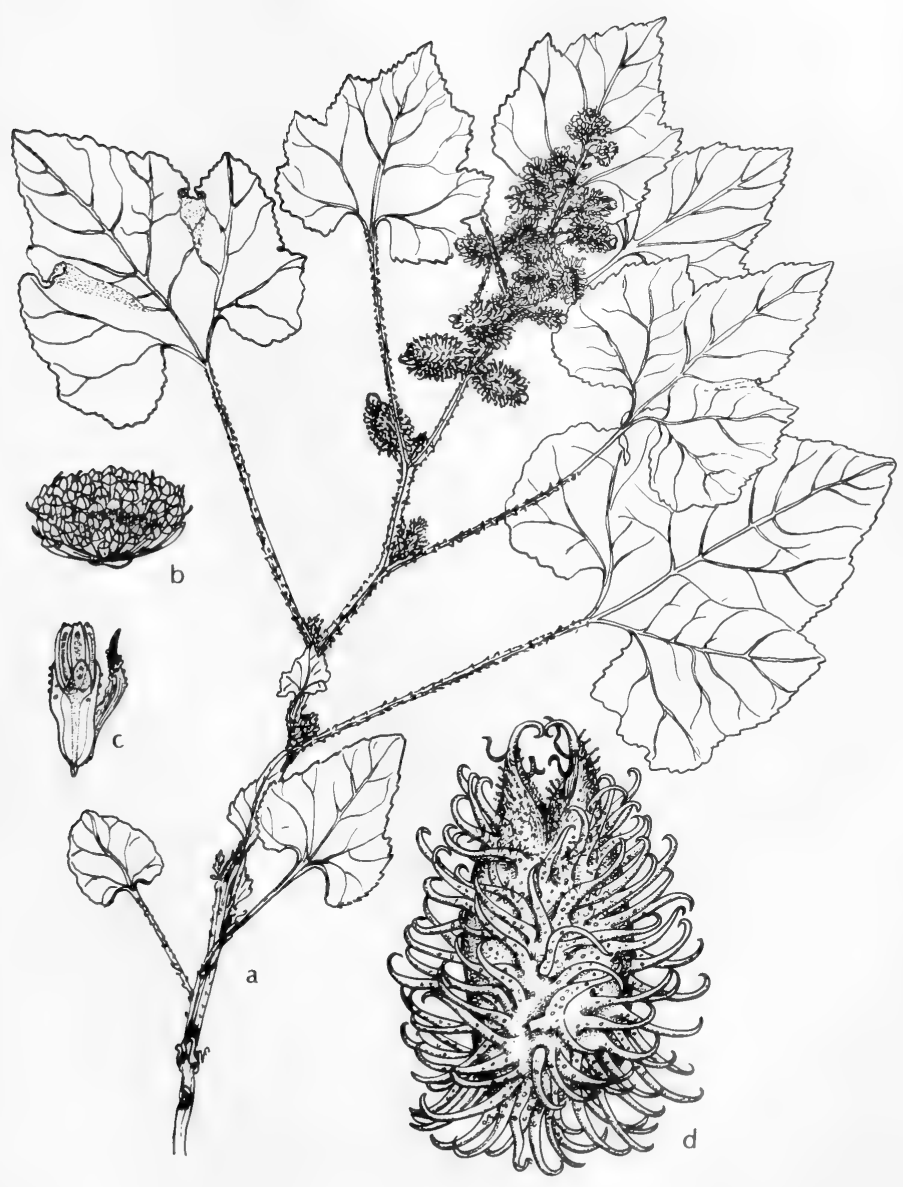

Fig. 759: Xanthium strumarium: a, habit, $\mathrm{x} 1 / 2 ; \mathrm{b}$, head of staminate flower, $\mathrm{x}$ 2; c, staminate flower, $\times 5$; d, pistillate head (bur) of 2 flowers (note the exserted style branches), x 2. (V. F.). 

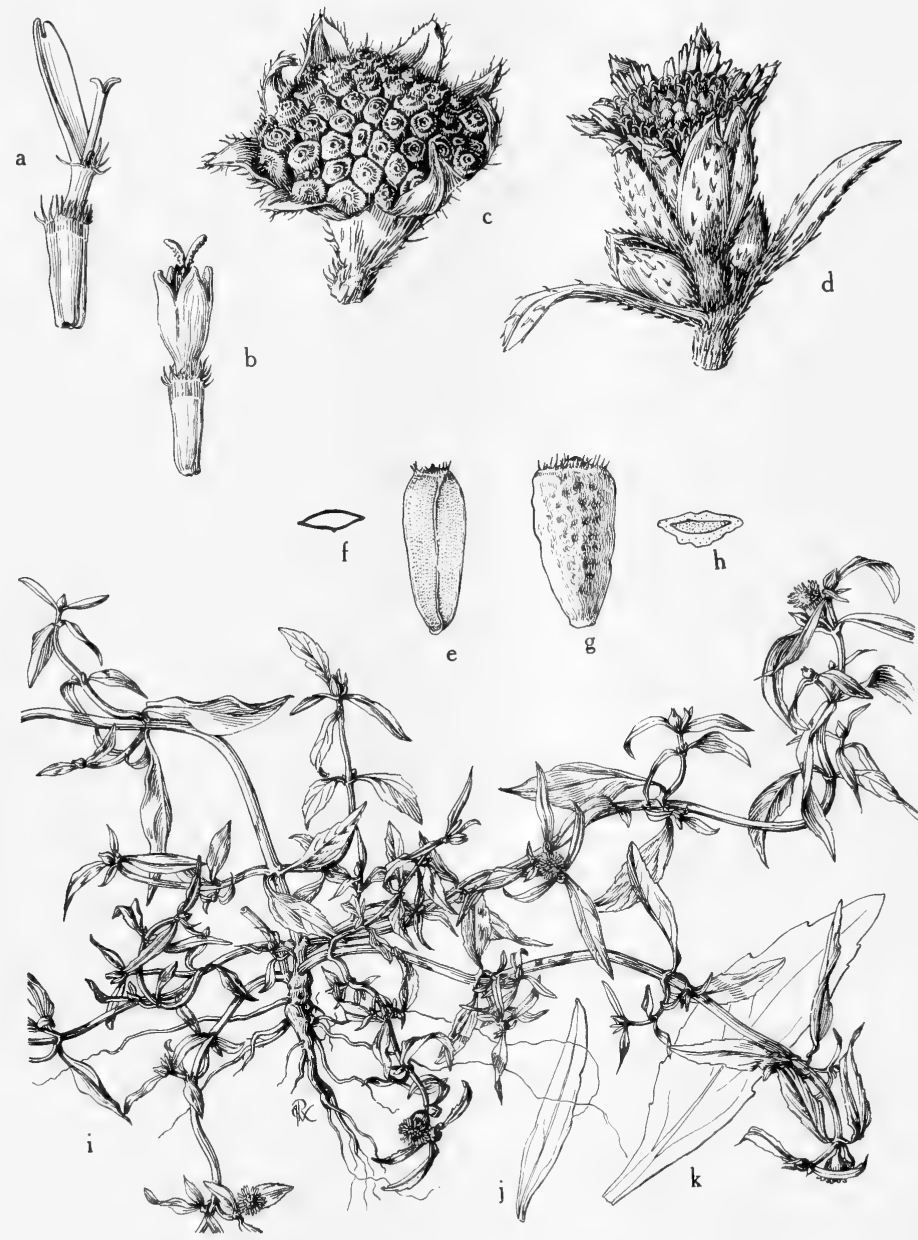

Fig. 760: Eclipta alba: a, ray flower, x 10; b, disk flower, x 10; c, flowering head, showing mature achenes, $x$ 4; $d$, flowering head, the central flowers in bud, the marginal ones with styles exserted, $\mathrm{x} 4$; e and $\mathrm{f}$, achene of the thin-walled flattened type, side view and cross section, $\mathrm{x} 10 ; \mathrm{g}$ and $\mathrm{h}$, achene of the thick-walled tuberculate type, side view and cross section, $\mathrm{x} 10$; $\mathrm{i}$, habit, $\mathrm{x} \mathrm{2/3}$; $\mathrm{j}$ and $\mathrm{k}$, leaves, $\mathrm{x} 11 \frac{1}{2}$. (From Mason, Fig. 354). 
phyllaries about 6 , oblong-obovate, apiculate, blunt, inner series fewer, shorter and narrower; receptacle slightly convex, chaffy throughout, the linear pales bristlelike; ray flowers numerous, pistillate, fertile, the linear rays minute and white; disk flowers numerous, perfect, fertile, the corollas minute and whitish; achenes laterally compressed, rhombic in transection, narrowed to the base, each side with an elongate medial patch of verrucose projections; pappus absent or represented merely by slight points above the corners of the achene.

In mud at the edges of fresh water bodies, nearly throughout our area though rare in the Trans-Pecos and the higher parts of the Plains Country of Tex., summer-fall; warmer parts of the world.

Some authors claim that the species is indigenous to the Old World and introduced in the New World.

\section{Tithonia J. F. GMEL.}

About 10 species in southwestern United States, Mexico, Central America and the West Indies.

\section{Tithonia Thurberi Gray.}

Slender moderately branched annual to about $2 \mathrm{~m}$. tall; stems whitish, striate, sparsely to densely hispid-pilose with spreading tuberculate-based rather coarse hairs interspersed with finer ones, eventually glabrate; lower leaves opposite, the upper ones alternate; petioles $2-10 \mathrm{~cm}$. long, the margin irregularly dentate on large leaves; blades ovate to broadly triangular-ovate, acute to acuminate, to $27 \mathrm{~cm}$. long and wide, cuneately decurrent along petiole from a cuneate to broadly cordate base, crenate-dentate with mucronulate teeth, deep-green and hispidulous with incurved hairs above, pale-green and sparsely granular or hispidulous and hispid-pilose on veins beneath; peduncles striate, 1-3 dm. long, spreading hispid-pilose and finely hispidulous; heads $2.5-3.5 \mathrm{~cm}$. wide; involucres of graduated bracts in 3 series, 1-2 cm. high; outer bracts lanceolate to obovate, acute to acuminate, pilose, indurated below, herbaceous at tip; innermost bracts broadest, submembranaceous, obtuse to submucronulate at tip, only granular or strigose; rays 5 to 10 , orange-yellow, oval-oblong, $7-12 \mathrm{~mm}$. long, 4-6 $\mathrm{mm}$. wide; disk corollas about $6 \mathrm{~mm}$. long, hispidulous on lobes, the tube about $1 \mathrm{~mm}$. long, the throat cylindrical; receptacular bracts $1-1.5 \mathrm{~cm}$. long, oblong, abruptly acuminate with a small tooth on each side near tip, striate-ribbed, smooth; achenes oblongobovate, about $9 \mathrm{~mm}$. long; pappus awn solitary on outer angle of achene, linearsubulate, 5.5-8 $\mathrm{mm}$. long; squamellae 4 to 8 , unequal, lanceolate, $4 \mathrm{~mm}$. long or less.

In rich moist or wettish soil near and along streams and ditches, and in muddy soil on margin of lakes and reservoirs, usually in shade, in Ariz. (Pima and Santa Cruz cos.), Aug.-Sept.; s. to cen. Son.

\section{Spilanthes JACQ.}

A world-wide genus of about 60 species.

\section{Spilanthes americana (Mutis) Hieron. var. repens (Walt.) A. H. Moore. CreEP-} ING SPOT-FLOWER. Fig. 761.

Perennial herb extensively creeping and rooting at many nodes, also rhizomatous, only the flowering branches ascending; leaves opposite; blades narrowly rhombic-ovate or deltoid-ovate, $2-4 \mathrm{~cm}$. long, serrate; petiole $1-2 \mathrm{~cm}$. long; heads solitary, about $1 \mathrm{~cm}$. high, on naked axillary peduncles $5-15 \mathrm{~cm}$. long; involucre about $5 \mathrm{~mm}$. high, of 2 series of subequal linear phyllaries; receptacle very highconic, chaffy throughout, the pales enfolding the flowers and about equaling them; ray flowers few, pistillate but infertile; rays only a few $\mathrm{mm}$. long, yellow, irregu- 


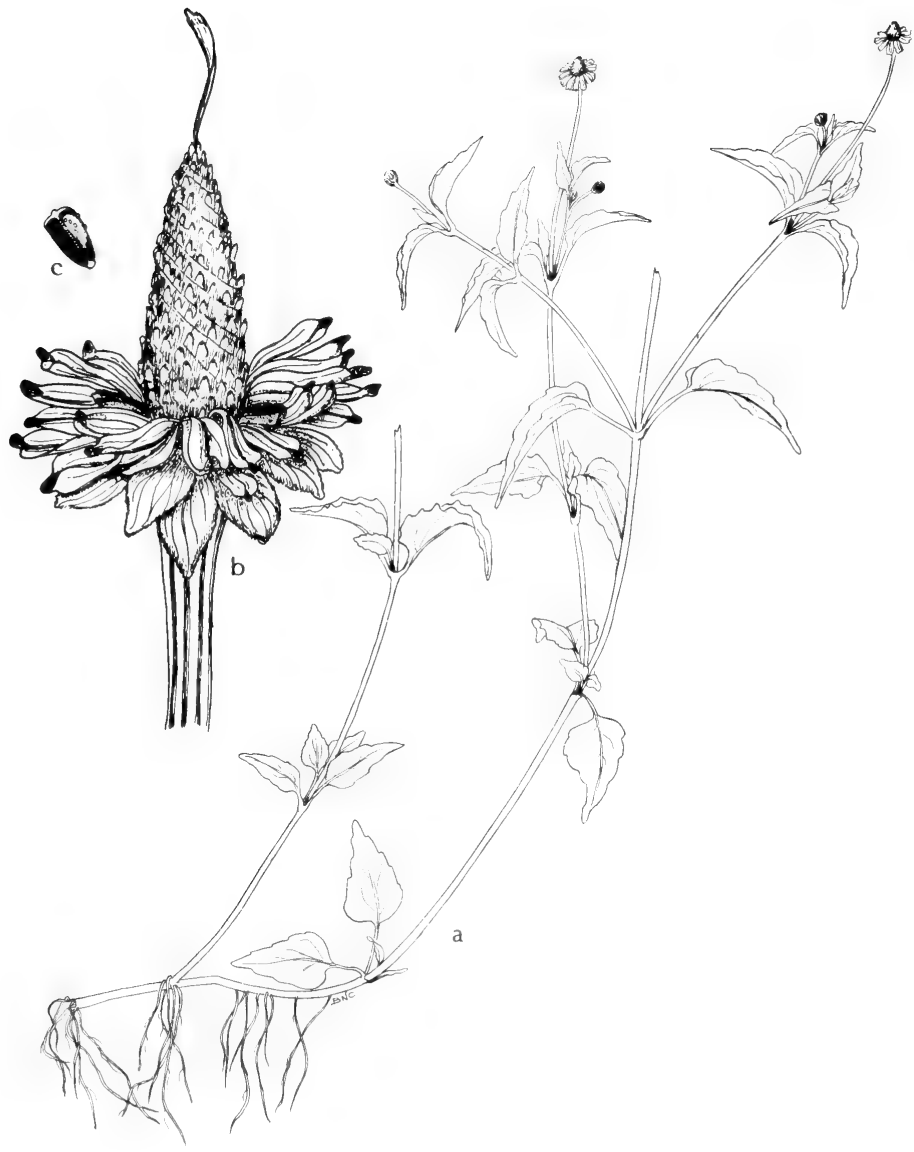

Fig. 761: Spilanthes americana: a, habit, x 1/2; b, head, x 5; c, achene, x 6. (Courtesy of R. K. Godfrey). 
larly 3-toothed terminally; disk flowers numerous, perfect, fertile, the corolla yellow and 5-toothed; achenes somewhat laterally compressed but not flat (elliptic in transection and with 2 rounded edges), blackish; pappus absent or rarely of one or two awns. S. repens (Walt.) Michx.

Local in mud along streams, bayous, lakes, ditches, etc., in Okla. (McCurtain Co.) and s.e., e. and n.-cen. Tex., late summer-fall.

The var. repens occurs in s.e. U.S., other varieties occur in North America and South America,

\section{Rudbeckia L. Brown-eyed Susan. Cone-Flower}

Perennial or annual herbs; leaves alternate (the extreme basal ones sometimes opposite); involucre hemispheric; phyllaries imbricated in 2 or more series; receptacle conical, chaffy throughout, the pales acute; ray flowers present, infertile (styles absent); rays yellow or with a brown spot basally, rarely slightly reddish all over, never white, vaguely 3-toothed apically; disk flowers numerous, perfect, fertile, the corolla tubular, equally 5-toothed terminally and brown (at least terminally), the style branches with blunt or subulate pubescent tips; achenes truncate apically, 4-angled; pappus when present merely a toothed crown of 2 to 4 short teeth.

An American genus of perhaps 30 species.

1. Achenes with 4 nearly equal facets which are flat or convex, commonly expanded by the mature ovules, typically truncate basally and basally attached to the receptacle; pales of the receptacle characteristically 1.5 to 2 times as long as the achenes (2)

1. Not as above (3)

2(1). Style branches apically elongate, slenderly subulate.................. R. hirta. 2. Style branches short and blunt.................................................... R. fulgida.

3(1). Leaf blades entire or merely toothed............................... $R$. maxima. 3. Leaf blades (at least those of the lower leaves) deeply lobed or divided (4)

4(3). Stem densely short-hairy (at least above the middle); leaves pubescent on both surfaces; disk nearly always purple or brown, ovoid or hemispheric, not elongating in fruit............................. $R$. subtomentosa.

4. Stem essentially glabrous; leaves subglabrous at least on upper surface or on both; disk yellow or gray, often elongating to become subcylindric in fruit.

4. R. laciniata.

\section{Rudbeckia hirta L.}

Annual or short-lived perennial herb, with roughly pubescent herbage; leaves narrowed to a subpetiolar base or nearly sessile, unlobed but often obscurely toothed, variable in shape but nearly always longer than broad; rays yellow with red-brown spots basally or in the lower half; style branches (of the disk flowers) apically elongate, slenderly subulate (absent in ray flowers); achenes equally quadrangular in transection, the sides flat or slightly bulging.

Usually growing in dryish situations but occasionally forming large colonies in wettish meadows and marshy land; its several variants are found from Nfld. to B.C., s. to Fla., Tex., and in the Rocky Mts. to Mex. We have 2 varieties.

Var. pulcherrima Farw. Annuals usually branching above the middle (if simple, the peduncle not more than a third as long as the height of the plant). R. serotina Nutt., R. flexuosa T. V. Moore. Nfld. to B.C. and s. to n. Mex.

Var. angustifolia (T. V. Moore) Perdue. Short-lived perennial, branching at or near the middle (if simple, the peduncle at least half as long as the height of the plant); leaves relatively narrow. $R$. divergens T. V. Moore. Frequent in sandy wooded areas, e. and s.e. Tex., spring-summer; Ga. and Fla. to Tex. 
Some plants in east and southeast Texas are intermediate between the two varieties.

\section{Rudbeckia fulgida Ait. var. palustris (Eggert) Perdue.}

Stoloniferous perennial, most of the leafy tufts arising at the ends of the stolons; herbage nearly glabrous to hirsute or strigose; basal leaves elliptical to ovate or orbicular; stem leaves lanceolate to ovate-lanceolate, gradually reduced upward, the uppermost bracteiform; pales apically ciliate; rays mostly $15-30 \mathrm{~mm}$. long; style branches short and blunt; achenes equally 4-faceted, facets flat or bulging. $R$. Cory $i$ Shinners.

On wet ledges, in wet and swampy meadows usually fed by seepage, and along streams, in Okla. (Arbuckle Mts.) and in e. and n.-cen. Tex., to Edwards Plateau, summer; Mo., Ark., Okla and Tex.; the entire species widely distributed in e. U.S.

\section{Rudbeckia subtomentosa Pursh.}

Perennial from a stout woody rhizome; stem 6-20 dm. tall, glabrous below, densely pubescent above with short usually spreading hairs; leaves firm, petiolate, densely pubescent with short loosely spreading hairs, ovate to sometimes ellipticlanceolate, serrate, some of the larger ones deeply trilobed; heads several; disk brownish or dark-purple, $8-16 \mathrm{~mm}$. wide; involucral bracts narrow, spreading or reflexed, subequal, green, more or less canescent-strigose; rays usually 12 to 20 , yellow, 2-4 cm. long; receptacle bracts obtuse to acutish, canescent near tip with short viscidulous white hairs; style appendages short and blunt; achenes quadrangular; pappus a minute crown.

In low wet meadows and prairies, thickets and on stream banks, in e. Okla. (Waterfall), reported from Tex., July-Oct.; Wisc., Ia. and Kan., s. to La. and (?) Tex.

\section{Rudbeckia laciniata L. Cutleaf CONEFlower. Fig. 762.}

Plants 6-15 dm. tall, cinereous-pubescent, branched above; leaves petioled, some or all of the lower ones 3-lobed or 3-parted, the terminal lobe elliptic to lanceolate, acuminate, serrate, the lateral lobes smaller and narrower, the upper stem leaves mostly undivided; heads numerous; phyllaries linear or nearly so, acuminate; pales apically canescent; rays several, yellow, $2-3 \mathrm{~cm}$. long.

In wet soil along boggy streams and sloughs and about lakes, in wet thickets and swampy or marshy areas, in n.e. Okla. (Waterfall), e. Tex., N.M. (widespread) and Ariz. (Apache, Navajo and Coconino, s. to Cochise and Pima cos.), summer-fall; Me. to Sask. and Ida., s. to Fla., Tex., N.M. and Ariz.

\section{Rudbeckia maxima Nutt.}

Plants 1-3 m. tall, smooth, glaucous; leaf blades unlobed, ovate to broadly ovate or oblong, $6-20 \mathrm{~cm}$. long, mostly obtuse, undulate to repand-denticulate or entire, the upper sessile and partly clasping; heads large; phyllaries linear or linear-lanceolate, acute, short; rays several, 15-40 mm. long; disks 25-60 mm. long, oblong usually; pales abruptly short-pointed, apically pubescent; achenes 6-8 $\mathrm{mm}$. long; pappus of small teeth.

Moist open places, especially in wet swales and marshy areas, in Okla. (McCurtain and Choctaw cos.) and in e. Tex., spring-summer; Ark., Okla., La. and Tex.

\section{Dracopis CASS.}

A monotypic genus, closely related to the Ratibida-Rudbeckia alliance.

\section{Dracopis amplexicaulis (Vahl) Cass.}

Annual herb 3-7 dm. tall (rarely to $1.2 \mathrm{~m}$.), usually branched above; leaves 


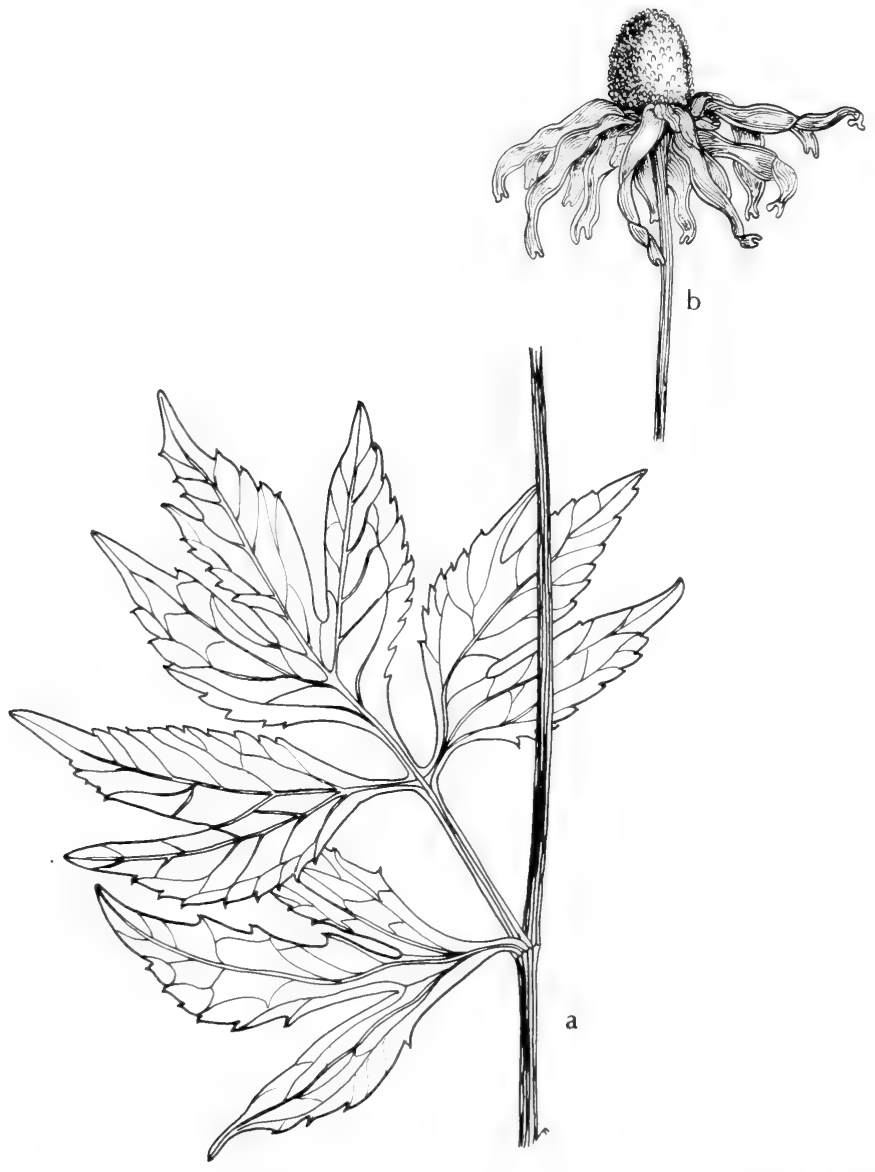

Fig. 762: Rudbeckia laciniata: a, part of stem and leaf, $x 1 \frac{1}{2}$; $b$, flower head, $x$ 1/2. (V. F.). 


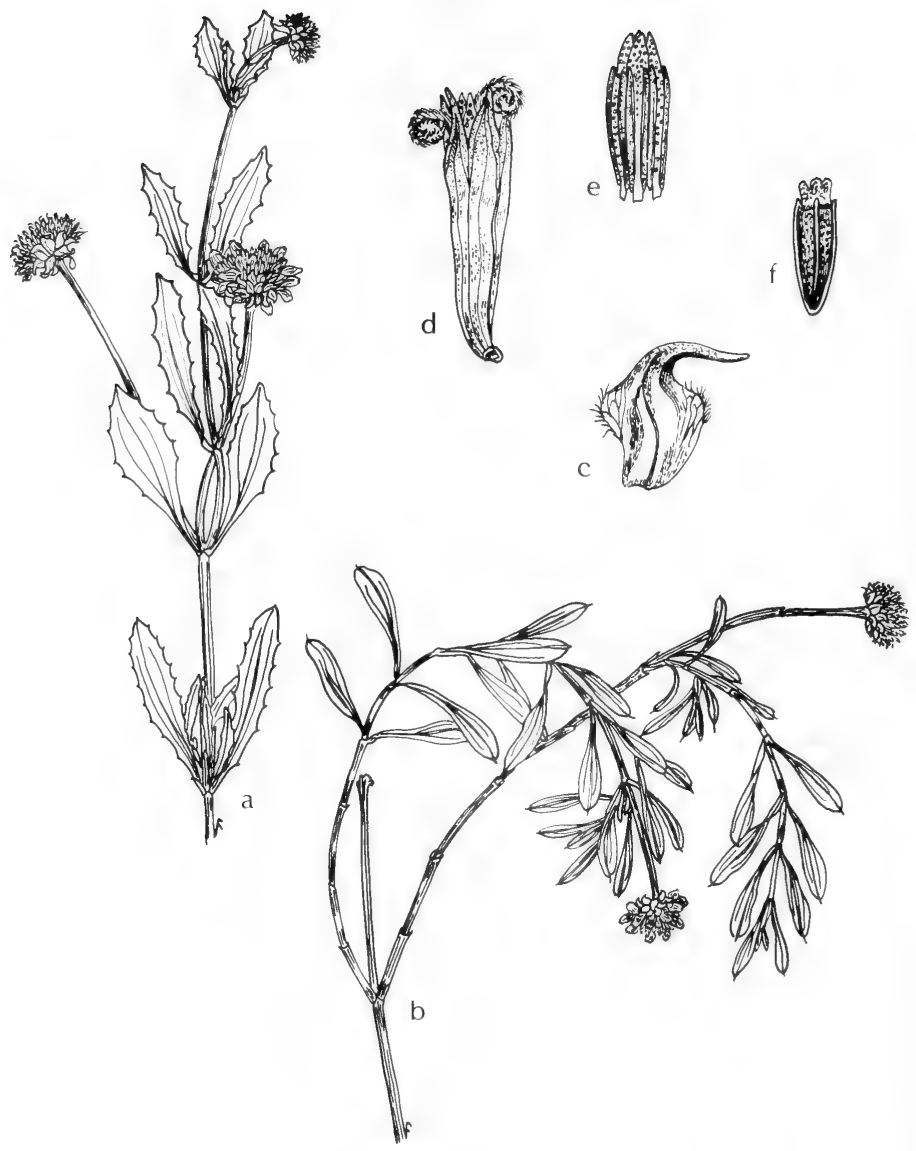

Fig. 763: Borrichia frutescens: $a$ and $b$, top of 2 different plants to show leaf variation, x 1/2; c, phyllary, x 5; d, disk corolla, x 5; e, anthers, x 5; f, achene, x 5 . (V. F.). 
alternate, simple, spatulate to oblong-lanceolate or ovate, sessile, clasping, 4-10 $\mathrm{cm}$. long, often obscurely serrate; phyllaries biseriate, the inner ones half as long as the outer, the outer ones few and somewhat foliaceous, 6-10 $\mathrm{mm}$. long, lanceolate to linear-lanceolate; receptacle columnar, slender; ray flowers present, 5 to 9, styleless, infertile; rays yellow or often red-brown or brown-purple basally, 10-25 mm. long; disk oblong-cylindric at maturity; disk flowers numerous, perfect, fertile, the corollas brownish and 5-toothed terminally; style branches with small pubescent appendage; mature achenes terete, minutely transversely wrinkled, about $2 \mathrm{~mm}$. long; pappus absent. Rudbeckia amplexicaulis Vahl.

Moist or wet places in the e. half of Okla. (Waterfall) and the e. two thirds of Tex., rare in Plains Country and Rio Grande Plains, spring-summer; Coastal States, Ga. to Tex. and Okla.

\section{Borrichia ADANS.}

A tropical genus of perhaps 5 species.

\section{Borrichia frutescens (L.) DC. SEA OX-EYE DAISy. Fig. 763.}

Rhizomatous subshrub (2-) 4-8 (-12) dm. tall, much-branched but the branches all rather stiffly ascending; leaves opposite, variable in size and shape, obovate to oblanceolate or spatulate, 2-6 cm. long, sessile or narrowed to a subpetiolar base, acutish or obtuse, entire or spinulose-dentate or even with small lobelike teeth on the sides near the base, thick and somewhat fleshy, gray-green, densely but minutely pubescent; heads terminating the branches on upwardly slightly expanded peduncles 1-3 cm. long; involucre hemispheric, about $5 \mathrm{~mm}$. high; phyllaries rather indurate, in roughly 2 series; outer phyllaries about half to two thirds as long as the inner, acute, in texture and pubescence and color much like the leaves; inner phyllaries spinose-squarrose, nervate, less pubescent than the outer; receptacle flat or very slightly convex, chaffy throughout; pales firm or indurate, nearly linear but with a stout noxious spine-tip; ray flowers 15 to 30 , pistillate, fertile; rays 5-10 mm. long, yellow or orangish, 3-toothed apically; disk flowers numerous, perfect, fertile, the corolla yellow and 5-toothed terminally; achenes prismatic, those of the ray flowers trigonous, of the disk flowers tetragonous; pappus a low crown of persistent brown scales, one over each angle of the achene.

Extremely abundant in coastal areas of Tex. and inland in local areas of poor drainage and salt accumulation to Gonzales and Webb cos,, nearly all year; coastal areas, D.C. to Ver.; also S.L.P.; much of W.I.

\section{Helianthus L. Sunflower}

Annual or perennial herbs; stems simple or branched; leaves always opposite at least at the base of the stems and usually alternate above (usually alternate for most of the length of the plant, but opposite nearly throughout in some species), usually coarse-textured, 3-nerved (this obscure in some species), at least the lower ones usually narrowed to a petiole or a subpetiolar base; heads usually borne singly at the ends of nearly naked terminal peduncles; involucre usually saucershaped to hemispheric; phyllaries in 2 to 4 series, either subequal or strongly graduated, often ciliate-margined; receptacle plane to convex, chaffy throughout; pales folded around the disk achenes; ray flowers uniseriate, usually pistillate but always infertile, the yellow rays 3-toothed apically; disk flowers very numerous, perfect, fertile; corolla tubular, mostly yellowish but with 5 equal teeth terminally which are yellow to brownish or reddish to purplish; disk achenes laterally compressed but not thin-edged, often subrhombic in transection, often emarginate apically as seen from the side; pappus usually of two elongated awns over the 
thinner shoulders of the achene and often with a small accessory palea on each side of each awn, sometimes with small intermediate scales between the 2 principal awns, all of these pappus members readily caducous.

An American genus of about 67 species, made difficult taxonomically by the tendency toward hybridization between many of its constituents or at least by the evidence of past genetic intercontamination.

1. Plants blue-green, strongly glaucous; stems rarely more than $7 \mathrm{dm}$. tall; leaves nearly all opposite; phyllaries obtuse to acute, glabrous dorsally, white-ciliate, ovate to oblong, closely imbricated, shorter than the disk. 1. H. ciliaris.

1. Plants not strongly glaucous nor blue-green and not with the combination of other characters given (2)

2(1). Disk corollas with red-brown to purple-brown lobes; leaves and the base of the stem scabrous; involucre scabrous; rhizome a short erect crown............................................................ $\mathrm{H}$. angustifolius.

2. Disk corollas with yellow lobes (3)

3(2). Main stem glabrous; leaves narrowly linear-lanceolate, decurrent below confluence of lateral veins into a winged petiole nearly one fourth the length of the blade; rays $20-25 \mathrm{~mm}$. long............4. H. Nuttallii.

3. Main stem scabrous-hispidulous or at least hirtellous; leaves lanceolate, gradually acuminate to both ends, sessile; rays $25-35 \mathrm{~mm}$. long........

3. H. Maximiliani.

\section{Helianthus ciliaris DC. BLUE-WEed. Fig. 764.}

Perennial from slender rhizomes; stems 1 to several, 5-7 dm. tall, glabrous, glaucous; midstem leaves opposite, sessile or very short-petiolate, linear to broadly lanceolate, entire to somewhat pinnately lobed, glabrous and glaucous, conspicuously 3-nerved when lanceolate; heads 12-25 $\mathrm{mm}$. across; phyllaries obtuse, ovate to broadly lanceolate, ciliate, glabrous or slightly puberulent dorsally, 5-7 mm. long, about $3.5 \mathrm{~mm}$. broad; rays 12 to 18 , about $1 \mathrm{~cm}$. long; disk corolla 5-6 $\mathrm{mm}$. long, basally puberulent and yellow, the lobes reddish or sometimes the entire corolla red; pales entire to 3-cuspidate, the tips obtuse to acute and puberulent; achenes about $3 \mathrm{~mm}$. long, black or grayish at maturity; pappus of the disk of 2 broadly ovate-acuminate scales; ray pappus absent or of 1 to 3 linear to lanceolate scales.

Locally abundant near streams or canals, often in subalkaline desert soil in w. Okla. (Waterfall) and Tex. in the Trans-Pecos and Plains Country, infrequent in Rio Grande Plains, N. M. (Quay, Roosevelt, Chaves, Eddy, Otero, Dona Ana and Socorro cos.) and Ariz. (Apache to Mohave, s. to Cochise and Pinal cos.), summer-fall; Kan., Okla., Tex., N.M., Ariz., Chih., Coah., N.L., Tam. and S.L.P.

\section{Helianthus angustifolius L. Fig. 765.}

Perennial herb; roots fibrous; rhizomes few, very slender, 5-15 cm. long; stems 10-17 dm. tall, leafy, mostly simple, usually scabrous, hispid; leaves mostly alternate, variable but mostly linear or narrowly lanceolate, $1-2 \mathrm{dm}$. long, 13-15 (-20) mm. broad, obtuse, sessile, very firm, very scabrous above, pubescent beneath, often with resin-dots; upper branching open-paniculiform; phyllaries narrowly lanceolate, slightly acuminate, usually shorter than the disk, very loose, setose or scabrous, scarcely ciliate; pales 3 -cuspidate; disk about $1 \mathrm{~cm}$. across; lobes of disk corolla purple, puberulent; achene slender, glabrous, about $4 \mathrm{~mm}$. long; pappus of 2 lanceolate awns, without intermediate scales.

Moist places, s.e. Okla. (Waterfall) and in e. and s.e. Tex., late summer-fall; N.J. s. to Fla., w. to Ia. and Tex. 


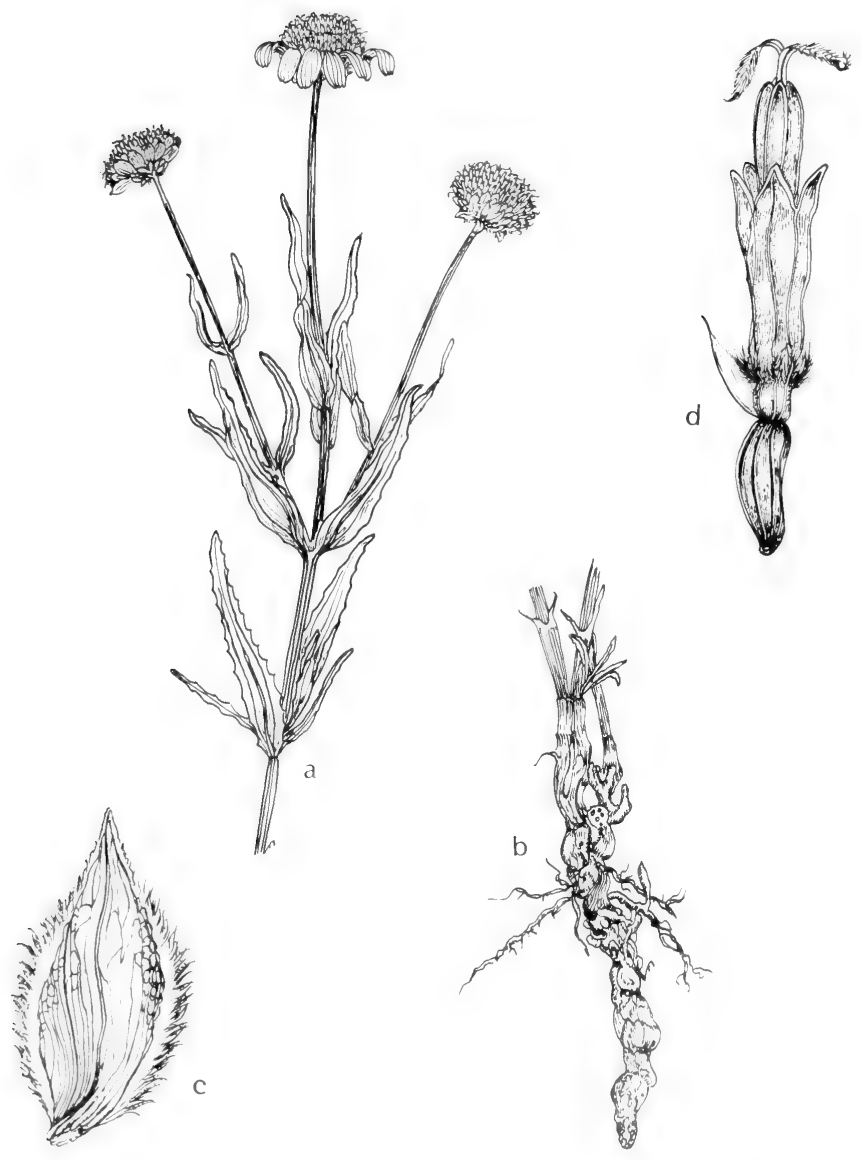

Fig. 764: Helianthus ciliaris: a, top of plant, $\mathrm{x} 1 \frac{1}{2} ; \mathrm{b}$, basal part of plant, $\mathrm{x} 1 / 2$; $\mathrm{c}$, phyllary, x 5: d, disk flower and achene, x 5. (V. F.). 


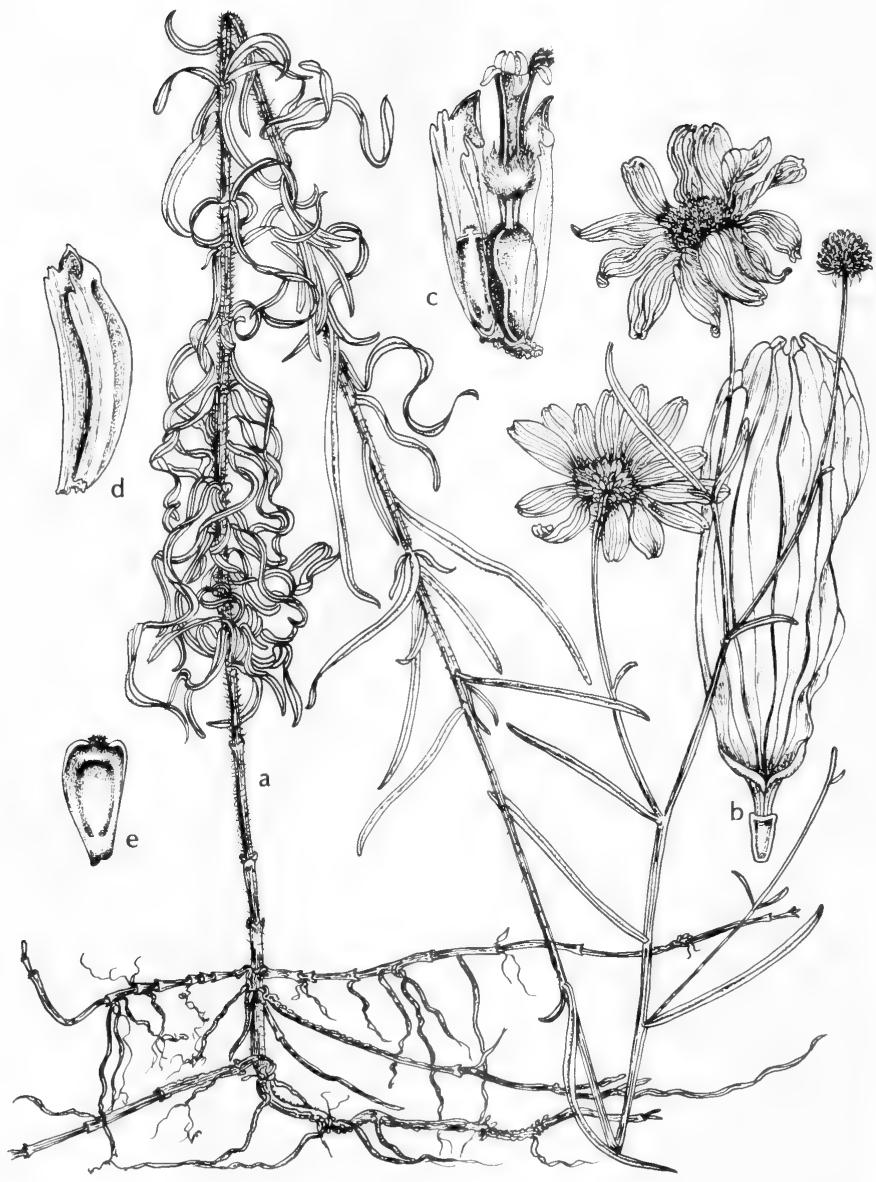

Fig. 765: Helianthus angustifolium: a, habit, $\mathrm{x} 1 / 2$; b, ray flower, $\mathrm{x} 5$; c, disk flowers, x 5; d, bract, x 5; e, achene, x 5. (V. F.). 
A very closely related form, but with an entirely yellow disk and reputed to be more robust with woodier rootstocks, is $H$. simulans E.E.Wats. It is rare in boggy areas in east Texas (Robertson Co. and probably elsewhere) and Louisiana. Its degree of distinctness needs further investigation.

\section{Helianthus Maximiliani Schrad. Maximilian sunflower.}

Stout perennial, with usually several mostly simple stems $3-30 \mathrm{dm}$. tall from the woody crowns or short rootstocks, rarely with lateral branches near the top, scabrous or with abundant short white hairs; leaves alternate, lanceolate, gradually acuminate to both ends, mostly 14-30 cm. long, 20-55 mm. broad, marginally entire, sometimes obscurely serrate, surficially with many short hairs imparting a grayish-green color, sessile; phyllaries 10-15 mm. long, densely pubescent, marginally strongly ciliate, spreading; heads in a simple terminal racemose arrangement, less commonly in a paniculiform grouping, 50-75 mm. across; disk florets $10-12 \mathrm{~mm}$. long, the base of the corolla puberulent; rays bright-yellow, 25-35 mm. long, concave; pale linear-acuminate, obscurely 3-cuspidate, apically pubescent.

Frequently in seasonally moist ditches, depressions or prairies, in Okla. (Waterfall) and in n.-cen. and s.e. Tex. and Edwards Plateau, infrequent in Plains Country and rare in the Trans-Pecos, (late summer)-fall; most of s. Can., s. in cen. U.S. to Tex. and in Coastal States to N.C.

\section{Helianthus Nuttallii T. \& G.}

Perennial from short tuberlike fascicled roots; stem 3-10 (or -20) dm. tall, simple or branched, smooth and glabrous, usually glaucous; leaf blades $5-15 \mathrm{~cm}$. long, about $1-2 \mathrm{~cm}$. wide, narrowly linear-lanceolate, acute to acuminate, entire to somewhat serrulate, tapering at base and gradually decurrent below confluence of lateral veins into a winged petiole about one fourth as long as the blade, scabrous or hispid, paler green beneath; heads few to several in a sometimes many-branched leafy-bracted cymose panicle, the peduncles long or short, scabrous below heads; phyllaries $12-20 \mathrm{~mm}$. long, lanceolate-subulate, gradually tapered from base to apex, seldom hispid but often clothed with whitish hairs, somewhat hirsute-ciliate on margins, the outer phyllaries often extending considerably beyond the disk and loose but not refexed; receptacle bracts linear, straw-colored, glabrous below, brown and pubescent on the back (especially toward the tip), entire or with 2 very obscure lateral teeth, the acute apex sometimes produced as a short mucro or awn from the distally somewhat keeled midrib, shorter than or of almost the same length as the mature disk flowers; rays 8 to $24,20-25 \mathrm{~mm}$. long; disk yellow, 15-20 $\mathrm{mm}$. across; achenes glabrous; pappus of 2 linear-lanceolate pales, rarely with some intermediate squamellae.

In springy or marshy places, sloughs, or on dry ground in valleys and plains, N.M. (San Miguel, Sierra, Socorro and Rio Arriba cos.) and Ariz. (Apache, Coconino and Yavapai cos.), Aug.-Sept.; Sask. to Alta., s. to N.M. and n. Ariz.

\section{Verbesina L. CROWN-BEARD}

About 150 species, native to America.

\section{Verbesina encelioides (Cav.) Gray. CoWPEN DAISY.}

Much-branched grayish-green or canescent-pubescent taprooted annual 1-9 dm. tall; leaves chiefly opposite, with a roughly deltoid lamina portion (coarsely dentate) and narrowed below to a broad subpetiolar base which usually clasps the stem, rarely the leaves with true unwinged petioles (var. exauriculata Robins. \& Greenm.); heads solitary on the pedunculiform ends of the branches or rarely 2 or 3 fairly closely aggregated, each $2-3 \mathrm{~cm}$. across (incl. the expanded rays); 
outer phyllaries long, green, much-surpassing the disk or else subequal; rays about $1 \mathrm{~cm}$. long; ray flowers fertile, yellow, showy, deeply 3-toothed terminally; wings of the achene rarely narrow or nearly vestigial, usually broad and acutish summitally. Ximenesia encelioides Cav. and var. cana DC., X. australis H. \& A., X. exauriculata (Robins. \& Greenm.) Rydb.

Very frequent in disturbed soils, especially common on floodplains and outwashes of winter streams, essentially throughout our region, summer; Fla., Tex., s.e. through most of the warmer parts of Am., adv. in Old World.

\section{Calyptocarpus LeSS.}

\section{A monotypic genus.}

\section{Calyptocarpus vialis Less. Hierba del caballo.}

Perennial herbs, with weak often sprawling stems (1-) 2-6 dm. long but only 2-9 cm. tall; leaves opposite, with deltoid marginally serrate strigose blades 1-3 $(-4) \mathrm{cm}$. long and petioles (or subpetiolar winged bases) about a third as long; peduncles naked, axillary, 3-50 $\mathrm{mm}$. long, topped by a solitary head; head less than $1 \mathrm{~cm}$. long; involucre obconical; phyllaries about 5 , slightly unequal (the inner ones shorter and narrower), leaflike in texture, obtuse and broadly overlapping; receptacle chaffy throughout, the scarious pales lance-subulate; ray flowers pistillate, fertile, the yellow rays spatulate; disk flowers perfect, fertile, the yellow corollas equally 5-toothed; achenes strongly dorsiventrally compressed, subulate; pappus of 2 awns, one over each corner of the achene. Zexmenia hispidula Buckl.

Frequent in low wettish woods, on edge of water of streams and sloughs, s.e. Tex. and Rio Grande Plains, infrequent n. to e. and n.-cen. Tex. and Edwards Plateau, nearly all year; Pan., C.R., Guat. and Mex., n. to Coah., Tex., La., Ala. and Fla.; Cuba.

A troublesome lawn weed.

\section{Coreopsis L. COREOPSIS. TICK-SEED}

Annual or perennial herbs, glabrous or pubescent; leaves opposite or more rarely (in the upper part of the plant) alternate, undivided and entire or dentate, or 1 to 3 times ternately or pinnately dissected; heads peduncled; phyllaries commonly in 2 or rarely ite 3 or 4 series, more or less connate at the very base (but not high up); outer phyllaries commonly herbaceous or submembranous and appressed or often spreading; inner bracts commonly larger, brown or yellow, membranous; receptacle flat or slightly convex, chaffy throughout; pales flat or somewhat concave, membranous, striate; ray flowers present, neuter or pistillate, usually infertile; rays spreading, yellow (in some species with two shades of yellow, in others with a red-brown spot basally), 3-toothed terminally; disk florets numerous, perfect and fertile, the corolla yellowish (often with reddish veins) and equally 5-toothed terminally; achenes dorsiventrally flattened, orbiculate to oblong or more or less oblong-linear, often 2-winged (the wings membranous or induratethickened, entire or not, flat or incurved), glabrous or especially at the margin villous; pappus usually present, usually of 2 awns over the two shoulders of the achene and with or without intermediate scales, persistent.

A genus of probably 100 species widely distributed.

1. Achenes wingless, narrowly oblong, slender flattish.................... C. tinctoria.

1. Achenes winged (2)

2(1). Achenial wings entire

2. C. cardaminaefolia.

2. Achenial wings dissectedly fimbriate-pectinate. 3. C. linifolia. 


\section{Coreopsis tinctoria Nutt.}

Annual herb, erect, glabrous, 6-12 dm. tall; stems foliose, much-branched; leaves opposite, subsessile or short-petiolate, usually 5-10 cm. long, 1- or 2-pinnate or the uppermost ones undivided; segments (or blades) narrowly linear or linearlanceolate; heads numerous, 2-3 cm. broad, 4-6 mm. high; outer phyllaries about 8 , more or less biseriate and imbricate, linear-oblong or more often triangulate, about $2 \mathrm{~mm}$. long; rays about 7 or $8,7-15 \mathrm{~mm}$. long, obovate, commonly 3-lobate apically, often with a red-brown spot near the base; style branches apically obtuse; achenes wingless, black, $1.2-4 \mathrm{~mm}$. long.

Abundant in seasonally moist or wet soils, in Okla. (Atoka and Craig cos.) and in the e. half of Tex. and less frequently nearly throughout Tex., N.M. (San Juan Co.) and introd. in Ariz., spring-early summer; Minn., Sask. and Wash. s. to La., Tex., N.M. and Calif.

\section{Coreopsis cardaminaefolia (DC.) Nutt. Manzanilla silvestre.}

Annual herb, glabrous, erect, slender, suberectly branched, 2-5 dm. tall; stems subterete, foliose; leaves opposite, remote, shorter than the internodes, all but the sessile topmost ones with petioles commonly $1-4 \mathrm{~cm}$. long, the lower and midstem leaves 1- or 2-pinnate with elliptic-oblong or widely or narrowly linear segments, the upper ones sometimes pinnately few-lobed or sometimes simple; peduncles glabrous, 1-5 cm. long; heads often numerous, 16-24 mm. broad, 6-8 mm. high; outer phyllaries 6 to 9 , more or less lanceolate and irregularly placed, often subacute, 1-2 mm. long; rays about 7 or 8 , about $1 \mathrm{~cm}$. long, with a red-brown spot near the base (or this absent and rays all yellow in a rare form known as C. stenophylla Boynt.); style branches obtusely conic; achenes strongly winged, 2-3 mm. long or occasionally less, the body black; awns of the pappus (one over each of the two shoulders, between the wing and the body) minute or in a coastal race $(C$. similis Boynt.) to $0.5 \mathrm{~mm}$. long. $C$. stenophylla and $C$. similis Boynt.

Abundant in seasonally wet or moist soil in Okla. (Jefferson Co.), essentially throughout Tex., in N.M. (McKinley Co.) and Ariz. (Coconino and Yavapai cos.), spring-early summer, occasionally again in fall; La., Okla., Tex., Neb., N.M. and Ariz., s. to Tam., Coah. and Chih.

Some Arizona specimens are said to be $C$. Atkinsoniana Dougl. because of the size of the achenes, but otherwise they are like $C$. cardaminefolia of the same area.

\section{Coreopsis linifolia Nutt. Fig. 766.}

Perennial herb, glabrous, pale, erect, 5-7 dm. tall; stems slender, corymbosely branched above; leaves opposite or the lower alternate, marginally entire but indurate or calloused, the lower ones spatulate or oblanceolate, shorter than the internodes (or the basal ones at times twice as long), 4-10 (-14) $\mathrm{mm}$. broad, apically rounded, basally petiolate (petioles usually $1-4 \mathrm{~cm}$. long) or the other ones sessile, linear, often truncate or exceedingly obtuse at the apex, much smaller; peduncles usually 3-7 cm. long; heads few, 2-3 cm. broad, about 6-7 mm. high; outer phyllaries about 6 to 11 , glabrate, often irregularly placed, ovate to lanceolate-deltoid, lengthwise pluristriate, coriaceous, scarious at the margins, subacute or rounded apically, 1-3 mm. long; rays 7 or $8,10-15 \mathrm{~mm}$. long, obovate, apically 3-lobed with the median lobe emarginate; style branches obtusely conic; achenes winged, the wings lacerate or dissected-fimbriate-pectinate.

Rare in wet or boggy soil, e. Tex., spring-early summer; Va. to Fla. and w. to Tex. 


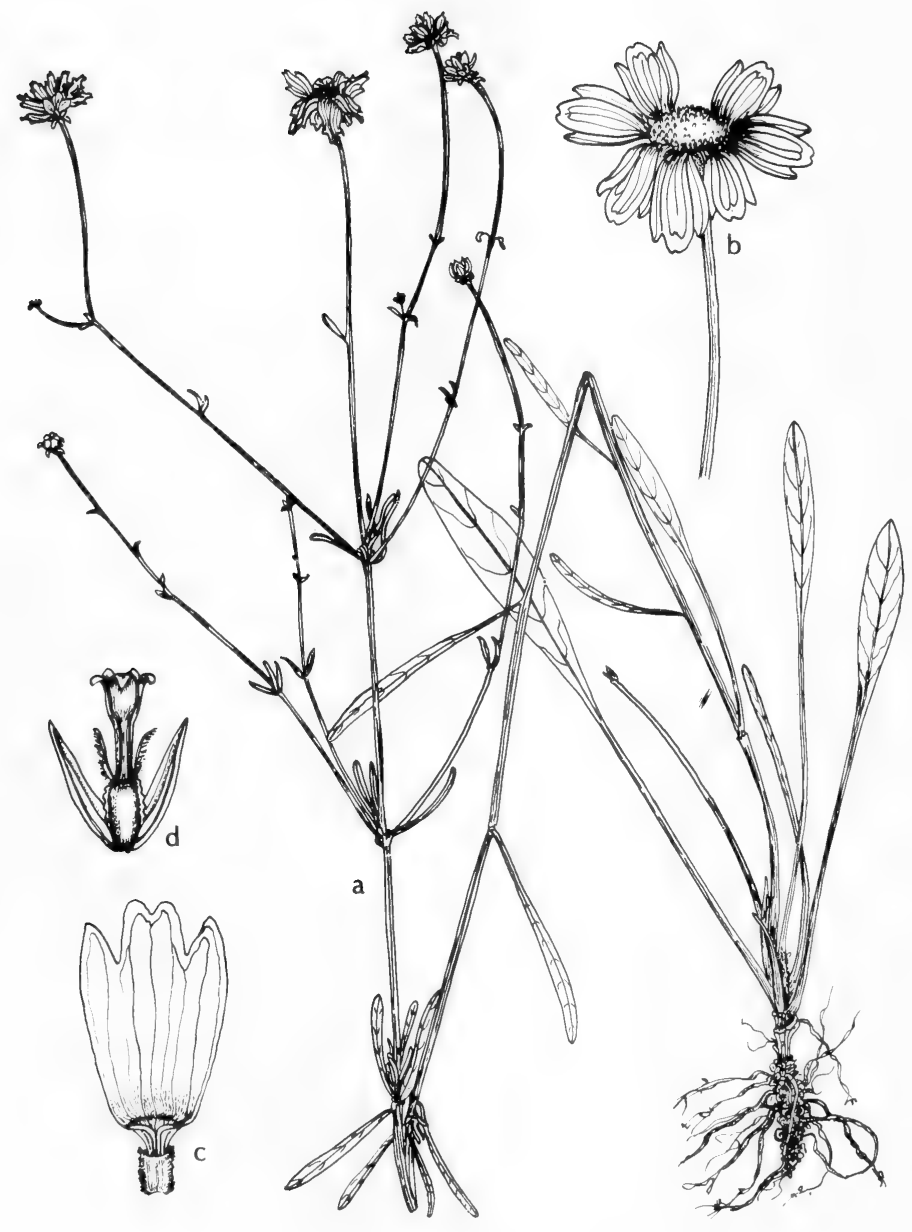

Fig. 766: Coreopsis linifolia: a, habit, $\mathrm{x} 1 \frac{1}{2}$; b, flower head, $\mathrm{x} 1$; $\mathrm{c}$, ray flower, $\mathrm{x}$ $2 \frac{1}{2}$; d, disk flower, x 5 . (V. F.). 


\section{Bidens L. BegGar-TICKS. Bur-MARIGOld}

Annual taprooted herbs or less commonly perennial herbs with taproots or fibrous roots; leaves opposite, entire or dentate or incised, or 1-, 2- or 3-ternately or -pinnately dissected; upper leaves sometimes alternate; involucre usually campanulate or subhemispheric; phyllaries commonly biseriate, at the base often very shortly connate; outer phyllaries usually herbaceous in texture, sometimes short, sometimes expanded into leaflike members; inner phyllaries usually membranous, usually hyaline- or yellow-margined; receptacle flat or convex, chaffy throughout, the pales narrow and flattish; ray flowers present or absent, when present neuter or less commonly pistillate but infertile; rays when present whitish or yellow or less commonly rosy or a shade of red, usually shallowly 3-lobed apically; disk flowers numerous or less commonly few, perfect, fertile; corolla equally 5-toothed, usually yellow; style branches bearded above, tipped with short and acute or longer and subulate appendages; achenes dorsiventrally compressed or less commonly triangular or rhombic in transection; pappus awns absent or 1 to 8 in number and commonly persistent, usually more or less antrorsely or retrorsely barbed.

A genus of possibly 150 species in the warmer parts of the world, often separated on the most technical sort of characters, thus difficult to key out unless with patience and a good lens; heads both in anthesis and in fruit. The kinds with retrorsely barbed pappus awns are efficiently dispersed, becoming attached easily in fur and clothing.

1. Rays yellow, at least $10 \mathrm{~mm}$. long (sometimes absent in $B$. cernua and $B$. laevis) (2)

1. Rays white or rosaceous to red (if yellow less than $10 \mathrm{~mm}$. long) or absent (7)

2(1). Pappus of 2 to 4 retrorsely barbed awns (3)

2. Pappus awns smooth, antrorsely setose or absent (5)

3(2). Achenes flattened or 3- or 4-angled but the median keels not developed.... 1. B. laevis.

3. Achenes cuneate, 4-angled in cross section, both margins and median keels prominent or callous thickened (4)

4(3). Ray flowers 5 or 6; achenes black or dark-gray, more or less papillose toward the base; awns 1.5-2.7 $\mathrm{mm}$. long...

2. B. aurea.

4. Ray flowers (when present) 6 to 8 ; achenes purplish, usually strongly callousthickened on the angles; awns 3-4 $\mathrm{mm}$. long.

3. B. cernua.

5(2). Achenes black, the body $2.5-4.5 \mathrm{~mm}$. long; outer phyllaries 7 to $10 \ldots \ldots$.

5. Achenes brown or blackish, the body $5-7.5 \mathrm{~mm}$. long (6)

6(5). Outer phyllaries mostly 8 to 12 , glabrous or moderately ciliate, usually shorter than the inner ones........................................5. B. aristosa.

6. Outer phyllaries 12 to 20 , very ciliate or coarsely hispid, commonly longer than the inner ones.

6. B. polylepis.

7(1). Achenes broadly or narrowly cuneate, not narrowed below the apex (8)

7. Achenes linear or clavate but never manifestly cuneate, often attenuate above (11)

8(7). Achene bodies striate; leaves simple or deeply incised (9)

8. Achene bodies not striate; leaves at least 1 - or 2-pinnate, the terminal leaflet commonly petiolulate (10)

9(8). Leaves sessile, undivided; achene body 6-9 $\mathrm{mm}$. long, retrorsely barbed on the angles. 1. B. laevis. 
9. Leaves borne on evident sometimes winged petioles up to $3 \mathrm{~cm}$. long; achene body $4-8 \mathrm{~mm}$. long, of ten tuberculate......................

10(8). Outer phyllaries 3 to 5 (commonly 4), not manifestly ciliate; pappus awns erect-hispid or smooth.

8. B. discoidea.

10. Outer phyllaries 5 to 8 , regularly and copiously ciliate; pappus awns retrorsely barbed.

9. B. frondosa.

11(7). Achenes 5 to 9 (rarely 13)

11. Achenes 14 to 50 (12)

12(11). Leaves all pinnately 3- or 5-parted with lance-oblong to rhombic-ovate serrate to incised divisions........................................11. B. pilosa.

12. Leaves all once or twice pinnately dissected (13)

13(12). Outer and inner phyllaries more or less densely pilose or hirsute; leaves 2 or 3 times dissected into linear lobes..................12. B. tenuisecta.

13. Outer and inner phyllaries glabrous or merely short-ciliate, rarely sparsely pilose (14)

14(13). Achenes dimorphic, a few peripheral ones clavate with a body only 4-7 $\mathrm{mm}$. long; body of inner achenes $8-13 \mathrm{~mm}$. long after anthesis; awns 2, sometimes 3.....................................13. B. Bigelovii.

14. Achenes nearly all alike, the body often longer than $12 \mathrm{~mm}$; awns 3 or 4 ...

14. B. bipinnata.

1. Bidens laevis (L.) B.S.P. Fig. 767.

Annual or perennial herb, erect or procumbent at base, 3-10 dm. tall; leaves sessile, undivided, linear-lanceolate to lanceolate or rarely ovate-lanceolate, narrowed at each end or at the base sometimes broad and connate, apically often acuminate, regularly serrate with the teeth often slender and almost subulate, glabrate or on the margin often sparsely ciliate, $5-15 \mathrm{~cm}$. long; heads commonly few, 3-7 cm. broad, $8-11 \mathrm{~mm}$. high; involucre commonly hispid at base; outer phyllaries 6 to 8 , scarcely foliaceous, linear-lanceolate, apically obtuse or acute, marginally subsparsely aciculate-ciliate, very rarely longer than the head; ray flowers rarely absent, usually 7 or 8 ; rays golden-yellow, $15-30 \mathrm{~mm}$. long, obovate-lanceolate, apically rounded and often minutely 2- or 3-denticulate; achenes narrowly cuneate, flat or 3- or 4-angulate, on the angles retrorsely barbed, the body 6-9 $\mathrm{mm}$. long; pappus awns 2 to $4,3-5 \mathrm{~mm}$. long, retrorsely barbed. B. Nashii Small.

Scattered near and in water of sloughs, lakes and streams, in marshes, irrigation ditches and wet meadowlands, in Okla. (Waterfall) and in e., s.e., n.-cen. Tex. and Edwards Plateau, rare in the Trans-Pecos, N.M. (San Juan and Taos cos.) and Ariz. (Apache, Navajo, Yavapai and Santa Cruz cos.), summer; most of U.S. except higher mt. areas.

\section{Bidens aurea (Ait.) Sherff.}

Erect perennial herb but often flowering first season, with tetragonous simply branched stems to $1 \mathrm{~m}$. tall; herbage glabrous or sometimes pubescent on young growth; leaves thin, linear to lanceolate or elliptic-oblong, $0.5-1.2 \mathrm{~cm}$. wide, to $10 \mathrm{~cm}$. long, sharply serrate-dentate, undivided or less commonly lower ones 3 - to 5-parted, with petioles to $4 \mathrm{~cm}$. long; heads radiate, $2-5 \mathrm{~cm}$. broad, about $1 \mathrm{~cm}$. high; outer involucral bracts 8 to 17 , linear, acute and somewhat indurated at apex, hispid-ciliate on margins but glabrous on face, 3-6 mm. long, $1 \mathrm{~mm}$. wide or less; inner bracts thinner, slightly wider but about as long; ray flowers 5 or 6 , yellow; ligules 10-30 mm. long, conspicuous, obovate; achenes linear-cuneate, slightly quadrangular in cross section, black or dark gray, often more or less papillose toward base, body 4-7 $\mathrm{mm}$. long, tipped with 2 yellowish retrorsely barbed awns $1.5-2.7 \mathrm{~mm}$. long. 


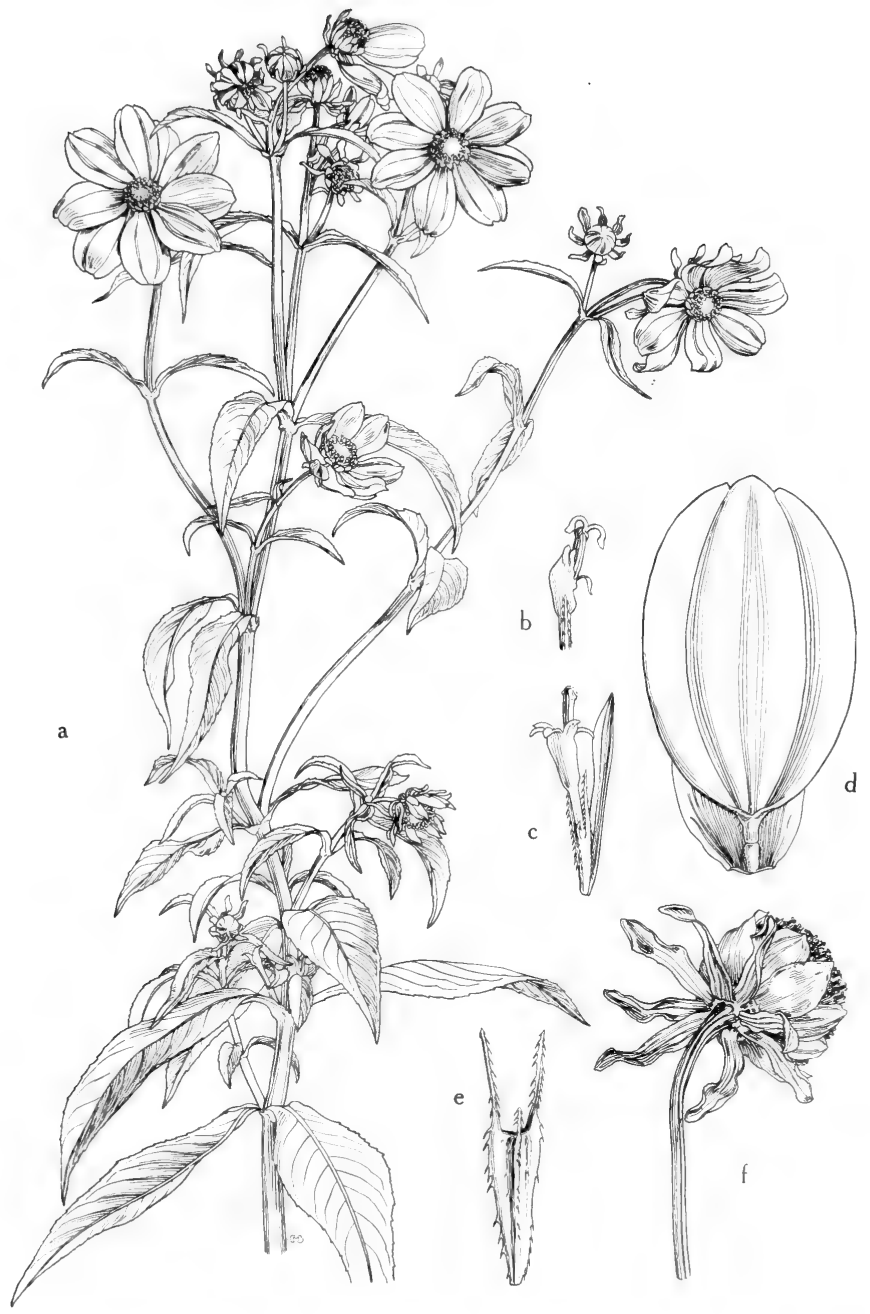

Fig. 767: Bidens laevis: a, habit, upper part of plant, $\mathrm{x} 2 \%$ b and $\mathrm{c}$, disk flowers, showing stages in anthesis of style and stamens, $\mathrm{x} 2 \frac{1}{2} ; \mathrm{d}$, ray flower and base of adjacent phyllary, $\times 2 \frac{1}{2}$; e, mature achene, showing pappus awns and retrorse pubescence, $x 4 ; \mathrm{f}$, flowering head, showing the outer and the inner phyllaries (rays removed), $x 4 / 5$. (From Mason, Fig. 351). 


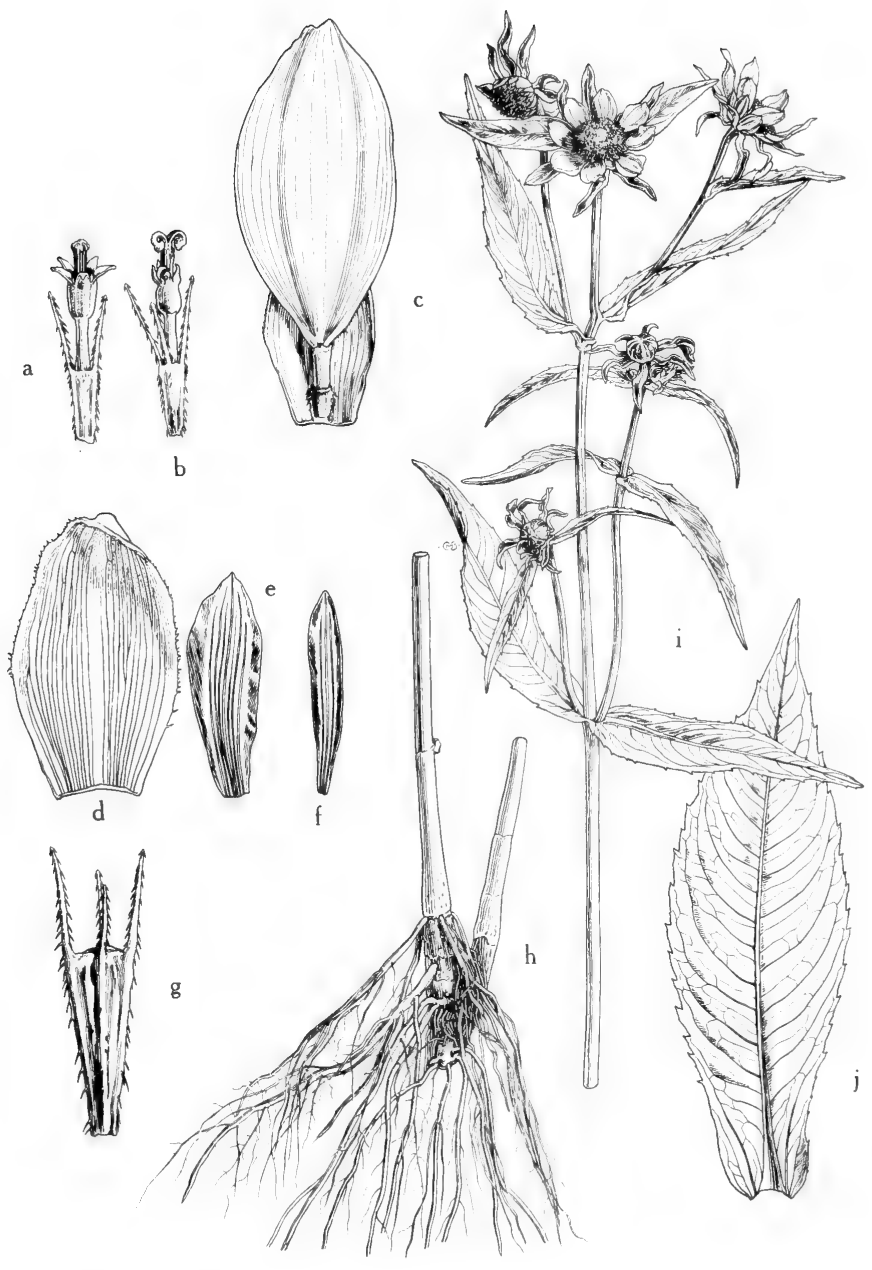

Fig. 768: Bidens cernua: a and b, disk flowers, showing stages of anthesis of stamens and style, $\mathrm{x} 3$; c, ray flower and base of adjacent phyllary, $\mathrm{x} 3$; d, inner phyllary, $\mathrm{x} 4$; $\mathrm{e}$ and $\mathrm{f}$, receptacle bracts, $\mathrm{x} 4$; g, mature achene, showing the callousthickened margins, the 4 pappus awns, and retrorse pubescence, $x 4$; h, base of plant, showing the fascicled roots, $x 2 \% ; \mathrm{i}$, upper part of plant, showing leaves and inflorescence, $x 2 \%$; j, leaf, x $2 \%$. (From Mason, Fig. 350). 
In moist soil near and along streams, springs and ditches, s. Ariz. (Cochise, Santa Cruz and Pima cos.) to Guat., spring-autumn.

\section{Bidens cernua L. Fig. 768.}

Annual; stems erect or ascending, 1-10 dm. tall, occasionally somewhat succulent, glabrous to scabrous-hispid; leaves normally opposite, sometimes verticillate, linear-lanceolate or lanceolate, unequally serrate, narrowed to sessile or subsessile, with connate base, $4-17 \mathrm{~cm}$. long; heads at first erect, becoming nodding, radiate or discoid, in anthesis 1-5 cm. wide, 6-12 $\mathrm{mm}$. high: outer phyllaries 5 to 8 , foliaceous, linear-lanceolate, sparsely acicular-ciliate or glabrous, unequal in length, usually longer than the disk flowers (to $4 \mathrm{~cm}$. long), the inner phyllaries membranous, striate, orange-brown, ovate-lanceolate to obovate-lanceolate, scarcely longer than the disk flowers; receptacle bracts similar but narrower; ray flowers when present 6 to 8 , ovate-lanceolate, 10-15 (-20) $\mathrm{mm}$. long, about 1 to 2 times as long as the disk; achenes often purplish, normally cuneate and apically thickened, marginal and median angles mostly prominent and usually strongly callous-thickened, the body thus more or less 4-angled and quadrate in cross section (at least subapically), 5-6.5 mm. long, retrorsely hispid (especially on angles); awns 4 (sometimes only 2 or 3 ), usually 1 at each angle of achene apex, 3-4 mm. long, retrorsely barbed.

Marshy ground, wet lowlands and along sloughs, in Okla. (Alfalfa Co.) and N.M. (Colfax and Rio Arriba cos.), June-Oct.; N.B. to B.C., s. to N.C., Okla., N.M. and Calif.; widespread in Old World.

\section{Bidens mitis (Michx.) Sherff. Fig. 769.}

Annual herb, more or less glabrous, 3-10 dm. tall; leaves petiolate (petioles 3-30 $\mathrm{mm}$. long), including the petioles $4-12 \mathrm{~cm}$. long, membranous, variable, lanceolate or ovate, serrate, acute or acuminate, sometimes entire or more often pinnately 3- to 7-parted, the terminal leaflet commonly very elongate, the blade or segments linear and commonly entire or broader and incised-serrate, very rarely decompound; peduncles $2-12 \mathrm{~cm}$. long; heads $2-5 \mathrm{~cm}$. broad; involucre glabrous or sparsely hispid at the base; outer phyllaries 7 to 10 , linear or linear-spatulate, usually ciliate, acute or obtuse, 5-10 $\mathrm{mm}$. long, the inner phyllaries often shorter; rays about 8 , golden-yellow, 12-27 $\mathrm{mm}$. long, oblanceolate or elliptic-obovate, entire or very minutely denticulate; achenes flattish or scarcely trigonal in transection, broadly cuneate, black, the body $2.5-4.5 \mathrm{~mm}$. long; pappus awns $0.6-1$ $\mathrm{mm}$. long, antrorsely setose.

Rare in wet places, especially brackish or fresh-water swamps, in s.e. Tex., in moist soil, spring-early summer; s.e. U.S. (Md. to Tex.).

\section{Bidens aristosa (Michx.) Britt. Tickseed sunflower.}

Annual or biennial herb, glabrate or scarcely pubescent, 3-10 (-15) dm. tall; leaves petiolate [petioles 10-15 $(-30) \mathrm{mm}$. long], including the petiole $5-15 \mathrm{~cm}$. long, pinnate or bipinnate; blade segments lanceolate or linear-lanceolate, acuminate, incised-serrate or pinnatifid, membranous, ciliate, scarcely pubescent on the lower surface; heads $2-5 \mathrm{~cm}$. broad, 7-9 $\mathrm{mm}$. high; involucre often hispid; phyllaries subequal, the outer ones 8 to 10 , linear, sometimes scarcely ciliate, sometimes very ciliate, 5-12 mm. long; rays 6 to 10 , golden, 10-25 mm. long, oblong-oblanceclate, apically obtuse and entire or subdenticulate; achenes to 6.5 $\mathrm{mm}$. long, flat or flattish, blackisn or yellowish-black; pappus awns rarely absent (var. mutica Gray), usually present and smooth or antrorsely ciliate.

In moist or seasonally moist soil, e. and s.e. Tex., infrequent, spring-early summer; most of the e. U.S. 


\section{Bidens polylepis Blake.}

Annual or biennial herb, glabrous, 3-10 dm. tall; leaves petiolate (petioles to $25 \mathrm{~mm}$. long), including the petiole $8-15 \mathrm{~cm}$. long, commonly bipinnate; leaflets lanceolate or linear-lanceolate, acuminate, sharply serrate, membranous, ciliate; heads $2-5 \mathrm{~cm}$. broad, 7-9 mm. high; outer phyllaries numerous, commonly 15 to 20, usually spreading or reflexed, linear-elongate, conspicuously hispid-ciliate, dorsally hispid or glabrate, 10-27 mm. long; inner phyllaries lanceolate, shorter; rays about 8 , golden-yellow, $10-25 \mathrm{~mm}$. long, oblong-oblanceolate, apically entire or obscurely denticulate; achenes flat, brown or blackish-brown, 5.5-7.5 mm. long; pappus awns nearly obsolete or slightly developed and with erect-hispid teeth.

In wet prairies, low meadows, low swampy woods, borders of oxbow lakes, in river floodplain and upland ponds, waste ground, sandy flats at edge of lakes in Okla. (Creek, Pittsburg, Pushmataha, McCurtain, LeFlore and Ottawa cos.) and e. and s.e. Tex., spring-early summer; midwest U.S. and s. to Tex.

\section{Bidens tripartita L.}

Annual, nearly or quite glabrous, 1-20 dm. tall; leaves simple, serrate, often very sharply so, sometimes deeply tripartite, commonly $3-15 \mathrm{~cm}$. long and to $4 \mathrm{~cm}$. wide, borne on evident sometimes winged petioles to about $3 \mathrm{~cm}$. long; heads erect, rayless or occasionally with rays to about $4 \mathrm{~mm}$. long, broadly campanulate to hemispheric, at least the terminal one generally more than 30 flowered, the disk 8-20 mm. wide; outer phyllaries about 4 to 9 , herbaceous, often much-enlarged and leaflike; achenes cuneate or obovate-cuneate, flat or compressed-quadrangular, commonly with a median rib on at least one face, glabrous or somewhat short-hairy, brown or blackish to purplish, 4-8 $\mathrm{mm}$. long, often tuberculate; pappus of 2 to 4 awns.

A cosmopolitan weed of wet waste places, in Okla. (Waterfall) and reported from the Tex. Panhandle (Hemphill Co.), Aug.-Oct.; otherwise known from Eur. and adv. in Que. and N.H.

\section{Bidens discoidea (T. \& G.) Britt. Fig. 770.}

Annual herb, 3-18 dm. tall; leaves petiolate (petioles $1-4 \mathrm{~cm}$. long), including the petiole $5-12 \mathrm{~cm}$. long, membranous, tripartite; leaflets lanceolate or ovatelanceolate, acuminate, serrate, all commonly petiolulate, sometimes obscurely ciliate; heads numerous, the disk finally $7-9 \mathrm{~mm}$. broad and 6-7 $\mathrm{mm}$. high; involucre glabrous; outer phyllaries 3 to 5 (usually 4), foliaceous, linear-spatulate, membranous, not distinctly ciliate, commonly surpassing the disk, 7-25 mm. long; inner phyllaries oblong-lanceolate, membranous, subequal to the disk; ray flowers absent; achenes blackish, flattish, linear-cuneate, often tuberculate, pilose-hispid, the body 3-6.2 $\mathrm{mm}$. long; pappus awns $0.2-2.2 \mathrm{~mm}$. long, erect, hispid.

In swampy lowlands, alluvial bottomlands and sink-hole ponds, in Okla. (McCurtain Co.) and in e. and s.e. Tex., spring and early summer; Ala. to Tex., n. to N.S., Me., Que., Ont., Mich., Wis. and Minn.

\section{Bidens frondosa L. Beggar-TICKs, STICK-TIGHTS. Fig. 771.}

Annual herb, more or less glabrous, paniculate-branched, 5-12 dm. tall; leaves petiolate (petioles 1-6 cm. long), including the petiole $5-15(-20) \mathrm{cm}$. long, pinnately 3- or 5-divided, membranous, ciliate, on the upper surface commonly glabrate, on the lower surface glabrate or obscurely and sparsely or even rather densely clothed with minute setae; leaflets lanceolate, acuminate, serrate, the terminal one slenderly petiolulate; heads about $1 \mathrm{~cm}$. broad, $6 \mathrm{~mm}$. high; involucre basally hispid; outer phyllaries 5 to 8 or occasionally as many as 10 , conspicuously ciliate, often very long (even $3-5 \mathrm{~cm}$. long) and foliaceous, linear-spatulate; inner 


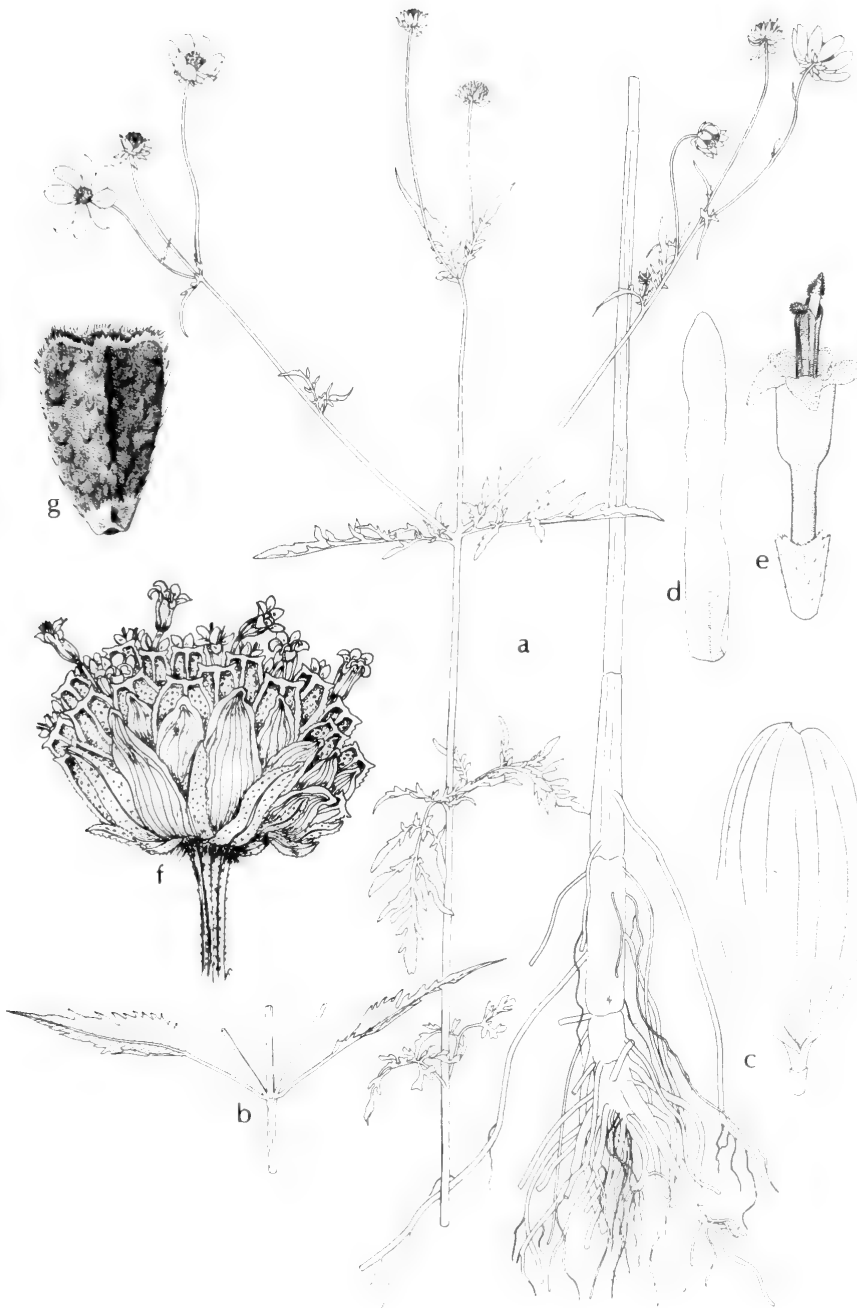

Fig. 769: Bidens mitis: a, habit, $\mathrm{x} 1 / 3 ; \mathrm{b}$, section of stem showing undivided leaves, $\mathrm{x} 1 / 3$; c, ray flower, $\mathrm{x} 2$; d, palea, $\mathrm{x} 9 ; \mathrm{e}$, disk flower, $\mathrm{x} 8$; $\mathrm{f}$, head of fruit, $\mathrm{x} 31 / 3$; g, achene, x 8. (Courtesy of R. K. Godfrey; f, V. F.). 


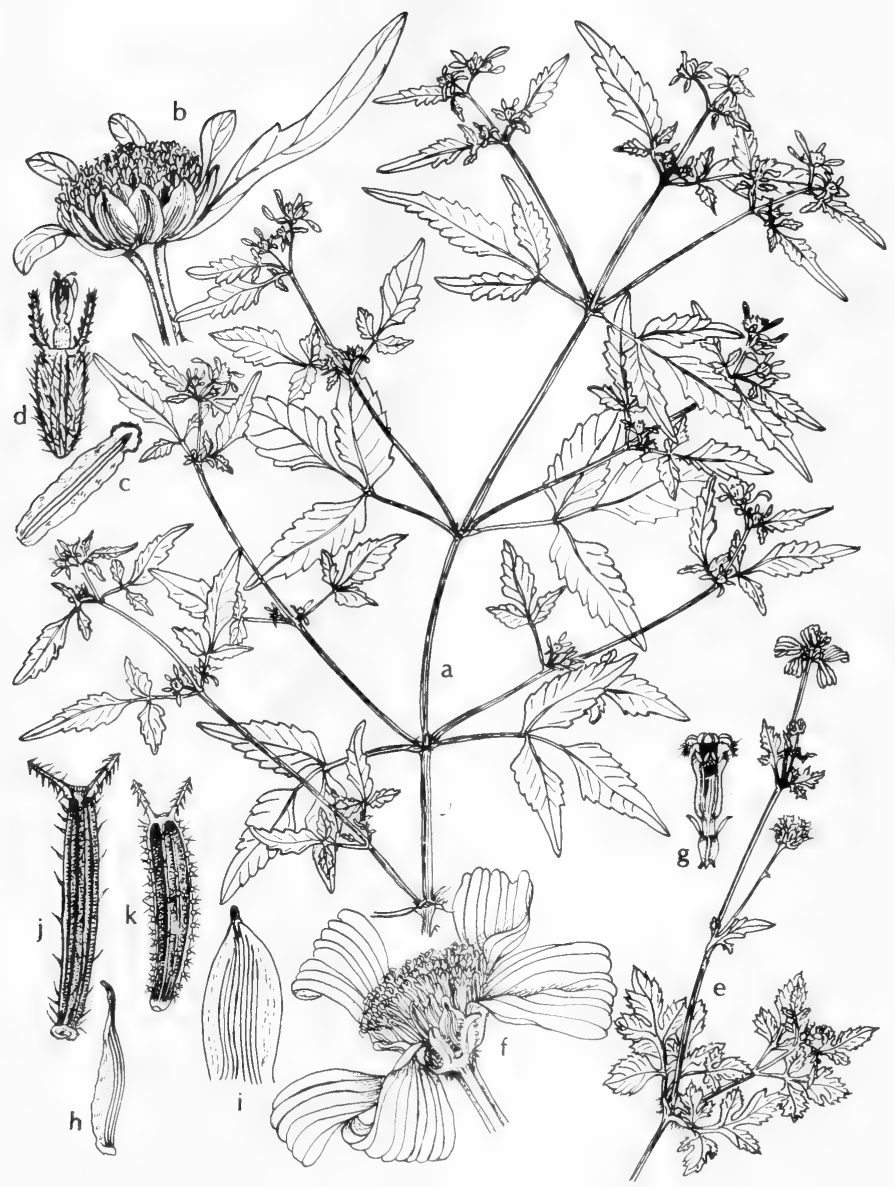

Fig. 770: a-d, Bidens discoidea: a, top of plant, $x 1 \frac{1}{2} ; \mathrm{b}$, head, $\times 2 \frac{1}{2} ; \mathrm{c}$, bract, x $21 \frac{1}{2} ; \mathrm{d}$, achene, $\mathrm{x} 5$. e-k, Bidens pilosa: e, top of plant, $\mathrm{x} 1 \frac{1}{2} ; \mathrm{f}$, head, $\mathrm{x} 21 / 2 ; \mathrm{g}$, disk flower, $\mathrm{x} 5 ; \mathrm{h}$, interior involucre bract from side, $\mathrm{x} 5$; $\mathrm{i}$, interior involucre bract, $\mathrm{x}$ $5 ; \mathrm{j}$, inner achene, x 5; $\mathrm{k}$, outer achene, x 5 . (V. F.). 
phyllaries ovate or ovate-lanceolate, shorter (finally 5-7 mm. long); ray flowers absent or if present minute, the golden-yellow ray $2-3.5 \mathrm{~mm}$. long, cuneateobovate. commonly 2- or 3-denticulate; achenes flat, narrowly cuneate, blackish, subglabrous or pilose-hispid, on each face strongly 1-nerved, the body 6-10 mm. long; pappus awns 2, retrorsely barbed, 3-4.5 $\mathrm{mm}$. long.

In moist woods, swampy meadows, alluvial thickets, borders of streams, ponds, sloughs, swamps, ditches, fields, waste ground, in Okla. (McIntosh, Comanche, Delaware, McCurtain and Cherokee cos.) and in e. half of Tex., recently reported from Hemphill Co. in the Panhandle, N.M. (Bernalillo and San Juan cos.) and Ariz. (Greenlee and Yavapai cos.), spring-early summer; e. Can., most of the U.S.

10. Bidens leptocephala Sherff. Fig. 772.

Annual herb, 1-5 dm. tall, branched; leaves petiolate (petioles 3-40 mm. long), including the petioles $2-10 \mathrm{~cm}$. long, $15-55 \mathrm{~mm}$. broad, bipinnate, minutely ciliate, hispid or glabrate, the segments sometimes linear or sometimes ovate; peduncles $2-8 \mathrm{~cm}$. long; heads $4-8 \mathrm{~mm}$. broad, $3-5 \mathrm{~mm}$. high (in fruit to $15 \mathrm{~mm}$. high); involucre subglabrous at the base; outer phyllaries 4 to 6 , linear, ciliate, $10-25 \mathrm{~mm}$. long, inner ones half again as long, lanceolate, glabrous or at the apex pubescent; rays occasionally absent, usually 3 , only $2.5 \mathrm{~mm}$. long and 1.2 $\mathrm{mm}$. broad, whitish, entire or bidentate; achenes 5 to 9 , rarely to 13 , subquadrangulate, linear, the inner ones blackish, 9-14 $\mathrm{mm}$. long, some of the outer ones sometimes shorter and browner; pappus awns 1-3 $\mathrm{mm}$. long, retrorsely barbed.

Frequent in moist canyons, along streams, in the Tex. Trans-Pecos mts., N.M. (Grant and Guadalupe cos.) and Ariz. (Cochise, Santa Cruz and Mohave cos.), summer; Chih., Tex., N.M., Ariz. and Baja Calif.

\section{Bidens pilosa L. Fig. 770 .}

Annual herb, erect, branched, 3-18 dm. tall; petioles 10-65 mm. long; leaves including petioles $5-20 \mathrm{~cm}$. long, membranous, on the margins ciliate and serrate, on each surface subglabrous or scatteringly pilose with unequal and appressed hairs or sometimes densely tomentose-pilose, the lowermost often simple, ovate, apically acute, the midstem leaves 3- to 5- (or even 7-) partite, the uppermost leaves simple and lanceolate; heads $7-8 \mathrm{~mm}$. broad, 5-7 $\mathrm{mm}$. high (at anthesis); peduncles 1-9 cm. long; involucre basally hispid; outer phyllaries 7 to 9 , linear or linear-spatulate, indurate-apiculate, ciliate, 4-5 $\mathrm{mm}$. long, shorter than the lanceolate inner phyllaries; rays commonly absent or when present minute (2-3 $\mathrm{mm}$. long) or well-developed (to $15 \mathrm{~mm}$. long), white or pale-yellowish-white; achenes linear, straight or the marginal ones incurved, obcompressed-quadrangulate or flattish, glabrous below, tuberculate-strigose above, 4-16 $\mathrm{mm}$. long, the inner ones longer than the outer; pappus awns 2 or 3 (rarely to 5), yellowish, retrorsely barbed.

Infrequently (probably repeatedly) waifed along sloughs and in resacas in extreme s.e. and Trans-Pecos Tex. and Ariz. (Cochise, Santa Cruz and Pima cos.), summer-fall; an exceedingly common weed of disturbed moist soil in all the warmer parts of the world, not hardy in the temp. parts but repeatedly introd.

\section{Bidens tenuisecta Gray.}

Stems 2-8 dm. tall, more or less branched especially above, glabrous or sparsely hairy; leaves at least basal petioled, usually 2- to 3-pinnately dissected into narrowly linear ultimate segments $0.5-2.5 \mathrm{~mm}$. wide; heads about $6-10 \mathrm{~mm}$. high and 4-10 $\mathrm{mm}$. wide; outer phyllaries 6 to 12, about 5-7 $\mathrm{mm}$. long, linear, inner phyllaries subequal; rays inconspicuous, 4-6 $\mathrm{mm}$. long, yellow or lacking; achenes linear but tapering to apex, inner $8-15 \mathrm{~mm}$. long, outer shorter and broader, different; pappus of 2 or rarely 3 retrorsely barbed awns $1.5-3 \mathrm{~mm}$. long, at least on inner achenes. 
Moist ground, wet meadows, seepage areas and along streams, in N.M. (Colfax, Otero and Union cos.) and Ariz. (Apache, Coconino, Cochise and Pima cos.), July-Oct.; s.e. Ida., s. through Colo., N.M., Ariz. into Chih.

\section{Bidens Bigelovii Gray. Fig. 772.}

Annual herb, erect, almost glabrous, 4-10 dm. tall; leaves petiolate (petioles 10-25 $\mathrm{mm}$. long), including the petiole to $8 \mathrm{~cm}$. long, tripartite, the segments 3- to 5-partite, their lobes oblong or cuneate and pinnatifidly incised (with the rather few teeth mucronate), membranous, more or less ciliate; peduncles to $15 \mathrm{~cm}$. long; heads subsolitary, at anthesis about $6-9 \mathrm{~mm}$. broad and equally tall; involucre basally hispid; outer phyllaries 6 to 9 , linear, dorsally glabrous, marginally ciliate, terminally sharp-apiculate, 5-7.5 $\mathrm{mm}$. long; inner phyllaries lanceolate, often shorter; rays absent or 3 to 5 in number, whitish, $5-7 \mathrm{~mm}$. long, oblong-obovate; achenes subquadrangulate, dimorphic, the 1 to 4 exterior ones linear-cuneate, truncate, papillose-hispidulous and very scabrous, often castaneous, the body $5-7 \mathrm{~mm}$. long, the apex either essentially awnless or with 2 or 3 short retrorsely barbed pappus awns; inner achenes narrowly linear, black, glabrate below but commonly erect-hispid above, the body 8-12 $\mathrm{mm}$. long; pappus awns 2 or 3 , retrorsely barbed, $1.5-3 \mathrm{~mm}$. long.

Rather frequent in moist canyons, on wet stream banks and wet shady places in the Tex. Trans-Pecos mts., N.M. (Dona Ana, Grant, Sierra and Socorro cos.) and Ariz. (Apache, Greenlee, Gila, Cochise and Santa Cruz cos.), summer; Colo., N.M., Tex., Ariz. and Son.

\section{Bidens bipinnata L. Spanish needles. Fig. 773.}

Annual herb, erect, commonly glabrous but rarely minutely setose-hispid, branched, 3-12 $(-17) \mathrm{dm}$. tall; leaves petiolate (petioles 2-5 cm. long), including the petioles 4-20 cm. long, normally 2- or 3-pinnate, membranous, ciliate, the ultimate segments often deltoid- (or rhombic-) lanceolate, toward the base cuneate; peduncles to $1 \mathrm{dm}$. long; heads 5-7 $\mathrm{mm}$. high, 4-6 $\mathrm{mm}$. broad; involucre pubescent at base; outer phyllaries 7 to 10 , linear, apically acute (var. bipinnata) or distally dilate (var. biternatoides Sherff), 3-5 mm. long; inner phyllaries linearlanceolate, half again as long; rays inconspicuous, yellowish-white, not exceeding the disk florets, lanceolate or obovate-lanceolate, apically entire or 2- or 3-lobulate; achenes linear, tetragonal, the body commonly black, distally attenuated and often sparsely setulose, glabrate below, $10-18 \mathrm{~mm}$. long (the outer shorter and often castaneous); pappus awns usually 3 or 4 , yellowish, retrorsely barbed, $2-4 \mathrm{~mm}$. long.

In rich alluvial soils and other wet places in Okla. (Dewey and Ottawa cos.) and e. Tex., rare (var. biternatoides) in moist canyons of Trans-Pecos mts. and N.M. (Dona Ana Co.) and Ariz. (Greenlee, Cochise and Santa Cruz cos.), summer; most of e. U.S.; Mex.; Braz., Arg., Chile, etc.; widely adv. in Old World.

\section{Cosmos Cav. Cosmos}

A genus of perhaps 50 species of the warmer parts of America.

\section{Cosmos parviflorus (Jacq.) Pers.}

Annual herb, erect, slender, often branched above, 3-9 dm. tall; leaves scarcely petioled or with petioles wing-margined and to about $5 \mathrm{~mm}$. long, with total length of about $3-7 \mathrm{~cm}$., bipinnate; segments very narrowly linear, only 0.1-0.6 $\mathrm{mm}$. broad, glabrous above and below, often strongly spinulose-ciliate, apically acute or subobtuse, the rachis and its branches somewhat winged; heads singly terminating peduncles 1-3 dm. long, 15-25 mm. broad, 6-9 mm. high; outer phyllaries commonly 8 , lance-acuminate or linear-elongate, often spreading or even reflexed, on the outer surface green and marked with 3 to 5 black nerves, 

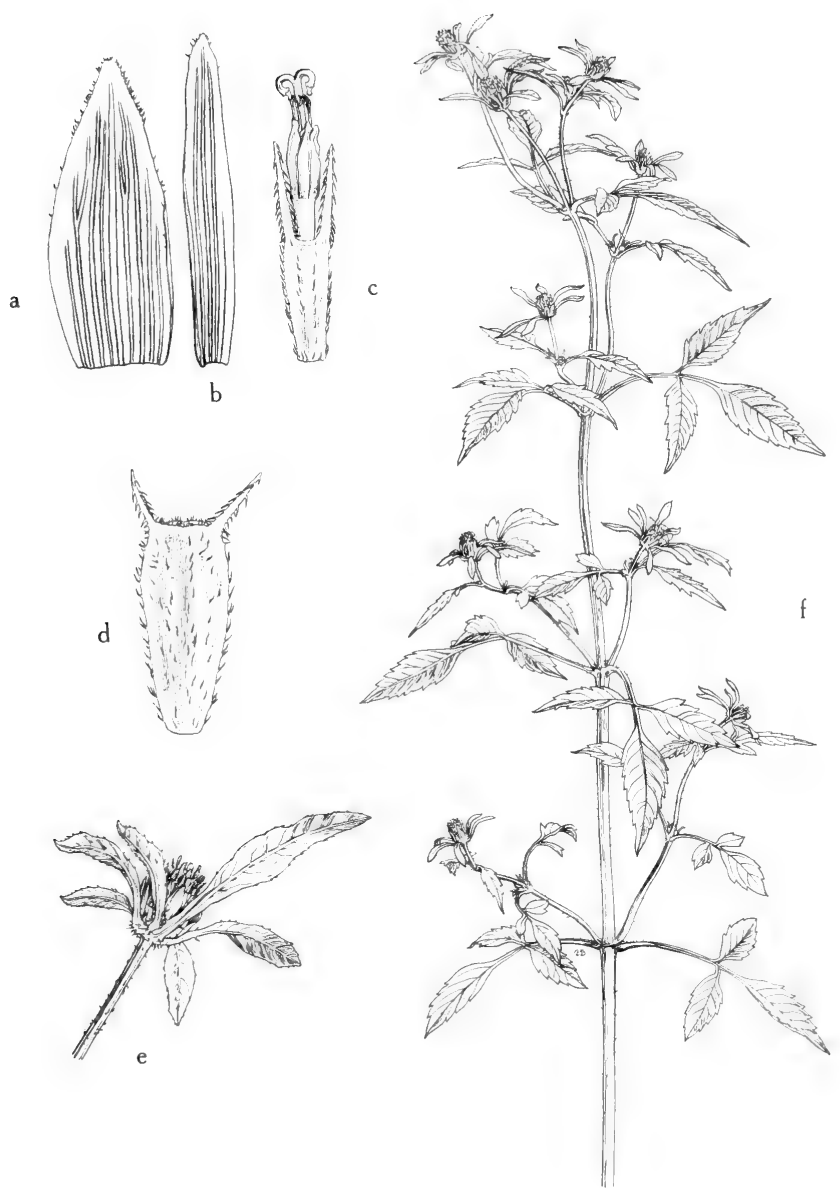

Fig. 771: Bidens frondosa: a, inner phyllary, x 6; b, receptacle bract, $x$ 6; c, disk flower, x 6; d, mature achene, showing divergent pappus awns with retrorse barbs, and margins of achene with ascending hairs, x 4; e, flowering head, showing the foliaceous outer phyllaries, $x$ 4/5; f, habit, upper part of plant, $x$ 2/5. (From Mason, Fig. 352). 


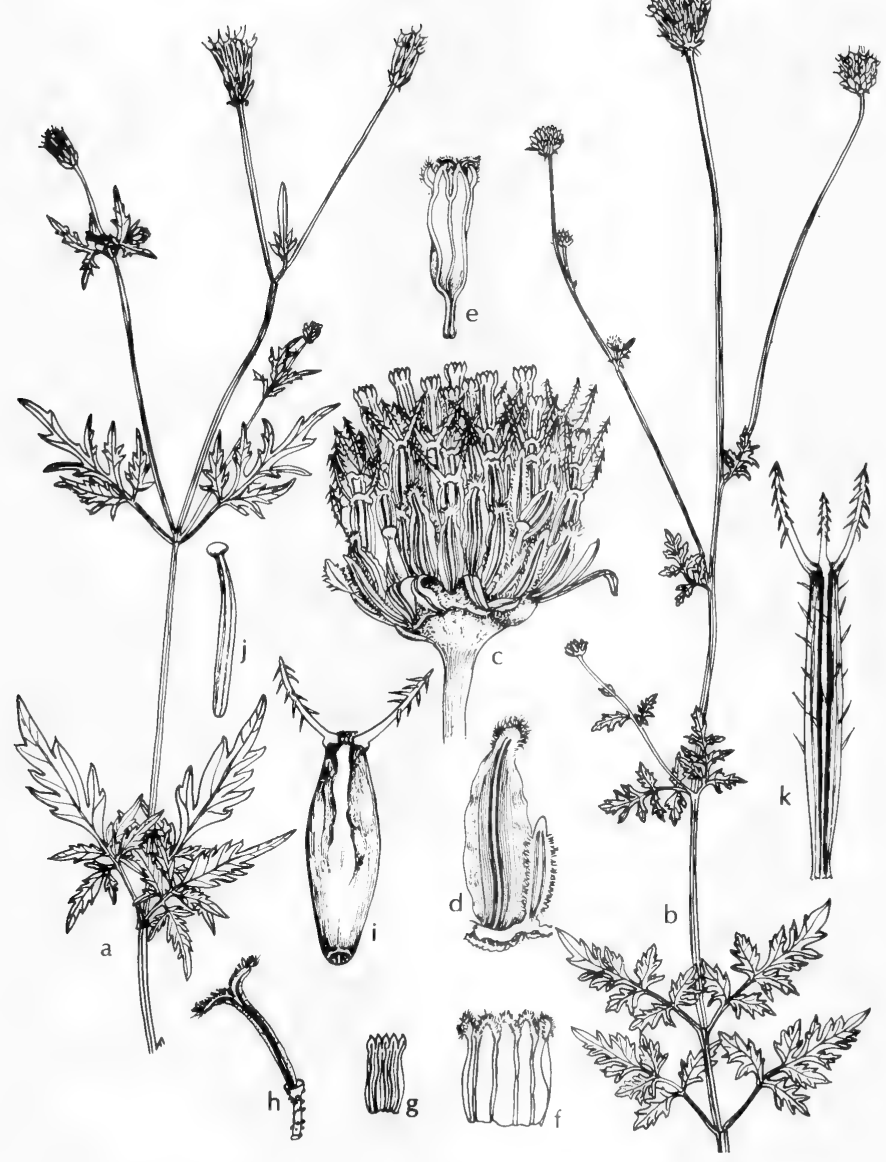

Fig. 772: a, Bidens leptocephala: a, habit, upper part of plant, x 1/2. b-k, Bidens Bigelovii: $\mathrm{b}$, habit, upper part of plant, $\mathrm{x} 1 / 2 ; \mathrm{c}$, head, $\mathrm{x} 21 \frac{1}{2} ; \mathrm{d}$, inner and outer involucre bracts, x 5; e, disk flower, x 5; f, corolla spread out, x 5; g, stamens spread out, x $5 ; \mathrm{h}$, style branches, $\mathrm{x} 5$; i and $\mathrm{j}$, outer achenes ( $\mathrm{j}$, sterile), x 5; $\mathrm{k}$, inner achene, x 5. (V. F.). 
6-9 mm. long; inner phyllaries oblong, acute, a little shorter than the outer; rays about 8 , whitish to roseate, $5-9 \mathrm{~mm}$. long, cuneate-obovate, apically 2- or 3-dentate; disk corollas yellow; achenes subfusiform, linear, 9-16 mm. long; pappus awns 2 to 4 , erect, retrorsely barbed, about $2 \mathrm{~mm}$. long.

Infrequent in wet meadows, seepage areas and along streams and on shores of lakes in the Tex. Trans-Pecos mts., N.M. (widespread) and Ariz. (Apache and Coconino to Cochise, Santa Cruz and Pima cos.), summer-early fall; Tex., Colo., N.M., Ariz., s. and s.e. to Pue. and Michoac.

\section{Marshallia Schreb. Barbara's-Buttons}

Perennial erect herbs from caudexes or rhizomes with fibrous roots; leaves alternate, simple, entire, 1- to 3-nerved, glabrous, sessile or contracted into subpetiolar bases, the stem leaves somewhat clasping when present; heads solitary at the end of the stem or branches; involucres hemispherical or campanulate; phyllaries herbaceous, often with hyaline margins, subequal, in 1 or 2 series, imbricated or merely approximate and not at all imbricate; receptacle convex or conical, chaffy throughout; pales herbaceous, often hyaline-margined below, narrowly linear in outline, longer than the achenes, semirigid; ray flowers absent; disk flowers perfect, fertile; corollas white, cream-colored, pale-lavender or purplish, never yellow, longer than the pales, externally pubescent, the tubes slender, the 5 equal lobes of the limb long and linear-obtuse; achenes turbinate or clavate, truncate, somewhat 5-angled, 10-ribbed, the achene-surface between the ribs concave and usually beset with minute resin-dots, these rarely absent; pappus scales 5 (sometimes 6), erect or spreading, forming a crown at the summit of the achene, membranous-scarious, white-hyaline or ferrugineous, ovate to ovatelanceolate or triangular-lanceolate, sessile, the apexes acuminate or acute, the margins regularly or irregularly serrulate or lacerate.

About 10 species, in southern United States.

1. Phyllaries and pales merely acute or obtuse, not subulate-tipped, glabrous; phyllaries not winged; flowering in the spring and early summer....

1. Phyllaries ........................................................................ M. caespitosa. and pales strongly acuminate or subulate-tipped, pubescent; phylearly fall.................................................................2. M. tenuifolia.

\section{Marshallia caespitosa DC.}

Perennial herb (1-) 2-4 (-6) dm. tall with a short rhizome; leaves entire, gradually tapering below the middle into a winged subpetiolar base; lowermost leaves when present 2-8 $(-18) \mathrm{cm}$. long and (3-) 5-10 (-20) $\mathrm{mm}$. broad, with obovate to spatulate or oblanceolate obtuse blades; leaves of midstem when present (4-) 5-15 $(-16) \mathrm{cm}$. long and 2-10 (-12) $\mathrm{mm}$. broad, linear or linear-lanceolate with obtuse rarely acutish apexes; heads solitary on the stems; involucres (5-) 6-12 (-15) mm. high; phyllaries herbaceous, green except for the white-hyaline margins below, glabrous, entire, subequal in 1 or 2 series, the outer usually but scarcely imbricate, 5-12 (-15) $\mathrm{mm}$. long, 1-2 (-3) $\mathrm{mm}$. broad, linear-oblong or linear-lanceolate with obtuse or merely acutish apexes; pales $5-8 \mathrm{~mm}$. long, linear with merely acute apexes, slightly dilated at the summit; corollas usually white or cream-colored, only occasionally pale-lavender; pappus scales $(1.5-) 2-3(-4) \mathrm{mm}$. long; achene (2-) 3-4 (-4.5) $\mathrm{mm}$. long.

In marshland and in spring seepage areas, in s.e. Okla. and the e. half of Tex., w. to Taylor, Val Verde and DeWitt cos., Apr.-May (-June); Miss., Ark., Okla., Tex. and $\mathrm{La}$.

We have two varieties. 


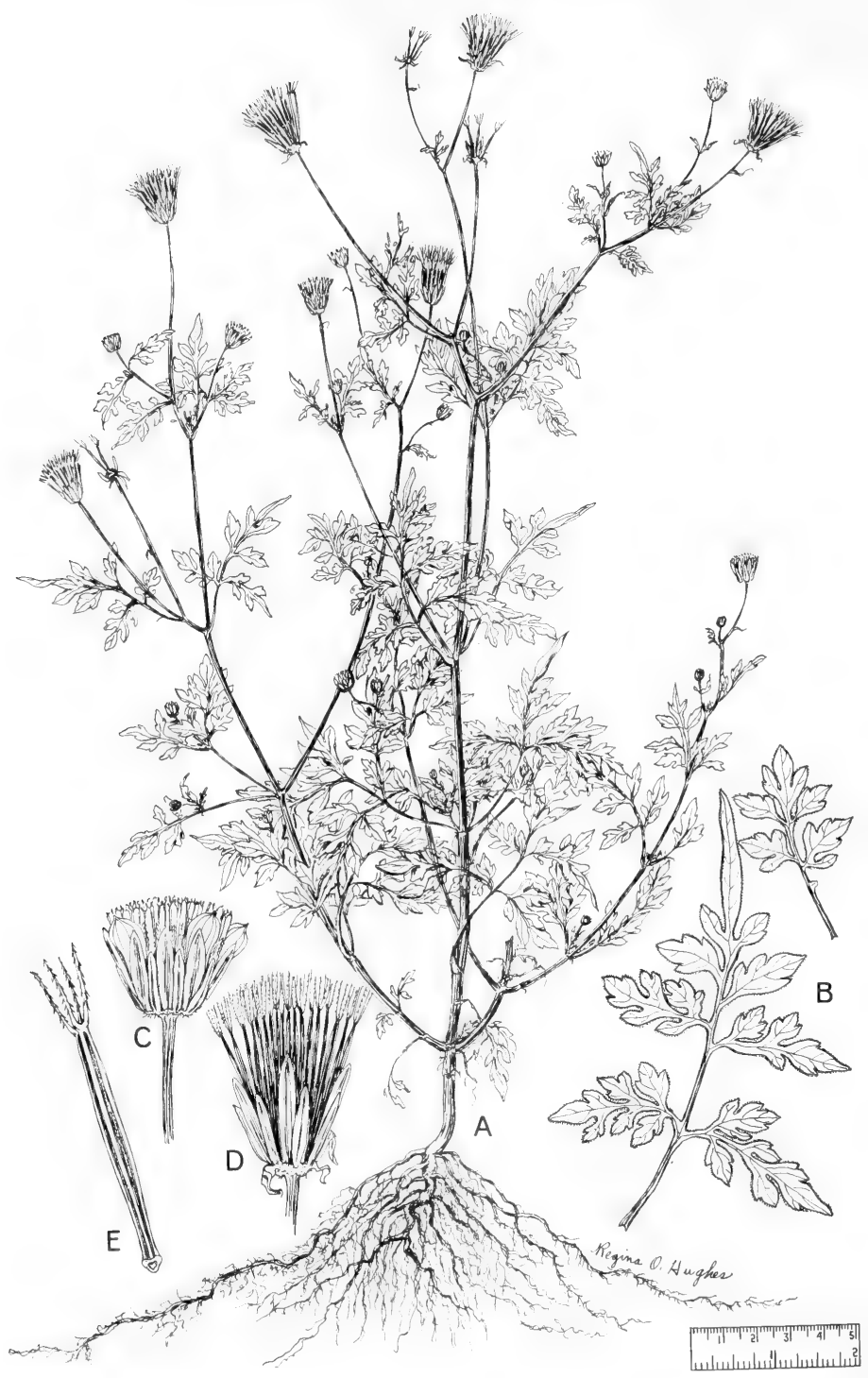

Fig. 773: Bidens bipinnata: A, habit, x 1/2; B, leaves, x 1; C, flower head, x 11/2; D, mature achenes, x 11/2; E, achene, x 3. (From Reed, Selected Weeds of the United States, Fig. 185). 
Var. caespitosa. Leaves all crowded near the base of the plant.

In s.e. Okla. and s.e. and n.-cen. Tex., s. to Refugio and w. to Navarro and Bastrop cos.; Miss., Ark., Okla. and Tex.

Var. signata Beadle \& Boynt. Stems leafy nearly throughout except for the uppermost peduncular flowering portion.

Abundant on the Edwards Plateau and in limy cuestas of n.-cen. Tex., the Rio Grande Plains and the e. part of the Plains Country, s. to DeWitt Co. and w. to Val Verde and Taylor cos.; endemic.

\section{Marshallia tenuifolia Raf.}

Leafy-stemmed perennial (2-) 4-10 (-12) dm. tall from a caudex; stem usually branched near the middle, the branches strictly erect; radical leaves spreading, thin-textured, obovate or spatulate, obtuse; stem leaves numerous, gradually reduced upward, glabrous, entire, the lowermost ones (2-) 3-4 cm. long and (4-) 5-10 (-13) $\mathrm{mm}$. broad, mostly 3-nerved, spatulate to obovate or oblongobovate in outline, with obtuse sometimes emarginate bladelike portion gradually narrowed basally into broad-winged subpetiolar bases shorter than the blades; lower stem leaves elongate, linear to linear-oblong or linear-lanceolate, attenuate, (2-) 4-20 (-22) cm. long, (1-) 2-13 (-14) $\mathrm{mm}$. wide, broadest near the middle, gradually tapering to obtuse or acutish apexes and more or less sessile somewhat clasping bases, prominently 1 - to 3-nerved; upper stem leaves narrowly linear, attenuate, acute, gradually reduced in size upwards to the linear-subulate bracts of the peduncles; heads singly terminating the pedunculiform upper portion of the branches; involucres (5-) 10-15 (-20) mm. high; phyllaries herbaceous, subequal in about 2 series, linear-lanceolate to lanceolate or somewhat rhomboidal in outline, with strongly subulate apices, (2-) 4-5 (-6) $\mathrm{mm}$. long; pales linear-attenuate, strongly subulate-tipped, 4-7 $\mathrm{mm}$. long, longer than the phyllaries; corolla purple or pale-lavender, 6-14 mm. long; pappus scales $(0.7-) 1-2(-2.5) \mathrm{mm}$. long, achenes $1.5-3 \mathrm{~mm}$. long.

Infrequent in sandy usually wet or moist soil, in wet savannahs and on seepage slope, occasionally in boggy soils with pitcher plants, and in wettish forests of e. and s.e. Tex., late summer-Oct.; Coastal States, Ga. to Tex.

\section{Helenium L. SNeEzeweed}

Annual or perennial caulescent herbs usually with taproots; stems 1-20 dm. tall, usually simple below, ascendingly branched above; leaves alternate, usually ascending, in some species decurrent, essentially sessile, the lowest ones often pinnately lobed, the upper usually not, all beset with microscopic droplets of resinlike exudate; peduncles monocephalous, terminal; receptacle usually globose or prolate (or globose but basally truncate), naked or rarely with a few short bristles in the peripheral zone; involucre usually flat or even inverted-saucershaped; phyllaries about 16 , in 2 series of about 8 , lanceolate to subulate, herbaceous in texture, usually pubescent and resin-atomiferous, the outer somewhat longer than the inner, usually reflexed at maturity; ray flowers absent or present, about 8 , pistillate or not, fertile or infertile; rays yellow (or red-brown with a yellow tip), apically 3-lobed, often reflexed, dorsally often hairy and resinatomiferous; disk usually globose or prolate; disk flowers numerous, perfect, fertile; corollas yellow mostly, with 5 moniliform-pubescent triangular lobes which are either yellow or red-brown; style branches unappendaged, truncate, penicillate; achenes obpyramidal, 4- or 5-angled, short and squatty, usually antrorsely hairy at least in the basal part; pappus of 5 translucent scales each of which usually is prolonged into an awnlike tip, occasionally the whole scale narrow and awnlike.

About 40 species, mostly in western America. 
1. Cauline leaf bases not decurrent along the stem, the stem thus not winged; plants subtomentose when young; leaves thickish......1. H. Hoopesii.

1. Cauline leaf bases more or less decurrent along the stem to form wings (at least for several $\mathrm{mm}$.) on the stem (2)

2(1). Rays absent (3)

2. Rays present (5)

3(2). Plants of southern Arizona and Mexico; annual or biennial; pappus scales broadly ovate to suborbicular, obtuse or rounded, ribless and awnless......................................................................2. H. Thurberi.

3. Plants of Oklahoma and Texas; perennial or taprooted annuals; pappus scales lanceolate or acute (4)

4(3). Perennial with short fibrous rooted caudex; disk red-brown; pappus scales awned, about $1 \mathrm{~mm}$. long.

4. H. flexuosum.

4. Annual; disk reddish to yellowish; pappus scales acute, less than $0.5 \mathrm{~mm}$. long.

3. H. microcephalum.

5(2). Ray flowers neutral, sterile (6)

5. Ray flowers styliferous, fertile (tardily so in some) (7)

6(5). Disk yellow; stem nearly simple

5. H. Drummondii.

6. Disk red-brown; stem branched.

4. H. flexuosum.

7(5). Leaves not uniform; stem not winged throughout; disk more than $15 \mathrm{~mm}$. thick, the disk corollas tipped with purple several-celled hairs.

7. H. arizonicum.

7. Leaves essentially uniform; stem almost entirely winged throughout; disk less than $15 \mathrm{~mm}$. thick, the disk corollas yellowish, not tipped with purple several-celled hairs.

6. H. autumnale.

\section{Helenium Hoopesii Gray. Orange sneezeweed, owl-claws.}

Perennial with 1 or more leafy stems; stem 3-10 dm. tall, more or less puberulent, pubescent or tomentose when young, soon glabrate; basal leaves $1-3 \mathrm{dm}$. long, oblanceolate to oblong-oblanceolate, entire, wing-petioled; upper leaves lanceolate to lance-ovate, sessile but not decurrent; involucres $7-10 \mathrm{~mm}$. high; rays 15-30 mm. long, subentire, golden-yellow to orange; disk flowers about $5 \mathrm{~mm}$. long; pappus about 2-3 mm. long; achenes about $3 \mathrm{~mm}$. long.

In marshes, wet $\mathrm{mt}$. meadows and in rich soil in conifer forests, in N.M. (widespread) and Ariz. (Apache, Coconino, Greenlee, Graham, Cochise and Pima cos.), June-Sept.; Wyo. to Ore., s. to N.M., Ariz. and Calif.

This plant is poisonous to sheep causing "spewing sickness." It is poisonous to cattle but not often eaten by them.

\section{Helenium Thurberi Gray.}

Ascending much-branched annual, 4-10 dm. tall, with slender puberulent obviously winged stems and branches; lower leaves oblanceolate, 5-15 cm. long, more or less puberulent and subentire to sharply dentate, narrowing to a slightly winged petiole; upper leaves narrowly lanceolate to linear-spatulate, $2-7 \mathrm{~cm}$. long, entire; peduncles slender, 3-10 cm. long, striate; heads discoid, broadly ovoid to subglobose, more or less corymbose, 5-12 mm. in diameter; involucral bracts linear, 3-7 mm. long, granuliferous and slightly hirsutulous; corollas greenish yellow, faintly tinged with purplish or brownish at tips of lobes, about $1 \mathrm{~mm}$. long, tube virtually lacking, throat campanulate, granuliferous; achenes barely $1 \mathrm{~mm}$. long, hirsutulous along low ridges; pappus scales broadly ovate to suborbicular, obtuse or rounded, ribless and awnless, about $0.2 \mathrm{~mm}$. long, subhyaline.

Marshy places along streams, ditches and about ponds, in s. Ariz. (Pinal, Gila, Cochise, Pima and Yuma cos.), Mar.-Aug.; also Mex. 


\section{Helenium microcephalum DC. SNEEZEWEED.}

Taprooted annual (2-) 3-6 (-8) dm. tall, usually simple-stemmed basally, bushybranched above, the stems winged; leaves narrowly elliptic or narrowly oblongelliptic, usually serrate or undulate-serrate-margined, blunt, ascending, decurrent; peduncles short so that the heads usually just barely emerge above the foliage mass; receptacle usually short conic-globular: rays entirely yellow, (1-) 2-3 (-5) $\mathrm{mm}$. long; disk pale-red-brown, usually slightly higher than thick; achenes mostly $0.8-1 \mathrm{~mm}$. long; pappus scales $0.2-0.4(-0.5) \mathrm{mm}$. long, ascending. H. ooclinium Gray.

Abundant in overgrazed areas, especially in low seasonally moist areas of clay soil, in seepage areas and along streams in s.w. Okla. (Waterfall) and w. half of Tex., infrequently e. to Brazos and San Patricio cos., summer- (fall); also Tam., N.L. and Coah.

\section{Helenium flexuosum Raf. Fig. 774.}

Perennial herb perennating by rosetted offshoots at the crown; stems 3-10 dm. tall, simple basally, profusely branched, winged below; radical leaves usually withered by flowering time, linear-lanceolate to elliptic-lanceolate or oblanceolate to spathulate, entire to pinnatifid-incised, 3-21 cm. long, 4-30 mm. broad; stem leaves mostly entire, linear-lanceolate, decurrent, much-reduced upward; heads usually many, globose; receptacle subglobose to conical-subglobose; ray flowers when present infertile (style usually absent); rays yellow, umber or suffused with red or purple, 10-21 mm. long; disk red-brown to red-purple, 7-20 mm. thick, 5-15 mm. high, the corollas predominantly 4-merous; achenes $1-1.5 \mathrm{~mm}$. long, columnar to truncate-turbinate; pappus scales usually 5, lanceolate, acute and awned apically. $H$. nudiflorum Nutt.

Infrequent in moist sandy places, in swamps, swampy meadows, along ditches, sloughs and streams and about ponds, in s.e. Okla. (McCurtain Co.) and s.e. Tex. (s. to Calhoun Co.), rare in e. Tex., spring (to first week in June); e. U.S. w. to Mo., Okla. and Tex.

\section{Helenium Drummondii Rock. Fig. 774.}

Perennial herb perennating from rosette-leaved off-shoots of the crown; stems (19-) 47-54 (-60) cm. tall, solitary, simple, subscapose, monocephalous, winged below; radical leaves usually present at flowering time, linear-lanceolate to ellipticlanceolate or less commonly spatulate or oblanceolate, marginally entire to repand, dentate to pinnatifid; stem leaves narrower, nearly linear, very strongly reduced upward, the uppermost (near the middle of the stems) being mere bracts; receptacle convex to hemispherical; ray flowers astylous, infertile, the yellow rays 12-22 mm. long; disk yellow, 9-14 (-18) mm. high, 12-22 mm. thick, the corollas 5-lobed; achenes columnar to truncate-turbinate, $1-1.5 \mathrm{~mm}$. long, hairy on the ribs; pappus scales 5 to $10,2-3.5 \mathrm{~mm}$. long, deeply divided into capillary segments.

Infrequent in poorly drained areas and seepy soils on edge of woods and thickets, in s.e. Tex., rare in e. Tex., spring; Tex., La. and Fla.

\section{Helenium autumnale $L$.}

Perennial herb from a fibrous-rooted subrhizomatous base; stems erect, 3-10 $\mathrm{dm}$. tall, branched above, winged; leaves mostly linear-elliptic, usually serrated, 3-15 cm. long, 3-18 mm. broad, acute, decurrent; peduncles $3-6 \mathrm{~cm}$. long; receptacle roughly globose; ray flowers pistillate, tardily fertile, the rays yellow; disk globose, 8-13 $(-20) \mathrm{mm}$. thick, yellow, the corollas 5-merous; achenes about $1.5 \mathrm{~mm}$. long, hairy on the ribs; pappus scales lanceolate, erose-fimbriate, acuminate, about a fourth as long as the tube. $H$. canaliculatum Lam., H. edwardsianum Cory. 


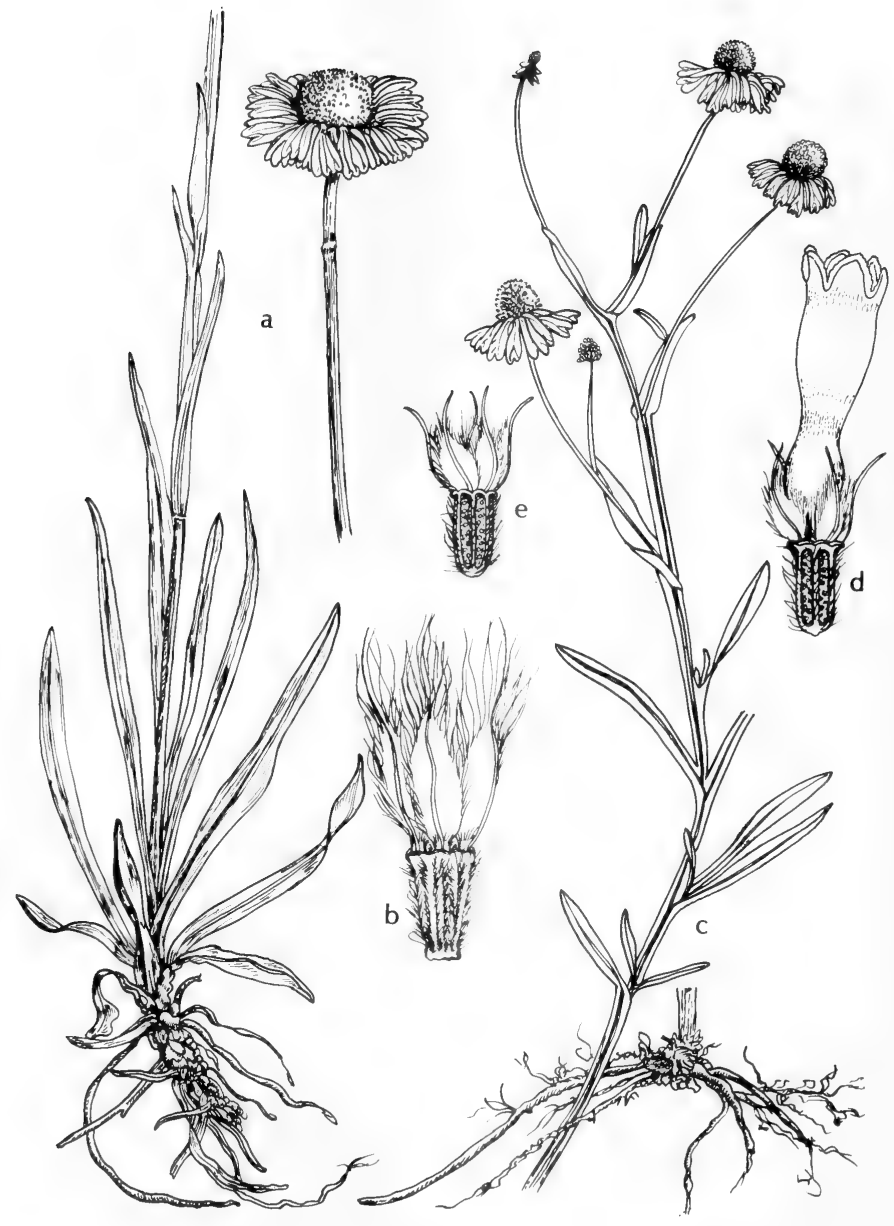

Fig. 774: a and b, Helenium fiexuosum: a, habit, $\mathrm{x} 1 / 2 ; \mathrm{b}$, achene, $\mathrm{x} 10 . \mathrm{c}-\mathrm{e}$, Helenium Drummondii: c, habit, $\mathrm{x} 1 / 2$; d, disk flower, $\mathrm{x} 10$; e, achene, $\mathrm{x} 10$. (V. F.). 
In moist usually calcareous places, in marshes along streams and along irrigation ditches in Okla. (Waterfall), in n.-cen. and e. Tex. and the Edwards Plateau and Plains Country, N. M. (Sierra, Taos, Chaves, Otero and San Miguel cos.) and Ariz. (Navajo, Yavapai and Cochise cos.), (Aug.-) Sept.-Oct.; widespread in temp. N.A.

\section{Helenium arizonicum Blake. Fig. 775.}

Root biennial, vertical, slenderly conic, about $10 \mathrm{~cm}$. long, $1 \mathrm{~cm}$. thick above, with few strong rootlets; stem solitary, erect, stout, striate-angled and sulcate, greenish-white, erect-branched essentially from base to apex, obscurely incurvedpuberulous below, nearly glabrous above, dotted with yellow-brown glands; lower leaves $8-10 \mathrm{~cm}$. long (including petiole, this about $2 \mathrm{~cm}$. long, narrowly margined, at base ampliate, purplish and about 7-nerved), 6-10 $\mathrm{mm}$. wide, triplinerved, essentially glabrous, densely glandular-punctate on both sides, pale green; stem leaves numerous, semiamplexicaul and decurrent for 1-4 mm., the uppermost smaller; peduncles solitary at tips of stem and branches, enlarged just below the head, many-sulcate, $2-11 \mathrm{~cm}$. long; involucre soon reflexed; phyllaries about 14, narrowly triangular, acuminate, 7-9 $\mathrm{mm}$. long, 1-1.5 $\mathrm{mm}$. wide at base, sparsely pilose below, densely so toward tip, punctate; disk subglobose, 12-17 mm. high, 15-20 mm. thick; submature receptacle $5 \mathrm{~mm}$. long, $3 \mathrm{~mm}$. thick; rays about 12 or more, cuneate, deeply 3-lobed (lobes blunt, $2.5-3.3 \mathrm{~mm}$. long), 9- to 11-nerved, 12-13 mm. long, 6-7 mm. wide, densely gland-dotted outside; disk corollas yellow, tipped with purple-brown, short-pilose on teeth with several-celled hairs, $3.4 \mathrm{~mm}$. long; disk achenes erect-pilose on the ribs with rufescent hairs, sessile-glandular between the ribs, $2 \mathrm{~mm}$. long; pappus scales 6 or 7 , subequal, $1.8-2.3 \mathrm{~mm}$. long, the body lanceolate or lance-ovate, gradually narrowed into the awn.

In wet meadows and on edge of ponds, in Ariz. (Coconino Co.), Aug.-Sept.; endemic.

\section{Clappia Gray}

\section{A monotypic genus.}

\section{Clappia suaedaefolia Gray.}

Subshrub from taproots, only slightly woody below, much-branched, the upper third or fourth of the height being nearly naked fistulose peduncles; leaves opposite on the lowest part of the stem but mostly alternate, crowded, confined to the lower two thirds or three fourths of the plant, fleshy and almost terete, linear, rarely with a lateral lobe or trifid in the distal half, often having lines of black (glandular?) dots visible under a lens, grayish-green when fresh; heads solitary, on the ends of the enlarged peduncles; involucre hemispheric, $8-10 \mathrm{~mm}$. high; phyllaries in about 4 or 5 series, strongly graduate, linear-oblong, definitely rounded apically, rather firm-membranous with an exceedingly narrow scarious margin, often witn parallel dark or subglandular longitudinal striae; receptacle convex, decidedly fimbriate-setose around the sockets but not chaffy; ray flowers about 12, pistillate, fertile; rays yellow, linear, terminally 2- or 3-toothed; disk flowers numerous, perfect, fertile, the corolla yellow and 5-toothed; style-branches hispidulous, with ovate tips; achenes about $3.5 \mathrm{~mm}$. long, columnar or slightly tapered to the base, black, about 10-ribbed, the ribs hispidulous; pappus of 15 to 25 unequal coarse stiff slightly tawny dorsiventrally flattened persistent bristles about as long as the achene.

Locally abundant in subsaline or alkaline poorly drained clay flats, Rio Grande Plains, spring-fall, less commonly summer and winter; also N.L. and Tam. 


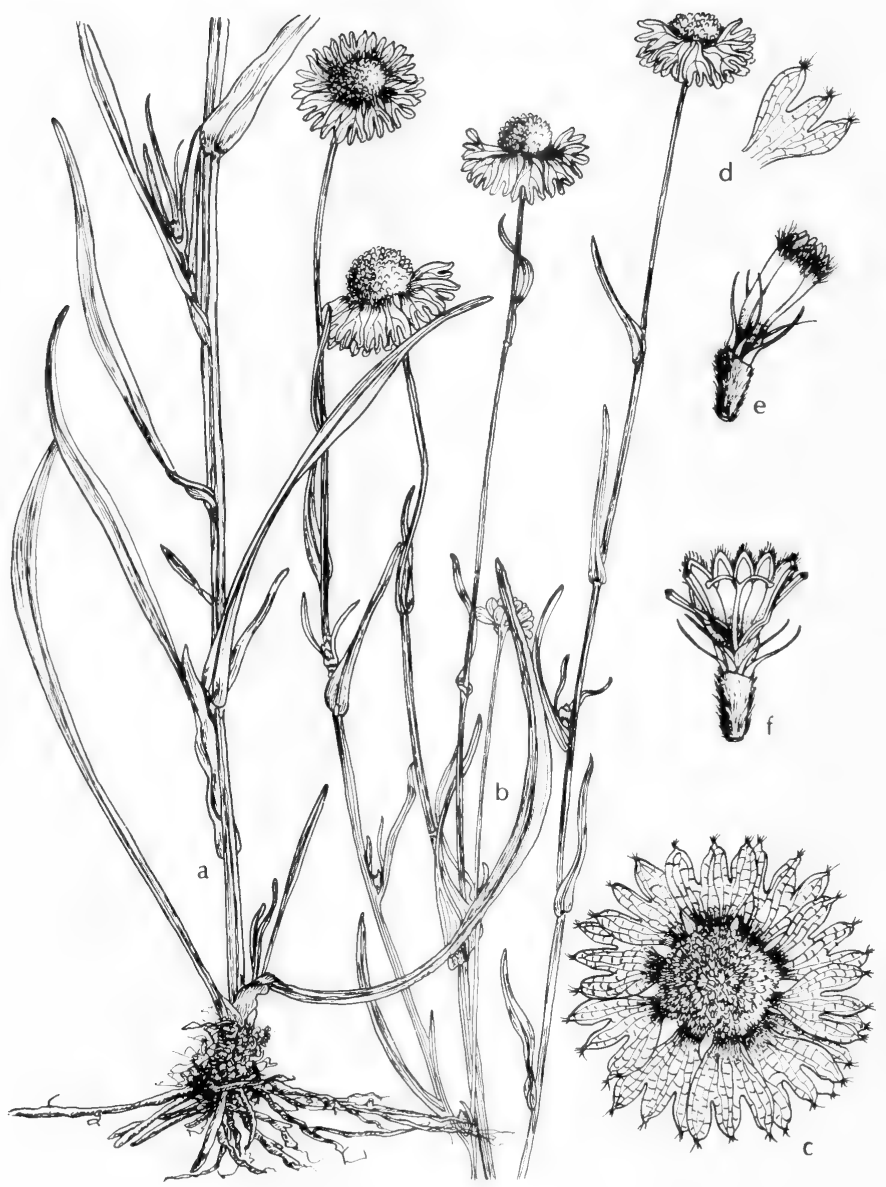

Fig. 775: Helenium arizonicum: a, basal part of plant, $\times 1 / 2 ; \mathrm{b}$, upper part of plant, $\mathrm{x} 1 / 2$; $\mathrm{c}$, head, $\mathrm{x} 1$; $\mathrm{d}$, ray, $\mathrm{x} 1$; e, disk flower, $\mathrm{x} 10$; $\mathrm{f}$, disk flower spread open. (V. F.). 


\section{Flaveria Juss.}

Glabrous or puberulent herbs, usually annual; leaves opposite, narrow, entire to dentate, sessile, often more or less connate; heads numerous, sessile or shortpedunculate, in dense glomerules or cymelike clusters; involucre usually narrowly campanulate to nearly cylindric; phyllaries 1 to 8 subequal and often 1 or 2 smaller outer ones; receptacle small, naked or setose; ray flowers solitary, pistillate and fertile or absent; rays entire, emarginate or 3-dentate terminally, yellow, inconspicuous; disk flowers 1 to 15 , perfect, fertile; corolla yellow, 5-toothed terminally; style 2-parted, reflexed, obtuse; achenes oblong, somewhat compressed, 10-ribbed; pappus absent or in $F$. chloraefolia present and of 2 to 4 distinct irregular scales.

A genus of about 20 species in the warmer parts of America.

1. Pappus of 2 to 4 scales; leaves connate-perfoliate, broad; throat of the disk corollas elongate, funnelform................................ F. chloraefolia.

1. Pappus absent; leaves barely connate (2)

2(1). Phyllaries 3 , rarely 4

2. Phyllaries 5 to 7 .

2. F. campestris.

\section{Flaveria chloraefolia Gray. Fig. 776.}

Herb to $2 \mathrm{~m}$. tall, the herbage glaucous; leaves ovate-oblong to lanceolate, 25-100 mm. long, 10-35 mm. broad, glabrous, connate-perfoliate; heads in open cymose clusters, 11- to 13-flowered; phyllaries 5, oblong, 6-7 mm. long, the outer calyculate ones 2, lanceolate; receptacle naked; ray flower absent; disk corolla $6 \mathrm{~mm}$. long, glabrous; achenes $3 \mathrm{~mm}$. long; pappus of 2 to 4 hyaline unequal incurved scales, the larger about $0.5 \mathrm{~mm}$. long.

Infrequent to rare in mud along creeks in calcareous or alkaline areas in the Tex. Trans-Pecos, rare to w. part of Edwards Plateau, and N.M. (Chaves and Guadalupe cos.), late summer-fall; Tex. to N.M., Dgo. and N.L.

\section{Flaveria campestris J. R. Johnst.}

Taprooted annual, the erect stems glabrous or pubescent only at the nodes; leaves linear or linear-lanceolate, serrulate, 3-ribbed, narrowed basally, slightly connate, 25-70 mm. long, 10-25 mm. broad; heads 4- or 5-flowered; phyllaries 3, nearly equal, $5 \mathrm{~mm}$. long, the outer shorter ones 2 and unequal, 1-3 $\mathrm{mm}$. long, linear-lanceolate; receptacle naked; ray oval, reflexed, $2.5 \mathrm{~mm}$. long; disk flowers 3 or 4 ; corollas $3 \mathrm{~mm}$. long; achene $2.5-3 \mathrm{~mm}$. long, that of the ray slightly larger than the rest; pappus absent.

Frequent in low waste ground or disturbed ground, in alkali flats, low moist or wet prairies, in alluvial thickets along streams, and in seepage areas and about ponds, in w. half of Okla. (Waterfall), the Tex. Plains Country and N.M. (Valencia Co.), late summer-fall; Mo. to Colo., N.M. and Tex.

\section{Flaveria oppositifolia (DC.) Rydb.}

Taprooted annual 3-10 dm. tall, simple below; leaves glabrous, broadest at the sessile base, nearly linear, entire or rarely spinulose-denticulate; heads of 10 to 15 flowers in ample rather open cymose clusters; phyllaries 5 to 7 , oblong, $4 \mathrm{~mm}$. long; receptacle naked; ray flower absent; disk corolla $3 \mathrm{~mm}$. long, glabrous; achenes $1.5 \mathrm{~mm}$. long; pappus absent.

Locally abundant in poorly drained or marshy coastal areas, Rio Grande Plains and s. part of s.e. Tex., late summer-fall; Tex., Tam., N.L., Coah., Ver. and perhaps elsewhere in Mex. 


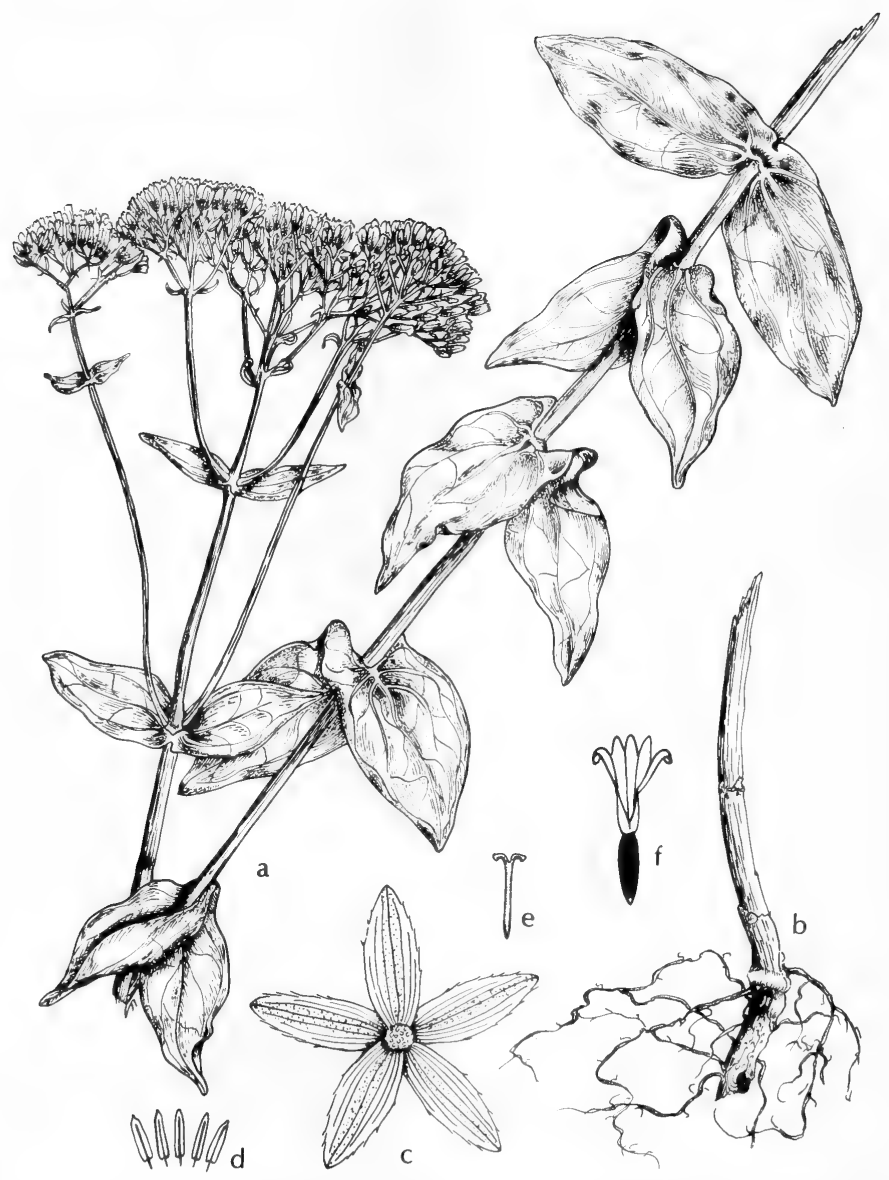

Fig. 776: Flaveria chloracfolia: a, upper part of plant, $\mathrm{x} 1 \frac{1}{2} ; \mathrm{b}$, lower part of plant, $x 1 \frac{1}{2} ; c$, involucre, $\times 2 \frac{1}{2} ; d$, anthers, $x 2 \frac{1}{2}$; e, style, $x 2 \frac{1}{2} ;$ f, corolla split, $x$ $2 \frac{1}{2}$. (V. F.). 


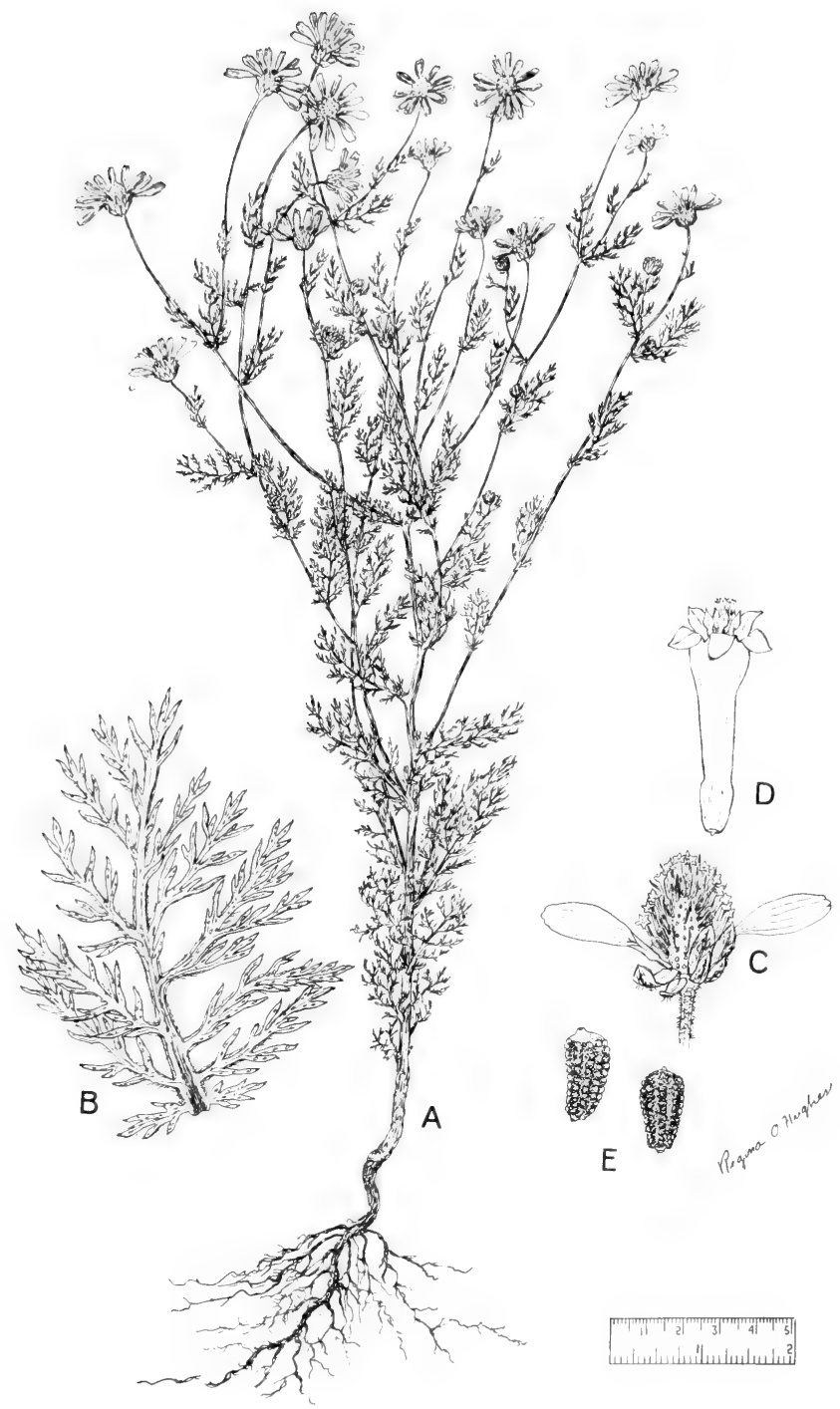

Fig. 777: Anthemis Cotula: A, habit, x $1 \frac{1}{2}$; B, leaf, $x ~ 2 ; C$, flower head, $x 1 \frac{1}{2}$; $\mathrm{D}$, disk flower, $\mathrm{x} 8$; E, achene, x 8. (From Reed, Selected Weeds of the United States, Fig. 182). 


\section{Anthemis L. Camomile}

A genus of several species, mostly European; one is adventive with us. $A$. nobilis L. is the usual source of "camomile," a useful stomach drug. Maruta Cass.

\section{Anthemis Cotula L. Mayweed, dog-Fennel. Fig. 777.}

Ill-scented taprooted annual 2-5 dm. tall, usually with several stems from the base; leaves alternate, bipinnatifid, the divisions linear; heads terminal and solitary on the branches which are naked for the upper $1-3 \mathrm{~cm}$; involucre saucer-shaped, about $3 \mathrm{~mm}$. high, 6-8 mm. broad; phyllaries in 2 series, subequal, mostly scarious, elliptic, obtuse or acutish, pubescent; receptacle high-conic, chaffy toward the apex, the subulate pales stiff; ray flowers 10 to 15 , infertile; rays white, $6-8 \mathrm{~mm}$. long, about $2 \mathrm{~mm}$. broad; disk flowers numerous, perfect, fertile; corolla greenish-yellow, glandular-granuliferous, $2 \mathrm{~mm}$. long, with 5 teeth; achenes cylindric, $1-1.5 \mathrm{~mm}$. long, nearly ribless or very weakly 10 -ribbed; pappus absent.

Scattered in waste places, sometimes in wet meadows and marshy lowlands, in the e. half of Okla. and the e. two thirds of Tex., N.M. (Bernalillo Co.) and Ariz. (Coconino, Yavapai, Maricopa, Pinal, Cochise and Pima cos.), escaped from cult., Mar.-July; a Eur. herb now widely adv. in the world.

\section{Achillea L.}

A large genus of north-temperate areas.

\section{Achillea millifolium L. CoMmon yarrow, milfoll. Fig. 778.}

Perennial herb with 1 to several stems from the base, 2-10 dm. tall; leaves alternate, bi- or tripinnatifid, variably pubescent, rather fernlike; heads with about 10 to 20 flowers, in terminal corymbose rather dense clusters; involucre turbo-cylindric, 4-5 mm. high, 2.5-4 mm. thick; phyllaries in about 4 series, graduated, mostly scarious; receptacle chaffy, the stiffish pales oblong; ray flowers present, 5 to 12 ; rays white; tube of disk corolla more or less flattened; corolla whitish or yellowish-white, 5-toothed; achenes more or less obcompressed, subrhombic to obliquely triquetrous in transection, oblong or obovate in outline, callous-margined, glabrous; pappus absent.

Frequent in disturbed soil, more or less ubiquitous, sometimes abundant in wet meadows, seepage areas and marshlands, in the $\mathrm{n}$. half of Tex., throughout Okla., N.M. and Ariz., spring-summer; nat. of Eur. and Asia, with varieties nat. to nearly all of N.A.

Ours are the var. occidentalis DC. with rays about $2 \mathrm{~mm}$. long, and the var. lanulosa (Nutt.) Piper with rays $2.5 \mathrm{~mm}$. long or longer.

\section{Cotula L.}

About 50 species that are native chiefly to the Southern Hemisphere, mainly in the Old World.

\section{Cotula coronopifolia L. Brass Buttons. Fig. 779.}

Low diffuse strong-scented glabrous perennial herb; stems many, decumbent, to $3 \mathrm{dm}$. long; leaves alternate, $2-6 \mathrm{~cm}$. long, entire to toothed or pinnatifid, linear to oblong, sheathing stem at base; heads on slender naked peduncles, discoid, bright-clear-yellow, depressed, to $1 \mathrm{~cm}$. broad; phyllaries thin, scarious, greenish, in 1 or 2 ranks; receptacle essentially flat, naked; ray flowers absent, their places taken by 1 outer row of pistillate flowers which lack corollas and are on stipes as long as the involucre; central (disk) flowers with 4-toothed corollas, on shorter stipes; achenes pedicellate, compressed, papillate on inner 


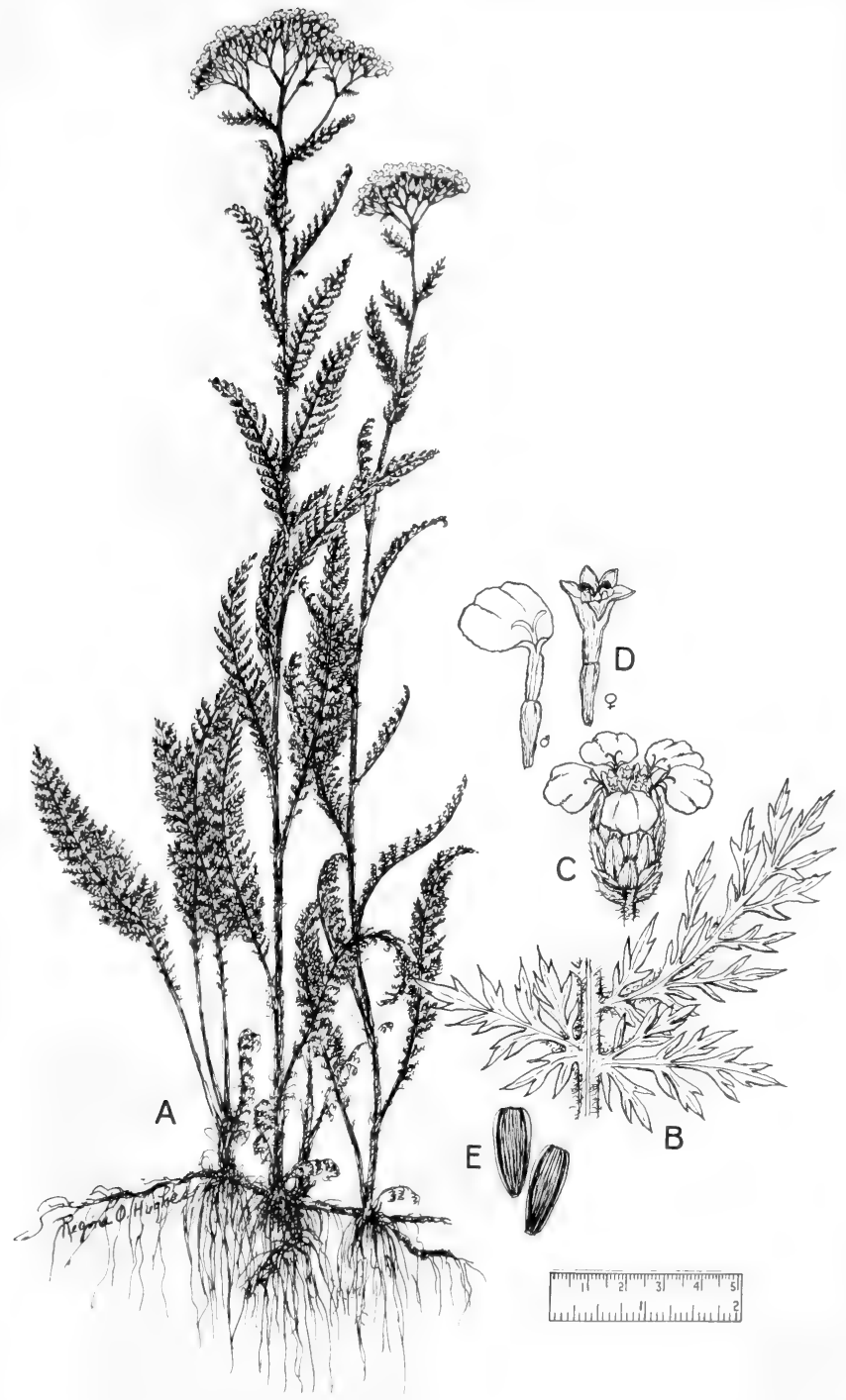

Fig. 778: Achillea millefolium: A, habit, x $x_{2}^{\prime}$; B, enlarged leaf and stem, x 5; C, flower head, x 4; D, female and male flowers, x 5; E, seeds, x 6. (From Reed, Selected Weeds of the United States, Fig. 178). 


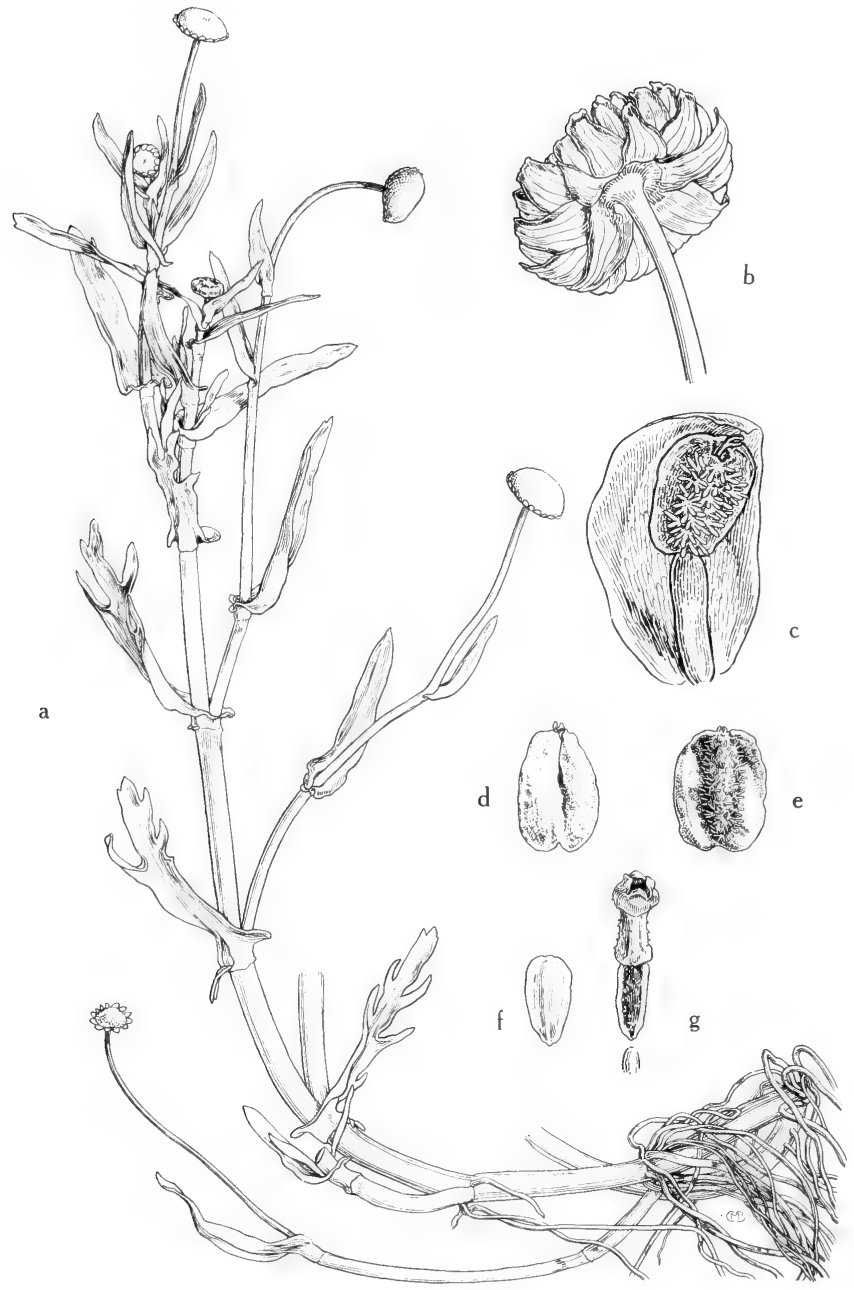

Fig. 779: Cotula coronopifolia: a, habit, showing decumbent stems rooting at the nodes, $\mathrm{x} \% 3$; b, flowering head, showing phyllaries, $\mathrm{x} 3$; $\mathrm{c}$, outer pistillate flower and subtending phyllary, showing the long stipe supporting the ovary, $\mathrm{x} \mathrm{16}$; $\mathrm{d}$ and $\mathrm{e}$, mature achenes of outer pistillate flower, showing the inflated membranous coat, the smooth abaxial surface, and the papillate adaxial surface, $x 8 ; f$, mature achene of disk flower, showing smooth abaxial surface, $\mathrm{x} 8$; $\mathrm{g}$, disk flower, showing achene with narrow membranous margin and papillate adaxial surface, x 8. (From Mason, Fig. 353). 
face, smooth on outer face, those of the outer pistillate flowers with a loose membranous coat which is expanded on the margins and extends over the back, those of the central flowers with a narrow membranous margin; pappus wanting.

In wet saline soils and marshy situations, often almost aquatic, in Ariz. (Mohave and Yuma cos.); weed introd. from S. Afr.

\section{Artemisia L. Wormwood. Sagebrush}

A genus of a few hundred species in the cooler, drier parts of the world. The plants are wind-pollinated and have toxic, allergenic pollen. The beverage absinthe is made by steeping the leaves of $A$. absinthium L. in alcohol. Tarragon, an herb used in cooking, is the herbage of $A$. Dracunculus L. The over-abundant "sagebrush" of the western plains is $A$. tridentata Nutt. Most of our species afford some low-quality forage for livestock, but only one is a wetland plant.

\section{Artemisia biennis Willd.}

Coarse essentially inodorous glabrous annual or biennial to about $3 \mathrm{~m}$. tall; leaves alternate, $5-15 \mathrm{~cm}$. long, pinnatisect almost to the midrib into several narrow lobes that are usually again sharply toothed or with the lower bipinnatifid; inflorescence dense, spikelike or of several spiciform branches; heads numerous, crowded, urceolate, scarcely pedunculate; involucre glabrous, $2-3 \mathrm{~mm}$. high; flowers all fertile, the outer pistillate; receptacle glabrous; phyllaries with very broad scarious margins; achenes ellipsoid, 4- to 5-nerved, glabrous.

Edge of marshes, stream banks, river beds and waste places generally, in N.M. (Rio Arriba, San Juan and San Miguel cos.) and Ariz. (Coconino and Pinal cos.), June-Sept.; Can. to N.J., Ky., Mo., N.M., Ariz. and Calif., where native, elsewhere naturalized.

\section{Arnica L.}

About 35 species of circumboreal distribution; most highly developed in western North America.

\section{Arnica Chamissonis Less.}

Perennial from long nearly naked rhizomes; stems solitary, 2-10 dm. tall; herbage variously pubescent but not silvery-tomentose nor pilose, becoming somewhat glandular above; leaves simple, opposite; cauline leaves mostly in 5 to 10 pairs, not much reduced upwards, lanceolate to oblanceolate, sessile or with the lowermost connate-petiolate, slightly toothed to entire, $5-30 \mathrm{~cm}$. long, mostly $1-4 \mathrm{~cm}$. wide, rarely more; heads usually several, campanulate to hemispheric; involucre mostly $8-12 \mathrm{~mm}$. high, its bracts obtuse or merely acutish and bearing an apical or internally subapical tuft of white hairs; rays commonly about 13, usually pale, $1.5-2 \mathrm{~cm}$. long; achenes shortly hairy and glandular to subglabrous; pappus tawny or whitish, barbellate to subplumose. A. foliosa Nutt.

In wet meadows, alluvial soils, in wet soil along streams and about lakes, in N.M. (Rio Arriba and Taos cos.) and Ariz. (Coconino Co.), July-Sept.; Alas. to N.M., Ariz. and Calif.

\section{Senecio L. Groundsel. Ragwort. Squaw-weed}

Herbs or subshrubs; leaves alternate, often pinnatifid; involucre usually campanulate or obconic-campanulate (or urceolate at anthesis); phyllaries usually in 2 sizeclasses; longer (inner) phyllaries 12 to 25 , equal in length, in a double row, linear, often acute, with a herbaceous median area and usually thin margins; outer phyllaries much shorter, subulate-setaceous, forming a calyculum or in many species entirely absent; receptacle slightly convex, essentially naked; ray flowers present, pistillate, fertile; rays linear or elliptic-linear, yellow, terminally 3-toothed; 
disk flowers numerous, perfect, fertile; corolia equally 5-toothed, yellow; achenes columnar, nearly terete, several-nerved, alike in ray and disk; pappus of numerous capillary bristles.

An enormous world-wide genus of between 2,000 and 3,000 species, reputed to be among the several largest seed-plant genera.

1. Woody, moderately branched shrub; old bark gray, new bark reddish, youngest twigs green and finely striate; ray flowers 2 to 8 , ligules about 6

1. Annual or perennial herbs (2) $\mathrm{mm}$. long, pale yellow; southern Arizona....................7. S. salignus.

2(1). Annual; terminal lobes of leaves in lower half of stem usually $1-3 \mathrm{~cm}$. wide.

1. S. glabellus.

2. Perennial (3)

3(2). Plants of eastern Oklahoma; phyllaries purple tipped; achenes glabrous...

2. S. aureus.

3. Plants of New Mexico (4)

4(3). Cauline leaves well-developed, only gradually reduced upwards; no welldeveloped tuft of basal leaves present (5)

4. Cauline leaves generally strongly and progressively reduced; basal or lower cauline leaves well-developed (6)

5(4). Cauline leaves (at least in part) sessile, with broad more or less clasping base; phyllaries with a blackish tip......................... 3. S. crassulus.

5. Cauline leaves (except sometimes the reduced upper ones) petiolate or tapering to a narrow base, the lower leaves triangular with deltoid to cordate base................................................................. S. triangularis

6(4). Basal leaves (or some of them) cordate or subcordate, sharply toothed; cauline leaves laciniate-pinnatifid at least toward their bases........

5. S. pseudaureus.

6. Basal leaves not cordate nor subcordate but rather elliptic or oblanceolate, crenate or serrate to subentire. 6. S. pauperculus.

\section{Senecio glabellus Poir. Butterweed.}

Annual 1-4 (-10) dm. tall; leaves pinnately lobed, lateral lobes oblong, undulate-margined, basally (toward the axis) not or only slightly constricted, the terminal lobe irregularly undulate.

Rare in sandy soil and moist or wet shady places in Okla. (Waterfall) and e. Tex. (Gregg and San Augustine cos.), spring; s.e. U.S., n. to N.C., Ill. and Mo., w. to Kan., Okla. and Tex.

\section{Senecio aureus $\mathrm{L}$.}

Perennial from a branched rhizomatous caudex or creeping rhizome, sometimes with coarse and leafy offshoots; herbage lightly floccose-tomentose when young, glabrescent; stem 2-12 dm. high; basal leaves long-petioled, cordate, suborbicular to ovate, crenate or serrate; cauline leaves variously pinnatifid, usually reduced and becoming sessile upward; heads few to many, with golden-yellow ligules 6-13 $\mathrm{mm}$. long (rarely ray flowers absent), the disk 5-12 $\mathrm{mm}$. wide; involucre 5-10 $\mathrm{mm}$. high, the phyllaries often purple-tipped; achenes glabrous.

Swamps and wet or moist woodlands in Okla. (Delaware Co.), Apr.-Aug.; Lab. to Ga. and Ala., w. to Minn. and e. Okla.

\section{Senecio crassulus Gray.}

Perennial plant; stem 2-5 dm. high, rarely less, mostly leafy to the apex; leaves $8-15 \mathrm{~cm}$. long, oblong-lanceolate to linear-oblanceolate or obovate, denticulate, glabrous or essentially so, lower leaves cuneate to a winged petiole, the upper sessile and partly clasping, sometimes strongly reduced; heads $10-15 \mathrm{~mm}$. high, 
erect, few to several, corymbose; involucres broadly campanulate; phyllaries fleshy thickened on back and near base, blackish-hairy near apex; rays 7-10 mm. long, yellow. S. semiamplexicaulis Rydb., S. lapathifolius Greene.

Wet meadows in mts. of N.M. (Rio Arriba Co.), June-Aug.; S.D. to Ida., s. to N.M. and Ut.

\section{Senecio triangularis Hook.}

Perennial or biennial; stems erect, 1 to a few from a heavy horizontal rootstock, 5-20 dm. tall; herbage tomentose when young, usually becoming glabrous; leaves many, gradually reduced upward, lanceolate to triangular-ovate, $5-20 \mathrm{~cm}$. long, cordate, hastate or merely truncate at base, sharply serrate, dentate, denticulate or nearly entire, the lower leaves on petioles as long as the blade; heads usually many in an open or dense corymbose terminal cyme; involucre $6-8 \mathrm{~mm}$. high; rays 6 to $12,8-10 \mathrm{~mm}$. long.

Bogs, marshy areas, and stream margins, in N.M. (Taos, Rio Arriba, San Miguel and Santa Fe cos.), June-Sept.; Alas. and Yuk., s. to Sask., N.M. and Calif.

\section{Senecio pseudaureus Rydb.}

Perennial plant with definite ascending or horizontal rootstocks; stems 3-7 dm. tall, erect, glabrous or tomentose in axils of leaves or in inflorescence; basal leaves 1-10 cm. long, ovate-rotund to oblong-ovate, crenate to doubly serrate, usually rounded at apex, some cordate at base, long-petioled; stem leaves more or less lyrate-pinnatifid, short-petioled or sessile and clasping, reduced upwards, glabrous or glabrate; heads $8-10 \mathrm{~mm}$. high, erect, few to many in a corymbose cyme; involucre campanulate, calyculate; phyllaries about 21 , rarely as few as $13,6-8$ $\mathrm{mm}$. long, glabrous except at apex; rays yellow, 10 to $13,6-9 \mathrm{~mm}$. long; achenes glabrous.

Wet meadows and wet stream banks, N. M. (Rio Arriba Co.), June-Aug.; Sask. to B.C., s. to N.M. and Calif.

\section{Senecio pauperculus Michx.}

Fibrous-rooted perennial with a rather short simple or slightly branched caudex, occasionally with some very short slender stolons, 1-5 dm. high, lightly floccosetomentose when young, glabrescent except at the very base and in the leaf axils; basal leaves petiolate, the blade oblanceolate to elliptic or occasionally suborbicular, crenate or serrate to subentire; cauline leaves more or less pinnatifid, the lower sometimes larger than the basal, the others conspicuously reduced and becoming sessile, all relatively thin and not at all succulent; heads several, the disk 5-12 $\mathrm{mm}$. wide; involucre mostly 6-9 mm. high; rays mostly 5-10 $\mathrm{mm}$. long, or rarely wanting. $S$. flavovirens $\mathrm{Rydb}$.

Swamps, meadows, stream banks in N.M. (San Miguel, Rio Arriba, Socorro and Sierra cos.), May-Oct.; Lab. to Va., w. to s. Yuk., B.C., Ore. and N.M.

\section{Senecio salignus DC.}

Woody, moderately branched shrub to $2.5 \mathrm{~m}$. tall, glabrous throughout; bark reddish-brown on younger branches, tawny to gray on old growth, youngest twigs green and finely striate; leaves narrowly lanceolate or narrowly elliptic, to $1 \mathrm{dm}$. long, 5-10 mm. wide, tapering gradually toward each end, usually serrate, the teeth somewhat callous-tipped, dark green on upper surface, paler beneath; petioles gradually merging with blade; inflorescence corymbose, cymes to $1 \mathrm{dm}$. wide; heads radiate, 10-12 mm. high; involucres campanulate, phyllaries 7 to 9 , broadly oblong or oblanceolate, 5-6 $\mathrm{mm}$. long, 2-2.8 $\mathrm{mm}$. wide, obtuse or rounded at the tip, somewhat hardened at the base, thin, with the margins scarious; ray flowers 2 to 8 , sometimes wanting, ligules pale-yellow, 5-7 $\mathrm{mm}$. long, about $2 \mathrm{~mm}$. wide, 


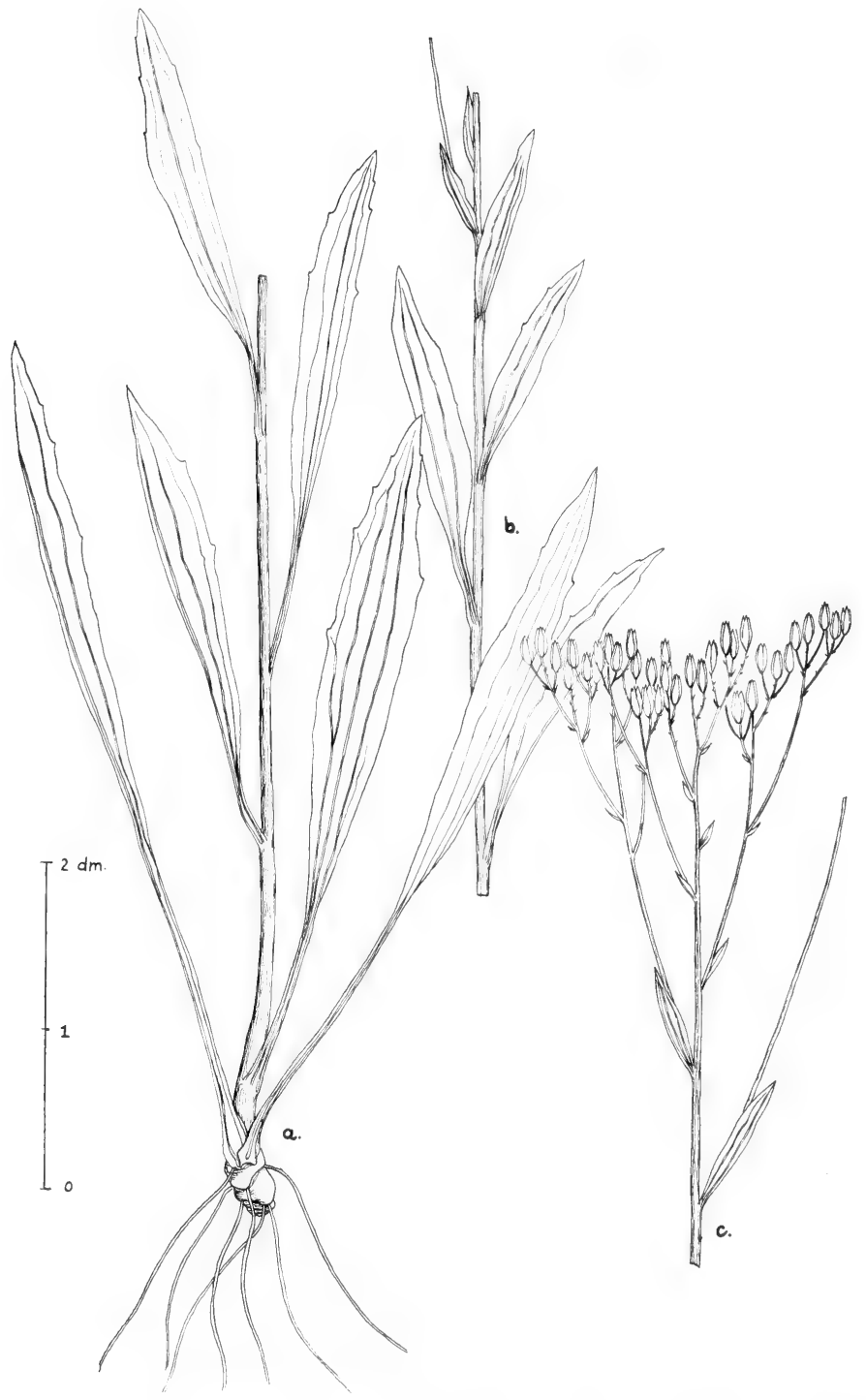

Fig. 780: Cacalia lanceolata: a, basal portion of stem and caudex; $\mathbf{b}$, a midportion of stem; c, portion of inflorescence. (From Kral and Godfrey, Quart, Jour. Fla. Acad. Sci. 21(3), fig. 4. 1958). 
lightly rolled downward; disk flowers 15 to 25 , slender, 7-8 mm. long, abruptly expanded at base of tube, slightly expanded to a narrow throat, teeth narrowly triangular-lanceolate (about $1.5 \mathrm{~mm}$. long) and curled downward; achenes brownish, 2.5-3 mm. long, weakly 8- to 10-ribbed, sparsely strigillose; pappus bristles 5-6 mm. long, white.

Rich soil along streams in Ariz. (Santa Cruz and Pima cos.), Feb.-Apr.; s. Ariz. to Guat.

\section{Cacalia L. Indian Plantain}

Strongly perennial essentially glabrous herbs; stems stout, 5-20 dm. tall, mostly simple and erect except at the extreme top; leaves alternate, the blades lanceolate or elliptic to rhombic-ovate or rhombic-oblanceolate, the lower ones usually longpetioled, the distal margin often undulate or remotely dentate; unlobed heads in a close corymbose arrangement at the tip of the plant; involucre short-urceolate, 5-10 mm. long; phyllaries about 5, broad, yellow-green; receptacle slightly convex, naked; ray flowers absent; disk flowers few, perfect, fertile, the corolla paleyellowish or nearly white with its limb equally 5-toothed; achene columnar, smoothish; pappus persistent, of numerous very slender white bristles.

About 50 species, mostly in eastern Asia.

1. Phyllaries wing-keeled; basal and lower stem leaves ovate or rhombic-ovate, usually broadly so; plant usually flowering April-June

1. Phyllaries ............................................................................ . . plantaginea. not wing-keeled; basal and lower stem leaves lanceolate; plant flowering July-October...... 2. C. lanceolata.

\section{Cacalia plantaginea (Raf.) Shinners.}

Lower stem leaves ovate to rhombic, usually broadly so; each phyllary at least by anthesis with a narrow median dorsal keel. C. tuberosa of auth.

Frequent in open areas, in water of marshes and in low depressions or swales, in s.e. Okla. (McCurtain Co.) and e., s.e. and n.-cen. Tex., Apr.-June and less commonly again in late Sept.-Nov.; widespread in e. U.S.

\section{Cacalia lanceolata Nutt. Fig. 780 .}

Lower stem leaves narrower than in $C$. plantaginea, usually lanceolate; phyllaries not wing-keeled even after anthesis.

Infrequent in wet mud about ponds and lakes, on edge of ditches and wettish meadows, in e. and s.e. Tex., July-Oct.; coastal s.e. states. C. plantaginea and C. lanceolata intergrade to some extent.

\section{Erechtites RaF. FireWEed. BurnWEed}

A genus of about 15 species in America, Australia and New Zealand.

\section{Erechtites hieracifolia (L.) Raf. var. intermedia Fern.}

Annual herb with stubby taproots and numerous adventitious roots, the lower parts of the stem occasionally propped in the mud by adventitious roots at the lower nodes, leafy, usually with one stem and few branches, to $1 \mathrm{~m}$. tall; leaves alternate, irregularly and often doubly serrate, the lower ones narrowed to a subpetiolar base and broadly oblanceolate, the higher ones semiamplexicaul and the teeth tending to be incised very deeply almost forming shallow lobes; heads on slender peduncles $2-18 \mathrm{~cm}$. long; receptacle essentially flat, naked; involucre cylindric or slightly urceolate at anthesis, becoming narrowly campanulate in fruit; principal phyllaries equal, linear, about 13 or 14 in number, in a double row, 9-13 mm. long; outer phyllaries few, setaceous, 1-3 mm. long, forming a weak calyculum; flowers of 2 kinds; peripheral flowers pistillate, fertile, with a 
yellowish-white filiform-tubular corolla which at the tip is microscopically unequally toothed with 3 of the teeth much longer than the other 2 (the 3 longer teeth corresponding to the 3 teeth at the end of a ray and oriented to the outside of the head); central flowers numerous, perfect, fertile, the corollas with basal tube and a flaring equally 5-toothed limb; achenes all alike, columnar; pappus of copious soft white capillary bristles.

Infrequent in muddy places, about seepage and lakes, along streams, in s.e. Tex. and s. part of e. Tex., Aug.-Nov.; e. U.S.

\section{Cirsium Mill.}

\section{Thistle. Plumed Thistle}

Winter annual, biennial or perennial herbs; leaves alternate, entire or often lobed, usually also irregularly serrate, the whole blade plus each lobe plus each tooth usually ending in a spine-tip, sessile, often narrowed to a subpetiolar base, often slightly decurrent on the stem, often with a thin floccose wool beneath or on both surfaces; heads singly terminating the pedunculiform upper parts of the branches; involucre ovoid or subcylindric to urceolate or nearly globose, usually much broader and more saucer-shaped after anthesis and when the achenes are mature; receptacle covered with soft hairlike bristles; phyllaries in many series, strongly imbricated, mostly lanceolate and nearly always each one ending in a spine-tip (not in C. muticum); ray flowers absent; disk flowers numerous, perfect, fertile; corolla usually mauve, reddish-purple, purple or pink, rarely white or yellowish (in $C$. horridulum), deeply and subequally 5-lobed; filaments separate; achenes mostly oblong or elliptic-oblong, flattish, unribbed, attached basally to the receptacle; pappus of numerous bristles united in a ring at the base, the lower part of each bristle plumose, the entire pappus deciduous as a unit.

A north-temperate genus of about 150 species. Differing from Carduus only in that each unit of the pappus is decidedly plumose in the lower part; probably should be submerged in Carduus.

1. Distribution in eastern Texas and/or eastern Oklahoma (2)

1. Distribution in mountains of New Mexico and Arizona (3)

2(1). Flowers pinkish or yellowish; phyllaries of the true involucre all with weak flat tips but the large heads $(4-8 \mathrm{~cm}$. broad) subtended and often equalled or surpassed by a false involucre of large very spinescent appressed bracteal leaves.....................................1. C. horridulum.

2. Flowers purple or rarely whitish; outer phyllaries barely pointed, scarcely prickle-tipped; inner phyllaries with broadly lanceolate tips; heads essentially naked..

2. C. muticum.

3(1). Corollas yellow or greenish-yellow; at least some phyllaries usually pectinate-ciliate (4)

3. Corollas purple, pink, red or white; phyllaries typically not pectinate-ciliate (6)

4(3). Phyllaries not densely arachnoid on backs

3. C. inornatum.

4. Phyllaries typically densely arachnoid throughout (5)

5(4). Inner phyllaries with dilated-lacerate tips. 4. C. Parryi.

5. Inner phyllaries without dilated-lacerate tips. 5. C. pallidum.

6(3). Outer phyllaries strongly refiexed for half their length, purple; entire plant commonly tinged with brownish-purple..................6. C. vinaceum.

6. Outer phyllaries not strongly reflexed for half their length, only the tips purple at most; entire plant not purplish (7)

7(6). Inner phyllaries elongate, attenuate, plane. 7. C. nidulum.

7. Inner phyllaries with dilated twisted frequently fimbriate tips......8. C. foliosum. 


\section{Cirsium horridulum Michx. Bull thistle, yellow thistle.}

Winter annual or biennial, $1-10 \mathrm{dm}$. tall, rarely taller; stems commonly 5-10 $\mathrm{mm}$. thick basally; flowering stem commonly solitary at the base, rarely muchbranched above, usually with a solitary terminal head; leaves in over-all outline often broadly linear to lanceolate or oblanceolate, pinnatifid with shallow spiny lobes; heads subtended closely by a false involucre or calyculum of large very spiny appressed bracteal leaves as long as or longer than the true involucre; involucre 4-8 cm. broad; phyllaries of the true involucre all with weak flat tips; corolla pinkish or yellowish. Carduus spinosissimus Walt.

In wet meadows and depressions, in water at edge of ponds and lakes, in Okla. (Ottawa and McCurtain cos.) and e. and s.e. Tex. and coastal part of Rio Grande Plains, Mar.-May; mostly on the Coastal Plain, Me. to Tex. and e. Okla.

\section{Cirsium muticum Michx. Swamp-thistle.}

Biennial supposedly; stems thick and hollow, 4-30 dm. tall; leaves thinnish, very deeply pinnatifid, the lobes almost half the total breadth; involucre ovoidcylindric, 20-35 mm. high; outer phyllaries blunt and merely subulate-mucronate, not spiny-tipped; flowers purple or rarely whitish.

Very rare in moist sand, usually acid areas, in swamps and wet meadows and seepage areas, in e. Tex., July-Oct.; s.w. Can. and n.e. U.S. s. to N.C., Tenn., La. and Tex.

\section{Cirsium inornatum (W. \& S.) W. \& S.}

Biennial about $1 \mathrm{~m}$. tall; stem stout, simple below but above with a few ascending branches, striate, sparingly arachnoid, becoming nearly glabrous with age; basal leaves narrowly oblanceolate, with remote triangular spine-tipped teeth; lower cauline leaves linear-lanceolate, to about $18 \mathrm{~cm}$. long and $2 \mathrm{~cm}$. wide, with a few remote triangular spine-tipped teeth, the margins beset with fine spines, glabrous beneath except on midvein, sparingly villous above with long weak white hairs; upper cauline leaves lanceolate to oblong, acute or subacuminate, sessile and clasping the base, the auricles rounded, the margins irregular and bearing numerous slender yellow spines; heads few, occasionally solitary at end of the branches but usually in clusters of about 3, pedunculate, campanulate, about 2.5 $\mathrm{cm}$. high and slightly less broad, subtended by numerous spiny reduced bracteate leaves; phyllaries of involucre in several series, successively shorter outward; outer phyllaries linear-lanceolate with long-attenuate tips, mostly glabrous on the back, rarely slightly arachnoid, spine-tipped, the margins bearing weak yellow spines; inner phyllaries broader, scaberulous, mostly abruptly dilated at the tips into a lanceolate or oval often laciniate spine-tipped portion; corollas yellow; achenes obovate, compressed, brownish, $4-5 \mathrm{~mm}$. long, the pappus about $10 \mathrm{~mm}$. long.

In wet meadows, edge of streams and in seepage areas, in N.M. (Otero and Taos cos.), June-Sept.; apparently endemic.

\section{Cirsium Parryi (Gray) Petrak.}

Perennial or (?) biennial 3-10 dm. tall; stems more or less arachnoid-pubescent; leaves lanceolate to oblong-lanceolate, sinuate-dentate to sinuate-lobed, with spines 2-15 mm. long, glabrate; heads solitary or 2 to 4 clustered at end of stem and branches, occasionally in the upper axils, $2-3 \mathrm{~cm}$. high and about as wide; involucre phyllaries rather densely arachnoid, with a glutinous dorsal ridge; phyllaries (at least some) spinulose-ciliate, with a terminal spine 1-5 mm. long, with at least some of the inner phyllaries with a dilated fringed tip; corollas light greenish-yellow.

In wet meadows, on seepage slopes and in conifer forests, in N.M. (Blake) and 


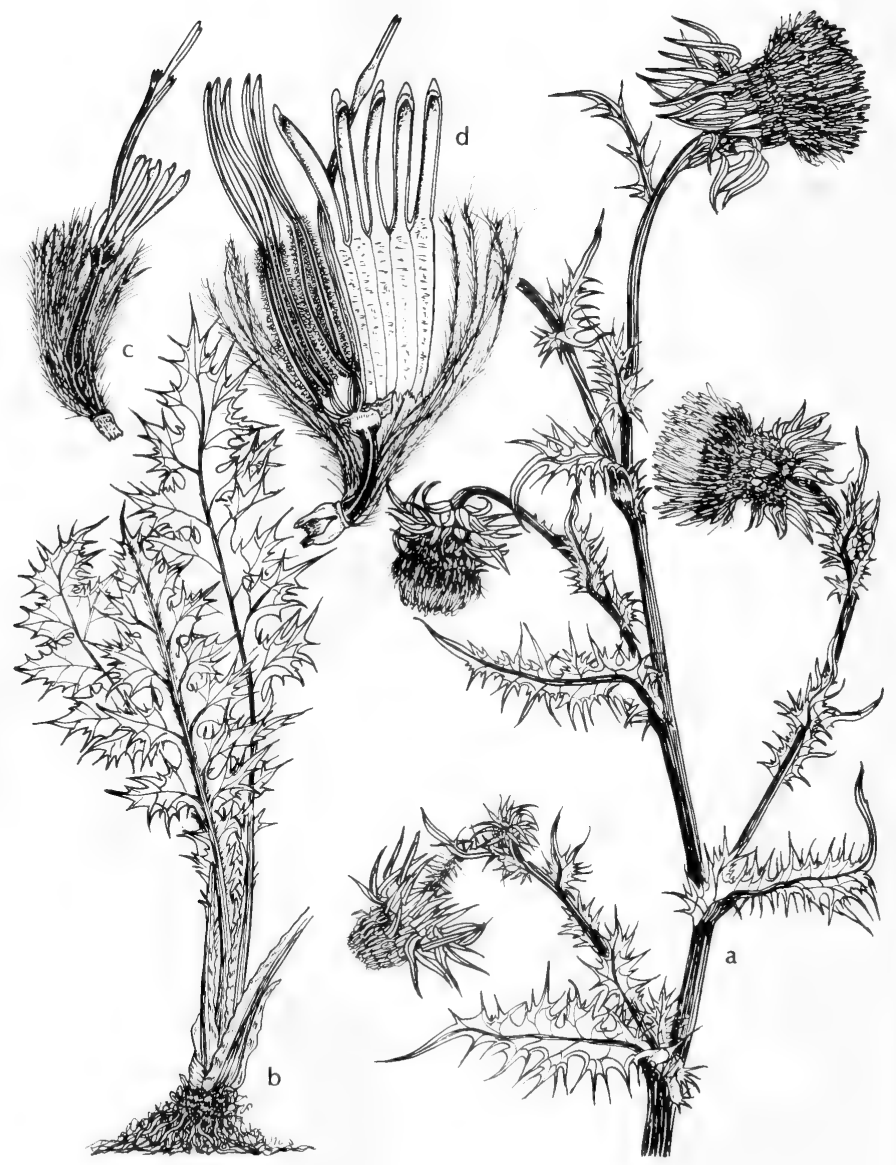

Fig. 781: Cirsium vinaceum: a, top of plant, $\mathrm{x} 1 \frac{1}{2} ; \mathrm{b}$, basal leaves, $\mathrm{x} 1 / 2$; $\mathrm{c}$, flower, x $1 \frac{1}{2}$; d, flower with corolla spread open, $x 2 \frac{1}{2}$. (V. F.). 
Ariz. (Apache, Coconino, Graham and Greenlee cos.), July-Sept.; also Colo. and Ut.

\section{Cirsium pallidum (W. \& S.) W. \& S.}

Biennial 1-2 m. tall; stem simple, leafy, sparingly branched about the inflorescence, arachnoid above, becoming glabrate below, striate; lower cauline leaves lanceolate, acute, attenuate to the base, irregularly serrate-dentate with the teeth tipped with short weak spines; upper cauline leaves narrowly oblong to triangularlanceolate, clasping at the base, with rounded auricles, acute, irregularly dentate or shallowly lobed, the margins spine-tipped, glabrous beneath, sparingly whitevillous above, lanate along midrib; inflorescence of few heads crowded when young but racemose with age; heads stout-pedunculate or sessile, subtended by reduced very spiny leaves, campanulate, $3 \mathrm{~cm}$. high and about as broad or smaller; phyllaries linear; outer phyllaries arachnoid on the backs and margins, tipped with a long slender spine and usually bearing 2 or more slender lateral spines just below the tip; inner phyllaries lanceolate, thick and firm, scaberulous, with slender flat weak tips; corollas greenish-yellow; achenes oblong-obovate, darkbrown, glabrous and shining.

In swamps, marshes, wet meadows and along streams, in N.M. (widespread in mts. ), June-Oct.; also Colo.

\section{Cirsium vinaceum W. \& S. Fig. 781.}

Robust biennial 1-2 m. tall, with numerous ascending branches; stems brownishpurple, striate, slender, glabrous; basal leaves glabrous, green, 3-5 dm. long, to $2 \mathrm{dm}$. wide, elliptic-oblong in outline, pinnatifid nearly to the midrib, the overlapping segments laciniately lobed; lobes of leaf segments oblong-lanceolate, acute, the teeth tipped with short slender yellowish spines; heads very numerous, naked, campanulate, commonly nodding; phyllaries in numerous series, narrowly lanceolate, with long flat weak spreading tips, deep-reddish-purple throughout, glabrous on the back, scarcely keeled, ciliate or puberulent on the margins, tipped with short slender yellowish spines; inner phyllaries with long slender twisted tips; entire head about $5 \mathrm{~cm}$. in diameter and $4 \mathrm{~cm}$. high, sometimes smaller; corolla lobes long and narrow, purplish; achenes obovate, brown, glabrous, with tawny plumose pappus $1.5-2 \mathrm{~cm}$. long.

In water and mud of springs and streams, in N.M. (Otero Co.), July-Sept.; endemic.

\section{Cirsium nidulum (Jones) Petrak.}

Root perennial; stem erect, branched above, 5-8 dm. tall, arachnoid-tomentose; basal leaves $2-3.5 \mathrm{dm}$. long, deeply and regularly sinuate-pinnatifid, the short lanceolate lobes with long yellow spines; upper cauline leaves reduced, sessile, very spiny; heads solitary, ovoid; involucre about $3.5 \mathrm{~cm}$. high; phyllaries glabrous except for the arachnoid margins, with a rather faint glutinous ridge; outer phyllaries somewhat spreading-reflexed, these and the middle ones terminated by yellow spines to $2.5 \mathrm{~cm}$. long; inner phyllaries acuminate, not spine-tipped; flowers light red-purple, well-exserted.

In marshes below springs and in wettish soils along streams, in Ariz. (Coconino Co. ), June-Oct.; Ariz., Ut., Nev. and Calif.

\section{Cirsium foliosum (Hook.) DC.}

Perennial with a taproot; stem to $6(-10) \mathrm{dm}$. tall or sometimes muchabbreviated, thick and succulent, edible, usually only slightly if at all tapering above, more or less crisp-arachnoid; leaves more or less arachnoid-villous above, rather thinly tomentose or subglabrous beneath, weakly spiny, pinnatifid or merely 
coarsely toothed; heads clustered at the summit of stem or rarely solitary, usually overtopped by the subtending leaves or the inflorescence sometimes elongate but still dense; involucre $2-3.5 \mathrm{~cm}$. high, usually glabrous or nearly so; phyllaries rather broad, well-imbricate, the outer with a short mostly erect spine tip, the inner innocuous and often with a dilated scarious fringed tip; corollas whitish to pale-pink or purplish, unequally cleft, the deepest sinuses mostly $5-8 \mathrm{~mm}$. deep, the tube mostly 1 or 2 times as long as the throat. C. Drummondii T. \& G., C. acaulescens (Gray) Danieis.

In wet meadows, low woods along streams and seepage areas, in N. M. (Rio Arriba and Taos cos.) and Ariz. (Apache, Coconino and Greenlee cos.), JulySept.; Sask. to B.C., s. to N.M., Ariz. and Calif.

\section{Lactuca L. LetTuce}

Mostly biennial or winter annual herbs; leaves alternate, lobed or not, marginally serrate and often with each tooth slightly spinose, the upper ones (at least) often clasping; stems tall, erect, mostly simple except in the upper (headbearing) region; involucre narrowly urceolate just before anthesis, usually after anthesis becoming more or less campanulate; phyllaries well-imbricated, mostly erect (tips sometimes spreading), ovate-lanceolate to lanceolate or lance-linear, green with narrow white margin; receptacle flattish, naked; flowers 5 to 35 per head, perfect, fertile; corollas yellow, blue, white, rosy-white or lavender, bilaterally symmetrical, the raylike portion terminally 5-toothed; achenes definitely flattened, some extremely flat and even slightly winged, with a definite body portion below which is usually obovate or elliptic in outline and abruptly narrowed to a long or short thick or thin (or even filiform) beak, the microscopic apex flared as a pappus pedestal; pappus of numerous white or whitish capillary bristles, persistent or tardily deciduous as individual bristles (not as a unit).

An Old World genus of perhaps 100 species. Lactuca sativa L., the cultivated lettuce, a native of Europe, is probably the best-known species of the genus, but most of our species are native. Some of our species hybridize, thus making determinations troublesome. The young leaves of all species are used for salads and greens.

1. Achenial beak absent or stout, only $0.5-1 \mathrm{~mm}$. long (2)

1. Achenial beak filiform, $2-4 \mathrm{~mm}$. long (3)

2(1). Rhizomatous perennial; involucre at anthesis $12-15 \mathrm{~mm}$. high.

2. Annual; involucre at anthesis $9-10 \mathrm{~mm}$. high.

4. L. pulchella.

5. L. floridana.

3(1). Achene about a third as thick as broad, on each face with about 7 distinct longitudinal nerves, the short wings of the upper sides being pubescent .................................................................... L. Serriola.

3. Achenes very flat, each face with 1,2 or 3 longitudinal nerves the wings (if present) not pubescent (4)

4(3). Lower leaves mostly linear, 10-33 cm. long, 5-12 mm. broad.

3. L. graminifolia.

4. Lower leaves not linear or (if so) proportionately broader.......2. L. canadensis.

\section{Lactuca Serriola L. Prickly Lettuce. Fig. 782.}

Taprooted annual or winter annual; stems (3-) 5-20 dm. tall, erect, simple except in the uppermost reaches; leaves usually pinnatifid (except the uppermost) and usually clasping, the margins usually finely spinose-dentate; involucres 8-11 $\mathrm{mm}$. long at anthesis, 9-13 $\mathrm{mm}$. long in fruit, the inner (longer) phyllaries after anthesis becoming filiform-involute for most of their length; corollas yellow (often the extreme tip discolored bluish or purplish); achene body $2.5-3 \mathrm{~mm}$. long, 


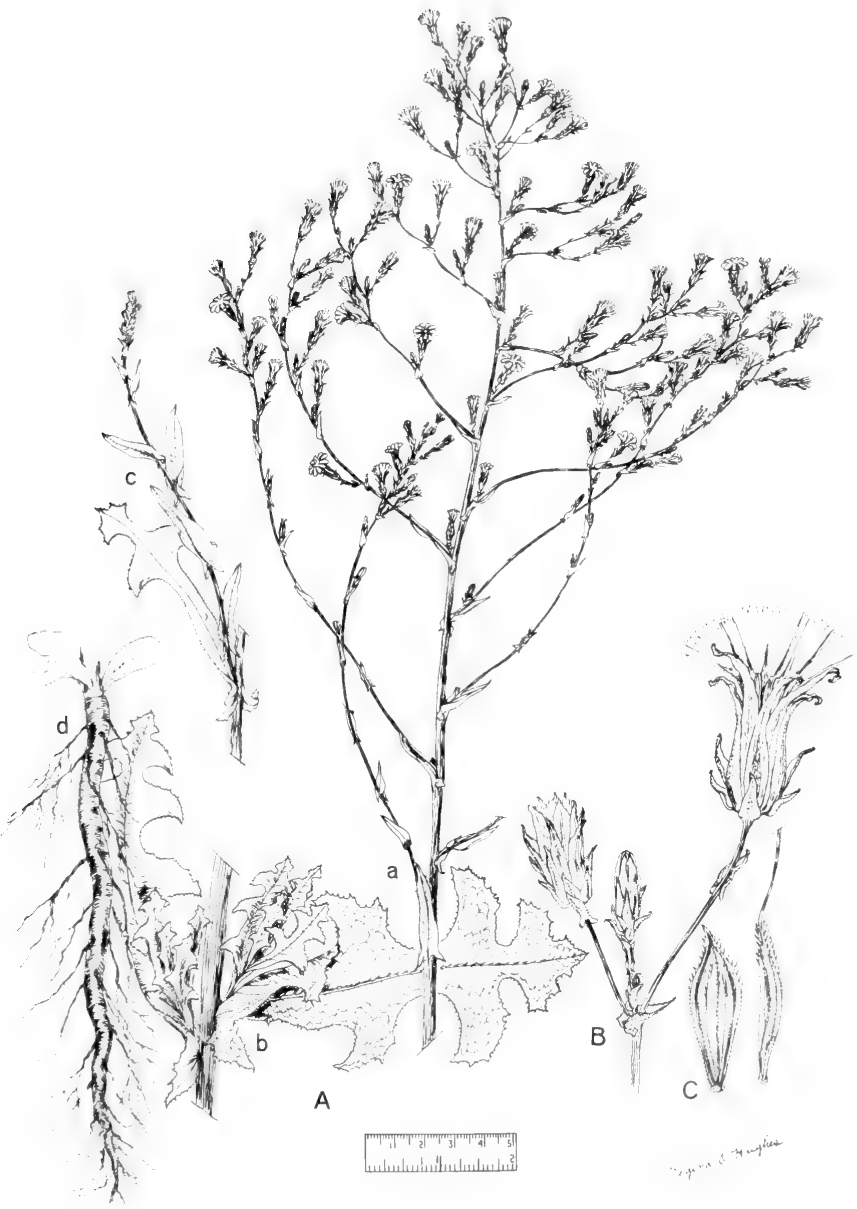

Fig. 782: Lactuca Serriola: A, habit, x 1/2; - a, upper part of plant, x 1/2; b, lobed lower leaves, $x$ 1,2; c linear upper leaves, x $1 \frac{112}{2} ; \mathrm{d}$, root, $\mathrm{x} 11 \frac{1}{2} ; \mathbf{B}$, flower heads, $\mathrm{x} 3$; C, achenes, x 8. (From Reed, Selected Weeds of the United States, Fig. 210). 


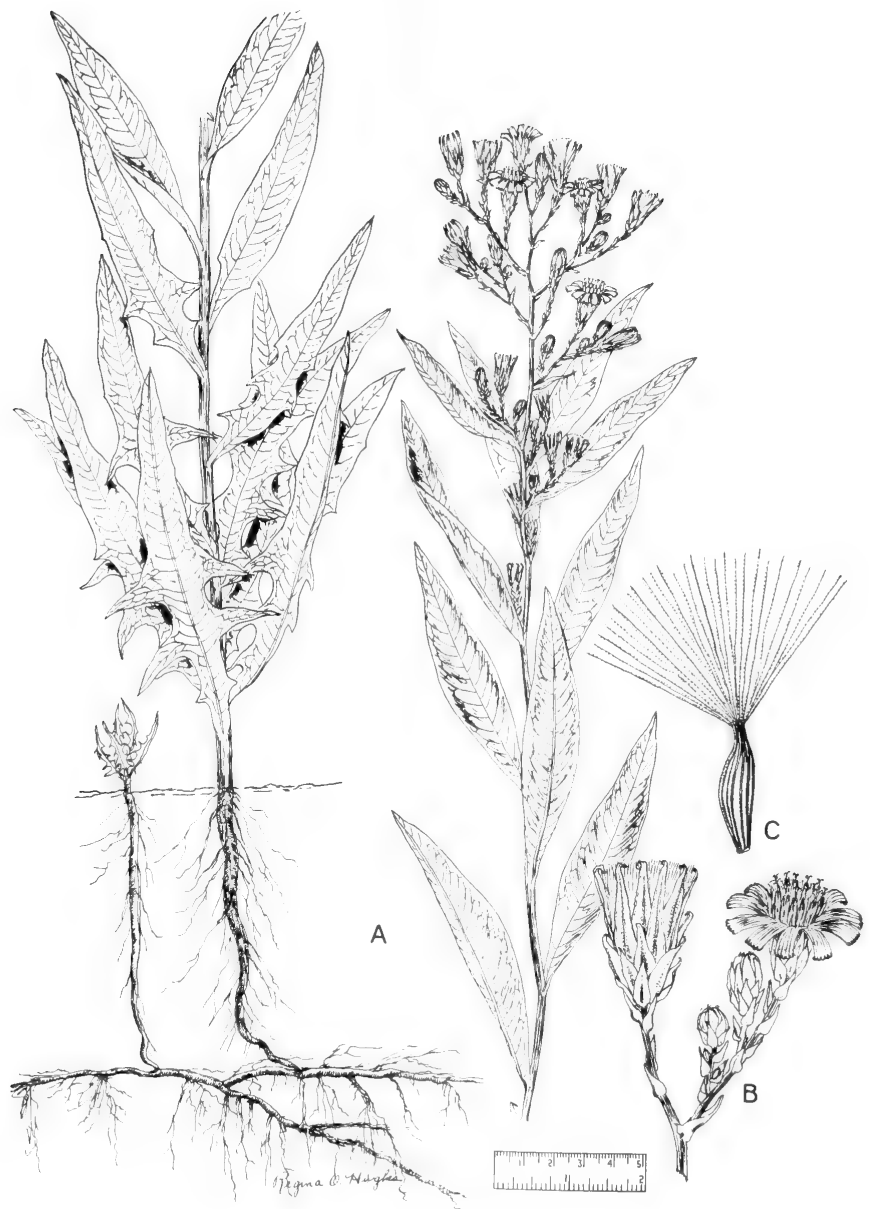

Fig. 783: Lactuca pulchella: A, habit, $x$ 1/2; B, involucre and flowers, $x$ 11/2; C, achene, x 5. (From Reed, Selected Weeds of the United States, Fig. 209). 
somewhat compressed but still lenticular in transection and about a third as thick as broad, brownish, oblanceolate or linear-obovate, on each face with about 7 distinct longitudinal nerves, not winged or only very shortly winged on the upper shoulders near the junction with the beak and these thin shoulders microscopically ciliate, the beak filiform and $3-4 \mathrm{~mm}$. long.

Frequent in disturbed soil, especially if wet, in marshes and on edge of lakes among Typha in Okla. (Grady Co.) and in n.-cen. Tex. and Edwards Plateau, infrequent in e. and Trans-Pecos Tex. and Plains Country, N.M. (widespread) and Ariz. (Santa Cruz, Pinal, Navajo, Coconino, Greenlee, Cochise, Pima and Yuma cos.), June-July; nat. of Eur., now widely adv.

The name is sometimes misspelled "scariola."

\section{Lactuca canadensis $\mathrm{L}$.}

Biennial (?) with crowns 1-3 cm. thick; stems 5-25 dm. tall, mostly simple except in the upper fifth of the height where branched, most of the stem leafy; lowermost leaves (in the lower fifth of the height) usually pinnately lobed (rarely even up to half the leaves lobed) but usually most leaves nearly lobeless; upper leaves usually narrowly obovate, acute and basally narrowed to a nonclasping base; leaf margins not spiny-dentate, some with weak teeth; involucres about $1 \mathrm{~cm}$. long at anthesis, later 13-15 mm. long in fruit, the larger outer phyllaries about 1.8-2 $\mathrm{mm}$. broad; corollas yellow: achene body obovate, $3.5-4.5 \mathrm{~mm}$. long, about 1.5 to 2 times as long as broad, very flat and somewhat winged, darkbrown or usually black, each face with 2 or 3 longitudinal nerves and numerous weak transverse ridges, the filiform beak $2.2-2.5 \mathrm{~mm}$. long.

Infrequent in sandy soil, in marshes, alluvial thickets, muddy seepage banks and on sandy-gravel bars along streams in Okla. (Waterfall) and e. Tex., rare in n.-cen. and s.e. Tex., June-July (-Aug.); s.e. Can. and e. U.S.

\section{Lactuca graminifolia Michx.}

Biennial or weak perennial with taproots; stems erect, (3-) 5-9 dm. tall; basal outer leaves sometimes runcinately pinnatifid but most of the lowest stem leaves unlobed and linear, 10-25 $(-33) \mathrm{cm}$. long, 5-12 $\mathrm{mm}$. broad, remotely toothed or entire marginally; leaves of midstem much-reduced upward, lance-linear or linear, entire, tapered to a fine point; upper 1-2 dm. of plant essentially leafless, sparingly branched; involucres $10-12 \mathrm{~mm}$. long at anthesis, $15-16 \mathrm{~cm}$. long in fruit; corollas lavender or yellow; achene body very flat, about $5 \mathrm{~mm}$. long, oblong or oblong-elliptic in outline, 2 to 2.5 times as long as broad, black, with 2 or 3 longitudinal nerves on each face plus numerous weak transverse ridges, the slender beak 2-4 mm. long, often drying flat.

Rare in moist canyons, on open seepy slopes and wet meadows in the higher parts of Davis and Guadalupe mts. in the Tex. Trans-Pecos, N.M. (rather widespread) and Ariz. (Apache, Coconino, Yavapai, Greenlee, Gila and Pima cos.), June-Sept.; s. U.S. from N.C. to Fla. and w. to Ariz., s. to n. Mex.

Not clearly separated from $L$. pulchella and probably grading into it.

\section{Lactuca pulchella (Pursh) DC. Blue LetTuce. Fig. 783}

Perennial; rhizomes scaly, extensive, 3-5 mm. thick; aerial shoots erect, 3-8 $\mathrm{dm}$. tall, simple and leafy for nearly the entire length; leaves not greatly reduced upward (those at midstem more than half as long as those at base), mostly linear and unlobed (in some specimens with very remote teeth marginally) or uncommonly nearly all the leaves runcinately pinnatifid; involucre $12-15 \mathrm{~mm}$. long at anthesis, 15-20 mm. long in fruit; corollas blue or lavender-blue; achene compressed, the body oblanceolate, about $4 \mathrm{~mm}$. long, about $1 \mathrm{~mm}$. broad, fuscousblack, with about 5 longitudinal nerves and very weak internerve-roughening, near 


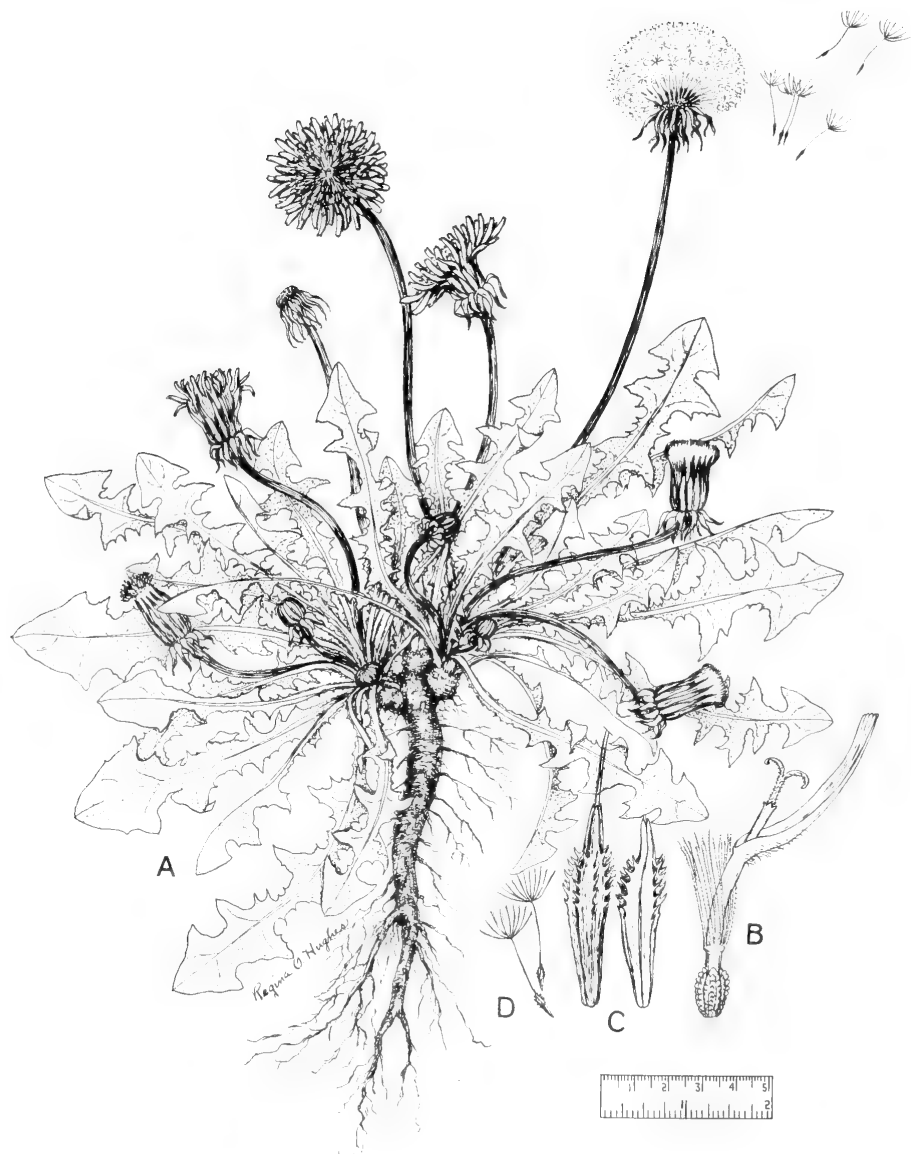

Fig. 784: Taraxacum officinale: A, habit, x 1/2; B, flower, x 3; C, achene, x 71/2; $\mathrm{D}$, achene with pappus, $\mathrm{x}$ 1. (From Reed, Selected Weeds of the United States, Fig. 216). 
the top tapering shortly into the stout beak which is $1 \mathrm{~mm}$. long and about 0.4 $\mathrm{mm}$. thick.

In wet meadows and wet soils in ravines, in Okla. (Washita Co.) and very rare if not extinct in the Davis Mts. in the Tex. Trans-Pecos, N.M. (widespread) and Ariz. (Apache, Navajo, Coconino and Cochise cos.); widespread in Rocky Mts. and s. to Mex. and Guat,; also Mich., Wisc., Ia., Mo. and Que. to Alas.

\section{Lactuca floridana (L.) Gaertn.}

Robust annual (5-) 10-25 (-33) dm. tall, the stem simple for nearly the entire height or branched only very near the top; leaves nearly all deeply runcinatepinnatifid but with an extremely ample triangular terminal portion and only 1 (or 2) large lateral lobes on each side, marginally toothed; involucres 9-10 mm. long at anthesis, to $10-12 \mathrm{~mm}$. long in fruit; corollas bluish or white; achene body oblanceolate, 4-4.5 mm. long, flattened but not at all winged, about 3 times as long as broad, with 2 or 3 longitudinal nerves on each face and many weak transverse internerve ridges, mottled black and brownish-gray, shortly tapered apically to a stout somewhat beaklike cylindrical apex (0-) $0.5-1 \mathrm{~mm}$. long and $0.5 \mathrm{~mm}$. thick. L. villosa Jacq.

Along streams, in wet thickets and alluvial woods, swampy ground and in wet sands in e. Okla. (Waterfall) and in n.-cen. and e. Tex., rare to s.e. Tex., Aug.-Oct.; e. U.S.

\section{Crepis L. Hawk's-BEARD}

A genus of perhaps 200 species of the Northern Hemisphere and Asia.

\section{Crepis runcinata (James) T. \& G.}

Essentially glabrous perennial from woody or slightly fleshy rootstocks to 5-10 $\mathrm{mm}$. thick, these apparently branched well-underground; leaves all crowded at the base, 5-12 cm. long, 15-30 mm. broad, oblanceolate, nearly entire or rarely with a few teeth or shallow lobes, rather fleshy and glaucous, essentially sessile; cauline leaves only 1 or 2 per stem and much-reduced to mere bracts, entire and oblanceolate, appressed; scapelike stems sparingly branched, the branches ascending with each terminating in a head; heads few; involucre narrowly campanulate, 12-20 mm. long, an inner double series of subequal linear-subulate thin-membranous scarious-margined phyllaries and 8 to 10 much shorter calyculate ones at the base; receptacle convex, naked or with a few minute hairs; rays yellow, 5-toothed terminally; achenes $4-5.5 \mathrm{~mm}$. long, slightly attenuate apically but not beaked, nearly columnar or the outer ones somewhat compressed, with 10 to 13 ribs; pappus rather persistent, of a number of white fine capillary bristles which are lightly coherent basally. $C$. perplexans $R y d b$.

Rare in open seasonally moist prairies and about playa lakes in the higher parts of Tex. Plains Country (Dallam Co.), and N.M. (eastern half), summer; very widespread in Great Plains and trans-Montane basins.

\section{Taraxacum ZINN DANDELION}

A Temperate Zone genus of perhaps 50 species. Hundreds of species have been proposed, based largely on apomictic populations.

\section{Taraxacum officinale Wiggers. COMMON DANDELION. Fig. 784.}

Winter annual or perennial herb from deep taproots to $1 \mathrm{~cm}$. thick; leaves all crowded in a basal rosette, 5-15 cm. long, runcinately pinnatifid; stems scapose, 3-20 cm. tall, solitary or few, each topped by a solitary head; involucre broadly obconic, 1-2 cm. broad and high; phyliaries in 2 definite size-classes; inner (longer) phyllaries in 2 equal series, linear-subulate, thin-membranous with hyaline margins, at anthesis appearing very slightly coherent at the overlapping margins but with age pulling apart and eventually spreading at maturity of fruit, 
each near the apex dorsally with a minute glandular spot which usually during maturation of the fruit proliferates into a low crest or minute horn, making the phyllary appear double-tipped or -appendaged; outer (shorter) phyllaries about half or less as long as the inner, of the same texture and shape, spreading during anthesis, calyculate; receptacle very slightly convex, naked; flowers all perfect, fertile, in some races parthenogenetic and lacking functional stamens; corolla yellow, bilaterally symmetrical, the raylike portion 5-toothed terminally; achene very slightly flattened (the exterior ones sometimes roughly trigonous but plump and rounded), the basal fusiform body with about 5 major rounded ribs and some lesser intermediate ones, the one in the anterior portion often with a row of antrorse spinose projections, the body giving way abruptly to the filiform beak as long as or longer than the body and slightly flared apically; pappus of a large number of whitish or yellowish-white fine capillary bristles which are either persistent or break off separately but not falling together. T. erythrospermum Besser, plus a number of other synonyms.

Locally abundant in lawns, roadsides and other disturbed favorable places, common in wet meadows in mts., essentially throughout our entire region, springsummer; nat. of Eur., now widely adv.

A troublesome lawn weed whose leaves are used as a pot herb when young. The color of the achene varies from grayish or buffy to rich-chestnut.

\section{Agoseris Raf.}

Perennial or rarely annual scapose herbs; leaves narrow, entire to pinnatifid; heads solitary on long naked scapes; involucre usually graduated; receptacle naked; corollas yellow, orange or purple; achenes subfusiform, ribbed, smooth, beaked; pappus of soft white capillary bristles.

About 25 species that are native to North America and southern South America.

1. Beak of achene rather stout, nerved throughout; flowers yellow, with age drying pinkish. 1. A. glauca.

1. Beak of achene slender, not nerved throughout; flowers burnt-orange, with age often drying to purple or deep pink 2. A. aurantiaca.

\section{Agoseris glauca (Pursh) Steud.}

Glabrous or nearly so and somewhat glaucous perennial, to about $7 \mathrm{dm}$. tall; leaves linear to oblanceolate, to $35 \mathrm{~cm}$. long and $3 \mathrm{~cm}$. wide, entire or occasionally with a few scattered teeth or shallow lobes; phyllaries imbricate or subequal, mostly sharply pointed, sometimes purple-spotted; flowers yellow, often drying pinkish; achenes 5-12 $\mathrm{mm}$. long, often hirtellous-puberulent, the body tapering gradually to a stout evidently striate beak to about half as long.

Wettish prairies and wet subalpine meadows, in N.M. (McKinley and San Juan cos.) and Ariz. (Apache to Mohave, s. to Graham and Pima cos.), MayOct.; B.C., s. to N.M., Ariz. and Nev.

\section{Agoseris aurantiaca (Hook.) Greene.}

Perennial, glabrous to somewhat villous, 1-6 dm. tall; leaves to $35 \mathrm{~cm}$. long and $3 \mathrm{~cm}$. wide, rounded to acuminate at apex, entire or with a few divergent slender teeth or lobes; phyllaries narrow, equal or somewhat imbricate, sharply pointed or the outer ones obtusish, often purplish along the midrib and sometimes purple-dotted; flowers burnt-orange, commonly turning purple to deeppink in age; achene body 5-9 $\mathrm{mm}$. long, abruptly narrowed to the slender scarcely or obscurely striate beak that varies from distinctly longer to scarcely more than half as long as the body.

In wet subalpine meadows and on seepage slopes, open conifer forests, in N.M. (Rio Arriba, San Juan and San Miguel cos.) and Ariz. (Apache, Coconino, Yavapai, Gila, Cochise and Pima cos.), June-Aug.: B.C. to N.M. and Ariz. 


\section{Glossary}

(Based primarily on the compilation by Herbert L. Mason in "A Flora of the Marshes of California" (1957); with permission.)

$A-$. A prefix denoting without, such as asexual.

Abaxial. Pertaining to the side of an organ away from the axis, such as the lower surface of a leaf (fig. 256). Compare Adaxial.

Abbreviated. Shortened, as when one part is shorter than another.

Abscission. Act or process of cutting off. Abscising: to cut off.

Acaulescent. Seemingly without a stem; term applied to a plant which is apparently stemless, the stem being very short or subterranean (fig. 789).

Accrescent. Becoming enlarged, as do certain parts of a flower after anthesis.

Accumbent. Lying against anything; applied to cotyledons having edges against the radicle.

Acerose. With a sharp, slender, needlelike point.

Achene. A hard, dry indehiscent, one-seeded fruit with a single cavity (fig. 789). Acicular. Needle-shaped.

Acropetal. Produced in a succession toward the apex, as applied to the development of organs.

Actinomorphic. Exhibiting radial symmetry, as a regular flower.

Acumen. A tapering point. A point the margins of which are not exactly straight but bow inward.

Acuminate. Tapering gradually to a sharp point at the end (fig. 787).

Acute. Ending in a point which is less than a right angle, but not so tapering as "acuminate" (fig. 787).

Adaxial. Pertaining to the side of an organ toward the axis, such as the upper surface of a leaf (fig. 256). Compare Abaxial.

Adnate. United to an organ of a different kind, as are the stamens in flowers of the Scrophulariaceae (epipetalous), or stipules in certain members of Potamogeton (fig. 32).

Adventitious. Occurring out of regular order in either time or place; term applied, for example, to a bud developing on a tree trunk.

Adventive. Applied to an introduced plant, not definitely established or naturalized.

Aerial. Epiphytic plants; plants or parts of plants living above the surface of the ground or water.

Aestivation. The arrangement of the perianth in the bud.

Alate. Winged.

Alkaline. Of, pertaining to, or having the properties of an alkali (a soluble mineral salt present in some soils of arid regions).

Alliaceous. Having the odor of onions.

Alluvial. Soils deposited by running water.

Alpine. Strictly applicable to plants growing above timber line.

Alternate. Said of leaves occurring one at a node, those of successive nodes forming a definite sequence around the stem; said also of members of adjacent whorls in the flower when any member of one whorl is in front of or behind the junction of two adjacent members of the succeeding whorl. 
Alveolate. Pitted, honeycombed, as are the seeds in certain Scrophulariaceae.

Ament. A lax, spikelike inflorescence, as in the willows or alders (fig. 788).

Amphibious. Capable of living on land or in water.

Amphitropous. Turned both ways; applied to an ovule with hilum intermediate between the micropyle and chalaza.

Amplexicaul. Clasping the stem (fig. 481).

Anastomosing (-ed). Netted; particularly applied to veins so connected by cross veins as to form a network.

Anatropous. An inverted and straight ovule, with the microplye next to the hilum.

Androecium. A collective term applied to all structures in the stamen whorl or whorls.

Androgynous. Having staminate and pistillate flowers in the same inflorescence, or in Carex in the same spikelet, the former above the latter.

Angiosperms. Plants having their seeds enclosed in an ovary.

Annual. A plant which completes its life history within a year.

Annular. In the form of a ring.

Annulus. A ring-shaped part or organ, such as surrounds the sporangium in some ferns.

Anterior. Pertaining to the side away from axis.

Anther. The pollen-bearing part of a stamen.

Antheridium. The male sexual organ of ferns; analogous to the anther.

Antheriferous. Anther-bearing.

Anthesis. The period during which a flower is open; the act of opening of a flower.

Anthodium. A head which resembles a flower, as in the sunflower (figs. 741, 788).

Antrorse. Directed forward and upward.

A petalous. Without petals (fig. 25).

A phyllopodic. The lower leaves bladeless or nearly so.

A phyllous. Leafless.

Apical. At the apex or tip.

A piculate. Ending abruptly in a minute point.

Apomixis. Any form of asexual reproduction.

Apophysis. An enlargement or swelling of the surface of an organ; the part of a cone scale that is exposed when the cone is closed.

Appendage. A lateral organ on a stem, usually at a node.

Appressed. Closely pressed against.

Aquatic. Living in water.

Arachnoid. Covered with long hairs so entangled as to give a cobwebby appearance (fig. 785).

Arborescent. Treelike in tendency.

Arcuate. Curved as a bow (fig. 41).

Areolate. Bearing areoles, divided into distinct spaces.

Areole. A small angular pit on a surface, as may occur between the veins of a leaf or on a seed coat.

Argillaceous. Clayey, growing in clay or clay-colored.

Aril. A process of the placenta adhering about the hilum of a seed. Arillate: with an aril. Arilliform: bag-shaped.

Aristate. Awned; provided with a bristle, usually at the end. (fig. 763).

Aristulate. Bearing a short awn.

Arroyo. A water course, or channel or gully, often dry, carved by water.

Articulation. A joint; the area in a stem or in a leaf petiole where separation occurs naturaliy.

Ascending. Directed or rising upward obliquely. 
Asepalous. Without sepals.

Asexual. Characterized by reproduction which does not involve the fusion of a sperm and an egg.

Attenuate. Gradually narrowed to a point at apex or base.

Atypical. Not typical; departing from the norm.

Auricle. An earlike appendage (fig. 25).

Auriculate. Eared (fig. 787).

Autumnal. Belonging to autumn; flowering at, or developing vegetative growth peculiar to, that season.

Awl-shaped. Tapering gradually from the base to a slender tip, as does a needle. $A w n$. A stiff, bristle-like appendage, usually at the end of an organ, (fig. 112).

Awned. Provided with an awn (fig. 741).

Axil. The upper angle between an organ and the axis which bears it, such as the angle between the leaf and the stem bearing the leaf.

Axile placentation. Placentation in fruits the seeds of which are borne attached to the placenta situated in the angles of the cross walls along the axis (fig. 789). Axillary. Growing in an axil.

Axis. The main or central line of development of a plant, structure, or organ, such as the main stem.

Baccate. Berrylike and pulpy.

Balanced hair. A hair seemingly attached at the middle (fig. 786).

Banner. The upper, broad, more or less erect petal of a papilionaceous flower; standard (fig. 501).

Barbed. Furnished with reflexed projections (figs. 170, 364).

Barbellate. Finely barbed (fig. 741).

Barbulate. Having fine beards.

Basal placentation. The attachment of the ovule at the base of the ovary.

Base. Basal or lower part of a plant or organ; through growth this basal part may eventually become uppermost.

Basifixed. Attached by the base.

Bayou. A creek, often slow-moving.

Beak. A long, substantial point, which may be terete or angular (fig. 741).

Beaked. Ending in a beak (fig. 741).

Bearded. Furnished with long, stiff hairs or bristles.

Berry. A fleshy fruit, few- to many-seeded.

$B i$ - or Bis-. Latin prefix signifying two, twice or doubly.

Bibracteate. Having two bracts. Bibracteolate: the diminutive.

Bidentate. Two-toothed (fig. 272).

Biennial. A plant requiring two years in which to complete its life history; the first year the vegetative growth occurs, and the second year it flowers, seeds and dies.

Bifid. Split into two parts; two-cleft.

Bifoliolate. A leaf composed of two leaflets.

Bifurcate. Forked; said of Y-shaped hairs, for example.

Bilabiate. Divided into two separate parts or lips (fig. 656).

Binomial. The combination of a generic and specific name to denote a given organism, as Ulmus americana.

Bipartite. Divided into two parts almost to the base; two-parted.

Bipinnate. Said of leaves wherein both the primary and the secondary divisions are pinnate.

Bisexual. Having both sexes on the same individual; a hermaphrodite.

Bisulcate. Having two grooves or furrows. 


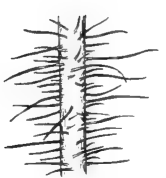

PILOSE

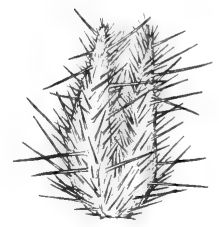

HISPID

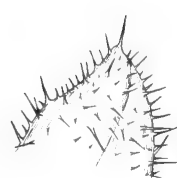

HISPID

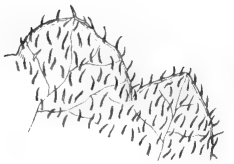

PILOSE - HISPID

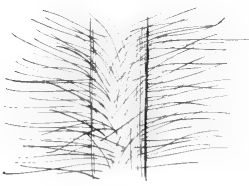

HIRSUTE

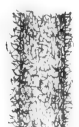

LANATE

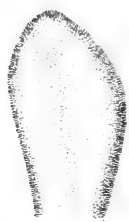

VELUTINOUS
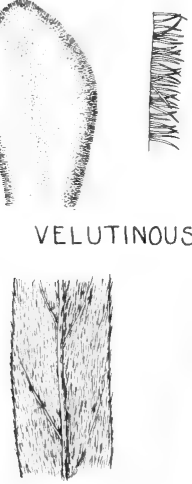

STRIGOSE
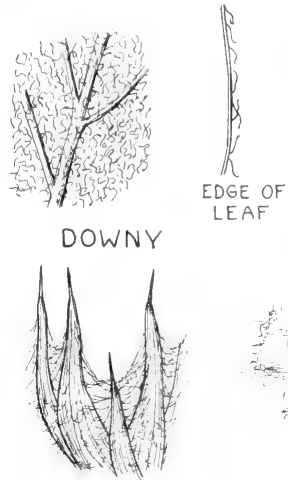

ARACHNOID

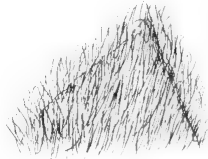

HIRSUTE-VILLOUS

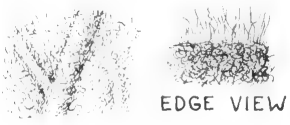

TOMENTOSE

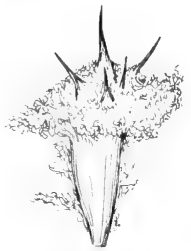

ARACHNOIDFLOCCOSE FLOCCOSE
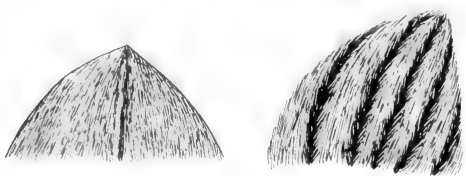

SERICEOUS

Fig. 785: Types of pubescence. (From Mason, Fig. 363). 
Biternate. Said of leaves wherein the three main divisions are themselves divided into three parts.

Bladdery. Appearing as though inflated.

Blade. The lamina, or expanded part of a leaf (fig. 787).

Bloom. The white powder or dust covering stems, leaves, fruits or flowers.

Brackish. Said of water with a high concentration of dissolved substances, usually somewhat salty.

Bract. A reduced or modified leaf, particularly the scalelike leaves in a flower cluster. Also said of any bractlike emergence.

Bractiform. Having the form of a bract.

Bractlet. A small bract, or sometimes applied to bracts in secondary positions.

Bristle. A stiff, sharp hair (fig. 786).

Bulb. A much shortened axis bearing fleshy leaf blades.

Bulbiferous. Bulb-bearing.

Bulblet. A small bulb, especially one borne in a leaf axil.

Bulbose, bulbous. Having bulbs or the character of a bulb.

Bullate. Blistered or puckered.

Bur. A fruit or fruiting involucre bearing prominent spines or hooks (figs. 57, $741)$.

Bush. (Cf. shrub).

Caducous. Falling off early or prematurely, as do the petals of Rhexia.

Calcareous. Containing an excess of available calcium, usually in the form of the compound calcium carbonate. "Limy".

Caliche. A crust of calcium carbonate formed on stony soils in arid regions.

Callus. A thick, leathery, or hardened protuberance, or part of an organ; new tissue covering a wound (fig. 402).

Callous grain. Callus on perianth segments of Rumex.

Calycine. Resembling a calyx; said of involucres or involucels.

Calyculate. Having bracts around an involucre or calyx, these bracts resembling an outer involucre or calyx, as in the common dandelion.

Calyx. The outermost whorl of the floral envelopes, composed of separate or united sepals; it may sometimes be petaloid.

Campanulate. Bell-shaped.

Campylotropous. (ovule or seed). So curved as to bring apex and base nearly together.

Canaliculate. Longitudinally channeled or grooved.

Cancellate. Latticed, or resembling lattice construction.

Canescent. Gray-pubescent.

Capillary. Hairlike, threadlike, very slender.

Capitate. Aggregated into a dense, compact cluster or head.

Capsule. A dry, dehiscent fruit originating from two or more carpels.

Carinate. Provided with a longitudinal ridge on the lower, or abaxial, surface; keeled.

Carpel. One of the foliar units of which a pistil is composed. If one carpel forms the pistil the latter is simple; if more than one, the pistil is compound.

Carpophore. A prolongation of the floral axis between the carpels, as that which supports the pendulous fruit of the Umbelliferae.

Cartilaginous. Hard and tough.

Caryopsis. An achene in which the pericarp is united with the seed; developed from a superior, one-carpeled ovary (fig. 108).

Catkin. A deciduous, erect or lax spike, consisting of unisexual, apetalous flowers (fig. 788). 
Caudate. Having a long, soft, terminal, tail-like appendage.

Caudex. The trunk or stem of a plant; a term applied particularly to the persistent stem of an herbaceous perennial.

Caudicle. Sterile stalk of the pollen mass of certain orchids (fig. 363).

Caulescent. Having an evident stem above the ground level (fig. 789).

Cauline. Pertaining to the stem (fig. 363).

Cell. A cavity of an anther containing the pollen, or of an ovary containing the ovules. Cellulous, cellular, cellulose: made up of cells or marked off so as to resemble cells.

Cespitose, caespitose. In little tufts or dense clumps; said of low plants of turfy habit.

Chaff. Thin, dry scales or bracts. Chaffy: paleaceous.

Channeled. Deeply grooved longitudinally, like a gutter.

Chartaceous. Thin but stiff; having the texture of thin paper.

Choripetalous. Term applies to a corolla having its petals distinct from one another.

Ciliate. Having marginal hairs that form a fringe (fig. 786).

Cilium (pl. cilia). Used generally in the plural to denote marginal hairs.

Cinereous. Ash gray.

Circinate. Coiled downward and inward, like the scroll of a fiddle (fig. 650). See Scorpioid.

Circumpolar. Occurring around the pole, as of arctic plants mostly confined to far northern latitudes.

Circumscissile. Dehiscent by a horizontal line cutting through the middle, the top part falling away as a lid (fig. 789).

Cirrhose. Tendrilled; with a wavy hair-point.

Cladode. A branch of a single internode simulating a leaf; a cladophyll. Cladophyll: a branch assuming the form and function of a leaf; a cladode.

Clavate. Club-shaped; gradually thickened upward (fig. 35 ).

Claw. The narrowed, petiole-like base of some petals or sepals.

Cleft. Cut about halfway to the midvein (fig. 787).

Cleistogamous. Said of self-fertilized flowers that never open.

Clinandrium. The anther bed in orchids, that part of the column in which the anther is concealed.

Coalescence. Union of similar parts or organs, as of petals to form a corolla.

Coccus (pl. cocci). A berry; in particular one of the parts of a lobed fruit with one-seeded cells; part of a schizocarp or lobed fruit.

Cochleate. Coiled like a snail shell. Cochleiform: shaped liked a snail shell.

Coetaneous. Of the same age; existing at the same time.

Coherent. Having like parts united; said of two or more organs of the same kind which are united in the same whorl by ontogenetic fusion.

Cohesion. The state of cohering.

Collar. Outer side of the grass leaf at the junction of sheath and blade.

Column. Structure formed by the union of filaments of stamens, or by the union of stamens and pistils; term also applied to the receptacle structure around which the carpels are situated in Malvaceae and related groups (fig. 519).

Coma. The tuft of hairs which is to be found at the end of some seeds (fig. 564).

Commissure. The line of meeting of the margins of carpels; the plane or face along which two carpels adhere.

Comose. Said of organs, such as seeds, which have a tuft of hairs at one end.

Compound. Formed of several parts united in one common whole, as is a compound pistil; or of leaves composed of two or more distinct leaflets (fig. 787). 
Compressed. Flattened laterally.

Concavo-convex. Concave on one side and convex on the other, as an eggshell or a lens.

Cone. The fruit of some fern allies, or a pine or fir-tree with scales forming a strobile; an inflorescence of fruit with overlapping scales. Conlet: a small cone. Conoid: conelike.

Confluent. Blending of one part into another.

Connate. United; a term especially applied to similar structures as the bases of two opposite leaves joined through toral growth.

Connective. The tissue connecting the two "cells" of an anther.

Connivent. Approximate but not organically united.

Conspecific. Of the same species.

Contracted. Narrowed in a particular place, or shortened; the opposite of open or spreading (inflorescence).

Convoluted. Said of flower parts when rolled in the bud with the edge of one part overlapping the adjacent part.

Cordate. Heart-shaped, such as the base of a leaf (fig. 787).

Cordate-clasping. Said of sessile appendages the basal lobes of which surround the stem (fig. 751).

Coriaceous. Leathery.

Corm. A solid, bulblike stem, usually found underground.

Corniculate. Furnished with horns or hornlike processes.

Cornute. Horned or spurred.

Corolla. The second whorl of the floral envelope, the units of which are petals; frequently the showy part of a flower.

Corrugated. Crumpled or folded irregularly.

Corymb. A racemose type of inflorescence in which the lower pedicels are successively elongate, thus forming a flat-topped inflorescence in which the outer flowers open before the inner ones do (fig. 788).

Corymbose. Said of flowers arranged in corymbs.

Costa (pl. costae). A rib; the midrib of a leaf. Costate: ribbed; having longitudinal elevations.

Cotyledon. One of the embryo leaves to be found in a seed.

Crateriform. Shallowly cup-shaped.

Crenate. Having a margin with low, rounded lobes (fig. 787).

Crest. An elevation or ridge upon the summit of an organ.

Crisped, cristate. Irregularly curled (said of hairs or leaf margins).

Crown. The persistent base of an herbaceous perennial; the top of a tree; a circle of appendages on the throat of a corolla, etc.

Cruciate. Cross-shaped, used especially for the flowers of Cruciferae. Cruciferous: cross-bearing; a flower with four petals placed opposite each other at right angles. Cruciform: cross-shaped.

Crustaceous. Having a surface with a crustlike texture.

Cucullate. Hooded, or hood-shaped.

Culm. The aboveground stem of grasses or grasslike plants (fig. 93).

Cuneate. Wedge-shaped; tapering toward the point of attachment (fig. 787).

Cuneiform. The same as Cuneate.

Cusp. A sharp, rigid point. Cuspidate: tipped with a cusp, or short, rigid point.

Cymba, cymbiform. A boat or boat-shaped.

Cyme. A form of inflorescence in which the main axis terminates in a single flower which opens before the lateral flowers arising beneath (fig. 788).

Cymose. Bearing cymes. 
Cystolith. Mineral concretions, usually a calcium carbonate on a cellulose stalk, occurring in special cells in the Urticaceae, etc.

Deciduous. Losing leaves seasonally.

Decompound. Said of compound leaves having divisions that are again dissected (fig. 787).

Decumbent. Reclining on the ground, with ascending apex (fig. 108).

Decurrent. Extending down the stem below the insertion; said of leaves or ligules.

Decussate. With successive pairs of organs arranged at right angles to one another, causing them to appear 4-ranked.

Deflexed. Turned back from point of attachment.

Dehiscent. Opening and shedding contents; said of fruits and stamens (fig. 789).

Deltoid. Triangular (fig. 787).

Dendritic hairs. Hairs that branch like a tree (fig. 786).

Dentate. Having marginal teeth pointing outward and not forward. Compare Serrate.

Denticulate. Bearing minute teeth directed outward.

Depauperate. Much reduced and imperfect in structure and development.

Determinate. Said of an inflorescence (as a cyme) in which the terminal flower blooms slightly in advance of its nearest associates; limited in number and extent.

Di-. Dis-. Greek prefix meaning two or double.

Diadelphous. Stamens united by their filaments into two sets.

Diaphragm. A dividing membrane or partition as that in the pith of grape vines and the pith in Juglans.

Dichotomous. Repeatedly forking in pairs. Dichotomy: a condition of being dichotomous.

Dicotyledons (abbr. dicots). A class of angiosperms differentiated by possession of two cotyledons.

Didymous. Twin; found in pairs.

Didynamous. With four stamens in two pairs of unequal length as in most Labiatae.

Digitate. Fingered; shaped as an open hand; compound with the members arising from one point.

Dimorphic, dimorphous. Having two forms, as flowers with short stamens and long styles or long stamens and short styles.

Dioecious. Having staminate and pistillate flowers in different plants.

Discoid. Disklike, in the Compositae, a head without ray florets. Disciform: flat and circular like a disk. (fig. 741).

Discrete. Separate, not coalescent.

Disk, disc. A fleshy development of the receptacle about the base of the ovary; in Compositae, the tubular flowers (disk florets) of the head as distinct from the ray.

Disparate. Unequal; dissimilar.

Disposed. Referring to the ultimate arrangement, irrespective of point of origin; thus, spirally arranged leaves may be disposed in two ranks so as to appear as though coming from opposite sides of the stem.

Dissected. Divided into several to many separate parts; said, for example, of the blade of a leaf (fig. 787).

Dissepiment. A partition in an ovary or pericarp caused by the adhesion of the sides of the carpellary leaves.

Distal. Opposite the point of attachment; apical; away from the axis.

Distichous. In two vertical rows or ranks.

Divaricate, divaricately. Widely divergent. 
Divided. Referring to the blade of an appendage when it is cut into distinct divisions to, or almost to, the midvein, as though cut with scissors (fig. 787).

Dorsal, dorsally. Pertaining to the back; the surface turned away from the axis. Dorso-: used in combination to denote the back of. Dorsum: the back or parts of the flower that face the outside.

Dorsifixed. Attached by or to the back.

Dorsiventral. Having distinct dorsal and ventral surfaces.

Downy. Covered with very short, weak hairs (fig. 785).

Drupe. A fleshy, one-seeded indehiscent fruit containing a stone with a kernel; a stone-fruit such as a plum. Drupelet: a diminutive drupe. Drupaceous: resembling a drupe, possessing its character, or producing similar fruit.

$E$-, Ex-. Latin prefix meaning without, out of, from, as "ebracteate."

Echinate. Prickly, a hedgehog.

Ecology. The study of organisms in relation to their environment.

Edaphic. Pertaining to, or influenced by, soil conditions.

Elater. An appendage within the sporangium which aids in dispersal of spores; in Equisetum, the clubbed hygroscopic bands attached to the spores.

Elliptic. In the form of a flattened circle, usually more than twice as long as broad. Ellipsoid: an elliptic solid.

Emarginate. Said of leaves, sepals, or petals, and other structures that are notched at the apex (fig. 787).

Embryo. Rudimentary plant within the seed.

Emersed, emergent. Raised above and out of the water.

Endemic. Restricted to a particular area or condition.

Endoglossum. A transverse projection from the dorsal wall of the carpel to make it almost completely septate.

Endosperm. The nutritive tissue surrounding the embryo of a seed and formed within the embryo sac.

Ensiform. Sword-shaped.

Entire. Having a margin devoid of any indentations, lobes, or teeth; said of the margin of appendages such as leaves, bracts, stipules, sepals and petals (fig. 787).

Epetiolate. Without petals.

Ephemeral. Referring to an organ living a very short time, usually a day or less. Epi-. Prefix meaning upon, such as "epiphyte."

Epigynous. Said of a flower having sepals, petals, and stamens that are borne on a structure at the top of the ovary, the ovary thus being inferior.

Epipetalous. Said of stamens when they are inserted on the corolla.

Epiphyte, epiphytic. Characterized by growing on other plants or objects but not parasitically, such as orchids, bromeliads and ferns.

Equitant. Said of leaves disposed in a plane parallel to the radius of the axis clasping the stem, such as the leaf of Iris and some species of Juncus (fig. 321).

Erose. Uneven; said of margins that give the appearance of having been torn, or of margins with very small teeth of irregular shape and size.

Escape. A cultivated plant found growing as though wild, dispersed by some agency.

Estipulate. Without stipules. (Cf. exstipulate).

Evergreen. Retaining leaves throughout the year.

Excurrent. Projecting beyond the edge, as the midrib of a mucronate leaf or nerve of a floral segment. 
Exserted. Extending beyond (some enclosing part of the plant); said of any structure in respect to its position relative to another structure, such as stamens that extend beyond the corolla.

Exsiccatae. Dried plant specimens, usually in sets for sale or for subscribers, or for exchange.

Exstipulate. Without stipules.

Extrorse. Facing outward from the axis, as the dehiscence of an anther.

Face. That surface of an organ that is opposed to the back, usually the upper or inner side.

Falcate. Curved like a sickle; said of appendages.

Farinaceous. Containing starch or starchlike substance; term applied to a surface with a mealy or scurfy coating. See Scurfy.

Fascicle. Borne as though in bundles tied at base, or as though branching from a common base (fig. 24).

Fastigiate. Clustered, parallel, erect branches.

Faucal. Pertaining to the throat of a gamopetalous corolla.

Favose. Pitted in a manner to give the appearance of a honeycomb.

Fenestrate. With transparent areas or windowlike openings.

Ferruginous. Rust-colored.

Fertile. Said of seed-bearing fruit or flowers capable of producing seeds, or of pollen-bearing stamens; also applied, incorrectly, to female flowers.

-fid. A suffix meaning deeply cut.

Filament. The stalk bearing the anther, or any threadlike structure.

Filamentose. Having the character of a filament (fig. 182).

Filiform. Filament-like, long and very slender. (fig. 46).

Fimbriate. Lacerate into regular segments so as to appear fringed (fig. 786).

Fistulous (fistulose). Hollow; said of some stems or petioles, or of leaves such as those of the onion.

Flabellate, flabelliform. Fan-shaped; broadly wedge-shaped.

Flange. A part that spreads out like a rim.

Flavescent. Yellowish, becoming yellow. Flavo-: used in combinations to denote yellowish.

Flexuous. More or less zigzag or wavy (fig. 271).

Floccose. Said of pubescence which gives the impression of irregular tufts of cotton or wool, the hairs usually loosely tangled. (fig. 785).

Flora. The aggregate of plants of a country or district, or a work which contains the enumeration of them.

Floral. Of or pertaining to flowers. Floral tube (or cup): a more or less elongate tube consisting of perianth or other floral parts.

Floret. One of the flowers in a close inflorescence of small flowers, such as in the spikelet of a grass or in the head of a member of the Compositae.

Floricane. The flowering cane, usually the second year's development of the primocane, in Rubus, etc.

Floristic. Having to do with the composition and organization of a flora.

Floristics. That aspect of phytogeography that deals with taxonomic composition and the geographic and quantitative relations of floras.

Flower. An axis bearing either functional stamens or pistils or both, these either naked or subtended by a perianth.

Foliaceous. Leaflike.

Follicle. A fruit, usually developing from a simple pistil and dehiscing along one margin (fig. 449). 
Fornix, fornices (pl.). Small arched scales in the throat of a corolla.

Fovea (pl. Foveae). A depression or pit, as in the upper surface of the leaf base in Isoetes, that contains the sporangium; the seat of the pollinium in orchids.

Fractiflex. Bending alternately and sharply in opposite directions; zigzag.

Free. Neither attached to a member of the same whorl nor to a member of another whorl.

Free-central. Said of placentation when the seeds are attached to a column which arises from the base and is not otherwise attached to the ovary wall (fig. 789).

Frond. Leaf of a fern, including the stipe and blade.

Fruit. The matured pistil or pistils and their accessory structures, bearing the ripened seeds.

Fruticose. Shrubby; shrublike.

Fugacious. Falling soon after maturing, as do flowers or flower parts.

Funiculus. The stalk which connects the ovule to the placenta.

Funnelform. Having the shape of a funnel; said of corolla or calyx.

Furfuraceous. Scurfy; covered with branlike scales.

Fusiform. Tapering at both ends; term applied to any structure.

Galea. That part of an irregular sympetalous corolla (usually the upper lip) that is extended as a spur or helmet (fig. 706).

Gametophyte. The gamete-producing form of the plant (as in ferns) contrasted with the spore-producing form of "sporophyte."

Gamopetalous. Corolla with petals united. Same as sympetalous and monopetalous.

Gamosepalous. Calyx with sepals united.

Geminate hair. Pair of hairs from a common base (fig. 786).

Genus. (pl. genera). The natural group containing distinct species; a group of one or more related species.

Gibbous. Said of a calyx or corolla tube or segment which has a distended, rounded swelling on one side.

Glabrous. Without pubescence of any kind.

Gladiate. Flat, straight or slightly curved, with acute apex and approximately parallel edges; ensiform; swordlike.

Gland. Any special secreting organ; (as commonly employed) any regularly occurring, anomalous, small protuberance anywhere on the plant (fig. 629).

Glandular. Bearing glands or having any glandular secretion.

Glaucous. Having a frosted or whitish waxy appearance from a waxy bloom or powdery coating.

Globose. Shaped like a globe or sphere.

Glochidia. A barbed hair or process.

Glochidiate. Having barbs.

Glomerate. Gathered in compact groups; said of flowers occurring in small clusters.

Glomerule. A small cluster of flowers consisting usually of a compacted cyme.

Glume. A member of a pair of bracts (often chaffy) subtending the spikelet of the grasses (fig. 131).

Glutinous. Sticky.

Graduated. Said of phyllaries when the outer ones comprising the involucre are successively shorter than the inner ones.

Grain. The seed or seedlike fruit of a member of the grass family; a small, hard, often superficial structure having the appearance of a grain, such as the callous grain in Rumex (fig. 400). 


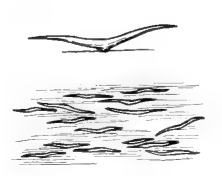

BALANCED
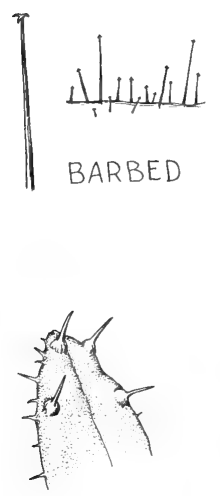

PUSTULATE

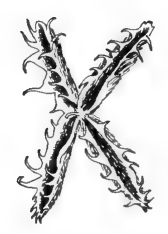

PECTINATE
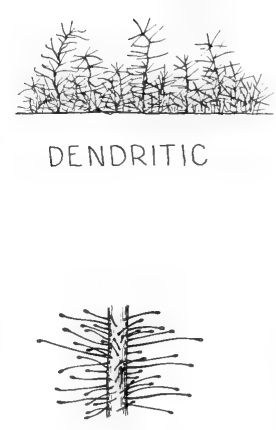

GLANDULAR
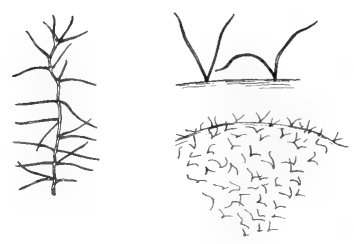

GEMINATE

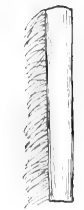

CILIATE
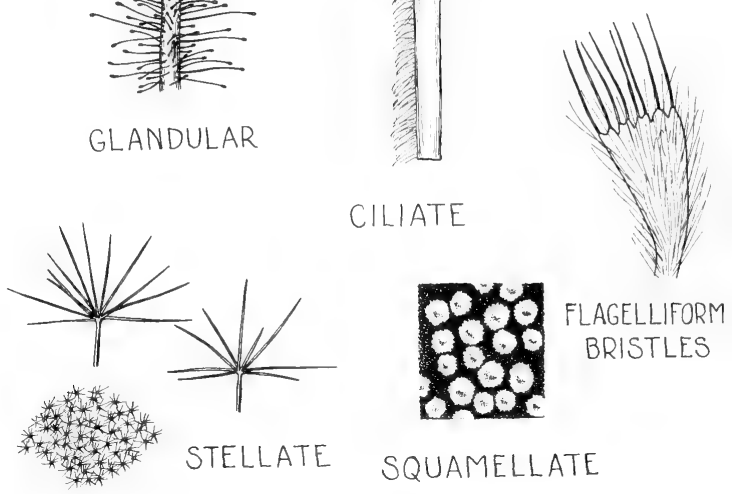

BRISTLES

SQUAMELLATE

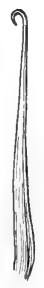

MONILIFORM FIMBRIATE

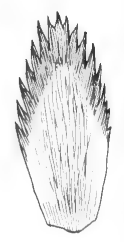

HAMATE

Fig. 786: Types of hairs and processes. (From Mason, Fig. 364). 
Granular, granulose. Covered with very small grains or granules; minutely mealy. Granuliferous: granule-bearing.

Gymnosperms. Plants with naked (uncovered) ovules, such as the conifers.

Gynandrous. Stamens adnate to the pistil.

Gynecandrous. Having staminate and pistillate flowers in the same spikelet, the latter above the former.

Gynobase. An enlargement of the torus or receptacle to form a platform or disk upon which the ovary rests.

Gynobasic. Applied to a style which adheres by its base to a prolongation upwards of the torus between carpels.

Gynoecium. That part of the flower in which fertilization takes place and in which the seeds develop; the total of structures, including carpels and accessory parts, occurring on the axis of the flower morphologically above the stamens or androecium.

Gynophore. The prolonged stipe of a pistil, as in Cleome.

Habit. The growth form of the plant.

Habitat. The precise set of environmental conditions in which the plant occurs.

Halophyte. A plant of salty or alkaline soils. Halophytic (adj.).

Hamate. Said of a spine which is hooked at the tip. (fig. 786).

Hastate. Said of arrow-shaped leaves with basal lobes that spread or extend downward and outward (figs. 424, 787).

Haustoria. The suckerlike attachment organs of parasites like Cuscuta.

Head. A dense globular cluster of sessile or subsessile flowers arising essentially from the same point on the peduncle; capitulum. (fig. 788).

Hemi-. Prefix meaning half.

Herb. A plant, either annual, perennial, or biennial, of which the parts aboveground are not woody.

Herbaceous. Having the structure or texture of an herb, not woody.

Herbage. All of the aboveground, non-woody part of a plant.

Hermaphrodite. With stamens and pistil in the same flower.

Heterogamous. Producing two or more kinds of flowers.

Heterosporous. Having spores of two sizes or shapes.

Heterostylic. Having long styles in some flowers and short styles in others on the same plant, or in different plants of the same species.

Hibernacle, hibernaculum. A winter bud.

Hilum. The scar of the point of attachment of a seed.

Hippocrepiform. Horseshoe-shaped.

Hirsute. Clothed with long, shaggy hairs, often rough to the touch (fig. 785).

Hirsutulous. Minutely hirsute.

Hirtellous. Minutely hirsute.

Hispid. Clothed with stiffish hairs that are sometimes spinelike (fig. 785).

Hispidulous. Having fine, short, stiff hairs.

Homo-. A Greek prefix denoting all alike or of one sort.

Hood. Cf. cucullate.

Host. A plant that nourishes a parasite.

Hyaline. Of thin, membranous, transparent or translucent texture.

Hydathode. An epidermal structure, usually marginal or terminal, which excretes water.

Hydrophyte. Partially or wholly immersed water plant. Hydrophilic, hydrophilous: dwelling in wet places or water; pollinated by water.

Hygroscopic. Susceptible of extending or shrinking on the application or absence of water or vapor. 
Hypanthium. A cup-shaped enlargement of the receptacle on which the calyx, corolla, and often the stamens are inserted; in perigyny the "calyx tube".

Hypogeous. Occurring below the surface of the ground.

Hypogynium. The perianthlike structure subtending the ovary in some genera of the Cyperaceae.

Hypogynous. Said of flowers in which the perianth and stamens are inserted upon the receptacle below the gynoecium.

Imbricated. Said of organs that are so placed as to overlap like the shingles on a roof (fig. 741).

Immersed. Growing under water.

Imperfect flower. Having either stamens or pistils, but not both.

Incised. Having the margin deeply cleft.

Included. Not projecting beyond (an enclosing part of the plant); said of an inner structure of a flower relative to an outer structure when the inner structure does not extend beyond the outer one or beyond some specified part of the outer one; for example, of stamens included in the corolla tube (fig. 650).

Incrassate. Made thick or stout, as the leaves of some species of Sedum.

Incumbent. Lying upon anything; said of cotyledons when the back of one rests against the stalk of the embryo.

Indehiscent. Said of fruits that remain closed and do not shed their seeds.

Indeterminate. Said of inflorescences in which the terminal flowers open last; also said of conditions in which growth and differentiation are not arrested.

Indurate. Hardened and thereby often persistent.

Indusium. The scale-like covering that invests the sorus in ferns.

Inferior. Occurring below; said of the ovary when it occurs in such a manner as to appear to be below the other flower parts (fig. $3 \mathrm{~b}$ ).

Inflated. Hollow and swollen in a manner to appear as if distended with air.

Inflorescence. An aggregation of flowers occurring clustered together in a particular manner which is usually characteristic of a given kind of plant (fig. 788).

Infrastamineal. Below the stamens.

Infrastipular. Below the stipules.

Infructescence. The inflorescence in a fruiting stage; collective fruits.

Insectivorous. Consuming insects, i.e., by digesting out the organic parts.

Insertion. The place of attachment of one structure on another.

Interlacunar. Between air spaces.

Internode. The part of a stem between any two adjacent nodes.

Introgression. Entrance; going in; used for hybridization and repeated back-crossing which can result in genetic contamination of one taxon by another. Introgressant: that which goes in; used for the organisms which show the results of introgression.

Introrse. Turned inward, toward the axis.

Involucel. A secondary involucre, such as one subtending an umbellet in a compound umbel. (fig. 788).

Involucre. A group of closely placed, free or united bracts that subtend or enclose an inflorescence (fig. 788).

Involute. Said of margins that are rolled inward (toward the adaxial side), as in a petal or a leaf.

Irregular. Said of the members of a given kind of structure when they are unlike in shape or size, such as the unequal lobes of a corolla (fig. $3 \mathrm{~b}$ ).

Joint. The internode of a grass culm; an articulation, as in fruits of Desmodium. (fig. 82c).

Jointed. Having one or more constrictions marking a point of articulation (fig. $420 \mathrm{~b})$. 
Keel. The folded edge or ridge of any structure, alluding to its resemblance to the keel of a boat (fig. 218); in papilionaceous flowers, the two united front petals (fig. 503).

Key or Key fruit. A winged fruit, like the maples, samara (fig. 620).

Labia, labiate. Lipped; a member of the Labiatae.

Lacerate. Torn irregularly.

Laciniate. Deeply incised into irregular, pointed lobes.

Lacuna (-ae). An air space in the midst of tissue; said of the vallecular canals of Equisetum; a hole or cavity.

Lamina $(-a e)$. The blade or expanded part of a leaf, petal, etc. Laminar: of the blade.

Lanate. Woolly, with long, intertwined, curled hairs (fig. 785).

Lanceolate. Much longer than broad; from a broad base tapering to the apex; lance-shaped (figs. 414, 787).

Lax. Loose and often scattered; often said of flowers in an inflorescence.

Leaflet. A discrete segment of a compound leaf.

Legume. A one-celled fruit dehiscent on two sutures; specifically, the fruit of a member of the pea family.

Lemma. The outer (abaxial) bract subtending a floret in the flower of a grass, often chaffy (figs. 3a, 108).

Lenticels. Corky spots on young bark, arising in relation to epidermal stomates. Lenticellate: having lenticels.

Lenticular. Shaped like a lens, having opposite sides convex (fig. 412).

Ligulate. Shaped like a ligule (fig. 741).

Ligule. An elongate, flattened structure; specifically, in monocotyledons, especially grasses, the bractlike emergence from the top of the leaf sheath at the base of the blade (fig. 108); in the Compositae, a strap-shaped corolla (fig. 741). (All corollas are ligules in the tribe Cichoreae; in many other Compositae only the marginal ray corollas are ligules.)

Limb. The spreading part of a sympetalous corolla or synsepalous calyx; usually referring only to the corolla lobes (fig. $3 \mathrm{~b}$ ).

Linear. Long and slender, with more or less parallel sides (fig. 787).

Lip. The upper or lower part of a bilabiate corolla or calyx.

Littoral. Of a shore, particularly of the seashore.

Lobe. An outward projection from the margin of an organ, usually with the margin indented on either side of the projection, as in leaves.

Lobed. Characterized by having lobes.

Locule (loculus). A compartment or cell, such as that of an ovary or anther.

Loculicidal. Said of capsules that are dehiscent along the loculus or back of the carpels (fig. 789). Compare Septicidal.

Lodicule. One of two or three scales at the bottom of the ovary, as in many grasses (fig. 3a).

Loment. A flat legume that is constricted between the seeds, falling apart at the constrictions when mature into one-seeded joints.

Lyrate. Lyre-shaped; pinnatifid, with the terminal lobe considerably larger than the others.

Macrosporangium. The organ in which macrospores are produced.

Male (plant or flowers). Having stamens but no pistils.

Malpighiaceous hairs. Straight appressed hairs attached by the middle and tapering to the free tips.

Marcescent. Withering, but remaining attached.

Marginal. Of, pertaining to, or attached to the edge. 
Marine. Growing within the influence of the sea or immersed in its water.

Maritime. Occurring in an area near the sea that is strongly influenced by environmental conditions imposed by the sea.

Marsh. A tract of wet or periodically inundated treeless land, usually characterized by grasses, cattails or other monocots.

Massula (-ae). A group of cohering pollen grains produced by one primary mother cell, as in the orchids; pollen mass.

Medifixed. Fixed or attached by the middle.

Megasporangium. The sporangium in which megaspores are developed or contained.

Membranous. Having a thin, soft, pliable texture.

Mericarp. One of the two seedlike carpels of an umbelliferous fruit.

Meristem. An area of actively dividing and growing cells, as at stem and root tips.

-merous. A suffix indicating the number of members in any given structure or whorl, such as a whorl of flower parts; for example, 5-merous or few-mercus.

Mesic. Characterized by or pertaining to conditions of medium moisture supply.

Mesophyte. A plant that grows under medium moisture conditions.

Micro-. Greek prefix meaning small.

Microsporangium. The organ in which microspores are produced.

Midrib. The conspicuous central vein in the vascular system of an appendage.

Monadelphous. Having the stamens united into a single structure. Compare Diadelphous.

Moniliform. Constricted so as to simulate a string of beads (fig. 786).

Monochasium $-a(\mathrm{pl}$.$) . A one branched cyme, either pure or resulting from the$ reduction of cymes.

Monocotyledon. A plant the seeds of which bear only one cotyledon.

Monoecious. Having the stamens and pistils in different flowers on the same plant.

Mucro. A sharp, abrupt point or spiny tip.

Mucronate. Said of appendages that come to an abrupt point (fig. 787).

Mucronation. The abrupt point of an appendage.

Mucronulate. Coming to a small, abrupt point.

Muricate. Having a rough surface texture owing to many small, sharp projections (fig. 459).

Muticous. Pointless, blunt, awnless.

Naked. Without vestiture of any kind.

Naturalized. Of foreign origin, but established and reproducing itself as though a native.

Nectariferous pit. A depression or cavity bearing nectar, which may occur on a sepal, petal, or stamen (fig. 463).

Nerve. A vein.

Net-veined. Having the veins intricately branched and anastomosing.

Node. The region on the stem where a leaf or leaves occur.

Nodose. With knobs or knots. Nodulose: the diminutive.

Nut. An indehiscent, one-seeded fruit from more than one carpel and having a woody coat.

$O b$-. Latin prefix signifying the reverse or contrariwise.

Obcompressed. Flattend at right angles to the radius of the axis.

Obcordate. Heart-shaped, with the notched part away from the point of attachment (fig. 787).

Oblanceolate. Pointed at the apex, broadest above the middle, and tapering to the base (fig. 787). 
Oblate. Flattened at the poles.

Oblique. Said of a leaf having one side of the blade lower on the petiole than the other (fig. 787).

Oblong. Longer than broad, the sides nearly parallel for most of their length (fig. 787).

Obovate. Ovate in shape, but with the broadest part near the distal end (fig. 787).

Obovoid. Inversely ovoid.

Obsolete. Rudimentary or not evident: applied to an organ that is almost entirely suppressed; vestigial. Obsolesent br coming rudimentary or extinct.

Obtuse. Having a blunt or rownded terminat part (fig. 787).

Ochrea (ocrea). A nodal sheath formed by the fusion of stipules, as in the Polygonaceae. (fig. 413).

Odd-pinnate. Said of a pinnately compound leaf having a terminal leaflet, thus having an odd, rather than an even, number of pinnae. (fig. 787).

Operculate. Having a lid.

Operculum. A lid.

Opposite. As said of leaves; occurring two at a node on opposite sides of the stem. As said of flower parts; when one part occurs in front of another.

Orbicular. Circular in outline.

Orifice. The mouthlike opening of a tubular corolla at the junction of limb and throat or tube.

Orthotropous. Said of seeds that are erect and having their micropyle at the apex.

Ovary. The part of the pistil bearing the ovules and maturing to form at least part of the fruit which bears the seeds.

Ovate. Said of a plane structure having the shape of the outline of an egg (fig. 787).

Ovoid. Egg-shaped.

Ovule. An unfertilized egg.

Palea(e). A hyaline scale; specificaliy, in the gräses, the upper bract of two sterile bracts, subtending a floret; in the Compositae, said of the scalelike pappus (fig. 741).

Paleaceous. Scalelike.

Palmate. Having several lobes radiating from a common base like the fingers from the palm of the hand (fig. 787).

Palmately compound. Said of a leaf divided into discrete segments to a common basal area at the top of the petiole (fig. 787).

Palmately lobed. Said of appendages when the lobes are so disposed as to appear to radiate from a common basal point (fig. 787).

Palmately veined. Said of veins when they radiate from a common basal point.

Paludal. Pertaining to marshes, wet all through the year.

Palustrine. Occurring in marshy places.

Paludose. Occurring in marshy places.

Panicle. A compound inflorescence, that is, one in which the axis is branched one or more times (figs. 108, 788).

Pannose. Feltlike in texture or appearance.

Papilionaceous. Butterfly-like; said of the flowers of leguminous plants having a corolla composed of an upright banner and two lateral wings, each representing a single petal, and a keel comprised of two petals variously united (fig. 503).

Papilla (-ae). A short protuberance.

Papillate, papillose. Bearing papillae.

Pappus. The chaffy, scaly, bristle-like, or plumose structure at the junction of the achene and the corolla in the Compositae (fig. 741). 

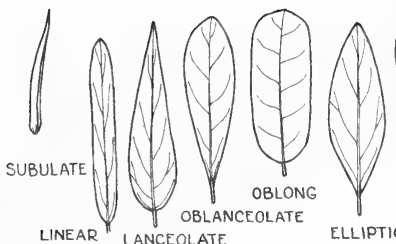
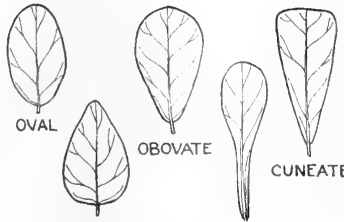

AF SHAPES

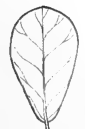

SPATULATE

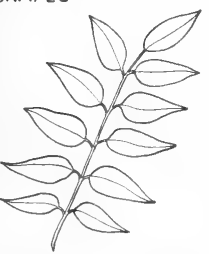

PINNATELY COMPOUND

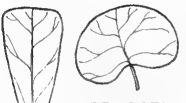

RENIFORM

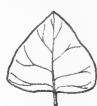

DELTOID

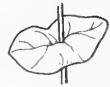

PERFOLIATE

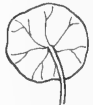

PELTATE

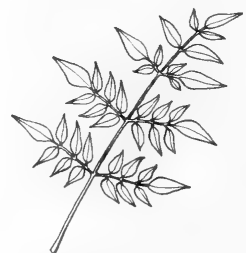

BIPINNATELY COMPOUND APEX OF BLADE

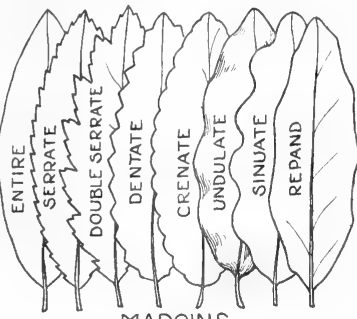

MARGINS
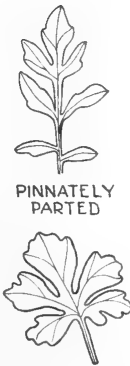

PALMATELY PARTED
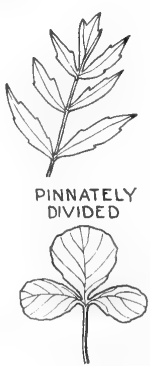

PALMATELY DIVIDED
aRISTATE

MUCRONATE $\neg$ CUSPIDATE $\frown$ ROUNDED $\frown$ OBCORDATE $\sim$ EMARGINATE $\sim$ RETUSE $\longrightarrow$ TRUNCATE OBTUSE

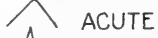
$\bigwedge$ acuminate BASE OF BLADE Y CORDATE TRUNCATE 7 ROUNDED GN SAGITTATE $\lfloor>$ HASTATE UN AURICULATE $\checkmark$ CUNEATE OBLIQUE

Fig. 787: Leaf characters. (From Mason, Fig. 365). 
Papule. A nipple-like projection.

Parallel-veined. Said of an organ in which the veins are so placed relative to one another that they approximate parallel lines.

Parietal placentation. Said of ovaries in which the seeds are borne on structures on the ovary wall, or on structures raised from the ovary wall (fig. 789).

Parted. Cleft to below the middle.

Pectinate. Said of an organ which is cleft into divisions in such a way as to resemble a comb (fig. 786).

Pedicel. Stalk or stem of a flower in a flower cluster (fig. 788).

Peduncle. The stem of a solitary flower or the main stem of a flower cluster (fig. 788 ).

Pellucid-punctate. Having translucent dots.

Peltate. Said of a plane structure that is attached at a point on its surface rather than on the margin, such as the leaf of the garden nasturtium, Tropaeolum (fig. 446) or Nelumbo.

Pendulous. Hanging.

Penicillate. Like a brush, such as the tuft of hairs on the style in certain vetches, or at the tip of the phyllaries in certain Compositae.

Pentamerous. With parts of fives, as a corolla of five petals.

Perdurant. Very long lasting.

Perennial. Living three or more seasons.

Perfect. Said of flowers that have both stamens and pistils.

Perfoliate. Said of opposite or whorled bracts or leaves that are united into a collar-like structure around the stem that bears them (fig. 787).

Perianth. The nonessential appendages of the flower situated outside the stamen whorl, and including both sepals and petals or other segments homologous with them.

Pericarp. The ovary wall as it matures in the fruit.

Perigynium. The sac or sheath enveloping the fruit in Carex and often appearing as though it were the ovary wall (fig. 264).

Perigynous. Said of flowers in which the perianth and stamens are inserted on the receptacle around the gynoecium, or of flowers in which the ovary is partly embedded in the receptacle, e.g., the flowers of cherries and plums.

Persistent. Said of an organ that remains attached after ceasing to perform its usual biological function.

Petal. A unit segment of the corolla presumed to be homologous with a leaf.

Petaloid. Having the form and structure and sometimes also the arrangement of petals.

Petiole. The stem or stalk of a leaf (fig. 787).

Petiolule. The stalk of a discrete segment of a compound leaf.

Phyllary. A bract of the involucre in the Compositae (fig. 741).

Phyllopodic. Having the lower leaves with well-developed blades.

Pilose. Having a vestiture or pubescence of scattered, long, slender, but not harsh, hairs (fig. 785).

Pilosulous. Finely pilose.

Pinna (-ae). A leaflet or primary segment of a pinnately compound leaf.

Pinnate. Having a common elongate rachis or axis, with segments arranged either oppositely or alternately along either side (fig. 495).

Pinnately compound. Said of structures the lateral segments of which are discrete and arranged along a common axis (fig. 787).

Pinnatifid. Cleft in a pinnate manner.

Pinnule. A secondary pinnately disposed part of a twice or more pinnately compound leaf. 
Pistil. One of the essential organs of a flower, consisting usually of stigma, style, and ovary, the ovary containing the ovule or ovules.

Pistillate. Bearing pistils only.

Placenta. The structure or tissue in the ovary bearing the ovules.

Placentation. Disposition of the ovules on the placentae within the ovary.

Plaited. With more or less equal lengthwise folds; plicate.

Plane. With a flat surface; projected in the manner of a plane from some designated point or level.

Plano-convex. Flat on one side and convex on the other.

Plicate. Repeatedly folded, usually lengthwise, though not necessarily so; plaited. Plicatulate: the diminutive.

Plumose. With hairlike branches as in a feather; said of pappus segments and sometimes of branched hairs (fig. 741).

Pollen. The powdery grains which bear the sperm nuclei and which are contained in the anther.

Pollinium (pollinia). A mass of coherent pollen grains characteristic of orchids and milkweeds (fig. 363).

Polygamo-dioecious. Polygamous but chiefly dioecious.

Polygamo-monoecious. Polygamous but chiefly monoecious.

Polygamous. Having perfect, pistillate, and staminate flowers on an individual plant.

Polymorphous. Occurring in more than one form.

Polypetalous. With many distinct petals.

Primocane. The first year's cane (usually without flowers) of Rubus and similar genera.

Procumbent. Trailing or lying flat, but not rooting.

Proliferous. Bearing supplementary structures such as buds or flowers, either in an abnormal manner, or in a manner that is normal but from adventitious tissues.

Prostrate. Prone, said of stems or leaves that lie on the ground.

Protandrous. With anthers maturing before the pistils in the same flower.

Prothallium $(-a)$. A cellular, usually flat and thalluslike growth, resulting from the germination of a spore, upon which are developed sexual organs or new plants.

Pruinose. Having a waxy secretion forming a powdery covering.

Pseudo-. A Greek combining form to denote false.

Pteridophyta. The ferns and fern allies.

Puberulent. Covered with a pubescence of very fine, short hairs, not densely spaced.

Pubescent. Hairy; the general term for hairiness (fig. 785).

Pulverulent. Dusted as with fine powder.

Punctate. With depressed dots scattered over the surface. Punctuate. Dotted.

Puncticulate. With very fine depressed dots.

Punctulate. Marked with small spots.

Pungent. Having a long, sharp point; or penetrating, as said of an odor.

Pustulate hair. Hair with a bulbous base (fig. 786).

Putamen. The shell of a nut; the hardened endocarp of stone fruits.

Quadrate. Four-angled in cross section.

Raceme. An inflorescence with a single axis, the flowers arranged along it on pedicels (fig. 788).

Racemose. Characterized by having its parts disposed as in a raceme.

Rachilla. The axis of a spikelet, bearing the florets in the Gramineae (fig. 83). 
Rachis. The prolongation of the peduncle through a flower cluster, or of a petiole through a compound leaf (fig. 121).

Radiate. Disposed in a plane from a common center like the spokes of a wheel; also said of inflorescences in which the marginal corollas spread in this manner (figs. 444, 741).

Ray. Any spreading segment of a radiate structure; often used specifically for the marginal, ligulate corollas of the Compositae (fig. 741).

Ray flower. One of the marginal flowers in Compositae when the flower head bears ligulate corollas, in contrast to the tubular disk corollas of the central flowers (fig. 741).

Receptacle. The axis of a flower and its toral proliferation that bears the flower parts; term also applied to the discoid platform which bears a group of flowers in the headlike inflorescence of members of the Compositae (figs. 377, 741).

Recurved. Turned backward in a curving manner.

Reflexed. Turned backward from the point of attachment.

Regular. Said of a flower or of parts of a flower when the members within each whorl are alike.

Remote. Separated from one another.

Reniform. Kidney-shaped (fig. 787).

Repand. Exhibiting a slightly uneven margin when viewed at right angles to the plane (fig. 787).

Repent. Creeping (prostrate and rooting).

Replum. The marginate septum of certain pods that persist after the valves have fallen, as in the fruit of Cruciferae.

Resaca. A former course or channel of a stream, commonly water-filled to form narrow oxbow or meandering lakes.

Resupinate. Upside down, inverted by the twisting of the pedicel, as the flowers of orchids.

Reticulate. Netted.

Retrorse. Having hairs or other processes turned or pressed toward the base.

Retuse. With a shallow, rounded notch at the apex (fig. 787).

Revolute. Said of margins that are rolled backward (toward the abaxial side), as in some leaves.

Rhizome. A horizontal underground stem.

Rhombic. Somewhat diamond-shaped. Rhombiform: rhomb-shaped. Rhomboidal: a solid with a rhombic outline.

Rib. A thickened structure, usually surrounding a primary vein on a leaf; also, one of more or less parallel ridges on fruits, seeds, or stems

Ringent. Gaping, as the mouth of an open-throated bilabiate corolla.

Rootcap. Large cells that form a caplike covering for the smaller cells in rear (growing point).

Rootstock. A horizontal underground stem bearing both roots and aerial stems along its axis or from its tip.

Rosette. A group of organs, such as leaves, clustered and crowded around a common point of attachment.

Rosulate. Having the form of a rosette.

Rotate. Radiately spreading in one plane.

Rudimentary. Said of organs in which development has been arrested.

Rugose. With a wrinkled surface.

Runcinate. Deeply incised, with the segments directed toward the base.

Runner. A horizontal stem with long internodes that trails along the surface of the ground (fig. 789). See Stolon. 

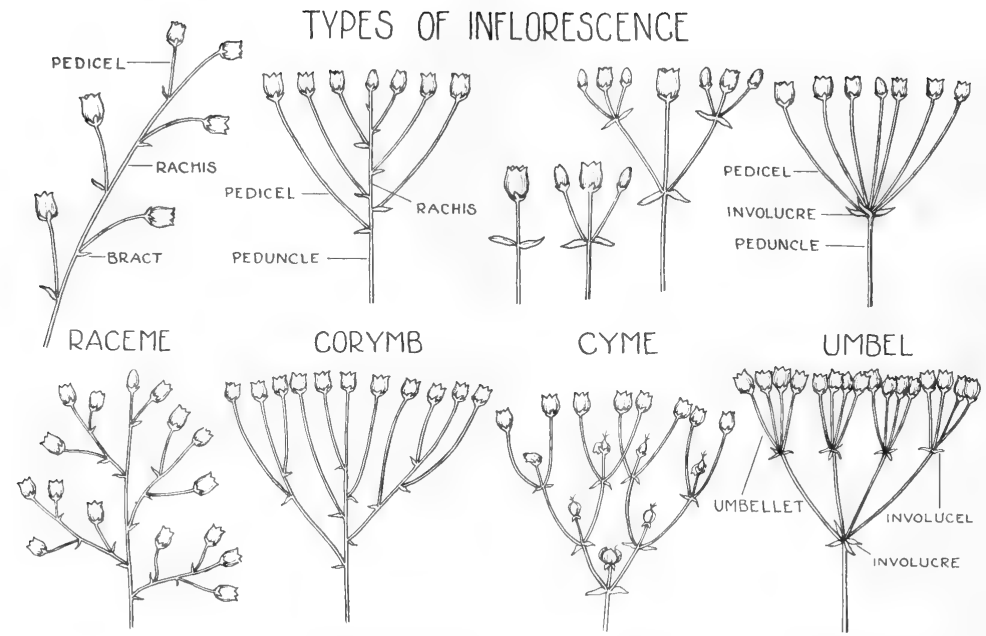

PANICLE COMPOUND CORYMB
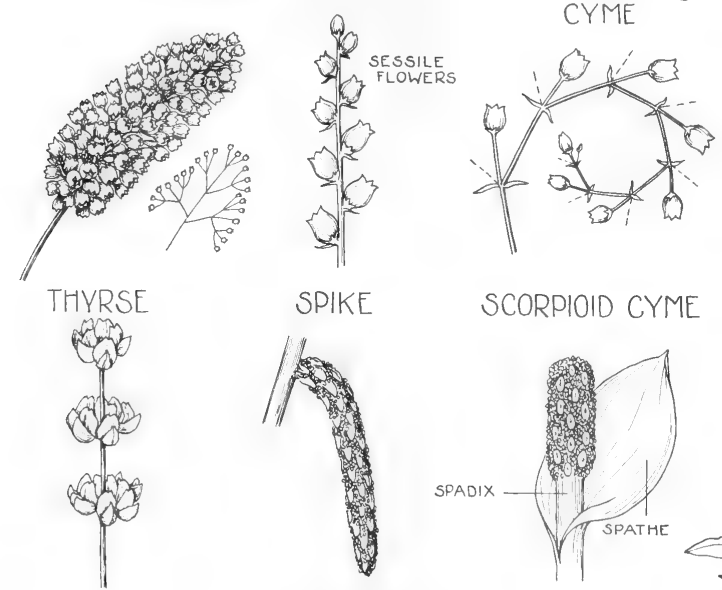

SPIKE

DICHOTOMOUS

COMPOUND UMBEL CYME 
Saccate. Having a saclike swelling; said of petals or sepals and sometimes of stamens and leaves (fig. 366).

Sagittate. Shaped like an arrowhead; said of the basal margins of a leaf which are drawn into points on either side of the petiole (fig. 65).

Saline. Of or pertaining to salt; growing in salt marshes.

Salverform. Said of a corolla in which the tube is essentially cylindrical and the lobes are rotately spreading.

Samara. A dry, indehiscent, one-seeded fruit bearing a wing, or two wings in a double samara (fig. 789).

Scaberulous. Finely scabrous.

Scabrellate. Rough as a result of minute surface protuberances.

Scabrid. Slightly rough.

Scabrous. Rough; said of a surface that is rough and harsh to the touch.

Scale. A small, thin, platelike lamina arising from the surface of a stem or other organ.

Scale leaf. A leaf having the size and form of a scale.

Scandent. Climbing without aid of tendrils.

Scape. An erect, naked peduncle of an acaulescent plant arising at the surface or from below the surface of the ground (fig. 788).

Scapose. Bearing a scape.

Scarious. Thin and membranous, usually dry.

Schizocarp. A pericarp that splits into 1-seeded portions, mericarps.

Scorpioid. Said of structures that grow as though uncoiling (fig. 650).

Scurfy. Having flakes or scales adhering to the surface.

Secund. Disposed on one side of a stem.

Seep $(s)$. A moist spot where underground water comes to or near the surface.

Segment. An ultimate natural division of an organ or whorl of organs.

Semi-. A prefix meaning half.

Sepal. One of the segments of the calyx.

Septate. Partitioned by walls (fig. 320).

Septicidial. Said of carpels dehiscing at their junction (fig. 789). Compare Loculicidal.

Sericeous. Covered with soft, silky hairs, which usually point in one direction and thus give the appearance of silk (fig. 785).

Serotinous. Produced or occurring late in the season.

Serrate. Having marginal teeth pointing forward (fig. 787).

Serrulate. Having very small marginal teeth; minutely serrate.

Sessile. Joined directly by the base without a stalk, pedicel, or petiole (fig. 27).

Seta. A bristle (fig. 786).

Setaceous. Bearing bristles.

Setose. Bearing bristles.

Sheath. The basal part of a lateral organ that closely surrounds or invests the stem.

Silicle. A short, two-celled fruit, usually broader than long, composed of two valves which separate from the central partition; a shortened silique (fig. 789).

Silique. An elongate, many-seeded, two-celled fruit with two parietal placentae, usually with two valves that separate from the partition on dehiscence, occasionally indehiscent (fig. 789).

Silky. Having the appearance or texture of silk.

Simple. Neither branched nor otherwise compound.

Sinuate. Having a wavy margin in the plane of the blade (fig. 787).

Sinus. The angle between lobes, as between two sepals of a synsepalous calyx, or petals of a sympetalous corolla.

Slough. A wet place or deep mud or mire; a sluggish channel. 
Smooth. Not rough to the touch; cf. glabrous, without hairs, which may be either smooth or scabrous.

Sori (sorus). The clusters of sporangia appearing as dots on the back of a leaf of a fern.

Spadix. The spikelike inflorescence enclosed in a spathe (fig. 788).

Spathe. A sheathing lateral organ or pair of organs usually open on one side and enclosing an inflorescence (fig. 788).

Spatulate. Shaped like a spatula, that is, gradually widening above and rounded at the tip (fig. 787).

Spheroidal. Shaped like a sphere or ball.

Spicate. Arranged in such a way as to resemble a spike.

Spike. A type of inflorescence in which the axis is somewhat elongated and the flowers are numerous and sessile (figs. 26, 788).

Spikelet. The segment of the inflorescence of grasses enclosed by a pair of glumes.

Spine. A rigid, sharp-pointed structure usually modified from a stem.

Spinescent. Bearing spines.

Spinose. Bearing spines.

Spinule. A diminutive spine.

Spore. The reproductive body of pteridophytes and lower plants, analogous to the seed. Sporeling: a young plant from germinated spore. Sporiferous: spore-bearing. Sporogenous: producing spores.

Sporophyll. A spore-bearing leaf.

Spreading. Diverging almost to the horizontal; nearly prostrate. Spreading hairs: not at all appressed, but erect. Spreading lower lip: diverging from the main axis of the flower.

Spur. Any hollow, elongate, pointed or blunt outgrowth of the corolla or calyx, as in Delphinium (fig. 363).

Squamellate. Having a vestiture of scales (fig. 786).

Squamellae. Small scales.

Squarrose. Having thickly crowded but spreading rigid leaves, bracts, or other processes.

Stalk. A short or elongate structure bearing or supporting another structure.

Stamen. The pollen-bearing organ; usually consisting of the stalk or filament and the anther containing the pollen.

Staminate. Said of plants or structures bearing stamens and not bearing pistils.

Staminodium. A sterile organ in the stamen whorl, presumed to be of staminal origin.

Standard. The broad, usually upright, petal in a papilionaceous flower such as that of the pea (fig. 503).

Stellate. Star-shaped; said of hairs or scales that branch in such a manner as to radiate from a central point of attachment (fig. 786).

Stem. The part of the plant bearing the foliar and floral organs and composed of nodes and internodes, or the latter much reduced.

Stigma. That part of the pistil that receives the pollen and in which pollination is effected (figs. $3 \mathrm{a}, 3 \mathrm{~b}$ ).

Sterile. Not fertile; said of flowers which for any reason are not bearing fruit. Sometimes, but not correctly, applied to staminate flowers.

Stigmatic. Pertaining to the stigma.

Stipe. The stalk of an ovary, or, in the Compositae of an achene (fig. 741).

Stipitate. Said of glands or of ovaries when they are borne on stalks.

Stipule. An appendage frequently occurring at the base of a leaf.

Stolon. A stem with elongate internodes that trails along the surface of the ground, often rooting at the nodes. See Runner. 
Stoloniferous. Bearing stolons, as in the strawberry.

Stramineous. Straw-colored.

Striate. Marked with fine parallel lines (fig. 292).

Strict. Erect and straight.

Strigose. Characterized by stiff, often appressed hairs, these usually pointing in one direction (figs. 416, 785).

Strobilus, strobile. Conelike aggregation of sporophylls. Strobilaceous: relating to or resembling a cone.

Strophiolate. Said of seeds having a strophiole.

Strophiole. An appendage at the hilum of some seeds.

Style. A short or long, simple or branched stalk arising from the ovary and bearing the stigma or stigmas; the part of the pistil which connects ovary and stigma (figs. 3a, 3b).

Stylopodium. An outgrowth from the base of the style and covering the top of the ovary, as in the Umbelliferae (fig. 574).

Subacute. Between acute and obtuse.

Subcoriaceous. Somewhat leathery.

Submerged, submersed. Growing under water.

Subulate. Shaped like an awl or prong (fig. 787).

Succulent. Fleshy; composed of soft, watery tissue.

Suffrutescent. Woody, at least at the base, said of a subshrub.

Suffruticose. Woody at base and definitely herbaceous above.

Sulcate. Bearing grooves.

Superior. Wholly above and not adnate to other organs, as a surperior ovary (fig. 3a).

Surficial. Of or pertaining to a surface, as the face of umbelliferous seeds.

Suture. A groove marking the line along which a structure opens; any lengthwise groove that forms a junction between two parts.

Swale. A moist meadowy area lower than the surrounding areas.

Symmetrical. Possessing one or more planes of symmetry (i.e., planes which divide the object into mirror-image halves).

Sympetalous. A corolla in which the petals are united.

Syn-. Greek prefix meaning united; adhesion or growing together.

Syncarpous. Having the carpels fused to form a compound pistil.

Synsepalous. Having the sepals united.

Taproot. A single, main primary root bearing small lateral roots (fig. 789).

Tawny. Of the color of natural leather, light-brown with a dull reddish or yellowish hue.

Taxon. A concept of a class of organisms at any categorical level that is predicated on the similarity of the constituents to one another with respect to a set of properties taken as the defining type of the class.

Tendril. A modified stem, leaf, or part of a leaf, in a climbing plant, that twines around an object and thus supports the plant.

Tepal. Used in the plural for sepals and petals of similar form and not readily differentiated, as in Amaryllidaceae.

Terete. Cylindrical or tapering and circular in cross section, as said of the stem of a plant.

Ternate. Thrice-forked, -branched, or -divided.

Tessellate. Having a checkerboard appearance or pattern.

Thallus. A flat leaflike organ; used sometimes for entire plant in Lemnaceae.

Throat. The usually expanded part of the corolla tube immediately below the lobes. 

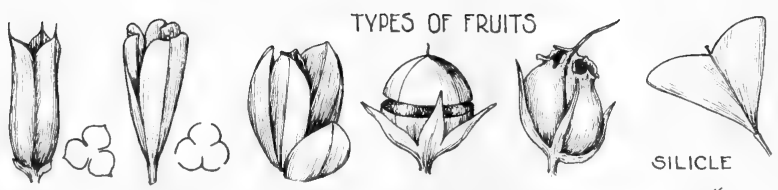

SEPTICIDAL LOCULICIDAL VALVULAR CIRCUMSCISSLE OPERCULATE
DEHISCENCE DEMISCENCE CAPSULE CAPSULE CAPSULE CAPSULE CAPSULE
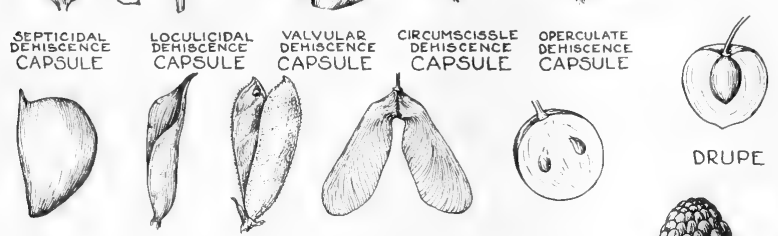

SILIQUE

ACHENE FOLLICLE LEgUME SOUBLE

BERRY
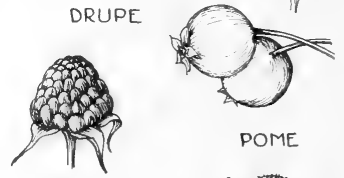

PLACENTATION
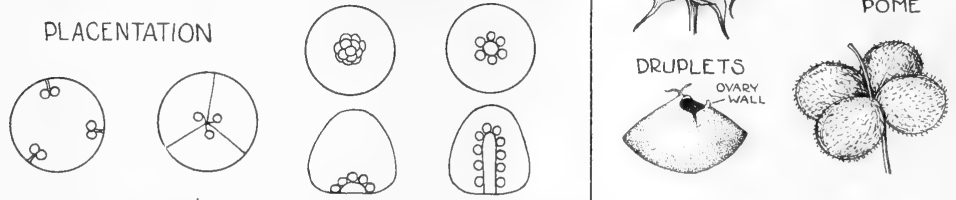

PARIETAL AXILE

BASAL FREE CENTRAL

UTRICLE

NUTLETS
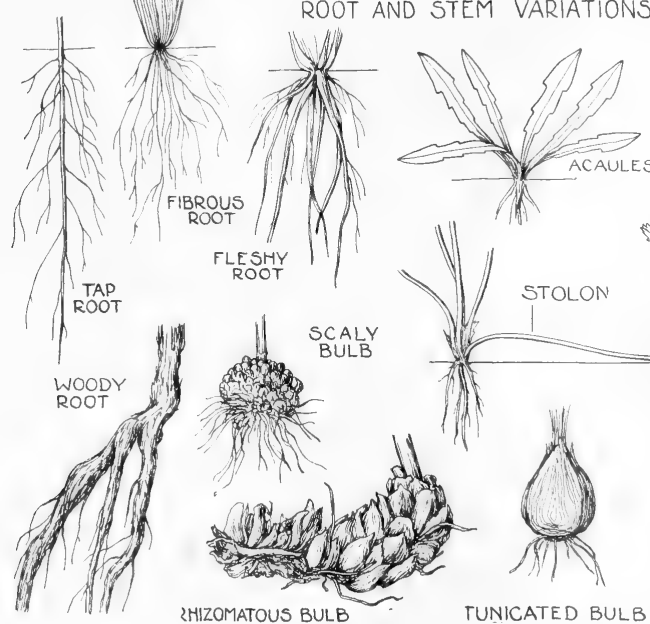

CAULESCENT
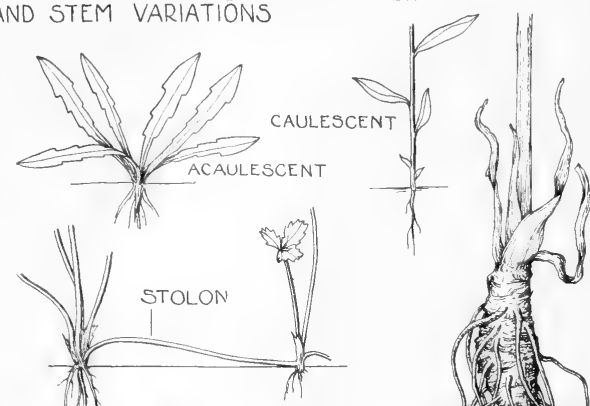

LMIZOMATOUS BULB
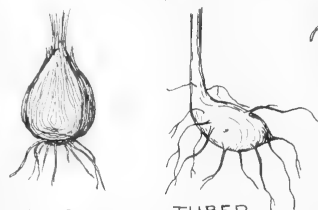

TUNICATED BULB

TUBER

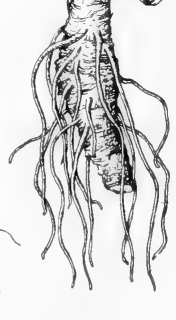

CAUDEX

Fig. 789: Types of fruits, and root and stem variations (From Mason, Fig. 367). 
Thyrse. A compact, compound panicle with an indeterminate axis (fig. 788).

Tomentose. Densely covered with short, matted hairs (fig. 785).

Tomentum. Pubescence of densely matted short hairs.

Toothed. Bearing teeth.

Torus. Specifically, the structure of a flower surrounding the gynoecium and bearing the other flower parts on its margin; may be used for any tubular outgrowth that originates as a ring of growth from the meristem.

Tri-. A Latin prefix signifying three, thrice, or triply.

Trichome. A hair or hairlike structure.

Tricostate. Having three ribs.

Trifid. Cleft into three parts.

Trifoliate. Bearing three leaves, as does Trillium.

Trifoliolate. Having a leaf comprised of three leaflets, as does clover.

Trigonous. Said of an achene or other structure which is three-sided or triangular in cross section (fig. 222).

Triquetrous. Having three projecting angles.

Truncate. Cut squarely across, either at the base or at the apex (fig. 787).

Tube. The narrow basal portion of a gamopetalous corolla or a gamosepalous calyx. Tubiform: tubular or trumpet-shaped.

Tuber. An enlarged, fleshy, underground stem, such as the potato (fig. 234).

Tubercle. A nodule on the surface, or a thickened, solid or spongy crown or cap, as on an achene.

Tuberculate. Bearing tubercles on the surface.

Tubular. Cylindrical and hollow.

Tufted. With a dense cluster of elongate structures spreading from what appears as a common point of attachment.

Tumid. Swollen.

Tunicated. Said of a bulb having its scales arranged in concentric layers as in the bulb of an onion (fig. 789).

Turbinate. Inversely conical, or top-shaped.

Turion. A scaly, often thick and fleshy, shoot produced from a bud on an underground rootstock, as in some species of Potamogeton.

Umbel. An inflorescence of few to many flowers on stalks of approximately equal length arising from the top of a scape or peduncle (fig. 788).

Umbellate. Arranged like an umbel (fig. 223).

Umbellet. The umbel-like segment of a compound umbel (fig. 788).

Uncinate. Hooked at the tip. Uncinulate: the diminutive.

Undulate. Having a wavy margin; said of leaves, petals, or sepals (fig. 787).

Uni-. A prefix, meaning one.

Unisexual. In flowering plants, said of a plant or flower that either bears only stamens or only pistils, but not both.

Urceolate. Said of a corolla with united petals and a tube that is expanded below the middle and narrowed at the top.

Utricle. A usually one-seeded, indehiscent fruit with a thin, bladdery, persistent ovary wall (fig. 789).

Vaginate. Loosely surrounded by a sheath. Vaginiform: sheath-shaped.

Valvate. Said of appendages (leaves, sepals, petals, or carpels) when arranged margin to margin with adjacent structures in the bud, or in the fruit.

Valve. A rigid or semirigid segment joined to adjacent structures by its margin.

Vascular bundles. The elements of the conducting or vascular system of a plant. 
Veins. The ultimate branches or divisions of the vascular system, as in leaves or petals.

Velum. A veil; a membranous indusium, as in Isoetes (fig. 7).

Velutinous. Having pubescence which is velvety in texture (fig. 785).

Venation. The pattern of the veins in an organ.

Venous. Characterized by having more or less conspicuous veins.

Venter. Under part.

Ventral. Pertaining to the under (or front) side of a structure. See Adaxial.

Ventricose. Swelling unequally or inflated on one side.

Vernal. Occurring in springtime; said of pools that contain water in spring and are dry in summer.

Vernation. The arrangement of leaves in the bud.

Verrucose. Having wartlike nodules on the surface.

Versatile. Turning freely on its support, as an anther attached crosswise at its mid-point to the apex of the filament.

Verticil. A ring of organs or flowers at a node; a whorl.

Verticillate. Occuring in verticils (fig. 788).

Vespertine. Blossoming in the evening.

Vestiture. That which covers the surface, as hair, scales, etc.

Villous. Densely beset with shaggy hairs.

Virgate. Long, slender, and straight, like a wand.

Viscid. Sticky.

Viviparous. Germinating or sprouting from spores or buds while still attached to the parent plant.

Whorl. A ring of leaves, flower parts, or flowers occurring at a single node (fig. 788). See Verticil.

Whorled. Occurring in a whorl (fig. 722).

Wing. A thin, flat extension from an angle or margin (fig. 503).

Woolly. Densely beset with wavy, curly, or twisted hairs (fig. 753).

Zygomorphic. Having the members of any whorl unlike; irregular (fig. 354). 


\section{Abbreviations and Signs}

Adj., adjacent.

Adv., adventive.

Afghan., Afghanistan.

Afr., Africa.

Ags. or Aguasc., Aguascalientes.

Ala., Alabama.

Alas., Alaska.

Alt., altitude(s).

Alta., Alberta.

Am., America or American.

Arct., Arctic.

Arg., Argentina.

Ariz., Arizona.

Ark., Arkansas.

Assoc., association(s).

Atl., Atlantic.

Auct., auctor (originator).

Austral., Australia.

Auth., author(s).

Bah. I., Bahama Islands.

Baja Calif., Baja California.

B.C., British Columbia.

Berm., Bermuda.

Bol., Bolivia.

Braz., Brazil.

Br. Gui., British Guyana.

Br. Hond., British Honduras.

C.A., Central America or Central American.

Calif., California.

Can., Canada.

Carib., Caribbean.

Cen., central.

Cf., compare, confer.

Chih., Chihuahua(n).

Chis., Chiapas.

$\mathrm{Cm}$., centimeter(s), the 100 th part of a meter $=$ about $2 \%$ of an inch.

Co. or cos., county (ies) .

Coah., Coahuila.

Col., Colombia.

Colo., Colorado.

Conn., Connecticut.

Cont., continental.

Corr., corected, as "(Corr. Willd.)"

C.R., Costa Rica.

Cult., cultivated or cultivation.

D.C., District of Columbia.

Del., Delaware.

Descr., description.
D.F., Distrito Federal.

Dgo., Durango.

Disj., disjunct.

Dm., decimeter(s), the 10th part of a meter $=$ about 4 inches.

E., east or eastern.

Eastw., eastward.

Ecu., Ecuador.

E.I., East Indies.

Elev., elevation(s).

Emend., emendavit (emendate).

Eng., England.

Err., error.

Eur., Europe, European.

Euras., Eurasia (n).

F., filius, son, or the younger (when following the name of an author); form (forma), in relation to a plant variant.

Fl., flower.

Fla., Florida.

Fr., France, fruit.

Ft., feet.

Ga., Georgia.

Gr. Ant., Greater Antilles.

Greenl., Greenland.

Gro., Guerrero.

Gto., Guanajuato.

Guat., Guatemala.

Gui., Guyana(s).

Hgo., Hidalgo.

H.I., Hawaiian Islands.

Hisp., Hispaniola.

Hond., Honduras.

I. or Is., island(s).

Ia., Iowa.

Icel., Iceland.

Ida., Idaho.

Ill., Illinois.

Illegit., illegitimate.

Incl., including.

Ind., Indiana.

Introd., introduced.

Ire., Ireland.

Isr., Israel.

It., Italy.

Jal., Jalisco.

Jam., Jamaica.

Kan., Kansas.

Ky., Kentucky. 
La., Louisiana.

Lab., Labrador.

Less. Ant., Lesser Antilles.

L.I., Long Island.

M., meter $(s)=$ about 39.3 inches.

Madag., Madagascar.

Man., Manitoba.

Mass., Massachusetts.

Md., Maryland.

Me., Maine.

Medit., Mediterranean.

Mex., Mexico.

Mich., Michigan.

Michoac., Michoacan.

Midwest., midwestern.

Minn., Minnesota.

Miss., Mississippi.

MM., millimeter(s) = about $1 / 25$ of an inch.

Mo., Missouri.

Mont., Montana.

Mor., Morelos.

Mt., mts., mountain(s).

N., north or northern.

N.A., North America or North American.

N.Afr., North Africa.

Nat., native.

Nay., Nayarit.

N.B., New Brunswick.

N.C., North Carolina.

N.D., North Dakota.

N.E., New England.

N.e., northeast or northeastern.

Neb., Nebraska.

Nev., Nevada.

Nfld., Newfoundland.

N.H., New Hampshire.

N.Hemis., Northern Hemisphere.

Nic., Nicaragua.

N.J., New Jersey.

N.L., Nuevo Leon.

N.M., New Mexico.

Nom. conf., nomina confusa (confused name).

Nom. rej., nomina rejicienda (rejected name).

Northw., northward.

N.S., Nova Scotia.

N.w., northwest.

N.Y., New York.

N.Zeal., New Zealand.

O., Ohio.

Oax., Oaxaca.
Okla., Oklahoma.

Ont., Ontario.

Ore., Oregon.

Orthogr., orthographical.

$\mathrm{Pa}$., Pennsylvania.

Pac., Pacific.

Pan., Panama.

Pantrop., pantropical.

Parag., Paraguay.

P.E.I., Prince Edward Island.

Pen., peninsula(r).

Phil., Philippines.

Polyn., Polynesia.

P.p., pro parte (in part).

P.R., Puerto Rico.

Pue., Puebla.

Que., Quebec.

Queensl., Queensland.

Qro., Queretaro.

Q. Roo., Quintana Roo.

Ref., reference.

R.I., Rhode Island.

Russ., Russia.

S., south or southern.

S.A., South America or South American.

S.Afr., South Africa.

Salv., Salvador.

S.C., South Carolina.

Scot., Scotland.

S.D., South Dakota.

S.e., southeast or southeastern.

Sect., Section.

Sens, amplo (or s. amplo), sensior amplo (broad sense).

Sens. lat. (or s.1.), sensior latior (broad sense).

Sens. str., sensior strictior (strict sense).

Sensu, in the sense of.

Ser., Series.

Sib., Siberia.

Sin., Sinaloa.

S.L.P., San Luis Potosi.

Son., Sonora.

Sp. or spp., species.

S.Pac., South Pacific.

Southw., southward.

Southwestw., southwestward.

Subg., subgenus.

Subsp. or ssp., subspecies.

Subtrop., subtropical.

S.w., southwest.

Tab., Tabasco.

Tam., Tamaulipas. 
Temp., temperate.

Tenn., Tennessee.

Tex., Texas.

Trin., Trinidad.

Trop., tropical or tropics.

U.S., United States.

Urug., Uruguay.

Ut., Utah.

Va., Virginia.

Var., variety.

Venez., Venezuela.

Ver., Veracruz.

Vic., vicinity.
Virg., I., Virgin Islands.

Vt., Vermont.

W., west or western.

Wash., Washington.

Westw., westward.

W. Hemis., Western Hemisphere.

W.I., West Indies.

Wisc., Wisconsin.

W.Va., West Virginia.

Wyo., Wyoming.

Yuc., Yucatan.

Yuk., Yukon Terr.

Zac., Zacatecas.

$?=$ Indicates doubt

$\mathrm{X}=$ Crossed with, the symbol for a hybrid.

Figures or words connected by the short dash indicates the extremes of variation, as " $5-10 \mathrm{~mm}$. long; few- to many-flowered," i.e., varying from five to ten millimeters in length, and from few- to many-flowered.

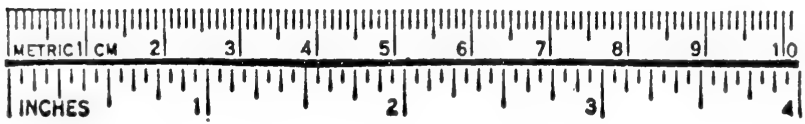





\section{Selected References}

Abrams, Leroy. Illustrated Flora of the Pacific States. Vols. I-III. 1940-1951; Vol. IV (with Ferris, Roxana S.). Stanford University Press. 1960.

Arber, A. Water Plants: A Study of Aquatic Angiosperms. University Press, Cambridge. 1920. Reprinted with an introduction by Stearn, W. T. as Historiae Naturalis Classica, 1963.

Barkley, T. M. A Manual of the Flowering Plants of Kansas. Manhattan. 1968.

Bennett, George W. Management of Artificial Lakes and Ponds. Reinhold Publishing Corp. New York. 1962.

Benson, L. A treatise on North American Ranunculi. Am. Midl. Nat. 40: 1-261. 1948.

Benson, Lyman and Darrow, Robert A. The Trees and Shrubs of the Southwestern Deserts. The University of New Mexico Press. 1954.

Bogin, C. Revision of the Genus Sagittaria (Alismataceae). Mem. N. Y. Bot. Gard, 9(2): 179-233. 1955.

Boyd, Claude E. Vascular Aquatic Plants for Mineral Nutrient Removal from Polluted Waters. Economic Botany 24(1): 95-103. 1970.

Correll, Donovan Stewart and Johnston, Marshall Conring. Manual of the Vascular Plants of Texas. Texas Research Foundation, Renner, Texas. 1970.

Correll, Donovan Stewart. Native Orchids of North America, north of Mexico. Waltham, Mass. 1950.

Coulter, John M. Botany of Western Texas (Contrib. U. S. Nat. Herb. Vol. 2). Washington. 1891-1894.

Coulter, J. M. and Rose, J. N. Monograph of the North American Umbelliferae (Contrib. U. S. Nat. Herb. Vol. 7:1-256). Washington. 1900.

Daubs, Edwin Horace. A Monograph of Lemnaceae. Illinois Biological Monographs. The University of Illinois Press. Urbana. 1965.

Fassett, N. C. Callitriche in the New World. Rhodora 53: 137-155, 161-182, 185-194, 209-222. 1951.

Fassett, N. C. A Manual of Aquatic Plants. University of Wisconsin Press. Revision Appendix by Ogden, Eugene C. 1957.

Fernald, Merritt Lyndon. Gray's Manual of Botany. Eighth Edition. American Book Co. New York. 1950.

Gleason, Henry A. The New Britton and Brown Illustrated Flora of the Northeastern United States and Adjacent Canada. 3 Vols. New York Botanical Garden. 1952.

Harrington, H. D. Manual of the Plants of Colorado. Denver. 1954.

Hermann, Frederick J. Manual of the Carices of the Rocky Mountains and Colorado Basin. Agri. Handbook No. 374. Forest Service, U. S. Dept. of Agri. 1970.

Hitchcock, A. S. Manual of the Grasses of the United States (2nd ed. revised by Chase, Agnes). (U. S. Dept. Agri. Misc. Publ. 200). Washington. 1951.

Hitchcock, C. Leo, Cronquist, Arthur, Ownbey, Marion and Thompson, J. W. Vascular Plants of the Pacific Northwest. Parts 1-5. University of Washington Press. Seattle and London. 1955-1969.

Hotchkiss, Neil. Pondweeds and Pondweedlike Plants of Eastern North America. Circular 187. U. S. Dept. of the Interior, Fish and Wildlife Service. Washington. 1964.

Hotchkiss, Neil. Bulrushes and Bulrushlike Plants of Eastern North America. Circular 221. U. S. Dept. of the Interior, Fish and Wildlife Service. Washington. 1965.

Hotchkiss, Neil. Underwater and Floating-leaved Plants of the United States and Canada. Resource Publication 44. U. S. Dept. of the Interior, Bureau of Sport Fisheries and Wildlife. Washington. 1967.

Ingram, W. M. and Tarzwell, C. M. Selected Bibliography of Publications Relating to Undesirable Effects upon Aquatic Life by Algicides, Insecticides, Weedicides. Publ. Health Bibliog. Ser. 13: 1-28. 1954.

Kearney, Thomas H. and Peebles, Robert H. Arizona Flora (2nd Ed. with Suppl. by Howell, John Thomas and McClintock, Elizabeth). University of California Press. Berkeley. 1960. 
Kral, Robert. Xyris (Xyridaceae) of the Continental United States and Canada. Sida 2 (3): 177-260. 1966.

Kral, Robert. Eriocaulaceae of Continental North America north of Mexico. Sida 2 (4) : 285-332. 1966.

Lundell, C. L. and Collaborators. Flora of Texas. Vols. I, II, III. Texas Research Foundation, Renner, Texas. 1942-1969.

MacKenzie, Kenneth Kent. North American Cariceae. N. Y. Bot. Garden. New York. 1940.

Martin, Alexander C., Zim, Herbert S. and Nelson, Arnold L. American Wildlife \& Plants. McGraw-Hill Book Co., Inc. New York. 1951.

Mason, Herbert L. A Flora of the Marshes of California. University of California Press. Berkeley. 1957.

Matsumura, Y. and Harrington, H. D. The True Aquatic Vascular Plants of Colorado. Tech. Bull. Colo. Agri. Exp. Sta. 57. 1955.

Mitchell, Richard S. Variation in the Polygonum amphibium complex and its taxonomic significance. University of California Publications in Botany. Vol. 45. 1968.

Muenscher, W. C. Aquatic Plants of the United States. Comstock Publishing Co., Inc. Ithaca. 1944.

Munz, Philip A. and Keck, David D. A California Flora. University of California Press. Berkeley and Los Angeles. 1959.

Niering, William A. The Life of the Marsh. McGraw-Hill Book Co., Inc. New York. 1966.

Pennell, F. W. The Scrophulariaceae of eastern North America. Acad. Nat. Sci. Phila. Monogr. 1:1-650. 1935.

Rechinger, K. H., Jr. The North American species of Rumex. Field Mus. Nat. Hist. Bot., Ser. 17: 1-151. 1937.

Reed, Clyde. Selected Weeds of the United States. Agri. Handb. No. 366, Agri. Res. Serv., U. S. Dept. of Agri. 1970.

Reid, George K. Ecology of Inland Waters and Estuaries. Reinhold Publishing Corp. New York. 1961.

Sculthorpe, C. D. The Biology of Aquatic Vascular Plants. St. Martin's Press. New York. 1967.

Shinners, Lloyd H. Spring Flora of the Dallas-Fort Worth Area Texas. Dallas. 1958.

Shreve, Forrest and Wiggins, Ira L. Vegetation and Flora of the Sonoran Desert. Stanford University Press. 1964.

Small, John Kunkel. Manual of the Southeastern Flora. New York. 1933.

Standley, Paul C. Trees and Shrubs of Mexico (Contrib. U. S. Nat. Herb. Vol. 23). Washington. 1920-1926.

Steyermark, Julian A. A Flora of Missouri. The Iowa State University Press, Ames. 1962.

Waterfall, U. T. Keys to the Flora of Oklahoma. Oklahoma State University Press. Stillwater. Ed. 3. 1966.

Willis, J. C. A Dictionary of the Flowering Plants and Ferns (7th ed. revised by Shaw, H. K. Airy). Cambridge University Press. 1966.

Wooton, E. O. and Standley, Paul C. Flora of New Mexico (Contrib. U. S. Nat. Herb. Vol. 19). Washington. 1915.

Young, Gordon. Pollution, Threat to Man's Only Home. Nat. Geograph. Mag. 138(6): 738-780. 1970. 


\section{INDEX}

(Page numbers in bold face indicate where the genus or species is treated. Names in italics are considered to be synonyms in our area. In the case of multiworded vernacular names the hyphen is used to denote sequence of words.)

Abrojo, 1646

Absinthe, 1689

Abutilon, 1113

Acacia Smallii, 1039

Acalypha, 1082

Acanthaceae, 1525

Acanthus family, 1525

Acer, 1104, 1369

barbatum, 1105

floridanum, 1105

Negundo, 1104 texanum, 1104

rubrum, 1105

Drummondii, 1105

rubrum, 1105

trilobum, 1105

saccharum

floridanum, 1105

Aceraceae, 1104

Acetosella Acetosella, 798

Achillea, 1686

millifolium, 1686

lanulosa, 1686

occidentalis, 1686

Achyranthes philoxeroides, 868

Acnida, 857, 862

alabamensis, 864

cuspidata, 864

tamariscina, 864

Aconitum, 921

columbianum, 921

Acorus, 563

Calamus, 563

Adder's-tongue, 49

bulbous, 49

common, 50

Family, 47

fragile, 50

limestone, 50

Adiantum, 63

Capillus-Veneris, 63, 65

modestum, 63

pedatum, 65

tricholepis, 65 glabrum, 63

Adicea pumila, 795

Aeschynomene, 9, 1065 evenia, 1067

indica, 1065, 1067

Aesculus, 1495

Agalinis, 1495

fasciculata, 1498

heterophylla, 1497

maritima, 1497

grandiflora, 1497

prairie, 1497

purpurea, 1498

spiciflora, 1497

tenuifolia, 1497

leucanthera, 1497

Agastache, 1416 nepetoides, 1416

Agoseris, 1704 aurantiaca, 1704 glauca, 1704

Agrimonia, 1037 parviflora, 1037 striata, 1037

Agrimony, 1037

Agropyron, 208, 212

repens, 210

Smithii, 210

molle, 210

Palmeri, 210

subsecundum, 208

Agrostis, 226

alba, 231

exarata, 234

gigantea, 231

hyemalis, 228, 231

tenuis, 231

idahoensis, 231

palustris, 234

perennans, 231

scabra, 231

semiverticillata, 226, 228

stolonifera, 231

Ahuehuete, 82

Aizoaceae, 870

Alacrancillo, 1389

Alamillo, 745

Alamo, 738, 748

temblon, 751

vine, 1359

Alder, 779
Arizona, 782

black, 1098

New Mexican, 782

smooth, 782

thin-leaf, 782

white, 1267

Aletris, 660

aurea, 5,660

farinosa, 660

Alfalfa, 1046

Alfalfilla, 1047

Alfombrilla, 1401

Alhagi, 1065

camelorum, 1065

Alisma, 3, 7, 135

brevipes, 137

Geyeri, 135

gramineum, 135

angustissimum, 135

Geyeri, 135

parviflorum, 137

Plantago-aquatica brevipes, 137 americanum, 137

Michaletti, 137

parviflorum, 137

subcordatum, 135

triviale, 137

Alismataceae, 133

Alkali

cordgrass, 265

-grass, 179,650

mallow, 1124

weed, 1351

Allenrolfea, 836, 1367

occidentalis, 839

Alliaceae, 656

Alligator

-bonnet, 902

weed, $4,11,866$

Allium, 655

canadense canadense, 656

Geyeri, 656

mutabile, 656

Alnus, 779, 1369

incana, $\mathbf{7 8 2}$

rugosa 
occidentalis, 782

maritima, $\mathbf{7 8 2}$

oblongifolia, 782

rugosa, 782

serrulata, $\mathbf{7 8 2}$

Alopecurus, 236

aequalis, 236

carolinianus, 238

geniculatus, 238

myosuroides, 236

pratensis, 236

Alpine timothy, 240

Alsatian clover, 1053

Alsike clover, 1053

Alsine baicalensis, 894

Alternanthera, 11, 866, 1361

philoxeroides, 4, 11, 866

Althaea. 1113

officinalis, 1113

Altingiaceae, 1012

Amamastla, 801

Amaranth, 858

Family, 857

sandhills, 862

Amaranthaceae, 857.

Amaranthus, 858, 1361, 1365

albus, 861

arenicola, 862

australis, 864

californicus, 858, 861

crassipes, $\mathbf{8 5 8}$

graecizans, 861

microphyllus, 861

Palmeri, 862

spinosus, 861

tamariscinus, 866

Warnockii, 858

Amarella strictiflora, 1323

Amaryllidaceae, 664

Amaryllis

Belladonna, 664

Family, 664

Ambrosia, 1365, 1369, 1586, 1642

aptera, 1645

Grayi, 1642

Lindheimeriana, 1645

psilostachya, 1645

trifida, 1645

texana, 1645

American

beautyberry, 1395

brooklime, 1493

cowslip, 1281

featherfoil, 4, 1277

frog-orchid, 711

frog's-bit, 159

germander, 1408 holly, 1102

hornbeam, 778

manna-grass, 185

milfoil, 1205

pillwort, 57

potato bean, 1069

slough grass, 259

water-willow, 1531

winter cress, 981

Ammannia, 9, 1161

auriculata, 1162

arenaria, 1162

coccinea, 1162

teres, 1162

Ammoselinum, 1220

Butleri, 1223

Amorpha, 1055

californica, 1055

fruticosa, 1056 angustifolia, 1056

croceolanata, 1056

fruticosa, 1056

occidentalis, 1056

paniculata, 1055

texana, 1056 glabrescens, 1056

Ampelopsis, 1112

arborea, 1112

cordata, 1112

Amsinckia, 734

Amsonia, 1333

glaberrima, 1333

illustris, 1333, 1334

tabernaemontana, 1333

Gattingeri, 1333

salicifolia, 1333

Anacardiaceae, 1091

Anacharis

canadensis, 165

densa, 163

Nuttallii, 165

occidentalis, 165

Anagallis, 1291

arvensis, 1291

caerulea, 1291

Anchistea virginica, 67

Anchusa, 1384

Andropogon, 338

glomeratus, 338

virginicus abbreviatus, 338

Androsace, 1284

diffusa, 1287

glandulosa, 1287

occidentalis, 1284 arizonica, 1287

occidentalis, 1287

pinetorum, 1287

septentrionalis, 1287

glandulosa, 1287 puberulenta, 1287

subulifera, 1287

Anemopsis, 737

californica, 737

subglabra, 737

Angelica, 1249

pinnata, 1249

Angel's hair, 1360

Angiospermae, 82

Anise-root, 1223

Annual hairgrass, 222

Anoda, 1125

cristata, 1125

hastata, 1125

lavaterioides, 1125

Antenoron virginianum, 810

Anthaenantia, 280

rufa, 283

villosa, 283

Anthemis, 1686

Cotula, 1686

nobilis, 1686

Anthopogon

barbellatus, 1322

elegans, 1323

Aparejo muhly, 248

Apios, 1069

americana, 1069

turrigera, 1069

Apium, 1230

ammi, 1230

graveolens, 1233

leptophyllum, 1230

Apocynaceae, 1331

Apocynum, 1334

angustifolium, 1337

cannabinum, 1337

glaberrimum, 1337

pubescens, 1337

hypericifolium, 1337

sibiricum, 1337

cordigerum, 1337

salignum, 1337

Suksdorfii, 1337 angustifolium, 1337

Apple haw, 1020

Applemint, 1443

Apteria, 689

aphylla, 5, 689

setacea, 689

Aquifoliaceae, 1097

Aquilegia, 917

chrysantha, 918

coerulea, 917

Hinckleyana, 917

longissima, 918

Arabis, 964

divaricarpa, 965 
Drummondii, 965

hirsuta

pycnocarpa, 964

ovata, 965

oxyphylla, 965

Araceae, 556

Araucaria, 79

Arce, 1104

Arctic bluegrass, 189

Arenaria, 894

alsinoides, 897

confusa, 897

lanuginosa, 897 cinerascens, 897

lanuginosa, 897

obtusiloba, 895

patula, 995

patula, 895

robusta, $895, \mathbf{8 9 7}$

rubella, 895

saxosa, 897

serpyllifolia, $\mathbf{8 9 7}$

Argentina

Anserina, 1031

argentea, 1031

Arisaema, 557

Dracontium, 557

quinatum, $\mathbf{5 6 0}$

triphyllum, $\mathbf{5 5 7}$

pusillum, 557

Arizona

Stewardsii, 557

-alder, 782

-ash, 1305

-dewberry, 1036

-sycamore, 1015

-walnut, 772

Armoracia, 7, 9, 979

aquatica, 979

rusticana, 979

Arnica, 1689

Chamissonis. 1689

foliosa, 1689

Aronia

arbutifolia, 1017 macrophylla, 1017

Arrow-arum, 560

Arrow-vine, 810

Arrow-weed, 1637

Arrow-weed family, 129

Arrow-wood, 1556

Arrowhead, 3, 4, 142

Arrowroot family, 686

Arroyo willow, 764

Artemisia, 1365, 1689

absinthium, 1689

biennis, 1689

Dracunculus, 1689

tridentata, 1689

Arum family, 556
Arundinaria, 175 gigantea, 175

Arundo, 202

Donax, 202

Asclepiadaceae, 1339

Asclepias, 1339, 1365 curassavica, 1345 galioides, 1345

incarnata, 1345 incarnata, 1347

longifolia, 1347

pulchra, 1347

lanceolata, 1342

paupercula, 1342

Lindheimeri, 1341

longicornu, 1341

longifolia, 1345

oenotheroides, 1341

perennis, 1347

purpurascens, 1341

rubra, 1342

speciosa, 1340

subverticillata, 1342

texana, 1347

Ascyrum, 1128

hypericoides, 1128

hypericoides, 1129

multicaule, 1128

oblongifolium, 1129

stans, 1128

Ash, 1303

Arizona-, 1305

Carolina-, 1303

desert-, 1305

Mexican-, 1305

pop-, 1303

red-, 1305

velvet-, 1305

water-, 1303

white-, 1305

Ash-leaved maple, 1104

Aster, 1362, 1365, 1367,

\section{5}

adscendens, 1622

chilensis, 1622

coerulescens, 1622

dumosus, 1625

coridifolius, 1625

subulaefolius, 1625

Eulae, 1626

exilis, 1621

falcatus, 1621

foliaceous, 1622

frondosus, 1621

hesperius, 1622

hydrophilus, 1623

intricatus, 1621

lateriflorus, 1623, 1624, 1625

flagellaris, 1624 indutus, 1624

marsh-, 1622

marsh alkali-, 1622

novae-angliae, 1623

ontarionis, 1623, 1624

pantotrichus, 1624

pauciflorus, 1622

praealtus, 1622, 1625

scabricaulis, 1625

shrubby alkali-, 1621

simplex, 1624

spinosus, 1618, 1621

euroauster, 1618

subulatus, 1618, 1621

australis, 1621

euroauster, 1621

ligulatus, 1621

subulatus, 1621

tenuifolius, 1618, 1621

tephrodes, 1623

umbellatus

latifolius, 1626

vallicola, 1622

vimineus, 1624

Astragalus, 1061, 1065

alpinus, 1061

dasyglottis, 1062

goniatus, 1062

Lambertii

abbreviatus, 1063

Atamosco

pulchella, 669

texana, 671

Athyrium, 67

asplenioides, 69

Filix-femina

asplenioides, 67, 69

californicum, 69

Atriplex, 849, 1361, 1367

argentea, 851

expansa, $\mathbf{8 5 3}$

hortensis, 851

lentiformis, $\mathbf{8 5 0}$

patula

hastata, 851

semibaccata, $\mathbf{8 5 0}$

Atropa Belladonna, 1449

Aunt Lucy, 1377

Australian saltbush, 850

Autumn bentgrass, 231

Avens, 1031

big leaf-, 1033

white-, 1033

Avicennia, 1393

germinans, 1393

nitida, 1393

Avicenniaceae, 1392

Avocado, 961

Axocatzin, 1125 
Axonopus, 287

affinis, 287

compressus, $\mathbf{2 8 7}$

furcatus, 287

Azalea, 1271

canescens, 1272

early-, 1274

hoary-, 1272

nudiflora, 1274

oblongifolia, 1272

viscosa, 1272

Azolla, 3, 9, 57, 564

caroliniana, 59

filiculoides, $\mathbf{5 9}$

mexicana, 59

Baccharis, 1367, 1369, 1606

Emoryi, 1607

glutinosa, 1607

salicina, 1607

sarothroides, 1606

viminea, 1608

Bacopa, 1458

acuminata, 1467

caroliniana, 1458

Monnieri, 1458

cuneifolia, 1458

rotundifolia, 1461

Bag-pod, 1059

Bald cypress, 81

Bald rush, 489

Balsam, 1105

Balsam-apple, wild-, 1570

Bamboo-vine, 663

Barbara's-buttons, 1675

Barbarea, 981

americana, 981

orthoceras, 981

vulgaris arcuata, 981

Barley, 215

foxtail-, 215

meadow-, 215

Barnyard grass, 329

Bartonia, 1329

paniculata, 1329

texana, 5, 1329

verna, 1329

Basil, 1446

Bassia, 842 hyssopifolia, 845

Bastard indigo, 1056

Bataceae, 868

Batatas, 1354

Batidaceae, 868

Batis, 868

maritima, 870

Bay

-gall bush, 5, 1099 -laurel, 5

red-, 961

swamp-, 961

sweet, 961

Bayberry family, 967

Beach morning glory, 1357

Beach panic, 320

Beak-rush, 467

Beaked sedge, 532

Beaked willow, 765

Bear-berry, 1560

Beard-tongue, 1487

Bearded

grass-pink, 5, 719

sprangletop, 253

wheatgrass, 208

Beardgrass, bushy-, 338

Beardless wild-rye, 212

Beautyberry, 1395

American-, 1395

purple-, 1395

Beaver-poison, 1237

Beckmannia, 259

Sysigachne, 259

Bedstraw, 1539

bluntleaf-, 1540

catchweed-, 1543

dye-, 1542

fragrant-, 1543

stiff marsh-, 1542

Bee-plant

Rocky Mountain-, 988 yellow-, 988

Beech, blue-, 778

Beech family, 783

Beefsteak plant, 1434

Beggar-ticks, 1663, 1668

Belladonna, 1449

Bellflower, 1572

Belvedere, 845

Bent-awn plumegrass, 336

Bentgrass, 226

autumn-, 231

creeping-, 234

redtop-, 231

spike-, 234

spring-, 228

water-, 228

Bequilla, 1059

Bergamont, wild-, 1434

Bergia, 1145

texana, 1145

Bermuda grass, 256

Bermuda-mulberry, 1395

Bertholetia sericea, 1637

Berula, 1234

erecta, 1234

pusilla, 1234

Besseya, 1489

arizonica, 1490 plantaginea, 1489

Betony, shade-, 1431

Betony, wood-, 1499

Betula, 778

fontinalis, 779

nigra, 779

occidentalis, 779

Betulaceae, 777

Bidens, 1663

aristosa, 1667

mutica, 1667

aurea, 1664

Bigelovii, 1672

bipinnata, 1672

bipinnata, 1672

biternatoides, 1672

cernua, 1667

discoidea, 1668

frondosa, 1668

laevis, 1664

leptocephala, 1671

mitis, 1667

Nashii, 1664

pilosa, 1671

polylepis, 1668

tenuisecta, 1671

tripartita, 1668

Bifora, 1365

Big

-blue lobelia, 1580

-cordgrass, 262

-leaf avens, 1033

-quaking grass, 192

-red sage, 1433

-shellbark hickory, 777

Bigtree hawthorn, 1020

Bilderdykia

Convolvulus, 813

cristata, 813

Bilsted, 1012

Bindweed, black-, 813

Bindweed, hedge-, 1353

Birch, 778

family, 777

river-, 779

water-, 779

Bishop's-weed, mock-, 1243

Bistorta vivipara, 817

Bitter

-bloom, 1315

-cress, 967

-cress, hairy-, 968

-dock, 805

-pecan, 775

Bitternut hickory, 775

Black

-alder, 1098

-bindweed, 813

-currant, 1010 
-eyed pea, 1069

-greasewood, 842

-gum, 1265

-haw, southern-, 1556

-mangrove, 1393

-mangrove family, 1392

-medick, 1046

-sedge, 464

-snakeroot, 653

-titi, 1095

-willow, 757

Blackberry, 1035

Bladder pod, 1059

Bladderwort, 4, 1513

common-, 1519

cone-spur-, 1522

family, 1510

floating-, 1519

horned-, 1516

purple-, 1519

Blaspheme-vine, 663

Blazing-star, 1595

Bledo, 862

Blephariglottis

Blephariglotis, 697

Chapmanii, 700

ciliaris, 697

Blepharodon, 1609

Blite, sea-, 846

Bloodleaf, 866

Blooming-sally, 1190

Blue

-beech, 778

-cardinal flower, 1580

-elder-berry, 1559

-eyed grass, 673

-flag, southern-, 682

-hyssop, 1458

-jasmine, 923

-joint, 226

-lettuce, 1701

-star, 1333

-stem goldenrod, 1612

-vervain, 1399

-violet, common-, 1154

-violet, woolly-, 1153

-water-lily, 902

-waxweed, 1167

-weed, 1656

Bluebell, 1321, 1391, 1574

family, 1571

Blueberry, 1269

Elliott's-, 1270

-hawthorn, 1019

Bluebonnet, 1045

Bluegrass, 185

Arctic-, 189

bog-, 190

Canada-, 189

fowl-, 190
Kentucky-, 189

Nevada-, 190

Bluehearts, 5, 1498

Bluestem, 338

Bluets, 1543

Bluntleaf bedstraw, 1540

Boehmeria, 791, 1362, 1368,1369

cylindrica, 791

cylindrica, 791

Drummondiana, 791

scabra, 791

Bog

-bluegrass, 190

-button, whitehead-, 5, 593

-hemp, 791

-marsh-cress, 976

-mat, 575

-orchid,

boreal-, 710

green-flowered-, 706

slender-, 709

sparsely-flowered-, 709

tall white-, 710

Thurber's-, 703

-rush, 606

Bogmoss, 5, 578

family, 578

Boltonia, 1630

asteroides, 1631

diffusa, 1631

latisquama, 1631

Bonamia

aquatica, 1353

Michauxii, 1353

Boneset, 1601

Borage family, 1383

Boraginaceae, 1383

Boreal bog-orchid, 710

Borrichia, 1367, 1655 frutescens, 1655

Bottle -brush, 46

-caric-sedge, 527

-gentian, 1326

Bottomland post-oak, 785

Box, running-, 1551

Boxelder, 1104

Bramble, 1035

Bramia Monnieri, 1458

Brasenia, 3, 4, 909

purpurea, 909

Schreberi, 909

Brass buttons, 1686

Brazilian vervain, 1397

Breweria

aquatica, 1353

Michauxii, 1353

Breynia, 1082
Bristle grass, 332

Bristly sedge, 527

Briza, 192

maxima, 192

minor, 192

Broad

-beech fern, 72

-leaved pondweed, 117

-leaved twayblade, 713

-lipped twayblade, 713

Broadfruited bur-reed, 91

Brome, 175

Bromus, 175, 177

ciliatus, 177

japonica, 177

Richardsonii, 177

Brook

-feather, 915

-pimpernel, 1493

-saxifrage, 1002

Brooklime, American-, 1493

Brookweed, 1277

Broom-wood, 1127

Broomweed, 1608

Brown-eyed Susan, 1651

Brunnichia, 795

cirrhosa, 796

ovata, 795

Buchnera, 5, 1498 americana, 1499

breviflora, 1499

floridana, 1499

Buena moza, 1453

Bugle-weed, 1437

Virginia-, 1437

Bulbostylis, 400, 473

capillaris, 402

ciliatifolia, $\mathbf{4 0 0}$

Funckii, 402

juncoides, $\mathbf{4 0 2}$ ampliceps, 402

Bulbous adder's tongue, 49

Bull paspalum, 292

Bull thistle, 1695

Bulrush, 3, 4, 5, 344

giant-, 357

great-, 360,363

hard-stem-, 360

river-, 349

salt-marsh-, 349

soft-stem-, 363

three-square-, 357

Bunchberry, 1395

Bunchflower, 655

Bur

-clover, 1046

-cucumber, one-seeded-, 1571 
-marigold, 1663

-oak, 784

-reed, 3, 4, 89

broadfruited-, 91

-family, 89

Burhead, 137

Burmannia, 686

biflora, 689

capitata, 689

family, 686

Burmanniaceae, 686

Burning-bush, 1103

Burnweed, 1693

Burro weed, 836

Bursting-heart, 1103

Bush

$$
\begin{aligned}
& \text {-cinquefoil, } 1025 \\
& \text {-clover, } 1067 \\
& \text { Japanese-, } 1068 \\
& \text { Korean-, } 1068 \\
& \text {-palmetto, } 556 \\
& \text { pigeon-, } 1560
\end{aligned}
$$

Bushmint, cluster-, 1416

Bushy beardgrass, 338

Bushy lippia, 1401

Butomaceae, 153

Buttercup, 928

creeping-, 933

cursed-, 949

large-, 939

prairie-, 939

spring-, 941

Butterweed, 1690

Butterwort, small-, 5, 1522

Button

brass-, 1686

-hemp, 791

-snakeroot, 1254, 1595

Buttonbush, 4, 1548

common-, 1548

-dodder, 1362

Buttonweed, 1551, 1552

rough-, 1555

slender-, 1552

smooth-, 1552

Buttonwood, 1012

Cabomba, 4, 7, 906 caroliniana, 3, 906, 1513

Cacalia, 1693

lanceolata, 1693

plantaginea, 1693

tuberosa, 1693

Cacao family, 1125

Caesalpinia, 1045

Cakile, 981

fusiformis, 983 geniculata, 983

Calamagrostis, 224 canadensis, 226 canadensis, 226

robusta, 226

inexpansa, 226

brevior, 226

inexpansa, 226

Calamintha arkansana, 1449

Calamus, 563

Calico bush, 1400

Callicarpa, 1367, 1395

americana, 1395 lactea, 1395

Callitrichaceae, 1085

Callitriche, 7, 9, 1085

Austinii, 1091

deflexa

Austinii, 1091

hermaphroditica, 1088

heterophylla, 1088

Nuttallii, 1091

palustris, 1088

peploides, 1091

terrestris, 1091

verna, 1088

Calonyction, 1354

Calopogon, 719

barbatus, 5, 719

pulchellus, 5, 720

Caltha, 915

leptosepala, 915

Calyptocarpus, 1660 vialis, 1660

Calystegia, 1353

fraterniflora, 1353

sepium, 1353

fraterniflora, 1353

repens, 1353

Camassia, 657

angustata, 657

scilloides, 657

Camel-thorn, 1065

Camelina, 985 sativa, 985

Camomile, 1686

Camote-de-raton, 1045

Campanula, 1367, 1572

rotundifolia, 1574

Parryi, 1574

petiolata, 1574

Campanulaceae, 1571

Camphor daisy, 1610

Camphor-weed, 1634

Campion, 887

moss-, 887

Canada

-bluegrass, 189

-garlic, 656

-wild-rye, 212

Canaigre, 797

Canary grass, 268
Canary grass, reed-, 268

Cancer-weed, 1433

Cancerwort, 1490

Candle-berry, 769

Cane, Georgia-, 202

Cane, giant-, 175

Canela, 1634

Canna, 684

family, 684

flaccida, 684

glauca, 684

indica, 684

Cannaceae, 684

Cañuela, 46, 47

Canyon grape, 1111

Cape-weed, 1405

Caper family, 987

Caperonia, 1083 palustris, 1083

Capparaceae, 987

Capparidaceae, 987

Caprifoliaceae, 1555

Capsella, 985

Bursa-Pastoris, 985

Capsicum, 1449

Cardamine, 9, 967

bulbosa, 968

cordifolia, 968

hirsuta, 968

macrocarpa

texana, 968

parviflora

arenicola, 971

pensylvanica, 971

Cardinal flower, 1583

blue-, 1580

Carduus, 1694 spinosissimus, 1695

Careless-weed, 862

Carex, 3, 4, 343, 489, 490

alata, 513

albolutescens, $\mathbf{5 1 2}$

albonigra, 540

alma, 504

amphibola, 554

globosa, 555

rigida, 555

turgida, 555

annectans, 504

aquatilis, 519

athrostachya, $\mathbf{5 0 8}$

atlantica, 508

aurea, 518

Bebbii, 512

bella, 540

Bicknellii, 513

blanda, 550

Bolanderi, 507

brevior, 515

Brittoniana, 515 
Bulbostylis, 555

Bushii, 546

Buxbaumii, 539

canescens, 502

capillaris, $\mathbf{5 5 3}$

caroliniana, $\mathbf{5 4 7}$

cuspidata, 546

cephalophora, 502

angustifolia, 502

comosa, 527

complanata, 546

Crawei, 553

crinita, 518

brevicrinis, 518

Mitchelliana, 518

crus-corvi, 506

debilis, $\mathbf{5 5 2}$

decomposita, $\mathbf{5 0 2}$

disperma, 499

Douglasii, 496

eburnea, 538

Emoryi, 522

festivella, 511

festucacea, $\mathbf{5 1 2}$

fissa, $\mathbf{5 0 6}$

flaccosperma, $\mathbf{5 5 5}$

folliculata australis, 532

Frankii, 524 gigantea, $\mathbf{5 3 5}$

glaucescens, 544

granularis, $\mathbf{5 5 3}$

Haleana, 553

Grayi, 532

grisea, 555

Hassei, 515

hirsutella, 546

Howei, 508

hyalina, 513

hyalinolepis, 525

hystericina, $\mathbf{5 2 7}$

hystricina, 527

incomperta, 508

inflata, 532

interior, $\mathbf{5 0 7}$

intumescens, 535

Joorii, 541

Kelloggii, 519

lanuginosa, 544

Leavenworthii, 502

laevivaginata, $\mathbf{5 0 7}$

leptalea, 489, 537

Harperi, 537

leptopoda, $\mathbf{5 0 7}$

lonchocarpa, 532

Longii, 512, 513

louisianica, 535

lupuliformis, 535

lupulina, 535 lurida, $\mathbf{5 2 9}$

media, 538

mesochorea, 502

microdonta, 554

microptera, $\mathbf{5 1 1}$

muskingumensis, 508

nebraskensis, 521

nigromarginata

floridana, $\mathbf{5 3 7}$

nigromarginata, 538

normalis, 512

nova, 541

oxylepis, $\mathbf{5 5 0}$

physorhyncha, 538

praegracilis, 499

reniformis, $\mathbf{5 1 5}$

rostrata, 532

scoparia, 511

senta, 518

serratodens, 539

Shortiana, 541

simulata, 499

squarrosa, $\mathbf{5 2 5}$

typhina, 525

stipata, 506, 507

maxima, 506

stricta, 521, 522

Thurberi, 529

triangularis, 504

tribuloides, 511

typhina, $\mathbf{5 2 5}$

uberior, 506

ultra, 522

verrucosa

glaucescens, 544

vesicaria, 529, 532

viridula, 547

vulpinoidea, 504

platycarpa, 504

vulpinoidea, 504

Caric-sedge, 489

Carolina

-ash, 1303

-jessamine, 1311

-silver-bells, 1299

Carpenter-weed, 1419

Carpet

-grass, 287

-weed, 872

-family, 870

Carpinaceae, 778

Carpinus, 778 caroliniana, $\mathbf{7 7 8}$

Carrizo, 202

Carya, 773, 1367, 1369

aquatica, 775

cordiformis, $\mathbf{7 7 5}$

illinoinensis, 774, 775

laciniosa, 777

Lecontei, 775 myristicaeformis, 774

ovata, 775

Pecan, 774

Caryophyllaceae, 884

Cassava, 1082

Cassytha, 962

filiformis, 962

Castalia

elegans, 902

lekophylla, 902

odorata, 902

Castilleja, 1504

coccinea, 1505

confusa, 1508

exilis, 1505

lauta, 1508

lineata, 1507

luteovirens, 1507

miniata, 1507

minor, 1505

occidentalis, 1507

rhexifolia, 1508

septentrionalis, 1507

sulphurea, 1507

trinervis, 1508

Castor-bean, 1082

Cat

-brier, 663

-tail, 3, 4, 6, 11, 85

-family, 85

Catbird grape, 1110

Catchfly, 887

-gentian, 1318

-grass, 274

Catchweed bedstraw, 1543

Catclaw, 1041

Catmint, 1419

Catnip, 1419

Caucalis, 1226

microcarpa, 1226

Cayaponia, 1570

Boykinii, 1570

quinqueloba, 1570

Cebolleta, 669

Cedar, salt-, 1148

Celastraceae, 1103

Celeri graveolens, 1233

Celery, 1230

wild-, 1233

Cenchrus, 334

myosuroides, 334

Cenicilla, 876

Centaurium, 1317

Beyrichii

Beyrichii, 1318

glanduliferum, 1318

calycosum

breviflorum, 1318

calycosum, 1317, 1318 
exaltatum, 1318

nudicaule, 1318

Centaury, 1317

Centella, 1219

asiatica, 1219

erecta, 1220

Centunculus, 1291

minimus, 1291

Cephalanthus, 1362, 1367, 1369, 1548

occidentalis, 1548

californicus; 1551

pubescens, 1551

salicifolius, 1551

Cerastium, 889

arvense, 891

axillare, 889

brachypodum, 891 compactum, 891

nutans, 893

obtectum, 893

sericeum, 893

triviale, 891

vulgatum, 891

holosteoides, 891

Ceratophyllaceae, 912

Ceratophyllum, 3, 4, 9, 912

demersum, 913, 1513 echinatum, 913

echinatum, 913

Ceratopteris, 3, 9, 77

deltoidea, 79

pteridoides, 79

thalictroides, 77, 79

Cerothamnus ceriferus, 769

Chaerophyllum, 1226

procumbens, 1229

Tainturieri

dasycarpum, 1229

Tainturieri, 1229

texanum, 1229

Chaff-flower, 866

Chaffweed, 1291

Chain fern, 67

Virginia-, 65

Chapman's holly, 1101

Chara, 3

Chasmanthium, 202 latifolium, 202

Checker-mallow, 1114

Chenopodiaceae, 834

Chenopodium, 853

album, 853, 855

ambrosioides, 854

anthelminticum, 854

Botrys, 854

chenopodioides, 855

Fremontii, 855

farinosum, 855

Pringlei, 855 glaucum, 855

humile, 855

quinoa, 853

rubrum, 855

viride, 857

Watsonii, 855

Chervil, 1226

wild-, 1223

Chess, 175

Chicken grape, 1111

Chicken spike, 1572

Chickweed, 889, 893

family, 884

Indian-, 872

water-, 1085

Chico, 842

Chinese parasol-tree, 1125

Chintul, 432

Chionanthus, 1307

virginica, 1307 maritima, 1307

Chloris, 265

Chokeberry, red-, 1017

Chondrophylla Fremontii, 1325

Choristylis, 1008

Cicely, sweet-, 1223

Cicuta, 1237

Curtissii, 1240

Douglasii, 1240

maculata, 1237

mexicana, 1240

occidentalis, 1240

Cidrilla, 1401

Cinchona, 1538

Cinco llagas, 1510

Cinna, 234

arundinacea, 234

latifolia, 236

Cinnamon fern, 51

family, 51

Cinquefoil, 1021

bush-, 1025

shrubby-, 1025

Ciprés, 82

Circaea, 1199

alpina, 1199

pacifica, 1199

Cirsium, 1694

acaulescens, 1698

Drummondii, 1698

foliosum, 1697

horridulum, 1694, 1695

inornatum, 1695

muticum, 1694, 1695

nidulum, 1697

pallidum, 1697

Parryi, 1695

vinaceum, 1697

Cissus, 1112, 1367, 1369
Ampelopsis, 1112

arborea, 1112

incisa, 1112

Cladium, 461

californicum, 464

jamaicense, 464

chinense, 464

Clappia, 1681

suaedaefolia, 1681

Clearweed, 792

Cleavers, 1539, 1543

Cleistes, 719

divaricata, 719

Clematis, 923, 1367

crispa, 923

Walteri, 923

cylindrica, 923

virginiana, 923

Cleome, 987, 989

lutea, 988

multicaulis, 988

serrulata, 988

sonorae, $\mathbf{9 8 8}$

Cleomella, 988

angustifolia, 989

longipes, 989

Clethra, 1267, 1369

alnifolia, 1267

Clethraceae, 1267

Climbing dogbane, 1334

Climbing hemp-weed, 1599

Clinopodium glabrum, 1449

Clover, 1047

Alsatian-, 1053

alsike-, 1053

bur-, 1046

bush-, 1067

jackass-, 989

owl-, 1508

red-, 1052

strawberry-, 1049

sour-, 1047

sweet-, 1046

white-, 1052

Clubmoss, 5, 39

family, 39

southern-, 39

Cluster bushmint, 1416

Clustered field sedge, 499

Coastal dropseed, 252

Cocklebur, 1037, 1646

spiny-, 1646

Codiaeum, 1082

Coffea, 1538

Coffee bean, 1059

Cola

-de alacran, 1385

-de caballo, 46 
-de mico, 1386

Colic-root, 660

Collomia, 1375

linearis, 1375

Colorado River hemp, 1059

Columbine, 917 longspur-, 918

Rocky Mountain-, 917

Commelina, 593, 595

communis, 595

diffusa, 596

virginica, 595

Commelinaceae, 593

Common

-adder's-tongue, 50

-bladderwort, 1519

-blue violet, 1154

-buttonbush, 1548

-cat-tail, 87

-dandelion, 1703

-devil's claw, 1510

-elder-berry, 1559

-evening primrose, 1198

-fennel, 1229

-frogbit, 4, 159

-frog-fruit, 1405

-green-brier, 663

-hornwort, 913

-lousewort, 1501

-meadow beauty, 1172

-mouse-ear, 891

-plantain, 1536

-poolmat, 117

-reed, 205

-self-heal, 1419

-water-nymph, 126

-yarrow, 1686

Compositae, 1369, 1504, 1586

Coneflower, 1651

cutleaf-, 1652

Cone-spur bladderwort, 1522

Conioselinum, 1249

scopulorum, 1249

Conium, 1233

maculatum, 1233

Conobea multifida, 1470

Conoclinium, 1601

betonicifolium, 1605

betonicum, 1605 integrifolium, 1605

coelestinum, 1603

Greggii, 1605

Convolvulaceae, 1350

Convolvulus

fraterniflorus, 1353

sepium, 1353

fraterniflora, 1353 repens, 1353

Conyza, 1630

Coulteri, 1630

Coon-tail, 912

Cooperia, 669

Drummondii, 669, 671

Copper lily, 671

Coral-berry, 1550

Coral green-brier, 664

Cordgrass, 4, 259

alkali-, 265

big-, 262

gulf-, 262

prairie-, 265

saltmeadow-, 265

smooth-, 262

Coreopsis, 1660

Atkinsoniana, 1661

cardaminaefolia, 1661

linifolia, 1661

similis, 1661

stenophylla, 1661

tinctoria, 1661

Corkwood, 769

family, 769

Corn salad, 1565

Cornaceae, 1262

Cornel, 1265

Cornus, 1265

asperifolia, 1266

candidissima, 1266

Drummondii, 1266

foemina, 1266

racemosa, 1266

stolonifera, 1266

stricta, 1266

Correhuela de las doce, 1359

Cosmos, 1672 parviflorus, 1672

Cotton

-batting, 1632

-grass, 363

-gum, 1265

Cottonwood, 738

eastern-, 748

lanceleaf-, 739

narrowleaf-, 742

plains-, 748

Rio Grande-, 745

smooth-barked-, 739

Cotula, 1686

coronopifolia, $\mathbf{1 6 8 6}$

Cow

-itch, 1112

-lily, 4

yellow-, 906

-parsnip, 1253

Cowbane, 1251

spotted-, 1237
Cowpen daisy, 1659

Cowslip, American-, 1281

Crabgrass, 283

northern-, 283

Crack-willow, 760

Cranesbill, 1071

Crassula

aquatica, 994

Drummondii, 994

Crassulaceae, 994

Crataegus, 1017

abbreviata, 1021

arborea, 1020

berberifolia, 1020

berberifolia, 1021

edita, 1021

brachyacantha, 1019

Davisii, 1021

edita, 1021

microcarpa, 1019

mollis, 1021

opaca, 1020

pyracanthoides, 1020

arborea, 1020

uniqua, 1020

rivularis, 1020

spathulata, 1019

uniqua, 1020

velutina, 1021

viridis, 1021

abbreviata, 1021

velutina, 1021

Crazy-weed, 1062

Cream-pea, 1069

Creeping

-bentgrass, 234

-buttercup, 933

-foxtail clubmoss, 39

-primrose-willow, 1187

-spike rush, 381

-spot-flower, 1649

Crepis, 1703

perplexans, 1703

runcinata, 1703

Cress

American winter-, 981

bitter-, 967

bog marsh-, 976

hairy bitter-, 968

lake-, 979

rock-, 964

spring-, 968

water-, 971, 974

winter-, 981

yellow-, 971

Cressa, 1351, 1367

aphylla, 1351

depressa, 1351

leafless-, 1351

nudicaulis, 1351 
truxillensis vallicola, 1351

Crested fringed orchid, 5, 700

Crested shield fern, 77

Crimson monkey-flower, 1474

Crinum, 671

americanum, 671

bulbispermum, 671

strictum, 673

strictum, 673

Traubii, 673

Croton, 1082

Crow-poison, 653

Crowfoot, 928

family, 913

white water-, 957

yellow water-, 953

Crown-beard, 1659

Crucifer, 7

Cruciferae, 962

Cryptotaenia, 1223

canadensis, 1223

Cucurbita, 1569

Pepo, 1570

texana, 1569

Cucurbitaceae, 1569

Cudweed, 1631

lowland-, 1633

purple-, 1632

Culantrillo, 63

Cupgrass, 283

prairie-, 285

Cuphea, 1167

carthagensis, 1167

glutinosa, 1167

petiolata, 1167

viscosissima, 1167

Curled pondweed, 103

Curly dock, 802

Currant, 1008

black-, 1010

golden-, 1010

Indian-, 1560

Cursed buttercup, 949

Cuscuta, 962, 1359, 1368

arvensis, 1365

campestris, 1365

Cephalanthi, 1362

compacta, 1369

Coryli, 1367

cuspidata, 1368

denticulata, 1368

glabrior

glabrior, 1365

pubescens, 1365

glandulosa, 1362

Gronovii calyptrata, $\mathbf{1 3 6 8}$

Gronovii, 1368

latiflora, 1368

indecora

indecora, 1367

longisepala, 1367

obtusiflora

glandulosa, 1362

pentagona, 1362

Polygonorum, 1362

salina, 1365

squamata, 1369

umbellata, 1361

reflexa, 1361

Warneri, 1361

Cutleaf coneflower, 1652

Cycads, 79

Cylindric-fruited ludwigia, 1187

Cymodocea, 9, 120, 129

filiformis, 4, 120

manatorum, 120

Cymodoceaceae, 120

Cynanchum, 1349

angustifolium, 1349

palustre, 1349

Cynoctonum, 1311

Mitreola, 1311

sessilifolium, 1311

Cynodon, 256

Dactylon, 256

maritimus, 256

Cynosciadium, 1246

digitatum, 1246

pinnatum, 1249

pumilum, 1249

Cyperaceae, 341, 604, 606

Cyperus, 4, 9, 415, 416, 473

acuminatus, 438

albiflorus, 445

albomarginatus, $\mathbf{4 2 6}$

alternifolius, $\mathbf{4 4 7}$

amabilis

macrostachyus, 435

arenicola, 443

aristatus, 435

Runyonii, 435

articulatus, $\mathbf{4 3 2}$

bipartitus, 429

brevifolius, $\mathbf{4 2 2}$

cayennensis, 459

compressus, 449

cyrtolepis, 438

densicaespitosus, 423

difformis, 435

digitatus, 449

dissitiflorus, 459

Eggersii, 432 elegans, 451

major, 454

erythrorhizos, 447

esculentus, 456

angustispicatum, 456

macrostachyus, 456

ferax, 432

ferruginescens, 432

filicinus, 426

filiculmis, 451

flavescens, $\mathbf{4 2 6}$ poaeformis, 429

flavus, 459

giganteus, 447

globulosus, $\mathbf{4 6 1}$

Haspan, 445

americanus, 447

hermaphroditus, 459 angustior, 459

Houghtonii Bushii, 451

huarmensis, 459

inflexus, 435

Iria, 432

juncoides, 447

laevigatus, $\mathbf{4 2 0}$

lentiginosus, 457

macrocephalus, 432

melanostachys, 429

niger, 429

capitatus, 429

castaneus, 429

obesus, 459

ochraceus, 441

odoratus, 429

onerosus, 449

ovularis, 461

cylindricus, 461

robustus, 461

sphaericus, 461

oxylepis, 454

Parishii, 451

phaeolepis, 445

polystachyos

leptostachyus, 426

paniculatus, 426

polystachyos, 426

texensis, 426

Pringlei, 459

pseudovegetus, 441, 443

reflexus, 438,443

retrorsus, 461

rivularis, 429

rotundus, $\mathbf{4 5 4}$

rufescens, 445

seslerioides, 435

sesquiflorus, $\mathbf{4 2 3}$

setigerus, 456

speciosus, 432

strigosus, $\mathbf{4 5 7}$ 
gracilis, 457

surinamensis, 438

tenuifolius, $\mathbf{4 2 3}$

tenuis, $\mathbf{4 5 7}$

lentiginosus, 457

thyrsiflorus, 459

virens, 441, 443

vulgaris

teretifructus, 426

Wolfi, 461

Cypress

bald-, 81

southern-, 81

summer-, 845

Cyrilla, 1095, 1369

family, 1095

racemiflora, 5, 1095

Cyrillaceae, 1095

Dactylis, 202 glomerata, 202

Dahoon, 1102 -holly, 1102

Daisy

camphor-, 1610

cowpen, 1659

sea ox-eye-, 1655

Dallis grass, 292

Dandelion, 1703 common-, 1703

Danthonia, 224 intermedia, $\mathbf{2 2 4}$

Dasistoma, 1495 macrophylla, 1495

Dasystephana

Bigelovii, 1326

interrupta, 1326

Parryi, 1326

Romanzovii, 1325

Dasystoma, 1495

Daubentonia, 1059 Drummondii, 1061

Day-flower, 595

Death camus, 650

Deciduous holly, 1099

Decodon, 5, 1154, 1157 verticillatus, 7, 1157

Deer-grass, 1169

Deer vetch, 1053

Deerberry, 1269

Delphinium, 913, 918

andesicola, 919

amplum, 921

sapellonis, 919

tenuisectum, 921

amplibracteatum, $\mathbf{9 2 1}$

Deringia canadensis, 1223

Deschampsia, 222

caespitosa, 224

holciformis, 224 danthonioides, 222

elongata, 222

Descurainia, 967

californica, 967

Desert

-ash, 1305

-lavender, 1416

-olive, 1308

-tobacco, 1453

Devil's

-claw, 1510

common-, 1510

darning-needle-, 923

-gut, 1360

Devil-weed, Mexican-, 1618

Dewberry, 1035

Arizona-, 1036

Dewdrop, purple-, 1580

Diamond-leaf frog-fruit, 1404

Dianthera

americana, 1531 subcoriacea, 1531

lanceolata, 1533

Diapedium brachiatum, 1528

Dichondra, 1350

carolinensis, 1351

micrantha, 1351

recurvata, 1351

repens

carolinensis, 1351

Dichromena, 435, 464

colorata, 467

latifolia, $\mathbf{4 6 7}$

nivea, 467

Reverchonii, 467

Dicliptera, 1528

brachiata, 1528 glandulosa, 1528

Ruthii, 1528

Dicotyledoneae, 23, 734

Didiplis diandra, 1164

Digitaria, 283

adscendens, 283

diversiflora, 283

sanguinalis, 283

Diodia, 1552

teres, 1555

angustata, 1555

setifera, 1555

virginiana, 1552

Diplanthera

Beaudettei, 120

Wrightii, 120

Disc water-hyssop, 1461

Distichlis, 200

spicata, 4, 200

spicata, 200 stricta, 200

stricta, 200

Ditch

-grass family, 123

-polypogon, 240

-stonecrop, 999

Ditchmoss, 163

Dock, 797

bitter-, 805

curly-, 802

fiddle-, 805

golden-, 807

pale-, 801

sour-, 802

swamp-, 800

yellow-, 802, 805

Dodder, 1359

button-bush-, 1362

field-, 1365

hazel-, 1367

pretty-, 1367

smartweed-, 1362

Dodecatheon, 1281

alpinum majus, 1283

dentatum Ellisiae, 1284

Ellisiae, 1284

Meadia, 1283

pulchellum, 1284

radicatum, 1284

Doellingeria, 1626

umbellata

latifolia, 1626

Dog-fennel, 1686

Dogbane, 1334

climbing-, 1334

family, 1331

prairie-, 1337

Dogwood, 5, 1265

English-, 1266

family, 1262

poison-, 1093

red-osier-, 1266

rough-leaf-, 1266

Dollar weed, 1124

Downy lobelia, 1580

Downy shield fern, 74

Draba, 984

aurea, 985

leiocarpa, 985

Helleriana, 985

Dracocephalum, 1419

Correllii, 1426

parviflorum, 1419

Dracopis, 1652

amplexicaulis, 1652

Dragon

-head, 1419 
false-, 1422

-root, 557

Dropseed, 250

coastal-, 252

mesa-, 252

Dropwort, water-, 1251

Drosera, 5, 990

annua, 993

brevifolia, 993

capillaris, 993

intermedia, 993

Droseraceae, 990

Drymaria, $\mathbf{8 8 7}$ pachyphylla, $\mathbf{8 8 7}$

Drymary, 887

Drymocallis arizonica, 1029 glandulosa, 1029

Dryopteris, 75

cristata, 77

dentata, 74

ludoviciana, 77

normalis, 75

Lindheimeri, 75

Duchesnea, 1021 indica, 1021

Duck-potato, 150

Duckmeat, 3, 4, 564, 565

Duckweed, 3, 4, 565 family, 563

Dulichium, 344 arundinaceum, 344

Dwarf palmetto, 556

Dye bedstraw, 1542

Eardrop vine, 795

Early-azalea, 1274

Eastern cottonwood, 748

Eastern gamagrass, 341

Echinochloa, 326

colonum, 326

crusgalli, 329

crusgalli, 329

cruspavonis, 329

frumentacea, 329

macera, 329

microstachya, 329

mitis, 329

muricata, 329

zelayensis, 329

cruspavonis, 329

paludigena, 329

polystachya, 332

Walteri, 329

Echinocystis, 1571

lobata, 1571

Wrightii, 1571

Echinodorus, 7, 137

Berteroi, 139

lanceolatus, 142 cordifolius, 139, 142

parvulus, 139

radicans, 142

rostratus, 139

lanceolatus, 142

rostratus, 142

tenellus

parvulus, 139

Echinopepon, 1570

Wrightii, 1570

Echinopsilon hyssopifolius, 845

Echium, 1384

Eclipta, 1646 alba, 1646

Eelgrass, 161

Egeria, 3, 9, 161

densa, 161

Egg-plant, 1449

Egletes, 1631

viscosa, 1631

bipinnatifida, 1631

Eichhornia, 11, 598

azurea, 598

crassipes, 3, 4, 11, 598, 868

Eichornia, 598

Elatinaceae, 1142

Elatine, 1142

americana, 1145

brachysperma, 1145

californica, 1145

chilensis, 1145

triandra, 1145

brachysperma, 1145

Elbow-bush, 1308

Elder

-berry, 1556

blue-, 1559

common-, 1559

red-, 1559

marsh-, 1637

Mexican-, 1560

poison-, 1093

Eleocharis, 3, 4, 366

acicularis, 372

acutisquamata, 399

albida, 393

arenicola, 399

atropurpurea, 384

austrotexana, 399

Baldwinii, 366, 390

bella, 372

Brittonii, 393

calva, 381

caribaea, 384

cellulosa, 381

compressa, 396, 399, 400

cylindrica, 396

elliptica compressa, 399

elongata, 393

Engelmannii, 378

equisetoides, 378

fallax, 399

fistulosa, 375

flavescens, 381

geniculata, 384

interstincta, 378

lanceolata, 375

Lindheimeri, 372

Lundellii, 393

macrostachya, 381, 399

melanocarpa, 375

membranacea, 387

microcarpa, 390

minima, 366, 390

montana, 378

montevidensis, 396, 399

obtusa, 366,375

detonsa, 378

lanceolata, 375

obtusa, 378

ovata, 378

ocreata, 384

olivacea, 384

ovata, 378

Palmeri, 396, 399

palustris, 381

Parishii, 396

parvula, 366, 384

anachaeta, $\mathbf{3 8 7}$

parvula, 387

pauciflora, 387

quadrangulata, 372, 375

radicans, $\mathbf{3 7 2}$

Reverchonii, 372

rostellata, 375, 387

tenuis, 399

verrucosa, 393, 396

tortilis, 387

tuberculosa, 369

Wolfii, 369

xyridiformis, 381

Eleogiton radicans, 372

Elephant's head, 1501

Elk's lip, 915

Elliott's blueberry, 1270

Ellisia, 1377

Nyctelea, 1377

Elm family, 788

Elm, water-, 788

Elodea, 3, 9, 163

bifoliata, 163

canadensis, 165

densa, 163

longivaginata, 165

Nuttallii, 165

Elymus, 210, 212 
canadensis, 212

brachystachys, 212

robustus, 212

villosus, 212

Smithii, 210

triticoides, 212

villosus, 212

virginicus, $\mathbf{2 1 2}$

australis, 212

glabriftorus, 212

intermedius, 212

Enchanter's nightshade, 1199

English dogwood, 1266

English plantain, 1534

Epazote, 854

Epilobium, 1190 adenocaulon, 1193

perplexans, 1193

alpinum, 1193

angustifolium, 1190

californicum, 1193

ciliatum, 1193

coloratum, 1193

glandulosum, 1190

Halleanum, 1193

Hornemannii, 1193

oregonense, 1193

saximontanum, 1193

Watsonii, 1193

occidentale, 1194

Parishii, 1194

Epipactis, 716

gigantea, 716

Equisetaceae, 45

Equisetum, 45, 47

arvense, 46 caespitosum, 46

ramulosum, 46

variegatoides, 46

hyemale, 47

affine, 47

Drummondii, 47

robustum, 47

texanum, 47

kansanum, 46

laevigatum, 46

Funstonii, 46

laevigatum, 47

scabrellum, 47

prealtum, 47

robustum, 47

Eragrostis, 192

cilianensis, 196

diffusa, 196

Elliottii, 198

glomerata, 198

hirsuta, 196

hypnoides, 194

megastachya, 196 pectinata, 196

perplexa, 196

pilosa, 196

reptans, 194

Erechtites, 1693

hieracifolia intermedia, 1693

Erianthus, 336

alopecuroides, 336

compactus, 338

contortus, 336

divaricatus, 336

giganteus, 338

laxus, 338

saccharoides, 338

strictus, 336

Tracyi, 338

Ericaceae, 1267

Erigeron, 1626

Coulteri, 1629

formosissimus, 1630

flagellaris, 1629

lonchophyllus, 1629

minor, 1629

myrionactis, 1627

peregrinus, 1629

philadelphicus, 1629

pulchellus, 1627

Eriocarpum, 1609 megacephalum, 1610

Eriocaulaceae, 588

Eriocaulon, 5, 588 compressum, $\mathbf{5 9 0}$

decangulare, 590

Körnickianum, 590

septangulare, 592

texense, $\mathbf{5 9 2}$

Eriochloa, 283

contracta, 285

punctata, 285

Eriogonum, 795

Erioneuron, 205

Eriophorum, 363

angustifolium, 365

polystachion, 363

Eryngium, 1253, 1367

heterophyllum, 1257

Hookeri, 1260

integrifolium, 1260

nasturtiifolium, 1260

phyteumae, 1257

prostratum, 1262

sparganophyllum, 1254

synchaetum, 1257

yuccifolium

synchaetum, 1257

yuccifolium, 1254, 1257

Eryngo, 1253

Erythraea
Beyrichii, 1318

calycosa, 1317

Eschenbachia Coulteri, 1630

Euonymus, 1103

americanus, 1103

atropurpureus, 1103

atropurpureus, 1103

Cheatumii, 1103

Eupatorium, 1601

betonicifolium, 1603

coelestinum, 1603

Greggii, 1605

leucolepis, 1605

maculatum, 1603

Bruneri, 1603

perfoliatum, 1601

purpureum, 1603

pycnocephalum, 1605

Euphorbiaceae, 1082

Eurystemon, 604 mexicanum, 604

Eustoma, 1318

exaltatum, 1321

albiflorum, 1321

grandiflorum, 1321

bicolor, 1321

Fisheri, 1321

flaviflorum, 1321

roseum, 1321

Russellianum, 1321

silenifolium, 1321

Euthamia, 1609

camporum, 1609

Evening primrose, 1194

common-, 1198

family, 1175

Everlasting, 1631

Exogonium, 1354

Fabaceae, 1039

Fagaceae, 783

Fagopyrum sagittatum, 795

Fall panic, 323

False

-asphodel, 650

-dragon-head, 1422

-flax, 985

-hellebore, 655

-nettle, 791

-pimpernel, 1484

-Solomon's seal, 657

Fanwort, 3, 906

Feather-geranium, 854

Featherfoil, 1277

American-, 1277

Felwort, 1327

Fennel, 1229

common-, 1229 
dog-, 1686

hog-, 1251

Fern, 37

allies, 37

broad beech-, 72

chain-, 67

Virginia-, 65

cinnamon-, 51

crested shield-, 77

downy shield-, 74

hairy maidenhair-, 65

lady-, 67

southern-, 67

mosquito-, 57

royal-, 51

sensitive-, 65

southern marsh-, 72

water-, 3, 57

Fescue

nodding-, 179

perennial-, 177

red-, 179

Festuca, 177

obtusa, 179

rubra, 177, 179

Fetter-bush, 1274

Fiddle dock, 805

Fiddle-leaf tobacco, 1453

Field dodder, 1365

Field mint, 1443

Figwort family, 1456

Filigrana, 1395

-de mazorca, 1395

-de piñar, 1395

Fimbristylis, 400, 402

alamosa, 411

annua, 408

autumnalis, 405

Baldwiniana, 410

capillaris, 402

caroliniana, 407

castanea, 411

dichotoma, 408

miliacea, 405

puberula, 413

interior, 413

puberula, 413

thermalis, $\mathbf{4 0 7}$

tomentosa, $\mathbf{4 0 7}$

Vahlii, 411

Fire-bush, Mexican-, 845

Fire willow, 766

Fireweed, 1190, 1693

Firmiana simplex, 1125

Five-finger, 1021

Flatsedge, 415

Flaveria, 1683

campestris, 1683

chloraefolia, 1683

oppositifolia, 1683
Flax, 1073

false-, 985

family, 1073

sucker-, 1073

Fleabane, 1626

marsh-, 1633

Philadelphia-, 1629

running-, 1629

stinking-, 1634

Flecha de agua, 150

Fleur-de-lis, 676

Floating

-bladderwort, 1519

-fern family, 77

-heart, 1331

yellow-, 1331

-knotweed, 820

-primrose-willow, 1187

Florida ladies' tresses, 730

Florida maple, 1105

Flowering-rush family, 153

Foeniculum, 1229

vulgare, 1229

Forestiera, 1307

acuminata, 1307

vestita, 1308

neomexicana, 1308

arizonica, 1308

pubescens, 1308

glabrifolia, 1308

sphaerocarpa, 1308

Forget-me-not, 1384, 1391

Fowl bluegrass, 190

Fowl manna-grass, 183

Fox grape, 1111

Foxberry, 1395

Foxglove, mullein-, 1495

Foxtail, 236

barley-, 215

-clubmoss, 39

meadow-, 236

-muhly, 248

short-awn-, 236

water-, 238

yellow-, 334

Fragile adder's tongue, 50

Fragrant bedstraw, 1543

Fragrant-orchid, 710

Franseria, 1642 tomentosa, 1645

Fraxinus, 1303

americana, 1305

Berlandieriana, 1305

caroliniana, 1303

Ornus, 1065

pensylvanica, 1305

lanceolata, 1305

subintegerrima, 1305

Standleyi, 1305

velutina, 1305, 1307 glabra, 1307

Toumeyi, 1305

French-mulberry, 1395

French spinach, 851

Fresno, 1305

-de Guajuco, 1104

Fringe-tree, 1307

Fringed grass-of-Parnassus, 1008

Frog-fruit, 1401

common-, 1405

diamond-leaf-, 1404

northern-, 1403

Texas-, 1404

wedge-leaf-, 1405

Frog orchid, 711

Frog's-bit

American-, 159

common-, 159

family, 156

Frost grape, 1111

Fuirena, 365

breviseta, 365

hispida, 365

scirpoidea, 365

simplex, 365

squarrosa, 365

Funastrum cynanchoides, 1350

Gaillardia, 1504

Galium, 1538, 1539

Aparine, 1543

Vaillantii, 1543

asperrimum, 1542

boreale, 1543

Brandegei, 1540

mexicanum

asperulum, 1542

microphyllum, 1540

obtusum, 1540

tinctorium, 1542

subbiflorum, 1542

trifidum, 1540, 1542

latifolium, 1540

pusillum, 1540

triflorum, 1543

uncinulatum, 1542

obstipum, 1542

Gallberry, 1098

Gamagrass, eastern-, 341

Garden orache, 851

Garlic, 655

Gastridium, 243

ventricosum, 243

Gatesia laetevirens, 1531

Gaura, 1365

Gay-feather, 1595, 1597

Gelsemium, 1311 
sempervirens, 1311

Gentian, 1321

bottle-, 1326

catchfly-, 1318

family, 1312

moss-, 1325

rose-, 1313

soapwort-, 1326

spurred-, 1327

Gentiana, 1321

affinis, 1326

algida, 1325

amarella, 1323

barbellata, 1322

Bigelovii, 1325

detonsa, 1322

elegans, 1323

Fremontii, 1325

grandis, 1323

Parryi, 1326

Romanzovii, 1325

Saponaria, 1326

strictiflora, 1323

superba, 1323

tenella, 1323

thermalis, 1323

Gentianaceae, 1312

Georgia cane, 202

Georgia holly, 1101

Geraniaceae, 1071

Geranium, 1071

caespitosum, 1073

eremophilum, 1071

family, 1071

feather-, 854

Richardsonii, 1071

Gerardia

fasciculata, 1498

heterophylla, 1498

maritima, 1497

purpurea, 1498

salt marsh-, 1497

seaside-, 1497

tenuifolia, 1497

leucanthera, 1497

Germander, 1408

American-, 1408

Geum, 1031

aleppicum, 1033 decurrens, 1033

camporum, 1033

canadense, 1033 camporum, 1033 texanum, 1033

macrophyllum perincisum, 1033

oregonense, 1034

rivale, 1034

Rossii

turbinatum, 1034 strictum, 1033

triflorum, 1034

turbinatum, 1035

Giant

-bulrush, 357

-cane, 175

-helleborine, 716

-ragweed, 1645

-reed, 202

-spiral-orchid, 730

Gigante, 1453

Gilia, 1373

calcarea, 1373

gilioides, 1373

pinnatifida, 1373

straggling-, 1373

viscida, 1373

Ginkgo tree, 79

Glasswort, 835

Glaux, 1288

maritima, 1288

Gleditschia, 1043

Gleditsia, 1043

aquatica, 1045

Glinus, 872

Cambessedesii, 875

lotoides, 872

radiatus, 872

Globe-flower, 1548

Globifera umbrosa, 1487

Glottidium, 1059

vesicarum, 1059

Glyceria, 181

arkansana, 183

borealis, 183

elata, 183

grandis, 185

pauciflora, 185

septentrionalis, 183

striata, 183

Glycyrrhiza, 1063

glabra, 1063

lepidota, 1065

Gnaphalium, 1631

chilense, 1632

Grayi, 1632

obtusifolium, 435

palustre, 1633

purpureum, 1632

strictum, 1633

sulphurescens, 1632

Goat-foot morning glory, 1357

Gold-of-pleasure, 985

Golden

-Alexanders, 1230

-club, 560

-currant, 1010

-dock, 807

-hedge-hyssop, 1468
Goldenrod, 1610

blue-stem-, 1612

seaside-, 1612

Goose-grass, 1543

Gooseberry, 1008

Goosefoot, 853

family, 834

Gossypium, 1113

Gourd family, 1569

Gourd, Texas-, 1569

Gramineae, 169, 604

Grandfather's-beard, 1034

Grape, 1109

canyon-, 1111

catbird-, 1110

chicken-, 1111

family, 1108

fox-, 1111

frost-, 1110, 1111

graybark-, 1109

gulch-, 1111

Missouri-, 1110

pigeon-, 1110

possum-, 1112

red-, 1110

riverbank-, 1110

summer-, 1110

sweet-, 1109

winter-, 1111

Grass, 3, 4, 5

family, 169

-leaved ladies' tresses, 730

-of-Parnassus, 5, 1005 fringed-, 1008

-pink, 5, 720

bearded-, 719

Gratiola, 1467

brevifolia, 1467

Drummondii, 1468

flava, 1468

gracilis, 1468

neglecta, 1468

pilosa, 1467

pusilla, 1468

ramosa

Drummondii, 1468

Torreyi, 1468

virginiana, 1468

Gray sandbar willow, 761

Graybark grape, 1109

Greasewood, black-, 842

Great bulrush, 360, 363

Great lobelia, 1580

Green

-brier, 663

-dragon, 557

-flowered bog-orchid, 706 
-hawthorn, 1021

-lip ladies' tresses, 727

-orchid, tall leafy-, 707

-orchid, tall northern-, 706

-parrot's-feather, 1208

-rein-orchid, 710

-sedge, 547

Groenlandia, 95

Grossularia, 1010 inermis, 1010

Grossulariaceae, 1010

Groundnut, 1069

Groundsel, 1689 -tree, 1606

Gulch grape, 1111

Gulf cordgrass, 262

Gum

black-, 1265

cotton-, 1265

sour-, 1262

Gut, Devil's-, 1360

Gut, tangle-, 1360

Gymnadeniopsis clavellata, 711

integra, 700

nivea, 703

Gymnospermae, 19, 79

Gyrostachys

gracilis, 730

odorata, 727

praecox, 732

\section{Habenaria, 691}

Blephariglottis, 697, 700

Chapmanii, 700

ciliaris, 5, 697, 700

clavellata, 5, 710

cristata, 5, 700

dilatata, 710

flava, 703

hyperborea, 706

integra, 700

lacera, 695

limosa, 703

nivea, 5,700

Nuttallii, 697

quinqueseta, 695

repens, 9, 697

saccata, 709

sparsiflora, 709

brevifolia, $\mathbf{7 1 0}$

laxiflora, $\mathbf{7 1 0}$

viridis

bracteata, 711

Habranthus, 671

texanus, 671

Hachinal, 1157

Hackelia, 1389

floribunda, 1391 virginiana, 1389

Hairgrass, 222

annual-, 222

slender-, 222

tufted, 224

Hairy

-bitter-cress, 968

-hedge-hyssop, 1467

-maidenhair fern, 65

-pepperwort, 55

-pipewort, 593

Halberd-leaved rosemallow, 1118

Halenia, 1327

recurva, 1327

Rothrockii, 1327

Halesia, 1296

carolina, 1299

diptera, 1299

Halodule, 9, 120, 129

Beaudettei, 4, 120

Wrightii, 120

Halophila, 9, 129, 168

Engelmannii, 4, 168

Haloragaceae, 1201

Haloragidaceae, 1201

Hamamelidaceae, 1011

Haplopappus, 1609 phyllocephalus, 1610 rubiginosus, 1610

Hard-stem bulrush, 360

Harebell, 1574

Harvest-lice, 1037

Haw

apple-, 1020

pasture-, 1019

possum-, 1099, 1556

red-, 1017

Hawk's-beard, 1703

Hawthorn, 1017

bigtree-, 1020

blueberry-, 1019

green-, 1021

Hazel dodder, 1367

Hazel-nut family, 777

Heal-all, 1419

Heart-leaved twayblade, 713

Heart sorrel, 800

Heath family, 1267

Hedge

-bindweed, 1353

-hyssop, 1467 golden-, 1468

hairy-, 1467

sticky-, 1467

-nettle, 1429

Hedyotis, 1543

Boscii, 1545

corymbosa, $\mathbf{1 5 4 5}$ pygmaea, 1545

uniflora, 1545

fasciculata, 1545

Wrightii, 1545

He-huckleberry, 1276

Heimia, 1157

longipes, 1158

salicifolia, 1157

Helianthium parvulum, 139

Helianthus, 1367, 1368, 1369,1655

angustifolius, 1656

ciliaris, 1369, 1656

Maximiliana, 1659

Nuttallii, 1659

simulans, 1659

Helenium, 1367, 1677

arizonicum, 1681

autumnale, 1679

canaliculatum, 1679

Drummondii, 1679

edwardsianum, 1679

flexuosum, 1679

Hoopesii, 1678

microcephalum, 1679

nudiflorum, 1679

ooclinium, 1679

Thurberi, 1678

Heliophytum glabriusculum, 1385

Heliotrope, 1384

seaside, 1386

Heliotropium, 1384

curassavicum

curassavicum, 1386

obovatum, 1386

oculatum, 1386

glabriusculum, 9, 1385

Greggii, 1386

indicum, 1389

molle, 9, 1385

oculatum, 1386

procumbens, 1386

spathulatum, 1386

Hemicarpha, 343, 415

micrantha, 415

aristulata, 415

Drummondii, 415

micrantha, 415

minor, 415

Hemlock, poison-, 1233

Hemlock, water-, 1237

Hemp

bog-, 791

button-, 791

Colorado River-, 1059

Indian-, 1334, 1337

water-, 862

-weed, climbing-, 1599 
Henbane, 1449

Heracleum, 1253 lanatum, 1253

maximum, 1253

Heteranthera, 601

dubia, 601, 604

Liebmannii, 604

limosa, 604

mexicana, 604

peduncularis, 604

reniformis, 604

Hevea, 1082

Hibiscus, 1113, 1117, 1365

cubensis, 1118

dasycalyx, 1118

esculentus, 1113

incanus, 1121

lasiocarpos, 1121

leucophyllus, 1121

militaris, 1118

Moscheutos, 1121

Hickory, 773

big shellbark-, 777

bitternut-, 775

nutmeg-, 774

pignut-, 775

shagbark-, 775

water-, 775

Hicoria

aquatica, 775

cordiformis, 775

laciniosa, 777

minima, 775

myristicaeformis, 774

ovata, 777

Pecan, 774

Hiedra, 1093

Hierba

-buena, 1401

-buena montes, 1404

-de cristo, 1400

-de zizotes, 1341

-de la vírgen María, 1405

-del buey, 1112

-del caballo, 1660

-del cáncer, 1161

-del marrano, 1618

-del negro, 1401

-del pájaro, 1291

-del sapo, 1260

-negra, 1401

Hierochloë, 268

odorata, 268

Hilaria, 990

Hippuridaceae, 1208

Hippuris, 1208

vulgaris, 1211

Hoary azalea, 1272

Hoffmanseggia, 1045 densiflora, 1045

falcaria, 1045

glauca, 1045

Hog-fennel, 1251

Hog-potato, 1045

Holcus, 224

lanatus, 224

Holly, 5, 1097

American-, 1102

Chapman's-, 1101

dahoon-, 1102

deciduous-, 1099

family, 1097

Georgia-, 1101

-leaved water nymph, 126

Hollyhock, wild-, 1114

Holy grass, 268

Honewort, 1223

Honey-balls, 1548

Honey locust, 1043

Honeysuckle, 1274, 1560

family, 1555

Japanese-, 1560

Hooded ladies' tresses, 724

Hordeum, 215

brachyantherum, 215

jubatum, 215 caespitosum, 215

Horehound, water-, 1437

Horn, ram's-, 1510

Hornbeam, 778

American-, 778

Horned

bladderwort, 1516

pondweed, 117

family, 117

-rush, 471, 473

Hornpod, 1311

Hornwort, 3, 912

common-, 913

family, 912

Horse

-brier, 663

-purslane, 875

-radish, 979

-sugar, 1301

Horsemint, 1434

long-flowered-, 1434

Horsetail family, 45

Hottonia, 1277

inflata, 4, 1277

palustris, 1277

Houstonia, 1543

Wrightii, 1545

Hubam, 1046

Huckleberry, he-, 1276

Huckleberry, squaw, 1269

Huisache, 1039
Hyacinth, water-, 3, 4, 11, 868

Hyacinth, wild-, 657

Hydrocharitaceae, 156

Hydrochloa, 280 caroliniensis, 280

Hydrocleys, 156 nymphoides, 156

Hydrocotyle, 1214 australis, 1219

bonariensis, 1219

Canbyi, 1219

ranunculoides, 1219

umbellata, 1214, 1216

verticillata triradiata, 1219 verticillata, 1216, 1219

Hydrolea, 1383

affinis, 1383

ovata, 1383

spinosa, 1383

uniflora, 1383

Hydrophyllaceae, 1375

Hydrophyllum, 1377

Fendleri, 1379

occidentale, 1379

virginianum, 1379

Hydrotrida caroliniana, 1461

Hygrophila, 1525

lacustris, 4, 1525

Hymenocallis, 666

caroliniana, 666

caymanensis, 666

Eulae, 666

galvestonensis, 666

Liriosme, 666

occidentalis, 667

Hymenoclea, 1368

Hyoscyamus niger, 1449

Hypericaceae, 1127

Hypericum, 5, 1128, 1129, 1368

anagalloides, 1130

apocynifolium, 1134

cistifolium, 1134

densiflorum, 1133 densifforum, 1133

lobocarpum, 1133

Drummondii, 1140

fasciculatum, 1134

formosum, 1130

galioides, 1134

fasciculatum, 1134

gymnanthum, 1137

hypericoides, 1128

multicaule, 1128

lobocarpum, 1133

mutilum, 1137 
latisepalum, 1137 nudiflorum, 1134 petiolatum, 1140 prolificum, 1133 punctatum, 1133 setosum, 1137 spathulatum, 1133 stans, 1128 tubulosum, 1140

Walteri, 1140 virginicum, 1140 Walteri, 1140

Hypoxis, 667 erecta, 667 hirsuta, 667 leptocarpa, 667 humilis, 669 leptocarpa, 667 rigida, 667

Hyptis, 1416 alata, 1416 radiata, 1416

Hyssop, blue-, 1458

Hyssop, hedge-, 1467

\section{Ibidium}

cernuum, 727

floridanum, 730 gracilis, 730 laciniatum, 732 praecox, 732 vernale, 732

Ilex, 1097, 1369

Cassine, 1102 latifolia, 1102 coriacea, 5, 1099 decidua, 1099 glabra, 1098, 1099 longipes, 1101 hirsuta, 1101 longipes, 1101 opaca, 1102 verticillata, 1098 vomitoria, 5, 1101

Iliamna, 1114 grandiflora, 1114

Illysanthes dubia, 1484 gratioloides, 1484 inaequalis, 1468

Impatiens, 1105, 1362 biflora, 1108 capensis, 1108 pallida, 1108

India lovegrass, 196

Indian

-blanket, 1504

-chickweed, 872

-currant, 1560

-hemp, 1334, 1337 -paint-brush, 1404, 1505

-plantain, 1693

-shot, 684

-strawberry, 1021

-turnip, 557

Indigo, 1054, 1055

bastard-, 1056

Indigofera, 1054

Lindheimeriana, 1054

suffruticosa, 1055

tinctoria, 1055

Inflated duckweed, 573

Inflated sedge, 529

Ink-berry, 1098, 1560

Inland sea oats, 202

Iodanthus, 964 pinnatifidus, 964

Iodine bush, 839

Ipomoea, 1353 acuminata, 1355 amnicola, 1357

barbigera, 1355

Batatas, 1354

carolina, 1359

cathartica, 1355

coccinea, 1355 hederifolia, 1355

commutata, 1359

congesta, 1355

dissecta, 1359

hederacea, 1355 integriuscula, 1355

hederifolia, 1355

heptaphylla, 1357

lacunosa, 1359

Leari, 1355

littoralis, 1357

mutabilis, 1355

pandurata, 1357

Pes-caprae brasiliensis, 1357 emarginata, 1357

pulchella, 1357

sagittata, 1357

sinuata, 1359

spiralis, 1357

stolonifera, 1357

trichocarpa, 1359

Torreyana, 1359

trichocarpa, 1359

trifida, 1359

triloba, 1359

Wrightii, 1355

Iresine, 866

celosioides, 866

rhizomatosa, 866

Iridaceae, 673

Iris, 676

brevicaulis, $\mathbf{6 8 2}$

caroliniana, 682 family, 673

foliosa, 682

fulva, 679

hexagona

flexicaulis, 682

missouriensis, 679

pallida, 676

Pseudacorus, 679

Shrevei, 682

tingitana, 676

versicolor, 682

virginica, 682

Shrevei, 682

xiphium, 676

Ironweed, 1592

plains-, 1593

Ironwood, 778

Isoetaceae, 41

Isoetes, 43

Bolanderi, 43 pygmaea, 43

Butleri, 45

lithophylla, 43

melanopoda, $\mathbf{4 3}, 45$ pallida, 45

Itea, 5, 1008

virginica, 1008

Iteaceae, 1008

Iva, 1367, 1369, 1586, 1637

axillaris, 1640

frutescens, 1640

frutescens, 1640

oraria, 1640

xanthifolia, 1640

Ivy

-duckweed, 567

marine-, 1112

poison-, 1093

-treebine, 1112

Jack-in-the-pulpit, 557

Jackass clover, 989

Jacob's ladder, 1370

Jamesia, 1011

americana, 1011

Japanese

-bush clover, 1068

-chess, 177

-honeysuckle, 1560

-millet, 329

Jara, 1607

Jasmine, 1301

blue-, 923

rock-, 1284

Jasminium, 1301

Jerusalem oak, 854

Jessamine, Carolina, 1311

Jessamine, yellow, 1311 
Jewel-weed, 1105

Joe-Pye weed, 1603

Johnson grass, 338

Joint-tail, 338

Joint vetch, 1065

Jointed rush, 631

Juglandiaceae, 769

Juglans, 772

major, 772

microcarpa, 773

Stewartii, $\mathbf{7 7 3}$

rupestris, 773

Jump seed, 810

Juncaceae, 604

Juncaginaceae, 129

Juncus, 606

acuminatus, 637 sphaerocephalus, 637 acutus

sphaerocarpus, 615

albescens, 631

aristulatus, 624

arizonicus, 621

curtiflorus, 621

articulatus, 631

badius, 634

balticus, 610,612

littoralis, 610

mexicanus, 612

montanus, 610

biflorus, 624

brachycarpus, 637

brevicaudatus, 628

brunnescens, 628

bufonius, 615, 618

halophilus, 618

castaneus, 631

caudatus, 631

confusus, 618

Cooperi, 615

coriaceous, 612

debilis, 643

dichotomus, 621

diffusissimus, 643

Drummondii, 610

Dudleyi, 621

effusus, 606 brunneus, 612

exiguus, 612

solutus, 612

Elliottii, 645

ensifolius, 627

filiformis, $\mathbf{6 1 0}$

filipendulus, 624

interior, 621

arizonicus, 621

neomexicanus, 621

longistylis, 624

scabratus, 627

macrophyllus, 627 marginatus, 624

paucicapitatus, 624

setosus, 624

megacephalus, 637

Mertensianus, 634

mexicanus, 612

neomexicanus, 621

nodatus, 645

nodosus, 634

meridianus, 634

texanus, 637

parous, 628

polycephalus, 640

repens, 621

Roemerianus, 615

saximontanus, 628

brunescens, $\mathbf{6 2 8}$

scirpoides, 640 meridionalis, 640

sphaerocarpus, 618

tenuis, 618, 621

anthelatus, 618

Dudleyi, 621

texanus, 634

Torreyi, 631

Tracyi, 628

trigonocarpus, 628

validus, 643

fascinatus, 640, 643

validus, 643

xiphioides, 627

Jungle-rice, 326

Jussiaea, 1175

decurrens, 1178

leptocarpa, 1181

Michauxiana, 1184

repens

glabrescens, 1181

peploides, 1181

suffruticosa, 1181

ligustrifolia, 1181

octofila, 1181

uruguayensis, 1184

Justice-weed, 1605

Justicia, 1362, 1365, 1531

americana, 11, 1362, 1531

lanceolata, 1531

ovata

lanceolata, 1533

Kentucky bluegrass, 189

Kickxia, 1490

Elatine, 1490

King-nut, 777

Kitten-tails, 1489

Knotgrass, 298

Knotweed, 807, 816

family, 795

floating-, 820
Kochia, 845

alata, 845

americana, $\mathbf{8 4 6}$

vestita, $\mathbf{8 4 6}$

scoparia, 845

culta, 845

subvillosa, 845

Korean bush clover, 1068

Kosteletzkya, 1117

althaefolia, 1117

virginica, 1117 althaefolia, 1117

Kyllinga, 415, 416

brevifolia, 423

odorata, 423

pumila, 423

Labiatae, 1407

Lace-lip spiral-orchid, 732

Lachnocaulon, 593 anceps, 5, 593

Lactuca, 1698

canadensis, 1701

floridana, 1703

graminifolia, 1701

pulchella, 1701

sativa, 1698

Serriola, 1698

villosa, 1703

Ladies' tresses, 5, 723

Florida-, 730

grass-leaved-, 730

green-lip-, 727

hooded-, 724

nodding-, 727

spring-, 732

Texas-, 730

western-, 724

Lady fern, 67

Lady's thumb, 830

Lake cress, 979

Lamb's-quarters, 855

Lampazo amarillo, 902

Lampazos, 902

Lance-leaved violet, 1152

Lance-leaved water-willow, 1531

Lanceleaf cottonwood, 739

Lantana, 1400 horrida, 1400

Texas-, 1400

Lanten, 1536

Laportea, 791 canadensis, 791

Large buttercup, 939

Large marsh-pink, 1315

Larkspur, 918

Larrea, 988

densiflora, 1045 
Lathyrus, 1069 arizonicus, 1069

Lauraceae, 961

Laurel family, 961 -oak, 787 -oak, swamp-, 787

Lavender, desert-, 1416

Lavender, sea-, 1295

Leaf-flower, 1082

Leafless cressa, 1351

Leafy lobelia, 1579

Leatherwood, 5, 1095

Leavenworthia, 962, 984 aurea, 7, 984

Lechillo, 778

Leek, 655

Leersia, 271

hexandra, 274

lenticularis, 274

oryzoides, 274

virginica, 274

Legume family, 1039

Leguminosae, 1039

Leitneria, 769

floridana, $\mathbf{7 6 9}$

Leitneriaceae, 769

Lemna, 3, 4, 564, 565, 578 aequinoctiales, 571 gibba, 571, 573 minima, 570 minor, 563, 571 obscura, 571 perpusilla, 571 trinervis, 571

trinervis, $\mathbf{5 7 1}$ trisulca, 565, 567 valdiviana, 570, 571

Lemnaceae, 9, 563

Lemon lily, 657

Lens-scale, 850

Lentibulariaceae, 1510

Leptasea chrysantha, 1002

Leptochloa, 252 fascicularis, 253

filiformis, 256

Nealleyi, 256

panicoides, 253

uninervia, 253

Leptoloma, 283

Lepuropetalaceae, 999

Lepuropetalon, 999 spathulatum, 999

Lespedeza, 1067 stipulacea, 1068 striata, 1068

Lettuce, 1698 blue-, 1701 miner's-, 881 prickly-, 1698 water-, 3, 4

Leucospora, 1470 multifida, 1470

Leucosyris spinosa, 1618

Leucothoë, 1274 elongata, 1274 racemosa, 1274

Liatris, 1365, 1369, 1595 acidota, 1597

lancifolia, 1597

pycnostachya, 1597 lasiophylla, 1597 pycnostachya, 1597

Licorice, 1063, 1065

Lilaeopsis, 1240 recurvata, 1240

Liliaceae, 646

Lilium, 657 Parryi, 657

Lily, 657

Lily family, 646

Limestone adders'-tongue, 50

Limnanthemum trachyspermum, 1331

Limnobium, 159 Spongia, 4, 159

Limnophila, 1473 sessiliflora, 1473

Limnosciadium, 1246 pinnatum, 1246 pumilum, 1249

Limonium, 1295 angustatum, 1296 carolinianum, 1296 angustatum, 1296 compactum, 1296

limbatum, 1295 glabrescens, 1295 , 1296 limbatum, 1296

Washii, 1296 angustatum, 1296 Nashii, 1296

Limosella, 1461 acaulis, 1461 aquatica, 1461

Linaceae, 1073

Linanthastrum, 1370 Nuttallii, 1370

Lindernia, 1484 anagallidea, $\mathbf{1 4 8 4}$ dubia, 1484 major, 1484

Linum, 1073 medium texanum, 1073 striatum, 1073

Lippia, 1401 alba, 1401 bushy-, 1401

cuneifolia, 1405

geminata, 1401

incisa, 1404

lanceolata, 1403

nodiflora, 1405

strigulosa, 1404

Liquidamber, 1012 Styraciflua, 1012

Liro de San Pedro, 1321

Listera, 711

australis, 713

convallarioides, 713

cordata, 713

Little quaking grass, 192

Little walnut, 773

Lizard's-tail, 737

family, 734

Lobelia, 1574

anatina, 1576

appendiculata, 1579

Berlandieri, 1576

Berlandieri, 1576

brachypoda, 1576

big blue-, 1580

Cardinalis, 1583

graminea, 1583

multiflora, 1583

phyllostachya, 1583

pseudosplendens, 1583

downy-, 1580

fenestralis, 1579

flaccidifolia, 1579

floridana, 1579

great-, 1580

leafy-, 1579

Louisiana-, 1580

puberula, 1580 pauciflora, 1580

Reverchonii, 1580

siphilitica, 1580

ludoviciana, 1583

splendens, 1583

Loco, purple-, 1062

Loco weed, 1061, 1063

Locust

honey-, 1043

mock-, 1055

swamp-, 1045

water-, 1045

Logania family, 1308

Loganiaceae, 1308

Lolium, 215 multiflorum, 218 perenne, 215

Lomatogonium, 1327 rotatum, 1327

Long 
-bracted habenaria, 711

-bracted orchid, 711

-flowered horsemint, 1434

-horned habenaria, 695

-pedicelled willow, 760

Longspur columbine, 918

Longtom, 295

Lonicera, 1560

involucrata, $\mathbf{1 5 6 0}$

japonica, 1560

Loosestrife, 1158, 1291

family, 1154

swamp-, 1157

Lophotocarpus calycinus, 145

Lorinseria, 67 areolata, 67

Lotus, 1053

alamosanus, 1054

oblongifolius, 1054 yellow-, 912

Louisiana lobelia, 1580

Lousewort, 1499 common-, 1501

Love-vine, 962, 1359

Lovegrass, 192

India-, 196

Lowland cudweed, 1633

Lowland purslane, 879

Lucerne, 1046

Ludwigia, 4, 5, 9, 868, 1175, 1365

alternifolia, 1184 pubescens, 1184

bonariensis, 1181

decurrens, 1178

cylindric-fruited-, 1187

glandulosa, 1187

Torreyi, 1187

hirtella, 1184

leptocarpa, 1181

linearis, 1184 puberula, 1184

natans, 1187

rotundata, 1187

octovalvis octovalvis, 1178

palustris, 1175,1187

americana, 1187

nana, 1187

peploides

peploides, 1181

pilosa, 1184

repens, 1187

sphaerocarpa, 1187

uruguayensis, 1181

Lupinus, 1045

Kingsii, 1045
Luzula, 645

bulbosa, 645

campestris bulbosa, 646 multiflora, 646

multiflora

bulbosa, 646

parviflora, 646

Lycopersicon esculentum, 1449

Lycopodiaceae, 39

Lycopodium, 5, 39

adpressum, 39

alopecuroides

adpressum, 39

alopecuroides, 39

pinnatum, 39

carolinianum, 41

prostratum, 39

Lycopus, 1362, 1368, 1369, 1437

americanus, 1440

scabrifolius, 1440

asper, 1440

lucidus, 1440

rubellus, 1440

arkansanus, 1443

rubellus, 1443

sinuatus, 1440

uniflorus, 1437

virginicus, 1437

Lyonia, 5, 1274

ligustrina, 1276

capreaefolia, 1276

salicifolia, 1276

mariana, 1276

palustris, 1349

Lyre-leaf sage, 1433

Lysichitum americanum, 563

Lysimachia, 1291

ciliata, 1292

validula, 1292

hybrida, 1292

lanceolata, 1292

hybrida, 1292

radicans, 1292

Lythraceae, 1154

Lythrum, 9, 1154, 1158

alatum, 1161

breviflorum, 1161

lanceolatum, 1161

californicum, 1161

dacotanum, 1161

lanceolatum, 1161

lineare, 1158

linearifolium, 1161

ovalifolium, 1158

parvulum, 1161
Machaeranthera, 1609

Boltoniae, 1610

Coulteri, 1610

phyllocephala, 1610

Macuillamia rotundifolia, 1161

Mad-dog skullcap, 1416

Madder family, 1538

Madia, 1642 glomerata, 1642

Magnolia, 961, 1369

family, 958

glauca, 961

virginiana, 5, 961 australis, 961

Magnoliaceae, 958

Maidencane, 314

Maidenhair fern, 63

Malaxis, 734

unifolia, 734

Maleberry, 1276

Mallow

alkali-, 1124

checker-, 1114

family, 1113

marsh-, 1113

prairie-, 1114

rose-, 1117,1121

Malva, 1113

Malvaceae, 1113

Manatee-grass, 120

Mandioca, 1082

Mangle blanco, 1393

Mangrove, black-, 1393

Mangrove, red-, 1393

Manihot, 1082

Manisuris, 338

altissima, 341

rugosa, 341

Manna, 1065

-grass, 181

American-, 185

fowl-, 183

northern-, 183

weak-, 185

Manzanilla silvestre, 1661

Maple, 1104

ash-leaved-, 1104

family, 1104

Florida-, 1105

red-, 1105

scarlet-, 1105

southern sugar-, 1105

Marantaceae, 686

Mare's-tail, 1208

family, 1208

Marigold, bur-, 1663

Marigold, marsh-, 915

Marine-ivy, 1112

Mariscus, 416 
huarmensis, 459

Marsh

-alkali aster, 1622

-aster, 1622

-cress, bog-, 976

-elder, 1637

-felwort, 1327

-fleabane, 1633

-mallow, 1113

salt-, 1117

-marigold, 915

-pink, large-, 1315

-purslane, 1187

-rosemary, 1295

-St. John's-wort, 1140

-skullcap, 1415

Marshallia, 1675

caespitosa, 1675

caespitosa, 1677

signata, 1677

tenuifolia, 1677

Marsilea, 53, 56

Fournieri, 56

macropoda, 55, 56

mexicana, $\mathbf{5 5}$

mucronata, 55, 56

tenuifolia, 56

vestita

tenuifolia, 56

uncinata, 56

vestita, 56

Marsileaceae, 53

Martynia louisianica, 1510

Martyniaceae, 1508

Maruta, 1686

Masterwort, 1253

Mat-grass, 1405

Mat muhly, 248

Maximilian sunflower, 1659

Mayaca, 578

Aubletii, 5, 578

fluviatilis, 578

Michauxii, 578

Mayacaceae, 578

Mayhaw, western-, 1020

Mayweed, 1686

Meadow

-barley, 215

-beauty, 5, 1169

common-, 1172

-foxtail, 236

Meadow-rue, 957 purple-, 958

Meadow spikemoss, 41

Meadow violet, 1154

Mecardonia, 1464 acuminata, 1464 montevidensis, 1464 peduncularis, 1464 procumbens, 1464

vandellioides, 1464

viridis, 1464

Medicago, 1046

lupulina, 1046

sativa, 1046

Medick, 1046

black-, 1046

Melanthium, 655

virginicum, 655

Melastoma family, 1169

Melastomataceae, 1169

Melilotus, 1046

albus, 1046

indicus, 1047

officinalis, 1047

Melochia, 1127

corchorifolia, 1127

pyramidata, 1127

pyramidata, 1127

Meloncito, 1570

Melonette, 1570

Melosma

cubense, 1411

laevigatum, 1412

Melothria, 1570

chlorocarpa, 1570

pendula, 1570

chlorocarpa, 1570

Mentha, 1437, 1443

arvensis, 1443

glabrata, 1443

villosa, 1443

canadensis, 1443

Penardii, 1443

piperita, 1446

rotundifolia, 1443

spicata, 1446

Menyanthaceae, 1312, 1331

Mermaid-weed, 1201

Merremia, 1354

dissecta, 1359

Mertensia, 1391 ciliata, 1392

franciscana, 1391

Mesa dropseed, 252

Metasequoia, 79

Mexican -ash, 1305

-devil-weed, 1618

-elder, 1560

-fire-bush, 845

-tea, 854

-thistle, 1257

Micranthemum, 1487 umbrosum, 1487

Micranthes arguta, 1005

rhomboidea, 1005 texana, 1001

Micromeria, 1448

Brownei pilosiuscula, 1448

pilosiuscula, 1449

Microsteris, 1375

gracilis, 1375

micrantha, 1375

Mikania, 1599

scandens, 1599

pubescens, 1601

Milfoil, 3, 1686

American-, 1205

water-, 1202

Milk-vetch, 1061

Milkweed, 1339

family, 1339

purple-, 1341

showy-, 1340

swamp-, 1345

Milkwort, 5, 1074

family, 1074

sea-, 1288

Millet, 332

Japanese-, 329

pearl-, 334

Mimosa, 1041

malacophylla, 1042 glabrata, 1042

strigillosa, 1042

Wootonii, 1042

Mimosaceae, 1039

Mimosopsis, 1042

Mimulus, 1368, 1473

alatus, 1474

Cardinalis, 1474

verbenaceus, 1477

dentilobus, 1480

Eastwoodiae, 1480

floribundus, 1477

glabratus, 1483

Fremontii, 1483

guttatus, 1483

puberulus, 1483

nasutus, 1483

pilosus, 1480

primuloides, 1477

ringens, 1474

rubellus, 1477

Mina, 1354

Miner's lettuce, 881

Mint, 1443

family, 1407

field-, 1443

mountain-, 1446

roundleaf-, 1443

Missouri grape, 1110

Mist-flower, 1603

Mitchella, 1551 
repens, 1551

leucocarpa, 1551

Miterwort, 1311

Mitreola petiolata, 1311

Mock

-bishop's-weed, 1243

-cucumber, wild-, 1571

-locust, 1055

-orange, 1299

Moco de guajolote, 830

Modiola, 1124

caroliniana, 1124

Moldavica parviflora, 1419

Mollugo, 872

verticillata, $\mathbf{8 7 2}$

Monanthochloë, 198 littoralis, 198

Monarda, 1434 austromontana, 1434

citriodora, 1434

clinopodioides, 1434

fistulosa, 1434

punctata, 1434

Monkey-flower, 1473

crimson-, 1474

Monkshood, 921

Monocotyledoneae, 19, 85

Montezuma bald cypress, 82

Montia, 881

Chamissoi, 881

perfoliata, $\mathbf{8 8 1}$

Morning glory, 1353

beach-, 1357

family, 1350

goat-foot-, 1357

Mosquito fern, 57

Moss campion, 887

Moss gentian, 1325

Mountain

-mint, 1446

-ninebark, 1016

-pink, 1318

-sorrel, 796

Mouse-ear, 889

common-, 891

Mousetail, 924

Mud

-flower, shade-, 1487

-midget, 575

-plantain, 135, 601

Mudwort, 1461

Muhlenbergia, 169, 243

andina, 248

asperifolia, $\mathbf{2 4 8}$

filiformis, $\mathbf{2 4 8}$

frondosa, $\mathbf{2 4 9}$

mexicana, 249

minutissima, 246

pectinata, $\mathbf{2 4 6}$ racemosa, 249

Richardsonis, 248

Schreberi, 250

sinuosa, 246

sylvatica, 249

texana, 246

utilis, 248

Muhly, 243

Aparejo-, 248

foxtail-, 248

mat-, 248

nimblewill-, 250

pull-up-, 248

scratchgrass-, 248

wirestem-, 249

Mulberry

Bermuda-, 1395

French-, 1395

Spanish-, 1395

Mule-fat, 1608

Mullein foxglove, 1495

Muricauda Dracontium, 557

Museniopsis texana, 1220

Mustard

family, 962

tansy-, 967

-tree, 1453

tumble-, 965

Myosotis, 1384, 1391

scorpioides, 1391

Myosurus, 924

aristatus, 924

cupulatus, 924

minimus, 924

Myrica, 767, 1368, 1369

cerifera, $\mathbf{7 6 9}$

heterophylla, $\mathbf{7 6 7}$

Myricaceae, 767

Myriophyllum, 3, 4, 7, 9, 1202, 1513

brasiliense, 1202

exalbescens, 1202, 1205

heterophyllum, 1202 . 1208

pinnatum, 1208

proserpinacoides, 1205

scabratum, 1208

spicatum, 1205, 1208

exalbescens, 1205

verticillatum, 1205

Naid, 3

Najadaceae, 117, 123, 129

Najas, 3, 6, 9, 10, 126

flexilis, 126

guadalupensis, 126

marina, 126

Nama, 1380

jamaicensis, 1380

stenocarpum, 1380 torynophyllum, 1380

Napier grass, 334

Narrow

-leaved cat-tail, 87

-leaved prairie willow, 766

-leaved vetch, 1068

plumegrass, 336

Narrowleaf cottonwood, 742

Nasturtium officinale, 974

Necklace weed, 1491

Needles, Spanish-, 1672

Neeragrostis reptans, 194

Nelumbo, 7, 900, 912

lutea, 912

Nepeta, 1419

Cataria, 1419

Neptunia, 1042

floridana, 1043

Lindheimeri, 1043

lutea, 1043

multipinnatifida, 1043

Palmeri, 1043

plena, 1043

pubescens, 1043

microcarpa, 1043

pubescens, 1043

Nesaea

longipes, 1158

salicifolia, 1158

Nettle, 792

false-, 791

family, 788

hedge-, 1429

wood-, 791

Nevada bluegrass, 190

New Mexican alder, 782

New Mexican vervain, 1399

Nicotiana, 1368, 1449, 1450

glauca, 1453

plumbaginifolia, 1455

Roemeriana, 1453

repanda, 1453

Tabacum, 1449, 1450

trigonophylla, 1453

Nigella, 913

Nightshade, 1449, 1450

enchanter's-, 1199

family, 1449

Nimblewill muhly, 250

Ninebark, mountain-, 1016

Ninfa acuatica, 902

Nit grass, 243

Nitella, 3

Nitrophila, 842, 1367

occidentalis, $\mathbf{8 4 2}$ 
Nits-and-lice, 1140

Nodding

-bluegrass, 190

-fescue, 179

-ladies' tresses, 727

-nixie, 5, 689

Nogal, 772, 774

-morado, 774

-silvestre, 772

Northern

-crabgrass, 283

-frog-fruit, 1403

-manna-grass, 183

-reedgrass, 226

-wild rice, 277

Nuez encarcelada, 774

Nuphar, 3, 4, 7, 900, 906 advena, 906 tomentosa, 906

luteum, 4 macrophyllum, 906 ozarkanum, 906 polysepalum, 906

microcarpum, 906

ovatum, 906

polysepalum, 906

puberulum, 906

Nut-grass, 454

yellow-, 456

Nut-rush, 489

Nutmeg hickory, 774

Nuttall's water-hemp, 864

Nymphaea, 3, 4, 7, 900, 901

elegans, 902

flava, 902

lekophylla, 902

mexicana, 902

microcarpa, 906

odorata, 902

gigantea, 902

villosa, 902

ovata, 906

puberula, 906

spiralis, 902

tuberosa, 902

Nymphaeaceae, 734, 900

Nymphoides, 7, 9, 1312,

\section{1}

aquatica, 1331

peltata, 1331

Nyssa, 1262

aquatica, 1265

biflora, 1265

sylvatica

biflora, 1265

caroliniana, 1265

dilatata, 1265

sylvatica, 1265

uniflora, 1265
Oak, 783

bur-, 784

Jerusalem-, 854

laurel-, 787

overcup-, 784

pin-, 786

poison-, 1093

Spanish-, 785

water-, 787

willow-, 786

Oatgrass, 224

timber-, 224

Obedient-plant, 1422

Oenothera, 1194, 1365

biennis, 1198

biennis, 1198

canescens, 1198

hirsutissima, 1198

canescens, 1197

flava, 1197

Hookeri, 1198

Hewettii, 1198

irrigua, 1198

hirsutissima, 1198

Jamesii， 1199

Kunthiana, 1197

longissima, 1199

Clutei, 1199

pratincola, 1198

rhombipetala, 1198

rosea, 1197

sessilis, 1194

Simsiana, 1198

tetraptera, 1194, 1197

texensis, 1197

Okra, 1113

Old-man's beard, 1307

Oldman-whiskers, 1034

Oldenlandia

Boscii, 1545

corymbosa, 1548

uniflora, 1545

Oleaceae, 1301

Olive, desert-, 1308

Olive family, 1301

Ombligo de Venus, 1216

Onagraceae, 1175

One-seeded bur-cucumber, 1571

Onion, 655

Onoclea, 65

sensibilis, 65

Operculina, 1354 dissecta, 1359

Ophioglossaceae, 47

Ophioglossum, 49

crotalophoroides, 49

Engelmannii, 50

nudicaule

tenerum, 50 palmatum, 49

petiolatum, 50

pusillum, 49

vulgatum, 50

Engelmannii, 50

O'possum-wood, 1299

Opulaster monogynus, 1016

Orange sneezeweed, 1678

Orchard grass, 202

Orchid

American frog-, 711

crested fringed-, 5, 700

family, 690

frog-, 711

long-bracted-, 711

ragged fringed-, 695

satyr-, 711

small wood-, 5, 710

snowy-, 5, 700

water-spider-, 697

white fringed-, 697

yellow fringed-, 5, 697

yellow fringeless-, 700

Orchidaceae, 690

Orégano de burro, 1401

Orontium, 560

aquaticum, 560, 563

Orpine, 997

family, 994

Orthocarpus, 1508 luteus, 1508

Oryza, 271

sativa, 271

Osmunda, 51

cinnamomea, 51

regalis spectabilis, $\mathbf{5 1}$

Osmundaceae, 51

Osmorhiza, 1223

longistylis, 1223

villicaulis, 1226

Ostrya, 778

Ottelia alismoides, 169

Overcup oak, 784

Owl-claws, 1678

Owl clover, 1508

Oxypolis, 1251

Fendleri, 1253

filiformis, 1251

rigidior, 1251

Oxyria, 796

digyna, 796

Oxytria crocea, 655

Oxytrope, rock-loving, 1063

Oxytropis, 1062

Lambertii, 1063 articulata, 1063 
Bigelovii, 1063 oreophila, 1063

Parryi, 1063

splendens, 1062

\section{Pagesia}

acuminata, 1467

peduncularis, 1464

vandellioides, 1464

Paintbrush, Indian-, 1504, 1505

Painted cup, 1504, 1505

Pale dock, 801

Pale-seeded plantain, 1537

Palm family, 555

Palmae, 555

Palmas del mar, 167

Panic

beach-, 320

fall-, 323

-grasses, 304

Panicum, 169, 304, 314, 326,332

agrostoides, 317

ramosius, 317

amarulum, 320

amarum, 320

anceps, $\mathbf{3 1 7}$

Ashei, 312

barbulatum, 307

bulbosum, 320

capillare, 323

occidentale, 323

colonum, 326

commutatum, 312

condensum, 317

crusgalli, 329

cruspavonis, 329

dichotomiflorum, 323

dichotomum, 307

ensifolium, $\mathbf{3 1 0}$

geminatum, 312, 314

gymnocarpon, 314

hemitomon, 314

hians, 304, 317

Joorii, 312

lanuginosum, 310

leucothrix, $\mathbf{3 0 7}$

longiligulatum, 310

lucidum, 307

microcarpon, 307

nitidum, 307

obtusum, 314

paludivagum, 314

polyanthes, 310

polystachyum, 332

Ravenelii, 312

rhizomatum, 317

rigidulum, 317

scabriusculum, 312 scoparium, 312

stipitatum, 317

tenerum, $\mathbf{3 2 0}$

Thurowii, 310

virgatum, 320

Walteri, 329

Wrightianum, 310

Yadkinense, 307

Paniquesillo, 985

Papilionaceae, 1039

Parapholis, 218

incurva, 218

Parasol-tree, Chinese-, 1125

Parentucellia, 1499 viscosa, 1499

Parkeriaceae, 77

Parkinsonia aculeata, 1039

Parnassia, 1005 asarifolia, 5, 1005 fimbriata, 1008 grandifolia, 1005 parviflora, 1008

Parnassiaceae, 1005

Parra del monte, 1111

Parra silvestre, 1109

Parrot's-feather, 4, 1202 green-, 1208

Parsley family, 1211

Parsley, sand-, 1220

Parsnip, cow-, 1253

Parsnip, water-, 1234

Partridge-berry, 1551

Paspalidium

geminatum, 314

paludivagum, 314

Paspalum, 289

acuminatum, 301

bifidum, 290 projectum, 290

Boscianum, 292

bull-, 292

circulare, 295

dilatatum, 292

dissectum, 304

distichum, 298 indutum, 301

floridanum, 290 glabratum, 290

fluitans, 304

Hartwegianum, 298

laeve, 295

lentiferum, 295

lividum, 295

longipilum, 295

praecox, 295

pubiflorum, 298

glabrum, 298

repens, 304

Urvillei, 292 vaginatum, 301

virgatum, 292

Pasture haw, 1019

Pata de gallo, 256

Pea

black-eyed-, 1069

cream-, 1069

rush-, 1045

-vine, 1069

Peach-leaf willow, 759

Pear, 1017

Pearl millet, 334

Pearlwort, 897

Peat moss, 5

Pecan, 774

bitter-, 775

Pedicularis, 1499

canadensis, 1501

groenlandica, 1501

Grayi, 1504

Parryi, 1501

Peltandra, 4, 560

Tharpii, 560

virginica, 560

Penny, tinker's-, 1130

Pennywort, water-, 1214

Penstemon, 1487

Digitalis, 1488

laxiflorus, 1487

Rydbergii, 1488

stenosepalus, 1488

tenuis, $\mathbf{1 4 8 8}$

virgatus, 1489

Whippleanus, 1488

Penthoraceae, 999

Penthorum, 999, 1362, 1365

sedoides, 1001

Pentodon, 1548

Halei, 1548

pentandrus, 1548

Peplis, 9, 1162

diandra, 1162

Pepper

-bush, sweet-, 1267

red-, 1449

-vine, 1112

Peppermint, 1446

Pepperwort family, 53

Pepperwort, hairy-, 55

Perennial

-fescue, 177

-smartweed, 826

-summer-cypress, 847

Perideridia, 1233

Gairdneri, 1234

Parishii, 1234

Perilla, 1434

frutescens, 1434 
Peritoma, 989

integrifolia, 988

serrulatum, 988

sonorae, 988

Persea, 961

americana, 961

Borbonia, 961

palustris, 962

pubescens, 962

Persian wiregrass, 814

Persicaria, 808

bicornis, 823

coccinea, 823

densiflora, 826

Hydropiper, 830

hydropiperoides, 834

opelousana, 834

lapathifolia, 826

Muhlenbergii, 823

orientalis, 826

pensylvanica, 820

punctata, 826

setacea, 834

vulgaris, 830

Perularia

bidentata, 703

scutellata, 703

Petunia, 1449, 1455

axillaris, 1455

parviflora, 1455

seaside-, 1455

violacea, 1455

wild-, 1455

Phacelia, 1377

heterophylla, 1377

magellanica, 1377

Phalaris, 268

angusta, 271

arundinacea, $\mathbf{2 6 8}$

caroliniana, $\mathbf{2 6 8}$

Pharbitis, 1354

cathartica, 1355

Philadelphia fleabane, 1629

Philibertella cynanchoides, 1350

Philoxerus, 868 vermicularis, $\mathbf{8 6 8}$

Phleum, 240

alpinum, 240

pratense, 240

Phlox family, 1369

Phoenix, 556

Pholiurus incurvus, 218

Phragmites, 205 communis, 205

Phyla, 1401

cuneifolia, 1362, 1405

incisa, 1404

lanceolata, 1403

nodiflora, 1405 longifolia, 1405

reptans, 1405

strigulosa, 1404

parviflora, 1404

sericea, 1404

yucatana, 1404

Phyllanthus, 1082, 1365

caroliniensis, $\mathbf{1 0 8 3}$

ericoides, 435

pudens, 1083

Phylloglossum, 39

Physocarpus, 1016 monogynus, 1016

Physostegia, 1362, 1422 angustifolia, 1425

Correllii, 1426

Digitalis, 1426

edwardsiana, 1425

intermedia, 1425

micrantha, $\mathbf{1 4 2 5}$

obovata, 1426

praemorsa, 1425

pulchella, 1426

serotina, 1426

Phytolacca, 870

americana, $\mathbf{8 7 0}$

decandra, 870

rigida, 870

Phytolaccaceae, 870

Piaropus crassipes, 598

Pickerel-weed, 4, 601

family, 597

Pickle-weed, 839

Pigeon-bush, 1560

Pigeon grape, 1110

Pigmy

saxifrage, 1002

-weed, 994

water-, 994

Pignut hickory, 775

Pigweed, 853, 855, 858 spiny-, 861

Pilea, 792 pumila, 792

Deamii, 795 pumila, 795

Pillwort, 57

Pilostaxis

nana, 1081

ramosa, 1081

Pilularia, 57

americana, 57

Pimpernel, 1291

brook-, 1493

false-, 1484

scarlet-, 1291

water-, 1277

Pin oak, 786

Pinguicula, 1522

pumila, 5, 1522
Pink

family, 884

grass-, 5

mountain-, 1318

-smartweed, 823

Pinkweed, 820

Pipewort, 5, 588 family, 588

Pistia, 563

Stratiotes, 3, 4, 563

Pitcher plant, 5, 990

family, 990

Plains cottonwood, 748

Plains ironweed, 1593

Plane-tree family, 1012

Planer-tree, 788, 1012

Planera, 788 aquatica, $\mathbf{7 8 8}$

Plantaginaceae, 1533

Plantago, 109, 1365, 1533

elongata, 1538

eriopoda, 1534

heterophylla, 1538

hirtella

Galeottiana, 1536

mollior, 1537

hybrida, 1537

insularis, 1536

fastigiata, 1536

lanceolata, 1534

major, 1536

pusilla, 1538

rhodosperma, 1537

Rugelii, 1536

virginica, 1537

viridescens, 1537

Plantain, 1533

common-, 1536

English-, 1534

family, 1533

Indian-, 1693

pale-seeded-, 1537

red-seeded-, 1537

Robin's-, 1627

Platanaceae, 1012

Platanus, 1012

occidentalis, 1015

attenuata, 1015

glabrata, 1015

racemosa

Wrightii, 1015

Wrightii, 1015

Pleurogyna rotata, 1327

Pluchea, 1367, 1633

borealis, 1637

camphorata, 1634

foetida, 1634

purpurascens, 1634

rosea, 1634 
sericea, 1637

Plumbaginaceae, 1295

Plumbago family, 1295

Plumed thistle, 1694

Plumegrass, 336

bent-awn-, 336

narrow-, 336

silver-, 336

sugarcane-, 338

Poa, 185, 231

ampla, 192

arctica, 190

compressa, 189

glaucifolia, 189

Grayana, 189

interior, 190

juncifolia, 192

leptocoma, 190

nevadensis, 190

palustris, 190

pratensis, 189

reflexa, 190

Poaceae, 169

Podostemaceae, 993

Podostemon, 994

Ceratophyllum, 994

Pogonia, 716

divaricata, 719

ophioglossoides, 5, 716

rose-, 5, 716

Poison

-bean, 1059

beaver-, 1237

-dogwood, 1093

-elder, 1093

-hemlock, 1233

-ivy, 1093

-oak, 1093

-sego, 650

-suckleya, 849

-sumac, 5, 1093

Pokeberry, 870

Pokeweed, 870

family, 870

Polemoniaceae, 1369

Polemonium, 1370

filicinum, 1373

foliosissimum, 1371

albiflorum, 1371

robustum, 1371

grande, 1371

Hinckleyi, 1371

pauciflorum, 1371

Hinckleyi, 1371

pauciflorum, 1371

reptans, 1371

Polycodium stamineum, 1269

Polygala, 5, 1074

cruciata, 1079
Harperi, 1079

Hookeri, 1076

incarnata, 1075

leptocaulis, 1076

lutea, 1081

mariana, 1079

nana, 1081

polygama, 1075

obtusata, 1075

ramosa, 1081

sanguinea, 1079

verticillata, 1076

ambigua, 1076

dolichoptera, 1076

isocycla, 1076

sphenostachya, 1076

viridescens, 1079

Polygalaceae, 1074

Polygonaceae, 795

Polygonum, 807, 1361, 1362,1367

amphibium, 7, 820

emersum, 823

stipulaceum, $\mathbf{8 2 3}$

arenastrum, 816

argyrocolon, 814

aviculare, $\mathbf{8 1 6}$

bicorne, $\mathbf{8 2 3}$

bistortoides, $\mathbf{8 1 7}$

buxiforme, 816

coccineum, 823

confertiflorum, 814

Convolvulus, 813

cristatum, 813

densiflorum, 826

Douglasii, 816

Hydropiper, 826

hydropiperoides, $\mathbf{8 3 0}$

hydropiperoides, $\mathbf{8 3 4}$

opelousanum, 834

setaceum, 834

Kelloggii, 814

lapathifolium, 823

incana, 826

longistylum, 823

natans, 823

opelousanum, 834

orientale, $\mathbf{8 2 6}$

pensylvanicum, 820

Persicaria, 830

punctatum, 826, 830

ramosissimum, 817

sagittatum, 810

scandens

cristatum, 813

setaceum, 834

texense, 813

virginianum, 810

viviparum, 817

Watsonii, 815
Polypappus sericeus, 1637

Polypodiaceae, 61

Polypogon, 4, 238

ditch-, 240

elongatus, 240

interruptus, 240

monspeliensis, 238

semiverticillatus, 228

Pond-nut, 912

Pondweed, 3, 4, 95

broad-leaved-, 117

curled-, 103

family, 95

sago-, 95, 100

western-, 100

Pontederia, 601

cordata, 4 cordata, 601

lanceolata, 601

lanceolata, 601

Pontederiaceae, 597

Ponthieva, 723 racemosa, $\mathbf{7 2 3}$

Pony-foot, 1350

Poolmat, common-, 117

Poor joe, 1555

Poor man's rope, 1311

Poor man's soap, 1267

Poorman's-weatherglass, 1291

Pop ash, 1303

Populus, 738

acuminata, 739, 745

angustifolia, 742, 745

arizonica, 745

deltoides, 748, 751 occidentalis, 751

Fremontii, 745, 748

arizonica, $\mathbf{7 4 5}$

pubescens, 745

Hinckleyana, 742

Sargentii

Sargentii, 748, 751

texana, 751

texana, 751

tremuloides, 751

aurea, 752

Wislizenii, 745, 751

Porcupine caric-sedge, 527

Porterella, 1583

carnulosa, 1583

Portulaca, 881, 1361

coronata, 884

lanceolata, 884

oleracea, $\mathbf{8 8 4}$

umbraticola, $\mathbf{8 8 4}$

Portulacaceae, 879

Posidonia, 9, 129

oceania, 4, 129 
Posidoniaceae, 129

Possum-grape, 1112

Possum-haw, 1099, 1556

Post-oak, bottomland-, 785

Post-oak, swamp-, 784

Potamogeton, 3, 4, 5, 7, 9, $10,95,126$

alpinus, 117

americanus, 114

amplifolius, 111, 117

angustifolius, 114

Berchtoldii

tenuissimus, 106

clystocarpus, 105

crispus, 103

diversifolius

diversifolius, 108

trichophyllus, 108

filiformis, 100

foliosus, 103

foliosus, 105

macellus, 105

gramineus, 114

illinoensis, 114

latifolius, 100

lucens, 114

natans, 117

nodosus, 7, 111, 114

pectinatus, 95, 100

pulcher, 108

pusillus, 105

Potamogetonaceae, 95, 129

Potato, 1449

-bean, 1069

American-, 1069

family, 1449

hog-, 1045

sweet-, 1354

wild-, 1357

Potentilla, 1021

Anserina, 1031 concolor, 1031

arguta

Convallaria, 1029

atrorubens, 1025

biennis, 1027

diversifolia, 1028

filipes, 1028

fruticosa, 1025

glandulosa, 1029

arizonica, 1029

gracilis, 1028

brunnescens, 1028

grabrata, 1029

pulcherrima, 1028

Macdougalii, 1029

monspeliensis, 1025

norvegica, 1025

hirsuta, 1025

paradoxa, 1027 pentandra, 1025

plattensis, 1029

pulcherrima, 1028

rivalis, 1027

Thurberi, 1025

atrorubens, 1025

Thurberi, 1025

Powderpuff, 1042

Powdery-thalia, 686

Prairie

-agalinis, 1497

-buttercup, 939

-cordgrass, 265

-cupgrass, 285

-dogbane, 1337

-mallow, 1114

-wedgescale, 218

Pretty dodder, 1367

Prickly lettuce, 1698

Primrose, 1287

evening-, 1194

family, 1276

spotted-, 1197

water-, 1175,1187

-willow, 1178

creeping-, 1187

floating-, 1187

Primula, 1287

angustifolia, 1287

Ellisiae, 1288

Parryi, 1288

Rusbyi, 1288

Primulaceae, 1276

Princess-feather, 826

Privet, swamp-, 1307

Proboscidea, 1510

Jussieui, 1510

louisianica, 1510

Proserpinaca, 7, 1201

palustris, 1201

amblyogona, 1201

creba, 1201

pectinata, 1201

Prostrate vervain, 1400

Prunella, 1419

vulgaris, 1419

hispida, 1422

lanceolata, 1422

Psilactis, 1609

asteroides, 1610

Coulteri, 1610

lepta, 1610

Psilocarya, 489 nitens, 489

Psilotaceae, 37

Psilotum, 37 nudum, 37

Pteridophyta, 17, 37

Ptilimnium, 1243

capillaceum, 1243 costatum, 1243

Nuttallii, 1243

texense, 1243

Puccinellia, 179

airoides, 181

distans, 181

Nuttalliana, 181

Parishii, 181

pauciflora, 185

Pull-up muhly, 248

Purple

-beautyberry, 1395

-bladderwort, 1519

-cudweed, 1632

-dewdrop, 1580

-loco, 1062

-meadow-rue, 958

-milkweed, 1341

-rocket, 964

-wen-dock, 909

Purslane, 881, 884

family, 879

horse-, 875

lowland-, 879

marsh-, 1187

sea-, 875

speedwell-, 1491

water-, 1162

Pycnanthemum, 1446

albescens, 1448

flexuosum, 1448

tenuifolium, 1446

virginianum, 1448

Pycreus, 416

Pyrus, 1017

arbutifolia, 1017

Quackgrass, 210

Quail-brush, 850

Quaking

-aspen, 751

-grass, 192

-grass, little, 192

Quamasia hyacinthina, 657

Quamoclit, 1354

coccinea, 1355

hederifolia, 1355

Quelite, 855, 862

espinoso, 861

salado, 847

Quercus, 734, 783

aquatica, 788

Ashei, 785

digitata, 786

falcata, 785

laurifolia, $\mathbf{7 8 7}$

lyrata, 784

macrocarpa, 784

nigra, 787

tridentifera, 788 
obtusa, 787

palustris, 786

Phellos, 786

rhombica, 787

rubra, 786

digitata, 786

leucophylla, 786

pogodaefolia, 786

triloba, 786

similis, 785

stellata, 785 paludosa, 785

Quillwort, 43

family, 41

Rabbitfoot grass, 238

Radish, horse-, 979

Ragged fringed orchid, 695

Ragweed, 1642

giant, 1645

western, 1645

Ragwort, 1689

Railroad vine, 1357

Rain-lily, 669

Ram's horn, 1510

Ranunculaceae, 734, 913

Ranunculus, 7, 928

abortivus, 945

acris, 933

apricus, 939

aquatilis, 955 capillaceus, 955

cardiophyllus, 944 subsagittatus, 944

carolinianus, 936 villicaulis, 939

circinatus subrigidus, 957

Cymbalaria, 953 Cymbalaria, 953 saximontanus, 953

Eschscholtzii, 943

fascicularis, 939 apricus, 939 cuneiformis, 939

flabellaris, 952, 953

flammula, 946 ovalis, 946

glaberrimus, 945 ellipticus, 946

Gmelinii Hookeri, 952

hydrocharoides, 946 stolonifer, 946

inamoenus, 944

laxicaulis, 949

longirostris, 957

Macauleyi, 943

Macounii, 936

macranthus, 939 muricatus, 941

parviflorus, 941

pedatifidus, 944 affinis, 945

pensylvanicus, 935

pusillus, 949

angustifolius, 949

ranunculinus, 955

recurvatus, 935

repens, 933

pleniflorus, 933

Sardous, 941

sceleratus, 949

septentrionalis

pterocarpus, 936

subrigidus, 957

tener, 949

texensis, 949

uncinatus, 933

Earlei, 935

Rapé, 1453

Raspilla, 1042

Ratibida, 1652

Rattle-box, 1184

Rattlebush, 1059

Rattlesnake-master, 1254

Red

-ash, 1305

-bay, 961

-berried bamboo, 664

-chokeberry, 1017

-clover, 1052

-elderberry, 1559

-fescue, 179

-flag, 679

-grape, 1110

-haw, 1017

-mangrove, 1393

-maple, 1105

-oak, southern, 785

-pepper, 1449

-osier dogwood, 1266

-root, 862

-seeded plantain, 1537

-sprangletop, 256

-top bentgrass, 231

-willow, 760

Reed canary grass, 268

Reed

common-, 205

giant-, 202

-grass, 224

Reedgrass, northern, 226

Relbunium microphyllum, 1540

Retama, 1039

Reynoutria

Convolvulus, 813

scandens

cristatum, 813
Rhexia, 5, 1169

alifanus, 1175

ciliosa, 1172

interior, 1172

lutea, 1172

mariana

exalbida, 1172

interior, 1172

mariana, 1172

petiolata, 1172

virginica, 1172

Rhizophora Mangle, 1393

Rhizophoraceae, 1393

Rhododendron, 5, 1271

atlanticum, 1272

canescens, $\mathbf{1 2 7 2}$

subglabrum, 1274

Coryi, 1271, 1272

nudiflorum, 1274

oblongifolium, 1272

prinophyllum, 1274

viscosum, 1272

Rhus, 1093, 1367, 1369

radicans 1095

Rydbergi, 1095

verrucosa. 1095

vulgaris, 1095

Toxicodendron, 1093

eximia, 1095

microcarpa, 1095

quercifolia, 1095

radicans, 1095

Toxicodendron, 1095

vulgaris, 1095

Vernix, 5, 1093

verrucosa, 1095

Rhynchospora, 4, 464, 467, 489

caduca, 487

capillacea, 474

capitellata, 475

corniculata, 473

corniculata, 473

interior, 473

macrostachya, 471

cymosa, 489

divergens, 473

Elliottii, 484

fascicularis, 478

filifolia, 478

globularis, $\mathbf{4 8 7}$

recognita, 489

glomerata, 475

angusta, 475

glomerata, 475

gracilenta, 481

Grayi, 481

Harveyi, 481

indianolensis, $\mathbf{4 7 3}$ 
inexpansa, 484

intermixta, 474

macra, 475

macrostachya, 471

microcarpa, 484, 487

mixta, 484

nivea, 467

obliterata, 489

oligantha, 478

perplexa, 487

Plankii, 481

plumosa, 478

pusilla, 473

rariflora, $\mathbf{4 8 1}$

schoenoides, 484

semiplumosa, 478

Rhyncospora, 469

Ribes, 1008

americanum, 1010

aureum, 1010

inerme, 1010

mogollonicum, 1011

Wolfii, 1011

Ribwort, 1534

Riccia fluitans, 578

Ricciacarpus natans, 578

Rice, 10, 271

-cutgrass, 274

Richweed, 792

Ricinus, 1082

Rio Grande cottonwood, 745

Rio Grande vervain, 1400

River

-birch, 779

-bulrush, 349

-walnut, 773

-weed, 994

family, 993

Riverbank grape, 1110

Robin's-plantain, 1627

Rock

-cress, 964

-jasmine, 1284

-loving oxytrope, 1063

Rocket

purple-, 964

sea-, 981

yellow-, 981

Rocky Mountain beeplant, 988

Rocky Mountain columbine, 917

Rompevientos, 1149

Rorippa, 9, 971

curvisiliqua, 976

hispida, 976

islandica, 976

Fernaldiana, 976

hispida, 976 islandica, 976

Nasturtium-aquaticum, 971,974

obtusa, 976, 979

palustris, 976

ramosa, 979

sessiliflora, 974

sinuata, 974

sphaerocarpa, 976

teres, 979

Walteri, 979

Rosa, 1038, 1369

arizonica, $\mathbf{1 0 3 8}$

Fendleri, 1038

Woodsii

Fendleri, 1038

Rosaceae, 999, 1015

Rose, 1038

family, 1015

-gentian, 1313

mallow-, 1121

-mallow, 1117

halberd-leaved-, 1118

scarlet-, 1118

swamp-, 1121

woolly-, 1121

-pink, 1315

-pogonia, 5, 716

-sundrops, 1197

Rosemary, marsh, 1295

Roseroot, 997

Rosita, 1317

Rotala, 1164

dentifera, 1164

ramosior, 1164

interior, 1164

ramosior, 1164

Rough

-butterweed, 1555

-leaf dogwood, 1266

-skullcap, 1412

Round-fruited toad rush, 618

Roundleaf mint, 1443

Royal fern, 51

Rubiaceae, 1538

Rubus, 1035, 1369

abundiflorus, 1036

argutus, 1036

arizonensis, 1036

arvensis, 1036

largus, 1037

louisianus, 1036

oklahomus, 1036

oligospermus, 1036

putus, 1037

ramifer, 1036

texanus, 1036

valentulus, 1037

Rudbeckia, 1651 amplexicaulis, 1655

Coryi, 1652

divergens, 1651

flexuosa, 1651

Fulgida palustris, 1652

hirta, 1651

angustifolia, 1651

pulcherrima, 1651

laciniata, 1652

maxima, 1652

serotina, 1651

subtomentosa, 1652

Ruellia, 1527

ciliosa, 1527

humilis, 1527

depauperata, 1528

expansa, 1528

frondosa, 1528

longiflora, 1528

strepens, 1527

cleistantha, 1527

strepens, 1527

Rulac Negundo, 1104

Rumex, 797, 798

Acetosella, 798

alluvius, 805

altissimus, $\mathbf{8 0 1}$

Berlandieri, 802

californicus, 801

chrysocarpus, 801, 802

conglomeratus, 805

crispus, $\mathbf{8 0 2}, 805$

ellipticus, 801

Engelmannii, 800

fueginus, 807

hastatulus, 800

hymenosepalus, 797

Langloisii, 802

maritimus, 807

fueginus, 807

mexicanus, 802

obtusifolius, $\mathbf{8 0 5}$

occidentalis, 802

pulcher, 805

spiralis, 801

stenophyllus, $\mathbf{8 0 5}$

triangulivalvis, 802

utahensis, 801

verticillatus, $\mathbf{8 0 0}$

violascens, $\mathbf{8 0 7}$

Running box, 1551

Running fleabane, 1629

Ruppia, 6, 9, 123

maritima, 123

Ruppiaceae, 123

Rush, 3, 5, 606

family, 604

-pea, 1045

Russian thistle, 839 
Ryegrass, 215

Rynchospora, 469

Sabal, 556

louisiana, 556

minor, 556

Sabatia, 1313

angularis, 1315

arenicola, 1315

calycina, 1317

campestris, 1315

carnosa, 1317

dodecandra, 1315

dodecandra, 1315

foliosa, 1315

gentianoides, 1313

Sabbatia, 1313

Sabino, 82

Sacahuista, 262

Sacciolepis, 323

striata, 323

Sacred bean, 912

Sage, big red-, 1433

lyre-leaf-, 1433

wood-, 1408

Sagebrush, 1689

Sagina, 897

decumbens, 899

saginoides, 897 hesperina, 899

Sagittaria, 3, 4, 7, 9, 10 , 133,142

ambigua, 147

arifolia, 153

brevirostra, 153

calycina, 145

cuneata, 153

cycloptera, 145

Engelmannia brevirostra, 153

falcata, 147

graminea, 145 platyphylla, 147

Greggii, 150

lancifolia, 147 media, 147

latifolia, 150

hastata, 150

latifolia, 150

obtusa, 150

pubescens, 150

longiloba, 150, 153

montevidensis, 145

calycina, 145

papillosa, 147

platyphylla, 147

pubescens, 150

Sago pondweed, 95, 100

Salad, corn, 1565

Saladilla, 835
Salicaceae, 737

Salicornia, 835, 1367

Bigelovii, 836

perennis, 836

utahensis, 836

virginica, 836

Salix, 752, 1362, 1367, 1368

amygdaloides, 759 amygdaloides, 759

Wrightii, 759

arctica, 763

Bebbiana, 765

Bonplandiana, $\mathbf{7 6 0}$

Toumeyi, 760

caroliniana, $\mathbf{7 6 0}$

caudata, 760

Drummondiana, 767

exigua

exigua, 761

nevadensis, 761, 763

stenophylla, $\mathbf{7 6 1}$

fragilis, 760

Geyeriana, 766

glauca, 764

Gooddingii

variabilis, 759

Humboldtiana, 757

humilis rigidiuscula, 766

interior, 763 angustissima, 763 interior, 763 pedicellata, 763

irrorata, 764

laevigata, 760 araquipa, 760

lasiandra, 759

lasiolepis, 764 Bracelinae, 764

linearifolia, 763

longifolia, 763

longipes, 761

lutea, 765

monticola, 765

myrtillifolia, 765

nigra, 757, 759

Lindheimeri, 757

nigra, 757

stipulacea, 759

nivalis, 763

padophylla, 765

petrophylla, 764

phylicifolia, 766 monica, 767

pseudocaudata, 765

pseudomonticola, 765

rigida, 764

saximontana, 763

Scouleriana, 766 subcocrulea, 767

taxifolia, 761

microphylla, 761

Wardii, 761

Wrightii, 759

Salsola, 839, 1367

Kali, 839

tenuifolia, 839

pestifer, 839

Salt

-cedar, 1, 1148

-marsh

-bulrush, 349

-mallow, 1117

-gerardia, 1497

-sand-spurrey, 900

Saltbush, 849

Australian-, 850

silver-, 851

Saltgrass, 200

Saltmeadow cordgrass, 265

Saltwort family, 868

Salva colorado, 1401

Salva dó Brasil, 1401

Salvia, 1433

lyrata, 1433

penstemonoides, 1433

Salvinia, 57

family, 57

Salviniaceae, 57

Sambucus, 1556

caerulea, 1559

arizonica, 1560

mexicana, 1560

canadensis, 1559

submollis, 1559

glauca, 1559

mexicana, 1560

microbotrys, 1559

neomexicana, 1559

racemosa, 1559

Rehderana, 1560

Samolus, 1277

cuneatus, 1279

ebracteatus, 1279

cuneatus, 1279

floribundus, 1281

parviflorus, 1281

vagans, 1281

Samphire. Utah, 836

Sand

-parsley, 1220

-spurrey, 899

salt-marsh-, 900

-weed, 1134

Sandbar willow, 763

Sandhills amaranth, 862

Sandpaper vervain, 1397 
Sandwort, 894 thyme-leaved-, 897

Sanguisorba, 1037 minor, 1037

Sarcobatus, 842 vermiculatus, $\mathbf{8 4 2}$

Sarcostemma, 1349 cynanchoides, 1349 cynanchoides, 1350 Hartwegii, 1350 heterophyllum, 1350

Sarothra Drummondii, 1140

Sarracenia, 990 alata, 5, 990 purpurea, 990 Sledgei, 990

Sarraceniaceae, 990

Satureja, 1449 arkansana, 1449

Brownei, 1449 glabella angustifolia, 1449 glabra, 1449

Satyr orchid, 711

Saúco, 1560

Saururaceae, 734

Saururus, 737 cernuus, 737

Saúz, 757

Saw-grass, 464

Saxifraga, 1001 arguta, 1002 chrysantha, 1001 debilis, 1002

Reevesii, 1001 rhomboidea, 1005 texana, 1001

Saxifragaceae, 999

Saxifrage, 1001 brook-, 1002 family, 999 pigmy-, 1002

Scait-seed, 1220

Scariet -creeper, 1355 -maple, 1105 -pimpernel, 1291 -rose-mallow, 1118

Schoenolirion, 655 croceum, 655

Schoenus, 464 nigricans, 464

Scirpus, 3, 4, 10, 344, 365, 415

acutus, 360, 363

americanus longispicatus, $\mathbf{3 5 7}$ polyphyllus, 357 atrovirens, 352 atrovirens, 352

georgianus, 354

pallidus, 352

Bergsonii, 357

californicus, 357

chilensis, 357

cubensis, 349

cyperinus

cyperinus, 352

rubricosus, 349,352

etuberculatus, 360

fluviatilis, 349,360

fontinalis, $\mathbf{3 5 4}$

georgianus, $\mathbf{3 5 2}$

heterochaetus, 360

koilolepis, 355

lacustris, 363

condensatus, 363

glaucus, 363

occidentalis, 363

lineatus, 354

maritimus, 349

macrostachyus, 349

paludosus, 349

micranthus, 415

microcarpus, $\mathbf{3 5 2}$

molestus, 354

nanus, 387

Olneyi, 357

pallidus, 352

paludosus, 349

radicans, 372

robustus, 349

rubricosus, 352

saximontanus, 355

supinus, 355

Hallii, 355

saximontanus, 355

supinus, 355

Tabernaemontani, 363

validus, 363

Wilkensii, 355, 357

Scleria, 489

Muhlenbergii, 489

setacea, 489

Scoke, 870

Scouring-rush, 47

family, 45

smooth-, 46

summer-, 46

Scratchgrass muhly, 248

Screw-stem, 1329

Scrophulariaceae, 1456

Scutellaria, 1412

cardiophylla, 1415

epilobiifolia, 1415

galericulata, 1415

integrifolia, 1412

hispida, 1415

integrifolia, 1415 rhodantha, 1415

lateriflora, 1416

Sea

-blite, 846

-lavender, 1295

-milkwort, 1288

-oats, inland, 202

-ox-eye daisy, 1655

-purslane, 875

-rocket, 981

Seasinore saltgrass, 4

Seaside

-gerardia, 1497

-goidenrod, 1612

theliotrope. 1386

-petunia, 1455

Sedge, 3, 4, 5, 489

family, 341

three-way-, 344

Sedum, 997

pulchellum, 997

rhodanthum, 997

Rosea, 997

Seedbox, 5, 1175, 1184

Seepweed, 846

Seepwillow, 1607

Selaginella, 41

apoda, 41

ludoviciana, 41

Selaginellaceae, 41

Selenia, 983

dissecta, 984

grandis, 983

Jonesii, 984

Self-heal, common, 1419

Seneca grass, 268

Senecio, 1689

aurea, 1690

crassulus, 1690

flavovirens, 1691

glabellus, 1690

lapathifolius, 1691

pauperculus, 1691

pseudaureus, 1691

salignus, 1691

semiamplexicaulis, 1691

triangularis, 1691

Sensitive fern, 65

Serapias gigantea, 716

Sesbania, 9, 1056, 1367

Drummondii, 1059

exaltata, 1059

macrocarpa, 1059

vesicaria, 1059

Sesuvium, 870, 875, 1361

erectum, 879

maritimum, 876

Portulacastrum, 876

sessile, 879 
trianthemoides, 876

verrucosum, 879

Setaria, 332

geniculata, 332

glauca, 334

lutescens, 334

magna, 334

verticillata, 334

Seutera palustris, 1349

Seymouria macrophylla, 1495

Shade betony, 1431

Shade mud-flower, 1487

Shadow-witch, 723

Shagbark hickory, 775

Sheep sorrel, 798

Shellbark, 775

Shepherd's purse, 985

Shinnersia rivularis, 1599

Shooting-star, 1281

Short-awn foxtail, 236

Short-beaked sedge, 499

Showy-milkweed, 1340

Shrubby

-alkali aster, 1621

-cinquefoil, 1025

-St. John's-wort, 1133

Shumac, 1093

Sibara, 965 virginica, 965

Sicklegrass, 218

Sicyos, 1571 angulatus, 1571

Sida, 1124

alba, 1125

hederacea, 1124

leprosa

hederacea, 1124

rhombifolia, 1125

Sidalcea, 1114

candida, 1117

neomexicana, 1114, 1117

Sieversia turbinata, 1035

Silene, $\mathbf{8 8 7}$

acaulis subacaulescens, $\mathbf{8 8 7}$

Silkweed, 1339

Silver

-bells, 1299

Carolina-, 1299

-plumegrass, 336

-saltbush, 851

Silverhead, 868

Silverweed, 1031

Silvery desert willow, 761

Sisymbrium, 965 altissimum, 965

Sisyrinchium, 673 angustifolium, 675 atlanticum, 675 bermudianum, 675

biforme, 676

Brownii, 675

cernuum, 674

demissum, 676

dimorphum, 676

exile, 675

gramineum, 675

graminioides, 675

laxum, 675

longipedunculatum, 676

longipes, 674

micranthum, 675

minus, 675

montanum, 675

rosulatum, 675

sagittiferum, 675

texanum, 675

Thurowii, 675

Sium, 1234

cicutaefolium, 1237

suave, 1234

Skullcap, 1412

mad-dog-, 1416

marsh-, 1415

rough-, 1412

Skunk-cabbage, 655

Slender

-bog-orchid, 709

-buttonweed, 1552

-clubmoss, 41

-hair grass, 222

-rush, 618

-water-nymph, 126

Slough grass, American-, 259

Small butterwort, 5, 1522

Small wood orchid, 5, 710

Smartweed, 4, 897, 820

-dodder, 1362

perennial-, 826

pink-, 823

water-, 820,826

willow-, 823

Smilacaceae, 663

Smilacina, 657

stellata, 657

Smilax, 663

laurifolia, 663

rotundifolia, 663 quadrangularis, 664

Walteri, 664

Smooth

-alder, 782

-barked cottonwood, 739

-buttonweed, 1552

-cordgrass, 262

-scouring-rush, 46

-yellow violet, 1152

Smother-weed, 843
Smutgrass, 252

Snakeroot

black-, 653

button-, 1254, 1595

Snakeweed, 817, 1608

Sneezeweed, 1677, 1679 orange, 1678

Snow-berry, 1560

Snowdrop-tree, 1299

Snowy orchid, 5, 700

Soapwort gentian, 1326

Soft rush, 612

Soft-stem bulrush, 363

Solanaceae, 1449

Solanum, 1449, 1450

Douglasii, 1450

Melongena, 1449

nigrum, 1450

nodiflorums, 1450

tuberosum, 1449

Solidago, 1362, 1365, 1367, $1368,1609,1610$, 1611

altissima, 1613 canescens, 1613

pluricephala, 1613

angustifolia, 1612

arizonica, 1613

aspera, 1612

caesia, 1612

decumbens, 1615

gigantea, 1613

leiophylla, 1613

occidentalis, 1615

rugosa, 1613

aspera, 1613

celtidifolia, 1612

salicina, 1612

sempervirens

mexicana, 1612

sempervirens, 1612

spathulata

nana, 1615

stricta, 1612

ulmifolia, 1612

Solomon's seal, false, 657

Sombrerillo, 1219

Sophronanthe pilosa, 1467

Sorghum, 338

halepense, 338

Sorrel

heart-, 800

mountain-, 796

sheep-, 798

Sour

-bush, 1395

-clover, 1047

-dock, 802

-gum, 1262 
South American vervain, 1397

Southern

-black-haw, 1556

-blue-flag, 682

-clubmoss, 39

-cypress, 81

-lady fern, 67

-marsh fern, 72

-red oak, 785

-rein-orchid, 703

-sugar maple, 1105

-swamp lily, 671

-twayblade, 713

-water-hemp, 864

-wild-rice, 280

Southwestern black willow, 759

Spanish

-mulberry, 1395

-needles, 1672

-oak, 785

Sparganiaceae, 89

Sparganium, 3, 10, 89

americanum, 93

androcladum, 93

angustifolium, 93

emersum, 91, 93

multipedunculatum, 93

eurycarpum, 91

minimum, 91

multipedunculatum, 93

simplex, 93

Sparsely-flowered bogorchid, 709

Spartina, 4, 259

alterniflora, 262 glabra, 262

cynosuroides, 262

gracilis, 265

patens, $\mathbf{2 6 5}$

pectinata, 265

Suttiei, 265

spartinae, 262

Spatter-dock, 906

Spearmint, 1446

Speedwell, 1490

purslane-, 1491

water-, 1493

Spergula platensis, 899

Spergularia, 899

echinosperma, 900

marina, 900

platensis, 899

salina, 900

salsuginea

bracteata, 900

Spermacoce, 1551

glabra, 1552 tenuior, 1552

Spermatophyta, 79

Spermolepis, 1220

divaricata, 1220

Sphagnum moss, 4, 5

Sphenoclea, 1572 zeylanica, 1572

Sphenocleaceae, 1572

Sphenopholis, 218 intermedia, 220 obtusata, 218

Spider flower, 987

Spider lily, 596, 666

Spiderwort, 596

Spiderwort family, 593

Spike

-bentgrass, 234

chicken-, 1572

-trisetum, 222

Spikemoss family, 41

Spikemoss, meadow, 41

Spikerush, 3, 366

creeping-, 381

Spilanthes, 1649

americana

repens, 1649, 1651

repens, 1651

Spinach, French, 851

Spindle-root, 1184

Spindle-tree, 1103

Spiny

-cocklebur, 1646

-pigweed, 861

-rush, 615

Spiral-orchid, giant, 730

Spiral-orchid, lace-lip, 730

Spiranthes, 5, 723, 730

brevilabris, 730

cernua, $\mathbf{7 2 7}$

cernua, 727

odorata, 727

gracilis

brevilabris, 730

floridana, 730

gracilis, $\mathbf{7 2 7}, 730$

graminea, 732

laciniata, 732

longilabris, 730

praecox, 730, 732

Romanzoffiana, $\mathbf{7 2 4}$

vernalis, 732

Spirodela, 3, 4, 564

oligorhiza, 564

polyrhiza, 564

Sporobolus, 169, 250

flexuosus, 252

indicus, 252

Poiretii, 252

texanus, 250

virginicus, 252
Spot-flower, creeping, 1649

Spotted

-cowbane, 1237

-primrose, 1197

-touch-me-not, 1108

Sprangletop, 252

bearded-, 253

red-, 256

Spreading pogonia, 719

Spring

-bentgrass, 228

-buttercup, 941

-cress, 968

-herald, 1308

-ladies's tresses, 732

Spurge family, 1082

Spurred gentian, 1327

Squaw-huckleberry, 1269

Squaw-weed, 1689

St. Andrew's-cross, 1128

St. John's-wort, 1129

family, 1127

marsh-, 1140

shrubby-, 1133

St. Peter's-wort, 1128

Stachys, 1367, 1429

agraria, 1431

crenata, 1431 albiflora, 1431

floridana, 1433

Nuttallii, 1431

palustris, 1431, 1429

nipigonensis, 1431

pilosa, 1431

tenuifolia, 1431

Staff-tree family, 1103

Stagger bush, 1276

Star-glory, 1355

Star-grass, 660

Starflower, 657

Starwort, 893

Steironema

ciliatum, 1292

lanceolatum, 1292

pumilum, 1292

radicans, 1292

validulum, 1292

Stellaria, 893

gonomischa, 894

longifolia, 894

longipes, 894

umbellata, 893

Stemodia, 1468 durantifolia, 1468

Stenophyllus, 400

Sterculiaceae, 1125

Stick-tights, 1668

Stickseed, 1389

Sticky hedge-hyssop, 1467 
Stiff marsh bedstraw, 1542

Stinkgrass, 196

Stinking fleabane, 1634

Stinking-willow, 1055

Stinkweed, 1633

Stone-rush, 489

Stonecrop, 997 ditch-, 999

Stonewort, 3

Storax, 1299 family, 1296

Stout woodreed, 234

Straggling gilia, 1373

Strangle vine, 1360

Strawberry

-bush, 1103

-clover, 1049

Indian-, 1021

Streptopus, 659 amplexifolius, 659

Stretch-berry, 1308

Stylisma, 1353 aquatica, 1353

Stylites, 43

Styracaceae, 1296

Styrax, 1296, 1299

americana, 1299 pulverulenta, 1299

platanifolia, 1299 stellata, 1301

pulverulenta, 1299

Suaeda, 846, 1361, 1367

conferta, 849

depressa, 846 erecta, $\mathbf{8 4 7}$

linearis, 847

mexicana, $\mathbf{8 4 7}$

nigrescens glabra, 847

Torreyana, 847

Sucker flax, 1073

Suckleya, 849

poison-, 849

suckleyana, 849

Sugarcane plumegrass, 338

Sumac, 1093

family, 1091

poison-, 1093

Summer

-cypress, 845

perennial-, 847

-grape, 1110

-scouring-rush, 46

Sump-weed, 1637

Sundew, 5, 990

family, 990

Sundrops, rose, 1197

Sunflower, 1655

Maximilian-, 1659

tickseed-, 1667
Susan, brown-eyed, 1651

Svida stricta, 1266

Swamp

-bay, 961

-dock, 800

-laurel oak, 787

-locust, 1045

-loosestrife, 1157

-milkweed, 1345

-post-oak, 784

-privet, 1307

-rose-mallow, 1121

-thistle, 1695

Sweet

-bay, 961

-cicely, 1223

-clover, 1046

white-, 1046

yellow-, 1047

-grape, 1109

-grass, 268

-gum, 1012

-leaf, 1301

family, 1301

-pepper-bush, 1267

-potato, 1354

-spire, 1008

Sweetflag, 563

Swertia, 1327

palustris, 1327

perennis, 1327

Switchgrass, 320

Sword-grass, 357

Sycamore, 1012

Arizona-, 1015

Symphoricarpos, 1367 ,

1560

orbiculatus, 1560

spicatus, 1562

vulgaris, 1562

Symplocaceae, 1301

Symplocos, 1301

tinctoria, 1301

Syringodium filiforme, 120

Tabaquillo, 1453

Tall

-leafy green-orchid, 706 -northern green-orchid, 706

-scouring-rush, 47

-white bog-orchid, 710

-white northern-orchid, 710

Tamaricaceae, 1148

Tamarisco, 1149

Tamarisk, 1148

family, 1148

Tamarix, 1, 196, 845,

1148, 1368 africana, 1149

aphylla, 1149

aralensis, 1149

canariensis, 1149

chinensis, 1149

gallica, 1149

parviflora, 1149

ramosissima, 1151

Tangle gut, 1360

Tansy-mustard, 967

Tapegrass, 161

Tapioca, 1082

Tapiro, 1560

Taraxacum, 1703

erythrospermum, 1704

officinale, 1703

Taray, 763

Tarragon, 1689

Tarweed, 1642

Tassel-white, 1008

Tauschia, 1220 texana, 1220

Taxodiaceae, 79

Taxodium, 81 distichum, $\mathbf{8 1}$

family, 79

mucronatum, 82

Tea, Mexican, 854

Tearthumb, 810

Tecoma, 1369

Té de castilla, 1401

Tessaria, 1637

borealis, 1637

sericea, 1637

Teucrium, 1362, 1408

canadense, 1408

angustatum, 1411

canadense, 1411

occidentale, 1411

virginicum, 1411

cubense, 1411

chamaedrifolium, 1412

cubense, 1412

densum, 1312

laevigatum, 1412

depressum, 1412

laevigatum, 1412

occidentale, 1411

virginicum, 1411

Texas

-frog-fruit, 1404

-gourd, 1569

-ladies' tresses, 730

-lantana, 1400

-wildrice, 277

Thalassia, 9, 129, 167

testudinum, 4, 167

Thalia, 686 
barbata, 686

dealbata, 686

Thalictrum, 957

dasycarpum, 958

dasycarpum, 958

hypoglaucum, 958

Fendleri, 958

hypoglaucum, 958

Thelyptris, 69

dentata, 74

hexagonoptera, 72

Kunthii, 75

normalis, 75

ovata

Lindheimeri, 74

palustris

Haleana, 72

quadrangularis versicolor, 74

Torresiana, 72

versicolor, 74

Theobroma cacao, 1125

Thin-leaf alder, 782

Thistle, 1694

bull-, 1695

Mexican-, 1257

plumed-, 1694

Russian-, 839

swamp-, 1695

white-, 850

yellow-, 1695

Thorn, 1017

camel-, 1065

Thoroughwort, 1601

Thread-foot, 994

Three

-square bulrush, 357

-sternis. d rush, 627

-way sedge, 344

Thurber's bog-orchid, 703

Thyme-leaved sandwort, 897

Tickseed, 1660

-sunflower, 1667

Tillaea, 994

aquatica, 994

Drummondii, 994

Drummondii, 994

Tillaeastrum

aquaticum, 994

Drummondii, 994

Timber oatgrass, 224

Timothy, 240

alpine-, 240

Tiniaria

Convolvulus, 813

cristata, 813

Tinker's penny, 1130

Tithonia, 1649

Thurberi, 1649
Tmesipteris, 37

Toad-rush, 615

Tobacco, 1449, 1450

desert-, 1453

fiddle-leaf-, 1453

-root, 1562

tree-, 1453

wild-, 1453

Tobaco cimarrón, 1453

Tofieldia, 650 racemosa, 650

Tomato, 1449

Tooth-cup, 1162, 1164

Toronjil de España, 1401

Torreyochloa pauciflora, 185

Touch-me-not, 1105

family, 1105

spotted-, 1108

Tovara virginiana, 810

Toxicodendron

eximium, 1095

quercifolium, 1095

radicans, 1095

eximium, 1095

verrucosum, 1095

Tracaulon sagittatum, 813

Trachelospermum, 1334

difforme, 1334

Tradescantia, $\mathbf{5 9 6}$

canaliculata, 597

edwardsiana, 596

ohioensis, 597

reflexa, 597

Wrightii, 597

Tragiola pilosa, 1467

Trautvetteria, 928 grandis, 928

Tree tobacco, 1453

Treebine, ivy-, 1112

Trefoil, 1053

Trepocarpus, 1226

Aethusae, 1226

Triadenum

petiolatum, 1140

tubulosum, 1140

virginicum, 1140

Walteri, 1140

Trianthema, 875, 1361

Portulacastrum, 875

Trichachne, 283

Trichloris, 265 crinita, 265

Trichocoronis, 1599

rivularis, 1599

Wrightii, 1599

Tridens, 205

albescens, 205, 208

ambiguus, 208

strictus, 205
Trifolium, 1047, 1365

amabile, 1052

dasyphyllum, 1051

Fendleri, 1049

fragiferum, 1049

hybridum, 1053

lacerum, 1051

longicaule, 1049

microcephalum, 1048

nanum, 1051

neurophyllum, 1052

Parryi, 1051

pinetorum, 1049

pratense, 1052

repens, 1052

Rydbergii, 1052

stenolobum, 1052

Willdenovii, 1049

Wormskjoldii, 1049

Triglochin, 131

concinnum

debilis, 133

debilis, 133

maritimum, 131 elata, 131

palustre, 131

Trilliaceae, 659

Trillium, 659

pusillum ozarkanum, 660

recurvatum, 660

Shayi, 660

texanum, 659

Tripsacum, 341

dactyloides, 341

occidentale, 341

Trisetum, 220

montanum, 220

spicatum, 222

spike-, 222

Wolfii, 220

Wolf's-, 220

True fern family, 61

Trumpet, 990

yellow-, 990

Tuckahoe, 560

Tufted hair grass, 224

Tule, $89,357,360$ -espadilla, 87

Tulillo, 454

Tumble-mustard, 965

Tumbleweed, 839

Tupelo, 1262, 1265

Turbina, 1354

Turkey-tangle, 1405

Turkeyberry, 1395

Turnsole, 1384, 1389

Turre hembra, 1404

Turtle-grass, 167

Twayblade 
broad-leaved-, 713

broad lipped-, 713

heart-leaved-, 713

southern-, 713

Twin-berry, 1560

Twisted-stalk, 659

Two-eyed berry, 1551

Typha, 3, 4, 6, 10, 85, 231, 1701

angustifolia, $\mathbf{8 7}, 89$

domingensis, 89

latifolia, 11, 87

truxillensis, 89

Typhaceae, 85

Ulmaceae, 788

Ulmus rubra, 435

Umbrella

-flatsedge, 447

-grass, 365

-plant, 447

Umbelliferae, 1211

Unicorn-plant, 1510

family, 1508

-root, 660

Uniola latifolia, 202

Urtica, 792

Breweri, 792

dioica

gracilis, 792

gracilis, 792

angustifolia, 792

holosericea, 792

procera, 792

gracilenta, 792

gracilis, 792

Serra, 792

viridis, 792

Urticaceae, 788

Utah samphire, 836

Utricularia, 9, 1513

biflora, 1522

cornuta, 1516

fibrosa, 1522

gibba, 1522

inflata, 1519

minor, 1519

juncea, 1516

macrorhiza, 1519

pumila, 1522

purpurea, 1519

radiata, 1519

subulata, 1516

cleistogama, 1516

vulgaris, 1519

americana, 1519

Vaccinium, 5, 1269, 1369

amoenum, 1270

arkansanum, 1271 atrococcum, 1271

caesium, 1270

corymbosum, 1271

Elliottii, 1270

stamineum, 1269, 1270

virgatum, 1270

Valerian, 1562

family, 1562

Valeriana, 1562

capitata, 1563 acutiloba, 1563

edulis, 1565

occidentalis, 1563

texana, 1563

Valerianaceae, 1562

Valerianella, 1565

amarella, 1566

florifera, 1566

locusta, 1565

radiata

Fernaldii, 1569

radiata, 1568, 1569

stenocarpa

parviflora, 1568

stenocarpa, 1568

texana, 1568

Woodsiana, 1566

Vallisneria, 161

americana, 161

spiralis, 161

Vanilla grass, 268

Vasey grass, 292

Veintiunilla, 1345

Velvet ash, 1305

Velvet grass, 224

Veratrum, 655 californicum, 655

Verbena, 1365, 1396

bonariensis, 1397

bracteata, 1400

bracteosa, 1400

brasiliensis, 1397

hastata, 1399 scabra, 1399

Macdougalii, 1399

Runyonii, 1400 rosiflora, 1400

scabra, 1397 angustifolia, 1397

urticifolia, 1399 leiocarpa, 1399

Verbenaceae, 1393

Verbesina, 1659 encelioides, 1659 exauriculata, 1659

Verdolaga, 884

-blanca, 875

-de agua, 1181

Vergonzosa, 1042
Vernonia, 1362, 1367, 1592

altissima, 1595

crinita, 1593

Drummondii, 1595

fasciculata, 1593

Lettermannii, 1593

marginata, 1593

missurica, 1595

tenuifolia, 1593

Veronica, 1490

americana, 1493

Anagallis-aquatica, 1493

catenata, 1493

connata

glaberrima, 1493

peregrina, 1491

peregrina, 1491

xalapensis, 1491

serpyllifolia, 1491

Wormskjoldii, 1491

Vervain, 1396

blue-, 1399

Brazilian-, 1397

family, 1393

New Mexican-, 1399

prostrate-, 1400

Rio Grande-, 1400

sandpaper-, 1397

South American-, 1397

white-, 1399

Vesiculina purpurea, 1519

Vetch, 1068

deer-, 1053

joint-, 1065

milk-, 1061

narrow-leaved-, 1968

Viburnum, 5, 1556

cassinoides

nitidum, 1556

nitidum, 1556

nudum, 1556

angustifolium, 1556

rufidulum, 1556

Vicia, 1068

angustifolia, 1068

Vidrillos, 870

Vigna, 1069

luteola, 1069

repens, 1069

unguiculata, 1069

Vine-mesquite, 314

Viola, 1151

eriocarpa, 1152

esculenta, 1152

lanceolata, 5 lanceolata, 1152

vittata, 1152

Langloisii, 1154 
missouriensis, 1154

nephrophylla, 1153 arizonica, 1153 nephrophylla, 1153

papilionacea, 1154

primulifolia, 1152

villosa, 1152

pubescens

eriocarpa, 1152

septemloba, 1152, 1153

sororia, 1153

Violaceae, 1151

Violet, 1151

family, 1151

lance-leaved-, 1152

meadow-, 1154

smooth yellow-, 1152

water-, 1277

woolly blue-, 1153

Viorna crispa, 923

Virginia bugle-weed, 1437

Virginia chain fern, 65

Virgin's-bower, 923

Vitaceae, 1108

Vitis, 1109, 1369

aestivalis, 1110

arizonica, 1111

arizonica, 1111

glabra, 1111

cinerea, 1109

canescens, 1110

cinerea, 1110

palmata, 1110

riparia, 1110

Treleasei, 1111

vulpina, 1110, 1111

Wahoo, 1103

Wake-robin, 659

Walnut, 772

Arizona-, 772

family, 769

little-, 773

river-, 773

Wapato, 150

Washingtonia, 556

Water

-ash, 1303

-bentgrass, 228

-birch, 779

-bonnet, 563

-celery, 161

-chickweed, 1085

-chinquapin, 912

-clover, 53

-cress, 971, 974

-crowfoot

white-, 957

yellow-, 953

-dropwort, 1251 -elm, 788

-feather, 1202

-fern, 3, 57

-foxtail, 238

-grass, 326

-hemlock, 1237

-hemp, 862

Nuttall's-, 864

southern-, 864

-hickory, 775

-horehound, 1437, 1440

-hyacinth, 3, 4, 11, 598, 868

-hyssop, 1458

disc-, 1461

-lentil, 571

-lettuce, 3, 4, 563

-lily, 4, 901

blue-, 902

family, 900

white-, 902

yellow-, 902

-locust, 1045

-meal, 3, 573

-milfoil, 1202

family, 1201

-motie, 1607

-nymph, 126, 901

common-, 126

family, 123

holly leaved-, 126

slender, 126

-oak, 787

-parsnip, 1234

-pennywort, 1214

-pigmy-weed, 994

-pimpernel, 1277

-plantain, 3, 135

family, 133

-poppy, 156

-primrose, 4, 1175, 1187

-purslane, 1162

-shield, 3, 909

-smartweed, 820, 826

-speedwell, 1493

-spider orchid, 697

-star grass, 601

-starwort, 1085

family, 1085

-violet, 1277

-wally, 1607

-willow, 11, 1157

American-, 1531

lance-leaved-, 1531

Waterleaf, 1377

family, 1375

Waterpepper, 830

Waterweed, 3, 163

Waterwort, 1142

family, 1142
Wax-myrtle, 5, 767, 769

family, 767

Waxweed, blue-, 1167

Weak manna-grass, 185

Wedge-leaf frog-fruit, 1405

Wedgegrass, 218

Wen-dock, purple-, 909

Western

-dock, 802

-iris, 679

-ladies' tresses, 724

-mayhaw, 1020

-pondweed, 100

-ragweed, 1645

-wheatgrass, 210

Wheatgrass, 208

bearded-, 208

western-, 210

Whisk fern family, 37

White

-alder, 1267

family, 1267

-ash, 1305

-avens, 1033

-camas, 650

-clover, 1052

-fringed orchid, 697

-grass, 274

-sweet clover, 1046

-thistle, 850

-top sedge, 464

-topped umbrella grass, 467

-tridens, 208

-vervain, 1399

-water-crowfoot, 957

-water lily, 3, 902

Whitehead bog-button, 5, 593

Whitlow-grass, 984

Widgeon-grass, 123

Widow's-tears, 595

Wild

-balsam-apple, 1570

-bergamont, 1434

-celery, 1233

-chervil, 1223

-hollyhock, 1114

-hyacinth, 657

-mock-cucumber, 1571

-petunia, 1455

-potato, 1357

-rice, 277, 280

northern-, 277

southern-, 280

Texas-, 277

-rye, 210

beardless-, 212

Canada-, 212

-tobacco, 1453 
Willow, 752

arroyo-, 764

beaked-, 765

black-, 757

family, 737

fire-, 766

gray sandbar-, 761

-herb, 1190

long-pedicelled-, 760

narrow-leaved prairie-, 766

-oak, 786

peach-leaf-, 759

primrose, 1178

red-, 760

sandbar-, 763

silvery desert-, 761

-smartweed, 823

southwestern black-, 759

stinking-, 1055

water-, 1157

yellow-, 759, 764

yew-leaf, 761

Wind-bags, 573

Winter

-berry, 1098, 1099

-cress, 981

American-, 981

-grape, 1111

Wire rush, 610

Wiregrass, 816

muhly-, 249

Persian-, 814

Wislizenia, 987, 989

refracta, 989

Witch-hazel family, 1011

Witches' shoelaces, 1360

Witchgrass, 323

Withe-rod, 1556

Woe-vine, 962

Wolffia, 3, 4, 573

columbiana, $\mathbf{5 7 5}$

papulifera, $\mathbf{5 7 5}$

punctata, 575

Wolffiella, 564, 575

floridana, $\mathbf{5 7 8}$

gladiata, $\mathbf{5 7 8}$

lingulata, 4, 578

Wolf's trisetum, 220

Wood

-betony, 1499

-nettle, 791

-sage, 1408

Woodreed, 234

stout-, 234

Woodrush, 645

Woodwardia, 65

angustifolia, 67

areolata, 67 virginica, 65

Woolly

-blue violet, 1153

-rose-mallow, 1121

-sedge, 544

Wormseed, 854

Wormwood, 1689

Xanthium, 1365, 1586,

$$
1646
$$

cenchroides, 1646

chinense, 1646

italicum, 1646

orientale, 1646

pensylvanicum, 1646

saccharatum, 1646

speciosum, 1646

spinosum, 1646

strumarium, 1646

Xanthocephalum, 1608

gymnospermoides, 1608

Xanthorhiza, 915

simplicissima, 915

Ximenesia

australis, 1660

encelioides, 1660

cana, 1660

exauriculata, 1660

Xylorhiza, 1609

Xyridaceae, 578

Xyris, 580

ambigua, $\mathbf{5 8 1}$

arenicola, 583

Baldwiniana, $\mathbf{5 8 1}$

tenuifolia, 581

caroliniana, $\mathbf{5 8 3}$

difformis, $\mathbf{5 8 7}$

Curtissii, 588

difformis, 588

elata, 588

Elliottii, 581

flexuosa, 583

iridifolia, 585

Jupicai, 587

platylepis, $\mathbf{5 8 3}$

tenuifolia, 581

torta, $583, \mathbf{5 8 5}$

occidentalis, 585

Yarrow, common-, 1686

Yaupon, 5, 1101

Yeatesia, 1528

viridiflora, 1528

Yellow

-bee-plant, 988

-cow-lily, 906

-cress, 971

-dock, 802, 805

-eyed grass, 580

family, 578 -flag, 679

-floating-heart, 1331

-foxtail, 334

-fringed orchid, 5, 697

-fringeless orchid, 700

-jessamine, 1311

-lotus, 912

-nut-grass, 456

-puff, 1043

-rocket, 981

-star-grass, 5, 660, 667

-sunny-bell, 655

-sweet clover, 1047

-thistle, 1695

-trumpet, 990

-violet, smooth-, 1152

-water crowfoot, 953

-water lily, 3, 902

-willow, 764

-willow tree, 759

-wood, 1301

Yellowroot, 915

Yerba de tago, 1646

Yerba mansa, 737

Yew-leaf willow, 761

Zannichellia, 6, 9, 10, 117 palustris, 117

Zannichelliaceae, 117

Zephyr-lily, 669

Zephyranthes, 669

brazosensis, 669

candida, 669

chrysantha, 669

Herbertia, 669

pulchella, 669, 671

refugiensis, 671

texana, 671

Zerna Richardsonii, 177

Zexmenia hispidula, 1660

Zigadenus, 650

densus, 653

elegans, 650

glaberrimus, 653

leimanthoides, 653

porrifolius, 653

virescens, 653

Zizania, 277

aquatica, 277

angustifolia, 280

texana, 277

Zizaniopsis, 280

miliacea, 280

Zizia, 1230

aptera, 1230

aurea, 1230

Zosterella

dubia, 604

longituba, 604 





